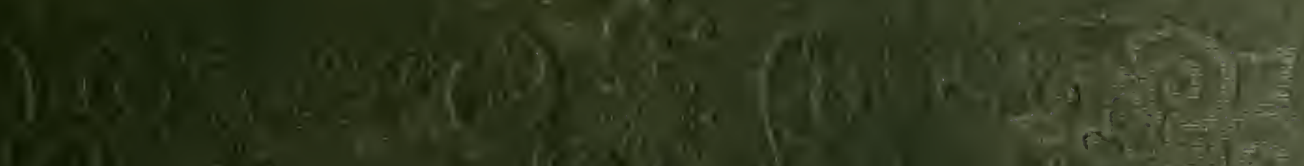
50.

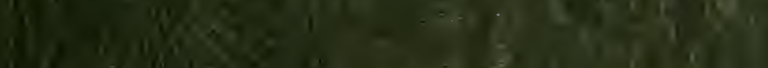

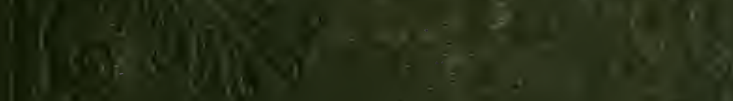

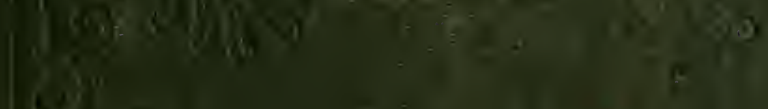

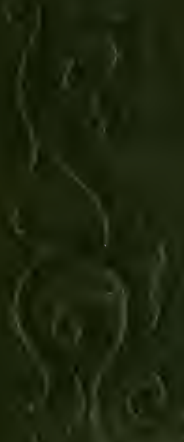

3. $18=1$.

$\left.\frac{15}{7}\right)(2,8)$

$(1+1)$

(3)

$\int^{6} x^{2}$

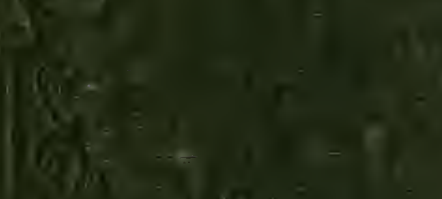

(1) $-1 / \sqrt{2}$

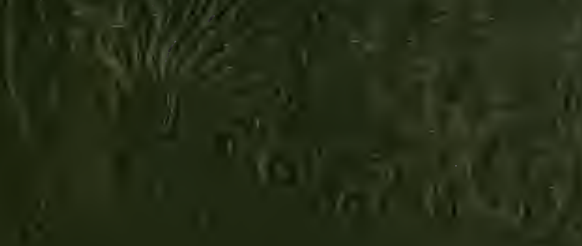

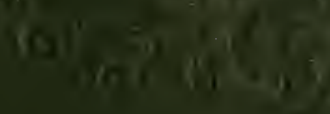

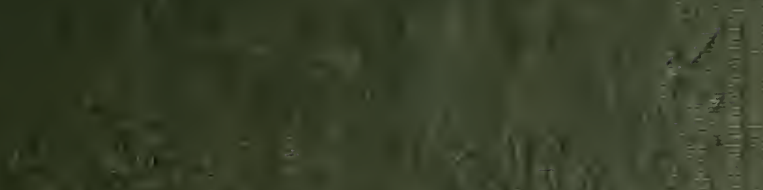
wastis

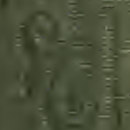

$\left.\begin{array}{c}9 \\ 7,3 \\ -3\end{array}\right]$

e. 


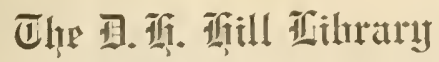

Sorth Carolima Siate Callege

QK97

fD5

. 3 


\section{8}

This book must not be taken from the Library building.

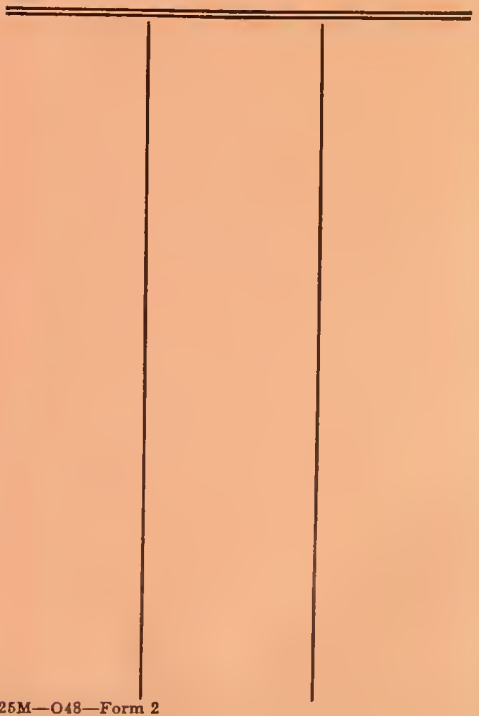





\title{
GENERAL HISTORY
}

OF THE

\section{I C H LA M Y D O U S P L A N T S, \\ COMPRISING COMPLETE}

\section{DESCRIPTIONS OF THE DIFFEREN'T ORDERS;}

\author{
TOGETHER WITH THE
}

CHARACTERS OF THE GENERA AND SPECIES, AND AN ENUMERATION OF THE CULTIVATED VARIETIES;

THEIR PLACES OF GROWTH, TIME OF FLOWERING, MODE OF CULTURE, AND

USES IN MEDICINE AND DOMESTIC ECONOMY;

THE SCIENTIFIC NAMES ACCENTUATED, THEIR ETYMOLOGIES EXPLAINED, AND THE CLASSES AND ORDERS ILLUSTRATED BY ENGRAVINGS,

AND PRECEDED BY INTRODUCTIONS TO THE LINNAAN AND NATURAL SYSTEMS,

AND A GLOSSARY OF TIE TERMS USED:

THE WHOLE

ARRANGED ACCORDING TO THE NATURAL SYSTEM.

BY GEORGE DON, F.L.S.

IN FOUR VOLUMES.

VoL. III.—CALYCIFLORÆ.

LONDON :

PRINTED FOR J. G. AND F. RIVINGTON; J. AND W. T. CLARKE; LONGMAN AND CO.; T. CADELL; J. RICHARDSON ; JEFFER ${ }^{\prime}$ AND SON; BALDWIN AND CRADOCK; J. BOOKER; J. BOOTH; HARVEY AND DARTON; S. BAGSTER; SHERWOOD AND CO.; HARDING AND LEPARD; J. F. SETCHEL; WHITTAKER AND CO.; SIMPKIN AND MARSHALL; AND E. HODGSON. 



\title{
INDEX TO THE THIRD VOLUME,
}

\author{
COMPRISING THE
}

SYSTEMATIC AND ENGLISH GENERIC NAMES, AND THE ENGLISH AND SYSTEMATIC SYNONYMES.

*." In this Index the systematic names used, and the English names in common use, are in Raman letters; the synonymes in Italics; the names of Classes, Sub-classes, and Orders in large capitals; and the names of Sub-orders and Tribes in small capitals.

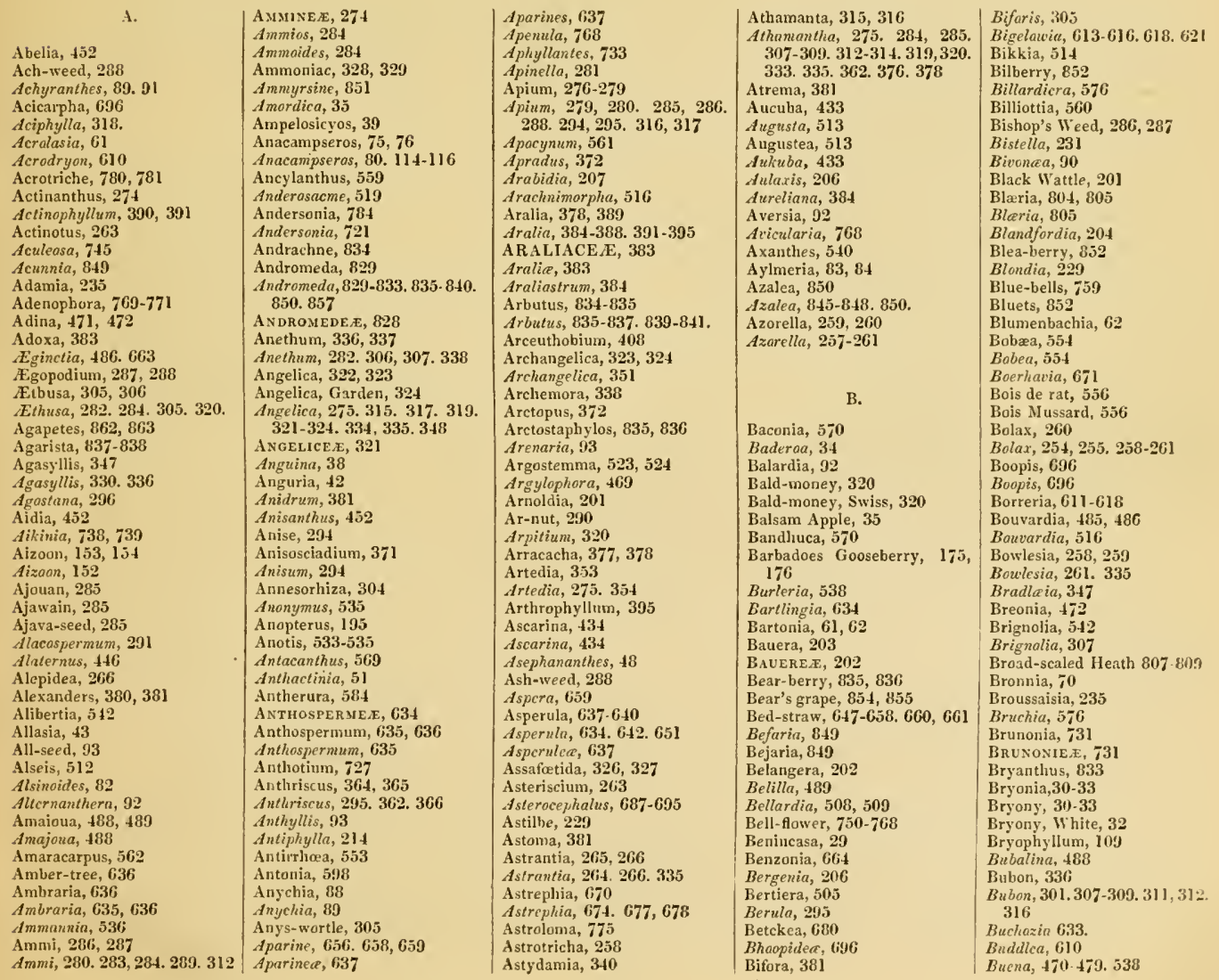

a 2 
Bulbocastanum, 289 Buglossmm, 728 Bulliarda, as

Bulliardu, 98

Butium, 289-291

Buтіum, 262. 284-285. 288 289. 307.319

Bupleuroides, 635

Bupleurun, 296-301

Bupleurum, 280.301.376

Buyrestis, 297. 30

Bur-parsley, 360

Burcardia, 7o

Burchellia, 488

Burghartia, 70

Burnet-saxifrage, 291-294

Burneya, 554

Button-wood, 610-611

Button-weed, 615-628

\section{c.}

Cachrys, $37-2-374$

Cachrys 275. 353. 321. 347. 354. $374-376$

Cactere, 156

Cucti, 156

Cactinere, 156;

Cactoidece, 156

Cactus, 15\%-177

Carlamba, 550

Caiophora, 65

Calanchoe, 108, 109

Calandrinia, $78-80$

Caldasia, 368

Caldcluvia, 200

Calico-bush, 850

Callicocea, 604-608

Callicoma, 201, 202

Callipeltis, 661

Calliphyllum, 213

Callista, 812-816

Callisace, 336

Callogync, 726

Calluna, 828

Calycera, 696

CALYCERE. E, 696

Calyconis, 201

Calysphyrum, 665

Calycophyllum, 486, 487

Cameraria, 82

CAMPANiE.e, 731

Campanula, $750-768$.

Campanula, 731-746.750.768 7733

CAMPANULEF, 746

C.AMPANULACE E, 73]

Campanumea, 735, 730

Campderia, 307

CamplosperM E, 35?

Canaria, 736

Canarina, 736

Canela, 478

Canephora, 488

Canephora, 488

Canonantlus, 718

Canterbury bells, 757

Canthium, 562, 563

Canthium, 506, 507. 562. 564, 560 )

Cantua, 71

Capnophyllum, 337

Capnophyllum, 347

CAPIIIFOLIACE.E, 435

Caprifolium, 444-44!

Caprosma, 634, 635

Caquepiria, 198

Carapichea, fin

Caraway, 288, 289
Cardionema, 90

Careum, 288

Carica, 11

Caricee, 43

Carissa, 562

Carota, 351

Carphalea, 520

Carphalea, 486

Carrot, 353-35?

Carrot, Candy, 316

Carrot, Common, 354-359

Carum, 288, 289

Carum, 284. 310. 322

Carvi, 288

Cascarilla, 474.478, 479

Cassaudra, 830

Cassidocarpus, 269

Cassiope, 829

Cassupa, 492

Cassytha, 176

Catcliweed, 658

Calepha, 257

Catesbæa, $5[0,5]\rfloor$

Catesbar, 517. 569

CAUCALINE.E, 360

Caucalis, 360

Caucalis, 264. 347. 352, 353, $35-4.361,362$

Cedrela, 196

Celeriac, 277

Celery, 277-279

Celosia, 91

Cenolophium, 313

Centella, 254, 25.

Centrantlus, 67

Cerhelide. E, 604

Cephælis, 604.608

Cepharis, 488. 585. 591. 608, 609

CePhala:thex, 60?

Cephalanthus, 610

Cephalanthus, 467-468

Cephalaria, 684-686;

Cephalaria, 684. 688

Cephaleis, 604

Cephalina, 187

Cephalostigma, 735

Ceratopetahm, 202

Ceratopetalum, 202

Ceramia, 806, 8177

Ceratosanthes, 39

Ceratostema, 863

Cerdia, 93

Cerefolium, $36-1-366$

Cereus, 164-171

Cereus, Creeping, 168

Cereus, Niglit-flowering, 168

Cereus, 163. 170, 171

Cerionanthus, 684, 685

Ceriscus, 494. 500, 501

Cervaria, 333

Cervicaria, 750. 755

Cervicina, 742

Cestrum, 486. 599

Cevallia, 697

Charophyllum, 365-368

Chorophyllum, 291. 362-365. 368,369

Chamecerasus, 446. 449, 450 Chamaledon, 850, 851.

Chamæsciadium, 289

Chamdedaphne, $5+3$

Chanderoba, 3

Chapeliera, 503

Charantia, 35

Chasalia, 603

Chate, 27

Cliay, or Che, 529, 5.t

Chayota, 37

Chayote, 37

Checsemrcunet, 65.
Chenocarpes, 619

Chervil, 364, 365

Chervil, Garden, 365

Chervil, Great, 369

Chervil, Siveet, 369

Chervil, Wild, 360

Chimaphila, 865

Chimazt, 865

Chimarrhis, 513

Chiococea, 568, 569

Chiococca, 520. 569

Chicoinda, 555

Chione, 554

Choco, 37

Chlorophytum, 611

Chloranthus, 134

CHLORANTHE $\mathbb{E}, 433$

Chomelia, 56 ?

Chomelin, 553

Chona, 817, 818

Chondrocarpus, 248.253

Chondrosea, 213-217

Cliristimia, 485

Chrysosplenium, 227

Chu-Lan, 434

Cianitis, 234

Cicely, 365-368

Cicuta, 275, 276

Cicuta, 283. 285, 286. 306. 313. 337. 377

Cicutaria, 275, 276. 304. 364

Cieca, 48

Ciliaria, 212, 213

Cinchona, 473-179

Cinchona, 468. 479-483. 486 . 488. 511. 632

CINCIYONACE.E, 166

Cinchone王, 472

Citrullus, 10

Cladothamnus, 865, 866

Claytonia, 8082

Claytomia, 76-80

Cleavers, 658

Clermontea, 698

Clethra, 811, 842

Cliffortia, 637

Cnidium, 313, 314

Cnidium, 313. 315. 317-319. 333. 369

Cobra, 416

Coccocypselum, 508, 509

Coccocijssilum, 485-508

Coccocypsilum, 484. 509. 538.

Collia, 202

Codia, 201

CODIEA, 20:2

Codoniam, 432

Codonopsis, 736

Collosperma, 381

Coelospermum, 558

Coffe, 57!

Coffea, 579.584

Coffea, 4411. 567. 569. 576. 578, 579. 603

COFFEACE $56^{\circ}$

Cofiee-tree, 579.584

Coftce-tree, Common, 5†9.581 COFFEE $\pi, 562$

Colladonia, 375

Colladonia, 598

Colobanthus, 83

Colocynth, 28

Colocynth, False, 41

Colocynthis, 28

Colambaria, $6 !) 1$

Condalia, 508, 503

Condaminea, 511, 519

Contlylocarpus, 346

Conioselinum, 32

Coniun, 376,37

Conium, 291. 305. 314. 33\%.

341.347 .360 .378

Conopodium, 290, 201

Conotrichia, 485

Conyza, 532

Cordiera, 543

Cordierese, 543

Coriander, 382

CORIANDREæ, 381

Coriandrum, 382

Coriandrum, 275. 306. 377. 381,382

Corion, 381

Cormigonus, 514

Corn-Salad, 668

COR NE $\approx, 398$

Cornelian Cherry, 400

Cornidia, 234

Cornus, 398-401

Cornus, 442

Corrigiola, 86

Corrigiola, 89

Cortia, 337

Cosmelia, 784

Cosmia, 78

Cosmibuena, 479

Cosnibuena, 478

Cotyledon, 109-111

Cotyledon, 99. 108, 109. 111 . 113. 214. 219

Coussaria, 576

Coutarea, 472

Covelia, 619

Cowbane, 276

Cow-berry, 856

Cow-parsnip, 34I-34t

Cow-parsley, Smooth, 36-

Cranberry, Common, 858

Cranberry, American, 858

Crantzia, 255

Crassouvia, $109^{\prime}$

Crassula, 99-103

Crassula, 80.98-108. 118, 119

CRASSULACE.A, 97

Crassulea, 97

Crassule, 98

Crethamus, 321

Creodus, 434

Critamus, 285

Crithmum, 321 
INDEX TO THE THIRD VOLUME.

Diodia, 624-626

Diodia, 485. 612. 615. 620. 623. 621i, 627

Diototheca, 681

Diplecosia, 838

Diplospora, 565

Diposis, 262

DIPSACE E, 681

Dipsacus, 682-684

Diptera, 206

Dipterygia, 263

Discopleura, 283

Disemma, 56

Disodea, 560

Distylis, 726

Ditoca, 95

Dog-branble, 178

Dog's-poison, 306

Dogwood, 398-401

Dogberry-tree, 399

Donatia, 231

Dondia, 265

Dondisia, 559

Dondisia, 265

Dorema, 328

Dortmanna, 715

Dracophyllum, 785

Dracophyllum, 785

Drepanoplylluni, 285, 295

Dringi, 29

Drummondia, 228

Drusa, 261

Dufresnia, 667

Duthamelia, 489. 540-542

Dunalia, 536

Duroia, 495

Dwarf elder, 436

Dysoda, 633

E.

Earth-nut, 289-291

Earth-chestnut, 290, 291

Ecbalium, 36

Echeveria, 113

Echeveria, 70, 71

Echinocuctus, 161.163.

Echinocactus, 157. I61

Echinophora, 371

Echinophora, 353. 360. 373

Ectasis, 826, 827

Elæoselinum, 360

ELAOSELINEA, 359

Elaterium, 34

Elaterium, 36

Elatine, 768

Elder, 436-438

Elytranthe, 425-428

Endressia, 315

Enkianthus, 833, 834

Enymonospermun, 378

Epacris, 781-783

Epacris, 778. 781. 783-785

EPACRIDE 7,773

EPACNIEA, 781

Epigæa, 841

Epiphyllum, 170, 171

Epithinia, 56:

Eremia, 828

Erica, $790-800$

Erica, 800-828. 833.

ERICEA, 790

ERICACEE, 780

Erigenia, 256

Erinean, 750

Eriocalia, 263

Eriodesmia, 827, 828

Eriogynia, 220

Eriosynaphic, 329
Erithalis, 5.57

Erithalis, 543. 554

Erithodes, 725

Ernodea, 633

Ernodea, 514. 634

Eropheron, 206

Eryngium, 266-274

Eryngium, 263

Eryngo, 266-274

Erythrodaumm, 547,548

Erythropalum, 29

Escallonia, 192-195

ESCALLONIE $E, 192$

Eubasis, 433

Eulophus, 381

Eumachia, 566

Euosma, 539

Eusmia, 539

Eurylepis, 807-809

Eurystegia, 809, 810

Euryloma, 816, 817

Eurothia, 608

EUSPERMACOCEN, 611

Euthales, 726

Evea, 606

Evosma, 510. 539

Evosmia, 538, 539

Exocantha, 371, 372

Exostema, 480

Exostemma, 480-483

Eyselia, 647

F,

Falcaria, 285

Famarea, 578

Faramea, 578

Fareiria, 473

Fedia, 671

Fedia, 666-671. 680

Female Cornel, 399

Fennel, 306, 307

Fennel, Giant, 325-328

Fernelia, 509

Fernelia, 48

Ferula, 325-328

Goat's Fennel, 373, 374 332. 334. 330

Ferulago, 325

Ferularia, 3:5

Fevillcea, 39

Feuillea, 3

Fever-wort, 443, 444

Fevillea, 3

Ficoidea, 153

FICOIDE $\mathrm{E}, 125$

Field Madder, 637

Fig Marigold, 125-15]

Finocchio, 306

Fischera, 257, 85]

Floerkea, 769.77

Flowk Wort, 248

Fœniculum, 306, 307

Fonieulun, 336

Fool's Parsley, 306

Forgesia, $19 \overline{5}$

Forstera, 722

Fothergilla, 397

Fothergilee. 397

Fouquiera, 70

Fouquiera, 71

FOUQUIERACEA, 70

Fragosa, 259

Fragosa, 260, 26

Franciscea, 107

Francoa, 204

Francoacea, 203

Fralichia, 450. 576

Fuchsia, 542

\begin{tabular}{|l|}
\multicolumn{1}{|c|}{ G. } \\
Gaiadendron., 431, 432 \\
Gaillonia, 632 \\
GALACINA, 203 \\
Galax, 204 \\
Galbanophora, 336 \\
Galbanum, 348 \\
Galea, 637 \\
Galium, 647-661 \\
Galium, 637-640. 645, 646.
\end{tabular}

Galium, 631,662
661,

GaJopina, 635

Galvania, 599

Gambier, 469, 470

Gambir, 460,470

Gardenia, 496-499

Gardenia, 494, 495. 499-504. 506. 511.542 .562 .564

GaRDENIACEA, 487

GARDENIE $A, 488$

Gastonia, 388

Gastonia, 387

Gater Tree, 399

Gaultheria, 839-841.

Gunltheria, 84I

Gaya, 320

Gaylussacia, 858-860

Geissois, 203

Genipa, 495

Genipa, 505. 542

Genipella, 542

Geophila, 608, 609

Geryonia, 206

Gerontogea, 529-531

Geunsia, 79

Gilibertia, 387

Gingidium, 353, 354

Ginginsia, 83

Ginseng, 384

Glacliohus, 715

Glinus, 154

Glinus, 153, 154

Globulea, 105, 106

Glossoma, 401

Glyceria, 218

Gohoria, 287

Gomare, 99

Gonozia, 547

Gonotheca, 532

Gout Weed, 288

Gonzalea, 537,538

Gonzalagunia, 537

GOODENIE F, 73

Goodenia, 723-726

Goodenia, 726. 729-731

GOODENOYIE, 722

Gooseberry, 177-185

Gooseberries, 179-185

Goose-grass, 658-660

Gooseshare, 658

Gosling-weed, 658

Gourds, 40.42

Gourd, 4, 5

Gourd, Bottle, 4

Gourd, Trumpet, 4

Gourgourde, 4

Gourgourdette, 41

Gourd, Cheese, 40

Gourd, Orange, 11

Grahamia, 75

Grammanthes, 100

Grammatocarpus, 6:

Grammosciadium, 370

Granadilla, 5I-53. 55

Gronovia, 43

Grossularia, 177

GROSSULARIE $A, 177$

Ground-nut, 291

Grulhamannia, 611

Grumilea, 577

Grumilia, 577

Grunilea, 577

Guelder-rose, 443

Gilettarda, 550-553

Guettarda, 538. 553, 554. 586

Guettardaces, 544

GuetTardex, 547

Guilleminea, 96

Gurn-ammoniac, 328, 329

Gum-galbanum, 348

Gymnocarpon, 87

Gymnocarpos, 87

Gymnocarpum, 87

Gymnocarpas, 87

Gymnopleura, 60)

Gynocthodes, 558

Gynopachys, 492

Giynopera, 200

Gytonanthus, 666

Gypsocallis, 800-804

II.

Hacquetia, 265

Hacquetia, 263

IIrenkea, 80. 432

Hensclera, 380

IIagea. 90, 91.93

IIalesia, 550

HAMANELEF, 396

HAMAMEL]DE $\approx$, 395

Hamamelis, 396

Hamamelis, 397

Hamelia, 540-542

Hamelia, 451, 489

HAMELIE.S, 538

Hamiltonia, 554, 555

Hamiltonia, 555

Ifare's-ear, 296-301. 635

Hariota, 176

Hart-wort, 346

Hasselquistia, 345

Hawk-nut, 290

Heath, 790-800

Heath, Cantabrian, 833

Hedera, 39I-395

Hedera, 385, 386. 390

Hedge-parsley, 361, 362

Hedgehog-thistle, 161-163

Hedyosmum, 434

HEDYOTE $\pi, 524$

HEDYOTIDE $\&, 511$

Hed yotis, 524-527

Hedyotis, 516, 517. 524. 527-

536. 538. 618. 621. 663

Heinsia, 503

Ilelleborus, 266

Helosciadium, 281-283

Helospora, 504

Henesotria, 670

IJemlock, $\mathbf{3 4 7}$

II emlock, Water, 276

Heracleum, 34l-34t

Heracleum, 243. 340,341 . 345 346

Herb Gerard, 288 
J.

Janipaba, 495

Jackia, 604

Jaracatio, 4:

Jasione, 733,734

Jasione, 266

Javilla, 3

Johrenia, 345

Jasminum, 496

Jasmine, Cape, 496

Jatamangsi, or Jatamansi, $66^{7}$

Jolifia, 3i, 40

Juncaria, 93

Jupiter's beard, 124

Jupiter's Eye, 124

Juvanee, 285

K.

Kadna, 533

Kalanchoe, 108

Kalmia, 850

Kalosanthes, 107

Karpaton, 453

Kentranthus, 672

Kingstonia, 211

Kinkina, 474. 482

Klaprothia, 66

Knautia, ti86-688

Krautia, 688, 1839

Krawel, 95

Kunotgrass, 88

Knoxia, 628,629

Knoxia, 532, 535. 568. 612. 623. 633

Kohantia, 532

Kolbia, 43

Krubera, $31 \%$

Kundmannia, 307

Kutchubæa, 492

Kyrtanthus, 493

L.

Labrador Tea, 851

Lady's bed-straw, 655

Lagenaria, 4

Lagecia, 370

Lagecia, 2838

Lahaya, $91-93$

Lamb's lettuce, 667-67

Lampra, 25fi

Laniprotis, 810-812

Landia, 491

Laretia, 26]

Larochea, 106. 108

Laserpitium, $350 \cdot 352$

Laserpitium, 313-315. 317 . 320-324. 327. 335. 341. 348. 352. 354. 360. 374,

Laserwort, $350-352$

Lasianthus, 548.555

Lasionema, 479

Lasiastoma, 547

Laugcria, 551, 552554

Lauristine, 439 .

Lauristinus, 434

Lawsonia, 520

Lecananthus, 472

Lechenaultia, 727

Lecockia, 375

Ledeburia, 293

Lecontea, $\mathbf{5 6 1}$

Ledun, 85

Ledum, 851

Legouzia, 743. 768, 769
Leiospermum, 200

Leiotulus, 340

Leiophyllum, 851

Lemia, 73

Lentaga, 438. 440

Lepeastegeres, 427

Lepicephalus, 684-686

Leptarrhena, 226

Leptasea, 212, 213

Leptocaulis, 283, 284

Leptodermis, 55.5

Leptrina, 82,83

Lepuropetalum, 231

Lessonia, 274

Leucolera, 258

Leucopogon, 777. 780

Lencothoe, $831,83^{\circ}$

Levenhookia, 722

Levisticum, 321

Lewisia, 77,78

Leycesteria, 451

Libanotis, 311.313

Libanotis, 316

Lichtensteinia, 301

Lichtensteinia, 423

Lightfootia, 734, 735

Lightfootia, 514. 744

Ligularia, 208

Lignsticnm, 317, 318

Ligusticunu, 279. 284, 285. 288. 304, 306, 307. 312-

315, 319-321, 325. 327. 330. 333. 335, 351. 369. 378-380

Limnia, 81, 82

Ling, 828

Ling-heatber, 828

Ligustrum, 520

Linnæa, 45

Linum, 536

Lipostuma, 663

Lissanthe, 776

Listeria, 528

Lithophila, 94

Litosanthes, 557

Loasa, 62-65

Laasa, 62 65

LOASE $\mathbb{E}, 6$

Labaria, 210). 224, 225

Lobelia, 704-715

Lobelia, 698-704. 715-719. 728. 735.742

LOBELIACEA, 697

Loeflingia, 46, 97

Loeffingia, 90. 9 :

Loiseleurin, 850, 851.

Lomatium, 327

Lonicera, $444-451$

Lonicera, 424. 4.44. 451. 488. 568

LONICEREE, 443

Laasa, $6 \overline{2}$

Lophandra, 810

Lophosciadium, 352

LORANTHACE E, 401

Loranthee, 4(9)

Laranthidece, 40

Loranthus, 4199. 430,431

Lorantluss, 404. $406,409-432$. 450

Lovage, 317-319

Lovage, Consmon, 32

Loxanthera, 430

Lucinza, 487,488

Luculia, 480

Lucya, 536

Luffa, 28, 29

Lussacia, 85!

Lychniscabiasa, 686

Lycizm, 633
Lygistum, 484. 538

Lygodysodea, 560

Lygad ysodea, 561

Lygad lysadeacea, 560

Lyonia, 83i, 831

Lysinema, 783

Lysipomia, 716,717

Lysipomia, 726

II.

Machaonia, 63

Macrocnemum, 512

Mecrocnemum, 478.487 .489

492. 501. 511.513

Madder, 642. 647

lladder, Dyers', 643, 644

Madder, Indian, 529, 530 . 642

Magydaris, 375

Malabaila, 340

Malanea, 553

Malanea, 483. 553, 554

Ialesherbia, 60

IALESHERBIACE, E, 60

Maleslerbia, 60.

Male cornel, 400

Mammillaria 157. 160

Nanettia, 483.485

Manettia, 490

Mapouria, 588

Maralia, 387

Marathrum, 309

Margaris, 569

Marianthemum, 750

Marlea, 396

Marquisia, 565

Iaschalanthe, 540

Mlasterwort, Great, 335

Masterwort, 265, 266. 335, 336

lasterwort, Wild, 288

Mastixia, 40$]$

Matthiola, 551

Marchartia, 281

May-apple, 53

Meadow-saxifrage, 308311

Medium, 750, 751

Meerburgia, 94

Megasea, 206

Meludora, 833

Melanopsidium, 542. 560

Melanoselinum, 352

Melanosilinum, 318

Melichrus, 775,776

Mela, 5

Melon, 5-15.27

Melon, Water, 28

Melons, 5.15

Melons, Maltese,

Melons, Persian, 6,7

Melons, Cantaluup, 5, 6

Nelocactus, 160,161

Melon thistle, 160,161

Melopepo, 40

Melnthria, 37

Memecylum, $8+1$

Ienestoria, 504

Mentzelia, 65,66

Mentzelia, (;1

Menziesia, 850.

Menziesia, $\mathbf{3 : 3 3}$

Mephitidin, 548,549

Merciera, 772

Mercurialis, 254

Merida, 73

Meridiana, $73-75$

Tesembryanthenum, 125.15

Netabolos, 536, 537

Men, 320

Meum, 320

Мечm, 281, 282. 289. 336, 307 $315,316.320 .336$

Me ynea, 550

Michauxia, 750

Micranthes, 217

Microcodon, 737

Micropetalum, 208

Micropleura, 256

Milk-Parsley, 322

Milkwort, 759

Miltus, 154

Mindium rhazes, 750

Minnartia, 96

Minuartica, 96

Misodendron, 408,400

Mistletoe, 402-409

Mistletoe, Common, 403

Mitcliella, 518

Mitella, 227, 228

Mitella, 228

Titracarpum, 630, 631

Mitrophora, 671

Mniarum, 95

Modecca, 58, 59

Nollia, 91-93

Molopospermum, 368

Momordica, 35-37

Momordice, 29. 34.39. 42

Monanthes, 124

Moneses, 865

Monopsis, 717

Nonotoca, 780

Monotoca, 781

Monotropa, 866

Monotropa, 866

Monotrope.

Montia, 82

Mloor-Heath, 800-80.

Moquinia, 423

Morelia, 543

Norinda, $544-547$

Marinda, 488560.600

MIORINDE.F, 544

Norina, 681, 682

MORINEA, 681

Moschatell, 384

Woschatellina, 383, 384

Nouffeta, 666

MULINE王, 260

Mulinum, 261

Mulinum, 261-263

Munjith, 612

Muricia, 42

Murncuja, 56

Muricuja, 56-58

Muscaria, 218, 219, 222, 223 
Padavara, 546

Pæderia, 561, 562

Pcederia, 483. 48.

P.EDERIE. $x, 560$

Palicourea, 598-603

Palicourea, 591

Palicurea, 586. 599

Palimbia, 329, 330

Panax, 384-386

Panax, 265. 389

Panke, 204

Papaw tree, 44-45

Papaya, 44

Papayce, 43

PAPAYACE E, 43

Papilla, 677

Papularia, 72

Parustranthus, 716

Paratropia, 395

Paronychia, 88-90

Paronychia, 87. 88-93

PARONYCIIIEE, 84

Paropsia, 46

Paropsief, 46

Parsley, 279-280

Parsley, Macedonian, 316

Parsnip, 338-340

Parsnip, Garden, 338340

Paschanthus 58

Passion-flower, 46-55

Passiflura, 46-5

Passifora, 56-58

PASSIFLOR EE, 45

PASSIFLORE VERE, 46

Pastinaca, 338-340

Pastinaca, 323, 324. 327. 336. 338.345. 354

Patabea, 609

Patabea, 488

Patima, 343

Patrinia, 666

Patrinia, 667

Pautsauvia, 390

Pavate, $\mathbf{5 7 4}$

Pavetta, 574-570

Pavetta, 562. 571, 572. 599. 634

Peach, African, 487

Pearl-berry, 569

Pecheya, 576

Pecten veneris, 363

Pectophytum, 260

Peganum, 155

Penarvalli, 4

Penny-wort, 248-255

Pentachondra, 781

Pentacæna, 90

Pentacrypta, 276

Pentagonion, 768

Pentaphragma, 731

Penthorum, 125

Peplis, 530

Pepa, 40

Pepper Saxifrage, 319

Pereskia, 175, 170

Periclymenum, 444-140

Perlebia, 375

Pernettya, 836, 837

Perojoa, 779

Peruvian bark, Yellow, 474477

Peruvian bark, Red, 478

Peruvian bark, Pale, 474

Petagnia, 263, 264

Petesia, 507, 508

Petesia, 484. 515. 520. 527. 560

Petitia, 314

Petola, 29

Petromarula, 749

Petroselinum, 279, 280
Petroselinum, 310

Petunga, 509, 510

PEucedane

Peucedanum, 330.335

Peuredanum, 281. 286. 289. 290. 313. 319. 320. 325 330. 335. 340. 344

Phacospernia, 79

Phalerocarpus, 841.

Phallaria, 559

Pharnaceum 83. 92

Phellandrium, 262. 304. 320

Pluemeranthus, 76

Phosanthus, 538

Phthirusa, 421

Phu, 676

Phu, 679

Phyllachine, 72

Phyllactis, 672, 673

Phyllarthus, 170

Phyllis, 635

Phyllis, 635

Phyllodoce, 832, 833

Physocalycium, 109

Physospermum, 379, 380

Physospermum, 378

Phyteuma, 746-749

. $749,750.763$

Phyteumoides, 521

Picnocomon, 684. 695

Pieris, 832

Pig-nut, 290

Pimpinella, 281-284. 288. 320

Pimpinella, 291-294

Pimpernel, 291-294

Pinknea, 480

Pinckneya, 480

Piringa, 498

Piriqueta, 70

Pistorinia, 111

Pithuranthos, 307

Pitonia, 481

Placoma, 634

Platanocephalus, 610

Platycodon, 737

Platylophus, 200

Platymerium, 664

Platyspermum, 353, 354

Plectritis, 671

Plectronia, 564

Plectronia, 385

Plenckia, 154

Pleurospermum, 378

Poaya, 615. 617

Poaya do praya, 615

Plocama, 634

Podagraria, 286, 287

Podopetalum, 315

Poiretia, 535

Polia, 90

Pollichia, 94

Pollichie $x, 94$

Polycarpæa, 90

PolycarpeE, 90

Polycarpon, 93

Polycarpan, 231

Polygonifolia, 86

Polyosma, 401

Polyozus, 577

Polyphragrnon, 543

Polypremum, 536. 67

Polipremum, 667

Polystemon, 203

Polyscias, 388

Polytænia, 345

Pomangium, 524

Pomatium, 504

Pomax, 662

Pompion, 40

Ponceletia, 78
Poppya, 35

Porophyllum, 21

Porphyreon, 213

Portlandia, 513

Portlandia, 472, 482.514

Portulaca, 73-75

Portuluca, 75-78 80. 154

Portulacaria, 80

PORTULACACE $\approx$, 7$]$

Pusoqueria, 493 503

Pasaria, 493

Potima, 578

Pouchetia, 506

Pozoa, 262, 263

Pozoa, 263

Prangos, 374, 375

Pratia, 699, 700

Prick wood, 399

Prismatocarpus, 743, 744

Prismatocarpus, 768, 769

Prianitis, 285

Prionotes, 783, 781

Proustia, 263

Psathura, 555

Psathyra, 555

Psatura, $\mathbf{5 5}$

Psiguria, 42

Psilobium, 664

Psittacanthus, 415-418

Psychotria, 584-598

Psychotria, 546. 554. 557.559.

583 , 584. 599-603. 608,

Psychotriacea, 562

Psychotrophum, 592. 594. 608

Psydrax, 564

Psyllocarpus, 629, 630

Psyllocarpus, 567

Pterocephalus, 688, 689

Pteronarathrum, 374

Pterophylla, 201

Pterospora, 860

Ptychotis, 28

Ptychodea, 520, 521

Purgosia, 103-105

Pumilea, 68

Pumpkin, 40

Purslane, 73-75

Purslane, Common, 73

Purslane-tree, 80

Putoria, 634

PUTORIEA, 633

Pyrola, 863, 864

Pyrola, 865

Pyrole,e, 863

Pyrostria, 556

Pyrostria, 55.

Pyxidanthera, 231

Q

Queria, 96

Queria, 88

QUERIACEA, 96

Quino, or Quina, $174-479$. 482

Quinquina, $474-477.481,482$.

Quintinia, 195

R.

Rachicallis, $\mathbf{5 3 5}, 536$

Radiana, 73

Rampion, 746-750. 765

Rampion, Small, 765

Rampion, Garden, 765

Randia, 499-503

Rundia, 495. 510,511.56.

Repunculus, 746, 747-765

Rannnculum, 746

Rapuntia, 750

Rapuntium, 706. 711. 717. 746

Raroumowslia, 40

Reaumuria, 155

REAUAURIACE A, 155

Relbum, 640

Remijia, 478, 479

Retiniphyllum, 557

RuIPSAL10E王, 176

Rhipsalis, 176, 177

Rhodora, 848

RHODOREA, 842

Rhododendron, 843-848

Rhododendion, 848

Rhodiala, 111, 122

Ribes, 177-191

Ribesiea, 177

Richardia, 627, 628

Richardsonia, 627, 628

Richea, 785

Rigocarpus, 5

River-wood, 513

Robertsonia, 206, 207

Rocama, 72

Rochea, 106, 107

Rochea, 107, 108

Roella, 745, 746

Illo, 734. 738, 742,744. 772

Roioc, 544, 545

Rolofa, 154

Rollandia, 698

Ronabea, $\mathbf{5 8 1}$

Rondeletia, 514-517

Rondeletia, 491, 492.501.506, $507.517-521.560$

RoNDELETIEA, 51

Rose-bay, 843

Rose-root, 114

Rothmannia, 498, 502

Roucelu, 750. 761

Rubeola, 638, 639. 641, 642

Rubia, 642 647

Rubia, 96. 627. 638, 639, 611

RUBIACE $\approx, 453$

Rubiaides, 662, 663

Rudgea, 584

Rudgea, 583 
Sherardia, 634, 6.59

Shepherd's-needle, 363

Sicelium, 508, 509

Sickingia, $t ; i ; 4$

Sicyoides, 33

Sicyos, 33, 34

Sicyos, 36, 37. 261

Siderodendron, 565

Sideraryloades, 565

Siebera, 257

Silaus, 314

Siler, 347,346

Siler, 3311 347.35

SILERINE.E, 347

Simira, 588, 58!

Sipanea, 520-521

Sipanea, 521

Siphocampylus, 700-704

Sisarum, 2ft4

Siser, 338

Sison, 286

Sison, 256. 264. 276. 280. 282$29.4 .286-2013.294,295.330$ 338. 377381

Sium, $294-296$

Sium, 277. 280-282. 284, 285.

289-291. 304. 307.308.310, 311.319. 330. 338

Skirret, 294-296

Smallage, 277

Smeathmanisia, 46

SMYRNex, 370

Smyrnium, 380

Smyrnium, 276. 286. 315.327. 380

Snake-gourd, 38, 3!

Snake-root, $521-523$

Suow-ball Tree, $44^{3}$

Snow-berry, 568, 569. 841.

Solandra, $25 \overline{5}$

Solera, 31, 493

Soranthus, 307, 308

Sorv-fennel, 330

Sowa, 337

Spaltanzania, 514

Spananthe, 262

Spananthe, 262

Spatularia, 2117, 208

Specularia, 7683,769

Specularia, 717

Speculum veneris, 768

Sphenotoma, 785

Spermacoce, (i19-623

Spermacoce, 611-618.624-633 636

SPERMACOCE辰, 609

Spermadictyon, 551-555

Spermatura, 369

Sphallerucarpus, 368

Spielmannia, 281

Spikenard, 666;, 667

Spikenard, American, 388

Spica Nardi, bitiz

Spignel, 316.320

Spirca, 20

Spiradiclis, 524

Spirostylis, 430

Spondylium, 341-34t

Spotted-leaved Laurel, 433

Sprengelia, 784, 785

Spurred Valerian, 672

Squash, 40

Staclia, 631,632

St. 1)abcoc"s Ifeath, 833

Stauraspermum, 630
STELLATA, 6:37

Stemanthera, 77

Stenoccelium, 347

Stchostcmum, 553

Stenustomum, 553

Stephanium, $(602$

Stereaxylon, 192-195

Stevensia, 472

Stigmanthus, 560

Stigmatanthus, 560

Stilbe, 610

Stipularia, 66i-1

Stipulicida, !13

Stone-crop, 114-122

Stone-parsley, 286. 312, 313

Straopha, 434

Strap-wort, 80

Strawberry-tree, 834, 835

Strempelia, 579

Struthanthus, 409-415

Strumpfia, 560

Strumplia, 560

Sturmia, 553

St, Peters'-wort, 45l-452

STYLIDE.E, 619

Stylidium, (619-622

Stylidium, 390

Stylis, 396

Stylocerina, 540

Stylocoryna, 494

Stylocoryna, 506

Styphelia, 774-77.5

Styphelia, 775.778. 780, 781

STYPHELIE. .77

Succisa, 684-686, 690692.695

SUCCULENTE, 97

Sulphur-wort, 330-335

Suteria, for

Sweet-cicely, 369

Symphyandra, 771, 772

Symuphoria, 451, 152

Symphoricarpa, 451

Syniphoricarpos, 451, 452

Symphoricarpos, 432. 448

SYMPIIYGYYEI, 203

Sympieza, 805

Syringodea, 818-820

Symphyoloma, 341

\section{T.}

Tacsonia, 57

Tacsonia, 5 -

Tafalla, 434, 435

Talinum, 76,77

Tulinum, 75, 76. 78-80. 154

Tangaraca, 541

Tapogomea, 604-606. 608

Tarenna, 507

Teazle, 682 684

Teazle, Fuller's, 682, 683

Teazle, Wilk, fi82

Tclephiastrum, 75

TElnPhie:, 85

Telephium, 85, 86

Telephium, 110

Telfairia, :39

Tellima, 228

Tenoria, 501.341

Tepesia, 538

Terebrusia, 552

Terra Japonica, 46 ?

Tertrea, 56 il

Tessicra, 632
Tetilla, 204

Tetragunia, 151, 152

Tetragonia, 79

Tetragonocarpus, 151

Tetramerium, $\mathbf{5 7 8 , 5 7 9}$

Tetter-berry, 32

Thapsit, 349

Thapsia, 315. 350, 351, 353. $360.374,375$

THAPSIE 310

Thaspium, 315

Thaspium, $27 \mathrm{j}$

Thibaudia, 860-869

Thibandia, 859. 862, 863

Throat-wort, Great, 757

Throat-wort, 769

Thunbergia, 498

Thymelae 6,633

Thysselinnm, 322. 332, 333.

Tiarella, 228, 229

Tiarella, 229, 230

Tiedemannix, 337

Tillæa, 98

Tillea, 99. 118.125

Timonius, 554

Tinus, 438, 439

Tucoyena, 492, 493

Tocoyena, 501

Tontanea, 5099

Torch-thistle, 164-171

TORDYLINEE, 345

Tordylioides, 346

Tordylopsis, 346

Tordylium, 345, 396

Tordylium, 310.345 .347 .361 , 362

Toricellia, 388

Torilis, 361,362

Torilis, 361.365

Tournefortia, 636

Trachelium, 769

Trachelium, 744. 750. 755. $756.77^{2}$

Trachymene, 257

Trachymene, 256,257

Trachypleurum, 296

Trachysperman, 284.291

Tragium, 292-294

Tragoselinum, 288. 292

Trepocarpus, 318, 349

Trianthema, 52

Trianthema, 87. 153

Tricalycia, 543

Trichera, 687. 689

Trichlis, 93

Trichocladus, 397

Triclosanthes, 38, 39

Trichosunthes, 3-37

Tridactylites, 225,226

Trigonophyllum, 214

Trilophus, 396

Trinia, 281

Trinia, 275

Triodon, 626, 627

Trosteum, 443

Triosteum, 5.39

Triplinerviun, 218

Triplostegia, 680

Tristerix, 118

Trochiscanthes, 315

Trochocarpa, 781

Trochocarpa, 776

Tula, 524

Tuna, 171-173

Tupa, 700

Turgenia, 361

Turgosin, 103

Turia, 30

Turk's-cap, 160

Turnera, $67-70$

Turnera, 70

TURNERACE $\mathrm{E}, 66$

U.

Ueriana, 493

Ullucus, 80

Ulospermum, 3ł7

Umbellata, 235

UMBELLJFER \&, 235

Umbilicus, 111,112

Uncaria, 469-47

Uncaria, 468

Uraspermum, 369, 370

Urophyltum, 540)

Urceolarix, $54^{\circ}$

Uva-ursi, 835

I.

$V_{\text {ACCINIE }} 851$

Vaccinium, 851-857

Vaccinium, 833. 841. 857, 858

Vahlia, 23!

Vaillantia, 662

Vaillantia, Gisf

I'alantia, 616. 656-659. 661, 662

Valentiana, 453

Valerian, 672. 680

Valerian, Garden, 676

Valerian, Officinal, 679,680

Valeriana, 672-680

Valeriana, 6ij6-672. 680

VALERIANE.E, 665

Valerianella, 667-67

Valerianella, 635, 666

V anguiera, 5 4!)-550

Vangueria, 549

Vareca, 5!)

Vauanthus, 106

Tavanga $\mathbf{5 4 9}$

Vegetable marrow, 4

Ientenatio, 720,775

Velæa, $\mathbf{3 6}$ :

Velleia, 726-7:27

Velleia, 726

Venus's comb, 363

Venus's looking-glass, 768 , 769

Terea, 108

Vereia, 108

Verulamia, 570

Peslingia, 153

Viburnum, 438-443

T'iburnaru, 233, 234. 400

Vicatia, 377

Virecta, 521

Virecta, 520, 521

Vireya, 848

I'iscoides, 593

Viscum, 402.408

Yiscum, 408, 40 ?

I'isnaga, 287

Titicella, 204 


\section{GARDENER'S AND BOTANIST'S DICTIONARY.}

Order CIII. CUCURBITA'CEE (plants agreeing with Cucúrbita in important characters). Juss. gen, p. 393. D. C. fl. fr. 3. p. 688. Aug. St. Hil. in mem. mus. 9. p. 190-221. Ser, in mem soc. hist. nat. gen. vol, 3. p. 1. D. C. prod. 3. p. 297. Lindl, introd. nat. syst. p. 19?.

Flowers hermaphrodite, monoecious or dioecious (f. 1. b.c. f. 3. b. c.), axillary. Calyx gamosepalous (f. 3. a. b.), 5-toothed, sometimes obsolete. Corolla 5-petalled (f. 2. $a$. f. 1. c. f. 3. c.), but usually only 5 -parted, distinct from the calyx, and sometimes somewhat continuous with it, rising from the margin of the torus, sometimes fringed, constantly yellow, white, or red, very cellular, with strongly marked, reticulated veins. Stamens 5 , either distinct, or joined in 3 parcels, and sometimes all together; filaments rarely pilose ; anthers 2-celled, very long, sinuons, rarely ovate and short. Style rarely almost wanting, crowned by $3-5$ 2-lobed stigmas, which are thick and velvety, but rarely fringed. Ovarium 1-celled, with 3 parietal placentas. Fruit fleshy, more or less succulent, crowned by the scar formed by the calyx, 1-celled (f. 3. e. f. 2. b.), with 3 parictal placentas, which are indicated on the outside by nerves. Umbilical funicle tumid towards the seeds. Seeds frequently obovate, flat, fixed to the parietes of the fruit, enveloped in an arillus, which is either juicy, or dry and membranous; testa coriaceous, often thick at the margins; hylum oblique at the top of the seed. Embryo straight, flat, without albumen. Cotyledons foliaceous, palmately nerved; radicle basilar, directed towards the hylum.Roots annual or perennial, fibrous or tuberous. Stems herbaceous, climbing by means of tendrils. Leaves palmate, or with palmate ribs, succulent, covered with numerous asperities. Tendrils solitary, lateral, divided or undivided. Flowers solitary, panicled, or in fascicles. Bracteas usually wanting. Branches rising between the leaves and tendrils.

This ordcr is nearly related to Passiflorce, to which they are so closety allied, as hardly to be distinguishable, except in their monopetalous corolla, sinuous stamens, unisexual flowers, and exalbuminous seeds, the habit of both being nearly the same. There is an affinity between the order and Campanulacece in the VOL. 111. perigynous insertion of the stamens, the inferior ovarium, the single style with several stigmas, the quinary division of the flower, connected with the ternary division of the fruit, and some aralogy in the nature of the floral envelopes. The small tribe Nhandiròbece consists of plants having the habit of Cucurbitàcce, but some resemblance in their fruit to that of Lccythidece, which, as is well known, border close upon MIyrtàcea; but beyond this resemblance of the fruit, which appears altogether to be a structure of analogy rather than that of affinity, there is nothing to confirm the approachment. Cucurbitàcece is one of the most useful orders in the vegetable kingdom, conprehending the melon, the cucumber, the choco, and the various species of gourd and pumpkin, all useful as food for man. A bitter laxative quality perhaps pervades all these, which in the colocynth is so concentrated as to become an active purgative principle. The colocynth of the shops is prepared from the pulp of Cúcumus colocýnthus; it is of so drastic and irritating a nature, as to be classed by Orfila among his poisons; but, according to Thunberg, this gourd is rendered perfectly mild at the Cape of Good Hope, by being properly pickled, Ainslie 1. p. 85 . The bitter resinous matter in which the actire principles of colocynth are supposed to exist, is called by chemists colocynthine. A waxy substance is secreted by the fruit of Bcnincisa ceriffera. It is produced in most abundance at the time of its ripening. Delisle descrip. The leaf of Feuillea cordifolia, is asserted by M. Drapiez to be a powerful antidote against vegetable poisons. Edinh. phil. journ. 4. p. 221. The fruit of Trichosanthes palmàta, pounded small, and intimately blended with warm cocoa-nut oil, is considered a valuable application in India for cleansing and healing the offensive sores which sometimes take place in the inside of the ears. It is also supposed to be a useful remedy poured up the nostrils in cases of ozæma. Ainslic 2. p. 85. The root of Bryònir possesses powerful purgative properties, but is said to be capable of becoming wholesome food, if properly cooked. The perennial roots of all the order appear to contain similar bitter drastic virtues, especially that of Momórdica elaterrium or Squirting 
Cucumber. An extremely active poisonous principle, called elatine, has also been found in the placentas of the fruit of this plant. It exists in such extremely small quantity, that Dr. Chutterbuck only obtained 6 grains from 40 fruit. Edinb. phil. journ. 3. p. 307. An ingenious explanation of the cause of the singular ejection of the seeds of this plant will be found in Dutrochet's Nourelles Recherches sur l'Exosmosc. The root of Bryònia rostràta is prescribed in India internally in electuary in cascs of piles. It is also used as a demulcent, in the form of powder. That of Bryònia cordifòlia is considered cooling, and to possess virtues in complaints requiring expectorants. Ainslie 2. p. 21. The root of Bryonia epiga'a was once supposed to be the famous colomba-root, to which it approaches very nearly in quality. The tender shoots and leaves of Bryònia scàbra are aperient, having been previously roasted. Ainslie 2. p. 212. The seeds of all the species are sweet and oily, and capable of forming very readily an emulsion. Those of Ampclosicyos scándens are as large as chestnuts, and said to be as good as almonds, luaving a very agrecable flavour. When pressed they yield an abundance of oil, equal to that of the finest olives. De Candolle remarks that the seeds of this family never participate in the property of the pulp that surrounds them.

\section{Synopsis of the Genera. \\ Trire I.}

Nhandro' веE. Tendrils axillary, in the place of peduncles. Floners dioecious.

1 Feuíltea. Calyx of the male flowers 5-cleft. Petals 5, joined at the base. Stamens 5 , inserted with the petals, sometimes 10 , but 5 of them are sterile. Calyx of the female flowers 5-cleft. Petals 5, distinct. Styles 3 ; stigmas broad, bifid. Fruit globose, fleshy.

2 Zanònia. Male flowers. Calyx 3-lobed (f. 1. a.). Petals 5 , joincd into a 5 -parted rotate, spreading corolla (f. 1. b. c.). Stamens 5 , joined at the base; anthers 1 -celled. Female flowers. Calyx with a long turbinate tube, and a 5 -lobed limb. Corolla as in the male flowers. Styles 3, spreading, bifid at the apex. Fruit long, turbinate, fleshy ; seeds winged (f. 1. d. e.).

\section{Tribe II.}

Cucurbítes. Tendrils lateral, stipular. Floners hermaphrodite, dioccious, or monoccious.

3 Lagena'nia. Calyx campanulate, with subulate or broadish segments ; corolla white; petals obovate. Stamens 5, triadelphous. Stignas 3, thick, 2-lobed. Fruit 3-5-celled. Flowers dioecious.

4 Cu'cumis. Calyx tubularly-campanulate, with subulate segments. Petals almost distinct. Stamens 5 , in 3 parcels. Stigmas 3, thick, bipartite. Fruit 3-6-celled. Flowers monoecious or hermaphrodite, yellow.

5 Lu'rfa. Male flowers panicled; tube of calyx hemispherical. Petals distinct. Stamens 5, free; anthers very sinuous. Female flowers solitary; tube of calyx clavate. Stigmas reniform. Fruit ovate, 3-celled. Flowers yellow.

6 Beninca'sa. Flowers polygamous, monoecious, solitary; calycine segments with undulated, toothed margins. Petals obovate, spreading, curled. Stamens in 3 parcels; anthers irregular, with distant circumvolutions. Stigmas very thick. Flowers yellow.

7 Erythropallum. Flowers monoecious. Limb of calyx obsoletely 5 -toothed. Petals 5 , bicallous at base inside. Stamens 5 , rising from the edge of the tube. Style short. Fruit clavate, 1-celled, 3-valved, 1 -seeded.

8 'Tu'ria. Flowers monoecious. Male ones umbellate. Calyx 5-parted. Corolla 5 -petalled. Stamens 5 , in 3 parcels ; anthers irregularly undulated. Stamens barren in the female flowers. Stigmas 3, 2-lobed. Fruit cylindrical, villous, warted.

9 BRyònis. Flowers̉ monoecious or dioccious; petals almost distinet. Male flowers. Calyx 5-toothed. Stamens in 3 parcels. Anthers flexuous. Female flowers. Style trifid. Fruit ovate or globose, smooth. Tendrils usually simple, seldom bifid.

10 Sícxos. Flowers monoecious. Male flowers. Calyx 5-toothed. Corolla 5-parted. Filaments 3. Female flower. Style trifid ; stigmas thickish, trifid. Fruit I-seeded from abortion, ustally beset with spines. Peduncles many-flowered.

11 Elate'rum. Flowers monoccious; male ones racemose or corymbosc. Calyx with inconspicuous teeth. Corolla hardly gamopetalous. Filaments and anthers joined. Female flowers solitary. Calyx echinated at the base, with the neck filiform. Style crowned by a capitate stigma. Capsule coriaccous, reniform, echinated, 1-celled, 2-3-vaived, many-sceded, bursting elastically. Flowers yellow or white.

12 Monórdica. Flowers monoccious; peduncles filiform, unibracteate. Male flowers. Calyx 5-cleft, with a very short tube. Corolla 5 -parted. Stamens in 3 parcels; anthers connected. Female flowers with 3 sterile filaments. Style trifid. Ovarium 3-celled. Fruit generally muricated, bursting elastically when mature.

13 Neurospérma. Flowers monoecious. Male flowers. Calyx and corolla 5-parted. Stamens 5, diadelphous, having 2 glands alternating with the bundles. Female flowers. Calyx and corolla parted. Ovarium beset with 8 scries of warts. Style trifid, girded by 3 glands at the base; stigmas 2 -lobed. Fruit fleshy, 3-celled, but when mature 1-celled, ż-9-seeded.

14. SE'chum. Flowers monoecions, yellow. Calyx 5-toothed, with 10 foveole. Corolla joined with the calyx. Stamens 4-5, monadelphous. Style thick; stigma capitate, 3-5-cleft. Fruit obcordate, 1 -seeded.

15 Melóturia. Flowers monoecious. Calyx 5-toothed. Corolla campanulate; petals ciliated or toothed, ncver fringed. Filaments 5 , in 3 parcels. Style 1 ; stigmas 3 , fringed. Fruit 3-celled, many-seeded.

16 Trichosánthes. Flowers monoecious, white. Male flowers. Calyx subclavate, 5-parted, appendiculate. Corolla 5-parted, ciliated(f. 2. a.). Filaments 3. Anthers joined. Female flowers. Calyx 5-toothed. Corolla 5-parted, laciniately ciliated (f. 2. a.). Style trifid (f. 2. d.). Stigmas oblong, subulate. Fruit oblong (f. 2. b.), 1 or 3-9-celled.

17 Amperosícros. Flowers dioecious. Male flowers. Calyx turbinate, 5-cleft (f. 3. a.); segments denticulated (f. 3. b.). 
Corolla 5-petalled (f. 3. c.); petals oblong, fringed (f. 3. d.). Stamens 5 , in 3 parcels. Female flowers. Limb of calyx 5 -toothed. Corolla as in the male. Stigma capitate, 3-lobed, ex Bojer. Fruit fleshy, 2-3 feet long, and 8 inches thick, elongated, furrowed (f. 3.e.). Flowers purple.

18 Cucúrbita. Flowers monoecious, yellow. Petals joined together, and with the calyx. Male flowers. Calyx campanulate. Stamens 5 , in 3 bundles and syngencsious. Anthers curved at both ends. Female flowers. Calyx clavate, narrowed towards the apex. Stigmas 3, thickish, 2-lobed. Fruit 3..5celled.

19 Involtcra'ria. Flowers monoecions. Male ones umbellate, sessile; bracteas reniform, fringe-toothed, involucrumformed. Tube of calyx obconical ; sepals linear, acute. Anthers joined together. Female flowers solitary, on long peduncles.

20 Murícia. Flowers monoecious. Calyx 5-parted, inclosed in a large undivided, 1-flowered sheath. Corolla campanulate, 5 -petalled. Stamens 5 , in 3 bundles, and syngenesious. Style 1 ; stigmas 3 , sagittate, horizontal. Berry muricated, 1 celled, many-seedcd.

21 Angv'ria. Flowers monoecious. Male flowers. Calyx campanulate, 5-toothed. Corolla joined with the calyx, ventricose, red, 5-parted. Stamens 2. Female flowers with a calyx and corolla as in the males, and 2 sterile stamens. Style semibifid ; stigmas bifid. Fruit 2-4-celled, many-seeded, somewhat tetragonal.

\section{† Genera not sufficiently known.}

22 Zu'ccs. Flowers solitary, axillary. Bractea large, concave, involving a large, coloured, 5 -sepalled calyx, and girded by 5 scales at the base. Stamens 5 .

23 Alla'sia. Flowers hermaphrodite. Calyx gamosepalous, girded by a short involucrum. Segments 5 , acutish, pilose. Corolla 4-petalleà; petals pilose. Stamens 4, but more probably 8 , joined by twos; anthers 2-lobed. Style subulate, crowned by an acute stigma. Berry fleshy, large, oblong, obtuse, 1-celled, many-seeded.

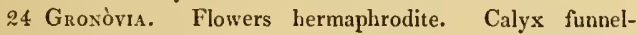
shaped, 5-parted ; scales 5, linear, petal-formed, pellucid, alternate with the calycine segments. Stamens 5 , free, alternating with the scales. Style crowned by a capitate stigma. Berry dry, nearly globose, 1-seeded, crowned by the dry permanent calyx.

25 Kóldia. Flowers dioecious? Calyx gamosepalous, with a crenulated cdge. Corolla gamopetalous, 5-lobed; lobes with glandular edges. Nectary? 5-leaved; lobes with feathery ciliated edges. Stamens 5, monadelphous; filaments short; anthers long, conniving.

\section{Tribe I.}

NHANDIROBEE (plants agreeing with Nhandiròba in important characters). St. Hil. ann. mus. 9. p. 215. Turp. dict. sc. nat. atlas. icon. 2. D. C. prod. S. p. 297. Tendrils axillary, peduncular. Flowers dioecious.

I. FEUI'LLEA (in honour of Louis Feuillée, a traveller in Chili ; author of Journal des Observations physiques, mathéma- tiques, et botaniques, faites dans l'Amerique Meridionale, \&c. 3 vols, 4to. Paris, vols. 1 and 2. 1714. and 3. 1725.). Lin. gen. 1118. Juss. gen. 397. Lam. ill. t. 815 . D. C. prod. 3. p. 297.-Fcvíllea, Pers, syst. regl. ed. 15. p. 929.-Nhandiròba, Plum. gen. 20. t. 27.

Lin. syst. Dioc̀cia, Pentándria. Flowers dioecious, Male flowers. Calyx 5-cleft beyond the middle. Petals 5, rather joined at the base, inserted in the throat of the calyx, and alternating with the sepals. Stamens 5 , inserted with the petals, and alternating with them, sometimes 10 , but when this is the case, 5 of which are always sterile. (ex Juss.) Anthers 2-celled, didymous. Female flowers. Tube of calyx adnate to the ovarium; limb 5-cleft. Petals 5, distinct, or joined at the base, oblong. Lamellæ or abortive stamens 5 , sometimes alternating with the petals (ex Juss.). Styles 3. Stigmas broad, bluntly bifid. Fruit globose, fleshy, 3-celled, indehiscent, with solid bark and a large fleshy trigonal central axis; cells many ovulate. Ovula erect from the centre. Seeds compressed, oval. Embryo straight. Cotyledons flat, rather fleshy.-Intratropical American, rather frutescent climbing herbs. Leaves alternate, petiolate, exstipulate, palmately nerved, cordate, glabrous. Tendrils axillary, spirally twisted, in place of peduncles. Peduncles axillary, 1 or many-flowered. Flowers small. Seeds oily, bitter. This genus has a habit emulating Passiftora. Fruit in the form of that of Couroupita, a genus of Lecythidec.

1 F. puncta'ta (Poir. dict. 4. p. 418.) leaves 3-lobed or ternate, beset with glandular dots on both surfaces along the nerves, but more especially beneath; lobes of leaves lanceolate, rather cut. 4. $\mathrm{S}$. Native of St. Domingo. Trichosánthes punctàta, Lin. spec. 1432. amœn. acad. 3. p. 423. exclusive of the country. Fevíllea trilobàta, Reich. syst. 4. p. 253.

Dotted-leaved Feuillea. PI. cl.

2 F. TRILOBA'TA (Lin. spec. ed. 1. p. 1014.) leaves rather glandular on both surfaces, 3-parted or trifid; lower lobes obtuse, upper ones acute. $\quad 4 . \curvearrowleft$. S. Native of Brazil. F. scándens $\beta$, Lin. spec. ed. 2. p. 1457. F. hederàcea, Poir. dict. 4. p. 419. Chandiròba or Nhandiròba, Margr. bras. 46. lower figure.

Three-lobed-leaved Feuillea. Pl. cl.

3 F. condifòlı (Poir. dict. 4. p. 418.) leaves glandless, cordate, acuminated, or somewhat 3-lobed, and rather serrated. 4. $\cap$. S. Native of the West Indies. Plum. ed Burm. t. 209. F. scándens $a$, Lin. spec. ed. 2. p. 1457. F. hederàcea, 'Turp. in dict. sc. nat. with a figure. The leaves of this species are said to be a powerful antidote against vegetable poisons.

Hcart-leaved Feuillea. Pl. cl.

4. F. J AvílLA (H. B. et Kunth, nov. gen. amer. 2. p. 124.) leaves glandless, roundish, sinuately cordate, acuminated. 4 . . S. Native of New Granada, in woods near Turbaco, where it is called Javilla by the inhabitants. Seeds with subalate margins, hence this species agrees with the genus Zanonia.

Javilla Feuillea. Pl. cl.

Cult. A light rich soil will suit the species of Fcuillea; and cuttings of them will root readily under a hand-glass, in heat. They are well fitted for training up rafters in stoves.

II. ZANO'NIA (named in memory of Giacomo Zanoni, formerly Prefect of the Botanic Garden at Bologna, author of Istoria Botanica, Bol. 1675. fol. edited in Latin by Monti, 174\%. He died 1682, aged 67.). Lin. gen. 1117. Juss. gen. 397. Lam. ill. t. 816 . Blum. bijdr. p. 937. D. C. prod. 3. p. 298. but not of Plum.

Lin. syst. Dioècia, Monadélphia. Flowers dioecious. Male. Calyx 3-iobed (f. 1. a.). Petals 5, joined into a 5-parted rotate corolla (f. 1. b. c.). Stamens 5 (f. 1. c.); filaments flat, connected at the base ; anthers 1-celled, adnate to the tops of the filaments. Female. Tube of calyx long, turbinate; limb 5B 2 
lobed. Corolla as in the male. Styles 3, spreading, bifid at the apex. Fruit long, turbinate, fleshy, having a eircular line at the apex, formed from the restige of the calyx, opening by 3 valves at the top, 8 -celled; the rind solid: central placenta Heshy, large, trigonal; cells biovulate. Seeds ovate, margined by a foliaccous wing (f. 1.e. d.), exalbuminous. Embryo inverted.-Smooth, climbing, Indian plants. Leaves alternate, petiolate, exstipulate, ovate-lanceolate, cordate at the base, acuminated, quite entire. Tendrils axillary. Peduncles also axillary and racemose. This genus, from the general form of the fruit, is like the genus Couritàri, but from the characters it is allied to Fenillea. The interior fabric of the seeds is unknown.

Sect. I. Zaxònia (see genus for derivation). Blum. l. c. Cells of fruit ' 2 -seeded. Fruit elongated, somewhat tetragonal.

I Z. I'xica (Lin. spec.

1157.) leaves elliptic, acute, rather cordate at the base; racemes axillary. $h . \neg . S$. Native of Mlabar, Ceylon, and Java. Blum. l. c. Penarválli, Rheed. mal. 8. t. 47 and 48 .

Indian Zanonia. Pl. cl.

Sect. II. Alsomitra

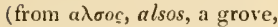
and $\mu т \rho \alpha$, mitra, a girdle ; the plants grow in groves and entwine round the trees by means of ring-like tendrils.). Blum. l. c. Cells of ovarium many-seeded. Fruit hemispherical, truncate at the apex, or elongated.

2 Z. macroca'ky (Blum. l. c.) leaves ovate-elliptie, acutish, rounded at the base; racemes axillary. $h \cdot \cup$. S. Native of Java, on the mountains of Parang.

Large-fruited Zanonia. Pl. el.

3 Z. SARCoPHY'LLA (Wall. pl. rar. asiat. 2. p. 28. t. 133.) leaves trifoliate; leaflets thick, fleshy, ovate, obtuse, quite entire. $\eta \cup$. S. Native of the East Indies, in sterile exposed situations along the banks of the Irawaddi. The plant climbs by means of simple and slender tendrils. The leaves are of a pale glaucous colour. Flowers small, very numerous, forming ample, greenisl, nodding panicles. The differcnt sexes are produced in distinct plants.

Fleshy-leared Zanonia. Shrub el.

4. Z. cLavígera (Wall. l. c.) smooth ; leaves trifoliate; leaflets oblong, acuminated, quite entire; fruit large, clavate. $h \cdot \cup . S$. Native of Silhet, where it is ealled in the Bengalee language Kishnobera. The fruit is 3 inches long, and as thick as a thumb. Club-beasing Zanonia. Shrub cl.

5 Z. ANgula'ta (Wall. 1. c.) smooth; stem angular; leaves simple, somewhat hastately lanceolate, cordate at the base; fruit large, clavate. $h \cdot \cup$. S. Native of Silhet. 'The fituit is as long as a finger, and very thick.

Angular-stemmed Zanonia. Shrub cl.

$6 \%$. cissioides (Wall. l. c.) stem filiform, angular; leaves pedate, with 5 or 7 leaflets; leaflets lanceolate, acuminated at both ends, coarsely and cuspidately serrated; petioles and peduncles pilose. h. ᄂ. S. Native of Nipaul.

Cissus-like Zanonia. Shrub cl.

7 Z. LA'XA (Wall. 1. c. p. 29.) stem filiform, much branched, bifariously pilose; leaves trifoliate; leaflets acuminated, serrated, intermediate one lanceolate, lateral ones half cordate; petioles and peduneles pilose. $r_{\varsigma} \cdot \cup$. S. Native of Silhet.
Loose Zanonia. Shrub el.

8 Z. Hетеrospé RMA (Wall. l. c.) stem filiform, very slender; leaves pedate, with 5 leaflets; leaflets lanceolate, acuminated, serrated; eapsule clavate, angular, borne on very long capillaceous peduncles; seeds scabrous from scales. $\zeta . u$. S. Native of Mlount Taong Dong, near Ava. Capsule chartaceous, trigonal, 8 lines long, with a 3 -toothed mouth. The scales on the seeds are elegantly imbricated, and girded by a narrow margin.

I'ariable-seeded Zanonia. Shrub cl.

Cult. See Feuillea, p. 3. for the culture and propagation of the species.

\section{Tribe II.}

CUCURBI'TEE (plants agreeing with Cucúrbita in important characters). D. C. prod. 3. p. 299. Tendrils lateral, stipular. Flowers hermaphrodite, dioecious, or monoecious.

11I. LAGENA'RIA (from lagtna, a bottle; form of fruit of some of the species). Ser. diss. 1. c. D. C. prod. 3. p. 299.Cucúrbita species of authors.

Lin. syst. Dioècia, Polydélphia. Calyx campanulate; segments subulate or broadish, shorter than the tube. Corolla white; petals obovate, rising from beneath the margin of the calyx. Male. Stamens 5, in 3 parcels, the fifth one free. Female. Style almost wanting; stigmas 3, thick, 2-lobed, granular. Fruit 3-5? celled. Seeds obovate, compressed, 2-lobed at the apex, with tumid margins. Flowers monoecious.

1 L. vulga'ris (Ser. mss. ex D. C. prod. 3. p. 299.) plant musky scented, clothed with soft pubescence; stems elimbing; tendrils 3-4-cleft; leaves eordate, nearly entire, biglandular at the base, pilose, rather glaucescent ; flowers monoecious, stellate, spreading much, in fascicles; connectives of anther's beset with oblong-ovate, acute papillæ; fruit pubescent, but when mature quite smooth; flesh white, edible. $\odot \cdot \smile$. H. Native witlin the tropics. Cucúrbita lagenària, Lin. spec. 1434. Sieb. hort. 1. t. 69.-Rumph. amb. 5. t. 144.-Mor. hist. 2. p. 23. seet. 57. t. 5. f. 1, 2, 3. Flowers large, white. Fruit shaped like a bottle; when ripe of a pale yellow colour, some near 6 feet long, with a roundish bottom and a neck; the rind becoming hard, and being dried, contains water : it is then of a pale bay colour. The bottle-gourd is called Charrah by the Arabians. The poor people eat it, boiled with vinegar, or fill the shells with rice and meat, tlus making a kind of pudding of it. It grows in all parts of Egypt and Arabia, wherever the mountains are covered with rich soil. In Jamaica and many other places within the tropies, the shells are generally used for holding water or palm wine, and serve as bottles. The pulp of the fruit is often employed in resolutive poultices; it is bitter and purgative, and may be used instead of colocynth.

Iar. $\alpha$, goúrda (Ser. mss. ex D. C. l. c) fruit unequally biventricose.-Moris, list. sect. 1. t. 5. f. 1. Dodon, pempt. 668 . f. 1. Bottle gourd. Gourde des jélerins.

lar. $\beta$, gougoúrda (Ser. l. c.) fruit ventricose at the base, neck oblong.-Rminph. amb. 5. p. 398. t. 144. Braam. icon. chin. t. 17. Commonly called Gougourde.

Var. $\gamma$, depréssa (Ser. l. c.) fruit globose, depressed.

Iar. $\delta$, turbinàta (Ser. l. c.) fruit somewhat campanulately pear-shaped. Mor. hist. scet. 1. t. 5. f. 2. Dodon. pempt. t. 669 . f. 1 .

Var. $\varepsilon$, clavita (Ser. mss.) fruit obovate-oblong, club-shaped. -Moris. hist. sect. 1. t. 5. f. 3. Dodon. pempt. 669. f. 2 . Gourde trompettc, Gourde massue, or Trumpet gourd.

Cummon Bottle Gourd. Fl. Jul. Sept. Clt. 1597. Pl. trail. 2 I. viтta'ta (Ser. l. c.) leaves roundish-cordate, somewhat repand, obsoletely denticulated, rough; peduncles crowded, 1flowered; fruit pear-shaped, striped lengthwise, puberulous. 
$\odot$. H. Native country unknown, but collected in the gardens of India. Bonteng-suri of the Hindoos. Cucúrbita vittata, Blum, bijslr. p. 93:.

Ribbed Gourd. Pl. cl.

3 I. ? II'spida (Ser. l. c.) greyish, pilose; leaves cordate, 5 -angled, acuminated, denticulated, beset with pedicellate glands beneath; stem and petioles denscly hispid; flowers densely clothed with ferruginons hairs. $\odot$. F. Native of Japan and the East Indies. Cucúrbita híspida, Thunb. fl. jap p. 322. and Willd. spec. 4. \%. 608. Naluh of the Indians. Perhaps only a variety of $L$. vulgàris.

\section{Ilispid Gourd. Pl. trailing.}

4. L. ? idolátrica (Ser. l. c.) leaves cordate, cuspidate, obsoletely S-lobed, pubescent, biglandular at the base; lateral lobes very short and cuspidate; fruit pear-shaped. ๔. F. Native of Guinea and the East Indies. Cucúrbita Idolátrica, Willd. spec. 4. p. 607. Blum. bijdr. p. 930. Labu-eyer and Kukuk of the Hindoos. Perhaps only a variety of $L$. vulgàris. In India the fruit of this plant is held in great veneration by the Hindoos, in their religious ceremonies.

Worshipped Gourd. Pl. trailing.

Cult. See Cucúrbita, p. 41. for culture and propagation.

IV. CUCUMIS (said to be from kitvos or Stkvos. Varro says, "Cucumeres dicuntur a curvore, ut curvimeres dicti"). Lij. gen. no. 1479. Juss. gen. p. 395. Gærtn. fruct t. 88 . D. C. prod. 3. p. 299.-Cùcumis and Melo, Tourn. inst. p. 104. Colocínthis, Tourn, inst. p. 107.-Rigocárpus, Neck. elem. bot. no. 386 .

LıN. sYST. Dioècia, Polyadélphia. Calyx tubularly campanulate; segments subulate, hardly the length of the tube. Petals hardly joined together or to the calyx.-Male. Stamens 5 , in 3 parcels.-Femalc. Stigmas 3 , thick, bipartite. Fruit 3-6-celled. Seeds ovate, compressed, not marginate. Flowers monoecious or hermaphrodite, yellow.

1 C. ME' Lo (Lin. spec. 1436.) stem trailing, scabrous, cirrhiferous; leaves roundish, angular, petiolate; male flowers having the tube of the calyx rather ventricose at the base, and rather dilated at the apex; stamens inclosed; anthers shorter than their connectives; the hermaphrodite flowers with the anthers as in the males; stigmas $3-4$, shortly 2 -lobed; fruit ovate or sub-globose, 8-12-furrowed; flesh sugary, yellow, red, or white. $\odot$. F. Native of Asia. Called rhetimou by the Hindoos; Melon, Engl. and Fr.; Mclone, Germ.; Mellone, Ital.

The melon is a tender annual, producing one of the richest fruits brought to the dessert, and has been cultivated in England since 1570 , but the precise time of its introduction is unknown. It was originally brought to this country from Jamaica, and was, till within the last fifty years, called the musk-melon. The fruit, to be grown to perfection, requires the aid of artificial heat and glass throughout every stage of its culture. Its minimum temperature may be estimated at $65^{\circ}$, in which it will germinate and grow; but it requires a heat of from $75^{\circ}$ to $80^{\circ}$ to ripen its fruit, which, in ordinary cases, it does in 4 montlis from the time of sowing the seed.

Varicties.-There are numerous varieties, many of which, especially those raised from seeds brought from Italy and Spain, are not worth cultivating. The best sorts are included under the name of Cantaloups, an appellation bestowed on them from a seat of the Pope near Rome, where this variety is supposcd to have been originally produced. The general character of the Cantaloups is a roundish form, rough, warty, or netted outer rind; neither very large in fruit or leaves. The Romanas, an Italian sort, is next in esteem, are generally oval-shaped, regularly netted; the fruit and leaves middle-sized, and the plants great bcarers. Many varietics of both these sorts, however, that were formerly in estecm, are now lost, degenerated, or supplanted by others of Spanish or Persian origin. The following is a descriptive list of the sorts.

$$
\text { List of Mclons. }
$$

Vur. a, reticulàtus (Ser. in D. C. prod. 8. p. 300.) fruit roundish or oblong, with a grey reticulated rind.-Blackw. herb. t. 329. The following sorts of melons belong to this variety :-

1 Becchrood melon. 'This is an excellent, early, greenish yellow kind, with a netted rind and a greenisli-white flesh, of a middle size.

2 Melon maraicher. The flesh of this sort is very thick and watcry; hardly swcet-scented.

3 Melon de L'onflcur. A late melon, with a thin yellow rind, and pale red sugary flesh. It is of inferior quality but large in size.

4 Mclon des Carmes. A well-flavoured large fruit, with a thick orange rind, and juicy sugary pulp.

5 Mclon de Langeais. A middle-sized, ribbed fruit, with orange-coloured, sugary, sweet-scented flesh.

6 Melon sucrin de Tours. Fruit large, with firm, sugary, orangc-coloured flesh.

7 Sucrin à chair blanche.

8 Sucrin à chassis.

9 Sucrin vert.

10 Sucrin à petits grains.

11 Succada. A late green middle-sized netted melon.

Var. B, Cantalipo (Ser. in D. C. prod. 3. 13. 300.) fruit lar e, with broadly ribbed, and furrowed, warted, thick rind. The following sorts belong to this variety.

1 Early Cantaloup. A deep-furrowed, early, middle-sized kind, with white, deeply-furrou ed, thin skin; and orange-coloured flesh, not very lighly flavourcd. It sets wcll, and is a great bearer.

2 Silcer cantaloup. Cantaloup argenté. A shallow-furrowed, middle-sized fruit, and before it is full grown is mixed with silver and grcen.

3 Large black Holland cantaloup. Cantaloup gros noir de Hollande. A large fruit, with green, furrowed, thin rind: and rcd rather coarse flesh.

4 Hybrid cantuloup. A small good early fruit, with a whitish rind and red pulp.

5 Montagu cantaloup. This is a variety produced from the Italian green-fleshed and the smooth scarlet-fleshed cantaloup. A middle-sized, carly good fruit, but with a thick, yellow, furrowed rind and pale red flesh, which is soft and juicy, and completely melting in the mouth.

6 Netted cantaloup, or Whitc-secded cantaloup. This is a very juicy, highly-flavoured, small fruit, with a thin, netted, yellow rind.

7 Orange cantaloup. A small, round, pale yellow, netted fruit. The flesh, when just fit for cutting, is orange; but when riper it is more red. In respect to flasour, it is excelled by none of the melon tribe, being juicy, sugary, and rich. The plant is a free grower, an early sctter, and a great bearer.

s Black rock cantaloup. A large late melon, with a thick dark green rind, and salmon-coloured flesh. It is juicy, but not very ligh flavourcd.

9 Carbuncled rock cantaloup. Vory like the black rock, as to colour and flavour, but differs in bcing cheese-shaped. There are a small and a large kind of this; the smaller kind is the best.

10 Lcc's rock cantaloup. Rather long tlian round, and more green than black. Much the same in flavour as the preceding.

11 Scarlet-fleshed cantaloup. A middle-sized carly good fruit, with a thick yellow rind and red swcet flesh. It is particularly high flavoured. 
12 Italian green-flcshed. A middle-sized carly good fruit, with a thick yellow rind and green flesh: in flavour both rich and sweet.

13 Lonian green-fleshed cantaloup. A large thin-skinned lemon-coloured and lemon-scented fruit, of excellent flavour, but not a great bearer.

14 Egyptian green-fleshed. A middle-sized early good fruit, with a thin white netted skin and green flesh : in flavour resembling the preceding.

15 Dutch grcen-fleshed. An indifferent sort.

16 Crimea green-fleshed. A useless late fruit, of middling size, with a thin green skin and pale red flesh.

17 Persian green-fleshed. A middle-sized, green, thinskinned sort, with green flesh. Not good.

18 Green-fleshed Masulipatum. A very small and excellent early sort, with green skin and green flesh.

19 Green-fleshed r'alparaiso. Not very good.

20 Red-fleshed I'alparaiso.

21 Dutch rock. A rather large good fruit, with a thick yellow rind, and orange-coloured flesh.

22 Early rock. A good early fruit.

23 Golden roek. A middle-sized fruit, with a thick yellow rind and pale red flesh, of excellent flavour.

24 Scarlct rock.

25 Silver rock. A large late fruit, with a thick yellow rind, and pale red flesh, which is juicy, sweet, and well-flavoured.

26 Netted searlet-fleshed. A good sort.

27 Smooth scarlet-flchlied. A middle-sized fruit, of excellent flavour. The rind is thick, smooth, and yellow, and the flesh orange-coloured.

$28 \mathrm{H}^{\prime}$ indsor scarlet-feshed. A rather large, excellent-flavourcd, late kind, with thick green rind, and salmon-coloured flesh.

29 Lee's Romana. $\Lambda$ middle-sized, longish, shallow-furrowed truit. Rind hard, partly netted, and pale yellow : the flesh full yellow and pretty high flavoured, but not very juicy.

so Large netted Romana. The largest of the romanas, regularly netted all over, and shallow-furrowed, often attaining a large size. Rind hard and pale yellow, the flesh full yellow, but not very juicy : very ligh-flavoured, if eaten sharp ripe.

31 Fair's Romana. A small oval fruit, the rind greenish yellow when ripe, and the flesh a pale yellow, not very juicy; but well-flavoured and agreeable.

82 Early Polignae. An early rich middle-sized fruit, with a thick yellow rind, and pale red flesh. It is in frequent cultivation.

33 Portugal. There are two varieties of this kind, a small and a large sort; they are noted as good bearers and early.

34. Snect Italian. A large orange-coloured sort, of moderate quality.

35 Netted suecado. A middle-sized late green-skinned sort.

36 Small Lerant. A middle-sized sort, with a thick green skin and pale red flesh. Not of good quality.

37 Smooth yellon-fleshed Valparaiso. A middle-sized, late, green, thin-skinned sort; the flesh white, of moderate flavour.

ss brasilian. An inferior niddle-sized sort, with thin green skin and orange-eoloured flesh.

39 Melon d'été d'Odesse. A rather large, later, indifferent fruit, with thin orange skin and white flesl.

40 Melon d'Olor. A very small fruit, witl yellow skin and white Hesh, of good quality.

41 Nelled French melon. A rather large late fruit, with a thick yellow rind and yellow flesh, of bad quality.

42 Nutmeg. A late green, thick-skinned sort, with white t]esh.

43 Quecn Ann's melon, early queen, or quecn's pocket melon. A very small fruit, with ornamental striped thin skin, and white ficsh.
44 Carthagcna. A large high-flavoured fruit, with a thick orange-coloured rind and pale red flesh.

45 Cassabar. A large late fruit, with green thin skin, and white flesh.

46 Cephalonia. A large oblong fruit, with thin yellow skin and green flesh, of tolerable flavour.

47 Choufleur. A large fruit of little use; the skin is thick and yellow, and the flesh pale red.

48 Gahoon. A large late fruit, of little value; with yellow skin and yellow flesh.

49 Gerce, ostrich egg. A middle-sized late fruit, of excellent flavour: the skin as well as the flesh is green. The plant is rather tender.

50 Gros Preseott fond blanc. A large late fruit, with a thick yellow rind, and orange-coloured flesh.

51 Petit Prescott. Fruit depressed, crowned at the top; ribs warted: flesh delicious.

52 Cantaloup natif d'Allemagne. An early fruit, with a greenish-yellow smoothish rind, but not of good quality.

53 Cantaloup boule de Siam. Fruit very much depressed,

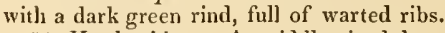

54 Hardy ridge. A middle-sized late fruit, with a thick yellow rind and red flesh, of good flavour.

$A$ list of melons which are hardly known; but none of them are perhaps worth cultication.

1 De Andalousie. 2 Cantaloup à chair verte. 3 Cantaloup à fond noir. 5 Cantaloup Galleux. 6 Chili musk. 7 Crimea. 8 Citron. 9 D'Espagne. 10 Fagos. 11 Fin hatif. 12 Golden cgg. 13 Grand Mogul. 14 Green Spanish oval. 15 Gros Galleux à chair verte. 16 Hardy scarlet-fleshed. 17 Highclerc. 18 D'Hiver. 19 Large Astrachan. 20 Levant. 21 Mclon gris des Carmes. 22 Melon of IIonda. 23 Mclon of Jaffa. 24 Mclon Turc. 25 Madcira. 26 Mendoza. 27 Le Mogul. 28 Du Peron. 29 Pine apple or Melon d'Ananas. 30 Musk melon. 31 Carthagena musk melon. 32 Murray's pine-apple. 33 Noir de Hollande très gros. 34 Turkish melon. 35 V'alentia or winter melon. 36 IIynestay.

lar. $\gamma$, Malténsis (Ser. in D. C. prod. 3. p. 300.) fruit with a smooth thin rind. This variety is divisible into two parts, as Maltese Melons and Persian Melons.

\section{* Maltese melons.}

1 Melon de Malle blanc or Melon de Malte à chair blanche. An early middle-sized ovate-oblong fruit, with white watery sugary flesh.

2 Melon de Malte jaune. Flesh of fruit orange-coloured, sweet-scented.

3 Melon de la Morée ou de Candie, or Melon de Malte d'hiver. This kind is cultivated in various countries bordering on the Mediterranean sea, and particularly in the orange gardens at Hiers, near Toulon, whence its fruit is sent to Paris. The skin is thin; the flesh wlite, firm, sugary, and juicy; not rich, but pleasant. The shape oval, size about a foot long and eight inclies broad; of a dark green colour. This fruit is regularly imported, and may be had in the fruit shops from September to January.

$$
\text { * Persian mclons. }
$$

1 Daree. A good-sized fruit; skin thin and green; flesh white, high-flavoured. A late fruit.

2 Dampsha melon. An exeellent, late, rather large fruit, of nearly a cylindrical form, and netted; rind thin and yellow when ripe; flesh green, quite melting, and of excellent flavour. The fruit will keej", if hung up by its stalk, for some time.

3 Large germek. An excellent early green-skinned sort, of considerable size; flesh green. 
4. Small germek. This is much smaller than the last-named sort; the skin is yellow and the flesh green.

5 Goorgab. A middle-sized late fruit, with yellow rind and white fleslı. $\Lambda$ useless sort.

6 Green Hoosainee. A middle-sized late sort, of good quality; rind thin, green ; flesh white.

7 Striped Hoosaince. A very good late sort, with greenishyellow rind, and white flesh.

8 Kasan sugar melon. A good sort.

9 Keiseng. This is said to be one of the best Persian melons; the skin is thin, pale yellow, and red, and the flesh white.

10 Kurehaing. A very good sort, of considerable size; the skin is lemon-coloured, and the flesh white.

11 Melon of Erivan.

12 Melen of Gerger. A middle-sized good fruit, with yellow skin and red flesh.

13 Melon of Nukshevan. This is an excellent late kind; the skin is yellow, and the pulp white.

14. Melon of Nusserabad.

15 Melon of Scen. A middle-sized fruit of indifferent quality. It is a late sort, with yellow rind and green flesh.

16 Green Persian. A fruit of indifferent flavour.

17 Oldaker's Persian. A fruit of considerable size but no merit ; the rind is orange-coloured, and the flesh green.

18 Sir Gore Ouseley's Persian. A large fruit of good quality; the skin is yellow and the flesh white.

19 Sweet melon of Ispahan. This is said to be one of the very best melons. It grows to a large size; the skin is yellow and the flesh green, crisp, sugary, and rich in taste.

20 Talibee melon.

21 Teheran melon.

22 Salonica. A round fruit, with a gold-coloured rind, and white flesh; improves in flavour and richness till it becomes quite soft; consistence of its pulp nearly that of a water melon, and very sweet.

On the degeneracy of the larger varieties of Persian melons.Mr. Knight thinks that it would be strange if every large and excellent variety of melon did not degenerate, under our ordinary modes of culture. For every large and excellent variety of melon, must necessarily have been the production of ligh culture and abundant food; and a continuance of the same measures to it, in its lighly improved state, must be necessary to prevent its receding in successive generations from that state. Abundant food, it is true, is generally, perlaps always, given by the British gardener to his melon plants : but sufficient light, under the most favourable circumstances, can only be obtained during a part of the year, and a sufficient breadth of foliage to enable the melon plant properly to nourish a fruit of large size and rich saccharine quality, so that it may obtain the highest state of growth and perfection which it is capable of acquiring, has rarely, and probably never, been given in any season of the year, by any British gardener. Mr. Knight has cultivated the Sneet Ispahan melon, and found it a very superior variety. He has cultivated this variety generally in brick pits, surrounded by hollow walls, through which warm atmospheric air at all times enters abundantly; putting each plant in a separate large pot, and suffering it to bear one melon only: but the fruit sets sufficiently well in a common hot-bed. The rind of the Ispahan melon, being very soft and thin, the fruit is apt to sustain injury on the lower side; they should be raised above the ground a little by some means while young, so as the air may pass under them. When seeds of the Ispahan melon are only wanted, it is quite time enough to sow in the begimning of A pril, so that the fruit may ripen in August. Very valuable varieties of melons may be obtained, for one generation at least, by cross breeding among the smaller and more hardy varieties of green and white-fleshed melons and the large Persian varieties. It is generally supposed that the offspring of crossbred plants, as of animals, usually present great irregularity and variety of character; but if a male of permanent character and habits, and, of course not cross-bred, be selected, that will completely overrule the disposition to sport irregularly in the crossbred variety; alike in the animal and vegetable world, the permanent habit always controlling and prevailing over the variable. The finest varieties of melon are usually supposed by gardeners to be fruits of as easy culture as the pine-apple, but experience has led us to draw a contrary conclusion. If the leaves of the melon plant be suddenly exposed to the influence of the sun in a bright day, which has succeeded a few cloudy days, for a short time only, they frequently become irreparably injured. If the air of the bed be kept a little too damp, the stems of the plants often canker, and the leaves and stalks sustain injury in the common hot-bed; and, if the air be too dry, the plants, and consequencly the fruit, are injured by the depredations of the red spider.-Loud, gard. mag. vol. 7. pp. 186, 187, 188.

In the cultivation of the melon, Knight observes, " it is a matter of much importance to procure proper seed. Some gardeners are so scrupulous on this point, that they will not sow the seed unless they have seen and tasted the fruit from which they were taken. It is proper, at least, not to trust to seeds which have not been collected by judicious persons. Some make it a rule to preserve always the seeds of those individual specimens which are first ripe, and even to take them from the ripest side of the fruit. A criterion of the goodness and probable fertility is generally sought by throwing them into a vessel containing water; such as sink are considered as good, and likely to prove fertile, and those that float imperfect. It is remarked of seeds brought from the Continent, that they must have more bottom heat, and the young plants less water, than are necessary for seeds ripened in this country, or young plarits sprung from these."

The culture of the melon is an object of emulation among gardeners, and tle fruit of the best sorts have a peculiarly rich flavour, thought by some to bear some resemblance to that of the pinc-apple. " Ripe fruit," Abercrombie observes, " may be had by forcing at any season, but the main crops, raised for the general demand, are seldom cut, at the earliest, before May, and the last succession mostly ceases to yield fruit after October." "To ripen the best largest fine kinds," M'Phail observes, " as great an atmospherical heat, and a bottom heat to its roots also, is required as is sufficient to ripen the pine-apple in this country; but as the melon is produced from an annual plant, the seeds of which must be sown every year, it requires a different mode of culture. Different methods of culture, and various kinds of eartl and of manures liave been recommended and used successfully in rearing of melons. The great thing, after planting, is to gire them plenty of atmospherical heat, and a sufficiency of external air, and water. Those methods which are most simple and the least expensive, and best calculated to assist in making a suitable climate for the melon to grow in and ripen its fruit well, should be preferred."

Soil.-Abercrombie says "The melon will succeed in any unexhausted loam, rich in vegetable rudiments, with a mixture of sand, but not too light. 'The following is a good compost : two-thirds of top-spit earth from a shecp common, adding sharp sand, if the earth contains little or none, till half is sand; onesixtl of vegetable mould; and one-sixth of well-consumed horse-dung. Or, if the earth is not obtained from a pasture, rotted slieep-dung may be substituted for the last. The ingredients should have been incorporated and pulverized by long previous exposure and turning over. The compost slould be dried under shelter before it is used, and warmed in the frame 
for potting." M'Phail says, "Mclons will grow and produce fruit of a good flavour, if they be planted in any kind of earth, not of too light a texture, whether it be taken from a quarter of the kitchen garden or from a corn-ficld, mixed wcll with good rotten dung; but eartb of a loamy nature is the best, because it retains moisture longer than lighter earth. Earth, dug from the surface of a common, where sheep and cattle have lon been pastured, is excellent for the melon. It should be broken well, and lie a few months before it is used, and if it be exposed to a winter's frost it will do it good. This sort of earth, if it be taken from the surface of the common, will require no manure the first year of using. I would here mention that unless the earth which I used for the melon plants was very strong, I made it a practice, when the melon-beds were wholly earthed up, to tread the surface all over, which mahes the earth retain its moisture longer than if it were left loose." Earth for melons, accorling to Nicul, " may be thus composed: one-lialf strong brown luan from a pasture, a quarter light sandy earth, an eighth part vegetable mould of decayed tree leaves, and an eiglith part rotten stable-yard dung. The mould for both cueumbers and melons should be well incorporated, should be exposed to frost, and be frequently turned over to ameliorate." It appears from a passage in Morier's second jouruey into Persia, p. 14.7., that pigeons' dung has from time immemorial been much sought after for manuring melons. Immense pigeon-louses are built on purpose to collect it, and when there is a dearth, as melons produce the earliest return of food, every one is eager to cultivate them, and that kind of manure, being then in great demand, sells very high. During the famine in Samaria, mentioned in $2 \mathrm{~K}$ ings, ch. vi, it is said to have sold for five pieces of silver the cub.

$A$ correspondent in the gard. mag. 2. p. 404. on melon compost, and on the influence of soil on Ilydiangea horténsis, has always used for his melons the compost to which the Dutch so strongly adhere, viz. one-third strong lazel loam, one-third seouring of ditches, and one-third rotten dung, exposing the mixture two years to the influence of the summer and winter, to evaporate what noxious qualities maylurk in the earths: for it is well known, that in proportion to the degree of salt of iron, it will be proportionably sterile. He had often observed the leaves of his melon plants turn yellow, occasionally plants died, for which he could not accuunt; he suspected iron, as it pervaded his district, to be the cause; but as a magnet would not take up any of the compost, lis attention was diverted from that point. Similar results in future seasons again called his attention to it, and he adeled lime, to correet the sulphate of iron, if any; but he lost his whole crop, which he fancied by the application of the lime. As during winter a red oxide filtered from the compost lieap, he again felt certain of the presence of iron. Ile submitted the compost to the test of burning, and having by that means got rid of the superabundant carbon, the magnet immediately detected the iron. He changed his soil, and has never lost since any melon plants. The experiment proves that the old test of the loadstone may be defeated by the presence of other adherent matter; fur though it was inactive over the cold soil, it acted in full force upon the soil when, by roasting, it had discharged its gas. While a profitable experinent resulted on the one hand, a great amuscment occurred on the other, with some greenhouse plants. Ile mised the compost fiesh from the diteh with water, and fond a precipitation of iron. He used the soil and water to IIydicingra horténsis, a cutting from the common piuk variety, and it so altered the pink colour of the flower to purple, as to form a new plant. He applied the same to other plants, in some of which it altered the colour of the flowers, but in others it had no effect.

Estimatc of sorts.-Examine the list. The cantaloups are in the highest estimation for quality and neatness, although not uniformly such great bearers as others in the list.

Time of beginning to force.- " From the time of sowing, ripe fruit may be cut in about fifteen weeks, as an average period; when many short and winter days fall in the course, it may last eighteen weeks; but when the forcing is not commenced until the days are nearly twelve hours long, and continually lengthening, ripe fruit is sometimes cut in ten weeks. The period also depends upon the sort. Little time is gained by beginning excessively early. The early and main crops are commonly originated from the middle of January to the first week of $\mathrm{Fe}$ bruary, the latter or stecession crops at the beginning of Marcli; and late crops, intended to fruit at the end of summer, in the middle of April. MIPhail and Nicol sow in January. "The latter says, "I formerly cut melons for three years successively on the 15th, 12th, and 10th of May, and never sowed before the lust week of January or 1st of February. In 1788, when at Rainham Hall in Norfolk, I sowed melons on the 12th of March, and cut ripe fruit on the 20th of May. The kind was the Early golden cantaloup. This shows how little is to be gained, or rather how much may be lost by early forcing."

Forming the seed-lyed.-The plants may be originated in a cucumber-bed, and this is the general practice ; but $A$ bercrombie prefers a separate bed, built a slight degree higher than for the cucumber at the same scason, and adapted to a one or two-light frame, according to the quantity to be raised." Nicol raises the melon almost exactly in the same manner as he does the cucumber.

Choice of seed.- " Seed under the age of two years is ajt to run too much to vine, and show more male than fimale blossoms; but new seed may be mellowed by being carricd in the pocket a fortuight or more, till the heat of the body has dried and hardened it Seed 20 years old has been known to grow and make fruitful plants, but seed that has been kept 3 or 4 years is quite old enough, and less likely to fail than older." M'Plıail says it is best not to sow melon seed till it be 2 or 3 years old. It cannot be too old if it be sound and grow well. Nieol says, "I have sown melon seeds 20 years old, from which I have raised very healtlıy anil fruitful plants." Kal. p. 396. Miller and Nicol say young melon seeds may be wors in tlie pocket, near the body, for several months previous to sowing, which has the effect of fully maturing them. "If seeds of the last season," Nicol observes, "be sown without taking this precaution, or something similar, the plints will not be fruitful, but will rum much to vine, and show chiefly male blossoms."-Kal. p. 396.

Soning,-Abercrombie says, " Having moulded the bed, and proved the heat, sow in pans 3 inches or pots 4 inches deep, ratlier than in the earth of the bed. Sow a second portion in 5 or 7 days, to provide against failure. Do not at once plunge the pots to the rims."-Pr. gard. p. 10 s.

Trcatment till removed to the fruiting-pil.-_"As soon as the plants appear, give air cautiously, guarding the aperture with matting at night and on frosty or gloomy days. At favcurable opportunities wipe the condensed steam from the glasses. When the seed-leaves are about half an inch broad, prick the plants jnto small pots, 5 inches in dianeter, 3 in each pot, giving a little aired water just to their roots, then plunge the pots into the earth of the hot-bed partially or to the rims, according to the heat. Admit fresh air every day in moderate weather, at the upper end of the lights, raised an inch or two, according to the temperature of the external air, more freely when sunny than cloudy, shutting closer or quite close as the afternoon advances towards the evening, or sooner, if the weather changes cuttingly cold, and cover the glasses every night with mats, and uncover in the morning, as soon as the sum js high enough to reach the 
frames. Give occasionally a very light watering, when the earth appears dry. As the plants advance into the first rough leaves, the first runner-bud in the centre should be stopped, by cutting or pinching the top off, close to the first or second joint, an operation which strengthens the plants, and promotes a lateral issue of fruitful runners. Be careful to support a regular tenor of heat in the bed, by laying first an outward casing of straw-litter round the sides, to defend it from the weather; afterwards, if the heat declines, remove the above casing, and apply a moderate lining of hot dung to one or more of the sides. In matting at night, be careful not to drive the rank steam of the linings into the beds, by letting the ends of the mats hang down."

Fruiting-bed.-Form it as directed for the cucumber-bed, but 6 inches deeper. M'Plıail says, " 4 feet high, and after it has stood about a week, tread it down, and make it level, and set the frames upon it."

Moulding the bed.-Abererombie directs to "mould it by degrees to 8,10 , or 12 inches' depth, first laying the compost in little hills of that thickness, one under each light, with the intervals earthed only 2 or 3 inches for the present, till the general heat is moderated." M'Phail lays in, under each light, a small hill of earth about 1 foot high.

Planting.-When the earth of the hills is warmed by the heat of the bed, and the plants have leaves 2 or 3 inches broad, or have begun to push lateral runners, turn them out of the pots, with the ball of earth entire; set a ball containing one plant in the middle of each hill, inserted clean over the ball; or set at most 2 plants under the centre of a large light. After planting, give a gentle watering over the hills and round the roots, avoiding to wet the shanks of the plants; shut down the glasses close, till the heat and steam arise, then give air moderately. Extend a slight shade over the glasses in the middle part of warm summer days, if the plants shrink or flag their leaves before fully rooted in the hills, which they will be in 2,3 , or 4 days after planting."

Temperature.-" The melon requires a minimum heat of about $65^{\circ}$ from the time of germination till the fructification, and the heat of about $75^{\circ}$ to fruit in." -A Abercombie. M'Phail, as appears from the table in his "Gardener's Remembrancer," kept his melon and cucumber frames at the same temperature; stating, that if any person kept melon or cucumber plants in the same degrees of heat, they will not fail of success, Nicol's medium heat for melons is $70^{\circ}$. The proper temperature must be kept up by repeated linings, at least till the middle of July. After that, sun-heat may suffice to ripen the crop. Till this season the greatest care is necessary not to burn or overheat the plants. M'Phail says, " examine daily with your hand the heat of the bed, pushing your fingers into the dung immediately under the hills of earth in which the plants grow; and if you find the heat likely to be too powerful, pour cold water all round the bottom of the hills of earth, to lower the heat of the bed. Remember this must be daily attended to till the heat of the bed be so cleclined in the middle, that the roots of the plants be in no danger of being hurt by the heat of the dung under them. In case this necessary precaution has been neglected, till the heat immediately under the stems of the plants has become too hot, pour plenty of water $80^{\circ}$ warm round about the sides of the hills in which the plants grow, and among the stems of the plants, which will bring the earth and dung immediately under the plants to the same degree of heat as the water which is poured into it. When the heat in the midale of the bed becomes so cool that there is no fear of its being too great for the roots of the plants, watering that part of the bed to keep the burning heat down of course must cease, and as the roots of the plants extend, earth may be added to the hills. As voL. III. soon as the heat of the bod declines, linings must be applied to it, which will set it into a fresh fermentation, and then the surface upon the bed must be examined occasionally, by pushing the hand into it in different parts, and when a burning heat is felt, pour in some water as before directed. In this way you should persevere, still keeping a strong heat in the linings. Remember that the surface of the bed alt round about the hills should be left uncovercd with earth, and the dung should be loosened occasionally, to let the lieat rise freely to nourish the plants." In July, "melons will do without heat in the linings, but I found by experience that they do best by keeping a heat in the linings all the summer. If a heat be kept on constantly in the linings, and the plants watered sufficiently, they will continue to produce fruit till the middle of October."

Air.-As long as weak steam is perceived to rise from the bed, leave an aperture, even at night, for it to escape; guarding against the influx of cold air by a curtain of matting. Admit fresl air to the plants by tilting the glasses more or less at the most favourable hours in a dry day. After the bed has come to a sweet heat, shut down close at night. As the fruit enlarges, it becomes more necessary to seize every proper opportunity of admitting air; raising the lights from 1 to 4 inches, according to the season, the lieat of the bed, and temperature of the external air, shutting close if that should turn cold, and always timely towards evening. As confirmed summer approaches, admit air still more freely. Nicol says, " air should be freely admitted, though not in such quantity as for the cucumbers, which do not require so high a temperature as melons do. In sunshine, however, the mercury in the thermometer should be kept down, by the admission of air to about $80^{\circ}$ or $75^{\circ}$." M'Phail says, "look into your melon-pits in the morning, and if there is a dew on them, standing like beads round the edges of the young leaves, it is a good sign; but if there is no dew on them, in the form I have described, they are not in a very prosperous condition. The air in the frames is not sweet; they either want water or sprinkling of water, or else the heat of the air in the frames is too great in the night. In hot weather melons are better to have air left at them all night, and in very warm weather to take the glasses entirely off in the evening, and put them on again in the morning: by this means the plants will get refreshment from the dew in the night."

Water.-After the plants are placed on the hills, give opportunely gentle waterings, increasing them as the season and the growth of the plants advance. "Water circumspectly and scantily while the fruit is setting or young in growth, as too much moisture would make it decay. Take a warm morn. ing for watering before the middle of May; in suminer the afternoon or evening. Use soft water warmed to the air of the frame, and let as little as possible fall on the setting or new set young fruit; nor much near the main head of the plants, for fear of rotting that part. Shut down the lights after watering for a short time; and if in the morning part, and a strong sun, spread a mat over, to prevent the sun from injuring the plants by acting on the water lodged on the spray of the leaves. As a strong steam will now arise, remove the mats in an hour or two, and raise the glasses at the top, to give vent to the steam and give air to the plants. As the fruit becomes nearly ripe, Icssen the quantity of water given, barely keeping the plant from flagging, and withhold water when the fruit begins to turn colour." Nicol says, "water once in 4 or 5 days in the afternoon, watering over the foliage. Repeat the waterings oftcner, as the season and the growth of the plants and fruit advance, in order to swell them out the better."-Kalendar, p. 387. M·Phail says, "If the weather is warm and dry, the melons will probably sometimes require water twice a week; if the weather is wet and cloudy, they will not require it so often."-Gard. C 
Rem. p. 300. Kinight, finding that the leaves of melons sustained great injury from the weight of the water falling from the watering-pot, pours the water on the tiles which cover the surface of the bed. See Training.

Earlhing.-Perform this operation as directed for the cucumber, after the heat of the dung has become moderate, earthing up by degrees the intervals betwcen the hills, till the depth of the earth becomes equal. Eight or ten inches' depth of earth M'Pliail states to be enough for the roots of the plants to run in, provicled the bed or fermenting mass beneath be made of leaves of trees, or of dung well prepared; for if the bed under the eartl be in a good state, the roots will grow into it, and draw from thence considerable nourishment to the plants. 'The roots of the melon do not naturally run deep, they extend horizontally not far from the surface, especially in forcing frames, where the moist warm air is more confined than in the open atmosphere.-Gard. Rem. 1. 63. In early forcing, leave unfilled up with earth a space of about 7 or 8 inches wide, against the inside of the frames, immediately adjoining the hot linings. "By this method the heat of the linings do more powerfully warm the air in the frames, than if the earth was made level home to the sides of the boards of the frames to which the linings adjoin. But if melons be not planted earlier than the month of May, this precaution need not be attended to, unless the weather prove uncommonly cold, and but little sunshine."

Training.-As the plants advance into the first rumners, 3 or four joints in length, if no fruit be shown, stop them at the third joint, in order that they may produce fruitful laterals; and as the runners extend, train them over the surface of the bed with neat pegs. Many of these runners, as the plant proceeds, will show embryo fruit at the joints; but a great many barren ones are occasionally produced, and hence it becomes necessary to regulate them. Abercrombie says, "cut out the superabundant, unfruitful, or evidently useless shoots, especially the very weak and most luxuriant, for the middle-sized are the most fertile." Nicol says, " melons should be kept moderately thin of vines, though not so thin as cucumbers (the foliage being smaller), which should never be much lopped at one time, as they are also apt to bleed. All bruised, damped, or decayed lcaves should be carefully picked off as they appear, and the plants should be kept clear from weeds, or any rubbish that nay be conveyed into the frames by wind or otherwise. M'Phail directs to " cut out from the melon-frames all superfluous or decaying shoots. Stop shoots a joint or two before the fruit, and also cut off the ends of the long running shoots immediately before slowing fruit, if there is a leading shoot coming out by the side of it; for you ought to remember always in pruning melons, that a fruit will not swell well except there be a growing shoot before it; and this shoot, which is called a lcader, because it leads or draws the sap from the roots to and past the fruit, should be stopped before a joint, that will, if the plant is in good health, sprout out again. Do not let your plants get too full of leaves, and cut off the oldest and worst leaves first. This ought to be rlone at least once or twice a week, by which method they will be nearly always in a medium state of thinness, and the plants and fruit will derive advantages which they would be deprived of were they suflered to become over-crowled with leaves and shoots, and then a great many cut out at one time. If melons are of a large kind, no more than one or two should be left on a plant to swell off at one time; if smaller three or four fruit may be left."-Gard. liem. 1. 27s. Knight, in an ingenious and philosophical paper on the eulture of the melon, states "that his crops of melons failed, because watering over the foliage, pruning, weeding, \&c. lad removed the leaves, on the extended branclies, from their proper position, and these leaves, being heavy, broas, slender and feeble, on long footstalks, were never able to regain it. In consequence, a large portion of that foliage which preceded or was formed at the same period with the blossoms, and which nature intended to generate sap to feed the fruit, became diseased and sickly, and consequently out of office, before the fruit acquired maturity." To remedy this defect, the plants were placed at greater distances from each other, viz. one plant of the Salonica variety, to each light of 6 feet long by 4 feet wide. The earth was covered with tiles, and the branches trained in all directions, and hooked down over them with pegs. They were thus secured from being disturbed from their first position, the leaves were held erect, and at an equal distance from the glass, and enabled, if slightly moved from their proper position, to regain it. "I, however, still found that the leaves sustained great injury from the weight of the water falling from the watering-pot; and I therefore ordered the water to be poured from a vessel of a proper construction, upon the brick tiles, between the leaves without at all tonching them, and thus managed, I had the pleasure to see that the foliage remained erect and healthy. The fruit also grew with very extraordinary rapidity, ripened in an unusually short time, and acquired a degree of perfection which 1 had never previously seen. As soon as a sufficient quantity of fruit, between 20 and 30 pounds on each plant, is set, I would recommend the further production of foliage to be prevented, by pinching off the lateral shoots as soon as produced, wherever more foliage cannot be exposed to the light. No part of the full grown leaves should ever be destroyed; however distant from the fruit and growing on a distinct branch of the plant, they still contribute to its support ; and hence it arises, that when a plant has as great a number of growing fruit upon part of its branches, as it is capable of feeding, the blossoms upon other branches, which extend in an opposite direction, prove abortive."-Loud. encycl. gard. p. 618.

Setting._." As the fruit bearers come into blossom, you may assist the setting of the fruit, by impregnating some of the female blossoms with the male flowers, as described for the eucumber. 'The melon, however, will also set naturally, and produce fertile seeds, if the time of fructification fall at a season when the glasses can be left almost constantly open."-Abercrombie. Nicol says, " he has proved experimentally, that melons not impregnated will not swell off so fair and handsome as impregnated ones, and, therefore, considers it more necessary to attend to this operation in melons than in cucumbers. Therefore let nature be assisted in this work, considering that she is more under restraint here than if the plants grew in the open air, where the wind, insects, and other casualties, might be helped."-Kalend. p. 384.

Care of fruit.- "As the fruit increases to the size of a walnut, place a flat tile or slate under each to protect it from the damp of the earth; the slab thus interposed will also assist the fruit to ripen, by reflecting the rays of the sun."-Abercrombie. M'Phail says, "The fruit should lie upon dry tiles. When the fruit is young, it is better to have a gentle shade of leaves, but when it is full swelled, it should be entirely exposed to the sun." Nicol advises placing the fruit on bits of slate or glass some time before it begins to ripen, as the flavour might else be tainted, but by no means slate or moss the whole surface of the bed, lest you encourage the red spider. Think on the reflection of the sun upon the slates or tiles, in hot weather particularly, and of his additional force in shining through glass. It is more consonant to the nature of the plants that they be trained on the earth. By mossing the surface, the indolent may find a pretext, as it no doubt, in some measure, lessens the labour of watering. But it is wrong to do so, in so far as it harbours and encourages the breeding of various insects, and as the fruit approaches to maturity, taints it with an unpleasant eflluvia." 
Time of maturation.- "The interval between the setting of the fruit and perfect maturity is generally from 30 to 40 days; but the plants in the same bed, and the vines on the same plant, often sliow some difference in the time of reaching maturity." Abercrombie.

Cutting the frutt.-" Ripe melons are distinguished by their full size; sometimes by turning yellowish, more constantly by imparting an agreeable odour, often by the base of the footstalk, close to the fruit, cracking in a little circle. On these inclications, the fruit slıould be cut before too mellow or dead ripe, that it may eat with a lively sharp flavour. The morning is the time for cutting." Melons, Nicol observes, "if allowed to remain on the plant till they be of a deep yellow colour (which many do) lose much of their flavour. 'They should, therefore, be cut as soon as they hegin to change to a greenisl yellow, or rather, as soon as they begin to smell ripe. They may lie in the frame for a day or two, if not immediately wanted, where they will acquire sufficient colour. But if they are let remain many days in the frame, they will become as insipid as if they had been left too long on the plant."

Sacing sicd.-" The ordinary mode is to request the seels of particularly fine fruits, of approved sorts, to be returned from table. The best way, however, is to pick some of the best ripe fruit, take out the seed, clean it from the pulp, and let it be well dried and hardened, and then put it up in paper."Abercrombie. Nicol says, "wash it very clean, skimming off the light seeds, as those only that sink in water will grow." Kal. p. 396. Great care must be taken that the sorts, from which seeds are saved, are genuine and distinct. When different sorts are planted in the same frame, this cannot be the case.

Sccond crop from the same plants. - "When the fruit of the first crop is off, a second crop may be obtained from the stools, which often proves more productive than the first. If the first crop is taken before the middle of June, the second will come in at a very good time. For this purpose, as soon as the fruit is cut, prune the plant, shorten the vigorous healthy runners at a promising joint. At the same time take off all lecayed leaves, stir the surface of the mould, and renew it partially by 3 inches' depth of fresh compost. Water the plant copiously, shutting down the glasses for the night. Shade in the midlle of lot days, and give but little air until the plants have made new radicles and shoots. Afterwards repeat the course of culture above described, from the stage when the first runners are sent out till the fruit is cut." Nicol says, "When alt the fruit of the first crop are cut, suppose in 3 or 4 weeks, the plants may be pruned for the production of a second crop, equal and perliaps superior to the first. 'They should be cut pretty much in, in order to cause them to push plenty of new vines, which will be very fruitful, observing always to cut at a joint of some promise, and to thin out all decayed or unhealthy vines, dead leaves, \&c. Observe also to cut an inch or two above the joint you expect to push, and then to bruise the end of the stem so lopped with the thumb and finger, which will, in a great measure, prevent it from bleeding. The plants should be shaded from the mid-day sun for a week or ten days, exposing them to his full rays by degrees. Now, also, let the mould in the frame be well watered, in order to put the roots in a state of active vegetation; point over the surface with a small stick, or little wedge, and cover the whole with about 2 inches of fresh mould. This will greatly encourage the plants, and cause them to make new fibres near the surface. At this periou air need not be admitted very freely, especially while the glasses are covered, but rather as it were endeavour to force the plants into new life. After they begin to shoot, water, admit air, prune, train, and otherwise manage the plants as before directed. If the season be fine, they may yield you a third crop by a repetition of the above rules, coming in in september, which miglit be very gratifying. I once had 52 full-sized fruit produced in a 3 -light frame, a second crop, and two dozen on a third off the same plants, the early golden cantaloupe. Of the first crop 26 fruit, two were cut the 10 th of May. 'Thus, a 3-light box produced, in one season 102 full matured melons." M'Phail says "if you intend to have melons as long as there is a sufficiency of sun to ripen them tolerably well, you had best put linings of warm dung to some of your beds. These, if applied in time and kept on, will cast fresh heat into the beds, and, with other necessary assistance, the plants will grow as long as you want them."

Plan of obtaining a second crop of mclons.-- "When the first crop of fruit is nearly gathered, cuttings are taken from the extrcmities of the shoots which show the most fruit; these are cut off close under the second advanced joint, or about the fifth leaf from the top; the two largest leaves at the bottom of the cutting are taken off, and thus prepared, are inserted in 24sized pots, two in each pot, in light rich soil, gently shaken tlown. After being watered, the pots are placed in a 1-liglst frame, on a hot-bed previously prepared, and plunged in the moderately dry soil, with which it is covered. The frame is kept close and shaded for a few days, and in a week the cuttings will have struck root. The old melon-plants, with the soil in which they grew, are now all cleared out of the frames, fresh soil to the depth of 12 inches put in, and the bcds well lined with fresh dung. In 10 days from the time of inserting the cuttings they will be ready to plant out, which is done in the usual way. When the plants have pushed about 14 inches, the end of each slioot is pinched off, to cause tliem to produce fresh runners, and the fruit which showed on the cuttings will swell rapidly, and in 3 weeks after replanting the beds, abundance of fine fruit may be expected. This way of getting a second crop is far more certain than either pruning back the old plants, or planting seedlings; because cuttings grow less luxuriantly, are less liable to casualties, and are much more prolific."-Harrison ex Loud. gard. mag. 2. p. 414.

Cultivation of the Persian varieties of the melon,-T. A. Knight (Hort. reg. no. 6. p. 263.) erected a small forcinghouse for the exclusive culture of this fruit, and grew them by means of fire heat. 'This house consists of a back wall, nearly nine feet ligh, and a front wall nearly 6 feet, inclosing a horizontal space 9 feet wide and 30 feet long. The firc-place is at the east end and very near the front wall; and the flue passes to the other end of the house, within 4 inches of the front wall, and returns back again, leaving a space of 8 inches only between the advancing and returning course of it, and the smoke escapes at the north-east corner of the building. The front flue is composed of bricks laid flat, in order to give a temperate permanem heat, and the returning one with them standing on their edges, the usual way. The space between the flues is filled with fragments of burnt bricks, which absorb mucl water, and generally give out moisture to the air of the house. Air is admitted through apertures in the front wall, which are 4 inches wide and nearly 3 in height, and which are situated level with the top of the flues, and are 18 inches distant from each other. The air escapes through similar apertures near the top of the back wall. These are left open, or partially or wholly closed, as circumstances requirc. Thirty-two pots are placed upon the flues, each being 16 inches wide and 14 inches deep; but they are raised by a piece of stone or brick to prevent their coming in actual contact with the flues. In each of these pots one melon-plant is put, and afterwards trained upon a trellis, placed about 14 inclies distant from the glass, and each plant is permitted to bear but one melon only. 'The height from the ground at which the trellis is placed, is such as can be conc 2 
veniently walked under, to discover the appearance of red spiders or other noxious insects; and by this method two, and even three crops may be obtained in one season. Being so liable to burst, Mr. Kuight raised the points of the fruit higher than the stems, and not one failed to ripen in a perfect state; they were found to ripen very well hanging perpendicularly, but the Ispahan grew very deformed.

Late crop un old hot-beds.-To ripen melons, not earlier than the month of August, M'Phail " generally made beds of dung which had first becn used for linings to the early cucumber and melon-beds. For this purpose, this kind of dung is better than new dung, because it does not heat violently, and for a considerable time keeps its heat. Leaves of trees make very good melon-beds, but they do not produce heat enough alone for linings; but of whatever materials melon-beds be made, the air in the frames among the plants should be kept sweet and strong, otherwise the plants will not grow freely. It may be known whether the air be sweet or whether it be not, by putting the head in under the lights and smelling it. But it frequently happens to be difficult to bring dung-beds into a requisite state of kindliness for these delicate plants, for if the dung by any means get and retain too much water, before its noxious vapours pass off by evaporation, it will stagnate and become sour, and until these pernicious qualities be removed, which requires time and patience, the plants will not grow kindly; and besides this, although corrupted, stinking air hinders the growth of plants of the melon kind, it greatly promotes the health and forwards the breeding of different kinds of insects, which feed upon and otherwise hurt fruits and plants, and esculent vegetables of various kinds."

$A$ method of groning the melon, adopted by Mr. Lovell, (Gard. mag. 7. p. 461.) varies in one or two very essential points from any that he has seen practised; first in well bedding and firmly rooting the plants to support a good crop of fruit ; second in early setting and preserviug the first fruit, and forcing the whole of the plants luxuriantly through the whole of the period necessary for their maturity. To effect this he prepares his bed with dung well watered and fermented, or tan, not wishing such a strong heat as for cucumbers. He sows his seeds in pots, in which the plants remain until they are turned into the hills, leaving only 3 plants in each pot. These he places in the dung, in order to start them as soon as the bed is made up, unless there should be another bed in use at the same time. As soon as the second rough leaf appears, he puts a hill of good melon soil under each light, composed of good loam and turf, adding a sixth part of good rotten dung, well mixed with the spade, but not sifted. This he waters if dry, and treads in the hills firmly, making a hole in the centre, and turning out a pot of plants with the ball entire into each hole. Should the weather be very warm, he waters them overhead abundantly, and in the space of a fortnight they will have grown to four or five joints each : he then stops them down to three joints. By this time the heat of the bed will have become reduced to such a temperature as to allow of moulding up the plants, wcll heading in and watering as you proceed. As the plants will at this time be strongly rooted, and in vigorous growth, in the course of three days they will have puslied a strong shoot from each of the three eyes in a horizontal direction, and they will seldom fail of showing fruit at the first joint; you may rely at least on two out of three of these fruits setting. Before the fruit comes to blossom, the bed must be covered $1 \frac{1}{2}$ inch thick with dry sand, but mould will do, and do not water the bed any more for at least 3 weeks. This prevents the newly formed fruit from turning yellow and damping off. All shoots that appear, except the three above mentioned, must be removed. As these shoots will show fruit at the first or second joint, if such fruit be set and taken care of, it will be three parts grown before the vines will have reached the outside of the bed, arriving at perfection in nearly half the time it would have done if the vines had been left in confusion. Particular care must be taken in pruning, never to stop the three shoots that bear the fruit, nor yet the lateral ones produced from the same joint as the fruit. These lateral shoots will show fruit at the first joint, which fruit must be preserved until the other is swelling, then take off this lateral shoot, but do not stop the vine. But should any accident lappen to the other fruit, the shoot bearing it must be taken off, and the lateral shoot treated as a main one, when the fruit on it will swell accordingly; and all the laterals that spring from the main shoot must be stopped, leaving one joint and leaf only.

On the cultivation of the melon.-J. Holland (Gard. mag. 7. p. 575.) plants off his seedlings singly in 60-sized pots, and when sufficiently advanced in growth they are stopped so near the seed-leaf, as only to admit of them throwing out 2 lateral shoots, and when these principal leaders extend to 2 or 3 joints, they are finally planted out into frames or pits, having the bottom heat arranged according to the advanced state of the spring months. Five melons were produced by a plant set in the centre of a two-light frame in the beginning of May, upon an old bed that had been previously employed for raising radishes. A dung lining was alded to the back and one end of the frame, which was all the artificial heat the plant received, one vine wastrained to the back and the other to the front of the frame. His practice is never to stop the vines until they have extended as far as their confinement will permit, and the laterals from the two leading vines, as they advance in growth, are trained to the right and left over the bed with neat pegs, and every fruit blossom, as it expands, is carefully impregnated and placed upon a tile under the shade of a neighbouring leaf. In a day or two, or as soon as he thinks the fruit will set, he stops the vine at the first or second joint beyond it. In this way he proceeds, in setting all the fruit he can, until the surface of the bed is covered with foliage, which is never deranged more than can be avoided. While the fruit is setting, he gives air very freely, sometimes he draws the lights quite off for a few hours on sunny days, and he also, by applying or withholding heat or water, endeavours to keep them in a state betwixt luxuriance and debility, for in either extreme they will not set well. Having advanced thus far, he commences swelling them off. He begins this with pinching off all the ends of the lateral shoots that have not already been stopped to assist the young fruit. He now gives no more air than will prevent the sun from scorching their leaves. He looks over them every morning, and takes off all the blossoms as they appear, and stops every young shoot back to one joint above that of the vine which produces it. He watches over them every afternoon in fine weather, and before the sun has quite left the frame, he sylinges or waters them all over, leaves, fruit, and all, and shuts down the glasses for the night. He always prefers performing this while the departing rays of the sun have sufficient strength to raise a sweet vaporous heat of about $90^{\circ}$, which serves them to feast upon long after the sun has disappeared. A few days of such treatment will determine which fruit will take the lead in swelling off, out of which he selects 2 or 3 to each plant, according to the sort, and all the rest he cuts away. As the fruit advances in growth, it is necessary at intervals to turn them a little on the tiles, to prevent them from growing flat, and discolouring on one side, and also from rotting. When they have attained as large a size as he thinks the sort will admit, he leaves off watering, and again gives all the air he can, by taking the lights entirely off when the weather is favorable; and if the season is not too far advanced, he leaves them to ripen without any other assist- 
ance. For an early crop of melons, he grows the small early cantaloup, I plant in a light when the frame is narrow, and 2 if wide, with 2 or 3 fruit on each plant, which in general weigh from 2 to $s$ pounds each. He succeeds these with the scarlet and green-flesh, planted and trained as above, the produce of which is from 2 to 6 pounds. His principal crop is, however, from the black rock, which he has grown of all sizes up to $13 \frac{1}{2}$ lbs. weight; the plants are much more hardy than many other sorts, it is a good bearer, the fruit handsome, and the flavour excellent. The sort which he grew so large was originally from France, and in its primeval state was a rock; but it has lately been strongly impregnated with the scarlct flesh, which fruit it now resembles in all its characters, except in

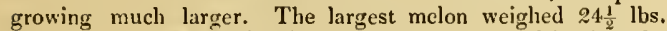
The above is Mr. Holland's general practice of cultivating the melon, which practice he says he will still continue to adhere to unless fully convinced he can adopt a better.

Insects and diseases.-To prevent melon plants from being infested with insects or injured by diseases of any kind, no better method can be adopted than to keep the plants constantly in a healthy, vigorous, growing state; for this purpose, M'Phail observes, "they must be constantly attended to, giving them plenty of heat and water. In warm weather in the spring and the summer, they should be watered occasionally all over the fruit and leares, till the earth in which they grow be thoroughly moistened, and a stronger heat than usual be kept in the frames about the plants for a few hours; also the lights should be shut down every afternoon, with a good strong heat among the nlants. If there be sufficient moisture in the earth the greatest sun heat in the afternoon will not hurt the plants, but it might scorch the sides of the large fruit, exposed to the sun-beams operating upon the glass, which should be guarded against. The frames and lights should be kept clean and painted over once every year. Melon plants are subject to be infested and hurt by the mildew and by the canker. These diseases come upon them because they are not in a good climate, they have not a sufficiency of heat, or the dung and earth of the bed is in a stagnated state. Melon plants are liable to be greatly injured by an insect called the red spider, which increases surprisingly in hot dry weather. As I said before, nothing will prevent plants from the inroads of disease and insects but heat, sweet air, and a sufficiency of water, which sweetens the atmosplere, and makes it healthy for vegetables as well as for animals. And nothing will eradicate disease and insects from melon plants but good management, strong heat, and plenty of water given all over them. Diseased plants, or plants much infested with insects, cannot produce good healthy fruit. The mildew is a most pernicious disease to all sorts of plants. On melons it generally makes its first appearance on the oldest leaves and on the extremities of the young shoots. The cause of it, I apprehend, is unhealthy nourishment comprehended in the elements, or their not harmonising in the promotion of the growth of the plant; for by practitioners it may be observed, that when a dung hotbed gets into a stagnated sour state, the plants do not grow kindly, the air in the frames is saturated with unhealthy particles, and so also must be the juices drawn into the plants by their roots. These must breed diseases, if preventive means be not applied. It cannot be reasonably supposed that plants of a delicate nature will continue in a healthy state growing upon a heap of stinking dung, and in confined air. When melon plants have become diseased, or much infested with the red spider, they should either be destroyed, or effectual means used to cure them. To destroy the plants is easy; to cure them let the following methods be put in practice : get plenty of horse-dung thrown up in a large heap, turn it over once or twice, shaking and mixing it well, and let it lie till its rankness be somewhat evaporated, and if there be linings at the beds, take then entirely away, examine the dung of the beds, and if it be wet and has a bad smell, take a sharp-pointed stake, and make holes all round in the sides of the beds unto their centre, in such a slanting way that the water may easily run out of them; then make a strong lining of the prepared dung all round the beds, and by occasional augmentations, kcep up the linings nearly to a level with the surfice of the earth in which the plants grow. As soon as the linings have cast a strong heat into the beds, scatter some flour of sulphur all over the plants, and keep as strong $a$ heat in the frames as the plants can bear; a heat of $120^{\circ}$ will not destroy them, if the steam of the linings be prevented from getting in among the plants. Water the plants all over their leaves about once a week, with clean water $100^{\circ}$ warm, and if the sun shine keep the lights close shut down all day, and cover them up in the evenings, leaving a little air all night at each light, to prevent a stagnation of air among the plants. Continue this process till the mildew and the insects disappear, and the plants appear to grow freely, and afterwards manage them in the usual way, taking care to kecp up a good strong heat in the linings. This method sets the old stagnated bed in a state of fermentation, which makes the moisture run out of it, and dries it so, that water given to the plants has free liberty to pass off. If the linings do not heat the air in the frames sufficiently, let some of the earth in the inside all round the sides of the boards be removed, to let the heat from the linings rise freely in the frame."

Culture of melons in a dung-pit.-" A glazed pit to receive either stable-dung, leaves, or tanners' bark, is calculated to ripen superior fine fruit. The well of the pit may be formed either by a nine-inch wall, or by strong planking, a yard in depth, from 6-8 feet wide, and in length from 10-20 feet or more as required. A low glass-case is to be fitted to it, adapted to the growth of the melon. Having raised the plants in a small seedbed, as for the frame crop, ridge them out into the pit in the usual manner. Give the proper subsequent eulture, and when the strength of the fermenting mass begins to decline, add linings outside the pit, if inclosed by boards, but if inclosed by a nine-inch wall, cut away as much of the dung and eartl within, and throw it out, as will admit a lining of well-tempered dung." - Abercrombie.

Cullure of mclons in a flued pit.-One such as that proper for the nursing pinery is here understood; and the plants being raised in the usual way, and the bed, whether filled with dung, tan, or leaves, or a mixture of these, being moulded, plant about the end of July. Nicol prefers for such late crops "the carly golden cantaloup, the orange cantaloup, and the netled cantaloup, planting a part of the pit with each." A very mild bottom heat is sufficient for the purpose here in view; and if the pit has been occupied in forcing asparagus, French-beans, or strawberries, on a bark, or a bark and dung, or on a bark and leaf heat, it will require no other preparation than to be stirred up and have a little fresh materials added, keeping the fresh bark, dung, or leaves well down, and finishing the bed with some of the smallest and best reduced. When it has settled a few days, let it be moulded all over to the thickness of 12 or 15 inclies; previously laying on a little more of the above small materials, in order to keep the plants well up to the glass, as the bed will fall considerably in the settling. It should be formed, and the mould sliould be laid on in a sloping manner from back to front, so as in some measure to correspond with the glasses. AlI being ready for tho plants, they may either be planted in a row, in the middle of the pit, at 2 feet apart, or may be planted in 4 rows at 4 feet apart; or, if they have been planted in nursing, 3 in a pot; plant in the centre of each light, as directed for the common hot-bed, in March. Let them have a litule water 
and be shaded from the sun for a few days, exposing them to lis rays by degrces. The future management of the plants differ in nothing from that of melons in a hot-bed till September, when it will be proper to apply fire heat."- " A bout the beginning of September it will be proper to apply fire heat, in order to further the progress of late fruit, and to dry off damps. Let the fires be made very moderate at first, however, and increase their strength as the season becomes more cold and wet. Keep the mercury up to $70^{\circ}$ in the night, and in the day by the addition of air keep it down to about $80^{\circ}$ or $75^{\circ}$. Very little water will now suffice for the plants, as their roots will be fully established, and be spread over the whole bed; the heat of which will also now have subsided. They should only, therefore, have a little water once in 8 or 10 days, and as the fruit begin to ripen off, entirely withhold it. Keep the plants moderately thin of vines and foliage; be careful to pick off all damped leaves as they appear; and fully expose the fruit to the sun as it ripens, in the manner directed for melons in the hot-bed. In this manner I have often had melons in October and November fully swelled, and in good, but not of course in ligh perfection, for want of sun to give them flavour. Any who have a pit of this kind, however, for the forcing of early vegetables, strawberries, flowers, \&c. cannot, perhaps, occupy it to a better purpose in the latter part of the season, as the trouble is but little, and the expence not wortls mentioning."

Culture of melons in M'Phail's pit.-The inventor of this pit says, "For the purpose of raising melons early, for many years I cultivated them on a brick bed, on the same construction as that which I invented for rearing early cucumbers, excepting only that through the pit of each 3 -light box I carried no cross flues. When this bed was first set to work, I had the pits filled level with the surface of the flues, with well fermented dung or with the dung of old linings from the cucumber-berl. In each 3 -light division I made the pit about 3 feet 6 inches wide and 10 feet long, and 3 feet deep below the surface of the flues. On the sturface of the dung in the pits, I had laid abont 10 inches thick of good earth, in a ridge of about 20 inches wide, from one end of the pit to the other. When this was done, I made a lining round the bed, and as soon as the earth became warm, I set the plants into the ridge of the earth, and gave them a little water, and kept a strong heat in the frames, and filled up the pit gradually as the roots and plants extended themselves." - "The dung or leaves of trees in the pit require not to be changed every year, neither need the earth for the plants be removed entirely every season, for by experience I found it to do very well by digging, and mixing with it some fresh eartl and manure in winter, and exposing it to the rains, the frost, and the snow."- "In forcing melons early, the surface of the cross flues, as well as the surrounding and outside oncs, should be kept bare of mould till the days of the spring get long, which will let the heat of the linings arise freely through the covers of the flues to warm the air among the plants. After the cross flues are covered with earth, those which surround each frame may be left uncovered till the month of May or Jume."-Gard. rem. p. 64.

The culture in the brick bed is, in other respects, the same as that already given for melons in frames, and cucumbers in brick beds. See the monthly table of temperature under the cucumber.

Culture under hand-glasses.- "A successive or late crop, to fruit in August and September, may be raised on hot-bed ridges under hand-glasses. Sow in a lot-bed from the midlle of March to the middle of April. When the plants have been up a few days, while in the seed-leaves, prick some into small pots, two plants in each; water and plunge them into a hot-bed, managing as clirected for the young frame plants, till the rougl leaves are from $2-4$ inches long, and the plants ready to sloot into runners. From the middle of March to the third week of May, when the plants are a month or five weeks old, they will be fit to ridge out under hand-glasses. With well-prepared stable-dung, or, with a mixture of fermented tree-leaves, build the hot-bed four feet wide and $2 \frac{1}{2}$ feet thick, the length according to the number of glasses intended, allotting the space of 4 feet to each. In a week or ten days, or when the dung and leaves are brought to a sweet or well-tempered heat, mould the bed 10 or 12 inches thick, then place the glasses along the middle, and keep them close till the bed has warmed the earth. The same, or next day, insert the plants; turn them out fron the pots with the ball of earth entire, and allotting plants for each glass, insert the ball into the earth, clean down over the top, closing the mould about the stems. Give a little water and place the glasses over close. From about nine in the morning till three in the afternoon, of the first two or three days, shade the plants till they have taken root, when admit the sun inore freely, yet only by degrees from day to day, till they can bear it fully without flagging much. Give air daily, in temperate weather, by tilting the edge of the glasses on the south side, an inch or two; but in the present stage of the plants shut close at night. Cover with mats till morning, constantly keeping the glasses over. Give occasional moderate waterings with aired water. Cover in the day time with mats in bad weather, or heavy or cold rains; and continue the night covering until confirmed summer in July. Meanwhile attend to the heat of the bed; if this be declined, so that the minimum temperature be not $65^{\circ}$ at night, with the aid of matting, line the sides with hot dung, covered with a layer of mould. The revived heat from the linings will forward the plants in fruiting, while the earth at top will enlarge the surface for the runners, and the bed for the roots. When the rumners have extended considerably and filled the glasses, they must be trained out. Accorlingly, at the beginning of June, in favourable settled warm weather, train out the runners, cutting away dwindling and useless crowding shoots; then the glasses must be raised all round, 2 or 3 inches, upon props to remain day and night. Cover with mats in cold nights and bad weather, but first arch the bed over with rods or hoop-bands to support the mats. Apply moderate waterings as necessary in the morning or afternoon. Oiled paper frames, formed either archwise, or with 2 sloping sides, about 2 feet or $2 \frac{1}{2}$ feet high, and of the width of the bed, are very serviceable in this stage. Some persons use them from the first, under a deficiency of hand-glasses. But the proper time for having recourse to them, is when the plants have been forwarded in hand-glasses till the rumers require training out beyond the limits of the glasses, some time in June; then removing the glasses, substitute the oiled frames, as these paper screens will entirely afford protection from heavy rains or tempests, as well as from nocturnal cold, and also screen the plants from the excessive heat of the sun, while, being pellucid, they admit its infuence of light and warmth effectually. Give proper adnission of free air below, and occasional watering. With respect, however, to the crop for which no oiled paper frames luave been provided, continue the hand-glasses constantly on the bed, over the main head and stem of the plants throughout the season, to defend those capital parts from casual injuries by the weather. Throughout June, and thence to the decline of summer, be careful, if much rain or other unfavourable weather, or cold nights occur, to shelter the beds occasionally, with an awning of mats or canvass, particularly when the jlants are in blossom. Likewise turn in some of the best full set exterior fruit under the glasses, or some spare glasses might be put over the outside melons, to forward them without check to maturity. Some will be ready to cut in July, others in August, the more general time, and in September; they being generally, after setting, from 30-40 days 
in ripening. The crop coming in at the decline of summer will not ripen well, unless guarded from cold at niglits, and assisted by linings. The fruit that do not ripen may be used for mangoes.

"Wille ridge, or the fruiting-bed, may be made 6,7 , or 8 feet wide, for the plants to have an ample surface for their extending runners, defended either with a regular frame, and glasses of proportionate dimensions, or a case furmed of an inch and a half boarding, ranged connectedly along both sides of the bed, without any external cross divisions, other than top cross bars, to stay the sides and support the glasses."

Method of growing crops of melons in the open borlers.-The mode of growing cucumbers on ridges of shallow beds of half-spent dung in the open air, is well known to garleners; and in warm situations melons may be grown in the same manner. The sorts grown by Mr. Greenshields were the black rocks, green-fleshed, nettcd, and carly cantaloup. The seeds of the first crop were sown about the middle of $\mathrm{March}$, in pots in a cucumber-frame, and the bed or ridge was prepared in the first or second week in May, 4 feet wide, and 1 foot higher at the back or north side than in front. Hand-glasses, with 2 or 3 plants in each, are placed, 4 feet apart, along the centre of the bed. Very little air is given till the plants have filled the glasses, but when these appear to get crowded with vines, the glasses are raised up, and the plants allowed to grow up in the manner of ridged cucumbers. If the vines are very thick, a few of the weakest may be pinched off, and the top of each leading shoot or vine removed. No more pruning will be necessary for the season. Setting the fruit at this season of the year is quite necessary. To have bandsome fruit, not more than one or two should be left on the plant. They will begin to ripen about the first week in August, and continue to be produced through that month and part of September. To prolong the season, seeds may be sown three weeks later, planted out like the first crop, and when there is appearance of frosty nights, a cucumber-frame and sashes may be placed over them. By this means tolerably good melons may be had till the end of October.-Greenshields, ex Loud. gard. mag. 3. p. $18 \%$.

There is another method of cultivating melons in the open air; that is, to raise a bed of old tan, and tramp it well and firmly down, placing some stakes and boards behind to keep up the tan, so that the bed may slope in front; 6 inches of mould should be placed on the tan, and the melon plants planted into it. Grass or leaves may be placed at the back of the bed to keep up the beat. The plants should be reared on a hot-bed.

Melon. Fl. July, Sept. Clt. 1597. Pl. tr.

2 C. DELiciòsus (Roth. cat. 3. p. 307.) angles of leaves blunt; fruit roundish-ovate, pubescent, with white, very fragrant flesh, and a thin rind. $\odot$. F. Native of the East Indies, but now cultivated in Spain. Perhaps only a variety of the common melon.

Delicious Melnn. Fl. June, Sept. Clt. 1818. Pl. tr.

3 C. sarivos (Lin. spec. 1437.) stems rough, bearing tendrils; leaves cordate, obscurely 5-lobed, petiolate, terminal lobe the largest; flowers on short peduncles, largish, usually by threes; male flowers having the tube of the calyx tubularlycampanulate, and with a spreading deflexed limb; fruit long, somewhat triquetrous, smooth or prickly, and usually shining, having the carpels distinctly separable in the inside. ๑. F. Native of Tartary and the East Indies.-Blackw. lierb. t. 4.Lob. stirp. 363. f. 1. The cueumber is called Ketimou and Timou by the Hindoos. Flowers yellow, as in the rest of the species.

The cucumber is called concombre in French ; gurke in German; and Citriuolo in Italian; it is a tender annual, a native of the East lndies, and was introduced in $15 \% 3$. It is a trailing and elimbing plant, with large, roundish, rough leaves, furnished with tendrils, and if sown in the open air in May, produces flowers from July to August. 'The cucumber is of nearly as great antiquity as the vine, for Mloses, the earliest Jewish author, mentions it as abounding in Egypt when the children of Israel were there, above 3000 years ago. (Numbers, clıap. ii.) In England it is cultivated generally and extensively in forcing frames, and in the open air, and especially near larese cities and towns. "Not only gentlemen," as M'Pliail observes, " but almost every tradesman who las a garden and dung, luave their cucumber-frame." In Hertfordshire, whole ficlds are annually seen covered with cucumbers, without the aid of dung or glass, and the produce of which is sent to the metropolis for pickling. In march, cucumbers fetch in the London market a guinea a dozen ; in August and September a penny a dozen. The village of Sandy, in Bedfordshire, has been known to furnish 10,000 bushels of pickling cucumbers in one week.

Usc.-The green fruit is used as salad; it is also salted when half grown; and preserved in vinegar wlien young and small. In Germany and Poland, barrels of half, and also full grown cucumbers, are preserved from one year to another by immersion in deep wells, where the uniform temperature and exclusion of air seem to be the preserving agents.

I arieties.-The principal of these are as follow :-

\section{List of cucumbers.}

1 Early long prickly. - This fruit is from 5-7 inches long, of a green colour, with few prickles. The plant is a good bearer, and upon the whole this is the best cucumber for the general summer crop, the flesh being very crisp and pleasant.

2 Largest green prickly.-From 7-10 inches long; it has a dark green skin, closely set witl small prickles. This is a bardy sort, but does not come early.

3 Early short prickly.-Not more than 4 inches long; the skin green and rather smooth, but witl a few small black prickles. This is one of the hardiest and earliest sorts, and is often preferred for the first crop.

4. Dutch or nhite short prickly.-Though not mucls cultivated, is recommended by some as preferable even to the carly long prickly; it has fewer seeds, is evidently different in taste from most other cucumbers, but of agreeable flavour.

5 Cluster cucumber. - $A$ very early sort ; the flowers appear in clusters of 3 or 4 together; the fruit is seldom more than 5 inches long; it is at first of a fine green colour, but becomes yellowish as it ripens. The stems of this variety are much inclined to climb by means of their tendrils upon sticks; the leaves are small, and the plant altogether occupies but little room.

6 Smooth green Roman.-An early sort; the fruit becomes large and long, and is quite smooth; the plants grow very strong, and require a good deal of room.

7 Thite Turkcy.-The stalks and leaves are larger tluan in the other varieties ; the fruit also is very long, sometimes from 10 15 , or even 20 inches; it is quite straight, and bas a smooth skin, destitute of prickles; it is produced sparingly, and late in the season.

8 Long grcen Turkey.-Sometimes sown for the late crop. Late cucumbers, however, are much less cultivated than the early varieties, most gardeners being of opinion, that those kinds which are best for the early crop, are also best for the late.

$9 \mathrm{Nipaul}$ - Fruit very large, usually weighs upwards of 12 lbs., measures in girth 24 inches, and in length 17 inches; flarour pleasant, and esteemed for standing. It is a native of Nipaul, from whence it was introduced to the botanical garden at Calcutta; but it is not likely that it ever will be much cultivated in this country.

Culturc.-The culture of the cucumber, as a table esculent, 
is chicfly carried on by artificial heat, and is therefore treated of under that head. For pickling it is chiefly cultivated in the open ground, by what is termed drilling. To have a crop in the natural ground, the seed is sown in warm compartments of ricl carth, towards the end of May or beginning of June, when the weather is settled, warm and dry. The plants should mostly remain where sown, to produce late fruit tuwards the end of July, or more generally in August and September; small for pickling, and in larger growth for ordinary consumption. Sow a portion in a warm border, and the main crop in an open compartment. Dig the ground neatly even. Trace lines with intervals of 5 or 6 feet; and in the lines mark stations $3 \frac{1}{2}$ feet distant, then with a trowel at each of these spots, form shallow circular saucer-lorm cavities in the surface, 10 or 12 inches wide and about an inch deep in the middle. Sow in the middle of each cavicy 8 or 10 seeds, half an inch deep. When the plants are come up, and begin to put forth the first leaves in the centre, thin them to 3 or 4 of the strongest in each hole. Earth these up a little between and close round the stems, pressing them a little asunder, and give them some water to settle the earth below and above. In their advancing growth train out the leading runners, supplying them with requisite waterings in dry weather 2 or 3 times a-week, and sometimes every day in very dry hot weather, in July, August, or Septem. ber. At this season water early in the morning and late in the afternoon towards evening."

Gathering.- "The crop comes in sometimes towards the end of July, but more generally not before August in full production; continuing till about the middle or end of September, when the plants decline. Be careful to gather the fruit in a fine state both for pickling and other purposes. They must be quite young for pickling, not exceeding 2 or 3 inches in length." - A bercrombie.

Forcing cucumbers.-To produce cucumbers at an early season, is all object of cmulation with every gardener; and there is scarcely any person who has not a cucumber-bed in his garden. We shall lay down a systematic view of the practices of the most approved gardeners in the culture of this plant, as has been our usual custom with other garden plants. Cucunbers are forced in hot-beds, pits, and lot-houses, and the heat of fire, and warm water, and steam, and dung, have been applied to their culture; but dung, as the author last quoted observes, is the only thing yet found out, by the heat of which the cucumber may be advantageously cultivated.

Soil.-Cucumbers, like every other plant, will grow in any soil, though not with the same degree of vigour, provided they be supplied with a sufficiency of heat, light, water, and air. For early forcing, Abercrombie recommends a mould or com. post of the following matcrials : "One third of rich top-spit earth, from an upland pasture, one-third of vegetable mould, and one-sixth of well decomposed lorse-dung, with a sinall quantity of sand." M'Plail used vegetable mould made from a mixture (accidental) of the leaves of elm, lime, bcecl, syca. morc. liorse and sweet chestnut, spruce, and Scotch fir, walnut, laur l oak, evergrcen oak, ash, \&.c. and among them withered gras. and weeds of various kinds. "This vegetable mould," lie says, "without a mixture of any thing besides, is what I used for growing cucumbers in, and by experience I found it preferable to any other moulds, earths, or composts whatever, either in my new method of a brick bed, or in the old method of a bed made of horse-rlung." Nicol says, "soil thus composed will produce cucumbers in great abundance : three-fourths light rich black earth from a pasture, an cighth part vegctable mould of decayed tree-leaves, and an eighth part rotten cosv-dung." Kal. p. 393. W. T. Aiton gives the following as the compost used in Kew Gardens: "Of light loam a few months from the common, one-third part, the best rotten dung one-third part, leaf-mould and heath-earth of equal parts, making one-third part. The whole well mixed for use." G. Mills states that the soil he uses "is half-bog or black monld, got from a dry beathy common, and half leaf-mould : after lying 12 months in a heap, the compost is fit for use."

Time of beginning to force.-A bercrombie says, "Managers who have to provide against demands for early cucumbers, must raise the seedlings from 10-12 weeks before the fruit will be required, according to the length of the days in the interval. In proportion as the entire course embraces a greater part of the mid-winter, the liability of failure from obstacles in the weather will be greater. The last fortnight in January, or first week in February, is a good time for beginning to force the most early crop. In the subsequent months, both main and secondary crops may be started as required, and will come forward more freely. To have a constant succession, seedlings should be raised twice a month. As the course of forcing more coincides with the natural growing season, the length of it will be reduced to 8,7 , or 6 wceks." M'Phail says, "those who are desirous of having cucumbers early, had best sow seeds about the 20 th of October; they may be sown at any time of the year, but the spring and autumn are the best seasons. Cucumber plants may be made to bear fruit plentifully from about the middle of March till the middle of September; but from the middle of September till the middle of March their produce will be but scanty. Cucumber-plants, raised from seed in October, will begin to produce fruit in February or March, and will continue to bear till the following month of October, provided they be kept in frames and get plenty of heat and water." Nicol recommends the middle of January. He says " Some begin sooner, but it is striving hard against the stream to little purpose. If the dung be prepared and the bed be got ready, so as to sow about the first of February, the success will often be greater than by sowing a month earlier, the growtls of the plants being frequently checked by bad weather, and sometimes they are entirely lost." Aiton, in the paper above quoted, sowed on the $12 \mathrm{tl}$ and 20 th of August, with a view to cultivate in stoves, a regular supply of this vegetable being annually required for the royal tables. G. Mills sows on the first of October.

Sorts.-Abercrombie recommends the short prickly for very early fruit, and the long priekly kinds for the chief early and main summer crops. Nicol says every gardener has his favourite sort of cucumber, and it is no easy matter to advise. He names as early sorts generally known, the carly short prickly as the earliest; the carly smooth green, a long fruit, the long green prickly, and the white prickly, a white fruit.

Choice of sced.- "It is advisable," Abercrombie observes, " to have that at least from 2-4 years old, in prefercnce to newer seed, which is more apt to run luxuriantly in vine, and the plants from it do not show fruit so soon or so abundantly as those from seed of greater age. But when seed has been kept more than 4 years, it is sometimes found to be too much weakened."

Forming the seed-bed.- "A one-light frame," Abercrombie says, "will be large enough for ordinary purposes. Choose a dry sheltered part of the melon-ground, and form a bed for a 1light frame. When high winds are suffered to blow against a cucumber-bed, they have a very powerful effect on it, for in that case the heat will not only be greatly abated, but also forced and driven into the corners of the frames, and, consequently, some parts thereof are rendered too cold, whilst other parts are made too hot, and of course the plants are all equally endangered, retarded in their growth, and perhaps some, if not all of them, totally destroyed. Therefore, when a cucumber-bed is about to be built, the first object of consideration should be, to have it, as well as possible, sheltered from the high winds and 
boisterous, stormy weather." Having put on the frame and waited till the bed is fit for moulding, lay in five or six inehes' depth of the proper earth or compost. M.Phail "makes up a bed of good dung, four feet high, for a 1-light box." Nicol " builds a bed of dung, earefully fermented, to the height of 5 feet at back, and 4 at front, keeping it a foot larger all round than a 1-light frame, or about five or six feet by three or three and a half. He then covers with turf, and on that lays fine sand, as free of earth as possible, to the depth of about 6 inches, laying in a sloping manner, corresponding with the glass and within 6 inches of it; over which lay an inch or two of dry light earth." Aiton and Mills also prepare a bed for a 1-light box; the latter forms it on a stratum of wood 1 foot high for drainage, and 8 inelies higher in the middle than at the sides, as the sides are liable, from the weight of the frame, to settle faster than in the middle, which causes the piles of earth to crack; by which in fruiting-beds more especially the roots of the plants are greatly injured.

Sowing.-Abererombie sows some seeds in the layer of the earth, which he spreads over the bed, putting them in half an inch deep. He also sows some seed in 2, 3, or more small pots of the same kind of eartl, which may be plunged a little into that of the bed. M'Phail sows in a pot filled with rich earth, eovers about 2 inches thiek, and sets the pots on the surface of the naked dung on the bed. Nicol sows immediately after the bed is made, without waiting till the heat arises, which he says is losing time, and the opportunity of bringing on vegetation by degrees as the lieat rises. He sows in a broad pan 4 inches deep, or in small pots 4 or 5 inches in diameter, and as much in depth. These he fills with "fine light earth" or vegetable mould, and covers the seeds 2 inches. He plunges these to the brim in the baek part of the bed (which, it will be recolleeted contains a stratum of earth 6 inches thick, over one of sand and another of turf), puts on the light, and lets the frame be matted at night, in the ordinary way.

Raising plants from cultings.-M'Phail says, "Instead of raising cucumber plants from seeds, they may be raised from cuttings, and thus kept on from year to year, in the following manner; the metlod of stieking them in is this: take a shoot which is just ready for stopping, cut it off just below the joint, behind the joint before which the shoot should have been stopped, then cut snooth the lower end of the sloot or cutting, and stick it in fine leaf or other rich mould, about an inch deep, and give it plenty of heat, and shade it from the rays of the sun till it be fairly struck. By this method, as well as by that of laying, eueumber plants may readily be propagated." J. Mearns, gardener at Shobden Court, near Leominster, propagates his cucumber-plants for a winter erop in this way, and "finds that the plants raised from eutings are less succulent, and therefore do not so readily damp off, or suffer from the low temperature, to which they are liable to be exposed in severe weather; that they come into bearing immediatcly as they have formed roots of sufhicient strength to support their fruit, and do not run so much to barren vine as seedlings are apt to do." He takes the cuttings from the tops of the bearing shoots, and plants them in pots 9 inclses deep, half filled with mould. He then waters them, covers the tops of the pots with flat pieces of glass, and plunges them into a gentle bottom heat. "The sides of the pot aet as a sufficient sliade for the cuttings during the time they are striking, and the flat glass, in this and in similar operations, answers all the purposes of bell-glasses. The euttings form roots, and are ready to pot off in a fortnight.

Temperalure of the seed-bed.-Abererombie says, "The minimum heat for the cucumber is $58^{\circ}$ at the eoldest time of night, in the day-time $65^{\circ}$ is sufficient for the maximum; beeause air admitted, when the sun has great influence, will do more good VOL. III. than a higher heat. M'Phail says, "If it were possible to kec] the heat in the frames always to $80^{\circ}$, with the coneurrence of proper air and moisture, I am of opinion that that would be a sufficient heat for the production of the eucumber." Nicol keeps the air in the bed to abont $65^{\circ}$ in the night, allowing a few degrees of a rise in sunsluine. Aiton rears and fruits his plants in a stove. Miller says, "The heat I wish to have in the seed-frame is from $65^{\circ}$ to $75^{\circ}$."

Treatment of the plants until removed to the fruiting-bed.After sowing, A bercrombie " continues the glasses on the frame, giving oceasional vent above for the steam to evaporate, that the bed may keep a moderate heat, and not become too violent. The plants will be up in a few days, when it will be proper to admit air daily, but more guardedly, at the upper end of the light, which may be raised from half an inch to an ineh or two, aecording to the temperature of the weather, that the plants may not draw up weak, or be injured by the steam. In frosty weather hang part of a mat over the aperture. When the plants are a little advanced, with the seed-leaves about half an inch broad, take them up, and prick some in small pots of light earth, previously warmed by the bed. Put 3 plants in cach pot, and insert them a little slopingly, quite to the seed-leaves. Plunge the pots into the earth, and you may priek some plants also into the earth of the bed. Give a very little water just to the roots ; the water slinuld be previously warmed to the temperature of the bed. Draw on the glasses; but admit air daily to promote the growth of the plants, as well as to give vent to the stean rising in the bed, by tilting the lights behind, from half an inch to an incl or two high, in proportion to the heat of the bed and temperature of the weather. Cover the glasses every night with garden-mats, and remove them timely in the morning. Give twice a-week, once in two days, or daily, aecording to the season, a very light watering; keep up a moderate lively heat in the bed by requisite linings of hot dung to the sides.' $\mathrm{M}$ 'Plaail, having sown, and placed the pots on the naked bed, says, "the plants will eome up in a few days, and when they have fully expanded their seed-leaves, transplant them into small pots, 3 plants in each pot. Set them on the surface of the dung in the bed, and let a little air be left at the light day and night, to let the steam pass off freely."- " When the seedling plants have one or two joints, stop them, after which they generally put forth 2 shoots, each of whieh let run till they have made 1 or 2 elear joints, and then stop them, and afterwards continue throughout the season to stop the plants at every joint." Nicol direets to guard the seed from mice, which generally swarm about hot-beds, by laying a pane of glass over the pot or pan till they come up; and afterwards at night by covering with a pot of equal size, till the seed-leaves have expanded and the lusks liave dropped; for until then the plants are liable to be destroyed. The cover, lowever, should always be removed by sunrise, and be replaced in the evening. It is at night these vermin generally commit their depredations. No air need be admitted till the heat begins to rise, and steam begins to appear; but after that the lights should be tilted a little every day, in whatever state the weather may be, until the plants break ground. Air must then be admitted with more care, and if frosty or very clill, the end of a mat should be hung over the opening, that the air may sift through it, and not immediately strike the plants. A little aired water may be given once a day, from the time the seeds begin to chip; and if a very strong heat rise, the pots should be raised a little to prevent the roots from being injured. They should be frequently examined on this aceount, and if the licat be violent, sliould be set loosely on the sand, or be placed entirely on the surface. The air of the bed should be kept to about $65^{\circ}$ in the night, allowing a few degrees of a rise in the sunshine. If the weather be severe, the mats must be doubled 
or tripled, and if mild perhaps a single one will suffice, But unless in very bad weather they should always be removed by sunrise, in order to almit all the sun and light possible to the plants, which are very essential to their welfare. When the plants are about an inch and a half high, they are then fit to be pricked out into nursing pots. These pots should be about $3 \frac{1}{2}$ or 4 inclies in diameter at top, and as much in depth. The mould to be used should be the same as that in which the seeds are sown, and should be laid in the frame a few hours previous to potting, in order to bring it to a proper degree of warmth, that the tender fibres be not chilled by it. Let the pots be filled about one half with the earth, turn the plants carefully out of the seed-pot; place three in each, against the side of the pot, and so as their leaves may be just above its margin; then cover the roots with the mould, rubbing it fine between the fingers, and filling the pots nearly to the brim. Work over the sand in the frame to its full depth, plunge the pots to within an inch of their rims, and cover the whole surface with a little dry earth as at first, making it level with the tops of the pots. Then give a little aired water, in order to settle the earth to the roots of the plants. 'The plants will now require due attention. Let air be admitted to them as freely as the state of the weather will allow, and supply them moderately with water once in 2 or 3 days. Examine the pots frequently, if the lheat be violent, lest the roots be scorched, setting them loosely or pulling them up in that case, or if thought necessary, placing them entirely on the surface. If much steam ahound in the bed at this time, it may be proper to leave the light tilted half an inch in the night, observing to hang the lap of a single mat 2 or 3 inches over the tilt. But if the bed was carefully turfed over, as directed at making up, this will seldom be necessary, never but in thick hazy weather. Mat up carefully at night, but make a point to almit all the sun and light possible to the plants; therefore, uncover always by sun-rise; and frequently wash and wipe the glasses clean, outsile and inside, as they are often clogged by a mixture of steam and dust. Also, occasionally stir the surface of the sand or earth in the frame with the point of a stick, in order to extirpate vapour, that hovers on the surface, and so purify the internal air of the bed. If the heat begin to decrease, and particularly if the weather be severe, it may be necessary to line one or more sides of the bed, that the plants may receive no clicck in their growth. If it be a 1-light box, both back and front may be lined at the same time, and, if necessary, in 10 or 12 days, the two sides; and if much steam arise from the linings after they come into heat, be careful in matting at night, to tuck up the edges of the mat, lest it be thrown into the bed." Mills, as soon as the sced-leaves of the plants are fully expanded, transplants them singly into pots of 48 th size, gives a little water and air night and day. His temperature for scedlings, as already stated, is from $65^{\circ}$ to $75^{\circ}$. With this heat and water, as the eartl in the pots becomes dry, and a little air night and day, so as to keep the internal air in the frame sweet, and fluctuating between the degrees of heat above mentioned, the plants will he fit for finally transplanting ont in a month, that is, by the 14th of November, into the fruiting-frames.

Forming the fruiting bed.-A bercrombie directs, "When the plants are advancel in some tolerable stocky growth, that is, when the first rongh leaves are 2 or 3 inches broad, or when the plants have been raised about five weeks, transplant them to the larger hot-bed, with a 2-light or 3-light frame, sometimes called the ridging-out-bed." Form the bell on general principles, of superficial extent, according to the frame it is to support, leaving from 4 to 6 inches all round, and fixing the height according to the season. Thus in January, Abercrombie directs "the bed to be 3 feet 9 inches high in front, 4 feet 6 inches at the back, and 6 inches larger than the frame all round. In February,
3 feet 3 inches high at the front, 4 feet at the back, and 4 inches to spare round the frame. In March, 3 feet ligh in front, 3 feet 6 inches at back, and 4 inches beyond the frame every way." "Put on the frame and glasses presently after the body of the dung is built up, to defend it from the weather. At the same time raise the glasses a little at the upper end, in order both to draw up the heat sooner, and to give vent to the rising steam, until the bed is reduced to a regular temperature. In connection with the thermometer, the cultivator may be assisted to form a judgment of this by trying sticks, that is, 2 or more sharppointed smooth sticks, thrust down in different parts of the bed, which at intervals may be drawn up, and felt by a quick grasp of the hand. The smell of the vapour is also a criterion; it should not be strong and fetid, but mild and sweet. While taking care that the heat is not so intense as to burn the mould when applied as below, let it not be suffered to evaporate unnecessarily by delay. If the temperature appear to be not sufficiently high, take off the frame, and add another course of dung." M'Phail, when he fruits the cucumber on dung beds, begins to make preparation for the fruiting-bed, about 3 weeks before the plants are ready to be planted for good. The dung collected, after being well worked, is " made up into a bed of about 4 or 5 feet high, and the frames and lights set upon it. It is afterwards suffered to stand for a few days to settle, and until its violent heat be somewhat abated; and when it is thought to be in a fit state for the plants to grow in, its surface is made level, and a hill of mould laid in just under the middle of each light, and when the mould gets warm the plants are ridged out in it. After this, if the bed has become perfectly sweet, and there be heat enough in it, and the weather prove fine, the plants will grow freely." Nicol builds his fruiting-bed about 4 feet high in front, keeping it fully a foot broader than the frame all round. He turfs it, and lays on sand as in forming the seed-bed, if the dung has not been well fermented. "But otherwise, placing a thick round turf, a yard over, in the middle of each light, so as that its centre may be exactly under the plants, will generally be found sufficiently safe." The frames are now put on, and the beds matted up at night to make the heat rise the sooner. Mills says, "Well preparing the dung is of the greatest importance in forcing the cucumber, and if not done before it is made into a bed, it cannot be done after, as it requires turning and watering to cause it to ferment freely and sweetly; fresh dung from the stable will require at least 6 wecks' preparation before it will be fit to receive the plants. $\Lambda$ month before it is made up into a bed, it should be laid up into a heap, turned three times and well shaken to pieces with a fork; and the outsides of the heap turned into the middle and the middle to the outsides, that the whole may have a regular fermentation, and if any appear dry, it should be made wet, keeping always between the two extremes of wet and dry. A dry spot of ground should be chosen to prepare the dung on, that the water may drain away from the bottom of the heap. The dung baving been a month in heap, I make the betl as follows: I form a stratum one foot high of wood of any kind, but if larger the better (old roots of trees or any other of little value will do). This is to drain the water from the bottom of the bed, for after a month's preparation, with every care, it will frequently heat itself dry, and require water in large quantities, which, if not allowed to pass off freely, will cause an unwholesome steam to rise, in which the cucumber plant will not grow freely. On this bottom of wood, I make the bed 4 feet high with dung, gently beating it down with a fork. This is done about the lst of November, and by the month of February the 4 feet of dung will not be more than 2 feet thick, which, with a foot of wood, at the bottom, will make the bed $s$ feet high. This I consider a good height; for if lower, it cannot be so well heated by linings, which is the 
only method of warming it in the months of Fehruary and March, as by that time the first heat of the bed will have quitc declined. Having made the bed, I put on the frames and lights, which I shut close till the heat rises. I then give air night and day, sufficient to allow the steam to pass off, and once in 2 days I fork the surface over, about 9 inches deep, to sweeten it, and if in the operation I find any part dry, I earefully wet it. The bed being quite sweet, I prepare it for the mould, by making the middle about 8 inches lower than the sides, as the sides are liable from the weight of the frames to settle farther than the middle, which often causes the hills of earth to crack, by which the roots of the plants are greatly injured."-Mills ex Loud. encycl. gard. p. 632.

Moulding.-_" As soon," Abercrombie observes, "as you deem the bed to have a lively, safe, well-tempered heat, which may be in a week or 10 days after building, proceed to mould it. Earth the middle of each light, laying the mould so as to form a little hill from 6 to 10 inches in leight, according as seed is to be sown, or plants from the seed-bed inserted. Then earth over the intervals between the hills, and the sides of the frame only, from 2 to 4 inches, as a temporary measure, until the heat is ascertained to be within safe limits. After the whole bed has been for some time covered, examine the mould; if no traces of a burning effect appear discoverable by the mould turning of a whitish colour, and caking, it will be fit to receive the plants. But if the earth appears burnt, such part should be replaced by fresh, and vacuities made to give vent to the steam, by drawing every part of the hills from the centre. When the bed is in fit order, level the mould to 6 inches deep to receive the seeds; but to receive plants in pots the hills of earth should be liept 10 inches deep or more. If there be any motive for haste, while an excess of heat is to be suspeeted, the danger from burning may be obviated by leaving vacancies in the top of the mould; by placing patches of fresh cow-dung or decayed bark to receive the pots of seeds or plants; and by boring holes in the bed with a round pole, sharpened at the end, which holes should be filled up with hay or dung when the heat is sufficiently reduced. Some persons place a layer of turf with the sward downwards between the dung and the mould; but this, if ever expedient, is only in late forcing; for in winter the full effect of a sweet welltempered heat is wanted, much of which, by being confined at the top, may be forced out at the sides." M'Phail, in moulding common hot-beds, also raises hills in the centre of each light in the usual way. Gard. rem. p. 51. Nicol gathers up from the surface of the beds a sufficient quantity of earth to raise hills whereon to plant; one exactly in the middle of each light, about a foot broad at top, and to within 6 inches of the glass. If the frames be a proper depth, they should be 12 or 15 inches high above the turf. Kal. p. 365. Mills puts under the centre of each light one solid foot of earth, the top of which is bardly within 9 inches of the glass, and the top of the plants when planted in it will be within 3 inches of the glass.

Planting out.-Abcrcrombie, when the temperature is ascertained to be right, brings the plants in their pots ; turns over the hills of mould, forming them again properly, and then proceeds to planting. "Turn those in pots clean out, one pot at a time, with the ball of earth whole about the roots, and thus insert one patch of three plants which have grown together, with the ball of earth entire, into the middle of each hill, earthing them neatly round the stems. Also any not in pots, having been pricked into the earth of the bed if required for planting, may be taken up with a small ball of earth, and planted similarly. With water warmed to the air of the bed, give a very light watering about the roots, and shut down the glasses for the present, or till next morning. Shade the plants a little from the mid-day sun a few days till they have taken root in the hills, and cover the glasses every evening with large mats." Nicol, before planting, if the beds lave settled anywise unequally, rectifies and sets level the frames, by placing boards, slates, or bricks under the low corners, so as to make them correct. He then makes up the outsides of the bed with dung a few inclies ligher than the bottoms of the frame, over which he lays some dry litter or fern fronds, and planks at top to walk on. He then takes the pots of plants, each of which are supposed to have got two or three rongh leaves, and making a hole in each hill, full large enough to receive the balls, turns them out of the pots as entire as possible, placing them level with the surface of the hill, fitting the earth round their sides, and settling all with a little water. In the case of planting older plants than the above, at a farther advanced period of the season, or such as have quite filled the pots with their roots, the balls may be reduced a little, and the fibres should be singled out, if anywise matted. But the above plants are supposed to have barely filled the pots with roats, and then the balls should be kept entire, that they may not receive a check in transplanting.

Teniperature for fruiting plants.-A bercrombie's minimum is $55^{\circ}$, and maximum in the day time $65^{\circ}$, the same as for the secdbed. M'Phail says, "It appears that during the winter and spring months the medium heat of the air in the frames should be $75^{\circ}$, and the maximum heat $80^{\circ}$. But when the sun shines the heat of the air in the frames is increased to a much higher degree; so that reckoning this heat, the medium for that of the air in the frames may be $80^{\circ}, "$ Gard. rememb. p. 59. Nicol's medium leat for cucumbers is $60^{\circ}$; in sunshine he admits as much air as will keep down the thermometer to $65^{\circ}$. Kal. p. 366 . Mllls, in the fruiting frames, wishes "to have at all times from 70 to 80 degrees of heat, which I regularly keep up by applying linings of hot dung, prepared one month previously, in the same manner as that for the beds. For the first month I cover the glass with a single mat only; and as the nights become cold, I increase the covering, using hay, which I put on the glass, and cover that with a single mat. I regulate the heat at night by the warmtl of the glass under the hay, for when the glass is warm, which should be in two hours after covering up, a little air is required. When the glass and hay covering are warm, which is easily known by putting the hand under the hay on the glass light, the internal lieat of the bed will be about 78 degrees, in which degree of heat the eucumbers have grown in length in 16 hours one inch and a quarter. I give a little water round the insides of the frames, as often as I find them dry, which causes a fine steam to rise, and I think it better than watering the mould, for if this latter practice is often repeated in winter, when the sun's power is insufficient to absorb the moisture, and the glasses can be but little open to allow the damp to pass off, the earth in a few weeks will lose its vigour, and the roots of the plants will perish. Great care should also be taken, at this season, not to injure the roots by too much heat, which is not less detrimental than too much moisture: they can only be secured by keeping up a regular warmth, just sufficient to expel the damp, which arises in the night from the fermenting dung."

Linings. - The requisite degree of heat, $A$ bercrombie is careful to support in the bed when declining, " by timely linings of hot fresh dung, which may be applied to the sides 15 or 18 inches in width, and as high as the dung of the bed. Generally line the back part first, and the other in a week, or from 10 days to a fortnight after, as may seem necessary by the degree of lieat in the bed. Sometimes if the heat has fallen abruptly below the minimum degree, it may be proper to line both sides moderately, at once to recover the temperature sooner, and with better effect; but be particularly carcful never to over line, whicls would cause a too violently renewed heat, and stcam in the bed. The dung for linings must be fermented, as in first D 2 
building a bed." When the heat decreases, Nicol cuts away the old dung perpendicularly by the frame, and adds new linings, (generally beginning with the back first,) 2 feet broad to the lieight of 6 inches about the botton of the bed frame. As it will sink considerably in heating, he adds to it in a few days. Mills applies linings of hot dung prepared a month previously.

Covering.-This must be nightly performed till June, proportioning the warmth of the cover to the heat of the air in the bed, and that of the external air. Mats are laid next the glass; on these a layer of hay, and over these mats, made fast by boards, but not hanging over the linings, is the usual mode, early in the season. M'Phail says, "My method of covering up was as follows: in the first place I laid clean single mats on the light in length and breadth, just or nearly to cover the sashes, taking care not to suffer any part of the mats to hang over the sashes, on or above the linings, for that would be the means of drawing the steam into the frames in the night time. On these mats was spread equally a covering of soft hay, and on the hay was laid another covering of single mats, upon which were laid two, or sometimes three or four rows of boards, to prevent the covering from being blown off by the wind. The mats laid on next to the glass are merely to keep the seeds and dust, which may happen to be in the hay, from getting into the frames among the plants. If the bed be high, in covering up steps or short laclders must be used by those whose office it is to cover and uncover; and great care must be taken not to break or injure the glass."

Air.-Abercrombie directs to "admit air every day when the weather is moderate, without much wind; and always more freely on sunny days, than when cloudy or cold and frosty. Open the lights behind, only a little at first, sooner or later in the day, according to the temperature of the season; increasing the opening from about half an inch to 1,2 , or 3 inches, or very little more (decrease the opening occasionally, if the weather in the early part of the season changes very cold); and shut close in the same gradual order towards afternoon, generally shutting close in the evening, unless in the early state of the bed, a considerable heat and steam continues. In this case you may occasionally leave open about half an inch, hanging the end of the mat before each openin." M'Phail says, "A cucumber plant delights in a strong heat, and in sweet wholesome air ; but if the air in which it grows be contaminated, unhealthy, or im. pure, the plant will not continue long in a healthy flourishing condition. Whatever is disagreeable to the smell becomes in time hurtful to the cucumber plant; therefore whoever would wish to know if the air in a cucumber frame be in a healthy nature for the plants, should smell to it." He adds, in giving and taking away the air, do it gradually, that is, by little and little at a time, which without donbt is the best way: for sudden changes are always attended with unpleasant consequences. A due proportion and continual supply of fresh air is at all times necessary, and more or less is required according to the heat of the linings, the temperature of the weather, and the thickness of the coverings put on at nights. Gard. rememb. p. 42. Nicol admits air regularly in as large portions as the state of the weather will allow, being careful to let off rank steam, if it abound, by leaving a tilt, even in the night. Mills says, "My usual time of giving fresl air to the frames, and permitting the foul to escape, in the winter months, (that is, from the middle of November to the middle of February,) is as follows: between 8 and 9 in the morning I raise the lights, and let the confined air pass off, shutting them again; about $10 \mathrm{I}$ give a little air; at 11 more; at one 1 lower the lights a little, and between 3 and 4.1 close them entirely. About two hours after the covering of hay has been put on, I give a little air for the night. Should the weather be changeable, the lights must be raised or lowered more or less, as circumstances may require; but some air about the times of the day above mentioned is absolutely necessary to keep the plants in a free growing state."

IVater.-Give necessary waterings with water warmed to the air of the bed, mostly in the forenoon of a mild day, in early forcing; and in the morning or afternoon in the advanced season of hot sunny weather."-Abercrombie. M'Phail says, "The quantity of water requisite to be given to the plants depends upon the heat of the bed, the strength and age of the plants, and also on the temperature of the weather. When the weather is cold, wet, and gloomy, and the air moist, they require less water than when the weather is clear, and the air more dry. If too much water be given, or if water be given too often, it will hinder the fruit from setting and swelling kindly; and if too little water be given, the plants will grow weak, and the fruit hollow. I seldom watered the plants with water warmer than $85^{\circ}$, nor colder than $65^{\circ}$; although in general I tried by the thermometer the warmth of the water I used, yet it is not necessary so to do. A good way to know if the water be of a proper temperature is to take a mouthful of it, and when it feels neither hot nor cold, then it is in a fit state for accelerating the growth of the plants, or for making them grow fast. I made a constant rule never to water the plants but with clean sweet water; and if the water be clean and sweet, I am of opinion it makes little or no difference whether it be pump water, spring water, rain water, or river water. However, it is a good quality in water to bear soap, and make a lather therewith, which rain and river water readily do; but the pump and spring waters are found too hard to do it, yet this may easily be remedied in them, by letting them stand a few days in the open air, and sun's rays. With regard to the time of the day in which the watering ought to be performed, I think it is not material, nor did I ever make any rule with respect to the time, but gave them water at any hour of the day, when I saw they stood in need of $\mathrm{jt}$, and when it best suited my conveniency. Those who have hot-houses may get their water warmed there, and those who bave no hot-houses may get some from the house, or from some other place where water is frequently heated. One gallon of lot water will properly water several gallons of cold water." Tate says " in spring and in the summer months the water may be warmed by exposure to the rays of the sun." Nicol airs his water "by some means or other ;" waters once in two or three days after planting, and liberally from the rose of the watering pot as the plants advance. The time chosen is the afternoon about 4 or 5 o'clock, in order not to scorch the plants, which, he says, often happens, when, after morning waterings, the sun's rays suddenly dart on the plants. Kal. p. 366-395. J. Mearns, already mentioned, uses water impregnated with sheep's dung, as does Mr. Knight. Mearns tried this water first " on some cucumber plants in the pine stove, which had been planted in January, but which in consequence of dull weather had become weak, and of a pale green colour; he applied the liquor to the roots, and in a few days a great change in the appearance of the plants was produced; the foliage assumed a hardy green, the shoots acquired an unusual degree of strength, with short joints, and although the stove had scarcely any air given to it, yet the fruit swelled rapidly, and attained a large size." These plants continued in bearing till May, and were then cut back to within 6 inches of the root, when they started again with vigour. "No water was ever given over the leaves, but a continued supply of the liquid pigeon-dung manure to the roots." Mearn. ex Loud. ency. Gard. p. 635. For Mills's practice as to watering see his process under temperature.

Earthing.- " Observe," says Abercrombie, " in proper time when the first lieat of the bed is moderate, to begin adding more earth between the hills, as the extending roots require to be 
covered, or the runners to be supported with mould; raising it by degrees equal with the tops of the hills, all in level order from 8 to 10 inclies thick." Pract. Gard. p. 72. Nicol, "by the time the plants have sent out runners, and the roots spread quite over the hills, enlarges them; beginning by stirring up the earth in the other parts of the frame to its full depth with a hand-fork or weeding-iron, breaking it fine if anywise caked by the heat. To this add fresh mould, sifted or finely broken, and in a dry state, so as to raise the surface nearly to the level of the hills; laying it in a sloping manner from back to front. Previously he rectifies the position and level of the frames, and raises them so that the glass may be eight or nine inches above the mould in the centre." Kal. p. 367.

Training.-To force the cucumber into early fruit, Abercrombie directs to "stop the runners as soon as the plants have made two rough leaves; as the bud that produces the runner is disclosed at the base of the second rough leaf, it may be cut off or picked out, or if the runner has already started it may be pinched off close. This is called stopping at the first joint, and is necessary for a stronger stocky growtl, and an emission of fruitful laterals; and from these other prolific runners will be successively produced. The vines, without the process of stopping, would generally be both weaker, and so deficient of fertile runners, that they would sometimes extend 2 or 3 feet without showing fruit. When plants which have been once stopped have extended the first runners to three joints without showing fruit, they are to be again stopped for the purpose of strengthening the plant, and disposing it for bearing. As fertile runners extend, train them out regularly along the surface, fastening them down neatly with pegs." M'Phail stops his plants when they have two joints; and "when the plants shoot forth again after the second stopping, they seldom miss to sliow fruit at every joint, and also a tendril ; and between the tendril and the showing fruit, may clearly be seen the rudiment of another shoot, and when the leading shoot has extended itself fairly past the showing fruit; so that in pinching off the tendril and the shoot, the showing fruit is not injured. This stopping the leading shoot stops the juices of the plant, and is the means of enabling the next shoot (the rudiment of which was apparent when the leading shoot was stopped,) to push vigorously, and the fruit thereby also receives benefit. When the plants are come into bearing, if the vines are suffered to make two joints before they are stopped, at the first of these joints, as I before said, will be seen show ing fruit, a tendril, and the rudiment of a sloot; but at the second joint there is seldom to be seen either showing fruit or the rudiment of a shoot; but only a tendril, and the rudiments of male blossons. It is therefore evident, and but reasonable, that the shoot shonld be stopped at the first of these joints; for were the shoot to be let run past the first joint, and stopped before the second, perhaps no shoot would ever spring forth at the said second joint, but only a cluster of male blossoms or leaves, wlich would serve for no good purpose, but would rather exhaust the juices of the plant, which ought to be thrown into the productive parts of it. If the plants are suffered to bear too many fruit, that will weaken them, and in such case some of the shoots will lose their leaders, that is, the rudiments of some of the shoots will not break forth, the numbers of fruit having deprived them of their proper share of the vegetative juices. The rudiments of some of the shoots may also be injured by accident, which sometimes prevents their pushing; but from whatever cause this happens it matters not, for by the losing of its leader the shoot is rendered unfruitful, and therefore should be cut entirely off. In tlie course of the spring and summer months, several shoots break forth here and there from the old oncs. When too many break out, cut off the weakcst of them close to the old shoots, and those which remain, with re- gard to stopping, serve nearly in the same manner as young plants. If the old shoot from which the new one bursts forth lie close to the moulds, it sometimes sends forth roots from the same joint from which the young shoot proceeded, by which the young shoot is much invigorated, and the old plant in some ineasure renovated. When this young plant is fairly formed on the old shoot, it somewhat resembles a young plant formed and struck root on a strawberry runner; and if the shoot were to be cut off on each side of the newly formed plant, and no part of the plant left in the frame but itself, by proper treatment it would soon extend itself all over the frame. In winter, when the plants are young, and before they come into bearing, it sometimes happens that they send forth too many shoots; in that case, cut the weakest of them off, not suffering them to become crowded and thick of vines, for tliat would weaken, and prevent the plants from bearing so early as they ouglit to do. Keep the leaves of the plants always regularly thin. The oldest and worst of them cut off first, and cut off close to the shoot on which they grow. This is necessary and riglit, for if any part of the stalk of the leaf were to be left, it would soon putrify and rot, and perliaps destroy by damp the main branch from which it proceeded." Nicol. "Cucumber plants will put out runners or vines, whether the heart-buds be jicked out or not, which is a matter of trivial concern, although much insisted on by some, as being necessary to their doing so at all. For my own part I never could discover any difference, and I have repeatedly made the coniparison in the same bed, which otherwise of course could not be fair. When the vines have grown to the length of 4 or 5 joints, and if fruit appear on them, they may be stopped at one joint above the fruit; but otherwise, they may be allowed to jun the length of 7 or 8 joints, and may then be stopped, which will generally cause them to push fertile shoots. These should be regularly spread out, and be trained at the distance of 8 or 10 inches apart."

Pruning and training cucumber plants.-W. P. Vanghan, (Gard. mag. 7. p. 462.) considers the productiveness of cucumber plants as depending principally on pruning, and the age of the seed; his system of management is therefore as follows. As he saves a few seeds annually he has always some three years old; these he sows in shallow pans in a dung heat not under $70^{\circ}$, and by the time the plants have spread their seminal leaves, lie has soil and 32-sized pots ready dried in the frames, and plants them so as they will just reach over the rim of the pot when planted 3 or 4 in each pot, making them form a triangle or square; he then fills the pots to within half an inch of the tol', waters them, and keeps them in a brisk heat of from $65^{\circ}$ to $75^{\circ}$ And as soon as they have spread their first rough leaves, lse picks out the leading bud from each plant close to the second leaf, and in a few days afterwards each plant will put forth two shoots, and they are ready for plunging in the hills without breaking the balls of earth, that is, one potful in each hill. When the lateral shoots have made two joints, they must be stopped at the second as before, and pegged down with a piece of straight stick, 6 inclies long, broken half through in two places, so as to form a square. Each shoot will now produce two more, which never fail to show fruit at the first joint, and must be stopped at the second, which operation must be done to all as they make two joints. Picking off the male blossoms and setting the fruit, as they open, should be done in the morning just before the sun comes strong on the frames, until the weather will admit of the lights being open a great part of the day ; watering should also be performed at the same tins, shutting the frame close for a few minutes after. Cuttings taken from the tops of the shoots about 4 inches long, and planted in a pot deep enouglı to admit a flat pane of glass on the top, will strike freely, and these plants so produced will come into bearing 
sooner than those raised from seeds, but they are not of so long duration.

Upright training.- "Cucumber plants being climbers by means of their tendrils, some branchy sticks being placed to any advancing runners, they will ascend and produce fiuit at a distance from the ground, in a clean growth, free from spots, and well flavoured."

Setting the fruit. - "The cucumber," Abercrombie observes, "bears male and female blossoms distinctly on the same plant. The latter only produce the fruit, which appears first in miniature, close under the base, even before the flower expands. There is never any in the males; but these are placed in the vicinity of the female blossoms: the fruit of which will not otherwise swell to its full size, and the seeds will be abortive. The early plants under glass, not having the full current of the natural air, nor the assistance of bees and other winged insects, to convey the farina, the artificial aid of the cultivator is necessary to effect the impregnation. At the time of fructification watch the plants daily; and as soon as a female flower, and some male blossoms are sufficiently expanded, proceed to set the fruit the same day, or next morning at farthest. Take off the male blosson, cletaching it with part of the foot-stalk. Hold this lietween the finger and the thumb; pull away the flower leaf close to the stamens and anthers, which apply close to the stigma of the female flower, twisting it a little about, to discliarge thereon some particles of pollen or fertilizing powder. Proceed thus to set every fruit, as the flowers of both sexes open, while of a lively full expansion, and generally perform it in the early part of the day, using a fresh male if possible for each impregnation, as the males are usually more abundant than the female blossoms. In consequence the young fruit will soon be observed to swell freely. Cucumbers attain the proper size for gathering in about 15,18 , or 20 days from the time of setting, and often in succession for 2 or 3 months or more in the same bed by good culture. The above artificial operation will be found both necessary and effectual in forcing the cucumber, between the dechine of autumn and May, while the plants are mostly shut under glass. In plants more fully exposed to the free air, in the increasing warmth of spring, and in having the full open air in summer, from June and July till September, the impregnation is eflected mostly or wholly by nature. The male flowers being by some ignorantly denominated false blossoms, are often plucked entirely off as useless, under the notion of strengthening the plant; but this should not be generally done. Where crowded too thick in clusters, some may be thinned out moderately; but their agency being absolutely necessary in fertilizing the females, they should only be displaced as they begin to decay, except where they are superabundant."- "It is the female blossoms of flowers," M'Phail observes, "that bear the fruit; but if they were not to be impregnated by the male flowers they would prove barren and unfruitful. The female blossoms are easily to be distinguished from the male ones, for the rudiment of the fruit is apparent at the bottom of the female flower, and the flowers have no stamina, but have three small pointed filaments, without summits; whereas the male blossoms lave not any rudiment of fruit about them, but in the centre of the flower are three short stamina, which are inserted in the corolla. When the female or fruit blossoms are in full blow, take the male blossom which is in full blow, and holding it in one hand, with the other split and tear off the corolla, taking care not to part the stamina or male parts. Then hold the male blossom thins prepared between the finger and thumb of the right hand, and with the left hand gently lay hold of the female blossom, and holding it between the two fingers, put the prepared male blossom into the centre of the female blossom, and there the farina or pollen of the anthers clings or sticks to the stigmas, and thus the impregnation of the fruit is effectuated, and the plants are therelsy rendered fruitful, which, being in frames in a climate by art made for them, would otherwise in a great degree be rendered barren and unproductive; and which I have frequently known to have been the case, even when at the same time the plants were in a vigorous flourishing state. Generally leave the prepared part of the male blossom sticking in the centre of tlie female one, and take a fresl male blosscm to every female blossom. But if the male blossoms run scarce, which seldom or never happens, make one male blossom do for two or three females." Nicol states, that cucumbers will grow and will arrive at full size without the female flowers bcing impregnated : the seeds, however, will prove abortive. The directions he gives for impregnating are in substance the same as those of M'Phail. The fruit being set and swelling, some lay fragments of glass or slate beneath it in order to keep it clean, and to admit as much air and light as possible to the under side, so as to cause its approach in greenness to the upper.

On keeping a fine bloom on cucumbers.-The art of producing and keeping a fine natural bloom on cucumbers, either for a gentleman's table for show, or for the market, merits great attention, both as to the perfect appearance of the fruit, and also to the general culture of the plant, after the fruit is set. From that time a strong bottom heat should be given with dung linings; or, if late in the spring, slort grass laid round the frame on the dung, will cause a very strong heat. Water ought then to be given plentifully, always at the back part of the frame; and at no time should the plants be watered over their leaves, when the fruit is wanted for its fine dclicate bloom and long regular shape. A fine foliage over all the bed is likewise a very essential point; and leaves should never be picked off near the fruit, as it thereby deranges the juices of the plant, and consequently the fruit does not swell off finely. Air also shonld be given very sparingly in the middle of the day, even in bright sunshine, and generally there slould be a little left in the night, when the bottom heat is very strong, as by that means the air in the frame is kept sweet. When the fruit is fit to eat, for any of the above purposes, great care should be taken to pack it in narrow wooden boxes, in the largest nettle-leaves that can be got, filling 11 ) the interstices with well-beaten moss, and covering over with soft leaves of any kind. It may then be sent to a great distance with a fine bloom, and, upon the whole, in a perfect state.Geo. Fulton, ex Loud. gard. mag. 6. p. 709.

Gathcring the crop.-Cucumbers are used green and unripe, and before they have attained their full size. They are cut and gathered when $4,5,6$, or 8 inches lon, according to the kinds. To this size they attain in 10 days or a fortnight in the best part of the season.

To sarc sccd.—" Select some best summer fruit, from good productive plants, which permit to continue in full growth till they become yellow. Then cut them from the vine, and place them upright on end in the full sun for 2 or 3 weeks, when they may be cut open, and the seed being washed out from the pulp, spread it to dry and harden; then put it up in papers and bags for future sowing. It will remain good many years; and seed of 3 or 4 years' keeping is preferable for early frame crops."

On forcing cucumbers.-In growing cucumbers under lights, " the most obvious defects," according to Mr. Allen, " are compost of too light a quality," and "dung not sufficiently worked before it is earthed over." Mr. Allen has been in the habit of growing early cucumbers under frames, on common dung-beds, for twenty years, always producing abundance of fruit from March till October. In 1823 he worked 70 lights for the London market, the produce of which was 3360 eucumbers, or 4 dozen to a light, "a greater product than is usually obtained 
by any of the ordinary methods of treatment." The beds are made in December or January, the hot horse-dung having been previously turned and watered 5 or 6 times. Before earthing it, round flat mats, about 15 inches in clameter, formed by coiling up a band of straw, 1 inch in diameter, and 10 feet long, are to be prepared and placed on the dung, under the centre of each light. Rye straw is preferred for these mats, as it does not encourage mice. A bushel of compost, consisting of loam and rotten dung, is placed on each mat, and 1 plant in preference to more, on the top of each hillock; the top of the plant should be left about 3 inches from the glass; the mould should then be dressed up round the hillock, and be pressed close to the roots, and within 1 inch of the seed-leaves of the plant; these, at no time of earthing, slould be covered, for this is very apt to cause canker. The earth should be kept within the bounds of the straw mat, and not be suffered to mix with the dung, as that would cause a burning, which is not only troublesome, but in many instances fatal to the prosperity of the plant; because if the earth is once burnt, its vegetative quality is destroyed, and water will have no effect on it. The only remedy in such a case is to remove the mould, fork up and water the dung, lay on a little rye straw, and replace the earth. After ridging out, from one quarter to one inch of air is given in the day, and about one quarter during the night. The covering must be very slight for the first 3 or 4 weeks, and must not hang over the sides. "The heat must be kept up by augmenting the linings once a-week, turning over and watering them when they heat so as to become dry. The bed inside the frame will require forking up about 9 inches deep, 3 times aweek; the hillocks at the same time should be examined, and a round pointed stick, of about an inch in diameter and 18 inches long, must be thrust about 12 inches in the dung, under the straw mat, making 5 or 6 perforations under each hillock. Into each of the holes so formed, pour from the spout of a watering-pot as much water as the state of the bed seems to require; this may be ascertained from the facility with which the perforator goes into the bed. If the bed is husky or burning, the stick will go in with difficulty, and then a large pot of water is required to a hillock; on the contrary, if the bed is in a free state of working, the perforator will go into it very easily, and then a sprinkling from tlie rose of the pot will be sufficient." A great object of Mr. Allen seems to be to sweeten, rot, and moisten the dung under the frame for the roots of the plants, while the heat is principally supplied by the linings. "The dung," he says, "from the continued forking and watering, will become in a fine state to receive the roots of the plants; these, after passing through the proper depth of compost, placed over the dung, which is about 8 inches, will readily strike into the dung, and bear a productive crop of cucumbers thronghout the summer, withont their leaves flagging or requiring any shade. For ascertaining the proper periods to make additions to the earth, the best criterion is the appearance of the roots tlurough the sides of the hillock. This should be earthed over about 3 inches, each time forking out the dung 2 inches below the mat, to give a greater depth of earth each time of performing the operation. The last time this is done, the depth of mould at the back of the frame should be 20 inches. It will be necessary to raise the frame and lights as the plants advance in growth." Water should be given plentifully 3 times a-week, without wetting the leaves or fruit, "pouring it against the back of the frame, for the mould will dry faster against the back than the front, in consequence of the heat being there greater, and the air being admitted there." "In pruning, the runners should not be cut or thinned out, the tops only should be pinched, and at every joint, beginning where the plant has 2 rough leaves, and the second rough leaf is about an inch in diameter. That will cause the plant to produce fruit and a fresh runner in succession at every joint ; it will likewise add to the strength of the plant." Pinch off the tendrils and male blossoms, and fecundate artifieially in the carly part of the season. The sort of cucumber which Mr. Allen finds most productive is the Southgate, and he prefers seed 3 or 4 years old to new seed.-Loud. gard. mag. vol. 1. p. $4.16,417$.

Insects and diseases. - The thrips sometimes attack early c1cumbers, and are to be destroyed by fumigation. The red spider rarely makes its appearance; when he does water must have been improperly withleld. Some soils produce canker in the shoots, especially where they branch from tle main stem. When this is the case, the only resource is to renew the soil and the plants.

Growing the cucumber under hand-glasses.-The following method is given by M'Phail as that generally practised: "The seeds are sown some time about the middle of April in a cucum. ber or melon-bed, and when they come up, they are potted out into small pots, 2 or 3 plants in each pot, and are kept properly watered, and stopped at the first and second joints. About the middle of May, a warm situation, where the mould is very rich is pitched on, and a trench is dug out about 2 feet deep, 3 feet broad, and the length is proportioned according to the number of glasses it is intended for. This trench is filled with good warm dung, and when the dung has come to its full heat, it is covercd over with 8,10 , or 12 inches' depth of rich mould. The glasses are then set upon it about 8 feet distant from each other, and when the mould gets warm under them, the plants are turned out of the pots with their balls whole, and plunged into the mould under the glasses, and a little water given them to settle the mould about their roots, the glasses set over them, and after they have made roots, and begin to grow, in fine days the glasses raised a little on one side, to let the plants have the free air; and as the weather gets warmer and warmer, air is given more plentifully to harden the plants, so that they may be able to bear the open air and run from under the glasses. When the plants begin to fill the glasses, they are trained ont horizontally, and the glasses are set upon bricks or such like, to bear them from the plants. After this the plants require nothing more but to be supplied with water when the summer showers are not sufficient, and to stop them when they run too thin of branches, and thin them of leaves or branches when they are likely to become over-crowded. In warm summers and in warm situations, by this mode of management, the plants will bear plentifully for about 2 months, provided they be not attacked by insects or weakened by diseases." A bercrombie describes the practice somewhat different, but with his usual detail and order. He says, "To have a general summer crop, to fruit in hot-bed ridges under hand-glasses, sow some seed of the long prickly kind in a hot-bed, under a frame or hand-glass, or in any cucumber lot-bed in cultivation, about the middle of March, or thence till the middle of April. When the plants have been up 3,4 , or 5 days, prick some in the same or another hot-bed, 3 or 4 inches asunder. A portion may be put in small pots, 3 plants in each, and plunged in a bed. Give water, and shade from the sun till they take root; and manage as for the frame crop. In 3 or 4 weeks, when advanced in the first rougl leaves, about 2 inclies loroal, and stopped at the first joint as directed in the early crop, the plants should be ridged ont, that is, transplanted into hot-bed ridges, under hand-glasses, to remain for fruiting. The period for this may fluctuate fiom the middle of April to the beginning of May. Having a suflieient quantity of prepared dung, make a hot-bed on the level ground, $3 \frac{1}{2}$ or 4 feet wide, and $2 \frac{1}{2}$ feet high, the length as required, according to the number of hand-glasses intended. Warth it at top 6 or 8 inches thick, and place the hand-glasses along the 
middle at $3 \frac{1}{2}$ feet distance. Sometimes the bed is made in a moderate trench, 12 or 15 inches deep, in some good soil in the kitchen-garden, in order to have the excavated earth of the trench ready at hand for moulding the bed. When the earth under the glasses is warm, proceed to put in the plants, removing them from the nursery-bed, with as much earth as will adhere ahout the roots. If you have any plants in small pots, turn them out with the ball entire, and plant 3 plants under each glass. Give a light watering; put down the glasses, and shade the plants from the sun, till they have taken root, after which let them enjoy the sun and light fully, only covering the glasses and bed every night with mats till June, or commencement of warm weather. Admit air every mild day, by propping up the soutliward side of the glasses 1 or 2 inches; moderate waterings will be necessary twice a-week or oftener. As the plants push runners of considerable length, train them regularly. When extended to the limits of the glasses, and when the weather is settled warm, about the beginning or midlle of Jume, they should be raised upon 3 props 2 or 3 inches ligh, and the runners trained out in regular order, but cover them on cold nights with mats, for the first week or two. Continue the glasses, and circumspectly water in dry weather, as may be necessary; the plants will produce fruit in June, July, August, \&c. in plentiful succession. To obtain a crop from hot-bed ridges, under handglasses, you may, in default of plants raised in a previous nursery-bed for transplanting, sow seed under the glasses in April or May, inserting several seeds in the central part under each glass. When the plants have been up a few days or a week, thin them to 8 or 4 of the strongest in each patch, managing them afterwards as the others. They will come into bearing towards the end of June or July, and thence to September. (Should there be a scarcity of dung to make a regular bed,) in the last week of April, or in May, you may dig circular holes 2 fect wide, a spade deep, and 4 or 5 feet asunder; fill them with hot dung, trodden down moderately firm, and carthed over 6 inches. In these put either plants or seed, and place on the glasses; the plants will produce fruit in June or July till September. (In default of hand-glasses,) make a hot-bed, or holes of dung, as above, in May; put in plants or seed, and defend with oiled paper frames, to remain constantly, day and night, till settled warm weather in Jume or July. Give the additional protection of mats over the paper frame in cold nights and bad weather. In the culture of all the crops, give proper supplies of water in dry warm weather, 2 or 3 times a-week, or every day in the hottest season of June, July, and August. In the lot-bed ridges, made above ground in April or May, if in 3 or 4. weeks or more after making, the lieat be much declined, and the nights or general season remain cold, let a motcrate lining of hot dung be ajplied to the siles, which will both throw in a reviving lieat, and widen the bed for the roots and runners of the plants to extend."

Cultitation of the cucumber in a flucd pit.-Nicol says, "Those who would have cncumbers on the table at Christmas (a thing sometimes attempted), will find it more practicable, and less troublesome, if the plants be grown in a flued pit, in the manner of late melons, than if they be grown in a common hot-hed. In this case the cucumbers should take place of the melons planted in this compartment in July, and which will, by the middle or end of the month, lave ripened ofl all their fruit of any consequence. The sceds of some of the early sorts (those best for early being also best for late) should be sown in small pots about the first of the month, and should be placed in the pit along with the melons, or under a hand-glass, on a slow dung lieat; where let the plants be nursed, and be prepared for planting alout the second or third week in the month, as hinted at above. Observe to sow old seeds, not those saved this season, which would run more to vine than to fruit. Let the pit be prepared for their reception, by trenching up the bark or dung, and by adling fresh materials, in so far as to produce a moderate growing heat; observing the directions given for preparing the pit for the melons in July, and moulding it (however with proper cucumber earth) all over to the depth of a foot or 14 inches. The plants may be placed closer in planting them out than is necessary in a spring hot-bed. They may be planted at the distance of a yard from each other, and 2 rows lengthwise in the pit, as they will not grow very vigorously at this late season. They should be moderately supplied with water once in 4 or 5 days, and should always be watered over the foliage, the more especially when strong fire-heat becomes necessary, as cucumbers naturally like a moist rather than a dry heat. The temperature should be kept up to about $64^{\circ}$ or $65^{\circ}$ in the night, by the aid of the flues, and by matting, or otherwise covering the pit. Air should be as freely admitted as the state of the weather will allow, and so as to keep the mercury down, in sunshine to about $70^{\circ}$. The plants will require little other pruning than to stop the vines, as they show fruit at the joint or two above it ; for they will not pusl many superfluous shoots. $\mathrm{Ob}$ serve to pick off all damped leaves as they appear; and otherwise carefully attend to them, as above directed, while they continue to flourish, or to do any good worthy of such attendance."

Cultivation of the cucumber in M'Phail's brick-bcd pit."When I used," observes IIPhail, " to cultivate cucumbers on a dung-bed, the fruit were sometimes watery and ill-tasted; but after I began to cultivate them on a brick bed, the fruit were constantly firm and well flavoured, which is certainly occasioned by the goodness and wholesomeness of the food with which the plants are fed or nourisherl." M'Phail's pit has many advantages over a common hot-bed: there is no clance of burning the roots of the plants in it, the linings being placed all on the outside, without any dung underneath the plants. "All the materials of my newly-invented bed are clean and sweet; and the fines being made perfectly close, no tainted or bad-smelling air can get through them into the bed; so that it is of little or no concern whether the dung of the linings be sweet or otherwise, or whether the linings be made of dung or of any thing else, provided tliere be a sufficient heat kept in them, and no pernicious stearn be drawn in among the plants by the current of air." A sheltered dry situation is of the first consequence for this pit. The bed being built, "when the frame is about to be set upon it, a layer of mortar is spread all round upon the upper course of brick-work, on which the bottoms of the frames are to rest. Thus the frames are set in mortar on the bricks; and the flues are, with a bricklayer's brush, well washed, and rubbed with a thick grout, made of lime and water, which stops every crack or hole, and prevents tlie steam of the linings from getting into the frames. This washing of the flues $I$ lad done once a-year, for no crack or hole must ever be suffered to remain unstopped in the flues. I found little or no trouble in keeping the flues perfectly close, nor is it indeed likely that they should become troublesome, if the bed stands on a sound foundation, for the heat of the dung has not that powerful effect on the flues, as fire-heat has on the flues of the hot-house ; because the licat of dung is more steady and not so violent as the heat of the fire, and, besides, the flues of a cucumber-bed are almost always in a moist state, which is a preventive in them against craeking or rending. When the bed is first built, the pits are about 3 feet in depth below the surface of the flues. The pits I had filled up about a foot high, some of them with rough chalk, some of them with small stones, and some of them with brickbats; this is to let the wet drain off freely from the mould of the beds. After this filling up with chalk, stones, and broken 
bricks, there is a vacancy in the pits, about 4 feet decp below the surface of the flues; this vacaney I lad filled to a level with the surface of the flues, with vegetable or leaf mould; and in putting it in, it was gently pressed, to prevent it from sinking too much afterwards. On the surface of the mould with which the pits were filled, under the middle of each light, and which is just in the centre of the mould in each pit: make hills of mould, in the same form as is commonly done on a dung-bed. These hills are to set the plants in, and are to be raiscd at first nearly close to or within a fow inches of the glass. Raising the mould at first pretty nigh the glass is necessary, on account of the siuking of it; for as the frames are set on bricks, they cannot sink ; but mould newly put in is sure to scttlc, and the measure of the settlement will ever depend upon the lightnes. and texture of the mould with which the pits are filled. Therefore, these and such-like matters must be left to the discretion of those who are intrusted with the direction and management of the frames. When the bed is thus finished, and ready for the reception of the plants, if the flues be strewed over with mould, so that their surface be just covered, to a stranger it is altogether a deception, for in every respect it has the appearance of a dung-bed. The sashes of the frames which I used were glazed in lead; but if any person who rears early cucumbers have lights which are not glazed in lead, but are slateglazed, the vacancies between the glass had best be filled up close with putty, to prevent too much air from getting into the frames in the cold days of winter. The frames under my management were constantly kept in good repair, and painted over once every year. This methot, I am clearly of opinion, is more profitable than if the frames were neglected for 2 or 3 years, and then hive a thorough repair, with 2 or 3 coats of paint. When frames are new painted, they should be suffered to lie and sweeten for some time, at least for 2 or 3 weeks, or until the disagreeable smell of the paint is somewhat lessened. Although the frames I used were of a very good size, yet if they were a little smaller or larger, they would answer the purpose very well. Therefore those who intend to build a bed after my plan, have no occasion to make new frames merely for the purpose, but they may get the bed built to fit the frames they are already in possession of. The linings are to be applied to the bed a few days before the plants are ready for finally planting out, in order that the mould and every thing in the frames may be properly warmed for their reception. The dung, of which the linings are to be made, may either be cast together into a heap, to bring it to a heat before it be laid round the bed, or it may be laid round the bed as it is brought from the dung-yard; but whichever of these methods be taken, when the linings are mahing up, the dung should be well shaken, and laid up lightly, so that the heat of it may come up freely. As it takes some days before the linings are able to warm the earth in the bed sufliciently for the reception of the plants, the rank steam of the new dung linings is evaporated, unless the dung came immediately from the stables, which seldom is the case. The linings are to be made nearly 3 feet broad in their foundation, and tapered up to about 30 inches at the top, by which they will retain their heat long, and in sinking will keep close to the bed, which is what should at all times be paid proper attention to. In the winter and spring montlıs, the linings should be trodden "1pon as little as possible, for treading on them would be the means of stagnating the heat. But slould it at any time, in managing the plants, be found necessary to stand or kneel upon them, boards should be laid on thcir tops for that purpose; which will prevent the weight of a person from taking that effect on them which it otherwise would do. As the linings sink they are to be raised with fresh dung, but they should seldom be raised higher than the level of the mould in the frames on which the voL, III.

plants grow, especially when there is a strong heat in them; for when there is a great heat in them, if they are kept higher than the level of the mould, the heat dries the air in the frames too much. Nor should they be suffered to sink much below the level of the mould in the frames, for that, on the contrary, would cause too much moisture in the frames, especially in the winter and spring montls. When the heat begins to be too little, notwithstanding the linings being kept to their proper height, the fresh unexhaustel dung underneath shoukl be taken away, and that which was laid aside put in the foundation, and fresh dung laid above it, in lieu of that which was carried away. Both the side linings may be raised at one time, but both of them should never be renewed together; for if both were to be renewed at the same time, it would for a time cool the frames too much, and when the heat of both came to their full strength, it would probably be too powerful to the roots of the plants when extended to the flues. 1 sellom or never renew the end linings, bccause 1 found the heat of the side ones fully sufficient; for as there are flucs or vacuities in every part of the bed, the steam being fluid, circulates in and warms every part thercof. And for the very same reason there is no occasion for having a strong heat in both the side linings at one and the same time, except in very cold weather. In making up and pulling flown the linings, care should be taken not to injure the brick-work. The covering the lights in the winter and spring is absolutely necessary ; for, notwithstanding the heat of the linings, it would be impossible to keep up a proper degree of heat in the frames for the plants without covering. Therefore, the covering up in the evenings and uncovering in the mornings must be particularly attended to, and more or less put on according to the heat of the linings and temperature of the weather. After the bed is set to work, heat and sweet moisture are the two principal agents required for promoting the growth and vigour of the plants; therefore if there be a heat kept in the linings, strong enougin to keep the heat in the centre of the pits of mould fluctuating between $80^{\circ}$ and $90^{\circ}$, cold water may be poured on the flutes twice or thrice a week. 'There is no danger of creating damps or impure air in the frames by watering the flues; for the water is no sooner poured on them, than it runs down their sides, and passes clear off through the drains of the bed; consequently, water being poured upon the flues, gives only a momentary check to the heat of the frames; for the flues being at all tines full of hot steam, when the watering is finjshed, the heat quickly resumes its former vivacity, and raises a warm vapour in the frames, well adapted for promoting vegetation, and for increasing the growth, and invigorating the plant in all its parts. 'The mould round about the sides of the pits close against the inner sides of the tues, should be kept nearly on a level with the surface of the fures, and as it is the mould that joins to the flues which receives the first and greatest heat from the linings, it should be continually kept in a moist state; for if the mould against the fites be suftered to become dry and lusky, air will be gencrated in the frames disagrecable to the plants." In all other respects, the culture of cucumber or melon, on M'Phail's brick-bed, corresponds with the culture of these fruits on common dung-beds. MrPhail has, in his "Gardener,' Remembrancer," as well as in his "l'reatise on the Cucumber," given the temperature of one of his beds for every day in the year, of which the following table slow's the extremes for every montl :-

morn.

January from $58^{\circ}$ to $86^{\circ}$ from $56^{\circ}$ to $86^{\circ}$ from $51^{\circ}$ to $77^{\circ}$

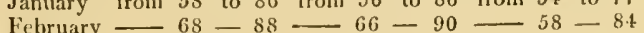

March -62-83-65-90-62-85

April $-69-84-68-93-64-90$

May E 


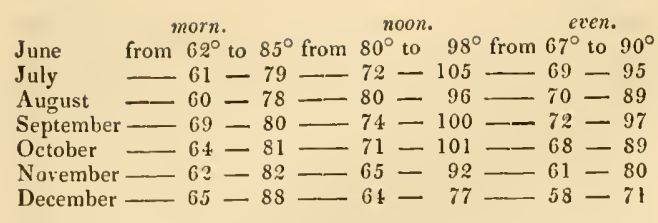

"By the heat described in these tables, and plenty of water, the cucumber plants, the seeds of which were sown on the $22 \mathrm{~d}$ day of October, were maintained in a healthy fruit-bearing state in the brick frame of my inventing, from the month of Jannary to the beginning of December." The melon plants in the management of the author, were kept in about the same degree of heat which he has given for the culture of the cucumber, in the forcing frames; and he ventures to predict that if any person keep melon or cucumber plants in nearly the same degrees of heat, as is set down in the foregoing plain tables, and manage the plants well in other respects, the way to do which lie thinks he has clearly pointed out in this treatise, he is persuacled they will not fail in having success. He adds, that notwithstanding the objections of some who have not been successful in making trial of his bed, " it is now generally approved of, and in practice by numbers of the best gentlemen's gardeners in the kingdom, and by various market gardeners in the neighbourhood of London." West's pit, however, seems superior to M'Phail's, as requiring much less dung, presenting a much more neat and orderly appearance, and giving a greater command of temperature.

Cultivation of the cucumber in a common pit without flues.Some form a narrow dung-bed along the middle of each pit, leaving room for adding a lining on each side when the heat declines. The method succeeds very well late in the season; but at an early period the sinking of the bed from the glass leaves the plants at a great distance from the light.

Cultivation of the cucumber in storcs. - " Cucumber plants," M'Phail observes, "will grow in a hot-house, where the pineapple is cultivated; but they will not be very long lived there, for that is not a healthy climate for them." "In August sow the seeds in boxes filled with vegetable or other liglit earth, and place them on shelves on the back side of the hot-house, where the sun may not be interrupted from shining on them in the short days. They may perhaps produce a few fruit in the month of December or January." Gard. rememb. p. 301. A bercrombie says, "some gardeners, ambitious of early fruit, try a sowing in the stove under the disadvantages of December. Fruiting this plant in the house in narrow boxes 3 feet long, and full 20 inches deep, may be found more commodious than pots. The boxes may stand upon the crib-trellising over the flues, or be suspended near the back wall, 18 inches from the upper tier of lights, so as not to shade the regular house plants : this is the best situation for a very early crop. The plants may be originated in small pots, plunged into the bark-bed, in order to be transplanted with a half ball of earth into the borders. Those who aim to have fruit at Christmas introduce scedlings about the middle of August." "The chief deviation from the course of the hat-bed is, that the plants must be trained in the house upright, for which purpose form a light temporary trellis of laths. Give water every other day at least." Pract. Gard. p. 618. We have already quoted the particulars of Aiton's method of raising cucumber plants in $\Lambda$ ugust, with a view to their being fruited in the stove through the winter. We now subjoin the remainder of that paper. "The plants being raised on a well prepared onc light hot-bed, when the cotyledons or seed-leaves became nearly of full growth, the plants were potted out, two into each pot, known to gardeners about London by the name of upright thirty-twos. When these pots became filled with roots, the plants were again shifted into larger ones, called sixteens, and removed from the secd-bed into a three light frame, with a sufficient bottom heat to allow a considerable portion of air being given day and night, both in the front and back of the frame. A bout the middle of September, the plants having again filled their pots with roots, and become stocky, were taken from the fiame to the stove, and after a few dlays received the last shifting into larger pots of the following dimensions : at top 14 inches over, the bottom 10 inches across, and 12 inches deep, all inside measure; each pot at equal distances apart, having three side drain holes near the bottom, and a larger one in the centre of the bottom, and containing about three pecks of solid earth. The cucumber plants were fruited this season in a pinery. On the front edge of the back flue of this stove, a fascia-boarding, 6 inches deep, was affixed the whole length of the building, forming all along a trough or inclosure for a reserve of compost, after the exhaustion of the mould in the pots had taken place. The pots were now placed in regular order upon the mould-trough over the flue at 3 feet apart, and remained in this station for good, for succession. A setting of the second sowing was placed upon the end flues of the house ; underneath each pot were set an upright circular garden pan, 6 inches deep, and 14 inches in diameter, which being filled with earth, the pots were plunged therein about 2 inches deep, and the drain holes being sufficiently covered with mould, served as outlets to the roots. From this time the fire heat of the stove was kept day and night at $60^{\circ}$ or $65^{\circ}$ of Fahrenheit's thermometer, varying only a few degrees when the sudden influences of the sun or steam produced an additional glow of climate. The plants being now established and vigorous, required stopping the laterals and fruit; and these second and third lateral shoots in their turn were stopped also, and the blossoms from time to time set, as usual, for succession of supply. Waterings were necessary only when the surface of the earth was evidently dry, and light sprinklings of soft water, tempered in the stove, were occasionally given over the leaves of the plants and path with good effect. Steam from a well regulated flue was considered always favorable to the cultivation, but applied sparingly on account of its scalding effect upon the leaves, when the vapour proved overheated. For the mildew, flower of brimstone, coloured leaf-green by a little soot, has been applied with the best success in all stages of the disease, and copious fumigations of tobacco were used for the destruction of the sevcral species of the aphis tribe. Under this simple practice winter cucumbers have been produced abundantly in the months of October, No-

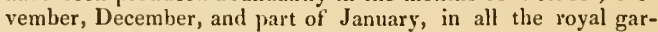
dens of His Majesty during a series of years." Aiton ex encycl. gard. p. 642, 643 .

Cultivation of the cucumber in Weel's patent frame.-Only two instances in which this ingenious invention has been tried are known to us, both of which are mentioned at the end of "Week's Forcer's Assistant." The clief objection to it is, that the bed or stratum of earth in which the plants are grown, being but of moderate depth, and surrounded by air above and below, is extremely difficult to retain at an equable moisture. There are several other structures for growing cucumbers and melons in besides those mentioned above; but none of them appear to us to be of much importance.

On a mode of producing a crop of cucumbers during winter.James Reed, (Gard. mag. 3. p. 23.) places his winter cucumber bed in a vinery. In this vinery the air could be admitted both by the front and top lights. About the 20 th of September the cucumber seeds were sown on a moderate hot-bed in the open air, and heated in the usual manner until they were ready to ridge out. This generally happened about the beginning of 
November, at which time the shoots of the vines were withdrawn from the house, and a dung-bed formed in the floor of the vinery in the usual way. After placing the frame and mould on the bed, it may be left without the lights until the rank steam has passed oft. After this, the plants being placed in the hills, and the sashes put on, the following are the leading features of management during the winter. Make fires in the evening, so as to warm the air of the house to from $56^{\circ}$ to $60^{\circ}$, and in very severe frosts it may be raised to $70^{\circ}$. In the mornings of the coldest weather, and sliortest days, make a strong fire, so as to raise the heat to nearly $70^{\circ}$ when the house is shut up. About 8 o'clock, and from that time to lialf past 9 , give plenty of fresh air, by opening the front sashes and top lights, after which, and luring the remainder of the day, give plenty of air to the cucumbers, by tilting the sashes in the usual way. In mild weather, and during sunshine, the lights may be taken entirely off the cucumbers for some hours each day; and immediately after forming new linings, the top lights may be left open a little all night to permit the escape of rank steam. The advantage of this mode of growing cueumbers during winter is, the comparative certainty of an early and good crop at one-third of the trouble and expence of the common method out of doors. By this practice fruit may be cut in January. The vines may be introduced in the beginning of March, and will break beautifully and regularly in consequence of the genial steam of the dung. In April the shade of the vine leaves will have rendered the house too dark for the culture of the cucumber, and as by this time cucumbers are plentiful in the common hot-beds out of doors, the bed in the vinery may be cleared away, and the vines treated in the usual way till the following November.

Common or Cultivated Cucumber. Fl. July, Sept. Clt. 1573. Pl. trailing.

4 C. Flexuòsus (Lin. spec. 1437.) stems trailing, scabrous, flexuous, cirrhiferous; leaves cordate-ovate, somewhat lobed, denticulated, stalked; flowers in fascicles in the axils of the leaves ; calyx very pilose ; fruit long, cylindrically-clavate, furrowed, flexuous, replicate, white or yellow. $\odot . F$. Native of the East Indies.-Lob. stirp. p. 363. f. 2. Dodon. pempt. p. 66. f. 2. Ger. herb. p. 763. f. 3. Fruit the size of a large pear, eatable, and delicious. It is cultivated about Nagasaki and elsewhere in Japan; is ripe in June, and is called by the Dutch Banket Melon.

lar. $\beta$, reftéxus (Ser. mss.) leaves angularly-lobed. C. réflexus, Zieh.

Flexuous-fruited or Banket Melon. Fl. May, Sept. Clt. 1597. PJ. tr.

5 C. JAMaice' Nsis (Bert. ex Spreng. syst. 3. p. 46.) leaves cordate, 3-lohed, quintuple-nerved, glabrous, quite entire, beset with scabrous dots beneath; lobes acuminated; fruit ncarly globose. $\odot$. F. Native of Jamaica.

Jamaica Melon. Fl. June, Sep. Clt. 1824. Pl. tr.

6 C. Macroca'rros (Wenderoth ex Mart. reise. bras. ex Linnæa. 5. p. 39.) leaves cordate, rather angular, acutish, sharplydenticulated, scabrous from hairs ; fruit oblong, obsoletely striated and spotted, remotely tuberculated. $\odot$. F. Native of Brazil.

Long-fruited Cucumber. Pl. tr.

7 C. Cha'te (Lin. spec. 1437.) plant rery villous; stems trailing, bluntly pentagonal, flexuous; leaves petiolate, roundish, bluntly angled, denticulated; flowers small, on short peduneles; fruit pilose, elliptic, tapering to both ends. $\odot$. F. Native of Egypt and Arabia.-Alp. exot. ægyp. p. 54. t. 40.-Bauh. hist. 2. p. 24.8. f. 3. The fruit is rather watery; the flesh almost of the same substance with the melon; the taste somewhat sweet, and eool as the water-melon. The grandees and Europeans in Egypt eat it as the most pleasant fruit they have, and that from which they have least to apprehend. With us it is very indif- ferent. It is most common in the fertile soil around Cairo, after the inundation of the Nile. Chate is the Egyptian name of the plant.

Chate or Hairy Cucumber or Melon. Fl. June, Aug. Clt. 1759. Pl. tr.

8 C. Duna'ı (Lin. spec. 1437.) plant hispid; lower leaves roundisl, upper ones somewhat 5-lobed, cordate at the base, denticulated; tendrils simple; petals ovate-roundish; male flowers having the calyx rounded at the base, the throat dilated, and with the comnectives longer than the anthers; hermaphrodite flowers having the tube of the calyx ovate and pilose; stigmas 4-6; fruit globose, smoothish, variegated, rarely wartcd: with white sweet-scented, but insipid flesh. $\odot$. F. Native of Persia. And. bot. rep. t. 548. C. odoratissimus, Møench, meth. 654.-Dill. hort. elth. 223. t. 177. f. 218.-Waltl. hort. p. 133. t. 21. The fruit is variegated with green and orange, and oblong unequal green spots; when full ripe becoming yellow, and at length whitish. It has a very fragrant vinous musky smell, and a whitish, fiaccid, insipid pulp. Dudaim is the Hebrew name of the fruit, rendered mandrake in Scripture, whicl is perhajs $C$. prophetàrum.

Dudaim or Apple-shaped Melon. Fl.Jul.Aug. Clt.1705. Pl.tr.

9 C. Cónomon (Thunb. jap. p. 324.) plant rather pilose; stem trailing, striated; leaves cordate, somewhat lobed, stalked, rather pilose; flowers small; fruit oblong, glabrous, 6-10-furrowed; flesh firm. $\odot$. F. Native of Japan. Fruit larger than a man's head. Flowers aggregate, on rather hispid stalks. This plant is cultivated every where in Japan for the sake of its fruit, which, when preserved, is sold under the name of Connemon, and is a common food among the Japanese. It is also frequently eaten by the Dutch at Batavia, and is sometimes brought to Holland.

Conomon Melon. Pl. tr.

10 C. sE'pium (Meyer, prim. esseq. p. 278.) leaves cordateovate, somewhat 5-lobed; fruit oval, muricated, acuminated at both ends. $\odot$. F. Native of Guiana, in the island of Wachanama. C. angùria, Ræusch, but not of Lin. ex Steud. nom. It dificrs from our $C$. angùria in the leaves being subpalmate, with angular recesses, and in the fruit being globosely-elliptic.

Hedge Melon. Pl. tr.

11 C. Linea'rus (Bosc. journ. hist. nat. 2. p. 251. t. 37.) stem climbing, pentagonal; tendrils trifid, longer than the leaves; leaves cordate, palmate, acutish, scrrulated; petioles short; flowers usually $\mathrm{t}$ win, almost sessile; female ones having an oblong-ovate calyx, and lanceolate segments; petals orate, retuse; fruit ovate-oblong, lined with green, 10 -ribbed. $\odot$. F. Native of Cayenne.

Lined-fruited Melon. Fl. June. Aug. Clt. 1825. Pl. tr.

12 C. Prophet八'rum (Lin. spec. 1436. amon. acad. 4. p. 295.) stem trailing, striated ; leaves cordate, 5-lobed, denticulated; lobes obtuse; flowers axillary, 2-5-together, stalked; male ones with a campanulate calyx, and obovate petals; calyx of the female flowers globose at the base, 12-striped, and hispid: limb campanulate, crowned by teeth; fruit globose, echinated, variegated, size of a cherry. $\odot$. F. Native of Arabia. Jacq. hort. vind. 1. t. 9.-Blackw. herb. 589. C. grossularioides, Hortul. The plant has a nauseous odour. The fruit equals the Colocynth in hitterness.

Prophet's or Globe Cucumber. Fl. Ju.Sept. Clt. 1777. Pl.tr. 13 C. Afruci'nus (Lin. fil. suppl. p. 423.) stems trailing, angular; leaves cordate, 5 -lobed; lobes acutislı; peduncles filiform; fruit ovate-oblong, much echinated. §. F. Native of the Cape of Good Hope. Lindl, bot. reg. t. 980.-Herm. par. p. 134. t. 36 . Flowers small. Very like $C$. prophetàrum.

African Cucumber. Fl. June, Aug. Pl. Ir.

14 C. angu'ria (Lin. spec. 1436. but not of Ræusch. ex Steud. E 2 
nom.) stems rather filiform, cirrhiferous ; leaves palmately-sinuated, cordate at the base, scabrons; flowers usually solitary, size of those of Bryonia dioica; fruit globose, echinated, white. $\odot$. F. Native of Jamaica. C. eclinàtus, Moench, meth. p. 654.-Mill. icon. t. 33.-Pluk. pliyt. t. 170. f. 3. Very like C. prophetarum. The fruit of this kind of cucumber is eaten when green by the inbabitants of the West India Islands; but these are far inferior to our common cucumber. The fruit seldom grows so large as a pullet's egg, and is shaped like it; and the rind is closely beset with blunt prickles. It is frequently used in the sugar islands with other herbs in soups, and is esteemed an agreeable and wholesome ingredient in them. aryouptov, angourion, one of the Greek names of the cucumber; hence the specific name.

Anguria or Round Prickly. fruited Cucumber. 11. June, Aug. Clt, 1692. Pl. tr.

15 C. citru' llus (Ser. mss. in D. C. prod. 3. p. 301.) plant very pilose; stems trailing, cirrhiferous; lcaves bluntly pinnate, or many-parted, rather glaucous ; flowers solitary, each furnislied with one oblong bractea; fruit nearly globose, glabrous, with starry spots. $\odot$. F. Native of tropical Africa and the East Indies. Cucúrbita citrúllus, Lin. spec. 1435. Cucúrbita anłùria, Duchesn. in Lam. dict. 2. p. 158.-Blackw. herb. t. $15 \%$-Lob, stirp. t. 361 . f. 2, Park. Theatr. 771. f. 772.-Rumph. amb. 5. t. 146.f. 1. Samanka of the Hindoos.

lar. a, Pasteca (Ser. 1. c.) flesh of fruit firm, yellow, but not very watery. This is the Yellon-feshed I'ater Mclon of the English, and the Pasterne of the French.

I ar. $\beta$, Jàce (Ser. l. c.) flesl very watery, redelish. This is the Red-ficshed Water Melon of the English, Melon d'eau of the Frencl, and the Jace of the Brazilians.

The water-melon is called rasser-melon in Germany, and cocomero in Italy. The plant serves both for food, drink, and pliysic to the Egyptians. The fruit is eaten in abundance during the season, which is from the beginning of May until the overflowing of the Nile, that is, to the end of July. It is the only medicine the common people nse in ardent fevers: when it is ripe or almost putrid, they collect the juice, and mix it with rose-water and a little sugar. The fruit should be eaten cautiously by Europeans, especially when taken in the lieat of the day ; but it is much used within the tropics, and in Italy. The fruit is large, grcen externally, white fleshed, reddish towards the centre, juicy, and refreshing, but not high flavoured. It is generally considered the melon of the Jews, mentioned in various parts of the Bible. It requires nearly the same treatment as the common melon, but a larger frame to adnit its more extended shoots to spread themselves.

Citrul or Water Melon. Fl. May, Sep. Clt. 1597. Pl.tr.

16 C. murica'tus (Willd. spec. 4. p. 613.) leaves cordate and angular, rather hoary; angles rounded; fruit cylindrical, muricated; male flowers aggregate, nearly sessile; female ones solitary. $\odot$. F. Native of 'Tranquebar.

IVartcd Cucumber. Fl. June, Aug. Clt. 1817 . Pl. tr.

17 C. MEGACÁRPUS ; leaves palmate ; fruit long, ovate, very full of anastonosing fibres, which look like net-work when the fruit is dried up. $\odot . F$. Native of Sierra Leone.

Large-fruited Cucumber. Pl. tr.

18 C. PUbe'scens (Willd. I. c. p. 614.) leaves cordate, rather angular, acutish, sharply tootled, scabrous: fruit, elliptic, obtuse, pubescent, green, painted with more obscure narrow stripes. $\odot$. F. Native country unknown. Fruit $\&$ inches long, clliptic, and an inch thick, obtuse at both ends, covered witl fine down.

Don'ny Cucumber. Fl. July, Sep. Clt. 1815. P'. (r.

19 C. macula'sus (Willd spec. 4. p. 611.) leaves cordate, obsoletely angular, roundly obtuse, denticulated, scabrous; fruit elliptic, narrow at the base, glabrous, when young painted with broad green stripes; but when mature, white, variegated with green spots; connectives much longer than the anthers. $\odot . F$. Native of Guinea. Fruit smooth. Ser. diss. l. c. t. 3.

S Fotted Cucumber. Fl. June, Aug. Clt. 1820. Pl. tr.

20 C. colocy'sturs (Lin. spec. 1435.) stems trailing, rather hispid; leaves cordate-ovate, multifidly lobed, covered with white pili beneath; lobes obtuse ; petioles equalling the limb of the leaf; tendrils short; flowers axillary, solitary, pedunculate; female ones having the tube of the calyx globose, and rather hispid, crowned by a spreading campanulate limb, and narrow segments; petals small; fruit globose, glabrous, yellowish at maturity, with a thin solid rind, and very bitter flesh. $\odot . F$. Native of Japan and 'lurkey.-Blackw. herb. t. 441.-Sabb. hort. 1. t. $70 .-$ Nor. hist. sect. 1.t. 6. f. 1. Fruit about the size of an orange. The colocynth is a native of Turkey. The fruit is about the size of an orange; its medullary part, freed from the rind and seeds, is alone made use of in medicine; this is very light, white, spongy, composed of membranous plates, of an extrenely bitter, nauseons, acrimonious taste. 'The fruit is gathered in autumn, when it begins to turn yellow, and is then peeled and dried quickly, either in a stove or in the sun. Newmann got from 7680 parts, 1680 alcolsolic extract, and then 2160 watery; and inversely 3600 watery, and 224 alcoholic. The seeds are perfectly bland, and lighly nutritious; and we learn from Captain Lyon, that they constitute an important article of food in Northern Africa. The extract of colocynth is one of the most powerful and useful of cathartics, but there is no more eflicacious way of lessening its violence than by reducing its dose. Pl. $t r$.

Coloeynth or Bitter Cucumber. Fl. May, Aug. Clt. 1551.

21 C. Canpechuinus (H. B. et Kuntl, nov, gen. amer. 2. p. 123.) sten cirrhiferous; leaves cordate-roundish, sinuately 5lobed, toothed; lobes rounded, intermediate one the largest; male flowers racemose, few ; tube of calyx villous; fruit unknown. $\odot . F$. Native on the shores about Campeachy. Perhaps a variety of $C$. prophctierun, according to Spreng. syst. 3. p. 4\%. Campeachy Cucumber. Pl. tr.

22 C. PERE' NNIS (E. James, exped. rock. mount. 2. p. 345. and in isis $1824 . p$. 235.) !eaves triangularly cordate, with mdulated margins; tendrils trichotomous; lobes of calyx subulate; fruit orbicular, smooth, usually 4 -celled; seeds ovate, gibbous, with an acute margin. 4. F. Native of or cultivated in North America. Flowers about the size of those of Cucurbita Pèpo. Fruit ncarly sessile.

Perennial Cucumber. Pl. tr.

Cult. See culture of the Cucumber and Mclon in the open air in the proper place, for the culture of the rest of the species.

V. LU'FFA (Louff is the Arabic name of L. Egyptiaca). Cav. icon. 1. p. 7. t. 9. D. C. prod. 3. p. 302.-Cùcumis species of authors, and Momórdica species of authors.

Lın. syst. Monce'cia, Pentándria. Male flowers yellow, in panicles; tube of calyx hemispherical, with the segments longer than the tube. Petals free, deciduous from being ruptured at the base. Stamens 5, not joined. Anthers very flexuous. Female flowers solitary; tube of calyx oblong-clavated, with the segments shorter than the tube. Stamens almost abortive. Stigmas reniform. Fruit ovate, 3-celled. Seeds 2-lobed at the base, reticulated. Flowers yellow.

1 L. FE'TIDA (Cav. icon. 1. p. 7. t.9.) stem furrowed: leaves cordate, 5-7-angled, scabrous; the angles acute and serrated; tendrils umbellate; fruit mucronate, not crowned by the limb of the calyx. $\odot . F$. Native of the East Indies, the islands of Bourbon and France, as well as in many places on the western 
coast of $\Lambda$ frica, in fields, hedges, and among bushes. Sims, bot. mag. 16s8. Ojong Bultstru is its Hindoo name.

Fetid Luffa. Fl. June, Oct. Clt. 1812. Pl. tr.

2 L. cordifòlı (Blume, bijdr. p. 929.) leaves cordate, acuminated, sharply toothed, scabrous; flowers dioecious ; male ones rather umbellate: female ones solitary; fruit furrowed and wrinkled. $\odot$. F. Native of Java, on the mountains, where it is called by the natives Aroy kajoraajan, Aroy Kalayar burriet, but 'limuk by the Hindoos.

Heart-leated Luffa. PI. tr.

3 L. acuta'sgula (Ser, in D. C. prod. 3. p. 302.) stem twisted; leaves cordate, somewhat 5-lobed, acutely toothed; tendrils undivided, or 2-3-cleft; fruit clavate, 10 -angled, crowned by the linear calycine segments: the rind hard; sceds flat, roundish-oblong, black and shining at maturity. ๑. F. Native of China, and plentiful in India near the labitations of the Indians Cùcumis acutángulus, Lin. sper. 1436. Jacq. hort. vind. 3. p. 73, 7. ex Lam. dict. 2. p. 74.-Rheed. mal. 8. t. 7. -Rumph. amb. 5. p. 408. t. 149. Dringi is the Hindoo name of the plant. Leaves like those of Tussilàgo Petásites or I'itis, with the scent of Datura stramonium. Male flowers umbellate, female oncs solitary. Fruit insipid, but is eaten by the natives of India boiled or pickled.

Acute-angled Luffa. Fl. June, Oct. Clt. 1692. Pl. tr.

4 L. Plukenetia'na (Ser. imss. in D. C. prod. 3. p. 302.) leaves cordate, doubly toothed; tendrils 2 -3-cleft; fruit obovate, crowned by the marcescent limb of the calyx. $\odot . F$. Native of the East Indies. Cùcumis acutángulus $\beta$, Lam. dict. 2. p. 7 \%.-Pluk. phyt. t. 172 . f. 1.

Plukenet's Luffa. Pl. tr.

5 L. Cátru-picina (Ser. mss. in D. C. prod. 3. p. 303.) stem tetragonal; leaves cordate, roundish, somewhat 5 -lobed, angular; sepals broadly ovate, acuminated; fruit oblong-elliptic, mucronate, lined with warts, and crowned by the calycine segments; sceds ovate. $\odot$. F. Native of Malabar.-Cáttupicinna, Rheed. mal. 8. p. 15. t. 8. Leaves nearly the size and form of those of Althce'a ròsca. Male flowers size of those of Paònia tenuifòlia.

Caltu-picinna Luffa. Pl. tr.

6 L. Egrptinca (Mill. dict.) leaves roundish-cordate, lobed; lobes angular, cut at the base, with incumbent margins; tendrils simple; fruit obovate-clarate, 10-angled, crowned by the segments of the calyx. $\odot$. F. Native of Arabia. Mlomórdica Lúffa, Lin. spec. 1433. L. Arábum, Alp. pl. ægypt. p. 199. t. 58.-Mor. hist. 2. p. 35. sect. 1. t. 7. f. 1, 2.-Sabb. hort. 1. t. 62. 'The Arabians call the plant Liff or Louff; they cultivate it, and it climbs up the palm-trees, covering, and elegantly adorning their trunks. It is also cultivated largely in China and Cochin-china, if Loureiro's plant be the same (Coch. $p$. 590.). The fruit when young is made into a pickle, like the mango, but it has a disagreeable taste, and is not accounted very wholesome.

Egyptian Luffa. Fl. June, Oct. Clt. 1739. Pl. cl.

7 L. PE'tola (Ser. mss. in D. C. prod. 3. p. 803.$)$ stems teretc; leaves curdate, 5 -7-lobed; lobes acute, serrated, middle one very long ; tendrils bifid; segments of the calyx oblong and bluntish; petals obcordate, toothed, shorter than the calycine segments ; fruit obovate-clavate, mucronate, woolly, afterwards furrowed, green, spotted with white, with watery flesh. $\odot . F$. Native of the East Indies.-Pétola, Rumph. amb. 5. p. 405. t. 147 .

Petola Luffa. PI. tr.

8 L. PENTA'NDRA (Wall. cat. nio.6751.) leaves cordate, downy, 5-7-lobed, mucronately denticulated: middle lobe the longest; female peduncles 1 -flowered, solitary : male ones umbellate? $\odot$. F. Native of the East Indies, in Rungpur and Munggeri.
Pcnlandrous Luffa. Pl. tr.

9 L grave'olens (Roxb. ex Wall. eat. no. 6752.) downy; leaves cordate, obsoletely lobed, and mucronatcly denticulated; flowers axillary, 2-4-together, on very short peduncles; fruit muricated. $\odot$. F. Native of the East Indies, in Munikapur.

Strong-scented Luffi. Pl. tr.

10 L. AMA'ra (Wall. cat. no. 6754. ) scabrous ; leaves cordate, 5-7-lobed, middle lobe the longest, all acute; female peduncles 1-flowered, solitary: male ones racemose; fruit long, downy. $\odot$. F. Native of the East Indies, in Rungpur and Gualpara.

Biller Luffa. P'l. tr.

11 L. henera'cen (Wall. cat. no. 6755.) leaves cordate, palmately 5-lobed, mucronately denticulated; female peduncles 1-flowered, solitary: male ones racemose; fruit oblong. $\odot . F$. Native of the Burman Empire, at Amlerst, and below Melloon. Ivy-like Luffa. Pl. $\mathrm{tr}$.

12 L. есHina'ta (Roxb. ex Wall. cat. no. 6756.) scabrous; leaves cordate, 5 -lobed; lobes rounded, mucronately denticulated; female peduncles 1-flowered, solitary; male ones umbellately racemose; fruit roundish, chinated by spines. $\odot$. F. Native of the East Indies, in Bandil, Deyra, and Dhoon.

Echinaled-fruited Luffa. Pl. tr.

13 L. sati'A'ta (Hamilt. ex Wall. cat. no. 6r57.) scabrous; leaves cordate, angularly toothed; peduncles racemose. $\odot . F$. Native of the East Indies, in Nathpur, where it is called Satpatia.

Satpatia Luffa. PI. tr.

14. L. PA'rvela (Hamilt. ex Wall. cat. no. 6758.) roughish; leaves 5 -7-lobed; lobes acuminated, mucronately denticulated; female peduncles 1-flowered, solitary; fruit long, downy when young. $\odot$. H. Native of the East Indies, in Puraniya.

Small Luffa. Pl. tr.

Cult. Sow the seeds in a hot-bed, and afterwarls treat the plants as recommended for ridging out cucumbers.

VI. BENINCA'SA (in honour of Count Benincasa, an Italian nobleman). Savi, mem. cucurb. 1818 . p. 6 . with a figure. Delile, mem. acad. sc. par. 1824. 7. p. 995 . D. C. prod. 3. p. 303.

LıN. syst. Polygàmia, Monoc̀cia. Flowers polygamous, monoecious, solitary, yellow. Segments of the calyx short, broad. with undulated, toothed margins. Stamens in 3 bundles in the male flowers, divaricate. Petals obovate-roundish, curled, and undulated ; anthers very irregular, with distant convolutions. Female flowers with the stamens as in the malcs, but usually nearly abortive. Stigmas very thick and irregular. Secds with thickish margins.

1 B. ceríferA (Savi, 1. c.) plant very hairy, with a musky scent; leaves cordate, somewhat 5-lobed; lobes acutish and crenated ; tendrils simple; fruit ovate-cylindrical, woolly, pendulous, green. $\odot$. F. Native of the East Indies. Cucúrbita cerífcra, Fisch. cat. hort. Gorenk. ex Savi, l. c. B. cylíndrica, Hortul. Cumbùlam, Rheed. mal. 8. p. 5. t. 3. The fruit is either short or long, but always covered with numerous fragile. hairs, and clothed with glaucous, glittering bloom. Flowers sometimes hermaphrodite.

I'ax-bcaring Benincasa. Fl. May, Jul. Clt. 1827. Pl. tr.

Cult. Sow the seeds on a hot-bed in spring; and afterwards treat the plants as in ridging out cucumbers.

VII. ERYTHROPA'LUM (from e

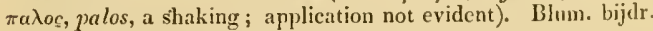
p. 921 . D. C. prod. 3. p. 303.

Lix. sxst. Monoècia, Pentándria. Flowers monoccious, perhaps only from abortion. Limb of calyx obsoletely 5 toothed. Petals 5, ovate, alternating with the tecth of the 
calyx, bicallous at the base inside. Stamens 5 , opposite the petals, borne at the margin of the tube; filaments short; anthers erect, dehiscing at the side. Style short. Fruit clavate, 1celled, 3-valved; valves fleshy, partible into two. Seed one coated.

1 E. sca'Ndens (Blum. bijdr. p. 922.) shrub climbing; leaves stalked, rather peltate, oblong, acuminatel, quite entire, glabrous; peduncles branched, axillary ; pedicels rather umbellate. $\eta$. . S. Native of the East India Islands, on the mountains, particularly in Java, where it is called Aroy wuat Ban kong by the natives.

Climbing Erythropalum. Shrub cl.

Cult. A mixture of loam, peat, and sand, or vegetable mould, will suit this plant; and cuttings will grow freely in the same kind of soil, if placed in lieat.

VIII. TU'RIA (Arabic name of one of the species). Forsk. fl. agypt. p. 165. no. 35 . Lam. dict. 8. p. 139. D. C. prod. 3. 1. 303.

Lin. syst. Monoc̀cia, Pcntándria. Flowers monoecious, male ones umbellate. Calyx 5-parted; scgments lanceolate, spreading. Corolla 5-petalled, rotate, yellow. Stamens 5, erect, filiform, in 3 bundles; anthers irregularly curled; rudiment of germ half globose. Female flowers having the calyx and corolla as in the male, but with the stamens castrated. Germen cylindrical, thickened. Stigmas 3, 2-lobed. Fruit cylindrical? attenuated, villous, warted.

I 'T. cylíndrica (Forsk. 1. c.) stems twining, 5-angled, scabrous; leaves palmate; lobes toothed; tendrils trifid; fruit terete, attenuated at both ends, villous, crowned by the style and calyx.-Native of Arabia Felix. Gmel syst. nat. 1. p. 403. ex Lam. dict. 8. p. 140. Flowers yellow.

Cylindrical-fruited Turia. Pl. tw.

2 T. LelòsA (Forsk. l. c. p. 165.) stem striated, mealy; leaves 3-lobed, cordate at the base; lobes angular, middle one longest, but not lobed; fruit conical, glabrous; seeds size of a small pea. \%. F. Native of Arabia. Gmel. syst. nat. 1. p. 40s. ex Lam. dict. 8. p. 140. Leloja is the Arabian name of the plant. Flowers green.

\section{Leloja Turia. Pl. tw.}

3 'T. CORDA'TA (Lam. dict. 8. p. 140.) leaves cordate, angulár, ciliated, 2 inches long.-Native of Arabia Felix. The fruit, when matured, opens at top by a lid, and ejects its seeds with force. Forsk. fl. ægypt. p. 166.

Cordate-leaved 'Turia. Pl. trailing.

4 T. Gíuef (Forsk. l. c. p. 166.) stem 6-angled, scabrous ; leaves 3 -lobed, denticulated, scabrous on both surfaces ; fruit wate, 10-furrowed, glabrous.-Native of Arabia, Flowers small, green. Fruit smaller than a nut, greyish at maturity, dehiscing, witl revolute valves. Gijcf is the Arabic name of the plant.

Gijef Turia. Pl. trailing.

5 T. Móghand (Forsk. agypt. 1. c.) stem terete, sinootl ; leaves 3-lobed, quite entire; lateral lobes somewhat 3-lobed; fruit oval-oblong, quite glabrous.-Native of Arabia Felix. Flowers large, white. Immature fruit green, spotted with white, but when mature yellow and eatable. Moghadd is the Arabian name of the species.

Moghadd Turia. Pl. trailing.

Cult. See Cucúrbitu, 1. 41. for culture and propagation.

IX. BRYO'NIA (from $\beta \rho v \omega$, bryo, to sprout up; in reference to the rapid growth of the annual stems, or because the species raise themselves by laying hold of other slurubs with their tendrils). Lin. gen. no. 1480 . Juss. gen. p. 394. Gærtn. fruct. ^. 88. D. C. prod. 3. p. 304 . Solèna, Lour. coch. Cùcumis species of some authors, Cucumeroides, Gærtn. fruct. 2. p. 485. t. 180 . f. 4 .

LıN. syst. Monoècia, Polyadélphia. Flowers monoecious or dioecious. Petals joined at the base. Male flowers with a 5 -toothed calyx. Stamens in 3 bundles; anthers flexuous. Female flowers with a trifid style. Fruit ovate or globose, smooth; perhaps always few-seeded. Seeds ovate, hardly compressed, more or less margined. Tendrils simple, rarely forked.

\section{* Leaves angular.}

1 B. rostra'ta (Rottl. nov, act. berol. 4. p. 212. and Willd. spec. 4. p. 616.) stem filiform, furrowed; leaves cordate, obtuse, denticulated, scabrous; peduncles axillary, solitary ; fruit ovate, angular, acuminated. $\odot$. F. Native of Tranquebar. Fruit the size of a pea. Plant scabrous, but when cultivated it becomes smooth in every part. The root of this species is prescribed in India internally in electuary, in cases of piles.

Rostrate-fruited Bryony. Pl. cl.

2 B. Perrotetia'na (Ser. mss. in D. C. prod. 3. p. 304. ) tendrils simple, capillary ; leaves broadly cordate, ungulate, sessile, villous, scabrous, with undulated margins; male flowers twin, on pilose peduncles : female flowers sessile ; fruit ending in a long taper point, sessile, clothed with very long and very numerous hairs; seeds compressed, bay-coloured, granularly edged, and covered with adpressed hairs. 4.S. Native of Senegal. Flowers white.

Pcrrotet's Bryony. Pl. cl.

3 B. mucrona'ta (Blume, bijdr. p. 923.) leaves cordateovate, mucronate, rather angular, and repandly denticulated, scabrous from dots above, and smooth beneath; flowers in fascicles, dioecious; berry oval. $\psi$. S. Native of the East Indies, on the mountains, where it is called Pariagengie by the natives.

$V^{\prime} a r . \beta$, denticulàta (Ser. in D. C. prod.3. p. 304.) leaves all undivided, obsoletely denticulated; fruit usually contracted in the middle. 4 . S. Growing among bushes about Buitenzorg in Java.

Mucronate-leaved Bryony. Pl. cl.

4 B. sca'BRA (Thunb. prod. 13.) leaves cordate, angular, toothed, beset with callous dots above and with pili beneath, therefore scabrous on both surfaces; flowers umbellate; fruit globose; seeds smooth. 24. G. Native of the Cape of Good Hope. The tender shoots of this plant are aperient, having bcen previously roasted.

Scabrous Bryony. Fl. Sept. Oct. Clt. 1774. Pl. cl.

5 B. verrucosa (Ait. lort. kew. ed. 1. vol. 3. p. 285 . ed. 2. vol. 5. p. 246.) leaves cordate, angular, beset with callous dots beneath as well as on the veins above; tendrils usually simple; fruit globose, nearly sessile. 4. G. Native of the Canary Islands. Willd. spec. 4.p. 616. Fruit the size of a sloe.

Warted-leaved Bryony. Clt. 1779. Pl. cl.

6 B. scaвra'ta (Blum. bijdr. p. 923.) leaves cordate, cuspidate, undivided, and somewhat angular, denticulated, scabrous above, rough on the veins beneath; flowers monoecious; umbels on short peduncles; fruit globose.-Native of the East Indies, on the mountains, particularly in Java. Cucúrbita scàbra, Blum. cat. hort. buit. no. 105. Aroy korreg kottok of the Javanese. Allied to B. scàbra and B. Japónica.

Rough Bryony. Pl.cl.

7 B. PUNcta'ta (Thunb. prod. 13.) leaves cordate, angular, callous above, and pilose beneath; peduncles 1 -flowered. 4 . G. Native of the Cape of Good Hope.

Dottcd-leaved Bryony. Pl. cl.

8 B. REPA'NDA (Blum. bijdr. p. 923.) leaves cordate, cuspidate, repandly denticulated, scabrous above and puberulous beneath; umbels pedunculate; flowers dioecious; berries globose. 
4. S. Native of Java, in the higher mountain woods of Burangrang.

Repand-leaved Bryony. P]. cl.

9 B. corda'ta ('Thumb. in Hoffin. phyt. blatt. 5, ex Pers. ench. 2. p. 594 .) leaves cordate, scabrous, denticulated; flowers axillary, twin. 4 . S. Native country unknown. B. Thunbergiana, Dietr. ex Steud. nom.

Heart-leaved Bryony. Pl. cl.

10 B. AnguLA'TA (Thunb. prod. 13.) leaves 5-angled, scabrous on both surfaces; flowers umbellate. $4 . \mathrm{G}$. Native of the Cape of Good Hope.

Angular-leaved Bryony. Pl. cl.

11 B. Leucocárpa (Blume, bijdr.p. 924.) leaves ovate-oblong, acuminated, deeply cordate at the base, somewhat repandly denticulated, beset with rough dots above, paler beneath; peduncles usually twin, few-flowered ; flowers monoecious ; berries globose. 4 . S. Native of Java, at the foot of Mount Salak.

White-fruited Bryony. Pl. cl.

12 B. AcUta'ngula (Thunb. prod. 13.) leaves angular, entire, smootl, glabrous. 24.G. Native of the Cape of Good Hope.

Acule-angled-leaved Bryony. Pl. cl.

13 B. GRA'NDIs (I,in. mant. p. 126.) Jeaves cordate, lobed, beset with callous dots above and glandular at the base beneath: terminal lobe obtuse; tendrils simple; fruit oblong, prickly at the base; pricklcs few, reflexed (ex icon. Burm.) reddish. $4 . \mathrm{S}$. Native of the East Indies. Lour. coch. 595.-Rumph. amb. 5. t. 166. f. 1. Peduncles 1-flowered. Flowers large, whitish, androgynous. Berries red.

Grcat Bryony. Fl. May, Aug. Clt.1783. Pl. cl.

14 B. Mousò (Ser. mss. in D. C. prod. 3. p. 305.) leaves cordate, 5-angled, acutely denticulated: terminal angle elongated and acute; tendrils simple; fruit prickly at the base; prickles few, reflexed; fruit red. 4. S. Native of Ceylon and of Senegal, in hedges, in which last place it is called Moimoi, according to Adanson. Seneg. p. 159. Burm. zeyl. t. 19. f. 1. Flowers large, white.

Moimoi Bryony. Pl. el.

I5 B. Geuixa'ta (Blum. bijdr. p. 924.) leaves ovate-cordate, or somewhat hastate, b]untish, obsoletely denticulated, scabrous from dots ; Howers pedunculate, twin, monoecious ; berries oval. 4. S. Native of Java, about Linga-jattie at the foot of Mount Tjerimai, where it is called Wavaluhan by the natives.

Twin-flowered Bryony. Pl. cl.

16 B. Cochinchise'nsis (Lour. coch. 595.) leaves 5-angled, rough; flowers monoecious, large, axillary, solitary, on long peduncles; fruit ovate, acutish at both ends, 10-angled, red, smooth; sceds oblong-ovate, compressed, smooth. 24. G. Native of Cocisin-china, in hedges. Flowers white.

Cochin.china Bryony. 1). cl.

17 B. Anyssínica (Lam. dict. 1. p. 497.) sten villous at the apex; tendrils simple; leaves cordate, tootlied, large, soft, nearly glabrous : upper ones angularly-lobed; petioles and peduncles very villous; flowers twin, yellow; fruit unknown. 4. G. Native of Abyssinia and neighbouring parts of Africa.

\section{Abyssinian Bryony. Pl. cl.}

18 B. Ja pónica (Thunb. jap. p. 325.) leaves cordate, undivided, and angular, toothed, green above, and beset with very minute hairs: pale beneath, and beset with scaly dots. $2 . \mathrm{G}$. Native of Japan, near Nagasaki.

Japan Bryony. Pl. cl.

19 B. sagitta'ta (Blum. bijdr. p. 925.) leaves on short petioles, sagittate, glaucescent beneath ; male peduncles subumbellate, female ones 1-flowered. 4 . S. Native of Java, about Batavia, in liumid bushy places. Alied to $B$. heterophýlla and B. umbellàta.
Sagittate-lcaved Bryony. Pl. cl.

20 B. But'mei (Ser. mss. in D. C. prod. 3. p. 305.) leaves ovate-cordate, or cordately-sagittate, acuminated, repandly denticulated, scabrous; towers monoecious, male ones umbellate, female ones solitary; berries oblong. 4 . S. Native of Java, near Batavia, among busles. B. heteroplıýlla, Blum. bijdr. p. 925., but not of Stend. Allied to $B$. marginàta.

Blume's Bryony. Pl. cl.

21 B. MARginatita (Blum. bijdr. p. 924.) leaves cordate-ovate, acuminated, rather angular at the base, obsoletely denticulated, marginate, rough; umbels on long peduneles; berries oblong. 4. S. Native of Java, about Rompien, where it is called Korroronteng Kambien by the natives.

Marginate-leaved Bryony. Pl. cl.

22 B. umbella'ta (Klein ex Willd. spec. 4. p. 618.) leaves oblong-cordate, glabrous on both surfaces, dotted above, remotely denticulated, rather angular at the base: upper ones liastately 2-lobed ; peduncles axillary, umbellate; fruit unknown. 4. S. Native of the East Indies. B. Teedonda, Roxb. B. hastàta, Lour. coch. 594.?-Rheed. mal. 8. p. 51. t. 26.? Flowers white. Berries red.

Umbellate-flowered Bryony. Pl. cl.

23 B. Amplexicau'Lis (Lam. dict. 1. p. 496.) stem angular, glabrous; leaves smooth, cordate, rather angular, stem-clasping, dotted, and glaucous beneath; upper leaves generally narrowly 3-lobed; flowers small, solitary, axillary, pedunculate ; fruit solitary, acuminated, smooth. 4 . S. Native of the East Indies, Flowers white.

Stem-clasping leaved Bryony. Pl. cl.

24. B. ? neteropiýlida (Steud. nom. p. 123.) lower leaves cordate, upper ones cordate or denticulated; tendrils solitary ; flowers solitary, pedunculate, hermaphrodite; fruit searlet; seeds blackish. 2. S. Native of Cochin-china and China. Solèna heteroplıýlla, Lour. coch. p. 514. Flowers pale.

Variablc-leaved Bryony. Pl. cl.

25 B. Pubéscens (Poir. dict. suppl. 1. p. 781.) stem pilose; leaves cordate, somewhat 5 -lobed; lobes acute, with spiny teeth; petioles villous; tendrils long, much branched; flowers small, white, downy, umbellate. $4 . G$. Native of the Levant. Flowers whitish.

Downy Bryony. Pl. cl.

26 B. Maderaspata'na (Berg. pì. cap. p. 351.) stem angular, cirrhose, glabrous ; leaves cordate, oblong, acuminated, toothed, scabrous from small callose dots above, hairy beneatlı; stipulas? awł-shaped, solitary; flowers twin, axillary. $\odot . S$. Native of the East Indies. Cùcumis Maderaspatana, Lin. spec. 1438.-Pluk. alm. t. 170. f. 2.

Madras Bryony. Pl. cl.

27 B. HEDERTYò̀ia (Jacq. fragm. 73. no. 230. t. 113.) dioecious ; root thick, fleshy; stem terete, glabrous, with the internodes distant: tendrils very long, simple; leaves cordate, somewhat 5-angled, quite entire, rather wrinkled above, and hispid beneath; racemes simple, many-flowered; calycine segments of the male flowers lanceolate and acute; lobes of the corolla ovate, acute, yellowish. 4 . S. Native of Teneriffe. Flowers yellowish.

Ivy-leaved Bryony. Pl. cl.

28 B. ALtheoides (Ser. mss. in D. C. prod. 3. p. 306.) stem filiform, furrowed, rongh, with the internodes longer than the leaves; tendrils simple, narrow, and spirally twisted; leaves cordate, lanceolate, on short petioles, somewhat 5 -angled, bluntly toothed, clothed with a kind of rough tomentum beneatlı; terminal lobe elongated; fruit thin, glohose, sessile, smooth ; seeds wrinkled from dots, gircled by a slender zone. $4 . S$. Native of the island of Timor. Flowers white,

Althou-like Bryony. Pl. cl.

29 B.? reduncurósa (Ser. mss. in D. C. prod. 3. p. 306.) 
plant pilose; stem filiform, striated, laving distant internodes; tendrils bifid; leaves on long petioles, cordate, long-acuminated, crenately toothed, beset with long, distant hairs ; flowers large, in loose racemes; peduncles longer than the leaves; pedicels long, pilose; fruit unknown. 4. G. Native of Nipaul.

Long-peduncled Bryony. Pl. cl.

SO B. RiE'EDI (Blum. bijdr. p. 925.) leaves on short petioles, oblong, eordate, rather angular at the base, remotely denticulated, smoothish, dotted above, glaneous beneath; upper leaves liastately 3 -lobed; male pedicels disposed in dense raeemes, 1-flowered, bearing one bractea in the middle of each, female pedicels solitary, 1-flowererl. $4 . \mathrm{S}$. Native of Java and Malabar, on the mountains. Rheed. mal. 8. t. 26. The plant is called Aroy-hui-Walleh by the natives of Java.

Rheede's Bryony. Pl. el.

\section{** Leaves lobed.}

31 B. TrIGE'A (Rottl. in nov. act. berol, 4. p. 223.) stem furrowed, glabrous; leaves coriaceons, somewhat cordately 3 -lobed, obsoletely dentieulated, rongh: lateral lobes somewhat 2-lobed, intermediate one elongated, acuminated ; flowers monoecious, male ones umbellate, female ones solitary; berries globose. 4. S. Native of Java, about Rompien, in corn fields. IVilld. spec. 4. p. 610.-Blum. bijdr. p. 925. Corro-konteng of the natives of Java. The root of this species was once supposed to be the famous colomba-root, to which it approaches very nearly in quality.

Earth Bryony. Clt. $1815 . \quad$ Pl. cl.

32 B. scarrét.ra (Lin. suppl. 4.2t.) stem muricated, hispid; leaves 3 -lobed, toothed, eallosely hispid on both surfaces: lateral lobes dilated, angular, intermediate one elongated; petioles hispil; flowers axillary, nearly sessile, numerous; fruit nearly globose, beset with a few obverse strigre; seeds muricated. (๑) F. Native of the East Indies. Willd. spec. 4. p. 619. Baboon tengang of the Hindoos. Flowers yellow. Habit of Melothria.

I ar, a; leaves smaller; seeds tuberculated. Blume, l. c.

$\operatorname{Iar} . \beta$; leaves coarsely toothed, as in the preceding variety, and beset with setaceous strigr ; berries elliptic-globose. Blume, 1. $c$.

Roughish Bryony. Fl. May, July. Clt. 1781. Pl. cl.

33 3. Latebròsa (Ait. hort. kew. ed. 1. vol. 3. p. 384. ed. 2. vol. 5. p. 347.) leaves somewhat 3-lobed, pilose, attenuated at the base, hardly cordate, running down the petiole on one side only. 24.G. Native of the Canary Islands. Flowers whitish.

Dark Bryony. l'. June. Clt. 1779. Pl. cl.

34 B. ткиова'та (Thunb. prod. 13. but not of Lour.) leaves 3-lobed, smooth above, and scabrous beneath. 4. G. Native of the Cape of Good 1lope.

Tlure-lobed-leaved Bryony. Pl. el.

35 13. stipula'eea (IVilld. spec. 4. p. 620.) stem shrubby? furrowed; tendrils trifid; leaves cordate, 3-lobed, toothed, glabrous, smooth on both surfaces; stipulas rounclish, concave, serrated; flowers monoecious, solitary; fruit ovate, acutish, glabrous, yellow, 5-celled, many-seeded. 4. G. Native of Cochinchina. B. triloba, Lour. coch. p. 595. but not of Thunb. B. agr'éstis, Rausch. ex Steud. nom. phan. p. 123. Flowers white.

lar. $\beta$; perpusilla (Blum. bijdr. p. 926.) leaves membranous, deeply cordate, 3-lobed, obsoletely denticulated, scabrous from dots above, smooth beneath: lateral lobes rather angular, intermediate one elongated, acuminated; flowers umbellate, monoecious; fruit pea-formed. 24. S. Cueúrbita perpusílla, Blum. cat. hort. buit. p. 105. Native of Java, in the shady parts of mountains. The plant is called Hampru Bogor, and Korres koda by the Javanese.

Large-stipuled Bryony. Pl. el.

36 13. Ameriea'Na (Lam. diet. 1. p. 498.) root thick; stem angular; leaves cordate, 3-lobed, angular, wrinkled, with spine- formed teeth ; lobes of corolla narrow, white inside; fruit ovate, red, few-seeded; seeds compressed. 4 . S. Native of the Antillis.-Plum. spee. 3. icon. p. 66. ex Willd. spec. 4. p. 620.

American Bryony. Pl. el.

37 B. Guiné' Nsis ; leaves cordate, petiolate, 5-lobed ; lobes acute, toothed; peduncles axillary, many-flowered; tendrils axillary. $\not 2$.$) . Native of Sierra Leone. Flowers red.$

Guinca Bryony. Pl. tw.

38 B. condfólia (Lin. spec, p. 1438.) leaves cordate, oblong, 5 -lobed, toothed, scabrous, bidentate at the top of the petiole. 21.S. Native of Ceylon. Flowers white. The root of this plant is considered eooling, and to possess virtues in complaints requiring expectorants.

Heart-leaved Bryony. Pl. cl.

39 B. A' цва (Lin. spec. p. 621.) stem climbing; leaves eordate, 5 -lobed, toothed, scabrons from callous dots; terminal lole hardly longer than the rest; tendrils twin; flowers racemose, monoecious; stamens distinct; fruit globose, black; seeds unknown. 4. H. Native of Europe, in woods and hedges, as in Sweden, Denmark, and Carniola. Lam. ill. t. 769. Fl. dan, t. 813. Flowers whitish or vellowish.

Black-berried whitc Bryony. Fl. Ju. Jul. Clt. 1807. Pl el.

40 B. dior'ca (Jacq. Hl. austr. t. 199.) stem climbing: leaves cordate, palmately 5 -lobed, toothed, scabrous from eallous points ; terminal lobe the longest and very dissimilar, perbaps always; tendrils simple; flowers racemose, dioecious; filanents pilose at the base; fruit globose, red; seeds obovate-globose, rather compressed, grey, variegated with black. \%. H. Native of Europe, in hedges ; plentiful in England, particularly in calcareous counties. Smith, engl, bot. t. 439 . Mlill. fig t. 71 .Blackw. herb. t. 37. B. álba, Huds. 437. Wood. med. bot. t. 189. Flowers white, with elegant green ribs and veins. The root grows sometimes to an immense size ; it is a fanous hyclrogogue, and highly purgative and acrid, a drachm of it in substance, or half an ounce of it infused in wine, is said to be a full dose; orhers give 2 drachms in dropsical cases. As a purgative it has great effect on some, while on others it has hardly any; hut it frequently becomes diuretic and diaphoretic. A cold infusion in water is used externally in sciatic pains. A eataplasm of it is a most powerful discutient The best season to take up the roots for use is in autumn. It is called in English, white wild vine, wild hops, white Bryony, nild nep, Tetter-berry.

I ar. $\beta$, lìtca (Ser. mss. in D. C. prod. l. c.) leaves deeply lobed; lateral lobes nearly linear, terminal one lanceolate, bidentate laterally; fruit and seeds ycllow. 2. H. Native of Auvergne, in hedges and woods.

Dioecious-flowered or red-berried white Bryony. FI. May, Sept. Britain. Pl. el.

4.1 B. Nírids (Link. emun. 2: p. 40 1.) leaves cordate, 5-lobed, apiculated, scabrous from hairs: peduncles umbelliferons. 4 . H. Native conntry unknown.

Shining Bryony. Fl. July, Sept. Clt. 1824. Pl. el.

42 B. Crétich (Lin. spec. 1439.) root fleshy; stems climbing; leaves cordate, 5 -lobed, quite entire, ciliated, muricated on both surfaces: terminal lobe the largest; tendrils simple, spiral; flowers dioecious: female ones axillary, twin; fruit globose, red; seeds smooth, obovate. $\odot$. H. Native of Candia. Desf. coroll. p. 91. t. 70, ann. mus. 12.t. 17. Flowers pale.

Cretan Bryony. Fl. July, Sept. Clt. 1759. Pl. el.

43 B. QUINQUE'Loba (Thunb. prod. 13.) flowers dioecious; leaves 5 -lobed, seabrous above; lobes very blunt, mucronately toothed, aurieled behind; tendrils simple; peduncles of male flowers 1-flowered, twin; calyx broadly eampanulate, and acutely toothed; corolla campanulate, half 5-cleft; fruit unknown. 4. G. Native of the Cape of Good Hope. Ker, bot. reg. 82. Sims, bot. mag. 1820. Flowers brown.

Five-lobed-leaved Bryony. Fl. June, Oct. Clt.? Pl. cl. 
44 B. Nipaulénsis (Ser. mss. in D. C, prod. 3. p. 307.) stems numerous; leaves palmately 5 -lobed, scabrous ahove, smooth beneath; lobes narrow, very acute, almost entire: terminal one very long: lateral ones divaricate, lower ones very short or wanting; petioles slort; male flowers in fascicles, numerous, small; peduncles unequal; fruit unknown. ๑.? 11 . Native of Nipaul.

Nipaul Bryony. Pl. cl.

45 B. ficı́òlia (Lam. dict. I. p. 498.) leaves 5-lobed, somewhat denticulated; lobes deep, obtuse: petioles and stem hispid. 4. G. Native of Buenos Ayres, B. Bonariénsis, Mill, dict. -Dill. hort. e] th. p. 58, t. 50. f. 58 . Flowers whitish.

Fig-leaved Bryony. Fl. July, Aug. Clt. 1710 . 1'?. cl.

46 B.? Acv'тA (Desf. fl. atl. 2. p. 360.) stem slender; leaves somewliat 7 -lobed; lobes lanceolate, acute, entire, or toothed; tendrils simple; male peduncles many-flowered; calycine segments narrow, acute; fruit unknown. 24. H. Native of the kingdom of Tunis, in hedges. Corolla campanulate, spreadingly 5 -cleft, twice the size of that of $b$. alba.

Acutc-lobed Bryony. Pl. cl.

47 B. variega'ta (Mill, dict.) leaves palnate, with lanceolate segments, which are dotted above and smooth beneatl. 4.S. Native of America. Fruit ovate, seattered.

laricgaled Bryony. Pl. cl.

48 B. uncropuy'lla (Ser. in D. C. prol. 3. p. 308) stem thick, striated; leaves cordate, lobed; angles cut ; lobes toothed; petioles long; male flowers large, racemose, on long peduncles : female ones solitary, perlunculate; fruit oblong, pilose. 24. S. Native country unknown. Leaves large, size of those of the common vine.

Large-leaved Bryony. Pl. cl.

\section{* * Leaves palmate.}

49 B. RAcenòsa (Mill. dict. and Swartz, prod. 116. fl. ind. occid. 2. p. 1148.) lower leaves rather palmate, upper ones 8 lobed and undivided; segments of the leaves ovate; flowers racemose; pedicels rather secund; fruit oval. 24.S. Native of Jamaica and St. Domingo, in woods and hedges.-Plum. amer. 83. t. 97. Root oblong, fleshy. Flowers yellowish.

Racemose-flowered Bryony. Pl. el.

50 B. PINNatírida (Burch. eat. geogr. no. 2098. voy. 1. p. 54\%.) leaves ternately perlate, with pinnatifid lobes, and linear and oblong, obtuse, veinless segments. 2. G. Native of the Cape of Good Hope.

Pinnatifid-leared Bryony. Fl. Jul. Aug. Clt. 1815. Pl. cl. 51 B. Teñfòlis (Gill. mss. ex Hook. et Arn. in bot. misc. 3. p. 234.) leaves 3-parted; segments bipinnatifid; female peduncles solitary, simple, equal in length to the petioles; fruit oval, smooth, 2-seeded. $\%$. $\checkmark$. G. Native of Chili, in the Pampas, in the province of Cordova; and in sandy places near Santa Fe, and also of Buenos Ayres. The vernacular nane of the plant is $A g i$ del Torvo.

Fine-leaved Bryony. Pl. cl.

52 B. L.E'vis (Thunb. prod. 13.) leaves cordate, palmate, serrated, smooth; flowers axillary, rather umbellate. 4 . G. Native of the Cape of Good Hope.

Smooth Bryony. Pl. el.

53 B. palsis'ta (Lin. spec. 1438.) leaves cordate, palnate, smooth, 5-parted, with lanceolate, repandly serrated segments, lateral seginents the shortest; fruit large, globose. $4 . \mathrm{S}$. $\mathrm{Na}-$ tive of Ceylon.

Palmate-leaved Bryony. Fl. Jul. Aug. Clt. 1778. Pl. cl. 5.t B.? Garcisi (Willd. spec. 4. p. 623.) leaves palmately 5 parted, with roundish-obovate, toothed lobes, scalsrous above; stipulas, (probably bracteas,) kidney-shaped and ciliated. 4 . S. vol. III.
Native of Ccylon. Burm. fl. ind. 311. t. 57. f. 3. Sícyos Gareini, Lin. mant. 297. Perliaps a species of Momórdica. Garcin's Bryony. Fl. July, Aug. Clt. 1812. 1'l. cl. 55 B. Alcexiólia (Willd. 1. c. p. 624.) leaves palmately 5 parted: with linear-lanceolate, 3-parted lobes, having scabrous margins; tendrils simple; peduncles axillary, 1-flowered. $\%$. S. Native of the East Indies.

\section{IIollyhoek-lecued Bryony. I'I. cl.}

56 L. Lacinıòsa (Lin. spec. 624.) leaves palmately 5-parted, cordate, rough, and blistered: with oblong-lanceolate, acuminated, serrated segments; petioles muricated; peduncles 1-flowered, muricated; corollas hairy inside, or tomentose, but smooth on the outside; fruit the size of a cherry, striated with white; seeds obovate, circled by a longitudinal elevated zone. 4. S. Native of Ceylon. Herm. hort. lugd. 95. t. 97. Aroy-peringinge of the Hindoos. Flowers yellow.

Jagged-leaved Bryony. Fl. July, Aug. Clt. 1710. Pl. cl. 57 B.? cucumeroìdes (Ser. in D. C. prod. 3. p. 308.) seeds rusty, transversely oblong, surrounded by a very thick dottel zone. 4 . S. Native country unknown. Cucumeroides, Thunb. ex Gærtn. fruct. 2. p. 485 .

Cucumber-like Bryony. Pl. cl.

58 B. Africa'ta (Thunb, prod. 13. but not of Lin.) root tuberous; upper leaves palmately 5-parted; lobes oblong, deeply toothed; lower leaves corlate, having the angles toothed. 4. G. Native of the Cape of Good Hope. Willd. spee. 4. p. 624.-Herm. par. 107.t. 108. Male flowers in subumbellate panicles. Fruit mucronate.

African Bryony. Fl. July, Ang. Clt. 1759. Pl. cl.

59 B. NA'NA (Lam. dict. 1. p. 497.) stems slender; lower leaves roundish-cordate, quite entire : upper ones deeply 3-lobed; lobes obtuse. \%. S. Native of Africa.

Dwarf Bryony. Pl. cl.

60 B. Disse'cta (Thunb. prod. 1. p. 497.) leaves palmately 5-parted: with linear pinnatiful segments, having revolute scabrous margins; male flowers? umbellate; fruit solitary, roundish, mucronate, bluntly angular, yellow; seeds $3-4$. 4 . G. Native of the Cape of Good Hope. Willd. spec. 4. p. 625. B. Africàna, Lin. spec. 1438. Flowers white? Probably distinct from the preeeding species.

Dissected-lenved Bryony. Fl. July, Aug. Clt. 1710. IP. cl. 61 B. Digita'ta ('Thunb. prot. 13.) leaves digitate: with linear 2-lobed scabrous segments; flowers umbellate. 4. G. Native of the Cape of Good Hope.

Digitale-leaved Bryony. Pl. cl.

62 B. Wallichiana (Ser. mss. ex D. C. prod. 3. p. 309. ) stem filiform, striated; leaves nearly sessile, sagittate, rugged from warts; terminal lobe lanceolate-linear, very long, somewhat denticulated; lateral lobes oblong, reflexed, remotely denticulated; male Howers in fascicles, mumerous, on short peduncles; fruit unknown. 4.G. Native of Nipaul. B. titifórmis, Roxb.

Wallieh's Bryony. Pl. el.

Cult. The hardy perennial species are plants of easy culture, only requiring to be planted in the ground. The stove perennial species should be grown in pots, and the stems trained up the rafters. The seeds of annual kinds require to be sown in a hotbed in spring, and when the plants are of sufticient size may be planted out in a sheltered situation. All the species are propagated by seeds. None of them are worth growing, except in botanic gardens.

X. SI'CYOS (from ouver, sicyos, the Greek name for the cucumber; resemblance and affinity). Lin. gen. no. $14 \mathrm{S1}$. Juss. gen. no. 39 t. Gartn. fruct. 2. p. 45. t. 88. f. 1. Sicyoides, Tourn. inst. 103. t. 28 . 
Lin. syst. Monce'cia, Polyadélphia. Flowers monoecious; male ones with a 5 -toothed calyx, and a 5 -parted corolla; teeth of calyx subulate. Filaments 3 ? or more probably 5 , in 3 bundles. Female flowers with a trifid style, and a thickish trifid stigma. Fruit 1 -seeled from abortion, usually beset with spines. Seed obovate. Male and female peduncles many-flowered, usually rising together from the same axillæ.

1 S. ANGULA'TUS (Lin. spec. 1438.) leaves cordate, angular, denticulated, scabrous; lobes 3-5, acuminated; tendrils umbcllate; male flowers in corymbose heads, each head on a long common peduncle; female flowers sessile, in bundles at the tops of the peduncles; fruit ovate, spinescent, and tomentose; seeds truncate at the base, and very bluut at the apex. $\odot . F$. Native of North Anerica. Lam. ill. t. 796. f. 2.-Dill. elth. 58. t. 5 I. f. 59. Flowers sulphur-coloured. Fruit beset with yellow spines, and curling tomentum.

Angular-leaved Single-seeded Cucumber. Fl. June, July. Clt. 1710 . Pl. tr.

2 S. BRYONIÆfólius (Moris, hort. taur. sem. 1831.) leaves cordate and angular, denticulated, hispid below; teeth of calyx obsolete; capsule clammy and wartcd. $\odot$. S. Native country unknown. This species differs from $S$, angulatus and $S$. parviflòrus in the stem being hardly pilose about the joints, the rest smooth; in the peduncles being short, the flowers umbellate; male ones 5-8 pedicellate, female ones almost sessile.

Bryony-lared Single-seeded Cucumber. Pl. cl.

3 S. PARvirtòrus (Willd. spec. 4. p. 626.) branches glabrous; leaves cordate, rather angular, denticulated, roughish ; tendrils trifid; male flowers racemose, on long pedicels : female ones in sessile capitate umbels; fruit crowned by the permanent calyx, size of an orange; seeds unknown. $\odot . F$. Native in the temperate parts of mountains about Quito, near Clillo, at the lieight of 4000 feet. Not of $\mathbf{M e x i c o , ~ H . ~ B . ~ e t ~ K u n t h , ~ n o v . ~ g e n . ~ a m e r . ~}$ 2. p. 119. Flowers whitish. Fruit rarely solitary.

Small-flowered single-seeded Cucumber. Fl. June, Sep. Clt. 1823. Pl. cl.

4. S. BADERòa (Hook, et Arn. in bot. misc. 3. p. 234.) leaves cordate, angular, minutely denticulated, glabrous on both surfaces; angles acuminated; lobes at the base of the leaf lying over cach other; tendrils trifid; flowers few, capitate in both sexes; female peduncles one-lialf shorter than the male ones; fruit ovate while young. $4 \cdot \cup$. G. Native about Valparaiso. Baderòa bryonixfòlia, Bertero.

Badero's Single-seeded Cucumber. Pl. cl.

5 S. PENTA' NDRUs (Wall. cat. no. 6682.) leaves cordate, denticulated ; flowers racemose; racemes numerous, sometimes aggregate, and branched. $h_{2} \cup$. S. Native of the East Indies.

Pcntandrous Single-seeded Cucumber. Shrub cl.

6 S. DE' Prer; leaves broadly cordate, 7-lobed; lobes acuminated, middle lobe the longest; margins acutely denticulated, rough on both surfaces from conical lairs ; male racemes elongated; fruit glomerate, ovate, nearly glabrous, but beset with strong retrograde prickles. $\odot$. S. Native of Mexico, near Jalapa. Flowers smaller than those of $S$. angulàtus, but larger than those of $S$. parvifornus. Sícyos, nov. spec. Schlecht. et Cham. in Linnaa, vol. 5. 1. 88. Seeds the size of those of Citrus mèdica.

Deppe's Single-seeded Cucumber. Pl. tr.

7 S. Acưtus (Rafin, f. lud. p. 113.) climbing; leaves lobed ; fruit glomerate, ovate, acute, bristly ; bristles echinated, interwoven. $\odot . F$. Native of Louisiana.

Acute-fruited Single-secded Cucumber. Pl, cl.

8 S. microphy'LlU' (H. B. et Kunth, gen, et spec. amer. 2. p. 119.) branches roughish; leaves sinuately-cordate, 7 -lobed, denticulated, roughish ; tendrils smoothish, trifid; male fowers on long peduncles and pedicels; female flowers in crowded, nearly sessile heads; fruit echinated from bristle-formed hairs, size of an apple seed; seeds unknown. $\odot$. F. Native of Mexico, on the burning Mount Jorullo, at the height of 1620 feet.

Sinall-leaved Single-seeded Cucumber. Fl. July, Sep. Clt. 1823. Pl.tr.

9 S. PAchyca'rpus (Hook. et Arnott, in Beech. bot. p. 83.) branches glabrous; leaves cordate, 5-7-lobed, denticulated, glabrous above and papillose, scabrous beneath; tendrils glabrous, trifid; male flowers in panicles; female ones in crowded heads; fruit ovate, rostrate, unarmed. $\odot . F$. Native of the Island of Oalu, on the Diamond Hill among the volcanic rocks. Allied to S. microphýllus.

Thicl-fruited Single-seeded Cucumber. Pl, prostrate.

I0 S. vitifolius (Will. spec. 4. p. 626.) the whole plant clothed with very fine clammy down; leaves cordate, with a roundish recess, 5 -lobed, toothed. $\odot$. F. Native country unknown. Flowers yellow, twice the size of those of $S$. angulatus.

Iine-lcaved Single-seeded Cucumbers. Clt.? Pl. tr.

11 S. LAcinia'tus (Lin. spec. 1459.) stem glabrous ; leaves cordate, palnate, glabrous above, but echinated from stiff hairs beneath; lobes lobulate; petioles short; tendrils trifid; male flowers somewhat panicled: female ones glomerate, sessile; peduncles slort; fruit very spiny. $\odot$. F. Native of South America.-Plum. ed. Burm. pl. amer. t. 243. Flowers yellow.

Jagged leaved Single-seeded Cucumber. Fl. July, Aug. Cli. 1824. Pl, tr.

12 S. Tríqueter (Moc. et Sesse, f. mex. ined, ex D. C. prod. 3. p. 309.) stem bluntly furrowed; leaves cordate, 5lobed; lobes broad, obtuse, somewhat denticulated; tendrils much branched; calycine and corolline lobes 3 ? male flowers racemose, pedunculate, aggregately subverticillate; female flowers subumbellate; fruit elongated, unarmed, triquetrous; seed oblong-cylindrical. $\odot$. F. Native of Mexico, in Chilappa. Flowers yellow. Fruit 6 lines long, acuminated, somewhat 3-winged.

Triquetrous-fruited Single-seeded Cucumber. Pl. tr.

Cult. Sow the seeds in the hot-bed in spring, and treat the plants as directed for Gourds, p. 42. Not worth growing except for curiosity.

XI. ELATE'RIUM (fiom $\varepsilon \lambda a r \eta \rho$, elater, an impeller; in reference to the elastic seed vessels). Lin. gen. no. 1398. Juss. gen. p. 394. lacq. amer. 241. t. 154. D. C. prod. 3. p. 310.Nomórdica, Neck. elem. bot. no. 390.

Lin. syst. Monácia, Monadćlphia. Flowers monoecious, white or yellow; male ones disposed in racemes or corymbs; calyx petaloid, campanulate, with hardly conspicuous teeth, and with the corolla hardly gamopetalous. Female flowers solitary, or rising from the same axils with the males. Calyx elongated, petaloid, echinated at the base, and girding the carpels; neck filiform, more or less elongated, at length dilated, and bearing the corolla and stamens. Style thick; stigma capitate. Capsule coriaceons, reniform, echinated, 1-celled, 2-3-valved, many-secded, opening elastically, and ejecting the seeds.

1 E. GeME'LlUM (D. C. prod. 3. p. 310 .) Jeaves cordately subsagittate, somcwhat 5 -angled, with the middle angle acuminated; tendrils bifid; male flowers in long racemes; neck of calyx long, campanulate; petals ovate, acutish; fruit curved, 3celled; prickles distant. $\odot$. F. Native of Mexico. Moc, et Sess. fl, mex. icon. ined.

Twin-tendrilled Squirting Cucumber. Pl. cl.

2 E. Carthagenénse (Lin. spec. 1.575.) leaves cordate, angular, denticulated, petiolate, roughish above; flowers white, sweet-scented: male ones in panicles: female ones solitary; tube of calyx tercte above the ovarium, not dilated at the apex; petals linear-lanceolate, acute; fruit kidney-shaped, hispid; 


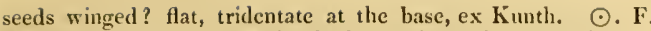
Native of South Amcrica, in the hot regions of the province of Caraccas, on the shore of Lake Tacarigna, in Laguna deValencia ; and in the Island of Cura, at the height of 690 feet. Lam. ill. t. 743. Jacq. amer. 241. t. 154, icon. pict. p. 118. t. 232. Corolla yellow. Fruit size of an olive.

Carthagenian Squirting Cucumber. Fl. June, July. Clt. 1823. Pl. cl.

S E. TAunoìns (Willd. enum. p. 950.) leaves cordate, acuminated, remotely serrated, smoothish above, and hairy beneath; flowers yellowish; female flowers having the tube of the calyx campanulate above the ovarium; petals $4-7$, ovate; style very short; stigma large, flat; fruit 2-valved, few-seeded; seeds unknown. $\odot . F$. Native of Mexico. E. hastàtum, Brouss. but not of H. B. et Kunth.

Tamus-like Squirting Cucumber. Fl. June, July. Clt. 1820. Pl. tr.

4 E. Hasta'tum (H. B. et Kunth, nov. gen. amer. 2. p. 120.) leaves cordately sinuated, triangularly hastate, acuminated, denticulated, rather scabrous above, and glabrous beneath; tendrils simple or bifid; male flowers racemose, pedicellate, minute; fruit oblong, reniform, muricated, 2-valved, size of an olive; sceds 6 , roundish, compressed, tridentate at the base. $\odot . F$. Native of Mexico, on the declivities of the burning Mount Jorullo, and the temperate regions near Patzcuara, at the height of 1620 or $\$ 390$ feet. Habit of Melóthria péndula, according to Kunth.

Haslate-leaved Squirting Cucumber. Pl. tr.

5 E. QUAdrífinum (D. C. prod. 3. p. 310.) stem, peduncles, petioles, and tendrils downy ; leaves cordate, orbicular, 7 -angled; tendrils bifid, pilose; male flowers umbellate; calyx long, tubular, articulated towards the base, and dilated at the apex, with the limb hardly evident; petals 4 , linear-lanceolate, acute ; female flowers hardly pedunculate, like the male ones; style filiform, crowned by an ovate stigma; fruit very pilose. $\odot$. F. Native of Mexico. Moc. et Sesse, fl. mex. icon. ined. Flowers white.

Quadrifid Squirting Cucumber. Pl. tr.

6 E. bracuysta'chyum (D. C. prod. 3. p. 310.) leaves 3lobed, quite entire, ciliated: middle lobe oblong, acuminated ; flowers cream-colourcd; male ones in spikes; tube of calyx campanulate at the apex; female flowers with a very gibbous hispid calyx, and a short neck, which is campanulate at the apex; capsule oblique, incurved, echinated with 8-10 long soft prickles, 2-3-valved, larger than those of the other species. ○. F. Native of Mexico.

Short-spiked Squirting Cucumber. Pl.tr.

7 E. roreuA'rum (D. C. prod. 3. p. 310.) leaves somewhat peltately cordate, 5-lobed, denticulated; terminal lobe the longest, and acuminated; tendrils trifid; flowers greenish-white ; males ones in racemes: female ones solitary, echinated at the base, with the neck long and bell-shaped at the apex; petals oblong, bluntish; capsule oblong, 2-valved, acuninated, echinated, with soft prickles. $\odot$. F. Native of Mexico. Fl. mex. icon. ined.

Collared Squirting Cucumber. Pl. tr.

8 E. TRIFolia'tum (Spreng. syst. 3. p. 47.) leaves ternate, cut. $\odot$. F. Native of Virginia.

Trifoliate-leaved Squirting Cucumber. Pl. tr.

Cult. Sow the seeds in a hot-bed in spring, and put the plants out as directed for Gourds, p. $4 \%$.

XII. MOMO'RDICA (from mordeo, to bite; the seeds have the appearance of being bitten). Lin. gen. no. 1477. Juss. gen. 395. Gartn. fr. 2. p. 48. t. 88. f. 4. D. C. prod. 3. p. 311. -Elatèrium and Sícyos species of authors. $-\Lambda$ mórdica, Neck. elem. bot. no. 392.-Poppỳa, Neck. 1. c. no. 391.-Ecbàlium, Rich.

Iin. syst. Mone'cia, Polyadélplia. Flowers monoecious, white or yellow, on filiform umibracteate peduncles, perhaps always. Male flowers with a 5-cleft calyx, and a very short tube. Corolla 5-parted. Stamens in 3 bundles; antliers connate. Female flowers with 3 sterile filaments, or probably 5, joined in 3 bundles, a trifid style, and a 3-celled ovarium. Fruit usually muricated, (perhaps always) opening elastically at maturity, and expelling the seeds. Seeds compressed, reticulated, perhaps always.

1 M. Balsa'mea (Lin. spec. 1453.) leaves palmately 5-lobed, toothed, glabrous, shining ; fruit roundish-ovate, attenuated at both ends, angular, tuberculated, orange-coloured, splitting irregularly and laterally; bractea cordate, toothed, in the middle of the peduncle; aril red. $\odot$. F. Native of the East Indies. Lam. ill. t. 79 1. f. 1. Charántia, Lob. pempt. t. 670.-Ludvo. ect. t. 127.-Blackw, herb. 6. t.539. a. b. Flowers yellow. This plant is famous in Syria for curing wounds. They cut open the unripe fruit, and infuse it in sweet oil, and expose it to the sun for some days until the oil becomes red. It is applied to a fresh wound on cotton. The Syrians esteem this next to balsam of Mecca. The plant is also used to form arbours or bowers.

Balsam Apple. Fl. June, July. Clt. 1568. Pl. cl.

2 M. murica'ta (Willd. spec. 4. p. 602.) leaves somewhat palmately 7 -lobed, cordate at the base; lobes remotely toothed, acuminated; tendrils almost simple; fruit ovate, acuminated, muricated; bractea cordate, quite entire. ๑. F. Native of the East Indies, Pavel, Rheed. mal. 8. t. 10.

Muricaled Momordica. Fl. June, July. Clt. 1817. Pl. tr.

3 M. Charántia (Lin. spec. 1438.) leaves somewhat palmately 7-lobed, dentate, rather hairy ; tendrils downy; fruit oblong, acuminated, angular, tuberculated, copper-coloured or red ; pulp yellow and soft; bractea cordate, quite entire, below the middle of the pedicel; seeds oblong, tuberculated (ex Rumph); arillus of a reddish blood-colour. $\odot$. F. Native of the East Indies. Sims, bot. mag. t. 2455.-Rheed. mal. 8. p. 17. t. 9. Paparel of the Hindoos. Corolla yellow. Seeds wrinkled very irregularly, yellow bay-coloured, and irregularly tubercled towards the margin. Allied to the preceding species, but very distinct.

Var. $\beta$, abbreviàta (Ser. in D. C. prod. 3. p. 311.) fruit shorter than that of the species, very ventricose, beset with acute tubercles. M. Zeylánica, Mill. dict. 3. ex Lam. dict. 4. p. 239 . Pl. cl

4 M. Roxburghina'na downy; leaves cordate, palmately 7-9-lobed, and lobately toothed; tendrils simple; peduncles 1flowered, solitary, bearing a bractea under each flower; fruit long, muricated. $\odot$. H. Native of the East Indies, in Patna. M. charántia $\beta$ of authors. M. muricàta, Roxb. but not of Willd. Roxburgh's Momordica. Pl. tr.

5 M. Senegale'nsis (Lam. dict. 4. p. 239.) leaves deeply palmate, somewhat serrated, pale and villous beneath; fruit ovate, mucronate, tubercular, orange-coloured or red. ๑. F.

Native of Senegal.

Senegal Mlomordica. Fl. July, Aug. Clt. 1822. Pl. cl.

6 M. CYLI'NDRICA (Lin. spec. 1433.) stem 5-angled; leaves cordate, somewhat lobate, angular, toothed; flowers yellow ; fruit cylindrical, very long, rather villous, reticulated; bractea quite entire at the base of the pedicel; seeds black. $\odot . F$. Native of Ceylon and China. Willd. spec. 4. 1).605. The fruit of the species, according to Rumphius, does not open elastically, being composed of so many reticulated tough fibres.

Cylinilrical-fruited Momordica. Pl. tr. 
7 M. Hexnea'sa (Wall. cat. no. 6744.) leaves S-lobed, mucronately denticulated ; peduncles 1-flowered, solitary, furnished each with a large bractea under the flower, which cncloses it before expansion; tendrils simple. $\odot . ?$ F. Native of the East Indies. Flowers large.

Heyne's Momordica. Pl. tr.

8 M. subangula'ta (Blum. bijdr. p. 928.) leaves deeply cordate, acuminated, rather angular, mucronulately denticulated, scabrous above; flowers dioecious; bractea cordate, quite entire at the top of the peduncle. $\odot$. F. Native of Java, on Mount Salak, where it is called by the natives Aroy Gambas. Allied to $M$. cylindrica and $M$. dioica. The inflorescence of this plant agrees with the figure in Rumph. amb. 5. t. 150. ex Blume. Fruit fibrous.

Angular-leaved Momordica. Pl. cl.

9 II. Paina (Hamilt. ex Wall. cat. no. 6742.) leaves cordate, triangular or hastate, sometimes lobed at the base, acuminated at the apex, coarsely toothed; tendrils simple; female peduncles 1-flowered, solitary; male ones racemose; racemes aggregate; fruit round, beset with a few scattered prickles. $\odot$. F. Native of the East Indies, in Goyalpara.

Paina Momordica. Pl.tr.

10 M. тuвrz Lòra (Roxb. ex Wall. cat. 6749.) plant white from down; leaves round, angularly and roundly lobed, cordate at the base; tendrils simple; fruit oblong, acuminated, ribbed; peduncles 1-flowered, solitary, bracteate. $\odot . F$. Native of the East Indies.

Tube-flowered Momordica. Pl. tr.

11 N. Pu'rgaxs (Mart. reise. bras. ex Linnaca. vol. 5. p. 40.) stems angular, climbing, clothed with resinous farina at top; leaves ovate-orbicular, acuminated, with a roundish recess, cordate, obsoletely 5-lobed, denticulated; male corymbs ercet, axillary; female flowers solitary, axillary, drooping; fruit oblong, crested longitudinally from warts. $\odot$. F. Native of Brazil.

Purging Momordica. Pl. cl.

12 M. opercula'ta (Lin. spec. 1433.) leaves 5-lobed, toothed; fruit elliptic, angular, tuberculated, operculated by a deciduous beak. $\odot . F$. Native of America. Comm. rar. 22. t. 22. ex Lin. and Willd. spec. 1. p. 603. This plant is probably referrible to the genus Liffa. The top falling off from the fruit when it is grcen.

lid-fruited Momordica. Fl. June, Sep. Clt. 1731. Pl. cl.

13 M. elaxe'rium (Lin. spce. 1434.) plant scabrons, hispid, and glaucescent ; stems dwarf, without tendrils ; leaves cordate, somem hat lobed, crenate-toothed, very rugged, on long petioles; fruit ovate, obtuse, hispid, and scabrous, on long peduncles ; seeds bay-coloured. 4 . F. or $\odot$. II. Native of the south of Enrope. Sims, bot. mag. t. 1914.-Blackw. herb. t. 108. Woodv. med. bot. t. 4.3. Elatèrium cordifòtium, Hoench. meth. p. 563. Ecbàlium L. C. Rich. Root thick. Flowers yellow. Fruit green, expelling the seeds when ripe. Perhaps a proper genus. Dr. Clutterbuck has lately ascertained that the active principle of wild cucumber is contained almost cxclusively in the juice around the seeds, and that genuine claterium is the matter which subsides spontaneously from the juice obtained without pressure. He found that the eighth part of a grain thus prepared seldom failed to purge violently, and of this according to Dr. Barry, from 55 to 64 per cent, only were soluble in alcohol of 0.809 . The bitter principle found in it is not in itself purgative, but quickens the action of elatin when combined with it. Elatin is a new principle obtained by Dr. Barry of a green colour; it is purgative in very minute quantities. In medicine a few grains of elaterium operates as a drastic purgative, and was sometimes used in dropsies. It is high priced, and seldom used, though recommended by Dr. Ferriar.
Elaterium or Common Squirting Cucumber. Fl. Jume, July. Clt. 1548. Pl. tr.

14 M.? Ianmertia'sa (Ser. in D. C. prod. 3. p. 311.) hispid; stems prostrate, flexuous; tendrils nearly simple; leaves cordate-roundish, 5-lobed, denticulated, scabrous; petioles short; flowers? fruit solitary, elliptic, pilose; peduncles short, hispid. ○. F. Native of the East Indies. Ecbàlium L. C. Rich. Allied to $M$. clatèrium, but distinct.

Lambert's Momordica. Pl. tr.

15 M. ecinna'ta (Muhl. ex Willd. spec. 4. p. 605.) leaves cordate, with 5 lobed angles; lobes acuminated, quite entire, glabrous; tendrils multifid; fruit roundish, 4 -seeded, echinated by bristles. $\odot$. H. Native of the western parts of Pennsylvania, near the river Ohio. Sícyos lobàta, Michx. amer. 2. p. 217. Fruit roundish, size of a gooseberry, beset with long subulate bristles, very like those of Sicyos, but 4-seeded. Flowers yellow.

Echinated-fruited Momordica. Pl. tr.

16 M. nioíca (Roxb. ex Willd. spec. 4. p. 605.) stem angular, climbing ; leaves cordate, acuminated, toothed, glabrous on both surfaces; tendrils filiform; flowers dioecious; female ones solitary; fruit elliptic, muricated. $\odot$. F. Native of the East Indies.

Dioecious-flowered Mlomordica. Pl. cl.

17 M. renígera (Wall. cat. no. 6743.) leaves cordate, dentate or distantly and mucronately denticulated; peduncles long, 1flowered, solitary, furnished each with a kidney-shaped hooded bractea, just below the flower; tendrils simple. $4 . \mathrm{S}$. Native of the Burman Empire, about Prome.

Kïdney-bcaring Nomordica. Pl. cl.

18 M. Hasiltonia'na (Walt. cat. no. 6748.) leaves cordate, toothed, crenated, acuminated; bractea toothed; peduncles 1flowered, solitary; tendrils simple; fruit hispid. $h . \cup . \mathrm{S}$. Native of the East Indies, in Goyapara and Gongachora. Flowers large.

\section{IIamilton's Nomordica. Pl. cl.}

19 M. Bícolor (Blum. bijdr. p. 928.) leaves deeply cordate, somewhat 5-angled, bluntish, glabrous, mucronately denticulated, with rather strigose margins (when dry dotted above), glandular beneath; flowers dioecious, pedunculate, axillary, usually 3-together; fruit oblong, glabrous, variegated with reu. $\odot$. F. Native of Java, in calcareous soil near Kuripan, where it is calted Aroy Pupassang by the natives. Nearly allied to $M$. dioíca.

I ar. $\boldsymbol{a}$; base of leaves deeply cordate. Native of the Moluccas.

I ar. $\beta$; leaves cordately 3-lobed; lateral lobes angular. Native of Java, on Mount Parang.

Tuo-colourcd-fruited Mlomordica. Pl. tr. or cl.

20 M. ACUleA'ta (Poir. dict. suppl. 3. p. 723.) stem slender, climbing; leaves palmately pedate, with 5-7 dentately lobed segments, having white scattered dots above, but with the nerves and petioles beset with sliort prickles beneath; petioles and middle nerves clothed with rough reflexed hairs; male flowers racemose, on long peduncles; female flowers solitary, hardly pedunculate; fruit subglobose, glabrous, size of a pea. $\odot . \vec{F}$. Native country unknown.

Prickly Momordica. Pl. cl.

21 M. my'strix (Gill. mss. ex Hook. et Arn. in bot. misc. 3. p. 234.) leaves 5-lobed, glabrous, smooth, somewhat cuncated at the hase; lobes mucronate, denticulated, middle lobe the longest; tendrils simple; male and female flowers rising from the same axils: male ones disposed in racemes: female ones solitary, pediunculate; fruit oblique, ovate, echinated with strong bristles. $\odot . F$. Native of Bucpos Ayres.

Porcupine IIomordica. Pl. tr. 
22 M. LANA'TA (Thunb. prod. 13.) leaves ternately pinnatifid, scabrous; fruit woolly. $\odot . F$. Native of the Cape of Good Hope.

Noolly-fruited Momordica. Pl. cl.

23 M. ? sicroides (Ser. in D. C. prod. 3. p. 312.) stems twining, terete; tendrils simple; leaves triangularly cordate, somewhat 5-lobed, serrulated; female flowers pedunculate, solitary; calyx ovate, pilose, with narrow linear segments; fruit ovate mucronate, very pilose, of a yellowish orange-colour at maturity; seeds subglobose. $\odot$. F. Native of China-Braan. icon. chin. t. 12.

Sicyos-like Momordica. I'l, tw.

24. M. spica'ta (Lin. mss. ex Smith in Rees' cycl. vol. 23.) stems furrowed, rugged; leaves cordate, 3-5-lobed, undulated, rugged from tubercles; male flowers racemose; racemes on long peduncles; tube of calyx very long; bracteas dilated, toothed, scabrous; female flowers solitary, on short peduncles; seeds elliptic, furrowed, hispid. $\odot . F$. Native country unknown.

Stike-flowered Momordica. Pl. cl.

Cult. M. Elatèrium and $M$. Lambertièna being hardy, their seeds should be sown in the open border. The seeds of the rest of the species should be sown on a hot-bed in spring, and the plants planted out afterwards as directed for Gourds, p. 42.

XIII. NEUROSPE'RMA (from vevpoy, ncuron, a nerve, and $\sigma \pi \varepsilon \rho \mu a$, sperma, a seed; in reference to the seeds, which are reticulated with anastornosing nerves). Rafin. in journ. phys. et chim. 1S19. p. 101. Spreng. neue. entd. 1. p. 144. D. C. prod. 3. p. 312 .

Lis. syst. Moncécia, Monadélphia. Flowers monoecious. Male flowers with a 5-parted calyx: and a 5-parted corolla, having an undulated erose margin. Stamens 5, diadelphous, having a gland alternating with each fascicle; one of the fascicles bearing 2 anthers, the other trigonal, and bearing 3 anthers. Anthers sessile, stellate. Female flowers with a parted corolla and calyx. Ovarium inferior, beset with 8 series of warts. Style trifid, girded by 3 glands at the base; stigmas 2 -lobed. Fruit flesly, 3-celled, but when mature 1-celled, 3-9-sceded. Seeds gircled by mucilaginous red aril, flat, nerved, with anastomosing reins, and a rugged edge. Perlıps a proper genus.

1 N. cuspida'ta (Rafin. l. c.) Native of Kentucky, North America. Perhaps the same as Momórdica balsàmca?

Cuspidate Neurosperma. ['], tr.

Cult. Sce Sícyos p. 34. for culture and propagation.

XIV. SECHIUM (from oextלo, scliso, to fatten; given to hogs for that purpose). Browne in Lin. gen. no. 148\%. Juss. gen. p. 391 . Lam, dict. 7. p. 50. I). C. prod. 3. p. 313.

Lin. syst. Moncécia, Monadélphia. Flowers monoecious, yellow. Male flowers with a somewhat 5-toothed calyx, excavated into 10 hollows, and with the corolla joined with the calyx. Stamens 1-5, monadelphous, free at the apex, diverging; anthers cordate, distant. Female flowers witl a calyx and corolla, as in the male, but without stamens. Style thick; stigma subcapitate, 3-5-cleft. Fruit obcordate, 1-seeded. Seed ovate, flat, compressed.

1 S. EDU'LE (Swartz, f. ind. occid. 2. p. 1150.) stems terete, striated, smooth; leaves cordate, angular, rugged beneatl ; lobes conniving at the base, toothed; terminal angle longest and acuminated; tendrils 4-5 cleft; male flowers racemose; female flowers solitary, rising from the same axils as the males; fruit large, olovate, 5 -furrowed, gibbous at the apex, cchinated by stiff lıairs. $\odot$. F. Native of the West Indies, common. Sícyos edulis, Swartz, prod. 116. Lam. dict. 1. p. 156.-Jacq. amer. p. 258, t. 163. Chayòta edùlis, Jacq. amer. 2. t. 245. This plant is known in South America under the name of choko and chaiote. The fruit is green, shining on the outside, whitish, and fleshy within, differing in size and singular in structure, containing one seed each, which is sometimes an inch long, and placed at the very top of the fruit; when it is ripe it protrudes itself a little, and puts forth many fibres at its extremity. In many of the West Indies the inhabitants put the fruit into soups or puddings, or boil it and eat it with their meat as a substitute for turnips or greens, in which state it is generally looked upon as wholesome and refreshing, but it is too insipid to be much liked. The fruit serves to fitten hogs in the mountains and inland parts of Jamaica, where the plant is much cultivated. The natives of Cuha notice two varieties; one which is most common they call simply chayote: it is beset with larmless prickles, sometimes in great abundance, and sometimes with very few, and is about 4 inches in length; the other, less frequent, called chayote frances, is for the most part entirely destitute of prickles, and is about the size of a hen's egg.

Eatable Choko. Fl. July, Aug. Clt. I816. Pl. cl.

2 S. America' num (Lam. dict. 7. p. 50.) leaves cordate, angular; Howers racemose; fiuit glabrous, a little compressed, size of a pigeon's egg; seed oval-elliptic. $\odot$. F. Native of Jamaica. Fruit eatable like the last. This is perlaps the chayote frances mentioned above.

Ancrican Choko. Pl, cl.

3 S. PALMA'TUM (Ser, in D. C. prod. 5. p. 313.) stems terete, bluntly furrowed; tendrils umbellate; leaves palmately lobed, scabrous; stipula or bractea sessile, cordate, deeply 3-lobed; male flowers racemose; common peduncle short, many-flowered; filaments monadelphous at the base, and divaricate towards the apex; female flowers twin, nearly sessile ; fruit prickly, green, size of a filbert. $\odot$. F. Native of Mexico, in Acahualtempa. S. palmàtum, Moc. et Sesse, fl. mex. ieon. ined.

Palmate-leaved Choko. Pl. cl.

Cult. See Cucúrbita, p. 42. for culture and propagation.

XV. MELO'THRIA ( $\mu \varepsilon \lambda_{0} \vartheta \rho \circ \nu$ of Theophrastus, supposed to be Bryony). Lin. gen. no. 68. Juss. gen. p. 395. D. C. prod. 3. p. 313.-Trichosánthes species of Jacq.

Lin. syst. Monce'cia, Polyadélphia. Flowers monoecious. Male flowers with a 5 -toothed calyx and a campanulate corolla; petals ciliated or toothed, not fringed. Filaments 5 , in 3 parcels. Female flowers. Style 1; stigmas 3, fringed. Fruit 3-celled, many-seeded. Seeds unknown.

1 M. PÉndula (Lin. spec. p. 49.) leaves cordate, 5-lobed, toothed; tendrils simple; female flowers solitary, on long peduncles; corolla rather pilose, denticulated; fruit ovate, nearly globose, pendulous. $\quad \psi$. S. Native of South America, and the southern parts of North America. Lam. ill. t. 28. f. 3.-Pluk. alm. t. 85. f. 5.-Sloan. jam. p. 227. t. 142. f. 1. -Plum. spec. 3. t. 66. f, 2. Stems rooting at every joint. Flowers small, pale yellow. Fruit about the size of a pea, changing to black when ripe. In the West Indies these are pickled when green by the inhabitants.

Pendulous-fruited Melothria. Fl. Ju. Sept. Clt. 1752. Pl. cr.

2 M. va'tid. (Desr. in Lam. dict. 4. p. 87.) root Heshy, turnip-formed; leaves cordate, a little toothed, pilose, almost sessile; tendrils simple; male flowers racemose; peduncles short, few-flowered; female flowers solitary, sessile along with the males ; fruit ovate, muricated, mucronate, pilose, of a dirty yellowcolour; secds obovate, compressed. 22.S. Native of Guinea. Trichosánthes foctidíssima, Jacq. coll. 2. p. 3\$1. icon. rar. 3. 1. 624. Flowers yellow. Herb fetil when bruised.

\section{Fetid Melothria. Fl. June, Sept. Clt. 1520. I']. cl.}

3 M.? I'Nnes (Lour, coch. p. 35.) stems angular; leaves triangular, denticulated, rough, small, on long petioles; flowers usually solitary, pedunculate, white; frut ovate-oblong, snooth, small, whitish green. $\%$. S. Native of Cochin-china, in heclges. -Rumpl., amb. 5. t. 171. f. 2. ex Lour. l. c. Flowers white. 
Indian Melothria. Pl. tr.

Cult. See Sicyos, p. 34. for culture and propagation. The plants will exist through winter if kept in a stove.

XVI. TRICHOSA'NTHES (from $\approx \rho t z r \rho t \chi o s$, thrix trichos, a hair, and $a v i o s$, anthos, a flower ; fringed or ciliated corollas). Lin. gen. no. 1476. D.C. prod. 3. p. 313.-Ceratosánthes, Juss. gen. p. 396.-Anguina, Mich. gen. 12.

Lin. syst. Moncécia, Monadélphia. Flowers monoecious, white. Male flowers. Calyx rather club-shaped, 5-parted; lobes appendiculated, furnished with 5 teeth on the outside, which alternate with the lobes. Corolla 5 -parted, eiliated; filaments 3 , but probably 5 , joined by twos; anthers joined, with very flexuous cells. Female flowers. Calyx 5-toothed. Corolla 5-parted (f. 2. $a$.), ciliately jagged. Style trifid (f. 2. d.). Stigmas oblongly subulate. Fruit oblong, 1 ? or 3-9-celled (f. 2. c.). Seeds compressed, tunicated, blunt, very much deformed ?

1 T. Anguina (Lin. spec. 1432.) stem pentagonal ; leaves cordate, 3-lobed, repandly toothed, puberulous; tendrils trifid, very long: male flowers racemose; racemes on long peduncles; calycine lobes very short, tooth-formed; lobes of corolla ovate, ciliately jagged; fruit terete-oblong, ending in a long beak, lispid, splitting. $\odot . F$. Native of China. Lam. ill. $t$. 794. Sims, bot. mag. 472.-Mill. fig. t. 32.-Mich, gen. 12. t. 9 . Cùcumis anguinus, Lin. spec. 1437. ex Lam. diet. 2. p. 75 .Rumph. amb. 5. p. 407 . t. 148. Kutukjanjang of the Hindoos.
FIG. 2 .

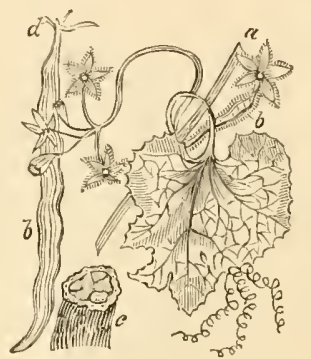

Flowers white, Fruit near a foot long.

Snakc-Gourd. Fl. May, June. Clt. 1755. Pl.tr.

2 'T. $\operatorname{costa'tA~(Blum.~bijdr.~p.~933.)~leaves~cordate,~3-lobed,~}$ denticulated, scabrous; lateral lobes somewhat 2 -lobed; male flowers racemose, bracteate; female ones solitary ; fruit ovate, oblong-ribbed. $\odot$. F. Native of Java, about Batavia and the western provinces, on the margins of rivers, where it is called lopan by the natives.

Ribbed-fruited Snake-Gourd. Pl. tr.

3 T. colubrina (Jacq. fil. eclog. t. 128.) stems furrowed, thickish; tendrils bifid; leaves roundish, cordate, 3-5-lobed; lobes short, broad, toothed; male flowers in panicles; common peduncles very long; fenale flowers sessile, solitary or in the same axils with the males; calyx very lorg, with a reflexed limb; fruit nearly terete, very long, lined; seeds olovate, red. $\odot$. F. Native country unknown.

Viper Snake-Gourd. Pl. tr.

4. T. Nervifòlia (Lin. spec. 1432.) stem slender; leaves cordate, 3-nerved, toothed; petiole short; tendrils bifid; male flowers racemose ; racemes on long peduncles; lobes of corolla oblong, ciliately jagged; female flowers solitary; fruit ovate, acutish, green, lined with white, about the size of a hen's egg. $\odot$. F. Native of the Last Indies. Rheed. hort. mal. 8. t. 17.

Nerve-leaved Snake-Gourd. Pl. tr.

5 'T. officiss'Lis (Hamilt. ex Wall. cat. no. 6694.) scabrous ; leaves cordate, denticulated; petioles hispid; female peduncles 1-flowererl, solitary; fruit round, smooth. $\odot$. S. Native of the East Indies, in Chihmari.

Officinal Snake-Gourd. [']. cl.

6 T. ScA'BRA (Lour. coch. p. 589 .) branches woody, furrowed ; leaves cordate, roundisl, wrinkled, scabrous; tendrils bifid; flowers monoecious ; corolla shortly ciliated ; fruit roundish, red, 10-angled, 5-celled; seeds flat, oblong. h. G. Native of Cochin-china. Flowers white. Fruit small.

Scabrous Snake-Gourd. Shrub el.

7 T. cuspidA'TA (Lam. dict. 1. p. 188.) stem twining; leaves cordate, oblong, acute, toothed; tendrils simple; male flowers unknown; female flowers nearly sessile, on short peduncles; calyx long, tubular, with nearly linear, acute, stalked, ciliately fringed segments; fruit ovate, ending in a long point. $\odot$. F. Native of the East Indies.-Rheed. mal. 8. t. 16. T. caudata, Willd. spec. 4. p. 600 .

Cuspidate-fruited Snake-Gourd. Pl. tw.

8 T. angula'ta (Lam. dict. 1. p. 190.) stems angular, very slender, villous ; leaves cordate, roundish, small, angular; tendrils forked, longer than the leaves; male flowers panicled; common peduncles much longer than the leaves; female flowers solitary, pedunculate. $\odot . F$. Native of the East Indies. Petals fringed.

Angular-stemmed Snake-Gourd. Pl. tr.

9 T. villòsa (Blum. bijdr. p. 934.) leaves cordate, tricuspidate, obsoletely denticulated, villous; peduncles 1-flowered; fruit nearly globose, striated with white. $\odot$. F. Native of Java, about Rompien and Buitenzorg, where it is called Badujut by the natives. Fruit indehiscent.

Fillous Snake-Gourd. Pl. tr.

10 T. ovígera (Blume, l. c.) leaves deeply cordate, mucronate, sometimes sinuated, mucronately denticulated, shining above, and rough beneath: female peduncles 1 -flowered; fruit ovate, vittate. $\odot . F$. Native of Java, on Mount Salak, where the plant is called Tinuk by the natives.

Egg-bearing Snake-Gourd. Pl. tr.

11 T. Grandiflòra (Blum. l. c.) leaves large, quintuplenerved, ovate, sometimes tricuspidate, quite entire, coriaceous, quite glabrous; flowers bracteate, disposed in dense spikes. $\odot$. F. Native of Java, in humid places on the mountains, where the plant is called by the inhabitants Kalayar Badak.

Grcat-flowered Snake-Gourd. Pl. tr.

12 'T. CORIA'CeA (Blum. l. c. p. 935.) leaves somewhat quintuple-nerved, cordate, acuminated, quite entire, coriaceous, reticulated above and glabrous, but paler and rough beneath; male flowers bracteolate, in loose racemes, on elongated peduncles. $\odot . ?$ F. Native of Java, on Mount Salak, where the plant is called by the inlabitants Piet-tjun-tjclling. Allied to T. grandiftòra.

Coriaceous-leaved Snake-Gourd. Pl. tr.

13 T. heteróclita (Roxb. ex Wall. cat. 6684.) leaves smooth, coriaceous, 3-lobed, seldom 5 -lobed ; lobes acuminated, entire ; peduneles racemose; tube of calyx long. $h . \cup . S$. Native of the East Indies, in Goyalpara.

Fariable-holloned Snake-Gourd. Slirub cl.

1. T. cUCUME'RINA (Lin. spec. 1432.) fetid; stems tetragonal, rather pilose; leaves cordate, angular, rather villous, petiolate, with white nerves, and muricated petioles; tendrils bifurcate; male flowers disposed in something like umbels; female flowers solitary, on short peduncles ; calycine lobes ovate ; petals fringed at the apex; fruit ovate, mucronate, smooth, green, lined with white, but at last becoming orange-coloured; seeds with sinuated margins. $\odot . ?$ F. Native of Java, in the province of Bantam. Blum. bijdr. p. 934.-Rheed. mal. 8.t.15. Flowers white. The seeds are sometimes used in disorders of the stomach and bowels, and the plant is celebrated for its virtues in Hortus Malabaricus.

Cucumber-like Snakc-Gourd. Fl. Ju. Jul. Clt. 1804. Pl.tr.

15 T. AMA'RA (Lin. spec. 1432.) stems terete, glabrous; tendrils simple; leaves cordate, triangular, sinuated, scabrous from dots, stalked; female flowers solitary; peduncles longer than the leaves; calyx long, tubular, with lanceolate, acute segments; petals roundish-ovate, fringed; fruit obovate-oblong, 9-celled, green, striped with longitudinal white lines; flesh white and 
bitter; seeds oblong, narrow. $\odot$. F. Native of St. Domingo. -Plum. descr. pl. amer. t. 100.

Bitter-fruited Snake-Gourd. Pl. tr.

16 T. HEXASPE'RNA (Blum. bijslr. p. 935.) leaves 3-nerved, ovate, tricuspidate, quite entire, coriaceous, glabrous; male flowers braeteate, disposed in racemes : female flowers solitary; fruit globose, 6-seeded. ○.? F. Native of Java, at the foot of Mount Salak, where it is called Aroy-pitjung-Tjelleng by the natives.

Six-secded Snake-Gourd. Pl.tr.

17 T. Russelia'xa (Wall, cat. no. 6696.) smoothish; leaves cordate, hastately 3 -lobed, nearly entire; tendrils simple; peduneles 1-flowered. $h$. S. Native of the East Indies.

Russel's Snake-Gourd. Shrub el.

18 'T. macrocárpa (Blum. l. c.) leaves cordate, orbicular, 5 -lobed, but sometimes 3 -lobed, eoriaceous, glabrous; lobes ovate, acuminated, quite entire : lateral lobes rather bifid ; fruit large, globose; stem suffruticose. h. . S. Native of Java, on the mountains.

Long-fruited Snake-Gourd. Shrub cl.

19 'T. TRICUSPIDA'TA (Lour. coch. 589.) stems shrubby; tendrils trifid; leaves cordate, tricuspidate, denticulated, glabrous, many-nerved; stipulas roundish, thick, crenated ; flowers spicate, or perhaps panieled; bracteas large, toothed; fruit yellow, small, ovate, 2 -celled, 2 -seeded. $\odot$. F. Native of Cochin-ebina; and amorig bushes and on the margins of rivers in Java. Flowers white.

Tricuspidate-leaved Snake-Gourd. Pl. el.

20 T. Prlòsa (Lour. eoch. p. 588.) stems suffruticose, very long, furrowed; tendrils bifid; leaves cordate, denticulated, pilose on the veins, lower ones palmate, upper ones 3-lobed; male flowers? in spikes; bracteas large, laneeolate, ciliated; fruit ovate, acute, scarlet, 1-eelled; seeds rhomboid, compressed, lobed, brown. $\zeta$. u. S. Native of Cochin-china. Flowers white as in the rest of the species, fringed with curling hairs.

Pilose Snake-Gourd. Shrub cl.

21 T. LAcisiòsa (Klein, ex Willd. spec. 4. p. 601.) stems filiform, angular, glabrous ; leaves deeply cordate, palmately 5-7-lobed, remotely toothed, glabrous on both surfaces; male flowers disposed 4 or 6 in a corymb : petals ovate, toothed; female flowers solitary : petals ciliately fringed. $\odot$.? F. $\mathrm{Na}$ tive of the East Indies.

Jagged-leaved Snake-Gourd. Pl. tr.

22 'T. consicura'ta (Lam. dict. 1. p. 191.) root large, fleshy, warted; stems very long; tendrils simple; leaves digitately palmate; lobes oblong; petals crenulated, bearing each 2 curling horns towards the apex; male flowers in faseicles; fruit ovate-oblong, smooth, green, variegated with white, 4-eelled. 4. S. Native of the Antilles. T. tuberosa, IVilld. spec. 4. p. 601. Sims, bot. mag. t. 2703. Ceratosánthes tuberòsa, Spreng. syst. 3. p. 18.-Plum. ed. Burm. amer. fasc. 1. p. 14. t. 24. Flowers white.

Horned-petalled Snake-Gourd. Fl. Jul. Aug. Clt. 1810. Pl.cl.

23 T. Chixe'nsis (Ser. in D. C. prod. 3. p. 315.) leaves eordate, triangular, bluntish, rather angular; petioles short; tendrils simple; male flowers solitary; calyx long, clavate, rather pilose; petals obovate, with fringed margins; female flowers solitary, almost sessile; tube of calyx ovate, acuminated, pilose : petals not fringed ; fruit ovate, striated, ending in a long point. -Native of China. Braan. ieon. t. 13.

China Snake-Gourd. Pl. tr.

2.4 T. Tasinifòla (Poir. dict. suppl. 1. p. 386.) stems glabrous, striated; tendrils simple; leaves ovate-roundish, rather lobed, or entire, scabrous above; male flowers small, in loose racemes; petals villous? reflexed; fruit ovate, mucronate, glabrous.- Native of Porto Rico.
Tamnus-leaved Snake-Gourd. Pl. tr.

25 '. PU'BERA (Blum. bijdr. p. 936.) leaves deeply eordate, trieuspidlate, denticulated, rather tomentose beneath; female flowers solitary ; fruit ovate, acute.-Native of Java, on the mountains, where the plant is called by the natives Aroy-kalayar-burrum.

Don'ny Snake-Gourd. Pl. tr.

26 'I. glodòsa (Blum. bijdr. p. 936.) leaves palmately 3 or 5 -lobed, quite entire, glabrous; lobes linear, acute; male flowers bracteate, disposed in dense spikes, on thick peduncles; female flowers solitary; fruit globose.-Native of Java, on Mount Salak, where the plant is called Aroy-jantang by the natives.

Globose-fruiterl Snake-Gourd. 1'l. cl.

27 'T. PALMA'TA (Roxb. ex Wall. eat. 6688.) puberulous; leaves cordate, $3-5$-lobed ; lobes denticulated; peduncles racemose; corolla fringed. $h$.. $\mathrm{S}$. Native of the Last Indies. Bracteas toothed.

Palmate-leaved Snake-Gourd. Shrub cl.

28 T. trifolia'ta (Blum. l. c.) leaves ternate; leaflets denticulated, scabrous : lateral ones gibbous at the base; male flowers bracteate, disposed in something like racemes; female flowers solitary ; fruit ovate, murieated (ex Rumph); seeds complanate, denticulated?-Native of Java, in the province of Krawang, near Tjiradjas. Momórdica trifoliàta, Lin. spec. 1434. Amàra sylvéstris, Rump. amb. t. 152. f. 2.

Trifoliate-leaved Snake-Gourd. Pl. cl.

29 T. LовA'TA (Wall. cat, no. 6693.) downy or puberulous ; leaves $5-7$-lobed ; lobes mucronate at the apex, narrowest at the base, denticulated ; tendrils branched ; peduncles long, bearing a raceme of flowers at the top. $\odot . \cup$. S. Native of the East Indies. Lobcd-leaved Snake-Gourd. Pl. cl.

Cult. Sow the seeds in a hot-bed in spring, and afterwards treat the plants as if they were cucumbers. The shrubby and perennial species should be protected from the frost and cold by placing them in the stove in winter : cuttings will root readily.

XVII. AMPELOSl'CYOS (from $a \mu \pi \varepsilon \lambda o s$, ampelos, a vine, and ouvor, sicyos, a cucumber; intermediate habit.) Pet. Th. veg. d'A fr. p. 68. t. 22.-Telfàiria, Hook, bot. mag. no. 2751. and 2752. (July 1827.) Feuillæ'a, spec. Smith, in bot. mag. t. 2681. Joliffia, Bojer in litt. (1826.) and Delill. mem. soc. hist. par. vol. 3. p. 314. (July 1827).

Lin. syst. Dioècia, Monadélphia. Flowers dioecious. Male flowers. Calyx turbinate (f. 3. a.), 5-cleft; segments acutely denticulated (f. 3. b.). Corolla 5-petalled (f. 3. c.); petals oblong, fringed. Stamens 5, disposed in 3 bundles. Female flowers. Limb of calyx almost wanting, 5-toothed (ex Smith). Corolla as in the male. Stigma capitate, 3-lobed (ex Bojer), 5lobed (ex Smith). Fruit fleshy (f. 3. e.), 2-3 feet long, and 8 inches thick, elongated and furrowed, divided into 3 twin cells (ex Bojer), into 5 (ex Smith). Seeds compressed, nearly orbicular, reticulated on the outside. Cotyledons thick, oily. A elimbing plant, with pedate leaves and showy purple flowers.

1 A. sca'ndens (Pet. Th. 1. c.) $4 . \mathrm{S}$. Native of the southeastern coast of Africa, on the shores of Zanquebar. It has also been gathered in the Manritius,

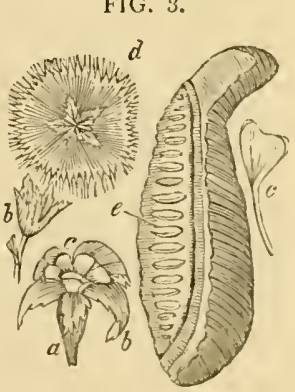
where it is called by the negroes Kouémé. Feuille'a pedàta, Smith, 1. c. t. 2681. a female plant. Telfàiria pedàta, 11ook, bot. mag. t. 2751 and 2752 . with male flowers and fruit. Jol- 
liffia Africàna, Delill. l. c. t. 6. Male plant and seed. The seeds are as large as cluestnuts, and as good as almonds, and when pressed they yield an abundance of oil, equal to that of the finest olives.

African Ampelosicyos. Fl. July. Clt. 1825. Pl. el.

Cult. Any light soil will suit this plant, and cuttings root readily under a hand-glass, in heat. It is a strong coarse growing plant, and therefore reguires a great deal of room, both for the roots and the branches, or it will not flower.

XVIII. CUCU'RBITA (from eurvitts, crookedness, according to Scaliger; in reference to the shape). Lin. gen. no. 1478. Juss. gen. p. 396. Gærtn. fruet. 2. p. 49. t. 88 . f. 5. exelusive of $C$. Lagenaria of authors. Citıúllus, Neck. elem. bot. no. 389. Melópepo, Tourn. inst. p. 106. t. 34. Pèpo, Tourn. J. c. p. 105. t. 33 .

Lix. sist. Monoèeia, Monadétphia. Flowers monoecious. Corolla campanulate, yellow; petals joined together and to the calyx. Male flowers. Calyx hemispherically campanulate. Stamens 5, in 3 bundles, or joined at the apex; anthers abruptly curved, both at the base and the apex, the rest straight and parallel. Female flowers. Calyx obovate-clavate, narrowed towards the top, or campanulate, and always circumeised under the limb after flowering. Anthers usually sterile. Stigmas 3, thickish, 2-lobed. Fruit 3-5-celled. Seeds ovate, compressed, with hardly tumid margins.

1 C. MA'xima (Duch. in Lam. diet. 2. p. 151.) leaves cordate, very rugged; petioles hispid; tube of ealyx obovate, ending in a short neck; fruit globose, somewhat depressed, yellow, red, or green. ๑. F. Native country unknown. Tourn. inst. j. 106. no. 2. t. 34. Lob. icon. 641. f. 2. Cucúrbita Potiro, Pers, ench. 2. p. 593.

I'ar, a, Potiro (Ser in D. C. prod. 3. p. 3I6.) stems very long, climbing; tendrils strong; fruit large, yellow, or orange-coloured, hollow at maturity. Common ycllow gourd, potiron jaunc commun, gourge of the French. The shells of the fruit are generally used for holding water.

Fa. $\beta$, viridis (Ser. in D. C. prod. 3. p. 316.) stems very long, climbing; fruit green, large, hollow at maturity. Large grem gourd. Gros potiron vert of the French. The shells of the fruit of this sort are also used as calabashes.

Var. $\gamma$, Goúrgero (Ser. diss. in mem. soc. gen. vol, 3. pt. 2. t. 1.) stems assurgent, dwarf; nodes elose; tendrils abortive; leaves ovate, cordate, $3-5$-lobed, somewhat coclleate; lobes narrow; fruit small, green, or yellow, full at maturity. Gourgeron or petit potiron vert.

Large Hollow Gourd. Fl. Jul. Aug. C\}t.? Pl. el. or tr.

2 C. Melópero ( $\mathrm{Lin}$. spec. 1435.) leaves cordate, obtuse, somewhat 5-lobed, denticulated; tendrils usually transformed into very imperfect leaves; calyx hemispherieally campanulate, short, having the throat much dilated; fruit depressed; carpels irregular, rising beyond the throat of the ealyx; flesh dry, spongy, white; ce!ls 4-5. ๑. F. Native country unknown. Willd. spec. 4. p. 610 . C. polymórpha Melópepo, Duch. in Iam. dict. 1. p. 157.-Bauh. hist. 2. p. 224. with a figure. Pèpo máximus clypeàtus, Mor. hist. 1, sect. 1. t. 8. Fruit flatted at both ends. It is of great use in long voyages, for it can he kept several months in a fresh state, and is commonly make into pies, like the pumpkin, or boiled and eaten with meat instead of turnips or potatoes. Bonnct d'clecteur, bonnct de prêtie, and pastisson of the French.

Srquash Gourd. F]. May, Sept. Cit. 1597. Pl. tr.

3 C. Mosein't (Duch. ex dict. sciene. nat. 11. p. 234.) corolla campanulate, Eery narrow at the base; lcaves soft, tomentose; fruit oval or spherieal, depressed; flesh yellow or orange-coloured, musky. ๑. F. Native of Martinique. C. l'ndica rotúnda, Dalech. hist. 616 . f. 3.
Musky Gourd. Fl. June, Alig. Clt.? Pl, tr.

4 C. ceratócreas (Mart. reise, in bras. ex Linnæa. 5. p. 39.) leaves cordate, nearly orbicular, bluntly somewhat 5-lobed, denticulated ; fruit large, oblong-pear-shaped, or cylindrical, lined longitudinally, glabrous; flesh subgranular. $\odot . F . ~ N a-$ tive of Brazil.

IIorned-fruited Cucurbita. Pl. tr.

5 C. vıııòs (Blum. bijdr. p. 931.) leaves roundisl, cordate, 5 -lobed, scabrous; lobes acute, sinuately denticulated; peduncles 1-flowered, those of the male longer than those of the female flowers; fruit oblong, villous. $\odot . F$. Gathered in the garlens in the East Indies. By the Javanese it is called Laligo.

Villous Gourd. Pl. tr.

6 C. PE'ro (Lin. spec. 1435.) leaves cordate, obtuse, somewhat 5 -lobed, denticulated; calyx ending in a neck beneath the limb; fruit roundish or oblong, smooth. $\odot . F$. Native of the Levant. C. polymórpha oblónga, Duch, in Lam. dict. 2. p. 155. This species is called Pumplin and pompion, in English ; Giraumon, Citrouille iroquoise, gourge de Saint Jean in French; Popone in Italian. There are several varieties of pompion, but the most striking are the two following :

Var. a, subrotinda (Willd. spec. 4. p. 609.) fruit roundish. C. màjor subrotúnda, \&c. Bauh. pin. 213.

lar. $\beta$, oblónga (Willd. 1. c.) fruit oblong. Pèpo oblóngus, Banl, pin. p. 311 .

The pumpkin is the melon or millon of our early horticulturists, the true melon being formerly distinguished by the name of musk melon. Tlongh commonly cultivated in gardens for curiosity, yet in some country villages in England, the inhabitants grow it on dunghills, and train the shoots to a great length on the grass. When the fruit is ripe, they cut a hole on one side, and having taken out the seeds, fill the void space with sliced apples, adding a little sugar and spice, and then having baked the whole, eat it with butter. On the Continent, as well as in many other parts of the world, the fruit is a good deal used in soups, and also stewed or fried in oil or butter. Pumpkin-pie is also very common in many parts of the world.

Modes of dressing some varieties of the gourd.-Mr. Crichton (Cal. mem. vol. 4.) prefers the clieese-gourd, some of which have weighed with him 1 ewt., and the regetable marrow; but he very judiciously attaches much more importance to the kind of cooking than to the varicty cultivated. He therefore subjoins two receipts for the use of the chcese-gourd, and one for vegetable marrow.

To make soup of cheese-gourd.-Take the fleshy part of the gourd when ripe, and cut it into small pieces; put it into a pan with a small bit of butter, set upon a slow fire until it melt down to a puré; then add milk, in the proportion of half a gallon to 4 lbs. of gourd, let it boil a short time with a little salt and sugar, enough to make it taste a little sweet; then cut some slices of bread very thin, toast them very well, and cut them into small dice, put them in a dish, and pour the pure over them, and serve it up.

Checse-gourd dressed in the Spanish nay.-When ripe cut the fleshy part into slices about half an inch, score it across into small dice about half through on one side of the slices; scrape a little of the fat of bacon, and put it into a saueepan, with a little parsley, shallots, and mushrooms chopped very small, adding a little salt and pepper; put them on a slow fire to fry a little, and place this seasoning upon the cut sides of the gourd slices. Put the whole into a quick oven, with a little butter or olive oil, and when baked a little serve up in a dish.

Pumpkin or Pompion. Fl. Jume, Aug. Clt. $15 \% 0$. Pl. tr.

7 C. farinòsa (1Blume, bijdr. p. 931.) leaves roundish, cordate, rather angularly 7 -lobed, a little strigose; lobes acuminated, toothed; peduncles 1-flowered; fruit oblong, large, covered with a kind of glaucous mealiness. $\odot . F$. Native of Java, in 
fields and in gardens, where the plant is called Daligo by the natives. Allieil to C. P'c̀po. Compare Rumph. amb. 6. t. 143. according to Blume.

Mealy-fruited Gourd. Pl.tr.

8 C. verrucòsa (Lin. sprec. 1435.) leaves cordate, deeply 5lobed, denticulated; middle lobe narrow at the base; fruit roundish-elliptic, warted. $\odot$. F. Native country unknown.Bauh. hist. 2. p. 222. with a figure. C. polymórpha verrucòsa, Duch. in lam. dict. 2. p. 155. The plant, flowers, and seed Sc. are like those of $C$. Pèpo, but the fruit is smaller, with a harder, almost woody rind. Called Barbarinc, and Barbaresque saurage in French. The warted gourd is common in most parts of America, where it is eultivated as a culinary fruit. It varics in form and size, being round, flat, shaped like a bottle, or oblong; the rind is white when the fruit is ripe, and covered with large protuberances or warts. It is commonly gathered when half grown, and boiled by the inhabitants of $A$ meriea, to eat as a sauce to their meat. In England it is only eultivated as a curiosity.

Warted Gourd. Fl. June, July. Clt. 1658. Pl. tr.

9 C. subverrucosa (Willd. spec. 4. p. 609.) Jeaves cordate, deeply 5 -lobed, denticulated; middle lobe narrow at the base; fruit clavately-elliptic, rather warted. $\odot$. F. Native country unknown. Perhaps a hybrid from C. verrucosa, lut the fruit is very different.

Subierrucose-fruited Gourd. Fl. June, Jul. Clt.? I'l.tr.

10 C. AURA'́ntia (Willd. l.c. p. 667.) plant very scabrous; leaves subcordate, 3-lobed, cuspidate, sharply denticulated; fruit globose, smooth, having the appearance and colour of an orange. $\odot$. F. Native country unknown. The orange-gourd is rather more tender than the other sorts. It has been hitherto chiefly cultivated for curiosity, and when trained spirally round a pole, or against a wall, and loaded with its yellow fruit, it is very ornamental. The fruit should be used like those of other sorts of pumpkin or gourd.

Var. a, orángina (Ser. in D. C. prod. 3. p. 317.) fruit globose, 3-celled; pulp fibry, yellow, nearly dry, with a solid dark green rind, which at length becomes orange-coloured.-Orangine or Fausse orange in French; orange-gourd, English.

Var. B, colocynthoides (Ser. in D. C. prod.3. p. 317.) rind of fruit thinner and variegated; pulp dry. Called Coloquinelle or Faussc coloquinte in French, and False colocynth in English.

Orangc Gourd. Fl. June, Aug. Clt. 1802. Pl. cl.

11 C. coccínea; fruit round, scarlet, about the size of an orange. $\odot$. F. Native of Sierra Leone.

Scarlet-fruited Gourd. Pl. tr.

12 C. ovíferA (Lin. mant. p. 126.) leaves cordate, angular, 5 -lobed, denticulated, pubescent; calyx obovate, ending in a short neck, and cut round after flowering to the neck. $\odot$. F. Native of Astracan. C. polymórpha pyridàris, Duch. in Lam. dict. 2. p. 154.-J. Bauh. hist. 2. p. 222 and 223. f. 1. C. sylvéstris, Dod. pempt. 670. f. 1. C. pyrifórmis, Lob. hist. 367. f. 2. Herb and flowers very like those of C. Pèpo, but less scabrous. Fruit obovate or ovate, smooth, greenish or yellowish, figure of an egg. Called in French Gougourdette, and Vegctablc marron', in English.

Iar. ", pyriformis (Ser. diss. I. c. t. 1.) leaves 5-lobed with undulated margins; lobes oblong-obovate, denticulated, rarely lobulate; fruit pear-shaped, green, or yellow, lined longitudinally with white.

Var. $\beta$, subglobòsa (Ser. in D. C. prod. 3. p. 318.) leaves bluntly lobed; lobes broad, short ; fruit obovate, globose, green lined with white; flesh red.

Var. $\gamma$, grísca (Ser. l. c.) leaves 3-5-lobed, narrow; middle lobe trapeziform, usually lobulate; fruit larger, greenish grey, spotted with white, bardly lined.

voL. III.
Far. ¿, oxdta; fruit large, ovate, whitish when ripe.

The first kind of vegetable marrow was introduced to Britain from l'ersia within the last few ycars, where it is ealled Cicader. The fruit of this sort is of a uniform pale yellow or light sulphur colour : when full grown it is about 9 inches in length, 4 inches in diameter, of an elliptic shape, the surface bcing renderest slightly uneven by irregular longitudinal ribs, the terminations of which uniting form a projecting apex at the end of the fruit, which is very unusual in the gourd or pompion tribe. $\mathrm{lt}$ is useful for eulinary purposes in every stage of its growth; when very young, it is gool if fried with butter; when large, or about half grown, it is excellent cither plain boiled or stewed with rich sauce; for either of these purposes it slıould be cut in slices. The flesh has a peculiar tenderness or sofuess, from which eircumstance it has received its name, much resembling the butery quality of the beure-pear, and this property remains with it until it is full grown, when it is used for pies. It is, however, in its intermediate state of growth that it is likely to be most approved. There are now several kinds of vegetable marrow in cultivation.

To dress regetalle marron.-Take the fruit when about half grown; cut it lengthwise through the mirldle (if large cut it into 3 or 4 slices); take off the outer skin, eut it into small dice, about half through one side of the slices, then serape a little of the fat of bacon, and put it into a saucepan, with a little parsley, shallots, and mushrooms, chopped very small, and let them fry a little; then add about a table spoonful of flour, with a little salt and pepper, mixed all together; then put the slices of the vegetable marrow into a stewpan witl a cover, and put the fried seasoning over the stices, and let them stew a little on a slow fire, with a little fire on the cover. When enou,h done, serve up."-Crichton, Cal. mem. vol. 4. The Caledonian Horticultural Society's silver medal was given to Mr. Chrichton for this receipt, and the other two upon the clicese-gourd. We think it ought to have been given to the cook.

Egg-bearing Gourd or Vegetable-marrow. Fl. July, Sept. Clt.? Pl. tr.

13 C. Fetidíssima (H. B. et Kunth, nov. gen. amer. 2. p. 123.) leaves deeply cordate, ovate, sinuately angular, narrowecl above, toothed, strigose above, but white and villous beneath; female flowers axillary, solitary, pedunculate; calyx campanulately funnel-shaped above, with ovate-oblong, acute scgments. $\odot$. F. Native of Mexico, near Guanaxuato, at the height of 3240 feet.

l'ery foetid Gourd. Pl. cl. or tr.

14. C. umbella'ta (Klein, ex Willd. spee. p. 608.) stem furrowed, glabrous; leaves cordate, with 5 narrow, denticulated scabrous lobes; male flowers in umbels, female ones solitary, pelunculate; fruit elliptic, tomentose. $\odot$. F. Native of the East Indies.

Umbcllate-flowered Gourd. Pl. tr.

15 C. aspera'ta (Gill. mss. ex Hook et Am. in bot. mise. 3. p. 234.) flowers dioecious; stems glabrous; leaves palmatcly 5 -parted, rough from eallous dots on both surfaces, which are more numerous beneath; segments sinuately pinnatifil; tondrils simple; male flowers in capitate racemes, on short peduncles, female ones peduneulate, solitary; fruit nearly globose, few-seeded. $\odot$. F. Native of Chili, in the province of Mendoza, in uncultivated places, where it is called by the natives Sandillo del campos. This plant agrees in many respects with the $C$. manmeata, Mol. but that species is from Chili.

Rough Gourd. Pl. tr.

16 C. creera'ria (Nolina, Chili ed germ. p. 316.) leaves roundish, angular, tomentose; fruit woody, glohose. $\odot . F$ Native of Chili.

Intoxicating Gourd. Fl. June, Aug. Clt.1824. Pl. tr. $\mathrm{G}$ 
17 C. Mammea'ta (Molina, 1. c.) leaves many-parted; fruit spherical, beset with protuberances. $\odot$.F. Native of Chili.

Teated Gourd. Pl. tr.

18 C. Llanòs (Mill, dict.) leaves rough, lobed; fruit woody. $\odot$. F. Native of South America. This is a large gourd, and is enltivated for the sake of the shell of the fruit, which will frequently contain between 2 and 3 quarts. Where aloes is manufaetured in any quantity, it is commonly preserved in these shells; but in Jamaica they are used to hold water, and small grain.

Hoody-fruited Gourd. Fl. June, Aug. Clt.? Pl. tr.

19 C. multiflòra (Forst. ex Spreng. syst. 5. p. 45.) leaves broadly cordate, 3 -lobed, acute, dentieulated, glabrous; flowers minute, crowded in cymes. $\odot$. F. Native of the Soeiety Islands.

Many.foncred Gourd. Pl. tr.

Cult. The species of Cucurbita are propagated from seeds, which are large, and require to be covered nearly an ineh. Sow in April in a hat-bed, under a frame or hand-glas i, to raise plants for transferring to the open garden at the end of May, under a warm aspect, or for planting out in the middle of May on a trench of hot dung under a hand-glass or lialf shelter; otherwise sow at the beginning of May, under a hand-glass, without bottom heat, for transplanting into a favorable situation; or sow 3 weeks later (after the 20th) at once in the open garden, under a south wall, for the plants to remain. The smaller fruited kinds do best trained to an upright pole or trellis. From time to time earth up the stems of the plants. As the shoots extend 5 feet or more, peg down at a joint, and they will take root. Water copiously whenever warm weather without showers makes the ground arid. Mr. Gray (Gard. mag. vol. 1. p. 150.) plants in paths between asparagus beds, and lets the vines of the gourds run over them; and he considers that their large leaves do good to the asparagus roots, by proteeting them from the sun, while the tall stems of the asparagus afford a shelter to the leaves of the gourds. In very dry seasons they are an excellent substitute for cabbages and turnips, when the drought is apt to burn up these vegetables. Mr. Gray therefore recommends, espeeially where the soil is liable to be burnt up in summer, planting the vegetable marrow and other cueurbitaceous plants as a reserve crop. The tender tops of all the edible speeies of Cueurbitàcce, boiled as greens or spinage, are a fully more delieate vegetable than the fruit. It must be worth something to gardeners and cooks to know that eitler or both may be used for this purpose when seareely any thing else can be got.

XIX. INVOLUCRA'RIA (involuerun, an involucre; in reference to the umbels of male flowers being involuerated by bracteas). Ser, diss, in mem, soe. hist. nat. gen. vol. 3. pt. 2. D. C. prod. 3. p. 318.

Lin. syst. Monocicia, Monadélphia. Flowers monoceious. Male flowers umbellate, sessile, involucrated by reniform bracteas, wlich are dentately fringed at the apex; common pedunele very long, furnished each with an oblong bractea at the base. Mlabastra nearly like those of the rose. Tube of calyx obconical; Jimb with aeute linear sepals. Corolla, stamens, and filaments unknown. Anthers joined, with the eells as in the rest of the Cucurbitàcee. Female flowers solitary on long peduncles, rising from the same axilla as the males, as well as of the same form.

1 I. Wallicimaina (Ser. l. c. t. 4.) leaves deeply 5-lobed, cut, seabrous ; lobes obovate-oblong, coarsely toothed; tendrils quinquefid. $\odot$.? F. Native of Nipaul.

Il'alliel's Involucraria. Pl. cl.

Cult. See Cucurbita for eulture and propagation.
XX. MURI'CIA (from muricatus, muricated; in reference to the warted berries). Lour. coch. p. 596. D. C. prod. 3. p. 318 . Lin. syst. Monoècia, Monadélphia. Flowers monoecious. Calyx of 5 sepals, inelosed in a large, undivided, 1-flowered sheath; sepals subulate, striated, eoloured, joined together at the base. Corolla eampanulate; petals 5, ovate-laneeolate, nerved. Stamens 5 , in 3 bundles, and with the anthers conneeted at the apex. Style 1; stigmas 3, sagittate, horizontal. Berry muricated, 1-eelled, many-seeded. Seeds orbicular, large, reticulated, with tubercular margins.

1 M. Cochinchine'ssis (Lour. 1. e. p. 596.) a large shrub, with 5 -lobed leaves, the 3 superior lobes acuminated, and the inferior ones obtuse, short, and dentieulated ; flowers yellow, solitary, on long peduncles; fruit reddish purple both inside and outside, scentless. h.G. Native of Coehin-china and China. Momórdica Cochinchinénsis, Spreng. syst. 3. p. 14. The seeds and leaves are aperient and abstergent.

Coehin-china Murieia. Slurub.

Cult. A mixture of peat and sand will answer this slirub; and cuttings will root in the same kind of soil.

XXI. ANGU'RIA (one of the Greek names for the cucum-

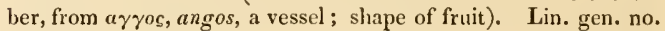
399. Juss. gen. p. 395 . Lam. ill, t. 747 . D. C. prod. 3. p. 318.-Momórdica spee. of authors,-Psigùria, Neek, elem, bot. no. 384 .

Lin. syst. Monoècia, Diándria. Flowers monoecious, Male flowers. Calyx campanulate, 5 -toothed. Corolla joined to the calyx, ventricose, red, with a 5 -parted spreading border. Stamens 2, opposite. Female flowers with a calyx and corolla, as in the males. Stamens 2, sterile. Style semi-bifid; stigmas bifid. Fruit 2-4-celled, many-seeded, somewhat tetragonal. Seeds unknown. Roots thick, warted.

1 A. integrifòlia (Nees et Mart. in nov. act. bonn. 12. p. 9.) leaves ovate, dentieulated, 3-nerved, glabrous; peduncles 4-6-flowered, bractless; female flowers unknown.-Native of Brazil, at the river Itheos. Flowers red.

Intire-leaved Anguria. Pl. el.

2 A. тRILobA'ta (Lin. spec. 1376.) root bitter; stems slender; leaves decply 3-lobed, or somewhat 5 -lobed, veiny; lobes a little toothed; tendrils simple; male flowers large, in raeemes, female ones solitary, almost sessile ; fruit ovate-oblong, umbilieate, green, spotted with white; seeds oblong, fulvous. 4 .U.S. Native of Martinieo.-Plum. ed. Burm. pl. amer. t. 22. Jacq. amer. p. 243. t. 156. ed. pict. p. 119. t. 23\%. Flowers vermilion eoloured.

Three-lobcl-leaved Anguria. Fl. Ju.Jul. Clt. 1793. Pl, cl. 3 A. PEDatise'cta (Nees et Mart. in nov. aet. bonn. 12. p. 10.) leaves pedately 5 -parted; lobes quite entire; tendrils subumbellate; corymbs many-flowered; flowers triandrous? fruit oblong, striated, attenuated both at the base and apex; pulp white, spongy, rather aeid: aril black. $\odot$. . F. Native of Perı. Momórdica pedisécta, Lin. spec. 1434. Lam. dict. 4. p. 241.-Feuill. per. 1. p. 754. t. 41. Flowers white. Two outer segments of leaves lobed. The Peruvians use the fruit in soups.

Pcdate-cut-leaved Anguria. Pl. cl.

4 A. PEDA'TA (Lin. spee. p. 1376.) stems slender, terete; leaves pedately 5-parted; lobes laneeolate, toothed; tendrils longer than the leaves; flowers inolorous, male ones in raeemes; racemes on long peduncles; female ones solitary ; fruit oval-oblong, green, variegated with white. $4 . \cup: S$. Native of St. Domingo. Jaeq. amer. 242. t. 155. ed. pict. t. 233.Plum. ed. Burm. pl. amer. 23.? Flowers with orange-coloured petals.

Pedate-leaved Anguria. Fl. Ju. Jul. Clt. 1820. Pl, cl. 
5 A. Ròsea (H. B. et Kuntl, nov. gen. amer. 2. p. 122.) branches glabrous; leaves truncately cordate at the base, quite entire, 3-lobed at the apex, glabrous, membranous; tendrils undirided, glabrous; male flowers disposed in racemes; calyx cylindrically campanulate, ventricose at the base, with a 5 -parted rose-coloured limb, having the segments roundish and longer than the tube; stamens 2, sessile. 4 . $\cup$. S. Native of New Granada, in temperate places near Turbaco, at the licight of 6000 feet. Flowers rose-coloured.

Rose-coloured-flowered Anguria. Pl. cl.

6 A. umbròs (H. B. et Kuntl, l. c. p. 121.) leaves pedately 5 -parted, sinuately cordate; lobes quite entire, ovate-lanceolate, outer ones much the shortest and divaricate ; flowers panicled; peduncles very long; calyx ronghish, having the tube ventricose at the base, of a vermilion colour; stamens 2, free; anthers linear; female flowers unknown. $\psi$. $\cup$. S. Native of the temperate provinces of New Andalusia, near Bordones and $\mathrm{Cu}$ manacoa.

Shaded Anguria. Fl. June, July. Clt. 1827. Pl. cl.

7 A. TRIFOLIA'TA (Lin. spec. 1576.) stems thickish, terete, rugged; tendrils simple; leaves palmately ternate; leaflets entire: lateral ones unequal-sided ; male flowers in racemes purple; tube of calyx long and rentricose; peduncles short ; fruit irregularly ovate-oblong, bluntly mucronate, 4-celled, green, lined with white; flesh of fruit red, and sweet. $\psi \cdot \cup$. S. Native of St. Domingo.-Plum. pl. amer. t. 99.

Trifoliate Anguria. Fl. June, July. Pl. cl.

Cult. The species of this genus delight in a light rich soil, and may be propagated either from seeds or cuttings.

\section{$\dagger$ Genera allicd to Cucurbilàcea, but are not sufficiently knon'n.}

XXII. ZU'CCA (meaning unknown), Comm. in Poir. suppl. 5. p. 526. Ser, in D. C. proil. 3. p. 319 .

Lis. syst. unknown. Flowers solitary, axillary. Bractea large, concave, involving a large, coloured, 5 -sepalled calyx, and girded by 5 scales at the base. Stamens 5.-A doubtful genus, said to be related to the order Passifforea ; but according to St. Hilaire (mem. mus. 9. p. 190.) it belongs to Cucurbitàcce, from the lateral situation of the tendrils.

1 Z. Commersonia'na (Ser. in D. C. prod. 3. p. 319.) Native country unknown.

Commerson's Zucca. Pl, cl.

Cult. See Angùria for culture and propagation.

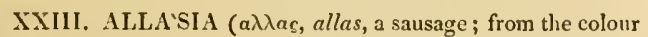
and form of the fruit resembling a sausage). Lour, coch. p. 85 . D. C. prod. 3. p. 319.

Lin. syst. Tetrándria, Monogýnia. Flowers hermaplrodite. Calyx gamosepalous, girded by a short involucrum; segments 5 , acutish, hairy. Corolla 4-petalled; petals roundish, very hairy, small. Stamens 4 or perhaps 8 joined by twos; anthers 2lobed? Style subulate; stigma acute. Berry fleshy, large, oblong, obtuse, pendulous, 1-celled. Seeds imbedded in the pulp, ovate, compressed, tumid.

1 A. PA'Yos (Lour. l. c.) a tree, with spreading unarmed branches; opposite digitate leaves; the lobes 5 , oval, quite entire and pilose ; flowers nearly terminal, pale ; peduncles manyflowered. $h$. S. Native of the eastern coast of A frica, on the shores of Mozambique. Jaracatia Brasiliàna, Pison, bras. p. 160. ex Lour. 1. c. Flowers pale. Fruit brownish-red.

Payos Allasia. Tree.

Cult. A light rich soil will suit this tree, and cuttings will strike root in the same kind of soil under a loand-glass in heat.
XXIV. GRONOVIA (so named by Houston, in lonour of John Frederick Gronovius, M.D, a learned botanist of Leyden). Lin. gen, no. 391. Juss. gen. p. 394. 11. B. et Kunth, nov. gen. arber. 2. p. 119.

Lin. syst. Pentándria, Monogýnia. Flowers hermaphrodite. Calyx funnel-shaped, 5-parted, coloured. Scales 5, linear, petal-formed, pellucid, alternating witls the calycine segments. Stamens 5, free, alternating with the scales. Ovarium inferior. Style 1, crowned by a subcapitate stigma. Berry dry, nearly globose, 1-seeded, crowned by the dry permanent calyx.Climbing herbs, adhering by tendrils, with leaves like those of Bryònia. Peduncles opposite, rather umbellate. Flowers disposed in unilateral spikes, cymose, sessile, bracteate.

1 G. sca'sdens (Lin. spec. 292.) $\odot$. U. S. Native of Vera Cruz. Jacq. coll. 3. p. 197. icon. rar. t. 338. Lam. ill. t. 144. f. 2. G. Humboldtiàna, Rom. et Schult. syst. 5. P. 492. Fruit ribbed, while young. Flowers greenish-yellow. Leaves 5 -lobed. The hairs on the leaves sting like those of a nettle.

Climbing Gronovia. Fl. June, July. Clt. 1731. Pl. cl.

Cult. Being a tender anumal plant, the seeds of it require to be sown on a hot-bed; and after the plants have grown a sufficient size in the sced-pot, they should be potted off singly into other pots, and after a time placed in the stove, and trained upon sticks.

XXV. KO'LBIA (this genus is dedicated to l'eter Kolbe or Kolben, a German traveller, who published a description of the Cape of Good Hope). Beauv, fl. d'ow. 2. p. 91. t. 120. D. C. prod. 3. p. 320.

Lin. syst. Dicécia, Monadélphia. Flowers dioecious. Male flowers with a gamosepalous calyx, composed of 5 joined sepals, having a crenulated margin; the corolla is gamopetalous, and 5 -lobed; lobes lanceolate, with glandular edges. Nectarium? 5-leaved, having lanceolate lobes, which taper to the base, with their edges plumosely ciliated. Stamens 5 , monadelphous; filaments short; anthers long, conniving. Pistillum unknown.

$1 \mathrm{~K}$. E'Legans (Beauv. I. c.) stem sarmentose, bearing tendrils; leaves glabrous, petiolate, cordate; peduncles 4 -flowered. 4. . S. Native of the western coast of Africa, in the kingdom of Benin. Flowers red. Nectarium blue.

Elegant Kolbia. Pl. cl.

Cult. A light rich soil will suit this elegant plant, and cuttings will root in the same kind of mould under a hand-glass in heat.

Order CIV. PAPAYA'CEA (this order contains only the Papaw trees). Martius, 1829.-Papàyæ, Agardl. 1824.Caríceæ, Turp. in atl. du dict. des sc, nat.

Flowers unisexual. Calyx inferior, minute, 5-toothed. Corolla monopetalous; in the male tubular, with 5 lobes and 10 stamens, all arising from the same line, and of which those that are opposite the lobes are sessile, the others on short filaments; anthers adnate, 2-celled, bursting longitudinally; in the female divided nearly to the base into 5 segments. Ovarium superior, 1-celled, with 5 parietal polyspermous placentas. Stignia sessile, 5-lobed, lacerated. Fruit succulent, indehiscent, 1-celled, with 5 polyspermous parietal placentas. Secds enveloped in a loose mucous coat, with a brittle pitted testa. Embryo in the axis of the fleshy albumen, with flat cotyledons, and a terete radicle, turned towards the hilum.-Trees, without branches, yielding an acricl milky juice. Leaves alternate, palmately lobed, standing on long terete petioles.

It was the opinion of Jussieu that the genus upon which this G 2 
order is founded, held a sort of middle station between Urticece and Cucurbiticece. Auguste St. Hilaire has, however, well remarked upon this subjeet, that the only relation that it has with l'ricea consists in the separation of sexes, its milky juice, its habit, which is like that of some speeies of Fieus or Fig, its foliage, which is not very different from the Ceeròpia, and the position of its stigma; and to these he wisely attaches very little importanee. Its fruit brings it near Cueurbitàcece; but its true place is probably nearer to Passiflorece, with which it altogether agrees in the appearance of its testa, in its unilocular fruit, with parietal polyspermous placentas, and its having a calyx and eorolla present, differing, however, widely in its habit, and monopetalous flowers.

The fruit of the Papaw is eaten when cooked, and is esteemed by some persons; but it appears to have little to recommend it. Its great peeuliarities are, that the juice of the unripe fruit is a most powerful and most effieient vermifuge; the powder of the seed even answers the same purpose, and that a principal constituent of this juice is febrine, a prineiple otherwise supposed peculiar to the animal kingdom, and to fungi. The tree has moreover, the singular property of rendering the toughest animal substanees tender, by eausing a separation of the muscular fibre; its very vapour even does this.

I. CA'RICA (erroneously supposed to be a native of Caria). Lin. gen. no. 1127. Schreb. 1536.-Papàya, Tourn. 441. Juss. 399.

Lin. syst. Dice'cia, Decandria. Character the same as the order.

1 C. Papa'ya (Lin. spee. 1466.) leaves palmately 7-lobed; segments deeply lobed, oblong, acute; male flowers corymbose. h.S. Native of both Indies.-Rumpl, amb. 1. t. 50, 51.-Merian, Surim. t. 40. Rheed. mal. 1. t. 15. f. 1. Hook. bot. mag. 2898. Ker. bot. reg. 459. The papaw tree is a native of South America and the West Indies, whence it was brought by the Spaniards and Portuguese to the Philippines and the Moluceas; and from these Islands, it being of very quick growth, it spread to all the other countries of India. In three years from seed a papaw tree will be 20 feet ligh, and loaded with flowers and fruit ; and for the sake of this fruit the plant is generally eultivated; it has a pleasant sweetish taste, and is much liked by many people; when young it is generally used for sauce; and when boiled and mixed with lime-juice and sugar, is not unlike, or mueh inferior to, that made of real apples, for which it is eommonly substituted. But Sloane says, the fruit is not in general gathered before it is ripe ; cut into sliees, soaked in water till the milky juice is out, and is then boiled and eaten as turnips, or baked as apples. The juice of the pul]?, according to Descourtilz, in the "Flore Medicale des Antilles," is used as a cosmetic to remove freekles on the skin, caused by the sun; and the negroes in the Frenel eolonies employ the leaves to wash their linen instead of soap. As a medicinal plant the pajaw tree is particularly deserving of notice. Hernandez long ago spoke of the milky juice of the unripe fruit as a powerful vermifuge; whieh has becn confirmed by $M$. CharpenterCossigni, as mentioned in the Asiatic lesearches by Dr. Heming (vol. 2. 1. 162.). A single dose, that gentleman says, is sufficient to eure the disease, however abundant the worms may be. Another writer (l'ourpee Desportes) recommends the use of the powder of the seed instead of the juiee. But the most extraordinary property of the papaw tree, is that which is related first, I believe by Browne, in his natural history of Jamaica, namely, that " water impregnated with the milky juiee of this tree is thought to make all sorts of meat washed in it tender: but 8 or 10 minutes' steeping, it is said, will make it so soft that it will drop in pieces from the spit before it is well roasted, or turn soon to rags in the boiling." This eircumstance has been repeatedly confirmed, and moreover, that old hogs and old poultry which are fed upon the leaves and fruit, however tough the meat they afford might otherwise be, is thus rendered perfectly tender, and goot if eaten as soon as killed, but that the flesh passes very soon into a state of putridity. In the third volume of the Wernerian Society's Memoirs there is a highly interesting paper on the properties of the juice of the papaw tree, by Dr. Holder, who has witnessed its effects in the Island of Barbadoes, and speaks of them as known to all the inhabitants. The juice causes a separation of the museular fibres. Nay, the very vapour of the tree serves this purpose ; henee many people suspend the joints of meat, fowls, Se. in the upper part of the tree in order to prepare them for the table. Such is the effect upon hogs that feed upon the fruit, that the good housewives reject the flesh of sueh if it be destined for salting, well knowing that it is not sufficiently firm for the purpose. It is not known whether the power of hastening the deeay of meat be attributable to the animal matter or febrine contained in the juice of the Papaw. Two speeimens of the juice were brought from the Isle of France; in the one the juice had been evaporated to dryness, and was in the state of an extract; in the other the juice was preserved by being mixed with equal bulk of rum. "Botlı were subjected to analysis by Vauquelin. The first was of a yellowish whitecolour, and scmitransparent; its taste was sweetish; and it had no smell, and was pretty solid; but attracted moisture when kept in a damp place. The second was reddish brown, and had the smell and taste of boiled beef. When the first specimen was macerated in cold water, the greatest part of it dissolved; the solution frothed with soap. The addition of nitric acid coagulated it, and rendered it white; and when boiled, it threw down abundance of white flakes. When the juice of the papaw tree is heated with water, the greatest part dissolves; but there remains a substance insoluble, which has a greasy appearance. It softens in the air, and becomes viseid, brown, and semitransparent. When thrown on burning coals it melted, let drops of grease exude, emitted the noise of meat roasting, and produced a smoke which had the odour of fat volatilized. It left behind it no residue. The substance was febrine. The resemblance between the juice of the papaw tree and animal matter is so elose, that one would be tempted to suspect some imposition, were not the evidence that it is really the juice of the tree quite unquestionable. 'T'homson's System of Chemistry, extracted from the Annales de Chimie, vol. 43. p. 267. Febrine had been previonsly supposed to belong exelusively to the animal kingdom; but it has since been found in other vegetables, especially in Fungi. The name papaw is abridged from papaia-marum, its name is Malabar.

Common Papaw Tree. Fl. July. Clt. 1690. Tree 10 to 20 feet.

2 C. eitrifórmis (Jacq. fil. ex Spreng. syst. 3. p. 905.) leaves palmately 7-cleft; segments oblong, aeute, middle one trifid; fruit oval, smooth. h.S. Native of Peru, about Lima. Flowers yellow. Fruit the shape and size of an orange, edible like the rest.

Citron-formed Papaw, Clt. 1820. Tree 10 to 20 feet.

3 C. pyrifórmis (Willd. spee. 4. p. 815.) leaves eordate, 3lobed; lobes angular; angles acute; flowers corymbose; fruit pear-sliaped. h.s. Native of Peru, and Chili, on rocky cliffs along the shore of $\mathrm{Val}$ paraiso. Feuille, per. 2. p.52. t. 39. f. 1 . C. Prosopòsa, Lin, spec. 11.66.? Flowers rose-coloured. Fruit 
yellow, pear-shaped. A doubtful speeies of the genus, from its small size and branched stem.

Pear-shaped Papaw. Clt. 1823. Shrub 3 to 6 feet.

4 C. cauliflòra (Jacq. schœenbr. 3. p. 33. t. 311.) leaves palmately 5 -lobed; intermediate lobe sinuated; segments lanceolate, acuminated; male peduncles usually 5 -flowered, rising from tubercles on the trunk. h. S. Native of South America, in the province of Caraccas and of Trinidad. Flowers yellowish.

Stem-floncred Papaw. Clt. 1806 . Tree 10 to 20 feet.

5 C. мuсroca'rpa (Jacq. schwenbr. 3. p. 32. t. 309 and 310.) leaves $\$$ or 5 -lobed : intermediate lobe 3-lolved; male flowers corymbose. h. S. Native of Caraceas and Chili. Flowers yellowish. Fruit the size of a cherry.

$V^{\prime a r}$. $\beta$, monoíca (Desf. in ann. mus. 1. $\beta$. 273.) lower leaves entire (smaller), cauline ones 3 -lobed, upper ones 5 -lobed ; lobes somewhat pinnatifid; flowers monoecions, subracemose, ereet. h. S. Native country unknown. Petioles cliannelled.

Small-fruited Papaw. Tree 10 to 12 feet.

6 C. spısòsa (Willd. spec. $1 . p$. 81 J.) leaves digitate; leaflets 7, oblong, acuminated, quite entire ; trunk spiny. h.S. Native of Guiana and Brazil, in Maranham and Para. C. digitàta, Aubl. guian. 2. p. 908. t. $246 . \quad$ A branched tree.

Spiny Papaw. Clt. 1821. Tree 20 to 30 feet.

Cult. These trees grow well in any light rielı soil. They may be brought into a fruit bearing state in our stoves, by planting them in large pots, or in tubs made for the purpose.

Order CV. PASSIflo'REE (plants agreeing with Passiflora in important characters). Juss. ann. mus. 6. p. 102. D. C. prod. 3. p. 321.

Calyx of 5 (f. 5. a.) or 10 sepals (f. 4. $a$. f. 6. $a$. f. $7, a$.), combined into a short or elongated tube (f. 7.e.), free at the apex, disposed in 1 or 2 series; outer lobes large, foliaceous; inner ones alternating with the outer ones, and more petal-jike than them, sometimes these last are wanting altogether; the sides or throat are lined by filamentous (f. 4. $a$.) or annular (f. 5. b. f. 6 c.) or membranous coloured processes, which are disposed in one or more series, having the bottom usually closed by a lid-formed appendage. Petals 5 in the tribe Paropsièce, but wanting altogether in the tribe Passiftorece. Stamens 5 (f. 4. $b$. f. 5. $l$. f. 7. c.), but indefinite in the genus Smeathmánnia. Filaments opposite the exterior lobes of the calyx, joined into a long tube which sheaths the stipe of the ovarium; anthers fixed by the back, peltate (f. $4 . b$. f. $5 . c$.), reflexed, turned outwards, but reversed they are turned inwards, 2-celled, bursting lengthwise. Torus elongated into a long cylintrical stipe. Ovarium seated on the stipe, ovate, free. Styles 3 , rising from the same point (f. 6. $e$. f. $5 . d$. f...,$d$.), crowned by a stigma each, which is somewhat 2-lobed. Fruit naked (f. $7 . g$. ), or surrounded by the calyx (f. $8 . a$.), stalked, 1-celled, 3-valved, having a polyspermous parietal placenta in the middle of each valve; the valves sometimes dry and dehiseing, sometimes fleshy and indehiscent. Seeds attached in several rows to the placentas, usually clothed with a large pulpy aril, eompressed, and generally scrobiculate. Embryo straight, in the centre of the fleshy thin alhumen, having a terete radicle, which is turned towards the lyylum; cotyledons flat and foliaceous.-Herbs or shrubs for the most part climbing. Leaves of many forms, alternate, stipulate, usually bearing glands on the limb or petiole. Peduncles axillary, some of which are changed into tendrils from abortion, others are simple, and bear 1 flower each, very rarely branched and many-flowered; however, all the peduncles are floriferous in the upright species, or those that do not climb: always articulated under the flower, and generally furnished with a 3-leaved involucrum at the articulation.

The real nature of the floral envelopes of this remarkable order, is a question upon which botanists entertain very different opinions, and their icleas of its aflinities are consequently much at variance. According to Jussieu (Dict. scien. vol. 38. p. 49.) the " parts taken for petals are nothing but inner divisions of the calyx, usually in a coloured state, and wanting in several species;" and therefore, in the judgment of this venerable botanist, the order is apetalous, or monochlamydeous. De Candolle adopts the same view of the nature of the floral envelopes as Jussieu; but he nevertheless considers, we think with propriety, the order polypetalous. Other botanists consider the outer series of the floral envelopes as the calyx, and the inner as the corolla; the one is green and the other coloured. The nature of the filancntous appendages, or rays as they are called, which proceed from the orifice of the tube, and of the membranous or fleshy, entire or lobed, flat or plaited annular processes, which lie between the petals and the stamens, are ambiguous, but are probably abortive stamens. With regard to the affinity of Passiforca, Jussieu, swayed by the opinion he entertains of their being apetalous, and De Candolle, who partly agrees and partly disagrees with $\mathbf{J}$ ussieu in his view of their structure, both assign the order a place near Cucurbitàcece; but when we consider the stipitate fruit, oecasionally valvular, the parietal placentas, the sometimes irregular flowers, the stipulate leaves, and the climbing habit of these plants, it is not diffieult to admit their affinity with Capparidece and Violarièce, the dilated disk of the former of which is probably analogous to the innermost of the annular processes of Passiftorce.

The plants composing the Passiftorea, are the produce of South America and the West Indies, where the woods are filled with their species, which climb about from tree to tree, bearing at one time flowers of the most striking beauty, and of so singular an appearance, that the zealous Catholics who discovered them adapted Christian traditions to these inhabitants of the South American wildernesses, and at other times fruit tempting to the eye and refreshing to the palate. Several are found in Africa, and a few in the East Indies, of which the greater part belong to the genus Modécea.

Nothing is known of the properties of this order, further than that the sueculent fruit and pulp that surround the seeds are fragrant, juicy, cooling, and pleasant in several species.

\section{Synopsis of the genera. \\ Tribe I.}

Paropsie's. Pctals 5. Ovarium sessile. Upriglit shrubs without tendrils.

1 Sieatima'xinia. Nectarium 1-leaved, urceolate, surrounding the base of the stamens. Stamens indefinite; anthers incumbent. Stigmas 5, peltate. Capsule inflated, papery, 4-5-valved. 
2 Parópsia. Capillary threads simple, disposed in 5 bundles, rising from the base of the calyx. Stamens 5 ; anthers erect. Capsule bladdery, 3-valved.

\section{Tribe II.}

Passiflòrefe-vere. Calyx 5-sepalled. Petals 5 or manting. Stamens 5, in one species only 4. Ovarium stalked. Some of the pedicels changed into tendrils. Stems generally climbing.

3 Passiflòra. Tube of calyx very short, having the throat ornamented with a filamentous crown (f. 4. a.). Berry usually pulpy, rarely membranous.

4 Dise'sma. Tube of calyx short, furrowed below, having a double crown in the throat; the outer crown composed of distinct threads, the inner one with the threads joined into an entire or toothed membrane. The rest as in Passiftora.

5 Tacsònia. Tube of calyx long (f. 7. e.); limb 5-lobed. Petals 5. Throat of calyx furnished with a scaly membrane.

6 Munucu'ia. Tube of calyx furrowed below; crown of throat simple, erect, tubular, truncate (f. 5.6. f. 6. c.). Habit of Passiftora.

7 Paschántuus. Flowers polygamous. Calyx tubular; limb 5-cleft. Petals 5, oblong-linear. Stamens 5, free; anthers linear, inserted by the base. Capsule subbaccate, 6-seeded. Habit of Passiflòra.

8 Modécca. Flowers dioecious. Calyx campanulate; limb 5-parted (f. 8. b. a.). Petals 5 (f. 8. e.). Scales 5-10 (f. 8. c.), rarely wanting, rising from the calyx. Stamens 5 , inserted in the torus, monadelphous. Anthers standing. Ovarium on a short stipe. Stigmas 3, starry (f. 8. e.). Capsule bladdery.

9 Deida'ma. Calyx 5-8-parted; lobes petaloid; flamentous crown simple, rising from the outer part of the calyx. Stamens the same number as the lobes of the calyx; filaments joined into a column at the base. Styles 3-4. Capsule pedicellate, 3-4-valyed.

10 Vare'ca. Flowers unknown. Berry 1-celled; pulp divided for the seeds into many partial cells. Placentas 3 , parietal, polyspermous.

\section{Tribe I.}

PAROPSIE'E (this tribe contains plants agreeing in important characters with Parópsia). D. C. prod. 3. p. 322. Petals 5. Ovarium sessile. Upright shrubs without tendrils. Perhaps a proper order.

1. SMEATHMA'NNIA (in honour of Smeathmann, a German, who travelled in many parts of western Africa, and collected many specimens of plants, particularly at Sierra Leone). Sol. and Banks, herb. ex Brown. congo. p. 20. Lin. trans. vol. 13. p. 220. D. C. prod. 3. p. 322.

Lin. sxst. Polyándria, Polygýnia. Nectarium 1-leaved, urceolate, surrounding the stamens at the base. Stamens numerous, distinct, seated on a short column; anthers incumbent. Stigmas 5, peltate. Capsule inflated, 4-5-valved. Seeds dotted.-Upright shrubs, with white, showy, axillary flowers.

1 S. PUBE'scens (Sol, in herb. Bank. ex R. Br. in Lin. trans. vol. 13. p. 221.) branches downy ; leaves oblong-ovate; top of nectarium bearded. $々$. S. Native of Sierra Leone, in the low lands.

Downy Smeathmannia. Fl. Mar. Shrub 6 to 8 feet.

2 S. Lxviga'Ta (Sol. l. c. ex R. Br. l, c.) branches glabrous; leaves oblong, acute at the base, shining; nectarium cut, beardless. h.S. Native of Sierra Leone, in the mountains, where we have seen it growing in great plenty, and where it forms beautiful upright bushes, loaded with delicate white flowers.

Smooth Smeathmannia. Fl. March, April. Clt.1823. Slirub 6 to 8 feet.

3 S. ME'Dla (R. Br. in Lin. trans. 13. p. 221.) branches glabrous; leaves obovate-oblong, obtuse at the base, glabrous, rather opaque, 々. S. Native of Sierra Leone. Flowers white.

Intcrincdiate Smeathmannia. Shrub 6 to 8 feet.

Cult. These elegant shrubs grow best in a mixture of loam, peat, and sand; and young cuttings of them strike root freely in the same kind of soil under a bell-glass, in heat.

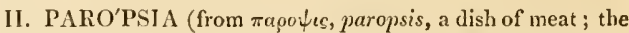
seeds are inclosed in a fleshy arillus, of an agreeable sweet taste, much esteemed by the natives of Madagascar, as well as by Europeans). Du Pet. Tl. pl. afr. 2. p. 59. t. 19. D. C. prod. 3. p. 322 .

Lin. syst. Monadélphia, Pcntándria. Capillary threads disposed in 5 bundles, in a single series, rising from the base of the calyx. Stamens 5, monadelphous a short way at the base; anthers erect. Stigmas 3. Capsule bladdery, 3-valved.

l P. Edu'zis (Du Pet. Th. I. c.). 々. S. Native of Madagascar. Shrubs 5-6 feet ligh. Leaves ovate-oblong, deeply serrated. Pedicels axillary, in bundles. Aril of seeds edible. Flowers white.

Edible Paropsia. Shrub 5 to 6 feet.

Cult. For culture and propagation see Smeathmánnia.

\section{Tribe II.}

PASSIFLO'RE E-VER E (true passion-flowers). Calyx with a 5 -parted limb. Petals 5 or wanting. Stamens 5 in all, except one plant, which has only 4. Ovarium pedicellate. Some of the pedicels changed to tendrils. Stems generally climbing.

III. PASSIFLO' RA (from passio, passion, and flos, a flower; resemblance in crown of appendages to the passion of Christ). Juss. gen. p. 397. D. C. prod. 3. p. 322.-Granadilla, Tourn. inst. t. $123,124$.

Lin. sist. Monadélphia, Pentándria. Tube of calyx very short, having the throat ornamented with a multiple filamentous crown $\left(f, 4 . a_{1}\right)$. Berry generally pulpy, rarely somewhat membranous.

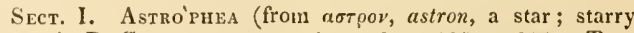
flowers). D. C. mem. soc. gen. 1. pt. 2. p. 435. p. 322. Tendrils none. Involucrum none. Limb of calyx 5-lobed. Petals 5 . Stems arboreous. Perhaps species of Parópsia.

1 P. glav'ca (Humb. et Bunpl. pl. equin. 1. t. 22.) arboreous; leaves obovate-oblong, glaucous beneath, and bearing glands in the axils of the reins; petioles glandless; peduncles dichotomous, 3-5-flowered. $h$. S. Native of South America, on Mount Quindiu. P. amethýstina, Mikan. P. arbòrea, Spreng. syst. 3. p. 42. Flowers white. Crown tipped with yellow.

Glaucous Passion-flower. Tree 20 to 30 feet.

2 P. emargina'ta (Humb. et Bonpl. l. c. t. 23.) arborescent ; leaves obovate-lanceolate, acuminated, or emarginate, pubescent beneath, and biglandular at the base; petioles glandless; peduncles dichotomous, 3-5-flowered. h. S. Native of Peru, on the Andes. Flowers white?

Emarginate-leaved Passion-flower. Shrub 10 to I 6 feet.

3 P. ova't A (Martin. ined. D. C. prod. l. c.) arborescent ; leaves oval, obtuse at both ends, somewhat cuneated at the base, glabrous, glandless beneath; petioles biglandular at the apex; peduncles 2-flowered. h. S. Native of French Guiana.

Ovate-leaved Passion-flower. Shrub. 
Sect. II. Polyánthema (from $\pi 0 \lambda v$, poly, many, and $a \nu \theta 0 s$ anthos, a flower; in reference to the peduncles bearing many flowers). D. C. mem. soc. gen. 1. pt. 2. p. 435. prod. 3. p. 322. Peduncles many-flowered, sometimes twin, with a tendril in the middle, sometimes solitary and branched, the middle ending in a tendril. Involucrum wanting or very small. Limb of ealyx 5-lobed. Petals 5. Stems climbing.

4 P. cirriflòra (Juss. in ann. mus. 6. t. 41. f. 1.) leaves pedate, glabrous; petiole branched, biglandular above the base; leaflets $\boldsymbol{\gamma}$, ovate, with 1 tooth on each side at the base; peduncles branehed, bearing flowers and tendrils. $\iota . u$. S. Native of French Guiana, in woods. Form of leaves like those of $P$. pedita. Crown variegated with white, yellow, and red.

Tendril-flowered Passion-flower. Slirub cl.

5 P'. septena'ta (D. C. prod. 3. p. 323) leaves pedate; petioles branelied, glandless; leaflets oblong, having 1 tooth on each side at the base; tendrils simple, distinct from the peduncles. $h$. $\smile$. S. Native country as well as the flowers unknown. Septenate-leaved Passion-flower. Shrubel.

6 P. holoserícea (Lin. amœn. 1. p. 226. f. 15.) clothed with soft velvety down; leaves ovate, somewhat 3 -lobed, aristately toothed at the base; petioles biglandular. $h$.. $\mathrm{S}$. Native of Vera Cruz. Sims, bot. mag. t. 2015. Ker. bot. reg. t. 59. Flowers white, spotted with red. liays variegated with purple and white.

IIhole-silky Passion-flower. Fl. May, Ang. Clt. 1733. Sh. cl. 7 P. sexfòra (Juss. l. c. t. 37. f. 1.) elothed with soft velvety down; leaves cordate at the base, very broad, truneate at the apex, 3-lobed; petioles glandless. $\zeta . \cup$. S. Native of St. Domingo and Jamaica.

Six-flowered Passion-flower. Shrub el.

8 P. Geminiflòra (D. C. prod. 3. p. 322.) pubescent; leaves cuneated at the base, very broad, truncate, sinuately 3 -lobel at the apex, glandular beneath and shining above; petioles glandless. $\quad h \cdot \cup . S$. Native of Brazil.

Trin-flowered Passion-flower. Shrub cl.

9 P. Molucca'sa (Reinw. in Blum. bijulr. p. 938.) leaves oblong, mucronate, somewhat emarginate at the base, quite entire; petioles biglandular; cymes bifid, many-flowered. $h$. $\checkmark$ S. Native of the Moluceas.

Molucca Passion-flower. Shrub cl.

Sect. 11I. Tetrapatimea (from teтpa, tetra, four, and $\pi \alpha \theta 0 c$, pathos, passion; signifying passion-flowers with 4-lobed flowers). D. C. in mem. soc. gen. 1. pt. 2. p. 435 . prod. 3. p. 328. Calyx 4-lobed. Petals wanting. Stamens 4. Involucrum wanting or very small. Branches of peduncles 3-flowered. Tendrils simple, rising from different axils from those of the peduncles.

10 P. tetrándra (Banks, herb. ex D.C. prod. 3. p. 323.) glabrous; leaves oval-oblong, acuminated, quite entire, glandless. h. $\iota$. S. Native of New Zealand. Flowers small, greenish.

Tctrandrous Passion-flower. Shrub el.

Sect. IV. Cif'ca (meaning unknown). Med. malv. p. 97 D.C. prod. 3. p. 393.-A sephanánthes and Monactineírma, Bory. ann. gen. 2. p. 138. Calyx 5-lobed. Petals wanting. Involucrum wanting or very small. Peduncles 1-flowered, and simple tendrils usually rising from the same axils.

11 P. PÁllida (Lin. amon. 1. p. 213.t. 10. f. 2. exclusive of the synonymes) leaves glabrous, ovate, acuminated, 3-nerved; petioles biglandular above the middle; perlicels $1-3$ together. h.u. S. Native of St. Domingo and Brazil.-Plum. amer. p. 73. t. 89 . Ker. bot. mag. t. 660 . Flowers small, yellowishgreen.
Pale-flowered Passion-flower. Fl. Aug. Sept. Clt. ? Sh. el.

12 P.cu'prea (Lin. amcen. I. p. 219. t. 10. f. 3.) leaves glabrous, ovate, glandular beneath, between the axils; petioles glandless; pedicels solitary. $h . \cup$. S. Native of the islands of Providence and Balıama, Jacq. ieon. rar. 3. t. 606 . Flowers blood-coloured, an inch and a half in diameter. Berries purplish.

Copper-coloured-flowered Passion-flower. Fl. July, Aug. Clt. 172.t. Shrub cl.

13 P. Cavanille'su (D. C. prod. 3. p. 323.) leaves glabrous, ovate, glandless, ciliated with stiff hairs; petioles glandless; pedicels solitary. h. . S. Native of the West India Islands. P. cùprea, Cav. diss. 10. p. 448. t. 273. lilowers pale purple ; crown copper-coloured, but violaceous at the base.

Cavanilles's Passion-flower. Clt. 1822. Shrub el.

14 P. multiplòra (Lin. amœen. 1. p. 221. t. 10. f. 7.) leaves ovate-oblong, entire, clothed with velvety down beneatlı; petioles very short, biglandular at the apex; pedicels numerous in the axils of the leaves. $h \cdot \checkmark$. S. Native of St. Domingo, Cav. diss. 10. t. 272. There are varieties with the leaves either glabrous or downy above. Plum. amer. t. 90. Flowers greenish. Style purplish.

Many-flonered Passion-flower. Fl. June, Sept. Clt. 1731. Shrub cl.

15 P. Auricula'ta (H. B. et Kunth, nov. gen. amer. 2. p. 131.) leaves glabrous, ovate, rounded at the base, glandular beneath; petioles auricled by 2 glands bencath the middle; pedicels 1 or 2 together. $\quad h \cdot \cup$. S. Native of the banks of the Orinoco, in shady places, at the cataract of Maypure. Flowers whitish, but the ealyx is greenish on the outside.

Auricled-leaved Passion-flower. Fl. June, Aug. Clt. 1820. Shrub cl.

16 P. Nipaule'nsis (Wall. tent. t. 11.) smooth; leaves cordate-acute, quite entire, 5-nerved, glandular beneath and on the petioles; peduncles bracteate, aggregate; crown triple, exceeding the calyx. $h . \cup$. S. Native of Nipaul, on woody hills in the great valley. Leaves glaucous, furnished with 2 glands underneath at the insertion of the nerves, and 2 in the middle of the petioles. Peduneles 2-3-flowered. Flowers small, white, with a greenish crown. Berry yellow, about the size of a small cherry.

Nipaul Passion-flower. Shrub cl.

17 P. uitrora'Lis (H. B. et Kunth, 1. c. p. 133.) leaves beset with silky hairs on both surfaces, hastately 3 -lobed, and nearly entire; petioles bearing 2 stipitate glands above; pedicels $2-3$ together. h.u. S. Native of Peru, on the sea-shore near Patibilca, and in the valley of Lima. Flowers with a green calyx.

Sea-shore Passion-flower. Shrub cl.

18 P. GLabra'ta (H. B. et Kunth, l. c. p. 135.) leaves glabrous, shining, glandular beneath, half orbicular, truneately 2 . lobed; lobes very short, spreading; petioles glandless ; pedicels solitary, or twin. $h$. U. S. Native of New Granada, near Turbaco. Related to Murucüja accellàta. Flowers small, white; crown yellow.

Smooth Passion-flower. Shrub cl.

19 P. pube'scens (H. B. et Kunth, 1.c. p. I32.) leaves semiorbicular at the base, lunately 2 -lobed; lobes orate-oblong, acute, divaricate, with an awn in the recess between the lobes, and are as well as the petioles downy and glandless; peclicels solitary. $h \cdot \cup$. S. Native of South America, in shady places of the province of Caraccas. P. Lockhártii, G. Don, in Loud. hort. brit. p. 269. Flowers small, greenish white.

Donny l'assion-flower. Shrub el.

20 P. віцова'та (Juss. ann. mus. 6. p. 107. t. 37. f. 2.) leaves smooth, 2-lobed, rounded at the base, 9-nerved, glandless; lubes 
obtuse, emarginate, rather diverging; petioles short, glandless; pedicels twin. $h \cdot \cup$. S. Native of St. Domingo. Tacsonia bilobàta, Spreng. syst. 3. p. 44. Flowers very small, greenish? Tro-lobel-leaved Passion-flower. Shrub cl.

21 P. Mexicina (Juss. ]. c. p. 108. t. 38, f. 2.) leaves glabrous, 2-lobed, rounded at the base, 3-nerved; lobes oblong, diverging a little, glabrous beneath; petioles short, glandless; pedicels twin, I . U. S. Native of Mexieo, about Acapulco. Flowers small, whitish.

Mexican l'assion-flower. Clt. 1820. Shrub el.

22 P. Dictámo (Moc. ct Sesse, fl. mex. ieon. ined. ex D. C. prod. 3. p. 32.4.) leaves glabrous, 2 -lobed, somewhat emarginate at the base, 3-nerved, glandless beneath; lobes oblong, divaricate; petioles glandless; pedicels twin. $h . \cup$. S. Native of New Spain, where it is called Dictamo.

Dictamo Passion-flower. Slurub el.

23 P. Norma'Lis (Lin. amon. 5. p. 408.) leaves glabrous, 3nerved at the base, somewhat cordate, glandular beneath, somewhat 3-lobed; middle lobe small, lateral ones so much divaricate its to form a straight angle; petioles very short, glandless. h. S. Native of Jamaiea. Brown, jam. p. 328. Flowers small, pale coloured. Fruit purple, downy.

Normal Passion-flower. Fl. May, June. Clt.1771. Sh. cl.

24 P. Bauhinitolia (H. B. et Kunth, l. e. p. 132.) leaves downy beneath, and rather glandular, elliptic, rounded at the base, 2 -lobed at the apex; lobes oltuse; petioles glandless, downy; pedicels solitary or twin, downy. $\hbar_{2} \cdot \cup$. S. Native of Quito, in temperate plaees. Flowers small, whitisl.

Bauhinia-leaved Passion-flower. Shrub cl.

25 P. trisetòsa (Moe. et Sesse, fl. mex. icon. ined. ex D. C. prod. 3. p. 324.) leaves glabrous, glandular beneath, ovate, 3nerved, equally 3 -lobed at the apex; lobes mucronated by a bristle each; petioles glandless; pedicels twin. $h_{c} \cup$. S. Native of Mexieo.

Three-bristled Passion-flower. Shrub el.

26 P. Mísera (H. B, et Kunth, nov. gen. amer. 2. p. 136.) leaves glabrous, reticulately 3-nerved, cordate, 3-lobed; lobes obtuse, emarginate, and are, as well as the petioles, glandless ; pedieels solitary. $h_{\text {. }} \cup$. S. Native of South Ameriea, between Turbaco and Cartluagena, in very lot places. Flowers small, with a grecnish ealyx, and violaceous erown.

Miscrable Passion-flower. Shrub el.

27 P. consa'cea (Juss. in anu. mus. 6. p. 109. t. 39. f. 2.) leaves smooth, coriaceous, glandular beneath, peltate, 3 -lobed; middle lobe obtuse : lateral ones acuminated, 2-nerved; petioles biglandular in the middle; pedicels twin. $h \cup$. S. Native of South America, near Honda; and perhaps also in Mexico, aceording to icon. fl. mex. ined. Flowers small, greenish.

Coriaccous-leaved l'assion-flower. Shrub el.

28 P. Dif т́́mis (H. B. et Kunth, l.e. p. 136.) leaves glabrous, eoriaceous, glandular beneath, peltate, somewhat 3-lobed, transversely lanceolate; petioles biglandular in the middle; pedicels solitary? $h, \mathrm{~S}$. Native of New Granada, in temperate plaees on the Andes. Allied to $P$. coriàcea. Perhaps the same as the figure in Hern. mex. p. 435. upper figure. Flowers with a greenish calyx, and violaceous crown tipped with yellow.

Deformed Passion-flower. Shrub el.

29 ]'. Angustifòita (Swartz, prod.p. 97.) leaves glabrous, glandless, somewhat peltate : lower ones ovate, the rest lanceolate, 2 or 3-lobed; petioles short, biglandular above the middle; pedicels solitary or twin. $h$. $\cup$. S. Native of the Caribbee Islands. Ker, bot. reg. t. 180. P. heteroplyýlla, Jaeq. hort. schoenbr. t. 181. Cièca heterophýlla, M Ionch. P. Jongifòlia, Lam. dict. 3. p. 40. Flowers yellowish, with the rays purple at the base.
Narrom-leaved Passion-flower. Fl, Jume, Sept. Clt. 1773. Shrub el.

30 P. maevia'ta (Sean, eat. hort. bon. and Coll. hort. rip. p. 101.) leaves glabrous, deeply 3-lobed, painted with white on the upper surface; lobes nearly equal, oblong, acute: 1tpper ones bluntly trifid. intermediate one rather larger than the others; petioles glandless; pedicels solitary or twin, rather pilose. $I_{2}$. V. S. Native of Curassoa. Pluk. t. 210. f. 3. Perhaps the same as P.minima of lin. Flowers greenish.

Spotted-leaved I'assion-flower. Fl. June, July. Clt. 1820. Slurub cl.

31 P. Gra'ellis (Link, enum. hort, berol. 2. p. I82.) leaves subcordate, glabrous, 3-Jobed; lobes roundish, beset with 2.4 glands; petioles biglandular; peduneles axillary, solitary; fruit egg-shaped. $h_{2} \cup$ S. Native country unknown. Lindl. bot. reg. t. 870. Flowers whitish. Rays blue and white.

Slcnder Passion-flower. Fl. Aug. Clt. 1823. Shrub el.

32 P. Lu'tea (Lin. amœn. 1. p. 224. t. 10. f. 13.) leaves almost glabrous, cordate, trifid; Johes ovate, mucronate by a bristle, and are, as well as the petioles, glandless ; pedicels twin. 4. $\checkmark$. H. Native of Virginia and Florida, and of the West Indies. Jaeq. icon. rar. 3. t. 607. Ker, bot. reg. t. 79. Flowers pale yellow.

Yellon-flowered Passion-flower. Fl. May, June. Clt. 1714. Slırub cl.

33 P. mínina (Jaeq. hort. vind. t. 20.) leaves glabrous, glandless, 5-nerved, trifid: lobes ovate, middle one drawn out most ; petioles biglandular at the apex; pedicels twin. $h \cdot \cup$. S. Native of Soutl Ineriea. Sowerby in Lin. trans, 2, p. 27. $t$. 5. f. 6. Ker, bot. reg. t. 144. P. hederatea, Lam. Flowers greenish yellow, with white rays. Neetarium fourfold, inner one with an entire brown rim, the onter plaited, of a dusky purple colour, the other ciliated, with capillary black laairs, with yellow tips; outmost one having the filamentous appendages twiee as long as the others, dark purple at the base, and yellow from the midlle to the tip.

Least Passion-flower. Fl. July, Aug. Clt. 1690. Shrub el.

34 P. mRsu'ta (Lin. amoen. 1. 13. 227. t. 10. f. 16. exelusive of the synonymes of Hern. and P'luk.) leaves rather hairy beneath, glandless, somewhat 5 -nerved, 3 cleft; lobes ovate, middle one much the largest; petiole biglandular above the middle; pedicels $t$ win. $h_{c} \cdot \mathcal{V}$. S. Native of the West lndies. Plum. amer. t. 88. A.-B. P. parvifòlia, Swartz, prod. p. 97. Flowers whitish.

IIairy Passion-flower. Fl. Sept. Clt, 1778. Shrub el.

35 P. suberòsa (Lin. 1. c. p. 226. t. 10. f, 14.) leaves glabrous, somewhat ciliated, 5 -nerved at the base, ovate, somewhat cordate, usually 3 -lobed; lobes ovate, aeute: middle one larger than the rest; petioles biglandular above the middle; pedicels twin. h.u.S. Native of the West Indies and South Amcrica. Smitl, exot. bot. 1. t. 28. Plum. amer. t. 84. Jaeq. schoenbr. 2. t. 163. Flowers of a greenish yellow-eolour; erown purple at the bottom. Fruit purple when ripe.

Corli-barlied Passion-flower. Fl, June, Sept. Clt. 1759. Slirub cl.

36 P. pelta'ta (Cav. diss. 10. p. 447. t. 275.) leaves pubescent above, glandless, 3-nerved, rather peltate, 3-lobed beyond the middle; lobes laneeolate, divarieated; petioles biglandular in the middle; pedicels solitary. b.. S. Native of the Antilles, in hedges, as well as in Virginia. Ker. bot. reg. 505. -Plum. amer. t. 85. Flowers greenish.

Peltate-leaved Passion-flower. Fl. Ang. Sept. Clt. 1778. Shrub cl.

37 P. IIEdera'eea (Cav. I. e. p. 448.) leaves somewhat puberulous, glandless, 3-nerved, trifid : lobes ovate, obtuse; petioles biglandular in the middle; pedicels solitary. $\zeta \cup . \mathrm{S}$. 
Native of the Antilles, in hedges. Plum, amer, t. 84. Flowers whitish?

Ivy-likc Passion-flower. Fl. June, Aug. Shrub cl.

38 [. PAxixosa (Snith in Recs' cyel. no. 28.) leaves clothed with velvety hairs on both surfaces, glandless, cordate, unequally 3.lobed, rarcly 2-lobel; lobes oltuse; petioles velvety; pedicels bearing 3 bracteoles each. $h . \cup$. S. Native of the West Indies. Allied to P. rùbra. Flowers snall, greenish.

Clolh-leaved Passion-flower. Slirub cl.

39 P. Berteria'na (13alb, in litt. ex D. C. prod. 3. p. 325.) leaves glabrous, glandless, clivided into 9 parts even to the base; leaflets petiolate, trifid, attenuated at the base, and very blunt at the apex; pellicels solitary or twin. $\zeta . \cup . S$. Native of St. Domincro.

Berlero's Passion-flower. Shrub cl.

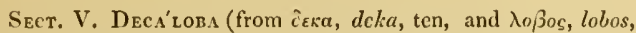
a lobe; in reference to the 10 calycine lobes). D. C. mem. soc. gen. 1. pt. 2. p. 435. prod. 3. p. 325.-Passifiòra, Bory, ann. gen. ?. p. 138. Calyx 10-lobed, the 5 inner are probably petals. Involucrum wanting or very small, and distant from the flower. Peduncles 1-flowered, rising from the same axils as the simple tendrils.

40 P. Perfolia'ta (Lin. 1. c. p. 222.t. 10. f. 8.) leaves glabrous, cortate at the base, glandular beneath, somewhat 3lobed: middle lobe very short; petiole glandless, very short ; pedicels solitary or twin, rather downy. h. . S. Native of Jamaica, in hedges on the mountains. Ker. bot. reg. t. 78 . Murucùja perfòliata, Spreng. syst. 3. p. 43.-Sloan. jam. 1. p. 230. t. 142. f. 3, 4. Flowers crimson or scarlet; rays flesliy, green, with blunt searlet tips.

Perfoliate-leaved Passion-flower. Fl. July, Aug. Clt. 1800. Slirub el.

41 P. RU'Bra (Lin. amœen. 1. p. 222. t. 10. f. 9.) \}eaves velvety, cordate at the base, 2 -lobed, with an awn in the recess between the lobes, glandless beneath, and on the petioles; pedicels solitary; ovarium hairy, subglobose. $h . \checkmark$. S. Native of the West Indies and the adjacent continent. Plum. amer. t. 83 . Ker, bot. reg. t.95. Stem reddish, hairy. Flowers of a greenish yellow colour; erown red. Berry red.

Red-berried Passion-flower. Fl. April, Sept. Clt. 1831. Slirub cl.

42 P. capsula'ris (Lin. 1. c. p. 23\%) leaves downy, cordate at the base, 2 -lobed, with an awn in the recess between the lobes, and are, as well as the petioles, glandless: pedicels solitary; ovarium elliptic-oblong, and is, as well as the fruit, acutcly lexagonal, glabrous. $h_{\text {. }}$. S. Native of the West Indies. Plum. icon. amer. t. 138, f. 2. The flowers are reddish according to Plumier, but according to other authors they are whitish. Fruit small, purple when ripe.

Iar. $\beta$, acutiloba (D. C. prod, 3. p. 325.) leaves deeply 2lobed, hardly pubescent above, painted with white. $\zeta \cdot \cup$. S Native of Brazil.

Var. $\gamma$, geminifòlia (D. C. l. c.) leaves glabrous, hardly cordate at the base; branches triangular; pedicels twin. $\downarrow . \smile$. S. Native of Jamaica. P. capsulàris, Smith in Rees' cycl. no. 22.

Capsular Passion-flower. Fl. Ju. July. Clt. 1820. Shrub el.

43 P. Birlòra (Lam. dict. 1. no. 36.) leaves glabrous, glandular beneath, cordate at the base, 3-nerved, truncate, somewhat 2 or 3 -lobed; petioles short, glandless; pediccls twin. $h$. $\checkmark$. S. Native of the West India Islands, and South America, P. lundta, Smith, icon. pict. t. 1. Ker, bot. reg. 577 . P. Vespertílio, Lawr. pass. t. 8 . Flowers white; rays of crown yellow. The Mexican plant differs in the leaves being roundly cuneated at the base, not cordate, and in the lobes being less divaricate.

rol. 111.
Tro-flonered Passion-flower. Fl. Ju. Aug. Clt. 1800 . Slı, cl.

4.4. I'. Lescinanútin (D. C. proul. 3. p. 326.) leaves semiorbicular at the base, somewlat truncate at the apex, tricuspidate, pubeseent on the nerves beneath, glandless; petioles bi-

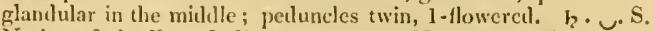
Native of the Last Indies, among the Neelgherry Mountains, where it is called by the inhabitants covaymunkou. Bryonia tricuspidita, Lesch. herb. Flowers unknown.

Leschicnaul's l'assion-flower. Shrub $\mathrm{cl}$.

4.5 P. $\Lambda$ inersònı (D. C. l. c.) leaves glabrous, glandular beneath, cuncately-rotunded at the base, 3-nerved, truncate at the apex, sublunate; petioles long, glanilless; pedicels twin, hardly longer than the petioles. $h . u$.S. Native of the Island of St. Lucia. Flowers party-coloured.

Anderson's Passion-flower. Fl. July, Oet. Clt. 1823. Slı. cl.

46 P. Ro'nrir (D. C. I. c.) leaves nearly glabrons, ovate, somewhat truneate at the base, 3 -nerved, blunt and somewhat 3-lobel at the apex; petioles biglandular, rather velvety; pedicels solitary. h. $\checkmark$. S. Native of Cayennc.

Rohr's P'assion-flower. Shrub cl.

47 P. Penduliflòra (Bert, in herb. Balb. ex D. C. 1. e.) leaves glabrous, roundly obovate, 3 -nerved, glandular beneatlı; nerves extending beyond the border of the leaf; petioles glandless; peduncles solitary or twin, mucl longer than the petioles, pendulous, bracteolate beneatl the middle. $h . \cup$. S. Native of Jamaica, on the mountains. Flowers pale: threads of crown few and glanilular.

Pcudulous-flonered Passion-flower. Shrub cl.

48 P. heniev'cla (Meyer, prim. esseq. p. 225.) leaves glabrous, glaucous and glandular beneath, 3-nerved at the base, semicireular, somewliat 3 -lobed at the apex; petioles pubescent, glandless; pedicels twin, shorter than the petioles. $\eta$ ๖. S. Native of Guiana, about Essequibo; and of Trinilad. Flowers wlite.

Half-circular-leaved Passion-flower. Clt. 1817. Shrub cl.

49 P. vespertílio (Lin. amœn. 1. p. 223. t. 10. f. 11.) learcs glabrous, glandular beneath, 1 -nerved, cuneated at the base, divaricately 2 -lobed, rarely somewhat 3 -lobed; petioles very short, glandless; peclicels solitary. $h . \cup$. S. Native of South America.-Dill. hort. elth. t. 137. f. 164. Flowers white, small.

Bat-wing-leaved Passion-flower. Fl. May, June. Clt.1732. Shrub el.

50 P. RLtu'sa (Hook. et Arnott, in bot. misc. 3. p. 235.) leaves smoothish, biglandular beneath, cuneated at the base, or rounded, 3-nerved, 3-lobed; lobes mucronulate, middle one truncate, latcral ones divaricate, prolonged; petioles glandless; peduncles solitary, excecding the petioles. $h_{c} \cup$. S. Native of Brazil, on the banks of the Uraguay; and at Santa Borga. Closely allied to $P$. respertilio.

Retuse-leaved Passion-flower. Shrub cl.

51 P. Maximitra'sa (Cory, ann. gen. 1819. vol. 2. p. 149. t. 24.) leaves glabrous, divaricately 2 -lobed, drawn out a little in the middle, somewhat cordate at the base, red and biglandular beneatlı; petioles glandless; pedicels solitary or twin, longer than the petioles. $h$. $\checkmark$. S. Native of Brazil. P. díscolor, Link et Otto, ablı. 1. p. 13. t. 5. Lodd. bot. cab. t. 565. P. vespertílio, Ker, bot. reg. t. 597. This plant differs from $P$. rcsperlilio in the leaves being cordate at the base, not cuneated, blood-coloured beneath; and in the pedicels being three or four times longer. Flowers greenish; crown white.

Prince Maximilian's Passion-flower. Fl. May, Junc. Clt. 1800. Slırub cl.

52 P. Jorulle'nsis (1I. B. et Kunth, nov. gen, amer. 2. p. 133.) leaves glabrous, glandular beneath, semiorbicular at the base, 3-nerved, truncate at the apex, 2-lobel; petioles puberu11 
lous and glandless; pedicels twin. $\eta$. . S. Native of Mexico, on the burning Mlount Jorullo. Flowers greenish?

Jorullo Passion-flower. Shrub cl.

53 P. sicroìdes (Schlecht. et Cham. in Linnæa. vol. 5. p. 88.) leaves cordate, 3 -lobed, sharply subdentate or quite entire, glaucous beneath, hairy, biglandular in the recesses, smoothish above; lobes triangularly acuminated, middle lobe the longest; petioles hairy, biglandular in the middle; glands large, clasate; stipulas half ovate, cuspidately acuminated; peduncles twin; lracteas filiform, small, approximating the flower. $h$ :u. S. Native of Mexico, in woods near Jalapa. Flowers pale. Habit of Bryònia.

Sicyos-like Passion-flower. Slirub cl.

54 P. oblonga'ta (Swartz, prod. p. 97.) leaves glabrons, glandular beneath, oblong, rounded at the base, 3-nerved, 3jobed at the apex; petioles glandless; pedicels solitary. $h_{.} \cdot$. S. Native of Jamaica, among bushes. 1'. elongàta, Poir. suppl. 2. p. 839 .

Oblong-leaved Passion-flower. Fl. June, Aug. Clt. 1816. Shrub cl.

55 P. LYr fròlia (Tuss. ant. t. 4.) leaves glabrous, glandular beneath, ovate at the base, 3-nerved, 3-lobed at the apex; lobes straight, acuminated, middle lobe small ; petioles glandless; pedicels solitary or twin. $\hbar_{\varepsilon} \cup$. S. Native of Jamaica, on Mount St. George. Probably sufficiently distinct from the preceding and following species.

Lyre-leaved Passion-flower. Fl. Ju. July. Clt. 1816. Sh. cl.

56 P. тuberòsa (Jacq. hort. schœenbr. t. 496.) leaves glabrous, glandular beneath, rounded at the base, 3-nerved, 3lobed at the apex; lobes oblong, acute, middle lobe very small; petioles glandless; pedicels twin; branches of root tuberous. h. ๖. S. Native of South America. Ker, bot. reg. t. 432. P. punctàta, Lodd. bot. cab. t. 110. Lower leaves usually painted with white on the upper surface. Flowers greenish white; outer crown green at the base, tipped with purple and white, Style purple.

Tuberous-rooted Passion-flower. Fl. June, Oct. Clt. 1810. Slirub cl.

57 P. rotunnifòlia (Lin. J. c. p. 235.) leaves rather glandular, velvety beneath, nearly orbicular, 3-nerved, 3-lobed; petioles glandless; pedicels twin; berries globose, hairy. $h . v$. S. Native of the Antilles. Plum. icon. amer. t. 138, f. 1. Cav. diss. t. 290. Flowers whitish.

$\operatorname{Var} \beta$, Jaequini (D. C. 1. c.) leaves glabrous beneath; pedicels solitary; leaflets of involucrum ovate. $h \cup . S$. Native of Cartlagena, in the woods. P. rotundifolia, Jacq. obs. t. 46. f. 1. Petals whitish; rays of crown yellow.

Íar. $\gamma$, Sn'́rtzii (D. C. prod. 3. p. 327.) leaves glabrous beneath; herry ovate, glabrous. $h$. $\cup$. S. Native of the south of Jamaica. P. rotundifòlia, Swartz, abs. p. 337. Flowers greenish.

Round-leaved Passion-flower. Fl. May, Aug. Clt. 1779. Slirub cl.

58 l'. ALNifòdia (H. B. et Ḱunth, nov. gen. amer. 2. p. 136.) leaves puberulous beneath, glandular, ovate, rotndly truncate at the base, 3-nerved, roundly 3 -lobed at the apex; middle lobe emarginate; petioles glandless, and are, as well as the pedicels, downy, and twin; berries splerical, glabrous. h.u. S. $\mathrm{Na}$ tive of South America, on Mount Quindiu, at the river Cuello. Flowers large.

Alder-leaved Passion-flower. Shrub cl.

$59 \mathrm{P}$. obscu'ra; leaves 3-lobed, somewhat cordate, truncate, velvety: lateral lobes divaricate: intermediate one obsolete, emarginate; petals emarginate, shorter than the calyx ; tube of calyx rotate, depressed; inner crown pubescent, plicate, lying on the base of the stipe, in the disc, outer crown radiate; ovarium vil- lous. $h \cdot$. S. Native of the north-eastern coast of South America, but in what place we gathered it is now forgotten. Flowers small, pale green, with a downy pedicel: the inner crown is downy and purple: the outer crown has its lower half purple, and its upper white. This species seems to come nearest to P. alnifolia of Bonpland.

Obseure Passion-flower. Fl. Aug. Nov. Clt. 1823. Sh. cl.

60 P. No'Llis (H. B. et Kunth, 1. c. p. 137.) leaves canescent beneath, glandular, ovate-cordate at the base, 3-nerved, 3lobed at the apex: lateral lobes very small; petioles glandless, and are, as well as the pedicels, pubescent ; pedicels twin; berries globose, puberulous. $\quad h . \cup$. S. Native of South America, on Mount Quindiu. Flowers not seen.

Soft Passion-flower. Shrub cl.

61 P. puncta'ta (Lin. amon. 1. p. 224. t. 10. f. 12.) leaves glabrous, transversely oval, glandular beneath, 3-nerved at the base, and emarginately cordate, very bluntly 3 -lobed at the apex ; petioles glandless; pedicels solitary, longer than the petioles. h. G. G. Native of Peru. Feuill, per. 2.t. 11. Flowers with whitish petals: and violet rays, tipped with yellow.

Dotted-leaved Passion-flower. Shrub cl.

62 P. BRYonioides (H. B. et Kunth, l. c. p. 140.) leaves hispid, cordate at the base, 5 -nerved, palmately 5-lobed, sharplytoothed ; petioles biglandular at the apex, hairy ; pedicels hairy, twin; berries elliptic, glabrous. $h \cdot \cup . S$. Native of Mexico, near Santa Rosa. Flowers greenisl.

\section{Bryony-like Passion-flower. Shrub cl.}

Sect. VI. Granadílda (Granadilla or Granadille is the French name of some Passion-flowers, so called from the resemblance of the fruit, in size and colour, to a pomegranate, with this difference, that it is not crowned by the calyx). D. C. in mem. soc. gen. 1. pt.2. p. 435. prod. 3. p. 327.-Anthactínia, Bory, ann. gen. 2. p. 138. Involucrum 3-leaved under the flower; leaflets entire or toothed, never jagged. Calyx 10 -lobed; the 5 inner lobes are probably petals. Pedicels 1 -flowered, rising from the same axils as the tendrils, which are simple.

\section{* Leaves entire.}

63 P. serratiòdia (Lin. amcen. 1. p. 217. t. 10. f. 1.) leaves pubescent beneath, ovate-lanceolate, acute, serrulated, feather-nerved; petioles bearing 4 glands, and are, as well as the pedicels, pubescent. $h_{\imath} \cdot \cup$.S. Native of South America. Cav. diss. t. 279. Sims, bot. mag. t. 651. Jacq. hort. schœenb. 1.p. 4. t. 10. Mart. dec. 4. t. 36. Flowers with purple petals, and the filaments of the crown pale purple at the base, and from thence bluish.

San-leaved Passion-flower. Fl. May, Oct. Clt. 1731. Sh. cl.

64 P. Nítida (H. B. et Kunth, l. c. p. 130.) leaves glabrous, oblong-elliptic, acuminated, serrulated, feather-nerved; petioles biglandular. h. . S. Native in woods about the Orinoco. Very nearly allied to the preceding species. Flowers abont the size of those of $P$. ecerulca, with a reddish calyx : crown with blue filaments, ringed with white.

Shining-leaved Passion-flower. Shrub cl.

65 P. guazumeròla (Juss, ann. mus. 6. t. 39, f. 1.) leaves glabrous, ovate-oblong, acuminated, denticulated; petioles biglandular; crown one-half shorter than the calycine lobes. $h_{2}$. $\checkmark$. S. Native of New Granada, in very hot places. Flowers large, witl a whitish calyx.

Guazrma-leaved Passion-flower. Shrub cl.

66 P. coccínea (Aubl. guian. 2. t. \$24.) leaves glabrous, ovate, coarsely toothed, acutish; petioles bearing 4-6 glands ; bracteas ovate, subscrrated, velvety. h. u. S. Native of Guiana, where it is also cultivated; and Maranham, in Brazil. Cav. diss. t. 280. Flowers scarlet, with orange-coloured rays. Fruit full of juicy sweet edible pulp. 
Scarlet-flowered Passion-flower or Granadilla. Fl. June, Nov. Clt. 1820. Shrub el.

67 P. returi'sa (D. C. prod. 3. p. 327.) young leaves pubescent, at length glabrous, cordate, acutish, sinuately Jobed, serrated; petioles biglandular; bracteas glandularly serrated. $\eta$. . S. Native of Brazil. Allied to $P$. coccinca. Flowers perhaps red or scarlet.

I'electy Passion-flower. Shrub cl.

68 P. GLANdulòsa (Cav. diss. t. 281.) leaves glabrous, ovate, coarsely toothed, acutish; petioles biglanclular; bracteas entire, biglandular at the base. $h . \cup$. S. Native of Cayennc. Tacsònia glandulòsa, Spreng. syst. 3. p. 43. Fruit the size of a hen's egor.

Glandular Passion-flower. Shrub cl.

69 P. mocrona'ta (Lam. dict. 3. p. 33.) leaves glabrous, orate-cordate, obtuse, entire; petioles biglandular; stipulas broad-ovate, awned; bracteas oblong, serrate-crenated. $h \cdot \cup . S$. Native of Brazil, at Rio Janeiro. Cav. diss. t. 282.

Mucronate-leaved Passion-flower. Fl. June, Aug. Clt. 1820. Shrub cl.

70 P. MaLifo'rsis (Lin. amœn. 1. p. 220. t. 10. f. 5.) leaves glabrous, ovate, somewhat cordate at the base, acuminated, entire; petioles biglandular; bracteas ovate, acute, joined at the base, larger than the flower. $\eta_{.} \cup \mathrm{S}$. Native of St. Domingo, Porto-Rico, Se. Plum. icon. amer. t. 82. Ker, bot. reg. t. 94. Leaves long and broad. Flowers large, swcet-scented, and beautiful, of various shades; the petals white, and the rays blue; the outer divisions of flowers are red. This species is called the apple-fruited Granadilla or sweet calabasl?. The fruit round, smooth, about 2 inches in diameter, of a dingy yellow-colour when ripe; the coat is laard and stringy, nearly a quarter of an inch in thickness, full of very agreeable gelatinous pale yellow pulp, which is eaten with wine and sugar.

Apple-formed-fruited Passion-flower or Granadilla. Fl. July, Nov. Clt. 173I. Shrub cl.

71 P. trilefòlta (Lin. amœn. 1. p. 219. t. 10. f. 4.) leaves glabrous, cordate, entire, acute ; petioles glandless; stipulas and bracteas entire, oval, acuminated. $\eta$. . G. Native of Peru. Feuil. per. 2. t. 12. Flowers red; rays crimson, with a white line. Fruit globose, variegated with red and yellow, containing a sweet watery pulp. (f. 4.)

Lime - tree - leaved Passionflower or Granadilla. Fl. June. Clt. 1823. Shrub cl.

72 P. serratistipula (Moc. et Sesse, fl. mex. icon. ined. ex D. C. prod. 3. p. 328.) leaves glabrous, cordate, acute, entire; petioles bearing 4 glands; stipulas and bracteas ovatc, acute,

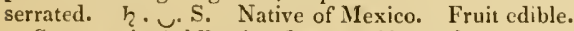

Serratc-stipuled Passion-flower. Shrub el.

73 P. LigUlA'ris (Juss. ann. mus. 6. t. 40.) leaves glabrous, cordate, acuminated, entire; petioles bearing 4-6 cylindrical glands; stipulas ovate-lanceolate, acuminated ; bracteas ovate, entire. $\quad h . \cup . S$. Native of Peru. Flowers party-coloured.

Var. $\beta$, geminiftòra (D. C. prod. 3. p. 3ュ8.) pedicels twin. Native of Caraccas.

Ligular-stipuled Passion-flower. Fl. Sept. Clt. 1819. Sh. cl.

74 P. QUadrangtea'ris (Lin. spec. 1356.) leaves glabrous, cordate at the base, ovate, acuminated; petioles bearing 4-6 glands ; stipulas orate, and are, as well as the bracteas, entire; branches tetragonally winged. $k \cdot \cup$. S. Native of Jamaica and Soutls America, Kcr, bot. reg. t. 14.-Jacq. amer. t. 143. pict. 218. Flowers highly odoriferous; calycinc lobes white within; petals of the same shape, red within, and white outside. Crown 5 -fold; outer rays in a double row, longer than the petals, round, white, and variegated with violet. The common granadilla or gronadilla vine bears large fruit, of an oblong shape, about 6 inehes in diameter, and 15 inches in circumference. It is externally of a greenish yellow, when ripe soft and leathery to the touch, and quite smooth; the rind is very thick, and contains a succulent pulp of a purple colonr, which is the edible part. Wine and sugar are commonly adled to it. The flavour is sweet and slightly acid, and is very grateful to the taste, and cooling in a hot climate. It has been successfully cultivated for its fruit in a few places in this country.

Iar. $\beta$, sulcùta (D. C. prod. 3. p. 328.) fruit furrowed transversely.

Cultivation of Granadilla ( $P$. quadrangulàris). Mr. Miteheson keeps a plant in a box 18 inches square, fixed on a level with the curb in one corner of a tan-pit. The sides of the box are perforated, to admit the roots to run among the tan, and the shoots are trained like vines, under the rafters. In autumn the shoots are pruned back to within two or three eyes of the old wood; and in March following, or just before the plant begins to break, it is taken out of the box, the root and ball reduced, and repotted in fresh compost. Abundance of water in the flowering season enables the plant to set its fruit without artificial impregnation. A strong plant will produce 40 fruits in a season in regular succession, from the end of June till Christmas. Half that number will grow to a larger size. Gard. mag. 2. p. 203. The Pass. laurifólia and Pass. edulis may be cultivated in the same way for their fruit.

Quadrangular-stemmed Passion-flower or Granadilla. Fl. Aug. Sept. Clt. 1768. Shrub cl.

75 P. Maunitia'sa (Pet. Th. ann. mus. 6. p. 65.) leaves glabrous, cordate at the base, ovate, acuminated; petioles bearing 4-6 glands; bracteas lanceolate, acuminated, denticulated. h. .. S. Native of the Mauritius.

Mauritian Passion-flower. Shrub cl.

76 P. ALA'ta (Ait. hort. kew. 3. p. 306.) leaves glabrous, somewhat cordate, ovate, acute; petioles bearing 4 glands; stipulas lanceolately falcate, somewhat serrated; pedicels terete; branches tetragonally winged; bracteas a little toothed. $\eta_{\imath} . \cup . S$. Native of Peru. Sims, bot. mag. t. 66. Sowerby in Lin. trans. 2. p. 23. t. 3. t. 6. Flowers very sweet-scented, the upper side of the calyx and petals decp crimson; rays variegated with purple, white, and crimson.

IIInged-stemmed Passion-flower. Fl. April, Aug. Clt. 1772. Slirub cl.

77 P. latifòlia (D. C. prod. 3. p. 328.) leaves glabrous, broadly cordate, acuminated; lateral nerves approximate at the middle of the base; petioles glandular; stipulas and bracteas oval-oblong, entire; branches terete. $々 . \cup$. S. Natire of Peru. Flowers pale red.

Broad-leaved Passion-flower. Shrub cl.

78 P. A'LBIDA (Ker, bot. reg. 677.) leaves glabrous, roundishcordate, entire; petioles biglandular in the middle; stipulas ovate-lanceolate, setosely apiculated; bracteas approximating the flowers, soon falling off; pedicels twice the length of the leaves. $\quad$. . . S. Native of Brazil, near Rio Janeiro. Flowers white, not pale red as in the preceding. Cohunn inclined. Stamens secund. Crown yellowish.

tih hitish-flowered Passion-flower. Fl. Aug, Sept. Clt, 1 S16. Shrub el.

79 P. orna'ta (H. B. et Kunth, nov. gen. amer. 2. p. 129.) leaves glabrous, ovate•elliptic, acute, crenulated; petioles bi$11 \stackrel{2}{2}$ 
glandular; axils glandular; bracteas ovate, large, entire. $h$. $\checkmark$. S. Native of New Granada, in temperate places. Flowers whitish, with blue rays mingled with wlite.

Plumed Passion-Hower. Shrub cl.

80 P. Lo'Ngipes (Juss. ann. mus. 6. t. 33. f. 1.) leaves glabrous, oval-lanceolate, somewhat cordate at the base, entire; petioles biglandular at the apex; stipulas and bracteas lanceolate; pedicels twice the length of the leaves. $h \cdot \cup$. S. Native of New Granada, on Mount Quindiu. Flowers about the size of those of $P$. ccerulca, pale red.

Long-stalked Passion-flower. Shrub cl.

81 P. Laurifòla (Lin. 1. c. p. 220, t. 10. f. 6.) leares glabrous, ovate.oblong, entire; petioles biglanilular at the apex; stipulas setaceous, lengtl of petioles; bracteas obovate, glandularly serrated at the apex. $h_{\text {. }} \cup$. S. Native of the West India Islands and South America. Plum, amer, t. S0. Ker, bot. reg. t. 13. Jacq. liort. schœnbr. 2. t. 162. amer. pict. 2. t. 219. Sowerby in Lin. trans. 2. t. 4. f. c. Marquiaas, Merian. sur. t. 21. The French call it fomme de lianc, and the English honcysuckle: but in most parts of South America the fruit is known by the name of murucuja or granatilla; for which the plant is cultivated almost throughout South America, the fruit being agreeable to most palates. The $P$. laurifolia is called also natcr-lemcn. The flowers are red and violet and sweet-scented; the fruit about the size of a hen's-egg, but rather more elongated, and tapering equally at both ends; when ripe it is yellow, and dotted over with white spots. It contains a whitish watery pulp, which in the West Indies is usually sucked throu h a small hole made in the rind, which is tough, soft, and thin: the juice has a peculiar aromatic flavour, is delicately acid, and allays thirst agreeably.

Laurel-leared Passion-flower or Granadilla. Fl. June, July. Clt. 1690. Shrub cl.

82 P. rivifòtia (Juss. 1. c. t. 41, f. 2.) leaves glabrous, oblong, entire; petioles biglandular in the middle; stipulas setaceous; bracteas oblong, hardly crenated. h.u. S. Native of Cayenne, and about Essequibo. Very like P. laurifólia.

Tinus-leaved Passion-flower. Fl. July. Clt. 1824. Sh. cl.

S3 P. Acumna'ta (D. C. prod. 3. p. 328.) leaves glabrous, ovate-lanceolate, acuminated, entire; petioles biglandular at the apex; bracteas oblong, obtuse, entire. $\zeta$.. S. Native of Brazil.

Acuminated-leaved Passion-flower. Shrub cl.

* Leaves lobed, parted, or cul to the basc.

84 P. indeco'ra (H. B. et Kunth, l. c. p. 131.) leaves puberulous beneath, rather glandular, semi-orbicular, lunate, subcordate; lobes ovate, divaricate; petioles glandless, pubescent ; stipulas linear, pubescent ; bracteas ovate. $\eta$. S. Native of New Granada, in temperate places. Perhaps belonging to the section Dccáloba.

Indecorous Passion-Hower. Shrub cl.

85 P. ruicuétla (H. B. et Kunth, l. c.) leaves glabrous, somewhat glandular, semiorbicular, truncately 2 or 3-lobed ; petioles glandless; stipulas linear-subulate; bracteas oblong, large, entire. $\quad h . \cup$. S. Native of South America, in the province of Caraccas. Flowers white, with yellow rays ringed with blue.

Neat Passion-flower. Shrul, cl.

86 P. RAcemòsA (Brot. in Lin. trans. 12. t. 6.) leaves quite glabrous, rather peltate, glaucous beneath, for the most part 3 -lobed; petioles usually bearing 4 glands; pedicels twin, forming terminal racemes, in consequence of the upper leaves being abortive. $\quad$.u. S. Native of Brazil. Sims, bot. mag. 2001 . P. prínceps, Lodd. bot. cab. t. 84. Flowers of a deep red or scarlet colour. Racemes pendulous. There is a variety having the outer ray of the crown white.

Racemose Passion-flower. Fl. Mar. Oct. Clt. 1815, Sh. cl.

87 P. sanguínea (Colla. mem. acad. taur. ined. hort. ripul. append. t. 6.) leaves glabrous, cordate, glaucous beneath, 3-5parted; lobes oblong, entire; petioles bearing 4 glands; stipulas auriculately fajcate, apjiculated, somewhat serrated: pedicels axillary, solitary, I-flowered. $\zeta \cdot \cup$. S. Native country unknown. Probably a hybrid between $P$, racemòsa and $P$. alàta. Flow ers large, of a deep, scarlet or blood-red colour.

Blood-coloured-flowered Passion-flower. Fl. Ju. Oct. Clt.? Shrub cl.

88 P. carvileo-racemòsa (Sab. in hort. trans. 4. p. 758. t. 9.) leaves quite glabrous, rather coriaceous, 3-5-lobed; lobes undulated, somewhat toothed at the base; petioles bearing 4 glands; pedicels axillary, solitary, 1-flowered. 々. ๖. S. A hybrid raised from the seed of $P$. racemosa, impregnated by the pollen of $P$.ccerilea. Like the male parent, it will live throughout the winter in the open ground, with a little protection in severe weather. Lodd. bot. cab. t. 573. Flowers purple.

Blue-racemose Passion-flower. Fl. June, Oct. Hybrid 1820. Shrub cl.

89 P. Ala'to-ceru'LeA (Lindl, bot. reg. t. 848.) leaves glabrous, cordate, 3 -lobed; lobes quite entire, ovate-lanceolate; petioles bearing $2-4$ glands; stipulas auriculated, acuminately apiculated, entire; pedicels terete, much longer than the petioles; branclies quadrangular. $h_{\text {. }} \cup$. S. A hybrid, raised from the seeds of $P$. alcita, impregnated by the pollen of $P$. ccerulca. Lobes of ealyx rose-coloured on the outside. Petals white inside. Crown triple; outer filamentous appendages variegated with black, blue, and white.

Hinged-blue Passion-flower. Fl. June, Oct. Hybrid 1823. Shrub cl.

90 P. stipula'ta (Aubl. guian. 2. p. 325.) leaves glabrous, glaucous beneath, cordate at the base, 5 -nerved, trifid; lobes ovate, entire; petioles bearing 2-4 glands; stipulas oblong, somewhat auricled, mucronate, and are as well as the bracteas entire; peduncles about equal in length to the petioles. $\zeta . \cup . S$. Native of Cayenne and Brazil ; and of Mexico, near Jalapa. P. glaúca, Ker. bot. rey. t. 88 . but not of Humb. Flowers whitish ; crown variegated with purple and white.

Stipulate Passion-flower. Fl. Aug. Sept. Clt. 1779. Sh.cl.

91 P. RADDiA'Na (D. C. prod. 3. p. 329.) leaves glabrous, somewhat cordate at the base, 5-nerved, trifid; lobes ovate, glandularly subserrated at the base; petioles bearing 2 glands in the middle; stipulas ovate, dimidiate, awned; peduncles 4times longer than the petioles. $\zeta$. $\cup$. S. Native of Brazil, where it was detected by Raddi.

Raddi's Passion-flower. Shrub cl.

92 P. A'LBA (Link. et Otto. abhl. t. 33.) leaves glabrous, ghaucescent beneath, somewhat cordate at the base, 5-nerved, S-lobed; lobes oval, somewhat glandularly serrated at the base ; petioles biglandular in the middle; stipulas cordate; superior peduncles longer than the petioles. $h . \cup . S$. Native of Brazil. Flowers white. Very nearly allied to P. Raddiùna.

White-flowered Passion-flower. Shrub el.

93 P. seta'ceA (D. C. l. c.) leaves velvety beneath, 3-nerved at the base, somewhat corlate, trifid; lobes ovate-oblong, acute, serrulated; petioles velvety, biglandular at the base; bracteas ovate, acuminated, ciliately serrated. $\eta_{\text {. }}$. S. Native of Brazil, near Rio Janeiro.

Setaceous-bractead Passion-flower. Shrub el.

94 P. menispernifòlia (H. B. et Kunth, nov, gen. amer. 2. p. 137.) leares hairy beneath, pubescent above, roundish-cordate, angularly 3-lobed, sliarply toothed; petioles hairy, usually bearing 4 glands; stipulas large, dimidiately subcordate, awned, 
hence toothed on one side. $\boldsymbol{h} . \mathbf{S}$. Native of Soutl America, near Jaen de Bracamorns. Flowers unknown.

Moon-seed-leaved Passion-flower. Slurul cl.

9j P. stapelta'ta (Ort. dec. 6. p. 7S.) lcaves glabrous, cordate, 3-lobed; lobes serrated: middle lobe more extended than the side ones; petioles bearing $2-4$ glands in the mildle; stipulas semi-cordate, mucronate; bracteas cordate. Native of New Spain.

Subpeltate-leaved Passion-flower. Shrub el.

96 P. Puxícea (liuiz et Pav. ined. ex D. C. prod. 3. p. 329.) leaves velvety beneath, rather scabrous above, 5 .nerved, broadly subcordate, trifid; lobes sharply serrated, acute; petioles velvety, glandless; stipulas setaceous; bracteas oval, serrated. h. S. S. Native of Soutl America, probably of Peru. Flowers scarlet. Agreeing in habit with Taesonia.

Scarlet-flowered Passion-flower. Slirub el.

97 P. 1xcarna'ta (Lin. amcen. 1. p. 230. t. 10. f. 19.a.e.) leaves glabrous, somewhat cuneated at the base, 5 -ncrved, deeply trifid; lobes lanceolate, serrated; petioles biglandular at the apex; stipulas small; bracteas glandularly serrated; ovarium villous. h. u. G. Native of South America and Virginia. Ald. hort, farn. t. 50, 52, 5s. Mor. ox. 2. p. 6. sect. 1. t. 1. f. 9. Calycine lobes pale green. Petals wlite; crown with a double circle of purple rays. The Flesh-eoloured Granalilla, or May-apple, is a perennial, sending up annually a number of lierbaceous shoots. 'The flowers are sweet-scented, variegated with purple. The fruit, when ripe, is about the size of an apple, orange-coloured, with a sweetish yellow pulp.

I'ar. 3 , integriloba (D. C. prod. 3. p. 329.) lobes of leaves entire. Ker. bot. reg. t. 332. P. Kèrii, Spreng. syst. 3. p. 39. Flowers pink.

Flesh-coloured-florrered Passion-flower or Granadilla. Fl. July, Aug. Clt. 1629 . Pl. el.

98 P. EDu'LIs (Sims, bot. mag. t. 19S9.) leaves glabrous, 3lobed, serrated; petioles biglandular at the apex; bracteas glandularly scrrated; crown about equal in length to the calycine lobes; ovarium glabrous. $\zeta . \cup . S$. Native of Brazil. Flowers whitish. Fruit purple, edible. Purple-fruiting Passiflòra, Sab. in hort. trans. 3. p. 99. t. 3. Purple-fruited Granadilla, Sab. The flowers are fragrant, of a white colour tinged with purple. The fruit changes to a dark livid purple on becoming ripe, and much resembles the fruit of the purple eggplant. The shape is elliptic, an inch and a half in diameter, and 2 inches from the stalk to the top; the pulp is orange-coloured, and the seeds numerous; the taste acid, and the flavour somewhat like that of an orange. It produces fruit abundantly in stoves.

Edible-fruited Passion-flower or Granadilla. Fl. July, Aug. Clt.? Shrub el.

99 P. serrula'ta (Jacq. obs. 2. t. 46. f. 2.) leaves glabrous, 3-lobed, finely serrulated; lobes oblong, midele one the longest ; petioles biglandular in the middle; bracteas entire. h. Native of South America, in the woods of Carthagena. Flowers variegated with crimson and white, sweet-scented, $2 \frac{1}{2}$ inches wide. Serrulated-leaved Passion-flower. Shrub cl.

100 P. cuserfòlia (Cav. diss. 10. t. 292.) leaves glabrous, 3-lobed, serrated; lobes ovate, acuminated: petioles biglandular; bracteas large, ovate, entire; crown 3 times longer than the ealyx. h. S. Native of South America.

Wedge-leaved Passion-flower. Fl. Jul. Aug. Clt. 1825. Sh.cl.

101 P. Trílona (Ruiz et Pav. ined. ex D. C. prod. 3. p. 330.) leaves glabrous, cordate, 3-lobed; lobes ovate-roundish, obtuse, somew hat denticulated; petioles biglandular at the apex; stipulas ovate-cordate, denticulated; bracteas large, ovate, mucronate. $h . \cup$. S. Native of Peru.

Three-lobed-leaved Passion-flower. Slirub cl.
10尺 P. vitifòisa (H. B. et Kunth, nov. gen. amer. 2. p. 138.) leaves downy beneatl, cordate, deeply 3-lobed; lobes ovate, acuminated, sharply toothed, with the sinuses biglandular; petioles biglandular at the base, pubescent; bracteas glandularly toothed. $h_{\text {. }}$. S. Native of South America, on the banks of the rivers Maurdalena and Cassiquiares. Flowers yellowish; outer crown orange-coloured; inner crown white.

Vine-leaved Passion-flower. Clt. 1823. Shrub cl.

103 P. pulòsa (Ruiz et Pav. ined. ex D. C. prod. 3. p. 330.) plant hispid from rigid hairs; leaves cuneated at the base and cordate, 3-lobed; lobes coarsely toothed, ovate-lanceolate; petioles biglandular; stipulas ovate-cordate; bracteas oblong, ciliated. $h$. u.S. Native of Mexico. (v. s. in herb. Lamb.)

\section{Pilose Passion-flower. Slurub cl.}

104 P. adexópoda (Moc. et Sesse, fi. mex. icon. ined. ex D. C. prod. 3. p. 330.) leaves glabrous, cordate at the base, 5 nerved, 5-lobed; lobes ovate, acuminated, somewhat serrated ; petioles bearing 2 pedicellate glands; bracteas dceply serrated. h. $\checkmark$. S. Native of Mexico.

Stalleed-glanded Passion-flower. Shrub cl.

105 P. Filanentosa (Cav, diss. 10. t. 291.) leaves glabrous, 5 -parted, serrated; petioles biglandular in the middle; bracteas serrated; crown longer than the calyx or nearly equal to it. h. . S. Native of South America. Sims, bot. mag. 2023. Flowers with whitish petals and blue crown, coloured very like those of $P$. ecerulea.

Filamentous Passion-flower. Fl. Ju. Oct. Clt. 1817. Slı. cl,

106 P. PAlMa'ta (Lod. bot. cab. no. 97. Link, enum. 2. p. 183.) leaves glabrous, palmately 5-parted, somewhat serrulated; serratures glandular; crown a little shorter than the calyx. h. U. S. Native of Brazil. P. filamentòsa $\beta$, Ker. bot. reg. 584. Flowers the size of those of the following species, bluish ; crown variegated with blue, purple, and white.

Palmate-leaved Passion-flower. Fl. Ju. Oct. Clt. 1817. Sh. cl.

107 P. corv'lea (Lin. amon. 1. p. 23I. t. 10. f. 20.) leaves glabrous, j-parted; lobes oblong, quite entire; petioles bearing 4 glands at the apex; stipulas falcate; bracteas orate, entire; crown shorter than the calyx. $5 . \checkmark s$. Native of Brazil and Peru. Curt. bot. mag. t. 28. Herb. amat. t. 102. Sowerby in Lin. trans. 2. p. 25. t. 4. f. 4 . Calycine segments pale grcenish ishite; the petals are nearly of the same shape and size. Styles purplish. Rays of the crown in two circles, purple at bottom, white in the middle, and blue at the ends. Fruit egg-shaped, size of a Mogul plum, yellow when ripe. The flowers have a fuint scent, and continue but one day, like many other species of this genus. This is the only kind which can be considered truly hardy.

I ar. $\beta$, angustif òlia; lobes of leares narrow ; plant flowering later than the species. A hybrid.

I'ar. $\gamma$, glaucophílla; leaves glaucous beneath.

I'ar. $\hat{c}$, Colcillei (Sweet, fl. gard. t. 126.) lobes of leaves oblong-lanceolate, serrulated; petioles biglandular at the apex; stipulas rather lunate, serrulately ciliated; bracteas ovate, obtuse, scrrulated; threads of crown rather shorter thau the corolla. Һ. H. A hybrid. Flowers whitish; petals tinged with blue; outer crown variegated with purple, white, and blue.

Blue-flowered or Common Passion-flower. Fl. June, Oct. Clt. 1699. Shrub cl.

los P. serra'ta (Lin. amon. 1. p. 232. t. 10. f. 21.) leaves glabrous, 7-parted, 7-nerved; lobes serrated ; petioles bearing 4 glands; bracteas joined to the middle, acnte, entire. $r . \cup . S$. Native of Martinico. Plum. amer. 1. 79. Petals violet-coloured. Crown variegated wilh purple, violet and white.

Yar. $\beta$, digitàla (liuiz ct lav. ined. ex herb. Lamb. D. C. prod. 3. p. 330 .) lobes of leaves hardly serrated. $5 . \cup . S$. Native of Peru. 
Serratcd-leaved Passion-flower. Clt. $1800 . \quad$ Shrub cl.

109 P. Loureíril; leaves glabrous, 5-parted; lobes quite entire; petioles biglandular. h. . F. Native of China and Cachin-china. P. coerùlea, Lour. coch. p. 527. but not of Lin. P. Chinénsis, Sweet? Flowers greenish yellow, with a blue crown.

Lourciro's Passion-flower. Fl. Ju. Oct. Clt. ? Shrub cl.

110 P. PEDA'TA (Lin. amoen. 1. p. 233. t. 10. f. 22.) leaves pedate, in consequence of the petiole being branched at the top; petiole biglandular; segments of leaves oval, acuminated, serrated; bracteas dentately fringed. $h_{\text {. }}$. S. Native of St. Domingo and Trinidad. Plum, amer. t. 81. Calycine segments pale green, with abundance of little red spots on the upper surface. Petals or inner calycine segments blue. The rays of the crown are very close, decp red, with 2 or 3 white rings, very slender, violet at the ends; they are twisted so as to resemble the serpents about Medusa's head. Fruit the size of a middling apple, green, and dotted.

Pedatc-leaved Passion-flower. Clt. 1781. Shrub cl.

Sect. VII. Tacsonioides (plants resembling Tacsònia in habit). D. C. prod. 3. p. 330. Tube of calyx rather elongated, nevertheless much shorter than the limb. The rest as in section Granadilla. Leaves 3-lobed, with the recesses and petioles glandular. An intermediate section between the genus Papiflòra and Tacsònia.

111 P. REFLEXIflòra (Cav, icon. 5. t. 425.) glabrous; leaves subpeltate, 3 -lobed; lobes obtuse, quite entire, recesses and petioles bearing 6 glands; calycine lobes reflexed; crown very short or almost wanting. $\quad h . \cup$. S. Native of Panamaide, and near Bodegas, in South America. Tacsònia reflexiflòra, Juss. ann. mus. 6. p. 393. Flowers scarlet.

Reflexcd-flowered Passion-flower. Slarub cl.

112 P. pictura'ta (Ker. bot. reg. t. 673.) glabrous; leaves subpeltate, reddish beneath, 3-lobed; lobes quite entire, mucronate by a bristle; recesses and petioles bearing 4 glands; calycine Jobes reflexed, twice the length of the filamentous crown. $\quad$. . S. Native of Brazil. P. picturàta, Lodd. bot. cab. t. 1050. differs in the lobes of the leaves being glandless. Flowers red; onter crown beautifully variegated with blue and white.

Painted-leaved Passion-flower. Fl. Sept. Clt. 1820. Sh.cl.

SEct. VIII. Drsósmia (from covowins, dysodes, fetid, and $o \sigma \mu \eta$, osme, a smell; the species contained in this section have a bad smell). D. C. in mem. soc. gen. 1. pt. 2. p. 436. prod. 3. p. 33I. Involucrum 3-leaved, under the flower; leaflets divided into many setaceous lobes, which are tipped with glands. Calyx 10-lobed, or the 5 inner ones are petals. Pedicels solitary. Fruit subcapsular.--Perhaps this scetion will form a proper genus.

118 P. Inibiscifòlia (Lam. dict.3. p. 39.) stem, petioles, and leaves clothed with soft velvety down on both surfaces; leaves truncatc at the base, 5 -nerved, trifid; lobes ovate-acuminated, somewhat dentate. $I_{2} \cup$. S. Native of the West India Islands. P. fo'tida, var. a, Lin. amon. 1. p. 228. t. 10. f. 17. Plum. amer. t. S6. P. gossypif òlia, Desv. in IIam. prod. p. 48.?Giseck, icon. fasc. 1. t. 20. Flowers whitish. Plant fetid when bruised.

Ilibiscus-lcaved Passion-flower. Fl. July, Aug. Clt. 1731. Shrub cl.

114 P. FE'TIDA (Cav. diss. 10. t. 289.) stems and petioles hispid; leaves villous on both surfaces, 5-nerved, cordate at the base, 3-lobed; lobes nearly entire, lateral ones very short, middle one acuminated. $\delta$. or 4 . $\checkmark$. S. Native of the Caribbee Islands and Soutl America. Sims, bot. mag. 2619. Ker. bot. reg. 321. P. foétida, var. $\beta$, Lin. amœn. P. variegàta, Mill. P. hirsùta, Lodd. bot. cab. 138. P. hircina, Sweet, hort brit. Flowers whitish; crown variegated with purple and blue. Plant fetid when bruised.

Fetid Passion-flower. Fl. Mlay, Oct. Clt. 1731. PI. cl.

115 P. AcERifòlia (Schlecht. et Cham. in Linnæa. 5. p. 89.) the whole plant scabrous from hairs; leaves deeply cordate, pedately $5-7$-nerved, cuneated within the recesses, 5 and sometimes 7-lobed; paler and glandless beneath; lobes acuminated, subserrated; teeth mucronate; petioles biglandular at the apex; glands stipitate, recurved at the apex; stipulas semiorbicular, simmately toothed; teeth subulate; peduncles twin, involucrated in the middle; involucrum multifidly jagged, hardly glandular. $h . \cup$ S. Native of Mexico, in woods near Jalapa. Flowers a little larger than those of $P$. $f e^{\prime}$ tida.

Sycamore-lcaved Passion-flower. Slirub cl.

116 P. cilia'ta (Ait. hort, kew. 3. p. 310.) stem glabrous; petioles rather pilose; leaves glabrous, somewhat 5 -nerved, cordate at the base, trifid; lobes acuminated, ciliated. $\psi \cdot \mathcal{} . \mathrm{S}$. Native of Jamaica. Curt. bot. mag. t. 288. Petals greenish on the outside and red within. Rays of crown variegated with white and purple. Stipe of ovarium deep purple, with darker spots.

Ciliated-leaved Passion-flower. Fl. Jul. Sept. Clt. 1783. Pl. cl. + Specics not sufficiently known.

\section{* Leaves entire.}

117 P. appendicula'ta (Meyer, esseq. p. 223.) leaves glabrous, glandular beneath, 3-nerved, rounded from the base, oblong, mucronate; petioles biglandular, puberulous; pedicels twin, shorter than the petioles; involuerum wanting. $h . \cup . S$. Native of Guiana, in shady sandy places. Perhaps belonging to either section Cièca or Dccáloba. Flowers yellow.

Appendiculated Passion-flower. Slurub cl.

118 P. cyatnópnora (Desv. in Ham. prod. p. 48.) leaves oblong-lanccolate, undivirled, undulated and narrowed in the middle, mucronulate, 3-nerved, subcordate at the base, quite glabrous above and nerved, glaucescent beneath; petioles biglandular ; glands large, lateral, hollow, cup-shaped, usually twin; involucrum wanting. $h \cup$. S. Native of Guiana. Perhaps belonging to section Cièca or Decáloba.

Cup-bearing Passion-flower. Shrub cl.

119 P. PYrifónmis (D. C. prod. 3. p. 331.) leaves glabrous, ovate, acuminated, feather-nerved; petioles biglandular; pedicels solitary; fruit pear-shaped. $h \cdot \smile$ S. Native of Brazil.

Pear-shaped-frnited Passion-flower. Shrub cl.

120 P. LANCEOLA'Ta (Desv. l. c.) branclies compressed, angular, ciliated with down; leaves lanceolate, acute, mucronulate, rounded at the base, with the sides subauricled, pilose on both surfaces, quite entire; petioles biglandular; pedicels twin, capillary; fruit on a long pedicel. $\eta_{2}, u$. S. Native of the Antilles. Flowers scarlet. The rest unknown.

Lanceolate-leaved Passion-flower. Shrub cl.

121 P. Tetrade'na (D. C. prod. 3. p. 331.) leaves ovate, quite entire? petioles bearing 4 glands; bracteas toothed; stem tetragonal, membranous. $\quad h . \cup$. S. Native of Brazil. Vand. f. lus, et bras. in Roem. script. 148. Perhaps $P$. alàta or $P$. quadranguiàris.

Four-glanded Passion-flower. Shrub cl.

122 P. Tneobrontália (D. C. prod. 4. p. 331.) stems erect; leaves cordate, ovate, acuninated, mequally serrated, rather puberulous; calyx double; petals? spatulate. h.S. Native country unknown. Flowered in the Botanic Garden at Schoenbrun. P. guazumaf òlia, Jaeq. fragm. p. 13. but not of Juss. This plant perliaps belongs to a different genus, not belonging to this order. 
Cacao-lcated Passion-flower. Shrub 4 to 6 feet.

123 P. Cocun-cunne'xsis (Spreng. syst. apl? p. 346.) leaves opposite, glabrous, ovate, Individed, quite entire; petioles biglandular ; flowers axillary, $t$ win, 5 -eleft ; berry ovate. $h \cdot \cup . G$. Native of Cochin-china, among bushes. P. pállida, Lour. coch. 1. 527. This species diflers from all the other Passifloras in the opposite leaves; it is perhaps therefore a species of $\mathrm{Mal}$ pighia. Flowers large, pale.

Cochin-china Passion-flower. Shrub cl.

124 P. Sicoaforia'na (Wall. cat. no. 1232.) leaves glabrous, oblong; the rest of the plant unknown. h.u. S. Native of Singapore, in the East Indies. Like $P$. laurifolia.

Singapore Passion-flower. Shrub cl.

125 P. ['Enangu'na (Wal]. cat. no. 1239.) leaves ovate-oblong, entire, acuminated; tendrils trifid. $h . \cup$. S. Native of Penang. Flowers unknown.

Penang Passion-flower. Slirub cl.

\section{* Lcaves 2-lobcl.}

126 P. LUna'ta (Juss. herb. ex D. C. prod. 3. p. 331.) leaves rather downy beneath, glandular, 3-nerved, ovate at the base, lunately truncate at the apex; nerves ending each in a bristle; petioles glandless; pedicels twin; bracteas linear. $h . \cup . S$. Native of Peru. Perhaps belonging to the section Cieca or Decalcba.

Moon-shaped-leaved Passion-flower. Shrub cl.

127 P. contraye'rva (Smith, in Rees' cyel. no. 23.) leaves glabrous, deeply 2-lobed; lobes oblong, obtuse, hardly diverging; calyx mujtifid. b. ᄂ. S. Native of Mexico.-Hern. mex. p. S01. lower figure. Allied to P. Mexicàna and P. Dictàmo, but differs from them in the flowers being multifid, not 5.cleft. The root is famous for its medicinal virtues, being sweetish with some pungency and fragrance, and is considered a powerful counterpoison, deobstruent, cordial, \&c.

Contrayerva Passion-flower. Shrub cl.

128 P. cuneA'ta (Willd. enum. p. 696.) leaves glabrous, glandular beneath, cuneated at the base, somewhat 2-lobed at the apex, with a mucrone between the lobes ; petioles glandless; pedicels twin; calyx 10-eleft, the 5 inner divisions are called petals. $\zeta$. S. Native of Caraccas. Perlaps belonging to section Dccáloba or section Granadilla.

Cuneate-leaved Passion-flower. Fl. Ju. Aug. Clt.? Sh.cl. 129 P. Bicórnis (Mill. dict. no. 13.) leaves glabrous, stiff, 2-lobed; pedicels long, horizontal; fruit oval. h.u.S. Natire of Soutb America, at Carthagena. Flowers small, white.

Tno-horned-leaved Passion-flower. Shrub c].

130 P. érpea'ta (Smith, in Rees' cycl. no. 20.) leaves peltate, glandular beneath, 5-7-nerved, reticulately veined, 2-lobed, furnished with a mucrone between the lobes; petioles bearing 2 or 4 glands. $h$. . S. Native of New Granada. Flowers unknown. Buckler-leaved Passion-flower. Shrub cl.

$$
\text { * Leaves 3-lobcd. }
$$

131 P. cephaleima (Bory, ann. gen. 2. p. 152. t. 22. f. 2.) leaves glabrous, rather glandular beneath, somewhat 8 -lobed, emarginate at the base ; lobes divarieate, linear, obtuse, rounded; petioles very short, biglandular beneatl the middle. $\zeta \cdot \cup$. S. Native country unknown, and has never flowered in the gardens of Europe.

Headcd-flowered Passion-flower. Clt. 1826. Shrub cl.

132 P. multifórmis (Jacq. fragm, no, 169. t. 67. f. 1.) leaves glabrous, wrinkled beneath, cordate at the base, simple, 2 or 8 lobed, acuminated, very minutely serrated ; petioles biglandular. h. S. Native of South America, at Caraccas. Willd. enum. 697. Flowers unknown. The plant agrees with $P$. incarnita in the shape of the leaves.

Many-formed l'assion-flower. Clt. 1820. Sbrub cl.
133 P. Heteropay'Lla (Lam. dict. 3. p. 41.) leaves glabrous, acute, lower ones lanceolate, nearly sessile : middle ones on short petioles, 3-parted: "1]per ones pedate, in consequence of the petiole being branclied at the apex; tendrils wanting; pedicels solitary, without an involucrum; calyx 10 -lobed, or the 5 inner lobes, so called, are petals. h. S. Native of St. Domingo. Plum. ed. Burm. t. 199. f. 1. Perlaps belonging to section Dccáloba or section Astròphca? Flowers yellowish.

Fariable-leaved Passion-flower. Clt.1817. Slirub el.

194 P. Hermánni (D. C. prod. 3. p. 392.) leaves velvety, 3-lobed; involucrum small, of 3 entire leaflets; calyx 10 -

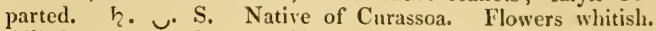
Allied on one hand to $P$. hirsuita and on the other to $P$. hibiscifolia.

Hermann's Passion-flower. Shrub cl.

135 P.? tubiflòra (H. B. et Kuntl, nov, gen. amer. 2. p. 139.) leaves glabrous, coriaceous, rounded at the base, 3-lobed; lobes oblong-lanceolate, equal, entire; petioles biglandular in the middle; pedicels twin; tube of calyx about equal in length to the 5 lobes of the limb. $h .$. S. Native of Mexico, in arid places near Acapulco and Etambo del Egido. Probably a species of Tacsònia. Flowers with a greenish calyx.

Tube-flowered Passion-flower. Shrub el.

Cult. All the species of this elegant and curious genus, are well suited for elimbers in eonservatories and stoves, being free growers and of easy culture. They thrive well in very light rich soil, and the more room they are allowed, both for roots and stems, the freer they wil] grow and flower. They are all easily raised from cuttings planted in sand or mould, placed in heat; and the younger the cuttings are, the sooner they will strike root. Most of the species ripen fruit in our stoves, and consequently many fine varieties have been raised by impregnating the stigmas of one with the pollen of another. Several hybrids, raised from seeds set by the pollen of $P$. ccerulea are nearly hardy. Several of the species are marked greenhouse, in which they will grow and flower freely. Passiftora coerulea is the only species that can be considered quite hardy, and it requires a sheltered situation; it is therefore safest to plant against a wall, that it may be protected by a mat in severe weather : it thrives well in any soil, and cuttings of it are readily rooted, under a hand-glass.

Culture of the edible species of Granadilla.-All the species will fruit even in large pots; but it is best to plant them in an angle of a stove, which has been parted off, either by boards or brick-work, as low as the pit goes. At the bot tom of the cavity formed by this division, should be laid some brick rubbish, over which may be thrown a little dead tan, and the whole be then filled with equal parts of very old tan, and a compost of leaf-mould and rotten dung; therein the roots will strike freely, and will even spread through the partition into the pit. They do not require the full beat of a pine-stove, for they flourish best in a temperature of from $65^{\circ}$ to $70^{\circ}$; but they will not bring their fruit to perfection if kept in a common greenhouse or conservatory, though they will grow and flower in it. The shoots as they advance may be trained near to and under the inclined glass of the stove; the first flowers will appear in May, and the blooming will continte until September, the fruit setting the whole time; but if it does not set well it will be adviseable to impregnate the stigmas, by applying the pollen with a feather. $\Delta$ s tlscy grow, the very strong shoots should be cut out from their origin; for these do not bear fruit so abundantly as those which are less vigorous; but the fruiting-branclies must not be slortened on any account. The temperature must bc kept up cqually during the time of flowering and fruiting; the crop will begin to come in August, and will continue until January, but the carlier produce is the best. When the crop is all off, which will be early in January, 
the heat must be reduced to about $50^{\circ}$, so as to check and stop the growth. This being effected, the shoots must be well cut in. As little old wood as possible, besides the main stem, which rises from the pit to the glass, and a few pieces (about 2 or 3 feet of each) of the old branches should be retained; for all that is to be trained under the glass to bear in each year, ought to be the growth of the same scason. It is found that the shoots break better and in greater quantity from the older wood than from that of two years' standing. In this dormant and reduced state it is to be kept during January and February, after which the necessary lieat may be applied to cause it to resume its functions for the ensuing season.

IV. DISE'MMA (from is, dis, two, and $\sigma \tau \varepsilon \mu \mu a$, stemma, a crown; in reference to the crown of the flower being double, or in two). Lab. sert. caled. p. 78. D. C. prod. 3. p. 332.

Lin. syst. Monadélphia, Pentándria. Tube of calyx short, furrowed below. Crown of throat double; outer one composed of distinct filamentous threads; inner one tubular, with an entire or toothed border. The rest as in Passiflora. All the species are either natives of New Holland or New Caledonia.

\section{* Petioles biglandular at the apex.}

1 D. AURA'NTia (Labill. caled. t. 79.) leaves glabrons, ovate at the base, broadly 3 -lobed; lobes obtuse, middle lobe the longest: lateral ones furnished with a kind of appendage each on the outside; bracteas bristle-formed, glandular at the apex, rather remote from the flower; petioles biglandular at the apex; threads of outer crown about equal in length to the inner lobes of the calyx or petals. $h_{2} \cup$. G. Native of New Caledonia. Passifiòra aurántia. Forst. prod. p. 326. Cav, diss. 10. p. 457. Murucùja anrántia, Pers. ench. 2. p. 222. Flowers orangecoloured, with the tube of the inner crown green, longer than the simple upright rays that surround it.

Orange-flowered Disemma. Shrub cl.

2 D. Hereertina (D. C. prod. 3. p. 332.) leaves pubescent, cordate at the base, broadly 3 -lobed; lobes ovate, acut.sh ; petioles biglandular at the apex; pedicels twin, 1-flowered; bracteas bristle-formed, very remote from the flower; threads of outer crown 3 or 4 -times shorter than the inner calycine lobes or petals. $\quad \checkmark$ G. Native of New Holland, in the interior. Passifiòra Herbertiàna, Ker, bot. reg. 737. Murucùja Hcr. bertiàna, Sweet. Flowers white and greenish, with the crown yellow.

I'ar. $\beta$, Caleyàna (D. C. prod. 3. p. 333.) leaves semiorbicular at the base, hardly subcordate; bracteoles situated in the middle of the pedicel. $h_{\imath} \cup$. G. Native of New Holland. Passifiòra biglandulosa, Caley. in herb. Lanı. Perhaps a proper species.

IHerbert's Disemma. Fl. Jul. Sept. Clt. 1821. Shrub cl.

3 D. BAUE'R1 ; leaves 3-lobed, sparingly glandular beneath ; lobes oblong, retuse, middle one more prolonged; bracteas and stipulas setaceous; rays filiform, longer than the corolla, which is plicate; disk 5-lobed. h. . G. Native of Norfolk Island. Fruit oval, blood-coloured. Flowers at first pale yellow, but at length orange-coloured, with the segments keeled and rather undulated, green on the outside. Murucùja Bauèri, Lindl. coll. t. 36.

Baucr's Disemma. Shrub cl.

4 D. coccinea (D. C. prod. 3. p. 333.) leaves glabrous, glandular beneath, cuncated at the base, 3-nerved, bluntly 3-lobed; petioles biglandular at the apex, longer than the pedicels; bracteas subulate, scattered, remote from the flower. $h_{2} \cup . S$. Native of Neu Holland. Passiflora coccínea, Banks, but not of Aubl. Flowers scarlet. Crown slort, double. Fruit globose. Scarlet-flowered Disemma. Shrub cl.

\section{* Petioles glandless.}

5 D. adiantifòlia (D. C. 1. c.) leaves glabrous, glandular beneath, truncate at the base, 3-5.lobed; lobes obtuse, somewhat 3 -lobed; petioles glandless, a little longer than the pedicels; bracteas subulate, scattered. $5 . \cup$. G. Native of Norfolk 1sland. Passiflòra adiantifòlia, Ker. bot. reg. 233. Passiflòra aurántia, Audr. bot. rep. t. 295. but not of Forst. Passiflòra glàbra, Wendl. coll. 1. t. 17. Passiflòra Adiảntum, Willd. cnum. 698. Murucìja adiantif òlia, Sweet. Flowers yellow at first, fading to an orange-colour, with the inner crown green, longer than the purple rays that surround it.

Aliantum-lcaved Disemma. Fl. Ju. Aug. Clt. 1792. Slı. cl. Cult. See Passiforra, p. 55. for culture and propagation. Splendid and curious elimbing shrubs.

V. MURUCU'JA (a name given to many species of Passionflower, especially those with edible fruit, by the natives of Brazil). Tourn. inst. t. 215 . Juss. gen. p. 398. D. C. prod. 3. p. 333.

Lin. syst. Monadélphia, Pentándria. Tube of calyx furrowed below. Crown of throat simple, erect, tubularly-conical, truncate (f. 5. b. f. 6.c.) ; threads of crown not free, but joined together into a tube.--Habit of Passifiora. Petioles glandless. - Species all natives of the West Indies.

Sect. I. Penta'ria (from $\pi \varepsilon v \tau \varepsilon$, pente, five ; calyx 5-lobed). D. C. prod. 3. p. 333. Calyx 5-lobed (f. 5. a.).

1 M. onbicula'ta (Pers, ench. 2. p. 222.) leaves glabrous, glandular beneath, 3-nerved, orbicular, somewhat 3-lobed; petioles glandless, twisted; tendrils few ; bracteoles narrow, very acute. 々. ᄂ. S. Native of St. Domingo. Passiflòra orbiculàta, Cav. diss. 10. t. 286. Flowers crimson.

Orbicular-leaved Murucuja. Shrub el.

Sect. 1I. DeCA'riA (from cहki, dcka, ten; in reference to the calyx being 10 -lobed). D.C. prod.3. p. 333. Calyx 10-lobed (f. 6. a.); the 5 inner lobes probably petals.

2 M. ocella'ta (Pers. l. c.) leaves glabrous, glandular beneath, emarginate at the base, truncately 2 -lobed at the apex; lobes obtuse, divaricate; petioles glandless, shorter than the pedicels; bracteas narrow, very acute. h. S. S. Native of the Antilles, in woods. Passiflòra Murucùja, Lin. amœe. 1.t. 10. f. 10. Cav. diss. 10. t. 287. Ker. bot. reg. t. $574,-$ Plum. amer. t. 87. Flowers deep red. Berry size of a pigeon's egg, flesh-coloured when ripe. Both the syrup and decoction of the plant is much used in the leeward parts of $\mathrm{Ja}$ maica, where it is frequent; and it is said to answer effectually all the purposes for which syrup of poppies and liquid laudanum are

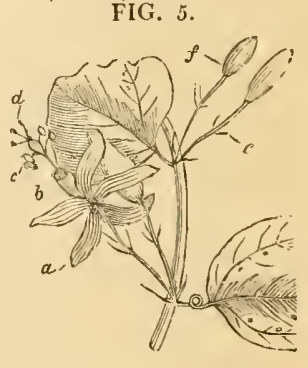
generally alministered. The flowers are most in use ; they are commonly infused in, or powdered and mixed immediately with 
wine or spirits; and the composition is generally tlought a very cflectua! and easy narcotic. Browne names it bull-hoof or Dutchman's laudanum, which are probably the vulgar names of the plant in Jamaica.

Far. $\beta$; leaves rounded at the base, somewhat 3-lobed. Cav. l. c.

Small-cyed Murucuja. Fl. July, Aug. Clt. 1730. Sh. el.

Cult. Climbing slurubs, with the habit of Passiftora, bearing beautiful flowers. Their culture and propagation are the same as that recommended for that genus, see p. 56 .

VI. TACSO'NIA (Tacso, the name of one of the speeies in Peru). Juss, gen. p. 398 . ann, mus. 6. p. 388 . D. C. prod. 3. p. 333 .

LIN. syst. Monadélphia, Pcutlindria. Tube of calyx long (f. 7.e.), with a 10-cleft limb (f. 7. a.).; the 5 inner lobes probahly petals; throat furnisbed with a scaly membrane. Habit of Passifidra.

Sect. I. Evtacsonis (eu, well or good, and Tacsònia; this section contains the genuine species of the genus). D. C. prod.3. p. 333. Involucrum large, 3 -leaved $(\mathrm{f} .6 . f$.$) ; bracteas sometimes$ free, sometimes joined together.

\section{* Leaves undivided.}

1 T. AdUlterina (Juss. ann. mus. 6. p. 393.) leaves woolly beneath, glabrous above, ovate, almost entire, with revolute edges; petioles glandless; stipulas toothed, linear-lanceolate. $h . \cup$. S. Native of New Granada. Passiflòra adulterìna, Lin. fil. suppl. p. 408. Smitl, pl. ined. t. 24. Flowers purple. Berry ovate, spotted.

Adulterated Tacsonia. Sh. cl.

2 T. LANA'Ta (Juss, ann. mus. 6. t. 59. f. 1.) leaves woolly beneath, glabrous above, ovate-cordate, entire, with somewhat revolute edges; petioles glandless ; stipulas narrow, hidden among the tomentum of the stem. 々. . S. Native of the Andes, about Quindiu. H. B. et Kunth, nov. gen. amer. 2. p. 141. Flowers white?

Woolly Tacsonia. Shrub cl.

$$
\text { * Leaves 3-lobed. }
$$

3 T. Trifolis'ta (Juss. l. c. p. 393.) whole plant white from silky tomentum; leaves trifoliate; leaflets ovate-oblong, quite entire; petioles glandless; stipulas half stem-clasping, ciliated with glands. $h^{-} \cup$. S. Native of Peru, in the valley of Canta. Trifoliate Tacsonia. Shrub cl.

4 T. Sanguíiea (D. C. prod. 3. p. 334.) leaves tomentose beneatl, reticulately veined, smooth above, deeply 3 -lobed; lobes acute, serrated; petioles glandless; bracteas glandularlytoothed. . . S. S. Native of the West Indies. Passiflora sanguínea, Smith, in Rees' cycl. no. 45. Flowers deep red.

Blood-coloured-flowered Tacsonia. Shrub cl.

5 T. Pinnatistírula (Juss. l. c.) leaves white from velvety down beneath, trifid beyond the middle ; lobes serrated ; stipulas pinnate; petioles witl 4-8 glands. $\zeta . \smile$ S. Native of Chili. Sweet, A. gard. new. ser. 2. t. 156. Passiflòra pinnatistípula, Cav. icon. 5. t. 428. Flowers rose-coloured or purplish; crown deep blue.

I ar. $\beta$, pénnipes (Smith, in Rees' cycl. no. 48. under Passifiora) stipulas palmately parted into subulate lobes, one of which is pinnate at the apex.

vol. III.
Pinnate-stipulcd Tacsonia. Clt. I828. Shrub cl.

6 T. MCRADE'Na (D. C. prod. 3. p. 334.) cloched with velvety tomentum; leaves trifid, somewhat cordate, 3-5-nerved; lobes ovate-lanceolate, scrrated; petioles bearing small glands, which are hidden among the tomentum; stipulas palmately parted into capillary lobes.

Small-glanded Tacsonia. Slirub cl.

7 T. Tomentòsa (Juss. l. c. p. 394.) leaves tomentose, trifid beyond the middle, 3 -nerved; lobes ovate, serrated; petioles bearing 6 pedicellate glands; stipulas falcate, serrulated on the ontside. h.u. S. Native of Peru. P. tomentòsa, Cav. diss. 10. t. 275, 276. Flowers rose-coloured.

Tomentose Tacsonia. Shrub cl.

8 T. manica'ra (Juss. l. c. t. 59. f. 2.) leaves somewliat tomentose beneath, trifid beyond the middle; lobes oval-oblong, serrated; petioles bearing $3-4$ glands at the apex; stipulas roundish, spreading, crestedly toothed on the outside. $\zeta$. . S. Native of Peru, about Loxa. II. B. et Kunth, nov, gen. ainer. 2.p. 139.

$\operatorname{Var} \beta$; lobes blunter and more tomentose beneath. Native of Villa de Ybarra.

Var. $\gamma$ ? petioles bearing many glands. On Mount Quindiu. I ar. $\delta$; bracteas joined together at the base. On Mount Saraguru.

\section{Manicatcd-stipuled Tacsonia. Shrub cl.}

Sect. II. Bracteoga'ma (from Bpanos, brakys, a cover, and yapus, gamos, marriage; in reference to the bracteas of the involucrum being joined together). D. C. prod. 3. p. 334. Bracteas of involucrum 3 , joined together into a tube.

9 T. TRIgònA (D. C. prod. 3. p. 334.) leaves clothed with hoary hairs beneath, pubescent above, deeply 3-lobed; lobes oblong, diverging, serrulated; petioles bearing 2-4 glands; stipulas manicated, denticulated, awned at the apex. $h \cdot \cup$. S. Native of Peru. Passiflòra trigòna, Ruiz et Pav, ined. (v.s. in lierb. Lamb.)

Trigonal Taesonia. Shrub el.

10 'T. PEDuncula'ris (Juss. 1. c. p. 395.) leaves downy on the nerves beneath, cordate at the base, 3-nerved, trifid; lobes ovate, obtuse, serrated; petioles bearing 4 glands; stipulas ovate-lanceolate, acuminated, serrated. h. S. Native of Peru. Passiflòra pedunculàris, Cav, icon. 5. t. 426. Murucùjas pedunculàris, Spreng. syst. 3. p. 43. Flowers purple or rosecoloured.

Var. $\beta$, Dombeyàna (D. C. prod. 334.) lobes of leaves acute; bracteas entire.

Peduncular Tacsonia. Clt.? Shrub cl.

11 T. moluíssima (H. B. et Kunth, nov. gen. amer. 2. p. 144.) leaves clothed with canescent tomentum beneath, and pubescence above, cordate at the base, 5-nerved, 3-lobed; lobes ovate, acute, sharply toothed; petioles bearing 12 glands; stipulas semi-ovate, acuminated, denticulated. $h . u$. S. Native of Santa Fe de Bogota. Muructija mollíssima, Spreng. syst. 3. p. 43. Flowers rose-coloured.

J'ery soft Tacsonia. Slirub el.

12 T. TRipartita (Juss. l. c. t. 60.) leaves rather tomentose beneatl, smooth above, 3-parted; lobes lanceolate, serrated; petioles bearing 6-8 glands; stipulas manicated, crestedly toothed. h.u.S. Native of South America, in woods about Quito. 11. B. ct Kunth, 1, c. 2. p. 142. Flowers rose-coloured. Tripartitc-leaved Tacsonia. Slirub cl.

13 T. mixtA (Juss. l. c. 394.) leaves glabrous, 3-lobed; lobes oblong, serrated; petioles bearing 6 glands; stipulas oblong, acuminated, serrated on the outside. h. $\checkmark$. S. Native of New Granada. Passiflòra míxta, Lin. fil. suppl. 40S. Smith, icon. ined. t. 25. 
Var. $\beta$, longifiora (D. C. prod. 3. p. 335.) leaves pubescent beneath; lateral lobes sometimes 2-lobed. $h \cdot \cup$. S. Native of Peru. T. longifòra and T. Tásco, Pers. ench. 2. p. 223. Flowers rose-coloured or purplish.

Mixed Tacsonia. Shrub cl.

14 T. speciòsa (H. B. et Kunth, nov. gen. amer. 2. p. 143.) leaves glabrous, cordate at the base, reticulately 5 -nerved, deeply 3-lobed; lobes ovate-oblong, sliarply serrated; petioles bearing 6-8 pedicellate glands ; stipulas suborbicular, awned, denticulated. $\zeta . \cup$. S. Native of Santa Fe de Bogota. Murucujja speciosa, Spreng. syst. 3. p. 43. Flowers rose-coloured.

Showy Tacsonia. Shrub cl.

15 T. gLAbE'rRima (Juss. ann. mus. 6. p. 394.) leaves glabrous, coriaceous, 3-lobed; lobes oval-lanceolate, stiffly serrated; petioles bighandular at the apex; stipulas glove-formed, dentately crested. $\zeta$. $\checkmark$. S. Native of Peru, on the Andes in sliady places. Flowers purple.

Quite-glabrous Tacsonia. Shrub cl.

16 T. anastonòsans (Lamb. herb. ex D. C. prod. 3. p. 335.) leaves glabrous, coriaceous, cuneated at the base, 3-nerved, trifid; lobes ovate-lanceolate, callously serrated; petioles bearing 4 glands; stipulas ovate, awned, callously serrated. $\zeta \cdot \cup \cdot \mathrm{S}$. Native of Peru.

Anastomosing-veined Tacsonia. Shrub cl.

17 T. PARvifòlia (D. C. prod. 3. p. 335.) leaves glabrous, glaucous beneath, 3-5-nerved, trifid; lobes ovate-lanceolate, acutely serrated; petioles bearing 4 glands; stipulas semi-cordate, acuminated, nearly entire. $h^{\prime} \cdot$. S. Native of Peru. Ruiz et Pav. (v. s. in herb. Lamb.)

\section{Small-lcaved Tacsonia. Shrub el.}

Sect. III. Distepha'na (from ǐs, dis, double, and oteфaros, stephanos, a crown; in reference to the double crown in the throat). Juss. 1. c. D. C. prod. 3. p. 335.-Distèphia, Salisb. in litt. Involucrum small, 3-leaved; leaflets free, biglandular in the axils. Throat of calyx bearing a membranous tube, and a series of ligulæ.

18 T. glandulòsa (Juss. 1. c. p. 391.) leaves glabrous, coriaceous, ovate, acuminated, quite entire, feather-nerved; petioles biglandular at the base, about equal in length to the pedicels; bracteas subulate, near the flower. $\zeta$. S. Native of Cayenne. Passiflòra glandulòsa, Cav, diss. 10. t, 281.

Iar. $\beta$, canaliculàta (D. C. 1. c.) petioles thicker, and channelled at the base.

Glandular Tacsonia. Shrub cl.

19 T. Rohria'na (D. C. prod. 3. p. 335.) leaves glabrous, coriaceous, ovate-oblong, acuminated, quite entire, feathernerved; petioles biglandular at the base, one-half shorter than the pedicels; bracteas subulate, remote from the flower. $\zeta \cdot v$. S. Native of Cayenne.

Roht's T'acsonia. Slirub cl.

20 T. Stoupya'na (D. C. l. c.) leaves glabrous, coriaceous, ovate, acuminated, quite entire, feather-nerved; petioles biglandular at the base; bracteas oval, obtuse, foliaceous. $h . \mathrm{S}$. Native of Cayenne. Cav, diss, 10. t. 281. lit. x.

Stoupy's Tacsonia. Shrub cl.

21 'T. citrifòcıa (Juss. 1. c. p. 392. in a note,) leaves oval, coriaceous, quite entire, feather-nerved; petioles biglandular at

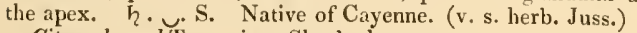

Citron-lcaved Tacsonia. Shrub cl.

\section{+ Species belonging to section Distephàna, but doubtful.}

22 T. QUADRiglandulòsa (D. C. 1. c.) leaves glabrous, obtuse at the base, unequally serrated: superior ones oblong; inferior ones 3-lobed: recesses of the lobes of the leaves, petioles, and bracteas bearing 4 glands each. $\zeta . \cup$. S. Native of Guiana, in woods, in the Island of Arowabisch. Passiflòra quadriglandulòsa, Meyer, esseq. p. 226.

Four-glanded Tacsonia. Shrub cl.

23 T. Quadridenta'ta (D. C. l. c.) leaves glabrous, ovatelanceolate, feather-nerved, with a few coarse acute teeth; petioles biglandular at the base; bracteas oblong, biglandular. $h$. . S. Native of the West Indies.

Four-toothed-leaved Tacsonia. Shrub cl.

24 T. pubéscens (D. C. l. c.) leaves pubescent, ovate, lanceolate; petioles biglandular at the base; bracteas ovate-lanceolate, acuminated, glandularly serrated, and glandular on the back. $5 . \cup . S$. Native of the East Indies.

Downy Tacsonia. Shrub cl.

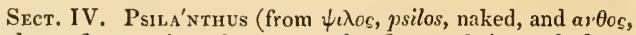
anthos, a flower; in reference to the flowers being naked, or without the involucrum). D. C. prod. 3. p. 335. Involucrum none under the flower.

25 'T. TRINE' RVIA (Juss. 1. c. t. 58.) leaves tomentose beneath, oval, 3-nerved; nerves protruding so much as to form teeth; petioles glandless; calyx 10 -lobed. $h . \cup$. S. Native of South America, in shady places at the river Cassiquiare. H. B. et Kunth, l. c. p. 142. Flowers rose-coloured?

Three-nerved-leaved Tacsonia. Shrub cl.

26 T.? viridiflòra (Juss. ann. mus. 6. p. 389.) leaves peltate, 3-lobed; calyx 5-lobed. b.U. S. Native of Mexico, in the vicinity of Actpulco. Passiflòra viridiflòra, Cav. icon. 5 . t. 424. Intermediate between Tacsònia, Passiflòra, and Murucùja. Flowers green.

Green-fonered Tacsonia. Shrub cl.

Cult. The species have the habit of Passiflora, and some of them are equally showy. Their culture and propagation are the same, see p. 56.

VII. PASCHA'NTHUS (from $\pi a \sigma \chi \omega$, pascho, to be in a passion, and ar.os, anthos, a flower; the same meaning as Passiflora). Burch. trav. 1. p. 543. D. C. prod. 3. p. 336.

Lin. syst. Polygàmia, Monoècia. Flowers polygamous. Calyx permanent, tubular, 10-cleft ; 5 outer lobes ovate : 5 inner ones oblong-linear, petaloid, or rather truly petals. Stamens 5, free. Anthers linear, inserted by the base. Ovarium stipitate. Stigmas 3, very short. Capsule subbaccate, 3-valved, 6-seeded. Seeds ornamented with red fleshy aril.-Habit of Passiflora.

1 P. REPA'NDUs (Burch. l. c.) leaves glabrous, glaucous, oblong-linear, repand, 1-nerved, bearing 3 glands beneath; petioles very short, glandless; peduncles bearing a tendril, and two 1flowered pedicels. $\quad$. $\cup$. G. Native of the Cape of Good Hope.

Rcpand-leaved Paschanthus. Shrub cl.

Cult. This very singuiar plant, being a native of the Cape of Good Hope, will thrive in a green-house, and will form an excellent climber for the rafters. Its culture and propagation are the same as that recommended for Passiflòra, see p. 56 .

VIII. MODE'CCA (East Indian name of one of the species). Rheed. mal. 8. t. 20-23. Lam. dict. 4. 1. 208. Blum. bijdr. p. 938. D. C. prod. 3. p. 336.

Lin.syst. Dioècia, Monadélphia. Flowers dioecious. Calyx permanent, campanulate, 10-cleft (f. 8, b.): 5 outer lobes oval acute : 5 inner lobes petaloid or probably petals (f. 8. b.). Scales $5-10$ (f. 8. c.), rarely wanting, rising from the calyx. Stamens 5 , inserted in the torus? monadelphous: anthers standing. Ovarium (f. 8. d.) on a short stipe. Stigmas 3, petaloid (f. 8.e.). Capsule bladdery, 1 -celled, 3-valved, one or many-seeded. Seeds furrowed by rows of tubercles (f. $8 . f$.), arillate, fixed to 3 parietal placentas, which are adnate to the middle of the valves.Habit of plants between Passiflòra and Bryònia. 
1 M. Palma'ta (Lam. lict. 4. p. 209.) leaves glabrous, variously palmately lobed, glandular beneatl ; stipulas spinescent; pedicels bractless. $\zeta$. u. S. Native of Malabar. Flowers yellowish. Probably many species are confused under this name.

Var. a, Naròla (D. C. prod. 3. p. 336.) lobes of calyx acuminated; petaloid lobes or petals wanting ; fruit globose.-lilieed. mal. 8. t. 20.

Var. $\beta$, palmodécca (D. C. l. c.) lobes of calyx acutish; petaloid lobes or petals feathered palmately ; fruit globose. $\zeta . \cup$. S. Rheed. l. c. t. 21 .

Var. $\gamma$, Mótta (D. C. l. c.) lobes of calyx very much acuminated; petaloid lobes or petals wanting; fruit ovate.-Rheed. l. c. t. 22 .

Palmate-leaved Modecca. Shrub cl.

2 M. гова'ти (Jacq, fragm, t. 131.) leaves glabrous, cordate at the base, 3-5-7-lobed, glandless ; petioles biglandular at the apex; pedicels bractless. $\eta$. $\checkmark$. S. Native of Sierra Leone. Ker, bot. reg. t. 131. Flowers yellowish. (f. 8.)

Lobcd-leaved Modecca. Fl. Aug. Clt. 1812. Shrub cl.

3 M. integrjfòlia (Lam. dict. 4. p. 209.) leaves glabrous, ovate-lanceolate, usually entire, much acuminated; pedicels bractless, very short, few-flowered; fruit globose. $\zeta \cdot \cup$. S. Native of Malabar.-Rlieed. mal. 8. t. 23.

Entire-leaved Modecca. Shrub cl.

4 M. Wightin's (Wall. cat, no. 6764.) smooth; leaves cordate, triangularly ovate, entire; tendrils simple; capsule bladdery ; seeds scrobiculate. $h_{.} \cdot \mathrm{S} . \mathrm{S}$. Native of the East Indies, on the Gingee Hills. Like M. integrifolia, Lam.

Wight's Modecca. Shrub cl,

5 M. ALIE'Na (Wall. cat. no. 6766.) leaves deeply cordate at the base, oblong, acuminated; lobes at the base rounded; pedicels umbellate on the top of shortish peduncles; tendrils simple. h. ..S. Native of Silhet.

Alien Modecca. Slurub cl.

6 M. Асumna'ta (Blum. bijdr. p. 940.) leaves ovate-oblong, acuminated, somewhat cordate at the base, and biauriculate; flowers racemose, rising from elongated axillary tendrils ; fruit ovate, acuminated. h. $\cup$. S. Native of Java, on Mount Salak. Allied to M. integrifolia according to Blume.

Acuminated-fruited Modecca. Shrub cl.

7 M. IETEROPHY'LLA (Blum. bijdr. p. 940.) leaves undivided or \$-lobed, acuminated, somewhat cordate at the base, and somewhat biauriculate; fruit oblong, acuminated at both ends. $\zeta$. . S. Native of Java, on Mount Gede.

Variable-leaved Modecca. Shrub cl.

8 M. Diversifolia (Wall. cat. no. 6763.) smooth; lower leaves triangularly ovate; upper ones 3 -lobed, peltate at the base: lateral lobes sometimes bifid; pedicels 1 -flowered, bractless; tendrils simple. $\quad$. . S. Native of the East Indies. Fruit bladdery, 3-valved. Koot tuberous. Momórdica heterophýlla, Wight, mss.

Diverse-leaved Modecca. Shrub cl.

9 M. cordifolia (Blum. bijdr. p. 939.) leaves membranous, on short petioles, cordate, mucronulate, biauriculate at the base; flowers corymbose, dichotomous, rising from elongated axillary tendrils. $h_{2} \cup$. S. Native of Java, on Mount Salak.
Heart-leaved Modecca, Shrub cl.

10 M. овтU'sa (Blum. bijdr. p. 939.) leaves coriaccous, oblong-cordate, obtuse, biauriculate at the base; Howers corymbose, dichotomous, rising from short axillary tendrils. h. ${ }^{\circ} \mathrm{S}$.

Native of Java, on Mount Salak.

Oblusc-leaved Modecca. Shrub cl.

11 M. PArvirlóra; leaves oblong-lanccolate, entire, acuminated, glabrous; tenlrils simple; peluncles axillary, dichotomous. $h$. u. S. Native of Sierra Leone. Flowers small, yellow.

Small-flonered Modecea. Slirub cl.

12 M. macropiry'Lla (Blum. bijdr. p. 939.) leaves coriaceous, oval, bluntish at both ends, somewhat auriculated at the base; flowers corymbose, dichotomous, rising from axillary tendrils. h.u. S. Native of Java, on Mounts Salak, Parang, \&c. Long-leaved Modecea. Shrubcl.

13 M. austra'lis (R. Br. ined. ex D. C. prod. 3. p. 337.) leaves glabrous, somewhat peltate at the base, cordate, running down the petiole in an auriculated manner at the base, acute, entire, glandless. $h \cdot \cup$. S. Native of New Holland, in the gulph of Carpentaria.

Southern NIodecca. Shrub cl.

14 M.? BRactea'ta (Lam. dict, p. 210.) leaves scabrous from tubercles on both surfaces, palmately lobed, emarginate at the base; pedicels bracteate, racemose; calyxes somewhat serrated. $\eta$. . S. Native of the East Indies.

Bracteated Modecea. Slirub cl.

Cult. Sce Passifiora, p. 56. for culture and propagation. The flowers of the species are by no means showy.

IX. DEIDA'MIA (a mythological name, daughter of Lycomedes, king of Scyros). Pet. Th. gen. pl. afr. 2. p. 61. t. 20. D. C. prod. 3, p. 337.

Lin. syst. Monadélphia, Penta-Oetándria. Calyx 5-8-parted ; lobes petaloid; crown a simple series of filamentose appendages, rising from the interior part of the calyx. Stamens equal in number to the lobes of the calyx; filaments joined at the base into a column. Ovarium ovate. Styles 3-4. Capsule pedicellate, 3-4-valved. Seeds arillate.-Climbing Madagascar shrubs, with axillary tendrils, impari-pinnate leaves, and glandular petioles.

1 D. Noronura'sa (D. C. prod. 3. p. 337.) leaflets obovate, somewhat cuneated at the base, emarginate at the apex; peduncles 2-3-flowered; flowers pentandrous. $h$. S. Native of Madagascar. D. alàta, Pet. Th. 1. c. t. 20. Flowers brownish. Noronh's Deidamia. Shrub cl.

2 D. Commersoniana (D. C. l. c.) leaflets elliptic, mucronate at the apex; peduncles 5-7-flowered; flowers pentandrous. h. S. Native of Madagascar.

Commerson's Deidamia. Shrub cl.

3 D. Trompsoniana (D. C. prod. 3. p. 337.) leaves elliptic, hardly mucronate, rather coriaceous; peduncles 5-7-flowered; flowers octandrous, $\zeta . \cup$. S. Native of Madagascar. Passiflòra octándra, 'Thompson in lierb. Lamb.

Thompson's Deidamia. Slirub cl.

Cult. See Passiftora, p. 56. for culture and propagation.

X. VARE'CA (altered from Malwareka, the name of the fruit in Ceylon). Gærtı. fruct. 1. p. 219. t. 6. f. 6. D. C. prod. 3. p. 337.

LiN. sysr. unknown. Flowers unknown. Berry 1-celled; pulp divided into numerous partial cells for the reception of the seeds. Placentas 3, parietal, many-seeded.

1 V. ZEYLA'NicA (Gartn. 1. c.) Native of Ceylon. Nothing but the fruit of this plant is known.

Ceylon Vareca. Shrub cl.? I 2 
Cult. See Passiflora, p. 56. for culture and propagation.

Order CVI. MALESHERBIA'CE $Æ$ (this order only contains the genus Maleshérbia). D. Don, in edinb. pliil. journ. 1827. p. 321.-Passiflòreæ, Tribe III.-Malesherbièæ, D. C. prod. 3. p. 337.

Calyx tubular (f. 9. h.), membranous, inflated, 5-lobed (f. 9. a.); lobes imbricated in astivation. Petals 5 (f. 9.6 .), alternating with the segments of the calyx, permanent, convolute in astivation, arising on the outside of the short membranous crown (f. 9. e.). Stamens $5-10$, perigynous ; filaments filiform, distinct, or connected with the stipe of the ovarium ; anthers versatile. Ovarium superior (f. 9. g.), stipitate, 1-celled, with the placentas at the base, from which the ovules arise by the intervention of umbilical cords. Styles 3 , filiform, very long, arising from distinct points at the apex of the ovarium (f.9. $d_{0}$ ) ; stigmas clavate. Fruit capsular, 1-celled, 3-valved, membranous more or less, many-sceded. Seeds attached by umbilical cords to placentas, arising either from the axis of the valves, or from their base; testa crustaceous, brittle, with a fleshy crest, and no arillus. Embryo terete in the centre of fleshy albumen, with the radicle next the hylum.-Herbaceous or half shrubby plants, clothed with glandular pubescence. Leaves alternate, simple lobed, without stipulas. Flowers axillary or terminal, solitary, yellow or blue.

This order agrees with Passiflorece on the one hand, and Turneràcce on the other. From the former they differ in the insertion of their styles, in their versatile anthers, in their short placentas, membranous fruit, terete embryo, want of arillus, and stipulas; and altogether in their habit. From Turneràcce, to which their habit nearly allies them, they differ in the presence of a perigynous membrane, in the remarkable insertion of the styles, and in the want of all trace of an arillus; agreeing with that order in the astivation of the corolla, and in the principal otler points of their structure. The plants are unknown except as objects of great beauty.

1. MALESHE'RBIA (in memory of Christian William de Lamoignon Malesherbes, born at Paris in 1721, a great patron of the sciences). Ruiz et Pav. prod. p. 45. D. Don, l, c. D. C. prod. 1. c.-Gynopleùra, Cav, icon. 4. p. 51.

Lin. syst. Pcntándria, Monogýnia. Character the same as that of the order.

1 M. thy rsiflòra (Ruiz et Pav. prod. p. 457. et Hook. bot. misc. vol. \%. p. 220.) leaves linear-lanceolate, acute, sinuately toothed, tomentose; tube of caly $\mathrm{x}$ long, with a contracted throat ; crown I0-cleft, with the segments 2-4-toothed. h. G. Native of Peru, in exposed argillaceous soil. Gynopleùra tubulòsa, Cav, icon. 4. t. 375. Flowers yellow.

Thyrse-flowercd Malesherbia. Shrub 1 to 2 feet.

2 M. Panicula'ta (D. Don in edinb. phil. journ. 1827. p. 321.) leaves oblong, obtuse, ciliated, pinnatifid: upper ones nearly entire; throat of calyx dilated; crown simple, acutely toothed. 2.G. Native of the north of Chili. Howers yellow?

Panicled-flowered Malesherbia. Shrub 1 to 2 feet.

3 M. linearifòlia (D. Don in edinb. phil. journ. Jan. 1832.) villous; leaves linear, entire; throat of calyx dilated; crown 10-cleft, with toothed segments. h.? G. Native of Chili, especially in the tract of Portilla, near Mendoza. Gynopleùra linearifòlia, Cav. icon. 4. p. 52. t. 376 . Flowers wlite.
Linear-leaved Malesherbia. PI. 2 to 3 feet.

4. M. Hu'Mris (D. Don, l. c.) plant very villous; leaves jagged; throat of calyx dilated; crown simple, erosely toothed; anthers roundish. $\eta$. G. Native of Chili about Coquimbo. Stems procumbent. Flowers white.

Dnarf Malesherbia. Fl, Aug. Clt. 1832. Pl. procumbent.

5 M. corona'ta (D. Don, l.c.) plant clothed with glandular pubescence; leaves linear, sinuately toothed; throat of calyx dilated; crown simple, toothed. $h$. G. Native of Chili, at Valparaiso. Flowers blue; crown white. Sweet, fl. gard. new. ser. t. 167. (f. 9.)

Cromned Malesherbia. Fl. Aug. Oct. Clt. 1832. Pl. 2 to 3 feet.

6 M. Fascicula'ta (D. Don, l. c.) leaves lanceolate, acuminated, quite entire; flowers in fascicles; crown 10-cleft, with the segments tridentate. $々 \cdot G$. Native of Chili. A stiff erect shrub. Flowers small, in bundles at the tops of the branches.

Fascicled-flowered Malesherbia. Shrub 1 to 2 feet.

7 M. tenuifòlia (D. Don in edinb. phil. journ. Oct. 1832.) leaves nearly pinnate; segments linear; calyx tubular; crown deeply lobed. $\odot$. G. Native of the south of Peru, in the province of Tarapaca at Huataconda, where it is commonly called Agi de Zorra, i. e. Fox capsicum. Flowers reddish, according to the dried specimen.

Fine-lcaved Malesherbia. Fl. Feb. Pl. $\frac{1}{2}$ foot.

Cult. This genus is composed of curious plants, bearing very showy singular flowers, and are therefore worthy of culture as ornaments. A mixture of loam, peat, and sand, or any light rich earth is a good soil for them. The shrubby species may either be increased by seeds; or young cuttings will root if planted in light soil, under a hand-glass. The seeds of annual kinds require to be sown in a hot-bed, in order to forward the plants; and after they have grown an inch in height, they may be potted off into small pots, and afterwards shifted into pots of increasing size, as they grow. Some of them may be planted out into the open border, in a sheltered situation, where they will probably flower and seed freely.

ORDER C'VII. LOA'SEæ (plants agreeing with Loàsa, in important cliaracters). Juss. ann. mus. 5. p. 18, dict. sc. nat. 27. p. 93. D. C. prod. 3. p. 339.-Loàseæ-veræ, H. B. et Kunth, nov, gen. amer. 6. p. 115.

Tube of calyx adhering to the ovarimm, or girding it closely (f. 10. a. f. 12. a.); limb 5-parted (f. 11.a. f. 12. a.), rarely 4-parted, permanent. Petals equal in number to the lobes of the calyx (f. 12. b. f. 11.b.), with an inflexed valvate restivation, or double that number (f. 10, b.), and disposed in 2 series; those of inner series, when present, usually much smaller (f. 10. b.) than those of the outer, scale-formed and truncate at the apex, inserted in the throat of the calyx. Stamens indefinite, arising from within the petals, disposed in several series, either distinct (f. 10. c.), or joined at the base in several parcels before each petal, within the cavity of which they lie in æstivation; filaments subulate (f. 10. g.), unequal, the outer ones frequently destitute of anthers. Ovarium adnate 
to the calyx (f. 10.a. f. 11.e.), or inclosed within it, 1-celled, with several parietal placentas (f. 11.), or with 1 free central lobed one. Style 1, composed of 3-5-7-joined ones, crowned by as many lobes or stigmas. Capsule dry or succulent, crowned by the calyx (f. 10. d. f. 11. g. f. 12. c.), 1-celled, with several parietal placentas (f. 11.), originating at the sutures, and therefore may be called marginal, $3-4-7$-valved; placentas equal in number to the valves, sometimes drawn out so far as to form dissepiments (f. 11.f.). Seeds numerous, without arillus. Embryo lying in the axis of a fleshy albumen; with the radicle pointing to the hilum, and flat small cotyledons.-American herbs more or less pilose or hispid, with the hairs or bristles usually stinging like those of the rettle, in consequence of their secreting an acrid juice. Leares opposite or alternate, exstipulate, simple, but usually variously divided. Peduncles axillary, 1-flowered. Flowers elegant. This order is distinguished from Onagrarièa by its unilocular ovaria, and indefinite stamens, part of which are sterile; and perhaps by the latter character, and the additional 5 petals, connected with Passifturè , with which they sometimes also accord in habit. Their rigid stinging hairs, climbing habit, and lobed leaves resemble those of some Urticeae. On the same account they may be compared with Cucurbitàcece, with which they further agree in their inferior unilocular fruit, with parietal placentas, and in the very generally yellow colour of their flowers. This, indeed, is the order with which, upon the whole, Loàsea must be considered to have the closest affinity.

\section{Synopsis of the genera.}

1 Bartònia. Tube of calyx cylindrical (f. 10. a.); limb 5parted (f. 10,a.). Petals 5-10 (f. 10.b.), about equal in shape. Stamens numerous (f. 10.c.). Capsule 3-7-valved; each placenta bearing 2 rows of seeds.

2 Bunmenbáchia. Tube of calyx spirally twisted (f. 11.e.); limb 5-parted (f. 11.g.). Petals 10 (f. 11. b.); 5 outer ones cucullate, and the 5 inner ones scale-formed, each scale inclosing 2 sterile filaments. Fertile stamens disposed in 5 bundles ( $\mathrm{f}$. 11. b.). Fruit dividing into 10 parts at the base.

3 Los'sa. Tube of calyx not twisted (f. 12. a.) ; limb 5 parted (f. 12. c.). Petals 10 (f. 12.b.); the 5 inner ones scaleformed, bearing 2 sterile filaments inside. Outer series of stamens sterile and free; inner ones disposed in 5 bundles, but distinct. Capsule 1-celled, 3-valved at the apex.

4 Caróphora. The fruit is oval, bursting into 3 valves from the base upwards; the placentas then separate from the sides of the capsule, and have the appearance of 3 arched columella. The rest as in Loàsa.

5 Mentze'lia. Tube of calyx cylindrical (f. 13. b.); limb 5-lobed (f. 13. d.). Petals 5 (f. 13. a.). Stamens free, usually disposed in bundles (f. 13. e.). Capsule turbinate, 3-valved, few-seeded (f. 1s.f.).

6 Klapròtuia. Calyx with a turbinate tube, and a 5parted limb. Petals 4 . Stamens numerous, 4-5 sterile in front of each sepal, and 4-5 fertile in front of each petal. Fruit baccate, few-seeded.
I. BARTONIA (Benj. S. Barton, M. D., professor of botany at Philadelpluia). Sims, bot. mag. t. 1487. Nutt. gen. amer. 1. p. 297. Pursl, H. amer. sept. 1. p. 327. D. C. prod. 3. p. 339. but not of Willd.

Lin. syst. Icosandria, Monogýnia. Tube of calyx cylindrical (f.10,a.), closely girding the ovarium, but probably distinct from it ; limb 5-parted (f. 10. $a_{\text {. }}$ ), permanent. Petals 5-10 (f. 10. b.), unguiculate, the same shape, inserted in the calyx. Stamens indefinite (f. 10. c.), inserted with the petals, but shorter than them; filaments free (f. 10, c.); outer oncs sometimes sterile; anthers oblong. Style filiform (f. 10.. .), marked with 3-7 spiral stripes (f. 10. c.). Capsule oblong, 1-celled, 3-7-valved; placentas bearing 2 rows of seeds each. Seeds compressed.-Herbs downy from stiff and bearded hairs. Leaves alternate, interruptedly pinnatifid. Flowers large, terminal, solitary, white or yellow, expanding in the evening, becoming reddish as they fade.

1 B. ORNA'TA (Nutt. gen. amer. 1. p. 297.) lobes of leaves acutish ; capsule surrounded by bracteas, $5-7$-valved; seeds somewhat emarginate. $\delta$. F. Native of $\mathrm{U}$ pper Louisiana, in argillaceous soil, on the banks of the river Missouri. B. decapétala, Sims, bot. mag. 1487. Petals 10, white.

Ornamental Bartonia. Fl.Jul. Sept. Clt. 1811. Pl. 1 to $2 \mathrm{ft}$.

2 B. Nu'DA (Nutt. 1. c.) lobes of leaves obtuse; capsule 3valved, naked; seeds winged; outer stamens petaloid, usually sterile. f.F. Native on the banks of the Missouri, on gravelly hills. Petals 10 .

Naked-fruited Bartonia. Fl, Jul. Sept. Clt. 1811 . P1.1 to $2 \mathrm{ft}$.

3 B. Levicau'LIs (Daugl, mss. ex Hook, fl. bor. amer. 1.p. 22I. t. 69.) petals 5 ; petaloid stamens 5 ; bracteas wanting; stems very smootl ; seeds winged. $\odot$. H. Native of North America, on the gravelly islands and rocky sliores of the Columbia, near the Great Falls. Flowers shining, yellow. An ornamental plant, not inferior to $B$. ornita, but differs from it in the want of the large, jagged bracteas, as well as in its fewer petals and winged seeds.

Smooth-stemmed Bartonia. Pl. 2 to 3 feet.

4 B. Parviflòra (Dougl. mss. ex Hook. fl. bor, amer. 1. p. 221.) petals 5 ; petaloid stamens $5-7$; bracteas wanting ; stem scabrous; sceds winged. \$.F. Native of North America; abundant in calcareous rocky situations, and micacious sandy banks of streams, in the interior parts of Columbia. Flowers smaller than those of the preceding species, but it is probably laadly more than a variety of that plant. It differs from $B$. nüla, Nutt. in the number of the petals. The name would be more applicable to the following species.

Small-flowered Bartonia. Pl. 1 to 2 feet.

5 B. Aleicau'lis (Dongl. mss. ex Hook. fl. bor. amer, 1. p. 222.) petals 5, obovate, small ; petaloid stamens wanting; brac-

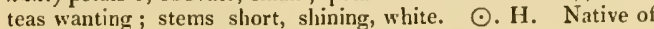
North America, on arid sandy plains of the river Colombia, under the sliade of Púrshia tridentita. Mentzèlia albicaúlis, Dougl. mss. Acrolàsia bartonioldes, Presl. reliq. Hank. 2. 1). 39. t. 55. Petals yellow.

Whitc-stemmed Bartonia. Pl. decumbent.

6 B. ALBE'scens (Arnott, in Cheek, journ. 3. p. 273.) stem with a white shining epidermis; leaves sinuately toothed; capsule naked, 3-valved; seed broadly marginate; flowers dis- 
posed in a leafy panicle. $\delta$. F. Native of Chili, in the Jarillal, or uncultivated grounds between Mendoza and the mountains; generally by the side of dry water courses, at about 3000 feet above the level of the sea. Sweet, fl. gard. new ser. t. $18 \%$. B. siuuàta, Presl. reliq. Hænk. 2. p. 38 . Petals 10, pale yellow. Filaments all dilated. Stigmas 3-lobed. This species does not turn black on drying, as in the other species, and is readily distinguished from them by the beautiful white down on the stem. Iloary Bartonia. Fl. July, Sept. Clt. 1831. Pl. 1 to 4 feet.

Cult. The seeds of the species should be raised in a gentle heat in spring; and when the plants are of a proper size, they siould be potted separately in small pots, and shifted from size to size of pots as they grow; the pots should be well drained with sherds; and in the winter they should be placed on a dry shelf in a greenhouse or frame. The flowers are very showy, and the plants are therefore worth cultivating in every garden.

I1. BLUMENBA'CHIA (in honour of Joln Freder. Blumenbach, MI.D. professor of medicine at Göttingen, chiefly distinguished as a comparative anatomist). Schrad. in goett. anz. 1825. p. 1707. Comm. soc. goett. vol. 6. with a figure. D.C. prod. 3. p. 340 . but not of $\mathbf{K}$ ol.

Lin. sysx. Polydélphia, Polyándria. Calyx 5-parted (f. 11. g.), with the tube adhering to the ovarium. Petals 5 (f. 11 . b.), inserted in the top of the calycine tube, cucullate, equal, spreading. Scales 5 (f. 11. b.), alternating with the petals, and inserted with them, furnished with $S$ sterile filaments at the back of each, and clasping 2 subulate appendages inside. Stamens indefinite, inserted in the top of the calycine tube (f. 11. b.), disposed in 5 bundles, one opposite each petal ; anthers 2-celled, bursting inwardly. Ovarium joined to the tube of the calyx. Style simple (f. 11. f.). Capsule marked with 10 spiral ribs, 1-celled, 10-valved; 5 of the valves thicker and broader than the other 5 , with the placentas not reaching the axis; the other 5 narrower, with placentas almost reaching the axis (f. 11.h.), and bearing the seeds. Seeds rugged.-Branched, climbing, or trailing herbs, covered with stinging hairs. Leaves opposite, lobed. Flowers axillary, solitary, bracteate.

1 B. Insignis (Schrad. 1. c.) lower leaves 7-5-lobed; upper ones deeply bipinnatifid. $\odot$. H. Native of Chili and Brazil, in the provinces of Cisplatine and Rio Grande do Sul, and abont Monte Vileo; also of Buenos Ayres. Reich. icon. exot. t. 121. Sweet, A. gard. t. 170. B. parviflòra, Gill. mss. Lodsa pahnàta, Spreng. syst. 3. p. 601. Trevir. in act. bot. 13. p. 181. t. 12. Loàsa pàtula, Graham, in edinb. plìl. journ. Oct. 1827. Flowers with whitish petals and reddish-yellow scales.

Shony Blumenbachia. Fl. July, Nov. Clt. 1826. Pl.tr.

2 B. palma'ta (St. Hil. fi. bras. 2. p. 208.) leaves deeply and palmately 3-5-lobed; lobes pinnatifid. $\odot$. H. Native of Brazil, on the confines of the province of Rio Grande de St. Pedro do Sul. Flowers with white petals ; scales with ciliated edges, yellow at the base, lined with white, and red above it, tipped with vermilion colour.

Ialmate-leaved Blumenbaclia. Pl. tr.

3 B. latifòla (St. Hil. f. bras. 2. p. 209. t. 118.) leaves trifoliate; lateral segments 3lobed, unequal-sided, terminal one equal-sided, 3-5-lobed. $\odot$. H. Native of Brazil, in the province of St. Paul, between the towns of Rio Grande de St. Peuro do Sul and St. Francisco de Paulo. Flowers with white petals, and yellow scales tipped with orange colour. (f. 11.)

Broad-leaved Blumenbachia. Pl. tr.

4. B. PuníceA; plant very hispid; leaves opposite, pinnatifid, having the segments jagged; calycine lobes jagged, shorter than the petals, which are cucullate; bundles of stamens polyandrous. $\odot$. H. Native of Peru. Loàsa punícea, Ruiz et Pav. A. per. 5. t. 446. ined. (v. s. herb. Lamb.)

Searlet Blumenbachia. Pl. 1 to 2 feet.

5 B. тterospéraA; hispid; leaves opposite, pinnatifid, rather cordate at the base; segments toothed; peduncles long, 1flowered, axillary; calycine segments toothed, shorter than the petals, which are cucullate; bundles of stamens polyandrous; stem climbing; sceds bordered by a wing. $\odot$. H. Native of Perı. Loàsa pterospérma, Ruiz et Pav. fl. per. 5. t. 448. (v. s. herb. Lamb.)

Winged-seeded Blumenbachia. Pl. cl.

6 B. SEPIA'RA ; stem climbing; leaves opposite, pinnatifid, with the segments pinnatifid or coarsely toothed; peduncles long, axillary, 1-flowered; calycine segments jagged, linear, longer than the petals, which are cucullate; bundles of stamens polyandrous. $\odot$. H. Native of Peru. Loàsa sepiària, Ruiz et Pav. fl. per. 5. t. 449 . ined.

Hedge Blumenbachia. Pl. cl.

7 B. micrA'NTHA; hispid; leaves opposite, ovate, serrated, petiolate; peduncles many-flowered, racemose, terminal, and rising from the forks of the stem; calycine lobes ovate, much shorter than the petals, which are cucullate, and holding 2 stamens each. $\odot$. H. Native of Peru. Flowers very small. Loàsa micrántha, Rujz et Pav. fl. per. 5. t. 442.

Small-flowered Blumenbachia. Pl. 1 foot.

S B. orandiflóra; leaves opposite, petiolate, oblong, runcinate, acute, somewhat cordate at the base; pedicels 1 -flowered, rising from the forks of them; stem climbing. $\odot . H . \quad$ Native of Peru. Loàsa contórta, Lam. dict. 3. p. 579 . D. C. prod. 3. p. 340. Juss. ann. mus. 5. p. 25. t. 3. f. 1. Loàsa physiopétala, Ruiz et Pav. fl. per. 5. t. 447. ined. Flowers yellow.

Great-flowered Blumenbachia. Pl.cl.

Cult. Elegant anuual plants, with very showy flowers; their culture and propagation are the same as that recommended for the species of Locisa, see p. 64 .

III. LOA'SA (meaning unknown to us). Adan. fam. 2. p. 501. Jacq. obs. 2. p. 15. Schreb. gen. no. 908 . Juss. gen. p. 322. ann. mus. 5. p. 24 . Lam. ill, t. 426 . D. C. prod. 3. p. 340.-Ortiga, Feuill. per. 2. p. 757. Neck. elem. no. 1221. Loòsa, Lin. prael. ed. gis. p. 334 .

Lin. sysr. Polydélphia, Polyándria. Calyx 5-cleft, with the tube adhering to the ovarium (f. 12, a.). Petals 5 (f. 12. b.), cucullate, equal, spreading, inserted in the top of the tube; scales 5 , inserted with the petals, furnished with 3 sterile filaments on the back of each, and girding 2 subulate appendages inside. Stamens indefinite, inserted in the top of the calycine tube, disposed in 5 bunules (f. 12. b.), opposite the petals; anthers 2-celled, bursting inwardly. Ovarium joined to the calyx. Capsule crowned by the lobes of the calyx (f. 12.a.), 3-valved at the top, 1-celled; placentas linear, alternating with the valves. Seeds rugged-Branched, decumbent, or climbing herbs, beset with stinging hairs. Leaves alternate, or opposite, toothed or lobed. Flowers axillary, extra-axillary, or opposite the leaves, solitary or racemose.

\section{* Leaves opposite.}

1 L. твíloba (Juss. ann. mus. 5. p. 24. t. 1. f. 3.) leaves cordate at the base, usually 3 -lobed: lobes acute, toothed; middle lobe usually somewhat 3 -lobed; pedicels axillary; caly- 
cine tobes small, acute. $\odot$. H. Native of Peru and Chili, about Valparaiso. Ruiz et Pav. fl. per. 5. t. 444. ined. Scales petaloid, equally and bluntly 3-lobed. Flowers small.

Three-lobcd-leaved Loasa. Pl. 1 foot.

2 L. AcERIfòli (Juss. l. c. p. 24. t. 1. f. 2.) leaves nearly opposite, cordate at the base, 5-7-lobed; lobes acute, tootlied; pedicels shorter than the floral leaves; calycine lobes oblong, acuminated. $\odot$ ? H. Native of Chili and Peru. Loàsa vitifolia, Ruiz et Pav, H. per. 5. t. 443. ined. L. tricolor, Ker. bot. reg. 667. Scales as in L. triloba, but the calycine lobes are twice the length. Flowers with yellow petals and red scales. Maplc-lcaved Loasa. Pl. tr.

S L. BRYonizfòlia (Schrad. cat. hort. gœtt. 1823. pl. rar. hort, goett. with a figure) leaves cordate, lower ones 5 -lobed, stalked, upper ones 3 -lobed, almost sessile; all the lobes are sinuately lobed; pedicels exceeding the floral leaves; lobes of calyx a little toothed, acuminated. $\odot$. H. Native of Chili. Stem erect, bristly. Flowers yellow, hardly smaller than those of $L$. acerifolia. Stigma blunt. Seeds without aril ; hylum lateral.

Bryony-leaved Loasa. Pl. 1 foot.

4 L. Nitín (Lam. dict. 3. p. 581.) leaves cordate at the base, many-lobed; lobes acute, toothed, lower ones usually pinnatifid; pedicels axillary; calycine lobes oblong, toothed, shorter than the petals; wings of the corona very small, toothed, and stalked; stamens much shorter than the petals; style straight, shorter than the stamens; sepals erect, much shorter than the pear-shaped fruit. $\odot$. H. Native of Chili and Peru, on the mountains. Juss, ann. mus. 5. p. 25. t. 2. f. 2. Trat. tabl. 1. t. 23. Hook, exot. fl. t. 83. bot. mag. 2572. Ruiz et Pav. fl. per. 5. t. 445. Petals spreadingly reflexed, yellow, red at the base; scales red. Lobes of leaves bluntish. Stems prostrate.

I'ar. $\beta$; leaves more deeply lobed; lobes narrower.-Chili, about Valparaiso. L. tricolor, Lindl. bot. reg. 667.

Shining Loasa. Fl. June, Sept, Clt. 1822. Pl. tr.

5 L. sagitra'ta (Hook. et Arn. in bot. misc. 3. p. 298.) stems twining, pubescent; leaves all petiolate, opposite, cordatelysagittate, acuminated, with rather lobed margins: the lobes crenated; peduncles axillary and terminal, few-flowered; calycine lobes orate-oblong. $\odot . \frown . H$. Native of Chiloe. There has none of the stinging hairs, so peculiar to this genus, been observed on this species.

Sagiltate-leaved Loasa. Pl. tw.

6 L. Elosga'ta (Hook. et Arn. in bot. misc. 3. p. 239.) stems much elongated, nearly simple, shining; leaves remote, opposite, petiolate, cordate at the base, 5-7-lobed; peduncles axillary, few-flowered, twice the length of the leaves; calycine lobes broadly ovate, shorter than the petals, which are red; fruit hemispherical. $\odot . H$. Native of Chili, about Coquimbo.

Elongated-stemmed Loasa. Pl. 2 to 3 feet.

7 L. Prostra'ta (Gill. mss. ex Arnott, in Cheek, edinb. journ. 3. p. 274.) stems prostrate, flexuous; leaves opposite, sessile, cordate, ovate, deeply angular; peduncles axillary, 1 -flowered, about twice the length of the leaves; calycine lobes lanceolate, longer than the fruit, and about equal in length to the petals; valves of capsule closely beset by long, rigid hairs; seeds eggshaped, large, with a smooth testa. $\odot . H$. Native of Chili, on La Cuesta de los Manantiales, Cerro de San Pedro Nolasco, \&.c. Plant covered with long, rigid, stinging hairs.

lar. $\beta$, Cumingii (Hook. et Arnott, in bot. misc. 3. p. 230.) segments of leaves bipinnatifidly and sinuately toothed. About $V$ alparaiso, and on the mountains near Aconcugua. In the speeies the segments of the leaves are simply and sinuately toothed. Prostrate Loasa. Pl. prostrate.

8 L. PA'LLidA (Gill. mss. ex Arn. in Cheek, cdinb. journ. 3. p.
274.) epidermis of stem loose, and shining ; leaves opposite, all petiolate, ovate, coarsely toothed; panicles opposite, axillary, muclı longer than the leaves; pedicels short, in the forks, about equal in length to the flowers; calycine lobes linear-oblong, one half shorter than the petals. $\odot$. II. Native of Chili, among loose debris, on the banks of the Lil Rio del Yeso, near Arroyo de San Nicholas, at the elevation of about 5000 feet, $\&$ c., where it is called by the inhabitants Cavalluna. The plant is most nearly allied to $L$. sclarecefolia, Juss. but that does not appear to have the loose epidermis on the stem, and the leaves are much larger. The pedicels in the forks of the panicle are elongated.

\section{Pale Loasa. I’l. prostrate.}

9 L. Laterirsa (Gill. mss. ex Arnott, in Cheek, edin. journ. 3. p. 275.) stems almost wanting; leaves opposite, on long petioles, pinnate; segments roundish, crenated, lobed; peduncles twin, 1-flowered, terminal, about equal in length to the lcaves; calycine lobes oval, exceeding the tube, but one half shorter than the corolla. $\odot$.H. Native of Chili, at Los Imposibles, near the foot of the descent from the Planchon towards Chili, and in El Valle de Tray Carlos, at the base of the volcano of Pateroa, at an elevation of 9000 feet. This species is readily distinguished by its large flowers of a brick red colour, and by its very short stems and radical branches, each of which bear 1 or 2 pairs of opposite leaves, and between the upper pair of which arise 2 1-flowered peduncles, terminating the branch. Seeds with a strongly reticulated testa like the next species; and as in it the hairs are short and not stinging.

Brick-coloured-flowered Ioasa. Pl. prostrate.

10 L. Pinnatírida (Gill. mss. ex Arnott in Cheek, edinb.journ. 3. p. 275.) stems nearly erect ; leaves opposite, on long petioles: radical and lower ones pinnate: segments pinnatifid, with roundish approximate lobes; upper leaves pinnatifid; peduncles axillary, usually I-flowered; calycine lobes ovate, much shorter than the corolla, and half the length of the fruit. $\odot$. H. Native of Chili, at La Cuesta del Inga, at an elevation of about 9000 feet. Plant with short rigid, but not stinging hairs.

Pinnatifid-leaved Loasa. Pl. 1 foot.

11 L. Dissécra (Hook. et Arn. in bot. misc. 3. p. 210.) stem erectish, strong, a little branched at the apex, with a loose white epidermis; petioles opposite, lower ones elongated, becoming gradually shorter to the top of the stem; leaves tripinnatifid, with the ultimate segments ovate-obtuse; pedicels short, rising from the forks of the stem; calycine lobes narrow-oblong, not lialf so long as the petals. $\odot$. H. Native about Valparaiso, Los Ogos de Agua, and Aconcugua.

Dissected-leaved Loasa. PI. I foot.

12 L. HeteropIrýL A (Hook. et Arn. in bot. misc. 3. p. 228.) stem prostrate, dichotomous ; leaves opposite, on short petioles ; lower ones small, hastately triangular, coarsely toothed : lower floral ones nearly reniform, 5 -lobed, with the lobes nearly equal, and furnished with 1 or 2 teeth each; but the middle lobe of the uppermost leaves is rather lengthened; peduncles in the forks longer than the leaves; calycine lobes oblong-lanceolate, about equal in length to the petals; fruit conically hemispherical. $\odot$. H. Native about Valparaiso? and at Los Ogos de $\mathbf{\Lambda}$ gua. 'The stem is rarely pubescent; but the branches, particularly in their upper part, and the turbinate tube of the calyx, are providert with long sharp spreading hairs.

Variablc-lcaved Loasa. Pl. prostrate.

18 L. Acanturyòu (Lam. dict. 3. p. 579.) leaves cordate at the base, pinnatificl ; lobes acuminated, sinuately toothed; pedicels axillary, and also from the forks, solitary, 1-flowered; lobes of ealyx narrow, acuminated, reflexed, equal in length to the petals, which are bidentate. $\odot$. H. Native of Chili. Juss. ann. mus. 5 . p. 25. t. 3. f. 2 . L. nitida, bot. mag. 2372 ? L. cymbæpétala, liuiz et l'av. fl. per. 5. t. $1+2$. b. ined. Ortiga 
Chilénsis, Feuill. obs. 2. p. 757. t. 43. Petals yellow. Scales red. Herb erect, 4 feet high. The leaves are often alternate. Acanthus-leaved Loasa. Pl. 4 to 5 feet.

14 L. Ruiziana; leaves opposite, ovate, coarsely serrated, hoary from down, petiolate; peduncles axillary and terminal, 1flowered; calycine segments acute, much shorter than the petals, which are cucullate. $\odot$. H. Native of Peru. L. incana, Ruiz et Pav. fl. per. vol. 5. t. 44 I. ined. (v. s. herb. Lamb.)

Ruiz's Loasa. Pl. 1 foot.

15 L. sclarefròlia (Juss. 1. c. 5. p. 25. t. 1. f. 1.) leaves ovate-oblong, sinuately lobed; lobes acute, toothed; upper leaves sessile; pedicels solitary, 1-flowered in the forks of the stem; calycine lobes oblong, acuminated, shorter than the petals. ○. H. Native of Chili, where it is called Urtìca bràva, Tratt. t. 22. Scales emarginate at the apex.

Selary-leaved Loasa. Pl. $t r$.

16 L. PlA'cer (Lindl. in hort. trans. 6. p. 97.) leaves cordate at the base, many lobed: upper ones sessile; pedicels axillary; sepals hardly toothed, refiexed, length of petals; the wings of the corona sessile, and quite entire; the longest of the stamens as long as the petals; style bent, longer than the stamens; capsule obovate, shorter than the reflexed sepals. $\odot . H$. Native of Chili. L. acanthifölia, Ker, bot. reg. t. 785. but not of Juss. Flowers yellow, with red scales.

Plaee's Loasa. Fl. June, Sept. Clt. 1822. PI. 4 to 6 feet.

17 L. GRANDifLòra (Lam. dict. 3. p. 580.) lower leaves opposite; upper ones alternate, cordate at the base, 5 -lobed; lobes deeply toothed; flowers axillary and terminal, on long pedicels; lobes of calyx acuminated, shorter than the petals. $\odot$. II. Native of Peru. Juss. ann. nus. 5. p. 26. t. 4. f. 2. Tratt. tab. t. 29. Ruiz et Pav. fl. per. 5. t. 440. Lower leaves on long, and upper on short petioles. Flowers yellow. Scales oblong, 2lobed, not appendiculate on the outside.

Great-flowered Loasa. Fl. Ju. Sept. CIt. 1825. Pl. 2 to $3 \mathrm{ft}$.

18 L. FLORIBU'NDA (Hook, et Arn. in bot. misc. 3. p. 239.) root simple, fusiform; stem short, with a loose epidermis, simple beneath the inflorescence, but much branched and panicled above; leaves oval-oblong, petiolate: cauline ones opposite, sinuately lobed, coarsely toothed, cordate at the base: lower floral ones alternate, sinuately lobed: upper fioral ones smaller, cuneated at the base, tootled or quite entire; pedicels short, rising from the forks of the stems; calycine lobes elliptic, acute, : ttcnuated at the base, shorter than the apiculated petals; scales furnished with 3 appendages each on the back above the middle. $\odot$. H. Native about Valparaiso, and on the Cordillera of Chili.

Bundle-flowered Loasa. P]. 1 foot.

\section{* Leaves alternate.}

19 L. Lose' Nsis (H. B. et Kunth, nov, gen. amer. 6. p. 116.) leaves alternate, and nearly opposite, ovate-oblong, 3-5-lobed; lobes irregularly toothed; middle lobe very large; flowers terminal and axillary, somewhat racemose; lobes of calyx ovate, acuminated, 3-nerved. h. S. Native of Peru, near Loxa. Leaves white beneath. Flowers yellow. Scales rounded at the apex, drawn out into a lobe at both ends. Herb suffruticose branched.

Loxa Loasa. Shrub.

20 L. ARgemonoides (Juss, ann. nus, 5. p. 26.) leaves cordate, sinuately lobed, tomentose on both surfaces, white beneath; flowers terminal and axillary, pedicellate; lobes of calyx lanceolate, one-half shorter than the petals. 4 . S. Native of South America, near Santa le de Bogota. Humb. et Bonpl. pl. cquin. 1. p. 53. t. 15. H. B. et Kunth, nov. gen. amer, 6. p. 26 . T'ratt. tab. t. 30 . Flowers nearly 3 inches in diameter. Scales bifid, furnished with 2 acute lobes, which are gibbous at the base.

Argemone-like Loasa. Pl. 6 to 10 feet.
2 L L. Ranunculifòla (Humb. et Bonpl. pl, equin. I. p. 50. t. 14.) leaves all alternate, somewhat orbicular, cordate, toothed, clothed with yellowish tomentum above, and silky white tomentum beneath; flowers terminal and axillary, somewhat racemose ; lobes of calyx ovate-lanceolate, acute. 4.S. Native of Peru, on the Andes near Caxamarca. H. B. et Kunth, nov. gen. amer. 6. p. I 17. Tratt. tab. t. 27. Flowers large, yellow. Scales bifid, bigibbous at the base.

Crow-foot-leaved Loasa. Pl. 2 feet.

22 L. Inca'na (Graham in edinb. phil. journ. Oct. 1830.) plant suffruticose, reddish, erectish; leaves scattered, petiolate, ovate-lanceolate, hoary, deeply serrated, scabrous; peduncles 1-flowered, opposite the leaves. $\boldsymbol{h} . \mathrm{G}$. Native of Peru, from Yazo to the valley of Canta. Corolla white. Whole plant covered densely with harsh barbed white hairs, intermixed by a few stinging ones. Cuticle papery, and pealing off.

Hoary Loasa. Fl. Oct. Nov. Clt. 1830. Pl. 2 feet.

23 L. Xanthifòlia (Juss. l. c. t. 2. f. 1.) leaves petiolate, cordate, oblong, acute, coarsely toothed; pedicels extra-axillary; lobes of calyx oblong, hardly acute. $\odot$. H. Native of Peru. Flowers small, yellow. Stems a foot and half high. Trat. tab.t.26. Xanthium-leaved Loasa. Pl. $1 \frac{1}{2}$ foot.

24 L. chenopodifòlia (Lam. dict. 3. p. 550.) leaves petiolate, somewhat ovate, deeply toothed ; racemes loose, leafy, terminal; flowers drooping. $\odot . \mathrm{H}$. Native of Peru. Perhaps a mere variety of the preceding, according to Juss. ann. mus. 5. p. 26.

Goosefoot-leaved Loasa. PI. 1 to 2 feet.

25 L. PARViflòra (Schrad. pl. rar. bras. ined. ex D. C. prod. 3. p. 342.) leaves on long petioles, ovate-cordate, sinuately 3-7lobed, hairy; flowers racemose; racemes extra axillary, fewflowered, shorter than the leaves; lobes of calyx acutish. $\odot . H$. Native of Brazil, in the provinces of the Mines. Peduncles and calyxes bristly. Flowers with white petals and brown scales. Bristles or sterile stamens at back of scales white.

Small-flowered Loasa. Pl. trailing.

26 L. A'SPera (Ruiz et Pav. fl. per. 5. t. 441. b.) hispid; leaves alternate, angularly lobed, and coarsely toothed; peduncles solitary, lateral; calyx long, very hispid; calycine segments ovate, longer than the petals. $\odot$.H. Native of Peru.

Rough Loasa. Pl. 1 to 2 feet.

27 L. AMBRosieròlia (Juss. l. c. t. 4. f. 1.) leaves petiolate, bipinnatifid; lobes and lobules bluntish; pedicels extra-axillary; lobes of calyx lanceolatelinear, acute, shorter than the

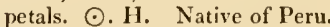
Stem a foot high, liardly branched. Herb beset with yellowish prickles. Flowers yellow, an inch in diameter. Tratt. tab. $t$. 31. Scales bifid, not appendiculate on the outside.

Var. $\beta$, hispida (D. C. prod. 3. p. 342.) lobes of leaves very numerous, broader and more crowled. Loàsa ùrens, Jacq.

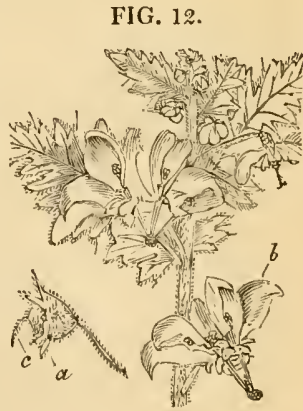
obs. 2. p. 15. t. 33 . Lan. dict. 3. p. 578. Tratt. tab. t. 32. L. híspida, Lin. syst. ed. 12. p. 364. L. bipinnatífida, Ruiz et Pav. fl. per. 5. t. 439. ined.

Ambrosia-leaved Loasa. PI. 1 foot.

28 L. volu'Bilis (Juss. l. c. t. 5, f. 1.) leaves alternate and opposite, bipinnatifid; lobes linear, obtuse; flowers terminal and axillary, pedicellate; lohes of calyx a little toothed, one half shorter than the petals; stem twining. $\odot$. H. Native of Chili, near Conception, in sandy places; and of Peru. Tratt. tab. 
t. 34. L. multífida, Ruiz et Pav, fl. per. 5. t. 443. b. Scales 2-lobed. Flowers small, yellow.

Trining Lonsa. Pl, tw.

29 L. TRIPHY'LLA (Juss. 1. c. p. 27. t. 5. f. 2.) leaves for the most part cut into 3 stalked, oblong, toothed segments : a few tripartite; pedieels extra-axillary ; calycine lobes elliptic-oblong. $\odot$. II. Native of Peru, on the Andes, in the high plains. Tratt. tab. 1. t. 21. H. B. et Kunth, nov. gen. amer. 6. p. 118. Stems ascending.

Threc-leacel Loasa. Pl. ascending, 1 foot.

30 L. PAPAVErifòlia (II. 13. et Kuntl, nov. gen. amer. 6. p. 11S.) leaves trifoliate; segments or leaficts stalked, oblong, tootled: middle leaflet large, pinnatifid; flowers opposite the leaves, disposed in something like racemes; iobes of calyx elliptic, 3-nerved. $\odot$. H. Native of the Andes, about Quindiu. Stem simple, ascending. Flowers white. There is a figure in the Flora Mexicana which agrees with this plant, except that the petals are drawn bifid at the apex.

Poppy-leaved Loasa. Pl. 1 loot.

Cult. All the species of Loàsa bear such beautiful flowers, that they are all worth cultivating for ornament, but they are so full of stings that it is impossible to liandle them. The sceds of the annual species should be sown early in spring in the open ground, and the plants so raised will flower and produce seed the same season; or the seeds may be sown in pots, and reared in a hot-bed, and the plants may afterwards be planted out in the open border, in any convenient situation. All the species require a rich light soil and a warm situation. Some of the species are said to be perennial: we suppose all would be so if they were protected from frost.

IV. CAIO'PHORA (meaning not explained). Presl. in reliq. Hænk. 2. p. 43.

Lin. siss. Polydélphia, Polyándria. Calyx 5-parted; segments jagged. Petals 5 , unguiculate, concave. Scales 5 , petaloid, emarginate, or 4-toothed at the apex, each furnished with 4 sterile filaments inside. Stamens numerous, disposed in 5 bundles. Style trigonal, permanent; stigmas 3 , conniving. Capsule ovate-oblong, with elevated spiral ribs, crowned by the reflexed calyx, 1-celled, many-seeded, opening at 3 of the sutures. Placentas marginal in the valves, but at length distinct from them. Seeds angular, echinated by bristles or reticulated. -Usually climbing plants, with the habit of Loàsa, beset with stinging hairs. Peduncles 1-flowered. Flowers yellow. 'T his genus differs from Loc̀sa and Blumenbùehia in the debiscence of the capsule, in the scales being furnished with 4 sterile filaments instead of 3 , and in many other points. There are several plants now referred to the genus Blumenbachia which belong to this genus; viz. B. grandiflòra, which is Caióphora contórta, Presl. reliq. Hænk. 2. p. 42. and B. punicea, which is evidently the Caióphora circiifölia, Presl. l. c. t. 54 . and carduifòlia, P'resl. l. c. p. 42.

1 C. corona'ta (Hook, et Arn. in bot. mise. 3. p. 238.) stems short; leaves opposite, petiolate, pinnate; segments bipinnatifitl : lobules denticulated ; peduncles axillary, 1-flowered, elongated; calyeine lobes pinnatifid, with linear segments, longer than the ovarium. $\odot$. H. Native of Chili, on both sides of the Cordillera of the Andes, between Mencloza and Chili, at an elevation of 8500 to 11,000 feet. The furrows of the fruit are nearly straight, or hardly spiral, so that this species partakes in some degree of the characters of Locisa. Loàsa coronàta, Gill. mss, ex Arnott, in Cheek, in edinb. journ. 3. p. 274 . C. absinthæéòlia, Prest. in reliq. Hank. 2. p. 4.3.

Cron'ned Caiophora. Pl. prostrate, rising 1 to 2 feet.

Cult. See Loàsa for culture and propagation.

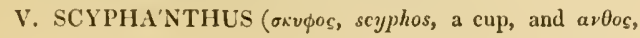
VoL. III. anthos, a flower; in reference to the form of the flower). Swcet, H. gard, t. 288.

Lix. sxst. Pulyadél hlia, Polyándria. Calyx deeply 5parted, permanent, equal. P'etals 5 , unserted in the base of the caly $x$, on very short claws, coneave, equal. Scales inscrted with the petals, peltate at the apex, lobed, 3-horned. Stamens numerous, perigynous, the 10 exterior ones destitute of anthers; and these are plaeed by twos opposite the scales, and are longer than the rest, which are disposed in 5 fascicles opposite the petals; anthers 2-celled, ereet. Ovarium prismatic, siliqueformed; style one, ereet, trigonal. Capsule prismatic, siliçueformed, crowned by the tube of the calyx, 3-valved at the apex; seeds oval, wrinkled. $-\Lambda$ twining herb, having its branches beset with retrograde strigx. Leaves opposite, pinnatifil; superior ones bipinnatifid, hispid from hairs. Ilowers sessile, ereet, solitary, yellow.

1 S. E'LEgans (Sweet, 1. c.). ๑. H. Native of Chili. Stem dichotomous. Segments of leaves obtuse, ciliated. Grammatocárpus volúbilis, Presl. symb. bot. 1. p. 61. t. 38.

Elegant Scyphanthus. Fl. Aug. Sept. Clt. 1824. Pl. cl.

Cult. An elegant plant. For its culture and propagation, see Loàsa.

VI. MENTZELIA (in honour of Christian Mentzelius; physician to the Elector of Brandenburgh; published Centuria Plantarum Circa Gedanum, 4to. 1650. and Index nominum Plantarum Multilinguis, fol. 1682. 1696. and 1715.). Plum. nov. gen. 40. t. 6. Lin. gen. no. 670. Juss. ann. mus. 5. p. 94. Lam. ill. t. 4.25. H. B. et Kunth, nov. gen, amer, 6. p. 119 D. C. prod. 3. p. 343.-Onàgræe spec. Tour.

LIN. syst. Icosándria, Monogýnia. Calyx permanent, with a cylindrical, somewhat 5 -furrowed tube, and 5 lanceolate or subulate, equal lobes (f. 13. d.). Petals 5 (f. 10.a.), equal, inserted in the upper part of the tube of the calyx. Stamens indefinite (f. 13. e.), multiple the number of the petals, and inserted with them; filaments free, usually disposed in 5 bundles; anthers erect, ovate, bilocular. Ovarim adnate to the ealycine tube. Styles 3, connected to the middle or to the top, marked by 3 corresponding stripes. Capsule turbinately cylindrical, crowned by the calycine lobes (f. 13. f.), 1-celled, 3valved at the apex. Sceds 3-6-9, or irregular in number in consequence of abortion, inserted in 3 parietal placentas.-Erect, branched, dichotomous herbs, rough from bearded or glochidate stiff hairs. Leaves alternate, or nearly opposite, coarsely toothed. Flowers of a deep orange colour, solitary, almost sessile in the forks of the stem, or pseudo-axillary from one of the branches being abortive, expanding in the height of the sun.

* Stamens 20-25, all nearlycqual. Secds 3-6. Floners smaller.

1 M. A'spera (Lin. spec. ed. 1. p. 516.) petals roundish-oval, obtuse, hardly longer than the ealycine limb, but much exceeding the stamens. ๑. F. Native of the Antilles (Plum. ed. Burm. t. 174. f. 1.); Jamaica (P. Browne, jam. p. 219.); st. Domingo (Bertero). Seeds 5; parietal smootl, compressed. Hairs on plant glochidate at the apex.

Rough Mentzelia. Ill. July, Aug. Clt. 1733. Pl. 1 to $2 \mathrm{ft}$.

2 M. oligospe'rma (Nutt. in Sims, bot, mag. t. 1760.) petals oval, acuminated, longer than the calyx, but very little longer than the stamens. 4. G. Native of Louisiani, on the banks of the river MI issouri, among rocks. MI. aúrea, Nutt. gen. amer. 1. p. 300 . Root tuberous, succulent. Seeds 3 , smooth, linearoblong. Hairs on plant bearded their whole lengtls.

Few-sceded Mentzelia. Fl. May, Jul. Clt. 1812. Pl. 1 to $2 \mathrm{ft}$.

* Stamens 30.100, the 10 exterior oncs the longest. Sicds 6-9. Flowers larger than those of the last section.

3 M. níspida (Willd, spec. 2. p. 1176.) petals obovate, muK 
cronately acuminated, longer than the calyx ; stamens $30-35$; leaves and flowers nearly sessile. 4. G. Native of Mexico. Juss. ann. mus. 5. p. 24. M. aspera, Cav. icon. 1. p. 51. t. 70. exclusive of the synonyms. Flowers 15 lines in diameter. Seeds 6, ovate, compressed. Root violently purgative, and is used in the cure of syphilis. The Mexican name of the plant is Zazale.

Hispid Mentzelia. Fl. June, July. Clt. 1820. Pl. 3 feet. 4 M. strigòsa (H. B. et Kunth, nov. gen. amer. 6. p. 120.) petals obovate, mucronately cuspidate, 2 or 3 times longer than the calyx; stamens about 50 ; leaves and flowers almost sessile; hairs on the branches retrograde. $\psi$. G. Native of Mexico, near Rio SarFIG. 13.

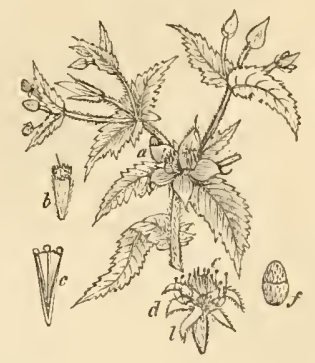

co. Filamcuts of outer stamens dilated at the apex. Ovula 10. Strigose Mentzelia. PI. 1 to 2 feet.

5 M. sca'bra (H. B. et Kunth, l.c.) petals obovate, acute, a little longer than the calyx; stamens 100-110; flowers sessile in the forks of the stems; leaves petiolate. $4 . \mathrm{G}$. Native of New Granada, on the Andes about Pasto. Seeds scabrous, 6-9. Scabrous-seeded Mentzelia. Pl. 1 to 2 feet.

6 M. grandiflòra (Ruiz et Pav. fl. per. 5. t. 441. ined.) petals obovate, pointed, much longer than the calyx; calycine lobes ovate-lanceolate, acuminated, reflexed when the flowers are open; stamens numerous, from $30-40$, unequal, outer ones the longest; leaves alternate, ovate, coarsely toothed, on short petioles. 4 . G. Native of Peru.

Grcalflowercd Mentzelia. Pl. 2 to 3 feet.

7 M. nírta (Pav. in herb. Lamb.) calyx covered with long hairs; calycine segments lanceolate, much slorter than the petals ; stamens numerous ; leaves cordate, lobed, obtuse, alternate, clothed with soft pubescence; peduncles many-flowered. 4. G. Native of Mexico. (v. s. in herb. Lamb.)

Ilairy Mentzelia. Pl. I foot.

8 M. stinta'ta (Moc. et Sesse, fl. mex. icon. ined. ex D. C. prod. 3. p. 343.) petals oval, mucronately cuspirlate, much longer than the calyx; stamens $30-40$; flowers and leaves stipitate. 4. G. Native of Mexico. Presl. in Hank. reliq. 2. p. 40. Branches, pedicels, and ovaries scabrous from hairs. Leaves ovate, acuminated, 3-lobed, doubly toothed. Flowers lateral and terminal, solitary.

Stipitate-flowered Mentzelia. Pl. 1 to 2 feet.

Cult. The species grow well in any light rich soil; and cuttings will root readily in sand, under a hand-glass. They are also easily reared from seeds, which ripen in this country.

VII. KLAPRO'THIA (in honour of Martin Henry Klaproth, of Berlin, a celebrated chemist, and great friend of Humboldt). 1I. B. et Kunth, nov, gen. amer. 6. p. 121. t. 537 . D. C. prod. 3. p. 343 .

LiN. syst. Icosándria, Monogýnia. Calyx permanent, with a turbinate tube and a 4 -parted limb; lobes ovate, equal. Petals 4 , on very short claws. Stamens numerous, especially $4-5$ fertile ones in front of each petal; these are longer than the others, and 4-5 sterile ones in front of each sepal ; these are pilose, and somewhat dilated at the apex into a 2-lobed membrane. Styles 4 , connected together almost to the apex in one. Ovarium 1celled, 8-nerved inside, and 4-ovulate; ovula pendulous, fixed to the nerves opposite the sepals. Fruit baccate. Herb twining ; branclies scabrous fiom retrograde hairs. Leaves oppo8 site, sharply toothed, stalked. Peduncles cymosely corymbose at the tops of the branches. Flowers white.

I K. Mentzeljoìdes (H. B. et Kunth, l. c.). $\odot$. H. Native of the Andes, about Quindin, near the volcanos.

Mentzelia-like Klaprothia. Pl. $\mathrm{tw}$.

Cult. For culture and propagation see Loàsa, p. 65.

Order CVIII. TURNERA'CE (plants agreeing with Turnèra in important characters). H. B. et Kunth, nov. gen. amer. 6. p. 123. D. C. prod. 3. p. 345.

Calyx free, usually coloured more or less, profoundly 5-cleft (f. 14. a.), deciduous; lobes equal, imbricate in æstivation. Petals 5, equal (f. 14.b.), inserted into the upper part of the tube of the calyx, and alternating with its lobes, narrow at the base, twisted in æstivation. Stamens 5 , inserted in the upper part of the tube of the calyx below the petals, and alternating with them; filaments free, flat; anthers oblong, erect, 2-celled (f. 14.c.). Ovarium free, 1-celled (f. 14. d.), many-ovulate. Ovula ascending (f. 14.f.), fixed to 3 linear parietal placentas. Styles 3 (f. 14. e.) or 6, usually more or less deeply bifid, and cleft into many stigmas at the apex (f. 14.c.). Capsule 3valved, l-celled (f. 14.f.); valves bearing the seeds in their middle, along a longitudinal placenta, opening from the apex as far as the middle. Seeds subcylindrical, carved, crustaceous, reticulated, furnished with a thin, membranous arillus on one side. Hilum situated at the base of the seed. Embryo in the centre of a fleshy albumen, somewhat incurved, spatulate, with the radicle turned towards the hilum, and with plano-subconvex cotyledons.-Shrubs, subshrubs, and herbaceous plants, with a simple pubescence. Leaves alternate or scattered, simple, exstipulate, with occasionally 2 glands at the apex of the petioles, toothed, rarely pinnatifid. Flowers axillary, sessile, or pedunculate; the peduncles either distinct or connected with the petioles, simple and 1 -flowered or branched and manyflowered, articulated in the middle or furnished with 2 small bracteoles. Petals yellow or yellowish, rarely blue. This order is placed by De Candolle between Loàsce and Fuuquicràcce, chiefly it would seem on account of its manifest relation to the former, and its perigynous stamens. With Maliàcece it agrees in the twisted restivation of the corolla and habit. With Loàsece and Passiftòrece, they have also much in common. In the structure of the fruit it agrees with rivlarièce and Cistinece, but differs in the petals and stamens being inserted into the calyx, and the circmmstance of their certain relationship to Cistince gives great weiglit to the ingenious approximation, by II. Du Petit Thours, of Passiflorece to Violariče. The presence of glands upon the ends of the petioles of Tumeràcece is a confirmation of their affinity to the former. It is distinguished from Loàsece by the fruit being superior and I-celled, with parietal placentas, and hy the definite stamens; the former character is, however, weakened by the nearly superior fruit of some Loùscce.

\section{Synopsis of the Genera.}

1 Turne'ra. Styles 3 (f. 14. e.), simple, divided at the apex into multifid stigmas (f. 14,e.). Capsule opening from the top to the midale. 
2 Perique'ta. Styles 3, deeply 2-parted, crowned by 2 multifid stigmas each. Capsule opening from the top to the base.

I. TURNERA (so named by Linnæus in memory of William Turner, M.D., Prebendary of York, Canon of Windsor, and Dean of Wells ; student of Pembroke Hall in Cambridge, 1538 ; died 1568. Author of a New Hcrbal, London, 1551. fol. Second part, Cologn, 1562. Second edition, Collen, 1566, with the addition of a third part, S.c.). Plum. gen. p. 15.t. 12. Lin. gen. 376. Juss. gen. 313. Gartı, fruct, 1.p. 366, t. 76. H. B. et Kunth, nov. gen. amer. 6. p. 123 . St. Hil. fl. bras. 2. p.212. -Turnèra, sect. 1. Lam. ill. t. 212. dict. 8. p. 141.

Las. sysr. Pentándria, Trigýnia. Calyx tubularly funnelshaped (f. 14. a.). Styles 3 (f. 14.e.), simple, cleft at the apex into multifid stigmas (f. 14. e.). Capsule opening from the apex to the middle.

\section{$\$ 1$. Peduneles joined with the petioles, bibracteate. * Leaves biglandular at the base.}

1 T. vemiròla (Lin. spec. ed. 1. p. 965.) leaves oblong, acute, serrated, pubescent above, but clothed with white tomentum bencath, and biglandular at the base; flowers almost sessile; styles shorter than the stamens. 8.S. Native of South Amcrica every where ; common in Brazil. Lin. hort. cliff. 122. t. 10.-Sloan. hist. 1. t. 127. f. 4-5.-Mill. fig. t. 268. f. 2. Flowers yellow, about the size of those of Linum trigynum.

Var. $\hat{\beta}$, angustifolia (D. C. prod. 3. p. 346.) leaves oblonglanceolate. $h_{2}$.S. Native along with the species. T. angustif òlia, Curt. bot. mag. t. 281. Link. enum. 1. p. 293. T. ulmifòlia $\beta$, Willd. spec. 1. p. 1503.

Elm-leaved Turnera. Fl. Ju. Sept. Clt. 1733 . Sh. 2 to $4 \mathrm{ft}$.

2 T. cuneirórmis (Juss. in Poir. dict. 8. p. 142.) leaves cuneiformly obovate, coarsely serrated, pubescent above, but clothed with white tomentum beneath, and bighandular at the base; flowers nearly sessile. $\eta_{2}$. S. Native of Brazil, about Rio Janeiro. Spreng. nov. prov. 42. St. Hil. fl. bras. 2. p. 213. Otto, in hort. berol. 36. 'T. obtusifòlia, Smith, in Rees' cycl. rol. 36. no. 3. Petals yellow, with the claws brownish. Capsule globose.

Var. $\beta$; leaves and branches closely clothed with tomentum; stem dwarf. T. odoràta, Vahl. in herb. Juss.

Wedgc-formed-leaved Turnera. Fl. June, July. Clt. 1821. Shrub i to 3 feet.

3 T. Trionif Lòr a (Sims, bog. t. 2106.) leaves oblong-lancenlate, coarsely serrated, cuneated at the base, and quite entire, pubescent; flowers sessile; styles excecding the stamens. $h$.S. Native of Brazil, island of Trinidad, and Mexico. 'T. élegans, Otto, 1. c. Link, enum. 1. p. 293. Petals pale yellow, or sulphur-coloured, with purplish-brown claws. Bracteoles subulate. Flowers as large as those of Bladder-ketmia.

Kietmia-flonercd Turnera. Fl. year. Clt. 1812. Pl. 1 to $2 \mathrm{ft}$.

4. T. IAMnFònı (St. Hil. fl. bras. 2. p. 213.) leaves roundishobovate, unequally crenate-toothed, clothed with soft hairs above and woolly tomentum beneath, biglandular at the base; flowers on short peduncles; styles a little shorter than the stamens. $h$.S. Native of Brazil, in the southern part of the province of Goyaz. Petals yellow, rather truncate at the apex.

Dead-nettle-leared Turnera. Shrub 1 foot.

5 T. inceola'ta (St. Hil. fl. bras, 2. p. 214.) leaves linearlanceolate, acute, nearly entire, hairy, biglandular at the base beneath ; flowers almost sessile. $h$.S. Native of Brazil, in the provinces of Goyaz and Minas Geracs. Petals obovateoblong, yellow. Styles exceeding the stamens a little.

Lanceolate-leaved Turnera. Shrub $\frac{1}{2}$ foot.

6 T. oblongiròtia (St. Hil. A. bras. 2. p. 215.) leaves oblong, acute, obsoletely and dentately serrated, beset with rufes- cent hairs, biglandular at the base beneath; flowers almost sessile; styles a little longer than the stamens. $\zeta . S$. Native of Brazil, in the provinecs of Minas Geraes and St. Paul, in grassy pastures and ficlds. Pctals oblong, obovate, yellow.

Oblong-leated 'Turnera. Shrub to 1 foot.

7 'T. caru'lea (Noc. et Sesse, fl. mex. icon. ined. ex D. C. prod. 3. p. 3.46.) leaves oblong, coarsely serrated, but quite entire at the base, and hardly attenuated, clothed with adpressed villi beneath, biglandular at the top of the petiote; flowers sessile; styles longer than the stamens. 4. S. Native of Mexicn. This species is very like 'T', trioniflira, but differs in the leaves being on shorter petioles, and in being hardly attenuated at the base, as well as in the laairs on the lower surface of the leaves being adpressed. Bulb subfuscous. Flowers blue.

Blue-flowered Turnera. PI. $\frac{1}{2}$ to 1 foot.

8 T. subula'ta (Smith, in Rees' cycl. vol. 36. no. 2.) leaves ovate, acute, serrated, clothed with white soft hairs; bracteoles linear-subulate; flowers sessile. 4. S. Native of New Granada. Capsuie pilose. Glands of leaves broad.

Subulate-bractead Turnera. PI. I foot.

9 T. ACo'TA (Spreng. syst. 1. p. 940.) leaves lanceolate, acuminated at both ends, crenately serrated, glabrous; flowcrs sessile. $々$. S. Native of Jamaica. Flowers yellow, about the size of those of Linum trigynum. Petioles 3-4. lines long. Bracteoles setaceous, adpressed to the calyx. Perhaps T. acuita, Willd. rel. in Roem. et Schultes, syst. 5. p. 678, exclusive of the country.

Acute-leaved Turnera. Shrub 1 foot.

10 T. Arífena (Mart. reis. bras. ex D. C. prod. 3. p. 346.) plant downy ; leaves linear-lanceolate or lanccolate, acute, attenuated and biglandular at the base, remotely and acutely serrated, pubescent; stem suffruticose; branches twiggy ; flowers petiolar; bracteas shorter than the calyx. $h$. S. Native of Brazil, at Rio Jaquitinhonha and Rio Verde Grande.

Bee-bearing Turnera. Shrub 1 foot.

11 T. SEriceA (H. B. et Kunth, nov. gen. amer. 6. p. 127.) leaves oblong, crenately serrated, soft, clothed with adpressed pubescence above, and white, silky down beneath; flowers sessile; styles exceeding the stamens. $\eta_{2} . S$. Native of South America, about Cumana and between Popayan and Almagner. T. Peruviàna, Willd. in Rom. et Schultes, syst. 6. p. 679. Petals yellow, violaceous at the base. Shrub branched, rather prostrate.

Silly Turnera. Shrub 1 to 2 feet.

12 'T. mótuts (H. B. et Kunth, l. c. p. 126.) leaves ovateoblong, coarsely crenate-serrated, clothed with silky hairs on both surfaces, cancscent beneath; flowers sessile; styles pilose. h.S. Native of New Granada, near Honda. Petals yellow, with violaceous claws. Capsule roundish-ovate.

Soft Turnera. Shrub 1 foot.

13 T. Longir Lòra (St. Hil. fl. bras. 2. p. 216.) leaves oblong, obtuse, crenately toothed, biglandular at the base beneath, woolly on both surfaces, but especially beneath; flowers sessile; styles 3-times longer than the stamens. $h$. S. Natirc of Brazil, in the province of Minas Geraes. Petals obovate-oblong, yellow, red at the base.

Long-flowered Turnera. Shrub 1 to $1 \frac{1}{2}$ foot.

14. T. LUtéscens (St. Hil. A. bras. 2. p. 217.) leaves lanceolate, acute, crenately toothed, lower ones glandless, upper biglandular at the base beneath, clothed with silky pubescence on the upper surfaces, and with yellowish tomentum bencath; flowers sessile in fascicles. $h$. S. Native of Brazil, in the province of Minas Geraes. Petals oblong-obovate, of a golden yellow colour.

Íllonish Turnera. Shrub 2 to 3 feet.

15 'T. INCA'NA (St. Hil. fl. bras. 2. p. 217.) leaves oblong or K 2 
oblong-laneeolate, acutish, erenately-toothed, elothed with velvety pubescence above, and hoary tomentum beneath, and biglandular at the base; flowers sessile; styles one half shorter than the calyx. $h$.S. Native of Brazil, in the province of Goyaz. Petals yellow, obovate-oblong.

Hoary Turnera. Shrub 1 to 2 feet.

16 T. nermannoìnes (St. Hil. fl. bras. 2. p. 218.) leaves obovate-oblong, cuneated, unequally toothed, elothed with white tomentum on both surfaces, biglandular at the base beneath; flowers sessile; styles a little longer than the stamens. h. S. Native of Brazil, in that part of the province of Minas Geraes called Minas Novas. Petals oblong, marked with brown veins.

IIcrmannia-like Tumera. Shrub 1 to $1 \frac{1}{2}$ foot.

17 T. nelochioìes (St. Hil. A. bras. 2. p. 219.) leaves oblong, obtuse, narrowed at the base, unequally erenate-toothed, rather roughish above, and clothed with rufescent tomentum beneath, biglandular at the base; flowers sessile; styles a little shorter than the stamens. $\zeta$. S. Native of Brazil, in the province of Minas Geraes. Petals obovate, yellow.

Melochia-like Turnera. Shrub 1 to 2 feet.

18 T. NA'Na (St. Hil. fl. bras. 2. p. 219.) leaves oborate, rounded at the apex, crenated, pubescent on both surfaces, but especially beneatb, biglandular at the base; flowers sessile; styles $y$-times longer than the stamens. h.S. Native of Brazil, in the province of Minas Geraes. Petals obovate, yellow.

Dwarf Turnera. Pl. $\frac{1}{4}$ foot.

19 T. Piniròla (St. Hil. fl. bras. 2 p. 220.) leaves linear, acute, almost quite entire, biglandular at the base beneath; flowers nearly sessile; styles shorter than the stamens. 々.S. Native of Brazil, in the southern part of the province of Goyaz, on a mountain called Serra dos Pyreneos, near the town called Meia. Petals oblong, pale yellow.

Pine-lcaved Tumera. Shrub 1 foot.

$$
\text { * Lcaves glandless. }
$$

20 T. Gr.sistoides (St. Hil. fl. bras. 2. p. 220.) leaves linear, acutish, glandless, hairy ; flowers sessile ; styles twice the length of the stamens. $\boldsymbol{h}$. S. Native of Brazil, in the province of Minas Geraes, near Tejuco. Petals obovate-oblong, glabrous.

Genista-like Turnera. Shrub $\frac{1}{2}$ to 1 foot.

21 ' $\mathrm{I}$ '. chamedrufòla (St. Hil. fl. bras. 2. p. 221.) leaves oblong, acute, deeply toothed, glandless, pubescent on both surfaces, but especially beneath; flowers on short peduncles; styles exceeding the stamens. $h . S$. Native of Brazil, in that part of the province of Minas Geraes called Minas Novas, on the banks of the river Jiquitinhonha. Petals rose-coloured?

Germander-lcaved Turnera. Shrub $\frac{1}{3}$ to 1 foot.

22 '. Pinnatífida (Juss. in Poir. diet. 8. p. 144.) Jeaves obovate-oblong, cuneated, toothed, or pinnatifid, glandless, bairy or tomentose ; flowers pedunculate; styles 3-times longer than the stamens, purple. $h_{c} . S$. Native of Brazil, in the provinee of Cisplatin, in pastures and fields. Petals searlet, denticulated at the apex.

Var. $\beta$, angustiloba (1. C. prod, 3. p. 347.) stems diffuse; leaves hairy, pinnatifid: lobes narrow, acute; flowers of a dirty red or copper colour. 々. S. Native of Brazil, about Monte Video, and in the provinee of Cisplatin.

I'ar. $\gamma$, cárnea (St. Hil. fl. bras. 2. p. 222.) stems ascending, 6 inches high ; leaves hairy, oblong-lanceolate, cumeated, deeply toothed; petals pale red, usually marked at the base with a dark purple spot each; filaments puberulous. $\zeta$. S. Native of Brazil, in the province of Cisplatin.

Pinnatifid leaved Turnera, Shrub $\frac{1}{2}$ foot.

23 T. sritòsa (Smith, in Rees' cycl, no. 6.) leaves obovatewedge-shaped, serrated or pinnatific, very hairy on both sides, without glands; peduneles axillary, partly combined with the footstalks; outer calyx linear. দุ.S. Native of Monte Video and Buenos Ayres. Flowers tawny, red.

Bristly Turnera. Pl. $\frac{1}{4}$ to $\frac{1}{2}$ foot.

24 T. pumilea (Lin. amœen. 5. p. 395.) leaves broad-lanceolate, deeply serrated, hairy ; flowers sessile, propped by 2 linear bracteas; styles and stamens length of petals. $\odot$. S. Native of Jamaica, in arid fields. Swartz, obs. 116.-Sloane, jam. hist. t. 127. f. 6.-Pumílea, no. 1. P. Browne, jam. 188 . Stem hardly 3 inches long. Plum. icon. t. 150. f. 1. Flowers small, yellow.

Dnarf Turnera. Fl. July. Clt. 1796. Pl. $\frac{1}{4}$ foot.

25 T. merophy'Lla (D. C. prod. 3. p. 347.) leaves oblong, attenuated at the base, crenated, wrinkled, clothed with white tomentum beneath; flowers sessile, bearing 2 linear, adpressed bracteoles at the base. h. S. Native of St. Domingo. T. pumílea, Poir. dict. 8. p. 143. but not of Swartz. Petiv. gaz. t. 38. f. 9. T. diffùsa, Willd. rel. in Rœm. et Sehultes, syst. 6. p. 679. This plant differs from T. pumilca in the stem being suffrutescent, nearly a foot high, and much branched. Perhaps T. microphylla, Desv. in Hamilt. prod. p. 33. is referrible to this plant.

Small-lcaved Turnera. Shrub 1 foot.

\$2. Peduncles distinet from the petioles, axillary. Flowers bibractcolate.

26 'T. RUPE'strus (Aubl. guian. 1. p. 289. t. 113. f. 1.) leaves linear, serrated, glabrous, glandless ; flowers nearly sessile, bearing 2 setaceous bracteoles at the base. $\eta$. S. Native of Guiana, in the fissures of humid roeks, at the river Sinemari. Petals yellow, somewhat toothed at the apex, 3 lines long. Flowers small,

Rock Turnera. Fl. Ju. Sept. Clt. 1824. Slurub 2 to $3 \mathrm{ft}$.

27 T. FRUTE'scens (Aubl. l. c. p. 290. t. 113. f. 2. but not of Mill.) Jeaves lanceolate, acuminated, equally serrated; Howers nearly sessile, bearing 2 sessile, lanceolate-linear bracteoles. h.S. Native of Guiana, in the fissures of rocks, on the banks of the river Sinemari. Very like $T$. rupéstris, but differs in the leaves being broader, and in the serratures being more crowded. Flowers small, yellow,

I'ar. $\beta$, latifólia (D, C. prod. 3, p. 347.) leaves ovate, acute. h. S. Native of Cayenne.

Shrubby Turnera. Shrub 5 to 8 feet.

2S T. тоmentós (H. B. et Kunth, nov. gen. amer, 6. p. 125. but not of Willd.) leaves oblong, irregularly crenate-serrated, pubescent above, but clothed with canescent tomentum beneatl, glandless at the base; flowers sessile, with 6 stamens and 6 petals, h. S. Native of South Ameriea, in the province of Venezuela. Styles hairy, about equal in length to the stamens. Petals yellow.

Tomontose Turnera. Slurub 1 foot.

29 T. sidoines (Lin. mant. p. 58.) leaves obovate-cuneated, serrated, quite entire at the base, rather tomentose on both surfaces, pilose on the veins and margin beneatl; flowers on very short pedicels; bracteoles linear, hairy. $\zeta$. ? S. Native of Brazil. Habit of T. cistoides. Petals obovate, yellow.

Sida-like Turnera. Shrub $\frac{1}{2}$ foot.

30 T. carpinifòla (H. B. et Kunth, l. e.) leaves oblonglanceolate, doubly serrated, puberulous, biglandular at the base; flowers on short pedicels; bracteoles ovate, acuminated, serrated. $\boldsymbol{z}$. S. Native on the humid banks of the river Orinoco, near Maypures. T. acuta, Willd. rel. in Roem. et Sehult. syst. 6. p. 678. ex Kunth. Flowers yellow. According to Willd. the flowers are petiolar; if such be the case, the plant belongs to the preceding section.

IIorncbeam-leaved Turnera. Shrub 1 to 2 feet.

31 'T. Duarten'na (St. Hil. fl. bras. 2. p. 223.) leaves ovate, 
obtuse, crenated, glandless, pubeseent above, hairy, tomentose beneath, white ; peduneles simple. $h . S$. Native of Brazil, in the western part of the province of Minas Geraes. Styles shorter than the stamens. Petals 3 -times longer than the calyx, erose, or rounded at the apex, rose-coloured when dry. Bracteas small, deciduous.

I ar. $\beta$, rotundifölia (St. Hil. 1. c.) leaves smaller, ovateroundish ; flowers yellow. This variety will perhaps constitute a distinct species.

Duarte's 'Turnera. Shrub I foot.

32 T. Hellavtiremoides (St. Hil. l. c. p. 224.) leaves oblong or oblong-lanceolate, acutish, unequally denticulated, glandless, pubescent above, but clothed with white tomentum beneatlı; flowers axillary; peduncles simple; bracteas small, deciduous. r. S. Native of Brazil, in the southern part of the provinee of Goyaz, on the banks of the river Paraliyba. Petals obovate. Styles about equal in length to the stamens.

Sun-rose-like Turnera. Pl. $\frac{1}{2}$ to 1 foot.

33 T. ròsea (St. Hil. l, c. p. 225.) leaves linear-lanceolate, obtuse, obsoletely denticulated, glandless, rather pilose on botll surfaces; pili rufescent; peduncles simple ; bracteas snuall, deciduous. $々$. S. Native of Brazil, in the province of St. Paul, not far from the town called Franca. Petals rose-coloured, obovate, erose at the apex. Styles twice the length of the stamens.

Rose-coloured Turnera. $\frac{1}{2}$ to 1 foot.

34 T. SiD.eròdia (St. Hil. I. c. p. 227. t. 124.) leaves oblong,

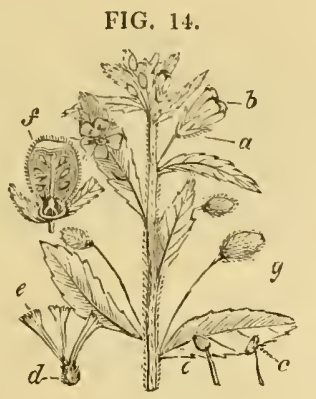
obtuse, crenated, glandless, ra-

ther scabrous above, but elothed with hoary tomentum beneath ; peduncles axillary, I-2-flowered; bracteas small, subulate, tomentose. $々$. S. Native of Brazil, in the province of Minas Geraes, at a place called Aldea da boa Vista. Petals obovate, obsoletely crenulated, yellow. Styles shorter than the stamens.

Sida-lcaced Turnera. Shrub $\frac{1}{2}$ to 1 foot.

35 T. AU'REA (St. Hil. l. c. p. 226.) leaves oblong, narrowed at the base, acute, or rounded at the apex, serrately toothed, glandless, beset with golden hairs; peduncles simple, articulated in the middle. $\xi_{\text {. }}$ S. Native of Brazil, in the province of Minas Geraes, near the town of St. Joao del Rey. Petals twice or thrice the length of the calyx, cuneated at the base and rounded at the apex, rose-coloured or flesh-coloured; each marked by a dark purple spot at the base. Styles shorter than the younger stamens.

Goldcn-haired Turnera. Shrub $\frac{1}{4}$ to 1 foot.

$\S 3$. Floners disposed in axillary and terminal raccmes.

36 T. RAcemòsa (Jacq. hort. vind. 3. t. 94.) leaves oblong, or oblong-lanceolate, acutisl, unequally denticulated, glandless, pubescent above, and elothed with white tomentum beneath; upper flowers leafless at the base, and therefore disposed in a terminal raceme; peduncles simple. $\odot$. S. Native of Brazil, in the province of Minas Geraes, on the banks of the river Jiquitinhonha; and of St. Domingo. Stem and peduncles hispid. Petals ovate, yellow, furnished each with a small jagged appendage on the inside at the base. Styles longer than the stamens.

Rncemose-flowered Turnera. Fl. July, Aug. Clt. 1789. Pl. 1 to 2 feet.

37 T. salscifòlia (St. Hil. 1. c. p. 227.) leaves lanceolate, acuminated, serrated, glandless, smoothish ; peduncles axillary, many-flowered. h. S. Native of Brazil, near Rio Janciro. Petals obovate, striated, yellow, denticulated at the apex. Styles about equal in lengtl to the calyx.

Willow-lcavcd Turnera. Shrub 2 to 9 feet.

38 T. capita'ta (St. Hil. l. c. p. 215.) leaves elliptic-oblong, or oblong-lanceolate, acute, dentately serrated, nearly glandless, pubescent above, and clothed witl yellowish tomentum beneath; tlowers sessile, forming a many-flowered head at the tops of the branches. h.S. Native of Brazil, in the province of Minas Geraes, on the margins of woods near Poso Alto, not far from the confines of the province of St. Paul, and on the iron mountains near Nossa Snra da Concecao. Petals obovate-oblong, pale yellow. Styles much shorter than the stamens.

Capitate-flowered Turnera. Shrub 2 to 3 feet.

39 T. GuiAnE'ssis (Aubl. guian. 1. p. 291. t. 114.) leaves linear, acuminated, remotely serrated, biglandular at the base, glabrous on both surfaces; racemes terminal, few-flowered; pedicels leafless at the base, but bibracteolate under the calyx. $\odot$.S. Native of Guiana, in moist meadows, and in the plains of Caraccas. H. B. et Kuntl, nov. gen. amer. 6. p. 124. 'T. IIumbóldtii, Spreng. syst. 1. p. 241. Glands small, sometimes 1-2, abortive. Bracteas glandular at the base. ex Aubl. Capsule ovate, trigonal, 3 or few-seeded. Flowers yellow. Perhaps Humboldt's plant is the same as that of Aublet.

Guiana Turnera. Fl. Ju. Jul. Clt. $1823 . \quad \mathrm{Pl} .1$ to 2 feet.

4.0 T. gLA'BRa (D.C. prod. 3. p. 347.) leaves linear, obtuse, subserrated, narrowed at the base, glandless; racemes fewflowered; pedicels rising from the axils of small linear leaves and longer than them, articulated and bractless above the middle. $\odot$.? S. Native of St. Domingo. Stems erect, glabrons. Flowers yellow?

\section{Glabrous Turnera, Pl, 1 to 2 feet.}

41 T. cistoìdes (Lin. spec. 387.) leaves linear-lanceolate, serrated, pubescent above, tomentose beneath, glandless at the base; racemes terminal, leafy ; pedicels rising from the axils of lanceolate leaves, and shorter than them, artieulated and hractless above the middle. $\odot$.S. Native of South America, in sterile places, Surinam, Jamaica, St. Domingo, Georgia, S'c. Sloan. jam. hist. 1. p. 127. f. 7. Plum. ed Burm. t. 150. f. 1. Swartz. obs. 117. T. hirsùta, Bert. mss. Flowers small, yellow. Rock-rosc-like Turnera. Fl. June, Oct. Clt. 1774. P'l. $\frac{1}{2} \mathrm{ft}$.

42 T. ÁSpera (Poir. dict. 8. p. 144.) leaves elliptic, sessile, a little toothed, pubescent abore, and rather tomentose beneath, glandular; stem hardly pubescent, rough ; racemes leafy, terminal; pedicels rising from the axils of the leaves, and shorter than them, articulated above the middle. $\odot . S$. Native of French Guiana. Flowers yellow. Perhaps a variety of $T$. cistoìdes or of Periquèta villòsa.

Rough Turnera. Pl. $\frac{1}{2}$ foot.

\section{$\dagger$ Specics not sufficicntly knonn.}

43 T. odora'ta (Rich. in act. soc. hist. nat. par. 1792. p. 107.) shrubby, much branched ; flowers small; leaves ovate, acute, toothed, tomentose. $\eta_{2}$. S. Native of Cayenne. Flowers yellow?

Snect-scented Turnera. Shrub.

44 T. nírta (Willd. rel. in Rom. et Schult. syst. 5. p. 678.) leaves linear-lanceolate, unequal, bluntly serrated, clotled with stellate tomentum ou both surfaces; flowers axillary, solitary; stem branched, hairy. $\odot$. S. Native of Brazil. Flowers yellow.

IIairy 'T'unera. Fl. June, July. Clt. 1818 . 1']. $\frac{1}{2}$ to $1 \mathrm{ft}$.

45 T. Brazis:é sisis (Willd. rel. l.c.) leaves lanceolate, quite entire, clothed with hispid pubescence; flowers axillary, sessile,

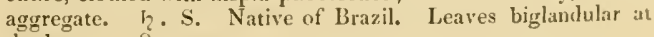
the base. ex Spreng. 
Brazilian Turnera. Fl. Ju. Jul. Clt. 1810. Pl. $\frac{1}{2}$ to $1 \mathrm{ft}$.

46 T. integrisòia (Willd. rel. 1. c.) peduncles 1-flowered, axillary; leaves linear-lanceolate, pubescent, glandless.-Native country unknown. Leaves revolute, sessile, strigose above, but c'othed with stellate tomentum beneath. P'eduncles branched, bractless. (ex Spreng. syst. 1. p. 942.)

Entire-lcaved Turnera. Pl.?

47 'T. virga'ta (Willd. rel. l. c.) leaves ovate, serrated, plicate, biglandular at the base; flowers bibracteate; bracteas linear-sctaceous. $\odot$. S. Native of Brazil.

Triggy Turnera. Pl. $\frac{1}{2}$ to 1 foot.

48 T. corcioriròma (Willd. rel. l. c.) leaves oblong, doubly serrated, tomentose beneath. $\odot$. S. Native of Brazil. The rest unknown.

Corchorus-lcaved Turnera. Pl. $\frac{1}{2}$ to 1 foot?

49 T. Desvau'xir (D.C. prod. 3. p. 348.) stem suffruticose, branched; branches assurgent, hairy ; leaves ovate, obtuse, crenately toothed at the base, rather pilose beneath; flowers axillary, on long peduncles.-Native of Guiana. T. lúrta, Desv. in Hamilt. prod. p. 33. but not of Willd.

Destaux's Turnera. Pl. 1 foot.

Cult. All the species of Turnèra are elegant plants when in flower, and thrive well in any light rich soil. They seed frecly in this country, and may be propagated by that means : cuttings also root freely, under a liand-glass, in heat. The seeds of annual species may be reared on a hot-bed in spring; and some of the plants may be planted ont in to the open border, in a warm sheltered situation, where they will probably flower and ripen their seeds, if the summer prove dry and warm.

II. PIRIQUE'TA (meaning not explained by Aublet). Aubl. guian. 1. p. 298. t. 117 . Juss. gen. 294. H. B. et Kunth, nov, gen. amer. 6. p. 127. D. C. prod. 3. p. 348.- Burghártia, Neck, elem. no. 1186 .-Burcárdia, Scop. ex Sclıreb. gen. no. 530. but not of Schmied. nor Duham. nor Neck. nor R. Br. -Turnèra species, Lam. and Willel.

Lin. srst. Pentándria, Tri-Hexagýnia. Calyx campanulate. Style 6 , or 3 bipartite ones; stigmas multifid, flabellate. Capsule 3-valved from the apex to the base. Perhaps this genus is sufticiently distinct from the preceding. Habit of Tu . nèra raccmosa, but which plant is only furnished with 3 styles, not 6 . Flowers pedicellate, in the axils of the upper leaves. Pedicels bractless, articulated above the middle.

1 l'. villòsi (Aubl. l. c.) leaves ovate-oblong, eroscly toothed, wrinkled, clothed with rufous villi. $\odot$. S. Native of Guiana, in sand by the sea-side. Turnèra rugòsa, Willd. spec. 1. p. 1504. Poir. dict. 8. p. 145. Turnèra villòsa, Rausch. Corolla yellow.

Villous Piriqueta. Pl. 2 feet.

2 P. TounenòsA (H. B. et Kunth, nov. gen. amer. 6. p. 128.) leaves oblong, acutish at both ends, irregularly crenate-serrated, pubcsccnt above, clothed with soft hoary tomentum beneath. $\odot$. S. Native of South America, between Atures and Maypures, on the Orinoco. Turnèra tomentòsa, Willd. rel. in Rocm. et Schultes, syst. 6. p. 678. but not of H. B. et Kunth, Corolla yellow.

Tomcntose Piriqueta. Shrub 1 to 2 feet.

Cult. The culture and propagation of these plants are the same as for the annual species of Turnèra, see p. 70.

Order CIX. FOUQUIERA'CEE (plants agreeing with Fouquièra in important characters). D. C. prod. 3. p. 319.Portulàceis affines, H. B. et Kuntl, nov, gen. amer. 6. p. 81.

Calyx of 5 permanent sepals; sepals imbricated, ovate or roundish. Petals 5, combined into a tube, inserted in the bottom of the calyx or torus; limb of corolla 5-lobed, regular. Stamens 10-12, inserted with the corolla, exserted; anthers 2celled. Ovarium frec, sessile. Style filiform, trifid at the apex. Capsule trigonal, 3-celled; valves bearing dissepiments in their middle, which go as far as the centre of the fruit, and therefore the capsule is 3-celled. Sceds compressed, winged, fixed to the centre of the fruit or axis, few when the capsule is mature, but numerous when it is in a young state. Embryo straight, in the centre of a fleshy albumen, with flat cotyledons. -Trees or slurubs, natives of Mexico. Leaves in fascicles when young, in the axils of spines or cushions, quite entire, oblong, and rather fleshy. Flowers scarlet, disposed in a terminal spike or panicle.

This order is separated from Portulicea by De Candolle, as he tells us, (Mem. portul. p. 4.) for the following reasons : first, because their petals cohere into a long tube, of the same nature as that of gamopetalous Crassulàcece; second, becanse their capsule consists of 3 loculicidal cells, that is to say, which separate through the middle, forming 3 septiferous valves; and thirdly, because their embryo is straight, with flat cotyledons, and stationed in the centre of a fleshy albumen. They approach the monopetalous Crassulacese in the structure of thcir flowers; and Turncràcece and Loàsece in the form of their fruit.

\section{Synopsis of the genera.}

1 Fouquie'ra. Sepals ovate, mucronate, free, 2 exterior and 3 interior. Limb of corolla spreadingly reflexed. Stamens 10-12, hypogynous.

2 Brónnia. Sepals roundish; limb of corolla erect. Stamens 10 .

I. FOUQUIE'RA (in honour of Peter Edward Fonquiere, M. D. of Paris, and Professor of Medicine there). H. B. et Kunth, nov. gen. amer.6. p. 81. t. 527 . D. C. prod. 3. p. 349. -Echevèria species, Moc. et Sesse, icon. ined.

LiN. syst. Decándria, Monogýnia. Calyx coloured; sepals ovate, mucronate, 2 exterior and 3 interior, free. Corolla liypogynous; tube cylindrical, a little arched; limb spreadingly reflexed, nearly regular. Stamens 10-12, hypogynous, exserted; filaments ciliated below, and cohering together; anthers cordate. Ovulas 18 , on each placenta, in 2 rows. Fruit unknown. A somewliat spinose slirub. Spikes terminal, erect. Flowers scarlet. Leaves oblong, rather fleshy.

1 F. Forsòs (H. B. et Kuntl, l. c.). দ. S. Native of Mexico. Echevèria spicàta, Moc. et Sesse, fl. mex. icon. ined. Flowers flesh-coloured, an inch long. Leaves scattered, according to Kunth's figure ; but according to the figure in the fl. mex. they are a little narrower and in fascicles: therefore the 2 figures mentioned are very unlike each other.

Showy Fouquiera. Shrub 6 to 10 feet.

Cult. A light rich soil will suit this very showy shrub; and young cuttings will root freely under a hand-glass, in heat.

II. BRO'NNIA (in honour of Henry George Bronn, a young botanist, who has written on the form of leguminous plants). H.B. et Kuntl, nov. gen. amer. 6. p. 83. t. 528. D. C. prod. 3. p. 349.-Echevèria species, Moc. et Sesse, fl. mex. icon. ined.

Lin. syst. Decándria, Monogýnia. Calyx permanent ; sepals 5 , roundisl. 'Tube of corolla cylindrical, straight ; limb 
ereet. Stamens 10 ; filaments filiform, exserted; anthers ovate. Style exceeding the stamens. Cells of fruit 1 -seeded when mature. A spinose shrub, with fascicles of obovate-oblong, membranous leaves in the axils of the spines. Flowers panicled, scarlet. It differs from the last genus in the placentas being drawn in more to the centre of the fruit.

1 B. spindsa (II. B. et Kunth, l. e.). h. S. Native of Mexico. Echevèria paniculata, Moc. et Sesse, fl. mex. icon. ined. Fouquièra spinòsa, H. B. et Kunth, nov, gen. amer. 3. p. 452. Cảntua spinòsa, Willd. in Rœm. et Schultes, syst. 4. 1). 369 .

Spiny Bronnia. Tree 12 to 14 fect.

Cull. See Fonquièra, p. 70. for culture and propagation.

Order CX. PORTULACEE (plants agreeing in important characters with Portulàca). Juss. gen. p. 318. exclusive of some genera. D. C. f. fr. ed. 3. vol. 4. p. 398. prod. 3. p. 351. St. Hil. pl. lib. p. 42.

Calyx free, or somewhat adnate to the very base of the ovarium (f. 15.a.f. f. 18. a.), nsually of 2 sepals (f. 16. $a$. f. 18. a.), seldom of 3 or $5(f .20, a$.), coliering at the base. Petals usually 5 (f. 15.b. f. 17. b.), but sometimes 3-4-6, very rarely wanting altogether, either distinct (f. 18, b.), or cohering into a short tube at the base (f. $15, b$.), alternating with the sepals when the number is equal. Stamens inserted along with the petals, irregularly into the base of the calyx, and sometimes perhaps in the torus, variable in number in the specics of the same genus, all fertile; filaments distinct, adnate to the base of the petals ( $f$. 15. g.), and usually opposite them where the number is equal ; anthers ovate, 2-celled, opening lengthwise, versatile (f. 18. c.). Ovarium one, usually roundish (f. 15.e.), 1-celled (f. 15. f.). Style sometimes single, filiform, cleft into numerous stigmas at the apex (f. 15. c.); sometimes wanting or nearly so ; when this is the case the stigmas are distinct (f. 17, c.), and rise in numbers from the top of the ovarium. Capsule 1-celled, opening either transversely (f. 15. f.), or by the 3 valves from the base to the apex; but they are also occasionally 1 -seeded and indehiscent. Seeds numerous when the fruit is dehiscent, attached to the central placenta (f. 15. f.). Albumen farinaceous. Embryo curved round the circumference of the albumen, with a long radicle, and oblong cotyledons.-Fleshy shrubs or herbs. Leaves alternate, rarely opposite, entire, usually succulent, without stipulas, or sometimes with membranous ones on each side of the petioles. Flowers axillary or terminal, usually expanding in the sun, and of short duration. The 1-seeded genera of this order agree in character with the order Paronychiè a, and the apetalous genera with the order Ficoidece. This order is related in nearly every point of view to Caryophyllea, from which they scarcely differ except in their perigynous stamens, which are opposite the petals when equal to them in number, and two sepals; the latter character is not, however, very constant. The presence of scarious stipulas in several Portulàcea, although perhaps an anomaly in the order, indicates their affinity with Paronychiè, from which the monospermous genera of Portulacce are distinguished by the want of symmetry in their flowers, and by the stamens being opposite the petals, instead of the sepals. So close is the relationship between these orders, that several of the genus Ginginsia in P'ortulicce liave been referred to Pharnaceum in Caryophigllece, ant several Portulàcea lave been described by authors as belonging to genera of I'aronychièce. De Candolle remarks, that his Ginginsia brevicaúlis resembles certain species of Andrósace, and that Portuliccae have been more than once compared to l'rimulicece (mem. p. 14.), and the same author remarks in lis prod. 3. p. 351 . that the genera with definite stamens, and hairy axilla approach Cáctea, while the apetalous genera tend towards apetalous Ficoídece.

Insipidity, want of smell, and a dull green colour, are the usual qualities of this order, of which the only species of any known use are common Parslane and Claytònia perfolicita, which resemble each other in properties.

\section{Synopsis of the genera.}

1 Trú'sturma. Sepals 5 , concrete at the base, coloured. Petals wanting. Stamens 5, rarely 10 or more. Styles or stigmas 1-2, rarely 3. Capsule opening transwersely.

2 Crpse'LeA. Caly $x$ campanulate, 5 -parted, coloured. Petals none. Stamens 2-3. Style hardly any, bipartite, or probably : stigmas. Capsule opening transversely.

3 Portula'ca. Calyx bipartite (f. 15. a.), at length falling off. Petals 4-6, equal (f. 15. b.), free or concrete at the base. Stamens 8-15 (f. 15. g.). Style one, 3-6 cleft at the apex (f. 1j. c.); or style wanting, and the stigmas $3-8$ elongated. Capsule opening transversely $(\mathrm{f}, 15, f$.).

4. Grain'mis. Calyx of 2 white permanent sepals, girded by $8-9$ bracteas. Petals 5 , obovate. Stamens numerous, united at the very base. Style 1; stigmas 4-5, revolute. Capsule 1celled, 5-valved, many-seeded. Seeds compressed, winged.

5 Anaca'mpseros. Sepals 2 (f. 16. $a$.), eolering at the basc. Petals 5 (f. 16. b.), very fugaceous. Stamens 15-20 (f. 16. $c_{\text {. }}$ ). Style filiform, trifid at the apex (f. 16. d.). Capsule conical, svalved (f. 16. c.). Sceds winged.

6 Talisum. Sepals 2 (f. 17, a.), dcciduous. Petals 5 (f. 17. b.), free or somewhat concrete at the base. Stamens 10-20. Style filiform, 3-cleft at the apex (f. 17. c.). Capsule 3-valverl. Seed wingless.

7 Lewísia. Calyx of 5 sepals. Petals 9-12. Stamens 1216 , hypogynous. Style deeply 6 -parted, with the segments filiform, and the stigmas obtuse.

8 Calandrínia. Calyx 2-parted (f. 18, a.). Petals 3-5 ( $f$. 18. b.), free or rather connate at the base. Stamens 4-15) (f. 18 . c.). Style one, very short, tripartite at the apex (f. I8. c.); lobes clavate. Capsule oblong-elliptic, 3-ralved. Sceds wingless.

9 Portulaca'ria. Calyx of 2 sepals, membranous. Petals 5 , permanent. Stamens 5, or probably 10,5 of which are abortive. Style wanting; stigmas 3 , spreading, glandular. Frui triquetrous, winged, indeliscent, 1-seeded.

10 L'iluces. Sepals 2, coloured, deciluous. Petals 5 , connected into a very short tube at the base. Stamens 5 , short. Style filiform; stigma simple. Capsule 1-celled, 1-sceded. 
11 Claytònia. Sepals 2 (f. 19. a. f. 20. a.), permanent. Petals 5 , unguiculated (f. 19. b. f. 20.b.); claws connate at the hase. Stamens 5 (f. $20 . d_{\text {. }}$ ). Style one, trifid at the apex (f. 19. c. f. 20. c.); lobes stigmatose inside. Capsule 3-valved (f. 20. c.), 3-seeded.

12 Móntia. Calyx of 2, rarely of 3 sepals. Petals 5, rather connate at the base, 3 of which are a little smaller than the rest. Stamens usually 3 in front of the smaller petals, making 9 , very rarely $3-4$. Capsule 3 -valved, 3-seeded.

13 Lceptrina. Calyx 3-parted. Petals wanting. Stamens 3. Styles 3, short, acute. Capsule 3-valved, 3-seeded.

14 Colobánturs. Calyx 4-5-parted. Petals wanting. Stamens 4-6. Stigmas 4-5. Capsule 4-7-valved, many-seeded.

15 Ginginsia. Calyx 5-parted, permanent, petaloid on the margins and in the inside. Petals wanting. Stamens 5. Ovarium girded by a 5 -lobed fleshy seale. Capsule 3-valved, manyseeded.

16 Ayche'ria. Calyx 2-parted, coloured. Petals 5. Stamens 10 , menbranous, connected into a hypogynous tube, the 5 inner ones abortive. Style one, crowned by a depressed capitate stigma. Capsule bladdery, membranous, valveless. Seeds numerous in the bottom of the cell.

17 IYdropr'xis. Calyx 5-parted, permanent. Corolla unequally 5 -lobed. Stamens 4,2 long and 2 slort, inserted in the corolla. Ovarium superior. Style simple, crowned by a 3-lobed, capitate stigma. Capsule triangular, 1-celled, many-seeded, opening transversely.

I. TRIA'NTHEMA (from $\tau$ pess, trcis, three, and $r e q 0 s$, anthos, a flower; flowers are usually disposed by threes). Sauv. meth. fol. p. 127. Lin. gen. no. 537. D. C. prod. 3. p. 351.Zalèya, Burm. fl. ind. p. 110.-Rocàma and Papulària, Forsk. dese. 69 , et 71 .

Lrs. syst. Pent-Decándria, Monogýnia. Sepals 5, permanent, connected together at the base, rather coloured on the inside, and mucronated under the apex. Petals wanting. Stamens $5-10$, rarely more, distinct, inserted in the bottom of the calyx ; anthers kidney-shaped. Ovarium ovate. Styles or stigmas filiform, 1-2, rarely 3 . Capsule opening transversely below the middle; the upper valve, which separates like a lid, is hollow, and contains a seminiferous cell ; therefore both cells are either simple, or of two divisions, one or few-seeded.-More or less fleshy herbs, which are sometimes suffruticose at the base. Leaves opposite, quite entire, petiolate. Petioles dilated into a stipula-formed membrane on both sides. Flowers axillary, sessile, usually by threes.

Sect. l. 'ZnLe'ya (meaning not explained by Burmann). Burm. fi. ind. p. 110 . D. C. prod. 3. p. 35\%. Stamens 10 or more.

1 T. POLYA'NDRA (Blum. bijulr. p. 1137.) stems herbaceous, procumbent; branches terete; leaves linear, obtuse; flowers pedunculate, solitary, polyandrous, trigynous. $\%$. S. Native of Batavia, in bogs.

Polyandrous Trianthema. Pl. er.

2 '. govínnis (Ham. ex Wall. cat. no. 6838.) stems suffruticose, trailing ; leaves opposite, elliptic, emarginate at the apex; those opposite each other of unequal size ; flowers axillary, aggregate, sessile. h.S. Native of the East Indies, in Mungger. Plant glaucous. The number of stamens and styles unknown. Govindia l'rianthema. Shrub prostrate.

3 T. DECA'NdRA (Lin. mant. p. 70.) stem herbaceous, gla- brous, diffuse, terete; Jeaves elliptic, acute. $\odot$. F. Native of the East Indies. Zalèya decándra, Burm. l. c. t. 31. f. 3. Petioles furnished at the base on both sides with a broad membrane. Flowers on short pedicels, disposed in fascieles in the axils. Sepals mucronate at the apex. Stamens 10-12. Styles 2. Dccandrous Trianthema. Fl. July, A ug. Clt. 1762. Pl. tr.

4 T. Tríuetra (Rottl. et Will. in nov. aet. nat. berol. 4. p. 180.) stem herbaceous, dichotomous, branched; branches compressedly triquetrous; leaves somewhat spatulate, petiolate; flowers axillary, sessile.-Native on the coast of Coromandel. Structure of flower unknown.

Triquetrous Trianthema. Pl. diffuse.

5 'T. Humfu'sa (Thunb. f. cap. p. 389.) stems frutescent, trailing, terete; leaves lanceolate, attenuated at both ends. ?. G. Native of the Cape of Good Hope, in Konde Bokeveldt. Stamens 10 , alternate ones shorter. Thunberg in his prodromus says the flowers are monogynous, but in his flora he says they are digynous.

lar. $\beta$; stamens 10 , one-half shorter than the calyx, fixed by pairs to the base of the calycine segments. - Native of the Cape of Good Hope, at Ilex River.

Trailing Trianthema. Slırub tr.

6 T. A'NCEPs (Thunb. f. cap. p. 399.) stem frutescent, diffuse, 2-edged ; leaves lanceolate, attenuated at both ends, acu-

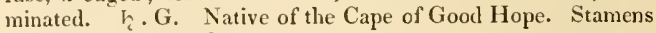
10. Style 1 , very short.

Two-edged-stenmed Trianthema. Shrub diffuse.

SEct. II. Roca'ma (Rokama is the Arabie name of T. pentándra). Forsk. descript. p. 71. D. C. prod. 巳. p. 352. Stamens 5 .

7 T. PENTÁNDRA (Lin. mant. p. 70.) stem rough from velvety hairs; leaves elliptic, obtuse, flowers crowded in the axils of the leaves. 24. (ex Forsk.) $h_{c}$. (ex Lin.) Native of Arabia. Rocàma dígyna, Forsk. l. e. Rocàma Arábica, Gmel. syst. 1. p. 455. Pluk. phyt. t. 120. f. 3. ex Lin. T. pentándra, Gartn, fruct. 2. p. 213. t. 128. f. 5. Lam. ill. t. 375. f. 2. Stamens 5. Styles 2. Perhaps 2 species are here confused, the stems being, according to Linnæus, erect and shrubby, and according to Forskal annual and prostrate.

lar. 3, obcordàta (D. C. prod. 3. p. 352.) leaves obovate, bluntly emarginate at the apex.-Native of the East Indies. T. obcordata, Roxb. lrort. beng. p. 34.

Pentandrous 'Trianthema. Fl. July, Aug. Clt. 1820. Pl. pr.

8 T. monógrna (Lin. mant. p. 69.) stem herbaceous, diffuse, dichotomous, branched, glabrous ; leaves oval, obtuse, opposite, one of them smaller than the other; flowers axillary, sessile, bibracteolate. $\odot$. S. Native of Jamaica, Curassoa, and Mlexico. D. C. pl. grass, t. 109 . Lam. ill. t. 375. f. 1 . T. portulacástrum, Sauv. meth. p. 127. Lin. spec. 635. T. procúmliens, Mill.-Pluk. alm. t. 95. f. 4. Stamens usually 5, alternating with the sepals, but sometimes 10 . Styles 1 or 2. Lower cell of capsule about 4-seeded: upper one 1-seeded.

Monogynous Trianthema. Fl. July, Aug. Clt. 1710. Pl. pr.

9 T. crystállina (Vahl. symb. 1. p. 32.) stem shrubby, difluse, tercte, glabrous, papulose; leaves linear or lanceolate, opposite, one of them smaller than the other; Howers crowded, axillary. $\eta_{2}$ G. Native of Arabia and the East Indies. Papulària crystállina, Forsk. desc. p. 69. Stamens alternating with the petals. Style 1 .

Icy Trianthema. Shrub diffuse.

Cult. The seeds of the species of Trianthema require to be sown on a hot-bed in spring; and about the end of May they may be planted out in the open border in a warm sheltered situation, where they will probably flower and seed. Some are said 
to be shrubby, these it will be requisite to treat as other stove plants ; and cuttings of them will be easily rooted.

HI. CYPSE'LEA (from $\kappa v \psi \varepsilon \lambda \eta, k y p s c k$, a bee-hive; in reference to the form of the capsule). Turp. in ans. mus. 7. p. 219. t. 121. f. 5. D. C. prod. 3. p. 353.-Radiàna, liafin. speech. 1. p. 88 .

Lı. syst, Di-Triándria, Digǵnia. Calyx campanulate, permanent, coloured, 5 -parted; lobes obtuse, 2 of which are smaller than the other 3. Corolla wanting. Stamens 2-3, inserted in the calyx and alternating witl its lobes (ex Turp.), or opposite the smaller lobes (ex Rafin.). Ovarium frec, 1-celled Style hardly any, 2-parted, or stigmas 2. Capsule 1-celled, many-seeded, opening transversely. Seeds fixed to an oval, central placenta, very small, and very numerous.-Herbs, natives of St. Domingo, with the habit of MIontia or Crypta, rather succulent, annual, and glabrous. Leaves opposite, obovate; petioles widened into a stipule-formed, jagged membrane. Flowers axillary, small, greenish, solitary, on short pedicels.

l C. Humiru'sa (Turp. l. c.). $\odot$. S. Native of St. Domingo. Tratt. obs. bot. 2. p. 41. t. 72. Radiàna petiolàta, Rafin. 1. c. Millegràna Surian, in herb. Juss.

Trailing Cypselia. PI. tr.

Cult. Sow the seeds thinly in a pot, and place them in a hot-bed, or in a stove, with a pan of water under the pot. Not worth growing, except in a botanic garden.

HI. PORTULA'CA (from yorto, to carry, and lac, milk; plants milky). Tourn. inst. t. 118. Adans. fam. 2. p. 242. Juss. gen. p. 312.-Portulàca species of Lin.-Meridiàna, Lin. et Schrank.-Lèmia, Vand. in Rcem. script. p. 116. t. 7. f. 15. - Merida, Neck.

Lin. syst. Octo-Dodecándria, Monogýnia. Calyx free from or adhering to the ovarium at the very base, bipartite (f. 15. $a_{0}$ ), at length cut round about at the base, and falling off. Petals 4-6 (f. 15. b.), equal, distinct, or joined together at the very base, inserted in the calyx. Stamens 8 (f. 15. g.) -15; filaments free, sometimes adnate to the bottom of the corolla ( $\mathrm{f}$. 15.g.). Orarium roundish. Style 1 (f. 15. d.), 3-6-cleft at the apex (f. 15. c.), or the style is wanting; but in this case, the stigmas are 3-8 and elongated. Capsule sub-globose (f. 15 . $f$.), 1-celled, opening transversely in the middle. Seeds numerous, fixed to a central placenta (f. 15. f.).-Humble fleshy herbs. Leares scattered, quite entire, thick, usually bearing hairs in the axils, crowded, or somewhat verticillated about the flowers. Flowers expanding from 9 till 120 'clock in the morning, if the sun shine, otherwise they remain closed.-This is a heterogenenus genus, and probably divisible, but easily distinguished by the capsule opening transversely.

\section{* Flowers yellow. Axils of leaves naked.}

1 P. olera'ceA (Lin. spec, p. 638.) leaves wedge-shaped, Heshy; axils and joints naked; flowers sessile. $\odot$. H. Native nearly throughout the whole world. D. C. pl. grass. t. 123. Schkubr. handb. t. 130. Petals concrete at the base. Stamens 10-12, adnate to the corolla. Style wanting. Stigmas 5, elongated. Perhaps specifically distinct from the following varieties. -Blackw. icon. t. 287.

Var. a, sylcéstris (D. C. prod. 3. p. 353.) stem and branches prostrate and trailing. $\odot$. H. Native of Europe, in cultivated fields; and very common in Java (ex Blum.); in North America, about Norway House, and banks of the Hill river (Hook). Smith, fl. grac. 457. Lob. icon. t. 388 . P. oleràcea, Haw. misc. p. 126. syn. p. 122 .

Iar. $\beta$, sativa (D.C. prod. 3. p. 353.) stems diffuse; branches erectish. $\odot$. H. Native of South America, and now cultivated in some parts of Europe. P. doméstica, Lob. icon. p. 388. P. vol. III. satìn, Haw. misc. p. 136. syn. 122. P. latif òlia, Ilorn. hort. hafi. 2. p. 491. There is a variety of this with green leaves (P. víridis, Hortul.), and yellowish leaves (P. aúrea, Hortul.). The young shoots and succulent leaves are estecmed cooling, and are used in spring and summer as an ingredient in salads, and as pot-lierbs and pickles. The plant was formerly in much more request than at present. IBoth the green and yellowleaved sorts are raised from seed, and for a bed 4 feet by 4 feet, sown either broadcast or in drills, 9 inches apart, one-cighth of an ounce will suffice. "Each variety is somewhat tender; the grcen, which is usually preferred, is perhaps rather the hardiest. An early crop may be sown in February or March, on a moderate hot-bed; the plants will require the aid of a gentle heat till the midlle of May, when the seed may be sown in a warm border. If a continued succession is required, sow every month during summer, till August, or while the plant can be raised; generally in small drills, from 3-6 inches asunder. 'The plants will soon come up; they should remain where sown. In very dry hot weather, water thrice a-week. The shoots may be gathered for use when they are from 2-5 inches in licight, and are well furnished wilh leaves. Cut them off low, and the bottom part will soon sprout out again. When seed is recpuired, leave some of the first open border plants to run; they will give ripe seed in autumn."

Cultizated or Common Purslane. Fl. Aug. Sept. Clt. 1582. Pl. prostrate or ereck.

2 P. Parvifòlı (Haw. syn. p. 122.) leaves cuneiform, minute, fleshy; stem much branched, prostrate; flowers sessile, or on long peduncles. $\odot$. H. Native of Jamaica. Probably only a variety of $P$. sativa, but the plant is much smaller, and the leaves are 10 -times smaller.

$$
\text { Small-leaved Purslane. Fl. Aug. Clt. 1799. Pl.pr. }
$$

\section{* Flowers yellow. Axils of leaves or joints pilose.}

3 P. Foliòsa (Ker. bot. reg. 793.) stem diffuse; branches erect; leaves subulate; flowers solitary at the tops or in the forks of the branches, surrounded by white hairs and a manyleaved involucrum; petals retuse or a little emarginate. $\odot . F$. Native of Guinca, near Accra. P. Guineénsis, Spreng. There is a plant figured in fl. mex. of Moc. et Sesse, called by them $P$. stclliformis, a native of Mexico, which is very like this species. Flowers small, yellow.

Leafy Purslane. Fl. June, July. Clt. 1822. Pl. $\frac{1}{4}$ to $\frac{1}{2} \mathrm{ft}$.

$4 \mathrm{P}$. sufrruticòsa (Wight, ex Wall. cat. 6842.) shrubby, branched; leaves linear, nearly terete, glabrous or downy; flowers solitary at the tops of the branches, h. D. S. Native of the East Indies. Flowers surrounded by a whorl of leaves.

\section{Suffruticose Purslane. Fl. Ju. Jul. Shrub 1 foot.}

5 P. Lanuginosa (H. B. et Kunth, nov. gen. amer. 6. p. 74.) stems procumbent, branched; leaves terete, obtuse, upper ones in whorles; flowers in elusters of $2-5$, surrounded by soft hairs ; petals obovate-spatulate, obtuse. $\odot$. F. Native of South America, on the banks of the Amazon. Style 1; 3-5-cleft at the apex. Petals 4-5, yellow.

Ifoolly Purslane. Pl. pr.

6 P. margina'ta (H. B. et Kunth, l. c. p. 72.) stems ratler dichotomous; leaves cuncately spatulate, rounded at the apex, subverticillate, obsoletely veined, margined with red; axils hairy; flowers 5-7 in each head, involucrated. $\odot$. F. Native near Caraccas, in Venezuela. Said to be allied to $P$. olericea. Flowers yellow.

Marginel-leaved Purslane. Pl. pr.

7 P. Laruotenána (St. Hil. fl. bras. 2. p. 190.) stem suffruticose at the base, pilose in the axils of the leaves; leaves lanceolate, flattish, narrowed at the base, acute, longer than the hairs; flowers crowded at the tops of the branches; petals ob$\mathbf{L}$ 
cordate, mucronulate, shorter than the calyx. $\eta_{.} . S$. Native of Brazil, in that part of the province of Minas Geraes called Minas Novas, near Nossa Snzra da Penha. Flowers yellow, surrounded by hairs and crowded leaves.

Laruotle's Purslane. Shrub $\frac{1}{2}$ to $\frac{3}{4}$ foot.

8 P. HALIuoldes (Lin. spec. 639.) stem erect, diffuse, corymbose at the apex; leaves oblong, fleshy, crowded abont the flowers at the tops of the branches; flowers surrounded by dense villi. $\odot$. F. Native of Jamaica. Sloane, jam. hist. 1. p. 205. t. 129. f. 3. P. Browne, jam. p. 206 . Lun. hort. jam. 2. p. 108. Petals connected at the base. Stamens 8-10. Style s-5-parted.

IIalimum-like Purslane. Fl. Ju. Jul. Clt. 1823. Pl. $\frac{1}{2} \mathrm{ft}$.

9 P. rubricaúlis (H. B. et Kunth, nov. gen. amer. 6. p. 73.) stems ascending, corymbosely branched above; leaves lanceolate, acute, nerveless; upper leaves in whorles; axils pilose ; flowers 4-8, erowded into a head. $\odot$. F. Native of South America, in sandy places and on dry mountains on the sea-shore near Laguna. Petals 5, obovate-oblong, emarginate, orangecoloured. Stamens 27-30. Style 6-8-cleft. Said to be allied to $P$. halimoides.

Red-stemmed Purslane. Pl. ascending $\frac{1}{2}$ foot.

10 P. hirsutíssima (St. Hil. A. bras. 2. p. 121. t. 114.) stem suffruticose at the base, pilose at the axils of the leaves; leaves approximate, oblong-lanceolate, flattish, tapering to both ends, acute, shorter than the hairs; flowers crowded at the tops of the branches; petals obcordate, mucronulate, a little longer than the calyx. h. S. Native of Brazil, in that part of the province of Minas Geraes called Minas Novas, near Bom-Tim and Nossa Snra da Penha, and also near Tejuco. Flowers yellow, surrounded by a whorl of the upper leaves and axillary hairs.

Very hairy Purslane. Slurub $\frac{1}{4}$ to $\frac{1}{2}$ foot.

11 P. mucrona'ta (Liuk, enum. hort. berol. 2. p. 2.) stem erect ; leaves obversely oblong, with a slort taper point; floral leaves 8, constituting an involucrum; axils pilose; flowers terminal, sessile. $\odot$. F. Native country unknown.

Mucronate-leaved Purslane. Fl. Ju. Clt. 1822. Pl. $\frac{1}{4}$ to $\frac{1}{2} \mathrm{ft}$.

12 P. QUADRífida (Lin. mant. p. 78.) stem prostrate ; joints pilose; leaves elliptic-oblong, fleshy, flat; flowers terminal, sessile, quadrifid. $\odot$. H. Native of Egypt, A rabia, and India. Jacq. coll. 2. p. 356. t. 17. f. 2. P. linifölia, Forsk. descr. p. 92. Illécebrum verticillàtum, Burm. fl. ind. p. 66. Stems red. Flowers small, yellow. Petals 4, rarely 5 , joined a little way at the base. Stamens 8 , rarely more. Stigmas 4.

Far. $\beta$, Meridiàna (D. C. prod. 3. p. 354.) Howers usually tetrandrous. $\odot$. H. Native of the East Indies. P. Meridiàna, Lin. fil. suppl. p. 248. Nelatsjìra, Rhecd. mal. 10. t. 31. and Roxb. There is hardly any difference between this and $P$. quadrifida. Flowers surrounded by wool and 4 leaves, like those of $P$. quadrifida.

Quadrifid-flowered Purslane. Fl. Aug. Sept. Clt. $1773 ; \beta$ in 1791 . Pl. prostrate.

* ** Flowers purple; axils pilose, or perhaps sometimes naled.

13 P. Pılòs (Lin. spec. 639.) stem diffuse ; joints beset with long hairs; leaves alternate, linear-lanccolate, convex on the back, bluish, about equal in length to the axillary hairs; floral leaves in whorles; flowers crowded at the tops of the branches, sessile, surrounded by long hairs; petals ovate, acutish, a little longer than the calyx. $\odot$. F. Native of South America, about Curassoa, in Brazil, Martinico, Jamaica, \&c. in sandy places near the sea. Gærtn. fruct. 2. p. 212. t. 128. f. 4. Haw. misc. p. 137. Ker. bot. reg. 792, - Wolk. norib. 341 . with a figure. Herm. par. 215. Comm. hort. amst. 1. t. 5. Flowers 5parted, pale purple, expanding from 10-120'elock in the morning, if the sun is out. Stamens about 20. Root tuberous.

Tar. 3 , seticea (D. C. prod. 3. p. 354.) leaves subulate; stems erectish. $\odot$. F. Native along with the species. P. setacea, Haw. misc. 159. Herm. par. 214, with a figure. Pluk. phyt. t. 246. f. 6. and 105. f. 4. Flowers purple.

Pilose Purslane. Fl. Ju. Clt. 1690. Pl. $\frac{1}{4}$ to $\frac{1}{2}$ foot.

14 P. LANA'TA (Rich. act. soc. hist. nat. par. 1792. p. 109.) stems diffuse; leaves linear-sublanceolate, flat; hairs of the axilla and joints longer than the leaves; flowers terminal, surrounded by hairs and a whorle of leaves. $\odot$. F. Native of Cayenne. Petals red, obcordate. Stamens 15 and more. Perhaps only a variety of $P$. pilòsa.

Woolly Purslane. Pl. $\frac{1}{4}$ to $\frac{1}{2}$ foot.

15 P. pilosíssima (Hook, bot. misc. 2. p. 221.) plant annual? small ; stems branclued, decumbent; leaves terete, oblong;

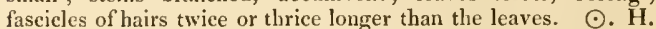
Native of Peru, at Yazo, in the valley of Canta. The flowers are concealed by long white solitary tufts of hairs. It comes nearest to the $P$. lanata, Rich.

I'ery pilose Purslane. Pl. $\frac{1}{4}$ to $\frac{1}{2}$ foot.

16 P. umbratícola (H. B. et Kunth, nov. gen. amer. 6. p. 72.) stems branched; axils sparingly pilose; leaves scattered, lanceolate, acute, veiny ; flowers twin? on very short peduncles, terminal. $\odot$. F. Native of New Andalusia, near $\mathrm{Cu}$ mana and Bordones. Flowers 5-parted, rose-coloured. Stamens 12. Style 4-cleft.

Shaded Purslane. Pl. $\frac{1}{2}$ to $\frac{3}{4}$ foot.

17 P. pusílua (H. B. et Kunth, l. c.) stems branehed; axils naked? leaves scattered, elliptic, nerveless, rounded at both ends ; flowers solitary? almost sessile. $\odot$. F. Native on the Orinoco, among rocks near Maypures, and of Trinidad. Flowers rose-coloured, 4-5-petalled. Stamens 11-14. Style trifid.

Small Purslane. Fl. June, July. Clt. 1824. H]. 1 to 2 in.

18 P. Hilairea'na; stem trailing, herbaceous, pilose in the axils of the leaves; leaves linear-lanceolate, convex on the back, flat in front, acute, longer than the axillary pili; flowers crowded on the tops of the branches; petals obcordate, much longer than the calyx. $\odot$. F. Native of Brazil, in the province of St. Paul. P. grandiflòra, St. Hil. fl. bras. 2. p. 192. but not of Hook. Flowers purple, surrounded by crowded leaves and hairs.

St. Hilaire's Purslane. Pl. $\frac{1}{4}$ to $\frac{1}{2}$ foot. trailing.

19 P. Grandifiòra (Hook, in bot. mag. 2885.) stems diffuse, branched ; leaves seattered, cylindrical, acute, with pilose axils ; flowers 3-4 together, terminal, crowded, surrounded by a whorl of leaves and crowded hairs; petals longer than the calyx; style 8-9-cleft at the apex. 4.F. Native of Chili. There are varieties of this plant with either purple or yellow large flowers. Root tuberous.

lar. a, màjor; (Hook, in bot. misc. 3. p. 241.) leaves an inch or an inch and a half long.-Bot. mag. t. 2885.

Iar. $\beta$, mierophýlla (Hook. et Arn. l. c.) leaves hardly half an inch long. P. Mendocinénsis, Gill. mss. Both varieties are found between Rio Saladillo and Mendoza.

Grcat-flowered Purslane. Fl. June, July. Clt. 1827. Pl. $\frac{1}{2}$ to $\frac{3}{4}$ foot.

20 P. Gillie'sir (Hook. bot. mag. 3064.) stems erectish, branched at the base; leaves oblong-cylindrical, rather compressed, obtuse, dotted; axillary fascicles of hairs erect, adpressed; flowers terminal, usually solitary ; petals longer than 
the ealyx, obovate-roundish. $4 . \mathrm{G}$. Native of Chili, in the plains near Mendoza. Plant stout, in proportion to its height. Flowers large, bright reddish purple.

Gillies's Purslane. P'l. $\frac{1}{4}$ to $\frac{1}{2}$ foot.

21 P. teretifòla (H. B. et Kunth, l. e.) stems ereeping, corymbosely branched; axils rather pilose; leaves scattered, terete, aeutish; flowers $3-5$ in a heap, sessile, involucrated, and surrounded hy hairs. $\odot$. F. Native of South America, on the sandy banks of the river Orinoco and Rio Negro, near Carichana, Maypures, San Carlos, \&c. Very like P.rubicaúlis, but differs in the flowers being purple. Stamens 18-24.

Teretc-lcared Purslane. Pl. creeping.

22 P. Axilliflòra (Pers. ench. 2. p. 6.) stems procumbent; leaves oblong, fleshy, in young plants they are opposite; flowers solitary, axillary. $\odot$. F. Native country unknown. Meridiàna axilliflòra, Schrank. bot. zeit. 1804. p. 354. Corolla and stamens rose-coloured.

Axil-flowered Purslane. P1. pr.

\section{$\dagger$ Species not sufficiently known.}

23 P. imbrica'ta (Forsk. descr, 92.) leaves crowded, ovate, acute, flat beneath, and conrex above, opposite; joints hairy at

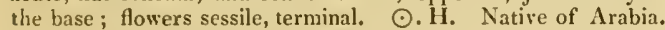
Flowers yellow, large. Sureuli as if they were tetragonal, from the leaves being imbricated on them in 4 rows.

Imbricate-leaved Purslane. Pl. pr.

2.4 P. CA'Frra ('Thunb. fl. cap. p. 399.) stem weak, branched, glabrous; leaves linear-oblong, alternate; flowers axillary, pedicellate; pedicels bibracteate. $\odot$. F. Native of the Cape of Gond Hope. Corolla yellow, 6-petalled. Style trifid. Capsule probably 2-celled and 2 -valved.

Caffrarian Purslane. Pl. pr.

25 P. Ara'sica (Forsk. descr. 92. no. 81.) calyx of 4 permanent sepals. - Native of Arabia. The rest unknown.

Arabian Purslane. Pl.?

26 P. FLA'va (Forst. pl. esc. p. 72.). ๑. F. Native on the shores of the Society Islands, where it is boiled and eaten by the natives, and called by them Aturi. This plant has not been described, and is probably nothing else but $P$. olcràcca.

Fellon-flowered Purslane. Pl. pr.

27 P. Wigutis'xa (Wall. cat. no. 684.5.) plant diffuse; leaves small, intermixed with numerous soft leafy stipulas; flowers sessile, terminal, almost hidden by the white bracteas. h.S. Native of the East Indies, at Sadras, in moist sand. A singular species.

Tight's Purslane. Pl. $\frac{1}{4}$ foot.

Cult. Being mostly annual plants, growing naturally in sandy soil near the sea, the seeds should be sown in dry warm situations in spring: or it is perliaps better to sow them on a lotbed in spring, and plant them out towards the end of May into the open border; or they may be grown in pots and set in the greenhouse or in a frame.

IV. GRAHA'MIA (in honour of Mrs. Maria Grabam, a great traveller in South America, particularly in Brazil, Peru, and Chili.) Gill. mss. ex Hook. et $\Lambda$ rn. in bot. misc. 3. p. 241 .

LIx. syst. Icosándria, Monogýnia. Calyx of 2 permanent, oblong-lanceolate, mueronate, concave, stiff sepals, propped by 8 or 9 imbricate bracteas, similar to the sepals. Petals 5, oborate, mueronulate. Stamens numerous, about 40 ; filaments fliform, monadelphous at the base; anthers erect, 2-celled. Ovarium oblong, l-celled. Style filiform, thickened upwards; stigmas 4, but usually 5, linear. Capsule 1-celled, 5-valved. Seeds numerous, compressed, broadly winged, each fixed by a podosperm to the central axis. - A smootl branched shrub, with alternate, terete, oblong, obtuse, fleshy leaves, bearing hairs in the axils. Flowers solitary, terminating short or elongated branches, with white sepals and petals; and having the filaments purple at the base, and the anthers and stigmas yellow.

1 G. Bractea'ta (Gill. mss. ex Hook. et Arn. I. c. p. 24.2.). 々. D. G. Native of Chili, among bushes, in the Travèsia between San Louis and Mendoza, especially near the river Desaguadern, at the altitude of 1500 feet. Xeránthus salicòsus, Mlicrs. chil. vol. 2. p. 529.

Bracteatc-flowered Grahamia, Slırub I foot.

Cult. See Portulacìria for culture and propagation.

V. ANACA'MPSEROS (from avara $\mu \pi \tau \omega$, anacamplo, to cause return, and $\varepsilon \rho \circ$, cros, love; supposed effects). Sims, bot. mag. (1811) no. 1357 . D. C. eat. hort. monsp. p. 77. but not of Haw.-Telephiástrum, Dill. elth. p. 376.-likulingia, Haw. suce. pl. syn. (1812.) p. 12\%. but not of R. Br.-l'ortulatea species of Lin.-Kulingia species of Elırh.--Talinum species of Willd.-Portulàce gíbbre, IIaw, misc. nat. p. 141 .

L1N. syst. Dodccándria, Monogýnia. Calyx of 2 sepals (f. 16. a.); sepals opposite, oblong, rather concrete at the base. Petals 5 (f. 16. b.), very fugacious. Stamens 15-20 (f. 16.d.); filaments distinet, inserted in the bottom of the calyx along with the petals, and adhering a little to them. Style filiform, trifid at the apex (f. 16.d.). Capsule conical, 1-celled, 3-valved (f. 16. c.), with the valves cleft longitudinally in the middle, and therefore the eapsule appears as if it was 6 -valved (f. 16. $c_{0}$ ). Seeds numerous, winged, fised to a central placenta.-Very dwarf herbs or subshrubs, natives of the Cape of Good Hope. Leaves ovate, fleshy. Axils bearing filamentous subscarious stipulaceous hairs. Bracteas membranous, usually lobed into setaceous segments. Pedicels 1-flowered, elongated, disposed in racemes. Flowers of a rose-purple colour or white, expanding only in the heat of the sun.

1 A. telepinástrum (D. C. I. c.) leaves ovate, difformed, glabrous; axillary hairs filamentous, shorter than the leaves; racemes few-flowered, subpanicled. h. D. G. Native of the Cape of Good Hope.-Dill. hort. ehth. t. 281. Comm. hort. amst. t. 89. Portulàca Anacámpseros, Lin. spec. 639. IIaw. misc. p. 111. Talinum Anacámpseros, Willd. spec. 2. p. S62. D. C. pl, grass, t. 3. Haw. syn. 124. Rulíngia vàrians, Haw. ex Spreng. Rulíngia Anacámpseros, Ehrh. beitr. 3. p. 133. Anacámpseros vàrians, Sweet. Flowers reddish. Seeds very much winged. Cotyledons in the germinating plant 2 , thick, somewhat trigonal, convex beneath, with a very short caulicule.

Telephium-like Anacampseros. Fl. July, Aug. Clt. 1813. Pl. $\frac{1}{4}$ foot.

2 A. INTERME'Dia ; leaves very numerous and dense, expanderl, flat, convex on the outside, retusely deltoid at the apex; axillary threads twisted, brown. h. D. G. Native of the Cape of Good Hope. liulingia intermèdia, Haw, in phil. mag. march 1828. Very like $A$. polyphýlla, but almost one half smaller, but talier; also like $A$. filamentosa, but broarler; the leares more numerons, more crowded, paler; and the axillary tlireads are yellow, not white.

Intermediate Anacampseros. Fl. Ju. Jul. Clt. 1824. Pl. $\frac{1}{4} \mathrm{ft}$.

3 A. Aracinoìns (sims, bot. mag. t. 1368.) leares nvate, acuminated, difformed, green, shining, cobwebbed ; axillary hairs filamentous, shorter than the leaves; racemes simple; petals lanceolate. 2 . D. G. Native of the Cape of Good Hope. J'ortulàca arachnoìdes, Haw. misc. p. 142. liulíngia arachnoìles, Haw. syn. p. 125. Talinum araclınoides, Ait. hort. kew. ed. 2. vol. 3. p. 149. Flowers white, hardly with a tinge of purple. Bracteas scarious, jagged. Sceds with a short wing.

Cobwcbbed Anacampseros. Fl. July, Aug. Clt. 1790. P]. $\frac{1}{2}$ to $\frac{3}{4}$ foot.

4 A. Ru'bens (D. C. prod. 3. p. 356.) leaves ovate, acuninated, difformed, shining, dark green, somewhat reflexed at the 工 2 
apex; axillary hairs shorter than the leaves; racemes simple. h. D. G. Native of the Cape of Good Hope. Portulàca rùbens, Haw. misc. p. 142. Rulíngia rùbens, Haw. syn. p. 125. Leaves and peduncles purplish. Flowers red.

Red Anacampseros. Fl. Jul. Sept. Clt. 1796. Pl. $\frac{1}{2}$ to $\frac{3}{4} \mathrm{ft}$.

5 A. FILAMENTòsa (Sims, bot. mag. t. 1967.) leaves ovateglobose, gibbous on both sides, and cobwebbed, rather rugged above; stipulas ramentaceous, longer than the leaves; petals oblong. h. D. G. Native of the Cape of Good Hope, in Carro near Hartiquos Kloof. Portulaca filamentòsa, Haw, misc. p. 142. Rulingia filamentosa, Haw. syn. p. 125. Talìnum filamentòsun, Ait. lıort. kew. ed. 2. vol. 3. p. 149. Portulàca stipulàris, Dyandr. mss. Petals reddish or deep rose coloured.

Filamentose Anacampseros. Fl. Aug. Sept. Clt. 1795. Pl. $\frac{1}{2}$ to 1 foot.

6 A. Lanceora'Ta (D. C. prod. 3. p. 356.) leaves lanceolate, fleshy, glabrous, convex beneatl; axillary hairs very long; scape leafy, generally 1-flowered. h. D. G. Native of the Cape of Good Hope. Portulàca lanceolàta, Haw. syn. p. 126. Stems very short. Calyx reddish. Petals reddish. Seeds almost 3-winged.

Lanccolate-leaved Anacampseros. Fl. Aug. Sept. Clt. 1796. Pl. $\frac{1}{2}$ foot.

7 A. angustifòlia (D. C. prod. 3. p. 356.) leaves flesliy, narrow-lanceolate, expanded; stem short, branclied. h. D. G. Native of the Cape of Good Hope. Rulingia angustifolia, Hav. rev. p. 60. Very like the preceding species, but smaller. Flowers red.

Narron-leaced Anacampseros. Fl. July, Aug. Clt. 1820. Pl. $\frac{1}{4}$ foot.

8 A. RUféscens (D. C. I. c.) leaves crowded, expanded and recurved, ovate, acute or somewhat acuminated, thick, green, usually dark purple beneath. 万. D. G. Native of the Cape of Good Hope. Rulíngia ruféscens, Haw. suppl. pl. suce. p. 64. syn. p. 60. This is the largest of all the species. Flowers like those of A. Telephiástrum.

Rufescent Anacampseros. Fl. July, Aug. Clt. 1818. Pl. $\frac{1}{2} \mathrm{ft}$. 9 A. trigòna (D. C. l. c.) leaves ovate, trigonal, acute, erect, woolly in the axils and on the stem between the leaves. h.D. G. Native of the Cape of Good Hope, in Carro. Burm. afr. p. 79. t. 30. f. 2. Portulàca trigòna, Thunb. f. cap. p. 399. Petals flesli-coloured, oblong, acute.

Trigonal-leaved Anacampseros. Pl. $\frac{1}{4}$ to $\frac{1}{2}$ foot.

10 A. LANígera (Burcl. cat. geogr. pl. afr. austr. no. 2196.) leaves ovate, obtuse, small, very densely clothed with long wool. そ. D. G. Native of the Cape of Good Ilope. Very like the preceding species. Flowers unknown.

Hool-bearing Anacampseros. Pl. $\frac{1}{4}$ foot.

11 A. Polyphýlla (D. C. 1. c.) h. D. G. Native of the Cape of Good Hope. Rulingia polyphýlla, Haw. suppl. 65. syn. 61.-Pluk. pliyt. t. 41. f. 6 .

Many-leaved Anacampscros. Fl. Jul. Aug. Clt. 1818. Pl. $\frac{1}{4} \mathrm{ft}$.

Cult. The species of this succulent genus of plants grow freely in sandy loam, mixed with some lime rubbish; they requirc but little water. Cuttings root freely if laid to dry a few days before planting. Leaves taken off close to the plants, and laid to dry a few days, and then planted, will take root and shoot out young plants at their base.
VI. TALI NUM (probably from $9 a \lambda \iota a$, thalia, a green branch; durable verdure). Sims, bot. mag. no. 1357. Haw. syn. p. 123. D. C. prod. 3. p. 356.-Talìnum species, Adans. fam. 2. p. 145. Juss. gen. p. 312.-Portulàca species, Lin.-Rulingia species, Ehrh.

Lin. syst. Deca-Dodecándria, Monogýnia. Calyx of 2 ovate sepals, deciduous. Petals 5 (f. 17. b.), hypogynous, or inserted in the bottom of the calyx, distinct or joined a little way at the base. Stamens 10-20, inserted along with the petals, and generally adhering a little to them, and joined together at the base. Style filiform, cleft at the apex into 3 spreading or close stigmas. Stigmas bearing papillæ inside. Capsule 3-valved, 1-celled, many-seeded. Seeds wingless, kidney-shaped, seabrous, fixed to the central placenta.-Fleshy herbaceous, or suffrutescent plants. Leaves alternate, quite entire, exstipulate. Flowers very fugaceous, expanding only in the heat of the sun, eymose or racemose. Cymes or racemes usually forming terminal panicles.

Sect. I. Phemera'nturus (from $\phi \eta \mu \eta$, pheme, fame, and av $\theta 0 s$, anthos, a flower; in reference to the beauty of the flowers). Rafin. speech. 1. p. 86. D. C. prod. 3. p. 356.-Talinum, Pursh, and Nutt. Stigmas 3, close together, and appearing like a simple stigma. Flowers disposed in dichotomous corymbose cymes.-Perennial herbs, natives of North America.

1 T. teretifòlium (Pursh. f. bor. amer. 2. p. 365.) root fibrous; cauline leaves terete, subulate, fleshy, cyme terminal, dichotomous, corymbose; stamens 20. 4. F. Native of Virginia, Louisiana, and Delaware, among rocks exposed to the sun. Lodd. bot. cab. t. 819. Phemerántlus teretif òlius, Rafin. specch. p. 86. Talinum trichótomum, Desf. hort. par.-Pluk. alm. t. 223. f. 2. Flowers of a rose purple-colour. Root tufted, fibrous.

Terete-leaved Talinum. Fl. Aug. Clt. 1823. Pl. $\frac{1}{2}$ foot.

2 T. Napifórue (D. C. prod. 3. p. 357.) root tuberous; radical leaves terete, fleshy; cymes terminal, dichotomous, corymbose; stamens 5 , alternating with the petals. 2 . F. Native of Mexico. Claytònia tuberòsa, Moc. et Sesse, fl. mex. icon. ined. Root tuberous, turnip-formed. Stems numerous from the neck of the tuber, almost leafless at the base, but cymose and dichotomous at the apex. Flowers white. This species from habit and infloreseence agrees with the preceding, but differs materially in having only 5 stamens, and a tuberous root. It is not a Claytonia, in consequence of the stamens alternating with the petals, not opposite them; nor a Calandrinia from the calyx not being deciduous.

\section{Turnip-formed-rooted Talinum. Pl. $\frac{1}{2}$ to 1 foot.}

Sect. II. Talina'strum (an alteration from Talinum). D. C. prod. 3. p. 357.-Talinum, Sims and Haw. Style filiform. Stigmas 3, distinct, spreading. Ovarium globose (f. 17. c.). Leaves flat, rather fleshy. Stems suffrutescent, fleshy, ereet.

3 T. crassifòluum (Willd. spec. 2. p. 862.) stem shrubby, erect; leaves flat, obovate-lanceolate, mucronate; flowers disposed in an elongated panicled corymb; peduncles triquetrous. $h$.D.S. Native country unknown, but probably of the West Indies. Haw. syn. p. 123. Portulàca crassifòlia, Jacq. hort. vind. 3. t. 52. Haw. mise. p. 140 . ' $T$. paniculàtum, Moench. meth. p. 23\%. but not of Gartn. nor Ruiz et Pay. Flowers red.

I ar. $\beta$, albiflòrum (D. C. prod.
FIG. 17.

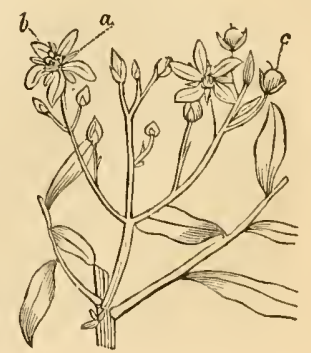


3. p. 357.) Howers white. 々. D. G. Native of South America, by the sea side. Comm. hort. 1.p.7.t.4. Portulàca fruticòsa, Murr. sy'st. veg. but not of Thunb. Portulitca paniculàta, Lin. spec. 2. p. 640. Talìnum fruticòsum, Willd. spec. 2. p. 864 . The calyx is said to be of 5 sepals, but this assertion we suspect to be erroneous.

Thick-leavel Talinum. Fl. Aug. Scpt. Clt. 1800 . Sh. $1 \mathrm{ft}$.

4. 'T. trianoula're (Willd. spec. 2. p. 862.) stem slurubby, erect: leaves flat, channelled, wedgc-shaped, emarginate, mucronate; racemes simple; rachis triquetrous. h. D. S. Native of the Antilles, on the sea shore. Plum. ed. Burm. t. 150. f. 2. Portulitca racemosa, Lin. spec. 640. Haw. misc. p. 139. Portulàca triangulàris, Jacq. obs. 1. p. 35. t. 28 . Rulíngia triangulàris, Elırh. beitr. 3. p. 13.. Flowers yellow, size of those of the preceding speeies.

Triangular Talinum. Fl. Aug. Sept. Clt. 1739. Pl. $\frac{3}{4} \mathrm{ft}$.

5 T. PA'Tens (Willd. spec. 2. p. 863. var. a.) stem suffruticose, erect; leaves flat, glabrous, lower ones obovate, obtuse, upper ones lanceolate, acute; panicle terminal ; peduncles alternate, dichotomous, bractless; petals oblong, acutish, 3 times longer than the calyx. $\zeta$. D. S. Native of Martinico, St. Domingo, Mexico, New Granada, and Brazil, on rocks by the sea side; also of Buenos Ayres. Portulàca paniculata, Jacq. amer. p. 148. Portul. pàtens, Jacq. hort. vind. 2. t. 151. Rulíngia pàtens, Ehrh. beitr. 3. p. 135 . T. paniculàtum, Gærtn. fr. 2. p. 219. t. 128. but not of Monch. nor of Ruiz et Pav. Flowers small, red, 3 lines in diameter. The leaves of the plant are used in the same manner as common purslanc in Brazil.

Spreading-panicled Talinum. Fl. Aug. Oct. Clt. 1776. Sh. 1 to 2 feet.

6 T. A NDRE'wsII (Sweet, hort. brit. p. 170.). stem suffruticose, erect; leaves glabrous, ovate-lanceolate, sessile; panicle branched, terminal; petals oblong, obtuse. $\zeta$. D. S. Native of the West Indies. T. patens, Andr. bot. rep. t. 253. Flowers large, red.

Andrew's Talinum. Fl. Aug. Oct. Clt. 1800. Sh. 1 to $2 \mathrm{ft}$.

7 'T. REFLE'XUM (Cav. icon. 1. p. 1. t. 1.) stem suffruticose, erect; leaves flat, lanceolate or oval, obtuse, usually opposite; panicle tcrminal; peduncles usually opposite, dichotomous, hractless. 8. D. S. Native of South America. Sims, bot. mag. t. 15.43. Haw. syn. p. 124. Portulàca refléxa, Haw. misc. p. 141. T. pàtens $\beta$, Willd. spec. 2, p. 863 . T. dichótomum, Ruiz et Pav. syst. fl. per. p. 118. This species is very nearly allied to $T$. pattens, but differs in the flowers being yeliow, not red or purple, as in that plant, and the plant is probably biennial.

Reflexed Talinum. Fl. Aug. Oct. Clt. 1800. Pl. 1 foot.

8 T. cunetròluur (Willd. spec. 2. p. 864 .) stem shrubby, erect; leaves flat, wedge-shaped, obtuse, mueronate; panicle terminal; lower peduncles 3-flowered. 2. D. G. Native of Arabia Felix, about Surdud and Hadie; and also of the East Indies. Portulàca cuneifòlia, Vahl. symb. 1. p. 333. Orígia portulacifolia, Forsk. descript. p. 103. Flowers of a reddish violetcolour.

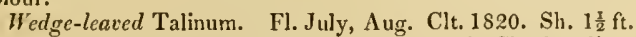

$9 \mathrm{~T}$. polygaloìnes (Gill. mss. ex Arnott, in Cheek, edinb. journ. vol. 3. p. 354 .) stem shrubby, erect, branched a little; branches striated, angular; leaves flat, linear, mucronate (when dry very narrow, with revolute edges); peduncles bibractcate at the base, when bearing the fruit deflexed, axillary, cmulating a simple raceme. h. D. G. Native of Chili, in the Jarillal, and along the foot of the mountains near Mendoza, at an elevation of 3000 to 4000 feet above the sea. Flowcrs about a fourth of an inel in diameter, yellow, fading to red. The stem appears not to be at all fleshy, according to the dried specimens.

Polygala-like Talinum. Pl. $\frac{1}{4}$ to $\frac{1}{2}$ foot.
Sect. III. Taline'llum (a diminutive of Talinum). D. C. prod. 3. p. 358. - Talinum, Ruiz et Pav. syst. fl. per. p. 65. Style thick. Stigmas 3, thick, flattish.-Generally annual herbs; and probably should have been joined with the genus Calandrinia.

10 'T. Revolu'tum (II. B. et Kunth, nov. gen. amer. 6. p. 76.) stem erect, simple; lcaves glabrous, lanceolate, obtuse, narrowed at the base, with revolute margins; peduncles terminal, somewhat dichotomous, few-flowered; petals awned, glandular towards the base. $\odot . F$. Native of South America, in shady places near Cumana. Flowers yellow. Stamens about 48 . Fruit unknown.

Revolute-leaved Talinum. P1. $\frac{1}{2}$ foot.

11 T. mucrona'tum (H. B. et Kunth, l. c.) stems erectish: leaves glabrous, oblong or oblong-lanccolate, obtuse, somewhat mucronate, cuncated, and narrowed at the base; peduncles terminal, 2-3-cleft, many-flowered; flowers racemose; jetals mucronate. $\odot$. D. F. Native of New Andalusia, near Bordones, in shady humid places. Petals yellow, length of calyx. Stamens about 50 .

Mucronate-leaved Talinum. Pl. $\frac{1}{2}$ to $\frac{3}{4}$ foot.

12 'T. POLYA'NDRUM (Ruiz et Pav. syst. fl. per. p. 115.) leaves roundish-obovate, acuminated; flowers racemose, polyandrous; petals obcordate, quite entire. ๑.F. Native of Peru, on the hills called Lomas towards Pongo. Herb a foot high, noxious to cattle. The rest unknown.

Polyandrous Talinum. Pl. 1 foot.

13 T. chena'tum (Ruiz et Pav. 1. c.) leaves roundish-obovate, acuminated; flowers racemose; petals crenulated; stamens about 20.-Native of South America, on hills about Pongo in the province of Atiquipa. Herb a foot high, and is called by the natives Langua de $V a c a$, as well as the preceding plant. The rest unknown.

Crenated-petalled Talinum. Pl. 1 foot.

11. T. MENZ1E'sir (Hook. fl. amer. bor. 1. p. 223. t. 70.) caulescent; leaves linear-spatulate : lower ones on long petioles; margins naked : superior ones and sepals acutely keeled, glandularly ciliated on the back; flowers pedunculate, axillary. $\odot$. H. Native of the north-west coast of America, south of Columbia. The habit is that of a species of Talinum, without having seen the flowers; it may, lowever, when better examined turn out to be a species of Calandrinia. Root annual, rather fusiform.

Menzics's Talinum. Pl. $\frac{1}{2}$ foot.

Cult. Pretty succulent plants, most of which require the heat of a stove; a mixture of loam, peat, and sand, or any light soil will suit them; and cuttings of them are very readily rooted. The seeds of the annual species may be reared on a hot-bed, and afterwards planted out in the open border about the end of May.

VII. LEWI'SIA (in honour of Captain M. Lewis, who accompanied Captain Clarke to the Rocky Mountains of North America). Pursi. fl. amer. sept. 2. p. 368. Hook. in bot mise. 1. p. 345 . t. 70. fl. bor. amer. 1. p. 223.

Lis. syst. Dodecúndria, Monogýnia. Calyx of 5 sepals; sepals rather membranous. Petals 9-12, inner ones gradually the smallest. Stamens 12-16, hypogynous; anthers linear. Ovarium globose. Ovula many, fixed to a free central receptacle. Style dceply 6-parted : segments filiform; stigmas obtuse.-P'lant herbaccous, stemless. Roots fascicled. Leaves terete, fleshy. Scapes 1-flowered.

1 L. REDiviva (I'ursl. 1. c. Hook. l. c.) 4 .H. Native of North America.

Irar, a ; root blood-coloured; flowers white. Native on the banks of Clarke's river. 
I ar. $\beta$; root white; flowers rose-coloured. Native of the subalpine regions of the Rocky Mountains, on the west side, and abundant at the junction of the Spokan river with the Columbia, on dry stony rocks; also of the Flathead and Salmon rivers, in similar situations. The roots of this variety are gathered in great quantities by the Indians on the west side of the Rocky Mountains, and highly valued on account of their nutritive qualities. They are boiled and eaten as salep or arrow-root, and are admirably calculated for carrying on long journeys ; two or three ounces a day being quite sufficient for a man, even while undergoing great fatigue. Perfect flowers of the plant have not yet been seen by any botanist, and therefore the genus is not well known; and probably may hereafter verge into Talinum.

Revived Lewisia. Clt. 1826. Pl. $\frac{1}{2}$ foot.

Cull. A mixture of loam and brick-rubbish will be a good soil for this plant; and it may be propagated by dividing the plant at the root, by cuttings, or by seeds.

VIII. CALANDRI'NIA (in honour of L. Calandrini, an Italian botanist, who lived in the beginning of the 18th century). H. B. et Kunth, nov. gen. amer. 6. p. 77. D. C. prod. 3. p. 358.-Cósmia, Domb. mss. Juss. gen. 312.-Geúnsia, Moc. et Sesse, fl. mex. icon. ined.-Phacospérma, Haw. in pliil. jour. 1527. p. $12 \%$.

Lin. sist. Dodecándria, Monogýnia. Calyx permanent, bipartite (f. 18, a.); sepals roundish-orate. Petals 3-5 (f. 18. b.), hypogynous, or inserted in the bottom of the calyx, distinct or connected together at the very base, equal. Stamens 4-15, inserted in the torus or base of the petals, distinct, generally alternating with the petals. Style 1 , very short, tripartite at the apex; lobes collected into a clavately capitate stigma (f. 18, c.). Capsule oblong-elliptic, 1-celled, 3-valved, many-seeded. Seeds adhering by capillary funicles to the central placenta.-Succulent or fleshy glabrous American herbs, having the habit of Sámolus. Leaves quite entire, radical or alternate. Pedicels 1flowered, axillary or opposite the leaves. This genus hardly diflers from Talinum, as far as its characters are yet known.

\section{Stamens 10-15.}

I C. paxictia'ta (D. C. prod. 3. p. 358.) plant caulescent, branchcd; leaves obovate-oblong, acuminated; flowers panicled; pedicels 5 times longer than the bracteas. $\odot . F . ~ N a-$ tive of Peru, in the province of Chancay, commonly called Lomas, on sandy hills; and in the province of Atiquipa, at Pango, where the plant grows a foot high, and is called there Orejas de Perro and Castannuelas. Talìnum paniculàtum, Ruiz et Pav. syst. A. per. p. 115. Portulàca carnòsa, Domb. herb. Leaves glabrous, fleshy. Stem erect, paniculately branched at the apex. Sepals 2, ovate, permanent. Stamens 10-15. Capsule 3-valved, lcrigtl of the calyx. Flowers purple.

Panicled Calandrinia. Fl. July, Ang. Clt. I816. Pl. 1 foot.

? C. Lingula'ta (D. C. l. c.) plant caulescent, and branched from the base; leaves linear, tongue-shaped; flowers panicled. $\odot$. F. Native of Peru, at Chancay near Jequan, in sandy places. Talinum lingulàtum, Ruiz et Pav. fl. per. p. 115. Portulàca lineàris, Domb. Sepals 2, ovate, permanent. Stamens 10-15. Capsule 3-valved, shorter than the sepals.

Tongue-leaved Calandrinia. Pl. 1 foot.

3 C. cistiflòra (Gill. mss. ex Arnott, in Cheek, edinb, jour. 3. p. 355.) glabrous; stem ascending, suffruticose; branches leafy at the base, and nearly naked towards the apex; leaves linear-lanceolate, acutish; raceme terminal, few-flowered; pediccls elongated; bracteas mimute, foliaceous: sepals ovate, acute; stamens numerous. h. D. G. Native on the Andes of Mendoza and Chili, in many places at an elevation above the sea, from 9,000 to 10,000 feet. The flowers are pretty large, and purple. It ranks near $C$. lingulata.
Rock-rose-flonered Calandrinia. Pl. ascending.

4. C. Arrinis (Gill. mss. ex Arnott, in Cheek, edinb. journ. 3. p. 355.) plant glabrous and stemless ; leaves elongated, linear, obtuse, attenuated into the petiole ; indurated bases of petioles imbricated and dilated; peduncles radical, 1-flowered, naked, one-half shorter than the leaves. 4. D. G. Native on the Andes of Chili, at El Serro de San Pedro Nolasco. This species is closely allied to $C$. acaúlis, but differs in the flowers having numerous stamens.

Allied Calandrinia. Pl. $\frac{1}{4}$ foot.

5 C. CAP1TA'TA (Hook. et Arn. in bot. misc. 3. p. 244.) root annual; stems erectish, smooth, and nearly simple; leaves linear, smoothish, ciliated; racemes capitate, many flowered, terminal, and axillary, pedunculate ; flowers nearly sessile; sepals roundish, tridentate at the apex, beset with long pili on the back. $\odot$. F. Native on the Cordillera of Chili, and near Collina.

\section{Capitate-Howered Calandrinia. Pl. $\frac{1}{2}$ foot.}

6 C. ramosíssina (Hook, et Arn. in bot. misc. 3. p. 244.) root annual; stems many from the same neck, leafy, branched; axillary branches horizontal ; leaves linear, pilose, ciliated with long hairs at the base; racemes short, few-flowered; sepals roundish, truncate, bluntly tridentate at the apex, and beset with long pili on the back. $\odot$. F. Native of Chili, about Valparaiso.

\section{Much-branched Calandrinia. PI. $\frac{1}{2}$ to 1 foot.}

7 C. Cumixgir (Hook. et Arn. in bot. misc. 3. p. 244.) root slender, annual ; stems many from the same root, procumbent, leafy, dichotomously branched; leaves linear, attenuated at the base, beset with adpressed hairs; racemes few-flowered, terminal; sepals roundish, tridentate at the apex, pilose on the back. $\odot$. F. Native of Chili, about Valparaiso; and on the Cordillera of Chili. The upper part of the stems, racemes, and calyxes are beset with glandular viscid hairs. The whole plant has a purplish hue. In character this species approaches near to $C$. ramosissima, but in habit they are very distinct.

Cuming's Calandrinia. Pl. procumbent.

8 C. umbelia'ta (D. C. prod. 3. p. 358.) stem erectish, nearly naked; leaves radical, linear, acute, pilose; corymb cy-

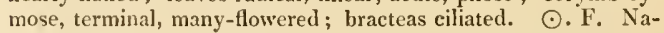
tive of Chili, at Conception in sandy places. Talinum umbellàtum, Ruiz et Pav. syst. fl. per. p. 117. Portulàca prostràta, Domb. herb. Sepals nearly orbicular, permanent. Stamens 10-15. Ovarium prismatically conical, tapering a long way. Habit almost of a species of Andrósace.

L'mbellatc-flowered Calandrinia. Pl. $\frac{1}{2}$ foot.

9 C. PÍcta (Gill. mss. ex Arn. in Cheek, edinb. journ. 3. p. 356.) plant caulescent, sparingly branched, perennial, glabrous ; leaves obovately spatulate, attenuated into the petiole at the base, glaucous; corymb cymose, terminal; pedicels much exceeding the bracteas, which are roundish, membranous, and edged with purple; sepals roundish, reticulated by purple; stamens numerous. 24. D. G. Native on the Andes of Mendoza, in many places at the elevation of 10,000 feet above the sea. This is one of the most beautiful of the species; and according to habit comes near $C$. glaúca, but differs in the stamens being numerous.

Painted Calandrinia. Pl. 1 foot.

10 C. ARENA'ria (Cham. mss, ex Hook, et Arn, in bot. misc. 3. p. 246.) plant glaucous; stems numerous, prostrate, glabrous, leafy ; leaves linear; common peduncle terminal, naked, simple or branched; racemes corymbose; pedicels a little longer than the bracteas; bracteas oval, membranous, painted by a dark purple branched middle nerve; seeds glabrous. $\odot . ? \mathrm{~F}$. $\mathrm{Na}-$ tive of Chili, about Valparaiso. Closely allied to C. pícta, Gill. but very distinct from it. 
Sand Calandrinia. Pl. prostrate.

11 C. Livearifòlia (1). C. prod. 3. p. 359.) stem ascending, a little branched at the base; branches erect, radical and cauline lcaves linear, glabrous, bluntish; corymb terminal, a little branched; calyx glandular. $\psi$. D. G. Native of South America. Perhaps the same as Talinum lineàre, H. B. et Kunth, nov. gen. amer. 6. p. 77. which is found in the arid valleys of Mexico.

Linear-leatcd Calandrinia. Pl. ascending.

12 C. Pilosiu'scula (D. C. l. c.) stems erectish, angular, rather pilose; leaves linear-spatulate, rather pilose; pedicels axillary, 1-flowered, rather adnate to the floral leaves, constituting a terminal or sultterminal panicle. $\odot$. F. Native of Chili, about Conception. Lindl. in hort. trans. 6. p. 291. T. ciliatum, Hook. exot. fl. 1. t. 82. but not of liuiz et Pav. Talinum lineàre, Hoffm. verz. 1827. p. 217. Flowers rose-colourcd. Stigmas 3, rose-coloured, nearly as in Papàver, laving the styles radiating at the apex. Stamens $10-15$, not 5 , as in Talinum ciliàtum of liuiz et $\mathrm{Pav}$.

Hairy Calandrinia. Fl. Aug. Clt. 1823. Pl. $\frac{1}{2}$ to 1 foot.

13 C. serícea (Hook. et Arn. in bot. misc. 3. p. 244.) root perennial, woody, with a multiple neck; stcms erectish, very leafy at the base; leaves linear, aeute or subulate, elothed with silky hairs; raceme few-flowered, eorymbose; upper pedicels hardly equal in length to the bracteas ; sepals ovate, tridentate at the apex, clothed with long silky villi; stamens numerous. 4. D. G. Native of Chili.

I ar. a, lóngipes (Hook. et Arn. 1. c.) lower pedicel elongated, slender, much longer than the rest and the bractea. On Sierra Bella Vista, and Acancugua; and on the Cordillera of Chili.

I'ar. $\beta$, céquipes (Hook. et Arn. l. c.) pedicels all nearly equal. Near Collina and Questa. In both varieties the leaves vary much in length, from 1 to 2 or even 3 inclses.

Silky Calandrinia. Pl. 1 foot.

14 C. TeNe'Lla (Hook. et Arn. in Beech. bot. p. 24.) stems ascending, branched at the base; leaves narrow-linear, glabrous ; racemes terminal, branched; sepals glabrous, triangular, cordate, acuminated. $\odot$. ? G. Native of Chili, at Valparaiso. Very closely allied to C. pilosiuscula, but differs from it in being quite glabrous and in its smaller size. This is said to be only a variety of C. pilosiúseula. Hook. et Arn. in bot. misc. 3. 1. 245 .

Weak Calandrinia. Pl. ascending.

15 C. PHacospérua (D. C. l. c.) stems weak, somewhat hexagonal; leaves linear-lanceolate, hispid on the margins; flowers racemose. §. F. Natice of Peru. Phacospérma Peruviàna, Haw. in phil. journ. 1827. p. 124. Tetragònia Peruviảna, hort. Chelsea, ex Haw. Flowers reddish. Peduncles ereet, shorter than the foliaceous bractea. Sepals quadrangular, curled. Stigma 6-lobed.

Lentil-seeded Calandrinia. Fl. June, July. Clt. 1820. Pl. 1 to 3 feet.

\section{* Stamens from 1 to 9.}

16 C. caule'scens (H. B. et Kunth, nov. gen. amer. 6. p. 78. t. 526.) plant caulescent and branched; leaves alternate, spatulately lanceolate, acute; pedicels axillary and opposite the leaves, 1-flowered, bractless. $\odot$. F. Native of Quito, near Chillo, and near the city of Mexico. Geúnsia ròsea, Moc. et Sesse, fl. mex. icon. ined. Talinum cauléscens, Spreng. syst. 1. p. 453. Cósmia montàna, Domb. herb. Stem diffuse or procumbent. Flowers rose-coloured.

Caulescent Calandrinia. Pl.pr.

17 C. Procu'miens (Moris. hort. taur. sem. 1831.) glabrous, caulescent, filiform, procumbent, branched; leaves succulent, linear, obtuse, alternate; pedicels axillary, and opposite the leaves; sepals triangular; flowers triandrous or liexandrous; capsule s-celled. ๑. II. Native of South America. This species cliffers from $C$. compréssa of Sclirad. in being glabrous, in the stems being procumbent, in the stamens being $3-6$, and in the sepals not being cordate at the base, \&c.

Procumbent Calandrinia. Pl. pr.

18 C. compréssa (Seliral. in litt. ex D. C. l. c.) plant caulescent and succulent ; leaves linear, ciliated; flowers racemose; calyx compressed ; sepals triangular, cordate, unequal, acuminated. $\odot$. F. Native of Chili. Plant a span high, erect, simple, or somewhat divided, with short hairs on the preduncles and calyxes. Leaves obtuse, marked with a longitudinal line above, somewhat kccled beneath: radical ones $1 \frac{1}{2}$ or 2 inches long. Pedicels an incl and a half long. Flowers small, purple. Stamens 3-4. Capsule 3-4-valved. Schrad. mss.

I ar. $\beta$, adscéndens (D.C. l. c.) plant smaller; stem ascending. Talinum adscéndens, Hort. berol.

Compressed-calyxed Calandrinia. Pl. $\frac{1}{2}$ foot.

19 C. Denticula'ta (Gill. mss. ex Hook. et Arn. in bot. misc. 3. p. 243.) plant glabrous; stem suffruticose, leafy ; leaves lanccolate, acute, attenuated at the base; raeeme terminal, 1-3 or few-flowered; pedicels elongated; sepals roundish-ovate, with denticulately-serrated margins. $\zeta$. D. G. Native of Chili, along with $C$. andicola. The lower part of the stem is muelı branched.

Denticulated-ealyxed Calandrinia. Shrub 1 foot?

20 C. andícola (Gill. mss, ex Hook, et Arn. in bot. misc. 3. p. 242.) plant wholly glabrous ; stem suffruticose, leafy towards the apex: leaves cuneate-oblong, acute, attenuated at the base; raceme terminal, $1-3$ or few-flowered; pedicels elongated; sepals roundish, hardly mucronulate at the apex, witl quite entire margins; pctals a little longer than the calyx; flowers with, few stamens. h.D.G. Native of Chili, on the eastern side of the Cumbre, and at El Alto de la Laguna. Closely allied to C. cistiflòra, but apparently quite distinet. From $C$. denticulata it can only be distinguished by the entire margins of the sepals.

Andes Calandrinia. Pl. $\frac{1}{2}$ to 1 foot.

21 C. $\operatorname{Acau}^{\prime} L I s$ (H. B. et Kunth, l. e.) plant stemless; leaves elongated, linear, obtuse ; peduncles radical, 1-flowered, bibracteate in the middle, one half shorter than the leaves. 4. D. G. Native of Quito, on Mount Rucu-Pichincha, in humid places. Cósmia prostràta, Domb. luerb.

Stemless Calandrinia. Pl. $\frac{1}{4}$ foot.

22 C. Trífida (Hook. et Arn. in bot. misc. 3. p. 243.) root annual, slender; stems erectish, simple, rather leafy, pilose; leaves linear, acute, pilose; radical ones elongated; upper cauline ones edged with long hairs, embracing a few Howers in their axils; raceme corymbose, dense, terminal; bracteas ciliated with long hairs: lowcr ones exceeding the racemes; sejals ovate, trifid at the apex, with a few hairs on the back, but more numerous on the margins; stamens 5. $\odot . H$. Native of Chili, about Valparaiso. This and $C$. Gilliesii and $C$. sericca seem closely allied to $C$. umbellàta.

Trifid-bractead Calandrinia. Pl. $\frac{1}{2}$ foot.

23 C. Gillie'siı (Hook. et Arn. in bot. misc. 3. p. 249.) ront perennial, woody, with a multiple neck; stems erectisl, simple, very leafy at the base, but sparingly so at the apex; leares oblong-linear, beset witl adpressed hairs; raceme corymbose ; lower bracteas liardly equal in length to the pedicels; sepals ovate, somewhat tridentate at the apcx, and beset with long pili on the back; stamens 5. 4. D. G. Native of the Andes, of Mendoza, and Chili; Cordillera of Chili; and Los Ojos de Aqua. C. umbellàta, Gill, inss.

Gillies's Calandrinia. Pl. $\frac{1}{3}$ foot.

24 C. Dirfu'sa (Gill. mss. ex Arnott, in Clicek, edinb. jourm. 
3. p. 355.) plant caulescent, glabrous, diffuse ; branches leafy at the base and nakedish at the top, 1-2-flowered; leaves spatulate-lanceolate, acute, quite entire; flowers terminal ; sepals orbicular, quite entire. $h_{2}$.D. G. Native of the Andes of Chili, near El Paso de los Petrquenes, at an elevation above the sea of 10,000 feet. The number of stamens in the flowers of this species has not been determined.

Diffuse Calandrina. P1. 1 foot.

25 C. GLAv'ca (Selirad. in litt. ex D. C. l. c.) plant caulescent, glabrous; leaves spatulate-lanceolate, acute, fleshy, glaucous ; racemes few-flowered; fruit-bearing peduncles, $1 \frac{1}{2}$ inch long, reflexed ; bracteas ovate, acute, membranous, and spotted with purple. 4. D. G. Native of Chili. Stem a foot high. Leaves an inch and a half long, thick, tapering into the petioles. Flowers a little larger than those of $C$. compréssa. Sepals broadly ovate, purple, coneave, reticulated with black. Capsule larger than the calyx, 3*valved. (Schrad. mss.)

Glaweous Calandrinia. Pl. 1 foot.

26 C. confe'Rta (Gill, mss. ex Arnott, in Cheek, edinb. journ. 3. p. 356.) plant caulescent, perennial, glabrous ; branches numerous from the neck of the root, simple, leafy at the base, nakedish towards the apex; leaves narrowly spatulate, glaucous; racemes crowded, terminal ; pedicels hardly longer than the bracteas; sepals broadly ovate; flowers witl few stamens, 3-4. 24. D. G. Native on the Andes of Mendoza, at El Portezuela del Valle Hermosa.

Cronded racemed Calandrinia. Pl. I foot.

27 C. cessitòs a (Gill. mss. ex Arnott, in Cheek, edinb. journ. 3. p. 356.) plant tufted, stemless; leaves linear-spatulate; peduncles radical, 1-flowered, naked, 3-times longer than the leaves; sepals broadly ovate; flowers with few stamens; stigmas $4-5$; capsule 4-5-valved. 24. D. G. Native on the Andes of Mendoza and Chili, and many places, at the elevation above the sea of from 9000 to 11,000 feet.

Tufted Calandrinia. Fl. Mar. April. Pl. tufted.

28 C. GRandiflòra (Lindl. bot. reg. t. 1194.) plant glaucous; stem suffruticose; leaves fleshy, rhomboid, acute, petiolate; raceme simple, loose; calyx spotted; stamens numerous; petals obcordate. 4. D. G. Native of Chili. Flower of a rosepurple colour. (f. 18.)

Great-flonered Calandrinia. Fl. Ju. Jul. Clt. 1826. Pl. $1 \mathrm{ft}$.

29 C. cima'ra (D. C. l. e.) leaves linear-oblong, ciliated; flowers solitary, always pentandrous. $\odot$. F. Native of Peru, at Huassa-Iluassi, among rubbish and in cultivated fields. 'Ta-

linum ciliàtum, Ruiz et Pav. syst. p. 116. prod. p. 65. but not of Hook. Hlowers purple.

Ciliated-leaved Calandrinia. Pl. $\frac{1}{2}$ foot.

30 C. ? ÁLBA (D. C. prod. 3. p. 359.) leaves spatulate-lan-

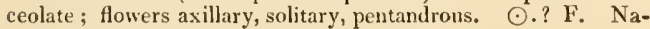
tive of leru, about Chancay and Lima, among rocks. Herb a foot high. Talìnum álbum. Ruiz et Pav. l. c. Flowers white. White-flowered Calandrinia. Pl. 1 foot.

81 C. NílidA (D. C. l. e.) steins ascending, glabrous, leafy; leaves oblong-spatulate, acutish, glabrous, attenuated at the base; peduncles axillary, solitary, shorter than the leaves; sepals roundish, obtuse, pilose on the backs; stamens 1-9. $\odot$. F. Native of Clili, in fields and waste places, at Conception, in the tract of Hualpen and Moquita; also about Valparaiso and Quillota. Herb half a foot high. Talinum nítidum, Ruiz et Pav. 1. c.

Nitid Calandrinia. Pl. $\frac{1}{2}$ foot.

32 C. monándra (D. C. l. c.) leaves spatulate-lanceolate; flowers in spikes, secund, monandrous. $\odot$.? F. Native of Chili, on arid bills about Conception, near the river Andalien. Talinum monándrum, Ruiz et Pav. l.c. Herb a liand and a half light.

Monandrous Calandrinia. Pl. $\frac{3}{4}$ foot.

Cult. Calandrinia is a fine genus of succulent plants; their culture and propagation are the same as that recommended for the species of Talinum, p. 77. The seeds of annual species may be sown in a lot-bed in spring, and the plants planted out into the open border, in a dry sheltered situation, about the end of May.

IX. PORTULACA'RIA (altered from Portulàca). Jacq. coll. 1. p. 160. D. C. prod. 3. p. 360.-Hæ'nkea, Salisb. prod. p. 174.- Anacámpseros speeies, Lin. hort. cliff.

Lin. syst. Pentándria, Monogýnia. Calyx of 2 permanent membranous sepals. Petals 5 , permanent, equal, obovate, hypogynous. Stamens 5, inserted with the petals, but disposed without any respect to the number of petals, hence there are probably 10, 5 of which are abortive; anthers short, usually barren. Ovarium ovate-triquetrous. Style wanting; stigmas 3 , spreading, muricated with glands on the upper side. Fruit triquetrous, winged, indehiscent, 1 -seeded.-A glabrous slurub, native of $A$ frica. Leaves opposite, roundish-obovate, flat, fleshy. Peduncles opposite, denticulated, compressed; pedicels I-flowered, 3 rising from each notch in the peduncle. Flowers small, rose-colomred. Fabric of seeds unknown.

1 P. A'rra (Jacq. l. c. t. 22.). h. G. Native of the South of Africa. D. C. pl. grass. t. 13\%. Claytònia Portulacària, Lin. mant. P. 211. Lam. ill. t. 144. f. 2. Crássula Portulacària, Lin. spec. p. 406. Ha'nkea crassifòlia, Salisb. prod. 174. Portulàca fruticosa, Thunb. fi. cap. p. 399. exclusive of the synonyms.-Dill. lort. elth. 1. t. 101. f. 120. The plant seldom flowers in the gardens: at Genoa in the garden of Grimaldi.

A frican Purslane-tree. Clt. 1732. Shrub 3 to 6 feet.

Cult. This plant will grow in any dry light soil ; and young cuttings will root readily in sand under a hand-glass.

X. U'LLUCUS (Ulluco or Melloco is the name of the plant in Quito). Lozano, in senan. nuov, gran. 1809. p. 185 . D. C. prod. 3. p. 360.

Lin. syst. Pcntándria, Monogýnia. Calyx of 2 opposite, roundish, concave, pellucid, coloured, deciduous sepals. Petals 5 , longer than the calyx, cordate, attenuated at the apex, connected at the base into a short tube. Stamens 5 ; filaments very short, erect; anthers 2-celled, erect. Ovarium sub-globose. Style filiform, length of stamens; stigma simple. Capsule 1celled. Seed one, oblong.-Herb smooth. Root tuberous. Stem branched, angular. Leaves alternate, cordate, quite entire, thick, petiolate. Flowers disposed in a terminal, simple, drooping raceme. Pedicels furnished with very short bracteas.

1 U. Tuberósus (Loz. 1. c.). 4. D. G. Native of South America, in the province of Quito, growing in gardens, where it is called Ulluco or Melloco. The root is mucilaginous and eatable.

Tubcrous-rooted Ullucus, Pl. 1 foot.

Cult. For the culture and propagation of this succulent plant see Anacámpscros, p. 76.

XI. CLAY'TO'NIA (in honour of Joln Clayton, who collected plants, mostly in Virginia, and sent them to Gronovius, who published them in his Flora Virginica). Lin. gen. 28\%. 
Juss. gen. 314. Lam. ill. t. 14t. Gartn. fr. 2. p. 220. t. 129. St. Hil. mem. mus. 2. p. 197 . t. 4. f. 15 -Límnia, Lin. act. ups. 1746. p. 130.-Claytònia and Límnia, Ilaw. syn. p. 11.

Lix. syst. Pentándria, Monogýnia. Calyx of 2 oval, opposite, permanent sepals (f. 20. $a$. f. 19. b.). Petals 5, obcordate (f. 20. b.), or obovate (f. 19. a.), hypogynous, equal, unguiculate; claws connate at the base. Stamens 5 (f. 20. b.), inserted at the claws of the petals. Ovarium sessile. Style 1, trifid at the apex; lobes stigmatose inside. Capsule 1-celled, 3-valved, 3-seeded. Seeds sessile.-Herbs glabrous, rather succulent, usually perennial. Leaves quite entire : radical ones petiolate; upper usually opposite and sessile, and sometimes connate. Racemes terminal. Flowers white or rose-coloured.

1. Scape with 2 opposite leaves, which are sometimes connate.

\section{- Roots fibrous, annual.}

1 C. perfolia'ta (Donn, hort. cant. p. 25.) leaves witlout nerves: upper ones connate or perfoliate, forming a roundish disk; radical leaves petiolate, oval-rhomboid; lower pedicels of raceme in bundles; petals entire or somewhat emarginate. $\odot . H$. Native of Mexico, on the mountains of St. Augustin; and on the rocky mountains in North America; also of Cuba, if $C$. Cubénsis, Bonpl. ann. mus. 7. p. 82. t. 6. pl. equin. t. 26. be the same.-Sims, bot. mag. 1336. Límnia perfoliata, Haw. syn. p. 12. Flowers small, white. Root fibrous. Leaves edible, and used like those of the Purslane.

Perfoliate Claytonia. Fl. May, Aug. Clt. 1794. Pl. $\frac{1}{4}$ to $\frac{1}{2} \mathrm{ft}$.

2 C. Alsinoìds (Sims, bot. mag. 1309.) root fibrous; leaves reticulately veined, rhomboid, acute; upper leaves opposite, sessile, ovate, mucronate : radical ones petiolate, ovate, acuminated; pedicels of raceme for the most part solitary, bractless; petals emarginate. $\odot . H$. Native of the north-west coast of America, at the sources of the Columbia; particularly plentiful about Indian villages, where it seems to hold the place of chickweed in our country. Flowers white.

$V$ ar. $\beta$, ròsea (D. C. prod. 3. p. 361.) flowers rose-coloured; leaves almost nerveless. $\odot$. H. Native of Nootka Sound. C. Sibírica, Sims, bot. mag. 2243. Sweet, br. f. gard. t. 16. but not of Pall.

Chicknced-like Claytonia. Fl. Mar. June. Clt. 1794. Pl. $\frac{1}{2}$ foot.

3 C. Unalasche'nsis (Fisch. in Rœm. et Schultes, syst. 5. p. 434.) leaves nerved: upper ones opposite, sessile, rhombovate: radical ones petiolate, ovate-lanceolate, acuminated; racemes twin; bracteas ovate; pedicels solitary, twice longer than the bracteas; petals emarginately bifid. $\odot$. H. Native of the Island of Unalaschka, in humid sandy places. C. bífida, Willd. herb. The petals are said to be white in the dried state.

Unalasehka Claytonia. Fl. Mar. Jil. Clt. 1820. Pl. $\frac{i}{4}$ to $\frac{1}{2} \mathrm{ft}$.

4. C. PARvifiòra (Dongl. mss. ex Hook. fl. bor.amer. 1. p. 225. t.73.) root fibrous; radical leaves numerous, linear-spatulate, 3nerved, with anastomosing veins, on long petioles; the 2 cauline ones joined into a perfoliate, ovate leaf, which is reticulately veined; racemes solitary, rather compound, unibracteate. $\odot .11$. Native of North America, abundant along the course of the Columbia, in open parts of the forest, voL. III. where wood has been burnt, or the ground turned up by deer. Flowers rose-coloured and white. This species diflers from $C$. perfoliàta in its lincar-spatulate radical leaves, ovate bracteas, and profusion of small Howers. (f. 19.)

Small-flowered Claytonia. Pl. 1 foot.

5 C. spatula'ta (Dougl. inss. ex Hook. f. amer. bor. 1. p. 226. t. 74.) plant minute; root fibrous ; radical leaves numerous, narrow, linear-spatulate; the 2 cauline ones ovate, acute, and sessile; racemes solitary, unibracteate; petals entire. $\odot . H$. Native of the north-west coast of America, in the valleys of the Rocky Mountains. Corolla longer than the calyx. Stems many from the same root. This is the smallest of all the species. Spatulate-leaved Claytonia. Pl. $\frac{1}{8}$ foot.

6 C. sarmentòsa (Meyer. nov. pl. in mem. acad. de Mourou. vol. 17.) sarmentose; leaves nerved : radical ones oblong, obtuse, petiolate : cauline ones ovate, somewhat corrlate, stemclasping, but distinct: racemes terminal, solitary, bractless; petals emarginate.-Native of St. George, one of the Aleutian Islands.

Sarmentose Claytonia. Hl. sarmentose.

\section{* Roots tuberous or fusiform.}

7 C. VIRGI'Nica (Lin. spec. 394.) leaves all narrow, linear, obsoletely 3 -nerved, with anastomosing veins : radical ones very few; racemes solitary, nodding; pedicels elongated: lower ones bracteate; petals emarginate. $4 . H$. Native of Nortl America, in New England, Virginia, and Carolina, in humid woods; and of Kotzebue's Sound. The leaves of the plant, from the last-mentioned habitat, are remarkable for their broadness. Pluk. alm.t. 102. f. 3. Flowers white.

l'irginian Claytonia, Fl. Mar. Aug. Clt. 1768. Pl. $\frac{1}{4} \mathrm{ft}$.

8 C. GRANDifiòra (Sweet, fl. gard. t. 216.) root tuberous : leaves linear-lanceolate, attenuated at both ends; racemes solitary, many-flowered; petals oval, obtuse, entire; sepals very blunt. 24.H. Native of North America, near Montreal, and on the Saschatchawan. C. Virgínica, var. $\beta$, mèdia, D. C. prod. 3. p. 361. D. C. pl. grass. t. 131 . Flowers pink or rose-coloured, with darker branehed veins, and a yellow spot on the claw.

Great-flowered Claytonia. Fl. Mar. May. Clt.? Pl. $\frac{1}{4}$ foot.

9 C. Acutifròra (Sweet, hort. brit. edit. 2.) root tuberous ; leaves all loner, linear-lanceolate, 3 -nerved, with anastomosing reins; racemes solitary, nodding: pedicels elongated: lower ones bracteate; petals elliptic, entire, acute at both ends; sepals acutish. 4. H. Native of North America, in humid parts of woods. C. Virgínica, Sims. bot. mag. 941. C. Virgínica, var. $\boldsymbol{\alpha}$, acutiflòra, D. C. prod. 3. p. 361. Flowers white.

Acute-flowered Claytonia. Fl. Mar. May. Clt.? Pl. $\frac{1}{4} \mathrm{ft}$.

10 C. Caroliniána (Mich. f. bor. amer. 1. p. 175.) root tuberous; radical leares subspatulate: cauline ones oblong; racemes solitary, nodding ; pedicels elongated: lower ones bracteate; petals obovate, somewhat emarginate; sepals very blunt. 4. H. Native of North America, in Carolina. C. spatulafòlia, Salisb. prod. p. 71. C. Virgínica $\gamma$, spatulæfòlia, D. C. prod. 3. p. 361. Flowers pink or rose-coloured.

Carolina Claytonia. Fl. Mar. May. Clt. 1789. Pl. $\frac{1}{4}$ foot.

11 C. lanceola'ta (Pursh, f. bor. amer. 1. p. 175. t. 3.) root tuberous; radical leaves very few, oblong, on long petioles: cauline ones elliptic, sessile, all 3 -nerved, with anastomosing veins; racemes solitary, nodding; pedicels elongated: lower ones bracteate; petals deeply emarginate. 2 . H. Native of North America, in the valleys of the Rocky Mountains, in a rich soil; and perlaps in Eastern Siberia. Flowers large, white. It is very nearly allied to $C$. I'estianna of Fisch.

Lanecolate-leaved Claytonia. Fl. Mar. May. Clt, 1812. Pl. $\frac{1}{4}$ foot.

12 C. Áretica (Adams, act. nosc. 5. p. 94.) leaves nerveM 
less, fleshy ; cauline ones sessile, ovate ; radical ones petiolate, subspatulate; racemes secund; petals obovate, somewliat emarginate. 4. H. Native of Arctic Siberia, towards the mouth of the Lena. C. Chamissòi, Led. ex Spreng. syst. 1. p. 790. Flowers large, white, or pale yellow, with an orange throat.

Arctic Claytonia. Pl. $\frac{1}{6}$ foot.

$13 \mathrm{C}$. VESTIA'NA (Fisch. in litt.) root tuberous; leaves veinless : radical ones oblong : cauline ones opposite, ncarly sessile ; stem dichotomous ; peduncles long, somewhat corymbose ; petals entire. 4. H. Native of Siberia. C. Joanuiàna, Rœem. et Schultes, syst. 5. p. 434. This species differs from the true $C$. Sibirica in the leaves being narrower, in the petals being white, and in the inflorescence. Flowers secund, at first nodding. $\mathrm{Ca}-$ lycine lobes obtuse. Corolla appearing as if it were pedicellate.

Vest's Claytonia. Fl. Mar. Aug. Clt. 1827. Pl. $\frac{1}{4}$ foot.

14 C. acutifolia (Pall. ex. Willd. rel. in Røm. et Schultes, syst. 5. p. 436.) leaves oblong, nerved, acute; petals emarginate; branches numerous from the sides of the root. $4 . \mathrm{H}$. Native of Eastern Siberia. Flowers white. Stems 3-4 hands higl.

Acute-leaved Claytonia. Fl. May, Ju. Clt. 1827. Pl. $1 \frac{1}{2} \mathrm{ft}$.

15 C. тureròsa (Pall. ex Willd. rel. in Rom. et Schultes, 5. p. 436.) root tuberous; Jeaves linear-lanceolate, attenuated; petals retuse. 4. H. Native of Kamtschatka and Eastern Siberia, among hypnums. Leaves 2, alternate. Tubers edible, like a potatoe.

Tuberous-rooted Claytonia. Pl. $\frac{1}{4}$ to $\frac{1}{2}$ foot.

I 6 C. Sibírica (Lin. spec. 294.) root fusiform ; leaves veined: radical and cauline ones oval; raceme secund; petals bific. 4. H. Native of Siberia, in boggy places. Limnia, Lin. act. holm. 1746. t.5. Radical leaves quite glabrous, petiolate : cauline ones 2, opposite, sessile. Stamens inserted in the petals. Flowers rose-coloured.

Siberian Claytonia. Fl. Mar. Ju. Clt. 1768. Pl. $\frac{1}{4}$ to $\frac{1}{2} \mathrm{ft}$.

\$2. Stem leafy. Leaves all alternate. Plants resembling Calandrinia in habit.

17 C. LINEA'ris (Dougl. mss. ex Hook. fl. bor. amer. 1. p. 224. t. 71.) stems branclied; leaves narrow-linear, obtuse, 3nerved; racemes terminal, secund, bracteate at the base; petals entire. $\odot$. H. Native of North-west America, in moist rocky places; on the Great and Little Falls of the Columbia, abundant. Stems filiform, leafy. Petals obovate. (f. 20.)

Linear-leaved Claytonia. $\frac{1}{4}$ to $\frac{1}{2}$ foot.

18 C. Filicaúlis (Dougl. mss. ex Hook. fl, bor, amer. 1. p. 224. t. 72.) stems branched at the base: lower leaves obovate, acute, reticulately veined, running into petioles; cauline leaves linear-spatulate; racemes terminal ; flowers bracteate; petals entire. $\odot . H$. Native of the north-west coast of America, on rocks in Nootka and Qucen Charlotte's Sound; plentiful on moist rocks of the Columbia, near the ocean. Flowers largish.

Thread-stemmed Claytonia. PI. $\frac{1}{4}$ foot.

10 C. stolonifera (Meyer. l. c.) stem erect, branched, bearing stolons at the base; leaves nearly sessile, oblong-spatulate, acute, a little nerved; racemes subcorymbose, lateral, bractless; petals entire. 4 . H. Native of Unalaschka.

Stoloniferous Claytonia. Pl. $\frac{1}{4}$ foot.

20 C. PARvifòlia (Moc. icon. pl. nootk. ined. ex D. C. prod. 8
3. p. 361.) leaves nerveless; cauline ones alteruate, elliptic, acute, attenuated at the base; radical ones like the cauline ones on slort petioles; racemes few-flowered; pedicels solitary, bracteate; petals acutely emarginate. $\odot$.? H. Native of North-west America, at Nootka Sound. Flowers rose-coloured. Small-leaved Claytonia Pl. $\frac{1}{4}$ foot.

\section{$\uparrow A$ very doubtful species.}

21 C. NEMonòsa (Willd. rel. in Rœm. et Schultes, 5. p. 436.) leaves ovate: superior ones tern; racemes twin. $4 . S$. Native of South America, in the shady woods of Javita. Perhaps this plant onght to be removed from the genus. ex H. B. et Kunth, nov. gen, amer. 6. p. 80 . The plant, according to Bonpland, has a quadrangular stem; opposite petiolate leaves : terminal dichotomous spikes; a 5-parted calyx; a semi-5-cleft corolla; a short style, 2 stigmas, and a 1-celled, many-seeded capsule.

Grove Claytonia. Pl. ?

Cult. The greater part of the species of Claytonia are very delicate little plants, especially those with tuberous roots : these grow best in a border of peat soil, and are increased by seeds, which sometimes ripen plentifully. 'The fibrous-rooted kinds, being all annual, the seeds of them only require to be sown in the open border, in a rather moist sladed situation; and if they are allowed to scatter their seeds, plants will rise every year in abundance.

XII. MO'NTIA (so named by Micheli, in honour of Joseph Monti, Ph. D. Professor of Botany, and Prefect of the Medical Garden at Bologna ; author of Agri Bononiènsis stirpium Catalogi Prodromus, 1791, 4to.). Mich. gen. 17.t. 13. Gærtn. fr. 2. p. 220. t. 129. Lin. gen. no. 101. Juss. gen. 313.-Camerària, Dill. nov. gen. p. 114. t. 6 . but not of Lin.-Alsinoìdes, Vaill.

Lin. syst. Triándria, Trigýnia. Calyx of 2, rarely of 3 sepals. Petals 5, connected a little way at the base, 3 of which are smaller than the other 2. Stamens inserted in the claws of the petals, usually 3 in front of each of the smaller petals, very rarely more. Ovarium sessile. Style very short, 3-parted; divisions spreadingly reflexed. Capsule 1-celled, 3-valved, 3seeded.-European, glabrous, aquatic, or bog herbs. Leaves opposite. Flowers axillary, small. This genus is hardly distinct from Claytònia.

1 M. Fonta'na (Lin. spec. p. 129.). ๑. W. H. Native of Europe and North America; also of South America, in bogs, ponds and ditches.

Var. a, minor (Willd. spec. 1. p. 4.15.) stem erectish, divaricate; leaves rather connate. $\odot$. B. H. Native of humid sandy woods and springs.-Micl. gen. t. 13, f. 2.-Fl. dan. t. 131. Smith, engl, bot. t. 1206.-Schkuhr. handb. t. $20 . \mathrm{M}$. fontàna $\beta$, erécta, Pers. ench. 1. p. 111. M. minor, Gmel. $f$. bad. 1. p. 301 .

Var. $\beta$, màjor (Willd. spec. l. c.) stems weak, creeping, dichotomous; leaves sessile. $\odot$. B. H. Native of rivulets. Mich. gen. t. 13. f. 1. M. rèpens, Gmel. fl. bad. 1. p. 302 . M. fon. tàna $\beta$, rèpens, Pers. ench. 1.p. 111 . M. rivulàris, Gmel.

Fountain or Water-chickweed. Fl. April, May. Brit. Pl. $\frac{1}{3}$ to $\frac{1}{4}$ foot.

Cult. This plant will grow in any moist soil, or in water.

XIII. LEPTRI'NA (meaning unknown to us). Rafin. journ . phys. 1819 . aug. p. 95 . D. C. prod. 3. p. 362 .

LiN. syst. Triandria, Trigynia. Calyx 3-parted; lobes elliptic, obtuse. Petals wanting. Stamens 3, alternating with the parts of the calyx, and liypogynous. Ovarium 1, oval. Styles 3, short, acute. Capsule 1-celled, 3-valved, 3-seeded. 
Seeds fixed to the central placenta.-A small smooth herb, native of North America. Radical leaves 3, entire, lincar-lanceolate, acute. Scape I-flowered, length of leaves. This genus is hardly known, but it only appears to differ from Móntia in the want of petals.

1 L. Autuma'Lis (Rafin. l.c.). ○. B.H. Native of North America, on the banks of the Ohio.

Autumnal Leptrina. Pl. $\frac{1}{8}$ to $\frac{1}{4}$ foot.

Cult. The seeds of this plant only require to be sown in the open ground, in a moist situation; and if the plant is allowed to scatter its seeds, there will be plenty of plants each year.

XIV. COLOBA'NTHUS (from ro roßos, kolobos, maimed, and $a v \theta 0 s$, anthos, a flower; in reference to the want of petals). Presl. in reliq. Hank. 2. p. 13. t. 49, f. 2.

Lin. syst. Tetra-Hcxándria, Tetra-Pentagýnia. Calyx 4-5parted. Petals wanting. Stamens 4-6, alternating with the segments of the calyx. Stigmas 4-5. Capsule 4-7-valved, many-seeded. Both Bartling and $\mathbf{K}$ unth insert this genus in the order Caryophýllece, while the stamens are decidedly perigynous, and therefore ought to come among the Portulàcece.

1 C. ARETioldes (Gill. mss. ex Hook, et Arn. in bot, misc. 3. p. 246.) root perennial, with a multiple neck; calyx 5-parted; segments ovate; capsule 5-valved. 4. F. Native of Chili, at Los Hornillos, El Paramillo San Isedro, and on the Andes of Mendoza.

Aretia-like Colobantlus. Pl. $\frac{1}{4}$ foot.

2 C. Quite'ssis (Bartling, in Presl. reliq. Hænk. 2. p. 13. t. 49. f. 2.) root annual, with a multiple neck; calyx 5-parted; segments lanceolate; capsule 5 -valved, $\odot$. H. Native about Quito, and on the Cordillera of Chili. Sagina Quitensis, H. B. et Kunth, nov. gen. amer. 6. p. 19.

Quito Colobanthus. Pl. $\frac{1}{8}$ foot.

3 C. saginoides (Bartl. in Presl. reliq. Hænk. 2. p. 13. t. 49. f. 1.) root annual, with a multiple neck; calyx 4-parted; segments ovate; capsule 4-valved. $\odot$. H. Native of Chili.

Sagina-like Colobanthus. Pl. $\frac{1}{8}$ foot.

Cult. See Portulàea for culture and propagation, p. 75.

XV. GINGI'NSIA (in honour of M. Gingins, who has written upon the genera Viola and Lavándula). D. C. prod. 3. p. 362.-Pharnàceum species of authors.

LiN. syst. Pentándria, Trigýnia. Calyx 5-parted; lobes oval, permanent, petaloid on the inside and at the margins. $\mathrm{Pe}$ tals wanting. Stamens 5 , inserted in the bottom of the calyx, and alternating with its lobes; anthers 2 -celled, inserted by the base. Ovarium surrounded at the base by a 5 -lobed fleshy scale. Style wanting. Stigmas 3, crest-formed. Capsule 3valved, 1-celled. Seeds numerous, fixed to the central placenta. -Cape subshrubs. Leaves irregularly verticillate, opposite or alternate, filiform or linear, furnished with scarious stipulas at the base. Peduncles axillary, elongated, bearing umbels of pedicellate Howers at the apex; branches of umbels numerous, divided, many-flowered. This genus differs from Pharnàecum and all the other Caryophyllaceous genera in the stamens being perigynous, and in the leaves being usually alternate; and from all the genera in the order Paronychieg in the stamens alternating with the sepals, not opposite them.

\section{\$1. Leaves lincar.}

1 G. Brevicav'tis (D. C. in mem, soc, hist. nat. par. vol. 4. with a figure. D.C. prod. 3. p. 362.) plant almost stemless; leaves linear, mucronate, crowded in whorls, almost radical ; stipulas membranous, ciliately jagged at the apex. $h$. G. Native of the Cape of Good Hope. Pharnàceum lineàre, Thunb. fl. cap. 274. but not of others. Stems very short. Leaves rather spreading, unequal.

Short-stemmed Ginginsia. Pl. $\frac{1}{6}$ foot.

2 G. elonoa'ta (1).C. I. c. with a figure; prod. I. e.) leaves alternate, lincar, crowded at the tops of the branches; stipulas linear-elongated, ciliately jagged; peduncles more than 3-times longer than the stem. h. G, Native of the Cape of Good Hope. Pharnàceum incinum, Lin. mant. p. 358. but not of others. Pharnàceum lineàre, Andr. bot. rep. t. 329. Flowers whitish.

Elongated Ginginsia. Fl. May, June. Clt. 1795. Pl. $\frac{1}{4}$ to $\frac{1}{2}$ foot.

3 G. Aura'ntia (D. C. prod. 3. p. 363.) caulescent; leaves linear, crowded in whorls; whorls distant ; stipulas small. $h . G$. Native of the Cape of Good Hope. Pharnaceum lincàre, Andr. bot. rep. t. 326. Ait. hort. kew. ed. 2. vol. 2. p. 174. Flowers of an orange-copper eolour. Branches shrubby, white. This species differs from Pharn. lineàre of Thunb, in the stems being suffruticose, not herbaceous, and elongated, not short.

Orange-flowered Ginginsia. Pl. $\frac{1}{4}$ to $\frac{1}{2}$ foot.

\section{\$2. Leaves filiform.}

4. G. A' Lbens (D. C. l. c.) plant caulescent ; leaves filiform, mucronate, irregularly whorled or alternate; stipulas small. h. G. Native of the Cape of Good Hope. Pharnàceum álbens, Thunb. fl. cap. p. 274. ? Pharn. lineàre flòre álbo, Andr. bot. rep. t. 329.? but the leaves are linear in Andrews's plant, not filiform. Flowers greenish on the outside, but yellowish inside and on the edges.

Whitish Ginginsia. Pl. $\frac{1}{4}$ to $\frac{1}{2}$ foot.

5 G. confe'rta (D. C. I. c.) plant eaulescent; leaves opposite, crowded, terete, mucronate; stipulas cut into many setaceous hairs, one half shorter than the leaves. $h . G$. Native of the Cape of Good Hope. Lam, ill. t. 214. f. 3. Pharnatceum incànum, Thunb. fl. cap. 273.? Sims, bot. mag. 1883 . but not of Lour.

Cronded Ginginsia. Fl. MLay, Oct. Clt. 1782. Pl, $\frac{1}{4}$ to $\frac{1}{2} \mathrm{ft}$.

$6 \mathrm{G}$. PRUinòsa; stems branched, thickish; branches pale from membranous stipulas; leaves crowded, filiform, acute, terete, fleshy, mealy or pruinose. h. G. Native of the Cape of Good Hope. Plıarnàceum pruinòsum, Haw. pl. succ. p. 15.

Pruinose Ginginsia. Fl. Ju. Aug. Clt. 1817 . Pl. $\frac{1}{4}$ to $\frac{1}{2} \mathrm{ft}$.

7 G. microphy'lia (D. C. 1. c.) plant caulescent ; leaves terete, obtuse, in fascicles at the nodes, the rest scattered; stipulas woolly; branches scattered, divaricate. $\eta$. G. Native of the Cape of Good Hope. Pharnàceum mierophy'llum, Lin. fil. suppl. 185. T'luunb. Al. cap. p. 27\%. Mollùgo microplıýlla, Ser. in D. C. prod. 1. p. 329. Said to be very like $G$. conférta. Small-leaved Ginginsia. Pl. $\frac{1}{4}$ to $\frac{1}{2}$ foot.

8 G. teretifòlia (D. C. l. c.) plant caulescent; leaves filiform, mucronate, whorled on the branches; stipulas unknown; branches opposite, divaricate. $h$. G. Native of the Cape of Good Hope. Pharnàceum teretif òlium, Thunb. fl. cap. p. 274. Mollùgo teretifòlia, Ser. in D. C. prod. 1. p. 393 . Stem a foot high. Leaves half a line long. Peduncles shorter than the leaves.

Terete-leaved Ginginsia. Shrub I foot.

Cult. A mixture of loam, peat, and sand will answer the species of this genus; and the pots in which they are grown should be well drained with sherds. The best way of propagating them is by seeds.

XVI. A YLME'RIA (in honour of Aylmer Bourke Lambert, F.R.S. F.S.A. and V.P.L.S. the celebrated botanist, 10 whom we owe many obligations in the prosecution of the present work). 
Mart, amaranth. p. 68. nov. act. bonn. 13. p. 276. D.C. prod. 3. p. 263.

Lin. syst. Monadélphia, Pentándria. Calyx 2-parted, coloured. Petals 5 . Stamens 10 , joined into a membranous hypogynous tube; the 5 outer ones abortive; and the 5 inner ones opposite the petals, bearing 2-celled anthers. Style 1; stigma depressed, capitate. Utriculus membranous, valveless. Seeds numerous, lentiform, in the bottom of the cell. - A ustralian perennial herbs. Stems terete, jointed, dichotomous upwards. Leaves linear, opposite, or in whorls. Stipulas scarious. Flowers beautifully coloured, in terminal corymbs. According to Martius, the genus is related to Paronychice, but this is doubtful, in consequence of the stamens being lyypogynous, and also particularly so in their being opposite the sepals. The calyx is of 2 sepals, as in Portulàca, and the petals are 5 , as in most of the order, and the stamens are 10, as in Triánthema.

1 A. kòsea (Mart. 1.c.) stems straightish, and are, as we]l as the leaves, glabrous; stipulas ciliately serrulated; corymb compact. 4. G. Native of New Holland, on the western coast. Flowers rose-coloured.

Rosc-coloured-flowered Aylmeria. Pl. 1 foot.

2 A. viola'cen (Mart. l. c.) stems diffusely dichotomous, and are as well as the leaves glabrous; stipulas quite entire; corymb loose. 4. G. Native of New Holland, on the west coast. Flowers violaceous.

I iolaccous-flowered Aylmeria. P1. 1 foot.

Cult. See Ginginsia for culture and propagation, p. 83.

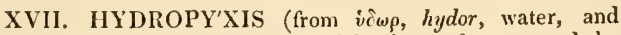
$\pi v \xi e s$, pyxis, a box; the plant is an inhabitant of water, and the capsule resembles a box, from its opening transversely). Rafin. fl. lud. p. 94 . D. C. prod. 3. p. 364.

Lin. syst. Tetrándria, Monogýnia. Calyx permanent, 5parted, bibracteate on the outside; the two inner lobes the smallest. Corolla peripetalous (perhaps inserted in the calyx), crateriform, unequally 5 -lobed. Stamens 4 , didynamous, inserted in the corolla; anthers hastate. Ovarium superior. Style simple, crowned by a capitate 3-lobed stigma. Capsule I-celled, many-seeded, triangular, opening transversely. Central placenta free. This genus is likely to be nearer related to Utriculària than to any other.

1 H. Palu'strus (Rafin. 1. c.) Native of Louisiana, in ditches and marshes. Pourpicr des marais, Robin. voy. p.488. Stems creeping, prostrate. Flowers axillary, pedunculate, solitary, white.

Marsh Hydropyxis. Pl. creeping.

Cult. This plant should be grown in a pot filled with peat, and placed in a deep pan of water. It is easily propagated by separating the runners.

Order CXI. PARONYCHIE'A (plants agreeing with $\mathrm{Pa}$ ronỳchia in important characters). St. Hil. plac. lib. p. 56. Juss. mem. mus. 1. p. 387.-Herniàriæ, Cat. hort. par. (1777.). Illecébreæ, R. Br. prod. p. 413. Lindl. intr. nat. ord. p. 164.

Calyx of 5 sepals (f. 21. a. f. 22. a.), seldom of 3-4; sepals sometimes separate to the base, sometimes joined to the middle (f. 22. a.), and sometimes nearly to the apex (f. 24.a.). Petals small, scale-formed (f. 22. a.), emulating sterile stamens, inserted upon the calyx between the lobes, occasionally wanting (f. 23. a.), or converted into superabundant stamina. Stamens perigynous, exactly opposite the sepals (f. 22, a.), if equal to them in number, but sometimes fewer by abortion; flaments distinct; anthers 2-celled (f. 21.c.). Ovarium free. Styles 2-3, either distinct (f. 24. a.), or partially combined (f, 22. d.). Fruit small, dry, 1-celled, usually membranous, either valveless and indehiscent, or opening with 3 valves. Seeds either numerous, fixed to a free central placenta, or solitary and pendulous, upon a funicle, arising from the base of the cavity of the fruit. Albumen farinaceous. Embryo cylindrical, lying on one side of the albumen, curved more or less, with the radicle always pointing towards the hylum. Cotyledons small.-Herbaceous or half-shrubby branching plants, with opposite or alternate, often fascicled, entire, sessile leaves and scarious stipulas. Flowers small, usually whitish green, sometimes sessile and axillary, and sometimes variously disposed in terminal cymes. Bracteas scarious, analogous to the stipulas.

This order comes very near Portulàcea, Amarantàcea, and Caryophyllea, from which it is distinguished with difficulty. By excluding the section Scleránthea, their scarious stipula will distinguish them from the two last-mentioned orders, and there is scarcely any other character that will; for there are Caryophýllece that have perigynous stamens, as Lárbrea and Adenàrium; and Paronychièa which have hypogynous ones, as Polycarpa'a, Stipulácida, and Ortègia. From Portulàcea it is scarcely to be known with absolute certainty, except by the position of the stamens before the sepals instead of the petals. With Crassulàcea, particularly Tilląa, they agree very much in habit, but their concrete carpella will always distinguish them. De Candolle comprehends in the order various plants without stipulas; but as the latter organs seem to be an essential part of their character, the tribes Queriàcęe and Minuartièce are excluded, and will be found elsewhere.

\section{Synopsis of the genera.}

\section{Tribe 1.}

Telephie's. Calyx 5-parted(f. 21.a.). Petals and stamens 5 , inserted in the bottom of the calyx (f. 2I. b.). Styles 3 (f. 21. e.) free, or connected togcther a little at the base. Leaves alternate, stipulaceous.

I Tele'pusum. Styles 3, spreadingly reflexed, concrete at the base. Capsule pyramidal, trigonal, 3-valved, 3-celled at the base, and 1-celled at the apex. Seeds numerous, fixed to the central placenta, in 6 rows.

2 Corrigiola. Style short; stigmas 3 (f. 21.e.). Capsule 1 -seeded, indehiscent, covered by the calyx. Seed suspended by a funicle, originating at the bottom of the capsule.

\section{Tribe II.}

Illece'brex. Calyx 5-parted (f. 22, a.). Petals 5 or wanting. Stanens 2-3, insertcd in the bottom of the calyx (f. 22. a.). Styles free or somewhat concrete at the base (f. 22.d.). Capsule indehiscent, 1-seeded. Funicle long, rising from the bottom of the capsule, bearing a subpendulous seed at the apcx.-Herbs, rarely subshrubs. Leaves opposite, acute, with scarious stipulas.

3 Hernia'ria. Calyx almost 5-parted. Scales or petals 5 , filiform, entire, but sometimes wanting or very small. Stamens 5 , or only 2-3 from abortion. Styles 2, short, distinct, or concrete at the base. Capsule covered by the calyx. 
1. Grunocárpum. Calyx almost 3-parted. Petals 5, emulating sterile filaments. Stamens 5. Style 1 ; stigma simple. Capsule valveless, covered by the indurated calyx.

5 Axr'cun. Calyx 5-parted. Petals and scales wanting. Stamens 3-5, distinct. Style none; stigmas 2, subcapitate. Capsule covered by the calyx.

6 IlLe'cenrus. Calyx 5-parted, or nearly 3-sepalled, ending on the back at the apex, in an awned horn. Petals wanting, but there are 5 subulate scales in place. Stamens 2-5. Style hardly any ; stigmas $\stackrel{2}{\sim}$, capitate. Capsule covered by the calyx, divisible into 5 at the stripes.

7 Paronýchia. Calyx 5-parted (f. 22. a.). Petals or scales 5, lincar. Stamens 5 (f. 22. a.). Style 1; stigmas 2 (f. 22. d.). Capsule indehiscent or 5 -valved, covered by the calyx.

8 Pentacźna. Calyx 4-parted; segments very unequal, outer 3 spiny at the apex, inner 3 navicular, armed on the back. Stamens 5. Stigmas 2, short. Capsule 1-secded.

9 Cardione'ma. Calyx 5-parted; lobes drawn out on the back at the apex into a straight horn. Petals wanting. Stamens 5,2 sterile ones obcordate, flat, 3 fertile ones obcordate at the base, bearing each an antheriferous filament in the reccss. Styles 2, hardly concrete at the base, long, revolute. Fruit oval-oblong.

\section{Tribe III.}

Polycarpa's. Calyx 5-parted (f. 23. a.). Petals 5, or nanting. Stamens 1-5, inserted in the bottom of the calyx. Styles 2-3, sometimes distinct, sometimes concrete. Capsulc 1-eelled, nany-seeded. Sceds fixed to the central placenta.-Herbs or subshrubs. Leaves opposite. Stipulas scarious. The stamens in this tribe are almost hypogynous, and truly so in some genera, as in Polycarpo' $a$, Stipulácida, and Ortègia, and thercfore vcrge closely on the order Caryophýllea.

10 Polycarpe's. Lobes of calyx with membranous edges (f. 20. a.). Petals 5. Stamens 5, nearly hypogynous (f. 23, a.). Styles 3, concrete at the base. Capsule 1-celled, 3-valved, many-seeded.

11 Strpulícida. Lobes of calyx with membranous edges. Petals 5. Stamens 3 , inserted in the torus. Style short, crowned by 3 stigmas. Capsule 1-celled, 3-valved, few-seeded.

12 Bala'rdia. Lobes of calyx flattish. Petals 5. Stamens 2-3-4, inserted in the receptacle. Styles 3, very short, papilliferous inside. Capsule 1-celled, 3-valved, many-sceded.

13 Ave'rsta. Lobes of calyx thickened in the middle, keeled. Petals 5, or only 3 from abortion. Stamens 3 , inserted in the bottom of the calyx. Style 1, trifid at the apex. Capsule 1-celled, 3-va'ved, many-seeded.

14 Orte'gia. Lohes of calyx keeled a little. Stamens 5, 3 fertile, inserted in the torus, the other 2 scale-formed and sterile. Style 1, capitate at the apex or bifid. Capsule 3-valved, manysceded.

15 Polyca'rpon. Lobes of calyx with membranous edges, concave, keeled, and mucronate. Pctals 5, cmarginate. Stamens 3-5. Styles 3, very short. Capsule 1-celled, 3-valved, many-seeded.

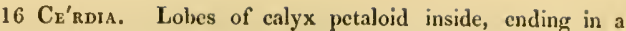
bristle cacls at the apex. Petals wanting. Stamen one, in front of one of the sepals. Style filiform, bifid at the apex. Capsulc 1-celled, many-seeded.

\section{TRIBE IV.}

Polniche'x, Calyx 5-toothed; tube urceolate. Stamens 1-2, inserted in the throat of the calyx. Petals wanting. Stigma bifid. Utriculus or fruit valveless, 1-sceded. Bractcas and calyx increasing aftcr flonering, and beconing fleshy, so as 10 form something like a berry.-Suffruticose herbs, with opposite or subverticillate stipulaccous lcaves.

17 Pollíchia. Character the same as that of the tribe.

\section{† Genera belonging to Paronychièce, but are not sufficiently knonn.}

18 Litnóphila. Calyx 3-parted, acute. Petals 3. Scales or abortive stamens 2, opposite the sepals. Stamens 2, placed at one side of the ovarium. Style thick, bluntly emarginate at the apex. Fruit unknown. A very minute glabrous herb.

19 Sellòwia. Calyx urceolate, 5-cleft, membranous, 10 ribbed. Petals 5, alternating with the lobes of the calyx. Stamens fixed in the middle of the segments of the calyx, and shorter than them; anthers didymous. Style I; stigma obtuse. Capsule 3-valved, 1-celled, 1-seeded. A smooth herb, with the habit of Illécebrum verticillàtum.

\section{Tribe I.}

TELEPHIE' $\mathrm{E}$ (plants agreeing with the genus Telephium in important characters). D. C. prod. 3. p. 366. Calyx 5-parted (f. 21. a.). Petals and stamens 5 (f. 21. b.), inserted into the bottom of the calyx. Styles 3 (f. 21.e.), distinct, or somewhat concrete at the base.-Leaves alternate, stipulaceous.

I. TELE'PHIUM (so named from Telephus, son of Hercules by Auge, and according to some king of Mysia). Tourn. inst. t. 128. Lin. gen. 377. Gæertn. fr. 2. p. 221. t. 129. Lam. ill. t. 213. Juss. mem. mus, 1. p. 389. St. Hil. plac. lib. p. 44 .

LiN. syst. Pentándria, Monogýnia. Calyx 5-parted, permanent ; lobes oblong, concave. Petals 5, inserted in the bottom of the calyx, and alternating with its lobes, and about equal in length to them. Stamens 5, opposite the sepals, and inserted in their bases. Styles 3, spreadingly reflexed, concrete at the base. Capsule pyramidal, trigonal, 3-valved, 3-celled at the base, and 1-celled at the top from the dissepiments not being extended so far. Sceds numerous, disposed in 6 rows on the central placenta. Embryo lateral, curved, but not annular. Albumen mealy.- Subshrubby, procumbent, many-stemmed, glabrous, glaucous herbs. Leaves alternate, rarely opposite, stipulaceous. Flowers white or greenish white.

1 T. IMPERA'TI (Lin. spec. 388.) leaves alternate; flowers in racemose corymbs, rather crowded. 4 . H. Native of the south of Europe, particularly in the south of France, Italy, Spain, Switzerland, \&c. D. C. fl. fr. 4. p. 400. Lam. ill. t. 213. Schkulur. handb. 1. t. 85 . T. rèpens, Lam. fl. fr. 3. p. 71. T. alternifolium, Mœench, meth. 231. Flowers white, sometimes tinged with red.

Imperati's Orpine. Fl. June, Aug. Clt. 1658. Pl. tr.

2 T. oppositifòliom (Lin. spec. 388 .) leaves opposite; flowers in racemose corymbs, crowded. 4 . H. Native of Barbary. 
Shaw, spec. p. 572, with a figure. Flowers white. Perhaps only a variety of the preceding.

Opposite-lcaved Orpine. Pl. tr.

3 'T. LAXiflònum (D. C. prod. 3. p. 366.) leaves alternate ; peduncles opposite the leaves, trifid at the apex; middle pedicel I-flowered, lateral ones elongated, and usually 3-flowered. 4 . G. Native of the Cape of Good Hope. Herb glaucous. Leaves alternate, distant, obovate, mucronate; petiole shorr, margined, with a membrane. Capsule subglobose, 3-celled nearly to the apex. Perlaps a proper genus, but the habit is truly that of Telc̀phium.

Loose-flonered Orpine. Pl. tr.

Cult. All the hardy species of Orpine grow well in any light soil ; and may either be increased by cuttings or parting at the root; they are well adapted for ornamenting rock-work. The last species being a native of the Cape of Good Hope, requires the protection of a green-house in winter.

II. CORRIGI'OLA (a diminutive of corrigia, a shoe string; trailing flexible plants). Lin. gen. no. 378. Juss. mem. mus. 1. p. 389. Lam. ill. t. 213. D. C. prod. 3. p. 366. Polygonifòlia, Vaill. Adans. Dill.

L1N. syst. Pentándria, Trigýnia. Calyx 5-parted (f. 21.a.), permanent. Yetals 5 (f. 21.6 .), equal to the calyx and inserted in it, and alternating with its lobes. Stamens 5 , opposite the sepals. Style short; stigmas 3 (f. 21.e.). Capsule 1-seeded, indeliscent, covered by the calyx. Secd suspended by a funicle, which rises from the bottom of the capsule.-Procumbent glatcous berbs, with alternate stipulaceous leaves, and terminal racemose corymbs of small flowers. Habit of Teliphium.

1 C. telephifòlia (Pourr. chl. narb. 20. act. tol. 3. p. 316.) stems naked in the floriferous part. $\%$. H. Native about Perpignon and about Madrid, in sandy places; also of Chili about Valparaiso. D. C. fl. fr. suppl. p. 527. Flowers white.

I'ar. $\beta$, imbricàta (Lapeyr. abr. p. 169.) stems short; lower leaves rather imbricated. \%. H. Native about Vinca and Nyer.

Orpine-leaved Strap-wort. Fl. July, Aug. Clt. 1822. Pl. procumbent.

2 C. LitTora'Lis (Lin. spec. p. 388.) stems leafy in the floriferous part. $\odot$.H. Native thronghout Europe, on sandy shores. Found by Hudson in England on the Slapham Sands beyond Dartmonth, and near Star-point. EEed. H. dan. t. 334. Smith, engl. bot. 668. fl. græc. t.292. Polygonifòlia, Dill. giss. append. t. 3. Lind. als, t. 2. Flowers white.

Shore Strap-wort. Fl. June, Aug. Britain. Pl. tr.

3 C. Deltoídea (Hook. et Arnott, in Beech, bot. p. 24.) stems prostrate; leaves deltoid, long, spatulate; racemes lateral, furnished at the base by a spatulate bractea. 2.? G. Native of Chili, about Conception and Valparaiso. This plant bears a strong resemblance to $C$. littoràlis. Flowers white.

Deltoid-leaved Corryiola. Pl. prostrate.

4 C. squanòsa (Hook, et Arn. in bot. misc. 3. p. 247.) caudex perennial, a little branched, very scaly at the apex, from which many stems issue; stems prostrate; leaves linear, oblong; racemes corymbose, leafless. 4. G. Native of Chili, abont Valparaiso, Vina de la Mar, and Playa Ancha. The lower part of the stem, which is here called a caudex, from its resemblance to that part of ferns, is to be seen in no other species of the genus; the scaly appearance at its summit is obviously caused by a congeries of stipulas. Flowers white.

Scaly Strap-wort. Pl. prostrate.

5 C. CAPE'Nsis (Willd. spec. 1.p. 507.) flowers sessile; calyx hardly with membranous margins. $\odot$. H. Native of the Cape of Good Hope. Thunb. fl. cap. p. 272. C. littoràlis, Thunb. prod. p. 55. Perhaps sufficiently distinct from C. littoràlis.

Cape Strap-wort. Fl. June, Aug. Clt. 1819. Pl. tr.

Cult. The seeds of the annual kinds should be sown in dry light soil. The culture of the peremnial kind is the same as that recommended for the hardy species of Telèphium.

\section{Tribe II.}

ILLECE'BRE $\mathrm{E}$ (this tribe contains plants agreeing with Illéccbrum in some particular characters). D. C. prod. 3. p. 367. Calyx 5-parted (f. 22. a.). Petals 5, or wanting. Stamens 2-5, inserted in the bottom of the calyx. Styles distinct, or somewhat concrete at the base. Capsule indehiscent, l-seeded. Funicle long, rising from the bottom of the capsule, bearing a somewhat pendulous seed at the top.-Herbs, rarely subshrubs. Leaves opposite, acute, with scarious stipulas.

III. HERNIA'RIA (from hernia, a rupture; supposed effect in curing). Tourn. inst. t. 288. Lin. gen. no. 308. Lam. ill. t. 180 . Juss. mem. mus. 1. p. 389 . D. C. prod. 3. p. 367.

Lin. syst. Pentándria, Digýnia. Calyx nearly 5-parted, somewhat coloured inside. Scales or petals 5, filiform, quite entire, alternating with the sepals, sometimes wanting or very small. Stamens 5, or only 2-3 from abortion, opposite the sepals. Styles 2, short, distinct, or concrete at the base. Capsule Iseeded, indehiscent, covered by the calyx.- Prostrate suffruticose small herbs, with branched stems. Leaves opposite, stipulaceous: stipulas solitary between the leaves, broad at the base. Flowers glomerate in the axils of the leaves. Bracteas small.

$\S 1$. Herniarice verce (true species of Herniària). Stems prostrate, small; flowers glomerate in the axils of the leaves, puberulous or hairy on the outside.

1 H. cine'rea (D. C. fl. fr. suppl. p. 375. mem. par. t. 3.) plant of many stems, herbaceous, clothed with cinereous hairs ; branches ascending; leave's oval, acute at both ends; flowers crowded, axillary. $\odot$. H. Native about Montpelier, Narbonne, plentiful in Spain in dry gravelly or sandy places. In Spain the plant is called Quebrantapiedras. H. ánnua, Lag. gen. et spec. P. 12. and perhaps H. latifölia, Lapeyr. abr. p. 127 .

Cinereous Rupture-wort. Fl. June, Aug. Clt. 1823. Pl. tr.

2 H. viréscens (Salzm. pl. exsic. ex D. C. prod. 3. p. 367.) herb ascending, Inany stemmed, smoothish; leaves oval, ciliated; bundles axillary, few-flowered; calyx rather pilose. $\odot$. H. Native of Mauritania, about Tangiers. It differs from $H$. cinèrea in the greenish habit, nearly as $H$. hirsùta does from $H$. glàbra, or as II. alpina does from $H$. incàna.

Grcenish Rupture-wort. Pl. tr.

3 H. gla'bra (Lin. spec. p. 317.) plant herbaceous, glabrous, prostrate; leaves oval; bundles many-flowered. $4 . \mathrm{H}$. Native of Europe and Siberia, in exposed gravelly places. In England, at the Lizard-point, and near Newmarket. Oed. A. dan. t. 529. Smith, engl. bot. t. 206. Sclikuhr, handb. t. 56 . Blackw. herb. t. 320. H. alpéstris, Aubr. H. fruticòsa, Gouan, This and the two following species are confounded by Spreng. in his syst. 1. p. 929. under the name of $H$.vulgàris.

Glabrous Rupture-wort. FI. July, Aug. England. Pl. tr.

4. H. Hisu'ta (Iin. spec. p. 31\%) plant herbaceous, prostrate, hairy; leaves oval-oblong; bundles sessile, few-flowered. 
4. H. Native throughout Europe, in gravelly places. In England, near Barnet; and in Cornwall. Smith, engl. bot. 1379. Mor. hist. sect. 5. t. 29. f. 2. Petiv, brit. t. 10. Tandich, icon. t. 284. This plant is in every respect the same as $I I$. glàbra, except in the hairiness.

Var. $\beta$, pubéscens (D. C. prod. 3. p. 368.) leaves ciliated, smoothish; stipulas larger. Paronýchia pubéscens, D. C. f. fr. 3. p. 403 .

IIairy Rupture-wort. Fl. July, Aug. England. Pl. tr.

5 H. incs'va (Lam. dict. 3. p. 124.) suffruticose, prostrate, hoary from villi; leaves ovate-oblong; flowers somcwhat pedicellate, in loose clusters. 4. H. Native of Italy, Provence, Dauphiny, \&c. in barren placcs. D. C. fl. fr. suppl. 375 . H. lenticulàta, Lin. spec. p. 317 . exclusive of the synonymes. $H$. alpina, Lois. but not of $\mathrm{V}$ aill.

Hoary Rupture-wort. Pl. tr.

6 H. Besse'ur (Fisch. ex Horn. suppl. p. 127.) stems slirubby at the base, somewhat ascending; branches elongated; leaves oblong-lanceolate, pubescent; bundles axillary, many flowered, rather loose. 4 . H. Native of Tauria and Podolia. H. incàna, Bieb. suppl. p. 173. H. liirsùta, D'Urv, cnum. p. 28. H. Millegràna, Pall. ex Spreng. and perhaps H. microcárpa of Presl. del, prag. which was collected on the mountains of Sicily.

Eesser's Rupture-wort. Fl. June, Aug. Clt. 1822. Pl.tr.

7 H. macroca'rpa (Sibtl. et Smith, fi. græc. t. 252.) stems fruticulose at the basc, ascending; branches sctosely pubescent; leaves obovate-lanceolate, hairy on both surfaces, as well as on the calyxes; bundles few-flowered. 2. H. Native of Laconia, and by the way side between Smyrna and Bursa; also in the Balearic Islands.

Large-fruited Rupture-wort. Pे.tr.

8 H. Alpina (Vill. dauph. 2. p. 556. exclusive of the synonyme, root becoming woody at length; stems prostrate, tufted, densely leafy, suffruticose; lcaves oval, rather villous, ciliated ; flowers few towards the tops of the branches, somewhat glomerate. 24. H. Native of Provence, Dauphiny, and Savoy on the Alps. D. C. f. fr. suppl. p. 375. H. alpéstris, Lam. dict. 3. p. 125. This plant is distinguished from $H$. ineàna at first sight by its greenish habit, not hoary.

Alpine Rupture-wort. Fl. May, Aug. Clt. 182\%. Pl. tr.

9 H. America'na (Nutt. in Sillim, amer. journ. 5. p. 822. p. 291.) smoothish, procumbent; leaves linear-oblong, much shorter than the internodes; stipulas minute; bundles manyflowered. 24. H. Native of Eastern Florida. Anýchia herniarioìdes, Ell. sketch. 1. p. 308. but not of Michx. ex Nutt. Camphorósma glàbra of authors. Stcm clothed witl retrograde down. Racemes 3-5-flowered. Lobes of calyx obtuse, coarctate, white inside.

American Rupture-wort. Pl. pr.

10 H. setígera (Gill. mss, ex Hook, et Arn. in bot. misc. 3. p. 247.) plant perennial, herbaceous, puberulous, many-stemmed, prostrate; leaves oblong-lanceolate, furnished with spiny bristles at the apex; flowers almost sessile, axillary, and usually solitary, puberulous on the outside; stamens 3 ; styles united at the base. 4 . F. Native of Chili, at El Aquadita, near La Punta de San Luis. This species has no scales or abortive petals, and but only one style, and stigmas have been perceived.

Bristle-bearing Rupture-wort. Pl. prostrate.

11 H. FRUticòsa (Lin. amœen. 4. p. 269.) stem shrubby, very humble, much branched, tufted; branches short, villous; leaves small, obovate, thickish, crowded ; flowers glomerate, hairy, 4cleft. 々. H. Native of Spain, in dry exposed places; and of Mauritania, near Mascar. Desf. fl. atl. 1. p. 213.-Lob. icon. t. 85.-Barrel. icon. t. 713.

Shrubby Rupture-wort. Fl. May, Aug. Clt. 1814. Pl. proc.
2. Polygonoidea (plants with the habit of Polygonum). Stens ercet, dichotomous at the apcx. Iflowers glabrous, disposed in loose cymes. Perhaps a proper genus.

12 II. rolygonoìnes (Cav, icon. 2. t. 137.) erect, glabrous, shrubby ; branches dichotomous at the apex; leaves ovate, cuspidate, distant. $々$. H. Native of Mauritania, near Mascar; and on the bills of Spain, in Valentia, as well as in Provence. Illécebrum suffruticòsum, Lin. spec. p. 298. Paronýchia suffruticosa, Lam. fl. fr. 3. p. 230. Herniària érecta, Desf. alt. 1. p. 214. H. Joanncàna, Rœm. et Scluultes, syst. 6. p. 297. This species differs from Paronychia, in the fruit being indeliscent. The habit is very dissimilar from the other species of Herniària, but emulates Anýchia and Paronýchia.

Polygonum-like Rupture-wort. Fl. May, Aug. Clt. 1752. Pl. $\frac{1}{2}$ foot.

\section{+ Speeies not sufficiently knonn.}

13 H. Dichó toma (D. C. prod. 3. p. 368.) stems erect, numerous, dichotomous, herbaceous; leaves distant, oblong, mutic, and are, as well as the branches, powdery from short down; flowers cymose. 4.? H. Native country unknown. Paronychia dichótona, D. C. in Lam. dict. ency. 5. p. 25 . Illécebrum dichótomum, Pers. ench. 1. p. 261. "Calyx glumaceous, striated at the base and pubescent, profoundly 5-cleft; segments bluntish, with scarious margins; sterile threads 5 , alternating with the sepals, and 5 antheriferous ones opposite them, hardly shorter than the sterile ones. Style bidentate at the apex. Ovarium attenuated at the base. Ovulum one, pendulous, suspended from the top of a thread, which arises from the bottom of the capsule." Adr. Juss, in litt. 1827.

Dichotomous Rupture-wort. Pl. $\frac{1}{4}$ to $\frac{1}{2}$ foot.

14 H. Lenticula'ta (T'Tunb. f. cap. p. 245.) suffruticose, hairy, decumbent, clothed with cinereous villi; leaves ovate, fleshy. $々$. G. Native of the Cape of Good Hope. H. incàna Capénsis, Pers. This is a very obscure species. The Linnean plant under this name, according to $\mathrm{Vahl}$ and Smith, is Créssa Crética; but we know not what Thunberg's plant is.

Lenticular Rupture-wort. Pl. procumbent.

Cult. All the species are weedy looking plants, most of them with the habit of wild-thyme, and therefore are only worth culivating in botanic gardens. The plants grow best in lry light sandy soil, and are increased by seeds.

IV. GYMNOCA'RPUM (from $\gamma v \mu \nu$ s, gymnos, naked, and картоs, karpos, a fruit). Forsk. descr. p. 65. icon. t. 10. Desf. atl. 1. p. 203. St. Hil. plac. lib. p. 73. Juss. mem. mus, 2. p. 388. D. C. prod. 3. p. 369.

Lin. syst. Pentándria, Monogýnia. Calyx almost 9-parted, permanent; segments coloured inside. Petals 5, emulating sterilc filaments. Stamens 5, inserted in the bottom of the calyx. Style one, crowned by a simple stigma. Capsule valveless, 1seeded, covered by the indurated calyx.-Diffuse subshrubs, with opposite stipulaceous leaves, usually bearing fascicles of rameal leaves in the axils. Pedicels axillary, solitary, opposite, appearing crowded at the tops of the branches, from the internodes being short. The name of this genus is spclt variously by authors, viz. Gymnocarpos (Forsk.), Gymnocarpus (Viv.), Gymnocarpon (Pers.), Gymnocary um (Steud.).

1 G. Fruticosum (Pers. ench. 1. p.636.). h. F. Native of the deserts of Barbary, Egypt, \&c. G. decándrum, Forsk. l. c. Viv. f. lib. 13. t. 10. f. 1. Desf. 1. c. Triánthema fruticòsa, Vahl. symb. 1. p. 32. Lobes of calyx violaccous inside, somewhat cucullate at the apex, and furnished with an awn on the back.

Shrubby Gymnocarpum. Shrub 1 foot.

Cult. This shrub will require to be protected from frost in 


\section{Vi. Illecebrum. ViI. Paronychia.}

winter, and for this purpose it should be grown in a pot. A mixture of sand and loam will suit the plant very well, and it may either be increased by seeds or cuttings.

V. ANY'CHIA (so named from its affinity to Paronýchia). Michx. f. bor. amer. 1, p. 113. Juss. mem. mus, 2. p. 389. Torr. f. unit. stat. 1. p. 272. D. C. prod. 3. p. 369.-Quèria, Gært. fr. 2. t. 128. Nutt. gen. amer. p. 158.

Lin. syst. Tri-Pentándria, Digýnia. Calyx 5-parted; sepals conniving, somewhat saccate, and callous at the apex. Petals and scales none. Stamens $3-5$; filaments distinct. Style none. Stigmas 3, subcapitate. Capsule indehiscent, 1-seeded, covered by the calyx.-North American, erect, dichotomous, annual herbs, with the habit of Linum catharticum. Leaves opposite, furnished with scarious stipulas at the base. Flowers solitary in the axils of the branches, and in fascicles at the tops of the short branches, green.

1 A. Diсио́тома (Michx. l. c.) stem covered with retrograde pubescence; leaves cuneate-oblong; stipulas longer than the flowers; flowers in fascicles. $\odot . H$. Native of Virginia, New York, Kentucky, and Canada, in dry woods and on hills. Quèria Canadénsis, Lin. spec. Ort. dec. t. 15. f. 2. Nutt. 1. c. Anýchia dichótoma var, $\boldsymbol{a}$. Torr. fl. unit. stat. 1. p. 273. A. Canadénsis, Elliott. car. 1. p. 307.

Dichotomous Anychia. Fl. May, Aug. Clt. 1806. Pl. $\frac{1}{4}$ to $\frac{1}{y}$ foot.

2 A. capilda'cea (D. C. prod. 3. p. 369.) stem quite glabrous, smooth; leaves ovate; stipulas shorter than the flowers ; flowers remote. $\odot$. H. Native of New Jersey and New England, in pine barrens. Quèria capillàcea, Nutt. gen. amer. 1. p. 159. Anýchia dichótoma $\beta$, Torr. 1. c. According to Torrey, this is only a smooth variety of the last.

Capillaceous Auychia. PI. $\frac{1}{4}$ to $\frac{1}{2}$ foot.

Cult. The seeds of these plants only require to be sown in the open border in a dry warm situation in a light soil.

VI. ILLE'CEBRUM (from Illecebra of Pliny, which is from illicio, to allure; pretty enticing plants). Gærtn. fil. carp. p. 36. t. 184 . Juss. mem. mus. 2. p. 386 . R. Br. prod. p. 4.16. in a note.-Paronýchia species, Tourn. Juss. Lam. and D. C.-Illécebrum spccies of Lin.

Lin. syst. Di-Pentándria, Digánia. Calyx 5-parted, nearly 3-sepalled; sepals subcucullate, thickencd, ending in an awnlike horn at the apex on the back. Petals wanting, or 5 subulate scales in place of the petals, alternating with the lobes of the calyx. Stamens 2-5, oppositc the sepals, and inserted in their base. Style hardly any; stigmas 2, capitate. Capsule covered by the calyx, 5 -valved, or divisable into 5 at the stripes. Seed solitary from abortion, inserted in the side of the capsule. Embryo hardly curved, placed on one side of the albumen, which is farinaceous. $-\Lambda$ small trailing herb, with opposite leaves, furnished with scarious stipulas at the base. Flowers axillary or cymose. Bracteas scarious, smaller than the flowers.

1 I. verticilia'tum (Lin. spec. p. 280.) stems trailing, filiform, glabrous; leaves roundisb; flowers crowded in the axils of the leaves, verticillate. 2 .H. Native of Europe, in bogs and wet meadows. In England in the western part of Cornwall, about Penzance, and in Devonshire, in marshy boggy ground. Sclikulır, handb. t. 50. Vill. in Schrad. journ. 1801. p. 409. t. 4. Smith, engl. bot. t. 895. Fl. dan. t. 335.-Vaill, bot. par. t. 15. f. 2. Flowers snow white, furnished with scarious bracteas at the base. Calyxes cartilaginous. Stamens 2 ex Juss., the rest abortive, 5 ex Sclakuhr. Root creeping.

Whorled Knot-grass. Fl. July, Aug. England. P]. tr.

Cult. The seeds of this plant should be sown in a moist situation, where the plants will thrive and flower freely; and if the seeds be allowed to scatter themselves, the plants will rise regu. larly every season. It is worth cultivating, being a small delicate beautiful plant.

VII. PARONY'CHIA (from rapa, para, near, and ovv onyx, a claw ; supposed to cure a tumour which rises near the nail). Juss. mem. mus. 1. p. 388 . D. C. prod. 3. p. 370 . St. Hil. f. bras, 2. p.185.-Paronýchia species of Tourn. Juss. gen. -Illécebrum species of Lin.

Lin. syst. Pcnténdria, Monogýnia. Calyx 5-parted (f. 22. f.) ; lobes concave, cucullate, generally mucronate at the apex (f. 22. b.). Petals or scales 5, subulate, alternating with the lobes of the calyx. Stamens 5 (f. 22. a.). Style one, entire or bifid (f. 22. d.); lobes papilliferous inside. Capsule 1-seeded (f. 22. e.), membranaceous, indehiscent or 5-valved, covered by the calyx.-Herbaceous or suffrutescent much branched plants. Leaves opposite, stipulate; stipulas scabrous, twin on both sides between the leaves. Young leaves frequently in fascicles in the axils of the old leaves. Flowers cymose or glomerate, but usually crowded in the axils of the leaves.

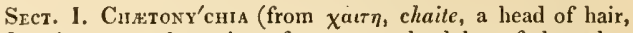
and ovu, ony $x$, a claw; in reference to the lobes of the calyx ending in a bristle each). D. C. prod. 3. p. 370 . Lobes of calyx equal, dilated at the apex, membranous, ending in an awn on the back. Scales or petals, or abortive stamens perhaps wanting. Flowers cymose.

1 P.? cymòs (D. C. in Lam. dict. 5. p. 26. A. fr. 3. p. 402.) stems erect, branched, divaricate, puberulous; leaves linear, nearly terete, glabrous, awned; flowers cymose, ultimate ones in fascicles. $\odot$. H. Native of Spain, Greece, Mauritania, in sandy places. Illécelurum cymòsum, Lin. spec. 299. exclusive of Bocc. syn. Vill. in Sclirad. journ. 1801.p. 408, t. 4. Flowers greenish. This plant is allied to Illécebrum, but is probably a distinct genus.

$$
\text { Cymose Paronychia. Fl. July. Clt.1820. PJ. } \frac{2}{4} \text { foot. }
$$

Sect. II. Euny'crima (altered from Paronýchios. This section is supposed to contain the genuine species of the genus). D.C. prod. 3. p. 370 . Lobes of calyx equal, awned, mueronate or nearly unarmed, not dilated at the apex. Flowers crowded in the axils of the leaves.

2 P. есніла'та (Lam. f. fr. 3. p. 232. exclusive of Lin. syn.) stems branched, prostrate, smoothish; leaves oval, glabrous; flowers subsecund, crowded in the axils of the leaves, puberulous; lobes of calyx drawn out into somewliat divaricate awns. $\odot$. H. Native of Mauritania, Portugal, Corsica, Sicily, Provence, in sand by the sea side. Illécebrum echinàtum, Desf. atl. 1. p. 204. Vill. in Schrad. journ. 1801 . p. 409. t. 4. Smitl, f. græe. t. 245.-Bocc. sic. t. 20. f. 3. Flowers greenish.

Echinatcd-flowered Paronychia. Fl. July. Clt. 1821. P]. prostrate.

3 P. Brasilia'na (D. C. in Lam. dict. 5. p. 23.) stems trailing, puberulous; leaves oblong-lanceolate, narrowed both at the base and apex, mucronate, pubescent on both surfaces ; flowers crowded in the axils of the leaves; calyx glabrous, deeply 5parted: lobes ending in a long mucrone each. $々$. G. Native of Buenos Ayres and Monte Video, by road sides. P. Bonariénsis, D. C. prod. 3. p. 370. Flowers white.

Brazilian Puronychia. Fl. May, July. Clt. 1820. Pl. tr.

4 P. commu'sts (St. Hil. f. bras. 2. p. 186.) stems trailing, puberulous; leaves oblong-lanceolate, narrow at the base and the apex, mucronate, pubescent on both surfaces; flowers crowded in the axils of the leaves; calyx turbinate, pubescent ; lobes cqual, ending in short points. 4 . G. Native of Brazil, in pastures in that part of the province of St. Paul called Cam- 
pos Geraes, and by the sea side in the province of St. Catlarine. Flowers deep brown.

Common Paronychia. Pl. tr.

5 P. Cuile'ssis (D.C. prod. 3. p. 370.) stems diffuse, tufted; leaves crowded, oblong-linear, mucronate, smoothish; flowers crowded in the axils of the leaves; lobes of calyx hardly mucronate at the apex. $\boldsymbol{u}$. F. Native of Chili, about Conception and Valparaiso. Lcaves of the younger branches subspinose at the apex, of the adult ones acutc. Stipulas oblong, scarious.

Chili l'aronychia. I'l. $\frac{1}{4}$ foot.

6 P. campliorosmoides (St. Hil. f. bras. 2. p. 187.) stems diffuse, pubescent ; leaves linear-subulate, keeled, mucronatc, puberulous; flowers crowded in the axils of the lcaves; calyx turbinate, smoothislı: lobes equal, acutish. $\odot$. H. Native of Brazil, in that part of the province of St. Paul called Campos Geraes, near Egreja Velha.

Camphorosma-like Paronychia. Pl. $\frac{1}{2}$ to 1 foot.

7 P. ArÁbica (D. C. cat. hort. monsp. 1813. p. 130.) stems diftuse, branched ; leares oblong-linear, glabrous, awnedly mucronate: flowers sessile, rather crowded : lobes of calyx ending in a long awn each. $\odot$. H. Native of Arabia and Egypt. Corrigiola albélla, Forsk. descr. p. 207. Illécebrum Arábicum, Lin. mant. p. 51. Pers. ench. 1. p. 261. Bracteas silvery, awned at the apex.

Arabian Paronychia. Pl. diffuse.

8 P. polygonifòla (D. C. fi. fr. ed. 3. vol. 3. p. 403.) stems trailing, branched; leaves oblong-linear, smoothish, acute, not mucronate; flowers rather crowded in the axils of the leaves; lobes of calyx ending in a short mucrone each. $4 . \mathrm{H}$. Native of Dauphins, Spain, and Balearic Islands. Illécebrum polygonif òlium, Vill. in Schrad. journ. 1801. p. 410. t. 4. Illécebrum verticillàtum $\beta$, Willd. spec. 1. p. 1205. Illécebrum alpìnum, Vill. dauph. 1. p. 29G. This plant hardly differs from $P$. argéntea, unless in the leaves being narrower.

Knot-grass-leaved Paronyclia. Pl. tr.

9 P. ARGE'NTEA (Lam. fl. fr. 3. p. 230.) stems trailing, branched ; leaves ovate, smoothish, acutish ; flowers axillary and terminal, crowded; lobes of calyx ending in a short mucrone each. 24. I. Native of the south of Europe, in dry exposed places. D. C. fl fr. ed. 3. vol. 3. p. 404. Illécebrum Parony'chia, Lin. spec. p. 299. Smith, fl. grac. t. 246.-Barrel. icon. t. 726. P. arğéntea and P. Hispánica, D. C. dict. ency. 5. p. 24. There is a variety with rounder glabrous leaves. Bracteas white, shining, acuminated. Perhaps the same as Illecebrum Itálicum and 1li. Narbonénse, V'ill. in Schrad. journ. 1801. p. 411.

I'ar. $\beta$, Mauritánica (D. C. prod. S. p. 371.) leaves broader ; heads large, distant. 4 . II. Native of Mauritania and the Archipelago. Illécebrum Mauritánicum, Willd. rel. in Rœm. et Schultes, syst, 5. p. 516 .

Silvery Paronychia. Pl. tr.

10 P. captta'ta (Lam. A. fr. 3. p. 229.) stems erectish; leaves oblong, keeled, ciliated, pubescent; bracteas acuminated; heads of flowers terminal; lobes of calyx linear, unequal. $4 . \mathrm{H}$. Native of the south of Europe, in arid places. D. C. fl. fr. ed. 3. vol. 3. p. 40. P. rígida, Mnench. meth. p. 315 . Illécebrum capitàtum, Lin. spec. 1. p. 299. Smith, f. græc. t. 247-Lob. icon. 420, f. 1. Flowers white. Perhaps the same as lllécebrum Lugdunénse, Vill. in Schrad. journ. 1801. t. 4.?

Capilate-flowered Paronychia. Fl. June, Aug. Clt. 1683. Pl. $\frac{1}{4}$ to $\frac{1}{2}$ foot.

11 P. Serpyllifòlia (D. C. in Lam. dict. 5. p. 24. fl. fr. ed. 3. vol. 3. p. 404.) stems prostrate, creeping, knotted, branched; leaves obovate, flat, rather flesly, with ciliated margins; flowers terminal; bracteas acuminated; lobes of calyx awnless. $4 . \mathrm{H}$. Native of the south of Europe, in arid places. Illécebrum serpyllifòlium, Vill. in Schrad. journ. 1801.1. 4. Flowers white. voL. IIt.
Iar. $\beta$, herniarioides (Pourr. chl. narb. p. 321.) leaves subcordate.

Wild-thyme-leaved Paronychia. Fl. June, Aug. Clt. 1818. 11. prostrate.

12 P. Nívea (D. C. dict. ency. 5. p. 25.) stems ercetish, much branched; leaves oblong, acutc, flattish, pubesecnt; bracteas large, short-acuminated; heads of flowers terminal; lohes of calyx awnless. 24.? H. Native of Spain, Italy, the Levant, Sc. in arid places.-Barrel, icon, t. 687. and 725.? Illécebrum níveum, l'ers. ench. 1. p. 261. Illécebrum cephalòtes, Bieb. fl. taur. suppl. p. 169. Perhaps the same as Ill. maritimum, Vill. l. c. P. Arragónica, Schultes, syst. 5. p. 520.? Flowers snow white.

Snomy Paronychia. Fl. June, Aug. Clt. 1812. Pl. $\frac{1}{5}$ to $\frac{1}{2} \mathrm{ft}$. 13 P. aretoides (1. C. prod. 3. p. 371.) stems fruticulose, ascending, much branched; branchlets hairy; leaves clothed with silky pubescence, oval-oblong, obtuse, not exceeding the stipulas; bractcas obtuse; heads of flowers terminal. $4 . \mathrm{H}$. Native of Spain, in the province of Valentia. Illécebrum aretioides, Pourr. ined. ex L. Dufl. in litt.

Aretia-like Paronychia. Pl. $\frac{1}{8}$ to $\frac{1}{4}$ foot.

14 P. Canakie'vse (Juss. mem. mus. 1. p. 389.) stem slirubby, erect, branched at the apex; branches rather hoary from short white hairs; leaves ovate, acute, downy; cymes panicled, branched, loose; bracteas mucronately awned at the apex, but not hiding the flowers. h. G. Native of 'l'eneriffe. Habit of Polycarpáa Canariénsis, but differs in the ovarium being 1-seeded.

Canary Paronychia. Pl. $\frac{1}{4}$ to $\frac{1}{2}$ foot.

15 P. Sнítнu (Choisy, mss. ex D. C. prod. 3. p. 371.) stem shrubby, erect, branched; leaves linear-oblong, acuminated, nerveless, and are, as wcll as the branclies, glabrous; cymes few-flowered, loose : lobes of calyx mucronately awned. h. G. Native of the Canary Islands.

Smith's Paronychia. Shrub $\frac{1}{4}$ to $\frac{1}{2}$ foot.

16 P. herniarioìes (Nutt. gen. amer. 1. p. 159.) plant herbaceous, trailing, crowded, downy all over ; leaves oblong-oval, ciliated, terminated by a bristle; lobes of calyx subulate, ending each in a spreading setaceous acumen. 24. H. Native of South Carolina, in arid sandy places. Anýchia herniarioìles, Michx. fl. bor. amer. 1. p. 113. Anýchia Herniàriæ, Pers. encl. 1. p. 261.

Rupture-wort-like Paronychia. Pl. tr.

17 P. nicuó тома (Nutt. gen. amer. 1. p. 159.) plant rather herbaceous, tufted, procumbent, glabrous; leaves linear, acerose, acute, marked by a double line on the back; stipulas bifid: cymes dichotomous; bracteas shorter than the flowers; lobes of calyx ending in a short mucrone each. $4 . \mathrm{H}$. Native of Virginia, on rocks at the river Shenondoah. A chyránthes dichótoma, Lin. mant. p. 51.

\section{Dichotomous Paronychia. Pl. procumbent.}

18 P. argyró́coma (Nutt. l. c. p. 160.) plant herbaceons, tufted, procumbent, pubescent; leaves linear, acutely pungent, villous, nerveless; stipulas entire; cymes dichotomous; bracteas about equal in length to the flowers; lobes of calyx mucronate. 4.11 . Native of Lower Carolina and of Tennessee, among rocks on the mountains. Anýchia argyrócoma, Michx. f. bor. amer. 1. p. 114. In habit this plant approaches the preceding. Stipulas elongated. Bracteas acuminated. Flowers white.

Silvery-tufted Paronychia. Pl. procumbent.

19 P. sessilir lòra (Nutt. 1. c. p. 1 60.) plant densely tufted, much branched, glabrous; leaves linear-subulate, acute : superior ones longer, recurved; stipulas about equal in length to the leaves, bifid; flowers terminal, sessile ; lobes of calyx arched on the inside at the apex, and ending in a long awn cach on the

$\mathrm{N}$ 
outside. 2 . H. Native of North America, on the more elevated hills about the Missouri, near Fort Mandan; on the dry banks of the north branch of the Saskatchawan, between Carlton House and Edmonton House. Hook. fl. bor. amer. 1. p. 227. t. 75 . (f. 22.)

Sessile - flowered Paronychia. Pl. $\frac{1}{4}$ foot.

Sect. III. Acantiony'chia (from akuv $\sigma_{0 c}$, acunthos, a spine, and $o v v \xi$, onyx, a claw; in reference to the 3 outer lobes of the calyx, Leing each furnished with an awn-like spine at the apex). D. C. prod. 3. p. 372. Lobes ${ }^{\circ}$ caly $\mathrm{x}$ unequal, 3 outer ones furnished each with an awn-like spine at the apex, 2 inner ones small, and nearly unarmed. Stigmas 2 , sessile.

20 P. Rose'tтa (St. Hil. fl. bras. 2. p. 188. t. 113.) stems trailing, woolly ; lcaves lincar-subulate, mucronate, smoothish; lobes of calyx unequal, 3 outer ones the largest, and furnished with a long mucrone each : 2 inner ones smaller, and nearly awnless. Flowers crowded in the axils of the leaves. 24. G. Native of Brazil, in the province of St. Catharine, in sand by the sea side, where it is called by the inhabitants Rosetta. Probably a species of Pcntace'na.

Rosctta Paronychia. Pl. tr.

\section{$\dagger$ Specics not sufficiently known.}

21 P. TENuifòlia (D. C. prod. 3. p. 372.) stem branched, diffuse, hairy; leaves linear-lanceolate, somewhat ciliated; flowers axillary, longer than the stipulas. $\odot$. H. Native country unknown. Illécebrum tenuifòlium, Willd. enum. suppl. p. 12.

Fine-leaved Paronychia. Fl. June, July. Clt. 1820. Pl. procumbent.

22 P. sedifòlia (Salt. itin. abyss. ed germ. 1. p. 476. ex Rom. et Scluultes, syst. 5. p. 523.) This species is not described.

Stonc-crop-leaved Paronychia. Pl.

+ Plants referred by authors to the genus Paronýclia, which are to be excluded.

1 P. lamuginòsa (Poir. suppl. 4. p. 302.) is probably a species of Gomphrèna.

2 P. Bengalénsis (Rom. et Schultes, syst. 5. p. 521. but not of Juss.) is probably a species of Achyránthes.

3 P. tenélla (Hortul. or Illécebrum tenéllum of Desf.) is perhaps a species of Alternanthèra.

4 P. dichótoma (D. C. in Lam. dict. but not of Nutt.) is Herniària dichótoma.

5 P. subulata is Polycarpa'a spadícea.

$6 P$. linearifolia is now Polycarpæ'a linearifòlia.

Cult. All the species of this genus are well adapted for ornamenting rock-work, from their dwarf stature, and generally trailing habit. Most of them, however, grow best in small pots in sand and loam, filling the pots half way with sherds; and they are easily increased by dividing the plants at the root, or by cuttings under a hand-glass, or by seeds. The seeds of the annual species only require to be sown in the open border or on rock-work. Some of the species are marked grcen-house and frame; these require to be protected from frost in winter.

VIII. PENTACE'NA (from $\pi \varepsilon \nu \tau \varepsilon$, pente, five, and akas $a$, akaina, a thorn; in reference to the 5 spiny lobes of the calyx). Bartling in reliq. Honk. 2. p. 5. t. 49. f. 1.

Lin. srst. Pentándria, Digýnia. Calyx 5-parted; segments very unequal: 3 outer ones spiny at tlie apex, and woolly on the margins : 2 inner ones much shorter, boat-shaped, and armed on the back. Stamens 5, without any sterile filaments; anthers 2celled. Stigmas 2, short. Fruit 1-seeded.

1 P. ramosíssima (Hook. et Arn. in bot. misc. 3. p. 248.) stems trailing, woolly; leaves linear-subulate, mucronate; lobes of calyx unequal, all linear and hood-formed, ending eacls in a very long point on the back; flowers sessile, axillary, crowded. 4. G. Native of Brazil, on the confines of the province of Rio Grande de St. Pedro do Sul, and of the province of Cisplatin; and among rocks about Monte Video; of Chili, in Las Achiras, province of Cordova, Valparaiso, and Buenos Ayres; also of Mexico, at the foot of Mount Orizaba. Paronýchia ramosíssima, D. C. prod. 3. p. 37\%. mem. paron. p. 12. t. 4 . Loeflíngia ramosíssima, Weinm. in bot. zeit. p. 608. Pent. polychnemonoìdes, Bartl. in Presl. reliq. Hænk. 2. p. 5. t. 49. f. 1. Stipulas scarious, woolly.

Much-branched Pentacæna. Pl. tr.

Cult. See Paronýchia for culture and propagation.

1X. CARDIONE'MA (from kapica, cardia, the heart, and $\nu^{\prime} \eta \mu$, nema, a filament; in reference to the sterile filaments being obcordate). D. C. prod. 3. p. 372.-Bivonæ'a, Moc. et Sesse, fl. mex. ined. but not of D. C. nor Spreng.

Lin. syst. Pentándria, Digýnia. Calyx 5-parted; lobes conniving, rather coloured inside, and rather concave, drawn out on the back at the apex into a long straight conical horn each. Petals wanting. Stamens 5 , opposite the lobes of the calyx, and inserted in their base; 2 of which are sterile, obcordate, and flat: and 3 fertile, obcordate at the base, bearing each a slender antheriferous filament in the recess; anthers roundish, 2-celled. Styles 2, hardly concrete at the base, long, revolute. Fruit 1-seeded, ovate-oblong.-A small many-stemmed herb. Leaves opposite, crowded, rather distich, linear, acute. Flowers sessile, axillary, small, greenish white, each furnished with 5 bracteas, 4 of the bracteas linear and entire, the fifth larger and serrulated.

1 C. multicau'Le (D. C. prod. 3. p. 373 . mem. par. t. 1.) 4. G. Native of Mexico. Bivonæ'a multicaúlis, Moc. et Sesse, ff. mex. icon. ined.

Many-stemmed Cardionema. Pl. sinall.

Cull. This plant is to be cultivated and propagated in the same manner as that recommended for the species of Paronýchia. It will require protection in winter, by placing it in a frame or green-liouse.

\section{Tribe III.}

POLYCARPA:E (this tribe contains plants agreeing with Polycarpe' $a$ in important characters). D. C. prod. 3. p. 373. Calyx 5-parted (f. 23. a.). Petals 5 (f. 23. d.) or wanting. Stamens 1-5, inserted in the bottom of the calyx. Styles 2-3, sometimes distinct from the base, and sometimes connected. Capsule 1-celled (f. 23. e.), many-seeded. Seeds fixed to the central placenta.-Herbs or subshrubs. Leaves opposite. Stipulas scarious. The stamens in some of the genera are nearly hypogynous, as in Polycárpon, and altogether so in Polycarpa a, Stipulicida, and Ortègia, and therefore these genera verge very closely on the order Caryophifllce, but are distinguished from them in the presence of stipulas, and number of stamens : the habit agrees with Paronychièce.

X. POLYCARPF'A (from $\pi \circ \lambda v$, poly, many, and k $\alpha \rho \pi o s$, carpos, a fruit; a name, however, only indicating its affinity with Polycarpon). Lam. journ. hist. nat. 2. p. 8. t. 25. D. C. prod. 3. p. 373 . St. Hil. fl. bras. 2. p. 182.-Hagæ'a, Vent. tabl. 2. 
p. 240.-Móllia, Willd. hort. berol. 1. p. 11.-Lahàya, Rœm. ct Sclıultes, syst. 5. p. 402.-1 lyàla, Llıer. mss.-Anthýllis species, Adans.-Pòlia, Lour.

Lis. syst. Pentándria, Monogýnia. Calyx more or less deeply 5-parted, permanent; lobes membranous, flattish, neither keeled nor mucronate. Petals 5 , inscrted in the bottom of the calyx, and opposite its lobes. Style one, 3-furrowed at the apex. Capsule 1 -celled, trigonal, 8 -valved, many-sceded. Sceds rather reniform.-Branched dichotomous licrbs. Leaves opposite, stipulate, young ones disposed in fascicles in the axils of the old leaves. Flowers cymose; cymes usually forming a terminal corymb.

1 P. gNapiatòdes ('oir. suppl. 4. p. 473.) stems suffruticose, prostrate ; leaves oblong, clothed with hoary tomentum; flowers crowded into terminal subcapitate cymcs. 4 . F. Native about Mogodor, on the coast of Africa, in sandy places; and of the Grand Canary Island and Teneriffe. Illécebrum gnaphalòdes, Schousb. mar. 1. p. $11 \%$. Polycarpæ'a microphýlla, Cav. anal, scienc. no. 7. p. 25 . Hàgea gnaphalòdes, Pers. ench. 1. p. 262. Lahàya gnaphalòdes, Schultes, syst. 5. p. 405 . Móllia gnaplılodes, Spreng. syst. 1. p. 794. Flowers white.

Cottony Polycarpea. Fl. June, July. Clt. 1818. Pl. pros.

2 P. latjòlia (Poir. l. c.) stems suffruticose, lliffuse; leaves obovate, mucronate by an awn; cauline leaves usually 6 in a whorl, those of the branclies opposite; cymes terminal, corymbosely capitate; stipulas, bracteas, and calyxes scarious, and acuminated. $\xi$. F. Native of Teneriffe, among rocks in woods. Móllia latifòlia, Willd. enum. 1. p. 269. Schrank, pl. rar. hort. mon. t. 29. Lahàya latifòlia, Schultes, syst. 5. p. 403. Flowers white.

Broad-leaved Polycarpæa. Fl. June, Aug. Clt. 1810. Pl. $\frac{1}{4}$ foot.

3 P. Teneriffex (Lam, journ. hist. nat. 2. p. 8. t. 25.) stem branched, diffuse; cauline leaves petiolate, ovate, usually 6 in a whorl; cymes dichotomous, corymbose, many-flowered; lobes of calyx with membranous margins. $\odot . H$. Native of Teneriffe, by way sides. Illécebrum divaricàtum, Ait.hort. kew. ed. 1. vol. 1. p. 291. Hàgea T'eneriffæ, Pers. ench. 1. p. 262. Móllia diffùsa, Willd. hort. berol. 1. t. 11. Lahàya diffùsa, Sclutt. syst. 5. p. 402. Flowers white.

Teneriffe Polycarpæa. Pl. $\frac{1}{4}$ to $\frac{1}{2}$ foot.

4 P. Arista'ta (Chr. Smith in litt. ex D. C. prod, 3. p. 373.) stems branched, suffruticulose; leaves usually 6 in a whorl, lanceolate-linear: young ones silky, mucronated by an awn: old ones nearly glabrous, and almost awnless; cymes corymbose, terminal ; calyxes with membranous margins. h.F. Native of the Canary Islands, on the Pico de Teyde. Illécebrum aristàtum, Ait. hort. kew. ed. 1. vol. 1. p. 290. Móllia aristàta, Ait. hort. kew. ed, 2. vol. 2. p. 62. Lahàya aristàta, Schult. syst. 5. p. 403. Stems erect or diffuse. Flowers white.

Anncd-leaved Polycarpaa. Fl. June, July. Clt. 1780. Pl. $\frac{1}{4}$ to $\frac{1}{2}$ foot.

5 P. Mеманítica (Delil. fl. egypt. p. 67. t. 24. f. 2.) stems herbaceous, diffuse, branched, villous; leaves usually 6 in a whorl, oval-oblong, narrowed into the petiole; cymes terminal, few-flowered; calyx pubescent, with membranous margins. $\odot$. H. Native of fields about Cairo, and along the banks of the Nile, and in its islands. Style very short: stigmas 3, nearly sessile. Petals quite entire. This plant, although very distinct, is joined with $P$. gnaphalddes by Spreng.

Meniphitic Polycarpaca. Pl. diffuse.

6 P. PRA'Gilis (Delisle, fl. egryt. p. 65. t. 24. f. 1.) stems herbaceous, prostrate, brittle; leaves opposite, aggregate, lanceolate, mucronate, with replicate edges ; cymes corymbose, terminal, many-flowered. 4 . F. Native of Egypt, in the deserts about the pyramids, \&c. Móllia frágilis, Spreng. syst. 1. p.795. Style filiform, length of petals. Sceds 8-10. Flowers white.
Var, a, incina (D. C. prod. 3. p. 374.) stem and leaves clothed with grey tomentum.

Var. $\beta$, virens (D. C. 1. c.) leaves glabrous.-Corrigiola rèpens, Forsk. deser. p. 207. ex Delisle.

Brittle Polycarpaea. Pl. prostrate.

7 P. stelta'ta (D. C. prod. 3. j. 374 .) stems diffuse, much branched, suffruticulose ; leaves usually 6 in a whorl, linear, flat, and are, as well as the branches, rather pilose ; cymes terminal, many-flowered, corymhose; calyxes scarious. $\odot$. F. Native of Guinea. Achyránthes stellàta, Willd. spec. 1. p. 1195. Móllia stellàta, Willd. hort. berol. Lahàya stellàta, Schultes, syst. 5. p. 403 Root perpendicular, simple. I Iabit of P. Teneriffe, but differs in the leaves being linear.

Stellate-leaved Polycarpæa. Fl. June, Aug. Clt. 1820. Pl. $\frac{1}{4}$ foot.

8 P. corymnòsa (Lam. ill. no. 2798.) stems erect, herbaccous, tomentose; branches divaricate; leaves usually 6 in a whorl, linear, awned; cymes corymbose, loosish; calyxes scarious, acuminated. $4 . ?$ F. or $\odot$. Native of Ceylon. Achyránthes corymbòsa, Lin. spec. p. 296. (exclusive of the synonyme of Plukenet, which is referrible to Celosia Monsonia). iVilld. spec. 1. p. 1196. (exclusive of the synonyme of Loureiro, which is referrible to Polycarpa'a spadieca). Lahàya corymbòsa, Schultes, syst. 5. p. 404. Pol. I'ndica, Lam. journ. list. nat. 2. p. 8. Celòsia corymbòsa, Roxb. fl. ind. 1. p. 310. ?-Bocc. mus. 4.4. t. 39. good.-Burm. zeyl. t. 65. f. 2. Flowers white.

Corymbose-flowered Polycarpæa. Fl. July, Aug. Clt. 1823. Pl. 1 foot.

9 P. sPadíceA (Lam. l. c. no. 2799.) stems ascending, diffuse, branched, suffruticose at the base; branches tomentose; leaves linear, bluntish, when young rather tomentose; cymes terminal, corymbose ; calyxes scarious. 4 .? h.? S. Native of the East Indies, on the coasts of Malabar and Tranquebar.-Rheed. mal. 10. t. 66. Celòsia corymbòsa, Willd. spec, 1. p. 1200. exchusive of the synonyme of Retz. Móllia spadicea, Willd. hort. berol. Lahàya spadícea, Schultes, syst. 5 . p. 405 . Pòlia arenatria, Lour. coch. p. 164. Allied to $P$. corymbòsa, but is more diffuse in habit ; leaves bronder and shorter, in more distant whorls; lobes of calyx less acuminated. Perhaps Paronýchia subulàta, D. C. in Lam. dict. 5. p. 25. or Illécebrum subulàtum, Pers. ench. 1. p. 261. is referrible to this species.

Chestnut-bron'n Polycarpæa. Pl. 1 foot, diffise.

10 P. Brasilie'nsis (St. Hil. fl. hras. 2. p. 183.) stems erect, puberulous; leaves linear-subulate, with revolute margins, mucronate, puberulous; cymes corymb-formed; calycine lobes very acute, puberulous; petals ovate-orbicular, one-half shorter than the calyx. 24. S. Native of Brazil, in that part of the province of St. Paul called Campos Geraes, near Fazenda de Jaquariahiba. Flowers densely clothed with white tomentun. Petals at first white, but at length of a dirty yellow-colour. Root fusiform, with many stems rising from the neck.

Var. $\beta$, ramosissima (St. Hil. 1. c.) stems much branched; leaves setaceous; cymes branched; flowers a little smaller than those of the species. Native of Brazil, in the province of Goyaz, on the sandy Mountain called Serra dos Pyreneos; also on the road to Campo Allegre, in the province of Minas Geraes.

Brazilian Polycarpaa. Pl. $\frac{1}{2}$ to $\frac{3}{\ddagger}$ foot.

11 P. tenuifolia (D. C. prod. 3. p. 374.) stems erect, branched; leaves opposite, linear-subulate, keeled below ; cymes terminal, dichotomous, corymbose; calyxes scarious, length of capsule. 々. S. Native of Sierra Leone. Achyránthes tenuifỏlia, Willd. spec. 1. p. 1196 . Móllia tenuifòlia, Willd. lort. berol. Lahàya tenuif olia, Schult. syst. 1. p. 404. Leaves with revolute margins. Stipulas minute, diaphanous.

Fine-leaved Polycarpxa. Fl. June, Aug. Clt. 1817. Pl. $\frac{1}{2}$ to $\frac{3}{5}$ foot. 
12 P. glabrifòlia (D. C. l. c. and mem. par. t. 5.) stems erect, branched, suffruticose; branches pubescent ; leaves glabrous, oblong-linear, bluntish, twice the length of the stipulas; cymes terminal, dense, many-flowered, in crowded heads. 4.? S. Native of Sierra Leone. This species differs from $P$. tenuifolia in the leaves not being subulate, nor keeled, nor with revolute edges; in the stipulas being large, and in the flowers being capitate.

Glabrous-lcaved Polycarpæa. Pl. 1 foot.

13 P. Linearifolla (D. C. I. c. and mem. par. t. 6.) stems ercet, or somewhat ascending at the base, branched; branches pubescently hairy; leaves linear, elongated, pubescent, 3 times longer than the stipulas; cymes crowded into a dense terminal roundish head. ๑. F. Native of Senesal. Paronýchia lincarifòì, D. C. in Lam. dict. 5. p. 26. Illécebrum linearifòlium, Pers. encl. 1. p. 261. Alternantlièra erécta, Rchb. in Sieb. pl. exsic. seneg. no. 60. Habit of Celòsia, but the characters are those of Polycarpaca.

Linear-leaved Polycarpea. Pl. 1 foot.

14. P. frankenioides (Presl. in Honk, reliq. 2. p. 6.) stems much branched, diffuse, procumbent, roughish; branches opposite; leaves opposite, oblong, obtuse, clothed with rough pubescence; flowcrs in dichotomous corymbose panicles; sepals bluntisl, pilose. $\odot$. H. Native of the lsland of Luzon.

Frankenia-like Polycarpaa. Pl. procumbent.

† Species not sufficiently known.

15 P. carnòsa (Chr. Smith in Buch. can. p. 142.) stem shrubby ; leaves 6 in a whorl, fleshy: lower ones spatulate: upper ones lanceolate; stipulas very short, jagged. $\zeta . \mathrm{G}$. $\mathrm{Na}$ tive of the Canary Islands.

Fleshy Polycarpæa. Shrub $\frac{1}{4}$ foot.

$16 \mathrm{P}$. Smírum (Link in Buch. can. p. 142.) leaves 6 in a whorl, linear, glabrous, obtuse; stipulas very short; panicle dichotomous; branchlets divaricate; bracteas ovate, slorter than the calyx. h.G. Native of the Canaries, in the island of Palma, at Cumbre de Caldera. Very nearly allied to P. stellàta but differs in the panicle.

Smith's Polycarpæa. Pl. $\frac{1}{4}$ to $\frac{1}{2}$ foot.

17 P.? Minuartinides (D.C. prod. 3. p. 375.) stem slirubby, branched; branches tomentose; lcaves subulate, crowded; cymes axillary, few-flowercd. $\quad$. F. Native of the south of Spain. Móllia minuartioìdes, Spreng. mant. 1.p. 37. ex Schultes. Lahàya minuartioides, Schultes, syst. 5. p. 406. This is a very doubtful species, being omitted in Spreng. syst.

Minuartia-like Polycarpxa. Fl. Ju. Aug. Clt. 1826. Pl. $\frac{1}{4} \mathrm{ft}$

18 P.? vepke'ssa (D. C. l. c.) stems herbaceous, depressed, diffuse; leaves opposite, crowded into something like whorles, wedge-shaped; stipulas 4-cleft? flowers terminal, triandrous; calyx fleshy; petals linear, 4-toothed at the apex. $\odot$. F. Native of the East Indies. Pharnàceum depréssum, Lin. mant. p. 564. Loflíngia I'ndica, Retz, ind. p. 48. Roxb. fl. ind. 1. p. 169. This plant is certainly neither a Loffingia nor a Mliarnaceum; from the stipulas and many-seeded capsule, $j$ agrees more nearly with Polycarpaca, but differs in the fleshy calyx, and triandrous flowers : perhajes it is nore nearly allied to Pollichia, but the caly $\mathrm{x}$ in this plant is said to be 5 -parted.

Depressed Polycarpea. Pl. depressed.

Cult. The seeds of the annual species of Polycarpe' $a$ should be reared on a hot-bed early in spring. The perennial and shrubby species being either green-house, or frame plants, rcquire to be kept in their respective places : they are easily increaserl by cuttings under a liand-glass, those of the stove species in heat.

XI. STIPULI'CIDA (from stipula, a stipula, and credo, to cut ; stipulas cut or jagged). Miclix. fl. bor, amer. 1. p. 26. t.
6. Ell. sketch. p. 51. Nutt. gen. amer. 1. p. 29. D. C. prod. 3. p. 375.-Polycárpon species, Pers. Rœm. and Spreng.

Lin. syst. Triándria, Monogýnia. Calyx 5-parted; lobes oval, with membranous margins. Petals 5, cuneate-oblong, entire. Stamens 3, inserted with the petals into the disk or torus. Style short; stigmas 3. Capsule 1-celled, 3-valved. Seeds few, fixed by funicles to the central placenta.-Small perennial dichotomous herbs, native of North America. Radical leaves almost like those of Polycarpa'a Teneriffe, ovate, petiolate; cauline leaves sessile, opposite, small. Stipulas jagged. Flowers small, tern, terminal. An intermediate genus between Polycárpon and Polycarpa' $a$, from the sepals being flattish as in $P_{0-}$ lycarpe' $a$, and in the stamens being 3, as in Polycárpon; but differs from both in the petals and stamens being expressly hypogynous according to Richard in Michx. l. c.; the genus therefore perhaps ought to have been placed in Caryophýllece.

1 S. Seta'cea (Michx. 1. c.) 4. F. Native of Lower Carolina, in sandy arid places. Polycárpum stipulífidum, Pers. ench. 1. p. 11 1. Pursh, fl. amer. sept. 1. p. 90. Plant glabrous, setaceous, erect, many times dichotomous.

Setaceous Stipulicida. Pl. $\frac{1}{4}$ foot.

Cult. See Ortègia, p. 93. for culture and propagation.

XII. BALA'RDIA (in honour of M. Balard, of Montpelier, who was the first to detect a new chemical principle called brome). St. Hil. Al. bras. 2. p. 180 .

Lin. syst. Di-Tetrándria, Trigýnia. Calyx 5-parted almost to the base, permanent; segments flattish. Petals none. Stamens 2-3-4, inserted in the receptacle. Styles 3, very short, papilliferous inside. Capsule 3-valved, many-seeded; valves membranous. Seed subovoid, fixed to the central placenta. An annual, branched, dichotomous herb, with opposite, stipulate leaves, and cymose flowers.

1 B. Plate'nsis (St. Hil. fl. bras. 2. p. 181. t. 111.) leaves linear, about equal in length to the internodes, mucronulate; cymes branched, many-flowered. $\odot$. H. Native of Brazil, in the southern part of the province of Cisplatine, near Povo de Canelones; and in the western part near Pueblo de las Viboras ; also of Buenos Ayres.

Plate Balardia. Pl. $\frac{1}{2}$ foot.

Cult. The seeds of this plant should be sown on a hot-bed in spring, and the plants may be planted out in the open border in the montl of May, in any warm dry situation. Not worth cultivating, excepting in a botanic garden.

XIII. AVE'RSIA (in honour of M. Avers, D. M. P., who has written a dissertation on the Nicotiana Tabácum, in which he treats of its various qualities). St. Hil. fl. bras. 2. p. 184.

Lin. syst. Triándria, Monogýnia. Calyx deeply 5-parted, permanent; lobes thickened in the middle, keeled. Petals 5, inserted in the bottom of the calyx. Stameus 3, inserted with the petals; filaments dilated at the base, joined to the petals and together at the base. Style 1, trifid; lobes papilliferous inside. Capsule 3-valved, many-seeded; valves membranous. Seeds fixed to the central placenta, cylindrical. Embryo in the middle of fleshy albumen, not at one side as in Polycarpacia.A trailing branched herb, with opposite stipulate leaves; young leaves or abortive branches in fascicles in the axils of the older leaves. Cymes branched, many-flowered.

1 A. FRANKEntoldes (St. Hil. l. c. t. 112.) stems trailing, branched ; leaves lanceolate, bluntish, narrowed into the petiole, pubescent; cymes many-flowered; segments of calyx obtuse, pubescent; petals and stamens one half shorter than the calyx. C. H. Native of Brazil, on the sandy banks of the rivers Parahyba, Rio Doce, Jiquitiuhonha, Rio de St. Francisco, \&c. Flowers white. 
Frankenia-like Aversia. Pl, trailing, $\frac{1}{2}$ foot.

Cult. See Balárdia above for culture and propagation.

XIV. ORTEGIA (in honour of Joseph E. de Ortega, a Spanish botanist, companion of Loffing in his travels. See Layflingia). Loff. itin. p. 112. Lin. gen. no. 51. Gærtn. fr. 2. p. 224 t. 129. f. 8. Ser. in D. C. prod. 1. p. 388 . and 3. p. 375.-Ortègra, Lin. spec, es. 1.-Juncària, Clus.

LiN. syst. Triándria, Monogýnia. Calyx of 5 sepals, or 5-parted ; sepals erect, oblong, a little keeled. Petals wanting. Stamens 5,3 of which are fertile, inserted in the torus in front of 3 of the sepals; the other 2 almost vanished, or small, sterile, and scale-formed. Orarium ovate. Style 1, capitate at the apex, or bifid. Capsule 3-valved. Seeds numerous, fixed to the central placenta. Embryo straight, placed on the back of the albumen.Erect, much-branched herbs. Leaves opposite, linear, with 2 black dots at the sides, from which the stipulas have fallen. Cymes dichotomous, many-flowered. Flowers greenish-white. Stamens hypogynous, as in Stipulicida and Polycarpa'a.

1 O. Hispa'sica (Ln. spec. ed. 1. p. 560.) stigma capitate. 4. H. Natire of Spain, about Madrid and many other places. Cav. icon. 1. t. 47.-Clus. list. 2. p. 174. f. 2. Vahl. enum. 2. 1. 25.

Spanish Ortegia. Fl. Ju. Jul. Clt. 1768 . Pl. $\frac{1}{2}$ foot.

2 O. pichórosa (Lin. mant. p. 175.) stigma trifid. 4. H. Native of Italy and Piedmont, about Giavena. All. act. taur. 8. p. 176. t. 4. f. 1. D. C. fl. fr. ed.3. vol. 4. p. 726 . Vabl. symb. 2. p. 25. Cyme more loose than that of the first species, and therefore it is more distinctly dichotomous, but divided in a similar way.

Dichotomous Ortegia. Fl. Aug. Sept. Cl. 1781. Pl. $\frac{1}{2}$ foot.

Cult. The species thrive best in light soil; and are increased by cuttings or seeds. They are well fitted for rock work, or to be grown in small pots among other alpine plants.

XV. POLYCA'RPON (from $\pi \circ \lambda v$, poly, many, and k $\alpha \rho \pi o s$, karpos, a seed; seeds numerous). Loef. in Lin. gen. no. 10.5 . Gertn. fr. 2. t. 129 . Lam. il]. t. 51. Juss. mem. mus. 2. p. 390. D. C. prod. 3. p. $376 .-$ Tríchlis, Hall. gœtt.-Anthýllis species, Adans.

Lin. srsr. Tri-Pentándria, Trigýnia. Calyx deeply 5cleft (f. 23.a.), permanent; segments concare, keeled, mucronate at the apex. Petals 5 (f. 23. b.), emarginate, inserted in the tube of the calyx. Stamens $3-5$, inserted in the tube of the calyx. Style trifid; lobes papilliferous inside. Capsule 1-celled, 3-valved (f. 23.e.), many-seeded. Seeds nearly ovoid, a little curred, fixed to the central placenta.-Annual, branched, dichotomous herbs. Leaves opposite, or 4 in a whorl; young ones usually disposed in fascicles in the axils of the old leaves. Flowers in cymose corymbs. Stipulas and bracteas small, scarious.-This genus agrees with $A d c n a ̀ r i u m$, but differs in the stamens being equal in number to the petals, not as in Caryophíllece, double that number.

\section{* Floners triandrous.}

1 P. APUrésse (H. B. et Kuntl, nov. gen. amer. 6. p. 40.) flowers triandrous; petals emarginate? leaves $5-10$ in a whorl. $\odot$. H. Native of South America, on the banks of the river Apures, in the province of de Varinas. Stems diffuse, pubescent. Leaves linear-spatulate. Cymes dichotomous. Lobes of calyx obtuse. Stamens and styles 3 .

Apures All-seed. Pl. $\frac{2}{8}$ to $\frac{2}{4}$ foot.

2 P. теtraphy' luum (Lin. fil. suppl. 116.) flowers triandrous; petals emarginate; lower leaves 4 in a whorl; rameal ones opposite, obovate-oblong, rounded at the apex, mucronulate, shorter than the internodes. $\odot$. H. Native of Europe, Canary Islands ; Brazil on walls, about the town of St. Paul. In England, on the west coast ; on various parts of the coast of Devonshire, Somersetshire, and Portland Island.- Smith, engl. bot. t. 1031 . Krock. A. siles, t. 42. Mollùgo tetraphýlla, Lin. spec. 1. p. 89.

iar. $\beta$, diphíllum (D. C. prod. 3. p. 376.) leaves all opposite. $\odot$. H. Polycárpon diphýllum, Cav. icon. 2. p. 40. t. 151. f. 1. Paronýchia striàta, D. C. in Lam. dict. 5. p. 25.? Illécebrum striàtum, Pers. ench. 1. p. 261.

Four-leaved All-sced. Fl. Ju. Jul. Engl. Pl. $\frac{1}{4}$ foot.

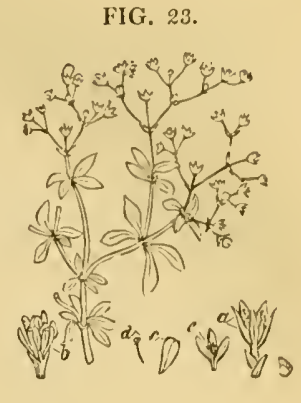

\section{* Floners pentandrous.}

3 P. Alsinetòlues (D. C. prod. 3. p. 370 .) flowers pentandrous; petals nearly entire : leaves oval, rather fleshy; flowers crowded into terminal cymes. $\odot$. H. Native of Sicily, France, between Cetta and Narbonne, and also of the Capje of Goorl Hope and New Holland, on the sandy sea-coast. Bocc. sic. p. 71. t. 38. Hàgea alsinefölia, Biv. manip. 3. p. 7. Lahàya alsinefòlia, Schultes, syst. 5. p. 405 . Móllia alsinefòlia, Schultes, syst. 1. p. 795. Holosteum tetraphýllum, Thunb. fi. cap. p. 120. Polycárpon sjec. Sieb. Al. nov. holl. no. 570 . Illècebrum alsinef òlium, Lin. mant. 51.? Very like $P$. tetraphýllum, but differs in the leaves being smooth and oval; and in the flowers bcing pentandrous, larger, fewer, and more crowded.

Chicknecd-leaved All-seed. Fl. Ju. Aug. Clt. 1817. Pl. $\frac{1}{4} \mathrm{ft}$.

4 P. Perloìdes (D. C. prod. 3. p. 376.) flowers pentandrous ; petals quite entire; leaves opposite, obovate; flowers crowled into terminal cymes. \%. F. Native of Sicily: France about Perpignon. Hàgea polycarpoides, Biv, manip. 2. no. 3. Móllia Polycárpon, Spreng. nov. prodl. p. 28. Lahàya polycarpoides, Schultes, syst. 5. p. 404. Arenaria peploìles, Lapeyr. abr. p. 251. but not of Lin. Very like P. tetraphligllum, and, as in it, the leaves are sometimes 4 in a whorl ; but besides these characters, it differs in the leaves being rounder; cymes denser; flowers a little larger, and pentandrous, $\delta \mathrm{c}$.

Water Purslane-like Polycarpon. P]. $\frac{1}{2}$ foot.

Cult. The seeds of the annual species of the genus only require to be sown in the open border in spring. The last species being perennial, should be grown in a small pot, and placed anong other alpine plants.

XVI. CE'RDIA (in honour of Juan de Dios Nizente de la Cerda, an artist attached to the Mexican expedition). Moc. et Sesse, H. mex. icon. ined. D. C. prod. 3. 1. 377.

Lin. syst. Monándria, Monogýnia. Calyx 5-parted ; lobes oblong; petaloid inside, drawn out each into a long mucrone at the apex. Petals wanting. Stamen 1 , in front of one of the calycine segments. Ovarium ovate-ylobose. Style filiform, bifid at the apex. Capsule 1-celled, many-seeded,-Dwarf Mexican lierbs, intermediate between Herniaria and Pollichict. Roots perennial, simple. Stems spreading. Leaves opposite, or in something like whorls, linear, cuspidate. Stipulas membranous, solitary between the opposite leatcs. Flowers small, axillary, subpedicellate; pedicels furnislied with 1-2 bracteas.

1 C. viréscens (Moc. et Sesse, H. mex. icon. ined. ex D. C. prod. 3. p. 377.) lenves opposite. \%. G. Native of Míexico. D. C. mem. par, t. 2. Flowers greenish-white inside.

Grecnish-flowered Cerclia. 1']. pr.

2 C. purpura'scers (Moc. et Sesse, l.c.) leaves 4 together in 
a kind of whorl. $4 . \mathrm{G}$. Native of Mexico. Flowers purplish inside.

Purplish Cerdia. PI. pr.

Cult. These plants will grow well in a mixture of loam and sand, and are easily increased by dividing at the root, by cuttings, or by seeds.

\section{Tribe IV.}

POLLICHIE' $\rightleftarrows$ (this tribe only contains the genus Pollichia). D. C. prod. 3. p. 37\%. Calyx 5-toothed; tube urceolate. Stamens 1-2, inserted in the throat of the calyx. Petals wanting. Stigma bifid. Fruit or utriculus valveless, 1-seeded. Bracteas and calyx becoming large and fleshy after flowering, and forming something like a berry.- Suffiuticose lerbs, with opposite, subverticillate stipulaceous leaves.

XVII. POLLI'CHIA (in honour of Joln Adam Pollich, M.D., author of a History of the native plants of the Palatinate of the Rhine). Sol. in Ait. hort. kew. (1789) 1. p. 5.; 3. p. 505. Juss. nem. mus. 2. p. 388. but not of Med. nor Roth. nor Willd.-Neckèria, Gmel. syst. (1796) 1. p. 16. but not of Hedw. nor Scop.-Meerbúrgia, Mœnch, suppl. (1802) p. 116.

LiN. syst. Monánária, Monogýnia. Calyx campanulately urceolate, 5-toothed, permanent. Petals wanting, unless the scales at the throat are to be taken for them. Stamen 1 (ex Moncb. rarely 2) inserted in the throat of the calyx. Style filiform; stigma bifid. Capsule valveless, 1-seeded, inclosed in the thickened tube of the caly $x$. - A suffiruticose branched herb. Leaves linear, opposite, but at first sight appear verticillate, in consequence of 2 rameal leaves rising in each axil, furnished with scarious acute stipulas. Flowers small, aggregate, sessile, bracteate.

1 P. campéstris (Ait. l. c. Snith. spicil. 1. t. 1.). h.? Ұ.? F. Native of the Cape of Good Hope. Neckèria campéstris, Gmel. 1. c. Meerbúrgia glomeràta, Mœnch. l. c. Flowers greenish. Bracteas mixed with the flowers, ciliated; scales full of sweet juice.

Field Pollichia. Fl. Sept. Clt. 1780 . Pl. $\frac{1}{2}$ foot.

Cult. The seeds of Pollichia must be raised on a hot-bed; and when the plants are 2 inches high, they may be planted out singly into pots, placed among the greenhouse plants, and afterwards treated like them.

\section{+ Gcncra plaeed in Paronychièa, but are not sufficicntly knonn.}

XVIII. LITHO'PHILA (from $\lambda_{\imath} \theta 0$, lithos, a stone, and $\phi i \lambda \varepsilon \omega$, phileo, to love ; this plant delights to grow among stones). Swartz, A. ind. occ. 1. p. 47. t. 1. D. C. prod. 3. p. 380.

LiN. syst. Diandria, Monogýnia. Calyx profoundly 3parted, acute. Petals 3, ovate-lanceolate. Scales, nectaries, or abortive stamens 2, opposite the segments of the calyx. Stamens 2, at one side of the ovarium. Style thick, bluntly cmarginate at the apex. Fruit unknown.-A very minute glabrous herb. Leaves stem-clasping, linear, obtuse. Flowers white, crowded.

1 L. muscoides (Swartz, 1. c. p. 48.).-Native of the desert island of Navaza, among rocks.

Moss..like Lithophila. Pl. 1 inch.

Cult. This plant is not worth cultivating, unless in botanic gardens. Should it ever be introduced to our gardens, we would recommend its being grown in a pot filled with broken stones, having the crevices filled with vegetable mould. It may probably be propagated by seeds.

XIX. SELLO'WIA (in honour of Frederick Sello, a German botanist, who was lately drowned in some creek of the
Amazon ; and who has sent home many fine collections of Brasilian plants). Roth. nov. spec. p. 162. D. C. prod. 3. p. 380.

Lin. syst. Pentándria, Monogýnia. Calyx urceolate, 5cleft, membranous, 10-ribbed; lobes short, lanceolate; ribs bearing alternately a petal and a stamen. Petals 5, oval, alternating with the calycine lobes. Stamens 5 , fixed in the middle of the calycine lobes, and shorter than them; anthers didymous. Style 1; stigma obtuse. Capsule 3-valved, 1-celled, 1-seeded.-A quite glabrous herb, with the babit of Illéecbrum verticillatum. Leaves opposite, oblong-oval. Flowers 1-2 in the axils of the leaves, small, white, and somewhat pedicellate. $\mathrm{It}$ is not known whether the leaves are stipulaceous or naked.

1 S. Uliginosa (Roth. l. c. p. 163.). Native of the East Indies, in bogs.

Bog Sellowia. Pl. proc.

Cult. Place a pan of water under the pot in which this plant is grown.

ORDER CXII. SCLERA'NTHEÆ (plants agreeing in important characters with Scleránthus). Link. enım. p. 417. Bartl. ex Mart. amarant, p. 67.-Paryonychièæ, Tribe V. Scleránthea, D.C. prod. 3. p. $377, \& c$.

Flowers hermaphrodite. Calyx 4-5-parted (f. 24.a.). Stamens from 1 to 10 , inserted in the orifice of the tube (f.24.a.). Ovarium simple, 1-seeded. Styles 2 (f. $24 . e$.) or 1, emarginate at the apex. Fruit a membranous utricle, inclosed within a hardened calyx. Seed hanging from the apex of a funicle, which arises from the bottom of the cell. Embryo cylindrical, curved round farinaceous albumen.-Small herbs. Leaves opposite, without stipulas. Flowers axillary, sessile. This order has been referred by De Candolle to Paronychiè , from which it differs in the absence of petals and stipulas, and therefore appears to constitute a distinct order, more nearly related to Chenopòdcce than Paronychice, from which the plants chiefly differ in the indurated tube of the calyx, from the orifice of which the stamens proceed, and in the number of the latter exceeding that of the divisions of the calyx. The tribe Minuartiece is probably not distinguishable from Seleranthece, notwithstanding the supposed presence of petals, which would perhaps be more properly called abortive stamens. All the plants contained in this order are uninteresting weeds, of no known use.

\section{Synopsis of the genera. \\ TriBe I.}

Sclera'nthes. Calyx 4-5-toothed (f. 24. $a$.), with an urceoiate tube. Petals none. Stamens 1-10, inserted in the throat of the calyx (f. 24. a.). Styles 2 (f. 24.e.) or 1, cmarginatc at the apex (f. 24. b.). Fruit an utriele, covcred by the induratcd tube of the calyx, 1-secdcd. Seed hanging by a funicle, which arises from the bottom of the capsule.

1 Mnia'rum. Calyx 4-cleft, with an urceolate tube. Stamens 1. Styles 2 .

2 Sclera'ntuus. Calyx 5-cleft (f. 24. a.), with an urceolate tube. Stamens from 2 to 10 . Styles 2 (f. 24. e.).

3 Gullemínea. Calyx 5-cleft, with a campanulate tube. Stamens 5. Style 1, emarginate at the apex.

\section{Tribe 11.}

Queria'ces. Calyx 5-parted. Petals none. Stamens 10, 
inserted in the bottom of the ealyx. Capsule 3-valved. Secd hanging from a long funiclc, which ariscs from the centre of the ccll.

4. QuE'ria. The claracter is the same as that of the tribe.

\section{TRIBE III.}

Minvartie's. Calyx 5-parted. Pctals wenting or very minute. Stamens $3-10$, inserted in the bottom of the calyx. Styles 3. Capsule 1-celled, 3-valved. Sccds viumerous, fixcd to the central placenta.

5 Minua'rtia. Lobes of calyx quite entire. Styles 3.

6 LerL1'sora. The 3 outer lobes of calyx bisetose at the base. Style 1, trifid at the apex.

\section{Tribe 1.}

SCLERA'NTHEE (plants agreeing with Scleránthus in important characters). Paronychièx, Tribe V. Sclerántheæ, D. C. prod. s. p. 377. Calyx 4-5-cleft, with an urceolate tube. Petals wanting. Stamens 1-10, inserted in the throat of the calyx. Styles $\mathbf{z}$ or 1 , emarginate at the apex. Fruit a 1 -sceded membranous utricle, covered by the indurated tube of the calyx. Seed hanging from a long funicle, which arises from the bottom of the cell, and which is recurved at the apex.-Herbs, with opposite exstipulate leaves.

I. MNIA'RUM (from $\mu$ raoos, mniaros, mossy; in reference to the moss-like habit of the plants). Forst. gen. 1. t. 1. Lin. fil. suppl. 18 . R. Br. prod. p. 412 . St. Hil. plac. lib. p. 58. Juss. mem. mus. 2. p. 387. D. C. prod. 3. p. 378.-Ditòca, Banks ex Gærtn. fr. 2. p. 196. t. 126.

Lin. syst, Monándria, Digýnia. Calyx 4-cleft, permanent, with an urceolate tube. Petals wanting. Stamen one, inserted in the throat of the calyx. Ovarium free, 1 -seeded. Styles 2. Capsule valveless, membranous, covered by the indurated tube of the calyx. Seed one, as in Scleránthus.-Australian herbs. Leares opposite, subulate. Peduncles axillary, bearing 4 bracteas and 2 flowers at the apex, becoming after flowering elongated and stiff. The ovarium, according to Forster, is sometimes 2-seeded.

1 M. BıfLònum (Forst. l. c.) stems tufted; branches quite glabrous; leaves denticulated at the base, the rest quite entire. 4. G. Native of Van Diemen's Land, Maria Island in New Holland, New Zealand, and of the Straits of Magellan. R. Br. prod. p. 412. Forst. comm. gœtt. 1789. t. 1. M. pedunculàtum, Labill. nov. holl. 1. t. 2. Ditòca muscòsa, Gærtn. l. c.

Two-flonered Iniarum. Fl. June, July. Clt. 1823. Pl. $\frac{1}{4} \mathrm{ft}$.

2 M. Fascicula'tun (R. Br. prod. p. 412.) stems many from the same neck, procumbent, branched; branches clothed with fine pubescence; leaves denticulated their whole length. 4 . G. Native of Van Diemen's Land.

Fascicled Inniarum. Pl. procumbent.

Cult. A mixture of loam, peat, and sand, will suit the species of Mniàrum, and they may be propagated either by seeds or cuttings.

II. SCLERA'NTHUS (from $\sigma \kappa \lambda \eta p o s$, scleros, hard, and $a v$ Sos, anthos, a flower; in reference to the dry juiceless calyx). Lin. gen. no. 562. Gærtn. fruct. t. 126. R. Br. prod. 1. p. 412. St. Hil. pl. libr. p. 58. Juss. mem. mus. 2. p. 887.

Lix. srst. Penta-Decándria, Digýnia. Calyx 5 -cleft (f. 24. a.), permanent, with an urceolate tube. Petals wanting. Stamens inserted in the throat of the calyx, 10 (f. 24. $a$.), rarely 5 or 2. Ovarium free, 2-seeded. Styles $2($ f. 24.e.). Capsule very thin, valveless, covered by the indurated tube of the calyx. Seet one, hanging from a long funicle, which arises from the bottom of the capsule, and is recurved at the apex.-Small herbs, with opposite linear leaves, which are rather connate at the base. l'lowers small, greenish white, sessile in the axils of the forks of the branclies.

1 S. perv'rnis (Iin. spec. 580.) flowers decandrous; lobes of fructiferous calyx closed, obtuse, with white and membranous edges. 24. H. Native of Europe and the Levant, in dry sandy fields. In England, on high open sandy fields, rare; as about Eldon, Suffolk, and plentifully near Snettinglam, Norfolk; near Bury St. Edmunds; and Scotland, on a gravelly bank near Forfar. Schkuhr, handb. t. 120. Fl. dan. t. 563 . Smith, engl. bot. t. 352.-Ray, syn. p. 160 . t. 5. f. 1. The Polish cochincal (Cóccus Polónicus) is found upon the roots in the summer months.

Perennial Knawel. Fl. July, Ang. England. Pl. prostrate. 2 S. polycárpus (Lin. spec. p. 581.) flowers subdecandrous; lobes of the calyx when in fruit rather spreading, and without any margin, acute, shorter than the tube. $\odot . \mathrm{H}$. Native in sandy fields about Montpelier, but never gathered elscwhere in France; also of Italy, according to Linnæus.-Column. ecphr. 1.t. 294. It differs from $S$. ánnuus at first sight, in the flowers being one-half smaller; but it is probably merely a variety of it.

Many-fruited Knawel. Pl. procumbent.

3 S. A'svuus (Lin. spec. p. 580.) flowers subdecandrous; lobes of fructiferous calyx spreading, immarginate, acutish, about equal in length to the tube. $\odot$. H. Native of Europe, the Levant, also of North America, in dry sandy cultivated fields; plentifil in some parts of Britain. Fl. dan. 504. Smith, engl. bot. t. 351. Knawel ánnuum, Scop. carp. p. 501. There is a variety, according to Leers. which has only 5 or 7 stamens to each flower. The Sivedes and Germans receive the vapour arising from a decoction of it into their mouths to cure the tootli-ache.

Annual Knawel. Fl. July, Aug. Britain. Pl. $\frac{1}{4}$ foot.

4 S. Hirso'tus (Presl. del. p. 65.) flowers with 5 petals and 5 stamens; calyxes conniving, obtuse; stamens equalling the calyx in length ; anthers hairy; stems pubescent. $\odot$. H. Native on Mount Etna, in the open regions. Leaves subulate, gla . brous. Flowers capitate.

Hairy Knawel. Pl. prostrate.

5 S. PO'NGENS (R. Br. prod. p. 412.) flowers pentandrous, particularly having 5 fertile and 5 sterile stamens; lobes of fructiferous calyx spreading; leaves subulate, triquetrous, mucronate, pungent, rough on the keel and margins. ๑.? H. Native of New Holland, on the south coast.

Pungent-leaved Knawel. Fl. July, Aug. Clt. 1826. Pl. procumbent.

6 S. DIA'NDER (Rr. Br. prod. p. 412.) flowers diandrous stamens mixed with scales; lobes of fructiferous calyx erect; leaves subulate, keeled, mucronulate, almost naked on the keel and margins. $\odot$. H. Native of Van Diemen's Land.

Diandrous Knawel. Pl. procumbent.

Cult. The sceds of these plants only require to be sown in the open border. None of the species are worth cultivating except in botanic gardens. 
11I. GUILLEII'NEA (in honour of John Anthony Guillemin, an acute French botanist, who has written on the family of plants called Gentiance, \& c.). H. B. et Kunth, nov, gen. amer. 6. p. 41 . t. 518 . I. C. prod. 3. p. 378.

Lis. syst. Pcntándria, Monogínia. Calyx 5-cleft, with a campanulate tube; lobes equal. Petals wanting. Stamens 5, inserted in the top of the tube, opposite the calycine lobes, short: anthers 1-celled. Style 1, somewhat emarginate at the apex. Fruit an indehiscent 1 -seeded utricle, covercd by the calyx. Secd hanging by a funicle, which arises from the bottom of the capsule.-A South A merican trailing herb, with opposite branches. Stems woolly. Leaves glabrous, oblong, opposite, exstipulate, but the petioles are comnate at the base. Flowers capitate, axillary. Bracteas under each flower.

1 G. Illecebrioides (H. B. et Kunth, l. c.) 4. G. Native of South America, near Quito, in the valley of St. Jago.

lllecebrum-like Guilleminea. Pl. tr.

Cult. Any common light soil will suit this plant, and it may be propagated from cuttings or sceds.

\section{Tribe II.}

QUERIA'CEE (this tribe contains nothing but the genus Quèria). Calyx 5-parted. Petals wanting. Stamens 10, inserted in the bottom of the calyx. Capsule 3-valved. Seed 1, "in a long funicle, which rises from the centre of the capsule.Herbs, with opposite exstipulate leaves.

IV. QUERIA (in honour of Joseph Quer y Martinez, M.D. professor of botany at Madrid; author of Flora Espanola, 1762). Loef. itin. p. 48. Lin. gen. no. 108. Lam. ill. t. 52. St. Hil. plac. lib. p. 58 . Juss. mem. mus. 2. p. 387 . D. C. prod. 3. ข. 379 .

Lin. syst. Dccándria, Trigýnia. Stamens 10, slender, unequal, sometimes 5 of which are sterile. Styles 3 , very slender. Capsule membranous, 1-celled, 3-valved. Seed reniform when mature.-.Small stiff annual herbs. Leaves opposite, crowded, setaceons, connate, recurved at the apex. Flowers in the axils of the upper branches and superior leaves, sessile, solitary. This genus is hardly distinct from Minuartia, unless in the styles heing 3 ; in the valves being 3 , and form of the seeds, which are evidently solitary from abortion.

1 Q. Hispa'nica (Lin. spec. p. 132.) ๑. H. Native of spain, in dry exposed places. Quer, fl. esp. 6. t. 15. f. 2. Ort. cent. t. 15. f. 1 .

Spanish Queria. Fl. Aug. July. Clt. 1800. P]. 1 to 2 inclies.

\section{$\uparrow A$ doubtful spccics.}

2 Q. тRicú́toмa (Thunb. in Lin. soc. trans. 2. p. 529.) ๑. H. Native of Japan. Rùbia, Thunb. fl. jap. p. 357. Stem trichotomous. Flowers racemose. Corolla cylindrical, below the fruit, Thunb. This plant does not probably belong to the order.

Trichotomous Queria. Pl. $\frac{1}{4}$ foot.

Cult. 'The seeds only require to be sown in the open ground in any dry situation.

\section{Tribe III.}

MINUARTIE' $\mathrm{E}$ (plants agreeing with Minuártia in important characters). Paronychièæ, Tribe V11. Minuartièæ, D. C. prod. 3. p. 379. Calyx 5-parted. Petals wanting or very small. Stamens $3-10$, inserted in the bottom of the calyx. Styles 3 . Capsule 1-celled, 3-valved. Seeds numerous, fixed to the central placenta.-Annual herbs, natives of the south of Europe, vitlı ojposite exstipulate leaves.
V. MINUA'RTIA (so named from Joln Minuart, a Spanish apothecary, restorer of botany in Spain; he constituted the genus Cerviàna, now Pharnaceum, and is commended by Loffling). Lœf. itin. p. 48. Lin. gen. no. 107. Lam. ill. t. 52. St. Hil. mem. plac. p. 59 . Juss. mem. mus. 2. p. 386. D. C. prod. 3. p. 379.

Lis. syst. Pentándria, Trigýnia. Sepals 5, hardly joined at the very base, quite entire. Petals or abortive stamens 5 , small, alternating with the sepals. Stamens 5, opposite the sepals, and longer than the petals. Styles 3, filiform. Capsule 1-celled, 3-valved. Seeds few, fixed to the central axis.Small annual herbs. Leaves opposite, sctaceous, 3-5-nerved at the base, quite entire. Flowers in the forks of the branches, and in the axils of the upper leaves, solitary, small, sessile, or on short pedicels; constituting a leafy, dense, diclıotomous cyme. Petals bifil, or rather nectaries. (ex Lofl.) Stamens 10,5 abortive. (Steven.) Petals and stamens 10. (St. Hil.) According to several specimens examined, the stamens are 10, and the 5 alternate ones are sometimes converted into petals. The genus differs from Loflingia in the sepals being quite entire, and from Quèria in the fruit being many-seeded.

1 M. campe'stris (Lœfl. itin. p. 122.) flowers distinctly pedicellate, equal in length, or a little longer than the floral leaves; sepals very unequal, 3 large and 2 smaller. $\odot$. H. Native of Spain, in dry sandy fields. Habit almost of Bufònia. Act. holm. 1758. t. 1. f. 3.

Field Minuartia. Fl. Ju. Jul. Clt. 1806 . Pl. $\frac{1}{8}$ to $\frac{1}{4}$ foot.

2 M. діснótoma (Lofl. 1. c. p. 121. t. 1. f. 3.) flowers almost sessile, in fascicles, shorter than the floral leaves; sepals nearly equal; mucrone of leaves oblique. $\odot$. H. Native of Spain, on bills. Act. holm. 1758. t. I. f. 5. Plant stiff, dusky.

Dichotomous Minuartia. Fl. Ju. Jul. Clt. 177 \%. Pl. $\frac{1}{8}$ to $\frac{1}{4} \mathrm{ft}$.

3 M. montána (Lofl. 1. c. p. 122. t. 1. f. 4.) bundles of flowers about cqual in length to the bracteas; sepals nearly equal; mucrone of leaves straight. $\odot . H$. Native of Spain, Tauria, and Iberia, on dry hills.-Bieb. fl. taur. 1. p. 90.

Mountain Minuartia. Fl. Ju. Jul. Clt. 1806 . Pl. $\frac{1}{8}$ to $\frac{1}{4} \mathrm{ft}$.

Cult. The sceds only require to be sown in the open ground, in any dry situation, in a light soil.

VI. LCEFLI'NGIA (so named in honour of Peter Lofling, one of the disciples of Linnæus, who travelled in Spain and America, and died on his travels in 1756 .). Lin. act. holm. 1758. p. 15. t. 1. f. 1. gen. p. 52. Lam. ill. t. 19. St. Hil. mem. plac. lib. p. 59 . Juss. mem. mus. 2. p. 386 . D. C. prod. 3. p. 380 .

Lin. syst. Pentándria, Monogýnia. Sepals 5, connected at the base, 3 outer ones bisetose at the base. Petals 5, small, conniving, inserted in the bottom of the calyx. Stamens 5, alternating with the petals, or 3,2 of them being abortive? Style 1 , trifid at the apex, or divided into 3 from the base. Capsule 1-celled, 3-valved. Seeds numerous, fixed to the central placenta.-Small, annual herbs. Leaves opposite, exstipulate, margined on both sides at the base, and appendiculated, these appendages probably supply the place of stipulas. Flowers in the forks of the branches, and in the axils of the upper leaves, solitary, sessile.

1 L. Hispa' nica (Lin. spec. p. 50.) flowers triandrous; style 1, trifid at the apex. $\odot$. H. Native of Spain, Mauritania, and South of France, in dry sandy places. Lofl. itin. t. I. f. 1. Cav, icon. 1.t. 9.4. L. prostràta, Mœnch. Herb clammy, pubescent. Corolla white; petals obovate, emarginate.

Spanish Loeflingia. Fl. Ju. Jul. Clt. 1770. Pl. $\frac{1}{4}$ to $\frac{1}{2}$ foot. 2 L. pentándra (Cav. icon. 2. t. 148. f. 2.) flowers pentandrous; styles 3 , distinct from the base. $\odot$. H. Native along 
the Mediterranean Sea, in the sand; and of Spain, near Valentia. Perlapes sufficiently distinct from the first.

Pentandrous Loeflingia. Fl. Ju. Jul. Clt. 1820. Pl. $\frac{1}{4}$ to $\frac{1}{2} \mathrm{ft}$.

† Species not sufficicntly knon'n.

3 L. CA'spica (Ginel. syst, 1. p. 105.) plant smooth in every part. Found on the shores of the Caspian Sea, by Gmelin. Gmel. itin. 3. p. 310 . t. 35. f. 1.

Caspian Loeflingia. PI. $\frac{1}{4}$ foot.

4 L.? REXifòli (Lag. gen. et spec. p. 2.) flowers pentandrous; leaves orbicularly reniform. ๑. H. Native of Mcxico. Kidney-leaved Loeflingia. PI. $\frac{1}{4}$ foot.

Cult. The seeds only require to be sown in the open border in any dry lightish soil.

Order CXIII. CRASSULA'CEA (plants agreeing with Crássula in important claracters). D. C. bull. philom. 1801. no. 49. p. 1. f. fr. ed. 3. vol. 4. p. 382. prod. 3. p. 381.-Sempervìv, Juss. gen. p. 237.-Succuléntæ, Vent. tabl. vol. 3. p. 271.-Succuléntæ $\beta$, Lin. ord. nat.-Crássulæ, Juss. dict. 11. p. 369 .

Sepals from 3 (f. $25 . e$. ) -20 (f. 30 . a.), more or less united at the base, and therefore the calyx is many-parted (f. 26. b.). Petals equal in number with the sepals (f. 25. b. f. 26. a.), and alternating with them, either distinct (f. 27. b.) or united into a gamopetalous corolla (f. 26. a.), inserted in the bottom of the calyx. Stamens inserted with the petals, either equal to them in number (f. 25. c.) and alternating with them, or twice as many (f. 27. c.); those opposite the petals being shortest, and arriring at perfection after the others; filaments distinct, subulate; anthers oval, a-celled, bursting lengthwise. Nectariferous scales several, one at the base of each ovarium sometimes obsolete. Ovaria of the same number as the petals, opposite to which they are placed around an imaginary axis, usually distinct, but in some of the anomalous genera rather concrete, all 1 -celled, and tapering into 1 stigma each, opening when ripe by a longitudinal clink in front, but in the genus Dimorpha on the back. Seeds attached to the margins of the suture, in 2 rows, variable in uumber. Albumen thin, fleshy. Embryo straight in the axis of the albumen, having the radicle directed to the bilum.-Fleshy herbs or shrubs. Leaves entire or pinnatifid, witbout stipulas. Flowers usually in cymes, sometimes rising in the forks, often arranged unilaterally along the divisions of the cymes.

The plants contained in this order are all remarkable for the succulent nature of their stems and leaves, in which they resemble Cáctea, Portulicea, and certain genera of Euphorbiàcece, \&c. but this analogy goes no farther. Their real affinity is probably with Saxifragea, through Penthònu, which is not succulent, like the rest of the genera; and with Paronychièce, through Tille' $a$, as De Candolle has remarked. In both those orders, the nectariferous scales of Crassulàcca are wanting. De Candolle observes (mem. crass. p. 5.) that there is no instance of a double flower in the order, although this might have been expected from their analogy in structure with Caryophýllea. Sempervivum tcctòrum almost constantly exhibits the singular phenomenon of anthers bearing ovules instead of pollen. VOL. 111 .
These plants are found in the driest situations, where not a blade of grass nor a particle of moss can grow, on naked rocks, old walls, sandy lot plains, alternately exposed to the heaviest dews of night, and the fiercest rays of the noon-day sun. Soil is to them a something to keep them stationary, rather than a source of nutriment, which in these plants is conveyed by myriads of mouths, invisible to the naked eye, but covering all their surface, to the juicy beds of cellular tissue which lie beneath them.

Refrigerent and abstergent properties, mixed sometimes with a good deal of acridity, distinguish them. The fishermen of Madeira rub their nets with the fresh leaves of Semperivum glutinosum, by which they are rendered as durable as if tanned, provided they are steeped in some alkaline liquor. Malic acid exists in Sempertivum tectòrum, combined with lime.-Turner, p. 634 .

Synopsis of the gencra.

TriBe I.

Crassula'cex legítine. Carpella distinet, opening when mature by a longitudinal fissure in front (f. $26, b$.).

1 Tille'A. Divisions of calyx, petals, and stamens 3-4. (f. 25. a. b. c.). Nectariferous scales none or very small. Carpels $3-4$ (f. $25 . d_{\text {.) }}$, constricted in the middle, 2 -sceded.

2 Bulliárda. Divisions of calyx, petals and stamens 4. Nectariferous scales 4, linear. Carpels 4, many-seeded.

3 Dasyste'mon. Sepals 3-7, filiform, unequal, hardly joined at the base. Petals $3-7$, often 5 , hardly joined at the base, rather revolute at the apex. Stamens 3-7; filaments thick. Carpels 3-5.

4. Séptas. Calyx 5-9-parted. Petals 5-9, stellately spreading. Stamens 5-9; filaments slender. Scales 5-9, small, roundish. Carpels 5-9, many-secded.

5 Crássula. Calyx 5-parted. Petals 5, distinct. Stamens 5 ; filaments subulate. Scales 5 . Carpels 5, many-seeled.

6 Purgosia. Calyx 5-parted. Petals 5, imbricating at the base. Stamens 5 ; scales 5 , emarginate. Carpels 5 , gibbous on the outside, and flat inside, many-seeded.

7 Globu'cea. Calyx 5-parted. Petals 5, bearing a waxy globule each at the apex. Stamens 5. Scales 5. Carpels 5.

8 Curtógrne. Calyx 5-parted. Petals united into a 5parted corolla. Stamens 5. Scales 5. Ovaria 5, gibbous at the apex, ending each in a long sublateral style.

9 Gramin'ntues. Calyx 5-cleft. Corolla gamopetalous ; lobes 5 , rarely 6 , expanded. Stamens $5-6$, inserted in the tube of the corolla. Scales none. Carpels 5.

10 Ròches. Calyx 5-lobed. Petals 5, united into a gamopetalous corolla, with a spreading 5 -lobed limb. Stamens 5 . Glands and carpels 5 .

11 Kalosa'ntues. Calyx 5-]obed (f. 26. b.). Petals united into a 5-parted corolla (f. 26. $a$.), with the tube cylindrical, 2 or 3 times longer than the spreading limb. Stanens 5 , inserted in the tube of the corolla. Glands and carpels 5 .

12 KALANcuòe. Calyx 4-parted; sepals hardly united at the base. Corolla gamopetalous, with a 1-partcd, spreading 
border. Stamens \&, adnate to the base of the tube of the corolla. Scales 4 , linear. Carpels 4 ; styles filiform.

13 Bryopirýlum. Calyx inflated before flowering, hardly 4-cleft to the middle. Corolla gamopetalous, hypogynous; lobes 4 , acute. Stamens 8 , adnate to the base of the tube of the corolla. Glands 4.

14. Cotrlédon. Calyx 4-parted. Corolla gamopetalous, with a 5 -lobed, spreadingly reflexed limb. Stamens 10 , adnate at the base to the tube of the corolla. Seales oval. Carpels 5 , each drawn out into a subulate style.

15 Pistorínia. Calyx 5-parted. Corolla gamopetalous, with a 5-parted spreading border. Stamens 10, adnate their whole length to the tube of the corolla. Scales 5 . Carpels 5, ending each in a long filiform style.

16 UnBílicus. Calyx 5-parted. Corolla campanulate, 5cleft; lobes acute. Stamens 10 , inserted in the corolla. Scales 5. Carpels 5 ; styles subulate.

17 Echeve'ria. Calyx 5-parted (f. 27. a.); sepals erect. Petals 5, united at the base (f. 27. b.), thick, and erect. Stamens 10 (f. 27. c.), united to the petals at the base. Scales 5 . Carpels 5 , each ending in a subulate style.

$18 \mathrm{SE}^{\prime}$ dum. Calyx 5-parted (f. 29, a.); sepals turgid, leafformed. Petals 5 (f. 29. b.), usually spreading. Stamens 10 (f. 29. c.). Scales 5. Carpels 5.

19 Sempervivum. Calyx 6-20-parted (f. 30. a.). Petals 6-20 (f. 30.6 .). Stamens twice the number of the petals (f. 30. $c$.). Scales toothed or jagged. Carpels equal in number to the petals.

\section{TrIBE JI.}

Crassula'cee aNómale. Carpels united at the base into a many-celled capsule.

20 Diamórpua. Calyx 4-lobed. Petals 4. Stamens 8. Carpels 4, united at the base, opening longitudinally on the back or outside.

21 Penthòrus. Calyx 5-parted. Petals 5. Stamens 10. Scales wanting? Carpels 5, united at the base into a 5-beaked, 5 -celled capsule, which is pentagonal at the apex, and opening under the beaks. Seeds small, numerous.

\section{Tribe 1 .}

CRASSU'LEA or CRASSULA'CE E LEGI'TIMA (this tribe contains the legitimate plants of the order). Carpels distinct; when mature opening on the inside by a longitudinal fissure.

I. TILLE'A (so named in honour of Michael Angelo Tilli, M. D. F.R.S., born 1653. Professor of Botany at Pisa ; author of Horti Pisani Catalogus, 1723 , fol. with 50 plates. It contains a few rare plants, observed by him in his voyages to Constantinople and Tunis). Mich. gen. 22, t. 20. D. C. bull. philom. no. 49. p. 2. prod. 3. p. 381.-Tillæ'a species of Lin.

Lin. sxst. Tri-Tetrándria, Tri-Tetragýnia. Calyx 3-4parted (f. 25. a.). Petals 3-4. (f. 25. b.), oblong, acuminated. Scales none, or very small. Carpels $3-4$, somewhat constricted in the middle, 2-sceded. - Small, glabrous, annual herbs, inhabitants of exposed sub-humid places. Leaves opposite. Flowers small, white, for the most part axillary--Many of the exotic species may probably belong to Bulliárda.

1 T. muscòsa (Lin. spec. 186.) stems branched at the base, decumbent ; leaves connate ; flowers axillary, sessile, trifid. $\odot$. H. Native of Europe in many places, in dry, barren, sandy, and gravelly soil; plentiful in Britain, on the most barren sandy heaths; frequent in Norfolk and Suffolk. It is a troublesome weed in the gravel walks of Holkham. Bocc. mus. t. 22. Mich. gen. t. 20. Lam. ill. t. 90. D. C. pl, grass. t. 78. Smith, engl. bot. 116. Reich. icon. t. 191. Bocc. sic, t. 29. In exposed situations. this plant becomes reddish; hut in that state it is not the $T$. rùbra of Gouan.

Mossy Tillæa. Fl. June, Oct. Britain. Pl. trail.

2 T. símplex (Nutt. gen. amer. append. et journ. acad. philad. 1. p. 114.) stem erect, simple ; leaves connate, oblonglinear, acute ; flowers alternate, sessile; petals 4 , erect, twice the length of the calyx. $\odot$. H. Native of North America, in humid gravelly places.

Simple-stemmed Tillæa. Pl. $\frac{1}{8}$ foot.

3 T. aroscha'ти (D. C. prod. 3. p. 382.) stem prostrate at the base; branches ascending; leaves connate, oval-oblong; flowers 4-cleft, sessile in the axils of the superior leaves. $\odot . H$. Native of the Straits of Magellan, on the mountains; and of the Maclove Islands. Crássula moschàta, Forst. in act. soc. gœett. 9. p. 26. Bulliárda Magellánica, D. C. bull. philom. no, 49.

Musk Tillæa. Pl. prostrate.

4 T. mísima (Miers, chil. 2. p. 530.) stems diffuse, branched; leaves minute, connate at the base, oval-oblong; flowers 4-cleft, crowded into whorls in the axils of the leaves, on short pedicels; petals 4, acuminated, shorter than the calyx; carpels 1-2-seeded. -Native of Chili, about Conception and Coquimbo. T. erécta, Hook et Arnott, in Beech, voy. bot. 1. p. 24. Allied to $T$. moschàta and verticillàris.

Least Tillaea. Pl. $\frac{1}{4}$ foot.

5 T. Verticilla'ris (D. C. l. c.) stems prostrate at the base, rooting; branches ascending; leaves opposite, oblong-linear; flowers 4-cleft, crowded in whorls in the axils, some of which are sessile and others pedicellate. $\odot$. H. Native of New Holland. Tillæ'a pedunculàta, Sieb. pl. exsic. nov. holl. no. 173. but not of Smith. Petals acuminated, longer than the calyx. Habit almost of Illéccbrum verticillàtum.

Verticillate-flowered Tillæa. Pl. pr.

6 T. Peduncula'ris (Smith, in Rees' cycl, vol. 35. no. 4.) stem erect, simple; leaves rather connate, lanceolate, acute; pedicels axillary, solitary, twice or thrice longer than the leaves; carpels truncate at the apex. (․ H. Native about Monte Video and Buenos Ayres, in humid places. Bulliárda Bonariénsis, D. C. bull. plitom.

Peduncled-flowered Tillæa. Pl. $\frac{1}{8}$ foot.

7 T. RUBE'scens (H. B. et Kunth, nov. gen, amer. 6. p. 43.) stems branched, prostrate ; leaves oblong-lanceolate, ovate, mucronate, rather fleshy, connate at the base; flowers 4-cleft, on long pedicels; petals shorter than the calyx. ○. H. Native about Quito, near Alansi. Flowers white. Carpels 2-seeded. T. connàta, Ruiz et Pav. f. per. 1. p. 70. t. 106. f. $a$., which was found in Peru, about Chancay, on humid hills, appears to differ from Kunth's plant in the stems being rather erect. 
Redelish Tillea. Pl. pr.

Cult. Sow the seeds among gravel, and keep it moist, either in pots or in the open ground.

II. BULLIA'RDA (in memory of - Bulliard, author of Herbier de la Irance, 600 planches in fol. 1780, and other botanical works). D. C. bull. plilom. no. 49. p. 1. prod. 3. p. 382.-Tillæ'a species, Lin.

Lis. syst. Teirándria, Tetragýnia. Calyx 4-parted. Petals 4, oval or oblong, acute. Stamens 4. Scales 4, linear. Carpels 4, many-seeded.-Small, glabrous, annual, subaquatic herbs. Leaves opposite. Flowers small, white, axillary, sessile, or pedicellate. The parts of the flower are sometimes quinary, and therefore differ from Crássula in the form of the scales, and from Tilla' $a$ in the many-seeded carpels, as well as in the number of the parts of the flower.

1 B. VaILlA'N TII (D. C. pl. grass, t. 74.) stem erect, dichotomous; leaves oblong, acute; pedicels longer than the leaves. $\odot$. H. Native of France, at Fontainbleau, in humid slady places, \&c. Vaill. bot. t. 10. f. 2. Tilla’a aquática, Lam. ill. t. 90. but not of Lin. Tillà a Vaillántii, Willd. spec. 1. p. 720. Corolla pale flesh-coloured. Stems sometimes erect and sometimes prostrate, generally rooting at the lower nodes. T. prostràta $\beta$, Poir. dict. 7. p. 674 . is perhajs referrible to this plant.

Vaillant's Bulliarda. Fl. June, Aug. Clt. 1825. Pl. erect or prostrate.

2 B. AQUA'TICA (D. C. bull. phil. no. 49.) stem erect, rather dichotomous; leaves linear-lanceolate; flowers sessile, or on very short pedicels. $\odot$. H. Native of Sweden, Norway, and Germany, in places where water stagnates. Tillàa aquática, Lin. fl. suec. no. 156 . Wahl. fl. suec. no.210. Stuck. p.6. t. 1.

$V_{a r} \beta$, prostràta (D. C. prod. 3. p. 382.) stems procumbent. Tilla'a prostràta, Schkuhr, in Ust, ann. 2. p. 21. t. 3. Horn. f. dan. t. 1510. Stuck, p. 21. t. 3. In Hornemann's plant the flowers are either sessile or on short pedicels.

Aquatic Bulliarda. F1. Ju. A ug. Clt. 1816. Pl. pr.

Cult. See Tilla' $a$ for the manner of growing these plants.

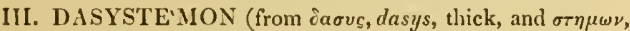
stemon, a stamen; in allusion to the thick filaments). D.C. prod. 3. p. 382.

Lix. syst. Tri-Heplándria, Tri-Penlagýnia. Sepals 3-7, leaf-formed, unequal, hardly united at the base, equalling the corolla in length. Petals $3-7$, but generally 5 , erect, hardly united at the base, and revolutely spreading at the apex. Stamens $3-7$, alternating with the petals, and longer than them; filaments thick; anthers erect. Carpels 3-5.-An Australian herb, covered all over with scaly papule. Root fibrous. Stem branched at the apex. Leaves opposite, connate, linear.

1 D. calycines (D. C. I. c. mem. crass. t. 3.). ๑. H. Native of New Holland. Crássula calycina, Desf. cat. hort. par. 1815. p. 187. Herb $3-4$ inches long, rather aseending at the base, dichotomously branched at the apex. Leaves thick, flattish, rather convex below. Flowers greenish-white.

Large-calyxed Dasystemon. PI. $\frac{1}{4}$ foot. soil.

Cult. Sow the seeds of this plant thinly in pots, in gravelly

IV. SE'PTAS (from septem, seven; the number 7 prevailing in the fructification). Lin. gen. 465. Haw. syn. 61. D. C. prod. 3. p. 383.-Crássula species of Thunb. and Willd.

Lis. syst. Penta-Enncándria, Penta-Enneagýnia. Calyx 5-9-parted, shorter than the corolla. Petals 5-9, stellately spreading. Stamens 5-9; filaments slender, acuminated; scales $5-9$, small, roundish. Carpels 5-9, many-sceded.-Herbs, native of the Cape of Good Hope. Roots tuberous, quiescent in winter; tubers roundish; fibres capillary. Stems simple, terete. Leaves of 2 opposite pairs, and the pairs sometimes approximate so near as to make the leaves appear in whorls. Ilowers white, disposed in something like umbels. The habit of the plants is referrible to some Saxifràgec.

1 S. CAPE' xsıs (Lin. amoen. 6. p. 87.) leaves roundish, broadly crenated, tapering into the petioles; and the base of the petioles is rather connate; petals spreading. 24. D. G. Native of the Cape of Good Hope. Andr. bot. rep. 90.-Pluk. alm. 340. f. 9. bad. Lam. ill. t. 276. Crássula Séptas, 'Thunb. H. cap. p. 291. There are varieties of this plant, differing in the number of the floral parts from 5-9, but generally 7 ; and witl fewflowered or many-flowered umbels ; and with leaves more or less stalked, having the crenatures either simple or subcrenated. Flowers white or red.

Var. $\beta$, globifcra (D. C. prod. 3. p. 383.) umbels manyflowered, compound; leaves revolute at the apex, doubly crenated. 4. D. G. Native of the Cape of Good Hope. Sćptas globífera, Sims, bot. mag. t. 1472. Stems red. Flowers white.

Cape Septas. Fl. Mar. Aug. Clt. 1774; $\beta$ in 1809 , Pl. $\frac{1}{2} \mathrm{ft}$.

2 S. UMBE'LLA (Haw, syn. p. 62.) leaves 2, united together into an orbicular disk, broadly sub-crenated; petals reflexed. 4. D. G. Native of the Cape of Good Hope. Crássula umbélla, Jacq. coll. 4, p. 172. icon. rar. t. 352. Tratt. tab. t. 259. Leaves red beneath. Flowers 5-6-cleft, reddish.

Umbelled Septas. Fl. July. Clt. 1800 . Pl. $\frac{3}{4}$ foot.

Cult. A mixture of sand, loam, and peat suit the species of this genus; and they should be watered but sparingly when not in a growing state. They are readily increased by separating the tubers of the roots.

V. CRA'SSULA (a diminutive of crassus, thick; in reference to the fleshy leaves and stems). Haw. syn. p. 51. D.C. prod. 3. p. 383. mem. crass, t. 1. f. 2.-Crássula species of Lin. -Crássula, Haw, rev. p. 8-9.-Gomàra, Adans. farn. 2. p. $24 \mathrm{~S}$.

Lin. syst. Pentándria, Pentagýnia. Calyx 5-parted, much shorter than the corolla; sepals flattish. Petals 5 , stellately spreading, distinct. Stamens 5 ; filaments subulate. Scales 5 , ovate, short. Carpels 5, many-seeded.-Fleshy shrubs or herbs, generally natives of the Cape of Good Hope. Leaves opposite, quite entire, or sub-crenated. Flowers white, rarely rose-coloured.

\$1. Latifolia (from latus, broad, and folium, a leaf; leaves broad). Shrubby. Leaves broader, flat, nith the surface and margins smooth.

1 C. ARBORE'SCENS (Willd. spec. 1. p. 1554.) stem slırubby, erect, terete ; leaves opposite, roundish, mucronate, fleshy, flat, glaucous, dotted above, glabrous ; cymes trichotomous. h. D. G. Native of the Cape of Good Hope. C. Cotylèdon, Curt. bot. mag. t. 384. Jacq. misc. bot. 2. p. 295. t. 19. Cotylèdon arboréscens, Mill. dict. ed. 6. Flowers large, rose-coloured, spreading stellately. Shrub, with the leaves and habit very similar to those of Colyledon orbiculàta.

Arborescent Crassula. Fl. May, June. Clt.1739. Shrub 2 to 3 feet.

2 C. Portula'cea (Lam. dict. 2. (1786.) p. 172.) stem erect, fleshy, thick ; leaves opposite, oblique, acute, distinct, glalrons, slining, dotted; cymes trichotomous. $\zeta_{\text {. }}$ D. G. Native of the Cape of Good Hope. D. C. pl. grass, t. 79. C. obliqua, Ait. hort. kew. ed. 1. (1789.) vol. 1. p.393. Cotylèdon ovata, Mill. dict. no. 8. C. portulàcea and C. oblìqua, Pers. ench. 1. p. 337. C. articulàta, Zucca, curt. no. 59. Flowers rosecoloured. Like C. Cotyledon.

$$
\text { o } 2
$$


Portulaca-like Crassula. Fl. April, May. Clt.1759. Shrub 3 to 4 feet.

S C. LA'CTEA (Ait. hort. kew. ed. 1. p. 496.) stem shrubby, terete, branched, twisted below ; leaves ovate, attenuated at the base, and connate, glabrous, dotted within the margin; cymes many-flowered, panicle-formed. h. D. G. Native of the Cape of Good Hope. D. C. pl. grass. t. 37. Smith, exot. bot. t. 39. Sims, bot. mag. t. 1771 . Jacq. schœnbr. t. 430. Thunb. H. cap. p. 289. no. 45. Leaves pale green. Flowers snow white, stellately spreading.

Milk-coloured-flowered Crassula. Fl. Sept. Oct. Clt. 1774. Shrub $\frac{3}{4}$ to $I$ foot.

4. C. ARGE'NTEA (Lin. fil. suppl, p. 188.) leaves connate, ovate, entire, fleshy, glabrous, silvery ; stem shrubby ; corymbs supradecompound. $\zeta$. D. G. Native of the Cape of Good Hope. Thunb. fl. cap. p. 289. Flowers white; anthers black. Stem a foot or more in height. Leaves obtuse, with an acumen.

Silvery Crassula. Shrub $1 \frac{1}{2}$ foot.

5 C. TELEPHoides (Haw, rev. succ. p. 9.) stems herbaceous? erect; leaves obovate-oblong, stem-clasping, minutely and punctately crenated below; flowers cymose. the Cape of Good Hope. Leaves 3 inches long and 18 lines broad. Petals pale rose-coloured. Scales square. Habit almost of Sèdum Telèphium, but smaller and more humble; and differs in the stamens being 5. D. C. Perhaps Anacámpscros, Burm. afr. t. 25. f. 2. is referrible to this plant.

Orpine-like Crassula. Fl. July. Clt. 1818. Shrub 1 foot.

\$2. Subulàres (from subula, an awl; form of leaves). Shrubby. Liaves subulate. Haw. syn. p. 51.

6 C. rayòsa (Ait. hort. kew, 1. p. 390.) shrubby, glabrous, branched at the base ; leaves subulate, flat above, connately perfoliate, smooth, much spreading ; peduncles elongated, cymosely corymbose. h. D. G. Native of the Cape of Good Hope. Thunb. fl. cap. p. 284. Haw. syn. p. 51. according to whom it is nearly allied to $C$. perfoliata, C. dichótoma, Lin. fil, suppl. p. 188. ex Willd. Flowers pink.

Branched Crassula. Fl. July, A ug. Clt. 1774. Sh. 2 to $3 \mathrm{ft}$.

7 C. FRuticuròsa (Lin. mant. p. 61.) stem slırubby, smooth; leaves opposite, subulate, acute, much spreading, and a little recurved; peduncles solitary, subumbellate. $\zeta$.D. G. Native of the Cape of Good Hope. Flowers small, white, campanulate; anthers purple. Very like C.perfoliàta, according to Thunberg; but it differs in the leaves being reflexed.

I ar. $\beta$, Càfra (Lin. mant. p. 222.) stem suffruticose.

Shrubby Crassula. Shrub 2 to 3 feet.

8 C. REvót LEens (Haw. phil. mag. 1824. p. 188.) stem suffruticose, slender, a little branched; branches erect; leaves linear, lean, acute, revolutely reflexed, and arched, rather distant. $h$. D. G. Native of the Cape of Good Hope. Flowers small, white, in dense terminal heads. Perhaps not distinct from $C$. fruticulòsa.

Revolving-leaved Crassula. Fl. Ang, Sept. Clt. 1820. Shrub 1 foot.

9 C. TEtragòna (Lin. spec. 404.) stem erect, shrubby, terete, leaves decussately opposite, depressed above, subulate, somewhat tetragonal, incurved, spreading, glabrous. h. D. G. Native of the Cape of Good Hope. Bradl. succ. pl. dec. 5. $t$. 41. D. C. pl. grass. t. 19. Flowers small, white, nearly urceolate, disposed in a pedunculate fastigiate cyme. Stems sometimes rooting.

Tetragonal Crassula. Fl. Aug. Clt. 1711. Shrub 2 feet.

10 C. Biplana'ta (Haw, phil. mag. 1824. p. 186.) stem suffruticose, erect, with spreading branches ; leaves erectish, smootl, subulate, acute, flat on both surfaces, channelled beneath. $h$.
D. G. Native of the Cape of Good Hope. Very like the following. Bracteas larger. Flowers white; anthers reddish.

Biplanate-leaved Crassula. Fl. Sept. Clt. 1823. Sh. $1 \mathrm{ft}$.

11 C. Acutifòlıa (Lam. dict. 2. p. 175.) stem suffruticose, decumbent, branched, terete; leaves opposite, fleshy, terete, subulate, spreading, glabrous; cymes small, pedunculate. $\quad$ h. D. G. Native of the Cape of Good Hope. D. C. pl. grass. t. 2. Allied to C. tetragòna, but is rather more herbaceous, decumbent, and rooting. Leaves usually reflexed. Flowers white.

Acute-leaved Crassula. Fl. Sept. Nov. Clt. 1795. Pl. decumbent.

12 C. Bibractea'ta (Haw. in phil. mag. 1824. p. 187.) plant effuse, decumbent, rooting; leaves subulate, expanded, flat or furrowed above; bracteas two on each peduncle. $\zeta$. D. G. Native of the Cape of Good Hope. Flowers white; anthers sulphur-coloured, but at length becoming brown. Allied to $C$. acutifòlia.

Var. a, minor (Haw. l. c.) plant usually rufescent; leaves less furrowed above or flat, full of rufous dots beneath.

$\operatorname{Var} . \beta$, mìjor (Haw. 1. c.) greenish; leaves usually furrowed above, and often dotted with brown; branches longer than in var. $\alpha$.

Bibracteate Crassula. Fl. Aug. Sept. Clt. 1823. Pl. $\frac{1}{2}$ foot.

13 C. Filicav'us (Haw. in phil. mag. 1824. p. 188.) plant effusely dichotomous; leaves spreadingly recurved, lanceolatesubulate, smooth, convex beneath; branches rooting, filiform. s.? h.? D. G. Native of the Cape of Good Hope. Flowers white, disposed in a kind of cyme; anthers yellow. Allied to the two preceding species.

Thread-stcnmed Crassula. Fl. Aug. Sept. Clt. 1820. Pl.pr.

§. Squamulòsa (from squamulosus, covered with little scales). Frutescent. Leaves lincar-lanceolate, rough from scaly papula. Haw. rev. succ. p. 11.

14 C. SCA'BRA (Lin. spec. p. 405.) stem suffruticose, erect, terete, branched, covered with retrograde rugosities ; leaves opposite, spreading, connate, linear-lanceolate, acute, scabrous, ciliated; flowers corymbose, terminal. $h$.D. G. Native of the Cape of Good Hope. Dill, hort. elth. t. 99. f. 117. Mart. cent. t. 24. Segments of flowers spreading, or a little revolute, white at first, but becoming at length brownish.

Scabrous Crassula. Fl. June, July. Clt. 1730. Pl. $1 \frac{1}{2}$ foot.

15 C. SCABRE'LLA (Haw. rev. succ. p. Il.) leaves linear-lanceolate, acuminated, expanded, and are, as well as the stems, rough from scales. $\zeta$. D. G. Native of the Cape of Good Hope. Allied to C. scàbra and C. squamulossa. Flowers white? Roughish Crassula. Fl. Ju. July. Clt. 1810 . Pl. $\frac{1}{2}$ to $1 \mathrm{ft}$. 16 C. squanulòsa (Willd. enum. suppl. p. 15.) the whole plant scaly from diaphanous papulæ; leaves lanceolate; flowers capitate. h. D. G. Native of the Cape of Good Hope. Haw. rev, succ. p. 11. Flowers white. Said to be nearly allied to $C$. scìbra.

Scaly Crassula. Fl. June, July. Clt. 1817. Pl. $\frac{1}{2}$ foot.

17 C. Bullula'ta (Haw. rev. succ. p. 11.) leaves lorate-lanceolate, and are, as well as the stems, roughish from whitish blisters; flowers cymose. $h$. D. G. Native of the Cape of Good Hope. Cotylèdon, \&c. Mart. cent. t. 24. Ftuwers said to be yellow. Allied to C. scàbra, according to Haworth.

Little-blistercd Crassula. Fl. Aug. Sept. Clt. 1800. Shrub 1 foot.

18 C. pruivòsa (Lin. mant. p. 60.) stem shrubby, dichotomous; branchlets and leaves subulate, scabrous from papula; flowers corymbose. দ. D. G. Native of the Cape of Good Hope. Flowers white. Leaves opposite, linear, rather connate at the base. Thunb. prod. p. 55. Al. cap. p. 283.

Pruinose Crassula. Shrub I foot. 
19 C. wurica'ta (Thunb. prod. p. 55. fl. cap. p. 283.) stem frutescent, erect; branches tetragonal; leaves conuate, trigonal, scabrously ciliated, obtuse ; flowers subumbellate. Native of the Cape of Good Hope. It differs from C. tetragona in she stem being erect, and in the lcaves being scabrous.

Muricated Crassula. Slurub 1 foot.

$\$ 4$. Columnares (from columua, a column; disposition of leaves on the branches). Frutesccnt. Leavcs broadcr, densely imbricated along the stems and branchcs. Maw. syn. p. 54.

20 C. colvma'ris (Lin. fil. suppl. p. 191.) stem erect, simple, an inch high; leaves connate, roundish, glabrous, very closely imbricated; flowers disposed in a roundish terminal fas. cicle. h. D. G. Native of the Cape of Good Hope. Burm. afr. p. 19. t. 9. f. 2. Flowers whitc, small, very copious.

Columnar Crassula. Clt. 1789 . Pl. $\frac{1}{8}$ foot.

21 C. Lycoponioídes (Lam. dict. 2, p. 173.) stem slurubby, branclied, covered with leaves on all sides; leaves decussate, ovate, acute, smooth, imbricating in 4 rows; flowers axillary, sessile, bracteolate. h. D. G. Native of the Cape of Good Hope. C. imbricàta, Ait. hort. kew. 1. p. 393. C. muscòsa, Lin. spec. p. 405 . Thunb. fi. cap. p. 281. ex Thunb. in litt. Corolla small, purple at the base. There is a variety of this plant having the stems naked at the base, according to Thunberg.

Club-moss-like Crassula. Shrub tr.

22 C. enICo'Des (Haw, in phil. mag. 1825. July, p. 30.) plant between erect and decumbent; branchlets distant; leaves orate-oblong, sniall, flat, closely imbricated in 4 rows; flowers $5-10$, disposed in an umbellate cyme. h. D. G. Native of the Cape of Good Hope. An elegant species, not allied to any unless perhaps to $C$. pyramidalis. Flowers small, snow white. Leaves 3 to 4 lines long.

Heatl-like Crassula. Fl. Sept. Clt. 1820. Shrub $\frac{1}{2}$ foot.

23 C. vesti'ra (Lin. fil. suppl. p. 188.) leaves connate, deltoid, obtuse, quite entire, covered with white powder, more frequent an the upper ones; flowers terminal, capitate. $h$. D. G. Native of the Cape of Good Hope. Thunb. fl. cap. p. 290. Stem a hand high, erectish, branched, naked at the base. Flowers yellow, aggregate and sessile on the branches.

Clothed Crassula. Shrub $\frac{i}{2}$ foot.

§5. Perflata (from per, through, and flum, a thread; in reference to the thread-like stems). Frutcscent or nearly herbaccous. Leaves flat, broader, glabrous, connate, usually glaucous. Haw, syn. 1). 54 .

24 C. PERfóssa (Lam. dict. (17S6) 2. p. 173.) stem suflruticose, decumbent, slender, a little branched; leaves connately perfoliate, roundish, and rather acute, glabrous, dotted above, but not ciliated ; thyrse elongated, composed of cymose pedunculate opposite branchlets. h. D. G. Native of the Cape of Good Hope. D. C. jl. grass, t. 25. Jacq. hort. schoenbr. t. 432. C. perfilàta, Scop. del, insub. (1788) 3. p. 12. t. 6. C. punctàta, Nill. C. coronàta, Donn, hort. cant. Flowers yellow.

Deep-pitted Crassula. Fl. Sept. Clt. 1785. Pl. decumbent.

25 C. PERfora'ta (Lin. fil. suppl. p. 190. Thunb. f. cap. p. 287.) stem shrubby, erect; leaves grsen, connately perfoliate, ovate, remote, glabrous, with cartilaginously ciliated margins; thyrse interrupted. $\boldsymbol{h}$. D. G. Native of the Cape of Good Hope.

Perforated Crassula. Shrub 1 foot.

26 C. margixa'Lis (Ait. loort. kew. 1. p. 306.) stem perennial, herbaceous, glabrous, pellucid; leaves connately perfoliate, roundish-orate, ending in a recurved mucrone, flat, spreading, glabrous, flotted within the margin; flowers disposed in umbellate corymbs. 4 . D. G. Native of the Cape of Good Hope.
Jacq. schœubr. 4. t. 471. C. marginàta, Thunb. prod. p. 56. f. cap. 287. Stems prostrate, jointed, rooting. Leaves reddish beneath, quite entire, with cartilaginous margins, whiclı are at first redklish, but at length becoming white from farina. Pechuncles terminal, with two lateral ones, rising from the axils of the upper leaves. Flowers white; petals lanceolate, acute. The characters and synonymes are taken from the manuscript of the Prince de Salm-Dyck.

Marginal-leaved Crassula. Fl. July, Aug. Clt. 1774. Pl.cr.

27 C. PELLU'CidA (Lin. spec. p. 406.) stems nearly lierbaceous, flaccid, creeping ; lcaves opposite, obovate, attenuated at the base, glabrous, glandularly toothed, crowded at the tops of the branches; cymes subumbellate. $h, 1)$. G. Native of the Cape of Good Hope.-Dill. hort. elth. t. 100. f. 119. Jacq. fragm. t. 44. f. 3.? Thunb. fi, cap. p. 283. Very like $C$. spatulata, but differs in being more herbaceous, in the leaves not being petiolate, in the flowers being a little larger, and more crowled; the rest similar, according to the figure of Jacquin. Flowers pink.

Pellucid Crassula. Fl. June, Sept. Clt. 1732. Pl. tr.

28 C. prostra'ta (Thunb. prod. p. 54. fl.cap. p. 282.) stems herbaceous, decumbent, pellucid, glabrous; leaves lanceolate, acute; flowers subumbellate. 2.D.G. Native of the Cape of Good Hope. Like C. pellucida, but differs in the form of the leares.

Prostrate Crassula, Pl. prostrate.

29 C. centaurioldes (Lin. spec. p. 404.) stems herbaccous, dichotomous, prostrate; leaves opposite, sessile, fiat, oblongovate, glabrous, punctately toothed on the margins; pcduncles axillary, I-flowered. $\odot$. D. G. Native of the Cape of Good Hope. Sims, bot. mag. t. 1765. C. pellucida, Jacq. fragm, t. 44. f. 3.? Flowers rose-coloured, nearly like those of C. spatulàta; the ultimate ones somewhat corymbose.

Centuary-like Crassula. Pl. prostrate.

$\S 6$. Petiolìres (from petiolus, a leaf-stalk; in reference to the leaves being stalked). Frutescent. Leaves flat, broader, petiolate. Haw. syn. p. 55.

30 C. conda'ta (Ait. hort. kew. ed. 1. vol. 1. p. 396.) stem shrubby ; leaves opposite, petiolate, cordate, obtuse, quite entire, dotted above, glabrous; cymes panicle-lormed. $h$. D. G. Native of the Cape of Good Hope. D. C. pl. grass. 2. t. 121. Jacq. schœenbr. t. 431 . Flowers reddish. Allied to $C$. perforata. C. cordata, Willd. spec. 1. p. 153. but the C. cordàta of Thunb. appears to be a distinct plant, who says that his plant is annual, and that the flowers are solitary. Plant glaucous.

Cordatc-leaved Crassula. Fl. May, Aug. Clt. 1774. Pl. prostrate.

31 C. Spatula'ta (Thunb. prod. 58. fl. cap. p. 293.) stems suffruticose, decumbent, branched; leaves petiolate, roundisl, crenated, glabrous, shining above; corymbs panicle-formed. 々. D. G. Native of the Cape of Good Hope. - D. C. pl. grass. t. 49. C. Jùcida, Lam. dict. 2. p. 173. C. cordàta, Lodd. bot. cab. t. 359. Flowers rose-coloured; petals acute. Herb very smooth.

Spatulate-leaved Crassula. Fl. July, Sept. Clt. 1774. Pl. prostrate.

\$. Deltoidca (leaves resembling in figure the Greek delta). Plants suffrutescent. Learcs deltoid, sessile.

32 C. DeltoíneA ( Lin. fil. suppl. p. 189.) leaves connate, deltoid, spreading, approximate, glabrous, powdery, glaucous ; flowers corymbose, subfastigiate. $\mathcal{\psi}$.? D. G. Native of the Cape of Guod Ilope. 'Thunb. A. cap. p. 2S8. Stem erect, branched, naked at the basc, lleshy, half a finger in length. 
Leaves almost like those of Mesembryánthernum deltoideum. Corymbs few-flowered; pedicels angular. Root fusiform. Deltoid-leaved Crassula. Pl. $\frac{1}{4}$ foot.

33 C. cora'Llina (Lin. fil. suppl. p. 188.) leaves opposite, deltoid, obtuse, approximate, dotted; flowers in umbellate corymbs; stems erect, diclıotomously branched. h. Lin. 4. Thunb. D. G. Native of the Cape of Good Hope. Thunb. fi. cap. p. 290. Stem an inch high. Leaves nearly orbicular, white, and powdery at the apex, 1-2 lines long, longer than the internodes.

Coralline Crassula. Pl. 1 inch.

34 C. PUBE'scens (Lin. fil. suppl. p. 190.) leaves connate, ovate, acute, fleshy, villous, spreading; stem erect, branched, glabrous ; flowers corymbose. $\%$. D. G. Native of the Cape of Good Hope. Thunb. fl. cap. p. 285. Flowers small, white, according to the dried specimen. Calyx puberulous.

Pubescent Crassula. Pl. $\frac{1}{6}$ foot.

6. Rosulìres (from rosa, a rose; leaves spread like the petals in a double rose). Plants herbaccous, perennial. Radical leaves opposite, flat, disposed in a dense expanded disk, formed like the flower of a rose. Scapes ncarly nalied. Flowers small, glomerate; bunilles of flowers opposite. Haw. rev. succ. p. 13 .

35 C. orbicula'rus (Lin. mant. p. 361.) radical leaves oblong, obtuse, cartilaginously ciliated, flat, rosulate; runners or twigs rising from the root; scape nearly naked; bundles of flowers opposite, pedunculate. 24.D. G. Native of the Cape of Good Hope.-Dill. elth. t. 100. f. 118 . D. C. pl. grass. t. 43. C. sedioìdes, Milt. rlict. no. 9. Herb 4-5 inclies high. Petals grecnish white, rose-coloured at the apex. Stigmas purple.

Orbicular Crassula. Fl. July, Sept. Clt. 1731. Pl. $\frac{1}{4}$ to $\frac{1}{2} \mathrm{ft}$.

36 C. rosula'ris (Haw, rev, succ. p. 13.) leaves radical, obtuse, minutely ciliated, flat, rosulate; runners or twigs none; scape nearly naked; bundles of flowers opposite, pedunculate. 4. D. G. Native of the Cape of Good Hope. Very like $C$. orbiculàris, but differs in the plant being 3 times the size, destitute of runners, and in the flowers being 4-5-cleft and white; it is, however, probably only a variety of it.

Rosulate Crassula. Fl. July. Clt, 1819 . Pl. $\frac{1}{2}$ foot.

\$9. Glomeritce (from glomero, to heap up in a lump; ultimate flowers). Plantsherbaceous, dichotomous, annual. Leaves opposite. Floncrs small: lower ones solitary in the forks of the stems, the rest glomerate. Han, revis, suce, $p .12$.

37 C. glomera'ta (Lin. mant. p. 60.) stems herbaceous, scabrous, dichotomous; leaves linear-lanceolate; flowers solitary in the forks of the stems, ultimate ones glomerate. ๑. D. G. Native of the Cape of Good Hope. D.C. pl. grass. t. 57. C. scleranthoides, N. L. Burm. prod. p. 8. Habit of Scleránthus or Ialerianella. Herb bardly a finger in length. Flowers white.

Glomerated Crassula. Fl. Aug. Oct. Clt. 1774. Pl. $\frac{1}{2} \mathrm{ft}$.

38 C. GLA'BRa (Haw. syn, p. 58. rev, p. 12.) stem herbaceous, glabrous or rather pubescent, dichotomous; leaves linearlanceolate; flowers solitary in the forks, ultimate ones glomerate. ○. D. G. Native of the Cape of Good Hope. C. glomeràta $\beta$, Ait. hort. kew. 1. p. 392. Flowers white.

Glabrous Crassula. Fl. June, Oct. Clt. 1774. Pl. $\frac{1}{4}$ foot.

39 C. strigòsa (Lin. amœn. 6. p. 86.) stems lierbaceous, erect, rather his]id, dichotomous; leaves obovate, obtuse, strigose; pedicels 1-flowered. $\odot$. D. G. Native of the Cape of Good Hope. Lam. dict. 2. p. 174. Petals ovate, length of the calyx.

\section{Strigose Crassula. Pl. $\frac{1}{2}$ foot.}

10. Tillaoidea (plants with the habit of Tilla'a). Small subaquatic glabrous herbaceous plants, having 4-cleft flowers.

40 C. NA'tans (Thunb. prod. p. 54. fl. cap. p. 281.) stems erect, dichotomous; leares connate, linear-oblong, obtuse ; pedicels axillary, opposite, shorter than the leaves; petals obovate, a little longer than the calyx. ๑. B. G. Native about Cape Town, in ditcles and other watery places. Tille'a Capénsis, Lin. fil. suppl.

Floating Crassula. Pl. fl.

41 C. JNA'Nis (Thunb. l. c.) stem erect, simple, branched at the apex; leaves perfoliate, ovate, obtuse; flowers corymbose; petals ovate-lanceolate, twice the length of the calyx. ๑. D. G. Native of the Cape of Good Hope. Tilla' a perfoliàta, Lin. fil. 1. c.

Drarf Crassula. Pl. $\frac{1}{4}$ foot.

42 C. vмвецla'ta (Thunb. I. c.) stem simple, erect; leaves on short petioles, ovate, obtuse ; flowers umbellate. $\odot$. D. G. Native of the Cape of Good Hope. Tilla'a umbellàta, Willd. spec. 1. p. 721 .

Umbellate-flowered Crassula. Pl.

43 C. Decu'niens (Thunb. 1. c.) stem erect or decumbent ; leaves connate, terete, subulate ; flowers pedicellate, fastigiate at the tops of the branches. $\odot . D . G$. Native of the Cape of Good Hope. C. Thunbergiàna, Schultes, syst. 6. p. 733 . The stems are said to be decumbent in the diagnosis, but in the description erect. Scales very short, red.

Decumbent Crassula. Pl. decumbent.

\section{+ Species not sufficienlly known.}

\section{* Leaves oppositc.}

44 C. negle'cta (Schultes, syst. 6. p. 722.) stems herbaceous; leaves petiolate, cordate, and are as well as the branches glabrous; Howers solitary. $\odot$. G. Native of the Cape of Good Hope. C. cordàta, Thunb. nov. act. nat. cur. 6. p. 330. fl. cap. p. 293. but not of others.

Neglected Crassula. Pl. $\frac{1}{2}$ foot.

45 C. Expa'nsa (Ait. hort. kew. 1.p. 390.) stems herbaceous, dichotomous ; leaves semicylindrical, subulate, channelled above, spreading; peduncles axillary, solitary, 1-flowered. ๑. G. Native of the Cape of Good Hope. It is not known whether the leaves are opposite or alternate.

Expanded Crassula. Fl. June, July. Clt. 177 $\quad$ Pl. $\underset{2}{1}$ foot. 46 C. Diffu's a (Ait. hort. kew. ed. 1. vol. 1. p. 395.) stems herbaceous; leaves oblong, attenuated at the base, crenated; peduncles opposite the leaves and axillary, solitary. $\odot$. G. Native of the Cape of Good Hope. Flowers pink? The rest unknown.

Diffuse Crassula. Fl. June, July. Clt. 1774. Pl. $\frac{1}{4}$ foot.

47 C. subula'TA (Lin. mant. p. 360.) stem herbaceous, branched; leaves opposite, terete, spreading; flowers capitate. $\odot$. G. Native of the Cape of Good Hope. Herm. lugd. bat. 552. with a figure. Flowers white, ex Herm. and Petiv. gaz. t. 89. f. 8 .

Subulate-leaved Crassula. Fl. June, July. Clt. 1800 . Pl $\frac{x}{2} \mathrm{ft}$.

48 C. sYcra'tica (Licht. in Schultes, syst. 6. p. 726.) stem herbaceous, dichotomous, beset with strigose hairs; leaves obovate-oblong, with the margin and base beset with strigose hairs; flowers terminal and axillary, solitary.-Native of the Cape of Good Hope. The rest unknown.

Hood Crassula. Pl. ?

49 C. ADsce'ndeNs (Thunb. nov, act. nat. cur. 6. p. 341.) stem suffrutescent, decumbent; branches erect, filiform above, 
and naked; leaves connate, triquetrous, entire, spreading, glabrous ; corymb compound. $々$. D. G. Native of the Cape of Good Hope. This plant is omitted in Thunberg's flora, cap. and prod. and is therefore doubtful.

A scending Crassula. Pl. decumbent.

50 C. ? A LDA (Forsk. descr. 60. but not of Hortul.) stem simple; leaves opposite, crowded, sheathing, lanceolate, cartilaginously ciliated; peduncles dichotomous; flowers corymbose.Native of Arabia, on the mountains of Hadie and Boka. Flowers white, 5 -parted.

White-flowered Crassula. PI. $\frac{1}{2}$ foot.

51 C.? lineola'ta (D. C. prod. 3. p. 590.) stem herbaceous; leaves cordate, sessile; peduncles nearly terminal, axillary, approximate, umbel-formed. $₫ . D . G$. Native of the Cape of Good Hope. Sims, bot. mag. 1765. Flowers yellow. Mr. Haworth las placed this species between $C$. retroftéxa and $C$. centaurioides; but $C$. retroflexa is now referrible to Grammanthes, and therefore this species is probably a species of that genus.

Lined-leaved Crassula. Fl. June, Aug. Clt. 1774. Pl. $\frac{1}{2} \mathrm{ft}$.

52 C. ? Agarduina (Schultes, syst. 6. p. 718.) stem suffrutescent, twisted, branched; branches naked; radical leaves ovate, imbricated; cauline ones remote, alternate. h. D. G. Native of the south of Spain. According to the description this is a species of Sèdum or Sempervivum.

$$
\text { Agardli's Crassula. Pl. } \frac{1}{2} \text { foot. }
$$

* Alternifolia. The lcaves being alternate in the following plants, they are probably species of Sidum.

53 C. ? Microca'rpa (Sibth et Smith, fl. græc. prod. 1. p. 217.) leaves oblong; stem thickened; capsule angular, dotted, mutic. $\odot$. H. Native of the island of Cyprus, among rocks.

Small-fruited Crassula. P]. $\frac{1}{2}$ foot.

54. C.? pulchélza (Ait. hort. kew. ed. 1. vol. 1. p. 392.) leaves ovate-oblong, fleshy, reflexed; stem herbaceous, dichotomous; flowers pedunculate in the forks; peduncles turbinate. ○. G. Native of the Cape of Good Hope. Haw. suec, p. 12. Lobes of calyx leaf-formed, spreading, 2 short, and 3 about equal in length to the petals, which are ovate and acute. Flowers pink.

Neal Crassula. Fl. July. Clt. 1810 . Pl. $\frac{1}{2}$ foot.

55 C.? sra'rsa (Ait. l. c. p. 395.) stems herbaceous; leaves alternate, rather spatulate, acute, quite entire; racemes compound. s.D. G. Native of the Cape of Good Hope. Flowers white?

Scatlered Crassula. Fl. June, July. Clt. 1774. Pl. $\frac{1}{2}$ foot.

N. B. Plants formerly ineluded in the genus Crássula, but are now to be excluded from the order.

1 C.? alternifolia (Lin. hort. cliff. p. 497. according to the figure in Burm. afr. p. 58. t. 24. f. 1.) is probably a species of Borraginea, and perhaps $B$. cilicila.

2 C. ? PINNA'Ta (Lour. coch. p. 185.) is a plant far separated from Crássula, and most probably belonging to the order Terebinthàcea. C. pinnata of Dum. Cours. is a species of Bryophýllum or Kalanchìe. The C. pinnàta of Lin. fil. suppl. 191. is probably the same plant as Loureiro's.

Cult. Crássula is an extensive genus of rather ornamental plants, and some of which are rather grotesque. A mixture of loam, sand, and brick rubbish, is the best soil for them. Cuttings root very readily if dried for a few days, after being cut off from the plants before being planted. The seeds of the annual species should be sown in pots, and when the plants have grown a little may be separated, and planted into other pots. All the species are well fitted for a dry stove, or to be placed on shelves crected in a green-house.

VI. PURGO'SI A from $\pi$ voros, pyrgos, a tower; in reference to the disposition of the clusters of tlowers). Haw. in phil. mag. 1828. p. 184. Turgòsia, Ilaw. rev. suce. p. 14.

Lın. sysr. Penténdria, P'entagźnia. Calyx 5-parted, much sliorter than the corolla. Petals 5, imbricating at the base, mucronulate beneatl the apex. Stamens 5; filaments subulate. Scales 5, emarginate. Carpels 5, flat inside, and gibbous on the outside. - Herbaceous half naked plants. Leaves for the most part radical. Inflorescence spicatcly thyrsoid. Flowers in whorles, almost sessile. The species are probably all biennial.

\$1. Linguafoliae (from lingua, a tongue, and folium, a leaf; form of leaves). Leaves lorately longue-formed, thick, aeutish. llaw. l. $c$.

1 P. Linguefòla (Haw. rev, succ. p. 14.) lower leaves distinct, opposite, tongue-formed, ciliated, pubescent; stem leafy ; flowers verticillate, crowded, sessile. 4. or 8 . D. G. Native of the Cape of Good Hope. Crássula linguxfòlia, Haw. misc. nat. p. 175. Stem sinple, a foot high. Corolla ampullaform, from green to white. Perhaps only a variety of $P$. lomentosa.

Tonguc-leaved Purgosia. Fl. Aug. Clt. 1803. Pl. 1 foot.

2 P. romentòsa (Llaw. rev. succ. p. 14.) radical leaves oblong-lanceolate, imbricated, bluntish, villous, ciliated; stem nearly naked; flowers verticillate. $2 /$ or $\delta . D . G$. Native of the Cape of Good Hoje. Crássula tomentòsa, Lin. fil. suppl. p. 190. Stem erect, angular, villous, a foot high. Flowers white.

Tomentose Purgosia. Fl. April, May. Clt. 1 790. Pl. $1 \mathrm{ft}$.

3 P. pertu'sa (Haw. rev. succ, p. 14. in phil. mag. 1828. p. 185.) leaves lorate, acuminated, incurved, semicylindrical; superior bracteas ovate-lanceolate, cartilaginously serrulated, ascending; scape thyrsoid. \$. D. G. Native of the Cape of Good Hope. Crássula corymbulòsa, Link, enum. 1. p. $\$ 01$. Link et Otto, abbild. p. 39. t. 16. A'loe pertùsa, Haw. rev. succ. 15 and 201. Flowers white; petals erect, about equal in length to the stamens.

Pertuse-leaved Purgosia. Fl. Nov. Clt. 1818 . Pl. 1 foot.

4. P. Pertu'sula (Haw. in phil. mag. 1828. p. 184.) leaves lanceolate, recurved, beset with impressed dots on both surfaces; upper bracteas cordate, entire; scape panicled. §. D. G. $\mathrm{Na}$ tive of the Cape of Good Hope. Corolla snow white.

Impressed-dotted-leaved Purgosia. Fl. Oct. Nov. Clt. 1824. Pl. 1 foot.

5 P. н'́хт ; radical leaves lanceolate, hairy; stem herbaceous, erect, nearly naked, rather pubescent; heads of flowers verticillate. $\delta$. D. G. Native of the Cape of Good Hepe. Crássula lírta, Thunb. fl. cap. 284. Like P. spicàla. Leaves flesliy, white, erect, acute. Flowers white.

Ilairy Purgosia. Pl. $\frac{1}{2}$ to 1 foot.

6 P. cephalópjora; radical leaves connate, linear-oblong, obtuse, entire; stem nearly naked, erect; lieads of fiowers opposite, pedunculate. $\delta . ?$ D. G. Native of the Cape of Good Hope. Crássula cephalóplıora, Lin. fil. suppl. p. 190. Thunb. A. cap. p. 287. Flowers white. Leaves long.

Head-bearing Purgosia. P]. $\frac{1}{2}$ foot.

7 P. crenula'ta; leaves connate, lanceolate, obtuse, punctately crenulated, glabrous; stem herbaceous, erect, glalorous, terete; corymb decompound. \$. D. G. Native of the Cape of Good Hope. Crássula crenulàta, Lin. fil. supj]l. p. 189. Thunb. fi. cap. p. 287. Flowers white.

Crenulated Purgosia. Pl. 1 foot. 
2. Ovatifòlia (from ovatus, ovate, and folium, a leaf). Leaves ovate, oval, or obovate.

8 P.? cılia'Ta ; stem suffruticose, sparingly branched, terete; leaves oval, obtuse, flattisl, distinct, ciliated; corymbs terminal. 4. D. G. Native of the Cape of Good Hope. Crássula ciliàta, Lin. spec. p. 405. D. C. pl. grass. t. 7.-Dill. elth. t. 98. f.116. Cilia of leaves white, cartilaginous, usually retrograde. Flowers cream-coloured.

Ciliated Purgosia. Fl. July, Aug. Clt. 1732. Pl. $\frac{1}{2}$ foot.

9 P. concínsa; leaves obovate, ciliated, rather imbricated. 4. D. G. Native of the Cape of Good Hope. Crássula concinna, Haw. rev. succ. This is a much larger plant than the following, to which it is nearly allied. Flowers white.

Neat Purgosia. Fl. July, Aug. Clt. 1818. Pl. $\frac{1}{2}$ foot.

10 P. concinnélea ; leaves obovate, with densely ciliated silvery margins. 4. D. G. Native of the Cape of Good Hope. Crássula concinnélla, Haw. in phil. mag. 1823. p. 351. Allied to $P$. concinna, but weaker, and 4 or 5 times smaller in every part, densely ciliated. Leaves rather imbricated, and appearing as if they were disposed in 2 compressed rows. The rest unknown.

Small-neat Purgosia. Fl. July. Clt. 1823. Pl. $\frac{1}{2}$ foot.

11 P. cotyle'donis; radical leaves conmate, oblong, obtuse, tomentose, ciliated; stem nearly naked, herbaceous, somewhat tetragonal ; flowers disposed in a corymb composed of fascicles. 4. D. G. Native of the Cape of Good Hope. Crássula cotylèdonis, Lin. fil. suppl. 190. Crássula Cotylèdon, Haw. syn. p. 56. but not of Jacq. Stem simple, erect, a foot high. Leaves an inch broad, and a finger in length, erect. Flowers white.

Cotyledon Purgosia. Pl. 1 foot.

12 P. capitella'ta (Haw. rev. p. 17.) leaves connate, oblong, glabrous, cartilaginously ciliated, spreading, longer than

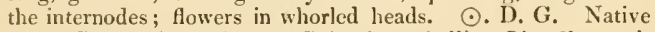
of the Cape of Good Hope. Crássula capitellàta, Lin. fil. suppl. p. 190. 'Thunb. A. cap. 286. Stem glabrous, terete, erect. Flowers white, approximate, sessile.

Headed Purgosia. Fl. July, Aug. Clt. 1774. Pl. $\frac{1}{2}$ foot.

13 P. ALPE'STRIS; leaves connate, ovate, acute, imbricating in 4 rows; heads pedunculated; stem leafy, glabrous. 24. D. G. Native of the Cape of Good Hope. Crássula alpéstris, Lin. fil. suppl. p. 190. Thunb. fl. cap. 286. nov. act. nat. cur. 6. p. 336. t. 56. f. 4. Allied to Crássula montàna, but differs in the leaves being more acuminated, not ciliated, in the stem being thicker, and clothed with leaves, and in the flowers being larger. Als Purgosia. Pl. $\frac{1}{2}$ foot.

14. P. I EMrsprésica; lower leaves connate, roundish, imbricated into a round heap, cartilaginously ciliated; stem nearly naked; flowers rising in fascicles from the axils, forming a panicled spike. ๑. G. Native of the Cape of Good Hope. Crássula henispha'rica, Thunh. prod. p. 57. fl. cap. p. 292. Floral leaves very short. Flowers small, white.

Hemisplerical Purgosia. Pl. $\frac{1}{2}$ foot.

15 P. thy rsiflòra (Haw. rev. succ. 17.) leaves perfoliate, nvate, obtuse, ciliated, glabrous, erectly spreading; thyrse branched, spicate. f. D. G. Native of the Cape of Good Hope. Crássula thyrsifiò, Lin. fil. suppl. 190. Thumb. fl. cap. 283. Stems herbaceous, terete, erect, a span high. Flowers white.

Thyrse-flowercd Purgosia. Pl. $\frac{1}{2}$ foot.

16 P. oвova'ta (Haw, rev, succ. p. I6.) leaves opposite, decussate, obovate, ciliated, full of minute impressed dots; stem rather hispid; flowers axillary, in a thyrsoid spike. §. D. G. Native of the Cape of Good Hope. Crássula obovàta, Haw. suppl. p. 17. Flowers white. Allied to $P$. aloides.

Obovate-leaved Purgosia. Fl. June, July. Clt. 1818. Pl. 1 ft.
17 P. aloides (Haw, rer. succ. p. 16.) stem simple, rather pilose; leaves ovate or spatulately lanceolate, distinct, ciliated, full of impressed dots; heads of flowers axillary, constituting a tliyrsoid spike. 8. D. G. Native of the Cape of Good Hope. Crássula aloìdes, Ait. lort. kew. 1. p. 394 . Petals mucronulate, white, with a red rib. Stem half a foot high.

Aloe-like Purgosia. Fl. June, Aug. Clt. 1774. Pl. $\frac{1}{2}$ foot.

18 P. puncta'ta; stems simple, smooth; leaves opposite, ovate, dotted, ciliated: lower ones oblong; corymbs axillary, very short. $h_{2}$. D. G. Native of the Cape of Good Hope. Crấssula punctàta, Lin. spec. p. 406. Ait. hort. kew. ed. 2. vol. 2. p. 193. exclusive of the synonyme of Miller, ex Haw. syn. p. 154. Corolla campanulate, white ; limb reflexed; anthers purple.

Dotted-leaved Purgosia. Fl. April, Aug. Clt. 1759. Pl. $1 \mathrm{ft}$.

19 P. RAmuliflòra ; stem fruticulose, beset with retrograde hairs; leaves opposite, obovate, acute, rather connate, ciliated; branches axillary, few-flowered; petals lanceolate, erect, shining at the apex. b. D. G. Native of the Cape of Good Hope. Crássula ramuliflòra, Link. enum. 1. p. 301. Otto. et Link. abbild. p. 41. t. 17. Flowers white. Calyx and leaves usually reddish at the apex.

Branch-flowered Purgosia. Fl. Ju. Jul. Clt. 1822. Sh. $\frac{1}{2} \mathrm{ft}$.

20 P. turitita (Haw. rev. succ. p. 16.) radical leaves opposite, connate, ovate-oblong, acute, imbricating in 4 rows, villously ciliated; stem leafy at the base ; flowers in whorls. §. D. G. Native of the Cape of Good Hope. Crássula turrita, Thunb. prod. 3. p. 55. f. cap. p. 283. Jacq. schœenbr. 1. t. 52. Stem simple, a foot high. Corolla pale, reddish at the apex.

I ur. $\beta$, ròsca (Haw. l. c.) flowers red.

Tomer Purgosia. Fl. Feb. Mar. Clt. 181 s. Pl. 1 foot.

21 P. BARBA'TA; radical leaves opposite, connate, crowded, imbricated into a round heap, reticulated, bearded; stem nearly naked; Howers in whorls. 8. D. G. Native of the Cape of Good Hope. Crássula barbàta, Thunb. prod. p. 57. fl. cap. p. 292. Lin. fil. suppl. 188. Floral leaves not exceeding the flowers. Stem glabrous, a span high.

Bearded Purgosia. Pl. $\frac{1}{2}$ foot.

22 P. montA'NA; leaves connate, ovate, acute: radical ones approximate : cauline ones distant ; flowers in whorls, in the axils of the upper leaves: ultimate ones capitate. 4 . D. G. Native of the Cape of Good Hope. Crássula montàna, Lin. fil. suppl. p. 189. Thunb. fi. cap. p. 285. Stem filiform, simple. Calyxes ciliated.

Mountain Purgosia. Pl. $\frac{1}{2}$ foot.

23 P. DEnTA'TA; plant glabrous, nearly leafless; leaves almost radical, petiolate, toothed, roundish-cordate ; flowers subumbellate. fo ? D. G. Native of the Cape of Good Hope, among rocks on the mountain called Ribekcasteel. Crássula dentàta, 'l'hunb. prod. p. 57. fl. cap. p. 293. Umbels of Howers radical. Peduncles shorter than the leaves.

Toothed-leaved Purgosia. Pl. $\frac{1}{4}$ foot.

24. P. PYramida'ls; leaves connate, imbricating in 4 rows, ovate, obtuse, entire, glalırous ; heads terminal, sessile, globose. 4. D. G. Native of the Cape of Good Hope. Crássula pyramidalis, Lin. fil. suppl. p. 189. Thunb. H. cap. p. 287. nov; act. cur. 6. p. 336. t. 5. b. f. 3 . Stems flexuous, erect, covered over with leaves. Leaves a line long. Said to be allied to Crássula museòsa.

Pyramidal Purgosia. Pl. $\frac{1}{2}$ foot.

25 P.? DE'nILIs; stem herbaceous, dichotomous, straightish; leaves opposite, glabrous, crowded, nearly terete, concave, papulose ; flowers pedicellate; petals linear. of? D. G. Native of the Cape of Good Hope. Crássula dèbilis, Thunb. fl. cap. p. 280 . 
II cak Purgosia. Pl. $\frac{1}{2}$ foot.

26 P. RUPE'stris ; leaves connate, orate, quite entire, glabrous, approximate, convex and carinated beneath; corymbs trichotomous, fastigiate, supra-decompound. 4. D. G. Native of the Cape of Good Inope. Crássula rupéstris, Lin. fil. suppl. p. 189. Thunb. fl. cap. 288. Pedicels glabrous, of a purplish colour. Petals whitc. Stem crect, a hand high or more.

Rock Purgosia. Pl. $\frac{1}{2}$ foot.

27 P. TE'cta; leaves almost radical, connate, ovate, obtuse, imbricated, cartilaginously ciliated, and clothed with greyish powder; scape nearly naked, filiform ; flowers sessile, capitatc. §. D. G. Native of the Cape of Good Hope. Crássula técta, Lin. fil. suppl. p. 190. Thunb. fl. cap. 290. Flowers small, white. Scape an inch high.

Clothed Purgosia. Pl. 1 to 2 inches.

28 P.? мísims; glabrous, nearly stemless; leaves petiolate, roundish, entire; peduncles nearly radical, 1 -flowered. \$. D. G. Native of the Cape of Good Hope. Crássula mínima, Thunb. prod. p. 57. f. cap. p. 292.

Least Purgosia. Pl. $\frac{1}{8}$ foot.

29 P. spica'ta; radical leaves glabrous, connate, linear-subulate; stem erect, herbaceous, nearly naked; heads of flowers verticillated. \$? D. G. Native of the Cape of Good Hope. Crássula spicàta, Lin. fil. suppl. p. 189 . Thunb. f. cap. p. 2S4. Whorls of flowers sessile, many-flowered, approximate.

Spike-flowered Purgosia. Pl. $\frac{1}{2}$ to 1 foot.

Cult. The greater part of this genus of succulent plants being biennial, the seeds of them should be sown in spring or summer, in pots filled with gravelly sand and loam, well drained in the bottom. Cuttings of them are also easily rooted, if laid to dry a few days after they are cut, before being planted, especially of those species which are permanent. Brick rubbish, mixed with loam, is a good soil for the grown up plants.

VII. GLOBU'LEA (from globulus, a globule or small globe; in reference to the waxy globules with which the petals are tipped). Haw. syn. p. 60. rev. succ. p. 17. phil. mag. 1824. sept. p. 189.- Crássula species of Lin. and others.

L1x. syst. Pentándria, Pentagýnia. Calyx 5-parted. Petals 5 , erect, bearing each a waxy globule at the apex. Stamens 5 , shorter than the petals. Scales 5 , short, broad, obtuse. Carpels 5.-Herbs, natives of the Cape of Good Hope. Leaves flat, rather cultrate : cauline ones few: radical ones crowded, opposite, not always decussate, but more or less disposed by pairs, in a spiral manner, about the base of the stem. Flowers in dense corymbs, subcapitate, small, of a pale cream colour or white.

\$1. Cultràtce (from cultratus, made like a knife; form of leaves like a pruning knife). Lcaves cuneatcly-oborate, cultrate. Stem suffruticose. Haw. in phil. mag. 1824.p. 190.

1 G. cultra'ta (Haw. syn. p. 60.) erect; leaves obovateelliptic, acutish, obliquely subreflexed, connate, flattish, shining. h. D. G. Native of the Cape of Good Hope. Crássula cultràta, Lin. spec. 2. p. 405. Sims, bot. mag. t. 1940.-Dill. hort. elth. p. 115. t. 97. f. 114. Flowers cream-coloured.

Cultrate-leaved Globulea. Fl. Jul. Aug. Clt. 1732. Sh. $1 \mathrm{ft}$. 2 G. RaDicans (Haw. in phil, mag. 1824. p. 27.) plant erect, bushy; branches crowded, rooting downwards ; leaves lanceolate-ovate, cultrate; flowers in dense heads. h. D. G. Native of the Cape of Good Hoje. It differs from the preceding in the sepals being obtuse, in the heads of flowers being more dense, and in the flowers being smaller. Flowers white.

Rooting Globulea. Fl. Ju. Oct. Clt. 1823, Sh. 1 foot.

3 G. Atropurpulaea (Haw. in phil. mag. 1824. p. 189.) roL. III. leaves obliqucly cuneate-obovate, dark purple; scape or flower hearing stem, very long, and panicled. h. I).G. Native of the Cape of Good Hope. Crássula oblìqua $\beta$, Haw. rev. succ. p. 20\%. It approaches very near $G$. cultràta, but differs in the inflorescence. Flowers white.

Dark purple-lcaved Globulea. Fl. Aug. Clt. 1823. Shrub $\frac{1}{2}$ to 1 foot.

§ 2. Linguàtae (from lingua, a tongue; form of leaves). Leavcs lorate, obtuse, convex bencath, or narrow tongue-formed, imbricating exactly in 4 rows. Stcm very short or herbaccous. Seapes or floriferous stems naked. Ilam. in phil. mag. 1824. 2. 191.

4 G. Língua (Haw. in phil. mag. 1824. p. 28.) leaves elongated, lorate, ventricosely semi-lanceolate, cultrate, and are as well as the calyxes ciliated. 4. D. G. Native of the Cape of Good Hope. Leaves without dots. Flowers panicled, white ; anthers yellow.

Tongue-leaved Globulea. Fl. Ju. Jul. Clt. 1823. Pl. I ft.

5 G. uísgura (Haw. l. c. p. 29.) leaves rather elongated, ventricosely semi-lanceolate, cultrate, thin, flaccid. $\psi$. D. G. Native of the Cape of Good Hope. Very like the preceding, but much smaller.

Small-tongue-leaved Globulea. Fl. June, July. Clt. 1823. Pl. $\frac{x}{2}$ foot.

6 G. capita'ta (Haw, rev. succ. p. 17.) leaves ventricosely lanceolate, cultrate, rather convex beneath, imbricately decussate, when young hoary. 4. D. G. Native of the Cape of Good Hope. Crássula capitàta, Salm-Dyck, cat. 1820. p. 14. but not of Lam. Very like $G$. obvallàta, but larger, and the leaves are more acinaciform, usually an inch and a half broad.

Capitate-flowered Globulea. Fl. June, Jul. Clt. 1819. Pl. $\frac{1}{2}$ to 1 foot.

7 G. obvalda'ta (Haw. syn. p. 60.) leaves opposite, connate, sublanceolate, cultrate, with cartilaginously ciliated edges : radical ones approximate; panicle clongated; peduncles opposite, cymose. $\zeta$. or 4 . D. G. Native of the Caye of Good Hope. Trew. pl. rar. 1. t. 11. Crássula obvallàta, Lin. mant. p. 61 . D. C. pl. grass, t. 61. Crássula obfalcàta and obvallàris, Hortul. Flowers white.

Guarded-leaved Globulea. Fl. Jul. Aug. Clt. 1795. PI. $\frac{1}{2} \mathrm{ft}$.

8 G. cane'scens (Haw, syn. p. 61.) leaves all radical, decussately imbricated, ciliated, lorately lanceolate, bent, cultrate, canescent. 4 . D. G. Native of the Cape of Good Hope. Crássula canéscens, Schultes, syst. 6. p. 734. An intermediate species betwcen $G$. obvallàta and $G$. nudicaúlis.

Cancscent Globulea. Fl. Jul. Aug. Clt. 1800 . Pl. $\frac{1}{2}$ foot.

\$3. Angustatce (from angustus, narrow; leaves). Icares linear, semi-terete, furroned, or tcrete. Stems herbaceous, tuftcd. Scapes lcafless. Haw. in phil. mag. 1824.p. 191.

9 G. Nudicaúlis (Haw, syn. p. 61.) stemless; leaves radical, crowded, rosulate, semi-terete, subulate, acute, rather pubescent; scape nearly naked; heads of flowers somewhat verticillate, glomerated at the apex of the scape. 4. D. G. Native of the Cape of Good Hope. Crässula nudicaúlis, Lin. spec. p. 405. D. C. pl. grass. t. 132.-Dill. hort. elth. p. 116. t. 99. f. 115. Flowers white.

Naled-stemmed Globulca. Fl. May, Sept. Clt. 1732. Pl. $\frac{1}{4}$ to $\frac{1}{2}$ foot.

10 G. succ'ta (Haw, rev. p. 18.) stemless; leaves incurved, subulate, semi-terete, deep grcen, shining, broadly cliannelled. \%. D. G. Native of the Cape of Good Hope. Very like $G$. nudicaúlis, but differs in being glabrous, and in the leaves being broadly furrowed above.

Furroned-leaved Globulea. Fl. Ju. Sept. Clt. 1818. Pl. $\frac{1}{4}$ ft. I 
\$4. Loràta (from loratus, lorate; shape of leaves). Leaves lorate, narronest at the apex, convex beneath, tufted, imbricating in 4 ron's. Sicms herbaccous. Scapes leafy.

11 G. IMPRE'ssa (Haw. in phil. mag. 1824. p. 189.) plant stemless ; leaves lorately-lanceolate, green, full of impressed dots; dots large, scattered, numerous. 4. D. G. Native of the Cape of Good Hope. Leaves crespitose, decussate, rather ciliated at the base. Flowers small, pale.

I ar. $\beta$, minor (Haw. l. c.) smaller; dots on leaves more obsolete.

Impressed-dotted Globulea. Fl. Aug. Sept. Clt. 1820. Pl. $\frac{1}{4} \mathrm{ft}$.

12 G. panicula'ta (Haw. in phil. mag. 1825. p. 29.) leaves borate, acuminated, green, beset with minute impressed dots; branches of panicle spike-formed. 24. D. G. Native of the Cape of Good Hope. Plant stemless, smooth. Leaves convex beneath and channelled above, with cartilaginously sub-ciliated margins. Flowers snow white; anthers yellow.

Panicled-flowered Globulea. Fl. Jul. Clt. 1823. Pl. $\frac{1}{4}$ to $\frac{1}{2} \mathrm{ft}$.

13 G. nispida (Haw. l. c. p. 30.) leaves crowded, lorate, acuminated, convex beneath, hispid; stem suffruticose, hispid. h. D. G, Native of the Cape of Good Hope. Flowers white. Hispid Globulea. Fl. Nov. Clt. 1823. Pl. $\frac{1}{2}$ foot.

\$. Subulàtce (from subula, an awl; shape of leaves). Leaves subulate, fleshy, flattish above. Stems suffruticose, branched. Flowers disposed in dense, cymose, terminal heads. Haw. in phil. mag. 182 . p. 191.

14 G. mesemeryantuemoides (Haw. 1. c. p. 190.) stems suffruticose, bushy, erect; leaves subulate, and are as well as the branches, branchlets, and calyxes hispid. h. D. G. Native of the Cape of Good Hope. Flowers glomerate, in dense fascicles, cream-coloured.

Iar. $\beta$; plant a little taller ; flowers not so crowded.

Fig-marigold-like Globulea, Fl. Aug. Sept. Clt. 1820. Pl. $\frac{1}{4}$ to $\frac{1}{2}$ foot.

$15 \mathrm{G}$, subinca'na (Haw. l. c.) stem suffruticose, erectly decumbent; leaves semiterete, subulate, acute, a little incurved, and are as well as the branchlets covered with soft hoary down. 5. D. G. Native of the Cape of Good Hone. Flowers white. There are decumbent and erect varieties of this plant.

Hoaryish Globulea. Fl. Aug. Clt. 1823. Pl, $\frac{1}{2}$ foot.

16 G. Mólzis (Haw. l. c. p. 191.) leaves semi-cylindrical, acute, gibbous below, smooth, erectish, finely tomentose; cymes terminal, compound. $\zeta . D . G$. Native of the Cape of Good Hope. Crássula móllis, Lin. fil. suppl. p. 189. Thunb. fl. cap. p. 284. Stem frutescent, angular, a foot high, simple, erect. Leares somewhat triquetrous, and therefore it is probably a distinct genus according to Haworth. Flowers white.

Soft Globulea. Fl. Aug. Clt. 1774. Shrub 1 foot.

Cult. Globùlea is a very pretty genus of succulent plants. Sandy loam and brick rubbish is a good soil for them; and the pots should be well drained. Cuttings root easily if laid to dry a few days after cutting off, before they are planted, to dry up the wound, that they may not rot. A good situation for the plants is on the shelves of a greenhouse.

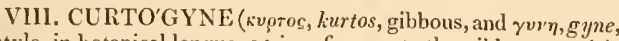
a style, in botanical language; in reference to the gibbous ovaria). Haw. rev, suce. p. 8 . D.C. prod. 3. p. 392.

Lin.syst. Pentándria, Pentagýnia. Calyx 5-parted, mucl shorter than the corolla. Petals 5 , united at the base into 5 parted corolla. Stamens 5. Scales 5, short. Ovaria 5, tereteoblong, giblous at the apex, ending each in a long sublateral style.-Subshrubs, natives of the Cape of Gool Hope. Leaves opposite, flat, rather fleshy, cartilaginously ciliated, ovate. In- florescence disposed in umbellate cymes, Flowers white.-This is an intermediate genus between Crássula and Ròchea.

1 C. unda'ta (Haw. rev. p. 8.) leaves oblong, or ovate-

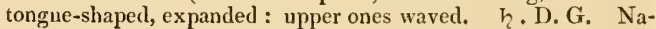
tive of the Cape of Good Hope. Curtogyne dejécta, D. C. prod. 3. p. 392. Crássula dejécta, Jacq. schoenbr. t. 433. Crássula undàta, Haw. suppl. 19. Stems much branched, weak. Petals snow white, spreading; anthers exserted, purple, but at length blackish.

Wavy-leaved Curtogyne. Fl. July, Aug. Clt. 1818. Pl. decumbent.

2 C. undula'ta (Haw. rev. p. 9.) leaves connate, ovate, expanded, cartilaginously crenated : superior ones ovate-elliptic, undulately incurved; stems dichotomous. h.D.G. Native of the Cape of Good Hope. Crássula mudulàta, Haw. syn. p. 53. Similar to the first species, but differs in all the parts being much smaller and more branched. Flowers white.

Undulate-leaved Curtogyne. Fl, Aug. Clt. 1797. Sh. $\frac{1}{2} \mathrm{ft}$.

3 C. undòsa (Haw. in plil, mag. 1827. p. 184.) leaves ovatetongue-shaped, curled: those of the flowering branches retroflexed. h. D. G. Native of the Cape of Good Hope.

Haved-leaved Curtogyne. Fl. Jul. Aug. Clt. 182t. Sh. $1 \mathrm{ft}$.

Cult. The culture and propagation of the species of this genus are the same as that recommended for Globùlea, above. A pretty succulent genus.

IX. GRAMMA'NTHES (from $\gamma \rho \propto \mu \mu \alpha$, gramma, a writing, and avtos, anthos, a flower; in consequence of the segments of the corolla having some supposed resemblance to the letter $\mathrm{V}$ marked on them; hence also its synonymous name Vaún. thes). D. C. prod. 3. p. 392 . mem. crass. t. 1. f. 6 . Vauánthes, Haw, rev. p. 18.-Crássnla species of Lin. and others.

LıN. syst. Pentándria, Pentagánia. Calyx campanulate, 5 -cleft, erect. Corolla gamopetalous, having the tube the length of the calyx ; and the lobes 5-6, oval, expanded. Stamens 5-6, alternating with the lobes, inserted in the tube of the corolla, and inclosed within it. Scales wanting. Carpels 5.-Herbs annul. Leaves opposite, ovate-oblong, remote, flat, sessile. Flowers disposed in cymose corymbs.

1 G. chloreflòra (Haw. 1. c.) leaves oblong. ๑. D. G. Native of the Cape of Good Hope. Herm. lugd, bat. p. 553, with a figure. Crássula retrofléxa, Thunb. fl. cap. p. 282. but not of Meerb. Crássula dichótoma, Lin. amœen. 6. p. 86. Ait. hort. kew. ed. 1. vol. 1. p. 392. Pedicels lateral. Flowers yellow. The segments of the corolla elegantly marked with the inverted letter $\vec{V}$. in red.

$\operatorname{Var} . \beta$; flowers orange-coloured. Crảssula retrofléxa, Ait. hort. kew, ed. 2. vol. 2. p. 194. Haw. syn. p. 57.

Chlora-flowered Grammanthes. Fl. Jul. Clt. $17 \% 4 . \mathrm{Pl}, \frac{1}{2} \mathrm{ft}$.

2 G. gentianoldes (D. C. prod. 3. p. 393.) leaves ovateoblong. $\odot$. G. Native of the Cape of Good Hope. Crássula gentianoides, Lam. dict. 2. p. 175.-Pluk. mant. 89.t. 415. f. 6. Flowers pale blue, ex Pluk, and Lam. but the flowers are more likely yellow, and have become bluish on drying. Perhaps sufficiently distinet from the preceding.

Gentian-like Grammanthes. Pl. $\frac{1}{2}$ foot.

Cult. Sow the seeds thinly in pots filled with a mixture of gravelly sand or lime rubbish and loam, draining them well with sherds, The species are singular succulent plants.

X. ROCHEA (in honour of M. de la Roche, author of a monograph on the genus Erýngium, Sc.). D. C. pl. grass. no. 103. prod. 3. p. 393. mem. crass, t. 1. f. צ. Laròchea, Pers. ench. no. 753. Roem. et Schultes, syst, no. 1255. Haw. syn. p. 50 , 
Lis. syst. Pcntándria, Pentagýnia. Calyx 5-lobed. Petals 5, united into gamopetalous hypocrateriform corolla; with a short tube, equal in length to the spreading limb, or shorter than it. Stamens 5, alternating with the petals, a little exserted. Glands and carpels 5.-Tall, fleshy, simple, succulent shrubs. Leaves opposite, connate at the base, thick, white. Flowers disposed in terminal corymbs, without any bracteas.

I R. FALCA'tA (D. C. pl. grass. t. 103.) leaves rather connate, thick, glaucous, oblong, bluntish, bent down in the form of a sickle. h. D. G. Native of the Cape of Good Hope. Laròchea falcàta, Haw. syn. p. 50. Tratt. thes. t. 20. Crássula falcàta, Willd. enum. p. 341. Sims, bot. mag. t. 2035. Crássula retrofléxa, Meerb. with a figure. Crássula oblìqua, Andr. bot. rep. p. 414. exclusive of the synonyms. Craissula Swellingrebliàna and $\mathrm{Cr}$. decussàta, Hort. gall. Flowers scarlet, witl the tube about 4 lines long, forming a large, dense, terminal corymb.

Far. $\beta$, minor (Haw. rev. succ. p. 3.) all parts of the plant smaller.

Sickle-leaved Rochea. Fl. Ju. Sept. Clt. 1795. Sh. 8 to $8 \mathrm{ft}$.

2 R. PERfolla'ta (Haw. rev. p. 6. under Laròchea) leaves connate, lanceolate, acuminated, rather channelied above, convex beneatl, of a greenish glaucous colour. h. D. G. Native of the Cape of Good Hope. Crássula perfoliàta, Lin. spec. 404. Haw. syn. p. 51. Flowers scarlet, disposed in large, terminal corymbs. Leaves said to be ciliated.

I ar. $\beta$, albiflora (Haw. l. c.) flowers white. Crássula perfoliàta, D. C. pl. grass. t. 13.-Dill. hort. elth. f. 113 . Mill. fig. t. 108. Comm. pral. t. 23. without any flower, and is therefore referrible to $A$ loe pertùsa, Haw, in Lin. trans. 7. p. 25 .

Perfoliate-leaved Rochea. Fl. July, Aug. Clt. 1700. Sh. 3 to 6 feet.

3 R. AlBiflòra (D. C. prod. 3. p. 393.) leaves distinct, ovate, acuminated, spreading, cartilaginously ciliated. h.D. G. Native of the Cape of Good Hope. Crássula albiflòra, Sims. bot. mag. t. 2391. Flowers white, disposed like those of $\boldsymbol{R}$. falcàta, but larger than those of $R$. perfoliata. Anthers blackish, and a little more exserted than those of the other species.

White-flowered Rochea. Fl. July, Aug. Clt. 1800. Shrub 2 to 3 feet?

Cult. Large, succulent plants, elegant when in flower. Their culture, propagation, and treatment are the same as that recommended for Globùlea, p. 106.

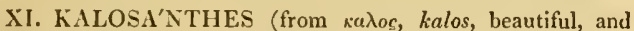
$\alpha \nu \theta o c$, anthos, a flower; flowers elegant). Haw. rev. succ. 1821. p. 6. but not of Blume.-Dietrichia, Tratt. tab. t. 449. arch. gew. (1812.) no. 449. but not of Ræusch.-Ròchea, sect. 2. Francíscea, D. C. prod. 3. p. 393.

LiN. syst. Pentándria, Pcntagýnia. Calyx 5-lobed (f. 26. a.). Petals 5, united into a gamopetalous liypocratriform corolla (f. 26. a.), with a cylindrical tube 2 or 3 times longer than the spreading $\operatorname{limb}($ f. $26 . a$.). Stamens 5 , alternating with the petals; anthers in the throat of the tube of the corolla. Glands and carpels 5.-Succulent slurubs. Leaves opposite, oval, or oblong, connate, flat, cartilaginously ciliated. Flowers disposed in cymose umbels or heads, involicrated with numerous bracteas.

$1 \mathrm{~K}$. coccinen (Haw. rev. p. 18.) leaves connate and sheathing at the base; ovate-oblong, acutish. $々$. D. G. Native of the Cape of Good Hope. Laròchea coccinea, Haw, syn. p. 50. Crássula coccínea, Lin. spec. Curt. bot. mag. t. 495 . Dietrichia coccinea, Tratt. thes. t. 19.-Comm. rar. t. 24. Bradl. succ. t. 50. Burm. afr. t. 23. f. 1. Flowers scarlet; tube an inch long. According to Breyn. prod. 3. t. 20. f. 1. there is a variety with flesh-coloured flowers; and according to Bradl. succ. t. 50. and Ilaw, rev. p. 8. there is a variety with white flowers, but in the gardens it is not to be found but with scarlet flowers.

Scarlct-flowered Kalosantlies. Fl. June, Aug. Clt. 1710. Shrub 1 to 3 feet.

2 K. ME'DIn (Haw. rev. p. 7.) leaves oblong-lanceolate, connate, stem-clasping; flowers variable in colour. $\zeta$. D. G. Native of the Cape of Good Hope. Ròchea mèdia, D. C. prod. 3. p. 39.4.

Middle Kalosanthes. Fl. Ju. Jul. Clt. 1810. Slirub | ft.

3 K. versícolor (Haw. rev. p. 7.) leaves oblong-lanceolate, acute, connate and sheathing at the base; stem erect, branched; flowers in umbellate heads. $々$. D. G. Native of the Cape of Good Hope, on the Table Mountain. Crássula versícolor, Burch, ex Ker, bot. reg. t. 320. Ròchea versícolor, D. C. prod. 3. p. 394. Flowers about the size of those of $K$. coccinca, laving the tube white, and the segments of the limb oval, white in the middle, edged with scarlet. Calyx as long as $\frac{3}{4}$ of the tube of the corolla.

Party-colourcd-flowered Kalosanthes. Fl. Mar. Sept. Clt.

1817. Shrub 1 to 2 feet.

$4 \mathrm{~K}$. odoratíssima (Haw. rev. p. 7.) leaves linear-lanceolate, gradually acuminated, connately stem-clasping ; flowers in umbejlate heads; segments of the corolla oblong, acutish. $\hbar$. D. G. Native of the Cape of Good Hope. Crássula odoratíssima, Andr. bot. rep. t. 26. Jacy. liort. schoenbr. t. 434. Laròchea odoratíssima, Haw. syn. p. 51 . Dietríchia odoratíssima, Tratt. Ròchea odoratíssima, D. C. prod. 3. p. 394. The flowers are yellow, according to Andrews; yellowish, Haworth ; but with red claws and white lamina, according to Jacquin; they have the scent of those of Polyanthus tuberosus, or T'ubc-rose.

lar. 3 , alba (D. C. prod. 3. p. 394.) flowers white. h. D. G. Native of the Cape of Good Hope. Crássula capitàta, Lodd. bot. cab. t. 1029. Leaves less ciliated, according to the figure, than those of the species.

Siveet-scented Kalosanthes. Fl. Ju. Jul. Clt. 1793. Sh. $1 \mathrm{ft}$.

5 K. Bícolok (Haw. rev. p. 7.) flowers capitate, sessile, yellow, and scarlet. h. D. G. Native of the Cape of Good Hope. Very like the preceding species, but larger and more rigid, and the leaves are more acute.

T'wo-colourcd-fiowered Kalosanthes. Fl.Ju. Jul. Clt. 1810 Shrub 1 foot.

6 K. FLA'va (Haw. syn. p. 50 . under Laròchca) leaves connate, sheathing, smooth, approximate, linear, thick, acute h. D. G. Native of the Cape of Good Hope. IBurm. afr. t. 23. f. 3. Pluk. alm. t. 314. f. 2. Crássula flàva, Lin. mant. p. 60. Flowers yellow, disposed in a panicled eorymb.

Yellow-flowered Kalosanthes. Shrub 1 to 2 feet?

$7 \mathrm{~K}$. cymòsa (Haw, rev. p. 7.) leaves connate, sheatling, linear; cymes terminal; stem shrubby. $\zeta$.D.G. Native of the Cape of Good Hope. Crássula cymòsa, Lin. mant. 229. C. capitàta, Lam. dict. 2. p. 171. Laròchea cymòsa, Haw. syn. p. 50. Flowers red.

Cymose-flowered Kalosantlies. Fl. Aug. Clt. 1800. P1. $\frac{1}{2} \mathrm{ft}$. 8 K. Jasmínea (Haw. rev. p. 6.) leaves lanceolate, sessile, bluntish; flowers few, capitate; stems suffruticose, decumbent. h. D. G. Native of the Cape of Good Hope. Crássula jasminiflòra, Haw. Crássula jasminea, Sims, bot. mag. 2178. 
Lodd. bot. cab. 1040. Crássula obtùsa, Haw. suppl. p. 16. Ròchea jasmínea, D. C. prod. 3. p. 394. Flowers white at first, but becoming reddish as they fade, very like those of the common jasmine, scentless. Tube of corolla almost 3 times longer than the calyx. Heads containing 2-4 flowers.

Jasminc-flowered Kalosanthes. Fl. April, May. Clt. 1815. Shrub decumbent.

9 K. Biconve'xa (Haw. in phil. mag. 1824. p. 185.) leaves narrow-linear, distinctly convex on both surfaces. $h . \mathrm{D} . \mathrm{G}$. Native of the Cape of Good Hope. Crássula biconvéxa, Haw. misc. p. 175. syn. 53. Ròchea biconvéxa, D. C. prod. 3. p. 394. Flowers white?

Double-convex-leaved Kalosanthes. Fl. Jul. Aug. Clt. 1823. Shrub $\frac{x}{2}$ to 1 foot.

10 K. Fascicula'ris (Schultes, syst.6.p. 709. under Laróchea, leaves connately sheathing at the base, linear-lanceolate; flowers in fascicles; segments of the calyx lanceolate, acute, ciliated. দ. D. G. Native of the Cape of Good Hope. Crássula fasciculàris, Lam. dict. 2. p. 171. Leaves glabrous, cartilaginously ciliated. Corolla almost as in $K$. coccinca, but is a little shorter.

Fascicled-leaved Kalosanthes. Shrub 1 to ? feet.

Cult. Elegant succulent shrubs, wortl cultivating in every collection for the beauty of their flowers. The culture, propagation, and treatment they require are the same as that recommended for Globùlea, p. 106.

XII. KALANCHO'E (Chinese name of one of the species). Adans. fam. 2. p. 248. D. C. pl. grass. no. 64. D. C. prod. 3. p. 394. Haw. in phil. mag. 1829. p. 301.-Calanchòe, Pers.Verèia, Andr. bot. rep. t. 21. Verea, Willd.

Lis. syst. Octándria, Tetragýnia. Calyx 4-parted (rarely 5 -parted); sepals united only at the very base, lorate, acute, spreadingly recurved at the apex. Corolla gamopetalous, hypoerateriform with an obversely clavate tube, and a 4-parted (rarely 5-parted) spreading limb. Stamens 8, 4 of which are adnate to the tubc, nearly to the middle, the other 4 almost to the apex. Scales 4 , linear, but almost obsolete in the $K$. vàrians. Carpels 4 , continuous, with the filiform styles.-Succulent subslurubs, from 1 to 2 feet high, erect, a little branched. Leaves opposite, fleshy, more or less irregularly impari-pinnate, or ovate, toothed or serrated, and often of a glaucous hue. Flowers disposed in loose cymose terminal panicles, yellow, or rufescent, rarely white, scentless. This is a very natural genus.

\section{* Leaves pinnatifid.}

I K. CERAtopuy'Lla (Haw, rev. p. 23. phil. mag. 1. c.) leaves pedately bipinnatifid, deeply and broadly toothed, pale green; stem branched. $々$. D. S. Native of China. Flowers yellow. Braan. icon. chin. t. 9 .

Horn-leaved Kalanchoe. Fl. July, Aug. Clt. 1820. Shrub 1 to 2 feet.

2 K. Lacinı'ta (Haw. syn. p. 111.) leaves simply pinnatifid, glaucous; segments deeply and broadly toothed. $h$. D. S. Native of Java, Moluccas, and Mauritius; and of Egypt. D.C. pl. grass. t. 100. Planta anàtis, Rumpl. amb. 5. t. 95. Cotylèdon laciniàta, Lin. spec. 1. p. 615.-Weinm. phyt. t. 435. Flowers yellow.

Jagged-leaved Kalanchoe. Fl. July, Aıg. Clt, 1781. Shrub 1 to 2 feet.

* Lcaves simple; but in $K$. vàrians some of them are tricuspidatc.

3 K. va'rians (Haw, in phil. mag. 1829. p. 302.) smooth, glaucous; leaves oval, broadly toothed: upper ones sometimes tricuspidate. $々$. D. S. Native of the East Indies. Flowers yellow, sometimes 5 -cleft.

Varying Kalanchoe. Fl. July, Aug. Clt. ? Shrub 2 feet.

4 K. crena'ta (Haw. syn. p. 109.) leaves oblong-lanceolate, broadly toothed, crenated : crenæ usually double. ?. D. S. Native of Sierra Leone. Kalanchòe Vèrea, Pers. ench. 1. p. 446. Verèia crenàta, Kennedy in Andr. bot. rep. 1. t. 21. Cotylèdon crenàta, Sims, in bot. mag. 1436. Vent. malm. t. 49. Cotylèdon Vèrea, Jacq. schœnbr. t. 435.-Pluk. alm. t. 228. f. 3. Flowers yellow.

Crenated-leaved Kalanchoe. Fl. Aug. Sept. Clt. 1793. Sh. I to 2 feet.

5 K. Acutif lòra (Haw. syn. p. 109.) leaves broad-lanceolate, crenated, glabrous, thick; segments of attenuated corolla acute. h.D.S. Native of the East Indies. Verèia acutiflòra, Kennedy in Andr. bot. rep. t. 560 . Flowers whitish.

Acute-flowered Kalanchoe. Fl. Ang. Sept. Clt. 1806. Slorub 1 to 2 feet.

6 K. Lanceolatita (D. C. prod, 3. p. 395.) leaves lanceolate, crenated at the apex; stem, peduncles, calyxes, and corollas, villous; cymes panicled. $h$. D. G. Native of Arabia. Cotylèdon lanceolàta, Forsk. desc. p. 89. Flowers said to be reddish yellow, that is, probably brownish.

Lanccolatc-leaved Kalanclioe. Shrub 1 to 2 feet.

7 K. Brasinie'vsis (St. Hil. fl. bras. 2. p. 196.) puberulous; lower leaves roundish : middle ones obovate-lanceolate : upper ones linear; all crenately serrated; cymes dense; lobes of corolla very acute. $\zeta$. D. S. Native of Brazil, near Rio Janeiro by the sea side. Corolla with a yellow tube, and a rosecoloured limb. This plant seems to be an exception from the exciting and acrid properties peculiar to the rest of Crassulàcece, it being used by the Brazilians in their domestic medicine.

Brazilian Kalanchoe. Slırub 1 to 2 feet.

8 K. Alte'rnans (D. C. prod. 3. p. 395.) leaves roundishspatulate, quite entire; panicles glabrous. 々. D. G. Native of Arabia, on mountains. Cotylèdon altérnans, Vahl. symb. 2. p. 51. but not of Haw. Cotylèdon orbiculàta, Forsk. cat, arab. p. 112. Segments of corolla reddish yellow, that is, probably brown.

Altcrnating Kalanchoe. Shrub 1 to 2 feet.

$9 \mathrm{~K}$. Rотundifória (Haw. in phil. mag. July, 1825. p. 31.) plant straight and slender; leaves thick: lower ones roundish : upper ones obovate, and almost entire; flowers small. h. D. G. Native of the Cape of Good Hope. Flowers rufescent or yellow. Round-leaved Kalanchoe. Fl. July, Aug. Clt. 1820. Shub 1 to 2 feet.

10 K. Egyrtiaca (D. C. pl. grass. t. 64. prod. 3. p. 395.) leaves obovate-spatulate, crenated: lower ones obtuse, and rather concave: upper ones acute; cyme a crowded panicle. $h . \mathrm{D}$. G. Native of Egypt, on Mount Melhan. Cotylèdon intègra, Medik. comm. pal. 3. p. 200. t.9. Cotylèdon nudicaúlis, Vahl. symb. 2. p. 59. Cotylèdon defíciens, Forsk. descr. p. 89. Flowers orange-coloured.

Egyptian Kalanchoe. Fl. July, Aug. Clt. 1820 . Slı. 1 to $2 \mathrm{ft}$. $11 \mathrm{~K}$. spatula'ta (D. C. pl. grass. t. 65.) leaves obovatelyspatulate, crenated, glabrous : lower ones obtuse : upper ones acute; cymes panicled, loose. $\eta_{\text {. D. D. Native of China. }}$ Cotylèdon hýbrida, Hort. par. Cotylèdon spatulàta, Poir. suppl. 2. p. 373 . Flowers yellow.

Spatulate-leaved Kalanchoe. Fl. July, Aug. Clt. 1820. Sh. 1 to 2 feet.

Cult. The species of Kalanchòe being succulent, require very little water unless when growing freely; and the pots in which they are grown ought to be well drained with sherds. A mixture of loam and sand appears to be the best soil for them. The species are easily increased by cuttings. A leaf taken off any 
of the species, and laid on the pot of mould, or on a tan-bed, will shoot ont young plants from the notches on the edges of the leaf.

XIII. BRYOPHY'LLUM (from $\beta \rho v \omega$, bryo, to sprout, and $\phi v \lambda \lambda o v$, phyllon, a leaf; plants spring from the notches on the edges of the leaves when taken off the plant, and placed in a moist situation). Salisb. par. 3. D. C. prod. 3. p. 395.-Crassoúvia, Comm. mss._Physocalj̧cium, Vest. in f. 1820. p. 409.-Cotylèdon species, Lam.-Calanchòe species, Pers.

Lin. sysx. Octándria, Tetragýnia. Calyx inflated, bladdery before flowering, hardly 4-cleft to the middle; lobes 4 , valvate. Corolla gamopetalous, hypogynous, having a long cylindrical tube, which is bluntly tetragonal at the base; and the lobes of the limb triangular and acute. Stamens 8 , adnate to the base of the tube. Glands 4, oblong.- $\boldsymbol{\Lambda}$ flesliy, erect, branched, glabrous shrub. Leaves opposite, thick, petiolate; some impari-pinnate, witl one or 2 pairs of segments, the terminal segment large; others solitary, all ovate and crenated; crenæ bearing an opaque dot in each, which is easily made to evolve into a plant. Cymes panicled, terminal. Flowers yellowish red, or green and red. Calyx almost like that of Silène inflàta.

1 B. calycinum (Salisb. 1. c.) h. D. S. Native of the MoJuccas and the Mauritius. Sims, bot. mag. 1409. herb. amat. t. 317. Crassoúvia floripéndula, Comm. mss. Cotylèdon pinnàta, Lam. dict. 2. p. 141. Calanchòe pinnàta, Pers. encl. 1. p. 446. Cotylèdon calyculàta, Soland. in herb. Banks. Cotylèdon rehizoplýlla, Roxb. Cotylèdon calycina, Roth, nov. spec. $21 \%$.

Largc-calyxed Bryophyllum. Fl. April, July. Clt. 1806. Shrub 2 to 3 feet.

Cult. See Kalanchòe above for culture and propagation.

XIV. COTYLEDON (from korv $\eta$, kotyle, a cavity; cuplike leares of some species). D.C. bull. phil. 1801. no. 49. p. 1. prod. 3. p. 396. mem. cras. t. 1. f. 7. Cotylèdones Capénses, Lin. Burm. Haw, S.c.

Lin. syst. Dccándria, Pentagýnia. Calyx 5-parted, much shorter than the tube of the corolla. Corolla gamopetalous; tube ovate-cylindrical; limb 5 -lobed, spreadingly reflexed or revolute; lobes obtuse. Stamens 10 , adnate to the base of the tube of the corolla : the upper part free, exserted or almost inclosed. Scales oval. Carpels 5, continuous, with the styles, which are subulate-Fleshy sirubs, native of the Cape of Good Hope. Leaves usually scattered. Flowers loose, panicled, purplish or orange-coloured. This genus has been divided into sections from the form of the corolla by the Prince Salm-Dyck, hut the corolla being unknown in a great many of the species we cannot follow these divisions.

\section{- Leaves opposite.}

1 C. undula'ta (Haw. suppl. 20. rev. 20.) leaves opposite, rhomboid-ovate, with an acumen, pale green: older ones large and very thick, margined with red at the apex : when young lean and waved. $h$. D. G. Native of the Cape of Good Hope. Flowers unknown. Very similar to C. orbiculata, but the stem is more humble, and the leaves longer, and less obtusc at the apex. SalmDyck. in litt.

Undulated-leaved Cotyledon. Fl. Ju.Jul. Clt. 1818. Sh. $1 \mathrm{ft}$.

2 C. orbicula'ta ( Lin. spec. 614.) leaves opposite, flat, obovately-spatulate, obtuse, with an acumen, glaucous, and mealy, margined with red; flowers panicled; caudex erect, branched. h. D. G. Native of the Cape of Good Hope. D. C. pl. grass. no. 76. Ait. hort. kew. ed. 2. vol. 3. p. 108. Flowers reddish.

Far. a, rotundifolia (D. C. prod. 3. p. 396.$)$ leaves roundish.
-C. orbiculata, Haw. succ. syn. p. 105. C. orbiculata $\gamma$, rotúnda, D. C. l. c.

I ar. $\beta$, obovita (D. C. l. c.) leaves obovate, margined with red.-C. ovàta, Haw. l. c. C. orbiculàta var. $a$, D. C. pl. grass. t. 76. Curt. bot. mag. t. 321.-Mor. oxon. sect. 12. t. 7. f. 39. Herm. lugd. bat. 551. with a figure.

Var. $\gamma$, oblónga (D. C. l. c.) leaves oblong.-C. oblónga, Haw. 1. c. C. orbiculàta $\beta$, Ait. 1. c.

V́ar. $\delta$, clìta (Salm-Dyck. in litt.) leaves orbicularly obovate, white, and mealy; stem tall, firm, a little branched. C. clàta, Haw. suppl. p. 20.

I'ar. $\varepsilon$, ramòsa (Salm-Dyck. in litt.) leaves ovate-spatulate, white, and mealy; caudex inuch branclied; branches effuse. C. ramòsa, Haw. suppl. p. 20. C. ramosíssima, Mill. dict. C. orbiculata $\gamma$, A it. hort. kew.

Orbicular-leaved Cotyledon. Fl. July, Aug. Clt. 1798. Slirub 2 to 4 feet.

3 C. crassifòlia (Haw, in pliil. mag. 1826. p. 272.) stem erect, shrubby ; plant white from mealiness ; leaves rhomboid, obcuneated, thick. $々$. D. G. Native of the Cape of Good Hope. Leaves distant, decussately opposite, edged with brownish purple on the margin above the middle. Flowers not seen. Thick-leaved Cotyledon. Clt. 1824. Shrub $1 \frac{1}{2}$ to 3 feet.

4 C. víridis (Haw. in phil. mag. 1826. p. 272.) stem slurubby, erect, nearly simple; leaves obovate-cuneated, green. $々 . D . G$. Native of the Cape of Good Hope. Leaves middle-sized, lean. In habit it follows $C$. crassifòlia.

Green Cotyledon. Slirub 2 to 4 feet.

5 C. ramosíssima (Haw. suppl. p. 25.) leaves oblong-spatulate, farinose, margined witl red at the apex; caudex much branched; young branchlets erect: old ones twisted, and crowded. h. D. G. Native of the Cape of Good Hope. C. paniculàta, Lin. fl. suppl. Flowers unknown. Leaves not half the size of those of the smallest variety of C. orbiculita, hardly 15 lines long, and 9 lines broad.

Most-branched Cotyledon. Fl. May, Ju. Clt. 1816. Slirub 1 to 2 feet.

6 C. coru'scans (Haw. suppl, p. 21.) leaves decussate, aggregate, cuneate-oblong, channelled, with thickened margins, apiculated, covered with white mealiness; flowers pendulons, disposed in umbellate panicles. $\zeta$. D. G. Native of the Cape of Good Hope. Sims, bot. mag. 2601. Lodd. bot. cab. t. 1030. C. canalifòlia, Haw in phil. mag. 1825. July, p. 33. Flowers orange-coloured like those of $C$. orbiculata, but paler and rather longer.

Glittering Cotyledon. Fl. June. Clt. 1818 . Sh. 1 to $2 \mathrm{ft}$.

7 C. ungula'ta (Lam. dict. 2. p. 139.) leaves opposite, semicylindrical, channelled, glabrous, purple, and furnished with a callous point at the margin near the apex; flowers in a kind of panicle, glabrous; caudex erect. h. D. G. Native of the Cape of Good Hope. Burm. afr. dec. 3. p. 24. t. 22. f. 1. Flowers purplish, pendulous. Very like $C$. orbiculàta.

Claw-leaved Cotyledon. Shrub 1 to 2 feet.

8 C. Papilla'ris (Lin. fil. suppl. p. 242.) leaves opposite, terete-ovate, fleshy, glabrous, acute, erect ; flowers in panicles, glabrous ; caudex decumbent, clothed with fine villi. h. D. G. Native of the Cape of Good Hope. Haw. suppl. p. 21. Thunb. fl. cap. p. 397. C. decussàta, Sims, bot. mag. t. 2518. Lindl. bot. reg.t. 915 . Corolla red, ungtricular, with a somewhat pentagonal tube, and oblong acute rcflexed lobes. Leaves as in $C$. corúscans, and $C$. ungulàta, truncate at the apex, and with a marginal claw or point.

Pajillose Cotyledon. Fl. Aug. Clt. 1819. Shrub I to $2 \mathrm{ft}$.

9 C. Trieuspida'ta (Haw. in phil. mag. 1825. July, p. 32.) plant white from mealiness; leaves narrow, usually deeply tricuspidate. $h$. D. G. Native of the Cape of Good Ilope. 
Very like C. papillàris, but differs in the leaves being tricuspidate.

Trieuspidate-leaved Cotyledon. Clt. 1823. Shrub 1 foot.

10 C. purpu'rea (Thunb. fl. cap. p. 396.) leaves opposite, linear-oblong, fleslyy, concave, glabrous ; flowers panicled, glabrous; caudex erect, nearly herbaceous. $h_{\text {. }}$ D. G. Native of the Cape of Good Hope. Corolla purple, an inch long.

Purple-flowered Cotyledon. Shrub 1 foot.

11 C. TERetifòlia (Thunb. prod. p. 83. f. cap. p. 397. but not of Lam.) leaves opposite, nearly terete, fleshy, laairy, obtuse, with an acumen; flowers panicled, hairy; caudex erect, simple. h. I. G. Native of the Cape of Good Hope.

Terete-leaved Cotyledon. Shrub 1 foot.

12 C. cunelfo'rmis (Haw. in phil. mag. March, 1828. p. 185.) stems short, branched; leaves crowded, obovate, mucronate, rather white from mealiness. $h$. D. G. Native of the Cape of Gnod Hope. Like C. crassif òlia, but much more humble.

Hidge-leaved Cotyledon. Shrub 1 foot.

\section{* Leaves alternate, mareeseent.}

13 C. curviflòra (Sims, bot. mag. t. 2044.) leaves scattered, semicylindrical, glabrous; cicatrices of the stem, where the old leaves have fallen off, rather prominent; flowers panicled, nodding; calyxes loose; tube of corolla pentagonal, incurved. দ. D. G. Native of the Cape of Good Hope. Flowers of a dirty yellow-colour, almost reddish, about an inch long. Styles longer than the stamens.

Curve-flowered Cotyledon. Fl. Oct. Clt. 1818 . Sh. 1 to $2 \mathrm{ft}$. 14 C. tuberculòsa (Lam. dict. 2. p. 139.) leaves seattered, subcylindrical, linear-oblong, acute; cicatrices of the old leaves tubcrcular; flowers subpanicled, erect; peduncles and calyxes pubescent. দ. D. G. Native of the Cape of Good Hope. -Burm. afr. t. 20. f. 1. C. grandiflòra, N. L. Burm. prod. fl. cap. 13. C. tuberculosa, D. C. pl. grass. 1. t. 86 . Flowers showy, orange-coloured, tubular, an inch or more long; limb spreading, not replicate.

Tubercular Cotyledon. Fl. June, Aug. Clt. 1820. Shrub 1 to 2 feet.

15 C. cacalioìdes (Lin. fil. suppl. p. 242.) leaves scattered, terete, acute; cicatrices of the old leaves pitted; flowers panicled, erect, seated on a long, elongated, nearly naked stem. . D. G. Native of the Cape of Good Hope. Burm. afr. t. 20. f. 2. Flowers yellow, rather villous, half an inch long. Leaves deciduous when the plant is in flower; hence Burmann called it C. aphílla.

Cacalia-like Cotyledon. FI. May. Clt. 1818. Sh. 1 foot.

16 C. ventricòsa (N. L. Burm. prod. fl. cap. p. 13.) leaves scattered, linear-oblong, acute at both ends; cicatrices on old stcms tubercular; flowers in loose racemes, pedicellate, erect; tube ventricose, pentagonal; lobes acute. h.D. G. Native of the Cape of Good Hope. Burm. afr. dec. 3. p. 51.t. 21. f. 1. llowers greenish, almost like those of $C$.hemisphe'rica. Leaves like those of $C$. tuberculosa, according to Burm.

Icntricose-flowered Cotyledon. Shrub 1 to 2 feet.

17 C. spu'ria (Lin. spec. p. 614.? exclusive of the synonymes, ) leaves almost radical, terete, oblong, fleshy, obtuse, narrower at the hase; candex very short, thick; flowering stem erect, naked; flowers somewhat panicled. h. D. G. Native of the Cape of Good Hope. Burm. afr. p. 43.t. 19. f. I. Pluk. alm. t. 323. f. 1.-Willd. spcc. 2. p. 754. C. teretifolia, Lam. dict. 2. p. 139. but not of 'Thunb.

Spurious Cotyledon. Fl. July, Aug. Clt. 1731. Shrub $1 \mathrm{ft}$. 18 C. Fascicula'ris (Ait. hort. kew. ed. 1. vol. 2. p. 106.) leaves scattered, but in fascicles at the tops of the branches, cuneiform, obtuse, flat, thick; caudex thickened, branched; flowers panicled, pendulous, with revolute limbs. 々. D. G.
Native of the Cape of Good Hope. Burm. afr. p. 41. t. 18. C. paniculàta, Thunb. fl. cap. p. 396. ex Burm. syn. C. tardiflòra, Bonpl. nav. t. 37. Corolla with a short, greenish, broad, subpentagonal tube, and a reddish revolute limb.

Fascicled-flowered Cotyledon. Fl. July, Sept. Clt. 1759. Shrub 1 foot.

\section{* * Leaves alternate, permanent.}

19 C. Triflòra (Thunb. prod. p. \$3. fl. cap. p. 396.) leaves scattered, oblong-spatulate, obtuse, fleshy, of a greyish shining colour ; flowers by threes, in spikes, approximate, with replicate limbs; stem suffrutescent. h. D. G. Native of the Cape of Good Hope, near Zehorivier. Salm-Dyck. obs. p. 6. C. elàta, Haw. suppl. Corolla with a green tube, and an acute limb, variegated with white and purple.

Three-flowered Cotyledon. FI. MIay, July. Clt. 1821. Shrub 1 to 2 feet.

20 C. Macula'ta (Salm-Dyck. obs, p. 5.) leaves scattered, ovate-spatulate, somewhat auriculated at the base, fleshy, shining, marked with dark red spots on both surfaces; flowers spicate, almost alternate : limb spreading; stem suffruticose. $h_{2}$ : D. G. Native country unknown. C. altérnans, Haw. suppl. ex Salm-Dyck. but not of Vahl. Spike terminal, generally simple. Tube of corolla green, subventricose, with the segments of the limb acute, variegated with white and purple.

Spotted-leaved Cotyledon. Fl. July, Aug. Clt. 1816. Sh. $1 \mathrm{ft}$.

21 C. knowbifòlia (Haw. in phil. mag. 1825. July, p. 33.) leaves approximate, obovate-rhomboid, mucronate, white and mealy ; stem branched, strong, decumbent. h.D.G. Native of the Cape of Good Hope. Allied to C. hemisphe'rica, but more humble and branched, and the leaves are rliomboid, and more acuminated. Flowers unknown.

Rhomb-leaved Cotyledon. Clt. 1823. Shrub decumbent.

22 C. Jasminif Lóna (Salm-Dyck, obs. Haw, rev, p. 20.) leaves rather crowded, green, rhomboid-spatulate, fleshy; stem humble; peduncle terminal, branclied; flowers erect, with a green tube, and a revolute limb, variegated with white and purple; perdicels long, thickened. $\eta$. D. G. Native of the Cape of Good Hope. Allied to $C$. hemispha'rica, but the stems are more humble, thickened from the root; the leaves longer, and the flowers with the tube and limb more ample, and more like a jasmine flower. Salm-Dyck in litt.

Jasmine-flowered Cotyledon. Fl. July, Aug. Clt. 1818. Sh. 1 foot

23 C. HEMISPHE'rica (Lin. spec. p. 614.) leaves scattered, ovate-roundish, thick, dotted, glabrous ; flowers nearly sessile, erect, along an elongated peduncle; lobes of corolla spreading. h. D. G. Native of the Cape of Good Hope.-Dill. elth. 2. t. 95. f. I11. C. liemisphæ'rica, D. C. pl. grass. 1.t. 87. Flowers small, with a green tube, and the limb variegated with white and purple.

Hemispherieal Cotyledon. Fl. Ju. July. Clt. 1731. Sh. $1 \mathrm{ft}$.

24 C. rotundifòla (Haw. in phil. mag. 1826. p. 273.) shrubby, dwarf; leaves straight, crowded, roundish, dirty green ; hranches short, decumbent. h. D. G. Native of the Cape of Good Hope. Leaves flat, convex beneath, mealy. Allied to C. hemispha'rica.

Round-leaved Cotyledon. Shrub decumbent.

25 C. Mamila'ris (Lin. fil. suppl. p. 242.) leaves scattered, crowded into something like whorles, terete, ovate, obtuse, glabrous ; flowers spreading on short pedicels, which are seated on an elongated peduncle; stem creeping. $h_{c}$. D. G. Native of the Cape of Good Hope, near Olyfants Bad. Thunb. fl. cap. p. 397. Haw, rev. p. 21. suppl. 22. Corolla tubular, glabrous, with a green tube, and a spreadingly reflexed limb, which is variegated with white and purple. 
Mamillary Cotyledon. Fl. June, July. Clt. 1818. Sh. cr. 26 C. cunea'ta (Thunb. 11. cap. p. 395.) leaves radical, cuneated, fleshy, hairy, with purple margins; stem erect, somewhat herbaceous, pubescent, viscid; corolla lairy. Һ. D. G. Native of the Cape of Good Hope.

Cuncaled-leared Cotyledon. Fl. May. Clt. 1818. Sh. $1 \mathrm{ft}$.

27 C. ixterjécta (Haw. in pliil. mag. March, 1828, p. 185.) lcaves glaucescent, narrow-oblong, acute, incurved, channclled; stem short, strong. $h_{c}$. D. G. Native of the Cape of Good Hope. Very like C. spuria, but diflers in being higher, in the leaves being shorter, thicker, and narrower, more channelled, and without doubt incurred.

Cast Cotylcdon. Clt. 1823. Shrub $\frac{1}{2}$ foot.

28 C. caryopiylla'cea (N. L. Burm. prod. fl. cap. 13.) leaves aggregate, ovate, thick, flat, glancous; flowers panicled, on long erect pedicels; stem branched. $\zeta$. D. G. Native of the Cape of Good Hope. Burm. afr. dec. 2. p. 39. t. 17. Corolla tubular, form of the bud of a clove; lobes spreading, ovatc, acute, flesh-coloured, with a red line. Very like $C$. hemispha'rica, but differs in the flowers being distinctly pedicellate.

Clove-like Cotyledon. Stem I foot.

29 C. yucrona'ta (Lam. dict. 2. p. 11.2.) leaves nearly radical, oval, flat, with undulated margins, mucronate at the apex; stem branched, very short; floriferous stem naked; flowers erect, in loose panicles. Ђ. D. G. Native of the Cape of Good Hope. Burm. afr. p. 44. t. 19. f. 2. C. undulàta, Haw. Lobes of corolla acute.

Mucronate-leaved Cotyledon. Fl. June, July. Clt. 1818. Slirub $\frac{1}{2}$ foot.

\section{† Spccies not sufficiently known.}

30 C. RETICULA'TA (Thunb. f. cap. p. 393.) lcaves scattered at the tops of the branches, terete, acute, erect, soft, glabrous; stem erect, shrubby, fleshy; flowers erect, in dichotomous panicles. h. D. G. Native of the Cape of Good Hope, in Carro. Caudex a hand high. Panicle decompound.

Reticulated Cotyledon. Shrub $\frac{3}{4}$ foot.

31 C. Dichó тома (Haw. suppl. 27. ex rev. 22.) leaves channelled; cymes dichotomous, puberulous, bracteated by spines; tube of corolla somewhat bottle-formed, with a replicate limb. h. D. G. Native of the Cape of Good Hope.

Dichotomous Cotylerlon. Shrub $\frac{1}{2}$ to 1 foot.

32 C. PA'RVUla (Burch. cat. geogr. no. 1818. ex voy, cap. 1. p. 219.) leaves oval, rather compressed, thick; panicle dichotomously branched; perlicels erect, very long, capillary; stem

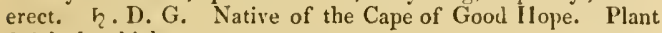
6-9 inches ligh.

Small Cotyledon. Pl. $\frac{1}{2}$ to 1 foot.

33 C. Trígra (Burch. trav. afr. 2. p. 226.) stemless; leaves glabrous, flattened, fleshy, cuneate-oval or nearly orbicular; flowers erect, alternate on an elongated simple scape, rarely on a bifid one. h. D. G. Native of the Cape of Good Hope. Corolla cylindrical, purplish, with a short reflexed limb, and a purple throat. Carpels 3.

Trigynous Cotylerlon. Pl. $\frac{1}{2}$ to 1 foot.

34. C. crista'ta (Haw. phil. mag. 1827, April 1, p. 123.) leaves jetiolate, cuncately triangular, curled and crested at the apex. $\eta$. D. G. Native of the Cape of Goorl Hope. Herb succulent, leafy, evergreen. Stem short, with the surculi densely clothed with rufous hairs. Leaves erect, an inch long, thick, purplish at the apex, beset with dots of scurfy down. Spikes terminal. Flowers small, open in the morning.

Crested Cotyledon. Fl. Sept. Clt. 1820 . Pl. 般 foot.

35 C. clavifòlı (Haw. l. c.) leaves petiolate, club-formed, incurved, acuminated, and rather curled at the apex. h. D. G.
Native of the Cape of Good Hope. Allied to the preceding species; but the flowers are about twice the size, and purple.

Club-lcaved Cotyledon. Fl. Sept. Clt. 182\%. 1'. $\frac{1}{2}$ foot.

Cult. Cotylèdon is a genus of pretty succulent plants. The culture, propagation, and management of tic species are the same as that for Globulca, p. 106.

XV. PISTORI'NIA (meaning unknown to us). D. C. prod. 3. p. 399 . mem. crass. p. 25. t. 10. f. 5.-Cotyledon species of authors.

Lin. syst. Dccándria, Pcntagýnia. Calyx 5-parted, much shorter than the tube of the corolla. Corolla gamopetalous, fumel-shaped; tube long, terete; limb spreading, 5-parted. Stamens 10, adnate the whole length of the tube, but free at the throat, and exscrted. Scales 5, oblong, obtuse. Carpels 5, each ending in a long filiform style.-Lrect annual or biennial herbs. Leaves nearly terete, obloing, scatterch, sessile. Flowers cymose, red. Habit of the plants belonging to that section of $\mathrm{Um}$ bilicus called Mucizonia, and the flowers like those of Cotylicdon.

1 P. Hispa'nica (D.C. prod. 3. p. 399.) ๑. or \&. H. $\mathrm{Na-}$ tive of Spain and Barbary, in exposed sandy places. Cotylèdon Hispánica, Lœef. itin. p. 77. t. 1. Lin. spec. 615. D. C. pl. grass. t. 122. Cotyledon Pistorínia, Ort. mon. 1772. with a figure.

Spanish Pistorinia. Fl. Junc, July. Clt. 1796. Pl. $\frac{1}{4}$ foot.

Cult. Sow the seeds in any dry situation in a light soil in the open border, or on rock-work.

XVI. UMBILICUS (from unbilicus, the navel; hollow leaves of some species). D.C. in bull. plit. 1801. no.49. prod. 3. p. 399.

Lis. syst. Dccandria, Pentagýnia. Calyx 5-parted. Corolla gamopetalous, campanulate, 5 -cleft; lobes ovate, acute, erect, about the length of the tube. Stamens 10, inserted in the corolla. Scales 5, obtuse. Carpels 5, attenuated at the apex. Styles subulate.-Herbs, indigenous to the south of Europe and the Levant. Leaves rosulate or alternate, quite entire, or a little toothed. Flowers white or yellow, in branched or simple terminal racemes, never in cymes.

Sect. I. Rosula'ria (from rosa, a rose; in reference to the leaves being rosulate, or disposed like the petals in the flower of a rose). D. C. prod. 3. p. 399 . Scpals equal to the tube of the corolla. Leaves radical, rosulate. Scapes subpanicled, annual.-Perennial herbs, natives of the Levant, with the babit of Semperivum.

1 U. Libanóticus (D. C. prod. 3. p. 399.) leaves radical, rosulate, cuneated, thickish, papillose; scape naked; panicle racemose, loose. 4 . H. Native of Mount Libanon, and near Damascus. Cotylèdon Libanótica, Labill. syr. dec. 3. p. 3. t. 1. Flowers yellow?

Libanon Navel-wort. Pl. $\frac{1}{2}$ foot.

2 U. sempervivum (D. C. 1. c.) leaves radical, rosulate, crowded, cuneated, ciliately scabrous; scaje naked; panicle racemose, loose. $\quad$ 4. H. Native of Eastern Caucasus, among stones on the mountains. Cotylèdon sempervivum, Bieb. casp. p. 176. append. no. 46 . ann. bot. 2. p. 444 . fl. taur. 1. p. 351 Perhaps sufficiently distinct from the preceding species.

Houseleck-like Navel-wort. Pl. $\frac{1}{2}$ foot.

3 U. PUBÉscens (Meyer in verz. pflanz. p. 150. under Cotylèdon,) plant pulcscent; lcaves linear-oblong, bluntish : radical ones rosulate, cauline ones scattered, erectly spreading; racemes corymbose; corolla twice the length of the calyx, with the segments of the limb acute and spreading at the apex; stem herbaceous, simple. $\%$. H. Native of Caucasus, among rocks in shady places on the mountains of Talush, at the altitude of 1200 to 2700 feet. Sèdum pilosum, 13ieb. fl. taur. 1. 1). 35\%. Flowers reddish. 
Pubescent Navel-wort. Pl. $\frac{1}{4}$ foot.

4 U. SA'mus (D. C. 1. c.) radical leaves narrow, spatulatelanceolate, Jong, fleshy; cauline lcaves sessile, linear; stem simple, glabrous, leafy; flowers racemose, pedicellate, usually twin. 4. H. Native of the Island of Samos, among high naked rocks, and of Palestine. Sèdun Libanóticum, Lin. spec. 617. Cotylèdon Simium, D'Urv. enum. arch. p. 50. no. 402. Flowers yellow?

Samos Navel-wort. Pl. $\frac{1}{6}$ foot.

Sect. II. Mucizònıs (meaning unknown to as). D. C. prod. 3. 1. 399 . Cauline leaves alternate. Annual herbs, with the habit of Sèdum.

5 U. n'spidis (D. C. prod. 3. p. 399.) stems diffuse, erect, pubuscent; leares glabrous, oblong, terete; racemes terminal, leafv, clothed with clammy villi. $\odot$. H. Native of Spain, Barbary, and Teneriffe, on the mountains. Cotylèdon Mucizonia, Ort. mon. 1772, with a figure. Jacq. col]. 5. p. 112. t. 13. f. 2. Cotylèdon viscòsa, Vahl. symb. 2. p. 51 . Cotylèdon híspida, Lam. dict. 2. p. 141. Desf. atl. 1. p. 359. Flowering branchics opposite the flowers. Flowers white or dirty reddish. IIispid Navel-wort. I']. $\frac{1}{4}$ to $\frac{1}{2}$ foot.

6 U. SEDroides (D. C. prod. 3. p. 400 . mem. crass. pl. 4. f. B.) stcms rooting a little, glabrous; leaves oblong, convex, obtuse, glabrous; flowers few, at the tops of the stems, almost sessile. $\odot$. 11. Native of the higher Pyrenees, particularly on the castern side. Cotylèton sedioìdes, D. C. rap. 1808. p. 78. f. fr. suppl. p. 521. Poir. suppl. 2. p. 373. Cotylèdon sedifórmis, Lapeyr. Herb small, simple, or branched, almost with the appearance of Scdum atratum. Flowers large for the size of the j)lant.

$$
\text { Stone-crop-like Navel-wort. Pl. } \frac{x}{8} \text { foot. }
$$

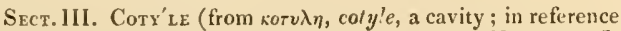
to the cup-like leaves). D. C. prod. 3. p. 400 . Umbilicus J. and C. Bauh. Roots tuberous. Stems usually branched. Radical leaves petiolate, eucullate, more or less peltate. Corolla hardly 5 -cleft to the middle.

7 U. PENdulixus (D. C. pl. grass. t. 156.) lower leaves peltate, concave, repandly crenated, roundish; bractcas entire; flowers tubular, pendilous, or spreading. 4. H. Native of Europe, among stones and rocks, on walls and under hedges: in Britain, on moist dripping rocks and old walls. Cotylèdon Limbilieus, Lin. spec. 615. var. $\alpha$. Sow. eng]. bot. t. 325. Cotylèdon unbilicata, Lam. C. rupéstris, Salisb. Cotylèdon Umbilicus véneris, l3lackw. herb. t. 263. Root tuberous. Flowerhearing stem branched; with its branches bearing racemes. l'lowers yellow.

Var. $\beta$, pcliàtus (D. C. prod. 3. p. 400.) raceme simple. 4. II. Cotylèdon peltàtum, Wendl. obs. p. 49. Hardly distinet from the species.

Drooping or Common Navel-wort. Fl. Ju. Jul. Brit. P!. $\frac{x}{2} \mathrm{ft}$.

8 U. Eиє́ctus (D. C. fl. fr. 4. p. 384. exclusive of the country) lower leaves peltate, dentately crenated, roundish; bracteas a little toothed; flowers crect. 4. H. Native of England, on moist walls and rocks, but rare, particularly in the W'st Rieling of Yorkshire; and of P'ortugal. Doclart. pempt. p. 73. with a figure. Cotylèdon Unbilicus, Lin. spec. 615. Cotyledon lùtea, Hurls. angl. p. 194. Simith, engl. bot. 1522 . Cotylèdon Lusitánica, Lam. dict. 2. p. 140. Root fleshy, creeping. Flowers yellow, larger than those of the first species.

Ercet Navel-wort. Fl. June, Jul. Brit. P]. $\frac{x}{2}$ foot.

9 U. parvielòrus (D. C. prod. 3. p. 100.) lower leaves petiolate, cucullate, orbicular, ratlicr repand : upper ones ovate ; flowers sub-campanulate, in dense raccmes. 4. H. Native of Candia, on the splıaccotic mountains. Cutylèdon parviftòra,
Sibth. et Snith, fl. graec. t. 445. Desf. cor. Tourn. 75. t. 57. C. Crética tuberòsa radice flore luteo parvo. Tourn. cor. 2. Flowers yellow, smaller than those of $C$. pendulinus. Racemes branched, cylindrical, dense-flowercd. I,eaves lined with red. Small-floncred Navel-wort. P]. $\frac{3}{2}$ foot.

I0 U. nokizonta'Lss (D. C. prod. 3. p. 400.) stem nearly simple: lower leaves peltate, concave, repandly crenated, roundish; bracteas entire, linear-setaccous, longer than the pecluncles; corolla at first erect, but at length becoming horizontal, with acuminated segments. 4 . H. Native of Sicily and Naples, among stones and on walls. Cotylèton horizontalis, Guss. ind. sem. hort. pan. 1826 . p. 4 . Ten. f. neap. app. 5. p. 13. Flowers yellow. Differs from $U$. pendulinus in the flowers being nearly sessile, and horizontal, not drooping.

$1 /$ rizontal-flowered Navel-wort. 1'. $\frac{1}{2}$ foot.

Sect. IV. Pistorinioides (plants intermediate between Pistorinia and $U$ mbilicus). Roots perennial, thick, woody. Leaves terete, subulate. Stenss numerous, erect, simple, fistular, densely leafy, for the most part naked below, in consequence of the leaves having fallen.

11 U. Lieve'su; glabrous; stems herbaceous, erect, simple; leaves scattered, crowded, nearly terete, bluntish; flowers eymose; limb of corolla erect. 4. H. Native of Altaia, between the river Irtysch and Lake Noor-Saisan, in dry saltish fields ; in fields on the mountain of Kurtehum, Arkaul, and at the rivulet called Urmichaika, near Buchtorminsk. Cotylèdon Lievènii, Led. fl, ross. alt. t. 57. f. alt. 2. p. 197. Corolla fine red. Carpels 5-6.

Licren's Navel-wort. F]. May. Pl. $\frac{x}{2}$ to $\frac{3}{4}$ foot.

12 U. subula'ta; plant quite smootl, glaucescent; leaves all scattered, terete, subulate, acute, erectly spreading; racemes corymbose; corolla twice the length of the calyx, with the segments of the limb acute and erect; stem herbaceous, very simple. 4. HI. Native of Caucasus, among stones, on the mountains of 'Talusch, at the altitude of 2700 to 3300 feet. Cotylèdon subulata, Meyer. in verz. pflanz. p. 150. Very nearly allied to $U$. Licvonii, but the leaves are acute and erectly spreading, and the corolla is white, twice the length of the calyx, not rose-coloured, and 4 times longer than the calyx.

\section{Subulate-leaved Navel-wort. Pl. $\frac{1}{2}$ foot.}

Sect. V. Oro'stacurs (from ipos, horos, the ends, and oraxvs, stachys, a spike; the spike of flowers terminate the scapes). D. C. prod. 3. p. 400 . Oróstachys, Fisch. eat. gor. 1808. 1. 99. lioots not tuberous. Stems simple. Leaves not peltate nor cueullate; radical oncs rosulate. Corolla 5 -parted.

13 U. serra'tus (I. C. l. c.) leaves oblong, cartilaginously crenated; stems subspicate; peduncles 2-3.flowered; root fibrous. \&.? H. Native of Candia (Dill.) and of Galicia, on old walls. Bess, append. fl. gall. p. 352.-Dill. hort. elth. 1. t. 95. f. 112. Cotylèdon serratus, Lin. spee. p. 615. Smith, f. grae. t. 444. Flowers variegated witl white and red. Habit of Saxifraga lingularis.

Serratcd-leaved Navel-wort. Fl. Ju. Jul. Clt. 1732. Pl. $\frac{1}{2} \mathrm{ft}$.

1. U. spròsus (D. C. l. c.) leaves oblong, pointed by a spine at the apex, quite entire: radical ones rosulate, spatulate, convex beneath towards the apex: cauline leaves lanccolate, flat; corolla twice the length of the calyx; peduncles all 1-flowered; anthers of one colour; stems spicate, very simple. \&. H. Native of Siberia, China, and Japan. Cotylèdon spinòsa, Lin. spec. 615. Sèdum spinòsum, Thunb. fl. jap. p. 186.-II comm. gœtt. 7. p. 33. t. 5. Crássula spinòsa, Lin. mant. 388. Gmel. sib. 4. t. 67. f. 2. Oróstachys clılorántha, Fisch. in mem. soc. descr. nat. mose. 2. p. 274 . Sèrlum, \&c. Amm. ruth. p. 73. no. 95. Sempervivum cuspidàtum, Haw. misc. 186. syn. p. 170 , rev. p. 68.-Gmel. fl. sib. 4. p. 173. no. 87 . and 68. f. 2. 
Flowers yellow, 5-parted, on short pedicels, collected into a eylindrical spike.

I"ar. $\beta$, polystàchyus (Led. f. alt. 2. p. 200.) spikes numerous, rising from the axils of the radical or cauline leaves, somewhat fastigiate.

Spiny Navel-wort. Fl. June, Jul. Clt. 1810. Pl. 1 foot.

15 U. Malachorhy'luts (D. C. prod. 3. p. 400.) leaves lanceolate, acutish, unarmed, quite entire; radical ones rosulate before flowering; stem spicate, simple. \&. HI. Native of Dahuria, among mountain rocks. Cotylèdon malachophýlla, Pall. jtin. S. append. t. O. f. 1. ed. gall. 8 vo. 8. p. 312. t. 70. f. 1. Oróstaehys malachophýlla, Fiscl. cat. gor. Flowers white, 5 -parted, crowded into a dense cylindrical spike.

Soff-learcel Navel-wort. Fl. June, July. Clt. 1815. Pl. $\frac{1}{2} \mathrm{ft}$.

16 U. THY rstelòrus (D. C. 1. c.) leaves oblong, quite entire, ending eacls in a soft spine; radical ones rosulate; stem spicate, simple. $\delta$. H. Native of the mountains of Siberia, at Aga. Sèdum cotylèdonis facie floribus carneis, Amm. ruth. p. 72. no. 94. Oróstachys thyrsiftòra, Fisch. cat. gor. Flowers white and flesh-coloured (ex Fisch), 5-parted. Allied to $U$. malachophíllus.

Thyrse-flowered Navel-wort. Pl. $\frac{1}{4}$ to $\frac{1}{2}$ foot.

17 U. LECCA'хтнA; leaves terminated by a spine; radical ones rosulate, spatulate, convex beneath towards the apex : cauline ones teretely trigonal; corolla thrice the length of the calyx : peduncles all 1-flowered; anthers discoloured. \$. H. Native of Altaia, in very sterile fields in the Soongarian desert, between the mountains of Arkat and Kar-karaly; and among stones in the tract of the river Katunja. Root fusiform, or a little branched. Corolla white. Cotylèdon leucántha, Led. fl. ross. atl. ill. t. 395 . f. atl. 2. p. 198.

White-flowered Navel-wort. Fl. Aug. Pl. $\frac{1}{2}$ to $\frac{1}{2}$ foot.

Cult. The hardy perennial species of this genus thrive wcll on rock-work, or on old walls; they will also grow freely in pots, in a soil composed of loam, peat, and sand, which should be placed annong other alpine plants; these are propagated by offsets from the roots or by seeds. The seeds of annual and biennial kinds should be sown on rock-work, or in the open border, in a sandy or gravelly soil.

XVII. ECHEVE'RIA (this genus is named after MI. Echeveri, author of the fine drawings of the Flora Mexicana, commenced under the direction of MM. Sesse, Mocino, and Cerrantes). D. C. prod. 3. p. 40 I. mem. crass. p. 28.-Cotylèdon species of authors.

Lin. syst. Decándria, Pentagýnia. Calyx 5-parted; sepals erect, referrible to leaves, united at the very base (f. 27. $a$.) Petals 5 (f. 27. b.), also united at the base, erect, thick, stiffish, thickest at the middle nerve, and nearly trigonal at the base, acute. Stamens 10 (f. 27.c.), shorter than the petals, and adnate to them at the base.

Scales 5, short, obtuse. Carpels 5 , ending each in a subulate style. -Fleshy shrubs, natives of Mexico. Leaves alternate, cauline, or rosulate, and nearly opposite, nerreless. Flowers sessile, disposed along the rachis or branches of the cyme, scarlet or yellow.

- Shrubs. Flowers panicled or spicate, scarlet.

1 E. GRANDifòla (Haw, in phil. mag. sept. 1828. p. 26I.) leaves orbicularly cuneated; petioles thick; flowers in spicate vol. III.

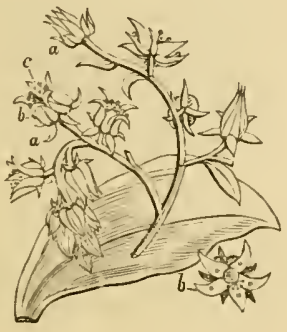

panicles. h. D. G. Native of Mexico. Swcet, fl. gard. 275. Lower leaves rosulate, all white or glaucous. Corolla of a redklish orange-colour, with a tinge of purple. Stamens white.

Great-lenved Leheveria. FI. Oct. Clt. 1828. 1']. I to $2 \mathrm{ft}$.

2 E. gibitilòra (D. C. prod. 3. p. 401 . mem. crass. p. 29. t. 5.) leaves tlat, cuneiform, acutely inucronate, crowded at the tops of the branches; panicle spreading; flowers on short pedicels along the branches of the panicle. h. D. G. Native of Mexico. Moc, et Sesse. fl. mex. icon. ined. Petals yibbous at the base, between the lobes of the calys, straight, acute, white at the base, and rather scarlet at the apcx.

Gibbous-flowered Echeveria. Fl. July, Oct. Clt.1826. Sh. 1 to 2 feet.

3 E. coccíneA (D. C. prod. 3. p. 4.01.) plant soft, pubescent ; leaves spatulately lanceolate; spikes of flowers axillary, elongated, leafy. h. D. G. Native of Mexico. Cotylèdon coccinea, Cav. icon. 2. p. 54. t. 170 . Lodd. bot. cab. t. 832. Sèdum spicàtum, Moc. et Sesse, fl. mex. icon. ined. Corolla scarlet on the outside, and yellow on the inside, or paler. Stamens yellowish.

Scarlct-flowered Echeveria. Fl. Oct. Dec. Clt. 1816. Sh. 1 to $\approx$ feet.

4. E. Racenòsa (Schlecht. et Cham. in Linnæa 2. p. 554.) plant quite glabrous; radical leaves thickish, elliptic, acute awnless, rosulate; scapes simple, naked; scales of scape alternate, and bracteas scale-formed and caducous; racemes spikeformed and elongated; flowers alternate, erect, on short pedicels. 4. D. G. Native of Mexico, on walls at Jalapa. Leaves an inch or 2 inches long. Flowers scarlet, and are in every respect like those of $E$. coccínea, as well as every other part of the plant; but the sepals are shorter and mucronate, not acuminated, and the petals are narrower.

Racemose-flowered Echeveria. Pl. $\frac{1}{2}$ to $1 \frac{1}{2}$ foot.

5 E. TERETifòlia (D. C. prod. l. c. mem. crass. p. 29. p]. 1. f. 1.) leaves terete, acute, scattered, almost loose at the base ; spikes secund, few-flowered. h. D. G. Native of Mexico. Sèdum teretifólium, Moc. et Sesse, fl. mex. icon. incd. Very nearly allied to $E$. coccinea.

Teretc-leaved Echeveria. Shrub 1 to 2 feet.

6 E. Lu'ridA (Haw. in phil. mag. 1831. p. 416.) plant rather tufted; lower leaves lanceolate-cuneated, of a livid colour: superior ones lanceolate; flowers disposed in racemose spikes. そ. D. G. Native of Mexico. Corolla as in E. grandifólia, but more scarlet.

Lurid-leaved Echeveria. Fl. Jul. Clt. 1830. Pl. 1 foot.

\section{* Plant subhcrbaccous. Flowers subcymose, ycllon.}

7 E. c.spitòsa (D. C. prod. 3. p. 401.) leaves rosulate, narrow, tongue-formed, obcuneated at the apex, and rather mucronate; flowers cymose. 4. D. G. Native of California. Cotylèdon cæespitosa, Haw. misc. p. 180. Coty. linguifórmis, Ait. hort. kew. 3. p. 109. Sèdum Cotylèdon, Jacq. fil. eclog. 1. f. 17. Cotyl, refléxa, Willd. enum. suppl. p. 2\%. Flowers yellow.

Tufted Echeveria. Fl, Jul. Aug. Clt. 1796. Pl. 1 foot.

Cult. Fine glaucous, succulent plants, which deserve to be cultivated in every collection. Their culture, propagation, and treatment are the same as that recommended for Globùlca, p. 106.

XV111. SEDUM (from sedco, to sit ; manner of growth, upon stones, rocks, walls, and roofs of houses). D. C. in bull. phil. no. 49. mem. crass. t. 1. f. 1. Sèdum and Rhodiola, Lin. spec. -Sèdum and Anacámpseros, 'Tourn. Haw.-Anacámpseros, Adans. fam. 2. p. 248.

Lis. sist. Declindria, Pentagýnia. Calyx 5-parted (f. 29.a.); sepals ovate, usually turgid, leaf-formed. Petals 5 (f. 29. b.), Q 
generally spreading. Stamens 10. Nectariferous scales entire, or hardly emarginate. Carpels 5.-Herbs or subshrubs. Stems usually branclied from the base. Sterile stems or surculi usually crowded with leaves. Leaves alternate, rarely opposite, fleshy, terete or flat, quite entire, rarely toothed. Flowers cymose, white, purple, or bluc, but usually yellow; in some species the flowers are 4 or $6-7$-petalled, and the stamens always double that number.

\section{- Leavesfat. Flowers yellow.}

1 S. Ruodiola (D. C. fl. fr. ed. 3. vol. 4. p. 386. pl. grass. c. 14.) leaves oblong, serrated at the apex, glabrous, glaucous ; root rather tuberous; stems simple; flowers corymbose, usually of 4 petals, octandrous, and dioccious from abortion. 4 . H. Native of middle Europe, on the mountains; of Siberia, and of North America, on the Arctic Sea shore, and Islands; of Newfoundland and Labrador; and on the Rocky Mountains, Kotzebue's Sound, S.c. ; in Britain, in the north of England, Scotland, and Wales, on the mountains. Rhodiola ròsea, Lin. spec. 1465. Snith, engl. bot. t. 508 . fl. dan. t. 183. Plant glaucous. The fowcrs are yellow, and are said to be sometimes hermaphrodite, but are usually of different sexes on different plants. The root is sweetish when dried; in this state a fragrant water may be distilled from it. The inbabitants of the Farro Island use it as a remedy for scurvy. In Greenland they eat it as garden stuff. A cataplasm of the fresh roots, applied to the forchead, is said to relieve the licad-ache, and to heal malignant ulcers. The specific name is from joi $o v$, a rose; in reference to the fragrance of the roots.

Rhodrola or Common Rose-root. Fl. May, July. Brit. Pl. $\frac{1}{2}$ to $\frac{3}{4}$ foot.

2 S. Asia'ticum (D.C. prod. 3. p. 401.) leaves linear-lingulate, quite entire, obtuse; umbels few-flowered; calycine segments 4, oblong, obtuse; flowers 4-petalled, hermaphrodite. 4. H. Native of Gosainsthan, in Nipaul. Rhodiola Asiática, D. Don, prod. fl. nep. p. 213. Root fleshy ; caudex very thick, 3-t inches long, turgil. Stems tufted, ascending. Leaves 1-2 lines long, glaucous. Flowers corymbose, octandrous, and tetragynous, of a golden yellow colour.

Asiatic Rose-root. Pl. $\frac{1}{4}$ foot.

3 S. elonga'tum (Led. fl. atl. 2. p. 193.) leaves scattered, oblong, almost quite entire, glabrous, hardly glaucescent; root rather tuberous; stems simple; flowers in cymose corymbs; pedicels hardly exceeding the flowers in length; nectariferous scales 3 times longer than broad; carpels recurved. 2 . H. Native of Altaia, in alpine humid places, on the edges of rivulets. Plant glaucous. Flowers yellow? hermaphrodite, but sometimes dioccious or polygamous from abortion, as in S. Rhodiola. Stamens 8 or 10 .

Elongatcd Rose-root. Fl. May, July. Pl. 1 foot.

4 S. Alta'icum; leaves scattered, obovate-lanceolate, serrated at the apex, glabrous, glaucous; root rather tuberous; stems simple; flowers in cymose corymbs ; pedicels shorter than the flowers; nectariferous scales about as long as broad; carpels erect. 4. II. Native of Altaia and Siberia. S. Rhodiola, Led. A. alt. 2. p. 194. Rhodiola Sibírica, Hortul. Flowers yellow, octandrous, dioecious or polygamous.

Aliaian Rose-root. Fl. May, Junc. Clt. 1827. Pl. $\frac{1}{2}$ foot. 5 S. HIMALE'Nsis (D. Don, prod. fl. nep. p. 212.) stem crect; leaves oval-lanccolate, flat, acute, toothed, glancous, smooth; corymbs almost simple; root thick. 4 . H. Native of Gosainsthan, in the alpine regions of the Himalaya or Emodi. Habit of $S$. Rhodiola. Flowers yellow.

Himalaya Stoncerop. Pl. $\frac{1}{2}$ foot.

6 S. AIzo'on (Lin. spec. 61\%.) leaves lanceolate, flat, serrated, alternate, glabrous; stems erect; cymes terminal, crowded. 4. H. Native of Siberia, in woods; on shady rocks, at Lake
Teletzkoi. D. C. pl. grass. t. 101.-Amm. ruth. no. 96. t. 11. Perhaps Anacámpseros Aizòon, Haw. syn. p. 112.? Flowers yellow, varying with from 4-6 petals and 8-12 stamens. Root branched, fascicled, thickish.

Evcr-living Stonecrop. Fl. Jul. Sept. Clt. 1757. Pl. $1 \mathrm{ft}$.

7 S. HY' BRIDUm (Lin. spec. 617.) leaves cuneiform, rather concave, bluntly serrated, rather crowded, alternate, glabrous; those of the branches crowded; stems ascending, rooting at the base ; cymes terminal. $4 . \mathrm{H}$. Native of Altaia and Tartary, at the bottom of the Ural mountains; on the upper Irtish. Murr. nov. comm. goett. 6. p. 35. t. 5.-Gmel. fl. sib. 4. p. 171. no. 851 . t. 62. f. 1. Anacámpseros liýbrida, Haw. 1. c. Flowers sulphur-coloured. This is not a hybrid, but a true species. $\mathrm{S}$. Altàica, Bess, enum. sem. crem. 1823.

Hybrid Stonecrop. Fl. May, Jul. Clt. 1766. Pl. 1 to $2 \mathrm{ft}$.

8 S. spatulifòlum (Hook, fl. bor. amer. 1. p. 227.) glabrous; stem erect; leaves obovate-spatulate, flattish, acute : upper ones linear; cyme terminal, leafy, trichotomous; flowers pedicellate, decandrous; petals linear-spatulate, much longer than the calyx. 24. H. Native of the north-west coast of America; common on dry rocky places of the Columbia river. Flowers yellow, very like those of S. stenopétalum. Lower parts of stems decumbent.

Spatulatc-leaved Stonecrop. P1. $\frac{1}{4}$ to $\frac{1}{2}$ foot.

9 S. Dougla'sil (Hook, fl. bor. amer. 1. p. 228.) stem erect, proliferous above from recurved branches; leaves linear-subulate, very acute, flat on the inside, and a little keeled on the back, with dry membranous edges; cymes dichotomous; flowers sessile, decandrous; petals narrow-lanceolate, twice the length of the calyx. $\odot$.H. Native of North America ; common on rocky places on the Columbia to the mountains. Flowers yellow, like those of $S$. stenopétalum.

Douglas's Stonecrop. Pl, $\frac{1}{2}$ foot.

10 S. A' LGIDUM (Led. fl, ross, alt. ill. t. 418.) leaves scattered, linear, quite entire, flat, glabrous ; root thick, of many necks ; stems numerous, simple; corymb terminal, simple; pedicels about equal in length to the flowers; breadth of nectariferous scales exceeding their length; petals longer than the stamens. 4.H. Native of Altaia, on the higher alps, about the fountains of the rivers Inja, Uba, and Sentelek, and on the mountains Kokorga, at the sides of rivulets. Flowers at first yellow, but fading to a dirty red. Allied to $S$. quadrifidum.

Algid Stonecrop. Fl. June, July. Pl. $\frac{1}{2}$ foot.

\section{* Lcaves flat. Flowers nite.}

I1 S. involucra'tum (Bieb. fl. taur. 1. p. 952.) leaves cuneiform, crenated, opposite, pubescent, ciliated; stems declinate, hairy; corymbs crowded, involucrated; petals subulate. $4 . \mathrm{H}$. Native of Caucasus, among stones, at the foot of Mount Kaischaur. Flowers white, about the size of those of S. híbridum.

Involucrated Stonecrop. Pl. I foot.

12 S. Latriòlum (Bert. amon. itin. p. 366.) leaves ovate, cordate, very blunt, serrated, glabrous, usually opposite; corymbs cymose, on long peduncles; stamens longer than the corolla. 4. H. Native of Switzerland, on the mountains; Germany, Italy, France, Sc.-Clus, hist. 2. p. 66. f. 1. S. Telèphium, var. máximum, Lin. spec. 616. S. máximum, Hoffm. germ. 1. p. 156. Flowers greenish-white. Anacảmpseros máxima, and probably A. álbicans, Haw. syn. p. II 1.

Broad-lcaved Orpine. Fl. July, Sept. Clt. I794. PI. 2 fect.

13 S. овтusı fòıum (Meyer. verz. pflanz. p. 150.) plant glabrous, green; stems crect; leaves orbicularly-obovate, obtuse, nearly quite entire, with scabrous margins: lower ones opposite; rays of cyme elongated, spreading, and leafy; flowers nearly sessile; petals acute, longer than the calyx. $4 . H$. Native of Caucasus, on the Talusch mountains, towards Perim- 
bal, at the height of 3000 feet. Flowers white. This species differs from S. latifolium, Telèphium, and $S$. Anacúmpseros in the inflorescence; and from $S$. hýbridum, involucràtum, spúrium, stoloniferum, and oppositifolium, in the erect sterns and form of the leaves.

Blunt-leared Stonecrop. Pl, 1 foot.

14 S. Pectina'tum (D. C. prod. 3. p. 403.) leaves lanceolateoblong, pectinately toothed; flowers terminal, capitate, 4-cleft. 4. 11. Native country unknown. Anacámpseros pectinàta, Haw, rev. p. 24. Petals greenish-white. Habit of P'enthòrum. Pectinated-leaved Stonecrop. Fl. April, Aug. Clt. 1818. Pl. $\frac{1}{2}$ foot.

15 S. L1'vinus (Willd. enum. suppl. p. 24.) stems ascending; leaves glaucous, oblong, somewhat attenuated at the base, glabrous, and somewhat crenated at the apex; flowers cymose, terminal. 4. H. Native country unknown. Anacámpseros livida, Haw. rev. p. 25. Flowers white.

Livid Stonecrop. Fl. June, Aug. Clt. 1816. Pl. $\frac{1}{2}$ foot.

16 S. crucia'tum (Desf. cat. p. 162. D. C. fl. fr. 4. p. 389.) leaves flattish, thick, convex beneath, 4 in a whorl; stems branclied at the base, diffuse, ascending, pubescent at the apex; flowers subpanicled, on long pedicels; petals acuminated. $\boldsymbol{4}$. H. Native of Piedmont, in mountain valleys about Monregal. Balb. misc. p. 23. t. 6. Reich. icon. 3. f. 438. Flowers white, almost like those of $S$. Cepce'a.

Cross-leaved Stonecrop. Pl. $\frac{1}{2}$ foot.

17 S. Magelle'nse (Ten. fl. neap. pr. p. 26.) stem erect, or ascending, herbaceous; leaves obovate-oblong, sessile; flowers racemose, scattered, pedunculate; petals lanceolate, acute. $\mathcal{H}$. H. Native of Samnius, on many of the mountains, in shady groves, and on mossy rocks, and at the roots of old trees; of Naples, in the groves of Magella. Racemes terminal, nodding before expansion. Flowers dirty white.

Magella Stonecrop. Pl. from $\frac{1}{8}$ to 1 foot.

18 S. oppositifòlium (Sims, bot. mag. t. 1807.) leaves cuneately-spatulate, toothed above, opposite, puberulous on the margins, rib, under side, as well as on the stems; cymes sessile, terminal, crowded; petals oblong, acute. 4. H. Native of Caucasus. S. denticulàtum, Donn, cat. ed. 8. Anacámpseros ciliàris, Haw. syn. 113. rev. p. 25. Flowers white. Stems decumbent, rooting; floriferous ones erect. Crássula erenàta, Desf. choix. cor. Tourn, t. 58. ann. mus. 11. t. 46 .

Opposile-leaved Stonecrop. Fl. Ju]. Sept. Clt.? Pl. dec.

19 S. Lanceola'tum (Torrey. in ann. lyc. new york. 2. p. 205.) leaves flat, rather alternate : lower ones crowded, oblonglanceolate, acutish, glabrous, with glandularly serrulated edges; stems branched, assurgent; flowers in cymose corymbs; petals lanceolate, spreading. 4 . H. Native of North America, near the Rocky Mountains. Stem a little branched at the base, creeping. Leaves about half an inch long. Flowers white, decandrous. Petals 7 .

Lanceolate-leaved Stonecrop. Pl. cr.

20 S. terna'tum (Miclix. f. bor. amer. 1. p. 277.) leaves flat, glabrous, quite entire ; lower leaves obovate, attenuated at the base, 9 in a whorl, upper ones sessile, lanceolate, inordinate; cymes trifid; flowers sessile along the branches; petals oblong, acute. 2. H. Native of Pennsylvania, Virginia, and $\mathrm{Ca}$ rolina, on rocks, and on the rocks about Niagara and Lake Erie, common. Ker. bot. reg. t. 142. Sims, bot. mag. 1977. S. portulacoìdes, Willd. enum. p. 484. S. defíciens, Donn, hort. cant. S. octogònum, Hortul. Anacámpseros ternàta, Haw. Flowers white.

Ternate-leaved Stoneerop. Fl. Ju. Aug. Clt. 1789. Pl. $\frac{1}{4} \mathrm{ft}$.

21 S. poptlifoldum (Lin. fil. suppl. p. 242.) leaves scattered, fiat, coarsely toothed, petiolate, glabrous : lower ones cordate: upper ones ovate; stems much branched, erect, shrubby: co- rymbs rather panicled, terminal, many-flowered; petals oblonglanecolate. h. H. Native of Siberia, on the mountains, in many parts. D. C. pl. grass. t. 110. Curt. bot. mag. t. 211. -Pall. itin. 3. p. 730 . append. no. 89. t. O. f. 2. Flowers white; anthers purple. There is a variety of this plant with ovate leaves and few flowers, and is perliaps referrible to $S$. Notarjánni.

Poplar-leaved or Shrubby Stoneerop. Fl. July, $\Lambda$ ug. Clt. 1780. Shrub 1 foot.

22 S. Notarja'Nni (Ten. A. neap. 1. p. 245. t. 40.) stems ascending, suffruticose ; leaves petiolate, flat, ovate, bluntly and sinuately toothed, glabrous; Howers solitary or few, terminal; petals lanceolate. h. H. Native of Naples, near Funda, among calcareous rocks. S. Notarjánni, Ten. cat. 1819. p. 49. Very like $S$. populif oltum, but differs in the stems being almost herbaceous, in the leaves not being cordate, in the flowers being nearly solitary, and in the anthers being yellow.

Notarjanni's Stonecrop. Shrub 1 foot.

23 S. stella'tum (Lin. spec. 617.) leaves flat, roundish, angularly tootherl, tapering into the petioles, opposite, or alternate, glabrous ; flowers axilary, sessile along the branches of the cyme; petals lanceolate. $\odot$. H. Native of the Islands of Corsica, Melos, and of Italy, and the south of Switzerland. Smith, fl. græe. 446. Comm. hort. 7. t. 2. Col. phyt. 32. t. 11. Petals white, tinged with red.

Starry-flowered Stonecrop. Fl. Ju. Jul. Clt. 1614. Pl. $\frac{1}{2} \mathrm{ft}$.

24. S. CEP.E'A (Lin. spec. 617.) stem herbaceous, terete, pubescent; leaves flat, quite entire; lower ones rather spatulate : upper ones ohiong or linear; flowers panicled; petals ending in an awned point. $\delta . H$. Native of middle and south Europe, in hedges and among bushes. Smith, fl.græe. 447.-Clus. hist. 2. p. 68. with a figure.-Mor. hist. 3. p. 4.73. sect. 12. t. 7. f. 37. -S. paniculàtum, Lam. - Anacámpseros Cepæ'a, Haw. Flowers white.

Var. $\beta$, galioides (D. C. prod. 3. p. 404.) upper leaves nearly opposite: lower ones in whorls, spatulate. S. galioìdes, All. pedem. no. 1742 . t. 65 . f. 3. S. verticillàtum, Latour, but not of $\mathrm{Lin}$.

Var. $\gamma$, alsincfolium (D. C. l. c.) leaves oval, for the most part alternate. S. alsinef òlium, All. ped. no. 1740 . t. 22. f. 2. bad. Petals acuminated.

Cepaea or Purslanc-leaved Stonecrop. Fl. July, Aug. Clt. 1640. Pl. $\frac{1}{2}$ to 1 foot.

25 S. spatula'tum (Waldst. et Kit. pl. rar. hung. 2. p. 108. t. 104.) stem herbaceous, terete, pubescent; leaves flat, entire, nearly all alternate, spatulate : upper ones cuneiform; flowers panicled; petals ending each in an awn. $ォ$. H. Native of Hungary. S. Cepæ'a, var. $\gamma$, spatulàtum D.C. prod. 3. p. 404. Flowers white.

Spatulate-leaved Stonecrop. Fl. Ju. Jul. Clt. 1815. Pl. $1 \mathrm{ft}$. 26 S. tetrapiy'llum (Smith, f. græc. t. 448. prod. 1. p. 809.) plant pubescent; leaves spatulate, quite entire, four in a whorl; stem branched at the base; peduncles axillary, fewflowered, the whole forming a terminal panicled raceme; petals ending in a long point. $\$ . H$. Native of Greece. Ray. syn. ext. 233. Petals white, with a red keel.

\section{Four-leaved Stonecrop. Pl. $\frac{1}{2}$ foot.}

27 S. ERIoca' RPum (Smith, f. græe. t. 449.) stem twisted, pubescent above; leaves smooth, alternate, oblong, obtuse ; stems cymose; flowers axillary, nearly sessile; petals mucronated; calys glabrous; ovaries hairy. ๑. H. Native of Greece. Flowers red.

II'oolly-fruited Stonecrop. Fl. June, July. Clt. ? Pl. $\frac{1}{4}$ to $\frac{1}{2} \mathrm{ft}$.

\section{* * Lcaves flat. Floners purple or red; rarcly blue.}

28 S. CYANE'rM (Rud. mem. petersb. 1811.p.351. t. 2. f. 2.) Q 2 
stems simple; Jeaves flat, nearly lincar, entire, sessile; cymes leafy. 8. 11. Native of Eastern Siberia. Flowers blue.

Bluc-flowered Stonecrop. Pl. $\frac{x}{2}$ foot.

29 S. delto'́deum ('Ten. cat. 1819 . p. 49.) stems erectish; leaves alternate, fat, deltoidly-cuneiform, unequal, crenated, and toothed; cymes lateral. $\odot$. H. Native of the kingdom of Naples, on Monte Novo and Goat's Island. Flowers purple. 'Tlie rest unknown.

Delloid-leaved Stonecrop. Pl. $\frac{1}{2}$ foot.

30 S. sempervivum (Led. ex Spreng. syst. 2. 1). 434.) leaves spatulate-ovate, acute, flat, quite entire, pubescent : lower ones collected into a circle: cauline ones half stem-clasping; stems simple; corymb rather panicled; petals lanceolate-subulate. If. H. Native of Iberia. S. sempervivoides, Fisch, mss. Bieb. suppl. p. 318 . Sims, bot. mag. t. 3474 . Habit of a species of Sempervicum. Flowers deep purple, showy, size of those of $S$. spùrium.

Ilouscleek-like Stonecrop. Fl. Jul. Aug. Clt. 1823. Pl. $\frac{\pi}{2} \mathrm{ft}$.

31 S. нлматo'drs (Mill, dict. no. 15.) stems erect, fleshy; leaves oratc, quite entire: upper ones stem-clasping; corymbs terminal. 4. H. Native of Louisiana. There are two varicties of this plant, one with white and another with purple flowers. Said to be allied to S. Tclèphium and S. Anacámpseros.

Bluody Orpine. Fl. July, Sept. Pl. 1 to 2 feet.

82 S. Axacánipseros (Lin. spec. 616.) leaves cuneiform, obtuse, quite entire, almost sessile, alternate, flat, glabrous; stems decumbent; flowers corymbose. 4. Native of Provence, Piedmont, Savoy, Switzerland, \&c. on rocks among the mountains. D. C. pl. grass. t. 33 . Curt bot. mag. t. 118 . -Lob. jcon. 1. t. $\$ 90$. f. 2. S. rotundif òlium, Lam. dict. fl. fr. 3. p. 82. Anacámpseros sempervirens, Haw. syn. p. 112. Flowers purple.

Anucampseros or Evergreen Orpine. Fl. July, Aug. Clt. 1596. Pl. trailing.

33 S. PU't.cHRum (Michx. fl. bor. amer. 1. p. 277.) stems assurgent, glabrous; leaves scattered, linear, obtuse; cymes of many spikes; flowers sessile, of 4 petals and 8 stamens. $4 . \mathrm{H}$. Native of the mountains of Virginia, Carolina, and Georgia, on the banks of the river Ohio. Flowers purple. Allied to S. refléxum, according to Pursh, but according to Nutt. to $S$. ternàtum. Fair Stonecrop. Pl. trailing.

34. S. DENTA'Tum (D. C. prod. 3. p. 403.) leares alternate, glabrous, cuncate-ohovate; upper ones pinnatifidly toothed dowiw ards, and more petiolate; cyme sessile, terminal. 2 . H. Native country unknown. Anacámpseros dentàta, Haw. rev. p. 26. Allied to S. spùrium and $S$. oppositifolium. Perhaps the same as S. dentàtum, Donn, lıort. cant. Flowers purple.

Twothed-leaved Stonecrop. Fl. Ju. July. Clt. 1810. Pl. $\frac{1}{4} \mathrm{ft}$.

$35 \mathrm{~S}$. IBE' ricum (Stev. in Bieb. fl. taur. suppl. p. \$12.) leaves cuneiformly obovate, repandly crenated, petiolate, with scabrous margins: cauline leaves opposite; cymes leafy, dichotomous; flowers nearly sessile; petals subulate. $4 . \mathrm{H}$. Native of the north of Iberia, in subalpine places. Flowers reddish. Habit of $S$. spurium.

llberian Stonecrop. Pl. $\frac{1}{4}$ foot.

36 S. nòseum (Stev. mem. soc. nat. cur. mosq. 3. p. 263.) leaves spatulately ohovate, opposite, quite entire, feshy, glabrous, imbricated at the tops of the surculi; stems much branclied, loose, creejing; cymes terminal ; petals lanceolatesubulate. 24. II. Native of Eastern Caucasus, among stones. Bieb. suppl. 314. Flowers almost like those of $S$. spurium, of an elegant rose-colour.

Rose-coloured-flowered Stonecrop. Pl. $\frac{1}{4}$ to $\frac{1}{2}$ foot.

97 S. su'vium (Bicb. fl. taur. 1. p. 852.) leaves cuneiformlyobovate, crenately toothed in front, pubescent beneath, somewhat ciliated; cauline leaves opposite; radical ones in fascicles usually alternate; corymbs terminal, compound ; petals lanceolate. $4 . \mathrm{H}$. Native of Caucasus, among rocks. Sims, bot. mag. t. 2370.-Buxb. cent. 5. p. 33. t. 61. f. 2. Anać́mpseros spưria, Haw, rev. p. 25. Flowers purple.

Spurious Stonecrop. Fl. July, Sept. Clt. 1816. Pl. $\frac{1}{4}$ foot.

38 S. EwE'ksi (Led. 月. alt. ill. t. 58. f. alt. 2. p. 191.) leaves opposite, obsoletely denticulated, adnate: inferior ones broadelliptic : superior ones sessile, cordate; corymbs terminal, compound; petals lanceolate, acute, a little longer than the stamens. 24. H. Native of Altaia, at the rivers Uba, Buchtorm, and Kokoryo; and at the Golden Lake Teletz-koe Osero. Flowers purple. Stem rooting at the base.

Ewers's Stonecrop. Fl. July, Aug. Clt. 1829. Pl. $\frac{1}{4}$ foot.

39 S. TeLEPnioides (Michx. fl. bor. amer. 1. p. 324.) leaves orate, flat, acutish at both ends, toothed; corymb compound, in fascicles. 2.H. Native of Virginia and Carolina, on rocks among the mountains. Anacámpseros telephioides, Haw. syn. 114. Flowers pale purple. Hardly distinct from S. Telèphium according to Nuttall.

Orpine-like Stone-crop. Fl. July, Sept. Clt. 1810. Pl. I to 2 feet.

40 S. Tele'pnum (Lin. spec. 616. $a, \beta$, et $\gamma_{\text {s }}$ ) leaves oblong or oval, attenuated at the base, flat, toothed, glabrous; stems erect; cymes corymbose, terminal; stamens not exceeding the corolla. 4. H. Native of Europe, in exposed places; in Britain on the borders of fields, or in bedges or bushy places, on a gravelly or chalky soil. Smith, eng. bot. 1 y19. Curt. lond. 3 . t. 25, 210. Oed. f. dan. 686. Blackw. 191. There are several varieties of this plant :-1, leaves opposite (Anacámpseros álbida, Haw. syn. p. 111.) -2, leaves 3 in a whorl (Anacámpseros triphýlla, Haw. syn. p. 111. Sèdum triphýllum, Haw.)-3, leaves alternate; flowers purple (D.C. pl. grass. t. 92. Anacámpseros purpùrea, Haw. syn. p. 111. Fuschs, hist. 801 . with a figure), and white (Fuschs. hist. l. c. t. 800. Anacámpseros vulgàris, Haw. syn. p. 111.)-4, leaves oblong-lanceolate, sharply toothed (Anacámpseros argùta, Haw. Sèdum argùtum, Haw.) -5, leaves cuneately obovate, slightly 4-toothed towards the apex; stems decumbent (Anacámpseros paúcidens, Haw. rev. p. 24.). All these are referrible to this species. A decoction of the leaves in milk is a forcible diuretic. It has been given with success in the cure of hæmorrhoids.

Orpinc. Fl. July, Sept. Britain. Pl. 2 to 3 feet.

41 S. vulga're (Link. enum. pl. hort. berol, 1. p. 437.) leaves nearly opposite, ovate-clliptic, obtuse, rounded at the base, exactly sessile, bluntly and dentately serrated; panicle subcorymbose; stamens shorter than the corolla. 24. H. Native of Siberia, on the mountains near Kolywan; and also in sandy woods about Barnaoul. S. Telèphium $\alpha$, Willd. spec. 2. p. 760 . S. Telèphium, Patrin, fl. barn. mss. Bieb. fl. taur. 1. p. 351. S. Telèphium, Besser. enum. pl. voll. p. 17. S. Telèphium $\gamma$ mìnus, Falk, topog. 2. no. 52\%. Anacámpseros vulgàris, Haw. succ. p. 112. Flowers whitish or purplish.

Common Orpine. Fl. June, Sept. Clt.? Pl. 1 to 2 feet.

42 S. verticilla'tum (Lin. amoen. 2. p. 352. t. 4. f. 14. exclusive of the synonyme of Ray, stem erect; leaves 4 in a whorl, lanccolate, serrated; racemes axillary, few-flowered, shorter than the leaves. 4. H. Native of Kamtschatka. Leaves a finger in length. Flowers small, purple? or pink? This species is allied to S. Teliphium according to Steven.

Whorlcd-leaved Orpine, Fl. July, Sept. Clt.? PI. I foot.

\section{** * Lcaves terete. Flowers white.}

43 S. Morane'nse (H. B. et Kuntl, nov. gen. 6. p. 44.) stems branched, creeping at the base, ascending, glabrous; leaves scattered, loosened at the base, thick, fleshy, obtuse ; cymes secund; flowers nearly sessile; petals 5 , oblong-linear, bluntish. $4 . \mathrm{H}$. 
Native of Mexico, near Real de Moran. The colour of the flowers is unknown, but the plant is said to be very like $S$. A'nglicum, and the flowers are therefore perhaps white.

Moran Stonecrop. Pl. $\frac{1}{8}$ foot.

41 S. A'xglicum (Iluds. angl. p. 196.) stems ascending, humble, branched at the base; leaves crowded, alternate, short, ovate, gibbous, loosened at the base, glabrous; cyme branched, few flowered; flowers sessile along the branches; petals acuminately awned. 24. H. Native of Norway, Britain, west of France, Portugal, on walls, roofs of liouses, meadows, on cxposed stony hills, and among rocks. In England on the sandy or rocky sea coast, as well as upon mountains ; in Scotland and the nortl of England frequent. Smith, engl. bot. 171. S. rùbens, Occl. fl. dan. t. 82. Lightf. scot. 235. S. arenàrium, Brot. 11. lus. 2. p. 212. phyt. t. 1. f. 2. S. Guettárdi, Vill. dauph. 3. p. 678 . in a note. S. atràtum, Aubl. S. ánnuum, Gunn. but not of Lin. Petals white, witl a red keel.

Iar. $\beta$, microphyllum; plant very small.

lar. $\gamma$, Hibérnicum; plant large, rather downy.

English Stonecrop. H]. June, Aug. Britain. PI. $\frac{1}{8}$ foot.

45 S. oblo' NGum (Haw. rev. p. 29.) leaves ovate, parabolically-oblong, convex beneath, 4 lines long, rather distant; scales of germens brown. \%. H. Native of England. Petals white, with a red keel. Very like $S$. anglicum, but twice the size, the leaves fewer, and more distant.

Oblong-leaved Stone-crop. Fl. June, Aug. Brit. Pl. $\frac{1}{8} \mathrm{ft}$. 46 S. Atra'tum (Lin. spec. 1673.) stem erect, branched at the base; leaves scattered, terete, obtuse, glabrous, loosened at the base; cymes corymbosely fastigiate; petals ovate, hardly mucronate; carpels stellately spreading. $\odot$. H. Native of the Alps of Europe and the Pyrences, among rocks. D. C. pl. grass. t. 120. All. pedem. t. 65. f. 4. Jacq. aust. 1. t. 8 . S. hamatódes, Scop. carn. 4. p. 323. but not of Mill. Petals small, white. Plant red when old. Carpels dark red.

$\operatorname{Var} \beta$; lower branches lying on the ground. Native of the Alps. D. C. fl. fr. ed. 3. vol. 4. p. 391. exclusive of the synonymes.

Dark Stone-crop. Fl. Aug. Clt. 1795. Pl. $\frac{1}{8}$ foot.

47 S. GLAu'cum (Waldst. et Kit. pl. rar. hung. 2. p. 198. t. 181.) stem erectish, puberulous ; leaves nearly terete, glaticous, a]ternate; sterile branches crowded, erect; cymes trifid, fewflowered; petals 6 , mucronate. $\succsim$. H. Native of Hungary, on sandy hills. Willd. enum. p. 486. S. Hungáricum, Poir. S. Andersonii, G. Don in Loud. hort. brit. p. 184. Aceording to Willd. this species differs from $S$. séxfidum in the stem being a little branched at the base, in the petals being 1-nerved, not finely 3-nerved. Flowers sometimes hexandrous.

Glaucous Stonecrop. Fl. June, July. Clt. 1816. Pl. $\frac{1}{4} \mathrm{ft}$. 48 S. SE'XFidum (Bieb. fl. taur. suppl, no. 874.) stem erectish, branched, when young rather procumbent; lcaves nearly teretescattered, spreading, glaucous, glabrous ; cymes somewhat panicled; flowers sessile along the branches; petals 6 , acuminated. $\odot$. H. Native of Caucasus, on rocks. Willd. enum. 487. Flowers white; anthers bay-coloured. The flowers contain also 12 stamens, and are allied to $S$. rùbens. The petals are said to be 3 -nerved, the lateral nerves very fine.

Six-cleft-flowered Stonecrop. Fl. June, July. Clt. 1816. Pl. $\frac{1}{8}$ foot.

49 S. ANDEgave'NSE (D. C. prod. 3. p. 406.) stem erect, simple at the base, trichotomous at the apex; leaves gvate, obtuse, erect, fleshy, glabrous: lower leaves opposite, the rest. alternate; flowers pentandrous in the forks, and scattercd and sessile along the branches; petals ovate, acutish. $\odot . H . ~ N a-$ tive of Andegavany, on walls and on schistous rocks. S. atràtum, Bast. ess. fl.p. 167. exclusive of the synonyme. Crássula Andegavénsis, D. C. suppl. fl. fr. p. 522. Truly distinct from
S. alritum, but perlıaps only a pentandrous variety of $S$. dasyphijllum, and the flowers are probably white like it.

Andesatcrny Stonecrop. Pl. $\frac{1}{4}$ foot.

50 S. DASYPiy'Llum (Lin. spcc. p, 618.) stems weak, decumbent; leaves ovate, nearly globose, flesly, glabr us, opposite, rarely alternate; sterile branches rather imbricated; cymes pu. berulous, few-flowered, terminal; petals bluntish. 4.H. $\mathrm{Na}$ tive of Europe, on walls and rocks. In Enyland plentiful ahout London, as at IJammersmitl, Kew, Chelsea, Sc. ; on walls at Malton, Yorkshire, and at Clifton near Bristol. Jacq. hort. vinc]. t. 153. D.C. pl. grass, t. !3. Smith, engl. bot. t. 656. Curt. fl. lond. 3. t. 26.147. S. glaúcum, Lam. 11. fr. Flowers white, sometimes composed of 6 petals? Perhaps S. reticulatum, Schrank. bot. beob. in dennsk. baier. ges. 1815. is different from $S$. dasyphýllum. Plant glaucous.

Thick-leaved Stonecrop. Fl. June, July. Brit. Pl. $\frac{1}{4}$ foot. 51 S. BRevifólius (D. C. rapp. voy. 1808, p. 79, suppl, no. 3615. a, mem. crass. t. 4. f. A.) stems fruticulose, glabrous, twisted at the base; leaves opposite, ovate, obtuse, short, thick; cymes quite glabrous, loose, terminal; petals bluntish. 4 . H. Native of the Pyrenees and of Corsica, among rocks in dry pastures. S. sphæ'ricum, Lapeyr. abr. 1813. p. 259. Sepals of calyx thin, not as in $S$. dasypliyllum (to which species it is nearly allied) thick.

Short-lcaved Stonecrop. Pl. $\frac{1}{4}$ foot.

52 S. Córsicum (Duby, in D. C. syn. fl. fr. ed. 2.) stems ascending, branched at the base, twisted; leaves ovate, obtuse, hispid; sterile shoots crowded; cymes terminal, few-flowered, glabrous; petals acutish. 4. H. Native of Corsica, where it was detected by $\mathrm{Ph}$. Thomas, on the walls of the city of Corte; and of Sardinia, at the town of Jessu. Flowers smaller than those of $S$. dasyphyllum, appearing of a dirty pale purple in the dried specimen; but white in the recent state.

Corsican Stonecrop. Pl. $\frac{1}{4}$ foot.

53 S. inrsu'tum (All. ped. no. 1754. t. 65. f. 5.) floriferous stems erect, nearly naked; leaves remote, alternate, oblong-cylindrical, obtuse, hairy ; sterile stems crowded ; cymes terminal, few-flowered; petals acuminately awned. ‡. H. ex All. $\mathcal{\psi}$. H. ex Pourr. Native of the Alps of Piedmont, Provence, Cevennes, Pyrences, and on the mountaius of Leone and Corsica, especially among schistous rocks. S. globiferum, Pourr. act. tol. 3. p. 327. S. híspidum, Poir. dict. 4. p. 633. but not of Desf. Petals white, downy, marked with a purple line.

Hairy Stonecrop. Pl. $\frac{1}{4}$ foot.

54 S. pılòsum (Bieb. fl. taur. 1. p. 352.) stems ascending, leafy; leaves oblong, obtuse, rather fleshy, hairy, alternate; radical ones in fascicles; cymes terminal, corymbose; petals lanceolate, hardly twice the length of the sepals. $4 . H$. Native about the port of Caucasus, among rocks. Allied to $S$. hirsutum, but differs in the leaves being flattish, in the sepals of the calyx being twice the length, and in the duration being perennial, not biennial.

Pilose Stonecrop. Pl. $\frac{\mathrm{I}}{4}$ foot.

55 S. Hispa'nicum (Lin. spec. 618.) stem erect, branched, glabrous; leaves scattered, terete, acutish, glaucous; sterile stems rosulate, crowded; cymes branched; flowers sessile, along the branches of the cyme; petals 6 , acuminately awned. $4 . \mathrm{H}$. Native of Spain, Switzerland, and the south of Germany. Jacq. aust. 5. t. 47.-Dill. hort. elth. 2. p. 332. S. aristàtum, Tenore, fl. neap. 1. p. 250. Petals white, with a dirty red keel. Carpels glabrous. Very like S. glaúcum and $S$. rùbens, but the root is perennial.

Spanish Stonecrop. Fl. June, July. Clt. 1732. Pl. $\frac{1}{2}$ foot. 56 S. A'LBUm (Lin. spec. 619.) branches perennial, rooting, when young rather puberulous; leaves ovately club-shaped, green, nearly terete, glabrous; cymes branched, terminal, sub- 
corymbose; petals bluntish. 24. H. Native of Europe, in dry meadows, on walls and rocks. In England on walls and roofs, not common; at Kentish Town and Bromley, Middlesex; on rocks about Great Malvern, Worcestershire; upon walls at Peterborough ; but rare in Scotland. Smith, engl. bot. t. 578. Curt. lond. 1. t. 31. Oed. A. dan. t. 66. All. ped. 1751. t. 65. f. 2 . S. álbum var. $\gamma$ túrgidum, D. C. prod. 3. p. 406. Flowers cymose, white.

White Stonecrop. Fl. June, July. Britain. Pl. $\frac{1}{4}$ foot.

57 S. mora'NTHUM (Bast. in litt. D. C. suppl. fi. fr. 3613. Haw, in phil. mag. Sept. 1831, p. 415.) branches perennial, rooting, slightly puberulous; leaves clavately oblong, green, nearly terete, glabrous; cymes branched, terminal, subcorymbose; petals bluntish. 4 . H. Native of France, in Andegaveny. In England ncar Gloucester. S. túrgidum, Bast. ess. p. 167. S. álbum $\beta$ micrántlinm, D. C. prod. 3. p. 406 . Very like $S$. álbum, but is 2 or 3 times larger; flowers more numerous, and the petals narrower.

Small-flowered Stonecrop. Fl. June, July. Brit. Pl. $\frac{1}{4} \mathrm{ft}$.

58 S. GRA'cile (Meyer, verz. pflanz. p. 151.) plant glabrous and grcen; stems herbaceous, diffuse; leaves subulate, bluntish, loose at the base, those of the sterile branches imbricated ; rays of cyme elongated, much spreading ; flowers decandrous, almost sessile; petals acuminated, longer than the calyx; style rather longer than the breadth of the acute capsule. $\%$. H. Native of Cancasus. Flowers white.

I'ar. a, minus (Meyer, l. c.) flowers smaller. On Mount Gutgora at the altitude of 3300 feet.

I'ar. $\beta$, majus (Meyer, l.c.) flowers almost twice the size of those of var. $a$. On the Talusch Mountains, at the altitude of 1400 to 2700 feet.

Slender Stonecrop. Pl. diffuse.

59 S. TeRETifòlum (Lam. fi. fr. 3. p. 84. Haw, in phil. mag. Scpt. 1831, p. 415.) branches elongated, rooting, perennial, quite glabrous; leaves equally terete, rather elongated, a listle depressed, green, glabrous ; cymes branched, terminal, subcorymbose; petals bluntish. 24. H. Native of Europe, on walls, rocks, and in dry pastures. In England near Hereford. S. álbum, D. C. prod. 3. p. 406.-Fuschs, hist. 35. with a figure. Oed. A. dan. t. 66. D. C. pl. grass. t. 22. S. teretifolium $a$, Lam. f. fr. 3. p. 84. Flowers white.

T'crete-lcaccd Stonecrop. F\}. June, July. Brit. P], $\frac{1}{2}$ foot. 60 S. Atróvi (D.C. prod. 3. p. 407.) stems erect, a Jittle crceping at the base; leaves semi-cylindrical, short, remote, and arc, as well as the stem, glabrous; cyme terminal, somewhat corymbose, many-flowered; petals acute. 4 . H. Native on the top of Nlount $\Lambda$ tlıos. S. túrgidum, D. Urv. enum. p. 51 . exclusive of the synonymes. Flowers white, like those of $S$, illum, but the petals are acnte and distinet.

Athos Stonecrop. Pl. $\frac{1}{2}$ foot.

$$
\text { *.. Leaves tcrete. Floners red or blue. }
$$

61 S. carnu'lecm (Vahl. symb. 2. p. 51.) stem flat on the ground at the base, ascending ; leaves oblong, alternate, obtuse, looscned at the liase; cymes bifid, glabrous; petals 7, obtuse. $\odot$. H. Native of 'Iunis, in the fissures of rocks. Shaw, itin. 550. with a figure. Sims, bot. mag. 2224. Ker. bot. reg. 520 . S. azùreum, Desf. f. atl. 1. p. 362. Flowers FIG. 28 .

not bluc, but at first purplish, and fading to blue (f. 28.).
Blue-flowered Stonecrop. Fl. July, Aug. Clt. 1822. Pl. $\frac{1}{8}$ foot.

62 S. neptape'talum (Poir. voy. barb. 2. p. 169. dict. 4. p. 630.) stems ercct, branchied at the apex; leaves ovate-oblong, scattered, depressedly gibbous; cymes panicled; petals 7 , acuminated. $\odot$. H. Native of Barbary, Corsica, and Malta, on rocks by the sea-side. D.C. f. fr. 4. p. 392. Flowers purplish as in $S$. coerùleum, fading to blue. S. heptapétalum, Horn. hort. hafn. suppl. p. 138. said to be originally from the Russian empire, is perhaps distinct from this species, but is not sufficiently known.

Seven-petalled Stonecrop. Pl. $\frac{1}{4}$ foot.

63 S. ввастеA'tuи (Viv. fl. Jyb. 24. t. 8. f. 3.) stems erect, branched at the apex, beset with spreading hairs, as well as the leaves; leaves alteruate, linear, thick, obtuse; cymes trichotomous; flowers on short pedicels along the branches of the cyme; petals 5, elliptic, keeled. $\odot . H$. Native of the Great Syrtus, in Lybia on the sea shore. The colour of the flowers agrces with that of $S$. corùleum, but the habit is that of $S$. Hispánicum. Nectariferous scales emarginate.

Bracteated-flowered Stonecrop. Pl, $\frac{1}{4}$ foot.

64. S. viLlòsum (Lin. spec. 620.) stem erect, almost simple, beset with viscid hairs; leaves semi-terete, rather remote, erect, also beset with viscid pili; cymes terminal, few-flowered; petals acutish. ○. H. Native of Europe, in boggy places. In England in wet mountainous pastures, and the clefts of moist rocks ; in the north of Westmoreland, Durham, and the nortli-west part of Yorkshire, not unfrequent. More abundant in Scotland.Smith, engl. bot. t. 394. Oed. f. dan. t. 24. D. C. p]. grass. t. 70.-Mor. hist. sect. 12. t. 8. f. 48.-Petiv. brit. t. 42 . f. 7 . Flowers pale red.

I ar. $\beta$, pentândrum (D. C. A. fr. suppl. p. 524.) stamens 5 (especially those that are epipetalous are abortive) or 6 ; the 4 epipetalous ones of which having vanished.

Villous Stonecrop. Fl. June, July. Britain. Pl. $\frac{1}{8}$ to $\frac{1}{4} \mathrm{ft}$. 65 S. RU'BENS (D. C. prod. 3. p. 405.) stem erect, branched; leaves oblong, obtuse, nearly terete, sessile, spreading, glabrous; cymes branched, pubescent; flowers sessile, unilateral along the branches of the cyme, pentandrous; petals 5 , acuminately awned. $\odot$. H. Native of south and middle Europe, in cultivated sandy ficld̀s. Crássula rùbens, Lin. syst. veg. p. 253. D. C. pl. grass. t. 55. S. rùbens $\beta$ pentándrum, D. C. prod. 3. p. 405 . Flowers pale red. Mature carpels puberulous. The epipetalous stamens are all or for the most part abortive, and therefore the flowers are pentandrous.

Reddening-flowered Stonecrop. Fl. May, June. Clt. 1769. Pl. $\frac{1}{4}$ to $\frac{1}{2}$ foot.

66 S. PUBE'RUIUM (D. C. mem. crass. p. 33.) stems erect, branched, pubcrulous; leaves scattered, terete, acutish, glabrous; cymes branched; flowers scssile along the branches of the cyme; petals 6 , acuminately awned. $\odot$. H. Native of Calabria. This species comes very near $S$. pallidum and $S$. riubens.

Puberulous Stonecrop. Pl. $\frac{1}{4}$ foot.

67 S. PA'LLIDUM (Bieb. fl. taur, 1. p. 353.) stem erect, branched; leaves oblong, obtuse, nearly terete, spreading, glabrous; cymes branched, pubescent; flowers sessile, unilateral along the branclies of the cyme, decandrous ; petals acuminately awned. $\odot$. H. Native of Caucasis. Flowers pale red or white. Mature carpels puberulous.

Pale Stonecrop. F]. Junc, July. Clt. 1817. Pl. $\frac{1}{4}$ foot.

$68 \mathrm{~S}$. cespitòsum (D. C. prod, 3. p. 405.) leaves ovate, turgid, imbricated, glabrous; stems nearly simple, glabrous; flowers Jateral, sessile, solitary; carpels stellately spreading. $\odot . \mathrm{H}$. Native of Spain, Provence, Tauria, in exposed places. Magn. bot. p. 238. and 237. with a figure. Crássula Magnòlii, D. C. f. fr. suppl. no. 3604. Tillæ'a rùbra, Gouan. Lort. p. 77. 
Tillæ'a erécta, Sauv. monsp. p. 129. Crảssula verticillàris, Lin. mant. 261.? Crássula caspitòsa, Cav. icon. t. 69. f. 2. Bieb. fl. taur. 1. p. 257 . Flowers pale red. The 5 fertile stamens alternating with the petals, and the rudiments of the 5 sterile ones in front of the petals.
Tufted Stonecrop.

$$
\text { Fl. June, July. }
$$
Clt. 1788. Pl. $\frac{1}{4}$ foot.

\section{* Laves terete. Flowers yellow.}

69 S. QUADRI'FIDUM (Pall. itin. 3. p. 730, append. no. 90. t. P. f. 1.) leaves scattered, terete, bluntish ; root thick, of many necks ; stems numerous, erect, simple ; corymbs terminal, fewflowered, simple; pedicels about equal in length; lengtls of nectariferous scales exceeding the breadth; flowers octandrous, 4-cleft; stamens a little longer than the petals. 4 . H. Native of Dahuria, the Ural Mountains, and Altaia, in lumid stony places, on the tops of the Alps. Pall. ed. gall. in 8 vo. vol. 8 . p. 311 t. 104. f. 4. S. quinquuéfidum and S. hexapétalum, Haw. rev. p. 26.? Flowers yellow.

Quadrifi-flowered Stonecrop. Fl. July. Clt. 1800. Pl. $\frac{1}{4} \mathrm{ft}$.

70 S. A'cre (Lin. spec. 619.) stems rather creeping at the base; branches erect; leaves ovate, adnate, sessile, gibbons, erectish, alternate, glabrous; cymes trifid; flowers sessile along the branches of the cyme; petals lanceolate, acuminated. $4 . \mathrm{H}$. Native of Europe, common on walls, roofs of houses, rocks, and dry sandy ground; plentiful in Britain. Bull. herb. t. 30. 1. C. pl. grass. t. 117. Sinith, engl. bot. 859 . Woodv. med. bot. t. 231. Curt. lond. 1. t. 32. Flowers yellow. The whole plant is acrid, and chewed in the mouth has a hot biting taste; whence, and from its common place of growth, it has the name of wallpepper. Applied to the skin it blisters, and taken inwardly it excites vomiting. In scorbutic cases and quartern agues, it is an excellent medicine under proper management. For the former, a luandful of the herb is directed to be boiled in eight pints of beer till they are reduced to four, of which 3 or 4 ounces are to be taken every morning. Milk has been found to answer tlis purpose better than beer. Not only ulcers simply scorbutic, but those of a scrofulous or even cancerous tendency, have been cured by the use of this plant. It is likewise useful as an external application, in destroying fungous flesh, and in promoting a discharge in gangrenes and carbuncles.

I ar. $\beta$, diminùtum (Haw, in phil. mag. 1831. p. 416.) much smaller than the species, hardly an inch high; stem creeping. 4. H. Native of the higher Alps of Provence; also on Swaffan Heath, Norfolk. S. àcre $\beta$ graciàle, D. C. prod. 3. p. 407. S. glaciàle, Clarion in D. C. fl. fr. 4. p. 393.

lar. $\gamma$, clongàtum (Haw. l. c.) pendulous branches 7 inclues high : erect ones 4 inches; leaves loosely imbricating.

Acrid Stonecrop. Fl. June, Britain. Pl. $\frac{1}{8}$ to $\frac{1}{4}$ foot.

71 S. sexangula're (Lin. spec, 620.) stems branched at the base, floriferous ones erect; leaves nearly terete, adnate-sessile, usually by threes on the flowering stems, and 3 in a whorl on sterile branches, imbricating in 6 spiral rows; cymes trifid; petals lanceolate, acuminated. 4 . H. Native of Europe, in dry sandy ground, and on walls. In England, but not common; as near Northfleet, Sheerness, and on the Isle of Sheppy ; on Greenwich Park wall on the south side, near the western corner; on the famous rotten walls of Old Sarum; also of Cambridgeshire. D. C. pl, grass. t. 118. Curt. lond. 4. t. 33. Smith, engl. bot. 1646. S. àcre $\beta$, Huds. Lam. fl. fr. S. spiràle, Haw. in phil. mag. 18\%4. no. 176.-Cam. epit. 856. with a figure. Flowers yellow. Habit of $S$. àcre.

Sixangled Stonecrop. Fl. June, July. Britain. PI. foot. 72 S. BoroxiE'xSE (Lois. not. p. 71.) stem branched at the base; floriferous ones erect; leaves nearly terete, obtuse, loosened at the base, glabrous, imbricated on all sides; cymes trifid; flowers sessile, along the branches; petals acuminated. 4. I1. Native of sandy woods, about Bologna. D. C. suppl. 529. Root creeping. Sepals cylindrical, obtuse. Branches of cyme 6-10-flowered. S, schistòsum, Lejeune, fl. spa. Flowers yellow. Perhaps sufficiently distinct from $S$. sexangulàre.

Bologna Stonecrop. Pl. $\frac{1}{4}$ foot.

73 S. AMPlexicau'Le (D. C. rapp. voy. 2. p. 80. suppl. $H$. fr. p. 526. mem. cras. t. 7.) stems branclied at the base, erect; leaves terete, subulate, glabrous, dilated at the base into a stemclasping membrane; cymes bifid ; flowers remote, sessile along the branches of the cyme; petals 5-7, lanceolate, acutc. $4 . \mathrm{H}$. Native of Spain, south of France, Italy, Candia, \&c. in dry mountain pastures. S. rostràtum, Tenore, fl. neap. prod. p. 26. S. tenuifolium, Sibth, prod. fl. græc. 1. p. 335. and Sieb. herb. cret. Sempervivum anómalum, Lag. nov. spec. 17. Flowers yellow, alınost like those of S. refléxum. Sepals subulate, acute.

Stem-clasping Stonecrop. Pl. $\frac{1}{2}$ foot.

74. S. RUPE'stre (Lin. spec. p. 618.) stcms branched at the base, floriferous ones erect; leaves terete-subulate, glaucous, loosened at the base; sterile stems cylindrical, densely imbricated; flowers cymose, 5-7-petalled; sepals bluntish. 4. H. Native of Europe, on walls and rocks. In England on St. Vincent's rock, Bristol ; on Chedder rocks, Somersetshire, and upon walls about Darlington. Engl. bot. t. 170. -Dill. elth. 2. f. 333. Reich. icon. 3. f. 439 . S. minus, Haw. in phil. mag. 1825. p. 174.? S. refléxum, D. C. pl. grass. t. 116.

(f. 29.).

Rock Stonecrop. Fl. July, Aug. England. Pl. $\frac{1}{4}$ foot.

75 S. Septangula're (Haw. syn. 116. and in phil. mag. 18 24. p. 175.) glaucous; leaves imbricating in 7 rows, incurved, spreading, middle-sized, acute. 4 . H. Native of Europe. Flowers yellow. S. rupéstre $\hat{\beta}$, septangulàre, D. C. prod. 3. p. 407. S. rupéstre, D. C. pl. grass. t. 115. Very like S. cœruléscens, but is distinguished by the shorter and hardly subulate leaves, and in being more branched, and the branches shorter.

Seven-angled Stonecrop. Fl. June, July. Clt. 1795. Pl. $\frac{i}{4} \mathrm{ft}$. 76 S. ALBE'SCENS (Haw, rev. succ. p. 28.) stems branched at the base; flowers erect; leaves terete-subulate, glaucous, loosened at the base; sterile stems elongated, with spreading leaves; flowers cymose, 5-7-petalled; sepals lanceolate. 4 . H. Native of England and Denmark, on barren sandy hills and walls. In England, especially on the sides of some rough hills near Mildenhall, Suffolk. S. glaúcum, Smith, engl. fl. 2. p. 321. engl. bot. 2471 . but not of Waldst. et Kit. S. refléxum, fi. dan. t. 113. Flowers yellow.

Whitish-leaved Stonecrop. Fl. July, Aug. Brit. Pl. $\frac{1}{4}$ foot. 77 S. Forsteria'num (Smith, comp. 71. engl. bot. 1802.) stems branched at the base; flowers erect; leaves semicylindrical, bluntish, green tinged with red; sterile stems short; leaves crowded, somewhat rosulate at the tops of the branches; flowers cymose, 5-7-petalled; sepals obtuse. 24. H. Native of Wales, on rocks at the falls of Rhydoll, near the Devil'sbridge, Cardiganshire; on the rocks of Hisval, overhanging the little valley of Nant-phrancon. S. Forstèrii, Haw. syn. p. 117. S. rupéstre, D. C. pl. grass. 115.? Flowers yellow.

Forster's Stonecrop. Fl. July, Aug. Wales. Pl. $\frac{1}{4}$ font.

78 S. REFLE'Xum (Lin. spec. 618. Smith, fl. brit.p. 490.) stems branched at the base; floriferous ones erect; leaves teretesubulate, green, loosened at the base; sterile shoots somewhat 
cylindrical, spreading; flowers cymose, 5-7-petalled; sepals bluntish. $\%$. H. Native of Europe, in fields and on walls; in Britain on walls and thatched roofs, abundant. Smith, engl. bot. t. C95.-Park. theat. 1. t. 794. f. 1. Flowers yellow. I'ar. 3, recurvitum (D. C. prod. 3. p. 408.) leaves glaucescent; sterile stems somewhat reflexed. S. recurvàtum, Willd. enum. stppl. 23. Perbaps a variety of $S$. albéscens, according to Ilaw.

I'ar. $\gamma$, collinum (D. C. l. c.) leaves glaucescent ; sterile stems spreading. S. collinum, Willd. 1. c. p.25. S. élegans, Lejeune ti. spa. 1. p. 205.?

Vur. $\hat{\varepsilon}$, cristàtum (D. C. l. c.) sterile hranches crestedly somewhat fasciculate; leaves green, spreading. S. cristàtum, Schrad. hort. gœett. t. 10. S. Portlándicum, Lob. icon. 380.

Reflexcd-leaved Stonecrop. Fl. June, July. Brit. Pl. $\frac{1}{2} \mathrm{ft}$.

$79 \mathrm{~S}$. virans (Ait. hort. kew. 2. p. 110.) leaves scattered, subulate, green, loosened at the base; flowers cymose; petals lanceolate, much longer than the sepals. น. H. Native of Portural. S. refléxum, Willd, enum. suppl. p. 25. S. crassicaúlc, Link. enum. 1. p. 438 . Flowers yellow. Very like $S$. rcféxum, and probably only a variety of it.

Grecn Stonecrop. Fl. June, July. Clt. 1774. Pl. $\frac{1}{2}$ foot.

80 S. viRE'SCENS (Willd. enum suppl. p. 25.) stems branched: floriferous ones erect ; leaves terete-subulate, those of the sterile branches spreading and glaucescent; flowering stems spreading, compressed; branches of cyme crowded, erect. $\Psi$. H. Native of Siberia. The leaves, according to Haw. in rev. p. 29. are green, and the flowers nearly white; but according to Willd. 1. c. the leaves are glaucescent, and the flowers greenish-yellow, therefore two species are probably confounded under this name, and perhaps both are only varieties of $S$. refléxum.

Greenish-flowered Stonecrop. Fl. Ju. Aug. Clt. 1815. Pl. $\frac{1}{2} \mathrm{ft}$.

$81 \mathrm{~S}$. susclava'rum (Haw. in phil. mag. 1831. p. 414.) leaves imbricated, rosulate at the tops of the branches, somewhat clavate, turgid, green, attenuated towards the apes, and acute. 24. H. Native of North America. Flowers not seen. From habit this species appears to come nearest $S$. Forstcriunum. Sublatale-leaved Stonecrop. Clt. 1830 . Pl. $\frac{1}{2}$ foot.

82 S. stenopétalun (Pursh, f. amer. sejt. 1. p. 324.) stems assurgent, glabrous; leaves scattered, crowded, adnate-sessile, compressed, subulate, acute ; cymes terminal, trichotomous, and dichotomous; spikes recurved; flowers sessile, decandrous ; petals 5, linear, muel longer than the calyx. 24. H. Native of North America, on the banks of Clark's river, and the Koostioosky; and frequent on the east side of the Rocky Mountains. Flowers golden yellow. Said to be allied to $S$. refléxum.

Narron'-petalled Stonecrop. Fl. Ju. Jul. Clt. 1826. Pl, $\frac{1}{2} \mathrm{ft}$. 83 S. co:ruléscfos (Haw. in. phil. mag. 1825. p. 174.) leaves long, spreading, subulate, acute, bluish-glaucous, flattish above. 2. I1. Native country unknown. Very like S. altissimum, but not half the size, more bluish-glaucous ; leaves more distant, petals more acute, pale yellow.

Blucish Stonecrop. Fl. June, July. Clt. 1820. Pl. $\frac{1}{4}$ foot.

84 S. altíssisus (Poir. dict. 4. p. 634.) stem fruticulose, branched at the hase; florifcrous ones erect; leaves ncarly terete, acute, glaucous, glabrous : superior ones scatter $(-d$, Hat tish above; those of the sterile branches imbricated; crines brauched, many-flowered; flowers sessile along the branclies of the cyme, which are twisted at the apex; petals $6-8$, lanccolate, acnte, spreading. 24. II. Native of the south of Europe. I. C. pl. grass. t. 116. Sempervivum sedifórme, Jacq. hort, vind. $t$. 81. and var. monstròsa misc. 1. 1. 133. t. 5. S. fruticulosum, Brot. fl. lus. 2. p. 206 . S. ruféscens, Tenore, fl. neap. t. 41 . S. Nicæénse, All. ped. no. 1752. t. 90. f. 1. S. Jacquíni, Ilaw, in phil. mag. 1825 . p. 174 . S. rupéstre $a$, Gouan. S. diojeum,
Donn, hort, cant. Flowers cream-coloured. Lobes of calyx bluntish. A large, strong, glaucous plant.

Tallcst Stonecrop. Fl. Jul. Aug. Clt. 1769. Pl. 1 foot.

85 S. ochrolev'cun (Smith, in Lin. trans. 10. p. 7.) stem branched; leaves glaucous, scattered, acute: lower ones terete: upper ones elliptic, depressed ; cymes branched, many flowered; flowers sessile along the branches of the cyme; calycine segments acutish; petals oblong-spatulate. 24. H. Native of the south of Europe. S. altíssimum $\beta$, ochroleǹcum, D. C. prod. 3. p. 4.08. Flowers pale yellow. Very like $S$. altissimum, but rather larger.

Crcam-coloured-flowered Stonecrop. Fl. July. Clt. 1818. Pl. 1 foot.

86 S. anopét talum (D. C. rapp. 2. p. 80. suppl. fl. fr. p. 526. mem. crass. t. 8.) stems branched at the base, erect; leaves nearly terete, rather depressed, loosened at the base, glaucous, mucronate; those of the sterile branches imbricated; cyme 4cleft, corymbose; petals lanceolate, acuminated, erect. $4 . \mathrm{H}$. Native of the south of France, on calcareous rocks, and among stones. Baub. hist. 3. p. 428. S. Hispánicum, D. C. f. fr. no. 1326. but not of Lin. S. rupéstre, Vill. dauph. 3. p. 678 . but not of Lin. S. anopétalum, Spreng. syst. 2. p. 435. exclusive of the synonyme of Tenore. Flowers cream-coloured. There is also a variety with orange-coloured flowers, according to Haworth.

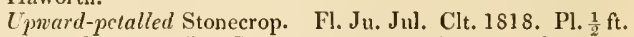
87 S. URViLleI (D. C. prod. 3. p. 408.) stems glabrous; erect, creeping, and branched at the base; leaves scattered, nearly terete, obtuse, dilated, and stem-clasping at the base; cyme 2-3-cleft; flowers sessile along the branches; petals acuminately awned. $\odot$. H. Native of the 1sland of Lazaretto. S. pállidum, D'Urv. enum. p. 51 . but not of Bieb. Flowers yellow. Capsules pale, somewhat stellate.

D'Urville's Stonecrop. Pl. $\frac{1}{4}$ foot.

88 S. v1RI'Dulun (Haw. in phil. mag. 1827. p. 183.) leaves erectish, linear-subulate, green, somewhat mucronulate on one sicle. 4.H. Native country unknown. Very like S. virens, and $S$, recurcatum, Willd. but the leaves are a little larger and flatter, greener and blunter. It is less than $S$. anopćtalum.

Small-green Stonecrop. Fl. Ju. Jul. Clt. 1820 . Pl. $\frac{1}{2} \mathrm{ft}$.

89 S. ustoreun (Guss. pl. rar. 1\% 185. t. 37. f. 2.) stem erect, branched at the base; branches ascending; leaves spatulate-cuneated, semiterete, obtuse, glabrous; Howers sessile, lateral, solitary. $\odot$. H. Native of Calabria, among rubbish by the sea-side. Flowers pale yellow, alternate. Petals a little longer than the calyx, linear-lanceolate.

Sea-shore Stonecrop. Pl. 2 inches high.

90 S. saxA'TuL (Willd. spec. 2. p. 706.) stem erect, branched from the base; leaves scattered, ratlier remote, terete, obtuse, loosened at the base; cymes leafy, spreading; flowers on short perlicels, along the branches of the cyme; petals oblong, mucronate. $\odot$. H. Native of Europe, among rocks; in Norway, Germany, Switzerland, Dauphiny, Denmark, Mount Cenis, Sc. D. C. pl. grass. t. 119 . Smith, fl. græc. t. 450 . S. astivum and saxátile, All. pedem. no. 1746. and 1749 . t. 65 . f. 6 . S. alpéstre, Vill. dauph. 3. p. 684 . S. rupéstre, C.d. H. dan. t. 59. but not of Lin. S. QEdèri, Roth. prod. f. scand. ed. 2. no. 562 . S. annuum, Lin. spec. 620 . exclusive of the character and synonymes. S. divaricàtum, Lapeyr, abr. 260. but not of Ait. S. schistòsum, Lejeune, f. spa. 1. p. 206. Herb 2-4 inches long. Flowers yellow or pale yellow.

Rock Stonecrop. Fl, Ju. Jul. Clt. 1820. Pl. $\frac{1}{4}$ foot.

91 S. TENÉluum (Meyer, verz. pfl. p. 152.) plant glabrous, glaucescent ; stems herbaceous, erectish ; leaves subulate, bluntish, loose at the base; those of the sterile branches imbricated; rays of cyme short, few-flowered, coarctate; flowers decandrous, 
rather shorter than the pedicels; petals aeute, longer than the calyx ; capsule truncate at the apex, and apiculated by the short styles. 4 . H. Native of Caucasus, in stony places, at the altitude of 3000 feet. F'lowers orange-coloured.

Tender Stonecrop. Pl. 1 font.

92 S. RE'PENS (śchleich. in 1). C. fl. fr. suppl. 525.) stems ascending, creeping, and branched at the base ; leaves scattered, semiterete, obtuse; cymes few-flowered; petals ovate. 4. 11. Native of the higher Pyrences. S. Guettárdi, Vill. dauph. 3. t. 45. exclusive of the synonymes. S. rùbens, Hank. sıd. 114? S. ánnuum, All. peden. no. 1763.? S. Monregalénse, Balb.? S. atràtum $\hat{\beta}$, D. C. Al. fr. no. 3615 . An intermediate plant between $S$. atràtum and $S$. saxítile. Petals pale yellow.

Creeping Stonecrop. Fl. Ju. Jul. Clt. 1817 . Pl. $\frac{1}{8}$ foot.

93 S. PUBE'sCENs ( ahl. symb. 2. p. 52.) stem erect, branched, pubescent; leaves alternate, elongated, obtuse, rather pilose

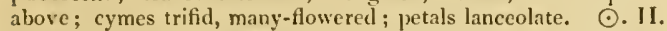
ex Desf. fl. atl. 1. p. 360 . Native of Tunis, in the fissures of rocks. Petals yellow, pubescent on the outside.

Pubcscent Stonecrop. Pl. $\frac{1}{4}$ foot.

94 S. Irispioum (Desf. fl. atl. 1. 1. 361. but not of Poir.) stem erect, branched above, hispid; leaves scattered, nearly terete, depressed above, spreading; branches of cyme filiform, rather panicled; flowers pedicellate; petals 5-6, lanceolate, acute.-Native of the north of Africa, on Mount Atlas. S. Atlánticum, Pers. ench. no. 35. S. filifórme, Poir. Flowers golden yellow.

Hispid Stonecrop. Pl. $\frac{1}{4}$ foot.

\section{+ Species not sufficiently knonn. - Shrubby spccies.}

95 S. NU'DUM (Ait. hort. kew. 2. p. 112.) stem shrubby, branched, erectish; branches twisted, glabrous; leaves scattered, oblong-cylindrical, obtuse; cymes terminal, and are as well as the calyxes glabrous. h. D. G. Native of Madeira. Petals 5, yellow, lanceolate. Scales orange-coloured, thick, and obtuse. Leaves a!most like those of $S$. álbum.

Naked Stonecrop. Fl. Jul. Aug. Clt. 1777. Shrub $\frac{3}{4}$ foot.

96 S. Laxiflónum (D. C. prod. 3. p. 409) stem shrubby, branched, ascending, glabrous; branches twisted; leaves scattered, ovate-cylindrical, thick, obtuse, glabrous; cymes loose, diraricate; flowers pedicellate, beset with glandular pubescence. 々. D. G. Native of Teneriffe. Petals small, apparently white. Sepals broad.

Lax-flowered Stonecrop. Shrub 1 foot.

97 S. oxypétalum (H. B. et Kunth, nov. gen. amer. 6. p. 45.) stem shrubby, glabrous, branched; Jeaves alternate, flat, quite entire, obovate-spatulate, rounded at the apex, and somewhat emarginate; cynes terminal, somewhat dichotomous; Howers secund, sessile; petals 5 , linear, each ending in a narrow acumen. $々$. D. G. Native of Mexico, in gardens. Flowers redclish.

Sharp-petalled Stonecrop. Shrub 5 feet.

98 S. dendroideum (Moc. et Sesse, fl. mex. icon. ined. ex D. C. prod. 3. p. 409 . mem. crass. t. 9.) stem shrubliy, branched, erect; leaves scattered or opposite, oborate-cuneated, glabrous; those of the sterile branches rosulate; thyrse panicled, much divided; flowers secund, sessile, bractless; petals 5, lanceolate. そ.D.G. Native of Mexico. Flowers yellow. Very like a species of Scmpervìum.

Trec-like Stonecrop. Shrub I to 2 feet.

99 S. eRracteátus (Moc. et Sesse, f. mex. icon. incd. ex D. C. prod. 3. p. 409. mem. crass. t. 6. f. ß.) stem shrubby, fleshy, twisted at the base, creeping; flowering stems erect; leaves scattered, glabrous, ovate, thick, obtusc: those of the flowering stems spreading, those of the sterile stems imbricated; thyrse panicled; flowers secund, sessile, bractless: petals 5 , lanceolate. h. D. G. Native of Mexico. Flowers white. Habit of a species of Scmpcrvivum.

bractless Stoncerop. Slirub $\frac{1}{2}$ foot.

$$
\text { - Herbaceous plants. }
$$

100 S. A'Ltus (Clark, in Spreng. nene. entd. 3. p. 161.) floriferons stems erect; leaves lanceolate, acute, quite entire; racemes subfastigiate; pedicels short, secund; petals 6 , lanceolate.-Native of Palestine. The rest unknown.

Kigh Stonecrop. Pl. 1 foot.

101 S. 'T'ORREYI; leaves roundish, flat, entire, scattered; cymes terminal, trichotomous. 4. H. Native near the liocky Mountains. Sèdum, nov. spec. Torrey. in amer, lyc. new york. 2. p. 205.

Torrey's Stonecrop. Pl.?

102 S. LINEA're ('I'hunb. fl. jap. 187.) stem glabrous, a little branched; leaves terete, linear, opposite, stem-clasping, acute, spreading; cyme trifid.-Native of $\mathbf{J}$ apan. Flowers yellow.

Lincar-leaved Stonecrop. Pl. $\frac{1}{4}$ foot.

103 S. TENE'LLUM (Bieb. fl. taur. suppl. p. 315.) stems branched at the very base ; floriferous ones erect; leaves scattered, oblong, obtuse, nearly terete, loosened at the base ; corymb simple, few-flowered; petals 5 , lanceolate-subulate, twice the length of the calyx. $\odot . H$. Native of Caucasus, on the alps. Flowers smaller than those of $S$. álbum, but the colour is unknown.

Slender-Stonecrop. Pl. $\frac{1}{4}$ foot.

104. S. ARista'TUM (Vill, dauph. 4. p. 680, t, 45.) stems lying on the ground at the base: floriferous ones erect; leaves terete, acute at both ends, loosened at the base; those of the sterile stems densely imbricated; cymes few-flowered; petals 5 , acuminately awned. 4 . H. Native of Dauphiny, near Segoyer. Petals white. Perhaps only a variety of $S$. anopétalum.

Awned-petalled Stonecrop. Pl. $\frac{1}{4}$ to $\frac{1}{2}$ foot.

105 S. PRUINA'TUM (Brot. f. lus. 2. p. 209.) stem ereet, branched at the base, glabrous, glaucous, pruinose ; leaves Heshy, oblong, convexly Hattish, loosened at the base; cymes bifid; sepals and petals 6 , lanceolate, acuminated, spreading. $\odot . H$. Native of Portugal. Sempervivum pruinàtum, Spreng. syst. 2. p. 169. Colour of flowers unknown.

Frosted Stonecrop. Pl. $\frac{1}{2}$ foot.

106 S. confértum (Delil. fl. eg. ill. no. 451.) leaves subulate, scattered, crowded.-Native of Egypt, about Cairo. Sèdum no. 243 , Forsk. fl. xgyp. p. 71 . The rest unknown.

Cronded-leaved Stonecrop. Pl. $\frac{1}{4}$ foot.

107 S. Quite'Nse (H. B. et Kunth, nov. gen. amer. 6. p. 16.) stems herbaceous, glabrous; leaves alternate, flat above, convex beneatl, spatulately-lanceolate, acutish, quite entire; racemes elongated; flowers pedicellate; petals 5 , oblong, acuminated. 4 . D. G. Native of South America, among rubbish, near Guameabamba, and on the walls of the town of Quito. Flowers orange-coloured. Perhaps a species of Echcrìria. There is a variety of this plant having the leaves margined witlı red.

Quito Stonecrop. P1. $\frac{1}{2}$ foot.

108 S. Bícolor (H. B. et Kunth, I. c. p. 45.) stem herbaceous, glabrous ; leaves alternate, flat, obovate-spatulate, acutish, quite entire; racemes terminal, flowers pedicellate; petals 5 , oblong, acute. 4. D. G. Native near Caraccas, in bumid places, and among rocks at Meneses, near Pasto. Petals yellow inside, and red or orange-coloured outsicle. Perhaps the flowers are truly racemose, and the plant is therefore probably a species of Echerèria.

Tno-eolourcd-flowered Stonecrop. P]. $\frac{1}{2}$ foot.

109 S. Borya'num (D. C. prod. 3. p. 410.) stems naked, R 
erect; flowers yellow, disposed in short recurved spikes ; leaves linear, scale-formed, reflexed.-Native of Spain, on the rocks called Borrequillos, in Sierra Nevada. Perhaps a species of Sempervivum, ex Bory. ann. gen. 3. (1820.) p. 14. The rest unknown.

Bory's Stonecrop. PJ. $\frac{1}{2}$ foot.

110 S. MELANANTHE'rum (D. C. prod. 3. p. 410.) stems weak; leaves ovate, attenuated at the apex; flowers in corymbose panicles.- Native of Spain, in Sierra Nevada, on the rocks of Borrequillos. Flowers small, densely panicled, rather sweet scented. Anthers black. The rest unknown.

Black-anthered Stonecrop. Pl. $\frac{1}{4}$ foot.

\section{$\uparrow$ Species only known by name.}

1 S. stolonifierum (Gmel. itin. 3. t. 35. f. 2.).

2 S. liliciceum (Led. ex Steud. nom.).

3 S. procumbens (Sclırank, bav. p. 726.).

4. S. Monregalénse (Balb.).

N.B. Rhodiola biternata, Lour. coch. p. 627. is totally different from Rhodiola, Lin, and is perhaps a plant belonging to Sapindicce.

Cult. The greater part of the species being quite hardy, and all succulent, they therefore succeed best on rock-work, for which they are well adapted. Some of the rarer kinds may be grown in small pots. They succeed best in light, sandy soil, or one composed of loam and brick rubbish. All are readily increased by cuttings. The seeds of the annual species only require to be sown on rockwork. There are a few of the species marked greenlouse; these will require the same treatment as that recommended for the species of Globùlea, see p. 106.

XIX. SEMPERVIVUA (from semper vivo, to live for ever; the tenacity of life of the Houseleek tribe is well known). Lin. gen. no. 612. Lam. ill. t. 413 . D. C. in bull. philom. no. 49. prod. 3. p. 411.

Lin. syst. Dodecándria, Dodccagýnia. Calyx 6-20-parted. Petals 6-20, oblong, acute. Stamens double the number of the petals. Scales at base of carpels toothed or jagged at the apex. Carpels equal in number to the petals.- Herbs sometimes stemless, with young plants rising from the axils; or caulescent, without any young plants; or shrubby and fleshy. Leaves usually revolute. Branches of cymes sometimes disposed into a corymb, and sometimes into a paniele. Pctals yellow, white, or purplish.

Sect. 1. Curonòium ( $x$ poros, chronos, time, and ßtow, bioo, to live; plants living only for a time, and are not so tenaeious of life as those of the following section). D. C. pl. rar. gard. gen. no. 21. Young plants, none from the axils. Flowers usually yellow, rarely white. Species all natives of the Canary Islands.

\section{* Shrubby species.}

1 S. Alzoides (Lam. dict. 3. p. 290.) stem frutescent, erect, branched; leaves scattered, obovate, flat, quite entire, glabrous ;

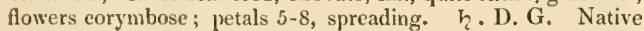
of Madeira. Sèdum aizoides, D. C. pl. grass, t. 4. Sèdum divaricàtum, Ait. hort. kew. ed. 1. vol. 2. p. 108. Perhaps also Anacámpseros divaricita, Haw. syn. p. 113.? Flowers yellow.

Aizoon-lilic Houseleek. Fl. May, Jul. Clt.? Shrub $1 \mathrm{ft}$.

2 S. тоrтùsum (Ait. hort. kew. ed. 1. vol. 2. p. 148.) stem frutescent, ercet, branclied; leaves obovate-spatulate, scattered, rather convex beneath; petals 7-8, sjreading; scales 2-lobed. $\zeta_{\text {. I }}$. G. Native of the Canary Islands. Curt, bot. mag. t. 296. D. C. pl. grass. t. 156. Flowers yellow. Leaves 11-12 lines long and 4-5 lines broad.
Tnisted Houseleek. Fl. Jul. Aug. Clt. 1779. Sh. $\frac{1}{2}$ to $\frac{3}{4} \mathrm{ft}$. 3 S. villòsum (Haw. syn. p. 166. res. 65. but not of Ait.) stem frutescent, erectish, twisted; leaves obovate, crowded, gibbous beneath, villous; scales of flower fringed. $h_{\text {. D. G. }}$ Native of the Canary Islands. Flowers yellow. Leaves 5 lines long and 3 lines broad. S. villosum, Ait. is referrible to $S$. stellàtum.

Iillous Houseleek. Fl. Ju. Jul. Clt. 1777. Sh. $\frac{1}{2}$ to $\frac{8}{4} \mathrm{ft}$.

4 S. cilia'tum (Willd. enum, 1. p. 508. mem. crass. t. 10.) stem frutescent, glabrous; leaves oblong-obovate, somewhat spatulate, mucronate, cartilaginously ciliated; thyrse panicled, having the branches crowded, with flowers at the apex; petals 6-7. h. D. G. Native of the Canary Islands. Coll. hort, rip. append. 4.t. 7. Flowers pale yellow.

Ciliatcd-leaved Houseleek. Clt. 1815. Shrub 1 to $1 \frac{1}{2}$ feet.

5 S. GLANDULòsum (Ait. 1. c. p. 148.) stem frutescent; leaves orbicularly spatulate, with clammy margins; glands globose; scales of flower wedge-shaped, truncate. h. D. G. Native of Madeira. Flowers yellow. Glands fringed, yellow, ex Haw. rev. p. 65 .

Glandular Houseleek. Fl. Mar. May. Clt. 1777. Shrub $\frac{1}{2}$ to 1 foot.

6 S. GLuTinòsum (Ait. 1.c. p. 147.) stem frutescent; leaves cuneiform, viseid, rather scattered, fringed with adpressed, cartilaginous ciliæ; petals 8-10. h. D. G. Native of Madeira. Jacq. hort. schœenbr, 4. t. 464 . Sims, bot. mag. t. 1963 . Ker. bot. reg. t. 278. Branclues of panicle loose. Flowers golden yellow. The stem rises to the height of 2 feet, and even more, according to Prince de SalmDyck. 'The fishermen of Madeira rub their nets with the fresh leaves of this species, by which they are rendered as durable as if tanned, provided they are steeped in some alkaline liquor. (f. 30.)

Clammy Houseleek. Fl. July, Aug. Clt. 1777. Shrub 1 to 2 feet.

7 S. u'rnicum (C. Smith, mss. Horn. suppl. p. 66. Haw. in plit. mag. 1827. p. 125.) stem frutescent, erect, leafy at the top; leaves broad, cuneiform, glabrous, cartilaginously ciliated on the margins, running into the petiole at the base, broad and blunt at the apex, and ending in a small point. $\zeta$. D.G. Native of the Canary Islands, on the walls of towns and the roofs of houses. Leaves green. Flowers yellow. Perhaps the same as S. latifolium. Hoffm. verz. 2. p. 208. Haworth's plant is probably the same as that of Hornemann.

City Houseleek. Fl. Ju. Aug. Clt. 1816. Shrub 1 to $2 \mathrm{ft}$.

8 S. RETU'sUM (Haw, in phil. mag. 1827. p. 125.) stem frutescent, simple, leafy at the apex; leaves broadly cuneated, expanded, smooth, eiliated, somewhat cuneated at the apex, truncate and retuse. $\quad$. D. G. Native of Teneriffe, on walls and the roofs of houses. Flowers yellow. Very like $S$. úrbicum, but differs in the form of the leaves.

Retuse-leaved Houseleck. Fl. June, Aug. Clt. 1824. Sh. 1 to 2 feet.

9 S. ARBòrEUM (Lin. spec. p. 664.) stem arborescent, smooth, branched; leaves cuneiform, glabrous, ciliated, spreading and rosulate at the tops of the branches; panicle loose; petals 9-11. 々. D. G. Native of Portugal, Barbary, Candia, \&c. Bradl. succ. pl. 1. t. 31 . Ker. bot. reg. 99 . D. C. pl. grass. t. 125. 
Smith, fl. græe. 473. Shrub from 3-6 feet. Flowers golden yellow.

Var. $\beta$, variegàtum; leaves margined with white or purple.

Tree Houseleck. Fl. Mar. Dec. Clt. 1640. Sh. 3 to $6 \mathrm{ft}$.

10 S. Frute'scens (Haw. pliil. mag. 1827. p. 125.) stem shrubby, simple; leaves crowded in a rosulate manner at the tops of the branclies, spatulately cuncated, green, ciliated. h. D. G. Native of Teneriffe. Flowers yellow. Very like $S$. arborcum, but the plant is not above half a foot bigh.

Frutescent Houseleek. Fl. Mar. Dec. Clt. 1824. Pl. $\frac{1}{2}$ to $1 \mathrm{ft}$.

11 S. TABULafórae (Haw, suppl. p. 69. rev. 63.) stem frutescent, erect, simple; leaves spatulate, Hat, ciliated, attenuated at the base, crowded at the top of the stem, and forming a rosulate flat disk, in consequence of the leaves being so closely imbricated over each other. h. D. G. Native of Madeira. Stems branching after the first time of flowering. Petals 10-12, linear-lanceolate, very pale sulphur-coloured. Glands minute, pedunculate.

Table-formed Houseleek. Fl. Ju. Jul. Clt. 1817. Pl. $1 \mathrm{ft}$.

12 S. CaNarie'NSE (Lin. spec. p. 664.) stem short, frutescent; radical leaves expanded, rosulate, obovately-spatulate, villous, large; leaves scattered along the flowering stem, ovate; branches of panicle cxpanded; flowers pedicellate; petals 9-10. h. D. G. Native of the Canary Islands.-Comm. hort. amst. 2. t. 95. D. C. pl. grass.t. 141. Petals white, linear.

Canary-Island Houseleek, Fl. Jı. Jul. Clt. 1699. Slı. $1 \frac{1}{2} \mathrm{ft}$.

13 S. Suítun (Sims, bot. mag. t. 19S0.) stems frutescent, erect, hispid; leaves scattered, obovate, acuminated, flat, concave, a little spotted; branches of panicle revolute at the points, bearing sessile flowers on the upper side; petals 12 . h. D.G. Native of the Canary Islands. S. foliossum, C. Smith, hort. berol, p. 38. Petals pale yellow, oval-oblong, spreading. Glands wanting, ex Haw. rev. p. 63.

Smith's Houseleek. Fl. Jul. Aug. Clt. 1815. Shrub $1 \mathrm{ft.}$

14 S. barba'tum (C. Smitl, in loort. ber. p. 37.) stem frutescent; leaves ovate-spatulate, acute, with eartilaginously ciliated margins, marked with brown lines on both surfaces; flowers panicled; petals 6 . 々. D. G. Native of the Canary Islands. S. lineolàre, Haw. suppl. p. 69. rev. p. 65 . S. spatulàtum, Horn. suppl. p. 60. Flowers yellow.

Iar. B, hybridum (Salm-Dyck. and Haw.) all parts of plant larger.

Beardcd Houseleek. Fl. Jul. Aug. Clt. 1815. Slı. 1 to $2 \mathrm{ft}$.

15 S. c.espı ròsum (C. Smith, in hort. berol. p. 38.) stem frutescent, very short, at length a little branched, leafy at the apex ; leaves oblong-linear, glabrous, stiffly ciliated, marked with brown lines on both surfaces, crowded in a rosulate manner, but the cauline ones are scattered; flowers in cymose corymbs, with the branchlets dichotomous; petals $7-8$, spreading. h. D. G. Native of the Grand Canary Island, on rocks on the lighest mountains. D. C. rapp. jard. bot. 1822 . no. 13. S. ciliàre, Sims, bot. mag. t. 1978. but not of Willd. S. ciliàre, Haw. rev. p. 64. S. Símsii, Sweet, hort. suburb. p. 230. S. barbàtum, Horn. suppl. p. 61. but not of Smith. Flowers yellow. This plant survived 18 months in paper in the herbarium of $\mathbf{C}$. Smith, and afterwards when put into the earth grew.

Tufted Houseleek. Fl. Apr. Sept. Clt. 1815. Sh. $\frac{r}{2}$ foot.

\section{* Herbaccous plants.}

16 S. DOdRANTA'Le (Willd. enum. p. 508.) stem herbaceous, erect, glabrous ; leaves flat, glabrous, quite entire; radical ones obovate, attenuated at the base, disposed in a spreading rosulate manner: cauline ones erect, oval, sessile, obtuse at both ends; cymes corymbose; petals 20 . \$. D. G. Native of the Canaries, D. C. mem. crass, t. 11. Pedicels puberulous. Corymbs few-flowered. Petals linear; pale when dried.
Nine-inch Houselcek. Fl. July, Aug. Clt. 1815. Pl. $\frac{1}{2} \mathrm{ft.}$

17 S. Au'reum (C. Smith, in hort. berol. p. 37.) stem herbaceous, ereet, glabrous ; leaves obovate-spatulate, with membranaceonsly cartilaginous, quite entire margins, glaucous; branelies of panicle dichotomous, many-flowered; petals 20 . $t$. or $\hbar$. D. G. Native of 'Teneriffe, on the mountains. S. calyciforme, Haw. suppl. p. 69. Ker. bot. reg. t. 892. Flowers yellow. Petals linear, and are as well as stamens 20, and the pistils are numerous, according to C. Smitl. Perhaps the same as $S$. dodrantaile, Willd.

Golden Houseleek. Fl. Jul. Aug. Clt. 1815. Pl. 1 foot.

18 S. Puncta'tum (C. Smith, in Buch. can. p. 155.) stem herbaceous, crect, branched; leaves scattered, obovate, petiolate, flat, glabrous, crenated on the margin at the top, dotted in the recesses of the crena; panicle loose ; pedicels puberulous ;

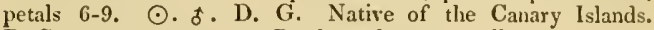
D. C. mem. crass. t. 12. Petals oval, acute, yellow.

Dotted-leaved Houseleek. Pl. 1 foot.

19 S. stella'tum (Smith, in Lin. soc. trans. 1. p. 251.) stem herbaceous, erect, branched, pubcrulous; leaves scattered, oblong, spatulately cuneiform, obtuse, villous; flowers panicled ; petals 6-8, spreading; scales palmate, with subulate lobes. $\odot$. D. G. Native of Madeira. S. villosum, Ait. hort. kew. ed. 1. vol. 2. p. 148. Sims, bot. mag. t. 1809. Flowers golden yellow. Herb 6-8 inches high.

Stellate Houseleek. Fl. Jul. Aug. Clt. 1790. Pl. $\frac{1}{2}$ foot.

20 S. рiснótosium (D. C. jard. gen. t. 21.) stem herbaceous, terete, erect, dichotomous, beset with soft spreading hairs; leaves obovately spatulate, tapering into the petiole, dotted with soft villi ; flowers in loose corymbs; petals $8-9$, spreading; scales of flower 2-lobed, small. of. D. G. Native of the Canary Islands, among rocks. S. láxum, Haw, rev. 65. Nearly allied to $S$. hirtum, ex Buch. cat. Flowers yellow. This plant is nearly allied to $S$. tortuòsum, but differs in being luerbaceous.

Dichotomous Houseleek. Fl. Jul. Aug. Clt. 1815. Pl. $\frac{1}{2} \mathrm{ft}$.

21 S. PYgmèum (C. Smith, in Buch. can. p. 155.) stem declinate, few-leaved, 1-flowered; leaves spatulate, attenuated at the base, retuse, hairy ; calyx villous ; petals awned-Native of the Island of Lancerotta. Flowers small, yellow. Plant hardly an inch high. The rest unknown.

Pygmy Houseleek. Pl. 1 incl.

Sect. II. Jovibárba (Jupitcr, Jovis, Jupiter, and barba, a beard; Jupiter's beard; application not evident). D.C. pl. rar. gen. no. 21. obs. prod. 3. p. 413. Young plants rising from the axils of the lower leaves. Flowers purplish or pale yellow. European species.

\section{* Flowers yellowish.}

22 S. Hírtum (Lin. spec. p. 605.) leaves somewhat ciliated; young plants globose; petals 6 , erect, fringed. $4 . H$. Native of 'Thuringia and Carinthia, on walls ; and in woods about Moscow. D. C. pl. grass. t. 107. S. soboliferum, Sims, bot. mag. t. 1457. S. globíferum, Hoppe, cent. Haw. rev. p. 67. Jacq. aust. 5. p. 50. append. t. 40. Leaves of the flowering, stems lanceolate, imbricate, loose, disposed in 3 spiral series. Offsets falling off of themselves. Petals pale cream-coloured, twice the length of the calyx.

Hairy House-leek. Fl. June, July. Clt. 1801. Pl. I foot. 23 S. globífercm (Lin. l. c.) leaves ciliated; offsets rather contracted; petals $15-20$, spreading, very long. 4 . H. Native of Vallais, on rocks; and probably of Austria. Curt. bot. mag. t. 507. Schrad. icon. 95. t. 26. S. grandiflòrum, Haw. rev. 66. Petals yellowish, 3 times longer than the calyx.

Var. $\beta$; offsets rather loose; petals 12 . $\psi$. H. Sims, bot. mag. 2115 . More villous and pale than the species. 
Globe-bcaring or Hen and Chicken House-leek. Fl. Ju. Jul. Clt. 1751. Pl. $\frac{1}{2}$ to I foot.

$$
\text { * Flowers purplish. }
$$

24. S. TEctònrs (Lin. spec. p. 664.) leaves ciliated; offsets spreading; petals $5-9$, spreading; scales of flowers cuneiform, carunculate. $4 . \mathrm{H}$. Native of Europe, on rocks and roofs of houses; also in many parts of Britain, on walls and cottage roofs, but perhaps not properly indigenous. D. C. pl. grass. $t$. 104. Smith, engl, bot. 1320. Curt. lond. 3. t. 29. Oed. fl. dan. 601. Blackw. t. 366 . Sèdum tectòrum, Scop. carn. ed. 2. no. 529. Flowers purplish. Stamens sometimes cluanged into carpels according to Pet. Thouars, in bull. phil. nov. 1807. The juice of the common house-leek either applied by itself, or mixed witl cream, gives present reliet in burns, and other external inflammations; it is also said to cure corns. With honey it is a useful application in the thrush. Boerhaave found 10 ounces of the juice beneficial in dysenteries, and others have found it useful in gonorrhoeas; but it is not admitted into modern practice. The bouse-leek had several names formerly, as sengrcen and aygreen, both translations of Sempervirum. It lias also been called jupiter's eye, bullock's eyc, and jupiter's beard. In German it is ealled hauswur ; in French la grande joubarbe, and in Italian sempervivo maggiore.

Roof or Common House-leek. Fl. June, Sept. Britain. Pl. 1 foot.

25 S. FLAGeldifórme (Fisch. in Link, enum. 2. p. 20.) leaves ovate, mucronate, papillose, with papillously ciliated margins; offsets spreading, lateral; branches of cyme bifid. $4 . \mathrm{H}$. Native of Siberia. Allied to $S$. montimum, but differs in being larger, and in the offsets being at the ends of long flagellæ. The leaves of the offsets terminate in a stiff brown point; cauline leaves narrower. Corolla reddish.

Flagelliform Houseleek. Fl. July, Aug. Clt. 1823. Pl. $\frac{1}{2}$ to $\frac{3}{4}$ foot.

$26^{4} \mathrm{~S}$. monta'num (Lin. spec. p. 665.) leaves of the offsets obovate-oblong, shortly acuminated, beset with glandular pubeseence on both surfaces, obsoletely ciliated, entire, pubescent; offsets rather contracted; flowers rotate; petals 10-14, lanceolatc, acuminated, spreading, 3 times longer than the calyx, seales of flowcrs small, nearly quite entire; style discoloured at the apex. 24. H. Native of the Pyrenees and the Alps of Europe, Sc. on rocks. D. C. pl. grass. t. 105 . Jacq. H. aust. 5. append. t. 41. Flowers deep red. This species differs from $S$. tactorum in the smaller stature, and in tlue nectariferous scales bcing almost wanting; and from $S$. arachooidcum in the abscnce of the cobwebbed wool. Scales of flower square and retuse.

Iountain House-leck. Fl. Ju. July. Clt. 1752. Pl. $\frac{1}{2}$ to $\frac{3}{4} \mathrm{ft}$.

27 S. F'NKIn (Braun, in bot. zeit. Jan. 1832. p. 4. t. I.) leaves of the offsets oblong, shortly acuminated, beset with glandular pubescence on both surfaces, with ciliated margins; flowers rotate; petals lanccolate, acuminated, about 3 times longer than the calyx; germens dilated, ovate; style discoloured at the apex. 4. II. Native of the Alps of Europe, as in Switzerland, Piedmont, S.C.

Funl's House-lcek. FI. Junc, July. Clt.? Pl. $\frac{1}{2}$ foot.

28 S. ARAcinóloevm (Lim. spec. 665.) leaves covercd with interwoven cobwebbed hairs or wool; offsets globose; petals 8.9, spreading; scales of flower truneately enarginate. భ. 1 . Native of the Alps of Europe and the Pyrenees, Sc. among rocks. D.C. pl. grass. t. 106 . Curt. bot. mag. t. 68. Jacq. austr. 5, append, t. 12. Flowers purple.

Cobncbbed House-lcek. FI. Ju. July. Clt. 1699. Pl. $\frac{1}{2} \mathrm{ft}$. 29 S. pu'muvm (Bieb. fl. taur. 1. p. 381.) leaves lanceolate, icute, ciliated by long hairs; offsets glohose; stem few-flowered; petals 12 , hairy. $4 . \mathrm{H}$. Native of Caucasus, at the torrent of
Terek, on rocks. Flowers rel. Very like $S$, arachnoideum, but differs in the hairs on the leaves being distinet, not cobwebbed.

Dwarf House-leek. Fl. June, July. Clt. 1824. Pl. $\frac{x}{2}$ foot.

30 S. TENufólum (Smith, fl. græe. prod. 1. p. 335. fl. grac. t. 474.) leaves subulate: lower ones dilated at the base, and sheathing ; cauline ones adnate, sessile, prolonged at the base; flowers with 7-10 styles; offsets cylindrical. \%. H. Native of Calabria, on arid hills. Sc̀uum rostràtum, Ten. fl. nap. prim. p. 26. Sèdum amplexicaúle, D. C. fl. fr. suppl. p. 526. Sèdum carinàtum, Link. Sempervivum anómalum, Lag. ex Spreng. Petals yellow. More the habit of a Sèdum than a Sempervivum, and has much the habit of Sèdum mipéstre.

Fine-leaved House-leek. Pl. $\frac{1}{4}$ foot.

Sect. 1II. Monánthes (from povos, monos, one, and avos, anthos, a flower; flowers one on each peduncle). Haw, rev, succ. p. 68. D. C. prod. 3. p. 414. Real offsets none. Leaves clavate, crowded in a somewhat rosulate manner. Flowers purple. Glands large, orbicularly cochleate, serrulated when examined through a lens, one-halif shorter than the petals, but 4 times broader, and rufous. Haw. $-A$ very small nearly stemless herb.

31 S. mona'ntues (Ait. hort. kew. ed. 1. vol. 2. p. 149.) leaves terete, clavated, glabrous, crowded in a rosulate manner; peduncles naked, generally 1 -flowered, rarely few-flowered; petals 6-9, hardly longer than the calyx; scales of flower obcordate. 4. D. G. Native of the Canary Islands. Curt. bot. mag. t. 93 . D. C. pl. grass. t. 157 . Monánthes polyphýlla, Haw, rev. p. 68 . Flowers small, purplish. Plant tufted.

Onc-flowered House-leek. Fl. July, Sept. Clt. 1777. Pl. 1 or 2 inches.

\section{$\dagger$ Specics hardly knon'n.}

32 S. Africa'num (Mill. dict. ed. 8. no. 7.) margins of leaves serrately toothed; offsets spreading. \%. D. G. Native of the Cape of Good Hope. Haw. syn. ?. 367. This species has never been seen except by Miller; it is therefore doubtful. Sprengel says it is the same as $S$. arboreum.

African House-leck. Clt. 1768. Shrub.

33 S.? Seguie'ri (D. C. prod. 3. p. 414.) stem herbaceous, erect; leaves opposite, obovate.-Native on Mount Baldo. Sèdum pertræ'um, Sc. Scarella in Seg. ver. 2. p. 360. t. 17. S. stellatum, Poll. fl. ver. 2. p. 11 t. exclusive of the synonyme of Smith. It is probahly a variety of Sèdum dasyphýllum, but the flowers are said to be yellow. The plant is therefore very doubtful.

Seguicr's House-lcek. Pl. $\frac{1}{4}$ foot?

34 S.? Hispánicum (Willd. enum. p. 508.) leaves subulate, semi-terete, ciliated, imbricated; cymes bifid. 24. H. Native of Sprain. The rest unknown. Perhaps a species of Sìdum.

Spanish House-leek. Pl. $\frac{1}{4}$ to $\frac{1}{2}$ foot.

35 S. clavicula'tum, Sieb.? These two species are only $36 \mathrm{~S}$. мuta'bile, Schlecht. ' known by name.

Cull. The greenhousc kinds of house-leek are chiefly natives of the Canary Islands. $\Lambda$ mixture of sand, loam, and brick-rubbish is a good soil for them; and care must be taken not to gire them too much water when not in flower. Cuttings taken off the plants, and laid to dry a few days, will strike root freely without any covering of glass. Cuttings of some species are difficult to obtain, such as of S.tabuliforme, \&c. ; the best way in such cases is to cut the top ont, and lateril shoots will be immediately produced. The hardy kinds are well fitted for rock-work, or to grow on walls; and they are easily increased by the offsets, which are issued in great abundance. A light soil suits them best.

\section{Tribe II.}

CRASSULA'CEÆ $A N O^{\prime} M A L E$ (the plants contained in this 
tribe are anomalous in the order, in consequence of the carpels being united into a many-celled capsule, and dehiscing on the outside). D.C. prod. 3. p. 41\%. Carpels united at the base into a many-celled capsule.

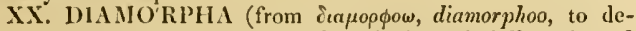
form; in reference to the fruit, which is formed differently and contrary to the rest of the order). Nutt. gen. amer. 1. p. 293. D. C. prod. 3. p. 414 .

Lin. syst. Octándria, Tetragýnia. Calyx 4-lobed. Petals 4. Stamens 8. Carpels 4, united at the base, but diverging at the apex, cuspidate, opening on the outside, usually containing about 4 seeds. - A small biennial herb. with the branches disposed in whorles from the base. llowers small, white, disposed in cymes. Leaves alternate, nearly terete.

1 D. rust'lla (Nutt. l. c.) §. H. F. Native of North Carolina, about Camelen, among moss on rocks. Sèdum pusíllum, Michx. fl. bor. aner. 1. 1. 276. Tilla'a cymòsa, Nutt. gen. amer. 1. p. 110.

Small Diamorpha. Pl. 1 inch.

Cult. The sects of this plant should be sown in a pot, filled with peat, and the plants need not be shifted into other pots; but be preserved through the winter by a frame.

XX1. PENTHORUM (from $\pi \varepsilon v \tau \varepsilon$, pente, five, and $\delta \rho s_{\text {, }}$ horos, a boundary; in reference to the 5 beaks which terminate the capsule). Lin. gen. no. 580. Gartn. fruct. 1. p. 312. t. 65. D. C. prod. 3. p. 414 .

Lin. słst. Decándria, Pentagýnia. Calyx 5-parted. Petals 5. Stamens 10. Scales wanting? Carpels 5, united at the base, in a 5 -beaked 5 -celled capsule, which is pentagonal at the apex, and opening under the beaks. Seeds numerous, small, fixed on every side of the broad placenta, and probably exalbuminous.-Erect perennial herbs, with scattered, membranous, oblong-linear, unequally serrated leaves: and unilateral cymes, which are turned back at the points.

1 P. SEDIoides (Lin. spec. p. 620.) stem a little branched; leaves lanceolate; cymes numerous, panicled, many-flowered; seeds scobiform. 4. H. Native of North America, in bogs, from New England to Carolina, and on La Grande Chaudiere. Lin. act. ups. 1744, t. 2. Lam. ill. t. 390 . Flowers white or pale yellow.

Sionecrop-like Penthorum. Fl. July, Aug. Clt. 1768. Pl. $1 \mathrm{ft}$.

2 P. Cunnénse (Pursl. f. amer. sept. 1. p. 323. in obs.) stem simple; leares long, linear-lanceolate; cynes few, corymbose, few-flowered; seeds ovate, horny. \%. H. Native of China. D. C. mem. crass. pl. 13. Very like P. sedivides, but the seeds are certainly distinct. Stems, as in it, terete at the base, and angular at the apex.

China Penthorum. Pl. 1 foot.

Cult. The species of this genus grow freely in light sandy soil, and are easily increased by dividing at the roots. Cuttings also strike freely under a hand-glass. $P$. Chinénsis, if ever it should be introduced to the gardens, will require protection in winter until its hardiness be ascertained.

ORDER CXIV. FICOI'DEE (plants agreeing in character with Mesembryánthemum, or Fig-marygold, in particular characters). Juss, gen. p. 315 . dict. sc. nat. 16. p. 528. D. C. prod. 3. p. 415 .

Calyx constantly of a definite number of sepals, usually 5 , but rarying from 4 to 8 , more or less united at the base, either cohering with the ovarium, or almost distinct from it, equal or unequal, quincuncial or valvate in restivation. P'etals indefinite, coloured, narrow, a little combined at the base, sometimes want- ing, but in that case the inside of the ealyx is coloured. Stamens indefinite, arising from the calyx, distinct; anthers oblong, incumbent. Ovarium distinct, or adnate to the calyx, manycelled, crowned by numerous distinct stigmas. Capsule either girded by the flesliy calyx or naked, usually many-celled, but often 5 -celled, opening in a stellate manner at the apex. Seeds attached to the inner angle of the cells, definite or indefinite. Embryo lying on the outside of a mealy albumen, curved.Shrubby or lierbaceous plants, variable in habit. Leaves fleshy, opposite, simple. Flowers usually terminal.

'The curved embryo and mealy albumen, along with the superior calyx, and distinctly perigynous stamens, characterise these among their neighbours, independently of their suceulent habit. With Crassulicece, Chcnopòlca, and Caryophyllewe they are more or less closely related. Reaumurièce and Nitrariùcea are families different in affinity. The hottest sandy plains in the Cape of Good Hope nourislı the largest part of this order. A few are found in the south of Europe, north of Africa, Chili, China, Peru, and the South Seas. The succulent leaves of a few of the species are eaten, as of Tctragònia expánsa, Mesembryánthemum edùle, and Sesùvium portulacástrum; others yield an abundance of soda. Mcsembryánthemum nodiflòrum is used in the manufacture of Moroquin leather.

\section{Synopsis of the genera.}

1 Mesembryánthemum. Calyx of 5, rarely of $2-8$ sepals. Petals indefinite, linear. Stamens indefinite, inserted in the top of the calyx along with the petals. Capsule adnate to the calyx, from 4 to many-celled; cells many-seeded.

2 Tetragònia. Calyx 4, rarely 3-cleft; lobes coloured inside. Petals wanting. Stamens variable in number. Capsule 3-8-celled; cells 1-seeded.

3 Sesu'vium. Calyx 5-parted; lohes coloured inside. Petals wanting. Stamens $15-30$, inserted in the top of the tube of the calyx. Capsule 3, rarely 4-5-celled; cells many-seeded.

4 Aızòon. Calyx 5-parted, coloured iuside. Petals wanting. Stamens about 20 , inserted in the bottom of the calyx, 3-5 in each fascicle. Capsule 5-celled; cells many-seeded.

5 Glixus. Calyx 5-parted, coloured inside, with 3 inner sepals and 2 outer ones. Petals 5-20, tongue-slaped, 2-4-eleft at the apex. Capsule covered by the calyx, 5-celled; cells many-sceded.

6 Ory'gia. Calyx 5-parted. Petals numerous $(\approx 0)$, lanceolate. Stamens indefinite. Capsule globose, 5-celled, many-seeded.

I. MESEMBRYA'NTHEMUM (from $\mu \varepsilon \sigma \eta \mu \beta \rho t r$, mesembria, mid-day, and $a v\{\varepsilon \mu o r$, anthemon, a flower). Lin. gen. 628. Gærtn. fruct. 2. t. 126. Lam. ill. t. 438. Haw. obs. mes. 1. vol. 3. 1794 . misc. 1 s03. p. 15 . syn. pl. succ. 1819 . p. 202. D. C. prod. 3. p. 415.—Mesembryánthemum and IIymenógyne, Haw, rev. succ. p. 74 . and p. 192.

LrN. syst. Icosándria, Tetra-Polygýnia. Calyx of 5 , rarely of 2-8 sepals; sepals united to themselves, and to the ovarium even to the middle; lobes unequal, ustally leaf-formed. P'etals innumerable, in one, but more often in many series, united among themselves at the base. Stamens indefanite, disposed in many series, inserted with the petals at the top of the calyx. Ovarim adnate to the calyx, many celled inside $(4-20)$, but usually $5-$ 
celled. Stigmas 4-20, but usually 5. Capsule many-celled, opening stellately at the apex, achate to the permanent calyx. Sceds numerous. Embryo curved at the side of a mealy albumen. Cotyledons thick, very blunt.-Subshrubs, rarely herbs, almost all natives of the Cape of Good Hope. Leaves usually opposite, thick, fleshy, flat, terete or trigonal. Flowers terminating the branclies, white, yellow or purple, the greater part of which open in the heat of the sun, very few of them opening in the evening. Fruit opening in a humid atmosphere, and relieving the seeds, which are then dispersed by the wind along with the sand.

In consequence of this genus being very large, we think it necessary to give a synoptical table of the sections, in order to render a reference to the species more easy.

Synoptical Table of the Sections.

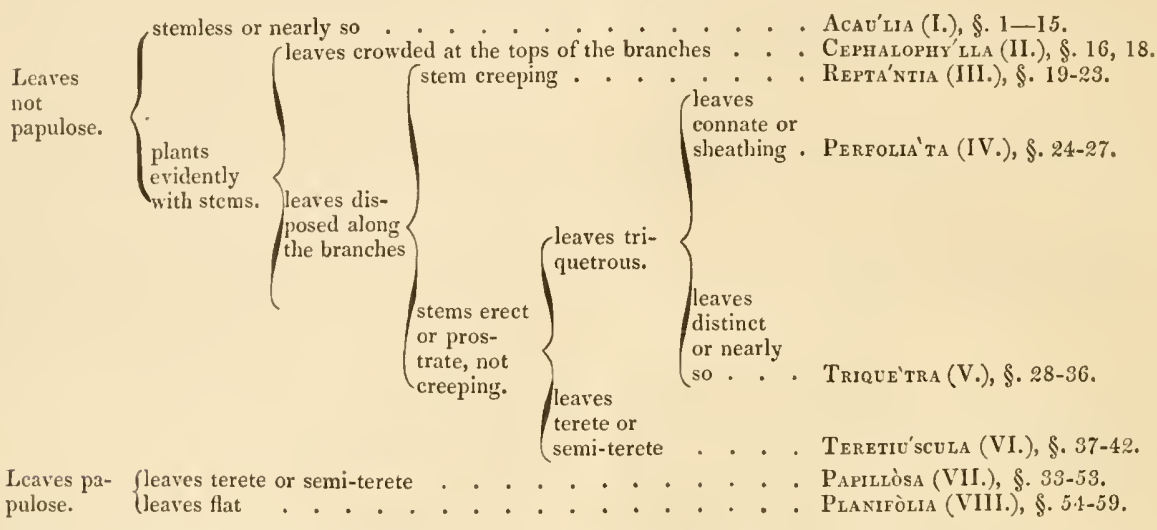

Subdivision I, Acaútia (acaulis, without a stem; plants stemless or nearly so). Haw. rev. succ. p. 81. Stems wanting or very short. Root perennial. Leaves large, variable in form and thickness, but not flat.

\$1. Sphceroidea (from $\sigma \phi a \iota \rho$, sphaira, a sphere; in reference to the leares being joined together into a globe). Salm-Dyek.Minima el Sphceroidea, Hav. rev. suee. Plants stemless. Leaves opposite, vcry blunt, joined evcn to the apex into a globe, but separating at length at the apex, and becoming marcescent, but still sheathing at the base. Flowers solitary, sessile, central. Calyx 4-5-eleft. Stigmas 4-5. Petals joined into a loose tube.

1 M. mал'тсм (Haw. obs. 126. misc. 21. rev. 82.) plant stemless, obconical, glaucous, without spots; flowers long, tubular. 24. D. G. Native of the Cape of Good Hope. Sims, bot. mag. t. 1376 . Plant hardly the size of a common bean. Petals pale reddish in the free part, spreading; tube slender, half an incl long, inclosing the ovarium.

Minute Fig-marigold. Fl Sept. Nov. Pl. $\frac{1}{2}$ incl.

2 M. M'Nixum (Haw. obs. 126. misc. 21, syn. 203. rev. p. 82.) plant stemless, obconical, glaticescent, with confluent rather branched spots; ovarium exserted. 24.D. G. Native of the Cape of Good Hope. Petiv. gaz. t. 39. f. 3. ? ex Haw. Flowers very pale yellow, almost white, sessile. The cultivated plants of this species are sometimes somewhat eaulescent. Offsets fewer from this species than from the other allied species.

Smallest Fig-marigold. Fl. Sept. Dec. Clt. 1776. PI. $\frac{1}{2}$ inch.

3 M. perpesíclum (Haw. rev. p. 82.) plant stemless, obconical, green, with strong confluent branched dots; ovarium inclosed. 2 . D. G. Native of the Cape of Good Hope. Very nearly allied to $M$. minimum, but the colour of the flowers is deepcr, and the offsets more numerous. inch.

V cry-small Fig-marigold. II. Scpt. Dec. Clt. 1819. PI. $\frac{1}{2}$

4 M. obcorde'llum (Haw. misc. 2I. syn. 203. rev. 82.) plant stemless, obconical, glaucescent, with confluent branched dots; ovarium inclosed. 4. D. G. Native of the Cape of Good Hope. Sims, bot. mag. 1647. Flowers small, sessile, nearly white. Petals twice the size of those of $M$. perpusillum, to which it is very nearly allied.

Small-obcordate Fig-marigold. Fl. Feb. Oct. Clt. 1776. Pl. $\frac{1}{2}$ inch.

5 M. obconéludm (Haw. misc. 2I. syn. 203. rev. 83.) plant stemless, obconical, green, with confluent, rather tubercleformed dots; ovarium inclosed. $\quad$ \&. D. G. Native of the Cape of Good Hope. Calyx 4-cleft. Corolla white.

Little-cone Fig-marigold. Fl. Feb. Oct. Clt. 1786. Pl. $\frac{1}{2}$ in.

6 M. ricifórse (Haw, rev. p. 83.) plant stemless, rather pyramidal or pear-shaped, glaucous, retusely obtuse at the apex, with the dots usually distinct, greenish, and nearly obsolete. 4. D. G. Native of the Cape of Good Hope. Plant pale. Flowers unknown.

Fig-formed Fig-marigold. Fl. Feb. Oct. Clt. 1819. Pl. $\frac{1}{2}$ in.

7 II. Truncatéllum (Haw. misc. 22. syn. 203. rev. 83.) plant stemless, much depressed, and rather glaucous, with the dots rather distinct; ovarium exserted. 24.D. G. Native of the Cape of Good Hope. Flowers straw-coloured.

Small-truneatcd Fig-marigold. Fl. Feb. Oct. Clt. 1795. Pl. $\frac{1}{2}$ incl.

8 M. Fibulæfórne (Haw. misc. p. 22. syn. 203. rev. p. 83.) plant stemless, rather eanescent, and somewhat pubescent, very much depressed, and spotless. 24. D. G. Native of the Cape of Good Hope. Flowers unknown.

Button-shaped Fig-marigold. Fl. ? Clt. 1795. Pl, $\frac{1}{2}$ inch.

9 M. turbinifórme (Haw. rev, p. 84.) plant stemless, obconical, exactly truncate, and therefore top-formed, obscurely dotted. 2. D. G. Native of the Cape of Good Hope. Burch. cat. 1630.2 voy. 1. p. 310 . This species is twice or thrice the size of $M$. truneatum.

Top-shaped Fig-marigold. PI. 2 inches. 
10 M. uværónme (Haw. rev. p. 84.) plant stemless, nearly globose, green, form and size of a grape herry, with small, rather confluent deeper dots. 4 . D. G. Native of the Cape of Good Hope. Burm. afr. t. 10. f. 2.?

Grape-formed Fig-marigold. Fl.? Clt. 1820. Pl. $\frac{1}{2}$ inch.

11 M. Nucifórme (Haw. obs. 129. misc. 22. syn. 204. rev. 84.) plant stemless, glaucous, without dots, nearly spherical; tops of leaves unequal, distinct, flat above. 2. D. G. Native of the Cape of Good Hope. Flowers unknown.

Nitt-formed Fig-marigold. Clt. 1790, Pl. 1 inch.

§ 2. Subquadrifolia (the plants belonging to this section are usually furnished with about 4 leaves). Salm-Dyck, obs. 17.Semiorata and Obtùsa, Haw. rev. p. 85. Plants almost stemless. Leaves 4-6, decussate, quite entire, obtuse, flat above, convex beneath. Flowers nearly sessile, solitary. Calyx 4-6-cleft. Stigmas 4-6. The upper lcaves are usually connate, as in section Spharoidece, and at length separate, but more distinetly.

12 M. Trunca'tusr (Thunb. f. cap. p. 412.) plant stemless; leaves spheroid-obconical, umbilicately truncate; peduncle solitary, 1-flowered, compressed; calyx 4-cleft. 4.D. G. Native of the Cape of Good Hope.

Truncate Fig-marigold. $\mathrm{Pl} .1$ to 2 inches.

13 M. testicula're (Ait. hort. kew. 2. p. 181.) plant stemless; leaves 4-8, white, smooth, semi-terete, ovate or parabolic, expanded. 4. D. G. Native of the Cape of Good Hope. M. testiculàre, Thunb. fl. cap. p. 412. Hew. obs. 133. syn. 205. exclusive of variety $\beta$ and $\gamma$, misc. 24. rev. 35. Flowers white.

Testicular Fig-marigold. Fl. Nov, Clt. 1774. Pl. 1 inch.

14 M. осторич́llus (Haw. rev. p. 85.) plant stemless; leaves 6-8, white, smooth, rather erectish, convex beneath, flat above. $\psi$. D. G. Native of the Cape of Good Hope. M. testiculàre $\gamma$, Haw. misc. p. 24. M. testiculàre $\beta$ et $\gamma$, Haw. syn. 205. M. testiculàre $\beta$, Sims, bot. mag. 1573. Flowers yellow, and when expanded they are 8 or 10 lines in diameter. Calyx 6-cleft, furnished with two leaf-formed bracteas at the base. According to the Prince de Salm-Dyck, this is merely a variety of $M$. testiculdre.

Eight-leaved Fig-marigold. Fl. Nov. Clt. 1819. Pl. $\frac{1}{8} \mathrm{ft}$.

15 M. овте'sum (Haw. misc. 25. syn. 206. rev. 86.) plant green, almost stemless; leaves unequal, semi-terete, acinaciform, obtuse; flowers almost sessile; calyx 6-lobed. 24. D. G. Native of the Cape of Good Hope. M. fissoides, Haw. obs. I35. Old stem 2 inches high. Flowers pale red, bibracteate at the base; petals an inch long. Styles 6 .

Blunt Fig-marigold. Fl. March, April. Clt. 1792. Pl. $\frac{1}{8} \mathrm{ft}$.

16 M. fr'ssum (Haw. obs. 134. misc. 25. syn. 205. rev. 86.) plant almost stemless; leaves equal, half-terete, very blunt, glaucescent. 4. D. G. Native of the Cape of Good Hope. Old stem 1 or 2 inches high; branchlets very short, and alternate. Flowers unknown.

Cleft Fig-marigold. Clt. 1776. Pl. $\frac{1}{8}$ foot.

17 M. DIGiTifo' RuE (Thunb. fl. cap. p. 412.) plant stemless; leaves $3-4$, terete, smooth, obtuse ; flowers sessile, solitary, axillary. 4. D. G. Native of the Cape of Good Hope. M. digitàtum, Ait. hort. kew. 2. p. 181. Flowers white, according to Thunberg. Leaves alternare. Perhaps belonging to a different section.

Finger-shaped Fig-marigold. Clt. 1775. Pl. 1 inch.

5. Monilifórmia (from monile, a bracelet, and forma, form ; appearance of stems). Haw. and Salm-Dyck, l.c. Stems very short, moniliform, leafless in the summer. The tno first leaves united cren to the apex, and deciduous; the two folloning leaves elongated, and joined at the base, marcescent, and deciduous. Calyx 4-6-elcft, and is, as well as the leaves, full of crystalline papula. Stigmas 7-8.

18 M. pisifórme (Iaw. misc. 23. syn. 205. rev. 93.) leaves full of crystalline papulæ; the first two united into the form of a pea: the following 2 semi-terete; caulex mueh branched, and very dwarf. 4 . D. G. Native of the Cape of Good Hope. The first leaves are produced in autumn, and the second in winter. Flowers unknown.

Pea-formed Fig-marigold. Clt. 1796. Pl. 1 inch.

19 M. MON1Lifo'rMe (Haw, obs. 132. misc. 24. syn. 207. rev, 93.) first leaves joined into a spherical form; the following ones half-terete; subulate, very long, green, and somewhat recurved. 4. D. G. Native of the Cape of Good Hope. Thunb. fl. cap. p. 413. Peduncles 2 inches long, terminal. Calyx 4-cleft. Petals snow white. Styles 7, ex Haw.

Necklace-formed Fig-marigold. Fl. March, April. Clt. 1791. Pl. $\frac{1}{8}$ foot.

\$ 4. Aloidea (plants resembling Aloe in habit). D.C. prod. 3. p. 419. Aloidea and Magnipúncta, Han. rev. p. 86. and 87. Ringéntia intègra, Salm-Dyck. obs. p. 20. Plants stemless. Leaves triquetrous, gradually thickened towards the apex, having the carinal angle gibbous; the two superior ones entire. Flowers central, sessile, yellow.

20 M. No' вıLE (Haw. in phil. mag. 1823. p. 381.) plant rather caulescent; leaves coarsely and triquetrously clavate, obtuse, somewhat recurved, rather concave above, marked by large elevated tubereles. 24.D. G. Native of the Cape of Good Hope. Flowers large, sessile, opening before meridian, yellow, scentless, bibracteate at the base. Calyx 6-cleft, according to Salm-Dyck.

Noble Fig-marigold. Fl. July, Aug. Clt. 1822. Pl. $\frac{1}{8}$ foot.

21 M. magnipu'sctum (Haw. rev. p. 86.) plant stemless; leaves perfect, usually about 4 , large, clavately triquetrous, very thick, glaucescent, flat above, keeled beneath, obtuse at the apex, marked with very large and numerous dots. 21. D. G. Native of the Cape of Good Hope. M. magnipunctàtum, Haw. suppl. p. 87. Flowers yellow, sessile.

Large-dotted Fig-marigold. Clt. 1822. Pl. $\frac{1}{4}$ foet.

22 M. сA'Num (Haw. obs. p. 158. misc. 25. syn. 219. rev. 87. but not of Salm-Dyck,) plant stemless; leaves hoary, semiterete at the base, attenuated, gibbously keeled at the apex. $\boldsymbol{\psi}$. D. G. Native of the Cape of Good Hope. Very like M. magnipunctum, but is easily distinguished by its hoary aspect. Flowers unknown.

Hoary Fig-marigold. Clt. 1795. Pl. 1 to 2 inches.

23 M. ALoìdes (Haw. suppl. 88. rev. 87.) plant stemless; leaves entire, semi-terete, green, marbled with white dots, acute upwards, rather concave above, carinately triquetrous at the apex. 4. D. G. Native of the Cape of Good Hope. Old plant tufted; root fusiform. Flowers sessile, central, yellow, middle-sized. Perhaps the same as $\boldsymbol{M}$. comipáctum, no. 86. Perliaps M. aloides, Burch. trav. afr. 2. p. 332.

Aloe-like Fig-marigold. Fl. Sept. Clt. 1819. Pl. $\frac{1}{8}$ foot.

\$ 5. Albindta (from albus, whitc, and nota, a mark; plants marked with white). Ham. in phil. mag. Aug. 1826. p. 126. Plants almost without stems, tufted. Roots perennial. Leaves decussate, entire, obliquely incurved, green, spreading, full of large tubercular white dots, semi-terete at the base, acinaciformly triquetrous at the apex, or nearly cqual-sided, more or less mucronulated. Flowers central, solitary, sessile, yellow. Stamens erectly spreading, as in those of section Ringéntia.

24. M. albinòtum (Haw, in plil. mag. Aug. 1826. p. 126.) leaves acinaciformly triquetrous upwards, with a recurved 
mucrone, full of seattered, rather elevated whitish dots. $\boldsymbol{\psi}$. D. G. Native of the Cape of Good Hope. Flowers yellow.

Whitc-markel Fig-marigold. Fl. Sept. Clt. 1824. Pl. $\frac{1}{8} \mathrm{ft}$.

25 M. A Lbариста'тum (Haw. l. c.) leaves semi-terete, beset with white tubercular dots. 4 . D. G. Native of the Cape of Gool Hope. Flowers yellow. Very like $M$. albinòtum, but the leaves are twice or thrice smaller, and more numerous. There is also a larger variety of this species mentioned by Haworth.

Whitc-dolted Fig-marigold. Fl. Sept. Clt. 1824. Pl. $\frac{1}{8} \mathrm{ft}$.

\$6. Ringéntia from ringens, gaping; appearance of the two upper leaves of the plants). Haw. syn. p. 216. phil. mag. 64. p. 110 . Spreng. syst. p. 515. D. C. prod.3. p. 419.-Ringéntia ciliàta, Salm-J)yeli.Ringéntia et Seapígera, IIan. rev. p. 87, 88. Plants stcmless. Lcaves triquetrous, gradually thickening to the top or gibbons, usually ciliately toothed, without papulce. Floners ycllow, oponing after meridian. Calyx 4-5-cleft. Stigmas 4. 5 .

26 M. mustellinum (Salm-Dyek and Haw. suppl. p. 87. rev. p. 89.) plant almost stemless, green, full of pellucid dots ; leaves triquetrous, gradually thickening towards the apex, ciliately toothed, pustulately gibbous on the inside at the base; flowers on short pedicels; calyx 4-cleft. 4. D. G. Native of the Cape of Good Hope. Salm-Dyck, obs. 1820. p. 9. Flowers yellow, expanding in the evening, sweet-scented.

Weascl-chop Fig-marigold. Clt. 1820. Pl. $\frac{1}{8}$ foot.

27 M. erminivum (Haw. in phil. mag. Aug. 1826. p. 126.) plant almost stemless, glaucous; leaves wrinkled from large dots; margins with short teeth at the apex. 4. D. G. Native of the Cape of Good Hope. Herb densely tufted. Flowers solitiry, terminal, yellow, opening in the evening. Nearest allied to $M$. murinum.

I ar. $\beta$, màgus (Haw. l. c.) corolla yellow, red at the apex.

Ermine-clıop Fig-marigold. Fl. May, Jul. Clt. 1824. Pl. $\frac{1}{8} \mathrm{ft}$.

28 M. agninum (Haw. in phil. mag. Aug. 1826. p. 126.) plant almost stemless, eanescent, wrinkled from dots; leaves semi-terete, serrulated from elevated dots, and hence somewhat toothed, pustulate on the inside at the hase. 4. D. G. Native of the Cape of Good Hope. Leaves with a large white pustule on the insicie at the base. Flowers sessile, solitary, central, expanding in the evening.

$J^{\prime}$ ar. $\beta$; plant a little smaller; teeth of leaves more obscure.

I $u$ r. $\gamma$; leaves more erect, entire.

lamb-chop Fig-marigold. Fl. May, June. Clt. 1824. Pl. $\frac{1}{8} \mathrm{ft}$.

29 M. mukisum (Haw obs. p. 165. mise. p. 30. syn. 217. rev. 90. phil. mag. 64. p. 111.) plant almost stemless, glaucous; leares ciliately denticulated, 3 rows on each side, and full of tubercular dots, with the margins and keel ciliately denticulated at the apex; flower sessile. 4.D. G. Native of the Cape of Good Hope. Flowers small, yellow. Styles 5, very short, erect, green, a little thickened towards the apex.

Mouse-chop ligr-marigold. Fl. siept. Clt. 1790. P. $\frac{1}{8} \mathrm{ft}$.

30 M. plinum (Haw, obs. p. I6I. mise. p. 31. syn. p. 216. rev. p. 8.) plant stemless, glaucescent; leaves ciliated with long teeth, olsoletely dotted, eartiliginously keeled at the apex, full of pellucid dots when examined by the light; flowers sessile. 4. J). G. Native of the Cape of Good IJope. D. C. pl. grass. t. $158 .-1$ 1)ill. hort. eltlı, f. 220 . M. ríngens $\beta$, Lin. spee. p. 698. Flowers yellow, expanding after meridian. Styles 5, fliform, equal in length to the stamens.

Cat-chop Fig-marigold. Fl. Aug. Nov. Clt. 1730. Pl. $\frac{1}{8} \mathrm{ft}$. 31 M. Luxixum (Haw, in plit. mag. 64. p. 111.) plant stemless; leaves glaucescent, marginal cilia very long, and very numerous. 4. 1). G. Native of the Cape of Good Hope. Very like M. felinum, but differs according to Salm-Dyck in the leaves being narrower, more attenuated, and in the ciliæ being longer and more numerous, but probably it is only a mere variety of it.

Holf-chop Fig-marigold. PI. $\frac{1}{4}$ foot.

32 M. tigrinum (Haw. ols. p. 164. misc. p. 21. syn. 216. rev. p. 89.) plant stemless, greenish ; leaves stem-clasping, ovatecordate, expanded, marbled with white, flat above, ciliated with long hairs, cartilaginously keeled at the apex; flowers sessile. $\boldsymbol{4}$. D: G. Native of the Cape of Good Hope. Ker. bot. reg. t. 280. Flowers yellow, expanding after meridian, large, central. Styles 4, filiform, equal in length to the stamens.

Tiger-chop Fig-marigold. Fl. Sept. Nov. Clt. 1790. Pl. $\frac{1}{4}$ foot.

33 M. caninum (Haw. obs, p. 159. syn. 217. rev. p. 87.) plant almost stemless; leaves glaucous, carinately triquetrous, rather club-shaped, incurved towards the apex, and somewhat toothed, as well as the bracteas; peduncles longer than the leaves. 4. D. G. Native of the Cape of Good Hope. D. C. pl. grass. t. 95.-Dill. elth. f. 231.-Bradl. succ. t. 17. M. ríngens a, Lin. spec. 698. Flowers of a yellowish orange-colour, opening after meridian.

Dog-chop Fig-marigold. Fl. Ang. Oct. Clt. 1717. Pl. $\frac{1}{4} \mathrm{ft}$.

34 M. vulpinum (Haw. syn. p. 4I7. rev. p. 88.) plant almost stemless; leaves glancous, earinately triquetrous, rather clubshaped, with large teeth at the apex or entire; old leaves horizontal; bracteas entire; peduncles longer than the leaves. $\psi$. D. G. Native of the Cape of Good Hope. M. caninum $\beta$, Haw. mise. p. 32. Very like $\boldsymbol{M}$. canimum, but taller, and the leaves are longer and greener, with fewer teeth. It is, however, perhaps only a variety of it. Flowers yellow.

Fox-chop Fig-marigold. Fl. May, Oct. Clt. 1795. Pl. $1 \mathrm{ft}$.

35 M. IY '́ BRIDUm (Haw.syn. 218. rev. p. 88.) plant stemless, smooth, white; leaves semi-terete, entire, carinately triquetrous above, and a little thickened, ending in a recurved mucrone each. 4. D. G. Raised in the gardens from the seeds of $M$. allidum, inpregnated by the pollen of $M$. caninum.

Hybrid Fig-marigold. Fl. May, Oct. Pl. $\frac{1}{4}$ foot.

36 M. musculivum (Haw. in phil, mag, nov. 1826. p. 328.) margins and keel of leaves usually bearing but one tooth each; branches prostrate, half a foot long. 4 . D. G. Native of the Cape of Good Hope. Flowers yellow, opening in the morning, scentless. This plant is very like $M$. murinum, but differs in the prostrate branches, and in the teeth of the leaves being fewer. It comes perhaps nearest in habit to $M$. crminimum, but differs in the petals being a line broad, not capillaceous.

Little-mouse-chop Fig-marigold. Fl. July, Aug. Clt. 1824. Pl. prostrate.

\$ 7. Rostràta (from rostrum, a beak). Han.syn.p. 211. SalmDyck, obs. bot. 1820. p. 20. Plants stemless or nearly so. Leaves 4-6, crectish, connate, scmi-terete, attenuatcd, rather liccled, and somenhat denticulated at the apex. Flomers solitary, pedunculate, yellon. Culyx 4-8-clcft. Stigmas 8-12.

37 M. Álbidum (Lin. spec. p. 699.) plant stemless, sinootl, whitish; leaves thick, subulate, triquetrous, obtuse, with an acumen, but scmi-terete at the base : all quite entire. 4. D. G. Native of the Cape of Good Hope.-Dill. hort. elth. f. 232. Bradl, suce. t. 43. Sims, bot. mag. t. 1824. Haw. rev. p. 88 . Flowers large, yellow, opening early in the morning, but afterwards remaining expanded through the whole day, sweetscented. Stigmas 11. This plant is intermediate between the section Ringćntia and Rostràta.

White Fig-marigold. Fl. July, Aug. Clt. 1714. Pl. 1 foot. 38 M. nenticula'tum (Haw. obs. 149. mise. 30. syn. p. 215. rev. 91.) plant stemless; leaves very glancous, subulately triquetrous, compressed, dilately keeled at the apex; keel usually 
denticulated; scape bibracteate, 1-flowered; styles 15 . 2. D. G. Native of the Cape of Good Hope. Flowers pale strawcolour, 3 inclics in diameter.

l'ar. a, cìnum (Haw. obs. 149.) leaves canescent from minute down.

I'ar. B, glaúcum (Haw, obs. p. 151.) leaves glancous-white, rather dilated at both ends, a little toothed.

Iar. $\gamma$, candidissimum (Haw. I. c.) leaves white, elongated, a little toothed, compressed on hoth sides.

Denticulated Fin-marigold. F1. April, Clt. 1793. Pl. $\frac{1}{5} \mathrm{ft}$.

39 М. вови'sтем (Haw. misc. p. 28. syn. 211. rev. p. 91.) stem robust, a little branched, short, decumbent ; leaves obtuse, dotted, subulate, pustulate inside at the base. 2. D. G. Native of the Cape of Good Hope. Flowers unknown.

Robust Fig-marigold. Clt. 1795. PI. $\frac{1}{4}$ foot.

40 M. compa'ctus (Ait. hort. kew. 2. p. 191.) plant stemless ; leaves connate, dotted, semi-terete, triquetrous at the apex, rather reflexed, acute; flowers sessile ; calyx subcylindrical, 6 cleft. 24. D. G. Native of the Cape of Gond Hope. Haw. syn. 211. rev. 91. Flowers yellow. A very doubtliul species, and probably the same as $M$. nóbile, no. 20.

Compact Fig-marigold. Fl. Nov. Clt. 1780. Pl. $\frac{1}{4}$ foot.

41 M. Quadríridum (Haw. misc. 28, syn. 212. rev. 91.) plant almost stemless, at length branched; leaves subulate, obtuse, hoary-glaucous, marked by a few dots towards the apex; scape terminal, I-flowered, longer than the leaves; calyx 4-eleft. 2. D. G. Native of the Cape of Good Hope. Old stems 2-8 inches long. Fluwers yellow. Styles about the length of the stamens.

Four-cleft Fig-marigold. Fl. Nov. Clt. 1795. Pl. $\frac{1}{4}$ foot.

42 M. B'́fideM (Haw. misc. p. 29. syn. 212. rev. p. 92.) plant almost stemless; leaves subulate, glaucous, obtuse, with many dots; scape nearly terminal, I-flowered: calyx bifid. 2. D. G. Native of the Cape of Good Hope. Flowers yellow. Lobes of calyx 2, unequal. Allied to $M$. quadrifidum, but weaker, and the leaves are shorter and blunter.

Bifid Fig-marigold. Fl. Nov. Clt. 1795. Pl. $\frac{1}{4}$ foot.

43 M. BibracteA'tUM (Haw. syn. p. 215. rev. 92.) plant almost stemless, branched; leaves elongated, subulate, dotted, very glaucous; bracteas 4 , decussate, shorter than the scape; calyx 5-cleft. 24. D. G. Native of the Cape of Good Hope. Very like $M I$. rostràtum. Flowers yellow, expanding in the sun. Stylcs 10, subulate, erect, length of stamens.

Bibractcate Fig-marigold. Fl. $A$ pril, Nov. Clt. 1803. Pl. $\frac{1}{3} \mathrm{ft}$.

4.4 M. PURPUra'scess (Salm-Dyck, obs. bot. anı. 1822.) plant almost stemless, branched ; leaves dotted, smooth, gibbous inside at the base, of a bluish glaucous-colour, obtuse, and triquetrous at the apex; keel usually extended; sheaths purplisls. $\psi$. D. G. Native of the Cape of Good Hope.

Purplish Fig-marigold. Pl. 1 foot.

45 M. Rostra'tum (Lin. spec. p. 696.) plant stemless; leaves subulate, elongated, acute, dotted; bracteas 2, longer than the scape; calyx 4-cleft. $\%$. D. G. Native of the Cape of Good Hope-Dill. elth. f. 229, without a flower. Haw. obs. p. 152 . misc. 29. syn. 214. rev. 92. Flowers yellow, expanding in the sun. Styles very short, approximate.

Var. $\beta$, tuberculàtum (Mill. dict. ed. 8. no. 82.) leaves tubercular on the outside.

Bealird Fig-marigold. Fl. April. Clt. 1742. Pl. $\frac{1}{4}$ foot.

46 M. Ramulòsr'm (Haw. misc. 29. syn. 215. rev. p. 92.) young plant nearly stemless; old stem 3 inches high, branched, and decumbent; leaves subulate, obtuse, pustulate inside at the base : when old expanded; scape terete, bracteate at the base; calyx 5-cleft. 4. D. G. Native of the Cape of Good Hope. M. rostratoides, Haw. obs. 154. Flowers yellow. 'This is the smallest of all the section.

YoL. III.
Small-branched Fig-marigold. Fl. March, Nov, Clt. 1791. Pl. 1 foot.

§. 8. Linguafórmia (from lingua, a tongue, and forma, a forin; shape of leaves). HIaw. misc. p. 32. rev. p. 03. SalmDyck, obs. 18. Plants stemless or ncurly so. Lcaces more or less tonguc-shaped, flat above, and convex bencath, snft, and shining. Flowers solitary, large, sessile, or pedunculate. Calyx usually 4-cleft, rarcly 5-cleft. Petals shining, ycllow, broadish. Stigmas 8, rarcly 10. Capsule 8-10-celled.

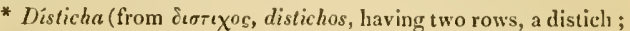
leaves disposed exactly in two opposite rows). Haw misc. p. 32. -Linguceförmia, Haw. rcv. p. 93.-Glossoidea, Spreng. syst. 2. p. 514. Leaces exactly distieh.-Pcrhaps all the plants containcd in this division are nothing more than varictics of one specics, and probably of garden origin. The whole have bccn collccted under the name of M. lingua forme in Lin. spec. p. 699. and D.C.pl. grass. no. 71 .

47 M. scalpra'tum (Haw, obs, p. 187. misc. p. 82. syn. p. 220. rev. p. 94.) plant stemless; leaves sloped down much, scalprate, very broad, one of the margins thicker than the other, pustulate inside at the base; flowers sessile. 2. D. G. Native of the Cape of Good Hope--Dill. elth. f. 224. M. obliquum, Willd. spec. 2. p. 1027. ex Salm-Dyck, obs. 1820. p. 19. M. linguæfórme $a$, Lin. spec. p. 669 . Flowers yellow.

Kinife-leaved Fig-marigold. Fl. Aug. Oct. Clt. 1714. I1. $\frac{1}{2}$ foot.

48 M. Fra'Grans (Salm-Dyck, obs. 1820. p. 8.) plant almost stemless; leaves tongue-shaped, thick, one side rather convex. and obtuse at the apex, the other sicle thrown out into a keel; flower nn a short peduncle. 4. D. G. Native of the Cape of Good Hope. Haw. rev. p. 95. Hoftmans, verz. I. p. 220. Otto et Link, abb. gew, t. 48. Flowers fragrant, yellow, 8 inches in diameter. Calyx 5-cleft. Allied to M. scalpratum, butt the leaves are narrower and thicker.

Fragrant Fig-marigold. Fl. Aug. Pl. $\frac{1}{2}$ foot.

49 M. prepíngue (Haw. obs. 179. nisc. p. 35. syn. p. 292. rev. p. 95.) plant stemless; leaves olliquely tongue-shaped, pale green, very soft, when young ciliated with pubescence, ending in an incurred point at the apex; flowers nearly sessile; calyx 4 cleft. 24. D. G. Native of the Cape of Good Hope. Willd. enum. p. 529. M. heterophýllum, Andr. bot. rep. t. 540.? but not of Haw. Capsule 8-celled, conically depressed. Old stenı half a foot long, procumbent. Flowers yellow.

lery-fat-leaved Fig-marigold. Fl. Aug. Oct. Clt. 1792. Pl. $\frac{1}{2}$ foot.

50 M. gRANDIFLònd (Haw. in phil. mag. nov. 1826 . p. 323.) leaves broad tongue-shaped, long, thick, having a large pustule on the inside at the base; petals very broad. 4. D. G. Native of the Cape of Good Hope. Flowers yellow, almost scentless, large, sessile; petals 3 -4 lines broad. Leaves $3 \frac{1}{2}$ inches long, and 15 lines broad. Capsule subconical. This is the largest species in the present section.

V'ar. $\beta$ (Haw. l. c.) leaves deeper green.

Great-flowered Fig-narigold. Fl. July. Clt. 1824. Pl. $\frac{1}{4} \mathrm{ft}$.

51 M. ME'DUU (Haw. suppl. p. 88. rev. p. 95.) plant almost stemless; leaves tongue-formed, sloping, cultrate, deep green, without any claw-like point at the apex; peduncles loncrer than the flowers. 24. D. G. Native of the Cape of Good Hope. Leaves 4 inches long, and an inch broad. Peduncles an inch long. Flowers yellow.

Niddle Fig-marigold. Fl. Aug. Oct. Pl. $\frac{1}{3}$ to $\frac{1}{2}$ foot.

52 M. cultra'tum (Salm-Dyck, obs. 1820. p. 7.) plant almost stemless; leaves distich, exactly tongue-shaped, cultrate at the margin and apex; peduncles compressed, rather longer than the 
flowers; calyx 5-cleft. 4. D. G. Native of the Cape of Good Hope. Haw. rev. p. 95 . Leaves $3-4$ inches long. Petals of a shining yellow above, and reddish beneath.

Cultrate-lcaved Fig-marigold. Fl. Aug. Oct. Clt. 1820, $\mathrm{Pl}, \frac{1}{2}$ foot.

53 M. Lósaux (Haw, obs. p. 177.) plant stemless; leaves elongated, tongue-shaped, shining, deep green; flowers pedicellate. $\%$. D. G. Native of the Cape of Good Hope-Dill. eltl. f. 227. M. linguafórme ì, Lin. spec. p. 699 . D. C. pl. grass. t. 71. M. lùcilum, Haw. rev, p. 95. Flowers yellow.

I'ar. $\beta$, fláccilum (D. C. prod. 3. p. 421.) flowers almost sessile. M. lóngum a, Haw rev. 96. M. depréssum, Sims, bot. mag. t. 1866.

Lon $\mathrm{s}$-lcaved Fig-marigold. Fl. Aug. Oct. Clt. 1725. Pl. $\frac{1}{2} \mathrm{ft}$. 54 M. ADSCE'NDENS (Haw. syn. 220. rev. p. 96.) plant stemless; leaves broadly tongue-sliaped, very blunt, ascending, green; flowers pedunculate. 24. D. G. Native of the Cape of Good Ilope. Flowers yellow. Probably only a variety of H. lóngum.

Ascending Fig-marigold. Fl. Aug. Nov, Clt. 1805. Pl. $\frac{1}{2} \mathrm{ft}$.

55 M. pustula'tum (Haw. suppl. p. 88. rev. p. 96.) plant stemless: leaves tonguc-shaped, ascending, elongated, furnisher with large pustules on the inside at the base. $4 . \mathrm{D}, \mathrm{G}$. Native of the Cape of Good Hope. Leaves 5-6 inches long, and 3-11 lines broad. Flowers yellow.

Blistercd Fig-marigold. H1. Aug. Clt. 1818. PI. $\frac{1}{2}$ foot.

56 M. hingu éórne (Haw. obs, p. 188 . misc. p. 33. syn. p. 221. rev. p. 97.) plant stemless; leaves unequally tonguc-shaped, thick, green, keeled on one side; flower on a very short peduncle; calyx 4-cleft. \%. D. G. Native of the Cape of Good Hope.-Dill. clth. f. 226. M. linguæforme $\gamma$, Lin. spec. 669. M. oblìquum; Pers, but not of Haw. Flowers yellow.

I $a$ r. 3 , ruféscens (Haw. syn. p. 221.) leaves very closely imbricated, rufescent.

Tongue-forned-leaved Fig-marigold. Fl. Mar. Nov. Clt. 1732. Pl, $\frac{1}{2}$ foot.

57 M. ен'тuм (Haw, obs, 186. misc. p. 32. syn. p. 220, rev. p. 98.) plant stemless; leaves tongue-shaped, grcen, obtuse, thick, usually sloping, and somewhat excavated; flowers nearly sessile ; calyx 5-cleft; capsule large, conical. 4. 10. G. Native of the Cape of Good Hope--Dill. elth. f. 225. M. linguafórme $\beta$, Lin. spec. 699 . Flowers yellow.

I ar. B, brivc (Haw, rev. p. 99.) leaves short, very blunt, depressed on the ground; capsule small, depressed.

Eroal-leaved Fig-marigold. Fl. Mar. Nov. Clt. 1620. Pl. $\frac{1}{4} \mathrm{ft}$.

58 M. DLPRE'Ssear (Haw. misc. p. 33. syn, 221. rev. 99.) plant almost stemless, prostrate; leaves pale, narrow-tongueshaped, obtuse, recurved, depressed, variously incurved at the apex; capsule depressed. 24. D. G. Native of the Cape of Good Hope.-Dill. elth. f. 226.? Flowers yellow.

I ar. $\beta$, lividum (Ilaw. I. c.) leaves of a livid rufescent colour

Depressed Fig-marigold. Fl. Sept. Nov. Clt. 1795. Pl. $\frac{1}{2} \mathrm{ft}$.

* Cruciàta (from crux, a cross; leaves disposed crosswise more or less). IIan. syn. p. 222.-Cruciuta and Difformia, Llaw. rer. 100. and 101. Lcavcs morc or less cruciate, usually obliqucly decussatc.

59 M. CRUCIA'TUM (Haw. obs. p. 179. misc. 35. syn. 224. rev. 35.) plant nearly stemless; leaves linear-tongue-shaped, semi-cylindrical, very soft, cruciate; peduncles 2-edged; calyx 4-cleft. 2 +. D. G. Native of the Cape of Good Hope. Old stems 3 inches high. Peduncles $1-2$ inches. Corolla large, yellow.

Cross-leaved Fig-marigold. Fl. May, Nor. Clt. 1792. Pl. $\frac{1}{4} \mathrm{ft}$.

60 M. taurixim (1law. syn. p. 22.l. rev. 100.) plant almost stcmless; leaves disposed in 2 rows, obliquely cruciate, semi- terete, obtuse, very thick, of a yellowish green colour, incurved; flowers sessile; calyx bifid? 2. D. G. Native of the Cape of Good Hope. Calycine segments unequal. Styles 8. Old stem branched at the base, half a foot high. Flowers yellow.

Bull's-horn Fig-marigold. Fl. Sept. Nov. Clt. 1795. Pl. $\frac{3}{4} \mathrm{ft}$.

61 M. SA'Lmi (Haw. suppl. p. 89. rev, p. 100.) plant nearly stemless; leaves decussate, semi-cylindrical, attenuated and acute at the apex, or oblique and bluntish; flowers exactly sessile; calyx 4-cleft; capsule half closed. 2. D. G. Native of the Cape of Good Hope. Salm-Dyck. obs. bot. 1820. Link, et Otto. abb. gew. t. 44. Flowers large, yellow. Leaves pustulate at the base, according to Haworth.

I ar. $\beta$, semi-cruciàtum (Salm-Dyck. 1. c.) leaves obliquely distich, straight, and more tongue-shaped than the species.

Salm-Dyck's Fig-marigold. Fl. Sept. Nov. Clt. 1818. PI. $\frac{1}{2} \mathrm{ft}$.

62 M. surréctus (Haw. rev. p. 101.) leaves decussate, erectish, or spreading, more or less semi-terete, subulate, acute, soft, usually pustulate at the base; ovarium exserted, somewhat pedunculate. 4. D. G, Native of the Cape of Good Hope. Flowers yellow.

Raiscd Fig-marigold. Fl. Sept. Nov. Clt. 1819. Pl. $\frac{1}{2} \mathrm{ft}$.

63 M. heterophy'llua (Haw. obs. p. 420. misc. 36. syn. 225. rev. 10l.) plant stemless; leaves green, difformed, without dots; upper ones the longest. 4 . D. G. Native of the Cape of Good Hope. Flowers yellow. Leaves obliquely cruciate: lower ones like those of $M$. cinum: upper ones like those of $M$. difforme.

Variable-leaved Fig-marigold. Clt. 1795. I'l. $\frac{3}{2}$ foot.

64. M. Angu'stum (Haw, obs. 176. misc. p. 34. syn. 222. rev. p. 101.) plant almost stemless; leaves linear-tongue-shaped, scmi-cylindrical, very long; flowers nearly sessile; calyx 4cleft. 4 . D. G. Native of the Cape of Good Hope. Flowers yellow, having the petals broader than any other species of this section. Calyx 4-cleft; stigmas 10, according to Haworth.

Íar. $\beta$, pállidum (Haw. rev. p. 101.) leaves paler, obliquely cruciate. Perliaps this plant appertains to $M$. heterophyllum. Andr. bot. rep. t. 510 .

Narrow Fig-marigold. Fl. Mar. Oct. Clt. 1790 . Pl. $\frac{1}{2} \mathrm{ft}$. 65 M. DIFfórme (Lin. spec. p. 669.) plant nearly stemless; leaves obliquely cruciate, long, semi-cylindrical, oblique, furnished with 1-2 obscure teeth at the apex; flowers nearly sessile; calyx 4-cleft. 2 . D. G. Native of the Cape of Good Hope.-Dill. elth. f. 242 . Haw. obs. p. 169 . misc. 35 . syn. 225 . rev. p. 103 . Old stems $2-3$ inches long, decumbent. Flowers large, yellow, fading to a copper colour. Styles 8.

Yar. $\beta$, brcvicaúle (Haw. rev. p. 103.). Caudex shorter.

Difformed Fig-marigold. Fl. Aug. Clt. 1732. Pl. dec.

66 M. вigibbera'tum (Haw. in phil. mag. nov. 1825. p. 329.) leaves obliquely somewhat cruciate, semi-cylindrical, pale green, varying at the apex, usually with 2 gibbositics; capsule depressed. 24. D. G. Native of the Cape of Good Hope. Very like $M$. difforme, but smaller and slenderer. Flowers yellow.

Tno-bunchcel-leaved Fig-marigold. Fl. Aug. Clt. 1820. Pl. $\frac{1}{4}$ foot.

67 M. вidenta'tum (Haw. suppl. p. 89. rev. p. 103.) plant stemless; leaves semi-cylindrical, thick, sof, oblique at the apex, and difformed, bearing 2 large, almost opposite, fleshy teeth in the middle. $4 . \mathrm{D} . \mathrm{G}$. Native of the Cape of Good Hope. Flowers large, ycllow, on short peduncles; petals erosely toothed at the apex. Capsule a little depressed.- The figure in Dill, hort. elth. f. 241 . is referrible to this plant and not to the next.

Bidcntate-leaved Fig-marigold. Fl. Ang. Clt. 1818. Pl. $\frac{1}{2} \mathrm{ft}$. 68 M.semicylíndricum (Haw. obs. p. 238. misc. p. 36. syn. 225. rev. 103.) plant rather caulescent; leaves very narrow, tongue-shaped, semi-terete, oblique towards the apex, furnished 
with 1 obsolete tooth on one side, and another stronger one on the other; flowers on sliort pedicels; calyx 4-cleft. 2.1). H. Native of the Cape of Good Hope-Pluk. mant. t. 325. f. 4 . Flowers yellow, size of those of M. linguafórme. Styles 8 .

Semi-cylindrical-leared Fig-marigold. Fl. Mar. Nov. Clt. 1732. P]. $\frac{1}{2}$ foot.

\$9. Dolabrifórmia (from dolabra, an axe or hatchet, and forma, form; shape of leares). Salm-Dyck. obs. p. 19.-Dolabrifómia and Curinántia, IIan. rev. p. 90. Plants stemless, or on short stems. Leaves decussate, with a kecled gibbous angle. Floners yellon. Calyx 5-eleft. Stigmas 5. Capsule 5-celled.

69 M. DoLABrifórue (Lin. spec. p. 699.) young plant stemless, but as it grows old it hecomes caulescent and ercet; leaves glaucous, dotted, exactly dolabriform, $i$. $e$. depressed at the base, and compressed at the apex, obtuse, and somewhat emarginate; flowers on slort pedicels. 々. D. G. Native of the Cape of Good Hope,-Dill. hort, eltlı. f. 237 . D. C. pl. grass, $t, 6$. Curt. bot. mag. t. 32 . Haw. obs. p. 366. misc. p. 37. syn. 1. p. 219. Flowers yellow, opening in the evening. Styles 5, filiform, longer than the stamens.

lar. $\beta$, minus (Haw. l.c.). M. dolabriformoìdes, Haw. obs. 168.

Ilatchet-form-leaved Fig-marigold. Fl. May, Nov. Clt. 1 705. Pl. $\frac{1}{2}$ foot.

70 M. Carísaxs (Haw. rev. p. 90.) plant nearly stemless; leaves elongated, somewhat incurved and spreading, semiterete at the base, compressed at the apex, and dilated into a keel, whitish and dotted. 2 . D. G. Native country and flowers unknown. M. cànum, Salm-Dyck. obs. p. 20. but not of Haw. Flowers by threes, yellow, expanding in the evening. Very like $M$. dolnbrifórme.

Keeling Fig-marigold. Fl. Aug. Sept. Clt. 1818 . Pl. $\frac{1}{2} \mathrm{ft}$.

71 M. scá PIGer (Haw, in plil. mag. dec. 1824. p. 423.) plant almost stemless; leaves carinately triquetrous, green, roughish and dotted on the margins; scape strong, 2-cdged, bracteate, rather panicled. 4 . D. G. Native of the Cape of Good Hope. Flower middle-sized, yellow. Calyx 5-cleft. Stigmas 5 , slender.

Scape-bearing Fig-marigold. Fl. Aug. Sept. Clt. 1823. Pl. $\frac{1}{2}$ foot.

$\$ 10$. Gibbòsa (from gibbosus, crooked-backed or bunched; back of some of the leaves). Haw, rev. p. 104.-Abbreviàta, Haw. mise. 1. p. 36.-Incequif òlia gibbòsa, Salm-Dyek. obs. p. 18. Plants nearly stemless. Leaves difformed, eonnate a great way at the base, large, uncqual, one of nhich is short and gibbous, the other usually oblique. Flowers sessile, or on short pedieels, small, reddish. Calyx 6-eleft. Stigmas 6.

72 M. GIB Bòsum (Haw. obs. p. 137. misc. p. 36. rev. p. 104.) plant nearly stemless ; leaves connate, difformed, of a yellowish green colour, spreading, ovate, semi-cylindrical, very rarely keeled at the apex; peduncles short, 2-edged. 2 . D. G. Native of the Cape of Good Hope. Petals reddish, with paler edges. Stigmas 6 , very short. Calyx 6-lobed; lobes unequal.

Gibbous-leared Fig-marigold. Fl. Jan. Apr. Clt. 1780. Pl. $\frac{1}{2} \mathrm{ft}$.

$7 S$ M. LU'Teo-víride (Haw. syn. p. 226. rev. p. 104.) stem short, prostrate, weak; leaves connate, oblong, semi-cylindrical, triquetrous at the apex, grecnish-yellow; flowers sessile. $\boldsymbol{\psi}$. D. G. Native of the Cane of Good Hope. M. perviride $\beta, \mathrm{Haw}$. misc. p. 37. Stem 1-2 inches. Calyx 6 -cleft. Styles 6 , very short, at length spreading. Petals reddish, marked by a dceper line each. Perhaps only a variety of $M$. perviride.

Fellowish-green Fig-marigold. Fl. Jan. Clt. 1795. Pl. $\frac{1}{4} \mathrm{ft}$.

74 M. PERTíride (Haw. obs. p. 136. misc. p. 37. exclusive of var. $\beta$, syn. p. 227. rev. 104.) stem weak, prostrate; leaves comnate, semi-cylindrically triquetrous, or somewhat ovate, very green; pedicels very short, 2-edged. ․ D. G. Native of the Cape of Good Hope. Calyx small, 6-eleft. Petals readish, paler than those of $\boldsymbol{M}$. gibbosum. Styles 6 , much spreading, length of filaments. Stem 2.3 inches long. Leaves slorter and broader than in $M$. lùteo-viride.

I'ty-green Fig-marigold. Fl. Jan. Aug. Clt. 1792. Pl. pr.

75 M. PUBE'scens (Illaw. ols. p. 138. misc. 137. syn. 227. rev. p. 101.) plant almost stemless; leaves pubescent, hoary, or silky, smooth, semi-cylindrical, oblique at the apex. 4.D.G. Native of the Cape of Good Ilope. Flowers unknown. The form of the plant agrees with the 2 preceding species, but diflers in bcing silky or downy.

Pubeseent Fig-marigold. Fl. Jan. May. Clt. 179\%. Pl. $\frac{1}{4} \mathrm{ft}$.

$\$ 11$. Calamifórmia (from calamus, a reed, and forma, form ; long taper leaves). IIan. rev. p. 104. Plants almost stemless. Leaves numerous, nearly terete, greenish, dotted. Flowers on short peduneles, of a dirty white eolour. Calyx 5-eleft. Stigmas 8.

76 M. calamiórme (Lin. spec. 690.) stemless; leaves subulate, nearly terete, glaucescent, dotted, Hat above; flowers on short peduncles. 2\%. D. G. Native of the Cape of Good Hope,-Bradl. succ. f. 19.-Dill. elth. f. 228 . D. C. pl. grass. t. 5. Haw obs. p. 140. misc. p. 26. syn. 208. rev. 105. Calyx 5-cleft, with 3 of the lobes tleshy, and 2 of them membranous. Petals whitish. Stigmas 8, acute. Capsule 8-celled.

Reed-shaped-leaved Fig-marigold. Fl. Jul. Sept. Clt. 171\%. Pl. $\frac{1}{4}$ foot.

77 M. obsubula'tum (Haw, misc. 26. syn. 208. rev. p. 105.) stemless; leaves inversely subulate, or gradually thickening towards the apex, thick, obtuse, greenish. 4 . D. G. Native of the Cape of Good Hope. Flowers unknown. Very like $M$. calamiforme.

Obsubulate-leaved Fig-marigold. Clt. 1796. PI. $\frac{1}{4}$ foot.

\$12. Teretifolia (from teres, cylindrical, and folium, a leaf). Ilaw. rev. $p$. I05. Plants stemless or subeaulesecnt. Leares nearly terete, greenish, dotted. Flowers peduneulate, showy, very pale red. Calyx 4-cleft. Stigmas 12.

78 M. cxlíndricuM (Haw, obs. p. 411. misc. 27. syn. p. 209. rev. p. 102.) plant almost stemless; leaves triquetrously terete, rather glaucous, dotted, but when young more glatcous and more triquetrous; peduncles compressed at the base, bibracteate. 2\%. D. G. Native of the Cape of Good Hope. Leaves 3 inches long. Peduncles 1-2 inches long. Bracteas filiform. Old stems 2 inches long, crowdedly branched. Flowers red.

Cylindrical-leaved Fig-marigold. Fl. Feb. Sept. Clt. 1792. P]. $\frac{1}{4}$ foot.

79 M. теretifòlium (Haw. syn. p. 210. rev. p. 105.) plant subcaulescent: leaves nearly terete or cylindrical, greenish, ratler dotted: but when young polished, very green, and semiterete; peduncle nearly terete, bibracteate. $\%$. D. G. Native of the Cape of Good Hope. M. cylindricum $\beta$, Haw. misc. p. 37. Branclies procumbent. Bracteas filiform. Leaves 4 inches long. Flowers red.

Terete-leaved Fig-marigold. Fl. Feb. Sept. Clt. 1794. Pl. ${ }_{2}^{1}$ foot.

80 M. teretiv'sculum (Haw. obs. 410. misc. 27. exclusive of the synonymes) plant stemless; leaves triquetrously tercte, firm, thick, green, dotted. 2\%. D. G. Native of the Cape of Good Ilope. Leaves 2 inches long. Flowers unknown, but probably red.

Nearly tercte-leaved Fig-marigold. Clt. 1794. Pl. $\frac{1}{4}$ foot.

\$13. Bellidiftora (from bellis, a daisy, and flos, a flower; the flowers bear some resemblance to those of the daisy). IIaw. rev. p. 106. Plants stemless or caulescent. Leaves triquetrous, 
acute at the angles, toothed at the apex. Floners solitary, pedicellate. Petals purple on the ribs and white on the margins. Calyx 5-cleft. Capsule 5-celled. Stigmas numerous, small, hair-formed.

81 M. BELLIDH Lòrum (Lin. spec. p. 690.) caudex short, suffruticose; leaves triquetrous, compressed, rather acinaciform, denticulated at the apex; pedicels slort. 4 . D. G. Native of the Cape of Good Hope. Petals red and white.

liar. $\beta$, glancéscens (IIaw, rev. p. 105.) leaves rather glancons, with the teeth in 3 rows at the apex.-Dill. elth. f. 233.

lar. $\gamma$, víride (Haw. rev. p. 105.) leaves pale green, toothed beneath on the keel.

Daisy-flowercd Fig-marigold. Fi. June, Aug. Clt. 1717. Pl. $\frac{1}{4}$ foot.

82 M. sUbUta'tum (Mill. dict. ed. 8. no. 10.) eaudex branched; leaves rather glaucous, triquetrously subulate, denticulated at the apex. \%. D. G. Native of the Cape of Good Hope. Haw. syn. 208. M. bellidiflòrum símplex, D. C. pl. grass. t. 41. Flowers reddish. The plant is very like $M$. bellidifiorum, but is mucl smaller and more branched.

Subulatc-leaved Fig-marigold. Fl. Ju. Jul. Clt.? Pl. $\frac{1}{4} \mathrm{ft}$. 83 M. BurMa'NNi (Haw. rev. p. 106.) floriferous stems erect, simple; leaves triquetrous, with 3 rows of tceth at the apex; pedicels rather elongated. 24. D. G. Native of the Cape of Good Hope.-Burm. afr. t. 25. This species is hardly known. Burmann's Fig-marigold. Pl. $\frac{1}{4}$ foot.

§ 14. Acùta (from acutus, acute; leaves acute). Ilan. rev. 107. Plants stemless or nearly so. Leaves semitcrete, subulate, incurved, triquetrous at the apex, green, full of pellucid dots. Floners pedicellate; petals deep purple. Calyx 5 cleft. Stigmas 10?

84 M. acu' tum (Haw. misc. p. 26. syn. 207. rev. 107.) plant stemless; leaves semi-cylindrical, acute, green, full of pellucid dots, finely wrinkled. 4 . D. G. Native of the Cape of Good Hope. M. subulatoides, Haw. obs. p. 141. M. subrostràtum, Willd. enum. 1. 529 . ex $\mathrm{H}_{\mathrm{a}}$. Allied to $M$. dimimùtum, but larger. Scape bibracteate at the base; bracteas filiform. Calyx 5-cleft. Petals purple, cleft at the apex. Stigmas 10, length of filaments.

Acute-leaved Fig-marigold. Fl. Apr. Nov. Clt. 1793. Pl. $\frac{1}{4} \mathrm{ft}$. 85 M. huncta'tum (Haw. obs. p. 411. rev. p. 107.) plant smooth, stemless; leaves semiterete, triquetrous at the top, flat above, full of pellucid dots, pale green, furnished with a minute white point at the apex. 4 . D. G. Native of the Cape of Good Hope. Flowers unknown. Perhaps only a variety of $M$. diminùtum.

Dotted-leaved Fig-marigold. Fl. April, Nov. Clt. 1793. Pl. $\frac{1}{4}$ foot.

86 M. diminu'tum (Haw. misc. p. 26. syn. p. 230. rev. 107.) plant nearly stemless, stnooth, shining ; leaves semiterete, triquetrous at the apex, flat above, full of pellucid dots, terminating in a white point at the apex. 24. D. G. Native of the Cape of Good Hope. M. corniculàtum, Haw, obs. p. 226. exclusive of the synonymes. Ml. loreum, Lin. spec. and Haw. exclusive of the synonyme of Dillenius ex Haw. Flowers red or purplish.

I ar. $\beta$, cauliculitum (Iaw. suppl. 90. rev. 107.) stem half erect; leaves longer, and with larger dots, but is perlaps only atr old plant.

Diminished lig-marigold. Fl. Apr. Clt. 1789. 1'!. $\frac{1}{4} \mathrm{ft}$.

\$ 15. Macrothiza (from $\mu$ cexpos, makros, long, and $\dot{\rho} \iota, \alpha$, rhiza, a root; root large and tuberous). D. C. prod. 3. p. 425. Plant nearly stemless. Leaves opposite, connate, triquetrous, crowded. Floners pedicellate, white. Calyx 5-cleft, having 2 of the lobes very long. Stigmas 5. Capsule subglolose.

87 M. Macrorhizem (Haw. 1. c. D. C. 1. c.) stem very short; root large, tuberous ; leaves connate, bluntly triquetrous, crowded, spreading ; branches erect, bent; flowers 1-3 together, nearly terminal, pedicellate. 4 . D. S. Native of the Island of Bourbon, among scoria near the sea. Stems 3 inches high. Flowers small, white, numerons. The leaves have an acrid taste when eaten, as those of Salsòla. La Lavangere, Comm. mss. and figure. Ficoìle, De Pet. Th. mel. bot. p. 37.

Large-rooted Fig-marigold. Fl. Ju. Jul. Clt. 1823. Pl. $\frac{1}{4} \mathrm{ft}$.

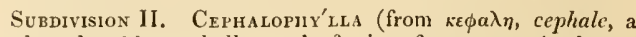
head, and $\phi v \lambda \lambda o v$, phyllon, a leaf; in reference to the leaves being collected in heads at the tops of the branches). Haw. rev. 10s. Stems suffruticose, decumbent. Leaves long, triquetrous, or nearly cylindrical, disposed in heads. Flowers pedunculate, yellow. Calyx 5-cleft. Stigmas 10-20.-This division is perhaps not very natural.

\$16. Corniculàta (from corniculàtus, horned; shape of leaves). IIaw. rev. p. 108.-Prostràta, Haw. mise. p. 38. syn. 220.-Calamifórmia prostràta, Salm-Dyck. Caudex branched, prostrate, rather strumose at the knots, and nearly sarmentaccous. Leaves crovded at the nodi, clongated, triquetrous, or nearly cylinilrical, glabrous, and without any papule. Floners pedunculate, yellow. Calyx 5-cleft. Stigmas 10-20. Otarium depressed.

88 M. Lòreum (Haw. syn. p. 229. rev. 108.) stems prostrate, rather nodose: adult ones nearly terete; leaves crowded in heads, semi-cylindrically triquetrous, elongated, recurved, rather glaucous. $々$. D. G. Native of the Cape of Good Hope. -Dill. elth. f. 255. Peluncles solitary, an inch and a half long, bibracteolate at the base. Flowers straw-coloured. Calyx 5-6cleft. Styles 15-18.

lar. $\beta$, congéstum (Haw. 1. c.) plant more greenish; lower pair of leaves very long.

Thong Fig-marigold. Fl. Sept. Clt. 1732. Pl. pr.

\$9 M. diversifoliva (Haw. misc. p. 38. syn. p. 230. rev. p. 108.) stems prostrate, rather nodose : adult ones robust, angular, red, and yellow; leaves very long, triquetrously semicylindrical, rather recurved, green, crowded in heads. h. D.G. Natives of the Cape of Good Hope.-Dill. elth. f. 252. M. diversiphýllum, Haw obs. p. 228. M. corniculatum $\beta$, Willd. Flowers pedunculate. Calyx 5-cleft. Petals of yellowish brown colour, striated by a red line on the outside. Styles 17. ex Haw.

lar. a, glaúcum (Haw. l. c.) leaves rather glaticous.

$\operatorname{Var} . \beta$, brcuifolium (Haw. l. c.) leaves shorter than in any of the other varieties.

I'ar. $\gamma$, la'te-virens (Haw. l. c.) leaves pale green.

Iar. $\delta$, atrovircns (Haw. l. c.) leaves dark green.

Diverse-leaved Fig-marigold. Fl. Mar. Oct. Clt. 1726. Pl.pr.

90 M. Decípiess (Haw, rev. p. 110.) stems prostrate, with rather distant nodi; leaves rather crowded, long, arcuately ascending, triquetrously semi-cylindrical, green, shining, minutcly and finely wrinkled. 2. D. G. Native of the Cape of Good Hope. illowers pale yellow.

Decciving Fig-marigold. Fl. Hay. Cl. 1820. Pl. pr.

91 M. Du'bium (IIaw. misc. p. 39. syn. 231. rev. 110.) stems prostrate, nearly terete, with the nodi contiguous; leaves rather crowded, longish, triquetrously semi-cylindrical, ascending, green, shining; stigmas 12. $\quad$. D. G. Native of the Cape of Good Hope-Bradl. succ. t. 40. Petiv. gaz. 77. f. 10. l.eaves 2 inches long, but shorter than those of $M$. corniculdum. Peduncles torminal, shorter than the leaves. Petals sulphur- 
coloured on the inside, and of an orange red colour on the outside.

Doubtful Fig-marigold. Fl. May, Nov. Clt. 1800. Pl. pr.

92 M. CoRniculA'TuM (Lin. spec. 676.) stems spreading, angular, with distant nodi; leaves rather crowded, triquetrously semi-cylindyical, very long, glaucous, incurved; stigmas 12-18. h. D. G. Native of the Cape of Good Hope-Dill, elth. f. 254. D. C. pl, glass, t. 108 . Haw. misc. 39. syn. 231. rev. 110. Peduncles slender, length of leaves. Calyx 5-cleft. Petals yellow, with a red dorsal line. Stigmas purple. Capsule many-celled.

Horned Fig-marigold. Fl. May. Clt. 1732. Pl. pr.

\$17. Procumbéntia (procumbcns, procumbent; plants). Han. in phil. mag. dec. 1826. p. 329. Old stems procumbent. Lea1es connate at the base, long, scmitcrcte or cylindrical.

93 MI. PRocu'ribens (Haw, rev, 111.) stems flexuous, procumbent; leaves by pairs, recurved, corniculate, semi-cylindrically triquetrous, glaucescent. h. D. G. Native of the Cape of Good Hope. M. dùbium, Salm-Dyck. obs, p. 22. Allied to $M$. tricolor, but the leaves are shorter and more expanded, \&c. Procumbent Fig-marigold. Fl, Mar. May. Clt. 1820. Pl.pr.

94 M. тricolónum (Haw obs. 233. misc. 39, syn, 232. rev. 111.) stems prostrate; branches distant; leaves exactly cylindrical, acute, green; stigmas 20, short, expanded. h.D. G. Native of the Cape of Good Hope. M. stramineum, Willd. enum. p. 533. ex Salm-Dyck. obs. p. 22. Flowers large, shining. Petals straw-coloured, blood-coloured at the base; anthers brown; stigmas green.

Three-coloured-flowered Fig-marigold. Fl. Apr. May. Clt. 1794. Pl. pr.

95 M. PURPU'reo-a'LBUM (Haw. in phil. mag. dec. 1826. p. 329.) branclies sliort, angular, prostrate, furrowed, yellowish ; leaves green, triquetrously semi-cylindrical, full of little dots, upper ones crowded. $h$.D. G. Native of the Cape of Good Hope. Peduncles filiform. Flowers showy; petals white, polished, naked, with a broad, dark, purple line. Styles 10 , reddish. Purple and nhite-flowered Fig-marigold. Fl. Aug. Clt. 1824. Pl. pr.

\$18. Capitàta (from capitatus, headed; leaves crowded into heads at the top of the stems or branches). Haw. syn. 227, rcv. 111. Salm-Dyck. obs, p. 30. Caudex erect, much branched. Lcaves cronded at the tops of the branches, alternate, very long, triquetrons, or semi-terete, nithout either dots or papulce. Floriferous branches disposed in somcthing like whorls, decumbent. Pcduncles bracteate at the base. Floners large, yellow. Calyx 5-lobcd; lobes elongated. Petals ciliated at the base. Stigmas 10-20. The species are very nearly allicd to cach other.

96 M. PUglonifónme (Lin. spec, 699.) stem suffruticose, erectish; branches few, terete, decumbent; leaves alternate, crowded at the tops of branches, glaucous, triquetrous; petals shorter than the calyx ; stigmas 15 , expanded. h.D. G. $\mathrm{Na}$ tive of the Cape of Good Hope-Dill. elth. f. 269. Bradl. succ. t. 14. D. C. pl. grass. t. 82. Haw. misc. 42. syn. 218. rev. 112. Flowcrs large, pale yellow. Perhaps the flesh-coloured and purple-flowered varieties mentioned in Breyn. cent. p. 164. belong to this species.

Dagger-formed-leaved Fig-marigold. Fl. July, Sept. Clt. 1714, Slirub 1 foot.

97 M. саріта'тuм (Haw. misc. p. 41. syn, 228, rev. 112.) stem simple, suffruticose, with the leaves alternate and crowded at its top, rather glaucous, and triquetrous; petals length of calyx; stigmas 16, straight, setaceous. h.D. G. Native of the Cape of Good Hope. Ker, bot. reg. 49 1. M. pugionifórme, Haw obs. p. 390 . Stcm simple. Flowers pale yellow.
Lar. $\beta$, ramigcrum (IIaw. 1. c.) stem a little branclied. Capitate Fig-marigold. Fl. Jul. Sept. Clt. 1717. Sh. $1 \mathrm{ft}$. 98 M. Brevicaúle (Haw. suppl. p. 91. rev. 113.) candex suffruticose, simple, crect, with the leaves alternate, greenisl, triçuetrous, and crowded at its ajex. h. D. G. Native of the Cape of Good Hope. Breyn. cent. p. 165. Much sinaller than M. capitàtum. Flowers palc yellow.

Short-stcmmed Fig-marigold. Fl. Jul. Sept. Clt, 1820 . Sh. $\frac{1}{2} \mathrm{ft}$.

99 M. coru'scans (Haw. suppl. 90. rev. 113.) stem shrubby; leaves alternate, dagger-shaped, long, glittering, crowded at the top of the stem. h. D. G. Native of the Cape of Goorl Hope. Flowers yellow.

Glittering Fig-marigold. Fl. July, Sept. Clt. 1812. Sh. $1 \mathrm{ft}$. 100 M. elonga'tuM (Haw, obs. p. 2s6. misc. p. 40. syn. p. 228. rev. p. 113.) stem weak, flexuous; leaves crowded at the top of the stem, alternate, rather glaucous, bluntly triquetrous, channelled or semiterete : root large, tuberous, fleshy. h.D.G. Native of the Cape of Good Hope. Flowers yellow. Stigmas 12-19. D. C. pl. grass, t. 72.

Var. $\beta$, minus (Haw. 1. c.) corolla a little smaller ; petals hardly cilitted. Ker. bot, reg. t. 493.

Var. $\gamma$, fusifórme (Haw, l. c.) root fusiform. Breyn, cent. p. 33. M. fusiforme, Haw, misc. p. 41.

Elongated Fig-marigold. Fl. May. Clt.1793. Sh. 1 foot.

Subdvision III. Reptántia (reptans, creeping; plants creeping). Haw. rev. p. 114. Stems suffrutescent, decumbent, creeping; branches angular. Leaves opposite, connate at the base, acutely triquetrous. Flowers pedunculate, reddish except in M. edule. Stignas 5-20.

§19. Sarmcntàsa (from sarmentosus, full of twigs ; branches numerons and twiggy). Salm-Dyck. obs. 38. Han. rcv. p. 114. Stcms shrubby, decumbent; branches rooting, sarmentaccous. Lcatcs opposite, connate, acutely triquetrous, dotted with scrrulatcd margins. Peduncles usually ternate, bibractcate. Flower. middle-sized, reddish, with a deeper-coloured dorsal line. Calyx 5-cleft. Stigmas 5.

101 M. gemiviflòrum (Haw. rev. 114.) stem shrubby, diffuse ; branches elongated, slender, creeping ; leaves triquetrous, nearly equal-sided, rather connate at the base, acute, and a little looked at the apex, dotted; pedicels twin or tern; stigmas 5. h. D. G. Native of the Cape of Good Hope. II. geminàtum, Jacq. fragm. t. 50. but not of Haw. Petals purple. Flowers hardly half an incls in diameter. Leares 12-15 lines long, scabrous from elevated dots.

Twin-flonerd Fig-marigold. Clt. $1819 . \quad$ Pl. creeping.

102 M. símle (Haw. rev. p. 115.) stems slirubby, firm, procumbent; leaves triquetrous, equal-sided, glaucescent, full of very small dots, straight at the apex, longer than the internodes: margins not serrulated. $々$. D. G. Native of the Cape of Good Hope. Flowers unknown. Allied to $M$. gcminiflornm, but the branches are shorter; and to $M$. láxum, but tlie internodes are shorter.

Similar Fig-marigold. Clt. 1819. Pl. pr.

103 11. Láxum (Willd. enum. p. 536.) stem loose, difluse, shrubby ; branches creeping, very slender ; lcaves connate, compressed, triquetrous, more green than the others, tubercularly dotted, ustally shorter than the internodes: with the margins and kecl finely denticulated. h. D. G. Native of the Cape of Good Hope. Haw. rev. 115. Flowers reddish.

Loose Fig-marigold. Fl. May. Clt. 1820. Pl. creeping.

10. M. Sarmentòsum (Haw. syn. 238. rev. 115.) stem shrubby, diffuse; branches prostrate, rooting, sarmentaceous; leaves crowded, compressed, triquetrous, pale green, roughish on the edges; peduncles club-shaped above; stigmas j. 々. D. G. 
Native of New Holland. Branclies short, opposite. Leaves 2 inches long. Calyx 5-cheft. Petals reddish, with a deepercoloured linc. Styles short, recurved at the apex, greenish yellow.

Tnigury Fig-marigold. Fl. April. Clt. 1805. Pl. pr.

105 II. RIGIDICAU'LE (Haw. rev. p. 116.) stem firm, procumbent, not pendulous; leaves long, triquetrous, equal-sided, straight, with roughish margins. h. D. G. Native of the Cape of Good Hope. The rest unknown.

Stiffsh-stemmed Fig-marigold. Fl. May, Ju. Clt. 1819. Pl.pr.

106 M. va'Lidus (Haw, in phil. mag. dec. 1826. p. 329.) leaves long, pale green, with roughish margins; branches robust, stiff, decumbent; flowers usually by threes; keel of bracteas entire. h. D. G. Native of the Cape of Good Hope. Flowers slowy, rose-coloured, with a deeper coloured line in the middle.

Sirong Fig-marigold. Fl. May, Ju. Clt. 1824. Pl. pr.

107 M. Schólli (Salm-Dyck, obs. 1820. p. 10. Haw. rev. p. 116.) stems firm, decumbent, sarmentose; leaves connate, compressed, triquetrous, spreadingly recurved, dotted, serrulated on the lateral angles, and on the upper part of the keel; peduncles tern, bibracteate in the middle; stigmas 5. h. D. G. Native of the Cape of Good Hope. M. aduncum, Jacq. fragm. t. 51 . f. 2 . but not of Willd. M. recúrvum, Haw. suppl. p. 90. but not of Monch. Petals reddish, acute, with a deeper-colomred line in the middle of each.

Scholl's Fig-marigold. Fl. May, June. Clt. I810. Sh. dec.

\$20. Humillima (from humillimus, very lumble). Han. rex. p. 121.-Reptántia, Salm-Dyck. obs. p. 30.-Reptántia lumillima, Han. sym. p. 241. Sicms suffruticose, and are as nell as the branches humble, prostratc, and creeping, rooting at the joints. Leaves opposite, rather connatc, triquetrous, usually crowded, with smooth margins. Flowers pedunculate, middlesized, reddish. Calyx 5-cleft. Stignas 5.

108 M. RE'PTANs (Ait. hort. kew. vol. 2. p. I85.) stems filiform, very slender, creeping; leaves much crowded, triquetrous, acute, glaucous, scalorous from large pellucid dots. $h$. D. G. Native of the Cape of Good Hope. Flowers reddish. (ex Ait.), yellow (ex Salm-Dyck.), rarely flowering (cx Haw. obs. p. 349. misc. 80. syn. 212. rev, 12J.).

Creeping Fig-marigold. Fl. Jul. Aug. Clt. 1774. Pl.cr.

109 M. crassifòlium (Lin. spec. p. 693.) stem semi-terete, creeping; leaves triquetrous, dotless, very green, smooth, semicylindrical at the base; peduncles a little compressed; stigmas 5, spreading. 5. D. G. Native of the Cape of Good Hope. - Dill. elth. f. 257.-Bradl. suce. t. 38. Haw. obs. 350 . misc. 78. syn. 241. rev. 122. Flowers middle-sized, deep red. Peduncles $1-2$ inches long. Calyx 5-cleft. Stigmas broad at the base, and subulate at the apex.

Thicli-lcaved Fig-marigold. Fl. May, $\Lambda$ ug. Clt. 1727. Pl.cr. $110 \mathrm{M}$. DE'BILE (Haw. in phil. mag. dec. 1826. p. 531.) plant smooth; branclies filiform, a little compressed; leaves crowded about the knots of the crceping stems, bluntly and acinaciformly triquetrous, glancescent. $h^{2}$. D. G. Native of the Cape of Good Ilope. This species differs from $M$. réptans in leing smooth, not rough. Flowers unknown.

Ileak Fïg-mariggold. Clt. 1824. Pl. creeping.

111 M. Clavkla'tum (Haw. misc. 79. syn. 212. rev. 122.) branches angular, crecpingr ; leaves crowded, expanded, obsoletely triquctrous, firm, clavate, very blunt, mucronulate, green ; peduncles ratlier compressed; stigmas 5 , very slender. h.D.G. Native of $\mathrm{New}$ Holland. Flowers like those of $M$. crassif $\dot{o}_{-}$ lium, but more beautiful and of a deeper red. Calyx 5-cleft ; stigmas setaceous, grecn.

Small-club-leaved Fig-marigold. Fl. June, Jul. CIt. 1803. shrub creeping.
112 M. austra'Le (Ait. hort. kew. 2. p. I87.) stems semiterete, creeping ; leaves triquetrous, glancescent, dotted, smooth, incurved; peduncles bluntly 2-edged, bibracteate at the base ; stigmas 5 , subulate. $\zeta$. D. G. Native of New Holland. Flowers middle-sized, pale red. Calyx 5-cleft. Haw. obs. p. 349. misc. 79. syn. 241. rev. 122. M. demíssum, Willd. enum, suppl. p. 36.

Southern Fig-marigold. Fl. Jul. Aug. Clt. 1773. Pl.cr.

$\$ 21$. Rubrieaúlia (ruber, red, and caulis, a stem; stems red). Salm-Dyck. obs. p. 29. Han'. rev. p. 116. Stems suffruticose; branches usually reddish, ercct, hardly decumbent. Leates triquetrous, rather acinaeiform, opposite, connate, rough and serrulated at the anglcs. Flowers pedicellate, solitary, braetless, deep red. Calyx 5-cleft. Stigmas 5-8.

113 M. filamentòsum (Lin. spec. 694.) stems short, decumbent; leaves compressed, triquetrous, rather acinaciform, crowded, thick, pale green, dotted, longer than the internodes, roughly serrulated on the edges; flowers solitary; stigmas 5 . h. D. G. Native of the Cape of Good Hope.-Dill. elth. f. 273. Haw. obs. 350. misc. 78. syn. 238. rev. 116. Flowers middle-sized, deep red. Calyx 5-cleft.

Filamentose Fig-marigold. Fl. Nov. Dec. Clt. 1795. Pl.pr.

114 M. SERRULA'tum (Haw. misc. 77. syn. 239. rev. 117.) stem shrubby, when young erect; branches erectly decumbent; leaves compressed, triquetrous, rather acinaciform, and rather glaucous, usually longer than the internodes, with the margins minutely serrulated, but hardly cartilaginous; flowers solitary; stigmas 7-8, ramentaceous. $々$. D. G. Native of the Cape of Good Hope. Flowers reddish, and ternately disposed, as in M. rubricaule: lateral ones usually abortive.

lar. $\beta$, viridius (Haw. l. c.) leaves green.

Serrulate-leaved Figmarigold. Fl. Nov. Dec. Clt. 1795. Shrub pr.

115 M. Rubricau'Le (Haw. misc. p. 77. syn. 239. rev. 117.) stem shrubby, when young erectish; branches opposite, rather effuse ; leaves compressed, triquetrous, usually shorter than the internodes, cartilaginous and serrulated on the margins; flowers solitary ; stigmas 5, expanded. $\zeta$. D. G. Native of the Cape of Good Hope. Willd. enum. p. 536. Flowers middle-sized, pale purple. There is a more dense rariety, and a greenish one.

Red-stemmed Fig-1marigold. Fl. Feb. Dec. Clt. 1802. Pl.pr.

\$22. Acinaciformia (from akivakns, akinakes, a Persian sword or scymitar, and forma, form; shape of leaves). SalmDyck. obs. p. 20. Haw. rer. p. $118 .-$ Reptántia majòra, Haw. syn. p.233. Stcms suffruticose, robust, rather dccumbent; branches angular, prostrate, or decumbcnt. Lcaves opposite, connate a short way at the lase, acinaciform, triquetrous, thick. Floners solitary, terminal, large, reddish (or as in M. edule yellon). Fruit fleshy. Stigmas 6-10.

116 M. EDU'LE (Lin. spec. 695.) branches expanded, with quite entire angles; leaves equally triquetrons, dotless, a little channelled, attenuated at both ends, with the keel serrulated; stigmas S. h. D. G. Native of the Cape of Good Hope.Dill, elth. 272. Seb. thes, 1. t. 19. f. 6. Haw, obs. 392. misc. 76. syn. 234, rev. 110. Flowers large, yellow. Calyx 5 -cleft. Capsule $\mathrm{S}$-celled, with the baccate calyx edible. Rarely flowering in the gardens.

Edible Fig-narigold or Hottentot Fig. Fl. July, Aug. Clt. 1690. Shrub pr.

117 M. Acinacifónme (Lin. spec. 695.) stems rather procumbent, long; leaves opposite, compressed, triquetrous, acinaciform, rather curled at the edges, and roughish; flowers solitary, terminal; stigmas 12-17. h. D. G. Native of the Cape of Good Hope.-Dill. elth. f. 270, 271. Andr. bot. rep. 508. Salisb. par. t. 90 . Haw, obs. 397. misc, 76, syn. 233. rev. 118 . 
Flowers large, reddish. There are two varieties of this species, one with short and the other with longer branches.

Scymitar-formal-leared Fig-marigold. Fl. Aug. Sept. Clt. 1714. Shrub pr.

118 M. L.eviga'tum (Haw, syn. 233. rev. 118.) stems rather procumbent, long; leaves acinaciform, smootl, glaucous, with cartilaginous, entire margins. h. D. G. Native of the Cape of Good Hope. Flowers unknown. Allied to M. acinaciforme, but differs in being smaller, and the branclses being angular, \&c.

Smooth Fig-marigold. Fl. June. Clt. 1802 . Pl. pr.

119 M. Rubrocínстum (Haw. syn. p. 284. rev. 118.) stems rather procumbent, long; leaves acinaciform, with rough red edges and keel. h. D. G. Native of the Cape of Good Hope. There is a variety of this species with thicker and more compressed leaves.

Red-bordered-leawed Fig-marigold, Fl, May. Clt. 1811. Pl. pr.

120 M. subala'tum (Haw. misc. 76. syn. 235. rev. 199.) branches 2 -edged at the apex, somewhat undulately winged; leaves compressed, triquetrous, equal-sided, dotless, rather acinaciform, with cartilaginous margins, which are scabrous on both sides. h. D. G. Native of the Cape of Good Hope. Flowers unknown, but probably reddisl.

Rather-ninged Fig-marigold. Clt. 1796. Shrub pr.

121 M. LA'CERUM (Salin-Dyck. obs. 1820. p. 31.) stem shrublyy, erect; branches erectly spreading, 2-edged; leaves rather acinaciform, acutely triquetrous, rather compressed, glancous, full of pellucid dots : with the keel lacerately toothed; stigmas 10, very short, approximate. 4. D. G. Native of the Cape of Good Hope. M. acinaciforme, D. C. pl. grass. t. s0. M. dimidiatum, and probably $\mathrm{M}$. làcerum, Haw. rev. 119. and 131. M. Millèri, Willd. enum. suppl. 31. and M. gladiàtum, Jacq. ex Salm-Dyck. Flowers large, red, opening in the sun; petals linear, very numerous. Calyx 5 -cleft; lobes leaf-formed. Stigmas for the most part 10 , but sometimes even to the number of 20 .

Jaggcd-keeled Fig-marigold. Clt. ? Shrub 1 to 2 feet.

122 M. virens (Haw. rev. 121.) stem erectish; branches at length spreading; leaves compressed, triquetrous, rather acinaciform, smooth, dotted, green, pustulate on the inside at the base, having the keel roughisl at the apex. $\quad$. D. G. Native of the Cape of Good Hope. Flowers reddish, disposed by threes. This species hardly belongs to this section, according to Salm-Dyck.

\section{Green Fig-marigold. Fl, June. Clt. 1821. Pl. I foot.}

\$23. Carnicaúlia (from caro, carnis, flesh, and caulis, a stem; stems fleshy while young). Haw. in phil. mag. dec. 1826. p. 330. Stems usually clongated, neak, prostrate, and crecping: when young thick and fleshy. Leaves triquetrous, with the sidcs nearly equal, thick, usually soft. Floners solitary, terminal, reddish, large, shomy, and hexagynous. Capsule pulpy on the outside, even then ripe.

123 M. equllatera'le (Haw. misc. 77. syn. 237. rev. 120.) stems weak, prostrate ; leaves almost equally triquetrous, greenish; peduncles angular, thickening towards the top; calyx 5cleft; stigmas 6, short, erect. ?. D. G. Native of New IIolland. Flowers showy, reddish.

Var. $\beta$, decágynum (D. C. prod. 3. p. 429.) stigmas 10 ; branches sliorter.

Equal-sidcd-leaved Fig-marigold. Fl. Ju. Clt. 1791. Sls. pr.

124 M. Glauce'scexs (Haw. syn. p. 236. rev. 120.) stems robust, decumbently prostrate; young leaves a little incurved, triquetrous, with the sides equal, soft, glaucous: with cartilaginous, smoothish margins; flowers solitary, sessile ; stigmas 7 . そ.D. G. Native of New Holland. Branclses furrowed at the top. Calyx 5-cleft. Petals pale purple.
Glauccsecat Fig-marigold. Fl. July. Clt. 1804. Sh. pr.

125 M. lióssil (Ilaw, rev, p. 1\%0.) stems decumbently prostrate; leaves acinaciform, or compressedly triquetrous, glaucescent, with red, smootl, cartilaginous edges. h. D. G. Native of Van Diemen's Land. Flowers unknown. Very like M. glaucésccis.

lioss's Fig-marigold. Clt. 1820. Shrub pr.

126 M. AввREvia'tum (Haw. in plil. mag. dec. 1826. p. 330.) plant tufted; stems short, coarse, and prostrate, crowded; leaves acutely triquetrous, thick, green, much longer than the internodes, which are short. h. D. G. Native of New IIolland. This species comes very near to $M$. glaucéscens, but the leaves are more crowded. Flowers not seen.

Short-stemmed Fig-marigold. Clt. 1825. Shrub pr.

127 M. vire'scens (Haw. syn. p. 296. rev. 120.) stems decumbently prostrate; leaves triquetrous, with the sides nearly equal, greenish; peduncles terminal, solitary, 2-edged, winged; calyx 4-cleft; stigmas 8, filiform. $r_{c} . D$. G. Native of New Holland. Corolla showy, pale red; petals white at the base, and obtuse at the apex.

\section{Greenish Fig-marigold. Fl. June. Clt. 1804. Shrub pr.}

Subdivision IV. Perfolia'ta (from per, through, and folium, a leaf; stem ruming through the leaves). Haw. rev. p. 123. Usually erect shrubs, with erect or decumbent branches. Leaves opposite, connate, and sheathing at the base, usually triquetrous towards the top, and for the most part hooked at the apex. Flowers white, red, or reddish. Calyx 5-cleft. Stigmas 5.

\$24. Forficàta (from forfex, a pair of scissors; form and disposition of leaves). Salm-Dych, obs. p. 33.-Forficata Ge. minàta, \&־. Haw. Stcms frutescent; branches ercet or decumbcnt. Lcavcs opposite, triquetrous, compresscd, scissor-shaped, crcct, with the carinal angle drawn out. Floners reddish, solitary, on short peduncles. Calyx 5-cleft; petals very narrou. Stigmas 5, short, thick.

12S M. heterophy'LuU (Haw, misc. 67. syn. 294. rev. 12S.) stem shrubby, short; branches crowded, ascending; leaves crowded, glaucous, compressed, triquetrous, rather acinaciform : with cartilaginous edges, and a jagged keel; petals unequal, shorter than the calyx, which is large and 5-horned; stigmas 5 , very short. ?. D. G, Native of the Cape of Good Hope. Willd. enum. suppl. 36 . Petals white.

Various-leaved Fig-marigold. Fl. May, Aug. Clt. 1794. Shrub 1 to 2 feet.

129 M. MUtábile (Haw, ols. 377. misc. 74. syn. 294. rev. 133.) stem shrubby, erect; branches 2-edged; leaves nearly distinct, crowded, triquetrous, dotted: with a cartilaginous, entire keel; petals subulate; stigmas 5, short, thick. h. D. G. Native of the Cape of Good Hope. Flowers reddish.

Changcable Fig-marigold. Fl. Jul. Sept. Clt, 1792. Sh. $1 \frac{1}{2} \mathrm{ft}$.

130 M. glaucinum (Haw. suppl. 97. rev. 132.) stem slirubby, erect ; leaves much crowded, compressed, triquetrons, rather acinaciform, glaucescent, entire, with subcartilaginous edges, a little dotted; petals subulate ; stigmas 5, short, thick. ケ. D. G. Native of the Cape of Good Hope. Flowers reddish. Perhaps sufficiently distinct from $M$. mutálile.

Glaucous Fig-marigold. Fl. Jul. Aug. Clt.? Shrub $1 \frac{1}{2} \mathrm{ft}$. 131 M. margina'tum (Haw, obs. p. 412. mise. p, 73 . syn. 294. rev. 129.) stem dwarf; branches erect; leaves triquetrous, rather acinaciform, glaucous, with whitened margins. ? $_{\text {. D. G. }}$ Native of the Cape of Good Hope. Stem 4 inclies high. Leaves small. Flowers unknown.

White-edgcd-leaved Fig-marigold. Clt. 1793. Shrub $\frac{1}{2} \mathrm{ft}$.

132 M. INcLU'Dexs (Haw. syn. 295. rev. 133.) stem shrubby: leaves triquetrous, rather deltoid, smooth, green, with a gibbous 
crenulated keel; iuner petals very short, and imbricated. h. D. G. Native of the Cape of Good Hope. Andr. bot. rep. t. 38 . Sims, hot. mag. 1663. Flowers deep red, always expanded. Petals broader than in any of the allied species. Stigmas 6, thick.

Encompassing Fig-marigold. Fl. Ju. Sept. Clt. 1805. Sh. 1 to 2 feet.

183 M. Forfici'tum (Lin, spec. 695.) stems suffrutescent, decumbent; leaves opposite, compressed, triquetrous, green, ending in a spimulose mucrone at the apex; peduncles ancrular; petals in 1 series; stigmas 5 , very short. h. D. G. Native of the Cape of Good Hope. Haw. obs. 394. descript. misc. p. 78. syn. 280 . rev. 123 . Jacq. vind. 1. t. 26 . M. filamentòsum 3 , D. C. Petals purplish, with a decper-coloured keel.

Scissor-leaved Fig-marigold. Fl. Sept. Oct. Clt. 1758. Shrub decumbent.

134. M. geminatтu (Haw. misc. p. 92. syn. 280. rev. 123.) stem suffruticose, dwarf; branchlets dichotomous, ascending; leaves connate a long way, triquetrous, erect, glaucous, smooth, cartilaginous at the margins. $h$. D. G. Native of the Cape of Good Hope. Flowers unknown, but probably white.

Trin-shooted Fig-marigold. Clt, 1792. Shrub 1 foot.

\$25. Rostcllàta (from rostellum, a little beak; leaves tipped with a little beak). Jlaw. rev. p. 123. Stems prostrate. Leaves terete, subulate, connate at the base, recurved. Floners white and red. Calyx 5-cleft. Stigmas 5.

135 M. Rostella'tum (Haw. rev. 123.) stems branclied, prostrate; leaves beaked, connate, semi-terete, subulate, recurved, dotted, green; peduncles clavate, bibracteate at the base; stigmas 5, spreading. h. D. G. Native of the Cape of Good Hope. Calyx with 5 long lobes. Corolla expanded before meridian, whitish, tipped with red.

Little-beaked-leaved Fig-marigold. Fl. Ju. Clt. 1820. Sh. pr.

$\$ 26$. Uncinàta (from uncinalus, hooked; points of leaves). Haw. rev. 124.-Perfoliata, Salm-Dyck, obs. p. 24.-Perfoliàta axilliria, IIaw. syn. 2S1. Stems shrubby, erect; branches hard. Leaves opposite, dotted, connate and shcathing at the base; sheaths obconical, fleshy, covering the internodcs; limbs of lcaves rather triquetrous at the apex, acutc, toothed inder the keel. Floriferous branches axillary, 1-floncred. Floners middle-sizcd, redulish. Calyx 5-cleft. Sligmas 5-7.

136 M. perfolia'tum (Mill, dict. ed. S. no. 19.) stem shrubby, erect, with few branches; leaves connate and sheatlling at the base, rather decurrent, triquetrous, hard, whitish-glancous, dotted, acuminated at the apex, recurved; keel tridentate bencatl. ?. D. G. Native of the Cape of Good Hope. Haw. misc. 92. syn. 281, rev, 124.-Dill. elth. 240. Bradb. succ. 46. M. forcinatum $\beta$, Lin. spec. 690. D. C. pl. grass. no. 54. likwers red.

Jar. ỉ, monacánthum (Bradl. succ. f. 26.) keel of leaves furuished with only one tooth beneatl.

I'ar. $\gamma$, cdéntulum (Haw, rev. p. 125.) keel of leaves tootlless. Burm. afr. t. 26. f. 3 .

Perfoliate-leaved Fig-marigold. Fl. June, Aug. Clt. 1714. Slirub 1 to 3 feet.

137 M. uncinéluem (Salm-Dyck, in litt. and Haw, rev. p. 124.) stem shrubby, erect, with numerous branches; leaves connate and sheathing at the base, rather decurrent, triquetrous, thick, whitish, dotted, recurved at the apex; keel furnished with

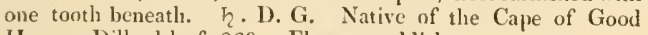
Hope.-Dill. elth. f. 239 . Flowers reddish.

Small-hooked-leaved Fig-marigold. Fl. June, Aug. Clt. 1819. Shrub 1 foot.

138 M. semidenta'tum (Haw. suppl. 95. rev, 125.) stem shrubby, with simple striated branches; leaves connate and sheathing at the base, triquetrous, compressed, white, dotted; keel furnished with 1-4 teeth. of Good Hope. Salm-Dyck, obs. 1820. p. 9. Leaves 2 inches long. Flowers on short peduncles, reddisl. Differs in the length of the leaves from $M I$. perfoliatum.

Half-toothed-leaved Fig-marigold. Fl. Aug. Clt. 1820. Shrub 1 foot.

139 M. uncina'tum (Mill. dict. ed. 8, no. 18.) stem shrubby, erect; leaves connatc, and sheathing at the base, rather decurrent, green, dotted, triquetrous, furnished with 2 spines underneath at the apex. $h$. D. G. Native of the Cape of Good Hope. Bradl. succ. f. 27. M. uncinàtum $a$, Lin. spec. 692. D. C. pl. grass. t. 54. Flowers red.

Ilooked-leaved Fig-marigold. Fl. Aug. Clt. 1725. Shrub 1 to 2 feet.

1 t. M. v'rIDE (Haw, obs, p. 314, misc. 93. syn. 282. rev. 126.) stem shrubby; leaves comnate and sheathing at the base, quite entire, deep green, dotless, smooth, uncinately recurved at the apex; stigmas 7 , subulate. $\quad$. D. G. Native of the Cape of Good Hope. Peduncles clavate, bibracteate, axillary. Calyx 5-cleft. Petals pale red, expanded both by night and by day.

Green Fig-marigold. Fl. July. Clt. 1792. Shrub 1 foot.

141 M. U'Nidens (Haw. in phil. mag. Dec. 1826. p. 331.) plant depressed, stiff; branches crowded ; leaves rather acinaciform, white, with large dots; keel bearing one tooth near the top. h. D. G. Native of the Cape of Good Hope. Leaves less perfoliate than any other of the section. Flowers not seen.

One-toothed Fig-marigold. Clt. 1824. Slurub $\frac{1}{2}$ to 1 foot.

§27. Paniculàta (fiom panicula, a panicle; disposition of flowers). Haw. syn. 283. Salm-Dyck, ols. p. 33.-I Iaginàta, Lincìla, and Tumidula, Haw. rev. 126-129. Shrubby, erect; branches hard. Leaves connate and sheathing at the base, with the longitudinal lines of the sheath more or less distinct, for the most part glaucous and triquetrous. Flowers panieled, numerous. Peduncles bractcate. Calyx 5-cleft. Stigmas 5. Petals nhite, rarely reddish.

1.2 M. тunídulum (Haw. syn. p. 286. rev, p. 129.) stem erect, with spreading branches; leaves connate and sheathing at the base, remote, green, smooth, rather recurved at the apex;

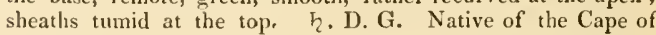
Good Hope. Leaves an iuch and a halflong. Flowers reddislı. Tumid-sheathed Fig-marigold. Fl. March. Clt. 1S02. Sirub 2 feet.

143 M. foliòsum (Haw. misc. 97. syn. 287. rev. 130.) stem erect, much branched; branches crowded, hardly ercet; leaves connate and sheathing at the base, rather glaucous, smooth, crowded, obtuse, ending in a rather recurved inucrone; slieaths thickened at the top. $\xi_{2}$. D. G. Native of the Cape of Good Iope. Leaves an inch long. Petals reddish, with a deeper coloured line. Stigmas 5, expanded at lengtl.

Leafy Fig-marigold. Fl. Sept. Clt. 1802. Shrub 2 to $3 \mathrm{ft}$.

144 M. umbella'tum (Lin. spec. 689.) stem erect, with crectly spreading branches; leaves connate and sheathing at the base, remote, nearly terete, and rather glaucous, scabrous from dots, slender, recurved at the apex; sheaths tumid at the apex. h. D. G. Native of the Cape of Good Hope-Dill. elth. f. 266. Haw. obs. p. S36. misc. 97. syn 2S7. rev. 129. Leaves 1-2 inches long. Peduncles furnished with 2 bracteas. Flowers middle-sized, white. Stigmas 5 , erect.

lar. $\beta$, apétalum (Haw. rev. p. 129.) petals wanting. M. anómalum, Willd. enum. p. 531. suppl. p. 36.

U'mbellate-flowered Fig-marigold. Fl. June, Sept. Clt. 17 27. P'. 2 to 3 feet.

14.5 M. 1звліса'тum (Haw, obs. p. 317. misc. 96. syn. 255. 
rev. 12S.) stem and branches erect, subtetragonal; leaves connate and sheathing at the base, glaucous, remote, smooth, dotted, rather compressed, triquetrous; calyx turbinate, much attenuated at the base. h. D. G. Native of the Cape of Good Hope. Peduncles bracteate even to the calys. Corolla white, nearly an inch in diameter. Leaves nearly an inch long.

Far. $\beta$, màjus (Haw. syn. 285.) leaves green, an inch and a half long.

Imbricated-leaved Fig-marigold. Fl. July. Clt, 1792. Slırıb $\approx$ to 3 fect.

146 M. multiflòrus (Haw, obs. p. 318. misc. 96. syn. 285. rer. p. 128.) stem and branches erect; leaves connate and slieathing at the base, remote, glaucous, somewhat compressed, triquetrous, smooth, dotted; calyx cylindrical, hardly attenuated at the base. $\boldsymbol{h}$. D. G. Native of the Cape of Good Hope. Peduncles bracteate even at the calyx. Flowers white, larger than those of M. imbricàtum.-Pluk. phyt. t. 117. f. 1.

lar. $\beta$, rùbrun (Haw. suppl. 95.) fowers reddish; leaves greenish. Perhaps a proper species.

Iar. $\gamma$, minus (Haw, rev, p. 128.) leaves glaucous; calyx turbinate, much attenuated at the base. Perhaps a variety of $M$. imbrieàtun.

I'ar. ¿, pàtens (Haw. l. c.) stem spreading; flowers solitary. M. pàtens, Willd. enum. suppl. p. 37 .

Var. $\varepsilon$, nitens (Haw. J. c.) smooth ; branches spreading; leaves green. Perhaps a proper species.

Many-flonered Fig-narigold. Fl. July, Sept. Clt. 1792. Slirub 2 to 3 feet.

147 M. Rígidum (Haw, misc, 95, syn. 283. rev. 127.) stem erect; branches rery stiff, spreading a little ; leaves connate, and sheathing at the base, horizontal, and are, as well as the sheaths, glabrous, but with the keel seabrous at the apex. $\zeta$. D. G. Native of the Cape of Good Hope. Allied to M. tencllum. Leaves 3 lines long. Peduncles bracteate nearly to the apex. Petals snow white, shining.

Stiff Fig-marigold. Fl. A ug. Clt. 1793. Shrub 1 foot.

148 M. TeNélum (Haw, obs. 315. mise. 94. syn. 283. rev. 127.) stem erect, bushy; branches filiform, decumbent ; leaves connate and sheathing at the base, rather spreading, slender, and are, as well as the sheaths, seabrous at the margins. $h . D$. G. Native of the Cape of Good Hope. Flowers panicled, snow white. Calyx 4-5-eleft. Stigmas 5, erect, subulate. Leaves 3 lines long, glaneons.

Pliant Fig-marigold. Fl. Aug. Clt. 1792. Shrub 1 foot.

149 M. сúrтum (Haw. syn. p. 334. rev. 126.) stem ereet, bushy; leaves connate and sheathing at the base, usually approximate, incurred, smooth, green, with the angles rough at the top. h. D. G. Native of the Cape of Good Hope. Flowers unknown, but probably white.

V ar. $\beta$, politum (Haw. rev. p. 126.) less smooth, and leaves shorter. M. vaginàtum $\hat{\beta}, \mathrm{Haw}$, syn, p. 284. Perhaps a proper species according to Haw. in phil. mag. 64. p. 424.

Var. $\gamma$, minus (D. C. prod. S. p. 432.) smaller in all its parts. M. hamàtum, Willd. ex Haw. Perhaps a proper speeies.

Short-sheathed Fig-marigold. Shrub 1 to $1 \frac{1}{2}$ foot.

150 M. acuta' ngulum (Haw, in phil. mag. 64. p. 424.) stem erect, bushy; leaves connate and sheathing at the base, forming a kind of rectangle, triquetrous, acuminated, incurved, green, with rouglhish margins. $h$. D. G. Native of the Cape of Good Hope. Allied to $M$. cúrtum, but much more dwarf. Flowers unknown.

Acute-angled Fig-marigold. Clt. 1821. Shrub $\frac{1}{2}$ to 1 foot.

151 M. vagina tux (Haw. mise. 95. syn. 284. exelusive of var. $\beta$, rev. 127 . but not of Lam.) stem erect, bushy; leaves spreading, straight, remote, triquetrous, rather reeurved at the apex, and are, as well as the sheaths, green and glabrous, but vol. 111. with the angles rough near the top. h. D. G. Native of the Cape of Good Hope. Flowers panieled, wlite, small, numerous. Leaves an inch long.

Sheathed ligg-marigold. Fl. July, Aug. Clt. 180\%. Slirub $1 \frac{1}{2}$ foot.

152 M. parvifiòrum (Haw. misc. 95. syn. 284. rev. 127. but not of Jacq.) stems and braneles ereet; leaves connate and sleathing at the base, glabrous, erectish; kce] finely serrulated. 々. D. G. Native of the Cape of Good Hope. l'exluncles braeteate even to the calyx. Corolla white, small. Lcaves half an inch long.

Small-flonered Fig-marigold. 11. Aug. Clt. 1800. Slirub 1 to 2 feet.

153 M. Lincola'tum (Haw. rev. p. 130.) stem short, depressed ; branches spreading; leaves eonnate, incurved and a little recurved, obtuse, triquetrous, with nearly equal sides, and having the keel ronghish at the apex; sheaths with a short impressed line. h. D. G. Native of the Cape of Good Hope. Hlowers small, terminal at the tops of the branches, solitary. Peduncles an inch long, compressed, smooth, bibracteate at the base. Calyx 5-cleft, wrinkled. Petals in one series, obtuse, redlish, with a deeper coloured middle line, expanded, rather incurved. Stamens collected; filaments white at the base, and reddish at the apex; anthers pale yellow. Styles 5 , subulate, diverging in a stellate manner. This is rather an anomalous species, but it approaches nearest to the seetion Uncinuta.

I'ar. $\beta$, minus (Haw. l. e.) margins of leaves roughish.

Jar. $\gamma$, nitens (Haw. l. c.) leares shining, greener.

Lined-sheathed Fig-marigold. Fl.Jul. Sep. Clt.1819. Slı. $\frac{1}{2} \mathrm{ft.}$

Subdivision V. Trique'tra (from triquetrus, triangular; triangular leaves). Haw. rev. 135. Subshrubs. Leaves opposite, distinet more or less, triquetrous. Flowers usually solitary, terminal. Calyx 5-eleft. Stigmas 5 .

$\$ 28$. Deltoidea (in reference to the leaves having the outline of a Greek 1). Salm-Dyck, obs. 32.-NTuricata, IIaw. rev. 133.-Carinàlia, IIan. syn. 292. exclusite of some species. Stems shrubby, branched, erect. Leaves opposite, nearly distinct, glaucous, deltoil, that is, short, thick, and triquetrous: with the angles muricately toothed. Floners numerous, aggregate, rose-coloured, small, and sneet-scented.

154. M. eaule'scens (Mill. dict. ed. 8. p. 12.) stem ereet, branched; leaves much erowded, glaueous, rather long, triquetrously deltoid, with the sicles hardly toothed, and the keel entire. h. D. G. Native of the Cape of Good Hope.-Dill. elth. f. 243, 244. M. cauléscens, Haw. obs. 367. mise. 74. syn. 296. rev. 133. M. deltoides $\beta$ símplex, D. C. p], grass. no. 53. Flowers red, sweet-scented. Stigmas 5, short, thick, erect.

Caulescent Fig-marigold. Fl. May, July. Clt. 1731. Slırub $1 \frac{1}{2}$ foot.

155 M. Deltoìnes (Mill. dict. ed. 8. p. 13.) stem erect, branched; leaves crowded, very glaucous, triquetrous, deltoid, trifariously toothed; keel of the bracteas and the lobes of the ealyx entire. $\zeta$. D. G. Native of the Cape of Gool Hope. D. C. pl. grass. t. 53.-Dill. elth. f. 245. and 247. M. deltoìdes a, Lin. spee. 690. Haw, mise, 74. syn. 296, rev, 133, Flowers red. Very like $\boldsymbol{M}$. cauléscens.

Deltoid-leaved Fig-marigold. Fl, May, Clt. 1731. Slı. $1 \frac{1}{2} \mathrm{ft.}$

156 M. murica'tum (Haw, obs. p. 364. mise. 75. syu. 297. rev. 139.) stem erect, branched; leaves crowded, doltoid, glancous, and are, as well as the bracteas, and lobes of ealyx trifariously dentieulated. I2. D. G. Native of the Cape of Good Hope-Dill. elth. f. 246. Flowers red. Very like the two $\mathrm{T}$ 
preceding species, but smaller. Stigmas erect, hardly the length of the filaments. Capsule more depressed.

Muricated Fig-marigold. Fl. May. Clt. 1731. Sh. $1 \frac{1}{2}$ foot.

\$29. Falcita (from falcatus, hooked; leaves hooked or falcate). Han. misc. p. 69.-Iunàta and Falcàta, Salm-Dyck, obs. 31. and 32. Lunàta, Pallidiflòra, and Glomeràta, Haw, rev. 135. 138. Stcms fruticose or suffruticose; branches erect or divaricate. Leares opposite, distinct, compressed, iriquetrous, falcale, glaucous, usually dottcd. Flowers pedunculate, flesh-coloured or pale red.

\section{* Flowers aggregate, reddish.}

157 M. MA'ximum (Haw. obs. p. 402. misc. 66. syn. 292. rev, 135.) stem woody, erect, busliy; leaves crowded, large, very much compressed, triquetrous, incurvedly half-moon shaped, quite glaucous, obtuse, full of pellucid dots, half-stem-clasping. h. D. G. Native of the Cape of Good Hope. Andr. bot. rep. t. 358 . Willd enum. 539. Flowers small, terminal. Peduncles bibracteate. Calyx 5-eleft. Corolla reddish.

Largest Fig-marigold. Fl. March, Aug. Clt. 1787. Sl. $1 \frac{1}{2} \mathrm{ft}$.

158 M. LUNA'TUM (Willd. enum. p. 538.) stem woody, erect; branches aggregate; leaves small, much crowded, dotless, rather connate, compressed, triquetrous, incurvedly half-moon shaped. h. D. G. Native of the Cape of Good Hope. Haw, rev. 136. Flowers rose-coloured.

Lunatc-leaved Fig-marigold. Fl. July. Clt. 1812. Sh. $1 \mathrm{ft}$.

159 M. Falcifónde (Haw. syn. 299. rev. 127.) stem suffruticose, at length decumbent ; leaves much crowded, small, thick, falcate, acinaciform, glaucous, largely toothed; flowers somcwhat fastigiate. . D. G. Native of the Cape of Good Hope. Flowers reddish, showy, an inch and a half in diameter.

Sicklc-formed-leaved Fig-marigold. Fl. July, Aug. Clt. 1805. Shrub $1 \frac{1}{8}$ foot.

160 M. FALCA'TUM (Lin. spec. 694.) stem woody, erect; branches nunerous, panicled, filiform; leaves minute, distinct, compressed, triquetrous, falcate, rather glaucous. $h . D . G$. Native of the Cape of Good Hope.-Dill. elth. f. 275. and 276. Haw. obs. 366. misc. 72. syn. 298. rev, 136. Flowers small, numerous, pale red, expanded through the day, sweet scented.

Falcate-leaved Fig-marigold. Fl. June, $\Lambda$ ug. Clt. 1727. Shrub 1 foot.

161 M. vira 'rum (Haw. misc. p. 88. syn. 290. rev. 142.) stem suffruticose, weak; branches twiggy, distant ; leaves compressed, triquetrous, acute, rather glaucous, remote, dotted; flowers few. $々$. Đ. G. Native of the Cape of Good Hope. M. conpréssum, Haw. obs. 416. not 326. Flowers small, light red. Stigmas 5, longer than the filaments, subulate, revolute. Peduncles bractless.

Tniggy Fig-marigold. Fl. Feb. Apr. Clt. 1793. Sh. 2 to $3 \mathrm{ft}$.

\section{* Floners solitary, rose-coloured or pale red.}

162 M. Decu'mbens (Haw, obs. 352. misc, 69. syn. 300. rev. 136.) branches much crowded, decumbent ; leaves compressed, triquetrous, incurved, attenuated at both ends, very glaucous. h D. G. Native of the Cape of Good Hope. Flowers 2 inches in diameter, almost white, or very pale red.

Dccumbent Fig-marigold. Fl. Ang. Oct. Clt. 1759. Shrub decumbent.

163 .1. incu'rvus (Haw. misc. j. 69. syn. 300. rev. 136.) stem suffruticose, erect; branches slender, effuse, Jcafy; lcaves compressed, triquetrons, very glaucous, attenuated at both ends, acinaciform. $b_{2}$. D. G. Native of the Cape of Good Hope. Flowers pale red.

Far. $\beta$, dititans (Iaw. syn. 300. rev. 13\%.) leaves gibbously dilated below, at length defiexed.
Var. $\gamma$, ròseum (Willd. enum. p. 535.) leaves obtuse, attenuated at the base.

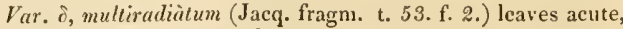
spreading, blunt on the back.

Incurved-leaved Fig-marigold. FI. June. Clt.1802. Sh. $1 \frac{1}{2} \mathrm{ft}$.

16.4 M. confe'rtum (Haw. syn. p. 301. rev. 137.) stem erect, much branched; leaves triquetrous, crowded, robust, incurved, very glaucous. $h_{2}$. D. G. Native of the Cape of Good Hope. Flowers showy, pale red. Perhaps only a variety of $M$. incúrvum.

Cronded Fig-marigold. Fl. Sept. Oct. Clt. 1805. Sh. $1 \frac{1}{2} \mathrm{ft}$.

$\S 30$. Stèna (from $\sigma \tau \varepsilon v^{\prime} o s$, stenos, narrow; leaves and petals). Haw. in phil. mag. Sept. 1831. Small subshrubs, with the branches nearly half a foot high, effuse, and are, as nell as the leaves, filiform. Petals very narrow, or setaceous, very pale red.

165 M. STE'Num (Haw. in phil. mag. 1831. p. 420.) branches effusely decumbent, flexuous, filiform; leaves slender, falcately incurved, triquetrously terete, mucronate, with few dots, glancescent; flowers 1 or 3 together, terminal. h. D. G. Native of the Cape of Good Hope. Flowers expanding before meridian, of a violaceous reddish-colour.

Narrow Fig-marigold. Fl. Aug. Clt. 1829. Slırub $\frac{1}{2}$ foot.

166 M. DE BILE (Haw. in phil. mag. Nov, 1826. p. 331.) smooth; branches filiform, a little compressed ; leaves crowded at the nodes of the reptant stems, bluntly and acinaciformly triquetrous, glaucescent; flowers few, terminal. h. D. G. Native of the Cape of Good Hope. Flowers very pale red, or nearly white, expanding before meridian.

Weal Fig-marigold. Fl. Aug. July. Clt. 1824. Pl. creeping.

\$1. Microphýlla (from $\mu$ usos, micros, small, and $\phi v \lambda \lambda o v$, phyllon, a leaf; in reference to the small leaves of the species). Salm-Dyck, obs. 33. Han. rev. 134. syn. 297. cxclusive of some species. Planls small, suffruticose, much branched; branches very humble, procumbent, divaricate. Leaves very small, connate, triquetrous, mucronate, crovded, remaining on the plant cven when dried. Floners solitary, small, reddish.

167 M. Mcrophy Llum (Haw. obs. 417. syn. 297. rev. 134.) stem short, densely branched, decumbent; leaves connate, triquetrous, acuminated, a little awned, green, dotted, pustulate on the inside at the base; flowers solitary on short peduncles. $h$. D. G. Native of the Cape of Good Hope. Flowers small, reddish. Calyx 5-cleft. Stigmas 5-6, green, with spreading subulate tops.

S'mall-lcaved Fig-marigold. F]. May. Clt. 1795. Sh. dec. 168 M. nucrona'tum (Haw. misc. 73. syn. 297. rev. 134.) stem very short, erect, branched; leaves oblong-ovate, triquetrous at the ajex, connate at the base, glaucescent, terminating in a white mucrone, coarsely dotted. h. D. G. Native of the Cape of Good Hope. Flowers unknown. Leaves 3 lines long. Mucronute-leaved Fig-marigold. Clt. 1794. Sh. $\frac{x}{4}$ to $\frac{x}{2} \mathrm{ft}$.

169 1.. PYGs.e'vm (Haw. suppl. 99. rev. 134.) stem very short, branched ; leaves connate at the base, oblong-ovate, semiterete, awnless, in winter united nearly to the top. $\zeta$. D. G. Native of the Cape of Good Hope. Flowers unknown, but probably pale red.

Pygmy Fig-marigold. Clt. 1805. Shrub $\frac{1}{4}$ foot.

170 M. POLCHÉLlum (Haw. misc. 72. syn. 298.) stems decumbent; leaves acutely triquetrous, with equal sides, somewhat boat-slaped, hoary, obsoletely dotted, ciliated with pubescence on the angles, but especially on the keel, terminating in a recurved mucrone. $\quad$. D. G. Native of the Cape of Good Hope. M. canéscens, Haw. rev. 135. M. pulchéllum, Willd. enum. 537. Corollas small, red. Stigmas 5 , subulate, longer than the filaments, greenish, recurved at the apex. 
I'ar. $\beta$, revolùtum (Haw. rev. p. 135.) branches secund, recurved.

Neat Fig-marigold. Fl. April. Clt. 1793. Shrub dec.

\$ 32. Scábrida (a dim. of scaber, rough ; rough or scabrous leaves). Ilaw. misc. 71.-Scàbra, Salm-Dyck, obs. 27.-Asperifòlia, Haw. rev. 138. Stcns suffruticose; branches expanded, filiform. Leaves more or less triquetrous, rather compressed, scabrous from dots, usually a little incurved. Flowers pedunculate, reddish, milllle-sizcd.

\section{- Stamens collected.}

171 M. sca'вruм (Lin. spec. 692.) stem slurubby, branclucd; leaves rather triquetrous, green, straight, very rough from shining warts; lobes of calyx ovate, acuminated; petals crenated at the apex; stamens collected. h. D. G. Native of the Cape of Good Hope.-Dill, elth, f. 251.-Haw, obs. 345. misc. 71. syn. 267. rev. 138. Flowers rose-coloured.

Var. $\beta$, purpùrcum; flowers purple.

Scabrous Fig-marigold. Fl. July. Clt. 1731. Sh. I foot.

172 M. versícolor (Haw. misc. 71. syn. 268. rev. 139.) stem shrubby, branched ; leaves almost triquetrous, glaucescent, scabrous from warts; lobes of calyx ovate, acuminated; petals somewhat bidentate at the apex; stamens collected. h. D. G. Native of the Cape of Good Hope. Petals variable, expanding in the heat of the sun, of a shining white or silvery colour, but when closed in the morning and evening they are pale reddish.

Party-coloured-flowered Fi-marigold. Fl. May, Aug. Clt. 1795. Shrub 1 foot.

173 M. retrofle'xum (Haw. misc. 71. syn. 269. rev. 139.) stem suffruticose; branches decumbent; bark white; leaves rather triquetrous, very glaucous, scabrous; lobes of calyx retroflexed; petals distant; stamens collected. h. D. G. Native of the Cape of Good Hope. M. emarginatoides, Haw obs. 343. M. leptàleum, Haw. rev. 140. and perhaps M. élegans, Jacq. schenbr. 4. p. 18. which is referred to by the Prince de Salm-Dyck, and therefore it is M. defléxum of Salm-Dyck, obs. 27. but not of Hawortl. Petals reddish.

Retroflexed-calyxed Fig-marigold. Fl. May, Oet. Clt. 1724. Shrub dec.

17t M. I' мвRicaxs (Haw. suppl. p. 94.) stem erect, shrubby; leaves linear, obsoletely triquetrous, smoothish, of a whitish glaucous-colour, imbricately crowded at the tops of the canes-

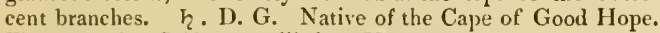
Flowers red. Said to be allied to $M$. rclrofléxum.

Imbricating-leaved Fig-marigold. Fl. May, Oct. Clt. $181 \mathrm{s.}$ Shrul, 1 foot.

175 M. DEFL'XuM ( $\Lambda$ it. hort. kew. 2. p. 187.) stems shrubby, rather crowded, deflexed; leaves rather triquetrous, glaucous, roughish, attenuated downwards; petals numerous, much imbricated; stamens collected. Ћ. D. G. Native of the Cape of Good Hope. Haw. obs. 347. misc. 71. syn. 269. exclusive of the synonymes, rev. 140. There are two varieties of this species, the one haring the petals pale reddish and purple at the base, the other having the petals of a deeper colour.

Deflexcd-branched Fig-marigold. Fl. July, Oct. Clt. 1774. shrub 1 foot.

\section{* Slamens cxpanded.}

176 M. polyáxtucs (Haw. syn. 270. rev. 140.) branches bushy, expanded, crowded; bark on young stems rufous; leaves small, glaucous, triquetrous, scabrous; flowers very numerous, panicled; petals imbricated. 2. D. G. Native of the Cape of Good Hope. Flowers small, very pale red. M. fléxile, Haw. rev. $11 \mathrm{I}$. is orly a variety of this species in a younger state, which has been confirmed by Salm-Dyck.
Many-flonerel Fig-marigold. Fl. Aug. Clt. 1803. Shrub 1 to $1 \frac{1}{2}$ foot.

$177^{2}$ M. PolypuY'Llum (Haw. rev. 141.) branches bushy, decumbent, assurgent; leaves much glomerated, rather robust, somewhat incurvedly recurved, clavately and bluntly triquetrous, compressed, scabrous from dots, glaucous. h. D. G. Native of the Cape of Good IIope. Flowers pale red. Stamens expanded, as in $M$. cmarginàtum. Like $M$. defléxum, but double the size.

Many-leaed Fig-marigold. Fl. June, Oct. Clt. 1819. Shrub 1 to 2 feet.

178 M. violáceun (D. C. pl. grass. t. 84.) stem shrubby, erect; branches expanded; leaves triquetronsly semi-tercte, rough from dots, acute, glaucous; peduncles 1 -flowered, naked or bracteate at the very base; lobes of caly x spreading, unarmed, but prickle-formed. h. D. G. Native of the Cape of Good Hope. Haw. rev. 141. M. parvifòlium, Lam. dict. 2. p. 482. exclusive of the synonymes. M. puniceum, Jaeq. schonbr. $t$. 442. Flowers flesh-coloured, expanding in the heat of the sun. Stamens not collected, but rather expanded.

Iiolaccous-branched Fig-marigold. Fl. June, Oct. Clt. 1820. Shrub 1 to 2 feet.

179 M. emargina'tum (Lin. spec. 692.) branches expanded; leaves triquetrous, scabrous, glancescent ; peduncles bibracteate ; lobes of calyx unarmed, but spine-formed; petals deeply emarginated at the apex. $h_{2}$ D. G. Native of the Cape of Good Hope.-Dill. elth. f. $250,-$ Haw. obs. 340 . misc. 70 . syn. 268. rev. 142. Flowers pale red, like those of $M$. violiceum. Stamens expanded.

Emarginate-petalled Fig-marigold. Fl. Jume, Aug. Clt. 1732. Shrub I to 2 feet.

§33. Bractcìta (bractcatus, bracteate; flowers girded by bracteas). Salm-Dyck, obs. 28. Haw, rev. 143.-Adúnca Inclaudéntia, Ilaw. syn. 288. Stcms ercet, shrubby; branches much compressed. Lcares distinct, triquetrous, hooked at the apcx, more or less scabrous from dots. Flowers girded by 2-4 broadly orate licelcd bracteas, which clasp the calyx, solitary, reddish, alnays cxpanded; inner petals thrcad-formed.

180 M. BRactea'tum (Ait. lort. kew. 2. p. 185.) stem shrubby, erect; branches compressed, of a reddish brown colour; leaves green, triquetrous; bracteas 4, hroadly ovate, keeled, clasping the calyx. h. D. G. Native of the Cape of Good Hope. Haw. misc. 90. syn. 289. rev. 143. Lodd. bot. cab. 251. Petals reddish, white at the base.

Bracteate Fig-marigold. Fl. July, Oct. Clt. 1774. Shrub $1 \frac{1}{2}$ foot.

181 M. A'NCEPS (Haw. syn. 289. rev. 143.) stem shrubby; branches decumbent, 2-edged, of a brownish canescent-colour; leaves acinaciformly triquetrous: sides rather membranous below ; dots large, pellucid, elevated. h. D. G. Native of the Cape of Good Hope. Flowers of a deep red colour.

Var. $\beta$, pállidum (Haw, rev. 143.) branches of a rufous coppery colour; leaves rather incurved; petals pale reddish.

Tno-edged-branched Fig-marigolcl. Fl. Sept, Oct. Clt. 1811. Slirub $1 \frac{1}{2}$ foot.

182 M. GRA'CILE (Haw. rev. 144,) stem shrubby; branches very slender, straight; leaves glaucescent, slender, rather scabrous; bracteas ovate, acute, almost clasping the calyx. $h_{c}$. D. G. Native of the Cape of Good Hope. N1. stellatum, Haw. obs. 416. mise. 91. syn. 290. but not of D. C. There are varicties of this species with deep red, and pale red flowers.

Slender Fig-marigold. Fl. A ug. Nov. Clt. 1794. Slı, $1 \frac{1}{2} \mathrm{ft}$.

183 M. RADIA'TUM (Haw. obs. 232. misc. 90. syn. 289. rev. 144.) stem slırubby; branclies crowded; bark eanescent; leaves glaueescent, attenuated, and hooked at the apex; bracteas т 2 
broadly ovate, clasping the peduncles above. h. D. G. Native of the Cape of Good Hope.-Dill. elth. f. 249. Corolla reddish, larger than those of its allies.

Ray-flowered Figr-marigold. Fl. Aug. Nov. Clt. 1732. Sh. $1 \frac{1}{2}$ foot.

184 M. coMPRE'SSUM (Haw. obs. 326, not 416 . misc. 91. syn. 289. rev. 144.) sten shrubby; branches rather compressed; leaves glaucescent, triquetrous, with equal sides, very rough; bracteas ovate, acutc, clasping the tops of the peduncles. $h$. D. G. Native of the Cape of Good Hope. Flowers middlesizcd, reddish. Perhaps M. compréssum, Horn. hort. hafn. 2. p. 4.54 , is the same species.

Compressed-branched Fig-marigold. Fl. July, Sept. Clt. 179\%. Slurub $1 \frac{1}{2}$ foot.

185 M. Pátulum (Haw. syn. p. 334. rev. 145.) stem shrubby; branches hardly erect; leaves linear, half erect, glau. ciscent, roughish from pellucid dots. h. D. G. Native of the Cape of Good Hope. This species comes near to $M$. compréssum, but is less stiff, the leaves shorter and thicker, and the flowers are larger and paler.

Spreading Fig-marigold. Fl. Oct. Nov. Clt. $1 \$ 11$. Sh. $1 \frac{1}{2} \mathrm{ft}$.

$1 S 6$ M. A'srerum (Haw, rev. p. 145.) stem shrubby ; leaves compressed, triquetrous, longish, of a bluish green-colour, full of pellucid dots, very scabrous, hooked at the apex; keel furnished with one tooth. h. D. G. Native of the Cape of Good Hope. Flowers unknown. Perhaps this species does not belong to the present section.

liongh Fig-marigold. Clt. 1818 . Shrub $1 \frac{x}{2}$ foot.

187 M. sERRA'TuM (Lin. spec. 696.) sten erect, branched; leaves opposite, distinct, triquetrous, subulate, having the carinat angle serrated, with the serritures turned backwards. $\eta$. D. G. Native of the Cape of Good Ilope.-Dill. eltl. f. 238. Flowers solitary, terminal, pedunculate. Calyx 5-cleft, attenuated at the base. Petals yellow, copper-coloured at the apex. Stignas 5, short, obtuse, approximate. This species was formerly cultivated by Dillenius, but has now vanished from the gardens, and is therefore very little known.

Serrated-kceled Fig-marigold. Fl. June, July. Clt. 1707. Slirub 1 to 2 feet.

§ 34. Conférta (from confertus, crowded thick together; branches). Ilan. syn. 240. Salm-Dyck, obs. 29.-Eximia and Blínda, Ilaw.rev. 145-147. Stems shrubby; branches crowded, asccnding. Lcates opposite, rather connate, cronded, triquetrous, cntive, acutc, with the angles smooth. Flowers pedunculate, solitary or by threes, shomy, expanding in the sun, reddish or pale rose-colourcil.

188 M. амж'num (Salm-Dyck in litt, ex D.C. prod. 3. p. 436.) stem branched, strubby; leaves green, crowded, elongated, ncarly triquetrous, bluntish, with a mucrone; flowers terminal, showy, disposed by threes. 々. D. G. Native of the Cape of Good Ilope. Flowers red.

Pleasing Fig-marigold. Shrub 1 foot.

189 M. rokmòsu (IIaw. rev. 145.) stems suffruticose, lumble; branclies rather decumbent, elongated; leaves triquetrous, long, green, glittering in sunshine, much crowded, but more remote on the branches; flowers terminal, disposed by threes; stigmas 5-6, shorter than the filaments, rather lanceolate. F. D. G. Native of the Cape of Guod Hope. Petals beautiful red, blunt.

Bcautiful Fig-marigold. Fl. Aug. Sept. Clt. 1828. Sh. $1 \mathrm{ft}$.

190 M. splcta'en.e (Haw. obs. 385 . misc. 68. syn. 240. rev. 145.) stems rather humble; floriferous ones ascending or erect; leaves glaucous, triquetrous, and are, as well as the branches, crouded; stigmas 5, obovatc, onc-half shorter than the stamens, wlich are white. h. D. G. Native of the Cape of Good
Hope. Curt. bot. mag, t. 396. D. C. pl, grass. t. I53. Leaves rather connate, sometimes furnished with one tooth at the top of the keel. Flowers beautiful reddish, 2 inches in diameter.

Showy Fig-marigold. Fl. May, Aug. Clt. 1787. Shrub $1 \mathrm{ft}$.

191 M. consricuum (Haw. syn. 240. rev. 146.) floriferous stems erect; leaves green, glittering in sun-shinc, triquetrous, and are, as well as the branches, crowded; stigmas lanceolate, length of the stamens. h. D. G. Native of the Cape of Goud Hope. M. conspícuum, Spreng. nov. prov. 27. but the leaves are there said to be semi-terete. Flowers beautiful red.

Conspicuous Fig-marigold. Fl. Sept. Oct. Clt. 1806 . Sh. $1 \mathrm{ft}$.

192 M. turbina'tum (Jacq. hort, vind. t. \$76.) stem shrubby, branched, diffuse ; leaves glaucous, elongated, acute, triquetrous, crowded; flowers on long peduncles, reddish; ovarium contracted into a neck beneatli the calys, $々 . D$. G. Native of the Cape of Good Hope. Petals numerous, linear, spreading much. Salm-Dyck. in litt.

Turbinate Fig-marigold. Slurub 1 foot.

193 M. BLA'NDUM (Haw. suppl, 95. rev. 147.) stem shrubby; branches numerous, compressed, ascending; leaves compressed, triquetrous, crowded, narrow, acutish, smooth ; peduncles equal, longer than the bracteas; stigmas 5 , short, ramentaceous. $\zeta$. D. G. Native of the Cape of Good Hope. Ker. bot. reg. 582. Lodd. bot. cab. 599. Flowers large, at first white, but at length rose-coloured or pale red. Branches of a rufous chestnut colour. There are varieties of this species with glaucous and green leaves. Bland Fig-marigold. Fl. June. Clt. 1810. Shrub 1 foot.

19.4 M. curvifòluu (Haw. rev. p. 47.) stem shrubby, branches robust, terete; leaves compressed, triquetrous, glaucescent ; peduncles elavate, length of bracteas ; petals incurved. h. D. G. Native of the Cape of Good Hope. Branches rufous or bay-coloured. Leaves twice the thickness of those of $M$. blandum, to which it is nearly allied, and the corolla is less open. It is, however, perhaps only a variety of it.

Curved-leaved Fig-marigold. Fl. Ju. Clt. 1818. Sh. $1 \frac{1}{2} \mathrm{ft}$.

$\S 35$. Cymbiformia (from cymba, a boat, and forma, form ; leaves). Salm-Dyck, obs. p. 33. Haw. rex. 149.-Tardiflòra, Haw. syn. 261. Stcms fruticose or suffruticose, with straight, usually dccussate branches. Lcavcs small, distinct, turgidly triquctrous, obtuse, boat-shaped, short. Floners solitary, rcddish, rose-coloured, or yellow.

195 M. Tetragònum (Thunb. prod. 91.) stem erect, tetragonal, shrubby; leaves cylindrically trigonal. $\zeta . \mathrm{D} . \mathrm{G} . \mathrm{Na}$ tive of the Cape of Good Hope. Haw, rev, 149. Corolla yellow. This species is omitted by Haworth.

Tetragonal-stemmed Fig-marigold. Shrub 1 foot.

196 M. stríctun (Haw. misc. 82. syn. 262. rev. 149.) stem woody, branched, very stiff, straight ; leaves triquetrous, obtuse, expanded, glaucescent, beset with large dots. ${ }_{2}$. D. G. Native of the Cape of Good Flope. This species grows 2 or 3 feet ligh in the gardens, but has never yet flowered. But from a specimen of it received from the Cape by Haworth, they are said to be showy and yellow.

Straight Fig-marigold. Clt. 1795. Shrub 2 to 3 feet.

197 II. crimbifórme (I Haw, obs. 264. misc. 82. syn. 263. rev. 149.) stcm suffruticose; branches erectish, filiform, crowded;

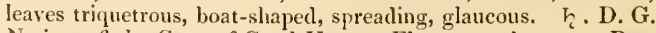
Native of the Cape of Good Hope. Flowers unknown. Perhaps M. séssile, Thunb. f. cap. 419. belongs to this species, which 'Thunberg says has red flowers.

Boat-formed-leaved Fig-mariguld. Clt, 1793. Sh, $1 \mathrm{ft}$.

198 M. Mólte (Ait. hort. kew. 2. p. 192.) branches crowded, 2-edged, decumbent; leaves spreading, turgidly triquetrous, firm, canescent, with the margins blunt, and lined with dots. h.D. G. Native of the Cape of Good Hope. Haw. obs. 
misc. S3. syn. 261. rev. 149. Flowers solitary, red, small, and terminal.

Soft Fig-marigold. Fl. Oct. Clt. 1774. Shrub 1 foot.

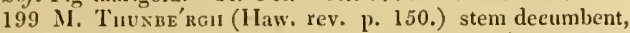
articulated; leaves comate, trigonal, smooth, dotless, erect; Howers solitary, terminal. h. D. G. Native of the Cape of Good Hope. M. lie've, Thunb. fl. cap. 425. but not of Ait. Flowers yellow. Calyx 4-cleft. Perhaps this species belongs to another division of the genus.

Thunberg's Fig-marigold. Slirub decumbent.

200 M. cхмвиólius (Haw. in phil. mag. 1824. vol. 64. p. 424.) stem slirubby, erectislı; branclies few, 2-edged, hoary; leaves trigonal, boat-shaped, pale green, beset with large dots. h. D. G. Native of the Cape of Good Hope. Flowers unknown. This species appears to be intermediate between $M$. aúrcum and $M$. cymbifórme.

Boat-leaved lig-marigold. Clt. 1822. Slurub 1 to 2 feet.

$\$ 86$. Aúrea (from aureus, of gold; in reference to the yellow flowers). Haw. rev. 148.- Equilaterùlia, Salm-Dyek, obs. 33.-Frequentiflòra, IKan. syn. 263. exclusive of some species. Stems suffruticose, and are as well as the branches crect. Leaves distinet, dolled, bluntly or acutely tripuetrous, elongated, glaueous. Floners large, solitary, yellow, or eoppercoloured, expanding in sun-shine. Stigmas thich.

201 M. GLAU'cum (Lin. spec. 1. 696.) stem suffruticose, erect; leaves triquetrous, mueh compressed, glaucous, roughish; lobes of calyx ovate, cordate; stigmas yellow. $\zeta$. D. G. Native of the Cape of Good Hope-Dill. elth. f. 248. D. C. pl. grass, t. 146. Bradl. succ. t. 37. Haw. obs. 829. misc. 83. syn. 264. rev. 148. Petals of a yellow sulphur colour.

Glaucous Fig-marigold. Fl. Ju. Jul. Clt. 1696 . Sl. $1 \frac{1}{2} \mathrm{ft}$.

202 M. aurantiacum (Haw. misc. 84, syn. 264. rev. 148.) stem suffruticose, erect; leaves bluntly triquetrous, somewhat compressed, very glaucous ; bracteas semiterete ; lobes of calyx oblong-ovate; alternate stigmas purple. $\zeta . D$. G. Native of the Cape of Good Hope. M. glaucoides, Haw. obs. p. 390. M. aurántium, Willd. enum. 537. Flowers of a deep orangecolour, smaller than those of $M$. glaúcum. Perhaps a hybrid between $\boldsymbol{M}$. aúreum and $M$. glaxeum.

Orange-coloured-flowered Fig-marigold. Fl.June, Aug. Clt. 1793. Shrub 1 to 2 feet.

203 M. An'reum (Lin. syst. nat, ed. 10. p. 1050.) stem suffruticose, erect; leaves cylindrically triquetrous, rather connate at the base, spreading, acute, full of pellucid dots, glaucous; stigmas dark purple. $h_{2}$. D. G. Native of the Cape of Good Hope. Curt. bot. mag. t. 262. D. C. pl. grass, t. 11. Haw. obs. 333. misc. p. 84. syn. 263. rev. 148. Corollas of eoppery golden colour, 2 inches in diameter, expanding in sunshine.

Golden-flowered Fig-marigold, Fl, Mar. Oct. Clt. 1750. Shrub 1 to 2 feet.

Stebivision V'1. Teretiu'scula (a din, of teres, cylindrical; leaves nearly cylindrical). Haw, rev. 150. Subshrubs, Leaves distinct, rarely connate at the base, nearly terete, without any papulæ. Calyx 5-cleft. Stigmas 5 , except in one of the species, which vary to 7 .

§37. Verruculata (from verrucula, a little wart; plants beset with little warts). D. C. prod. 3. p. 438.-Perfoliòsa, IIaw. mise. 81.-Calamifórmia erécta, Salm-Dyek, obs. 22.- Seljàcea, Haw. rev. p. 155. Stems shrubby, erect, with short branches. Leaves crowded, connale, cylindrical, obluse, mealy-glaueous, soft, dolless, without papula. Flowers yellow or croccous. Calyx 5-cleft. Stigmas 5. Capsule small.

204 M. verrucula'tum (Lin. spec. 696.) stem erect; leavcs much crowded, very glaucous, cylindrical, hatdly triquetrous, obtuse, and a little mucronate, sebaceous, longer than the internodles. h. D. G. Native of the Cape of Good Ilope.Dill. elth. 259. 1). C. pl. grass, t. 36. IJaw. obs. 260. misc. 81. syn. 258. rev. 155. Flowers small, yellow, subumbellate, expanding in the evening. 'The stigmas are said to be 5 , but Dillenius las seen then varying from $5-7$.

II arted Fig-marigold. I1. May, Ju. Clt. 1731. Sh. $1 \frac{1}{2} \mathrm{ft}$.

§S. Cròcea (from croceus, like saffron; colour of flowers). Ilaw. in phil. mag. aug. 1896. p. 128. Sub-shrubs with secund branches. Leaves thick, of a bluish glaucous colour, semi-terete at the base, obsoletely triquetrous at the apex. Floners terminal, solitary, small, or middle-sized, seentless, at first ycllow, but as they become older change to a copper-colour. P'eduneles suceulent. Calyx sueculent, unequal.

205 M. Lu'teum (Haw. in phil. mag. ang. 1826. p. 128.) leaves obtuse ; flowers small; stem branched, erect, stiff, ivith the nodes tumid, and throwing out roots. h. D. G. Natise of the Cape of Good Hope. This species comes very near $M$. cròeeum, var. $\gamma$, flào-cròceum, but is taller, more slender, and more branched, and the leaves and flowers are much smaller. Corolla pale yellow, but becoming of a deeper colour as they fade.

Yellow-flowered Fig-marigold. Fl. June, July. Clt. 1820. Shrub 1 to 2 feet.

206 M. Lute'olum (Haw. l. c. p. 129.) leaves crowded, acute at the apex, and a little recurved; branches slender and dense ; flowers small. 々. D. G. Native of the Cape of Good Hope. M. læ've, Thunb, prod.? Flowers yellow, and more numerous than those of the last species. It differs from the last in the leaves and in the more dwarf stature.

Small-yellow Fig-marigold. Fl. Ju.Jul. Clt. 1820. Sh. $\frac{1}{2} \mathrm{ft}$.

207 М. скосеим (Jacq. fragm. t. 11.f. 2.) stem erect; leaves crowded, semi-cylindrical, mealy, glaucous, bluntish, shorter than the internodes, somewhat seluaceous ; lobes of ealyx somewhat unequal. ?. D. G. Native of the Cape of Good Hope. Haw. rev. 156. Leaves evidently comnate. Petals obtuse, copper-coloured.

Var. $\beta$, purpùreo-cròceum (Haw, obs. 257. misc. 81. syn. 259. rev. 155.) flowers copper-coloured, purple on the outside. M. insitítiun, Willd. enum. 536. Hardly distinet from the species, and ouglit probably to be joined with it, according to Salm-Dyck. in litt.

I'ar. $\gamma$, flàro-cròceum (Haw, rev. 155.) flowers yellow on both sides, but as they fade become copper coloured.

Copper-coloured-flowered Fig-marigold. Fl, Aug. Oct. Clt. 17 80 . Shrub 1 foot.

§39. Tenuifiòra (from tenuis, slender, and flos, a flower ; slender flowers). Salm-Dyek, obs. 24. IIan'. rev.-Frequentiflòra, IIan. syn. 203. exclusive of the specics. Stems shrubby; branches slender, effuse. Leaves opposite, distinet, nearly terete, rather triquetrous or somenhat eompressed, without papula. Floners solitary, pedunculate, cxpanding in the morning, yellow or searlet. This section is nearly allied to Airea.

208 M. coccíneum (Haw. obs. 247. misc. 85. syn. 265. rev. 150.) stem shrubby, erect; leaves teretely triquetrous, ratlier compressed, obtuse, glaueescent ; peduncles smooth at the base ; lobes of calyx bluntish, nearly equal. দ. D. G. Native of the Cape of Good Hope. 1). C. pl. grass. t. 83. Lodd. bot. cab. t. 1033. Curt. bot. mag. 59. M. bicolòrum minus, Ilaw. obs. 246. M. bicolòrum coceineum, Willd. sp̣ec. 2. p. 1059. Leaves shorter than in the following species. Petals scarlet on both surfaces. There are 2 varieties of this plant, the one with obtuse leaves and the other with acute leaves.

Searlet-flowered Fig-marigold. Fl. May, Sept. Clt. 1696. Slurub $1 \frac{1}{2}$ foot. 
209 M. Btcolòru (Lin. spec, ed. 1. p. 485.) stem shrubly, erect; leaves rather triquetrous, acute, green; peduncles and calyxes scabrous; calycinc lobes unequal. দ. D. G. Native of the Cape of Good Hope.-Dill, elth. f. 258. Haw. obs. 241. mise, 85 , syn. 265. rev. 151 . This species is nsually confused with $\boldsymbol{M}$. coccincum, but the leaves are longer and the petals are yellow inside and scarlet outside. Stigmas shorter than the filaments. There are 2 varieties of this plant, one with erect branches and the other with spreading branches.

Tro-coluared-flowered Fig-marigold. Fl. May, Sept. Clt. 1732. Shrub $1 \frac{1}{2}$ foot.

210 M. IN שQVA'LE (Haw, syn. 266. rev. 151.) stem shrubby, erectish; branches effusely decumbent; leaves rather triquetrous, deep green; fructiferous peduncles compressedly clavate; lobes of calyx very uneģual. $h$. D. G. Native of the Cape of Good Hope. Bradl. succ. 7. bad. ex Haworth. Very like M. bicolorum, but differs in the branches being effuse, the flowers being paler on the outside, and in the calycine lobes being longer than the membrane.

Lncqual-calyxed Fig-marigold. Fl. May, Sept. Clt. 1716. Shrub 1 foot.

211 M. TENufòlitu (Lin. spec, 693.) stem shrubby, ereetislı; leaves semi-terete, rather compressed, subulate, green, glabrous, longer than the internodes; peduncles elongated, naked. h. D. G. Native of the Cape of Good Hope.-Dill. etth. f. 236. D. C. pl, grass. t. 8\%, Bradl. suce. t. 9. Haw. obs. 239. misc. p. 86. syn. 267. rev. 151. Flowers of coppery red colour. There are varieties of this species with erect and procumbent stems.

Slender-lcazed Fig-marigold. Fl. June, Sept. Clt. 1700. Sibrub 1 foot.

212 M. variábile (Haw. mise. 85. syn. 266. rev. 152.) stcin shrubby, effuse, rather decumbent; leaves somewhat triquetrous, compressed, glaucous, scabrous; lobes of calyx nearly

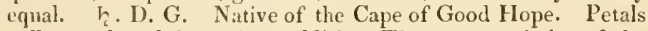
ycllow, at length becoming reddish. There are varieties of the species witl distant and crowded leaves and branches.

lariable Fig-marigold. Fl. Ju. Aug. Clt. 1796. Sh. $1 \frac{1}{2} \mathrm{ft.}$

$\$ 40$. Alunca (from aduncus, hooked; leaves liooked at the apex). Salm-Dyck, obs. 25. IIaw. rcv. 152.-Adúnca claudéntia, IIan'. mise. 87. Stcms suffruticose, hardly half a foot high. Lcares nearly tcrete, subulate, usually incurvad, acutcly hooked at the apex. Floners solitary, cxpanding before moridian, and closing in the cecning, small, reddish. Petals usually striatcd or whitc at the base.

213 M. spisifórue (Haw, obs, 240. misc, 87. syn. 291. rev. 152.) stem suffruticose, with erect branches; leaves cylindrical, subulate, spine-formed, erect, recurved at the apex; peduneles and keels of the bracteas ratler scabrous. h. D. G. Native of the Cape of Good llope. Bark of branches dark. Flower. small, pale red, with the petals paler at the base.

l'ar. 3 , subadincum (Haw. suppl. 96. ex rev. 152.). Leaves less hooked.

Spine-slaped Fig-marigold. Fl. Sept. Oct. Clt. 1793. Sh. ${ }_{\sigma}^{2}$ it.

214. M. cukvionum (Haw. mise. p. 88. syn. 290. rev. 152.) stcms snlliuticose; branches firm, erectish, ronghish, angularly compressed; leaves rather distant, expanded at the base, and

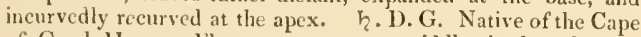
of Good llope. lilowers numerous, middle-sized, pale red. Stigmas blackish. M. ecratophýllım, Willd. enum. suppl. p. 37 . is reforred to this species by the Irince de Salm-Dyck, but this is doubted by Haworth, who gives a different character to the plant.

Curce-leated Fig-marigold. F]. Oct. Clt. 1799. Sh. $\frac{1}{2} \mathrm{ft}$.

215 M. Flexio olium (Ilaw. suppl. 98. rer. 159.) stem suf- fruticose; branches filiform, compressed, flexuous, decumbent, crowled; leaves subulate, triquetrous, incurved below, recurved and rather flexuous above, and a little hooked at the apex. $\zeta_{2} . D$. G. Native of the Cape of Good Hope. This plant is 3 times smaller than the preceding species, and more depressed. Flowers unknown. There are varieties of this species with pale green and dark green leaves.

Bent-leated Fig-marigold. Fl. Oct. Clt. 1820. Sh. dee.

216 M. 1nconspícuem (Haw. in phil. mag. ang. 1826. p. 128.) stems suffruticose, very stiff; leaves trigonal-semiterete, small, hooked; flowers solitary, minute, terminal. $\zeta_{2}$. D. G. Native of the Cape of Good Hope. A small, busliy subshrub, with spreading, ascending, or incurved, hard, glittering branches; leaves glittering in the sunshine from papulæ. Flowers deep red, expanding in the morning.

Inconspicuous Fig-marigold. Fl. Ju. Aug. Clt. 1823, Sh. $\frac{1}{2} \mathrm{ft}$.

217 M. ADU'NCUM (Haw. syn. 291. rev. p. 153.) stem shrubby; branches erect, much crowded; leaves crowded, semi-cylindrical, acuminated, very much recurved at the apex. 2. D. G. Native of the Cape of Good Hope. Flowers small, reddish, tipped with a deeper colour. Stigmas subulate, spreading, greenish yellow. This species is very like $M$. flcxifolium, but is less erect.

Hooked-leaved Fig-marigold. Fl. Feb. Mar. Clt. 1795. Shrub $\frac{1}{2}$ foot.

218 M. Filicaúle (Haw. syn. 291. rev. 153.) stems tufted, sufiruticose, filiform, very weak, creeping; leaves much crowded, semi-cylindrical, acuminated. $h$. D. G. Native of the Cape of Good Hope. Peduncles elongated, flexuous, bibracteate in the midlle. Petals pale red inside, but of a deeper colour on the ontside, and more so at the apex. Stigmas erect, subulate, green.

Throad-stemmed Fig-marigold. Fl. Aug. Sept. Clt. 1808. Shrub $\frac{1}{2}$ foot.

\$ 41. Hanorthiàna (in honour of A. H. Haworth, F.L.S.; who has done more to elucidate the succulent tribes of plants than any other individual), D. C. prod. 3. p. 439.-Corállina, Haw. $r c v .154$. cxclusive of $M$. corallina perhaps.-Teretiúscula, Haw. syn. 301.-Rubicúnda, Salm-Dyck. obs. 23. Stcms suffruticose, smooth, crect; branches decussate, numerous, of a chestmut colour. Leares somcn hat cylindrical, subulate, elongated, glaucous. Floners solitary, showy, reddish, or white.

219 M. Produ'ctum (Haw. in phil. mag. 1824. p. 424.) stem sufficicose, erect; branches finely decussate, numerous; leaves crowded at the tops of the branches, semi-cylindrical, glaucous, rather incursed, full of pellucid dots; flowers terminal, by threes; calycine lobes unequal, two of which are long and the other three short. $\quad$. D. G. Native of the Cape of Good Hope. Corolla rose-coloured. Stigmas 5, erect.

Produced-calyxed Fig-marigold. Fl. May, June. Clt. 1822. Slirub 1 foot.

220 M. stipula'ceum (Lin. spec. 693.) stem shrubby, and is as well as the branches erect; leaves teretely triquetrous, long, subulate, ineurved, glancous, full of pellucid dots, margined at the base. F. D. G. Native of the Cape of Good Hope.Dill. elth. f. 267 . and 268 . IIaw. obs. 256. misc. 65. syn. 30 ]. rev. 15\%. Axils usually bearing leaves, hence the metaphorical name of stipulàccum, there being no stipules. Corolla light red, paler on the under side, 2 inches in cliameter.

Stipulaceous Fig-marigold. Fl. May, Ju. Clt. 1723. Sh. $1 \mathrm{ft}$.

221 M. II awórthir (Willd. enum. suppl. 36. Donn, hort. cant. rd. 6.) stem shrubby, erect; leaves crowded, compressedly cylindrical, attenuated at both ends, erect when young, but spreading and glaucous when old. (Salm-Dyck. in litt.). $h_{\text {. }}$. D. G. Native of the Cape of Good Hope. Haw. syn. 302. rev. 
154. Corolla purple, 2 inches in diameter. Bark of branclies rufous or castaneous. Leaves distinct (ex Haw.), connate (ex Willd.), therefore perhaps there are 2 species confused.

IIanorth's Fig-marigold. lil. Ju. Jul. Clt. 1793. Sh. $1 \mathrm{ft}$.

222 M. LE' Pidus (Haw. in phil. mag. 1826. p. 130.) leaves recurved at the apex, rather mucronate; segnents of calyx acuminated, spreading, marcescent after flowering. h.D.G. Native of the Cape of Good Hope. An erect, slender shrub. Leaves nearly as in $M$. prodictum. Flowers large, white, slowy, opening before meridian, longer than the perluncles.

Pretty Fig-marigold. Fl. Aug. Sept. Clt. 1823. Slı. $1 \mathrm{ft}$.

223 M. L.E'VE (Haw, misc. 64. syn. 302. rev. 154. but not of Thunb.) stem suffruticose, crect; leaves crowded, cylindrical, obtusc, arched, very glaucous, smooth. $h_{\text {c }}$ D. G. Native of the Cape of Good Hope. M. la've, Ait. hort. kew. 2. p. 187.? Flowers unknown (ex Haw.), purple (ex Willd. and Salm.Dyck.). Smooth Fig-marigold. Fl. Jul. Sept, Clt. 1774 . Sls. $1 \frac{1}{2} \mathrm{ft}$.

2:4 M. corA'LlixuM (Haw, rev, 154. but not of Thunb.) stem straight, much branclued; leaves nearly terete, incurved, smooth, rather thicker in the middle, glaucous. $h_{c} . D . G$. Native of the Cape of Good Hope. Very nearly allied to $M$. Hanórthii, but the stems are one half taller and the flowers smaller (ex Salm-Dyck. in litt.). Bark dark and bay-coloured (ex Haw.).

Coral-stemmed Fig-marigold. Fl. May, June. Clt. 1820. Shrub 1 foot.

\$ 42. Spinòsa (from spinosus, full of thorns; the branches become hard and spinose at the tips after flowering). SalmDyck. obs. 25. IIaw. rev. 153.-Teretiúscula species, Haw. syn. Stems shrubby, erect; branches stiff, hard, floriferous, usually spinescent after flowering. Lcaves terctely triquetrous, distinct. Flowers reddish.

225 M. spixòsum (Lin. spec. 693.) stem shrubby, erect ; branches hard, dichotomous, spinose after flowering; leaves nearly distinct, teretely triquetrous, dotted..,$D$. G. Native of the Cape of Good Hope.-Dill. elth. f. 265. Bradl. succ. t. 39. Haw. obs. 338. misc. 66. syn. 303. rev. 153. Flowers sniall, purple.

Spinose Fig-marigold. Fl. Ju. Sept. Clt. 1714. Sh. $1 \mathrm{ft}$.

226 M. sucroniferum (Haw. in phil. mag. 1823. p. 381.) stem shrubby, erect, straight ; leaves glaucescent, dotted, spreading, bluntly triquetrous, mucronulate ; flowers reddish, disposed by threes; peduncles permanent after flowering and spinose. দ. D. G. Native of the Cape of Good Hope. M. pulveruléntum, Willd. enum. 583. ex ill. Pr. Salm-Dyck.

Mucrone-bearing Fig-marigold. Fl. Jul. Ang. Clt. 18刃1. Shrub 1 foot.

Subdivision VII. Papulòsa (from papulosus, full of blisters; leaves beset with papula). D. C. prod. 3. p. 440.Papulòsa-teretif òlia, Haw. rev. p. 79. Shrubs, sulsshrubs or herbs. Leaves opposite, very rarely alternate, distinct, nearly terete, or thick at one end, channelled above, narrow, more or less beset with glittering papilla. Calyx 4-6, but usually $5-$ cleft. Stigmas just so many.

\$ 43. Barbàta (from barbalus, bearded; points of leaves). Salm-Dyck. obs. 27. IIan. rcv. 190.-Barbifòlia, IIan. syn. 277. Stems suffruticose, branched. Lcates nearly tercte, distinct, rather papulose, thick, bearded at the apex by 5 pulc hairs, which are 5-10, rayed at the apex. Floners flesh-coloured, rarely white, expanding in the sun. Calyx 5-8-cleft, with as many lark green tubercles on the torus. Stigmas 5-8.

227 М. ваRва'тUм (Curt. bot. mag. t. 70.) stem erect; branches effusely procumbent ; Icares rather remote, spreading, culing in 5-6 radiating luairs at the apex; base of ealyx glabrous; lobes 5 , nearly equal. h.D. G. Native of the Cape of Good Ilopre.-Dill. elth. f. 234. I). C. pl. grass, t. 28. M. barbàtum a, Lin. spec. 691. M. stelligerum, Haw, syn. 278. rev. 190. but not of phil. mag. M. barbàtum, Ilaw. phil. mag. 1824. p. 61. Tubercles 5, dark green within the flower. Stigmas 5. Flowers flesh-coloured.

Bcardcd-leaved Fig-marigold. F. Junc, Aug. Clt. 1705. Slirub $\frac{1}{2}$ to $\frac{3}{4}$ foot.

228 M. stellígenum (Haw. in phil. mag. 1824. p. 61. but not of his syn.) branches procumbent, elongated; leaves remote, half erect, terminating in 5 radiating hairs at the apex; calyx glabrous at the base; lobes very unequal. $h . D . G$. Native of the Cape of Good Hope. M. barbatum, IIaw. syn. 277. rev, 190. but not of phil. mag. Bradl. succ. t. 5. Curt. bot. mag. 70. Perhaps merely a variety of M. burbàtum.

Stur-bearing Fig-marigold. Fl. May, Oct. Clt. 1793. Slı. $\frac{1}{2}$ to $\frac{3}{4}$ foot.

229 M. intóssum (Haw, in phil. mag, 1824. p, 62.) branclies erectly decumbent, effuse, hispid; leaves terminating in $10 \mathrm{ra-}$ diating hairs at the apex; calyx girded by a black beard. $t_{2}$. D. G. Native of the Cape of Good Hope. Flowers reddisl.

Var. $\beta$, álbum (Haw. l. c.) flowers at first white, but at length becoming reddish as they fade.

Unshared Fig-marigold. Fl. July. Clt. 1824. Slurub $\frac{1}{2} \mathrm{ft}$.

230 M. Bulbòsum (Haw. in phil. mag. 1824. p. 4.28.) root tuberous; branches rather villous ; leaves horizontal, crowded, terminating in 10 radiating hairs. $\zeta . D$. G. Native of the Cape of Good Hope. Root referrible to that of $M$. tuberisum: the rest of the plant comes nearcst to $M$. intonsum. Flowers middle-sized, reddish.

Bulbous-rooted Fig-marigold. Fl. Aug. Clt. 1820. Sh. $1 \mathrm{ft}$. 231 M. stella'tum (Mill. dict. no. 14.) branches short, thick; leaves tufted, hoary, thick, scabrous from papulæ, terminating in many radiating bairs at the apex, and ciliated at the base, greenish; peluncles very hairy; calyx hairy at the base, 6-8-lobed. h. D. G. Native of the Cape of Good Ilope. D. C. pl, grass. t. 29.-Dill. elth. f. 235. M. barbàtum $\beta$, Lin. spec. 691. M. hirsùtum, Haw, misc. 105. syn. 279. M. stcllàtum, Haw. rev. 191. phil. mag. 182.4. 1. 62. but not of his syn. Flowers pale red.

Starry-haired Fig-marigold. Fl. Sept. Oct. Clt. 1716. Shrub $\frac{3}{4}$ foot.

232 M. DE'xsum (Haw obs. p. 302. misc. 105. syn. 279. rev. 191. phil. mag. 1824 . p. 62 .) plant densely tufted; leaves semiterete, scahrous from papulse, terminating in many radiating hairs, rather ciliated at the base, greenish; peduncles very hairy as well as the calyx, which is 6-cleft. $h^{2}$ D. G. Native of the Cape of Good Hope.-Dill. elth. f. 236. without a flower. Sims, bot. mag. t. 1220. Old stem thick, branched, very short. Flowers expanding in the heat of the sun, purple, larger than those of $M$. stellitum.

Dense Fig-marigold. Fl. May, Aug. Clt. 1732. Sh, $\frac{1}{4}$ ft.

\$41. Echinita (from cchinalus, set with prickles; leaves). Salm-Dyck, obs. 27. Haw. rev, 189.-Hispifólia, IIan. syn. 275. Stems suffruticose, much branched. Leaves nearly tcrete, distinct, more or less hispid all over, as nell as the branches. Lobes of calyx 5, leaf-formed. Corolla white or pale ycllon. Stigmas 5.

233 M. EcInNirum ( Ait. hort. kew. 2. p. 194.) stcm erect, branched; leares oblong-ovate, filled, rather triquetrous, gibbous, ramentaccously-echinated; lobes of calyx leaf-formed,

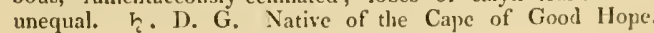


Haw, obs. 288. misc.103. syn. 276. rev.189. D.C.pl. grass. t. 24. Jacq. schoubr. t. 487. M. setòsum, Møench. Flowers yellow. l'ar. $\beta$, álbum (Haw. l. e.) flowers white.

IIcdge-hog Fig-marigold. Fl. Jul. Oet. Clt. 1774. Sh. $\frac{1}{4}$ to $\frac{1}{2} \mathrm{ft}$. 2S.t M. srrusrosum (Haw. rev, 190.) stems decumbent, branched; leaves crowded, depressedly cylindrical, hispid all over; lohes of ealyx nearly equal; root at length tuberous. n. D. G. Native of the Cape of Good Hope. Corolla pale straw-coloured or white.

Strumose Fig-marigold. Fl. Aug. Clt. 1820 . Sh. $\frac{1}{4}$ to $\frac{1}{2} \mathrm{ft}$.

8 45. Mispida (from hispidus, bristly; branclies rough from bristles). D. C. prod. 3. p. 441.-Hispicaúlia, Ham. syn. 273. rev. 185. Salm-Dyck. obs. 26. Stems suffruticose, bushy; branches hispid from bristles. Lcaves distinet, cylindrical, papulose. l'cduncles hispid. Floners middle-sized, expanding before neridian, reddish, or rose-coloured, rarely white. Calyx 5-cleft. Stigmas 5 .

235 M. calycínum (Haw, rev. 187.) branches effuse; leaves cylinulrical, rather filiform, obtuse, papulose; two of the calycine lobes are foliaceons, much exceeding the other three in length; stamens longer than the stigmas. $\zeta . D . G$. Native of the Cape of Good Hope. Flowers white.

Long-caly.ed Fig-marigold. Fl. Jul. Aug. Clt. 1819. Slı. $\frac{3}{4} \mathrm{ft}$. 236 M. tubercula'tum (D. C. in Pers, ench. 2. p. 44.) stems decumbent, much branched; branches ascending; leaves terete, acute, papulose, soft; branches, peluncles, and calyxes hispid ; calyx campanulate at the base; stamens hardly exceeding the stigmas. h.D.G. Native of the Cape of Good Hope. M. hispif olium, Haw. suppl. 94. rev. 189. Petals rose-coloured, but purplish above, with a deeper-coloured middle line. There is also a variety of this with white flowers.

Tubercled Fig-marigold. Fl. Oct. Clt. 1818. Shrub dec.

287 M. Aттекиa'tum (Haw. rev, 188.) plant slender; branches decumbent, filiform; leaves semi-cylindrical, filled, obtuse, or nearly terete, papulose ; peduncles elongated ; calyxes hairy at the base. $h^{2}$. D. G. Native of the Cape of Good Hopc. Petals at first white, or with a rose-coloured middle line, whence there is a rose-coloured circle in the flower.

Attenuted-branched Fig-marigold. Fl. May, Oct. Clt. 18\%1. Shrub decumbent.

238 M. stria'tua (Haw. obs. 280. misc. 188.) stem erect; leaves semi-cylindrieal, subulate, papulose ; calyx woolly; stamens collected, length of stigmas. $\zeta$. D. G. Native of the Cape of Good IIope. Capsule angular at the apex.

lar. a, ròseum (Haw. rev. 188.) petals pale rose-coloured, with a deeper-coloured line in the middle.-Dill. elth. f. 281 .

Var. $\beta$, púllens (Haw. I. c.) petals white, each with a red line at the base. D.C. pl. grass. t. 13?.

Striated-flowered Fig-marigold. Fl. May, Oct. Clt. 1727. Slirub $\frac{3}{4}$ foot.

239 M. FLoRIBU'xdim (Haw, misc. p. 100, syn. 274. rev. 187.) branches spreading, very numerous; leaves almost cylindrical, somewhat incurved, papulose, obtuse ; calyxes hemispherical, beset with pajulose pili ; stamens not equalling the stigmas in length. $\quad 2.1)$. G. Native of the Cape of Good Hope. M. lispidum $\beta$, pállidum, IIaw, obs. 279. Flowers numerous, pale red; with the petals white at the base.

Var. P, torquàtum (Haw. rev. 187.) flowers fewer, larger and more remote; stamens exceeding the stigmas. According to Salm-1)yck this is not distinct from $M$. floribundum, which are both perliaps referrible to $M$. striàtum, var. $\beta$.

Bundle-flonercd Fig-marigold. Fl. May, Oct. Clt. 1704. Shrub $\frac{1}{2}$ foot.

240 M. ca'nnens (Haw. rev. p. 186.) branches long, weak, procumbent or prostrate; leaves cylindrical, incurved, canes- cent, and glittering, obtuse. 々. D. G. Native of the Cape of Good Hope. Flowers unknown. Leaves shining in the sun from papula. M. hirtéllum, Salm-Dyck. obs. p. 24. but not of Haw. Perhaps only a variety of $\boldsymbol{M}$. hirtéllum.

I'ur. a, glaucésccns (Salm-Dyck. in litt.) leaves glaucescent. M. cándens, var. $\boldsymbol{\alpha}$, mínus, Haw. in phil. mag. dec. 1831. p. 422.

Far. $\beta$, viréscens (Salm-Dyck, in litt.) leaves greener; branches less clongated. M1. cándens $\beta$, virideus, Haw. l. c.

Glittering Fig-marigold. Clt. 1820. Shrub pr.

24.1 M. HRtélum (Haw. obs. 284. exclusive of the synonymes, misc, 102. syn. 274. rev. 186.) stem erect, bushy; leaves crowded, cylindrical, very blunt, beset with glittering papulæ; calyx turbinate, beset with papulose pili; stamens equal in length to the stigmas. $\zeta$. D. G. Native of the Cape of Good Hope. Flowers larger than those of any other species of this section, showy; petals pale red, white at the base.

Bristly Fig-marigold. Fl. May, Nov. Clt, J792. Sh, $\frac{1}{2}$ to $1 \mathrm{ft}$.

21.2 M. subcompre'ssum (Haw. in plil. mag. Alig. 1826. p. 131.) plant erect and twiggy ; leaves greenish-canescent, compressedly scmi-terete, obliquely obtuse; upper part of branches rather pilose. h. D. G. Native of the Cape of Good Hope. Flower of a reddish violaceous colour.

I ar. $\beta$, minus (Haw, 1. c.) plant not lalf the size of the species.

Subcompressed-leaved Fig-marigold. Fl. July. Clt. 1825. Shrub 1 foot.

243 M. Turfu'reum (Haw, in phil. mag. Dec. 1831. p. 421.) shrub bushy; branches crowded, straightish, stiff, furfuraccous; leaves cylindrical, very blunt, and are, as well as the calyx, beset with obsolete crystalline papulae; flowers small, numerous. h. D. G. Native of the Cape of Good Hope. Flowers terminating the branches, usually solitary, very pale red.

Furfuraceous lig-marigold. Clt. 1830 , Shrub 1 foot.

244. M. n'spidum (Lin. spec. 691.) stem erect, bushy ; leaves cylindrical, very blunt, green, glabrous, and covered with glittering papule, as well as the calyx, which is conical; stamens exceeding the stigmas. $h_{c}$. D. G. Native of the Cape of Good Hope--Dill. elth. f. 278 . D. C. pl. grass. t. 66. M. híspidum $a$, Ilaw. obs. 277. M. híspidum, Haw. syn. 273. rev. 186. Flowers deep purple.

Hispid Fig-marigold. Fl. May, Oct. Clt. 170\%. Sh. $\frac{1}{2}$ to $1 \mathrm{ft}$.

245 M. subuíspidum (Haw. in phil. mag. Dec. 1831.p. 421.) stem erect; branches and peduncles usually witlsout hairs; leaves eylindrical, very blunt, and are, as well as the obconical calyses, glabrous, greenish, and covered with glittering papulæ. $h_{\imath}$. D. G. Native of the Cape of Good Hope. M. híspidum $\beta$, platypétalum, Haw. rev. 186 . Petals pale purple, whitish at the base, emarginate at the apex. Very like M. hispidum, but taller, less branched; but the branches are longer, more erect, and straight, and the flowers paler.

Subhispid Fig-marigold. F1. May, Oct. Clt. 1704. Sh. I foot.

$\S$ 46. Aspericaúlia (from asper, rough, and caulis, a stem; stems rough). Haw. mise. 97. rev 182. Salm-Dyek, obs. 26. Stcms shrubby, hardly a foot and a half high; branches fliform, scribrous. Lcaces distinet, remote, nearly terete, glittering frem papula. Floncrs expanding before meridian; reddish or copper-coloured. Calyx 5-cleft. Stigmas 5, but in one of the species the calyx is 6-cleft, and the stigmas are 6.

\section{* Floners reddish.}

2.16 M. MUlyeruléntum (Haw, obs. 265. mise. 89. syn. 272. rev. 185. but not of Willd.) stem ercet; branches crowded; leaves cylindrically triquetrons, obtuse, dotted with white, powdery, scabrous; calyx 6 -cleft. h. D. G. Native of the Cape 
of Good Hope. Flowers almost like those of $\boldsymbol{M}$. barbàtum, reddisl. Stigmas 6 , recurvel at the apex.

Pondery Fig-marigold. Fl. May. Clt. 1792. Sh. $\frac{1}{2}$ to 1 foot. 247 M. séssil. ('Tluub. H. cap. 419.) stem erect, terete; branches flexnous, divaricate; leares globoscly trigonal, very blunt, glabrous; flowers sessile. of Good Hope. Leaves a line long. Flowers red.

Sessile-flowered Fig-marigold. Shrub 1 foot.

248 M. subolobosca (IIaw. syil, 273, rev. 185.) branclics numerous, filiform, divaricate, rather decumbent; leaves expasded, ratlier papulose, very slort, cylindrically subglobose. h. D. G. Native of the Cape of Good Hope. M. capillatre, Thumb. fl. caj). 419. but not of others. M. suluglobòsum and II. brevifülium a, Haw, misc. 62. and 99 . Flowers red.

Subglobosc-leaved Fig-marigold. Fl. July, Oct. Clt. 1 r95. Shrub 1 foot.

249 Ml. BREviròntua (Ait. hort. kew. 2. p. 188.) stems crectislı; branches diffuse, filiform, numerous; leaves cylindrical, very blunt, spreading, papulose. $\hbar_{\text {. }}$ D. G. Native of the Cape of Good Hope. M. brevifòlium, Haw. misc. p. 99. var. $\beta$, syn. 272. rev. 185 . M. erigerifòlium, Jacq. hort. vind. t. 477. ex Salm-Dyck in litt. Corolla small, red.

Short-lcaved Fig-marigold. Fl. July, Oct. Clt. 1777. Sh. $1 \mathrm{ft}$.

250 M. PARvifólium (Haw. rev. 184. bnt not of Lam.) stem erectish; branches rather crowded, filiform, rough, hard; leaves grain-formed, expanded, bluntly triquetrous, rather glittering from papulice. h. D. G. Native of the Caje of Good Hope. Corolla expanding in the day time, deep purple, nearly like that of $M$, hispidum, but one-half smaller. Stigmas 5 , erect, green.

Small-leared Fig.-marigold. Fl. Aug. Clt. 1820 . Sh. $\frac{1}{2}$ to $1 \mathrm{ft}$.

251 M. obu'Quem (Haw, rev, 183. but not of Willd̄.) stem erect ; branches filiform, hard, roughish, erectish ; leaves distant, cylindrical, obtuse, small, glittering from papulæ, with one of the pair deflexed, and the other opposite it ascending. Native of the Cape of Good Hope. Ker, bot. reg. 863. Petals purple, spreading, acute. Stamens erect, collected, white. Flowers 9-10 lines in diameter.

Oblique-leased Fig-marigold. Fl. Aug. Clt. 1819. Sh. $1 \mathrm{ft}$.

\section{* Floners copper-coloured or yellow.}

25.2 M. ruA'vu (Haw. rev. 183.) stem erectish; branches very slencler, scabrous from dots; leaves nearly terete, rather attenuated at both ends, glittering from papulæ, erectly incurved or variously bent ; lobes of calyx obtuse, nearly equal. $h . D$. G. Native of the Cape of Good Hope. Corolla expanded half an inch broad, of a golden yellow-colour, rather reddish on the outside; filaments white.

Yellon-flowered Fig-marigold. Fl. Aug. Clt, 18?0. Shrub $\frac{1}{2}$ to 1 foot.

253 M. Micans (Lin. spec. 696.) stem erect; branches scabrous; leaves semi-cylindrical, bluntish, rather recurved, glittering from papula; lobes of calyx and petals acutish. h.D. G. Native of the Cape of Good Hope.-Dill. elth. f. 283. and 423. Bradl. succ. t. 8. Curt. bot. mag. 448. D. C. pl. grass. t. 158. Haw, obs. 268, and 423, misc, 98, syn. 271. rev. 182. Flowers pedunculate, copper-coloured, an inch and a half in diameter, with dark sterile filaments. Stigmas 5, thick, and greenish.

Glittering Fig-marigold. Fl. May, Aug. Clt. 1704. Sh. $1 \frac{2}{2} \mathrm{ft}$.

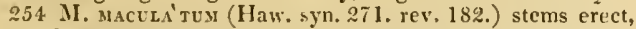
covered with rough spots; leaves expanded, remote, obtuse, semi-cylindrical, and ratlier compressed, papulose. h. D. G. Native of the Cape of Good Hope. M. maculatum and M. micans $\beta$, Haw. misc. 99. Flowers tnknown.

Spotted-stamened Fig-marigold. Clt. 1732. Shrub $1 \frac{1}{2}$ foot. 255 M. spectòsust (Haw. obs. 367. misc. 98. syn. 270. rev. VOL. III.
182.) stem erect, with scabrous branches ; leaves semi-cylindrical, subulate, acutish, incurved, glittering a little from papulae; lobes of calyx and petals obtuse; corolla rather funnel-sliaped. h. 1). G. Native of the Cape of Good IIope. Corolla large, decp scarlet, with a green base, less than that of $M$. micans, expanding in the height of the sun.

Elegant Fig-marigold. Fl. May, Oct. Clt, 1793. Shrub $1 \frac{1}{2} \mathrm{ft}$.

\$ 47. Trichótoma (the flowers are dinposed by threes, or in a trichotomous manner). IIan. rcv. 178. 'Tuberòsa. Salm-Dyck, obs. 25. Erect branchcd subshrubs. Leates usually nearly cylindrical, and glittering in the sun from papulce. Calyx 5-clcjt. Flowers small, disposed by thrces, of various colours, but usually of a yellowish coppery-colour.-An artificial scction.

256 M. TUBERòsur (Lin. spec. 693.) stcm erect, branched ; leaves ratlier triquetrous, compressed, beset with minute papulae, recurved at the apex; flowers trichotomous; root tuberous, hard. h. D. G. Native of the Cape of Good Hope--1)ill. elth. f. 264. D. C. pl. grass, t. 78. Haw, obs. 271. misc. 89. syn. 253. rev. 170. Peduncles usually permanent and spinose, as in M. spinòsum. Flowers small, flesh-coloured. Stigmas 5, rarely 6 , ex Haw.

Tuberous-rooted Fig-marigold. Fl. June, Oct. Clt. 1714. Slirub 2 to 3 feet.

257 M. MEgarit'zuM ; root large, tuberous; stem erect, branched; leaves recurvely hooked; branches erect, thongformed, flexile. $\quad$ h. D. G. Native of the Cape of Good Hope. Very like $\boldsymbol{M}$. tuberòsum, but differs from it in the principal stem being more equal in thickness; and in the flowers heing more numerous and white. M. macrorlsizum, Haw. in phil. mag. Nov. 1826. p. 332. but not of D.C.

Large-rooted Fig-marigold.

Shrub 2 feet.

258 M. TESTA'CEUM (Haw. suppl. 97. rev. 178.) stem slurubby, erect; leaves semi-terete, rather triquetrous, glaucescent; flowers disposed in trichotomous umbels. h.D. G. Native of the Cape of Good Hope. Stems 2-3 feet high. Flowers sinall, of a coppery-colour, pedunculate. Petals in one series. Both the fertile and sterile stamens are snow white, collected into a cone.

Testaccous-flowered Fig-marigold. Fl. Aug. Sept. Clt. 1820. Shrub 2 to 3 feet.

259 M. тRiciótомим (Thunb. f. cap. 419.) stem straight ; branches divaricate; leaves connate, trigonal, obtuse; flowers terminal, sessile; calyx 4-cleft. h.D.G. Native of the Cape of Good Hope. It differs from 1 . geniculiflorum in the leaves being connate, and without papulæ, and in the flowers being red. Stigmas 4, purple, short.

Trichotomous Fig-marigold. Shrub 2 to 3 feet.

260 M. subinca'suy (Haw. in phil. mag. Dec. 1824. p. 427.) stem firm, branched, erect; leaves expanded, compressed, trigonal, rather canescent, soft, recurved, and mucronulate at the apex; flowers terminal, disposed by threes; lobes of caly'x 5 , unequal. 々. D. G. Native of the Cape of Good Hope. Flowers middle-sized, snow white, expanding before meridian. This species is most nearly allied to $M$. trichótomum.

Rather-hoary Fig-marigold. Fl. Aug, Sept. Clt. 1820. Sh. 2 to 3 feet.

261 M. Decussa'tum (Thunb. A. cap. p. 414.) stem shrubby, trichotomous ; branches erect ; leaves conuate, linear-semiterete, rather papulose; flowers pedunculate, solitary. h. D. G. Native of the Cape of Good Hope. Flowers spreading, snow white. Calyx 5-cleft.

Dicussate-leaved Fig-marigold. Slurub 2 to 3 feet.

262 M. BRAchítus (Ait. hort. kew. 2. p. 119.) stem much branclied; branches triclıotomous, papulose ; leaves cylindrical, 
papulose. 2. D. G. Native of the Cape of Good IIope. Haw. obs. 25. misc. 58. (cxclusive of the synonyme of Thunb.) syn. 234. rev. 178. but not of D. C. Flowers yellow.

Armed Fig-marigold. Fl. June, Aug. Clt. 1774. Sh. $1 \frac{1}{2}$ foot.

\$ 48. Spinulifora (from spinula, a little thorn, and fero, to bear; leaves appearing like little thorns, when old). Haw rev. 176. Salm-I)yck, obs. 26. Stems suffruticose, usually strumose at the base; branches rather ficshy, papillose, when old they appear as if they were spiny from the permanent rcmains of the dried lcaves. Leaves eylindrical, papulose, opposite, somenhat channclled. Flowers expanding bcfore meridian, fulvous or greonish rad. Calyx 5-cleft. Stigmas 5.

269 M. SpInUlíperum (Haw. obs. 206. and 443. misc. $5 \%$. syn. 25\%. rev. 176.) caudex and branches crect and thickened; leaves crowded, semi-tcrete, channelled, papulose; peduncles terminal, subumbellate. $\quad$. D. G. Native of the Cape of Goot Hope. Corolla an inch in diametcr, straw-coloured.

Spinc-bearing Fig-marigold. Fl. Ju. Oct. Clt. 1794. Sh. $1 \mathrm{ft}$. 264. M. Longisin'sulum (Haw, in phil. mag. Dec. 1824. p. 426.) branches few, procumbent, nodosely strumose at the base; leaves linear, channelled, and are, as well as the branches, papulose; old leaves permanent, long, hard, and spine-like; flowers usually solitary; peduncles strong, subclavate. $h_{\text {c }}$, D. G. Native of the Cape of Good Hope. Petals pale yellow or strawcoloured. Stigmas 5 , erect.

Long-spincd Fig-marigold. Fl. Aug. Nov. Clt. 1820. Shrub procumbent.

265 M. salxòneuy (Haw, rev. p. 176.) stems rather filiform, weak, elongated, prostrate ; leaves linear, furrowed, longer than the internodes, beset with sordid papula; roots at length strumuse above. h. D. G. Native of the Cape of Good Hope. Flowers trichotomous, small, at first of a salmon colour, but afterwards becoming white inside. Stigmas 5 , erect.

Salmon-colourch-flowered Fig-marigold. Fl. Aug. Oct. Clt. 1819. Slrub pr.

266 I. canalicula'tum (Haw. obs. 218, misc. 57. syn. 253. rev. 177.) stems procumbently prostrate, filiform ; leaves linearsemiterete, covered with shining papulæ. F. D. G. Native of the Cape of Good Hope. Corolla pale rose-coloured. Old stems half a foot high.

Channclled-leaved Fig-marigold. Fl. July, Oct. Clt. 1794. Shrub pr.

267 M. viridiflònum (Ait, hort. kew. 2. p. 196.) caudex thickened; branches diffuse, knotted; leaves semitcrete, beset with papulose hairs; calyx hairy, pedunculate. 々. D. G. Native of the Cape of Good Hope. Curt. bot. mag. t. 326. D. C. pl. grass. t. 159. Jacq. fragm. t. 5\%. f. 2. Petals very narrow, greenish. Stigmas 5, joined in one body.

Grecn-flonercel Fig-marigold. Fl. July, Nov. Clt. 177t. Shrub 1 to 2 feet.

268 М. сkóssum (IJaw. misc. p. 57. syn. 252. rev. 176.) caudex thickened; branches effusely decumbent; leaves linear, nearly terete, obtuse, attenuated at both ends, papulose. $h$. D. G. Natire of the Cape of Good Jlope. M. gróssum, M. cárneum, and M. aggregàtum, IJaw. obs. 205, 206. and $\$ 19$. Corolla middle-sized, pale, at length becoming of a reddish straw colour.

Coarsc Fig-marigold. Fl. Aug. Oct. Clt. 1774. Shrub $1 \mathrm{ft}$. 269 M. TENUfLònu (Jacq. fragm. t. 32. f. 3.) stems diffuse, weak, cinereous; leaves semiterete, obtuse, channelled, spreading, besct with crystalline papulæ; flowers 1-2, terminal, on short peduncles. 5 . D. G. Native of the Cape of Good Hope. Petals linear-filiform, of a dirty red-colour.

Slcnder-flonercd Fig-marigold. lil. July, Nov. Clt. 1820. Shrub I foot.
270 M. N' '́ndu (Haw. obs. 412. misc, 5\%. syu. 243. rev. 177.) stem erect; branches slender, effuse, knotted ; leaves semiterete, besct witl glittering papulæ; flowers terminal, usually by threes. h. D. G. Native of the Cape of Good Hope. Flowers yellow. Salm-Dyck ex Spreng. nov. prov. 27. M. brachiàtum, D. C. pl. grass, t. 129. M. pruinòsum, Thunb. A. cap. 425. ex Salm-Dyck and Spreng. but according to Haworth this species differs in the stem being decumbent, and in the branches being bent.

Shining Fig-marigold. Fl. July, Oct. Clt, 1790. Sh. I to $2 \mathrm{ft}$.

\$49. Noctiftora (from nox, the night, and flos, a flower; flowers expanding at night). IJaw. syn. 259. rev. 179. SalmDycli, obs. 23. Slcnder subshrubs, almost without leaves at the basc, at length becoming thickened at the roots; nith elongatcd branches. Lcavcs distinct, eylindrical, glaucous, rcmote, dotless, soon falling off: Floners usually by threcs, terminal, nhite, rosecoloured or stran-colourcd on the outside, cxpanding in the evening. Calyx turbinate, 4-cleft. Stigmas 4 .

271 M. Noctıflòrum (Lin. spec. 689.) stems suffruticose; branches erect, with white bark; leaves rather remote, obsoletely semicylindrical, glaucous; peduncles biternately cymose. h. D. G. Native of the Cape of Good Hope. Haw. rev. 179. Lodd. bot. cab. 495 .

Iar, a, Phceniceum (Haw, rev. 179.) flowers white inside, and scarlet outside, very sweet-scented.-Dill. elth. f. 262. M. noctiflòrum, D. C. pl. grass, t. 10. Haw. obs. 251. misc. 63. syn. 260 .

Var. $\beta$, stramineum (Haw. rev, 179. but not of Willd.) flowers white inside, and straw-coloured on the outside.-Dill. elth. f. 263.

I'ar. $\gamma$ ? elàtum (Haw, rev. 180.) leaves longer, semi-erect, white from mealiness, cylindrically triquetrous, at length reflexed; flowers by threes, white inside, and rose-coloured on the outside. Perhaps a proper species.

Night-flowering Fig-marigold. Fl. June, Aug. Clt, 1714. Shrub 1 to 2 feet.

272 M. FU'LvUM (Haw, rev. p. I80.) stem suffiuticose; bark of branches brownish-grey; leaves remote, nearly cylindrical, glaucescent, exactly half erect ; flowers by threes. h. D. G. Native of the Cape of Good Hope. M. strarníneum, Haw, obs. 252. (exclusise of the synonyme of Dillenius,) misc. 63. syn. 261. but not of Willd. Flowers fulvous, but white on the inside. Ovarium top-formed. Perhaps distinct from the preceding species, according to the Prince de Salm-Dyck in litt.

Fulcous-flowered Fig-marigold. Fl. June, Aug. Clt. 1820. Slirub 1 to 2 feet.

273 M. cLAVA'Tus (Jacq. hort, schœnbr. t. 108.) stem erect, sparingly branched; leaves nearly terete, remote, liorizontal; pecluncles clavate, aggregate, eymose. ?. D. G. Native of the Cape of Good Hope. M. defoliatum, Haw, misc. 83. rev. 181. Flowers white.

lrar. $\beta$, horizontàle (D. C. prod. 3. p. 445.) flowers strawcoloured, but white on the inside, disposed by threes. M. horizontàle, Haw. syn. 261. rev. 181, M. stramíneum a, Haw. misc. 63. exclusive of the synonymes. Perhaps a proper species.

Clavate-peduncled Fig-marigold. Fl. June, Aug. Clt. 1795. Slirub 1 to 2 feet.

$\S 50$. Geniculiftòra (from geniculum, a little knee, and flos, a flower; from the flowers rising in the knees or forks of the branches). D. C. prod. 3. p. 445. Stems frutcscent, erect. Lcaves opposite, distinct, papulose, scmi-tcrcte. Flowers sessile in the forlis of the branchics, solitary, ycllonish, exp anding in the day time.

274 M. Gexiculifiòru (Lin. spec. 688.) stem frutescent, erect; leares distinct, semi-terete, papulose ; flowers sessile and 
solitary in the forks of the branclies; calyx 4-cleft. $h$. D. G. Native of the Cape of Good Ilope, and of Egypt and Arabia,Dill. elth. f. 261 . Bradl. succ. t. 34 . D. C. pl. grass. t. 17. Haw. syu. 25.. misc. 59. rev. 167. Petals pale yellow. Stigmas 4 , erect, short.

Knce-flonered Fig-marigold. Fl. July, Sept. Clt. 1727. Slirub 1 foot.

$\S 5$ I. Splendéntia (from splcudens, shining; in reference to the leaves, which are covered witl glittering papula, which shine in the sun). D. C. prod. 3. p. 445.-Digitiftora and Crassulina, Haw. ret. 170. and 172.-Teretiúscula albiflòra, Salm-Dyck, obs. p. 23. Stems suffruticose, branched, crect. Leaves opposite, distinct, somcnhat cylindrical, when young furroncd aborc, beset with papillee more or less, which glitter in the sun. Floners middlc-sizcd, solitary, rarely by thrces, white, cxpanding before meridian. Calyx generally 5-lobed, rarely 4 or 6-lobed, usually leaf-formod. Stigmas as many as there are calycinc lobs.

275 M. crassulinum (D. C. prod. 3. p. 445.) stem suffruticose, erect, decumbent; branches numerous, rather effuse ; leaves crowded, thick, linear-lanceolate, channelled, almost without japulæ, green; flowers solitary; 3 of the segments of calyx membranous at the base, and 2 larger than the rest. $h$. D. G. Native of the Cape of Good Hope. M. crassuloides, Haw, rev, 170. Flowers expanding before meridian; petals 4 lines long, white, but at length becoming pale rose-coloured. Stigmas 5, which after fecundation are very conspicuous above the anthers.

Crassula-like Fig-marigold. Fl. July, Aug. Clt. 1819. Sh. decumbent.

276 M. Ixcónptus (Haw. suppl. 96. rev. 171.) stem suffruticose, branched, bushy; leaves crowded, rather papulose, erectly imbricating, semi-terete, firm, almost subulate; flowers by threes; peduncles clavate; lobes of calyx finger-shaped, acute. h. D. G. Native of the Cape of Good Hope. Plant half a foot high, pale green. Corolla snow white. Stigmas 5, ramentaceous, equal in length to the anthers.

Undecked Fig-marigold. Fl. July, Aug. Clt. 1819. Sh. $\frac{1}{2} \mathrm{ft}$.

277 M. spLE'NDExS (Lin. spec. 689.) stem shrubby, erect, much branched; leaves distinct, crowded, semi-terete, obtuse, spreading, somewhat recurved, dotless, rather papulose; flowers solitary; lobes of calyx finger-shaped. h. D. G. Native of the Cape of Good Hope.-Dill. elth. f. 260 . D. C. pl. grass. t. 35. Haw obs. 209. misc. 61. syn. 257. rev, 172. Flowers middle-sized, white, shining. Calyx 5-cleft. Stigmas 5, thick, but subulate at the apex.

Shining Fig-marigold. Fl. July, Aug. Clt. 1716. Sh. $1 \frac{1}{2} \mathrm{ft}$.

278 M. sulch'тuM (Haw. rev, p. 173.) stem shrubby, erect; leaves crowded, linear-subulate, semi-terete, channelled, palegreen, adult ones expanded, semi-terete; lobes of calyx leafformed, acute. $\quad$. D. G. Native of the Cape of Good Hope. Flowers white. Stigmas 5, erect, not exceeding the stamens. Perhaps only a variety of $M$. spléndens.

Furroxed Fig-marigold. Fl. Aug. Sept. Clt. 1819. Slırub 2 to 3 feet.

279 M. Acuma'tum (Haw, in plil. mag. 1824. vol. 64. p. 426.) stem and branches erect; leaves crowded, semi-terete, acuminated, green; lobes of calyx 5, 2 of which are much more prolonged than the other 3. $h$. D. G. Native of the Cape of Good Hope. Allied to $\boldsymbol{M}$. sulcatum, but differs from all the species of this section in the lobes of the calyx being very unequal. Corolla white, expancling before meridian.

Acuminated-leaved Fig-marigold. Fl. Aug. Sept. Clt. 1820. Shrub 1 to 2 feet.

280 M. Albicav'le (Haw, in phil. mag. Nov. 1826. p. 331.) stem and branclies erect, slender, and whitish ; leaves subulate, green, semi-terete, a Jittle recurved, and mucronulated at the apex. h. D. G. Native of the Cape of Good Hope. Flowers white. Like $M$. acuminàtum in habit, but three times smaller.

IThite-stcmmed Fig-marigold. Fl. Aug. Sept. Clt. 1824. Slirub I foot.

281 M. Flexuòsum (Jaw. misc. p. 61. syn. 257. rev. 172.) stem suffruticose, and is, as well as the branches, flexuous, slender, and shining; leaves crowded, flexuously incurved, very green, semi-terete; lobes of calyx finger-shaped. h. D. G. Native of the Cape of Good Hope. Flowers white, reddish on the outside. Stigmas $4-5$.

Flexuous-branched Fig-marigold. Fl. July, Aug. Clt. 1795. Shrub $1 \div$ foot.

282 M. Fastigia'tum (Haw. rev. 173. but not of Thunb.) stems slender, erect at first, but at length becoming decumbent; leaves crowded, flexuously reflexed, subulate, semi-terete, glaucescent; lobes of calyx equal, 3 of which are membranous on both sides, $h$. D. G. Native of the Cape of Good Hope. Corolla of a dirty fulvous-colour on the outside, white and paler on the inside. M. fastigiàtum, Haw. misc. p. 60. exclusive of the synonyme of Bradl.

rar. $\beta$, refléxum (Haw. rev. p. 173.) lobes of calyx unequal ; stem erect. M. refléxum, Haw, misc. 60 . var. $a$.

Fastigiate Fig-marigold. Fl. July, Sept. Clt. 1794. Sh. $1 \mathrm{ft}$. 283 M. umbelliflókum (Jacq. ex Willd. enum. 534.) stem erect; leaves distinct, nearly terete, papulose ; branchlets 1-flow-

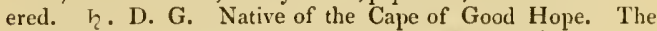
rest unknown. Perhaps only a variety of M. fastigiàtum, Haw. or a proper species, ex Haw. rev. 174.?

Umbel-fon'cred Fig-marigold. Fl. Aug. Sept. Clt. 1820. Shrub $1 \frac{1}{2}$ foot.

284 Ml. Longı'stylua (D. C. pl. grass. t. 147.) stem suffruticose; branches elongated; leaves opposite, distinct: when young linear-filiform, but at length becoming a little keeled, acute, and minutely papulose; peduncles 1 -flowered; calyx 5cleft, with 2 or 3 of the lobes having hyaline margins; stigmas 5 , exceeding the stamens. $\zeta$. D. G. Native of the Cape of Good Hope. M. pállens, Jacq. hort. schœenbr. 3. t. 279. but not of Ait. M. palléscens $\beta$, Haw. rev. p. 174. Flowers white, or somewhat rose-coloured, half an inch in diameter.

lar. 3 , purpuráscens (D. C. prod. \&. p. 446.) flowers purplish. M. palléscens $a$, Haw. rev. 174. M. refléxum $\beta$, Haw. misc. 61 .

Long-styled Fig-marigold. Fl. Aug. Sept. Clt. I820. Shrub $1 \frac{1}{2}$ foot.

$\$ 52$ Júncca (from junceus, like a bull-rush, slender; stems). Haw. rev. p. 175.-Articulita, Salm-Dyck, obs. p. 24. Stems suffruticose or herbaceous, rather ercet; branches slender, grcen. Leaves opposite, distinct, small, linear-subulate, slender, deciduous when dry, whence the stems appear to be articulatcd from the cicatrices of the fallen lcates. Floners small, pedunculate, white or reddish. Calyx 4-cleft. Stigmas 4.

285 M. зU'хсеим (Haw. misc. 175. syn. 255. rev. 59.) stem shrubby, much branched; branches articulated, filiform; leaves subulate, semi-terete, acute, remote ; flowers terminal, dichotomous; lobes of calyx 4 , very unequal. $h$.D.G. Native of the Cape of Good Hope. Corolla small; petals reddish, but whitish at the base. Stigmas 4, erect, a little longer than the filaments. M. aphýllum, Hortul. M. articulàtum, Thunb. fl. cap. 415.?

Rushy Fig-marigold. Fl. Aug. Oct. Clt. 1800 . Sh. $1 \mathrm{ft}$.

286 M. GKANULicau'Le (Haw, in phil. mag. 1824. vol. 64. p. 424.) stem very slender, suffruticose; branches terete, dotted from numerous grains; leaves very narrow, obtuse, glaucescent, semi-terete, longer than the internodes. h. D. G. Native of the Cape of Good Hope. Flowers unknown. 
Granular-stemmed Fig-marigold. Clt. 1890. Shrub $1 \frac{1}{2}$ foot. 287 M. Micra'ntium (Haw. sym. 257. rev. 174.) stem suffruticose, slender, much branched; leaves linear, keeled, dotless, distinct; peduncles 1-flowered; calyx 4 -cleft, having 2 of the lobes very long, and 2 very short. $h_{c}$. D. G. Native of the Cape of Good Illope. M. parviflàrum, Jacq. hort. schœnbr. 3. t. 278. but not of Haw. Corolla small, snow white, shorter than the calyx. Stigmas 4, spreading.

Small-fowered Fig-marigold. Fl. June, July. Clt. 1804. Shrub $1 \frac{1}{2}$ foot.

288 M. TE'NUE (Haw, rev. p. 175.) stem suffruticose; branclies effuse, very slender, rather secund, articulated; leaves lincar, clannelled, erect, very slender. $h$. D. G. Native of the Cape of Good Hope. Leaves hardly half an inch long. Flowers unknown. Perhaps different from 1 . micrinthum.

Weak Fig-marigold. Clt. 1819. Shrub 1 foot.

289 Ml. RAPA'CEU (Jacq. fragm. 49. t. 52. f. 1.) root ttlberous; stem herbaccous; branclies terete, and somewhat articulated; leaves distinct, terete, obtuse, dotted, spreading much; peduncles 1 -flowered; lobes of calyx filiform; stigmas 5, spreading. 4. D. G. Native of the Cape of Good Hope. Flowers snow white, 9-10 lines in diameter. Lobes of calyx nearly equal, or very unequal.

\section{Turnip-like-rooted Fig-marigold. Pl. 1 foot.}

§53. Nodiflora (from nodus, a knot, and flos, a flower ; flowers rising from the knots of the stem, or axils of the leaves). D. $C$. prod. 3. p. 446.-Cylindràcca, Ilaw. rev. 163. Salm-Dyck, obs. 15. Roots annual. Stems herbaceous, branched. Leaves nearly teretc or linear, thick, opposite, rarcly alternate, papulose. Flowers axillary, ncarly sessile. Calyx 4-5-lobed, excecding the petuls, nhich are small and white. Stigmas 4-5.

290 M. Nodiflònum (Lin. spec. 687.) stem erectish; leaves opposite and alternate, nearly terete, obtuse, ciliated at the base; flowers axillary, nearly sessile; lobes of calyx very unequal, exceeding the petals, which are small. $\odot$. D. G. Native of Egypt, Barbary, Corsica, and Naples, in sandy places by the sea side. D. C. pl. grass. t. 88. Smith, fl. græe. t. 480.-Moris. hist. sect. 5. t. 37. f. 7.-Haw. rev. I66.-Column. ecplur. 2.t. 73. This species is often confused with the two following. Perhaps the calyx is 4 -cleft, as mentioned by Hawortl, but in some plants which have been examined it has been found to be 5 -cleft.

Knot-flonered Fig-marigold. Fl. Aug. Oct. Clt. 1739. Pl. 1 foot.

291 M. Córticum (Lin. spec. 688.) stem nearly crect; leaves distinet, semi-terete, papulose ; flowers sessile in the forks of the loranches; calyx 5-cleft, exceeding the petals, which are small. ๑. D. G. Native of Egypt. WVilld. spec. 2. p. 1097. Coptic Fig-marigold. Pl. 1 foot.

292 M. аре'тахuм (Lin. fil. suppl. p. 258.) stem diffuse, rather prostrate ; leaves papulose, listinct, stem-clasping, linear, Alat above, longer than the internolles; flowers pedunculate; calyx 5 -cleft, much exceeding the petals, which are very small. $\odot .1)$ G. Native of the Cape of Good Hope. M. apétalum, Ait. hort. kew. 2. p. 180. Haw. rev. 165. M. Cópticum, Jacq. lort. vind. 3. t. 6. Petals 14-18, white. Stigmas 5, short. Perhaps sufficiently distinet from $M$. Cópticum.

Apetalous Fig-marigold. Fl. July, Aug. Clt. 1774. Sh. pr.

293 M. cadu'cum (Ait. hort. kew. 2. p. I79.) leaves semitcrete, filiform, distinct, beset with ovate papulae; flowers latera], sessile, terminal, girded by a pair of leaves. $\odot$. D. G. Native of the Cape of Good Hope. The rest unknown.

Caducous Fig-marigold. Fl. July, Aug. Clt. 1774 . Pl. $1 \mathrm{ft}$.

Subdivision Vill. Planifolia (from planus, level or flat, and folium, a leaf; leaves flat). Haw. misc. p. 43. but not of rev.-Papulòsa, with flat leaves, Haw. rev. 79.-A'nnua planifòlia, Salm-Dyck, obs. 15. Herbs or subshrubs. Leaves flat, beset with pajulæ.

§54. Scapòsa (from scapus, a scape or stalk; in reference to the peduncles). D. C. prod. 3. p. 447.-Limpida, Han. rev. 162. Annual ncarly stcmless herbs. Leaves opposite, almost all radical, linear or cunciform, quite entirc, papulose. Peduncles 1-flowered, rising from the root like scapes. Floners expanding in sunshine. Lobes of calyx 5, unequal. Petals disposed in one or two series. Sterile filament none. Stigmas 5. The four last species of this section are hardly known.

294 M. cuneIfòlium (Jacq. coll. 2. p) 319. icon. rar. 3. t. 488.) stem short, branclied from the base, herbaceous; leaves opposite, cuneiform, flat, obtuse, rather scabrous from papulæ ; flowers pedunculate; lobes of calyx 5, unequal, larger ones oblong, and contracted in the middle. $\odot . D . G$. Native of the Cape of Good Hope. D. C. pl, grass. t. 134. M. limpidum, Ait. hort. kew. 2. p. 183. Haw. misc. 36. syn. 245 rev. 162. Petals purple, paler on the outside. Stamens very short. Stigmas 5 , erect.

Hclgc-leaved Fig-marigold. Fl. July. Clt. 1774. Pl. $\frac{1}{2} \mathrm{ft}$. 295 M. pyro'peus (Haw. suppl. p. 99.) plant almost stemless; leaves linear, broadest at the apex, obtuse, rather scabrous from papulæ; flowers pedunculate; lobes of calyx 5, oblong, one of them very long. $\odot$. D. G. Native of the Cape of Good Hope. M. trícolor, Willd. hort. berol, t. 22. Sims, bot. mag. t. 2144. but not of Haw. M. pyròpeum $a$, Haw. suppl. 99. M. trícolor a, Haw. rev. 163. but not of his syn. P'etals shining, greenish-purple, white at the base. Anthers black.

Var. $\hat{\beta}$, ròseum (D. C. prod. 3. p. 447.) flowers rose-coloured. M. pyròpeum var. $\beta$, Haw. suppl. 99 . M. ròseum, Haw.

l'ar. $\gamma$, álbum (Haw. rev. 163.) flowers white. M. lineàre, Thunb. fl. cap. 411 .

Wheat-leaved Fig-marigold. Pl. $\frac{1}{2}$ foot.

296 M. GRAMI'NEUM (Haw. misc. 55. exclusive of the syn. of Thumb.) plant almost stemless; leaves linear; scapes filiform; lobes of calyx 5 , lanceolate, longer tlan the corolla. $\odot . D . G$. Native of the Cape of Good Hope-CPetiv. gaz. t. 88. f. 7. Corolla yellow. This species is not sufficiently known. Perhaps it comes nearest to $M$. tricolor.

Grassy-leaved Fig-marigold. Pl. $\frac{1}{4}$ foot.

297 i. crinjrórem (Hout. pfl. syst. 2. p. 53.) plant almost stemless; leaves radical, connate, obovate, papulose; peduncles rising from the root like scapes; calycine lobes 5, oval, 3 of them longer than the rest. $\odot . D . G$. Native of the Cape of Good Hope. Thunb. fl. cap. 411. Ml. spatulàtum, Thunb. in Willd. spec. 2. p. 1025. Flowers white.

llair-floncred Fig-marigold. Pl. $\frac{1}{4}$ foot.

298 M. sabuzòsum (Thunb. f. cap. 422.) plant almost stemless; leaves radical, stem-clasping, oblong, flat, acutish, furrowed above; calycine lobes 5 , oblong. $\odot$. D. G. Native of the Cape of Good IHope. Flowers yellow.

Gravelly Fig-marigold. Pl. $\frac{1}{15}$ foot.

299 M. clavifónue (D. C. prod. 3. p. 448.) plant almost stemless; leaves clavate, obtuse ; flowers terminal. $\odot . D . G$. Native of the Cape of Good Hope--Petiv. gaz. t. 85. f. 7. M. claratum, Haw, obs. 471. misc. 56. rev. $16 \%$ but not of Jacq. Flowers golden yellow. Species hardly known.

Club-formed-leaved Fig-marigold. Pl. $\frac{1}{4}$ foot.

$\S 55$. Platyphýlla (from $\pi \lambda a \tau v s$, platys, broad, and $\phi v \lambda \lambda o v$, phyllon, a leaf; leaves broad). Haw.rer.p. 156. Roots anmual or bicnial. Stems herbaecous. Lcaves fat, variable in form, and are papulose, as well as the branches. Floners of various colours. Calyx 5-cleft. Stigmas 5. 
300 M. crystálanum (Lin. spee. 688.) plant diflisely procumbent, herbaceous, covered with large glittering papulae on every part, which makes the plant appear as if covered with icc; leaves ovate, alternate, stem-clasping, undulated ; flowers axillary, almost sessile. $\odot$. H. Native of the Cape of Gool Hope, Canary Islands; and of Grecec, about Athens, in the sand by the sea side. Smith, fl. grac. t. 481.-Dill. elth. f. 29. Bradl. succ. t. 48. D. C. pl. grass. t. 128. Haw. misc. 43. Flowers white. 'There are two varietics of this plant; one a biennial, which is said to be the true $\boldsymbol{M}$. crystalliuum; and the other an anmual, which is the common icc-plant of the gardens, which is called by Haw. $M$. glaciale. 'T'he whole plant is covered with glittering white papula, that shine in the sun, whence it is called ice-plant; others name it the diamonl-plant.

Crystalline Fig-marigold or Ice-plant. Fl. May, Aug. Clt. 1775. Pl. procumbent.

301 M. críspum (Ilaw. misc. 44. rev. 157.) leaves alternate, ovate, petiolate, undulated; petals minute. $\odot . H$. Native of the Cape of Good Hope--Petiv. gaz. t. 88. f. 5. M. crispàtum, Haw, obs. 470. Flowers reddish. This species is bardly known.

Curlcd-leaved Fig-marigold. Pl. pr.

302 M. pixsatífidea (Lii. fil. suppl. 260.) stems diffuse; leaves opposite, oblong, bluntly pinuatifid, papulose; petals shorter than the calyx, $\odot$. H. Native of the Cape of Good Hoje, and also said to be a native of Chili. Curt. bot. mag. t. 67. D. C. pl. grass, t. 142. Haw obs. 112. misc. 44. syn. 244. rev. $15 \%$. Stems reddish, papulose. Petals small, yellow in one series. Stigmas 5, ascending. Flowers small in the forks of the branches, pedunculate.

Pinnatifid-leaved Fig-marigold. Fl. May, Oct. Clt. 1774. Pl. pr.

303 M. sessiliflòrum (Ait. hort. kew. 2. p. 193.) branches divaricate; leaves flat, spatulate, and are, as well as the stems, beset with papula; flowers sessile. $\odot$. H. Native of the Cape of Good Hope. Flowers yellow. Haw. syr. 13. 247.

Var. 13, album (Haw. rev. 158.) Howers white; leaves uvate, petiolate: upper ones alternate; flowers panicled, small. $t$. D. G. Perhaps a proper species, but is not sufficiently known. Sessile-flonered Fig-mariugold. Fl. July. Clt. 1774. Pl. pr.

30.4 М. LAxceora'TuM (Haw. misc. 45. rev. 159.) stems decumbent ; leares alternate, lanceolate, bluntish, papulose ; calyx and peduncles beset with crystalline dots. $\odot$. D. G. Native of the Cape of Good Hope. M. Volckamèri, Haw. obs. p. 426. - Volck. norib. p. 266. with a figure? M. filifórme, Thunb. A. cap. 417.? Flowers white.

I ar. $\beta$, ròseum (Haw. rev, 159.) flowers reddish ; leaves lanceolate-spatulate.

Lancolate-leaved Fig-marigold. Fl. May, Aug. Clt. 1795. Pl. dec.

305 M. LA' xсеим (Thunb. fl. cap. 417.) stem erect, rather tetragonal; leaves lanceolate, flat, connate, acute, papulose; Howers terminal. $\odot . H$. Native of the Cape of Good Hope. Haw. rev. 170. Flowers white.

Lance-leaved Fig-marigold. Pl. $\frac{1}{2}$ foot.

306 M. PAPULIFERU (D. C. prod. 3. p. 4.18.) stem very short; branches almost radical, somewhat fastigiate, gradually thickened, and are as well as the leaves and calyxes beset with papula; leaves connate, ovate; flowers terminal, sessile, 1-3

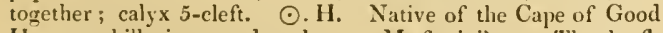
Hope, on hills in very dry places. M. fastigiàtum, Thunb. f. cap. 413. but not of Haw. Flowers white. Lobcs of calyx purple. This species differs from $\boldsymbol{M}$. réctum of Haw. in bcing annual, not slirubby.

Papule-bearing Fig-marigold. Pl. $\frac{1}{4}$ to $\frac{1}{2}$ foot.

307 M. PAPLLOSA (Lin. fil. suppl. 259. exclusive of the synonymes) branches decumbent, terete; leaves opposite, spatulately oblong, papulose; flowers pedunculate, rising from the forks of the stem; lobes of calyx linear. $\odot$. I1. Native of the Cape of Good Hope. Haw. misc. 48. rev. 158. Corolla yellow, hardly longer than the calyx.

Papulose ligr-marigold. 1'. dec.

308 M. cLandestinum (Haw. in plit. mag. ang. 1826. p. 129.) branches procumbent, papulose; leaves acutely ovate, petiolate; flowers usually terminal, solitary or by threes, on a terete, clavate peduncle; petals very small. Ђ.D. G. Natire of the Cape of Good Hope,

Hidden-flowered Fig-marigold. Fl. May, $\mathbf{u n g}$. Clt. 18:2. Pl. pr.

309 M. pubérulum (Haw. in plil. mag. sept. 1831. p. 419.) stems branched, procumbent, papulose ; floriferous branches and margins of leaves pubescent; leaves opposite or alternate, obovate-spatulate, channelled, kecled; peduncles subcylindrical. ๑. D. G. Native of the Cape of Good Hope. Very like M. papulòsum. Flowcrs white.

Puberulous Fig-marigold. Fl. Ju. Aug. Clt. 1829. Pl. pr.

310 M. Angula'tum ('Thunb. fl. cap. 426.) stem herbaccous, deeumbent, angular, branched ; leaves opposite, ohovate, sessile,

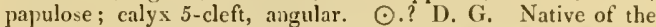
Cape of Good Hope. Flowers yellow, as in $1 I$. papulosum, but the stems are angular, not terete. The stems are angular, however, in $M$. Aitonis, but the flowers are pale red, not yellow.

Angular-stemined Fig-marigold. Pl. pr.

311 M. Aıтònıs (Jacq. hort. vind. t. 7.) branches decumbent, angular ; leaves opposite or alternate, ovate-spatulate, papulose ; pedicels short; calyxes angular. 8. D. G. Native of the Cape of Good Hope. Haw. misc. 48, rev. 158. Flowers expanding in the evening, pale reddish, about the size of those of $M$. cordif òlium. Lobes of calyx very unequal. Stigmas 5 , erect, recurved at the apex.

Aiton's Fig-marigold. Fl. June, Oct, Clt. 1774. Pl. pr.

$\$ 56$. Cordifolia (from cor, the heart, and folium, leaf; sliape of leaves). D. C. prod. 3. p. 449. Stcme suffruticose. Leaves opposite, distinct, peliolate, flat, ovate, cordate, rather. papulose. Flon'crs purple. Calyx 5-lobed; having 2 of the lobes larger than the rest. Stigmas 4.

312 M. cordifòrıum (Lin. fil. suppl. 260.) stems suffruticose, diffuse; leaves opposite, flat, petiolate, ovate-cordate, rather papulose ; calyx 4-cleft, 2-horned. $\odot$. or $\zeta$. D. G. Native of the Cape of Good Hope. Glox, obs, t. 1. f. a. Smith, pict. t. 6. Jacq. icon. rar, t. 487 . D. C. pl. grass, t. 102. Haw. misc. 50. syn. 218. rev. 159. Branches procumbent, ratlier herbaceous. Flowers solitary, terminal, or rither lateral on the elongated branches. Corolla red. Stigmas $f$, erect.

Ifart-leaved Fig-marigold. Fl. May, Sept. Clt. 1774. Pl. diffuse.

\$57. Expánsa (from expansus, expanded; stems). D. C. prod. 3. p. 449.-Planif òlia $+\dagger$, IIan. rcv. 167. Stems suffruticose, diffuse, or procumbent, terete. Leaics flat, opposite, almost without papula, stem-clasping, a little kecled. Flowers white or pale yellow, rarely pale red. Tube of calyx somenhat pearshaped; lobes 4-5, unequal. Stigmas 4-5.

313 M. Expa'xsum (Lin. spec. 697.) stems divaricate, loosely expanded; leaves distinct, remote, opposite or alternate, flattisl, ovate-lanceolate, dotless. h. D. G. Native of the Cape of Good Flope.-Dill. elth. f. 223. M. tortuòsum, D. C. pl. grass. t. 94. exchusive of the synonymes. M. expansum, Haw obs. 195. misc. 50. rev. 168. Lobes of calyx 5, unequal. Cornlla large, pale yellow. Stignas $4-6$, short, ercet. 
Expanded Fig-marigold. Fl. July, Aug. Clt. 1705. Pl. 1 foot.

314. M. VA'rians (IIaw. misc. p. 51. syn. 249. rev. 168.) branclies prostrate; lcaves opposite, lanceolate, acuminated, keeled, hence they are bluntly triquetrous and channelled; peduncles very thick. ケ. D. G. Native of the Cape of Good Hope.-Petiv. gaz. t. 78. t. 10. The whole plant is beset with papule. Calyx 4-5-cleft. Corolla white on the outside and yellow on the inside; but according to Haworth it is whitish, and according to Petiver yellowish. Stigmas 5, short.

I'arying Fig-marigold. Fl. July, Oct. Clt. 1706. Sh. pr.

315 M. tortuosum (Lin. spec. 697.) stems divaricate, procumbent, twisted: leaves flattish, ohlong-ovate, rather papulose, crowded, connate; lobes of ealyx 5 , very unequal, 2 of which are hardly evident. $\zeta_{\text {. }}$ D. G. Native of the Cape of Good Hope.-Dill, elth. f. 222. M. tortıòsum, Haw, obs. 196. misc. 51. syn. 250. rev. 168. M. àridum, Mcench. Flowers pale yellow.

Thisted-stcmmed Fig-marigold. Fl. June, Oct. Clt. 1705. Slirub procumbent.

816 M. conca'vum (Haw. rev. 168.) stem procumbent; leaves concave, ovate-lanceolate, alternate, thick ; flowers terminal, solitary. 々. D. G. Native of the Cape of Good Hope.-Burm. afr. dec. 3. t. 26. f, 1. Flowers yellowish. This is a very doubtful species.

Concare-leaved Fig-marigold. Slirub pr.

317 M. PA'LLENs (Ait. hort. kew. 2. p. 182.) stems diffuse leares stem-clasping, distinct, glaucous, oblone-lanceolate; inflexcdly coneave, bluntly kceled, beset with minute papulae; lobes of calyx 5, ovate-oblong. $5 . D . G$. Native of the Cape of Good Hope. Haw. obs. 197. misc. 52. syn. 250. rev. 168. M. expánsıun, D. C. pl. grass. t. 47. M. articulàtum, Thunb. 11. cap. 415.? Corolla whitc, rather longer than the calyx (ex D. C.), but aceording to Haworth shorter than the ealyx.

Pale Fig-marigold. Fl. July, Aug. Clt. 177t. Sh. diffuse. 318 M. Lora'tun (llaw. rov. 168.) stems diffuse; leaves lorate, canaliculately-inflexed, obtuse, very glaucous, convex

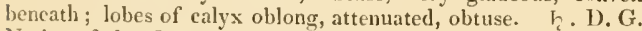
Native of the Cape of Good Hope. Flowers white. Perhaps only a variety of $1 \%$. paillens.

Lorrte-leaved Fig-marigold. Fl. Jul. Aug. Clt. 1819. Sh. $\frac{1}{2} \mathrm{ft}$. 319 M. crassicau'Le (Ilaw, in pliil. mag. 1824. p. 425.) caudex very short and thick; branches cxpanded; lcaves crowded, flat, lorate, acuminated, green, glabrous, a little incurved; peduncles furnished with 4-5 bracteas; lobes of ealyx 5 , one of which is smaller than the rest. $h$.D. G. Native of the Cape of Good Ilope. Flowers pale yellow, cxpanding before meridian. Stigmas very short.

Thiek-stemmed Fig-marigold. Fl. May, July. Clt. 1815. I'. $\frac{1}{4}$ foot.

320 M. Relaxa'tum (Willd. enum. supp]. p. 36.) stems decumbent, tcrete, flexuous; leaves linear-lanceolite, obtuse, of a livid glaucous colour, chanuclled, dotted from pajula, costately liceled; lobes of calyx 5 , foliaceous, one of which is very small. F. I). G. Native of the Cape of Good Hope. Spreng. nov. prov. 28. Haw. rev. 169 . Flowers purple (ex Willd.), rosecoloured (ex Spreng.), reddish or nearly scarlet (ex Haw.).

Relaxed Fig-marigold. Fl. July, Aug. Clt. 1815. Sl. dee.

321 M. Акатовичим (Ilaw. misc. 50. syn. 249. rev. 169.) stems filiform, proeumbent ; leares opposite, lanceolate-elliptic, full of erystalline papulæ, when dead the nerve alone remains permanent. h. D. G. Native of the Cape of Good llope.

Far. $\beta$, frígile (Haw. rev. 169.) leaves large, coneave, greener than the species.

lar. $\gamma$, emárcidum (D. C. prod. 3. p. 450.) stems crectislı. M. emárcidum, Thunb. fl. cap. 415 . Perhaps a proper species.
Skelcton-leaved Fig-marigóld. Fl. July, Aug. Clt. 1803. Slirub pr.

322 M. ova'тum (Thunb. fl.cap. 417.) stem decumbent, rather angular, papulose; leaves ovate, flat, ohtuse, spreading ; flowers

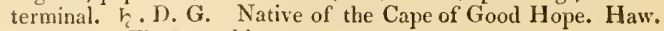
rev. 170, Flowers white.

Oratc-leaved Fig-marigold. Shrub dec.

323 M. нumfu'sum (Ait: hort. kew. 2. p. 179.) stems suffruticose, trailing; leaves stem-clasping, spatulate, keeled, scabrous from conical papulæ; petals very minute. of the Cape of Good Hope. Corolla whitc. The rest unknown.

Trailing Fig-marigold. Fl. Jul. Aug. Clt.1774. Sh. tr.

\$58. Tripolia (tripolium is the name of the Sea Starwort, or Aster tripòlium; leaves resembling it). D. C. prod. 3. p. 450. Roots biennial. Stems herbaceous, loose. Radical leaves cronded: rameal ones alternate, flat, nearly destitute of papula. Floners pedunculatc, nhite. Calyx acutcly pentagonal, 5 -cleft. Stigmas 5 .

324. M. TRIPòlium (Lin. spee. 690.) stems herbaceous, loose, simple; radical leaves flat, crowded, rameal ones altcrnate, lanceolate, dotless, almost destitute of papulæ; flowers pedunculate; calyx pentagonal, 5-cleft. 8.D.G. Native of the Cape of Good Hope.-Dill. elth. f. 220.-Pluk. mant. 329. f. 4. Haw obs. 122. misc. 49. syn. 247. rev. 167. Flowers middlesized, white. There is no ally to this species, necording to Haworth.

Aster-leaved Fig-marigold. Fl. Ju. Oet. Clt. 1700. Sh. $\frac{1}{2} \mathrm{ft}$.

$\S 59$. Helianthoidea (from Heliánthus, sunflower, and idea, form; flowers). D. C. prod. 3. p. 450.-Pemcridiàna and Hymenógyne, Han. rev. 160. and 192. Roots annual. Stems herhaceous, tercte, branched. Leaves lanceolate or spatulate, almost destitute of papula, flat, attenuated at the base, opposite, distinct. Peluncles axillary, very long. Flowers ycllon', large, cxpanding after meridian, or in the day time. Calyx rather angular at the base; lobes 5, clongated. Ovarium depressed. Stigmas 10-20, sometimes connate.

325 M. pomeridia'num (Lin, spec. 698.) leaves broad-lanceolate, flat, smooth, eiliated, nearly distinct; stems, peduncles, and calyxes hairy; petals shorter than the calyx; stigmas 12 . ○. D. G. Native of the Cape of Good Hope. Lin. fil. dec. 1. t. 13. Jacq. icon. rar, t. 489 . Curt, bot. mag. 54.0. Haw. rev. 160. Flowers yellow.

l'ar. $\beta$, glàbrum (Haw. rev. p. 160.) plant more glabrous and naked; upper leaves a little ciliated; petals longer than the calyx. $\odot$. D. G. Andr. bot. rep. t. 57. Haw. misc. 44. but not of Ait. Perhaps a proper species.

Pomeridian Fig-marigold. Fl. Jul. Aug. Clt. 1774. Pl. 1 ft.

326 M. IELAanthoides (Ait. hort. kew. 2. p. 198.) leaves flat, s]atulate, smooth; peduncles very long; calyxes flat and angular at the base; stigmas usually 10 , connate at the base. $\odot$. D. G. Native of the Cape of Good Hope. Haw. rev. 161. Flowers ycllow.

Sun-floner-like Fig-marigold. Fl. Aug. Oet. Clt. 1774. Pl. $\frac{3}{4}$ foot.

327 M. calendeda'ceum (Haw, rev, l61. but not of his mise.) leaves linear-lanceolate, hardly spatulate, ciliated; peduncles scabrous; petals about equal in length to the lorately-linear, thick, ciliated, ealycine lobes; ovarium sparingly pubescent. $\odot$. D. G. Native of the Cape of Good Hope. Stem much branched. Hairs on the ovarium or tube of the calyx white and short. Flowers ycllow. The rest unknown.

Pot-marigold-like Fig-marigold. Fl. Aug. Clt. 1819. Pl. $\frac{3}{4} \mathrm{ft}$. 328 M. vLAccidum (Jacq. hort. vind. t. 475.) leaves lanceolate, acute, flat, glabrous, quite entire; peduncles 1-flowered, erectisl, glabrous, very long. §.D. G. Native of the Cape 
of Good Hope. Petals linear, acute at both cnds, yellowish. Styles 5. Root biennial (ex Salm-1)yck. in litt.).

Flaccid Fig-marigolel. Clt.? Pl. $\frac{1}{2}$ foot.

329 M. Candólln (Haw. rev. p. 160.) leaves lanceolate, flat, acute, ciliated a little, distinet ; peduncles very long, hairy ; lobes of calyx acuminated, exceeding the petals; stigmas 16-20. ๑. D. G. Native of the Cape of Good Hope. M. helianthoides, D. C. pl. grass. t. 135 . Salm-Dyck. obs. p. 15. but not of Ait. ex Haw. Calyx angular at the base. Flowers yellow.

De Candolle's Fig-marigold. Fl. Aug. Oct. Clt. 1774. Pl. $\frac{3}{5}$ foot.

330 M. pilòsum (Haw, rev. p. 161.) leaves linear-lanceolate, ciliated; stems effuse ; peduncles, bracteas, and calyxes clothed with wool-like villi; petals longer than the calyx ; stigmas 15 -

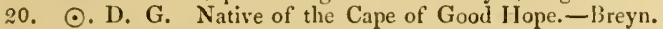
cent. t. 79,-Mor. hist. sect. 12. t. 6. f. 13. M. pilòsum and M. calendulàceum, Haw. misc. 47. Perlaaps sufficiently distinct from M. Candóllii. Flowers yellow.

Pilose Fig-marigold. Fl. June, Aug. Clt. 1800. Pl. $\frac{3}{4} \mathrm{ft}$.

331 II. GLA'brum (Ait. hort. kew. 2. p. 198.) leaves petiolate, spatulately-lanceolate, dilated at the base, and are as well as the branches glabrous; base of calyx hemispherical, with linear, unequal lobes; stigmas usually 12, mnited into a tube at the base. ○. D. G. Native of the Cape of Good Hope. Hymenógyne glàbra, Haw. rev. 192. Corolla straw-eoloured; petals rufescent at the base; sterile filaments copper-coloured. Habit almost of $M$. Candóllii. Sceds winged.

Glabrous Fig-marigold. Fl. Jul. Oct. Clt. 1 i87. Pl. $\frac{3}{6} \mathrm{ft}$.

\section{$\dagger$ Species not sufficiently knonn.}

332 M. HU'MLE (Haw, misc. 80, rev. 122.) stems prostrate; leaves triquetrous, subulate; calyx 4-cleft. tive of the Cape of Good Hope. Leaves opposite, or probably ternate.

Var. a, rùbrum (Haw. 1. c.) flowers red.-Petiv. gaz. t. 89. f. 8. Haw. obs. 471.

Var. 3 . lùteum (Haw. l. e.) flowers yellow.-Pet. gaz. t. 8s. f. 8.

Humble Fig-marigold. Pl. prostrate.

333 M. A RBomifórme (Burch. voy. 1. p. 343. eat. geogr. 2004.). h. D. G. Native of the Cape of Good Hope. Allied to $M$. parvifolium. Shrub 1-2 feet high, branched, with the trunk for the most part simple. Cymes 3-times dichotomous. Flowers minute, of a testaceous colour.

Tree-formed Fig-marigold. Shrub 1 to 2 feet.

334 M. campe'stre (Burch. cat. geogr. 1340. ex voy. 1. p. 259.). 々. D. G. A plant a foot and a half high, straight. Flowers rose-coloured. Allied to $M$. pulchéllum.

Field Fig-marigold. Shrub $1 \frac{1}{2}$ foot.

335 MI.? LaURifòlium (Haw. obs. 470. misc. 49. rev. 157.) root fusiform; stem very flexuous; leaves opposite, cuneately oborate. 4. D. G. Native of the Cape of Good Hope. -Petiv. gaz. 83. f.4. Anthers and petals purple. Perhaps a species of Othòna.

Laturel-leated Fig-marigold. PI. 1 foot?

336 M.? cilis'tum (A it. hort. kew. 2. p. 179.) leaves opposite, connate, semi-terete; stipulas membranous, reflexest, jagged, in the form of ciliz. 5. D. G. Native of the Cape of Good Hope. Corolla white. The rest unknown. Stipulas in all other species of Mesembryanthemum are wanting; it is then probably a species of Arenaria.

Ciliated-stipuled Fig-marigold. Clt. 1774. Pl. $\frac{1}{2}$ foot.

397 M. corin'ricm (Burch. cat. geogr. 2487. ex trav. 1. p. 243.). $h$. D. S. Natise of the Cape of Good Hope, where it is used in tanning leather. Said to be allied to $M$. uncinatum. Hide Fig-marigold. Shrub
338 MI.? viliòsum (Lin. spec. 695.) stem slırubby, thickened at the base; branches prostrate; leaves connate, linear, semiterete, channelicd, puhescent; peduncles trichotomous; llowers apetalous. h. D. G. Native of the Cape of Good IIope. Haw. obs. 222. and 441. misc. 58. syn. 254. rev. 125 . Calyx 5-cleft, purplish inside. Capsule Ileshy, 5-6-celled. Perlaps a species of Aizòn, Tctragonia, or Sesuvinm, but the description is not sufficient to decide this point.

Villous Fig-marigold. Shrub prostrate.

339 M. granifórme (Haw. misc. 82. syn. 263. rev. 149.) stems expanded, short, suffruticose; leaves distinct, rather trjquetrous, ovate grain-formed; stamens collected. $h_{2}$. 1). G. Native of the Cape of Good Hope. Bradl. succ. t. 20. Stems 3 inches ligh. Leaves 3 lines long. Flowers yellow, expanding in the evening. This species is entirely unknown at the present day, having been only known to Bradley. According to $\mathrm{Ha}_{\mathrm{a}}$ worth's opinion, it comes in section Cymbiförmin.

Grain-formed-leaved Fig-marigold. F1. Sept. Oct. Clt. 1727 Slirub 1 foot.

Cult. This is a vast genus of what are called succulent plants, that is, fleshy-leaved plants. The shrubby kinds should be grown in pots, in a very sanily or gravelly soil ; they should be kept almost quite dry, while in a dormant state, but when growing freely and in the flowering season, they require a considerable supply of water. The poorer the soil is, the more dwart" the plants will grow, and bear flowers more alundlantly. The shelves in a greenhouse are a good place to preserve them through the winter, however, a good dry frame will answer the purpose equally well, if not better, with a covering of mats in frosty weather. Cuttings of all of them strike root readily, if planted in pots of the sanie kind of earth recommended for the plants, and kept dry till they begin to wither, when they may have a little water given to them; and under this treatment they will root very soon. There are also several snnual and biennial kinds, most of them handsome and curious. The seeds of these should be sown in pots early in spring, and raised in a frame, hot-bed, or greenhouse; and when the plants are of sufficient size, plant them singly in small pots, and set them in the greenhouse, until the warm weather commences, when they may be set out of doors along with the shrubby kinds, where they will flower and seed freely, if the summer proves fine. The same soil and treatment recommended for the shrubby kinds will also suit these well. The ice-plant, $M$. crystállinum, and also $M$. pinnatiffilum do well if planted out on rockwork or among stones, where they will make a very curious appearance.

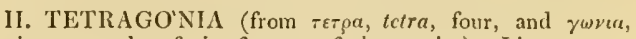
gonia, an angle; fruit of some of the species). Lin. gen. no. 627. Gærtn. fruct. 2. t. 127. and 179. Lam. ill. 437. D. C. prod. 3. p. 451 . - Tetragonocárpus, Commel.

LiN. syst. Icosíndria, Tri-Octogýnia. Calyx 4-cleft, rarely 3-cleft, with the tube adhering to the ovarium, and 4-5-horned; lobes coloured on the inside. Petals wanting. Stamens variable in number. Ovarium 3-3-celled. Styles 3-8, rery short. Nut bony, winged, or horned, indehiscent, 3-8-celled inside. Seeds solitary in the cells.-Herbs or sub-shrubs. Leaves alternate, flat, fleshy, undivided, usually quite entire. Flowers axillary, pediccllate, or sessile.

Sect. I. Tetragonoides (altered from Tctragònia). D. C. prod. 3. p. 452. Stamens in fascicles, or solitary in the recesses of the calyx. Nuts usually horned. - Annual or biennial herbs. Flowers sessile or on short pedicels. Horns of calyx sometimes bearing acce-sory flowers.

1 'T. ExpA'NsA (Ait. hort. kew. 2. p. 178.) herhaceous leares petiolate, ovate-rhomboid; flowers sessile; fruit 4-hornerl, 6-8seeded. ๑. II. Native of New Zealand and Japan, also of 
Chili, about Conception, and Valparaiso. Murr. comm, goett. 1783. t. 5. Scop. inst. t. 1.t. D. C. pl. grass, t. 114. 'T. cornùta, Gartn. fruct. 2. p. 179.f. 3. T. Japónica, Tlıunb. jap. 208. T'. lialinif òlia, Forst. prod. p. 223. Roth, abh. t. 8. Demidòvia tetragonoides, Pall. loort. dem. t. 1. Stamens 4-5 in cach fascicle, 1 fascicle in every recess of the calyx. From all the species this differs in the cells of the pericarp being donble the number of calycine lobes, not equal to them in number, as in the rest of the species. The Now Zealand spinach is a spreading, rather prostrate plant, with yellow flowers, and leaves an inch and a half long. The whole plant is studded with very minute crystalline dots. It is a native of New Zealand, by the sides of woods, in buslyy sandy places, and though not used by the inhabitants, ret, being considered by the naturalist who accompanied Cook, as of the same nature as the Chenopollium, it was served to the sailors boiled every day at breakfast and dinner. It was introduced to this country by Sir Joseph Banks in 1772, and treated as a greenhouse plant; but it has been found to grow in the open garden as freely as the kidney-bean or nasturtium, and has been used as a spinach plant. In the Earl of Essex's family, at Cashiobury, no other spinach was used during the whole summer of 1821 , and it is now commonly cultivated for that purpose. It grows so fast that a few plants will suffice for a large family. There are three varieties of this species found in Chili : 1. with leaves smooth on hoth surfaces: 2. with leaves hoary beneath: and 3. a small grabrous variety.

Expanded 'Tetragonia or New Zealand Spinach. Fl. Aug. Scpt. Clt. 177\%. Pl. pr.

2 'T. (RYSTÁlisisa (Lher. stirp. nov. 1. p. 81. t. 39.) plant herbaceous, pruinose; leaves ovate, sessile ; flowers almost cessile; fruit tetragonal, incurved, 1 -seeded. $\odot$. or $\hbar_{c} . \mathrm{F}$. Native of Pern and Chili, about Talparaiso and Coquimbo. D. C. pl. grass. t. 34. Calyx 3-4-loberl. Stamens 3-4 in each fascicle, 1 fascicle in each recess of the calyx.

Crystalline Tetragonia. F1. June. Clt. 1788. Pl. $\frac{1}{2}$ foot.

3 'T. echins'ta (Ait. hort. kew. 2. p. 177.) plant herbaceous; leares petiolate, orate-rhomboid; flowers on short pedicels; fruit echinated, 3-4-sceded. $\odot$. or $8 . F$. Native of the Cape of Good Hope. D. C. pl. grass, t. 113. Calyx 3-4-lobed. Stamens 3-4, 1 in each recess of the calyx. Calyx beset with crystalline papulae.

Echimuted-fruited Tetra:onia. Fl. May, Aug. Clt. 1774. 1'l. $\frac{3}{4}$ foot.

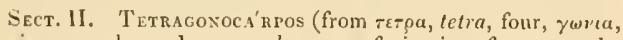
gonia, an anglc, and kapros, larpos, a fruit; in reference to the fruit being usually furnished with 4 wings). Comm. ex D.C. prod. 3. p. 152 . Stamens disposed in 1 series at the base of the calycine lobes. Fruit usually winged.-Herbaccous, perenniat, or suflruticose plants. Flowers on long pedicels.

4 T'. ursu'ta (Lin. fil. suppl. 258.) plant herbaceous, decumbent; leaves ovate, villous, sessile; flowers 3 together, on short pediccls; fruit tetragonal, with a wing on each angle, 4secded. 4. D, G. Native of the Cape of Good Hope. Thunb. fl. cap 108. Stamens numerous, inscrted in the middle of the calyx by bundles, as deseribed by 'llumberg. Perhaps not distinct from T. villosa, Poir. dict, $\tau$. p. $60 \%$.

IIairy Tetragonia. P' decumbent.

5 T. Spica'ta (lin. fil. suppl. 258.) plant lierbaccous, erect; leaves petiolate, glabrous: lower ones ovate: upper ones lanceolate; flowers pedicellate, branched. 2. D. G. Native of the Cape of Good Hope. 'Tluunb. fl. cap. 409. wherc it is called T. raccmòsr. Pedicels numerous, aggregatc.

Spiked-flowered Tetragonia. Fl. Jul. Clt. 1795. Pl. $1 \mathrm{fe}$.

6 'T'. in вва'сеа (Lin. spec, 687.) plant somewhat herbaceons, rather decumbent, smooth ; leaves ovate, petiolate; flowers on long pedicels ; frnit 4-winged, 4-6-seeded; root strumose. $\psi$. D. G. Native of the Cape of Good Hope. Thunb. fl. cap. 109. Haw, misc, 121.-Conm. hort. amst. 2. t. 102. Pedicels 1-3 together, nearly an inch long. Flowers 4-cleft, but the terminal ones are 5 -cleft. Root fleshy.

Ilerbaccons Tetragonia. Fl. Ju. lul. Clt. 1752. Pl. dec.

7 T'. Decúmens (Mill. dict. no. 2.) plant suffruticose, decumbent, pruinose; leaves on sliort petioles, obovate-oblong; flowers 3 together on short pedicels; fruit 4-5-angled, with a wing on eacli angle. $h_{2}$. D. G. Native of the Cape of Good Hope. D. C. pl. grass. t. 23. Mill. fig. t. 263. f. 1. Flowers 4-5-cleft. Styles 4-5. Calyx and anthers of a pale sulphur colour.

Decumbent Tetragonia. Fl. Jul. Sept. Clt. 1758. Sh. dec.

8 T. Fruticosa (Lin. spec. 687.) shrubby, erect; leaves oblong, on very short petioles; flowers 1 or 3 together, on short pedicels; fruit bluntly 3-4-angled, each angle furnished with a wing. $\zeta$. D. G. Native of the Cape of Good Hope-Comm. hort. amst. 2. t. 103.-Sèba, thes. 2. t. 11. f. 8. Haw. misc. p. 120.- Mill. fig. 2. t. 263. f. 2, Calyx green withont and yellow within.

Shrubby T'etragonia. Fl. Jul. Sept. Clt. 1712. Sh. 2 to $4 \mathrm{ft}$.

9 T. TETRA'PTERIS (Haw. misc. p. 121.) plant suffruticose, erect; leaves oblong-lanceolate, nearly sessile; flowers pedicellate, racemose; fruit furnished with 4 large wings, and other 4 alternate small ones. $h$. D. G. Native of the Cape of Good Hope. Tetrápteris, Scc. Pluk. amalth. t. 200. Nut 4 -seeded. Four-ninged-fruited Tetragonia. F!. July, Sept. Clt. 1794. Shrub 1 to 2 feet.

10 T. LINEA'ris (Haw. rev, p. 73.) plant shrubby and diffusely decumbent; leaves linear, rather revolute at the sides, engraven above by a dorsal line; flowers terminal, racemose. h. D. G. Native of the Cape of Good Hope. Leaves greenish. Linear-leaved Tetragonia. Fl. Sept. Clt. 1819. Sh. dec.

11 'T. oвova'ta (Haw, rev. p. 73.) plant suffiruticose, decumbent, pruinose; leaves obovate or oval; petioles winged, stemclasping, somewhat decurrent. $h_{\imath} .10 . G$. Native of the Cape of Good Hope. Flowers unknown. Very like $T$. decúmbens, but one half larger.

Oborate-leaved Tetragonia. Clt. 1821. Shrub dec.

Cult. The same culture, propagation, and treatiment as that recommended for Mescmbryanthemum will suit the species of Tetragonia. The T.expainsa, when wanted for spinach, may be planted out in the open gromnd, about April or May.

1II. SESU'VIUM (a name not explained by the author). Lin. gen. 624. Lam. ill. t. 434. D. C. prod. 3. p. 453.

Lıs. srst. Icosándria, Tri-Pentagýnia. Calyx 5-parted, permanent; lobes colourcd on the inside. Petals wanting. Stamens 15-30, inserted at the top of the calycine tube, which is short. Ovarium distinct, sessile. Style wanting. Stigmas 3-5. Capsule 3 , rarely 4-5-celled, circumcised, having the placentiferous ax is permanent. Seeds numerous. Embryo hooked. -Smooth fleshy herbs, inhabitants of the sea-side; with opposite, quite entire, veinless leaves ; and axillary, solitary, alternate flowers, which are either sessilc or on short pedicels. Calyx purplish inside.

1 S. Pontulaca'strum (Lin. spec. 446. exclusive of the syn. of Rumplaius) leaves linear or lanceolate-oblong, flat; flowers pedicellate. 4. D. G. Native of the West Indies, Mexico, and Senegal, by the sea-side.-Phum. ed. Burm, t. 223. f. 2 . -Jacq. amer. 1. 95. Aizòon Canariénse, Andr. bot. rep. 201. Calyx green outside, and reddish within. Stamens 25-30.

Far. $a$, pedunculàtum; flowers pedicellate. S. pedunculàtum, Pers. ench. 2. p. 39. Lam. ill. t. 434. f. 1.

$I^{*}$ tr. $\beta$, séssile; flowers nearly sessile. S. séssile, Pers. ench. 
2. p. 39. D. C. pl. grass. t. 9. The plant is very succulent and full of neutral alkalescent salt, which may be easily extracted, and would probably answer all the purjoses for which the salts of the kali are now used.

Sea Purslane. Fl. June, July. Clt. 1692. Pl. dec.

2 s. Longifòlıus (Willd. enum. p. 521.) leaves linear-spatulate; joints of stem equal; 1lowers pedicellate. 24. 1). S. Native of South America, by the sca-side. S. Portulacistrum, H. B. et Kunth, nov. gen. amer. 6. p. S6. from Peru am Cumana. Stamens 70.75 (ex Kunth, l. e.). Leaves nearly 2 inches long witl the petioles.

Long-learcd Sesurium. Fl. July, Aug. Clt.1816. Pl. dec. S S. Revolutifóliva (Ort. dec. p. 19.) leaves ovate-oblong, with revolute margins; flowers sessile. 4 . D. G. Native of Cuba, by the sea-side. S. Portulacástrum $\beta$, Sinıs, bot. mag. t. 1701. Stamens very numerous. Stigmas 5-6. Leaves rather glaucous, not deep green, as in $S$. Portulacástrum.

Revolute-leated Sesuvium. Fl. July, Aug. Clt.? Pl. dec.

4 S. RE'ग'ENS (Willd. enum. j. 521.) leaves spatulate-lanceolate; joints of stem rooting, filiform ; flowcrs pedicellate. $\odot$. ? D. S. Native of the East Indies.-Rumpb. amb. 5. p. 165. t. 72 . f. 1.

Creeping Sesuvium. Fl. July, Aug. Clt. 1816. Pl. creep.

5 S. Mcropuy'tuvm (Willd. l. c.) Jeaves roundish or lanceolate; stems trailing, having equal joints; flowers pedicellate. $\mathcal{\not}$. D. S. Native about the Flavannah, by the sea-side. Humb.et Bumpl. S. spatulàtuns, H. B. et Kunth, nov. gen. amer. 6. p. 87. Leaves 5 lines long with the petioles. Stamens 20 . Stigmas 8.

Small-leaved Sesurium. Pl. creejing.

6 S. Parvirlònum (D. C. prod. 3. p. 45.3.) leaves linearoblong, flat; flowers sessile. 4 . D. G. Native about Monte Video by the sea-side; and of Chili, ncar Laguna del Arbolita, on the west side of Rio Saladillo. Sestivium, Lam. ill. t. 434. f. 2. Triánthema Americàna, Gill. mss. ex Arn. in Cheek. edinb. journ. 1831. p. 354. Perhaps S. Portulacástrum $\beta$. Flowers red, one half smaller than those of $S$. Portulacástrum.

Small-flowered Sesuvium. Pl. trailing.

Cult. A mixture of loam, peat, and sand will suit this genus of succulent plants; and they require but little water. Cuttings planted (after being dried a little) in the same kind of soil, root freely, in heat.

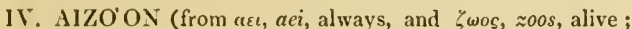
succulent plant, which will live under most circumstances). Lin. gen. no. 629. Gærtn. fruct. 1. t. 76. Lam. ill. t. 437. D. C. prod. 3. p. 453.-Veslingia, Fabr. liclıst. p. 363.-Ficoídea, Dill. Boerh.

Lix. syst. Icosánuria, Pentagýnia. Calyx 5-parted, coloured, and petaloid inside. Petals wanting. Stamens about 20, inserted in the bottom of the calyx, and disposed in 3-5 bundles. Ovariun distinct, 5-angled. Stigmas 5, thick, sessile. Capsule 5 -celled, oprening at the apex by 5 chinks, which are disposed in a stellate manner; cells many-seeded.-Humble herls or subshrubs. Leaves fleshy, quite cntirc, alternate or opposite. Flowers sessile in the axils of the leaves or forks of the stems, rarely pedicellate, greenish on the outsicle.

\section{* Leaves alternate.}

1 A. Canariénse (Lin. spec. 700. but not of Andr.) stems herbaceous, procumbent, branclıed, villous; leaves alternate, obowately cuneiform, pubescent; flowers sessile, rather adnate at the origin of the hranches. 4 . D. G. Native of the Canary Islands and Egypt, along the sea shore. D. C. pl. grass. t. 1yG. Glìnus crystállinus, Forsk. descript. p. 95. t. 14. Ficoídea, Niss. act. par. 1711. t. 13. f. 1. Veslíngia cauliflòra, Møench. vot. 111.
Veslingia Heistèri, Fabr. Calyx 5 -angled, ycllowish inside. Stamens 2-4 at the fifth lobe of the calyx.

Canary-Island Aizoon. Fl. July, Aug. Clt. 1731. Pl. pr.

2 A. ó,1noìns (Iin. fil. suppl. 261.) stems herbaccous, decumbent, hairy ; leaves alternate, obovate, petiolate, pubescent ; flowers sessile, axillary, hairy. 2/. D. G. Native of the Cape of Good Hope. Thunb. H. ca]s. 410. Calyx lieset with white liairs on the outside, and coloured on the inside; when dry rather rose-coloured. Limb of leaves about equal in length to the petioles.

Glimus-like Aizoon. Fl. June, Aug. Clt. 1774. Pl. dec.

$$
\text { * Lcaves opposite. }
$$

S A. Hispásicum (Lin. spec. 700.) stem herbaccous, erect, branched; branches spreading and erect, rather papulose at the apex; leaves opposite, linear, lanceolate, glabrous, scssile; flowers solitary, somewhat pedicellate, in the forks of the branches. ๑. H. Native of Spain, Calabria, and Barbary, by the sea side. D. C. pl. grass. t. 30.-Dill. clth. 1. f. 143. Aizoon sessiliflòrum, Moench, meth. Calyx white on the inside, and rather greenish on the outside. The plant from the Cape of Good Hope under this name is different.

Spanish Aizoon. Fl. July, Aug. Clt. 1728. Pl. from 1 incl to $\frac{1}{2}$ foot.

4. A. tomentòsum (Lam. dict. 3. p. 418.) stem suffruticose, tomentose, branched ; leaves opposite, tomentose, lincar-lanceolate, narrowed at the base, rather spatulate at the apex; flowers sessile in the forks of the stem. h. D. G. Native of the Caje of Good Hope. A. Hispánicum, Burm. cap. prod. p. 154. Calyx yellowish inside, 5-lobed, rarely 4-lobed. Stamens 15.

Tomenlose Aizoon. Slirub ] foot?

5 A. stella'tum (Lam. dict. 3. p. 418.) stem suffruticose, branched, hispid at the apex; leaves opposite, linear-spatulate, hairy; flowers panicled: pedicels and calyxes hairy. Ћ. I. G. Native of the Cape of Good Hope. Calyx yellowish inside. Stamens about 20 .

Stellate Aizoon. Shrub 1 foot.

6 A. Perfolia'tum (Lin. fil. suppl. p. 261.) stem suffruticose, erect, tomentose, branched; leaves oppositc, conuate, obovateoblong, full of crystalline dots ; flowers axillary, pedunculate, solitary. h. D. G. Native of the Cape of Good Hope. Thunb. A. cap. 411. Margins of leaves reflexed.

Perfoliate-leaved Aizoon. Fl. Ju. Aug. Clt. 1818. Sh. $1 \mathrm{ft}$.

7 1. sakMENTòsum (Lin. fil. suppl. 260.) stem suffruticose, crectly diffuse, glabrous, branched ; leaves opposite, linear-filiform, rather connate, glabrous; branches rather villous, 3-flowered at the apex, the two lateral flowers are bracteated, and spring from the sides of the middle one. $\zeta . D . G$. Native of the Cape of Good Hope. Thunb. fl. cap. 410.-Burm. afr. t. 26. f. 2. good. Mesembryánthemum hexaphýllum, Haw. rev. p. 165. ex syn. Burm. This species differs from all in the inflorescence. The peduncles and fruit of the preceding year are permanent and lateral.

Sarmentose Aizoon. Shrub sarmentose.

8 A. Panicula'rum (Lin. spec. 700.) stems herbaceous, decumbent, hairy ; leaves opposite, lanceolate, hairy ; flowers nearly sessile on trichotomous peduncles. h. D. G. Native of the Cape of Good Hope. '1hunb. fl. cap. 410

Panicled Aizoon. Pl. decumbent.

\section{+ Species not sufficicntly known.}

9 A. RíGidum (Lin. fil. sujpl. 261.) sten suftrutescent, decumbent; hranclies hoary ; leaves ovite, acute, coscred with glaucous tomentum; flowers sessile, alternatc, sccund, remote. F. D. G. Native of the Cape of Good Hope. 'I'hunb. It. cap. p. 409. In the character of this species it does not say 
whether the leaves are alternate or opposite. The leaves are said to be ovate in the diagnosis, and in the description obovate.

Stiff Aizoon. Shrub decumbent.

10 A. FRUTicosum (Lin. fil. suppl. 1. c.) stem shrubby, erect, glabrous, stiff; leaves lanceolate, glaucous, attenuated at the base; flowers sessile. $h$. D. G. Native of the Cape of Good Hope. Thunb. f. cap. 410. The description does not mention whether the leaves are alternate or opposite.

Shrubby Aizoon. Shrub 1 foot.

11 A.secu'NDUM (Lin. fil. suppl. 1. c.) stem herbaceous, hairy, decumbent ; leaves ovate, acute, rather petiolate, beset with silky villi; flowers sessile, secund, axillary.-Native of the Cape of Good Hope. Thunb. fl. cap. 409. Leaves a line long; in the diagnosis they are said to be ovate, but in the description obovate.

Secund-flowered Aizoon. Pl. decumbent.

Cult. This genus of succulent plants is not worth growing except in botanical gardens. The culture, treatment, and propagation recommended for the genus Mesembryánthcmum will answer well for the species of Aizòn also.

V. MI'LTUS (from $\mu$ c $\lambda_{\text {ros, }}$ miltos, vermilion ; in reference to the deep red colour of the whole plant). Lour. coch. p. 302. D. C. prod. 3. p. 454.

Lix. syst. Icosándria, Pentagýnia. Calyx 5-parted, permanent, spreading, coloured. Petals wanting. Stamens 12, inserted in the bottom of the calyx; anthers standing. Ovarium roundisl. Style wanting; stigmas 5 , linear. Capsules 5 , connate, each containing one seed.-A prostrate shrub, with oblong, opposite, crowded leaves; and crowded lateral flowers. This genus differs from Glinus in the petals being absent in the spreading calyx, and in the capsules being 1 -seeded.

1 M. Africanus (Lour. l. c.) h. D. S. Native of the eastern coast of Africa, in arid places, in the islands of the Mosambique. Glìnus Míltus, Ræusch. nom. Glìnus Mosambicénsis, Spreng. syst. 2. p. 467. The whole herb is reddish.

African Miltus. Shrub prostrate 4 feet long.

Cult. See Sesùvium, p. 153. for culture and propagation.

VI. GLINUS (a name given by Theophrastus to the maple). Lin. gen. no. 610. Juss. gen. 316. Lam. ill. 413. D. C. prod. 3. p. 455. - Rolófa, Adans. fam. 2. p. 256.

Lin. srst. Dodecándria, Pentagýnia. Calyx 5-parted, conniving, permanent, coloured inside, with 3 of the sepals exterior, and the other 2 interior. Petals strap-formed, $2-4$-cleft at the apex, from 5 to 20 in number, shorter than the calyx. Stamens about 15. Ovarium distinct. Style very short or wanting; stigmas 5. Capsule covered by the calyx, 5-valved, 5-celled. Seeds numerous, minute, hanging by a very long involute funicle each. Embryo spiral.-Branched procumbent tomentose herbs, with alternate leaves or in unequal pairs. Flowers axillary almost sessile. The plants have the habit of Aizoon, but the embryo is that of Caryophyllece.

Sect. I. Glinòda (an alteration from the generic name). D. C. prod. 3. p. 455 . Alsìne species, Tourn. G]inus, Rafin. Petals 5. Capsule truly 5-celled.

1 G. Lotoides (Lin. spec. 663.) plant clothed with white wool, diffusc, herbaceous ; leaves obovate, fascicled, unequal; pedicels

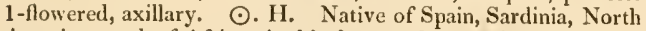
America, north of Africa, Archipelago, and Senegal, Egypt, Asia, \&c. in inundated places; also of Chili, about Buenos Ayres. Smith, fl. græc. t. 472.-Burm. fl. ind. t. 36. f. 1.-Barrel, icon. t. 386.-Bocc. sic. t. 11. G. lotoides and G. dictamnoides, Lam. dict. 2. p. 728. ill. 413. f. 1, 2. Sepals white inside, with red margins. Pedicels aggregate.

Lotus-like Glinus. Fl. July. Clt. 1788. Pl. prostrate.
2 G. DICtaminor'des (Lin. mant. 243.) plant clothed with white tomentum, prostrate, suffruticose; leaves orbicular, flat, on very short petioles; flowers axillary, nearly sessile. h.G. Native of the East Indies. Vahl, symb. 4.p. 64.-Pluk. amalth. t. 306. f. 6. Petals yellow.

Dictamnus-like Glinus. Shrub prostrate.

Sect. II. Rolòfa (meaning unknown). D. C. prod. 3. p. 456. -Plénckia, Rafin. speech. 1.p. 194. Petals numerous. Capsule probably 1 -celled.

3 G. setiflòrus (Forsk. descr. 95.) plant hoary, suffruticose, diffuse; leaves nearly orbicular, in whorles, petiolate; flowers axillary, capitate. $\zeta$. G. Native of Arabia Felix, about Dahi, in inundated places. Vahl. symb. 3. p. 64. Plénckia setiflòra, Ralin. J. c. Petals numerous, linear, yellow, divided into 3-4 bristles at the apex. Capsule 1-celled, ex Forsk. Very like Glinus lotoides ex Vahl.

Bristle-flowercd Glinus, Shrub diffuse.

\section{+ Spccies not sufficiently known.}

4 G.? triantuemoìdes (Roth, nov. sjec. 231.) plant prostrate, glabrous ; leaves obovate, wedge-shaped, rounded, mucronate; panicles loose, terete, opposite the leaves.-Native of the East Indies. This plant differs from Glinus in the petals being wanting. It is therefore perhaps a species of Miltus; but this is still doubtful because the number of the seeds are unknown.

Trianthema-like Glinus. PJ. prostrate.

Cult. These plants will grow well in a mixture of sand, peat, and loam; and young cuttings of the shrubby kinds will strike root readily in the same kind of soil. The seeds of the annual species had better be reared on the hot-bed, and when the plants are of a sufficient size, they sliould be planted out into a warm damp situation.

VII. ORY'GIA (altered from the Arabic name of the plant Hörudjrudj). Forsk. descr. p. 103. Juss, gen. p. 317 . dict. sc. nat. 36. p.512. D. C. prod. 3. p. 455.-Portulàca species, Vahl.

LiN. syst. Icosándria, Pentagýnia. Calyx 5-parted, permanent. Petals numerous (20?), lanceolate. Stamens indefinite. Ovarium distinct. Stigmas 5, filiform. Capsule globose, girded by the calyx, 5-celled, 5-valved, many-seeded.-An Arabian decumbent small silurub, with mealy ovate acute leaves, and reddjsh violet flowers. $O$. portulacifolia is a species of Talinum.

1 O. Decu'mbens (Forsk. I. c.) h. D. F, Native of Arabia Felix. Portulàca decúmbens, Vahl. symb. 1. p. 33. Talinum decúmbens, Willd. spec. 2. p. 864. Leaves bluish.

Decumbent Orygia. Pl. decumbent.

Cult. A gravelly or sandy soil will suit this plant, and cuttings will root readily in the same kind of soil.

Order CXV. NITRARIA'CE $Æ$ (this order only contains the genus Nitrària). Lind]. introd. nat, syst. p. 163.

Calyx inferior, 5 -toothed, fleshy. Corolla of 5 petals, which arise from the calyx, inflexed, valvular in æstivation. Stamens 3 times the number of the petals, perigynous; anthers innate, with 2 oblique, longitudinal lines of dehiscence. Ovarium superior, 3 or more celled, with a continuous fleshy style, at the apex of which are as many stigmatic lines as there are cells in the fruit; ovula pendulous, by means of a long funicle. Fruit drupaceous, opening by 3 or 6 valves. Seeds solitary, without albumen. Embryo straiglit, with the radicle next the hylum.Shrubs with deciduous, succulent, alternate leaves, which are 
sometimes in fascicles. Flowers in cymes, or solitary. The affinity of Nitrària with Ficoidce is undoubtedly great, especially with Tetragònia; but its very different embryo, and the peculiar aestivation of the petals, which is much more like that of Rhámnce remove it from that order.

I. NITRA'RIA (so named by Schreber, who first found it in Siberia, near the nitre works, with other marine plants). Lin. gen. no. 632. Lam. ill, t. 403 . Gartn. fruct. 1. t. 58. D. C. prod. 3. p. 456.

Lis. syst. Dodecándria, Monogýnia. Character the same as that of the order.

1 N. ScıöвE'ri (Lin. spec. 685.) leaves cuneate, obtuse, mucronate, quite entire. $h$. H. Native of Siberia, about the nitre works; and of the Soongarian desert, in salt fields every where, and about Loktewsk, as well as on the borders of the Caspian Sea. Pall. fl. ross. 1. t. 50. f. a and b. Lam. ill. t. 403. f. 1. Flowers white, disposed in panicled cymes. The Siberian and Caspian varieties are not different, unless in the more luxuriant growth of the Caspian kind, which is owing to its growing in a more humid situation than that of the Siberian variety.

Schober's Nitraria. Fl. May, Aug. Clt. 1778. Sh. 3 feet.

2 N. tridenta'ta (Desf. f. atl. 1. p. 372.) leaves cuneated, retuse, somewhat tridentate at the apex; drupes ovate. $\zeta . H$. Native of Barbary and Egypt, in sandy fields. Péganum retùsum, Forsk. èx. Dill. ill. A. ægyp. Branches spinose. Flowers white, in panicled cynes. Fruit red.

Tridentate-leaved Nitraria. Clt. 1820, Shrub $1 \frac{1}{2}$ foot.

3 N. SENEGALE' NsIS (Lam. ill. t. 403. f. 2. dict. 4. p. 493.) leaves obovate, obtuse, quite entire; drupes trigonal. $h . S$. Native of Senegal. Flowers white, in panicled cymes. This species is easily distinguished from the rest by its pyramidal trigonal drupe.

Senegal Nitraria. Shrub 1 to 2 feet.

$$
\dagger A \text { doublful species. }
$$

4 N. Billardie'rit (D. C. prod. 3. p. 456.) leaves linear, attenuated at the base, acutish, quite entire ; drupes ovate, acuminated. $\eta$. G. Native of New Holland. Very nearly allied to $N$. Schüberi, Labill. mss. but very different from it in the fruit being ovate conical, as well as from growing in a different part of the world.

La Billardier's Nitraria. Shrub 1 to 2 feet.

Cull. This is a genus of singular shrubs : they thrive best in a sandy or gravelly soil, and should be occasionally refreshed with salted water, or they will not flourish; they may be increased by layers; or cuttings planted in sand, with a hand-glass over them, strike root readily. The $N$. Senegalénsis, being a stove plant, and $N$. Billardièri should be grown in pots, in order that they may be placed in their respective situations.

ORDER CXV1. REAUMURIA'CEE (plants agreeing with Reaumùric in important characters). Reaumuriè, Elirenberg in ann. des. sc. 12. p. 78. (1827). Lindl. introd. bot. p. 48 .

Calyx 5-parted (f. 31. a.), surrounded externally by imbricating bracteas. Petals 5 (f. $31 . b$.), hypogynous. Stamens definite or indefinite (f. 31 .), hypogynous, with or without a hypogynous disk; anthers peltate (f. 31. d.). Ovarium superior. Styles several (f. 31. f.); filiform or subulate. Fruit capsular

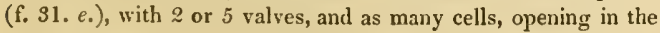
middle of the cells. Seeds definite, villous. Embryo straight, surrounded by a small quantity of mealy albumen, with the radicle next the liylum. Shrubs, Leaves fleshy, scale-like or small, and alternate, without stipulas. Flowers solitary. Dr. Lhrenberg suggests (ann. sc. 1. c.) that Rcaumùria and Mololáchna, both of which have according to him hypogynous stamens, may constitute a little group to be called Rcaumurièce. The order appears to be more nearly related to Hyporicince than to either Ficoidece or Nitrariàcece, and ought perhaps to have followed that order among the Thalamiforce in vol. I. From the former it chiefly differs in its succulent habit, and definite villous seeds, agreeing with Rcaumùria, at least even in the obliquity of the reins of the petals, and in the lcaves being dotted. From Ficoidce its hypogynous stamens and sceds distinguish it; from Tamariscinea, its plurilocular ovarium and distinct styles; from Nitrariàcea, its erect villous secds, distinct styles, and hypogynous stamens. Saline matter is present in these plants in great abundance.

\section{Synopsis of the gencra.}

1 Reaumu'ria. Calyx 5-parted (f. 31. a.), involucrated by crowded leaves on the outside. Filaments indefinite (f. 38.), joined at the base into 5 bundles.

2 Hololáchna. Calyx 4-5-parted. Stamens 8-10, monadelphons.

I. REAUMIURIA (so named by Haselquist in honour of René Antoine Ferchault de Reaumur, member of the Academy of Sciences at Paris, \&c.; author of several Memoirs, Histoire des Insects, \&c. He died in 1757). Lin. gen. 686. Lam. ill. 489. D. C. prod. S. p. 456.

LuN. syst. Polyándria, Pentagýnia. Calyx 5-parted (f. 51 . a.), involucrated by leaves on the outside. Petals 5 (f. 31.b.), furnished with a ciliated appendage on each side at the base. Ovarium distinct. Stigmas 5-6, filiform (f. 31.f.). Capsule 5 -celled, 5 -valved; dissepiments easily separated from the valves. Seeds 2 in each cell, very villous.-Oriental shrubs, with fleshy, alternate, glaucous, dotted leaves, exuding globules of a saline alkali. Flowers solitary at the tops of the branches.

1 R. vermedla'ta (Lin. spec. 754.) leaves subulate, semiterete, imbricated, crowded on the branches. h.F. Native of Sicily, Barbary, and Egypt, on the sea shore. Lam. ill. 489. f. 1. Desf. atl. 1. p. 481 .-Lob. icon. 380 . Flowers white or pale red. Habit of Chenopòdum fruticosum. Hairs on the seeds rufous, and very stiff.

I'ermiculated Reaumuria. Fl. July, Oct. Clt. 182s. Sh. $1 \mathrm{ft}$.

2 R. HYPERICOIDES (Willd. spec. 2. p. 1250.) leaves lanceolate, flat, rather remote. $h_{\text {. }}$ F. Native of Syria, Tauria, and Persia, in arid places. Lam. ill. 489. f. 2. Ker. bot. reg. t. 845 . Hypéricum alternifòlium, Labill. syr. dec. 2. t. 10. R. linifòlia, Sal. par. lond. t. 18. R. cistoides, Willd. enum. p. 578 . R. vermiculàta var. $\beta$, and perhaps also var. $a$, Bieb. fi. taur. 2. p. 17. Buxb. cent. 2. t. 35. Flowers of a purplish rose-colour. Hairs on seeds woolly. (f. 31.)

St. Jolin's-nort-like Reaumuria. Fl. Jul. Oct. Clt. 1800 . Sh. 1 to 2 feet.
F1G. 31.

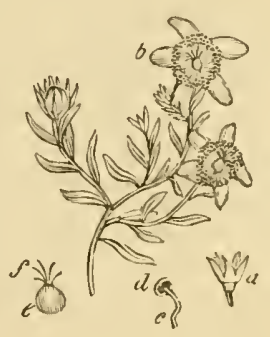


Cult. Elegant little shrubs of easy culture; they thrive best in a mixture of sandy loam and peat; and young cuttings readily strike root under a hand-glass.

II. HOLOLA'CHNA. This genus having already been described under the order Tamaracince, it is only necessary here to refer to vol. II. p. 728 . where all the details of the genus will be found.

ORDER CXVII. CA'CTEA (this order contains the genus Cactus, and all the genera recently separated from it). D.C. prod. 3. p. 457. mem. cact. in mem. mus. vol. 17. p. 1-119. -Cactoílex, Vent. tabl. 3. p. 289.-Nopàleæ, D. C. theor. elem. 216.-Cácti, Juss. gen. p. 310. exclusive of Grossularièæ.—Opuntiàceæ, Juss. dict. 35. p. 144. exclusive of Grossularièze. H. B. et Kunth, nov. gen. amer. 6. p. 65.-Cáctus, Lin. gen. no. 613. Willd. enum. hort. berol. p. 30. Link. enum. 2. 1. 21. \&c.

Calyx composed of many sepals, usually indefinite in number, and confounded with the petals, united and adnate a great length to the ovarium; with the tube smooth in the genera $\mathrm{Mam}$ millìria, Mclocáctus, and Rhipsalis; or with the lobes of the sepals crowning the fruit, and having the tubescaly as in the genera Céreus, Opúntia, and Peréskia. Petals disposed in two or more series, hardly distinguishable from the inner sepals, and somewhat united to them; sometimes irregular, and disposed in a long tube at the base, but distinct at the apex, as in the genera Mammillària, Melocáctus, and Cércus; sometimes equal and distinct to the very base, forming a rotate corolla, as in the genera Opuntia, Peréskia, and Rhípsalis. Stamens indefinite, disposed in many series, more or less colhering with the petals or inner sepals; filaments slender, filiform: in the genus Opuntia they are irritable to the touch; anthers ovate, versatile, 2-celled. Ovarium obovate, fleshy, 1-celled: with numerous ovula, arranged upon parietal placentas, which are equal in number to the lohes of the stigma. Style filiform, sometimes full and sometimes fistular; stigmas numerous, either spreading or collected into a cluster. Fruit fleshy, 1-celled, many-seeded, either smooth and crowned by the calyx, or covered with scales, scars, or tubercles, and umbilicate at the apex. Seeds, when young parietal, but when mature imbedded in the pulp with which the cells are filled, oval or obovate, without albumen. Embryo either straight, curved, or spiral; with a short, thick, obtuse radicle; cotyledons flat, thick, foliaceous in Opúntia and other leaf-bearing genera, very small in Melocáctus, and perhaps almost obsolete in Mammillària and other leatless genera.

This order contains fleshy or succulent shrubs, very variable in habit. Stens usually angular, winged, or regularly beset with tubercles, rarely terete, usually jointed; joints compressed. Leaves usually wanting, but when present small, caducous, and terete, sometimes like those of Sèdum, rarely flat and expanded, sometimes alternate and disposed in a spiral order, always glabrous and fleshy. P'rickles or bristles disposed in fascicles, rising from the axils of the leaves; in the leafless genera the fascicles of spines are disposed on the angles of the stem, rising from tubercles. Flowers very variable, showy, or minute, usually solitary, sessile, rarely in fascicles, eplemeral, expanding by night or by day.

It has already been remarked, on more than one occasion in this work, that the state of that remarkable distention or increase of cellular tissue of vegetables, from which the name of succulent is derived, is no indication of natural affinity, but rather to be considered a modification of structure, which may be common to all tribes. Hence the immediate relationship of Cáctece is neither with Euphorbiàcece, nor Lauinece, nor any other tribe of succulent plants, but with Grossularièa, in wlich no tendency whatever to an increase of cellular tissue exists. Through Rhipsàlis, which is said to have a central placenta, Cáctece are connected with Purtulacece, to which also the curved embryo of the section of Opuntiòcear probably indicates an approach. De Candolle further traces an affinity between these plants and Ficoidece. For an elaborate account of this order, see his Memoir above quoted.

The fruit is very similar in properties to those of Grossularia, some being refreshing and agreeable to the taste, others mucilaginous and insipid; they are all, however, destitute of the excessive acidity of some gooseberries and currants. The fruit of Cactus Opintia, has the property of staining red the urine of those who eat it. The juice of Mammillària vulgàris is remarkable for being slightly milky, and at the same time sweet and insipid.

\section{Synopsis of the genera.}

Tribe I.

Opunta'cese. Ovula, and therefore the seeds, fixed to the parietes of the fruit.

I Mammlen'ria. Tube of calyx adhering to the ovarium; lobes 5-6, coloured, crowning the young fruit. Petals 5-6, hardly distinguishable from the calyx. Stamens disposed in many series. Stigma 5-7-cleft. Berry smooth.

2Menoca'ctus. Tube of calyx adhering to the ovarium; lobes 5-6, petaloid, crowning the young fruit. Petals 5-6, united into a long tube with the sepals. Stamens disposed in many series. Stigma 5-rayed, Fruit smooth.

3 Ecmunocáctus. Sepals numerous, imbricate, adhering to the ovarium : outer ones in the form of an involucrum: inner ones petal-formed. Stamens numerous. Style multifid at the apex. Berry scaly from the remains of the sepals.

4. CE'revs. Sepals very numerous, imbricate, adnate to the base of the ovarium, united into an elongated tube: outer ones shorter and like a calyx : middle ones longer and coloured, innermost ones petal-formed. Style multifid at the apex. Berry areolate, tubercular or scaly from the remains of the sepals.

5 Epiphy'zlum. Tube of calyx very long, furnished with remote scales; limb of corolla multifid, rosaceous or ringent. Branches flat.

6 OPU'NTIA. Sepals numerous, leaf-formed, adnate to the ovarium: "pper ones flat and short: inner ones petal-formed, obovate and expranded, with no tube above the ovarium. Stamens numerous, shorter than the petals. Stigmas numerous, 
ereet, thick. Berry oval, umbilicate at the apex, either tubercled or spiny.

7 l'ERE'SKiA. Sepals leaf-formed, numerous, adnate to the ovarium, and usually permanent above the fruit. Corolla rotate, almost as in Opuntia. Stamens numerous, much shorter than the petals. Stigmas aggregate, in a spiral manner. Berry globose or ovate.

\section{TRIBE II.}

Ruusazioes. Ocula, and therefore the secds fixed to the central axis of the fruit.

S Ruípsals. Tube of ealyx smooth, adhering to the ovarium ; limb superior, 3-6-parted, short. Petals 6, oblong, inserted in the calyx. Stamens 12-18, fixed to the petals. Stigmas $3-6$, spreading. Berry roundish, pellucid, erowned by the dead calyx.

\section{Tribe I.}

OPUNTIACE.E (plants ogreeing with Opúntia in important characters). D.C. prod, 3. p. 458, Ovula, and therefore the seeds fixed to the parietes of the berry.

I. MAMIIILLA'RIA (from mamma, the nipple; the plants are covered with mammaform tubercles, spirally disposed, the mamme bearing radiating spines at the apex and decidnous tomentum). Haw. sỳn. 17\%. D. C. prod. 3. p. 458.-Cáctus and Mamnillària, D.C. cat. hort. monsp. p. 83.-Echinocáctus, Willd. enum. suppl. 30 . exclusive of some species.-Cáctus, sect. A. Link. enum. 2. p. 21.

Lis. syst. Icosándria, Monogýnia. Tube of calyx adhering to the ovarium; lobes 5-6, coloured, crowning the young fruit. Petals 5-6, hardly distinguishable from the calyx, and longer than it, united into a tube with the sepals. Stamens filiform, disposed in many series. Style filiform. Stigmas 5-7, radiating. Berry smooth. Sceds imbeded in the pulp. Cotyl dons obsolete (ex Nutt.). Fleshy, succulent, shrubby plants, of a roundish or subcylindrical form, destitute of a woody axis (perhaps in all ?), lactescent, leafless; bearing rather conical, mammaform, crowded tubercles, which are disposed in a spiral manner, terminating in radiating spines and deciduous tomentum. Flowers sessile at the base of the mamme, usually d'sposed in a transverse zone around the plant. Berries obovite, eatable, crowned by the marcescent ealyx, which at length becomes decidnous. Tubercles of the stem very sinnilar to the leaves of Mesembryánthemum barbàtum.

1 M. Magxima'ma (Haw, in phil. mag. vol. 63, p, 41.) plant nearly glohose, depressed; tubercles or manme large, hard, and very green, when young woolly at the apex, but when old quite smooth, each terminated by 4 very stiff, radiating, recurved, yellow spines: the upper one of which is very minute, and the lower one much elongated. $h_{\text {. }}$. D. S. Native of Mexico. This is a very pretty species. The tubercles are large, tetragonal, and cylindrical, very broad at the base, and much depressed; the spines very strong and very stiff, broadisl, reeurved, furrowed longitudinally, when young pale brown and black at the apex, but when old wholly black, and with wool at the base; wool at the base of the spines vanishing.

Large-teated Mammillaria. Clt. 1823. Shrub $\frac{1}{4}$ to $\frac{1}{2}$ foot.

2 M. corona'ria (Haw. rev. p. 69.) plant simple, eylindrical, when young clavate; tubercles or mammæ large, ovate, woolly, and spiny at the apex; spines stiff, rising from white tomentum, exterior ones white: interior ones brown. h. D. G. Native of Mexico. Cáctus coronàtus, Willd. enum. suppl, 30. Cáctus cylindricus, Ort. dec. p. 128. t. 16. but not of Lam. This is a very beautiful species, and the tallest of all the genus; it is about 5 feet high, and hialf a foot in diameter. Flower's scarlet. Tubereles or mamma at the top of the stem are the longest, and as if they were forming in a crown.

Cron' Mammillaria. Fl. June, Aug. Clt. 1817. Sh. 5 feet.

3 M. díscolor (Haw, syn. 177. 1). C. diss. t. 2. f. 2.) plant glohose, somewhat depressed, alınost simple, with glabrous axils ; tubcreles or mamme ovate, laardly woolly at the tips, but bearing spines: outer spines setaceous and white, spreading and stiflish: inner ones fewer and brown, straight and more rigicl. দ. D.S. Native of South America. Colla, hort. ripul. append. 3. t. 11. Cáctus depréssus, 1). C. cat. hort. monsp. p. 84 . Cáctus pseùdo-mammillàris, Salm-Dyck, mss. C. Spinii, Cólla antol. 6.p. 501. Plant 3-4 inches high. There are 13-15 series of tubereles, winding to the right. Flowers longer than the tubercles, more spreading at the apex than in $\hat{M}$. simplex, white inside, but of a dirty reddish colour on the outside.

Two-coloured-spined Mammillaria. Fl. June, Aug. Clt. 1800. Shrub $\frac{3}{4}$ to $\frac{1}{2}$ foot.

4 M. lanífera (Haw. in phil. mag. vol. 63. p. 41. D. C. diss. t. 4.) plant simple, terete, obovate, clothed with woolly tomentum all over; tubercles or mamma bearing 20 or more radiating, straight, spreading spines at the apex: outer spines smaller and white: inner ones strong and fulveseent. $\zeta$. D.S. Native of Mexieo. Cáctus canéseens, Moc. et Sesse, fl. mex. icon ined. Plant 3-4 inches ligh. Flowers red, longer than the tubercles (ex fl. mex.).

IVool-bearing Mammillaria. Clt. 1823. Shrub $\frac{1}{4}$ foot.

5 M. Flavéscens (D. C. prod. 3. p. 4.59.) plant obovate, rather proliferous at the top; axils woolly ; tubereles or mamma. ovate, woolly at the apex, and bearing spines; spines stiff, long, straight, yellowish. $\zeta$. D. S. Native of South America. Cáctus flavéscens, D. C. cat. hort. monsp. p. 83. M. stramínea, Haw, ex Salm-Dyck. in litt. Cáctus flavéscens and C. stramíneus, Spreng. syst. 2. p. 494 . Plant 4-5 inches high. The tubercles are disposed in 13-14 series, which wind to the right.

Vellowish-spined Mamillaria. Fl. June, Aug. Clt. 1811. Shruh $\frac{1}{2}$ to $\frac{1}{2}$ foot.

6 M. Fulvisrixa (Haw. in phil. mag. oct. 1899. p. 106.) plant roundish; tuhercles or mamma bearing about 1 s spines each at the apex, about 4 of which are a little longer than the rest: outer ones horizontal. $h_{2}$. D. S. Native of Brazil. Flowers large, red, nearly like those of $M$. rhodantha (Otto), but probably larger, and the spines are longer; lower spines 3 lines long, white, almost covering the whole plant: and the 4 upper ones spreading, and 2 or 3 times longer than the rest, of a fulrous colour.

Bronn-spined Mammillaria. Fl. Sept. Clt. I 829. Sh. $\frac{1}{4}$ to $\frac{1}{2} \mathrm{fr}$.

7 M. Prolífera (Haw. syn. 177. suppl. 71.) plant obovate, proliferous at the base; axils wnolly; spines long, straight, of a whitish straw-colour. $\zeta$. D. S. Native of South Americi. Cáctus mammillàris prólifer, Ait. hort. kew. ed. 2. vol. 3. p. 175. Offsets rising from the plant at the very base, from which it is easily known from $M$. flavéscens (ex Salm-Dyck.).

Proliferous Mammillaria. Fl. June, Aug. Clt. 1800. Sl. $\frac{1}{4}$ to $\frac{1}{2}$ foot.

8 II. DE'xsa (Link. et Otto, pl. rar. hort. berol. t. 35.) plant eylindrical, glaucescent; tubereles or mammæ conical, dense; spines numerous, yellowish, 1 of which in each fascicle is larger than the others. h. D.S. Native of Mexico, on the mountains.

Dense Mammillaria. Clt.? Shrub $\frac{1}{4}$ foot.

9 M. Bícolor (Lehm. in pl. nov. hort. hamb. ex bot. zeit. 18\%1. p. 132.) plant obovate, proliferous at top; axils woolly mamma twisted spirally, ovate, pyramidal, woolly at the apex, 
and bearing spines; spines setaceous, divaricate, white, 2 of which are crect in each fascicle, and much longer than the rest, spaceolate at the apex. $\zeta$. D. S. Native of Mexico, on the mountains.

Two-roloured Mammillaria. Clt.? Shrub $\frac{1}{4}$ foot.

10 M. sivplex (I Iaw. syn. 177.) plant simple, obovate; axils glahrous; tubercles or mamma ovate, bearing stiff, straight, radiating spines at the apex. $\zeta_{2}$. D. S. Native of South America, and the islands. Cáctus mammillàris, Lin. spec. 666. D. C. jl. grass, t. 3. Cat. hort. monsp. 83. Plant 6-8 inclies long. There are about 18 or 20 series of tubercles, winding to the left. Spines shortish and red. Tomentum short, deciduous. Axils, when young, rather tomentose. Flowers white. Berry red.

Simple Mammillaria. Fl. Ju. Aug. Clt. 1688. Sh. $\frac{1}{4}$ to $\frac{1}{2} \mathrm{ft}$.

11 M. Parvina'ma (Haw. suppl. 72.) plant nearly globose, prolifcrous at the top; tubercles or mammæ numerous, small, clothed with white tomentum at the apex, each terminating in 10 or 12 rather stitf, dark purple spines. 24. D. S. Native of South America. Cáctus microthèle, Spreng. syst. 2. p. 494. The character is from Salm-Dyck. in litt.

Small-teated Mammillaria. Clt. 1817. Pl. $\frac{1}{4}$ to $\frac{1}{2}$ foot.

12 M. elonga'Ta (D. C. mem. eact. in mem. mus. vol. 17. p. 109.) plant usually multiple at the base, cylindrical, elongated, a little branched, with the axils broad and naked; mammæ or tubercles very short, broad at the base, obtuse at the apex, with the areolæ of the younger ones rather tomentose; prickles setiform, 16-18 in each fascicle, radiating, yellow, much longer than the mammæ, without any central ones. $h$. D. S. Native of Mexico, where it was discovered and sent to Europe by Dr. Coulter, as well as all the following species.

Elongated Mammillaria. Clt. 1830. PI. $\frac{1}{2}$ foot.

13 M. EchinA'ria (D. C. l.c. p. 110.) plant usually multiple at the base, cylindrical, elongated, with the axils broad and naked; mamma naked, very short, broad at the base, and obtuse at the apex, with the areolæ of the younger ones rather tomentose ; prickles bristle-formed, 16-18 in a fascicle, radiating, spreadingly recurved, yellow, much longer than the mamma, with the 2 central ones stiffer and brownish. $h$. D. S. Native of Mexico. Flowers bearded at the base, sessile in the axils, small and pale.

IIedgchog Mammillaria. Clt. 1830. Pl. $\frac{1}{2}$ foot.

14 M. suвcrócea (D. C. l. c.) plant usually multiple at the base, cylindrical, with narrow, rather woolly axils; mammæ ovate, short, with the areole of the younger ones rather tomentose; prickles bristle-formcd, 16.18 in a fascicle, radiating, yellow, longer than the mammæ, but when old becoming coppercoloured, without any central ones. 々.D.S. Native of Mexico. Coulter, no. 36. Flowers small, sessile, solitary in the axils of the manmie, forming a circle round the top of the plant. Style permanent; stigma many-cleft. Berry ovate, about the size of a jea, crowned by the floral remains. Plant 2-3 inclies high, and 9-11 lines in diameter, with 12-15 mammæe in each series, which series bend to the left.

Subcroccous-spined Mammillaria. Clt. 1830. Pl. $\frac{\pi}{4}$ foot.

15 M. TE'surs (D. C. l. c.) plant multiple at the base, cylindrical, with narrow, naked axils; mammæ ovate, with the areolæ of the young ones rather woolly; prickles bristle-formed, 20.25 in a fascicle, yellow, radiating, a little longer than the mamma, without any central oncs. h. D.S. Native of Mexico. Coulter, no. 3\%. Plant 3-4 inches higl, and 5 lines in diameter.

I'ar. $\beta$, mèdia (D. C. l. c.) stem thicker; central prickles wanting or solitary. 々. D.S. Native of Mexico. Plant 1012 lines in diameter. Perhaps a proper species, or perhaps $M$. caspitisa, Hort. berol. according to Salm-Dyck.

Slender Mammillaria. Clt. $1830 . \quad$ Pl. $\frac{1}{3}$ foot.

16 M. INterte'xta (D. C. J. c.) plant multiple at the base cylindrical, with narrow axils; mammæ ovate, much crowded hidden by the congerics of prickles, with the areolæ smoothish; prickles 20-25 in a fascicle, stifl, yellow, radiating, interwoven from the mammæ being so close togetler. $\eta_{\text {. }}$ D. S. Native of Mexico. Coulter, no. 37. Plant 4 inches high, and 1 inch in diameter. Prickles 3-4 inches long, sometimes somewhat echinated. According to a letter received from Dr. Coulter to De Candolle, this and the 4 preceding species will form, as he conceives, only one species; the appearance of these plants have a striking likeness to each other, but these differences appear to De Candolle real, and permanent, and he considers them as forming a small group of the genus, remarkable for the elongation of their stems, and for their yellow appearance.

Iuternoven-spined Mammillaria. Clt. 1830. Pl. $\frac{1}{3}$ foot.

17 M. cylíndrica (D. C. l. c. p. 111.) plant simple, cylindrical, witl a few bristles in the axils; mammæ ovate, with smoothish areolæ; bristles $20-25$, in a fascicle, radiating, white, shorter than the mamma : the 2 central prickles stiff and diverging, twice the length of the surrounding bristles. $h$. D. S. Native of Mexico (Coulter). This plant is easily distinguished from all the preceling, in the colour of the mamma being deep green, not yellow. Plant 5 inches high, and 1 inch in diameter. Bristles $1 \frac{1}{2}-2$ lines long, and the central prickles $3 \cdot 4$ lines long. Cylindrical Mammillaria. PI. $\frac{1}{2}$ foot.

18 M. E'LEgANs (D. C. l. c.) plant simple, obovate, somewhat umbilicate at the apex, with naked axils; mammæ ovate, having the areolæe of the young ones rather tomentose; bristles $25-30$ in each fascicle, white, radiating, stiffish, and with 1-3 stiff, erect prickles, which are a little longer than the bristles that surround them. . D. S. Native of Mexico. Coulter, no. 48. Plant 2 inclies high and 2 inches in diameter.

I ar. $\beta$, minor (D. C. 1. c.) plant exactly obovate, one half smaller than the species, but it is probably a young plant of the same.

Iar. $\gamma$, globòsa (D. C. 1. c.) plant larger, globose, with the upper axils bearded. Perhaps the same, but an old plant.

Elerant Mammillaria. Pl. $\frac{1}{8}$ foot.

19 M. r A'DIANs (D. C. l. c.) plant simple, nearly globose, with naked axils; mamma ovate, large, with the areola smoothish; prickles $16-18$ in a fascicle, radiating, white, stiff, when young rather tomentose, without any central ones. $\eta$. D. S. Native of Mexico. Coulter, no. 35. There are varieties of this plant eitlicr with an obtuse or a depressed apex, and the spines either white or yellowish. Plant about 3 inches ligh, and the same in diameter. Prickles 5-6 lines long.

Radiating-prickled Mammillaria. Pl. $\frac{1}{4}$ foot.

20 M. IRREgula'ris (D. C. I. c.) plant multiple, and rather tuberous at the base, witl ovate offsets, and naked axils; mammæ oblong, with smoothish areolæ; bristles 20-25 in each fascicle, whitc, a little reflexed, without any central prickles. $\zeta$. D. S. Native of Mexico. Coulter, no. 31. Plant 2 inches high, with offsets an inch in diameter. Bristles 2 lines long.

Irregular Mammillaria. Pl. $\frac{2}{8}$ foot.

21 Il. cremerspina (D.C. l. c.) plant multiple at the base; offsets ovate; axils naked; mamme ovate, short, crowded, with the areola smoothish; prickles straight, onter $16-17$ radiating and white, central 3 brown and erect. $h$. D. S. Native of Mexico. Coulter, no. 14. Plant 2 inches high and $1 \frac{1}{2}$ inch in diameter. The prickles, from the mammæ being close, nearly hide the stem.

Thick-spined Mammillaria. Pl. 2 inches.

22 M. conoìta (D. C. l. c. p. 112.) plant simple, ovate-conical, with the axils woolly in the young state; mammæ ovate, crowded, with the areolæ rather tomentose while young; prickles straight, stiff, the outer $15-16$ radiating, but the central $3-5$ are erectly diverging, brown, and rather longer than the ray ones. 
h. D. S. Native of Mexico. Coulter, no. 22. Allied to $M$. crebrispina, and is perhaps $M$. cónica, Haw. Flowers of a reddish-violaceous colour, few in number, rising near the top of the stem.

Conoid Mammillaria. Pl. $\frac{1}{1}$ foot.

23 M. compre'sSA (D. C. I. c.) plant simple, cylindricallyclavate; axils when young woolly and bristly; mamme ovate, short, angular at the base, and as if they were compressed beneath, with the areole rather tomentose; prickles $4-5$ in each fascicle, nnequal, white, lower one the longest. $\subsetneq$. D. S. Native of Mexico. Coulter. I'lant 5 inches higl, an inch broad at the base, and $1 \frac{1}{2}$ inch in diameter at the top.

Compressed Mammillaria. Pl. $\frac{1}{2}$ foot.

24 M. cornífera (D. C. I. c.) plant simple, globose, with naked axils; mamme ovate, thick, crowded, with the arcola smoothish; outer prickles $16-17$, radiating grey, with a strong, longer, erect, rather incurved one in the middle of each fascicle. h. D. S. Native of Mexico. Coulter. Plant 3 inches in diameter, $2 \frac{1}{2}$ broad. Ray prickles 5-6 lines long, and the central one 7-8 lines long.

Horn-bcaring Mammillaria. PI. $\frac{1}{4}$ foot.

25 II. crivit (D. C. l. c.) plant globose, depressed, multiple at the base; axils naked; mammæ ovate, thick, with the areolæe sinoothish; bristles $15-20$ in each fascicle, white, elongated, rather radiating: central prickles yellow, stiff, hooked at the apex, length of the bristles that surround them. $h . D$. S. Native of Mexico. Coulter, no. 28. Plant 1 inch high, $1 \frac{1}{2}$ inch in diameter. Bristles 8-9 lines long.

Var. $\beta$, paucisètae (D.C. l. c.) axils woolly ; bristles $8-10$ in a fascicle. Sometimes the bristles are nearly all deciduous. Coulter, no. 29.

Hairy Mammillaria. Pl. 1 inch.

26 M. cespititia (D. C. 1. c.) plant multiple at the base, tufted, aggregate, globose; axils naked; mammæ few, ovate, with the areolæ smoothish; prickles straight, stiff, when young whitish-yellow, but in the adult state greyish: outer ones 9-11 in each fascicle, radiating, with 1-2 longer, erect, central ones. . D. S. Native of Mexico. Coulter. Tufts 4 inches broad. Offsets an inch in diameter.

\section{Tufted Mammillaria. Pl. $\frac{1}{4}$ foot.}

27 M. subangula'ris (D. C. l. c.) plant simple or multiple at the base, nearly globose, depressed; axils for the most part woolly; mammæ ovate, thick, short, angularly tetragonal from pressing so close against each other, with the areolæ of the young ones tomentose ; prickles $6-8$ in each fascicle, erectly diverging, unequal, of a pale grey colour. $\zeta$. D. S. Native of Mexico. Coulter. Plant nearly 3 inches high and $1 \frac{1}{2}$ broad. Prickles \$-10 lines long.

Subangular-teated Mammillaria. Clt. 1830. Pl. $\frac{\tau}{4}$ foot.

28 M. macraca'ntua (D. C. l. c. p. 113.) plant simple, globose, depressed, with some of the axils naked, and some of them bearded with wool; mamme ovate, rather tetragonal, with the areolæ of the young ones rather tomentose; prickles 1-2, very

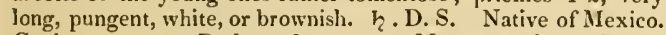
Coulter, no. 44. Perhaps the same as M. magnimamma, Haw.? Prickles 2 inches long. Plant $1 \frac{1}{2}-2$ inclies high, and 3-6 inches in diameter. Prickles rather angular.

Long-spined Mammillaria. Pl. $\frac{1}{3}$ foot.

29 M. Lonoma'sma (D. C. l.c.) plant simple, or rather multiple at the base, ovate, or nearly cylindrical; axils woolly; mammæ ovate-oblong, dense, with the areolæ tomentose ; prickles 9-10 in each fascicle, pungent, of a greenish brown colour. $h$. D. S. Native of Mexico. Coulter, no. 30. Plant 3-4 inclies high, and 2 inches broad. Prickles 6-9 lines long.

Long-teated Mammillaria. Pl. $\frac{1}{3}$ foot.

30 M. остасл'мtнa (D. C. I. c.) plant simple, ovate-oblong, 8 nearly cylindrical; axils naked; mamme oblong, rather tetragonal, with the areolae of the young ones rather tomentose; prickles stifl, the outer 7 in each fascicle radiating and white, with a central one, which is stiffer, longer, and of a fuscescentcolour. $\quad$. D. S. Native of Mexico. Coulter, no. 39. Plant 3 inches high, 2 inches broad. Outer prickles $3-4$ lines long; central one 6 lines long.

Eight-spincd Mammillaria. Pl. $\frac{1}{4}$ foot.

31 M. Levcaca'ntia (D. C. l.c.) plant multiple at the base, ovate; axils naked; mamma few, ovatc-tetragonal, with the areolæ of the young ones glabrous; prickles 6-7 in each fascicle, stiff; white, sometimes all radiating, and sometimes the one in the centre is erect. $\quad$. D. S. Native of Mexico, Coulter. I'lant an inch and a half high, and hardly an inch broad. Prickles b lines long.

White-spined Mammillaria. Pl. $\frac{1}{8}$ foot.

32 M. Dive'rgens (I. C. 1. c.) plant multiple at the base, nearly globose, depressed; axils woolly and bristly; mammx ovate, crowded, with the areolæ of the young ones woolly; prickles 5-6 in each fascicle, unequal, pungrent, white, but brownish at the apex, diverging, and somewhat tetragonal. $h$. D. S. Native of Mexico, Coulter. Perhaps only a varicty of $M$. macracantha. ' $\Gamma$ ufts $6-7$ inches broad, and 2 inches high.

Diverging $\cdot$ spined Mammillaria. Pl. $\frac{1}{8}$ foot.

39 M. TRiAcA'ntira (D. C. 1. c.) plant simple, obovate, nearly cylindrical, bluntly truncate; axils hardly woolly, but with a few bristles; mammæ ovate, much crowded, with the areolæ of the young ones tomentose; prickles 3 in each fascicle, erect, white, lower one the longest, tending downwards, 2 lateral ones very short. $\zeta$. D. S. Native of Mexico, Coulter, no, 46. Plant 3 inches high, and $1 \frac{x}{2}$ inch broad. Sometimes therc is a fourth prickle in each bundle, but when this is present it is rery short.

Thrce-spincd Mammillaria, Pl. $\frac{1}{4}$ foot.

34 M. sempervivi (I. C. 1. c. p. 114.) plant simple, attenuated at the base, depressed at the apex, disk-formed; axils woolly ; mammæerect, ovate-tetragonal, with the areolæ smoothish; bristles 3-4 in each fascicle, stiff, short, and white, and 2 thick, short, diverging prickles. $\quad$. D. S. Native of Mexico. Coulter, no. 57. Plant $2 \frac{1}{2}$ inches broad, and $1 \frac{1}{2}$ high.

I ar. $\{3$, tetracantha (D.C. l. c.) plant densely bearded in the axils; bristles none; prickles 4 , short, diverging. $\eta_{2}$ D. S. Native of Mexico.

Sempervium-like Mammillaria. Pl. $\frac{1}{8}$ foot.

35 M. Discifó ruis (D. C. l. c.) plant simple, depressed, diskformed; axils naked; mammæ crowded, short, depressed, tctragonal, with the areolæ of the young ones rather tomentose, and of the adult ones somewhat unarmed; prickles 5 , in each central mamma, stiff, white, erect. $h . D$. S. Native of Mexico. Coulter, no. 50. Plant 3 inches broad, and hardly an inch ligh.

Disk-formed Mammillaria. Pl. 1 inch.

36 М. Lатима' мма (D. C. I. c.) plant simple, depressed, somewhat discoid : with the younger axils woolly ; mammæ short, broadly ovate, at length depressed, transverscly oblong, with the areole of the young ones woolly; prickles 16-17 in each fascicle, stiff, yellowish, rather fuscescent at the apex, diverging,

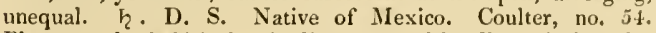
Plant 5 and a half inches in diameter, and hardly an inch and a half high.

Broad-tcatcd Mammillaria. Pl. 1 inch.

37 M. Gemsispina (Haw. in phil. mag. 63. p. 42. D. C. diss. t. 3.) plant simple, cylindrically columnar; axils very woolly tubercles or mammæ small, very numerous; spines small, white, interwoven, 2 of which in each fascicle are much longer than the rest. h. D. S. Native of Mexico. Cáctus columnàris, Moc. et Sesse, fi. mex. icon, ined. Plant half a foot high. Flowers 
red, a little longer than the tubereles. Haworth's plant appears to be different from that of De Candolle.

Tuin-spined Mammillaria. Clt. 1823. Shrub $\frac{1}{2}$ foot.

S8 M. vivípara (Haw. suppl. p. 72.) plant multiple; offsets nearly globose; tubercles or mammae eylindrically ovate, bearded, marked by a proliferous furrow above; flowers central, large, exserted. h. D. F. Native of Louisiana, on hio h hills about the river Missouri. Cáctus vivíparus, Nutt. gen. amer. 1. p. 995. Spreng. syst. 2. p. 494. exelusive of Haw. syn. Each tuft of the plant in its native place of growth is 2 or 3 feet in diameter. Ilowers decp red, almost like those of C'reus flugelIformis. Outer lobes of calyx ciliated. Berries about the size of grapes, fusiform, greenish.

Viviparous Mlan millaria. Fl. June, Aug. Clt. 1811. Pl. $\frac{1}{2} \mathrm{ft}$.

39 M. glomera'ta (D. C. prod. 3. p. 459.) plant tufted; tubcreles or mammæ elavate, glaucous, tomentose, furnished with a stellate bunch of spines each at the apex. h. D. S. Native of St. Domingo, in marshes. Plum. ed. Burm. 201. f. I. Cáetus glomeràtus, Lam. dict. 1. p. 257. Spreng. syst. 2. p. 494. exelusive of the synonyme of Hawortl. Flowers red.

Glomerate Mammillaria. Shrub $\frac{1}{2}$ foot.

40 M. pusílLA (D. C. diss. t. 2. f. 1.) plant multiple, roundish ; axils a little bearded; tubereles or manmæ ovate, bearing radiating spines at the apex, outer spines hair-formed and white, inner ones stiff and pale yellow, pubescent when examined under a lens. 5. D. S. Native of South America. Mill. diet. no. 6. Cáctus pusíllus, D. C. eat. hort. monsp. p. 185.-Pluk. phyt. t. 29. f. 2.? Plant very small, rather glaucescent, hardly 2 inches high. The tubereles or mammæ are disposed in 5 or 7 series, which wind to the left. Flowers large, white or pale red, with the backs of the petals reddish.

Small Mammillaria. Fl. June, Aug. Clt. 1820. Pl. $\frac{1}{8}$ foot.

41 M. stella'ta (Haw, in phil. mag. Feb. 1830.) plant irregularly tufted, beset with radiating faseicles of white pubescent spines; the lower ones of which are hair-formed, with a few of the upper ones much stronger and more horizontal, and strawculoured at the apex. h. D. S. Native of South America. Cáctus stellàris, Willd. enum. p. 30. M. stellàris, Haw. suppl. 1. 72. Lodd. bot. eab. 79. but not M. pusílla, D. C.

Starry Mammillaria. Fl. June, Aug. Clt. 1815. Pl. $\frac{1}{8}$ foot.

42 M. Missourie'ssis (Sweet, hort, brit.p. 171.) mammæ or tubercles ovate, terete, bearded; flowers liardly exserted ; berries searlet, about equal with the mamma. $h$. D. F. Native of Louisiana, on the high mountains about the Missouri. Cáctus mammillàris, Nutt. gen. amer.1. p. 295. Flowers white. Berries searlet. This is a much smaller plant than $M$. simplex, to which it is nearly allied.

Missouri Mammillaria. Fl. June, Aug. Clt. 1818. Shrub $\frac{1}{4}$ to $\frac{1}{2}$ foot.

\section{+ Species not sufficienlly known.}

43 M. IIelícteres (D. C. diss. t. 5.) plant simple, obovate, glabrous; tubereles or mamma disposed in numerous, nearly vertical, regularly spiral series, bearing spreading, straight, spines at the apes. . D. S. Native of Mexico. Cáctus Helícteres, Moe. et Sesse, fl. mex. icon. ined. Plant 3-4 inches ligh. Flowers rose-eoloured, a little longer than the mamma.

Serew Mammillaria. Pl. $\frac{1}{4}$ to $\frac{1}{3}$ foot.

44 M. NU'DA (I). C. prod. 3. p. 460.) plant simple, cylindrieal, ascending, glabrous; tubereles or mamma unarmed. Ђ.D. $\therefore$ Native of Mexico. Cáetus nùdus, Moc, et Sesse, fi. mex. icon. ined. Flowers rose-coloured.

Naked Mammillaria. ['l. $\frac{1}{4}$ to $\frac{1}{2}$ foot.

‡ The folloning species are hardly knon'n unless by name; some of these names may, honcter, be referrible to those described above.

1 M. milis; Mill. diet. 2 M. cónica, Наw. suppl. $3 \mathrm{M}$. caspitòsa, Hort. berol. $4 \mathrm{M}$. canéseens, Hort. berol. $5 \mathrm{M}$. angulàris, Hort. berol. $6 \mathrm{M}$. chrysántha, Hort. berol. $7 \mathrm{M}$. aurìta, Hort. berol. $8 \mathrm{M}$. fuscùta, Hort. berol. 9 M. atràtu, Hort. berol.

\| The folloning species mere raised in the gardens in 1827 from seeds brought from Chili by Dr. Gillies, but have not yet been deseribed. The species we have referred to this genus only from their seedling state, nithout any knowledge of them when full gronn. The names are under the genus Cictus in Gillies's mss.

$1 M$. spinòsa, Gill. 2 $M$. quadràta, Gill. $3 M$. caudàta, Gill. $4 M$. coccinea, Gill. 5 M. solitaria, Gill.

Cult. Mammillaria is a genus of small singular grotesque suceulent plants. A mixture of sand, loam, and peat, or loam mixed with brick rublsish, is a good soil for them. The pots in which the species are grown should be as small as the plants will allow, and they shouid be well drained with sherds; they require very little water. The pots should be placed on slielves ereeted for the purpose in a stove, should there be no house for the purpose of growing suceulent plants, called a dry stove. The plants are increased by offsets.

II. MELOCA'CTUS (fiom $\mu \eta \lambda o v$, melon, a melon, and kakros, cactos, a name applied to a spiny plant by 'Theophrastus; the plants are in the form of a melon, and the angles are beset with tufts of spines). C. Bauh. pin. 384. D. C. diss. 1826. Link et Otto, diss. 1827. p. 8. D.C. prod. 3. p. 460.-Cáctus, Haw. syn. 172. exclusive of some species. Cáctus, sect. B, Link, enum. 2. p. 21.

Lin. syst. Icosándria, Monogýnia. Tube of ealyx adhering to the ovarium; lobes 5-6, petaloid, crowning the young fruit. Petals 5-6, united into a long cylindrical tube with the sepals. Stamens filiform, disposed in many series. Style filiform; stigmas 5, radiating. Berry smooth, crowned by the dry lobes of the corolla and calyx. Seeds imbedded in the pulp. Cotyledons small. Plumule large, nearly globose (D. C. Organogr. t. 48. f. 3.) Fleshy globose simple roundish shrubs, with deep furrows, alternating with rertical ribs, which are ornamented with confluent tubercles, each tuberele furnished with a starry fascicle of prickles or spines. Spadix or flowering head terminal, eylindrical, composed of mammæform, mucl crowded tomentose or setiferous tubercles. Flowers immersed in the wool of the head under its apex.

1 M. commu'sis (Limk et Otto, ]. c. diss. p. 8. t, 11, D. C. diss. t. 6.) plant ovate-roundish, deep green, with II or 18 augles; ribs straight ; spines strong, pale brown, unequal, 9 in each fascicle: lower one th:e longest: middle one erect. $\zeta_{\text {. }}$ D. S. Native of the West India Islands, in salt marshy places near the sea; and probably on the main land of South Ameriea. Cáctus Mclocáctus, Lin. spee. 666. D. C. pl. grass. t. 112. Cáctus Melocáctus, and C. coronàtus, Lam. diet. 1. p. 53i.-Bradl. suee, t. 32. Ribs 12-18. Flowers tubular, red. Fruit red, nearly like those of Mammillaria, but larger, oblong, and deciduous, protruding from the wool on the head.

lar. $\beta$, oblóngus (Link et Otto, l. e.) plant smaller; prickles weaker, and more red. Stem 6 inclies high, and $3 \frac{1}{2}$ thick.

Iar. $\gamma$, macrocéphalus (Link et Otto, l. c.) plant thicker, 14 inches high, and 9 inclies broad.

Common 11 tun-thistle, or Turk's-cap. Fl. July, Aug. Clt. 1688. Shrub 1 foot

2 M. LAmÁrekit; plant ovate, flattish at tlie base, with It-20 angles at the top, which are rather oblique and bluntish 
on the back; spines red, stiff, rather incurved, disposed in apjroximate fascicles, which are very woolly towards the tops of the angles; cap roundish, furnished with a few red setaceous spines; flowers red. $\vdash$. D. S. Native of South America. Cáctus Lamárckii, Coll. hort. ripul. append. 3. t. 7.

\section{Lamarck's Melon-thistle. ['l. s foot.}

3 M. Macracáxtuts (Link et Otto, diss. p. 9. t. 12.) plant roundish, light green, with 14 angles; ribs straight ; spines in fascicles, very thick, whitish, but of a brownish red-colour at the apex: outer 12 radiating, central, 4 large and straight. h.D. S. Native of St. Domingo. Cáctus macracánthos, Salm-Dyck, obs. 1820. 1. 1. Haw, rev. p. 69 . Flowers unknown, bnt the spadix or woolly head is depressed at the top.

Long-spined Melon-thistle. Clt. 1820. Shrub I foot.

4 MI. prrandisis (Link et Otto, diss. p. 10, t. 25.) plant conical or pyramidal, with 17 angles; ribs rather oblique, crenated; spines rery long, in fascicles, of a brownish red colour: outer 14 radiating in 2 scries, with 2 or 3 straight and very long. $\eta_{c}$. D. S. Native of Curassoa. Cáctus pyramidàlis, Salm-Dyck, obs. 1820 . p. 4. Stem when young crowded with spines. Spadix or woolly head eylindrical, depressed at the apex.

Pyramidal Melon-thistle. Shrub 1 foot.

5 M Placentifóruis (D. C. prod. 3. p. 460.) plant hemispherical, depressed, green, with 12 or 14 angles; ribs very blunt; prickles $8-12$ in a fascicle, unequal, recurved, strong. ケ. D. S. Native of Brazil. Cáctus Melocáctus, Besl. hort. evistet. 4. ord. f. 1. but not of Lin. C. placentifórmis, Lelom. ind. sem. hort. hamb. (1826). Melocáctus Beslèri, Link et Otto, diss. $(182 \tau)$. p. 11. t. 21. Lehman's name being older than Link's has been here adopted, as being more apt; but Link's figure and description are far better. Spadix or woolly head nearly globose, impressed in the vertex. Flowers reddish. Prickles blackish.

Placenta-formed Melon-thistle. Shrub 1 foot.

6 M. Langsnó RFII (D. C. prod. 3. p. 461.) plant oblong, with $1 \tau$ angles; spines slender, stiff, spreading: top of plant floriferous, very villous and very spiny, $h_{2}$. D. S. Native of Brazil? Cáctus Langsdórfii, Lehm. in sem. hort. hamb. (1826). Flowers yellow. Stamens purple. The rest unknown.

Langsdorf's Melon-thistle. Shrub 1 foot.

\section{$\dagger$ Species not sufficiently known.}

7 M. Sellòwu (D. C. prod. 3. p. 461.) plant globose, depressed, glaucescent, woolly and flat in the vertex, with 10 arched ribs; prickles 7 in each fascicle, recurved: the central 5 much the largest. $々$. D. S. Native of Monte Video. Echinocáctus Sellòwii, Link et Otto, diss. p. 16. t. 22. Melocáctus species secundum Salm-Dyck, who confirms that the plant is woolly at the top, and is analogous to $M$. placentiformis. Plant 2 inches high, and $4 \frac{1}{2}$ inches thick. Prickles $8-10$ lines long, fuscescent. Flowers unknown.

Sello's Melon-thistle. P1. $\frac{1}{8}$ foot.

8 M. Polyaca'stuls (D. C. prod. 3. p 4.61.) plant oval, glaucescent, with a flat wonlly apex, and with 21 blunt vertical ribs; prickles 8 in each fascicle : the upper 2 of these smaller than the otliers. $\quad$. D. S. Native of Brazil in the province of Rio Grande. Echinocáctus polyacánthus, Link et Otto, diss. p. 13. t. 16. f. 1. Stem 4 inclies high, and 3 inches thick, attenuated at the base, with narrow furrows; prickles cinereous. Flowers unknown.

Many-spincd Melon-thistle. Shrub $\frac{1}{4}$ foot.

9 M.? Melocactoìes (D. C. prod. 3 . p. 461.) plant globose, with 10 angles, havirg the tops of the angles beset with a series of woolly tubercles; prickles 7 or 8 in a fascicle, rather recurved, pale, but becoming gradually brownish towards the apex. $r_{6}$. YoL. III.
D. S. Native of Brazil. Cíctus melocactoides, Hoffms, verz. 2.? (1826) 3. p. 24. Habit of $M$. commùis.

Melocactus-lilic Melon-thistle. PI. $\frac{1}{2}$ foot.

Cult. I grotesque and singular genus like the last, but of larger growth, and beset with stronger spines, without teats. 'The culture, propagation, and treatment of the species are the same as that recommended for the list genus.

III. ECHINOCA'CTUS (from Exeros, cchinos, a hedgehog, and saktos, cactos, a name given by Theoplurastus to the spiny plant; plants beset with spines like the hedgehog). link et Otto, diss. p. 11. Sahn-Dyck, in litt. D. C. prod. 3. p. 461.-Cáctus species of Haw.

Lux. syst. Icosándria, Monogýnia. Sepals numerous, imbricatc, adnate to the base of the ovarium, united into a short tube at the base: outer ones in the form of an involucrum: inner ones petal-formed. Stamens numerous. Style filiform, multificl at the apex. Berry scaly from the permanent remains of the sepals. Cotylerlons wanting?-Simple, grotesque, fleshy, ovate or globose, ribbed, leafless shrubs, with the labit of Melocáctus; ribs as if they were formed from confluent tubercles, bearing on their back fascicles of prickles. 'I'he woolly head or spadix, which is present in Mclocactus is wanting in this genus. Flowers rising from the fascicles of spines at the tops of the ribs very like those of the genus Cerreus, but the tube is almost wanting.

1 E. GıBвo'sus (D. C. prod. 3. p. 461.) plant ovate or nearly oblong, obtuse; ribs interrupted by tubercles; some of the tubercles rather tomentose at the apes, and tipped with fascicles of stiff straight needle-formed prickles; others in the outer series naked, elongated, and mammæform, and a little conpressed. 々. D. S. Native of Jamaica. Cáctus gibbòsus, Haw. syn. p. 173. bot. reg. 137. Plant nearly like that of Mammillària tubcrculosa, but is not lactescent? Flowers 2, Jarger than any other of the genus, quite at the apex of the plant, which is depressed. The tube of the flower is greenish, and the sepals distant, with a white expansled limb: lobes obovate, rather mucronate, disposed in 4 scrics. Genitals yellow.

Gibbous Hedgehog-thistle. Fl. July, Aug. Clt. 1808. Pl. $\frac{1}{2}$ foot.

2 E. subgibiòsus (Haw, in phil. mag. Oct. 1531, p. 418.) plant roundish-oblong, very spiny, with the spines interworen; angles or ribs about 16 in number, and are, as well as the recesses, profound and acute; fascicles of spines distant. $h_{c}$. D.S. Native near Valparaiso. Plant 5 inclies high, and 3 inches broad, woolly at the base of the fascicles of spines. Spines straight, 12-13 in each fascicle: the lower ones of these are whitish or pale, bristle-formed, nearly half an inch long, horizontal: the 6 upper ones prickle-formed, much larger, nearly ar inch long, bulbous, and yellowish at the base, and rufescent at the apex; the middle spine of the ultimate fascicles compared with the rest is straight.

$S u b$-gibbous Hedgehog-tlistle. Clt. $1830 . \quad$ Pl. $\frac{1}{2}$ foot.

3 E. Nó вIьIs (Haw. in plit. mag. Feb. 1830. p. 1 14.) plant crect, oblong: with many ribs, bevet with numerous, strong, straight, black fascicles of spines. $\zeta$.D. S. Native of Mexico. Cáctus nóbilis, Haw. syn. p. 174. but not of others. Cáctus redúctus, Jink, enum. 2. p. 21. Cèreus redúctus, D. C. prod. 3. p. 463. Plant 3 feet ligh. Fascieles of spines interwoven, imbricating.

Noble Hedgehog-thistle. Cht. 1796. Shrub 9 feet.

4. E. corvigerus (D. C. diss. t. 7.) plant subglobose, very obtuse; ribs atmost vertical, interrupted by tubercles, somewhat depressed: all prickly at the top; prickles unequal, straight, and needle-sliaped : the lower one broad, thick, and a little recurved at the apex. そ. D. S. Native of Mexico. Y 
Cáctus latispinus, Haw. in phil. mag. vol. 63. p. 41. Echinocáctus platycánthus, Link et Otto, diss. p. 14. t. 14. without a flower. Cáctus cornígrcus, Moc. ct Sesse, fl. nex. icon. ined. Flowers 2-3 at the top of the plant ex fl. mex, an inch long, with a short thick tube, and brownish imbricating sepals, with a purplish limb; lobes nearly linear, acute, disposed in one series.

Jorn-bearing Hedgehog-thistle. Clt. 1825. Pl. $\frac{1}{2}$ foot.

5 E. crispa'tus (D. C. diss. t. 8.) plant obovate, retuse at the apex, and rather umbilicate; ribs numerous, from 80 to 60 , nearly vertical, undulately curled, and tubercular; prickles in fascicles, unequal, straightish. h. D. S. Native of Mexico. Cáctus crispàtus, Moc, et Sesse, f. mex. icon. ined. Flowers smaller than any other of the genus, at the top of the plant, purple; sepals denscly imbricated along the tube, oblong-linear, acute, disposed in 2 series in the limb.

l'ar. $\beta$, hórridus (D. C. mem. cact. in mem. mus. 17. p. 115.) fascicles of spines approximate; prickles stronger, more erect and longer, of a greyish brown-colour.

Curled Hedgehog-thistle. Pl. $\frac{1}{2}$ foot.

6 E. orna'tus (D. C. mem. cact. in mem. mus. vol. 17. p. 114.) plant nearly globose: with 8 deep compressed vertical ribs, ornamented with transverse rows of flocky down, with 3 fascicles on each rib; prickles 7 in a fiscicle, straight, yellow, and one central. $\zeta_{2}$. D. S. Native of Mexico. Coulter, no. 40. Plant 5 inches in diameter. Prickles 8-10 lines long.

Ornamented Hedgehog-tlistle. Pl. $\frac{1}{2}$ foot.

7 E. tubercula'tus (Link et Otto, diss. t. 26.) plant nearly globose, with 8 nearly vertical ribs, and with the recesses narrow ; crests very obtuse, tubercled at the fascicles, of which there are 8 or 10 on each rib; areolas when young rather velvety; prickles 12-13 in each fascicle, grey, with one central straight strong one, the rest radiating. h. D. S. Native of Mexico. Coulter. Intervals on the ribs betwcen the fascicles of spines 8-9 lines. Prickles an inch long.

Var. $\beta$, spiralis (D. C. l. c.) ribs twisted spirally to the right. h. D. S. Native of Mexico. Coulter. Perhaps merely an older state of the species.

Tubercled Hedgehog-thistle. Pl. $\frac{1}{2}$ foot.

8 E.? cereirórmis (D. C. l. c. p. 115.) plant nearly cylindrical, green, with about 13 compressed ribs, with the recesses acute, and the crests bluntish; prickles 7 radiating, and one central, in each fascicle, greyish, stiff, slender, with 3 fascicles on each rib. $h$. D. S. Native of Mexico. Coulter. Perhaps a species of Cèreus.

Cereus-formed Iledgehog-thistle. Pl, $\frac{1}{2}$ foot.

5) E. (iLAUCE'scens (D. C. l. c.) plant nearly globose, depressed, glaucescent, with 11-13 vertical compressed obtuse ribs, with 6 fascicles on each rib; areolæ oval-oblong, when young velvety; prickles yellow, straight, with 6-7 radiating ones, and one central one in each fascicle. $々$. D. S. Native of Mexico. Coulter. Flowers solitary on the top of each rib, rising in the front of a fascicle. Scales of calyx imbricated, smooth, oval, acuminated, with membranous ciliated margins. Plant 3 inches ligh, and 5 inches in diameter. Intervals between the fascicles on the ribs half an inch. l'rickles an inch long.

Glaucescent Hedgelıg-thistle. Pl. $\frac{1}{4}$ foot.

10 E. Cous'Ts'u; plant nearly globose, depressed, green, with 13-18 vertical ribs, with both the recesses and ribs acute; fascicles 3 on each rib; arcolæ oval, when young velvety; prickles ycllow, stiff, with 7-8 radiating ones, and one erect central one, which is nearly twice the length of the others, in each fascicle. $h_{\text {. }}$ 1). S. Native of Mexico. Coulter, no. 43. E. lýstrix, 1). C. 1. c. but not of Haw. Plant 5-8 inches in diameter, and 3-4 inches ligls. Prickles an inch long, central ones 2 inches long. Intervals between the fascicles on the ribs 12-18 lines in lengtl.
Coulter's Iledgehog-thistle. Pl. $\frac{1}{3}$ foot.

11 E. obvalla'tus (D. C. diss. t. 9.) plant obovate-globose, depressed and umbilicate at the apex; ribs numerous, vertical ; prickles in fascicles, unequal, divaricate, long; flower solitary at the top of the plant, surrounded by spines. $h$. D. S. Native of Mexico. Cáctus obvallàtus, Moc. et Sesse, fl. mex. icon. ined.-Tepenexcomitl, Hern. mex. p. 410. with a figure. Spines whitish, needle-shaped, diverging, intricate. Flower erect, purple, with the margins of the lobes of the limb white.

Environed-flowered Hedgehog-thistle. Pl. $\frac{1}{3}$ foot.

12 E. TENuspinus (Link et Otto, diss. p. 12. t. 19. f. 1.) plant nearly globose, tumbilicately retuse at the apex ; ribs 1 ? bluntish; prickles in fascicles, slender, recurved, 3 or 4 of which are a little larger than the rest ; flowers girded by wool. $h$. D. S. Native of Brazil, in the province of Rio Grande. Plant green, 2 or 3 inclıes in diameter. Sides of ribs rather impressed. Flowers beyond 2 inches long, yellow; sepals lanceolate, acute ; petals dilated, obtuse, each mucronated by a red bristle. Style 12-15 parted.

Var. $\beta$, minor (Link et Otto, l. c. f. 2.) plant smaller; spines longer and slenderer, and more bent.

Slender-spined Hedgehog-thistle. Pl. $\frac{1}{3}$ foot.

13 E. melocactifórmis (D. C. diss. t. 10.) plant roundishovate, obtuse; ribs vertical, about 30 in number; prickles in fascicles, diverging, unequal ; flowers numerous, in a kind of whorl beneath the apex of the plant. $\zeta$.D.S. Native of Mexico. Cáctus multangulàris, Moc. et Sesse, fl. mex. icon. ined. but not of Willd. Spines brownish. Flowers whitish. Sepals numerous, purplish on the outside, imbricated, and adpressed to the tube; Jimb expanded; lobes oblong, acute, disposed in 2 or 3 series. Stigmas long, 8-12, exserted above the stamens.

Melon-thistle-shaped Hedgehog-thistle. 1'. $\frac{1}{2}$ foot.

14 E. Langsdó Rfi] (Lehm. ind. sem. hort. lamb. 1826, p. 17.) plant oblong, with 17 angles; spines slender, stiff, spreading; vertex of plant very villous and spiny, and bearing flowers. h. D. S. Native of Brazil. Plant green. Fascicles of spines approximating, rising from short wool, central spine in each fascicle an inch long, the 6 marginal ones unequal, reflexed, and spreading. Flowers 2-4, terninal, rising from among wool and spines. Calyx tubular. Petals about 20, yellow. Stigma manyparted, radiate, purple.

Langsdorf's Hedgehog-thistle. Shrub $\frac{1}{4}$ foot.

$\dagger$ The flowers of the following species being unknown, some of them are probably refcrrible to the genus Melocáctus.

15 E. tepiraca'ntius (Link et Otto, diss. p. 13. t. 14. f. 2 ) plant globose, glaucescent, impressed on the top, not tubercled ; ribs 15, acute; prickles 10 in each fascicle, spreading: the 4 central ones the largest. $h$. D. S. Native of Brazil, in the province of Rio Grande. The plant is hardly an inch high, and hardly the same in thickness. Prickles canescent, hardly an inch long. Flowers muknown.

Ash-coloured-spined Hedgehog-thistle. Clt. 1825. Pl. $\frac{1}{8}$ to 1 foot.

16 E. Recu'rvus (D. C. prod. 3. p. 462.) plant roundish, with 15 angles; prickles broad, very numerous. ${ }_{2}$. D. S. Native of Mexico. Cáctus recúrvus, Mill. dict. ed. 8. no. 3. Cáctus nóbilis, Lin. mant. 243. Willd. spec. 2. p. 939. Cáctus multangulàris, Voigt. ex Steud. Prickles of two forms, onter ones expanded, central ones long, brown and recurved at the apex.

Recurred-spined Hedgehog-thistle. Clt. 1796. Pl. 1 foot.

17 E. inтo'rtus (D. C. l. c.) plant oblong, with 13-16 angles; angles twisted like a spire at the apex; prickles middle-sized,

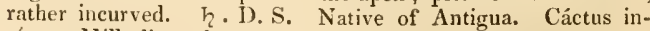
tórtus, Mill. dict. ed. 8. no. 2. Haw, syn. p. 174. 
I'ar. 3 , purpùrcus (D. C. prod. 3. p. 462.) Melocáctus purpùreus, striis in spiram contortis, Plum, spec. 19. mss. vol. $3 . t$. 8. Cáctus nóbilis, Lam. dict. 1. p. 537. Native of St. Domingo. The whole plant is purple, with white prickles. Perhaps a proper species, or a true species of Melocáctus, ex SalmDyck in litt.

Intorted-spined Hedgehog-thistle. Fl. June, July. Clt. 1768. Pl. 1 foot.

18 E. Salma'ves (Link et Otto, diss. p. 14.t. 18.) ribs 1415 , bluntish ; 8 central prickles erect, ray ones 15 , spreading, in each fascicle. $h$. D. S. Native of Curasson. I'lant 4 inches long, and $t \frac{1}{2}$ inches thick, with the furrows narrow. Prickles reddish. Top of plant impressed. Perlaps the same as Melocáctus pyramidilis, but in a young state. Flowers unknown.

Salm-Dych's Hedqehog-thistle. Pl. $\frac{1}{2}$ foot.

19 E. Hx'strix (Haw. in plil. mag. Feb. 1830, p. 115.) plant roundish, usually with 12 angles; spines straight, an inch and a half long, fulvous, much longer than the wool from which they rise. 々. D. S. Native of the West Indies. Cáctus hýstrix, Haw. suppl. p. 73. Cèreus hýstrix, Sweet. Flowers unknown. Like $E$. Salmiànus, but differs in the plant being more oblang, and in the spines being much fewer.

Porcupine Hedgehog-thistle. Clt. 1S08. Pl. $\frac{1}{2}$ foot.

20 E. тuhercula'tus (Link et Otto, diss. p. 16. t. 26.) plant nearly globose, green, depressed at the top; ribs 8 , bluntish; fascicles with 3 central straight prickles, and 7 spreading, rather recurved ray ones, which become gradually smaller from the centre. h.D. S. Native of Mexico. Plant 4 inches high, and $3 \frac{1}{2}$ inches thick, with the furrows narrow. Central prickles of the fascicle an inch long, the ray ones gradually decreasing in length. Flowers unknown.

Tubcrculated Hedgehog-thistle. Pl. $\frac{1}{4}$ to $\frac{1}{2}$ foot.

21 F. cladis'tus (Link et Otto, diss. p. 17. t. 17.) plant oval-oblong, glaucescent, depressed at the apex; ribs 14-22, bluntish; prickles $10 \mathrm{in}$ each fascicle, 8 central ones the largest, flattened, and elongated: middle one of the 3 erect: ray ones spreading much. Ћ., D. S. Native of Mexico. Plant 5 inches high, and 4 inches thick. Prickles canescent, crowded at the top, larger ones 2 inches long. Flowers unknown.

Gladiate-spined Hedgehog-thistle. Pl. $\frac{2}{2}$ foot.

22 E. subul'ferus (Link et Otto, diss. p. 16. t. 27.) plant subglobosc, green, not depressed at the apex; ribs $8-10$, blunt, tubercled; central prickles large, erectish, recurved, and 4-5 spreading, and the 4-6 outer ones, divaricate, and slender, in each fascicle. $h$. D. S. Native of Mexico. Plant $2 \frac{1}{2}$ inches high, and 2 inches thick, with the ribs evidently composed of conflated tubercles. Prickles hoary brown; the larger ones 2 inches long, and the smaller ones about 4 lines long. Flowers unknown.

An'-bearing Hedgehog-thistle. Pl. $\frac{1}{8}$ to $\frac{1}{3}$ foot.

23 E. DEPRE'ssus (D. C. prod. 3. p. 463.) plant nearly globose, depressed at the apex; ribs vertical, about 20 in number, obtuse, and somewhat tubercled; fascicles of prickles crowded; prickles rising from fascicles of white tomentum, stiff, very pale brown : central ones in each fascicle $3-4$, and $10-12$ ray ones: the lower onc of these very strong. $h$. D. S. Native of South America. Melocáctus? deprêssus, Salm-Dyck in litt. Cáctus depréssus, Haw. syn. 173.?

Depresscd Hedgehog-thistle. Clt. 1798. PI. $\frac{1}{4}$ foot.

24 E. orthaca'nthus (Link et Otto, diss. p. 18. t. 18.) top of plant depressed; ribs 18 , bluntish; prickles 7 in each fascicle : the central one of these strong, larger, and straight: the rest sprealing. $\zeta_{\xi}$. D.S. Native of Monte Vidleo. Plant $2 \frac{1}{2}$ inches in diameter, with narrow furrows. Prickles canescent: the larger ones 9 lines long, and the rest about 5 lines long. Flowers unknown.
Straight-spined Hedgelog-thistle. PI. $\frac{1}{4}$ to $\frac{1}{2}$ foot.

25 E. Akcus'tus (Link et Otto, diss. p. 15. t. 23.) plant subylobose, glaucescent, not depressed at the apex; ribs 20 , arched; prickles 7 in each fascicle, spreading, and recurved. h. D. S. Native of Monte Video. Plant $S$ inches higl, and $2 \frac{1}{2}$ thick, with broad furrows. Sides of ribs not impressed. I'rickles of a hoary fucesccnt colour, 4-6 lines long. I'lowers unknown.

Archcd-ribbed HIcdgehog-thistlc. I'1. $\frac{1}{4}$ foot.

26 E. Parvisitinus (D.C. prod. 3. p. 468. Haw, in plail. mag. Feb. 1830. p. 11\%.) plant ncarly glolose, umbilicate at the apex; ribs 15, compressed; prickles small, white, fulvous at the apex, rising from white tomentum, $7-9$ in each fascicle: the central one of these straight, and the ray ones $6-8$ in number, and a little recurved. $\quad$. D. S. Native of South America. Melocáctus parvispìnus, Haw. suppl. 73. Salm-1)yck in litt. Flowers unknown. Very like E. mconacínthus, Link et Otto.

Small-spincd Hedgelog-thistle. 11, $\frac{1}{4}$ foot.

27 E. Intrica'tes (Link et Otto, diss. p. 19. t. 2.4.) plant oval, green, with a depressed tubercled top; ribs 20, bluntish; fascicles of prickles crowded, $18-20$ in each fascicle : the 4 central ones of these larger and erect, the rest spreading, outermost ones divaricate. $h_{2}$. D. S. Native of Monte Vidco. Plant 4 inches high, and $3 \frac{1}{2}$ thick. Sides of ribs depressed. Prickles of a hoary-fuscescent colour: the larger ones 8 lines long. Flowers unknown.

Intricate Hedgelog-thistle. Pl. $\frac{1}{3}$ foot.

28 E. meonaca'́nthus (Link et Otto, diss. p. 19.t. 15.) plant oblong, glaucescent, with the top depressed ; ribs 14, arched; prickles 9 in each fascicle, short and straight, and one central. h.D.S. Native of Jamaica. Plant $6 \frac{\mathrm{T}}{2}$ inclies ligh, and $4 \frac{1}{2}$ broad; ribs usually bent. Prickles yellowish, rising from short wool, 4 lines long. The form of the plant is elongated, and like that of a crecping Cèrcus. Flowers unknown.

Less-spined Hedgehog-thistle. Pl. $\frac{1}{2}$ foot.

29 E. denuda'tus (Link et Otto, pl. rar. liort. berol. t. 9.) plant subglobose, green, with 6-8 bluntish ribs; spines $5-8$ in each fasciclc, all spreading; involucrum with few leaves. $\zeta$. D. S. Native of Brazil.

Naked Hedgehog-thistle. Pl.

30 E. Tortudsus (Link et Otto, pl. rar. hort. berol. t. 15.) plant nearly globose, depressed at the top, green, with 4 arched ribs; the 4-6 middle spines in each fascicle a little larger and thicker than the rest, which are numerous, but all are nearly cqual, spreading, and twisted. $h_{c}$. D. S. Native of Brazil.

Twistcd-spined Hedgehog-thistle. Pl.

31 E. erina'ceus (Haw. in phil. mag. Feb. 1830, p. 114.) plant globular, usually with 14 angles; spines inclining, 9 lines long, numerous, somewhat recurvedly divaricate, fulvous, shorter than the wool from which they originate; fascicles of spines approximate. $\quad$. D. S. Native of South America. Cactus erinàceus, Haw. suppl. p. 74. Very like Melocíctus polyacánthus, Link et Otto, in form, but differs from it in the number of the angles, and in the absence of the woolly flowering top; but the fascicles of spines are nearly similar.

Erinaceous Hedgehog-thistle. F1. June, Aug. Clt. 1818. Pl. $\frac{1}{2}$ foot.

+ The two following specics from their habit in a sccdling state appcar to belong to the present genus, but arc not described; they are in the gardens of Edinburgh and Glasgow under the name of Càctus, and have bccn brought from Chili.

1 E. corrugìta, Gill. mss. 2. E. foliòsa, Gill. mss.

Cult. See Mammillària, p. 160 . for culture and propagation. Grotesque plants, with the habit of the last genus.

$$
\text { Y } 2
$$


IV. CEREUS (from eereus, pliant; in reference to the slioots of some of the species). D. C. cat. hort. monsp. 1813. Haw, syn. 173. Salm-1) yck in hitt. D. C. prod. 3. p. 463.

Lix. srst. Icosindria, Monogínia. Sepals very numerous, imbricated, adnate to the base of the ovarium, united into an elongated tubc; outer sepals the shortest, forming the calyx, middle ones longer and coloured, innermost ones petal-formed. Stamens very numerous, united with the tube. Style filiform, multifid at the apex. Berry areolate, tubercular or scaly, either from the remains of the sepals, or from their cicatrices when they have fallen off. Cotyledons wanting? - Fleshy grotesque shrubs, with a woody axis, and medulliferons inside; angles vertical, bearing fascicles of spines, regularly furrowed. Angles or wings either numerous or very few. Flowers large, rising from the fascicles of spines or indentures on the angles.

$\$ 1$. Cereás'ri (an alteration from the generic name). Plants standing without support, never throning out roots. Stems upright.

\section{* Stems with many angles.}

1 C. multangula'ris (Haw, suppl. 75.) stem erect, with 18-20 angles; angles very close, blunt; prickles setaceous, yellow, longer than the wool from which they rise. $\hbar_{c} . D$. S. Native country and flowers unknown. Cáctus mulangulàris, Willd. enum. suppl. 33. Perhaps the same as Cáctus Kagenèkii, Gmel. ex Silm-Dyck in litt.

Many-angled Torch-thistle. Clt.1815. Shrub 1 foot.

2 C. scòpa (Salm-Dyck in litt. ex D. C. prod. 3. p. 464.) plant erect; stem with 30 vertical tubercled angles; fascicles of prickles crowded, rising from tufts of white tomentum : ray prickles setaceous, very numerous and white : central ones $3-4$,

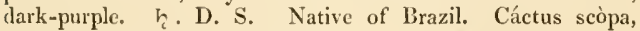
Link, enum. 2. p. 21. Spreng. syst. 2. p. 494. Plant clothed with short, stiffish, setaceous prickles.

Broom Torch. thistle. Shrub 1 foot.

3 C. seníls (Salm-Dyck in litt. ex D. C. prod. 3. p. 464.) plant erect, somewhat club-shaped; stem with 20.25 vertical tubercled ribs; fascicles of prickles crowded, naked at the base, each fascicle containing 15-20 radiating hair-formed curled bristhes, and a straight stiff central spine. $r_{c}$. D. S. Native of Mexico. Cáctus senilis, Haw. in phil. mag. vol. 63, p. 41. Cáctus brádypus, Lehm. ind. sem. hort. hamb. 1825. p. 17. This is a very singular plant, covered all over with dense hairlike bristles; it is of an oblong shape, about 3 inches high, of a greyish-colour, bent, and hanging, like the grey head of an old man, hence the specific name.

Old-man 'Torch-thistle. Clt. 1823. Shrub $\frac{1}{4}$ foot.

4. C. Lana'tus (II. B. et Kunth, nov. gen. amer. 6. p. 68.) stems erect, branched, with many angles, and clothed with white wool; angles membranous, tubercled, and beset with stellate fascicles of prickles; ccntral prickle 8-times longer than the rest. $\quad$. D. S. Native of Quito, near the rivers Aranza and Guamcabamba. Stem 10-12 feet ligh. Central prickle of each lascicle 1 or $1 \frac{1}{2}$ inch long. Flowers rising from lateral and longitudinal fissures of the stem, involved in wool. Fruit obovate, red, with a whitish green-coloured pulp.

Woolly 'l'orch-thistle. Shrub 10-15 feet.

5 C. micracánthus (D. C. mem. cact. in mem. mus. 17. p. 115.) plant dividing into many stems at the base, ovate-oblong, greenish, obtuse, with 13 vertical bluntish ribs, with the recesses broad, but hardly acute; fascicles of spines approximating, with tomentose arcola ; prickles 3 in each fascicle, short, setaceous,

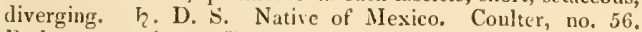
Perhaps a species of Echinocíctus. Plant hardly an inch high and the same in thickness.

Small-spined Torch-thistle. Pl. 1 inch.
6 C. pozyuòphus (D. C. I. c.) plant quite simple, erect, green, cylindrical, with 15-18 vertical ribs, and with the furrows acute; crests rather repand; fascicles of prickles approximating, with the young areolæ convex and tomentose; prickles $8-9$ in each fascicle, yellow, straight, diverging, but the central one is long and erect. 2 . D. S. Native of Mexico. Coulter, no. 15. Plant 30-40 feet in height, without any branch, according to Coulter.

Many-crested Torch-thistle. Shrub 30 to 40 feet.

7 C. Link11 (Lehm. ind. sem. hort. hamb. 1827. p. 16.) plant oval, green, with 13 angles; ribs ohtuse, bearing flowers at the top from the axils of the fascicles of spines; 3 central spines in each fascicte erectly spreading, and the 10 ray ones slenderer, much more spreading; stigmas $8 . h_{2}$. D. S. Native of Mexico. Calyx half an inch long, beset with greenish yellow scales, which are furnished with purple bristles and white cobwebbed wool. Petals numerous, truncate at the apex, yellow, with purple bases. Style yellow. Stigmas purple.

Link's Torch-thistle. Cht. 1828. Shrub $\frac{1}{2}$ foot.

8 C. LE' ссни (Coll. hort. ripul. append. 5.t. 2. under Cáctus) plant ovate, tapering to the apex, with numerous blunt angles; fascicles of spines approximate, woolly at the base ; spines white: ray ones spreading: central one long and straight. $\eta$. D. S. Native of South America.

Lecche's Cereus. Clt.? Shrub I foot.

$$
\text { * Stems with 6-12 angles. }
$$

9 C. hexago'nus (Willd. enum. suppl. 32.) plant simple, erect, large, usually with 6 strong ribs ; fascicles of spines middlesized; prickles short, hrown. $\mathrm{T}_{\mathrm{c}}$. D. S. Native of South America. Cáctus hexagònus, Lin. spec. 1. p. 667. Andr. bot. rep. t. 513. Cáctus Peruviànus, D. C. pl. grass, t. 58.-Bradl. succ. 1. p. 1. t. 1. The plant is about 40 feet high, usually without any branches, varying with $5-6-7$ angles. Flowers solitary: 6 inches long; having the sepals along the tube greenish and irregularly imbricated ; limb a little expanded, reddish outside and white inside. Stamens greenish. Fruit dark purple, according to Plumier.

Jar. F, abnórmis (Willd. enum. suppl. 31.) stem simple, oblong, irregularly furrowed, and tubercled; tubercles oblong, compressed, unequal, bearing prickles at the apex, and rather woolly. h. D.S. Native of South America. C. Peruviànus $\beta$, monstròsus, D. C. cat. hort. monsp. diss. t. 11 . Flowers twin, nearly as in $C$. hexagonus, but more expanded and larger, with the outer sepals reddish, but the inner ones are pure white and serrated; tube striated with green on the outside. Stigmas $9-13$, greenish.

Hexagonal 'T'orch-thistle. Fl. Jul. Aug. CIt. 1690. Tr. $40 \mathrm{ft}$.

10 C. Otrónis (Lehm. ind. sem. hort. hamb. 1827. p, 16.) plant oval, green, attenuated at the base, with 10 angles; ribs obtuse, bearing the flowers above from the fascicles of spines; 4 central spines in each fascicle, and 10-14 slender, spreading ray ones; stigmas $14 . h_{\imath}$. D. S. Native of Mexico. Calyx tubular; scales acute, greenish yellow, furnished with a fascicle of purple hairs, and white, cobwebbed wool. Petals numerous, erosely serrated at the apex, rather diaphanous, yellow. Style yellow. Stigmas purple.

Otto's Torch-thistle. Clt.? Slirub $\frac{1}{2}$ foot.

11 C. Peruvianus (Haw. syn. 171.) plant large, erect, with usually 8 angles or ribs; angles blunt, smooth, glaucous; spines whitish, rising from white tomentum, the lower one very small, and the central one very strong. $\zeta$. D. S. Native of Peru and Curassoa. Cáctus Peruviànus, Lin. spec. 667. Willd. enum. suppl. 32. Cèreus ebuirneus, Salm-Dyck, in cat. hort. Dyck. 18?2. Cáctus Coquimbànus, Molin, chil. ed. gall. p. 140. ex 
Bertol, virid. bon. 18:4. p. 4.- Bradl. suec. t. 12.-Lol, icon. 2. 1. 25.- Ilor. oxon. sect. 17. t. 37. Like C. hexagomus, but differs in being clotherl with glaucous bloom.

Var. 3 , monsiròsus (Salm-Dyck, 1. c.) ribs nearly olsliterated; fascicles of prickles spirally confluent.

Peruvian T'orch thistle. Fl. Aug. Clt. 1728. Tr. 20 feet.

12 C. nertagònus (Iaw, syn. 178.) plant erect, oblong, 7angled. h. D. S. Native of South America. Cáctus heterogònus, Lin. spec. 666. hort. eliff. 181. The plant is said lyy Linneus to be 1-2 feet high. Pelhaps distinet from $C$. hexagònus and $C$. striatus. Flowers white.

Seven-angled Torch-thistle. Fl. Jul. Clt. 1728. Sl., 1 to $2 \mathrm{ft}$.

13 C. Gaandispinus (Haw, in pliil. mag. feb. 1830. p. 111.) plant 8-angled; prickles nearly 3 inches long; flowers campanulate, without a tube; fruit globose, spiny. h. 1). S. Native of St. Domingo.-Plum. amer. t. [95. f. 2. Iarge, bluntly angled. Spines subulate, $12-13$ in a fascicle. Petals obtuse, lanceolate, serrated.

Great-spined Torch-thistle. Slirub large.

14 C. Serrulirlòrus (Haw. I. e.) plant 8-angled; bristles half an inch long; petals 5 -times shorter than the tube; fruit rather conieal, large, scaly, unarmed. $\zeta$. D. S. Native of St. Domingo.-Plum, amer. t. 195. f. 1. Large, bluntly angled. Bristles about 20 in each fascicle; fascicles remote. Petals narrow, lanceolate, serrulate, hardly an inch long, but the tube is $4 \frac{1}{2}$ inches long, and sealy. Very like $c$. hexagonus, but the spines are more numerous, longer, and slencterer.

Serrulatcd-petalled 'Torch-thistle. Shrub large.

I5 C. mosoctònos (D. C. prod. 3. p. 464.) plant tall, erect, with 8 angles; angles blınt, compressed; spines stellate, nearly equal; petals emarginate at the apex. h. D. S. Native of the Caribbee Islands.-Dlum. ed. Burm. t. 191. exclusive of the synonymes. Plumier has himself made his plant the same as C. Peruviànus, but by Linnæus it bas been referred to $C$. hexagònus, but it differs from both these species, in the petals being bluntly emarginate at the apex, and nearly obcordate. Limb of flower spreading. Style exserted; stigma 5-cleft. The name is derived from povos, monos, alone, and kilovos, klonos, a noise ; but the application is not evident to us.

Confused Torch-thistle. Shrnb 20 feet.

16 C. Fimnria'tes (Lam. dict. 1. p. 539. under Cáctus) plant tall, erect, bluntly 8 -angled; prickles setaceous, white; flowers with a short tuhe; petals fringed. $h_{c} . D$. S. Native of $S t$. Domingo, in arid woods.-Plum. ed. Burm. t. 195. f. 1. Stem the thickness of a man's leg, and about 18-25 feet high. Flowers rose-coloured, campanulate, with few jetals. Stamens very numerous; stigma multifid. Fruit globose, red, size of an orange, beset with prickly tubercles; flesh red.

Fringed-petalled Torch-thistle. Shrub 18 to 25 feet.

17 C. HÝstaix (Salm-Dyck. in litt. ex D.C. prod. 3. p. 4.61.) plant ereet, green, shining, 9-angled; ribs rather compressed; prickles rising from grey tomentum, with 9 radiating ones, 2 small upper ones, and 3.4 strong, central ones, which are painted with white and brown. h. D. S. Native of South America? Cáctus hýstrix, Salm-Dyck. obs. hot. 1822. Oid prickles grey, blackish at the apex. This is difterent from Cáctus la'tus of H. B. et Kunth, and from C. hystrix, Haw.

Poreupine Torch-thistle. Shrub.

18 C. FE'rox (Haw. in phil. mag. 1830. feb. p. 107.) plant oblong, nearly terete; with usually 8 ribs; spines clivaricate, brown, dense. h. D. S. Native of Brazil. Plant firm, green, thickly beset with horned spines, and of these there are usually 6 outer radiating ones, $4-5$ middle ones, and 1 long central one in each fascicle.

Fierce Torch-thistle. Clt. 1827. Shrub 1 foot.

19 C. gaíseus (Haw. syn. 182.) plant erect, longish, usually 8-angled, deeply furrowed, branched at the base; prickles when old half an inch long, white, hut tipped with black. h. U. s. Native of South Ameriea. The rest unknown.

(irey-spined 'Torch-thistle. Clt. 1809. Shrub 3 to it fect.

20 C. CuENLL.'TEs (Silm-1)yck, olss. bot. 182.) plant erect, greyish green, with $8-9$ angles; rihs blunt, crenulated ; prickles white, rising from grey tomentum, blackish at the apex, 9 in each fascicle, radiating and equat, and 1 loner central one. h. D. S. Native of South America. C. Royeni, Willd. suppl. enum. p. 32. Stem rather woolly at the apex; wool grey, at length falling oft:

Iar. $\beta$; plant rather slenderer than the species; and the prickles are shorter. Salm-Dyck, in litt.

Crenulated 'Torch-thistle. Clt. 1728. Shrub 2 to 3 feet.

21 C. cinera'seens (D. C. mem. eact. in mem. mis. 17. J) 116.) plant simple, erect, grcyish green; with 8 blunt tubereular ribs, and narrow recesses; areolee while young conves and velvety; prickles 14 in each fiscicle, white, setaceous, stiff, outer 10 ratliating, central 4. erectly diverging, and longer than the ray ones. 5 . D. S. Native of Mexico. Coulter, no. 23. Stem 6 inches high, and 2 inches in diameter. Outer prickles 6.9 lines long: central ones 12 lines long; in fascicles, which are 5-6 lines distant from each other.

Iar. $\beta$, crássior (D. C. ]. c.) stem thicker; fiscicles of spines more distant.

lar. $\gamma$, tcnùior (D. C. I. c.) stems slenderer ; ribs more approximate. Very like C. pentalophus, but differs in being $S$ angled, not 5 -angled.

Greyish Torch-thistle. Clt. 1830 . Shrub $\frac{1}{2}$ foot.

22 C. calve'scens (I. C. I. c.) plant simple, or a little brancherl at the apex, erect, green, obtuse, and rather umbilicate at the apex, with 7-8 vertical, obuse rihs, and acute furrows; areola, while young, convex and tomentose, but at length becoming nearly glabrous; prickles $8-9$ in each fascicle, brown, stiff; diverging: the central ones hardly to he distinguished fron the outer ones. そ. D. S. Native of IIexico. Coulter. Very like C: Per'viànus. Fascicles of spines 6-9 lines distant from each other.

Calescent Torch-thistle. Shrub 8 to 10 fect?

23 C. margina'tus (D. C. l. e.) plant simple, or a little? branched at the apex, crect, green, obtuse at the tip: with 7 vertical ribs, and acnte recesses; crests obtuse, woolly their whole length from white tomentum, in consequence of the oval arcolæ being confluent; prickles $7-9$ in a fascicle, stiff, grey, short: with the central ones bardly to be distingui-hed from the ray ones, $\zeta$. D. S. Native of Mexico. Coulter, no. 1:\%. Stem $2 \frac{1}{2}$ and 3 inches in diameter. Prickles $1-2$ lines long, A very distinct species.

Margined Torch-thistle. Shrub.

24. C. ALBispi'x Us (Salm-I)yek, obs. bot. 1822.) plant crect, greyish green, with 9 or 10 angles; ribs obtuse, very prickly; prickles grey, tipped with yellow, rising from grey tomentun, 11 radiating ones and $t$ central in each fascicle. $h_{\imath} .1$ ). . Native of South America. Very like $C$. crcnulitus, but more slender and more woolly. Old plant ouly woolly at the apex, but the young plant all over; the wool grey. Salm-Dyck, in lit.

IThite-spincd Torch-thistle. Shrub 2 to 3 feet.

25 C. REgAlis (Haw. suppl. p. 75.) plant erect, 9-angled, furrowed ; spines fulvous, elongated, when young about equal in length to the wool. $z$. J). S. Native of South America. Fascicles of spines mucli crowded.

\section{Royal Torch-thistle. Clt.? Slırub 10 feet.}

26 C. stríctus (Willd. enum. suppl. 13. 32. under Cáctus,) plant erect, "reen, shining, $7-9$-angled; ribs rather compressed repand; prickles brown, rising from brown tomcntum: each fascicle composed of 8 radiating ones, a small superior one, and 3 central ones, which are much longer than the rest. $19 . .2$. Native of South America. 'There is hardly any wool at the ton? of the stem; the rest muknown. Salm-Dyck. in litt. 
Slraight Torch-thistle. Clt. 1822. Shrub 3 to 4 feet.

27 C. IIAwóntun (Spreng. syst. 2. p. 495. under Cáctus) plant erect, large, 5-angled, with profound furrows: spines numerous, usually an inch long, brown. h. D.S. Native of the West Indies. C. nóbilis. Ilaw. syn. 17\%. This species is more formidable than the rest in the prickles being very large and numerous. The rest unknown. The Cáctus nóbilis, Lin. Haw. and Lam. are very different from each other, and constitute 3 distinct species.

Haworth's Torch-thistle. 1811. Shruh 3 to 4 fect.

28 C. Au'neus (Salm-Dyck. in litt. ex D. C. prod. 3. p. 465.) plant erect, green, 7 -S-angled; rilss compressed, very prickly; prickles yellow, rising from straw-coloured tomentum, with 8 radiating ones in each fascicle, and some central longer ones. h. D. S. Native country and flowers unknown. Difters from $C$. IIanorthii, in the prickles being yellow, and in their fascicles boing more closely crow ded.

Golden-spined T'orch-thistle. Shrub.

29 C. Niger (Salm-Dyck. hort. dyck. cat. 1822.) plant erect, blackislt, 7 -angled; ribs rather compressed; prickles slender, fulvous, rising from white tomentum : with 7 radiating ones in cach fascicle, the 3 lowest of these longer than the rest, and 2 or 3 central ones, the lowest one very short. h. D. S. Native of South America. Cáctus niger, Spreng. syst. 2. p. 495. Cèrcus niger, I Iaw, rev. 70 . Said to be allied to $C$. repándus. Top rather woolly; wool grey.

Black Torch-thistle. Cit. IS20. Shrub 2 to 3 fcet.

30 C. rulvispisòsus (Haw. syn. 183.) plant erect, tall, usually 9-angled, simple or branched; prickles strong, yellowish, when full grown nearly an inch long. $h$. D. S. Native of South America. Cáctus lioyèni, Milil. dict. ed. 8.

Tanney-spined Torch-thistle. Clt. 1796. Slurub 3 to $4 \mathrm{ft}$.

31 C. Nuavispines (Salm-Dyck. obs. bot. 1822.) plant erect, pale green, 8.10-angled; ribs rather compressed; prickles slender, yellowish, rising from white tomentum: with 8 radiating ones in cach fascicle, the upper ones of these very small, and 3-4 central ones, the upper one of these erect and very long. h. 1). S. Native of South America. Perlaps the same as ' favispinus of Colla, hort. rip. p. 24. Stem hardly woolly at the apex; wool grey. There is a variety of this species with 6angled stems and longer prickles. Salm-Dyck. in litt.

Yellom-spined Torch-thistle. Clt.? Shrub 2 to $S$ feet.

3: C. Cintorissis (Colla, pl, rar. hort. ripul. app. 2. p. 342.) plant ovate, ercet, 10-angled; angles blunt; prichles pale, pellucid, middle one of each fascicle the strongest; wool very short. 々. D. \&. Native of Chili. C. Coquimbàuts, Hort. but not of Molin.

Chiloc Torch-thistle. Shrub.

33 C. EUmornoides (Ilaw. suppl, p. 75.) plant ercet, usually 10-angled; angles strong; spines unequal, nearly naked at the base. I?. D.S. Native of tropical America. There are 3 middle-sized spines, 2 about 2 lines long, and 1 about 7 lines long in each fascicle.

Spurge-like Torch-thistle. Clt. ? Shrub 2 to 3 fcet.

3. C. liorrisi (Ilaw, syn. p. 102.) plant erect, bluntly 9angled; spines a little longer than the wool, from which they issue: floral tube unarmed: outer lobes acuminated, inner oncs the shortest. $h_{c}$. D. S. Native of the West Indies. Cáctus Royèni, Lin. spec. 668.-Royen, lugd. bat. 279.-D. C. pl. grass. t. 143. C. lanuginòsus, Mill, dict. no. 7. Floral tube greenish. Calyeine lobes rufescent; inner or corolline ones the longest, acuminated, and white. Stigmas 12. Fruit red, according to IIerm.

Royen's Toreli-thistle. Clt. 1728. Slurub 3 to 6 feet.

35 C. Lanvginosus (Haw. syn. 189.) plant erect, bluntly 8-9angled ; spines shorter than the wool from which they issue. h. D. S. Native of the West Indies. Ilerm. lugd. bat. par. t. 115. without a flower. C. repándus, Mill. diet. ed. 8. Cáctus lanuginosus, Lin. spec. 667. The fruit, according to Herm., is red, not spiny.

Hoolly Torch-thistle. Fl. Jul. Clt. 1690. Sh. 1 to $2 \mathrm{ft}$.

36 C. REPA'NDUs (Haw, syn. 183. D. C. diss. t. 13.) plant long, erect, with 8-9 blunt angles; angles rather undulated; spines longer than the wool from which they issuc; floral tube, and consequently the fruit, is unarmed: outer lobes of calyx narrow and much acuminated, almost exceeding the inner ones in lengtl. h. D. S. Native of the Caribbee Islands. Cáctus repándus, Lin. spec. 667 . Ker. bot. reg. t. 336 . Cèreus gràcilis, Mill. dict. ed. 8. no. 8.-Trew. ehret. t. 14. Tube of flower green; inner calycine or corolline lobes white. Stigmas 8-10. Fruit yellow, white inside.

Repand Torch-thistle. Fl. May. Clt. 1728. Sh. 10 to $20 \mathrm{ft}$. 37 C. subrepa'Novs (Haw. suppl. 78.) plant erect, with 8 angles; angles compressed, repand; prickles strong, of a pale colour; wool very short. 5. D. S. Native of the IVest Indies. Very distinct from $C$. erenatus.

Sulrepand Torch-thistle. Clt. 1817. Shrub 2 to 4 feet.

38 C. E'tujops (Haw. in phil. mag. feb. 18\%0. p. 108.) plant erect, bluntly 8 -angled; angles short; fascicles of spines very black, as well as the short central wool. $\eta_{\text {. }} \mathrm{D} . \mathrm{S}$. Native of Brazil. Very like C. repándus, but much more dwarf and simple, and very green ; with about $I 2$ spines in each fascicle. This is a singular plant, from its black spines and black beardlike terminal brush.

Black-spined Torch-thistle. Clt. 1829. Shrub.

39 C. polygònus (Lam. dict. 1. p. 539. under Cúctus) plant erect, branched, with 11 blunt angles, woolly at the apex; prickles setaceous, grey; flowers short, with the limb hardly spreading. h. D. S. Native of St. Domingo.-Plum, ed. Burn. t. 196. Flowers whitc. Fruit reddish brown, tubercled; flesh reddish. Stem 10 feet ligh, and 6-7 inches in diameter. This species is allied to $C$. repéndus, according to Lamarck, but Spreng. has joined it with $C$. griseus.

Many-angled Torch-thistle. Shrub 10 feet.

40 C. Mágnus (Haw. in phil. mag. feb. 1830.) plant very strong, simple, with usually 12 deep furrows, and as many ridges; spines unequal, very stiff, dark. $h$. D. G. Native of St. Domingo. Spines about 12 in each fascicle ; fascicles rather distant. Flowers large, white.

Large Torch-thistle. Clt. 1829. Shrub 3 to 4 feet.

41 C. dovarica'tus (Lam, dict. 1, p. 540. under Cáctus) plant ercet, branched, very spiny, and bluntly 10 -angled ; branches spreading. $\subsetneq$. D.S. Native of St. Domingo.-Plum. ed. Burm. t. 193. llowers lateral, hardly known. Fruit globose, golden yellow, warted by large points, or unarmed; pulp white and sweet.

Divarieatc Torch-thistle. Shrub.

4.2 C. chloroca'rpus (H. B. et Kuntl, nov. gen. amer. 6. p. 68.) plant erect, branched; branches fastigiate, 10-12-angled; angles tubercled; tubercles beset witl starry prickles; central prickle in each fascicle 4 times longer than the rest. $h_{\imath} . D . S$. Native of South America.

Green-fruited Torch-thistle. Shrub 10 feet.

49 C. Lz'tus (H. B. et Kunth, l. c.) plant erect, pale green, jointed; joints 7 -angled; angles tubereled, each tubercle furnished with a fascicle of spines. I2 . D. S. Native of Quito, near Sondorillo. The rest unknown.

Fruilful Torch-thistle. Shrub.

\section{* * Stems with 3-4 or 5 angles, very rarely with 6 angles.}

44. C. virens (D. C. mem. cact, in mem. mus. 17. p. 116.) plant simple, erect, pale green, with 5 vertical, obtuse ribs; fascicles of spines remote, having the areola velvety when young; 
prickles 8 in each fascicle, 4 of which are stiff, conical, and greyish, or blackish, 3 very short and diverging, and 1 large and horizontal. 々. D. S. Native of Mexico. Coulter. Largest prickle in each fascicle 8-10 lines long, smaller ones liardly 2 lines long.

Green Toreh-thistle. Shrub.

45 C. Anisacántius (D. C. 1. c.) plant simple, erect, deep green; ribs 5-6, with the furrows and crests both acute; fascicles of spines crowded, having the areolae convex and relvety while young; prickles 10-20 in each fascicle, setaccous, yellowish, stiff, very unequal, onter ones liverging. h. D. S. Native of Mexico. Coulter.

Iar. a, urthotopus (D. C. 1. c.) stems with 6 vertical ribs ; prickles 10 in each fascicle.

Far. $\beta$, subspirilis (D. C. l. c.) stems with 5, rather spirally twisted ribs; prickles 20 in each fascicle.

Unequal-spined Torch-thistle. Shrub.

46 C. PENTalòphus (D. C. I. c. p. 117.) plant crect, greyish green, obtusc; ribs 5 , vertical, obtuse ; fascicles of spines approximate, having the areola velvety when young; prickles $5-7$ in a fascicle, setaceous, diverging, when young very pale yellow, but grey in the adult state. $h$. D. S. Native of Mexico. Dr. Coulter subjoins the 3 following varicties to this species, which may probably hereafter turn out as many distinct species.

Iar. $a$, simplex (D. C. l. c.) stem simple, not rooting; ribs rather prominent ; furrows broad and obtuse; prickles white.

Var. $\beta$, subarticulàtus (D. C. l. c.) stem branched, a little articulated, but not rooting ; ribs irregular, rather repand; furrows narrow; prickles yellowish while young.

Var. $\gamma$, radicans (D. C. l. c.) stems rooting; ribs broad, short; prickles yellowish while young.

Five-crested Torch-thistle. Shrub.

47 C. GRA'NDis (Haw. suppl. p. 76.) plant large, exactly tctragonal, simple, erect; prickles usually an inch long, divaricate, almost interwoven among each other. $h$. D. S. Native of Brazil. The rest unknown.

Great-spined Torch-thistle. Clt. ? Shrub 3 to 4 feet.

48 C. Tetragònus (Haw. syn. 180.) plant tall, erect, usually 4-angled; angles compressed. h. D. S. Native of South America. Cáctus tetragònus, Lin. spec. p. 666. Angles plaited transversely (ex Spreng). Flowers white.

Tetragonal Torch-thistle. Fl. Jul. Clt. 1710. Sh. 4 to $6 \mathrm{ft}$.

49 C. Paxicula'tus (Lam. dict. 1. p. 540. under Cáctus) trunk erect; branches forming a kind of panicle at the top of the trunk, tetragonal, articulated at the base; spines short, in fascicles; petals rounded at the apex. $\eta$. D. S. Native of St. Domingo, in wild places.-Plum. ed. Burm. t. 192. Flowers white, lined with red. Fruit tubercled, yellow. Perhaps this species is referrible to Jamaciru prima, Maregr. bras. p. 125. f. 2 . but the figure given by him is too rude to determine this point.

Panicled Torch-thistle. Shrub.

50 C. Pitaja'ya (Jacq. amer. 151. under Cáctus) trunk erect; branches trigonal; spines in fascicles. $\zeta$. D. S. Native of Carthagena, in bushy places by the sea-side. Flowers opening in the night, white, 8 inches long. Fruit scarlet, shining, size and form of a hen's egg; pulp white. Pitajaya is the vernacular name of the plant.

Pitajaya 'Torch-thistle. Shrub.

51 C. undulòsus (D. C. prod. 3. p. 467.) trunk crect, very spiny, and is as well as the branches trigonal; spines in fascicles, black; limb of flowers spreading. h. D. S. Native of St. Domingo. Plum. ed. Burm. t. 194. Cáctus Pitajàya $\beta$, Lam. dict. 1. p. 539. Prickles 2 inches long. Flowers whitc, bealltiful. Fruit greenish yellow, about the size and form of an apple; pulp white.
Undulated Torch-thistle, Shrub.

52 C. oztu'sus (Haw. rev. p. 70.) plant ereet, pale green, triangular; ribs blunt; fascicles of prickles very remote; prickles tawny, rising from brown tomentum: with 4 radiating ones in each fascicle, and a central, elongated erect one. $h . \mathrm{D}$. S. Native country and flowers unknown.

Blunt-angled 'lorch-thistle. Clt. 1820. Shrub 4 to 6 feet.

53 C. Jamaca'ru (D. C. prod. \&. p. 467.) plant erect; branches 3-4-angled; prickles in fascicles, straights; flowers eylindrical, with an erect limb; genitals inclosed. $\zeta$. D. s. Native of Brazil. Jamacàru, Pison, hist. nat. bras, p. 100. f. 1. T'runk triangular, beset witl spines. Flowers white, scentless. Fruit red, size of a goose's egg. l'crhaps Jamaciort quäta species Maregr. hist. nat. bras. p. 127. f. 3 . is the same or a distinct species.

Jamacaru Torch-thistle. Shrub.

54 C. va'Lidus (Haw. in phil. mag. sept. 1831. p. 418.) plant tetragonal, firm, glaucous at the apex, with the sides nearly flat, or rather convex at first, with the angles very blunt and spiny in the middle. 2 . D. S. Native of South America. Spines brownish.

Strong Torch-thisile. Shrub.

\$2. Scrpcntini (from serpo, to crcep); stems ereeping and rooting). D.C. prod. 3.p. 467. Stems jointed, prostrale, rooting or twining.

\section{- Stems with many angles.}

55 C. serpentivus (Lag. anal. se. nat. 1801. p. 261.) plant creeping, flexuous, and somewhat climbing, with 11-12 very blunt angles; bristles in fascicles, much longer than the wool from which they issue, but which at length falls off; floral tube very bristly at the base. $\curvearrowleft . D$. S. Native of South America. Willd. enum. suppl. 31. Link, et Otto, abbild. t. 91. D. C. diss. t. 12. Flowers large, beautiful; lobes bluntish; outer ones greenish : middle ones purplish : inner ones white. Stigmas 7. This plant appears to hold a kind of middle station between the erect and creeping species of the genus, and rarely throws out roots from its stems. Bristles $7-8$ lines long, purplish, also crowded at the base of the floral tube.

Serpentine Torch-thistle. Clt.? Shrub 3 to 4 feet.

56 C. TUNicA'tus (T,ehm, ind, sem. hort. hamb. 182\%. p. 16.) plant erectish, articulately branched; joints attenuated at the base, tubercular; tubercles impressed at the apex, woolly ant bearing spines ; spines coated by a somewhat diaphanous, moveable membrane. $h_{\imath}$. D. S. Native of Brazil. Joints terete when young, $1 \frac{1}{2}$ inch long, furnished with fleshy, subulate leaves, which become at length deciduous.

Coatcd-spined Torch-thistle. Clt.? Shrub $\frac{1}{2}$ to $I$ foot.

57 C. An Bíguos (Bonpl. nav. t. 36. under Cáctus) plant erect, with 9-12 blunt angles; bristles spinescent, longer than the wool from which they issue; floral tube bearing bristles at the base. h. D. S. Native country unknown. Flowers very like those of $C$. serpentinus, of which it is probably only a variety, differing only in the stem being more erect, and in the bristles being shorter.

Ambiguous 'Torch-thistle. Slırub 2 to 3 feet.

58 C. TLAGELIfórmis (Mill, dict. ed. 8. no. 12. Haw, syn. 158.) stems prostrate, with about 10 angles: tubercles crowded, bearing bristles; style rather shorter than the petals. 5. D.S. Native of South America, and is now to be found in the Arabian deserts, but has been probably introduced there. Cíctus flagellifórmis, Lin. spec. 688 . Curt. bot. mag. t. 17 . D. C. pl. grass. 127. This species is very common in gardens, and has trailing stems, unless supported, which are therefore easily trained to any kind of trellissing. The flowers are so beantiful, and are produced in such profusion, that the plant is worth being conveyed 
into the house whilst in flower, to adorn any of the rooms: they are red or pink.

Ilagelliform Torch-thistle or Creeping Cereus. Fl. Mar. Ju. Clt. 1690. pl. trailing.

59 C. Le'ptopns (I). C. mem. cact. in mem. mus. 17. p. 117.) plant crecping a little, cylindrical, with $7-S$ very blunt, rather repand rilss; arcole velvety, but convex in the adult state; prickles $12-13$ in eacl, fascicle, stiffish, yellow, radiating, having the 2 or 3 eentral ones erectish. $h_{\imath}$. D.S. Native of Mexico. Conlter, no. 82. Habit of $C$. flagellifórmis, but 3 times slenderer.

Slender Torch-thistle or Creeping Cereus. Clt. 1830. Pl. pr.

60 C. Hunzóldtil (H. B. et Kunth, nov. gen. amer. 6. p. fi6. under Cáctus) stems procumbent, with 10 or 12 ribs, glabrous; :ugl's tubercled; tubercles bearing stiff bristles; style much acceding the corolla. b. D. S. Native about Quito, in fields hetwecn Somblorillo and San Felipe. Said to be very like $C$. flagelliförmis. Flowers red.

Ilumboldl's Tordh-thistle or Creeping Cereus. Shrub pr.

61 C. Icosigònus (H. B. et Kunth, 1. c.) stems procumbent, simple, usually with 20 angles; angles bearing fascicles of bristles: style lenirth of petals, 8 -cleft at the apex. $h$. D.S. Native of Quito, in dry places near Nabon. Accorling to the authors, this plant is sulficiently distinct from the foregoing. Flowers white.

Tnenly-angled Torch-thistle. Shrub proc.

62 C. SE'rum (H. B. et Kunth, l. c.) stem erect, with II angles; angles bearing fascicles of prickls ; stamens and style about equal in leng h, but excecding the corolla a little; stigna 8-parted. F. D. S. Native of Quito, in sandy places, rear Riombamba, at the foot of XI unt Chimborazo, where it is called Pitahaya by the natives. According to the authors this species is sufficiently distinct from $C$. Humbóldtii. Flowers rose-coloured. Fruit red.

Iledgre Torch-thistle. Shrub 6 feet.

63 C. Carire'ssts (1I. B. et Kunth, I. c.) stems in fascicles, elongated, creeping, branched, somewhat tetragonal; angles tubcrcled; cach tubercle bearing a fascicle of stellate bristles. $h_{c}$. D. S. Native of New Andalusiat, near Caripe, growing on rotten wood. Very like C. flagellifórmis in habit, but both the flowers and fruit are unknown, and therefore the place which it sloukl occupy in this genus is doubtful.

Caripe 'lorch-thistle. Shrub creeping.

\section{* * Stems with 5 or 6 angles.}

6.t. C. Grandflòus (Mill, dict. eł. 8. no. I1. IIaw, syn. 184.) stems rooting, diffuse, climbing, 5-6-angled; bristles 5-8 in cach fascicle, hard!y longer than the down from which they proceed. h. D. S. Native of the West Inclia Islands, and in many parts of the main land of South America. Cáctus grandiflörus, Lin spec. p. 668. D. C. pl. grass. t. 52. Andr. lot. rep. t. 50s.-Mill. lig. t. 90.-Trew ehret. t. 31,32 - Tolk. hesp. 1.t. 23t. I'his species, when of sufficient strength, will produce many excceding lirge, beautiful, sweet-scented llowers, lihe those of most wf the species of very short duration, hardly continuing 6 hours full blown, nor do the flowers ever open again when once closed. They begin to open between 7 and 8 o'clock, in the cvening, are fully blown by 11 o'clock, and by 3 or 1 o'clock in the morning they fade, and hang do in quite decayed; but during thuir short continuance there is harlly any flower of greater beauty, or that makes a more magnificent appearance; for the calyx of the flower, when ojx -1 , is near a foot in diameter, the inside of which being of a splenclid yellow colour, appears like the rays of a briglit star, the outside is of a dark brown; the petals being of a pure white add to the lustre; the vast number of recurved stamens in the centre of the flower, make a finc appearance: add to all this, the fine scent, which perfumes the air to a considerable distance; there is scarcely any jlant which deserves a place in the hot-house so much as this, especially as it may be trained against the wall, where it will not take up any room. The flowers make a most magnificent appearance by candle-light, sometimes there may be 6 or 8 flowers open upon one plant at the same time; and there will be a succession of them for several nights together, provided the plant is large and healthy.

Great-flowered Torch-thistle or Night-flowering Cereus. Fl. June, Aug. Clt. 1700 . Shrub cl.

65 C. spinulòsus (D. C. mem. cact. in mem, mus. 17. p. 117.) plant a little branched, creeping, and climbing somewhat, nearly terete, with 5-6 hardly exserted, acutish ribs, and with broad, bluntish furrows; areole, when young, velvety; prickles 8 in eacl fascicle, very short, stiff, when young yellowish, but afterwarls becoming brownish, the lateral ones radiating. $\zeta . \mathrm{D} S$. Native of Hexico. Coulter, no. 27. Habit of the stems like those of $C$. grandiflorus, but the prickles are very different.

Spinulose Torch-thistle. Shrub el.

66 C. Pentagònus (Lin. hort. cliff. p. 182.) plant erect, jointed, slender, pale green, 5 -angled; ribs repand; prickles naked at the base, nearly equal, slender, straw-coloured, with 5-6 radiating ones in each fascicle, and 1 central one. h.D.S. Native of South America. Cáctus pentagònus, Lin. spec. 666. Haw. syn. 180. rev, 77. Salm-Dyck, in litt. C. prismáticus and C. reptans, Willd. enum. suppl. 32. This is a very polymorphous species, varying with 3-4-5 angles, sometimes much compressed, and sometimes the angles are nearly obliterated. The plant never throws out lateral roots. Flowers large, white. Pentagonal-stemmed Torch-thistle. Fl. July. Clt. 1769. Shrub 3 feet.

67 C. Radicans (D. C. prod. 3. p. 468.) plant prostrate, jointed, pale green, with $3-5$ angles; prickles stiff, slender, rufors, naked at the base, with 6-9 racliating ones in each fascicle, and 1 central one, which is rather elongated. $\eta$. D. S. Native of South America. Cáctus réptans, Salm-Dyck, in litt. not Willd. It differs from $C$. pentagonus in the stems being prostrate and rooting, not ercet.

Rooting Torch-thistle. Shrub creeping.

68 (. нu'mlis (D. C. prod. 3. p. 468.) plant jointed, divaricate, rooting, green, with 4 or 5 angles; ribs much compressed and repand; fascicles of prickles crowded ; prickles about equal in length to the white tomentum from which they arise: $8-10$ radiating white bristle-formed ones in each fascicle and 3 stiffish straw-coloured, contral ones. 5 . D. S. Native country and flowers mnknown. C. gràcilis, Salm-Dyck. in litt. but not of Haw. Plant humble, with the joints a little elongated and divaricating, deeply furrowed.

Humble Torch-thistle. Shrub.

69 C. Aleisitòsts (Haw. rev. 77.) plant creejuing, green, with 5 angles; prickles bristle-formed, white, stellately expanded, shorter than the rufous wool from which they arise. $h$. D. S. Native of st. Domingo. The rest unknown.

Hhite-bristled Torch-thistle. Clt. 1816 . Shrub creeping.

$$
\text { ** * Stems with 3-4angles. }
$$

70 C. QUadrangula'ris (Haw. syn. p. 181.) plant creeping, 3-1-angled; angles hardly channelled; spines $5-7$ in each fas. cicle, Jardly stellate. $\zeta$. D. S. Native of the West Indies. -Plum. cil. Burm. t. 199. f. 1. Flowers white, opening at night, beautiful, and sweet-scented.

Quadrangular T'orch-thistle. Clt. 1809 . Shrub creeping.

71 C. Trit'Teris (Salı-Dyck. in litt. ex D.C. prod. 3. p. 468.) plant jointed, erectish, rooting, green, 3-4-angled; ribs much compressed, rather repand; fascicles of spines crowded, with 8 radiating oncs in each fascicle, and 3 stiffish central ones. 々. D. S. Native country unknown. It differs from C. gràcilis, 
to which it is nearly allied, in the stems bcing for the most part $\$$-angled, rarcly 4 -angled, and never 5 -angled, in being norc erect, and in the joints being longer and broader, as if they were winged, and also in the prickles bcing longer.

Three-vinged Torch-thistle. Clt.? Shrub.

72 C. speciosíssimes (Desf. mem. mus. 3. p. 190, t. 9. under Cáctus) plant erect, 3.4 -angled; angles toothed; prickles subulate, straight, rising from whitc tomentum ; limb of flower expanded; genitals declinate. h. D. S. Native of Mcxico. Cáctus speciòsus, Cav hort. madr. Willd. enum. suppl. p. 31. Colla, hort. rip. t. 10. but not of Bonpl. Cảetus speciosissimus, Ker. bot. reg. 486. herb. amat. t. 391. Flowers large, of a beautiful scarlet colour, somewhat violaceous inside. Genitals white. This is a most splendid plant when in flower, and is now very common in the gardens.

Var. $\beta$, bifrons (Haw. suppl. p. 76.) plant dwarfer, more decumbent, and throwing out more roots.

Iery shomy Torch-thistle. Fl. July, Aug. Clt. 1816. Sh. 3 to 6 feet.

73 C. triangula'ris (Haw. syn. p. 180.) plant creeping, trigonal; prickles short, 4 in a fascicle, somewhat decussate. $h$. D. S. Native of Mexico. Cáctus triangulàris, Lin. spec, 666. Lam. dict. 1. p. 541. Sims, bot. mag. 1884. Cáctus triangulàris aphýllus, Jacq. amer. p. 152.-Plum. ed. Burm. t. 200. f. 1. -Bradl. succ. pl. 3. without a flower. Flowers grcenish on the outside, and white inside, larger than any of the species. Fruit naked, scarlet, size and form of a goose's egg.

Var. B, májor (D. C. prod. 8. p. 468.). Native of St. Helena.

Var. $\gamma$, pictus (D. C. l. c.) variegated with yellow.

Triangular Torch-thistle. Fl. July, Aug. Clt. 1690. Sh. 1 to 2 feet.

74. C. uxpa'tus (Haw. in phil. mag. nov. 1829. p. 109.) plant large, climbing, triangularly furrowed; joints large, rather lobulately crenated, sometimes like a chain. $\zeta$. D. S. Native of China. Very like $C$. triangulàris, but much larger; and the branches are greener and more radicant. Fascicles of spines small.

Waved Torch-thistle. Clt. 1828. Shrub cl.

75 C. SE'TIGER (Haw, in phil. mag. nov. 1829. p. 108.) plant erectish ; branches few, quadrangular ; fascicles containing about 20 spines each, 3 or 4 of which are linear, radiating, and nearly

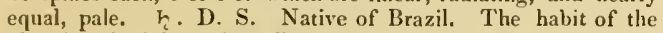
plant is referrible to Stapèlia astèrias, but taller and the angles more concave; wool at base of spines short.

Bristle-bearing Torch-thistle. Clt. 1828. Shrub.

76 C. Trieveter (Haw. syn. 181.) plant jointed, erectisl, rooting, green, triangular; angles repand, with the fascicles of prickles remote; prickles rising from fuscous tomentum, ray ones setaceous and deciduous, central 3-4, stiff, short, and fulvous. $\quad$. D. S. Native of South America. C. prismáticus, Desf. hort. par. Prickles dirty yellow, 2-3 lines long, rising from short tomentum. Stem 5-6 feet high, branched. Flowers unknown.

Triquetrous-stemmed Torch-thistle. Clt. 1794. Shrub 5 to 6 feet.

77 C. Tenuspisus (Haw, in phil. mag. feh. 1827. p. 125.) plant weak, branched, somewhat articulated, climbing and rooting; branches very slender and triangular; bristles very slender, bent, wool-formed. $h_{c}$. D. S. Native country unknown, but probably in some part of South America. Bristles in crowded interwoven fascicles along the angles of the stems, which they lide. Perhaps the same as $C$. Myosisus.

Slender-spined 'Torcls-thistle. Clt. 1826. Slirub 1 foot.

78 C. Trigònus (Haw. syn. 181.) plant creeping, triquetrous ; angles hardly channelled; prickles $5-7$ in a fascicle, stellate. 々. D. S. Native of the West India Islands. Cảctus triqueter VoL. III. ß, Haw. misc. nat. 199.-Plum. ed. Burm. t. 200. f. 2. Cáctus triangulìris foliòsus, Jacq. amer. 152. ex Lam. dict. 1. p. 541. Flowers white (ex Plum.) and the fruit of a violaccous scarlet colour; but the fruit, according to Jacquin, is of a shining scarlet colour; there are therefore probably two species confused under this name.

Trigonal-stamened 'T'orch-thistle. Clt, 1809. Shrub el.

79 C. prismáticus (Salm-Dyck. in litt. but not of Willd. ex D. C. prod. 3. p. 469.) plant articulated, crectish, rooting, green, triangular; ribs repand; fascicles of prickles crowded; prickles nearly equal, fulvous, rising from fuscous tomentum, 7 radiating ones and 2 or 3 central ones in each fascicle. $h$. D.S. Native country unknown. Plant slenderer and more humble than $C$. triqueter; prickles smaller and more numerous; and the fascicles are inore crowded.

Prismatic Torch-thistle. Clt. 1818 . Shrub cr.

80 C. coccíneus (Salm-Dyck. in litt. ex D. C. prod. 3. p. 469.) plant with long joints, rooting, deep green, triangular; ribs compressed, repand; prickles rising from yellow tomentum, radiating ones few, pilose, white, and 4 rather recurved, stiff, fulvous, central ones in each fascicle. 5 . J). S. Native of Brazil, among rocks on the mountains. Flowers said to be numerous, large, and scarlet.

Scarlet-flowered Torch-thistlc. Clt.? Shrub cr.

S1 C. ExTE'Nsus (Salm-Dyck, in litt. ex D.C. J. c.) plant with long joints, rooting, green, triangular; ribs repand; prickles rising from fulvous tomentum; radiating ones pilose, whitish, 10-12 in each fascicle, and 2-4 small, stiff, yellowish, central ones. h. D. S. Native country unknown. Perhaps only a variety of the preceding, but less spinose. Joints much extended, and while young margined with red; and with the prickles and hairs rose-coloured.

Extended Torch-thistle. Clt. ? Shrub cr.

82 C. squanulòsus (Salm-Dyck. in litt. ex D. C. 1. c.) plant erect, jointed, rooting a little, green, triangular ; ribs much compressed, repandly crenated, furnished with an ovate acute scale, and numerous white hairs in the crenatures. $\zeta . \mathrm{D} . \mathrm{S}$. Native of Brazil. This is a very singular plant, with the sides of the joints 2 inches broad, and 4-toothed at the angles, and for the most part margined with red; teeth as in Stapelia, furnished each with a marcescent scale or leaf. Flowers small, solitary, when dried permanent, yellow ; petals 6-8, acute. Style filiform, 8-cleft at the apex. Fruit unknown.

\section{Scaly Torch-thistle. Clt.? Shrub 1 to 2 feet.}

83 C. seta'ceus (Salm-Dyck. in litt. ex D. C. l. c.) plant jointed, erect, rooting a little, deep green, triangular; ribs rather compressed, somewhat repand; hairs rising from white tomentum, with $7-9$ radiating ones in eacl fascicle, and in the middle of each fascicle is a central soft prickle. $h$. D. S. Native of Brazil.

Bristly Torch-thistle. Clt. ? Shrub 1 to 2 feet.

84 C. Mrosu'rus (Salm-Dyck. in litt. ex D. C. I. c.) plant rather articulated, erect, rooting a little, slender, margined with red, 3-4-angled; ribs crenulated, furnished with pencil-like fascicles of white hairs at the crenatures. $\zeta$. D. S. Native of Brazil. Sicles of stem hardly 3 lines broad. Pili long, erect, especially on the young branches. The rest unknown.

Mouse-tail Torch-thistle. Shrub.

85 C. TE'Nuis (D. C. prod. 3. p. 469.) plant low, climbing, acutely trigonal, with some roots issuing from the sides; hairs in fascicles along the angles, clongated, soft and adpressed; flowers sessile, usually with 5 sepals and 5 petals. そ. D. S. Native of Brazil. Cáctus tènuis, Schatt. ined. Flowers small, rose-coloured, hardly open, rising from among the fascicles of hairs; tube very short.

Slender Toreh-thistle. Clt? Shrub.

$$
\text { Z }
$$


8 3. Opuntidcei (plants laving the habit of Opuintia). D. C. prod. 3. p. 470 . Stems coniposed of globose joints, horrific from direrging prickles. Floners tubular. Style much exserted, multifid at the apex. Perhaps a proper genus, intermcdiate betncen Cìreus and Opintia?

86 C. Monilizórmis (Lin. spec. 668. under Cáctus) plant diffusely procumbent, much branched; joints globose; prickles strong, diverging. দ. D. S. Native of St. Domingo. Plım. ed. Burm. t. 198. Cáctus monilifórmis, Lam. dict. 1. p. 541. Flowers and fruit red; floral tube elongated, as in Cìreus; limb short, sprearing. Style much exscrted. Stigmas 8-10, spreading.

Neeklacc-formed Torch-thistle. Shrub procumbent.

87 C. SE RPENS (H. B. et Kunth, nov. gen. amer. 6. p. 68. under Cáctus) plant creeping, branclsed, rather angular; areolæ 6-angled, prickly at the apex; Howers tubular. h. D. S. Native of Quito, on dry hills on the banks of the river Guancabamba, near Sondorillo. Flowers flesh-coloured; petals 8-12, acnte; stigmas 8 , approximate. Perhaps a species of Opúntia.

Crecping Torch-thistle. Shrubcr.

88 C. Na'Nus (H. B. et Kunth, 1. c. under Cáctus) plant creeping and jointed; joints terete, rather compressed, areolate, prickly, a little branched. $\%$. D. S. Native of Quito, near Sondorillo, on the banks of the Guancabamba. The rest unknown.

Dwarf Torch-thistle. Shrub proc. 2 to 3 inclses.

89 C. GRA'crLss (llaw, in phil. mag, feb. 1827. p. 126.) plant erectish, nearly tcrete; old spines solitary, straight, an inch long, but at first twin or more, white. $h$. D. S. Native of South America. Plant with the habit of Euphórbia hystrix, but less spiny and the spines shorter. It appears to be more nearly allied to $C$. nànus than to any other species.

Weak Torch-thistle. Clt.? Shrub.

+ The following species are in the gardens, but nothing is known of them but the names.

1 C. rosùccus, Hort. berol. 2 C. Déppii, Hort. berol. $3 C$. incrustàtus, Hort. berol. 4 C. exérens, Hort. berol. $5 C$. aff inis, Hort. berol. $6 \mathrm{C}$. proteifórmis, Hort, par. $7 \mathrm{C}$. Colvílli, Sweet. 8 C. ovàtus, Gill. (under Cáctus). 9 C. polymórphus, Gill. (under Cáctus).

Cult. The same kind of soil recommended for Mammillaria, p. 160. will answer the species of this genus; and they are casily propagated by cuttings, which if left to lie a few days after being separated from the mother plant, strike root readily. In order to have several species on one tree, insert them in a plant of Peréskia.

V. EPIPHY'LLUM (from $\varepsilon \pi \iota, e p i$, upon, and $\phi v \lambda \lambda o v$, phyllon, a leaf: flowers rising from the flat branches, which appear like leaves). Herm. par. bat. add. (ex Dill.). Haw. syn. succ. p. 197. phil. mag. aug. 1829, p. 108.-Phyllárthus, Neck. elem. 1. p. 85. Cèreus, \$3. Alàta, D. C. prod. 3. p. 469. Cáctus species of Lin. and others.

LıN. syst. Icosándria, Monogýnia. Tube of corolla very long, middle-sized, or very short, furnished with remote, unarmed scales, rising from the crenatures of the branches, among small innocuous spines. Limb of corolla fugaceous, deeply multifid, and as if it were polypetalous, rosaceous or more or less of a ringent form. Branched, slender, hardly climbing subshrubs, natives of South America, growing among rocks or on the trunks of old trees; branches much compressed, 2edged, thin but fleshy, lobately crenated, green, smooth; with a slender, woody, central axis. lilowers solitary, usually large and showy, white, rose-coloured, or scarlet, rarely sweet-scented.
The branches towards the roots are rather angular. The rest as in Cèreus, of which perhaps it is merely a section.

Sect. I. Noctu'na (from nocturnus, nightly, or in the night ; in reference to the time at which the flowers expand). Haw. in phil. mag. aug. 1529. p. 107. Corollas fugaceous, sweet-scented, white, expanding alone at night ; tube very long.

1 E. PHylla'Nthus (Haw, syn. 197.) corolla small, much shorter than the tube, which is nearly a foot in length; stigmas 10. そ. D.S. Native of South America, in Brazil, Guiana, Surinam, Guadaloupe, \&c. Cáctus phyllántlus, Lin. spec. 670. D. C. pl. grass. t. 145. Opúntia pliyllänthus, Mill. dict. no. 9. Cèreus phyllántlıus, D. C. prod. 3. p. $46 \%$-Dill. elth. t. 64 . f. 74 . Flowers white, 9-12 inches long, expanding at night, sweet-scented.

Leaf-flowering Epiphyllum. Fl. Ju. Clt. 1810. Sh. 1 to $3 \mathrm{ft}$.

2 E. Hooxe'Rı (Haw. l. c.) corolla micldle-sized, much shorter than the tube, which is about half a foot long; stigmas usually 13. h. D. S. Native of South America. Flowers white, sweet-scented. Cáctus phyllánthus, Hook. bot. mag. 2692. Flowers white, sweet-scented.

Hooker's Epiphyllum. Fl. June, July. Clt. ? Sh. 2 feet.

Sect. I1. Diu'RnA (from diurnus, belonging to the day-time; in allusion to the time of the blossoms expanding). Haw. in phil. mag. aug. 1829. Corollas scentless, open day and night; tube middle-sized or very short.

3 E. phyllanthoides (Haw. 1. c.) corolla large, rosaceons; tube middle-sized, shorter than the oblong-lanceolate petals; stigmas 7. দ. D. S. Native of Mexico. Cáctus phyllánthoides, D. C. cat. hort. monsp. 1813. p. 84. Sims, bot. mag. 2092. D. C. prod. 3. p. 469. Cáctus speciòsus, Ker. bot. reg. 304. Bonpl. nav. t. 3. Epiphýll. speciòsum, Haw. suppl. p. 84. Cáctus élegans, Link, enum. 2. p. 25. Cáctus alàtus, Willd. enum. suppl. 35.-Hern. mex. 292. f. 3. and t. 457.Pluk. phyt. t. 247. f. 5. Flowers pale rose-coloured, 4 inches long, scentless. Branches flat, without any spines in the notches except when young.

Phyllanthus-like or Common Epiphyllum. Fl. June, July. Clt. 1810. Slurub 1 to 3 feet.

4. E. VANDE'sil (Hortul.) branches flat or triquetrous, with no spines in the notches, except when young, when there are a few small ones at the base; branches rather convex. $\zeta$. D. S. A hybrid raised in the garden of the Count de Vandes at Bayswater, from the seed of $E$. phyllanthoides, impregnated by the pollen of Cèreus spcciosissimus. The flowers are large, and of a deep red colour, and, upon the whole, it may be considered the most splendid of the genus.

Count De I'andes' Epiphyllum, or Hybrid Cactus. Fl. June, July. Hybrid shrub.

5 E. JENKinsònII; branches round or triquetrous at the base, but always flat at the apex, with the notches more prominent and spiny than in any other species of the genus; the branches are likewise more convex and firm. Ђ.D.S. A liybrid, raised from the seeds of Cercus speciosissinus, impregnated by the pollen of Epiphýllum speciòsum. Cáctus Jenkensonii, Hortul. The flowers of this hybrid are large, and of a deep scarlet-colour, and are said even to outvie in splendour those of $E$. $I_{\text {andèsii. There }}$ are several other hybrids now in various gardens, raised from the same parents as the present plant, which may prove even superior in splendour to any of the genus, but they have not yet flowered.

Jenkinson's Epiplıyllum or Hybrid Cactus. Fl. Ju. July. Hybric. Pl. 2 to 3 feet.

6 E. oxype'talum (Haw. l. c.) tube of flower length of the acuminated lobes; flowers sessile; fruit nerved longitudinally. 
h. D. S. Native of Mexico Cèreus oxypétalus, D. C. prod. 3. p. 470. Flowers 4 inches long, reddish brown on the outside, and white inside. Berry red, oblong, ribbed, attenuated at both ends. Branches like those of E. phyllanthoides.

Sharp-petalled Epiphyllum. Shrub 2 to 3 fect.

i E. A LA'Tum (IHaw. suppl. p. 84.) corolla small, greenislı white; tube very short; berry blackish. $h^{2}$ D. S. Native of Jamaica, on the trunks of trees. Cèreus álatus, D. C. prod. 3. p. 470. Cáctus alàtus, Swartz. $f$. ind. occ. 878 . Link. enum. 2. p. 24. exclusive of the D. C. syn.

Hinged Epiphyllum. Fl. June. Clt. 1810. Sh. 1 to $2 \mathrm{ft}$.

8 L. AKernánni (Haw. in phil. mag. Aug. 1829.p. 108.) corolla large, rather ringent, assurgent before expansion, and acute at the apex, nearly 4 times longer than the tube; stigmas \%. h. D. S. Native of Mexico, from whence it was brought by a Mr. Akermann. Cáctus Akermánni, Hortul. Flowers large, scarlet. Petals keeled, a little recurved at the apex. Branches flat, thin, seldom with any spines in the notches except when young.

Akermann's Epiplyyllum. Fl. June, July. Clt. 1829. Shrub 1 to 3 feet.

9 E. crispattum (Haw. in plil. mag. Feb. 1830. p. 109.) branches cuneate-oblong, waved; margins appearing curled from large crenatures. $\quad$. D. S. Native of Brazil. Flowers not seen.

Curled-branched Epiphyllum. Clt. 1829. Shrub 1 to $2 \mathrm{ft}$.

10 E. TRUNCA'tum (Haw. suppl.p. 85, et in phil. mag. vol. 4. p. 188.) corolla reflexed, ringent; tube very short; branchlets dichotomous, truncate at the apex. $\zeta_{2}$. D. S. Native of South America. Cáctus truncàtus, Link. enum, 2. p. 24. Ker, bot. reg. 696. Sims, bot. mag. 2526. Hook. exot. fl. t. 20. Lodd. bot. cab. 1207. Cèreus truncàtus, D. C. prod.3. p. 470. Flowers rising from the truncate tops of the branches, red or rose-coloured, hardly 3 inches long, oblique ; stamens white, ascending; stigmas 7 , closely conniving. Joints of stem compressed. This species appears to be an intermediate plant joining Epiphýllum with Opúntia. It is a very elegant plant when in blossom.

Truncate Epiphyllum. Fl. July, Sept. Clt. 1818. Slırub 1 foot.

Cult. The species of Epiphyllum are extremely showy when in flower. Their culture and propagation are the same as that rccommended for the last genus. They are known at first from all the other genera of this order by their flat elongated branches.

VI. OPU'NTIA (some species grows plentiful near Opus, a city of Locris). Tourn. inst. 239. t. 122. Mill. dict. Haw. syn. 187. D. C. prod. 3. p. 471.-Tùna, Dill. hort. elth. f. 379. and 383.-Cáctus Opúntia, Willd. enum. suppl. p. 33. D. C. cat. hort. monsp. Link, enum. 2. p. 23.

Lis. syst. Icosándria, Monogýnia. Sepals numerous, leafformed, adnate to the ovarium: upper ones flat and short: inner ones petal-formed, obovate, rosaccous, expanded: without any tube above the ovarium. Stamens numerous, shorter than the petals. Style cylindrical, constricted at the base; stigmas many, thick, erect. Berry ovate, umbilicate at the apex, tubercled, and usually bearing spines. Embryo rather spiral, nearly terete. Cotyledons semi-terete (ex Gærtn. fruct. 2. t. 198.), after germination becoming foliaceous, and flat, but thickish. (see Dill. elth. f. S81.) Plumule small.-Shrubs, with the trunk at length becoming terete, but having the young branches very rarely cylindrical, but usually more or less compressed, and jointed; joints ovate or oblong, bearing fascicles of spines or bristles, which arc disposed in a quincuncial or spiral order. Leaves nearly the form of those of some species of Sèdum, but fall off very soon, one under each fascicle of spines or bristles on the branches when young. Flowers rising from the fascicles of spines or bristles, or from the edges of the joints, either yellow or reddish. Stamens rather irritable to the touch.

Sect. 1. Cylindra'cex (from cylindraceus, like a roller; in allusion to the cylindrical branclies). D. C. prod. 3. p. 471 . Stems cylindrical, neitler jointed, nor furrowed, but bearing areolate convex tubercles, and fascicles of prickles. The species of this section are not sufficiently known, or probably they would have constituted an intermediate genus betwcen C'ereus and Opúntia.

1 O. nòsea (D. C. diss. t. 15.) plant erect, rose-coloured; stems and branches tubercular; tubercles oblong, depressed, disposed in spiral series, bearing each at the apex a caducous leaf, and a fascicle of straight white prickles; flowers nearly rotate, usually by fours at the tops of the branches. $\zeta$. D. S. Native of Mexico. Cáctus subquadriflòrus, Moc. et Sesse, fl. mex. icon. ined. This is an anomalous species, as from the stems it agrees with Cèreus tuberculòsus, and from the rotate flowers it agrees with Opintia. Flowers flesh-coloured. Fruit white. Leaves terete, acute, soon falling off.

Rose-coloured Indian-fig. Shrub 2 to 3 feet.

2 O. CYLI'NDRICA (D. C. prod. 3. p. 471.) plant erect; stem and branches tubercular, areolate; tubercles rlıomboid, bearing each a caducous leaf, and a few white prickles. $\eta$. D. S. Native of Peru. Flowers unknown. Cáctus cylindricus, Lam. dict. 1. p. 539. but not of Ort. Cèreus cylíndricus, Haw. syn. 183.

Cylindrical-branched Indian-fig. Clt.1799. Sh. 2 to 3 feet.

3 O. iмвrica'ta (D.C. prod. 3. p. 471.) plant erect, terete, not furrowed, but superficially ribbed, and rather lobe-formed, somewhat imbricately tesselated in various ways. h. D. S. Native country and flowers unknown. Cèreus imbricàtus, Haw. rev. 70. Allied to $O$. cylindrica, but more robust according to Haworth, but according to the Prince de Salm-1yck it is slenderer.

Imbricate-tesseled Indian-fig. Clt. 1820. Shrub 2 to 3 feet.

4 O. stape'Lie (D. C. mem. cact. in mem. mus. 17. p. 117.) plant branched, irregularly tufted, deep green; joints ovate or oblong; areolæ small, tomentose in the axils of the tubercles; prickles $5-6$ in a fascicle, stiff, straw-coloured, setaceous, when old the epidermis or coat separates from them. h. D.S. Native of Mexico. Coulter, no. 38. Stem hardly an inch high. Habit almost of Stapèlia caspitosa, but which is without prickles.

Stapelia-like Indian-fig. Clt. 1830. Shrub 1 to 2 inches.

5 O. ExuviA'TA (D. C. 1. c. p. 118.) plant branched, erect, nearly terete; branches furnished with compressed tubercles, and irregular crests, so as to make them nearly pentagonal; areolæ orbicular, velvety at the axils of the tubercles; prickles 6-12 in a fascicle, stiff, straiglit, when old the epidermis separates from them. $\zeta$. D. S. Native of Mexico. Coulter, no. 18. Cáctus tunicàtus, Hort. berol. ex Salm-Dyck. Trunk a foot higl, and 18 inches thick.

Tar. $\beta$, angústior (D. C. l. c.) trunk slenderer; prickles fewer; areolæ narrower. Coulter, no. 17.

Var. $\gamma$, spinòsior (D. C. l. c.) stem dwarf; prickles longer and more numerous, and more spine-like.

Stripped Indian-fig. Clt, 1830 . Shrub 1 foot.

6 O. vecípiens (D.C. l. c.) plant erect, branched, green ; branches cylindrical, attenuated at the base; tubercles few spirally disposef; areolæ small; prickles of two forms, the lower one large and spreadingly deflexed : the rest, 3-4 in number, bristle-formed and radiating. $\eta$. D. S. Native of Mexico. Coulter, no. 20. Leaves small, ovate-oblong, deciduous. Large prickle an inch long, whenold the epidermis separates from it. The rest 1-2 lines long. Compare it with 0 . cylindrica. 22 
Dcceiving Indian-fig. Clt. 18s0. Slirub 2 to 3 feet.

7 O. KLEINı (D. C. l. c.) plant erect, branched, greyish grcen; branches crect, cylindrical, without tubercles; fascicles disposed in a spiral manner to the left; areolæ velvety; prickles of two forms, with numerous bristle-formed whitish brown ones in each fascicle, and one large spreadingly deflexed slender white one at the lower side of the fascicle. $\zeta$. D. S. Native of Mexico. Coulter, no. 21. Stem more than a finger in thickness, like the stem of Cacìlia Kleinice. Leaves small, oblong, deciduous. Large prickle an inch long.

Kleinia-like Indian-fig. Shrub 1 to 2 feet.

8 O. LEPTOCAU'LIS (D.C. l. c.) plant erect, branched; branches cylindrical, erect, without tubercles; fascicles disposed in spiral lines to the left; areolæ rather tomentose; prickles of two forms, the 3 lower ones in each fascicle setaceous, blackish, spreadingly deflexed, the rest bristly, crowded, and rufescent. h.D. S. Native of Mexico. Coulter, no. 22. Stem the thickness of the small finger. Referrible to the preceding species.

Slender-stemed Indian-fig. Shrub 1 to 2 feet.

9 O. levcótricha (D. C. l. c. p. 119.) joints oblong, erect, when young velvety; areolæ when young convex, velvety; prickles of two forms, 2 or $S$ of which in each fascicle are very long, setaceous, unarmed, white, and spreading, and 4-5 very small, bristle-like, straight, yellow ones. h. D. S. Native of Mexico. Coulter, no. 2. Larger prickles 10-12 lines long. Intervals between the fascicles of bristles distant.

White-haired Indian-fig. Shrub.

10 O. Otrònrs (Link et Otto, pl, rar. bort. berol. t. 16.) stem nearly cylindrical, with 12 bluntish ribs; the $3-4$ middle spines in each fascicle are erectish, slender, brownish, longer than the rest, which are $10-14$ in number, very slender, and spreading; petals acute, rather serrulated, cuspidate. $h$.D. S. Native of Brazil.

Otto's Indian-fig. Shrub.

11 O. Pulvinatia (D.C. 1. c.) joints oval, erect, velvety; areola convex, pulvinate, the whole occupied by innumerable, straight, crowded, yellow, fragile bristles, without any true prickles intermixed. Ђ. D. S. Native of Mexico. Coulter. A very distinct species. O. macrodàsys, Lehm. hort. hamb. ex Salm-Dyck in litt.

Pulvinate Indian-fig. Shrub.

Sect. II. Divarica'te (from divaricatus, divaricated; branches). Haw. syn. 195. Stems lumble; branches diverging; joints linear-lanceolate, thick, nearly terete. Prickles strong, in fascicles.

12 O. Longrsieins (Link et Otto, hort. berol. Haw. in phil. mag. Feb. 1830. p. 109.) joints compressedly terete : spines purplish, some of them small and fulvous, and a slender terete one (which is when full grown 3 inches long) in each fascicle. $h$. D. S. Native of Brazil.

Long-spined Indian-fig. Clt. 1829. Shrub.

13 O. glomera'ta (Hiaw, in phil. mag. Feb. 1850. p. 110.) branclies disposed in crowded tufts; central spines solitary in cach tuft, linear, acuminated, flat on both sides, very long. $h$. D. S. Native of Brazil. Branches thick, teretely lanceolate, greenish, hardly half an inch broad.

Glomeratc-branched Indian-fig. Clt. 1829. Slırub.

14. O. Foliòs (Salm-Dyck in litt. ex D. C. prod. 3. p. 471.) joints compressed, branched, pale grcen, when young leafy, when old prickly; prickles 1-2, elongated, pale straw-coloured, rising from yellowish tomentum. $\eta_{2}$. D. S. Native of South America. O. pusilla, Haw. syn. 195. but not of Salın-Dyck. Cáctus foliòsus, Willk. enum. suppl. 32. Flowers almost like those of $O$. vulgàris. Calyx of 5 sepals. Petals 8-10, yellow. Stigmas S-4, white.
Leafy Indian-fig. Fl. June. Clt. 1805 . Shrub $\frac{1}{2}$ to 1 foot.

15 O. Curassa'vica (Mill. dict. no. 7. Haw. syn. 196.) plant erect; joints brittle, cylindrically ventricose, compressed, very much divaricated, decp green; prickles 1-4 in each fascicle, whitish. h. D. S. Native of Curassoa. Bradl. succ. t. 4. Cáctus Curassávicus, Lin. spec. 670. Flowers yellow, an inch and a half in diameter. Stigmas 3-5.

Var. $\beta$, lónga (Haw. rev. p. 71.) branches more firm, and twice the length of those of the species. $\eta_{2}$. D. S. Native of Brazil. Perhaps a proper species. There are several other varieties mentioned by Haworth, but they appear to have sprung more from the state of the plants, and the manner of culture.

Curassoa Indian-fig. Fl. June, July. Clt. 1690. Shrub 4 to 6 feet.

16 O, FrA'GILIs (Nutt. gen. amer. 1. p. 296. under Cáctus,) joints short, oblong, nearly terete, fragile, doubly spinose ; fruit

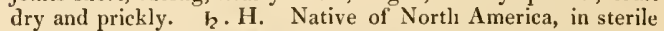
places about the river Missouri. Flowers small, yellow, solitary on the tops of the branches. Truly distinct from all the rest, and will perhaps form a distinct section along with two other unpublished species, which are now growing in the garden of the I'rince de Salm-Dyck.

Brittle Indian-fig. Clt. 1814. Shrub $\frac{x}{2}$ to 1 foot.

17 O. pusíl. (Salm-Dyck, obs. bot. 1822 . et in litt. 1827.) plant prostrate, divaricate, of a dirty-green colour ; joints cylindrical, cucumber-formed; fascicles of prickles crowded; prickles setaceous, white, rising from white tomentum, 1 or 2 in each fascicle are more elongated than the rest. $\zeta$. D. S. Native of South America. Joints rather attenuated at the apex.

\section{Small Indian-fig. Clt. 1817. Shrub prostrate.}

Sect. Ill. Grandispinòsæ (from grandis, great, and spinosus, full of spines; in reference to the prickles being large and numerous). Haw. syn. 195. Joints compressed, ovate or obovate. Prickles variable, the smaller ones setaceous, and the larger ones much longer and stronger.

18 O. Missovrie'nsis (D. C. prod. 3. p. 1.72.) joints broad, nearly orbicular, very prickly; prickles of 2 forms, larger ones radiating and permanent; flowers numerous; fruit dry and prickly. $\zeta . H$. Native of North America, in arid places about the Missouri, plentiful. Cáctus fèrox, Nutt. gen. amer. 1. p. 296. but not of Willd. O. polyacántha, Haw. rev. p. 82. Larger than $O$. vulgàris. Flowers pale yellow or sulphur-coloured. Stigmas 8-10, greenish. Prickles white.

Missouri Indian-fig. Fl. June, July. Clt. 1814. Sh. $1 \mathrm{ft}$.

19 O. FE'rox (Haw. supp]. p. 8.) joints oblong, elongated; prickles strong and setaceous, numerous, whitish, in fascicles, longer than the wool from which they issue, one of which in each fascicle is longer than the rest. $h$. D.S. Native of South America. Cáctus fèrox, Willd. enum. suppl. p. 35. but not of Nutt. The rest unknown.

Ficrce Inclian-fig. Clt. 1817. Shrub 2 to 3 feet.

20 O. spinosi'ssima (Mill. dict. ed. 8. Haw. syn. 193.) joints oblong; prickles yellowish, setaceous, and subulate, very numerous, in fascicles, longer than the wool from which they issue. そ. D. S. Native of Jamaica. Cáctus spinosíssimus, Iram. dict. 1. p. 537. Flowers yellow.

Very-spiny Indian-fig. Fl. July. Clt. 1732. Sl. 6 to 10 feet.

21 O. $110^{\prime}$ RIda (Salm-Dyck in litt. ex D. C. prod. 3. p. 472.) plant erect; joints cuneately obovate, repand, tubercled; fascicles of prickles remote; prickles of various forms, yellow, painted with brown, rising from setaceous yellow tomentum, one in each fascicle longer than the rest, about 2 inches in length. $h$. D. S. Native of South America. O. humilis, Haw. syn. 189. Cáctus hùnilis, Hax. misc. 187 . but the name is deceitful, the plant growing to a considerable height. Flowers yellow. 
Perhaps Cáctus hùmilis, Lag. nov. spec. is different from this. The plant often occurs in the gardens under the name of $O . T u{ }^{2}$. Horrid Indian-fig. Fl. July. Clt. 1795. Shrub 1 to 3 feet. 220 . DıLe'si (Haw. suppl. p. 79.) plant erect; joints roundish-oborate, undulated, erlaucous; prickles strong, divaricated, yellow, but the brush-like bristles by which they are surrounded are much shorter. h. D. S. Native of South America. -Dill. elth. f. 382. Cáctus Dillènii, Ker, bot. reg. 255. Flower's large, pale yellow. Ovarium shorter than the corolla, furnished at the summit by fascicles of bristles.

Dillenius's Indian-fig. Fl. Oct. Clt. 1810. Sh. 3 to 5 feet. 23 O. Tu'sa (Mill. dict. no. 3. Haw. l. c.) plant erect; joints broadly ovate-oblong; prickles subulate, long, yellow; wool at the basc of the spines short. $h$. D.S. Native of South America, at Cuenca in Quito. Cáctus Bonplándii, H. B. et Kunth, nov. gen. amer. 6. p. 69 -Dill. elth. $\$ 86$. t. 295 . f. 386. Flowers of an orange-colour, or iron grey-colour, or dirty red. Stigmas 8-10-cleft. This kind of Indian-fig makes strong fences. When the Island of St. Christoplier was to be divided between the English and the French, three rows of the Tuna were planted by common consent between the boundarics. Sloane. Sir James Sinith, in his paper upon the irritability of vegetables, informs us that the long and slender stamens of the flower are very irritable; and that if a quill or feather is thrust through them, in the space of 2 or 3 seconds they begin to lie down gently on one side, and in a short time become recumbent at the bottom of the flower. According to Humboldt and Bonpland the fine kind of cochineal is nourished by this plant.

Tuna Indian-fig. Fl. July, Aug. Clt. 1731. Sh. 3 to $6 \mathrm{ft}$.

24 O. Polya'stira (Haw. syn. p. 190.) plant erect; joints oblong and ovate; prickles very different in form, yellow, larger ones setaceous, erectly spreading; flowers numerous at the tops of rhe branches. $\zeta$. D. S. Native of South America. Cáctus Opúntia polyántha, D. C. j]. grass. no. 138. with a figure. Cáctus polyánthes, Sims, bot. mag. t. 2691. Flowers yellow. Style full, not fistular as in the other species. Stigmas 6 .

Many-flonered Indian-fig. Fl. July, Aug. Clt. 1811. Shrub 2 to 3 feet.

25 O. moxacántra (Willd. enum. suppl. under Cáctus, SalmDyck in litt. ex D.C. prod. 3. p. 723.) joints obovate-oblong; prickles solitary, subulate, strong. $h_{\text {. }}$ D. S. Native of South America. Cáctus Opúntia Tùna, D.C. pl. grass. no. 137.t. 2. Joints a foot long. Flowers yellow, verging to purple beneath.

One-spined lndian-fig. Clt. 1816 . Shrub 6 to 8 feet.

26 O. ELA'Tlor (Mill. dict. no. 4. Haw. syn. 187.) plant erect; joints broadly ovate-oblong; prickles subulate, very long, blackish, witls the wool from which they rise nearly obsolete. 々.D.S. Native of South America. Cáctus Tùna $\beta$, Willd spec. 2. p. 944.-Dill. elth. t. 294. f. 379 . Flowers yellow, varying to purple. Stigma 5-cleft. Adult stem nearly terete ex Jacq.

Taller Indian-fig. Fl. July, Aıg. Clt. 1731. Shrub 6 feet. 27 O. Nígricans (Haw. syn. 189.) plant erect; joints oblong and lanceolate; prickles very different in form, of a blackish brown-colour, larger ones divaricate. 々. D. S. Native of South America. Cáctus nígricans, Haw. 1937. Cáctus Tùna $\gamma$, nígricans, Sims, bot. mag. 1557. Cáctus pseudo-cocciníllifer, Bert. exc. p. 11. virid. 1824 . p. 4. exclusive of the synonymes. Flowers reddish on the outside, and yellow inside. Stigmas 5 , thick, greenish.

Blackish Indian-fig. Fl. Aug. Clt. 1795. Sh. 2 to 3 feet.

28 O. MA'xums (Nill. dict. ed. 8. no. 5.) plant erect; joints ovate-oblong, very thick; spines unequal. $h$. D. S. Native of South $\Lambda$ merica. Perhaps the same as $O$. Amýclca.

Grealest Indian-fig. Shrub 6 to 8 feet.

29 O. TRJaca'NTIIA (Willd. enum. suppl. under Cáctus,) joints ovate-oblong; prickles whitish, usually 3 together, strong, longer than the wool from which they issue. $h$.D.S. Native of South America. Very nearly allied to O. polyáutha ex SalmDyck in litt. but the joints are a little larger, and the prickles are white. Flowers unknown.

Threc-spincd Indian-fig. Shrub 2 to 3 feet.

Sect. IV. Parvispinòse (from parvus, small, and spinosus, full of spines ; in reference to the spines bcing small, equal, and numerous). D. C. prod. 3. p. 479 . P'rickles uniform, hairshaped, short or nearly wanting.

צO O. DEcUMA'NA (Haw. rev. 71.) joints ovate-oblong ; prickles deciduous, length of the wool from which they issue. 々. D. S. Native of South America. Cáctus decumànus, Willd. enum. suppl. 34. O. máxima, Mill. dict. col. 2. no. 5. Cáctus elongátus, Willd. enum. suppl. 3t. There are varietics of this plant with either ovate or lanceolate-oblong joints, almost unarmed or furnished with some short white prickles. Flowers yellow. The cochineal bug thrives almost as well on this species as on the next.

Huge Indian-fig. Clt. 1768. Shrub 5 to 10 feet.

S1 O. cochinillífera (Mill. dict. ed. 8. no. G. Haw. syn. 192.) plant erect; joints obovate, nearly unarmed; petals connivent; stamens and style exserted. $\zeta$. D. S. Native of South America. Cáctus cochinillífera, Lin. spec. 670. Hook. in bot. mag. 2741. and 2742.-Dill. elth. t. 297. f. 383 . Joints while young oblong, areolate, at length obovate-oblong. Flowers blood-coloured ex Dill. elth., small, spreading a little. Spines slender, blackish. The ripe fruit is said to check fluxes by its mild restringency. Flowers red. Perhaps Nopal de Castille Thierr-Menonville, voy. Guax. 2. p. 278. is the same as this plant.

Of the particular species of Opintia which nourishes the cochineal insect much doubt las existed. There is some reason to believe that the Opúntia cochinillifera, Haw. Cáctus, Lin. is not the plant which produces the best Mexican cochineal. Tilloa, on the authority of well informed travellers, states that the cochineal Cáctus has no spines, and a fruit imbued with deep red pulp. Clavigero, however, says, "In Misteca, where I was for five years, I always saw the insect upon prickly Nopals. M. de Raynal imagines that the colour of the cochineal is to be ascribed to the red fig on which it lives; but that author has been misinformed, for neither does the cochineal feed upon the fruit, but only upon the green part of the plant; nor does that species of Nopal bear red, but white figs. Clavigero adds, " it may be reared upon the species with red fruit, but that is not the proper plant of the cochineal." M. Thierry de Menonville, who procured the cochineal insect, and the Opuntia on which it feeds from Guaxaca in Mexico, and transported them to St. Domingo, and who unquestionably had the best means of determining the kinds of Cacti cultivated for the insect, describes particularly 3 sorts on which it may be reared, and cultivated to advantage. The first is the Cactier Nopal, upon which alone the cocbineal is reared in Mexico, both the fine and the common sorts, although there are throughout the country many other kinds of Opuntia. The two following, therefore, it is presumed are employed in St. Domingo. 2. The Cactier splendide, which may be used to equal advantage with the former; and 3 . The Cacticr de Campcche. Of these the first, as far as can be determined by description, is the Cáctus Tìna of Lin. which is the Opuntia Tùna of Mill. The second appears to be very similar to the former, but larger in its joints, and very glaucous. The third is without doubt the Cáctus cochinillifera, Lin. and which he says of it from his own experience, that it may be usefully employed for rearing the Cochinille sylvestre, and may even suj)port a small quantity of the fine kind. Humboldt also, althongh 
he allows that it is the plant upon which the cochineal has often heen sent to Europe, asserts that our Opuntia cochinillifcra is not the individual of the Mexican Nopaleries, which he makes a new species under the name of $O$. Bonplandii, and he quotes under it with a mark of doubt the Cáctus Tüna of Lin. At Rio Janciro, when that place was visited by the Chinese embassy under Lord Macartney, there were considerable plantations of Cáctus Tùna, now Opuntia Tùna, for rearing the cochineal, which had sometime previously been introduced to Brazil. In St. Vincent the Rev. L. Guilding las a considerable nurscry of the Opintia cochinillifera inhabited by thousands of the true cochineal; and he is in expectation of sending to the Society of Arts a lirge quantity of the dried insects. From all that has heen said we think it may be inferred with safety that in Mexico and Brazil the Opintia Tuna or Bonplundii is the favourite food of tle cochineal; and that in the West Indian Islands, where $O$. Tùna is perhaps less frequent, the $O$. cochinillifera is employed liy the natives, and answers the purpose sufficiently well.

Like all the species of Opuntia, the plants propagate readily by having the joints stuck into the ground, and the plants love dry and barren spots. If cultivated for the purpose of rearing the cochineal, it must be defended, at least in the rainy Island of St. Vincent, from storms and winds, by sheds placed to windward.

The cochineal insect, which feeds upon the kinds of Opuntia just mentioned, is too well known to need a particular description here; as are also its valuable properties in producing the dye which bears its name, and carmine. It is the Cóccus cácti of Linnæus, a small insect of the order Hymenóptera, having a general appearance not very dissimilar to that of the mealy-bug of our gardens, and equally covered with a white powdery substance. The male is winged. It is originally a native of Mexico, and was cultivated for its precious dye long before the conquest of that country; and these plantations, called Nopaleros, are most extensive in the Misteca and Oaxaca ; the latter district alone has exported, according to Humboldt, upon the average 32,000 arobas annually, estimated at $2,400,000$ piastres, above $500,000 l$, sterling.

In Sloane's Jamaica, vol. 1. t. 9. a representation of a Mexican Nopalery is given from a drawing made at Guaxaca, by an Indian. In these small plantations or enclosures they cultivated either the fine sort (Grana fina of the Spaniards), or the conmon kind (Grana sylvestre), which differ by the first having a finer quality and more powdery covering; whilst the latter, less valuable in its produce, has a cottony covering; but whether these two insects be specifically distinct has not yet been determincd. The placing of the females, when big with young, is called sowing. The proprietor of a Nopalery buys in April or May the branches of joints of the Tunas de Castilla (Opuntia Tuna), which are sold in the market of Oaxaca at about 3 franks a hundred, loaded with young cochineais (semilla). These are kept in cellars for 20 days, when they are exposed to the air, suspended under a shed. So rapid then is the growth of the insect, that by August or Septcmber the females are big with young, and ready for sowing, which is done in small nests, made of the fibrous parts of the foliage of a Tillandsia called Paxtle. In four months from the time of sowing the harvest commences. The insects are brushed off with a squirrel's or deer's tail by women, who sit during this operation, for whole hours at one Nopal plant; so that were it not for the extreme chcapness of labour in that country, Humboldt says, that the rearing of the cochineal would prove an unprofitable employment. After being gathered, the insects are killed by boiling water, or by exposing them in heaps to the sun, or by means of the vapour baths of the Mexicans (temazcalli); and when dry they are fit for exportation. By the latter method, the powdery substance is pre- served, which increases the value of the insects in commerce. Dr. Bancroft has estimated the annual consumption of cochineal in Great Britain only at about 750 bags or 150,000 lbs., wortl 275,000l. " a vast amount," as the authors of the introduction to Entomology observe, "for so small a creature, and well calculated to show us the absurdity of despising any animals, on account of their minuteness." According to the same writers, the only kind of cochineal that has been conveyed to the East Indies is the sylvestre or wild cochineal from Brazil, and the Court of Directors of the East India Company have offered a reward of $6,000 l$. to any person who should introduce the more valuable sort. The insects were introduced to the royal gardens at Kew in 1814 from Martinico, by M. Castleneau d'Auros, late superintendant of the botanic garden on that island. In 1820, the fine cochineal was introduced to the Apothecaries' botanic garden at Chelsea by $W$. Prinsep of Calcutta, from some ot the Nopaleries of Mexico.

Cochineal-bearing Indian-fig. Fl. July, Sept, Clt, 1688. Slurub 3 to 5 feet.

32 O. Fícus-I'NDICA (Haw. syn. p. 191.) joints ovate-oblong, obtuse at both ends; prickles setaceous, length of the wool from which they rise. $\zeta . D$. S. Native of South America. Cáctus Ficus I'ndica, Lin. spec. 670. Willd. enum. suppl. 34. Joints a foot long. Prickles all setaceous, and very short. Flowers sulphur-coloured. Fruit large, edible, deep purple. This is the most common kind of Indian-fig in Jamaica, and upon the fruit of it a wild kind of cochineal feeds. The plant is to be found in many parts of Asia, but has perliaps been transplanted thither.

Common Indian-fig. Fl. June, July. Clt. 1731. Shrub 2 to 3 feet.

33 O. PSEU'Do-Tu'NA (Salm-Dyck, obs. bot. 1822. et in litt. 1827.) plant erect, branched, light green ; joints obovate, compressed, large, thick ; fascicles of prickles distant ; prickles yellow, setaceous, collected into brush-like heaps: lower one of each heap strong, and subulate. h. D.S. Native of South America. Allied to O. Ficus-I'ndica, but more shining. This species occurs often in gardens under the name of $O$. T'una.

False-'T'una. Shrub 2 to 3 feet.

34 O. TomentòsA (Salm-Dyck, obs. bot. 1822, et in litt. 1827.) plant erect, tomentose ; joints lanceolate, compressed, thick; prickles setaceous, white: lower 4 or 6 in each fascicle elongated, unarmed. $h$. D. S. Native of South America. Cáctus tomentòsus, Link. cnum. 2. p. 24. Spreng. syst. 2. p. 497. Hairs of joints short, adpressed, and rather villous.

Tomentosc Indian-fig. Clt. 18\%0. Shrub 2 to 3 feet.

35 O. LANCEOLA'Ta (Haw. syn. 192.) plant erectish; joints lanceolate; spines uniform, very short. $h$.D. S. Native of South America. Cáctus lanceolàtus, Haw. misc. p. 188. Leaves larger in this species than any of its allies, generally they are more than 3 lines long. Flowers 4 inches in diameter, of a shining yellow-colour. Stigmas 5, sulphur-coloured.

Lanceolate-lobed Indian-fig. Fl. July. Clt. 1796. Shrub 2 to 3 feet.

36 O. tubercula'ra (Willd. enum. suppl. p. 34. under Cáctus, joints ovate-oblong, attenuated at both ends ; tubercles spinose; prickles setaceous, about equal in length to the wool from which they rise. $h$. D. S. Native of tropical America. Haw. rev. p. 80 . The rest unknown.

Warted Indian-fig. Clt. 1818. Shrub 1 to 2 feet.

37 O. inérmis (D. C. prod. 3. p. 473.) plant strictly erect ; joints fleshy, ovate-elliptic; spines uniform, very short, hairformed, very numerous. h. D. S. Native of South America. Cáctus Opuntia, D.C. pl. grass. no. 138. with a figure. Cáctus stríctus, Haw. misc. 188. but not of Willd. O, strícta, Haw. syn. 191. Flowers yellow on both sides, spreading. 
Cnarmed Indian-fig. Fl. July, Aug. Clt. 1796. Sh. 2 to $3 \mathrm{ft}$. 38 O. Asycle's ('Tenore, f. neap. append. 5. p. 15.) joints orbicular or elliptic, very broad, flat, compressed; prickles strong, diverging, white, without any wool at their base. $h$. F. Native of the kingdom of Naples, near Amyclea, and at Monticelli and Portella, on calcareous rocks. Joints 10 inches broad, and 15 inches long. Prickles 6.18 lines long, but sometimes wanting altogether. Flowers yellow. Fruit reddish yellow. Perlaps the same as O. máxima, Salm-Dyck.

Amyclea Indian-fig. Shrub 2 to 4 feet.

39 O. RuBE'scess (Salm-Dyck in litt. 1827. ex D. C. prod. s. p. 474.) plant erect; joints elongated, compressed, reddish green, somewhat tuberculately arcolate, unarmed ; leaves small, reddish, at the base of the white tomentum. $\zeta$. D. S. Native of Brazil. This plant is very showy when young, being of a reddish-colour, and the stem flat and elongated, nearly as in $O$. spinosissima, but absolutely without spines.

Reddish lindian-fig. Shrub 1 to 2 feet.

40 O. cra'ssa (Haw. suppl. p. 81.) plant erect; joints ovate or oblong, very thick, full of a fleshy substance ; fuscicles of bristles minute, unarned, yellowish. h. D. S. Native of Mexico.

Thick Indian-fig. Clt. 1817. Slurub 2 to 3 feet.

41 O. vulga'ris (Mill. dict. ed. 8. no. 1. Haw. syn. 190.) plant diffusely prostrate, rooting; joints ovate; prickles unequal, very short, and very numerous. 2. H. Native of North America, in the southern states; plentiful in the neighbourhood of New York, \&c.; and now frequent in the south of Europe. Hook. bot. mag. 2393. Cáctus Opúntia, Lin, suec. 669. Cáctus Opüntia vulgàris et nàna, $\mathrm{D}, \mathrm{C}$. pl. grass. no. 138. with a table. -Mill. fig. t. 191. Flowers yellow, spreading.

Common Indian-fig or Prickly-pear. Fl. July, Aug. Clt. 1596. Shrub $\frac{1}{2}$ to 1 foot, but usually prostrate and rooting.

42 O. Hernande'zil (D. C. diss. t. 16.) plant erect; joints thick, roundish-obovate, nearly unarmed; flowers expanded;

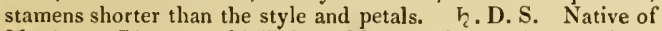
Mexico. Cáctus cochinillífera, Moc. et Sesse, fl. mex. icon. ined. Nopal Nochatzli, Hern. mex. 78. with a figure, and 489. f. 1. Nopal sylvéstre, Thierry-Menonv, voy. Guax. 2. p. 277. with a figure. According to Thierry, the Howers on the same plant vary from purplish to rose-colour, and greyish lilac. The cochineal thrives well on this species.

Hernandez's Indian-fig. Clt. 1827. Shrub 1 foot.

Sect. V. Tenuílobe (from tenuis, thin, and lobus, a lobe ; lobes of plant flat and thin). D. C. prod. 3. p. 474. Stems terete, when young. Joints flat, membranous.

43 O. BrAsilie'Nsis (Willd. enum. suppl. 33. under Cáctus) stem terete: joints of branches compressed, flat, ovate; spines strong, solitary. 々. D. S. Native of Brazil. Cáctus paradóxus, Horn. hort. hafn. 2. p. 443.-Hoffms. verz. 1826. p. 72. Pis, bras. p. 100. f. 2. Flowers yellow.

Brasilian Indian-fig. Fl. Jul. Aug. Clt. 1816. Sh. 4 to $6 \mathrm{ft}$.

† The folloning spccies are only knonn by name, not having bcen described.

10 . leucántha, Hort. berol. 20 . alàta, Hort. berol. 3 O. myriacántha, Hort. berol. 4 O. subinérmis, Link. 50. sulphùrca, Gill. (under Cáctus). 6 O. scricca, Gill. (under ('áctus).

Cult. The species of Indian-fig are of very easy culture : the soil reconmended for Mammillaria will suit them; and in order to propagate them, the branches should be separated at the joints, and allowed to lie a few days to dry after being so separated, and when stuck into the earth they will soon strike root.

VII. PERE'SK1A (named by Plumier in honour of Nicholus Fabr. Peiresk, senator of Aix in Provence, who collected a con- siderable library and herbarium, but published nothing). Plum. gen. p. 35. t. 26. Lin. gen. ed. 1. no. 40\%. Mill. dict. Haw. syn. 197. D. C. prod, צ. p. 474.

Lin. sist. lcosíndria, Monogýnia. Sepals numerous, alnate to the ovarium, and often remaining on the fruit, leafformed. Corolla rotate, nearly as in Opuintia. Stamens nizmerous, much shorter than the petals. Style filiform; stigmas collected, in a spiral manner. Berry globose or ovate. Seeds imbedded in the pulp.- Shrubs or trees. Branches terete. Prickles solitary at the axils of the leaves, and in fascicles on the stem. Leaves distinct, flat, larger than those of any other genus in the present order. Flowers somewhat panicled, solitary, terıninating the branches, or rather lateral.-Peréschia, Thierry Menonv, voy. guax. 2. p. 275. is probably a species of Opuntia.

1 P. aculea'ta (Mill. dict. Haw. syn. 198.) leares elliptic ; prickles solitary, in the axils of the leaves, but becoming at length in fiscicles on the stems; flowers rather panicled; fruit globose, bearing the foliaceous sepals. h. D.S. Native of the West Indies, where it is called American or Barbadoes Gooseberry by the inlrabitants, and by the Dutch Blood-apple. Plum, gen. t. 26.-Dill. hort. elth. t. 227. f. 294. Cáctus Peréskia, Lin. spec. 671. Prickles half an inch long. Buds rather woolly. Flowers white. Fruit yellowish, edible.

Prickly Barbadoes-gooseberry. Fl. Oct. Nov. Clt. 1696. Shrub 5 to 7 feet.

2 P. Longispina (Haw. syn. 178.) leaves elliptic; prickles twin, an inch and a half long, very woolly. $h$. D. S. Native of Sotth America. P. aculeata $\beta$, longispina, D. C. prod. 3. p. 475 .

Long-spined Barbadoes-gooseberry. Shrub 4 to 6 fect.

3 P. BLE'o (H. B. et Kuntl, nov, gen. amer. 6. p. 69.) leaves oblong, acuminated ; prickles axillary, 5-6 in a fascicle; flowers 2-4 together at the tops of the branches, each on a short peduncle; petals obovate, retuse. $\eta$. D. S. Native of New Granada, on the banks of the river Magdalena, near Badilla, where it is called Bleo by the inhabitants. Lindl. bot. reg. 1173. Flowers pale red. Stamens also red, but white at the base. Stigma 5-7-cleft.

Bleo Barbadoes-gooseberry. Fl. Oct. Jan. Clt. 1827. Pl. 8 to 10 feet.

4 P. nórrida (H. B. et Kunth, l. p. 70.) leaves oblong, acute at both ends; spines 1-3 together, subulate, in the woolly axils of the leaves; flowers 2-5 together, axillary, pedunculate, rising above the spines. $\zeta$. D. S. Native of South America, in the province of Jaen de Bracamoros, on the banks of the Amazon. Flowers small, red. Stigma 3-4-cleft.

Ilorrid Barbadoes-gooseberry. Shrub or tree.

5 P. Portulacafólia (Haw. syn. 199. in a note) leaves obovate-cuneated; prickles solitary, under the leaves, but at lengtl coming in fascicles on the stem; flowers solitary; petals emarginate; fruit globose, retuse, naked. $\zeta$. D.S. Native of the West Indies.-Plım. ed. Burm. 197. f. 1. Cáctus portulacifòlius, Lin. spec. 671. Lun. hort. jam. 2. p. 256. A bout the size of an apple-tree. Prickles blackish. Flowers terminal, purple; petals roundish. Fruit umbilicate, greenish, with white flesh, and numerous black seeds.

Purslane-leaved Barbadoes-gooseberry. Clt. 1820. Tree 20 to 30 fect.

6 P. zinnieflòra (D. C. diss. t. 17.) leaves ovate, acute, undulated; prickles axillary, twin: but at length somewhat fasciculate on the stem, about the cicatrices occasioned by the falling of the leaves; flowers solitary, terminal; petals obcordate; ovarium bearing the sepals. $h$. D. S. Native of Mexico. Cáctus zinniæflórus, Moc. et Sesse, fl. mex. icon. ined. Flowers of a deep reddish-violet colour, greenish on the 
outside, about an inch in diameter. Very like the preceding species.

Zimnia-flowered Barbadoes-gooseberry. Tree 10 feet.

7 P. Lychindr Lóra (D. C. diss. t. 18.) leaves ovate, acute; prickles solitary in the axils of the leaves, but perhaps in fas-cicles on the stems; flowers solitary, terminal; petals culeated, fringed at the apex; ovarium bearing the sepals. $h$. D. S. Native of Mexico. Cáctus fimbriàtus, Moc. et Sesse, H. mex. icon. ined. Flowers of a coppery peach colour, about 2 inches in diameter, similar to those of $L$ ýchnis coronatus.

Lychnis-flowered Barbadoes-gooseberry. Shrub.

8 P. oruntierlòma (D. C. diss. t. 19.) leaves obovate, mucronate, usually 2 together; prickles axillary, solitary, very long, but perhaps disposed in fuscicles on the stem? Howers ustally terminal, or nearly so, solitary ; petals ovate, acutish ; ovarium bearing fascicles of laairs. $h$.D. S. Native of Mexico. Cáctus opunticflorus, Moc. et Sesse, fl. mex. icon. ined. Flowers of a dirty scarlet colour, an inch in diameter; petals disposed in 2 seric's.

Indian-fig-flonered Barbadoes-gooseberry. Shrub.

9 P. Rotundifolia (D. C. diss, t. 20.) leaves roundish, mucronatc; prickles axillary, solitary, but perhaps disposed in fascicles on the stem ; flowers solitary, lateral? petals broad, roundish, mucronate; ovarium bearing the sepals ; fruit obovate, full of cicatrices. h. D. S. Native of Mlexico. Cáctus rotundifòlius, Moc. et Sesse, fl, mex. icon. ined. Flowers yellow, variegated a little with scarlet, 15 lines in diameter. Berry red, obovate.

Round-leaved Barbadoes-gooseberry. Shrub.

10 P. GRANDifòlı (Haw. suppl. p. 85.) leaves oblong-lanceolatc, sinooth above, beset with rough dots beneath; stem very spiny. 々. D. S. Native of Brazil. Cáctus grandif òlius, Link. enum. 2. p. 25 . Spreng. syst. 2. p. 498. Larger spines blackish, 2 inches long.

Great-leaved Barbadoes-gooseberry. Clt. 1818. Sh. 6 feet.

Cult. The species of this genus are very different in habit from the rest of the genera of the present order, from the branches being woody and furnished with proper leaves; but the flowers resemble the other genera of the order. They are of easy culture, growing freely in any light earth ; and cuttings of them are readily rooted in mould or sand, under a handglass, in heat. A large plant of any of the species has a very glotesque and ornamental appearance, when several species of Cercus and Epiphíllum has been grafted or inserted on it.

\section{Tribe 11.}

RHIPSALI'DEF (this tribe only contains the genus Rhipsalis). D. C. prod. 3. p. 475 . Ovula, and therefore the seeds are fixed to the central axis of the berry.

VIII. RHI'l'SALIS ( $\dot{\omega} \psi$, rhijs, a willow-branch; in reference to the flexible branches). Gærtn. fr. 1. p. 136. t. 28. Haw. syn. 186. D. C. prod. 3. p. 475.-Hariòta, Adans. fam. 2. p. 243.-Rhipsálides. Willd. enum. suppl. p 33.-Cact. parasítici, D. C. citt. hort. monsp. p. 83.

Lin. syst. Icosándria, Monogýnia. T'ube of calyx adhering to the ovarium, snooth; limb superior, 3-6-parted, short; teeth acuminated, membranous. Petals 6 , oblong, spreading, inserted in the calyx. Stamens 12-18, fixed to the base of the petals. Style filiform, crowned by $3-6$ stigmas. Berry pellueid, roundish, crowned by the marcescent ca!yx. Seeds imbedded in the pulp, without albumen; radicle of the embryo thick; cotyledons 2, short, obtuse. - Small shrubs, growing upon trees in the West Indies, ustally pendulous, branched, leafless, and terete, naked or bearing rather falcate small bristles; fascicles of bristles, when present, disposed in a quincuncial spiral order. Flowers lateral, sessile, small, white. Berries pellucid and white, nearly like that of l'iscum or Missletoe.

1 R. Cassy'tha (Gærtn. l. c. Haw, l. c.) plant pendulous : branches verticillate, naked, glabrous; calyx 6-parted; petals 5-6. h. D. S. Native of Jamaica, St. Domingo, Trinidad, \&.c. hanging on the branches of the tallest trees. Christy, in bot. mag. 3080. Cassỳtha baccífera, Mill. fig. Cassỳtha filifí rmis, Mill. dict. cd. 8. Cáctus péndlulus, Swartz, f. ind. occ. p. 876 . Flowers white. Berry white, about the size of those of a red currant, 12-seeded.

Yar. $\beta$, Mauritiàna (D. C. prod. 3. p. 476.) plant creeping? branches crowded, jointed. $h$. D. S. Native of the Mauritius, on the rock called Lapouce. Cáctus pendulinus, Sieb. f. maur. 2. no. 259. Perhaps this plant has been introduced to the Mauritius from the Brazils, as all the other species of this genus are natives of America. Flowers whitish. Berries white.

Cassytha Rhipsalis. Fl. Sept. Clt. 1758. Shrub 1 foot.

2 R. Hookeria'Na; plant pendulous; branches verticillate, naked, glabrous; calyx 4-parted; petals 4. h.D. S. Native of the West Indies and Mexico. R. Cassytha, Hook, exot. fl. t. 21. R. Cassytha $\beta$, Hookeriàna, D. C. prod. 3. p. 476 . Flowers white. Berries white, about the size of those of a red currant, 12-20-seeded.

IIooker's Rhipsalis. Fl. May, June. Clt.? Shrub 1 foot.

3 R. CAssytuoìnes; plant pendulous; branches verticillate, naked, glabrous; calyx 3-lobed: lobes broad at the base, and acuminated at the apex; petals 6 . $々$. D. S. Native of Mexico. Flowers white. Berries white, about the size of red currants. Cáctus cassythoides, Moc. et Sesse, H. mex. icon. ined. R. Cassỳtha $\gamma$, Mociniàna, D. C. prod. 3. p. 476. diss. t. 21 .

Cassytha-like Rhipsalis. Shrub 1 foot.

4 R. огсно́тома; plant pendulous; branches dichotomous ; calyx 3 -lobed; petals 6 , disposed in 2 series. $\zeta$. D.S. Native of New Andalusia and New Granada, growing on trees. Cáctus péndulus, H. B. et Kunth, nov. gen. amer. 6. p. 65. R. Cassỳtha o, dichótoma, D. C. prod. 3. p. 476. Flowers white. Berries white, about the size of gooseberries, $30-40$ seeded.

\section{Dichotomous Rhipsalis. Shrub 1 foot.}

5 R. Grandiflòus (Haw. suppl. pl. succ. p. 83, rev. p. 72.) plant sparingly branched; branches nearly erect, somewhat calamiform, naked: spines very minute, solitary, pale, closely adpressed, at nearly regular distances; flowers numerous, hardly an inch in diameter. $\zeta$. D. S. Native of Brazil. Hook. bot. marg. t. 274.0. R. funalis, D. C. prod. 3. p. 476 . Cáctıs funàlis, Salm-Dyck. in hort. dyck. 1822. Petals and calycine lobes 8 , pale yellow inside. Filaments numerous, white; anthers yellow. Stigmas 4 , rotate.

Great-flowered Rlipsalis. Fl. June, Jul. Clt. 1816. Sh. $1 \mathrm{ft}$.

6 R. FAscicula'ta (Haw. suppl. p. S3.) pendulous; branches terete, in fascicles; fascicles of hairs disposed in a spiral quil)cuncial order along the younger branches. $h_{2}$. D. S. Native of the West India lslands. Christy, in bot. mag. 3079. R. parasítica, Haw. syn. p. 187. Cáctus parasíticus, Lam. dict. 1. p. $54 \mathrm{l}$. D. C. pl. grass. t. 59 . Cáctus fasciculàtus, Willd. enum. suppl. p. 33. Flowers greenish-white, few, and confined to the main branches. Berry similar to $R$. Cassytha.

Fasciculate Rhipsalis. FI. July, Aug. Clt. 1817. Sl. I ft.

7 R. salicornioides (Haw: suppl. p. 83.) plant erect, branched, proliferous at the joints; joints short, obclavate, terete, and angular, with fascicles of very minute hairs, floriferous at the apex; flowers solitary. $\zeta$. D. S. Native of South America. Otto, et Link. abbl. t. 49. Petals 7-10, acute, yellow, longer than the stamens and style.

Salicornia-like Rhipsalis. Fl. June. Clt. 1817. Sh. 1 foot.

8 R. mesembryantuoides (Haw. rev. p. 71.) plant glomeratcly brancised; branches erect, terete, straiglit, bearing joints; 
joints lateral, crowded, terete, attenuated at both cnds, clouded, bearing theflowers in the middlc; fascicles of eapillaceous bristles white or pale, but when old and faded black; flowers solitary. h. D. S. Native of South America. Christy, in bot. mag. 3878 . C. salicornioides $\beta$, Haw. suppl. p. 83 . Joints at the sides of the branclies numerous, crowded, and ncarly ercet. Flowers solitary, rising from the middle, not from the tops of the joints, white. Fruit a white berry, smaller than those of $R$. Cassytha.

Fig.marigold-like Rhipsalis. 1J. Ju, Jul. Clt. 1817. Sh, 1 ft.

9 R. rarasitica (D. C. prod. 3. p. 476.) plant pendulous, branched, glabrous; branches striated, or undulatcly repand. h. D. S. Native of the West India Islands.-Plum. ed. Burm. t. 197. f. 2. Flowers like those of $R$. dichótoma. This species is hardly known, but distinct from the others in the stem being repand in an undulating manner.

Parasitic Rhipsalis. Shrub 1 foot.

10 R.? micrástia (H. B. et Kunth, nov. gen. amer. 6. p. 65. under Cáctus) plant glabrous, pendulous, branched; branches with 3-4 angles, or compressedly 2-eclged; flowers rising from the angles. ?. D. S. Native of Quito, in groves, near Olleros. Flowers white, minute.

Small-flowered Rhipsalis. Shrub $\frac{1}{2}$ foot.

Cult. This is a genus of singular plants, but without much beauty. Bcing parasites, on trees, they grow best in vegetable mould, mixed with a little brick rubbish; and they are easily increased by cuttings.

Order CXVIII. GROSSULARIE'Æ (this order only contains the genus Ribes, or gooseberry tribe). D. C. fl. fr. (1804) 4. p. 406. H. B. et Kunth, nov. gen. amer. 6. p. 58. Berlandier, mem. sae. phys. gen. 3. pt. 2. p. 43. t. 1-3. D. C. prod. 3. p. 477.-Kibèsiæ, Ach. Rich. bot. med. (1823) 2. p. 487.-Genera of Cấcteæ, Juss.-Genus of Saxifrìgeæ, Vent.-Genus of Portulàceæ, Adans.

Calyx superior (f. 32. d. f. 33. b.); limb 4-5-parted (f. 39. b. f. 32. a.), regular, coloured. Petals 5 , inserted in the throat of the calyx (f. 33. c.), and alternating with its segments, equal. Stamens 4-5 (f. 33. c.), very rarely 6 , very short, inserted alternately with the petals, equal; filaments conical or cylindrical, distinct: anthers 2-celled, opening lengthwise on the inside; but in the varieties of $R$. rübrum they burst laterally and transversely. Ovarium 1-celled, with 2 opposite parietal placentas; ovula numcrous. Style one, 2 (f. 32. e. f. 33. e.) -3 or 4-cleft. Fruit succulent (f. $32 . \ell$.), nearly globose, umbilicate at the apex from the permanent calyx (f. 3\%. d.), 1-celled, many-seeded. Seeds arillate, suspended by a long filiform podosperm; outer integument gelatinous or juicy, and membranous : under one a very thin membrane, adhering closely to the albumen; bluntish at the extremity opposite the hylum. Albumen horny, conforming to the seed, white. Embryo minute, placed at the sharpest end of the sced, excentral, with a blunt radicle, which is placed next the hilum.-Unarmed or spiny shrubs. Leaves alternate, lobed or cut, plaited while in the bud. There is one bractea at the base of each pedicel, which is cut more or less, and two much smaller ones called bractcoles under cach ovarium. Flowers greenish, white, yellow or red, very rarely urisexual.

This order was formerly confounded with Cáclę: notwithstanding the dissimilarity of their appearance they are most closely related; the principal differences between the two orders VOL, III. are, that in Cáctea the stamens are indefinite, the seeds without albumen, and the calyx and eorolla undistinguishable; while in Grossularice the stamens arc definite, the seeds albuminous, and the calyx and corolla distinet. There are spines in both orders, and some of the Cáctce have distinet leaves.

The properties of the gooseberry and currant are those of the generality of the order, except that in other species a mawkish or extremely acid taste is substituted for the refreshing and agreeable flavour of the former. Some are cmetic. 'I'he black currant, which is tonic and stimulant, has fragrant glands upon its leaves and flowers; these reservoirs are also found upon some other species. Malie acid cxists in currants and gooseberrics. Turncr, 634 .

I. RI'BES (the name of an acid plant mentioned by the Arabian physicians, which has been discovered to be the Rhèm lỉibes). Lin. gen. 2S1. Berlándier, mem, soc. phys. gen. 3. pt. 2. p. 43. t. 1-3. and D. C. prod. 3. p. 4.77.-Grossulària, Tourn. Gærtn.

Lin. syst. Pentándria, Monogýnia. Claracter the same as the order.

Sect. I. Grossula'ria (a dim. of grossus, thick; meaning a gooseberry bush; the species contained in this section all bear goosebcrries). Ach. Rich. 1. c. Berlandier, I. c. t. I. Stcms usually prickly (f. 32.). Peduncles I-2-3-flowered. Calyx more or less campanulate (f. 32. a.). Leaves plicate.

\section{* Floners greenish.}

1 R. oxyacantmoides (Lin. spec. 291.) plant prickly and bristly, nakedish; spines 1 or 3 , joined at the base; leaves cordate, 5.lobed, serrated, often pubescent beneath, and on the petioles; peduncles very short, usually 2 -flowered; tube of calyx glabrous, hairy inside, with a spreading limb, which is longer than the obovate petals; germs and pedicels naked. $4 . H$. Native of North America throughout Canada, and as far as the Saskatchawan, and of Newfoundland. Berlandicr, I. c. t. I. f. 1. The shrub varies much in the aculei and spines, in their number and colour, and in the more or less dense ramification, and pubescence. Mr. Drummond says, the fruit of this species is much like the common gooseberry, and is equally agrecable, either of a red or green colour.

Hamthorn-lilie Gooseberry. Fl. May, June. Sh. 3 to $4 \mathrm{ft}$.

2 R. setòsum (Lindl. bot. reg. t. 1237. Hook. fl. bor. amer. 1. p. 230.) branches beset with dense bristles; prickles unequal, subulate; leaves roundish, cordate at the base, pubescent, 3-5lobed, cleeply crenated; peduncles 2 -flowered, rather bracteate; calyx tubularly campanulate, with the segments linear, obtuse, and spreading, twice the length of the petals, which are entirc; berries lispid. h.H. Native of North America, on the banks of the Saskatchawan.

Bristly Gooseberry. Fl. May, April. Clt. 1810. Shrub 4 to 5 feet.

3 R. Triflòrum (Willd. hort. berol. t. 61.) prickles wanting; spines usually solitary; leaves cordate, 5-lobed, serrated, glabrous; peduncles elongated, 2-3-flowered; tube of calyx narrow, cylindrical, glabrous, with a spreading limb, which afterwards becomes reflexed; stamens exserted; ovarium naked. h. H. Native of North America, in mountainous situations to the west of the Rocky Mountains; and of Pennsylvania. Berlandier, I. c. t. 1. f. 4. R. staníneum, Horn. hort. hafn. p. 237. Berry reddish, glabrous. The species scems to be easily distingnished from $R$. Cynósbati by the constantly smooth fruit, very narrow flowers, and exserted stamens.

A a 
Three-flowered Gooseberry. Fl. April, May. Clt. 1812. Sh. 3 to 4 feet.

4 R. Cyxósbati (Lin. spec. 292.) stem unarmed, rarely prickly; spines usually twin; leaves cordate, 5 -lobed, serrated, more or less pubescent underneath, and on the petioles; pechuncles elongated, 2-3-flowered; pedicels divaricate; tube of calyx ovate-cylindrical; limb spreading, with the segments excecding the petals, which are obovate; stamens hardly exserted; ovarium bristly. H. II. Natice of Canada (Michx.), Japan ('Thunb.), Berlandier, 1. c. t. 1. f. 3. Jacq. vind. 2. t. 123. Berries bristly or prickly. It hardly differs from $R$. divaricatum, except in the brouder tube of the corolla, and the shorter stamens.

Far. $\hat{3}$; fruit unarmed. $\bar{h}$. H. Native of Hudson's Bay. R. oxyacanthoides, Richards in Frankl. first journ. ed. 2. append. p. 7.

Var. $\gamma$; branches prickly; peduncles shorter; flowers pubescent, purplish; fruit prickly. $\zeta_{\text {. }}$ H. Native about Iake Huron.

Dog-bramble Gooseberry. Fl. Apr. Cht. 1759. Sh. 3 to $4 \mathrm{ft}$.

5 li. Divarica'tcm (Dougl. in bot. reg. 1359.) branches divaricate, bristly, at length naked; spines 1-3 together, axillary, defiexed, large; leaves roundish, 3-lobed, deeply toothed, nerved, glabrous; peduneles 3 -flowered, drooping; calyx funnel-slaped: with the segments at length spreading, and twice the length of the tube; style and stamens exserted; berries glabrous. h.H. Native on the north-west coast of America, a common bush on the banks of streams near Indian villages. This species comes nearest to $R$. triflorum. Berries black, smooth, and spherical, pleasant to the taste. Petals white.

Ditaricate Gooseberry. Fl. April. Clt. 1826. Sh. 5 to $7 \mathrm{ft}$.

(i R. Irríguen (Doug, in hort. trans. 7. p. 516. Hook, fl. bor. amer. 1. p. 231.) prickles axillary, tern; leaves cordate, somewhat 5-lobed, toothed, ciliated, pilose on both surfaces, nerved; peduncles 3 -flowered, beset with glandular pili ; cals $x$ campanulate: segments linear, about equal in length to the tube; berries glabrous. $々$. H. Native of the north-west coast of America, on moist mountain rocks near springs and streams, on the Bluc Mlountains, and on the banks of the Spokan river. Berries spherical, half an inch in dianeter, smooth, juicy, and well flavoured. Apparently closely allied to R. triflürum.

II'cll-matered Gooseberry. Shrub 3 to 4 feet.

7 R. saxòscm (Hook. fl. bor. amer. 1. p. 231.) stem unarmed, rarely prichly; spines wanting, solitary or twin; leaves cordate, 5-lobed, serrated, smoothish; peduneles very short, deflexed, 1-2-flowered; calyx glabrous, with a campanulate tube: segments spreading, but at length reflexed, twice the length of the corolla, and about equal in length to the stamens; ovarium maked. h. H. Native of the north-west coast of America, common on the undulating grounds of the interior among stones ; and about Lake Huron, and on the ba: ks of the Saskatchawan; also near Boston. R. saxátile, Dougl. mss. R. triflorum, Bigel. fl. bost. ed. 2. p. 90. Fruit resembling a common gooseberry.

\section{Stone Gooseberry. Shrub 3 to 4 fect.}

8 R. hirtéli.ui (Michx. fl. bor. amer. 1. p. 479.) spinules nearly axillary; brancles beset with a few s! ort bristly hairs ; leaves small, semi-trifid; lobes few-toothed ; peduncles 1-flowered; berry glabrous, red. h. H. Native of Nortl America, in Canada, in stony places by the river Signey; and on the mountains of Virginia.

Iairy Gooseberry. FI. April, May. Clt. 1812. Shrub 3 to 4 feet.

9 R. Lacu'stre (Poir. encycl, suppl. 2. p. 856. Pursh. fl. amer. sept. 1. p. 161.) stem iery prickly; sjunes many-parted, slender; leaves cordate, decply 3-5.lobed, cut; racemes 5-8. flowered, loose; calyx rotate; germs and pedicels hispid, and glandular. দ. H. Native throughout Canada to Fort Frankfin and Bear Lake, near the Arctic circle; mouth of the Columbia ; mountains of the Columbia. and of North California ; also of Virginia, \&c. R. oxyacanthoides, Michx. f. bor. amer. 1. p. 111. R. echinàtum, Dougl, mss. This has the flowers of the currant, and the prickly stems of the gooseberry. The fruit is about the size of black currants, in pendulous racemes, purplish black, shining, clothed with hairs, unpleasant to the taste.

Lake Gooseberry. Fl. A pril, May. Clt. 1812. Sh. 4 to $5 \mathrm{ft}$.

10 R. rotundifòlum (Michx. fl. bor. amer. 1. p. 110.) spines nearly axillary, solitary ; leaves nearly orbicular, clothed with very minute down, a little lobed; lobes roundish, obtuse ; peduncles 1-flowered; limb of calyx tubular. 々. H. Native on the ligh mountains of Carolina. Berries glabrous.

Round-leaved Gooseberry. Shrub 3 to 4 feet.

11 R. GRA'CILE (Michx. fl. bor. amer. 1. p. 111.) spines nearly axillary, very short, solitary ; leares on slender petioles, lobed; lobes acute, cut; peduncles capillary, erect, usually 2flowered; calyx glabrous, tubularly campanulate, h. H. Native of North America, on the mountains of Tennessee; and in mountain meadows from New York to Virginia. Berry glabrous, purple or blue, with a very pleasant taste. Leaves pubescent.

Slender Gooseberry. Fl. April, May. Clt. 1812. Shrub 3 to 4 feet.

12 R. Cauca'sicus (Adams, in reliq. Willd. ex Rom. et Schultes, syst. 5. p. 507.) prickles stipnlar, tern; peduncles 1flowered, erect; leaves 5 -lobed, deeply toothed. $h . \mathrm{H} . \mathrm{Na}$ tive of Caucasus. Perhaps only a varicty of R. U'va-erispa.

Caucasian Gooscberry. Fl. May, June. Clt. 1819. Shrub 4 to 5 feet.

13 R. Microphy'́lum (H. B. et Kunth, nov. gen. amer. 6 . p. 62.) prickles usually solitary; leaves nearly reniform, small; peduncles very short, 2 -flowered; calyx campanulate : segments oblong, obtuse; petals spatulately obovate, retuse at the apex. h. H. Native of Mesico, in mountainous places near El Guarda, between Guchila and the city of Mexico, at the eleration of 4200 feet. Ovarium rather turbinate. Flowers red.

Sinall-leaved Gooseberry. Shrub 4 to 6 feet.

14. R. cuneifòctuar (Ruiz et Pav, f. per. 3. p. 239. f. c.) unarmed; leares cuneiform, cut, trifid; petioles not half the length of the leaves; perluncles solitary, axillary, 2-3-flowered, length of the petioles; bracteas 2, at the base of each flower. h.G. Native of Peru; on the Andes. Berry pale red. Habit of $R$. $U^{\prime} \cdot a$-crispa. Perbaps belonging to a separate section.

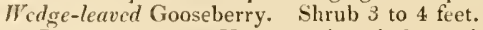

15 R. cuculla'tum (Hook. et Arn. in bot. misc. 3. p. 250.) unarmed; branches glabrous; leaves glabrous, somewhat 5 lobed, roundish-reniform, cucullate at the base, and cuneated : the lobes lying over each other, acutely and dceply lobed; petioles a little shorter than the leaves; racemes hardly puberulous, axillary, short, few-flowered; flowers nearly sessile, hardly excecding the bracteas, which are roundish. $h$.G. Native of the Curdillera of Chili. Nearly allied to $R$. cuneifòlium, but apparently quite distinct.

Hooded-leaved Gooseberry. Shrub 4 to 5 feet.

16 R. AciculA'RE (Smith in Rees' cycl.) very prickly; prickles stipular, 3.5-parted; leaves rather pubescent, nearly orbicular, 3-5-lobed; lobes bluntish, deeply serrated; peduncles usually 1-flowered, bracteolate in the middle; calyx campanulate, smoothish; berries bractless, and are, as well as the styles, quite glabrous. h. H. Native of Siberia, in stony roeky mountainous places. I.ed. fl. ross. alt. ill. t. 230 . R. U'va-críspa, Sievers in Pall. nord. beytr. 7. p. 274. Pall. fl. ross. 2. p. 37.? Stem erect or procumbent. Petals white. Berries glabrous, yellowish or puplish, sweet, with a grateful taste. 
Acicular-spined Gooseberry. Slırub.

17 R. grossuca'ra (Lin. spec. p. 291.) prickles 2 or 3 under each bud; branches otherwise smooth, and spreading or erect; pedicels 1-2-tlowered; leaves 3-5-lobed, rather villous; bracteas close together; calyx campanulate, with reflexed segments, which are shorter than the tube; petals rounded at the apex, glabrous, but bearded in the throat; style alwrys beset with long down. h. H1. Native of Europe and Nipaul, in woods and hedges; plentiful in some parts of Britain, in helges, thickets, and waste ground, as the woods and hedges about Darlington; apparently wild in IIamilton wood, Scotland. Smith, eng. bot. 1292. R. U'va-críspa, Oed. fl. dan. t. 5.16. Grossulària lirsuta, Mill. dict. no. 2. li. U'va-críspa var. $\zeta$ sativum, D. C. A. fr. 4. p. 408. Plench. icon. 148. 'The Nipaul plant has the stem thickly beset with bristles, and the spines strong and 3-parted. It is therefore probably a proper species.

Var. $\beta$, U'ta-crispa (Smith, engl. fl. 1. p. 333.) plant beset with spines all over; leaves small, rather villous; berries smaller, glabrous. そ.H. R. U'va-críspa, Lin. spec, 292. Smith, eng. bot. 2057. U'va-crispa, Fuch's hist. t. 187.-U'va spina, Math. valgr. 1. t. 151. f. 1.-Blackw, herb. 277.-Plench. icon. t. 149. -Dulam. arbr. 1.t. 109. Berlandier, l. c. t. 1. f. 6. R. U'vacrispa var. a sylvéstre, Berland. l. c. mss.

I'ar. $\gamma$, spinosissimum (Berl. mss.) plant spiny all over ; prickles scattered, reflexed. Native of Europe in stony places.

Lar. \&, reclinaitum (Berl. mss.) branches rather prickly, reclinate. R. reclinàtum, Lin. spec. 291. Grossulària reclinàta, Mill. dict. no. 1.

I ar. $\varepsilon$, Besseriàna (Berl. mss.) branches prickly; fruit pubescent, intermixed witl glandular bristles. Native of Cracovia, in hedges. R. hýbridum, Besser. prim. fl. galic. austr. p. 186 .

Jar. ל, subenérme (Berl. mss.) plant nearly glabrous; bark smooth, brown; prickles axillary; flowers and leaves small. Native about Geneva. I'erhaps a variety of $R$. rcclinàtum.

Var. $\eta$, macrocárpum (D. C. prod. 3. p. 478.) stigmas often longer than the petals; flowers and berries large.

Var. $\theta$, bracteàtum (Berl. mss.) berries clothed with 2-4-5 straight coloured, nearly opposite, bracteas and bristles, emulating sepals, which fall off before the berry arrives at maturity.

The gooseberry is called Groscille à maquereau, in French; Uca-spino in ltalian; Stachclbeerstrauch, in German; in scotland it is called Groscir; in Piedmont, where the gooseberry is found wild, and where the Italian botanists state the berries to be eatable, but astringent and neglected, it is called Griselle. Some derive our name gooseberry from gorzeberry, from the resemblance of the bush to gorze; olhers, as Professor Martyn, from its being used as sauce with young or green geese. Gerarde says it is called feaberry (feverberry) in Cheslire; and it has the same name in Lancashire and Yorkshire. In Norfolk this term is shortened to feabes, or, as they pronounce it fapes. Carberry is another British name for this fruit.

The gooseberry is a low, branching, prickly shrub, bearing pendulous, hairy, or smooth berries, of various colours; it is a native of several parts of Europe, and abounds in the Vallais, in copsewoods, where it produces a small, green, hairy, highflavoured fruit. In England it is naturalized in various places, as on old walls, ruins, and in the woods and hedges about Darlington. It is cultivated in greater perfection in Lancashire than in any other part of Britain; and next to Lancashire the climate and treatment of the Lothians seem to suit this fruit. In Spain and Italy the fruit is scarcely known. In France it is neglected and little esteemed. In some parts of Germany and Holland the moderate temperature and hunidity of the climate seem to suit the fruit ; but in no country is its size and bealty to be compared with that produced in Lancashire, or from the Lancashire varieties, cultirated with care, in the more temperate and humid distriets of Britain. Neill olsserves, that when foreigners witness our Lancashire gooscberries, they are ready to consider them as forming quite a different kint of fruit. Iappily this wholesome and useful fruit is to be found in almost every cottage-garden in Britain; and it ouglit to he considered a part of every gardener's duty to encourage the introduction of its most useful varieties in their humble enclosures. In Lancaslife, and some parts of the adjoining counties, almost every cottager, who has a garden, cultivates the gooscberry, with a view to prizes, given at what are called Gooseberry-prize Meetings, of which there is anuually published an account, with the names and weight of the successful sorts, in what is called the Manchester Gooscberry Book. The prizes vary from $1 l$, to $5 l$. or $10 l$. The second, third, to the sixth and tenth degree of merit, receiving often proportionate prizes. There are meetings held in spring, to " make up," as the term is, the sorts, the persons, and the conditions of exhibition ; and in August to weigh and taste the fruit, and determine the prizes.

Usc._' 1 he fruit was formerly in little estcem; but it has received so much improvement, that it is now considered very valuable for tarts, pies, sauces, and creams, before being ripe, and when at maturity, it forms a rich ctessert fruit for three months; and is preserved in sugar for the same purpose, and in water for the kitehen. Unripe gooseberries can be preserved in bottles of water against winter; the hottles are filled with berries, close corketl, and well scaled; they are then placed in a cool cellar till wanted. By plunging the bottles, after being corked, into boiling water, for a few minutes (heating them gradually to prevent cracking), the berries are said to keep better." -Neill.

Varietics.-Tlue gooseberry is mentioned by Turner, in 1573. Parkinson enumerates 8 varieties; the small, great, and long common, 3 reds, 1 blue, and 1 green. Ray mentions only the pearl gooseberry, but Rea has the blue, several sorts of yellow, the white Holland, and the green. Miller only says, there are several varicties obtained from seed, most of them named from the persons who raised them; but as there are frequently new ones obtained, it is needless to enumerate them. The present list of the Lonlon nurserymen contains from 80 to 100 names, but those of some of the Lancashire growers above 300. Forsyth, in 1800 , mentions 10 sorts as common; and adds a list of 43 new sorts, grown at Manchester. 'The following may be considered established varieties, and such as merit cultivation.

List of gooscberrics. - Those marked with a star may be considered the best ; the rest only second rate.

\section{Fruit grcen.}

\section{\$1. Branches spreading or pendulons. \\ * Berrics smooth, green.}

1 Barclay's grien champagne. Fruit roundish, middle-sized. 2 Perring's crergreen. Fruit large, oblong.

3 Fame. Fruit large, obovate. Branches pendulous.

4 Batcs's facourit. Fruit oblong, middle-sized. Branches pendulous.

5 Glory of Kingston. Fruit roundish, middle-sized.

6 Allen's glory of Ratcliff. Fruit oblong, middle-sized."

7 Horsefield's grcen gage. Fruit large, roundish.

8 Green globe. Fruit round, middle-sized.

9 Nixon's grecn myrtle. Fruit large, oblong. Branches pendulous.

10 Berry's greennood. Fruit large, oblong. Branches pendulous.

11 Massey's heart of oak. Fruit large, oblong. Branches pendulous. *

A a 2 
12 Grundy's high sheriff of Laneashire. Fruit obovate, middle-sized. Branches peudulous.

13 Edward's jolly tar. Fruit large, obovate. Branches pendulous.*

14 Minerra. Fruit large, oblong.

15 Taylor's no-bribery. Fruit large, obovate. Branches pendulous.

16 Northern hero. Fruit large, obovate.

17 Reformer. Fruit large, oblong.

18 Sabine's green. Fruit small, round.

19 Large smooth green. Fruit large, obovate."

20 Green Walnut, Belmont's, smooth green, nonpareil. Fruit middle-sized, obovate."*

\section{* Berries green, hairy, or donny.}

21 Colonel Anson's, Fruit large, oblong, hairy.

22 Holt's beauty. Fruit large, oblong, downy.

23 Early green hairy, early green, green Gascoigne. Fruit small, round. *

24 Lovart's Elija. Fruit large, roundish, hairy.

25 Glenton green, Jork sectling Fruit middle-sized, oblong, lairy. Branches pendulous.*

26 Green globe. Fruit small, round, hairy.

27 Green seedling. Fruit small, oblong, hairy. Branches pendulous."

28 IIodlinson's joke. Fruit large, roundish, downy. Branches pendulous.

29 Lovely Anne. Fruit large, oval, downy. Branches pendulous.

30 Gregory's perfection. Fruit large, roundish, downy, late. branches pendulous. *

31 Prophet's profit. Fruit large, oblong, downy.

32 Early royal George. Fruit middle-sized, oblong, hairy, tarly.

33 Ryder's triumph. Fruit small, obovate, hairy.

31. Moore's troubler. Fruit large, roundish-oblong, hairy.

35 Unicorn. Fruit large, oval, downy.

$$
\begin{aligned}
& \text { \$2. Branehes ereet. } \\
& \text { * Fruit green, smooth. }
\end{aligned}
$$

36 Pitmaston green-gage. Fruit small, obovate.**

37 Brigg's independent. Fruit large, obovate.

3.8 Merry lass. Fruit middle-sized, obovate.

39 Midsummer. Fruit small, roundish.

40 Royal George. Fruit middle-sized, oval.

$$
\text { * Fruit green, hairy, or donny. }
$$

11 Monck's Charles Fox. Fruit small, ovate, hairy.

12 Gireen oak. Fruit large, roundish, hairy.

$\$ 3$ Greensmith. Fruit middle-sized, roundish, hairy.

44 IIebburn's prolific. Fruit middle-sized, roundish, hairy."

45 Colliers's jolly angler, Lay's jolly angler, Collins's jolly ungler. Firuit large, oblong, downy.*

46 Mills's Langley green. Fruit large, roundish, hairy.

47 Late green. l'ruit small, obovate, downy.

48 Parkinson's laurcl, green laurel, green willow. Fruit large, obovate, pale green, nearly white."

19 IIopley's Lord Crew. Fruit large, oblong, hairy.

50 Mignonette, Fruit small, roundish, hairy.

51 Lovart's Moses. Fruit large, obovate, hairy.

52 Green Rumbullion. Fruit small, round, hairy.

53 Small green. Fruit small, globular, lowny.

54. Small hairy green. Fruit small, round, hairy.

55 Bratherston's Wistaston hero. Fruit large, oblong.
1I. Fruit yellow.

§ 1. Branches spreading or pendulous.

* Fruit yellow', smooth.

1 Amber, amber yellow, smooth amber. Fruit small, roundisl.

2 Diggles's Bonny Roger. Fruit large, obovate.

3 Capper's I'unlier's Hill. Fruit large, roundish.

4 Hopley's Cheshire eheese. Fruit large, oblong.

5 Forbes's golden ehain. Fruit large, oblong. Branches pendulous.

6 Bamford's golden Purse. Fruit large, obovate. Branches pendulous.

7 Beaumont's smiling beauty. Fruit large, oblong. Branehes pendulous."

8 Beardsell's smuggler. Fruit large, roundish, oblong. Branches pendulous.

9 Dixon's golden yellon. Fruit middle-sized, turbinate. Branches pendulous. *

10 Mather's victory. Fruit large, obovate. Branches pendulous.

11 Forester's Lord Combermere. Fruit large, obovate.

12 Saunder's Nopoleon. Fruit large, obovate.

13 Costerdine's Champion Goliath. Fruit large, oblong, smooth, golden yellow. Branches pendulous.

14 Large yellow. Fruit obovate, middle-sized, golden yellow, smooth. Branches pendulous.

15 Gorton's viper. Fruit large, obovate, golden yellow, smooth. Branches pendulous.

16 Long yellow. Fruit large, oblong, golden yellow.

$$
\text { * Fruit yellow, hairy, or downy. }
$$

17 Capper's bottom sanyer. Fruit large, obovate, downy.

18 Lister's Britannia. Fruit large, obovate, downy.

19 IIopley's globe. Fruit large, round, hairy. Branches pendulous.

20 Glory of England, Fruit large, obovate, downy. Branches pendulous.

21 Golden bees, Fruit small, oblong. Branches pendulous. 22 Jackson's golden orange. Fruit large, oblong, Branches pendulous.

23 Bratherston's golden sovereign. Fruit large, roundish, bairy.

24. Hill's golden gourd. Fruit large, oblong, hairy. Branches pendulous.

25 Ifilton's Kilton, Kilton hero. Fruit large, oblong, golden yellow, hairy. Branches pendulous.

26 Blomerley's John Bull. Fruit large, obovate, downy. Branches pendulous.

27 Ranger. Fruit small, roundish, hairy. Branches pendulous.

28 Sparklet. Fruit small, obovate, downy.

29 Hallow's Trafalgar. Fruit large, oblong, hairy. Branches pendulous.

30 Waverham's yellow. Fruit middle-sized, oval. Branches pendulous.

31 Weedham's delight. Fruit large, oblong, hairy.

$$
\begin{aligned}
& \text { \$2. Branches erect. } \\
& \text { * Fruit yellow, smooth. }
\end{aligned}
$$

32 Jellow ball. Fruit middle-sized, roundish.*

33 Blithficld. Fruit small, round, late.

34 Clegg's Tim Bobbin. Fruit middle-sized, oblong.

35 Old dark yellow. Fruit small, roundish.

36 White naluut. Fruit middle-sized, obovate, whitish yellow. 
* Fruit yellow, hairy, or donny.

37 Ilebburn yellow aston. Fruit small, roundish, laairy."

3s Fellow champagne, hairy amber. I'ruit small, roundish, hairy.

39 Catlow's conquering hcro. Fruit large, oblong, coarse, luairy.

40 Ileap's conquering girl. Fruit large, oblong, hairy.

41 Golden drop, golden lemon.

42 I'urt's golden flecee. Fruit large, oval, hairy.

43 Sulphur, rough ycllon. Fruit small, roundish, hairy."

4. Early sulphur, golden ball, golden bull. Fruit middle-

sized, rom dish-oblong, hairy.

45 Fostcr's husbandman. Fruit large, obovate, downy.

40 Hcynood's invincible. Fruit large, roundish-oblong, downy.

47 Hardcastle's jolly gunner, royal gunner. Fruit large, oblong, hairy.

48 Prophet's regulator. Fruit large, roundish, hairy.

49 Rumbullion, yellow globe, round yellow. Fruit small, roundish, downy.

50 Smooth ycllow. Fruit small, roundish, downy.

51 Williamson's yellow hornet. Fruit small, ovate, downy.

52 Iellon'smith. Fruit small, roundish-oblong, hairy.*

53 Kelk's yellow. Fruit middle-sized, oblong, downy.

11I. Fruit white, or greenish white.

\section{\$1. Branches ereet. \\ * Fruit smooth, white.}

1 Cranshaw's ambush. Fruit large, obovate, white.

2 White Damson. Fruit small, roundish.*

3 Iloney white. Fruit middle-sized, roundish-oblong.

4. Hoslam's smiling yellon. Fruit large, roundish-oblong.

5 Cook's mhite eagle. Fruit large, obovate."

6 Lovart's Queen Caroline. Fruit middle-sized, obovate.

* * Fruit grecnish white, hairy, or downy.

7 Large early white. Fruit large, obovate, downy.*

8 Sampson's Quecn Ann. Fruit large, oval, downy.

9 Pecrs's Queen Charlotte. Fruit middle-sized, oblong, lıairy.*

10 Morris's Queen Mary. Fruit middle-sized, ovate, downy.

11 Trueman. Fruit large, obovate, hairy.

* Fruit nhite, hairy, or donny.

12 Bonny landlady, noble landlady. Fruit large, oblong.

13 Hopley's lady of the manor. Fruit large, roundish-oblong, hairy.

14 Ihite lion. Fruit large, obovate, hairy.

15 Stringer's maid of the mill. Fruit middle-sized, obovate, downy.

16 Marchioness of Donnshire. Fruit middle-sized, oblong, hairy.

17 Early rough nhite. Fruit large, oval, hairy.

18 Saunder's royal roek getter, Audrcn's's royal rock getter.

Fruit large, obovate, downy.

19 White royal. Fruit small, round, lıairy.

20 Compton's Sheba Queen. Fruit large, obovate, downy.*

21 W'ellington's glory. Fruit large, roundish-oblong, downy.*

22 Moore's white bear. Fruit large, obovate, hairy.*

23 Nixon's white heart. Fruit middle-sized, heart-slıaped, hairy.

24 White lily. Fruit middle-sized, obovate, downy.

25 Woodnard's whitesmith, Sir Sidney Smith, Hall's scedling, Laneashire lass, Grundy's Lady Lillford. Fruit large, roundishoblong, Iowny.

26 Taylor's bright Venus. Fruit middle-sized, obovate, hairy."

27 Ithite ehampagne. Fruit small, roundish-oblong, hairy.*
28 Saumler's Cheshire lass. Fruit large, oblong, downy. *

29 Hedgchog. Fruit middle-sized, roundish, hairy."

\section{\$2. Branehes spreading or pendulous.}

* Fruit smooth, nhite.

So Crystal. liruit small, roundish.*

31 thite fig. Fruit small, obovate. *

32. P'arkinson's first rate. liruit larere, oval.

33 Leigh's fuller. Fruit middle-sized, oblong. Branches pendulous.

34. Grat Britain. Fruit large, oblong, greenish white.

35 White rasp. Fruit small, round.

36 Brundrett's mhite rock. Fruit large, obovate. Branclıes pendulous.

37 Diggles's wanton. Fruit middle-sized, roundish, greenish white.

38 Denny's Vietoria. Fruit large, obovate, greenish white.

* Fruit greenish white, smooth.

39 Stringer's dusty millcr. Fruit middle-sized, obovate. Branches pendulous.

40 Great Britain. Fruit large, oblong. Branclres pendulous.

4.1 Denny's Vittoria. Fruit large, obovate. Branches pendulous.

** Fruit white, hairy, or donny.

42 Capper's bonny lass. Fruit large, oblong, hairy.

43 White erystal. Fruit small, roundish, hairy or downy.

44 Early white. Fruit middle-sized, roundish, downy. *

45 Grundy's fowler. Fruit middle-sized, obovate, downy.

46 Large white. Fruit midllle-sized, oval, downy.

47 Smith's radical. Fruit large, roundi-h-oblong, hairy.

Branches pendulous.

48 Irish white raspberry. Fruit small, round, hairy.

49 Cleworth's white lion. Fruit large, obovate, downy. Branches pendulous. *

\section{**** Fruit greenish white, hairy or donny.}

50 Counsellor Brougham. Fruit large, oblong, downy.

51 Bratherton's governess. Fruit large, roundish-oblong, hairy.

52 Princess royal. Fruit large, obovate, hairy. Branclies pendulous. *

53 Leigh's toper, Fox's toper. Fruit large, oblong; downy. Branches pendulous.

54. Taylor's speednell. Fruit large, oblong, hairy. Branches pendulous.

\section{Fruit red.}

\section{$\$ 1$. Branches spreading or pendulous.}

* Fruit hairy or downy.

1 Alexander. Fruit large, obovate, hairy.

2 Ilamlet's beauty of England. Fruit large, oblong, hairy.

3 I'averham's black bullfinch. Fruit middle-sized, obovate, dark red, downy.

+ Shipley's black prince. Fruit middle-sized, roundish, downy, deep red.

5 Boardman's British cronn. Fruit large, roundish, lairy.

6 Milliams's conqueror. Fruit large, obovate, hairy.

7 Melling's crown bob. Fruit large, oblong, hairy. *

8 IVorthington's defianee. Fruit large, obovate, hairy. Branclies pendulous.

9 Earl Grosvenor. Fruit large, obovate, downy. Branches pendulous. 
10 Early black. Fruit middle-sized, oblong, dark red. Branches jendulous.

11 Early rough red. Fruit small, roundish-oblong.

12 Berry's farmer's glory. Fruit large, obovate, downy. Branches penchulous. "

13 Smith's favourite. Fruit middle-sized, roundisl-oblong, laairy.

14. Glory of Oldham. Fruit middle-sized, oblong, lairy.

15 Irommonger, hairy black. Fruit small, roundish, hairy.

16 Jaekson's slim. Fruit middle-sized, obovate, dark red, downy.

17 Keens's scedling, Keens's scedling Warrington. Fruit mid1le-sized, oblong. Branches pendulous. *

18 Bratherton's Lord of the Manor. Fruit large, roundish, lairy. *

19 Knight's Marquis of Stafford. Fruit large, roundish-oblong, hairy. *

20 H'right's matchless. Fruit middle-sized, oblong, darkred, hairy.

21 Miss Bold, pigcon's egg. Fruit middle-sized, roundish, downy, dark red, early. *

22 Bratherton's orcr-all. Fruit large, oblong, bairy. Branches penclulous.

23 Bratherton's pastime. Fruit large, roundish, hairy, dark red. Branelies pendulous.

24 Rasplocry, nutmeg. Fruit small, roundish, hairy, dark red. *

25 Red Mogul. Fruit snall, roundish, hairy. *

26 Large red otal. Fruit large, oval, hairy. *

27 Red rose. Fruit large, oblong, downy. Branches pendulous. *

28 Red Smith. Fruit middle-sized, oval, downy.

29 Acherley's Rodney. Fruit middle-sized, obovate, downy. Branches pendulous.

30 Rough red, little red hairy, old Scotch red, thick slinned retl. Fruit small, round, hairy. *

31 Small dark rough red, small rough red. Fruit small, round, hairy. *

32 Royal oak. Fruit middle-sized, roundish, hairy. *

33 Snall red. Fruit small, round, hairy. *

34. Capper's top samyer. Fruit large, roundish, hairy, pale red. Branches pendulous.

85 Denny's trimmphant. Fruit large, obovate, hairy. Branches pendulous.

86 Lomas's victory. Fruit large, roundish, hairy. Branches pendulous.

97 Red nalnut, Murrey, Rekersley's double betring, Ashton red. Fruit middle-sized, obovate, downy, early.

38 Warrington red, Aston, voluntcer. Fruit large, roundishoblong, hairy. Branches pendulous. This is one of the best, and hangs late. *

39 Knight's marrior. Fruit large, ovate, downy, pale red. liranches pendulous. hairy.

40 I'ilmot's late superb. Branches large, roundish-oblong,

$$
\text { * Fruil smooth, red. }
$$

41 Gerard's Ajux. Fruit large, roundish.

42 Red ball. Firuit small, roundish.

43 Claret. liruit small, roundish.

44. Worthington's eonqueror. Fruit large, obovate. Branclses pendulous.

45 Rival's enperor Napoleon. Fruit large, oborate. Branches pendulous.

46 Hhitton's glory. Fruit midllle-sized, oblong, dark red.

47 Hooper's grcat eaptain. Fruit large, oblong. 4s Ambersley hero. Fruit large, oblong, dark red.

49 Jagg's red. Fruit large, roundish. Brancles pendulous.

50 Eckersley's jolly printer. Fruit large, oblong, dark red.

51 Brannlie nutmeg. Fruit small, obovate.

52 Rider's Old England. Fruit large, roundisb-oblong, dark red. Branches pendulous.

53 Boarlman's Prince Regent. Fruit large, roundish, dark red.

54. Red Turkey, smooth red. Fruit small, obovate.*

55 W'ard's Richmond Ifill. Fruit large, obovate, dark red. Branches pendulous.

56 Johnson's ringleader. Fruit large, oblong. Branches pendulous.

57 Farron's roaring lion, great chanee. Fruit very large, oblong. Branches pendulous.

58 Snint John. Fruit middle-sized, obovate.

59 Rider's scented lemon. Fruit large, obovate. *

60 Grenves's Smolcnslco. Fruit large, obovate. Branches pendulous.

61 Chadnick's sportsman. Fruit large, obovate, dark red.

62 Bratherton's whipper-in. Fruit large, oblong, dark red. Branehes pendulous.

63 IIilmot's early red. Fruit large, roundish-oblong, dark red. Branches pendulous.

64 Vilmot's scedling red. Fruit large, oblong, dark red.

65 Halker's Bank of Englund. Fruit large, obovate. Branches pendulous.

\section{\$2. Branches erect. \\ * Fruit smooth, red.}

66 Small red glole, smooth Seotch. Fruit small, roundish.*

$$
\text { * Fruit red, liciry or donny. }
$$

67 Brundrett's atlas, Brundit's atlas. Fruit large, oblong, hairy.

68 Barton's red. Fruit middle-sized, roundish, ba ry.

69 Rod Champagne, red Turkey, countess of Errol, Ironmonger of many. Fruit small, roundislt-oblong, hairy. A 'ruit of unequalled ricliness. *

70 Dakins's black. Fruit middle-sized, oblong, dark :ed. A bad bearer.

71 Large red globe. Fruit large, roundish, hairy.

7尺 Barton's hairy red. Fruit small, roundish, hairy. A good bearer.

73 Bratherton's huntsman, Speechley's rough red. Fruit large, roundish, hairy. A good bearer.

74. Irish plum. Fruit middle-sized, roundish, hairy.

75 Hopley's jubilec. Fruit large, roundish, hairy, dark red.

76 Alleock's ling. Fruit large, roundish, hairy, dark red.

77 Lad Hartshorn's Laneashire. Fruit large, roundish, hairy, dark red. A good bearer.

78 Litle Juhn. Fruit small, oblong, hairy, dark red.

79 Bcaumont's red. Fruit middle-sized, roundish, hairy. *

so Leigli's rifleman, Alleoek's Duke of York, Iates's royal

Ann. Fruit large, roundish, hairy. A good bearer, and late. * S1 Rob Roy. Fruit middle-sized, obovate, hairy.

82 Searlet transparent. Fruit small, roundish, hairy. A batl bearer.

83 Seotch best jam, dumpling. Fruit small, hairy, roundish. * 84 Denny's Shakspeare. Fruit large, roundish, hairy.

85 Mcllor's Sir Francis Burdett. Fruit large, ohovate, pale red.

86 Hampson's Tantarara. Fruit middle-sized, obovate, downy. *

87 Specehley's Iaxley hero. Fruit large, obovate, hairy. * 
Sclection of sorts._-" It must be admitted," Neill observes, "that although large gooseberries make a fine appearance on the table, they are often deficient in flavour when compared with some of smaller size. Many of them have very thick strong skins, and are not catable unless thoroughly ripened. Some of the large sorts, however, are of very good quality, such as the red Champagne and the green notnut, S.c. For culinary use in the month of Mav, Wilmot's early red is larger and better than most others, the skin not being tough, and the whole berry melting to a fine consistence." Forsyth very judicionsly recommends cultivating the early and late sorts, in order to prolong the season of this fruit. But the best way of selecting sorts for any particular purpose is from the list given above, where those that are of particular excellence are marked by an asterisk.

Propagation.-The gooselerry may be propagated by all the modes applicable to trees or shrubs, even by pieces of the roots; but the mode by cuttings is usually adopted for continuing varieties, and that by seeds for proeuring them.

By seeds. - The scientific mode of impregnating one variety with another has, we helicve, not been applied to this fruit. In general the seed of some choice variety, thoroughly ripe, is taken and sown in autumn or early in spring, in beds or pots of rich light mellow earth; when the plants are a year old, they are planted out in nursery rows, to be cultivated and trained there a year or two; in general they will bear the third year. By preparing for the best of these seedlings a very rich soil, and by watering, shading, and thinning the fruit, the largest sorts have been obtained. Not content with watering at the roots and over the top, the Lancashire connoisseur, when he is growing for exhibition, places a small saucer of water immediately under each gooseberry, only 3 or 4 of which he leaves on the tree. This is techically ealled suckling. He also pinches off a great part of the young wood, so as to throw all the strength he can into the fruit.

By cuttings.-Miller says, the best season for planting gooseberry cuttings is in autumn, just before their leaves begin to fall. The cuttings should be taken from bearing shoots, rather than from those that issue from the main stem. Cut them to such a length as the strength and ripeness of the wood will bear, and cut off all the buds, excepting three, or at nost four at top, and train the plants with a single stem of ? inches or a foot high, from the top of which the branclies should radiate upwards at an angle of $40^{\circ}$, or better if $45^{\circ}$. Haynes alvises taking off cuttings in July, when the fruit is on the bush, in order to make sure of the sorts. IIe says, by immediate planting, watering, and shading, as good plants are produced as from ripe wooked cuttings. Treat. of the gooseberry, \&.c. p. 29.

Soil and site.-Any good garden soil, on a dry bottom, and well manured, will suit the gooseberry. That which is soft and moist jroduces the largest fruit. The situation should not be under the drip of trees, over much shaded or confined, otherwise the fruit will be small, ill flavoured, and the plants apt to mildew. Forsyth says, gooseberries should be dunged every year, or at least have a good coat of dung once in two years. Haynes recommends a mixture of peat and loam well manured, and a shaded situation. The last he proposes to effect by planting among his quarters of gooseberries, rows of Jerusalem articbokes in the direction of east and west.

Final planting. - "The season for planting gooseberries is any time during open weather, from October till March. When trees are procured from the public nurseries, choose such as are in some advanced state, about 3 years' growth, with pretty full heads, for immediate plentiful bearers. Let the general supply be in standard bushes, and plant principally in the kitchen garden, in single rows along the boundary edges of the main quarters or outward borders, from 6 to $\$$ feet apart, or some may he planted in cross rows, to subdivide extensive quarters. When the object is to raise large quantities of fruit, plantations are made in continued parallel rows, 8 or 10 feet asunder, by 6 feet in the row. It would be eligible to plant a few choice sorts against south and other sunny walts or paling, for earlier and larger fruit; and on north walls to ripen late in succession." Abererombie. Forsyth says, "The market gardeners aljout London plant them in rows, from 8 to 10 feet apart from row to row, and 6 feet from plant to plant in the rows. In snatl gardens I would recommend planting them in quarters by themselves, at the distance of 6 feet between the rows, and 4 feet from plant to plant; or you may plant them round the edges of the quarters about 3 feet from the path; you will then have the ground clear for eropping, and a man, by setting one foot on the border, ean gather the gooseberries without injuring the crop." Neil says, "In some places gooseberry bushes on the sides of the borders, are trained to a single tall stem, which is tied to a stake; this, though 6 or 8 feet high, accasions scarcely any shade on the border, and it does not occupy much room, nor exclude air; while, at the same time, the stem becomes close hung with berries, and makes a pleasant appearance in that state." Edimb. encycl. art. hort. \$ 161. Maher observes (Hort. trans. 2. p. 146.) " that as the crop of ripe fruit is often injured by having the largest and earliest berries prematurely gathered, whilst green, for tarts, a sufficient number of trees of such varieties as are earliest should be planted in a separate quarter of the garden, and devoted exclusively to the use of the kitchen, for tarts and sance."

Mode of bearing.—" The gooseberry produces its fruit not only on the shoots of last summer, and on shoots 2 or 3 years old, but also on spurs or snags arising from the elder branches along the sides; but the former afford the largest fruit. The shoots retained for bearers should therefore be left at full length or nearly so." Abercrombie.

Pruning._- The bushes will require a regular pruning twice in the year."

Summer pruning.- "Where any bushes are crowded with cross and water shoots of the same year, shading the fruit from the sun, and preventing the access of air, thin the heart of the plant and other tufted parts moderately, pinching off or cutting out close what spray is removed; but do not touch the summer shoots in general. Malier says, it will greatly contribute to the perfection of the fruit, if the very small berries are taken away with a pair of scissors about the middle or end of May; and these small berries will be found quite as good for sauce or gooseberry cream as the larger."

Winter pruning. - "You may proceed to the winter pruning any time from November until the end of February, or until the buds are so swelled, that further delay would endanger their being rubbed off in the operation. Cut out the eross-shoots and water-shoots of the preceding summer, and the superfluous among crowded branches. Prune long ramblers and low stragglers to some well placed lateral or eye ; or if any under straggler spring very low, cut it away. Of last year's shoots retain a sufficiency of the best well-placed laterals and terminals in vacant parts, to form successional bearers, and to sipply the places of unfruitful and decayed old-wood, which, as you proeced, should be removed. Mostly retain a leading shoot at the end of the prineipal branch, leaving it either naturally terminal, or, where the branch would thus be too extended, pruning in some competent lateral within bounds. The superflous young laterals on the good main brasches, instead of being taken off elean, may be cut into little stubs of one or two eyes; which will send out fruit-buds and spurs. Of the supply reserved for new bearers, a small number will probably require shortening, where too extended, or curred incommodiously; leave these from 8 to 
12 inelies in length, according to strength and situation; those of moderate extent and regular growth will require very little shortcning, and many none at all. Observe, too elose cutting or general shortening, oeeasions a great superfluity of wood in summer; for the multiplied laterals thus foreed from the eyes of the shortened branches, inerease to a thicket, so as to retard the growth, and prevent the full ripening of the fruit; on which account it is an important part of pruning to keep the middle of the head open and elear, and to let the oecasional shortening of the shoot be sparing and moderate. Between the bearing branches keep a regular distance of at least 6 inches at the extremities, which will render them fertile bearers of good fruit, Some persons, not pruning the gooseberry bush on right principles, are apt to leave the shoots cxcessively close and tufted, while they shorten the whole promiseuously; others sometimes elip them with garden shears to close round heads; in consequence of being pruned in these methods, the bushes shoot erowdedly, full of young wood in summer, from which the fruit is always very small, and does not ripen freely with full flavour." Forsyth says, "Many of the Laneashire sorts are apt to grow horizontally, and the branches frequently trail on the ground, which renders them liable to be broken by ligh winds, especially when they are loaded with fruit. In that ease I would recommend 2 or 3 hoops to be put round them, to which the branches may be tied to support them, and prevent their being broken by the wind." $S$. Jeeves has tried training gooseberries on an arehed trellis in the manner of a herceau or arbour-walk. For this purpose lie plants in rows, $5 \frac{1}{2}$ feet apart, and the plants 3 feet clistant in the row. He ehooses the strongest growing kinds, and trains 4 branches at 9 inches distance from each plant, till they meet at the top. The advantages of this plan are beauty of appearance, fruit not splashed by rain, easily gathered, and the ground more readily eultivated.

Insects and diseases, Se.-The caterpillars of saw-flies (Tenthredinidæ, Leach), of butterflies (Papilia, Lin.), and of moths (Phaliena, Lin.), are well known as serious enemies to gooseberries. The larva of the Tenthredinida lave from 16 to 20 feet, a round head, when touehed they will roll themselves together. They feed on the leaves of the gooseberry, apple, and most fruit trces, as well as on roses, and other shrubs and plants. When full grown they make, sometimes in the earth, and sometimes between the leaves of the plants on which they feed, a net-work ease, whieh, when eomplete, is strong and gummy, and in that ehange to the pupa ineomplete, which for the most part remains during the winter in the earth. The perfect fly emerges early in the ensuing spring; its serrated sting is used by the femalc in the mamer of a saw, to make ineisions in the twigs or strms of plants, where it deposits its eggs. The Caledonian Horticultural Soeiety having requested information respecting the best method of preventing or destroying the eaterpillar on gooseberries, received various communications on the subject, and the following are extracts from sueh as they deemed fit for publieation.

J. Gibb describes the large black, the green, and the white caterpillar, with his methods of destroying them:-

" Juring the winter months the large black kind may be obscrved lying in elusters on the under parts, and in the crevices of the bushes; and even at this season (Feb.) 1 find them in that state. In the course of 8 or 10 days, however, if the weather be favourable, they will creep up in the day time, feed on the buds, and return to their nest during the night. Whencver leaves appear upon the buslies they feed upon them till they arrive at maturity, which is generally in the nonth of June; after which they creep down 11pon the under sides of the branches, where they lodge till the erust or shell is formed over them. In July they become moths, and lay their egrgs on the under side of the leaves and bark. The produce of these eggs, coming into life during the month of September, feed on the leaves so long as they are green, and afterwards gather together in elusters on the under sicle of the branches, and in the erevies of the bark, where they remain all the winter, as already sail. Winter is the most proper time for attacking this sort witl success, as their destruction is most effectually aceomplished by the simple operation of pouring a quantity of boiling-hot water upon them from a watering-pan, while no injury is thereby done to the bushes.

"The green sort are at present (February) in the shelly state, lying about an inch under ground. In April they come out small flies, and immediately lay their eggs on the veins and under sides of the leaves. These eggs produce young caterpillars in May, which feed on the leaves till June or July, when they east a blaekish kind of skin, and afterwards crawl down from the bushes into the earth, where a crust or sliell grows over them, and in that state they eontinue till the following $\mathrm{A}_{\mathrm{p}}$ ril. The only method which 1 have hitherto found effectual for destroying these is, 1st, to dig the ground around the bushes very deep during the winter season, by which means the greater part of them are destroyed, or buried too deep ever to penetrate to the surface; 2ndly, in April, when the flies make their appearanee, to pick off all the leaves on which any eggs are observable; this is a tedious operation, but may be done by ehildren. If any of the enemy should escape both these operations, they will be discernible as soon as they come in to life, by their eating looles through the leaves, and may then casily be destroyed, without the least injury to the bushes or fruit.

"The white kind, otherwise ealled borers, are not so numerous as the other kinds, though very destructive; they bore the berry, and eause it to drop off; they preserve themselves during the winter season in the chrysalis state, about an inch under ground, and beeome flies nearly at the same time with the last mentioned kind; they lay their eggs on the blossoms, and these eggs produce young caterpillars in May, whieh feed on the berries till they are full grown, and then creep down into the earth, where they remain for the winter in the shelly state." Caled. mem. vol. 1.

Maemurray, in autumn, pours a little cow urine around the stem of each bush, as much as suffices merely to moisten the ground. 'The bushes which were treated in this manner remained free of caterpillars for two years; while those that were negleeted or intentionally passed over, in the same compartment, were totally destroyed by the depredations of the insects. A layer of sea-weed laid on in autumn, and dug in in the spring had the same effect for one year. Caled. mem. vol. 1. p. 95

R. Elliot says, "take 6 pounds of black eurrant leaves, and as many of elder leaves, and boil them in 12 gallons of soft water; then take 1.4 pounds of hot lime, and put it in $12 \mathrm{gal}$ lons of water; mix them altogether; then wash the infested bushes with the liand engine; after that is clone, take a little lot lime, and lay it at the root of each bush that has becn washed, which eompletes the operation. By these means you eompletely destroy the caterpillars, without hurting the foliage. A dull day is to be preferred to any other for washing. When the foliage is all off the bushes, wash them over with the hand engine to elean them of decayed leaves; for this purpose any sort of water will do; then stir up the surface of the earth all round the roots of the bushes, and lay a little hot lime about them to destroy the eggs. This I have never found to fail of success since the first trial, 6 years ago. The above mentioned proportion of leaves, lime, and water, will serve for 2 aeres of ground or more, covered with bushes or trees in the ordinary manner, and will cost very little money indced. The same proportion is 
to be observed in making a wash for the rest of the trees or bushes."

J. Machray procured some tobacco and soft or black soa], and boiled a quarter of a pound of tobacco with the one pound of soft soap in about 18 scotch pints of water; and kept stirring the liquid while boiling with a whisk, in orter to dissolve the soap; this liquor, when nilk-warm, or so cool as not to hurt the foliage, he applied to the bushes with a hand-squirt, in the evening, and in the morning found all the ground under the bushes covered with dead caterpillars. This practice he continued for six years, always when he saw any symptoms of the a)proach of caterpillars.

$\mathrm{J}$. 'Tweedie, in the course of any of the winter months, pares all the eartl from under the bushes to the depth of about 3 inches, into a flat ridge betwixt the rows; and on the first dry day following, either treads, beats, or rolls these ridges, and trenches the whole down $1 \frac{1}{2}$ or 2 spades deep, observing to tread the foul earth into the bottom of the trench.

Forsyth's method is as follows: "Take some sifted quicklime, and lay it under the bushes, but do not at first let any of it touch the branches or leaves; then shake each bush suddenly and smartly, and the caterpillars will fall into the lime; if the bush be not shaken suddenly, the caterpillars, on being a little disturbed, will take so firm a hold as not easily to be shaken off. After this is done, sift some of the lime over the bushes; this will drive down those which may have lodged on the branches. The caterpillars ought to be swept up next dlay, and the bushes well washed with clear lime-water mixed with urine; this will destroy any caterpillars that may still remain, and also the aphides, if there are any on the buslies."

Of all the methods for destroying caterpillars mentioned above, Gibb's appears to us the only plan on whicl any reliance can be placed.

Taking the crop.- "From gooseberries being useful for different purposes, both in a green and in a mature state, and from the compass of time afforded by early and late sorts, they are in season in great request 4 or 5 months in summer, from April till September. The early sorts on south walls come in for gathering in small green berries for tarts, \&c. in A pril or early in May, and attain maturity in June. From common standard bushes an abundant supply is yielded in May and June of gooseberries in a green state; and in proportion as part is reserved to ripen, a succession, in full size and maturity, is obtained in June, July, and August. Some late kinds, either planted in shady situations, or shielded with mats from the sun in their ripening state, continue good on the bush till September."

Prolonging the crop.-In addition to planting late sorts in shady situations, the bushes, whether standards or trained, may be matted over when the fruit is ripe, and in this way some of the reds, as the Warrington, and the thick-skinned yellow sorts, as the Mogul, will keep on the trees till Christmas.

Forcing.-The gooseberry may be forced in pots or boxes placed in pits, or in the peach-house or vinery. The plants in pots or boxes, are placed in pits, or in the peach-house in January, and has ripe fruit in the end of April, which is sent to table growing on the bush.

Common Gooseberry. Fl. March, April. Britain. Shrub 4 to 6 feet.

\section{* Flowers red.}

18 R. specióscu (Pursh. A. amer. sept. 2. append. 731.) shrub bristly and prickly; spines tripartite; leaves roundish-oval, 3-5-lobed, obtuse; peduncles few-flowered; bracteas broadly ovate; caly'x cylindrical, 4-parted, with erect glandular segments; germens and pedicels beset with glandular bristles. $\zeta_{.} \cdot \hat{H}$. Native of North California and Monterrey, and Mexico. Swect, f. gard. second ser. t. 149. Lindl. bot. reg. vol. 18, with a figure, R. VOL. III. stamíneum, Sinith in Rees' cycl. R. triacántha, Menzies. R. fuchsio:des, Moc. et Sesse, fl. mex. icon. ined. Flowers large, scarlet, pendulous, very like those of a I'úchsia. Stamens mucl exserted; style long, entire; petals cuneate, inserted on the very short tube of the calyx, the margins involute. Fruit hispid. (f. 32.) Show'y Gooseberry. Fl. May, June. Clt. 1824. Sh. 4 to $5 \mathrm{ft}$. 19 R. Menzie'sir (Pursh. fl. amer. sept. 2. append. p. 732.) plant very prickly : spines tripartite; leaves cordate, truncate at the base, 5-lobed, serrated, wrinkled from veins, clothed with pubescence beneath; peduncles usually 1-flowered; calyx cylindrically campanulate, deeply 5-parted, glandular; stamens 5 . inclosed; style a little exserted; germens and peduncles prickly. h.H. Native of North California, at Port Trinidad. R. fêrox, Smith in Rees' cycl. 'The present species and the preceding are very showy plants, from their large briglit red or crimson glandular flowers, and may be considered as holding the same rank among the gooseberries as $R$. sanguincum does among the currants.

\section{Menzies's Gooseberry. Slirub 4 to 5 feet.}

Sect. II. Botryca'rpun (from ßjotpus, botrys, a raceme, and кreтос, karpos, a fruit; fruit disposed in racemes). This is an intermediate section between sect. 1. Grossulària, and sect. 3 . Ribèsia, having the prickles of the former, and racemose flowers and small fruit of the latter. $R$. lacústre, no. 9. ought probably to have been placed in this section.

20 R. Orientale (Poir. encycl. suppl. 2. p. 856.) plant rather prickly ; leaves 3-5-lobed, orbicularly somewhat reniform, cut, hairy ; lobes rather deep, obtuse; petioles hairy; racemes erectish, few-flowered; bracteas longer than the flowers; style bifid at the apex. $h$. H. Native of Syria. Desf. arb. 2. p. 88. Flowers greenish yellow. Fruit like those of the currant.

Eastern Gooseberry. Fl. April, May. Clt. 1824. Shrub \& to 6 feet.

21 R. saxa'tile (Pall. nov, act, petr. x. p. 276.) prickles scattered; leaves roundisli-cuneiform, bluntly 3-lobed; racemes erect; bracteas linear, sliorter than the pedicels; calyx flat, scabrous; petals small, of a livid green colour. $\zeta$. H. Native of Siberia. Led. A. ross. alt. ill. t. 239. R. alpinum, Sievers in Pall. nord. beytr. 7. p. 345.? Flowers small, greenish purple. Petals spatulate. Berries smooth, globose, bractless, dark purple, when mature full of edible pulp, rarely so large as common currants, and like them.

Rock Gooseberry. Fl. April, May. Clt. 1819. Shrub 4 to 5 feet.

22 R. DiAcántha (Lin. fil. suppl. p. 157.) pricklestwin, stipular; leaves cuneiform, tripartite, quite glabrous, shorter than the petioles; lobes toothed; racemes long, erect; flowers oit long pedicels; bracteas length of tlowers; sepals roundish, yellowish; petals small, roundish. $h$. H. Native of Dahuria and Siberia. Berl. 1. c. t. 2. f. 8. Pall. ff. ross. 2. p. 36. t. 66. append. no. 79. t. 2. f. 2. Berrics about the size of currants, red, of a sweetish acid taste.

Two-spincd Gooseberry. Fl. May, June. Clt, 1781. Shrub 4 to 5 feet.

Sect. III. Ribe'sia (an alteration from Ribes). Shrubs unarmed (f. 33.). Racemes for the most part many-flowered (f. 33.). Leaves plicate. Calyx campanulate (f. 33. b.), or cylindrical. B B 


\section{- Floners greenish or grecnish-yellow.}

23 R. ALrixis (Lin. spec. 291.) leaves 3-5-lobed, obtuse, shining beneath, pilose above; racemes erect, rather crowded; bracteas lanceolate, rentricose, bearing a few glands, usually longer than the flowers; petals minute, almost abortive; anthers more or less nearly sessile; styles joined. $\zeta$. H. Native of Europe and Siberia, on the Alps; in Britain, in woods, in the north of England; near Bradford, Yorkshire; near Ripon and in Durlam; also of Scotland, lut rare. Smith, engl. bot. 704. Fl. dan. t. 698. Jaeq. aust. 1. t. 47. Flowers greenish-yellow. Berries red, elliptic, mucilaginous and insipid.

I'ar. a, stérile (Wallr. sehed. p. 108.) flowers flat, destitute of the germ, fugaceous; racemes dense, many-flowered ; anthers nearly sessile, bearing pollen, acute. R. dioícum, Moneh. meth. p. 683 .

I ar. $\beta$, baceiferum (Wallr. l. c.) flowers somewhat hypocrateriform; racemes few-flowered; anthers distinctly pedicellate, but imperfect; style hardly semibifid; germ large. Cultivated in gardens.

I ar. $\gamma$, pumilum (Lindl. in hort. trans. 7. p. 244.) in cvery respect the same as the species, but not one-third the size, never exceeding 3 feet.

Alpine Currant. Fl. April, May. Britain. Shrub 3 to $6 \mathrm{ft}$. 21. R. Resixòsum (Pursh, fl. amer. sept. 1. p. 163.) all parts of the shrub are full of resinous glands; leaves 3-5-lobed, roundish ; racemes erect; calyx flattish; petals bluntly rhomboid; bracteas linear, longer than the pedieels. 々. H. Native of North America, on the mountains. Sims, bot. mag. 1583. Berl. 1. c. t. 2. f. 10. Flowers greenish yellow. Berry hairy, red? Perhaps the flowers are dioecious. Very like $R$. alpinum.

Resinous Currant. Wl. April, May. Clt. 1800. Sh. 3 to $5 \mathrm{ft}$.

25 k. erla'tum (Willd. mss. ex Roem. et Schultes, syst. 5. p. 500.) plant beset with glands; leaves 5 -lobed, deeply cordate, doubly crenate-serrated, ciliated, glabrous above, but hairy on the nerves and veins beneath; lobes acute; petioles beset with glandular hairs; raeemes solitary. $々$. H. Native of Mexico, on the burning mount Jorullo, at the elevation of 1500 fect. R. Jorullénse, H. B. et Kiınth, nov, gen. amer. 6. p. 61 . Nearly altied to $R$. macrobotrys.

Ciliated Currant. Slirub 3 to 4 feet.

26 R. масково'тrys (Ruiz et Pav. fl. per. 3. p. 12. 1. 202. f. a.) leaves cordate, lobed, deeply serrated ; petioles ciliated at the base; racemes very long, pendulous, hairy: bracteas linearsubulate, pilose, nearly the length of the pedicels ; ealyxes rufescent; petals small, red. $h$. G. Native of Peru, on the Andes, in groves. Berl, 1. c. t. 2. f. 17. Berries greenisl, hairy.

\section{Long-racemed Currant. Shrub 4 to 5 feet.}

27 li. albifòlium (Ruiz et Pav. fl. per. 3. p. 12. t. 132. f. 6.) leaves rather cordate, deeply serrated; racemes twice the length of the leases, pendulous; bracteas spatulate, ciliated, length of pedicels; petals roundish, purplish; anthers nearly sessile. r. H. Native of Peru, in groves about Munna. Berl. l. c. t. 2. f. 18. Berries glowose, rather hairy. Allied to $R$. $m a-$ crobútrys.

IThitc-leaved Currant. Shrub $\&$ to 5 feet.

28 R. Bracteòsum (Dougl. mss, ex Hook, f. bor. amer. 1. p. 232.) leaves on long petioles, cordate, deeply 5-7-lobed; lobes acmminated, cut, doubly serrated, lispid above, but full of resinous dots beneatlı; racemes often terminal, at lengtl reflexed; pedicels crectly spreading, pubescent, exceeding the spatulate bracteas; calyx rotate, glabrous; petals minute, roundish; germens and berries full of resinous dots. 々. H. Native of the north-west coast of America, at the confluence of the Columbia witlı the ocean. This is a very remarkable and elegant shrub, with leaves nearly as large as, and resembling, those of the Sycamore; these, as well as the fructified racemes, lave a very strong resemblance to $R$. nacrobotrys; but the flowers are widely different. Flowers purplish-yellow. Berries about the size of those of $R$. rubrum.

Bractcate Currant. Shrub 5 to 8 feet.

29 R. Hírtum (Humb. et Bonpl. in Willd. herb. ex Rœm, et Seluultes, syst. 5. p. 501.) leaves ovate, rather cordate, 3-lobed, reticulated beneath from hairy nerves and veins, and pale, but blackish green above; lobes deeply serrated, middle one the largest ; petioles pilose, glanduliferous, and somewhat tomentose; racemes reflexed; bracteas dentately eiliated; petals roundishobovate; styles bifid. $h$. G. Native of South America, in cold places on Mount Antisana, at the elevation of 300 feet. Berl. 1. c. t. 2. f. 13. R. frigidum, H. B. et Kunth, nov, gen. amer. 6. p. 62. Flowers flesh-coloured. Berries hispid.

Mairy Currant. Shrub 4 to 5 feet.

30 R. Fra'Grans (Pall. nov, aet. pet. 5. p. 37\%. t. 9.) leaves glabrous, on long petioles, $3-5$-lobed, greener above than below ; racemes erect, stift; flowers campanulate, white, sweet-scented ; bracteas deciduous; petals lanceolate, acute, spreading. h. H. Native of Siberia, on the higher mountains. Berries red, of a very sweet taste. From the under surface of the leaves exudes, in very frequent little yellow drops, a very fragrant balsamic resin, having a strong smell of the black currant.

Fragrant Currant. Shrub 1 to 2 feet.

31 R. Procu'mibens (Pall. f. ross. 2. p. 35. t. 65.) leaves bluntly lobed; lobes serrated: lateral ones a little cut ; racemes erect; peduncles long, setaceous; segments of the limb of the flower pubeseent, acute, of a livid purplish colour; anthers hardly rising from the calyx. $々$. H. Native of Siberia, in moist sliady places. Flowers flattish. Berries very grateful to the taste, rufescent when ripe. Ait. hort. kew. 2. p. 41. R. polycárpon, Gmel. syst. veg. p. 419.

Procumbent Currant. Fl. May, Ju. Clt. 1804. Shrub pr.

32 R. PRostra'rum (Lher. stirp. 1. p. 3. t. 2.) leaves deeply cordate, 5-7-lobed, glabrous; lobes acute, cut, doubly serrated, naked on botl surfaces; racemes erect, loose, slender; bracteas small, obtuse, much shorter than the pedieels, which are beset with glandular bristles; calyx rotate; germens and berries beset with glandular bristles. $々$. H. Native of Newfoundland; throughout Canada; and in woods on the Rocky Mountains. Berl. 1. c. t. 2. f. 12. R. glandulòsum, A it. hort. kew. ed. 1. p. 279. R. rigens, Bigel. A. bost. ed. 2. p. 9. R. glandulòsum, Richards. in Frankl. 1st journ. ed. 2. append. p. 7. R. laxiflòrum, Richards. in Frankl. 1st. journ. ed. 2. append. p. 7. Berries large, reddish. This is a very distinct species.

lar. $\beta$; racemes pubescent; pedicels diraricate. $々 2 . \mathrm{H} . \mathrm{Na}-$ tive of the north-west coast of America. R. aft"ine, Dougl. mss. R. laxiflòrum, Pursh, fl. amer. sept. 2. p. 781.

Prostrate Currant. Fl. Apr. May. Clt. 1812. Shrub pr.

33 R. TRífidum (Mich. f. bor. amer. 1. p. 110.) leaves smoothish, moderately lobed; racemes loosely many-flowered, pubescent; flowers small; calycine segments rather trifid; berries hairy, red. h. H. Native of North America, near Quebec, and at Hudson's Bay. Lobes of leaves acutish. Racemes weak, nearly like those of $R$. rùbrum, but the flowers smaller. Petals purplish, spatulate, rounded at the apex. Perbaps this is the same as $R$. prostritum.

Trifid-calyxed Currant. Fl. April, May. Clt. 1823. Sh. pr. 34 R. TAKA'RE (D. Don, prod. fl. nep. p. 208.) leaves cordate, 3-lobed, acuminated, doubly serrated, pubeseent on both surfaces, as well as on the branches. $ᄃ$. H. Native of Nipaul, in Sirinagur. Leaves as large as those of the Sycamore. Flowers unknown. The bush is ealled Takare by the Nipaulese.

Takare Currant. Shrub. 
35 R. multifódum (Kit. in Rom. et Scluultes, syst. 5. p. 499. but not of H. B. et Kunth) leaves 5 -loberl, cordate, tomentose beneath; racemes rery long, pendulous, drooping; bracteas shorter than the flowers; petioles length of leaves; petals wedge-shaped; styles bifid, and sometimes distinctly trificl. I?. II. Native of Croatia. Sims, bot. mag. 2968. Berl. 1. c. t. 2. f. 11. Ri. spicàtum, Scluultes, ocstr. f. ed. 1. p. 433.

Many-flonered Currant. Fl. April, May. Clt. 1822. Shrub 4 to 6 feet.

36 R. Acumixa'tum (Wall, cat. no. 6834.) branches glabrous ; leaves glabrous above, but with a few scattered hairs beneatl, 3-5-lobed; lobes acuminated, serrated; racemes axillary, erect ; peduncles pubescent; berries nodding; calyx campanulate; petals rounded at the apex. $h$. H. Native of Nipaul, on Sirmore and Emodi. Berries red, about the size of red currants.

Acuminated-leaved Currant. Shrub 4 to 6 feet.

37 R. spicA'tum (Robs, in Lin. trans. 3. p. 240. t. 2l.) leaves roundish-cordate, 3-5-lobed, covered with soft pili above, and tomentum beneath; racemes erect; flowers more or less pedicellate; bracteas obtuse, tomentose, much sliorter than the pedicels; sepuls roundish-cuneated; petals oblong; styles bifid. h. H. Native of the North of England, in woods, near Richmond, in Yorkshire; and between Piersbridge and Gainford, Durham. Smitl, engl. bot. 1290. Berl. 1. c. t. 2. f. 16. Berries glabrous, globose, colour and taste of those of $R$. rubrunt. The tree currant affords a fruit rather smaller and more acid than the common red currant; but by crossing and cultivation might, no doubt, be greatly improved; and from its comparatively tree-like habits, miglit be a more convenient fruit shrub in respect to crops around it.

Spiked-flowered Currant. Fl. A pril, May. Engl. Slı, 4 to $6 \mathrm{ft}$.

38 R. PETRE'vM (Wulf. in Jacr. misc. 2. p. 36.) leaves acuminated, 3-5-lobed, rather cordate, deeply serrated, on long petioles, pilose above; racemes erect, crowded, rather pubescent ; bracteas shorter than the pedicels; sepals obtuse ; petals obcordate. $\eta$. H. Native of the Alps of Carinthia, Savoy, and on ahmost all the mountains of Europe. In England, near Eggleston and Conscliffe, in the county of Durham; and in Scotswood Dean, Northumberland. Berl. 1.c. t. 2. f. 14. Jacq. icon. 1. t. 49. Smith, engl, bot, 705. R. alpinum, Delarb. auvergn. p. 166. Petals small, white. Eerries large, deep red, with an acid taste. Fruiting racemes pendulous. The rock currant is sometimes called Hoolly-leaved currant, and Red Marsh mallowlcared currant.

Rock Currant. Fl. May. England. Slurub 3 to 4 feet.

39 R. Rìgexs (Michx. fl. bor. amer. 1. p. 110.) branches erect; leaves glabrous above, pubescent beneath, wrinkled reticulately; lobes and teeth acute; racemes rather loose, manyflowered, when bearing the fruit stiffish and erect. $h . H$. Native of Canada, and the mountains of Pennsylvania. Pursh, f. amer. sept. 1.p. 1\$6. Berries red, lispid.

Stiffish-racemed Currant, Fl. April, May. Clt. 1812. Sh. 4 to 6 feet.

40 R. villòsur (Wall. cat. no. 6832.) branches pubescent; leaves nearly orbicular, cordate, bluntly 3-]obed, villous as well as the petioles; racemes erect, few-flowered. h. H. Native of Sirinagur.

lillous Currant. Shrub 5 to 6 feet.

4. R. Albixé'rvius (Michx. ]. c.) leaves short, petiolate, deeply and acutely lobed, smoothish, with whitish nerves; racemes recurved. $h$. H. Native of Canada, and on the Catskill Mountains, in the state of New York. Flowers small. Berries red, glabrous.

Whitc-nericd Currant. Fl. Apr. May. Clt.? Sh. 4 feet.

42 R. Túulòsum (Eschscholtz, pl, calif. p. 281.) leaves cordate, 3 -lobed, clothed with white tomentose pubescence be- neatı; petioles angular, dilated at the base, and furnished with broacl, dilated, jagged, membranous stipulas ; racemes terminal, erect; bracteas entire, witl glandular margins; calycine segments short, roundish; petals oblong. h. H. Native of North California. Stem strigose, dark purple, pruinose; branches angular, covered with setose, deciduous bark. Pedicels and germs dotted with white tomentum. Petals pale brown. Very nearly allied to $R$. albiućrvium and $R$. sanguineum.

Tüular-tlowered Currant. Slurub 4 to 5 feet.

43 l. rubiflòrum (Meyer, in acad. Morou. vol. 7.) unarmed; hairs glandular, at length deciduous; adult leaves corlate, 5lobed, pubescont beneath; racemes somewhat spicate, terminal, drooping; calyx tubular, pubescent, exceeding the bracteas; petals nearly orbicular. $h_{2}$. H. Native of North California.

Tube-flowered Currant. Shrub to to 5 feet.

4.4 R. MAgellánicum (l'oir. suppl. 2. p. 856.) stems ratler prostrate: leaves 3-lobed, crenately undulated, glabrous beneath, and paler; racemes erectisl, thick; bracteas longer than the pedicels; petals reflexed at the apex. $\zeta .11$. Native of the Straits of Magellan.

\section{Magellan Currant. S'lırub pr.}

45 R. puncta'tum (Ruiz et Pav. fl. per. 3. p. 12. t. 233. f. a.) leaves 3 -lobed, serrated, beset with resinous glands beneath, as well as on the bracteas; racemes longer than the leaves, either drooping or erect; bracteas cuneate-oblong, obtuse, at length reflexed; calyx campanulate, yellowish; berries oblong, hairy. দ. F. Native of Chili, on hills. Petals small, yellow. Berries red, dotted. Berl. ]. c. t. 2. f. 19. Lindl. bot. reg. 1278.

Dotted-berried Currant. Fl. April, May. Clt. 1826. Sh. 3 to 4 feet.

46 R. ruscòsum (Ruiz. et Pav. fl. per. 3. p. 19.) leaves cordate, 5-lobed, crenated, rough, clammy, 5-nerved; racemes short, simple, solitary; bracteas lanceolate, length of calyx. 々. H. Native of Peru, on rocks. Corolla yellow. Calyx nearly of the same colour. Berries small, pale purple.

Clammy Currant. Slirub 4 to 5 feet.

47 R. heterótrichum (Meyer, in Led. fl. ross. alt. ill. $t$. 235. fl. alt. 1. p. 270.) stem erectisll; leaves pubescent, bristly, and glandular, nearly orbicular, 3-lobed; lobes obtuse, toothed ; racemes erect; pedicels equal in length to the bracteas ; calyx flat, pubescent ; berries puberulous, glandless, bractless. h. H. Native of Altaia, on rocks at the foot of the mountains, on the west of Buchtorminsk, towards the river Kurtschum; also on the mountains in the Kirghisean Steppe. Calyx of a livid purple colour; petals purple, rounded, and entire at the apex. Berries almost like those of $R$. rùbrum, but orange-coloured.

Iariablc-haircd Currant. Fl. April, May. Slurub 2 to $3 \mathrm{ft}$.

48 R. CARpa'tuicts (Kit. in Schultes, œstr. fl. 2. ed. 1. p. 432. ex Rocm. et Schultes, syst. 5. p. 493.) stem erect; leares 5 -lobed, cordate; racemes pendulous, and are as well as the calyxes pubescent; petals flattish, smaller than the calyx. $\zeta$. H. Native of the Carpathian mountains. R. acérrimum, Rochel. ex Rom. et Schultes, l. c. Perhaps only a variety of $R$. rùbrum.

Carpathinn Currant. Shrub 4 feet.

49 R. ru'brum (Lin. spce. 290.) leaves cordate, bluntly 3-5loberl, pubescent beneath, when young usually rather romentose, glabrous above; raccmes drooping; bracteas ovate, shorter than the pedicels; calyx flatly campanulate, spreading; sepals obtuse; petals obcordate; fruit quite glabrous. h. $\mathrm{H}$. Native of Europe and Siberia, in woods; and throughout Canada to the mouth of the Mackenzie; in monntainous woods, especially in the north of England and in Scotland, about the banks of rivers; undoubtedly wild on the banks of the Tees: in the Isle of 1sla, and in Culross woods, Scotland. Woodv. med. bet. B b 2 
t. 74. Fl, dan. 967. Blackw. herb. t. 285. Smith, engl. bot. 1289. Flowers yellowish.

lar. a, sylécstre (D. C. fl. fr. 4. p. 406.) leaves and berries smaller; lobes of leaves short.

lar. 3 , horténse (D. C. l. c.) leaves larger, sometimes variegated; berries sweeter and larger than in var. $a$. Cultivated in gardens. $R$, rùbrum, Lois. nouv. dict. 3.

V"ar. $\gamma$, cárncum (Berl. mss. ex D. C. prod. 3. p. 481.) leaves rather tomentose beneath; sepals red; eells of anthers distant; berrics pale red. R. rùbrum domésticum $\beta$, báccis cárneis, Wallr. sched. p. 106.

lar. i, variegàtum (D. C. prod. 3. p. \$81.) berries variegated. W'allr. l.c.

Far. $\varepsilon$, álbum (Desf. cat. bot. p. 161.) berries white. Ait. lort. kew. 2. p. 40. Wallr. sched. p. 106. Berl. 1. c. t. 2, f. 15. The red currant is ealled Groseille ordinaire à grappes, or doutre mer, in French; Johannisbecre, in German; and Uvetta, in Italian. It is a low shrub, with smooth branches, downy leaves, yellowish green flowers, disposed in pendulous racemes, which appear in May, and the fruit ripens in June and July. The berries of this shrub, in its wild state, are red; but cultivation has produced white and pale red berries. Professor Martyn observes, that "The eurrant does not seem to have been known to the ancient Greeks and Romans, as the southern nations of Europe have not even an appropriate name to it at this day. The old French name, groseilles d'outre mer, and the Dutch, beskins overzee, proelaim their having been strangers imported. Our English name of eurrant is evidently from the similitude of the fruit to that of the Corinth grape, the small grape of Zante, or the common grocers' Corinths or currants. The red currant has been long cultivated in Britain, and very much improved in the size of the bunch and berry."

Use.-The fruit is acceptable at the dessert, being of an agreeable acid taste. It is much used for jellies, jams, and wines. Forsyth says it is the most useful of all the small fruit, either for the table and kitchen, or for preserving, making wine, \&c., and continues longer in succession than any other. According to Withering, the juice forms an agreeable acid to punch; and Professor Martyn says it was a common beverage in Paris in 1763. Its medicinal qualities are similar to those of other subacerb fruits, allaying thirst, lessening an inereased secretion of the bile, and correcting a putrid and scorbutic state of the fluids.

larictics.-There are as follow:

\section{* Red eursants.}

1 Common red, groseillier rouge à petit fruit, groseillier ordinaire ì fruit rouge.

2 Red Dutch, large red Dutch, New red Dutch, large red, large bunched red, Morgan's red, rcd grape, groscillier rouge à gros fruit. This is the best of the red currants for all purposes.

3 Knight's large red.

4 Kinight's swect red currant.

5 Knight's carly red currant.

6 Champagne, groseillier à fruit coulcur de chair.

7 Striped-lcavcd currant, and variegated-lcaved currant.

8 Largc pale red Dutch.

\section{* Hhite currants.}

1 Common white currant, groseillicr à fruit blanc.

2 White Dutch currant, new white Dutch, Morgan's white, white crystal, white Leghorn, pearl whitc. 'This is one of the very best of the white eurrants.

3 Pearl white, blanc perli.

4 Speary's while.

Propagation and nursery culture.-The same as in the goose- berry. With a view to obtaining new improved varieties from seed, Mr. Knight procured euttings, in the year 1810, of the finest varieties of the red and white currants, which he planted in pots of very ricls mould, and placed under a south wall, to which the trees were subsequently trained. At the end of 3 years, within which period the pots had been as often changed, the trees were first suffered to produce blossoms. These were, with the exception of a very small number, removed from the white currant bushes, as soon as their buds unfolded; and those which remained were deprived of their stamens while immature, and subsequently fertilized by the pollen of the red variety. The seeds thus obtained were sown in pots, as soon as the fruit had become perfeetly mature, and were subjected early in the following spring to the artificial heat of a forcing-house; by which means, and by proper subsequent attention, the plants grew more than a foot in height the first season. At 2 years old, in the year 1816, several of the plants, and in 1817, the greater part of them, produced fruit of great varicty of character and merits; but out of about 200 varieties, only 3 red and 2 white appeared to possess greater merits than their parents.

Soil and site.-All the sorts are very hardy, will grow freely and bear plentifully almost any where, alike in open or shady situations, by which the fruit may be obtained early, in June and July, and prolonged for several months in succession till October. As to soil, the currant generally does well in any common garden-soil, well tilled and recruited: it bears the greater crop in a strong loam or improved clay, somewhat moist; the earlicr in a sandy light soil, which is not poor. Previous to planting, the ground should be dug 2 feet deep.

Final planting. The season for planting, on a dry soil, is any time in open weather from the fall of the leaf till $\mathrm{Fe}$ bruary or March. Plants expected to bear the following summer, are best moved in October, unless the ground be wet in winter. Allot a competent supply of standard bushes, to be planted ehiefly in the kitehen garden, in a single row, round the main quarters, or in the outward borders, or some in cross rows, to divide extensive quarters. Plant them from $5-10$ feet distance in the row. To raise large supplies, full plantations are formed in parallel rows, with intervals between the rows of 8 or 10 feet, and between the trees in eaeh row of 6 feet. Where convenient, have also some choice sorts, trained against walls, paling, or trellis-work, of different aspects, to obtain early and late fruit in perfection; some against a south exposure for early production; others on east, west, and north walls for intermediate succession and late fruit. Plant them at 6,8 , or 10 feet distance; letting them occasionally fill up the vacant spaces between other wall-trees. The branches slıould be allowed to advance from near the bottom, and be trained in a nearly horizontal direction, from 3-6 inehes asunder. Before nailing them, cut out superabundant and irregular growths, retaining a competency of regular shoots for orderly training, among which, if any are of very considerable length, prune them to moderate extent. Some may likewise be trained as espaliers, in a detached row in the borders or divisions of the quarters. The bushes so trained may either be left to grow without support, or be tied occasionally to stakes, and the branches thus will not overspread the ground. Being kept moderately thin and regular, they will bear fine large fruit, and make an agreeable appearance.

Mode of bearing.-Currant bushes, in general, bear the fruit both on the young wood of one, two, or three years' growth, and on the older branches from small spurs and snags along the sides, which continue for several years fruitful; but the fruit produced on the last year's shoots are always the finest, especially when the old mother bearers have borne more than 4 years. 
Pruning.-The chicf part of the future culture is scasonable pruning. After the plants are furnislied with full heads, they produce many superfluous and disorderly shoots every summer, crowding the general bearers, so as to require retrenchment and regulation, both in the young growth of the year and older wood. The season for the capital pruning is winter; but a preparatory part is performed in summer, to thin the superfluous shoots of the year where too crowded, excluding the sun and air from the fruit. First as to standards :-

Summer pruning.-In May or June cut out close the most irregular shoots, rising in the centre of the bush with all the cross and water shoots, to admit more frecly the essential influence of the air and sun, and promote the growth of the fruit and improve its flavour. Also twist off all root suckers as they appear.

Hinter pruning.-This extends both to the old and young wood; the time for it is when the plant is at rest. Of the shoots of the preceding summer, cut out the cross-placed and the otherwise irregular, with those which are not wanted for vacancies; but superlluous good lateral shoots are to be cut down to short stubs or artificial spurs, about half an inch long, so as to leave an eye or two, in order that they may send out fruit-shoots and spurs. With regart to the old bearers, take away those which are naked, or getting unfruitful, or of which the fruit is declining in size; reduce any of excessive length, pruning in to some well-placed lateral young shoot, to preserve the head within some regular compass; cut out also any decayed or cankery parts; retain a competency of the finest bestplaced new sloots above and below vacant parts, to come in for successional bearers, or to supply the places of defective old woot, and preserve a leading sloot to the principal branches, where within orderly limits, shortening such terminal shoots as are of greatest length to 10,12 , or 15 inches, according to their strength and the situation of the branches, and leaving those of small extent mostly entire. Take care of the small lateral fiuit-spurs, and occasionally select short lateral shoots of 1,2 , or 3 inches, for bearing fruit; or similar small shoots may be cut to short snags of an inch or two long, also for fruiting. Thin out spurs of the old branches where very thick. As the old fruit branches decline bearing, or decay, cut then away, taking care to provide young ones in succession; and thus keep the bushes always furnished with full-bearing branches, and advancing young bearers, in a regular open expansion, 6,8 , or 10 inches asunder at the extrenities, circumscribing the general head within the height of 3 or 4 feet, or 5 at most.

"Currants of the finest quality," Mr. Neill observes, "are raised by Macdonald, at Dalkeith House. $\Lambda$ good deal depends upon the way in which he manages the bushes, especially during the ripening of the fruit. He prunes the bushes at the usual scason of mid-winter, shortening the last year's shoots down to an inclı or an inch and a half. Next summer the plants show plenty of fruit, and at the same time throw out plenty of strong shoots. As soon as the berries begin to colour, he cuts off the summer shoots to within 5 or 6 inches before the fruit. This is commonly done with the garden shears, with which a man may go over half an acre of buslies in a day. Sun and air thus get more free access, and more of the vigour of the plant is directed to the fruit ; the berries are found not only to be of higher flavour, but larger than usual."-Neill, Cal. mem. vol. 2.

To rall-bushcs, espaliers, and fan-standards, without support, the same course of summer and winter pruning is applicable, with the obvious variations required by their figure. In training wall-trees, 2 branches are led in an horizontal direction along the bottom of the wall or trellis, perhaps half a foot from the surface of the earth, and the growths from these of all upright shoots, which will admit of being arranged at the distance of
5 or 6 inches from each other, is encouraged. Fan standards are sometimes trained in a manner nearly similar, and sometimes with the branches radiating from the crown of the stem.

Insects, S.c.-The red currant is occasionally attacked by the caterpillar, and very firequently by the àphis ribes, lin. whic] changes the colour of the leaves to red, pits and puckers them, and causes the fruit to be shrivelled and flavourless. Forsytl says, "As currants are very liable to be devoured by carwigs, which take shelter under their leaves and branclies, bundles of bean-stalks should be lung up some tinc before the bushes are covered with mats or nets. If proper attention be not paid to this, the fruit will generally suffer very much from these insects. After the bushes are covered, take the mats off once in 3 or 4 days, and kill the earwigs that lave got into the bean-stalks, which it will be necessary still to keep hung up. $\Lambda$ s there is a swcetness in the inside of bean-stalks which attracts the earwigs, they very regularly take shelter in them from rain."

Taking the crop and preserving. - The ripening fruit comes in for sinall gatherings in June, advances to maturity in July, and continues in perfection till the end of $\mathrm{August}$; or if trees in a full exposure are timely defended from birds and the full sun, with garden mats, or protected with nets where they grow against walls, the fruit may be continued good till September or October. Gather in a dry state, as in rainy weather they lose their flavour.

Forcing.-To obtain early currants by forcing, let some good bearing trees, in pots, be placed early in January or February, in any common forcing department: they will produce ripe fruit in April or May.

Fied and White Currant. Fl. April, May. Brit. Sh. 4 to $6 \mathrm{ft}$ 50 R. glandulòsum (Ruiz. et l'av. f. per. t. 233. f. 6. but not of Ait.) leaves cordate, bluntly 3-lobed, doubly serrated, rugged; racemes short; calyx glandular, pubescent. $h_{2} .11$. Native of Chili, on wooded hills. Berl. 1. c. t. 2. f. 20.

Glandular-calyxed Currant. Fl. April, May. Clt. 18:0. Shrub 4 to 6 feet.

51 R. campanula'tum (Humb. et Bonpl. in Willd. herb. ex Roem. et Schultes, 2. p. 500.) leaves somewhat 5-lobed, doubly crenated, cordate, hairy beneath; lobes obtuse; petioles ciliated with glandular hairs; racemes pendulous; calyx campanulate; petals oblong-spatulate; styles bilid. $r_{c}$. H. Native of Mexico, near Moran, at the height of $\$ 900$ feet. R. affine, H. B. et Kunth, nov. gen. et spec. amer. 6. p. 60. Flowers white. Hardly distinct from the following species.

Campanulate-calyxed Currant. Shrub 1 to 5 feet.

52 R. Ku'Nтнl (Berl. mss. ex D. C. prod. 3. p. 482.) leaves somewhat 5-lobed, doubly serrated, rather cordate at the base, pubescent ; racemes solitary or numerous, crowded, erect; calyx campanulate; petals spatulate, reflexel; stamens 5-6, hardly shorter than the petals; styles 3 -4-cleft; stigmas capitate. $r_{c}$. H. Native of Mexico, along with the preceding. R. multiflòrum, H. B. et Kunth, 1. c. but not of Kit.

Kunth's Currant. Shrub 4 to 6 feet.

53 R. Tríste (Pall. nov. act. petro. 10. p. 378.) leaves $j$ lobed; branches simple, twiggy, bearing leaves and racemes of flowers at the apex; racemes pendulous, botl when in flower and in fruit ; corollas flattish, reddish on the outside, and yellowish inside; petals revolute. h. H. Native of Sibcria, on the Mongol Mountains. Berries small, black, insipid. Koor creeping.

Dark-fruited Currant. Fl. April, May. Clt. 1820. Shruls 2 to 3 fcet.

$5+$ R. GLACIA'LE (Wall. cat. no. 6833.) branches smooth; leaves glabrous above, but with a few scattered bristly lairs beneath, cordate at the base, 3-5-lobed at the apex; lobes acute, serrated; petioles long, serrated at the base; racemes droop 
ing : calyx campanulate; petals longer than the ealys. ?.H. Native of Nipaul, on Emodi and Gosaingsthan. Flowers white. Berries black.

Icy Currant. Fl. April, May. Clt. 1823, Sh. 4 to 6 feet.

55 R. Nigrum ( $\mathrm{Lin}$. spec. 291.) leaves dotted from glands beneath, 3-5-lobed; racemes loose; bracteas minute, subulate or obtuse, much shorter than the pedicels; petals oblong; calyx campanulate, with reflexed segments. h. H. Native of Europe and Siberia, in woods; plentiful in some parts of Britain about the banks of rivers, in the north of England and in Scotland. Berl. l. c. t. 2. f. 21. Woodv. med. bot. t. 75. Fl. dan. 556. Blackw. 285. Smith, engl. bot. 1291. R. ólidum, Monch. meth. 683. Flowers whitish green; calyx often of a rich brownish redcolour. Stamens sometimes more than 5, and there are fewer petals; so that when there are 10 stamens, there are no petals; this change of petals into stamens is just the reverse of the process by which sinule flowers become double; but it is the only fact of the kind which has hitherto been observed. Stigmas bifid. Berries globose, black, glandular. The black currant is a shrub with smoothish branches, strong smelling leaves, with a solitary 1-flowered pedicel at the base of each raceme. The flowers appear in April, and the fruit ripens in $J_{\text {une and }} \mathrm{July}_{\mathbf{y}}$, and changes from a green to a black colour. It is a native of most parts of Europe, especially the more northern parts. It abounds in the woods in the north of Russia, and the subalpine regions of Siberia, where the branches and berries are very large, and sapid. In Britain it is found in wet hedges, on the banks of rivers, in alder swamps, and sometimes in woods.

Use.-The fruit, which has a peculiar flavour, and disliked by some, is seldom brought to the dessert: but it is eaten in puddings and tarts, and made into jellies and wines. The Russians put the berries jnto brandy, and the Irish into whisky, in the same way as the English put cherries: the Russians also ferment the juice with honey, and so form a strong and palateable wine. Many cottagers, who cannot afford to mix green tea with black, substitute one or two dried leaves of the black currant, the flavour produced by which few are so acute as to distinguish from that of the mixture of green and black tea.

The varieties are as follow:

1 Will black. 2 Black grape, Ogder's black grape. 3 Blach Naples, Cassis of the French; this is one of the best of black currants. + Grcen-fruited black; fruit of a dingy colour, of no value. 5 liussian green.

Fropagation.-By cuttings. See gooseberry.

Soil and site.-A moist soft soil, and shady situation; such as is aftorded by borders of north exposure is preferable. Miller says, "the fruit is always best when the plants are placed in an open situation, in light loamy soil."

F̈mal planting. - As only a few plants are in general required for private gardens, these may be placed at the distance recommencled for gooseberries, in the margin of a shady border, or against a wall of a north exposure. Mr. Neill says, it produces most fruit as a standard, but the largest berries when trained to a wall.

Morle of bcaring. - The black eurrant bears chiefly on the shoots of the precelling year, and also from snags and spurs, which, however, are less abundant, and of smaller size in the black currant thin in the gooseberry or red currant.

Insects and diseases. - T'lue black currant is seldom attacked by insects, though, like the elder tree, it has its own variegated caterpillar, which sometimes reduces it to a state of complete nudity.

Gathering the frait.- See red currant.

Forcing. - The black currant may be forced in pots like the goosuberry. In Russia this is often done for the sake of the fragrance of the leaves.
Black Currant. Fl. April. Britain. Shrub 4 to 6 feet.

56 R. Biebersteinis (Berl, mss, ex D. C. prod. 3. p. 482.) leaves cordate, acutely 3-5-lobed, sharply and doubly serrated, rather pilose above, and villously tomentose beneath; serratures numerous ; racemes nodding; petals minute. h. H. Native of Cancasus. R. Caucásieum, Bieb. fl. taur. suppl. 160. but not of Adams. Leaves having a strong scent like those of R. nigrum. Berries black.

Bieberstein's Currant. Shrub 4 to 6 feet.

57 R. Hudsonia'num (Ricbards in Frankl. first. journ. ed. 2. appent. p. 6.) branches erect; leaves 3-lobed, quite glabrous above, full of resinous dots beneath, and are, as well as the petioles, villous; germens dotted; berries globose, glabrous, black; racemes erect, pubeseent; bracteas short; segments of the caly $\mathbf{x}$, which is campanulate, spreading. h. H. Native of North America, from Hudson's Bay to the Rocky Mountains, in the west, and as far north as lat. $57^{\circ}$. Flowers small; petals white. The fruit, and peculiar odour of the plant, are that of $R$. nigrum.

$\operatorname{Var} . \beta$; racemes longer ; calyx smoothish. h. H. Native of the north-west coast of America, on the mountains of the Columbia, about the Kettle Falls. R. petiolàre, Doug. in hort. trans. 7. p. 514.

Hudson's Bay Currant. Shrub 3 to 4 feet.

58 R. FLóridum (Lher. stirp. 1. p. 4.) leaves full of resinous glands, 3 or 5-lobed, cordate, double-serrated; racemes pendulous, pubescent; bracteas linear, longer than the pedicels; calyx tubularly campanulate, glabrous : with the segments obtuse, and at length reflexed; germens and black berries oval-globose, glabrous. $\zeta . H$. Native throughout Canada; and of Pennsylvania. Ber]. 1. c. t. 2. f. 22 . R. nigrum $\beta$, Lin. spec. 291. R. Pennsylvánicum, Lam. dict. 3. p. 49. R. recurvàtum, Micbx. fl. bor. amer. 1. p. 109. according to Torrey.-Ribèsium nigrum, Sc. Dill. elth. 2. t. 244. f. 315 . This is in many respects allied to $R$. nigrum, but its more copious, denser flowers, and especially the long bracteas, and more tubular calyx, will always distinguish it ; the solitary pedicel too at the base of the flowers is wanting in this species. Petals oblong, rather erose at the apex.

Flowering Currant. Fl. April, May. Clt. 1729. Sh. 4 to $6 \mathrm{ft}$.

59 R. INE'BRIANS (Lindl. in bot. reg. 1471.) leaves roundish, deeply 3-5-lobed, and deeply toothed, truncate at the base, glandular on both surfaces; petioles pubescent; peduncles 3-5Howerer, pendulons ; flowers aggregate ; calyx tubular, glandular, with the segments recurved. $h_{2}$. H. Native of North America. Calyx greenish white, with the tube 4 lines long. Leaves smelling like those of $R$. flóridum. The species was received from Mr. Floy of New York, under the name of intoxicating currant, but without any account of its quality. The berries probably possess some narcotic quality.

Intoxicating Currant. Clt.1827. Fl. April. Shrub 3 to $4 \mathrm{ft}$.

60 R. CE'ReUM (Dougl. in hort. trans. 7. p. 512. bot. reg. 1263. Hook. fl. bor. amer. 1. p. 234.) leaves small, cordate, lobed, serrated, clothed with glandular pubescence, glabrous, glancous, full of white glands above; racemes pendulous, rather capitate; bracteas ovate, adpressed to the germens, which are glabrous; flowers nearly sessile, cylindrical, rather angular; calycine segments small, reflexcd. $h$. H. Native of Northwest America, on the banks of the Columbia, and its southern tributary streams, from the Great Falls to the Rocky Mountains, in gravelly or sandy soil. In the small foliage, and few-flowered racemes, this species resembles the gooseberry tribe, but without any thorns. The flowers are rather large and white, with a slight tinge of green, rather downy. White waxy dots like scales cover the upper surface of the leaf, whence the specific name.

H'axy-leaved Currant. Fl. April. Clt. 1827. Shrub 2 to $3 \mathrm{ft}$. 
6I R. viscosíssimum (Pursh. fl. amer. sept. J. p. 153.) leaves cordate, obtuse, 3-5-lobed, deeply crenated, viscid from glandular pubescence : glands on both surfaces; racemes crect, corymbose; bracteas linear-obovate, rather shorter than the pedicels, which are clothed with glandular hairs; calyx tubularly campanulate, with erectly spreading obtuse segments; germens and fruit ovate-oblong, clothed with viscid hairs. $h_{\text {. }}$ ll. Native of North America, on the Rocky Mountains, and in dry plains in partially shaded places towards the sources of the Columbia ; also on the summits of the hills near the Spokan and Kettle Falls, at an elevation of $\$ 000$ feet above the sea. Hook. fl. bor. amer. 1. p. 231. t. 74. Berries oblong-ovate, black. lilowers large, pale yellowish green. This is a very fine and remarkable species.

lery-clammy Currant. Fl. April, May. Clt. 1826. Shrub $t$ to 8 feet.

\section{* Floners deep red.}

62 R. atropurpu'reum (Meyer in Led. f. ross. alt. ill. t. 231. fl. alt. 1. p. 268.) stem erect ; leaves pubescent, nearly orbicular, cordate, 3-5-lobed; lobes acute, serrated; racemes drooping ; pedicels exceeding the bracteas; calyxes campanulate, ciliated ; berries glabrous, bractess. h. H. Native of Altaia, on mountains and subalpine places at the river Ursal, also at the river Tscharysch. Berries dark purple, size of those of the common currant.

lar. a; flowers deep purple; leaves rather pubescent beneath, but smooth and glabrous above, as well as the branches.

lar. $\beta$; leaves rather pubescent beneath, but hispid from bristles above, as well as the petioles and stems. Near the river Volschoi Ulegumen.

Var. $\gamma$; flowers paler; leaves pubescent above, but most so below; branches smooth.

Dark-purple-flowered Currant. Fi. A jril, May. Slhrub 4 to 6 feet.

63 R. sasguíneum (Pursh. f. amer. sept. 1. p. 164.) leaves cordate, somewhat 5 -lobed, serrated, veiny, smoothish above, but clothed with villous tomentum beneath; racemes drooping, pubescent, twice the length of the leaves; calyx tubularly campanulate, with oblong obtuse spreading segments, exceeding the petals, which are red, and quite entire; bracteas obovate-spatulate; berries turbinate, hairy. h. H. Native of the north-west coast of America, in abundance from lat. $35^{\circ}$ to $52^{\circ}$, usually growing in rocky situations by the sides of streams.

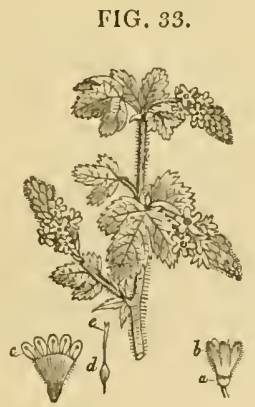

Dougl. in hort. trans. 7. t. 13 . bot. reg. 1349. Sweet, f. gard. n. s. t. 109. R. malvàceum, Smith in Rees' cycl. This is perhaps the most ornamental species of the genus, bearing a profusion of large racemes of deep rose-coloured flowers, and is therefore well adapted for ornamenting slirubberies and pleasure grounds. The berries are brownish black and bitter, completely destitute of the pulpy substance common to most of the species of the tribe.

Bloody-flowered Currant. Fl. April. Clt. 1820. Slirub 4 to 8 feet.

Sect. V. Srmphoca'Lyx (from $\sigma v \mu \phi v \omega$, symphuo, to join together, and $\alpha a \lambda v \xi$, calyx, a calyx; in reference to the calyx being tubular in all the species belonging to this section). Berl. l. c. t. 2 .
D. C. prod. 3. p. 483. Calyx tubular, yellow. Racemes manyflowered. Leaves compassing in the bud. Unarmed shrubs.

64 R. Av'reum (['ursh. fl. amer. sept. 1. p. 164.) quite glabrous; leaves 8 -lobed; lobes divaricate, with a few deep teeth, shorter than the petioles, which are ciliated at the base ; calyxes tubular, longer than the pedicels: tube slcnder: segments oblong, obtuse; petals linear, much shorter than the calycine segments; bracteas linear, length of the pedicels; style entire; berries glabrous. h. II. Native of North-west America, in light gravelly soils, from the Great Falls of the Columbia River to the mountains, and on the southern branches. Berl. l.c.t. 2 f. 23. Flowers golden yellow. Fruit yellow, seldom black, and of an exquisite flavour.

I'ar. a, práeox (Lindl. in hort. trans. 7. p. 242.) flowers earlier; leaves cuneated at the base, pubescent beneath; lobes deeply serrated; berries copious, earlier, turbinate; racemes bracteate. h. II. Native of North America.

Var. $\beta$, villòsum (D. C. prod, 3. p. 483.) leaves rather villous. R. longiflòrum, Fraser, cat, 1813.

Var. $\gamma$, scrótinum (Lindl. l. c.) flowers late; leaves of various forms, smoothish beneath; lobes deeply serrated; berries few, late, round; racemes naked. $\zeta$. H. Native of North America.

Golden-flowered Currant. Fl. April, May. Clt. 1812. Shrub 6 to 8 feet.

65 R. Tenuiflòrum (Lindl. in hort. trans. 7. p. 242. bot. reg. 1274.) unarmed, quite glabrous; leaves roundish, 3-lobed, mealy; lobes bluntly toothed at the apex; racemes pendulous, many-flowered; calyx tubular, glabrous, longer than the pedicels, coloured; petals quite entire, linear, one-half shorter than the segments of the calyx, which are oblong and obtuse ; bracteas linear, length of the pedicels; berries glabrous. h. H. Native of North America, common on the rocky tracts of the Columbia, near the head waters of the Missouri. R. aureum, Colla, hort. rip. append. 3. t. 1. f. A. R. flàvum, Berl. in D. C. prod. 3. p. 483. R. Missouriênsis, Hort. In habit this species is more erect than $R$. aúreum, and has the young wood more thinly clothed with leaves; its whole appearance is also paler during the early part of the season. 'The flowers are not more than half the size of those of $R$. aureum, and have entire, not notched petals. The fruit is the size of a red currant, of an agreeable flavour, but possessing little acidity.

lar. a, frúctu-nigro; berries changing from yellow to recl, and finally acquires a deep blackish purple-colour.

Iar. $\beta$, fiúctu-lùtco; fruit yellow, always retaining the same colour.

Slender-flowered Currant. Fl, April, May. Clt. 1812. Sh. 6 to 8 feet.

66 R. FLA'vus (Coll. hort. ripul. append. 3. p. 4. t. 1. f. $\beta$.) unarmed, quite glabrous; young leaves 3-lobed: adult ones usually 5-lobed, deeply toothed, about equal in length to the ciliated petioles; racemes short, 4-5-flowered; calyx tubular, much longer than the pedicels; tube slender: segments rather spatulate, reflexed; petals one-half shorter than the calycine segments; bracteas elliptic ; berries oblong, glabrous. h. $\mathrm{H}$. Native of North America. R. aúreum $\gamma$ sanguíneum, Lindl, in hort. trans. 7. p. 242. R. palmàtum, Desf, hort. par. R. aúreum, Ker, bot. reg. t. 125. but not of Pursh. Flowers yellow.

Iellow-flowered Currant. Fl. April, May. Clt. 1812. Shrub $G$ to 8 feet.

Cult. All the species of Ribes grow well in any kind of soil, and all root freely from cuttings planted in autumn, or early in spring. Those species, natives of Chili, Peru, Mexico, and other parts of South America, require slelter in severe weather. Some of the species are well adapted for ornamenting shrubberies and pleasure grounds. But the most ornamental and 
most wortlyy of cultivation are $R$. speciòsum, R. Mcnzièsii, $R$. sanguincum, R. atropurpùreum, and R. aürcum.

OrDER CXIX. ESCALLO'NEA (plants agreeing with $E s$ callonia in important characters). K. Brown, in Franklin's voy. p. 766. (1824.). Saxifràgex, Sect. I. Escallonièx, D. C. prod. 4. p. 4.

Calyx superior, 5-toothed (f. 34. b. f. 35. a.). Corolla of 5 petals (f. $34 . c$. f. $35 . b$.), alternating with the calycine segments, fron within which they rise, forming by their cohesion a tube (f. 34. e.), but finally separating from each other (f. 35. 6 .), imbricate in æastivation. Stamens arising from the calyx (f. 35. 6.), alternating with the petals (f. 35.6 .) ; anthers bursting lengthwise. Disk conical, epigynous (f. 34. c.), plaited, surrounding the base of the style (f. $34 . c_{\text {. }}$ ). Ovarium inferior (f. 34. a.), 's-celled, with 2 large polypernous placentas (f. $34 . f$.) in the axis. Style simple (f. 34. d.). Stigma 2-lobed. Fruit capsular, 2-celled, crowned by the style and calyx (f. 34.a. $b$. c. d.), which are permanent, splitting by the separation of the cells at their base. Seeds numerous, mintute, with a transparent membranous integument. Embryo minute, in the apex of an oily albumen, having the radicle pointing to the extremity opposite the hilum.-Shrubs or trees. Leaves alternate, exstipulate, simple, full of resinous glauds. Flowers axillary, conspicuous, white, rarely reddish.

This order is distinguished from Grossularice by the cohering petals, and by the radicle being at the extremity of the seed, opposite the hylum; the albumen is also oily, not horny, and the placentas are not parietal; from Philadélphece they are known by their glandular leaves and ninute embryo; from $\mathrm{Vac}$ ciniece, by the final separation of the petals, and by the anthers.

\section{Synopsis of the genera.}

1 Escallòna. Limb of calyx 5-toothed or 5 -lobed (f. 34 . b.). Stigma peltate, 2-lobed (f. 34. d.). Capsule baccate (f. 3.f. f.), somewhat 2-celled, opening by pores at the base. Seeds scrobiculate.

2 Rusnísia. Limb of calyx 5-toothed. Stigma peltately capitate, 4-5-lobed. Capsule 3-celled. Seeds compressed.

3 l'onge'sia. Limb of calyx 5-parted. Style finally divisible into 2 parts; stigma 2-lobed. Capsule 2-celled, dehiscing betwcen the parts of the style.

4 Anópterus. Calyx 6-lobed (f. 35. a.). Petals and stamens 6 (f. 35. b.). Stigma bifid (f. 35. c.). Capsule I-celled, 2-vilved (f. 35.d.). Seeds compressed, furnished with a wing at the top.

5 Iте'A. Calyx 5-cleft. Stigma capitate. Style finally divisible into 2 parts, Capsule compressed, 2-celled, separable into 2 parts.

I. ESCALILO'NIA (in honour of Escallon, a Spaniard, a traveller in South America, who found the first species of this genus in New Granada). Nutis, in Lin. lit. suppl. p. 21. Vent, choix. p. 54. Gertn. fr. carp. 3. p. 16. t. 18\%. H. B. et Kunth, nov, gen. amer. 3. p. 294. D. C. prod. 4. p. 2. Ste- reóxylon, Ruiz. et Pav. A. per. prod. p. 38.-Escallònia, Rom. et Schultes, syst. 5. no. 956. exclusive of Imbricaria.

Lin. sist. Pentándria, Monogýnia. Tube of calyx semiglobose, adnate to the ovarium (f. 34 . a.); limb 5 -toothed or 5 -lobcd (f. 34. b.). Petals 5, arising from the calyx. Stamens 5 ; authers ovate-oblong. Style filiform, permanent. Stigma peltate (f. 34. d.), somewhat 2 -lobed by a furrow. Capsule baccate (f. 34. f.), crowned by the calycine lobes and the style (f. 34. b. c. l.), sonewhat 2-celled, deliscing irregularly by pores at the base; dissepiment incomplete at the top, and therefore placentiferons. Seeds very numerous, scrobiculate.-Trees and shrubs, natives of South America, especially Chili, usually full of resinous glands. Leaves scattered, serrated, or entire. Flowers terminal, bracteate, variously disposed, white or red. In many of the species there is present a conical pervious urceolus, girding the base of the style; for this reason the species of the genus may hereafter be formed into sections.

\section{* Pcdiccls solitary, 1-flowered.}

1 E. SERra'ta (Smith, icon. ined. 2. p. 31.) shrub glabrous, erectisls; leaves obovate, obtuse, serrated, veinless beneath (except the middle nerve); flowers terminal, solitary; petals oblong, tongue-shaped. $h$. F. Native of the Straits of Magellan, at Terra del Fuego. Roem. et Schultes, syst. 1. p. 326. Stereóxylon serràtum, Poir. dict. 7.p. 435. Flowers white.

Serrated-leaved Escallonia. Shrub 3 to 6 feet.

2 E. myrtilloides (Lin. fil. suppl. p. 156.) shrub glabrous; branches spreading much; leaves obovate-oblong, acutish, crenately serrulated, veiny ; flowers terminal, solitary ; petals spatulate. h.F. Native of New Granada, every where on the Andes, in cold places. Smith, icon. ined. 2. t. 30 . H. B. et Kunth, nov. gen, amer. 3. p. 294. Stereóxylon pàtens, Ruiz. et Pav. fl. per. 3. t. 234. f. 6 . but the leaves and flowers are larger.

Myrtle-like Escallonia. Shrub 6 to 10 feet.

3 E. alpixa (Popp. pl. exsic. no. 820.) branches glabrous : leaves obovate, narrowed into short petioles, serrated at the apex, densely clothed with fine down beneath, and with scattered down above; flowers axillary, solitary, on short pedicels; tube of calyx puberulous, with subulate teeth; petals oblong-tongue-

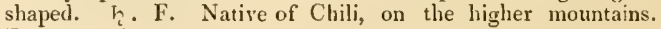
Flowers white.

Alpine Escallonia. Slrub 8 to 4 feet.

4. E. tortuòsa (H. B. et Kunth, nov. gen. amer. 3. p. 295.) shrub glabrous; branches spreading, twisted; leaves obovate, acute, reticulately veined, glandularly crenated, rather shining; flowers nearly terminal, solitary; lobes of calyx quite entire. $\zeta$.F. Native in very rougl mountainous places, on the Andes about Quito. Flowers white. Aliied to E. myrtilloides and E. corymbùsa. Fruit almost the size of that of Iaccinium myrtillius.

Tmisted Escallonia. Shrub 3 to 6 feet.

5 E. Berberifòlia (H. B. et Kunth, nov. gen. amer. 3. p. 296.) shrub glabrous; branches spreading; leaves obovate, bluntish, crenulately denticulated, reticulately veined; flowers terminal, solitary; lobes of calyx quite entire; petals rather spatulate, h.F. Native on the Andes, about Quito. Flowers white. Perhaps only a variety of L. tortuosa, according to the authors.

Barberry-leaved Escallonia. Shrub 3 to 4 feet.

6 E. corymbosa (Pers, ench. 1. p. 234.) shrub glabrous; branches erectish; leaves oblong, acute, serrulated; flowers terminal, solitary; lobes of calyx denticulated; petals oblong.

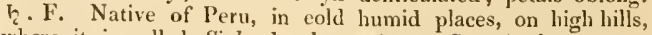
where it is called Siuba by the natives. Stereoxylon corymbòsum, Ruiz. et Pav. fl. per. 3. p. 14. t. 234. f. a. Peduncles 
straight, hearing 1 leaf each, just under the ealyx. Pctals white, spreadingly reflexed. Stigma peltate.

Corymbose-flowered Escallonia. Shrub 6 to 10 feet.

7 L. virga'ta (Pers. ench. 1. p. 23\%.) shrub glabrous; branehes erect; leares obovate, acute, scrrulated, veinless ; peduncles nearly terminal, 1-flowered; lobes of calyx denticulated; petals obovate. h. F. Native of South America, on mountains, and in humid woods in the province of liere, near Nacimiento. Stereóxylon virgàtum, Ruiz. et Pav. 1]. per. 3. p. 14. t. 295. f. 6. Stem much branched; branches cincreous, grey, rather spinose. Flowers white.

Triggy Eseallonia. Shrub 5 to 10 feet.

8 E. puneta'ta (D. C. prod. 4. j. 3.) shruh smoothish; branches erectish; leaves obovate obtuse, or lanceolate acuminated, serrated, full of resinous dots beneath; pedicels 1 flowered, arising from the axils of the upper leaves, each bearing 2 linear bracteoles; lobes of calyx long, dentieulated. $h_{\text {. }}$ F. Native of South Ameriea. Allied to $E$. virgàta, but differs in the leaves being dotted beneath ; to $E$. rùbra, but the flowers are on axillary, solitary, l-flowered pedicels. In this and in $E$. rùbra the urceolus is conical and perviousat the apex, 10-angled, and 10 -toothed, girding the style at the base.

Dotted-leaved Eseallonia. Shrub 5 to 8 feet.

9 E. FlóRIDA (Pœepp. pl. exsie. no. 843. ex D. C. prod. 3. p. 666.) shrub glabrous ; leaves linear-lanecolate, acuminated at both ends, with a few serratures, erowded; flowers on short pedicels, arising from the axils of the upper leaves, solitary, collected into an ovate raceme; limb of calyx 5 -cleft, witl obtuse recesses and artute lobes; petals obovate, on sliort claws. h.F. Native of Chili, probably on the mountains. Leaves 8-9 lines long, and $1 \frac{1}{2}$ line broad. Petals with obseure reins, which are pinnately disposed.

Florid Escallonia. Shrub 4 to 6 feet.

\section{* Flowers disposed in terminal racemes or panieles.}

10 E. RU'bra (Pers, ench. 2. p. 235.) shrui smoothish; branches ereet, when young elotbed with glandular villi; leaves obovate-oblong, acuminated, serrated, full of resinous dots beneath; peduncles 2-7-flowered, bracteate; lobes of calyx denticulated; petals spatulate. $h_{\imath}$. F. Native of Clili, on the mountains at Colocolo, in the fissures of rocks, and about Valparaiso. Hook. bot. mag. 2390. Stereóxylon rùbrum, Ruiz et $\mathrm{Pav}$. $\mathrm{f}$. per. 3. t. 236. f. b. Petals red, conniving, but spreading a little at the apex. (f. 34.e.)

lar. a, glabriúscula (Hook. et Arn. in bot. mise. 3. p. 252.) branches glandular, liardly pubeseent; leaves glabrous; flowers rect. দ. F. Native of Chili, near La Guardia, on the Andes of Clili, and about $\mathrm{Valparaiso.}$

$I^{\prime}$ ar. $\beta$, albiflòra (Hook.et Arn. l. c.) flowers white. h. F. E. glandulòsa, Lndd. bot. cab. t. 1291. Native of Chili; and the province of Maule.

Var. $\gamma$, pubéscens (Hook. et Arn. l. c.) branches hardly glandular, but clothed with villous pubescence; leaves pubescent on both surfaces, but more so beneath; flowers red. $h$. F. Native of the Andes of Clili. The leaves of all the varieties are spotted beneath with resinous dots.

voL. Ju.
Red-flowered Escallonia. Fl. July, Sept. Clt. 1827. Shrub 3 to 6 feet.

11 l. l'erpigia'sa (D. C. prod. 4. p. 3.) slirub smoothish ; liranchlets pubeseent, rather clammy; leaves oval, acute, tapering into the petiole, serrated, full of resinous dots beneath, rather elammy above; pedicels 1 -flowered, disposed in a fewflowered, terminal raceme; calyx glandular, with the tube drawn out beyond the ovarium: tceth subulate; petals crect, oblong. h. F. Native of Chili. E. rùbra, I'epp. pl. exsic. no. 81 . Flowers red. like $E$. rübra, but differs in the peduncles being I-flowered, in the teetl of the ealyx being subulate, in the urceolus not being prominent, and in the style being equal in length to the petals. 'There is a long-leaved variety of this, or a species, which was collected on the inountains in Clili, where it is called by the nacives Ripa.

Poppig's Escallonia. Shrub 4 to 6 feet.

12 E. Maera'ntua (Hook. et Arn. in bot. misc. 3. p. 251.) branches pubeseent, glandular; leaves ovate-ellintic, bluntish, cuncated at the base, glabrous, full of resinous dots beneath, bluntly erenate-serrated; lower peduncles simple, axillary: upper ones racemose; bracteoles wanting, or very minute; calyeine teeth subulate. $h$. F. Native of Chiloe. Petals connivent. The flowers are larger and the leaves broader than in $E$. rùbra.

Large-flonered Eseallonia. Shrub.

13 E. мyRtot'DeA (Bert. in litt. ex D. C. prod. 4. p. 666.) shrub glabrous; leaves lanceolate, serrated, attenuated at the base; racemes terminal, nearly simple, hardly longer than the leaves; limb of calyx campanulate, 5 -cleft : Jobes subulate, reflexed; petals obovate, on long elaws. $\zeta$. F. Native of Chili, at the river Cachapual near Rancagua, where it is commonly called Lun. 'The calyx agrees with that of $E$. revolùtu, but differs in the whole plant being smooth, and in many other points.

Myrtle-like Escallonia. Shrub 3 to 6 feet.

14 E. ILtinita (Presl, in reliq. Hænk. 2. p. 49. t. 59.) quite glabrous; branches spreading, anointed with resin ; leaves petiolate, obovate or oblong, obtuse, crenulated, attenuated at the base, beset with glandular dots above, and clanmy; panicle terminal, many-flowered, leafy; calycine segments acuminated, quite entire ; petals on long claws ; capsule turbinate, 5-nerved ; style furnished with a 10-toothed, 10-angled, pervious, cylindrical urceolus at the base, as in most of the species. h.F. Native of the Cordillera of Chili.

Iar, $a$; leaves beset with shining resinous dots on both surfaces, but especially beneath. $h_{2}$. F. Native of Chili, in El Arroyo de Los Lanes, Valle del Rio Tinguiririca, where it is called by the natives $L u n$.

Iar. $\beta$; leaves bearing minute glands beneath. $\zeta . \mathrm{F}$. Native of Chili, in La Siente Vieja, and La Cuesta de Chacabueo, and La Laguna near Valparaiso, where it is ealled by the natives Araca or Arayan. 'This variety is perhaps a distinet species; the glands beneath sometimes pass into a kind of pubescence.

Anointed Escallonia. Shrub 3 to 6 feet.

15 E. Argu'ta (Presl, reliq. Hank. 2. p. 4.8. t. 58.) quite glabrous; branches erect ; leaves obovate or oblong-lanceolate, mucronate, sharply serrated, attenuated into the petiole, discoloured beneath; panicle terminal, many flowered; rachis pubescent ; segments of calyx acute, quite entire; petals spatulate, on long claws; capsule turbinate, 10-nerved. দ. F. Native of Chili, at San Gabriel, La Guardia, and La Cuesta del Inga; Andes of Clili ; and Valle del Rio Claro. Lun is its vernacular name. E. microcárpa, Gill. mss. E. refléxa, Gill. mıs. E. myrtoídea, Gill. mss. laardly of Bertero. The raceme is very compact, and the flowers nearly sessilc. Perbaps afterwards it may prove a mere state of $M$, rùbra.

$\mathrm{C} e$ 
Sharp-serrate-leaved Escallonia. Shrub 3 to 6 feet.

16 E. REsinòsa (Pers. ench. 1. p. 235.) shrub glabrous; branches erect; branchlets anointed with resin; leaves oblong, obovate, hardly narrowed at the base, sessile, glandularly serrulated; panicles few-flowered, terminal; lobes of calyx quite entire; petals oborate-oblong. $r$. F. Native of Peru, on the cold parts of hills. H. B. et Kinth, nov. gen. amer. 3. p. 296. Stercíxylon resizosum, Ruiz et Pav. f. per. 3. p. 11. t. 235. f. 2. Strle permanent, hardly longer than the fruit.

Resinous-branched Escallonia. Tree 10 to 20 feet.

17 E. Grahamixa (Gill. mss. ex Hook. et Am. in bot. misc. p. 253.) plant glabrous ; branches straight, angular, rather resinous; leaves elliptic-oblong, bluntish, a little attenuated at the base, crenate-serrated, beset with a few resinous dots beneath; flowers in compact panicles, on short pedicels ; fruit obconical; calycine segments subulate. h. F. Native of Chili, in El Valle del Rio Tinquiririca. The branches of the panicle contain each 3 or 4 flowers, on pedicels hardly a line in length. The frut or tube of the calyx is abont twice as long as it is broad, and twice or thrice the length of the pedicels.

Graham's Escallonia. Shrub.

18 E. Sellowin'na (D. C. prod. 4. p. 4.) shrub glabrous; branches erect; leaves lanceolate, tapering into the petiole at the base, serrated, full of resinous dots beneath; panicles many flowered, terminal; teeth of calyx short, quite entire; petals spatulate. $\zeta$. F. Native of Brazil. E. resinòsa var. dodonaif òlia, Cham. in Linnæa. 1. p. 515. Very like E. resinòsa. Style hardly longer than the fruit. Flowers white.

lar. $\beta$, spircifolia (D. C. prod. 1. c.) leaves obovate, obtuse, tapering into the petiole at the base. $\zeta$. S. Native of Brazil. E. resinòsa spiræif olia, Cham, in litt.

Sello's Escallonia. Tree 10 to 20 feet.

19 E. Callcóttie (Hook. et Arn. in bot. misc. 3. p. 252.) branches smoothish, glandless: leaves ovate, oblong, oval or roundish, acute at both ends, petiolate, glabrous, glandless, with sharp adpressed serratures; flowers panicled; petals erect, on long claws; teeth of calyx subulate. $h$. F. Native of Juan Fernandez, where it was collected by Mrs. Callcott, late Mrs. Maria Gralıam. The lower peduncles of the raceme are branched, thus forming a panicle. The toothed urceolus at the base of the style is not so conspicuous in this as in other species of the genus.

Callcott's Escallonia. Shrub.

20 L. Montevidénsis (D. C. 1. c. p. 4.) shrub glabrous; branches erect; leaves oblong, cuneated at the base, acutish, finely serrated, full of resinous dots beneath ; paniele terminal, many-ftowered, crowded, intermixed with foliaceous bracteas; lobes of calyx acute, rather denticulated; petals obovate-oblong. $\eta$. F. Native of Brazil, in many places, but especially on the sandy banks and pastures of the Uruquay. E. floribunda var. $\beta$, Montevidénsis, Schlecht. in Linnæa. 1. p. 543 . Lindl. bot. reg. 1467. E. bífida. Link et Otto, abbild. t. 2S. Flowers white, very like those of the haw thorn. Style permanent, double the length of the fruit after flowering.

Monte-l Zideo Escallonia. Fl. July, Sept. Clt. 1827. Shrub 6 to 10 feet.

2) E. Flonibu'NDA (H. B. et Kuntl, nov. gen. amer. 3. p. 297.) shrub glabrous; branches covered with clammy resin; leaves oblong, obtuse, finely crenulated or quite entire, membranous ; corymbs terminal, rather panicled, much branched, leafy; teeth of caly $\mathrm{x}$ acute; petals obovate-spatulate. $h . F$. Native of New Granada, on the Andes. Siyle lengtl of the stamens. Leaves when young clammy and shining above. Flowers white. This species is said to come near $E$. euncifolia.

Bundle-flowered Fscallonia. Tree 10 to 0 feet.

22 E. Caracasa'va (H. B. et Kuntl, nov. gell. amer. 3. p.
297.) shrub glabrous; branchlets scattered, somewhat trigonal; leaves oblong, acute, cuneated at the base, petiolate, finely crenulated, membranous; panicle terminal, many-flowered, leafy ; teeth of calyx acute; petals obovately spatulate. $h, \mathrm{G} . \mathrm{Na}$ tive of Soutl America, in temperate places near Caraccas. Flowers white. Style shorter than the stamens. Very like $E$. floribúnda.

Caraceas Escallonia. Tree 12 to 20 feet.

23 E. specta'bilis (Hort. monac. ex D. C. prod. 4. p. 4.) branchlets pubescent: leaves oblong or elliptic, somewhat cuneated at the base, obtuse at the apex, serrulated, glabrous; panicle short, thyrsoid; bracteoles and lobes of calyx acute, somewhat serrated by black glands; petals obovate-spatulate. h. F. Native country unknown. Flowers red. Style length of the stamens. E. glandulòsa, Lodd. bot. cab. 1291.

Showy Escallonia. Fl. July, Sept. Clt. 1827. Sh. 3 to 6 feet.

24. E. Panicula'ta (Rœm, et Schultes, syst. 5. p. 328.) shrub glabrous; branches angular, rather clammy; leaves lanceolate-oblong, obsoletely serrulated; peduncles racemosely panicled; teeth of calyx very short; petals obovate. $h . F$. Native of Peru, in the groves of Pillao. Stereóxylon paniculitum, Ruiz et Pav. fl. per. 3. p. 16. t. 238. f. b. Flomers white. Style very short. Calyx nearly entire.

Panicled-flowered Escallonia. Shrub 5 to 8 feet.

25 E. Angustifòlia (Presl, in reliq. Hank. 2. p. 47.) glabrous; branches erect, glandular, resinous; leaves petiolate, linear-lanceolate, obtuse, dotted with glands, and glandularly serrulated, narrowed at the base; panicle terminal, many-flowered; segments of the calyx entire; style exceeding the capsule. h.F. Native of Peru. Style naked at the base, not furnished with an urceolus, as in those formerly named Steréxylon.

Narrow-leaved Escallonia. Shrub.

26 E. multiflòra (Presl, in Hænk. reliq. 2. p. 48. t. 57.) glabrous; branches spreading; branchlets glandular and glutinous; leaves nearly sessile, obovate, mucronate, glandularly serrulated, pale beneath, and glandularly ciliated at the base; panicles terminal, many flowered; teeth of calyx obtuse, quite entire; petals obovate; style equal in length to the ovarium,

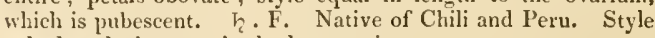
naked at the base, as in the last species.

Many-flonered Escallonia. Shrub.

27 E. Illave'scens (Presl, in reliq. Hænk. 2. p. 4S.) quite glabrous; branches erect; leaves obovate, recurvedly acuminated, glandularly serrulated, and pinnately veined, attenuated at the base; flowers terminal and axillary, sessile; teeth of calyx acuminated, glandular; capsule turbinate, 10-nerved. h. F. Native of the Cordillera of Chili. Style furnished with an urceolus at the base.

Yellowish Escallonia. Shrub.

28 E. cuneifòlia (Rom. et Schultes, syst. 5. p. 328.) branches spreading; leaves oblong-wedge-shaped, serrulated, nearly sessile, whitish beneath; panicle terminal, rather corymbose, hairy; teeth of calyx small; petals obovate, obsoletely crenulated. $\zeta$. F. Native of Peru, in woods on the Andes, at Chincao. Stereóxylon cuneifólium, Ruiz et Pav. fl. per. 3. p. 16. t. 238. f. a.

Wedge-leaved Escallonia. Shrub 5 to 8 feet.

29 E. Díscolor (Vent. chois. t. 54.) branchlets rather pubescent; leaves cuneiformly lanceolate, somewhat crenulated, or quite entire, of a different colour beneath, having the middle nerve hairy; panicles terminal, many flowered; calyx puberulous; petals obovate. h.F. Native of New Granada, on the Andes. Stereóxylon díscolor, Poir. dict. 5. p. 246. E. Tùbar Mútis ex Humb. tabl. nat. 1. p. 113. Kunth, nov. gen. amer. 3. p. 299. Hlowers white. Style length of the petals, shorter than in any other species, rather conical at the base, striated. 
Discoloured-leared Escallonia. Clt. 1820. Shrub 6 to $8 \mathrm{ft}$. S0 L. Revolu'ta (Pers. enelı, 1. p. 235.) slurub lairy in every part; branches crect, very hairy, but smoothish in the adult stato; leaves obovate, denticulated, revolute; raceme thyrsoid; tectlı of calyx subulate; petals linear-spatulate. h. F. Native of Chili, in shady moist places, and on the banks of rivulets about Conception, Valparaiso and Quillota, where it is called Liun or Lun by the inlabitants, and Siete Camisas. StercóxyIon revolitum, liuiz et Pav. fl. jer. 3. p. 15. t. 2S6. f. a. Flowers white?

Rerolute-leaved Escallonia. Tree 10 to 20 fcet.

SI E. pulverulénta (Pers. ench, 1, p. 235.) slurub hairy in every part ; branches rather erect, somewhat trigonal ; leaves elliptic, obtuse, on short petioles, scrrulated, ratlier clanmy above when young; racemes terminal, spike-formed, erect; teeth of calyx spreading; petals obovate. h. F. Native of Chili, between Conception and the tract of Carcano, where it is called Mardogno by the natives, and about Valparaiso. Pocpp. pl. exsic. no. 79. Clam. et Schlecht. in Linnaea. 1. p. 541. Stereóxylon pulveruléntum, Ruiz et P'av. f. per. 3. p. 15. t. 287. a. Flowers white, nearly globose, when in the bud. The style is shorter in this than in any other species.

Pondcred Escallonia. Shrub 6 to 10 feet.

32 E. Berteria'sa (D. C. prod. 4. p. 666.) shrub glabrous, clammy from resin; leaves elliptic, petiolate, serrated, shining above; racemes spicate, terminal, simple, twice the length of the leaves; calyxes shining and clammy, 5 -cleft; petals elliptic-oblong, sessile. $h_{\text {. }}$ F. Native of Clili, on the banks of rivers, and in valleys on the mountains, as at $\mathrm{La}$ Guardia del Maypu, banks of Rio Mlaule, Valle del Rio Tinquiririca, and Causa Blanea, and in woods near Raneagua. E. resinòsum, Bertero in litt. Leaves $2 \frac{1}{2}$ to 3 inches long, and $1 \frac{1}{2}$ broad. Petioles 3 lines long. Vernacular name of the shrub Corantillo.

Bertero's Escallonia. Shrub 5 to 6 feet.

33 E. culororny'lla (Cham. et Schleclit. in Limna. 1. p. 542.) shrub glabrous; branclies rather angular; leaves oborate-cuneated, mucronulate, quite entire, of a greyish white colour ; racemes terminal, clothed with powdery down; bracteas about equal in length to the peduncles; petals obovately spatulate. h. F. Native of Brazil. Flowers white?

Grecn-lcarcd Escallonia. Shrub.

3. E. FE'xdula (Pers. ench. 1. 1. 235.) branches erectly spreading, rather clammy when young; leaves oblong-lanceolate, acute, finely crenulated, hairy beneath, but especially on the nerves; racemes terminal, spike-formed, pendulous; calyx hairy, with the teeth acute; petals linear-spatulate. $h_{i}$. F. Native of Peru, in groves; and on the Andes about Losa, near Gonzanama. Stereóxylon péndulum, Ruiz et Pav. fl. per. 3. p. 16. t. 237. f. b. E. péndula, H. B. et Kunth, nov. gen, amer. 3. p. 29S. Perhaps the plant from Loxa is the same as that from Peru. Flowers white.

Pendulous-racemed Escallonia. Tree 10 to 14 feet.

35 E. нírta (Willd. in Rom. et Schultes, syst. 3. p. 329.) leaves obovate-oblong, almost quite entire, glabrous; panicle terminal; peduncles hairy. h.H. Native of Soutl America, where it is said to have been gathered by Humboldt and Bonpland, but it is not mentioned in the nov. gen. amer.

IIairy Escallonia. Shrub.

Cult. All the species of Escallònia are very fine ever-grcen slirubs; they grow best in a mixture of peat, sand, and loam; and cuttings strike readily in mould or sand under a hand glass. Host of the species will probably be found sufliciently hardy to stand in the open air in our climate, provided they are planted in a warm sheltered situation, particularly against a south wall or hot-house; and in winter they may be protected by throwing a mat over them.
1I. QUINTY'NIA (in memory of La Quintinie, who las written on gardening). Alph. D. C. in monog. campan. Paris, 1830, p. 92. D. C. prod. 4. p. 5 .

Lin. sxst. I'cutandria, Monogýnia. Tube of calyx adhering to the ovarium, marked by 10 nerves; limb 5 -toothed, jermanent. Petals 5, obovate. Stamens 5. Style columnar, filiform ; stigma peltately capitate, 4-5-lobed. Capsule crowned by the style and calycine teeth, 3-celled, with the dissepiments hardly complete; cells many-sceded. Śceds small, ovate, compressed.-Slirub smooth. Leaves alternate, pctiolate, oval, acuminated at the ajex, attenuated at the base, quite entire, coriaccous. Panicles terminal, composed of spreading racemose branches. Pedicels spreading, shorter than the fruit.

1 Q. Sube'ri (Alph. D.C. I. c.) h. F. Native of New Hollant.-Sicb. pl. exsic. nov. holl. no. 261.

Sieber's Quintinia. Shrub.

Cult. See Escallonia above for culture and propagation.

1II. FORGESIA (in honour of M. Desforges, Governor of the Isle of Bourbon, when Commerson investigaterl the vegetation of that country). Comm. in Juss. gen. p. 164. D. C. prod. 4. p. 5.-Defförgia, Lam. ill. t. 125.

Lin. syst. Pentándria, Monogýnia. Tube of calyx turbinate, adnate to the ovarium; limb 5-parted: Jobes Janceolate. Petals 5 , inserted in the calyx, linear-lanceolate, approximate at the very base, hardly longer than the calyx, somewhat valvate in astivation. Stamens 5 , erect; anthers ovate. Style filiform, finally scparable into 2 parts; stigma 2-lobed. Capsule half adnate, crowned by the erect separated styles, 2-celled, manyseeded, opening between the styles.-T'ree small, quite glabrous. L.caves alternate, coriaceous, lanceolate, attenuated at both ends, on sliort petioles, serrated. Racemes terminal, few-flowered, bracteate at the base of the pedicels.

1 F. Borbónica (Lers. ench. 1.p. 194.) 々. G. Native of the Island of Bourbon, in the high woods above the plains of the Caffres. Defförgia Borbónica, Lam. ill. p. 59. t. 125. Poir. suppl. 2. p. 460. Forgèsia racemòsa, Gmel. syst. veg. 1. p. 353. Bourbon Forgesia. Tree 20 fiet.

Cult. For culture and propagation see Escallonia above.

IV. ANO'P'TERUS (from $a v^{\prime} \omega$, ano, upwards, and $\pi \tau \varepsilon \rho o v$, ptcron, a wing; in reference to the seeds, which are winged at the apex). Labill. nov. holl. 1. p. 86. t. 112. R. Br. in Frankl. narr. journ. 756. verm. schrift. 1. p. $5 \$ 5$.

Lın. syst. Hexándria, Digýnia. Tube of calyx turbinate (f. 35. a.), adnate to the ovarimu at the base; lobes 6 , short, acute, permanent. Petals 6 (f. 35.6 .), alternating with the calycine lobes, and inserted in the calyx. Stamens 6 (f. 35. b.), inserted with the petals, shorter, and alternating with them. Style short; stigma bifid (f. 35. c.). Capsule oblong, 1-celled, 2-valved (f. 35. d.); valves opening from the apex to the base, with the placentas at the margins (f. 35 . e.). Seed ovate, compressed, furnished with a wing at the top.Tree, quite glabrous. Leaves alternate, rarely nearly opposite, ovate-oblong, attenuated at both ends, nearly scssile, coriaceous, callously toothed. Racemes simple, terminal. Flowers sometimes 7 -cleft.

1 A. Glandulòsa (Labill. I. c.) $h, F$. Native of Van Diemen's Land. Flowers white. (f. 35.)

c 2
FIG. 35 .

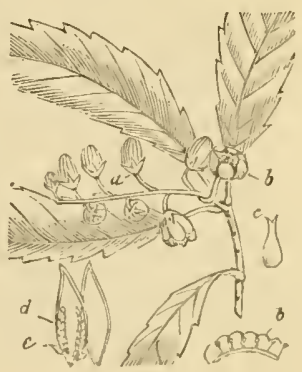
西

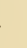

.


Glandular Anopterus. Tree 25 feet.

Cult. See Escallònia, p. 195. for culture and propagation.

V. I'TEA ( $r \varepsilon a$, itea, is the Greek name of the willow ; given to this genus on account of the quick growth of the I. I irginica). Lin. gen. 275. Rich. in Michx. fl. bor. amer. 1. p. 156. Gertn. fruct. 3. p. 142. t. 209. f. 4. D. C. prod. 4. p. 6. -Diconángia, Michx. gen. p. 5. Adans. fam. 2. p. 165.Cedrèla, Lour. but not of Lin.

LiN, syst. Pentándria, Monogýnia. Calyx regular, permanent, campanulate, 5-cleft, with the recesses obtuse, and the teeth subulate. Petals 5, lanccolate-linear, inserted in the upper part of the tube of the calyx, and alternating with its lobes, valvate in astivation. Stamens 5, alternating with the petals, and slorter than them; anthers oblong, rather bifid at the base, 2celled, bursting lengthwise. Ovarium oblong, free. Style I, but at length separating into 2 parts : stigma capitate, usually divisible in the furrow. Carpels 2, joined into a 2-celled compressed bisulcate capsule, which separate at length from each other from the base to the apex. Seeds numerous, disposed in 2 rows along the inflexed margins of the carpels.-Shrubs, with alternate simple exstipulate leaves. Flowers racemose, as in Weinmannia, but pentandrous, and as it were single styled. The character of the genus is alone taken from I. Iirginica.

1 I. Virgínica (Lin. spec. 289.) leaves lanceolate, acutely toothed; racemes simple, terminal. $\eta$. H. Native of North America, from Pennsylvania to Carolina. Lam. ill. 1. t. 147. f. 1. Lher. stirp. 1. p. 138. Lois. in Duham. abr. cd. 2. vol. 6. t. 9. Sims, bot. mag. 2409.- I'rew. ehret. $t, 98$. When this shrub is in vigour it is entirely covered with racemes of white flowers in July and August, and then makes a fine appearance.

Virginian 1tea. Fl. June, Aug. Clt. 1744. Sh. 6 to 7 feet.

† Asiatic shrubs related to I'tca, and referred to the genus by the authors, but will prolably constitute 2 or 4 different gcnera when the parts of fructification are properly examincd.

\section{* Leaves alternatc.}

2 I. ? vMBELLA'TA (Roxb. fl. ind. 2. p. 419.) leaves alternate, broadly lanceolate, entire, smooth; panicles axillary and terminal, composed of simple umbels, on long peduncles. h.S. Native of the Malay Islands. Capsule 1-celled, 2-valved, with 2 parietal placentas on each side. Flowers white.

Umbellate-flowered Itea. Shrub 6 to 8 fcet.

3 I. ? MACROPHY'LLA (Wall. in Roxb. fl. ind. 2. p. 419.) leaves alternate, elliptic-ovate, acuminated, callously serrated; racemes axillary, fasciculate, erect, equal in length to the leaves. $h$. G. Native of the East Indies, on the Khasee mountains bordering on the province of Silhet. Flowers yellow, fragrant, when young conical, and valvate in astivation. Ovarium half adhering to the calyx, 2-celled. Style columnar.

Long-lcaved Itea. Tree 20 feet.

\section{* Leaves oppositc.}

4 I. ? FRA'Grans (Wall. in Roxb. fl. ind. 2. p. 420.) leaves opposite, cuncate-lanceolate, entire ; racemes terminal ; flowers in sessile fascicles, tetrandrous, and pentandrous. そ. G. $\mathrm{Na}$ tive of the East Indies, in the Island of Singapore. Flowers yellow, fragrant. Calyx cup-shaped, 4-5-toothed. Petals 4-5, linear, valvate in astivation, longer than the stamens. Ovarium adnate to the calyx, 2-celled. Style colımnar. This species, with the preccling, will perhaps? form a new genus nearly allied to Escallòia.
Fragrant-flowered Itea. Shrub 5 to 6 feet.

5 I.? Rosmari'nus (Rom. et Schultes, syst. 5. p. 408.) leaves opposite, filiform, glabrous, hardish ; peduncles axillary, 1-flowered. $\quad$. F. Native of the north of Cochin-china, in sandy places, and in China about Macao. Cedrèla Rosmarìus, Lour. coch. p. 160. Calyx somewhat campanulate, 5-toothed, with the base permanent, and the teeth deciduous. Petals 5 , obtuse. Stamens 5, equal in length to the petals. Style 1. Capsule 3-celled, 3-valved, dehiscing at the apex, many-seeded. Leaves odoriferous, from containing a quantity of essential ceplalic oil. This plant hardly belongs to the order.

Rosmary-like Itea. Slurub 5 to 6 feet.

Cult. T'tea Virginica is a very pretty hardy shrub, well adapted for decorating the front of a shrubbery. It is increased by layers put down in the autumn. The rest of the species should be grown in pots, in order that they may be protected by a frame in winter, or to be grown against a south wall, where they may be easily preserved from the frost by mats; a light soil is best suited for them, and they may be either increased by layers put down in the autumn, or by cuttings.

ORDER CXX. CUNONIACER (plants agrceing with $\mathrm{Cu}$ nòia in important characters). R. Br. gen. rem. p. 16. D. Don in edinb. phi]. journ. April, 1830.-Saxifragàceæ, Tribe II. Cunonièæ, D. C. prod. 4. p. 7.

Calyx of many divisions (f. $36, a$. f. 37, a. f. 38. $a$. f. 39.a.), valvate in xstivation. Petals equal in number to the divisions of the calyx (f. 36. b. f. 38. b. f. 39. c.), and alternating with them, imbricate in restivation, sometimes wanting. Stamens inserted in a perigynous disk, definite (f. 37.6 .), rarely indefinite ; anthers peltate, 2-celled (f. 38. c. f. $39 . d$.), bursting lengthwise by a donble fissure. Ovarium 2-celled: ovula usually indefinite; styles 2 (f. $36 . e$. f. 37. d. f. $38 . e$. f. 39 . b.), rarcly connate : stigmas 2, simple, obtuse, pruinose. Capsule composed of 2 conflated follicles, which are applied to each other, rarely confluent, 2 -celled, 2 -valved; for the most part furnished with 2 beaks, and many-seeded; dissepiments double, from the inflexed edges of the valves. Placenta central, composed of fascicles of umbilical vessels. Seeds pendulous, sometimes winged; testa crustaceous or membranaceous. Albunen copious, fleshy. Embryo slender, straight, with the radicle turned towards the umbilicus, usually rather long.-Trees or shrubs, for the most part natives of the southern hemisphere. Leaves usually opposite, but sometimes verticillate, simple or compound. Stipulas interpetiolar, rarely wanting. Flowers usually disposed in spicate racemes or panicles.

The Cunoniàcece were first proposed by Dr. R. Brown as a separate family from Saxifragacea, to which they had been referred by Jussien, and to which they are intimately related, being chiefly distinguished by habit alone. M. Kunth considers them merely as a section of Saxifragàcea, but it appears preferable to regard them as a distinct family; for the advantages arising from dividing extensive families and genera are, that the individuals composing these become better understood, and their characters more accuratcly investigated. The Saxifragàcea are almost cxclusively confined to the northern, as Cunoniàcece are to the southern hemispluere. Some pass beyond these limits, but their number is very small. Both families agree in having entire 
and divided petals, and a superior and inferior ovarium. In the scries of natural affinities the Philadilphece clearly follow the Cunoniàces, with which they correspond in habit; and in Bauèra and Belangèra the stamens are indefinite, and the sceds of Caldclùia have a striking analogy to those of Philudélphus. The styles both in Saxifragàcece and Cunoniàcece are often 3, and in Cornidia of the Flora Peruviana that number is always constant.

A species of Wcinmánnia is used in Peru for tamuing leather, and its astringent bark is employed to adulterate the Peruvian bark. The Indian Weinmánnias appear to possess similar astringent qualities.

\section{Synopsis of the genera. \\ Tribe I.}

Cunonie's. Stamens definite. Ovarium distinct.

1 Weinmánia. Calyx 4-parted, permanent (f. 36. a.). Petals 4 (f. 36. b.). Stamens 8. Hypogynous disk urceolate (f. 36. d.). Styles 2. Capsule opening at the apex at the dissepiments; cells many seeded. Seeds reniform, hairy. Leaves simple or compound, with 3-5 leaflets.

2 Lejospérmus. Calyx 4-parted, deciduous. Petals 4. Stamens 8. Hypogynous disk flat, entire. Styles 2. Capsule opening in the manner of Weinmánnia; cells many-seeded. Seeds smooth. Leaves simple.

3 Caldclu'via. Calyx membranous, 4-partell, deciduous. Petals 4, unguiculate. Stamens 8. Hypogynous glands 8 . Styles 2. Capsule opening in the manner of Weinmánnia; cells 5-10-seeded. Seeds fusiform; with the testa membranous, and larger than the nucleus. Leaves simple.

4 Platrilopirus. Calyx 4-cleft, sometímes 5-cleft, permanent. Petals 4 , rarely 5 , trifid. Stamens 8 or 10 . Hypogynous disk urceolate, entire. Styles 2. Capsule membranous, 2-celled at the base, and ending in a flat bifid wing at the apex; cells 1 -seeded. Seeds large, arched. Leaves compound, with 3 leaflets.

5 Cuxòsı. Calyx 5-cleft; segments deciduous. Petals 5. Stamens 10. Hypogynous disk small. Styles 2. Capsule opening like that of Weinmánnia; cells many seeded. Seeds oblong, compressed, smooth, winged on one sidc. Leaves impari-pinnate.

6 Arnóldia. Calyx 4-parted, Petals 4. Stamens 8. Hypogynous glands 8. Styles 2. Ovarium didymous, biovulate. Carpels 2, connate at the base, solitary from abortion, beaked by the styles, opening on the inside, 1 -seeded. Leaves imparipinnate.

7 Pterophýl mens 8. Styles 2, very short. Ovarium 2-celled. Capsule unknown. Leaves impari-pinnate.

8 Caly'cous, Calyx 5-parted, permanent. Petals 5. Stamens 10. Hypogynous disk small. Styles 2, setaceous. Capsule globose, 2-celled, opening at the apex ; cells many seeded. Seeds minute, smooth. Leaves simple.

9 Callícosa. Calyx 4-parted, rarely 5-parted (f. 37.a.), permanent. Petals wanting. Stamens 8 , rarely 10 (f. 37.6. ).
Hypogynous disk small. Styles 2 (f. 37. d.), setaceous. Capsule inclosed in the caly $\mathrm{x}$, dehiscing at the dissepiments; cells ventricose, 1-2-sceded from abortion. Seeds rough from pitpillo. Leaves simple.

10 Ceratopétalum. Limb of calyx 5-parted (f. $38 . a_{0}$ ), permanent. Petals 5 (f. 38.b.), linearly multifid, permanent or wanting. Stamens 10; anthers beaked (f. 38. c.). Styles 2, short (f. 38. e.). Capsule 1-seeded from abortion, dchiscing at the apex. Leaves simple or ternate.

11 Scumzone'ria. Calyx 5-cleft, permanent. Petals 5, jagged, dcciduous. Stamens 10. Ovarium 2-celled; ovula many. Styles 2, short. Capsule baccate, closed at the apex. Icaves simple.

\section{Tribe II.}

CoDie's. Stamens definite. Ovarium inferior.

12 Codia. Limb of calyx 4-5-parted, permanent. Petals 4-5. Stamens 8-10. Styles pubescent. Capsule closed at the apex, usually 1 -seeded from abortion. Seeds roundish, smooth. Leaves simple.

\section{Tribe 111.}

BaUe'rex. Stamens indefinite. Ovarium frec.

13 Belange'ra. Calyx deeply 6-parted; segments deciduous. Petals wanting. Stamens numerous. Styles 2. Capsule superior, 2-celled, 2-beaked, opening at the dissepiments; cells many-seeded. Seeds compressed, winged at the apex. Leaves compound, with 3-5 leaflets.

14 Baue'ra. Calyx 6-10 parted (f. 39. a.). Petals 6-10 (f. 39. c.). Styles 2 (f. 39. b.), glabrous. Capsule superior, 2-celled, 2 -valved at the apex, opening by a transverse chink; cells few-sceded. Seeds scabrous from resinous dots. Leaves in whorles.

\section{Tribe IV.}

Srmpurogy'nee. Stamens definite. Ovarium free. Styles connate.

15 Gzíssors. Calyx 4-parted, deciduous. Petals wanting. Stamens 8. Style 1; stigmas 2. Capsule compressed, 2-celled, 2-valved; cells many seeded. Seeds compressed, wingcd. Leaves compound, with 5 leaflets.

\section{Tribe I.}

CUNONIE' $Æ$ (plants agreeing with Cunònia in having definite stamens). Stamens definite. Ovarium distinct from the calyx.

I. WEINMA'NNIA (in honour of John William Weinmanm, apothecary at Ratisbon, author of Phytanthoza Iconographica, in 4 vol. fol. Ratisbon, vol. 1. in 1737., vol. 2. in 1739., vol. 3. in 1742. , vol. 4. in 1745.) Lin. gen. no. 493. Juss. gen. p. 909. H. B. et Kunth, 6. p. 49. D. Don, in edinb. phil. April, 1830.-Windmámia, P. Brown, jam. ed. 2. p. 212.

LiN. syst. Octándria, Digýnia. Calyx permanent, 4-parted (f. 36. a.). Petals 4 (f. 36. b.). Stamens 8. Disk liypogynous, urceolate $($ f. 36 . $\boldsymbol{d}$.). Capsule opening at the dissepiments from the apex; cells many seeded. Seeds roundish-reniform. -Trees, natives of South America and the Mauritins. Ieaves compound or simple; petioles articulated. Stipulas undivided, caducous. 
Flowers hermaphrodite, racemose, usually white; pedicels in fascicles.

\section{- Lcares simple.}

1 W. ova'ta (Cav. icon. G. p). 45.t. 566.) leaves elliptic-oblong, bluntish, crenated, glabrous on both surfaces, as well as the branches, acute at the base. $\lceil$. S. Native of Peru, at the town of San Buenaventura. Leaves 2-3 inclies long, and an inch or an inch and a half broad. Riacemes 3 inches long, loose. Hypogynous disk with 8 glands (f. $36, d$. $)$.

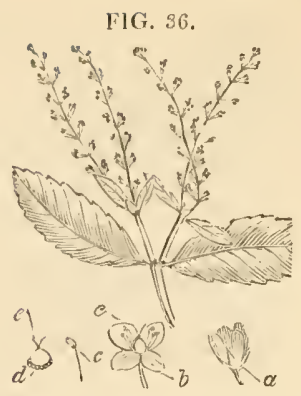

Orate-leaved Weinmannia. Fl. May, June. Clt 1824. Tree 12 to 20 fiet.

2 W. Kuntima'Na (D. Don in edinb. phil. journ. April, 1830.) leaves elliptic, crenated, euneated at the base, membranous, glabrous; racemes elongated; fascieles many flowered. $\zeta$. S. Native of New Granada, near Santa Fe de Bogota. W. ovàta, II. B. et Kunth, 6. p. 52. exclusive of the synonyme of Cav. Leaves with the nerves and veins beneath, rather pilose, 3-4. inclies long, and an inch and a half or 2 inches broad. Racemes a span long; fascicles 3-10-flowered.

Funth's Weinmannia. Tree 10 to 15 feet.

3 W. Batsisia'xa (H. B. et Kuntl, nov, gen. amer. 6. p. 5 I. t. 520.) leaves nearly sessile, ovate-lanceolate, rather acuninated, serrated, glabrous, attenuated at the base; fascicles of racemes many-flowered. $\zeta$. S. Native of Quito, in woods near Loxa. Leaves $1 \frac{1}{2}$ ineh or 3 inches long. Racemes loose, 2 inches long. Capsule ovate, glabrous.

Balbis's Weinmannia. Tree or shrub.

4. W. Lav'rina (H. B. et Kunth, ], e. 6. p. 51.) leaves oblong, acute, crenated, glabrous, attenuated at the base; fascicles of racemes many flowered. $h$. S. Native of South America. Leaves 3 inches long or more, puberulous on the veins beneath. liacemes 2 inches long.

Laurcl-like Weinmannia. Tree.

5 W. macrophy'Lla (H. B. et Kunth, 1. c. p. 52. t. 521.) leares nearly sessile, ovate, acuminated, serrated, glabrous on both surfaces, as well as on the branches, roumded at the base; fascicles of racemes many flowered. h. S. Native of the Andes of Quito, between Loxa and Nabon. Leaves 2-5 inches long, and $2-3$ inches broad, shining above. Racemes rather loose. Capsule terete, oblong, glabrous.

Lomg-leaved Weinmannia. Tree or slirub.

6 W. Latifòcia (Presl, in Haenke, reliq. 2. p. 51.) leaves ovate-elliptic, ohtuse, acute at the base, crenately serrated, coriaccous, quite glabrous above, hairy beneath; racemes longer than the leaves; stipulas oblong, obtuse, silky outside ; urceolus entire. T. G. Native of Peru, in mountain woods.

Broal-lcaved Weinmannia. Tree.

7 W. Llu' PTieA (H. B. et Kuntl, l. c. p. 50.) leaves petiolatte, elliptic, obtuse, crenated, glibrous on both surfaces, acutish at the bace; racemes loose. h.S. Native of Quito, near Losa. Leares an incli or an inch and a lialf long, coriaccous. Racemes $1 \frac{1}{2}$ or 2 inclies long. Capsule ovate, glabrous. Flowers purplish. Elliptic-leaved Weimmannia. Fl. Nay, June. Clt. I824. Tr.

8 W. ova'zis (Ruiz et Pav. A. per. 4. t. 333. f. a. ined.) leaves petiolate, ovil, crenated, quite glabrous on both surfaces, as well as the branches, shining, acute at the base; fascieles of racemes many flowered. $h_{2}$. S. Native of $\mathbf{P}$ (ru, on the Andes, in gruves at l'illao. Leaves coriaceous, 2 or 3 inches long. li accmes Joose, a hand long. Capsule ovate, quite smootl..
Oval-leaved Weinmannia. Tree.

9 W. crassifòula (Ruiz et Pav. fl. per. 4. t. 331. f. a. ined.) leaves nearly sessile, oval, coarsely crenated, rather pilose as well as the branches, rounded at the base; fascicles of racemes many flowered. $\zeta$. S. Native of Peru. Leaves 2 inches long, coriaceous, thick, pilose on the rib and veins beneath. Racemes 2-3 inches long. Capsule ovate-oblong, smooth.

Thick-leaved Weinmanuia. Tree.

10 W. suncorva'ta (Moricand, herb. ex D. C. prod. 3. p. 8.) leaves oval, obtuse, somewhat cordate at the base, dentately crenated, coriaceous, glabrous, shining above; racenes when in flower exceeding the leaves a little. $\zeta$. S. Native of Peru. Flowers on very short pedicels. Leaves 24-30 lines long, and 16-18 lines broad.

Subcordatc-leaved Weinmannia. Tree.

$$
\text { * Leaves simple and ternate. }
$$

1) W. IIEterophy'Lla (H. B. et Kunth, nov. gen, amer. 6. p. 52. t. 522.) leaves simple and ternate, ovate-oblong, acutely and coarsely serrated, rather pilose beneath; fascicles of racemes many flowered. $々$. S. Native of New Granada, near Santa Fe de Bogota. Leaves for tlie most part simple, glabrous above, pilose beneath, partieularly at the ribs, 3-5 inches long, and $1 \frac{1}{2}$ or 2 inches broad. Petioles half an inch long. Kaeemes loose, 4 inches long. Capsule ovate, smooth.

Itariable-lcaved Weinmannia. Tree.

I2 W. corda'ta (D. Don in edinb. jhil. journ. A pril, 1830.) leaves nearly sessile, cordate-ovate, bluntish, coarsely serrated, rather pilose beneath, and on the branches; faseicles of racemes many flowered. $h$. S. Native of Peru. W. heteroplyýlla, Ruiz et Pav, fl. per. 4. t. 331. f. b. Leaves simple or ternate, 2 inehes long. Racemes loose, 3 inches long.

Cordale-leaved Weinmannia. Tree.

$13 \mathrm{~W}$. aurievla'ta (D. Don, in edinb. phil. journ. April, 1830.) Jeaves elliptic, with revolute, serrated margins, rounded at the base, hairy beneath and on the branches; fascicles of racemes crowded, h. S. Native of Peru, in groves at Pillao. W. ovàta, Ruiz et Pav. fl. per. 4. t. 333. f. b. ined. W. dryadifòlia, D. C. prod. 4. p. 9. Leaves shining and glabrous above, but densely clothed with fulvous hairs beneath, an inch or an inch and a half long, ]-lobed at the base, and sometimes trifuliate. Racemes dense, spicate, $2-3$ inches long. Capsule roundish-ovate, and are as well as the styles rather hairy.

Aurielch-leaved Weinmannia. Tree.

14 W. Austra'Lis (Cunning. in Field's new soutls wales, p. 353.) leaves trifoliate; leaflets ovate-lanceolate, deeply and equally serrated, sessile; flowers terminal. $\digamma_{c} . G$. Native of New Holland, on moist shady rocks, at Springwood.

Southern Weinmannia. Slirub.

$$
\text { *** Leaves tcrnate and quinate. }
$$

15 W. pentapuýlla (Ruiz et Pav. f. per. 4. t. 330. f. a.) leaves ternate and quinate; leaflets $3-5$, ovate-lanceolate, acute, serrated, glabrous on botl surfaces; racemes loose. 々. S. Native of Peru. Branchlets pubeseent. Leaflets coriaceous, shining above, 2-3 inches long: lateral ones unequal-sided at the base. Racemes loose, a hand long; pedicels longish. Capsule ovate, smooth. Styles sometimes 3 , when this is the case the capsule is 3-celled.

Five-leaed Weinmannia. Tree.

16 W. crenu'ta (Presl, in reliq. Hrenk. 2. p. 51.) leaves of the branches with 2 pairs of leaflets and an odd one, those of the branchlets ternate; leaflets oblong, obtuse, broadly crenated, quite glabrous, coriaceous, terminal one oblong-lanceolace, attenuated at the base; wings of the rachis and petiole semi-obovate; racemes longer than the leaves, and are as well as the branches pubescent; flowers glomerate; segments of the calyx 
ciliated ; urceolus.crenated. ५.. G. Native of P'eru, in mountaill woods.

Crenated Weinmannia. Tree.

17 W. Mavrituina (D. Don, in edinb. plit. journ. $\Lambda$ pril 1830.) leaves ternate and quinate; leaflets $3-5$, obovate, or elliptic, obtuse, crenated, smoothish; racemes loose. h. S. Native of the Mauritius, where it is called La Lon. W. trifoliàta, Lam. diet. 7. p. 579 . ill. t. 313 . f. 2 . exclusive of the synonyme. Smith, in Rees' cyel. exclusive of the synonymes of Lin. Thuub. and Willd. W. Madagascariénsis, 1). C. prod. 4. p. 9. Leaflets coriaccous, pubescent beneath, $\frac{1}{2}$ or 1 inch long. Raccmes loose, 2 inches long; fascicles few-flowered.

Maurilian Weinmannia. Trec.

18 W. maroina'ta (Iloricand, mss. ex D. C. prod. 4. p. 10.) leaves with $3-5$ leaflets; leaflets ovate-lanceolate, acnte, serrated, attenuated at both ends: extreme one the largest ; petiole mar-

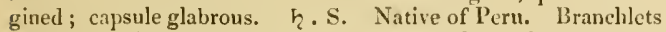
villous, by threes at the tops of the branches. Racemes exceeding the leaves. Leaflets 2-3 inches long, and 8-14 lines broal.

Marginate-petioled Weinmannia. Tree.

19 W. мicropir'LLA (H. B. et Kunth, nov. gen. amer. 6. p. 54. t. 523.) leaves ternate and quinate; leaflets $9-5$, obovate, crenated, glabrous; racemes very short, somewhat corymbose. h.S. Native of Quito, near Loxa. Leaves with sometimes only 2 leaflets; leaflets small, cuneate-obovate, crenated, quite glabrous, shining, 3 lines long. Capsule ovate, glabrous.

Small-learcd Weirmannia. Shrub.

\section{* * Leaves impari-pinnate.}

20 W. GLA'BRA (Lin. fil. suppl. p. 228.) leaves with many pairs of leaflets; leatlets obovate or oblong, crenated, rather pilose beneath; rachis with rhomboid joints; racemes loose. b. S. Native of the Islands of Santa Cruz and Martinique; and of Mexico, near San Salvador and Chiconquiera. Willd. spec. 2. p. 486. exclusive of the synonyme of Lam. W. pinnàta, Lin. spec, 1. p. 515. exclusive of the synonyme of Browne, jam. Flowers numerous, white.

Glabrous Weinmannia. Fl. May, June. Clt. 1815. Sh. $6 \mathrm{ft}$. 21 W. тRıсноsPE'rMa (Cav. icon. 6. p. 45. t. 567.) leaves with many pairs of leaflets; leaflets oblong, acutcly toothed, rather pilose beneath; joints of rachis exactly rhomboid. $h$. S. Native of the Island of San Carlos de Chiloe; and of Peru. W. dentàta, Ruiz et Pav. $\mathrm{f}$. per. 4. t. 394. f. c. W. pinnàta, Lin. and Cav. mss. Leaflets obliquely cuneated at the base, naked and shining above, but rather pilose on the nerves and veins beneath. Racemes loose. Capsule roundish-ovate, ribbed, glabrous. Hair-seeded Weinmannia. Shrub.

22 W. nírta (Swartz, prod. p. 69. f. ind. occid. 2. p. 691.) leares with 3 pairs of leaflets; leaflets elliptic, serrated, hairy beneath as well as the branches; joints of rachis cuneated. h.S. Native of Jamaica, St. Domingo, and Brazil. Windmánnia fruticòsa, \&c. Browne, jam. p. 212. Leaflets hairy, at length smoothish above, coriaccous. Racemes loose, very copious, 2 inches long.

Rough Weinmannia. Fl. May, Jul. Clt. 1820. Tr. 10 to $20 \mathrm{ft}$.

23 W. xítina (D. Don, in edinb. phil. journ. $\Lambda$ pril, 1830.) lcaves with usually 3 pairs of leaflets; leaflets obovate, crenated, glabrous, and shining on both surfaces; joints of rachis cuneated. $h . S$. Native of Jamaica. Weinmánnia hírta, var. Sinith, herb.

\section{Shining-leaved Weinmannia. Tree.}

24 W. glomera'ta (Presl, in reliq. Hænk. 2. p. 52.) leaves with 4-6 pairs of leaflets; leaflets oblong, obtuse, coriaceous, toothed towards the apex, bairy on the middle nerve beneath: terminal leaflet oblong-lanceolate, acute at both ends; wings of rachis semi-obovate; racemes spicate, longer than the leaves, and are as well as the branchlets and petioles very hairy; flowers glomerate, sessile; calyx smoothish; urccolus entire. h. G. Native of Peru, on the mountains.

Glomerate-flowered Weinmannia. Tree.

25 W. TIxcròuı (Smith, in Rees' cyel.) leaves with many pairs of leaflets; leaflets oblong, serrated, smoothish; joints of rachis spatulate; fascicles of racemes many-flowered. $\eta$. s. Native of the Island of Bourbon. W. glabra, Lam. dict. 7 . p. 578 . ill. t. 313. f. 1. W. macrostàchya, 1). C. prod. 1. 1. 10. The trce is called Tan rouge by the inhabitants of Bourbon, where it is used for dying red.

Dyers' Weinmannia. 'I'ree.

26 W. FAGAroides (H. B. et Kunth, nov, gen. anier. 6. p. 54. t. 52.1.) leaves with many pairs of leaflets; leafcts obovate or elliptic, crenated, glabrous on both surfaces, shining above; joints of rachis obcordate. $\zeta . S$. Native of Peru, at P'illao, and at Loxa. Branchlets with annular chinks, pubescent. Leaflets froin $5-15$, coriaceous, pilose on the joints beneatl, 3 lines long. Racemes 2 inches long; fascicles many-flowered. Capsule ovate-oblong, glabrous.

Fagara-like Weinmannia. Tree.

27 W. Parvifòla (Ruiz, mss. ex D. Don, in edinb. plil. journ. A pril, 1830.) leaves witl many pairs of leaflets; leaflets oblong, serrited, pilose beneath; joints of rachis obovate; racemes short. 々.S. Native of Peru, at Pillao, where it is commonly called Mucho and Arbol del Peregil by the inhabitants. W. microphýlla, liuiz et Pav. fl. per. 4.t. 334. f. a. Branchlets densely pilose. Leaflets from $9-15$, contiguous, naked and opaque above; 3.5 lines long. Racemes dense, cylindrical, hardly an inch long; fascicles many-flowered, crowded. Capsule roundish, ovate, glabrous.

Small-leaved Weimmannia. Tree.

28 W. Reticula'ta (Ruiz et Pav. fi. per, 4. t. 332.) leaves with many pairs of leaflets; leaflets elliptic, crenated, clothed with rusty tomentum beneath; joints of rachis obovate-oblong; fascicles of racemes crowded. $\zeta$. S. Native of Peru, at Pillao and Acomaya. W. pubéscens, Ruiz, mss. Branchlets densely clothed with rusty tomentum, usually with annular chinks. Leaflets $9-17$, pilose above and slining, reticulately veined, half an inch long. Racemes dense, cylindrical, 2 or 3 inches long; fascieles many-flowered, very pilose. Styles rather pilose at the base. Capsule ovate, smooth.

Reticulatcd-leaved Weinmannia. T'ree.

29 W. Lentiscifòlin (I’resl, in reliq. Hænk. 2. p. 52.) leaves with 3-5 pairs of leaflets ; leaflets oblong, obtuse, toothed, coriaceous, hairy on the nerves, racemes, and petioles: terminal one oblong-lanceolate, acuminated at both ends ; wings of petiole and rachis semi-obovate; flowers on long pedicels; segments of the calyx ciliated; urceolus angular and crenated. $h_{\text {. }}$ G. Native of Pern, on the mountains.

\section{Lentiscus-lecived Weinmannia. Tree.}

30 W. томелтòsa (Lin. fil. suppl. p. 277.) leaves with many pairs of leaflets; leaflets oval, with revolute margins, quite entire, clothed with hoary tomentum beneath; spikes cylindrical, much crowded. $\quad$. . S. Native of New Granada. H. B. et Kunth, nov. gen. amer. 6. p. 55. t. 525. Leaflets size of those of box leaves, 9-15, approximate, very blunt, convex and pubescent above, but at length green. Joints of rachis obovate, with revolute margins. Spikes cylindrical, obtuse, an inch long; fascicles many-flowered, much crowded; peduncles short, densely clothed with tomentum.

Tomentose Weinmannia. Tree.

31 W. ciNe'rea (Ruiz et Pav. 1. per. 4. t. 332. f. b.) leaves with usually 3 pairs of leaflets ; leaflets elliptic, serrated, reticulated, smoothish; joirts of rachis cuneate-oblong; racemes 
lonse. h.S. Native of Peru, in groves, at Pillan, where it is called Arbol del Peregil. W. sambúcuma, limiz, mss, W. diversifölia, Moricand, mss. ex 1). C. prod. 4. p) 10. Leaflets $7-9$, elliptic, coriaccous, stiff, an inch long. Peduncles very hairy. Racemes loose, $2-3$ inches long. Fascicles few-flowered. Capsule ovate, glabrous.

Cinereous Weinmannia. Tree.

32 W. subsessiliflòra (Ruiz et Pav. f. per. 4. t. 334. f. b.) leaves with many pairs of leaflets; leaflets oval or oblong, serrated, smoothish; spikes elongated, cylindrical; styles puberulous; capsule silky. $\zeta$. S. Native of Pern, on the Andes, at Pillao. W. polystàchya, Ruiz, mss. Ieaflets $11-15, \frac{1}{2}$ or 1 inch long, while young canescent on both surfaces. Joints of rachis obovate. Spike narrow, 3-4 inches long; fascicles crowded, many-flowered. Pedicels and calyxes silky.

Subsessile-flowercd Weinmannia. 'Tree.

33 W. HirTE'LLA (H. B. et Kunth, nov. gen. amer. 6. p. 56.) leaves with many pairs of leaflets; leaflets oblong, serrulated, pubescent beneath; racemes loose. h. S. Native of New Granada, near Santa Fe de Bogota. Branchlets tomentose. Leaflets 4-7 pairs, 8-9 lines long. Racemes loose, $2-8$ inches long. Ovarium ovate, glabrous.

Hairy Weinmannia. Tree.

34 IV. PUBE'scens (H. B. et Kunth, nov. gen. amer. 6. p. 56.) leaves with many pairs of leaflets; leaflets elliptic-oblong, serrated, pilose on both surfaces; capsule ovate, tomentose. In. S. Native of New Spain, on Mlount Avila, near Caraccas. Leaflets 4-6 pairs, 6-13 lines long. Racemes loose, 3-4 inches long.

Pubescent Weinmannia. Tree.

35 W. sorbiròla (H. B. et Kunth, l. c. p. 57.) leaves with usually 4 pairs of leaflets; leaflets oblong, acutish, serrated, rather pilose beneath; racemes loose ; ovaries glabrous. $h . \mathrm{S}$. Native of New Granada. Branclies glabrous. Leaflets oblong, acutish, glabrous above, 19-20 lines long and 6-7 broad, obliquely cuneated at the base. Racemes loose, 3-5 inches long: fascicles remote.

Sorbus-leaved Weinmannia. Tree.

36 W. CarIPE'xsis (H. B. et Kunth, l. c. p. 58.) leaves with usually 5 pairs of leaflets; leaflets oblong, bluntish, serrated, membranous, glabrous. $h$. s. Native of New Andalusia, near the convent of Caripe. Brarches pubescent. Leaflets 1015 lines long, and 4-5 broad, membranous. Racemes loose, $1-5$ inches long. Ovarium os'ate, glabrous.

Caripe Weinmannia. "Tree.

37 W. pozrpir'Lla (Moricand, mss. ex D. C. prod. 4. p. 11.) leaves with 8-12 pairs of leaflets; leaflets elliptic, obtuse, serrated, glabrous: onter one lanceolate; joints of rachis triangalar; branchlets, petioles, and the nerves on the under side of the leaves pilose; racemes exceeding the leaves. b.S. Native of Peru, near Guayaquil. Leaves 4 incles long ; leaflets 4.8 lines long, and $2-1$ lines broad.

Many-leated Weinmannia. Tree.

38 IV. pauliniferòta (Polıl, in litt.ex D. C. prod. 4. p. 11.) leaves glabrous, except the rachis, which is hairy; leaflets $7-9$, olilong, cuneated at the base, serrately toothed at the apex; joints of raclis oblong; racemes length of leaves. $h . \mathrm{S}$. $\mathrm{Na-}$ tive of Brazil.

Paullinia-learcl Weinmannia. Tree.

39 W. rone'cta (Moricand, mss. in D. C. jrosl. 4. p. 10.) leaves with 6-j pairs of leaflets; leaflets small, ovate, coarscly toothed, rather coriaceous, glabrous on both surfaces: onter one Congrated, acute, cuneated at the hase: joints of rachis scmiolowate; racenes dense, much longer than the lcaves, b.S. Nitive of l'eru. W. sessiliflòra, Pav. in herb. Moricand. Branclics pubescent. Extreme leaflet an inch and more long, the rest $4-5$ lines long, but the lower 2 are hardly 2 lines long. Flowers white. Pedicels length of flowers, and exceeding the bracteas.

Dramn-out-leaved Weinmannia. Tree.

Cult. The species of Weinmánnia will grow in any light rich soil; and cuttings will strike root in the same kind of soil, under a hand-glass, in heat. None of the species are worth cultivating for ornament.

II. LEIOSPE'RMUMI (from $\lambda \varepsilon เ o c$, leios, smooth, and $\sigma \pi \varepsilon \rho \mu a$, sperma, a seed; in reference to the seeds being smooth). D. Don, in edinb. phil. journ. april, 1830.-Weinnánnia, species of authors.

Lin. syst. Octándria, Digýnia. Calyx 4-cleft, deciduous. Petals 4. Stamens 8. Disk hypogynous, flat, entire. Styles 2. Capsule opening at the top at the dissepiments; cells manysecded. Seeds oblong, glabrous.-Trees, natives of New Zealand, with simple crenated leaves, jointed petioles, caducous stipulas, and racemose flowers; with the pedicels scattered, not in fascicles.

1 L. racemòsum (D. Don, l. c.) petioles jointed at the apex ; racemes usually solitary. $h_{c}$. G. Native of New Zealand. Weinmánnia racemòsa, Murr. syst. veg. p 376. Lin. suppl. p. 227. Leaves elliptic, beautifully veined beneath, 2-3 inches long. Racemes terminal, usually twin, 3-4 inches long.

Raccmose-flowered Leiospermum. Tree.

2 L. Parviflòrum (D. Don, l.c.) petioles jointed at the base; racemes corymbose. h.G. Native of New Zealand. Weinmánnia parviflòra, Forst. prod. p. 29. Leaves elliptic, recurved at the apex, an inch and a half long. Racemes numerous, $1 \frac{1}{2}$ or 2 inches long. Flowers 3 times smaller than those of the first species.

Snall-flonered Leiospernum. Tree.

Cult. For culture and propagation see Callicoma, p. 201. Not worth growing, unless in botanic gardens.

III. CALDCLU'VIA (named after Alexander Caldcleugh, F.R.S. F.L.S. who has collected and sent home many dried plants from Chili). D. Don, in edinb. phil. journ. A pril, 1830.-Dietérica, Ser. mss. in D. C. prod. 4. p. 8.

Lin. syst. Octándria, Dygúnia. Calyx membranous, 4-parted, deciduous. Petals 4, unguiculate. Stamens 8. Hypogynous g'ands 8 , alternating with the stamens; cells of ovariun many-ovulate, 20-30. Styles 2, rarely 3, thickish. Capsule opening from the top at the dissepiments; cells many seeded, usually 5-10. Placenta tetragonal. Seeds fusiform, glabrous ; testa larger than the nucleus, membranous, loose, elongated, and subarillate at the base. - A tree, native of Chili, with simple, serrated, glabrous leaves; jointless pedicels; $t$ win, subfalcate, toothed, caducous stipulas; terminal panicled flowers ; woody cap. sule, and the seeds nearly as in Philadélphus.

1 C. Pantcula'ra (D. Don, 1. c.) ケ. G. Native of Chili, near Talcahuano, and in moist places at Conception. Weinmánnia paniculàta, Cav. icon. 6. p. 44. t. 565. Weinm. corymbòsa, Ruiz et Pav. fl. per. 4. t. 330 . f. b. ined. Weinmánnia Chilénsis, D. C. prod. 4. p. 665 . Dietérica paniculàta, Scr. in D. C. prod. 4. p. 8 .

I'anicled-flowered Caldeluvia. Tree.

Cult. For culture and propagation see Callicoma, p. 201.

IV. PLATY'LOPHUS (from $\pi \lambda a \tau v s$, platys, broad, and

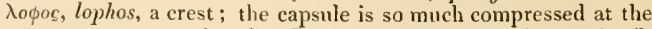
apex as to appear winged). D. Don, in edinb. phil. journ. April, 1830.-Wcimmánnia species of Lin.

Lin. syst. Octa-Dccándria, Digýnia. Calyx 4, but sometimes 5 -cleft, permanent. Petals 4 , rarely 5 , permanent, trifid; 
segments linear, acute, sometimes unidentate. Stamens 8 or 10 . Disk hypogynous, urceolate, entire; cells of ovarium biovulate. Styles very short. Capsule membranous, reticulated, flattened into a bifid wing at the apex, ventrieose at the base, 2 -celled ; cells 1 -seeded. Seed large, arched, with a smootl coriaceous testa.- In elegant tree, native of the Cape of Good Ilope. Leaves petiolate, ternate ; leaflets sessile, lanceolate, acuminated, sharply serrated, coriaccous, glabrous, reticulated with many reins. Flowers terminal, panicled.

1 l'. trifolin'tus (D. Don, l. c.) h. G. Native of the Cape of Good Hope, where the tree is ealled white ash by the English colonists. Weinmánnia trifoliàta, Lin. fil. suppl. 227. Thunb. prod. p. 77. exclusive of the synonyme of Lamark.

Trifoliatc Platylophus. Clt. 1820. Tree.

Cult. For culture and propagation see Callicoma, below.

V. CUNO'NIA (dedieated by Linnaeus to John Clrristian Cuno, of Amsterdam, who described his own garden in verse in 1750). Lin. gen. 556. ed. Schreb. 761. Juss. gen. p. \$10. Gartn. fruet. p. 344. t. 225. D. Don in edinb. plil. journ. 1830. A pril.-Ostes dýkia, Burm. afr. 259. t. 96.

Lis. syst. Decándria, Digýnia. Calyx 5-cleft; segments deciduous. Petals 5, entire. Stamens 10. Disk hypogynous, small. Capsule opening from the base at the dissepiments: cells many seeded. Seeds oblong, compressed, smooth, winged, with a rather loose membranous testa. Cotyledons somewhat foliaceous. - Smooth trees, with impari-pinnate leaves, serrated coriaceous leaflets, large caducous interpetiolar stipulas, and with the flowers disposed in axillary racemes or panicles.

1 C. CApe'vsis (Lin. spec, p. 569.) shrubby; leaflets 5-7, lanceolate, coriaceous, serrated ; racemes spicate, opposite; pedicels numerous, in fascieles. $h$. G. Native of the Cape of Good Hope. Lam. ill, t. 371. Lodd. bot. cab. t. 826. Flowers white.

Cape Cunonia. Fl. Aug. Clt. 1816. Shrub 6 feet.

2 C. I'vica (Blum. bijdr. p. 867.) slurubby; leaves somewhat ternately pinnate; leaflets ovate-oblong, acuminated, obliquely subcordate at the base, doubly serrated ; panicles axillary, clothed with rusty tomentum. 5. S. Native of Java, in wools on the higher mountains.

Indian Cunonia. Slırub 6 to 8 feet.

3 C. Celébiea (Blum. l.c.) arboreous; leaflets ovate-oblong, acuminated, serrated: lateral ones oblique at the base ; panieles corymbose, axillary. $h_{c}$. S. Native of the Celebes, on the mountains.

Celebes Cunonia. Tree 20 to 30 feet.

Cult. See Callicoma for eulture and propagation.

VI. ARNO'LDIA (named in memory of Joseph Arnold, M.D. who accompanied Sir Stamford Raffles to the East Indies, where he collected many plants; and the discoverer of the gigantic flower Raflèsia Arnóldi in the Island of Sumatra). Blım. bijdr. p. 868. D. C. prol. 4. p. 1\%.

Lis. srst. Octándria, Digýnia. Calyx 4-parted. Petals 4. Stamens 8 , interposed by glands. Orarium didymous, biovulate. Styles 2, incurved: stigmas simple. Carpels 2, connate at the base, solitary from abortion, beaked by the styles, 1seeded, opening lengtlwwise on the inside.-Indian slurubs, with opposite branches and leaves. Leaves impari-pinnate, glabrous. Stipulas interpetiolar, orbicular, deciduous. Racemes axillary and terminal, twin or tern.

1 A. Pıxi'ts (Blum, l. c.) leaves with $4-5$ pairs of laneeolate, bluntly serrated coriaceous leaflets; stipulas deciduous ; racemes usually twin. $h$. S. Native of Java, in mountain woods, where it is called Kiringit. Spira'a pinnàta, Blume, cat. lort. buit. p. 76 .

voL. III.
I'innale-]eaved Arnoldia. Shrub.

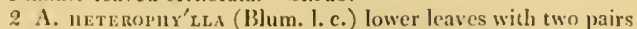
of leatlets, and an odd one : upper ones ternate or simple; leaflets lanceolate, clistautly serrulated; racemes twin or tern. $h$. S. Native of Java, in mountain woods in the province of Bamtam.

Fariable-leaved Arnoldia. Shrub.

Cult. l'or culture and propagation see Weinmánnia, p. 200.

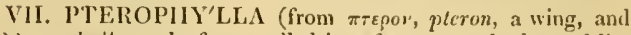
$\phi v \lambda \lambda o v$, phyllon, a leaf; so called in referenee to the large folia. ceous stipulas). D. Don, in ediub. phil. journ. A pril, 1830.

Lin. syst. Octándria, Digynia. Calyx 4-cleft, deciduous. Petals 4. Stamens 8. Styles 2 , very short, incurved. Ovariun 2-celled. Capsule?- $\boldsymbol{\Lambda}$ tree, native of the Moluecas. Icates impari-pinnate; leaflets lanceolate, bluntly acuminated, crenated, glabrous, glancous beneath, oblique at the base, 3 inches long: the odd or terminal one on a longer petiole than the othcrs. Stipulas large, foliaceous, reuform, quite entire, deciduous. Flowers minute, polygamous, in spicate racemes. Racemes erect, terminal, aggregate, rather panicled, a hand long. Ovarium densely clothed with wool.

l P. Fraxínea (D. Don, l. c.) h. S. Native of the Island of Honimao, one of the Moluceas. Weiumánnia? fraxínea, Sinitl, herb.

Ash-like Pterophylla. Tree.

Cult. Sce Heimmánnia, p. 200. for culture and propagation.

VIII. CALY'COMIS (from $\kappa a \lambda v \xi$, kalyx, a ealyx, and $\kappa \circ \mu \eta$, kome, hair; in allusion to the tufts of flowers). [R. Br. in gen. rem. p. 17. D. Don in edinb. phil. journ $\Lambda$ pril, 1830.

Lin. sist. Decándria, Digynia. Calyx 5-parted, permanent. Petals 5. Stamens 10. Disk hypogynous, very small. Styles setaceous. Capsule globose, 2-celled, opening at the apex ; cells many seeded. Seeds minute, smooth. - An Australian, erect, evergreen, branched shrub. Leaves simple, nearly' sessile, 3 in a whorl, oblongly cordate, acute, cuarsely serrated, coriaceous, glabrous, glaucous beneath. Stipulas peleaceous, permanent. Flowers small, white, copious, in whorles, pedicellate. Capsule membranous, gaping at the apex nearly as in Heuchèra.

1 C. verticilla'ta (D. Don, 1. c.) h. G. Native of New

Holland, among the mountains on moist rocks.

IVhorled-flowered Calycomis. Shrub.

Cult. For eulture and propagation see Callicoma.

IX. CALLI'COMA (from ka koc, kalos, heautiful, and ко $\mu$, kome, hair; appearance of tufted leads of flowers). Andr. bot. rep. t. 566 .

Lun. syst. Octo-Decáudria, Digýnia. Calyx 4-parted, rarely 5-parted (f. 37. a.), permanent. Petals wanting. Stamens 8, rarely 10 (f. 37. b.). Disk hypogynous, small. Ovarium distinct; cells many-ovulate. Styles 2 , setaceous (f. $37 . d$. .). Capsule iuclosed in the calyx, which is permanent, dehiscing at the dissepiuents; cells ventricose, 1-2-seeded from abortion. Seecis ovate, scabrous from minute papilla on every side, like those of Saxifruga; with a crustaceous testa.-T'rees, natives of Au:tralia. L.eaves simple, petiolate, serrated; petioles jointless. Stipulas membranous, bidentate, eaducous. I'lowers capitate; heads terminating the tops of the branchlets, pedunculate, globose.

I C. scrkatròlia (Andr. l, e.) Ieaves lanceolate, acuminated, hoary beneath, attenuated at the hase. $\eta$. G. Native of New Holland, where the tree is called black wattle by the English colonists. Delaun, herb. amat. t. 299. Sims, bot. mar. 1811. Còdia serratifólia, Ser. mss. ex 1. C. prod. 4. 1) $\%$ D d 
Flowers yellow. The twigs are used for making baskets in New Holland. Perhaps the flowers are dioecious. (f. 97 .)

Saw-leated Callicoma. Fl. May, Aug. Clt. 1793 . Shrub.

2 C. Ferrugínea (D. Don, in edinb. phil. journ. A pril, 1830.) leaves oblong, acute, cuneated at the base, clothed with rusty tomentum beneath, and on the brancblets. $h_{c}$. G. Native of New Holland, on the banks of rivers.

Rusty Callicoma. Shrub.

3 C. Billakdie'ri (D. Don, l.

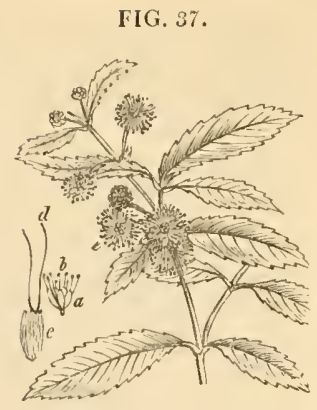

c.) leaves 3 in a whorl, nearly sessile, elliptic, retuse, erenulated, glabrous. h. G. Native of New Holland? Còdia montàna, Labill. mss. in herb. Lamb. La Billardier's Callicoma. Shrub.

Cult. A genus of very pretty shrubs; they will thrive well in a mixture of loam and peat; and ripened cuttings root readily in sand under a band-glass.

X. CERATOPE'TALUM (from kepac, keras, a horn, and $\pi \varepsilon \tau a \lambda o v$, petalon, a petal ; the petals are jagged so as to resemble a stag's horn). Smith, nov. holl. 1. p. 9. t. 3.

Lun. syst. Decándria, Digýnia. Calyx with a 5-parted permanent limb (f. 38. a.). Petals 5 (f. 3S.b.), linear, multifid, stiff, permanent, or wanting. Stamens 10 ; anthers cordate, terminated by a beak-formed process (f. 38. c.). Ovarium half inferior, 2-celled, few-ovulate. Capsule 1-seeded from abortion, dehiseing at the apex. Seed round, with a thick crustaceous testa.-Trees, natives of New Holland, with ternate or simple serrated glabrous leaves, standing on petioles, which are jointed at the apex. Stipulas undivided, rather foliaceous, caducous. Flowers terminal, panicled.

\section{* Leaves ternate; flowers with petals.}

1 C. Gummíferum (Smith, nov. holl. t. 3.) h. G. Native of New Holland, where it is ealled red gum-tree by the English colonists. (f. 38.)

Gum-bcaring Ceratopetalum. Clt. 1820. Tree 50 feet.

* Leaves simple; flowers apetalous.

2 C. APETALUM (D. Don, in edinb. plit. journ. April, 1830.) leaves lanceolate. 々.G. Native of New llolland. Ceratopétalum monopétalum, Caley, mss. Perhaps the flowers are sometimes furnished with one petal?

Apctalous Ceratopetalum. Tree.

3 C. montánum (D. Don, l. e.) leaves linear-lanceolate. G. Native of New Holland, on the mountains.

Mountain Ceratopetalum. Tree.

Cult. For culture and propagation see Callicoma above.

XI. SCHIZOME'RIA (from $\sigma \chi \iota \zeta \omega$, schizo, to eut, and $\mu \varepsilon \rho \iota$, meris, a part ; in reference to the cut petals). D. Non, in edinb. phil. journ. April, 1830. Lin. syst. Decándria, Digýnia. Calyx 5 -cleft, permanent.
Petals 5, jagged, deciduous. Stamens 10; anthers cordate, awnless. Ovarium superior, 2-celled; ovula many. Styles 2 , very short, recurved. Capsule baccate? closed at the apex. Seeds unknown.-A tree, native of New Holland. Leaves simple, petiolate, elliptic-oblong, acute, serrated, coriaceous, glabrous, with the veins numerous and reticulated beneath : petioles articulated at the base. Stipulas undivided, caducous. Flowers small, white, panicled. Paniele terminal, much branched. 1 S. ova'ta (1). Don, l. c.) h. G. Native of New Holland. Ceratopétalum ovàtum, Caley, mss.

Ovate-leaved Schizomeria. Clt. 1825. Shrub 8 to 10 feet.

Cuit. For culture and propagation see Callicoma above.

\section{Tribe II,}

CODIE E. Stamens definite. Ovarium inferior.

XII. CO'DIA (from $\kappa \omega \delta \varepsilon \iota x$, kodeia, a little ball, in reference to the flowers, which grow in little round heads). Forst. gen. p. 59. t. 50. Labill. sert. caled. p. 45. t. 46 .

Lin, srst. Octo-Decóndria, Digýnia. Calyx permanent, with a 4-5-parted limb. Petals 4-5. Stamens 8-10. Ovarium 2-celled? adhering to the tube of the calyx. Styles densely pubescent. Capsule closed at the apes, usually 1 -seeded from abortion. Seed roundish, smooth, with a bony testa; albumen very sparing; cotyledons rather foliaceous; radicle very short. -A shrub, with simple, elliptic, obtuse, quite entire, glabrous, coriaceous leaves; jointless petioles; caducous stipulas; and small, white, capitate flowers. Heads of flowers globose, pedunculate, axillary. Ovarium densely woolly. Stigmas simple, obtuse.

1 C. monta'na (Forst. gen. 1. c. icon. ined. t. 35. Labill. sert. l. c.). দ. G. Native of New Caledonia. Flowers yellow? Mountain Codia. Shrub 6 to 8 feet?

Cult. For culture and propagation see Callieoma above.

\section{Tribe III.}

BAUEREE (plants agreeing with Baucra in having indefinite stamens). Stamens indefinite. Ovarium distinct.

XIII. BELANGE'RA (in honour of - Belanger, Director of the Royal Garden at Pondicherry, who has travelled in many parts of Persia and India, where he collected a copious herbarium). Cambess. in St. Hil. f. bras. 2. p. 203.-Polystèmon, D. Don, in edinb. phil. journ. April, 1830.

LiN. srst. Icosándria, Diǵýnia. Calyx deeply 6-parted; segments reflexed, deciduous, valvate in astivation. Petals wanting. Stamens indefinite, disposed in many series; filaments subulate, glabrous ; anthers 2-celled, bursting lengthwise. Disk girding the base of the ovarium. Ovarium 2-celled; cells many-ovulate; ovula flattened, fixed to the middle of the dissepiment in 2 rows. Capsule superior, 2-celled, z-valved, 2beaked; valves at length bifid; cells many-seeded. Seeds compressed, ending in a wing at the apex.-Small, Brazilian trees, with opposite branches, and opposite stalked leaves. Leaves with 3 or 5 leaflets. Stipulas interpetiolar, foliaceous, deciduous. Flowers racemose; raeemes simple, axillary. Ovarium densely tomentose. Capsule coriaceous. Stamens erect in the bud.

1 B. GLA'BRA (Cambess. in St. Hil. fl. bras. 2. p. 204. t. 115.) leaves trifoliate; leaflets oblong, narrow at the base, serrated, glabrous; capsule smoothish. $h$. S. Native of Brazil, on Serra Negra, in the provinee of Minas Geraes.

Glabrous Belangera. 'Tree.

2 B. cunea'ta (Cambess. 1. c. p. 204.) leaves trifoliate; leaflets oblong-cuneated, sharply serrated, puberulous beneath ; capsule clothed with hairy tomentum: hairs rufescent. h.S. Native of Brazil, in the province of Minas Geraes. 
Cuncatc-leafletted Belangera. Tree.

S B. томехтòsa (Cambess. 1. c. p. 205. t. 116.) leaves trifoliate; leaflets oblong, acuminated, slarply serrated, tomentose beneath; capsule clothed with white tomentum. $h_{2} . \mathrm{S} . \mathrm{Na}$ tive of Brazil, in the province of Minas Geraes, near Tejuco, Barbacena, Sc., and near the town of St. Paul. Polystèmon triphýllus, D. Don, in edinb. phil. jourı. $\Lambda$ pril, ISs0.

Tomentose Belangera. 'Tree.

4 B. speciósa (Cambess. 1. c. p. 206. t. 117.) leaves of 5 leaflets; leaflets ovate-elliptic or lanceolate, acute, sharply serrated, glabrous. $\vdash$. S. Native of Brazil, in that part of the provinee of Minas Geraes called Minas Novas. Polystèmon pentaplíllus, D. Don, in edinb. phil. mag. April, 1830.

Bcauliful Belangera. Tree.

Cult. See H'cinmánnia, p. 200., for culture and propagation.

XIV. BAUERA (named in honour of Francis and Ferdinand Bauer, two celebrated German draughtsmen). Salisb. in ann. bot. p. 512. t. 10 .

Lin. syst. Icosándria, Trigýnia. Calyx 6-10-parted (f. 39. a.). Petals 6-10 (f. 39.e.). Stamens numerous, disposed in a double order; anthers peltate (f. $39 . d$.) ; cells connate, bursting lengthwise. Styles 2 (f. 39. b.), glabrous; stigmas simple, obtuse. Capsule superior, 2-celled, 2-valved, opening at the apex by a transverse chink; cells few-seeded; dissepiment placentiferous. Seeds oblong-cylindrical, erect, branched, leafy, roughish from resinous atoms. - Small shrubs, natives of New Holland. Leaves 6 in a whorl, approximating by threes, and therefore as it were opposite and ternate, exstipulate. Flowers rosaceous, axillary, solitary, pedunculate.

1 B. rubiafòlia (Salisb. in ann. bot. 1. p. 514. t. 10.) leaves lanceolate, crenated ; flowers polypetalous. h. G. Native of New Holland. B. rubioides, Andr. bot. rep. t. 198. Sims, bot. mag. 715. Vent. malm. t. 96. Calyx 8-10-cleft. Corolla S-10-petalled, pale red, or pink.

Rubia-leaved Bancra. Fl. Jul. Dec. Clt. $1793 . \quad$ Sh. 1 to $2 \mathrm{ft}$.

2 B. Hu'urrs (Sweet, hort. suburb. p. 124.) leaves oblong, crenated; flowers polypetalous. h. G. Native of New Holland. Lodd. bot. 1197. Calyx 8-10FIG. 39.

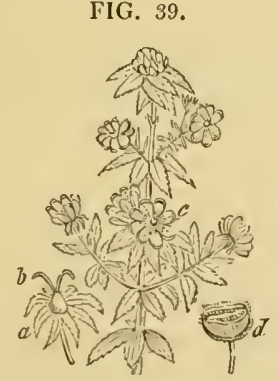

cleft. Corolla 8-10-petalled, red, one half smaller than those of $B$. rubice olia, and the plant is altogether much smaller.

Ilumble Bauera. Fl. July, Dec. Clt. 180\%. Shrub 1 foot.

3 B. Billardie'ri (D. Don, in edinb. phil. journ. $\Lambda$ pril, 1830.) leaves lanceolate, nearly quite entire; flowers with 6 petals. 々ุ. G. Native of Van Diemen's Land. B. rubioides, Labill. mss. Ilabit of the rest.

La Billardier's Bauera. Shrub 1 to 2 feet.

4. B. Mcrophy'Lla (Sieb. pl. exsic. nov. holl. no. 289. D. Don, in edinb. phil. journ. April, 1830.) leaves elliptic-oblong, quite entire; flowers with 6 petals. h.G. Native of New Holland. Leaves like those of Thijmus serpýllum. Flowers smaller than those of $B$. rubiafolia, red.

Small-leared Bauera. Shrub 1 to 2 feet.

5 B. capita'ta (Ser. mss. in D. C. prod. 4. p. 13.) Jeaves oblong, 3 -lobed at the apex; flowers terminal, capitate, sessile. দ. G. Native of New Holland, on the western coast.

Capitate-flowered Battera. Shrub.

Cult. The species of this genus are very pretty little slurubs, which flower nearly the whole year througlı; they are therefore very desirable plants for a greenhouse or conservatory. They are rather hardy, and easily cultivated. An equal mixture of sandy loam and peat is the best soil for them; and young cuttings root freely in the same kind of soil, under a bell glass.

\section{Tribe IV.}

SYMPHYO'GYNEE (from $\sigma v \mu \phi v \omega$, synphyo, to join, and

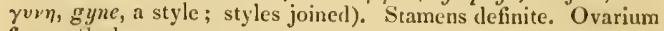
free. Styles connate.

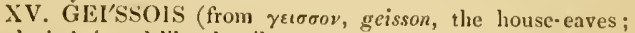
seeds imbricated like the tiles on a house). Labill. sert. cal. p. 50. t. 50 . I). Don, in edinb. plil. journ. April, 1830.

Lrn. syst. Octándria, Monogýnia. Calyx deciduous. Petals wanting. Stamens 8 . Style 1 , with the base remaining; stigmas 2, simple. Capsule compressed, 2-celled, 2-valved; cells many-seeded. Seeds compressed, winged, with a membranous testa. $-\boldsymbol{A}$ tree, with opposite, petiolate, quinate leaves; elliptic, obtuse, quite entire leaflets, which are pubescent beneath; oblong, ribhed, undivided, caducous stipulas; and axillary, many-flowered racemes, which are either solitary or by threes.

1 G. racemòsa (Labill. sert. caled. p. 50. t. 50.). 々 . G. Native of New Caledonia.

Racemose Geissois. Tree.

Cull. For culture and propagation see Callicoma, p 202.

Order CXXI. GALACI'N E (plants agreeing witl Galax in important characters). D. Don, in edinb. phil. journ. Oct. 1828.-Francoàceæ, Adr. de Juss. in ann. des scien. vol, 25. 1. 7 .

Calyx 4-5-parted, permanent. Petals 4-5, hypogynous, caducous, alternating with the calycine segments; stamens 8-10-16, liypogynous, joined into a tube, which is toothed at the apex, or distinet; filaments or alternate teeth antheriferous. Ovarium composed of 3 or 4 follicles, which are joined, therefore 3-4-celled; ovula indefinite ; stigma composed of $3-4$ joined ones, undivided or 4-lobed. Capsule 3-4-celled, 3-4-valved; valves bearing the dissepiments in the middle. Central placenta none. Seeds numerous, minute, scobiform, inserted in the inner angle of the cells ; outer testa loose, membranous, cellular: inner one very thin, closely adhering to the albumen. Albumen copious, fleshy. Embryo erect, terete, with short cotyledons, and a long cylindrical centripetal radicle.-Perennial American herbs. Lcaves radical, simple, lyrate, pinnatifid or serrated; the teeth tipped each by a gland. Flowers terminal, copions, disposed in spicate racemes; pedicels 1 -flowered, propped each by a permanent bracteole.

This order differs from Saxifragacea by the presence of sterile stamens, alternating with the fertile ones; in the absence of a central placenta; and in the frequent quaternary arrangement, in the parts of the calyx and corolla.

\section{Synopsis of the genera.}

$1 \mathrm{G}^{\prime}$ Lax. Calyx 5-parted. Petals 5. Stamens joined into a tube, which is 10-toothed: the alternate teeth antheriferous; anthers 1-celled. Stigma entire. Capsule 3-celled.

2 Fraxcòa. Calyx 4-parted. Petals 4. Stamens distinct, D d 2 
16, 8 of which are fertile; anthers 2-celled. Stigma 4-lobed. Capsule tetragonal, 4-celled.

9 Tetília. Calyx 4-parted. Petals 4, unequal. Stamens 8. Styles 2, very short. Capsule 2-celled.

I. GA'JAX (from $\gamma a \lambda a$, gala, milk; in reference to the whiteness of the flowers). Lin. gen. 276. Juss. gen. 420.Jlandfördia, Andr. bot. rep. t. 343.-Viticélla, Mitch, gen. 24.

Lis. syst. Pentándria, Monogýnia. Calyx 5-parted. Petals 5. Stamens joincd into a tube, which is 10 -toothed at the apex: the alternate teeth bearing anthers; anthers 1 -celled: cell transicrse. Stigna of 3 joined ones, therefore trigonal, 3-furrowed. Ovarium villous. Capsule 3-celled, destitute of any centra] column. Seeds mucronate at both ends, as in Acispora of De Candolle.-A small herbaccous plant; with radical cordate stiff crenated leaves; and naked scapes (f. 40.c.), bearing a loose, spicate raceme of small white flowers at the apex.

1 G. APIIY'LLA (Lin. spec. 289.). 2. H. Native of Virgrinia. Sims, bot. mag. 754 . Anonymus or Belvedere. Clayt. no. 4. Gron. virg. 25.-Blandfórdia cordàta, Andr. bot. rep. t. 343.

Leafless Galax. Fl. Ju. July. Clt. 1786 . Pl. $\frac{1}{3}$ to $\frac{1}{9}$ foot.

Cult. This is a pretty little plant ; succeeds best in peat soil, and if planted out in a moist situation, will grow and flower freely. lt is increased by dividing at the roots.

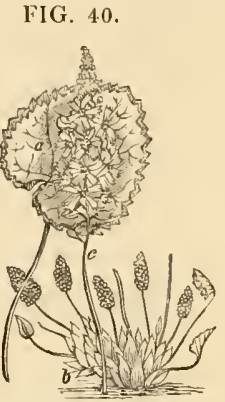

II. FRANCO'A (to the memory of F. Franco, M.D. of Valentia, a promoter of botany in the 16 th century). Cav. in ann. sc. nat. natr. 4. p. 237. icon. 4. p. 76. t. 596. D. Don, in edinb. phil. journ. Oct. 1826. Adr. de Juss. 1, c. p. 6.

Lın. sysr. Octándria, Tetragýnia. Calyx 4-parted. Petals 4 , spatulate, with their nerves pinnate and branched towards the aprex. Stamens 16 , only 8 of which are antheriferous, these are subulate or setaceous, and tapering at the apex; the 8 sterile ones are flattened, obtuse, slorter and broader; anthers cordate, 2-celled, 2-lobed at the base: cells confluent at the apex. Ovarium bluntly 4-sided, 4-celled, with \& furrows, which are opposite the dissepiments. Style very sliort, or wanting; stigma 4-lobed: lobes dilated, obtuse, and pruinose. Capsule tetragoual, having the angles drawn out a little at the apex into 4 tubercles, 4 -celled, 4-valved; cclls prominent, dehiscing by a longitudinal suture, many-sceded; dissepiments formed from a double lamina. Sceds ovate-oblong, fuscescent, smooth, mutic.-Perennial herbs, natives of Chili, beset with simple, deciduous hairs. Leaves lyrate, nearly like those of the turnip, reticulately veined; lobes roundish, toothed : terminal one large, cordate, obtuse, sinuately toothed; teeth terminated cach by a gland. Flowers red, terminal, copious, in spicate racemes, which are disposed in a panicle; pedicels 1-flowered.

1 F. APPEndicula'ta (Cav, in ann. sc. nat. matr. 4. p. 2i3. icon. 4. p. 76. t. 596.) stemless; leaves petiolate; racemes loose, secund; calycine segments lanceolate, acute; lobes of stigma cuncated, emarginate. 4. F. Native of the island of San Carlos de Chiloe. D. Don, in Sweet, fl. gard. new ser. $t$. 151.-Herb hairy. Leaves petiolate, lyrate. Scape nearly simple. Petals pale red, marked cach by a deeper spot in the middle. Fertile filaments 3 times longer tlaum the stcrile ones.
Appendiculated Francoa. Fl. Jul. Aug. Clt. 1830 . Pl. $2 \mathrm{ft}$ 2 F. sonchifóla (Cav. icon. 4 . in a note. D. Don, in edinb. phil. journ. Oct. 1826.) plant caulescent; leaves sessile; racemes loose, nodding; calycine segments dilated; petals with involute margius; stigmas elliptic, entire. 4 . F. Native of Clili. D. Don, in Sweet, fl. gard. new ser. t. 169. Pánke sonchifòlia, Willd. spec. 2. p. 487 . Herb hairy. Leaves sessile, lyrate, at length naked. Racemes nodding at the apex. Flowers secund, drooping. Flowers scarlet, marked with a deeper spot in the middle of each petal. Fertile filaments hardly 3 times longer than the more slender sterile ones.

Son-thistle-lcated Francoa. Fl. July, Aug. Clt. 1830. Pl. 2 to 3 feet.

3 F. RAmòs (D. Don, in edinb. phil. journ. Oct. 1826.) plant caulescent; leaves petiolate; racemes spicate, erect; calycine segments lanceolate, obtuse, nerveless; lobes of stigma cuneated. 4. F. Native of Chili, near Santiago. Herb erect, branched, hairy. Stem furnished with small, petiolate, simple, deeplytoother leaves. Radical leaves not seen, but they are probably lyrate. Flowers smaller and more numerous than in the rest of the species, neither are they secund, but disposed on every side of the racemes, erect; petals obovate, obtuse. Fertile filaments 4 times longer than the flattened, obtuse, sterile oncs. Style distinct, but very short; stigma 4-lobed; Jobes cuneated, emarginate, or 2-lobed, thick, with revolute margins.

Branched Francoa. Fl. Jul. Aug. Clt. 1831 . Pl. 2 to $3 \mathrm{ft}$.

Obs.-The Pantictinctoria of Molina belongs to a very distinct genus from Francòa.

Cult. The species of Francòa are beautiful plants when in flower, and deserve a place in every garden. A mixture of peat and sand is the best soil for them; they should be grown in pots, well drained with sherds, to prevent their rotting. The protection of a frame is sufficient for them in winter; or they may be planted out in the open ground, in a warm sheltered situation, where they will probably survive the winter by a little protection. They are only to be increased by seeds.

IIl. TETY'LLA (the Chili name of the plant). D. C. prod. 4. p. 667. Adr. de Juss. in ann. scienc. p. 7 .

Lin. syst. Octándria, Digýnia. Calyx 4-parted; lobes oval, equal. Petals 4 , the 2 superior ones roundish-ovate, large; the 2 inferior ones small, ollong. Stamens 8. Ovarium ovate, clothed with glandular pubescence. Styles :, very short, smoothish, slender. Capsule 2-celled, dehiscing at the apex at the disscpiments, many-seeded.-A smoothish slender herb. Radical leaves on long petioles, orbicular, profoundly cordate, with the recess closed, palmately 3-nerved, sinuately toothed; recesses broad, obıuse, mucronulate. Scape erect, naked, simple. Raccmes elongated; pedicels short, 1flowered, longer than the bracteas; larger petals cream-coloured, red at the base, smaller ones red.

1 T, hYDRocotylefòlia (I), C. 1, c.). 4. F. Native of Chili, at Concon, in the mountains of Leone, where it is called Tetilla by the natives.

Hodrocotyle-lcaved Tetilla. Pl. 1 to 2 feet.

Cult. This is a curious and beautiful plant. Its culture and propagation are the same as that recommended for the species of the genus I'rancò .

Order CXX11. SAXIFRAGA'CE无 (plants agreeing with Saxifraga in important characters). D. C. prod. 4. p. 1.Saxífragæ, Juss. gen. p. 308.-Saxifràgeæ, Vent. tabl. 3. p. 277. D. C. A. franc. 4. p. 358. 
Calyx either superior or inferior, of 4 or 5 sepals (f. 4 ?. $a$. f. 43. a.), which coliere more or less at their base. l'etals 5 ( $f$. 42. b. f. 4.5. d.) or wanting, inserted between the lobes of the calyx. Stanens 5-10, inserted either into the calyx or bencath the ovarium; therefore they are either perigynous or hypogynous ; anthers 2-celled, bursting lengthwise. Disk either hypogynous or perigynous, sometimes obsolete, sometimes annular and notched, rarely consisting of 5 scales, Ovarium inferior, or wearly superior, usually consisting of 2 or 5 carpels (f. $42 . d$. f. 46. e. f. 48 . e.) or follicles, coliering more or less on the inner side, but distinct at the apex; sometimes 2 -celled, witl a central placenta; sometimes 1-celled, with parietal placentas, rarely 4-5-celled. Styles none; stigmas sessile on the tips of the lobes of the ovarium (f. 42.e. f. 52.c.). Fruit generally a membranous 1-2-celled capsule, with 2 bracteas, rarely a 4-5celled 4-5-valved capsule, and sometimes a 4-celled berry. Seeds numerous, very minute, usually with long hexagonal reticulations on the side of a transparent testa. Embryo terete, in the axis of a fleshy albumen, with the radicle next the hylum.Slirubs or herbs, variable in habit. Leaves simple, either divided or entire, alternate, without stipulas. Flower-stems simple, often naked.

'Tlye plants of this order agree in some respects with the herbaeeous part of Rosècer, with which they agree in habit, and from which they differ in their polyspermous partially concrete earpella, albuminous seeds, and want of stipulas. From Cunoniacece they are divided by their habit, and by the want of stipulas. To Caryophýllece their habit allies them; but they differ in the insertion of their stamens, the situation of the embryo, and otherwise. Grossularièce agree very much in the structure of the flowers, but differ from them in the capsular fruit, usually 2-celled ovarium, in the seeds being without aril, furnished with a short podosperm, not gelatinous on the outside, and in the more fleshy albumen and habit. From Crassulàcece they differ in the fewer carpella, which are joined together, and usually with the calyx; and in having no glands on the inner side of the carpella. From $U_{\text {mbellif }}$ cree they are easily distinguished in the carpella or cells of the ovarium being dehiscent and many seeded, not indehiscent and $\mathbf{1}$-seeded, in the form of the petals, in the absence of vittæ, and in habit. From libirnea, to which the tribe $H_{y}$ drangece comes very near, in the fruit being capsular, not baccate, and in the styles being exserted, not wanting, \&c. From Iaccinièce, Campanulàcece, Ericca, Gentiance, in the corolla being polypetalous, not gamopetalous. 'The genus Drummóndia has the stamens equal in number to the petals, and opposite them; thus indicating some analogy to the inonopetalous Primulàcece.

According to De Canilolle the whole order is more or less astringent. The root of Heuchicra Americàna is a powerful astringent, whence it is called in North America alumroot, Barton, 2. p. 162. Otherwise they possess no known properties; for the old idea of their being lithontriptic appears to have been derived from their name, rather than their virtues.
Synopsis of the genera.

\section{Tribe I.}

SAXifra'geæ (plants agrecing with Sax'firaga in being herbaccous). I). C. prod. 4. p. 17.-Saxifrìgece, R. Br. gen, rem. exclusice of IIydrángece.

\section{$\$ 1$. Stamens twice the number of the petals or sepals.}

1 Saxífnaga. Calyx 5-parted (f. 41, a. f. 42, a.). Petals 5 (f. $4.1 . b$. f. $42 . b$. f. $46 . c$.), on slort claws, entire. Stamens 10 (f. 12. c. f. 46. d.). Capsule achate to the calys or free, composed of 2 carpella (f. 42.d.), which are usually joined even to the style, many secded (f. $42, f$ ).

2 Eriogr'nia. Calyx 5-cleft. Petals 5, hardly unguiculate. Stamens 20, monadelphous at the base. Ovaries 4-6, free, connected together by dense wool. Carpels distinct, 4-6, free from the calyx, many seeded.

3 Leptarrie'na. Calyx 5-parted (f. 47. a.). Pctals 5 (f. 47. b.), entire, on short claws. Stamens 10 ; anthers (f. $47 . c$.), 1-celled, 2-valved. Capsule composed of 2 carpels (f. 47.e.), which are joined at the base, many seeded.

4 Cirrysosple'num. Tube of ealyx adhering to the ovarium; limb 4-5-lobed. Petals wanting. Stamens 8-10. Styles 2. Capsule 2-valved and 2-beaked, at length 1-celled and many seeded.

5 Mitélea. Calyx 5-lobed. Petals 5, jagged or tootlied. Stamens 10. Styles 2, joined. Capsule 1-celled, 2-valved, many seeded.

6 TÉllma. Free part of the calyx inflated, 5-toothed (f: 49. b.), the adhering part conical. Petals 5 (f. 49. c.), jagged. Stamens 10 (f, 49, a.). Styles 2-3, distinet. Capsule (f. 4.9.f.), 1-celled, 2-valved at the apex.

7 Drumándia. Calyx with an obconical tube (f. 50. b.), and a 5-cleft limb. Petals 5 (f. 50. c.), pinnatifid. Stamens 5 . Stigmas 2, spreading, 2-lobed. Capsule 1-celled, 2-valved, many seeded (f. $50, d$.).

8 Tiarélla. Calyx 5-parted. Petals 5, unguiculate, entire. Stamens 10. Styles 2. Capsule 1-celled, 2-valved, adnate to the bottom of the calyx; valves unequal, dehiscing between the styles. Seeds numerous.

9 Astíl一e. Calyx deeply 4-5-parted, coloured. Petals wanting. Stamens 8-10. Styles 2 ; stigmas truncate. Capsule 2-celled, 2-beaked, many sceded.

\$2. Stamens equal in number to the petals, or fewer, and alternating with them.

10 Hevche'ra. Calyx 5-cleft (f. 51. b.). Petals 5 (f. $51 . a$.), undivided. Stamens 5. Styles 2 (f. 51. c.), very long, distinct. Capsule crowned by the dead flower, 1-celled, dehiscing betwces the styles $($ f. $51, d$.). Seeds rough.

11 Dona'tia. Tube of calyx turbinate; limb truncate, with 2 opposite acuminated triangular teeth. Petals 9 (8-10, Forst.), narrow. Stamens 3. Styles 3-5. Ovarium 2-3-celled; ovulit numerous. Fruit eapsular. 
12 Lepuropétalum. Calyx 5-parted. Petals 5, scaleformed. Stamens 5. Styles 3, somewhat concrete at the base. Capsule 1-celled, 3-valved at the apex, many secded.

13 VA'ulia. Limb of calyx 5-parted. Petals 5, spreading, unlivided. Stamens 5. Styles 2, eapitate at the apex. Capsule 1-celled, 2-valved at the apex, 5 -furrowed, crowned by the lobes of the calyx. Seeds consex on the ontside.

14. Cryptopétralum. Calyx turbinate, 5-eleft. Petals 5, minute, spatulate. Stamens 5. Styles 3. Capsule 1-celled, 8 -valved, opening at the cells in the free part, with a parietal placenta in the middle of each valve.

\section{T'RIBE II.}

Hrorange'玉 (plants agreeing with Hydrángea in being slirubby). D.C. prod. 4. p. 13.

15 Hydráxgea. Flowers usually of two forms, one fertile and hermaphrodite. Calyx globose, 10 -ribbed, rather truneate; limb 5-toothed. Petals 5. Stamens 10. Styles 2, distinct. Capsule 2-eelled, with bent-in valves, dehiseing by a hole between the styles.

16 Cornidis. Tube of calyx globose ; limb 4-toothed. Petals 4. Stamens 8. Styles 3-4, thick, fleshy. Fruit 4-celled, many secded.

17 Ciaxitrs. Limb of calyx 5-toothed. Petals 5, rather fleshy. Stamens 10. Styles 3-5; stigmas obtuse. Berry crowned by the teeth of the ealyx, somewliat $3-5$-celled, many seeded.

is Aра'ми. Limb of calyx with 5 short teeth. Petals 5. Stamens 10. Styles 5, ending in rather club-shaped 2-lobed stigmas. Berry crowned by the teeth of the calyx, somewhat 5-celled, many seeded.

19 Broussaísia. Calyx 5-parted, hemispherical, free from the ovarium. Petals 5, oblong, acuminated, with the acumen reflexed as in umbelliferous plants. Stamens 10, liypogynous. Orariun roundish, crowned by the short style and truncate stigma, 5-celled; eclls many seeded.

\section{Tribe I.}

SAXIFRA'GE E (plants agreeing with Saxifraga in being herbatceous). D. C. prod. 4. p. 17. Saxifràgex, R. Br. gen.

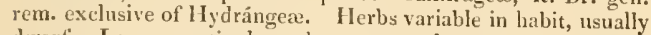
dwart. Leaves exstipulate, alternate, rarely opposite. Flowers disposed in racemes or panicles, rarely solitary, all fertile.

\section{\$1. Stamens twice the number of the petals and scpals.}

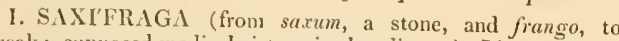
break; supposed medical virtues in that disease). Lin. gen. 764 . Juss. gen. p. 309. Lam. ill. t. 572. Gærtn. fruct. 1. p. 177. t. 36. D. Dun, in Lin. trans. Is. p. 341 . Sternb. enum. sax. et suppl. 1. Moretti, tent. sax. Gaudin, fl. helv. 3. p. 83. D. C. prod. 4. p. 17 .

Lin. syst. Decándria, Digýnia. Calyx 5-cleft (f. 4l. a. f. 12. u. 1. 46. a.). Petals 5 (f. $42 . b$. f. $46 . c$.), entire, unguiculate. Stamens 10 (f. 4.2. c. f. 16.d.); anthers 2 -eelled. Styles $\approx\left(\right.$ f. $\left.12 . c_{0}\right)$, permanent. Cajusule $($ f. 42. d.) 2 -celled, 2 -valved, 2-beaked, opening within the beak by an orbicular hole, many seeded. Seeds minute, smooth.

Sect. 1. Berge'Nia (in honour of Charles Aug. Bergen, author of Flora Francofurtana, in one vol. 8vo. 1750, and other botanical works). Moench, meth. 664. ex D. Don, in Lin. trans. 13. p. 343. Geryònia, Schrank, Tauch, and Sternb.-Eróplıeron, Tauch, hort. canal. fase. 1 . Megàsea, Haw. enum. sax. 6 . Caly x campanulate, 5-parted, wrinkled on the outside; segments conniving. Petals unguiculated, inserted in the calyx. Stamens inserted in the throat of the calyx; filaments subulate; anthers roundish. Styles hollow inside, full of seeds, joined at the base, at length turgid, and clianging into a profoundly bipartite capsule; stigmas semiglobose, glabrous; seeds cylindrical.-Perennial herbs, with thick woody roots. Leaves large, fleshy. Petioles furnished by entire membranous stipulas along both sides at the base. Flowers red, disposed in thyrsoid panicles.

I S. crassifòla (Lin. spec. 573.) leaves oval or obovate, very blunt, glabrous, serrulated; petals elliptic-oblong. h. H. Native of Siberia, on the Alps. Curt. bot. mag. 196. Gmel. f. sib. 4. p. 166. t. 56. Megàsea crassifolia, Haw. enum. sax. p. 6. Flowers large, red. The root is stiptic or astringent when chewed.

Var. $\beta$, IIaworthiàna (Ser. in D. C. prod. 4. p. 36.) leaves somewhat orbicularly cordate, flat, hardly crenated. $\psi$ \&. H. Native of Siberia. Megàsea mèdia, Haw. enum. sax. 7.

Thick-leaved Saxifraga. Fl. March, May. Clt. 1765. Pl. $1 \mathrm{ft}$.

2 S. cordifòlia (Haw. mise. nat. 157.) leaves orbicularly cordate, serrated, glabrous; petals roundish. 24. H. Native of Siberia, on the Alps. Megàsea cordifòlia, Haw. enum. sax. 7. Flowers large, red.

Heart-leaved Saxifraga. Fl. March, May. Clt. 1779. Pl. 1 ft.

3 S. Lugula'ta (Wall. in asiat. res. 13. p. 398. with a figure) leaves obovate, subcordate, denticulated, quite glabrous on both surfaces, but eiliated on the margins; panicle dichotomous; petals broad, orbicular. 2. F. Native of Nipaul, and the east of Bengal, on the alps. Lodd. bot. cab. 747. Sweet, fi. gard. t. 59. S. Pacúmbis, Buch. mss. Megàsea ciliàta, Haw. enum. sax. 7. Flowers very pale red, almost white.

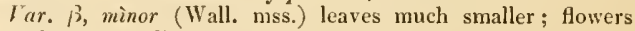
more loose, and distant.

Ligulate-leaved Saxifrage. Fl. Mar. May. Clt. 1821. Pl. $1 \mathrm{ft}$.

Sect. II. Gynópera (from $\gamma v v \eta$, gyne, a style, in botanical language, and $\pi \varepsilon \rho a$, pera, beyond; in reference to the styles being above the stamens). Diptera, Borkh. ex Tauseh, l. c. Auláxis, Haw. syn. sax. p. 46. Hydática, Tausch, hort. can. Neck. elem. 2. p. 387. Robertsònia, Haw. syn. succ. p. 311. enum. sax. p. 52. Calyx 5-leaved, reflexed. Petals hypogynous, sessile. Stamens hypogynous; filaments clavate; anthers kidney-sliaped. Styles comniving; stigmas simple, beardless. Capsule roundish, naked. Seeds spherieal.-Perennial tufted herbs, furnished with short surculi. Leaves fleshy, undivided, for the most part cartilaginously serrated. Scapes erect, branched. Flowers small, panicled, rose-coloured or white, dotted.

4. S. GE'UM ( $\mathrm{Lin}$. spec. 574.) leaves reniform, crenated, pilose on both surfaces, adult ones crowded and spreading; petioles very long, nearly terete, villous; calycine segments ovate, obtuse. 4 . H. Native of Siberia, Switzerland: and the liills in Irelaud, especially on a mountain, near Dingle, in the county of Kerry. Sterub. rev. sax. p. 15. Lapeyr. fl. pyr. t. 24. Smitl, engl. bot. 1561. S. punctàta, Sternb. sax. p. 18. S. umbròsa punctàta, Smith, engl. fl. 1. p. 263. Sax. liirsùta $\beta$, gèım, Arnott et Ser. in D. C. prod. 4. p. 42. Robertsonia gèım, Haw. enum. sax. p. 53.-Gmel. sib. 3. p. 161. t. 65. 1. 1. 
Petals white or pale red, furnished at the base with red and yellow spots.

Far. $\beta$, dentàta (I Iaw, enum. sax. p. 53.) leaves reniform, round, crenately toothed; petals marked with yellow and red dots. 24. H. Native on the mountains of Ireland. Robertsònia dentàta, Haw. syu. p. 323. Sax. dentàta, Loud. hort. brit. p. 176.

lar. $\gamma$, erenàta (Haw. l. c.) hairy; leaves reniform, round, bluntly crenated. $\psi$. I], Robertsònia crenàta, llaw.l. c. S. crenàta, Lond. hort. brit. p. 53.

Jar. $\hat{c}$, polita (Haw. l. c.) Jairy ; leaves reniform, roundish, sluarply toothed, with the surface naked and smooth. 2\%. H. Native on the mountains of Ireland. Robertsonia polìta, Haw. l. c. S. polìta, Loud. hort. brit. p. 176 .

Geum Saxifrage. Fl, May, July. Ireland, Pl. I foot.

5 S. 111Rsu'TA (Lin. spec. 574.) leaves oval, acutely serrated, rounded at the base or cordate, pilose on botls surfaces, when adult erect; petioles very long, nearly terete, villous ; pedicels clongated, 1-flowercd. 24. H. Native of the I'yrenees and Ircland, on moist rocks; in Ireland on mountains in the county of Kerry. Lapeyr. fl. pyr. sax. p. 45. t. 23. Smith, engl. bot. 2322. Sternb. sax. p. 14. Robertsòna hirsùta, Haw. enum. sax. p. 54. Petals white, furnished with numerous red and yellow dots. S. hirsìta, var. $a$, serràta, Arnott, in D. C. prod. 4. p. 42. S. élegans and S. gracilis, Mack. ex Hook, in litt. S. polita, Lirk. et Hort.

lar. $\beta$; leaves roundish, cordate, glabrous on both surfaces.

Iar. $\gamma$, spharoidca (Haw. enum. sax. p. 54.) leaves broadly oral, somewhat cordate, bluntly crenated, with the surface naked. 24. H. Native of the Pyrenees. Robertsonia sphæroídea, Haw. syn. \$22. S. sphæroídea, Loud. lıort. brit. 176 .

Hairy Saxifrage. Fl. May, June. Ireland. Pl. $\frac{1}{2}$ to $1 \mathrm{ft}$.

6 S. usrròsa (Lin. spec. p. 57 t.) leaves obovate, retuse, cartilaginously crenated, quite glabrous, crowded and spreading in the adult state; petioles short, compressedly dilated; pedicels few-flowered. 4 . H. Native of the Pyrenees and Ireland, in the clefts of rocks and on the mountains. In several parts of Ireland; plentiful on a mountain called the Mangeston, county of Kerry; on the mountains of Sligo; on Croagh Patrick, near the Lake of Killarney, in great abundance; in Thorp Arcl, woods, near Wetherby, Yorkshire; betwixt Arncliffe and Horton, in Craven. Mill. fig. 141. f. 2. Lapeyr. pyr. sax. p. 44. t. 22. Smith, engl. bot. 633. Sternb. sax. p. 14. Robertsònia umbròsa, brévipes, et lóngipes, Haw. sax. p. 55. S. spatulàris, Brot. fl. his. 2. p. 172. Petals oval, of a reddish white colour, full of scarlet and yellow dots, with 3 conspicuous branched nerves. The plant is very variable in habit.

Far. $\beta$, punctàta (D. Don, in Lin. trans. 13. p. 352.) leaves roundish, sharply serrated: adult ones erect; petioles longer. 4. H. Native of Siberia and Ireland, on the mountains; also of Kotzebue's Sound. S. punctata, Lin. spec. p. 574. Sternb. suppl. f. 1. S. gràcilis, Step. in Sternb. sax. suppl. ]. p. 5. t. 5. but not of Schleich. S. gèum, herb. Patrin. S. senidecándra, Worsm. and S. restivàlis, ex Fisch. in litt. Robertsònia punctàta, Haw. enum. sax. p. 55.-Gmel. sib. 4. p. 161. no. 71. t. 66 .

Var. $\gamma$, serratifólia (D. Don, in Lin. trans. 13. p. 352.) leaves oblong-ovate, deeply serrated : adult ones erect; petioles longer. 4. H. Native of Jreland, on the mountains. S. serratif òlia, Mackay, in lit. Robertsònia punctàta $\beta$, serràti, Haw. enum. sax. p. 55 .

Shady Saxifrage, None-so-pretty, or London-pride. Fl. April, June. Ireland. Pl. $\frac{1}{2}$ to 1 foot.

7 S. cunelrodia (Lin. spec. p. 574.) leaves cuneiform, repandly crenated, glabrous : adult ones crowded, spreading; petioles linear, very narrow, naked; calycine segments oblong, acute; petals spatulate. $\boldsymbol{4}$. IH. Native of the Pyrenees, $A l_{j}$ s of Switzcrlaud, Styria, Jungary, and Norway. Scop. carn. t. 3. Schmicd. fase. t. 12. 10. 37. Waldst. et Kit. hung. 1. p. 43. t. 4\%. Sternb. sax. p. I\%. S. punctàta, Gunn. fl. norv. no. 1076 . act. hafn. 10 . p. 445. t. 3. f. $10 .-$ Gesn. fasc. 19. t. 12. f. 37 . Morretti, tent. sax. p. 31 . Gaudin, fl. helv. 3. j. 97. Robertsonia cuneifolia, II aw. cuum. sax. p. $56 . \$$. cuneifòlia diversifòlia, Ser. in Meisn. anz. 1818. p. 73. Plant tufted. Petals spatulate, furnished with a solitary yellow spot.

Iar. $\beta$, Davùrica (D. Don, in Lin. trans. 13. p. 354.) leaves opaque, toothed; flowers larger. 4 . H. Native of Sibcria. S. Davùrica, IJort. but not of Willd. Robertsonia Dauricit, Haw, enum, sax. p. 56.

Wedge-leaved Saxifrage. Fl. May, June. Clt. 1768. Pl. $\frac{1}{6}$ to $\frac{1}{2}$ foot.

8 S. PAucrfò̀ra (Sternb. rev. sax. suppl. 1. p. 6. t. 4. f. 2.) root tufted; leaves roundish or ovate-roundish, tootlicd, cuneated at the base, running down the petiole, which is short; petals ovate, unguiculate, longer than the calyx. 24. IJ. Native of Siberia and Kamtschatka. Petals spotted.

Fen-flowered Saxifrage. Pl. $\frac{1}{2}$ foot.

9 S. spich'tA (D. Don, in Lin. trans. 13. p. 3.54.) leaves on long petioles, orbicularly cordate, sharply serrated, veiny, pilose; petioles dilated at the base; raceme elongated, spike-formed calycine segments very short. 4 . H. Native of Sledge Island, on the west coast of Amcrica. S. gèum, Pursh, f. amer. sept. 1. p. 311 . but not of Lin. Plant tufted. Petals elliptic-olslong, dotted, S-nerved, with the nerves branclied.

Spike-flowered Saxifrage. Pl. 1 foot.

10 S. Nelsonia'Na (D. Don, in Lin. trans. 13. p. 355.) leaves orbicularly-cordate, somewhat peltate, deeply serrated; petioles very long, filiform; thyrse ovate. $4 . \mathrm{H}$. Native of the northwest coast of America, at Cape Newnlam, and at Kotzebue: Sound. Hook. et Arn. in Beech, bot. p. 124. t. 29. Flowers on short pedicels; petals oval, white, dotless; filaments white. $A$ beautiful species.

Nclson's Saxifrage. Pl. $\frac{1}{2}$ to 1 foot.

11 S. Argu'ta (D. Don, in Lin. trans. 13. p. 356.) leaves roundish-reniform, deeply serrated, glabrous; petioles filiform: scape slender, smooth; calycine segments oblong, acute. $4 . \mathrm{H}$. Native of the western coast of America. Flowers white, size of those of $S$. stellàris.

Sharp-cul-leaved Saxifrage. Pl, $\frac{1}{2}$ foot.

12 S. STELLA'RIS (Lin. spec. p. 572.) leaves aggregate, rhonboid-ovate, sessile, acutely toothed, but narrowed, and quite entire at the base; petals ovate, acute, equal, unguiculate; scape nearly simple. 4 . H. Native on most of the mountains of Scotland, north of England, and nearly throughout the whole of Europe, Siberia, and the western coast of America, on wet shady rocks, and by the sides of rivulets. Fl. dan. t. 23. Jacq. coll. 1. p. 202. t. 13. Scop. carn. 1. p. 292. t. 13. Smitl. engl. bot. t. 167. Sternb. sax. p. 1]. S. Nootkàna, Moc. icon. ined. t. 422. Spatulària stellaris, Haw. enum. sax. p. 19. Petals white, elegantly 3-nerred, furnished with 2 yellow spots at the base.

Kar. $\beta$, elàta (D. Don, in Lin. trans. 13. p. 357.) scapes numerous, a foot ligh. 2 . H. Native of Siberia.

Var. $\gamma$, angustifolia (D. Don, 1. c.) leaves narrower aud longer, with few tceth at the apex. 4. H. Native of Siberia. Var. $\delta$, Schleichèri (D. Don, l. c.) leaves obovate, repandly crenated; scapes humble, flexuous. 4 . H. Native of Switzerland, on the $\mathrm{Al}_{\mathrm{p}} \mathrm{s}$. S. stellàris, Schleiclı, in litt.

Var. , Bellárdi (D. Don, l. c.) plant stemless; leaves roundisl, repand; flowers sessile. $4 . H$. Native of the Alps of Piedmont. S. Bellárdi, Allion. pedem. no. 1536. t. 88 . f. J. 
lar. $\zeta$, dissimilis, leaves with deep broad teeth. 4. H. Nalive of Scotland, on the western Highlands. S. dissimilis, G. $\mathrm{Don}$, in Loud. lhort. brit. p. 176.

lar. $\eta$, uniflòra (D. C. fi. fr. 4. p. 379. var. a.) plant very minute; scapes l-flowered. 2 . H. Native of Switzerland, on the Alps. S. stellàris 3 , pùmila, Gaudin, fl. helv. 3. p. 100.

l'ar. \&, acaúlis (Hall. fil. in Meisn. anz. 1818, p. 76) flowers sessile, in the heart of the leaves. 2 . H.

Stairy Saxifrage. Fl. June, Jul. Scotland. Pl. $\frac{1}{4}$ foot.

13 S. Foliolòsa (R. Br. in Parry's lst voy. app. p. 275.) radical leaves cuneated, a littletoothed; seape divided : branches bearing 1 flower at the apex, covered below by a fiscicle of small leaves; calyx inferior, obovate; segments of the petals cordate-lanceolate. 4 . H. Native of Lapland, Melville Island, and other aretic islands. S. stellàris $\gamma$, Lin. A. lapp. ed Smith, p. 144. t. 2. f. 3. S. stellàris $\beta$, comòsa, Willd. spee. 2. p. $64 \%$,

Leafy Saxifrage. Pl. $\frac{1}{4}$ foot.

14. S. leveanthemifolia (Michx. fl. bor. amer. 1. p. 260.) clothed with elammy pubescence; leaves crowded, lanceolatecuncated, acutely and coarsely toothed, quite entire at the base; scape much branched, diffuse; petals ovate, acute, unguiculate : 3 outer ones the largest. 4. H. Native of the Pyrenees; and of North America, in Belıring's Straits, Nootka Sound, on the Rocky Mountains, and at l'ortage, near the source of the Columbia. Lapeyr. pyr. sax. p. 49. t. 25. Hook, in bot. mag. 2959. S. Clùsii, Gonan. ill. p. 28. exclusise of the synonymes. Ser. in D. C. prod. 4. p. 40. S. forruginea, Graham in edinb. phil. journ. 1828. p. 34.8. Spatulària Clisiij and S. leucanthemifolia, Haw. enum. sax. p. 48. Petals white: 3 outer ones the largest, and with 2 spots at the hase: the 2 inner ones much smaller and spotless.

lar. $\beta$; plant clothed with pubeseent tomentum. 2 4. H. Native of the north-west coast of America, on Dundas Island, in Queen Charlotte's Sound.

Lcucanthemum-leaved Saxifrage. Fl. June. Clt, 1812. Pl. 1 to $\frac{3}{4}$ foot.

15 s. melalev'ca (Fisch. in Stemb. rev. sax. suppl. 3. t. 3.) leaves roundish ovate, acutish, somewhat denticulated, tapering into the petiole, glabrous; seape few-flowered, also glabrous; flowers disposed in a somewhat panicled corymb ; calycine segments ovate, acute; petals unguiculate. 24. H. Native of Aitaia, on the Alps at the river Tschulyschm, and at Lake Teletskoje Osero. \$. elongàta $\beta$, glabra, Sterub. rev. sax. p. 9. P'etals obovate, pale sulphur coloured, suffused with violet on the outside; filaments of a pale violet colour. Leaves greenish yellow ; upper part of plant of a deep violet colour.

Blacle and white Saxifrage. PI. $\frac{1}{2}$ to $\frac{3}{4}$ foot.

$16 \mathrm{~s}$. strigós (Wall. cat. no. 448 .) lower leaves sessile, somewhat rosulate, oblong-lanceolate, few-toothed, mucronate at the apex, clothed wih strigose hairs; cauline leaves lanceolatelincir, acute, entire, much smaller than the lower ones; stem simple, fen-flowered, and is as well as the pedicels beser with numcrous capitate lairs; sepals lanceolate, acute; petals 3-nerved, obtuse; styles very short; stigmas thickisl. 24. H. Native of Nijaul, on the Emodi mountains at Gosainsthan, and at Kamoon. Iares almost the size and form of those of frabis alpina. Filaments flat.

Strigose Saxifrage. Pl. $\frac{1}{2}$ foot.

I7 S. SARMENTósa (Lin. fil. suppl. p. 240.) stolous or yunners ereching; leaves orbicularly cordate, lolyately erenated, pilose, red beneath: petals unguiculate, the 2 outer ones large and flaccid. 4. F. Native of China and Japan, in moist places on mountains, among stones. Schreb. mon. dion. p. 16. t. 2. f. 3 . Curt. bot. mag. 92. S. stolonifera, Jacr. icon. rur. 1. t. 80 . Ligulària samentosa, Duval, pl. sec. p. 11. ex Haw. enum. sax.
1. 50. Díptera sarmentòsa, Borkh. in Rœm. mag. 1. p. 29. S. ligulàta, Murr. comm. 1781. p.26. t. 1. S. Chinénsis, Lour. cocl. p. 281. Petals white: 3 inner ones cordate; of these 3 the lateral ones are marked by a yellow spot at the base; and the central one by 2 scarlet sjots at the base : but the 2 outer petals are large, flaccid, and 3-nerved.

Yar. $\beta$, euscutafórmis (Ser. in D. C. prod. 4. p. 43.) plant much smaller; stem usually 3 -flowered; leaves ovate-roundish, coarsely and simply toothed; flowers less irregular; petals more acute. 4 . F. Native of Clina. S. cuscutæfórmis, Lodd. bot. cab. t. 186. Ligulària minor, Haw. enum, sax. p. 151. T'lie stolons or runners resemble dodder very much.

Creeping Saxifrage. Fl. June, July. Clt. $1771 ; \beta 1815$. Pl. $\frac{3}{4}$ foot.

18 S. ERòsa (Purshl, fl. amer. sept. 1. p. 311.) leaves lanceolate, acute, glabrous, runcinately serrated; panicle divaricate, pyramidal ; pedicels elongated, l-flowered; petals oblong-oval, obtuse, unguiculate. 24. H. Native of Carolina, on the higher mountains, in stony rivulets. S. Caroliniàua, gràeilis, and eròsa, Schleich. cat. 1821 . p. 63. Robertsònia micranthifòlia, Haw. syn. suce. 322. Auláxis mieranthif òtia, Haw. emun. sax. 1. 47. Petals white, 3-nerved, with a yellow spot at the base.

$\operatorname{rar} \beta$; leaves hairy.

Erose-leaved Sasifrage. Fl. May, Ju. Clt. 1812. Pl. 1 to $1 \frac{1}{2} \mathrm{ft}$.

19 S.? Nu’dA (Haw. enum. sax. 1. 47. under Auláxis) leaves naked, doubly and deeply toothed. 4 . H. Native country unknown.

Nakel-leaved Saxifrage. Fl. May, Ju. Clt. ? Pl. $\frac{1}{2}$ to $1 \mathrm{ft}$.

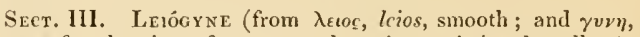
gyne, a female; in reference to the stigmas being beardless). 1). Don, in Lin. trans. 13. p. 34. Calyx deeply 5-cleft (f. 41. a.). Petals (f. 41.b.) sessile in most of the species. Stamens inserted in the throat of the calyx (f. 41.c.); filaments subulate. Styles straight; stignas orbicular, flattisl, beardless. Capsule free from the calys $(\boldsymbol{f}, 41, \boldsymbol{d}$.). Seeds roundish. - Humble herbs, rarely subshrubs. Roots fibrous, but in many of the species they are granular. Stents flexious, usually many-flowered and many-leaved. Leaves in all reniform and lobed. Flowers white or yellow.

20 S. ROTUNDIFóla (Lin. spec. p. 576.) leaves reniform, unequally and coarsely toothed: cauline ones petiolate; petals lanceolate, acute. 4 . H. Native of Austria, Switzerland, and Siberia. Mill. fig. t. 141. Curt. bot. mag. t. 424. Lapeyr. pyr. sax. t. 26. Micropétalum rotundifolium, Haw. enum. sax. p. 16-17. Petals white, marked witl scarlet dots, 3-nerved. Far. $\beta$, repánda (D. Don, in Lin. trans. 13. p. 361.) plant larger and more robust; leaves broader. 4 . H. Native of the $A$ lps of Caucasus. S. repánda, Sternb. rev. sax.p. 17. t. 5 . S. rotundifòlia, Bieb. fl. taur. 1. 1.315. Micropétalum màjus, Haw, enum. sax. p. 17.

Riound-leaved Saxifrage, Fl. May, Ju. Clt. 1596. Pl. $1 \mathrm{ft}$. 21 S. ну' вRIDA (Sternb. sax. p. 17. t. 8. f. 3.) radical leaves petiolate, roundish-cuneated, crenated : cauline ones minute, entire; stem panicled. 24. H. Native of the Pyrenees. Very like S. rolundifotia, but differs in the smaller statme and slenderer habit; in the leaves being acute at the base, not cordate, and in the cauline ones being minute, entire, and nearly sessile.

IIybrid Saxifrage. Pl. I foot.

22 S. Diversifòlia (Wall. cat. no. 4.52.) leaves thickish, more or less pilose, of many forms; lower ones cordate, petiolate: cauline ones petiolate, or sessile and stcm-clasping, entire, of a different colour beneath, reticulately veined, marked above by small depressed dots; flowers in panicled corymbs; bracteas and calyxes more or less ciliated with short, capitate 
hairs; pedicels beset with glandular hairs. $\mathcal{\psi}$. F. Native of Nipaul, in Enodi, Gosaingsthan and Kamaon. Root fibrous. Stem firm, leafy. Calycine lobes spreading. Jetals obovate, yellow, 5-nerved. Styles diverging at maturity. Stigmas thick.

Var, a, lanccolàta (Ser. in 10. C. prod. 4. p. 44.) leaves lanceolate: lower ones not scen : but the iniddle ones are attenuated at the base, and aeutish; calycine lobes oblong, beset with glan. dular hairs. 2. F. S. diversifòlia, Wall.

Var. $\beta$, parnassifolia (Ser. I. c.) radical leaves cordate, obtuse, on long petioles: cauline ones cordate, stem-clasping, obtuse; calycine lobes oblong, beset with glandular pili. $4 . F, S$. parnassif olia, Wall. cat. no. 451 .

Var. $\gamma$, Moorcroftiana (Ser. I. c.) lower lcaves elliptic: cauline ones stent-clasping, ovate-oblong, numerous; flwers larger; calyeine lobes more eiliated with glands. 2. F. S. Moorcroftiàna, Wall. cat. no. 4.53 .

Diverse-lcavcl Saxifrage. Pl. 1 foot.

23 S. parvirlòra (Biv. stirp. rar. fasc. 4. p. 1. t. 3.) stem branched at the basc, or simple; leaves reniform, 5-lobed: superior ones 3-lobed: uppermost ones entire, lanceolate ; peduncles spreading, opposite the leaves; petals obovate, longer than the ealyx. $\%$. F. Native of Sicily, in the mountains, on mossy rocks.-Cup. panpl. 3. t. 36. Flowers white, almost like those of Stcllària mèdia. Styles very sliort, diverging; stigmas spatulate, papillose. Capsule bladdery, slender.

Far. a, ramòsa (Ser. in D. C. prod, 4. p. 44.) stem branclied at the base, few-flowered; lower leaves 5-lobed, crenated: superior ones 3-lobed. 4 . F. Native among rocks, on Mount Maronis, near the monastery of St. Martini de Scalis. Bernardi, l. c. t. 3 .

Var. $\beta$, Bocconiàna (Ser. 1. c.) stem purple, ercct, 2-flowered: lower leaves 3-lobed, or lanceolate, entire. 4 . F. Native on the mountains, about Palermo. (ex Guss. Bocc, cent. 2. p. 4. t. 45 . f. 2.)

Small-flonercd Saxifrage. PJ. $\frac{1}{2}$ foot.

24. S. стивадA'ria (Lin. spec. 579.) lower leaves reniform, on long petioles, very bluntly 5 -lobed : upper ones 3-lobed or undivided; calycine scgments oblong, obtuse; petals ovate, acute, with branched nerves. 4 . H. Native of the Levant, on Parnassus Delplus and other Grecian mountains. Smith, fl. grac. 378. S. hederàcea, Bieb. H. taur. 1. p. 317. exclusive of the synonymes. Lobària cymbalària, Haw, enum. sax. p. 18 . -Buxb. cent. 2. p. 40. t. 45. f. 2.-Vaill. itin. ed. gall. t. 362. Flowers small, golden yellow. Stems numerous, leafy, slender, flaccid, creeping at the base.

Cymbalaria-like Saxifrage. Pl. cr.

25 S. HeDERA'cea (Lin. spec. 579.) lower leaves acutely 3lobed: upper ones ovate, entire; calycine segments ovate, acute; petals roundish, unguiculate. $\odot . H$. Native of Candia and Cyprus, among humid shaded rocks. Smith, fl. græc. t. 379. Lobària herleràcea, Haw, enum. sax. 19, Plant small ; stems numerous, filiform. Flowers small, white.

Iry-like Saxifrage. Fl. July. Clt. 1752. Pl. pr.

26 S. orienta' LIS (Jacq. olss. 2, p. 9. t. 34.) radical leaves roundish: cauline ones cuncated, acutely and coarsely toothed; calycine segments ovate, acute; petals oval, with simple nerves. $\odot$. H. Native of the Levant ; and of Caucasus, on the higher mountains of Talusch, near springs and on the banks of rivulets. S. reticulàta, Sternb. sax. p. 21. t. 18. S. paradóxa, Sternb. 1. c. p. 22. t. 14.? Lobària orientàlis, paradóxa, and reticulàta, Haw. enum. sax. pp. 18. and 20. Stems ereetish, branched, decumbent at the base. Petals golden yellow, size of those of S. hedericea.

Oriental Saxifrage. Pl. dec.

27 S. Ru'ssi (Pres], del. prag. p. 140.) radical leaves petiolate, repandly crenated, cordate at the base, somewhat 5 -lobed: roL, III. cauline ones sessile : lower ones 3 -lobed, middle lobe the longest; uppermost leares linceolate, cntire; sepals ovate; petals lanceolate, 3-nerved, twice the length of the calyx. 24. H. $\mathrm{Na}$ tive of Sicily, on rocks and among stones, about Giuliana. Plant 2-3 inches highl, beset with sliort glandular hairs. Flowers white.

Russo's Saxifrage. Pl. $\frac{1}{5}$ foot. 28 S. J A lyc. new york 2. p. 204.) plant beset with glandular pubescence; lower leaves on long petioles, reniform, crenately lobed; upper leaves tapering into the petiole, cuncated, nearly sessile; lobes of calyx triangularly ovate, acute; petals spatulate, acute, on long claws; racemes seeund; bracteas lanceolate; pedicels of calyxes glandular. 24. H. Native of North America, among the Rocky Mountains. Hook, $\mathrm{A}$. bor. amer. 1. p. 247. t. 74 . lilowers about the size and colour

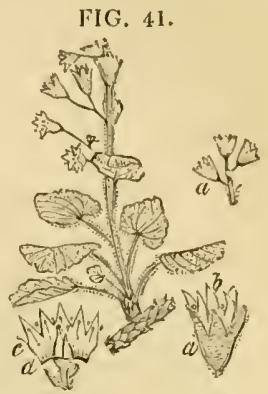
of those of S. oppositif olium (fig. 41.).

James's Saxiliage. P]. $\frac{1}{2}$ foot.

29 S. Richardsònn (Hook, f. bor, amer. 1. p. 247.) stem glanlular, leafy, pubescent above; leaves on long petioles, orbicularly cordate, crenately lobed, veiny, with the margins and veins glandular beneath; glands pedicellate; racemes rather compound; bracteas lanceolate, and are as well as the pedicels glanclular; petals obovate-clliptie, on short claws, very acute, nerved, about twice the length of the calycine segments, which are acuminated; stamens 5. 24. H. Native of the Arctic Sea shore, between the Mackenzie and Coppermine rivers; and of Kotzebue's Sound. S. Nelsoniàna, Hook. et Arn. in bot. Becch. p. 124. t. 29. but not of 1). Don. This and the preceding are very elegant plants.

Richardson's Saxifrage. Pl. $\frac{1}{2}$ foot.

30 S. Nudicau'Lis (D. Don, in Lin. trans. 13. p. 366.) leares reniform, palmate, glabrous: lobes ovate, mucronate; stem erect, naked, terete; flowers panicled; lobes of calyx triangularly ovate, acute; petals obovate, a little longer than the calyx. 4. H. Native of the nortli-west coast of America, Behring's Straits. S. gràcilis, Steph. in Sternb. rev. sax. suppl. p. 7. t. 5. f. 1.? Flowers panicled, white, size of those of S. rizularis. Nalcd-stemmed Saxifrage. Pl. J foot.

31 S. netera'stha (Hook. fl. bor. amer. 1. ). 252. t. 78. 3.) plant rather pubescent; radical leaves on long petioles, reniformly cordate, membranous, veiny, many-lobed: lobes short, somewhat tridentate : teeth acute, mutic; scape naked; flowers panicled, usually abortive; some of the filaments clavate, and others petal-formed; ovarium frce; calyxes reflexed; branches of panicle sometimes bearing bulbs below. $4 . \mathrm{H}$. Native of North America, common on moist rocks of the Columbia, from its source to its confluence with the sea. The leaves rescmble those of $S$. rotundifolia, but they are furnished with a long, membranous, sheathing base, and altogether radical.

\section{I ariable-flonercd Saxifrage. Pl. $\frac{1}{2}$ foot.}

32 S. oranula'ta (Lin. spec. p. 576.) plant liairy; radical leaves reniform, crenately lobed: cauline ones petiolate; calycine segments lanceolate, obtuse ; petals spatulate; root grantular. 4. H. Native of the north and middle of Europe, in dry fields and the borders of woods; plentiful in some parts of Britain. Jl. ılan. t. 514. Lam. ill. t. 272. f. 1. Smith, engl. bot, t. 500. Stem leafy, many-flowered; pedicels elongated, E e 
I-flowered, and are as well as the calyxes clothed with clammy down. lilowers snow-white; nerves of petals branched.

lar. 3 , plèna; flowers double. Common in gardens.

lar. $\gamma$, multicaúlis (Lapeyr. fl. pyr. t. 27.) stems numerous, short: lower leaves lobed, broadly crenated: upper ones obovate, acuminated, entire, rarely 1-2-tootled; peduncles manyflowered. $\%$. IH. Native of the Pyrenees. S. granulata $\gamma$, ramosissima, Ser. in D. C. prod. 4. p. 36.

Iar. $\hat{c}$, Cirsicàna (Ser. in Duby, bot. gall. 1. p. 2ll.) plant very small; stem 1-4-flowered; leaves small, crenately lobed; flowers hardly smaller than those of the species. \%. H. $\mathrm{Na}$ tive of Corsica, S. rivulàris, 1 h. Th. exsic.

lar. $\varepsilon$, pendulifiòra (Ser. in Duby, bot. gall. 1. p. 211.) leaves reniform, broadly crenated; flowers somewhat umbellate, pendulous; peduncles 1-flowered, weak. $\%$. H. Native of Auvergne. S. penduliflòra, Bast, in journ. bot. 1814 . p. 17. and D. C. 1]. fr. 5. p. 519.

lar. $\eta$, sessiliflora (Ser. in D. C. prod. 4. p. 36.) stems quite simple; leaves reniform, crenated; flowers sessile, subcapitate. 4. II. In dry places.

lar. $\zeta$, bulbillìis (Ser. l. c.) stem more or less branched; flowers numerous, sessile, abortive, transformed into little bulbs, which rise from the axils of the leaves. 2. H. Native of Sicily, S. granulàta gemmífera, Haw. enum. sax. p. 23.

Gramular-rooted Saxifrage. Fl. May. Brit. Pl. $\frac{1}{2}$ to $1 \mathrm{ft}$.

¿9 S. odontophy'LLA (IV̈all. cat. no. 454.) leaves reniform, bluntly lobed, rather pubescent; stem few-leaved, manyflowcred, and are as well as the pedicels and calyxes clothed with glanchlar pubescence; petals obovate, unguiculate; stigmas diverging, capitate. $\quad$ H. H. Native of Nipaul, in Kamaon. Roots woody, fibrous, Flowers white. Pedicels 1-flowered. Very like $S$. granulàta.

Tooth-leaved Saxifrage. PI. $\frac{1}{2}$ to $\frac{3}{4}$ foot.

34. S. Bulfífera (Lin. spec. 577.) radical leaves reniform, petiolate, crenated: cauline ones sessile, deeply lobed; calycine segments triangularly ovate, acute; stem branched, manyflowered. 24.II. Native of the south of Europe, as in Spain, in stony meadows and shady places; also of Switzerland, on lry lills. Sternb. sax. p. 15. t. 12. f. 1.-Mor. hist. 3. p. 474. sect. 12. t. 9. f. 24.-Column, ecphr. 1. p. 318. t. 317. S. vivipara, Vest, in flora, 1820. p. 405. Flowers white, smaller than those of S. gramulata. Peduncles elongated, 1-flowered, clothed with glutinous down as well as the calyxes. Stem beset with viscid hiars. Leaves pilose.

Var. B, reronica fòlia (Sternb. rev. sax. 16. t. 12. f. 1. and in Sturm, deutschl. fl. 35. with a figure). 2. H. Haw. enum. sax. 23. S. veronicaf òlia, Bertol. amoen. p. 361 . There is also a variety of this with a 1 -flowered stem, under the name of S. bulbifera lirctiea, Haw. enum. sax. p. 24.?

Bulb-beuring Saxifrage. Fl. Ju. Jul. Clt. 1819. Pl. $\frac{1}{2}$ to $1 \mathrm{ft}$.

35 S. CE'rNUA (Lin. spec. p. 577.) leaves glabrous, petiolate; radical ones reniform, deeply lobed: cauline ones palmate; calycine segments ovate, obuse ; petals spatulate, emarginate; stem quite simple, generally 1 -flowered. $\boldsymbol{\psi}$. H. Native of Lapland, lyrences, Switzerland, and Scotland, about alpine rills on the loftiest mountains. In North America, on the arctic shore and islands, and in Kotzebue's Sound; also of Siberia, on alpine rocks, at the rivers Ursal and 'Tschuja. In Scotland, on Ben Lawers and on Craigalleach. Fl. dan. t. 22. Gunn. f. norr. no. 528. t. 9. f. 2. Sternb. sax. 'p. 18. t. 12. f. 2. Lobària c'́mua, IIaw. cnum. sax. p. 20.-Lin. fl. lapp. p. 172. t. 2. f. 4. Bulbs scaly; scales fleshy, rising from the base of the petioles of the primordial leaves. Stcm simple, 1-flowered, leafy, with small aggregate bulbs rising from the upper leaves. Flowers solitary, large, campanulate, drooping, white; nerves of petals branched. The specimens fiom the liocky Mountains of North America are more leafy, especially on the stem amongst the bulbs, which are very numerous.

Var. 3 , ramòsa (Ser. in D. C. prod. 4. p. 36.) stem a little branclied, few-flowered; flowers nearly all transformed into bulbs. 4 . H. Native of the Alps of Lapland and Norway.

I'ar. $\gamma$, Ledebouri; stem branched; branches elongated, 1flowered; leaves crenated: lobes acutish. 24. H. Native of Altaia, on alpine rocks, at the rivers Tschuja and Ursal.

Var. ¿, multiflòra (Hook, et Arn. in Beecls. voy. pt. bot.) plant branched; each branch bearing a large flower, and no bulbs. 24. H. Native of Kotzebue's Sound. Perhaps S. Stejhaniàna, Sternb. sax. suppl. p. 8. t. 6. f. 2, may be correctly referred to this variety.

Drooping-flowered Saxifrage. Fl. June, July. Scotland. Pl. $\frac{1}{4}$ to $\frac{1}{2}$ foot.

36 S. Siвı' RicA (Lin. spec. 577.) root granular; leaves hairy, petiolate : radical ones reniform, palmately lobed : cauline ones cligitate; pedicels elongated, remote, capillary; petals obovate, with simple nerves; stem much branched, filiform. $4 . \mathbf{H}$. Native of Siberia, Altaia, and the Alps of Caucasus, among rather humicl sliaded rocks, or among stones; also of Labrador and Newfoundland. Sternb. sax. p. 23. t. 25. f. 1. Gnel. sib. 4. p. 162. no. 74. S. granulàta $\beta$, Steven de sax. cauc. in mem. mosq. 4. p. 77. no. 3. S. grandiflòra, Sternb. sax. t. 12. f. 4.? S. cymbalària, Bieb. f. taur. 3. p. 292. no. 750. Lobària Sibírica, Haw. enum. sax. 21. Lobes of calyx ovatelinear. Petals white. Stem beset with viscid hairs.

Sibcrian Saxifrage. Fl. June, July. Clt.1802. Pl. ascend. 37 S. BRACTEA'TA (D. Don, in Lin.trans. J 9. p. 367.) radical as well as cauline leaves on long petioles, reniform, and deeply lobed; flowers in crowded corymbs, bracteate; stem leafy, flexuous, branched, ascending, clothed with viscid villi. $4 . \mathrm{H}$. Native of Eastern Siberia. Flowers wlite, like those of $S$. cérnua, but a little larger; calycine segments broadly ovate, obtuse. Petals obovate, a little longer than the calycine segments.

Bracteated-flowered Saxifrage. Pl. $\frac{1}{4}$ foot.

38 S. RIYUla'ris (Lin. spec. p. 577.) stem weak, quite simple; leaves reniform, on long petioles, glabrous; flowers usually by threes, sessile, bracteate. $\odot$. H. Native of the ligher Alps of Europe, as in Lapland, Norway, as well as of Siberia. It is also found in North America, as in Labrador, Arctic Sea shore and Islands, Kotzebue's Sound, and in elevated places among the Rocky Mountains. In Scotland about Alpine rivulets, and in wet fissures of rocks, as on Ben Nevis, near the lake in the ascent: also on Ben Lawers, and at Loch Rannoch. Lin. f. lapp. no. 174. t. 2. f. 7. Fl. dan. t. 118. Smith, engl. bot. 2275 . Sternb. sax. p. I9. t. 12. f. 3. Plant annual. Stem weak, ascending, few-leaved, furnished with viscid hairs above. Leaves 5-6-lobed; lobes obtuse. Flowers small, white, bracteate. Calycine segments ovate, very blunt, obtuse, conniving. Petals oval, obtuse, triple nerved.

Brook Saxifrage. Fl. June, July. Scotland. Pl. 2 inches.

39 S. hyperdòrea (R. Br. in Parry's first voy. append. p. 274.) stem woolly, 2-flowered; leaves glabrous: radical ones palmate, on long petioles; petals 1-nerved. $\%$. H. Native of 1reland, and Aretic America. S. rivulàris $\beta$, Hook. $f$. bor. amer. 1. p. 246. Flowers white. Perhaps only a variety of $S$. rivulàris.

Northern Saxifrage. Pl. 2 inches.

40 S. Nu'tans (I. Don, in Lin, trans. 13. p. 268.) stem rather pubescent, decumbent at the base, jointed in the middle, and furnished with one leaf at the joint: raceme drooping, fewflowered : radical leaves on long petioles, reniform, deeply and coarsely toothed, with a few scattered stiff hairs on both sur- 
faces: cauline one petiolate; petioles hairy, 4 . Il. Native of the west coast of North America, in the Island of Unalaschka. Flowers white, size of those of $S$. bulbifcra; calycine segments lanceolate, acute; petals obovate, with branched flexuous nerves. Pedicels and ealyxes beset with erowded glandular laairs.

Nodding-flowered Saxifrage. Pl. $\frac{1}{4}$ foot.

41 S. ranunculifóla (Hook. Hl. bor. amer. 1. p. 246. t. 83.) plant clothed with glandular pubescence, slender: lower leaves on rery long petioles, reniform, 3-parted: segments broadly cuneated, deeply lobed; cuuline leaves few ; flowers corymbose, pentandrous; petals obovate, twice the length of the calyx; calyx beset with glandular hairs: segments acute. 2. H. Native of North America ; common on the high grounds around the Kettle Falls of the Columbia, and on the Rocky Mountains. Flowers white, size of those of $S$. slellàris. Petals obovate, unguiculate.

Crow-foot-lcaved Saxifrage. Pl. $\frac{3}{4}$ foot.

42 S. Exi'tus (Steph. in Sternb. sax. suppl. p. 8. t. 3. f. 1.) root tufted ; radicles capillary; radical leaves palmately 5-lobed, petiolate: cauline ones linear, entire; petals obovate-oblong, much longer than the 5-cleft calyx. 24. H. Native of Siberia, and probably of Kotzebue's Sound. Stem weak, 2-flowered. Flowers white.

Slender Saxifrage. Pl. $\frac{1}{2}$ foot.

13 S. Laurestia'sa (Ser. in D. C. prod. 4. p. 35.) plant with many stems; radical leaves on long petioles, reniform, $5-7$ lobed, crenated, reticulately veined lengthwise, glabrous; stems and peduncles ornamented with long intricate hairs; flowers few, somewhat capitate, involucrated by $3-4$ crenately lobed bracteas; lobes of calyx ovate, obtuse, shorter than the petals ; petals 3 -nerved towards the middle. $4 . H$. Native of the Island of St. Laurence in Behring's Straits. S. Chamissonis, Sternb. ined. but not S. Chamissòi, Sternb. Flowers white.

St. Laurence Saxifrage. Pl. $\frac{1}{2}$ foot.

44 S. Stephaniàa (Stern. suppl. sax. 1. p. 8. t. 6. f. 2.) plant tufted; stem usually 4-flowered, pilose ; radical, as well as the cauline leaves, petiolate, and palmately many-lobed, pilose; bracteas nearly linear; sepals linear, obtuse; petals obovate, many nerved. $\%$. H. Native of Siberia, Steph. S. palmàta, Steph. in litt. ex Sternb. l. c. Flowers white.

Stcphan's Saxifrage. Pl, $\frac{1}{2}$ foot.

45 S. Altífida (Haw. enum. sax. p. 24.) leaves deeply and palmately 3-parted : segments profoundly 3-5-cleft; peduncles subracemose, divaricate. 24. H. Native country unknown. S. adscéndens, Haw. exclusive of all the synonymes. Very nearly allied to $S$. granulàta, but truly distinet, and differs in the fissures of the leaves, and in the more decumbent stems. Flowers white.

Deep-cleft-leaved Saxifrage. Fl. May, June. Pl. $\frac{1}{2}$ foot.

Sect. IV. Hírculus (a name given by the ancients to a kind of spikenard or valerian, which has nothing to do with the present plant). Tausch, hort. canal. fasc, 1. Haw, enum. sax. p. 40. Kingstònia, Gray, brit. A. 2. p. 531. Calyx deeply 5-cleft (f. 42. a.), not adhering to the ovarium. Petals sessile (f. 4.2. b.) in most of the species. Stamens inserted in the throat of the calyx (f. 42. c.); filaments subulate. Styles straight ; stigmas orbicular, flattish, beardless. Capsule free from the calyx (f. 42. d. a.). Seeds oblong, wrinkled from dots.-Humble herbaceous evergreen plants. Stems leafy, stoloniferous. Leaves alternate, narrow, nerved, entire, but usually ciliated with stiff hairs, marcescent. Flowers white or yellow.

46 S. Hírcults (Lin, spec. 576.) leaves lanceolate, obtuse, not ciliated; calycine segments lanceolate, obtuse, usually ciliated; petals obovate, many nerved; styles almost wanting; stigmas spatulate, when young deflexed, afterwards divaricate. 4 . II. Native of Sweden, Switzerland, Lapland, Siberia, Caucasus, Germany, and in England, in boggy places. It is also found in North America, from the Saskatchawan to the Aretic sea shore and 1slands, where it seens most abundant; Behring's Straits, Cape of Good Ilope, Kotzebue's Sound, S.e. In Fncland in a turfy morass about the centre of Knutsford moor, Cheslire; and on Cotherstone Fell, near the junction of the Black Heath with the river Balder, Yorkshire. [1]. dan. t. 200. Snith, engl. bot. 1009. S. flàva, Lam. fl. fr. 3. p. 529. S. propinqua, R. Br. in Ross' voy. ed. 2. vol. 2. p. 192. Híreulus ranunculoides, Haw. enum. sax. P. 60.-Gmel. sib. 4. p. 165. t. 65. f. 3. Plant pale green, with numerous procumbent stolons. Stem from 4 . inches to 1 foot high. Peduncles long, 1-flowered, covered with clammy fuscous villi. Flowers large, showy golden yellow; sepals obtuse.

lar. $\beta$, elàta; stem a foot high, many flowered; peduncles very villous. $\psi$. IH. Native of Eastern Siberia.

liar. $\gamma$, acutùta (Ser. in D. C. prod. 4. p. 4.5.) segments of caly $\mathrm{x}$ acute; styles rather elongated.-Hall. hist. no. 972. t. 11.

Iar. ¿, Altäica; stem usually 1-flowered, pubescent; peduncles clothed with rufous villi. 2 . H. Native of Altaia, is lumid subalyne places at the rivers Ursul and Tschuja. S. Hírculus, Ledeb. fl. alt. 2. p. 121 .

Mirculus Saxifrage. Fl. Aug. England. Pl. $\frac{1}{3}$ to 1 foot.

47 S. мүозотіғòla (D. Don, in Lin. trans. 13. p. 373.) plant tufted, without any stolons or flagellæ; leaves ovate, acute, mutic, bristly; pelicels elongated, and are as well as the calyxes beset with glandular pili; stem nearly naked, usually 3 -flowered; calycine segments broally ovate, acute ; petals roundish, unguiculate, 5-nerved. 4. H. Native of Siberia. Sureuli very short, ereet, crowded. Stem 2-3-flowered, beset witl stiff hairs. Leaves ciliated with hairs on the margins, and on both surfaces. Flowers cream-coloured; filaments compressed, yellowish. Styles short, thick.

Mouse-ear-lcaved Saxifrage. Pl. 2 inches.

48 S. Flagella'ris (Sternb.

sax. p. 25. t. 6.) stolons or flagella filiform; stems erect, simple, 1-5-flowered, and are as well as the calyxes clothed with glandular pubescence; radical leaves as well as lower cauline ones obovately spatulate: superior ones rather villous; petals permanent, longer than the capsule, which is semi-superior. 4 . H. Native of the Alps of Caucasus; and of north-west America, at Cape Newuham, in Melville Island, Baffin's Bay, Behring's Straits, Arctic Islands, summits of the Rocky Mountains, Kotzebue's

Sound, \&c. Hook. fl. bor. amer. 1. p. 253. t. 7\%. S. setígera, Pursh. fl. amer. sept. 1. p. 312. S. áspera, Bieb. fl. taur. 1. p S14. exclusive of the synonymes. Hírculus flagellàris, Haw. enum. sax. p. 41. Stem leafy, 1-5-flowered. Radical leaves crowded, all ciliated on the margins, with cartilaginous spinules: calyx and pedicels clothed with glutinous down. Flowers yellow, size of those of S. IIirculus (f. 42.).

Var. a; stem 1-5-flowered; ovarium free from the calyx; sepals oblong. 4 . H. S. flagellàris, Willd. ex Sternb. sax. p. 25. t. 6. Bieb. fl. taur. 3. p. 291 . Ledeb. fl. ross. alt. ill. t. 321. S. áspera, Bieb. H. taur. I. p. 314 . S. myosotidifòlia, Pall. ex Spreng. syst. 2. 1). 364 .

Var. $\beta$; stem 1 -flowered; ovarium adhering to the calyx at E e 2 
the base ; calycine segments ovate. 4. H. S. flagellàris, R. Br. in Ross' voy, ed. 2, vol. 2. p. 192. D. Don, in Lin. trans. 13. p. 373. Hook. et Arn. in bot. Beech, voy. 1. p. 124. S. setigera, Pursl, fi. aner. sept. 1. p. 312.

Flagella-bcaring Saxifrage. Fl. May, July. Clt. 1819. 1). 1 foot.

49 S. Brinòniana (Wall. cat. no. 442.) tufted; stems 1-4flowered, bearing a few glandular hairs; stolons or surculi capillary, without any tuft of leaves at the points, rising from the axils of the leaves, as in S. flagellaris; leaves linear, with cartilaginous ciliately serrate edges, and terminated by a stiff mucrone; cauline leaves fewer, shorter; sepals ovate, very blunt; petals obovate-oblong, 3-nerved, yellow, much longer than the calyx; stigmas small. 4 . F. Native of Nipaul, in Emodi, and Kamaon. Flowers yellow. Pedicels slender, elongated.

\section{Bronn's Saxifiage. Pl. $\frac{1}{4}$ to $\frac{1}{2}$ foot.}

50 S. BRACHY' PODA (D. Don, in Lin. trans. 13. p. 378.) plant tufted; stems dense, simple, gemmiferous; leaves dense, linear, spreading, ciliated with bristles, 1-nerved, full of pellucid dots, of a different colour beneath; flowers solitary, terminal; pedicels clothed with unequal glandular hairs; sepals lanceolate, mucronate, ciliately serrulated, 3-nerved; petals obovate, 5-nerved, bluntish; stigmas thick, diverging. 4. F, Native of Nipaul, in Emodi, Gosaingsthan, and Kamaon. S. glandulosa, Wall. cat. no. 442. Pedicels nearly the length of the flowers. Leaves glancous beneath, quite glabrous, very numerous, wilh revolute edges. Buds echinated. Flowers yellow.

Short-peduncled Saxifrage. Pl. $\frac{1}{4}$ foot.

51 S. rimbria'ta (Wall. ('at. no. 443 ,) stem simple, gemmiferous, very leafy, bearing scattered glandular hairs; leaves lanceolate, very acute, of a different colour beneath, ciliated with stift bristles, marked above with fine parallel wrinkled lines: nerves $5-7$, nearly parallel, reticulated and pellucid; flowers small, subracemose, but often solitary; pedicels short, rather hispid; sepals lauccolate, rather cartilaginously serrulated, mucronate. 24. F. Native of Nipaul, at Gosaingsthan and Kamaon.

\section{Finged-leaved Saxifrage. P'. 1 foot.}

52 S. Alzoides (Lin. spec. p. 576 .) stems leafy; leaves linear, mucronate, glabrous, edged with stiff ciliæ; calycine segments broadly ovate; petals oblong-lanceolate, 3 -nerved : nerves simple. 24. 11. Native on the Alps of Switzerland, Lapland, Siyria, north of lingland and Scotland, on the borders of mountain rills, in a black boggy soil. In North $\Lambda$ merica, in the barren country from lat. $61^{\circ}$ to the Arctic sea and islands; in swamps and ritulets on the Rocky Mountains; also of Labrador and Newfoundland. Smith, engl. bot. t. 39. Sternb. sax. p. 25. t. 8. f. 1. Sturm, deutschl. fl. 35 . with a figure. S. autumnalis, Lin. spec. p. 575 . Fl. dan. t. 72 . Scop. carn. 1. p. 293. t. 14. Leptàsea aizoides, Haw. enum. sax. p. 39.-Breyn. cent. 106. t. 48.-Moris, hist. 3. p. 477. sect. 12. t. 6. f. 3. Plant green, growing in tufts. Surculi numerous, procumbent, leafy. Stems erect, leafy, many flowered, clothed with viseid down. Flowers somewhat racemose, yellow; calycine segments furnished with a membranous margin, which is jagged at the apex; petals spotted with copper-coloured dots.

lar. $\beta$, eròcca (Gandin, syn. sax. in Meisn. anz. 1s18. p. 66. fl. hels. 3. p. 102.) petals copper-coloured. 2 . I1. S. aizoides 3, 1). C. ff. fr. 4. p. 366. Leptàsea aizoìdes cròcea, Haw. enum. sax. 40. S. atrorubens, Bertol. in Desv. joum. bot. 4 . p. 76. and amoen. acad. 1819. Sternb. rev. sax. suppl. 1. p. 10. 'l'here are varieties of this with one or many flowered stems.

l'ar. $\gamma$, intèra (Ser. in D. C. prod. 4. p. 47.) leaves not eiliated. 4. 11. S. aizoìdes, Lin. spec. 5\%6. Leptàsea aizoides i intègra, Haw. enum. sax. p. 39.

Aizoon-like Saxifrage. Fl. July, Aug. Britain. Pl. $\frac{1}{4}$ foot.
53 S. BRoxchílus (Lin. spec. 572.) suffrutescent; leaves crowded, linear-subulate, triquetrous, mucronate, ciliatcd with stiff spinules; calycine segments ovate; petals oblong; stems few-leaved and many flowercd. 4. H. Native of Siberia ; north-west coast of America, Belring's Straits, Kotzebue's Sound, height of land at the portage of the Columbia river, on the west side of the Rocky Mountains. Ciliària bronchiàlis, Haw. rev. sax. 43.-Gmel. sih. 4. p. 164. t. 65. f. 2. Surculi numerous, erect, branched. Panicle terminal, few or many flowered. Flowers small, cream-coloured; petals obovate-oblong, 3-nerved, with numerous minute copper-coloured dots; anthers copper-coloured. This is very nearly allied to $S$.tricuspidala, but differs in the want of the lateral points to the leaves.

I'ar. $\beta$, Lenénsis (D. Don, in Lin. trans. 13. p. 377.) surculi shorter ; leaves longer, spreading ; panicle larger, spreading, fastigiate. $4 . H$. Native of Siberia, at the river I,ena.

Bronchial Saxifrage. Fl. May, June. Clt. 1819 . 1']. $\frac{1}{2} \mathrm{ft}$.

54 S. TFNE'LIa (Wulf. in Jacq. coll. 3. p. 144. t. 17.) plant tufted; leaves crowded, linear-subulate, flat, pungent, ciliated; stems slender, few-learcd, few-flowered; calycine segments linear-lanceolate; petals obovate. 4.H. Native of Carinthia, on the Alps. S. nítida, Wulf. in Jacq. coll. 3. t. 10. f. 4. Surculi numerous. Stems numerous, erect. Leaves imbricated, keeled below, glabrous. Peduncles by threes, long, capillary, 1-Howered, beset with glandular hairs, as well as the calyxes. Flowers white, spotless; anthers yellow.

Delicate Saxifrage. Fl. June, Aug. Clt. 1819. Pl. $\frac{1}{8}$ to $\frac{1}{4} \mathrm{ft}$. 55 S. Filicau'lis (Wall. cat. no. 445.) stems filiform, much branched, beset with capitate hairs; branches filiform, 1-flowered; leaves linear, sessile, full of pellucid dots, nerveless, ciliated by capitate bristles; sepals lanceolate-oblong, bluntish; petals obovate, obtuse, 3-nerved; styles much elongated; stigmas thickish, arched. 4.F. Native of Nipaul. Branches dense. Flowers golden yellow. Perlaps distinct from S. brachýpoda.

Tliread-stcmmcd Saxifrage. Pl. $\frac{1}{4}$ foot.

56 S. Kruhsia'na (Fisch. in litt. ex D. C. prod. 4. p. 46.) plant tufted; leaves dense, imbricate, ovate, ciliated, nerveless; flowers by threes; sepals lanceolate, obtuse; petals elliptic, much longer than the caly $x$, with pinnate nerves; capsule somewhat hemispherical; styles arched. 4. H. Native of Siberia, near Ijiga, where it was found by Kruhs, according to Fischer. This species is very distinet from $S$. áspera, in the leaves being oval, not linear-ovate, in being nerveless, not 3-nerved, and in the petals being feather-nerved, \&c. S. glandulòsa, Willd. herb. ex Stev, in litt. 1821 .

Krulh's Saxifrage. Pl. $\frac{1}{4}$ foot.

57 S. Stelleriana (Merk ex Fisch. in litt. ex D. C. prod. 4. p. 46.) plant tufted; leaves of the surculi or sterile branches small, numerous, oblong, ciliated and mucronate, hardly petiolate: cauline ones distant: uppermost ones acute, not ciliated; stems branched, 5-7-flowered; flowers distant; pedicels and calyxes glabrous ; calycine lobes oblong, acute ; petals oblong, 3-nerved, exceeding the calyx; ovarium conical; styles hardly diverging, length of the petals. 4. H. Native of Eastern Siberia.

Steller's Saxifrage. Pl. $\frac{1}{4}$ foot.

58 S. multiflòra (Ledeb. dec. pl. in mem. acad. des. scienc. petersb. 5. p. 532. no. 18 . f. ross. alt. ill. t. 335 .) leaves lanceolate-linear, scattered, cuspiclate, remotely and setaccously ciliated, and covered with cobwebbed villi; corymbs terminal, many flowered; calycine segments ovate, obtuse; petals elliptic, bluntish, 1-nerved, more than thrice the length of the calyx; stamens exceeting the corolla. 2\%. H. Native of Altaia. It differs from $S$. Qspera and $S$. Uronchicilis, and all the nearly 
allied species, in the many fowered corymbs, in the surfaces of the leaves and margins, $\delta \mathrm{c}$.

Many-floncrel Saxifrage. Pl. $\frac{1}{4}$ foot.

59 S. A'spre (Lim. spec. 575.) leaves flat, lanceolate-linear, scattered, pungent, remotely ciliated with spinules, glabrous; stem branched, few-flowered; calycine segments ovate, cuspidate; petals broadly elliptic, rounded at the apex, 5-7-nerved, twice the length of the calyx, and a little longer than the stamens. 24. 11. Native of Switzerland and the Pyrenees; also of Siberia. Jacq. austr. 5. apprend. 31. Sternb. sax. 29. t. 8 . f. 1.-Scheuch. itin. 2. p. 140. t. 20. f. 3.-Gesn. fasc. 22. t. 6. f. 27. S. úspera var. a elongàta, Gaudin, fl. helv. 3. p. 108. S. intermèdia, Heg. fl. helv. 1. p. 28s. Ciliària áspera, Haw. enum. sax. p. 42.-Moris. list. 3. p. 479. sect. 12. t. 10. f. 25. Plant grey : surculi elongated, decumbent, villous. Stem branched, reddisl, brittle, hispid from short hairs. Peduncles longish, sciff, 1-flowered, furnished with glanduliterous hairs, as well as on the calyxes. Nerves of petals branched. Flowers large, creaun-coloured.

Rough Saxifrage. Fl. Aug. Clt. 1752. Pl. $\frac{1}{4}$ foot.

60 S. BRYoides (Lin. spec. 572.) tufts of leaves at the tops of surculi glubose; leaves inbricated, subulate, mucronate, ciliated; calycine segments ovate, obtuse; petals oblong; stems few-leaved, l-flowered. 4 . H. Native of Austria, Switzerland, and the Pyrenees. Jacq. misc. 2. p. 49. t. 5. f. 1. Seop. carn. no. 497. t. 15. Sterub. rev, sax. p. 30. t. 8. and in Sturm, deutschl. A. p. 33. with a figure. Moretti. tent. sax. p. 32. t. 8. Ciliària bryoìles, Haw. enum. sax. p. 42.- Scheuch, alp. 142. t. 21. f. 2.-Col. ecphr. 2. p. 66. t. 67. f. 1-2. S. áspera $\beta$ bryoides, D. C. fl. fian. 4. p. 383. prod. 4. p. 46. Plant densely tufted, rosulate. Stem beset with glanduliferous pili. Leaves rather triangular, kecled. Flowers cream-coloured, size of those of $S$. áspera; calycine segments 5-nerved; petals 3 nerved, besct with scattered golden ycllow dots; anthers coppercoloured.

Bryum-like Saxifrage. Fl. June, July. Clt. 1752. Pl. $\frac{1}{b}$ foot.

61 S. cierlerioìdes (D. Don, in Lin. trans. 19. p. 382.) tufts of leaves on the tops of the surculi globose; leaves densely inbricated, spatulate, mucronate, ciliated; calycine segments semi-ovate, obtuse; petals olovate, 3 -nerved; stems filiform, many-flowered. 4 . II. Native of Kamtschatka. S. bryoìdes, Pall. mss. Plant tufted. Stems ascentling, 4-5-flowered, with a few small adpressed leaves. Flowers corymbose, cream-coloured, much smaller than those of $S$. bryoides. Pedicels 1flowered, furnished witls a few scattered glands, as well as the calyxes.

Cherleria-like Saxifrage. I'l. $\frac{1}{8}$ foot.

62 S. IIISpídeca (D. Don, in Lin. trans. 13. p. 380.) plant tufted, and hispid; stems filiform; leaves ovate, mucronate, bristly, with one tooth on each side; flower terminal, nearly sessile; calyx bristly; petals nearly orbicular, triple-nerved: nerves simple, straight. $\%$. H. Native of Nipaul, on the Alps. Flowers ycllow, on short pedicels, drooping in the bud. Styles incurved at the apex.

Rather-hispid Saxifrage. Pl. $\frac{1}{4}$ foot.

63 S. erolvuloides (Wall. cat. no. 447.) stems rery simple, 1-flowered, ornamented by long capitate spreading hairs; leaves ovate-lanceolate, acute, furnished with 1 or 2 teeth, nerveless, sessile, covered with strigose pili ; scpals ovate, mucronate by a bristle, and bearing strigose hairs; petals roundish-obovate, opaque, hardly longer than the calyx. 4 . F. Native of Nipaul, at Gosaingsthan and Kamaon. P'erhaps distinct from S. hispidula. Leaves small, superior ones broadest. Pedicels filiform, nearly twice the length of the flowers. I'lowers yellow.

Evolculus-like Saxifrage. I'l, 1 foot.

61. S. L.Evis (Bicb. Al. taur. 1. 1. 314. suppl. 291. but not of
Haw.) stems declinate, few-flowered; cauline leaves oblong, acutish, crowded, naked, unarmed, glauceseent ; flowers termina?, sessile; petals obovate-oblong, longer than the calyx. $4 . \mathbf{H}$. Native of the $\Lambda$ lps of Caucasus. l. lowers yellow. Very nearly allied to $S$. aizoides, but differs in the flowers being smaller and sessile.

\section{Simooth Saxifrage. Pl. $\frac{1}{8}$ to $\frac{1}{2}$ foot.}

65 S. spinulòsa (Adams, in mem. soc. mosc. 5. ex Spreng. netie. entd. 3. p. 225.) stem nearly naked, many flowered; leaves imbricate, undivided, ereet, linear-lanceolate, flat, ciliated, spiny. 4. H. Native combtry unknown.

Spinulose Saxifrage. Pl. $\frac{1}{1}$ foot.

66 S. Ciramissò (Stern. rev. sax. suppl. 1. p. 12. t. 10. f. 1.) plant tufted; stem generally 4 -Howered; lower leaves cuncated, cuspidately trifid, eiliated; cauline leaves linear-lanceolate, quite entire; sepals sinall, obtuse; petals oblong, minute, hardly longer than the sepals. 24. H. Native of the lsland of Uualasclska; and the subalpine regions of Mount Hood. S. tricuspidàta $\beta$, Ilook. fl. bor. amcr. 1. 1. 254. Flowers minute, white.

\section{Chamisso's Saxifrage. PI. $\frac{1}{8}$ to $\frac{1}{4}$ foot.}

67 S. тricuspıda'ta (Retz. prod. H. scand. ell. 2. no. 522.) stems straight, thick; lower leaves dense, coriaceous, cuneiform, tricuspidate, with the margins finely ciliated; flowers somewhat corymbose; peduncles short and stiff; calycine segments ovate; petals oblong or lanceolate, 3 times longer than the calyx; capsule conical, ending in diverging styles; stigmas subcapitate. 4. H. Native of Greenland, and of North America; from Lake Winepeg in lat. $50^{\circ}$ to the Arctic sea and islands; and from Hudson's Bay to the Rocky Mountains; Kotzebue's Sound, Newfoundland, se. liottb. in act. hafn. 10. p. 446. t. 6. Fl. dan. t. 976. Leptàsea tricuspidàta, Ilaw, enum. sax. p. 40. Plant densely tufted, glabrous : surculi very short. Stems ascending, many flowered. Superior leaves undivided. Pedicels elongated, glandular, as well as the calyxes. Flowers yellow, size of those of $S$. Ifirculus. Petals spotted, triplenerved: nerves simple.

Tricuspidate-leaved Saxifrage. Fl. May, June. Clt. 1824. Pl. $\frac{1}{4}$ to $\frac{1}{2}$ foot.

68 S. JUNIPE'RINA (Bicb. fl. taur. 1. p. 314. suppl. p. 291.) stems suffruticose, proliferous ; leaves crowded at intervals, subulate, triquetrous, stiff, pungent; flowers disposed in spikes; petals obovate, triple-nerved. 24. H. Native of the Alps of Caucasus, at the foot of the Kaischaur $A l p s$ frequent, and nearly throughout the whole of Caucasus. Sternb. Sax. p. 31. t. 10. Chondròsea junipérina, Haw. enum. sax. p. 15. Stems numerous, crowded with leaves, proliferously branched at the apex. Leaves flattish on the keel beneath, bisulcate above, furnished with an acicular spine at the apex, and finely serrulated at the base. Spike 6-10-flowered: pedicels short, besct witl clammy down. Bracteas linear, obtuse, ciliated with glands. Flowers yellow, size of those of $S$. áspera.

Var. a, Steveniana (Ser. in D. C. prod. 4. p. 23.) flowers crowded into an ovoid spike.

lar. $\beta$, Adamsiàna (Ser. 1. c.) flowers disposed into a capitate corymb, emulating that of Lýchnis alpina, Sternb. sax. p. 31. t. 10. a middle figure.

Juniper-like Saxifrage. Pl. $\frac{1}{4}$ to $\frac{1}{2}$ foot.

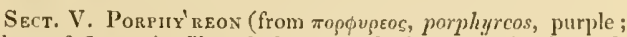
colour of flowers). 'T'ausch, hort. canal. fasc. f. 1. D. C. prod. 4. p. 17.-Antiphýlla species, Haw. enum. sax. p. 43.-Calliphýllum, Gaudin, fi. helv. 3. p. 94 . Calyx 5 -cleft, with a long, erect, permanent tube (f. 4.3. a.), joined to the ovarium or free from it. Petals sessile, perigynous. Stamens perigynous (f. 43. b. c.) ; filaments flat, gradually attenuated. Stigmas 
spreading, flat, spatulate, bearded with short down (f. 43, c.). Capsule covered by the calyx. Seeds angular, smooth or wrinkled.-Tufted evergreen herbs, with small opposite coriaceous or thick permanent leaves. Flowers red or violaceous. Elegant little plants.

69 S. oprositifòiı (Lin. spec. 575 .) stems 1 -flowered; leaves imbricated, ovate or ohovate, flat, obtuse, ciliated; segments of the calyx broadly ovate, obtuse; petals obovate, 5 -nerved; genitals shorter than the corolla. 4 . H. Native of Lapland, Switzerland, Spitzbergen, Pyrenees, Scotland, and England, on alpine rocks and precipices; also of North America, as in Newfoundland and Labrador; Antecosti, in the Bay of St. Laurence; Rocky llountains, near the highest summits, between lat. $52^{\circ}$ and $56^{\circ}$; Arctic sea shore and islands; Bay of Esehscholtz, \&c. In England on the west side of Ingleborough Hill, Yorkshire; on Snowdon plentifully; and on Ben Lomond and other Scottish mountains. Lin. A. lapp. p. 179. t. 2. f. 1. Fl. dan. t. 34. All. pedem. 1529. t. 21. f. 3. Lapeyr. pyr. sax. p. 36. t. 16. Smith, engl, bot. t. 9. Jlohenwatt in Reiner, itin. 1. p. 133. t. 3. S. cœrùlea, Pers. ench. 1.p. 488. Antiphýlla cœrìlea, Haw. enum. sax. p. 43. Plant forming a broad flat tuft; surculi short, procumbent, reddish. Leaves usually perforated at the apex by 1 or 2 pores. Flowers large, of a beautiful lilac colour.

I ar. $\beta$, distans (Ser. in D. C. prod. 4. p. 18.) leaves of the sterile branches loose and clistant. $\%$. H. Native of the Alps of Switzerland and the Pyrenees.

Opposile-lcaved Saxifrage. Fl. March, April. Britain. Pl. 1 inch.

70 S. Retu'sa (Gouan, ill. 28. t. 18. f. 1.) stems usually 3-flowered; leaves imbricated, oblong, trigonal, acute, full of perforated dots above; petals lanceolate, acute; styles much longer than the corolla. $\mathcal{~}$. H. Native of Piedmont, on the tops of the $A]_{p}$ s, as well as of Dauphiny and the Pyrenees. Lapeyr. pyr.

sax. p. 38. t. 18. Sweet, fl. gard. t. 49 . new ser. t. 49 . S. imbricàta, Lam. fl. fr. 3. p. 531. S. purpurea, All. pedem. 1531. t. 21. f. 2. S. oppositifòlia $\gamma$, Willd. spec. 2. p. 648. Antiphýlla retùsa, Haw. enum. sax. p. 44. Plant forming a very compact harsh tuft, glaucescent; surculi proeumbent, densely leafy. Stems erect, few-leaved. Leaves imbricated in 4 rows, like those of the last species, trigonal, glabrous, slining, ciliated at the base. Pedicels and calyxes clothed with short glandular down. Flowers purple. Calyeine segments oblong-ovate, obtuse. Petals triple-nerved, acute (f. 43.).

Rcluse-leaved Saxifrage. Fl. May, June. Clt. 1826. Pl. $\frac{1}{8} \mathrm{ft}$. 71 S. brtióra (All. pedem. 1530. t. 21. f. I.) stem usually 2-3-flowered; leaves flat, spatulate, ciliated, loose; petals linearoblong; calyeine lobes obtuse; genitals longer than the corolla. 4. H. Native of the Alps of Switzerland and the Pyrenees, near the limits of perpetual snow. Lapeyr. pyr. sax. p. 37. t. 17. Hohenwart and Reiner, itin. 1. p. 138. t. 2. f. 2. Antiphýlla hiflora, llaw. enum. sax. p. 44. S. oppositifolia $\beta$, Willd. spec. 2. p. 6.18. Plant tufted, greenish purple, like S. oppositifolia, but larger and more loose in habit. Flowers purplish or lilae. Leaves imbricating in 4 rows. Seeds obovate, triquetrous, truncate at the apex.

Tho-flowered sixifrage. Fl. April, June. Clt. 1820. P]. 1 to 2 inches.

72 S. Escuscuót Ltzir (Sternb. rev. sax. suppl. p. 9. t. 10. f. 2.) plant small, densely tufted; leaves closely imbricated, ob- ovate, concave, pectinately ciliated; flowers solitary on short peduncles; petals cochleate, ciliated; calyeine segments obtuse, ciliated. 4. H. Native of the north-west coast of America, at Cape Newnham and Behring's Straits. S. fimbriàta, D. Don, in Lin. trans. 13. p. 4.04. Plant canescent, forming a flat spreading tuft. Leaves glabrous, full of pitted dots. Peduncles solitary, 1-flowered. Flowers probably purple.

Eschscholtz's Saxifrage. Pl. 1 inch.

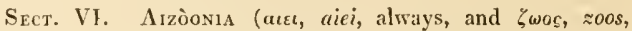
alive; succulent plants). Tausch, hort. canal. fasc. 1. D. C. prod. 4. p. 18.-Chondròsea, Haw. enum. sax. p. 10.-Cotylèdon, Trigonophýllum, and Porophýllum, Gandin, fl. helv. 3. p. 86. 89. and 91. Calyx 5-cleft, with a long tube adhering to the ovarium, erect, permanent. Petals sessile, perigynous. Stamens perigynous; filaments flat, gradually attenuated. Stigmas spreading, flat, spatulate, bearded with short down. Seeds ovate, triquetrous, wrinkled. Leaves alternate, thick, sessile, coriaceous, glaucescent, permanent, cartilaginously margined, usually marked with excavated dots towards the margin: radical ones rosulate. Flowers white, yellow or red.

\section{§1. Lcaves ligulate, obtusc, cartilaginously serrated.}

73 S. Cotyle'don (Lin. spec. 570.) leaves flat, spratulate, cartilaginously serrated; calyx densely beset with glands: with linear-laneeolate obtuse segments; petals oblong-spatulate. 4 . H. Native of the Alps of Lapland, Norway, Iceland, Switzerland, and the Pyrenees. Oed, fl. dan. t, 241. S. pyramidalis, Lapeyr. pyr. sax. p. 32. Sternb. sax. p. 2. t. 2. S. pyramidata, Mill. dict. no. 4. S. multiflòra, Ehrh. pl. sel. p. 74. Chondròsea pyramidalis, Haw, enum. sax. p. 10.-Lin. H. lapp. 177. t. 2. f. 2. Plant tufted. Stem erect, branched in a pyramidal form, many flowered. Leaves with silvery edges. Flowers large, white, dotless; petals conspicuously 3-nerved. Angles of seeds rougl.

Cotyledon or Pyramidal Saxifrage. Fl. May, July. Clt. 596. PI. 1 to 2 feet.

74. S. Lingula'ta (Bell. in act, taur. 5. p. 226.) leaves linearlingulate, channelled, tubercularly crenated; calyx densely beset with glands: with semi-ovate obtuse segments; petals oval. 4. H. Native of the tops of the $A$ ps of Switzerland; and the Pyrenees, on the Alps by the sea side, and other alpine places about Montregal. C. Cutylèdon, Mill. diet. no. 2. S. longifòlia, Lapeyr. pyr. sax. p. 26. t. 11. Chondròsea longifòlia, Haw. enum. sax. p. 11. Plant tufted. Stem erect, flexuous, branched in a pyramidal form, leafy, beset with glandular hairs. Leaves glaucous, ciliated at the base, recurved at the apex. Panicle nodding. Peduncles many flowered, and are, as well as the ealyxes, beset with rusty glandular down. Flowers flat, white, with numerous rose-coloured dots; petals conspicuously triple-nerved.

Y ar. $\beta$, mèdia (Sternb. sax. p. 1. t. 1. a. and in Sturm, deutschl. A. 33. f. a.) leaves shorter; stem panicled above; panicle ereet, pyramidal. $\%$. H. Native of the Alps of Carinthia. Chondròsea intermèdia, Haw. enum. sax. p. 11.-Hort. eyst. ord. 5. pl. 10. f. 1.-Pluk. phyt. t. 222. f. 1. Perhaps a distinct species.

l'ar. $\gamma$, crustàta (D. Don, in Lin. trans. 13. p. 391.) plant 4 times smaller than the speeies; leaves narrower, with more erustaecously porose margins; panicle few-flowered. $4 . \mathrm{H}$. Native of the Alps of Switzerland, Carniola, Carinthia, and the Pyrences. S. longif òlia $\gamma$ minor, Sternb. sax. t. 1. f. b. S. crustàta, Vest, man. bot. p. 656. S. lingulàta, Bell. in act. acad. tur. 5. p. 226. S. eallòsa, Smith in Rees' cycl, vol. 31. Panicle straight : peduncles 2-3-flowered. 
Iar. $\delta$, subnàna; flabelliform; stem single. Lapeyr. 1. c. 4. 11. Native on the tops of the P'yrenees.

Tonguc-leaved Saxifrage. Nl. May, July. Clt. 1800. Pl. 1 to $1 \frac{1}{2}$ foot.

75 S. Aizòox (Murr. syst. ed. 14. p. 41].) leaves short, cuncated, silvery serrated; flowers corymbose; calyxes glabrous, with acute segments; petals nearly orbicular. 4 . H. Native of Austria, Switzerland, Pyrences, and the Carprathian mountains; also of North America, in Labrador and on the Saskatchawan. Jacq. austr. 5. t. 438. Sternb. sax. p. 3. t. 3. f, $\boldsymbol{\alpha}$. Lapeyr. 11. pyr. p. 33. t. 15. S. paniculàta, Mill. dict, no. 8. Chondròsea Aizòon, Haw, enum. sax. 11.-Barrel. icon. t. 1310. -Moris. hist. sect. 12. t. 9. f. 19. Plant tufted. Stems erect, simple, leafy, shining, with a few scattered gland-bearing hairs. Radical leaves rosulate, glaucous, ciliated at the base: cauline leaves obovate-mucronate. Flowers corymbose, cream-coloured, marked with minute rose-coloured dots. Peduncles elongated, usually 2 -flowered.

Var. 3 , retùsa (D. Don, in Lin. trans. 13. p. 293.) one-half smaller than the species; leaves shorter and retuse. $4 . \mathrm{H}$. Native of the Pyrenees. S. Aizòn $\beta$ minor brevifolia, Sternb. 401. 1. c. t. 3. f. $\beta$. S. rosulàris, Sclileicl. cat. 1824 . p. 64 . Chondròsea Aizoòn $\gamma$ parviflòra and $\mathrm{C}$. rosulàris, Haw. enum. sas. 12. Chondròsea Aizoòn minor, Ilaw. 1. c. p. 11. S. rosulénta, Ehrlı. pl. sel. no. 51. There is another variety of this with still smaller leares, in Sternb. l. c. t. 36. f. 2. S. Aizoòn minima, Ser. anz. 182S. p. 73. S. Aizòon ôféscens, Gaudin, f. helv. 3. p. 88 .

Far. $\gamma$, rieta (Ser. in D. C. prod. 4. p. 19.) stems erect, many flowered; peduncles elongated, 3-4-flowered. 24. H. Native of the Alps of Switzerland and the Pyrenees. S. récta, Lapeyr. A. pyr. p. 83. t. 15 . D. C. f. fr.4. p. 361. 3. S. Aizòn $\gamma$, Gaudin. Petals without any dots. Gaudin, fl. 3. p. 88 .

Iar. $\hat{c}$, neglécta (Ser. in D. C. 1. c.) tufts of leaves globose; racene simple, few-flowered, somewhat eylindrical; petals rosecoloured, dotted with purple. 24. H. Native of Italy.-Sedum Barrel. icon. 1310. ex Tenore. S. neglécta, Tenore, append. prod. fl. neap. p. 19. S. Aizòn and S. érecta, Tenore, fl. neap. prod. p. 25. There is a rariety of this with a sessile corymb of flowers in the tufts of leaves; peduncles and calyx are quite glabrous, and the stem l-flowered.

Aizoon Saxifrage. Fl. May, July. Clt. 1731. P]. $\frac{1}{2}$ foot.

$76 \mathrm{~S}$. intacta (Willd. hort. berol. 2. p. 75. t. 75.) leaves linear, acute, straight, sharply and silvery serrated; calyx and pedicels sparingly glandular: with obtuse segments; petals oval. భ. H. Native of the Alps, about Tyrol, Pyrenees, and Caucasus. S. récta, Lapeyr. pyr. sax. p. 33. t. 15. S. Cotylèdon, Bieb. fl. taur. 1. p. 313 . exchusive of the synonymes. S. Aizòn, Steven, de sax. cauc. in mem. mosq. 4. p. 74. exclusive of the synonymes. S. cartilagínea, Sternb. sax. p. 5. t. 3. S. longifolia, Moretti notiz. ed. 1. p. 11. exclusive of many synonymes. S. lingulàta, Moretti notiz. ed. 2. in mem. t. 1. p. 262. Plant growing in conical tufts. Stems erect, leafy, clothed with glandbearing laairs. Leaves glaucous, ciliated at the base; cauline ones spatulate, rather adpressed, ciliately serrated. Flowers racemose; pedicels few-flowered. Petals cream-coloured, marked with a few rose-coloured dots.

Untouched Saxifrage. Fl. May, July. Pl. $\frac{1}{2}$ to 1 foot.

77 S. acstrális (Moric. f. ven. 1. p. 491.) plant quite glabrous; stem angular; leaves of the tufts oblong-spatulate, ciliated at the base, with crustaceous marrins: cauline leaves oblong, somewhat denticulated, acutish; panicle branched, many-flowered; petals ovate, obtuse, much longer than the calyx; styles straight, ascending. 2/. II. Native of Virgin Mount, ncar Naples. S. Aizòn, Guss, in litt. S. pyramidàlis,
Tenore, tl. neaj). prod. 1. p. 25. Petals yellow, as seen in a dried state. Flowers very like those of $S$. Cotylidon, and the leaves like those of S. Aizòon.

Southern Saxifrage. Pl. 1 foot.

78 S. cartilagínea (Willd. in litt. ex Sternb. sax. p. 5. t. 3. c.) leares of the tufts and stems lanceolate, acute, cartilaginously serrated; flowers panicled, somewhat corymbose; lcbes of calyx orate, about equal in length to the campanulate tube; calyx and peduncles beset with glandular pili ; petals obovate, contiguous at the base, spotless; styles diverging. 4. H. Native of Caucasus. S. Cotylèdon, Rieb. f. taur. 1. p. 313. 3. 12. 290. Cliondròsea cartilagínca, llaw. enum. sax. 12. Flowers eream-coloured, dotless. I'erhaps only a variety of $S$. Aizòn.

Cartilaginous-edged-leaved Saxifrage, Pl. 1 foot.

79 S. margina'ta (Sternb. rev. sax. suppl. 1.p. 1. t. 1. f. 1.) radieal leaves lingulate, ciliated at the base, having pitted lots within the edge; flowers somewhat corymbose; petals ovate, twice the size of the calyx. 4. H. Native of Naples. S. Cotylèdon, Tenore, cat. hort. neap. append. alter. p. 86 . and S. Aizòon, longifòlia, and récta, Tenore, fl. neap. prod. p. 25. ex Moretti, tent. sax, p. 35 .

Marginatc-leaved Saxifrage. Pl, 1 foot.

80 S. FLoribu'NDA (Moretti, tent. sax. p. 9.) radical leaves tufted, lanceolate, mucronate, ciliated : cauline ones linear ; stem fistular, bearing flowers from the base to the apex; flowers disposed in a racemose thyrse, white, or cream-coloured. $น .11$. Native on the mountains about Nice.

Bundle-flowered Saxifrage. Pl. 1 foot.

81 S. Muta't a (Lin. spec. 570.) leaves flat, spatulate, cartilaginously crenated and ciliated; calyx densely beset with glands: with broally ovate, acute segments; petals linear-lanceolate, acuminated. 4. H. Native of the $A$ lps of Switzerland, Carniola, Italy, and the Pyrences. Jacq. icon. rar. 3. t. 466 . Curt, bot. mag. t. 351. Chendròsea mutàta, Haw. enum, sax. p. 18.Hall. helv, 979. t. I6. Plant densely tufted. Stem erect, leafy, beset with glandular hairs. Leaves fringed with long villi: cauline ones obovate, ciliated at the base.

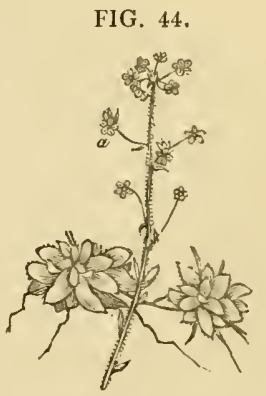

Flowers panicled, copper-coloured, marked with deeper-colonred dots. Peduncles and calyxes densely clothed with rusty clammy down (f. 44.).

Tar. $\beta$, macropétala (Ser. in D. C. prod. 4. p. 20.) petals ovate-oblong, spotted. 4 . H. Native of Switzerland. Hall. hist. no. 979 . t. 16. f. 2 .

Changed Saxifrage. Fl. Ju. Jul. Clt. 1779 . Pl. $\frac{1}{2}$ to $1 \mathrm{ft}$.

\$2. Lcares lingulatcly-spatulate, apieulaled, with quitc entire cartilaginous margins.

82 S. ME'DIA (Gouan, ill. 27.) radical leaves rosulate, lingulate, quite entire, with cartilaginous margins, dotted above ; petals obtuse, shorter than the calyx. 4 . H. Native of the Pyrenees, on calcareous rocks, and on Mount Olympus. Lam. encycl. 4. p. 675 . t. 372. f. 6. Smitl, fl. gracc. t. 376. S. calyciflòra, Lapeyr. pyr. sax. p. 28. t. 12. S. ca'sia, Lin. mant. 3S2. S. porophýlla, Bertol. in journ. bot. 4. p. 76 . and amœn. ital, dec. 4. p. 98. t. 3. Chondròsea calyciflòra, Ilaw. enum. sax. p. 13. Plant growing in conical tufts. Stems simple, beset with viseid, rusty, twisted villi, Leaves glaucous : 
radical ones rosulate, glabrous; cauline leaves cuneated, elothed with glandular hairs. Pedicels 1-flowered, and are as well as the calyxes clothed with viscid hairs. Petals obovate, dark purple. Genitals inclosed in the ealyx.

Middle Saxifrage. Pl. $\frac{1}{4}$ to $\frac{1}{2}$ foot.

83 S. Lapeyrou'sn (D. Don, in Lin. trans. 13. p. 397.) radical leaves aggregate, lingulate, quite entire, with cartilaginous margins; Howers panieled; petals obovate, quite entire, connivent, longer than the calyx. $4 . \mathrm{H}$. Native of the Pyrenees, on calcareous rocks. $\mathrm{S}$. hùteo-purpùrea, Lapeyr. pyr. sax. p. 29. t. 14. S. ambígua, D. C. Peduncles and calyxes elothed with purple down. Very like $S$. mèdia, but differs in the flowers being panicled, and eitron-coloured. Said to be a hybrid between $S$. mèdia and $S$. aretioides.

La Pcyrouse's Saxifrage. Pl. $\frac{1}{4}$ to $\frac{1}{2}$ foot.

84 S. aretioides (Lapeyr. pyr. sax. p. 28. t. 13.) leaves aggregate, linear-lingulate, upright, mucronulate, keeled, glaucous, with cartilaginous margins; stem clothed with clammy tomentum; petals linear-spatulate, erenulated at tle apex. 4 . H. Native of the Pyrenees, on calcareous rocks. Chondròsea aretioides, Haw. enum. sax. p. 1\%. Plant densely tufted. Leaves imbricate, ciliately toothed at the base, with a few perforated dots near the margin. Flowers by threes, griden yellow. Pedicels and calyxes clothed with clammy down Calycine segments ovate, acute. Very like the two preceding species, but thic plant is much smaller.

$$
\text { Arctia-like Saxifrage. Fl. May, Jul. Clt. 1826. Pl. } \frac{1}{8} \mathrm{ft} \text {. }
$$

\section{§3. Leaves triquetrous, obluse.}

S5 S. prapensioines (Bellardi, in act. acad. taur. 5. p. 227.) stems, peduncles, and calyxes glandular; leaves linear, erect, keeled, aggregate, imbricated, cretaceously glaucous; stem many-leaved, few-flowered; calycine segments elliptic-oblong. 14. H. Native of the $\Lambda$ ps of Piedmont and Switzerland. Lapeyr. append. fl. pedem. p. 21. t. 3. Sternb. sax. p. 35. t. 9. Chondròsea diapensioìdes, Haw, enum. sax. p. 13. S. cæ'sia $\beta$, Lam. dict. 4. p. 676. Plant densely tufted, Leaves with cartilaginous margins, ciliated at the base, and with 1 or 2 perforated dots at the apex, which is obtuse. Flowers $3-4$ or 5 , campanulate, white, disposed in a terminal head. Petals narrow at the base, with an orbicular, 5-nerved limb.

Diapensia-like Saxifrage. Fl. April, Ju, Clt. 1825. Pl. $\frac{1}{8} \mathrm{ft}$.

SG S. sQuarròsa (Sieb, in f. 1821. p. 99. and fl. austr. exsic. 110. 133.) stem pubescent below, usually 3-flowered; leaves linear-elliptic, rather retuse, stiff, squarrosely imbricated, permanent, when young powdery; branches diffise, flaccid; peduncles and stems glabrous. 4 . H. Native of the Alps of Tyrol. Flowers white, larger than those of $S$. ca'sia. Lobes of calyx broader than in $S$. ce'sia and $S$. diapcnsioùdes.

Squarrose-leaved Saxifrage. P]. $\frac{1}{8}$ foot.

87 S. ramulòsa (Wall. cat. no. 446.) plant densely tufted; stems 1-flowered, rery short; leaves of the barren stems or surculi acute and flattish at the apex, lined with rugged dots; the upper surface of the leaves have a regular marginal, double line of dots; margins of leaves thin and cartilasinous; lobes of ealyx acute; styles nearly parallel, longer than the calyx ; stigmas thickish, capitate. 2.F. Native of Nipaul, at Bhuddrinath. Very nearly allied to $C$. ce'sia, but perfectly distinct.

Branched Saxifrage. Pl. 1 inch.

S8 S. cre'sIA (Lin. spce. 5\% 1.) plant greenish glaueous; stems and peduncles smoothish; leaves linear-oblong, aggregate, recurved, keekd, the upper surface with marginal dots regularly disposed; petals roundish, unguiculate; stems few-leared, many-tlowered. 24. H. Native of the Alps of Switzerland, Austria, and the Pyrenecs. Jaeq. austr. t. 37\%. Scop. earn. ed. 2. p. 495. t. 15. Sternb. rev. sax. p. 34. t. 9. f, 1-2. and in Sturm, deutschl. f. p. 33. n. 16. with a figure. Lodd. bot. cab. 421. S, recurvifolia, Lapeyr. pyr. sax. p. 30. —Segu. ver. p. 449. t. 9. f. 2. Chondròsea cæ'sia, Haw. enum. sax. p. 14.-Sehench, alp. p. 49. 141. t. 21. f. 1. Surculi short, erect, forming compact tufts. Leaves concave above and keeled beneath, perforated by numerous minute holes, ciliated: cauline ones few, seale-formed. Flowers milk-coloured, disposed in a small panicle. l'edicels and calyxes with a few short, glandular hairs. Calycine segments very blunt. Genitals shorter than the corolla.

Íar. B, pàtens (Ser. in D. C. prod. 4. p. 22.) leaves loosely rosulate, not recurved at the apex, with a few crustaceous spots; stems short, usually 2-flowered. 24. H. Native of Vallais, on Mount Fouly. S. pàtens, Gaudin. in Meisner, anz. 1818. p. 65. A. helv. 3. p. 92. but not of Sternb. rev. sax. suppl. 1. 1. 1. f. 2. Chondrosea pàtens, Haw, enum. sax, p. 14. There is a variety of this without any stem and with 1 sessile flower in the middle of the leaves, which is a native of Upper Styria, and is deseribed by Vest, in flora. 1820, no. 26. p. 397.

Grey Saxifrage. Fl. May, June. Clt. 1752. Pl. I to $\frac{1}{4} \mathrm{ft}$.

89 S. Rocheli' na (Sternb. suppl. sax. 2. ex Host, f. austr. 1. p. 501.) flowers corymbose; sepals ovate; petals lanceolateovate, wice the length of the calys; lower leaves lingulate, glabrous, eiliated at the base, disposed in tufts: cauline ones clothed with clammy villi, pale green. $\%$. H. Native of Austria, in the fissures of rocks. Leaves white at the edges, and with distinct impressed dots. Flowers white. Perhaps a variety of $S$. cásia or $S$. I'aldénsis.

Rochcl's Saxifrage. Pl. $\frac{1}{8}$ to $\frac{1}{4}$ foot.

90 S. VALDE'Nsis (D. C. A. fr. 5. p. 51\%.) peduncles and calyxes very clammy, and beset with glandular hairs; leaves of the surculi and stems flat at the base, but more or less triquetrons at the apex, with the upper surface marked with dots, which are disposed without order. 24. H. Native of the Alps of Lyons, on the hill called Lacroix, near Abries and Pignerol; and on Mount Cenis. S. rupéstris, Thomas, exsic. S. cæ'sia, var. Willd. spee. 2. p. 649. in a note. S. cæ'sia $\gamma$, Moretti, tent. sax. p. 12. Flowers white, corymbose; peduncles sliort. Leaves lense, short.

I'ar. $\beta$, laxif òlia (Ser. in D. C. prod. 4. p. 22.) leaves loose, elongated; flowers very numerous, loose, disposed in panieled corynubs. 24. H. Native of Portugal and Italy. S. cæ'sia, var. ex alpibus Italicis, Lin. mant. j. 381. but not of his spec. S. cæ'sia 3 , màjor, D. Don, in Lin. trans. 13. 1 . 403. S. compácta, Sternb. suppl. 1. j. 9. t. 1. f. 3. under the name of $S$. pàtens.

Lyons Saxifrage. Fl. May, June. Clt.? Pl. $\frac{2}{4}$ foot.

91 S. seryylifòla (Pursh, fl. amer. sept. 1. p. 310.) surculi creeping; leaves rosulate, imbricately reflexed, oblong, obtuse, tapering into the petiole, coriaceous, quite glabrous; stem filiform, few-leaved, beset with glandular pubescence, 1flowered; calycine segments obtuse, not adhering to the ovarium; petals broadly obovate, somewhat 3-nerved. 4. H. Native of the north-west coast of America, at Cape Newnlam, Behring's Straits, and Unalaschka. S. Fischèri, Ser. in D. C. prod. 4. p. 22. S. Eschehóltzii, Cham. in litt. S. planif òlia, Cham. in herb. Hook. S. diapensioides, Fisch. in litt. but not of Bellardi. Plant green, tufted. Flowers large for the plant, apparently yellow, solitary, on slender, few-leaved, glandular stalks. Calyx wholly inferior.

Iild-thyme-leaved Saxifrage. P]. $\frac{1}{4}$ foot.

\section{§4. Leaves triquctrous, mucronately pungent.}

92 S. Nírida (Sclueb, in litt. ex Sternb. rev. sax. p. 32. t. 10. 
b. f. 4.) stems nearly naked, few-flowered; leaves densely imbricatcd, lanceolate, spinosely mucronate, and ciliated, shining beneath; flowers usually by threes, panicled ; calyx pilose: with ovite lobes, which end in a little spine each; petals olstuse, hardly longer than the calyx. 4. 11. Native country unknown. Chondròsea nítida, 1liw. enum. sax. p. 16 . Very nearly allied to S. tenélla. Flowers yellowish.

Shining Saxifrage, Il. May, Ju. Clt.? Pl. $\frac{1}{8}$ foot.

9S S. TENE'LL (Wulf. in Jacy. coll. 3. p. 144. t. 17.) leaves crowded, linear-subulate, flat, pungent, ciliated; stems slender, few-leaved, many-flowered; calycine segments linear-lanceolatc; petals obovate. $\quad$. H. Native of the Alps of Carinthia, Carniola, and of the Carpathian mountains; also about Prague. Clıoudròsea tenélla, Haw, enum. sax. p. 15. Plant tufted; surculi decumbent. Leaves crowded, inbricate, deep green, keeled beneath. Flowers panicled, white, Calyx beset with glandular liairs.

Delicate Saxifrage. Fl. Ju. Aug. Clt. $1819 . \quad$ Pl. $\frac{1}{8}$ foot.

94 S. ARENARioìdes (Brignoli, fasc. rar. pl. forogul. p. 24. Sternb. rev. sax. p. 59.) stem erect, nearly naked, branched in forks; surculi creeping, prostrate, covered with imbricated leaves; leaves linear, acuminated, ciliated at the base. $4 . H$. Native of the mountains of Matajura, in the fissures of rocks. Flowers white. Perhaps not distinct from $S$. tcnélla. (ex Moretti, tent. sax. p. 33.)

Sand-nort-like Saxifrage. Pl. $\frac{1}{8}$ foot.

95 S. Burseria'Na (Lin. spec. 572.) stem beset with glandular hairs ; leaves aggregate, subulate, pungent, smooth, glaucous; stems usually I-flowered; segments of the calyx ovate; petals roundish, with curled edges, and branched nerves. $\% . H$. Native of the Alps of Carinthia and Carniola; and in Üper ltaly, on the mountains. Wulf. in Jacq. mise. 1. p. 152. t. 17. f. 3. Sternb. sax. p. 33. t. 10. f. 1-2, and in Sturm, deutschl. fasc. 33. no. 10. f. a. b. c. d.-Seguier, pl. rar. 3. p. 201. t. 5. f. 2. Chondròsea Burseriàna, Haw. enum. sax. 15. Plant densely tufted. Surculi sliort, erect. Leaves rosulate, triquetrous. Flowers large, beautiful, milk-coloured, lined with branched, yellowish, flexuous nerves.

Var. $\beta$, subbiflòra (Sternb. 1. c. t. 10. ß3.) stems usually 2flowered.

Burser's Saxifrage. Fl. Mar. Ju. Clt. 1826. Pl. $\frac{1}{8}$ foot.

96 S. VANde'Llin (Sternb. rev. sax, p. 34. t. 10. b. f. 3. exclusive of the syn. of Jacq.) plant beset with glandular hairs ; leaves firm, ciliated: radical ones aggregate, dense; flowers corymbose, pedunculate; lobes of calyx ovate, acutish; petals obovate, cuneated, much longer than the calyx. 4 . H. $\mathrm{Na}$ tive on Mount Corni de Canzo, and of the Pyrenees. S. Burseriàna, Lapeyr. H. pyr. p. 35. but not of Lin. exclusive of many synonymes. S. Burseriàna $\beta$, spinòsa, Pers. ench. I. p. 488. S. Burseriàna $\gamma$, Vandélli, D. Don, in Lin. trans. 13. p. S98. Chondròsea Vandélli, Haw. enum. sax. p. 15. Stem usually 4 -flowered. Flowers milk-coloured.

Iandelli's Saxifrage. Pl. $\frac{1}{8}$ foot.

Sect. VII. Micránthes (from pexpos, micros, small, and avtos, anthos, a flower; flowers small). D. Don, in Lin. trans. 13. p. 345. Tausch, hort. canal. fasc. 1. Haw. syn. suce. p. 321. and enum. sax. p. 45.-Dermàsea, Haw. enum. sax. p. 8. Calyx 5-parted (f. 45. a.), spreading. Petals small (f. 45. b.), sessile, spreading, inserted in the calyx : as also the stamens; flaments very short, subulate (f. $45 . c$.). Styles very short, thick; stigmas capitate, glabrous. Capsule depressed, free from the calyx (f. 45.d.). Seeds oblong, smooth.-Perennial herbs, with fibrous roots and many-flowered scapes. Leaves undivided, spreading, lanceolate or ovate, serrated or crenated. Flowers YOL. III. corymbose, small, white or yellowish, disposed in terminal panieles.

97 S. Heracifòdia (Waldst. et Kit. hung. 1. p. 17. t. 18.) scape erect, hairy; leaves petiolate, elliptic, acute, repandly toothed, glabrous; pedicels aggregate, 1-flowered, disposed in spikes : petals lanceolate, acute. 4. H. Native of the Carpathian mountains, Grecnland: shores of the Arctic Sca, between the Mackenzie and Coppermine rivers, Aretic Islands; and of Siberia, at the mouth of the river Lena. S. plantaginif olia, llook. in Parry's $2 \mathrm{~d}$ voy, append. p. 39 \%. S. rigida, Christ. Smith, niss. S. uliginosa $a$, Fisch. in litt. 1529. S. nivàlis, var, racemòsa, Towns, itin. humg. p. 488 . t. 15. S. rotundifölia, Geners. elench. scap. no. 37\%. Micránthes hieracifölia, Haw. cnum. sax, p. 45. Leaves ciliated, with articulated hairs. Stem beset with glandular hairs, as well as the pedieels and calyxes. Bracteas lanceolate, obtuse, one under cach fascicle of flowers. Flowers small, of a brownish-bay colour.

Var. $\beta$, capitcllata (Ser. in D. C. prod. 4. p. 39.) flowers $\mathrm{fcw}$, somewhat capitate; leaves nearly entire; seape length of leaves. 4. H. Native of the Carpathian mountains, and the lsland of St. Lawrence. Micráuthes hírta, Haw. enum. sax. 1) 4.6.? S. uliginòsa $\beta$, atràta, Fisch. in litt.

Ilawknced-leared Saxifrage. Fl. May, Ju. Clt. 1789. Pl. $\frac{1}{2}$ to 1 foot.

98 S. Pennsylváxica (Lin. spec. 571.) leaves lanceolate, without petioles, sinuately denticulated, very hairy on both surfaces; scape branched; flowers disposed in corymbose heads, the whole forming a branched panicle; calycine segments ovate, acutish; petals linear, longer than the calyx. 24. H. Native of North America, in the states of New York and Virginia, in humid meadows; also of Canada, but rare. S. Caroliniàna and S. Marylándica, Hortul. S. palústris, Hort. engl. Link, enum. 1. p. 412. Micránthes Pennsylvánica, Hav, enum. sax. p. 45. -Dill. elth. 337.t. 253. f. 328. Leaves attenuated at the base. Scape beset with viscid hairs, and the pedicels and calyxes with glandular ones. Flowers of a squalid white colour.

lar. $\beta$, corymbifera (Michx. fl. bor. amer. 1. p. 269.) panicle loose ; flowers corymbose, distant.

Penusyleanian Saxifrage. Fl. Mlay, June. Clt. 1732. Pl. $1 \frac{1}{2}$ to 2 fect.

99 S. semipube'scess (Sweet, hort. suburb. p. 97.) leaves without petioles, oval-oblong, obtuse, quite glabrous, denticulated; scape branched; flowers in capitate corymbs, the whole forming a panicle; calycine segments ovate, acute; petals oval, about equal in length to the calyx, 4. H1. Native of North America. Mlicránthes semipubéscens, Haw. syn. succ. append. 321. S. Marylándica, Hortul. Micrántles hírta, llaw. enum. sax. p. 46. Stem beset with glandular hairs, as well as the calyxes and pedicels. Flowers small, yellowish.

Semi-pubescent Saxifrage. Fl. May, June. Clt. 3800. Pl. I to $]^{\frac{1}{2}}$ foot.

100 S. VIRGINIE'Nsis (Michx. f. bor. amer. 1. p. 269.) leaves ovate, acute, toothel, stalked ; calycine segments ovate, obtuse ; petals oval, with branched nerves; scape paniculately branched. 4. H. Native of Virginia, Carolina, and New England, on the mountains; also of Canada, near Montreal, and on the banks of the Saskatchawan. S. Virgíniea, Nutt. gen. amer. 1. p. 285. S. elongàta $\beta$, subspatulàta, Sternb. append. enum. sax. p. 4. Dermàsea pilòsa, Haw. enum. sax. j. 8.-Plık. alm. p. 331. t. 39 . f. 1. and t. 222. f. 5 . Leaves rather hairy on both surfaces. Scape beset with glandular hairs, naked above, dichotomously branched; branches elongated, ascending. Flowers disposed in unilateral spicate racemes, small, white. Pediccls numerous, 1-flowered, clothed with viscid down.

Virginian Saxifrage. Fl. May, Jul. Cle. 1790. Pl. $\frac{1}{8}$ foot.

101 S. verxa'Lis (Willd. hort. berol. t. 13.) leaves oblong or $\mathrm{F}$ f 
obovate, rather membranous, nerved, deeply crenate-toothed, tapering into the broad petiole; scape naked; flowers in panicled corymbs; calycine segments erect, obtuse; petals oblong, obovate, more than twice the length of the calyx. 4. H. Native of Canada, and to the mountains of the Columbia, and from Fort Vaneouver to the Kettle Falls. S. Virginiénsis, Torrey, fl. unit. stat. 1. p. 444. Flowers small, white, forming an imperfect corymb or thyrse. This species diflers from $S$. Virginiensis in the disposition of the flowers.

Far. a; flowers loosely panicled; seape longer. $\%$. H.

I ar. $\beta$; flowers compact, rather thyrsoid. 4 . H. Native on the banks of the Saskatchawan. General habit of $S$. nixalis.

$I^{\prime} a r . \gamma$, gracilis; corymb loose, few-flowered. 4. H. Native of North America. S. elongàta, Sternb. sax. p. 9. t. 4. Dermàsca elongàta, Haw. enum. sax. p. 9.

Spring Saxifrage. Fl. May, June. Clt. ? Pl. $\frac{1}{2}$ foot.

102 S. REFLE'XA (Hook, fl. bor. amer. 1. 1. 249. t. 85.) plant clothed with hoary down; leaves ovate, rather coriaceous, opaque, deeply serrated, tapcring into the petiole; scape naked; panicle quite glabrous, compact, corymbose; petals obovate, bimaculate; calyx reflexed. 4 . H. Native of North America, on the slores of the Arctic Sea, between the Mackenzie and Coppermine vivers. 'T'ogether with the harsh and rigid foliage of $S$. nivalis, the present species has a panjele more resembling that of $S$. verFIG. 45 . natlis; but the petals have 2 orange spots, similar to those of $S$. leucunthemifolia. The pubescence gives a whitish or hoary appearance to the whole plant, the panicle excepted; but as the pubescence is very variable in all the species of the present section, it camnot be depended upon. (f. 45.)

Reflexcd-calyxed Saxifrage. PI. $\frac{1}{2}$ foot.

109 S. integrifòlia (Hook. f, bor. amer. 1. p. 249. t. 86.) the whole plant clothed with clammy pubescence ; leaves radical, ovate, rather membranous, very blunt, quite entire, or sinuately crenated, reticulately veined; scape elongated, naked, panicled, at the apex; panicle loose, broad or contracted, bracteate; petals obovate, twice the length of the calyx, which is at first spreading, but at length reflexed; stamens short; styles diverging. 24. II. Native of the north-west coast of America, near the mouth of the Columbia. The leaves are short, in proportion to the beight of the plant.

Entire-leavel Saxifrage. Pl. $\frac{1}{2}$ to 1 foot.

104. S. NIVA'IIS (Lin. spec. p. 573.) leaves ovate or obovate, coriaceous, undulately crented, tapering into the broad petiole scape naked, simple; flowers in crowded heads; calycine segments erect, obtuse; pctals obovate, permanent, hardly one half longer than the calyx. 4. II. Native of Scotland, north of England, Lapland, on the loftiest mountains ; in North America, on the Arctie Sea-shore and islands, abundant ; Labrador, Canada, Spitzhergen, and the Rocky Mountains. In Britain, upon Snowlen, and on the summits of scveral hills about Snowden; on Ben Lawers, Clova, and other Highland mountains of Scotland; and near the top of Ben Lomond. Lightf. f. scot. with a figure. Smith, engl, bot. t. 410 . Sternb, in Sturm, deutselıl. fl. with a figure. S. congèsta, Haw. Dermàsea nivàlis, Haw. syn. sax. p. 9.-Lin. fl. stec. p. 176. t. 2. f. 5, 6.-Ray. angl. 3. 1. 354. t. 16. f. 1.-Oed. fl. dan. t. 28. Leaves glabrous above, villous beneath. Scape clothed with viscid hairs. Flowers disposed in crowded bracteate heads; bracteas ciliated.
Pedicels and calyxes clothed with viscid down. Petals white, but becoming reddish as they fade, triple-nerved; nerves simple. The American specimens of this plant are very variable in habit, and in many instances so closely approach the varieties of some of the preceding species, as hardly to be distinguished. It is therefore most casily to be recognised by its stiff and rigid habit, by the broad permanent petals, which remaining amongst the deep purple capsules form a singular contrast with them.

I ar. $\beta$, laxiflora; heads of flowers loose, branched.

Iar. $\gamma$, lènuis (Wahl. f. lapp. p. 113. Sternb. suppl. 1. p. 6.) flowers pedunculated, umbellately panicled. $4 . \mathrm{H} . \mathrm{Na}$ tive of Lapland.-Lin. fl. lapp. t. 2. f. 5. S. punctàta, Rottb. act. hafn. 10. p. 44.5. t. 10.

Snowy Saxifrage. Fl. June, July. Britain. Pl. $\frac{1}{4}$ foot.

105 S. Longíscapa (D. Don, in Lin. trans. 13. p. 388.) leaves ovate, serrated, on long petioles; thyrse of flowers ovate ; segments of the calyx ovate, acute; petals ovate, hardly longer than the calyx. 4. H. Native of Siberia. Leaves hairy. Scape filiform, beset with glandular hairs. Pedicels and calyxes downy. Flowers white. This plant scarcely differs from $S$. nivàlis var. $\gamma$, tèmuis.

Long-scaped Saxifrage. Pl. $\frac{1}{2}$ foot.

106 S. PA'LLIDA (Wall. cat. no. 450.) plant quite glabrous; leaves lanceolate, obtuse, obscurely crenated, petiolate; bracteas linear; flowers few, disposed in a loose panicle; pedicels filiform, longer than the fruit; petals obovate, longer than the calyx; calycine lobes lanceolate, length of tube, each terminated by a sessile gland? filaments clavate? cajsule rather bladdery, nerved, marked by minute elevated dots; stigmas sessile, thickish. 24.F. Native of Nipaul, at Gosaingsthan, Emodi, and Kamaon.

Pale Saxifrage. Pl. $\frac{1}{2}$ foot.

107 S. Danu'rica (Willd, spec. 3. p. 465.) plant quite glabrous; leaves cuneiform, on long petioles, attenuated at the base, coarscly and deeply serrated at the apex; flowers in loose panicles; calycine segments orate, acutc ; petals elliptic, acute. 4. I1. Native of Dahuria, on the tops of the Alps, near the limits of perpetual snow. In North America, at Behring's Straits; alpine rivulets of the Rocky Mountains, Kotzebue's Sound, and Bay of St. Lawrence. Leaves said to be pubescent ; the scape beset with glandular hairs, and the pedicels and calyxes clothed with clammy down. Petals white, marked with 2 yellow spots at the base. The broadly cuneate, or rather flabelliform leaves are very remarkable.

\section{Dahurian Saxifrage. Pl. $\frac{1}{2}$ foot.}

Sect. VIII. SAXIfragæ-VE'ræ (this section contains what are considered the true species of the genus). D. Don, in Lin. trans. 13. p. 345.-Daetyloìdes, Tausch, hort. canal. fasc. 1. D. C. prod. 4. p. 23.-Muscària and Saxífraga, Haw, enum. sax, p. 22-29.-Triplinérvium, Gaudin, fl. helv. 3. p. 116. Calyx 5-cleft (f. 46. $a_{\text {o }}$ ), erect, permanent, with the tube adhering to and involving the ovarium (f. 46. b.). Petals sessile, perigynous (f. 46.c.). Stamens perigynous (f. 46.d.); filaments flat, gradually attenuated. Stigmas spreading (f. 46.. .), flat, spatulate, bearded with short down. Capsule covered by the calyx (f. 46, b.), and closely adhering to it. Seeds obovate.-Perennial rarely annual, humble, densely tufted herbs, for the most part bearing surculi. Lcaves alternate, variously parted, rarely simple, usually green ; with the margins neither cartilaginous nor dotted. Stems leafy, few, or many-flowered. Flowers white or yellow, rarely red.

\$1. Perennial. Surculinumerous. Leaves undivided, rarely tridentate at the apex.

108 \$. Parnassifollia (D. Don, in Lin. trans. 13. p. 405.) stem erect, leafy, 3-t-flowered; leaves cordate, stem-clasping, 
glabrous; ealyeine segments ovate, mueronate; petals obovate, 5-nerved. 2. F. Native of Nipaul, on the Alps. Ilabit of plant referrible to Parnássia palustris. Stems numerous. Leaves ciliated with glandular hairs. Pedieels 1 -flowered, and are as well as the calyxes glandular. Flowers milk-eoloured. 'This is evidently only a small specimen of $S$. diecrsifólia var. $\beta$, parnassifolia, p. 209.

Parnassia-leated Saxifrage. Pl. $\frac{1}{3}$ foot.

109 S. Aхрrosi'ceA (Lin. spec. 571.) radical leaves crowded, elliptic or spatulate, obtuse, pilose, quite entire ; calycine segments obtuse; petals spatulate; stems nearly naked, usually ¿-flowered. 4 . I1. Native of Switzerland, Austria, and Carniola; and on the north-west coast of America. Jacq. anstr. 4. t. 389. Sternb. sax. 1) 4\%. t. 11. f. a. S. ciliaris, Lapeyr. ex Benth. cat. pyr. p. $11 \mathrm{~S},-\mathrm{H}$ all. itin. helv. no. 69. p. 292 , t. 2. S. androsicea $\gamma$, longifòlia, Gandin, fl. lielv, 3. p. 116.-Col. ecphr. 2. 1. 66. and 67. I'lant densely tufted. Stems beset with jointed glanduliferous hairs. Leaves hairy. Pedieels and calyxes clothed with viscid down. Flowers with white petals, and yellow filaments.

lar. $\beta$, tridentìta (Gandin, syn. sax. in Meisner, anz. $181 \mathrm{s.}$ p. 67. A. helv. 3. p. 115.) leaves cuneiform, more or less, 3-5tootlicl. 24. H. Native of the Alps, but rare. Sternb. rev. sax. t. 11. a. f. 4, and in Sturm, deutschl. fl. p. 33. no. 13. S. androsàcea trífida, Haw. enum. sax. p. 35. S. Pyrenàica, Scop. A. carn. no. 498. t. 16 . S. androsàcea trif òlia. Sternb. rev. sax. suppl. p. 11. t. 7. f. \&. S. tridens, Jan. in litt.

Androsace-like Saxifrage. Fl. May, Ju. Clt. 1792. Pl. $\frac{1}{4} \mathrm{ft}$.

110 S. spatula'ta (Desf. A. atl. 2. p. 342. t. 96. f. 2.) plant gemmiferous; surculi very leafy; leaves quite entire, spatulate, fringed; calycine segment ovate-oblong, obtuse; petals obovate; stem nearly naked, usually 2 -flowered. 2\% H. Native of Mount $\Lambda$ tlas, at the top near Belide. Antiphýlla spatulàta, Haw, enum. sax. p. 44. Plant densely tufted. Sureuli procumbent. Stems capillary, with a few short hairs, 1-3 or manyflowered. Pedicels and calyxes downy. Flowers with milkcoloured petals and yellowish filaments.

Spatulatc-leaved Saxifrage. Pl. $\frac{1}{8}$ foot.

111 S. SEDroides (Lin. spec. 572.) stems erectish; leaves linear-lanceolate, acute, glabrous ; peduncles elongated, capillary, 1-flowered; calycine segments ovate, bluntish; petals linear, mueronate, equal in length to the calyx. 4 . H. $\mathrm{Na}$ tive of the Alps of Carinthia, Carniola, Salisburgl, Pyrenees, Arragon, and Mount Baldo. Jacq. mise. 2. p. 134. t. 21 . f. 22. Sternb. sax. p. 27. t. 7. f. $\alpha$ and $\beta$, and t. 9. f. $\beta$, and in Sturm, deutschl. fl. fase. 35 . f. 10 . S. trichòdes, Scop. fl. earn. n. 496. t. 15. S. Hohenwártii, West. in Sternb. rev. sax. p. 26. t. 7. middle figure, and Sturm, deutsehl. A. fase. 3S. no. 6. f. $a_{\text {. }} \mathrm{S}$. Seguièrii, Sternb. rev: sax. p. 30. t.9. $\beta$. Spreng, cent. nov. in mant. hal. 46 . no. 38 . Gandin, fl. helv. 3. p. 112 . S. planifòlia $\gamma$, Seguièrii, Sternb. rev. sax. p. 30.t.9. b. S. angustifolia, Hall, fil. in Ser. herb. hort. no. 289. S. aphýlla, Tenore, f. neap. pr. append. 4. p. 21. but not of Sturm. S. androsàcea, Comoll. prod. p. 78. no. 507. but not of Lin. Plant tufted, pale green. Stem with a few scattered, glanduliferous hairs. Leaves ciliated witl glands. Peduncles 1-flowered, glandular. Flowers yellow.

Var. $\beta$, coloràta (D. Don, in Lin. trans. 13. p. 408.) petals and anthers purplish. 4 . H. Native of the Alps of Austria. S. Holenwártii $\beta$, purpuráseens, Sternb. sax. p. 26. t. 9. $\beta$. S. sedioides $\beta$, colorata, Sternb. rev. sax. p. 27. t. $9 . \beta$, f. 4 . and in Sturm, deutschl. A. p. 33. no. 6. b. S. sedioides $\beta$, Hohenwartiàna, Ser. in D. C. prod. 4. p. 23.

Stoncerop-like Saxifrage. Fl. May, Ju. Clt. 1820. Pl. $\frac{1}{8} \mathrm{ft}$.

112 S. TE'NERA (Sut. fl. helv. 1. p. 245.) surculi short, very leafy; leaves linear-oblong, obtuse, and are as well as the stems beset witl glandular hairs; calycine segments oblong-orate; petals obovate, retuse, excecling the calyx. 4. H. Native of the $\mathrm{A}$ ]ps of Switzerland, Piedmont, Pyrenees; and on Mount Cenis, Sternb. sax. p. 28. t. 9. f. 4. S. planifòlia, Lapeyr. A. pyr. sax. 1. 31. Sternb. sax. p. 28. t. 7. f. 3 . S. museoides, All. fl. pedem. no. 1528. t. 61 . f. 2 . exelusive of the synonymes. S. planifölia cítrina, Gaudin, syn. sax. in Meisner, anz. 1818. p. 66 . A. helv. 3. p. $113 . \alpha, \beta$. Ilant densely tufted. Sicms 1-3-flowered. Flowers crean-coloured, twice the size of those of $S$. sedioilcs. Easily distinguished from $S$. sedioides in the stems and leaves being densely beset with glandular hairs, and in the petals being obovate, retuse, and twice the length of the ealyx.

I ar. $\beta$, trifida (Gaudin, in Meisner, anz. p. 66. A. lielv. 3. p. 114.) some of the leaves trifid. 24. H. Native of Vallais, in the valley ealled Bagnes.

Tender Saxifrage. Fl. May, Jul. Clt. 1819. Pl. $\frac{1}{8}$ foot.

113 S. DEPRE'SSA (Sternb. rev. sax. 42, t. 11. a. f. 5.) stem roughish, few-flowered, furnished with 2 leaves, one of which is a little stem-clasping; leaves spatulate, entire, and cuneatcly tridentate at the apex, running in to the petiole at the base, rather seabrous beneath; petals hardly exceeding the ealyx, which is campanulate: calycine lobes triangular, broad. 24.H. Native of Italy, on Mount Alto. Haw. enum. sax. p. 31. It differs from $S$. androsàca, to which it is nearly allied, in the leaves running into the petiole at the base, and in the lower surface of the leaves being rouglish from short stiffish hairs, not pilose. Perhaps the same as $S$. androsicea $\beta$, tridentàta.

Depresscd Saxifrage. Fl. May, June. Clt.? Pl. $\frac{1}{8}$ foot.

114 S. ME'RKi1 (Fisch. in Sternb. rev. sax. 1. p. 1. f. 3.) stems tufted, usually 3-flowered; calycine segments ovate; petals obovate-roundish, longer than the calyx; capsule rather bladdery; styles parallel ; radical leaves rosulate, ovate or spatulate, entire, ciliated, glabrous: cauline ones smaller, few. 4. H. Native of Siberia, in humid places on Mount Jablonoi. Habit nearly of $S$. androsàcea, but differs in the eapsule being bladdery, much longer than the ealyx. Flowers white.

Merk's Saxifrage. Pl. $\frac{1}{8}$ foot.

115 S. cròces (Gaudin, syn. sax. in Meisner, anz. 1818. p. 70. A. lielv. 3. p. 133.) stems tufted, 3-5-flowered, covered with slort pubescence; terminal peduncle sessile: lateral ones very long, filiform; leaves linear-oblong, obtuse, or tridentate; calycine segments oblong-narrow, bluntish, clothed with clammy pubescence, longer than the tube; petals elliptic, bluntish, hardly equal in length to the calyx. 24. H. Native of Savoy, in the southern Alps. Muscària cròcea, Haw. cnum. sax. p. 38. Flowers copper-coloured.

Copper-coloured-flowered Saxifrage. Pl. $\frac{1}{8}$ foot.

$116 \mathrm{~S}$. Stexope'tala (Gaulin, syn. sax. in Meisner, anz. p. 70. A. luelv. 3. p. 132.) smoothish ; stems tufted, short; leaves cuneated and trifid, or spatulate and obtuse ; calycine lobes obtuse, nerveless; petals linear. 4. H. Native of Austria and Switzerland, about St. Gall. S. uniftòra and S. leptophýlla, Frælich. S. aphýlla, Sternb. sax. p. 40. t. 11. (3, and in Sturm, deutschl. f. p. 33. no. 11. with a figure. Muscària stenopétala, Haw. enum. sax. p. 39. S. muscoìdes, Wabl. carp. p. 122. Lower leaves usually trifid. Flowers yellow.

Narrow-petalled Saxifrage. Fl. May, June. Clt. Pl. $\frac{1}{8} \mathrm{ft}$.

\section{\$2. Percnnial. Sureuli numerous. Leaves 3-5-parted, petiolate.}

117 S. geranioides (Lin. spec. 578.) leaves reniform, 3-5lobed, pubeseent, on loug petioles: segments cuneated, deeply toothed; panicle coarctate, many-flowered; calycine segments linear-lanceolate, obtuse, reflexed; petals oblong, flat. $4 . \mathrm{H}$. Native of the Pyrences. Lapeyr. pyr. sax. p. 66. t. 4. S. paniculàta, Selıleich. cat. 1821. S. quinquéfida, Lam. f. fr. 3. F $\mathrm{f} 2$ 
p. 539.-Gouan, ill. p. 28. t. 18, f. 2. Plant tufted. Surculi reddish, stiff. Stems red, beset with glanduliferous hairs. Bracteas lanceolate, obtuse. Flowers campanulate, white; filaments yellowish. Pedicels and calyxes clothed with clammy down.

l'ar. (3, obtusíloba (Ser. in D. C. prod. 4. p. 30.) plant hardly pilose ; lobes and lobules of leaves hardly toothed ; flowers subumbellate; bracteas linear. 4 . $H$. Native of Switzerland. \$. geranioides, Schleich. cat. 1822. p. 63.

Geranium-like Saxifrage. Fl, Apr. May. Clt. 1770. Pl. $\frac{1}{2} \mathrm{ft}$. 118 S. rrrígua (Fisch. hort. gorenk. Spreng. cent. spec. min. cogn. p. 36.) radical leaves palmately 5-parted: cauline ones trifid, sessile; segments cuneate-oblong, mucronate, trifid; panicle loose, many-flowered; calycine segments linear, acute; petals spatulate. 2 . or $\delta$. H. Native of Tauria, among rocks, at the Salghir fountains; and of Siberia, especially in bogry fields, from the Aldan to the Urak, and among rocks, on the banks of the Jaika. Bieb. cent. pl. rar. ross. 2. t. 73. Sims, bot. mag. 2207. S. petræ'a, I'all. ind. taur. Habl, taur. p. 147. S. aquática, Bieb. fl. taur. 1. p. 317 . exclusive of the synonyme of Lapeyr. and Persoon. S. geranioides $\beta$, irrígua, Ser. in D. C. prod. 4. p. 30. Plant rather larger than the preceding, nuch softer and looser, without any surculi. Stems green, beset with jointed hairs. Petioles villous, viscid. Bracteas palmate. Flowers large, campanulate, white; filaments green ; anthers yellow. Peduncles and calyxes clothed with viscid villi.

Plushy Saxifrage. Fl. Ju. Jul. Clt. 1817. Pl. $\frac{1}{2}$ to 1 foot.

119 S. M.MERE'Nsts (D. Don, in Lin. trans. 13. p. 4.14.) surculi woody; leaves crowded, cuneiform, on long petioles, acute at the base, unequally and deeply lobed at the apex; calycirie segments broadly ovate, acute. 4. F. Native of Madeira. Plant densely tufted. Stems numerous, ascending, fikform, few-leaved, and few-flowered, beset with scattered glanduliferous hairs; lobes of leaves short, ovate, acute: uppermost cauline leaves undivided, acute. Petioles filiform, terete, ciliated. Pedicels and calyxes clothed with clammy down.

Madeira Saxifrage. Pl. $\frac{1}{4}$ foot.

120 S. PEDAtífida (Ehrh. exsic. no. 15. Smith, in Lin. trans. 10. p. 31\%.) radical leaves reniform, pedatifid, clothed with clammy villi: segments linear-lanceolate, acute; panicle fastigiatc; calycine segments linear-lanceolate, mucronate; petals narrow, spatulate. $4 . H$. Native of the Alps of Switzerland and the Pyrences; and on rocks in the highlands of scotland, especially on the Clova mountains, Angus-shire. Smith, engl. bot. 1278. S. quinquéfida $a$, Lam. A. fr. 2. p. 533. Donn, hort. cant. ed. 5. p. 137. S. frágrilis, Schrank, hort. mon. t 99. s. ladanífera $\beta$ pinnatífila, Duby, in bot. gall. 1. p. 210 . S.geranioides i pedatífida, Ser. in D. C. prod. 4. p. 30. Plant growing in dense conical tufts. Stems erect, red, smoothish. Petioles villons, compresscd, dilated at the base. Radical leaves 2.3cleft; lateral segments $2-3$-cleft: middle one cuneately trifid or entire; lobes linear-lanceolate, acute, awned. Lower cauline leaves tripartite, with linear entire lobes: upper cauline ones entire, narrow. Flowers white, smaller than those of S. geranioides; filaments yellowish green.

Pedatifid-leaved Saxifrage. Fl. May, June. Scotland. Pl. $\frac{1}{4}$ to $\frac{1}{2}$ foot.

121 S. viscòsa (Iaw. in misc. nat. 164. enum. sax. p. 26.) stems hairy; ralical leaves pedatifid: of the surculi, which are erect, 3-5-cleft : cauline ones trifil and lanceolate, 3-ncrved. 2 H. Native country unknown. Allied to $S$. geranioides and $S$. pedatifida, but much smaller and more clammy. Flowers white.

Clammy Saxifrage. Pl. May, June. Pl. $\frac{1}{4}$ to $\frac{1}{2}$ foot,

122 S. ceratopny'Lla (Dryander, in hort. kew. 3. p. 70.) surculi woodly; leaves 2-8-parted, petiolate, stiff; glabrous: segments subulate, with horny mucrones; stems clammy; calyx brownish, glabrous: with ovate segments, which are furnished each with a recurved mucrone at the apex; petals oblong. $\psi$. H. Native of Spain. Sims, bot. mag. 1651. S. trifurcàta, Schrad. hort. goett. fasc. 1. p. 13. t. 7. S. petre'a, Pavon. herb. Plant densely tufted, quite glabrous. Stems reddish at the base, covered with viscid juice. Petioles naked, channelled above. Flowers snow white, disposed in a loose branched panicle. Pedicels and calyxes covered with clammy juice.

Horn-leaved Saxifrage. Fl. May, June. Clt. 1804. Pl. $\frac{1}{4}$ to $\frac{1}{2}$ foot.

123 S. obtusífina (D. Don, in Lin. trans. 13. p. 416.) surculi woody; leaves 3-parted, stiff, and smooth, as well as the very narrow petioles; segments linear, very blunt; calyxes pubescent, with ovate obtuse segments; petals obovate. 2 . $\mathrm{H}$. Native of Spain. Plant densely tufted, quite glabrous, deep green. Stems few-leaved. Lateral segments of leaves lengthened, and usually bifid. Pedicels 1-flowered, pubescent. Flowers campanulate, white. Petals triple-nerved: nerves 2 -3-forked at the apex.

Blunt-cleft-leaved Saxifrage. Pl. $\frac{1}{3}$ foot.

124. S. AJUG Fòlia (Lin. amon. acad. 4. p. 271 .) surculi procumbent; leaves 5-parted: segments lanceolate, mucronate ; stem branched; calycine segments ovate, mucronate; petals flat, obovate. $\%$. H. Native of Provence, on the mountains, and of the Pyrenees. Lapeyr. pyr. sax. p. 56. t. 31. Sternb. sax. p. 46. Plant green, furnished with a few viscid hairs, which are more dense on the petioles: densely tufted at the time of flowering, but growing in a loose manner afterwards. Surculi long, reddisb, as well is the base of the stems. Leaves glabrous, but ciliated: cauline ones undivided, lanceolate. Flowers large, campanulate, white. Calyx heset with glanduliferous hairs. Petals triple-nerved: nerves simple.

Var. $\beta$, Aitònis (Haw. enum. sax. p. 29.) leaves of the prostrate stolons 3-5-cleft, soinewhat pedate; segments linear-lanceolate, awned, twice the length of the petioles. 4. H. Native of the mountains of Provence. S. ajugaf olia, Ait. hort. kew. ed. 2. vol. 3. p. 70 . S. ajugæf òlia $\delta$ lóngipes, Haw. 1. c.

Var. $\gamma$, fimbriata (Ser. in D. C. prod. 4. p. 28.) sepals and petals jagged. 4 . H. Native of the Pyrenees. Ramond, in D. C. Al. fr. 4. p. 372. in a note.

Ajuga-leaved Saxifrage. Fl. May, July. Clt. 1825. Pl. $\frac{1}{2} \mathrm{ft}$. 125 S. Affínis (D. Don, in Lin. trans. 13. p. 418.) surculi procumbent; leaves 5-parted: segments linear, mucronate; calycine segments linear, an ned; petals oblong, with inflexed elges. 24. H. Native of Ireland, as on the top of Brandon mountains, county of Kerry. Plant beautiful green, furnished with soft and viscid hairs, densely tufted before flowering, but afterwards loose. Surculi elongated, reddish. Stems shining, smooth, few-flowered. Leaves of the surculi for the most part 3-parted. Pedicels and calyxes clothed with viscid down. Flowers white, smaller than those of $S$. ajugafolia. Petals triple-nerved: nerves simple.

Allied Saxifrage. Fl. May, June. Pl. $\frac{1}{3}$ foot.

126 S. CAPıTA'tA (Lapeyr. fl. pyr. p. 55. t. 30.) stems thickish, prostrate, hardly pilose; leaves cuneated, 3-5-cleft, rather fleshy, nerved, crowded towards the tops of the surculi: lobes ovate, rather parallel; calycine lobes ovate-lanceolace, bluntish, length of tube when in flower; petals obovate, much longer than the calyx; styles very long, spatulate. 4 . H. Native of the Pyrenees. S. ajugæe òlia $\beta, D$. C. Al. fr. 4. p. 371. Sternb. rev. sax. p. 26. Petals white, 3-nerved above the base, lateral nerves confluent. Very like $S$, ajugafolia, but differs in the leaves being thicker and denser.

C'apitate-flowered Saxifrage. Fl. May, June. Pl. $\frac{1}{2}$ foot.

127 S. PENTAda'ctyls (Lapeyr. A. pyr. sax. p. 64. t. 40.) surculi short, erect; leaves on long petioles, glabrous, 5 -parted: 
segments linear, obtuse, ribbed beneath; calycine segments lanceolate, acute; petals obovate, with branched nerves. $4 . \mathrm{H}$. Native of the Pyrences. Herb glabrous, pale green, denscly tufted. Stems branched, terete, glabrous, flexuons. Petioles long, compressed, glabrous. Flowers white, disposed in loose panicles.

I'ar. (3, corymbòsa (Ser. in D. C. prod. 4. p. 30.) flowers numerous, in dense corymbs; peduncles more rigid and shorter.

Var. $\gamma$, capilellìta (Sicr. l. c.) Howers somewhat capitate; peduncles very short.

Five-fingered-leaved Saxifrage. Fl. May, June. Clt. 1815. Pl. $\frac{1}{4}$ to $\frac{1}{2}$ foot.

128 S. Latrífida (D. Don, in Lin. trans. 13. p. 420.) surculi erect, short; radical and sureuline leaves broadly cuneated, glabrous, 3-5-lobed: lobes broadly ovate; calyx glabrous, with ovate-lanccolate mueronulate segments; petals spatulate, with simple nerves. 4. H. Native of Spain. S. adseéndens, Pavon, herb. Plant quite glabrous, pale green, tufted. Stems many leaved, many flowered. Lower cauline leaves like the radical ones, but more profoundly lobed : lobes lanceolate; upper cauline leaves undivided. Peduncles elongated, 2-flowered. Flowers white.

Broad-clefl-leaved Saxifrage. Pl. $\frac{1}{2}$ foot.

129 S. DECí PIExs (Ehrl. beitr. 5. p. 47.) plant very villous ; leaves 5 -cleft or trifid: segments ovate-oblong, obtuse, mutic; calycine segments triangularly ovate, obtuse, mutic; petals orbicular. 2. H. Native of Germany and Bohemia, in exposed rocky places. In North Wales on the rocks of Cwn Idwell. In Ireland on the Galty mountains of Tipperary. Sternb. sax. p. 55 . t. 23. S. cæspitòsa, Oed. fl. dan. t. 71. S. petræ'a, Roth. tent. 1. p. 184 . With. brit. p. 890 . S. palmàta, Smith, brit. 2. p. 456. engl. bot. t. 455. Lapeyr. A. pyr. sax. p. 64. t. 41. S. villòsa, Willd, enum. 462. S. cæespitòsa, Smith, engl. fl. 2. p. 273. S. rupéstris, Schleich. eat. 1821. S. Lapeyroìii, Sternb. rev. sax. p. 51. S. decípiens lirsuta, Haw enum. sax. p. 31. S. decípiens canéscens, Haw. l. c. S. intermèdia, Tausch, ex Link, enum. 1. p. 415 . S. Steinmánnii, Tausch, hort. canal. fasc. 1. with a figure. S. hypnoides villosa, Arn. et Ser. in D. C. prod. 4. p. 32. Plant canescent, densely tufted before flowering, but afterwards beconing loose, and the surculi elongated and procumbent. Lowcr cauline leaves usually tripartite, upper eauline ones undivided. Stems many flowered. Flowers large, spreading, milk-coloured. Petals triplc-nerved: nerves simple.

Deceicing Saxifrage. Fl. May, June. Wales. Pl. $\frac{1}{2}$ foot.

130 S. Hírta (Donn, eant. ed. 5. p. 107.) plant very villous; radical leaves 5 -cleft: surculine ones trifid : segments ovatelanceolate, acute; calycine segments triangularly ovate, acute; petals obovate. $\psi$. H. Native of Ireland, among alpine rocks, western highlands of Scotland, and Wales; as on the Galty mountains, Tipperary; in the west part of Scotland; near Twll du in Cwn Idwell, also on the walls of Dolwyddelan castle, betwixt Capel Cory and Llandwst, North Wales. Smith, engl. bot. 2291. Plant canescent, densely tufted before flowering, but afterwards loose, with the surculi decumbent and flexuous. Stem many leaved, few-flowered, clothed with viscid hairs. Petioles dilated. Lower cauline leaves 3-parted, with linear segments: upper ones undivided. Flowers white, smaller than those of $S$. decipiens. Pedicels and calyxes elothed with glandular hairs. Petals triple-nerved: nerves simple.

Hairy Saxifrage. Fl. May, June. Ireland. Pl. $\frac{2}{4}$ to $\frac{1}{2} \mathrm{ft}$.

191 S. Platipe'tala (Smith, in Lin, trans. 10. p. 891 .) plant villous; sureuli elongated, prostrate; leaves $3-5$-parted: segnients linear, acute, and awned; ealycine segments ovate, mucronate; petals orbicular. 4 . H. Native of the Alps of Scotland and Wales; as upon Snowdon in Wales; and the Clova mountains in Angus-shire, Scotland. Smith, engl. bot. 2276.
S. recúrva, Schleieh. cat. 1821. S. hypnoides rhodopétala, Iaw. cnum. sax. p. 32. Plant densely tufted before flowering, but afterwards loose. Stems leafy, many flowered. Upper eauline leaves undivided. Flowers rather large, milk-coloured. Peduncles and calyxes clothed with glandular down. Petals red at the apex when in the bud, triple-nerved: lateral nerves ineurved, a little branched, middle one straight and simple.

Broad-pctalled Saxifrage. Fl. June. Britain. PI. $\frac{1}{2}$ foot.

132 S. incurvifòlı (D. Don, in Lin. trans. 13. p. 423.) plant smoothish; radical leaves 5 -eleft, sureuline ones trifid: segments lanceolate, obtuse, incurved; calycine segments ovate, acute; petals roundish, emarginate. 4. 11. Native of Ireland, on alpine roeks. $\mathbf{S}$. ineúrva, Mackay in litt. Plant green, densely tufted, glabrous at the time of flowering, but furnished with long viscid villi afterwards. Surculi short, erect. Stems leafy, 2-3-fiowered. Radieal leaves aggregate: upper eauline ones undivided. Petioles dilated. Flowers white. Pedicels and calyxes furnished with glanduliferous laairs. P'etals triple-nerved: nerves simple.

Incurced-leaved Saxifrage. Fl. MLay, June. Ireland. Pl. I ft.

139 S. DENUdA'ta (D. Don, in Lin. trans. 13. p. 424.) plant quite glabrous; radical leaves 5-cleft, surculine ones 3-parted: segments linear-subulate, acute, mucronate; calycine segments lanceolate, mucronulate; petals obovate, emarginate. $\mathcal{\psi}$. H. Native of Scotland, on the Clova mountains in Angus-shire. Herb pale green, growing in small dense tufts. Sureuli short, crowded, very leafy. Stems erect, few-leaved, 2-flowered, purplish, beset with glanduliferous hairs. Upper cauline leaves undivided. Flowers campanulate, white. Petals 3-nerved: nerves simple; filaments greenish rellow.

Naked Saxifrage. Fl. May, June. Scotland. Pl. $\frac{1}{8}$ foot.

134 S. Sternbérgit (Willd. enum. p. 462.) plant glabrous; radieal leaves 5 -cleft, palmatifid, those of the surculi trifid or undivided: lobes ovate, acute, mutic; calycine segments ovate, mueronate; petals obovate, with branched nerves. $\%$. H. Native of Germany, about Norimberg. Sternb. sax. p. 56. t. 24. S. palmàta, Pauz. in Sturm. deutschl. f. p. 26. half. t. 10. f. 2. S. decípiens contravérsa, Haw, enum. sax. p. 32. S. contravérsa, Hortul. but not of Sternb. S. elongàta, Panz. fl. norimb. mss. S. decipiens, Sieb. exsic. S. hypnoides latífida, Haw. enum. sax. p. 39. S. uniflòra, Sternb. rev, sax. suppl. p. 13. t. 9. S. intermèdia $a$, Gaudin, fl. helv. 3. p. 121. S. hypnoìdes $\eta$ Sternbérgii, Ser. in D. C. prod. 4. p. 32. Plant pale green, densely tufted. Sureuli very short, crowded. Stems $2-3$, rarely 4-flewered. Cauline leaves all undivided, cuneated, acute. Flowers large, white. Pedicels and calyxes beset with short glanduliferous hairs. Petals triple-nerved: nerves flexuous, much branclied.

\section{Sternberg's Saxifrage. Fl. May, June. Pl. $\frac{1}{3}$ foot.}

135 S. Pulehélla (D. Don, in Lin. trans. 13. p. 426.) plant glabrous ; radical leaves 5 -cleft, surculine ones trifid: seuments linear, obtuse, mucronate; ealycine segments broadly ovate, obtuse; petals orbicular, with branehed nerves. 4. H. Native of Germany. Herb deep green, densely tufted, furnished with a few glanduliferous hairs at the time of flowering. Sureuli short, erect. Stems 2-3-flowered, beset with a few glanduliferous hairs. Lower cauline leaves digitately 5-parted: upper ones 3-parted. Flowers milk-coloured, size of those of the preceding species. Pedicels and calyxes clothed witl glandular down. Petals triple-nerved.

Neat Saxifrage. Fl. May, June. Clt. 1S18. Ml. $\frac{1}{4}$ foot.

136 S. TRIDENTA'TA (D. Don, in Lin. trans. 13. p. 4.26.) plant glabrous; radical leaves 5 -cleft, surculine ones on long petioles, acutely tridentate; calyeine segments triangularly ovate, mucronate; petals spatulate. 4. H. Native country unknown. Herb densely tufted, quite glabrous before flowering, but fur- 
nished with some viscid villi afterwards. Surculi very sliort, very leafy. Stems erect, few-leaved, few-flowered, purplish, beset with glanduliferous hairs. Petioles slender, ciliated. Pedicels and calyxes clothed with viscid down. Pctals triplenersed: nerves simple. Flowers white; filaments green.

Tridentate-leaved Saxifrage. Fl. May, June. Pl. $\frac{1}{4}$ foot.

137 S. ANDícola (D. Don, in Lin. trans. 13. p. 427.) plant very villous; radical leaves trifid: segments lanceolate, acute : upper surculine leaves linear, sinuple, acute; calycine segments ovate, acute; petals obovate-orbicular, with branched nerves. 4. F. Native of Peru in very cold places on Mount RucuPichincha, at the elevation of 4000 or 5000 feet. H. B. et Kunth, nov. gen. amer. 6. p. 48. t. 519. S. villòsa, Pavon, mss. S. Cordilleriàna, Presl, in Hænk. rcliq. 2. p. 55. Plant densely tufted. Surculi slort, decumbent. Stems exect, leafy, 3-4flowered, clothed with viscid villi. Lower cauline and surculine leaves 3-parted. Flowers milk-coloured, subcorymbose. Calyx densely clothed with glandular hairs.

Andes Saxifrage. PI. $\frac{1}{8}$ foot.

138 S. cæspıtòsa (Lin. spec. 578.) radical leaves aggregate, 5-3-parted or undivided: segments linear-lanceolate, obttise; stems few-leaved, few-flowered; calycine segments ovate, obtuse; petals obovate-roundish, connivent. $4 . H$. Native of the Alps of Lapland, Sweden, Switzerland, Norway, and the Pyrences ; also of the north-west coast of America, Kotzebue's Sound, Arctic sea-shore, and of Greenland. In Wales and Ireland on the loftiest mountains; on the rocks of Troll dû Cwn Idwell, North Wales; on the lofty summits of Brandon mountains, county of Kerry. Gum. fl. norv, no. 1017. t. 7. f. 3. Smith, engl. bot. t. 794. S. Grœnlándica, Lin. spec. p. 578. Gunn. A. norv. p. 659. t. 7. f. 1. Lapery, pyr. sax. p. 39. t. 19.-Dill. elth. p. 337. t. 353. f. 329. Muscària caspitòsa, Haw. enum. sax. p. 37. Plant densely tufted, beset with glanduliferous hairs. Surculi short, very leafy. Stems 1-3-flowered, but in cultivation usually 4-flowcred. Lower cauline leaves palmate, upper ones for the most part 3-parted. Pedicels and calyxes clothed with viscid down. Flowers rather large, milk-coloured; filaments yellow; petals triple-nerved; nerves simple : lateral ones curved.

Tufted Saxifrage. Fl. June, July. Wales, Pl. $\frac{1}{8}$ foot.

139 S. univiona (R. Br. in Parry's first voy. append. p. 275. but not of Sternb.) radical leaves aggregate, trifid : cauline ones linear, undivided, distant; stem one-tlowered, and is, as well as the inferior ovarium, viscid; down glandular, very short; calycine segments obtuse; petals obovate-oblong. $\%$. H. Native of the Arctic Islands. S. caespitòsa, R. Br. in Ross' voy. ed. 2. vol. 2. p. 192. S. cæspitòsa $\beta$ uniflòra, Hook. Al. bor. amer. 1. p. 244. S. venòsa, Haw. enum. sax. p. 28. ? Flowers inilk-coloured.

One-flonered Saxifrage. Pl. $\frac{1}{8}$ foot.

140 S. stella'ta (Pavon, mss. ex D. Don, in Lin. trans. 13. p. 430.) leaves very numerous, adpressedly imbricated, 5-cleft or trifid: segments linear-oblong, obtuse; stem few-flowered; calycine segments ovate, acute; petals obovate. 24. F. Native of Peru, on the Andes in very cold places. Plant densely tufted. Habit of Fragòsa tomentòsa, beset with glanduliferons hairs. Stems erect, 2-flowered. Cauline leaves simple, obtuse. Petioles dilated. Flowers largish, milk-coloured. Calyx clothed with glandular down; petals obovate, triple-ncrved: nerves simple.

Strllate Saxifrage. Pl. 1 inch.

1.1 S. Bonplı́ NDI (D. Don, in Lin. trans. 13. p. 431.) plant puliescent; leares crowded, 5 -cleft or trifid: scgments linear, obtuse; calycine scgments lanceolate, acute; petals obovate. 4. H. Native of the Cordillera of Pern, in cold places. S. Peruviàna, Bonpland in Sternb. sax. p. 55. t. 22. S. Cordilleriàna $\beta$ Bonplándii, Presl, in reliq. Haenk. 2. p. 55 . S. al- pina, Pavon, mss. Plant densely tufted, beset with slıort glanduliferous hairs. Surculi sliort, very leafy. Stems clothed with glandular tomentum, as well as the calyxes, few-leaved. Lower cauline leaves 3-parted: upper cauline ones undivided, linearlanceolate. Petioles narrow, short. Flowers white, terminal, nearly sessile, by threes, rarely solitary; petals triple-nerved: nerves simple.

I $a r$. $\beta$, Ilacnkci; leaves densely glandular, 3-5-lobed: lobes ovate; surculi nearly globose; corymbs 6-10-flowered. 4 . F. Native in valleys on the Cordillera of Peru. S. Cordilleriàna var. $\gamma$ Hr'nkei, Presl, in Hænk. reliq. 2. p. 55.

lar. $\gamma$, láxa; stems elongated; leaves densely glandular, 35 -lobed, loosely imbricated: lobes ovate; surculi cylindrical, loose; corymbs many flowered. 4. F. Native of the Cordillera of Peru, in valleys. Petals white. S. Cordilleriàna ó láxa, Presl, in Hank. reliq. 2. p. 55.

Bonpland's Saxifrage. Pl. 1 inch.

142 S. Magella'Nica (Poir. dict. 6. p. 686.) stems tufted, procumbent; leaves linear or trifid, much crowded, glabrous; floriferous branches naked, axillary, very short, 1-flowered. 4 . F. Native of the Straits of Magéllan. Muscària Magellánica, Haw. enum. sax. p. 38. Plant tufted. Stems leafy. Lower leaves trifid. Flowers solitary, on short peduncles. Segments of the calyx linear, obtuse. Petals obovate, twice the length of the calyx.

Iar. a, integrifolia (Ser. in D. C. prod. 4. p. 24.) leaves spatulate, usually entire : upper ones puberulous: lower ones glabrous.

Far. $\beta$, triloba (Ser. l. c.) leaves all cuneated, 3-lobed at the apex, clammy. 24. F. S. Magellánica, Sternb. rev. sax. p. 39. t. 11. f. 1 .

Magellan Saxifrage. P1. $\frac{1}{8}$ foot.

143 S. Laneeola't (Haw. syn. succ. p. 324. enum. sax. p. 240.) leaves glabrous, ciliated; those of the surculi palmately 7-cleft: those of the stolons, which are very short and erect, 35-cleft: cauline leaves lanceolate; petals roundish, obovate. 4. H. Native of the Alps of Europe. Flowers white.

I ar. $\beta$, minor (Haw. enum. sax. p. 24.) leaves trifid and entire : lower cauline ones lanceolate-spatulate; petals oblong-cuneiform, distinct. 4 . H. Two or three times smaller than the species, and the leaves and petioles are very different. Haw. 1. c.

Iar. $\gamma$, obtìsa (Haw. 1. c. p. 24.) Jeaves cuneiform at the base or obovate: those of the rosula deeply 1-5-toothed, and brownish: those of the stolons usually abortive: lower cauline leaves elliptic; petals orbicularly obovate. $4 . \mathrm{H}$.

Lanceolate. leaved Saxifrage. Fl. May, June. Clt. 1800. Pl. $\frac{1}{4}$ to $\frac{1}{2}$ foot.

144 S. Dıспо'тома (Willd. in Sternb. sax. rev. p. 51.) radical leaves reniformly cordate, palmately parted: segments linear; cauline leaves nearly sessile, cumeated, 3-5-parted; flowers in dichotomous panicles; peduncles and calyxes pilose; calycine lobes lanceolate, acnte, length of the tube. 4 . H. Native of Spain. Haw. enumı. sax. p. 27. Flowers white.

Dichotomous Saxifrage. Pl. $\frac{1}{4}$ to $\frac{I}{2}$ foot.

145 S. exara'ta (Vill. dauph. 4. p. 674. t. 45.) plant pubescent ; radical leaves 5 or 3-parted: those of the surculi 3 parted: segments linear, very blunt, engraven above; stem many flowered; calycine segments ovate-oblong, obtuse; petals obovate, with simple nerves. 24. H. Native of the Alps of Daupliny, Savoy, Piedmont, and the higher Pyrences; also of Nortl America : frequent on the Rocky Mountains between lat. $52^{\circ}$ and $56^{\circ}$. S. nervòsa, Lapeyr. pyr. sax. p. 63. t. 39 . S. hypnoides, All. pedem. no. 1538 . t. 21 . f. 4 . S. intermèdia, Gaudin, fl. helv. 3. p. 122. S. striàta, Hall. fil. in herb. Gaudin, l. c. p. 129.? Plant densely tufted before flowering, afterwards 
loose and surculose, densely clothed with glandular down, Surculi stiflish. Cauline leaves profoumdly 3-parted, with the lateral segments generally bifid. I'etioles linear, flat. Pedicels filiform, 1-flowered, furnished each with a tripartite bractea at the base. Flowers white; filaments ycllow.

I ar. $\hat{\beta}$, pubésecns (D. Don, in Lin. trans. 13. p. 439.) radical and surculine leaves deeply 3-parted: lateral segments bifid; flowers on long peduncles, corymbose. 4 . H. Native of the Pyrenees and Newfoundland. S. pubéscens, Poir. act. toul. 3. p. 327. D. C. prod. 4. p. 27. S. míxta a and $\beta$, Lapeyr. pyr. sax. p. 41. t. 21. S. cæspitòsa, Vill. dauph. 4. p. 672 . S. moschàta, Lapeyr.

I"ar. $\gamma$, intricàta (D. Don, I. c.) radical leaves crowded, spreading, cuneated, 5-cleft; peduncles divaricate. $4 . H$. Native of the Pyrences. S. intricàta, Lapcyr. sax. pyr. p. 58. t. 39 .

Var. ¿, Prostiàna (Ser, in Benth. cat. p. 118.) stems fewflowered; leaves rosulate, sliort, reflexed: with short obtuse lobes, which hardly diverge; cauline leaves entire. $4 . \mathrm{IJ} . \mathrm{Na}-$ tive about Melda, Alps of Dauphiny, and on the Pic St. Loup, near Montpelier. S. míxta, Lapeyr. fl. pyr. t. 20. S. pubéscens $\gamma$ and $\delta$, D. C. fl. fr. 4. p. 375 .

Engraten-leaved Saxifrage. Fl. May, June. Clt. 1818. Pl. $\frac{1}{4}$ to $\frac{1}{2}$ foot.

146 S. Pavònı (D. Don, in Lin. trans. 13. p. 434.) plant pubescent; leares 3-parted: segments linear, acute, nerved; petioles linear, dilated, ribbed beneath ; calycine segments linearlanceolate, acute; petals obovate, with simple nerves. $4 . \mathrm{F}$. Native of the Andes of Peru, in very cold places. Herb growing in dense flat tufts. Surculi short. Stems few-leaved, 3-5flowercd, covered with short glandular hairs. Upper cauline leaves simple, linear, all the rest tripartite. Petioles linear, dilated. Peduncles and calyxes densely clothed with short glandular down. Flowers milk-coloured, fading to a yellowish colour.

Paron's Saxifrage. Pl. $\frac{1}{4}$ to $\frac{1}{2}$ foot.

147 S. Pedemonta'na (All. ped. no. 1540. t. 21. f. 6.) plant pubescent; leaves crowded, cumcatedly spatulate, engraven above, cut in a ligitate manner : segments linear-oblong, entire or triclentate; flowers corymbose ; segments of the calyx linear and elongated, acute; petals oblong-spatulate, with simple nerves. $\%$. H. Native of the Alps of Piedmont and Hungary. S. heterophy'lla, Sternb. sax. p. 50. t. 20. f. 1. and 2. S. cervicórnis, Viv. fl. cors. prod. append. p. 2. S. cymòsa, Waìdst. et Kit. loung. p. 91. t. 83 . S. Pedemontàna $a, \beta$, and $\gamma, D, C$. prod. 4. p. 29. Plant densely tufted. Surculi short. Stems many flowered, clothed with clammy down. Flowers large, campanulate, white. Calyxes and pedicels clothed with short riscid down.

Piedmont Saxifrage. Fl. May, June. Pl. $\frac{1}{4}$ to $\frac{1}{2}$ foot.

148 S. Qui'seuenens (Haw. syn. succ. p. 325. and enum. sax. p. 30.) naked; leaves of the twiggy surculi $3-5$-cleft, remote, length of the internodes; lobes subulatc, awned, equal in length to the petioles, which are ciliated; petals orbicular. $\psi$. H. Native country unknown.

Five-toothal-leaved Saxifrage. Fl. May, June. Pl. $\frac{1}{4}$ to $\frac{1}{2} \mathrm{ft}$. 149 S. Panicula'ta (Hort. madr. ex Horn. hort. hafn. 1. p. 402.) leaves glabrous, 3-parted : lobes trifid, linear; cauline leares tripartite, with entire lobes; stems ascending. $2 . H$. Native of Spain.

Panicled Saxifrage. Pl. $\frac{1}{4}$ foot.

150 S. Moscin't (Wulf. in Jacq. misc. 2. p. 128. t. 21. f. 2.) plant pubescent ; radical leaves trifid : surculine ones trifid or undivided, nerved; segments linear, acutish; stems filiform, somewhat raccmose; petals narrow-oval, hardly excecding the caly. 4. H. Native of the Alps of Carintlia, Carniola, Savoy, Salis- burgl, and the Pyrenecs. Lapeyr. pyr. sax. p. 61. t. 37. Stcrub. sax. p. 41. t. 11. f. 3 . S. cæespitòsa, Scop. carn. p. 494. t. 14. S. exirdata, All. pedem. no. 1539. f. 2. S. muscoides $\lambda$ prostràta, Gaudin, f. lıclv. 3. p. 131. and Ser. in D. C. prod. 4. p. 20. S. muscoides, Sternb. sax. p. 39. t. 11. f. 2. exclusive of var. $\beta$. and $\gamma$, and the synonyme of Smith. Plant densely tufted before flowering, smoothisl, but afterwards loose and surculose. Surculi erect, elongated, slender. Stems filiform, 3-5-flowered, rather naked. Petioles lincar, with a furrow. Flowers subracemose, on short pedicels, which are furnished each with a tripartite leaf at the base. Calyx denscly clothed with glandular down: with linear obtuse segments. Petals yellow, triple-nerved : nerves simple.

lar. $\beta$, atropurpùrea (Ser. in D. C. prod. 4. p. 26.) plant hartly with any clammy hairs; leaves rather loose: upper ones entire; stem smoothish, few-Howered; petals narrow, of a purplisli orange-colour, longer than the calyx. 24. H. Native of Carniola and Switzerland. S. atropurpurea, Sternb. rev. sax. t. 11. b. f. 2. and in Sturm, deutschl. f. p. 39. f. 11. Muscaria atropurpùrea, Haw. cnum. sax. p. 28. S. ampulàcea, Tenore, append. prod. fl. neap. 4. p. 20. S. muscoìles var. $\mu$, Ser. in D. C. prod. 4. p. 26.

Musky Saxifrage. Fl. May, June. Pl. $\frac{1}{4}$ foot.

151 S. muscoines (Wulf. in Jacq. misc. 2. p. 125.) plant quite glabrous; radical leaves entire or trifid : surculine ones all linear, undivided, obtuse, nerveless ; stems very slender, usually S-flowered; calycine segments lanceolate, blunt; petals linear, a little longer than the calyx. $4 . H$. Native of the Alps of Carinthia, Dauphiny, Switzerland, Caucasus, Persia, and the Pyrenees. In England on the mountains about Ambleside, in Westmoreland. S. cæspitòsa, Huds. angl. p. 181. exclusive of the synonyme of Lin. and Fl. dan. Lapeyr. pyr. sax. p. 59. t. 35. and probably 34. Sternb. sax. t. 11. f. 1. S. moschàta, Witl. brit. 2. p. 406. S. Pyrenàica, Vill. daupl. 3. p 671. S. muscoìdes $\delta$, Sternb. rev. sax. p. 40. Muscària muscoides $\beta$ elongélla, Haw. enum. sax. 37. S. elongélla. Haw. in misc. nat. p. 161. but not engl. bot. S. muscoìdes $\beta$ elàtior, Gaudin, syn. sax. and A. helv. 3. p. 31. Ser. in D. C. prod. 4. p. 26. Plant green, densely tufted. Surculi erect, longish, slender. Stems erect, nakedish, for the most part 3 -flowered, and beset with glands. Leaves rarcly with glands on the edges. Nerres of petals simple. Flowers of a pale yellow-colour.

I ar. $\beta$, crassifòlia (Gaudin, syn. sax. and in fl. helv. 3. p. 31.) leaves nearly sessile, fleshy, for the most part undivided; stems rather panicled. $4 . H$. Native of the Alps of Savoy. S. muscoìtes $\gamma$, D. C. prod. 4. p. 26.

Irar. $\lambda$, uniflóra (Gaudin, l. c.) sturculi densely tufted; leaves short, rather incurved; stems rather capillary, 1-flowered, or almost wanting. $\quad$ 4. H. S. cæspitòsa, Lapeyr. fl. pyr. t. 34. and 36 . S. muscoìdes $\beta$, Sternb. rev. p. 40. S. moschàta, var. Lapeyr. fl. pyr. t. 38. S. acaúlis, Gaudin, syn. sax. in Miesner, anz. p. 68. fl. helv. 3. p. 127. Muscària acaúlis, Haw. enum. sax. p. 38. S. muscoides nàna, Sternb. rev. sax. suppl. p. 11. t. 7. f. 2. S. muscoìdes $\varepsilon$, D. C. prod. 4. p. 26.

Var. $\delta$, capitàta (Gaudin, fl. helv. 3. p. 131.) surculi densely tufted; leaves slort, thickish; flowers sessile, capitate, few. 2. H. Native of Switzerland, in the grassy parts of the mountains. S. cæspitosa, Wahlenb. helv. p. 80 . cxclusive of the synonymes. S. muscoides $\zeta$, D. C. prod. 4. p. 26.

Moss-like Saxifrage. Fl. May, June. England. Pl. $\frac{1}{8}$ foot. 152 S. PYGM.E'A (Haw. misc. nat. p. 168.) plant quite glabrous; surculi very short, rosulate; leaves lanccolate, nerveless, glabrous, blunt, and rather cut at the apex; calycine segments broadly ovate; petals oval, hardly longer than the calyx. 4. H. Native of thic Pyrcnees. S. muscoìdes $\gamma$ hemispliaerica, Lapeyr. pyr. sax. p. 60. t. 36 . S. moschita, Smith, engl. 
bot, t. 221. exclusire of the synonymes. S. moschàta $\beta$, Lapeyr. pyr. sax. p. 62. t. 38 . S. moschàta $\gamma$, Sternb. sax. t. 11 . 13, f. 2. S. muscoides lineàta, Sternb. rev. sax. suppl. 1. p. 10. t. 7. f. 1.? S. muscoldes a microplyýlla, Gaudin, syn. sax. in Meisner, anz. 18\%9. p. 69. A. lielv. 3. p. 131. D. C. prod. 4. p. 26 . Plant densely tufted, spreading close on the ground. Surculi slort, rosulate, very leafy. Stems filiform, slender, fewleaved, 3-4-flowered, beset with glands. Flowers the smallest of all the section, of a yellowish colour. Calyx and pedicels glaudular. Nerves of petals simple. Filaments short, purple.

Pygmy Saxifrage. Fl. May, June. Scotland. Pl. 1 to 2 inclies.

$153 \mathrm{~S}$. Terekte'nsis (Bunge, in Ledeb. fl. ross. alt. ill. t. 398. fl. alt. 2. p. 123.) plant small, tufted; radical leaves much crowded, cuneated, trifid: segments oblong-linear, obtuse, ciliated with a few glands; cauline leaves few, trifid or entire; stem few-flowered, glandular; petals oblong, twice the length of the calyx. 24. H. Native of Altaia, in rough stony places on tops of mountains, betwcen the rivers Ursul and Koksun. Flowers pale yellow. Allied to $S$. moschàta, but differs in the flowers being twice the size, and in the petals being obovateoblong.

\section{Terck Saxifrage. Pl. $\frac{2}{4}$ foot.}

154 S. secu'idDA (Moretti, tent. sax. p. 20.) plant very villous; radieal leaves aggregate, cunciform, 3-5-cleft : lobes obtuse; stems few-leaved, rather corymbose; flowers secund; lobes of calyx ovate, obcuse; petals obovate, longer than the calyx. 4. H. Native of ltaly? S. caspitosa, Biroli, fi. acon. 1. p. 142. Poll. veron. 2. p. 33. but not of Lin.

Sccund-flowered Saxifrage. Pl. $\frac{1}{4}$ foot.

155 S. vexòsa (Haw, enum. sax. p. 2S.) plant almost stemless; leaves simple and trifid, nerved; scapes 1-flowered, furnished with linear entire leaves. 4 . H. Native of Melville 1sland. Perhaps only a variety of $S$. muscoìdes, uniflòra, or caspitòsa.

leiny-leaved Saxifrage. Pl. 1 to 2 inches.

156 S. GLABE'LLA (Bertol. virid. bonn. 1824. p. 80.) surculi densely leafy; stems few-flowered, glabrous; Jeaves all undivided, linear or spatulate, glabrous; peduncles and calyxes puberulous, viscirl; petals obovate, obtuse, length of the calyx, triple-nerved; capsule short, somewhat globose, inclosed in the calyx; styles short, diverging; seeds obovate, echinated, dark. 4. H. Native of Abruzzo, on humid grassy rocks. siad to be nearly allied to S. esaràta, Tenore, append. 4. fl. n'a). p. 19.

Simooth Saxifrage. Fl. July, Aug. PJ. $\frac{1}{8}$ to $\frac{1}{4}$ foot.

$157 \therefore$ QUINQUE' FIDA (Haw. in mise. nat. p. 163. enum. succ. 1). 26.) sureuli erect; leaves eleft into 5-11 parts, pedate: segments linear-lanceolate, furrowed by a line on the upper side. 4. I1. Native of Scotland, on the mountains. Perhaps the same as $S$. pedatifida.

Quinquefid-leaved Saxifrage. Fl. N]ay, June. Scotland. Pl. $\frac{1}{2}$ loot.

158 S. sulexiflòra (Cham. ex Hook. fl. bor. amer. 1. p. 24.).) plant tufted; surculi short; leaves stiff, rosulate, dense, 3-5.7-parted, shining, and as if they were varnished, many uerved, pubescent : segments linear, acutish; floriferous stems elongated, clothed with glandular down; flowers panieled, rather large; ovarium adhering to the tube of the ealyx, which is clohed with glandular down; calycine segments obtuse; petals ohovate, s-nerved, twice the length of the calyx. 4. H. Native of Behring's Straits. The inflorescence of this plant a good deal rescimbles $S$, hypnoides.

lar. F, uniflora (Hook. I. c.) stem 1-flowered.

Catchfly-flomercd Saxifrage. PI. $\frac{1}{4}$ to $\frac{1}{2}$ foot.

159 S. ADscéNDENS (Vahl. in act. nat. hist. hafn. 2. 1. p. 12.) leaves deeply tripartite; segments cuneated, multifid; peduncles many-flowered; calycine segments ovate-oblong, bluntish ; petals oval, entire; stem ascending, panicled. $4 . H$. Native of the Pyrenees, in springs. S. petras'a, Gouan. ill. p. 29.t. 17. f. 3. S. aquática, Lapeyr. pyr. sax. p. 53. t. 28 . Sternb. sax. p. 48. t. 19. f. 1 and 2 . Plant tufted. Surculi short, leafy. Stems ascending, a foot or more high, beset with glanduliferous hairs. Radical leaves 5-lobed, glabrous ; lobes deeply toothed. Petioles dilated at the base. Flowers disposed in coarctate panicles, white. Peduncles many-flowered, and are as well as the calyxes clothed with glandular down. Nerves of petals simple, reddish. Filaments yellow. This is the largest species of the whole section.

I ar. $\beta$, fávida (Ser. in D. C. prod. 4. p. 29.) stems firm, branched; flowers scattered, yellowish, large; antliers purple. 4. H. Native of the Pyrenees. S. aquática, var. Lapeyr. fl. pyr. p. 53. t. 29. Sternb. var. $\beta$ and $\delta$, rev. sax. p. 48 . t. 19. f. 2 .

I ar. $\gamma$, sccínda (Ser. l. c.) flowers secund. \%. H. Native of the Pyrenees. S. aquática, var. $\gamma$, Lapeyr. fl. pyr. p. 53. Sternb. rev. sax, p. 48. var. $\gamma$.

Íar. o, coronata (Ser. l. c.) peduncles lateral; stems leafy at the apex. $\psi$. H. Native of Corsica. S. adscéndens $\gamma, D . C$. fl. fr. 4. p. 370 .

lar. $\varepsilon$, glomeràta (Ser. I. c.) flowers nearly sessile, sub-capitate, yellow; stems lumble and weak. S. aquática $\beta$, Lapeyr. fl. pyr. p. 52 .

Ascending Saxifrage. Fl. May. Clt. 1752. Pl. 1 foot.

160 S. CUNEA'TA (Willd. spec. 2. p. 658.) glabrous; lower leaves on long petioles, cuneated, 5-lobed: upper ones nearly sessile, lanceolate, undivided; stems ascending, panicled; calycine segments ovate, acute; petals oblong. $4 . \mathrm{H}$. Native of Spain, on the mountains near Castellfort. S. cuneifolia, Cav. icon. 3. p. 25. t. 248. but not of fin. Lobària cuneifòlia, Haw. enum. sax. p. 19. Stems many, ascending. Lobes of leaves acute. Flowers panicled, white. Peduncles elongated, 1flowered, smootlish.

Cuneate-leaved Saxifrage. Pl. $\frac{1}{4}$ to $\frac{1}{2}$ foot.

161 S. globulifera (Desf. atl. 2. p. 342. t. 96. f. 1.) plant gemmiferous; surculi short; leaves of the surculi 5-cleft or trifid, and sometimes simple, lanceolate, acute, and awned; flowers panicled; calycine segments oval-oblong, obtuse ; petals obovate. 24. H. Native on the top of Mount Atlas. Plant tufted. Stems erect, filiform, glabrous, furnished with a few leaves. Segments of divided leaves lanceolate. Petioles ciliated. Axils of leaves furnished with globular buds, which are pedunculate, and formed of simple, ciliated, imbricated leaves ; these buds shoot out into surculi for the following year. Flowers white, one half smaller than those of $S$. hypnoides, 5-7, disposed in a panicle. Pedicels and calyxes clothed witl clammy down. Nerves of petals simple.

Far. $\beta$, Gibraltárica (Ser, in D. C. prod. 4. p. 31.) leaves much smaller: lobes short, ovate, acutish; buds in the axils of the leaves smaller, oblong, acutish; stems few-flowered. 4. H. Native of Gibraltar. Styles not exceeding the calyx at maturity.

Globule-bearing Saxifrage. Pl. $\frac{1}{4}$ foot.

162 S. Hrpoines (Lin. spec. p. 579.) plant gemmiferous; surculi very long, procumbent; radical leaves 5 or 3 -parted; surculine leaves simple, linear, stiff, ciliated, mucronately awned; calycine segments triangularly ovate, awned; petals roundishobovate. 24. 11. Native of the Alps of Switzerland, Austria, Pyrenees. In Britain, in the north of England, Scotland, and North Wales, on high rocky mountains; as well as on limestone rocks, walls, and roofs in less elevated situations, abundantly. Fl. dan. t. 348 . Vill. dauph. 4. p. 67 t. t. 45. Lapeyr. 
pyr. sax. p. 57. t. 32. Smitl, engl. bot. t. 454. S. elongélla, platipétala, dénsa, curvàta, densifòlia, Schleich. cat. 1821. Herb densely tufted before flowering, quite glabrous, but afterwards becoming loose, surculose, and villous. Surculi reddish as well as stems, which are erect, shining, brittle, and 2-1-flowered. Surculine leaves furnished witl ovate, acute buds in the axils. Cauline leaves few, lincar-lanceolate, undivided. Peduncies elongated, I-flowered, clothed with viseid down as well as the calyxes. Petals white, triple-nerved, rose-coloured on the outside at the apex; nerves simple.

I ar. $\beta$, viseòsa (D. Don, in Lin. trans. 13. p. 4.7.) plant softer and looser; flowers larger. 4. H. Native of the Alps of Seotland. S. viscòsa, Hortu].

I"ar. $\gamma$, angustif ólia (D. Don, l. c.) surculi ascending; leaves longer. $\quad$. H. Native of the Alps of Scotland. S. angustifólia, Hortul. S. hypnoides $\delta$, Aitòni, Haw. enum. sax. p. 332. S. Sponhèmica, Gmel. f. bad. 2. p. 224. ?

Iar. ¿, muscòsa (D. Don, 1. c.) plant one half smaller and slenderer; segments of leaves smaller; flowers smaller. $4 . \mathrm{H}$. Native of the Alps of Scotland.

Var. $\varepsilon$, pulchélla (D. Don, l. c.) plant more robust ; surculi thicker and stiffer, and more rigid; buds obtuse, more crowded; surculine leaves broader, with a furrow on the upper surface. 4. H. Native of the A]ps of Scotland.

Var. $\zeta$, spatulata (Haw. enum. sax. p. 33.) leaves of the surculi spatulate, hardly acuminated, somewhat tridentate; stem few-flowered. 4. H. Native of Switzerland. S. spatulata, Haw misc, nat. p. 165. Schleich. cat. 182I. but not of Desf. S. craterifórmis, hort. oxf. ex Schleich. eat. 1821. S. dùbia, Schleich, eat. 1821.

Hypnum-like Saxifrage. Fl. April, in Britain. Pl. $\frac{1}{4}$ to $\frac{1}{2} \mathrm{ft}$. 163 S. condensA'TA (Gmel. fl. bad. 2. p. 226. t. 3.) sureuli procumbent, short; radical leaves 5 -parted: surculine ones trifid: segments linear, glabrous, awned; calycine segments triangularly ovate, acute, mutic. 4 . H. Native of Sponhemia, among rocks, and on the Alps of Scotland; also of Kotzebue's Sound, if $S$. caspitòsa, Cham. in litt. be the same. S. dénsa and S. læ'vis, Hortul. S. palmàta, Lejeune, fl. spa. I. p. 194. S. Gmelini, Host. fl. aust. 1. p. 512. S. flavéscens, Sternb.rev. sax. suppl. p. 13. t. 9. f. 2.? S. læ'vis, trifida, rupéstris, and congésta, Schleich. cat. 1821. Plant quite glabrous, shining, of a beautiful green, densely tufted before flowering, but afterwards loose and surculose. Surculi procumbent, without buds. Stems numerous, nearly naked, glabrous, 2-3-flowered. Peduncles glabrous, 1-flowered, curved when the flowers are in the bud. Calyx rather downy. Petals white, triple-nerved, rose-coloured on the outside at the apex; nerves simple.

Condensed Saxifrage. Fl. May, Ju. Scotlant. Pl. $\frac{1}{4}$ foot.

164. S. ELONGE'ILA (Smith, in Lin. soc. trans. 10. p. 340. engl. bot. 2277. exclusive of the synonyme of Donn, eant.) surculi short, erect; radical leaves 5 -cleft or trifid; sureuline leaves for the most part tridentate: teeth mucronate; calycine segments ovate, awnless; petals obovate. 4. H. Native of Scotland, on humid rocks near Lintrathen, in Angusshire. S. hypnoides a, elongélla, Ser. in 1). C. prod. 4. p. 30. Herb quite glabrous, and densely tufted before flowering, but afterwards becoming loose and rather villous. Stems erect, nearly naked, a-3-florrered, smoothish. Petioles slender, dilated. Perol. III. duncles very long, I-flowered, beset with glanduliferous hairs. letals white, triple-nerved; lateral nerves curved, branclied: middle one simple, straight.

Longish-stalked Saxifrage. Fl. $\Lambda$ pr. May. Scot. PI. $\frac{2}{4} \mathrm{ft}$.

165 S. LEPTOPHY' LLA (Pers. syll. 1. p. 490.) surculi procumbent, very long, slender; radical leaves 5-parted: surculine ones 3-parted or undivided: segments linear-lanceolate, very acute, divaricate; calycine segments oblong-ovate; petals spatulate, quite entire. 4. 11. Native of the Alps of Switzerland, and on the mountains of Wales. S. retrofléxa, Hortul. Plant quite glabrous, and densely tufted before flowering, but afterwards loose, liffuse, and surculose, and beset with viscid villi. Stems numerous, flexuous, smoothish, shining, manyflowered. Leaves without any buds in the axils. Segments of leaves awned. Flowers drooping, white. Peduncles elongated, and are as well as the calyxes beset with glandular pili. Calycine segments ending in a reflexed mucrone each. Petals triplenerved, with the nerves simple.

Var. $\beta$, angustifida (D. Don, in Lis. trans. 13. p. 450.) plant slenderer; segments of leaves narrower. 4 . H. Native of Wales, on the mountains.

Slender-laved Saxifrage. Fl. May, Ju. Wales. Pl. $\frac{1}{4} \mathrm{ft}$.

$166 \mathrm{~S}$. Letevirens (D. Don, in Lin. trans. 19. p. 451.) surculi procumbent, elongated ; leaves 5 or 3 -parted : segments linear, acute; calycine segments lanceolate, mucronate; petals spatulate, emarginate. 2 . H. Native of the Alps of Scotland, on the loftiest rocks, in moist situations, in Angusshire and Aberdeenshire, and on the hills to the north of Loch Lomond. Herb pale green, densely tufted before flowering, and quite glabrous, but afterwards becoming loose, diffuse, and surculose, and beset with long scattered villi. Surculi destitute of buds in the axils of the leaves. Stems erect, few-leaved, usually 3flowered, rarely 1 -flowered. Radieal leaves 5 -parted: surculine ones 3-parted : lower cauline ones 5-prarted : upper cauline ones undivided, lanceolate, and acuminated. Flowers campanulate, white, drooping while in the bud. Petals triple-nerved; nerves simple, green.

Pale green Saxifrage. Fl. May, June. Scotl. Pl. $\frac{1}{4}$ foot.

$\S$ 3. Annual or bicnnial plants, without surculi. lioots fibrous. Petals usually emarginate.

167 S. aracit nódea (Sternb. rev. sax. p. 23. t. 15. and in Sturm, deutschl. fl. 35 . no. 7 . with a figure) stems weak, diffuse, much branched, very pilose; leaves very thin, somewhat cuneated, obovate, 3-5-notched ; flowers on long peduncles : peduncles divaricate; Jobes of calyx ovate-lanceolate, shorter than the tube, which is rather villous; petals ovate, entire, hardly exceeding the calyx; styles much shorter than the calyx, parallel. 4. (Sternb.) ๑. (Ser.) It. Native of Tyrol, in shady rocky places. Moretti, sax. p. 28. Lobària arachnoídea, Haw. enum. sax. p. 20. Flowers white.

Cobnebled Saxifrage. Fl. April, June. Clt.? Pl. $\frac{1}{4}$ to $\frac{1}{2} \mathrm{ft}$.

I 68 S. PETRA'A (Lin. spec. p. 578.) radical leaves palmately 5-lobed: cauline ones tripartite and eut; peduncles very long, 1-flowered; calycine segments linear, acute; petals obovate, truncate at the apex and emarginate, twice the length of the calyx. $\odot . H$. Native on Mlount Baldo, among broken rocks, and of the $A$ lps of Carinthia ; also of North America, in alpine rivulets on the Rocky Mountains. Wulf. in Jacq. coll. 1. p. 200. Jaeq. icon. rar. I. t. 81 . S. geranioides, Host, syn. 231. S. rupéstris, Willd. spec. 2. p. 653. S. Pònx, Sternb. sax. p. 47. t. 18. and t. 11. f. 6. and in Sturm, deutschl. fl. p. 35. fig. 16. S. álba petre'a, Pona, itin. p. 183. S. biánca, Calceol. itin. p. 12.-Pluk. ahn. p. 331. t. 222. f. 3.-Moris. hist. 13. p. 379. sect. 12. t. 9. f. 28 . S. petre'a $\alpha, \beta$, and $\gamma$, Ser. in D. C. prod. 4. 1. 34. Tridactylites petræ'a, Haw. enum. sax. p. 22. I'lant 
diffusely branched, furnished with glanduliferous hairs. Stems erect, branched at the base; branches elongated, fastigiate. Radical leaves on long petioles, somewhat reniform at the base; lobes obtuse ; cauline leaves all petiolate: upper cauline leaves undivided, acute at both ends: lower cauline ones tripartite; lobes acute. Peduncles and calyxes elothed with viscid down. Flowers white, much larger than those of S.tridactylites. Petals triple nerved; nerves simple.

Rock Saxifrage. Fl. April, May. Clt. 1752. Pl. $\frac{1}{4}$ to $\frac{1}{2} \mathrm{ft}$. 169 S. TRIDActycites (Lin. spec. 578.) primordial leaves cntire, and spatulate : cauline ones quinquefid or trifid; calyx urn-formed: with very short, obtuse segments; petals obovate, truncate at the apex. $\odot$. H. Native of Europe, in dry sandy places, and on walls and roofs of houses; plentiful in Britain. Curt. lond. fasc. 2. t. 28. Smith, engl. bot. t. 501. Sternb. sax. p. 44. t. 17. and in Sturm, deutschl. H. 33. no. 15. S. ánnua, Lapeyr. pyr. sas. p. 53. Tridactylites ánnua, Haw. enum. sax. p. 21.-Moris. hist. 3. p. 478. sect. 12. t. 9. f. 31. Stems erect, branched, flexuous, many-flowered, furnished with short glanduliferous hairs. Radical leaves crowded. Petioles ciliated with glands. Peduncles and calyxes clothed with viscid down. Flowers small, white; petals with 3 simple nerves.

Var. $\beta$, cxilis (Gaudin, fl. helv. 3. p. 116.) leaves all oblongspatulate; stem simple, few-flowered. $\odot . H$. Native of Switzerland, Italy, France, Sc. S. exilis, Poll. veron. 2. p. 31.

Three-fingercd-leaved or Wall Saxifrage. F]. April, May. Britain. Pl. $\frac{1}{4}$ to $\frac{1}{2}$ foot.

170 S. contrave'́rsa (Sternb. sax. p. 43. t. 16.) plant beset with glanduliferous viscid hairs; radical leaves crowded, 3-5toothed, or sometimes nearly entire; calycine lobes ovate, shorter than the tube at maturity; petals obcordate, larger than the calyx; styles much divaricate, longer than the calyx. $\odot$. H. Native of the Alps of Lapland, Norway, Savoy, Carinthia, Piedmont, Dauphiny, Carpathian Mountains, and the Pyrenees. S. tridactylites $\beta$, Lin. spec. ed. 1. p. 404. S. adscéndens, Lin. spec. p. 579 . mant. p. 884 . All. pedem. p. 1537. t. 22. f. 3. Wulf. in Jacq. coll. 1. p. 19\%. t. 11-12. f. 1-2. S. petræ'a, Gunn. norv. p. 427. t. 9. f. 1-3. exclusive of the syn. and deseript. of Lin. Fl. dan. t. 680 . D. C. A. fr. 4. p. 370 . S. hypnoides, Scop. carn. 499. t. 16. Gaudin, A. helv. 3. p. 117. S. Scopòlii, Vill. dauph. 4. p. 673. S. petræ'a integrifòlia, Gaudin, in Meisn, anz. 1818. p. 67. fl. helv. 3. p. 117. var. $\beta$. S. contravérsa $a$ and $\beta$, Ser. in D. C. prod. 4. p. 34. S. tridactylites $\beta$, alpícola, D. Don, in Lin. trans. 13. p. 441. Tridactylites petra'a, Haw. enum. sax. p. 22. Flowers corymbose, white, twice the size of those of $S$. tridactylites. The plant is much larger than $S$. iridactylites; the radical leaves more crowded: the cauline ones more numerous, and for the most part 5 -toothed.

l'ar. B, littorilis (Ser. in D. C. prod. 4. p. 34.) plant small, rery lcafy; leaves usually quinquefid; petals entire. $\odot . H$. In humid places on the banks of Lake Leman, S. petræa littoràlis $\delta$, Gaudin. fi. helv. 3. p. 117 .

I ar. $\gamma$, Bcllardiana (Ser. 1. c.) flowers usually twin, nearly sessile, in the heart of the crenulated leaves. $\odot$. H. S. pe-træ'a, Bellárdi, Gaudin. in Meisn. anz. 1818. p. 67. f. helv. 3. p. 118 . S. Bellárdi, All. pedem. no. 1356. t. 88. f. 1. Sternb. rev. sax. 1. 20 .

Contrary-turncd Saxifrage. Fl. May, Ju. Clt. 1800. Pl. $\frac{1}{2} \mathrm{ft}$.

Cult. Saxifraga is a most extensive genus of pretty alpine plants, the greater part of which are well adapted for rock work, or to be grown on the sides of naked banks to hide the surface. Many of the more rare and tender kinds require to be grown in pots, in light sandy soil, and placed among other alpine plants, so that they may be protected by a frame in winter. The species belonging to sections Micránthes and Hirculus grow best in a peat soil, which should be kept rather moist. The species belonging to the section Porphýrcon are so very pretty little plants as to be worth growing in pots for ornament, being clothed with elegant little red flowers early in spring : a mixture of peat and sand suits them well. S. sarmentosa does best in a greenhouse. All the species are easily increased by dividing. S. ligulata, cordif òlia, and crassifòlia are strong growing plants, well fitted for ornamenting flower-borders.

1I. ERIOGY'NIA (from epıov, erion, wool, and $\gamma v \nu \eta$, gyne, a female; in reference to the ovaries being woolly). Hook. in f. bor. amer. 1. p. 255 . t. 88 .

LiN. syst. Icosándria, Tetra-Hexagýnia. Calyx turbinate, 5 -cleft. Petals 5, hardly unguiculate. Stamens 20, inserted in the mouth of the tube, monadelphous at the base; anthers 2celled, roundish. Ovaries 4-6, distinct from the calyx, and from each other, but connected by dense wool. Styles elongated, deciduous, filiform. Carpels 4-6, distinct, oblong, acute, recurved at the apex, opening lengtliwise inside. Seeds dustformed, pendulous, inserted towards the tops of the valves at the margins. Albumen wanting.-A perennial herb, native of North America, with the habit almost of Saxifraga ceratophílla; stoloniferous. Leaves very stiff, coriaceous, 1 -nerved, quite glabrous, trifid; segments trifid or quadrifid: lobules linear. Flowers white, disposed in racemes, for the most part bracteate; pedicels 1 -flowered.

1 E. Pectina'ta (Hook. l. c.). 24. H. Native of Behring's Straits; height of land upon the Rocky Mountains, on the west side, near the sources of the Columbia. Saxífraga pectinàta, Pursh, fl, amer. sept. 1. p. 3I2. Sterile stems tufted, decumbent, stiff, stoloniferous. Lower leaves rosulate, with 3 trifid segments: lower cauline ones with 3 bifid segments: upper cauline ones or bracteas trifid.

Pectinated-leaved Eriogynia. Pl. $\frac{1}{2}$ foot.

Cult. This is a beautiful alpine plant. It should be grown in pots, in a mixture of peat and sand; and will be easily increased by dividing, or by cuttings.

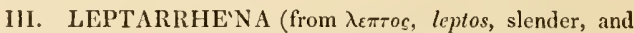

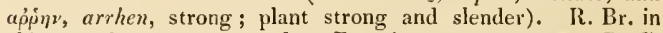
chlar. melv. p. 15 . append. to Parry's 1st voy. p. 273. D. C. prod. 4. p. 48. Hook. fl. bor. amer. 1. p. 256. t. 89.

Lıx. syst. Decándria, Digýnia. Calyx campanulate, short, 5 -cleft (f. 47. a.), with a broad tube. Stamens 10, inserted in the throat of the tube; anthers 1 -celled (f. 47. c.), 2-valved. Petals 5 (f. 47.6 .), linear. Ovaries 2 (f. 47.e.), free, tapering into the styles, which are permanent. Stigmas obtuse. Carpella 2 , opening lengthwise on the inside (f. $47 . d$.). Seeds scobiform, erect, inserted in the margins of the valves.-Herbs with a habit between Pyròla and those species of Saxifraga belonging to section Micranthes; inbabitants of cold places of North America. Scapes naked. Flowers disposed in racemose panicles. Leaves coriaceous, permanent, entire, coarsely serrated; petioles broar and slieathing.

I L. PYROLIFóla (R. Br. in Parry's 1st voy. append. p. 273. Hook. l.e.). 4.H. Native of the lsland of Unalaschka, Behring's Straits, height of land on the west side of the Rocky Mountains, in lat. $52^{\circ}$. L. amplexi-

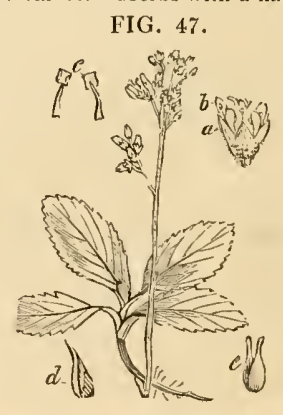


fòlia, Ser. in D. C. prod. 4. p. 48. Saxífraga pyrolifòlia, D. Don, in Lin. trans. 13. p. 359. Saxífraga amplexif òlia, Sternb. rev. sax. suppl. p. 2. t. 2. Saxifraga micräntha and S. coriàcea, Fisch. mss. Root rather fusiform, fibrous. Stems ascending, simple, or branched at the base, leafy. Leaves elliptic, grcen and shining alsove but palc beneath; petioles channelled, a little ciliated. Scapre a span to a foot high, furnished each with 2 oblong, obtuse scales, pubescent above. Racemes compound, somew hat corymbosely panicled. Flowers small, inconspicuous. Pyrola-leaicd Leptarrlicna. Pl. $\frac{1}{2}$ to 1 foot.

Cult. See Eriogýnia above for culture and propagation.

IV. CHRYSOSPLE NIUM (from $\chi \rho v \sigma o s$, chrysos, gold, and $\sigma \pi \lambda \eta \nu$, splen, the spleen; in reference to the golden colour of the flowers, and the supposed virtue of the plant in diseases of the spleen). Tourn, inst. t. 60. Lin. gen. 558. Gartn. fruet. 1. p. 208 . t. 44 . f. 7 . D. C. prod. 4. p. 48 .

Lis. srst. Octo-Decúndria, Digýnia. Tube of calyx adhering to the ovarimm; limb 4-5-lobed (f. 48. a.) : lobes obtuse. Stamens 8-10, alternating with the sepals, and opposite them. Styles 2. Capsule birostrate (f, 48. c. d.), 2-valved, at length 1-celled, many-sceded. Seeds very smooth, inserted towards the bottom of the capsule.-Perennial herbs. Leaves thickish, simple, petiolate, toothed. Flowers somewhat corymbose, yellow.

1 C. Altersifòlum (Lin. spec.

569.) leaves alternate, reniformly cordate, crenately lobed; Howers corymbose, dichotomous. $4 . \mathrm{H}$. Native of Europe, in moist shady places, and by the borders of shady rivulets, in Siberia and North America; in the woody and principally the barren country of British North America; to the extreme Arctic Islands, and on the Rocky Mountains; also in Kotzebne's Sound. In many parts of the north of England, but not so common as C. oppositifolium, as in Yorkshire, Portland Heath, near Norwich, in FIG. 4.8 .

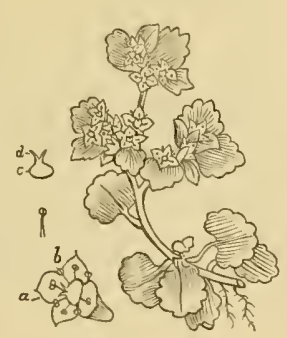

Worcestershire; and in lowlands of Scotland. Smith, engl. bot. t. 54. FI. dan. t. 366. - Moris. hist. p. 477 . sect. 12. t. 8. f. 8. Stems usually 3-cornered. Flowers yellow. Roots having offsets, but not creeping.

Var. B, Sibiricum (Ser. in D. C. prod. 4. p. 48.) stems and leaves smaller. $\%$. H. Native of Siberia, about the Baical, and of Dahuria. C. Sibiricum, Steph.? ex Fisch. in litt.

Altcrnate-leated Golden Saxifrage. Fl. April, May. Brit. Pl. $\frac{1}{4}$ foot.

2 C. ovalifolium (Bieb. herb. ex Led. fl. ross. alt. ill. t. 404. f. alt. 2. p. 115.) stems with many scattered leaves ; leaves ovateorbicular or elliptic, tapering into the petiole, crenately serrated or entire; corymb dichotomons, loose. 2\%. H. Native of the Altaian region. Root creeping. Stem pilose below. Flowers yellow, solitary in the forks of the corymb.

Oral-leaved Golden Saxifrage. FI. April, May. PI. $\frac{1}{4}$ foot.

3 C. oppositifòlius (Lin. spec. p. 569.) floriferous stems erect; leaves opposite, reniformly sub-cuneated, crenated; flowers corymbose. 4 . H. Native of Europe and America, in moist shady places, and by the sides of rivulets. In Britain, in many places, in like situations. Curt. lond. 2. t. 27. Smith, engl. bot. 490. Grertn. fruct. 1. t. 44. f. 7. Oed. fl. dan. t. 365. Root creeping. Stems quadrangular. Flowers yellow.

Far. $\beta$, Scoulèri (Hook. fl. bor. amer. 1. p. 242.) leaves pro- foundly crenately serrated. 24. H. Native of the north-west coast of America, on the banks of the Columbia river.

Oppositc-leaved Golden Saxifrage. Fl. Apr. May. Brit. Il] $\frac{1}{4} \mathrm{ft}$.

4 C. America'vum (Schweinitz, mss. Hook. fl. bor. amer. 1. p. 242.) stems slender, decumbent, loose, dichotomous at the apex; leaves opposite, roundish-cordate, obscurely and crenately lobed; Howers axillary, distant. 24. II. Natisc of Canada, Lake II uron, Saskatchawan, and other parts of North America. C. oppositif òlium, Michx. H. bor. amer. 1. p. 269. and other American botanists. Flowering branches never forming corymbs, but lengthened out and bearing distant small leaves and solitary flowers in the axils.

American Golden Saxifrage. Fl. April, May. Clt.? Pl. pr.

5 C. DU'BıU (Gay, ex Gaud. in herb. D. C. and prod. 4. p. 48.) leaves opposite, ovate, bluntly serrated. 2. H. Native of Calabria. Flowers yellow.

Doubtful Golden Saxifrage. Fl. A pril. Pl. $\frac{1}{4}$ foot.

6 C. Nipaulénse (D. Don, prod. fl. nep. p. 210.) Jeaves opposite, orbicularly subcordate, crenately serrated, glabrous. 4. H. Native of the $\mathrm{Al}_{\mathrm{l}} \mathrm{s}$ of Nipaul. Very nearly allied to C. oppositifolium, but differs in the leaves being more reniform, less manifestly crenated, and in the seeds being opaque, not shining. Leaves like those of Bétula nìna, but membranous. Flowers yellow.

Nipaul Golden Saxifrage. Fl. A pr. Ma. Clt. 1820. Pl. ${ }_{4}^{1} \mathrm{ft}$.

7 C. Nudicau'le (Bunge, in Led. fl. ross. alt. ill. t. 405.) cauline leaves wanting : radical ones reniformly orbicular, and are as well as the fioral ones, which are reniform, petiolate, and deeply lobed; flowers densely glomerate. 2\%. H. Native of Altaia, near springs at the foot of the Alps, about Chasin, near 'Tschetchulicha, at the river T'scharysch. Root creeping, furnished witl thick brown fibres. Plant quite glabrous, except sometimes on the under side of the leaves. Flowers greenish, much larger than those of $C$, alternif olium.

Nalied-stemmed Golden Saxifrage. Pl. $\frac{1}{4}$ to $\frac{1}{2}$ foot.

8 C. Kantscináticum (Fisch. in litt. ex D. C. prod. 4. p. 48.) stems erect, nearly naked, 2-leaved, the rest crowded near the flowers, cuneate, obtuse, somewhat crenated, glabrous. 4. H. Native of Kamtschatka.

Kamtschatka Golden Saxifrage. Pl. $\frac{1}{4}$ foot.

Cult. A moist shaded situation is the best for the species of Chrysospleninm, as under the shade of trees or bushes, or behind a north wall ; and they thrive best in peat soil. Easily propagated by dividing.

V. MITE'LLA (a diminutive of mitra, a mitre; the form of the fruit being somewhat like a mitre). 'Tourn. inst. 126. Lin. gen. 561. Gærtn. fruct. 1. p. 208. t. 44. f. 6. Lam. ill. t. 373. D. C. prod. 4. p. 49 .

Lin. syst. Decándria, Digýnia. Calyx campanulate, 5lobed, rather adnate to the base of the ovarium. Petals 5 , inserted in the calyx, jagged or toothed, longer than the calyx. Stamens 10. Styles 2, short, joined together in one; stigmas hardly distinct. Capsule 1-celled, 2-valved, adhering to the base of the calys a little way. Seeds numerous, erect, in the bottom of the capsule.-Perennial herbs. Leaves petiolate, cordate, mostly radical. Flowers on short pedicels, disposed in loose terminal racemes, white or red.

1 M. DIPHy' Lla (Lin. spec. p. 580.) radical leaves cordate, somewhat 3 or 5 -lobed, dentately serrated, on long petioles; cauline leaves 2 , opposite, smaller, and nearly sessile; capsule joined with the calyx only at the base; petals pinnatifidly fringed. \%. H. Native of Nortl America, in the United States; and Canada, about Quebec, Lake Huron, \&c. Lam. ill. t. 37S. f. 1. Gærtn. fruct. 1. t. 44. f. 6. Schkuhr, handb. t. 120. Ker. bot. reg. t. 166.-Mentz. pug. t. 10. Flowers white.

$$
\text { G } 2
$$


Two-leaved Mitella. Fl. Apr. May. Clt. 1731. Pl. $\frac{1}{2}$ to $\frac{3}{4} \mathrm{ft}$.

2 M. NU'DA (Lin. spec. 580.) plant usually stoloniferous; radical leaves reniformly cordate, thin, bluntly lobed, crenated, and somewhat ciliated; scapes slender, leafless ; calyx spreading: petals pectinately jagged; ovarium joined to the calyx only at the very base. 4 . H. Native of Canada, from Lake I Iuron to the Arctic Sea ; and from Hudson's Bay to the Rocky Mountains ; and of Siberia, at the river Lena. M. reniformis, Lam. ill. t. 373. f. 2. M. cordifòlia, Lam. dict. 4. p. 196. ill. t. 373 . f. 3. Michx. fl. bor. amer. 1. p. 270 . M. prostrata, Michx. A. bor. amer. 1. j. 270.-Gmel. sib. 4. t. 68. f. 2 . Flowers white. The plant here characterised is the acknowledged $M$. cordifólia of all American botanists. A comparison of it with the figure of Gmelin will show that it is the same with his species, and consequently the $M$. nùda, Lin., and among the numerous specimens gathered by travellers in North America, many throw out runners, which again bearing leaves and scapes, the plant becomes the $M$. prostrata of Michx.

Naked-stemmed Mitella. Fl. Apr. Ju. Clt. 1758. Pl. $\frac{1}{4}$ to $\frac{1}{2} \mathrm{ft}$.

3 M. TRífidA (Graham, in edinb, phil. journ. june, 1829. Hook. f. bor. amer. 1. p. 241. t. 82.) radical leaves cordate, bluntly lobed, crenated; scapes leafless; flowers pentandrous; calyx campanulate, with a spreading limb; petals trifid; ovary adhering to the calyx only at the base. 4. H. Native of North America, in alpine rivulets north of the Smoking River, on the cast side of the Rocky Mountains, in lat. $56^{\circ}$, but rare. Plentiful in woody situations, on the low ridge of the Blue Momntains of Lewis and Clark's River, west of the Rocky Mountains, in lat. $46^{\circ}$. M. parviflòra, Dougl. mss. Flowers white. This species has the petals similar to those of T'ellima parviflòra. Differs from the rest of the species in the petals being trifid, and in the stamens being only 5 instead of 10 , opposite the lobes of the calyx. Perhaps a species of Drummóndia.

Triful-petalled Mitella. Fl. May. Clt. 1829. Pl. $\frac{1}{2}$ to $1 \mathrm{ft}$.

Cull. The species of Mitclla are pretty plants, well suited for the front of flower-borders, or to grow on rockwork. They are readly increased by dividing. Any light soil suits them, although they grow most luxuriant in a peat soil.

VI. TE'LLIMA (an anagram of Mitélla; separated from it). R. Br. in Frankl. narr. journ. p. 766 . verm. schrift. 1. p. 545. 1)ougl, in bot. reg. 1178 . Hook, fl. bor. amer, 1. p. 239. D. C. prod. 4. p. 49.

Lın. syst. Decándria, Digýnia. Calyx adnate to the ovarium at the very base, having the free part inflated, ovate, and 5 -toothed (f. 49. b.), and the alhering part conical. Petals 5 (f. 49. c.), inserted in the calyx, jagged. Stamens 10 (f. 49. a.). Styles 2-3, distinct from the base: stigmas subcapitate, angular. Cajsule alnate to the calyx at the base: the other half superior and furnished with the permanent flower, 1-celled, 2-valved at the apex; placentas parietal, many seeded (f. $49 . f$.). This is an intermediate genus between IIeuchèra and Váhlia; it differs from Mitella in the styles being distinet, and the diflerent babit. Perennial herbs. Leaves all radical, roundish, cordate, b]untly lobed, in T'. parviftora compound, toothed, and hispid. Flowers of a dirty red-colour, rather large, disposed in racemose spikes.

I 'T'. GRANDIF Lòr A (Dougl. in bot. reg. t. 1178.) leaves cordate, lobed, dentately serrated; racemes elongated ; petals oblong-linear, pinnatifilly jagged; styles 2. 2. H. Native of the north-west coast of America, in shady pine woods, near springs along the shore. Mitélla grandifiora, Pursh. fi. ainer. scpt. 1. p. 31\%. This is a fine plant, with leaves as large as those of Málea rotundifolia. Flowers reldish. Stem and petioles generally thickly clothed with fulvous lairs.

Greut-flonered Tellima. Fl. April, May. Clt. 1826. Pl. $1 \mathrm{ft}$.
2 T. PARviflòra (Hook. fl. bor. amer, 1. p. 239, t. 78. A.) plant scalorous from hairs; leaves ternate; leaflets deeply pinnatificl; racemes short; petals unguiculate, trifid; styles 3 . $\psi$. II. Native of North California. A bundant in light gravelly soils, under the shade of sappling pines, near Fort Vanconver; plentiful in low hills at the grand rapids of the Columbia; and also at Spokan river. Root small, rather fusiform, more or less fibrous, and bearing tubers; tubers grannlar. Racemes terminal, curved. Flowers middle-sized, red. This is a curious and distinct plant,

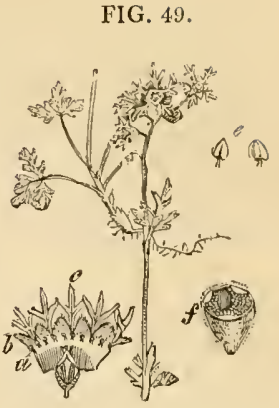
with something of the habit of slender specimens of Saxifraga granulìta.

Small-flowered Tellima. Pl. 1 foot.

Cult. See Mitélla, p. 227. for culture and propagation.

VII. DRUMMO'NDIA (named after Thomas Drummond, who accompanied Capt. Franklin and Dr. Richardson in their last journey in North America). D. C. prod. 4. p. 49.-Mitélla species, Graham.

Lis. sx'st. Pentándria, Digýnia. Calyx with an obconical tube (f. 50.6 .), adhering to the capsule a considerable way : limb 5-cleft: lobes triangular, valvate in astivation (f. 50. a.), and at length reflexed. Petals 5 , pectinately pinnatifid (f. 50. c.), alternating with the calycine lobes. Stamens 5 , in front of the claws of the petals, nearly sessile. Stigmas 2, spreading, 2-lobed. Capsule 1-celled, 2.valved at the apex, bursting long before the seeds are mature (f. $50 . d$.). Seeds numerous, disposed along 2 opposite placentas. - An herb, with a habit between Mitélla and IIeuchèra. It differs from Mitélla in the capsule adhering a greater length to the calyx, in the stamens being 5 , not 10 , and in the stigmas being spreading, not erect, and 2 -lobed, not entire; and from Heuchèra in the calycine lobes being valvate, not imbricate in æstivation.

1 D. mitelloìnes (D. C. l. c.) 4. H. Native of North America, in moist alpine woods on the Rocky Mountains. Mitélla pentảndra, Graham, in edinb. phil. journ. July, 18£9. Hook. in bot. mag. t. 2933. Radical leaves on long petioles, cordate, bluntly lobed. Scape leafless. Flowers yellowish. (f. 50.)

Mitclla-like Drummondia. Fl. May, June. Clt. 1827. Pl. $\frac{1}{2}$ foot. C'ult. For culture and propagation see Mitélla, p. 228.

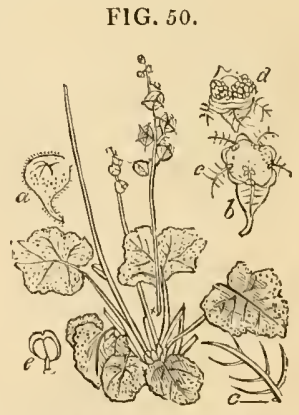

VIII. TIARE'LLA (a diminutive of tiara, a Persian diadem; in reference to the shape of the capsules). Lin. gen. no. 765 . Juss. gen. 1. 309. Lam. ill. t. 37 3. D. C. prod. 4. jo 50.

Lin. syst. Decándria, Digýnia. Calyx 5-parted, permanent, adhering at the base to the ovarium: lobes obtuse. Petals 5, unguiculate, entire, inserted in the calyx, and alternating with the calycinc lobes. Stamens 10. Styles 2, distinct. Ovarium 2ceiled. Capsule 1-celled, adnate to the calyx at the base, mem- 
branous, 2-valved; valves unequal, ojening between the styles (one of the valves or carpels usually abortive). Seeds fixed to the bottom of the capsule, along the margins of the carpels or valves.-Perential herbs, with the habit of Mitella. Stems crect, naked, or few-leaved. Leaves for the most part radical, petiolate. Racemes terminal, simple; flowers distant, pedicellate: pedicels incurvedly pendulous when bearing the fruit. A very lietcrogeneous genus, which may probably be liereafter divided.

\section{\$1. Leaces simple.}

1 T. cordifòlia (Lin. spec, p. 580.) stems leafless; stolons creeping; leaves cordate, acute, deeply lobed, serrated: teeth mucronate; racemes siniple. 4 . H. Native of Canada, about Montreal; and also of the north of Asia. Sims, bot. mag. 1589. Lam. ill. t. 373. f. 1. Flowers white. Habit of Mitélla diphýlla.

Cordate-lcaved Tiarella. Fl. April, May. Clt. 1731. Pl. $\frac{x}{2} \mathrm{ft}$.

\& T. unifolia'ta (Hook. f. bor. amer. 1. p. 238. t. 81.) plant smoothish; stems furnished with one leaf; leaves all petiolate, triangularly cordate, bluntly tootlied : teeth mucronate; panicle loose; flowers drooping; calyx campanulate; petals abortive. 4 . H. Native of North America, on the lieight of land on the Rocky Mountains, near the source of the Columbia, and at Portage river. Stems rather pubescent above. Leaves 3-5-lobed; lobes acutely toothed. This species has much the habit of Heuchèra glàbra, and is probably a decandrous species of that genus. The petals, if any exist, must be very fugacious, as nowe has been seen.

One-leaved Tiarella. Pl. 1 foot.

3 'T. MENziE'sil (Pursh, fl. amer. sept. 1. p. 313.) leaves oral-cordate, acute, toothed: cauline ones alternate, distant; racemes filiform, somewhat spicate; calyx tubular. $4 . \mathrm{H} . \mathrm{Na}$ dive of the north-west coast of Ameriea.

Mcnzies's Tiarella. Fl. April, May. Clt. 1812. Pl. 1 foot. 4. T. alternifòla (Fisch. in litt. ex D. C. prod. 4. p. 59.) stem leafy; lower leaves cordate: upper ones truncate at the base, all having $5-7$ short lobes, and these lobes are lobed again, sharply and coarsely toothed; lobes of calyx oblong, erect. 4 . H. Native of the north of Asia, in the island of Sitka. Radical leares on long, upper ones on short petioles. Flowers twice the size of those of $T$. polyphýlla.

Alternate-leaved Tiarella. Pl. 1 foot.

5 T. Polypiy'lla (D. Don, fl. nep. p. 210.) stem furnished with 3 leaves, beset with glandular hairs; leaves cordate, $3-5$. lobed, sharply serrated, pilose on both surfuces; lobes of calyx lanceolate, nucronate, pressed to the fruit; racemes loose. 4 . F. Native of Nipanl, Habit of T. cordifòlia or Mitélla diplijlla. Racemes many flowered. Frut pendulous.

Many-leaved Tiarella. Fl. April, May. Clt. 1820. Pl. $\frac{1}{2}$ to 1 foot.

\section{§2. Leares compound.-Blóndia, Neck. elem. 2. p. 115.}

6 T. Trifolis'ta (Lin. amoen. acad. 2. p. 351. spec. p. 580. ) stem furnished with 1 or 2 leaves, rarely naked; leaves all trifoliate: leaflets rhomboid-ovate, deeply toothed : teeth mucronate; panicle loose; flowers drooping; calyx small, campanulate; petals obovate, lanceolate. $\boldsymbol{4} . \mathbf{H}$. Native of the north of Asia, and the north-west coast of America; common on the coast, and on the Rocky Mountains, on the west side of the ridge. The specimens from the Rocky Mountains are glabrous, and many of those from the coast, while others are more or less pubescent. Two panicles are often produced on the same stem.

\section{Trifoliate Tiarella. P]. 1 foot.}

7 'T. LACiNia'ta (Hook. fl. bor. amer. 1. p. 239. t. 77.) plant rough and hairy; stems usually furnished with 3 leares; leaves trifoliate: middle leaflet trifid: lateral ones bifid, all broadly lanceolate, and pinnatilidly jagged; panicle loose; flowers drooping; calyx short, campanulate; petals wanting? $\mathbf{Z}$. $\mathbf{H}$. Native of the north-west coast of America. Roots rather horizontal. The petals, if any, must be very fugacious, as none have been seen.

Jagged-leaved T'iarella. Pl. $\frac{1}{2}$ to 1 foot.

8 'T. stenope'tala (Presl, in reliq. Hank. 2. p. 45.) stems 1-leaved, and are, as well as the branches, clotlied with glandular pubescence; radical leaves unknown: cauline one trifoliate: leaflets glabrous, deeply lobed, mucronately toothed, acute: lateral leaflets obliqucly ovate, middle one acute at the base; petals subulate, very narrow; capsules erect, dotted. 4 . H. Native of Nootka Sound. Panicle many flowered.

Narron-petalled Tiarella. Pl. 1 foot?

Cult. For culture and propagation see Mitélla, p. 228.

IX. ASTI'LBE ( $\alpha$. priv. and $\sigma \tau \iota \lambda \beta \eta$, stilbe, brightness ; plants opaque). Hamilt. in D. Don, prod. H. nep. p. 210. D. C. prod. 4. p. 51 .

Lin. syst. Oeto-Decándria, Digýnia. Calyx decply 4-5parted, coloured; segments oval, obtuse, concave. Petals wanting. Stamens 8-10, opposite the calycine lobes; filaments subulate; anthers spherical, 2 -celled. Styles 2 ; stigmas 2 , truncate, prumose. Capsule superior, birostrate, many secded,Perennial robust pilose herbs, with the appearance of Spirce $a$ Arúncus, inhabiting the banks of rivulets. Leaves large, biternate; leaficts coarsely serrated; petioles mucil dilated at the base. Flowers small, of a greenish yellow-colour, in spicate racemes, which are disposed in panicles.

1 A. rivula'ris (Hamilt. l. c.) flowers 4-cleft, octandrous ; leaves biternate ; leaflets ovate, doubly serrated, villous beneath, and on the petioles. 24.H. Native of Nipaul, at Narainherty. Bracteas usually jagged at the apex.

Rivulet Astilbe. Pl. 3 feet.

2 A. DEcA'ndra (D. Don, prod. Al. nep. p. 211.) flowers 5cleft, decandrous; leaves biternate; leaflets cordate, deeply lobed and serrated, beset with glandular pili beneath, and on the petioles. 4. I. Native of North America. Tiarélla biternàta, Vent. malm. t. 54. The petals are said to be 5 , and linear, in this plant, not as in the first species wanting. Leaflets ovate, broadly and bluntly serrated.

Decandrous Astilbe. Fl. May, June. Clt. 1812. Pl. 2 to $3 \mathrm{ft}$.

Cult. For culture and propagation see Heuchéra, p. 231.

\$2. Stamens cqual in number to the petals, or sometimes fener, alternating with the petals.

X. HEUCHE'RA (in lionour of John Henry de Hencher, once professor of medicine at Witterberg; author of Hortus Witterbergensis, 1711-1713.). Lin. gen. p. 320. Grertu. fruct. 1. p. 177 . t. 36. f. 2. Lam. ill. t. 184. f. 3. D. C. prod. 4. p. 51. Hook. fl. bor. amer. 1. p. 235.

Lin. syst. Pentándria, Digýnia. Calyx permanent, 5-cleft (f. 51. b.), imbricate in restivation. Petals undivided (f. 51.a.), nearly equal. Stamens 5. Styles 2 (f. 51.e.), very long, distinct, length of stamens : when young approximate and almost concrete, but afterwards diverging. Capsule crowned by the dry calyx, and adnate to it at the base, opening between the styles (f. 51. d.), 1-celled; placentas 2, adnate, many seeded. Seeds rough from dots or wrinkled.-Herbs, Leaves mostly radical, palmately lobed, toothed. Stems mostly leafiess. Flowers panicled or racemose.

l H. Anerica'sa (Lin. spec. 32S.) plant clothed with clammy pubescence, scapes and leaves roughish; leaves on long petioles, somewhat 5-7-lobed, toothed; thyrse clongated, panicled; calycine lobes short, obtuse; petals lanceolate, length of the calyx; 
stamens much exserted. 4 . H. Native of shady places from New England to Carolina, in the Illinois region; New Spain and Peru. Schkuhr, handb. t. 58. H. víscida, Pursh, fl. amer. sept. I. p. 187. H. cortùsa, Michx. fl. bor. amer. 1. p. 171. There is a variety of this species having 2 of the petals longer than the rest. Flowers reddish. Perhaps H. reniformis and H. glaúca, Rafin. med. f. 1. p. 244, are not distinet from this.

Var. $\beta$, slabriuscula (Schultes, syst. 6. p. 216.) leaves smoothish; panicle rather crowded.

lar. $\gamma$, foliòsa (Moricand, mss.) scapes furnished with a few long distant leaves. Native of Peru.

American Heuchera. Fl. May, July. Clt. 1656. Pl. $1 \frac{1}{2}$ foot.

2 H. DIvarica'ta (Fisch. in litt. ex D. C. prod. 4. p. 51.) scapes naked, glabrous; leaves glabrous, somewhat 5 -lobed : lobes toothed: tceth mucronate; branches of panicle divaricate; teeth of calyx bluntish; petals lanceolate, acute. $4 . \mathrm{H}$. $\mathrm{Na}$ tive of the north of Asia, in the islands of Kadiak and Sitka; also in Kamtschatka.

Divaricate Heuchera. P]. $1 \frac{1}{2}$ foot.

3 H. Pube'scens (Pursh, fl. amer. sept. 1. p. 187.) plant covered with powdery down; lower part of scape and under side of leaves glabrous ; leaves somewhat acutely lobed, toothed: tecth roundish, mucronate; branches of panicle short, crowded with flowers; calys broad, campanulate; petals spatulate, longer than the calyx; stamens exserted. 4. H. Native from Pennsylvania to Virginia, on the Blue Mountains. H. pulverulénta, Rafin. med. bot. 1. p. 213. Petals pale red, variegated with yellow. Flowers larger than in many other species.

Pruescent Heuchera. Fl, May, July. Clt, 1812. Pl. $1 \mathrm{ft}$.

4. H. m'spida (Pursh, fl. amer. sept. 1. p. 188.) plant hispid and scabrous; scapes, petioles, and under side of leaves glabrous; leaves acutely lobed, toothed, hispid from villi above: tecth short, rather retuse, mucronate; branches of panicle fewflowered; calyx middle-sized, with acutish lobes; petals spatulate, length of calyx; stamens exserted. 2\%. H. Native of Virginia and Carolina, on high mountains. Flowers reddish.

Hispid Heuchera. Fl. IIay, June. Clt. 1826. Pl. 2 to $3 \mathrm{ft}$. 5 H. mera'ntila (Dougl. in bot. reg. 1302.) lower part of scape and petioles beset with long fulvous hairs; leaves roundish-cordate, nearly naked, bluntly lobed, crenate : crenæ mucronate; lower bracteas foliaceous, cut: upper ones seticeous; panicle loose; petals linear, one-half sliorter than the long exserted stamens. 4 . H. Native of the north-west coast of America, on the stecp rocky banks of the Columbia, near the Grand Rapids. Flowers greenish-yellow.

Small-flowered Heuchera. Fl. June, July. Clt. 1827. Pl. 2 feet.

6 H. villòsa (Michx. fl. bor. amer. 1. p. 172.) lower part of scape and petioles beset with deflexed soft hairs; leaves cordate, acutely lobed, mucronately serrated, a little cut, nearly naked above, but very villous on the nerves beneath ; panicle loose ; peduncles capillary, dichotomous ; bracteas linear, ciliated ; flowers small; petals very long, narrow-spatulate, and are, as well as the stamens, much exserted. $\%$. H. Native of Upper Canada, and on the higher mountains of Virginia and Carolina. The leaves are very difierent from those of $H$. Amcricana, the flowers are sinaller, and the petals regularly long and narrow, white.

I"illous Heuchera. Fl. May, July. Clt. 1812. Pl, I foot.

7 H. GLA'BRA (Willd. in Schultes, syst. 6. p. 216.) seape leafy; leaves cordate, acutely lobed, glabrous, unequally and acutely toothed; lower stem ones or bracteas toothed; panicle loose; flowers small; calyx pubescent; petals linear; stamens exserted. 24. 11. Native of the north-west coast of America ; Nootka, in the vicinity of the Columbia river; Rocky Mountains, at Providence and Portage rivers. Hook. fl. bor. amer.
1. p. 236. t. 79. Tiarélla colòrans, Graham, in edinb. new. phil. journ. July, 1829. Petals white. Stipulas adnate, as in the genus Rosa, but free at the top.

Glabrous Heuchera. Fl. June, July. Clt, 1827. P], 1 foot.

8 H. caule'scens (Pursh, fl. amer. sept. 1. p. 188.) plant suffruticose at the base; lower part of scape and petioles pilose; leaves glabrous above, but pilose at the nerves beneath, acutely lobed, ciliated, toothed: teeth acute, mucronate; calyx short, villuus; petals linear, twice the length of the calyx ; stamens exserted. 24. H. Native of Carolina, on the mountains, and of Kamtschatka. Petals white.

Caulescent Heuchera. Fl. May, July. Clt. 1812. Pl. $1 \mathrm{ft}$.

9 H. Barbaróssa (Prest, in reliq. Hænk. 2. p. 56.) plant suffruticose at the base; floriferous stems clothed with rufous villi ; petioles very villous from rufous hairs; leaves roundishcordate, bluntly lobed, mucronately toothed, ciliated, puberulous; panicle loose, many flowered; petals linear-oblong, longer than the calyx; stamens exserted. 4 . H. Native of Nootka Sound. Plant small.

Barbarossa Heuchera. Pl. $\frac{1}{4}$ foot.

10 H. crlíndisica (Dougl. mss. ex Hook. fl. bor, amer. 1. p. 236.) scapes naked, and are, as well as the petioles, hairy; leaves cordate, deeply and roundly lobed, crenated, ciliated; truncate at the base, smoothish above, but very pilose at the veins beneath: teeth pilifcrous; panicle compact, cylindrical, ratlier spicate ; flowers rather large, apetalous; stamens inclosed. $\mathcal{H}$. H. Native of North America, on the declivities of low hills, and on the steep banks of streams on the west side of the Rocky Mountains. Like H. Richardsonii, but differs from it in the truncate base of the leaves, and in the spicate panicle, by having less oblique calyxes, very short stamens, and by the absence of petals.

Cylindrical-spiked Heuchera. Pl. 1 to $1 \frac{1}{2}$ foot.

11 H. Richardsòni (R. Br. in Franklin, Ist journ. ed. 1. append. p. 766. t. 29.) scapes and petioles rather pilose; leares cordate, with a deep recess, bluntly lobed, ciliated, crenated, rather pilose on both surfaces: teeth piliferous; panicle loose, thyrsoid; flowers large; mouth of calyx oblique; petals obovately cuneated, hardly longer than the calyx; stamens a little exserted. 4.H. Native of North America, on the dry banks of rivers from lat. $54^{\circ}$ to $64^{\circ}$.

Richardson's Heuchera. Fl. June, July. Clt. 1827. Pl. 1 to $1 \frac{1}{2}$ foot.

12 H. Menzie'sil (Hook. fl. bor amer. 1. p. 237 . t. 80.) plant hispid from pili; stems leafy ; leaves cordate, acutely lobed, deeply serrated; flowers racemose, apetalous ; calyx cylindrically funnel-shaped; stamens exscrted; ovarium free. 4 . $\mathrm{H}$. Native of the north-west coast of America ; at Banks's Isles, and from the coast of Columbia to Puget's Sound. Tiarélla Menzièsii? Pursh. f. amer. sept. 1. p. 313. Racemes terminal, elongated, solitary, many flowered. Stamens 3, exserted. Petals 5, linear, reflexed. (f. 51.)

I ar. $\beta$; plant less hairy. 4. H. Native along with the species, in shady woods. H. triândra, Dong. mss. ex Hook. l.c. Menzies's Heuchera. Pl. 1 to 2 feet.

13 II. BRACteA'TA (Ser. in D. C. prod. 4. p. 52.) plant pubescent; scapes racemose; leaves orbicularly cordate, serrately cut : teeth mucronate; flowers bracteate; petals narrow, hardly 
longer than the calyx; stamens not exserted. 4. II. Native of North America, on the liocky Mountains. Tiarélla? bracteàta, Torrey in ann. lyc. 2. p. 20.. Ilabit of a species of Saxifraga. Bractcate-flowered Heuchera. Pl. 1 foot.

14. H. LoNgire'tala (Moc. pl. nootk. incd. with a figure, ex D. C. prod. 4. p. 52.) scape pubescent; panicle sccund; petals linear, revolute at the apex, longer than the calyx. $4 . H$. Native of the north-west coast of America. Lobes of leaves broad, rather distinct, acutely toothed. Petals and styles white. Long-petalled Heuchera. Pl. 1 foot.

15 III. ACERIFòlia (Rafin. med. fl. 1. p. 211. t. 49.) petioles hairy; leaves smooth, glaucous beneath, acutely 5 -lobed, unequally toothed: teeth mucronate; scapes smooth; panicle elongated, loose; petals short; stamens exserted. 4.H. Native of North America, on hills and in the fissures of rocks, in Kentucky, T'ennessee, and west of Virginia, Maryland, and Ohio, \&.c.

Maple-lcaecd Heucliera. Pl. 1 foot.

16 H. squamòsa (Rafin. med. fl, p. 244.) petioles pilose; leaves rather hairy, ciliated, cordate, acutcly 7 -lobed, denticulated, glaucous beneath; scape pilose, furnished with distant oval scales; panicle short, oval, crowded, scaly ; pedicels short ; lobes of calyx obtuse; stamens exserted. 2. H. Native on the mountains of Maryland, Virginia, and Kentucky. Perhaps the same as $H$. bracteàta.

Scaly Heuchera. Pl. 1 foot.

Cult. The species of IIeuchera thrive in any light garden soil, and are readily increased by dividing at the roots. None of the species are showy.

XI. DONA'TIA (so named by Forster from Vitaliano Donati, of Padun, professor of botany at Turin). He travelled into Egypt and Arabia, and died on his journey). Forst. gen. t. 5. Juss. gen. p. 300 . St. Hil. mem. mus. 2. p. 119. D. C. prod. 4. p. 53.

Lin. syst. Triándria, Trigýnia. Tube of calyx turbinate, adnate to the ovarium; limb truncate, with 2 triangular acuminated nearly opposite teeth. Bracteoles linear, adnate to the tube of the calyx. Petals 9 (f. 52.e.), ( $8-10$ ex Forst.) linearoblong. Stamens 3 (f. 52.f.), short, alternating with the petals. Styles 3 (f. 52. b.) -5, filiform. Ovarium 2-3-celled. Ovula numerous, fixed to the top of the cells. Fruit capsular.-A nearly stemless herb, with the habit of Saxifraga cospitosa. Stems tufted. Leaves alternate, linear, obtuse, permanent, imbricated, thick, glabrous, woolly in the axils. Flowers terminal, sessile, solitary, white. Perhaps the petals are 6 , and the stamens 6,3 of them antheriferous, and the other 3 converted into petals.

1 D. MaGellánica (Forst. I. c.) 4.F. Native of the Straits of Magellan, on humid rocks. Lam. ill. t. 51. Polycárpon Magellánicum, Lin. fil. suppl. 115.

\section{Magrellan Donatia. Pl. $\frac{1}{4} \mathrm{ft}$.}

Cult. This plant will require to be grown in a small pot, well drained, in a mixture of sand, peat and loam; and placed among other alpine plants. It will be easily increased by dividing.

XII. LEPUROPE'TALUMI (from $\lambda_{\varepsilon} \pi v \rho i o v$, lepurion, a little scale, and $\pi \varepsilon \tau a \lambda o v$, petalon, a petal; in reference to the small scale-formed petals). Elliot, sketch 1. p. 370. D. C. prod. 4. p. 53 .
Lıx. sysт. I'entandria, Trigýnia. Calyx 5-parted, permanent: lohes ovate, obtuse. P'etals 5, permancnt, scale-formed, inserted in the calyx, and alternating with its segments. Stamens 5 , alternating with the petals. Orarium free at the apex. Styles 3 , short, rather concrete at the base. Capsule I-cclled, 3-valved at the apex. Sceds numerous, oval, fixed to the inflexed margins of the valves. - An annual glabrous branched tufted lerb. Leaves alternate, sessile, spatulately lanceolate, obtuse, entire. Flowers terminal, solitary, small, white.

1 L. spatula'tum (Eil. 1. c.) 4. F. Native of North America, in Georgia, in shady places. Pyxidantlièra spatulàta, Muhl. cat.

Spatulatc-leaved Lepropetalum. Pl. $\frac{1}{8}$ foot.

Cult. Sce Donatia above for culture and propagation.

XIII. VA'HLIA (in honour of Martin Vahl, a pupil of Linneus, regius professor of botany at Copenhagen, and member of several academics, anthor of Symboliæ Botanicæ, Eclogæ Americanæ, Sc. and one of the editors of Flora Danica). Thunb. gen. nov. 2. p. S6. witlı a figure. Juss. gen. p. 318 . Poir. dict. 8 . p. 284. Lam. ill. t. 183 . R. Br. in Frankl. narr. journ. 766. D. C. prod. 4. p. 53.-Bistélla, Caill. and Delil. but not of Adans.-Oldenlándia species, Retz, Roth, Smith, but not of Lin.

Lis. syst. Pentandria, Digýnia. Tube of calyx adhering to the ovarium: limb 5-parted, permanent, valvate in astivation. Petals 5 , spreading, undivided, shorter than the calyx. Stamens 5 : anthers versatile. Styles 2, capitate at the apex. Capsule 1-celled, 2-valved, truncate at the apex, 5-furrowed, crowned by the limb of the calyx, many seeded; placentas loose, langing from the top of the cavity of the cell. Seeds convex on the outside, and concave on the insidc.-Rather villons somewhat dichotomous herbs. Leaves opposite, exstipulate, lincar or lanceolate. Flowers white, axillary, pedicellate; pedicels twin, 1flowered, short.

\section{* African species.}

1 V. CAPE'Nsis (Thunb. fl. cap. p. 246.) leaves linear or narrow-lanceolate; branches velvety at the top; pedicels twin, 1flowered; styles exserted; capsules oblong. 4. G. Native of the Cape of Good Hope. Russèlia Capénsis, Lin. fil. suppl. p. 175. Plant almost with the habit of a Siline, from $\frac{1}{2}$ to 1 foot high. Flowers white.

Cape Vahlia. Pl. $\frac{1}{2}$ to 1 foot.

2 V. WELDE'Nin (Reich, liort. bot. t. 91.) leaves ovate, acute; pedicels twin, 1 -flowered; capsule globose. $\odot . H$. Native of Upper Egypt, of Nubia near Dongolals; and of Senegal. Bistélla geminiflòra, Caill. and Delil. pl. afr. p. 97. t. 69. f. 2. A much branched herb, beset with glandular hairs. Flowers white.

Velden's Vahlia. Pl. $\frac{1}{4}$ to $\frac{1}{2}$ foot.

3 V. ranosíssima (A ph. D. C. diss. ined. cx D. C. prod. 4. p. 54.) stem much branched, hairy : hairs bearing viscid glands at the apex; leaves linear, pubescent; peduncles 2-flowered, shorter than the leaves; capsule ovate. $\odot$. H. Native of Senegal. Flowers white. Habit of a Silène or Arenaria.

Much-branched Vahlia. Pl. $\frac{1}{4}$ to $\frac{1}{2}$ foot.

4 V. sileroìnes ( $A]_{\text {pl. }}$. D. C. diss. ined. ex D. C. prod. 4. p. 54.) stem branched, clothed with soft hairs; leaves linear, pubescent; pcduncles 2-flowered, shorter than the leaves ; capsule globose. $\odot$. H. Native of the Cape Verd Islands. Flowers white.

Catchfly-like Vahlia. Pl. $\frac{1}{2}$ foot.

5 V. tomentòsa (Alph. D. C. diss. ined. ex D. C. prod. 4. p. 54$.$) stem branched, tomentose; leaves linear-lanceolate, rather$ hairy; peduneles 2-flowered, shorter than the leaves: flowers on short pedicels; eapsule nearly globose. $\odot$. ? H. Natire of the nortl of $\mathrm{A}$ frica, in the kingdom of Cayor. Flowers whitc. 


\section{Tomentose Vablia. Pl. $\frac{1}{4}$ to $\frac{1}{2}$ foot.}

\section{* Asiatic species.}

6 V. OlDENLA'NDIE (D. C. prod. 4. p. 54.) stem erect; leaves linear, pubescent; peduncles axillary, 2-flowered, shorter than the leaves. $\odot$. F. Native of Tranquebar. Oldenlándia pentándra, Rets, obs. 4. p. 22. Nleuchèra dichótoma, Murr. comm. goett. 1772. p. 64. f. 1. Oldenlándia dichótoma, Spreng. pug. 2. p. 36. Flowers white. Perhaps Oldenlándia biflòra, Roth, nov. spec. 97 . but not of Lin. is sufficiently distinct from this; there are varieties of it with 4-5-parted flowers.

Oldenland's Vablia. Pl. $\frac{1}{2}$ foot.

7 V. sessiliflòra (D. C. prod. 4. p. 54.) stems decumbent; leaves lanceolate; flowers axillary, sessile. $\odot . ? H$. Native of Tranquebar. Oldenlándia dígyra, Retz, obs. p. 23. Oldenlándia decúmbens, Spreng. pug. 2. p. 36. Oldenlándia sessiliflòra, Smith in Rees' cycl. vol. 25. no. 2. Flowers pentapetalous, digynous, white.

Sessile-flowered Vahlia. Pl. decumbent.

Obs. The Oldenlándia depréssa of Willd. and Smith will prohably make an eighth species to this genus when properly examined.

Cult. The seeds of all the species should be reared on a hot-bed; and in the montl of May, when the plants will have obtained a considerable size, they may be planted out in the open border, in a warm sheltered situation. The $V$. Capénsis, being a herbaceous perennial shrub, will require the treatment of other green-house plants.

XIV. CRYPTOPE'TALUM (from k $\rho v \pi \tau o s$, cryptos, hidden, and $\pi \varepsilon \tau a \lambda o w$, petalon, a petal; petals minute, inclosed in the calyx). Hook. et Arn. in bot. misc. 3. p. 254.

Inn. syst. Pentándria, Trigýnia. Calyx turbinate, 5-cleft, green : segments ovate, acute, spreading. Petals 5, inserted in the tube of the calyx, and alternating with its segments, inclosed, minute, spatulate. Stamens 5 , inserted in the tube of the calyx, small, and almost inclosed, alternating with the petals; filaments filiform; anthers minute, roundish, orange-coloured, 2-celled. Ovarium subglobose, with the lower part adhering to the calyx: upper part free, 1-celled; placentas free, parietal, linear, divaricately bilamellate, many ovulate; ovula very slender, membranous. Styles 3, short, hardly united at the base; stigmas minutely papillose. Capsule globose, inclosed in the permanent calyx, 1-celled, opening at the cells, and 3 -valved in the free part; each of the valves terminated by a permanent style. Seeds numerous, pale, oval, obtuse at both ends, dotted ; albuinen thin, fleshy. Embryo straight, central.-A small annual smooth herb, about lialf an inch high. Stems erect, dichotomous, branched; branches divaricate. Leaves alternate, spatulate, quite entire, fleshy, bardly nerved. Flowers terminal, large for the size of the plant, emulating those of Chrysosplènium.

1 C. I'Usíluum (Hook, et Arn. l. c.) ๑. H. Native of Chili, at Quintero. This curious plant is placed at the end of Saxifragàces, because it scems more nearly allied to that order than to any other; it agrees witl Chrysosplenium in many particulars.

Simall Cryptopetalurs. Pl. $\frac{3}{2}$ inch.

Cult. Sow the secd in a small pot filled with a mixture of peat and sand.

\section{Tribe 11.}

IIY)RA'VGE $/$ (plants agrecing with IIydrangea in being slirubby). D. C. prod. 4. p. 13. Shrubs, with opposite simple exstipulate leaves. Flowers disposed in corymbs, having 5 petals, 10 stamens, and $2-3$ styles; outer ones, and sometimes all, are often sterile; these sterile ones are more ample and dilated than the fertile ones.

XV. HYDRA'NGEA (from $i \delta \omega \rho, ~ h y d o r$, water, and $a \gamma$. $\gamma \varepsilon t o v$, aggeion, a vessel; some of the species grow in water, and the capsule has been compared to a cup). Lin. gen. 557. Gærtn. fruct. 1. p. 150. t. 30 f. 7. Lam. ill. t. 370 . D. C. prod. 4. p. 13.-Hydrángea and Horténsia, Juss.

LıN. syst. Decándria, Di-Trigýnia. Flowers usually difformed (f. 53. a. b.) ; but some of them are fertile and hermaphrodite (f. 53. b.). Tube of calyx hemispherical, 10-ribbed, rather truncate, adnate to the ovarium: limb permanent, 5 toothed (f. 53. b.). Petals 5, regular. Stamens 10. Styles 2 (f. 53. c.), distinct. Capsule 2-celled, with introflexed valves, crowned by the teeth of the calyx and styles (f. 53. b. c.), flattish at the top, opening by a hole between the styles. Seeds reticulated, numerous.-Shrubs, with opposite leaves. Flowers corymbose, red or yellow, but usually white : the marginal ones sterile, and large, in consequence of the teeth of the calyx being dilated into broad petal-like coloured segments, the rest of the flower having the other parts abortive.

\section{* Species natives of America.}

1 H. ARBore'scens (Lin. spec. p. 568.) leaves ovate, rather cordate: superior ones lanceolate, coarsely toothed, pale and puberulous beneath; corymbs flattish; flowers nearly all fertile; alabastra obtuse. $h$. H. Native from Pennsylvania to Virginia. Flowers white, small, having an agreeable odour.

Yar. a, vulgàris (Ser. in D. C. prod. 4. p. 14.) nerves of leaves puberulous. $h$. H. H. vulgàris, Michx. fl. bor. amer. 1. p. 268. and probably of Pursh. H. arboréscens, Curt. bot. mag. 437. Lam. ill. t. 370. f. 1. Schkuhr, handb. t. 119. Mill. fig. 251. H. frutéscens, Mœench, meth. 1. p. 106. Du Ham. arb. 1. t. 118 .

I ar. $\beta$, discolor (Ser. l. c.) leaves almost white beneath from tomentum.

Arborescent Hydrangea. Fl.Jul. Aug. Clt. 1736. Sh. 1 to $6 \mathrm{ft}$.

2 H. conda'tA (Pursh, f. amer. sept. 1. p. 309. exclusive of the synonyme of Michx.) leaves broadly ovate, acuminated, rather cordate at the base, coarsely toothed, glabrous beneath ; flowers all fertile. $\quad$. H. Native of Carolina, on the mountains, and on the banks of the Missouri above St. Louis. Wats. dendr. brit. t. 42. Flowers sinall, white, sweet-scented. According to Torrey, this is merely a variety of $H$. arboréscens.

Cordate-leaved Hydrangea. Fl. July, Aug. Clt. 1806. Sh. 6 to 8 feet.

3 H. Peruvia'na (Moric. mss. with a figure, ex D.C. prod. 4. p. 14.) leaves oval, loosely serrated, coriaceous, reticulately veined, glabrous, rusty beneath, at the nerves, and on the petioles; young branches and peduncles clothed with purplish tomentum; outer flowers of the corymb large and sterile : inner ones hermaphrodite and petandrous. そ.G. Native of Peru, near Huyaquaquil. Perhaps a species of Cornidia, and probably C. Peruviàna.

Pernvian Hydrangea. Shrub 4 to 6 feet.

4. H. NiveA (Michx. fl. bor. amer. 1. p. 268.) leaves cordate, oval, acuminated, sharply toothed, clothed with white tomentum beneath, or pubescence; corymbs flattish; sepals of sterile flowers entire; alabastra depressed. $々$. H. Native of North America, about the Savannah river. Wats. dend. brit. t. 43 . Lam. ill. t. 307 . f. 2. H. radiàta, Walt. fl. car. 251. ex Michx. but not of Smith. Flowers white, rather large.

I'ar. $\beta$, glabélla (Ser. in D. C. prod. 4. p. 14.) leaves nearly glabrous beneath; flowers all fertile. $\boldsymbol{~} . \mathbf{H}$. This variety has probably originated from culture.

White-leaved Hydrangea. Fl. July, Aug. Clt. 1786. Shrub 4 to 6 fcet. 
5 H. Queresóla (Bartram, trav. ed. germ. p. 336.t. 7. ex Willd. spee. 2. t. 634.) leaves large, ovate, sinuately lobed, and toothed, pilose beneath; corymbs rather panicled, flattish ; sepals of sterile flowers entire; alabastra depressed. h. H. Native of Jlorida. Sims, hot. mag. t. 975. I1. radiata, Smitl, icon. pict. p. 12. but not of Wait. Flowers white; sterile or outer ones of the corymb large.

Oak-liavd Hydrangea. [1]. Jume, Sept. Clt. 1503. Shrub 4 to 6 feet.

\section{* Species natives of Asia.}

6 H. a tíssima (Wall. tent. fl. nep. 2. t. 50.) leaves ovate, acuminated, serrated, smoothish; corymbs Hattislı; sterile flowers few, on pilose peduncles; alabastra of fertile flowers conical. h. F. Native of the mountains of Nipaul. Flowers white; sepals of sterile flowers obovate, very blunt, quite entire. Styles 2, thick, diverging.

Tallest Hydrangea. Shrub 4 to 6 feet.

7 H. vesilta (Wall. tent. f. nep. 2. t. 49.) leaves ovate-lanceolate, acuminated, sharply serrated, almost glabrous abore, hut clothed with white tomentum beneath, as well as on the branches; corymbs flattish, large; pedun. cles viilous; sterile flowers few, glabrous; alabastra of fertile Howers nearly globose. $h$. F. Native of Nipaul, on the mountains. Flowers white, rather large. Sepals of sterile flowers serrated. (f. 53.)

Iar. a, integriloba (Ser. in D. C. prod. 4. p. 14.) sepals of sterile flowers obovate, reticulated, quite entire. 々. F. Native of Nipaul, at Kamaon.

Var. $\beta$, fimbriàta (Wall. 1. c.) sepals of sterile flowers ovate, acuminated, serrated. $\zeta_{c}$. F. Native of Nipaul, on the higher mountains.

Clothed Hydrangea. Slirub t to 6 feet.

8 H. Áspera (Hamilt. ex D. Don, prod. 1l. nep. p. 211.) leares lanceolate, acuminated, sharply serrated, pubescent above, but densely clothed beneath with hoary tomentum, as well as on the branchlets; corymbs panicled, diffuse; peduncles villous; rays or sepals of sterile flowers ovate, mucronate, sharply serrated, pubescent; alabastra of fertile flowers globose. $h$. F. Native of Nipaul, in watery places at Narainhetty. Horténsia áspera, Hamilt. Leaves a hand long, and $2 \frac{1}{2}$ inclies broad. Sterile flowers not near so large as those of the preceding species, white.

liough Hydrangea. Fl. Aug. Sept. Shrub.

9 H. oblongifólia (Blum. bijdr. p. 920.) leaves oblong, acuminated, doubly toothed, glabrous above, but clothed with white tomentum beneath, as well as on the branchlets; corymbs divaricate; sepals of sterile flowers oval, glabrous, serrated; fertile flowers containing 3-4 styles. $々$. G. Native of the western parts of Java, in woods on the higher mountains. Very like the two preceding species, but differs in the teetl of the leaves being unequal, and not so sharp.

Oblong-lcaved Hydrangea. Shrub 4 to 6 feet.

10 H. HeteromáLla (D. Don, prod. A. nep. p. 211.) Jeaves oval, acuminated, sharply serrated, tomentose beneatl, and pilose ; corymbs supra-decompound, diffuse, pilose; sepals of sterile flowers roundish-oval, quite entire. $5 . H$. Native of vOL. III.
Nipanl, at Gosainstlan. Leares 5 inches long, and nearly 3 inclies bioad. Flowers white.

I'ariable-surfaced-leaved Hydrangea. Clt. 18:1. Shrub \& to 6 feet.

11 11. axóma La (I). 1)on, prod. tl. nep. p. 211.) leaves ovate, acuminated, nearly naked, sinuately erenated; petioles and nerves pilose ; eymes terminal, hairy ; flowers uniform; rays or sepals of sterile flowers wanting. h. F. Native of Nipaul. Leaves 4 inches long, rounderl at the base; petioles an inel long. Flowers small. Styles very short, thick, recurved.

Anomalous llydrangea. Shrub 3 to 6 feet.

12 11. Honténsia (Sbld. in act. bonn. 14. p. 688. D. C. prod. 4. p. 15.) leaves broadly ovate, serrated, acuminated; thowers disposed in ample corymbs or cymes, all difformed, with 4-5 segments; segments obovate-roundish, quitc entire; fertile flowers very few, containing $2-3$ styles. $h_{2}$. F. Native of China and Japan, but now cultivated almost every where in gardens for the sake of its beauty. Horténsia opuloides, Lam. dict. 3. p. 136. Dum. Cours. bot. cult. ed. 2. vol. 4. p. 34.5. Duham. ed. nov. S. p. 97. t. 24. Hydrángea horténsis, Smith, icon. pict. 1. t. 12. Curt. bot. mag. 438. IIorténsia speciòsa, lers. Prímula mutábilis, Lour. coch. p. 10 \%. Vibúrnum serràtum, Thunb. fl. jajp. p. 124. ex Ren. et Schultes, or Vibúrnum tomentòsım, Thunb. ex Curt. but the descriptions of neither of these two plants agree with the present. The plant is ealled Temerihana, i. e. globe-flower, by the Japanese; and Fun-Dan Kn' $a$ by the Chinese. Flowers varying from rose-coloured to blue according to the soil in which the plant is grown; the sterile flowers are nearly always 4-cleft; but the fertile flowers are small and perfect. The plant is inuch valued on account of the great profusion of its very elegant flowers, which are monstrous, in the same manner as the Snow-ball Guilder Rose. It was introduced by Sir Joseph Banks in 1790. The plant was first called Peaùlia by Commerson, in honour of Dæ Hortense Lapeaute.

Hortensia's or Common Hydrangea. Fl. April, Sept. Clt. 1790. Slirub 2 to 3 feet.

13 H. AzisA'1 (Sbld. in act. bonn. 14. p. 6S9.) leaves ovate, acuminated, attenuated at the basc, crenately serrated; flowers disposed in cymes, difformed; corolline scgments 4. h. F. Native of Japan, along with the preceding species. The cymes of flowers are very ample. Flowers for the most part greenish, rarely white. The jlant is called Azisai by the Japanese, and $Z$ th-hats-scn by the Chinese. There is a variety of it with variegated leaves, called Fiuri-Azisai by the Clinese.

$A$ zisai Hydrangea. Slurub 2 to 3 feet.

14. H. JA pónica (Stuld. l. c. p. 689.) leaves ovate-oblong, acuminated, finely and glandularly serrated, quite glabrous on both surfaces; cymes crowled; flowers diflormed; corolline segments 6-10, unequal, ovate-rhomboid, $\zeta$. F. Native of $\mathrm{J}$ apan, where it is called Kakoosu. An clegant shrub, cultivated by the Japanese, about the size of the last.

lar. a; flowers red. Benkaku.

Var. $\beta$; flowers grey. Konkaku.

Japan Hydrangea. Slirub 2 to 3 feet.

15 H. Tirunbe'rait (Sbld. 1. e. j). 690.) leaves oblong, serrated, entire at the base, pale beneath; cymes crowded; flowers difformed; corolline seginents 4.8 , broadly obeordate, constantly of a greyish lilac-colour. $\zeta$. F. Native of Japan, on the highest mountains. Vibürnum serràtum, Thunb. jạ. p. 124. H. serrata, D. C. prod. 4. p. 115 . Slurub climbing. 'The plant grows in the mountains of Aiva and Sonaki, where the natives use the dried leaves instead of tea, and is ealled by them Amats$j a, \mathrm{i}$. e. sweet tea; and Do-Sioo-San by the Chinesc. According to the Japanese, there is a variety with bitter leaves, which they call Kakossoo.

$\mathrm{H} \mathrm{h}$ 
Thunberg's IIydrangea. Shrub el.

16 H. vínens (Sbld. ]. c. p. 690.) leaves ovate-oblong, acuminated, serrated at the apex, hispid above (Thunb.); cymes sinted: flowers difformed; corolline segments 2-3, unequal, white, 5 . F. Native of Japan, on the higher mountains, among Azalias, Euryas, Andromedas, \& c. H. scándens, D. C. prod. 4. 1\% 15. Vibúrnum virens, Thunb. 11. jap. 123. Vibúrnum scándens, Lin. fil. suppl. 184. Slrub 2 to 6 feet high, rarely climbing. It is called by the Japanese Janratoosin. Green II lydrangea. Slurub 2 to 6 feet.

17 H. PANicula'ta (Sbld. I. c. p. 691.) leaves elliptic, acuminated, glandularly toothed, scabrous, tern on the floriferous branches; panicle branched, rather secund; flowers difformed, very numerous; corolline segments $3-4$, obovate, white. h.F. Native of Japan. Shrub climbing, 5 feet high. The plant is called Tsurudemari by the Japanese, and Too-sinkjine by the Chinese. There is a variety with very pale red flowers, cultivated near the town of Posaka, very like the species, but does not climb, called Jamademai by the Japanese. l'erhaps Vibúrnum plicàtum, Thunb. is only a varjety of $H$. paniculata.

Panicled-flowered Hydrangea. Slorub 5 feet.

18 H. involucra'ta (Sbld. J. c. p. 691.) Jeaves ovate, acuminated, glandularly serrated, reticulately veined, hispid on both surfaces; cymes involucrated before flowering (involucrum caducous, 2-3-leaved), crowded; flowers difformed; corolline segments 8 , nearly orbicular. $々 . F$. Native of Japan. I'lant suffruticose, hardly a foot high.

I'ar. a; corolla lilac. Gimbaisoo of the Japanese; cultivated near the town of Oosaka.

I ar. $\beta$; corolla yellow. Kinbaisoo of the Japanese.

Involucrated Hydrangea. Shrub 1 foot.

19 H. Alternifòlia (Sb]d. l. c. p. 692.) leaves alternate; flowers cymose, polyandrous, difformed; corolline segments $2-6$, 3 of which are constantly ovate and acute. h. F. Native of $J a p a n$, where it is called by the natives Kusasimots-Ke.

Alternate-leaved Hydrangea. Shrub 1 foot.

20 H. Sítsitan (Sbld. l. c. p. 692.) leaves ovate, acuminated, acutely serrated, with the veins pubescent beneath; flowers cymose, diflormed, double ; corolline segments elliptic, of a fine rose-colour. $h_{2}$. F. Native of Japan. Shrub 2 feet high. Cultivated about the town of Miako, where it is called Sitsitan by the natives. Perhaps only a double flowering variety of H. Ifortinsia.

Sitsitan Hydrangea. Shrub 2 to 4 feet.

\section{+ Species natives of Japan, but hardly known.}

21 H. Macropur'teA (D. C. prod. 4. p. 15.) branchlets rather pilose; leaves obovate, acuminated, sharply serrated, rather pilose on botl surfaces; umbels terminal, compound, radiating. h. F. Natice of Japan. Vibúrnum macroplíllum, Thunb. f. jap 125 .

\section{Long-leaved Hydrangea. Shrub.}

22 11. n'́rta (Sbld. ex flora, 1828. nov. 21.) leaves ovate, scrrated, villous; petioles and peduncles hairy; umbels terminal, not radiating; stigmas 2-lobed. $\zeta$. F. Native of Japan. Vibúrnum lírtun, Thunb. fl. jaj. 124.

Hairy Hydrangea. Slirub.

Cult. The hardy species, or those natives of North America, are dwarf shrubs, and therefore proper for the front of slarubberies. II. quercifolia does best against a south wall. Those species natives of $\Lambda$ sia will require protection in winter, eitleer by placing them in a frame or green-house. Cuttings of all the species root readily if planted under a land-glass. H. IIorténsia is in general cultivation for the sake of its showy flowers; the blue-flowered variety is in greatest request, which may be obtained by planting out the common pink varicty in a bed of peat soil, and letting it remain there 2 or 3 years; for the longer it remains the deeper blue the flowers will become: the plants may then be potted before the huds begin to burst, and they will then flower in perfection, and the flowers will be of a beautiful blue colour.

XVI. CORNI'DIA (in honour of Joseph Cornide, a Spanish naturalist). Ruiz et Pav. H. per. 1. p. 43.--Sarcóstyles, Presl, in reliq. Hank. 2. p. 53. t. 6. D. C. prod. 4. p. 15.

Lin. sist. Octándria, Trigýnia. Calyx superior, 4-toothed, equal, deciduous, Stamens 8; filaments linear: anthers ovate, 2-celled, dehiscing longitudinally inside. Ovarium inferior, nearly globose, 3-celled, rarely 4-celled, many ovulate. Styles 3 , rarely 4, thick, fleshy, at length divaricate; stigmas obtuse, oblique. Capsule nearly globose, crowned by the permanent calyx and styles, deliscing between the styles, 3-celled, rarely 4-celled, many seeded; dissepiments entire, placentiferous. Seeds cylindrical.—Shrubs, with glabrous opposite serrated leaves, and involucrated cymes or corymbs of white flowers, with the habit of Hydrángea.

l C. Peruvia'sa (Ruiz et Pav. fl. per. l. c..) leaves oval or obovate, acuminated or obtuse, coriaceous, serrated at the apex; corymbs terminal, many rayed, involucrated by 4 large deciduous bracteas. $\zeta$. F. Native of Peru, on the mountains. Sarcóstyles Peruviàna, Presl, in Hænk, reliq. 2. p. 54. t. 60.

Peruvian Cornidia. Shrub.

2 C. INTEgé rrima (Hook. et Arn. in bot. misc. 3. p. 254.) leaves roundish-elliptic, glabrous, hardly acute at the base and apex; corymbs numerous, disposed in a terminal raceme, which much exceeds the leaves, $\quad$ z. F. Native of Chili, about $\mathrm{V}$ alparaiso, and near Bustamente. Hydrángea scándens, Poepp. ex D. C. prod. 4. p. 666.

Entire-leaved Cornidea. Shrub cl.?

3 C. serratifòria (Hook. et Arn. 1, c.) leaves obovate-oblong, acute, obtuse at the base, serrated upwards; floral ones or rameal ones smaller, ovate, with a few denticulations; corymbs numerous, disposed in a terminal raceme, which hardly exceeds the leaves. $々$. F. Native of Chiloe. Closely allied to the last species, but apparently distinct. Both, but especially the present, have several decussate, patent, concave, stiff bracteas, along the stalks of the corymbs.

San-lcaved Cornidia. Shrul.

Cult. The culture and propagation of the species of Cornidia are the same as that recommended for the species of Hydrángea. They require to be protected in winter by placing them in a frame or green-house.

XVII. CIANI'TIS (fron kvaveos, kyaneos, blue; colour of berries). Reinw. in Blume, bijdr. p. 921. D. C. prod. 4. p. 16.

L1N. syst. Decándria, Tri-P’entagýnia. Tube of calyx ad.hering to the ovarium: Jimb 5-toothed. Petals 5, rather fleshy, inserted in an epigynous disk. Stamens 10 ; anthers oblong, erect, dehiscing at the sides. Styles $3-5$, spreading: stigmas obtuse, adnate. Berry crowned by the teeth of the calyx, half 3-5-celled, many seeded; dissepiments incomplete, inflexed, fleshy, seminiferous.-A subshrub, with opposite, petiolate, oblong-lanceolate, smoothish leaves, which are serrated from the midclle to the apex; and panicled terminal cymes of flowers, with trifid branches.

1 C. sYlva'tica (Reinw. l. c.) cymes nearly undivided, on short peduncles, disposed in a coarctate panicle. $r_{c} . S$. Native of Java, on the mountains, where it is called by the natives Tivere-gil-gil. Flowers probably white.

l'ar. $\beta$, paniculita (Blum. mss.) cymes branched, on long peduncles, disposed in an elongated panicle. .5 . Native of Java. Perhaps distinct from the species. 
V'ar. $\gamma$, corymbòsa (Blunı. mss.) cymes branched, on long peduncles, disposed in somewhat fastigiate corymbs. Nacive of Java. Perhaps a proper species.

Wood Cianitis. Shrub 2 to 3 feet.

Cult. A mixturc of loam, pcat, and sand will suit these plants; and cuttings will root readily in the same kind of soil, under a band-glass.

XVIII. ADA'IIA (in honour of John Adam, some time Governor-General of India; a promoter of natural history). Wall. tent. fl. nep. p. 4.6. t. 36. D. C. prod. 4. p. 16.

Lis. syst. Decándria, Pentagýnia. Tube of calyx adnate to the ovarium; limb with 5 short teeth, having the recesses between the teeth broad and obtuse. Petals 5, alternating with the teeth of the calyx, surrounding the top of the ovarium. Stamens 10 . Styles 5 , ending in rather clavate, somewhat 2 -lobed stigmas. Berry crowned by the limb of the calyx, somewhat 5-celled, many seeded. Embryo terete, straight, in a fleshy abumen, witli the radicle turned towards the hilum.-A smooth branched shrub. Leaves opposite, exstipulate, petiolate, oblong-lanceolate, serrated. Panicle corymbose, terminal, many flowered. Flowers bluish. Berries blue. Perhaps not distinct from Cianitis.

1 A. crane'A (Wall. l. c.) 々. G. Native of Nipaul, in rocky places, on mountains near the Great Valley, where it is ealled Bansook by the natives. Hook. bot. mag. t. 3046. Wall. pl. rat. asiat. 3. t. 213.

Blue-berried Adamia. Fl. June, July. Clt. 1829. Shrub 4 to 6 feet.

Cult. See Cianitis above for culture and propagation.

XIX. BROUSSAISIA (in honour of the celebrated M. Broussais, MI.D. author of physiological medicine). Gaud. in Freyc. voy. t. 69. D. C. prod. 4. p. 17.

Lix. syst. Decándrin, Monogýnio. Calyx 5-parted, hemispherical, distinct from the ovarium : lobes ovate-deltoid, bluntish, equal. Petals oblong, acuminated, with a reflexed point (nearly as in umbelliferous plants) twice the length of the calyx, valvate in astivation. Stamens 10 , hypogynous, surrounding the base of the ovarium; filaments subulate, distinet; anthers ovate. Ovarium roundish, crowned by the short style and truncate stigma, 5-celled; cells many secded.-A slirub, with opposite oval petiolate sharply serrated leaves, and corymbs of fertile flowers. The shrub has the habit of Iydrángca, but differs in the ovarium being distinct from the calyx, in the style being short and solitary, not $2-3$, and in the fruit being 5celled.

1 B. Argu'ta (Gaud. l. c.) h. G. Native of the Sandwich Islands, at the altitude of from 1200 to 1500 feet above the level of the sea. A middle-sized tree.

Sharp-serrated-leaved Broussaisia. Tree.

Cult. See Cianitis above for culture and propagation.

Order CXXIII. UMBELLI'FER死 (from umbella, an umbel, and fero, to bear; this order contains only umbelliferous plants, such as the parsnip, celery, parsley, hemlock, carrot, coriander, \&c.). Juss. gen. 218. D. C. fl. fr. 4. p. 279. prop. med. ed. 2. p. 159. Spreng. umb. prod. 1813. and Rom. et Schultes, syst. 6. (1820.) p. 29. Hoffin. gen. umb. ed. 1st. 1814. ed. 2d. 1816. Vela and Lag. am. nat. esp. 2. I821. p. 61. Lag. ibid. p. 87. and obs. aparas. 1826. (in ocios.) Kock, umb. disp. in nov, act. bonn. 1824. vol. 12. p. 1. and p. 55.156. and the same in litt. 182S. D. C. coll. diss. mem. 5. with
19 plates. D. C. prod. 4. p. 55.-Umbellata, Tourn. inst. 304. Lin. pracl. ed gis. p. 508. Adans. fam. pl. 2. p. 89 . ('xclusive of some genera. Cusson, mem. soc. mel. par. 1782.Sciadophý:um, Nect. clem. 1. p. 162.

Calyx with the tube adliering to the ovarium (f. $55, F . h$. f. 55. C. c.); limb 5-toothed (f. 55. F. c.), or entire (f. 55. G.f.): lobes or teeth deciduous or permanent. Petals 5 (f. 57.c. f. 59. g.), inserted in the top of the tube of the ealyx, and alternating with its lohes, either entire (f. 57.c.), emarginate (f. 61 . b.), or 2-lobed, sometimes plain at the apex, but usually drawn out into a replicate or involute point (f. 61 . f. f. $63 . c$. f. 55. C. i.), somewhat imbricate in astivation, rarely valvate; the outer flowers of the umbel or ray of the umbel sometimes larger than the rest, the rest equal among themselves, rarely abortive. Stamens 5 (f. 55. C. b. \&.c.), alternating with the petals, and inserted along with them, and therefore opposite the calycine teeth or lobes, always distinct, replicate in astivation (f. $59 . \mathrm{g}$. S.e.); anthers ovate, 2-celled, somewhat didymous, opening by a double longitudinal chink. Ovarium inferior, 2-celled (f. 55 . E. c. f. 55. D.d. \&c.), (very rarely, and probably from abortion, 1-celled), adnate to the calyx; styles 2 , distinct (f. 55 . F. i. f. 5 j. G. i. f. 59.e. Sc.), when young erect, but at length thickened at the base into stylopodium (f. $64 . a$.), which covers the whole disk, forming a sort of crown to the fruit, diverging more or less, usually permanent, the outer one directed to the outside of the umbel, and the inner one tending to the centre. Fruit (called Diache'na, Polacha'na, and Cremocarp by many botanists) consisting of 2 carpella (called mericarps because (f. 55. D. d. f. 56. C. h. Sc.) they adhere to the calyx the half of their length, and therefore cannot be carpella or achenia in the strict sense of those terms), separable fiom a common axis (called a caryophore), to which (f. 56, G. a. f. 56. C. a. b. \&c.) they adhere by their face (called the commissuec); the fruit or cremocarp traversed by 10 elevated primary ridges, of which the 5 that represent the middle of the sepals are called carinal, because they are drawn out into calycine teeth at the apex : the other 5 , alternating with the firstnamed ones are called sutural, because they indicate the sutures where the divisions of the calyx are joined, and therefore tend to the recesses between the calycine teeth; besides these there are others which are apparent in some called secondary, because they alternate with the 10 primary nerves, and therefore indicate the sides of the divisions of the calyx ; all the sutural, carinal, and secondary ribs are either filiform, winged, or crested; these ridges or nerves are separated by channels or furrows called vallecula, below which, but usually in the channels, are placed in the substance of the pericarp, certain linear receptacles of coloured oily matter, called vittce, which are directed from the apex to the base: they are solitary, twin, or numerous, rarely wanting, and sometimes they are inclosed in a proper membrane, which is probably a true pericarp. Seeds solitary in each carpel, hanging from the top of the axis or carpoplore, inclosed in a proper membrane, the spermaderm, which is but rarely separable from the pericarp. Albumen large, fleshy, or rather horny, more or less convex on the outis h 2 
side. Embryo minute, hanging from the top of the carpophore, and therefore the radicle is superior; cotyledons 2 , oblong, changing into seminal leaves through germination.-Herbs or subshrubs. Roots various, but often fusiform. Stems cylindrical or angular, simple or branched, annual or perennial, with the bark or skin usually full of aromatic resinous gum; medulla in some, as in Férula, large, with medullary fibres in its substance, similar to the stems of monocotyledonous plants. Leaves alternate, very rarely opposite, except the seminal ones, usually divided into various segments; petioles usually sheathing at the base: in some, as in the gents Bupleurum, the petioles are changed into plyyllodia, as in the section of Acdicia called Phyllodinece. Flowers umbellate, white, yellow, pink, or blue, often with either the styles or stamens abortive, monoecious, dioecious, or polygamous, and some of them sterile. Umbels usually perfect, both general and partial, in both the rays are numerous, the greneral umbel usually surrounded by an involucrum, and the partial ones by an involucel.

\section{FIG. 54.}

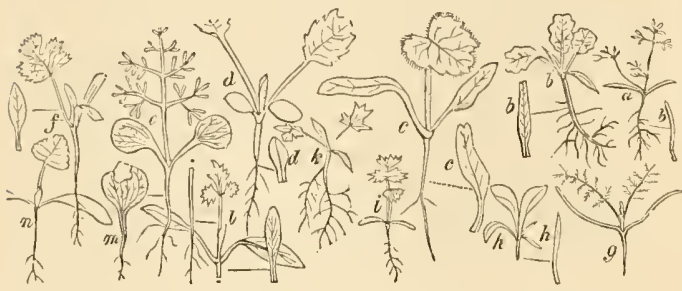

Umbelliferce hardly differs from Araliàcea, the next order. With Saxifragàcea it agrees in habit, if IIydrocótyle is compared with Chrysosplènium, and if the sheathing and divided leaves of the two orders are considered. To Gcraniàcece, De Candolle remarks, that they are allied in consequence of the coliesion of the carpella around a woody axis, and of the umbellate flowers, whieh grow opposite the leaves, and also because the affinity of Geraniàcece to $V^{\text {ritis, }}$ and of the latter to Araliàcea, is not to be doubted. The arrangement of this order has only within a few years arrived at any very definite state; the characters upon which genera and tribes could be formed, were for a long while unsettled ; it is, however, now generally admitted, that the number and developement of the ribs of the fruit, the presence or absence of the reservoirs called vittæ, and the form of the albumen, are the leading peculiarities, which require to be attended to. The plants are chiefly extra-tropical, inhabiting groves, thickets, plains, marshes, and waste places.

The properties of this order require to be considered under two points of view; firstly, those of the vegetation; and secondly those of the fructification. The character of the former generally is suspicions, and often poisonous in a high degree; as in the case of hemlock, fool's-parsley, watcr-hemlock, and others, which are deadly poison. Nevertheless, the blanched petioles and stems of cclery, the leaves of parsic $y$ and samphire, the roots of skirret, the carrot, the parsnip, the arracacha, and the tubers of Wnánthe pimpinelloìdes, and Bùnium bulbocks- tanum, are wholesome articles of food. The fruit, vulgarly called the seeds, is in no case dangerous, and is usually a warm and agreeable aromatic, as caranay, coriander, dill, anise, Sc. From the stem, when wounded, sometimes flows a stimulant, tonic, aromatic, gum-resinous concretion, of much use in medicine; as opopanax, which is produced from Opópanax Chirònium in the Levant, and assufoetida from the Férula of that name in Persia. Gum ammoniac is obtained from Dorèma Ammoniacum. It is a gum resin of a pale yellow colour, having a faint, but not unpleasant, smell, with a bitter nanseous taste. Internally applied, it is a valuable cleobstruent, and expectorant. It is said by Dr. Paris to be, in combination with rhubarb, a useful medicine in mesenteric affections, by correcting viscid secretions. (Ainslie 1. p. 160.) The substance called galbanum is produced by Gálbanum officinale, a plant of this order. It is a stimulant of the intestinal canal and uterus, and is found to allay that nervous irritability, which often accom. panies hysteria. (Ainslie 1. p. 143.). AEthùsa cynàpium has been found by Professor Ficinus, of Dresden, to contain a peculiar alkali, which he calls Cynapia. (Turner, p. 654.) The fruit of Ligústicum Ajanain of Roxb. the Ptychotis Ajonan of D. C. is preseribed in India in diseases of horses and cows. (Ainslie i. p. 38.) The Prángos pabulària is a valuable fodderplant in Thibet.

\section{Synopsis of the genera.}

Suborder I. Orthospérme. Albumen flat or flattish inside, neither involute nor convolute.

\section{§1. Umbcls simple or imperfect. Fruit destitute of vitta.}

\section{Tribe I.}

Hydrocoty'Lex. Fruit contracted from the sides; mericarps convex or acute on the back: with the 5 primary ribs at lcngth obsolete: lateral ones marginating or in the commissure, which is flat; intermcdiatc usually more than carinal. Petals cntire.

1 Hydrocótyle. Margin of ealyx obsolete; and the tube rather compressed. Petals ovate, with a straight point. Fruit biscutate. Mericarps with 5 filiform ribs: carinal and lateral ones often obsolete: the 2 intermediate ones joined.-Involucrum few-leaved.

2 Crántzia. Tube of calyx subglobose; limb very short, hardly any. Petals roundish, obtuse. Fruit roundish. Mericarp unequal, with $3-5$ filiform ribs. Vittæ 1 in each furrow and 2 in the commissure.-Involucrum 5-6-leaved.

3 Dimetópia. Teeth of calyx obsolete. Petals oval-oblong. Styles short. Fruit didymous. Mericarps somewhat contracted at the commissure, umequal, one muricated with tubercles, and the other echinated with conical prickles.-Involucrum of 5 linear leaves.

4 Erige'nia, Margin of calyx obsolete. Petals equal, obovate. Styles long. Fruit oval, laterally compressed. Mericarps gibbously convex, marked by 3 stripes. Commissure narrow, flat.- Umbels imperfect. True involucrum none, but in place of it there is a multifid leaf. Involucels of a few unequal leaflets. 
5 Microplev'ra. Margin of calyx obsolete. Petals equal, acute. Fruit deeply 2-lobed at the base, and emarginate at the apex; mericarps obliquely ovate, 7-ribbed ; ribs curvi-linear, ventricose at the base, marginal 2 straighti. Commissure narrow.

6 Dipiscus. Margin of calyx obsolete. Petals oval, bluntish, imbricate in rstivation (f. 57 . c.). Fruit didymous, cmarginate at the base. Mericarps rough from pilose striga, 5 ribbed: 2 middle ribs approximating the commissure.-Involucrum of many leaves which are concrete at the base (f. $57, a$.).

7 T'васитме'Ne. Margin of calyx 5 -toothed. Petals elliptic, acutish, somewhat valvate in astivation. Fruit didymous. Mericarps giblously convex, 5 -ribbed : the 3 dorsal ribs and the furrows between them muricated: and the 2 lateral ones marginating. - Umbels compound. Involucrum of many leaves.

8 Astrótricia. Margin of calyx liardly 5 -toothed. Petals oval, acutish, permanent (f. 58.6 .), velvety on the ontside from stellate down. Styles thickened at the base (f. 58.c.). Nericarps contracted at the commissure, having 3 primary lorsal ribs, and 2 acute nearly obsolete marginating ones, and 4 secondary ones. Conmissure furnished with 2 vitte, which are covered by a spongy pellicle, but none in the furrows.-Involucrum of a few linear leares.

9 Хахтнòsia. Margin of calyx 5-lobed. Petals stipitate, oval, cuspidate and replicate at the apex. Styles filiform, rising from the base of the stylopodium on the inside. Fruit compressed. Mericarps contracted at the commissure, with 7-9 filiform ribs: 2 lateral ribs marginating.

10 Bowle'sta, Margin of calyx 5-toothed ; tube compressedly somewhat tetragonal. Petals elliptic, entirc, acute. Fruit ovate, much contracted at the raphis, turgid, somewhat tetragonal, flattish on both sides at the back. Mericarps marked with an oval impression on the back, having 5 obsolete ribs: 2 lateral ribs flat, seated in the commissure.

11 Fragòsa. Margin of calyx 5-tootlied, permanent. Petals osal. Fruit didymous. Mericarps somewhat compressed from the back, and contracted at the commissure, having filiform ribs.-Involucrum equal in length to the pedicels.

12 Azorélla. Margin of calyx 5-toothed, permanent. Petals oval. Fruit ovate, contracted at the raphis, and rather compressed from the back. Mericarps semi-ovate, having the ribs hardly evident.-Involucrum about equal in length to the pedicels.

13 Peсторiту'тur. Margin of calyx entire. Petals unequal, with an acute inflexed point. Fruit ovate-elliptic; mericarps rather convex on the back, semi-oval, having 5 filiform ribs; commissure Hattish.-Flowers in crowded fascicles at the tops of the branches, solitary in the axils of the bracteas.

\section{TRIBE II.}

Mulixez. Mericarps contracted at the commissure, flat or flattish on the back, without villa, hence the fruit is squarc or parallclly biscutate. Petals entire.

14 Bòcax. Margin of calyx entire. Petals oval. Fruit tetragonal; mericarps with 5 nerve-formed ribs, I dorsal, and the 2 middle ones form the corners of the angles of the fruit, and the 2 inner ones are filiform; commissure very narrow.-Involuerum of 4 leaves, equal in length to the pedicels.

15 Murines. Margin of calyx 5 -toothed, permanent. Pctals oval-oblong, acute. Fruit 1 -winged; mericarps furnished with 5 ribs: middle one dorsal : 2 lateral ones nerve-formed: 2 intermediate ones expanded into lateral ample wings. - Involucrum of many leaves, shorter than the pedicels.

16 Lare'tia. Margin of calyx 5-toothed. Pctals ovate, entire. Fruit elliptic, square, flatly compressed from the back ; mericarps lenticular, with dorsal ribs and 2 lateral marginal ones, destitute of vittæ. Seed flat.

17 Dru'sa. Margin of calyx entire. Petals oval. Mericarps furnished with 5 ribs: the dorsal one and the 2 inner ones linear and hardly prominent: but the 2 intermediate ones are drawn out into marginal wings, which are repandly sinuated, having the angles expanding in a stellate tuft of uncinate spinules.-Involucrum wanting.

18 Huana'ca. Margin of calyx hardly 5 -toothed, Petals lanceolate. Fruit ovate, acutish; mericarps flat and furrowed on the inside, but convex on the back, and furnished with 3 elevated lines. Carpophore bifid.-Involucrum of many leaves.

19 Dipòsis. Margin of calyx bluntly 5-toothed. Petals oval. Fruit orbicular, constituting 2 parallel disks (f. $55 . A . b$.); commissure narrow; mericarps having 5 ribs: dorsal one filiform: 2 lateral ones hidden: and the 2 middle ones girding the disk; furrows broad and flat.-Umbels compound.

20 Spana'stre. Margin of calyx 5 -toothed. Petals elliptic, acutish, with a straight point. Fruit ovate, much compressed at the rachis; mericarps having 5 slender equal ribs: 3 intermediate ones dorsal: and the 2 lateral ones seated in the flat commissure.-Umbels rather compound. Involucrum of many leaves.

21 Homaloca'rpus. Margin of calyx 5-toothed; teeth subulate. Petals ovate, concave. Fruit roundish-ovate; mericarps having 5 filiform ribs, hidden in the substance of the pericarp, 1 dorsal : 2 lateral ones near the rachis: 2 middle ones forming the angles.

22 Pozòs. Margin of calyx 5-toothed, permanent. Fruit prismatic, tetragonal, 5-ribbed, emarginate at the apex; mericarps concave and channelled on the back; ribs lateral, dense, straight. - Involucrum crenately lobed, obsoletely toothed.

23 Asteríscium. Calyx 5-toothed, permanent; teeth ovate. Petals emarginate, with an inflexed point and a callous recess. Fruit compressed, tetragonally prismatic; mericarps with 5 ribs: the 2 intermediate ribs expanded into wings: the carinal one and the 2 placed near the raphis stripe-formed; commissure very narrow.-Involucrum of many leaves.

\section{Tribe 111.}

Sanicu'lex. Fruil ovate-globosc. Mericarps destitute of vitta, with 5 primary ribs; secondary ribs wanting or oblitcrated by being covered nith scalcs. Pctals ercct, cmarginate, from being bent back from the middle by a point. 
24. Actinòtus. Tube of calyx contracted at the apex; limb 5 -lobed : lobes oval-oblong. Petals wanting. Styles thickened and villous at the base. Fruit ovate, crowned by the lobes of the calyx, villous, 5-striped.-Involucrum of many radiating leaves, which are longer than the flowers.

25 Peta'Gia. Flowers dioecious, having the calyxes different in the distinct sexes. Styles filiform. Fruit ovate, compressed, 8-nerved, vacant inside, 1-seeded.-Umbellules 3flowered: central flower hermaphrodite, sessile: lateral ones male, pedicellate; pedicels rather concrete at the base, with the calyx of the female flower.

26 Sanícula. Tube of calyx echinated; lobes foliaceous (f. 59. c.), permanent. Pctals connivent, obovate, emarginate, with an inflexed point (f. $59 . g$.$) . Fruit nearly globose, echi-$ nated; carpophore not distinct.-Umbels compound. Leaves of involucrum few, divided; of the involucel numerous, linear.

27 Haceve'tia. Tube of calyx 10-ribbed; lobes foliaceous, permanent. Petals obovate, emarginate, with a bent in point. Fruit contracted from the sides; mericarps gibbously convex; ribs 5 , filiform, with a deep channel on the inside.-Involucrum of 5-6 obovate toothed leaves, which are longer than the umbel.

28 Astran'tia. Tube of calyx 10-ribbed, tuberculately plicate; lobes 5 , foliaceous. Petals erect, connivent, oblong-obovate, with an infracted point. Fruit rather compressed from the back; mericarps with 5 elevated, obtuse, plicately toothed, inflated ribs, inclosing in the cavity a smaller fistular rib. Carpophore not distinct - lnvolucrum variable : involucel of many leaflets.

29 Alepíden. Tube of calyx minutely tubercular. Petals inflexed. Mericarps without ribs, and without vittæe. Carpophore adnate the whole length of the seeds.-Habit of Erýngium, but the umbels are like those of Astrántia.

S0 Horsfiécdia. Margin of calyx quite entire. Petals ovate, cuspidate, flat. Fruit compressed, villous ; mericarps 3ribbed on the back.-A prickly shrub. Umbels capitate, sessile; receptacle chaffy. Involucrum of many leaves.

31 ERy'nciun. Tube of calyx rough from scales or vesicles; lobes foliaceous. Petals erect, connivent, oblong-obovate, emarginate, with an infracted point. Fruit obovate, scaly, or tubcrcular; mericarps semi-terete, without ribs, and without vittæ; carpophore adnate its whole length to the seeds.-Flowers crowded into dense heads; the lower bracteas forming an involucrum to them.

32 Actina'ntuus. Flowers monoecious: female ones capitate: male ones in capitate umbels, with the receptacle destitute of palea. Teeth of calyx permanent. Petals oblong, complicated at the apex, and rather cirrhose. Fruit compressed from the sicles; mericarps with 5 alternate, stronger, sutural ribs; vittæ 1 in each furrow, and 2 in the commissurc. Carpophore adnate.-Involucra wanting; involucels of many leaves.

\$2. Umbcls compound or perfect. Vitte on the fruit variable, rarely wanting.

$$
\text { * Fruit having only primary ribs present. }
$$

Tribe IV.

AмMín Ee. Fruit compressed from the sides or didymous; mericarps with 5 fliform ribs, which at length become a little winged: lateral ones marginating, all cqual. Seeds teretc or gibbously concex, flattish in front.

33 Ru'mia. Margin of calyx 5-toothed. Petals ovate, entire, with a short, coarctate, incurved point. Fruit roundish or ovate, plicately wrinkled; mericarps solid, with 5 thick, very obtuse, twisted plicate ribs, covering the furrows, which are ornamented with plicate tubercles, and furnished with 1 vittæ each. Carpophore bipartite.-Involucrum wanting or fewleaved; involucels of 3-8 leaves. Flowers yellow.

34 Cicu'TA. Margin of calyx 5-toothed, foliaceous. Petals obcordate, with an inflexed point. Fruit roundish, contracted from the sides ; mericarps with 5 flattish ribs, having the furrows between the ribs furnished with 1 vittae each, and the commissure 2 vittæ; vittæ filling the furrows, a little more elevated than the ribs, all concealed under a loose membrane. Carpophore bipartite.-Involucrum wanting, or few leaved; involucels of many leaves.

35 Zizia. Margin of calyx obsolete, or with 5 very short teeth. Petals elliptic, tapering into a long inflexed acumen. Fruit contracted from the sides, roundish or oval; ribs filiform, rather prominent; furrows furnished with 1 vittæe each, and the commissure with 2 ; carpophore bipartite.-Involucrum wanting ; Involucel of few leaves, variable. Flowers yellow, rarely white or dark purple.

36 Pentacrýpta. Calyx unknown. Petals equal, lanceolate, with an inflexed point. Fruit oblong-elliptic; the 3 dorsal ribs elevated, acute; furrows furnished with 1 vitta each. Albumen with 5 roundish angles. Flowers polygamous, dark purple.

37 A'pium. Margin of calyx obsolete. Petals roundish, entire. Stylopodium depressed. Fruit roundish, contracted from the sides; ribs fliform; furrows furnished with 1 vitta: outer ones with 2-3 vitta. Carpophore undivided.-Involucruın and involucel wanting. Flowers greenish white.

38 Petroserinum. Margin of calyx obsolete. Petals roundish, incurved, hardly emarginate, with an inflexed point at the apex. Stylopodium short, conical, subcrenulated. Styles diverging. Fruit ovate, contracted from the sides; ribs filiform : furrows furnished with 1 vitta each, and the commissure with 2 . Carpophore bipartite.-Involucrum few-leaved, and the involucel of many leaves. Flowers white or greenish.

39 Weyde'ria. Margin of calyx obsolete (f. 60.a.). Petals ovate-lanceolate, entire, with an incurved point (f. 60.c.). Fruit ovate, crowned by the short stylopodium and reflexed styles (f. 60, b.). Mericarps somewhat semi-terete, with contracted margins ; ribs filiform, bluntish; furrows broad, furnished with 1 vitta each, and the commissure with 2.--Involucrum wanting, or of 1 leaf; involucel of many leaves. Flowers white.

40 Trínia. Margin of calyx obsolete. Flowers usually dioecious from abortion. Petals of the male flowers lanceolate, 
ending in an involute point; of the licrmaphrodite flowers ovate, with a short inflexed point. Fruit ovate; ribs filiform, rather prominent; furrows without vitte, or furnished with 1 vitta cach. Carpophore Aat, bipartite from the base.-Umbels disposed in a panicle or thyrse, without any involucra; involucels usually wanting.

41 Heloscia'dium. Margin of calyx 5-tootled, or obsolete. Petals ovate, entire, with a straight or inflexed point. Styles short. Fruit ovate or oblong; ribs filiform, rather prominent; furrows furnished with 1 vitta each. Carpophore entire. Involucra variable in the different sections.

42 Discoplev'ra. Teeth of calyx 5, subulate, permanent (f. 61.e.). Petals ovate, emarginate (f. 61 . b.), with a replicate point (f. 61. f.). Fruit ovate (f. 61. c.). Three dorsal ribs filiform, exserted, and acutish : 2 lateral ones somewhat concrete with the thick accessory margin, forming a disk on both sides of the fruit : furrows furnished with 1 vitta each. Carpophore bifid.-Involucels of a few linear setaceous leaflets (f. 61.g.).

43 Leptocau'lis. Margin of calyx obsolcte (f. 62. a.). Petals elliptic, entire. Styles permanent. Fruit ovate (f. 62.a.); ribs hardly prominent; furrows furnished with 1 vitta. Carpophore bifid at the very apex.-Involucra wanting; involucels short, few-leaved.

44. Ртхсно'тіs. Margin of calyx 5-toothed. Petals obovate, bifidly emarginate, furnished by a transverse plait in the middle, which emits a little segment. Fruit ovate or oblong; ribs filiform; furrows furnished with 1 vitta each. Carpophore bipartite.-Involucrum variable; involucels of many leaves.

45 Falca'ria. Margin of calyx 5-toothed; tube wanting in the sterile flowers, but cylindrical in the fertile ones. Petals obovate, curved, having a broad emarginate recess, with a reflexed point. Styles divaricate. Fruit oblong; ribs filiform; carpophore distinct, bifid; furrows furnished with 1 filiform vitta each.-Involucrum of many leaves. Involucel somewliat dimidiate from the inner leaflets being small on one side.

46 Sisox. Margin of calyx obsolete. Petals roundish, curved, deeply emarginate, with an inflexed point. Styles very short. Fruit ovate; ribs filiform; vittæ 1 in each furrow, short, rather club-shaped ; carpophore bipartite.-Involucra and involucels of few leaves.

47 Scuv'stzia. Margin of calyx obsolete. Petals elliptic, with a short inflexed point. Stylopodium conical. Styles erect, somewhat capitate at the apex, permanent. Fruit cylindrically prismatic; ribs filiform; vittæ 1 in each furrow. Carpophore undivided.-Involucra and involucels of many multifid leaves.

4S A'mм. Margin of calyx obsolete. Petals obovate, with an inflexel point, emarginately 2 -lobed; lobes unequal, irregular; those on the outside of the umbels the largest. Fruit ovate-oblong; ribs filiform; vittæ 1 in each furrow. Carpophore distinct, 2-partcd.-Involucra of many trifid or pinnatifid leaves; involucels of many leaves.

49 Egopo'dius. Margin of calyx obsolete. Petals obovate. emarginate, with an inflexed point. Stylopodium distinct, conical, terminated by the long deflexed styles. Fruit ovate; ribs fliform; furrows without vitta; carpophore setaceous, forked at the ajex.-Involucra and involucels wanting.

50 CA'rum. Margin of calyx obsolete. Petals regular, obovate, emarginate, with an inflexed point. Stylopodiun depressed; styles deflexed. Fruit ovate or oblong, contracted from the sides; ribs filiform; vitta 1 in each furrow, and 2 in the commissure, which is flat; carpophore distinct, forked at the apex.-Involucra and involucels variable in the different species.

51 Chamesciadum. Margin of calyx toothed a little. Petals ovate-lanceolate, quite entire, with an oblique or inflexed point. Stylopodiun depressed; styles at length deflexed. Fruit ovate-oblong; mericarps solid ; ribs filiform; vittæ $3-4$ in eacl furrow, and $4-6$ in the commissure ; carpophore adnate, bifid at the apex.-Involucra and involucels of many leaves.

$52 \mathrm{Bu}^{\prime}$ Nicur. Margin of calyx obsolete. Petals obovatc, emarginate, with an inflexed point. Fruit linear-oblong; ribs filiform, obtuse ; vittæ $2-3$ in each furrow, and 4 in the commissure, all superficial. Carpophore distinct, bifid.-Involucra variable in the different species; involucels of few leaves.

53 Cryptote'n1A. Margin of calyx obsolete. Petals obovate, nearly entire, narrowed into an inflexed point. Fruit contracted from the sides, linear-oblong, crowned by the short stylopodium and straight styles; ribs filiform, obtuse : 2 lateral ones placed in front of the margins; vittæ numerous in the furrows, covered by a corky pericar $p$, and are not visible, unless when the pericarps are cut transversely.-Involucra wanting; involucels few-leaved.

54 Pimpinécla. Margin of calyx obsolete. Petals obovate, emarginate, with an inflexed point. Fruit ovate, contracted from the sides, crowned by the cushion-like stylopodium and styles, which are reflexed and somewhat capitate at the apex : ribs filiform; vittæ numerous on the furrows; carpophore distinct, bifid.-Involucra and involucels wanting.

55 Sivs. Margin of calyx 5-toothed, but at length obsolete. Petals obovate, cmarginate, with an inflexed point. Stylopodium pulvinate, with a depressed margin. Styles divergingly reflexed, somewhat capitate at the apex. Fruit compressed or contracted from the sides, crowned by the stylopodium and styles; ribs filiform, bluntish; vittæ many, both in the furrows and commissure. Carpophore bipartite, having the mericarps adhering to its parts. - Involucra of many leaves, rarely of 1 leaf; involucels of many leaves.

56 Buplev'ruir. Margin of calyx obsolete. Petals roundish, entire, closely involute, ending in a broad retuse segment. Fruit crowned by the depressed stylopodium; ribs winged, acute, filiform, or obsolete; furrows either with or without vitta, smooth or granular.-Involucra variable in the different species. Flowers white, yellow, and greenish.

57 Heteronórpha. Margin of calyx 5-toothed. Petals roundish, entire, closely involute, ending in a broad retuse point. Fruit obovately pear-shaped, 3 winged; mericarps of 2 forms : outer one 2 -winged: inner one 3 -winged; the wings running from the teeth of the calyx; vittæ 1 in each furrow, and 2 in 
the commissure.-A shrub witl yellow flowers and ternate leaves. Involucra and involucels of many short leaves.

\section{Tribe V.}

Seselínes. Fruit terete, or ncarly so, with a transverse section; or the mericarps are rather compressed on the back, with 5 fliform or ninged ribs: the lateral ones marginating, equal to the others, or broader. Seeds terctely conecx on the back. Raphe marginal or submarginal.

58 Lichitensteinia. Margin of calyx acutely 5 -toothed. Petals elliptic, with a long, inflexed point. Fruit nearly terete, crowned by the conical stylopodium and short styles; ribs filiform, equal; vitta large solitary under the ribs, but none in the furrows nor commissure.-Involucra and involucels of many short leaves. Flowers yellow.

59 Oтtòa. Margin of calyx obsolete. Petals equal, with an inflexcd subulate point. Styles arched, capitate at the apex. Fruit oblong, rather compressed at the commissure; ribs membranous.-Inrolucra and involucels none. Flowers polygamous.

60 ENA'Ntrie. Nargin of calyx 5-toothed, permanent. Petals obovate, emarginate, with an inflexed point. Stylopodium conical. Fruit cylindrically ovate, crowned by the long erect styles; ribs rather convex, obtuse, marginating ones rather the broadest; vitta 1 in each furrow; carpophore indistinct.Involucra variable in the different species, sometimes wanting; involucels of many leaves.

61 Annesonuiza. Margin of calyx 5-toothed, permanent. Petals elliptic, with an inflexed point. Fruit prismatically quadrangular, crowned by the calyx and reflexed styles; mericarps of 2 forms, one 3-winged, and the other 4 -winged from the ribs; vitta 1 in each furrow and 2 in the commissure. Carpophore bipartite.-Involucra and involucels of many leaves.

62 Scleroseindum. Calycine teeth 5 , conical, permanent (f. 56. F. h.). Petals obcordate, with an inflexed point (f. 56 . $F$. b.), which is bi or tridentate at the apex. Stylopodium conical; styles filiform (f. 56.F.e.). Fruit ovate-globose, solid (f. 56. F.g. h.); ribs much elevated, bluntish, equal; vitta 1 in each furrow and 2 in the commissure; carpophore distinct, undivided (f. 56. F. k. ).-Involucra almost wanting; involucels of 5-7 leaves.

63 Dasy lòma. Margin of calyx obsolete. Petals unknown. Stylopodium depressed; styles short. Fruit ovate; mericarps not scparating at maturity; ribs corky, cellular : 3 dorsal ones small: 2 lateral ones large and obtuse; furrows narrow, and furnished witl 1 vitta each, but the commissure is flat, and furnished with 2 ; carpophore indistinct.-Involucra and involuccls wanting.

64 Crnoscrádius. Calycine tectlı 5 (f. 63. c.), subulate, permanent. ['etals obovate, or nearly elliptic, entire, with an inflexed point (f. 63. e.). Stylopodium conical; styles short, reflexed (f. 63. d.). Fruit oval-oblong or orate (f. 63. b.), tapering at the apex; ribs thick, corky ; vitta I in each furrow, and $\mathcal{2}$ in the commissure.-Invo'ucra and involucels of many leaves (f. 63.f.g.).

65 Eтиu'sa. Margin of calyx obsolete. Petals obovate, emarginate, with an inflexed point; outer petals radiating. Fruit ovate-globose; ribs elevated, thick, acutely keeled: lateral ones rather the broadest; vittæ 1 in cach furrow, and 2 arched ones in the commissure ; carpophore bipartite.-Involucrum wanting or of 1 leaf; involucels of 1-3-5 leaflets, on one side of the umbellule.

66 Fenículum. Margin of calyx tumid, obsolete. Petals roundish, entire, involute, with a rather quadrate retuse point; ribs rather prominent, blunily keeled: lateral ones rather the broadest; vitta 1 in each furrow, and 2 in the commissure.Involucra and involucels wanting, or nearly so. Flowers yellow.

67 Kundmánia. Margin of calyx 5-toothed. Petals roundish, entire, involute, with a broad retuse point. Stylopodium conical. Fruit terete, 10 -furrowed; mericarps with 5 filiform, oltuse, equal ribs; vittæ many, both in the furrows and commissure; carpophore undivided.-Involucra and involucels of many filiform reflexed leaves.

68 Deve'rra. Margin of calyx obsolete. Petals ovate, with an inflexed acumen. Styles short. Fruit ovate or romdish, hispid from scales or hairs; mericarps semi-terete, with obsolete ribs; vitte 1 in each furrow, and 2 in the commissure. Carpophore bipartite. - An aromatic almost leafless slırub.-Involucra of 4-6 leaves; involucels of 4-6 ovate-lanceolate leaves.

69 Sora'ntuus. Margin of calyx obsoletely toothed. Petals broadly ovate, acuminated, permanent, with an inflexed point. Fruit a little compressed from the back: crowned by the divaricate styles; mericarps with 5 , hardly prominent ribs; vittæ 1 in each furrow, and 4 in the commissure. Carpopliore bipartite.-Involucra nearly wanting; involucels of 5-7 spreadingly reflexed leaves.

$70 \mathrm{SE}_{\mathrm{E}}$ SI:L1. Margin of calyx 5 -toothed; tectl short, thickish. Petals obovate, cmarginate or nearly entire, with an inflexed point (f. 55. E. i.). Fruit (f. 55. E. d. f. 55. D. a. b.) oval or oblong, crowned by the reflexed styles (f. $55 . E . b$. ); ribs filiform or elevated, rather prominent, thick, corky : lateral ones a little broader than the rest; vitta 1 in each furrow, sometimes 2 in the outer furrows, but always 2 or 4 in the commissure. -Involucra almost wanting; involucels of many leaves.

FIG. 55 .

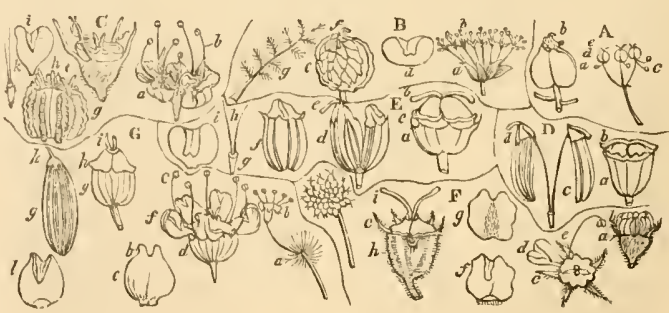


71 Libano'tis. This genus agrees in every respect with Séseli, but differs in the lobes of the calyx being slender, subulate, elongated (f. 55.F.c.), and coloured, deciduous.-Involucra and involucels of many leaves.

72 Cexolòruium. Margin of ealyx obsolete. Petals obovate, emarginate (f. $55 . G . b . f$. ), witls an inflexed point (f. 55 . G. l.) ; ribs equal, sharp, a little winged, lollow inside; vitta 1 in each furrow, and 2 in the commissure.-Involuera wanting, or of 1 leaf; involucels of many leaves (f. 55. G. a.).

73 Cxiduus. Differs from Cenolophium in the ribs of the fruit being furnished with membranous wings.-Involucra variable in the different species; involucels of many leaves.

74 Petítia. This genus differs from Séseli and Libanòtis by the margin of the calyx bcing entire; and from Cnidlum in the petals not being cmarginate, and in the ribs of the fruit not being winged.

75 Exdre'ssia. This genus differs from all the rest in the prescnt tribe, in the fruit being compressed from the sicles, in the ribs being obtuse and filiform, not winged; vittae 6 in the commissure, and 3 or 4 in the furrows.

76 Tha'spicm. Margin of calyx 5-toothed. Petals elliptic, with a long inflexed acumen. Fruit nearly elliptic; ribs winged; vittæ 1 in each furrow, and 2 in the commissure.-Involuera wanting; inrolucels of 3 leaves on one side.

77 Troсuiscánthes. Margin of calyx 5-toothed. Petals on long claws, spatulately obovate, with a triangular inflexed segment; ribs sharp, ratlser winged, equal; vittæ $3-4$ in each furrow, and 8 in the commissure. Carpoplore bipartite.-Involucrum wanting, or of 1 leaf; involucels of $2-5$ leaves.

78 Aтиaмástua. Margin of calyx 5-toothed. Petals obovate or entire: with a very short, inflexed, unguieulated point ; fruit attenuated into a neck; ribs filiform, wingless, equal ; vittæ 2-3 in each furrow.-Involucra few-leaved; involucels of many leaves.

79 Ligu'sticru. Margin of calyx 5-toothed or obsolete. Petals obovate, acute, emarginate, with an inflexed point; rils short, rather winged, equal; vittæ many, both in the furrows and commissure.-Involucra variable; involucels many-leaved.

So SirA'vs. Margin of calyx obsolete. Petals obovateoblong, entire, or rather emarginate, with an inflexed point; ribs sharp, rather winged, equal: vittæ many in each furrow, and so close together as to appear one ; commissure furnished with 4-6 vittæ.- - Involucra wanting or of few leaves; involucels of many leaves. Flowers cream-coloured or greenish.

81 Wallro'thia. Calycine teetl 5 , ovate-lanceolate, acute (f. 56. A. b.). Petals elliptic, entire, acute at both ends (f. 56 . A. d.). Mericarps with rather prominent, equal ribs; vittæ numerous in the furrows.-Involucra of 1-3 unequal leaves; involucels of $5-8$ unequal leaves.

82 ME'usr. Margin of calyx olsolete. Petals entire, elliptic, acute at both ends. Mericarps with rather prominent, equal, kecled ribs; vittæ many in each furrow, and 6-8 in the commissure.-Involucra wanting; involucels of many leaves.

83 GA'YA. Margin of calyx obsolete. Petals obovate, more or less emarginate, with a broad inflexed point. Fruit oval, a little compressed; ribs elongated, wing-formed, contiguous at voL. III. the base, at cqual distanees, obtuse ; vittæ none. Carpophore bipartite.-Involucra few-leaved.

81. Conjoselinum. Margin of calys obsolete. Petals obcordate or obovate, with an inflexed point. Styles at length reflexed. Iruit compressed or convex from the back; ribs winged: lateral ones twice the breadth of the rest; vitta 3 in cach furrow, but in the dorsal furrows sometimes only $2:$ and $4-8$ unequal ones in the commissure; carpopliore bipartite--Involuera wanting, or of few leaves; involucels of 5-7 linear-subulate leaves.

S5 Crítumum. Margin of ealyx obsolete. Petals roundish, entire, involute, with an obovate point. Meriearps with 5 elevated, sharp, somewhat winged ribs: the lateral ribs a little broader than the rest; pericarp spongy from large eells.-Involucra and involucels of many leaves. Seed semi-terete, constituting a distinct nueleus, covered with copious vittæ.

\section{Tribe VI.}

ANGeníces. Fruit compressed from the back, girded by 2 wings on cach side, from the raphe being central, or ncarly so; mericarps furnished with 5 ribs: the 3 dorsal ribs filiform or winged: and the 2 latcral ones always expanded into nings, and broader than the dorsal oncs. Seed rather convex on the back, and flattish in front.

86 Levístieum. Margin of calyx entire. Petals incurved, roundish, entire, with a short point. Mericarps with 5 wings; wings of the lateral ribs the broadest; vittæ 1 in eacl furrow, and 2-4 in the commissure. Carpophore bipartite.-Involucra and involucels of many leaves.

87 Selinum. Margin of calyx obsolete. Petals obovate, emarginate. Mericarps with 5 membranous wings; the wings of the lateral ribs twice the breadth of the rest; vittæ 1 in each furrow, but in the outer ones usually 2 , and always 2 in the commissure. Carpophore bipartite.-Involucrum of few leaves; involucels of many leaves.

S3 Ostérieum. Calyx 5-tootlied; tecth broad. Petals unguiculate, obovate, emarginate, with an inflexed point. Meriearps with 5 ribs: the 3 dorsal ones elevated and filiform: the 2 lateral ones dilated into wings, much broader than the rest; vitta 1 in each furrow. Carpophore bipartite.-Involucra of few leaves; involucels of many leaves.

89 ANGE'LICA. Margin of calyx obsolete. Petals lanceolate, entire, with a straight or incurved point. Mericarps with 5 ribs : the 3 dorsal ones filiform and elevated: and the 2 lateral ones dilated into membranous wings, which are broader than the rest; vittæ 1 in each furrow. Carpophore bipartite.-Involucrum wanting, or of few leaves; involucels of many leaves.

90 Archangélica. Margin of ealyx with 5 short teeth. Petals elliptic, entire, with an incurv $d$ point. Mericarps with 5 thickish, keeled ribs: the $S$ dorsal ones elevated: and the 2 lateral ones dilated into wings. Seed not adhering to its covering, but constituting a free nucleus, covered all over witl copious vittæ. Carpophore bipartite.-Involucra nearly wanting; involucels of many leaves, unilateral.

\section{Tribe VII.}

Peucenaned. Fruit compressed from the back, or lenticularly I I 
compressed, girdcd by a smooth, wingcd, flattencd, or rather con$v c x$, dilatcd, entire margin. Mericarps with 5 fliform ribs, rarcly wingcd; lateral ribs contiguous to the dilated margin, or lost in it. Raphe marginal, honce the fruit is only furnishcd with 1 wing on cach sidc, not with 2 wings, as in the last tribc, where the raphe is central. Seed flattencd, or rather convex on the back.

91 Orópanax. Margin of ealyx obsolete. Petals roundish, entire, involute, with an acutish point. Stylopodium broad, thick; styles very short; mericarps with 3 dorsal, filiform, very slender ribs : the 2 lateral ones wanting, or not distinct from the margin; vittæ 3 in each furrow, and 6-10 in the commissure. Seed ftat. -Involucra and involucels of many leaves. Flowers yellow.

92 FE'rula. Margin of calyx with 5 short teeth. Petals ovate, entire, with an ascending or incurved point. Fruit girded by a dilated flat margin; mericarps with 3 dorsal filiform ribs : the 2 lateral ones very obsolete, or not distinct from the dilated margin; vittæ 3 or more in the dorsal furrows, and 4 or more in the commissure. Seed flat. Carpophore bipartite.Involucra and involucels variable. Flowers yellow.

93 Dore'ma. The large, cup-shaped, epigynous disk, and the solitary vittæ in the furrows of the fruit, distinguish this genus from Férula and Opópanax. The flowers being completely sessile is also a remarkable character.

94. Eriosx'naphe. Calyx bluntly 5-toothed. Petals ovate, entire, with a short, incurved point (f. 56. E. f.). Fruit compressed (f.56. E.k.) fron the back, girded by a thickish margin: the 3 dorsal ribs filiform: and the 2 lateral ones running into the thickish margin, which is spongy inside; furrows broad, 2-3-striped, bearing 2-3 vittæ in each; and the commissure is without vittæ, but marked with a middle nerve and $\sim$ marginal ones, rather hollow and tomentose between the nerves. Seed flattish.-lnvoluera and involucels wanting. Flowers yellow.

95 Palímbia. Margin of calyx olssolete. Petals elliptic, with an acute inflexed point. Fruit oblong or oval. Mericarps compressed from the back : with 5 filiform, bluntish ribs : 2 marginal ones a little broader than the rest; vittæ 3 in each furrow, and 2 broad ones in the commissure. Seed oblong, free, striped. -Involucrum few-leaved or wanting. Flowers cream-coloured.

96 Pencedanum. Margin of calyx 5-toothed. Petals obovate, emarginate, or entire, with an inflexed point. Fruit girded by a flat margin; the 3 dorsal ribs filiform: and the 2 lateral ones more obsolete, contiguous to the dilated margin; vittæ in each furrow usually 1, and in the commissure 2. Carpophore bipartite. Seed flat in front.-Involucra variable in the different species; involucels of many leaves.

97 Inplratòra. All as in Peuccdìnum, but the margin of the calyx is obsolete.-Involuera wanting; involucels of few leaves.

98 Callísace. "Margin of calyx rather 5-toothed, or nearly obsolete. Petals oval, with an incurved point. Fruit nearly orbicular, emarginate at the base, with a winged margin; the 3 dorsal ribs obtuse and nerve-formed: the 2 lateral ones expanded into wings, which lie over the whole surface: vittæ 1 in each furrow, and 1 on each side of the commissure. Forks of carpophore adliering to the mericarps. - Involucra wanting, or of fcw leaves; involucels of many sctaceous leaves.
99 Bu’вon. Margin of calyx obsolete. Petals obovate, entire, with an acute involute point. Fruit girded by a flattened, dilated margin ; the 3 intermediate ribs filiform, and the 2 lateral ones going into the margins; vittæ covering the whole seed, 4 dorsal and 2 in the commissure. Carpophore bipartite. Seed flat in front and convex on the back.-Cape shrubs. Involucra and involucels of many leaves. Hlowers greenish yellow.

100 Aле'тнuм. Margin of calyx obsolete. Petals roundish, entire, with a rather square retuse point. Fruit girded by a flat margin; the 3 intermediate ribs acutely keeled, and the 2 lateral ones more cbsolete, and ruming into the margin; vitta broad, solitary in the furrows, and filling them, and twin in the commissure. Seed rather convex on the back.-Involuera and involucels wanting. Flowers yellow.

101 Cóntia. Teeth of calyx elongated, acute. Petals lanceolate, acuminated, entire. Stylopodium conical; styles diverging. Fruit elliptic, rather retuse at both ends; ribs winged: lateral one the broadest; vittæ 1 in each furrow, and 2 in the commissure, which is flat. Seed flattish.-Involucra of 2-3 multifid leaves; involucels of 5 linear, entire, or 2-3-cleft leaves.

102 Capnopirýlum. Margin of calyx obsolete. Petals oblong, rather emarginate, tapering into an inflexed acumen. Fruit girded by a flat, dilated margin; the 3 intermediate ribs thickish, keeled, rather flexuous, tubercular : the 2 lateral ones going into the dilated margin; vittæ 1 in each furrow, and 2 in the commissure. Seed rather convex on the back.-Involucra and involucels of 3-6 leaves.

103 TIEDEMA'Nnia. Margin of calyx 5-toothed (f. 64, $a$. ). Petals acuminated, reflexed. Fruit nearly ovate (f. 64. c.); mericarps with 5 filiform, subcarinated, approximate ribs : lateral ones dilated into a membranous margin, which is nearly the breadth of the fruit; vitta solitary in the furrows, and filling them, and twin in the commissure. Carpophore bipartite. Seed flat.-Involucra and involucels of 4-5 subulate leaves.

104 Arciemo'ra. Margin of calyx 5-toothed. Petals obcordate, with an inflexed point. Fruit compressed from the back, oval or obovate; mericarps with 5 filiform, rather keeled, approximate ribs: lateral ribs dilated into a broad membrane; vittæ solitary in the furrows, and filling them, and twin in the commissure. Carpophore bipartite. Seed flattened.-Involucra wanting or few-leaver ; involucels of many leaves.

105 Pastina'ca. Margin of calyx obsolete, or minutely denticulated. Petals roundish, entire, involute, with a broad retuse point. Fruit compressed from the back, girded by a flat dilated margin : the 3 intermediate ribs filiform, equidistant: lateral ones contiguous to the dilated margin; vittæe linear, acute, hardly shorter than the ribs, solitary in the furrows, and twin or more in the commissure. Carpophore bipartite. Seed flattened.-Involucra and involucels wanting or few-leaved. Flowers yellow.

106 Leiótulus. Teeth of calyx obsolete. Petals roundish, entire, involute, with a broad retuse segment. Fruit compressed, with a thickened dilated smooth margin; the 3 intermediate ribs approximate, and the 2 lateral ones marginal and remote; vittæ 1 in each furrow, filiform, distant in the coinmissure. In. volucra wanting; involucels of a few very fine leaves. 
107 AstYdA'ura. Margin of calyx 5-toothed (f. 56. D. a. $d$. f.). Petals obovate, entire, with an inflexed point. Stylopodium thick; styles very short (f. 56. D. gr.). Fruit compressed from the back (f. $56 . D . k$.), girded by a thick dilated margin; the 3 dorsal ribs crested, approximate : the 2 lateral ones running into the margin ; dorsal vitta very few, the commissural ones wanting or covered.-Involucra and involucels of many leaves. Flowers yellow.

108 Sympryolòna. Margin of calyx obsolete. Petals cqual, emarginate, with an inflexed point. Stylopodium without a margin ; styles reflexed. Fruit elliptic, compressed from the back; meriearps closely connate by their margins; with 5 filiform ribs: $S$ dorsal ribs equi-distant: lateral ones more remote, marginating; vittæ wanting or obsolete. Seed flattened, Carpophore none. Flowers red.

109 11eracle'va. Calyx 5-toothed. P'etals obovate, emargiuate, with an inflexed point: exterior petals usually radiating and bifid. Fruit compressed from the back, girded by a flat, dilated margin ; mericarps with very fine ribs : 3 dorsal ones equidistant : 2 lateral ones remote, contiguous to the dilated margin : vitta 4 on the back, solitary in the furrows, but usually with 2 in the commissure, all shorter than the fruit, and usually clubslaped; carpophore bipartite. Seed flat.-Involucra caducous, usually of few leaves; involucels of many leaves.

110 Zozíma. Calyx 5-toothed. Petals obovate, emarginate, with an inflexed point. Fruit compressed from the back, rather convex in the middle, hairy, girded by a smooth, tlickened, dilated margin ; ribs very thin : dorsal ones at equal distances: 2 lateral ones more remote, eontiguous to the dilated margin; vittæ covering the whole seed, solitary in the furrows, and twin in the commissure. Carpophore bipartite. Seed flat. - Involucra and involucels of many leaves.

111 Polyténia. Calyx 5-toothed. Petals oval, cmarginate, with an inflexed point. Fruit oval, compressed on the back, convex in the middle, glabrous; with a smooth tumid margin, and a depressed furrow on the back; ribs very slender, hardly distinct; vittæ twin between the ribs, but 6 in the commissure; carpophore indistinct. Seel flat.-Involucra none; involucels setaceous.

112 Johrénia. Teeth of calyx obsolete, very blunt. Petals unknown. Stylopodium short, conical, furrowed a little. Styles short, diverging. Fruit oval, lenticularly compressed on the back (f. 56. C. b.), quite glabrous; with a smooth tumid margin, and a flat, dorsal, coloured furrow ; mericarps witl 3 dorsal, filiform ribs, which probably contain vittæ: 2 lateral ones running into the dilated margin, hardly distinct, usually rufous, and the form of vittæ; commissure spongy, furnished with 2 lines, but without vittæ. Carpophore 2-parted (f, 56, C.b.a.). Seed flat.-Involucrum wanting, or of $I$ leaf; involucels of 4-5 linear, setaceous leaves.

\section{TR1Be VIII.}

Tordylínee. Fruil lenticularly or flatly compressed from the back, girded by a thickened, nodulose, or plaited, dilated margin. Mericarps with 5 very fine or obsolcte ribs: lateral ones contiguous to the dilated margin, or forming the same. Sceds flat- tenct. This tribe differs from Peucedinece in the margin of the fruit bcing plaited or nodulose, not smooth and entire.

113 Hasseqquístia. Margin of calyx 5-toothed. l'etals obovate, emarginate, with an inflexed point; outer petals radiating and bifid. The outerfruit of the umbel are compressed, girded by an aceessory, winged, thickened margin, which is hardly wrinkled; those of the disk dissimilar: one of the mericarps contracted into an hemispherical urccolus around the other, which is abortive; ribs very slender: the 3 dorsal ones equidistant : and the 2 lateral ones contiguous to the thickened margin, or hidden by it ; vitta 1 in each furrow, and 2 in the commissure. Carpophore bipartite. Seed flat.-Involucra of many leaves.

114 Tond'lum. All as in IIassclquistia, except that the vittæ are eitlier solitary or numerous in the furrows, and either 2 or more in the commissure; and in the fruit being equal, and girded by a tubercularly wrinkled, accessory, thickened margin. -Involucra of many leaves.

115 TorDy zópsis. Margin of calyx 5-toothed; teeth acute: outer teeth the largest, dilated at the base, and cuspidate at the apex. Outer petals of umbels larger, and obcordately 2lobed : the rest smaller, ovate, and cuspidate, usually entire, rarely somewhat 2-lobed. Stylopodium conical. Styles erect, elongated. Fruit hairy.-Involucra and involucels of 5-6 lanceolatelinear leaves.

\section{* Fruit furnished with both primary and secondary ribs.}

\section{TRIBE IX.}

Silerínee. Fruit lenticularly compressed from the back. Mericarps with 5 primary ribs: the latcral ones marginating; and usually with 1 sccondary, less prominent ones; all filiform and winglcss. Sceds flattish in the front.

116 Krube'ra. Margin of calyx 5-toothed. Petals obovate, emarginate, with an inflexed point. Mericarps with 5 plicately crenated, thick ribs : the 3 intermediate elevated, obtuse, and keeled: 2 lateral marginating and roundish, keeled near the raphe; vitta none. Carpophore bifid.-Involucra 25-leaved; involucels 4-5-leaved.

117 Pachy plev'rum. Margin of calyx obsolete, or minutely denticulated. Petals permanent; those of the inner flowers obovate-oblong, emarginate, with an acute, inflexed point ; those of the ray flowers of 2 forms : the 3 inner, ovate, hardly emarginate, with an acute inflexed point: 2 onter nearly orbicular, and profoundly emarginate, also with an inflexed point. Mericarps with elevated, thick, and corky ribs: the lateral ones marginating, and a little broader than the others; vittæ none.-Involucra and involucels of many leaves.

118 Agasy'tlis. Margin of calyx obsolete. Petals lanceolate, incurved. Fruit oval. Mericarps with 5 primary ribs : the 2 lateral ones placed in front of the accessory margin; the secondary ribs hardly visible. Seeds furnished with 8-10 dorsal vittæ, and 5-6 commissural ones.-Involucra wanting; involucels of many setaceous leaves.

119 Stenoce'luum. Margin of calyx 5-toothed. Petals obovately orbicular, somewhat emarginate, with an inflexed I I 2 
point. Mericarps with 5 rounded, thick, equal ribs; vitta 1 in each furrow.-Involucra and involucels of many leaves.

120 Siler. Margin of calyx 5-toothed. Petals obovate, enarginate, with an inflexed point. Ribs filiform, elevated, obtuse: primary ones 5 : lateral ones of these marginating: secondary ones 4, less prominent; vitta 1 in each furrow, under the secondary ribs.-Involucra none, or few-leaved, caducous.

121 Ga'lbanum. This genus differs from Siler in the absence of dorsal vitta to the fruit, and the commissure being furnished with only 2.

\section{TRIBE X.}

Cumine.e. Fruit contracted from the sides; mericarps nith 5 filiform, primary ribs: the lateral ones of these marginating; and + secondary more prominent ones; all ningless. Secd straight, flattish in front.

122 Cuminum. Calyx with 5 lanccolate, unequal, permanent tecth. Petals oblong, emarginate, with an inflexed point. Primary ribs minutely muricated: secondary ones prickly; vittae 1 in each furrow under the secondary ribs. Carpophore bipartite. Secd concave in front, and convex on the back. - Involucra of $2-4$ simple or divided leaves; the involucels dimidiate, of $2-4$ reflexed leaves.

123 Trepocárpus. Calyx with 5 subulate teeth, which fall off at length. Petals obcordate, inflexedly cmarginate. Fruit pyramidly angular, nearly terete; mericarps convex on the back; primaıy ribs margined with a fuscous, vittæ-formed line on each side; secondary ones furnished with 1 vitta on their inner sirle; commissure thick, furrowed in the middle, and furnished with vittæ inside. Seed straight, rather compressed on the back.-Involucra 1-3-leaved; involucels dimidiate, of 4-5 lincar, unequal leaves.

\section{Tribe XI.}

TuAPSiE's. Fruit compressed from the back; mericarps with 5 filiform primary ribs, which are now and then bristly: lateral oncs scated in the flat commissure; secondary 4 : inner ones of these filiform, and the outer ones or all are ninged: wings undivided, hence the fruit is cither 8-xinged, or furnished nith 2 wings on each side. Secd flattish, or tcretcly convex, flat in front.

124 'THA'Psia. Margin of calyx 5-toothed. Petals elliptic, entirc, with an inflexed or involute point ; 2 lateral secondary ribs winged, hence the fruit is 2 -winged on each side; furrows under the secondary ribs furnished with 1 vitta each. Carpophore bipartite. Seed flattish.-Involucra and involucels wanting, or of few leaves. Flowers yellow.

125 Crnópterus. Calyx minutely 5-toothed. Petals roundish-oval, inflexed at the apex. Fruit nearly elliptic, compressed, 7-8-winged, from all the secondary ribs being winged; wings undulated; furrows flat, 1-nerved; commissure naked, 3-striped. Carpophore not separable from the mericarps.-Involucra wanting ; involucels dimidiate, 5-7-parted.

126 Laserpítum. Margin of calyx 5-toothed (f. 55. C.f.). Petals obovate, emarginate (f. 55. C. $a$.), with an inflexed point (f. 55. C. i.). Fruit compressed from the back (f. 55.C.g.), or nearly terete, 8 -winged, in consequence of the 8 secondary nerves being winged; vittæ 1 in each furrow, unde $r$ the secon dary ribs. Carpophore free, bipartite (f. 55. C.l..).-Involucra and involucels of many leaves.

127 Lopmoscra'dum. Margin of calyx 5-toothed. Petals elliptic, entire, acuminated, involute at the apex (f. $55 . B . d_{0}$ ). Fruit compressed (f. $55 . B . e$.) on the back; the 2 lateral secondary ribs cxpanded into a subserrated wing each : the 2 dorsal ones expanded into an interrupted wing each, at first sight appearing like retrograde scales (f. $55 . B . e$.).--Involucra of 5-7 ovatelanceolate leaves ( f. $55 . B . a$. ); involucels of $5-7$ narrower leaves (f. 55. B.b.). Flowers ycllow.

128 Melanoselinum. Margin of calyx 5-toothed. Petals obovate, emarginate, with a reflexed point. Fruit compressed from the back; the 2 inner sccondary ribs filiform and very slender: the 2 outer ones expanded into a membranous serrated wing each; with oleiferous canals under all the ribs. Carpophore lipartite. Seed flat.-A shrub. Involucra and involucels of many leaves, the first composed of cut leaves, and the second of entire leaves.

\section{TrIBE XII.}

DaucínEe. Fruit lenticularly compressed from the back; mericarps with 5 bristly, fliform, primary ribs; lateral ones of these seatcd in the flat commissure, as in Thapsice; and nith 4 sccondary oncs, which are more prominent and prickly; the prickles free, or joined into a wing. Seedsflattish, or subsemiterete, or convex on the back, and flattish in front.

129 Arte'du. Margin of calyx obsolete. Petals obovate, emarginate, with an inflexed point: those on the onter part of the umbel radiating and bipartite. Secondary ribs 4 : the 2 inner ones filiform: the outer ones expanded into a sinuately lobed wing each; vitte none. Carpophore bipartite. Seed flat. - Leares of involucra and involucels divided into linear lobes.

130 OrLA'Ya. Margin of calyx 5-toothed. Petals obovate, emarginate, with an inflexed point: those in the ray of the umbel profoundly bifid. Secondary ribs of fruit furnished with 2 or 3 rows of prickles, outer ones more prominent, or a little winged; prickles hooked or rayed at the apex; vitta 1 in cach furrow under the secondary ribs. Carpophore bifid or undivided? Seed convex on the back.-Involucra variable; involucels of many leaves.

131 Dau'cus. Margin of calyx 5-toothed. Petais obovate, emarginate, with an inflexed point : outer ones usually radiating, and profoundly bifid. Fruit oval or oblong; the 4 secondary rilss more prominent and winged, divided into a simple series of prickles; vittæ 1 in each furrow, under the secondary ribs. Seed flattish in front.-Involucra of many trifid or pinnatificl leaves; involucels of many entire or trifid leaves.

Suborder 11. Campylospérme. Albumen involute, or marked by a longitndinal furrow or channel on the inner side.

\$ 1. Mericarps furnished with both primary and secondary ribs.

\section{Tribe XIII.}

Eleosefínes. Fruit cylindrical, more compressed from the 
back than from the sides; mericarps with 5 primary filiform ribs; and 4 sccondary ones: the 2 dorsal oncs of these latst nerveformcd, but the 2 latcral ones arc expanded into a ning cach; with the margins nerve or rib-formed. Sccls involute, semi-lunate.

132 Elfosecinou. Margin of calyx hardly 5-toothed. Petals obovate, emarginate, with an inflexed point. Fruit nearly tcrete, 4-winged; the 2 lateral primary ribs seated between the wings and the nerve-formed margins; vitta under all the ribs abounding in oil, those under the primary ribs narrower and slenelerer: in the commissure there are 4.- Involucra and involucels of many cuspidate, linear leaves. Flowers yellow.

\section{Tribe XIV.}

Caveali'Ne.e. Fruit contracted from the sides, or ncarly tercte. Mericarps nith 5 filiform, bristly, or prickly, primary ribs: latcral ones of these seated in the commissure, which is flat; the secondary 4 more prominent and very prickly. Seeds involutc, or inflcxed on the margin.

183 Cau'calis. Teeth of calyx 5, ovate-lanceolate. Petals obovate, emarginate, with an inflexed point: outer ray ones profoundly bifid. Fruit rather compressed from the sides; sccondary ribs deeply cleft into a simple series of prickles; vittæ solitary in each furrow, under the secondary ribs, and 2 in the commissure. Carpophore stiff, cleft at the apex.-Involucra none, or of 1-2 leaves; inrolucels of $3-8$ lanceolate leaves.

134. Turge'sia. Teeth of calyx 5, setaceous. Petals obovate, emarginate, with an inflexed point: outer ones radiating and bifid. Fruit subdidymous; lateral primary ribs with a simple series of warts or prickles, all the rest furnished with 2 or 3 rows of equal prickles; furrows furnished with 1 vittæ each under the secondary ribs. Carpophore setaceous, bifid.Involucra and involucels of 3-5 ovate, concave, equal leaves.

135 Toríls. 'Teeth of calyx 5, triangularly lanceolate, acute, permanent. Petals obovate, emarginate, with an inflexed point : onter ones larger and bifid. Secondary ribs having abundance of prickles occupying the whole furrows, which are furnished with 1 vitta each under the prickles. Carpophore setaceous, bifid. Involucra of 1-5 leaves; involucels of 5-6 lanceolate ciliated leaves.

\section{\$2. Mericarj,s only furnished with primary ribs. Tribe XV.}

Scandictines. Fruit evidently comprcssed, or contracted from the sides, usually beaked; mericarps with 5 filiform ribs, which are at length ninged: lateral ribs marginating, all cqual, but somctimes all obliterated at the base, and only conspicuous at the apex. Seeds teretely convex, having a deep furrow in front, or somenthat involute on the margin.

136 ScA'sdix. Margin of calyx obsolete, or somewhat 5toothed. Petals obovate, truncate, or emarginate, usually furnished with an inflexed point. Fruit compressed from the sides, with a very long beak; vittx wanting, or nearly obsolete. Carpophore undivided, forked at the apex-Involucra wanting, or of 1 leaf; involucels of $5-7$ leaves.
137 Axturíscus. Margin of calyx obsolete. Pctals obovate, truncate, or emarginate, with a very short inflexed point. Fruit contracted from the sides : having a beak, which is shorter than the secl; mericarps nearly teretc, destitute of ribs, the beak alone being furnished with 5 ribs. Carpophore bifid at the apex.-Involucra wanting; involucels of many leaves.

138 Cu.r.ropuy'tuum. Margin of calyx obsoletc. Petals obovate, emarginate, with an inflexed point. Fruit compressed from the sides, without any beak; commissure deep; vitta 1 in each furrow. Carpophore bifid.-Involucra wanting, or of few leaves; involucels of many leaves.

139 Calda'sia. Margin of calyx obsolete. l'etals ovate, with an cntire somewhat involute point. Fruit ovatc-oblong, rather compressed from the sides, crowned by the short diverging stylus; furrows between the ribs broad, flat, striated, and furnished with 1 vitta each; commissure furrowed in the middle. Carpophore bipartite. Seed rather convolute at the commissure.-Umbels simple, surrounded by a 20 -leaved involucrum.

140 Spualteroca'rpus. Teeth of calyx 5, subulate. Petals obovate-cuneated, emarginate, with an inflexed point (f. 56. $L$. b.): the outer ones of the umbel radiating. Stylopodium rather urceolate, toothed; styles short. Fruit elliptic-oblong (f. 56. $L$. $d$.), contracted from the sides, without a beak; firrows between the ribs convex, furnished with $2-3$ virtæ each, and the commissure with 4-6. Carpophore bipartite (f. 56. L. h.).Involucra wanting; involucels of 5-6 lanceolate leaves (f. 56 , L. a.).

141 Molopospéruum. Calyx 5-toothed, foliaceous. Petals lanceolate, entire, ending in a long ascending point. Fruit contracted from the sides. Nericarps with 5 winged ribs. Sced bluntly tetragonal or angular; channels empty between the seed and the commissure of the pericarp; furrows having I broad brown vitta each, but the commissure is very narrow, and without any vittæ. Carpophore bipartite.-Involucra of many elongated, membranous leaves, which are sometimes multifid; involucel of many leaves.

142 VELX'A. Margin of calyx oblitcrated. Petals unknown. Stylopodium conically depressed, short (f. 56. G. b.) ; styles erect, filiform. Fruit ovate (f. 56. G.e.b.), without a beak ; mericarps rather compressed from the sicles, with 5 ribs: the 2 lateral ones filiform, and the 3 dorsal ones winged; vittæ 3 , and sometimes 2 in each furrow, and 4 in the commissure. Carpophore bipartite (f. 56. G. h.) from the base.-Involticra and involucels none.

$143 \mathrm{Mr}^{\prime}$ Rrhis. Margin of calyx obsolete. Petals obovate, emarginate, with an inflexed point. Fruit compressed from the sides. Seeds involute, covered by a double membrane: outcr membrane furnished with 5 acutely keeled, sharp, equal ribs, hollow inside: inner one adnate to the seed; vittæ none. Carpophore cleft at the apex.-Involucra none; involucels of many lanceolate ciliated leaves.

144. Osmorhiza. Margin of calyx obsoletc. Petals obovate, hardly emarginate, with a short inflexed point. Fruit elon- 
gated, tapering into a tail at the base, solid, acutely angular; mericarps with hispid, rather furrowed angles; ribs 5 , acute; commissure furrowed; furrows flat, withont vittæ. Carpophore semi-bifid.-Involucra of 2-3 lanceolate, ciliated leaves; involucels of 5 lanceolate, ciliated leaves.

145 Gramoscia'dium. Teeth of calyx stiff (f. $56 . H . g$. ), permanent. Petals obcordate, with an inflexed point. Styles short, conical (f. $56 . H$. b.), diverging. Fruit cylindrical (f. 56. II. a. b.), without a beak; mericarps with 5 primary, flattish white ribs; furrows flat, furnished with 1 vitta each, and the commissure with 2.-Involucra of 5-7 multifid leaves; involucels of linear-subulate, rarely cut leaves (f. 56. H.e.).

\section{Tribe XVI.}

SMY'RNEE. Fruil turgid, usually compressed, or contracted from the sides; mericarps with 5 ribs: lateral ones marginating, or siluatcd in front of the margin; the ribs somctimcs almost obliterated. Secd involute, or with a furrow on the inside, semilunar or complicale.

146 Lagcicia. Calycine lobes large, pectinated. Petals obcordately bifid, shorter than the calyx; lobes awned. Orarium 2-celled, with 1 of the cells abortive. The fruit is therefore ovate, crowned by the calyx, pubescent : marked by a furrow on one side, indicating the place of the abortive seed.-Involucra of 8-10 pectinated leaves; and the involucel of 4 .

147 Olive'ria. Margin of calyx 5-toothed. Petals profoundly obcordate: lobes involute on the margin at the base, and excavated at the sides, undulated and reflexed at the apex. Fruit obovate, hairy: mericarps nearly terete; with 5 blunt ribs. Carpophore bifid at the apex.-Involucra of 3-4 trifid leaves, with the lobes usually tridentate; involucels of many cuneiform, trifid leaves.

148 Anisoscia'diun. Calycine lobes of the outer flowers of the umbed, large, ovate, and foliaceous : of the outer central ones stiff and hooked: of the other inner ones wanting or toothformed. Petals very unequal: outer ones obcordately bifid: inner ones small. Fruit rather downy, oblong-cylindrical, crowned by the calyx, and stiff conical styles; mericarps with 5 blunt ribs; vitta brown, 1 in each furrow, but none in the commissure.-Involucra of $4-5$ oblong, acute, unequal leaves ; involucels of $1-5$ leares.

149 Echinópuora. Margin of calyx 5-toothed. Petals emarginate, with an inflexed point : outer ones larger and bifid. Styles of the female flowers elongated, filiform (f, 65. h.). Fruit ovate (f. $65 . c$. ), nearly terete, inclosed in a hollow receptacle: with a short, emersed beak; mericarps with 5 undulated, equal depressed ribs; vittæ covercd with a cobwebbed membrane, 1 in each furrow.- Involucra and involucels of many leaves (f. (j5. a.).

150 Exoacástila. Flowers polygamous: central ones fertile, the rest sterile. Calyx in the sterile flowers obsolete. Petals obcordate, equal, inflexcd. Young fruit of the sterile flowers obovate, striated ; of the central flowers much more ovate, somewhat papillose, and crowned by 15 elongated stiff bristles.-
Involucra of 10-12 large, channelled, spinose leaves; involucels of $7-11$ spinose, very unequal leaves on one side.

151 Arctòpus. Flowers polygamous. Margin of calyx 5toothed. Petals lanceolate, with an incurved acute entire point. Fruit ovate, beaked, crowned by the calyx, conferruminated from the base to the middle with the involucrum, depressed in front, and marked by a furrow, not separable into 2 parts, but bilocular, 1 of the cells abortive.-Involucra of 4-5 concrete leaves.

$152 \mathrm{CA}_{\mathrm{A}}$ curys. Margin of calyx 5-toothed, rarely obsolete. Petals ovate, entire, involute at the apex or inflexed. Stylopodium depressed, hardly distinct in the mature fruit. Mericarps with 5 thick ribs, variable in the different sections of the genus ; commissure almost the breadth of the mericarps. Seed constituting a free nucleus covered with abundance of vittæ.Involucra and involucels of many leaves. Flowers yellow.

153 PrÁxgos. Margin of calyx 5-toothed. Petals ovate, entire, involute at the apex. Stylopodium depressed, hardly prominent in the fruit. Commissure broad. Mericarps compressed from the back, with 5 smooth ribs, which are thick at the base, and ending in vertical membranous wings on the back. Seed girded by an abundance of vittæ.-Flowers yellow.

154 Colladònia. Margin of calyx entire. Petals oval, entire, involute at the apex. Stylopodium depressed, hardly prominent in the fruit. Mericarps compressed from the sides, ending in 5 vertical membranous wings on the back, having 1 vitta in each furrow; commissure narrow, furnished with 2 vittæ.Involucra and involucels of many undivided leaves.

155 Lесок1A. Margin of calyx with 5 short teeth. Petals ovate, with an inflexed point. Stylopodia 2, distinct. Styles subulate. Fruit ovate, didymous, with a narrow commissure; mericarps semi-terete, with 5 obtuse, spongy ribs, which are beset with prickles on all sides. Seeds girded by copious vittæ. Involucels of 5-8 subulate leaves.

156 MAGYDA'ris. Margin of calyx obsolete. Petals obcordate, with an inflexed point. Fruit ovate (f. 56 . I. b.), tomentose; mericarps with 5 thick, blunt ribs, and narrow furrows. Seeds clothed on every sile with very slender vittæ, convex on the outside, and involute with a deep furrow on the inside.-Involucra and involucels present, of many undivided leaves.

157 HE'RMAs. Margin of calyx 5-parted, foliaceous, permanent. Petals oval-oblong, acute, keeled, entire, equal. Fruit ovate; mericarps rather inflated, compressed from the back, 5 ribbed: the dorsal rib exserted: the 2 middle ones larger: and the 2 marginal ones small, under the commissure; vittæ many in the furrows between the ribs, which are broad. Seed not adnate to its covering, rather hollow inside.-Involucra of many leaves; involucels of 3 leaves.

158 Cònum. Margin of calyx obsolete. Petals obcordate, rather emarginate, with a short inflexed point. Fruit coinpressed from the sides, ovate; mericarps with 5 , rather prominent, equal ribs, which are undulately crenulated; having the furrows between the ribs, furnished with many stripes, but without any vittæ. Carpophore bifid at the apex. Seed with a 
deep narrow furrow inside. - Involucra of $3-5$ leaves; involucels of $3-5$ leaves, dimidiate.

159 Vica'tia. Margin of calyx obsolete. Pctals unknown. Styles short. Fruit ovatc-oblong; mericarps nearly semi-terete, with 5 filiform, hardly prominent ribs; vitte small, many in the furrows, which are broad and flat; commissure narrow. Carpoplore thick, somewhat bifid at the apex. Albumen furnished with a furrow at the commissure, convex outside.-Involucra, and gencrally the involucels, are wanting.

160 Arraca'cis. Margin of calyx obsolete. Petals lanceolate or ovate, entire : with an inflexed point, which is curbed above the middle nerve. Fruit ovate-oblong, somewhat compressed from the sides; mericarps with 5 equal ribs; vittæ many in the furrows. Albumen nearly semi-terete, furnished with a furrow at the commissure.-Involucra wanting, or of 1 leaf; involucels of 3 leaves. Flowers polygamous.

161 Plecrospe'ruus. Margin of calyx 5-toothed. Petals obovate, entire, flat, or attenuated and inflexed at the apex. Fruit orate, somewhat compressed from the sides; mericarps furnished witl a double membrane: outer one furnished with 5 winged hollow ribs : the inner one alnate to the seed, and furnished with 5 elevated ribs under those of the outer membrane; furrows of the inner membrane furnislied with 1-2 vittæ each, and the commissure with 2. Carpophore filiform, bipartite.Involucra and involucels of many leaves.

162 Hynenolén. Ma. Margin of calyx obsolete. Petals obovate, entire, flat, or attenuated and inflexed at the apex. Fruit ovate or oblong; mericarps with 5 exserted, nearly equal wings ; commissure flat, furnished with 2 vittæ, and the furrows with 1 . Seed with a furrow in front, convex on the outside. Carpophore bipartite.-Involucra and involucels of many leaves.

163 Puysospe'rmum. Margin of calyx 5-toothed. Petals obovate, somewhat emarginate, with an inflexed point. Fruit contracted from the sides; mericarps reniformly globose, didymous, with 5 filiform equal slender ribs: the lateral ribs placed before the margins ; vittæ broad, 1 in each furrow. Seed semilunar.-Involucra and involucels of many leaves.

164. Sur'rouum. Margin of calyx obsolete. Petals lanceolate or elliptic, entire, with an inflexed point. Fruit contracted from the sides ; mericarps reniformly globose, didymous : with 3 dorsal, rather prominent ribs, and 2 lateral, marginating, nearly cbliterated ones; vittæ many in each furrow; carpophore bipartite. Seed involute.-Involucra and involucels variable in the different species.

165 Eu'LopuUs. Margin of calyx 5-toothed (f. 56. K. b.). Petals unknown. Fruit a little contracted from the sides (f. 56 . $K . a_{\text {. }}$ ); mericarps ovate, rather didymous, with 5 hardly prominent ribs; furrows baving 3 convex stripes, more prominent than the ribs, which are hollow inside and filled with oil ; commissure furnished with 4 similar vittæ. Seed semi-lunar. Carpophore bipartite.-Involucra and involucels of many linear leaves (f. $56 . K . \mathrm{c}$. ).

166 Scaligéria. Margin of calyx entire. Petals obcordate, with a short inflexed obtuse point. Stylopodia thick (f. 56. $B . h$. ), parallel. Styles filiform, bent outwardly. Fruit rather diclymous; mericarps ovate, contracted at the raphe, hardly compressed from the sides, with 5 filiform ribs; vittie $2-3$ in the furrows, which are rather convex, and 4-6 in the commissure, which is flattish. Albumen furnished with a furrow on the inside.Involucra wanting; involucels of a few small linear leaves.

\section{F1G. 56.}

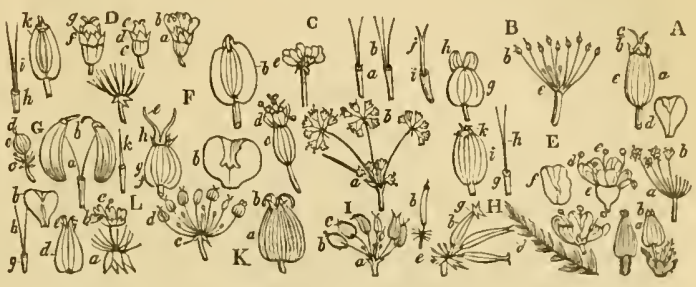

Suborder III. Ceelospérme. Albumen involutely curved from the base to the apex.

\section{Tribe XVII.}

Corin'ndRez. Fruit globose, or of 2 subglobose mericarps. Mericarps furnished with 5 primary, depressed, and flcxuous ribs: lateral ribs placed before the accessory margin; and 4 more prominent secondary oncs; all wingless.

167 Bífora. Margin of calyx obsolete. Petals obovate, emarginate, with an inflexed point: outer ones nearly equal or radiating and bifid. Fruit didymous; mericarps ventricosely subglobose, granularly wrinkled : marked with 5 impressed, obsolete stripes : the 2 lateral stripes semicircular, placed in front of the accessory margin; vittæ wanting; commissure baving 2 holes. Carpophore bipartite, adnate on both sides.-Involucra and in. volucels wanting, or of 1 leaf.

168 Astòma. All as in Bifor $r a$, but the fruit is evidently didymous; and the commissure is narrow, not perforated, nor dilated at the apex; styles rather diverging.-Involucra of 5-6 lanceolate leaves; involucels of 4-5 leaves.

169 Atre'sia. Tecth of calyx 5, acute, small, permanent. Petals obovate, emarginate, with an inflexed point. Fruit rather didymous; mericarps nearly glohose, ventricose, marked with 5 rather prominent ribs, without any vittæ; commissure narrow, closed.-Involucra and involucels of many leaves.

170 Corra'ndrum. Teeth of calyx 5 , acute, unequal, permanent. Petals obovate, emarginate, with an inflexed point : outer ones radiating, bifid. Fruit globose, 10-ribbed, hardly divisible; the 4 secondary ribs on each mericarp are more prominent than the primary ones, and keeled; vitta 1 in each furrow, and 2 in the commissure; carpophore free in the middle, but adnate at the base and apex. Seed hollow in front, covered by a loose membrane.-Involucra none; involucels usually of 3 leaves, dimidiate.

171 Crmbocánpum. Margin of calyx obsolete. Petals equal, obcordate, with an inflexed point. Stylopodium depressed; styles 
reflexed. Fruit nearly globose; mericarps solid, hemispherical : with 5 prinary, filiform, usually obliterated ribs, without any secondary ribs or vitta. Carpophore bipartite, free in the middle, but adnate at the base and apex. Seed hollowed in front.-Involuera and involucels composed of linear leaves.

Suborder I. ORTHOSPE'RMIÆ (from opsoc, orthos, straight, and $\sigma \pi \varepsilon \rho \mu a$, sperma, a seed). D. C. prod. 4. p. 58 . Albumen flat on the inner side, neither involute, nor convolute.

\section{\$1. Umbels simple or imperfect. Fruit destitute of vitta. T'ribe $\mathbf{I}$.}

HYDROCOTYLER (plants agreeing with Hydroeótyle in important characters), or Orthospérmeæ, Imperféctæ, Umbellàtæ, Compréssæ, D. C. prod. 4. p. 58.-Hydrocotýleæ, Spreng. in Schultes, syst. 6. p. 32 . Koch, umb. p. 141. exclusive of many genera. Fruit contracted from the sides; back of carpella or mericarps convex, rarely acute; the 5 primary ribs or nerves becoming immediately obsolete: lateral ribs marginating, or thrown hack into the fiat commissure: secondary ones permanent and filiform, sometimes absent or nearly so. Albumen fiatish in front. Petals spreading, entire, acute, straight, or rather inflexed at the point. This tribe represents the forms of nearly all in the different genera ; it is distinguished from nearly all the suborder Orthosperma, in the nmbels of flowers being imperfect; from Saniculece in the lateral compression of the fruit, and from Mulinece in the commissure not being gradually contracted.

1. HYDROCO'TYIE (from ioos $\rho$, hydor, water, and korv $\eta$, kotyle, a cavity: in reference to the plants growing in moist situations, and in the leaves being hollowed like a bowl). Tourn. inst. t. 173. Thunb. diss. 1798. in diss. ed. Pers. 2. p. 410. Spreng. umb. prod. p. 10. A. Rich. diss. 1820 , in ann. sc. phiys, vol. 4. p. 1. Lag. anı. nat. 2. p. 102. Koch, umb, p. I44. f. 64. and 65. D. C. coll. mem. v. p. $26 .-$ Hydrocótyle and Chondrocárpus (or Glycèria), Nutt. gen. amer. 1. p. 177.

Lin. syst. Pentándria, Digýnia. Tube of calyx rather compressed: limb with an obsolete margin. Petals ovate, entire, icute, with a straight apex. Fruit flatly compressed from the sides, biscutate. Mericarps or carpella without vittæ: having the 5 ribs or nerves nearly filiform: the carinal and lateral ones usually obsolete, and the 2 intermediate ones joined. Seed carinately compressed.-Usually slender bog herbs, rarely subshrubs. Umbel simple, surrounded by a few-leaved involucrum. Flowers sessile or pedicellate, white. This genus is composed of a heterogeneous mass of species, and is therefore probably divisible into several genera.

Sect. 1. Eunydroco'ryle (this section is supposed to contain the true species of the genus). D. C. prod. 4. p. 59 . Hydrocótyle, Lin. gen. no. 325 . Stems lierbaceous, of nearly all the species, creeping. Fruit compresscd; mericarps fur:ished with
$1-2$ ribs on each side.

\section{\$1. Lcaves peltate.}

I II. INTERu'Pta (Muhl, cat. p. 10.) leaves peltate, doubly crenated, 11 -nerved, and are, as well as the petioles, glabrous; flowers disposed in many, rather distant whorl s: ultimate ones umbellate; fruit rather attenuated at the base, coloured. 2. B. H. Native of Carolina, Porto-Rico, Cape of Good Hope, Japan, New Holland, Sandwich Islands, \&c. in marshy places. 11. vulgàris, Michx. fl. bor. amer. 1. p. 161. H. vertieillata, Thunh. diss. 2. p. 4 I5. t. 3 . 11. vulgàris $\beta$, Rich. 1. c. t. 50. f. I. b. II. commùnis, Cham. et Schlecht. in Linnæa. 1. p. 356. lar. $\beta$, tuberòsa (D. C. prod. 4. p. 59.) stems tumid at the nodes, and tuberous.

I'ar. $\gamma$, platyphýlla (D. C. prod. 4. p. 667.) leaves 11-13nerved, twice the size. 24. H. Native of Tropical Africa, in marshes at Cayor.

Interrupted-flowered Penny-wort. Fl. May, June. Pl. cr.

2 II. VULGA'RIS ( $\mathrm{Lin}$. spec. p. 338.) leaves peltate, orbicular, doubly crenated, 9 -nerved; petioles pilose at the apex; umbels capitate, usually 5 -flowered; fruit somewhat emarginate at the base, of one colour. 4 . B. H. Native nearly thronghout the whole of Europe, in marshy boggy places, and on the margins of clear rivulets, particularly on a peat soil: plentiful in some parts of Britain; also of North America, in Canada. Fl. dan. t. 90. Smith, engl. hot. t. 751. Curt. lond. 6. t. 19. Schkuhr, handb. t. 59. Rich. hydr. no. 1. t. 50. f. I. and t. 52. f. 1. exclusive of the variety. Stems creeping, rooting at the nodi. Peduncles of the umbels or scapes much shorter than the petioles. Flowers reddish white or rose-coloured. There is a variety, but it is rather rare, witl, smooth petioles, and with tlie limbs emarginate at the base or nearly entire, and with the scanes drawn out beyond the umbels of Howers, and bearing 2 umbels each. Gerarde calls this plant water penny-wort, sheep-lilling penny-grass; in the north of England it is calied white-rot, to distinguish it from red-rot; in Norfolk flomk-nort, from its being supposed to occasion the flukes in the liver of rotten sheep; and by the husbandman shecp's-bane, "because it killeth sheep that do eat thereof." This, however, is a vulgar error; for the rot in sheep is owing to their feeding in wet grounds, and perhaps to an insect (the Fasciòla hepática), which from its shape is called a fiuke or flounder, and abounds in such situations, adhering to stones and plants, as well as to the liver and biliary ducts of sheep affected with the rot. This, together with Drósera or Sunden, and Pinguicula or Butter-wort, are common in marsliy places, and therefore the rot in sheep has bcen ascribed to these; but it is pretty certain that neither sheep nor any other quadruped feed on these plants.

Common Penny-wort. Fl. May, June. Britain. Pl. cr.

3 H. Pusília (Rich. liydro. p. 27 . t. 5 \%. f. 2.) plant rather hairy; leaves orbicular, not emarginate at the base, obsoletely crenated, 7-nerved; flowers umbellate; umbels hardly containing so many as 12 flowers; scapes equal in length to the petioles. 4. F. Native about Monte Video, in arid places; and on shady rocks at Rio Paquaquer, in the province of Rio Janeiro; also of Buenos Ayres. Cham. et Schlecht. in Linnæa. 1. p. 357. Flowers small. Petioles biauriculate at the base, and as if they were minutely stipulate (Rich.). Fruit smooth; mericarps marked with a single elevated line on each side. The Buenos Ayrean plant differs from the Brazilian one in being perfectly glabrous.

Small Penny-wort. Pl. creeping.

4 H. Mode'sta (Cham. et Schlecht. l. c. p. 358.) leaves on long petioles, orbicularly reniform, glabrous, 9-nerved; petioles pilose at the apex, as well as the young branches; umbels on short peduncles, many rayed; fruit small, emarginate at both ends. 24. B. F. Native of Brazil, in the province of Monte Video; and of Chili about Valparaiso. Petioles 3-12 inches long. l'eduncles an inch long, rarely more, and sometimes only 3 lines. Fruit smaller than in any other species; mericarps marked with a hardly elevated line on the sides.

Modest Pensywort. Pl. cr.

5 H. Barbaro'ssa (Cham. et Schlecht. 1. c. p. 360.) leaves on long petioles, peltate, orbicular, 8-nerved, 8-lobed, and crenated, and are, as well as the petioles, clothed with rufous hairs; umbels on long peduncles, many $(50-60)$ rayed; fruit nearly globose, ovoid, rather emarginate, acutely ribbed. $4 . \mathrm{F}$. $\mathrm{Na}$ tive of Brazil, in sloady woods near New Friburg. Petioles 4-8 
inches lung, but rather shorter than the peduncles ; pedicels 3-6 tines long.

Barbarossa Penny-wort. P'l. cr.

6 II. vMBELLA'TA (Lin. spec. p. 23.) plant glabrous; leaves pclate, orbicular, emarginate at the base, doubly crenated, usually 11-12 nerved; scapes rather shorter than the petioles; umbels 20-30-flowered; flowers distinctly pedicellate. 24. B. F. Native of the West Indies, Peru, and at 'Tampico in the Bay of Mexico, as well as of Cuba and Nortl America. Spreng. umb. p. 1.t. 1. f. 1. Rich. hydr. p. 28. t. 52. f. 3. Unbels proliferous in the specimens received from $\mathrm{T}$ ampico, but simple in those from Cuba. Corolla white.-Acaricoba, Piso, bras. p. 9.-Cotylèdon aquática, Sloane, jam. 1. p. 212.

Var. $\beta$, umbcllulàta (Mlichx. fl. bor. anncr. 1. p. 161.) leaves obsoletely crenated, 9-nerved; scapes rather longer than the petioles; umbels 12-16-flowered. 4. B. H. Native of Carolina and Virginia. Rich. hydr. p. 29. t. 53. f, 4 . H, umbellàta, Pursh, Fill.

Umbellate-flowered Penny-wort. Fl. July, Aug. Clt. 1795. Pl. cr.

7 H. Bonarjéxsis (Lam. dict. 3. p. 147.) plant glabrous ; leaves peltate, orbicular, 15-20-nerved, doubly crenated; scapes hardly longer, but often shorter than the petioles, umbellate at the apcx, and umbellately branched; flowers disposed in interrupted whorles along the branchlets. 4 . B. F. Native of South America, in marshy places not far from the sea, where it assumes various forms. Cham, et Sclilecht. in Linnæa. 1. p. 35\%. H. umbellàta $\beta$, Bonariénsis, Rœm. et Schult. syst. 6. p. 345 .

Far. a, mullifiòra (Ruiz et Pav. fl. per, 3, p. 24. t. 246. f.a.) rays of umbel 8-10; whorles consisting of 15-20 flowers each. 4. B. G. Natire of Brazil, Peru, Buenos Ayres. H. Bonariénsis, Rich. Cav. icon. 5. t. 488.

Var. $\beta$, tribótrys (Ruiz et Pav. l. c. f. b.) rays of umbel 3; whorles 5-6-flowered. 2. B. Native of Peru and Brazil. H. polystàchya $a$, Rich. hydr. p. 31 .

Buenos Ayrcan Penny-wort. Fl. July, Aug. Clt. 1810. Pl.tr.

8 H. PETIOLA'ris (D. C. prod. 4. p. 60.) plant quite glabrous: leaves peltate, orbicular, 10-12-nerved, simply and broadly crenated, on long petioles; scapes equal in length to the petioles, umbellate at the apex, and umbellately branched; branches $2 \cdot 5$,

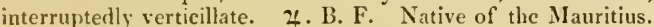
H. vulgaris, Bory, voy, ex Rich. H. quinqueradiàta, Pet. Th. mss. ex Rich. H. polystàchya $\beta$, Rich. hydr. p. 31. Nearly allied to $H$. Bonariensis, but differs in the lobes of the leares being simply crenated, in the petioles and scapes being nearly a foot high. Fruit nearly orbicular, emarginate at the base ; mericarps furnished with one rib on each side.

Peliolar Watcr Penny-wort. Pl. 1 foot, cr.

9 Hl. LasgspórfiI (D. C. prod. 4. p. 60.) plant glabrous or rather pilose on the leaves while young; leaves peltate, nearly orbicular, witl 5-7 short lobes, crenated, 5-7-nerved; peduncles much longer than the petioles; umbel simple, containing 15-20 pelicellate flowers, surrounded by an 8-10-leaved reflexed involucrum. 4. L. F. Native of Brazil, in the Island of St. Catharine. Stems long, creeping, slender. Peduncles 5-8 inches higl. Adult leaves glabrous on both surfaces; lobes either acute or obtuse. Pedicels 3 times the length of the involucrum.

Langsdorf's Penny-wort. Pl. cr.

10 H. Gra'cless (Ruiz et Pav, f. per. 3. p. 26. t. 247. f. 6.) leaves peltate, orbicular, 7 -angled, 7 -nerved, glabrous, crenated; petioles and scapes hairy; scapes shorter than the petioles; umbels 5-7-flowered. 2. B. F. Native of Peru, in stagnant watery places, and on the edges of rivulets. Rich. hydr. p. 32. Stems crecping. This species differs from all others in the present section in the leaves being acutely angled.

Slender Penny-wort. Pl. cr.

VOL. IJs.
11 H. Humrót.deru (Rich. hydr, p. 33. t. 53. f. 6.) leaves peltate, 5-6-lobed, hairy on both surfaces : lobes short, ovate, acute, (loubly serrated; petioles, stems, and peduncles glabrous ; umbels simple, 20 -flowered; fruit orbicular, nearly without ribs. 4. B. F. Native of the kingtom of Quito. $\psi$. B. et Kunth, nov. gen. amer. 5. p. 32. but Il. Humbóldtii, Willd. herb. is distinct trom this, but is referrible to $I I$. Bonplindii.

IIumboldt's l'enny-wort. Pl. cr.

12 H. Aste'rins (Cham. et Schlccht. in Linnæa, 1, p. 361.) stems decumbent, at length glabrous; leaves peltate, petiolate, 3-5-lobed, at length glabrous : lobes lanceolate, uncqually serrated; peduncles longer than the petioles; umbels simple, 1.1-18-flowercl; fruit tubercular, emarginate at the base, with conspicuous ribs. h. B. S. Native of Brazil, within the tropics. Lobes of leaves usually 4 , of various breadths. H. vàrians, Pohl, in litt.

Starry Penny-wort. Pl. decumbent.

13 H. Aconitı́ò̀ı (Rich. hydr. p. 35. t. 53. f. 5.) leares peltate, orbicular, hairy on both surfaces, 7 -lobed, 7-nerved: lobes lanceolate, acute, doubly serratcd; petioles, peduncles, and stems glabrous; umbels simple, 20-30-flowered; fruit orbicular, nearly without ribs. $\varkappa$. B. G. Native of New Granada, in shady places. H. B. et Kunth, nov. gen. amer. 5. p. 23.

Monk's-hood-leaved Penny-wort. Pl, cr.

14. H. Macropuy'Lla (Pohl, in litt. 1828.) plant creeping ; leaves peltate, 7 -cleft, 7 -nerved, rather hispid above, especially along the nerves, glabrous beneath; lohes lanceolate, doubly serrated; petioles and peduncles very long, glabrous; umbels simple, 40-50-flowered; fruit ribbed, emarginate at both ends. 4. B. F. Native of Brazil. Leaves 6 inches in diameter. Hairs crowded at the tops of the petioles at the insertion of the leaves.

Large-leaved Penny-wort. Pl. cr.

15 H. Quinquéloba (Ruiz et Pav. fl. per. 3. p. 25. t. 248. f. b.) plant hairy; leaves peltate, 5 -nerved, palmately 5 -cleft: lobes acute, doubly serrated : the terminal or middle lobe longer than the rest ; peduncles equal in length to the petioles; umbels simple, many flowered, globose. 2 . B. F. Native of Peru, in woods at Pillao; and of Brazil near Corvo-Sicco. Rich, hydr. p. 34. Cham. et Schlecht. in Linnæa. 1. p. 360. The whole plant is rufous from pili. Pedicels $40-50$ in each umbel, and when bearing the fruit they are about 3 lines long. Fruit emarginate at the base; mericarps acutely 3 -ribbed on the back.

Five-lobel-leaved Penny-wort. P!. cr.

16 H. ste'lla (Pohl, in litt. 1828. ex D. C. prod. 4. p. 61.) stems decumbent, villous; leaves on long petioles, peltate, 5nerved, 5-cleft, villous on both surfaces: lobes broad-lanceolate, doubly serratcd, rather unequal; umbels on long peduncles, many rayed; fruit pilose, ribbed, emarginate at the base. \%. B. F. Native of Brazil. Perhaps sufficiently distinct from the preceding species.

Star-leaved Penny-wort. Pl, decumbent.

17 H. Batracinoìdes (D. C. prod. 4. p. 667.) plant glabrous; stems rooting at the nodi; leaves on long petioles, somewhat peltate, 3-5-parted: lobes cuneated, obtuse at the apcx, entire or 2-3-cleft; peduncles much shorter than the petioles; umbels 3-5.flowered. $\quad$ 4. B. F. Native of Chili, in inundated places near Rancrgua, and in ditches. H. ranunculoìdes, Bertero, lierb. ; but not of Lin. Habit almost of Ranúnculus aquátilis or R. tripartita.

Batrachium-like Penny-w'ort. Pl. cr.

18 H. PoeppígII (D.C. l.c.) plant furnished wich a few scattered hairs; stems weak, elongated, not rooting at the nodi; petioles long, hairy at the apcx; leaves orbicular, cordate with the recess open, 9-nerved, bluntly 9-lobed, toothed; peduncles axillary, and opposite the leaves, shorter than the petioles; $\mathrm{K}$ k 
flowers i5-20 in an umbel, on long pedicels. \%. B. F. Native of Chili. Habit of II. Zeylínica, but the flowers are not capitate. The inflorescence is that of $H$. geranioides or $H$. alchemilloides, but the stems are not radicant.

Pocppig's Penny-wort. Pl. trailing.

\section{\$2. Leaves more or less cordate at the base. \\ * Floners umbcllate, distinctly podicellate.}

19 I1. acutifòlı (liuiz et Pav. fl. per. 3. p. 25. t. 248. f. a.) plant rather villous; leaves cordate, acute, sinuated at the base, unequally crenate-toothed on all sides; peduncles a little longer than the petioles; umbels many flowered, simple, ghobose; pedicels of flowers distinct; fruit almost didymous, bicostate on both sides. 24. B. F. Native of Peru, at Pillao. Spanainthe sinuata, Spreng. syst. 1. p. 878 . Allied to 11 . quinquéloba, but differs in the leaves not being peltate.

Acute-leaved Penny-wort. Pl. cr.

20 H. GERANIOIDES (Fich, hydr. no. 32. f. 21.) plant hairy; leaves orbicularly reniform, 9-nerved, bluntly 9 -lobed, crenated; petioles pubescent, rather higher than the pcduncles; umbels 20-flowcred; flowers pedicellate. 4. B. F. Native of Peru. Petioles a finger in length. Pedicels $3-4$ lines long. Involucrum many leaved : leaflets ovate, acute, small. Fruit nearly orbicular, didymous.

Gcranium-like Peuny-wort. Pl. cr.

21 H. Alcinemlooives (liich. hydr. no. 28. f. 31.) plant beset with spreading hairs; leaves orbicularly reniform, 9 -nerved, a litsle lobed, doubly crenated, cleft at the base into a narrow recess; petioles elongated, pilose; peduncles slender, shorter than the petioles; umbels 20 -flowered; flowers distinctly pedicellate; mericarps of fruit 3 -ribbed. 4 . B. F. Native of Peru, in shady humid places: and of New Andahusia, on Mount Cocollar. H. B. et Kunth, nov. gen. amer. 5. p. 24. Petioles 6-8 inches long. Pedicels 4-5 inches long.

Alchemilla-like ['enny-wort. P]. cr.

2Q H. Laxiflòra (D. C. prod. 4. p. 61.) plant villous; leaves orbicular, cordate, 9-nerved, 9-lobed: lobes obtuse, denticulated; peduncles opposite the catuline leaves, about twice the length of the petioles; umbels $40-45$-flowered; pedicels and fruit glabrous, 24. B. F. Native of New Holland. Pedicels about 3 lines long; the rest of the plant very like $H$. dcnsiftora. Loose-fomered Penny-wort. Pl. cr.

23 H. Bonpla'NDII (Rich. hydr. no. 27. f. 7.) plant hairy ; leaves reniform, 9-nerved, doubly erenated; peduncles an inch long, about equal in length to the petioles; umbels 10-12-flowered; flowers distinctly pedicellate. 4 . B. G. Native near Santa Fe de Bogota, H. B. et Kunth, nov. ges. amer. 5. p. 24. H. capitita, Willd. herb. and in Schultes, syst. 6. p. 356 . but not of Banks, nor l'et. 'Th. H. Humbóldtii, Willd. lierb. and Schultes, syst. 6. p. 356. but not of Ricl.

I ar. 13, Chilénsis (Cham. et Schlecht. in Linnæa. 1. p. 263.) umbels more dense; pedicels very short; leaves 7 -lobed, 7-nerved; petioles an inch and a half long. 4. B. F. Native of Chili, near Talcarruano.

Bonpland's l'enny-wort. Pl. cr.

24 H. Mexica'sa (Cham. et Sehlecht. in Linnæa. vol. 5. p. 208.) stems ereeping; branches erect; leaves reniform, usually 9-nerved, deeply lobed, hairy; umbels on long peduncles, many flowered, loose, globose; hairs on the petioles and peduncles reversed; styles spreaching. 4 . H. Native of Mlexico, near Jalapa in shady woods. Said to be allied to $I 1$. Icucocéphala and II. Bonplándii.

Mexican Penny-wort. Pl. cr.

25 H. numfe'sA (Pohl, in litt. 1828. ex D. C. prod. 4. p. 62.) plant creeping, glabrous; leaves on long petioles, reniform, nearly orbicular, broadly crenated, 9-nerved; peduncles length of the petioles; unbels 20 -flowered ; flowers distinctly pedicellate; fiuit ribbed, emarginate at both ends. 2. B. G. Native of Brazil. Leaves nearly like those of 11 . Americàna, but differs in the flowers being umbellate, not capitate. Perlaps Hydrocótyle, Lœfl. itin. p. 281. is referrible to this species.

Trailing Penny-wort. Pl. tr.

26 11. Leucocérmala (Cham. et Schlecht, in Linnæa. 1. p. 364.) plant creeping; leaves orbicularly reniform, usually 9nerved, doubly toothed or crenated, beset with a few scattered hairs on both surfaces, as well as on the pecluncles and petioles ; umbels 20-30-flowered, nearly globose; flowers distinctly pedicellate; mericarps of fruit smooth, at first cream-coloured, and acutely 3 -ribbed. $\quad$ $\psi$. F. Native throughout the whole of Brazil. Link et Otto, abbild. t. 21. Petioles 2-4 inches long. Pedicels of the umbel, which is milk-coloured, a line and a half long.

White-headed Penny-wort. Pl. cr.

27 H. NA'Tans (Cyr. pl. rar. neap. 1. t. 6. f. $\beta$.) plant creeping, glabrous; leaves orbicular, with a narrow corclate recess, reniform, bluntly and unequally 9-1 I-lobed, and 9-11-nerved, crenated; peduncles nuch shorter than the petioles; umbels capitate, 5-6-flowered; flowers on short pedicels. $4 . \mathrm{B} . \mathrm{H}$. Native of the kingdom of Naples, in bogs, ditches, and rivers; and in the river Anapo near Syracusa, and elsewhere in Sicily; Dombey gathered the same plant in Peru, and Chamisso at St. Francisco in North California.-Column, ecphr. p. 316 . with a figure. Rich. hydr. no. 29. f. 20. Claam. et Schlecht. in Linnæa. 1. p. 373. Petioles $3-10$ inches Iong. Peduncles laardly an inch long. Stems havin numerous roots, issuing from the joints. Fruit cordate, wrinkled a little.

Natant Penny-wort. Fl. July, Aug. Clt. 1819. Pl. trailing and floating.

28 H. Multífida (Rich. liydr. no. 44. f. 34.) plant glabrous; leaves palmately cut; segments 5 , somewhat 3 -lobed: middle segment the longest; peduncles glabrous, Jonger than the petioles, which are pilose; umbels 5-6-flowered; flowers distinctly pedicellate; fruit didymous, furnished with 2 ribs on both sides. 24. B. F. Native of New Granada, on the Andes, in humid shady places near Almaguer. H. B. et Kunth, nov. gen. amer. 6. p. 25. Willd. in Schultes, syst. 6. p. 656 .

ITultifid-leaved Hydrocotyle. Pl. cr.

* Umbcls capitate, 3-8-flowcrcl, sometimes the loner ones are only 1-flowered.

29 H. Ası́tica (Lin. spec. p. 234.) plant rather villous; leaves orbicularly reniform, equally crenated, 7 -nerved; petioles and peduncles in fascicles, pubescent; umbels capitate, on short peduncles, 3-4-flowered; fruit orbicular, furnished with 4 ribs ou both sides. 24. B. F. Native nearly throughout the southern hemisphere, as well as within the tropics, in humid watery places. Rich. hydr. no. 15. f. 1 I. Spreng. in Schultes, syst. 6. p. 348. Cham, in Schleclit. Linnæa. 1. p. 365. This species assumes many forms, especially in Manilla, Radacca, Chili (which there becomes H. triflòra, Ruiz et Pav. fl. per. 3. p. 24. t. 24.5. f. 6.), Brazil, and the Cape of Good Hope (which is H. Thunbergiàna, Spreng. neue entd. 1. p. 283. exclusive of the synonyme $H$. natans, Thunb. which is not obvious).

Asiatic Penny-wort. Fl. July, Aug. Clt. 1690. Pl. cr.

30 H. REPA'NDA (Pers. ench. 1. p. 302.) plant villous; leaves cordate, reniform, on long perioles, 9-nerved, repandly toothed; petioles villous, much exceeding the peduncles; umbels capitate, 3-flowered; fruit orbicular, furnished with 4 ribs on each side. 24. B. H. Native of Lonisiana, Carolina, Georgia, Chili, and the West India Islands, in humid and inundated places. Rich. hydr. no. 13. f. 14. exclusive of the synonyme of Ruiz et Pav. 
H. crécta, Lin. fil. suppl. 177.? I1. renifórmis and II. corlàta, Walt. fi. car, 113. H. ficarioldes, Michx. H. bor. amer. 1. y. 161. but not of Lam. H. reniformis, Bose. Poir. suppl. 3. p. 21. H. rejánda, Spreng. umb. no. 4. t. 2. f. 4. Glycèria repánda, Nutt. gen. amer. 1. p. 177. l'erhaps a variety of $\mathbf{H}$. Asiática, ex Cham, et Selılecht. in Linnæa. 1. p. 369.

Repand-leaved Penny-wort. Fl. June, July. Clt. 1806. Pl. creeping.

31 11. Frearioides (I Lam. diet. 3. p. 153. but not of Miehx.) plant glabrous; leaves cordately reniform, repand, 5-nerved, usually in fascicles; petioles longer than the limbs; umbels capitate, 3-5-flowered; perluncles one-lialf shorter than the petioles. 4. B. S. Native of the Mauritius. Rich. hydr. no. 12. f. 12. Flowers sessile in the umbels. Involucrum 3-5-leaved. Stems creeping. Fruit unknown.

Ficaria-like Penny-wort. Pl. er.

32 H. ріÁsтна (D. C. prod.4. p. 63.) plant glabrous; leaves distant, on short petioles, reniform, 7-9-toothed, nearly veinless; umbels opposite the leaves, on short peduneles, 2-flowered; fruit flatly compressed, orbicularly corlatc, with the mericarps having 2 ribs on both sides. 4 . B. F. Native of New Holland, at King George's Sound. Stems weak, dichotomous, elimbing a little. Leaves hardly twice the size of the fruit. Pedicels of the fruit longer than the peduncles of the umbel.

Tno-flowered Penny-wort. Pl, trailing or climbing.

33 H. ABERETIA'TA (Rich. hydr. no. 1\%. f. 19.) leaves reniform, with a broad recess, shorter than broad, with 9-11 erenatures, 7-nerved, glabrous; petioles pubescent, longer than the limbs; peduncles longer than the petioles; fruit rather turgid, furnished with 4 ribs on each side, reticulated. $\%$. B. F. Native of Madagascar and Cochin-china, in humid places. 'Trisánthus Cochinclinénsis, Lour. coch. p. 176. Stems tufted, ereeping. Petioles $7-8$ lines long; limbs of leaves 6 lines broad, and 2 lines long. Pedicels an inch long. Involucrum 2 -leaved. Very nearly allied to $I I$. dentatum, but differs in the leaves being much shorter.

Short-leared Penny-wort. Pl. cr.

3.4 H. Numularioldes (Rich. hydr. no. 11. f. 9.) leaves cordately reniform, 5-nerved, obsoletely crenated, with a narrow recess; petioles pubescent, longer than the limbs; umbels capitate, 8-flowered, on short peduncles; fruit orbicularly subglobose, striated. 4 . B. S. Native of the lsland of Bourbon, creeping along river banks. H. A siática var. Cham. et Selleeht. 1. c. Leaves 4-5 lines in diameter. Petioles 8-12 lines long. Jeduncles 2-3 lines long. The central flower in each umbel is fertile, and the 2 lateral ones sterile.

Money-nort-lilie Penny-wort. Pl.er.

35 H. IERECA'RPA (D. C. prod. 4. p. 63.) leaves orbicularly reniform, toothed at the base, 7-9-nerved, erenated at the apex, glabrous, on long petioles; surculi sarmentose, prostrate ; pedumeles axillary, villous, much shorter than the petioles: umbels capitate, few-flowered; fruit villous, retieulated ; mericarps furnished with 2-3 ribs on each side. 4 . B. F. Native of the Island of Timor. Petioles of radical leaves 4 inclies long: limbs of leaves $\approx$ inches broad. Three of the fruit in each umbel coming to perfection, rather large.

Iairy-fruited Perny-wort. Pl. prostrate.

36 H. Ixe' Qures (D. C. prod. 4. p. 69.) leaves when young, rather villous, but glabrous in the adult state: radical ones on long petioles, with a reniform crenated y-nerved limb, and a broad recess; umbels radical, on very short ineurved, rather villous peduncles; leaflets of involucrum 2, ovate; fruit glabrous; mericarps furnished with 4 stripes on each side. 4 . S. Native about Rio Janeiro. Petioles of radical leaves nearly a foot long. Peduneles haif an inch long. Stens short, rather sarmentose, bearing leaves, which stand on short petioles.

Cnequal-petioled Penny-wort. Pl. 1 foot.

37 H. PA'LLIDA (D. C. prod. 4. p. 6s.) leaves reniform, gla- brous, broally and shortly erenate-toothed; petioles rather d.lated at the base, longer than the peduncles; leaves of involucrum 2, ovate, obtuse, glabrous; umbels 3-flowered. 24. B. F. Native of the Cape of Goorl Hope. Burch. eat. geogr. no. I907. Fruit corlate, truncate at the ajex, marked on both sides by 3 veins, glabrous. Herb prostrate, pale green.

lar. 13? subintègra (D. C. prod. 4. p. 63.) leaves nearly entire, broadly reniform; peduneles rather villous, shorter. 4.13 . F. Native of the Cape of Good Hope.

Pale l'enny-wort. Pl. prostrate.

38 H. BRE'vH'S (D. C. prod. 4. p. 63.) stems elongated, prostrate, rooting at the nodi; leaves on long petioles, reniform, with broad large obtuse lobe-like teeth, pilose above, and on the petioles, smoothish beneath; peduncles axillary, very sliort; umbels few-flowered, capitate, villous. 4. B. S. Native of Jamaica. H. lejtóstaclıys ex Janıaica, spreng. syst. 1. p. 876. Allied to $H$. eriántha, but differs in being prostrate, as well as to II. mácrodus, but differs in the teeth of the calyx being blunt; also to $I I$. leptostachys, but the inflorescence is truly distinet.

Short-peduncled Penny-wort. Pl. prostrate.

39 H. вRACTEA'TA (D. C. prod. 4. p. 668.) leaves reniformly cordate, bluntly erenated, on long petioles; nerves, petioles, and peduncles rather hairy; peduncles much shorter than the petioles; umbels capitate, 2-3-flowered; leaves of involucrum 2, permanent, ovate, rather villous on the outside; meriearps very much compressed, reticulately 3-5-nerved, having the hack hairy at the apex. 24.S. Native of Africa, at Cape Verd, in marshes at Khami. Allied to $I I$. eriantha and $H$. jállida.

Bractcaled Penny-wort. Pl. er.

40 H. eria'ntia (Ricl. hydr. no. 18. f. 13.) leaves nearly orbicularly reniform, erenately toothed, glabrous; petioles dilated at the base, clasping the stem, length of the slender hairy peduncles : leaflets of involuerum 4, very pilose, exceeding the fowers; stems somewhat sarmentose, erectish. 2/.G. Native of the Cape of Good Hope, in sandy places on the Table Mountain. Cliam. et Sehlecht. in Linnæa. 1. p. 370. Sieb. f. cap. no. 247. H. cuspidàta, Willd. in Sehultes, syst. 6. p. 396. H. reniformis, Spreng. neue entd. 1. p. 382. syst. 2. p. 290. but not of 'Thunb, nor Walt. Fruit somewbat cordate, striated, ex Rich.

Hairy-flowered Penny-wort. Pl. sarmentose.

4.1 H. sa'crodes (Spreng. syst. 1. p. 877. exelusive of the synonymes,) the whole plant covered with spreading hairs; leaves cordately reniform, coarsely 3-9-toothed: teeth or lobules acute, equal, quite entire; peduncles shorter than the petioles; umbels capitate, few-flowered; leaves of involucrum 2, large, ovate, acuminated, pilose; fruit ovate, with many ribs, wrinkled. 4. G. Native of the Cape of Good Hope, on the Table Mountain. Cham, et Schlecht. in Linnæa. 1. p. 37\%. H. moschata, Spreng. in Scliultes, syst. 6. p. 951 . but not of Thunb.

Long-toothed-calyxed Penny-wort. Pl. tr.

4. H. calliodus (Cham. et Schlecht. in Linnæa. 1. p. 37 1.) leaves reniformly orbicular, 5-nerved, coarsely; sharply and unequally toothed, glabrous; peduncles hardly pubescent, capillary, in fascicles, almost longer than the petioles; leaves of involuerum smooth, one-half shorter than the fruit, which is obovate and many ribbed. 4. G. Native of the Cape of Goorl Hope. Allied to $I I$. erilintha, but easily tistinguished from it by its smoothness, by the teeth of the ealyx being acute, and by the nerves of the leaves being 5 , not 7 , Sie.

Beautiful-touthed-leaved Penny-wort. Pl. prostrate.

4.3 H. Amenica'na (Lin. spec. 234.) plant quite glabrons; leaves orbicularly reniform, a little lobed, doubly crenated, 9nerved; umbels capitate, 5-flowered: upper ones nearly sessile: lower ones on short peduncles. 2\%. B. II. Native of North $\Lambda$ merica, in boggy or swampy places, from Canada to $\mathrm{k} \mathrm{k} \approx$ 
Carolina; and probably of South America, if the synonyme of Lofling, itin. p. 281 . is referrible to the species. Lam. dict. 3. p. 152. Rich, hydr. no. 19. f. 10. Spreng. umb. no. 3. t. 2. f. 3.

Var, a, Acxicaúlis (Michx. f. bor. amer. 1. p. 162.) stems more firm, slorter, and as if they were flexuous.

l'ar. $\beta$, gràcilis (Michx. l. c.) plant more slender, filiform, not flexuous; leaves smaller.

American Penny-wort. Fl. May, Aug. Clt. 1790. Pl. cr,

4.4 I]. multicaúlis (Pohl, in litt. 1828. ex D. C. prod. 4. p. 64.) plant creeping; leaves on long petioles, glabrous, renjformly orbicular, 9-nerved, and somewhat 9-lobed: each lobe with 3 crenatures; petioles shorter than the peduncles, both bearded with pili at the apex; umbels capitate, 15-20-flowered; fruit glabrous, ribbed, emarginate at both ends. 24. B. S. Native of Brazil. Leaves and inflorescence like those of 11 . Americàna.

Many-stcmmed Penny-wort. Pl. cr.

45 H. Rotundifòlia (Roxb. lort. beng. p. 21.) plant tufted and creeping; leaves petiolate, reniformly orbicular, 7-nerved, bluntly 7 -lobed, dentately crenated, hispid beneath, glabrous above; umbels opposite the leaves, nearly sessile, 7-9-flowered; fruit glabrous, acutely 5 -ribbed. 4 . B. F. Native of the east of Bengal, in Silhet. Petioles twice the length of the limbs of the leaves, and are as well as the stems glabrous.

Round-leaved Penny-wort. Pl. cr.

46 H. TENF'́lLA (D. Don, prod. fl. nep. p. 183.) plant tufted and creeping; leaves reniform, somewhat 7 -lobed, crenated, quite glabrous, shining; umbels capitate, sessile, few-Howered. 4. B. H. Native of Nipaul. Allied to H. nituduls, but differs in the leaves bcing less lobed, in the petioles being shorter, and in the umbels being sessile.

Pliant Penny-wort. Pl. cr.

47 I. ALA'TA (Rich. hydr. no. 50. f. 28.) plant quite glabrous ; stems erect, winged, compressed; leaves cordate, bluntly hastate, on short petioles; peduncles longer than the petioles; umbels 4-6-flowered; pedicels quite distinct; fruit lenticular, compresscd, furnished with 10 ribs on both sides. $4 . \mathrm{B} . \mathrm{F}$. Native of New Holland. 11, pusilla, R. Br, ined. but not of Rich.

Winged Penny-wort. Pl. $\frac{1}{4}$ to 1 foot.

48 H. muscosa (R. Br. in Rich. hydr. no. 45. f. 27.) plant rather hairy; leaves palmate; segments $3-5$, narrow, cuneated, tridentate at the apex; peduncles shorter than the petioles; umbels somewhat capitate, 6-8-flowered, fruit orbicular, rather compressed, having 2 ribs on both sides. $\varkappa$. F. Native of New Ilolland. Petioles nearly an inch long, glabrous.

Mossy Penny-wort. Pl. cr.

49 II. trupartita (R. Br. in Rich. hydr. no. 46. f. 25.) plant rather pilose; leaves palmate : segments 3 , cuneated, deeply toothed : lateral ones usually bifid; peduncles much shorter than the petioles; umbels rather capitate, 6-10-flowered; fruit orbicular, didymous, furnished with 2 ribs on both sides. $4 . F$. Native of New Holland. Sieb. pl. exsic. nov. holl. no. 628. Flowers nearly sessile in the umbel, but after the flowers have decayed the pedicels lengthen a little.

Tripartite-leaved Penny-wort. Pl. cr.

*** L'mbels capitatc, many-floncred, cspecially nith from 8 to 30 ncarly sissile flowers.

50 H. PeEbe'1a (R. Br, in Rich. hydr. no. 20. f. 23) plant glabrous; leaves reniform, doubly crenated, 7-9-nerved; peduncles shorter than the petioles; umbels capitate, globose, 1215-flowered; fruit furmished with 2 ribs on each side. 4.B.F. Native of New Holland. Heads of flowers small : leares of involucrum ovate, acute. Stems trailing. Petioles 1-2 inches long.
Plebcian Penny-ivort, Fl. May, Aug. Clt. 1823. Pl. tr.

51 H. polymiliza (D. C. prod. 4. p. 65.) plant trailing, rooting at the joints ; leaves or iscular, cordate, with a narrow recess, crenated, 9-11-nerved, glabrous on hoth surfaces, as well as on the petioles; peduncles villous at the apex; umbels 20 -flowered, densely capitate; pedicels elongated after flowering, the fruit is therefore pedicellate; fruit orhicular, minutely dotted; mericarps furnisherl with one rib on each side. 4 . B. S. Native of Brazil, in the neighbourhool of Rio Janciro. l'eduncles shorter than the petioles, rarely longer. The disposition of the flowers is intermediate between the first and second division of the genus.

Many-rooted Penny-wort. Pl. er.

52 H. incrassa'ta (Ruiz et Pav. A. per. 3. p. 26. but not of Rafin.) plant glabrous; leaves reniform, $\tau-9$-lobed, crenately scrrated; scrratures thickened, whitish; petioles long; umbels many flowered, globose. 24. G. Native of Peru, in shady places at Tarma. Rich. hydr. no. 47.

Thiekened Penny-wort. Pl. cr.

53 H. Nepale'xsis (Hook, exot. fl. 1. t. 30.) the whole plant scabrous from short scattered hairs; leaves orbicularly reniform, 7-lobed, crenately toothed; flowers monoecious; umbels globose, many flowered, dense; fruit turgid, witbout ribs. 4. 13. H. Native of Nipaul, in wet places. Some of the unbels apparently contain only male flowers, while others contain only female ones; these flowers are on short pedicels while young, but afterwards these pedicels gradually lengthen out. It comes very near to $H$. capitàta, and according to Sprengel is probably not distinct from it.

I'ur. a, brévipes (D. C. prod. 4. p. 65.) peduncles at their greatest length shorter than the petioles.

Lar. $\beta$, longipes (D. C. 1. c.) peduncles when bearing the fruit longer than the petioles. H. híspida, D. Don, fl. nep. p. 183.

Nipaul Penny-wort. Fl. July. Clt. 1820. Pl. cr.

54 H. captea'ta (Pet. Th. fl. trist. d'ac. p. 43. t. 12, but not of Willd. nor Banks, ) the whole plant hispid from long bristles; leaves orbicularly reniform, bluntly and obscurely 7-lobed, unequally crenated; flowers monoecious; umbels globose, many Howered, dense, on short peduncles; fruit rather turgid, dotted, almost without ribs. 4 . B. F. Native of the Island of Tristan da Cunha. Rich, hydr. no. 22. t. 62, f. 29. Carm. fl. no. 15. H. criuita, Pet. Th. in herb. Juss.

\section{Capilate-flowered Penny-wort. Pl. cr.}

55 H. globirlòra (luiz et Pav. fl. per. 3. p. 25. t. 247. f. a.) plant hairy from short down; leaves roundish-reniform, 13nerved, ratlier lobulate, crenated; peduncles a little shorter than the petioles; umbels glohose, many flowered. 2. B. F. $\mathrm{Na}$ tive of Peru, in humid places in woods by stagnant water, near Muna. Nerves of leaves and fruit fulvous. Leaves of involucrum numerous, linear, and short. Flowers in each umbel about 200.

Glube-flowcred Penny-wort. Pl. cr.

56 H. citriodòra (Ruiz et Pav. fl. per. 4. p. 26.) leaves reniform, 7-9-lobed, crenated, and are, as well as the petioles, hairy, but pubescent beneatl, as well as on the branches; peduncles densely villous, length of the petioles; umbels small, many flowered, globose. 4 . B. F. Native of Chiti, in sliady humid places about Conception; and of Peru, in the tract of Huanaco, as well as of Brazil according to Pohl.

Citron-seented Penny-wort. Pl. cr.

57 H. ranunculoìdes (Lin. fil. suppl. p. 177.) plant glabrous ; leaves orbicularly reniform, 5-nerved, and somewhat 5 lobed; lobes obtuse, somewhat crenated: midlle lobe more prolonged than the rest; peduncles shorter than the petioles; umbels 5-12-flowered; flowers pedicellate. 4. B. H. Native of North America, in Pennsylvania and Mexico; and of South 
Ameriea, as in Cuba and Chili. Spreng. umbel. 2. t. 1. f. 1. Rich. liydr. no. 30. f. 18. Cham, et Schlecht. I. c. no. 372. 11. ranumenioides var. $\pi$, Schultes, syst. 6. p. 349. exclusive of the synonsmes. II. cymbalarifòlia, Mulıl. cat. p. 80 . Eill. sketch. 1. 1. 846 . Fruit orbicular, somewhat cordate, smooth, ex Cham. et Schlecht.

Cromfoot-like Penny-wort. Fl. July, Aug. Clt.1500. Pl. cr. 58 11. Sl'LÉNENS (Bhum. bijdr. p. 85\%.) stems crecping; leaves orbicularly cordate, obsolctely $\tau-9$-lobed, unequally crenated, shining on both surfaces, downy bencath ; umbels capitate, 8-10-1lowered, solitary, pedunculate. 2. B. S. Native of Java, in humid grassy places, about Buitenzorg.

Shining-leaved Penny-wort. Pl. cr.

59 H. sintuorpioides (Lam. dict. 3. p. 158.) plant quite glabrous; leaves orbicularly reniform, doubly crenated, obsoletely 7-lobed, 7-nerved; peduncles slender, about equal in length to the petioles; umbels 6-8-flowered, capitate; fruit rather didymous, furnished with 2 ribs on each side. $\odot$. F. Native of the Mauritius. Cham. et Schlecht. in Linnza. 1. p. 273. in a note. H. ranunculoides $\beta$, Schultes, syst. 6.1 . 349 . Chondrocármus sibthorpioides, Sweet, hort. brit. p. 185.

Sibthorpia-like Penny-wort. Fl. May, July. Clt. 1806. Pl. creeping.

60 11. E'LEGANS (Rich. hydr. no. 33. f. 32.) plant glabrous ; leaves semi-5-cleft: lobes triclentate at the apex; pedincles 3 times shorter than the petioles; umbels capitate, 6-8-flowered; fruit didymons, furnished with 2 ribs on each side. 4 . B. F. Native of New Holland. Leaves 4 lines in diameter: petioles nearly an inch long.

Elegant Penny-wort. Pl. cr.

61 H. pulciétla (R. Br. in Rich. hydr. no. 34.) plant glalorous; leaves reniform, rather peltate, 5 -nerved, 5 -lobed : lobes bluntly tridentate; peduncles equal in length to the petioles; unbels capitate, 10-flowered; fruit didymous, furnished with 2 ribs on each side. 4. B. G. Native of New Holland, near Port Jackson. Petioles an inch long. Heads of flowers small. Neat Penny-wort. Pl. cr.

62 H. Niríduca (Rich. lyddr, no. 35. f. 33.) plant quite glabrous; leaves orbicularly reniform, 5 -7-lobed : lobes tridentate ; petioles 2 or 3 times longer than the peduncles; umbels capitate, 6-10-flowered. 4. B. S. Native of Java. Hook. exot. fl. 1. t. 29. Allied to $\mathrm{H}$. pulchélla. Perhaps the same as $\mathrm{H}$. ranunculoides var. incisa, Blum. bijdr. p. 884 .

Small-shining Penny-wort. Pl.cr.

63 H. mav'ta ('Pohl, in litt. 1828. ex D. C. prod. 4. p. 66.) stems creeping; leaves on short petioles, orbicular, cordate, with a narrow recess, crenated, 7 -nerved, pilose above, and on the upper part of the petioles; peduncles rather pilose, 3 times longer than the petioles; umbels 8-10-flowered, rather capitate; fruit small, roundish. 4 . B. F. Native of Brazil. Petioles 2 lines long. Limb 2-3 lines in diameter. There is a variery with glabrous leaves aecording to Pobl.

Minute Penny-wort. Pl. cr.

64 H. INDEco'rA (D. C. prod. 4. p. 668.) stems creeping, smoothish; petioles hairy, 5 times longer than the limbs of the leaves, which are orbicularly cordate, 8 lobed, toothed, and rather pilose ; perluncles hairy, a little shorter than the petioles; fruit small, ovate, glabrous, densely aggregate into a globose head; mericarps furnished with one rib on each side. 4 . B.F. Native of Chili. Poepp. pl. exsic. no. 98. Habit of $H$. sibthorpioìles or $I I$. minùta.

\section{Undecked Penny-wort. Pl. cr.}

65 H. Heterosènia (Rich. hyclr. no. 36.) plant glabrous; leaves reniform, 7-nerved, 7-lobed: lobes obtuse, crenated; peduncles much shorter than the petioles, which are flaceid; umbels 6-8-flowercd, capitate ; fruit smooth on one side, and tubcr- cular on the other, wrinkled and discoloured, furnished with one rib on both sides, 24. B. 11. Native of New Zealand. H. fláccida, li. Br. mss. Petioles 2-4 inches long.

Variable-parfed l'enny-wort. 1'l. cr.

66 H. cospa'cta (Rich. hydr. no. 87.) plant villous; leaves orbicularly reniform, small, 7 -nerved, deeply toothed; peduncles very short, in fiscicles; umbels 15-20-llowered, densely capitate; fruit rather didymous, furnished with 2 ribs on each side. 4. 11. Native of New Zealand. I1. capitata, Banks and Sol, mss. but not of P'et. 'Il.

Compact-headed Penny-wort. Pl. cr.

67 H. JEDuncula'ris (R. Br. in Rich. hydr. no. 38. f. 26.) leaves small, orbicularly reniform, deeply toothed, rather 5 -cleft, glabrous above, hairy bencath; peduncles equal in length to the petioles; umbels capitate, 6-8-flowcred; fruit lenticular, with? nearly obsolete ribs on both sides. 24. B. F. Native of New Holland. l'erhaps the same as H. pedunculàris, Sieb. nov. holl. exsic. no. 114. which is said to be glabrous; or it is perhaps referrible to 11 . pulchélla.

Peduncular Penny-wort. Fl. May, Ang. Clt. 1823. Pl.cr. 68 H. intertéxta (R. Br. in Rich. hydr. no. 39.) plant glabrous ; leaves irregularly 3-5-lobed, 3-5-nerved : lobes denticulated: middle lohe more prolonged than the rest; petioles and peduncles equal among themselves; umbels densely capitate, 12-15-flowered; fruit scabrous from wrinkles, furnished with 2 ribs on both sides; carpophore permanent, undivided. 4 .? $\mathrm{F}$. Native of New Holland.

Interwoven Penny-wort. Pl. er.

69 H. H'́тA (R. Br. in Rich. hydr. no. 40.) leaves orbicularly reniform, hairy on both surfaces, 7-nerved, obsoletely 7 . lobed, crenated; petioles liairy; peduncles one-half shorter than the petioles; umbels densely capitate, 20 -flowered; fruit rather diclymous, furnished with \& ribs on each side. 2. B. F. Native of New Holland. Leaves distant. Petioles bardly an inch long. Stipulas membranous, permanent.

IIairy lenny-wort. Pl. cr.

70 H. NòvE-ZEELA'NDIE (D. C. prod. 4. p. 67.) leaves orbicularly reniform, hairy on both surfaces, as well as on the petioles, $\tau$-nerved, obsoletely $7 \cdot$ lobed, acutely and irregularly toothed; peduncles glabrous, 4 times shorter than the petioles; umbels densely capitate, 10-12-flowered; fruit rather didymous, furnished with one rib on each side. 4.? H. Native of New Zealand. Petioles 12-15 lines long. Stipulas as in H. hirta.

Nen-Zealand Penny-wort. Pl. cr.

71 H. DEnsiflòn a (D. C. prod. 4. p. 66.) plant hairy; leares orbicular, cordate at the base, 7-9-nerved, 7-9-lobed: lobes broad, hardly acute, a little toothed; peduncles opposite the leaves, about equal in length to the petioles; umbels densely capitate, 30-40-flowered; fruit rather didymous, and are as well as the pedicels glabrous; mericarps furnisherl with one rib on both sides. 24.? F. Native of New Holland. Nearly allied to $I$. hirta, but differs from it in the peduncles being the length of the petioles, not very short, and in the leaves being corlate, not reniform.

Dense-flowered Penny-wort. Pl. cr.

72 H. mnsu'ta (Blum. bijdr. p. $88 \%$, but not of Swartz nor Spreng.) stems creeping; leaves orbicular, cordate, somewhat 5-lobed, erenated, villous; umbels capitate, $7-1]$-flowered, pedunculate, usually solitary; mericarps furnished with 3 ribs. 4. ? S. Native of Batavia, in grassy places by the sea side. It differs in the intlorescence from $\mathrm{H}$. birsita of Swartz, which is the H. spicata of Lam. H. hirsuta of Spreng. is a congeries of species very lifferent from each other.

Hairy Penny-wort. P]. cr.

73 H. GLOBA'T (Blum. bijdr. p. 883.) stems erecping: leaves roundish-cordate, angular, and are, as well as the preduncles, 
hairy; umbels glomerate, solitary or crowded, unany flowered. 4.? S. Native of the lsland of Java, at the foot of Mount Tjerimai. Said to be allied to $H$. hirsùta.

Globose-flowered Penny-wort. Pl. cr.

74. H. Java' Nica (Thunb. diss. 2. p. 415. no. 17. t. 3.) plant glabrous; leaves orbicular, 7-lobed, 7-nerved; lobes angular, acute, crenated; peduncles shorter than the petioles; umbels densely capitate, 20-flowered ; fruit orbicular, didymous, dotted with purple. 24. B.S. Native of the Island of Java. Rich. hydr. no. 41. Lobes divided nearly to the middle of the limb, ex Rich., but less divided in the figure given by Thunberg. Peduncles 6-8 lines long, ex Rich., 1 inch long, ex Thunb.

Java Penny-wort. Pl. cr.

75 H. ZEYLA'NicA (D. C. prod. 4. p. 67.) leaves glabrous, orbicularly reniform, 7-nerved, 7 -lobed: lobes acutish, coarsely crenated; petioles long, puberulous at the apex, as well as the stems; preduncles puberulous: ultimate ones opposite the vanished leaves, racemosely umbellate; umbels densely capitate, 20Howered. 24.? S. Native of Ceylon, near Candy, in fertile places. Perhaps only a variety of $H$. Javanica. 'The heads or umbels being disposed in racemes on the peduncles, distinguishes it from all the species in this respect. Fruit when young purple, dotted, liut at length becoming fucescent.

I ar. $\beta$, Heyncrina (Wall. in litt. ex D. C. prod. 4. p. 67.) peduncles bearing $8-10$ small umbels at the apex; pedicels beset with retrograde hairs. H. ranunculoides, Heyne, mss. ex Wall. Native of the East Indies.

Ceylon Penny-wort. Pl. cr.

76 H. Suxna'ica (Blum. bijdr. p. 883.) stems sarmentose ; leaves roundish-cordate, a little lobed, coarsely and unequally crenated; petioles and peduncles hairy below; umbels sessile, a little branched; flowers in dense glomerules. 4 . B.S. Native of the Malay Islands, in humid places.

Sunda Penny-wort. Pl. sarmentose.

77 H. chamzmòus (Cham. et Schlecht. in Linnæa. 1. p. 303.) leaves reniform, somewhat 7 -lobed, doubly crenated, glabrous; peduncles short, and are, as well as the petioles, covered with retrograde hairs; umbels 20 -30-flowered, capitate; fruit full of resinous dots; mericarps with 3 ribs: ribs smooth : furrows convex. 4 . B. F. Native of Chili, near Talcaguano.

Cloud-Berry-like l'enny-wort. Pl. cr.

78 1I. Gaudichauma'sa (D. C. prod. 4.p. 67.) plant smoothish, dwarf, filiform; leaves reniform, nearly orbicular, 9-nerved, 9-lobed, puberulous beneath, glabrous above: lobes ovate, tridentate; peduncles much shorter than the petioles, which are puberulous; umbels capitate, 10-flowered; fruit glabrous; mericarps ovate, with hardly prominent ribs. 4. F. Natire of New I Iolland, near Bathurst. Allied to $H$. moschìta. Stipulas broad, ovate, dotted.

Gaulichaud's Penny-wort. P1. cr.

79 H. моsсnа'та (Forst, prod. 196. but not of Schultes,) plant hairy in every part: leaves reniform, somewhat 5-lobed, tootlied, 5-nerwed: lobes acute; peduncles shorter than the petioles, and more slender; umbels eapitate, 10-flowercd; fruit orbicular, didimous, furnished with 2 ribs on both sides. 24.? 1\%. Native of New Zealand. Petioles 1- $1 \frac{1}{2}$ inch long. Limbs of leaves 6 lines in dianeter. Thunb. diss. 2. p. 41\%. Rich. liydr. no. 12. f. 21.

Musky-scente.l Penny-wort. Pl. cr.

80 H. Grossularioides (Ricl. liydr, no. 43. f. 30.) plant hispid; leaves somewhat reniform, deeply 5 -cleft ; lobes cuneiform, obtuse, doubly serrated; peduncles length of petioles; umbels cajitate, 10-flowered. 24. B. S. Native of the Island of lourbon. Leaves of involucrum small, ovate-oblong. Petioles and peduncles 6-8 lines long.

Gooseberry-like-leaved l'enny-wort. Pl. cr.
**** Flon'ers disposed in verticillate interrupted spikes.

81 H. sptca'ta (Lam. dict. 3. p. 153.) leaves reniformly cordate, roundish, 7-nerved, crenated, rather hairy on both surfaces from scattered hairs; petioles and peduncles laairy, peduncles 3 times longer than the petioles; flowers in glomerate whorles, disposed in interrupted spikes; fruit didymous, withont ribs. 4.? B. S. Native of St. Domingo and Porto Rico, \&c. in liumid parts of mountain woods. Rich, hydr. no. 25. f. 15. Spreng. in Schultes, syst. 6. p. 351. H. hirsùta, Swartz, fl. ind. occ. 2. p. 560 . but not of Spreng. nor Blum.

Spikc-flowered Penny-wort. Fl. July, Aug. Clt. 1810. Pl.cr.

82 H. BRAcirsta'chy (D. C. prod. 4. p. 68.) stems filiform, low, smoothisls; leaves reniform-roundish, 7 -nerved, crenated, pilose on both surfaces; petioles shorter than the leaves, hairy; peduncles twice the length of the petioles, hairy; spikes oblong, continuous; fruit didymous, without ribs. 24.? S. Native of St. Domingo.

Short-spiked Penny-wort. Pl. cr.

S3 H. Leptosta'chy (Ricl, hydr, no. 26. t. 16. exclusive of the country,) leaves reniform, 7-nerved, crenated, rather pilose above, glabrous beneath; petioles nearly 3 times longer than the limbs, and are, as well as the peduncles, pilose; flowers disposed in interrupted spikes, with the whorles of flowers very remote; fruit orbicular, didymous, withost ribs, \%. B. S. Native of Cuba, in humid places near the Havannah. H. B. et Kuntl, nov. gen. amer. 5. p. 23. Spreng. syst. 1. p. 875. exclusive of the variety from Jamaica. Very like $H$. spicàta, but differs in the leaves being glabrous beneath, in the whorles being remote, and containing few flowers; and in the peduncles not exceeding the leaves.

Slender-spiked Penny-wort. Pl. cr.

Sect. II. Centélza (meaning unknown to us). Lin. gen. 1051. Lag. obs. aparas. 26. D. C. prod. 4. p. 68. Stems shrubby, erectish. Leaves cumcated at the base, with the exception of only one species, neither peltate nor cordate, as in the first section. Fruit less compressed, with many ribs. - This section will perhaps form a distinct genus when the fruit of the species is better known.

\section{* Petals villous.}

84. H. vrulòsa (Lin. fil. suppl. p. 175.) the whole plant more or less villous; leaves cordate, acute, nearly entire, 3-nerved; stem erectisl, branched; peduncles shorter than the petioles; umbels 3-flowered, capitate. h. G. Native of the Cape of Good Hope. 'Thunb. rliss. 2. p. 413. Cham. et Schlecht. 1. c. p. 273. Mercuriàlis A'fra, Lin. mant. p. 298. Centélla villòsa, Lin. syst. veg. 13. p. T08. There is a larger variety with leaves an incli long, and a smaller variety with leaves hardly $3-4$ lines long. Leaves nearly entire, obtuse, with a little point. Pedicels 1-flowered, some of them shorter than the petioles, but usually longer.

Iillous Penny-wort. Fl. Aug. Clt. 1795. Pl, $\frac{1}{2}$ foot.

85 H. tRidenta'ta (Lin. fil. supp]. 176. Thunb. prod. p. 49. diss. 2. p. 415. t. 3.) the whole plant clothed with tomentum; leaves oblong-cuneiform, narrow, $3-5$-toothed at the apex; stem erectish ; peduncles rising in fascicles, very short ; fruit elliptic, compressed, furnished with 4 ribs on each side. F2 $_{2}$ G. Native of the Cape of Cood Hope. Rich. hydr. no. 51. f. 37. Spreng. in Schultes, syst. 6. p. 35. Bòlax tridentàta, Spreng. $11 \mathrm{mb}$. prod. p. 34. Allied to $H$. villosa from the villo:s petals, and to H. Solindra in the form of the leaves.

Tridentatc-leaved Penny-wort. Pl. $\frac{1}{8}$ foot.

$$
\text { * Petals glabrous. }
$$

S6 H. tríloba (Thunb, diss. 2. p. 416. t. 8.) plant glabrous; leaves broadly wedge-shaped, 3-5-nerved, 3-5-toothed at the apex : teeth broad, acute; peduncles shorter than the 
petioles; umbels capitate, 3-flowered ; fruit compressed, somewhat diclymous, furnished with 2 ribs on each side. $\zeta . G$. Native of the Cape of Good Hope. Rich. hychr. no. 52. f. 36. Cliam. et Schlecht. Linnaea. 1826. p. 354. Bolax tríloba, Spreng. umb. prod. p. 3. Allied to $H$. tridentàta, but diflers in the smoothness of all parts of the plant. Bracteas longer than the flowers. Middle llower in each umbel fertile: lateral 2 sterile.

Threc-lobed-leaved Penny-wort. Fl. Junc, Aur. Clt. 1810. Pl. $\frac{1}{4}$ foot.

87 H. Sola'NDRA (Lin. fil. suppl. 176.) the whole plant clothed with hoary tomcntum, the petals only excepted; leaves petiolate, obovately cuneiform, bluntly 7 -toothed at the apex; umbels pedunculate, 5-6-flowered; flowers on short pedicels; leaves of involucrum ovatc-lanceolate, glabrous inside. $\eta_{\text {. G. }}$ Native of the Cape of Good Hope, on hills. Lam. dict. 3. p. 155. Rich. hydr. no. 53. H. tomentòsa, Thunb. diss. 2. p. 416. Spreng. in Schultes, syst. 6. p. 593. Solándra Capénsis, Lin. spec. 1407. exclusive of the synonymes. Perhaps numerous species are here confused.

Var. a, longipes (D. C. prod. 4. p. 69.) peduncles exceeding the leares in length.

I"ar. $\beta$, communis (D. C. l.c.) peduncles length of the leaves. -Lam. ill. t. 188. f. 5. Sicb. eap. exsic. no. 140.

Iar. $\gamma$.? longifolia (D. C. l. c.) peduncles much shorter than the leaves; leaves euncate, elongated. Native of the Cape of Good Hope. Burchell. Perhaps a proper species.

Solander's Penny-wort. Pl. $\frac{1}{8}$ foot.

88 H. Cextélula (Cham. et Schlecht. in Linnæa. 1, p. 375.) plant slurubby; leaves oblong, cuneated or lanceolate, 3nerved, quite entire; umbels pedunculate, $3-5$-flowered, with usually only one male flower; leaves of involucrum ovate-lanceolate; petals glabrous. $\zeta$. G. Native of the Cape of Good Hope, where the plant varies much in form and habit.

liar. a, glabréscens (D. C. prod. 4. p. 69.) adult leaves glabrous, oblong-lanceolate. H. glabràta, Lin. fil. suppl. p. 176. Spreng. syst. 1. p. 878. Centêlla glàbra, Lin. amœn. 6. afr. p. 100. H. glàbra, Thunb. fl. cap. 251.

tar. $\beta$, latifúlia (D. C. 1. c.) leaves glabrous, cuneiformly oval. H. bupleurifòlia, Rich. hydr. no. 55 . f. 39.

Iar. $\gamma$ : linifülia (D. C. 1. c.) leaves clothed with canescent hairs, linear-spatulate.-H. linif òlia, Lin. fil. suppl. 176. Thunb. diss. 2. p. 113. Rich. 1. c.

Var. $\dot{c}$, plantaginea (D.C. l. c.) leaves canescent from laairs, oblong.-H. plantagínea, Spreng. neue entd. 1. p. 284. grundz. t. 8. f. $5-7$.

Centella Penny-wort. Pl. $\frac{1}{5}$ foot.

89 H. мохтаха (Cham. et Schlecht. in Linnæa. 1. p. 874.) plant shrubby, when young villous, at length glabrous; leaves lanceolate, quite entire or somewhat tridentate, 3-nerved; petioles villows; umbels 3 -flowered, on short peduncles; leaves of involucrum 2, twice the length of the nearly orbicular corrugate fruit. h. G. Native of the Cape of Good Hope, on the iops of mountains. A humble depressed branched shrub. Mericarps tumid, with 5 filiform ribs, and flattish furrows.

Mountain Penny-wort. Shrub depressed,

90 H. virga'ta (Lin. fil. suppl.p. 176.) plant shrubby, erect, branched; leaves linear-filiform, quite entire ; umbels pedunculate, 1-3-flowered; flowers hardly pedicellate; leaves of involucrum lanceolate; fruit orbicular, obcordate, furnished with 2 ribs on cach sirle. $h$. G. Native of the Cape of Good Hope, ex Cham. et Schlecht. in Linnæa. 1. p. 979.

lar. a, glabćrrima (D. C. prod. 4. p. 69.) plant twiggy, quite glabrous; flowers polygamous and monoecious. H. virgata, Lam. ill. t. 188. f. 3. Spreng. syst. 1. p. 878.

Var. $\beta$, lanuginosa (D. C. l.c.) plant twiggy, clothed with lanuginous villi; flower polygamo-monoecious; leaves expanded into linear lamina at the apex. Cham. et Schlecht.

lar, $\gamma$, macrocírpa (D. C. l. c.) plant twiggy, glabrous; flowers polygamo-dioecious; fruit larger.-H. macrocárpa, Rich. hydr. no. 57. f. 40.-Pluk. alm. 1. 310 . f. 7.

Var. $\hat{\mathcal{C}}$ nàna (D. C. l. c.) plant short, glabrous; flowers polygamo-dioccious.

Tniggy Penny-wort. Pl. $\frac{1}{8}$ to $\frac{1}{5}$ foot.

$$
+ \text { Species not sufficiently known. }
$$

91 H. Fud'itass (D. C. prod. 4. p. 69.) stems submersed, straight, fistular; leaves peltate, orbicular, shining, floating ; petioles thickened from the base to the apex. 4 . IV. H. Native of Louisiana, floating in lakes and tranquil rivers, throngh immense tracts. H. incrassatum, Rafin. fl. lud. p. 81 . but not of Ruiz et Pav. Hydrocótyle Robin, Louis, p. 461. ex Rafin. It grows also in water in Florida, very common. The stems have numerous fibres, issuing from the joints. The leaves arc on long petioles, orbicular, peltate, and 15-20-nerved, glabrous, bluntly somewhat lobed, and crenated. Very like 11 . nàtans, but differs in the leaves being peltate.

Floating Penny-wort. Pl. floating.

92 H. HEDEREFòliA (Burch. cat. geogr. no. 558. trav. 1. p. 46.) plant decumbent, villous; leaves reniform, 3-5-angled; angles acute. 24. G. Native of the Cape of Good Hope. The rest unknown.

Ivy-leaved Penny-wort. Pl, decumisent.

93 H. racenòsa (Hoc. et Sesse, fl. mex. icon. ined. ex D. C. prod. 4. p. 70.) plant glabrous; leaves petiolate, orbicularly reniform, broadly erenated, with a narrow recess; peduncles twice the length of the leaves; flowers pedicellate, verticillate, disposed in interrupted racemes; fruit nearly globose. $4 . \mathrm{F}$. Native of Mexico. Stems crecping. Leaves rising from the norli of the stems in fascicles; petioles $12-15$ lines long. Allied to $H$. interrúpta, but the leaves arc not peltate; and to $H$. spicàta, but the flowers are evidently pedicellate.

Racemose-flowered Penny-wort. Pl. cr.

94 H. grumòsa (Moc. et Sesse, fl. mex. icon. ined. ex D. C. prod. 4. p. 70.) plant glabrous; stems ascending ; root grumose, fascicled; petioles dilated and stem-clasping at the base; leaves orbicular, cordate, crenated; umbels in fascicles ; flowers distinctly pedicellate. 4 . B. F. Native of Mexico.

Grumose-rooted Penny-wort. Pl.

95 H. Pinnatífida (Spreng. pug. 2. p. 47.) stems erect, glabrous; leaves pinnatifid; segments oblong, a little cut; umbels usually S-flowered, involuerated.-Native country unknown. In Sprengel's subsequent works this plant is not admitted, ant the name is omitted as a synonyme: it is therefore very doubtful.

Pinnatifid-leaved Pennywort. Pl.?

Cult. All the species arc of the most easy culture, hut require to be kept moist. The stove, greenhouse, and frame kinds should be grown in pots, under which should be placed pans of water.

I1. CRA'NTZIA (in honour of Henry John Nepom Crantz, author of Stirpium Austriacarum, 4to. Vienna, 1762-1768; Classis Umbelliferarum Emendata, Sc.) Nutt. gen. amer. 1. p 177. Koch, in litt. ex D. C. eoll. mem. 5. p. 27. prod. 4. p. 7 (). -Hydrocótyle species, Michx.

Lin. syst. Pentundria, Digynia. Tube of calyx nearly globose; limb very short or hardly any. Petals roundish, entire, obtuse. Styles obtuse. Fruit roundish, with the commissure nearly orbicular from the excavation; mericarps unequal, furnished with 3 ribs on the back (ex Nutt.), but according to Koch 5 filiform ribs: the lateral ones marginal, broader, thick 
white and spongy inside; the channels between the rilss furnished with 1 brown distinct vitta each, and the commissure with 2 vittæ.-Small, glabrous, creeping herbs. Leaves sessile, narrow, obtuse, quite entire, lined with 5 transverse nerves, as the seminal leaves and petioles of Erýngium cornieulàtum. Peduncles axillary, creet. Umbels simple, 8-10-flowered. Involuerum 5-6-leaved. Flowers white, pedicellate, hermaphrodite, uniform.

1 C. LINEA'ta (Nutt. l. e.) leaves sessile, euneate-linear, obtuse; peduncles length of leaves; umbels 8-10-flowered. 4 . B. H. Native of North America, in saltish, boggy, or inundated places, from New Jersey to Florida. Hydrocótyle lineàta, Michx. fl. bor. amer. 1. p. 162. Rich. hydr, no. 54. f. 38. Ell. sketch. 1. p. 247. H. ligulàta, Bose. herb. H. Chinénsis, Spreng. in Scliultes, syst. 6. P. 355. and perbaps of Lin. spec. p. 339.

Lined-leaved Crantzia. Fl. June, Aug. Clt. 1818. Pl. cr.

2 C. Attenuatia (Hook, et Ar1. in bot. mise. 2. p. 346.) leaves elongated, attenuated, 3-times longer than the peduncles. 4. B. F. Native of Buenos Ayres. Differing from C. lincrita remarkably in its much longer and attenuated foliage.

Altcnualed-leared Crantzia. Pl. cr.

Cult. See Hydrocótyle above for culture and propagation.

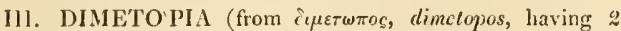
faces; in reference to the mericarps of the fruit being unlike each other). D. C. prod. 4. P. 71.

Lin. sxst. Pentándria, Digýnia. Teeth of calyx obsolete. Petals oval-oblong, entire. Styles short. Fruit didymous; mericarps nearly globose, rather contracted at the commissure, of unequal shape and size: the one muricated with rows of blunt compressed tubercles, the other echinated by conical tubercles, which are drawn out at the apex into soft priekles. Seed? - An annual herb, hardly a finger in height. Stem short, branched, beset with seattered pili. Leaves tripartite; lobes cuneate, linear-oblong, bluntly tridentate at the apex, or trifid. Peduncles opposite the leaves, and longer than them. Umbels simple, usually 5 -flowered. Involucrum of 5 linear-lanceolate leaves, which are the length of the flowers. Flowers white.Habit almost of Erigenia; the fruit agrees with that of Sanicula, and the peta!s with those of IIydrocótyle.

1 D. pusi'Lla (I). C. I. e.). $\odot$. II. Native of New Holland, at King George's Sound, and at Port Western.

Small Dimetopia. Pl. $\frac{1}{4}$ foot.

Cull. Sow the seeds in a warm sheltered situation, in the open ground.

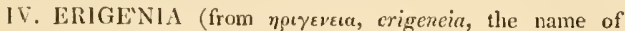
Aurora, the harbinger of day or of the spring; in allusion to the early appearance of the plant in spring). Nutt. gen. amer. 1. p. 187. D. C. coll. mem. 5. 1. 27. prod. 4. p. 71 .-Hydrocótyle species, l'ursh. and Spreng. - Sison, spec. of Michx.

Lin. syst. Pcntándria, Digýnia. Margin of calyx obsolete. Petals equal, obovate, expanded, entire. Styles permanent, subulate, very long. Fruit oval-lanceolate, laterally compressed; meriearps plbbously convex, marked with 3 stripes ; commissure flat, without a margin.-A small, smooth herb. lioot tuberous, globose. Leaves 1-2, radical, petiolate, biternate. Umbels irregular, imperfect, 3-4-rayed : umbellules 3-5-flowcred. True involucrum wanting, but in place of it there is a multifid leaf; leaves of involucel few, mequil. Petals white. Anthers exserted, clark purple. 'Jlis genus agrees with $A^{\prime} m m i$ in the compound inforescence, and with Bùnium in the tuberous root.

1 E. Bulbòsa (Nutt. I. c.). 24. B. H. Native of North America, in P'ennsylvania, Ohio, Missouri, Tenessee, Sc. in lumid and inundated places. Sison bulbòsum, Michx. f. bor. amer. 1. p. 169. Hydrocótyle compósita, and H. ambígua, Pursh. and Spreng. ex Nutt. l. e. Spreng. umb. spee. 5. t.5. f. 9.

Bulbous-rooted Erigenia. Pl. $\frac{1}{2}$ foot.

Cult. This plant should be grown in a pot, under which should be placed a pan of water.

V. MICROPLEU'RA (from $\mu$ croos, micros, small, and $\pi \lambda \varepsilon v \rho a$, pleura, a rib; the ribs of the fruit are small and capillary). Lag. obs. aparas. p. 15. D. C. coll. mem. 5. p. 27. prod. 4. p. $\tau 1$.

Lin, sxst. Pentándria, Digýnia. Margin of calyx obsolete. Petals equal, entire, acute. Fruit deeply cordate at the base, rather foliaceous, emarginate at the apex; mericarps compressed from the sides, obliquely ovate, 7 -ribbed; ribs capillary, curvilinear, ventricose below: the marginal 2 are shorter, and form a straiglit line; the commissure is very narrow, one half shorter than the mericarps.-Caulescent glabrous herbs, natives of Chili, with the habit of IIydrocótyle; but the umbels are rarely compound. Mericarps of fruit probably 9-ribbed, having 2 of them obsolete or hidden.

1 M. Renifòla (Lag. l. c.). Native of the Island of Chiloe. Petioles dilated at the base. Leaves alternate, petiolate, cordately reniform, 6-9-nerved, and reined, crenate, rather membranous. Umbels terminal, pedunculate, 4-5-rayed; involuerum foliaceous, composed of 1 leaf; umbellules 3-4-rayed, surrounded by small, 3-4-leaved involucels. Flowers 3, middle one fertile and nearly sessile, and the 2 lateral ones are male, on short pedicels.

Kidney-leaved Micropleura. Pl. cr.

Cull. See IIydrocólyle for culture and propagation, p. 255.

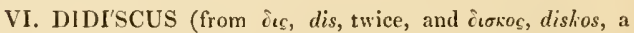
disk ; the mericarps appear like 2 disks). D. C. coll. mem. 5 . 1. 28. t. 4. Ilook. bot. mag. 1. 2875 .-Lámpra, Lindl.-Hugèlia, Relıb. consp. t, 144 .

Lin. syst. Pentándria, Digýnia. Margin of calyx obsolete. Petals oval, entire, bluntish (f. 57. c.), imbricate in æstivation. Styles diverging. Fruit nearly like that of Biseutélla, lience the name, emarginate at the base; mericarps very much compressed from the sides, without any vittre, a little murieated, or beset with dot-like lairs, 5-ribbed; ribs filiform: the 2 inner ones near the commissure, very short: the 2 middle ones short and curvilinear: and the dorsal one a little winged. Seed much compressed. Carpophore undivided.-Herbs, natives of New Holland. Stems terete, branched. Leaves variously parted, or lobed: lobes rather cuneated, cut. Umbels simple. Involucrum of many leaves, which are concrete at the base (f. 57, a.). Perhaps merely a section of Trachyminc, but the margin of the calyx is obsolete, not 5 -toothed; the petals obtuse, not acute, and ti:e fruit is compressed, not inflated, \&c.

1 D. cenu'leus (Hook. bot. mag. 2875. D. C. coll. mem. 5 . t. 4.) plant hairy; leaves petiolate, 3-parted; having the partitions 2-3-cleft, and the lobes 2 3-toothed; imbels simple, on long peduncles; involucrum of many leaves, when young reflexed. $\odot$. F. Native of New Holland. 'Trachymène cyanæe'a, Cunningl. mss. Trachymène cœrùlea, Graham, in edinb. phil. journ. 1828. Sept. p. 373. Lindl. bot. reg. no. 1225. Hugèlia eyanæ'a, Rehb. icon. exot. t. 201. Flowers blue; each umbel having

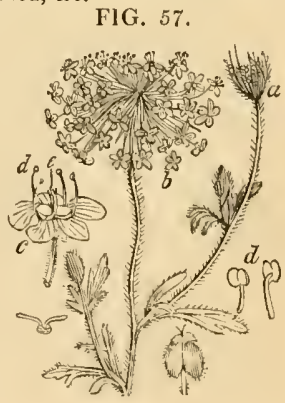


the appearance of a head of the flowers of Scabiòsa Caucásica, but the flowers are on longer pedicels : pediccls, after flowering, twisted inwards, bearing the fruit, which lies within the involucel, but crect at maturity. Fruit, when young, rather hairy, but in the adult state it is covered with minute tubercles. This is one of the most showy plants of the order.

Bluc-flowered Didiscus. Fl. July, Sept. Clt. 1827. Pl. 1 to 2 feet.

2 D. albiflònus (D. C. prod. 4. p. 72.) plant glabrous; radical leaves on long petioles, palmate; segments dilated at the apex, cut, toothed ; cauline leaves few, small ; umbels simple, on long peduncles. 4. G. Native of New Holland, at Port Jackson. Trachymènc incisa, Rudg. in Lin. trans. 10. p. 300. t. 21. f. 2. Fruit much compressed, beset with minute tubercles. Petals white.

White-floncred Didiscus. Clt. 1819. Pl. $1 \frac{1}{2}$ foot.

Cult. Sow the secd of these plants on a slight hot-bed in spring, and when the plants are 2 inches ligh, plant them separately into small pots, and shift them from size to size of pots as they grow.

VII. TRACHYME'NE (from tpaxvs, trachys, rough, and i $\mu \eta v$, hymon, a membrane; cliannels of fruit). liudge, in Lin. trans. 1811 . vol. 10. p. 300 . Spreng. umb. spec. p. 8 . Koch. umb. p. 143. D. C. coll. mem. 5. p. 28. prod. 4. p. 72.-Azorélla, Labill. nov. holl. 1. p. 74. Rich. hydr. p. 21. t. 52. f. 6. but not of Lam.-Azorélla species, Cav.-Fischèra species, Spreng. umb. prod. p. 27. but not of D. C.-Fischèra, Lag. am. nat. 2. p. 93. but not of D. C.-Catèpha, Leschen, ined.-Siebèra, Rchb.

Lix. syst. Pentándria, Digýnia. Margin of calyx 5-toothed. Petals elliptic, entire, acutish, straight at the apex, rather valvate in æestivation; styles diverging. Fruit didymous, compressed, and contracted from the sides; mericarps gibbously convex, without any vitta, 5 -ribbed: the 3 dorsal ribs and their channels muricated with tubercles: lateral ones marginal. Carpophore undivided. Seed gibbously convex, flattish in front.-Herbs or subshrubs, all natives of New Holland. Umbels compound, many-rayed: umbellules containing $9-12$ flowers. Involucrum of many leaves. This genus agrees with IIydrocotyle in the fruit being compressed; the rest agrees with Azorélla. Poranthira of Rudge agrees with this genus in habit, but the structure of the flowers is very different, and most probably belongs to the order Tremaindrea.

Sect. 1. Platyme'ne (from $\pi \lambda a r v s$, platys, broad; stems compressed). D. C. prod. 4. 1. 72. Plant herbaceous. Stems much compressed. Leaves small, cut.

1 T. A'xceps (D. C. prod. 4. p. 73.) plant glabrous, nearly leafless; stem 2-edged, branched ; leaves also at the tops of the branches cut into a few fine lobes. 24. G. Native of New Holland. It agrees with $T$. compressa in the stem being compressed, but it is one half narrower, the leaves more finely cut, the umbel more slender. The fruit has not been seen, but the analogy of the herb with the following species is sufficient to indicate its belonging to the same genus.

Tn'0-clgcd-branched T'rachymene. Pl. I foot.

2 T. compre'ssa (Spreng. umb. spec. p. 9. exclusive of the Chili specimen) plant glabrous, nearly leafless; leaves very few, small, binate or ternate: upper ones linear, entire; stem 2edged, branched. 24. G. Native of New Holland, on the sandy coast. Azorélla compréssa, Labill. nov. holl. 1. p. 75 . t. 101 . Fruit compressed, obovate; mcricarps convex on the back, 3-ribbed: ribs wrinkled from the tubercles. Involucrum shorter than the pedicels.

Compressed Tracliymene. Pl. 1 foot. voL. 111.
Sect. II. Dendroméne (from éficpov, dendron, a trce; in reference to the species being shrubby). D. C. prod. 4. p. 73. Plants shrubby. Leaves entire.

3 T. LINEA' brons, shrubby ; leaves scattered, erect, linear, subulate and acute at the apcx. h. G. Native of New llolland, at l'ort Jacksou. Sieb. pl. exsic. nov. holl. no. 126. Azorélla linearif òlia, Cav. icon. 5. t. 485. Azorélla lincarifólia, l'ers. ench. 1. p. 303. Fruit obovate, compressed; mericarps 3-ribbed; ribs rough from rows of tubcreles. Flowers yellow.

Lincar-leaved 'Trachymene. Fl. Ju. Aug. Clt. 1824. Sh. 1 to 2 feet,

4. T. TE'Nuis (D. C. prod. 4. p. 73.) shrublyy; branches tcrete, beset with glandular hairs at the apex; leaves scattered, spreading, linear, acute; umbels few-flowered, h. G. $\mathrm{Na}$ tive of New Holland. Branches very slender. Leaves hardly $\frac{1}{4}$ line broad, and 3-4 lines long. Umbel trifid: umbellules 3-5-flowered. Ribs of fruit scabrous from tubercles. Vcry like $T$, ericoides.

Slender Trachymene. Shrub 1 foot.

5 T. subvelutina (D. C. I. c.) shrubly; branches terete; leaves linear, thickish, acute, velvety from short crorvded down, as well as the branchlets; umbels crowded. h.G. Native of New Holland, at Port Jackson. The leaves are almost like those of $T$. cricoides, but differ in being velvety and erectisl. Branches hardly diverging.

Rather-eclecty Trachymene. Shrub 1 foot.

6 T. ericoides (Sieb. pl. exsic. nov. holl. no. 121.) shrubby ; branches rather angular, glabrous; leaves linear, acute, spreading; umbcls crowded. $h$. G. Native of New Holland. Branches numerous, spreading. Leaves a line broad, with the margins hardly revolute when dried. Umbels 5-cleft: umbelJules 5-6-flowered. Fruit scabrous from tubercles on the ribs.

Hcath-like Trachymene. Shrub.

7 T. Laxceola'ta (Rudge, l. c. Spreng. syst. 1. p. 879.) shrubby ; branchlets rather angular, glandular, and velvety when examined by a lens; leaves lanceolate-linear, nerved, erect ; numbels crowded, many-flowered. h. G. Native of New Holland. Azorélla lanceolàta, Labill. nov, holl. 1. p. 74. t. 99. Leaves an inch and a half long, and 2 lines broad. Leaves of the involucrum the length of the umbel. Umbels 5-8-rayed; umbellules $8 \cdot 10$ - flowered. Branches sometimes terminated by an 8-10-flowered, simple umbel.

Lanceolate-leaved Trachymenc. Shrub 1 foot.

8 T'. MYRTifòlia (Sieb. pl. exsic. nov. holl. no. 125.) shrubby ; branches rather angular, hardly glandular or puberulous, even when examincd by a lens : leaves oval-oblong, rather attenuated at both ends; umbels crowded, many-flowered. h. G. Native of New Holland. Very nearly allied to $T$. lanccolata, but differs in the leaves being 9-10 lines long, and 3 lines broad. Umbels 8-10-rayed: umbellules 8-12-flowered.

Myrtle-leaved Trachymene. Shrub.

9 T. ova'Lis (D. C. prod. 4. p. 73.) shrubby; branches densely clothed with short hairs; leaves oval, nerved, scattered, nearly scssile, hardly attenuated at either end; umbels manyflowered, crowded. $々$. G. Native of New Holland. T. ovata, Spreng. umb. spec. p. 8. (exclusive of the syn. of Labill.). Sieb. pl. cxsic. nov. holl, no. 124. Perhaps only a variety of $T$. myrtifòlia.

rar. $\beta$, conférta (D. C. I. c.) leaves and branchlets much crowded. $h$. G. Native of New Holland, at Port Jackson. Perhaps a proper species.

Oral-leaved Trachymene. Shrub 1 foot.

10 T. ova'ra (Rudge, 1. c. but not of Spreng. nor Sieb.) slurubby: branches smoothish; Jeaves broadly ovate, nearly sessile, hardly longer than broad; umbels crowded, many-flowered. L 1 
h. G. Native of New Holland. Azorélla ovàta, Labill. nov. holl. 1. p. 74. t. 100 . T. buxif òlia, Sieb. pl. exsic. nov. holl. no. 12\%. Leaves 4 lines long, and 3 lines broad. Umbels much crowded, small, 8-10-rayed.

Ovate-leaved Trachymene. Shrub.

Cult. All the species of Trachymène will grow well in a mixture of loam, peat, and sand; and they may be increased by cuttings, under a liand-glass, or by seeds.

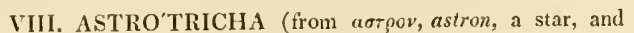

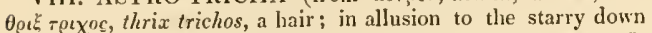
on the outside of the petals). D. C. coll. mem. 5. p. 29. t. 5 . and 6. prod. 4. p. 74.-Bòlax species, Sieb.

Lin. syst. Pcntándria, Digýnia. Tube of calyx ovate; limb small, hardly 5-toothed. Petals oval, acutish (f. $58 . b$ ), permanent, fiat, velvety from stellate down on the outside. Styles 2 , filiform (f. $58 . c$.), not gradually thickening to the base. Fruit crowned by the calycine lobules and petals; mericarps ovate-oblong, contracted at the commissure; ribs very blunt, liardly prominent: of the primary ones there are 3 dorsal, and 2 marginal, which are more acute and not so evident: of the secondary ones 4 ; vittæ wanting on the back, but there are 2 rather prominent ones in the commissure, which are covered by a spongy pellicle.-Australian, branched subshrubs, having the branches, petioles, under side of leaves, and umbels beset with white stellate hairs. Peduncles panicled, each ending in a simple, many-flowered umbel. Bracteas under the branches and branchlets solitary. Leaves of involucrum few and linear. Habit almost of Hérmas, but the fruit is very different. It differs from Bòlax in habit, and in the fruit not being tetragonal.

1 A. Floccòsa (D. C. l. c. t. 5.) the whole plant is clothed with flocky lanuginose down; leaves ovate-lanccolate, obtuse at the base, and acuminated at the apex. h. G. Native of New Holland. IBolax floccoìdes, Sieb. exsic. nov. holl. no. 258 . Leaves 3-6 inclies long and 12-15 lines broad ; petioles half an inch long. Flocky Astrotricha. Shrub.

2 A. Ledifòlia (D. C. I, c. t. 7.) plant clothed with short adpressed down; leaves oblonglinear, coriaceous, acutish at both cnds. 々. G. Native of New

Holiand. Bòlax ledifölius, Sieb. exsic. nov, holl. no. 257. Leaves 20 lines long and 3 broad; petioles 2 lines long.

Ledum-lcarcd Astrotricha. Shrub.

Cult. See Trachymène above for culture and propagation.

IX. XANTHO'SIA (from $\xi a \nu 0 o s, x a n t h o s$, yellow ; in allusion to the plants being clothed usually with yellow down) Rudge, iu Lim. trans. 1811. 5. 10. p. 361 . t. 22. f. 1. Spreng. in Schultes, syst. 6. p. 27. and $31 \%$ D. C. coll. mem. 5. p. 31. prod. 4. p. 74.-Leucolæ'na, R. Br. gen, rem. without a descrijption.- Cruciélla, Lesch. mss.

Lin. syst. Pcntándria, Digýnia. Tube of calyx ovate, compressed; limb 5-lobed; lobes ovate, acute, coloured a little. Petals stipitate, oval, cuspidate at the apex, replicate. Stamens opposite the calycine lobes. Stylopodia (glands, Rudge) 2, thick, villous at the tops of the mericarps. Styles 2, filiform, rising from the inner bases of the stylopodia. Fruit compressed, striated; mericarps contracted at the commissure, 7-9-ribbed: ribs filiform: 2 lateral ones marginal; channels withont vitta, as well as the commissure, which is very narrow.-Australian
IX. Xantuosia. X. Bowlesia.

subshrubs, usually covercd with stellate hairs. Leaves alternate, simple, or tripartite. Umbels variable.

Sect. I. Euxanthòsia (tluis section is supposed to contain the true species of Xanthòsia, from eu, well, and Xanthòsia). D. C. prod. 4. p. 74. Umbels axillary, simple, or bifid. Leaves of involucrum small.

1 X. nonta'n (Sieb. fl. nov. holl, exsic. no. 248.) the whole plant clothed with villi: some of them starry, and others simple and elongated; Jcaves ternate, rarely 3 -lobed; umbels axillary, nearly sessile, simple, 1-flowered; involucra and involucels 2-leaved. $h$. G. Native of New Holland, on the mountains. X. pilosa, Rudge; the flowers are only referrible to this plant.

Mountain Xanthosia. Shrub.

2 X. minsu'ta (D. C. prod. 4. p. 74.) the whole plant clothed with hairs, some of which are stellate, and others simple and elongated; leaves sinuated, rarely 3 -lobed; umbels axillary, pedunculate, bifid; umbellules 1-flowered; involucrum 2-leaved; involucels 3-leaved. $\eta$. G. Native of New Holland, near Port Jackson. X. pilosa, Rudge, only in the form of the leaves. Sieb. pl. exsic. nov. holl. no. 247.

Hairy Xanthosia. Shrub.

3 X. TRIDENTA'TA (D. C. prod. 4. p. 75.) young branches strigose : adult ones glabrous; leaves cuneated, acutely tridentate at the apex, tomentose from starry down beneatl, but glabrous in the adult state; umbels pedunculate, axillary, bifid: umbellules 1-flowered; involucrum 2-leaved; involucels 2-3leaved: leares lanceolate. $h . G$. Native of New Holland, at Port Jackson. Leucolæ'na tridentàta, R. Br. mss. ex lierb. mus. par.

\section{Tridentate-leaved Xanthosia. Shrub.}

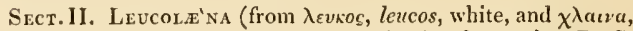
chlaina, a garment; in reference to the involucrum). D. C. prod. 4. p. 75. Umbels terminal, 3-4-rayed. Leaves of involucrum large, white.

4. X. notundifòlum (D. C. prod. 4. p. 75.) branches densely clothed with hairs, or rather rough from deciduous down; leaves reniformly orbicular, coarsely and acutely toothed ; umbels 3-4rayed: umbellules many-flowered; involucra and inrolucels 3-leaved. h. G. Native of New Holland, on the eastern coast. Cruciélla cándida, Lesch. in herb. Juss. Leaves of involucrum lanceolate, hairy at the base : those of the involucels broader, somewhat cordate, apiculated, glabrous. Fruit more compressed in the young state.

Round-lcaved Xanthosia. Shrub.

Cuit. For culture and propagation see Trachymènc, above.

X. BOWLE'SIA (in honour of William Bowles, an Irish botanist). Ruiz. et Pav. fl. per. prod. p. 44. t. 34. fl. per. 3. p. 28. Spreng. umb. prod. p. 24 . Lag. am. nat. 2. p. 94. Rich. lyydro. p. 21. t. 51. f. s. Koch, umb. p. 142. D. C. coll. mem. 5. p. 31. prod. 4. p. 75. but not of Poir.

Lis. syst. Pentándria, Digýnia. Tube of calyx compressedly tetragonal ; limb 5-toothed. Petals elliptic, entire, acute. Fruit ovate, much contracted at the raphe, turgid, rather tetragonal, flattish on both sides at the back; mericarps without vittæ, marked on the back by an oval impression; witl 5 obsolete ribs : the 3 niddle ones on the back: and the 2 lateral ones placed in the commissure, which is flat.-Weak, South American herbs, usually scabrous from stellate down. Leaves petiolate, oppositc, simple, lobed, or toothed. Umbels simple, axillary, fewflowered. This genus is allied to Spanánthe.

1 B. p.rma'ta (Ruiz et Pav. fl. per. 3. t. 251. f, a.) plant 
erectish, beset with scattered, stellate hairs in every part; leaves palmately parted; segments 3-5, jagged; umbels 3-flowered : upper ones on short, and the lower ones on long pecluncles. $\odot$. H. Native of Peru, in the province of Chancay, on sandy hilis. Plant 2 feet high, brittle, perhajs erect.

Palmate-leaved Bowlesia. 1'. 2 feet.

2 B. Loba'ta (Ruiz et Pav. l. c. t. 251 . f. b.) plant decumbent, covered all over with fascicles of bristles or stiffish hairs ; leaves reniform, 5-7-cleft, or with 5-7 deep crenatures; umbels 3-5-flowercd, pedunculate. $\odot$. H. Native of Peru, in busliy places, on the Andes towards Pillao. The bristles on the upper surface of the leaves are $3-5$ in a fascicle: those on the rest of the plant are 8 , and stellate.

Lobcd-leaved Bowlesia. Pl. decumbent.

3 B. Ixca'sa (Ruiz et Pav. 1. c. t. 268. f. a.) plant procumbent, hoary from crowded stellate fascicles of hairs; leaves reniform-roundish, bluntly $\$$-5-cleft ; lobes entire or tridentate ; umbels axillary, on short peduncles. ๑. H. Native of Peru, on hills in the tract at Huanaco Rondos and Pillao. Spreng. umb. spec. p. 13. t. 5.f. 10. Petioles permanent, rather tendri]formed. In cultivation the plant however becomes smoother, longer, and more procumbent than in the wild state.

Hoary Bowlesia. Pl. procumbent.

4 B. Tropeolifòlia (Gill. and Hook. in bot. misc. 1. p. 325.) plant clothed with stellate down; stems procumbent, slender; leaves palmately 5-7-parted; segments lanceolate, bluntish, quite entire, with acute sinuses: peduncles 8 -flowered; fruit small. 4.F. Native of Chili, in shady places at E] Salto de San Isidro, and in the valleys of the Andes, towards Mendoza. Stems filiform.

I ar. $\beta$, tripartita (Hook. et Arn. in bot. misc. 3. p. 346. ) the 2 lower lobes of the leaves approximating, small, coarsely tridentate from the middle. 4. F. Native of Chili, about Valparaiso.

Tripaolum-leaved Bowlesia. Pl. pr.

5 B. TE'NERA (Spreng. syst. 1. p. 860.) plant clothed with stellate pubescence; stems procumbent, slender; leaves on long petioles, reniform, 5-7-lobed : lobes obtuse, bifid or trifid; peduncles short, bearing a 3-flowered umbel each. 4. H. Native of Chili, about Conception, Valparaiso, Buenos Ayres, and Talcaguana; of Peru, on the mountains about Huanaco; and of Brazil, in dry fields about Monte Video, and at Porto Allegretto. Link. et Otto, abbild. t. 4. B. nodiflòra, Presl, in Hænk. herb. ex D.C. prod. 4. p. 75. B. geraniif òlia, Cham. et Schlecht, in Linnæa. 1. p. 382. Hook. et Gill. in bot. misc. 1. p. 324. B. incàna, Hort. par.

Slender Bowlesia. F\}. June, Aug. Clt. 1827. Pl. pr.

6 B. рисиórowa (Pœppig, diar. no. 363. pl. exsic. 95.) plant erect, dichotomous, hoary from stellate fascicles of hairs; leaves short, petiolate, obovate, coarsely tridentate at the apex; umbels 5-7-flowered, on long peduncles. $\odot$. H. Native of Chili, about Valparaiso and the baths of Collina. Peduncles of umbels about equal in length to the leaves, or longer; sometimes simple, bearing an umbellule at the apex: sometimes bifid at the apex, bearing 2 linear leaves, each of the branches bearing an umbellule. This species, like the others, varies much in the proportionate length of the peduncles: they are, however, isually much shorter than the petioles.

Dichotomous-peduncled Bowlesia. Pl. I foot.

Cult. The seeds may be reared on a hot-bed in spring; and when the weather gets warm, the plants may be planted out into the open ground, in any warm sheltered situation.

XI. FRAGO'SA (in honour of John Fragosa, first physician to Philip 11. King of Spain). Ruiz. et Pav.fl. per. prod. p. 43. t. 34. Lag. am. nat. 2. p. 93. Rich. hydr. in am. gen. sc. phys. 4. t.51. f. 4. D.C. prod. 4. p. 76.-Bòlax, spec. Spreng. Koch.-Azorélla, spec. Lam. and P'ers.

Lis. syst. I'entándria, Digýnia. Margin of calyx 5toothed, permanent. P'etals oval, entire. Styles short. Fruit ovate, almost didymous; mericarps ratler compressed from the back and contracted at the commissure; dorsal ribs filiform, with 2 other obsoletc oncs very like them at the commissure, vittre wanting.-Small, tufted, nearly stemless herbs, natives of the Andes of Peru. Leaves small, toothed, or 3-5-eleft, usually pilose. Umbels sessilc or pedunculate; pedicels about equal in length to the involucrum.

1 F. conymbòsa (Ruiz et Pav. fl. per. 3. p. 27. t. 250. f. a.) leaves imbricate, cunciform, trifid, small, pilose on both surfaces; umbels simple, few-flowered. 4 . F. Native of Peru, on the humid tops of the mountains called Muna at 'TamboNuevo. Azorélla corymbòsa, Pers. Bòlax Jycopodioides, Spreng. in Schultes, syst. 6. p. 361. Habit of Lycopòdium or Bòlax. Unbels 2-4-flowered. Superior leaves expanded in a stellate manner.

Corymbose-flowered Fragosa. Pl. $\frac{1}{4}$ foot.

2 F. multífida (Ruiz et Pav, fl. per. 3. p. 27. t. 249. f. a.) leaves ovate, deeply toothed, strigose above; petioles ciliated with bristles; umbels simple, 4. F. Native of Peru, on the Andes, near Huassa-Huassi. Azorélla multífida, Pers. Bòlax multifidus, Spreng. Roots fusiform. Herb very short. Leaves 3.4 lines long. Leaves of involucrum subulate. Umbels fewflowered. Rich. ann. gen. sc. phys. 4. t. 51. f. 4. fruit only.

Multifid-leaved Fragosa. Pl. $\frac{1}{4}$ foot.

3 F. crena'ta (Ruiz et Pav, fl. per. 3. p. 27. t. 249. f. c.) leaves obovate, or roundish-ovate, crenately toothed, beset with bristly hairs on both surfaces, and on the petioles; umbels sessile, simple. 4. F. Native of Peru, on cold hills at HuassaHuassi, in the province of Tarma, and in New Granada, ex H. B, et Kunth, nov. gen. amer. 5. p. 26. Azorélla crenàta, Pers. Bòlax crenàtus, Spreng. Branches pilose, very short. Herb low, tufted. Leaves numerous, 6-5 lines long. Umbels containing about 14 flowers. Involucrum composed of 7 linearlanceolate leaves.

Crenated-leaved Fragosa. Pl. $\frac{1}{4}$ foot.

4 F. cladorniza (Ruiz et Pav. Hi. per. 3. p. 27. t. 250. f. b.) leaves ovate, deeply serrated, shining above: each serrature terminated by an acumen; petioles winged, pilose, ciliated; umbels simple, nearly sessile, many-flowered. $4 . F$. Native of Peru, on cold hills in the tract of Chavin, near Huamalies. Azorélla cladorhìza, Pers. Bòlax cladorhìzus, Spreng. Root thick, much branched. Limbs of leaves length of petioles, about 3-4 lines long. Leaves of involucrum ciliated with pili.

Branch-rooted Fragosa. Pl. $\frac{1}{4}$ foot.

5 F. renifórmis (Ruiz ct Pav. f. per. 3. p. 26. t. 249. f. b.) the whole plant tensely clothed with pili ; leaves reniform, crenated; petioles more than twice the length of the limbs; scapes much shorter than the petioles; umbels simple, many-flowered. 4. F. Native of Peru, in shady places, at Huassa-Huassi, in the province of 'larma. Azorélla reniformis, Pers. Petioles 3-4 inches long, with the limbs $1 \frac{1}{2}$ inch in diameter. Scapes of umbels 10-12 lines long.

Reniform-leaved Fragosa. Pl. $\frac{1}{8}$ foot.

Cult. If any of the species of this genus should ever be introduced to our gardens, we would advise their being grown in pots, in a mixture of sand and peat, and placed among other alpine plants, so that they may be protected in winter by a frame.

X11. AZORE'LLA (meaning not explained). Gaud. in ann. L12 
se. nat. 5. p. 104. t. 1. f. 1. but not of Rich. D. C. prod. 4. p. 77.-Azorélla species, Lam.-Bòlax species, Spreng. Koch.

Lin. syst. Pentándria, Digýnia. Margin of calyx 5-tootlued, permanent. Petals oval, entire. Styles slort. Fruit ovate, contracted at the raphe, and rather compressed from the back; mericarps semi-ovate, without any ribs or vittæ; ribs filiform, hardly conspicuous. - Humble tufted herbs, natives of Magellan. Leaves imbricate, entire or trifid, with the petioles sheathing or dilated. Umbels nearly sessile, 2-8-flowered; pedicels about equal in length to the involucrum. Perliajs this genus is hardly distinct from Fragòsa.

1 A. Aretioides (Willd. herb. ex D.C. prod. 4. p. 77.) leaves imbricate, tripartite, coriaceous; lobes oblong, acutish ; petioles thick and rather corky, villous at the apex; umbels nearly sessile, simple, 4-flowered; leaves of involucrum 4, equal in length to the pedicels. 2.F. Native of Quito, on the ligh mounlain of Antisana. Fragòsa aretioides, Il. B. et Kunth, nov. gen. amer. 5. p. 27. t. 424. Bölax aretioides, Spreng. umb. spec. 1. 11. exclusive of the synonymes and character. B. caspitosa, Spreng. in Schultes, syst. 6. p. 358 . exclusive of the synonymes. Fruit a little ribbed. (ex Kunth.)

Arctictike Azorella. Pl. $\frac{1}{8}$ foot.

2 A. Lycopodoldes (Gaud. in ann. sc. nat. 5. p. 105. t. 3. f. 1.) leaves imbricate, sheathing at the base, trifid, coriaceous ; lobes subulate, acute; sheaths funnel-shaped, ciliately toothed ; umbels ahmost sessile, 2-3-flowered; leaves of involucrum 2, serrated. 4. F. Native of the Maclove or Falkland lslands. D'Urvil, fl. mal. p. 47 . This is a very different plant from Lúlax lycopodivides, Spreng, which is now Fragòsa corymbòsa.

Club-moss-like Azorella. Pl. $\frac{1}{8}$ foot.

3 A. Filanentòsa (Lam. ill. t. 189. f. 1. Valıl. symb. 3. p. 47.) leaves oblong, coriaceous, quite entire, crowded ; petioles dilated, eiliated with long bristles; umbels nearly sessile; leaves of involuerum somewhat ciliated and bristly. 4. F. Native of the mountains of Magellan and the Maclove Islands. A. eliamitis, Pers. ench. no. 3. D'Urv. fl. mal. p. 46. Bòlax filamentosus, Spreng. in Schultes, syst. 6. p. 359. There are varieties of this plant with either an elongated or crowded habit: and with the umbels either few or many-flowered, and the lower ones 1 -flowered. Perliaps the same as Chamitis integrifólia, Gærtn. fruct. t. 22. f. 4.

Filamentose Azorella. Pl. $\frac{1}{8}$ foot.

4. A. Gilliésu (Hook. et Ârn, in bot. mise. 3. p. 346.) plant densely tufied; leaves petiolate, trifid; umbels pedunculate, 4-10-flowered; fruit utricular. 4. F. Native of Cliti, in the valley of Uspallata, on the Andes of Mendoza, at the elevation of from 6000 to 12,000 feet. Bòlax Gillièsii, Gill. et Hook. in bot. misc. 1. p. 325 . t. 63 . Root long, descending. Plant 2 inches ligh. This plant yields abundantly a gummy substance, which is gathered by the natives, and enployed by them in the cure of headache.

\section{Gillies's Azorella. Pl. 2 inclies.}

5 A. cespitósa (Cav, icon. 5. p. 57. t. 484, f. 2.) leaves imbricated, spreading at the apex, thick, quite entire, and quite glabrous; umbels on short peduncles, 6-8-flowered; leaves of iwvoluerum one half shorter than the pedicels. 4 . F. Native of Chili, on the higher mountains, ealled the Cordillera del Planchon. A. crassifòlia, Pers. ench. 1. no. 2. Fruit ovate; having the mericarps furnislied with 3 slender stripes on the outside, as in the genus Fragòsa.

Tiufted Azorella. P1. $\frac{1}{8}$ foot.

6 A. Daucor'ves (D'Urv. Al. mal. p. 45.) leaves all radical, long, pinnate; segments or leaflets remote, opposite, short, pinmatificl : lobes alternate, acutely cut; scapes slort, very hairy ; involıcrum 8-10-leaved; fruit glabrous, striated, nearly sessile. 4. F. Native of the Straits of Magellan, along the rivulet called Bougainville River. Root thick, fusiform. Umbels 3-8flowered. Leaves bardly an inch long, but still longer than the scape.

Carrot-like Azorella. Pl. 1 incl..

7 A. ranu'nculus (D'Urv, fl. mal. 1. p. 46.) stem stoloniferous, very short ; leaves on long petioles, 5 -parted; partitions 3 .lobed at the apex, obtuse; umbels axillary, on short perluncles; leaves of involucrum 5 , lanceolate, acute, ciliated at the base, about equal in length to the flowers. 4 . F. Native of the Straits of Magellan, along with the last. Habit of a small Hydrocótyle or Ranúnculus. Fruit round, hardly pedicellate, crowned by the calycine teeth. Umbels 4-6-flowered. Petals greenish yellow.

Cronfoot-like Azorella. P]. $\frac{1}{4}$ foot.

Cult. See Fragosa, p. 259. for culture and propagation.

XIII. PECTOPHY'TUM (from $\pi \eta x т 0 \varsigma$, pelktos, compact, and $\phi v \tau o v$, phyton, a plant ; a compact tufted plant). H. B. et Kunth, nov. gen. amer. 5. p. 28. D. C. prod. 4. p. 78 .

Lin. syst. Pentândria, Digýnia. Margin of calyx entire. Petals unequal, acute, and a little inflexed at the apex. Styles short, straight. Fruit ovate-elliptic; mericarps ratber convex on the back, semi-oval, 5-ribbed, without any vittæ; ribs filiform; commissure flattish,-A tufted herb. Leaves crowded, imbricate, coriaceous, trifid, glabrous; petioles permanent. Flowers white, in crowded fascieles at the tops of the branches, and solitary in the axils of the bracteas, pedicellate. Bracteas ciliately toothed.-This genus is allied to Bòlax and Fragòsa, but it differs from the first in the form of the fruit, and from the last in the margin of the calyx being entire.

1 P. peduncula're (H. B. et Kunth, nov. gen. amer. 5. p. 29. t. 425.) 4. F. Native of Quito, in plains on the top of Mount Antisana. Bòlax pedunculàtus, Spreng. umb. spec. p. 10. Azorélla pedunculàta, Willd. herb.

Peduncled-flowered Pectophytum. Pl. $\frac{1}{4}$ foot.

Cult. See Fragòsa, p. 259. for culture and propagation.

\section{Tribe II.}

MULI'NEE (this tribe contains plants agreeing with Mulinum in important characters), or Orthospérmæe imperfectè Umbellàtæ, parallelè biscutàta, D. C. prod. 4. p. 78.-Hydrócotýleæ Mulínex, D, C. coll, mem, 5. p. 32. Mericarps much contracted at the commissure, without any vittæ ; ribs 5 , usually filiform. Fruit compressed from the back, hence it is square. Petals spreading, flat, entire in all the genera, with the exception of Astcriscium.

XIV. BO'LAX (from $\beta \omega \lambda a \xi$, bolax, a synonyme of $\beta \omega \lambda o r$, bolos, a bole or lump; the plant grows in dense tufts, hollowed in the middle). Comm. in Juss. gen. p. 226. Gaud. fl. mal. in ann. se, nat. 5. p. 104. t. 3. f. I. D. C. prod. 4. p. 78.-Bòlax species, Spreng. Azorélla species of Lam.

Lin. syst. Pcntándria, Digýnia. Margin of calyx entire, hardly conspicuous. Petals oval, entire. Styles short. Fruit tetragonal, concave in the disk; mericarps with 5 nerve-formed smooth ribs, 1 dorsal, 2 in the middle forming the angles, and 2 filiform inner ones; commissure very narrow. $-\boldsymbol{A}$ tufted herb, with the habit of Arctia. Leaves imbricate, trifid, glabrous, coriaceous : lobes ovate, obtuse; petioles membranous, rather corky, with the margins not ciliated. Unbels simple, nearly sessile, 4-flowered. Leaves of involuerum 4, about equal in length to the pedicels. Fruit while young furnished with stellate down.

1 B. Creba'ria (Comm. ined. ex Gaud, ann. sc. nat. 5. p. 104. t. 3. f. 2.) 4 . F. Native of the Straits of Magellan, on the mountains; in the Maclove or Falkland Islands; Chili and 
Patagonia. D'Urv. fl. mal. p. 47. Gommier, Pern, voy. 2. p. 7. and 65. ex D'Urv. IIydrocótyle gummifera, Lam. dict. 3. p. 156. ill. p. 189. f. 21. Bòlax gummífera and 13. complictita, Spreng. umb. spec. p. 9. and p. 10. Azorélla caspitòsa, Valıl, symb. S. p. 48 .

Clebaria Bolax. Pl. $\frac{1}{4}$ foot.

Cult. See Fragòsa, p. 259. for culture and propagation.

XV. MULI'NUM (an ancient name of an umbelliferous plant). Pers. ench. 1. p. $309 . \quad$ Lag. an. nat. 2. p. 94. D. C. coll. men. 5. p. \$2. D.C. prod. 4. p. 79. but not of Gaudin.Bòlax species of Spreng.- Selinum species of Cav.

Lin. sxst. Pentándria, Digýnia. Limb of calyx 5-toothed, permanent. Petals oval-oblong, acute, flat. Styles acute. Fruit 4-winged or parallelly biscutate; mericarps without vitta, very much contracted at the commissure, compressed on the back, 5 -ribbed; middle rib on the back nerve-formed, as well as the 2 lateral ones, the 2 intermediate ones expanded into ample lateral wings. - Suffruticose tufted herbs, natives of Chili. Leaves 3-5-cleft or undivided; petioles sheathing. Umbels simple; pedicels longer than the many leaved involucrum. Flowers yellow. This genus, according to Lagasca, is probably divisible into several.

1 M. sprxòsum (Pers. ench. 1. p. 309.) cauline leaves trifid; scgments subulate and spiny: lateral segments bipartite; petioles sheathing, glabrous; peduncles longer than the leaves; leaves of involucrum distinct, short, spreading a little; fruit orbicular. 24. F. Native of Chili, on the highest mountains, called Cordillera del Planchon and del Portillo, towards Mendoza; between Los Ojos de Agua, and El Rio de Los Ojos de Agua; Andes of Chili, and Cordillera of Chili, at the elevation of 5,500 or 7,000 feet. Selinum spinòsum, Cav. icon. 5. p. 59. t. 487. f. 1. Bòlax spinòsus, Spreng. in Schultes, 6. p. 362. exclusive of the synonymes. Stems half a foot high. Umbcls 10-12-flowered. Petals of a reddish yellow-colour.

Spiny Mulinum. Pl. $\frac{1}{2}$ foot.

2 M. prolíferum (Pers. l. c.) cauline leaves trifid; segments subulate, spinose; petioles sheathing, glabrous; leaves of involucrum short, distinct, rather spreading; umbels pedunculate, longer than the leaves; fruit orbicular. 4.F. Native of South Amcrica, at Port Desire; and of Chili, on the Andes of Mendoza between San Isedro and Portezuela, on the declivities of mountains at the elevation of 5,000 to 10,000 feet. Selinum prolíferum, Cav. icon. 5. p. 58. t. 486. f. 1. Bòlax prólifer, Spreng. in Schultes, syst. 6. p. 361 . Root twisted. Stems S-4 inches high, covered by the sheaths. Leaves glabrous. Umbels 5-7-flowered, sometimes proliferous. Petals yellow.

Proliferous Mulinum. Pl. $\frac{1}{3}$ foot.

3 MI. cuneA'Tum (Hook. and Arn. in Becch, bot. 1. p. 26.) leaves wedge-shaped, trifid, and sometimes 5-6-cleft: each lobe ending in a spiny point; sheaths of leaves elongated, stiff, ciliated; umbels many flowered, on short peduncles. $4 . F$. Native of Chili, about Valparaiso, and on the mountains of $\mathrm{Val}$ paraiso; and at Huilquilema, in the province of Rare. Azorélla spinòsa, Pers. ench. 1. p. 303. Fragòsa spinòsa, Ruiz et Pav. fl. per. S. p. 27.

Cuneated-leaved Mulinum. Pl. $\frac{1}{8}$ foot.

4. M. ulícrum (Gill. et Hook, in bot. misc. I. p. \$28. t. 64.) leaves trifid: segments subulate, spiny; umbels nearly sessile, tcrminating the very short branches; fruit elliptic. $h$. F. $\mathrm{Na}$ tive of Chili, near La Cienega de Bonillo, near the tops of the Uspallata range of mountains, at the elevation of 9,500 feet. II. echinus, D. C. prod. 4. p. 79. Bòlax cchìnus, Presl. mss. A glabrous, much branched, humble, odoriferous plant. Petals marked by an elevated longitudinal line in the middle. Leaves of involucrum linear-subulate.

Furze-like Mulinum. Shrub $\frac{1}{8}$ to $\frac{1}{5}$ foot.

5 M. micropuy' Lum (l'ers. 1. c.) cauline leaves imbricate, minute, tripartitc: lobes linear-lanceolate, cach terminated by a hair; petioles stem-clasping, ciliated at the base. h.F. Native of South $\triangle$ merica, at Port Desire. Selìnum microphýllum, Cav. icon. 5. p. 59. t. 486. f. 2. Petals reddish, yellow in the clried state. Stem shrubby, 3 inches long, branched, covered by the sheaths.

Small-leaved Mlulinum. I'l. $\frac{1}{4}$ foot.

6 M. albovagina'tum (Gill, et Hook. in bot. misc. 1. p. 328.) leaves trifid; segments oratc-lanceolate, mucronate; umbels axillary, small, few-flowered, sessile. h. F. Native of Chili, at Cerro de la Polcura, on the Andes of Mendoza. Shrub branched, diclotomous.

White-sheathed Mulinum. Pl. $\frac{1}{4}$ foot.

Cult. See Fragòsa, p. 259. for culture and propagation.

XVI. IARE'TIA (Llareta is the vernacular name of the plant). Gill. et llook. in bot. misc. 1. p. 329. t. 65.

Lin. syst. Pentándria, Digýnia. Margin of calyx 5-toothed. Petals ovate, entire. Fruit elliptic, square, flatly compressed from the back, 4-winged; mericarps lenticular, with dorsal ribs, and 2 lateral marginal ones, destitute of vittæ. Seed flat.

1 L. Acau'urs (Gill. et Hook. l. c.) 24. F. Native of the Andes of Chili, in Ell Valle de Fray Carlos, at the elevation of 10,000 feet; Cordillera of Chili, Los Ojos de Agua. Mulinum acaúle, Pers, ench. 1. p. 309 . Selìnum acaúle, Cav, icon. 5. p. 59. t. 487. Root thickish, rather fusiform, woody. Plant tufted. Leaves ovate, attenuated at the base; umbel radical, sessile.

Stemless Laretia. Pl. $\frac{1}{8}$ foot.

Cult. See Fragòsa, p. 259. for culture and propagation.

XVII. DRU'S $\Lambda$ (in honour of M. Le Dru, a French botanist and traveller). D. C. ann. mus. 10. p. 466. t. 38. Spreng. umb. prod. p. 15. f. 6. Lag. am. nat. 2. p. 94. D. C. prod. 4. p. 80.

Lin. syst. Pentándria, Digýnia. Limb of ealyx entire, not perspicuous. Petals oval, entire. Fruit oval; mericarps much compressed on the back, without any vitte: the dorsal rib and the 2 inner ones linear, and not prominent: the 2 intermediate ones are drawn out into marginal repandly sinuated wings, having the sinuses obtuse, and the angles furnished with hooked stellate spinules. Seed much compressed.-A decumbent slender stoniferous herb, native of Teneriffe. Leaves opposite, petiolate, broadly 3 -lobed, crenated. Hairs on divers parts of the plant very different, some of which are stiff, stellate, and hooked at the apex; others are solt, simple, solitary, or in stellate fascicles. Umbels axillary, pedunculate, 1-2-flowered, without any involucrum. Flowers small, white. Plant with the habit of Bonlesia, but the fruit is very different.

1 D. oppositufòlia (D. C. l. c.) $\odot$. H. Native of 'Teneriftè, on shady rocks between Port Orotava and Monte Verde. Sícyos glandulósa, Poir. diet. 7. p. 155. Bowlèsia oppositifolia, Buch. uebers. can. p. 34. Poir. ill. gen. 3. p. 590 . t. 934.

Opposite-leaved Drusa, Fl. July, Aug. Clt. 1824. Pl. cr.

Cult. Sow the seeds of this plant in the open ground in any warm situation.

XVIII. HUAN I'CA (meaning not explained), Cav, icon. 6. p. 18. t. 528. f. 2. D. C. coll. mem. 5. p. 32. prod. 4. p. 80.Oenánthe species, Spreng.-Spanánthe species, Lag. am. nat. 2. p. 93. 
Lis. syst. Pentándria, Digýnia. Margin of calyx hardly 5-toothed. Petals lanceolate, entire. Styles 2, divaricate. Fruit ovate, acutish; mericarps rather compressed on the back: flat inside, and with one furrow : convex on the outside, and furnished with 3 lines: lines or ribs rather elevated; carpophore bifid.-Herbs perennial. Roots thick. Leaves radical, petiolate, palmately 5-parted; petioles dilated and ciliated at the base. Stems or scapes naked. Umbels simple. Involucrum of many spiny-ciliated leaves. Flowers on long pedicels, of a reddish yellow-colour : outer ones of each umbel male. Allied to Mulinum and Spaninthe.

1 H. CAvanille'sn (D. C. prod. 4. p. S1.) stems scape-formed, trifid at the apex, and bearing 2 opposite sessile tripartite leaves; umbels 3 on each stem: lateral ones on long, and the middle on a short peduncle; segments of leaves filiform, multifid. 24. F. Native of South America, at the Straits of Magellan, and Port Desire. H. acaúlis, Cav. icon. 6. t. 528, f. 2. Oenánthe Huanàca, Spreng. umb. prod. p. 37. and in Schultes, syst. 6. p. 628. Spananthe Huanàca, Lag. 1. c.

Cavanilles's II uanaca. Pl. $\frac{1}{2}$ foot.

2 H. geranifòlia (D. C. prod. 4. p. 81.) scapes leafless, simple, bearing only one simple umbel; segments of leaves linear, undivided. ¥4. F. Native of Mexico. Bòlax geraniifòlius, Presl, mss. Herb 1-2 inches high. Scapes numerous, a little longer than the petioles. Umbels 15-20-flowered. Leaves of involucrum linear, few, ciliated at the base.

Geranium-leaved Huanaca. Pl, $\frac{1}{4}$ foot.

Cult. See Fragòsa, p. 259. for culture and propagation.

XIX. DIPO'SIS (from ì husband; in reference to there bcing 2 male flowers in each umbellule, and only one fertile). D. C. coll. mem. 5. p. 33. t. 3. f. O. prod. 4. p. 81.-Hydrocótyle species, Lam. Cav.-Spanánthe species, Spreng.

Lin. sYst. Pentándria, Digýnia. Margin of calyx bluntly 5-toothed. Petals oval, flat, entire. Styles short. Fruit orbicular, biscutate; mericarps compressed from the back, joined with the narrow commissure, and therefore constituting 2 parallel disks; dorsal rib filiform, 2 lateral ones hidden, and the middle ones girding the disk; vittæ wanting ; furrows between the ribs broad and flat.-Stemless glabrous herbs, natives of Chili and Brazil. Leaves all radical, petiolate, ternate: leaflets wedgeshaped, toothed or cut at the apex; the lateral segments sometimes 2-parted. Scapes longer than the leaves. Umbels compound, 6-8-rayed; peduncles much longer than the involucrum, which is 4-5-leaved. Umbellules 3-fiowered, middle flower fertile, lateral 2 male; hence the generic name. Flowers white. The fruit is like that of Mulinum, and the inflorescence that of Petágnia.

1 D. Saniculépòla (D. C. l. c.) roots fusiform; leaves ternate: leaflets wedge-shaped, tridentate : lateral leaflets sometimes 2-parted; umbels 6-8-rayed. 2. F. Native of Monte Video. Hydrocótyle saniculæfòlia, Lam. dict. 3. p. 154. Cav. icon. 5. p. 60. t. 488. f. 2. Spanánthe saniculafoolia, Spreng. in Schultes, syst. 6. p. 357. Mulinum saniculæe òlium, Desv, in herb. Juss.

Sanicle-leaved Diposis. PI. $\frac{1}{4}$ to $\frac{1}{2}$ foot.

2 D. Bulboca'stanum (D. C. prod. 4. p. 668.) root tuberous, globose ; leaves many-parted. 2.F. Native of Chili, in sterile pastures, at Rancagua. Bùnium Bulbocástanum? Bertero, herb. Herb glabrous. Root black on the outside, nearly like that of Càrum denuditum or C. Bulbocástanum. Umbels compound, 3-4-rayed, surrounded by a 3-5-leaved involucrum; umbellules 3 -flowered. Fruit parallelly biscutate.

Earth-nut Diposis. PI. 1 to 2 feet.

Cult. See Fragòsa, p. 259. for culture and propagation.
XX. SPANA'NTHE (from $\sigma \pi a v o s$, spanos, rare, and a 2 sos, anthos, a flower ; flowers few in the umbels). Jacq. coll. 3. p. 247. Spreng. umb. prod. p. 34. Rich. hydr. p. 20. t. 50. f. 2. Koch, umb.p. 142. f. 66-68. D. C. prod. 4. p. 81.

Lin. syst. Pentándria, Digýnia. Limb of calyx 5-toothed. Petals elliptic, entire, acutish, with a straight apex. Fruit ovate, much compressed at the raplic, flat, and compressed from the back on both sides; mericarps flat, without any vittæ; ribs 5 , very slender, equal, 3 intermediate ones on the back, and the 2 lateral ones seated in the commissure, which is flat. Seed flat.-A South American branched erect herb, glabrous in every part, except on the petioles, which are ciliated along the sheaths, and ornamented with a collar of hairs under the origin of the limb. Leaves cordate, toothed, acute. Umbels rather compound, proliferous. Involucra composed of many leaves. Flowers white on long pedicels.

1 S. PANicula'ta (Jacq. l. c. and icon. rar. 3. t. 350.) ९.S. Native of South America, in Trinidad, and the Spanish Main, as well as of Peru. Hydrocótyle spanánthe, Willd. spec. 1. p. 1363. Phellándrium ciliàtum, Willd. herb. Perhaps the Peruvian plant is the same as that from the Spanish Main, but it is much smaller and hardly panicled.

Panicled Spananthe. IIl. July, Aug. Clt. 1795. Pl. I to $2 \mathrm{ft}$.

Cult. The seeds of this plant should be raised on a hot-bed, and when the plants are of sufficient size plant them into separate pots, and then place them in the stove, where they will flower and seed; and some may be planted out in the open ground. Not worth cultivating except in botanic gardens.

XXI. HOMALOCA'RPUS (from i $\mu a \lambda$, and картоs, karpos, a fruit). Hook. and Arn. in bot. misc. 3. p. 34.8 .

Lis, srst. Pentándria, Digýnia. Margin of calyx 5-toothed: tecth subulate, minute, hardly permanent. Petals ovate, concave, entire. Styles 2, divaricate, short. Fruit roundish-ovate; mericarps compressed on the back, flat, wingless, constituting 2 parallel disks; commissure very narrow; ribs 5 , filiform, very slender, hidden in the substance of the pericarp, one dorsal, 2 lateral ones near the raphe, 2 middle ones forming the angles, without any vittæ; carpophore entire. Seed less than the cavity of the fruit.-Herb annual, erectisl, hoary from stellate hairs, dichotomously branched. Root slender, simple. Leaves petiolate, reniform-roundish, somewhat 5 -lobed; lobes equal, ovate, obtuse, quite entire or deeply lobed; lower leaves alternate: superior ones opposite. Peduricles axillary and terminal, about equal in length to the petioles. Umbels simple, 3-6-flowered. Teeth of calyx pilose, almost emulating a fascicle of hairs. Fruit nearly twice the length of their pedicels, which are a line long. This genus comes near to Spanánthe.

1 H. Bow LEstoides (Hook. et Arn. l. c.) ९. H. Native of the Cordillera of Chili. The ridges or ribs of the fruit are only to be seen on a transverse section of the fruit, because they are sunk in a thin substance of the pericarp. The middle ridges do not expand into wings as in Mulimum, and some other allied genera.

Bowlesia-like Homalocarpus. Pl. $\frac{1}{4}$ to $\frac{1}{2}$ foot.

Cult. See Spanínthe above for culture and propagation.

XXII. POZO'A (name given by Lagasca in honour of some Spanish botanist of the name of Pozo). Lag. gen. et spec. nov. p. 13. no. 163. am. nat. 2. p. 93. D.C. prod. 4. p. 82. Gill. et Hook. in bot. misc. 1. p. 330 . t. 66 .

Lin. syst. Pentándria, Digýnia. Calyx 5-toothed, perma- 
nent. Petals entire. Fruit prismatically tetragonal, 5-ribbed, crowned by the calyx, emarginate at the apex; mericarps concave and channelled on the back: lateral ribs close, nearly in straight lines; eommissure much contracted.-Herb. Leaves on long petioles, simple, euneated, profoundly toothed at the apex, quintuple nerved. Umbels simple. Involucrum obsoletely lobed, crenately toothed, many nerved : nerves branched a little.-This genus is allied to Astrántia and Mulinum.

1 P. corla'cea (Lag. gen. et spec. l. c.) 4. F. Native of the Cordillera of Cliili, in various places at Santa Madre Los Impossibles, and other places on the Andes of Chili between Mesdoza and Chili. Mulinum angulatum, D. C. prod. 4. p. 86. Hacquétia bracteógama, D. C. prod. 4. p. 668 . Coriaccous Pozoa. Pl. $\frac{1}{2}$ foot.

N.B. There are two other species of this genus mentioned by Lagasca in am. nat. 2. p. 94. under the names of $P$. denticulata and $P$. incisa, but these he has not described.

Cult. See Fragòsa, p. 259. for culture and propagation.

XXIII. ASTERI'SCIUM (from a $\sigma \tau \rho$, aster, a star; in reference to the starry involuccls or umbels). Cham. and Schlecht. in Linnea. 1. p. 254. t. 25. f. 1. D. C. prod. 4. p. 82.-Pozòa, spee. Spreng. syst. 2. p. 116.-Cassidocárpus, Presl, in herb. Hanke.

Lıx. syst. Pentándria, Digýnia. Calyx 5-toothed, permanent : teeth ovate. Petals ending in an inflexed point, emarginate, with the recess callous. Fruit compressed, tetragonally prismatic, crowned by the calyx, rounded at the base; mericarps 5 -ribbed, 2 intermediate ribs expanded into wings, central one as well as the 2 placed near the raphe stripe-formed: having the furrows between the ribs destitute of vittæ; commissurc very narrow. Seed unknown.-Quite glabrous percnnial herbs. Stems terete, branched, few-leaved. Leaves petiolate, simple, roundish-cuneated, unequally toothed, somewhat 3-lobed, 3-5nerved, rather coriaceous. Umbels simple, nearly globose. Involucrum many leaved, shorter than the umbel. Flowers either sterile and male, on long pedicels, or fertile and hermaphrodite in the same umbel.-This genus differs from P'ozòa and Mulinum in the petals being emarginate, not entire.

1 A. Chule' nsis (Cham. et Schlecht. 1. c.) leaves 3-lobed, deeply serrated; peduneles elongated, scattered; petals deeply emarginate, ending in a long involute point ; fruit narrowest at the hase; leaves of involucrum lanceolate, cut. 4 . F. Native of Chili, in dry sandy places about Talcaguano, and about Conception; Cuesta de Zapata, at the elevation of 6,000 feet; cliffs by the sea side at Valparaiso. Hook. bot. misc. 1. p. 332. t. 67. A. Inisillo vulgo Mouchu, Feuill, chil. 3. t. 2.

I ar. B, Ifc'nkei (D. C. prod. 4. p. 82.) lower leaves roundish, undivided, acutely few-toothed at the apex: upper leaves trifid. 4. F. Native of Chili. Cassidocárpus Chilénsis, Presl, in herb. Hænke. Erýngium tricuspidàtum, Domb. herb.

Chili Asteriscium. Pl. $\frac{1}{4}$ foot.

2 A. Pozprígir (D. C. prod. 4. p. 82.) leaves deeply trifid; lobes obovate, obtuse, regularly toothed. 4 . F. Native of Chili. Very like the preceding, but differs in the lobes of the leaves and recesses being obtuse, and regularly toothed all around.

Pocppig's Astericium. Pl. $\frac{1}{4}$ foot.

3 A. Polyce'phalum (Gill. et Hook, in bot. misc. 1. p. 332. t. $67 . \beta$, ) plant leafless? peduncles corymbose, numerous, sometimes abortive and spinose; petals entire, acute, with an involute apex; fruit broadly oblong; lcaves of involucrum linear, entire. 4.F. Native of Chili, in the valleys on the Andes near Ladera de la Jaula, and towards Uspallata in the province of Mendoza, at the elevation of 7,500 feet. Mulinum Dipterý- gia, D. C. prod. 4. p. 80 . The reflexed petals of this species and the next forbid their being united to Mulinum.

Many-hcaded Asteriscium. Pl. $\frac{1}{4}$ foot.

4. A. isatidicárpum (Hook. et $\mathrm{Arn}$. in bot. misc. 3. p. 352.) stem much branched; branches terete; umbels many, few-flowered, disposed in panicles; involucra of few leaves ; fruit oval, parallelly biscutate; mericarps approximate. $4 . \mathrm{F}$. Native of the Cordillera of Chili. Mulinum isatidicárpum, D.C. prod. 4. p. 80. Dipterýgia isatidicárpa, Presl, mss. Umbels small, very numerous. Carpophore bipartite ; mature mericarps yellow, rather cuncated at the base.

Isatis-fruited Asteriscium. Pl. $\frac{x}{4}$ foot.

Cult. Sce Fragòsa, p. 259. for culture and propagation.

\section{Tribe III.}

SANICU'LEE (this tribe contains plants agreeing with Sanicula in important characters). D. C. prod. 4. p. 82. or Umbellàtæ imperféctæ Orthospérmæ türgidæ, Koch. umb. 198.-Umbellàtæ disciscéntes, Spreng. in Schultes, syst. 6. p. 30 . exclusive of 3 genera. Transverse section of fruit nearly terete. Mericarps covered with scales, furnished with 5 equal primary ribs, without any secondary ones, and destitute of vittæ. Transverse section of seed semi-terete, flattish in front. Petals erect, bent inwards from the middle, and emarginate. Umbels fasciculate or capitate, simple or irregularly subcompound.

XXIV. ACTINO'TUS (from axтiv asizivos, actin actinos, a ray ; involucrum). Labill. nov. holl. (1804) 1.p.67.t.92. R. Br. gen. rem. p. 25. D. C. prod. 4. p. 83.-Eriocàlia, Smith, exot. bot. (1805) 2. p. 37. t. 78-79. Spreng. in Schultes, syst. 6. p. 31. and 639. Lag. am. nat. 1821. no. 2. p. 105.-Proústia, Iag. in litt. 1807 . but not of D. C.

Lin. syst. Pentándria, Digýnia. Tube of calyx ovate, contracted at the top; linb 5-lobed: lobes oval-oblong. Petals wanting. Stamens opposite the calycine lobes. Styles 2, thickened at the base and villous, but setaceous at the apex. Ovaritum 1-ovulate. Fruit ovate, villous, marked by 5 stripes, and crowned by the calyx.-Erect branched Australian herbs. Leaves alternate, petiolate, variously cut. Umbels simple, many flowered, capitate ; pedicels very short ; involucrum many leaved, radiating, longer than the flowers.

1 A. Helia' ntul (Labill. nov. holl. 1.p.67. t. 92.) the whole plant clothed with tomentose wool; leaves bipinnatifid: lobules bluntish; involucrum 10-18-leaved, clothed with soft tomentum. §. G. Native of New Holland, about Port Jackson, Sc. Erioeàlia màjor, Smith, exot. bot. t. 7 . Involucrum expanded $1 \frac{1}{2}$ or 2 inclies in diameter, yellow. Flowers white.

Sun-flover Actinotus. Fl. June. Clt. 1821. Pl. 2 feet.

2 A. Mi'vor (D. C. prod. 4. p. 83.) plant smoothish; leaves clothed with adpressed villi beneath, ternate; seginents or leaflets trifid, acute; involucrum 9-10-leaved, acute, clothed with silky villi. $\odot$. H. Native of New Holland, on the Eastern coast. Eriocàlia minor, Smith, exot. bot. t. 79. Sieb. pl. exsic. nov. holl. no. 127. Involucrum expanded, 5 lines in diameter, red.

Smaller Actinotus. Pl. 1 foot.

Cult. The seeds of these plants may be reared on a hot-bed in spring, and in the month of May the plants should be planted out in the open border in a warm situation, where they will flower and seed freely.

XXV. PETA'GNIA (in honour of Vincent Petagna, a Neapolitan botanist, author of Institutiones Botanicæ, in 5 rols. $8 \mathrm{ro}$. Naples, 1785-1787). Guss. prod. fl. sic. 1. p. 311. and in litt. D. C. coll. mem. v. p. 35. but not of Gmel. nor Rafin.-Heterosciadium, D. C. mss. in herb. Balb.

Lis. syst. Pentándria, Digýnia. Úmbellules containing only 
3 flowers; central one hermaphrodite, fertile, sessile: 2 lateral ones male, pedicellate; the pedicels rather concrete at the base, with the calyx of the fertile or central flower. Male flowers with the tube of the calyx almost wanting, but with an obsolete somewhat 5-toothed limb; petals oval-oblong, acute at both ends, inflexed at the apex; stamens 5, alternating with the petals, and longer than them. Female or hermaphrodite flowers, laving the tube of the calyx ovate and compressed, and the limb obsolete: petals the same shape as those of the male flowers, rather membranous, permanent; stamens 5 , caducous ; styles 2, filiform, divaricate, very long; fruit ovate, compressed, 8 -nerved, with 3 nerves on each side, particularly one central, indicating where the raphe is, 2 in the middle, and 2 more conspicuous, seated on the dorsal angle of the mericarps. Mericarps and carpophore not distinct. Fruit empty or containing one ovulum, from one of the mericarps being abortive.-Herb perennial, smooth. Root or rhizoma like that of Adóxa or Hacquêtia. Leaf radical, on a long petiole, rather peltate, 5parted: partitions oval-cuneated, somewhat 3-lobed at the apex, and toothed : teeth mucronate. Stem solitary, hardly half a foot high, bearing at the apex 2 almost sessile opposite 3 -lobed toothed leaves. Branches 2, bifid at the apex. Bracteas or leaves of involucrum 2, opposite, oblong, acute, mucronately serrated, seated just under the branches. Branches or rays of umbel 2, short, bearing each 3 flowers at the apex, furnished with 2 small bracteas under the ramifications. 'Tlis very singular genus is allied to Hucquètia and Sanicula.

1 P. santculafòlia (Guss. l. c.) 4. H. Native of Sicily, in groves by the sides of rivulets, in cool places. Sison Gussoniànum, Balb. herb. Sison Gussònii, Spreng. cur. post.

Sanicle-leaved Petagnia. Pl. $\frac{1}{2}$ foot.

Cult. Sce Ilacquètia, p. 265. for culture and propagation.

XXVI. SANICULA (from sano, to heal or cure; supposed healing effects of the S. Europe'a). Tourn. inst. p. 326. t. 173. Lin. gen. no. 326. Lam. ill. 191. Hoffm. umb. prod. 65. t. 1. f. l. Spreng. umb. p. 24. Lag. am. nat. 2. p. 105. Koch. umb. p. 1 39. D. C. coll. mem. v. p. 35.

Lin. syst. Pentándria, Digýnia. Tube of calyx echinated; lobes foliaceous (f. 59. c.), permanent. Petals erect, conniving, obovate, emarginate, with an inflexed point (f. $59 . g$. ). Fruit nearly ylobose, not separable into 2 parts spontancously ; mericarps destitute of ribs, but furnished with many vittre, and densely clothed with hooked prickles; carpophore not distinct. Seed semiglobosc.-Perennial herbs. Leaves radical, petiolate, palmate lobed : lobes cuneated, deeply toothed at the apex. Stems either naked or furnisled with a very few leaves. General umbel with few rays; leaves of involucrum few, and usually divided. Umbellules of many rays; leaves of involuccl many, entire. Flowers male, fumale, and hermaphrodite in the same umbel.

Sect. I. Sanícra (an alteration from the generic name). Tube of calyx echinated. Leaves palmate lobed.

1 S. Europe's (Lin. spec. 339.) leaves radical, palmateparted; lobes trifid, toothed; flowers polygamons, all nearly sessile, disposed in umbellules; lobes of ealyx denticulated. 4. H. Native throughout the whole of Europe and Caucasus, in woods and groves, and particularly by the sides of rivulets. Oed. f. dan. 293. Schkuhr, handh, t. 60. Hoffm. umb. p. 67. Smith, engl. bot. t. 98 . Blackw, lierb. t. 63 . S. officinàrum, Neck. gallob. p. 137. Astrántia Diapénsia, Scop. carn. 304. S. mas. Fuclss. hist. p. 671 . S. officindlis, Gouan, hort. 131. Caúcalis Sanícula, Crantz. Flowers white or tinged with red, sessile, disposed in little heads. The plant was much celebrated formerly as a vulnerary. It discovers to the taste a hitterness and roughness. It has, however, bcen long discarded in medi- cine, and in Sir James Smith's opinion it seems to partake of that poisonous acrimony, which is found in most umbelliferous plants growing in a moist rich soil.

Iar. $\beta$, Capénsis (Cham. et Schlecht. in Linnæa. 1. p. 253.) plant taller than the species; stems leafy, branched; panicle dichotomous. 24. G. Native of the Cape of Good Hope. S. Canadénsis, Thunb. fl. cap. 254. exclusive of the synonymes. Perhaps a proper species.

Europcan Sanicle. Fl. June, July. Britain. Pl. $1 \frac{x}{2}$ font.

2 S. MAKYLA' NDica (Lin. spec. 3.39.) leaves quinately digitate, deeply serrated: lower ones pedate, on long petioles; flowers polygamous: male ones pedicellate; lobes of calyx entire. 24. H. Native of North America, and as far as the Saskatchawan ; Newfoundland ; undulating gravelly soils, near Fort Vancouver; as well as of Carolina, Maryland, and Pennsylvania. Jacq. icon. rar. t. 348 . Lam. ill. t. 91. f. 2. S. Canadénsis, Lin. spec. p. 339. Flowers whitish or yellowish.

Maryland Sanicle. Fl. June, July. Clt. 1765. Pl. 2 feet.

3 S. Mexica'na (D. C. prod. 4. p. 84.) radical leaves, as well as the cauline ones, palmate; leaflets on short petioles, rather cuneated at the base: lateral leaflets parted: middle one, and inner lobe of the lateral ones, somewhat trifid: all cuspidately toothed, and quite smooth ; umbels 3-rayed; rays hardly longer than the floral leaf; male flowers on short pedicels. $\psi$. H. Native of Mexico, between Tampico and Real del Monte. Stem simple, hardly a foot high, furnished with 3-4 alternate leaves. Allied to $S$. Marylándica, but differs as above.

Mexican Sanicle. Pl. 1 foot.

$4 \mathrm{~S}$. Li'вектA (Cham. ct Schlecht. in Linnæa. 1. p. 253.) leaves 5-parted; partitions cuneated, 3-lobed, deeply serrated ; serratures cuspidate by bristles; flowers polygamous: male ones few, on capillary pedicels: female ones sessile. $4 . \mathbf{G}$. Native of Sonth America, near Caripe ; and of Chili near Talcaguano and Conception; valleys near Valparaiso, where it is called Pato de Leon by the natives. S. crassicaúlis, Poepp. diar. no. 227. pl. exsic. no. 92. Plant 4 feet ligh.

Frecd Sanicle. P]. 4 feet.

5 S. MENZIE'SII (Hook. et Am. in Beech. bot. roy. p. 142.) plant caulescent; leaves on long petioles, cordate, deeply trifid: segments broad, obovate, cuneated, variously lobed, deeply serrated: serratures very acute, ending each in a bristly point; umbels rather compound; leaves of involucels lanceolate, acute, equal in length to the umbellules. 24. H. Native of the northwest coast of America; on the banks of the Columbia in dry sandy places; as well as of California. Hook. f. bor. amer. 1. p. 290. t. 90. Root fisiform. Plant smooth. Stem leafy, panicled at the apex. Male flowers on short pedicels. Segments of cauline leaves lanccolate.

Menzics's Sanicle. Pl. 1 to $1 \frac{1}{2}$ foot.

6 S. ELA'ta (Hamilt. ex D. Don, prod. f. nep. p. 183.) leaves ternate or tripartite, glabrous; segments or leaflets sessile, ovate, acute, lobed, and serrated, cuneated at the base : lateral segments usually 2-parted; stem dichotomous at the apex; umbels trifid, few-fiowered; flowers polygamous: male ones pedicellate. 4. H. Native of Nipaul. S. Canadénsis, Thunb. fl. jap. p.116. Stem 1-2 feet high, erect, simple.

\section{Tall Sanicle. Pl. 1 to 2 feet.}

7 S. uermaphrodita (Hamilt. ex D. Don, prod. A. nep. p. 183.) leaves ternate, glabrous; leaflets ovate, acute at both ends, lobed, and serrated; umbels trifid, usually 5 -flowered; flowers all hermaphrodite and scssile. 4 . H. Native of Upper Nipaul, at Suembu. Stem erect, branched, slender, flexious, a span bigh or more.

Hermaphrodite Sanicle. Pl. $\frac{1}{2}$ to 1 foot.

8 S. J JVA'NacA (Blum. bijulr. p. 832.) leaves palmately 5lobed, setaccously serrated; lobes rather trifid; male flowers 
numerous, pedicellate. $4 . \mathrm{S}$. Native of Jara, on the top of Mount Gede. Perhapss this is the same as S. Javanica, Juss. from the description of the leaves; but the umbels are nakedish above, in the forks of the stem, and on the tops of the branches, each umbel bearing 3 nearly sessile fruit afterwards.

Java Sanicle. Pl. 1 foot.

9 S. Monta'sa (leinw, in Blum. bijdr. p. 832.) leares all ternate; leaflets somewhat 3 -lobel, rather ovate-rhomboid, decply and sctaccously scrrated; Howers all pedicellate. 4.S. Native of Java, in mountain woods in humid places. Said to be nearly allied to $S$. Canadénsis.

Mountain Sanicle. Pl. 1 to 2 feet.

10 S.? 'Trichínium (1).C. prod. 1. p. S5.) leaves on lang petioles, glabrous, ternate; leaflets oblong, unequally toothed, lobed at the apex; radical leaves rather palmate: lateral segments bipartite; flowers all hermaphrodite. 24. H. Native of Louisiana. Pànax, Robin. voy. Louis, p. 469. Triclínium odoràtum, Rafin. Al. lud. p. 79. Flowers greenish, sweet-scented. Siid to be a congener of $S$. Marylándica.

Triclinium Sanicle. P]. 1 to 2 feet.

11 S. Bipinnatifida (Dougl. mss. ex Hook. f. bor. amer. 1. p. 258. t. 92 .) plant caulescent ; leaves bipinnatifid: lower ones on long petioles; segments remote, obovate or obovate-lanceolate, acute, decply scrrated: serratures very acute; rachis winged, acutely toothed; peduncles elongated; umbels conpound, some what proliferous; umbellules globose. $4 \mathrm{H} . \mathrm{Na}$ tive of the north-west coast of America, at Fort Vancouver, on the Columbia. Root rather fusiform. Plant glabrous. Stem erect, branched, furnished with a few leaves. Segments of the upper cauline leaves narrow. Male flowers on short pedicels.

Bipinnatifid-leaved Sanicle. Pl. 1 foot.

12 S. ARCTOPODIOI'DEs (Hook. et Arn, in Beech. voy. pt. bot. p. 141.) plant almost stemless; leaves on long petioles, profoundly 3-parted; segments long, cuneated: lateral ones bifid: intermediate one trifid; all are somewhat ciliately pinnatifid; peduncle hardly longer than the leaves; leaves of involucrum foliaceous, lanceolate, quite entire, longer than the simple compact umbel. 2. H. Native of the north-west coast of America, and North California. Hook. f. bor. amer. 1. p. 258, t. 91 . Root fusiform. Habit of the genus Arctònus.

Arctopus-like Sanicle. Pl. $\frac{1}{2}$ foot.

Sect. 11. SAxicòria (an alteration from the generic name). D. C. prod. 4. p. 85 . Tube of calyx smooth, but perhaps only in the flowcring time. Leaves bipinnate-parted.

13 S. grave olexs (Poepp. diar. no. 222. pl. exsic. no. 93.) leaves bipinnate-parted; segments pinnatifid: lobes obtuse; flowering branches elongated, nearly naked, trifid at the apex ; umbellules by threes, on slort peduncles; flowers 12-15 in each umbellule : male ones nearly sessile : female one central. $\boldsymbol{\psi}$. F. Native of Chili. Leaves almost like those of Scrophularin canina. Umbels truly compound. Flowers yellowish in the dried state. Petals cuneatc, cmarginate, having the segment at the top reflexed. Filaments of young stamens inflexed. Styles very long. Male flowers more numerous in the umbels than the sessile female flowers. Calyx of the male flowers smooth, of the female echinated.

Strong-scented Sanicle. Pl. 1 foot.

Cult. The species of Sanicula grow best in a shaded rather vor. 111. moist sitnation, and they are casily propragated by dividing at the root. Some of the species being natives of warm climates, will recpuire to be protected in winter.

XXVII. IIACQUE'TIA (in homour of Balth IIacquet; author of Planta $\Lambda$ lpina Carniolica, 4to. Vicnna, (1782) Neck. clen. (1790) no. 306.) D. C. prod. 4. p. 85.-Dóndia, Spreng. mem. soc. mosc. 5. p. 8. umb. prod. p. 21. f. 2. Lag. am. nat. 2. p. 96. Koch, nmb. p. 140.-Astrántia species, Lin. fil.Domlisia, lichb. but not of 1). C.

Lin. srst. Pentandria, Iligýnia. Tube of calyx furnished with 10 ribs, and 5 lobes: lobes foliaccous, permanent. Petals erect, connivent, obovate: with the segment at the apex length of the limb of the petal, and bent in from the midlle. Fruit crowned by the calyx, contracted from the sides; mericarps gibbonsly convex, furnished with 5 fililorm ribs. $-\Lambda$ small perennial herb. Leaves radical, petiolatc, palmate; leaflets 3 . cuneated, 2-3-cleft, mucronately serrated. Scapes 1-3, bearing at their tops simple umbels. Involucrum of 5-6 obovate leaves, which are toothed at the apex, and longer than the umbels. Flowers yellow, on short pedicels, some male, and some femalc. Fruit compressed from the sides; mericarps with 5 broad ribs, which are rather connate at the base, but separaterl by channels above.

I H. Epipáctis (D. C. prod. 4. p. 85.) 24. H. Native of Rhatia, on the mountains in the valley of Angustana; Carinthia, Carniola, \&c. Astrántia Epipáctis, Lin. fil. supp. p. 177. Scop. carn. t. 6. Jacq. austr. 5. t. 11. Sturm, deutschl. H. with a figure. Dóndia Epipảctis, Spreng. in Schultes, syst. 6. p. 241. -Lob. icon. t. 664. Flowers yellow.

Epipactis Hacquetia. Fl. March, April. Clt. 1823. Pl. $\frac{1}{2}$ to $\frac{1}{2}$ foot.

Cult. See Sanicula above for culture and propagation. The plant, bowever, does best in a pot in a mixture of sand and peat, placed among other alpine plants.

XXVIII. ASTRA'NTIA (from arroor, astron, a star, and avt, anti, in composition signifying comparison; in reference to the appearance of the umbels of flowers). Tourn. inst. 166. Lam. ill. t. 191. Lag. am. nat. 2. p. 97 . Koch, umb. p. 137. f. 42, 43. D. C. prod. 4. p. 86.-Astrántia species, Lin. gen. no. 327. spreng. prod. p. 19.

Lin. syst. Pentándria, Digýnia. Tube of calyx 10-ribbed, with tubercular plaits; lobes 5 , foliaceous. Petals erect, connivent, oblong-obovate: bent in from the middle by a segment, which is nearly the length of the petal. Fruit rather compressed from the back; mericarps without any vitta, but having 5 elevated obtuse plicately toothed inflated ribs, inclosing in the cavity of eaclı a smaller fistular rib; carpophore not distinct. Seed semi-terete.-Perennial herbs, natives of Europe and Caucasus. Roots blackish. Radical leaves petiolate, palmately lobed: cauline ones few, sessile. Universal umbels irregular, of few rays, surrounded by variable involucra; partial umbels regular, and containing many flowers, surrounded by many leaved involuccls. Flowers white or rosc-coloured, pedicellate, usually polygamous, the female ones alone fertile.

1 A. м'хor (Lin. spec. p. 340.) leaves palmate; segments $7-9$, lanceolate, acute, profoundly and acutely toothed; leaves of involucruin entire, about equal in length to the umbel. $4 . \mathbf{H}$. Native of the higher Alps of France, Switzerland, Italy, Gcrmany, \&c. Lam. ill. 191. f. 2. Sturm, dentschl. f. with a good figure. Lodd. bot. cab. t. 93 . A. minor var. $\alpha$ and $\beta, D$. C. ff. fr. 4. p. 353. A. digitàta, Moench, meth. p. 94. Hall. hist. no. 791. Leaves of involucrum white and acute. Flowers white.

Var. $\beta$, macrodónta (D. C. prod. 4. 1. 86.) segments of lcaves lanccolate-linear, profoundly and sharply serrated; leaves of involucrum exceeding the umbel. 4. H. Native of the $A l p s$ of Piedmont.-Bocc. pl. sic. p. 10. t. 5. f. 111. $\mathrm{M} \mathrm{m}$ 
Smaller Master-wort. Fl. May, June. Clt. 1686. Pl. $\frac{1}{2}$ to $\frac{3}{4}$ foot.

2 A. pavciflòra (Bertol, journ. bot. 1813. p. 76. am. itin. 96. and 347.) leaves palmate; segments $5-7$, entire at the base, but finely and slarply serrated from the middle to the apex; Jeaves of involucrum entire, exceeding the umbel. $4 . \mathrm{H}$. Native of the mountains of Abruzzo and Naples. Very like $A$. minor. There is a variety having the segments of the leaves lincar' or oval-oblong.

Fer-flonered Master-wort. Fl. June, July. Clt. 1820. Pl. 1 ft.

3 A. Carnoólica (Jacq. fl. austr. 6. t. 10.) radical leaves palmate-parted: lobes $5-7$, oblong, acuminated, unequally serratcd, toothed; leaves of involucrum 12-13, quite entire, exceetling the umbel. 24. H. Natise of Carinthia, Carniola, in alpine meadows. Sturm, deutschl. fl. with a figure. A. màjor $\beta$, Spreng. in Sclultes, syst. 6. p. 34.1. A. minor, Scop. fl. carn. no. 305. t. 7. Smith, exot. bot. 2. t. 77. Habit of $A$. minor, but with the character of $A$. màjor. Leaves of involucrum white, with a green line running along the middle of each, tinged with red. Petals white. Cauline leaves 3-lobed or simple. Root dark brown, having an aromatic balsanic smell, with a taste at first slightly aromatic, but nauseous, and afterwards acid.

Carniolan Nlaster-wort. Fl. May, June. Clt, 1812. Pl. $\frac{1}{2}$ to 1 foot.

1 A. MA'Jor (Lin. spec. p. 339.) radical leaves palmateparted: lobes 5 , ovate-lanceolate, acute, rather trificl, toothed, ciliated with bristles; leaves of involucrum $15 \overline{5}-20$, linear-lanceolate, quite entire, hardly longer than the umbel. \%. H. Native nearly throughout the whole of Europe and Eastern Caucasus, in mountain meadows and wools. Lam. ill. t. 191. f. 1. Nees, ofi: pt. 12. t. 6. Hayn. arz. gew. 1. t. 13. Smitl, exot. bot. 2. t. 76. Rivin. t. 68. Plenck, icon. t. 225. A. nigra, Lob. icon. t. 681. Scop. carn. no. 306 . Blackw. t. 470. A. cándida, Mill. dict. no. 2. A. alpina, Munt. phyt. t. 111. Helléborus nìger, Gard. aix. t. 46. A. màjor $\alpha$, Spreng. in Schultes, syst. 6. p. 34t.

Var. $a$; leaves of involucel white; flowers white.

lar. $\beta$; leaves of involucel purplish; flowers tinged with red.

Larger Master-wort. Fl. May, Sept. Clt. 1596. Pl. 1 to $2 \mathrm{ft}$.

5 A. istermedia (Bieb. suppl. p. 194.) radical leaves palmate-parted: lobes 5 , rarely only 3 , oval-oblong, deeply biserratel, and ciliated with bristles; cauline leaves nearly palmate ; leaves of involucrum 12-13, oblong-lanceolate, bearing from 1 to 3 spines each at the apex, exceeding the umbel a little. 4. 11. Native of Caucasus, in mountain meadows. A. trífida, 11 llim. umb. ed. 2. vol. 1. p. 8. A. Caucásica, Spreng. uunb. p. 17. sy t. 8. p. 874. exclusive of the synonymes. Flowers pink?

$\operatorname{lar} . \beta$; leaves of involucel nearly entire. 4.11 . Native of Cancasus and the mountains of Naples. A. màjor, Bieb. fl. and suppl. no. 509 .

Inlermediate Master-wort. Fl. June, July. Clt. 1818. Pl. 1 ft.

6 A. nelleborifòlia (Salisb. par. lonil. 1. t. 60.) radical leaves palmate-parted; lobes 3 , ovate-lanceolate, unequally serrated, ciliated with bristles; leaves of involucrum 12-13, ovatelanceclatc, exceeding the umbel a little, ciliated with bristles their whole length. 24. H. Native of Eastem Caucasus, in the more elevated meadows. $\Lambda$. máxima, Pall. nov. act. petrop. 7 . p. 357. t. 11. Sims, bot. mag. 1553 . A. heterophlýlla, Willd. nov. act. berol. 3. p. 119. Bieb. fl. taur. 1. p. 202. suppl. p. 196. Involucrum and flowers pink. There are varieties of this species having the cauline leaves either 8 -lobed or undivided.

IIellebore-leated Master-wort. l\%. June, July. Clt. 180 \%. Pl. 1 to 2 feet.

Cull. The species of this genus grow well in any conmon garlen soil, and are well adapted for ornamenting flower-borders, being rather pretty; they are easily increased by dividing at the root. $A$. minor and $A$. Carmiólica, being more tender than the rest, sliould be grown in pots, and placed among other alpine plants.

XXIX. ALEPI'DEA (meaning unknown to us). Laroch. eryng. p. 19. t. 1. D. C. prod. 4. p. 87.-Astrántia species of Lin. fil.

Lin. syst. Pentándria, Digýnia. Tube of calyx beset with minute tubercles. Petals inflexed. Transverse section of fruit terete, ovate, tubercular on the outside; mericarps without ribs, and without vittæ; carpophore adnate its whole length to the seeds.-An lierb, with the liabit of Eringium nudicaúle, native of the Cape of Gcod Hope. Radical leaves petiolate, oblong, ciliately toothed from spinescent bristles. Stems nearly naked, branched, umbellate at the apex. Leaves under the branches small, and stem-clasping. Umbels like those of Astrantir. An intermediate genus between Astrántia and Erýngium.

1 A. cimin'ris (Laroch. l. c.) 4. G. Native of the Cape of Good Hope. Tratt. arch. t. 204. Astrántia ciliàris, Lin. fil. suppl. 177. Thumb. fl. cap. 2. p. 196. Jasiòne Capénsis, Berg. act. ups. 3. p. 187. t. 10. Unbel 3-rayed, surrounded by a 2-3-leaved involucrum. Leaves of involucel 10 , coloured, broadlanceolate, acute, longer than the flowers.

Ciliated-leaved Alepidea. Pl. 1 foot.

Cull. Any light rich soil will suit this plant, and it will be easily increased by dividing at the root.

XXX. IIORSFIE'LDIA (in honour of Thomas Horsfield, M.D. F.R.S. F.L.S. \&.c ; author of numerous works on Indian zoology). Blum. mss. but not of Willd. D. C. prod. 4. p. 87.Schubértia, Blum. bijdr. p. 884. but not of Mart. nor Nirb.

Lin. srst. Pentándria, Digýnia. Margin of calyx obsolete, quite entire. Petals ovate, cuspidate, flat. Fruit compressed, villous; mericarps 3 -ribbed on the back.-A prickly shrub. Leaves cordate, 5-lobed : npper ones 3 -lobed, clothed with stellate tomentum beneatl. Panicle terminal, densely clothed with stellate tomentum. Umbels capitate, sessile, surrounded by a many-leaved involucrum; receptacle of flowers chaffy.

1 H. aculea'ta (Blum. l. c.) h. S. Native of Java, on Mount Tjerimai, in the provinee of Cheribon, where it is called Gompong. The rest unknown.

Prickly Horsfieldia. Shrub.

Cull. Any light rich soil will suit this slurub, and cuttings will be easily rooted in the same kind of earth under a handglass, in heat.

XXXI. ERY'NGIUM (from $\varepsilon \rho \varepsilon \gamma \omega$, ereugo, to belch. Dioscorides declares that the plant is a specific for all complaints arising from flatulence). 'Tourn. inst. p. 327. t. 173. Lin. gen. no. 324. Gæertn. fruct. 1. p. 77. t. 20. Laroch. eryng. 1. vol. in fol. Par. 1808. Lag. am. nat. 2. p. 105. Koch, diss. p. 139. in nov. act, nat. cur. 19. p. 1.

Lin. syst. Pentándria, Digýnia. Tube of calyx rough from vesicles and scales; lobes 5 , foliaceous. Petals erect, connivent, oblong-obovate : bent in from the middle by a segment as long as the limb of the petal, which consequently appears emarginate. Fruit obovate, scaly or tubercular, with the transverse section nearly terete; mericarps semi-terete, without ribs, and without vitte; carpophore adnate its whole length to the sceds.Herbs, nsually perennial and spiny. Radical leaves, as well as the cauline nnes, sheathing more or less at the base. Flowers con. gregated into oblong or roundish dense heads. Lower bracteas usually the largest, and forming an involucrum round the head of flowers; the rest like chaff, mixed among the flowers.

\$1. Ramosinérvia (from ramosus, branched, and nervus, a 
sinew or nerve; in reference to the nerses of the leares being more or less branched and diverging). D. C. prod. 4. p. 88 . Limbs of radical leaces more or less distinet from the petioles: having the nerves more or less branched, and diverging, but neter parallel.

* Limbs of radical leares multifid.

1 F. campe'stre (Dod. pempt. 730. f. 2. Lin. spec. 337.) radical leaves mearly teruate; scgnents pinnatifid: lobes ovate; cauline leaves auriculated; stem panicled ; lcaves of involucrum lincar-ianceolate, nearly entire, excecding the head of flowers, which is roundish; palea among the flowers subulate. 4 . II. Native of South and Middle Lurope, and Caucasus; very common in dry sandy fields. In Britain not very common; on the coast near the ferry from Plymouth to Cornwall; and near the Devil's Point at Stonchouse, Plymouth; near Newcastle upon Tyne; on the shore called Friar's Goose, below Melling, in Yorkshire; also far inland opposite Brookhall, near Daventry, in Northamptonshire. Laroche, eryng. p. 22. Oed. f. dan. t. 554. Hayne, arz. gew. 7. t. 1. Smith, eng. bot. 57. Jacq. austr. 2. t. 155. Plench. t. 173. E. rulgàre, Baul., pin. 368. E. Mediterràneum, Ger. 999. Corollas blue, but sometimes white and yellow. Roots creeping. Plant rather glaucous.

V ar. $\beta$; radical leaves nearly entire. $4 . H$. Native of Portugal and the Levant.

Field Eryngo, Fl. July, Aug. Britain. Pl. 1 to 2 feet.

2 E. Bourgiti (Gouan, ill. p. 7. t. 3.) radical leaves orbicular, tripartite ; lobes pinnatifid or cut in a forked manner, quite entire between the divisions; stems simple, a little branched at the apex; leaves of involucrum 10-12, lanceolate, pungent, erect, furnished with 1 or 2 teeth on each side, much longer than the liead of flowers, which is ovate; palea among the flowers entire. 4.H. Native of the Pyrenees, but has not been found elsewhere. D. C. H. fr. 4. p. 355 . Larodh, eryng. j. 24. Tratt. arch. t. 207. E. amethýstinum, Lam. fl. fr. 3. p. 401. but not of Lin. E. Bourgàti, E. plànum, and E. alpìnum, Lapeyr. abr. p. 137. There are varieties of this species with either sky blue or pale flowers: and with the stems either bearing one or more heads of flowers. Plant glaucous.

Bourgati's Eryngo. Fl. June, Aug. Clt. 173I. Pl. I to $2 \mathrm{ft}$.

3 E. Billardiéri (Iaroch. eryng. p. 25. t. 2.) radical leaves nearly orbicular, tripartite; lobes lanceolate, pinnatifid, spiny, profoundly toothed all round; stems branched at the apex; leaves of involucrum 8 , linear-lanceolate, 3 times higher than the head of flowers, which is globosc; palex among the flowers entire. 2. H. Native of the Levant; and in fields on the mountains at the limits of the Turkish districts called Khoi, in the province of Aberdeidjen. Tratt. arch. t. 356. Very nearly allied to $E$. Bourgati, but differs in the lobes of the leares being tootlied all round, and in the palea being hardly longer than the calyxes. Flowers blue.

\section{La Billardicr's Eryngo. Pl. 1 foot.}

4 E. spiva-A'LBA (Vill. dauph. 2. p. 660.t. 15.) radical leaves 3-5-parted; lobes profoundly toothed, or cut in a forked manner; stem thick, nearly simple; leaves of involucrum 9-10, pinnatifid, very stiff, pungent, about equal in length to the head of the flowers, which is of an ovate-cylindrical form; paleæ among the flowers entire, or usually tricuspiclate. 4. H. $\mathrm{Na}$ tive of Dauphiny, Provence, $8 c$. in arid exposed places of mountains. D. C. fl. fr. p. 356. Laroch. eryng. p. 26. t. 3. E. rigidum, Lam. dict. 4. p. 752. E. alpinum, Lin. mant. p. 349. but not of his spec. E. alpinum $\beta$, Scluultes, syst. 6. p. 328. E. palléscens, Mill. dict. no. 5. Spina álba, Dalech. lugd. 1462. Both heads of flowers and herb are white. There are varieties with either dwarf stems, or a foot high.

White-spined Eryngo. Fl. July, Aug. Clt. 1791. Pl. 1 foot. 5 E. dilata'tus (Lam. dict. 4. p. 755.) radical leaves pimna- tifid: lobes spiny-toothed; upper leaves the largest; petioles pecinately ciliated from the base; stems nearly simple, beariner few licads; leaves of involuerum $5-7$, lanceolate, spiny toothed, longer than the head, which is roundish; palea among the flowers variable: outer ones liurnished witl one tooth on each side: iumer ones cutire. 4 . II. Native of Portugal, Spain, Mauritania, Etruria; and 'Turkey, in ficlds about Constiustinople. Laroch. eryng. p. 26. t. 4. E. purpuratum, Suith in Rees' cycl. vol. 13. L. Bourgàti, Valıl, symb. 2. p. 48. Ilost. austr. 1. p. 341. E. foétidum, Forsk. cat. coust. p. 135 . W. austràle, Wulf, et West, in Schultes, syst. 6. p. 333. E. ametlyýstinum, Salzm. pl. exsic.-Barrcl. icon. t. 36. Heads of flowers and stem of a violaceous colour.

Dilated-petioled Eryngo. Fl. July, Aug. Clt. 1821. Il. 1 to 2 feet.

6 L. crinitum (Presl, del. prag. p. 139.) radical leaves pinnatifid: outer lobes trifid, spiny toothed: lower ones much smaller and bristly, or jagged into bristle-formed tecth; petioles ciliated with bristles from the base; stems nearly simple, bearing few heads; leaves of involucrum 5-6, lanceolate, spiny ciliated, exceeding the head of the flowers, which is roundish; paleæ exceeding the flowers, outer ones spiny ciliated. 4.11 . Native of Spain. Very nearly allied to $E$. dilatatum, but it differs from it and all the others in the bristles being yellowish, and rather spiny along the petioles and the lower lobes of the leaves. Flowers blue?

\section{Ilairy Eryngo. Pl, 1 to 2 feet.}

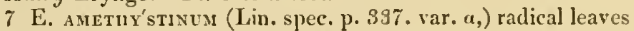
pinnatifid: lobes cut, spiny, somewhat pinnatifid; petioles entirc at the base ; stems smoothish, corymbosely branched at the apex; lcaves of jnvolucrum $7-8$, lanceolate, furnished with a few teeth at the base, much exceeding in length the head of flowers, which is globose; palea among the flowers entire: outer ones hardly furnished with a tooth on each side. \%. H. Native of Dalmatia, Croatia, and Belgimm, but in the last mentioned country it has probably escaped from the gardens. Waldst. et Kit. hung. 3. t. 215.-Besl. hort. eyst, ord. t. 8. f. 4. Tratt. arch. 206. E. campéstre azùreum, Lcjeun, in herb. Gay. E. cærùleum, Bauh, hist. 3. t. 86. f. 1. The upper part of the stem, and also the heads of fowers, are of the finest amethyst colour, so that they make a very finc appearance. This species is often confused with $E$. dilatalum, but is easily distinguished from that species in the petioles being entire, not pectinated.

Amethystine-flowered Eryngo. Fl. July, Aug. Clt. I648. Pl. I to 2 fect.

8 E. ANdersònir (Lag. in litt. Loud. hort. brit. p. 101.) radical and cauline leaves pinuatifid: 3 terminal segments large, lanceolate, and 3-lobed at the apex: the rest of the scgments small; all spiny toothed; stem smooth, striated, corymboscly and trichotomously branclied; leaves of involucrum 7-8-lanceolaic, spiny toothed, much longer tlian the head of the flower, which is rounded, furnished with retrograde forked or simple prickles on the lower sicle at the very base; upper palese among the flowers linear, entire, and the lower ones trifid, ending in spiny points, abaut the length or longer than the flowers. 24. H. $\mathrm{Na}$ tive country unknown. E. amethýstinum, Hort. Chelsea. Upper part of stem, and heads of flowers of a beautiful blue.

Auderson's Eryngo. Fl. July, Aug. Clt. ? Pl. 1 to 2 feet.

9 E. scariósum (Laroch. cryng. p. 28. t. 5.) leaves pimnatifid; lobes linear, distant, trifid, or entire; petioles with scarious margins; stem furrowed, branched at the apex; leaves of involucrum 5-8, linear, much longer than the head of flowers, which is globose; palea among the flowers entire. 4. H. Native of the Levant. Tratt. arch. t. 775. E. pentechinum, Sieb. herb. palest. Allied to $E$. amethystinum. Heads of flowers pale green. M $\mathrm{m} 2$ 
Scarious-petioled Eryngo. Pl. 1 to 2 feet.

10 E. glomera'tum (Lam. dict. 4. p. 755.) lcaves bipinnatifid; lobes linear, very stiff, divaricate; heads of flowers small, collected into a tliyrse; flowers small ; leaves of involucrum much longer than the head of flowers, and are as well as the paleæ nearly entire, and spinose. 4. H. Native of Crete. Laroch. eryng. p. 29. t. 6. Tratt. arch. t. 760. E. parviftorum, Smith, prod. fl. græc. 1. p. 175. Herb white, densely beset with leaves. P'erhaps the $E$. glomeratum, Sieb. herb. crete, which he gathered at the foot of Mount lda, is the same, but it differs from the figure given by Laroche, in the heads of flowers being disposed in a corymb, in the lobes of the leaves being broader, and in the leaves of the involucrum being furnished with a spinelike subulate divaricate tooth on each sicle.

Glomerate-headed Eryngo. Fl. Jul. $\Lambda$ ug. Clt. 1826. Pl. $1 \mathrm{ft}$. 11 E. rostra'tum (Cav. icon. 6. t. 552.) radical leaves long, lanceolate: outer ones spiny-ciliated: inner ones pinnatifid; stems a little branched; leaves of involucrum entire, rather shorter than the head of flowers, which is globose; palea among the flowers, entire: upper palea ending in a horn each, much longer than the flowers. $\mathcal{\Psi}$. H. Native of Chili, at Talcahuano, Conception, \&c. Laroch, eryng. p. 29. This species is intermediate between the section Ramosinérvia and Parallelinéria.

Beaked-scaled Eryngo. P]. 3 to 4 feet.

12 E. covo'sum (Laroch. eryng. p. 30. t. 7.) radical leaves bipinnatifid; lobes linear, winged; stem dichotomous at the apex, bearing many heads; leaves of involucrum 5-6, trifid, longer than the head of flowers, which is ovate; palea among the flowers simple: upper palea spiny-toothed, drawn out into a tuft. 24. F. Native of Mexico, in temperate p'aces between Rio Sacra and Tolucco. H. B. et Kuntl, nov. gen. amer. 5. p. 30. Flowers blue?

Tufted-scaled Eryngo. Fl. Jul. Aıg. Clt. 1818. Pl. $\frac{1}{2}$ to $1 \mathrm{ft}$. 13 E. Crét Ticum (Lam. dict. 4. p. 754.) cauline leaves almost pinnatifil; lobes lanceolate, spinose, ciliately toothed at the base; stems much branched at the apex, divaricate; leaves of intolucrum 5 , lanceolate-subulate, bearing $1-2$ spiny teeth on each side, mucl longer than the head of flowers, which is roundish; paleæ among the flowers, tricuspidate. 24. H. $\mathrm{Na}$ tive of the islands of Candia, Samos, and in all the islands of the Archipelago ; fiequent. Laroch. eryng. p. 30. t. 80. D'Urv. enum. 29. Sieb. hesb. cret. E. cyaneum, Sibth. fi. grac. t. 25s. prod. 1. p. 175 . Tratt. tab. t. 350 . Stems and heads of flowers of an amethyst colour. Floriferous branches elongated, or short and crowted.

Cretan Eryngo. Pl. 1 to $1 \frac{1}{2}$ foot.

14 E. multitidum (Sibth. et Smith, fl. grace t. 259. prod. 1. p. 175 .) leaves all bipinnatifi, somewhat lyrate, and palmateparted at the apex; lobes deeply lobed; stems corymbose, coloured at the top; leaves of involucrum linear-lanceolate, pinnatifid, or nearly entire, exceeding the head of flowers, which is ovate; palex among the flowers, entire. $2.1 \mathrm{H}$. Native of the hills of the Morea and Sicily. E. alpinum, elitius, \&c. Cup. pampl. 1. t. 29. Guss. prod. fl. sic. 1. p. 305. Top of stem and heads of flowers blue. Allied to E. amethýstinum and $E$.
Créticum.

Mullifil Eryngo. Pl. \& feet.

15 E. ovixum (Cunning. in Field's new south wales, p. 358.) stems erect, furrowed, dichotomous; leaves bipinnatifid; lobes linear, stiff, spinose, divaricate; lieads of flowers spherical, pedunculate; leaves of involucrum linear, mucronate, stiff. $4 . \mathrm{G}$. Native of New Holland, near Bathurst. Flowers white. The plant when young is much songht after by sheep.

Shecp Eryngo. Fl. July, Aug. Clt. 1824. Pl. $1 \frac{\pi}{2}$ foot.

* Limbs of radical leaces cordate at the base, undivided, or a little lobed.
16 E. Marítimum (C. Bauh. pin. p. 386. Lin. spec. p. 337.) leaves of a whitish glaucous hue, coriaceous; radical leaves on Jong petioles, roundish, cordate, spiny-toothed: superior ones stem-clasping, palmately lobed ; leaves of involucrum 5-7, ovate, spiny-toothed, exceeling the head of flowers, which is rourdish; paleæ among the flowers, tricuspidate, about equal in length to the calyxes. 24. H. Native throughout Europe, among the sand along the sea-shore; and on both sides of the Mediterranean Sea. It is to be found plentiful in some parts of Britain, on the sea-shore. Oed. fl. dan. t. 718. Tratt. arch. t. 209. Woodv. merl. bot. t. 102 . Smith, engl. bot. t. 718 . Roots creeping. Flowers very pale blıe. By English writers the Sea eryngo has been called sca holly, sea hulver, and sca holmc. The young flowering shoots of the plant, eaten like asparagus, are very nourishing, according to Linnæus. The leaves are sweetish, with a sliglit aromatic warm pungency. The roots are supposed to have the same aphrodisiacal virtues as the O'rchis tribe. They are kept in the shops candied, and are still regarded by the Arabs as an excellent restorative. Eryngo roots were first candied at Colchester about the beginning of the 17 th century by Robert Buxton, apothecary. His apprentice, Samuel Great, continued this business, and it has ever since been carricd on by the posterity of the latter.-Morant's Colchester, ]. 92 .

Sea Eryngo or Holly. Fl. July, Oct. Brit. Pl. 1 to $1 \frac{1}{2} \mathrm{ft}$.

17 E. Oliveria'sum (Laroch. eryng. p. 37. t. 12.) radical leaves on long petioles, roundish cordate; lower cauline leaves petiolate, 3-lobed, and deeply toothed: upper cauline ones stemclasping, s-parted, and cut; leaves of involucrum 10-12, lanceolate, stiff, having $5-6$ teeth on each side, which are more crowded towards the base, exceeding the head of flowers; paleæ among the flowers, tricuspidate, and entire. 4 . H. Native of the Levant. E.alpintum $\gamma$, Schulies, syst. 6. p. 323. Heals of flowers blue. Nearly allied to E. alpinum, but is constant to its characters, even in cultivation: it differs from it in the radical leaves being much less cordate, in the lower ones being more dissected, and in the leaves of the involucrum being stiff, and laving fewer tecth. The colour of the herb is green.

Olixer's Eryngo, Pl. 1 to 2 feet.

18 E. Gigante'um (Bieb. Al. taur. 1. p. 201.) radical leaves on long petioles, profoundly cordate, crenate-toothed; cauline leaves stem-clasping, deejly lobed, spiny-serrated; leaves of involucrum 8-9, large, ovate-lanceolate, deeply spiny-serrated, longer than the head of flowers, which is ovate; palea among the flowers tricuspilate. 4. H. Natire of the Alps of Caucasus, Armenia, and lleria. E. glaúcum, Willd. herb. ex Stev. in litt. E. asperifolium, Laroch. eryng. p. 36. t. 11. Poir. suppl. 3. p. 289 . Tratt. arch. t. 355 . Stem dicliotoinously branched, $3-4$ feet high, blue at the top as well as the heads of flowers. Lower leaves roughish, pubescent or glabrous beneath, reticulated with anastomosing nerves.

Giant Eryngo. Fl. Jul. Aug. Clt. 1820 . Pl. 3 to 4 feet.

19 E. AlPI'Nom (Lin. spee. p. 337.) radical and lower cauline leaves on long petioles, deeply cordate, serrate-toothed: upper cauline leaves palmately lobed, ciliately serrated; serratures spinulose; leaves of involucrum 10-20, rather soft, a little longer than the head of flowers, pinnatifilly serrated, having 12-15 cilia-formed serratures on each side: and with the lower serratures pinnatifid; palez among the flowers tricuspidate or entire. 4. H. Native of Switzerland, Piedmont, Germany, Croatia, Carniola, Sc. in alpine pastures. Jacq. icon. rar. 1. t. 55. Sims, bot. mag. t. 922. Tratt. arch. t. 205. Involucrum along with the upper part of the herb and the flowers are of a beautiful blue colour; but there is also a variety which is white in the last-mentioned parts: and another which has the paleæ among the flowers pinnatifid. Herb green. 
Alpine Eryngo. Fl. July, $\Lambda$ ug. Clt. 1597 . Pl. $1 \frac{1}{2}$ to $2 \mathrm{ft}$. 20 E. Pa'vom (Math. comm. p. 505. with a figure. Lin. spec. p. 337.) lower leaves on long petioles, oval, cordate at the basc, crenated, that: middle cauline leaves sessile, undivirled: superior ones 5-parted, serrated; leaves of involucrum 6-7, lanceolate, remotely spiny-serrated, spreading, about cqua! in length to the head of flowers, which is round; palese among the flowers entire, but the lower or onter ones are tricuspidate. 4. 11. Native of Austria, Russia, Siberia, Transylvania, Galicia, Caucasus, Mauritania, Provence, \&c. in meadows. Jacq. aust. t. 391. Tratt. arch. t. 214. Laroch, eryng. p. 40. Upper part of the stem, leaves of involucrum, and heads of flowers blue ; there is, however, a variety equally common in the gardens with white flowers. Herb green.

Flat-leaved Eryngo. Fl. July, Aug. Clt. 1596. Pl. $2 \mathrm{ft}$.

21 E. ти'QUetrom (Vahl. symb. 2. p. 46.) radical leaves petiolate, cordate, 3-lobed; lobes deeply spiny-toothed ; cauline leaves 3-5-parted, palmate; peduncles triquetrous; leaves of involucrum 3-4, lanceolate, pungent, keeled, entire, exceeding the head of flowers, which is round; paleze among the flowers entire. $\%$. H. Native of Tunis and Sicily in fields and on hills. Desf. atl. 1. p. 225. t. 54. Laroch. eryng. p. 43. 'Tratt. arch. $77 \%$-Zan. ist. t. 74 . and therefore E. Zanonii, Lam. dict. 4. p. 754. E. Créticum, Jan. ex Guss. prod. fl. sic. 1. add. p. 7. Heads of thowers blue.

Triquctrous-peduncled Eryngo. Fl. Jul. Aug. Clt.1824. Pl. 1 ft.

22 E. Falca'Tum (Laroch. eryng. p. 40. t. 13.) radical leares on long petioles, cordate, unequally spiny-serrated; cauline leaves sessile, palmately parted: lobes lanceolate, spreading, spiny-serrated; leaves of involucrum 5-8, lanceolate, furnished with 1-2 teeth on each side, twice the length of the head of flowers; outer paleæ tricuspidate: middle ones entire. 24. H. Native on Mount Lebanon. Tratt. arch. t. 363 . E. dichótomum $\beta$, Schultes, syst. 6 . p. 321 . The plant is easily distinguished fiom $E$. dichótcmum by the form of the radical leaves. Heads of flowers blue?

Falcate Eryngo. Pl. 1 to 2 fect.

23 E. Dichótomum (Desf. atl. 1. p. 226. t. 55.) radicalleaves petiolate, oblong, cordate at the base, toothed; cauline leaves palmately parted, spreading : lobes spiny-toothed; leaves of involucrum lanceolate, furnished with a few spiny teeth, much longer than the head of flowers, which is globose ; onter paleæ tricuspidate, the rest entire. 4 . H. Native of Asia Minor, Caucasus, Mount Lebanon, Candia, Mauritania, Sicily, and about Montplicr, in exposed places. Upper part of stems, leaves ol" involucrum, and heads of flowers bluc.

lar. a: stem tall, flexuous, much branched. Desf. l. c. Tratt. arch, t. 362. E. cœrùleum, Bieb. fl. taur. 1. p. 200.Mor. ox. scct. 7. t. 37. f. 13. and tlerefore E. Syriacum, Lam. dict. 4. p. 759 .

Var. $\beta$; stems dwarf; flowers crowded at the neck of the plant. Laroch. eryng. p. 40. t. 14.

Dichotomous Eryngo. Fl. Jul. Aug. Clt. 1820. Pl. 1 to $2 \mathrm{ft}$. 24 E. Difru'sum (Torr. rock. mount. no. 177.) leaves all digitately palmate; segments oblong, deeply serrated, spinose; stem dichotomously branched, difluse; heads of flowers globose; leaves of involucrum $4-6$, trific, deeply serrated, longer than the head of flowers; ovaries scaly. $\odot$. 11. Native of North America, on the banks of the Canadian river. Perhaps this species will form a proper section.

Diffuse Eryngo. PI. 1 foot.

* * Limbs of radical leaves oblong-obovate, or oval, never cordate at the base.

25 E. PUsíl Lum (Lin. spec. p. 397.) radical leaves lanceolate, entire, toothed or pinnatifid, attenuated at the base, petiolate: cauline leaves palmately parted, sessile; heads of flowers sessile; leaves of involucrum subulate, longer than the head of flowers, furnished with an appendage, or tooth at the base; palea among the flowers, entire. 24. H. Native of Spain, l'ortugal, Mauritania, Sicily, Sardinia, \&c. Laroch. eryng. p. 44. T'ratt. arch. t. 2 I $2 .-$ Barrel. icon. t. 1247 . IIcads of flowers greenish. 'This species is wearly allied to E. dichotomum, but differs from it in the radical leaves being attenuated at the base, never in any way cordate.

I'ar. (3, odorìtum (D. C. prod. 4. p. 91.) stem small, decumbent; heads few-flowered. Larocl. l. c. E. odoràtmm $\beta$, Lam. dict. 4. p. 756 .

lar. $\gamma$, galioides (D. C. I. c.) stem erectish; lower leaves somewhat pinnatifid, small; heads few-flowered. Laroch. 1. c. E. galioìctes, Lam. dict. 4, p. 757.

Iar. $\delta$, paludòsum (D. C. l. c.) stem nearly erect; lower leaves pinnatifid, large; heads few-flowered. Laroch. I. c. t. 16. E, odoràtum $a$, Lam. 1. c.

Small liryngo. Fl. June, Aug. Clt. 164.0. Pl. $\frac{1}{2}$ to 1 foot.

26 E. теим' tus (Poir. suppl. 4. p. 295.) radical leaves umdivided, lincar, spiny-toothed; cauline leaves tripartite ; leaves of involucrum lanccolate, cuspidate. 2\%. H. Native of Candia, on hills in rugged places. Tausch. hort. canal. with a figure and description. E. Tournefortiànum, Sternb. syll. pl. nov. 17. p. 32. ex Tausch. E. trifòlium, P. Alp. exot. 152. with a figure.-Mor. ox. 3. sect. 7. t. 36. f. 24. Laroch. eryng. p. 65. Heads of flowers blue?

Ternatc-leaved Eryngo. Clt.? Pl. 1 foot.

27 E. tripartitum (Desf. cat. hort. par. 1828.) radical leaves glabrous, petiolate, trifid ; leaves obovate-oblong, cuneated at the base, coarsely serrated : serratures distant, ending in spiny points; stem much branched; cauline leaves nearly sessile, 3-5-parted: lobes lanceolate, coarsely serrated; leaves of involucrum twice the length of the head of flowers, which is ovate-globose ; outer paleat tricuspidate : inner ones undivided. 4. H. Native country unknown.

Tripartite-leaved Eryngo. Pl. 1 foot.

28 E. AQuifòluum (Cav. anu. sc. nat. 3. p. 32.) radical leaves obovate-oblong, nearly sessile, attenuated at the base, coarsely ciliated or spiny-toothed from the base; cauline leaves somewhat stem-clasping, broadest at the base; leaves of involucrum 8 , ovatelanceolate, spiny-toothed, longer than the head of flowers, which is roundish; palex ending in 3 or 5 points. 24. H. Native of Spain. Laroch. eryng. p. 34. t. 10. Tratt, arch. t. 753. E. marítimum $\beta$, Pers. ench. p. 299. exclusive of the syn. of Fl. dan. Heads of flowers blue. 'The plant cultivated under this name has the lower leaves much longer and narrower at the base than those in the figure cited. Plant glaucous.

Holly-laved Eryngo. Fl. Jul. Aug. Clt. 1815. Pl. $1 \mathrm{ft}$.

29 E. cornicula'tum (Lam. dict. 4. p. 758.) radical leaves oblong-lanceolate, spiny-toothed; petioles fistular, septiferous ; cauline leaves stcm-clasping, trifid; leaves of involucrum 5, linear-subulate, quite entire, pungent; paleæ among the flowers, entire: ultimate ones drawn out each into a long horn at the apex. 4 . H. Native of Portugal and Spain, in boggy places. Brot. f. lus. 1. p. 416. Laroch. eryng. p. 42. t. 15 . Tratt. arch. t. 756. Sims, bot. mag. 1427. E. cornùtum, Donn, hort. cant. cd. 4. E. suavèolens, Brouss. ined. E. ouloràtum, Hort. par. E. paludósum, Hort. madr. lleads of flowers whitish, sweet-scented. llant glaucous. The leaves of the involucrum when the plant grows in dry places, about equal in length to the head of flowers. Horns sometimes on 2-3 of the paleæ, which are usually joined together.

Horncd Eryngo, Fl. Jul. Aug. Clt. 1803 . Pl. 1 foot.

30 E. Tricuspida'tum (Lin. spec. p. 337.? Desf. atl. 1. p 2\%.4.) radical and lower cauline leaves on long petioles, orbicular, 
cordate, acutely toothed ; cauline leaves sessile, palmate-parted: lobes lanceolate, spiny-serrated; leaves of involucrum lanceolate, spiny-serrated, exceeding the head of flowers, which is nearly globose; palez tricuspidate, longer than the calyxes. §. I. Native of Mauritania, Sardinia, Sicily, and the Morea, in cultivated fields and exposed places. Laroch, eryng. p. 33. t. 9. 'Iratt. arch. t. 211 . E. Buccòni, Lam. dict. 4. p. 754.-Boce. sic. SS. t. 47. Heads of flowers greenish. Flowers purplish. There are varieties of this species with tall and humble stems; and with the lobes of the leaves either linear or lanceolate.

Tricuspidate Eryngo. Fl. Sept. Clt. 1699. Pl. 1 to $2 \mathrm{ft}$.

31 E. inicifo'lum (Lam. dict. 4. p. 757.) radical leaves and lower cauline ones on short petioles, obovate, coarsely spinytoothed; petioles quite entire ; leaves of involucrum 5-6, dilated at the apex, and coarsely spiny-toothed, exceeding the head of flowers, which is ovate-oblong; palere tricuspidate, longer than calyxes. ○.H. Native of Mauritania, Spain, and Portugal. Brot. fl. lus. 1. p. 419 . Desf. atl. 1. p. 225. t. 53. Cav, ann. sc. 3. p. 51. Laroch. eryng. p. 34. Jleads of flowers blue? Herb a band high, stiff. There are varieties of this plant having the leaves of the involucrum cut or pinnatifid.

llex-lcaved Eryngo. Pl. $\frac{1}{2}$ foot.

32 E. TE'NuE (Lam. dict. 4. p. 755.) radical leaves obovatespatulate, deeply toothed: cauline ones palmate-parted: lobes linear, spreading, spiny-toothed; leaves of involucrum linear, spreading, spiny-toothed, exceeding the hearl of flowers, which is roundish; paler tricuspidate, bearing spines on the back, longer than the calyxes. $\odot$. H. Native of Spain, Portugal, and Mauritania, in cultivated fields, and on hills. Laroch. eryng. p. 32.-Clus. hist. 2. p. 159 . f. 1. E. pusíllum, J. Baul. hist. 3. p. 87.-Lob. icon. 2.t. 23. Flowers blue?

Slcnder Eryngo. Fl. July, Aug. Clt. 1814 . Pl. $\frac{1}{2}$ to $1 \mathrm{ft}$.

33 E. Nasturtifo'lium (Juss. in Laroch. eryng. p. 46. t. 17.) leaves all lanceolate, dilated at the apex, and somewhat pinnatifid; hranches decumbent; heads of flowers lateral, sessile, ovate; leaves of involucrum lanceolate-subulate, elongated, and entire, as well as the palea. $\odot$. S. Native of South America. Tratt. arch. t. 768 . Allied to E. vesieulosum, but differs in the angles of the ealyx being 5 , and in being rough from seales, not from vesicles.

N'asturtium-leaved Eryngo. PI. decumbent.

34 L. Cervante'su (Laroch. eryng. p. 47. t. 18. f. 1.) surculi decumbent; floral leaves trifid: lobes linear; heads of flowers axillary, peduneulate, roundish; leaves of involucrum 5 , subulate, spreading, exceeding the head of flowers a little. 7. H. Native of Mexico. 'Tratt. arch, t. 359 . F. vivipa. rum, Cerv. mss. Calyxes scaly. Allied to $E$. vesiculosum.

\section{C'creantes's Eryngo. Fl. Jul. Oct. Clt. 1820. Pl. dec.}

35 E. reostra'tum (Nutt. in litt. ex D. C. prod. 2. p. 92.) surculi creeping, filiform; leaves petiolate, ovate, unarmed, menloranous, some entire, and others are furnished with a tooth or lobule on each side; heads of flowers ovate, pedunculate, axillary; leaves of involucrum 5, oblong-linear, entire, deflexed; palea linear, snall; calyx papulose from vesicles. $\mathcal{L}$. H. Native of North America, in the Arkansa territory. Petioles variable in lengtl, some slorter than the limbs of the leaves, and others longer. Leaves rosulate, at the neck of the plant, but crowded at the node of the surculi, sometimes opposite. Peduncles 1 or $1 \frac{1}{g}$ inch long. Heads $2-3$ lines long.

Prostrale Eryngo. Pl. prostrate.

36 E. BaLdwini (Spreng. syst. 1. p. s7o.) leaves petiolate, oval, entire, or serrated; stem much branched, slender, usually prostrate; heads of flowers small, numerous; leaves of involucrum 2, tripartite : lobes linear, a little toothed at the base. ○. II. Native of Florida, in pine woods around St. Maria, and along the sea-shore near Augustine. E. gràcile, Baldw. in Nitt. gen. amer. 1. p. 175 . Ell. sketch. 1. p. 345. but not of Laroch. E. réptans, Willd. herb. ex Spreng.

Baldwin's Eryngo. Pl. prostrate.

37 E. vesiculo'sum (Labill. nov. holl. 1. p. 73. t. 98.) surculi creeping; radical leaves lanceolate, cuneate, and attenuated at the base, deeply toothed, almost pinnatifid; floral leaves trifid, with linear lobes; heads of flowers lateral, on short peduncles; leaves of involucrum 5, lanceolate-subulate, and are as well as the palea entire; calyx papulose. 2\%. G. Native of Van Dienen's Land. Laroch. eryng. p. 47. Tratt. arch. t. 780. Poir. suppl. 4. p. 291.

Bladdery-calyxed Eryngo. Pl. er.

38 E. subacau'Le (Cav. icon. 6. t. 556. f. 2.) radieal leaves petiolate, lanceolate, nearly quite entire; scape naked, bearing only 1 head of flowers, longer than the leaves: leaves of involucrum 8 , lanceolate, spinose, spreading, furnished each with I tooth on each side, longer than the liead of flowers, which is hemispherical; palea subulate, shorter than the calyx.-Native of Mexico, in Chalma. Laroch. eryng. p. 56. Tratt. arch. t. 778. Plant hardly more than a finger in height.

Nearly-stemless Eryngo. Pl. $\frac{1}{4}$ to $\frac{1}{2}$ foot.

39 E. RADiciflo'rux (Tratt, arch. t. 764 .) radical leaves sessile, ovate, spiny-serrated; heads of flowers solitary, roundish, sessile at the neck of the plant; leaves of involuerum 6 , ovatelanceolate, tridentate at the apes, discoloured, longer than the head; palex entire.-Native of New Granada, on the mountains of Pasto. E. hùmile $\gamma$. Laroch. eryng. p. 3\%. t. 18. f. 2 . H. B. et Kunth, nov. gen. aner. p. 34.

Rool-flowered Eryngo. Pl. $\frac{1}{4}$ foot.

40 E. Fla'ccidum (Hook. et Arn. in bot. misc. 3. p. 350.) radical leaves flaccid, on long petioles, deeply pinnatifid; segments linear, spinescent, bent downwards; stem slender, panicled at the apex; leaves of involucrum linear-lanceolate, stiff, acute, quite entire, abont equal in length to the head of flowers, which is elliptic; palex hardly equal in length to the flowers. $\odot . H$. Native of Buenos Ayres.

Flaccid-leaved Eryngo, Pl. $\frac{1}{2}$ foot.

4.1 E. coronatum (H, ok. et Arn. in bot. misc. 3. p. 350.) radical leaves lanceolate, spinosely pinnatifid; segments lanceolate-subulate, spreading; stem panicled at the top, many-headed; leaves of involucrum linear-subulate, spiny, quite entire, reflexed, abont equal in length to the head, which is cylindrical; palere oblong, acute, pale, equal in length to the flowers, the 2 or 4 superior ones protruding in long horns, which emulate the leaves of the involucrum. 24. H. Native of Buenos Ayres. Stem 6-8 inches ligh.

Cromned-headed Eryngo. PI. $\frac{1}{2}$ to $\frac{3}{4}$ foot.

42 E. IU'MuL (Cav. ann. p. 115 . icon. t. 556. f. 1.) radical leaves on long petioles, oval-oblong, spiny-serrated; cauline leaves 1 or 2 , oblong, sessile, serrated; stems bearing only 1 head of flowers, shorter than the radical leaves; leaves of involucrum 10, ovate-lanceolate, tridentate at the apex, coloured above, exceeding the head of flowers, which is globose and depressed at the apex; palexe entire. 2/.G. Native of Pert, on the mountains of Chimborazo and St. Antonio. E. lumile a, Laroch. eryng. p. 55 . Tratt. arch. t. 763.

Var. $\beta$; leaves of involucrum entire. Laroch, eryng. p. 55. H. B. et Kunth, J. c. On the mountains of Piclinea and Antisana. E. ranunculoides, Willd. herb.

Ilumble Eryngo. Pl. $\frac{1}{2}$ foot.

43 E. stella'tum (Mutis, in Laroch. eryng. p. 55. t. 25.) lower leaves petiolate, linear-lanceolate, crenated: upper ones sessile, opposite; branches elongated, bearing 1 head of flowers each; leaves of involucrum ovate, spiny-toothed, discoloured, exceeding the head; palex subulate, exceeding the flowers. 
4. G. Native of Santa Fe de Bogota. Tratt. arch, t. 777. II. B. et Kunth, nov, gen. amer. 5. p. 38. Leaves of involucrum smooth, yellow above.

Stcllate Eryngo. Pl. 1 foot?

44. E. Phyteu'sa (Laroch. eryng. p. 51. t. 21.) cauline leaves few, petiolate, linear-lanceolate, unarmed, crenated; crene mucronate; stem nearly simple, bearing $\approx$ beads of flowers; heads oblong, crowned by exserted foliaceous palea ; leaves of involucrum 3-10, linear, dellexed. 4. F. Native of Mexico, in meadows, near the town of Tolucco. II. B. et Kunth, nov. gen. 5. p. 30. Heads of thowers white.

Phytcuma-like Eryngo. Pl. 1 to $1 \frac{1}{2}$ foot.

45 E. GRA'cile (Laroch. eryng. p. 54. t. 24. but not of Nutt.) radical leaves petiolate, elliptic, very blunt at the base, crenated; stem nearly naked, few-flowered ; leaves of involucrum 8 , linearlanceolate, pungent, a little toothed, twice the length of the head of flowers; palex subulate, entire, longer than the ealyxes. 4 . F. Native of Mexico, in liumid places. H. B. et Kunth, nov. gen. amer. 5. p. 33. Plant a foot high. Ileads of thowers of an amethyst blue colour. Leaves of involucrum smooth and yellow above, but green beneatl.

Heak liryngo. Fl. July, Aug. Clt. 1821. Pl. 1 foot.

46 E. Bonplándi (Laroch. eryng. p. 52. t. 22.) radical leaves petiolate, ovate-oblong, erenated; stem nearly naked, 13-flowered; leaves of involucrum 8 , and are as well as the palex lanceolate; palex scarcely exceeding the calyses, of equa] size and shape. 4. G. Native of Mexico, in shatly woods. Tratt. arch. t. 754. E. Bonplandiànum, H. B. et Kunth, nov. gen. amer. p. 31. Tube of calyx tubereular.

Bonpland's Eryngo. P]. 1 to $1 \frac{1}{2}$ foot.

47 E. Nudicá'Le (Lam. dict. 4. p. 759. t. 187. f. 2.) radical leaves obovate, coarsely spiny-toothed: teeth ciliated; stem dichotomous, nearly naked, bearing few heads; leaves of involucrum lanceolate, spinose, equal in length to the head of flowers, which is roundish; palea subulate. $\psi$. H. Native of Monte Video; and of Chili, in the province of San Louis, on the tops of the mountains called Cerro del Morro, at the elevation of 4500 feet. Laroch. eryng. p. 51. Tratt. arch, t. 769. Cham. et Schlecht. in Linnaa. 1. p. 251. There are varieties of this species with bracteas all entire; or the outer ones are spinytoothed, and the rest entire; or all spiny-toothed ex Cham. et Schlecht. l. c. 'T he teeth of the leaves are sometimes entire and not again ciliated, and this brings the species very near E. scrratum.

Naked-slcmmed Eryngo. Pl. $\frac{1}{2}$ loot.

48 E. Serra'tuar (Cav. ann. 2. p. 132. icon. 6. t. 554.) radical leaves petiolate, lanceolate, profoundly serrated; stem nearly naked, and almost simple, few.flowered; leaves of involucrum 8-10, subulate, spreading, length of the head of flowers, which is globose; palea entire, subulate, excecding the flowers a little. 4. G. Native of Mexico. Laroch. eryng. p. 55. Tratt. areh. t. 776. Calyx covered with white scales. Stem a foot high. Perlaps the same as E. scrratum, Link, enum. 1. p. 260. but the leaves are not doubly serrated as described by him, but acutely crenated. Heads of fowers blue?

Scrrate-leaved Eryngo. Fl. Jul. Aug. Clt. 1800. Pl. 1 to $2 \mathrm{ft}$.

4.9 E. carlíse (Laroch. eryng. p. 53. t. 23.) radical leaves lanceolate, deeply spiny serrated, acute; cauline leaves palmatifid: lobes deeply serrated ; stem branched, bearing lew heads; leaves of involncrum $7-9$, ovate-lanceolate, deeply serrated; palex subulate, simple. 24 . G. Native on the mountains about the town of Mexico, and hetween Joya and Las Vigas, near Perote, and on Mount Orizaba. H. B. et Kunth, nov. gen. amer. 5. p. 32. Leaves of involucrum yellow above. Flowers blue.

I ar. a, eréctum (D. C. prod. 4. p. 91.) stem erect, solitary; leaves of involucrum ovate, twice the length of the head of flowers $\psi$. G. Laroch, eryng. 1. c. with a figure. Tratt. areh. t. 358 .

Iar. B, decumbens (1). C. I. c.) stem simple, diffuse; leaves of involverum equal in length to the head of thowers, which is oblong. $4 . \mathrm{G}$.

Carlina-like Eryngo. PI. 1 foot.

50 E. nomminoioes (D. C. prod. 4. p. 94.) leaves glabrous: radical ones unknown: cauline ones ending in a spine-like point: uppermost ones opposite; stem branched, bearing many heads; leaves of involucrum 10-12, oblong-lanceolate, spiny-serrated at the apex, white inside; palea forming a tuft at the top of the lieal of flowers. 4. G. Native about the town of Mexico. Allied to $E$. carline, but differs in the heads of flowers being oval and tufted at the apex.

IIorminum-like Eryngo. Pl. 1 foot.

51 E. cilia'tum (Cham, et Schleclit. in Linnaea. 2. p. 219.) radical leaves obovate-lanceolate, pectinately serrated: teetl, stiff, bristly; stem naked, bearing 1-3 heads: heads elliptic, echinated from the palez, which are subulately acuminated and smooth, and exceed the flowers; leaves of involucrum similar to the palea. 4. G. Native of Brazil, in the provinces of Cisplatine and Rio Grande, in fields. Heads coloured, 8-9 lines long.

Ciliatcd-leaved Eryngo. Pl. 1 foot.

52 E. E'Legans (Cham. et Schleeht. in Linnæa. 2. p. 248.) leaves linear-lanceolate, spiny-serrated, ciliated, tricuspidate at the apex; stem bearing many heads; heads globose, echinated; leaves of involucrum 10, lanceolate, spiny-toothed, tricuspidate at the aprex; paleæ tricuspidate, a little longer than the flowers, smooth. 4. G. Native of Brazil, in the provinces of Monte Vileo and Rio Grande do Sul. Root nearly globose, size of a filbert. Leaves 10 inches long, and 9 lines broad. Heads of flowers small, of one colour.

Elcgant Eryngo. Pl. 1 foot.

53 E. Nu'dum (Gill. et Hook. in bot. misc. 1. p. 334.) stem tall, panicled; leaves linear-subulate, channelled, spiny-ciliated: spines 2-3 together; heads of flowers globose. 4 . G. Native about Buenos Ayres, in the plains ealled the Pampas. Stem 4-5 feet. Allied to E. cbractcàtum, Lam.

Naked Eryngo. Pl. 4 to 5 feet.

54 E. divarica'tun (Hook. et Arm. in bot. misc. 3. p. 850.) stems prostrate, dichotomously divaricate, leafy, rigid; lower leaves bipinnatifid: cauline leares pinnatifid: segments linear, spinescent, divaricate; peduncles short, axillary, and in the forks of the stem; leaves of involuerum subnlate, reflexed, 4 times shorter than the head of flowers, which is elliptic. $\boldsymbol{\varkappa}$. F. Native of Buenos Ayres.

Divaricatc Eryngo. Pl. 1 foot.

35 E. sérra (Cham. et Schlecht, in Linnaea. 2. p. 246.) leaves ensiform, spiny-serrated, ciliated; stem panicled, bearing many heads; heads ovate, echinated; leaves of involucrum and outer palea lanceolate, subulately acuminated, spiny-toothed, smooth : inner palea entire, a little smaller than the outer ones. 4. F. Native of Brazil, in the province of Cisplatine, and near Monte Video. Radical leaves half a foot long. Heads unguicular, of one colour.

Saw-leaved Eryngo. Pl. 1 foot.

56 E. uncina'tum (Cham. et Sehlecht, in Linnæa. 2. p. 247.) leaves lanceolate, serrated ; serratures ending in recurved spines, ciliated; stem bearing few heads; heads globose, echinated; palere scabrous, tricuspidate; leaves of involucrum spinosely pinnatifid. 24. G. Native of the south of Brazil.

II. oked-spined Eryngo. Pl. 1 foot.

57 E. Floribu'nde (Cham. et Schlecht. in Linnea. 1. p. 245.) leaves ensiform, spiny-serrated, ciliated; stem panicled, bearing many heads; heads echinated by scabrous, subulately mucronulated paleæ; leaves of involucrum ovate, acuminated, 
subulate, hardly different from the palea. 4. G. Native of the south of Brazil. Stem fistular at the base.

Bundle-flowered Eryngo. Pl. 1 foot.

58 E. Aromáticum (Baldw. in Ell. sketch. 1. p. 344.) leaves cuspidate, pinnate, trifid at the apex, with cartilaginous margins; stem leafy, bearing many heads, corymbose; leaves of involucrum 5 , trifid, about equal in length to the head of flowers ; palex tricuspidate. 4 . H. Native of Florida, in dry pine woods. Stems 9-10 inclies high, numerous. Root aromatic.

Aromatic-rooted Eryngo. IJl. 1 foot.

59 E. FE'TIDUM (Lin. spec. p. 336. exclusive of the syn. of Gron.) radical leaves lanceolate, bluntish, attenuated at the base, spinulosely serrated; floral leaves palmate-parted, sessile; heads nearly sessile, cylindrical; leaves of involucrum lanceolate, spiny-serrated, much longer than the heads; palea among the flowers entire. 4 . S. Native of Jamaica, Cayenne, Demerara, Florida, Brazil, \&c. in fields and woods. Laroch. eryng. p. 50. Miclix. fl. bor. amer. 1. p. 163. Sloane, hist. 1. t. 156. f. $3.4 .-1$ lerm. lugd. t. 237. Plant with an ungrateful odour when bruised. Flowers white. Calys ornamented with roundish vesicles, not scales. The radical leaves are sometimes trifid at the apex in the plants we have seen growing in Brazil. The plant named $E$. foetidum by Ucria, a native of Sicily, is probably distinct from this. All parts of the plant are reckoned very powerful antilysterics, and much used by the negroes and poorer whites on all occasions of that nature, whence they call it flinecd. It is chiefly administered in decoctions or infusions.

Fetid Errngo. Fl. Ang. Oct. Clt. 171t. Pl. 1 foot.

60 E. H.e'Nke1 (Presl, in herb. Hanke, ex D.C. prod. 4. p. 94.) radical leaves lanceolate, 1-1erved, obtuse, attenuated at the base, furnished with spiny serratures from the base to the apex; canline leaves pinnatifidly serrated, palmately lobed at the apex: floral ones short, half stem-clasping; cymes twice forked; heads terminal, roundish; leaves of involucrum 5, much longer than the head of flowers, lanceolate-subulate, entire. 4. G. Native of Mexico, in grassy places towards Jalapa. E. Schiedeàum, Cham. et Sclilecht. in Linnæa. 5. p. 206. Habit of E. pusillum on the one hand, and of E. foe'tidum or E.virgatum on the other.

Hlanke's Eryngo. Pl. 1 to 3 feet.

61 E. virga'tum (Lam. dict. 4. 13. 757 .) leaves all on very short petioles, ovate, toothed: lower ones hardly subcordate at the base; stem rery simple, but branched divaricately at the apex; leaves of involucrum 6-7, linear, furnished with 1 tooth on each side, exceeding the head of flowcrs, which is globose; paleæ among the flowers tricuspidate. 2. H. Native of North America, in New Jersey, Carolina, and Georgia, in moist meadows and woods. Laroch. eryng. 1. 40. t. 20. Tratt. arch. t. 781. E. ovalifolium, Michs. f. bor. amer. 1. p. 165. Flowers pale blue?

Triggy Eryngo. Fl. June, July, Clt. 1810 . Pl. 1 foot.

62 E. Virginin'sum (Lam. dict. 3. p. 759.) leaves linearlanceolate, a little serrated ; leaves of involucrum $7-8$, longer than the head of flowers, entire or trificl; palea among the flowers tricuspidate. o. H. Native of North America, in pastures, by the sides of rivers, and in marshes which are inundated by the sea. Larocl, eryng. p. 48. t. 19. 'Tratt. arch. t. 78\%. Pursh, fl. amer. sept. 1. p. 189. E. aquáticum, Michx. f. hor. amer. 1. p. 163 . E. aquáticum $\beta$, Lin. spec. p. 336.Pluk, alm. t. 396. f. 3. Stem fistular. Ileads of flowers pale blue.

Virginian Eryngo. Fl. Jul. Sept. Clt. ? Pl. 2 feet.

63 E. macroce'plialum (Willl. herb. no. 5558 . Spreng. syst. 1. p. 871.) radical leaves oblong, glaucescent beneath, with cartilaginously crenated margius, haviug the rcesses between the crenæ glandular; cauline leaves very few ; peduncles elongated, naked; leaves of involucrum with cartilaginous margins, lanceolate, ending in spiny points, shorter than the head of flowers, which is small. $\psi$. G. Native of South America, according to Humb. trav. but the particular place is unknown. Leaves $1 \frac{1}{2}$ inches long, and 5-6 lines broad. Heads 3 lines in diameter. Palea not different from the leaves of the involucrum, unless that they are smaller, longer, and terminated by a mucrone, but without the cartilayinous margins.

Small-headed Eryngo. Pl. 1 foot.

64 E. DEPRE'ssum (Hook. et Arn. 1. c. 3. p. 351.) plant stemless; radical leaves linear-oblong, spatulate, spiny-toothed, having the nerves in the limb branched, with the branches diverging; branches of stem tufted, difluse, dichotomous, nu* merous fiom the neck of the plant; heads of flowers terminating the branches, and in the forks; leaves of involucrum and palea subulate, ahout equal, spiny, and entire, or furnished with a short spine on each side at the middle, much exceeding the flowers, which are sessile. $\odot$. H. Native of Chiloe; and of Clili, near Valparaiso, in Vina de la Mar.

'́ar. a, rigidum (Hook. et Arn. ]. c.) branches stiff, forked a little, ahout equal in length to the leaves.

I ar. $\beta$, fláceidum (Hook. et Arn. l. c.) branches elongated, slender, trichotomously divided. Chili at Valparaiso and Casa Blanca.

Depressed Eryngo. Pl. $\frac{1}{2}$ foot.

65 E. Axómalum (Hook. et Arn. in bot. misc. 3. p. 350.) root simple; leaves coarsely serrate-toothed at the apex : radical ones roundish, cuneated at the base, petiolate: upper cauline ones cuneated; heads on short peduncles; leaves of involucrum and chaff about equal, oblong, spiny-mucronate, quite entire, much exceeding the flowers, which are sessile; fruit papillose from vesicles. $\odot$. H. Native of Chili, about Valparaiso. The fruit and the palex among the flowers has induced the anthors to refer this plant to Erýngium, to which its appearance is altogether foreign.

\section{Anomalous Eryngo. Pl. $\frac{1}{2}$ to 1 foot.}

\$2. Parallelinérvia (from parallelus, parallel, and nerrus, a nerve; nerves of leaves parallel). D. C. prod. 4. p. 95. Nerves of radieal leaves parallel and longitudinal. Leaves narrow, and probably redueed to the dilated petioles.

66 E. aqua'ticux (Lin. spec. 336. var. $a$. exclusive of the syn. of Gron.) leaves broadly linear, with parallel nerves, remotely spiny-ciliated: lower leaves rather ensiform : floral ones lanceolate, toothed; leaves of involucrum $8-9$, shorter than the head of flowers, which is globose, and are as well as the paleæ entire; stems dichotomous. 24.H. Native of North America, from Penusylvania to Virginia; also of the Society Islands, California, and Buenos Ayres, in marshes, inundated pastures, and on the banks of rivers. Jacq. icon, rar. t. 347. Laroch. eryng. p. 5. Ker. bot. reg. t. 372. E. yuccæfòlium, Michx. f. bor. 1. p. $164 .-$ Pluk. alm. t. 975 , f. $4 .-$ Mor. ox. 3. p. 167. sect. 7. t. 37 . f. 21 . Stem erect, $2-3$ feet high, terete, simple below. Flowers white, or very pale blue. In North America the plant is called Rattle-snake-nced, from its use in curing the bite of that venomous reptile.

Aquatie Eryngo. Fl. July, Sept. Clt. 1699. Pl. 2 to $3 \mathrm{ft}$.

67 E. Longifòlium (Cav. ann. 2. p. 133. icon. 6. t. 555.) leaves broadly linear, with parallel nerves, remotely spiny-ciliated ; stem many times forked; leaves under the branches opposite, very short, 3-5-cleft ; leaves of involucrum 10, deflexed, lanceolate, rather shorter than the head of flowers, which is nearly globose; palea entire, exceeding the flowers. $4 . \mathrm{G}$. Native of Mexico, about Pachuca and Real del Monte. Laroch. eryng. p. 58. Tratt. arch. t. 766. Flowers white.

Long-leaved Eryngo. Fl. Jul. Aug. Clt. $18 \% 0$. Pl. 2 to $3 \mathrm{ft}$. 
68 E. angustifólium (D. C, prod. 4. p. 95.) radical leaves linear, with paralle! nerves, lobatcly serrated: serratures distant; cauline leaves few, opposite; heads of tlowers short; scales of involuerum and palea very long, linear-subulate, very aeute. 4. G. Native of New Holland. Stem terete, a foot high, striated, twice trifid, erect. Leaves of involucrum and palea half an ineh long, much longer than the flowers.

Narron-leaved Eryngo. 1). I foot.

69 E. casaliculatex (Cham. et schlecht. in Linnaa. 2. p. 23s.) leaves very narrow, ehanuelled, with parallel nerves, shining, spiny eiliated ; spines often accessory ; stem panicled, bearing many lieads : heads nearly unarmed, globose; leaves of involuerum comnate at the base, smooth, harlly larger than the palex. 2. G. Native of the interior regions of Brazil. Habit of $E$. pristis. Radical leates 2 lines broad. Spines $7-8$ in the space of an inch.

Channclled-leaved Eryngo. Tl. 1 foot.

70 E. pkistis (Cham. et Schleeht. in Linnaa. 2. p. 237.) leaves with parallel nerves, very narrow, flat, striated, spinyciliated, often with accessory spines; stem panicled, bearing many lieads: heads ulobose, echinated from subulate-spinescent bracteas; leaves of involuctum ovate, acuminated, scabrous, twiec the length of the calyxes, hardly diflerent from the palea. 26. G. Native of Brazil, in the province of lio Grande. Stem 4 feet high and more, solicl. Radical leaves tufted, a foot and a half long.

Grampus Eryngo. Pl. 4 feet.

71 E. PANDANifolivm (Cham. et Schlecht. in Linnæa. 2. p. 23i.) leaves with parallel nerves, linear, obsoletely and remotely spiny-toothed: stem panicled, hearing many heads: heads disposed in umbels, egg-shaped, unarmed: leaves of involucrum ovate, acuminated, smooth, hardly different from the paleæ, which are rather longer than the calyxes. 4. F. Native of Brazil, in the province of Cisplatine. Heads semi-unguicular, coloured. Radical leaves 18 lines long, broad at the base.

Scren-pine-leaced Eryngo. PI. 2 to $S$ feet.

72 E. PEtiola'tum (Hook. 11. bor. amer. 1. p. 259.) leaves with parallel nerves, lancenlate, tapering into long petioles, remotcly spiny-ciliated; upper leaves narrow, sessile; leaves of involucrum and palex subulate, spiny-ciliated, stiff, twice the length of the flowers. 24. H. Native of north-west Anerica, in moist soils on the plains of the Multnomali river. Perioles $4-6$ inches long. Heads echinated.

\section{Petiolate-leaved Eryngo. l'l. 2 feet?}

73 E. panicula'tum (Laroch. eryng. p. 59. t. 26.) leaves with parallel nerves, linear, spiny-ciliated: floral ones very short; stem nearly naked, bearing at the apex umbellate branches; branches bearing 1-3 heads; leaves of involucrun 9-10, lanceolate, and are as well as the palex entire. 4. G.

lar. a, Chrlénse (I). C. prod. 4. p. 96.) leaves of involuerum hardly different from the palcæ; leaves all spiny-ciliated. $\mathcal{~} 1$. G. Native of Chili. E. paniculatum, Cav. Domb. Laroch. 1. e. L. aquáticum, Cav. icon. 6. p. 17.

Var. i3, oligodon (1). C. I. c.) leaves of involucrum hardly different from the paleæ; lower leaves entire, or scarcely ciliated on the edges. $4 . \mathrm{G}$. Native of Brazil. E. paniculatum, var. $a$, Cham. et Schlechr. in Linnas. 2. p. 234.

Iar. $\gamma$, bracteosum (I). C. l. c.) leaves of involuerum elongated and reflexed. 4 . G. Native of Brazil, in the province of Cisplatine. Cham, et Schlecht. l. c.

Paniclcd-flowered Eryngo. 1'. 1 foot.

74 E. cymòsuy (Laroch. cryng. p. 63. t. 31.) leaves with parallel rerves: lowe ones linear, channelled, bearing very long, conjngate, subulate tceth; upper leaves pinnatifid; floral branches umbellate; leaves of involucrum 8-10, lincar, quitc entire, at length reflexed, longer than the head of flowers, which vol. 111 . is round: palea subulate, a little longer than the calyxes. 4 . F. Native of Ilexico, in the higher plains near lasco. 'T'ratt, arch. t. 361 . H. B. et Kunth, nov. gen. 5. p. 35.

Cymose-headed Eryngo. 1']. 2 feet.

75 E. luzurafócium (Cham. et Schlecht. in Linnea. 2. p. 2.0.) leaves with paralk.l nerves, linear, denticulated; lower teeth setiferous : upper ones obsolctely spinulose; stem bearing few heads: heads unarmed, glohose; leaves of involncrum ovate, acute, ronghish, hardly different from the paleze. 4 . G. Native of the sonth of Brazil. Leaves $2-3$ lines broad. Heads pale straw-coloured, as also the rest of the plant.

Linzula-leaced Eryngo. Pl. 1 foot.

76 E. GRamíneum (Laroeh. eryng. 60. t. 27.) leaves with parallel nerves, narrow-linear, remotely spiny-ciliated; sten bcaring only 2 heads ; leaves of involucrum $8-9$, lanceolatesubulate, nearly entire, spreading, a little shorter than the head of flowers, which is ovate; palex subulate, a very little longer than the flowers. 4. F. Native of Mexico, in shady woods near Santa liosa. H. B. et Kunth, nov. gen. amer. 5. p. 34. Tratt. arch. t. 761 . Stem simple, 2 feet high. Heads of tlowers of an amethyst colour.

Grassy-leaved Eryngo. P'l. 2 feet.

77 E. BRomelafóluu (Laroch. eryng. p. 60. t. 28.) leaves with parallel nerves: bearing large subulate teeth, which are shorter than the breadth of the leaves; raclical leaves very long, broadly lanceolate-linear: floral ones opposite, keeled, arched; leaves of invohicrum 10, lanccolate, acuminated, few-toothed, exceeding the head of flowers, which is round; paleæ entire, twice the length of the calyxes. 4 .F. Native of Mexico, in humid woods. Tratt. areh. t. $35 \%$. H. B. et Kunth, nov. gen. amer. 5. p. 3.. Flowers white?

Pinc-apple-leaved Eryngo. PJ. 3 to 4 feet.

78 L. Pectina'tum (Presi, in herb. Hank. ex D. C. prod. 4. p. 96.) leaves with parallel nerves, bearing twin, subulate tecth, 1 in each pair, very short, and the other longer than the breadth of the leaves: radical leaves long, lanceolate-linear: floral ones opposite; leaves of involucrum 10 , lanceolate, acuminated, coarscly spiny-toothed at the base. $4 . F$. Native of Mexico. E. Deppeànum, Schlecht. et Cham. in Linnæa. 5. p. 207. Very like $E$. bromelice ólium, but differs in the leaves being much narrower. Branehes of stem bearing either 1 or $y$ heads.

Pectinate-leaved Eryngo. Pl. 2 to 3 fect.

9 E. Hимвóldir (Laroch. cryng. p. 61. t. 29.) lenves with parallel nerves, lanceolate-linear, closely spiny-toothed: spinules in pairs; stem branched above; heads of flowers oblong, conglomerate; leaves of involucrum 7-8, lanceolate, toothed, usually shorter than the head of flowers; outer palex toothed: inner ones entire. $\%$. G. Native of New Granada, on Mount Quindiu. Tratt. arch. t. $76 \%$. E. Humbóldtiànum, H. B. et Kunth, nov. gen. amer. 5. p. 34.

II umboldis Eryngo. Pl. 2 to 3 feet.

80 E. prote.florum (Laroch. eryng. p. 62. t. 30.) leaves with parallel nerves; eauline leaves densely crowded, rather imbricated, lanceolate, coarsely spiny-toothed; heads of flowers large, oblong; leaves of involucrum 20-22, large, toothed, lanceolate, exceeding the lead of flowers; palex entire. 24. F. Native of Mexico, at the foot of the burning Mount Jorullo, and on Mount Orizaba. Tratt, arch. t. 773. H. B. et Kunth, nov. gen. amer. 5. p. 35 . Leaves of involuerum smooth and yellow above.

Protea-flonered Eryngo. Pl. 2 to 3 feet.

81 E. moxocérualum (Cav. ann. 2. p. 116. icon. t. 553.) lower leaves with parallel nerves, linear, channelled, bearing unequal, ternate, subulate teeth; upper leaves pinnatifid; stem bearing only 1 head of flowers; teaves of involuerum 20-24, lanceolate, furnished each with $1-2$ spreading spines, exceeding $\mathrm{N} n$ 
the head of flowers, which is roundish. 4. F. Native of Ilexico, near Huanajato and Chilpaneingo. Laroch. eryng. p. 62. Tratt. arch. t. 767.

One-headed Eryngo. Pl. 4 feet.

82 E. Ju'nceur (Cham. et Schlecht. in Linnæa. 3. p. 241.) leaves with parallel nerves, very narrow, inconspienously spinydenticulated, acute; stem bearing few heads; heads nearly unarmed, globose; leaves of involuerum 10.12, connate at the base, ovate, 5 -nerved, acuminated, and are as well as the palea smooth. 4. G. Native of Brazil. Heads of one colour, 5 lines in diameter.

Rushy Eryngo. Pl. 1 to 2 feet.

83 E. erióphorum (Cham. et Schlecht. in Linnæa. 3. p. 242.) leaves very narrow, linear, with parallel nerves, quite entire, fringed with villi at the base; stem bearing 1 or few heads; heads between egg-shaped and globose, unarmed; leaves of involucrum as well as the paleae elongated, acuminated, and striated. 24. G. Native of Brazil, in the province of Cisplatin and Rio Grande. Stem bearing few leaves, from 1 to $2 \frac{1}{2}$ feet ligh. Leaves a line broad: radical one a foot and more iong. Bracteas longer than the flowers. Habit almost of a Cypèrus.

$W_{0 o l}$-bearing Eryngo. Pl. 1 to 2 feet.

84 E. sangussore (Cham, et Sehlecht. in Linnæa. 3. p. 239.) leaves linear, with parallel nerves, spiny-serrated: serratures tnwards the apex of the leaf blunt and retrograde; stem naked, bearing few heads: heads ovate; leaves of involucrum as well as the palea subulately acuminated, a little longer than the Howers. 4 . F. Native of the south of Brazil, in the province of Rio Grande. Tube of ealyx clothed with searious seales at the angles. Heads echinated, coloured, 9-10 lines long.

Sanguisorla-like Eryngo. Pl. 2 feet.

85 E. ebractea'tun (Lam. dict. 4. p. 759.) leaves linear, with parallel nerves, usually ciliated at the base with long bristles; stem trichotomously corymbose; heads eylindrical, unarmed; leaves of involucrum as well as the palex entire, shorter than the flowers. 4.G. Native of the south of Brazil. Laroch. eryng. p. 64. t. 32. Tratt, arch. t. 758. Cham, et sehlecht, in linnæa. 2. p. 244. E. nudiflòrum, Willd. herb. which was collected about Ibague, in New Granada, is the same, according to Cham. et Schlecht. 1. c. Stem erect, 2 feet high. Habit of the last species. Calyx rough from scales.

Bractless Eryngo. Fl. July, Aug. Clt. 1817. Pl. 2 feet.

Subgenus I1. Lessònia (in honour of - Lesson, a writer on composita). Bertero, mss. Hook. bot. mise. 3. p. 351. Small shrubs or trees, with diehotomous branches, which are marked below by the cicatrices of the fallen leaves, but densely leafy at the extremities. Peduncles terminal, bearing a solitary, globose, or hemispherical head of Howers each.

86 L. Bupleuroides (Hook. et Arm. in bot. misc. 3. p. 352.) arborescent; leaves flat, serrated; leaves of involuerum shorter than the head of flowers. 2 . G. Native of Juan Fernandez, in woody, stony, elevated situations at El Portezuelo. Lessonia bupleuroides, Bertero, mss. Lessonia, Bertero, in ann. se. nat. rol. 21. t. 348. Stem 5-6 feet high, with forked terete branches. Leaves $3-4$ inelies long. Heads of flowers dense, hemispherical. Bupleurum-like Eryngo. Shrub 5 to 6 feet.

87 E. Sarcopiy yidum (Hook. et Arn. in bot. mise. 3. p. 35\%.) arboreseent; leaves cylindrical, fleshy; leaves of involucrum wanting. $々 . G$. Native at Massa Fuera, near Juan Fernandez. The heads of flowers are exactly globose, withont any involucra. Branches dichotomous.

Fleshy-leaved Eryngo. Shrub 5 to 6 feet.

\section{$\uparrow$ Species not sufficiently linown.}

SS E. Palle'scens (Mill. dict. no. 5.) radical leaves roundish, multifid ; heads pedunculate. 24. H. Native of Europe. E. alpinum amethýstinum, capitulo majore pallescénte, Tourn. inst. 327. Allied to E. amethystinum, according to Mill. but distinet from it.

Pale-blue-flowered Eryngo. Fl. Jul. Aug. Clt. ? Pl. 1 to $2 \mathrm{ft}$.

89 E. America'num (Walt. H. carol. p 102.) leaves entire: radical ones roundish: cauline ones ovate-lanceolate: uppermost ones trifid; stem procumbent. 4 . H. Native of Carolina.

American Eryngo. Pl. procumbent.

90 k. cartuanoides (Smith, in Rees' cycl. vol. 13.) leaves oblong, toothed, undivided, cordate at the base, and stemclasping; stem nearly simple, bearing few heads; leaves of involucrum few and ovate. 2 . H. Native of Mauritania. Perhaps the same as $E$, aquif otium?

Carthamus-like Eryngo, Pl. 1 foot.

91 E. cervileum stella'tum montis Liba'ni. Mant. phyt. p. 26. t. 127. differs from $E$. dichótomum in the radical leaves being bipinnatifid. ex Laroch. eryng. p. 66 .

Slarry-blue Eryngo of Mount Lebanon. Pl. 1 foot.

92 E. pa'rvum palia're fòlins serra'tis. Mor. oxon. sect. 7. t. 36. f. 13.

Small Eryngo with serrated leaves.

93 E. Mlexica'num follis lóngis denta'tis. Moris. oxon. p. 167. seet. 7. t. 37. f. 22. Scórdii spina, Hern. mex. p. 222. E. aquáticum $\beta$, Lam. dict. 4. p. 758. Native of Mlexico.

Mexican Eryngo with long toothed laves. Pl. 1 foot.

N.B. E. lateriftònum (Lam. diet. 4. p. 473.) or Gràmen orientàle spicìtum (Tourn. eor. p. 39.) is not a Cénchrus, as had been supposed by Linnæus, nor an Erýngium but Corispérnum púngens.

Cutt. Most of the species of this genus are extremely handsome and beautiful, and particularly so the hardy kinds, which are therefore well fitted for decorating borders. They all succeed well in common garten soil ; but the lighter and more sandy the soil is the better they will grow. The greenhouse or frame kinds slould be grown in pots, so that they may be sheltered in winter. All are readily increased by dividing at the root, or by seed.

XXXII. ACTINA'NTHUS (from acte, actin, a ray, and a $\theta 0 s$, anthos, a flower; involucels). Ehrenb. in Linnaa. 4. p. 398. D. C. prod. 4. p. 668 .

Lin. syst, Pentándria, Digýnia. Flowers monoccious, female ones capitate: male ones in capitate umbels: marginal ones joined, abortive, and spinescent, having the receptaele destitute of palea. Teeth of calyx permanent. Petals oblong, complicate at the apex, rather cirrhose. Fruit compressed from the sides; mericarjss with the 5 alternate sutural ribs strongest: having the furrows between the ribs furnished with 1 vitte each, and the commissure with 2 vittæ; carpophore adnate.-A stiff, squarrose plant. Lower leaves ternately bipinnate. Involucrum none; involucels of many leaves. Flowers white. This genus comes between Ocnánthe and Erýngium, aceording to the fruit, but from the inflorescence it is analogous to Echinóphora.

1 A. Srrinevs (Ehrengb. 1. c.). 4. H. Native of Syria, between the towns of Sachle and Balbec.

Syrian Actinanthus. Pl. 1 foot.

Cult. See Erýngium above for culture and propagation.

\$2. Umbels compound or perfect. Vitte on the fruit variable, rarely wanting.

* Fruit having only primary ribs present. Tribe IV.

AMIIINEA (plants agreeing with $A^{\prime} m m i$ in important 
characters) or Ortiospéri.E pacciJuaA'te contra'cta. Koch. umb. p. 114.-D. C. prod. 4. p. 98. Fruit evidently compressed from the sides, and for the most part contracted and didymous; mericarps with 5 filiform ribs, which are at length a little winged : lateral ribs marginal; all equal. Seed tercte or gibbously convex, flattish in front, or terete in every part. U IIbels perfectly compound.

XXXIII. RU'MIA (a mythological name; the goddess of young infants). Hoffm, umb, 171. in tit. f, 3-4-17-21. Koch. umb. p. 129. in add, no. 6I. D. C. coll. mem. 5. p. 36. prod. 4. p. 98. but not of Link.-Càchrys, species, Spreng.

Lis. syst. Pentándria, Digýnia. Margin of calyx 5-toothed. Petals oblong, ovate, entire, spreading, having an inflexed or involute point. Fruit roundish or ovate, didymous, plicately wrinkled; mericarps solid, with 5 thick, very blunt, circularly plicate ribs, covering the furrows; each furrow furnished with a vitta, and ornamented with plicate tubercles. Carpophore bipartite. Seed gibbously convex, flat in front.-Perennial smooth herbs, natives of the Levant. Leaves decompound. Umbels numerous. Universal involucrum wanting or few-leaved; involucels 3-8-leaved. Flowers yellow, dioccious, or polygamous. This genus differs from Càchrys in the sced not being involute nor frce, but straight, and adnate to the calyx. It differs from Séseli in the form of the petals and sunk ribs of the fruit, and from Hippomaruthrum in the secds being flatish in front, not with involute margins.

1 R. Taúrica (Hoffm. umb, et Koch. umb. l. c.) leaves decompound ; segments linear ; involucrum wanting ; male flowers numerous in the umbellules: but the fructiferous ones are few ; fruit nearly orate, rugosely plicate. $4 . H$. Native of Tauria, on grassy hills about Odessa and Karassusabar. Càchrys Taúrica, Willd. spec. I. p. 1410 . Bieb. fl. cauc. 1. no. 548. Schultes, syst. 6. p. 444. Artèdia squamàta, Pall. nov. act. petrop. 10. p. 308. Sanícula crithmifòlia, Willd. neu. scrift. d. berl. ges. 9. 1. 419. Laserpítium Armènum ferulæfòlia, scmine crispo, Tourn. cor. p. 23.

Taurian Rumia. Fl. July. Clt. 1819. Pl. $1 \frac{1}{2}$ foot.

2 R. Mскоса' RPA (Hoflm. umb. 175. fig. in tit. 3 and 21.) leaves decompound; segments linear-setaceous; involucrum many-leaved; flowers for the most part hermaphrodite: fruit subglobose, wrinkled. $\psi$. H. Native of Caucasus at Narzana, and of Iberia. Càchrys microcárpa, Bieb. fl. taur. 1. p. 218. (exclusive of the syn. of Mor.) suppl. p. 216. Spreng. in Schultes, syst. 6. p. 445. Càchrys Sícula, Giildl. trav. p. $154-$ 190. ex Bieb. Fruit roundish, rather didymous; ribs thick, concrete into a mass, which is grumose inside ; furrows narrow, each furnished with 1 vitta. Habit almost of Càchrys crispa, but differs in the true involucra not being pinnatifid, but the leaves are multifid and disposed in whorles under the flowering branches beneath the true umbel.

Var. $\beta$, rigídula (D. C. prod. 4. p. 98.) leaves more stiff and glaucous than the species. 4 . H. Natire of the Levant.

Simall-fruited Rumia. Pl. 1 foot.

3 R. Seseloides (Hoffm. umb. p. 174. tit. f. 4.) leaves decompound; segments cuneiform-lanceolate, cut; fruit oval, with tubercular ribs; involucrum of 1 leaf. $\psi$. $H$. Native of Siberia and Altaia. Càchrys seseloldes, Bicb. fl. taur. suppl. p. 217. in a note. Leaves of involucels sctaceous, numerous, minute. Séseli montànum, or Séseli glabràtum, Willd. herb. in Schultes, syst. 6. p. 406. Trínia seseloides, Led. fl, ross, alt. ill. t. 8. f. alt. 1. p. 357.

Sescli-like Rumia. Fl. July. Clt. 1820. Pl. 1 foot.

4 R. Leogòna (Meyer, verz. pflanz. p. 125.) leaves supradecompound; leaflets bifid or trifid; segments linear, shortish; involucels obsolete; fruit ovate; ribs straight, destitute of plaits and tubercles. 4. H. Native of Caucasus on the higher mountains of Talusch, at the clevation of 5000 to 6000 fect. 'T'rínia lloflinánni, 1). C. prod. 4. p. 104.

Var. $\beta$, microcirpa (Mcyer, l. c.). Native of Caucasus, on Mount Beschbarmak.

Smooth-angled-fruited liumia. Clt. ? I'l. 1 to 2 feet.

5 R. atiamanjioides (D. C. prod. 4. p. 98.) leaves decompound; segments cunciformly-ovate, pinnatifid, pubescent; leaves of both the involucrum and involucel unmerous, with membranous margins; fruit ovate, laving the ribs tubercular. 4 . I. Native of siberia. Càchrys athmanthoides, Bieb. suppl. p. 217. Ithamántha carvifolia, Willd. herb. is either referrible to this or to the preceding species.

Alhamantha-like liumia, Fl. July. Clt. 1818. Pl. 1 to $2 \mathrm{ft}$.

Cult. A light soil answers the species of this genus best; and they are easily increased by sects.

XXXIV. CICU'TA (a name of doubtful meaning, used by Pliny). Lin. gen. иo. 354. Hoffm. umb. 177. Spreng. umb. prod. p. 19. Lag. am. nat. 2. p. 96. Koch. umb. 129. f. 5\%. and f. 54. D. C. prod. 4. p. 99.-Cicutària, 'Touru. inst. t. 171. Jaam, dict. 2. p. 2. ill. t. 195.-Angélica species, Touru.

Lix. syst. P'ntándria, Digínia. Margin of calyx 5-toothed, foliaceous. l'ctals obcordate, with an inflexed point. Fruit roundish, contracted from the sides, didymous; mericarps witl 5 flattish, equal ribs: litteral ribs marginal; furrows furnished with I vitta each, which fills them, even in a dried state, but not elevated so much as the ribs. Commissure furnished with 2 vitta; vitta under a loose membrane; carpophore bipartite. Transverse section of seed teretc.-Perennial, glabrous, aquatic, poisonous lerbs. Stems terete, fistular. Leaves tripinnate, or biternate. Involucrum wanting or of very few leaves; involucels many-leaved. Flowers white.

\section{* Europcan species. Fibres of roots cylindrical and slender.}

1 C. vıròs A (Lin. spec. p. 368.) trunk of root hollow, divided into cells by transverse dissepiments; fibres of roots disposed in whorled fascicles; leaves triternate; segments lanccolate, serrated; umbels opposite the leaves and terminal. \%. W. H. Native of the north of Europe, from Lapland to Germany; and of Siberia in ditches, lakes, rivers; North America betwecn lat. $54^{\circ}$ and $64^{\circ}$. In England it is not common, but is found at Isleworth, in the Coln, near Colnbrook, and Uxbridge; on Hounslow Heatlı; in the Isle of Ely ; Lovingland, in Suffolk ; near Norwich and Yarmouth, \&c. In Scotland it is more common, as in the Lake of Forfar, and other lakes in Strathmore, \&.c. Oed. f.dan. t. 208. Nees. off. pflz, 12. t. 8. Hayne, arz. gew. 1. t. 37. Bull. herb. t. 31. Smith, engl. bot. t. 479. Blackw. t. 574. Plench, icon. t. 213. C. aquática, Wepfer. mon. phil. trans. 44. t. 237. t. 4-5. Cicutària aquática, Lam. dict. 2. p. 2. Coriándrum Cicùta, Roth. germ. 1. p. 130. Sìum Cicuta, Vest. cnch. no. 311 . Flowers white; antlier reddisl. Towards the end of autumn the root for the succeeding summer is formed out of the lower part of the stalk; this is divided transversely into many large unequal cells, so that it becomes specifically lighter than water, and in winter, when the rivers or pools swell, is buoyed up. The old root then rots, floats all the winter, and in rivers is frequently carried to great distances, In the spring the old root is washed asvay, and the new one, on coming near the soil, sends out many slender fibres, by which it is again fixed, grows, and flowers. Watson, in phil, trans. It is one of the rankest of our vegetable poisons. Numcrous instances are recorded of its fatality to the lumman species by Wepfer, Haller, and others, and in the phil. trans. by Dr. Watson. Linnæus relates its fatal effects on kine; and Dr. Withering relates that early in the spring cows often eat it, and are killed by it, but as the summer advances, and its scent becomes in 2 
stronger, they carefully avoid it : that goats, however, devour it greedily witls impunity, and that horses and sheep eat it with safety. Strong emetics are the most approved remedy for this poison.

Íar. $\beta$, tenuifólia (Schrank, akad. munch, philos. class. 7. j). 56. t. 4. f. I.) trunk of root slender, bearing fascicles of cylindrical fibres; leaves bipinnate; seginents linear, entire, and subserrated; umbels opposite the leaves, and terminal. 4 . W. 11. Native of Germany, near Fussen.

Poisonous Water Hemlock or Cowbane. Fl. July. Britain. Pl. 2 to 3 feet.

\section{* * American species. Fibres of roots oblong and fleshy.}

2 C. BULBIfFRA (Lin. spec. p. 367.) fibres of roots oblong, tuberous, fleshy; leaves biternate; segments linear-lanceolate, rather serrated; umbels terminal and axillary; axils and rays bcaring bulbs. 4. W. 11. Native of North America, in temperate and cold parts, from the river Delaware to Canada, in water, and on banks of lakes and rivers. Michx. fl. bor, amer. 1 . p. 165. Torr. fl. un. st. 1. p. 308 . Big. fl. bo:t. ed. 2. p. 115. Flowers white, having the smell of cumin-flowers.

Sulb-bearing Cowbane. Fl. July, Ang. Clt. 1810. Pl. I to 2 feet.

3 C. macula'ta (Lin. spec. p. 367.) fibres of roots oblong, fleshy, tuherous; leaves biternate; segments lanceolate or ovatelanceolate, acuminated, mucronately serrated; umbels terminal and lateral; stem spotted. 2. W. H. Native of North America, in watery places, from Carolina to New England, and hetween lat. 54 and $64^{\circ}$ north in the woody country: Canada, Lake Huron, Straits of De Fuca, and on the west coast. Bigel. fl. bost. 2. p. 115. amer. med. bot. 1. t. 12. Torrey, fl. un. st. 1. p.S08. Rafin. med. bot. 1. t. 22. Cicutària maculàta, Lam. dict. 2. p.2. Flowers white. Fruit a little larger than that of C. viròsa.

I ar. 3 , angustifolia (Hook. fl. bor. amer. 1. p. 259.) leaflets narrower. On the banks of the Saskatchawan.

Spolled-stemmed Cowbane. Fl. July, Ang. Clt. 1759. Pl. 2 to 3 feet.

Cull. The species should be planted in ponds or ditches, whese they will increase withont any further care.

XXXV. ZI'ZIA (in honom of J. B. Zizii, a German botanist ; author of a Flora of the Palatinate of the Rhine, in conjunction with Koch). Koch. umb. p. 129. D. C. prod. 4. p. 99.-Smýnium species of Lin.- Smýnium, Ell. sketch. 1. p. 359.-Smýrnium and Tháspium, Nutt. gen. amer. 1. p. 195 and 196.-Smýrnium species of authors.

Lix. srst. Pentándria, Digínia. Margin of calyx obsolete, or with 5 very short tecth. Petals elliptic, tapering into a long inflexer acumen. Fruit contracted from the sides, rather didymous, roundish or oval; mericarps with 5 filiform, prominent, equal ribs: lateral ribs marginal; furrows between ribs furnished with 1 vitta each, and the commissure with 2 vitte; carpophore bipartite. Seed teretely convex, scarcely flattish in front.-Perennial herbs, natives of North America. Stems ncarly simplc, arect. Leaves ternate or biternate; segments oblong, ovate, or cordate. Involucrum wanting; involucels few-leaved, variable. Hlowers yellow, rarely white, or dark purple. 'J'is genus differs from Smýnium in the seed not heing involute, and from $A$ prum in the petals ending in a long intlexed acumen each.

$1 \%$. AU'REA (Koch. l. c.) leaves biternate; segments oblonglanceolate, attenuated at the base, deeply serrated; involucels 3-leaved, unilateral. \%. 11. Native of North America, on rocky liths and moint pastures, from Carolina to Pennsylvania; and of Camada, about Lake Huron. Suýrnium aureum, Lin. spec. p. 377 . Miclıs. fl. bor. amer. 1. p. 171 . Ell. sketch.
1. p. 359. Nutt. gen, amer, 1. p. 195. Sison aúreus, Spreng. in Schultes, syst. 6. p. 410 . Torrey, f. un. st. 1.p. 805. Tháspium aúreum, Nutt. gen. amer. 1. p. 196. Rays of umbel short. Leaves of involncel 3, unilateral, rather concrete at the base. Flowers golden yellow.-The Simýrnium aúreum, Burm. fl. cap. p. 8 . appertains to this species, but the country from which it is said to come is truly doubtful, and is probably a mistake.

Var. 3 , aeuminàta (D. C. prod. 4. p. 100.) intermediate segment of leaves nearly pinnate, with 5 segments. \%. H. Growing along with the species. Smýrnium acuminatum, Smith, in Rees' cycl. vol. 33. no. 8.

Golden-flowered Zizia. Fl, May, Ju. Clt. 1699. Pl. 1 to $3 \mathrm{ft}$.

2 Z. CORDA'TA (Koch, l. c.) radical leaves undivided, cordate, crenated, petiolate : cauline ones nearly sessile, ternate; leaflets petiolate, ovate-corclate, serrated; involucel usually 1-leaved. 4. H. Native of Carolina, on moist mountains and pastures; and probably on the mountains of Virginia and Pennsylvania; plains of the Led River, Saskatchawan, and the river Winepeg and prairies of the Rocky Mountains. Smýrnium cordàtum, Walt. fl. carol. p. 114. Ell. sketch. 1. p. 359 . Schultes, syst. 6. p. 438. 'Torr, A. un. st. 1. p. 307. Sison trifoliàtum, Michx. fl. bor. ames. 1. p. 168 . Smýrnium trifoliàtum, Muhl. cat. p. 31. Nutt. gen. amer. 1. p. 195. Flowers golden yellow, very like those of the preceding species; but according to Nutt. they are white, and according to Elliot either white or yellow; there are therefore probably two species confused.

Cordate-leaved Zizia. Fl. Ju. Jul. Clt. 1597. Pl. 1 to $2 \mathrm{ft}$.

3 Z. integérrima (D. C. mem. soc. hist. nat. gen. vol. 4. p. 100.) leaves biternate, rather glaucous; leaflets ovate, quite entire; involucel 1-leaved, very short. 4. H. Native of Virginia, New York, and Carolina, on moist mountains, pasticularly on the Alleghany mountains. Smýrnium integérrimum, Lin. spec. p. 1468. Wichx. fl. bor. amer. 1. p. 171. Ell. sketch. 1. p. 360. Nutt. gen. amer. 1. p. 195. Sison integérrimus, Spreng. syst. 1. p. 887 . Torr. H. un. st. 1. p. 305. Flowers golden yellow.

Quite entire-leaved Zizia. Fl. Ju. Clt. 1758 . Pl. 1 to $2 \mathrm{ft}$.

Cult. A moist soil suits the species of this genus best; and they are easily increased by dividing or by seeds.

XXXV1. PENTACRY'P'TA (from $\pi \varepsilon \nu \tau$, pente, five, and $\kappa \rho v \pi \tau \omega$, lrypto, to hide; application not evident). Lelim. sem. hort, hamb, 1828 , p. 16. D. C. prod. 4. p. 100.

Lin. syst. Polygàmia, Moncécia. Calyx unknown. Petals equal, lanceolate, acuninated, inflexed. Fruit oblong-elliptic, compressed from the sides; mericarps witl 5 ribs, the 3 dorsal ones are elevated and acute, and the 2 marginating ones roundish: each furrow having 1 vittæ. Albumen 5-angled; angles roundish.-Herb suffruticose at the base. Leaves triternately pinnate. Flowers dark purple, polygamous. Perhaps sufficiently distinct from Thispium.

1 P. atropurpu'rea (Lehm. in sem. hort. hamb. 1828. p. 16.) 4. 1. Native of Mexico. Mature fruit browuish, and have a strong scent of parsley, as well as every part of the plant.

Dark-purplc-flowered Pentacrypta. Pl. 2 feet.

Cult. This plant will require to be protected in winter; it can only be increased by seeds.

XXXVII. A'PIUM (from apon, Celtic for water; habit. ation of plauts). Hoffm. umb. 1. p. 75. t. 1. f. 8. Koch, umb. 128. D. C. coll. mem. 5. p. 36. prod. 4. p. 100. A'pium species, Lin. Spreng, and Lag.

Lin, syst. Pentándria, Monog?́nia. Margin of calyx obsolete. Petals roundisl, entire. Stylopodium depressed. Fruit joundish, contracted from tlie sides, didymous; mericarps with 5 filiform equal ribs: lateral ribs marginal: furrows between the 
ribs having one vitte each, but the outer ones have $2-3$ vitte; carpophore mulivided. Seed gibbously convex, llattish in Iront. - Herbs, having the roots thickish at the neck. Stems furrowed, branched. Leaves pinnate; leallets cunciform, eut. Umbels axillary on the branchlets, and nearly sessile at the top of the stem. Involucri and involucels wanting. Flowers white or greenish.

Sect. I. Eun'pium (from cu, well, and apium, celery; this section is suppostel to contain the true species of the genus). I), C. prod. 4. p. 101. Point of petals elosely involute.

1 A. Gravéoless (Lin. spec. 37\%.) plant glabrous; leaves pinnate : upper ones ternate; leaflets cuneated, cut aud toothed at the apex. \$. H. Native nearly thronghout the whote of Europe, even to Caucasus, in ditehes; and also of Chili, near Mendoza, and of the Falkland lslands. D'Urv. f. mal. p. 457. In Britain it is a common weed by the sides of ditches, brooks of water, and marshy ground, especially towards the sea. Simith, engl. bot. t. 1210. Sichultes, syst. 6. p. 429. Hayn. arz. gew. 7. t. 24. F]. dan. t. 790. Plench, icon. t.217. Séschi gravèolens, Scop. carn. no. 360. Sìm A'piun, Roth, germ. 1. p. 128. Sìm gravèolens, Vest. man. bot. p. 517. Celery is known in Britain in its wild state under the name of smallage. The seeds and whole plant in its native ditches are acrid and dangerous, with a peculiar rank coarse taste and smell, and the effects of cultivation in prorlucing from it the mild sweet stalks of celery are not a little remarkable; for which, and its name, we are indebted to the Italians, and which has now supplanted our native Alesanłers (Smúrnium Olusàlrum).

Use.-The blanched leaf-stalks are used raw as a salarl from August till March; they are also stewed, and put in soups. In Italy the unblanched leaves are used for soups, and when neither blanched nor the green leaves can be had, the seeds bruised form a good substitute. The root only of the variety called the celeriac, is used, and is excellent in somps, in which, whether white or brown, slices of it are used as ingredients, and readily impart their flavour. With the Germans it is also a common salad, for which the roots are prepared by boiling, until a fork will pass easily tlirough them; after they are boiled and become cold, they are enten with oil and vinegar. They are also sometimes served up at table, stewed with rich sauces. In all cases before they are boiled, the coat and the fibres of the roots, which are very strong, are cut away, and the root is put in cold water on the fire, not in water previously boiling. The varieties are as follow :-

Var. 3 , dúlce (D. C. prod. 4. p. 101.) leaves erect; petioles very long; leatlets 5 -lobed, serrated. A'pium dúlce, Mill. dict. no. 5. A'pium Celleri, Gærtn. fruct. 1. t. 22. Colery of the English; eeleri or ache of the French; eppich of the Germans; and appio of the Italians. There are several sorts of the common or sweet celery, viz. 1 Common upriglit Italian. 2 Large hollow upright. 3 Solid stalked upright. 4. Large red stalked upright.

Var. $\gamma$, rapaceum (D.C. l. c.) leaves sprealing; petioles short; seginents of leaves 5 , serraterl; root roundish. A pium rapaceum, Mill. dict. no. 5. Celeriac of the English; celcrirave of the French; and knott-celleric of the Germans. There are 2 or 3 sorts of celeriac, viz. 1 Common celeriac or turniprooted celery. 2 Celeri-rave of the French; and 3 Knottcellerie of the Germans. This last is hardier than the other kinds, and will continue longer in spring. It is grown to a large size in the neighbourhood of Hamburgh, and is sometimes imported for the Londion market.

Var. $\delta$, Lusilúnicum (D. C. I. c.) radical leaves 3-lobal; cauline ones 5-lobed, crenated. A'pium Lusitánicum, Mill. dict. no. 7 .
Listimale of sorts. - The first three sorts of var. 13 are preferahle for general culture. T'lie red variety is rather coarse for salads, but is hardy to stand the winter, and well adapted for somps and stews. The sorts of var. $\gamma$ are cultivated for their roots, under the name of' celeriac, which are fit for use in September and October, and may be preserved in sand through the winter. Celery may be grown to $10 \mathrm{lbs}$. weight, and averaging Gibs. cacl head. $\Lambda$ lead of celery, we are informed (Cill. mem. vol. 2. 1. 297.), was dug up on the $4 . l_{1}$ of October, 1815, at Longford, near Manchester, which weighed 9lbs. when washed, with the roots and leaves still attached to it, and measured + fect 6 inches in leight. It was the red sort, perfectly solid, crisp, and firm, and remarkably well flavoured.

Propagation. - All the sorts are raised from seed; and half an ounce is reckoned sufficient for a seed-bed 4 . feet and a half wirie by 10 feet in length, of the upright sorts; but for celeriac, a quarter of an onnce will be enough for a bed it feet square.

Soil.-Celery delights in a soil rather moist, rich in vegetable mould, but not rank from new unrotted dung.

Times of sowing.-The most forward crop is slightly forced, Any of the varieties may be sown in the spring in the open garden, at 2 or 3 different times, from the 21 st of March until the first week of May; but the principal sowing should be made in the first fortnight of April.

Early crop.-For early summer and autumn eelery, sow a small portion towards the end of February, in a moderate hotbed. When the young plants are about 2 inches high, put out some into a warm border, 2 or 3 inches apart, or rather into a second slight hot-bed, if before the 2Ist of March, as well to protect the plants, as to expedite their growth for final planting. As soon as the leaves are 6 inches high, in May or June transplant them into trenches for blanching, as directed below for the main crops. But as these early sown plants will not continue long in full growth before many of them will pipe or run, you shoulit plant only a morlerate crop, for a temporary supply; when they are advanced in the trenches from 8 to 12 inches in growth, begin to earth them up several inclies on both sides of each row ; continue earthing up by degrees as they rise higher, till they are whitened from 6 to 12 inches in length; when they may be dug up as wanted.

Main crop.- - To raise the main crops for summer, autumn, and winter, make a considerable sowing at the commencement of April. Sow in beds of light mellow earth, and rake in the seed lightly and regularly. In very dry weather give moderate waterings, both before and after the plants come "1]. When they are $2-3$ or 4 inches high, thin the seed-bed, and prick out a quantity at successive times into intermediate beds, $3-4$ inches asunder. Water those removed, and till they have struck fresh root. D. Judd sows about the middle of January in a warm situation, on very rich ground, protecting it by mats at night. When the plants are from $2-3$ inches high, he pricks them out into a nursery-bed, immersing the plants, as he draws them, in water, so as they may remain moist while out of ground. 'I'he plants remain in the nursery-bed until they become very strong. Johı Walker, a gardener near $\mathrm{M}$ anchester, grows the red celery; sows for the early crop about the 1 st of $\mathrm{March}$, and for the late crop about the lst of April. "The seed-bed is formed of fresh dark loamy soil, mixed with old rotten dung, half and half, and placed on a lot-bed. The nursery or transplanting bed is formed with old hot-bed dung, very well broken, laid 6 or 7 inches thick, on a piece of ground which has lain some time undisturbed, or has been made hard by compression. 'The situation should be sunny. The plants are set 6 inches apart in the dung, without soil, and covered with hand-glasses. 'They are watered well whon plantel, and frequently afterwards. By hardening the soil under the thung in which the plants are set, 
the root is formed into a brush of fibres; and by thus preventing the pushing of a tap-root, the plant never runs to seed before the following spring."-Cal. hort, mem, vol. 2 .

Transplanting into trenches.- Whien either the plants left in the seed-bed, or those removed, are from 6 to 12 inches high, or when the latter have acquired a stalky growth, by 4 or 5 weeks' nurture in the intermediate bed, transplant them into trenches for blanching. For this purpose allot an open compartment. Mark out the trenches a foot wide, and from 3 feet to $3 \frac{1}{2}$ distant; dig out each trench lengthwise, a spade in width, and a light spit deep, that is, 6 or 8 inches, or even a foot. Lay the excavated earth smoothly in the intervals, making the edges of the trenches equally full and straight; also loosen the bottom moderately, in a level order, to receive the plants. Before inserting them, it would essentially strengthen the soil, to apply some goor rotten dung in each trench 3 inches thick, and let it he dug into the bottom regularly a moderate depth. Then having lifted the plants, just thin any long straggling tops of the leaves and fibres of the roots; also slip off side shoots; plant a single row along the bottom of each trench, 4 or 5 inches apart. Give a good watering directly, and occasionally after, if the weather be dry, till the plants take root, and show renewed growth. Continue planting out a monthly succession in June, July, August, and September; thus providing for a supply from July and August of the present summer throughout the course of itutumn and winter, till May in the following spring. Judd prepares his ground for transplanting by trenching in 2 spades deep, mixing with it in the operation a good dressing of well-reduced dung from the old forcing beds. He says, "1 give it a second trenching in order that the dung may be better incorporated with the mould, and then leave it in as rough a state as possible, till my plants are ready to be put out." In the ground thus prepared, he forms trenches 20 inches deep, and 6 feet distant from each other, measuring from the centre of each trench. Before planting he reduces the depth of the trenches to 3 inches, by digging in sufficient dung to fill them so much up. At the time of planting, if the weather be dry, the trenches are well watered in the morning, and the plants are put in, 6 inches apart in a row, in the evening, care being taken by the mode above mentioned, to keep the fibres quite wet whilst out of ground ; as they are drawn from the nursery-bed, the plants are dressed for planting, and then laid regularly in the garden pan. The trenches, in which his rows of celery are planted, being so very shallow, the roots of the plants grow nearly on a level with the surface of the ground: this he considers particularly advantageous; for as considerable cavities are necessarily formed on each side when the moulding takes place, all injury from stagnant water or excess of moisture is prevented. The trenches when planted are watered, as may be required. He prepares his ground for celery during the winter, and avoids putting much of a crop in the space betwcen the trenches, especially one that grows tall, as he finds celery does best when it grows as open as possible. Walker makes his trenches at 4 fect disrance, and 18 inches wide, 12 deep, and filled 9 inches with a compound of fresh strong soil, and well-rotted dung; threefourths dung, and one-fourth soil. Old hot-bed dung is the hest. The plants should be taken up with as much soil as will conveniently adhere to the roots, and the side-shoots are removed from the stems; thicy are then set with the hand at 9 or 10 inches apart, in the centre of each trench; it is necessary to water well until they are realy to be earthed, but not afterwards.

Landing or carthing up.-As the plants in trenches rise from 10 to 15 inclies ligh, Abercrombie begins to land-up for blanching, observing " to trim in the earth gently when first raised to the stems, with a hoe or spade, but mostly the latter. When the plants are of a more advanced growth, earth them up equally on both sides each row, $3-4$ or 5 inches, according to the strength and height of the different crops. Repeat this once a week or fortnight, till by degrees they are landed-up from 12 inches to $2 \mathrm{feet}$, in order to blanch them of some considerable length. Continue thus landing-up the different crops from July till February. As the autumnal and main winter crops attain full growth, give them a final landing-np near the tops, which will increase the length of the blanched part, and also protect the later crops more effectually during the winter." In landingup celery, Judd does " not think it well to load the plants with too much mould at first. The two first mouldings, therefore, are done very sparingly, and only with a common draw-hoe, forming a ridge on each side of the row, and leaving the plants in a bollow, to rcceive the full benefit of the rain and the waterings. When the plants are strong enough to bear 6 inches bigh of mould, the moulding is done with the spade, taking care to leave bases enough to support the masses of mould, which will ultimately be used in the ridge, and still keeping for some time the plants in a hollow, as before directed. The process of mould. ing is continued through the autumn, gradually diminishing the breadth of the top, until at last it is drawn to as sharp a ridge as possible to stand the winter. In the operation it is necessary, in order to prevent the earth from falling into the hearts of the plants, to keep the outer leaves as close together as possible; for this purpose, before I begin the moulding 1 take long bands of bass matting, tied together till of sufficient length to answer for an entire row, and 1 fasten this string to the first plant in the row, then pass it to the next plant, giving it one twist round the leaves, and so on till 1 reach the other, where it is again fastened; when the moulding is finished, the string is easily unravelled, by beginning to untwist it at the end where it was last fastened." Walker, having removed the lateral shoots, the leaves of each plant being held together with one hand, the soil pulverized, is drawn round with the other, taking care not to earth up too high at once, nor too close. The heart should always be left quite free. This may be repeated about once a fortnight until the plants are ready for use.

Late crop.-For late spring celery to stand till the end of May in the returning spring, without running considerably, it is expedient to make a small late sowing at the commencement of May. The plants when 6 weeks old may be pricked on intermediate beds, 6 inches by 3 asunder; to remain till September or October, then transplant them into moderate trenches; as they advance in growth, earth them up a little in winter, and finally in the spring in February and March.

Occasional shelter. $-\mathrm{O}_{\mathrm{n}}$ the approach of frost take up a part of the crop, and lay it by under dry sand for winter use. To preserve the plants left in the bed, lay some long dry litter over the tops, which remove in every interval of mild weather. It is a common complaint, that very fine looking celery is often found to be rotten at the base of the leaf-stalks; the fact being, that when it is full grown, and the blanching completed, it begins to decay, and will not keep good in the ground for more than a month at most. Some, therefore, take up and preserve in dry sand, but in that situation it soon becomes tough and dry. The best mode seems to be that of forming successive plantations.

Taking the crop.- It is best to begin at one end of the row, and dig clean down to the roots, which then loosen with a spade, that they may be drawn up entire without breaking the stalks.

Cultivation of celeriac.-The times of sowing are the same as that for other sorts of celery. The plants require a rich wellmanured soil, and according to an account communicated by Iord Stanhope to Mr. Sabine, the plants are reared on a hotbed under glass, and transplanted when 2 or 3 inches high to another hot-bed, and set an inch and a half apart. In the be- 
ginning or middle of June they are transplanted into flat beds in the open air, at the distance of 15 inches from each other, and not in trenches like other celery. They must be abundantly watered as soon as they are set out, and the watcring must be repeated every other day, or, if the weather should be warm, every day. As they increase in size they will require a greater quantity of water, and they must be occasionally loed. The rocts will be fit for use in September or October. Mr. Sabine states that he has been informed, that the plan of giving excess of water is peculiar, and that the vigorous growth of the plant is more dependent on richness of soil than on any other cause. Abercrombie directs to earth up the bulbs 4 or 5 inches to blanch them, when they are full grown.

To save sccd.-Either leave some establislied plants in the spring where growing; or in February or March dig up a competent number, cut down the top leaves, and set the plants in the ground full 2 feet asunder. They will produce seed in autumn. Walker grows only red celery, and in preparing plants for seed, chooses the most solid, of the reddest colour, and the smallest size. When taken out of the transplanting bed, the lateral shoots being removed, they should be planted in a dry warm situation, where the seed will ripen well.

Strong-scented Apium, Smallare, Celery, and Celeriac. Fl. June, Aug. Britain. Shrub 3 to 4 feet.

2 A. Cinle'vse (Hook. et Arn. in hot. nuisc. 3. p. 353,) plant glabrous; stem nearly terete, hardly angular ; leaves spreading, bipinnate: lobes cuneated, somewhat trifidly cut, quite entire petals involute at the apex. $\delta$. HI. Native about Valparaiso. The plant is much stouter than $A$. graceolens, and the stem is not deeply furrowed. The leaves resemble those of common parsley, but are much snaller, and more flaccid. The peduncles or short lateral branches are stout and firm. Fruit much larger than that of $A$. gratèolens. Involucrum and involucels wanting.

Chili Celery. Pl. 2 feet.

Sect. II. Oreosciádicm (opos opeos, oros oreos, a mountain, oxiac̀ ıov, skiadion, an umbel; habitat of plants). D. C. prod. 4. p. 101. Petals denticulated, with an inflexed point.

3 A. Monta' хем (H. B. et Kunth, nov. gen. amer. 5. p. 1\%.) leaves ternate; leaflets obovate-cuneated, trifid: lobes acute, quite entire. 4.F. Native of New Granada, in Paramo de Almaguer, at the height of 9,300 feet. Ligústicum ternàtum, Schlecht. in Schultes, syst. 6. p. 555.

Mountain Celery. Pl. 2 to 3 feet.

4. A. Ranuxculifòliự (H. B. et Kunth, l. c. p. 18. t. 421.) leaves somewhat ternate; lcaflets obovate-cuneated: lateral ones 5-lobed: intermediate one 3-parted; segments 2-3-lobed. 4 . F. Growing along with the preceding, of which it is probably only a variety.

Cronfoot-leaved Celery. Pl. 2 to 3 feet.

5 A. glauce'scens (H. B. et Kunth, l. c.) leaves subternate ; leaflets obovate-cuneated, tripartite; lobes bifid or trifid. $\psi$. F. Growing along with the two preceding species, of which it is perhaps only a variety.

Glaucescent Celery. Pl. 2 to 3 feet.

6 A. Commersonir (D. C. prod. 4. p. 101.) leaves pinnate; leaflets multifid: lobes linear. 4 . F. Native of South America. Styles a little longer and more divaricate than any other of the species. It is very nearly allied to $A$. ranunculifolium, but the segments of the leaves are narrower and more acute, and the lower leaves are pinnate.

Commerson's Celery. Pl. 2 to 3 feet.

\section{+ Spccies not sufficicntly known.}

7 A. Fractorily'Leus (Horn. hort. hafn. suppl. p. 128.) segments of radical leaves cordate, and truncate at the base, and trifid at tlie apex. §. H. Native country unknown. 'The fruit is very like that of $A$. graveolens.

Broken-leatcd Celery. Fi. June, July. Clt. 1826. Pl. 1 to 2 feet.

8 A. austra'ze (Pet. Th. f. hist. d'ac. p. 43.) leaves bipinnate: segments cuneiform; branches whorled; umbels sessile, crowded. \$. F. Native of the Island of Tristan da Cunlaa. Carm. descr. 1) 34. Flowers white. Pctals not described. Perhaps the same as $A$. Commersomii.

Southern Celery. P1. 1 foot.

Cult. 'The species will grow in any common soil, and are increased by seeds.

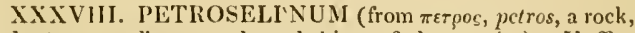
and $\sigma \varepsilon \lambda \iota \nu, y$, sclinon, parsley; habitat of the species). Hoffm. umb. 1. p. 78. t. 1. f. 7. Lag, am. nat. 2. p. 10\%. Koch. umb. p. 127. D. C. prod. 4. p. 102.-A pium specics of Lin. Spreng. and others.

Lin. syst. Pcntandria, Digýnia. Margin of calyx obsolete. Petals roundish, incurved, entire, hardly emarginate, witl an inflexed point. Stylopodium short, conical, rather crenulated. Styles diverging. Fruit ovate, contracted from the sides, somewhat didymous; mericarps with 5 equal filiform ribs: lateral ribs marginal; having the furrows between the ribs furnished with one vitta each, and the commissure with 2. Carpophore bipartite. Seed gibbously convex, flattish in front.-Branched glabrous herbs. Leaves decompound, with cuncated segments. Involucra few-leaved; involucels many-leaved. Jlowers white or greenish, uniform: those in the disk of the umbel frequently sterile. Stamens longer than the corolla.

1 P. Sativum (Hoffm, et Koch, l, c.) stem erect, angular ; leaves decompound, shining; lower leaflets ovate-cuneated, trifidly toothed : superior ones lanceolate, nearly entire; leaves of involucel filiform. §. H. Native of Sardinia, Greece, Archipelago, Turkey, Chili about Conception, \&c. on shaded rocks; and now cultivated in every culinary garden. Nees. off. pflanz. 16. t. 21. A'pium Petroselinum, Lin. spec. 379. Hayn. arz. gew. 7. t. 23. A'pium vulgàre, Lam. fl. fr. 3. p. 1027. A'pium tenuifölium, Riv. pent. irr, with a figure. The Parsley is called Persil in French, Petersilie in German, and Petroselino in ltalian. It is a hardy biennial; introduced to England in 15.18 from Sardinia. It is now so common as to be naturalised in several places both in England and Scotland. The root leaves are much curled in some varieties. The flowers are yellow, and appear in June; they have usually one leaf at the origin of the universal umbel; and the involucel often of from 6 to 8 short small leaves, fine almost as hairs to the partial umbels.

"It may be right to notice, that the poisonous plant called fools-parsley (Ethùsa Cynàpium), a common weed in rich garden soils, has sometimes been mistaken for common parsley. They are very easily distinguished : the leaves of fools-parsley are darker green, of a different shape, and, instead of the peculiar parsley smell, have when bruised a disagreeable odour. When the flower-stem of the fool's-parsley appears, the plant is at once distinguished by what is vulgarly called its beard, the 3 long pendant leaves of the involucrum. The tinid may sluun all risk of mistake by cultivating only the curled variety. This last it may be remarked, makes the prettiest garnish." Neill.

Varietics.-There are :

1. The common plain leaved, which is the true species, is seldom cultivated.

2 The curlcd-leaved. This is the most esteemed varicty. A'pium críspum, Mill, dict. no. 2. P. sativum $\beta$ críspun, D. C. prod. 4. p. 102.

3 The broad-leaved or largc-rooted Hamburgh, which is cultivated for its carrot-shaped roots. A pium latifolium, Mill. dict. 
no. 3. but not of Poir. P. sativum $\gamma$ latifòlium, D. C. prod. 4. p. 102.

Usc.-The leaves of the two first varieties are used as potherbs at all seasons of the year; also as a garnish. The third kind is esteemed for its large white carrot-slaped roots, drawn in winter like parsnips for the table; and occasionally to be used in medicine, being a gond remedy for the gravel.

Culture of the pol-herb kinds._- One sowing in spring will mostly furnisl young leaves all the ycar, though to answer a constant demand, many persons make successive sowings from lebruary to May. Some also sow early in autumn for young parsley in winter and spring; but such a supply is better provided by cutting down established plants. Sow in a single drill along the edge of any compartinent, or occasionally in rows 9 or 12 inches asunder. Draw small drills, something less than an inch deep, in which drop the seed moder:tely thick, and cover a little above lalf an inch. The plants will come up in 3 or 4 , weeks, and when 2 or 3 inches high, mav be gathered as wanted all the summer, winter, and following spring till May, when they will go to seed. Have always a young crop sown timely in the spring, to succeed the declining old plants. In wathering pot-herb parsley, cut close and regular. In summer, when the plants grow rank, yielding more leaves than can be used, cut them in close to the bottom, and they will shoot up stocky in a regular close growth. Observe also to do the same in autumn, about the end of September, that the plants may form heads of fresly young leaves before winter. On the approach of frosty weather protect them with haulm or reed-pannels, laid upon branches of birch or other light supports."

Culture of Ilamburgh parsley. - "To obtain large roots allot a compartment where the soil is deep, and has been well dug. Any common mould will suit, if dry and not too rank. Sow in February, March, or early in April, in one or more beds; either in drills 9 inches asunder, or broad-cast, and rake it. The plants should be thinned to 9 inches clistance, to give room for proper growth in the roats, for use in August, September, October, and thence till the following spring. On the approach of frost take up some roots, and preserve them in sand. A sowing may be male in the third week in $J_{u n e}$, when young roots are wanted in winter,"

To sace secd._-" Permit some old plants to run to stalks in May; they will produce plenty of seed, ripening in $\mathrm{Jull}_{\mathrm{y}}$ or A $\mathrm{u-}$ gust." Abercrombie.

Cultivatcd or Common Parsley. Fl. June, July. Clt. 15.48. I'l. 2 fcet.

2 1'. PEREgR'Num (Lag. am. nat. 2. p. 100. Koch, umb. 128.) stem erect, stiff, rather angular; petioles sheathing, scarious; leaves shining; leaflets on long petioles, cuncated, deeply serrated: leaves of both the involucrum and involucel linear. $\delta$. H. Native of Spain? Portugal? and on the mountains of Peru according to Hank. herb. A'mmi petroselinoides, Presl, mss. ligństicum peregrinum, Lin. spec. p. 368. Jacq. hort. vind. 3. t. 18. Sison peregrimus, Spreng. in Schultes, syst. 6. p. 4.09. A'pium latifolinm, Poir. dict. 4. p. 369. but not of Mill. Bupleirum petroselinoides, sipreng. $u$ mb. prod. p. 99 , and perhaps A pium Romànum, Zuce. cent. p. 57. Petals white, entire.

loreign Parsley. Fl. June, July. Clt. 1633. Pl. 2 feet.

3 l'. SLLINoides (D. C. prod. 4. p. 102.) stem striated; radical leaves tripinnate: cauline ones bipinnate; leaflets pinnatifid: lobes linear-lanceolate, acute, entire, or tripartite; umbels drooping a little; involucrum almost absent. 2. II. Native country unknown. Selinum peregrinum, Will, enum. p. 306. 'This plant differs from Guidium api ides, to which it is joined by Sprengel, in the segments of the leaves being much larger, in the petals being cream coloured, not white, and in being
(ntire, not ohcordate.
Selinum-like Parslev. Pl. 2 feet.

4. P. prostra'tum (D. C. prod. 4. P. 102.) stem procumbent, flexuons; Ileaves pinnate; leaflets petiolate, pinnatifid: lobes $5-7$-lanceolate: ultimate ones trificl at the apex; umbels nearly sessile, opposite the leaves; involucrum usually of one leaf. 4. F. Native of Van Diemen's Land. A'pium prostràtum, Labill. nov. holl. 1. p. 76. t. 103 . Vent. malm. t. 81 . Schultes, syst. 6. p. 1.30. Ilerb edible.

Prostrate Parsley. Pl. prostrate.

5 P. SE'fietum (Koch, umb. p. 128.) stem erect, twiggy, nearly naked; leaves pinnate; leaflets nearly sessile, roundishovate, pimnatifilly cut, mucronately toothed: upper lobes linear;

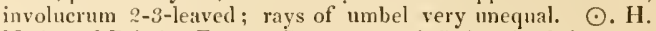
Native of Britain, France, Caucasus, and Switzerland, in cornfields, vineyards, and gardens. In Britain in a chalky rather moist soil, but not very common; as about Mipledurliam, Hants; at Binham, Norfolk; near Kelmarsh, Northamptonshire; at Walthamstow, Essex; and in the island of 'Tirèe, Scotland. Sison ségetum, Lin. spec. 362. Jacq. hort. vind. t. 134. Smith, engl. bot. 228. Sìum ségetum, Lam. dict. 1. p. 406._Mor. hist. 3. p. 283. sect. 9. t. 5. f. 6. Flowers and fruit agreeing with the rest of the genus Pctrosclinum, but the liabit is that of Pimpinélla. Flowers all fertile, white or even reddish. Teeth of calyx rather conspicuous. Perhaps Sison arvénsis, Brot. fl. lus. 1. p. 424. and Schultes, syst. 6. p. 418, is not distinct from this. The whole account of this herb by that accurate observer Goolyer, with the origin of honewort, from its curing a swelling in the cheek, called a hone, Sc. is a model of precise information.

Corn Honewort. Fl. July, Aug. Britain. Pl. I to $1 \frac{1}{2}$ feet.

Cult. The species will grow in any soil, and they are only to be propagated by seed.

XXXIX. WYDLERIA (in honour of H. Wydler, who has written a monograph of the genus Serophulària). D.C. coll. mem. v. p. 36. t. 7. prod. 4. p. 103.

Lin. srst. Pentándria, Digýnia. Margin of calyx obsolete (f. 60. a.). Petals ovate-lanceolate, entire, acuminated (f. 60. c.); acumen incurved. Fruit ovate, rather didymous, crowned by the short stylopodium, and short reflexed styles (f. 60.6 .); meriearps somewhat semi-terete, and rather contracted at the margins; furnished with 5 filiform thickish obtuse ribs at equal distances; having the furrows between these ribs furnished with one vitta each, but the commissure is narrow, and furnished with 2 vitta; all the vittae are very narrow. Carpophore bifid.A smooth West Indian lierb, wih a terete branclied erect stem; ternate leaves, with multifid leaflets, and cuneated lobes. Involucrum none or only of one leaf, but the involucels are many leaved. Flowers white, not sufliciently known. 'Tlis genus, according to Koch, is allied to Petrosclinum, but differ's both from it and Foniculum, in the petals ending in loug taper points. It is also to be distinguished from Chidium, in the fruit being somewhat contracted at the sides, and in the ribs not being winged; from Séscli, in the calyx being toothless, and from both these last genera in the petals being entire.

1 IV. Portoricénsis (D.C. 1. c.) $\odot$. F. Native of Porto Rico, on the west coast, where it is cultivated along with Mussa paradisiäca and Leqidium lirgínicum. l'lant a foot ligh and more.

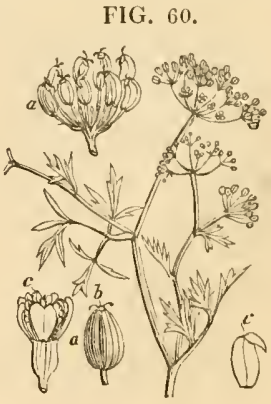


Leaves rather stiff. Umbels numerous, 12-14-raycrl. (fig. 60.)

Porto-Rico Wydleria. P'l. 1 font.

Cult. A plant of easy culture, and only to be propagated by seeds.

XI. TRI'NIA (in honour of Dr. Trinuus, a celebrated Russian botanist, who has written on Graminea). Hoffur, umb. gen. p. 92. Bieb. suppl. 24 1. Koch, umb. p. 127. 1). C. prod. 4. p. 103.-Pimpinélla species of Lin. Spreng. Lag.-A pinélla, Neck. elem. no. 325.-Spichnánnia, Cuss. mss. ex Juss, dict. sc. nat. 5.j. 1). 328 .

Lis. syst. Pentándria, Digýnia. Margin of calyx obsolete. Flowers usually dioccious from abortion, rarely monoecious. Petals of the male flowers lanceolate, ending in an involute segment; those of the female or hermaphrodite flowers ovate, and ending in a short inflexed point each. Fruit ovate, compressed from the sides; mericarps furnished with 5 filiform, rather prominent equal ribs: lateral ones marginal; liaving the furrows between the ribs either without vitta, or with one in each furrow; carpophore flat, bipartite from the base. Seed gibbously convex, flattish in front.-Much branched biennial herbs. Stems angular. Leaves bipinnate; leaflets triternate; lobes linear, pale or glaucescent. Umbels numerons, of many rays, without any involucrum, either disposed in a thyrse or panicle. Umbellules usually naked, seldom furnished with an involueel, sometimes proliferous or somewhat racemose. Flowers white, dioecious or polygamous.

1 T. Kitaibe'zn (Bieb. suppl. p. 246. Koch, umb. 127.) plant glabrous; involucels 4-5-leaved; ribs of fruit obtuse. s. H. Native of Tauria and the south of Russia, Volhynia, Sic. Pimpinélla glaúca, Hoffm. umb. 18. Waldst. et Kit. pl. rar. hung. 1. t. 72. Séseli pùmilum, Lin. spec. p. 378. Pimpinélla dichótoma, Lin. syst. p. 291. Spreng. syst. 1. p. 883.? Flowers white.

Kitaibcl's Trinia. Fl. July, Aug. Clt. 1800. Pl. 1 foot.

2 T. vulga'Ris (D. C. prod. 4. p. 103.) plant slabrous ; involucels wanting or of one leaf; ribs of fruit obtuse ; lobes of leaves linear, setaceous, very long. \$. H. Native of Europe and Caucasus, in exposed places. T. Henningii, Koch, umb. p. 127. Bieb. suppl. 245. Séseli montànum var. $\gamma$ Laneyr. abr. pyr. Pimpinélla dioíca, Bess. journ. galic. Pimpinélla glanica, Lin. spec. p. 378. Pimpinélla multicaúlis, Poir. suppl. 1. p. 684. Séseli pùmilum, Gouan. ill. 1 j. Flowers white.

Common Trinia. Fl. June, Aug. Clt. 1803 . Pl. 1 foot.

3 T. glaBE'rrima (Hoffm. umb. p. 93.) plant glabrous ; involucels wanting or of one leaf; ribs of fruit obtuse; leaflets linear-lanceolate, short, equal. \$.H. Native of Western and Central Europe, frequent. In England, on St. Vincent's rock near Bristol, and at $\mathrm{U}$ phill in Somersetshire. In Ireland near the clurch at Athboy, county of Meath, in great quantities. Pimpinélla dioíca, Lin. mant. p. 354. Smitl, enul. bot. t. 1209. Séseli glaúcum, Lam. fl. fr. 3. p. 436. Séseli pùmilum, Lin. spec. 373. All. fl. perlem. Pimpinélla grlaúca, spreng. syst. 1. p. 883 . Pimpinélla pümila, Jacq. hort. vind. t. 227. aust. 1. t. 28. Peucédanum minus, Huds. an $t$ l. ed. 8. p. I0I. Trínia vulgàris $\beta$, Jacquini, D. C. prod. 4. p. 103. Root tapering, fleshy. Herb glaucous. Umbels panicled. Flowers cream-coloured.

Var. $\beta$, Dalechámpii (D. C. prod. 4. p. 104. uncler T. vulzàris,) lohes of leaves linear, short; stem a finger in height; umbels numerous, many flowered. $\delta . H$. Native of the kingdom of Naples, and other parts of the south of Europe, in sterile fields. Mèum Dalechámpii, Ten. prod. f. neap. p. xix.Dalech. hist. 1. p. 749 .

Quitc-glabrous I'rinia. Fl. June, July. Britain. Pl. $\frac{1}{2}$ to $1 \mathrm{ft}$.

4 T. ramosissisa (Fiscli. ex Koch, in nov. act. bonn. 12. p. VoL. 111 .
127.) germens glabrous; ribs of mericarps very blunt, rounled; umbellules few flowered, furnished with involucels; fruit bearjur pedicels much longer than the eremocarps. \$. II. Native of Altaia, in plains at the river Irtysh near Krasnojarsk, and elsewhere; and about Buchtorminsk. It liffers from T: Kituibelii, in the involucels being present, and in the pedicels being more slender and elongated.

Much-branched Trinia. Pl. $\frac{1}{2}$ foot.

5 'J. I IowMA'NN1 (Bieb. suppl. p 24.) plant glabrous; involucels wanting or of one leaf; ribs of fruit, especially the carinal ones, acute. \&. Il. Native of Russia and 'lauria. Trínia glabérrima var. Iloffin. umb. 93. Flowers whitisl.

IIoffmann's Trinia. Fl. June, July. Pl. $\frac{1}{2}$ to 1 foot.

6 T. H'spida (Iloffin. umb. 94.) stem, leaves, and fruit puberulous from sliort scattered down; involucrum none, but when present of only one leaf; ribs of fruit acute. \&. II. Native of the south of Russia and Tauria, in dry desert places. 'T. Hoffmánni var. (3, Bieb. suppl. p. 245. Pimpinélla dióca Róssica, Fiscl. liort. gorenk. 1812. Pimpinélla dióea, D'Urv. enum. pl. orient. p. 34. Perhaps only a variety of the preceding. Flowers white.

Ilispid 'Trinia. Pl. 1 foot.

7 T. Durou'ril (D. C. prod. 4. p. 104.) stem and leaves smootlish ; involucels almost wanting; fruit puberulous, roundish, with obtuse ribs. $\delta$. 11 . Native of Spain, near Tudela. Séseli dioícum, Dufour in litt. Pedicels after flowering time very short, hardly longer than the fruit. Tlie species of this genus are very variable, and by no means easily distinguished.

Dufour's Trinia. Pl. 1 foot.

Cult. A light sandy soil suits the species, in which the seeds should be sown in spring.

XLI. HELOSCIA'DIUM (from è $\lambda o s$, helos, a marsh, and okuctor, shiadion, an umbel; meaning an umbelliferous plant inhabiting marshes). Koch, umb. p. 125. D. C. coll. mem. 5. p. 37. D. C. prod. 4. p. 104.-Sium, Adans. fam. 2. p. 97.Sium species of Lin.

Lin. syst. Pentándria, Digýnia. Margin of ealyx 5-tootled, or obsolete. Petals ovate, entire, with a straight or inflexed apex. Styles short. Fruit compressed from the sides, ovate or oblong; mericarps furnished with 5 equal, rather prominent filiform ribs, lateral ribs marginating: having the furrows between the ribs furnished with one vitta each ; carpophore entire, distinct. Seeds gibbously or teretely convex, flattish in front.-Herbs. Umbels eompound. Flowers white. Involucra variable in the different sections, which are probably genera.

Sect. 1. Maveija' Rtia (in honour of Bure. Dav. Mauchart, author of Dissertationis Butyrum Cacao, 4to. Tubingen, 1735 ). D. C. prod. 4. p. 104.-Neck. elem. no. 286.? Common involucra composed of from 1 to 3 leaves, rarely wanting; involucels of 5-6 leaves.-Procumbent or crepping aquatic herbs. with pinnate leaves.

1 H. cra'ssipes (Koch, 1. c.) stems creeping at the base, ascending; leaves pinnate: upper ones ternate; leaflets obovate, deeply toothed at the apex; umbels 3-5-eleft, without any involuera; pedicels of umbellules stiff, a little thickened at the base, and rather comute. 4 . H. Native of Corsica, in watery places about Bonifacio and Porto Vecelio; and of Sardinia. Reich. icon. bot. 3. p. 16. no. 365. t. 218. Sìm limòsum, Noris, in herb. Balb. Sium erássipes, Spreng. Lois. Flower's white.

Thick-pedicelled I Ielosciadium. Pl. creeping $\mathbf{1}$-foot.

2 H. Nontfóruy (Koch, umb, p. 126.) stem rooting, procumbent, striated ; leaves pinnate; leaflets oblong, equally serrated; umbels opjosite the leaves, sessile or on short peduncles; involucra wanting or few-leaved, deciduons. $\%$. W. H. Natise $\mathrm{O}$ o 
of many parts of Europe, in ditches and rivulets; plentiful in some parts of Britain. Sium nodiflòrum, Lin. spec. 361. Woodv. med. bot. 3. t. 182 . Smith, eugl. bot. t. 639 . but not of the lilora Danica. Sìson nodiflòrum, Brot. f. lus. 1. p. 423. Séseli nodiflorum, Scop. carn. 2. p. 353. Flowers white. There is a dwarf variety of this mentioned in D. C. A. fr. 4. P. 300 . which is lardly a finger in height; and a large variety, which grows even $1 \frac{1}{2}$ foot high. This plant was formerly admitted into the London Pharmacopoeia, in the character of an antiscorbutic, or rather as a corrector of acrid lumours, especially when manifested by cutaneous eruptions, and tumours in the lymplatic systcm. The best proofs of its efficacy are from Dr. Withering. A young lady was cured of a most obstinate cutancous eruption by taking three large tea-spoonfuls of the juice twice a day; and he bas repeatedly given to adults 3 or 4 ounces every morning, in similar complaints, with the greatest success. It is not nanseous, and children take it readily if mixed with milk. In the dose he has given it, it neither affects the head, the stomach, nor the bowels. This plant, therefore, if it should be eaten for water-cresses, does not seem to be very dangerous, or to require all that caution which Miller prescribes, to distinguish it from water-cresses.

Var. $\beta$, ochreàtum (D. C. prod. 1. 1. 104.) stems rather creeping; petioles membranous, and dilated at the base; umbels on rather longer peduncles than those of the species; involucrum permanent. 4. W. H. Native of ditches and rivulets about Lugdun. Sium rèpens $\beta$, D. C. fl. fr. $4.1 \% 300$. This variety is said to be intermediate between $H$. nodiflorum and $H$. rèpens.

Iar. $\gamma$ ? radiàtum (D. C. prod. 4. p. 105.) involucrum of one foliaceous, somewhat trifid leaf; leaves of involucel exceeding the flowers. 4. W. H. Native of the north of Africa. Sium radiàtum, Viv. A. lyb. 1. p. 16. t. 9. f. 2. Tordýlium Cyrenàicum, Spreng. syst. 1. p. 895.

K̈not-flowered Helosciadium. Fl. July, Aug. Britain. Pl. $\frac{1}{8}$ to 1 foot.

3 H. RE'PENS (Koch, l. c.) stem prostrate, rooting; leaves pinnate; leaflets roundish, dceply toothed; umbels on long peduncles, opposite to the leaves; involucrum of $2-1$ ovate-lanceolate permanent leaves. 4 . W. II. Native of France, Denmark, and Germany. In Britain in bogery meadows, or on watery commons; on Bullington Green and Cowley Bottom, near Oxford; on Coldham Common, Cambridgeshire; on Goldington Green and Stevington bogs; at Fisher Row and on Guillon links, near Edinburgh; and in ditches near Forfar. Sium rèpens, Liı. fil. suppl. 181. Fl. dan. 1514 . Jacq. aust. 3. t. 260. Suith, engl. bot. t. 1 $\$ 31$. Peduncles of umbels equal to the naked part of the petioles, which are in 11 . nodiflorum much shorter. Flowers white.

Creeping Heloseiadium. Fl. June, July. Britain. Pl. cr.

1. II. INUNDA'TUM (Koch, I c.) stems creeping; leaves pinnate: leaflets of the submersed leaves capillaccously multifid: those of the emersed ones cunciform and deeply trifid; umbels opposite the leares; peduncles bearing 2 rays or umbels, without an involucrum; umbellules 5-flowered. 4. W.II. Native of Europe, in marshes, bogs, ditches, pools, and wet ground over-flowed in winter; plentiful in some parts of Britaiu. sium iuusdatum, Wigger's, Ilolsat. p. 24. Hydrocótyle inundatum, Smith, fl. brit. 1. p. 290. Engl. bot. t. 227. Fl. dan. t. 89. Sison inundìtum, Willd. Mèum inundàtum, Spreng. umb. spec. 115.Pluk. alm. t. 61 . f. 3 . Flowers white.

Far. B, capilliccum (D. C. prod. 4. p. 105.) stems erect; leaves all eapillaceously multifd. Schum. zeel. 1. p. 90. ex ichultes, syst. 6. p. 435.

Inunduted Helosciadium. Fl. May, June. Britain. Pl. cr.

5 H. intrame'num (D. C. prod. 4. p. 105.) root rather bulbous, sto!oniferous; stem filiform, asceuding: leaves pinuate: leaflets verticillate, slort, trifid; umbels opposite the leaves, pedunculate, 4-5-rayed, involucrated. 24. W. H. Native of France, near Dax, in inundated places. Sison verticillàto-inundàtum, Thore, chl. land. p. 101. Sium intermèdium, D. C. f. fr. 4. p. 302. Sium bubòsum, Thore, journ. bot. 1. p. 193. t. 7. f. 2. but not of Poir. Helosciad. bulbòsum, Koch, umb. p. 126. Flowers white.

Intermediate Helosciadium. Fl. July, Aug. Clt. 1826. Pl. $\frac{1}{2}$ foot.

6 H. Califórnicun (Hook. et Arn. in Beech. bot. p. 143.) plant procumbent? leaves pinnate, with $8-11$ ovate, acute, deeply serrated leaflets; lower leaflets pinnatifid or pinnate, with few leaflets; umbels lateral and terminal; involucra and involucels of many leaves; styles elongated. \%. B. H. Native of North California, and on the low moist soils of the Columbia. The plant has a good deal the habit of $H$. rèpens. Douglas says the stems are $2-3$ feet high, from which expression it may be inferred that the plant is not procumbent.

Califormian Helosciadium. Pl. 2 to 3 feet.

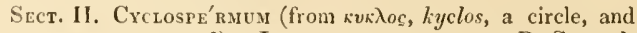
$\sigma \pi \varepsilon \rho \mu \alpha$, sperma, a secd). Lag. am. nat. 2. p. 101. D. C. prod. 4. p. 105. Both the involucra and involucels are wanting. Fruit quite glabrous.

7 H. LерториY'Llum (D. C. mem. soc. genev. vol. 4.) plant glabrous, ercetish or diffuse ; leaves many times ternately divided: leaflets capillary: cauline leaves nearly sessile; umbels op. posite the leaves, sessile or pedunculate, 2-3-rayed; umbellules pedunculate. $\odot$. H. Native nearly throughout the whole of America, especially in Chili, Mexico, St. Domingo, Brazil, and Louisiana. Sison A'mmi, Lin. spec. 36y.? Jacq. hort. vind. t. 200. Schultes, syst. 6. p. 412 . exclusive of Scliaw. and Poir. synonymes. Clam. et Schlecht, in Linnæa. 1. p. 386. Ethùsa A'mmi, Spreng. umb. prod. p. 22. Pinpinélla leptophýlla, Pers. ench. 1. p. 324. Schultes, syst. 6. p. 390. Pimpinélla lateriflòra, Link, enum. 1. p. 285. exclusive of the synonymes. Heliosciàdium lateriflòrum, Koch, umb. p. 126. Pimpinélla Domingénsis, Willd. herb. Ethùsa leptophýlla, Spreng. umb. prod. 22. Nutt. gen, amer. 1. p. 190. Sison fasciculàtum, Poh] in litt. Pimpinélla capillàcea, Poir, 1828. Anèthum pinnàtum, Ruiz et Pav. in herb. Deless. A plant in Sieb. fl. nov. holl. exsic. no. 481 . is apprarently referrible to this species, as also Sison Hæ'nkei, Presl, in herb. Hænke. Flowers white.

Slender-leaved Helosciadium. Fl. July, Aug. Clt. 1819. P]. 1 foot.

8 H. lacinia'tum (D. C. mem. soc. genev, vol. 4.) plant glatrous, ercet; leaves many times ternately divided: leaflets cut, oblong-linear : cauline leaves all petiolate ; umbels sessile, opposite the leaves, 3 -rayed, one-lialf shorter than the petioles. $\odot$. H. Native of Peru and of Chili, in stony pastures. Bertero, herb. no. 101. Poepli. no. 93. p. 281. Very like H. leptopliýllum, but differs in the leaflets being broader, and in the petioles of the cauline leaves being much longer. Sison laciniàtum, Lher. herb. in herb. Domb.

Jagged-leaved Helosciadium. Pl. 1 foot.

9 H. Rianunculifòlium (D. C. procl. 4. p. 105.) plant glabrous, erect, dichotomous; lower leaves bipinnate: upper pinnate and ternate, opposite; leaftets cuneated at the base, cut into acuminated lobes; umbels rising from the forks of the branclies, on short peduncles. $\odot$ ? W. H. Native of Chili, on the Andes in Rio Saladillo, in the province of Cordova; and about Conception. H. lateriflòm, Hook. et Arn. Some of the petals are entire, and some of them somewhat emarginate, from the point being bent in so much. Calyx obsolete. Fruit cordate at the base when young, more compressed, and less ribbed than in the rest. 
Cronfoot-leaved IJeloscialium. 1'. I foot?

10 H. TE'verum (D. C. prod. 4. p. 105.) plant glabrous, erect; leaves bipimnate : leaflets tripartite: lobes obovate, obtuse, small; umbels rising from the axils, pethuculate, 4-jrayed, without any insolucrum. - Native of Nipaul, on the high mountain of Sheopore. Sison? téner, Wall, mss. I Ierb 6-8 inches high. Sheath of petioles dilated and membranous. Fruit small, ovate, glabrous in the immature specimen. Sityles very short.

Tender Helosciadium. Pl. $\frac{1}{2}$ foot.

11 II. ? Ru'ta (D. C. prod. 4. p. 106.) stem multiple, diffuse; leaves biternate : lower ones on long petioles: lobes oval, confluent a great way, obtuse: upper leaves on short petioles, with oblong lobes; umbels opposite the leaves, sessile, 3-5-raycd: rays clongated.- Native of the Cape of Good Hope. Sinn fortè Africanum foliis trifidis seu Rutze hortensis Oldeul. lıcrb. Sison trífidum, Burm. herb. Sison liùta, Burm. f. cap. p. 7. A rather eloubtful species, but from the immature fruit it appears to belong to this genus.

Rue-leaved Heloscialium. Pl. difluse.

12 H. Hexnea'sum (D. C. prod. 4. p. 106.) stem nearly simple, erect; leaves on long petioles, ternite; leaflets petiolate, lanccolate, acuminated, decply toothed; umbels on long peduncles, opposite, with 5-6 clongated rays; and the umbellules 5-8flowered. $\odot . H$. Native of the East Indies, but in what place is unknown. Pimpinélla Heyneàna, Wall. mss. Mature fruit not scen. Allied to the following scction, but differs in the fruit being glabrous while young.

Heyne's Helosciadium. Pl. 1 foot.

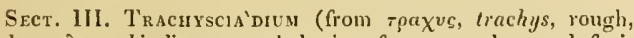
and oxicticos, skiadion, an umbel; in reference to the rough fruit of the species). D. C. prod. 4. p. 106. Both involucra and involucels are wanting. Fruit rough from short stiff hairs.

13 H. TRIFOLIA'TUM (D. C. prod. 4. p. 106.) stem glabrous, branched, crect : lower leaves $3-5$-parted, the rest ternate : leaflets nearly sessile, ovate-lanceolate, smooth above, but scabrous from pili along the nerves beneath, deeply toothed: teeth mucronate; fruit ovate, scabrous from rigid pili.-Native of Nipaul, on the bigher mountains about Gosaingsthan. Pimpinélla? trifoliàta, Wall. mss. Umbels terminal, and opposite the leaves, 6-8-rayed. Styles very short. Fruit rather didymous.

T'rifoliate Helosciadium. $\mathrm{Pl}$.

14 H. PubE'scens (D.C. prod. 4. p. 106.) stem erect, multiple, pubescent, as well as the petioles, rays of umbel, and under side of leaves: lower leaves ternate : leaflets ovate, toothed, stalked: upper leaves on long petiolcs, ovate-cordate, toothed, rarely cut; fruit scabrous.- Native of Kamaon, in the East Indies. Pimpinélla pubéscens, Wall. mss. Very like the preceding, but differs in the pubescence and structure of the leaves. The immature fruit has only been seen.

Pubescent Helosciadium. Pl.

Cult. Those species belonging to the first section of the genus being aquatic perennial plants, should be grown in ponds of water; the rest being annual, the seeds of them should be sown in any warm situation.

XLII. DISCOPLEU'RA (from ¿̇ $\pi \lambda \varepsilon v \rho a, p l c u r a$, a rib; the 2 lateral nerves of the fruit form a disk on both sides of the fruit). D. C. coll. mem. 5. p. 38. t. 8. and 9. prod. 4. p. 106.-A'mmi species of Michx. Ell. Sic.

Lis. syst. Pentándria, Digínia. Calycine teeth 5, subulate, permanent (f. 61.e.). Petals ovate, entire, each furnished with a replicate point (f. 61.f.). Fruit ovate (f. $61 . c$.$) , rather didy-$ mous; mericarps with 5 ribs; the $\$$ dorsal ones filiform, exsert- ed, and acutish: the 2 lateral ones rather concrete, with the thick accessory margin, forming a broad disk on both sides of the fruit: having the furrows between the ribs furnished with one vitta cach; carpophore bifid. Seed ncarly terete.-Smooth North American herbs. Stems terete. Leaves compound; leaflets linear-setaceous, some trifid, and others entire. Leaves of involucel fow, linear-setaccous. Flowers white. A genus of elcgant plants.

1 D. carillácla (D. C. I. C. t. 8. A.) plint erect or procumbent; umbels $3-10$-rayed ; leaflets of involucrum $3-5$, nearly all trifid. $\odot$. W. II. Native of North America, from Carolina to New York, in humid places; and of Nortl Cajifornia. A'mmi màjus, Walt. fl. carol. 6. p. 113. but not of Lin. A'mmi capillàceum, Spreng. in Scliultes, syst. 6. p. 4.11. exclusive of the synonyme of Nutt. and Pers. ex Torrey, fl. un. st. 1. p. 306 . Ethùsa capillàcca, Nutt. in herb. Mercier. Flowers white. (f. 61.)

Var. $\beta$ ? costata (D. C. I. c. t. 8. $\beta$,) plant large, erect; stem simple below; segments of the leaves somewhat verticillate; involucrum of 10 or 12 leaves; fruit deeply furrowed. $\odot$.W. H. Native of Georgia, in marshes on the banks of the river O rechee. A'mmi costàtum, Ell. sketch. 1. p. 350. Said to be nearly allied to the species, but differs according to Elliot, in the plant being of taller stature, 4-5 feet high, not 1 or 2 fect high, as in the species, and in the time of flowering, which is in autumn, and not in the spring, and in the leaves of the involucel being equal in length to the umbellules.

Capillary-leaved Discopleura. PI. 1 to 2 feet.

2 D. Nuttállit (D. C. l. c. t. 9.) plant erect: umbels 20rayed; leaves of involucrum $5-6$, and for the most part undivided; involucels of 5 leaves, about equal in length to the umbellules. $\odot$. H. Native of North America, at the Red river. Cicuta capillacea, Nutt. in litt. 1825 . Fibres of roots in fascicles. Stem simple at the base, 1-2 fect high. Involucrum deflexed.

Nuttall's Discopleura. Pl. 1 to 2 feet.

Cult. The seeds only require to be sown early in spring in the open border.

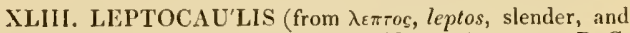
кavios, kaulos, a stem; slender stems). Nutt. in litt. 1825. D.C. coll. mem. 5. p. 39. t. 10. prod. 4. p. 107.

Lin. sust. Pentándria, Digýnia. Margin of calyx obsolete. Petals elliptic, entire. Styles permanent, short. Fruit compressed from the sides, ovate; mericarps with 5 lardly prominent ribs: having one vitta in each furrow between the ribs. Sced convex on the outside, and flattish on the inside; carpophore bifid at the apex.-Glabrous, slender, smooth, erect North $A$ merican annual herbs. Stcms terete. Leaves multifid; leaflets linear. Unbels pedunculate, opposite the leaves, and terminal, with few rays, destitute of involucra: rays of umbellules few and unequal; involucels short, few-leaved. Flowers small, white.

\section{\$1. Fruit neither scabrous nor echinated.}

1 L. INE'RMIS (Nutt. in litt. ex D. C. prod. 4. 1. 107.) fruit o 02 
unarmed, rather wrinkled. ๑. II. Native of North America, at the Red river. D. C. mem. 5. t. 10. f. $\beta$. Herb a hand high, smooth, slender. Lobes of leaves or leaflets capillaceous. Umbels 5-5-rayed. Involucel of 3-4 leaves. (f. 62.)

Cnarmed-fruited Leptocaulis. Pl. $\frac{1}{2}$ foot.

\section{\$2. Truit muricated or echi-} nated.

2 L. Diffu'sus (Nutt. in litt. ex D. C. 1. c.) fruit muricated from ratlier adpressed bristles; liranches and rays of umbel divaricate; umbels and umbellules 3-rayed; pedicels of umbellule about equal in length to the rays of the umbel. $\odot$. H. Native of North America, at the Red river. Stem erect, slender, branched at the apex. Lobes of leaves or leaflets capillary. Involucels of 1-2 leaves. Pedicels half an inch long. Flowers white.

Diffuse Leptocaulis. Pl. $\frac{1}{2}$ foot.

3 L. divarica'rus (D. C. mem. 5. t. 10. f. A.) fruit muricated from rather adpressed bristles; branches and rays of umbel clivaricate; umbellules 2-S-rayed; pedicels of umbellules one-lıalf shorter than the rays of the umbel; central flower nearly sessile. ○. H. Native of Lower Carolina, in dry pastures. Daúcus divaricàtus, Walt. car. p. 11 \%. Sison pusíllum, Michx. f. bor. amer. 1.p. 168. Ell. sketch. 1. p. 356. A'mmi divaricàtum and Ligústicum pusíllum, Michx. A. amer. bor. 1. p. 168 . Pers. ench. 1. p. 308. and 315. Sison divaricàtus, Spreng. umb. spec. 1. 113. Ethùsa divaricàta, Nutt. gen. amer. 1. p. 190. Flowers white.

Divaricate Leptocaulis. PI. 1 foot.

4 L. PA'Tens (Nutt. in litt. ex D. C. prod. 4. p. 107.) fruit muricated from tubercles; branches divaricate; rays of umbels and umbellules 4-5, rather contracted. $\odot$. H. Native of North America, at the red river. This is the largest species of the genus, being a foot high or more. Lobes of leaves or leafiets capillaceous. Flowers white.

Spreading Leptocaulis. Pl. I foot.

5 L. Echina'vus (Nutt. in litt. ex D. C. prod. 4. p. 107.) fruit echinated loy spreading bristles; branches at length divaricate; umbels and umbellules 5-layed, rather direrging. $\odot$. H. Native of North America, at the red river.

Echinated Leptocaulis. Pl. $\frac{1}{2}$ foot.

Cult. The seeds only require to be sown in spring.

XLIV. P'IYCIIO'TIS (from $\pi \tau v \chi \eta$, ptyehe, a plait, and ovs, wros, ous, otos, an ear ; the petals have a plait in the middle, emitting a litsle ear or segment). Koch, umb. 124. D. C. coll. mem. 5. 1). 59. protl. 4. p. 107 .-Bùnium, Lag. an. nat. 2. p. $104 .-$ séseli species of authors.-Ammoides, Adans. fam. 2. j. 96.

Lin. sxst. P'ntándria, Diǵńnia. II argin of calyx 5-tootlied. Petals obovate, bifidly emarginate, having a transverse plait in the micldle, which emits a little segment. Fruit compressed from the sides, ovate ( $r$ oblong; meriearps with 5 filiform equal ribs; latcral ribs marginating, having the furrows between the ribs furnished with one vitta each; carpophore bipartite. Seed terete or gibbously convex, flat in front.-Annual or biennial herbs. Cauline leaves multifilly capillaceous. Umbels compound, having the miversal involucra variable, and the partial ones of many leaves. Flowers white. 'This is a very distinct yenus from the form of the petals, having the segment not at the apex, but rising from the transierse platit.
Sect. I. Euptychòts (altered from the generic name). D. C. prod. 4. p. 108. Universal involucrum wanting. Ribs of fruit smooth, not muricated.

1 P. Heterophýlia (Koch, l. c.) stem erect, much branched, divaricate; radical leaves pinnate; leaflets roundish, deeply serrated; cauline leaves multifid, with linear-filiform segments ; fruit oblong; leaves of involucel all setaceous. 8. H. Native of the south of France, Piedmont, Switzerland, \&c. in gravelly and stony fields. Ethùsa Bùnius, Murr. syst. p. 236. D. C. ff. fr. 4. p. 293. Càrum Bùnius, Lin. syst. nat. 12. p. 733 . Jacq. vind. 2. t. 198. Ethùsa montàna, Lam. fl. fr. 3. p. 649 . Séseli saxifragum, Lin. spec. p. 374. I). C. Al. fr. p. 503. Pimpinélla Genevénsis, Vill. dauph. 2. p. 604. (exclusive of Barrel. syn.) Séseli Bùnius, Vil]. dauph. 2. p. 588 . Mèum heterophýllum, Mœnch, meth. p. 86 . Sìm saxífragum, Roth, fl. ferm. \% p. 338. Sison divaricàtus, Spreng. in Sehultes, syst. 6. p. 411.-Dalech. lıgd. P. 774. f. 2.

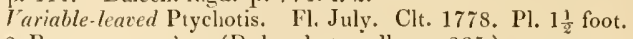

2 P. verticilatita (Duby, bot. gall. p. 235.) stem erect, branched ; leaves all cut into somewhat verticillate capillaceous multifi! segments ; fruit ovate; some of the leaves of the involucel

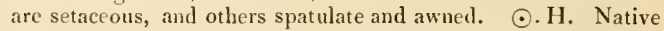
of Mauritania, Portugal, Sicily, Corsica, Sardinia, Etruria, Dalmatia, in fields. A'mmi Mattholi, Dalech. lugd. p. 695 . f. 2. Sison A'mmi, Ucr. hort. pan. p. 132. but not of Lin. ex Gutss. Séseli ammoides, Gouan. ill. p. 16. but not of Jacq. but perhaps also of Lin. and Spreng. Séselı Túrbith, Ten. ex Stendel. Séseli verticillàtum, Desf. atl. 1. p. 260. D. C. fl. fr. suppl. 5. p. 504. and probably of Spreng. and Link. Ptychòtis ammoides, Koch, umb. p. 12.. Séseli Córsicum, Link, enum. hort. berol. 1. p. 283. Séseli pusílum, Brot. fl. lus. 1. p. 457.

Whorled-leaved Ptychotis. Fl. Ju. July. Clt. 1820. Pl. 1 ft.

Sect. II. Tracirspénium (from toaxve, trachys, rough, and $\sigma \pi \varepsilon p \mu a$, sperma, a seed; in reference to the muricated fruit). Link, enum. 1. p. 267. Universal involucra composed of a few linear entire or trifid leaves. Fruit muricated.

3 P. Cóptica (D. C. mem. soc. gen. vol. 4.) stem erect, branched; leaves nearly all cut into linear multifid lobes : upper leaves simply pinnate-lobed; umbels 8.12 -rayed; leaves of involucra linear, rarely trifid; leaves of inrolucels linear; fruit ovate, muricated. $\odot$. H. Native of Egypt and Candia. A'mmi Cópticum, Lin. mant. p. 56. Jacq. bort. vind. 2. p. 196. Daúcus Cópticus, Pers, ench. 1. p. 30\%. Bùniun Cópticum, Spreng. prod. umb. p. 28. Trachyspérmum Cópticum, Link, enum. 1. p. 267. A'mmi, Riv. pent. irr. t. 95. Bùnium aromáticum, Lin. mant. 218. A'mmios Cóptica, Moencl. meth. p. 99.-J. Bauh. hist. 3. p. 2. p. 25. with a figure. Lob. icon. 725. f. 2. The petals exhibit a little segment, but it is adnate to the middle nerve. The plant is falsely called Conium Afrieanum in the gardens.

I'ar. $\beta$, feeniculif olia (D. C. prod. 4. p. 108.) umbels of 6-7 rays. $\because$ H. Native of Greece, in corn-fields. Séseli ammoides, Jacq. hort. vind. 1. t. 52 . Smith, prod. fl. græe. 1. p. 199. but not of Gouan, but probably of Lin. and Spreng. Séseli foeniculifòlium, Poir. dict. 7. 1\% 137. Sison A'mmi, Lam. herb. Ilabit of IIclosciadium capilliceum or II. leptophýllum, but with the petals of the rest of the genus Ptychotis.

Coptic Ptychotis. Fl. June, July. Clt. 1773. PI. 2 feet.

4. P. Aneturodia (D. C. prod. 4. p. 108.) stem ereet, brahched; leaves all multifid, with linear hair-like segments; umbels of 20 rays; rays rather pubescent; leaves of involucra linear, undivided. $\odot$.H. Native of Nipaul. Athamántha? anethifòlia, Wall. unss. Pimpinélla anethifỏlia, D. Don, prod. fl. nep. p. 18.4. Perhaps only an uncultivated variety of $P$. Ajòwan, ex Wall. but the leaves are nuch more jagged and larger, and the rays of the umbel more numerous. 
Fennel-leared Piychotis. Pl. 1 foot.

5 P. Aso'wan (1). C. menı. soc. gen, vol, 4.) stem ereet, lichotomous; leaves few, cut into multifid linear segments: upper leaves pinnatifid; umbels of $7-9$ rays; leaves of the involucra linear, undivided. $\odot$. II. Native of the East Indies, where it is called Juranee, Ajouan, Ajowan or Ajanain. Ligústicum Ajòuan, Roxb. hort. beng. p. 21. Athamántla Ajòwan, Wall. mss. Ligústicum Ajàwain, Schultes, syst. 6. p. 556. Fleming, ind. med. in asiarch. 1. p. 170. journ. bot. 4. p. 200. Ajava-secd, Perciv, ess. 1. p. 453. Very like P. Coptica, but diflers in the stem being less leafy, in the umbels being of fewer rays, in the rays being puberulous, and in the fruit being more ribbed, but puberulously tubercular in the same way. The fruit of this plant is prescribed in India in diseases of horses and tows.

Ajonan Ptychotis. P]. 1 to 2 feet.

6 P. Roxburghia ina (D. C. prod. 4. p. 109.) stem erect, dichotomous; leaves ternate; leaflets deeply pinnatifid: lobes oblong-linear; umbels of 6-8 rays; leaves of involucrum few. linear, undivided. $\odot$. H. Native of and cultivated in various parts of India, but particularly in Bengal, in the island of Singapore, and the mountains of Prome, Sc. ex Wall. A pium invofucràtum, Roxb. ex journ. bot. 1824. vol. 2. p. 188. Athamántha Roxburghiàna, Wall. mss. and herl.

Roxburgh's Ptychotis. Pl. 1 to 2 feet.

7 P. ACHillezilòla (D. C. prod. 4. p. 109.) stem erect, a little branched; leaves bipinnate; leaflets pinnatifid; lobes linear-subulate, trifid, stiffish; umbels of $6-8$ rays; leaves of involucra few, linear-lanceolate; fruit glabrous, rather muricated on the back along the ribs. $\odot . H$. Native of Nipaul and Kamaon. Athamántha achilleifòlia, Wall. mss. A very distinct species, hut the fruit on the specimen examined not being mature, the genus to which it belongs is still ratler doubtful.

\section{Milfoil-leated Ptychotis. Pl. 1 foot.}

Sect. 1Il. Heteróptycha (from érepos, heleros, variable, and $\pi \tau v \times \eta$, ptyche, a plait ; in allusion to the middle nerve of the petals being lamellate above, and varying in this respect from the rest of the sections). D. C. prod. 4. p. 109. Universal involucra none. Teeth of calyx nearly obsolete. Petals rather emarginate, having the middle nerve lamellate above. Fruit echinated by bristles. Styles long, diverging a little.Perhaps a proper genus. Mature fruit unknown, and therefore also the vittx.

8 P. Pube'Rula (D. C. prod. 4. p. 109.) stem erect; leares and rays of umbel beset with short hairs in every part. $\odot$. H. Native of the Levant, about Bagdad. Rays of umbel 6-9 lines long; and those of the umbellules 2 lines long.

Puberulous Ptychotis. Pl. 1 to 2 feet.

9 P. Barbatita (D. C. l. c.) stems erect, and are as well as the lobes of the leaves glabrous; but with the sheath of the petiole and limb of the leaf at the origin of the leaflets bearded with soft hairs. $\odot . H$. Native of the Levant, between Bagdad and Kermancha. Rays of umbel 5-6 lines long, and those of the umbellules hardly 2 lines long. Perlaps only a variety of the preceding speeies.

Bcarded P'ychotis. Pl. 1 foot.

10 P. VARGasia'xa (I). C. l. c.) stem much branched, erect, glabrous as well as the leaves: leaves pinnate: leaflets cuneated, cut at the apex; involuermm almost wanting ; fruit elothed with short pubescence. $\odot$. H. Native of South America, about Caraccas, where it was collected by Vargas. Perhaps this plant belongs to a different section of the genus.

Vargas's P'tychotis. Pl. 1 to 2 feet.

Cull. The species being natives of rather warm latitudes, bheir seeds will require to be sown in warm sheltercd situations, or they may be reared in a hot-bed in spring, and the plants afterwards plinted out in the open borler in May.

XLV. FALCA'RIA (from falx, a sickle). liv. pentap. (1699) no. 48. with a figure. liost, fl, austr. 1. p. 381. but not of Cav. 1). C. prosl. 4. p. 109.-Drepanophýllum, Koch, umb. p. 128. but not of Hook.-Drcpanoplyfllum species, Hoffin. umb. 110.-Critàmus, Bess. Vohl. 1).93. Koch, emend. numb. l. c. but not of Ilofhn.-Sium speeies of Lin.-Prionitis, Delarb. H. auv.-Critàmus species, Koch, deutsehl. 11. 2. p. 441.

Lin. syst. Pcntándria, Digýnia. Margin of calyx 5-toothed; the tube in the sterile flowers wanting, but those in the fertile flowers are cylindrical. Petals obovate, curved, emarginate, with a lroad recess, having the terminating segment reflexerl. Styles divaricate. Fruit oblong, compressed from the sides; mericarps furnished with 5 , filiform, equal ribs: lateral ribs marcinating; carpophore free, bifid; furrows between the ribs furnished with 1 fliform vitta each. Seed teretely convex, flattish in front.-Glabrous, perennial herbs. Leaves pimnate; leaflets broad-linear, decurrent, cartilaginously serrated. Unibels opposite the leaves and terminal, compound, of many rays ; involucra of many leaves; involucels somewhat dimidiate, in consequence of the inner leaves being small. Flowers white, having hermaphrodite, fertile ones, and male sterile ones in the same umbellule. This genus differs from Sium in the petals being curved, in the furrows of the fruit being furnished with 1 vitta each, and in the earpoplore being free and bifid.

1 F. Rivi'Ni (Host, l. e.) leaves pinnate, glaucescent; leaflets decurrent, linear-lanceolate, sharply serrated; serratures contiguous. 4 . H. Native of south and middle Europe, Caucasus, and Altaia, in plains at the river Irtysch ; and of the Levant, in the more elevated ficlels and pastures. Sium Falcària, Lin. spee. p. 362. Jueq. fl. aust. t. 257. Bunium Falcaria, Bieb. fl. taur. 1. p. 211. Drepanophýllum agréste, Hoffin. et Koch, I. e. Séseli falcùria, Crantz, austr. p. 208. Critàmus agréstis, Bess. enum. volh. p. 93. Sìm falcàtum, Dub. orl. p. 442.-Lob. icon. 2. t. 24. f. 1. Crítlumum umbelliferum, Bauh. hist. 3. p. 195. Rioots creeping under ground.

Rivin's Falcaria. Fl. July, Aug. Clt. 1726. Pl. 1 to 2 feet.

2 F. Danu'rica (D. C. prod. 4. p. 110.) leaflets somewhat serrated: serratures acute, distant. 24. H. Native of Dahuria. Sìm, Gmel. sib. 1. p. 200. no. 14. t. 47. Sium eicutif òlium, Gmel. syst. 2. p. 1. t. 182 . Sium latif òlium $\beta$, Bieb. fl. taur. 1. p. 243. Cicuta Dahùrica, Fisch. cat. hort. gor. p. 45. Spreng. in Schultes, syst. 6. p. $45 \%$ Critàmus Dahùricus, IIoffin. umb. p. 184. Furrows of the fruit, according to Hoffmann, furnished each with 1-3 vittæ, and the commissure with 4-5 vittæ. Flowers all fertile, according to the plants examined.

Dahuriun Palcaria. Fl. July, Aug. Clt. 1817. P1. 2 to $3 \mathrm{ft}$. + Speeies hardly knomn.

3 F. J AvA $^{\prime}$ ICA (D. C. prod. 4. p. 110.) leaves pirnate or bipinnate; leaflets ovate-oblong, deeply serrated; umbels opposite the leaves; involucrum wanting; but the involucels are of many setaceous leaves. $\quad$ 4. B. F. Native of Java, in marshes, where it is ealled Tespong by the natives. Simm Javánicum, Blum. bijdr. 1) 881 . The furrows of the fruit are furnisherl with I vitta each, and the commissure with 2 , as in the following species.

Jaca Falcaria. Pl. 1 to 2 feet.

4 F. Lacinia'ta (I). C. prod. 4. p. 110.) leaves bijinnate; leaflets pinnatifid umbels opposite the leaves; involucrum wanting; involucels of many setaceons leaves. 24. 13. 1. Native of Java, in the prosince of Batavia, in marshes. Sium laciniàtum, Blum. l. c. l'erhaps a species of Oenanthc.

Jagged-leaved Falcaria. P'l. 2 to 3 feet.

5 l.? Diversifolsa (D. C. l. c.) superior leaves ternate; 
leaflets petiolate, quite entire, some linear and others filiform. 4. H. Native of Nipaul. Sison? diversifòlius, Wall. mss. Stem much branched. Herb glabrous. Lower leaves unknown. Fruit ovate. Flowers all hermaphrodite. Mature fruit not secn, and therefore the vittæ are not well known. Both the involucra and involucels are composed of a few linear, short, acute, unclivided leares.

Diverse-lcared Falcaria. PI. 2 feet.

Cult. The two first species will grow in any soil, and under any circumstance. Those natives of Java will require to be grown in a stove.

XLVI. SI'SON (from sisum, Celt, a running stream; some plants formerly contained in this genus were inliabitants of running streams). Lag. am. nat. 2. p. 103. Koch, umb. p. 123. D. C. prod. 1. p. 110.- Sison species, Lin. and all otlicr authors.

Lix. sist. Pentándria, Digýnia. Margin of calyx obsolete. Petals roundisl, curved, deeply emarginate, with an inflexed point. Styles very short. Fruit compressed from the sides, ovate; inericarps with 5 filiform equal ribs; lateral ribs marginating : having one slort, club-shaped vitta in each furrow between the ribs; carpophore bipartite. Seed gibbously convex, flattish in front.-Herbs paniculately branched. Leaves pinnate; lower leaflets a little lobed, toothed, or cut : upper ones linear, multifid. Both the involucra and involucels are composed of few leaves. Umbels of 4 unequal, elongated rays; and the umbellules of 1-5short rays.

1 S. A mòmum (Lin. spec. p. 362.) stem erect, terete, paniculately branched; leaves pinnate; lower leaflets rather lobed and toothed: upper ones linear-multifid; upper leaves ternate. $\delta$. H. Native of Britain, France, Italy, Sicily, Greece, \&c. in fields, on a dry calcareous soil; in Britain not unfrequent in rather moist spots under hedyres, where the soil is marly or ehalky. Jacq. hort. vind. 3. t. 17. Hayn. term. bot. t. 36. f. 10. Schkuhr, handb. t. 65. Smith, engl. bot. t. 954. Sium aromáticum, Lam. dict. 1. p. 405. Séseli Amòmum, Scop carn. ed. 2. no. 355. Cicùta Amòmum, Crantz, aust. p. 96. Smýrnium heterophýllum, Moench, meth. p. 97. Flowers cream-colonred. Seeds aromatic and pungent when dry and ripe; but in an early state they, like the whole herb, have a peculiar nauseous smell.

Amomum or Ginger-seeded Stone-parsley. Fl. July, Aug. Britain. Pl. 2 to 3 feet.

\section{† Doubtful species.}

2 S. ? Sieberia'sum (D. C. prod. 4. p. 111.) plant glabrous, dwarf; leaves almost radical, ternate, or tripartite; segments approximate, cuneated at the base, very blunt at the apex, crenately toothed, or somewhat cut; involucrum wanting. $\odot . ? H$. Native of Candia, on the tops of the Sphaceotic mountains. Sison alpinus, Sicb. in Schultes, syst. 6. p. 414. Peucédanum Créticum, Sicb. herb. cret. 1826 . Spreng. neu. entıl. 2. p. 148. From the immature fruit this appears to be a species of $C$ irum or Binium, the fruit being compressed from the margin, not from the back. Stem a finger in height. Umbels 4-5-rayed.

Sieber's Stone-parsley. Pl. $\frac{1}{4}$ foot.

3 S. Trinérve (Hamilt. ex D. Don, protl. fl. nep. p. 184.) stem erect, terete, dichotomous, striated, nearly naked; leaves all radical, pimate; lcaflets laneeolate, acute, quite cntire, 3nerved, glabrous; involucrum 5-leaved; leaves of involucels lanecolate, awned. 4. H. Native of Nipaul, abont Bassaria. 'The fruit is undescribed, and the genus is therefore doubtful.

Three-nerved-leaved Stone-parsley. I'l. 1 foot.

Cult. The seeds of the species only require to be sown in spring, in any common earth.

XLVII. SCHU'LTZIA (in honour of John Ilenry schultze, a celebrated German botanist). Spreng. umb. spec. p. 102. anı in Seluultes, syst. 6. p. 44. Lag. am. nat. 2. p. 99. D. C. prod. 4. p. 112. Sison species, Pall.-Schúltzia, Spreng. umb. prod. p. 30.

Lin. srst. Pentándria, Digynia. Margin of calyx obsolete. Petals elliptic, terminated by a short inflexed point. Stylopodiun conical. Styles erect, rather capitate at the apex, permanent, at length diverging. Fruit cylindrically prismatic, the transverse section nearly terete; mericarps somewhat compressed from the sides, and furnished with 5 filiform, exserted ribs: the 2 lateral ribs nearly marginal: having the furrows between the ribs flat, and furnished with 1 vitta each. Carpophore undivided. Seed nearly terete. - Smooth peremnial herbs. Leaves eitler radical, or from the lower part of the stem, bipinnate; leaflets many-parted, decussate at the racluis: segments linear, acute. Umbels terminal, on long peduncles of many rays. Both the involucra and involucels are composed of many multifid leaves; the lobes linear and acute. Flowers white, ail fertile.

l S. crinita (Spreng. l. c.). §. H. Native of the Altaia, on the lighest of the mountains, not far from the torrent of Tegerek. Sison crinitum, Pall. act. petrop. 1779.12 p. 250. t. 7 . Willd. spec. 1 . p. 1438 .

Long-haired Schultzia. Fl. July, Aug. Clt. 1818. Pl. 1 ft. Cult. The seeds only require to be sown in the open ground.

XLVIII. A'MIMI (from a $\mu \mu \rho s, a m m o s$, sand; habitation of plants). Tourn. inst. t. 159. Lin. gen. no. 334. Spreng. umb. prod. p. 41. Lag, am. nat. 2. p. 104. Koch, umb. p. 122. D. C. prod. 4. p. 112.

Lin. syst, Pentándria, Digýnia. Margin of calyx obsolete. l'etals obovate, emarginately 2-lobed, with an inflexed point ; lobes of petals unequal, irregular, those of the outer part of the umbel usually the largest. Fruit ovatc-oblong, compressed from the sides; mericarps furnished with 5 equal, filiform ribs: lateral ribs marginating: having the furrows between the ribs furnished with one vitta each; carpophore free, bipartite. Seed teretely convex on the outside, and flattish in front.-Herls with the habit of Danicus, having fusiform roots and pinnate or many-parted leaves. Umbels compound, of many rays. Both the involucra and involucels are of many leaves; the leaves of the involncrum trifid or pinnatifid. Flowers white.

1 A. MA'Jus (Lin. spec. p. 3.19.) stem glabrous; leaves pinnate; leaflets with cartilaginous, sharply serrulated margins; those of the inferior leaves obovate-oblong, and those of the upper ones multifid, linear-lanceolate. $\odot$. II. Native of south and iniddle Europe, Egypt, and the Levant; also of Newfoundland. Lam. ill. 193. Smith, f. græc. t. 273. Schkuhr, handb. t. 61 . A'pium A'mmi, Crantz, aust. 21\%. A'mmi Boebèri, Hoeq. diss. abo. 1810 . and $A$. cicutæfòlium, Willd. lierb. ex Schultes, syst. 6. p. 591. do not differ in any particular from $A$. màjus. The A. Boebèri, Hoffm. umb. XVIII. Horn. suppl. p. 32. is merely a larger variety of the present species.-Lob. icon. t. 721 . f. I. Mill. fig. 25.-Plench. icon. 181. Blackw. t. 447. Flowers white: outer ones of the umbels large, like those of the rest of the species. Stem-leaves biternate.

Greater or Common Bishop's-weed. Fl. June, July. Clt. 1557. Pl. 3 to 4 feet.

2 A. Glaucifòlum (Lin. spec. 349. exclusive of the synonyme of J. Baul.) stem glabrous; leaves all bipinnate, jagiged ; segments narrow-linear, acute, and a little serrated. $\mathbf{\delta} . \mathbf{H}$. Native of France, at Lucon (Guett. etamp. 2. 1). 433.), about Paris (Thuill. par. 137.) Andegareny (Bast. ess. 105.), Rowen, Namnetes, and in Dauphiny (Vill. dauph. 2. p. 592.), Grecce, (Snith, prod. fl. græc. 1. p. 185.), Spain at Aranjuez, Sicily, Liguria. This species differs from $A$. majus in the characters mentioned above, and in the more branched habit and glaucous 
lrue. There is a monstrous varicty of this species, found about Ronen, which has the 2 carpels changed into petals, besides having also the usual number of petals.

Glaucons-leaved Bishop's-weed. Fl. June, July. Clt. 1816. Pl. 2 to 3 feet.

$3 \Lambda$. INTERME'diun (D. C. prol. 4. p. 113.) plant glabrous ; leaves all decompound, many-parted, greenish ; segments cut or toothed : lower ones cuncated: upyer ones linear-subulate, serrated, and encling in long taper points. $\odot$. H. Native of the l'yrenees, and the kinglom of Naples. $\Lambda$. glaucif olium, Lapeyr. f. pyr. p. 14. An intermediate plant between $A$. glaueif ólizm and $A$. Tisniga. It diflers from the first in the leaves being greenish, not glaucous, and in being tripinnate; from the last in the lobes or leaflets of the upper leaves being much acuminated and scrrated, and in the umbel sprearling alter flowering.

Intermadiate Bishop's-weed. Pl. 1 to 2 feet.

+ A. Visníga (Lam. dict. 1. p. 132.) stem terete, striated, glabrous; leaves decompound; lobes or leaflets linear, cuspidate, divaricate : rays of umbel contracted after flowering, and indurated. ๑. H. Native of the south of Europe, in fields; nortl of $\Lambda$ friea, Caucasus near $\mathrm{Kuby}$, and in plains towards the Caspian Sea, and the Lerant; also in Chili, at Mendoza and Hacienda de Vasquez, between Casa Blanca and Valparaiso. 1). C. f. fr. 4. p. 327. Daúcus Visnàga, Lin. spec. 3 18. Jacq. hort. vind. 3. t. 26. Visnàga daucoides, Gartn. fruct. 1. p. 92. t. 21. Visnàga, Vill. dauph. 2. p. 594. Daúcus gingídium, Lin. herb. ex Smith, Gohòria, Neck. elem. no. 287.-Garid. aix. t. 36.Lob. icon. 726. f. 1 . Umbels often not very much above the leares. Receptacle of the rays of the umbel not much dilated. Ray's crowded, very numerous, and at length they become so hard as to be used as tooth-picks, bence the name of the plant in France herbe aux curedents. In Spain, when they have served this purpose, they are chewed, and thus are supposed to be of service in cleaning and fastening the gums; however this may be, the leaves have a pleasant aromatic taste in the mouth. Flowers with white petals and purple anthers.

Tooth-pick Bishop's-weed. Fl. June, Aug. Clt. 1596. Pl. 2 to 3 feet.

5 A. Dauccints (Salzm. pl. exsic. ann. 1825. ex D.C. prod. 1. p. 113.) stem terete, striated, muricated, having a few seatterell bristles at the top of the petioles and branchlets; leaves bipinnate, rather eiliated; leaflets linear, cut, aeute; leaves of involucel either simple or trifid; fruit covered all over with small, obtuse tubercles. $\odot$. H. Native about Tangiers. Habit almost of Laúcus. Umbels nearly as in $A$. Ï̈snàga, having the receptacle of the rays of the umbel thickened, and the rays very numerons. lruit ribbed, as in the rest of the genus, but differs in being muricated.

Carrot-like Bishop's-weed. Pl. 2 feet.

6 A. Crisitum (Guss. pl. rar. p. 128. t. 25. prod. p. 332.) stem terete, striated, glabrous, rather setose at the apex; leaves supra-decompound; lobes or leaflets linear-setaceous, glabrous ; petioles bristly; maruins of the sleaths of the petioles searions; fruit glabrous, somewhat tetragonal. ○. H. Native of Calabria and Sicily, in fields. Leaves of involuerum multifid, reflexed. Flowers yellow in the dry state, as in Daúcus aúreus.

Ilairy Bishop's-weed. Pl. 2 to \& feet.

7 1. Axeturoòles (Lam. dict. 1. p. 132.) stem furrowed, glabrous; leaves decompounct ; lohes or leaflets multifid, capillary ; petioles channelled ; leaves of involucrum eapillary, trifid. §.? II. Native of the Levant, or Siheria. Daúcus meoides, Pers. ench. 1. p. 308 . Unbels terminal, flat. Stem and rays of umbel reddish. Fruit quite glabrous. Leaves of involucels sometines trifid.

Fenncl-leared Bishop's-weed. Fl. Ju. Jul. Clt. 1818. Pl. 2 fect.
8 A. Pu'mlus (1). C. prod. 4. p. 11 \%.) stem erect, angular, leafy, glabrous; leaves bipinnate; segments or leaflets pinnatifid; lobes linear; umbels opposite the leaves, pedunculate; leaves of involucels numerous, with scarious margins, and are rather seabrous, as well as the rays; some of the leaves of the involuera are trilid at the apex. ○. H. Native of Portugal, in sandy places, at the river Tavora, and elsewhere in Beira. Sison pumilus, Brot. fl. lus. 1. p. 425. Iruit, according to Brotero, like that of parsley. Lower leaves like 1 . glaucifolium. Petals obovate, unequally obcordate. Ilerb a foot high, not dwarf. 'I'his is joined by Sprengel with Ptychòtis verticillikt, but it is very distinct from that plant; but from the olssolete teeth of the caly $x$, and from the leaves of the involuerum being sometimes trificl, it comes nearest to the present genus, although it may hereafter form a proper genus, from the fruit being much more angular?

Dwarf Bishop's-weed. Pl. 1 to $1 \frac{1}{2}$ foot.

9 A. Broussonétil (D. C. prod. 4. p. 113.) stem erect, terete, leafy, glabrous, branched ; lower leaves unknown; upper ones tripartite: lobes cuneate-oblong, entire or tridentate; leaves of involnerum linear or rarely trifid; young fruit rather seabrous from adpressed short hairs. $\odot$.H. Native of Africa, probably about Mogador. Habit nearly of $A$. màjus and $A$. glaucifolium, but the involucra are very different.

Broussonct's Bishop's-weed. Pl. 1 to 2 feet.

10 A. еiсита'rius (Willd. rel. in Schultes syst. 6. p. 531.) stem angularly-furrowed, quite glabrous, furnished with few leaves; leaves ternately tri-pinnatifid : ultimate segments lanceolate, very acute, trifid; umbels with $6-8$ rays ; leaves of involucra bipinnate: having the lobes or leaflets linear, and deeply toothed. $\odot . ? H$. Native of South America, but in what place is unknown. Plant small. Schlecht in litt. Petioles 3 to 4 inches long. Rays of umbel stiff, angular, shorter than the involucrum. Leaves of involucel pinnatifid or trifid. Fruit ovate, compressed from the sides, glabrous; styles short, diverging. Ribs of mericarps rather prominent, having the furrows between the ribs furnished with 1 vitta each, and the commissure with 2 vittæ.

Cicuta-like Bishop's-weed. Pl. 1 foot.

\section{* Species not sufficicntly knonn.}

11 A.? Pyrenaicum (Lapeyr abr. p. 145.) stem glabrous, flexuous; leaves somewhat bipinnate; lobes or leaflets entire or eut, ultimate ones decurrent; leaves of involucels setaceous or trifid, twice the length of the umbellules. $\odot$. H. Native of the Pyrenees, in fields about Madres and St. Beat. The petals are said by La Peyrouse to be rounded (arrondis) which indicates that the plant does not belong to this genus.

Pyrencan Bishop's-weed. P!. I foot.

12 A. rubricav'te (Horn. liort. liafn. 1. p. 272.) stem unknown; leaves somewhat verticillately tripinnate: leaflets capillary; leaves of involucel compound, longer than the umbellule. ๙. H. Native of North America, near Baltimore. Perhaps the same as $A$. anethifolium.

Red-stemmed Bishop's-weed. Pl. 1 to 2 feet.

Cult. The species of $A^{\prime} m m i$ are very showy while in flower; the seeds of them only require to be sown in the open ground early in spring.

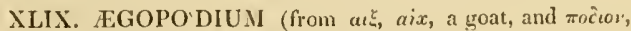
a dim. of tous, pous, a foot; probably fiom the shape of the leaves.) Lin. gen. no. 368 . Hothin. umb. gen. p. 82. 1. 1. f. 6. Koeh, umb. p. 122. D. C. prod. 1. p. 114.-Podagrària Riv. peut. t. 17 .

Lin. syst. Pentandria Digýnia. Margin of calyx obsolete. Petals obovate emarginate, with an inflexed point. Stylopodium 
distinct, conical, terminated by the long deflexed styles. Fruit compressed from the sides, ovate; mericarps with 5 filiform ribs: lateral ribs marginating; furrows between the ribs destitute of vittæ. Carpophore setaceous, forked at the apex. Seeds teretely convex on the outside, and flattish on the insile. Branching herbs, with creeping roots. Leaves biternate or triternate; upper cauline ones ternate: leaflets ovateoblong, acuminated, serrated. Umbels composed of many rays. Both the involucra and involucels are wanting. Flowers white: anthers when young purple.

1 E. PODAGRA'RIA (Lin. spec. p. 379.) stem furrowed; leaves biternate or tritemate; leaflets oblong-serrated, unequal at the base, lower ones binate. 24. H. Native throughout the whole of Europe, cven to Caucasus and Siberia, in hedges and orchards. Very common in some parts of Britain. Oed. fl. dan. t. 670 . Smith engl. bot. t. 940. Schkuhr, lıandb. t. 79 . Riv. t. 47. 'Tragoselinum angélica Lam. fl. fr. 3. p. 419. Pimpinélla angelicafolia, Lam. dict. 1. p. 451. Ligústicum podagrarì, Crantz. aust. p. 200. Séseli Ægopòdium, Scop. carn, ed. 2. no. 359. Podagrària Egopòdium Moench, Meth. p. 90. Sison Podagrària Spreng. umb, prod. p. 35.-Lob. icon. t. 700, f. 2. The plant is called IIerb Gerard, Gout-need, Ash-necd, or Aeh-need, and Wild Masternort, and being a great creeper, it cannot be admitted into gardens, for after it gets hold it is next to impossible to rradicate it again. Though it lias the quality of most umbelliferous plants, of being aromatic, yet it is not used at all in medicine; nor has it any title to its name gont-weed, though the Germans formerly used it to assuage the pain both of the gont and piles. Linnaus says it is eaten in Sweden, boiled for greens, when tender in the spring. The roots are sometimes sold for those of the true Masterwort, the Imperatòria Ostrüthium.

Gout-weed. Fl. May, July. Britain. 1'l. 2 to 3 feet.

2 E. Alpe'stre (Led. fl. ross, alt. ill. t. 7 . fl. alt. 1, p. 354.) stem smooth; lower leaves ternately pinnatè ; leaflets ovate, cut, lower and terminal ones somewhat tripartitc; upper leaves ternate, having the leaflets pinnate at the base, but drawn out at the apex, and nearly entire. $\%$. H. Native of Altaia, in slady places on the north sides of the mountains near Riddersk, about the fountains of the rivers Uba and Tscharuych. Root creeping. Flowers white.

Alp Gout-weed. Fl. Ju. July. Pl. 1 to 2 feet.

Cult. The plants will grow under any circumstance.

L. CARUM (so named from Caria, in Asia Minor; originally found there) Kock. umb. p. 121. D. C. coll. mem. 5. p. 41 . prod. 4. p. 414. Càrum, Sison, and Bùnium species of Lin. and Hoflím.-Càrum and Sium species of Spreng.

Lis. sxst. Pentándria Digýni Petals regular obovate, emarginate, with an inflexed point. Stylopodium clepressed; styles deflexed. Fruit contracted from the sides, ovate or oblong; mcricarps furnished with 5 filiform, equal ribs: lateral ribs marginating; having the furrows between the ribs furnished with one vitta each, and the commissure, which is flat, with two vittæ. Carpophore free, forked at the apex. seed terete, convex on the back, and flattish in front. Herbs glabrous, usually perennial. Roots tuberous, cdible. Leaves pinnate; segments or leaflets multifid. Both the involucra and involucels are variable. Flowers white.

Śct. I. CÁRVi (an alteration of the generic name). D. C. prod, 4. p. 11 5.-Càrun, Lin.-Càreum, Adans. fam. 2. p. 98. Involucrum wanting; involucels wanting, or of very fow leaves.

1 C. CÁrv (Lin. spec. 378.) root fusiform; leaves bipinnate; lcaflets decussate, multifid; stems furrowed; involucra and involucels wanting. 24. H. Native throughout the whole of Europe, in meadows and pastures; and of Altaia, in dry grassy places at the river Tscharaiych. Fre quent in Britain, but is only a naturalised plant. 11. dan. 1091. Smith, engl. bot. t. 1503. Nees, ofl. pfl. 14. t. 17. Mart. rust. t. 55. Hayn, aræn. gew. 7. t. 19 . Woodv. med. bot. Jacq. aust. t. 393. A'pium Cárvi Crantz, aust. p. $21 \AA$. Séseli Cárvi, Scop. carn. no. 361. Bùnium Cárvi, Biel). fl. taur. 1. p. 211. suppl. p. 206. Lagæ' cia cuminoides, Willem. phyt. 1. p. 254. but not of Lin. Cárvi, Riv, pent. irr. with a figure. Flowers white. Leaflets of leaves in sixes, appearing rather verticillate. The caraway is called Carci in France, Italy, and Scotland, and Kummel in Germany. The plant is cultivated chiefly for the seed, which is used in confectionary and in medicine. In spring the under leaves are sometimes put in soups; and in former times the fusiform roots were eaten as parsnips, to which Parkinson gives them the preference.

Garden culture.-The plant is raised from seed, of which a quarter of an ounce is sufficient for a seed-bed 4 feet by 6 . Sow annually, in antumn, soon after the seed is ripe: the seedlings will rise quickly, and should be thinned to a foot distance each way. In default of sowing in autumn, sow in March or April, either in drills or broad-cast ; but the plants so raised will not, in gencral, flower till the following year. When the seed is ripe, the plant is generally pulled up in gathering, especially in field culture.

Ficld culture.-The culture and management of the caraway is the same as that of Coriander. In all probability both plants would answer if sown like clover among a crop of corn, hoed and thinned when the crop was removed, and again in the following spring. The method of culture in Essex is, about the beginning of March to plough some old pasture land; if it has been pasture for a century the better; and the soil should be very strong claycy loam. Twelve pounds of caraway-seed are mixed with ten pounds of coriander, and twelve prounds of teazle-seed; this is sufficient for an acre, and is sown directly after the plough, harrowing the land well. When the plants appear of sufficient strength to bear the hoe, which will not be until about ten weeks after sowing, it must not be omitted; and in the course of the summer the crop will require three hoeings, besides one at Michaelmas. The coriander, being annual, will be fit to cut about the beginning of July. It is left in the field after cutting, and threshed on a cloth in the same manner as raje-seed. About April following the caraway and teazle will want a good hoeing, done deep and well, and another about the beginning of June. The caraway will be fit to cut the beginning of $J$ uly, and must be threshed in the same manner as the coriander. This compound crop is mostly sown on lands so strong as to require being a little exhausted to make it fit for corn. Caraway and coriander are oftenest sown without teazle; the latter being a troublesome and uncertain crop, and the produce of caraway much greater witlout it. The produce of caraway, on very ricl old leys, in the hunileds or low lands of Essex, has often been twenty cwt. to the acre. 'l'here is always a demand for the secd in the London market. The uses of caraway-seed are the same as those of coriander, and its oil and other preparations are more used in medicine. Dr. Anderson says, both the roots and tops may be given to cattle in spring. The seeds have an aromatic stnell, and warm pungent taste, and yield much essential oil. They are employed as stomachic and carminative, in flatulent colics. The oil is used in the same way as other volatile oils.

Yar. $\beta$, pterochle'num (D. C. prod. 4. p. 115.) leaves of involucrum few and multifid. $\odot$. H. Native of Montbelliard, in humid meadows not unfrequent.

lar. $\gamma$, nimum (I). C. l. c.) stems short. \%. H. Native of the Apenonines. l'impinélla vaginàta, Jan. herb.

Lar. i, elongàtum, segments of the leaves linear, elongated. 4. H. Native of Canada. C. Cárı, var. $\beta$, Hook, fi. bor. 
amer. 1. p. 661. Differing from the European plant in the leaves being remarkably long and slender.

Var. $\varepsilon$, ròseum, flowers rose-colouredl. 4. H. Native of Altaia, near Krasnajaparki, at the river Irtysl.

Common Carvi, or Caraway. Fl. May, Ju. Britain. Pl. $1 \frac{1}{2}$ foot.

2 C. Ricinulua (Koch, in litt. ex D. C. prod. 4. p. 115.) root fusiform; stem nearly naked, sparingly branched, quite glabrous; lower leaves pinnate : leaflets many-parted, even from the base: lobes linear-subulate, acute, individed or parted; upper sheaths adpressed, almost leafless; involucrum almost wanting; leaves of involucels linear-subulate, about equal in length to the umbellules; fruit glabrous. 4. H. Native of Liguria, about Sarzana, Sc. Selinum rigídulum, Viv. fl. ital. fragm. 1. p. 14. t. 15. ann. bot. 1. p. 2. p. 164. Spreng umb. spec. 76. Bertol. amœen. ital. p. 3+5. S. Appiànum, Pers. cnch. 1. p. 309. S. Appiànum, Viv. cat. Séseli pimpinelloìdes Lin. spec. p. 37\%. Willd. nov. act. mat. cur. 4. p. 109. spec. 1459 ; but the plant under this name from Sprengel is S. Peucédanum Chabræ'i, var. $\beta$, Podòlicum.

Stiff Caraway. Fl. July, Aug. Clt. 1826. I'l. 1 foot.

Sect. II. Bunboca'staxum (from bulbus, a bulb, and castanea, a chestnut; the root is bulbous, and tastes like a chestnut.) Adans. fam. 2. p. 97. but not of Lag. Both the involucra and involucels are many-leaved.

\section{* Root bulbous.}

S C. pulbocástanum (Koch, umb. p. 121.) root globose; stems terete, branched; leaves decompound; leaflets linear, cuspidate, a little channelled, quite entire, and rather bifid: leaves of involucra and involucels numerous, subulate. $\%$. H. Native of Europe in heaths, pastures, among bushes, and in woods. Bunium, bulbocástanum, Lin. spec. p. 319 . Fl. dan. t. 220. Lam. ill. t. 197. Bùnium mìnus Gouan. ill. p. 10. Bùnium flexuòsum, Smith. Sìum Bulbocástanum, Spreng in Schultes, syst. 6. p. 538. Scándix Bulbocástanum, Mœench, meth. p. 101.-Lob. icon. t. 745. f. 1. Tuber or root spherical, black on the outside and white inside, of an agreeable sweet taste. Root leaves tripinnate, cauline ones bipinnate.

Bulbocastanum, or Earth-nut. Fl. May, Ju. Pl. 1 to $2 \mathrm{ft}$.

$$
\text { * Rool fasciculale. }
$$

4 C. verticjlla'tum (Koch, umb. p. 122.) root fasciculate, with spindle-shaped branches; stem terete, hardly branched; leares pinnate; leaflets many-parted; segments crowded in a whorled manner, linear-filiform; leaves of both involucra and involucels numerous, short, and deflexed. 24. H. Native of the western parts of Europe, from Corsica to Britain; plentiful in the western parts of Scotland and Wales; in Ireland, near Lane bridge, Killarney, and between Bantry Bay and the river Kienmare. Sison verticillàtum, Lin. spec. 363. Smith, engl. bot. t. 995 . Lightf. scot. 1096. t. 35. Sium verticillatum, Lam. dict. 1. p. 407. Carvi foliis tenuissimis asphodeli radice, Tourn. inst. 306. Carvi Lusitánicum, Sc. Juss. herb. Sprengel refers to this the Ethùsa fàtua, Ait. Iort. kew, 1. p. 355. or Ilèm fătuum, Pers. ench. 1. p. 319. but it appears to have nothing to do with the present plant. Flowers whitc.

Whorled-leaved Caraway. Fl. July. Britain. Pl. 1 foot.

Cult. The more sandy the soil is the better the species will grow. They are increased either by dividing at the root, or by seed.

LI. CHAMESCIA'DIUM (from Xurat, chamai, on the ground, and oxiriove, stiadion, an umbel; in allusion to the plant being dwarf as well as umbelliferous). Meyer, verz. pflanz. p. 122.-Bùnium species of Bieb.

Lix. sxst. Pentandria, Digynia. Margin of calyx a little voL. III. toothed. Petals ovate-lanceolate, quite entire, oblique or inflexed at the apex. Stylopodium depressed, margined. Styles reltexed. linuit ovate-oblong, compressed from the sides; mericarps solid, having 5 equal filiform ribs: the lateral ribs inarginating; with the furrows between the ribs furnished with $3-4$ vittæe each. Sced somcwhat semi-terete, Hattish in front; carpophore adnate, bifid at the ajex.-An herb with a fusiform root, supra-decompound or bipinnate leaves: having the segments or leaflets divided into many setaceous lobes. Scapes radical. Involucra and involucels of many leaves. Petals yellow. Com. missure of fruit furnished with 4-6 vitta. The fruit is nearly like that of Sirum, and the petals that of $I$ closciadium.

1 C. Flave'scens (Meyer, I. c.). 2. II. Native throughout the whole of Caucasus, in grassy places, at the elevation of from 2400 to 8000 feet ; and of Cappadocia. Bininm acaúle, Hoffm. umb. 1. p. 87. and 108 . Bieb. fl. taur. suppl. p. 205. A'mmi acaúle, Schultes, syst. 6. p.530. Cárvi Cappadócicum acaúlon fòliis Chamameli, Tourn. cor. p. 21.

Fellowish-flowered Chamasciadium. Fl. June, July. Clt. 1820. Pl. 1 foot.

Cult. See Bùnium for culture and propagation.

LII. BU'NIUMl (from Bovvos, bounos, a hill; habitation of some of the species) Koch, in litt. 1828. Link, enum. 1. p. 267 ? D. C. coll. mem. 5. p. 41. prod. 4. p. $115 .-$ Bulbocástanum, Lag. am. nat. 2. p. 99. but not of Adans.-Mýrrhis and Wallróthia species Spreng.-Bùnium species of Lin.

Lis. syst. Pentándria, Monogýnia. Margin of calyx obsolete. Petals obovate, cmarginate, with an inflexed point. Fruit contracted from the sides, linear-oblong; mericarps furnished with 5 equal filiform, obtuse ribs: lateral ribs marginating; having the furrows between the ribs furnished with $2-3$ vitta each, and the commissure with 4 vittæ; the vittæ all superficial. Carpophore free, bifid. Sced teretely convex on the outside, and flattish in front. Herbs perennial. Roots usually tuberous and globose. Stems terete and attentrated at the base in the tuberous rooted species. Leaves decompound; segments or leaflets divided into many slender linear lobes; involucra various: involucels fewleaved. Flowers white, rarely yellow or green.

Sect. I. Cury'seun (from Xpvoos, chrysos, gold; in allusion to the yellow flowers of the species.) D. C. coll. mem. 5. p. 41 . prod. 4. p. 116. Both the involucra and involucels are manyleaved. Flowers yellow or greenish. Styles diverging. 'The vitte in the furrows of the fruit in the different species are variable in number. This section is intermediate between Càrum and Bùnium, but differs from both these genera in the flowers being yellow.

1 B. Peucedanoides (Bieb. fl. taur. 1. p. 211. suppl. 208.) root fusiform; stem striately furrowed, branched; leaves bipinnate: leaflets of the radical leaves decussated, with broader lobes; segments of the canline leaves linear and divaricate; leaves of involucra and involucels short and setaceous; rays of umbel very nnequal. 4. H. Native of Cancasus, about Nartzana, and on Mount Bechtau, among grass. Sium peucedanoides, Spreng. umb. spec. 41. no. 5. syst. 1. p. 906. Peucédanum carvifolium, Bieb. Petals pale yellow. The furrows of the fruit are only furnished with one vitta each, accorcling to Besser ; but in fruit of the plant sent from Fischer, the furrows are furnished with $2-3$ vitte each, rarely solitary.

Sulphur-norl-like Earth-nut. Fl. July, Aug. Clt. 1818. Pl. 1 to 2 feet.

2 B. vire'seens (D. C. mem. soc. gen. vol. 4. prod. 4. p. 116.) root fusiform; stem striately furrowed, branched; leaves bipinnate; leaflets of all the leaves linear; leaves of involucra and involucels short and setaccous; rays of umbel very unequal. 4. H. Native of Burgundy, on a mountain called $\mathbf{A}$ frichue, near $\mathrm{P}$ p 
Divion. Sium viréscens, Spreng. umb. spec. 94. syst. 1. p. 906. and in Schultes, syst. 6. p. 542 . Peucédanum Taúricum, hort. par. 18?1. Lor et Dur. cat. pl. côte-d'or, p. 37. Peucédauum alpéstre, Ster. in litt. 1819. Binnum peucedanoides, Bieb. ex Ster. Sium Cordiènii and Sium viréscens, Lois. fl. gall. ed. 2. p. 194. Pctals greenisl, nearly entire, at the apex involute; section of fruit nearly terete. Vittæ in the outer furrows of the fruit 3 ; 2 of these are incomplete; and 2 or 4 in the commissure.

Grecnish-flowered Earth-nut. Pl. 1 to 2 feet.

3 13. LU'TEUM (Hoffin. umb. p. 108.) root vearly globose ; stem terete, branched; leaves pinnate; leaflets decussate, pinnatifid: lobes linear, very fine; leaves of involucra and involucels very short, with membranous margins ; fruit linear-cyliudrical. 4. H. Native of Siberia, in deserts, at the river Don, near the colony of Sarepta. Bùnium lùteum, Bieb. suppl. p. 207. Sìnm lùteum, Spreng. syst. 1. p. 906. There are 3 vitta in each furrow of the fruit, according to Koch. Petals yellow.

Icllow-flowered Larth-nut. PI. 1 to 2 feet.

Sect. II. Caroides (from C'arum, the caraway, and idea, form; plants with the habit of Càrum,) D. C. coll. mem. 5. p. 41. prod. 4. p. 116 . Involucra usually of many leaves, rarely absent. Flowers white. Stylopodium depressed: styles diverging. This section is intermediate between the genera Càrum and Conopoùdium.

4. B. earvifòlita (D. C. prod. 4. p. 116.) root fusiform, terete, elongated; leaves hipinuate; leatlets divided into many linear acute lobes; stem flexuous, erect, furnished with a few leaves; leaves of involucrum and involucels linear acute. $\psi$. H. Native of Abruzzo, and on Mount Fiori among the Appenines; but not of Sicily, ex Guss. prod. 1. p. 339. Sison tlexuòsum, Ten. prod. f. neap. p. 67. Si son carvif òlium, Bert. in herb. Moric. Sison prólifer, Brochi and Jan. Petals of a greenish white colour when dried. The furrows of the fruit, when immature, are furnished each with 2 or 3 vitta.

Caranay-leaved Eartlı-nut. P1. 1 to 2 feet.

5 B. GLAuce'scens (D. C. prod. 4. p. 117.) bulb ovate-oblong; stem erect, straight, terete; branches alternate; leaves glancous : radical ones bi-tripinnate, with multifid leaflets, and linear short lobes ; cauline leaves distant, small, multifid; leaves of involucra as well as of involucels, 6-7 in number, linear-oblong, acute, white. 4.H. Native of Persia, in grassy valleys among the mountains about Seidklodzi. Stem $1 \frac{1}{2}$ foot high. Unbels 10-11-rayed. Flowers white.

Glaucescent Earth-nut. Pl. $1 \frac{1}{2}$ foot.

6 B. paccifòlium (D. C. prod. 4. p. 117.) bulb globose; stem erect, straight, terete; branches alternate; superior leaves tripartite, laving the lobes linear and entire; upper leaves undivided, linear; involucrum of 3-4-leaves, and the involucel of 5-6 linear white leaves. 24. H. Native of Persia, in grássy valleys of the mountains about Seidkhodzi. Ilerb 2 feet high. Lower leaves unknown. Flowers white. Umbels of $1-5$ rays. Fruit unknown.

Fen-leaved Earth-nut. Pl. 2 feet.

7 B. ApHx'Llus (Jan. lierb. ex D. C. prod. 4. p. 117.) root nearly globose, thick; stem terete, erect, nearly simple: cauline leaves striated at the sheaths, reduced to a short limb: both the involucrum and involucel are composed of $4-5$ acuminated leaves. 4. II. Native of Sicily, on the Nebrodes. Herb 4 to 5 inches high.

Leafless Earth-nut. Pl. $\frac{1}{2}$ foot.

8 13. Alpínu (Waldst. et Kit. pl, rar. loung. 2. p. 199. t. 182.) root nearly globose, thick; stem terete, flexuous, hardly longer than the radical leaves; segments of leaves linear-oblong, fleshy; involucra of 5 linear-subulate leaves. 24. H. Native of Croatia, on chalky mountains; and of Persia, in the province of Aderbijan. Wallróthia tuberòsa. Spreng. pug. 2. p. 52. and in Schultes, syst. 6. p. 556. Flowers white. There are 3 vittæ in each furrow of the fruit.

l'ar. (3, petrce'um (D. C. prod. 3. p. 117.) plant rather glaucous; leaves of involucrum oblong-linear. 4. H. Native of the kingdom of Naples, on mountains about Magella. Bùnium petræ'um, Ten. prod. H. neap. p. 60 . Perhaps Wallróthia divaricàta, Presl, del. p. 134. Tuber large, pushing out many fibres like the tuber of a $C$ ýclamen. Fruit uot seen.

Alpine Earth-nut. Fl. May, Jul. Clt. 1823. PI. $\frac{1}{2}$ foot.

9 B. Ferulafòlius (Desf. ann. mus. 11. p. 275. t. 30 . cor. Tourn. 55. t. 43.) root nearly globose; stem terete, dichotomous ; leaves all somewhat triternate: leaflets linear; leaves of involucrum 1-5, of the involucel 4-5, very short; fruit narrow, cylindrical. 4. H. Native of the islands of Cyprus, Candia, and Scio. Sium ferulæfòlium, Spreng. in Scluultes, syst. 6. p. 539 . B. ferulàceum, Smith. Tuber about the size of a filbert, rufous on the outside, and white on the inside. Flowers white. Fruit not sufficiently known. 'The involucrum is very variable in the number of leaves.

Ferula-leavcd Earth-nut. Fl. June, Jul. Clt. 1824. Pl. $1 \mathrm{ft}$.

10 B. conYDÁlinum (D.C. prod. 4. p. 117.) root globose ; stem flexuous; segments of leaves linear-oblong; involucrum almost wanting; involucels of few leaves. \%. H. Native of Corsica, on the mountains. B. petrac'um, Lois. fl. gall. ed. 2. vol. 1. p. 195. Tuber hardly so large as a pea. Stem 4-5 inches high, sparingly branched. Umbels of $3-5$ rays; and the umbellules of $8-10$ flowers; involucels of 5-6 leaves. Fruit oblong: liaving the furrows furnished with $2-3$ vittæ each.

Corydalis-like Earth-nut. Pl. $\frac{1}{2}$ foot.

11 B. Cre'ticum (D'Urv. enum. p. 31.) root turnip-formed; stem dichotomous, nearly naked; leaflets of radical leaves ovate and cut: of the cauline ones linear; involucrum none; involucels of few leaves. 4. H. Native of the Island of Cos, among rocks. Bulbocástanum Créticum, radice napiformi, Tourn. cor. 21. and therefore Sium napiforme, Spreng. and Bùnium napiförme, Willd. rel. in Schultes, syst. 6. p. 539. Flowers white. Fruit unknown.

Cretan Earth-nut. Pl. 1 foot.

Sect. III. Conofònum (from kovos, konos, a cone, and tous,

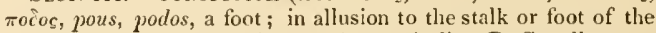
style, called the stylopodium, being conical). D. C. coll. mem. 5. p. 41. prod. 4. p. 117 .-Conopódinm, sect. 1. Koch, umb. p. 118. Involucrum wanting, or of few leares. Stylopodium conical, exserted. Styles straight.-Perhaps a proper genus.

12 B. DenUda'tum (D. C. fl. fr. 4. p. 525.) root globose; cauline leaves nearly sessile, with short sheaths and toothed or cut leaflets; involucels unilateral, few-leaved. 4. H. Native of the west and south of Europe, and Cancasus, in mountain meadows and grassy pastures and among bushes, especially on a gravelly soil ; plentiful in Britain. Mýrrhis capillifòlia, Guss. prod. fl. sic. 1. p. 351. Mýrrhis Bùnium, Spreng. umb. spec. 1. p. 131. syst. 1. p. 903 . exclusive of numerous synonymes. Bùnium flexuòsum, With. 291. Smith, fl. brit. 1301. engl. bot. 988. Bùnium bulbocástanum, Huds. angl. 122. Curt. lond. fasc. 4. t. 24. Bùuium màjus, Gouan. ill. p. 10. 'This species varies mucl in height. Styles long, pale, slıort, and reddish. Fruit ovate and oblong. Involucrum wanting, or 1-3-leaved. Segments of the leaves linear and lanceolate, more or less toothed. Sprengel refers Buntum ammoides, Link. or Mýrrhis ammoides, Spreng. in Schultes, syst. 6 . p. 517 . to the present plant ; and probably Mýrrhis tenérrima, Presl, del. prag. 131. is also referrible to it. Flowers white. There are probably numerous species confused under this name. The plant has several names in England, as earth-nut, pig-nut, ar-nut, lipper-nut, hank- 
nut, jur-nut, or yer'nut, earlh chestnut, and ground-nut; in Germany it is called erduuss; in Holland aardnoot; in Sweden jorduot; in l'rance suron, terre nois; in Italy castagna de terra; in Spain castanode tierra. lioot nearly globular, black, or chestnut-coloured on the outside and white inside ; aromatic, sweet, and mueilaginous, witl some acrimony: they are frequently dug up aud eaten by children. Swine are very fond of them, and will soon become fat with feeding on them. When boiled they arc very pleasant and delicious, and are supposed to aflord great nourishment. Thus prepared, they are said to be eaten in Holland and the $A l p s$, and in some parts of England in soup or broth. Roasted they are even superior to chestnuts.

Viar. 3, Pyrence'um (D. C. prod. 4. p. 118.) sheaths of leaves ciliated. If. H. Native of the Pyrenees. Bùnium denudatum, var. $\beta$, Pyrena'um, D. C. A. ['r. suppl. p. 511 . no. 3496. Iy'rrhis Pyrence'a, Spreng. in Schultes, syst. 6. p. 518. I sois. t. gall. ed. 2. vol. 1. p. 208. t. 5. Bùnium Pyrena'um, Lois. H. gall. p. 161. t. 5. Binium pilosum, Willd. rel. in Sclunltes, syst. 6. p. 500 .

Naked-stemmed or Common Earth-1sut. Fl. May, June. Britain. Pl. 1 to 2 feet.

13 B. ru'muL M (Smitl, f. graec. 274. prod. I. p. 187.) root globose; leaves bipinnate : cauline ones petiolate, pilose; sheaths short; segment of leaves cut and acute; involucrum wanting or 1-leared; involucels of many leaves. 4 . H. Native of Mount Parnassus. Fruit ovate-oblong. Flowers white.

Durarf Earth-nut. Pl. $\frac{1}{2}$ foot.

14 B. thxurfòlius (Salzm. pl. exsic. ex D. C. prod. 4. p. 118.) root unkuown: cauline leaves petiolate; sheaths elongated, glabrous; segments of leaves few, linear, very narrow, elongated, and quite entire; involucels of many leaves. 2 . H. Native of Mauritania, about Tangiers. Perhaps Bunium ammoirles, link. is referrible to this plant. Flowers white.

Fine-leaved Earth-nut. PI. I foot.

15 B. GLABE'RRIuUM (D. C. prod. 4. p. 118.) plant glabrous ; stem terete, striated; lower leaves biternate: leaflets ovate, lobed, and toothed; superior leaves biternate : leaflets laneeolate, quite entire; both the involucra and involucels are usually 1leaved. 1 . H. Native of Mount Atlas, near Tlemsen. Chæ. roplyyllum glabérrimum, Pers, encl. 1. p. 322. Poir. dict. 5. p. 136. Spreng. in Schultes, syst. 6. p. 523. Scándix glabérrimum, Desf. atl. 1. p. 260. t. 74. Flowers white. Immature fruit similar to that of $B$. denudàtum.

Quite-glabrous Earth-nut. Pl. 1 foot.

16 B.? Rigers (Spreng. in Schultes, syst. 6. p. 500.) root unknown; stem stiff, sheathed; branches spreading; leaves bipinnate; leaflets obtuse, conduplicate, crenulated ; involucrum of many short leaves. ?. G. Native of the Cape of Good Hope, and of the Mauritius. Cònium rígens, Lin. mant. p. 352. Thunb. prod. p. 50. f. cap. 2. p. 203. Dasyspérmum species, Neck. elem. p. 295. ('Trachyspérmum rígens, G. Don, in Lou!. hort. brit. 103.). Perliaps 2 species are confused here. Perhaps it is a true specics of Bùnium. Flowers white.

Sliff Earth-nut. Fl. Ju. Jul. Clt. 1787. Shrub $1 \frac{1}{2}$ foot.

Cult. A light sandy soil suits all the species best; and they can only be increased by seeds.

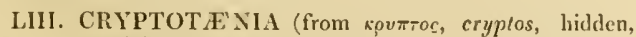
and ravea, tainia, vitta ; the vittæe of the mericarps are hidden by a pericarp, and are invisible, unless the mericarps are cut transversely). D. C. coll. mem. 5. p. 42. prod. 4 . p. $118 .-$ Conopòdium, sect. 2. Koch, umb. 119. Cyrtospérmum, Rafin. in litt. 1819.-Alacospérmum, Neck. elem. no. 276.?

Lis. syst. Pentándria, Digýnia. Margin of calyx obsolete. Perals obovate, nearly entire, ending in a narrow inflexcd point. Fruit contracted from the sides, lincar-oblong, crowned by a short stylopodium and 2 short styles; mericarps with 5, equal, liliform, obtuse ribs: the 2 lateral ribs placed before the margin; vitta in the furrows between the ribs numerous, covered by a somewhat corky pericarp, but closely adnate, and only visible when the carpels are cut transversely. Seed teretely convex, flattish in front. Carpophore free, bifid at the apex.-Perennial, glibrous, erect herbs. Lioots not bulbons. Leaves ternate; leaflets ovate, coarscly tootlicd: teeth mucromate. Umbels numerous, almost disposed in a panicle. Rays of umbels and um. bellules few, very unequal. Involucrum wanting; involucels few-leaved. Flowers white.

1 C. Cananénsis (I). C. prod. 4. p. 119.) lower umbels rising from the axils of the superior leaves; fruit oblong. $\boldsymbol{4}$. II. Natice of North America, in woods among rocks; Canada about Lake Huron and Quebee; frequent about Boston, in the United States. Sison Canadénse, Lin. spec. 363. Hollm. umb. p. 36. Sìum Canadénse, Lam. dict. 1. p. 407. Big. fl. bost. ed. 2. p. 114. Charophýllum Canadénse, Pers. ench. 1. p. 320. Mýrrhis Canadénsis, Mor. oxon. sect. 9. t. 11. Nutt. gen. amer. 1. p. 1 1. Gartn. fruct. t. 23. Conopòdium Canadénse, Koch, unb. 119. Mýrrhis ternata, Mœeneh, meth. p. 101. Sison trifoliàtum, Michx. A. bor. amer. 1.p. 168. ? Cyrtospérmum trifoliàtum, Rafin. in litt. Flowers white.

Canadian Cryptotania. Fl. Jul. Aug. Clt. 1699. Pl. $1 \frac{1}{2} \mathrm{ft}$. 2 C. Thoma'sir (D. C. prod. 4. p. 119.) umbels disposed in a naked leafless panicle; fiut ovate. 4 . H. Native of Ulterior Calabria, near rivulets, in groves on the mountains called Della Serra. Sison Thomàii, Ten. prod. neap. suppl. 2. p. 66. syn. p. 40 . Schultes, syst. 6. p. 412. A'pium trifoliàtum semínibus spársis péndulis diapénsiæe fòlio, Boce. mus. append. 4. ex herb. Vaill.

Thomas's Cryptotænia. Pl. I foot.

Cull. The speeies of this genus will grow in any soil ; and may either be increased by cuttings or by seed.

LIV. PIMPINE'LLA (altercd from bipinnale, twice pinnate; the leaves). Lin. gen. no. 366 . Koeh, umb. p. 120. f. 65. and 66. D. C. coll. mem. 5. p. 42. but not of Tourn. Gærtn. D. C. prod. 4. p. 119.-1'impinélla and 'Tràgiuın, Spreng. Hofim. Lag.

Lis. syst. Pentándria, Digýnia. Margin of calyx obsolete. Petals obovate, emarginate, with an inflexed point. Fruit ovate, contracted from the sides, crowned by the pulvinate stylopodium and reflexed styles, which are capitate at the apex; mericarps with 5 , equal, filiform ribs: lateral ribs marginating: having the furrows between the ribs furnished with many vitta; car* pophore free, bifil. Seed gibbously convex, flattish in front. -Herbs, for the most part natives of Europe. Roots simple. Radical leaves pinnate: leafiets roundish, toothed, rarcly undivided; cauline leaves more finely disseeted than the radical ones. Umbels and umbellules of many rays, without any involucra. Flowers usually white, rarely reddish or yellow.

Sect. I. Tragoselinum (from roayoc, tragos, a goat, and

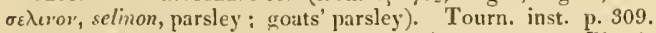
t. 163. Moench, meth. 99. D. C. prod. 4. p. 119.-Pimpinélla, Spreng. umb. prod. p. 35 . Schultes, syst. 5. p. 34. Hoffin. umb. 88. Fruit glabrous. Roots perennial.

I P. Rotundiròcia (Bieb. f. taur. 1. p. 242.) radical and caulinc leaves reniform, crenated; superior ones glabrous, lobed a little. 4 . or 8 . H. Native of Iberia and Caucasus, in groves. Hofin. umb. ed. 2. vol. 1. p. 92. Sìson rotundifòlius, Spreng. anleit. ed. 2. p. 2. t. 4. f. 1-4. umb. spec. p. I] 0. Leaves rather puhescent, of a form almost like those of Málea sylcéstris. Involucrum none. Petals white. Stigmas purple. P $\mathrm{P} 2$ 
Round-leaved Burnet-saxifrage. Fl. June, July. Clt. 1817. Pl. 2 feet.

2 1'. MA'GNA (Lin. mant. 217.) radical leaves pinnate; leaflets serrated and somewhat cut, ovate or oblong: the terminal one 3-lobed. 24. H. Native thronghout the whole of Enrope, Cincasus, and the Levant, in mountain meadows, pastures, and woods. In Britain it grows chiefly in woods and herges, in a ('aleareous soil. Smith, engl. bot. t. 408. Fl. dan. 1155. Hayn, arz. gew. 7. t. 21. Jacq. aust. 4. t. 396 . P. màjor, Mill. diet. no. 1. Gouan. ill. p. 21. P. saxífraga, Spreng. syn. 213. Tragoselıum màjus, Lam. fl. fr. 2. p. 448. 'Tragoselìnum mágnum, Mœnch, meth. 99.--Barrel. icon. t. 248. P. saxífraga, Ray. syn. 213. Petiv. brit. t. 26. f. 5. Saxífraga mágna, Dod. pempt. 315. f. 1. This and the following species partake nearly of the same qualities. The root is very acrid, burning the mouth like pepper. It affords a blue oil. Its acrimony has occasioned it to be used to cure tooth-ache, and to clear the skin from freckles. It is chewed to promote the secretion of saliva, and is used in gargles to dissolve viscid mucous in the throat. In Germany it is prescribed in the asthma and dropsy. Flowers either white or reddish.

tar. $\beta$, rübens (D. C. prod. 4. p. I20.) flowers reddish. P. rùbra, Hoppe. exsic.

Var. $\gamma$, oricntàlis (D. C. 1. c.) leaflets all pinnatifid; lobes lanceolate, acute; flowers white. P. orientàlis, Gouan. ill. $t$. 15. Jacq. aust. t. 397. Plenek, icon. t. 224. P. mèdia, Hoffm. ex Spreng.

I ar. 8, ròsea (Stev, in litt. ex D. C. prod. 4. p. 120.) leaflets acutely and deeply pinnatifid; flowers rose-coloured. $\mathrm{Na}$ tive of Caucasus, at Nartzana. P. dissécta, Bieb. fl. taur. 1. p. 241.

Far. E, dissécta (D. C. prod. 4. p. 120.) leaflets of the superior leaves bipinnatifid: having the segments linear-lanceolate. P. dissécta, Retz. obs. 3. t. 2. P. praténsis, Thuill. P. laciniàta, Thor. land. p. 108. Horn. hort. hafi. suppl. p. 36. Nees. off. pflz. 10. t. 19. P. peregrina, Lejeune, fl. spa. 1. p. 145. Flowers white.

Large Burnet-saxifrage. Fl. Ju. Aug. Brit. Pl. 3 to $4 \mathrm{ft}$. ¿ l'. SAXI'FRAGA (Lin. spec. 378.) radical leaves pinnate; leaflets of the radical leaves toothed or eut, roundish: of the uppermost in various linear segments. 4.H. Native throughout the whole of Europe, Tauria, Caucasus, and Persia, in dry sandy, gravelly, or chalky pastures, on banks, and on rocks; plentiful in soine parts of Britain. Smith, engl. bot. t. $40 \%$ llayne, arzo. gew. 7. t. 20. Schkubr, handb. t. 78. Hoffm. umb. 1. 90. Martyn. f. rust. t. 127. Woodv, med. bot. t. 179. Jaeq. austr. t. 395. FI. dan. t. 699. Tragoselinum minus, Lam. fl. fr. Tragoselinum saxífragum, Monch, meth. 99. P. erispa, Horn. hort. hafn. 1. p. 289. Flowers white. A very variable plant.

I ar. 3, nigra (1. C. prod. 4. p. 120.) plant pubescent; leaflets of lower leaves ovate, serrated, somewhat lobed, rather cordate at the base; the upper leaves bipinnate; root black. P. nigra, Wilkl. spec. 1. p. 1471.-J. Bauh. hist. S. p. 111. f. 2. lar. $\gamma$, hireina (D. C. I. c.) plant rather pubescent; leaflets of nearly all the leaves pinnatifid or jagged. P. hirchna, Monch, lass. no. 255. P. Genevénsis, Vill. dauph. 2. p. 604.

lar. $\hat{r}$, dissícta; leaflets all bipinnatifid, with narrow segments.

Common Burnet-saxifrage. Fl. Ju. Aug. Brit. Pl. I to $2 \mathrm{ft}$.

4 P. LU'TEA (Desf. atl. 1. p. 25.5. t. 76.) radical leaves pinnate, jubescent ; leaflets cordate, toothed, cut in front; superior leaves entire, small, and linear. 2. H. Native of Nomint Aılas. Tragoselìnum altíssimum Áfricànum, Tourn. inst. p. 309. P. máxima A fricàna, Magn. bot. monsp. app. ex herb. Vaill. Terminal leaflet of radical leaves somewhit 3-lobed.
Stem erect, branclied, dichotomous ; branches filiform, twiggy, almost leafless. Flowers yellow, with an aromatic odour.

Yellow-flowered Burnet-saxifrage. Fl. Ju. Aug. Clt. 1823. Pl. 3 to 4 feet.

5 P. Au'REA (D. C. prod. 4. p. 120.) lower leaves pinnate, glabrous; leaflets cuneated, 2-3-lobed at the apex: teeth large, few, mucronate; cauline leaves trifid or undivided and linear, few; petals ciliated, hardly emarginate. 2f. H. Native of Persia, in gravelly places at Khoi, in the province of Aderbeidjan. A very distinet species, with yellow flowers, differing from $P$. lutea in the plant being glabrous, in the form of the leaflets, and in the petals being ciliated. Fruit subglobose, didymons, compressed, furnished with many vittæ in the furrows. I'here is a variety with smaller bipinnate leaves, also a native of Persia.

Golden-flowered Burnet-saxifrage. Pl. 2 to 3 feet?

6 P. ramosíssima (D. C. I. c.) plant glabrous; lower leaves bipinnate; leaflets ovate-rhomboid, rather trifid, acuminated, quite entire at the base, deeply toothed at the apex, some of them crossed in a decussate manuer; stem much branched; the leaves under the branches reduced to short ligulæ; umbels 5rayed ; fruit glabrous, ovate, not contracted at the commissure. 4.? H. Native of Persia. lilowers unknown. Transverse section of fruit terete, as in the genus Séseli, but without either involuerum or involucel, but with the habit of Pimpinélla. Leaves like those of Pcucédanum cervària. I'erhaps a proper genus.

Much-branched Burnet-saxifrage. Pl.

7 P. ANisoìnes (Brign. act. acad. neap. 1819. vol. 1. p. I. t. 1.) plant glabrous ; radical leaves bipinnate; leaflets roundisbovate, serrated ; umbels numerous ; styles erect ; fruit glabrous. 4. H. Native of the kingdom of Naples. It differs from $P$. bubonoides, ex Guss. prod. 1. p. 331., in the fruit being glabrous, in the styles not being divaricate, and in the stigmas not being globose.

\section{Anise-like Burnet-saxifrage. Pl. 1 to 2 feet.}

Sect. II. Tra'guum (from toayos, tragos, a goat; odour of plants). Spreng. umb. prod. p. 26. Schultes, syst. 6. p. 35. Hoffin. umb. gen. p. 91 . t. A. f. 22 . D. C. prod. 4. p. 120.Bubon species, Lag. obs. apar. 26. Fruit villous. Roots perennial, rarely biennial. Radical leaves pinnate or bijinnate ; leaflets ovate.

8 P. DEPRE'SSA (D. C. prod. 4. p. 120.) stem pubescent; radical leaves pinnate; leaflets cuneated, pinnatifid, smoothish, ciliated: lobes lanceolate, obtuse ; cauline leaves pinnatifid, 1 under each branch; fruit rather puberulous from small, adpressed bristles. 4 . H. Native of Candia, on the Sphaciotic motuntains. Tràgium depréssum, Sieb, cret, exsic. Spreng. in Seluultes, syst. 6. p. 392. Herb I-2 inches high. Stem terete. Root woody. Flowers white.

Depresscd Burnet-saxifrage. Fl. June, Aug. Clt. 1822. Pl. $\frac{1}{8}$ to $\frac{1}{2}$ foot.

9 P. Nodòsa (D'Urv. enum. or. p. 33.) plant glabrous; stem branched, dichotomous; leaves many-parted, with linear segments; umbels numerous; petals glabrous; fruit small, ovate, with a few adpressed hairs. 2.H. Native of the Island of Samos, among stones, frequent, and on the old walls of cities. In the place of the stem where the involucrum ought to be, there is a thiek turbinate knot, probably eaused by insects.

Nodose Burnet-saxifrage. Pl. 1 foot.

10 P. тrágium (Vill. daupl., 2. p. 606.) stem canescent ; radical leaves pinnate, smoothish; leaflets cuneate-obovate, deeply serrated, usually variously ent; cauline leaves very few; petals pilose on the ontside ; fruit clothed with canesecnt tomentum. 4. H. Native of the south of France, Italy, Sicily, 
Podolia, and Tauria, in arid places, and among rocks. D. C. ff. fr. suppl. p. 50I. Bertol. amoen. ital. p. 850 . P. canéscens, Lois. not. p. 47. t. 4. Tràgium Colúmna, Spreng. umb. spec. 194. P. saxífraga $\gamma$, Lois, 1l. gall. 177. Flowers white. There are several varieties, which difler in height and size of leaves, but there are hardly any limits between these varieties.

I ar. $\beta$, glaúca (1). C. prod. 4. p. 12I.) plant of a canescent glaucous hue: radical leaves pinnate; leaflets roundish-ovate, somewhat 3 -lobed, toorhed, pubescent on both surfaces, the 3 or + superior lobes linear; petals and fruit clothed with adpressed villi. 24. H. Native of Sicily, on the Nebrodes. Tràgium glaúcum, Presl, del. prag. p. 125. Flowers white. Allied to P. Cumbre, but the leaflets are all 3-lobed, and the terminal one deeply so.

Var. $\gamma$, laciniata (D. C. l. c.) leaflets of all the leaves dissected into narrow linear segments. 4 . H. Native of Tauria. P. 'Tràgium rar. Bieb. suppl. p. 250 . P. petræ'a, Beaupre, ined. Perhaps a proper species. The whole plant is cloched with canescent pubescence.

Goats' Burnet-saxifrage. Fl. Ju. Jul. Clt. 1810. Pl. 1 to $2 \mathrm{ft}$. I I PERegrína (Lin. mant. p. 357.) plant pubescent; radical leaves pinnate; leaflets ovate-cordate, serrated : terminal one usually 3 -lobed; cauline leaves narrow, wedge-formed, jagged; frut hispid. $\delta . H$. Native from the south of France to sicily, Cancasus, and Tauria. Jacq. hort. vind. 2. t. 131. P. líspida, Lois. not. p. 48. Tràgium peregrinum, Spreng. umb. spec. p. 135 . syst. 1. p. $88 \%$. exclusive of the synonyme of Presl. Ledebùria pimpinelloìdes, Link, enum. 1. p. 286. Tràgium Taúricum, Ledeb.-Barr. icon. 1 I 8 4.-Column. ecphr. 1. t. 109. Flowers white. The herb varies in smoothness and hairiness; in the first state it is $P$. peregrinum, D. C. fl. fr. suppl. p. 502.: in the second it is $P$. hispida, Lois. ex. D. C. l. c. The first leaves are simple, the second ternate, but the succeeding ones are pinnate, also the lower stem ones; but the upper stem leaves are variously divided into lanceolate segments. The umbels are drooping before the expansion of the flowers. The seeds have no smell, and when first chewed have scarcely any taste, but in a short time are very acrimonious, and excite a great heat in the fauces.

l'ar. $\beta$, minor (D. C. prod. 4. p. 12I.) plant smaller. Native of Egypt, about Alexandria. Torilis trilobàta, Viv. herb.

Forcign Burnet-saxifrage. Fl. Ju. Aug. Clt. 1640. Pl. $2 \mathrm{ft}$.

12 P. BU boxoldes (Brot. A. lus. 1. p. 463. phyt. t. 35.) plant puberulous when young, but at length becoming glabrous; radical leaves bipinnate; leaflets roundish-ovate, serrated; umbels numerous; petals glabrous; fruit rather villons. $4 . H . \mathrm{Na}$. tive of Portugal, Sicily, and Calabria, in sandy places. Tràgium Brotèri, Spreng. in Schultes, syst. 6. p. 393 . P. anisoides, Guss. cat. hort. boccad. p. 50. but not of 3rign. Tenore, prod. p. 20. Tràgium Gussònii, Presl, del. prag. 1822. p. 126. Guss. pl. rar. 117. prod. f. sic. 1. p. 330. Perhaps Athamántha lasiäntha, Willd. herb. ex Schultes, syst. 6. p. 464. Flowers white.

Bubon-like Burnet-saxifrage. Fl. June, Aug. Clt. 1822. Pl. 1 to 2 feet.

I3 P. villòsa (Schoush. nuar. p. 125.) plant glaucous, rather pubescent ; radical leaves bipinnate; leafiets obovate-cuneated, crenated; stem nearly leafless, much branched; petals villous. 4. H. Native of the kingdom of Morocco at Mogodor and 'Tangiers. Salzm. exsic. Poir. suppl. 1. p. 68\%. Tràgium, Schousheci, Spreng. in Schultes, syst. 6. p. 394. Tràgium villòsum, Desf. hort. par. Leaves almost like those of $P$. bubanoides, but larger. 'I'his species differs from the preceding in the petals being villous not glabrous.

I'illous Burnet-saxifrage. Fl. Ju. Aug. Clt. 1817. Pl. $2 \mathrm{ft}$. 1. P. Cu'mbre (Buch, ubers, can. p. 29. and beschreib. d. can. ins. p. 152.) the whole plant is hoary from short dowu; rathical leaves pinnate ; leatlets $5-7$, ovate, deeply serrated, terminal one usually 3 -lobed: stem neariy leafless, branclied; petals villous. 4. G. Native of Teneriffe, on the highest mountains. Tràgium incunum, Chois, ined. Said to be allied to $I^{\prime}$. villosa, but dillers in being more hoary, and in the leaves being simply pinnate, not doubly pinnate. Root woody, throwing out many stems at the neck.

Cumbre liumet-saxifrage. Pl. 1 foot.

I5 P. PSEU'do-tra'cium (1). C. prod. 4. p. 122.) plant glatcous and canescent; radical leaves pinnate; leaflets roundis $]_{1-}$ ovate, somewlat 3 -lobed, deeply toothed, velvety-canescent on both surfaces : upper ones trifid: lower ones undivided, linear: petals rather villous on the outside; fruit very hairy. 4. H. Native of Persia, in dry exposed stony places about Seilkhodzi. This is an intermediate plant between $P$. tràgium and $I^{\prime}$. aromáticum. The fruit is larger than in either, and the hairs on the plant are soft and spreading, not as in $P$. tràgium, adpressed. Petals rather villous on the outside, not as in $P$. aromátic very hairy.

\section{False Tragium. Pl. 2 feet.}

16 P.? FLA'va (Meyer, verz. pflanz. p. 122.) the whole plant is canescent from minute down; radical leaves supra-decompound; leaflets eut: lobes lanceolate, mucronately acuminated ; sheaths of upper cauline leaves leafless; petals yellow, canescent on the back, as well as on the germs. 4. H. Native ot Caucasus, in dry stony places on the mountains of Talusch, near Swant, at the elevation of about 3000 feet.

Yellow-flowered Burnet-saxifrage. Pl. 1 to 2 feet?

17 P. aromática (Bieb. f. taur. 1. p. 241. suppl. 251.) plant clothed with hoary pubescence; leaves pinnate; leaflets of the lower leaves all cuneiform, deeply serrated at the apex, lined; petals and fruit tomentose. s. H. Native of Iberia and Eastern Caucasus, on the edges of woods, and the sides of torrents. Tràgium aromáticum, Spreng. umb. prod. p. 26. syst. 1. p. 884 . exclusive of the synonymes. Schultes, syst. 6. p.392. Hoffin. umb. ed. 2. p.91. Flowers white.

Aromatic Burnet-saxifrage. Fl. Ju. Aug. Clt. 1820. Pl. $1 \mathrm{ft}$.

18 P. diversifólia (D. C. prod. 4. p. 122.) leaves ternate or biternate: leaflets petiolulate, cordate, coarsely toothed, membranous, glabrous above, but puberulous along the nerves beneath; involucrum wanting ; involucels 3 -leaved ; rays of umbels and umbellules 15-20 in number, and are as well as the fruit pubescent. 4 . §. H. Native of the East Indies, in Sirmore. Herácleum diversif òlium, Wall. mss. Leaves as if they were pinnate, from the 2 lateral leaflets being undivited, and the middle one ternate. Teeth of lower leaves rounded and mucronate; of the superior leaves acute. The immature fruit has only been seen.

Diver se-lcarcd Burnet-saxifrage. Pl. 1 to 2 feet.

19 P. Leschenaútil (D.C. l. c.) radical leaves petiolate, orbicular, cordate, toothed, rather coriaceous, many-nerved at the base, glabrous above, velvety from short down beneath: cauline leaves few, parted, almost reduced to the sheaths; stem a little branched, glabrous. 4. H. Native of the East Indies, on the Nellygerry Mountains, where it is called by the natives Tourassou. Petals hardly emarginate. Young fruit rather puberulous, when examined under a lens, but at length becoming glabrous. Plant 1-2 feet ligh. Rays of umbel 5, of the umbellules 12.15. Flowers white.

Leschcnault's Burnet-saxifrage. Pl. 1 to 2 feet

20 P.? J AvA'NA (I). C. prod. 4. p. 122.) cauline leaves petiolate, cordate, acute, cartilaginously serrated, many-nerved at the base, velvcty beneath as well as the petioles, but pubescent above; sheaths ciliated; involucrum wanting, or of 1 linear leaf ; fruit hairy. 4 . H. Native of Java. Herb said to be 
$\approx$ feet high. Stem terete, velvety at the apex. Umbels of many rays. Fruit ovate, hairy. Styles diverging.

Jaca Burnet-saxifrage. Pl. 2 feet.

Sect. III. An'sum (the herb anise; containing plants agreeing with it). Adans, fam. 2. p. 95. Gærtn. fruct. 1. p. 102. -Bubon species of Lag. Fruit puberulous. Annual plants.

21 P. Axisum (Lin. spec. 399.) stem glabrous ; radical leaves corlate-roundish, lobed, deeply serrated : middle ones pinnatifid, with cuneate-lanceolate lobes: upper ones trifid and undivided, linear ; fruit bearing a few scattered hairs. $\odot$. H. Native of the Island of Scio, Egypt, and cultivated in Europe. Nees, off. pflz. 12. t. 17. Hayn. arz. gew. 7. t. 22. Woodv, med. bot. t. 180. Anisum vulgàre, Clus. hist. 2. p. 202. Gærtn. fruct. 1. t. 23. f. 1. Anisum officinàle, Mcench, meth. p. 100 . Sison anisum, Spreng. in Schultes, syst. 6. p. 407. A'pium anìsum, Trag.-Blackw, herb. t. 374.-Lob. icon. 731. Flowers of a yellowish white colour. Fruit pubescent when young. Styles short, straight. The anise is cultivated in Malta and Spain for its seeds, which are annually imported as medicinal, and for distillation and expression. In this country it is occasionally grown in the garden, to be used as a garnish, and for a seasoning like the fennel. For this last purpose, the seeds require to be sown in April, in a warm border, in a dry light soil, or raised in pots on heat, and removed to a warm site in May, where the plants will blossom and ripen their seeds in August, in favourable seasons. The plants should be thinned to 3 or 4 inches' distance.

Anise. Fl. June, Aug. Clt. 1551. Pl. 1 to $1 \frac{1}{2}$ foot.

22 P. CRe'tica (Poir. suppl. 1. p. 684.) plant dwarf; radical leaves roundish, 3-lobed, toothed; superior leaves small, ternately multifid; segments rather filiform; fruit puberulous. $\odot . H$. Native of Candia, Scio, and the Morea. A'pium Créticum minimum anisi facie, Tourn. herb. P.ténuis, Sieb. pl. exsic. Stems filiform, 4-5 inches high. Umbels spreading; with capillary rays; umbellules small. Fruit shorter than the styles, not glabrous, but puberulous, as in $P$, anisum, of which it is probably only a small variety. Flowers whitish.

Cretan Anise. Fl June, July. Clt, 18थ0. Pl. $\frac{1}{2}$ foot.

23 P. Dichóroma (Lin. mant. 58.) plant glabrous, dichotomously branched, erect; leaves biternate or triternate; leaflets linear; petioles wingell, membranous; peduncles opposite the leaves; fruit muricated from short hairs. $\odot$. H. Native of Spain, on hills about Aranjuez. Habit of Trinia, but differs from that genus in the flowers not being dioecious. P'etals all emarginate at the anex, from the point being incurved. Fruit nearly globose, striated. Styles reflexed. Flowers white.

Dichotomous Anise. Pl. $1 \frac{1}{2}$ foot.

\section{$\uparrow$ Species not sufficiently known.}

24 P. TEnuifòlia (D. C. prod. 4. p. 123.) plant glabrous ; leaves lecompound, glaucous, linear, somewhat divaricate; umbel terminal, compound.-Native of Persia. Tiàgium tenuifolium, Spreng. in Schultes, syst. 6. p. 393. Flowers white.

Fine-leaved Burnet-saxifrage. Pl. 1 foot.

25 P. errocírpa (Russel, beschr, alep. ex Schultes, syst. 6. p. 394.) radical leaves pinnate : leaflets cuneiform, cut, glabrous: superior ones filiform; fruit hispirl.-Native about Aleppo. 'I'ràgium eriocárpos, Schultes, 1. c. Pimpinélla ténuis, Sieh. Crete, exsic. ex Schultes, 1. c. Tràgium ténue, Link, enum. 1. p. 2S6. The same as P. tenuifolia, Spreng. syst. 1. 1. 284 . Flowers whitc.

Hairy-fruited Burnet-saxifrage. Pl. 1 foot.

26 P. Alpína (Host, $\boldsymbol{f}$. austr. 1. p. 399.) radical leaves pinnate, glabrous; leaflets of lower leaves ovate, cut : of the intermediate ones, pinnatifid, and of the upper ones linear-subulate, entire. $4 . H$. Native of the Alps of Styria and Austria, in stony places. The petals are said to be yellowish-white. Fruit striated, probably glabrous, or villous. This is perhaps only a variety of $P$. mágna.

Alpine Burnet-saxifrage. Fl. Ju. Jul. PI. 2 to 3 feet.

27 P. RUPE'sTris (Bory, ann. gen. sc. ph. 3. 1820. p. 12.) radical leaves on long petioles, pinnate; leaflets deeply crenated, acute; stems rather dichotomous. 24. H. Native of Spain, among stones, on Sierra Nevada. Plant glaucous, stiff, slender. Perbaps only a variety of $P$. saxifraga.

Rock Burnet-saxifrage. Pl. 1 foot.

28 P.? Capénsis (Thumb. prod. p. 51. fl. cap. 2. p. 207.) stem terete, striated, glabrous; leaves ternately decompound; leaflets lanceolate, acute, deeply pinnatifid; involucrum composed of many short leaves.- Native of the Cape of Good Hope, on the Table Mountain. Sison Capénsis, Schultes, syst. 6. p. 411. Flowers white. Fruit ovate, obtuse, striated: with the ribs obtuse.

Cape Burnet-saxifrage. Pl. 1 foot?

Cult. All the species are of easy culture.-A dry sandy soil suits them best; and they are only to be inereased by seeds, which ripen in abundance. Those species marked perennial are little better than biennial in the gardens.

LV. SI'UM (from siu, water in Celtic; luabitation of most of the species). Koch, umb. 117. D. C. prod. 4. p. 124.-Sium species of Lin. Spreng. and others.-Sisàrum, Adans. fam. 2. p. 97.

Lin. syst. Pentándria, Digýnia. Margin of calyx 5-toothed, now and then obsolete. Petals obovate, emarginate, with an inflexed point. Stylopodium pulvinate, depressed at the margin. Styles divergingly reflexed, rather capitate at the apex. Fruit compressed from the sides or contracted, and rather didymous, crowned by the stylopodium and styles; mericarps having 5 equal filiform bluntish ribs: with the furrows between the ribs, as also the commissure, furmished with many rittæ; carpophore bipartite; the stalks achate to the mericarps. Seed nearly terete. - Mostly aquatic lerbs. Leaves pinnate; leaflets ovate-oblong, toothed or many parted. Umbels terminal, many parted: surrounded by many leaved involucra, which are very rarely composed of one leaf. Umbellules many flowered, surrounded by many leaved involucels. Flowers white.

Sect. I. Sisn'rum (altered from the Arabic name of the plant dgizor; this word signifies a carrot in Persian, and Sisàrum has small bundles of roots resembling carrots). D. C. prod. 4. p. 124.-Sìm, Koch, cleutschl. fl. Lateral ribs of fruit marginating, having 3-4 superficial vitte in each furrow between the ribs. Seed terete, convex on the back, and flattish in front.

1 S. SisA'rum (Lin. spec. p. 361.) root composed of fascicles of fusiform tubers; stein terete; leaves pinnate, but the uppermost ones are ternate; leaflets ovate-lanceolate, acute, serrated; involucra of 5 reflexed leaves; calycine teeth almost obsolete. 24. H. Native of China, Japan, Corea, Altaia, Monrol, and Cochin-china, but only cultivated in Europe. Schkuhr, handb. t. 69.-Lob. icon. t. 710. f. 1. Col. phyt. 89. with a figure.Park. par. t. 507. f. 1. The commissure of the fruit, according to Koch, is furnished with 4 vittæ. Sium brevifolium and S. Podolicum are probably hardly varieties of this species. Flowers white. The tubers of the root are about the size of the finger, joined together at the crown or head; they were formerly much esteemed in cookery. The Skirret is called Chervis in French, Zuckerwurzcl in German, and Sisaro in ltalian; it is also cultivated in the north of Scotland, under the name of crummock. The tubers are boiled, and served up with butter, 
and are declared by Worlidge, in 1682 , to be "the sweetest, whitest, and most pleasant of roots." This plant grows freely in lightish soil, moderately good It is propagated both from seel and by offsets of established roots. The better metlod is to raise seedlings to have the root in perfection, young, and tender.

By seeds.- "Sow between the 21st of March and the $15 \mathrm{t}_{1}$ of A pril; a fortnight later, rather than earlier, for a full crop, as plants raised forward in spring are apt to start for seed in summer. Sow on an open compartment of light ground, in small drills 8 inches apart. When the plants are 1 or 2 inches high, thin them to 5 or 6 inches asunder. They will enlarge in growth to the chi of autumn; but belore the roots are full grown, in Angust, September, or October, some may be taken up for consumption, as wanted; those left to reach maturity will continue good for use throughout winter and in spring, till the stems run.

By slips.- "Having some plants of last year's raising, furnished with root oflsets, slip them off; taking only the young outward slips, and not leaving any of the large older roots adhering to the detached oftsets; which plant by dibble, in rows from 6 to 9 inches asunder. They will soon strike and enlarge, and divide into offsets; which, as well as the main roots, are eatable, and come in for use in proper season.

T'o save seed.- "Leave some old plants in the spring: they will shoot in stalks, and ripen seed in autumn."

I'ar. $\beta$, Ninsi; stem bulbiferous ; leaflets broader, rather cordate. Sium Nínsi, Burm. ind. t. 29. Thunb. jap. 118.

Skirret. Fl. July, Aug. Clt. 1548. Pl. 1 to 2 feet.

2 S. sisaroídeum (D. C. prod. 4 p. 124.) root unknown; stem furrowed; leaves pinnate; leaflets ovate, rather cordate at the base, toothed: upper leaves ternate, laving the leaflets oblong, acuminated, and serrated; involucrum of 4-5 reflexed leaves: calycine teeth almost wanting. 2. H. Native of Persia, in the province of Aderbeidjan, about Badelan, in shady sandy places, where it was collected by Szowits. The root is said to be creeping, but according to the specimens examined, they appear to be fasciculate like those of the common skirret. The whole plant is like $S$. Sisirum, and especially variety $\beta$, but differs in the stem being furrowed, in the leaves being broader, in the fruit being shorter, and in the fibres of the roots being cylindrical.

Shirrct-like Water-parsnip. Pl. I to 2 feet.

3 S. LANcı́òluu (Bieb. suppl. p. 230.) root creeping; leaves pinnate; leaflets lanceolate, equally and sharply serrated; involucrum of many leares; calycine teeth very short. $4 . \mathrm{H}$. Native of Tauria and Caucasus, in marshes and humid places; and of Altaia, at the river Irtysh. S. latifolium, Bieb. fl. taur. 1. p. 225. exclusive of the synonymes. S. latifolium Uhránicum, Fisch. cat. hort. gor. 1812. Bèrula lancifòlium, Bess. enum. pl. volh. p. 44. Very nearly allied to $S$. latif olium. The commissure of the fruit, according to Koch, is furnished with 4- 6 vittæ.

I ar. $\beta$; leafiets narrower, linear-lanceolatc. $\psi$ H. H. Gmel. sib. 1. p. 201. no. 14. t. 47.

Lance-lcaved Water-parsnip. Fl. July, Aug. Clt. 1819. Pl. 1 to 2 feet.

4 S. Latifòlium (Lin. spec. p. 361.) root creeping; stems angularly furrowed; leaves pinnate; leaflets lanceolate, acuminated, unequal at the base, serrated, rarely pinnatifid; involucrum of many leaves; calycine teeth clongated. 2. H. Native throughout the whole of Europe and North America, in ditches and marslıes. In Britain in rivers, ditclies, and fens. Jacq. f. austr. t. 66 . Smith, eng]. bot. t. 204 . Oed. H. dan. t. 246. Hayn. arz. gew. 1. t. 33 . good. Coriándrum latifölium, Crantz. austr. p. 219. Drepanophýllum palústre, Hoffm. umb. 110. The leaflets of the submersed leaves are in the same plant often multifuly jagged. The commissure of the fruit, according to Koch, is furnished with 6 vitta. Stem with whorles of fibres meler water. The plant is of an acrid poisonous quality, particularly the roots.

Broad-leacel Watcr-parsnip. Fl. July, Aug. Britain. Pl. 3 to 6 fect.

5 S. Longifolium (Presl, ti. cech. p. 65. but not of Pursh, root unknown; stem striated; lcaves pinnate; leaflets linearlanccolate, elongated, unequally toothed, very acute; involucrum usually one-leaved. 4. H. Native of Bolienia, in marshes and ditches.

Long-lcaved Water-parsnip. PI. 2 to 3 feet.

6 S. LINEA're (Michx. fl. bor. amer. 1. p. 167.) stem angularly furrowed; leaves pinnate; with 4-5 pairs of linear-lanceolate leaflets, which are acutely and finely serrated; involucrum of a few linear leaves. 4 . H. Native of North America, from Canada to Carolina; on the inountains and at the Saskatchawan, in marslies; watery places about Lake Huron; moist and overflowed grounds of the Columbia. Nutt. gen. amer. 1. p. 186. exclusive of the synonyme of Pursh ex Torrey, fl. un. st. 1. p. 311. The young submersed leaves are deeply multilid or tripinnate, with very narrow linear subulate segments.

Lincar-leaved Water-parsnip. Fl. July, Aug. Clt. 1810. Pl. 1 foot.

7 S. Dougla'sir (D. C. prod. 4. p. 125.) stem terete; leaves pinnate; lower leaflets ternate, the rest periolulate, ovate-oblong, coarsely serrated; umbels opposite the lcaves, and tcrminal, pedunculate, without an involucrum, of many rays. $4 . \mathrm{H}$. $\mathrm{Na}$ tive of the north-ivest coast of America. Stems and petioles reddish. Lower leaves $1 \frac{\pi}{2}$ foot long. Flowers white. Calyx 5-toothed.

\section{Douglas's Water-parsnip. Yl. 3 to 4 feet.}

SEct. II. BE'RULA (probably from ßnpos, beros, a cloak or garment). Koch, deutschl. fl. 2. p. 455 . D. C. prod. 4. p. 125. Lateral ridges of the fruit placel a little before the margins of the mericarps. Transverse section of seed perfectly terete.

8 S. Anoustifòlum (Lin. spec. 1672.) root fibrous, having stolons running from the neck; stem hardly striated; leaves pinnate; leaflets ovate, unequally lobed and serraterl; umbels pedunculate, opposite the leaves, and terminal; involucrum of many, rather pinnatifid leaves. 4 . B. H. Native throughout the whole of Europe, even to Caucasus and Persia, in ditches and rivulets; plentiful in some parts of Britain. Jacq. fl. anstr. t. 67. Hayne, arz. gew. 1. t. 39 . Smith, engl. bot. t. 199. Hook. fi. lond. fasc. 2. t. 111. S, nodiflòm, Fl. dan, 247. S. eréctum, Huds. ed. 1. p. 103. S. Bèrula, Gouan. fl. monsp. p. 218. A'pium Sium, Crantz, p. 215. Bèrula angustifòlia, Koch, deutschl. f. 2. p. 455. Root creeping extensively. Stem with whorles of fibres under water.

Narrow-leaved Water-parsnip. Fl. July, Aug. Britain. Pl. 2 to 3 feet.

9 S. Tirunbe'rgir (D. C. prod. 4. p. 125.) root fibrous, throwing out stolons from the neck; stem erect, striated; branches angular; leaves pinnate; leaflets ovate, acute, regularly and callously serrated; umbels pedunculate, opposite the leaves, and terminal; involucrum of 3-5 linear acute undivided leaves. 24. B. H. Native of the Cape of Good Hope, in marshes near Scckluwallei. Sìn angustifòlium, Thunb. prod. j. 51. Leaflets approximate and regularly disposed. Plant erect.

\section{Thunberg's Water-parsnip. Pl. 2 to 3 feet.}

$\dagger$ Species not sufficiently knonn, and arc therefore doublful whether they belong to the genus. 
10 S.? HísPIDUM (Thunb. prod. p. 51. f. cap. 2. p. 210.) stem branclsed, striated, glabrous, rather hispid at the nodi; leaves tripinnate, hispid beneath, as well as on the petioles; leaflets short, divided into multifid lobes; umbels opposite the leaves; involucrum of 5 leaves. 4. F. Native of the Cape of Good Hope. Anthríscus Capénsis, Spreng. in Schultes, syst. 6. p. 526. Sium híspidum, Spreng. umb. spec. 96. Root fusiform. Fruit unknown.

Hispid Water-parsnip. Pl. ?

1 I S.? A'sperum ('Thunb. prod. p. 51. f. cap. 2. p. 210.) stem striated, glabrous, erect ; leaves somewhat tripinnate, glabrous; leaflets multifid, lanceolate; petioles and peduncles scabrous: umbels terminal; involucrum of 6 leaves.-Native of the Cape of Good Hope. Spreng. umb. spec. 96. Fruit unknown.

Rough Water-parsnip. Pl. 1 to 2 feet.

12 S. villòsum (Thunb. I. c.) stem erect; branches divaricate, striated; leares tripinnate; leaflets ovate, deeply serrated, and are, as well as the petioles, ciliated with villi; umbels terminal; leares of involucrum 6, ovate, with scarious margins.Native of the Cape of Good Hope. Spreng. umb. spec. 97.

lillous Water-parsnip. Pl.

13 S.? Filifòlium (Thunb. prod. p. 50. fl. cap. 2. p. 207.) stem erect, flexuous, terete; radical leaves simple, linear-filiform, elongated; umbels terminal; involucrum of 8 leaves, which are about equal in length to the umbel.-Native of the Cape of Good Hope. Spreng. umb. spec. 99. exclusive of the synonymes. Schultes, syst. 6. 1. 54.4. exclusive of the synonymes.

Thread-leaved Water-parsnip. PI. 2 feet.

14. S. grandiflòrum ('Thunb. prod. p. 50. fl. cap. 2. p. 208.) stem erect, striated, branched a little ; leaves glabrous, bipinnatc; leaflets roundish, deeply toothed; umbels terminal; leaves of involucrum 8, ovate, acuminated. 24. G. Native of the Cape of Good Hope. Spreng. umb. spec. 99. Fruit said to be obovate, and striated.

Great-flowered Water-parsnip. Pl. 2 feet?

15 S.? PA'Tulum (Thumb. 1. c.) stem striated, glabrous ; branches divaricate; leaves bipinnate, somewhat fasciculate; leatlets lincar, trifid; umbels terminal; involucrum of 6 lanceolate leaves, with scarious margins.- Native of the Cape of Good Hope. Spreng. umb. spec. 89 . Fruit unknown.

Spreading Vater-parsnip. Pl. spreading.

16 S. Panicula'tum (Thunb. l. c.) stem terete, striated, glabrous, panicled; leaves bipinnate; leaflets deeply pinnatifid, linear, chanuelled; umbels terminal; involucrum of 6 lanceolate leaves, with scarious margins. - Native of the Cape of Good Hope. Spreng. umb. spec. 98. Fruit unknown.

I'anicled Water-parsnip. Pl.?

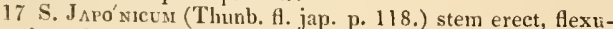
ous, branched above; leaves pinnate, glabrous; leaflets unerjual, oblong-obovate, deeply toothed at the top: upper ones lanceolate, quite entire; umbels terminal.-Native of Japan. Stem terete. Superior leares ternate. Umbels of many rays.

Japan Water-parsnip. Pl. 1 to 2 feet?

18 S.? DECu'Mrexs (Thunb. f. jap. p. 118.) stems decumbent; leaves hipinnate, on long petioles, glabrous ; leaflets trifid; umbels terminal, nearly simple. 2 . H. Native of Japan. P'crhaps S. Græ'cum, Lour. coch. p. 179. is referrible to this species.

Decumbent $\mathrm{W}$ ater-parsnip. Pl. decumbent.

19 S. ? oppositifòcıua (Kit. in Schultes, fl. austr. 2. p. 495. syst. 6. p. 506.) leaves nunerous, opposite, doubly pinnate; leaflets linear, acuminated, quite entire.-Native of Hungary, on the nomitains.

Opposite-lcared $\mathrm{W}$ ater-parsnip. Pl.?
Cult. All the species of this genus do best in a moist soil, and most of them altogether in water. They are increased by separating the roots and stolons.

LVI. BUPLEU'RUM (from ßovs, bous, an ox, and $\pi \lambda \varepsilon v \rho o v$, pleuron, a side : so called from a supposed bat quality in swelling kine that feed on some species of the genus). Tourn. inst. 309. t. 163. Lin. gen. no. 328. Lag. am. nat. 2. p. 100. Koch, umb. 114. f. 51, 52. Spreng. syst. 1. p. 880. D. C. prod. 4. p. 127.-Bupleùrum, Tenòria, Bupréstis, and Odontìtes, Spreng. prod.-Bupleìrum and T'rachypleurum, Reichb. consp. 1. p. 143. Bupleùrum, Diaphýllum, Isophýllum, and Odontites, Hoffm. umb.

Lin. syst. Pcntándria, Digýnia. Margin of calyx obsolete. Petals roundish, entire, strictly involute, with a broad retuse point. Fruit compressed from the sides or somewhat didymous, crowned by the depressed stylopodium ; mericarps with 5 filiform acute winged ribs, or with obsolete ones; lateral ribs marginating; furrows between the ribs either furnished with vittæo or without them, smooth or granular. Seed teretely convex, flattish in front.-Quite glabrous berbs or shrubs. Leaves rarely cut, but mostly quite entire in consequence of the limbs, which are supposed to be absent, and the petioles being dilated, and changed into quite entire phyllodia, as in many species of Acàcia. Umbels compound. Involucrum variable. Flowers yellow A very natural genus, with a distiuct babit from all other umbelliferous genera, but the fruit is variable in character.

$$
\text { * Annual plants. }
$$

1 B. PAPIliòsum (D. C. prod. 4. p. 127.) stem erect, brancli. ed; leaves linear, acute, stiffish; umbels terninal, of $3-4$ rays ; involucrum of 3-4 unequal leaves; umbellules 10-flowered; involucels of 5 reflexed leaves, longer than the fruit; fruit coarsely papillose all over. $\odot$. H. Native of the Levant. Allied to $B$. glaúcum and $B$. tenuissimum, but the branches of the umbel are perfect; and the fruit is beset with large, obtuse, white papillæ.

Papillose-fruited Hare's-ear. Pl. $\frac{1}{2}$ to 1 foot.

2 B. TEnuíssimum (Lin. spec. p. 343.) stem erect, branclied; leaves linear, tapering to each end, rather glaucous; umbels simple, alternate, of about 3-5 flowers, surrounded by 5 awlshaped bracteas; fruit roundish-ovate, with 5 ribs, and between the ribs beset with fine granulations. $\odot . H$. Native of middle and south Europe, even to Caucasus, in sterile grassy places, particularly by the sea-side. In England in muddy salt marshes; on the shore near Worthing; at Lynn, Wisbeach, Cley, Holkham, \&c. in salt water ditches or muddy places over-flowed by the tide. Fl. dan. t. 1090. Smith, engl. bot. t. 478. Reichb. icon. 2. p. 58. t. 167 . B. mínimum, Ray, syn. p. 221. Odontìtes tenuíssima, Spreng. prod. 33. Agostàna tenuíssinua, Bute, vol. 8. p. 299. B. jünceun, Poll, B. Pollíchii, Gmel. H. bad. 1. p. 613. B. júnceum var. $\gamma$, Schultes, syst. 6. p. $31 \%$ Barrel. icon. t. 1168 .

I ar. $\beta$, nànum (D. C. fl. fr. 4. p. 350.) stem very humble, and very much branched, diffuse. $\odot . H$. Native of Normandy and Picardy, by the sea-side. B. tenuíssimum, Bouch. A. abb. p. 20. Habit almost of $B$. glaúeum, but the leaves of the involucels are quite entire, and the fruit is furnished with 10 ribs.

Very-slender Hare's-ear. Fl. Aug. Sept. Britain. Pl. $\frac{1}{2}$ to 1 fuot.

3 B. procu'minens (Desf. fl. atl. 1. p. 230. t. 56.) stems procumbent, paniculately branched; lower leaves narrow-lanceolate, the rest linear-subulate; involucrum of 2 leaves; involucels of 5, nearly ovate, acute, very short leaves; fruit short and muricated by tubercles. $\odot$. H. Native about Tunis. Odontìtes procúmbens, Spreng. in Schultes, syst. 6. p. 383 . Habit 
almost of $B$. tcruissimum, but the stems are procumbent, and the umbels are 2-5-rayed.

Procumbent Hare's-ear. Pl. procumbent.

4 B. glav'crs (liob. et Cast. in D. C. suppl. A. fr. p. 515.) stem branched, diffuse; leaves linear; umbels terminal, usually of 3 rays: lateral rays incomplete; involucels of 5 lanceolate cuspidate denticulated leaves, exeeding the flowers and fruit; fruit without vittx, and almost without ribs, echinated with tubercles. $\odot$. H. Native of P'rovence, Nice, Corsica, Narbone, Spain, and Sicily, on the sea shore; and of Caueasus, on dry hills near Baku and Sallian. Rchb. icon. 2. p. 60. t. 178. Odontites glaíen, spreng. in Sehultes, syst. 6. p. 383. The whole plant is very humble and glaucous.

Glaucous Hare's-ear. Fl. July, Aıg. Clt. 1819 . Pl. $\frac{1}{2}$ foot.

5 13. Semeompósitum (Lin. spee. p. 342.) stem erect, branched ; leaves oblong-spatulate; umbels terminal, of 3-5 rays: lateral rays incomplete; leaves of involucels lanecolate, cuspidate, quite entire, 3-nerved, exceeding both the flowers and fruit; fruit withont vitta, and the ribs are obliterated, and the furrows are granular. $\odot . H$. Native of the south of France, Italy, Corsica, Sardinia, Dalmatia, Istria, Algiers, Grecce, Se. in cultivated ficlds. Gouan. ill. t. 7. f. 1. Smith, fl. græc. t. 261. Relıb. jcon. 2. p. 77. t. 183 . B. divaricàtum $\beta$, Lam. fl. fr. Odontìtes lutèola, Hoffin. umb. 209. t. 1. B. f. x. but not of Spreng.

Semi-compound-umbelled Hare's-ear. Fl. June, Aug. Clt. 17 . Pl. $\frac{1}{3}$ to $\frac{3}{4}$ foot.

6 B. GRA'ciLE (D. C. prod. 4. p. 128.) stem erect, much branclsed; leaves linear, acute; umbels terminal: lateral ones somewhat 3-rayed; leaves of involucel lanceolate, shorter than the fruit-bearing umbel; fruit gramular, having the ribs obliterated. ๑. H. Native of the south of Tauria, in gravelly saltish places; and of the plains of Caucasus, adjoining the river Tcrek. Odontites gràcilis, Bicb. suppl. p. 198. Allied to B. decompósitum, but differs in the involucels being shorter than the umbellules, not longer than them.

Weak Hare's-ear. Fl. July, Aug. Clt. 1820. Pl. $\frac{1}{4}$ to $\frac{1}{2}$ foot.

7 B. Chise'xse (D. C. prod. 4. p. 128.) stem with ereet branches; leaves broadly linear, 5-nerved ; umbels of 5-6 rays; involuera and involucels of 1-2 linear leaves, shorter than the flowers; fruit with 5 acutish ribs, having the furrows smooth. $\odot$. H. Native of China. Habit of $B$. témue, but differs in the involucels being narrower and fewcr, and in the pedicels being hardly equal in length to the flowers.

China Hare's-ear. Pl. $1 \frac{1}{2}$ foot.

S B. TE'NUE (D. Don, prod. fl. nep. p. 182.) stem erect, filiform, branched; leaves 7 -nerved; lower ones linear-mucronate, 5 -nervell : upper and rameal ones lanceolate; umbels of usually 4 rays; involucels of 4-5 elliptic mucronate leaves, which are about equal in length to the fruit; fruit acutely ribbed, with the furrows smooth. $\odot$. H. Native of Nipaul, at Narainhetty, Kamaon, and Gosaingsthan. B. vircatum, Wall. cat. 555. Very like $B$. tenuissimum, but differs in the umbels being of 4 rays, instcad of 6 , and in the leaves of the involucels being elliptic, not lanceolate, \&c. Umbcls numerous.

Var. $\beta$, flexuòsum (Wall. mss.) stem much branched, flexuous ; leaves having 7-9 nerres, and dotted between the nerves. $\odot$. H. Native of Nipaul.

Slender Hare's-ear. Pl. 1 to $\approx$ feet.

9 B. Gera'rdi (Jaeq. austr. 3. t. 256.) stem erect, branched; leaves linear, cutspidate; umbels terminal, of $5-7$ rays ; leaves of involucel linear, cuspidate, exceeding the flowers, which are 5 or 6 in each umbellule; ribs of fruit hardly elevated, and the

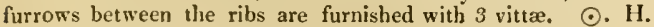
Native of Provence, Nice, Sicily, Austria, Tauria, Caucasus, \&c. in dry fields. Rehb. icon. 2. p. 56. t. 164. and t. 165. B. YoL. 111 . júnceum var. Lam. Spreng. B. filicaúle, Brot. ex Steud. Isophýllum Gerárdi, Hoflin. Bupréstis Gerárdi, Spreng.-Ger. Galloprov. t. 6. There are varieties of this plant with either erect or spreading branches, and with the involucels either shorter or longer than the flowers.

Gcrard's Ilare's-car. Fl. July, Aug. Cl. 1804. Pl. 1 to 3 fect.

10 B. Ju'ncyum (Lin. spec. p. 343.) stem erect, panicled; leaves linear-lanceolate, cuspidate; umbels terminal, of $\$$ rays; leaves of involucel lincar-lanceolate, cuspidate, shorter than the flowers, which are $3-5$ in cach umbel ; ribs of fruit elevated, acute: having the furrows smooth, and almost without vittæ. $\odot$. H. Native of south and middle Europe, even to Caucasus, in fields. Rehb. icon. 2. p. 57. t. 166. B. júnceum $\beta$, Lam. diet. 1. p.519. B. Gerárdi, Smith, fl. graec. t. 262. B. júnceum a, Spreng. in Scluultes, syst. 6. p. 371.-1.ob. icon. t. 243 , f. 1.

Íar. B, Rissòni (D. C. prod. 4. p. 128.) fruit-bearing peduncles short, axillary, hardly attaining one-half the length of the leaves.

Rushy Hare's-ear. Fl. July, Aug. Clt. 1772. Pl. 3 to $4 \mathrm{ft}$.

11 B. gluma'ceum (Smith, prod. fl. grace. 1. p. 177. but not of Spreng.) stem ereet, very slender, panicled ; leaves linear, 3 . nerved; involucra and involucels of 5 lanceolate cuspidate 3 . nerved leaves, which are pellucid between the nerves and veins, exceeding the umbels; furrows of fruit smooth, furnished each with one vitta, and the ribs are acute and very slender, $\odot . H$. Native of Calabria, in barren fields; island of Scio; about Constantinople, Cephalonia, Candia, and Cyprus. Rchb. icon. 2. p. 71. t. 179. B. flàvum, Forsk. eg. ar. suppl. p. 205.? B. gràcile d'Urvill. enum. 30. p. 250. but not of Bieb. Nearly allied to $B$. odontites, but perfectly distinct, in the leaves of the involucel being diaphanous between the nerves, not reticulated.

Glumaccous Hare's-ear. Pl. 1 foot.

12 B. Odonti'tes (Lin. spee. p. 342. exclusive of the syn. of Haller.) stem erect, panicled; leaves linear, 3-nerved; leaves of involucel 5, linear-lanceolate, cuspidatc, 3-nerved, reticulately veined from the middle nerve being pinnate; fruit having the forrows smooth, and furnished with one vitta each, and the ribs acute and very slender. $\odot$. H. Native of Italy, Sicily, Greece, Smyrna, Montpelier, and Mauritania. Jacq. hort. vincl. 3. t. 91. Rehb. icon. 2. t. 68. t. 177. B. Fontanèsii, Guss. ind. sem. hort. bocc. 1825. ex ind. sem. I826, pl. rar. 112. and prod. 1. p. 312.

Odontites Hare's-ear. Fl. Ju. Aug. Clt. 1749. Pl. 1 foot.

is B. ARISTA'TUM (Barth. in Rehb. ieon. 2, p, 70. t. 178.) stem erect, panicled; leaves lanceolate, linear, 3-nerved; leaves of involucel 5, elliptic, aristately cuspidate, reticulately veined, from the middle nerve being pinnate, exceeding the umbellules; fruit with smooth furrows, furnished with one vitta each, and acute very slender ribs. $\odot$. H. Native of England, France, Balearic Islands, Corsica, Sardinia, Sicily, Liguria, Dalmatia, \&.e. in dry fields and on hills. In England on a marble rock in Devonshire, unquestionably wild. B. divaricatum, Lam. fl fr. 3. p. 410. B. glumàceum, Spreng. umb. spec, 18, t. 3. f. 5 . but not of Sibth. B. Odontites, Smith, engl. bot. t. 2468. Odontites lùtea, Spreng. prod. 33. Schultes, syst. 6. p. 380 . but not of Hoffm. By most anthors this species has been confused with the preceding.

Awned Hare's-ear. Fl. July. England. Pl. $\frac{1}{4}$ to $\frac{1}{2}$ foot.

14 B. Nodip Lònum (Sibth and Smith, fl. græc. t. 260.) stem dichotomous or trichotomous from the base; branches spreading, forked; leaves linear: radical ones distich; umbels axillary and terminal, rather eapitate; leaves of involuerum 5, ovate, cuspidate, 3-nerved, transparent between the nerves, as well as the margins of the upper leaves; fruit with smooth furrows. $\odot$. H. Native of Candia, in corn-fields ; in Syria near Baruth ; and Egypt. B. nànum, Poir. suppl. 1. p. 750. B. Mareótieum, Q q 
Delil. ined. B. prolíferum, Delil. A. egypt. p. 61. t. 22. f. 2 . B. mínimum, Spreng. neue entl. 3. p. 163 . Fruit striated, not warted.

foot

Knot-flowered Hare's-ear. Fl. July, Aug. Clt. 1823. Pl. I

15 B. IEterophy'llum (Link, enum. 1. p. 262.) leaves stemclasping : lower ones lanceolate-linear: upper ones oblong-acuminated, almost perfoliate; umbels bifid; involucrum none; involucels of 5 ovate acuminated leaves. $\odot$. H. Native of Egypt; and the Levant, near Aleppo. B. Egyptiacum, Willd. B. lancilölium, Horn. cat. hort. taur. 1812. ex herb. Furrows of fruit granular, ex Koch, umb. p. 157. This species is confounded with B. protráctum by Spreng. in Schultes, syst. 6 . p. 365 .

Iariable-leaved Hare's-ear. Fl. May, July. Clt. 1818 . Pl. $1 \mathrm{ft}$.

16 B. protrá стum (Link, fl. port. 2. p. 387.) cauline leaves perfoliate, ovate-oblong, acuminated; umbels of 3 rays ; involucrum wanting; leaves of involucel 5 , mucronate; furrows of fruit granular. $\odot$. H. Native of the south of Europe, from Spain to Greece and Egypt, and from Mauritania to Andegavany. Camb. bal. p. s3. B. subovàtum, Spreng. in Sehultes, syst. 6 . p. 365 . exclusive of the synonymes. B. rotundifolium $\beta_{3}^{3}$ intermèdiun, Lois. not. 45. D. C. fi. fr. suppl. p. 514. B. rotundifòliun, Brot. fl. lus. 1. p. 452. Diaphýllum triradiàtum, Hoffm.

Protracted Hare's-ear. Fl. May, July. Clt. 1819. Pl. $\frac{1}{2}$ to $\frac{3}{4}$ foot.

17 B. Rotundròcium (Lin. spec. p. 340.) cauline leaves perfoliate, roundish-ovate; umbels of $5-6$ rays ; involucrum wanting ; involucels of 5 mucronate leaves; furrows of fruit smootl, and destitute of vittæ: ribs very slender. $\odot$. H. Native of Europe, in fields, especially in Caucasus, sonth of Siberia, and Persia ; in England in corn-fields, especially on a chalky soil. Smith, engl. bot. t. 99. Sturm, deutschl. fl. with a figure. Hayn. arz. gew. 7. t. 1. B. perfoliàtum, Lam. fl. fr. 3. p. 405. B. rotundifolium a, Spreng. in Schultes, syst. 6. p. 364.-Moris, hist. 3. p. 299. sect. 9. t. 12. f. 1 . This plant has been reckoned among the vulnerary herbs; but its virtues, whether ever experienced or not, are recorded in old herbals only.

Round-leaved Hare's-ear or Thorow-wax. Fl.July. England. Pl. 1 to 2 feet.

\section{* Perennial plants.}

18 B. Aúreum (Fisch. in Schultes, syst. 6. p. 366.) leaves coriaceous ; radical ones ovate, ovate-oblong, obovate, attenuated into the petioles at the base: cauline ones ovate, acute, stem-clasping; leaves of involucrum $3-5$, elliptic, or nearly orbicular, mucronate; of the involucels 5 , conforming to those of the involucrum, coloured, longer than the flowering umbels. 24. H. Native of Siberia, on mountains beyond the Baikal; and of Altaia. B. longifolium var. Spreng. umb. spee. p. 119. Very nearly allied to $B$. longifolium, but differs in the involucels being yellow, obtuse with a mucrone, not acuminated.

Golden-umbelled Hare's-ear. Fl. May, June. Clt. 18:0. 1). 1 to 2 feet.

19 B. Loxgifòlium (Lin. spec. p. 341.) leaves ovate-oblong : radical ones petiolate: cauline ones stem-clasping; leaves of involucrum 3-5, ovate, somewhat acuminated; of the involucels 5. 4. H. Native of France, Germany, Transylvania, Switzerland, Savoy, Sc, on the mountains,-J. Bauh. hist. 3. p. 199. f. 1. Cam. hort. t. 38. Umbellules 7-14 flowered. Fruit with elevated, sharp, rather winged ribs: and with the furrows between the ribs smooth, and furnished with 3 vitta each, which are full of pellucid dots, ex Koch, umb. p. 117.

Long-leaved Hare's-ear. Fl. Hay, July. Clt. $1713 . \mathrm{Pl}$. to 2 feet.
20 B. Pyrenzèm (Gouan, ill. p. 8. t. 4.) radical leaves lanceolate, elongated : cauline ones cordate-lanceolate, half stemclasping, acuminated; umbels of 5 , very rarely of 3 rays ; involucrum of 3 broadly ovate leaves; involucels of 5 obovate distinct leaves, which are almost twice the lengtl of the umbellules. $4 . \mathrm{H}$. Native of the Pyrenees, in rocky meadows, in the places called Llaurenti, Ereslids, Estive de Luz, Port d'Oo; and in the Eastern Pyrenees. D. C. fl. fr. 4. p. 346. P. Pyrenàicum, Willd. spec. 1. p. 1371. B. angulòsum var. $\alpha$, Lin. spec. p. 341. Leaves of involucrum rarely lobed at the base. Ribs of fruit broadly winged; wings sharply and membranously keeled; furrows smooth, furnished each with 3 vittæ, which are full of pellucid dots. Koch, umb. p. 116.

Pyrenean Hare's-ear. Fl. May, July. Clt. 1814. Pl. 1 ft.

21 B. stella'tum (Lin. spec. p. 340 .) radical leaves linearlanceolate, elongated : cauline ones almost wanting ; involucrum of 3 ovate-lanceolate leaves; involucels of 8 leaves, which are joined together into an 8 -cleft disk, longer than the umbellules. 4. H Native of the Alps of Switzerland, Piedmont, Dauphiny, and Savoy, in stony meadows; and of Corsica, on the mountains, and probably of the Pyrenees. D. C. fl. fr. 4. pr. 346.-Hall. helv. hist. no. 771 . t. 18 . Ribs of fruit broadly winged; wings sharply and membranously keeled; furrows smooth, each furnished with one vitta.

Stellate-involucelled Hare's-ear. Fl. May, July. Clt. 1775. Pl. 1 to $1 \frac{1}{2}$ foot.

22 B. Triradia'tum (Adams, ex Fisch. in litt. ex D. C. prod. 4. p. 130.) radical leaves linear-oblong: eauline ones 3 , stemclasping, oblong or ovate, hardly acute; umbels of 3 rays; involucrum of 3 obovate leaves; involucel of $7-8$ obovate leaves, which are scarcely longer than the umbellule. $4 . \mathrm{H}$. Native of Altaia or the mountains, and at Lake Baikal. Allied to $B$. Pyrcnce'um, but differs in the leaves being much less acute, in the umbels being of 3 rays, in the involucels being hardly longer than the flowers, and in the young fruit not being glaucous.

Three-rayed-umbelled Hare's-ear. Pl. 1 foot.

23 B. Multine'rve (D. C. mem. soc. gen. vol. 4.) radical leaves oblong-linear, attenuated at both ends : cauline ones stemclasping, ovate, acuminated, with many parallel nerves; involucra of 5 unequal leaves, having many parallel nerves; leaves of involucel 5, ovate, acuminated, coloured, hardly longer than the umbellule. \%. H. Native of Altaia, on the mountains. Allied on the one hand to $B$. aúreum and $B$. longifolium, and on the other to $B$. graminif òlium.

Var. 3 , angústius (D. C. prod. 4. p. 130.) cauline leaves narrower, more glaucous; involucrum of 2 leaves. 4. H. Native of Dahuria.

Var. $\gamma$, minus (D. C. I. c.) involucrum of $3-4$ leaves ; stem nearly simple; leaves narrow. 4 . H. Native of Altaia, on the mountains.

Many-nerved-leaved Hare's-ear. Pl. 1 foot.

24 B. GRAMINIFòlium (Vahl. symb. 3. p. 48.) stem nearly naked; leaves radical, linear; involucrum of 3-5 elongated leaves, about one-half shorter than the rays of the umbel; leaves of involucel 5-8, oblong, mucronate. 2. H. Native of the Alps of Europe and the Pyrenees. Rom. fl. eur. fasc. 7. with a figure. D. C. fl. fr. 4. p. 367. Spreng. in Schultes, syst. 6. p. 368. B. petræum, Vill. dauph. 2. p. 576. t. 14. Jacq. icon. rar. 1. t. 56 . This species differs from $B$. ranunculoides, in the leaves being all nearly radical, in the involucels being often $7-8$ leaved, in the leaves of the involucrum being more elongated. B. incúrvum, Bell. app. 77. t. 11. is lardly a variety of this species, unless that the leaves of the involucrum are more elongated. B. caricifolium and B. petræ'um of many authors are identical with this.

I'ar. $\beta$, bicalyculàtum (D. C. prod. 4. p. 131.) leaves of in- 
volucrum 10, disposed in two series. 24. H. Native of P'iedmont, on the mountains about Limone. B. bicalyculàtum, Bell. st. nov. p. 4. t. 2. in mem. acad. taur, vol. 7.

Grass-leaved Hare's-ear. Fl. May, July. Clt. 1768. Pl. $\frac{1}{2} \mathrm{ft}$.

25 B. RANUNculoides (Iin. spec. p. 342.) radical leares linear. lanceolate, attenuated towards the base : cauline ones stem-clasping, oblong-cordate, or ovate-corlate, striated ; involucrum of 3 mequal leares; involucels of 5 ovate or oblong nerved distinct mucronate leaves. 24. H. Native of the $\Lambda$ lys, Pyrences, Jura, A pennines, Siberia, in roigh exposed places ; and of North America, at Cape Mulgrave, in Belıring's Straits. Lam. dict. 1. p. 518. D. C. A. fr. 4. p. 3.18. B. angulosum, Spreng. in Schultes, syst. 6. p. 366.-Park. theatr. 58I. no. 7.-Baul. hist, 3. p. 199. f. 2. Ribs of fruit elevated and sliarp; and the furrows between the ribs smooth, and furnished with one vitta each, ex Koch, umb. p. 116. Habit of herb very variable, from a finger to a foot in height, simple or branched, bearing one or many umbels. Involucra of from 1 to 3 learcs, very variable in length, either broader or narrower than the leaves. The limits between the varicties are hardly perceptible, and to these may be referred the B. angulòsum, ranunculoides, rèpens, obtusatum, and graminifolium, Lapeyr.abr. and suppl. as well as B. gramineum and Vapincénse, Vill. B. caricifòlium and Burseriànum, Willu. 13. Baldénse, Hort. B. petræ'um, Geners. B. angulòsum $\beta$, Lin. Se.

I'ar. B, caricinum (D. C. prod. 4. p. 131.) radical leaves rather convolute, linear-subulate: cauline ones hardly dilated at the base. $4 . \mathrm{H}$. Native of the Apennines and the Pyrenees, in exposed rocky places. B. caricifolium of many herbaria. B. petra'um, Lin. spec. 340. ? but the leares of the involucel are distinct, not joined.

Var. $\gamma$, oblongifólium (Led. A. alt. 1. p. 348.) stem very simple ; radical leaves 2 , linear-oblong, $1 \frac{1}{2}$ to 2 inches long, and 2 to 3 lines broad, acutish; cauline leaves sessile, broader than the radical ones, of different shapes : the uppermost ones cordate-ovate, rounded at the apex, and mucronulate; involucrum of $3-8$ unequal leaves; umbels of 4 unequal rays; involucels of

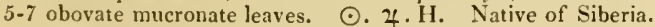

Cronfoot-like Hare's-ear. Fl. July, Aug. Clt. 1790. Pl. $\frac{1}{3}$ to $\frac{1}{2}$ foot.

26 B. BALDE' KSE (Host, syn. 141.) stem branched; leaves stenł-clasping, nearly linear, acute, nerved; radical ones tapering into the petioles; leaves of involucel oblong-linear, about equal in lengtls to the fructiferous pedicels; ribs of fruit sharp; vittæ 3 in each furrow. 4. H. Native of Mount Baldo; and of Altaia, at the rivers T'scharysch, Kerlyk, Bucktorminsk; and near Schulbinsk. B. bicaúle, Helm. in act. mosq. 2. p. 106. t. 8.-Gmel. sib. 1. p. 209. no. 24. Stems numerous, erect or ascending, simple at the base, and branclied at the apex. Radical leaves 2-6 inches long. Involucrum of 4-7 lanceolatc-linear leaves, but sometimes only of one elongated deciduous leaf. Umbels of 5-13 rays. Involucels of 5-9 oblonglinear acute 3-nerved leaves; umbellules of 10-20 flowers.

Var. $\beta$, multicaúle (Led. fl. alt. 1. p. 350.) plant tufted; leaves rather fleshy. 2. H. Native of Altaia, in saltish deserts at the river Tschuja.

Baldo Hare's-ear. Fl. June, July. Pl. $\frac{1}{2}$ to 1 foot.

27 B. LOXGICAU'LE (Wall. cat. no. 557.) stems erect, sparingly branched; leaves linear, acute, 5-7-nerved, rather membranous ; umbels 3-5-rayed; involucra of 1-3 ovate acute leaves; umbellules 15 -rayed; leaves of involucel 5 , ovate, mucronate, longer than the flowers, but shorter than the fruit; fruit 3 times longer than the pedicels, acutely ribbed; vitta 3 in each furrow. 4 . H. Native of Nipaul, at Gosaingsthan, Emodi, and Kamaon. Herb $1 \frac{1}{2}$ to 2 feet high, dividing into many stems at the neck. Leaves 3-6 inches long. Mature fruit 2 lines long.
Lonw-stcmmed llare's-ear. P]. 1 to 2 feet.

28 B. Candóllil (Wall. cat. no. 552.) stems rising from liorizontal surculi, erect, sparingly branclied; leaves lanceolate, acute, membranous, obliquely many nerved on both surlaces ; umbels 12-13. rayel ; involucrum of 2.3 ovate, acute, many nerved leaves; umbellules 12-15-rayed; involucels of 5 oval acute leaves, which exceed the fruit. $\mathcal{\psi}$. II. Native of Nipaul, at Gosaingsthan and Linodi. Herb 2 feet high. Immature fruit hardly longer than the pedicels, oblong, ribbel, with the furrows smootli.

De Candolle's Hare's-ear, Pl. 2 fect.

29 B. panicula'tum (Brot. f. Jus. 1. p. 455.) leaves linearnarrow, many nerved: radical ones very long; stem crect, panicled; umbels 2-3-rayed ; involucrum of $2-3$ small leaves; involucels of 4-5 subulate leaves, which are 3 or 4 timcs shorter than the umbellules; fruit oblong. 4 . H. Native of Portugal, on calcareous hills. Fruit with 3 ribs on each side, usually of one mericarp from abortion. Habit of $B$. frutéscens, but the stems are annual.

Panicled Hare's-ear. Fl. June, Aug. Clt. 1824. Pl. 1 to $3 \mathrm{ft}$.

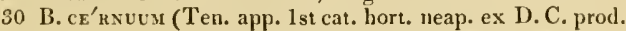
4. p. 181.) stems ercet, simple; leaves linear, acute, narrowed at the base so much as to form petioles, many nerved; umbels 5-9-rayed; involucra of 2-4 leaves; involucels of 5 setaceous leaves; furrows of fruit smooth. $\%$. H. Native of the kingdom of Naples, on calcarcous rocks. B. obtusifolium, Ten. prod. p. 18. Leaves acute. A very distinct species, although it has been joined by Sprengel with B. semicompósitum. Very nearly allied to $B$. paniculàtum.

Drooping Hare's-ear. P1. 1 foot.

31 13. ехадта'тun (Bieb. tabl. casp. p. 166.) leaves all linear, many nerved: lower ones elongated; stem erect, leafy, paniculately branched; umbels 5-10-rayed; involucra and involucels of $3-5$ subulate unequal, small leaves; fruit ovate. 4 . Bieb. $\delta$. Stev. H. Native of 'Tauria and Caucasus, in maritime meadows, and on hills. B. Baldénse, Willd. spec. 1. p. 1375. exclusive of the syn. Bieb. fl. cauc. no. 513. but not of Turr. nor Host. Allied to $B$. falcàtum, but differs in the fruit being shorter, and in the ribs being less acute.

Exalted Hare's-ear. Fl. July. Clt. 1807. Pl. 2 feet.

32 B. LiNeARIFòlivM (D. C. prod. 4. p. 131.) stem erect, paniculately branched; leaves linear, very long, hardly acute, many nerved; umbels of 5-6 rays ; involucra and involucels of 4-5 small acuminated leaves ; fruit linear-oblong, witl rather

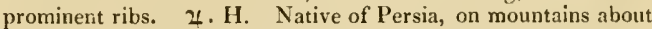
Badala, in the district of Khoi in the province of Aderbeidjan, where it was collected by Szowits. Very like B. exaltàtum, but differs in the fruit being longer. It is perhaps, however, only a variety of it.

Linear-leaved Hare's-ear. Pl. 1 foot.

33 B. scorzoneréfòliuM (Willd. enum. suppl. p. 30.) radical leaves lanceolate: cauline ones linear, all striated with 9-11 parallel nerves; stem paniculately branched; umbels 8-10-rayed; involucrum of 1-2 leaves; involucels of 4-5 lanceolate apiculated leaves, which are shorter than the umbellules. 24. H. Native of Siberia, at Lake Baikal. Allied to $B$. falcàtum, but differs in the leaves being narrower, and in the nerves being parallel and more crowded.

Scorzonera-leaved Hare's-ear. Fl. June, July. Clı. 1817. Pl. $1 \frac{1}{2}$ foot.

34 B. Lanceola'tum (Wall, cat. no. 551.) stem erect, sparingly branched; leaves lanceolate, mucl acuminated, glabrous, membranous, furnished with 2 oblique nerves on eacl side; umbels 5-6-rayed; involucrum of one small leaf; umbellules 5-8rayed; involucels of $1-2$ small leaves, rarely wanting; fruit ovateoblong, with the ribs hardly elevated, and the furrows smooth. e q 2 
4. H. Native of Nipaul, on the mountains. Herb 2 feet high, quite glabrous. Leaves 4 inches long, and an inch broad. Fruit a line and a half long. Furrows of immature fruit furnished with 3 vitta each.

Lanceolate-leaved Hare's-ear. Pl. 2 feet.

35 B. Margina'tum (Wall. cat. no. 556.) stems erectly ascending, sparingly branched; leaves linear, acute, stiff, 57 nerved; outer nerves nearly marginal; umbels 6-8-rayed; involucra of 3-5 acuminated lanceolate leaves; umbellules 10-12rayed; involucels of $3-5$ leaves, which are shorter than the pedicels; fruit oblong, ribbed, with the furrows smooth. $4 . \mathrm{H}$. Native of Nipaul and Kamaon. Root hard, branched, thick. Herb a foot and a half high. Lower leaves 3 inches long, and 3 lines broad, usually obtuse from some cause; nerves very prominent.

Marginate-leaved Hare's-ear. Pl. 2 feet.

36 B. trífidum (Tenore, prod. fl. neap. p. 18.) stem erect, branched; leaves lanceolate, 9-nerved: upper ones rather falcate, much shorter than the branchlets; involucrum of 3 very short linear-subulate leaves; involucels of 5 setaceous leaves, shorter than the umbellules, which are trifid. 2.H. Native of Calabria, on dry rocks. Perhaps only a var. of $B$. scorzonerafolitum or B. falcàtum.

Trifil-umbelled Hare's-ear. Pl. 1 to 2 feet.

37 B. FALCA'TUM (Lin. spec. p. 341.) leaves oblong : lower ones oblong, petiolate: cauline ones sessile, linear-lanceolate, attenuated at both ends; leaves of involucel oblong-lanceolate, acuminated, about equal in length to the fructiferous pedicels. 4. H. Native of Middle Europe, in hedges and among bushes in dry situations ; and of Siberia, on the Altaian mountains ; and throughout the whole of Cancasus. Jacq. austr. 2. t. 158. D. C. fl. fr. 4. p. 347.-Lob. icon. t. 456 . f. 1. Ribs of fruit elevated, narrow, and a little winged; vittæ 3 in eacl furrow : furrows smooth, ex Koch, umb. 116.

Var. $\beta$, pctiolàre (D. C. fl. fr. suppl. p. 514.) radical leaves ovate or oval, 7-nerved. 4 . H. Native of the Eastern Pyrenees. B. petiolàre, Lapeyr, abr. pyr. p. 141. B. rígidum $\beta$, Spreng. in Schultes, syst. 6. p. 370.

Falcate-leaved Hare's-ear, Fl. May, Sept. Clt. 1739. Pl. 1 to 2 feet?

38 B. R'Gidum (Lin. spec. p. 342.) lower leaves petiolate, oblong or oval, nerved, coriaceous: upper ones small; stem nearly naked, dichotomously panieled; involucra of 3 small leaves. 4. H. Native of the south of France, from Provence to Narbonne, in rugged sterile places. D. C. fl. fr. 4. p. 349. B. rigidum, Spreng. in Schultes, syst. 6. p. 370 . exclusive of variety $\beta$. B. falcà̀tum $\beta$, Lam. fl. fr. 3. p. 408.-Lob. icon. t. 456. f. 2.-Ger. 608. f. 2.-Bauh. hist. p. 200. f. 2. Umbels 3-rayed. Ribs of fruit acute, very slender, but not elevated furrows smooth, furnished with one vitta each, ex Koch, umb. 115.

Stiff Hare's-ear. Fl. May, July. Clt. 1820. Pl. 2 feet.

39 B. Nu'vum (Ait, hort. kew. 1. p. 331.) stem dichotomous, 2-leaved ; radical leaves decompound, flat, cut; involucrum of one leaf; involucels of 5 lanceolate acute leaves, which are shorter than the umbellules. 2\%. G. Native of the Cape of Good Ilope. Flowers pale yellow. The rest unknown.

Naked Hare's-ear. Fl. Oct. Clt. 1778. Pl, 1 l foot.

*** Shrubby species.--Tenória and Bupréstis, Spreng. l. c.

40 B. Mu'sntil (Clam. et Schlecht. in Linnæa. 1. p. 384.) shrubby, much branched; leaves linear-sctaceous; umbels 2-3rayed; involucels of 5 narrow lanceolate acute leaves, which are equal in length to the umbellules; fruit oblong, smooth. $\psi$. G. Native of the Cape of Good Hope. Lower leaves 8 inches long. B. sulcàtum $\beta$ Africànum, Berg. cap. 76. ? but the umbels are said to be 5 -rayed, and the involucels of 5 leaves.

Mundt's Hare's-ear. Shrub 1 to 2 feet.

41 B. Sibtiorpia'sum (Smith, fl. græc. t. 264. prod. 1. p. 179.) plant suffrutescent; leaves linear, rather falcate, with smooth margins; involucra usually of 3 leaves; leaves of involucel linear-lanceolate, cuspidate, shorter than the umbellules. h.H. Native of the Morea. A specimen collected near Teheran agrees very well with the character given to this; and is pro. bably the same. Plant only frutescent at the base.

Sibthorp's Hare's-ear. Shrub 1 foot.

42 B. spivòsum (Lin. fil. suppl. p. 178.) shrubby, erect; floriferous branches divaricate, stiff: the deflowered ones spinose; leaves linear-subulate, many veined, quite entire ; involuera of 3-5 small subulate leaves. $h . H$. Native of Spain and Mauritania. Gouan. ill. p. 8. t. 2. f. 3. Desf. atl. 1. p. 232. Tenòria spinòsa, Spreng. Ribs of fruit obtuse.

Spinose Hare's-ear. Fl. Aug. Sept. Clt. 1752. Sh. 1 foot. 43 B. Frutice'scens (Lin. amoun. 4. p. 269.) suffruticose, erect; branches slender, clongated, erect; leaves linear-subulate, stiff, striated, 5-7-nerved; involucra of $3-5$ very short subulate leaves. $\zeta$. H. Native of Mauritania, Spain, and between Perpignan and Narbonne. Cav. icon. 2. t. 106. Tenòria fruticéscens, Spreng. in Schultes, syst. 6. p. 376.-Barr. icon. t. 1255. Umbels small, 3-5-rayed. Ribs of fruit obtuse.

Frutescent Hare's-ear. Fl. Aug. Sept. Clt. 1752. Sh. 1 ft.

44. B. folıosum (Salzm. pl. exsic. ex D. C. prod. 4. p. 133.) suffrutescent, erect, nearly simple; leaves sessile, lualf stemclasping, linear-lanceolate, acuminated, undulated, crowded, 1 nerved, quite entire; leaves of involucra ovate. Һ. F. Native of Mauritania, about Tangiers. Stem a foot high. Leaves broad and half stem-clasping at the base. Involucra of 3 leaves; involucels of 4-5 leaves. Fruit ovate, with obtuse ribs.

Leafy Hare's-ear. Slirub 1 foot.

4.5 B. Ela'tum (Guss. prod. fl. sic. 1. p. 316.) plant suffrtttescent at the base; branches elongated; leaves membranous, many veined: radical ones oblong-lanceolate, tapering into the petioles: cauline ones sessile, linear-lanceolate; umbels 8-12cleft; involucra of 4-5 short leaves; leaves of involucels oblong, acuminated, longer than the umbellules. $h$. F. Native of Sicily, on calcareous rocks. Allied to B. plantagineum, but the plant is frutescent at the base, and the leaves are acute. Ribs of fruit smootll.

Tall Hare's-ear. Shrub 3 to 5 feet.

46 B. Cane'scens (Schousb. mar. beob. p. 113.) shrubby, erect, branched ; leaves oblong, membranous, very blunt, quite entire, sessile, with many parallel nerves; umbels 8-10-rayed; leaves of involucra oblong, obtuse, short. $\grave{z}_{2}$ F. Native of Mogodor. Branches of a greyish white-colour. Plant glabrous. Fruit like that of $B$. fruticosa. Leaves much thinner, and onehalf sinaller than those of $B$. plantagineum.

Canescent IJare's-ear. F\}. $\Lambda$ ug. Sept. Clt. 1809. Shrub 2 to 3 feet.

47 B. Plantagíneum (Desf. atl. 1. p. 233. t. 57.) shrubby, erect, branched; leaves lanceolate, mucronate, stiff, coriaceous, sessile, quite entire, many nerved; umbels 4-10-rayed; leaves of involucra elongated, subulate, acute. $\boldsymbol{b}$. F. Native of Mount Atlas, near Bougie. Tenòria plantagínea, Spreng. in Schultes, syst. 6. p. 376 . Nerves almost diverging from the base of the leaves, not parallel.

Plantain-leaved Hare's-ear. Fl. July, Aug. Clt. 1810. Shrub 2 to 3 feet.

48 B. Gibraltárica (Lam. dict. (1781.) 1. p. 520.) slurubby, erect, branched; leaves lanceolate, attenuated at both ends, 1 nerved, coriaceous, glaucous, oblique, quite entire, sessile; leaves of involucra lanceolate. h. F. Native of Gibraltar, on the 
rocks at Algesira. B. coriàceum, Lher. stirp. nov. fasc. 6. (1755.) t. 67. B. obliquum, Vahl. symb. 1. p. 24. B. arboréscens, Jacq. icon. rar. 2. t. $35 \mathrm{I}$. Tenòria coriàcea, Spreng. in Schultes, syst. 6. p. 3.5. Bupréstis coriàcea, Spreng. mag. B. verticale, Ort. fl. esp. The whole plant is rather fragrant when rubbed.

Gibraltar Hare's-ear. Fl. Junc, Aug. Clt. 1784. Shrub 2 to 3 feet.

49 B. Fruticòsum (Lin. spec. 343.) shrubby, erect, branched; leaves oblong, attenuated at the base, coriaceous, 1-nerved, quite entire, sessile; leaves of involucra oblong. দ. F. $\mathrm{Na}$ tive of Portuga], Spain, south of France, Nice, Corsica, Sicily, Mauritania, and Thessaly. Sibth. fl. græc. t. 263. Wats. dendr. brit. t. 14. Duham. arbr. 1. t. 43. Jaum. pl. fr. 1. t. 65. Mill. fig. 74. 'Tenòria fruticòsa, Spreng. in Schultes, syst. 6. p. 376. Bupréstis fruticòsa, Spreng. mag. Séseli Æithiòpicum, Bauh. pin. 161. Séseli frùtex, Mor. umb. 16. Ribs of fruit elevated, acute; vittæ broad. Bark of branches purplish. Leaves of a sea green colour.

Shrubby Hare's-ear. Fl. Jul. Aug. Clt. 1596. Sh. 3 to $6 \mathrm{ft}$.

50 B. DIFFó rME (Lin. spec. 343.) shrubby, erect, branched; leaves variable on the same branch, simple or ternate; leaflets undivided or cut; umbels terminal, 8-12-rayed; leaves of involucrum linear, acute, much shorter than the peduncles. $h$. G. Native of the Cape of Good Hope. Burm, afr. t. 71. f. 1. Cham. et Schlecht, in Linnæa. 1. p. 384. Thunb. fl. cap. 248. Tenòria diffŏrmis, Spreng. in Schultes, syst. 6. p. 377 . Bupréstis diflormis, Spreng. mag. Ribs of fruit rounder and tumid, lateral ones somewhat dilated; vittæ 2-3 in each furrow. This shrub sends out side branches, which in the spring have on their lower parts leaves, composed of many small flat leaflets, finely cut like those of coriander, and of a sea green colour; these leaves soon fall off, and the upper part of the branches are closely covered with long rush-like leaves, having 4 angles, coming out in clusters from each joint.

Difformed-leaved Hare's-ear. Fl. Aug. Sept. Clt. 1752. Sh. 4 to 6 feet.

\section{+ Species not sufficienlly known.}

51 B. Poly PHy' LLUM (Ledeb. mem. ac. sc. petrop. 5. p. 528.) stem erect, striated, branched above; leaves lanceolate, stemclasping; umbels of many unequal rays; involucrum almost wanting; involucels of 6 lanceolate acuminated leaves, which exceed the fruit. 4.H. Native of Caucasus. Flowers said to be solitary in the axils of the branches.

Many-leaved Hare's-ear. Fl. May, June. Clt. 1823. Pl. $1 \mathrm{ft}$.

52 13.? oppositifòliu (Lapeyr. abr. pyr. p. 141.) stem naked; branches umbellate; leaves opposite, lanceolate, obtuse, nerved; involucrum almost wanting; involucels of 5 lanceolate awned leaves. $\odot$. H. Native of the Pyrenees, at a place called Trancade d'Ambouilla. This species is very obscure, and very doubtful whether it is an umbelliferous plant at all.

Opposite-leaved Hare's-ear. Pl. 1 foot.

Cult. All the species grow well in any common garden soil. The seeds of the annual species only require to be sown in the open ground early in spring. The herbaceous perennial kinds are either increased by being divided at the roots, or by seeds; and the shrubby species by cuttings.

LVII. HETEROMO'RPHA (from ėтeos, hctcros, diverse, and $\mu \circ \rho \phi \eta$, morphe, form; leaves). Cham. et Schlecht. in Linna. 1. p. 385 . t. 5. f. 2. D. C. coll. mem. 5. p. 43. prod. 4. p. 134.-Bupleùrum species of authors.

Lis. syst. Pentándria, Digýnia. Margin of calyx 5-toothed. Petals roundish, entire, closely involute, ending in a broad retuse point. Fruit obovate-pyriform, 5 -winged; mericarps of 2 forms ; the outer one 2-winged, and tlie inner one 3-winged; wings ruming from the teeth of the calyx, and therefore are the carinal ribs extended; vittae one in each furrow, and 2 in the com. missure.-A glabrous Cape shrub, with the habit of Bupleurum fruticosum. Leaves petiolate, ovate or oblong, rarely somewhat triple-nerved, sometimes quite entire, sometimes 3-lobed, tripartite or ternate. Umbels of many rays. Involucra and involucels of many short leaves. Flowers yellow as in Bupleurum.

1 H. arboréscens (Cham. et Schlecht. l. c.) h. G. Native of the Cape of Good Ilope. Bupleùrum arboréscens, Thunb. prod. p. 50. fl. cap. 247. Bupleùrum trifoliàtum, Wendl. et Bartl. beitr. 2. p. 13. Tenòria arboréscens, Spreng. prod. umb. Arborescent Heteromorpha. Fl. Aug. Sept. Clt. 1810. Sl. 1 to 2 feet.

Cult. Any common soil will answer this shrub; and cuttings are easily rooted.

\section{Tribe V.}

SESELI'NEÆ (plants agreeing with Séscli in important characters) or Orthospérmæ paucijngatæ teretiusculæ, Koch, 11mb. 102. D. C. prod. 4. p. 135. Transverse sections of fruit terete, or nearly so. Mericarps with 5 equal filiform or winured ribs: lateral ribs marginating, and often a little broader than the rest. Seed somewhat teretely convex on the back, and flat. tish in front. Raphe marginal or submarginal.

LVIII. LICHTENSTEI'NIA (in honour of M. Von Lichtenstein, Professor of Medicine at Berlin, a celebrated German botanist). Cham. et Schlecht. in Linnæa. 1. p. 394. D. C. prod. 4. p. 135. but not of Willd. nor Wendl.

LıN. syst. Pentándria, Digýnia. Margin of calyx 5 -toothed. Petals elliptic, draw'n out into a long acumen, which is bent in nearly to the base. Fruit nearly terete, variable in length, crowned by the teeth of the calyx in the immature state, and by the stylopodium and short spreading styles. Mericarps smooth, with 5 filiform ribs, lateral ones marginating; vittæ large, solitary under each rib, but none in the commissure nor furrows.Perennial herbs, natives of the Caje of Good Hope, rielding an aromatic juice. Radical leaves cut. Stems erect, fistular, naked, branched, furnishcd with sheathing scales or abortive leaves. Terminal umbels compound, fertile: lateral ones often sterile. Involucra and involucels of many short marcescent leaves. Flowers yellow? This genus from the situation of the vittæ agrees alone with Melanosclinum, but the form of the fruit is very different.

1 L. LA'cera (Cham. et Schlecht. I. c. p. 395.) leaves scabrous, almost undivided or jagged : lobes irregularly serrated : serratures setaceously cuspidate; fruit oblong. $4 . G$. Native of the Cape of Good Hope, on the Devil's mountain. Sieb. pl. exsic. no. 213. Hérmas rudíssima, Reichb. in Spreng. syst. 4. p. 118 . Enánthe exaltàta, Thunb. prod. p. 50. fl. cap. p. 254. ex herb. Juss. Leaves like those of Eryngium. Umbel 15rayed; involucra of 10 leaves. Immature fruit blackish when dried.

Jaggcd-leaved Lichtensteinia. PI. 3 to 4 feet.

2 L. trífida (Cham. et Schlecht. 1. c. n. 39.) leares ghabrous, ternate, rarely $2-4$ cleft; leaflets lanceolate, entire or toothed; fruit elliptic. 24. G. Native of the Cape of Good Hope, at Schurfdeberg. Cinánthe obscùra, Spreng. syst. 1. p. 890. Umbels 10-20-rayed.

Trifid Lichtensteinia. Pl. 1 to 2 feet.

3 L. PYrethrifòlı (Cham. et Schlechit. 1. c. p. 397.) leaves glabrous, pinnatifid: lobes ovate, cut, serrated; fruit elliptic. 4. G. Native of the Cape of Good Hope, in the woods of Ruyterbosch. Sieb. pl. cap. exsic. no. 211. and 22\%. lBùbon prolíferum, Burm. fl. cap. p. 8. Enántle inèbrians, Thunb. 
prod. p. 40. fl. cap. 262. ex Spreng. syst. 4. p. 118 . CEnánthe Capénsis, Houtt.? Sprengel says bis plant has rough leaves, and Thunb. says his is glabrous; they are, however, only the same. The plant is called Gli by the Hottentots, and is made by them into an inebriating liquor.

Pyrethrum-leaved Lichtensteinia. Fl. Aug. Sept. Clt. 1816. P1. 1 to 2 feet.

4. L. PALMA'TA (D. C. prod. 4. p. 135.) leaves pilose on both surfaces, palmate; petioles broad, sheathing; lobes or leaflets 5 , oblong, rather cuneated, cartilaginously serrated; stem terete, glabrous, sparingly branched; petiolar sheaths short, leafless; fruit ovate. 4 . G. Native of the Cape of Good Hope.

\section{Palmate-leaved Lichtensteinia. Pl. ?}

Cult. The species of this genus require to be grown in pots so as they may easily be sheltered in the winter. Any light soil will suit them; and they may be easily increased by dividing at the root or by seeds.

LIX. OTTO'A (in honour of Frederick Otto, superintendent of the royal botanic garden of Berlin). H. B. et Kunth, nov. gen. amer. 5. p. 20. t. 423. D. C. prod. 4. p. 136.-Enánthe species of Spreng.

Lun. syst. Pentándria, Digýnia. Margin of calyx obsolete. Petals equal, with an inflexed point. Styles arcuately divaricate, capitellate at the apex. Fruit oblong; mericarps acutely 5 -ribbed, rather compressed at the commissure ; ribs membranous. - Smooth perennial herbs. Stems simple, with few leaves. Leaves (pliyllodia?) sheathing at the base, intercepted by transverse dissepiments. Umbels terminal, without any involucra, of many rays. Umbellules without involucels. Flowers white, polygamous, 3-4, hermaphrodite, and 6-7 male in each umbellule. This genus is allied to Enánthe, but differs in the margin of the calyx being obsolete, not 5-toothed; in the petals being entire, and in the styles being divaricate.

1 O. cenanthoides (H. B. et Kunth, l. c.) 4. G. Native of Quito, between St. Vincent and Ybarra. Enánthe Quiténsis, Spreng. syst. 1. p. 888 . Herb very like Tiedemània terctifòlia, but the generic character is different, and the involucrum is wanting.

Enanthe-like $\mathrm{O}$ ttoa. Pl. 1 foot.

Cult. Any soil will suit this plant, and it may either be increased by seed or by dividing at the root.

LX. OENA'NTHE (from ouvoc, oinos, wine, and artos, anthos, a flower; odour). Lam. dict. 4. p. 526. ill. t. 203. I.ag. am. nat. 2. p. 96 . Koch, umb. p. 112. diss. ined. in litt. 1828. D. C. jrod. 4. 1. 136.-CEnánthe and Phellándrium, Lin. gen. no. 352. and 353. Hoffin. umb. p. 73.—CEnánthe species of Spreng. prod. p. 37.

Lix. syst. Pentándria, Digýnia. Margin of calyx 5-toothed, permanent, somewhat accrete after flowering. Petals obovate, emaruinate, with an inflexed point. Stylopodiun conical. Fruit cylindrically ovate, erowned by the long ercet styles. Mcricarps with 5 rather convex obtuse ribs: lateral ribs marginating, and a little broader than the rest; vittæ one in each furrow. Carpophorc indistinct - Smooth usually aquatic lierbs, natives of Europe and Asia. Umbels compound. Involucra variable, usually wanting; involucels of many leaves. Flowers in the rays of the umbellules on long pedicels sterile; those in the disk on short pedicels fertile; petals white. The species of this genus are difficult to extricate, in consequence of the roots having been neglected by the authors who have described them.

$\$ 1$. Truc species, natives of Europe, \&c. but not of the Cape of Good Hope.

* Plants perennial. Ronts tuberous; tubers disposcd in fas-
1 E. Fistulòsa (Lin. spec, 365.) roots fasciculate, intermixed with oblong tubers; neck of root throwing out stolons; stems and leaves fistular; radical leaves bipinnate: leaflets cuneated, lobed; cauline leaves pinnate: leaflets filiform; umbels 3-4rayed, without any involucrum ; fruit turbinate, much crowded, ribbed. 4. H. Native of Europe and Cancasus, in ditches, ponds, and other watery places; plentiful in Britain. Drev. et Heyne. pl. curop. 5. t. 98. Fl, dals. t. 846 . Smith, engl. bot. t. 363. O, aquática, Bauh. pin. 162.-Bauh. hist. 3. p. 192. f. 1.-Petiv, herb, brit. t. 25, f. 5. and 6. There is a variety of this whose roots are composed of whorles of fibres. The plant has an unpleasant smell, and a hot nauseous taste, like many other umbelliferous plants. The roots and whole herbage are said to be poisonous. Flowers pale red.

Var. $\beta$, Tabernamontàni (Koch, ex D. C. prod. 4. p. 136.) radical leaves divided into many linear segments. 2\%. H. Native of Alsatia, in inundated places. O. Tabernæmontàni, Gmel. f. bad. 1. p. 676. exclusive of the syn. of Poll.

I ar. $\gamma$ ? lanceolàta (Spreng. ex D. C. prod. 4. p. 136.) radical leaves pinnate or bipinnate: leaflets or scgments linear-lanceolate; umbels bifid. 4 . H. Native of Mauritania, in humid places on the sea shore near Lacalle. CE. lanceolata, Poir. suppl. 4. p. 135. CE. fistulòsa, Poir. voy. 2. p. 137.

Fistular or Common Water-dropwort. Fl. June, Aug. Britain. Pl. 1 to 2 feet.

2 QE. Laciena'Ln (Gmel. fi. bad. 1. p. 6\%8.) fibres of roots cylindrical, rather fleshy, in fascicles; radical leaves somewhat bipinnate: leaflets cuneiform, obtuse, tridentate at the apex; cauline leaves pinnate: leaflets linear, entire; involucra wanting, or of few leaves. 24. H. Native of the north of Italy, Germany, valleys of the Rhine, in humid meadows; and of Caucasus, in marshes towards the Caspian sea between Sallian and Lenkeran. Koch, umb. p. I13. CE. pimpinelloìdes, Poll. pall. 1. p. 291. but not of Lin. C. Rhenàna, D. C. suppl. p. 506. C.. Megapolitàna, Willd. berl. mag. 3. p. 297. E. gymnorhiza, Brignoli, pl. forojul. 21. E. Jordàni, Tenore, add. 1827.? Styles white after flowering.

Var. $\beta$, approximàta (D. C. prod. 4. p. 197.) radical leaves pinnate; leatlets or segments trifid, obtuse, cuneated at the base. 4. H. Native about Paris, in lumid meadows. $O$. approximàta, Mer. fl. par. 115. D. C. suppl. p. 507.

I ar. $\gamma$, involucràta (D. C. l. c.) involucrum of many leaves. น. H. A. peucedanifòlia, Schleich. pl. exsic. CE. Fihenàna, Moricand, fl. ven. p. 149 . In some specimens the involucrum is absent. Fruit ovate, striated; pedicels not thickened after flowering.

La Chenal's Water-dropwort. Fl. June, Aug. Clt.1817. Pl. 2 to 3 feet.

3 C. peucedanifòlia (Poll. pal. 1. p. 289. f. 3.) tubers of roots sessile, elliptic, ending in a fibre each at the apex; radical leaves bipinnate: cauline ones pinnate; lobes or leaflets all linear; umbels 5-8-rayed; involucrum wanting, or of 1 leaf: fruit oblong, attenuated at the base, nearly sessile, coarctate beneath the calyx. $\%$. H. Native of middle Europe, in meadows, ditches, and bogs; as in France, Switzerland, \&c. In England, near Bury ; about Bedford; on the banks of the Isis, beyond Isley; and in peat bogs, under Headington Wick Copse, Oxfordshire. Umbellules dense, many-flowered, surrounded by the many leaves of the involucels, which are of equal length. Smith, engl. bot. t. 348. CE. filipenduloìdes, Thuill. fl. par. p. 146. CE. Pollichii, Gmel. fl. bad. 1. p. 679 . CE. peticedanoìdes, Roth. QE. pàtens, Mcench.-Lob. icon. 729. f. 2.-Dilech. hist. 773. f. 1. Flowers often reddish. The roots taste like the garden parsnip, but are probably dangerous food; yet they are not reckoned poisonous, though the roots of other species are virulent.

Sulphur-nort-leaved Water-dropwort. Fl. Ju. Brit. Pl. $1 \frac{1}{2} \mathrm{ft}$. 
4 CE. sizaifòlia (Bieb. suppl. p. 232.) knobs of roots of an oblong-fusiform slape, or cylindrical, fasciculate; leaves pinnate; leaflets of the lower leaves lanceolate: of the upper ones linear ; involucra almost wanting ; fruit ovate, crowded, sessile, liardly longer than the involucel. 4.11 . Native of the south of Tauria and Caucasus, in humid places; Montpelier, at Mireval; Geneva; Germany at Fuessen. (F. virgàta, Koch, in litt. and perhaps of Poir. CE. tenuifòlia, Froel. in litt. and is sometimes to be found in gardens, under the name of $U$. glaíca; the whole plant being rather glaucous. Perhaps truly distinct from CE. pcucedanifolia.

Silaus-leaved Water-dropwort. Fl. June, July. Clt. 1817. Pl. 2 feet.

5 (E. Pispixelloides (Lin. spec. 365.) roots of several slender, fleshy, cylindrical fibres, which are dilated into ovateglobose tubers at the apex; radical leaves bipinnate; leaflets cuneated, cut; cauline leaves pinnate; leaflets of the cauline leaves elongated, linear, and entire; involucra of many linear leaves; fruit cylindrical, striated, callous at the base, longer than the pedicels, which are thick and sliort. 4 . II. Native of Europe, in salt marshes. In Britain, as Quaplod, near Salping, Lincolnshire; near Aber, North Wales; Cambridgeshire ; also in Galloway, the Isle of Arran, and other parts of Scotland. Stem cylindricai, hollow, slightly branched. Flowers of a pale flesh colour.

Var. a, charophylloùles (D. C. prod. 4. p. 137.) tubers hanging by long fibres. 4 . II. E. chærophylloides, Pourr. act. tol. 3. p. 323.- E. pimpinelloìdes, Smith, engh. bot. 347. Jacq. aust. t. 394. CE. austràlis, Wulf. E. Kársthia, Hacq. carn. t. 3.? -Bauh. hist. 3. p. 191. f. 1. Mor, ox. sect. 9. t. 7. f. 3. Cam. epit. 610 . icon. Smith says the roots are of several slender, tapering, Heshy tubercles, intermixed with fibres.

Var. $\beta$, pimpinellaf òlia (D. C. prod. 4. p. 137.) tubers on short peduncles, intermixed with fibres.-Baul. hist. 3. p. 191. f. 2. E. pimpinelloides, Lam. dict. 4. p. 528. and probably of many other anthors. (E. virgàta, Poir. voy. 2. p. 188. Spreng, umb. 105.

Pimpernel-like Water-dropwort. Fl. Jul. Brit. Pl. 1 to $2 \mathrm{ft}$.

6 (E. callòsa (Salzm. mss. ex D. C. prod. 4. p. 137.) roots unknown; stem branched, striated; lower leaves bipinnate : leaflets ovate, deeply serrated; upper leaves pinnate: leaflets lanceolate-linear, acuminated; umbels of many rays; involucrum almost wanting; fruit cylindrically-oblong, striated, callous at the base and apex, longer than the pedicels, which are thick. 4. H. Native abont Tangiers. This species differs from $Q$. a piifolia in the fruit being callous, and from $Q E$. pimpinelloides in the involucrum being almost wanting. Fruit crowded in the umbellules.

Callous-fruited Water-dropwort. Pl. 2 to 4 feet.

7 G. Apiròlia (Brot. fl. lus. p. 420. phyt. t. 33.) knobs of roots sessile, oblong-fusiform; stem branched, furrowed : leaves bipinnate or tripinnate : leaflets wedge-shaped, deeply serrated; upper leaves pinnate, with narrower leaflets; umbels of many rays; involucrum almost wanting; fruit cylindrically-oblong, striated, longer than the pedicels. 4 . H. Native of Portugal, Corsica, sc. Willd. enum. p. 316 . Spreng. in Schultes, syst. vol. 6 . Stems purplish, particularly at the joints, by which it may be known at first sight from $Q E$. crocata, to which it is very nearly allied, and from which it only differs in the involucrum being alinost absent. Plant strong, very poisonous, abounding in less orange-coloured juice than $(E$. crocàta.

Celery-leated Water-dropwort. Fl. July. Clt. 1806. Pl. 2 to 5 feet.

8 E. croca'ta (Lin. spec. p. 365.) knobs of roots oblong or elliptic, sessile; stem branched, furrowed; leaves all bipinnate ; leaflets wedge-shaped, deeply toothed; umbels of many rays ; involucra and involucels of many leaves ; fruit linear-oblong, with slender intermediate ribs, longer than the pedicels. $\%$.H. Native of Europe, common. Plentiful in Britain, in watery places, osier holts, and about the banks of rivers. Jac!. vind. 3. t. 55. Sinith, engl. bot. t. 2313. Bull. herb. t. 113. Woodv. suppl. med. hot. t. 267.-Lob. icon. t. 730.-Mor. ox. sect. 9. t. 7. f. 2.-Matt. valg. 2. p. 220. f. 1. Leaves of involucra and involucels various in number and shape. Flowers white, tinged with purple. Plant strong. Roots abounding with an acrid, fetid, very poisonous saftron-coloured juice, such as exudes less plentifully from all parts of the herb, when wounded. Brood mares sometimes eat the root, according to Sir Thomas Franklin, and are poisoned by it. Ehret, the celebrated botanical draughtsman, experienced a giddiness from the scent of the herb. Dr. Pultney remarks, that the root is one of the most virulent poisons of all the vegetable poisons that Great Britain produces. In Westmorland the country people apply a poultice of the herb to the ulcer which forms in the fore part of the cleft of the hoof in horned cattle, which is called the foul. It may be safely used externally, but internally it should be taken witl caution, as is evident from the accounts given above, and others recited by Mr. Howell and Sir William Watson, in the Philosophical Transactions. The former of these says that two French prisoners at Pembroke died by eating the root, that the inhabitants call it five-fingered root, and that it is mucl used there in cataplasms. In the same 'Transactions, a case is related of eight young larls near Clonmel in Ireland, where the plant is called takow, mistaking its roots for the water-parsnip: five of them died. Mr. Miller informed Sir William Watson that a whole family were poisoned with it at Battersea. The more caution is necessary respecting this plant, because it is not uncommon in some places, its appearance and smell resemble smallage or celery, and the roots have not any flavour disagreeable enough to deter persons from eating them.

Saffron-coloured-juiced or Hemlock Water-dropwort. Fl. Jul. Britain. Pl. 2 to 5 feet.

9 (E. sarmentòsa (Presl, in herb. Hank. ex D. C. prod. 4. p. 138.) root unknown; stems branched, weak, rather scandent ; leaves bipinnate: leaflets ovate, toothed : terminal ones somewhat 3 -lobed; umbels opposite the leaves, of many rays; involucrum wanting; fruit oblong; styles very long. $\mathcal{\psi}$. H Native of North America, at Nootka Sound. Leaves nearly as in $E$. erocìta, but the umbels are those of $G$. phellándrium. Root unknown, and therefore its proper situation among the species is doubtful.

Sarmentose Water-dropwort. Pl. sarmentose.

10 (E. Globulòsa (Lin. spec. 365.) knols of roots oblong, atienuated at the base, but ending in an elongated fibre each at the apex; radical leaves bipinnate; leaflets lanceolate, cut ; cauline leaves pinnate, with lincar leaflets; umbel 5-6-rayed, without any involucrum; fruit nearly globose, sessile (the proper pedicels being almost wanting) spongy, with thick, obtuse ribs, and small furrows. 4 . H. Native of Etruria, Mauritania, Spain, Portugal, \&c. in meadows. Gouan. ill. p. 18. t. 9. Spreng. umb. spec. p. 106. OE. diflìsa, Lag. gen. et spec. p. 13. ex Spreng. Stem compressed at the base, diffuse. Fruit larger than in any other species of the genus. Umbels on long peduncles.

Globular-headed Water-dropwort. Fl. Ju. Aug. Clt. 1710. Pl. $1 \frac{1}{2}$ foot.

11 E. Prolífera (Lin. spec. p. \$65.) knols of roots fusiform, sessile; leaves bipinnate; leaflets cuneated, lobately toothed; umbels capitate, without an involucrum; outer pedicels of the umbel flat, branched, proliferous; fruit turbinate, 10-ribbed ribs thick: furrows deep. 24. H. Native of Candia, Calabria, Lycia, Da]matia, Carniola. Jacq. hort. vind. 3. t. 62.-['. $\mathrm{A}_{\mathrm{p}}$. 
N. 304. with a figure and p. 305. with a description,-Mor. ox. sect. 9.t. 7. f. 5 .

Proliferous-umbelled Water-dropwort. Fl. June, Aug. Clt. 1739. Pl. $1 \frac{1}{2}$ to 2 feet.

\section{* Annual or biennial plants, with fibrous roots.}

12 E. Phella'xdrium (Lam. f. fr. 3. p. 432.) root fusiform, with many whorled fibres; stem furrowed, fistular, branched; lcaves stalked, repeatedly pinnate, with innumerable, fine, expanded, dark green, narrow, wedge-shaped, cut, shining, acute, divaricate leaflets; umbels opposite the leaves, on short tumid peduncles, without involucra; involucels of many narrow, taper-pointed leaves; fruit ovate, with 5 broad ribs, and narrow intermediate furrows, rather slsorter than the pedicels. $\delta . \mathbf{H}$. Native of Europe, Tauria, and Siberia, in rivers, ditches, and lakes; plentiful in some parts of Britain, as in ditches in Battersea-fields, near London; and near Edinburgh. Phellándrium aquáticum, Lin. spec. 366. Fl. dan. t. 1154. Smith, engl. bot. t. 684. Schkuhr, handb. t. 71. Hoffm. umb. 1. p.71. descript. and icon, t. 1. f. 17. Hayne, arz. gew. 1. t. 40 . Nees. off. pfl. 14. t. 6. Woodv. med. bot. suppl. 266. Bull. fr. t. 147. Erh. pl. off. 24. (E. aquática, Lam. dict. 4. p. 530. Ligústicum phellándrium, Crantz. hort. fasc. 3, p. 84. Cicutària palústris, Ger. emac. 1063. f. 1. Lob. icon. 735. f. 1. Phellándrium, Dorl. pempt. 591.f. 1. Roth always writes the old name phelandrium, which agrees with an etymology hazarded by Sir James Smith, in Rees' cycl, vol. 27. from $\phi \eta \lambda \varepsilon \omega$, to be treacherous, alluding to the poisonous nature of the plant; $\phi \varepsilon \lambda \lambda o s$ avcoos, as Linnæus has it, cork of man, is not at all satisfactory. Linuæus informs us that the horses in Sweden are seized with a kind of palsy by eating this plant; hence Withering and Sibthorp liave named it horse-bane. This effect, however, is not to be ascribed to the plant, but to a coleopterous inseet breeding in the stalks, which he therefore names Curcullio paraplécticus. The leaves are sometimes applied to discutient cataplasms, and for this reason Boerhaave speaks highly of it. The seeds are recommended in intermittents, and are said to be diuretic, antiscptic, and expectorant. The efficacy of this plant rests chielly on the testimony of Ernstingius and Lange, by whom various cases of its successful use are published, especially in wounds and inveterate ulcers, and even in cancers ; also in phthisis, pulmonalis, asthma, dyspepsia, and intermittent fevers. Dr. Woodville rightly observes, that though the disorders here noticed are so dissimilar as to aftord no satisfactory evidence of the medicinal qualities of these seeds, yet they appear to be well deserving of farther investigation.

Plicllandrium or Fine-leaved Water-dropwort. Britain. Pl. 2 to 3 feet.

13 QE. STOLonífera (WVall. cat. no. 585.) stems creeping at the base, ascending, fistular striatcd; leaves bipinnate; upper ones pinnate; leaflets lanceolate, acuminated at the buse and apex, with a few coarse serratures; umbels opposite the leaves, exinvolucrate; fruit obovate-oblong, much shorter than the pedicels. 8.? H. Native of Silhet, in the east of Bengal, in rice grounds. Phellándrium stoloniferum, Roxb. hort. beng. j. 81 . 'Teeth of calyx 5, subulate. Styles permanent.

Stoloniferous Water-dropwort. Pl. creeping.

14 (E. LiNeA'RIS (Wall. cat. no. 586.) stems throwing out roots from the nodi at the base, erect, fistular; leaves pinnate ; leaflets of the lower leaves oval, inothed: of the upper ones linear, elongated, toothed, or undivided; umbets opposite the leaves, without involucra; rays compressed. 3. II. Native of Nipaul, in rice grounds. Fruit unknown.

Lincar-leaved Water-dropwort. Pl. $1 \frac{1}{2}$ foot.

15 OE. JAVA'NicA (D. C. prod. 4. p. 138.) stems terete, fistular; leaves divided into 3 parts above the sheaths of the pe. tioles, which are bipinnate; leaflets oval-oblong, cuneated at the base, deeply toothed at the apex; umbels opposite the leaves, pedunculate; involucrum of a few small leaves; leaves of involucels setaccous; fruit ovate. $\$ . S$. Native of Java. Sium Javánicım, Blum.?

Jaca Water-dropwort. Pl.?

16 E. Hu'miss (Rafin. prec. som. p. 41.) stem simple, pentagonal; leaves pinnate; leaflets of the lower leaves ovate, jagged: of the upper leaves lanceolate, entire; umbels erect, simple; flowers sessile. $\odot . H$. Native of Sicily, on the Nebrode mountains, in woods. The rest unknown. The plant is very doubtful.

\section{Humble Water-dropwort. Pl. 1 foot.}

\$2. Species, natives of the Cape of Good Hope, the greater part of which are hardly knomn, and all of them, most probably, bclong to different genera from the present.

17 (E. Filıfórais (Lam. dict. 4. p. 520. ill. t. 203. f. 2.) leaves simple, filiform, striated, bluntish; umbels 3-5-rayed; involucrum of 3-5 leaves. 24. G. Native of the Cape of Good Hope, on lills near Cape Town. E. filifórmis, Sieb. pl. exsic. cap. no. 209. Schultes, syst. 6. p. 427. exclusive of the synonymes. Séseli filifòlium, Thunb. fl. cap. p. 259. Cònium filif òlium, Vahl. symb. 3. p. 49. Sium filifòlium, Willd. berb. ex Cham. et Schlecht. in Linnæa. 1. p. 387. Ecklon, herb. no. 54. but not of Thunb. Fruit cylindrically prismatic, crowned by the 5 -toothed calyx. Styles erect. Petals emarginate.

Filiform Water-dropwort. Pl. 1 foot.

18 E. TENuifòlia (Thumb. prod. 49. A. cap. p. 253.) stem simple, striated; leaves bipinnate: leaflets linear-setaccous, deeply pinnatifid; upper leaves undivided, filiform; leares of involucra and involucels very short; ribs of fruit rather winged. 4. G. Native of the Cape of Good Hope. Spreng. umb. spec. p. 109.

Fine-leaved Water-dropwort. Fl. June, July. Clt. 1819. Pl. 1 to 2 feet.

19 (E. FERULA'cea (Thunb. prod. 50. A. cap. p. 259.) root unknown; stem branched, striated; leaves decompound; leaflets lanceolate, acute, furrowed on both sides; involucra of few leaves. 24. G. Native of the Cape of Good Hope. Spreng. umb. spec. p. 109 .

Ferula-like Water Drop-wort. Pl. 1 to 2 feet.

20 (E. interru'pta (Thunb. prod. p. 50. A. cap. p. 253.) root unknown; stem simple, terete, nearly leafless; leaves radical, petiolate, divided into 3 parts, and these parts are decompound; leaflets oblong, sinuately pinnatifid, mucronately toothed: lower ones reflexed; involucrum of 5 leaves. 4. G. Native of the Cape of Good Hope. Spreng. umb. spec. p. 107. Stem said by Thunberg to be villous at the base, but by Sprengel it is said to be smooth. Perhaps the same as Annesorhiza Ca. pénsis.

Interrupted Water-dropwort. Fl. Ju. Jul. Clt. 1818. Pl. $1 \mathrm{ft}$. Cult. Although all the species grow naturally in ditches, rivers, and watery places, they grow well in any kind of soil, whether dry or wet. Increased by dividing at the root, or by seeds.

LX1. ANNESORHIZA (from a $\gamma v \eta$, agnes, chaste, and pica, rhiza, a root; smell of root). Cham. et Schlccht. in Linnæa. 1. p. 398. t. 5. f. 4. D. C. prod. 4. p. 139.

Lin. syst. Pentándria, Digýnia. Margin of calyx 5 -toothed, permanent. Petals elliptic, acuminated, more or less emarginate, with an inflexed point. Fruit 5-angled, prismatic, crowned by the reflexed calyx and styles; mericarps convex on the back, unequal : one of them 3-winged, in consequence of the carinal and marginal ribs being winged, but the intermediate ribs are filiform: the other 4 winged, in consequence of the carinal 
rib being filiform, and the intermediate 2 and marginal 2 being winged; vittæ 1 in each furrow, and 2 in the commissure, which is flat. Carpophore bipartite.-An herb, native of the Cape of Good Hope. Root fusiform. Stem erect. Cauline leaves scale-formed. Umbels of $12-15$ rays. Involucra and involucels of many leaves, having hyaline margins.

1 A. Capéxsis (Cham. et Schlecht. l.c.). 24. G. Native of the Cape of Good Hope, on the sides of mountains. The root smells of anise, hence tlie name of the herb at the Cape, Anysnortel.

Cape Anise-root. Pl. 1 to 2 feet?

Cult. Any soil will suit this plant; and it will be easily increased by cuttings or by seeds.

LXII. SCLEROSCIA'DIUMI (from $\sigma \kappa \lambda \eta \rho o s$, skleros, hard, and oritaciov, skiadion, an umbel; in reference to the solid fruit). Koch, diss. ined. in litt. 1828. D. C. coll. mem. 5. p. 43. t. 2. f. F. prod. 4. p. 140 .

LiN. sצst. Pentándria, Digýnia. Teetl of calyx 5, conical, permanent. Petals obcordate, with an inflexed point, which is bidentate or tridentate at the apex. Stylopodium conical; styles filiform, at length diverging. Fruit ovate-globose, solid; meriearps with 5 thick, elevated, blunt, equal ribs; vittæ 1 in each furrow, which are narrow, and 2 in the commissure. Carpophore distinct, undivided. Seed terete, flattish on inside.Herb glabrous. Root fibry. Leaves divided into linear-oblong lobes or leaflets. Umbels axillary, sessile, almost without any involucrum; rays very unequal, that is, some of the umbellules are sessile, and some are on long peduncles in the same umbel. Involucels of 5-7 leaves, laving membranous margins. This genus is allied to Enánthe, from which it differs in the carpophore being free, in the stylopodium being conical, and in the ribs of the fruit being prominent, \&c. (f. $56 . F$.)

1 S. Hu'me (Kocl, l. c. D. C. I. c.). $\odot$. H. Native of fields, about MIogodor, and probably of Teneriffe. OEnánthe nodiflòra, Schousb. mar. p. 120. Cònium rígidum, Mert. herb. and perhaps the same as Bùnium rígens, Spreng. but neither the description nor the country agrees with the present plant.

Humble Sclerosciadium. Fl. Ju. Aug. Clt. 1820. Pl. $1 \mathrm{ft}$.

Cult. The seeds only require to be sown in the open ground in a warm sheltered situation.

LXIII. DASYLO'MA (from $\delta \alpha \sigma v s$, dasys, thick, and $\lambda \omega \mu \alpha$, loma, a fringe; in reference to the ribs of the fruit). D. C. prod. 4. p. 140.

Lss. srst. Pentándria, Digýnia. Margin of calyx obsolete. Petals unknown. Stylopodium depressed; styles short. Fruit ovate, with the transverse section terete; mericarps semiovate, not separating at maturity, with 5 corky, cellular ribs: the 3 dorsal ones small, and the 2 lateral ones large and blunt; vittæ 1 in each furrow, which are narrow, and 2 in the middle of the commissure, which is flat. Carpophore indistinct. Seed triangular, that is, convex on the back and angular at the commissure.-Herbs with the habit of Enánthe. Stems fistular. Leaves bipinnate ; leaflets cuneated, few-toothed at the apex. Uimbels opposite the leaves, 5-6-rayed. Umbellules crowded, many-flowered. Involucra and involucels none.

1 D. Bengale'ssis (D. C. prod. 4. p. 140.) umbels sessile. $\odot$. H. Native of the east of Bengal, in the province of Silhet. Séseli Bengalénsis, Roxb. Biforis Bengalénsis, Wall. Herb greenish, many-stemmed.

Bengal Dasyloma. Pl. 1 foot.

2 D. gLAU'ces (D. C. l. c.) umbels pedunculate. ๑. H. Native of Bengal. Biforis? glaíca, Wall. Differs from the preceding in the umbels being distinctly pedunculate, in the leaves roL. III. being larger and glaweous, in the dorsal ribs of the fruit being more acute, and the lateral ones smaller.

Glaucous Dasyloma. I']. I foot?

Cult. The seeds only require to be sown in the open ground.

LXIV. CYNOSCIA'DIUM (from kvwr, kvros, kyon, kynos, a dog, and oriaisos, skiadion, an umbel). D. C. coll. mem. 5 . 1. 44. t. ]1. prod. 4. p. 140.

Lax. srst. Pentándria, Digýnia. Tecth of calyx 5, subulate, permanent (f. 63. c.). Petals obovate, nearly elliptic, obtuse, entire, flat, with an inflexed point. Stylopodium conical, permanent; styles very short, reflexed. Fruit oval-oblong or ovate (f. 63. b.), attenuated at the apex; mericarps with 5 thick, corky ribs (f. 63. a.), 2 lateral ribs marginating; vittæ nearly straight, 1 in each furrow, and 2 in the commissure. Seed sub-semiterete. Carpophore bipartite- $\Lambda$ merican glabrous herbs. Stems angular, fistular, branched a foot high and more, with very few leaves. Leaves pinnate or palmate; leaflets linear, elongated, entire, articulated near the base, at which places the leaflets fall off: lower and upper ones undivided, linear, and elongated. Involucra and involucels of many leaves. Flowers white.-This is an intermediate genus between Enanthe and Ethùsa, but it differs from both, and from all its allies in the petals being flat and entire; it differs particularly from Ethùsa in the calyx being 5 -toothed, in the vittæ of the commissure being straightish, and in the involucra and involucels being of many leaves; from Séseli in the stylopodium being conical; and from CEnánthe in the carpophore being distinct.

1 C. digita'tum (D. C. l. c. t. 11. f. A.) leaves palnate; leaflets 3 , linear, quite entire ; fruit ovate at the base, but attenuated at the neck.-Native of North America, on plains of the Arkansa River. Enánthe digitàta, Nutt. mss. Umbels few-flowered. Involucrum of a few unequal leaves: leaves of involucel subulate, very short. Rays of umbel very long.

Digitate-leaved Cynosciadium. Pl. 1 to $1 \frac{1}{2}$ foot.

2 C. PINNA'TUM (D. C. l. c. t. 11. f. B.) leaves pinnate; leaflets distant, few pairs, linear, quite entire: terminal one very long; fruit oval-oblong.- $\mathrm{Na}$ tive of North America, along with the preceding species. Ethùsa pinnata, Nutt. mss. Pedicels a little longer than the leaves of the involucel. Leaves of involucrum 7-8, nearly equal, linear-subulate.

Piunate-leaved Cynosciadium. Pl. 1 foot.

Cult. Sow the seeds in the open ground, and the plants will rise and flower and seed freely.

LXV. FTHU'SA (from $\alpha \epsilon \omega \omega$, aitho, to burn; acrid taste). Lin. gen, no. 141. exclusive of some species. Hoffin. umb. p. 95.t. 1. f. 5. Spreng. prod. Lag. am. nat. 2. p. 96 . Koch, umb. p. 111. D. C. prod. 4. p. 141.-Wepf èria, Heist.

Lıs. sxst. Pentándria, Digýnia. Margin of calyx obsolete. Petals ohovate, emarginate, with an inflexed point: outer ones radiating. Fruit ovate-globose; mericarps with 5 elevated, thick, acutely kceled ribs: lateral ribs marginal, and a little broader than the rest, gircled by a somewhat winged keel; vittæ 1 in each furrow, and with 2 arched ones in the commissure. Seed semi-globose. Carpophore bipartite.-Erect, annual, poisonous herbs. Leaves uniform, multifid. Involucrum wanting $\mathrm{R} r$ 
or of 1 leaf; involucels of 3 or 5 spreading, or pendulous, setaceous leaves, situated on the outside of the umbellules, that is, unilateral. Flowers white. Three species of this genus are admitted, but they are probably only varieties of one.

$1 Æ$. CYNA'PIUM (Lin. spec. p. 367.) leaflets wedge-shaped, decurrent, with lanceolate segments; rays of umbel nearly equal; involucrum wanting; involucels of 3 leaves, which are longer than the umbellules. $\odot$.H. Native throughout the whole of Europe, in cultivated grounds: a common weed. Smith, engl. bot. 1192. Curt. lond. fasc. 1. t. 18, Bull. herb. t. 9 I. Hayn. arz. gew. 1. t. 35 . Hoffm. umb. p. 97. Coriándrum cynàpium, Crantz, fl. aust. p. 221. Cicùta cynàpium, Targ. ist. bot. Cynàpium, Riv. pentap. irr. t. 76. Cicutaria tenuifòlia, Raii, syn. 215. C. fàtua, Lob. icon. 2. p. 280. f. 1. Herb erect, lurid green, fetid, and reckoned dangerous. Great carelessness can alone cause this weed to be mistaken for garden pars'ey; yet such an accident sometimes happens. The 3 long pendulous bracteas under each umbellule distinguish it from all its tribe. Dr. Bigelow, of Boston in New England, observed this Aithùsa to be without scent in America, but seeds transmitted by him produced plants with the same nauseous garlick flavour as those of Great Britain. Some curious facts of a similar nature have been observed. The flowers of Ilésperis matronalis are said to lose their scent in America, after the first generation.

Dog's-poison, or Common Fool's-parsley. Fl. July, Aug. Britain. Pl. 1 to 2 feet.

2 E. crinaptoides (Bieb. fl. taur, 1. p. 227. suppl. p. 233.) segments of the leaves oblong, acute; rays of umbel nearly equal; involucrum wanting; involucel of 3 leaves, which are shorter than the umbellule; vittæ in the commissure contiguous at the base. $\odot$. H. Native of the Ukrane, in shady places. Hoffin. ed. 2. p. 98. and 205. and tit. f. 9. Very nearly allied to the first species, but differs in being larger, more branched, and $s$ feet in height, or more.

Cynapium-like Fool's-parsley. F1. July, Aug. Clt. 1817. Pl. 2 to 3 feet.

3 E. ELA'TA (Friedlander, ex Fisch. cat. hort. gor. 1813. p. 45.) segments of the leaves bluntish; involucrum usually of 1 leaf; involucels of I-3 leaves, which are longer than the umbellules; outer rays of umbel longest; pedicels twice the length of the fruit. $\odot$. H. Native of Podolia. Hoffm. umb. ed. 2. p. 98. Besser. enum. p. 54. Horn. cat. 4. hort. hafis. suppl. p. 34. Petals white, not as in E. cynàpium, greenish at the base. Styles purple after flowering. The plant is said to be edible, and not poisonous as the others.

Tall Fool's-parsley. FI. Jul. Aug. Clt. 1820. Pl. 2 to $3 \mathrm{ft}$.

Cult. The sceds only require to be sown in the open ground.

LXVI. FGENI'CULUM (the Latin name of the fennel, from frenum, hay; the smell of the plant resembling that of hay). Adans. fim. 2. p. 101. Gartn. fruct. 1. p. 105. t. 23. Hoffin. umb. p. 120 . t. 1. f. 13 . e. Lag. am. nat. 2. p.99. Koch, umb. p. 112. D. C. prod. 4. p. 142.-Anèthum species of

Lin. syst. Pentándria, Digýnia. Margín of calyx tumid, obsolete, toothless. Petals roundish, entire, involute, with a rather square retuse point. Transverse section of fruit nearly terete; mericarps with 5 prominent, bluntly keeled ribs : lateral ribs nırginal, and a little broader than the rest; vitta 1 in each furrow, and 2 in the commissure. Seed somewhat semi-terete. -Biennial or perennial herbs. Roots fusiform. Stems terete, striated, branched. Leaves triply pinnate, decompound: with linear, setaceous leaflets. Involucra and involucels almost wanting. Flowers yellow.-This genus diflers from Ancthum with which it was formerly combined, by the mericarps being more turgid: having the margin rather more compressed than the back; and the transverse section of the fruit is therefore nearly terete, or with the margin rather compressed.

1 F. vulga're (Ray, syn. 217. Gærtn. fruct. 1. p. 105.) stem terete at the base; leaves bipinmate, distich; leaflets awlshaped, drooping; umbels 13-20-rayed; involucra and involucels wanting. భ. H. Native of Europe, in exposed, nncultivated places; in Britain, on chalky clifls, very plentiful; and of Caucasus, near Baku, and in the plains between Sallian and Lenkeron. Anèthum Fœnículum, Lin. spec. 722. Smitl, engl. bot. t. 1208. Mill. fig. t. 13. Hayne, arz.gew. 7. t. 18. Fœnículum officinàle, All. pedem. no. 1359. Mèum Fonículum, var, $a$, Spreng. prod. p. 32. and in Schultes, syst. 6. p. 433 . Ligústicum Fonículum, Roth. germ. 1. p. 124. Fœenículum, Math. valgr. 2. p. 135.f. 1. Cam. epit. p. 534.f. 1 . The taste and aromatic flavour of this our garden fennel are well known, and has long been an inmate of our gardens. The tender stalks are used in salads; the leaves boiled enter into many fish sauces. The sweet and warm seeds are a common carminative medicine for infants. The blanched stalks of the next species, $F$. dulce, called finòchio, are eaten with oil, vinegar, and pepper, as a cold salad, and they are likewise sometimes put into soups. This thichened part is blanched by earthing up, and is then very tender. "Owing to the peculiar nature of this species," Mr. Neill observes, "it is more tender than the common fennel, and often perishes in the course of the winter. Misled by this circumstance, several horticultural writers describe it as an annual plant, under the name of Anèthum ségetum." All are raised from seed, of which half an ounce is sufficient for a seedbed 4 feet by 6 feet. Sometimes also they are raised from offsets from the old plants, where only a few are wanted. Sow in the spring in light earth, either in drills from 6-12 inches apart, or broad cast and raked in. When the plants are 3 or 4 inches high, thin or transplant a quantity 15 inches asunder. As the roots of old plants divide into offsets, tliese may be slipped off in spring, summer, or autumn, and planted a foot apart. They will produce immediate leaves for present supply and in contimuance; or for immediate larger supply of leaves, you may procure some established full roots, and plant as above; let them be well watered. The same plants remain several years by the root; but as fennel sends up strong stems for seed in summer, these, or a part of them, should be cut down, to encourage a production of young leaves below in succession. It is apt to spread more than is desirable, if suffered to seed. The swelling stems of the Finocchio or $F$. dulce, when of some tolerable substance, should be earthed up on each side 5 or 6 inches to blanch them white and tender. This will be effected in 10 days or a fortnight ; and by successive sowings or cutting down plants during summer, successive crops of blanched stalks may be had from June to December. In procuring seed, permit some of the best flower-stems to shoot; and they will produce large umbels of seeds in antumn.

Common Fennel. Fl. Jul. Aug. Brit. Pl. 4 to 6 feet.

2 F. DU'LCE (C. Bauh. pin. p. 147.) stem rather compressed at the base; radical leaves rather distich : leaves all tripinnate; with capillary elongated leaflets; umbels 6-8-rayed. of. H. Native of Italy, and Portugal, where it is cultivated for the sake of the blanched stalks, under the name of Finocchio. Finóchio dúlce, Targ. cors. agr. 2. p. 52 . Anèthum dúlce, D. C. cat. hort. monsp. p. 78. Fonículum dúlce, Sc. J. Bauh. hist. 3. p. 4. with a figure. It differs from the preceding species in being hardly a foot high, in the earlier florescence, in the darker hue, in the stalks being edible, and in the characters given above. The use of this kind of fennel is given above with the common fennel.

Sweel Fennel or Finocchio. Fl. May, June, Clt. ? Pl. I ft. 
3 F. piperitum (D. C. prod. 4. p. 142.) stem terete; leaflets subulate, very short, stiff, thick; umbels 8-10-rayecl. 2. II. Native of the south of Europe, especially in Sicily, Sardinia, Portugal, sc. Anc̀thum Fonículum $\beta$, piperitum, D. C. cat. hort. monsp. p. 79. Mèum piperitum, Scluultes, syst. 6. p. 455 . Guss. prod. H. sic, 1. p. 345 . Fonículum asininum, Cup. hort. cath. 79. ex Bert. The plant is called Finochio d'asino, or Asses' funochio, by the Sicilians; it has a lot biting taste, lience the specific name.

Pepper Fennel. Fl. June, July. Clt. 1824. Pl. 4 to $6 \mathrm{ft}$.

4 F. PANmo'rium (D.C. prod. 4.p. 142.) stem erect, branched; leaves supra-decompound; umbels of 10-12 unequal rays ; fruit oblong, deeply furrowed, destitute of wings. ๑. H. Native of the East Indies, where it is cultivated under the name of Panmuhoorce or Mudhoorika. Anèthum Panmòrium, Roxb. hort beng. p. 22. journ. bot. 18I4. vol. 2. p. 188. Said to be very like common fennel.

Panmuhoree Fennel. Pl. 2 to 3 fect.

5 F. CAPE'nse (D. C. l. c.) root fleslyy; radical leaves tripinnate; leaflets filiform, sctaceously acuminated, fastigiate.Native of the Cape of Good Hope, in the interior of the country. Anèthum Fœnículun, Thunb. prod. p. 51. Anèthum Capénse, Thunb. fl. caj. 262. Root esculent. Flowers unknown. Chamisso and Schlechtendal refer to this the $A$ 'pium radice crassâ aromaticâ of Burnı. afr. p. 197.t. 72. £. 1 .

Cape Fennel. PI. 2 to 3 feet?

Cult. See the first species for the culture and propagation of the rest.

LXVII. KUNDMA'NNIA (Kundmann, a botanist known to Scopoli). Scop. intr. (1777.) p. 116. no. 3S2. D. C. prod. 4. p. 143.-Brignòlia, Bertol. in Desv. journ. 4. (1815.) p. 76. amoen. ital. 97. Koch, umb. p. 107.-Campdèria, Lag. am. nat. 2. p. 99. (1821.)

LiN. syst. Pentándria, Digýnia. Margin of calyx 5-toothed, increased a little after flowering. Petals roundish, entire, involute, with a broad retuse segment: stylopodium conical; styles short, somewhat reflexed. Fruit terete, 10-furrowed; mericarps with 5 filiform, obtuse, equal ribs: lateral ribs marginal; vittæ many, both in the furrows and commissure. Carpophore undivided. A glabrous perennial herb. Root fusiform. Radical leaves rarely undivided, but usually pinnate, or bipinnate ; leaflets ovate or lanceolate, serrated; upper leaves ternate, and jagged. Umbels compound, terminal, of many rays. Involucra and involuccls of many filiform reflexed leaves. Flowers yellow. This genus is very nearly allied to Foniculum, but differs in the calyx being 5 -toothed and permanent.

1 K. Sícula (D. C. prod. 4. p. 143.). 2. H. Native of the Balearic Islands, Spain, Mauritania, Corsica, Sicily; and in Italy in waste fields about Rome, and on hills about Genoa; and the islands of the Archipelago, as in Melos, Samos, \&c. Sìm Sículum, Lin. spec. 362. Jacq. hort. vind. t. 133. D. C. A. fr. 6. p. 507. Ligústicum Baleáricum, Lin. mant. 218. Brignòlia pastinacæfòlia, Bert. in Desv. journ. 4. p. 76. amœen. 97. Mauri, fasc. rom. alt. p. 8. t. 2. I'resl. delic. p. 13\% Guss. prod. fi. sic. 1. p. 387. Campdèria Sícula, Lag. I. c. Mýrrhis Sicula pastinacifòlia et pastinacæ foliis latè virentibus, Tourn. herb. Athamánta Sícula Ucria, hort. panorm. p. 137. p. 542. Sium Græ'cum, Lin. hort. cliff. 98.? Sieb. pl. exsic. Sichultes, syst. 6. p. 542. Zan. hist. ed. Mont. 171. t. 128. There are varieties of this plant, having the leaves of the involucels either the length of the umbellules, or one half shorter than them.

Sicilian Kundmannia. F!. July, Aug. Clt. 1686. Pl. 2 feet.

Cult.-The plant will grow in any soil, and is easily increased by dividing at the root, or by seed.
IXVIII. DEVERRA (a goddess worshipped by the ancients for enconraging housewifery, or rather the goddess of broons ; the plane having much the appearance of a broom,) D. C. coll. mem. 5. p. 45. procl. 4. p. 143 . Bùbon specics of authors.

Lin. syst. I'entándria, Digýnia. Margin of calyx obsolete. Petals ovate, acuminated, with an inflexed point. Styles short, at length divaricate. Fruit ovate, or roundish, rather coinpressed from the sides, rough from scales or spreading pili; mericarps semi-terete, with obsolete ribs; vitte 1 in cach furrow, and 2 in the conmissure. Carpophore bipartite--Aromatic, leafless, glaucous, stiff, broom-like subshrubs, natives of Africa. Petioles sheathing, permanent; limbs of leaves wanting in the adult plants, or nearly so; but in young plants they are small and many-parted, with setaceously linear leaves. Umbels of few rays. Involucra of 4-6 small deciduous leaves; involucels of 4-6 ovate-lanceolate, deciduous leaves, with membranous margins. Flowers white.

Sect. I. Diverra'ria (an alteration from the generic name). D. C. prod. 4. p. 143. Fruit villous or hispid.

1 D. APly'r.LA (D. C. prod. 4. p. 143.) stems twiggy; sleaths all bereft of the limbs; fruit very hispid. $\eta$. G. Native of the Cape of Good Hope, at Warmwaterberg. Bùbon aploýllus, Cham. et Schlecht. 1. p. 389.

I'ar. $\beta$, Burchéllii (D. C. prod. 4. p. 143.) young fruit beset with short, tubercular villi. $h$. G. Native of the Cape of Good Hope. Very like the species, but the fruit is much less villous, and is therefore perhaps distinct.

\section{Leafless Diverra. Slirub.}

2 D. Tortuosa (D. C. prod. 4. p. 143.) stem much branched, twisted, divaricate; lower sheaths furnished with divided limbs, bearing subulate leaflets; fruit sparingly villous. h. F. Native of the north of Africa.

Var. a, virgàta (D. C. prod. 4. p. 143.) stem twiggy, bent a little. $h . F$. Native of the kingdom of Tunis, near Kerouan. Bùbon tortuòsus, Desf. fl. atl. 1. p. 357. t. 73 . Poir. suppl. 1. p. 733.

Jar. $\beta$, rigidior (D. C. prod. 4. p. 144.) stem much branched, stiff. $h_{2}$. F. Native of Egypt, at the Pyramids. Bùbon tortuòsus, Sieb. herb. egypt. Críthmum Pyrenàicum, Forsk. ex Delile, ill. fl. eg. p. 10. Athamántha tortuòsa, Spreng. syst. 1. p. 900 .

T'uisted Diverra. Fl. Ju, Ang. Clt. 1826. Shrub 1 foot.

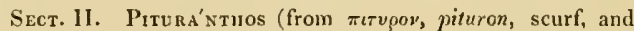
av $\theta 0$, anthos, a flower; in allusion to the fruit bearing scurflike seales). D.C. prod. 4. p. 144. Fruit covered with scales.

3 D. piturántuos (D. C. I. c.) stem twiggy; branches elongated, leafless, but furnished with sheaths; involucra, involucels, and fruit covered with scurf-like scales. h. F. Native of Lybia, in the north of Africa. Pithuránthos denudàtus, Viv, $H$. lib. p. 15. t. 7. f. 1-2. Bùnium pituránthos, Spreng. syst. 1. p. 901 . Habit nearly of D. tortuòsa.

Scurfy;flowered Diverra. Shrub 1 to 2 feet.

Cult. A mixture of loam, peat, and sand will suit the species of Divérra; and they can only be increased by sceds.

LXIX. SORA'NTHUS (from $\sigma \omega \rho \circ$ s, soros, a heap, and $\alpha v \theta 0 s$, anthos, a flower; in reference to the close capitate umbels of flowers). Led. fl. ross. alt. ill. t. 82. A. alt. 1. p. 344 . D. C. prod. 4. p. 669 .

LiN. srst. Pentándria, Digýnia. Margin of calyx obsoletely toothed. Petals broad-oval, permanent, with an inflexed point. Fruit a little compressed from the back, crowned by the divaricate styles: the transverse section elliptic; mericarps with 5 hardly prominent, equal ribs: lateral ribs marginating; vitta 1 in each furrow, and 4 in the commissure. Carpophore hipar$\mathrm{R}$ r 2 
tite.-An erect herb, with a habit between Séscli and Enánthe, but differs from the first in the tceth of the calyx being obsolete, in the petals being broad-ovate, not obovate, and in the ribs of the fruit being less prominent; and from the last in the sliape of the petals, in the styles and in the carpophore being present.

1 S. MEYE'Rl (Led. 1.c.). 24. H. Native of Siberia, at the river Irtysch, not far from the lake called Noor-Suisan; and at the river Bekin, in sandy places. Root fusiform. Stem erect, striated, simple at the base, and usually bearing $3-4$ verticillate branches at the apex; branches leafless, or furnished with membranous scales in the middle. Radical leaves $3 \cdot 4$, tripinnate: leaflets linear; cauline leaves $1 \%$. Umbels of $10-15$ rays, of these 4 are longer than the rest. Involucra wanting, rarely of 1 leaf; involucels of 6-8 leaves, which are ovate-lanceolate, pilose on the outside, and ciliated, shorter than the umbellules. Flowers sessile in the umbellules: outer ones female: intermediate ones hermaphrodite : central ones male.

Meyer's Soranthus. Pl. $1 \frac{1}{2}$ to 3 feet.

Cult. This plant will grow in any soil, and is casily increased by seed.

LXX. SE'SELI (Seycelyous is the Arabic name of an umbelliferous plant, but to what plant it was given is now unknown). Lin. gen. no. 560. Lag. am. nat. 2. p. 103. D. C. coll. mem. 5. p. 46. t. 3. f. R. prod. 4. p. 114. 一 Śseli and Bübon species, Spreng.-Séseli species, Koch.

Lin. syst. Pentándria, Digýnia. Margin of calyx 5-toothed; teetl short, thickish, and sometimes obliterated. Petals obovate, coarctate into an inflexed point at the apex, emarginate or nearly entire. Fruit oval or oblong (f. 55.D.a.E. a.), with the transverse section nearly terete, and crowned by the styles, which are reflexed (f. 55 . D. b. E. b.) ; mericarps with 5 prominent filiform or elevated thick corky ribs; lateral ribs marginating, and a little broader than the rest; vittæ one in each furrow, but there are sometimes 2 in the outer furrows, and al ways 2 in the commissure, but very rarely 4 . Seed somewhat semi-terete.-Usually glaucous biennial or perennial herbs. Leaves pinnate or ternately decompound. Involucrum wanting or almost so; involucels of many leaves. Flowers white, very rarely yellow.

Sect. 1. Hippomáraturum (from immog, hippos, a horse, and

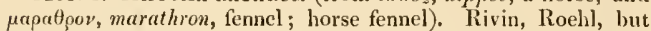
not of Link, I). C. prod. 4. p. 144. Involucra wanting. Leaves of involucels joined together nearly to the apex into a bowl-shaped cup, having a toothed margin.

1 S. Hippomáratirum (Lin. spec. 373.) stem terete, usually branched at the apex, and nearly naked; leaves glaucous, bipinnate; leaflets linear, trifid, acutish; petioles dilated and sheathing; fruit smoothish; involucel cup-shaped. 24. H. Native of Alsatia, Piedmont, and Germany, on chalky hills and rocks. Jacq. fl. austr. 2. t. 14.3. Sium Hippomárathrum, Roth, fl. germ. 1. p. 12S. Séseli articulàtum, Crantz, fl. austr. p. 205 . t. 5 . f. 1-2. Hippomárathrum pelvifórme, fl. wett. st. Hip], vulgàre, Røhl. Hippomárathrum, Riv. pent. irreg. t. 67. Flowers white. Umbels smoothish, not tomentose as in $S$. leucospérmum. Fruit pubescent while young, but glabrous or nearly so when mature. The wild plant is nearly simple, but the plant branches when cultivated in a garden.

l'ar. $\beta$, hebeáryum (D. C. prod. 4. p. 144.) fruit beset with down, even in the mature state. $4 . \mathrm{H}$. Native of Siberia. Nearly allied to S. tomentosum, but the habit is more that of $S$. IIppomáratlerum, and the umbel is downy, not tomentose.

Horse-fennel. Fl. July. Clt. 1656. Pl. 1 to 2 feet.

2 S. tomentòsum (Vis. dalm. spec. p. 6. t. 3. f. 1.) stem simple, terete; leaves biternate or triternate: leaflets filiform, chan- nelled: upper ones ternate; involucra wanting ; involucel cupshaped, and is, as well as the fruit, tomentose from stellate down. 4. H. Native of Dalmatia, on stony hills towards the sca. This species is intermediate between S. Hippomárathrum and $S$. leucospérmum, nevertheless it is more nearly allied to the former than to the latter.

I'omentose Meadow-saxifrage. Pl, I to 2 feet.

Sect. II. Hippomarathroides (agreeing with the plants in section Hippomárathrum; hence the name). D. C. coll. diss. 5. p. 47. prod. 4. p. 144. Involucra wanting or of few leaves. Leaves of the involucels joined to each other, particularly at the base. Flowers white.

3 S. Ledebov'Ru; stem a little branched; leaves glaucous, bipinnate or tripinnate; leaflets ternate, with the segments linear, upper sheaths ventricose, nearly leafless; involucrum of one lanceolate leaf; involucel cup-shaped, divided at the apex into long acuminated marcescent segments, about equal in length to the flowering umbellule; fruit prismatic, on sbort pedicels, pilose. 4 . H. Native of Altaia, in dry grassy places at the river Irtysch, near Loktewsk and Smejow. S. Hippomárathrum, Led. fl. alt. 1. p. 335 . Bess, enum. pl, volh. p. 13. no. 366.

Ledebour's Meadow-saxifrage. Pl. 1 to $1 \frac{1}{2}$ foot.

4 S. рiспо томим (Bieb. fl. taur. 1. p. 235. suppl. p. 245.) stem terete, erect, clothed with fine down; lower branches short: superior ones longer than the central umbel; leaves pinnate; leaflets multifid, with the segments linear; involucrum wanting; leaves of involucels joined together to about the middle, but ovate and mucronate in the free parts. 2. H. Native of Tauria, on chalky hills. Sims, bot. mag. t. 2073. Bùbon rigidior, Spreng. pug. 2. no. 101. and Bùbon rigidus var. $\beta$, Spreng. syst. 1. p. 900. Plant glaucous.

Dichotomous Meadow-saxifrage. Fl. June, July. Clt. 1818. Pl. 1 to 2 feet.

5 S. gummíferum (Smith, exot. bot. t. 120.) stem terete, thick, stiff, branched at the top, clothed with fine pubescence; leaves tripinnate, glaucous; leaflets cuneated, trifid; involucra of few leaves, rarely wanting; umbels 20-rayed; leaves of involucel joined together nearly the length of the pedicels into an expanded disk, having the free parts subulate, and exceeding the umbellules. \$. H. Native of Tauria. Sims, bot. mag. 2259. Bübon rígidus var. $a$, Spreng. in Schultes, syst. 6. p. 497 . B. eriocéphalus, Spreng. syst. 1. p. 900 . Stem yielding a gum when cut. This is a showy plant, $2-3$ feet ligh. Flowers white, tinged with pink.

I $a r$. crithmifòlia (D. C. prod. 4. p. 145.) stem, rays of umbels, and upper leaves rather velvety; segments of leaves elongated; central umbel surrounded by a 10-12-leaved involucrum. 4. H. Native of Greece and the islands of the $\Xi_{\text {gean sea. }}$ Apium Gracum saxatile crithmifolio, Tourn. cor. 21. voy. 1. p. 2צ0. witlı a figure. Athamántha crithmifỏlia, Juss. herb. Perhaps a proper species.

Gum-bcaring Meadow-saxifrage. Fl. July, Sept. Clt. 1804. P]. 3 to 4 feet.

6 S. Rígidur (Waldst. et Kit. rar. hung. 2. p. 156. t. 146.) stem terete, thick, rather tomentose, stiff, sparingly branched; leaves glaucous, tlurce or four times pinnate; leaflets linear, stiff, mucronate, rather pungent, usually trifid; involucrum none ; umbel 20 -rayed; leaves of involucel joined together at the base, equal in length to the umbellule; fruit tomentose. $4 . \mathrm{H} . \mathrm{Na}$ tive of Hungary, in the fissures of calcareous rocks. Bùbon rígidus var. $\gamma$, Spreng. in Schultes, syst. 6. p. 497. exclusive of the synonyme of Besser. Bùbon rígidus, Spreng. syst. 1. p. 900.

Stiff Meadow-saxifrage. Fl.'June, Aug. Clt. 1710 . Pl. $1 \frac{1}{2} \mathrm{ft}$.

7 S. cunEIfòliCM (Bieb. fi. taur. 1. p. 250. and suppl. 244. exclusive of the synonymes,) stem unknown; leaves several times 
pinnate ; leaflets broad, cuneiform, forked: superior ones oblong, entire; leaves of involucels very short, joined together at the base; fruit villous. 4. II. Native of Eastern Camcasus, in subalpine situations. Bùbon cuneifollius, Spreng. syst. 1.1\% 900. Hedge-leafleted Meadow-saxifrage. M. 1 foot?

8 S. peucenanifòlum (Bess. cnum. cont. p. 4.1.) stem terete, sparingly branclied at the apex, glaucous; leaves triternate; leaflets linear-lanceolate, acuminated ; sheaths adpressed ; involucrum almost wanting; leaves of involucel subulate, joined together at the base; flowers nearly sessile; fruit velvety from Hocky short down. 24.? H. Native of the south of Podolia. Trev. in act. bonn. 13. p. 172. in a note. S. prolíferum, Sureng. in Schultes, syst. 6. 1. 402.? Bùbon peucedanifòlius, Spreng. syst. 1. p. 900. Involucrum sometimes of few leaves.

Peucedanum-lcaeed Meadow-saxifrage. Fl. June, July. Clt. 1818. Pl. 1 foot.

9 S. Levcospe'ruum (Waldst. et Kit. pl. rar. hung. 1. p. 92. t. 89.) stem terete, flexuous, branched at the apex; leaves glaucous, decompound; leaflets setaceous, linear; petioles dilated, and sheathing; involucrum usually of one leaf; leaves of insolucels subulate, joined together at the base, and are as well as the fruit puberulous. 4 . or $\delta$. H. Native of Pannonia, about Buda on chalky hills. Athamántha leucospérma, Poir. suppl. 1. p. 534. Very nearly allied to S. Hippomárathrum, but differs in the leaves of the involucel being joined only at the base, not to the apex. Umbellules dense. Fruit witlı elevated corky ribs and narrow furrows, ex Koch, umb. p. 110.

Whitc-sccded Meadow-saxifrage. Fl. July. Clt. 1805. Pl. $1 \frac{1}{2}$ foot.

Sect. 11I. Euse'seli (so called from containing what are consiclered the true species of the genus). D. C. prod. 4. p. 145.Séseli vèra, Koch, umb. p. 110 .- Hippomárathrum, Duby, in D. C. bot. gall. 1. p. 234. but not of Link, nor Rivin. Involucra wanting or of few leaves. Leaves of involucels distinct, or sometimes somewhat concrete at the very base.

\section{- Flowers yellow.}

10 S. GRA'Cile (Waldst. et Kit. hung. 2. p. 122. t. 117.) stem terete; leaves triternate; leaflets triangularly setaceous, very thin and rather flaccid; rays of umbel elongated; involucra wanting or nearly so, very sliort. $\psi$. H. Native of Pannonia and Transylvania, on calcareous rocks. Baumg. fi. trans. 1. p. 238. Flowers yellow ; petals oval-oblong, incurved at the apex. Caudex ascending. Flowering stems erect. Sheaths of leaves entire. Fruit elliptic and smooth, like the rest of the plant. L'mbels opposite the leaves, drooping before expansion.

Slender Meadow-saxifrage. Fl. June, July. Clt. 1805. Pl. 1 to 2 feet.

11 S. triteria'tum (Pursh, fl. amer. sept. 1. p. 197.) root fusiform; leaves sheathing a long way, ternate, biternate, or triternate: leaflets or segments elongated, linear or linear-lanceolate, quite entire, petiolulate; stem leafy at the base; umbels compound, with nearly equal rays; umbellules capitate; flowers dioecious or polygamous ; immature fruit oblong, somewhat cylindrical; mericarps with 5 elevated acute ribs: involucrum and involucels wanting. 4. H. Native of North America, about the Columbia river; common on the dry gravelly soils near Fort Vancouver. Hook. fl. bor. amer. 1. p. 264. t. 94. This las much the habit of S. lciocárpum. Petals involute entire. Teeth of caly $\mathbf{x}$ obsolete. Flowers yellow.

Triternate-leaved Meadow-saxifrage. Fl. June, July. Clt. 1828. 1\%. 2 feet.

12 S. divarica'tum (Pursh, fl. amer. sept. p. 732.) stem dicliotomous, leafy ; leaves petiolate, with short slieaths, bipinnate or tripinnatifid; segments linear-oblong, acute, short; peduncles lateral and terminal; rays of umbels equal; leaves of involucels linear-subulate; fruit roundisli-ovate, crowned by the calycine teeth; mericarps rough, with 5 elevated ribs and many vitta. 4. H. Native of Nortl America, on the banks of the Missouri; and about Carlton House upon the Saskatchawan. Sims, bot. mag. 1742. Nutt. gen. amer. 1. p. 194. S. Jùcidum, Fras, cat. 1813. Márathrum, Rafin. journ. phys. 1820. Flowers yellow. The vitta are numerous, and abound in powerfully aromatic oil.

Divaricate Meadow-saxifrage. IYl. June, July. Clt. 1812. Pl. 1 foot.

13 S. LEloCA'RPUM (Hook. in fl. bor. amer. 1. p. 263. t. 93.) leaves with long sheaths, triternate or triternatcly pinnate ; leafle ts petiolate, oblong, entire, attenuated or trifid, glaucous; stem nearly naked; umbels compound, with the rays very unequal ; umbellules capitate; flowers divecious or polygamous; immature fruit very smooth; involucra and involucels wanting. 4 . H. Native of the north-west coast of America; on gravelly soils near Fort Vaucouver, on the Columbia. Flowers yellowish. Styles reflexed.

Smooth-fruited Meadow-saxifrage. Pl. $\frac{3}{4}$ foot.

14 S. DEEOLIA'TuM (Led. f. ross. alt. 1. p. 343.) radical leaves early, caducous; stem furnished with leafless sheaths; involucra and involucels of few leaves. 24. H. Native of Siberia, in the Kirghisean Steppe, in sandy wet salt situations. Plant with the habit of Férula sílsa. Root perpendicular. Stems solitary, simple at the base, divided into foriferous branches from the middle, which are branched again. Flowers yellow, polygamous. Carpels with 5 prominent equal filiform ribs; vitta one in each furrow, and 2 in the commissure.

Defoliate Meadow-saxifrage. Pl. 1 foot.

\section{* Flowers white.}

15 S. Ela'tum (Gouan, ill. 16. t. 8.) stem rather dichotomous, terete, few-leaved; leaves bipimate: leaflets linear-filiform, stiffisls ; involucra almost wanting; fruit ovate, tubercular while young, but glabrous in the adult state, crowned by the calyx. 4. H. Native of the south of France, Italy, Sic. in open situations. Gmel. syst. p. 48\%. D. C. H. fr. 3. p. 284. Spreng. umb. spec. 118. exclusive of the first and perhaps of the second synonyme. S. elàtum, Lin. spec. p. 375. is very probably a distinct plant.-Lob. icon. t. 727. f. 2. Plant glaucous.

Var. $\beta$, ligulàre (D. C. prod. 4. P. 146.) superior cauline leaves long-linear, quite entire. Native country unknown, but is usually to be found in gardens, under the name of $S$. glaúcum.

Tall Meadow-saxifrage. Fl. July, Aug. Clt. 17]0. Pl. 1 to 2 feet.

16 S. va'rtur (Trev, ind. sem. wratis. 1808 , nov, act. bonn. 13. p. 168.) stem terete; branches few, erect; petioles furrowed, as well as the leaves, which are tripinnate; leaflets linear, glabrous, glaucous ; involucrum almost wanting ; leaves of involucels short, subulate; fruit oblong, glabrous, not crowned. $\psi$. H. Native of Caucasus and Austria. S. vàrium, Koch, umb. p. 110 . S. Taúricum, Link, in Spreng. syst. 1. p. 884 . but not of Kocl. S. glaúcum, Bieb. fl. taur. 1. p. $23 \%$ supp]. p. 241. ex Trev. Differs from $S$. montànum and $S$. Pallàsii, in the fruit not being erowned by the teeth of the calyx

I'ar. $\beta$, brachycárpum (Bess. in litt. 1828.) fruit shorter. 4 . H. S. charophylloides, Hortul. but not of Thunb. Perhajs a proper species.

l'arious Meadow-saxifrage. Fl. Ju. July. Clt. 1817. Pl. $1 \mathrm{ft}$.

17 S. Ju'xceus (Sibth, et Smith, fl. grac. prod. I. p. 200.) stem much branched, divaricate, stiff, glabrous; leaves rather glaucous: radical ones triternate; leaflets kceled, trifurcate; cauline petioles very short, spreading; umbcls solitary, few- 
flowered. 4. H. Native of Greece. Perhaps sufficiently distinct from $S$. montànum.

Rushy Meadow-saxifrage. Pl. 1 foot.

18 S. nonta'vum (D. C. fl. fr. 4. p. 285, and suppl. p. 505.) stem striated; leaves glaucous, bipinnate, with entire sheaths, and narrow-linear mucronulate leaflets; involucra of 1-3 leaves, and the involncels of many linear-subulate leaves; fruit elliptic, glaucous, glabrous, or clothed with fine pubescence. $4 . \mathrm{H}$. Native from France to Tauria, in open inountainous places.

I ar. $\alpha$, laxiúsculum (D. C. prod. 4. p. 146.) leaflets flat; umbels rather loose; ribs of fruit triangular, rather prominent. 2. H. S. montanum, Lin. spec. p. 37\%. Schultes, syst. 6. p. 397. Koch, umb. p. 110.-Lob. icon. t. 77.

I $\operatorname{ar}$. $\beta$, glaúcum (D.C. I. c.) leaflets with an elevated nerve; umbellules crowded; ribs of fruit filiform. S. glauicum, Lin. spec. p. 37\%. Schultes et Koch, 1. c. Jacq. austr. 1. t. 45. S. ósseum, Crantz. austr. p. 207.

Iar. $\gamma$, multicaúle (D. C.prod. 4. p. 147.) stem multiple at the base; leaves strictly adpressed. 24. H. S. multicaúle, Retz. obs. 3. p. 27. Jacq. hort vind. 2. t. 129.

I Tar. o, peucedanifòlium (D. C. prod. 4. p. 147.) leaflets elongated. 24.H. S. peucedanifòlium, Merat, f. par. p. 115. S. elàtum, Thuill. par. p. 118.

Mountain Meadow-saxifrage. Fl. June, July. Clt. 1659. I'l. 2 to 3 feet.

19 S. Palla'su (Bess. cat. hort. crem. 1816. p. 130.) stem terete, branched at the top; leaves bipinnate or tripinnate; leaflets trifid; segments linear, flat, acutish, glabrous, glaucous ; upper leaves trifid or undivided; involucra wanting; leaves of involucels subulate, very short ; fruit ovate, glabrous, crowned by the short 5 -toothed calyx. $\Psi$. H. Native of Russia. D.C. mem. soc. gen. vol. 4. S. crassifolium, Schrad. and Hort. Unbels 10-rayed. Fruit elegantly striated with fuscous vittæ. Petiolar sheaths narrow, elongated. Allied to $S$. clatum, but the fruit is not tubercled when young; to S. leucospćrmum, but the fruit is glabrous. According to Koch, it is a variety of $S$. glaúcum.

Pallas's Meadow-saxifrage. Fl. Ju. July. Clt. 1818. Pl. $1 \mathrm{ft}$. 20 S. tenuròlum (Ledeb. fl. ross, alt. ill. t. 97. fl. alt. 1. p. 333.) stem branched, flexuous ; leaves bipinnate ; leaflets linear, stiffish; involucrum almost wanting; involucels short; fruit prismatic, tubercularly warted, rather shorter than the pedicels; receptacle with a membranous margin. 24. H. Native of A]taia, in dry open sterile places near Ustkamenogorsk, and in the Kirghisean steppe, between the first mentioned place and $\mathrm{Ab}$ laikit. Plant glaucescent. Stems many. Leaves with 5 opposite pinnæ, and each pinna bearing 3 or 5 , usually entire leaflets. Umbels 6-8-rayed. Involucrum usually wanting, rarely of one setaceous leaf; involucels of 7-8 small lanceolate membranous acuminated reflexed leaves. Styles and teeth of calyx reflexed on the fruit.

Finc-lcavcd Meadow-saxifrage. Pl. 1 foot.

21 S. corona'tum (Ledeh, fl. ross, alt. ill. 169. fl. alt. 1. p. 336.) stem branched; leaves bipinnate; leaflets linear-oblong, lecurrent, entire or tripartite; involucrum of 2 deciduous leaves; involucels of many lanceolate acute membranous reflexed leaves; fruit at length rather prismatic, wrinkled, crowned by the conical stylopodium. 24. Il. Native of Siberia, in the Soongarian dlesert. Plant glaucous. Radical leaves 8-10 inches long. Petioles dilated, and rather violaceous at the base, with white membranous margins. Umbels 6-8-rayed. Leaves of involucels inflexed at the points. Calyx obsoletely 5 -toothed. Styles reflexed.

Cronned Meadow-saxifrage. Fl. July, Aug. Pl. $1 \frac{1}{2}$ to $2 \mathrm{ft}$.

22 S. vagina'tum (Ledeb. H. ross. alt. ill. t. 171. fl. alt. 1. p. 336.) plant glaucescent; stem very simple; radical leaves pin- nate; leaflets entire or trifid, nearly linear, acuminated ; involucra and involucels of many broad linear leaves, with membranous margins: one of the leaves of the involucrum larger than the rest: those of the involucels equal in length to the umbellules. 4. H. Native of Dahuria, near Nertschinsk. Stem nearly leafless, beset with sheaths, which have membranous margins, and truncate at the apex. Umbels 10-12-rayed, equal in length. Flowers rather large. Fruit with prominent ribs.

Sheathed Meadow-saxifrage. P1. 1 to $1 \frac{1}{2}$ foot.

23 S. GilliE`sir (Hook, et Arn. in bot. misc. 3. p. 354.) plant clothed with hoary pubescence; stem angular; branches few, erect; leaves pinnate: leaflets of the lower leaves cuneated, and deeply toothed : of the superior ones linear and entire, or bipartite; involucra of few leaves or wanting; leaves of involucels linear, exceeding the pedicels; young fruit ovate, pubescent; styles elongated : stigmas globose, capitate. $\%$. H. Native of Chili, in Valle de la Punta des Vacas, Andes of Mendoza. Petroselinum sativum, Hook. et Gill. l. c. p. 335. Flowers white. The ribs of the young fruit are hardly visible.

Gillies's Meadow-saxifrage. Pl. 1 foot.

24 S. polyphýleum (Ten. ind. sem. 1825. p. 12. append. 5. f. neap. p. 10.) stems declinate, tufted, having a few short branches; leaves supra-decompound; leaflets trifid, linear, nearly terete, fleshy, rather mucronate; upper leaves reduced to the slieaths; umbels 15-20-rayed; leaves of involucel setaceous, shorter than the umbellules; fruit glabrous. 24. H. Native of Goat's Island and elsewhere, in the kingdom of Naples. Perhaps sufficiently distinct from $S$. montànum.

Many-lcaved Meadow-saxifrage. Pl. 1 foot.

25 S. cospitòsum (Sibth, et Snith, fl. græc. prod. 1. p. 200.) stem simple, nearly naked; radical leaves tufted, flat, pinnate; leaflets deeply trifid : ultimate ones decurrent; involucrum of $3-5$ very short leaves; fruit cylindrical, smooth, obscurely striated. 4.H. Native of the top of Mount Olympus. Sinith, in Rees' cycl, vol. 32. Spreng. umb. spec. 121. Radical leaves 3 lines long.

Tufted Meadow-saxifrage. Pl. 1 foot.

26 S. colora'tum (Ehrh. herb. p. 113.) stem striated, nearly simple; petioles straight, sheathing; leaves decompound, erect; leaflets or segments crowded, linear-cuspidate, having the margins and keel, as well as the rays of the umbel, rather puberulous: involucrum almost wanting; leaves of involucels with membranous edges, about equal in length to the umbellules; fruit glabrous, acutely ribbed. $\delta$. or $4 . H$. Native of France, Germany, Tanria, and Siberia, on mountains and hills. S. ánnuum, Lin. spec, p. 379. Schinltes, syst. 6. p. 398. Jacq. fl. austr. t. 55. hort. vind, t. 225. S. biénne, Crantz. austr. p. 204. Sium ánnutum, Roth, fl. germ. 1. p. 128. Selinum dimidiàtum, D. C. Al. fr. no. 3492. and suppl. p. 503. S. carvifolium, Vill. dauph. 2. p. 586 . Càrum símplex, Willd. spec. 1. p. 1410.Vaill. par. p. 54. t. 9. f. 4. S, alpinum, Bieb. fi. tanr. 1. p. 236.? but which is perhaps referrible to Cnidium venòsum. Flowers white, but often reddish when young. 'The plant not being annual, the name given by Linnæus is therefore not admissable. It differs from all the other species in the leaves of the involncel being equal in length or exceeding the umbellules.

I'ar. $\beta$, minus (Wallr. sched. crit. p. 124.) stem very humble. In dry situations.

l'ar. $\gamma$, ferulàceum (D. C. prod. 4. p. 147.) leaves of involucels exceeding the flowers, usually reflexed.

Coloured-flowered Meadow-saxifrage. Fl. June, July. Clt. 1817. Pl. 1 foot.

27 S. sтríctum (Led. f. ross. alt. ill. t. 174. fl. alt. 1. p. 338.) stem branched, straight ; leaves tripinnate: leaflets linear, elongated, straight ; petioles sheathing ; involucra wanting ; involucels of many setaceous leaves, which are shorter than the 
umbellules; fruit prismatic, glabrous. of. H. Native at the bottoms of the Altaian mountains, frequent; as near Sogra, Loktewsk, Sinejow, and elsewhere. lRoot fusiform. Rays of umbels 15-90, angular, roughish at the angles. Umbellules with 20-30 flowers. Mericarps witl 5 prominent ribs. Stylopodiun pulvinate. It differs from $S$. coloràtum, in the leatlets of the leaves not being roughish on the margins, in the rays of the unbel not being pubescent, and in the leaves of the involucel.

I ar. $\beta$ simplex; stem simple; leaves bipinnate: leaflets $2-3$ inches long, very narrow.

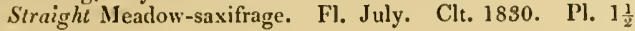
to 2 feet.

28 S. pubérulum (D. C. prod. 4. p. 147.) stem striated; petioles dilated at the base; sheaths with membranous margins; leaves decompound: leaflets few, linear, acute, glabrous; involucrum of one leaf; rays of umbels and fruit puberulous; involucels shorter than the umbellules. 4 . H. Native about Constantinople. Sheaths and bracteas coloured at the margins. Petals and styles purple. Allied to $S$. coloritum.

Var. $\beta$, pállidum (D.C. prod. 4. p. 14.7.) slieaths less dilated, witl pale margins; petals and styles white, or bardly reddish. 4. Il. Perhaps Selinum carvifolium, Vill. is referrible to this variety.

\section{Puberulous Mealow-saxifrage. Pl. I foot.}

29 S. tortuosum (Lin. spec. p. 373.) stem striated, stiff, much branched, divaricate; leaves bipinnate, stiffish: leaflets trificl: segments linear, slort, acutish, with the margins and keel rather scabrous; petioles sheathing, oblong ; involucrum wanting or of 1-2 leaves; umbels 5-10-rayed; leaves of involucel about equal in length to the umbellules. 4 . H. Native of the south of France. D. C. fl. fr. 4. p. 28.5. Scluultes, syst. 6. p. 401. Guss. prod. f. sic. 1. p. 3\$2. Enánthe rígicla striàta, Lin. hort. cliff. 99. Sium tortuòsum, Roth, fl. germ. 1. p. 128.-J. Bauh. hist. 3. p. 2. t. 16. f. 1.-Lob. icon. 78. The wlole plant is glaucous and stiff, but when growing in gardens it becomes green and flaccid. Flowers white. Fruit rather hairy, with triangular ribs, ex Koch, umb. p. 111.

Var. $\beta$, Taúricum (D. C. prod. 4. p. 148.) leaves bipinnate or tripinnate; leaflets trifid: segments linear, elongated, lardly glaucous. 4 . H. Native of Tauria, about Odessa; and of Galicia. S. tortuosum, Bieb. f. taur. 1. p. 235. suppl. 1. p. 242. Bess. Al. gal. 1. p. 221. Intermediate from habit between $S$. tortuosum and $S$. campéstre, but is referred to the first, from the involucra being absent, and from the leaves of the involucels being about equal in length to the umbellules, \&c.

I'ar. $\gamma, G r a^{\prime} c r m$ (D. C. l. c.) leaves bipinnate: petioles channelled; leaflets distant, trifid: segments rather broader at the apex, obtuse. 4.H. Native of Greece. S. tortuosum, Smith, prod. A. græc. no. 697. D'Urv. enum. 275.

Tnisted Meadow-saxifrage. Fl. Oct. Clt. 1597. Pl. 2 to $5 \mathrm{ft}$.

30 S. CAMpe'stre (Bess. enum. cont. p. 44.) stem terete, spreadingly branched at the apex, stiffish; leaves quadripinnate: leaflets ternate : segments linear, acutish, flat, liardly scabrous on the margins; involucra of 6-8 leaves; umbels 10-15-rayed; involucels shorter than the umbellules; fruit oblong, puberulous. 2. H. Native of tle Ukraine and Bessarabia, in sandy fields. Trev. act. bonn. 13. p. 170. S. arenàrinm, Bieb. fl. taur. suppl. p. 242. in a note. S. tortuósum, Trev. mag. nat. berl. 7 . p. 148 .

Ficld Meadow-saxifrage. Fl. Ju. July. Clt. 1823. Pl. $3 \mathrm{ft}$. 31 S. PETRE'vM (Bieb. H. taur. 1. p. 235. suppl. p. 243.) stem short, striated, branclied, clothed with velvety pubescence above, especially on the rays of the umbel and fruit ; leaves pinnate: leallets pinnatificl: segments lanceolate, attenuated at the base. 4. II. Native of Tauria and Caucasus. Bủbon glaúcus, Spreng. umb. 1. p. $1 \cup 6$. Schultes, syst. 6. p. $496 . \mathrm{Um}-$ bellules dense, white. Pedicels thickish, slıorter than the fruit. Fruit hairy, oblong, with fine filiform ribs, ex Koch, umb. p. 111. Rock Nieadow-saxifrage. Fl. Ju. July. Clt. 1817. P'. $1 \frac{1}{2} \mathrm{ft}$. 52 S. Buccònı (Guss. cat. pl. 1821. j. 80.) stem terete, suffruticose at the base; leaves ternately decompound: leaflets stiff, lanceolate-cuneated, acute, rather trifid; upper sheaths leafless, loose; involucra wanting; involucels of many setaceous leaves, which are about equal in length to the pedicels; fruit glabrous, ovate-oblong. 4 . H. Native of Sicily on the mountains among chalky rocks by the sea-side, near Palermo; and of Corsica, on rocks about Sagona. Spreng. neuc entd. 2. p. 146. syst. 1. p. 885 . Bùbon Sículus, Spreng. in Scluultes, syst. 6. p. 499. exclusive of the syn. of 13ieb. Crithmum Sículum, Bocc. sic. 53. t. 27, 28.-Cup. panpl. ed. 1. t. 105. ed. 2.t. 162. but in this last table it is delineated with the stem drooping at the apex, which is not the case.

Bocconi's Ieadow-saxifrage. Fl. June, July. Clt. 1820. Pl. 1 foot.

\section{$\dagger$ Specics not sufficiently knon'n.}

33 S. stria'tum (Thunb. prod. p. 51. fl. cap. 259.) stem terete, striated, nearly simple; leaves tripinnate : leaflets linearsubulate, furrowed; involucrum of 4 leaves ; umbel contracted; peduncles unequal; insolucels reflexed. $\delta$. G. Native of the Cape of Good Hope. Stem purplish, a foot high or more. Branclies few, divaricate. Leaves of involucrum ovate-lanceolate, concave. Leaves glabrous.

Striated Meadow-saxifrage. Fl. June, July. Clt. 1820. Pl. $1 \frac{1}{2}$ foot.

34. S. cherojlyyloi'Des (Thunb. prod. p. 51 . fl. cap. p. 254.) stem terete, striated, dichotomous at the apex; leaves ternately decompound: leaflets ovate, cut: segments linear, obtuse; involucra and involucels of 4 very short leaves. \$.G. Native of the Cape of Good Hope. Sheaths of cauline leaves membranaceous, ventricose, entire. Stem 2 feet ligh and more. Leaves glabrous, pale beneath. Leaves of iurolucrum ovate, obtuse.

Chervil-like Meadow-saxifrage. Fl. June, July. Clt. 1810. Pl. $2 \frac{1}{2}$ feet.

35 S. FrA'GILE (Gouan. ill. p. 15.) stem unknown; leaves tripinnate; leaflets ternate, brittle, articulated : segments linear; sheaths large, 2-lobed at the apex; involucra none; umbels 12 rayed; involucels of $7-9$ leaves, which are 3 times shorter than the umbellules. $\delta$. H. Native country unknown, as well as the flowers and fruit. Gouan cites under this plant the figures in J. Bauh. hist. 3. p. 18. f. 2. Clus. hist 2. p. 196. f. 1 Tabern. icon. t. 97 . f. 2 . but these figures are very different from each other, and therefore the plant is very doubtful.

Brittle Meadow-saxifrage. Pl. $1 \frac{1}{2}$ foot.

Cult. The plants of this genus are of casy culture; they require sandy or clialky soil, and are easily increased by seeds. 'Those species marked perennial prove seldom more than biennial when cultivated in gardens.

LXXI. LIBANO'TIS (from $\lambda_{4} \beta a r o s$, libanos, incense, and not from Mount Libanon, as the name would imply; L. vulgàris is supposed to exhale an odour like incense). Crantz. austr. p. 222. Gartn. fruct. 1. t. 21. D. C. coll. mem. 5. p. 17. t. 3. f. 5. prod. 4. p. 149. but not of Scop.-Athamántha, Scop. carn. no. 309. Lag. am. nat. 2. p. 103.- Séseli section, Koch, umb. 111. -Atlamantha species of Lin.

Lin. syst. Pentándria, Digýnia. All as in Séseli but differs in the lobes of the calyx being slender (f. 55. F. c. a.), subulate, elongated, colourcd, and deciduous, with the base hardly remaining; and in the involucra and involucels being both usually composed of many leaves. Leaves pinnate or bipinnate : leaflets ovate, cut or multifid: lower ones usually decussate. 
Sicct. 1. Eriòtis (from zocon, erion, wool, and ovc wTos, ous, otos, an ear; in allusion to the petals being covered witl sliort down). D. C. coll. mem. 5. p. 17. t. 3. f. 5. prod. 4. p. 149. Petals canescent from fascicles of short down (f. $55 . F . g$. .).

1 I. Bucutorménsis (D. C. coll. mem. 5. t. 3. f. 5. mem. soc. gen. vol. 4.) stem angular, branched; leaves stiff, bipinnate, shining : leaflets broad-ovate or oblong, serrated at the top, witls the serratures mucronate; peduncles stiff; involucrum almost wanting; involucels of many leaves, which are shorter than the umbellules; fruit villous from fascicles of hairs. $\psi$. H. Native of Siberia, very common in dry sterile places, especially about Buchtorminsk. Bübon Buchtorménsis, Fisch. in Spreng. pug. 2. p. 55. Schultes, syst. 6. p. 496. Athamánta rígida, Horn. hort. hafn. 2. p. 960 . Athamánta cervarizefolia, Schrad. ined. Séseli Buchtorménse, Koch, umb. p. 111. Habit almost of Libanotis vulgàris. Rays of umbel unequal in length. Leaves of involucel clothed with white down. Involucrum wanting, or of 2 or 3 entire or trifid or pinnatifid leaves.

Buchtorminsk Stone-parsley. Fl. July, Aug. Clt. 1816. Pl. 1 to 3 feet.

2 L. GRave'olens; plant clothed with hoary pubescence; stem branched; leaves pinnate; leaflets in fascicles, unequal, 2-3 times plicately pinnate: segments 2 or 3 -parted: lobes linear, cuspidate ; involucra variable ; involucels of many distinct leaves; fruit villously pubescent. 2. H. Native of Altaia, on rocks, but rare near the Fort called Ustkamenogorsk, but frequent beyond the river 1rtysch. Séseli gravèolens, Led. fl. ross. alt. ill. t. 164. fl. alt. 1. p. 340. Involucrum wanting or of one bipinnate leaf, or of many lanceolate-linear reflexed lsoary leaves. Leaves of involucel hoary, length of the umbellules. Petals pilose on the outside. The plant has a strong aromatic smell, and exudes a resinous gummy juice.

Strong-secnled Stone-parsley. Fl. June, July. Pl. 1 to $2 \mathrm{ft}$.

3 L. Patriniana (D. C. prod. 4. p. 150.) stem terete, branched; leaves bipinnate, canescent ; leaflets multifid: lobes short, linear-subulate; umbellules 30-flowered; fruit rather compressed. 24. H. Native of Altaia, on a schistous arid hill at the river Irtysch, and at Ustkamenogorsk. The plant exudes a yellow aromatic juice. Mericarps of fruit much compressed from the back, as in other species of Séscli and Libanòis. Involucrum of a few multificl leaves. Leaves of involucels linear, connected together a little way at the base. Perhaps the same as L. graciolens.

Patrin's Stone-parsley. Pl. 1 to 2 feet.

Sect. II. Eumbanòtıs (this section is supposed to contain the genuine species of the genus). D. C. l. c. Petals glabrous (f. 55. $F . f$.$) .$

4 L. vulga'rus (D. C. prod. 4. p. 150.) stem furrowed; leaves bipinnate: leaflets deeply pinnatifid: lower ones decussate : segments lanceolate; fruit ovate-oblong, villous. 2. H. $\mathrm{Na}$ tive of the temperate parts of Europe and Asia, on mountains and in fields. In England on elevated chalky pastures, but rare; as on Gogmagog bills, Cambridgeshire; and between Albany and Stony Stratford. Athamántha Libanòtis, Lin. spec. p. 351. Schultes, syst. 6. p. 488. Jacq. fl. austr. 4. t. 392 . fl. dan. 754. Smith, engl. bot. 138 . Séseli Libanòtis, Koch, umb. p. 111. L. daucoides, Scop. carn. no. 317 . L. montàna, All. pedem. 1368. t. 72. L. Diviniàna, Scop. carn. no. 316 . Athamáutha oreosclinum, Huds. angl. 115. Ligústicum férulàceum, Lapreyr. abr. p. 155. Lihanòtis, Riv, pentap. irr. t. 37.-Bauh. hist. 3. p. 2. 105. f. 1.-Pluk. phyt. t. 173. f. 1. Radical leaves bipinnate or tripinnate; leaflets opposite, deeply and sharply cut, smooth: the lowermost ones crowded, and often crossing each other. Flowers crowded, white or reddish. There are varieties of this plant with the fruit either pilose or nearly glabrons. The following varieties are probably so many species.

I ar. $\beta$, pubéscens (D. C. f. fr. no. 3481. var. $\gamma_{\text {, }}$ ) stem angular, pubescent; fruit more villous. 24. H. Native of the Pyrenees, in dry open places, and of the west of France. Athamánta pubéscens, Retz. obs. 3. p. 28. D. C. fl. fr. suppl. p. 511.

Var. $\gamma$, daucifòlia (D. C. prod. 4. p. 150.) stem angular: leaflets finely divided into linear-lanceolate lobes. $4 . \mathrm{H}$. $\mathrm{Na}$ tive of the Pyrenees, Auvergne, Austria, Siberia, Sc. on the mountains. Athamánta Pyrenàica, Jacq. hort. vind. 2. t. 197. Atluan. crithmoìdes, Lapeyr. abr. p. 148. Críthmum Pyrenàicum, Lin. syst. veg. ed. 15. p. 296. A'mmi daucifòlia, Host, fl. austr. 1. p. 362.-Gmel. sib. t. 40, f. 1. There are varieties of this having the leaves of the involucrum either entire or multifid.

Var. $\delta$, condensàta (D. C. prod. 4. p. 150.) stem nearly terete, striated; umbels very demse. 2 . H. Native of Siberia. A thamánta conelensàta, Lin. spec. p. 351 . Ligústicum vaginàtum, Spreng. pug. 2. p. 57. Schultes, syst. 6. p. 488.-Lam. ill. t. 194.f. 1 .

I Tar. $\varepsilon$, incàna (D. C. prod. 4. p. 150,) plant hoary from pubescence; leaves supra-lecompound; leaflets very minute, wedge-shaped, 4-toothed; leaves of involucra and involucels linear; umbels of many rays. $\%$. H. Native of Siberia.

Libanotis or Mountain Stone-parsley. Fl. July, Aug. Britain. I'. 1 to 3 feet.

5 L. Sibírica (Neyer, verz. pfl. p. 123.) leaves pinnate; leaflets pinnatifid or bipinnatifid: segments lanceolate or oblong, cuspidate ; involucra of many leaves or wanting ; leaves of involucels shorter than the umbellules; fruit pubescent, having the furrows furnished with 2 vittæe each. 2. H. Native of Siberia, very common; and of Caucasus, in the plains adjoining the mountains of Talusch. Athamánta Sibírica, Lin. mant. p. 56. Atham. Libanòtis $\gamma$ Sibírica, Schultes, syst. 6. p. 489. Séseli Libanòtis $\delta$, Koch, et Mertens in deutschl. fl. 2. 1. 412. Libanòtis vulgàris $\delta$, Sibírica, D. C. prod. 4. p. 150. Séseli athamanthoìdes, Led. fl. alt. 1. p. 342.-Gmel. sib. 1. p. 186. t. 40. f. 2. exclusive of the synonymes. It differs from $L$. vulgàris not only in the leaves being simply pinnate, but in the involucra being usually wanting, in the involucels being shorter than the umbellules, and in the furrows of the fruit being furnished with 2 vittx, and the commissure with 4 .

Var. $\beta$, acaúle (Led. fl. alt. 1. p. 34.2. under Séseli, leaves and umbels simple, rising in fascicles from the root.

Siberian Stone-parsley. Fl. July, Aug. Clt. 1771. Pl. 2 to 3 feet.

6 L. atmamanthoides (D. C. prod. 4. p. 150.) stem furrowed, angular, sparingly branched; leaves pinnate: radical ones petiolate: upper ones sessile, ncarly opposite : leaflets jinnatifid; lobes simple or trifid, linear, short, acute; leaves of involncra many, Jinear, ciliated, rarely cut. 4 . H. Native country unknown. Ligústicum athamanthoides, Spreng. umb. 126. exclusive of the synonymes. Fruit glabrous. It agrees in habit with Athamánta Pyrenàica, Jacq. loort. vind. t. 197., the Libanòtis vulgàris var. $\gamma$ daucifolia, but differs in the fruit being glabrous. Athamanta-like Stone-parsley. Fl. July, Aug. Clt. 1817. Pl. 2 to 3 feet.

7 L. verticilia'ta (D. C. prod. 4. p. 151.) stem terete, furrowed, naked at the aprex; leaves pinnate: leaflets pinnateparted, cut: lower lobes decussate; involucra of few leaves ; adult fruit naked. 4. H. Native of Mount Parnassus. There is a plant very similar to this grows about Bayonne, at a place called Chambre d'Amour. Athamánta verticillàta, Smith, fl. græc. t. 275. prod. 1. p. 188. The plant is very different from Pychòtis verticillàta, to which it has been joined by Sprengel.

Whorlch-leaved Stone-parsley. Pl. 1 to 2 feet. 
8 L. TENuifòtia (D. C. prod. 4. j. 151.) plant glalırous; stem terete; leaves supra-decompound: leaflets linear, divarieate; sheaths dilated; leaves of involucrum 5 , about equal in length to the micldle of the rays of the umbel; leaves of involucels with membranous ciliated edges, length of the umbellules; fruit glabrous. 4. 11. Native of Altaia. Athamainta tenuifólia, Pall. ex Scluiltes, syst. 6. p. 495 . Umbels lateral. Involucrum of few leaves; the outer leaf the largest. Calyxes glabrous. Mature fruit unknown.

Fine-lcared Stone-parsley. Pl. 1 to2 feet.

9 L. Stmpinaniaiva (D. C. prod. 4. p. 151.) stem simple, fistular, glabrous, striated ; leaves glabrons, pinnate; leaflets oblong or ovate, sessile, cut : uppermost leaflets rather trifid; petioles ending in a sheath at the base; lower cauline leaves larger than the radical ones, and on longer petioles; umbels dense, sheathed; sheatlis, as well as the involucra and involucels, are membranous and villous; involucrum of many obovate-cuneated leaves; involucels of many linear leaves. 2\%. H. Native of Altaia, in the more humid parts of the Alps, especially at the fountains of the river Tscharysch, and elsewhere. Athamánta compácta, Led. fl. ross. alt. ill. t. 81. fl. alt. 1. p. 327. Athamánta cervària ? Pall. itin. 2. p. 560 . Athamánta monstròsa, Steph. ex Willd. rel. in Scluiltes, syst. 6. p. 495. Ligústicum athamánticum, Adans, mss. P'etals erect, ovate-oblong, with an inflexed point. Styles equal in length or longer than the mericarps. Fruit nearly cylindrical, a little compressed from the sides, pilose, crowned by the permanent calyx and styles; mericarps with 5 filiform rilss: lateral ones marginating; vittæ 2 in each furrow, and 4 in the commissure.

$\zeta$ ar. $\beta$, pimnatifida; leares pinnate; leaflets pinnatifid; segments linear, a little cut.

Steplan's Stone-parsley. P]. 1 to $1 \frac{1}{2}$ foot.

10 L. Cachroìes (D. C. prod. 4. p. 151.) plant glabrous, glaucous; stem terete; leaves pinnate; leaflets multifid : lobes linear, entire; superior petioles dilated ; involucra and involucels of many elongated acuminated leaflets. \%. H. Native of Dahuria, near Nerstinski Sawod. Càchrys Sibírica, Steph. ex Fisch. in eat. sem. 1823. Spreng. syst. 1. p. 892. Trev. act. soc. nat. cur. 13. p. 168 . This species will probably form a proper genus, from the fruit being very much compressed from the back, in the dorsal ribs being prominent, and in the marginating ones being dilated into narrow wings. Vittæ 2 in the commissure, covered, and one in each furrow. Seed flat, not involute, as in C'ächyrs. Leaves of Séseli; calyx involucra, and petals of $\mathrm{Li}$ banòtis; fruit nearly of Peucédanum. Ovarium sometimes villous when young. Fruit glabrous. Petals glabrous. Perbaps this, with Séseli Patriniàna, will form a new genus, nearly related to Agasylllis in tribe Silcrinece.

Cachyrs-like Stone-parsley. 1'l. $1 \frac{1}{2}$ foot.

Cult. See Séseli, p. 31l. for culture and propagation.

LXXII. CENOLO'PHIUM (from kevos, kenos, empty, and Aooos, loplios, a crest; the ridges or ribs of the fruit are hollow inside). Koch, umb. p. J03. in ackl. no. 34. b. cliss. ined. in litt. 1828. D. C. coll. inem. 5. p. 48. t. 3. f. T. prod. 4. p. 151. - Crithmum species of Bieb.

Lıs. syst. Pentándria, Digínia. Margín of calyx obsolete. Petals obovate, cmarginate, with an inflexed point (f. 55.G.l.b.f.). Transverse section of fruit nearly terete; mericarps with 5 equal sharp, rather winged ribs, which are hollow inside: lateral ones marginating; vittæ one in each furrow, and 2 in the commissure. Seed semi-terete, inclosed in a dry pericarp, which is adnate to it whon young (f. $55, G$.).-Glabrous perennial herbs. Leares bipinnate or many times ternate; leaflets divaricate, rather trifid: segments lanccolate, cuspidate, quite entire, nerved. Involucrum wanting or of one leaf; involucels of voL. III. many leaves (f. 56. G. c.). Flowers white. This genus is nearly allied to Cuidium, but differs in the seed being inclosed in a dry loose pericarp when mature.

1 C. Fiscie'rr (Koch, I. c.) \%. II. Native of Siberia, in saltish humid fields on the lower Volga, about Sarejta; and of Lithuania at Grodna. Athamánta denudata, Fisch. hort. gor. Iorn. hort. hafin. suppl. p. 32. Crítlumum campéstre, Guld. itin. 1. p. 190.? ex Bich. Crítlimum Mo'ditcràneum, Bich. suppl. p. 215. Ligústicum Fischèri, Link, erum. 1. p. 276. exclusive of Conioselinum. Cnídlum Fischèri, Spreng. syst. 1. p. 888. Selinum carvitölia, Gilib, herl, grodn. ex Besser. Peucédanum állum, Hort, par. ex Desf. and thereforc P'eucédanum minus, Poir. dict. 5. p. 228. exclusive of the synonymes and country. Angélica Fischèri, Sprreng. in Schultes, syst. 6. p. 605, Stenis terete, striated.

Fischer's Cenolophium. Fl. June, Ang. Clt. 18ะ0. Pl. 2 ft.

Cult. This plant will grow in any common garden soil ; and is easily increased by secds.

LXXIII. CNJ'DIUMI (the ancient name of Orach). Cusson, mem. soc. med. par. 1782 . p. 280 . Hoftim. umb. 1. p. 157 . Koch, umb. 108. f. 48. D. C. prod. 4. p. 52.-Selìnum, Lag. am. nat. 2. p. 91. but not of Koch. - Cnídium and Ligústicum species, Spreng. Ligústicum species of Lin.

Lin. srst. Pentándria, Digynia. Margin of calyx obsolete. Petals obovate, emarginate, with an inflexed point. Transverse section of fruit nearly terete; mericarps with 5 equal winged ribs; wings rather membranous; lateral ribs marginal; vittæ one in each furrow, and 2 in the commissure. Secd semi-terete. Albumen flat on one side.-Herbs perennial, rarely suffruticose. Leaves pinnate or ternate; leaflets multifid: lobes lincar. Involucra variable; involucels of many leaves. Flowers white or rose-coloured. This genus is very nearly allied to Séscli, but differs in the ribs of the fruit being winged, and in the margin of the calyx being obsolete.

1 C. Monnie'Ri (Cuss. l. c.) sten branched, angular; leaves bipinnate: leaflets pinnatifid: segments linear-lanceolate, acute ; leaves of involucra and involucels setaceons. $\odot$. 11. Native of the soutl of France. Selinum Monnièri, Lin. spec. 351 . Jacc. hort. vind. 1. t. 62. Ligústicum mìnus, Lam. ff. fr. 3. p. 454 . Cicùta Sirénsis, Zuce. cent. no. 56. in Roem. coll. 1. p. 135. Athamánta Chinénsis, Lour. coch. p.? Lin. spec. p. 353. Cnídium confértum, Mionch, meth. 98. Involucra of 1-9 leaves. Ribs of fruit membranous. Flowers white.

Monnier's Cnidium. Fl. July, Aug. Clt. 1771. Pl. 2 feet. 2 C. Aproines (Spreng. umb. prod. p. 40.) stem branclied, striated; leaves bi-tripinnate; leafets pinnate-parted : segments linear-lanceolate, mucronate; involucrum almost wanting; leaves of involucels setaceous, equalling the umbellules in length. 4. H. Native of the cast of France, Germany, Switzerland, Transylvania, \&.c. Hoffin. umb. p. 157. Schultes, syst. 6. p. 552. exclusive of Willd. syn. Lignisticum apioìdes, Lnm. dict. 3. p. 577. Ligústicum cicutefölium, Vill. dauph. 2. p. 612. t. 15. Lig. Lobêlii, Vill. prosp. p. 24. Laserpítium silaifòlium, Jacq. austr. app. t. 44.-Lob. icon. 775. Flowers white or pale yellow?

Celery-like Cnidium. Fl. Ju.July. Clt. 1791. Pl. I to $2 \mathrm{ft}$.

3 C. petroselínum (D. C. prod. 4. p. 152.) stem striated; lower leaves on trifid petioles: the divisions bi-tripinnate; leaflets linear-lanceolate, quite entire, or trifict : upper ones pinnate, having the segments usually undivided; umbels erect, of many rays; involucrum almost wanting. 4 . H. Native country unknown. Peucédanum petroselinum, Desf. hort. par. $18 \geqslant 1$. Leaves large, with clongated segments or leaflets. Umbels 1220-rayed. Petals greenish-white, with an inflexed point. Calyx entire. 
Parsley-like Cnidium. Pl. 2 feet.

4. C. venòsum (Koch, umb. p. 109.) stem terete, smooth, straight, hardly branched above; leaves pinnate : leaflets pinnatifid or bipinnatifid: segments linear, or oblong-linear, acutish, quite entire or trifid; involucra wanting or of few leaves; leaves of involucels setaceous, about equal in length to the umbellules. 4. H. Native of Germany, about Halle and Witenberg; and of Caucasus and Siberia, in rather moist places. Séseli venòsum, Hoffm. f. germ. p.144. Séseli dùbium, Schkuhr, handb. 1.p. 217. schultes, syst. 6. p. 399 . Séseli saxífragum, Schott. barb. p. 307. Selìnm praténse, Spreng. f. hal. p. 92. t. 2. Séseli selinò̀des, Besser. cat, hort. crem. p. 130. Séseli alpìnum, Bieb. fl. taur. no. 587. ex suppl. p. 243.? Selìnum lineàre, Schum. enum. pl. sæland, 1. p. 95. Sheathes of leaves oblong; superior ones close. Involucra of few leaves. Leaves of involucra and involucels entire. There are varieties of this with more or less dissected leaves. Perhaps the German plant and the Siberian are the same.

Íciny Cnidium. Fl. Ju. Jul. Clt. 1817. Pl. 1 to 2 feet.

5 C. anómalum (Led. fl. ross. alt. ill. t. 311 . f, alt. 1. p. 330.) stem furrowed, glabrous, twiggy; leaves pinnate; leaflets bipinnately cut : segments cut or nearly entire, acnte; leaves of involucra oblong-linear, entire, pinnatifid, or bipinnatifid. f. $\mathrm{H}$. Native of Altaia, in fertile humid meadows, in the valleys of the rivers Tscharysch; and Kotsun, near Alexandrowsk. Gmel. H. sib. 1. p. 190. t. 42. and 43 'There is also a stemless variety found at the fountains of the river Tschegan. Root fusiform. Leaves pale green, glabrous. Involucra and involucels of many leaves; those of the involucels are oblong, entire, and ciliated, and about equal in length to the umbellules. $\mathrm{Pe}$ tals white. Fruit beset with glittering atoms; vittæ I-3 in each furrow, and 2 in the commissure. Stylopodium pulvinate. Calyx 5-cleft.

\section{Anomalous Cnidium. Pl. $1 \frac{1}{2}$ to 2 feet or more.}

6 C. cuneA'TuM (Led. fl. ross. alt. ill. t. 812 . f.alt. 1. p. 331.) stem furrowed, glabrous, branched: superior branches verticillate or opposite; leaves bipinnate : lower leaflets ternate : upper ones 2-3-parted, or cut, cuneated ; leaves of involucrum olblongelliptic, a little toothed at the apex; leaves of involucels broad, clliptic, entire, mucronate. $\delta$. H. Native of Siberia, in meadows at the river Kerlyk, but rare. Root fusiform. Leaves pale green, glabrous. Kays of umbel 12-20. Calyx with 5 minute teeth.

Cuncate-leafletted Cnidium. Fl. July. Pl. 1 to $1 \frac{1}{2}$ foot.

7 C. Fontanésil (Spreng. umb. spec. p. 41.) stem striated, dichotomous at the apex; leaves ternately decompound; leaflets rather trifid: segments linear, bluntish; leaves of involucra and involucels many, linear, acuminated. 4. H. Native of Algiers, in fields near Sbiba. Laserpítium peucedanoìdes, Desf. f. atl. 1. p. 254. t. 71. Laserp. Fontanèsii, Pers. encl. 1. p. 313. Laserp. Atlánticum, Poir. suppl. 3. p. 304. Ligústicum Fontanèsii, Spreng. in Schultes, syst. 6. p. 565. Perhaps the furrows of the fruit are furnished with 1 or many vittæ, and therefore may be either a species of Ligústicum or Cnidium; but the habit is that of Cnidium.

\section{Desfontaines Cnidium. Pl. 1 to 2 feet.}

8 C. Slffrutico'sum (Cham. et Schlecht. in Linnæa. 1. p. 387.) stem shrubby, naked, decumbent; branches erect, leafy; leares ternately decompound; leaflets short, rather trifid; sheathes of leaves permanent. b. G. Native of the Cape of Good Hope, in sand by the sea-side. Cònium suffruticosum, Berg. cap. p. 77 . The habit of this plant is very diflerent from all the other species.

Suffruticose Cnidium. Slirub decumbent.

9 C. DIFfu'sum (D. C. prod. 4. p. 158.) stein diffuse, striated; leaves pinnate; leaflets pinnatifid: segments cuncated, bluntly toothed at the apex; peduncles opposite the leaves; leaves of involucra numerous, linear, rather membranous. $\odot$. H. Native of Bengal. Ligústicum diff ùsum, Roxb. liort. beng. p. 21. Smith, in Rees' cycl. 21. no. 11. Willd. mss. in Schultes, syst. 6. p. 655. Athamánta diff ùsa, Wall. mss. Petals white, obcordate. Ribs of fruit prominent, rather crested, roughish from short down : vittæ $]$ in each furrow.

\section{Diffuse Cnidium. Pl. 1 foot.}

10 C. carvifòlum (Bieb. suppl. p. 212.) stem nearly simple ; leaves pinnate; leatlets cunciform, pinnatifid : segments linear, bluntish; involucra of 1 -2 elongated, somewhat pinnatifid leaves. 4. H. Native of Caucasus. Laserpítium Caucásicum, Bieb. f. taur. 1. p. 222. Said to he allied to Laserpitium Daúricum, and Mèum mutcllìnum. Leaves of involucels subulate, shorter than the umbellules. Stylopodium and styles dark purple.

Caranay-leaved Cnidium. Fl. Ju. Jul. Clt. 1820. Pl. 1 to $2 \mathrm{ft}$.

11 C. meifo'tum (Bieb. suppl. p. 212.) stem unknown; leaves pinnate : leatlets profoundly pinnatifid : segments linearsubulate; involucra and involucels of many subulate, reflexed leaves. $4 . \mathrm{H}$. Native of the Alps of Caucasus. Involucrum of 6-8 leaves. Involucels longer than the flowers. Flowers of a beautiful rose colour.

\section{Meum-leaved Cnidium. PI. 1 to 2 feet?}

12 C. Canade'xse (Spreng. in Schultes, syst. 6. p. 415. exclusive of many of the synonymes) stem angular, flexuous; leaves bipinnate, shining; leaflets many-parted: segments lanceolate; involucra and involucels of few leaves. 2. H. $\mathrm{Na}$ tive of North America, at the mouths of large rivers from $\mathrm{Ca}$ nada to Carolina; at the mouth of the St. Lawrence, in Canada. Selìnum Canadénse, Michx. f. bor. amer. 1. p. 155. A'pium bipinnàtum, Walt. carol. p. 115 . The fruit is unknown, and therefore it is a doubtful species of Cnidium. Flowers white.

Canadian Cnidium. Fl. Jı. Aug. Clt. 1817. Pl. 2 feet.

Cull. See Séseli, p. 3I1. for culture and propagation.

LXXIV. PETI'TIA (in honour of M. Felix Petit, author of a memoir on the genus Althenia, and who first made known the present plant by a figure and description). Gay, in ann. sc. nat. 26. p. 219.

Lin. syst. Pentándria, Digýnia. Calyx toothless. Petals lanceolate, entire, with an involute point. Fruit oblong, crowned by the reflexed styles; transverse section roundish-elliptic, furrowed on botls sides, from the raphe being nearly central, not marginal; mericarps rather convex on the hack, with 5 contiguous, thick, elevated, wingless, bluntly keeled ribs, therefore the transverse section is triangular, spongy inside; lateral ribs not broader than the rest, nor marginal. Vittre solitary in the furrows, which are narrow, and twin in the commissure. Seed adhering to the tegument, compressed, not angular.-A glabrous, green, biennial herb: with a very long, branched, thick root, which is spongy inside, and intercepted by transverse, membranous dissepiments. Steun short, nearly simple, thick, fistular, leafy at the base, striated above, and scabrous at the strix. Leaves tripinnate; sheaths large; rachis smoothish; lobes linear, scabrous on the margins, and on the dorsal nerve, mucronate at the apex. Umbels terminal, of many rays : rays 1433 , very rough, and very unequal: central ones much the shortest. Involucra wanting, rarely of 2 leaves; involucels of from 4-12 linear-subulate, quite entire leaves, which are mucl shorter than the umbels. Flowers greenish. Stylopodium large.

1 P. sca'bra (Gay, 1. c.). §. H. Native of the Eastern Pyrenees, in the valley called d'Eynes, at a place called La Cueillade de Nouri, among the debris of schistous rocks, at the elevation of 7200 fect, a little below the limits of perpetual snow. Selinum scàbrum, Lapeyr. abr. 1813. p. 147. Spreng. 
in Rom. et Sclıultes, syst. 6. p. 563. Angélica scribra, Petit, in ann. sc. obs. 1. p. 99. t. 3. D. C. prod. 4. p. 168.

Scabrous Petitia. Pl. $\frac{1}{3}$ to $\frac{1}{2}$ foot.

Cult. Sow the seeds in a dry situation in spring, in light earth.

LXXV. ENDRE'SSIA (in honour of M. Endress, a young botanist, who has travelled in the Pyrences). Gay, in ann. sc. nat. 26. p. 223.

Lix. sist. Pentandria, Digýnia. Teetlı of calyx at first obscurc, but increase in length as the fruit comes to maturity ; they are at last erect and subulate, and longer than the stylopodium. Petals without claws, quite entire, ovatc-lanceolate, acuminated, and very acute, with an involute point. Fruit conpressed a little from the sides, oblong-elliptic, crowned by the reflexed styles. Mericarps convex on the back; with 5 distant, equal, filiform ribs : lateral ribs marginating; furrows of fruit very broad ; vittæ 6 in the commissure, 4 in the lateral furrows, and 3 in the dorsal ones, all distinct. Seed adhering.-A peremnial, smooth herb; witl an oblique root, which is naked at the neck. Stem sleuder, quite simple, angularly striated, smooth, unless just under the umbel, where it is scabrous, a foot high, bearing 2 or 3 leaves. Lcaves pinnate; leaflets sessile, decussate, palmately 3 -parted: scgments palmately 3-5-cleft ; lobules linear, cuspidate. Umbels terminal, small, dense, when in fruit nearly globose; with short, stiff, smooth rays. Involucrum wanting, very rarely of 3-4. leaves; involucels of $1-5$ linearsubulate leaves, which arc about equal in length to umbellules, and sometimes much shorter. Petals white. Stylopodium small. Carpophore bipartite.

1 E. Pyrena'ica (Gay, l. c.). 4. H. Native of the Eastern Pyrenees, in alpine or subalpine pastures. Laserpítium símplex, Lapeyr. abr. p. 152. Ligústicum símplex, Benth. cat. pyr. p. 96. Mèum Pyrenàicum, Gay, in D. C. prod. 4. p. 162.

Pyrenees Endressia. PI. I foot.

Cult. See Cenolophium, p. 313. for culture and propagation.

LXXVI. THA'SPIUM (from the Isle of Thapsia, which gave the name to the Thapsia of the ancients; in allusion to its affinity with that genus). Nutt. gen. amer, 1.p. 196. exclusive of some species. D. C. prod. 4. p. 153.

Lis. syst. Pentándria, Digýnia. Margin of calyx 5-toothed. Petals elliptic, tapering into a long, inflexed point. Fruit not contracted from the sides, somewhat elliptic ; mericarps convex, with 5 winged, nearly equal ribs; furrows striated, each fur. nished with 1 vitta: and the commissure with 2. Seed terete. -Percnnial herbs, natives of North America. Involucra wanting; involucels milateral, of 3 leaves. This is a very distinct genus from Simýrnium and Zizia; but it is evidently allicd to Cnidium, from the fruit, but is distinguished from that genus in the calyx being 5 -toothed, in the petals not being emarginatc, in the inrolucels being 3-leaved, and in habit.

\section{\$1. Umbels opposite the laves. Floners dark purplc.}

1 T. atropurfu'reum (Nitt. gen. amer. 1. p. 196.) radical leates petiolate, cordate, undivided; cauline leaves pinnate, of $3-\tau$ ovate-oblong, cartilaginously toothed, petiolulate lcaflets. 2. H. Native from Carolina to Virginia, on hills; frequent about Philadelplia. Smýrnium atropurpùreum, Lam. dict. 3. p. 667 . Ell. sketch. 1. p. 366 . Cnídium atropurpùreum, Spreng. in Schultes, syst. 6. p. 418. Flowers greenish while young, but at length becoming clark purple. Fruit small, with the wings exserted, and membranous.

Dark purple-flowered Thaspium. Clt. 1810. Pl. 2 fect.

\section{\$2. C'mbels torminal. Flowers yellow.}

2 'T. BARbinóde. (Nutt. gen, amer. 1. p. 196.) lower leaves somewhat triternate: superior ones bitcrnate; leaflets ovatccuncated, acute, unequally and deeply serrated, but entire at the base. 2. 11. Native about l'hiladelphia, on the shady banks of the Schuylkill. Ligústicum barbinòde, Michx. fl. bor. amer. 1. p. 167. Sinýrnium, Muhl. cat. p. 32. 'T'hápsia trifoliàta, Mill. dict. no. 5.? Spreng. in Schultes, syst. 6. 1. 615. Umbels dichotomous, terminal. Fetals yellow. Fruit elliptic, with 7 wings: the alternating ones larger than the others. Stem pubescent at the joints, the rest glabrous.

Bearded-jointed Thaspium. Fl. June, July. Clt. 1700. Pl. 2 to 3 feet.

3 'I'. Actæı́òuvu (Nutt. l. c.) leaves biternate: leaflets oval, equally toothed; umbels somewhat verticillate: latcral ones sterile. 2. H. Native of Canata, on the banks of the St. Lawrence, near Tadoussach; and of Virginia. Ligústicum actieifolium, Miclıx. fl. bor. amer. 1. p. 166. Ilerb 3 feet higl. Leaves of involucels setaceous. Fruit oblong-oval, with 10 ratler winged ribs.

Actaca-leaved Thaspium. FI. Ju. Jul. Clt. $1810 . \quad \mathrm{Pl} .3 \mathrm{ft}$.

Cult. The species of this genus will grow in any common garden soil, but best in peat; and are easily increased by dividines at the root, or by seed.

LXXVII. TROCHISCA'NTIIES (from r a small wheel, and ar.0oc, anthos, a flower; shape of flowers). Koch, umb. p. 103. f. 95 . Gaudin, fl. helv. 2. p. 401. D. C. prod. 4. p. 154. Podopétalum, Gaud. mss.

Lin. sist. Pentándria, Digýnia. Margin of calyx 5-toothed. Pctals on long claws, spatulately obovate, with a triangular inHexed point. Fruit a little compressed from the sides; mericarps with 5 sharp, rather winged, equal ribs : lateral ribs marginating; vitte 3.4 in the furrows, which are broad, and 8 in the commissurc. Carpophore bipartite, Seed rather semiterete.-Glabrous, perennial herbs. Radical lcaf biternate; leaflets large, ovate-lanceolate, unequally serrated. Stem much branched, naked at the apex. Involucra wanting, or of 1 leaf ; involucels of 2-5 leaves. Flowers white, those in the disk of the umbcl sterile.

1 'T. NODHFLo'RUs (Koch, unıb. p. 10\%.). \%. H. Native of Upper Prorence, Dauphiny, Vallais, Piedmont, Hungary, Sc. in shady mountain woods. Smýrnium nodiflòrum, Alt. pedcm. 2 . p. 25. t. 72. Ligústicum nodiflòrum, Vill, dauph. 2. p. 608 . Angélica paniculàta, Lam. dict. 1. p. 1 2 . Imperatòria nodiflòra, Lam. A. fr. 3. p. 417. Lascrpítium verticillàtum, Waldst. et Kit. pl. rar. lung. 2. p. 186, t. 171. is perhaps properly referred to this by Sprengel, but it appears to differ in the form of the petals and fruit.

Anot-flowered Trochiscanthes. Fl. July, Aug. Clt. 1810. Pl. 3 feet.

Cult. Sce Tháspium above for culture and propagation.

LXXVIII. ATHAMA'NTA (some species found upon Nount Athamas, in Sicily). Koch, umb. p. 106. f. 19-50. but not of Scop. D. C. prod. 4. p. 154.-Bùbon and Athaninta, species of Lin. Athamánta species, Spreng.-Libanòtis, Scop. intr. no. 301. Lag. am. nat. 2. p. 100.

Lin. srst. Pentándria, Digýnia. Margin of calyx 5-toothed. Petals obovate, emarginate, or entire, with a very short unguiculate inflexed point. Fruit attenuated at the neek; transverse section nearly terete, or a little compressed from the sides; mericarps with 5 filiform, wingless, equal ribs: lateral ribs marginating; vittæ 2 or 3 in each furrow. Seel sonewhat semi-terete. Carpophore unknown.-Perennial or biennial herlss, usually velvety from villi on the stem, leaves, and fruit. 
Leaves triternate or pinnate; leaflets cut or multifid. Involucra of 1 or few leaves; involucels of many leaves. Flowers white.

1 A. cervarieròlia (D. C. prod. 4. p. 155.) stem suffruticose at thic base, caudex-formed; leaves glancous, glabrous, triternate; leaflets broad, ovate, cuspidately serrated: lateral ones somewhat bifid: terminal ones trifid; involucra of 1 or few leaves. 4 . or $々$. G. Native of 'Teneriffe. Séseli cervariafólia, D. C. cat. hort. monsp. p. 145. Schultes, syst. 6. p. 405. Athamánta máxima, Chois. ined. Flowers sweet-scented. Petals w hite, oblong, with an inflexed point. Fruit oblong, villous.

Chervil-leared Spignel. Fl. Ju. Jul. Cit. 1818. Sl. 2 ft.

2 A. Macedóxica (Spreng. in Schultes, syst. 6. p. 491.) stem panicled, clothed with soft, velvety villi; leaves almost glabrous; petioles twiee trifid, decompound; leaflets ovate, somewbat 3lobed, mucronately toothed; umbels very numerous, velvety. s. F. Native of Macedonia, Atlas, and according to Allioni about Nice. Bùbon Macedónicum, Lin. spec. p. 364. Desf. atl. 1. p. 256. Blackw. icon. 382. Plenclı, icon. t. 194. Daúcus Macedónicus, Riv. pent. irr. t. 48. A'pium Macedónicum, Moris. list. sect. 9.t. 9.- Lob. icon. 708. Fruit bottle-shaped, lispid, corered by 10-12 vittæ, having the ribs very slender.In some parts of the East they use this plant to scent their clothes; the smell is very strong, and rather disagreeable to Eurupeans. The plant, but especially the seed, is esteemed to be diurctic, emmenogogue, and carminative; the sceds are an ingredient in theriaca.

Macedonian Parslcy, or Spignel. Fl. June, Aug. Clt. 1596. Pl. 1 to 2 feet.

3 A. Ramosíssima (Port. in Schultes, syst. 6. p. 496.) stem erect, scabrous, much branched; radical leaves and lower cauline ones supra-decompound; leaflets filiform, mucronulate, stiff, glabrous: upper ones ternate; involucrum of many leaves; petals hairy on the outside as well as the fruit. $\%$. H. Native of Ditmatia. Host, fl. aust. 1. p. 364. Allied to A. Creténsis. Fruit ovate, not bottle-shapet, very hairy. Petals emarginate, very hairy on the outside. Involucra of $8-10$ linear leaves.

Much-branched Spignel. Pl. 1 foot.

4 A. Creténsis (Lin. spec. p. 352.) stem rather villous; leaves bipinnate; leatlets divided into linear, trifid lobes: lower ones hardly excceding the rest; involucra of 1 or few leaves; petals hairy on the back. f. H. Native of the south and midlle of Europe, in exposed situations. The leaves are said to be tripinnate by many authors. The seeds have been occasionally employed as carminatives, and were supposed likewise to be diuretic and emmenogogue; lately they have been little used, except as ingredients in theriaca and mitluradate. Haller, however, judges it to be much superior to the common carrot in medicinal eflicacy. It was celebrated anciently as a specific in the stone.

Iar. a, hivsùta (D. C. prod. 4. p. 155.) leaves clothed with hairs; lobes short. Libanòtis hirsùta, Lam. f. fr. 3. p. 498. Atlamánta Creténsis, Jacq. f. aust. t. 62 . hort. vind. t. 218. P'lench, icon. t. 284-Daricus Créticus, Cam. epit. 536. with a figure. Blackw. 4.71 .

F ar. $\beta$, mutellinuides (D. C. 1. c.) leaves nearly glabrous; lobes slenderer and more clongated.-Athamánta mutellinoides, Lam. dict. 1.p. 425. Atham. Mathioli, D. C. fl. fr. 4. p. 318. exclusive of the synonymes of Jacq. and Math. $\Lambda$. rupéstris, Vill. dauph. 2. p. 64S. A. ámua, Lin. spec. 353.?-Moris. oxon. sect. 9. t. 10.

Cietan Spignel or Candy Carrot, Fl. June, Jul. Clt. 1596. Pl. 1 foot.

5 A. Mattikioli (Wulf. in Jacq. coll. 1. p. 211, icon. rar. 1. t. 57.) stems glabrous, flexuous; leaves glabrous; leares 3-4 times ternate; leaflets linear-filiform, elongated, divaricate; involucra of 1 or many leaves; petals glabrous. 4. H. Native of the Alps of Carintbia, Carniola, and in fields about Nice. Libanòtis rupéstris, Scop. carn. no. 315. t. 9. Mèum Matth. ed. Bauh. 1. p. 569. f. 1. Stem glabrous, except under the origin of the leaves, where they are rather puberulous. Perhaps séseli Túrbith, Lin. is referrible to this plant, and probably A. ánnua, Lin. spec. 353. Leaves very fine like fennel.

Matlkioli's Spignel. Fl. Ju. Jul. Clt. 1802. Pl. $1 \frac{1}{2}$ foot.

6 A. Sícula (Lin. sprec. p. 352.) stems hoary from pubescence; leaves triternately decompound, rather villous; leaflets ovate, pinnatifid : scgments short, bluntish; petals villous on the outside. 4. H. Native on Mount Garganus, Apulia, Sicily, and among calcareous rocks, on Mount Atlas. Desf. H. atl. 1. p. 324. Schultes, syst. 6. p. 49I. exclusive of the syn. of Bocconj. Bubon Gargánicum, 'Ten. fl. neap. 1. 1. 123. t. 25. A. Creténsis, Ucria, ex Guss. prod. fl. sic. 1. p. 328.-Zan, ist. t. 48.-Moris. oxon sect. 9. t. 9. last figure. Leaves almost like those of Sisýmbrium Sòphlia.

Sicilian Spignel. Fl. June, July. Clt. 1686. Pl. 2 to $3 \mathrm{ft}$.

7 A. cane'scens (D. C. prod. 4. p. 155.) plant glabrous at the bottom, and canescent at the top from short crowcled down; leaves ternately decompound; leaflets cuneated, cut: lobes linear, bluntisl; ; involucra and involucels of 5 leaves; petals smoothish; fruit ovate, beset with very long, white, spreading hairs, which are rather capitellate at the apex. $\odot$. H. Native of the Levant, between Aleppo and Bagdad. Herb half a foot high, sparingly branched. Leaves of involucra and involucels oval-oblong, apiculated. Petals some of them cleft at the apex, and others entire. Immature fruit unknown, and therefore the genus is rather doubtful.

Canescent Syignel. Pl. $\frac{1}{2}$ foot.

$\uparrow$ Species not sufficiently known, and will perhaps, when more fully examined, be remored from the genus altogether.

8 A. DePre'ss. (D. Don, prod. fl. nep. p. 184.) leaves bipinnate, pubescent ; leaflets very slender, many-parted: segments linear, mucronate; scapes filiform, assurgent, velvety, exceeding the leaves; umbels simple or compound; involucrum of 5 pinnatifid leaves. 24. H. Native of Nipaul, in the alpine region of Gosaingsthan. Plant tufted. Root long, simple, fusiform, a finger in thickness. Scapes numerous, 3 inches high.

Depressed Spignel. Pl. $\frac{1}{4}$ foot.

9 A. GIGANtE'A (D. Don, prod. A. nep. p. 184.) leaves supradecompound; leaflets ovate, awned, deeply serrated, glabrous; involucra of many leaves ; petals bipartite; fruit ovate, pubescent. 4. H. Native of Nipaul. Root simple, fusiform. Stem furrowed, 3-4 feet high, branched. Petioles and rachis pubescent beneath. Umbels many-rayed, terminal. Petals white.

Guant Spignel. Pl. 3 to 4 feet.

10 A. TE'res (D. Don, prod. f. nep. p. 185.) leaves bipinnate, glabrous; leaflets pinnatifid: segments linear, acute, furrowed above; involucra of 5 short leaves; involucels of many leaves, equal in length to the rays; stem straight, terete, smooth. 4. H. Native of Nipaul. Stem 2 feet high, simple.

Terete-stemmed Spigncl. Pl. 2 feet.

11 A. carvifòmia (Steph. in Schultes, syst. 6. p. 496.) involucrum dimidiate; segments pinnatifid, linear, hoary. 24. H. Native of Siberia (ex Steph. in herb. Willd.). There are 3 specimens under this name in Willdenow's herbarium, which are very distinct from each other; one of which is Laserpitium Datricum; the second Rimia seseloides, and the third is Rumia athamathoides. The plant is therefore doubtful.

Caraway-learcd Spignel. Pl. 1 foot?

Cult. These plants will grow in any common garden soil; and are cither increascd by dividing at the root, or by seed. 
LXXIX. LIGU'S'TICUM (so named from some of the species growing abundantly in Liguria). Koch. $u$ mb. p. 104. f. 44-4.7. but not of Lag. D. C. prod. 4. p. 157.-Lig̨ústicum species of authors.

Lıx, syst. P'cntándria, Digýnia. Margin of calyx 5-toothed, or obsolete. Petals obovate, acute, emarginate, with an iuflexed point, on very short claws. 'l'ransverse section of fruit nearly terete, or a little compressed from the sides; mericarps witl 5 sharp, rather winged, equal ribs: lateral ribs marginating; vitta many, both in the furrows and commissure. Seed almost semiterete.-Herbs, for the most part perennial. Leaves decompound, or ternately divided. Involucra various; involucels of many leaves. Flowers white.

\section{\$1. Margin of calyx cuidently 5-toothed: tecth permanent.}

1 L. Scótıecs (Lin. spee. p. 359.) stem slightly branched at the upper part, striated, smooth; leaves biternate, opaque; leatlets rbomboid, broad, acute, smooth, serrated; involucra of uncqual, partly leafy, entire leaves; leaves of involucel more numerous, lanceolate, rather unequal. $4 . H$. Native of Lapland, Norway, Sc., North America, and Siberia; Kotzebue's Sound, and Kamtschatka; Scotland on the sea-coast about the Frith of Forth; also on the western coast; very abundant in rocky places; about Dunstonburgh Castle in Northumberland. Smith, engl, bot. t. 1207. Fl, dan. t. 207. 'lorrey, fl. un. st. 1. p. 813. Cham. et Scblecht. in Linnea. 1. p. 390. Angélica Scótica, Lam. dict. 1. p. 173. Séseli Scóticum, Riv. pent. irr. p. 59. A'pium ternàtum, Willd. herb. in Rœm. et Schultes, syst. 6. 1. 431. Flowers white, with a reddish tinge; anthers red. Frut oblong, having the commissure furnished with 6 vita. Root fusiform, warm, and pungent. The herb is eaten either crude or boiled by the natives of Scotland and its isles. The flavour is highly acrid, and though aromatic, and perhaps not unwholesome, is very nauseous to those who are unaceustomed to such food. L. Scóticum, Lour. coch. p. 183. cultivated in Cochin-china, belongs probably to a distinct genus, from the circumstance of the petals being entire.

Scotch Lovage. Fl. July. Britain. Pl. 1 foot.

\$2. Margin of calyx minutely 5-toothcd. Involucra of many leaves.

2 L. Cariólicum (Host, f. aust. 1. p. 378.) stem erect, branched, striated; radical leaves triternate ; leaflets decurrent, pinnate-parted: segments pinnatifid, mueronate; involuera of many leaves, wlich are toothed at the apex. 4. H. Native of Carniola, on a mountain ealled Grosskahlenberg; and of Silesia. Fruit large, nearly 3 lines long, ovate-oblong, having the ribs short and a little winged, and with the furrows broad and furnished with 3 vitta each. Teeth of ealys very small.

Carniolian Lovage. Pl. 2 to 3 feet?

S L. ALA'TUM (Spreng. umb. spec. p. 125.) stem furrowed and winged; leaves supra-decompound; leaflets petiolate, ovate, decurrent, pinnatilid: segments deeply serrated, oblong; involuera of few leaves; leaves of involucels setaceous, about equal in length to the umbellules. 4 . H. Native of Caucasus, in grassy places. Røem. et Schultes, syst. 6. p. 551 . A thamánta alàta, Bieb. fl. taur. 1. p. 214. Cnílium myrrhifòlium, Bieb. suppl]. p. 212. Flowers rose-coloured when young, but at length becoming white; anthers red. Margin of calyx short, 5toothed. The commissure, according to Koch, is furnished with 4-6 vittæ, and the furrows with as many, from which it differs from the genus Cnidium and especially from $C$. apiifolium, which is very like.

IIingch-stemmed Lorage. Fl. July, Aug. Clt. 1816. Pl. 4 to 5 ficet.
4. L. Ferula'ceua (All. perlem. no, 1319, t. 60, f, 1.) stem branched, striated; leaves supra-decompound; segments ratlier remote, linear, cuspidate; leaves of involuera pinnatificl at the apex. $\delta$. H. Native of Dauphiny, Piedmont, and Jura, on the lower alps, in open places; and of 1)auria, but not of the Pyrenees, because L. lerulàceum of Lapeyr. is Séseli Libanotis, Laserpitium Daúrieum, Jaẹ. Jiort, vind. 3. t. 38. Ligústicum Seguieri, Vill. daupl. 2. p. 615. exclusive of the synonymes. Furrows of fruit furnished with 3-4 vitta each, and the eommissure with 8 vittæ. ex Koch, umb. n. 10j. Stems usually spotted.

Ferula-like Lovage. Fl. Jul. Aug. Ch. 1775. Pl. 2 to $3 \mathrm{ft}$.

5 L. cynaphfòum (Viv, in litt. 1820. ex D. C. prod. 4 ). 158.) stem terete, branched; leaves decompound from the pretiole being much branched; leaflets multifid: segments linear, acute; involucra and involucels of many leaves; umbel of many rays; umbellules nearly globose, many-flowered. 4. H. Native of Corsica, in the fissures of rocks. Habit almost of Cnilium apioìles or Ligústicum Seguièrii, but is easily distinguished from them in the involuerum being of many leaves; and from $L$. ferulàceum it is distinguished by the stem being hardly striated, in the leaves of involucels being undivided, and in the umbellules being more crowded with flowers. Mature fruit not seen.

Fool's-parsley-leaicd Lovage. Pl. 3 to 4 feet.

6 L. connrólium (D. C. prod. 4. p. 158.) stem terete, branched ; leaves supra-decompound, glabrous; leaflets pinnatifid: lobes acutely toothed; involucra and involucels of many linear, acute, deflexed leaves, which are as well as the rays of the umbel and upper part of the stem pubescent. 4. H. Native of Nipaul, on high mountains. Laserpitium conif òlium, Wall. mss. Plant tall and very showy. Radical leaves 2 feet long, with trifid petioles. Mericarps witl 5 wings, and having many vittre in the furrows.

\section{Hemlock-leaved Lovage. PI. 4 to 6 feet.}

7 L. STRı'тим (D. C. prod. 1. p. 158.) stem terete, branched; leaves bipinnate; lobes or leaflets entire, acute, rarely cut; involuera and involucels of 5-6 linear, spreadingly-deflexed leaves, which are glabrous as well as the stems and rays of the umbel. 24. 11. Native of Nipaul, in the Great Valley, in rice-fields. Laserpitium striàtum, Wall. mss., but is referrible to the genus Ligústicum from the meriearps being furnished with 5 wings, and in the furrows being furnished with many vittr, \&e.

Striated Lovage. Pl. 3 to 4 leet.

8 L. cuneifòlium (Guss. pl. rar. p. 130. t. 26.) stem striated, branched; leaves shining, tripinnate; leaflets pinnatificl: segments short, cuneiform, trifid, obtuse, awned, approximate ; involuera permanent, of many leaves ; fruit oval, glabrous. $\psi . H$ Native of the kingtom of Naples, in Abbruzzo, in open places of valleys. Alliert to $L$. Pyrence'um.

Wedge-leafletted Lovage. Pl. 1 to 2 feet.

9 L. Díscolor (Ledeb. fl. ross. alt. ill. t. 310 . A. alt. 1. p. 321.) lower leaves teruately bipinnate; lower leaflets peciolate, ternate: upper ones and segments of the lower ones oblong, pinnatifid, or cut, decurrent; involucra of many lasceolate. linear, deciduous leaves; involucels of many linear, permanent leaves. 4. H. Native of Altaia, near Ritldersk, Mlexandrowsk, and Belaja at the river Buchtorminsk. L. Peloponnesiàcum, Pall. itin. 2. p. 528.? Root fusiform, stupose, prerhaps biennial. Stem solitary, branched, furrowed, glabrous. L,eaves pale green above, and pale glaucous bencath. Petioles of radical leaves half a foot long, ternate, and the divisions bipinnate. Rays of umbel variable in length. Calys with 5 minute teetl. Petals white. Meriearps with 5 rather winged ribs; having the furrows furnished with 3 vitte, and the commissure with 4-6. It differs from $L$. cándicans of Aiton, in the involucra being of many leaves. 
Tno-coloured-leaved Lovage. Pl. 4 to 5 feet.

10 L. ca'ndicans (Ait, hort. kew. 1. p. 348. ed. 2. vol. 2. p. 112.) leaves supra-decompound; leaflets cuneiform, cut, glabrous; involucra of 2 rather foliaceous leaves; ribs of fruit membranous, glabrous. 4 . H. Native country and the rest unknown.
Whitish Lovage.
Fl. July, Aug.
Clt, 1780, Pl, 3 to $4 \mathrm{ft}$.

\$3. Margin of calyx obsolete. Involucra nanting, or of fen lıtres. - Silàus species, Koch, in litt. 1828.

11 L. PYKENE'UM (Gouan, ill. 1\%. t. 7. f. 2. exclusive of the syn. of Seguier) stem branched, striated; leaves supra-decompound, shining; leaflets pinnatifid: segments linear, mucronate, short, divaricate; involucrum of a few caducous leaves. $4 . \mathbf{H}$. Native of the Pyrenees, in open places. D. C. fl. fr. 4. p. 309. Cnídium Pyrenæum, Spreng. umb. in Schultes, syst. 6. p. 416. L. Pyrenàicum, Koch, umb. p. I05. Séseli aristàtum, Ait. hort. kew. 1. p. 359. This plant is generally confused with $L$. fcrulìceum, but it is perfectly distinct. It is hardly to be distinguished from L. Seguieri, unless in the furrows of the fruit being furnished with many vittæ, and the commissure with 6-8 vitta.

Pyrenean Lovage. Fl. July, Aug. Clt, 1804. Pl. 3 to $4 \mathrm{ft}$. 12 L. SEGUIE'RI (Koch, umb. p. 105.) stem terete, striated; leaves decompround ; leaflets pinnatifid : segments remote, linear, rather falcate, cuspiclate; involucra wanting or of 1 leaf. $\Psi$. H. Native of the Apennines, Appuanos, Monnts Baldo and Generoso, Corsica, Carniola, sc. Selinum Seguièri, Lin. fil. supp]. p. 179. Jacq. hort. vind. 1. t. 61 . Imperatòria Seguièri, Spreng, nmb. spec. p. 65. Schultes, syst. 6. p. 618 . Melanoselìnum Seguièri, Swcet. hort. brit. 190. Ligust. Seguièr, Gaudin, fl. helv. 2. p. 398.-Seguier. pl. veron. 2. p. 41. t. 13. Axillary branches somewhat verticillate. Styles elongated, much divaricate. Vitta $3-4$ in each furrow of the fruit, and 4, 6 in the commissure.

Segnier's Lovage. li]. July, Aug. Clt. 1774 . Pl. 3 to 4 feet.

13 L. Córsicum (Gay, in am. sc. nat. 26. p. 222.) stem nearly simple, few-leaved, striated; leaves tripinnate; leaflets palmate-parted: lobules small, linear, cuspidate; involucra wanting, or of 1 leaf; rays of umbel muricated; involucels of many linear-subulate, serrulated leaves, which are about equal in length to the umbellules ; teeth of calyx obsolete; ribs of fruit scabrous from denticulations. $น$. H. Native of Corsica, on the mountains, at the elevation of 5000 or 6000 fect. Vittæ in the lateral furrows 3 , in the dorsal 4 , also 4 in the commissure. Habit of Mèum mutcllinum, from which it differs in the l:etals being emarginate, not entire.

Corsican Lovage. Pl. $\frac{1}{2}$ to 1 foot.

14. L. Peccedanos'des (Presl, in herh. Hænke, ex D. C. prod. 4. p. 158.) stem branclsed, furrowed; leaves decompound ; leaflets linear; umbels opposite the leaves ; rays angularly winged; involucra wanting, or of few leaves, which are multifid at the apex; involucels wanting, or of few leaves. 24. H. Native of Chili. The specimen is very like the rest, but varies in the involucra and involucels being sometimes wanting. Calyx obsolete. Petals entire.

Var. $\beta$, tenuifòlium (Presl. 1. c.) stem and branches thicker: leaves of involucra multifid; of the involucels linear, and longer than the umbellules; fruit ovate; mericarps with 5 ribs, furnished with many vittæ.

Var. $\gamma$, longifolium (Presl, 1. c.) segments of leaves very long. 4. H. Native of l'eru. Fruit wanting in the specimen, and therefore it is probably a proper species.

Peuccianum-like Lovage. Pl.?

15 L. PA'Nsic (Bert. herb. ex D. C. prod. 4. p. 669.) plant glabrous, erect, branched; leaves pinnate: leaflets multifid; lobes linear, acute; umbels terminal, or rising from the forks of the branches; involucra wanting, or of 1 many-parted leaf; involucels nearly wanting. 4. H. Native of Chili, in woods and hedges, at Rancagna and Valparaiso, where it is called Pansil. Limb of calyx obsolete. Petals white, emarginate, with an inflexed point. Fruit with winged ribs. Perhaps a species of Pleurospérmum.

Pansil Lovage. Pl. 1 to 2 feet?

\section{+ Species not sufficiently known.}

16 L. multífidum (Smith, in Rees' cycl. bot. 21. no. 8.) stem branched, fistular; leaves triplicately pinnate; leaflets linear, channelled, acute, decurrent; leaves of involucrum 7-8, lanceolate, with membranous margins; fruit ovate-roundish, with winged, curled ribs. 4 . H. Native of Siberia. Perhaps a species of Cnidium.

Mullifid-leaved Lovage. Pl. 3 to 4 feet.

17 L. DIVARica'tum (Led. sem. hort. dorp. 1824. p. 5.) leaves 4-times pinnate; terminal leaflets 3-parted: lateral ones simple, or bipartite; segments linear, cuspidate; involucra of 1 leaf. 4. H. Native of Altaia. Said to be allied to L. Fischèri, Link. Perlsaps a species of Cenolòphium.

Divaricale Lovage. Pl.?

18 L. Cr'prium (Spreng. umb. spec. p. 125.) stem terete, much branched, panicled ; leaves tripinnate; leaflets cut, bluntish, glabrons; involucra of few leaves. 24. H. Native of the 1sland of Cyprus. Athamánta multiflòra, Smith, fl. grac. t. 276 . prod. 1. p. 188. The vittre being unknown, the species is therefore still obscure. It is probably a species of Cnidium.

Cyprus Lovage. Pl. I foot.

19 L. овтusifòlium (Horn. hort. hafn. 1. p. 270.) stem unknoswn; leaves bipinnate; leaflets cordate, orbicnlar, sharply toothed; involucra and involucels of many leaves.-Native of Tangiers. Willd. enum. p. 312. Fruit unknown.

Blunt-lenfletted Lovage. Fl. Jul. Aug. Clt. 1824. Pl. $2 \mathrm{ft}$. 20 L.? Nepalénse (D. Don, prod. A. nej) p. 185.) stem terete, striated, glabrous, erect, very simple; leaves septinately pimnate; leatlets ovate, acute, dceply serrated, nerved, cuneated at the base: lower ones tripartite; involucels of many leaves, one half shorter than the umbellules. 24. H. Native of Nipaul, in Gosaingstban. Unbels terminal, solitary, of many rays. Calyx 5-toothed. Petals oval-oblong, cuspidate at the apex. Fruit undescribed. Probably a species of IIymenola'na.

Nipaul Lovage. Pl. $\frac{1}{2}$ foot.

21 L. Gingr'dium (Forst. fl. aust. p. 140.) stem striated; petioles sheatling, loose; leaves pinnate; leaflets rather obliquely cordate, oblong-ovate, obtuse, crenated, nerved. $\%$. H. Native of New Zealand, on the mountains. Gingídium montànum, Forst. gen. p. 42. t. 21. Involucra and involucels of 6 lanceolate-subulate leaves. Calyx 5-toothed, permanent. Petals emarginate, with an inflexed point. Fruit ovate, roundish, with 8 stripes.

Chervil Lovage. Pl. 1 to 2 feet?

22 L. АсірнY'LLA (Spreng. in Schultes, syst. 6. p. 554.) stem sheathed; leaves fan-shaped, multifid; Jeaflets linear, stiff, quite cntire, nerved, pungent; mericarps with 3 ribs. 4 . $\mathrm{H}$. $\mathrm{Na}$. tive of New Zealand. Aciphýlla squarròsa, Forst. gen. p. 136. t. 68. Laserpítium aciplaýlla, Lin. fil. suppl. 181. Probably a species of Cnidium, or a proper genus.

Pointed-leaved Lovage. Pl. 1 foot.

23 L.? рu'вIUм (H. B. et Kunth, nov. gen. amer. 5. p. 19.) stem branched, terete, striated, fistular ; leaves ternately decompound, rather hairy beneath; leaflets sessile, ovate-oblong, acute, sharply crenate-serrated, cuneated at the base. 24. H. Native of New Spain, in humid places. Flowers white. Fruit un- 
known. According to Kunth, this is perlaps a species of $I 1 C$ rácleum.

Doubtful Lovage. PI. 1 foot.

24 L.? Gr.'cun (D. C. prod. 4. J. I5\%.) sten ereet, branchet; leaves all bipinnate. 4. H. Native of Greece. Ligísticum Gràcum folio-apii, Tourn. cor. p. 23. According to the fruit, which is preserved in the lierbarium of the museum of Paris, it is a true species of Ligústicum. Sium Gra'cum, Lour. and S. Gra'cum, Lin. are very different plants from this.

Greek Lovage. Pl.?

25 L. CAPE'xSE (D. C. prod. 4. p. 159.) stem erect, branched; leaves bipinnate; leaflets short, thick; involucra and involucels of 3-5 leaves; fruit orate; calyx obsolete. 4. G. Native of the Cape of Good Hope: Atliamánta Capénsis, Burm. f. cap. p. 7. In Burmann's herbarium there are specimens of several plants fastened on the same slieet of paper, under the name of Athaminta Capénsis, therefore the one which he meant to go under this name is doubtful.

Cape Lovage. Pl. 2 feet.

Cult. See Athamánta, p. 316. for culiure and propagation.

LXXX. SILA'US (a name used by Pliny for an umbelliferous plant). Besser, in Scluultes, syst. 6. p. 34. in a note. Koch, umb. p. 105. D. C. prod. 4. p. 161.-Peucédanum species of Lin.

Lix. syst. Pentándria, Digýnia. Margin of calyx obsolete. Petals obovate-oblong, narrowed into an infiexed point, entire, or rather emarginate, appendiculate at the base, or sessile and truncate. Transverse section of fruit, nearly terete. Mericarps with 5 sharp, rather winged equal ribs : lateral ribs marginating; vitta many in each furrow, and so close together as to appear like a single broad one; and 4.6 in the commissure. Seed somewhat scmi-terete.-Glabrous, perennial herbs. Leaves cut into many parts ; leaflets linear. Involucra wanting, or of few lcaves: involucels of many leaves. Flowers cream-coloured or greenish. This genus is very nearly allied to Ligústicum.

1 S. Prate'ssis (Bess. enum. pl. vohl. p. 43. no. 1367.) stem angular; leaves supra-decompound; leaflets pinnate-parted: segments rather remote, lanceolate, nerved, a little channelled, cuspidate; involucra obsolete, or of 1-2 leaves. $4 . \mathrm{H}$. $\mathrm{Na}$ tive of humid meadows, from Europe to Tauria ; and Siberia ; in Britain, in rather moist meadows and pastures. Peucédanum Silàus, Lin. spec. 354. Smith, engl. bot. 21 42. Mart. rust. t. 128. Jacq. aust. t. 15. Hayne, arz. gew. 7. t. 5. Cnídium Silkus, Spreng. umb. prod. 40. Schultes, syst. 6. p. 416. Sium Silàus, Rotli, fi. germ. 1. p. 129. Séseli praténse, Riv. pent. irr. t. 5S. Crantz, austr. 3. p. 209. t. 6. f. 1. Séseli selinoìdes, Jacq. enum. vind. 227. Ligústicum Silàs, Duby, in D. C. bot. gall. 1. p. 230.-Mor. list. 3. sect. 9. t. 6. f. 10.-Lob. icon. 738. f. 5.-Petiv herb. brit. t. 28. f. 5. Root spindleshaped. Herb smooth, dark green. Leaves bipinnate; leaflets efliptic lanceolate, entire: either undivided or separated almost to the base into 2 or 3 segments of the same shape and magnitude. Uimbels of several unequal rays. Involucra of from 1.3 linear, white-edged leaves, but most frequently none at al]. Involucels of sereral linear leaves. Flowers yellow or greenish white. Fruit roundish-ovate. The whole plant, being fetid, when bruised, is supjosed in some parts of Norfolk to give a bad flavour to milk and butter; but cattle certainly do not eat it ; except accidentally, or in small quantities, sufficient perliaps to have the effect in question. Where this luerb abounds in pastures, it may be found partially cropped, tlough generally left almost entire.

Meadow Pepper-saxifrage. Fl. Aug. Sept. Brit. Pl. 1 to $2 \mathrm{ft}$.

2 S. TENuifôlits (D. C. mem. soc. gen. vol. 4.) stem terete, striated; leaves 3 or 4 times pinnate; leaflets pinnatifid or trifid: segments lincar, cuspidate, somewhat divaricate; involucrum wanting; fruit cylindrical. 4. 11. Native of Hungary and Tenerifle? ? Peucédanum tenuifòlium, Desf. lort. par. 1813. 1. 120. Poir. lict. 5. p. 228. but not of Thunb. Peucédanum serótinum, l'ers. enclı. 1. 1. 310 . P'euced. Mathìoli, Spreng. in Scluulics, syst. 6. p. 569 . Silàus Matholi, Koch, umb. p. 106. Spreng. pug. 2. p. 56. umb. spec. p. 113. This jlant is usually to be found in gardens under the name of Mčm Sibiricum.

Fine-leaved Pepler-saxifrage. Fl. July, Aug. Clt. 1818. Pl. 2 to 3 feet.

3 S. AlPE'stris (Bess. enum. pl. volil. p. 43. no. 1405.) stem striated; leaves bipinnate or tripinnate, with the ramifications spreading; leaflets pinnate; lower segments 3 or 4 -prarted: upper ones entire: lobes all entire, linear, cuspidate; iuvolucra almost wanting; leaves of involucels setaccous; fruit ovateoblong. 24. H. Native of the south of Podolia, in open fields; and of Altaia, near Schulbinsk, at the river Irtysch. I'eucédanum alpéstre, Spreng. umb. spec. p. 56. exclusive of the synonymes. Peuccl. Silàus, Bieb. fl. taur. 1. p. 215. Silàus Bessèri, D. C. prod. 4. p. 161. Flowers yellowish. Diflers from $S$. tenuifolius in the fruit being shorter and thicker, nearly ovate, not cylindrical. Compare it with Peucédanum alpéstré, Lin. which is not sufliciently known.

Alp Pepper-saxifrage. Fl. Jul. Aug. Clt. 1739. Pl. 1 to $2 \mathrm{ft}$.

4 S. LoNGifòlıus (Led. f. ross. alt. 1. p. 323.) leaves supradecompound, with the ramifications rather divaricate; leaflets somewhat tripartite: segments lanceolate or lincar, cuspidate ; involucra almost wanting; leaves of involucels setaceous. $\mathcal{\psi}$. H. Native of Siberia, in neadows, about the rivers Irtysch and Buchtorminsk. Ligústicum longifölium, Willd. spec. 1. p. 1428. Athamánta denudàta, Fisch. Angélica Fischèri, Spreng. in Schultes, syst. 6. p. 605. Críthmum Mediterràneum, Bieb. f. taur. 3. p. 215 . Ligústicum Fischèri, Link, enum. 1. p. 276. Cnítlium Fischèri, Spreng. syst. 1. p. 888.Gmel. sib. 1. p. 188. no. 4. t. 41. The Altaian plant differs from the one collected on the banks of the Volga, in the leaves being more profoundly divided, nearly ternate; in the segments being linear, not 3-5-parted; in the lobes being lanceolate; and in the involucra being usually of 1 leaf. Furrows of fruit furnished rith 1 vittæe each, but sometimes the outer ones lave 2.

lar. $\beta$, dicaricitum; segments of leaves longer. 4.11 . Cnídium divaricatum, Led, inı. sem. lort, dorp.

Long-leaved Pepper-saxifrage. Fl. July, Aug. Clt. 1820. Pl. 2 feet.

5 S. carvifo'lius (Meyer, pflanz. p. 125.) root fusiform; stem furrowed and striated, branched; leaves bipinnate; leaflets of the radical leaves decussate : of the cauline lincar, divaricate; involucra and involucels composed of short setaceous leaves; rays of umbel very umequal. 2. H. Native of Caucasus, on the ligher mountains. Bùnium peucedanoides, Bieb, f. taur. 1. p. 208. suppl. 211. D. C. prod. 4. p. 116. Sium peucedanoides, Spreng, umb. spec. 41. no. 5. Pencédanum carvif òlia, Bieb. Petals pale yellow. Vittæ solitary in the furrows, according to Besser: but there are $2-3$ vitta in nearly all the furrows, rarely solitary.

Caraway-leazed Pepper-saxifrage. Fl. July, Aug. Clt. 1818. Pl. $1 \mathrm{ft}$.

6 S.? PEUcedaxoines (D. C. prod. 4. p. 161.) root turnjpformed; stem striated, fistular, somewhat trichotomous at the apex; leaves nearly ternate; segments linear, acute, entirc, with revolute margins; involucra of 1 leaf; involucels wanting

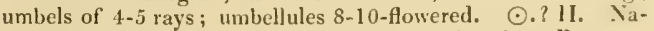
tive of South America, on temprerate mountains about Popayan. Cnidium peucedanoides, II. B. et Kunth, nov. gen. amer. 5. P. 
15. Peucédanum júnceum, Willd. mss. in Schultes, syst. 6 . p. 576 . From the yellow entire petals, it comes nearer Siluius than Cnidium, but the involucel is wanting.

Sulphur-nort-like Pepper-saxifrage. Pl. 2 feet?

Cult. See Athamánta, p. 116. for culture and propagation.

LXXX1. WALLRO'THIA (in honour of F. Wallroth, M. D. a German botanist). Spreng. in Schultes, syst. 6. p. 15. exclusive of some species. D. C. coll. diss. 5. p. 49 . t. 1. f. A. prod. 4. p. 162.-Ligństicum species, Røm. D. C. and Lapeyr.Mènm species of Duby.

Lin. syst. Pentáudria, Monogýnia. Teeth of calyx 5, ovatelanceolate, acute (f. 56.A.b.). Petals entire, elliptic, acute at the base and apex (f. $56 . A . d$. .). Transverse section of fiut nearly terete; mericarps with 5 prominent, equal ribs: lateral ribs marginating. Vittæ 1 in each furrow, and 2 in the commissure.-A smooth perennial herb. Radical leaves decompound; leaflets linear-lanceolate. Involucra of 1-3 unequal leaves; involucels of $5-8$ linear-lanccolate leaves. Flowers white. This genus is intermediate between Mèm and Ligústicum; it differs from the first in the calyx being evidently 5toothed, and from the last in the petals being entire.

1 W. tenuifo'lia (D. C. prod. 4. p. 162.). 2. H. Native of the central Pyrenees, among rocks, but rare, as at Port d'Aulus, Estive de Luz, L'hieris, Eaux-bonnes, \&c. Ligústicum tenuif òlium, Rom. in D. C. fl. fr. 4. (1805.) p. 309. Spreng. prod. 41. Ligust. spléndens, Lapeyr. abr. (1813.) p. 156. Wallròthia spléndens, Spreng. in Schultes, syst. 6. p. 557. Mèmm tenuif òlimm, Duby, in D. C. bot. gall. 1. 230. Daúcus Pyrenaicus tenuifolius lucidus, and Ligusticum Pyrenaicum foeniculi folio lucidum, Tourn. herb.

Finc-leared Wallrothia. Fl. Ju. Jul. Clt. 1825. PJ, $1 \mathrm{ft}$.

Cult. See Athamánta, p. 116. for culture and propagation.

LXXXII. ME'UM (from $\mu \varepsilon \iota \omega \nu$, meion, smaller; in reference to the delicacy of the leaves). Tourn. inst. p. 312. t. 165. Jacq. Pers. Gartn. Lag. am. nat. p. 100 . Koch, umb. p. 103. D. C. coll. mem. 5. p. 49,-Ligústicum species, D. C. A. fr.-Aithùsa, Athamánta, Ligísticum, and Phellándrium of authors.

Lin. syst. Pentándria, Digýnia. Margin of calyx obsolete. Petals entire, elliptic, acute at the base and apex. Transverse section of fruit nearly terete. Mericarps with 5 prominent, acutely keeled, equal ribs: lateral ribs marginating; vitta many in the furrows, and 6-8 in the commissure. Seed nearly semiterete.-Glabrous, perennial herbs. Stems nearly simple, terete, striated. Leaves supra-decompound, or pinnate; leaflets multifid: segments slender, linear, acute. Involucra alinost wanting; involucels of many leaves. Flowers white or purple. This genus is distinguished from Ligústicum in the calyx being withont teeth and in the petals being entire.

1 M. Aтиama'NTicum (Jacq. fl. austr, t. 303.) leaves smpradecompound, divided into numcrous, fine, setaceous leaflets or segnents ; stems leafy, not much branched; involucra of a few linear leaves, which are often 3 -cleft at the apex, but often wanting altogether; involucels of more numerous, entire, or cut leaves, somewhat dimidiate. 4. H. Native of Europe, in mountain pastures; plentiful on the mountains in the north of England; and abundant in the Highlands of Scotland. Smith, cngl. bot. 2249. Mèum, Raii syn. 207. Dod. pempt. 305. f. 1. Math. valgr. 1. p. 22. f. 1. Cam. epit. 7. f. 1. Riv. pent. irr. t. 63. Dalech. Luggl. 769. f. 1-2. Athamánta Mèum, Lin. spec. 353. Ligústicum capillàceum, Lam. fl. fr. 3. p. 454. Ligústicum Mèum, D. C. f. fr. 4. p. 310 . Crantz, aust. fasc. 3. p. 82. Hayne arz. gew. 7. t. 12. Athùsa Mèum, Lin. syst. veg. 287. Daúcus Créticus, Trag. hist. 445 f. 1.-Moris. list.
3. p. 270. sect. 9. t. 2. f. 2. Roots tapering. Stems liollow. Petals sometimes slightly obcordate. The whole plant, but especially the root, is highly aromatic, with a hot biting flavour like lovage, which it communicates to milk and butter, from the cows feeding upon its herbage in spring. A strong infusion of this herb is said to give cheesc the taste and odour of the Swiss chapziegar. The seeds, as well as the roots are recommended as carminatives and stomachics. The plant is called Spignel, Meu or Bald-money in England, and Highland-miken in Scotland. Athamarta-like or Common Bald-money. Fl. May, June. Britain. Pl. I to 2 feet.

2 M. Mutelitixa (Gæron. fruct. 1. p. 106. t. 23.) Jeaves bipinnate or tripinnate; leaflets lanceolate-linear, cut, acute; stem nearly naked, simple; involucra wanting: leaves of involucel lanceolate. 4 . H. Native of middle Europe, in high subalpine pastures, Mutellina, J. Bauh. hist. 3. p. 2. p. 66. Phellándrium mutellina, Lin. spec. p. 366. Jacq. austr. t. 56. hort. vincl. t. 223. Ligústicum mutellina, All. pedem. t. 60. f. 1. D. C. f. fr. 4. p. 310 . Ethùsa mutellìna, Lam. fl. fr. p. 1025. Enánthe purpùrea, Lam. dict. 4. p. 530.-Cam. epit. p. S. with a figure.-Park. theat. 889, f. 5. Herb and root aromatic. In Switzerland, Haller says, the goodness of the pastures are estimated by the abundance of this plant. The flowers are probably always purple while young.

Mutcllina or Swiss Bald-money. Fl. June, Aug. Clt. 1774. PI. $\frac{1}{2}$ to 1 foot.

Cult. See Athaminta, p. 116. for culture and propagation.

LXXXIII. GA'YA (in honour of M. Gay, a distinguished French botanist). Gaud. feuill, vaud. 1825. no. 157. p. 28. fl. helv. 2. p. 389. D. C. coll. diss. 5. p. 49 . prod. 4. p. 163. but not of Kunth. Laserpitium, spec. Lin. Hall. and Lam.-Ligústicum spec. All. Spreng. Koch.-Arpítium. Neck. elem. no. 278 .

Lin. syst. Pentándria, Digýnia. Margin of calyx obsolete. Petals obovate, more or less eniarginate, with a broad inflexed point. Fruit oval, rather compressed; mericarps with 5 elevated, wing-formed ribs, which are contiguous at the base, obtuse: outer ones marginal. Vittæ none. Carpophore bipartite. Seed nearly semi-terete, casily separated from the covering. - Perennial mountain herbs. Leaves all radical, pinnate; leaflets bipinnatifid: lobes linear. Stems naked, simple. Umbels compound. Involucra of few leaves. Flowers equal, fertile, white. This genus differs from Mèm in the petals being cmarginate, not entire; in the furrows of the fruit being without vitte, and in the fruit being rather bladdery.

1 G. si'mplex (Gaudin, 1. c.) leaves of involucra few $(7-10)$, somewhat trificl. 4 . H. Native of the ligher $A l_{l}$ s, from Dauphiny to Carintlia. Laserpitium simplex, Lin. mant. p. 56. Jacq. misc. 2. t. 2. Ligústicum símplex, All. pedem. no. 1324. Spreng. in Schultes, syst. 6. p. 553. Vill. dauph. 2. t. 14. Laserpitium lùcidum, Ait. hort. kew. ed. 1. vol, 1. p. 34.5. ex Spreng. Root branched. Flowers reddish.

\section{Simple-stemmed Gaya. Fl. Jul. Clt. 1775. Pl. $\frac{1}{2}$ foot.}

2 G. Prrena'ica (Gaudin, l. c. in a note) leaves of involucra 1-5, undivided. 24. H. Native of thic higher Pyrenees. Pimpinélla dioíca $\beta$, Lapeyr. abr. p, 166. Séseli nànum, L. Dufour, in litt. Séseli montinum, var. Benth. cat. It differs from the first in its more stiff', branched habit, in its glaucous colour, in its 1-leaved stem, in the leaflets and segments being lanceolate, in the ribs of the mericarps being less elevated. Plant small, glabrous. Root thick.

Pyrenean Gaya. Pl. $\frac{1}{2}$ foot.

Cult. These plants should be grown in pots, in a mixture of peat and loam, and placed among other alpine plants. They are increased by seeds. 
UMBELLIFERE. LXXXIV. CoNIOSELINUM.

LXXXIV. CONIOSELI'NUM (a name evidently composed of Cònium and Sclinum). Fisch. in Hoffm. umb. ed. 2. p. 185. tit. f. 5. Koch, diss. ined. D C. prod. 4. p. 163.

Lin. srst. Pentándria, Digýnia. Margin of calyx absolete. Petals obcordate or obovate, with an inflexed point. Styles at length diverging, reflexed. Fruit rather compressed from the back, or convex ; mericarps with 5 winged ribs; the lateral ribs twice the breadth of the others, and marginal; vittæ unequal, 3 in the lateral furrows, but usually 2 in the dorsal ones, and 4.8 in the commissure. Carpophore bipartite. Seed flat on one side-Glabrous, biennial herbs. Stems branched, fistular. Leaves bipinnate; leaflets pinnate-parted: segments oblonglinear. Umbels terminal, of many rays. Involucra wanting, or of few leaves. Involucels of 5-7 linear-subulate leaves, which are about equal in length to the umbellules, or longer. This is an ambigunus genus, intermediate between the tribe Peucclànce and Seselineas; with the first it agrees in the mericarps being winged, and with the last in the mericarps being convex on the back. Flowers white.

1 C. Fische'ri (Wimm, et Grab. ex flora 1828. p. 2i5.). f. H. Native of Siberia, Tartary, Ingria, Silesia, and Savoy, on the mountains; North America between the Coppermine and Mackenzie rivers; Labrador ; Straits of De Fuca, on the northwest coast; Kotzebue's Sound. C. Tatáricum, Hoffm. l. c. l'erhaps C. I'ngricum or C. negléctum, Fisch. in litt. is not distinct from this. Perhaps Ligústicum Gmehini, Cham. et Schlecht. in Linnæa. 1. p. 391. and Gmel. sib. 1. p. 195. t. 44. appertains also to this plant. Perlaps all these different names belong to different species, or probably to the same, but they are so much confused that it is impossible to extricate them.

Fischer's Conioselinum. Pl. I to 2 feet.

Cult. This plant is only to be increased by secd, which should be sown in the open ground early in spring. A light soil suits it hest.

LXXXV. CRI'THMUM (from $x \rho t \eta \eta$, krithe, barley; similarity in the seeds). Tourn. inst. p. 817.t.169. Lin. gen. no. 340. Koch, umb. p. 102. D. C. prod. 4. p. 16 t. Càchrys species, Spreng.

LıN. sYst. Pentândria, Digýnia. Margin of calyx obsolete. Petals roundish, entire, involute, ending in an obovate segment. Transverse section of fruit nearly terete ; mericarps with 5 elevated, sharp, rather winged ribs : lateral ribs a little broader than the rest, and marginating; pericarp spongy, with large cells. Seed semi-terete, constituting a free nucleus, which is covered with copious vittæ in every part.-A suffruticose, glabrous, fleshy herb. Petioles sheathing at the base. Leaves bipinnate; leaflets oblong-linear. Unsbels compound. Involucra and involucels of many leaves. Flowers white. This genus differs from all others in the present tribe as the genus Archangélica does from the rest of the genera in tribe Angc. licece, in the seed being a free nucleus, covered with copious ittæ.

1 C. Marírimum (Lin. spec. 354.). 2\%. II. Native of rocky sea-shores and cliffs; as along the Black Sea, in Tauria ; and along the Mediterranean Sea; and of Europe along the shores of the Western Ocean from Spain to Britain; and of the Canary Islands; in Britain, on the rocky sea-shore and cliffs. Snith, engl. bot. 819 . Jacq. hort. vind. 2. t. 87 . Càchrys marítima, Spreng. in Schultes, syst. 6. p. 442. Créthamus, Cord. hist. 201. f. 1. Sámpire, Petiv. hort. brit. t. 24. f. 8.-Lob. icon. 392. f. 1.-Bauh. hist. 3. p. 2. 194. f. 1. Moris. hist. 3. p. 289. sect. 9. t. 7. f. 1. Root branched, creeping extensively. Herb greenish-glaucous, salt, and pungently aromatic in flavour. Stems ascending. Leaves biternate; leaflets uniform, lanceolate, tapering at the base. Leaves of involucra and involucels ovate, acute, spreading, rather short. Flowers white, with yclvoL. III.
Lxixy. Crithanum. LxXXVi. Levisticum.

lowish anthers. Samphire is called Perce-pierre and Saint-picre of which our English name appears to be a corruption) in French; Meerfouche in German; and Finnochio marino in Italian. 'The herb makes an old-fashioned English pickle, as those know who read Shakspeare's King Lear. It is sold in the London shops; but there are many plants preferred for the same purpose, as Salicórnea herbiceca and Inüla crithmifölia, \&zc., and is a frequent addition in salads. In taste it is crisp and aromatic, and constitutes a light and wholesome condiment. It is generally gathered in places where it is found wild; and the allusion to the practice by Shakspeare, in his description of Dover Cliffs, is well known. The plant is also used medicinally.

Var. $\beta$, Canariénsc (Cav. anal. scienc. nat. 1801. vol. 3. p. 35.) lcaves more sheathing (ex Cav.), but the difference between the Canary Island plant and the Eurnpean is hardly discernible.

Sca-side or Common Samphire. Fl. Aug. Brit. Pl. 1 ft.

Cult. Samphire is propagated by parting the roots, or by sowing the sceds in April; but is rather difficult of cnltivation. Marshall says "it likes a cool situation; but yet prefers a sandy or a gravelly soil, and plenty of water. Some," he adds, " have found it to do best in pots, set for the morning sun only." J. Braddick placed it in a sheltered dry situation, screened from the morning sun, protected it by litter during winter, and in spring sprinkled the soil with a little powdered barilla. "This I do," lie says " to furnish the plant with a supply of soda, since, in its native place of growth, it possesses the power of dccomposing sea water, from which it takes the fossil alkali, and rejects the muriatic acid. With this treatment it has continued to flourish at Thames Ditton for some years, producing an ample supply of shoots, which are cut twice in the season, for pickling or to be used in salads.

\section{Tribe VI.}

$\triangle N G E L I^{\prime} C E$ E (this tribe contains plants agreeing in important characters with the genus Angélica) or Orthospérmæ paucijugàtæ tetrápteræ, Koch, umb. p. 98. D. C. prod. 4. p. 164 . Fruit compressed from the back, girded by a double dilated winged margin, from the raplse being central or nearly so, hence the fruit is furnished with 2 wings on both sides. Mericarps with 5 ribs : dorsal 3 filiform or winged : lateral 2 always expanded into wings, and always broaler than the dorsal ones, even if they also should be winged. Seeds rather consex on the back, and flattish in front.

LXXXVI. LEVI'STICUM (from levo, to assuage; said to relieve flatulency). Koch, umb. p. 101. f. 41 . D. C. prod. 4. p. 164.-Ligústicum, Lag. am. nat. 2. p. 91. but not of Koch. -Angélica species of Lam. All. and D.C.-Ligústicum species of Lin. and Spreng.

Lis. syst. Pentándria, Digýnia. Margin of calyx obsolete. Petals incurved, roundish, entire, with a short point. Fruit compressed from the back, having 2 wings on cach side : the mericarps gaping towards the margin. Mericarps with 5 winged ribs : the wings of the lateral ribs twice the breadth of the others; vittæ 1 in each furrow, and $2-4$ in the commissure. Carpophore bipartite. Seed convex on the back, and flattish in front.-A strong, perennial, glabrous, smooth herb. Stems terete. Leaves ternately decompound; leaflets obovate-cuneated, dceply toothed, rather coriaceous. Involucra and involucels of many leaves. Flowers yellow.

1 L. officina'Le (Koch, l. c.). 4 . H. Native of the Pyrenees, Cevennes, Dauphiny, Liguria, west of Germany, and Transylvania. Ligústicum Levísticum, Lin. spec. p. 359. Schultes, syst. 6. p. 567 . Hayn. arz. gew, 7. t. 6 . Wood: med. bot. t. 190. Blackw. icon. t. 275 . Angélica paludapifòlia, Lam. dict. 1. p. 173. Angélica Levísticum, All. pedem. no. 1309. Levísticum vulgàre, IIoris. hist. sect. 9. t. 3. 'The 
odour of this plant is strong aud peculiar; its taste is warm and aromatic. It abounds with a yellowish, gummy, resinous juice, very much resembling Opópanax. Its qualities are supposed to be similar to those of Angélica and Masterwort in expelling flatulences, and exciting perspiration; therefore chiefly used in hysterical disorders and uterine obstructions. The leaves, eaten as salad, are accounted as emmenagogue. The root, which is not so ungrateful as the leaves, is said to possess similar virtues, and may be employed in powder.

Officinal or Common Lovage. Fl. June, July. Clt. 1596. Pl. 4 to 6 feet.

Cult. This plant will grow in any soil ; and is casily increased by dividing at the root.

LXXXVIl. SELI'NUM ( $\sigma \varepsilon \lambda u v^{\prime} \sigma$, sclinon, is the Greek name for parsley ; similarity in the leaves). Hoffm. umb. 1. p. 150. Koch, umb. 100. f. 22-23. D. C. prod. 4. p. 165.-Mylinum, Gaudin, fl. helv. 2. p. 344. but not of Pers.-Angélica species of Spreng.-Celìnum species, Lin.-Thysselinum, Adans. fam. 2. p. 100 .

Lin. syst. Pentándria, Digýnia. Margin of calyx obsolete. Petals obovate, emarginate. Fruit compressed from the back, furnished with 2 wings on each side from the raphe being central ; mericarps with 5 membranous, winged ribs; wings of the lateral ribs twice the breadth of the others; vittæ 1 in each furrow, but there are often 2 in the outer furrows, and always 2 in the commissure. Carpophore bipartite.-Glabrous perennial herbs. Leaves ternately decompound or tripinnate ; leaflets pinnatifid. Umbels compound. Involucra of few leaves; involucels of many leaves. Flowers white.

1 S. CARvifòlıa (Lin. spec. p. 350.) stem angularly furrowed; rays of umbel glabrous; petals emarginate, with an inflexed point. 4. H. Native of Europe (Britain only excepted), in humid and stagnant shady places of woods. Jacq. aust. t. 16 . D. C. fl. fr. 4. p. 322. Oed. fl. dan. t. 667 . S. membranàceum, Vill. cat. strasb. t. 6 . S. angulàtum, Lam. fl. fr. 4 . p. 419. S. pseùdo-carvifòlia, All. pedem. no. 1306. Angélica carvifòlia, Spreng. in Schultes, syst. 6. p. 606. Laserpítium selinò̀les, Scop. carn. 1. p. 198. Carvifòlia, Bauh. pin. 158. Mylìnum carvifòlium, Gaud. fl. helv. 2. p. 344 . Càrum praténse, Park. theat. 910. no. 3. Angélica tenuifòlia, Riv. pent. t. 18. Thysselinum palústre, Vaill. bot. par. t. 5. f. 2.

Caramay-leaved Milk-parsley. Fl. July, Aug. Clt. 1774. Pl. 2 feet.

2 S. CAN dólLil (D. C. prod. 4. p. 165.) stem terete; rays of umbel pubescent; petals obcordate, having the middle nerve crested above. 4.H. Native of Nipaul, on the mountains at Komaon. Angélica? Candóllii, Wall. mss. Leaves ternately decompound; leaflets slender, multifid. Umbels terminal, of many rays. Involucra of many or of few leaves, or wanting, or soon falling off. Petals nearly as in the genus Ptychòtis. Fruit as in S.carvifolia, but larger, and more ovate. Seed furrowed on the back.

De Candolle's Milk-parsley. Pl. 2 feet.

3 S. теREBínthinum (Hook. fl. bor. amer. 1. p. 266. t. 95.) plant glabrous in every part ; leaves tripinnate, stiff, glaucous ; segments pinnatifid: lobes short, linear, acute; peduncles elongated; involucra wanting; leaves of involucels linear, short; mericarps with 5 broad, undulating ribs. 4 . H. Native of the north-west coast of America, common on the sandy grounds of Wallawallah river. Root fusiform. Rays of umbel very unequal. Fruit rather large, ovate, compressed. The genus to which this plant belongs is truly doubtful. The fruit not corresponding well with any described genus.

Turpentine Milk-parsley. Pl. $1 \frac{1}{2}$ foot.

4 S. stella'tum (D. Don, prod. fl. nep. p. 185.) leaves pin- nate; leaflets ovate, mucronate, 3 -lobed and deeply toothed, glabrous; involucra of 2-3 leaves; rays of umbel pubescent ; leaves of involucels large, coloured; fruit glabrous. $4 . \mathrm{H}$. Native of Nipaul. Astrántia spec. Wall. in litt. Stems branclied, erect. Rays of umbel equal. Leaves of involucels ellipticoblong, membranous, much longer than the umbellules.

Starry Milk-parsley. Pl. ¿ feet?

Cult. SeeAngélica, p. 323. for culture and propagation.

LXXXVIII. OSTE'RICUM (meaning unknown to us). Hoffm. umb. p. 162. Koch, umb. 100. D. C. prod. 4. p. 167. -Angélica species, Fisch. Spreng. and Lag.

Lin. syst. Pentándria. Digýnia. Calyx with 5 broad teeth. Petals unguiculate, obovate, emarginate, with an inflexed point. Fruit compressed from the back, furnished with 2 wings on both sides from the raphe being central. Mericarps with 3 dorsal elevated filiform ribs, but the 2 lateral ribs are dilated into much broader wings; vittæ 1 in each furrow. Carpophore bipartite. Seed flat.-A perennial herb. Stem furrowed, quite glabrous. Leaves ternately decompound, rough beneath; leaflets rather divaricate, ovate-cordate, unequally toothed. Umbels compound. Involucra of few leaves; involucels of many leaves. Flowers white.

1 O. pRate'nse (Hoffm. 1. c. p. 164.). 2. H. Native of Gallicia, in moist low meadows, about Erford and Charkow. Angélica praténsis, Bieb. in Spreng. umb. spec. p. 60 . Imperatơria palústris, Bess. fl. gal. 1. p. 214. O. palústre, Besser. in litt. Rchb. icon. t. 402. Selinum odoràtum, Bcrnh. ined. Angélica palústris, Bess. cat. hort. crem. 1816. p. 12.

Meadow Ostericum. Fl. Ju. Aug. Clt. 1818. Pl. 3 feet.

Cult. See Opópanax above for culture and propagation.

LXXXIX. ANGE'LICA (so named from the supposed angelic virtues of some species). Hoffm. umb. I. p. 158. Koch, umb. 99. f. 20-21. Gaudin, f. helv. 2. p. 340 . D. C. prod. 4. p. 167.-Angélica species, Lin. Spreng. and Lag.

Lin. syst. Pentándria, Digýnia. Margin of calyx obsolete. Petals lanceolate, entire, acuminated; points straight or incurved. Fruit compressed from the back, furnished with 2 wings on both sides from the raphe being central; mericarps with 3 dorsal, filiform, elevated ribs, and 2 lateral ones which are dilated into membranous wings, more or less broader than the dorsal ones ; vittæ 1 in each furrow. Seed nearly semi-terete. Carpophore bipartite, free.-Perennial or biennial herbs. Leaves bipinnate. Umbels terminal. Involucra wanting or of few leaves; involucels of many leaves. Flowers white.

Sect. I. Euange'́lica (from $c u$, well, and angelica; this section contains what are considered the true species of the genus). D. C. prod. 4. p. 167. Petals with a longish taper point, rarely obcordate. Vittæ one in each furrow, and 2 in the commissure. Stems leafy. Petioles much dilated.

1 A. Razou'LSII (Gouan. ill. 13. t. 6.) stem striated, pubescent at the apex; leaves bipinnate or tripinnate; leaflets lanceolate, serrated, acute, scabrous beneath, decurrent at the base, and sometimes 2-parted; involucra usually of one leaf only; pedicels pubescent. 4 . H. Native of the Pyrenees. D. C. fl. fr. 4. p. 305. and 5. p. 508. A. ebulifòlia, Lapeyr. abr. p. 156. A. Tournefortiàna, Cusson. A. Pyrenàica tenuifòlia, Tourn. herb.-Bocc. mus. t. 99 . The vittæ in the commissure is covered by a pericarp. The points of the petals are iucurved. The mericarps are ovate, and the stamens are very long. It was first discovered by M. Razouls, an apothecary at Perpignon. Flowers purple before expansion, but afterwards white.

V ar. $\beta$; leaves of involucels foliaceous, dilated; pedicels of umbellules few and elongaterl. 4. H. Native of the Pyrenees, about Querigut. D. C. fl. fr. 5. p. 508. 
Razouls's Angelica. Fl. June, Aug. Clt. 1816. Pl. 3 feet. 2 A. monti'va (Schleich. exsic. Koch, umb. 99.) stem striated, pubescent at the apex; leaves tripinnate; leaflets lanceolate or ovate, acuminated, quite glabrous, sharply and mucronately serrated : upper ones decurrent at the base; involucra of 1-3 leaves; pedicels pubescent. 24. or $8 . H$. Native of mountain pastures on the Alps of Jura, Cevennes, and Volhynia. Gaudin, fl. lıelv. 2. p. 341. A. Razùlii var. $\beta$, Lois. fl. gall. ed. 2. vol. 1. p. 202. Imperatòria montàna, D. C. fl. fr. 5. p. 504. Imp. flavéscens, Bess. prim. f. galic. 1. p. 213. Angel. Razoúlii, All. pedem. no. 310 . and Spreng. umb. spec. p. 61 . exclusive of the syn. Angel. sylvéstris var. C, C. Vill. dauph. 2. p. 628. Mericarps broad, ovate. Vittæ somewhat superficial. Stamens very long. Points of petals short and nearly straight. Involucra deciduous.

Mountain Angelica. Fl. July. Clt. 1818. Pl. 3 feet.

3 A. SyLVE'stris (Lin. spec. 361.) stem polished, striated, often purple, with wide spreading branches, pubescent at the apex, as well as the peduncles; leaves bipinnate or tripinnate, rather glaucous; leaflets ovate or ovate-lanceolate, acute, unequally and sharply serrated, never decurrent at the base ; involucra of 1..2 leaves. 4 . H. Native of Europe, Siberia, and Caucasus, in watery places, alder cars, and along the banks of rivers, common; plentifu] in like situations in Britain. Smitl, engl. bot. t. 1128. Woodv. suppl. t. 265. Ger. enac. 999. f. 1. Dodon, pempt. 318. f. 1. Camer. epit. 900. f. 1. Lob. icon. 699. Angélica palústris, Riv, pent. t. 17. Hayne, arz. gew. 7. t. 9. Water Angélica, Petiv. herb. brit. t. 24.t. 10. Imperatòria sy]véstris, D. C. fl. fr. 4. p. 286. Selinum sylvéstre, Crantz, austr. 177. Selìnum angélica, Roth, germ. 1. p. 133. Selìnum pubéscens, Mœnch, meth. p. 80. Úmbels convex, with numerous general and partial downy rays. Flowers white, but more generally flesl-coloured. Points of petals erectish. Vittæ in the commissure superficial. The flavour is more bitter, and less grateful than the Archangélica, but the virtues of botl are similar. The herb dyes a good yellow.

I'ild Angelica. Fu. July. Britain. Pl. 4 to 6 feet.

4. A. Lu'cibs (Lin. spec. p. 360.) stem terete, glabrous ; leaves bipinnate; leaflets equal, ovate, deeply serrated; sheaths dilated ; involucra and involucels of 5 leaves eacb. $\psi$. H. Native of North America, from Canada to Pennsylvania, in moist shady places. Pursh, fl. amer. sept. 1. p. 193. Jacq. hort. vind. 3. t. 24.-Moris, hist. sect. 9. t. 3. f. 8. Ang. lobàta, Walt. car. p. 115.? ex Torr. The petals are said to be elliptic, pale green, with an inflexed point. By Jacquin the flowers are said to be whitish, or of a pale yellow-colour.

Shining-leaved Angelica. Fl. July, Aug. Clt. 1640. Pl. $2 \mathrm{ft}$.

5 A. Trievina'ta (Miclix. fl. bor. amer. 1. p. 167.) stem terete, pubescent above ; leaves bipinnate ; leaflets on the lower branches of the petiole ternate : all oval and acuminated at both ends, sharply serrated; umbels clothed with velvety pubescence at the time of flowering. $\quad \%$. H. Native of North America, on dry hills and in woods. Nutt. gen. amer. 1. p. 186. Torrey, fl. un. st. 1. p. 315 . A. hirsùta, Muhl. cat. no. 30. Pastinàca triquinàta, Spreng. umb. spec. 68. t. 6. f. 2 . Férula villòsa, Walt. car. no. 115. Pursh, fl. amer. sept. 1. p. 192, exclusive of the synonyme.

Triquinate-leaved Angelica. Fl. July, Aug. Clt. 1810. Pl. 2 feet.

Sect. II. Pseudangélica (this section is supposed to contain false species of the genus; hence the name). D. C. prod. 4. p. 168.-Angélica species, Spreng. Koch.-Selìnum species, Gouan. -Séseli species, Lin. Petals elliptic, acuminated or mucronated. The fruit is like that of the last section, but differs in there bcing usually 4 vittæ in the commissure. Rays of umbels very unequal, the central ones very sliort.

6 A. PYRENA'A (Spreng. umb. spec. p. 62.) stem furrowed, simple, almost leafless; radical leaves somewhat bipinnate, glabrous; leaflets erectisl, pinnatifid; segments linear, acute; rays of umbel 4-7; involucra of one setaceous leaf. 2. H. Native of the Pyrenees and Cevennes, in mountain pastures. Séseli Pyrenæ'um, Lin. spec. 374. Selìnum alicástrum, Link. Selìnum Pyrenæ'um Gouan, ill. p. 11. t. 5. D. C. fl. fr. 4. p. 323. De La Chenal, in act. helv. 7. p. 332. t. 12. Selìnum Lachenàlii, Gmel. fl. bad. als. 1. p. 460. t 3.-Moris, hist, sect. 9. t. 9. f. 2. Mericarps ovate, elliptic, with superficial vittæ. Herb rather glaucous. Root flowing with milky juice. From the stem there is often one leaf, having a broad petiole, from the axil of which issues a branch. Involucels of many bristle-shaped leaves.

Pyrencan Angelica. Fl. June, Aug. Clt. 1800. Pl. 1 foot.

\section{$†$ Species not sufficiently known.}

7 A. integrifòlia (Walt. car. p. 1I5.) leaflets entire, petiolate. 4. H. Native of Carolina. The rest unknown.

Entire-leafletted Angelica. Pl. ?

8 A. Bractea'ti (Roxb. in Beats, trav. voy. append. p. 297.) stem fistular; leaves unequally pinnate; leaflets rather cordate, 3-7-nerved, finely jagged, serrated ; bracteas or sheaths broad, nearly orbicular at the base of the petioles, and between the segments; involucra and involucels of 6-10 broad lanceolate leaves each. 4 . H. Native of the Island of St. Helena, where it is called by the inhabitants common angelica. Petals white, oval-oblong, incurved. Umbellules globose. Fruit unknown. Perhaps a species of Archangélica.

Bracteate Angelica. Pl. 3 to 4 feet?

Cult. Any soil will suit the species of Angélica, and they are easily increased by seeds.

XC. ARCHANGE'LICA (from $a \rho \chi \eta$, arche, original, and angelica). Hoffm. umb. 1. p. 166. f. tit. 19, 20. Koch, umb. 98. f. 17-19. Gaudin, f. helv. 2. p. 342. D. C. prod. 4. p. 169.Angélica species, Lin. Spreng. Lag.

Lin. syst. Pentándria, Digýnia. Margin of calyx with 5 short teeth. Petals elliptic, entire, acuminated, with an incurved point. Fruit rather compressed from the back, furnished witl 2 wings on each side, from the raphe being nearly central. Mericarps with 5 thickish keeled ribs, the 3 dorsal ribs elevated, and the 2 lateral ones dilated into wings, which are twice the breadth of the others. Seed not adhering to its tegument, but distinct from it, and covered by copious vitta all over. Carpophore bipartite.-Perennial or biennial herbs. Leaves pinnate; leaflets broadly ovate, acute, coarsely toothed: terminal one lobed. Petioles large, sheathing, and rather bladdery. Involucra wanting or nearly so ; involucels dimidiate, of many leaves. Flowers white or greenish.

1 A. officina'lis (Hoffim. and Koch, l. c.) stem polished, striated, a little glaucous, branched in the upper part; leaves ternate, then pinnate; leaflets ovate-lanceolate or subcordate, cut, and sharply serrated, partly decurrent : the odd one deeply 3-lobed ; petioles dilated and tumid at the base ; involucra of a very few linear leaves, or wanting altogether ; leaves of involucels linear-lanceolate. $\quad$ t. H. Native of Europe, on mountains by river sides, particularly in Lapland, Sweden, Norway, Germany, Carpathian mountains; and from Unalaschka to the Bay of Eschscholtz; and now cultivated every where for the sake of its stalks. In Britain in watery places, rare, apparently a naturalized plant; as about the Tower of London, and on the banks of ditches frequent; in marshes among reeds by the side of the T 2 
Thames, between Woolwich and Plumstead, very abundantly; in the county of Durham; and at Broadmere, about 7 miles north-west from Birmingham. Angélica Archangélica, Lin. spec. 360 . Oed. fl. dan. t. 206. Nees, off. pfl. 9. t. I4. Hayn. arz. gew. 7. t. 8. Smith, engl. bot. 2561. Woodv. med. bot. t. 60. Angélica officinàlis, Moench, meth. p. 81. Angel. satìva, Mill. dict. no. 1. Riv. pent. t. 15. Petiv herb. brit. t. 24. f. 9 . Camer. epit. 899. f. 1.-Ger. emac. 1000. Flowers greenish. The garden angelica was formerly cultivated on account of its leaf-stalks, which were blanched, and eaten as celery; now they are used only when candied, being, when so prepared, acceptable to most people, and are not so powerfully aromatic; the young and tender stalks are for this purpose collected in May. Sometimes also the seeds and leaves are used in medicinal preparations. The root, which is the most efficacious part, is used in the aromatic tincture. Of the anti-pestilential virtues of the root, those who wish to be informed will find amusement at least in old Gerarde, p. 1000.

The plant delights in moist situaticns, or the bank of 1 unning water; but will grow freely in any soil or exposure. The plants are raised from seed, and for a bed $4 \frac{1}{2}$ feet by 6 , sown in drills a foot apart, to be transplanted; half an ounce of seed will be requisite. "Sow in August, or as soon as the seed is ripe, as the plants will come up earlier and stronger than from sowing in the spring. When the plants are advanced from 4 to 6 inches high, transplant them into rows 2 feet apart. They will soon strike root, and advance quickly in strong growth. In the second year these strong erect branehy stalks will be several feet high, producing large umbels of flowers and seed, ripening in autumn, which, as well as the leaves of the plant, are used in medicine. But for candying, the young sloots of the stem and stalks of the leaves are the useful parts; being cut while green and tender in May and June, they are made by the confectioners into the sweet-meat called angelica. In the second year, if seer is not wanted, cut the plants down in May, and the stock will send out side shoots; by repeating this practice every year, the same plant may be long continued."-A bercrombie.

Officinal or Garden-angelica. Fl. June, Sept. Britain. Pl. 4 to 6 feet.

2 A. Atropurpu'rea (Hoffm. umb. 169.) stem polished, purple, with a glaucous bloom, branched at the top; leaves ternate, then pinnate; leaflets ovate, acute, deeply serrated, and somewhat lobed: the terminal ones confluent; petioles dilated, and tumid at the base; branches and umbels pubescent; involucra wanting; the involucels of many narrow leaves. $\delta . \mathrm{H}$. $\mathrm{Na}$ tive from Canada to Virginia, in moist meadows. Angélica atropurpùrea, Lin, spec. 360 . Lam. dict. 1. p. 173. Torr. fl. un. st. 1. p. 316. Angélica triquinàta, Bigel. fl. lost. p. 68. ex Torr. -Corn. can. 199. with a bad figure.-Moris, hist. sect. 9. t. 3. f. 9. bal. Petals rusty purplish or white. The plant may be used in the same way as the $A$. offeinalis.

Dark-purplc-stemmed Archangelica. Fl. July, Ang. Clt. 1759. I'l. 4 to 6 feet.

3 A. DecúrRens (Led. f. ross. alt. ill. t. 166. fl. alt. 1. p. 316.) stem striated, with a glancous bloom, furnished with leaves and axillary branclies at the base; leaves pinnate or bijinnate : lower leafiets piunate, upper ones pinnatifid: segments ohlong, or ovate-oblong, acuminated, decurrent : odd one 3 -lobed ; involucra of many narrow leaves. 24. H. Native of Altaia, every where on the margin of rivulets, Flowers like those of $A$. officinalis, but varying more to yellow. Ilabit of $A$. officinulis, but differs in the leaves being mnch acuminated, those on the secondary branches of the petiole running down it a great way, and serrated their whole length. Fruit exhaling a heavy smell when rubbed.

Dccurrcut-leafletted Archangelica. Fl. year. Pl. 6 to $8 \mathrm{ft}$.
4 A. Littora'lis (Agardh, in litt. ex D. C. prod. 4. p. 170.) stem glabrous, terete, striated, hard; leaves bipinnate; leaflets ovate, acute, serrated: odd one 3 -lobed; sheatls large; leaves of involucels rather scabrous, one-half shorter than the umbellules. 4. H. Native of the north of Europe, on the sea shore. Archangélica spùria or A. littoràlis, Wahl. carp. p. 84. A. màjor, Lag. gen. nov. et spec. p. 13.?-Dodon. pempt. 818 . f. 1? Flowers whitish. Stem hard and acrid, not edible.

Sca-shore Archangelica. Pl. 4 to 6 feet.

5 A. Grelini (D. C. prod. 4. p. 170.) stem glabrous, terete, striated; leaves ternate; leaflets tripartite: lobes ovate, serrated, cuneated at the base ; sheaths middle-sized; leaves of involucels about equal in length to the umbellules. $2 . \mathrm{H}$. $\mathrm{Na}$ tive of Kamtschatka and Kotzebne's sound. Angélica Gmelini, Wormsk. ex Fisch. in litt. A'pium ternàtum, Pall. in Spreng. syst. 1. p. 890 . The plant is used for culinary purposes by the Russians in Kamtschatka. Fruit like those of $A$. officinalis, but more oblong, and the vittæ are fewer. There is a dwarfer variety of this found in Kotzebue's Sound.

Gmelin's Archangelica. Pl. I $\frac{1}{2}$ foot.

Cult. The species are of easy culcivation; and are only to be increased by seed.

\section{Tribe VII.}

PEUCEDA'NE $\mathbb{E}$ (so named from the plants agreeing with the genus Peucédanum in many points), or Orthospérmæ paucijngàtæ dipteræ.-Selíneæ, Koch, umb. p. 88. Fruit flatly or lenticularly compressed from the back, girded by an entire dilated smooth winged flattened or rather convex margin. Mericarps with 5 filiform ribs, which are rarely winged ; lateral ones contiguous to the margin, or running into it ; raphe marginal, hence the fruit is only furnislied with one wing on each side, not as in tribe Angelicece, furnished with 2 wings on each side from the raphe being central. Seed flattened or convex on the back.

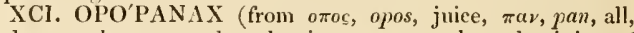
and asos, akos, a remedy; that is to say, a plant the juice of which is supposed to cure all diseases). Koch, umb. 96. D. C. prod. 4. p. 170.-Pastinàca and Laserpítium species.-Férula species, Spreng. Lag.

Lın. syst. Pentándria, Digýnia. Margin of calyx obsolete. Petals rounclish, entire, involute, with an acutish point. Stylopodium broad, thick. Styles very short. Fruit flatly compres. sed from the back, girded by a dilated convex margin. Mericarps with 3 dorsal filiform slender ribs: the lateral ones absent or not distinct from the margins ; vitte 3 in each furrow, and 6-10 in the commissure. Seed flat.-A perennial herb. Root thick. Stem rough. Leaves bipinnate; leaflets unequally cordate, crenated, obtuse. Umbels composed of many rays. Involucra and involucels of few leaves. Flowers yellow.

I O. Chinonium (Koch, l. c.) 24. H. Native of the south of France, in open situations; also of Italy, Sicily, Croatia, and Greece. Nees, off. ptl. 17. t. 11. Laserpítium Chirònium, Lin. spec. p. 376. Pastinàca Opópanax, Lin. spec. 376. Gouan. ill. t. 14. Waldst. et Kit. hung. 3. t, 211 . Smith, fl. græc. t. 288. Woodv. mied. bot. t. 113 . Selìnum Opóplanax, Crantz, austr. p. 53. Férula Opópanax, Spreng. umb. spec. 77. Schultes, syst. 6. p. 597. Pastinàca altíssima, Lan. fl. fr. 3. p. 465.Lob. icon. t. 702.-Moris, hist. 3. p. 315 . sect. 9. t. 17. f. 2. Sheaths at the flowering branches spathaceous, and sometimes destitute of leaves. Leaves hairy, especially beneath. Although the plant is a native of the south of Europe, the gum-resin, which is satid to be obtained by wounding the stalk or root, is brought from the Levant and the East Indies, sometimes in: round drops or tears, but more commonly in irregular lumps, of a reddish yellow-colour on the outside, with specks of white; 
inwardly of a paler colour, and frequently variegated with large white pieces. It is supposed to be an emmenagogue, but is seldom used.

Chiron's or Common Opopanax. Fl. June, July. Clt. 1640. Pl. 6 feet.

Cult. This is a plant of easy culture; and may be increased either by seeds or dividing at the root.

XCII. FE'RULA (from ferio, to strike; stems used as rods). Tourn. inst. 321. t. 170. Lin. gen. no. 343 . Spreng. umb. prod. 1. 13. exclusive of some species.-Férula and Ferulàgo, Koch, umb. p. 96 . and p. 97 .

Lis, syst. Pentándria, Digýnia. Margin of calyx with 5 short teeth. Petals ovate, entire, acuminated, with the points ascending or incurved. Fruit flatly compressed from the back, girded by a flattened dilated margin. Mericarps with 3 dorsal filiform ribs, and 2 lateral obsolete ones, which are lost in the dilated margin. Vittæ 3 or more in the dorsal furrows, and 4 or more in the commissure. Seed flat. Carpoplore bipartite. -Herbs, with thick roots, tall stems, and supra-decompound leaves : leaflets usually cleft into linear segments. Umbels of many rays : lateral ones usually opposite or verticillate. Involucra variable. Flowers yellow. Stems in many of the larger species filled with medulla, interspersed with fibres, as the stems of monocotyledonous plants.

Sect. I. Ferula'go (an alteration from the generic name). Koch, umb. 97. Dorsal and commissural vittre numerous, from 30 to 60 . Involucra constantly of 4-8 leaves. Stems usually striated or angular.

1 F. sxlva'tica (Bess. cont. enum. pl. vohl. et pod. p. 44. no. 1368.) stem terete, striated, rather angular; leaves pinnate, with 10-20 pairs of opposite bipinnate-parted leaflets; lobes or segments linear, setaceous, cuspidate; leaves of involucra ovatelanceolate, deflexed. 4 . H. Native of Volhynia, Cancasus, Podolia, and at the river Don, in woods and meadows. Pencédanum officinàle, Bess. prim. f. galic. et cat. hort. crem. 1816 . Férula noditiòa, Rochel. F. myriophýlla, Bieb. mss. Ferulàgo sylvática, Rchb. icon. bot. 4. p. 371. Leaves a foot or a foot and $\mathrm{a}$ half long.

Wood Giant-fennel. Pl. 6 feet.

2 F. PAuci'jugA (D. C. prod. 4. p. 171.) stem striated, angular; leaves pinnate, with $4-5$ pairs of opposite leaflets; leaflets bipinnatifid: lobes or segments linear; involucra of $2-5$ erect leaves, which are cuspidate at the apex, and membranously dilated at the base. 4 . H. Native of Persia, at the foot of the mountains about Badala, where it was gathered by Szowits. Allied to $F$. sylvática, but differs in the stem being more angular, and in the leaves being 3-4 inches long, and in the leaflets being only 4-5 pairs. Umbel terminal, of 12-14 very unequal rays. Herb glabrous, a foot and a half high.

Fen-paired-leaved Giant-fennel. Pl. $1 \frac{1}{2}$ foot.

3 F. Ferula'go (Lin. spec. p. 356.) stem terete, striated; leaves supra-decompound; leaflets pinnatifid, divaricate: segments linear, cuspidate ; leaves of involucra numerous, oblonglanceolate, reflexed. 4. H. Native on hills and exposed places in the islands of the Mediterranean, and the adjacent region ; and of Transylvania and Gallicia. Spreng. umb. prod. p. 82. F. nodifiòra, Jacq. austr. append. t. 5. and probably of all other authors.-F. latiore folio, Moris, ox. sect. 9. t. 15. Lob. icon. t. 779. Dodon. pempt. t. 321. f. 2.

Ferulago or Broad-leaved Giant-fennel. Fl. June, July. PI. 6 to 8 feet.

4 F. Genicula'ta (Guss. prod. A. sic. 1. p. 366.) stem terete, a little striated, gibbous at the nodi; leaves supra-decomponnd; leaflets decussate: segments linear, flat, acute, stiff, rather awned; floriferous branches alternate; leaves of involucra and involucels ovate-lanccolate, short; fruit oblong-elliptic, with acute prominent ribs. 24. H. Native of Sicily and the kingdom of Naples, on dry calcareous hills. F. rigida, Tenore, $\mathrm{f}$. neap. append. 4. p. 15. exclusive of the synonymes. Bùbon rígidus, Ucria ex Guss.-Bocc. mus. 2. t. 76.?

Geniculate-leaved Giant-fennel. Pl. 2 to 3 feet.

5 F. Tiyrsifzòra (Sibth and Smith, A. græc. t. 280. prod. no. 664.) stem angular and furrowed at the top; floriferous branches terminal, aggregate, compound; leaves supra-decompound; leaflets linear, elongated, roughish ; leaves of involucra 4-6, linear-lanceolate. 4 . H. Native of Candia, on rocks. Ferulàgo thyrsifòra, Koch, umb. p. 98 . Vittæ above 30 in the commissure, according to Koch, but in a specimen examined there are only from 20 to 25 .

Thyrse-flowered Giant-fennel. Fl. June, July. Clt. 1825. Pl. 4. to 6 feet.

6 F. sulcA'TA (Desf. atl. 1. p. 352. t. 67.) stem angular and furrowed; leaves supra-decompound ; leaflets pinnatifid : lobes linear, acuminated ; leaves of involucra many, oblong-linear, refiexed. 4. H. Native of Italy, Naples, Sicily, IIauritania, and Portugal, on hills. F. nodifiora, Spreng. umb. spec. p. 84 . but the figure of F. nodiflòra in f. græc. is destitute of involucra, and therefore does not belong to this plant; therefore the plant of Linnæus is truly doubtful. F. Barrelièri, Tenore, in herb. Merat. Ferulàgo nodifìra, Koch, umb. p. 98. Ligústicum lùteum, Poir, voy. barb. 2. p. 136. ex Poir. suppl. 3. p. 481 . Peucédanum Lusitánicum and rupéstre, Willd. herb. ex Spreng. syst. 1. p. 914. Vittæ 60 in the commissure, ex Koch.

Var. B, campéstris (Bess, in litt. ex Spreng. syst. 1. p. 914.) segments of leaves linear-elongated. $4 . \mathrm{H}$, Native of 'Tauria. Furroned-stemmed Giant-fennel. Fl. June, July. Clt. 1596. Pl. 3 feet.

7 F. strícta (Spreng, in Scluultes, syst. 6. p. 592.) sten straight, stiff, furrowed; leaves ternately supra-decompound, straight; leaflets triternate, triquetrous, filiform, glabrous; leaves of involucra ovate-oblong. 24.G. Native of the Cape of Good Hope.

Straight Giant-fennel. Fl. June, July, Clt, 1818. Pl. 2 feet.

Sect. II. Ferula ria (an alteration from the generic name). D. C. prod. 4. p. $172 .-F e ́ r u l a$, Koch, umb. p. $96 . \quad$ Vitta 3 in each of the dorsal furrows, and 4 in the commissure. Involucra wanting. Stems terete.

\section{* Stem leafy.}

8 F. commu'nis (Lin. spec. p. 355 ) stem terete, branched; leaves supra-decompound, green ; leaflets linear-setaceous, flaccid; central umbel nearly sessile : lateral ones male, pedunculate; involucra wanting; sheaths of upper leaves very large. 4. H. Native on hills in the region of the Mediterranean, from Portugal to Greece, and of Mauritania. D. C. A. fr. 3. p. 343. F. nodifiòra, Lin. spec. 356 ? Smith, fl. græc. t. 279.Dodon. pempt. p. 321. f. 1. Lob. icon. t. 778. f. 2.-F. fémina, Plum. Tourn. Moris, umb. 35. t. 2. hist. 3. p. 309. sect. 9. t. 15. f. 3. Lateral umbels usually opposite, rising from the axils of the sheathing petioles under the central umbel. Fruit 5 lines long, and 3 lines broad. There issues from the stem when cut a yellowish fetid juice, which hardens on the surface of the wound. The dry dead stem is full of white pith, which easily takes fire, and the Sicilians use it for tinder. Hence the fable of Prometheus. In Apulia, where the plant grows in great plenty, it is grateful to buffaloes, which form the chief part of the subsistence of many farmers there.

Common Giant-fennel. Fl. June, July. Clt. 1597. Pl. 8 to 12 feet. 
9 F. GLAU'CA (Lin, spec. p. 588.) stem terete, branched; leaves supra-decompound, glaucous beneath; leaflets linear, elongated, flat; involucra wanting; petioles of upper leaves dilated; central umbel pedunculate; lateral ones male, on longer peduncles. 4.H. Native of the south of France, at Merival, near Montpelier in the spot mentioned by Lobel; also of Provence, Italy, Sicily, Greece, \&c. F. fòlio glaúco, Baub. hist. 3. p. 2. p. 45 . with a figure. Férula et Ferulàgo, Lob. adv. p. 348 . F. cornmùnis, Gouan. hort. monsp. p. 140. F. glaúca, D. C. fl. fr. suppl. p. 514. Schultes, syst. 6. p. 588. Leaves of involucra many, linear-setaceous, caducous, ex Spreng. but in the plants examined there has been no involucra seen; therefore Sprengel's plant is probably distinct from this.

Glaucous Giant-fennel. Fl. June, July. Clt. 15:6. Pl. 6 to 8 feet.

10 F, rigídula (D. C. prod. 4. p. 172.) stem terete, branch$\mathrm{ed}$, and is, as well as the petioles, quite glabrous; leaves bipinnate; leaflets pinnatifid: lobes short, few, acute, channelled, stiffish, hardly puberulous; umbels rather panicled, without any involucra. 4 . H. Native of Persia, on rocks among the mountains about Seidlkhodz. Very like $F$. Cáspica in the inflorescence and fruit, but differs in the primary pairs of leaves being an inch and a half distance from each other, and the secondary pairs are more elongated; leaflets fewer; lobes fewer, stiffer, and rather fleshy. Sheaths larger, and rather glaucous.

Stiffish Giant-fennel. Pl. 3 feet?

11 F. CA'spica (Bieb. fl. taur. suppl. no. 551.) stem terete, branched; leaves triplicately pinnate: leaflets pinnatifid, soft, approximate; segments very short; umbels somewhat panicled; the peduncles of the lateral umbels furnished each with a subulate ligula at the base; involucra none. 2\%. H. Native of arid fields from Odessa to Sarepta; and of Caucasus, near Kisliar. Spreng. umb. spec. p. 81. F. cachroides, Fisch. in litt. 1822. There are varieties of this with either glabrons or pubescent leaves, according to Bieb. The habit is like that of Cachrys Odontálgica. Sheaths cucullate: upper ones almost destitute of leaves. Fruit oval, glabrous, 3 lines long, $1 \frac{1}{2}$ line broad. Commissure furnished with 4 vitta. Umbel-bearing branches alternate: lower ones often opposite, and upper ones in whorles. Perhaps a species of Peucédanum, according to Besser.

Caspian Giant-fennel. Fl. June, July. Clt. 1819. Pl. 2 to 3 feet.

12 F. ORIENTA'Lis (Lin. spec. p. 356.) stem terete, branched; leaves 5 times pimate; leaflets multifid, setaceous, apparently puberulous when examined by a lens; sheatlus large, cucullate; involucra wanting. 4 . H. Native of Asia Minor, Greece, Caucasus on Mount Beschbarmak, and perhaps of Numidia. Lam. dict. 2. p. 455. Spreng. umb. spec. p. 89 ? Tourn. trav. 2. t. 379. Branches of root thick. Leaves a foot and a half long. Upper sheatlis 3 inches long, and an inch broad. Sprengel refers to this the Fashook of Jackison's account of Morocco, 1. 7. Steven says it is the same as F. peucedanifolia, Willd. herb., but Pallas's figure, which is cited for it, is very different from our plant.

Eastern Giant-fennel. Fl. July, Aug. Clt. 1759 . Pl. 3 to 4 feet.

13 F. PÉrsica (Willd. spec. 1. p. 1413.) stem terete, glaucous; leaves ternately supra-decompound; leaflets rather remote or decurrcntly pinnate: segments linear-lanceolate, dilated, and cut at the apex; primordial umbel sessile; involucra and involucels wanting. 2. H. Native of Persia; and of Caucasus, on hills near Baku. Andr. bot. reg. 558. Sims, bot. mag. 2096. F. assafoétida, Mart. in Mill. dict. no. 9. exclusive of the synonyme of Koemf. Woodv. med. bot. 22. t. 8. Plench. icon. t. 203. Assafuétila, Hoppe, in phil. trans. 1785. p. 36 . t. 3. and 4. The plant smells very strong of assafoctida, and there is a yellow gummy juice very like it flows from the plant, which in all probability has the same virtues as that of the true assafoetida, $\vec{F}$. assafrétida. Plant of a yellowish hue.

Persian Assafoetida. Fl. June, July. Clt. 1782. Pl. 3 to $6 \mathrm{ft}$.

14 F. Tingita'na (Lin. spec. p. 355.) stem terete, branched; leaves supra-decompound, shining; leaflets or segments oblonglanceolate, deeply toothed; upper petioles large, sheathing; terminal umbels on short peduncles: lateral umbels few, male, on longer peduncles; involucra none. 4 . H. Native of Spain and Barbary, and in fields about Tangiers. Rivin. pentap. 3. t. 10. Herm. par. t. 165 . Moris. ox. sect. 9. t. 15. last figure. Desf. A. atl. 1. p. 25I. Fruit 6 lines long, and 3 lines broad. This plant is easily distinguished from the rest, in the leaflets being broader, and shining.

Tangier Giant-fennel. Fl. 'June, July. Clt. 1680. Pl. 6 to 8 feet.

15 T. NU'DA (Spreng. umb. spec. 81. t. 7. f. 15.) stem terete, striated, branched; leaves ternately bipinnatifid, glaucous ; segments obtuse, rather tridentate; involucra and involucels none. 4. H. Native of Siberia. Petioles sheathing at the base, glaucous. Branches spreading. Stem about the thickness of a goose quill, girded by fibres at the base, just at the neck.

Naked Giant-fennel. Fl. Ju. July. Clt. 1821. Pl. 1 to $2 \mathrm{ft}$.

16 F. 'Touvece'nsis (H. B. et Kunth, nov. gen. et spec. 5. p. 12. t. 418.) stem terete, fistular; leaves quadripinnate; leaflets or segments linear, acute, flat; involucrum of one leaf; involucels of 3-7 linear leaves, which exceed the fruit. 4 . F. Native of Mexico, in cold places near the town of Tolucco. Herb glabrous, a foot high, a little more. Rays of umbel unequal. Leaf of involucrum linear, shorter than the rays of the umbel. Leaves of involucels 5-6, very unequal, the longer ones exceeding the umbellules. Flowers many, abortive. Vittæ 4 in the commissure, and 3 in the furrows.

Tolucco Giant-fennel. Pl. $1 \frac{3}{2}$ foot.

17 F. petrola'ris (D. C. prod. 4. p. 173.) plant quite glabrous ; stems terete, branched, leafy at the base ; petioles biternate, having the ultimate divisions very long, and cylindrically conical, acute, bearing no foliaceous segments; upper sheaths smatl, undivided, acuminated; invohucra and involucels none. 4. H. Native of Persia, among stones on the tops of the mountains about Seidkhodz, where it was collected by Szowits. The species is very remarkahle in the absence of foliaceous leaflets, and therefore the leaves are reduced to the naked petioles. Ultimate lobes of petioles 7-8 incles long, usually knotted at the third part of their lengtb, as in Juncus articulatus, the knots indicating the places of the abortive branches. Umbels few-flowered. Young fruit oblong, glaucous.

Petiolar Giant-fennel. Pl. 2 to 4 feet?

18 F. SESELOIDEs (Meyer, pflanz. p. 126.) glabrous, glaucescent; stem rather angular, leafy, branched; lower leaves bipinnate : leaflets pinnatifid: lobes linear; sheaths narrow : upper sheaths leatless, acuminated; umbels all fertile, pedunculate; involucra almost wanting; leaves of involucel setaceous; vittæ $1-3$ in the furrows. 4 . H. Native of Caucasus, on Mount Beschbarmak. Leaves of Séseli montanum; but the petals are yellow like other species of Férula. Margin of calyx obsolete. Fruit nearly like Peucédanum.

Seseli-like Giant-fennel. Pl. 2 to 9 feet?

\section{* Stcms almost naked.}

19 F. A'SSA-FOE'TIDA (Lin. mat. med. 79.) stem terete, simple, furnished with leafless sheaths; radical leaves pinnate, having 1 or 2 pinnatifidly sinuated leaflets on each side: lobes oblong, obtuse; involucra wanting. $4 . H$. Native of Persia, in the provinces of Khorassan, Laar, and Fars. A'ssa-foe'tida, Kœmpf, amon. p. 535 . and p. 536. with a figure. Stem 
5-6 feet high. According to the testimony of Kœmpfer, this is the plant from which the real assafoetida is obtained. It is the concrete juice of the root, and is procured by the peasants who live in the neighbourhood of the mountains in the provinces of Khorassaan and Laar in Persia. When the leaves begin to decay the oldest plants are selected, not less than 4 years' standing. The earth is partly cleared away, so as to expose the upper part of the root. The leaves and stem are twisted off, and used as a covering to screen it from the sun. In this state the root is left 40 days, when the covering being removed, the top of the root is cut off transversely. It is then screened again 48 hours, when the juice is scraped off, and exposed to the sun to harden. 'This done, a second section is made; the screen again employed, and the juice obtained a second time as before. Thus the assa-faetida is 8 times repeatedly collected from the same root; but after a third section it remains 8 days to recover a sufficient stock of juice.

Assafoetida is well known by its peculiar nauseous fetid smell, the strength of which is the surest test of its goodness. This odour is extremely volatile, and of course the drug loses mucl of its efficacy in keeping. It comes in large irregular masses, composed of various shining little lumps or grains, partly whitish, partly brownish or reddish, and partly of a violet hue; those are accounted the best which are clear, of a pale red. dish-colour, and variegated with many fine white tears. It is a gummy resin, but has the gum in largest quantity. It is the most efficacions of the fetid gums, and is commonly used in hysteria hypochondriasis, some symptoms of dyspepsia, amenorrhoea and chlorosis, flatulent cholics, and most diseases termed nervous; it is thought to be the most powerful remedy we possess for those peculiar convulsive and spasmodic affections, which often recur in hysterics. It is recommended as an emmenagogue, antlselmintic, expectorant, antiasthmatic, and anodyne. Its action is quick and penetrating.

Assa-fatida. Fl. July, Aug. Pl. 6 to 7 feet.

20 F. Szowitsia'na (D. C. prod. 4. p. 173.) stem terete, nearly naked, branclsed, glabrous; leaves tripinnate, clothed with velvety pubescence; leaflets deeply toothed, obtuse ; umbels somewhat panicled, withont involucra; fruit oval-obovate, flat, longer than the pedicels. 4 . H. Native of Persia, at Seidkhodzi, in gravelly and stony places, where it was collected by Szowits. Neck of root appearing hairy from numerous erect fibres. Petioles of leaves trifid. Umbels terminal, on short peduncles. Fruit the size of $F$. commùis.

Szonits's Giant-fennel. Pl. 5 to 6 feet.

21 F. Pube'scens (Pall. ex Willd, rel. in Schultes, syst. 6. p. 598.) stem pubescent, panicled, nearly leafless; radical leaves clothed with hoary pubescence, ternately tripinnate; leaflets jagged : lobes linear, tripartite, obtuse; sheatlss opposite, small; involucra and involucels minute and caducous. $\quad$ \&.H. Native of Siberia.

Pubescent Giant-fennel. Fl. July, Aug. Clt. 1820. Pl. 1 to 2 feet.

22 F. Pu'vila (Pall. ex Willd. rel. in Schultes, syst. 6. p. 598.) stem smooth, panicled, leafless; sheaths naked; radical leaves pubescent, ternately tripinnate; leaflets pinnatifid; lobes decussate, bluntish. $\quad$ \%. H. Native of Siberia.

Dwarf Giant-fennel. Pl. 1 foot.

23 F. Arme'na (D. C. prod. 4. p. 174.) glabrous; petioles ternate at the base, having the divisions bipinnate; leaflets short, divided into thick, oblong, obtuse, aggregate, somewhat whorled lobes; stem naked, terete; leaves of involucra and involucels short, oblong; fruit elliptic. 4 . H. Native of Armenia. Oreoselinum Armènium Seseleos Massiliensis folio, Tourn. herb. Upper leaves reduced to short leafless sheaths.

\section{Armenian Giant-fennel. Pl. ?}

\section{$\dagger$ Litıle known speeies.}

24. F. BRevifòlia (Link, in Schultes, syst. 6. p. 592.) stem terete, glabrous; leaves supra-decompound; leaflets linear, channelled, divaricate, flaccid, cuspidate, elongated; involucra wanting; primordial umbels sessile. 4 . H. Native of Portugal.

Short-leaved Giant-fennel. Pl.?

25 F. capilla'ris (Link, in Spreng. umb. spec. 85.) stem terete, glabrous; leaves triternate; leaflets filiform, capillary, loose; sheaths of petioles almost wanting ; umbels axillary ; involucra of a few setaceous leaves. 4 . H. Native of Portugal. Narthècium, Dalech. lugd. p. 754. Férula tenuiori-fölio, Mlor. ox. sect. 9. t. 15 .

Capillary Giant-fennel. Fl. June, July. Clt. 1820. Pl. i to 2 feet.

26 F. Peucedanifòlia (Willd. herb. in Schultes, syst. 6. p. 592.) stem kneed, branched, leafy; leaves tri-ternate, stiff; leaflets trifidly pinnatifid, linear-subulate, elongated; involucra wanting; umbellules rather capitate. 2 . H. Native of Siberia, at the Volga. F. nodiflòra, Pall. itin. app. p. 39. t. N. ed. gall t. 56. F. Sibírica, Willd. spec. 1. p. 1411. Leaflets very long, nearly terete. Fruit unknown. The herbarium of Villdenow is said not to contain this plant.

Sulphur-nort-leaved Giant-fennel. Pl. 5 to 6 feet.

27 F. Nudicau'Lis (Spreng. neti endt. 2. p. 149. but not of Nutt.) stem naked, furrowed, glabrous; radical leaves bipinnate; leaflets deeply serrated, mucronate; sheaths of upper leaves abortive; leaves of involucrum linear-lanceolate. $4 . \mathrm{H}$. Native of Sicily, on the Nebrodes, in the higher pastures. Laserpítium resinòsum, Presl, sic. p. 136. Ligústicum resinòsum, Guss. ind. sem. 1826. prod. 1. p. 356. Fruit glatcous, compressed, marginated.

Naked-stemmed Giant-fennel. PI. 2 to 3 feet ?

28 F. Fenicula'cea (Nutt. gen. amer. 1. p. 183.) plant pubescent; stem short, naked, furrowed, glabrous; radical leaves pubescent, supra-decompound; leaflets linear, very narrow, acute, short : ultimate ones trifid; involucra wanting; involucels unilateral, digitate, with linear segments. 4. H. Native of North America, on the plains of the Missouri ; and on the northwest coast near Fort Vancouver, and barren sandy grounds on the Columbia river; low hills near the source of the Wallawalla river, and on the Saskatchawan at Carlton House. Pastinàca fœniculàcea, Spreng. in Schultes, syst. 6. p. 587. Flowers yellow. Herb smelling of fennel. Fruit furnished with 5 stripes, 3 of which are conspicuous. Umbel solitary, terminal. Sprengel refers to this Lomatium villosum, Rafin, in journ. phys. 1819. aug. 1. p. 101. and the flowers are said to be white by the author, but according to Nuttall they are yellow ; and it is therefore also the Cogswéllia villòsa, Schultes, syst. 6. p. 588 .

Fennel-scented Giant-fennel. Fl. July, Aug. Clt. 1820. Pl. 1 to 2 feet.

29 F. Canade'ssis (Lin. spec. p. 356.) segments of leaves branched, shining, linear.-Native of Canada. Lin. hort. ups. p. 61. Gron. virg. p. 147. This is a very obscure plant, and probably the same as Angélica lucida.

Canadian Giant-fennel. Pl. 2 feet.

30 F. Nuttálisi (D. C. prod. 4. p. 174.) plant small, almost stemless, glabrous; leaves supra-decompound; leaflets linear, short, acute ; scapes radical ; rays of umbel elongated ; involucra wanting; involucels unilateral, digitate, with linear segments. 4. H. Native of North America, on the plains of the Columbia; banks of streams among stones at the Great Falls of the same river. F. nudicaúlis, Nutt. gen. amer. 1. p. 183. but not of Spreng. Smýrnium nudicaúle, Pursh, fl. bor, amer. 1. p. 196. 
Pastinàca nudicaúle, Spreng. in Schultes, syst. 6. p. 587. Root fusiform. Plant having the odour of fennel, but more aromatic. This plant differs from the genera Férula, Pastinàca, and Smýrnium, in the flowers being white, not yellow, as in those genera.

Nuttall's Giant-fennel. Fl. July, Aug. Clt. 1817. Pl. I $\frac{1}{2}$ to 2 feet?

31 F.? PALMélda (Hook. in fl. amer. bor. amer. 1. p. 268.) plant glabrous, nearly stemless; leaves bipinnatifid, on longish petioles, glaucous; leaflets linear, bluntish: lower ones often again pinnatifid; peduncles rather shorter than the leaves; involucrum none; involucel unilateral, dimidiate, palmate, with the disk floriferous. 4 . H. Native of North America, about Carlton House on the Saskatchawan. Root large, thick, rather fusiform. The involucels are very remarkable, truly palnate, gradually tapering into the broad petiole or ray, and bearing a small umbellule of white flowers on the disk.

Palmella Giant-fennel. Pl. $\frac{1}{2}$ foot.

32 F. Afrinis (Bess. cat, hort. crem. 1816. p. 57.) Native near Odessa. This species is not described.

Allied Giant-fennel. Pl. 2 to 3 feet.

Cult. Any common garden soil answers the species of $F^{\prime}$ rula; and they are only to be increased by seeds.

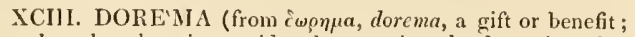
not that the plant is considered pre-eminently deserving that title, but that the name is also agreeable to the car). D. Don, in Lin. trans. vol. 16. p. 601.

Lin. syst. Pentándria, Digýnia. Flowers sessile, immersed in wool. Margin of calyx 5 -toothed. Petals ovate, with an inflexed point. Disk epigynous, cup-shaped, fleshy : with a plicate, rather lobulate margin. Style complanate, recurved at the apex. Stigmas truncate. Fruit elliptic, much compressed from the back, girded by a complanate broadish margin; raphe very narrow, usually closed. Nericarps 5 -ribbed; the 3 intermediate ribs distinct, filiform, at equal distances: lateral 2 confluent with the margins; vitte prominent, one in each furrow, and 4 in the commissure, which is flat. Carpophore bipartite, filiform. Seed flat.-A robust, greenish, glancous, Persian herb, with a perennial root, and clotlied with glandular down, almost with the habit of Opópanax Chirònium. Leaves large, petiolate, somewhat bipinnate, 2 feet long; pinnæ usually 3 pairs, each pair rather remote: lower leaflets distinct; superior ones confluent, deeply pimnatifid: segments oblong, mucronate, quite entire, or rarely a little lobed, coriaceous, veined beneath, I-5 inches long, and half an inch to 2 inches broad. Petioles and rachis terete, ribbed, pubescent, very much dilated at the base, and sheathing a little, with the upper margin winged and stipulaceous. Umbels proliferous, racemose; umbellules glohose, on short peduncles, usually disposed in a spicate manner. Peduncles terete, woolly. Involucra and involucels wanting. Petals white. Stamens and styles yellow. Ovarium densely woolly. Fruit naked.

I D. Ammoni'Acum (D. Don, l, c.) 4. H. Native of the south of Persia, in the vicinity of Jezud Khast, a town of lrak El Ajam, the ancient Parthia, abont 42 miles sonth of Ispahan. To discriminate and characterize those plants which more immediatcly administer to the wants and comforts of man, is one of the chief objects of practical hotany; but it is a task replete with difficulties; the countries whence many of the substances are derived, particularly those belonging to the Matesia Medica, being generally remote, and often inaccessible to travellers. Although the gum Ammoniacum has held a place in the Materia Medicit from a very early period, yet the plant from which it is obtained has hitherto remained almost totally unknown; and the same may be said of the analogous gum Galbanum, and many other articles derived from the vegetable kinglom, enumerated in the Pharinacopocia. It is true Dioscorides and Pliny mention the plant which yields the gum Ammoniacum, the former under the appellation of Agasyllis, and the latter under that of Metopium, and give Libya as its native country; but if the gum was anciently imported thence, it must have been the produce of a different plant than ours; and probably identical with the species of Férula, represented by Jackson in his account of Morocco, as the gum now comes to Europe by way of the Levant and India. Dioscorides, whose opinion is adopted by all subsequent writers, derives the nane Ammoniacum from Ammon or Hammon, the Jupiter of the Lybians, whose temple was situated in the desert of Cyrene, near to which the plant was said to grow. But it appears that Dioscorides was altogether mistaken as to its native country; and that the name Ammoniacum or Armoniacum, as it is indifferently written, is really a corruption of Armeniacum ; for it is now ascertained beyond all doubt, that the plant is a native of Persia, and that the gum must have been anciently brought to Europe by way of Armenia; and we sometimes find the name of the apricot written Malum Armoniacum. Willdenow, having sown some seeds picked from the gum-Am. moniacum, a species of Heräcleum came up, which he called Herácleum gummiferum, but this appears to be identical with Herácleum Pyrenàicum; but as the plant possesses no smell analogous to Ammoniacum, and affords no gummy substance wliatever, it is probable it was only an accillental weed.

The materials from $и$ hich the description was drawn wero procured by Lieut.-Colonel Wright, of the royal engineers, in the district where the gum Ammoniacum was collected, which is given above, and presented by him along with other dried plants to the Linnæan Society. Every part of the specimen is covered with drops of a gum possessing all the properties of Ammoniacum; and this circumstance alone, independent of any other evidence, would scem sufficient to remove all doubt on the subject; besides the specimen has been compared with the portions of inflorescence and fruit, which are found abundantly intermixed with the gum in the shops, and they are found to agree in every particular. The name applied to the plant by Dioscorides is already pre-occupied by another genus of Umbelliferce, and that of Pliny is scarcely unexceptionable, as originating in a mistake, Metòpium having been used by some ancient authors to denote the Gálhanum, and by others the gum-Arabic tree; but most writers seem to agree in considering it the appellation of an ointment, or some olcaginous substance, rather than of a plant. The name Dorèma has been given to avoid confusion.

The first volume of the Dictionnaire Universel de Matière Médicale, by Merat and De Lens, published at Paris in 1829, contains some valuable notices on the Ammoniacum plant, from which it appears that the plant was already known to $\mathrm{Mr}$. Brown, and had been determined by him to constitute a new genus. We also learn from the same work that M. Fontanier, a geologist sent into the Levant by the French government, had visited the district where the plant grows spontaneously, and transmitted a drawing, together with specimens of the herb and gum, to the museum of natural history at Paris. M. Fontanier was informed that the plant grows likewise in Khorassan.

In the appendix to the first volume of the transactions of the Medical Society of Calcutta, p. 369. is an extract of a letter addressed to Dr. Wallich by Lieut.-Colonel Kennett, accompanied by a rude figure of the plant, which yields the gum-Ammoniacum, of which the following is a copy: "I have the pleasure to forward you a drawing and description of Oshac, a Persian plant that produces the gum Ammoniac. It was procured by Capt. Hart, of the 5 th battalion Bombay native regiment, whilst on sick certificate in Persia; and understanding it was a lesideratum in botany, he has requested me to send it to you in his name. It is to be regretted that $\mathrm{Capt}$. Hart did not know enough of botany to give a particular description of the plant, 
flower, and seed; but he brought away a root, with a piece of the stem, and some dry leaves attached; and which I have forwarded in a box to your address. You will observe the account of the plant is dated in $\mathrm{July}, 1822$, though I only received it a short time ago. Hart.

"Description of the Oshac or gum-Ammoniac plant, by Capt.

" 'It having heen intimated to me while at Buslire by the Resident, Capt. Bruce, that the plant which produces the gumAmmoniac, called by the Persians Osliak, would be acceptable to botanists, as it was but imperfectly known, I procured the accompanying piece of stem, leaf, and flower, and took a drawing of one of the finest plants. Its height was 7 feet 2 inches, and the circunference of the lower part of the stem 4 inches. It grows principally on the plains between Yerdekaust and Kumisha, in the province of Irauk, without cultivation. The gum is so abundant, that upon the slightest puncture being made, it instantly oozes forth, even at the ends of the leaves. When the plant has attained perfection, innumerable beetles, armed with in anterior and posterior probe of half an inch in length, pierce it in all directions; it soon becomes dry, and is then picked off, and sent via Bushire to India and various parts of the world; and is an article of considerable export. I am of opinion it might be cultivated with success in many parts of Kattywar, and the experiment might be worth the consideration of government. The gum might easily be procured by artificial means, which would answer the purpose equally well.

" From the part of the stem attached to the roots of the specimen I sent you, a considerable portion of the gum will be seen exuded, in which respect it resembles the Assafoetida plant, which abounds in the mountains in the south of Persia, particularly in the province of Fars.' "

The gum is collected about the middle of June; a tenth is remitted as tribute to the government; the rest is sent to Bushire on the Persian Gulf. Part of that imported to this country comes from the Levant; but the largest quantity and the best comes by way of India.

According to Major Willock, who has visited the districts where the plant grows wild, the Ooshāk or gum-Ammoniac plant grows in great abundance over the arid plains in the vicinity of the town of Jezud Khāst, on the borders of the provinces of Fars and Irák, a district appertaining to the government of Ispalian. The white juice which forms the gum pervacles the whole plant, but exudes chiefly from the principal stems. It either remains on them in lumps, or, falling to the ground, is gathered by the villagers in the autumn, and is sold by them. The Ooslsak plant is to be met with nowhere but in the province of Irak, growing in very dry plains, gravelly soils, and exposed to an ardent sun.

Ammoniac has a nauseous taste, followed by a bitter one; and a peculiar smell, somewhat like that of Galbanum, but more grateful; it softens in the mouth, and acquires a white colour upon being chewed. It softens by heat, but is not fusible; wlen thrown upon live coals it burns away in flame. Such tears as are large, dry, free from small stones, sceds or other impurities, should be picked out, and preferred for internal use; the coarser kind is purified in solution, colature, and careful inspissation; but unless this be artfully managed, the gum will lose a considerable deal of its more volatile parts. These are often vended in the shops under the name of stained gum-Ammoniacum, a composition of ingredients much inferior in virtue.

The general action of gum-Ammoniac is stimulant. On many occasions, in doses from 10-30 grains, it proves a valuable antispasmodic, deobstruent or expectorant. In large doses it purges gently, excites perspiration, and increases the flow of urine. It is used with advantage to promote expectoration in some pulvoL. III. monary discases, especially asthma and chronic catarrh $;$ in dropsical affection to algment the flow of urine, and to sup:port the salivation in small pox. In long and obstinate cholics, proceeding from viscid matter lodged in the intestines, this gummy resin has produced good effects, after purges and the common carminatives had been used in vain. Externally it is supposed to soften and ripen lard tumours, is often applied as disctitient in white swellings of the knee, and other indolent tumours. A solution of it in vinegar has been recommended by some for resolving even schirrous swellings. It is exhibited internally combined with vinegar, vinegar of squills, assafœetida, Sc. and in pills, with bitter extracts, nyrrh, assafœtida ; externally, dissolved in vinegar, combined with turpentine, common plaster, Sc.

Ammoniac. Fl. June, July. Clt. 1831. Pl. 4 to 7 feet.

Cult. See Férula for culture and propagation, p. 328.

XCIV. ERIOSYNA'PHE (from eptov, erion, wool, and $\sigma v$ wa $\phi$, synaphe, connection; in reference to the commissure, which is the connection of the two mericarps that compose the fruit, and which is clothed with wool-like down in the hollows between the nerves). D. C. coll. mem. 5. p. 50. t. 1. f. 9 . prod. 4. p. $175 .-$ Férula species, Fisch.

Lin. syst. Pentándria, Digýnia. Limb of calyx with 5 short blunt teeth. Petals ovate, entire, acuminated; points short, incurved. Fruit compressed from the back, girded by a thickish margin. Mericarps with 3 dorsal filiform ribs, but the 2 lateral ones are lost in the thickish margin, which is spongy inside; furrows between the ribs broad, and furnished with $2-3$ striæ, and bearing 2-3 small vittæ; commissure without vittæ, marked by a middle nerve and 2 marginal ones, tomentose, and rather concave between the nerves. Seed complanate.-A perennial glabrous herb, with the habit of Férula. Leaves decompound: leaflets long, linear. Involucra and involucels none. Flowers yellow. This genus is very nearly allied to Férula, but the singularity of the commissure of the fruit distinguishes it from all other umbelliferous genera.

1 E. Longifolita (D. C. 1. c.) 2.H. Native of Siberia, in the region of the Volga at Sarepta. Férula cachroides, Cat. lort. orl. 1811. Férula longifòlia, Fisch. cat. hort. gor. 1812. p. 46. Stem terete, branchecl. Leaves glaucescent: leaflets an inch or more long. Upper petioles narrow, sheathing, awned at the apes. Unibels of many rays.

Long-leared Eriosynaphe. Fl. July, Aug. Clt. 1820. Pl. 4 to 5 feet.

Culı. See Férula, 1. 328. for culture and propagation.

XCV. PALI'MBLA (meaning unknown to us). Bess, enum. pl. vohl. p. 94. Koch, in litt. D. C. prod. 4. p. 175.-Pencédanum species, Pall. Sison species of Lin. fil. and Bieb._Siler or Agasýllis species, Spreng.-Sium species, Lam.

Lin. srst. Pentándria, Wigýnia. Margin of calyx obsolete. Petals elliptic, with an inflexed acute point. Fruit oblong or oval: the transverse section elliptic. Mericarps compressed from the back, having 5 filiform bluntish ribs: the 2 marginal ones rather the broadest; furrows betweer the ribs furnisher with 3 vittæ each; commissure bearing 2 broad marks. Seed oblong, with many stripes, free from the pericarp.-Glabrous perennial herbs. Leaves tripinnate; leaftets multifid. Stem terete, branched. Involucra of few leaves or wanting. Flowers cream-coloured. This genus differs from Peucédanum, in the furrows of the fruit being furnished with 3 vittæ each, instead of one.

1 P. SA'LsA (Bess. enum. pl. volıl. 55. no. 1484.) stem terete, branched, naked; radical leaves tripinnate; leaflets many$\mathrm{U} u$ 
parted : segments linear, somewhat verticillate; umbels panicled; involucra and involucels of 3-5 leaves; fruit oblong. $4 . \mathrm{H}$. Native of Bessarabia, Tauria, east of Russia in the region of the Volga, in arid salt fields. Peucédanum redivivum, Pall. act. petro]?. 1779. p. 252. t. 8. Sìson sảlsum, Iin. fil. suppl. p. 181. Bieb. f. taur. et suppl. no. 564. Sìson verticillàtus, Pall. itin. ex Bieb. Sium nudicaúle, Lam. dict. 1.p. 407. Agasýllis sálsa, Spreng. prod. umb. p. 22. Siler sálsum, Spreng. $11 \mathrm{mb}$. spec. 90. Schultes, syst. 6. p. $45 \mathrm{I}$. According to Ledebour, f. alt. 1. p. 344. the furrows of the fruit contain 4 vittæe each, and the commissure inany.

Salt-ficld Palimbia. Fl. June, July. Clt. 1804. Pl. 1 foot. 2 P. Ramosíssina (D. C. prod. 4. p. 176.) stem terete, much branched, sparingly leafy; leaves biternate: leaflets few, oblong, acutely cut; involucrum wanting; involucels of few leaves; fruit oblong. 24. F. Native of the East Indies, on the Pandua mountains on the confines of the province of Silhet. Selinum? ramosíssimum, Wall. mss. Root long, cylindrical, simple. Stem 2 feet high. Upper leaves reduced to the petioles. Fruit much flattened from the back ; furrows furnished each with $2-3 \mathrm{ob}$ scure vittæ; commissure covered with a pellicle, and therefore appearing withont vittæ at first sight.

Much-branched Palimbia. Pl. 2 to 3 feet?

3 P. ChaBRE'1 (D. C. prod. 4. p. 176.) stem striated, leafy ; leaves pinnate; leaflets decussate, 3-5-parted: segments linear, acute ; involucrum wanting; rays of umbel unequal; involucels of 3-4 linear-subulate leaves; fruit oval. $4 . \mathrm{H}$. Native of France, particularly in the eastern parts, Switzerland, Austria, Iberia, Sicily, \&c. in shady busliy places. Selìnum Chabræ'i, Jacq. austr. t. 72. Selinum carvifòlia, Crantz, austr. p. 162. t. 3. f. 2. Peucédanum carvifòlium, Vill. dauph. 2. p 630 . Imperatoria Chabræi, Spreng. umb. spec. 64. exclusive of the synonymes. Oreoselinum Chabræ'i, Bieb. f. taur. p. 209. Selinum palústre, Thuil. $\mathrm{fl}$. par. p. 139. Selinum lactéscens, Lam. fl. fr. 3. p. 418. Ligústicum decussàtum, Mœnch, meth. p. 81 . Peuced. mints, All. ex Balb. Peuced. Chabra'i, Gaud. fl. helv. 2. p. 330. Palímbia carvifòlia, Koch, in litt.-Chabr. sciagr. p. 389. f. 2. Flowers greenish-yellow. Vitta 2-3 in each furrow, and $4-6$ in the commissure Fruit nearly like that of F'rula. Habit of Percédanum, but the vittæ is that of the present genus, ex Koch, in litt. and umb. p. 93. no. 5. but according to Besser, in litt. the vittæ vary from $1-3$ in the furrows, and therefore this plant comes near to Peucédanum.

Var. $\beta$, Podólica (D. C. prod. 4. p. 176.) stem angularly furrowed; sheaths elongated, loose; leaves broader. 4. H. Native of Podolia. Oreoselinum Podólicum, Bess. enum. p. 12. no. 330. fl. gall. 2. p. 392. Bieb. suppl. p. 210.

Chabraus's Palimbia. Fl. July, Aug. Clt. 1791. Pl. 2 feet.

Cult. See Peucédanum, p. 335. for culture and propagation.

XCV1. PEUCE'DANUM ( Dioscorides; said to be from $\pi \varepsilon v \kappa \eta$, peulie, a pine, and $\delta$ avoc, danos, parched; the plant was so called on account of its strong smell, which resembles resin). Kocl, umb. 92. f. 28. and f. 29. D. C. prod. 4. p. 176.-Peucédanum, Selinum, and Férula, \&c. of authors.-Oreoselinum and Thysselinum, Hoffim. umb. p. 153. and 154.-Oreoselinuın and Peucédanum, Lag. am. nat. 2. p. 90.

Lin. srst. Pentándria, Digýnia. Margin of calyx 5 -toothed. Petals obovate, emarginate or entire, with an inflexed point. Fruit flattened from the back or lenticularly compressed, girded by a dilated complanate margin. Mericarps having the ribs at equal distances, the 3 intermediate ones filiform, but the 2 lateral ones are more obsolete, and contiguons to the dilated margin, or lost in it. Vittæe one in each furrow, but sometimes 2 , and usually 2 in the commissure. Carpophore bipartite. Secd flat in front.-Usually glabrous perennial herbs. Leaves simply pinnate, or many times pinnate, or ternately divided. Umbels compound, terminal. Involucra variable; involucels of many leaves. Flowers white or yellow or greenish yellow. According to Besser, the species with obcordate petals narrowed at the base are distinguished from the species with ovate petals, which are broadest at the base, and entire or a little emarginate at the apex. The first constitutes Oreoselinum, and the second the true species of Peucédanum.

Sect. I. Eupeucédanum (from eu, well, and Peucédanum; this section is supposed to contain the true species of the genus). D. C. prod. 4. p. 176.-Peucedana legítima, Koch, 1. c.Peucêdanum, Gæertn. fr. 1. t. 21. Spreng. syst. 1. p. 1082. Margin of mericarps narrow. Vittæ 2-4 in the commissure. Dorsal ribs of mericarps 5 , the outer 2 more remote than the rest. Involucra usually wanting or of few leaves, rarely of 5-8 leaves.

\section{* Flowers yellow.}

1 P. Panicula'tum (Lois. fl. gall. p. 722.) stem terete, striated, branched at the top; leaves 5 times ternate or trichotomous: segments linear; leaves of involucra 1-2, setaceous, caducons; involucels of many leaves. $4 . \mathrm{H}$. Native of Corsica. D. C. fl. fr. 5. p. 513. Scliultes, syst. 6. p. 565 . Umbels numerous, disposed in a panicle. Flowers yellow. Fruit unknown. This is a different plant from the Selinum paniculàtum of Spreng.

Panicled Sulphur-wort. Fl. May, June. Clt. 1818. Pl. 3 to 4 feet.

2 P. officina'Le (Lin. spec. p. 353.) stem terete, branched; leaves 5 times tripartite: segments linear, acute, flaccid; involucrum of 3 setaceous leaves, deciduous; pedicels much longer than the fruit. $\%$. H. Native of Europe, in humid meadows and shady places. In Britain in salt marshes, very rare; as in ditches near Shorehain, Sussex; and at Walton near Harwich, Essex. About a quarter of a mile below Faversham, by the river side. Smith, engl, bot. t. 1767. Hayne, arz. gew. 7. t. 4 . P. altíssimum, Desf. cat. hort. par. p. 119. P. Alsáticum, Poir. dict. 5. p. 22\%. Selinum Peucédanum, Sowerby, engl. bot. t. 1767. P. màjus Itálicum, Bauh. pin. 149. Moris, oxon. sect. 9. t. 15. f. 1.-Bauh. hist. 3. p. 2. 36. f. 1.-Trag. hist. p. 880 . p. 881. Hog's-fennel, Petiv. herb. brit. t. 2\%. f. 7. Herb smooth, with a resinous juice, and a strong sulphureous smell. In England, Gerarde says, it is called Horestrange and Horestrong (or Harestrang, from the German Haarstrang), Sonfennel or Hog's-fennel, Sulphur-wort, and Brimstone-wort. The root wounded in spring yields a considerable quantity of a yellow juice, which dries into a gummy resin, and retains the strong scent of the root. Many stimulating qualities have been attributed to the root, but it slould seem to be rather dangerous for internal use.

Var. $\beta$, Itálicum (Mill. dict. no. 2.) segments of leaves or leaflets very narrow, filiform. $4 . \mathrm{H}$. Native of the south of Europe. Lob. icon. t. 781. Leaves of involucra 3-4, as in the species. Leaves almost like those of $P$. longifolium. Perluaps a proper species or a varicty of $P$. longifulium or $P$. Morisoni, but very distinct from $P$. Parisiénse. It grows on low mountains, and also in valleys by the sides of rivers in Italy. It is altogether a larger plant than the species.

Officinal or Sea Sulphur-wort. Nl. July, Sept. Britain. Pl. 3 to 4 fect.

3 P. LEDenov'RI ; stem terete, branched; leaves 5 times tripartise ; segments linear, with roughish cartilaginously serrated margins; involucra of few leaves, caducous ; pedicels exceeding the fruit. 24. H. Native of Siberia, every where in open situ- 
ations, particularly on rocks. P. officinàle, Ledeb. fl. alt. 1. p. 304 . Bieb. fl. taur. 1. p. 215. in a note, 2. p. $21 \%$ no. 538. Segments of leaves covered with copious pellucid dots. Involucra for the most part of $S$ leaves: of these 1 is lanceolate, the other lanceolate-linear, and the third filiform, 2 are caducous, and the third permanent. This species differs from $P$, officinale in the margins of the leaves being cartilaginously serrated, and in the fruit being smaller, $\mathrm{Sc}$.

I'ar. $\beta$; leaves biternate; leaflets $5-6$ inches long; rays of imbel and umbellules elongated and divaricated.

Lcdcbour's Sulphur-wort. Fl. June, July. Pl. 3 to 4 feet.

4. P. EI, 'TUM (Led. fl. ross. alt. ill. t. 305,) stem terete; leaves glabrous, 3 or 4 times pinnate; pinnula pinnate; leaflets pinnatifid or cut or entire: lobes linear, acuminated, with smooth margins; primordial umbel nearly sessile; involucrum wanting; involucels short. 4. H. Native of Altaia, every where in exposed places on the declivities of mountains. Primary and secondary ramifications of the lcaves opposite, but the pinnulæ are alternate. Petals deep yellow: those of the male flowers ovate-oblong, attenuated : those of the hermaphrodite flowers obovate, all having inflexed points. Vittæ almost the length of the mericarps, 1 in each furrow, and 2 in the commissure.

Tall Sulphur-wort. Fl. May, June. Pl. 5 feet.

5 P. Longifòltu (Waldst. et Kit. pl, rar. hung. 3. t. 251.) stem terete, branched a little; leaves 5 times tripartite; leaflets triquetrously setaceous, channelled, elongated; involucra wanting or of one leaf; fruit with very narrow wings. $4 . \mathrm{H} . \mathrm{Na}$ tive of Hungary, on calcareous rocks. Sichultes, syst. 6. p. 567. Host, fl. austr. 1. p. 366 . Petioles of radical leaves terete. Flowers yellow. Fruit with 5 ribs, and 4 vittæ on the back; and the commissure with 2 vittæ.

Long-lcaed Sulphur-wort. Fl. June, July. Clt. 1823. Pl. 4 to 5 feet.

6 P. Ruthe'Nicum (Bieb. fl. taur, and suppl, no. 539.) stem terete; leaves triternately divided: segments or leaflets acute, ]-nerved, very long; involucra nearly wanting; pedicels length of fruit. $\quad$ \% H. Native of Caucasus, Tauria, and the south of Russia. P. 'Taúricum, Spreng. umb. spec. p. 53. Férula Ruthénica, Spreng. umb. prod. 14. pug. 1. p. 27. This species differs from $P$. officinale in the leaves being less divided, in the segments or leaflets being longer, and in the pedicels being onehalf shorter.

Var. $\beta$, Taúricum (Bieb. fl. taur. p. 540.) leaves 5 times tripartite; segments or leaflets linear, acute, short. $\quad$ \%. H. Native of Tauria and Caucasus, in mountain meadows.

Russion Sulphur-wort. Fl. May, June. Clt. 18I8. Pl. 3 to 4 feet.

7 P. Morisòni (Bess. in Schultes, syst. 6. p. 567. in a note, stem unknown; leaves triternately divided: leaflets linear, acute, long, stiff, 3-5-nerved; involucra wanting; involucels of many setaceous leaves. $\quad$. H. Native of Siberia. Ligústicum longifòlium, Willd. spec. 1. p. 1428. Peucédanum, Mor. oxon. 3. sect. 9. t. 15. f. 1 . Vittæ 2 in the commissure, but usually 4 , ex Koch, umb. 93.

Morison's Sulphur-wort. Pl. 3 to 4 fect.

8 P. BESSERIANoM (D. C. prod. 4. p. 177.) stem terete, a little branched; leaves triternate; leaflets linear, nerved, divaricate; involucrum nearly wanting; involucels of a few very short leaves. 4. H. Native on hills about Oćessa. Férula Besseriàna, Spreng. in litt. Peucédanum species, Bess. in litt. Herb and leaves nearly as in P. Parisiénse, but the flowers are yellow, and commissure is furnished with 4 , not with 2 vittre. Teeth of calyx short, not as in $P$. officinile subulate. Rays of umbel nearly equal. Fructiferous pedicels 3-6 lines long, not as in $P$. officinàle an inch long.

Besser's Sulphur-wort. Pl. 3 to 4 feet.
9 P. ARENA'Rium (Waldst. et Kit. pl. rar. lung. 1. t. 20.) stem terete, striated, branched; leaves tripinnate; leaflets linear, obtuse, stiffish, short ; involucra nearly wanting; rays of umbel few, uncqual; leaves of involucels linear-subulate. 24. H. Native of Iungary, in sandy places; and of Transylvania, in calcareous places; and of the south of Podolia. Spreng. umb. sprec. 51. Schultes, syst. 6. p. 568. Bess. cont. p. 43 . Allied to Palimbia Chabra'i. Vittæ one in each furrow, and 4 in the commissure, ex Koch, umb. 93.

Sand Sulphur-wort. Fl. June, July. Clt. 1816. Pl, 2 to $3 \mathrm{ft}$.

10 P. Siвínстм (Willd. spec. 1. p. 1406. Koch, umb. p. 93.) stems terete, almost without leaves; cauline sheaths large, pruinosely glaucous ; radical leaves on long petioles, triply pinnate, stiff, shining; leaflets linear, cuspidate, witl serrulated nuargins; involucrum almost wanting; central umbel sessile: lateral ones pedunculate. 2. H. Native of Croatia, Bessarabia, Caucasus, and Siberia. Férula Tatárica, Fisch. in litt. Spreng. umb. prod. 14. exclusive of the synonymes. Bieb. suppl. p. 219. Ferula Sibírica, Spreng. in Schultes, syst. 6. p. 592. Vittæ 1 in each furrow, but sometimes 2 in the lateral furrows, and always 4 in the commissure; lateral vittæ usually incomplete, and sometimes wanting in the same specimen. Habit and fowers like $P$. arenarium. The plant from Croatia is probably different from that of Siberia.

Siberian Sulphur-wort. Fl. June, July. Clt. 1804. Pl. 3 to 4 feet.

11 P. pisséctum (Led. fl. ross. alt. ill. t. 181. fl. alt. 1. p. 306.) stem terete, leafy; superior branches in whorles; sheaths spreading; leaves pubescent, 4 times pinnate; pinnulæ opposite, petiolate, pinnate; leaflets pinnatifid or entire: segments oblong, rather bifid; primordial umbels nearly sessile; involucra and involucels very minute. 4 . H. Native of Altaia, on hills at the river 'Talowka, near Buchtorminsk. Involucrum of one or few minute setaceous leaves. Petals golden yellow, ovate, acute, inflexed. Ribs of fruit filiform. Vittx 1 in each furrow, and $\approx$ in the commissure.

Dissected-leaved Sulphur-wort. Fl. June. Pl. 4 feet.

12 P. canéscens (Led. fl. ross. alt. ill. t. 105. fl. alt. 1. p. 307.) stem terete, leafy; intermediate branches opposite and tern; sheaths closely adpressed; leaves clothed with hoary pubescence, 3 times pinnate; pinnulæ opposite, petiolate, pinnate; lower serments pinnatifid: upper ones confluent: lobes broadovate, tridentate or entire, acute; involucrum wanting or of one leaf; involucels of many short leaves. 2. H. Native of Altaia, on rocks on Mount Arkaul. Leaves of involucels many, lanceolate, acute, with a yellow keel, and white margins. Flowers deep yellow. Petals ovate, acuminated, inflexed. Fruit not seen.

Canescont Sulplur-wort. Fl. May, June. Pl. 1 to 2 feet.

13 P. GRA'cil (Ledeb. fl. ross. alt. ill. t. 306. fl. alt. 1. p. 308.) stem leafless, branched; branches scattered; radical leaves clothed with hoary pubescence, but at length becoming glabrous, bipinnate; pinnula opposite, pinnate; leaflets nearly opposite, rather trifid; sheaths leafless, stem-clasjing, chartaceous, permanent. 4. H. Native of Altaia, in dry saltislı open places in the Kirghiscan-steppe, between Buchtorminsk and the lake callect Noor-Saisan. Root thick. Involucra and involucels wanting, or of one or two leaves, which are formed from the pclicels becoming abortive and leaf-like. Flowers polygamous, those in the terminal umbels hermaphrodite and fertile; and those in the lateral umbels male. Vitta 1 in each furrow, and 4 in the commissure. Petals golden yellow, obovate, acute, inflexed. Habit of a species of Férula, and probably the same as Férula pùmila, Pall. ex Schultes, syst. 6. p. 598.

lar. $\beta$, microcárpum (D. C. prod. 4. p. 309.) seed one-half smaller than in the species.

$$
\text { บ } 42
$$


Slender Sulphur-wort. Fl. May. Pl 1 to 2 feet.

14. P. Du' Bivm (Led. fl. alt. 1. p. 310.) stem leafless, branched; branches scattered : upper branches nearly opposite; leaves unknown; sheaths leafless, stem-clasping, chartaceous, permanent ; fruit orbicularly elliptic. 24. H. Native of Altaia, in exposed dry sterile places, at the river T'schuja. Habit more robust than that of the preceding species, and the stems more branched and more flexuous. Umbels polygamous. Involusa and involucels wanting, unless they are caducous. Vitta 1 in each furrow, and 4 in the commissure.

Doubtful Sulphur-wort. Pl. 2 to 3 feet.

15 P. Soonga'ricum; stem leafless from the base to the apex, branched; upper branches disposed in whorles; radical leaves clothed with hoary pubescence, 4 or 5 times pinnate; pinnulie opposite, pinnate-parted: segments obovate, cut; lobes acute; involucels very minute. 4 . H. Native of the Soongarian desert, between the river Jrtysch and the mountains of DolenKara, in saltish places. P. paniculàtum, Led. fl. ross. alt. ill. t. 199. fl. alt. 1. p. 311 . Involucrum wanting, unless it be caalucous. Umbelinles usually proliferous, hermaphrodite and male on the same specimen. Involucels wanting to the hermaphrodite umbellules, unless they are caducous; but usually of many lanceolate-linear acute leaves to the male umbellules. Flowers yellow; petals ovate-oblong. Vittæ 1 in each furrow, and 2 in the commissure. Perhaps the same as Férula Soongárica, Pall. ex Schultes, syst. 6 . p. 598 . The stem yields a gum which has a taste between gum-Ammoniac and parsley. Habit exactly of Ferula.

Soongarian Sulphur-wort. Fl. May, June. Pl. 3 to 4 feet.

16 P. Au'reum (Ait. hort. kew. 1. p. 341.) stem terete; leaves ternately supra-decompound, flaccid; leaflets pinnatifid, slender: segments linear, acute; leaves of involucrum 1-3, linear, acute; rays of umbel 40.50 ; fruit puberulous when young. s. F. Native of 'l'enerifle, and the Grand Canary Island, in mountain pastures. Ker, bot. reg. 559. Spreng. umb. spec. p. 58. Schultes, syst. 6. p. 570 . Férula aúrea, Link, in Buch. can. p. 152. Flowers golden yellow. Fruit, according to Sprengel and the bot. reg., oval, compressed from the back, with 5 ribs and 4 vitte, and crowned by the styles.

Golden-flowered Sulphur-wort. Fl. June. Clt. 1779. Pl. 8 to 4 feet.

17 P. callila'ceum (Thunb. prod. p. 50, fl, cap. p. 257.) stem terete, striated, naked, nearly simple; radical leaves 5 times trichotomous: segments subulate, furrowed above, stiff; involucra and involucels of 5-6 lanceolate-subulate leaves. $4 . \mathrm{F}$. Native of the Cape of Good Hope, on the mountains. Sieb. pl. exsic. no. 212. Flowers yellow, according to Thumberg. Fruit ovate, compressed, marginately winged, having 3 elevated ribs on each side, ex Thunb.

Capillary-leaved Sulphur-wort. Pl. 1 foot.

18 P. Tenufócium ('Thumb. prod. 50 . fl. cap. 257. but not of Poir.) stem striated, terete, a little branched; leaves bipinnatifil: segments lanceolate and alternate, marginated: sheaths broad, stipula-formed at the base of the petioles; involucra and involucels of 6 leaves, 4 . F. Native of the Cape of Good Hope, on the mountains. Spreng. umb. spec. p. 59. Fruit ovate, marginating, winged on the back, with 5 ribs, ex Thunb.

Fine-leaved Sulphur-wort. II, 2 to 3 feet.

19 P. virga'rum (Cham. et Schlecht, in Linnæa. 1. p. 392.) stem terete, slirubby; leaves stiff, pinnate; leaflets lanceolate, quite entire, mucronate, with revolute margins; involucra and involucels of many short leaves. $\eta$. G. Native of the Cape of Good Hope, on the mountains. Burchell, cat. pl. afr. austr. no. 2869. The whole plant is quite glabrous and coriaceous. Petals ovate, yellow, entire at the apex, or hardly emarginate. Fruit said to be elliptic, with 5 ribs on the back, having a complanate margin.
Twiggy Sulphur-wort. Shrub.

$$
\text { * Floners crcam-eolourcd. }
$$

20 P. Scnótтu (Bess, in litt, ex D. C. prod. 4. p. 178.) stem terete, a little branched; leaves pinnate-parted: segments linear, acute, entire or divided; involucra and involucels none. $4 . \mathrm{H}$. Native of Volbynia and Podolia. Imperatòria Chabre'i, Bess. A. gall. Very like Palimbia Chabrce'i, but differs in the lobes of the leaves being more diverging, in the rays of the umbels being quite smooth, in the involucels being wanting, and in the furrows being furnished with one vittæ each.

Schott's Sulphur-wort. Pl. 2 to 3 feet.

21 P. Orienta'te; stem terete, branched, fistular; leaves pinnate; leaflets bipinnatifid; lobes linear-oblong, acute; involucrum wanting; involucels of a few leaves. $\%$. H. Native of Nipaul, on the Himalaya at Gosaingsthan. P. disséctum, D. C. prod. 4. p. 178. but not of Led. Selinum? disséctum, Wall. mss. Habit of Athùsa or Thysselìnum. Fruit nearly orbicular, with a narrow margin. Vittæ all evident, solitary in the furrows, and twin in the commissure. Flowers cream-coloured or greenish, according to the dried specimen.

Eastem Sulphur-wort. I'. 1 to 2 feet.

\section{*** Flowers white.}

22 P. Parisiénse (D. C. f. fr. 4. p. 336.) stem terete, a little branched; leaves 3 or 4 times 3 -parted: leaflets linear, nerved, divaricate; involucra of $8-10$ linear-subulate leaves; leaves of the involucels setaceous. 2. H. Native about Paris, in dry fields; and of Occitania. Jaum, pl. fasc. 3. p. 2!6. P. officinàle, Thuil. fl. par. 140. but not of Lin. P. Gállicum, Pers. ench. 1. p. 310. P. Gállicum var. $\alpha$, Spreng. in Schultes, syst. 6. p. 565 . exclusive of var. $\beta$. Fruit oblong, ex Spreng. Commissure furnished with 2 vittæ, ex Koch. Flowers white.

Parisian Sulphur-wort. Fl. May, July. Clt. 1800. Pl. 4 to 5 feet.

2.) P. glau'cum (D. C. prod. 4. p. 179.) stem terete, branched; leaves biternate; leaflets broad-linear, elongated, acuminated, with a few awned serratures; involucra and involucels wanting; fruit with membranous wings. 24. H. Native of Nipaul, and at Deyra-Dhoon. Selinum? glaúcum, Wall. mss. Flowers white, but rose coloured in a dried state. The fruit is nearly like that of section 4 , but the involucra are wanting. Commissure furnished with 2 curved vittæ.

Glaucous Sulphur-wort. Pl. 2 to 3 feet.

24 P. vagina'tum (Led. 'fl. ross. alt. ill. t. 808 . fl, alt, 1. p. 312.) root creeping; stem simple; leaves pinnate; pinna opposite, pinnate; leaflets alternate, pinnate-parted, or tripartite, or entire: segments linear, acute; sheaths membranous; involncrum wanting; leaves of involucels linear, length of umbellules. 4. H. Native of Altaia, in meadows at the rivers Irtysch, and Koksun. Flowers white; petals tapering into an inflexed point. Vittæe 2 in each furrow, and 4 in the commissure. Stylopodium and styles purple. Margin of mericarps broad.

Var. $\beta$, puimilum (Led. A. alt. l. c.) differs from the species in the stems being only 3 inches high, furnislsed with leaves at the root; mericarps nearly one-half smaller.

Sheathed Sulphur-wort. Pl. $\frac{1}{2}$ to 1 foot.

Sect. II. 'Thyssen'num (from $\theta v \omega$, thyo, to burn incense, and $\sigma \varepsilon \lambda \iota v o v$, selinon, parsley ; acrid juice of the plants). Hoflim. umb. p. 153. Spreng. umb. spec. p. 70. Gaudin. fl. helv. 2. p. 331. D. C. prod. 4. p. 179.-Thyoselinum, Riv. pent. t. 19, 20. Spreng. syst. 1. p. 895 . Margin of mericarps narrow. Vitta in the commissure 2, covered by an indusium. Universal involucra of many leaves. llowers white. Perhaps this section may constitute a proper genus. 
25 P. sylvéstre (D. C. prod, 4. p. 179.) stem tercte, furrowed; leaves bipinnate or tripinnate: leaflets pinnatifid: segments linear-lanceolate, bluntishı; involucra and involucels of many leares; fruit lanceolate-elliptic. 24. H. Native of the north and east of Europe, in marshes and meadows. Selinum sylvéstre, Lin. hort. ups. p. 59. Oed. fl. dan. t. 412. D. C. fl. fr. 4. p. 319. Thysselinum, Riv. pent. irr. t. 19 and 20. Thysselìnum palústre, Hoffm. umb. ]) 154. Spreng. in Schultes, syst. 6. p. 463. exclusive of the synonyme of Lin. Peucédanum palústre, Mœench, metb. 8\%. Koch, umb. p. 94. Athamántha flexuòsa, Juss. hort. par. Athamántha Pisàna, Savi, in Ust. ann. 21. p. 7. Selinum Cantabrigiénse, Fisch. Selinum Schiweréckii and Sel̀̀num intermèdium, Bess. prim. fl. gall. 1. p. 205. Thysselìnum palústre and T'liyss. Plinii, Spreng. syst. 2. p. \$95. most probably appertains to this plant. Fruit brownish purple, 2 lines long. Root with many necks. Flowers white.

IVild Sulphur-wort. Fl. July, Aug. Clt. 1800. Pl. 2 to 3 feet.

26 P. Batcale'nse (Kocl, umb. p. 94.) stem furrowed at the top, much branched; leaves bipinnate ; leaflets pinnatifid : segments linear, acute; leaves of involucra many, rather toothed; leaves of involucels cohering at the base, exceeding the umbellules. 4. H. Native of Siberia, about Lake Baical; and of Hungary. P. terebinthinàceum, Fiscl, in litt. Selinum terebinthinàceum, Trev. nov, act. soc. nat. cur. 13. p. 166. S. collinum, Kit. in Willd. herb. The Hungarian plant is the same as the Siberian one.

Baical Sulphur-wort. Fl. June, Aug. Clt. 1820. Pl. 2 to 3 feet.

Sect. III. Cerva'ria (from cervus, a stig; the $P$. cervaria is said to be much sought after by stags). D. C. in Dub. bot. gall. prod. 4. p. 179.-Cervària, Gartn. fr. t. 21. f. 10. Gaudin. f. helv. 2. p. 324. Margin of mericarps narrow. Commissural vittæ 2, superficial. Dorsal ribs 5, approxinate. Vittæ solitary in the furrows. Involucra of many leaves.

27 P. Arsa'́ticum (Lin. spec. 354. but not of Poir.) stem angularly furrowed, branched; leaves tripinnate; leaflets pinnatifid : segments oblong, mucronate, with serrulately scabrous margins; involucra and involucels of many lanceolate-linear leaves, which are subulate at the apex; fruit elliptic-oblong. 4. H. Native of the Pyrenees, Provence, Alsatia, Switzerland, Austria, Transylvania, Tauria, and Siberia, in woods and meadows. Jacq. fl. aust. t. 70. D. C. fl. fr. 4. p. 337. Led. fl. alt. 1. p. 312. Daúcus Alsáticus, C. Bauh. prod. p. 7\%. Selìnum Alsáticum, Crantz. austr. p. 59. Cuídium Alsáticum, Spreng. in Scluultes, syst. 6. p. 417. Cervària Alsática, Gaudin. fl. lielv. 2. p. 327. Petals pale yellow.

Iar. $\beta$, albiflorum (D. C. prod. 4. p. 179.) stem more angular; flowers white. 24. H. Native of ltaly, Austria, and Vallais. Selìnum Venètum, Spreng. umb. spec. 73. Schultes, syst. 6. p. 561. Selinum Austriacum, Bertol. Selìnum Alsáticum, Crantz.

Alsatian Sulphur-wort. Fl. July. Clt. 1774. Pl. 3 to $5 \mathrm{ft}$. 28 P. Cerva'ria (Cusson, ex Lapeyr. abr. p. 149. Koch, umb. 94.) stem terete, nearly simple; leaves bipinnate, glancons; leaflets ovate, auriculated on the outside at the base, toothed: teeth mucronate; involucra of many leaves; fruit oval. 24. H. Native of iniddle Europe, from the Pyrenees to Austria.-Clus. hist. t. 193. f. 2. Athamántha Cervària, Lin. spec. p. 35\%. Jacq. austr. 69. Bertol. amoen. p. 139. Selinum Cervària, Lin. spec. ed. 1. p. 1194. Crantz, austr. t. 3. f. 1. Selìnum glaúcum, Lam. fi. fr. 3. p. 419. Cervària rígida, Mœnch, meth. 98. Cervària Rivini, Gærtn. fr. t. 21 . f. 10. Cervària glaúca, Gaudin, fl. helv. 2. p. 324. Ligústicum Cervària, Spreng. syst. 1. p. 907.-Plench. icon. t. 185. Corolla white, with a purplish outside. The plant is recommended in the gout; and in Styria they use it in intermittent fevers.

Var. $\beta$, latifólium (Viv. ital. fragm. 1. 1. 18. t. 22.) leaves broader and less glaucous. 4 . H. Native in rather boggy places.

I'ar. $\gamma$ ? disséctum (D. C. prod. 4. p. 180.) leaftets pinnatifid ; lobes 3-5-cleft. 24. H. Cervària le'vis, Gaudin, 1, c. in a note. P'erhaps l'. oreoselinum, var.

Stag's Sulphur-wort. FI. July, Aug. Clt. 1597. Pl. 4 to 5 feet.

29 P. cervariffòluum (Meyer, verz. pflanz. p. 126.) plant glabrous, glaucescent ; stem fistular, terete; leaves bipinnate and tripinnate; leaflets membranous, ovate, or a little cordate, cut, mucronately toothed; petioles nearly terete, fistular; sheaths narrow; leaves of both involucra and involucels setaceous; mericarps puberulous, with narrow margins; the 3 dorsal ribs sharp. 4. H. Native of Caucasus, on the Talusch mountains. Allied to $P$. Alsáticum, P. cervària, and Imperatòria Caucásica, but sufficiently distinet from all. Flowers greenish or dirty red.

Cervaria-leaced Sulplur-wort. Pl. 3 to 5 fect.

30 P. oreosel'num (Cusson, ex Lajeyr. abr. p. 149.) stem terete, striated; leaves tripinnate; petioles bent back; leaflets remote, ovate, deeply pinnatifid, divaricate, shining: teeth rather mutic ; fruit oval-orbicular. 4 . H. Native of midalle Europe and Cancasus, in open exposed places of hills. Athamántha oreoselìnum, Lin. spec. 352. Jacq. aust. 1. t. 68. Hayn. arz. gew. 7. t.3. Selinum oreoselinum, Scop. carn. no. 330. Oreoselìnum nigrum, Delarb. auv. 1. p. 428. Oreoselinum legítimum, Bieb. suppl. 210. Cervària oreoselinum, Gaudin, $f$. helv. 2. p. 324. Penced. oreoselinum, Moncb, meth. 82. Koch, umb. 94.-Dod. pempt. 696. with a figure. The plant is gratefully aromatic, and deserves to be better known. Flowers white, with a tinge of blush.

I ar. $\beta$, angulìtum (D. C. prod. 4. p. 180.) stem angularly furrowed, pubescent. 4. H. Native of the Central Pyrenees. Selinum oreoselinum $\beta$, D. C. fl. fr. suppl. no. 3485. p. 511 . Perhaps a proper species.

Mountain-parsley. Fl. July, Aug. Clt. 1810 . Pl. $3 \frac{1}{2}$ feet.

SEct. IV. SElixol'des (containing plants laving the habit of Selinum). D. C. prod. 4. p. 180.-Peucédlanum, sect. 4. a. Koch, umb. 94.-Oreoselinum species, Hoffm. Bieb.-Selinum species, Gaudin, fl. helv. 2. p. 333. Margin of mericarps diaphanous, very broad. Commissural vittæe 2 , rarely 4 , superficial. Dorsal ribs of mericarps 5 , and with 1 vittæ in each furrow between the ribs. Involucra and involucels of many leaves.

31 P. Austríacum (Koch, umb. p. 94.) stem sulcately striated ; leaves tripinnate; leaflets ovate, cuneated at the base, coarsely toothed, pinnatifid: teeth bluntish, mucronate ; leaves of involucra linear. 4. H. Native of Austria, Pannonia, Upper Italy, and probably of France. Selinum Austriacum, Jacq. aust. t. 71. vind. 49. Selinum argénteum, Crantz, austr. 174 . t. 4. f. 2. Selinum nigrum, Lam. fl. fr. 3. p. 420 . Oreoselinum Austriacum, Hoflm. umb. p. 155. Vittæe usually 4 in the commissure, and often 2 in the outer furrows, ex Koch, in litt. P. montànum, inxolucràtumi, and Rablénse, are probably only varieties of this species. Besser makes $P$. Austriacum and montànum one species and $P$. involucràtum and Rablénse another. The petioles of the radical leaves are divided into 3 branches.

Austrian Sulphur-wort, Fl. Jul. Aug. Clt. 1804. Pl. 2 to $3 \mathrm{ft}$. 32 P. monta'num (Kocl, umb. 94.) stem deeply furrowed, branched, and corymbose in the upper part, smooth, hollow; leaves thrice pinnate; leaflets pinnatifid, with elliptic-lanceolate segments ; Jeaves of involucrum lanceolate, pointed, dependent, 
entire, or 2-3-cleft, rarely pinnatifid; rays of umbel rongh; rilss of fruit broad, obtuse. $\%$. H. Native of England, Switzerland, and France, in boggy meadows. Selìnum montànum, Schleich. pl. exsic. Willd. enum. p. 306. Selinum palústre, Lin. spec. p. 350. Smith, engl. bot. t. 229. Fl. dan. 257. Crantz, f. austr. fasc. 3. p. 39 . t. 4. f. 1.? D. C. fl. fr. 4. p. 320. Selinum nígricans, Gaudin. fl. helv. 2. p. 333. Selinum Austrìacum, Hall. fil. in Rom. 1. f. 2. p. 4. Selinum polymórphum, Spreng. pug. 2. p. 50 . Schuites, syst. 6. p. 559 . Root tapering, simple. Flowers white. There are several barren or abortive flowers in each partial umbel. Leaves dark green. The root is said to serve the Russians for ginger; and the whole herb abounds with a white, bitter, fetid juice, of the consistence of cream, which soon dries to a brown acrid resin. The milky exudation is the only character by which Tournefort distinguishes his Thyoselinum from his Oreoselinum.

Mountain Milk-parsley or Sulphur-wort. Fl.July. Britain. Pl. 4 to 5 feet.

33 P. ALPE'stre (Lin. spec. 353.) stem terete, furrowed, branched; leaves thrice or 4-times ternate; leaflets linear, acute; involucrum of many reflexed leaves; umbels of many rays; involıcels of many linear, acute leaves, rather shorter than the umbellules. 4 . H. Native country unknown. P. álbum, Desf. hort. par. cat. 119. Horn. hort. hafn. 1. p. 276. P. minus, Poir. suppl. 5. p. 228.? but not of others. The leaves agree with those of $P$. montanum. Flowers yellow.

Alp Sulphur-wort. Fl. June, July. Clt. 1739. Pl. 2 to $3 \mathrm{ft}$. 34. P. Wallicmánum (D. C. prod. 4. p. 181.) stem terete, branched : leaves supra-decompound; leaflets linear, cuspidate, smooth; involucra and involucels composed of cut leaves; ribs of fruit elevated; vittæ in the commissure 4. 4. H. Native of the East Indies, at Sirinagur ; and of Nipaul at Kamaon and Gosaingsthan. Selìnum temuifòlium, Wall. mss. Leaves, habit, and involucrum like those of $P$. incolucratum. Ribs of fruit more elevated than in the rest of the species of the present genus, and nearly as in Sclinum exserted, but the commissure is broad, as in the other species of the genus.

Wallich's Sulphur-wort. Pl. 2 to 3 feet.

35 P. involucra'tum (Koch, umb. p. 94.) stem furrowed, angular, branched; leaves supra-decompound; leaflets linear, cuspiclate, with scabrous margins; leases of involucra cut; leaves of involucels lanceolate, with white membranous margins; umbels somew hat proliferous. 4. H. Native of the Alps of Piedmont, near Fenestrelle. Selìnm peucedanoìdes, Desf, cat. hort. par. 1813. p. 142. Spreng. umb. spec. 75. Horn. liort, hafn. acld. p. 960 . Oreoselinum pencedanoides, Hoffim. umb. p. 155 . S. argénteum, All. pedem. no. 1304. but not of Crantz. Flowers white.

Involucrated Sulplun-wort. 2 to 3 feet.

36 P. RАBLÉNSE (Koch, umb. p. 94.) stem sulcately striated; leaves supra-decompound; leaflets linear, cuspidate; involucra of many linear-subulate quite entire leaves; fruit elliptic, broadly margined. $4 . H$. Native of Carinthia, in the valley of Rablensi; and on the mountains in the Alps of Bormio and of Generoso; and of Zealand, on the sea-shore. F'́rula Rablénsis, Wulf. in Jacq. coll. 4. p. 312. Selinum lineàre, Schum. seel. 1. p. 95. Horn. fl. dan. t. 1330. Selinum élegans, Balb, hort. taur. fasc. 1. p. 23. t. 4. Oreoselinum Rablénse, Hoffm. umb. 155. Selìnum Rablénse, Gaudin, f. lselv. 2. p. 335 . Flowers white.

I'ar. $\beta$, Bellárdi (D. C. prod. 4. p. 181.) leaflets longer than in the species; involucrum of few leaves. $4 . \mathrm{H}$. Native of Piedmont. Sclinum Bellärdi, Balb. herb. cat. taur. 1821. p. 51 . Rablensi Sulphur-wort. Fl, Jul. Aug. Clt. 1817. Pl. I to $2 \mathrm{ft}$. 37 P. latifólium (D. C. prod. 4. p. 1S1.) stem terete, stri- ated; leaves pinnate, rather coriaceous; leaflets ovate-oblong, cartilaginously serrated, cut at the base; upper sheaths large, leafless; fruit elliptic, broadly margined. $2 / . H$. Native of grassy places at the river Volga, and of Caucasus. Selinum latifolium, Bieb. suppl. 211. Angélica lavigàta, Fisch. cat. hort. gor. 1812. Involucrum of many leaves. Teeth of calyx very short. Nearly as in Imperatoria.

Broad-leaved Sulphur-wort. Fl. July, Aug. Clt. 1816. Pl. 2 feet.

38 P. selinotdes (D. C. prod. 4. p. 181.) stem terete, smooth; leaves tripinnate; leaflets rather remote, cuneated, pinnatifid: with lanceolate, acute segments ; leaves of involucra membranous, cut a little. $\$$. H. Native of Siberia. Selinum Sibíricum, Retz. obs. 2. p. 15. Spreng. umb. spec. 71. Flowers white. Vittæ of fruit 4, parallel, and 2 superficial ones in the commissure, ex Spreng. Habit almost of Gàya simplex.

Selinum-like Sulphur-wort. Pl. 2 to 3 feet.

39 P. polyphy'llum (Ledeb. f. ross. alt. ill. t. 309. fl. alt. I. p. 314.) stem sulcately striated, branched; radical leaves numerous, bipinnate; leaflets pinnatifid, trifid, or entire: segments oblong or linear, acute, with smootl margins; leaves of involucrum lanceolate, with membranous margins, decictuous. $\psi . H$. Native of Altaia, on dry rocks at the rivers '1'scharysch and Kerlyk, near Riddersk, Loktewsk, and elsewhere; on sandy hills, about Schulbinsk at the river Irtysch. Involucels of many leaves, like those of the involucrum. Flowers white; outer petals deeply emarginate, with an inflexed point. Mericarps with rather prominent ribs, girded by a broad margin. Vittæ 2 in the commissure, and 1 in each furrow: the outer ones as broad as the furrows.

I'ar. $a$, pubéscens (Led. fl. alt. I. p. 315) segments of leaflets short, oblong, crowded, covered with fine down or thick short hairs; stem at most 2 feet high. 4 . H. Native on dry rocks, at the rivers Tscharysch, and Kerlyk.

l'ar. $\beta$, glàbrum (Led. I. c.) segments of leaflets longer, oblong-linear, more remote, glabrous; stem 3 feet high, or more. 4. H. Native in sandy places, near Schulbinsk and Loktewsk.

I ar. $\gamma$, lineàre (Led. 1. c.) segments of leaflets elongated, linear, rather falcate, remote, glabrous; stem about 2 feet high. 4. H. On rocks about Riddersk.

Many-leaced Sulphur-wort. Fl. June. Pl. 2 to 3 feet.

Sect. V. Angelicoives (containing plants having the habit of Angélica). D. C. prod. 4. p. 181.-Imperatòria, Koch, umb. 95. Margin of mericarps dilated. Commissural vittæ 2, superficial. Dorsal ribs 5 , at equal distances. Vittæ 1 in each furrow. Involucrum wanting. Involucels of many leaves. Perhaps a species of Imperatoria, but differs in the calyx being 5-toothed.

40 P. Verticilla're (Koch, umb. 95. in add.) stem terete, glaucous ; floriferous branches verticillate; leaves bipinnate or tripimnate; leaflets ovate, toothed, acute: lateral ones unequal at the base: terminal one cordate. 24. H. Native of Piedmont, near Torton (ex All. pedem. no. 1311 . exclusive of the synonyme of Lam.) ; and probably of Italy (ex J. Bauls. hist. 3. p. 2. p. 167. f. 1.). Angélica verticillàris, Lin. maut. p. 217. Jacq. hort. vind, t. 130. Imperatòria verticillàris, D. C. fl. fr. 4. p. 287. Koch, umb. 95. Flowers greenish-yellow. Habit of Imperatoria or Angélica.

Whorled-branched Sulphur-wort. Fl. July. Clt. 1683. Pl. 4 to 6 feet.

\section{$\uparrow$ Species not suffieiently known.}

41 P. Isete' Nse (Spreng. umb. spec. p. 57. and in Schultes, syst. 6. p. 569.) stem angular, much branched; leaves ternately decompound; leaflets trifid and pinnatifid; segments lanceolate, cuspidate, veiny ; umbels axillary ; involucra and involucels of 
many leares. 4. H. Native of Siberia, on the mountains.Gmel. sib. 1. p. 190. t. 42. Root thick, fusiform. Habit of Trinia. Flowers cream-coloured. Fruit oval, a little winged. This species probably appertains to sect. Thysselinum.

Isetsk Sulphur-wort. Fl. Ju. Jul. Clt. 1824. Pl. 2 to $3 \mathrm{ft}$. 42 P. Créticum (Lin. spec. 354.?) stem terete, knotted at the origin of the leaves; leaves glaucous, pinnate; leaflets multifid : segments linear ; umbel of $\$-10$ rays ; involucra of many short, reflexed leaves; fruit oblong, glabrous. $4 . \mathrm{H}$. Native of Candia. Ligústicum Créticum, foeniculi folio, caule nodoso, Tourn. cor. ex herb. Juss. The cut in Bauh. hist. 3. p. 2. p. 57 and 58. f. 1. agrees well with this plant, but the figure of $P$. Alp, exot. p. 328. cited by Linnæus, is very different from it.

Crctan Sulphur-wort. Pl.?

1.3 P. micropiýllum (Smith, in Rees' cycl. no. 11.) leaves tripinnate; leaflets 3-lobed, fleshy; involucrum bardly any. 4. H. Native of Siberia, in salt deserts about the Volga. Peucédanum salinum, Pall. in Spreng. syst. 1. p. 910. Athamántha tenuifòlia, Willd. herb. ex Spreng. Involucrum of I setaceous leaf, which is also sometimes absent. Fruit unknown. A doubtful species.

Small-lcaved Sulphur-wort. Pl. 2 to 3 feet?

44 P. Japónicum (Thunb. fl. jap. p. 117.) stem terete, flesuous, branched; leaves 5-times 3-parted; leaflets cuneiform, trifid; petioles broad, sheathing. 24. H. Native of Japan, on the sea-shore. Sam-Bofu, Kompf. amœn. exot. p. 825. The whole plant is glabrous, and hardly a foot high. Mericarps compressed, ovate, scarcely winged.

Japan Sulphur-wort. Pl. 1 foot.

45 P. terna'tum (Nutt. gen, amer. 1. p. 182.) stem striated, few-leaved; leaves on long petioles, ternate; leaflets long, linear, acute, quite entire, attenuated at the base; involucrum almost wanting; involucels very short, 5-6-leaved; fruit oblong, elliptic, winged. 4 . H. Native of Carolina, in woods by the sides of marshes. Flowers unknown. Calyx entire. Margin of calyx thick. Probably a species of Pastindca.

Ternate-leaved Sulphur-wort. Pl. 3 feet.

46 P. verticillatum (Rafin. fi, lud. p. 81.) leaves decompound; leaflets filiform: lower ones in whorls. $4 . \mathrm{H} . \mathrm{Na}$ tive of Louisiana, in humid places. Rob. trav. louis. 3. p. 461.

Whorled-leaved Sulphur-wort. Pl. 2 to 3 feet?

47 P. RUPE'stre (Hoffmans. and Willd. in Schultes. syst. 6. p. 572.) leaves supra-decompound; leaflets linear, very narrow, tripartite; involucra and involucels of many leaves; umbellules usually 5-flowered. 4 . H. Native of Portugal. The rest unknown.

Rock Sulphur-wort. Fl. Jul. Aug. Clt. 1818. Pl. 2 to $3 \mathrm{ft}$.

48 P.? genicula'tur (Forst. f. ins, aust. p. 136.) plant glabrous, branched, prostrate; stem terete, striated; leaves alternate, cuneated at the base, quite entire, semi-orbicular at the apex, and crenated; petioles shortly and bluntly auriculated at the base; umbels pedunculate, of $2-3$ rays; involucrum of 2-3 leaves ; umbellules many-flowered; petals inflexedly cordate at the apex. $\quad$ \%. H. Native of New Zealand. Bowlèsia geniculàta, Spreng. umb. spec. 14. t. 5. f. 11. But it certainly is not a species of Bonlesia, from the calyx being without teeth.

Kneed Sulphur-wort. Pl. prostrate.

49 P. Sprenge'li (D. C. prod. 4. p. 18\%.) stem terete, branched; leaves bipinnate, lanceolate; leaflets pinnatifid, sessile : segments lanceolate, mucronate, veiny, with serrulately scabrous margins; floriferous branches panicled. $4 . \mathrm{H} . \mathrm{Na}-$ tive country unknown. Selìnum paniculàtum, Spreng. pug. 2. p. 50 . syst. 1. p. 909 . Flowers yellow. Fruit with 3-winged margins, having the ribs obsolete, and the furrows planoconvex.

Sprengel's Sulphur-wort. Pl. 2 to 3 fect?
Cult. Any common garden soil will suit the species of Peucédanum ; and they are easily increased by seeds.

XCVII. IMPERATORIA (so named from its supposed imperial virtues in medicine). Lin. gets. no. 352. Lag. am. nat. 2. p. 90. Koch, umb. p. 95. in add. D. C. prod. 4. p. 183.Imperatoria species, Sprengel.-Peucédanum species, Koch.Angélica species, Hoffm.

Lin. sxst. Pcntándria, Digýnia. All as in Peucédanum, but the margin of the calyx is obsolete-Glabrous, perennial herbs. Stems terete, striated. Leaves biternate or triternate; leaflets ovate or oblong, serrated. Umbels large, compound. Involucra wanting; involucels of few leaves. Flowers white. Plants with the habit of Angélica.

1 I. Ostnu'thium (Lin. spec. 372.) lower leaves biternate: upper ones less compound ; leaflets broad, smooth, rough edged, finely and sharply serrated, partly cut or lobed, sometimes 3cleft; sheaths of leaves dilated. 4 . H. Native of Europe and Newfoundland, in rather moist meadows and in woods; in Scotland, on the banks of the Clyde in several places, and in the Isle of Bute, near Mount Stuart. Professor Hooker mentions several stations in Scotland, chiefly about ancient residences, indicating its being a naturalised plant. Smith, engl, bot. $t$. 1380. Woodv. med. bot. t. 35. Lob. icon. 700. f. 1. Hayn. arz. gew. 7. t. 15. Lam. ill. t. 199. f. 1. Angélica officinàlis, Bernh. Selìnum Imperatòria, Crantz, aust. 1746. Peucéda. num Ostrùthium, Koch, umb. 95. Nees. off. pfl. t. 7. I mperatòria, Rivin. pent. irr. t. 7. Ger. emac. 1001. f. 1. Mor. oxon. 3. p. 278 . sect. 9. t. 4. f. 1. I. màjor, Bauh. pin. p. 156. Gaud. prod. t. 55 . Laserpítium Germánicum, Fuchs. hist. 763 . with a figure. Astrántia, Dod. pempt. 320. with a figure. Clus. hist. vol. 2. p. 194. with a figure. Smýrnion, Trag. hist. 433. with a figure. Flowers white or pale flesh-coloured. Root fleshy, tuberous, somewhat creeping, of an aromatic and acrid quality; long supposed a sovereign counter-poison, and celebrated as a powerful exterual as well as internal remedy in numerous disorders. It is said to be a sudorific, diuretic, and sialogogue; recommended in dropsy and debilities of the stomach and bowels; an infusion of $j$ in wine is said to have cured quartans that have resisted the bark. When chewed it excites a copious flow of saliva, with a warm and not disagreeable sensation in the gums, and frequently cures the rheumatic tootluache. The mericarps are broadly winged. The plant is cultivated in several places for the London market.

$\operatorname{I} a$ r. $\beta$, triternata; leaflets 3 -parted, or neariy ternate. $\psi \mathrm{H}$. Native in the region of the Mediterranean. Imperatoria triternàta, Viv, in litt.

Sparrow or Common, or Great Masterwort. Fl. June, July. Britain. Pl. 1 to 2 feet.

2 I. Angustifòlia (Bell. in Horn, hort. hafn. 1. p. 286.) leaves biternate; leaflets oblong, attenuated at the base, acuminated at the apex, deeply serrated; sheaths dilated. 4. H. Native of Piedmont, in the Alps of Tenda, near Limon. Schultes, syst. 6. p. 609. Peucédanum Imperatoroides, Link, enum. 1. p. 269. Angélica angustifòlia, Hoffm. Immb. 161. Imperatòria mìnor, Mor. oxon. sect. 9. t. 4. Lob. icon. t. 700. f. 1. Flowers white.

Narrow-leaved Master-wort. Fl. June, July. Clt. 1819. Pl. 1 to 2 feet.

3 1. Cauca'sica (Spreng. prod. umb. 17. and in Schultes, syst. 6. p. 609.) leaves biternate; leaflets ovate, cuneated, deeply lobed: middle one petiolate, somewhat 3-lobed; involucri usually of I leaf; involucels unilateral, of 3 leaves, pendulous. 4. H. Native of Caucasus and Iberia, in woods. Selinum Caucásicum, Bieb. fl. cauc. 1. p. 213. Stev. mem. soc. mosc. ง. p. 259. Oreoselinum Caucásicum, Bieb. suppl. 209. The 
plant has the appearance of a species of Ligústicum. Fruit winged, as in Peucédanum, sect. Iv. but the calycine teeth are obsolete, and the involucrum is wanting, as in the other species of Imperatoria.

Caucasian Masterwort. Pl. 1 to 2 feet.

4. I. Mexica'na (Hort. Chelsea). 2. H. Native of Mexico. A broad-leaved species, received by Mr. Anderson, of the Chelsea Botanic Garden, from Mr. Otto, of the Botanic Garden at Berlin, in the year 1818 , but it has not yet flowered. It may jove hereafter to belong to a distinct genus.

Mexican Masterwort. Clt. 1818 . Pl. 3 to 4 feet.

Cult. Plants of easy culture; and may be either increased by dividing the roots or by seed.

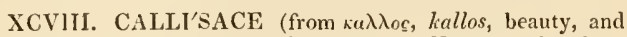
бakos, sukios, a buckler ; fruit). Fisch, in Hoffin. umb. ed. 2. p. 170. exclusive of some species. D. C. prod. 4. p. 184. Koch, iis litt.

L1x, syst. Pentándria, Digýnia. Margin of calyx somewhat 5 -toothed or nearly obsolete. Petals oval, acuminated, incurved. Fruit compressed on the back, winged on the margin, nearly orbicular, emarginate at the base. Mericarps with 3 blunt, dorsal, nerve-formed ribs; the 2 lateral ribs expanded into wings, which corer the whole surface of the fruit. Vittæ 1 in each dorsal furrow, which are narrow, and 1 on each side of the commissure at the margins. Parts of carpophore adnate to the mericarps. Seed complanate.-A perennial herb, with the habit of Angélica or Ostéricum. Sheaths of leaves large: upper ones leafless. Umbels pubescent, of many rays. Involucra none, or of few leaves. Umbeliules dense, nany-flowered. lnvolucels of many setaceous leaves. Flowers white. This is an intermediate genus between Angélica and Imperatòria.

1 C. Dahu'kica (Fiscl. in litt. D. C. prod. 4. p. 184.). \%. H. Native of Dahuria, near Nertschinsky-Sawod. Thysselìnum Dalùricum, Spreng. syst. 1. p. 894. Habit of Ostéricum praténsis, but more branched, firmer, and thicker in the stem. Habit also of Angélica Razoúlsii, but the leaves are more deeply serrated, the sheaths larger and inflated, and the involucrum composed of one or two leaves.

Dahurian Callisace. Fl. Jul. Aug. Clt. 1816 . Pl. 2 to $3 \mathrm{ft}$. Cull. See Imperatòria above for culture and propagation.

XCIX. BU'BON (from $\beta$ ov $\beta \omega \nu$, boubon, the groin, or a tumour in that part, or elsewhere, which this herb was supposed to cure). Koch, umb. 95 . D. C. prod. 4. p. 184. but not of Spreng.-Bùbon species, Spreng. in Schultes, syst.-Agasýllis species, Spreng. prod.-Galbanóplora, Neck. clem. no. 292.

Lin. syst. Pentándria, Digýnia. Margin of calyx obsolete. Petals obovate, entire, with an acute involute point. Fruit lenticularly compressed from the back, girded by a dilated complanate margin.. Mericarps with 5 ribs at equal distances: the 8 intermediate ones filiform: and the 2 lateral ones lost in the complanate margins. Vittæe covering the whole seed, 4 on the back and 2 in the commissure. Carpophore hipartite. Seed ratlier convex, flattish in front.-Quite smooth slirubs, natives of the Cape of Good Hope, abounding in a gummy, resinous, sweet-scented juice. Stems terete. Leaves liternate, glaucous, stiflish ; leaflets toothed or pinnatifid ; petioles sheathing. Umbels compound, of many rays. Involucra and involucels of many linear leaves. Flowers greenish yellow.

1 B. Gálbanum (Lin. spec. p. 364.) leaflets cuneated, rhomboid, deeply toothed at the apex : terminal ones 3 -lobed. $\mathbf{h}$. G. Native of the Cape of Good Hope, on liils. Jacq. vind. 3. t. 36. 'Thunb. fl. cap. 253. Berg. cap. 77. Woodv. med. bot. 34. t. 12. Sims, bot. mag. 2489. Selinum Gálbanum, Spreng. in Schultes, syst. 6. p. 563. Agasýllis Gálbanum,
Spreng, prod. 22. Pluk, alm. t. 12. f. 2. Herm, par, 163. with a figure. Dorsal vittæ of fruit under a thick pericarp. Stem with purplish bark, covered with whitish powder. 'This was formerly supposed to be the plant which yielded the drug called gum galbanum; but it has lately been discovered to be the produce of quite a different plant, a native of Persia, now called Gálbanum officinàle.

Galbanum Bubon. FI. Jul. Aug. Clt. 1596. Sh. 4 to $10 \mathrm{ft}$. 2 B. Guminferum (Lin. spec. 364 .) leaflets cuneated at the base, pinnatifid : segments lanceolate, acute. 5. G. Native of the south of Africa. Selinum gummiferum, Spreng. in Schultes, syst.6. p. 564. - Comm. hort. amst. 2. p. 115. t. 58. Like the prececting, but differs in the leaves being more finely divided. Dorsa] vittæ of fruit superficial.

Gum-bearing Bubon. F\}. Jul. Clt. 1731. Pl. 2 to 6 feet.

3 B. leviga'tum (Ait. hort. kew. ed. 1. vol. 1. p. 352. ed. 2. vol. 2. p. 146.) leaves bipinnate; leaflets lanceolate, bluntly and obsoletely crenated; fruit glabrous. h. G. Native of the south of Africa. Férula lævigàta, Spreng. umb. spec. p. 88. Flowers yellow. Fruit thick, solid, with 3 dorsal obtuse ribs (ex Spreng.). Leaves glaucous.

Smooth Bubon. Fl. Mar. Dec. Clt. 1774. Sh. 4 to $10 \mathrm{ft}$.

Cult. A mixture of loam, peat, and sand is a good soil for these shrubs; but they can only be propagated by seed.

C. ANE'THUM ( $a r y \theta o v$, anethon, of Theophrastus and Dioscorides, from $a v \omega$, ano, upwards, and $\theta \varepsilon \omega$, theo, to run; from the quick growth of the plant). Tourn. inst. p. 317. t. 69. Gærtn. fr. 91. t. 21. Hoftm. unb. 1. p. 117. t. I. f. 13. Lag. am. nat. 2. p. 91. Koch, umb. p. 91.-Anèthum species, Lin. -Pastinàca species, Spreng.

Lin. syst. Pentándria, Digýnia. Margin of calyx obsolete. Petals roundish, entire, involute, with a somewlat quadrate retuse point. Fruit lenticularly compressed from the back, girded by a complanate margin. Ribs of mericarps filiform, at equal distances: the 3 intermediate ones acutely keeled: and the 2 lateral ones more obsoletc, and running into the flattened margin. Vittæ broad, solitary in the furrows, and filling them, but twin in the commissure. Seed rather convex, flattisls in front. -Annual, crect, glabrous herbs. Leaves decompound, with linear-setaceous lobes. Involucra and involucels wanting. Flowers yellow, nearly like those of Pastinàca.

1 A. SE'Getum (Lin. mant. 219.) fruit oval, nearly destitute of the membranous margins. $\odot . H$. Native of France, Portugal, Sardinia, Greece, Persia, Sc. Jacq. hort, vind. t. 132. D'Urv. enum. p. 33 . Brot. fl. lus. I. p. 465. Mèum ségetum, Guss. prod. A. sic. I. p. 346. Anèthum gravèolens, Ucria, ex Guss, A. pusillum, Hortul. Perhaps only a variety of the following, according to Brotero; but it differs from it in the mericarps being almost without a margin, and in being rather more convex on the back, and therefore holds an intermediate station between Anèthum and Freniculum.

Corn-field Dill. Fl. Jume, Jul. Clt. 1796. Pl. $\frac{1}{2}$ to 1 foot.

2 A. GRAVE'oless (Lin. spec. 377.) fruit elliptic, girded by a flat, dilated margin. \&. H. Native of the south of Europe, Egypt, and about Astraclian, in corn-fields; and in meadows towards the Caspian sea, between Sallian and Lenkeran; also of the Cape of Good Hope and the Island of Timor; of South America, about Buenos $\Lambda$ yres. Fl. dan. 157\%. Brot. A. lus. 1. p. 464. Hayn. arz. gew. 7. t. 17. Woodv. med. bot. 159. Plench. icon, 215. Blackw. 545. Pastinàca Anètlıum, Spreng. in Schultes, syst. 6. p. 587. Anèthum minus, Gouan. ill. p. 20. Selìnum Anètlıum, Roth. fl. germ. 1. p. 1 13. Fœnículum vulgàre, Hook, in Beech. bot.-Riv, pent, t. 13.-Mor. umb. t. 1. f. 22.-Fuchs, hist. p. 30. Lob. icon. 776 . The common dill is a plant of upright growth, somewhat similar to fennel, 
but smaller and more glaucous; it has finely divided leaves, and a slender single stem. The whole plant is powerfully aromatic. The leaves are used to heighten the relish of some vegetable pickles, particularly cucumbers; and also occasionally in soups and sauces. The whole herb is also used in medicinal preparations. Dill is raised from seed, of which half an ounce is sufficient for a bed 3 feet by 4 fcet. Sow annually in February, March, or April, or occasionally in autumn, as soon as the seed is ripe, to come up stronger in the spring, in any open compartment, either in drills, 6 or 12 inches apart, or broad-cast thinly, and raked in evenly. The plants should remain where raised, and may be thinned moderately, should they rise too thick. They will shoot up in stalks, with leaves and seed umbels in summer and autumn, for use in proper season. Leave some plants when raised for seed; they will furnish plenty in the autumn. The bruised herb is anodyne and resolvent. The seeds are aromatic, and contain an etherial oil, and useful, therefore, in flatulencies; the essential oil is also good in the colic. A distilled water, drawn off to the quantity of a gallon to a pound of seeds, was ordered in the London Pharmacopæia, and occasionally made the basis of carminative draughts, and juleps ; its flavour is more agreeable than that of the seeds in substance. Along with the water arises a considerable quantity of essential oil, which is given from 1 to 3 or 4 drops, or more, as a carminative. This, however, is now altogether disused.

Strong-scentcd or Common Dill. Fl. June, July. Clt. 1573. Pl. 2 feet.

3 A. So'wa (Roxb. hort, beng. p. 22.) fruit oblong, nearly destitute of a membranous margin. $\odot$. H. Native of the East Indies, where it is called Son, , and where it is cultivated for its use in medicine. Fleming. ind. med. in soc. asiat. 11. p. 156. ex Schultes, syst. 6. p. 628 . Herb very-like the preceding. Rays of umbel 5-16. Fruit flat, 3-ribbed, almost wingless.

Sowa Dill. Fl. June, July. Clt. 1810. Pl. 1 foot.

\section{+ Species not sufficiently known.}

4. A. crunocárpem (D. C. prod. 4. p. 186.) fruit elliptic, puberulous on the outside, when examined by a lens, with a very narrow margin. ๑. H. Native of Persia, about Seidkhodzi, where it was collected by Szowits. Plant small, glabrous. Root slender, simple. Leaves many-parted: lobes linear. Umbels pedunculate, opposite the leaves, 3-6-rayed, without involucra. Umbellule 6-7-fiowered, surrounded by an involucel. Flowers unknown, but probably yellow, as the other species. Fruit appearing turgid at first sight, ellipsoid, but empty inside, from the mericarps being thin and concave. Carpophore filiform, bipartite. Mericarps of the same structure as the other species of the genus.

Boat-fruited Dill, Pl. 1 foot.

5 A.? ERYThRÉUM (D. C. prod. 4. p. 186.) fruit elliptic, glabrous, hardly marginate; mericarps flattish ; involucra and

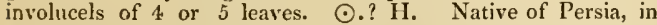
gravelly places, at the foot of Mount Avrin, in the district of Khoi, in the province of Aderlseijan, where it was collected by Szowits. Herb glabrous. Stem terete, purplish. Leaves small, multifid, with small obtuse lobes. Umbels on long peduncles, 7-12-rayed. Involucra of 5-7 leaves. Umbellules 12-15-flowered; involucels of 5-7 short leaves. Petals white, ovate, acute. Mericarps sometimes flat, and sometimes rather concave, fuscous on the outside, and purplish inside. Very like A. ségetum.

Red-stemmed Dill. Pl. 1 foot.

Cult. All the species grow very well in the open border, where the seeds should be sown.

vOL. III.
CI. CO'RTIA (in honour of Bonav. Corti, who was the first to discover the motion of molecules in the cells of plants). D. C. prod. 4. p. 186.-Schúltzia species, Wall.

Lin. syst. Pcntándria, Digýnia. 'Teeth of calyx elongated, acute. Petals lanceolate, acuminated, entire. Stylopodium conical ; styles diverging. Fruit elliptic, rather retuse at both ends; mericarps flattish, 5 -ribbed: ribs winged: lateral ribs the broadest; vittæ 1 in each furrow, and 2 in the commissure, which is broad and flat. Seed flattish.-A nearly stemless herb. Leaves petiolate, pinnate; leaflets divided into short, capillary segments. Scapes, some of them thick and stem-formed, bearing an involucrum, composed of 2-3 multifid leaves; others are elongated, and bearing an umbel, which is usually of few rays. Involucels of 5-7 linear, entire, or 2-3-cleft acute leaves. This genus differs from Schillzia in the calyx being 5 -toothed, and in the fruit being compressed from the back, not from the sides. evidently 5 - winged.

1 LiNDLE'II (D. C. prod. 4. p. 187.). ๑. H. Native of Nipaul, at Gosaingsthan. Schúltzia Lindlèii, Wall. mss. Habit almost of Caldàsia.

Lindley's Cortia. Pl. 1 foot?

Cult. Sow the seeds in the open border in spring, in a warm sheltered situation.

CII. CAPNOPHY'LLUM (from kanvos, kapnos, the Greek name for fumitory, and $\phi v \lambda \lambda o \nu, p h y l l o n$, a leaf; resemblance in leaves to those of fumitory). Gartn. fruct. 2. p. 32. t. 85. Koch, umb. p. 95. no. 24. in add.-Cònium species, Auct.Rùmia, Link. but not of Gartn.

Lin. syst. Pcntándria, Digýnia. Margin of calyx obsolete. Petals oblong, somewhat emarginate, tapering into an inflexed point. Fruit lenticularly compressed, girded by a conplanate, dilated margin. Mericarps laving the 3 intermediate ribs thickish, keeled, rather flexuous or tubercled : the 2 lateral ribs lost in the dilated margins. Vitta solitary in the furrows, and twin in the commissure. Seed rather convex, but flat in front.Annual herbs, natives of the Cape of Good Hope, with leaves almost like those of fumitory, whence the name. Leaves hoary, multifidly decompound, with linear, cuneated segments. Umbels opposite the leaves, or nearly terminal. Involucra and involucels composed of 3-6 leaves, with membranous edges. Flowers white.

1 C. Africa'num (Koch, l. c.) unibels of $2-5$ rays ; involucra and involucels of 3 leaves; central flower of each umbellule fertile and nearly sessile, the rest nearly all pedicellate and sterile. $\odot$. H. Native of the Cape of Good Hope, in sandy places. Cònium Africànum, Lin. mant. p. 352. Burch. cat. pl. afr. no. 362. Burm. pl. cap. p. 7. Thunb. fl. cap. 257. Koch, umb. 95. Rùmia Capénsis, Link. enum. hort. berol. 1. p. 271.

African Capnophyllum. Pl. 1 foot.

2 C. J AcQut'Ni (D. C. prod. 4. p. 187.) umbels of 9-10 rays; involucrum of 5-6 leaves; umbellules containing many fertile flowers. $\odot$. H. Native of the Cape of Good Hope. Cònium Africànum, Jacq. hort. vind. t. 194. Cicùta Africàna, Lam. dict. 2. p. 4. Conium rugòsum, Thunb. A. cap. p. 258. Leaves thicker than those of the first species.

Jacquin's Capnophyllum. Fl. June, Sept. Clt. 1759. Pl. 1 foot.

Cult. Sow the seeds in a warm sheltered situation in spring.

CIII. TIEDEMA'NNIA (in honour of Professor Tiedemann, of Heidelluerg, a vegetable physiologist). D. C. coll. diss. 5. p. 51.t. 12. prod. 4. p. 187.

Lin. syst. Pentándria, Digýnia. Margin of calyx 5-toothed (f. 64. a.). Petals acuminated, reflexed (Ell.); anthers erect, adnate to the sides of the filaments (Ell.). Fruit flatly com$\mathrm{X} \times$ 
pressed (f. 64.c.) from the back. Mericarps with 5 filiform, rather keeled ribs, at equal distances, approximate : lateral ribs dilated into a nembranous margin (f. $64 . c$.), broader than the fruit. Vittæ solitary in the furrows, and filling them, and twin in the commissure. Carpophore bipartite. Seed flat.-Glabrous herbs, natives of North America, in marshes. Stems terete. Leaves reduced to the petioles, which are terete, acute, fistular, and jointed, without any leaflets. Involucra and involucels of 4-5 subulate leaves. Flowers white.-Habit of Sìm, Enánthe, and Ottò, but the fruit is that of Anèthum, and the anthers are very different from those of all other umbelliferous plants.

1 T. teretifólia (D. C. prod. 4. p. 187.). $\odot$ ? H. Native of Carolina. Eusánthe filifórmis, Walt. car. p. 113 . but not of Lam. Enántlie Caroliniénsis, Pers. encl. 1. p. 318. Pursh, f. bor. amer. 1. p. 194. Sìum teretifòlium, Ell. sketch. 1. p. 354. (fig. 64.)

\section{Terele-leaved Tiedemannia.} Pl. 1 foot.

Cult. Sow the seeds of this plant in a pot filled with peat, and place a pan of water under it.

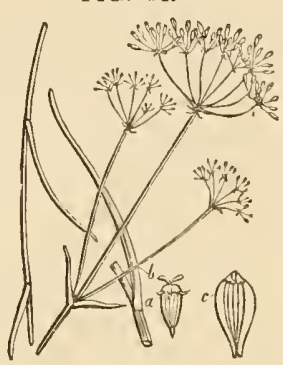

CIV. ARCHEMO'RA (from Archemorus, in mythology, son of Lycurgus, slain by an adder ; in reference to the poisonous quality of the plants). D. C. coll, diss. 5. p. 52. prod. 4. p. 188 .

Lin. syst. Pentándria, Digýnia. Margin of calyx 5-toothed. Petals obcordate, with an inflexed point. Fruit compressed from the back, flat, oval, or obovate. Mericarps with 5 filiform, rather kceled ribs at equal distances, approximate; lateral ones dilated into a membranous margin, which is almost broader than the seeds. Vittæ solitary in the furrows, and filling them; but twin in the commissure, Carpophore bipartite. Seed flat.Marsh herbs, natives of North America. Leaves pinnate. Involucrum wanting, or of few leaves; involucels of many leaves. Flowers white. Habit of Enánthe or Sium. Fruit of Pastinàca.

1 A. Ambígua (D.C. prod. 4. p. 1S8.) stem smooth; leaves pinnate: with $3-5$ pairs of linear, sessile, undivided, acute leaves; involucrum wanting: involucels of 3-5 subulate leaves; fruit oval. 2. B. H. Native of New Jersey, and about Philadelphia, in marslıes. Enánthe ambígna, Nutt. gen. amer. 1. p. 189. Pastinàca ambígua, Torr. H. un. st. 1. p. 315. Sium longif òlium, Pursh, fl. amer, sept. 1. p. 194. Habit almost of Enanthe peucedanifolia, ex Nutt. Hardly distinct from the foliowing. This is a truly poisonous herb.

Ambiguous Archemora. Pl. 6 to 10 feet.

2 A. Rígida (D. C. prod. 4. p. 188.) stem striated; leaves pinnate; leaflets sessile, oblong-lanceolate, marginate, almost entire ; involucrum wanting; involucels of 6-8 subulate leaves; fruit oval. 24. B. H. Native of New Jersey, Pennsylvania, Maryland, and Carolina, in bogs and marshes. Sium rígidus, Lin. spec. p. 362. Sison marginàtum, Michx. H. bor. amer. 1 . p. 168. QEnánthe rígida, Nutt. gen. amer. 1. p. 189. Pastinàca rígida, Spreng. in Schultes, syst. 6. p. 586 . Torr. fl. un. st. 1. p. 314. This plant is very poisonous, according to Barton, comp. fl. phil. 1. p. 142.

Stiff Archemora. Fl. July, Aug. Clt. 1774. Pl. 2 to $3 \mathrm{ft}$.

3 A. Tricuspida'tra (D. C. prod. 4. p. 188.) leaves pimate; lower leaflets lanceolate: upper ones obovate, tridentate; involucrum caducous. 4 . B. H. Native of Carolina, in lumid places. Sìum tricuspidàtum, Ell. sketch. 1. p. 354. Sìum rigídius, Walt. car. 114. According to Elliot, this is very like the preceding species.

Tricuspidatc-leafletted Archemora. Pl. 2 feet ?

4 A. Denticula'ta (D. C. prod. 4. p. 188.) leaves pinnate; with usually 3 pairs of oval, denticulated, acute leaflets ; involucra of 2 leaves, rarely wanting. 24. B. H. Native of Georgia, in humid places, and along the sides of water. Stem 3-4. feet high.

Denticulated-leaved Archemora. PI. 3 to 4 feet.

Cult. The species of Archemora grow best in peat earth, in a moist situation; and they will be easily increased by dividing at the root.

CV. PASTINA'CA (from pastinum, a dibble; in reference to the form of the root). Tourn, inst. 319. t. 170. Lin. gen. no. 362. Lag. am. nat. 2. p. 92 . Kuntl, umb. p. 90 . f. 26 and 27. D. C. prod. 4. p. 188.-Pastinàca and Malabaíla, Hoffm. umb. p. 122 and 125.-Pastinàca species, Spreng.

Lin. syst. Pentandria, Digýnia. Margin of calyx obsolete, or minutely denticulated. Petals roundish, entire, involute : with a broad, retuse point. Fruit compressed from the back, girded by a dilated, complanate margin. Ribs of mericarps very slender : the 3 dorsal ones at equal distances : and the 2 lateral ones contiguous to the dilated margin. Vittæ linear, acute, hardly shorter than the ribs, solitary in the furrows, but twin or more in the commissure. Carpophore bipartite. Seed flat.Herbs with fusiform, usually fleshy roots. Leaves pimate ; leaflets toothed, cut, or lobed. Umbels compound. Involucra and involucels none, or of very few leaves. Flowers yellow.

1 P. sativa (Lin. spec. 376. ) stem furrowed; leaves pinnate, downy beneath; leaflets ovate, serrated, and cut: the terminal one 3-lobed; involucra and involucels generally wanting, but there is occasionally a solitary leaf under the general as well as partial umbels; teeth of calyx obsolete; fruit oval ; commissure of fruit furnished with 2 vittæ. $\delta$. H. Native of Europe, even to Caucasus, in meadows. In Britain, about the borders of fields, on liillocks and dry banks in a.clialky soil. North America, on the banks of the Saskatchawan and Red river. South America, about Buenos Ayres. Hoffm. umb. 123. t. 1. f. 11. Hayn. arz. gew. 7. t. 16. Smith, engl. bot. t. 556. Mart. fl. rust. 83. Iam. ill. t. 206. Selinum Pastinàca, Crantz, aust. 161. Anètlum Pastinàca, Wib. werth. p. 911. P. opàca, Horn. hort. hafn. add. p. 961. P. sylvéstris, Huds. 125. P. sylvéstris, latifòlia, Raii, syn. 206. Mor. oxon. 3. p. 314. sect. 9. t. 16. f. 2. Pastinàca, Trag. liist. 439 . f. 440. Riv. pent. irr. t. 6. Siser sylvéstre, Fuchs, hist. 753. with a figure. Root spindle-shaped, white, aromatic, mucilaginons, and sweet, with a degree of acrimony, which it loses by cultivation, becoming var. $\beta$, the eatable garden parsnip. Flowers yellow: the innermost ones of the umbel frequently abortive. The leaves are sometimes downy on both surfaces.

$\operatorname{Var} \beta$, edulis (D. C. prod. 4. p. 189.) leaves glabrous on both surfaces, shining above; root thick, fleshy. \&. H. P. doméstica, Math. valgr. 2. p. 106. with a figure. Lob. icon. 709. Blackw. 379. Cam. epit. 507. with a figure. P. sativa, Nili. dict. no. 2.

The garden parsnip, is called Panais, in French, Pastinake in German, and Pastinaca in Italian. It has smooth leaves, of a light yellowish green colour, in which it differs from the wild plant, the leaves of which are downy and dark green; the roots also are thick and fleshy, and have a milder taste; it does not differ so much from the native plant, as the cultivated does from the native carrot.

Usc.--The parsnip has long been an inmate of the garden, and was formerly much used. In Catholic times it was a famons 
Lent root, being eaten with salted fish. "In the north of Scotland," Mr. Neill observes, " parsnips are often beat up with potatoes and a little butter; of this excellent mess the children of the peasantry are very fond, and they do not fail to thrive upon it. In the north of Ireland a pleasant table beverage is prepared from the roots, brewed along with hops. Parsnip wine is also made in some places; and they afford an excellent ardent spirit wlien distilled after a similar preparatory process to that bestowed on potatoes, destined for that purpose." The following are the varieties:-

1 Common parsnip, large swelling parsnip, swelling parsnip. -The leaves are long; roots generally from 20-30 inches long, and from $3-4$ in diameter.

2 Guernsey parsnip, Jersey parsnip, panais long of the French, panais coqune of Guernsey.-The leaves are somewhat stronger and taller than those of the common sort. The roots are also larger and more perfect, about 3 or 4 feet long.

3 Hollow-cronned parsnip, hollow-headed parsnip, panais Lisbonaise of Guernsey. - In this variety the leaves are shorter and not so numerous as in the common parsnip; the roots are oblong, about 18 inches long, more swollen at the top, and not tapering gradually, but ending rather abruptly, about 4 inches in diameter at the shoulder.

4. Turnip-rooted parsnip, panais rond, Siam parsnip.-The leaves of this sort are few, and do not exceed 12 or 13 inches; the roots are from 4-6 inches in diameter, funnel-shaped, tapering very abruptly, with a strong tap-root, the whole being from 12-15 inches long. The shoulder is broad, and grows above the surface of the soil. The flavour of this parsnip is superior, and when dressed is of a yellower colour than the other varieties.

Soil._-The soil most proper for the parsnip should be light, free from stones, and deep. It should be dug or trenched before sowing, at least 2 spits deep; and the manure should either be perfectly decomposed, or if recent, deposited at the bottom of the trencls.

Seed estimate and.sowing.--Sow in the end of February, or in March, but not later than April, and for a seed-bed 5 feet by 20 , the plants to remain thinned to 8 inches' distance, half an ounce of seed is the usual proportion. Having prepared either beds 4 or 5 feet wide, or one continued plot, sow broadcast, moderately thin, and rake the seed well into the ground.

Culture.-When the plants are about $1-2$ or 3 inches high, in May or June, let them be thinned and cleared from weeds, either by hand or by small hoeing, thinning them from 8 to 12 inches' distance. Keep them afterwards clean from weeds, till the leaves cover the ground, after which no further culture will be required. The roots will be pretty large by the end of September, from which time a few may be drawn for present use: but the parsnip is far best at full maturity, about the close of October, indicated by the decay of the leaf. The root will remain good for use till April and May following.

Preserving during winter.-The parsnip is not so liable as the carrot to be hurt by frost if left in the ground. But it would be proper in the beginning of November, when the leaves decay, to dig up a portion of the roots, and to cut the tops off close, laying them in sand, under cover, ready for use in hard frosty weather. The rest will keep good in the ground till they begin to shoot in the spring: then in February or March dig them up; cut the tops off; and, preserved in sand, the roots will remain sound till about the end of April.

To save secd.-T'ransplant some of the best roots in February, 2 feet asunder, inserted over the crowns ; they will shoot up in strong stalks, and produce large umbels of seeds, ripening in autumn.

Ficld culture of the parsnip.-The parsnip has been partially introduced of late years as a field plant, and is nearly equal to the carrot in its product of nutritive and saccharine matter. Its culture as a field plant has chiefly heen confined to the island of Jersey, where it attains a large size, and is much esteemed for fattening cattle and pigs. It is considered rather more hardy than the carrot, and its produce is said to be greater. It may be sown either in autumn or spring, and its seeds admit of drilling by machinery. The plants, when they come up, are more easily recognised than carrots, and therefore their culture is on the whole more simple, less dependent on manual labour, and therefore more suited to farming. For the rest their culture is the same as that of the carrot. The variety best suited for the field is the Large Jersey, the seed of which should be procured from the island, as that of the garden parsnip sold by seedsmen never attains the same size. The quantity of seed required for sowing in drills is from 4 to $5 \mathrm{lbs}$. per acre, and for broad-cast 6 or 8 lbs. It must always be new, as two year old seed does not come up freely. It may or may not be prepared by steeping, but it requires no earth or sand intermixed with $\mathrm{it}$, as it passes freely through the same drill that will sow tares or pease. The time of sowing is generally about the middle of February; but some sow in September, in which case the seed does not vegetate till early in spring. This last method is obviously against the culture of the soil, which must thus remain a year in a consolidated state. The manner of sowing is generally in drills 15 or 18 inches distant; but some sow broad-cast and harrow in the seed; and in Jersey, parsnips and beans are generally cultivated together. The beans are first dibbled in, and afterwards the parsnip seed scattered over the surface and harrowed. It is acknowledged that a good crop of both plants is never obtained; and therefore, though this mode may be found to answer in the mild climate of Jersey, it is not to be imitated in other places. Drills or broadcast, without any intermixture of plants, are the only adviseable modes. The after culture of the parsnip is the same as that for the carrot, with this difference, that the parsnip, when sown broad-cast, is generally thinned out to 12 inches at an average, plant from plant, and when in rows 18 inches apart, to 9 inches in the row. The produce of the parsnip is said to be greater than that of the carrot, and the economical application the same. In the fattening of cattle it is found equal if not superior, performing the business with as much expedition, and affording meat of exquisite flavour, and a highly juicy quality. The animals eat it with much greediness. It is reckoned that thirty perches, where the crop is good, will be sufficient to fatten an ox 3 or 4 years old, when perfectly lean, in the course of 3 months. They are given in the proportion of about 30 pounds weight morning, noon, and night; the large ones being split in 3 or 4 pieces, and a little hay supplied in the intervals of those periods. And when given to milch cows with a little hay in the winter season, the butter is found to be of as fine a colour and as excellent a flavour as when feeding in the best pastures. Indeed, the result of experiment has shown that not only in neat cattle, but in the fattening of hogs and poultry, the animals become fat much sooner, and are more bulky than when fed with any other root or vegetable; and that, besides, the meat is more sweet and delicious. The parsnip leaves being more bulky than those of carrots may be mown off before taking up the roots, and given to cows, oxen, or horses, by whom they will be greedily eaten. Their produce in nutritive matter is 99 parts in 1000 , of which 9 are mucilage and 90 sugar. Gerarde says, that a very good bread was made from them in his time. They afford as much spirit as the carrot. The parsni] being more hardy and luxuriant than the carrot, is less liable to the mildew and worms; but equally so to become forked if the soil be not deep and well pulverised, and if the manure be not minutely divided and equally distributed. 
Cultivated or Garden Parsnip. Fl. Jul. Brit. Pl. 3 to $4 \mathrm{ft}$.

2 P. latifo'lia (D. C. mem. soc. vol. 4. prod. 4. p. 189.) stem terete, striated, pubescent, as well as the petioles and leaves on the under surface; leaves pinnate; leaflets of the lower leaves large, and dilated at the base, and rather cut; of the cauline leaves ovate; involucra and involucels wanting; teeth of calyx obsolete; fruit oval: having the commissure furnished with 2 vittæ. 4. H. Native of Corsica, where it was gatbered by Soleirol. It differs from $P$. sativa in the stem being terete, not furrowed; and from $P$. divaricata in the fruit being oval, not orbicular, in the commissure being furnished with 2 vittæ, not with $4-6$; and from the other species in the leaflets of the radical leaves being large.

I ar. a, velutina (D. C. prod. 4. p. 189.) leaves clothed with velvety pubescence on both surfaces. 4. H. Native of Corsica, at St. Florent. P. Kòchii, var. latifòlia, Duby, in D. C. bot. gall. 1. p. 220 .

I ar. B, glabràta (D. C. prod. 4. p. 189.) leaves glabrous above, hardly pubescent beneath. 4. H. Native country unknown, but cultivated in the botanic garden at Geneva.

Broad-leaved Parsnip. Fl. Ju. Jul. Clt. 1830 . Sh. 3 to $4 \mathrm{ft}$.

3 P. Dlvarica'ta (Desf. cat. hort. par. 1815. p. 139.) stem terete, striated; leaves pinnate, clothed with short pubescence on both surfaces; radical leaves with 9-11 leaflets: cauline ones with $3-5$; leaflets ovate, cuneated at the base, or cordate, undivided, sharply serrated : teeth mucronate; terminal leaflet larger and somewhat 3 -lobed; involucra and involucels wanting; fruit nearly orbicular. 2\%. H. Native of Corsica, at Bastia. P. gravèolens, Salzm. exsic. Koch, umb. 91. but not of Bieb. P. sativa, Thom. exsic. P. velutìna, Koch, in litt. P. Kòchii, var. Duby, in bot. gall. 1. p. 230 . Vitta $4-6$ in the commissure, usually interrujted, 2 of which are generally larger than the rest.

\section{Divaricatc Parsnip. Pl. 3 to 4 feet.}

4 P. Lu'CIDA (Lin. mant. 58.) stem furrowed, muclı branched; leaves glabrous, stiff, crenated, reticulated beneath: radical ones cordate, usually lobed; cauline leaves ternate or quinate ; leaflets attenuated at the base : upper ones ovate-rhomboid; umbels numerous, rather panicled; involucra of 1 leaf; fruit orbicular. §. H. Native of Balearic Islands. Gouan. ill. 19. t. 11, 12. Jacq. hort. vind. t. 199. Root thick, milky. Stem when cut yielding a whitish, fetid, rue-like, tenaceous gum. Flowers yellow.

Shining Parsnip. Fl. June, Jul. Clt. 1771. Pl. 3 to $4 \mathrm{ft}$.

5 P. umbròs (Stev, in litt. ex D. C. prod. 4. p. 189.) stem furrowed, angular; leaves pinnate, pubescent on the nerves and petioles ; leaflets oval-oblong, serrate-toothed : terminal leaflet somewhat 3-lobed; umbels numerous, rather panicled ; involucels dimidiate; fruit oval. 24. H. Native of Tauria. This species was formerly confused with $P$. graveolens, but is truly distinct from it.

\section{Shadly Parsnip. Pl. 2 to 3 feet.}

6 P. Stenocárpa (D. C. prod.4. p. 189.) stem striated, glabrous; leaves smoothish, pimnate; leaflets decurrent, oblonglinear, cut, and toothed: involucra wanting; involucels of $\mathrm{few}$ leaves : fruit oblong. - Native of Siberia. Umbels and umberlules of many rays. Fruit 3 lines long and a line broad, quite glabrous; lateral ribs not expanded into wings, but all filiform, is well as the vittæ. Vitta twin in the commissure, solitary in the dorsal furrows, and often wanting in the lateral furrows.

Narron-fruited Parsuip. Pl. 2 to 3 feet?

7 P. GRave'olens (Bieb. A. taur. 1. p. 237.) stem furrowed; leaves pinnate, hoary from short down; leaflets ovate, lobed, and toothed; involucels dimidiate; fruit oval. 4 . H. Native of Caucasus, at Sarepta, and of Tauria and Podolia. Schultes, syst. 6. p. 584. Malabaíla gravèolens, Hoffm. umb. p. 126. and 209. t. 1. B. f. 6. Herácleum gravèolens, Spreng. umb. tent. 1. p. 12 .

Strong-seented Parsnip. Fl. Jul, Aug. Clt. 1817. Pl. $2 \mathrm{ft}$.

8 P. Sékakul (Russ. besch. alep. p. 157.) stem terete, downy, branched; leaves pimnate, puberulous; leaflets pinnatifid, cut, bluntly and unequally toothed; peduncles villous ; involucra none; involucels of $\mathrm{I}-2$ leaves; fruit ovate-orbicular. §. H. Native of Syria, about Aleppo; and of Egypt, near Alexandria. Herácleum pùmilum, Viv. in litt. Tordýlium suavèolens, Delille, ill. fl. ægypt. no. 323. Pastinàca dissécta, Vent. cels. t. 78. Sécacul, Rauw. reis. 1. p. 746. ex Vent. J. Bauh. hist. 3. p. 66, with a figure.-Moris, oxon. sect. 9. t. 4. ultimate figure, and therefore Tordýlium Sékakul, Mill. dict. no. 5. Root grey on the outside and white inside, edible. According to Olivicr this species of parsnip is cultivated in the Levant under the name of Sekakul.

Sckakul Parsnip. Pl. 1 to 2 feet.

9 P. PIMPinelloides (Bieb. f. taur. 1. p. 237. suppl. 247.) stem angular, branclied; leaves pinnate, pubescent; leaflets rather trifid, cut: segments cuneated, deeply serrated: lower ones reflexed: upper ones linear-lanceolate; involucra of 1-3 leaves; involucels of 4-5 leaves, dimidiate, deciduous; fruit orbicular. §. H. Native of Caucasus and Iberia, in grassy places; and of Persia, near Seidkhodzi, in sandy places. Buxb. cent. 3. t. 27. Mill. fig. t. 266. Malabaíla pimpinellifòlia, Hoffm. umb. 126. and 209. t. 1. f. 6. a. b. Heraclèum pimpinellif òlium, Spreng. tent. 12.

Pimpinella-like Parsnip. , Fl. Jul. Aug. Clt. 1818. Pl. 2 ft.

10 P. овтusifo'lia (D. C. prod. 4. p. 190.) plant glabrous; stem terete, a little branched; leaves pinnate and ternate; leaflets pimnatifid, thick : lobes obovate, obtuse, quite entire; involucra of a few very short leaves; fruit obovate. 24. $\mathrm{H}$. $\mathrm{Na}$ tive of Spain, and on the shore of the Euxine sea. Pencédanum obtusifolium, Sibth. and Smitl, fl. græc. t. 277. prod. 1. p. 189. and in Rees' cycl. no. 10. Petals cream-coloured. Fruit with rather tumid margins. Nearly allicd to $P$. pimpinellifollia.

Obtuse-leaved Parsnip. Pl. 1 to 2 feet.

Cult. The species are only to be increased by seed, which should be sown in spring in the open ground.

CVI. LEIO'TULUS (from $\lambda$ stos, lcios, smooth, and ovs wroc, ous otos, an ear; in allusion te the smooth dilated margin of the fruit). Ehrenb, in Linnæa. 1829. p. 399. D. C. prod. 4. p. 669.

Lin. syst. Pentándria, Digynia. Teeth of calyx obsolete. Petals roundish, entire, involute, with a broad retuse segment. Fruit flatly compressed, liaving a smooth thickened dilated margin: and 3 intermediate approximate ribs, and $\&$ very remote lateral ones; vittæ filiform, solitary in the furrows, and distant in the commissure.-Herb a span high. Leaves bipinnatifid. Involucrum wanting. Involucels of a few very fine entire leaves, but often wanting altogether. Flowers yellow.

1 L. Alexandrinus (Elirenb. l. c.)-Native of Egypt, near Alexandria, on hills towards Rosetta.

Alexandrian Leiotulus. Pl. $\frac{1}{2}$ to $\frac{3}{4}$ foot.

Cult. Sow the seeds in a warm sheltered situation in the open ground.

CVII. ASTYDA'MIA (a mythological name, daughter of Oceanus; the plant grows on the borders of the ocean, in the Canary Islands). D. C. coll. diss. 5. p. 53. t. 1. f. D. prod. 4. p. 190 .

Lin. syst. Pentándria, Digýnia. Margin of calyx 6-toothed. Petals obovate, entire, with an inflexed acumen. Stylopodium thick; styles very short. Fruit compressed from the back, girded by a thick, dilated margin; mericarps rather spongy, furnished with 3 crested, approximate, short ribs on the back: 
the 2 lateral ribs lost in the margin. Dorsal vittæ very few, and the commissural ones are either wanting or covered. Seed unknown.-A smootl, fleshy subshrub. Leaves pinnate; leaflets cuneated, deeply toothed at the apex: ultimate ones confluent. Umbels compound. Involucra and involucels of many leaves. Flowers yellow. It differs from Crithmum and Bupleurum in the fruit being compressed from the back, and in the calyx being 5 toothed; and from Heraclèum in the vittæ not being clubshaped, and in the petals being entire; and from Laserpitium in the ribs being hardly elevated, and in the petals being entire; and from Pastinaca, to which it is most nearly allied, in the fruit being rather fungous and a little crested, with the margins hardly flattened.

1 A. Canariénse (D. C. prod. 4. p. 190.). h. G. Native of Teneriffe, on rocks by the sea-side. Crithmum latif olium, Lin. fil. suppl. p. 180 . Tenòria Canariénsis, Spreng. umb. spec. p. 20. t. 6. f. 13. and in Schultes, syst. 6. p. 377 . exclusive of the synonyme of Cav. Laserpítium crithmifolium, Link, in Euch, can. p. 151. Herácleum Canariénse, Choisy, in herb. D. C. Root thick. Stem terete, sparingly branched, a foot high. Leaves rather glaucous; petioles sheathing. Upper leaves reduced almost to the petioles. Umbels 15-rayed; umbellules 10-12-rayed. Involucra of 5-7 oblong, rather concave leaves.

Canary-island Astydamia. Fl. Jul. Clt. 1780. Sh. $1 \frac{1}{2} \mathrm{ft}$.

Cult. This plant will require the same treatment as is recommended for Critlimum, p. 321 .; but it will require shelter in winter.

CVIII. SYMPHYOLO'MA (from $\sigma v \mu \phi v \omega$, synıphuo, to glue together, and $\lambda \omega \mu \alpha$, loma, a fringe ; the margins of the mericarps are closely joined together). Meyer, verz. pflanz. p. 127.

Lin. syst. Pentándria Digýnia. Margin of calyx obsolete. Petals equal, emarginate, with an inflexed point. Stylopodium without a margin. Styles reflexed. Fruit elliptic, compressed from the back, flat, with rounded margins; mericarps closely joined together at the margins; with 5 filiform ribs: the 3 dorsal ones at equal distances: and the lateral ones more remote and almost marginating. Vittæ wanting or obsolete. Seed complanate. Carpophore wanting. $-\mathbf{A}$ humble herb. Leaves with $5-5$, nearly orbicular leaflets. Involucra none. Petals red. Fruit very singular in its structure, by the mericarps being closely joined at the margins.

1 S. GRave'olens (Meyer, 1. c.). 4.? H. Native of the Alps of Tafandagh, in Eastern Caucasus, among fragments of schist.

Strong-scented Sympliyoloma. Pl. humble.

Cult. See Pastinàea above for culture and propagation.

CIX. HERACLE'UM (Heracles, Hercules; sacred to him). Lin. gen. p. 345. Lam. ill. t. 200. Lag. am. nat. 2. p. 92. Koch, umb. 89.-Heraclèm, Spondýlium, and Wéndia, Hoffm.-Spondýlium, Tourn. inst. p. 319.t. 170.-Heraclèum species, Spreng.

Lin. syst. Pentándria, Digýnia. Calyx 5-toothed. Petals obovate, emarginate, with an inflexed point : outer ones usually radiating and bifid. Fruit flatly compressed from the back, girded by a flat, dilated margin. Mericarps with slender ribs : the 3 dorsal ones at equal distances: and the 2 lateral ones remote from the others, contiguous to the dilated margin. Vittæ solitary in the furrows, and usually twin in the commissure, all flat: dorsal ones 4.-Strong, coarse, robust herbs, with broad, pinnate, ternate, or lobed leaves; petioles large and sheathing. Umbels of many rays. Involucra caducous, usually of few leaves; involucels of many leaves. The species are extremely intricate, and difficult to define.

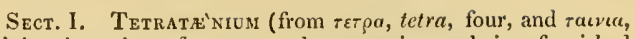
lainia, vitta; in reference to the commissure being furnished with 4 vitta). D. C. prod. 4. p. 191. Commissure furnished with 4 vittæ. Flowers not radiating, cream-coloured.

1 H. Nepale'nsis (D. Don, prod. fl. nep. p. 185.) stem furrowed, rather hairy; lower leaves having the petioles twice trifid, biternate: with tripartite leaflets; upper leaves ternate : with rather 3 -lobed leaflets; leaflets all ovate, acute, and equally serrated, rather hairy above, and pubcscent along the nerves beneath; fruit elliptic; commissure furnished with 4 vittæ. 4. H. Native of Nipaul. Flowers equal, yellowish, Knees of stems bearded witl white wool.

Nipaul Cow-parsnip. Pl. 3 to 4 feet.

2 H. ontusifòlum (Wall. mss. ex D. C. prod. 4. p. 191.) stem striated, pubescent ; leaves ternate or 3-lobed, roundishcordate; leaflets or lobes obtuse, with a few coarse teeth, rather hairy above, and beset with whitish pubescence beneath; umbels of many rays; fruit obovate; commissure furnished with 4 vittæ. 24. H. Native of Nipaul. Dorsal vittæ linear. Flowers not radiating, cream-coloured.

Obtuse-leaved Cow-parsnip. Pl. 9 to 4 feet.

3 H. Rígens (Wall. mss. ex D. C. prod. 4. p. 191.) stem striated, pubescent ; leaves ternate, with the petioles rather hairy ; leaflets petiolate, orbicular, rather cordate at the base, toothed, scabrous from hairs above, pubescent beneath; upper leaves bluntly trifid; fruit obovate-elliptic; commissure furnished with 4 vittæ. 4 . H. Native of the East Indies. Cònium rigens, Heyne, ex Wall. Leaves of involucels lanceolate, striated, puberulous on the outside. Flowers not radiating, creamcoloured. Dorsal vittæ of fruit linear.

Stiff Cow-parsnip. PI. 2 to 4 feet?

Sect. II. Eunerache'un (from $e u$, well, and Heraclèum; this section contains what are considered the true species of the genus). D. C. prod. 4. p. 191.-Heraclèum, Hoffm. umu. p. 141. D. C. prod. 4. p. 191. Commissure of fruit furnished with 2 vittæ. Umbels equal or radiating. Petals greenislyyellow.

4 H. Flave'scens (Baumg. fl. trans. 1. p. 214.) leaves pinnate, rough from hairs; leaflets ovate or oblong; flowers yellowish, not radiating; commissure furnished with 2 vittæ. 4 . H. Native from Dauphiny to Siberia, in the grassy parts of mountains. Jacq. aust. 2. t. 173.

I ar. a, latifolium (D. C. prod. 4. p. 191.) leaflets lobed or palmately-parted, unequally crenate-serrated; flowers uniform, not radiating; fruit orbicularly oval, glabrous, emarginate at the apex. \&. H. Native of Tauria, Caucasus, Siberia, Dahuria, and many other parts of Russia, in rather humid meadows. H. Sibúricum, Lin. mant. 354 . Bieb. fl. taur, and suppl. no. 558. Hoffin. umb. 143. t. 1. B. f. 1. Schult. syst. 6. p. 475. H. Austrìcum, Pall. ind. taur. Spondýlium conforme, Moench, meth. p. 83.-Gmel. sil). 1. t. 50. From this plant a spirit is drawn at Kamtschatka, called raka, as related in Cook's voy. 3. p. 337. where the process of making the spirit is described. It is used also as food.

Var. $\beta$, angustif òlium (D.C. prod. 4. p. 191.) leaflets oblong, lanceolate, or linear, sinuately toothed, ultimate ones confluent. 4. H. Native of Dauphiny, Vallais, Austria, Russia, \&c. in waste, grassy fields. H. angustifòlium, Lin. mant. 56 . Jacq. fl. aust. t. 173. H. Sibiricum of Lin. has been raised from the seeds of $H$. angustifolium.

Yellowish Cow-parsnip. Fl. Ju. Jul. Clt. 1789. Pl. 4 to $6 \mathrm{ft}$. 5 H. Orsi'si (Guss. pl. rar. p. 133. t. 27.) stem furrowed, muricated, almost simple; leaves simple, cordate, glabrous on both surfaces, rather coriaccous, obscurely lobed, and tripartite, 
crenate-serrated; lobes acuminated; flowers rather radiating; involucra almost wanting; leaves of involucels linear; fruit obovate. 4. H. Native of Abruzzo, in gravelly parts of mountains. Habit of $H$. alpinum, but the flowers are greenish. Commissure of fruit furnished with 2 vittæ.

Orsin's Cow-parsnip. Pl. 2 to 3 feet.

6 H. AU'REUM (Sibth. and Smith, fl. græe. t. 282. prod. 1. p. 192.) stem much branched; leaves pinnate; leaflets lobed, cut, pubescent : of the radical ones roundish ; umbels usually of 3 rays ; flowers radiating; fruit orbicular; involucra and involucels almost wanting; vittæ semi-circular. $\delta$. H. Native on Mount Parnassus. Habit of Pastinaca sativa; but the petals are obcordate, with an inflexed mucrone. Flowers golden yellow. Vitta linear.

\section{Golden-flowered Cow-parsnip. P!. 1 to 2 feet.}

Sect. III. Spondy'LiUM ( $\sigma \pi 0 v i v \lambda o c$, spondylos, vertebra; resemblance in the articulations of the stem). Hoffm. umb. p. 129. D. C. prod. 4. P. 192. Commissure of fruit furnished with 2 vittæ. Umbels of many rays, radiating. Petals white.

7 H. Longifòlium (Jacq. aust. t. 174.) leaves scabrous, pinnate, or pinnatifid from the coalition of the leaflets; leaflets or lobes elongated, deeply crenated; leaves of involucels linearsetaceous; fruit glabrous, cuneiform. 4. H. Native of Austria, in alpine meadows. Host. fl. austr. 1. p. 374. An intermediate species between $H$. flavéscens and Spondýlium. Petals at first green, but at length becoming white, obcordate: outer ones radiating a little. Fruit larger and much more cuneated than in the above-mentioned species.

Long-leavcd Cow-parsnip. Fl. May, Ju. Clt. 1800. Pl. $6 \mathrm{ft}$.

8 H. palmatílobum (D.C. prod. 4. p. 192.) upper cauline leaves 5-parted from the top of the sheath, or 3-parted; outer lobes bipartite, all elongated, coarsely toothed, glabrous above, but ronghish beneath; leaves of involucels linear-setaceous; fruit glabrous in all states, obovate. 24. H. Native country unknown. Flowers white, radiating a little. It differs from 11. Spondýlium in the leaves being palmate-parted, not pinnateparted, less rough, and in the fruit being more obovate. Probably $I I$. clegans of many authors is the same as this species.

Palmate-lobed-leaved Cow-parsnip. Pl. 4 to 5 feet.

9 H. Spondýlum (Lin. spec. 1. p. 358.) leaves ternate, pinnate, or pinnatifid from the coalition of the leaflets, scabrous; leaflets pinnatifid, cut, and serrated; leaves of involucels lanceolate, membranous, finely fringed, with long taper points ; fruit orbicular, glabrous. §.H. Native of Europe, and probably of Siberia, in hedges, the borders of fields, and rather moist meadows, vcry common; plentiful in some parts of Britain. Smith, engl. bot. t. 939 . Hayn. arz. gew. 7. t. 10. H. proteifórme, Crantz, aust. 3.p. 11. H. bránca ursìna, All. pedem. no. 1291. Spondýlium Raii, syn. 205. Ger. emac. 1009, with a figure. Camer. epit. 548, with a figure. Riv. pent. irr. t. 4. and of many other old authors. Spondýlium bránca, Scop. carn. no. 335. Spondýlium bránca ursìna, Hoftin. umb. 132. t. 1. f. 11.-Acánthus Germánica, Fuchs, hist. 53. with a figure. Cow-parsnip. Petiv. herb. brit. t. 24. f. 1. Root taper-shaped, whitish, aromatic, sweetish, and rather mucilaginous. Stem rough, with white hairs. Flowers more or less radiant, white or reddish. The whole plant is wholesome and nourishing food for cattle; and is gathered in Sussex for fattening hogs, being known by the name of hog-need. The seeds are strong-scented, and are accounted diuretic and stomachic. Linnacus says the plant is used in Scania against dysentery. Gmelin says that the inlabitants of Kamtschatka, about the beginning of $\mathbf{J u l y}$, collect the footstalks of the radical leaves, and after peeling off the rind (which is very acrid) dry them scparately in the sun, and then tying them in bundles, lay them up carefully in the shade in bags ; in this state they are covered with a yellow saccharine efflorescence, tasting like liquorice; this being shaken off is eaten as a great delicacy. The Russians distil an ardent spirit from the stalks thus prepared, by first fermenting them in water, with the greater bilberries (Vaccinium uliginòsum), which $\mathrm{Gme}$ lin says is more agreeable to the taste than spirits made from corn.

Var. $\beta$, angustifolium (Sinith, fl. brit. 307.) leaves deeply pinnatifid; the 2 lowest lobes elongated, and spreading in a radiating manner. $\delta$. H. Native of Yorkshire. Mr. Woodward has found this variety growing on the same root with the common kind.

Var. $\gamma$, élegans (Jacq. austr. t. I75.) leaflets decussate, narrow, toothed. $\quad$. H. Native of Austria, Piedmont, \&c.

I ar. 8, laciniàtum (Desf. hort. par. ex D. C. prod. 4. p. 192.) leaflets cuneated, ovate, coarsely and deeply serrated. \&. H. Native country unknown.

I $a$ r. E, subcanéscens (D. C. prod.4. p. 192.) leaves canescent beneath. $\delta$. H. Native of France. This variety differs from 1 . Pyrenàca in the ovaries being glabrous.

Spondylium or Common Cow-parsnip. Fl. Jul. Brit. Pl. $4 \mathrm{ft}$.

10 H. CA'spicum (Hortul. ex D.C. prod. 4. p. 192.) leaves pinnate, scabrous; leaflets elongated, cut, and toothed, acuminated; leaves of involncrum linear, broadest at the base; leaves of involucels setaceous, ciliated on both sides with long villi; fruit obovate, glabrous in all stages. $4 . \mathrm{H}$. Native about the Caspian sea. This spccies is sufficiently distinct from any of the varieties of $H$. Spondýlium.

Caspian Cow-parsnip. Fl. Ju. Jul. Clt. ? Pl. 4. feet.

11 H. ca'ndicans (Wall. mss. ex D. C. prod. 4. p. 192.) leaves ternate, clothed with loary tomentum beneath, as well as on the stems and pctioles, but smoothish above; leaflets petiolulate, cuneated at the base, trifid or pinnatifid: lobes irregularly toothed ; leaves of involucels linear, acuminated, about equal in length to the rays; fruit obovate-oblong; vittæ linear. $4 . \mathrm{H}$. Native of the north of India, at Deyradoon and Kamaon.

Whitencd Cow-parsnip. Pl. 4 to 5 feet.

12 H. LANA'tum (Miclix. f. bor. amer. 1. p. I66.) leaves ternate, petiolate, tomentose beneath: upper ones 3-lobed ; leaflets petiolate, broad-ovate, roundish-cordate, lobed; leaves of involucels small, subulate; fruit broadly obcordate, oval. 4. H. Native of Virginia, Pennsylvania, and Canada, as far as the Mackenzie river; moist banks of streams in north-west America, in humid pastures. Pursh, fl. amer. sept. 1. p. 181. Begel. fl. bat. p. 67. Torr. fl. bor. amer. 1. p. 813 . H. Spondýlium, Cham. et Schlecht. in Linnæa. 1. p. 39. Petals said to be oblong. The plant is said to be very nearly allied to $H$. Spondiflium, but very distinct. The roots and stems of this plant are eaten by the Chenook Indians; and by the Cree Indians, under the name of Penpoon antic; i.e. flute stem; and the young stems are used by them as a pot-herb.

Hoolly Cow-parsnip. Fl. Ju. Jul. Clt, 1810. Pl. 4 feet.

13 H. conda'tum (Presl, del. prag. p. 135.) leaves ternate; leaflets cordate-ovate, petiolulate, lobately pinnatifid, mucronately toothed, hispid beneath, as well as the petioles and stem, which is furrowed; leaves of involucels linear; involucra wanting; fruit glabrous, obovate, somewhat emarginate at the apex. 24. H. Native of Sicily, in humid groves on the Nebrodes. Root black, sweet-scented, and is called Angélica by the Sicilians, and is used for the same purposes by them. H. Spondylium and H. Pánaces Ucria, ex Guss. prod. fl. sic. 1. p. 364.

Cordate-leafletted Cow-parsnip. Pl. 4 to 6 feet?

14. H. Pyrena'jcum (Lam. dict. 1. p. 403.) leaves very large, palmatifid, hoary from tomentum beneath; leaflets lanceolate, toothed or ternate; involucra of few leaves: young fruit covered with long hairs: adult ones glabrous, nearly orbicular. 
\$. H. Native of the Eastern and Central Pyrenees, in rugged places; and of Italy, on the mountains; as well as of Croatia, Tyrol, and about Verona. D.C. fl. fr. 4. p. 315. H. amplifòlium, Lapeyr. abr, p. 153. Poll, ver. 1. p. 339. and H. setòsum, Lap. suppl. p. 44. ex Benth. cat. p. 89. H. platyphýllum, Ram. pyr. ined. H, alpinum $\beta$, Pers. All tlie other synonymes added to this plant by Spreng, in Schultes, syst. 6. p.577. are wrong or doubtful.

Pyrencan Cow-parsnip. Fl. June, July. Clt. 1798. Pl. 4 to 6 feet.

15 H. PÁnaces (Lin. spec. p. 358.) leaves pinnate, canescent beneath; leaflets on long petioles, cordate, usually 3 -lobed, toothed; leaves of involucels linear-setaceous; young fruit bearing a few scattered hairs. $\delta$. H. Native of the southern Alps of Europe. Lob. icon. t. 701. f. 2. Mor, ox. sect. 9. t. 17. f. 3. H. setòsum, Lapeyr. abr. p. 153 ?

True Cow-parsnip. Fl. July, Aug. Clt. 1796. Pl. 6 feet.

16 H. A'sPERUM (Bieb. fl. taur. suppl. p. 224.) stem rough from strigæ; leaves deeply lobed, serrated, acute, scabrous above, pubescent beneatb; umbels of 4.0 rays ; leaves of involucra setaceous; fruit orbicularly elliptic, when young rather scabrous. ‡. H. Native of the north of Caucasus, on Mount Beschtau; and according to Koch also of the Alps of Bavaria and Tyrol. Spondýlium ásperum, Hoffm. umb. p. 134. Dorsal vittæ 2 longer than the lateral ones; all filiform; those in the commissure evidently clavate. In the cultivated plant the fruit is nearly glabrous even when young.

Rough Cow-parsnip. Fl. June, July. Clt. 1818. Pl. 6 to $8 \mathrm{ft}$.

17 H. villòsum (Fisch. in Scluultes, syst. 6. p. 579.) leaves sinuately pinnatifid, sharply serrated, acuminated, clothed with hoary tomentum beneath; leaves of involucra and involucels setaceous, deflexed; umbels sparingly radiant; fruit elliptic, ciliated, woolly on the back. \$. H. Native of Caucasus, in gravelly places on the margins of rivulets. Stev. obs. 18\%8. p. 72. H. Pyrenàicum, Bieb. fl. et suppl. no. 559. but not of Lam. H. decipiens and $H$. marginàtum, Hoffm. umb. p. 134. and 135. and probably $H$. gigánteum, Horn. hort. hafn. ex Prescott. Leaves as in $H$. Pyrenaicum hoary beneath, but differs in the young fruit being tomentose, and in the adult ones being roughly ciliated. Vittæ broad; the dorsal ones drawn out beyond the middle, and filling the furrow's; the commissural ones short, rarely somewhat branched. There are varieties with larger and smaller fruit.

I ar. $\beta$, subvillòsum (Hoffm. umb. gen.) fruit covered by scattered rather loose hairs; leaves less canescent beneath.

Villous Cow-parsnip. Fl. July. Clt. 1826. Pl. 4 to 6 feet.

18 IJ. PUBE'Scens (Bieb. suppl. p. 225.) leaves pubescent beneath ; cauline leaves ternate; leaflets somewhat palmately pinnatifid, tootlied; segments and recesses acute; umbels of many rays; involucra of 1-2 leaves; involucels short, caducous, of few leaves; fruit elliptic, having the disk rather villous. f. H. Native of the south of 'Tauria, in slady places; and of Eastern Caucasus, in alpine places. Spondýlium pubéscens, Hoffm. umb. p. 134. H. speciòsum, Ledeb. hort. dorp. 77. H. Panàces, Steven. mem. mosc. 3. p. 259? To this species is pro. bably referrible the $\mathrm{H}$. gummíferum, Willd. enum. p. 31 . liort. berol. 1. p. 53 . t. 53. and t. 54. It differs, however, from $H$. Pyrenaicum and $H$. Panàces, in the young fruit being clothed with short down, not with long spreading down. Fruit glabrous in the adult state; having the dorsal vittæ slender, and drawn out beyond the middle, and being suddenly dilated into a club-shaped form at the apex. The young shoots are filled with a swcet aromatic juice, which is called Baldergan by the natives of Caucasus, and is eaten by them in a crude state.

Pubcscent Cow-parsnip. Fl. July. Clt. 1823. Pl. 4 to 5 feet.

19 H. Barba'tusi (Ledeb. f. ross. alt. jll. t. 303.) leaves pin- nate, with 2 pairs of leaflets; lower leaflets and terminal one sinuately pinnate-parted, petiolate: lobes acuminated, serrated: serratures ovate, acuminated ; umbels radiant: fruit elliptic, beset with a few pili, somewhat emarginate at the apex; vittæ in the commissure parallel. $\delta$. H. Native of Altaia, in mountain meadows. Stem furrowed like the rest, beset with rigid pili, which rise from a callous or blackish point, and which are usually retrograde on the lower part of the stem; bearded with numerous pili at the knees. Petioles hispid, bearded at the insertion of the petioles. Leaves pubescent beneath, but green and furnished with a few stiff hairs beneath at the veins. Involucrum of one or few leaves, caducous; involucels of a few linear permanent leaves. To this plant may be referred the one in Gmel. fl. sib. 1. p. 213. no. 29, which Linnæus has cited for his H. Panàces. It is called Sladkajatrawa, i. e. a sweet herb, by the natives of Siberia, a name given by them to many other plants, as to Liquorice and Milk-vetch, \&c.

Bcarded Cow-parsnip. Pl. 4 feet.

20 H. Disse'crum (Ledeb. fl. ross. alt. ill. t. 304. fl. alt. I. p. 301.) leaves ternate; leaflets petiolulate : lateral leaflets pinnateparted: terminal one palmate-parted : segments cut or pinnatifid, oblong, acuminated, serrated ; umbels radiant ; mericarps orbicularly elliptic, at length glabrous; conmmissural vittæ diverging. $\delta$. H. Native of Altaia, in meadows, near Tschetschulicha, and the metal mines at Riddersk; and clsewhere. $H$. laciniatum, Fisch. in litt.? Stem deeply furrowed, sparingly pilose, hispid at the joints, villous towards the top. Leaves hispid above from a few thick hairs, but paler and pubescent beneath. Involucra wanting; involucels of a few linear leaves, which are variable in length. Flowers white.

Dissected-leaved Cow-parsnip. Fl, July. Pl. 3 feet.

21 H. Dougra'sir (D.C. prod. 4. p. 193.) leaves scabrous beneath, and on the petioles, glabrous above, ternate; leaflets petiolulate, cordate, 3-5-lobed, acuminated, toothed; leaves of involucra numerous, subulate at the apex; fruit obovate, glabrous : dorsal vittæ elongated, rather club-shaped; commissural vittæ 2 , short, rather club-shaped, and 2 other small, nearly abortive ones. 4. H. Native of the north-west coast of America. This may prove nothing but a variety of $I I$, lanatum.

Douglas's Cow-parsnip. Pl. 3 to 4 feet.

22 H. cuneifónme (D. C. prod. 4. p. 194.) leaves hispid beneath, as well as the petioles, glabrous above, pinnate; leaflets 3-5, petiolulate, cordate, lobed; lobes toothed, hardly acumiuated; leaves of involucra many subulate; fruit obovate-cuneated, glabrous; dorsal vittæ filiform; commissural vittæ 2, rather clavate. 2 . H. Native country unknown, but probably of Siberia.

Cunciform-fruited Cow-parsnip. Pl. 4 feet?

23 H. ligusticifòlium (Bieh. A. et suppl. no. 560.) leaves decompound, ternate or quinately pinnate, smoothish; leaflets cuneated, obtuse, deeply serrated; fruit villous; vittæ filiform, acute. s. H. Native of Tauria, on stony hills; and of Caucasus, in subalpine places above Nikita, ex Stev. obs. 18\%8. p. 71. H. montànum, Georgi in Willd. herb. ex Stev. Stem angular, pubescent, as well as the young leaves. Flowers white, radiant. Commissural vittæe equal in length to the dorsal ones.

Lovage-leaved Cow-parsnip. Fl. June, July. Clt. 1816. Pl. 2 feet.

24. H. Cauca'sicun (Stev. mem. soc. hist. nat. mosc. 3. p. 259.) leaves ternate; leaflets on long petioles, toothed, glabrous above, pubescently scabrous bencath : intermediate one 3-lobed. ๘. H. Native of Caucasus, on the mountains, at the river Jucharibasch. Flowers white, rather radiant. A plant like this from Iheria has the upper leaves ovate and 3-lobed, on long petioles, and the young fruit bristly.

Caucasian Cow-parsnip. Fl. June, July. Clt. 1818. Pl. $4 \mathrm{ft}$. 
25 H. nu'mile (Sibth, et Smith, fl. græc. prod. 1. p. 193.) leaves rather bipinnate, cut, pubescent; stem nearly simple; umbels 4-7-rayed; fruit orbicular, smoothish. 24. H. Native of Greece, on Mount Olympus. Umbels large. Stems hardly a hand high. Vittæ of fruit 4, red, oblong: the dorsal ones attaining the length of the middle.

IIumble Cow-parsnip. Pl. $\frac{1}{2}$ to $\frac{3}{4}$ foot.

Sect. IV. Carie'zia (from Mount Carmelo, the habitation of the species). D. C. prod. 4. p. 194. Fruit ornamented with thick adpressed stiff bristles. Vittæ not sufficiently known, but there are probably 4 dorsal ones, and 2 filiform liardly clavate commissural ones. Petals hispid; exterior ones radiant. Perhaps a proper genus, or perhaps only a species of Zozimia or Pastinàca.

26 H. CARME'Li (Labill. syr. dec. 5. p. 3. t. 1.) leaves pinnate, scabrous from adpressed down beneath; leaflets orateoblong, deeply toothed: extreme one rather cordate, 3-lobed; rays of umbel 5 , very unequal, contracted after flowering. $\delta$. H. Native of Syria, on Mlount Carmel. Involucra and involucels composed of erect permanent setaceous leaves. Bristles on the stem and branches retrograde.

Carmelo Cow-parsnip. Pl. 2 to 3 feet?

Sect. V. WE'NDTia (in honour of Frederick de Wendt, M. D. Professor of Medicine at Erlang). D. C. prod. 4. p. 194. Wéndia, Hoffm. umb. p. 136. Bieb. suppl. 227. Commissure withont vittæ, or with 2 small obliterated vittæ. Umbels radiant. Petals white or rather rose-coloured.

27 H. ALPI'NUM (Lin. spec. p. 359.) leaves cordate-roundish, simootl, palmately 5-cleft: lobes bluntish, crenately toothed, rarely cut; leaves of involucels setaceous; fruit obovate-orbicular. 24. H. Native of the Alps of Jura, in pastures, and at the borders of woods; as well as of the Alps of Daupling, Provence, and the Pyrenees. D. C. fl. fr. 4. p. 316. H. testiculàtum, Lapeyr. suppl. p. 43.-C. Bath. prod. 83. with a figure--Barrel. icon. t. 55 .

Alpine Cow-parsnip. Fl. June, July. Clt. 1739. Pl. 1 to $2 \mathrm{ft}$.

28 H. Austri Acum (Jacq. austr. t. 61.) leaves pinnate, with 2-3 pairs of leaflets, scabrous from scattered bairs on both surfaces; leaflets ovate-lanceolate, doubly scrrated: terminal one somewhat 3-lobed. $\psi$. H. Native of Austria, Carniola, and Tuansylvania, in alpine ineadows. Crantz, austr. 153. t. 1. Spondýlium Austriacun, Scop. carn. ed. 2. vol. 1. p. 204. t. 1. To this Sprengel refers Tordýlium siifòlium, Scop. carn. no. 318. t. 8 . but it differs in the petals being red, and in the fruit being hispid from villi.

Austrian Cow-parsnip. Fl. June, July. Clt. 1752. Pl. $2 \mathrm{ft.}$ 29 H. Croroda'num (D. C. prod. 4. p. I94.) lower leaves ovate, some what lobed, serrated: superior ones cruciately pinnate; leaflets linear, all rather canescent beneath from down. $\delta . H$. Native of Caucasus, about Nartzana and Kobi, among grass on the momtains. Said not to be distinct from H. Austriacum by Stev. obs, 1828. p. 70. Heraclèum longifòlium, Bieb. fl. taur. 1. p. 223. exclusive of the synonymes. Wéndia Chorodànum, Hoffm. umb. 139. t. 1. $\beta$, and in lit. f. 12, 13 . Fruit obovate. Commissural vittæ wanting; but there are 4 dorsal ones which are clavate, and hardly attaining a third part of the length of the fruit. There is also a variety of this with rose-coloured flowers (H. ròseum, Stev. in mem. soc. mosc. 3. p. 260.) and more humble stem.

Chorodanum Cow-parsnip. Pl. 2 to 3 feet?

80 H. mísum (Lam. dict. 1. p. 403.) plant dwarf, glahrous; leaves nearly all radical, bipinnate: leafiets lanceolatelmear, cut a little; involucra usually of one leaf; involucels wanting. 4. H. Native of the Alps of Dauphiny, but rare.
D. C. f. fr. 4. p. 316 . H. bipinnàtum, Cuss. H. pùmilum Vill. dauph. 2. p. 640. t. 14. Peucédanum Vocontiòrum, Spreng. umb. spec. 51. Schultes, syst. 6. p. 571 . It differs from Peućdanum in the petals being deeply emarginate; in the fruit being oval and flattened; in the vittæ extending nearly to the middle of the fruit, filiform, not saccate. It may hereafter prove also to be generically distinct from Herácleum.

Small Cow-parsnip. Fl. May, July. Clt. 1810. Pl. 1 foot.

Sect. VI. Trichogònium (from $\theta \rho e \xi$ rotxos, thrix trichos, a hair, and $\gamma \omega r$, gonia, an angle; in reference to the stems being bearded at the joints or knees). D. C. prod. 4. p. 195. Commissure without any vitta. Umbels not radiant. Petals yellowish. Stems woolly or bearded at the joints.

31 H. WALLI'chII (D. C. prod. 4. p. 195.) stem terete, liairy at the base, glabrous except at the knees or joints; leaves ternate, having a few scattered pili above, and bearing a few small ones at the nerves beneath; leaflets lanceolate, acuminated, serrated, undivided, or the lateral leaflets of the lower leaves are 2-lobed, and the terminal one 3-lobed. Involucra of 1-2 deciduous leaves.-Native of Nipaul. Fruit obovate, nearly orbicular, with 5 slender ribs. Vittæ 4 , linear, drawn out a little beyond the middle of the mericarps.

\section{Wallich's Cow-parsnip. Pl. 2 to 4 feet?}

+ Species hardly knonn, but most of them may prove to be synonymous with those describcd above.

32 H. тuBERo'sum (Molin. chil. ed. germ. p. 115. ex Willd. spec. 1. p. 1423.) leaves pinnate: with 7 leaflets; flowers radiant; root yellow, composed of tubers. 4. F. Native of Chili. The rest unknown.

Tuberous-rooted Cow-parsnip. Pl. 2 to 3 feet?

33 H. TAU'RICUM (Fisch. in litt. ex Loud. hort. brit. p. 109.) ๙. H. Native of Siberia. Perhaps the same as $H$. villostum.

Taurian Cow-parsnip. Fl. Ju. July. Clt. 1820. Pl. 5 feet.

34 H. verruco'sum (Stev. in litt. ex Loud. hort. brit. p. 109.) $\delta$. H. Native of Tauria. Perhaps the same as $I$. ásperum.

Warted-stemmed Cow-parsnip. Fl. June, July. Clt. 1820. Pl. 7 to 8 feet.

Cult. All the species grow well in any soil, and are all easily increased by seed; and some of the perennial ones by dividing at the root.

CX. ZOZI'MIA (in honour of A. N. and Z. Zozima, distinguished editors of the Greek classics). Hoffm. umb. 1. p. 145. t. $1 . \beta$, f. 9 . (under Zozima,) Sinith, in Rees' cycl. vol. 39. Bieb. suppl. 229. Koch, umb. 8s. D. C. prod. 4. p. 195.-Hcraclèum and Tordýlium species of authors.

Lin. syst. Pcntándriat, Digýnia. Calyx 5-toothed. Petals obovate, emarginate, with an inflexed point. Fruit flatly compressed from the back, and rather convex in the middle, more or less hairy, girded by a smooth thickencd dilated margin. Mericarps with very slender ribs, the 3 dorsal ones at equal distances, and the 2 lateral ones more remote, and contiguons to the dilated margin. Vittæ covering the whole seed, the dorsal ones solitary between the ribs, 4 on the back of each mericarp, and so large as to fill the furrows; but having 2 broad ones in the commissure. Carpophore bipartite. Seed flat.--Herbs, natives of the Levant, with decompound leaves, compound umbels, many leaved involucra and involucels, and white flowers, which are not radiant. This is an intermediate genus between Heraclium and Tordylium; but differs from the first of these in the margin of the fruit being thickened, not flat; and from the last in the margin of the fruit being smooth, not tubercular; and from both in the form and disposition of the vittæ. 
1 Z. A Bsinthifòlia (D. C. prod. 4. p. 195.) stem furrowed; leaves supra-decompound, hoary and pilose; leaflets lanceolate, rather remote, and somewhat trifid, cuneate at the base, sliort. s. H. Native of the Levant, between Bagdad and Kermancha; of Siberia, about Tiflis ; of Caucasus, on Mount Beschtau, and on the mountains of Talusch, near Swant; and of Persia in stony places about Seidkhodzi. Heraelèum absinthifòlium, Vent. choix. t. 22. Sehultes, syst. 6. p. 582. Sibth, f. græc. t. 281. Heraclèum tomentòsum, Sinith, prod. 1. p. 192. 'Tordýlium absinthifòlium, Pers, ench. 1. p. 314. Zoż̀ma Orientảlis, Hoffm. umb. 1. p. 148. t. 4. Pastinàca incàna, Willd. herb, ex Stev, obs. ined. Pastinàca dissécta, Cels. hort. Leaves of involuera hoary; of the involucels about equal in length to the umbellules, which are dense. Fruit villous in the disk between the 3 dorsal ribs; but smooth on the margins.

Hormnood-leaved Zozimia. Fl. July, Aug. Clt. 1816. Pl. 2 feet.

2 Z. Anetirfo'lia (D. C, prod. 4. p. 196.) stem terete; lcaves supra-decompound, glabrous, glaucous; leaflets linear, acute. $\delta$. H. Native of Persia, between Teheran and Ispahan. Habit of the first species. Involucra small, glabrous. Fruit more of an orbicular form than in $H$. absinthifolium, and beset with scattered down over the whole disk, but when young rather pilose.

Fennel-leaved Zozimia. Pl. 2 feet.

Cult. The seeds of these plants should be sown in the open ground in spring. A light soil suits them best.

CXI. POLYTE'NIA (from $\pi o \lambda v$, poly, many, and raıve tainia, vitta; the mericarps are furnished with many vitta). D. C. coll. mem. v. p. 53. t. 13. prod. 4. p. 197.

Lin. sysr. Pentándria, Digýnia. Calyx 5-tnothed. Petals oval, emarginate, with an inflexed point. Fruit oval, compressed from the back, which is lenticular, quite glabrous, witl a smooth tumid margin, and a depressed dorsal area. Mericarps with very slender hardly distinct ribs. Vittæ twin between the ribs on the back, and 6 in the commissure. Carpoplore indistinct. Seed complanate.-An American glabrous herb. Upper leaves tripartite, opposite. Lateral flowering branches opposite. Umbels terminal. Involucra none. Leaves of involucels setaceous. Flowers yellowish in the dried state. This genus is allied on the one liand to Zozimia, and on the other to Tordylium.

1 P. Nuttáleli (D. C. l. c.) Native of North America, in the Arkansa territory. 'Tordýlium Americànum, Nutt. mss. Stem nearly terete. Leaflets trifir, cuneated at the base; lobes lanceolate, toothed at the apex.

Nuttall's Polytænia. Pl. I foot.

Cult. See Zozimia above for culture and propagation.

CX1I. JOHRE'NIA (in honour of Mart. Dan. Jolireni, who was the first to introduce the dichotomous method in botany). D. C. coll. mem. v. p. 54. t. 1, f. C. prod. 4. p. 196.

Lin. sysr. Pentándria, Digýnia. Teeth of calyx obsolete, very blunt. Petals unknown. Stylopodium short, conical, a little furrowed; styles short, diverging, at length deciduous. Fruit oval, lenticularly compressed from the back, quite glabrous, rather spongy and suberose, with a tumid smooth margin, and a flat rather coloured dorsal area. Mericarns with 3 dorsal filiform ribs, which at length become brownish, and therefore probably contain vittæ; the 2 lateral ribs usually indistinet in the lilated margin : but sometimes rufous, and of the form of vittæ. Commissure spongy, without any vittæ, but furnished with 2 lines. Carpophore bipartite. Seed complanate, $\mathbf{A}$ quite glabrous herb, native of the Levant. Stem terete, diclotomous. Lower leaves bipinnate; leaflets opposite, 2 pairs and an odd one, distant, divided into $2-5$ linear acute lobes, which are conVoL. III. fluent at the base; superior leaves parted into 3 linear elongater, quite entire lobes; upper ones reduced to a narrow elongated sheatl. Umbels of 6-8 rays. Involticrum wanting or of one leaf; involucels of 4.5 linear-setaceous leaves.

1 J. Dichótoma (D. C. 1. с.) - Native of the East, at Mount Lebanon. Hippomârathrum crithmi folio flore luteo, Vaill. lıerb.

Dichotomous Jolurenia. Pl. 1 to 2 feet?

Cult. Ste Zozimia above for culture and propagation.

\section{Tribe VIII.}

TORDYLI'NE (plants agreeing with Tordylium in important characters), or Orthospérmæ paucijugàtæ annulàtæ, Koeh, umb. p. 55 , D. C. prod. 4. p. 196 . Fruit lenticularly or flatly compressed from the back, girded by a thick dilated thickeried knotted or plicate margin. Mericarps with 5 very slender or obsolete ribs: lateral ribs contiguous to the dilated margin, or forming the same. Seed flat. This tribe diflers from tribe Peucedanea, in the margin of the fruit being ribbed or plicate, not smooth, and quite entire.

CXIII. HASSELQUI'ST'IA (so named by Linnæus in honour of his pupil Fred. Hasselquist, M.D. who travelled in the Holy Land, Sc. and died at Smyma in 1752: his travels are published). Lin. gen. 341. Spreng, umb. prod. p. 11. Kocl, umb. 88. D. C. prod. 4. p. 197.-Tordýlium species, Lam. ill. t. 193. Lag. am. nat. 2. p. 93.

Lix. sysr. Pentándria, Digýnia. Margin of calyx 5-toothed. Petals obovate, emarginate, with an inflexed point; outer ones radiant, bifid. Frnit rous the rays of the umbels flatly compressed, with a somewhat thickened accessory winged margin, which is hardly tubercularly wrinkled; those of the disk dissimilar, having one of the mericarps contracted into a hemisplierical urceolus around the other, wlich is abortive. Mericarps with very slender ribs, the 3 dorsal ones at equal distances, and the 2 lateral ones contiguous to the thickened margin, or covered by it. Vittæ filiform, one in each furrow, and 2 in the commissure. Carpophore binartite. Seed flattened. This genus hardly differs from Tordylium unless in the unequal mericarps of the fruit, and in their margins being hardly wrinkled, and quite smooth in the disk on both sides, as in Herácleum.

I H. Egyptiaca (Lin. amcen. 4. p. 270. exclusive of the synonymes,) stem hispid ; leaves scabrous, pinnate; leaflets pinnatifid; segments bluntly lobed; involuera and involucels small, setaceous. $\odot$. H. Native of Egypt and of Syria, on the sea shore. Jacq. hort. vind. t. 87. Tordýlium Egyptiacum, Lam. ill. t. 193. f. 2. Poir. dict. 7. p. 711 . Flowers white. In this species the flowers sometimes have $3-4$ styles. Carpophore green. Styles white, erect.

Egyptian Hasselquistia. Fl. July. Clt. 1768. Pl. $1 \frac{1}{2}$ foot. 2 H. corda'TA (Lin. fil. suppl. p. 179.) plant pubescent; lower leaves ternate; leaflets ovate, rather cordate; superior leaves simple, cordate, toothed; leaves of involucra and involucels numerous, setaceous, reflexed. $\odot$. H. Native of the Levant. Jacq. hort. vind. 2. t. 193. Tordýlium cordàtum, Poir. dict. 7. p. 712. Rays of umbels hispid. Leaves of iuvolucels subulate, longer than the umbellules. Flowers white. Fruit as in most of the species of Tordylium few, but unequal, as in Hassclquistia.

Cordate-leaved Hasselquistia. Fl. July. Clt. 1787. Pl. $2 \mathrm{ft}$.

Cult. The species being natives of warm elimates, the plants are difficult to preserve through tlse winter. 'The surest way to procure good seed is to sow in autumn, and preserve the plants in a frame or green-house till spring, when they should be planted out in a warm sheltered situation.

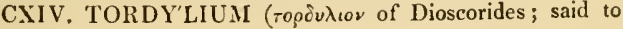
Y y 
be from topvos, tornos, a lathe, and $\iota \lambda \lambda \omega$, illo, to turn; seeds). Tourn. inst. 320. t. 170. Lin. gen. no. 330. Spreng. prod. umb. p. 11. D. C. prod. 4. p. 197.

Lin. syst. Pentúndria Digýnia. Margin of ealyx 5-toothed. Petals obovate, emarginate, with an inflexed point; outer ones radiating and bifid. Fruit flatly compressed from the back, girded by a rugged tubercular thick aceessory margin. Mericarps with rery slender ribs; the 3 dorsal ribs at equal distanees, and the 2 lateral ones contiguous to the thickened margin, or corered by it. Vittæ filiform, one or more in the furrows, and 2 or more in the eommissure. Carpophore bipartite. Seed complanate.-Herbs, with pinnare leaves; leaflets ovate, deeply toothed. Involucra of many leaves. Flowers white. The two sections differ from each other in the number of vittæ.

Sect. I. Eutordy'lium (from eu, well, and tordylium; this seetion is supposed to contain the true species of the genus). D. C. prod. 4. p. 197.-Tordýlium, Hoffm. umb. 1. p. 198. t. 3. f. 3-4. A. Koch, umb. 87 . f. 24,25 . Vittæ solitary in the furrows, and twin in the commissure.

I T. Syríacum (Lin. spec. p. 345.) plant pubescent; leaves pinnate; leaflets roundish, repandly toothed: terminal one ovate; involucra and involueels longer than the umbels. $\odot . H$. Native of Syria, Caria, Asia Mlinor, and Greece. Jacq. hort. vind. 1. t. 51. Riv pent. t. 3. Barrel. icon. t. 349.-Mor. ox. sect. 9. t. 16. f. 7. There is a variety of this with a simple erect stem; and another with difluse procumbent stems.

Syrian Hart-wort. Fl. July. Clt. 1597. Pl. 1 foot high or procumbent.

2 T. Ma'ximum ( $\mathrm{Lin}$. spee. 345.) stem scabrous or hispid from retrograde bristles; leaves pinnate; leaflets laneeolate, deeply serrated and notched : terminal one elongated; leaves of involucra and involucels linear, shorter than the umbels. $\odot$. H. Native of middle and south Europe, Caueasus, and the Levant, in eornfields. In England on banks and waste ground, but rare; about London; under a hedge on the north side of the parks, Oxford; in a hedge about half a mile from Eton. Smith, engl. bot. 1173. Jacq. austr. t. 142.-Mor. ox. 3. p. 316 . seet. 9. t. 16. f. 1.-Rivin. pent. irr. t. 1.-Lob. ieon. 737. Heraclèum Tordýlium, Spreng. spee. umb. 49. T. mágnum, Brot. and T. Lusitánicum, Willd. does not difler from this speeies aecording to Link. Stem erect, branched, hollow. Leaves densely clothed with fine close bristly hairs, all directed towards the point; leaflets oblong-lanceolate, the lower ones ovate. Umbels dense, bristly. Flowers reddish, the ontermost petal with equal lobes, the two next with extremely nnequal ones.

Great Hart-wort. Fl. June, July. Britain. Pl. 3 to 4 feet.

Seet. II. Condyloca'rpes (from kovivios, kondylos, a finger

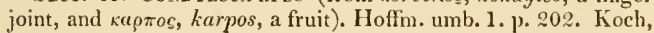
umb. p. 86 . but not of Desf. D. C. prod. 4. p. 198. Vittæ numerons both in the furrows and eommissure. In the eommissure there are 4 in $T$. Hasselquistice, and therefore it is an intermediate plant between the two sections, as there are 8-10 in the eommissure of the other speeies.

3 T. Il asselquístia (D. C. prod. 4. p. 198.) plant pubeseent; leaves pinnate; leaflets roundish, repandly toothed: the terminal one in the lower leaves is reniformly eordate; leaves of involuera setaceous, shorter than the tumbels : of the involueels similar, but longer than the umbellules. $\odot . H$. Native of the Levant. Like Hasselquistia cordata, but the eharacter of the fruit is the same as that of Tordylium. Habit of $T$. officinale. Vittæ in the eommissure 4,2 curved and 2 straight.

Hasselquist's Hart-wort. Pl. 1 foot.

4 T. officina'LE (Lin. spec. p. 345.) stem generally branched, furrowed, clothed with soft defiexed hairs; leaves pinnate, rough, hairy ; leaflets ovate, eut, crenate, the odd one the largest, leaves of involuera and involueels lanceolate, acute; those of the latter about equal in length to the umbellules; radiant petals in pairs, with very unequal lobes. $\odot$. H. Native of Portugal, south of Franee, Italy, Dalmatia, and Greece, in cultivated fields; possibly never seen at all in England, the T. maximum having been confounded with it; however, it is said to have been found hy Mr. Doody about Isleworth, Ray, and about London. Petivier. Smith, engl. bot. 2440. fi. græe. 3. t. 267. -Colum. ecplır. t. 124. f. 1.-Mor, ox. 3. p. 316. sect. 9. t. 16. f. 6.-Dod. pempt. p. 313 . f. 314 . Lob. icon. 736.-Bauh. hist. 3. p. 84. f. 2. Small Hart-wort, Petiv herb. brit. t. 24. f. 6. T. mierospérmum, Ten. add. 1827. Condylocárpus offieinàlis, Koch, l. c. Leaflets roundish or ovate, crenate, and variously cut. The radius of the umbellules formed of the very unequal onter petals of the flowers of the circumference, the large lobes of 2 flowers eoming together, and resembling a single petal. These lobes are sometimes reddish. Fruit hairy on the disk, brown, with scarcely any ribs or veins; the border greatly elevated, tumid, neatly erenate transversely. $T . A^{\prime}$ pulum is readily distinguished from this species by having in each marginal flower only one radiant petal, with 2 equal lobes.

Officinal Hart-wort. Fl. June, July. Britain. Pl. I to $1 \frac{1}{2} \mathrm{ft}$.

5 T. A'pulum (Riv. pent. t. 2.) plant erect, villous below; leaves pinnate; leaflets of the lower leaves roundish, cnneated at the base, lobately erenated: of the upper ones pinnatifid, linear, acute; leaves of involuera and involucels setaceous ; those of the latter shorter than the umbellules. $\odot . H . ~ N a t i v e$ of Apulia and Greece, in eultivated fields. Lin. spec. 345. exclusive of the synonymes.-Jaeq. hort. vind. t. 53. T. grandiflòrum, Mœnch, meth. p. 78. Condylocárpus A'pulus, Hoffm. ımb. p. 203. T. insulàre, Clark in Spreng. neue entd. 3. p. 165. There is a variety of this which is almost glabrous below. Stem hairy at the joints.

I ar. $\beta$, himile (D. C. prod. 4. p. 198.) plant of many stems; leaves for the most part radical: lower ones nearly bipinnatifid; involucels much shorter than the umbellules. $\odot$. H. Native of Tunis, Sardinia, Istria, Malta, and Melos, in cultivated fields. T. hùmile, Desf. atl. 1. p. 235. t. 58. Condyloeárpus hùmilis, Koch, umb. p. 87. 'T. A'pulum, Guss. prod. fl. sic. 1. p. 362. According to Smith in $\mathrm{fl}$. graee. p. 61 . there is no difference between $T$. hùmile and T. A'pulum.

Apulian Hart-wort. Fl. June, July. Clt. 1739. Pl. I to $1 \frac{1}{2}$ foot.

Cult. The seeds only require to be sown in the open border in spring. A light soil will suit the species best.

CXV. TORDYLO'PSIS (from Tordy'lium and ołes, opsis, appearance; plant resembling Tordy'lium). D. C. prod. 4. p. 199.-Tordylioìdes, Wall, mss.

Lin. syst. Pentándria, Digýnia. Margin of calyx 5-toothed: teeth acute : outer teeth the largest, dilated at the base, and cuspidate at the apex. Outer petals of umbels large and obeordately 2 -lobed; the rest smaller, ovate, and cuspidate, entire, rarely a little 2 -lobed. Stylopodium eonical; styles 2 , ereet, elongated. Fruit hairy when young. The rest unknown.Herb a foot high, more or less hairy. Stem terete, striated, erect, nearly simple. Pctioles sheathing at the base. Leaves with 1-2 pairs of ovate eut toothed leaflets, and an odd one. Umbels terminal, 6-8-rayed. Involuera of 5-6 lanceolate linear acuminated leaves, which are almost longer than the rays. Umbellules crowded, 15-18-flowered. Leaves of involucels eonforming to the leaves of the involucra, exceeding the flowers.Habit almost of Herácleum, but the involuera are of many leaves. It agrees also with Tordýlium in the hairiness, and in the corollas. The genus is rery doubtful, the perfect fruit being unknown. 
1 T. Brunònis (Wall. mss. ex D. C. prod. 4. p. 199.) 4. F. Native of Nipaul, in Kamaon, towards Emodi.

Brown's Tordylopsis. Pl. 1 foot.

Cult. This plant should be grown in a pot, so that it may be placed under shelter in winter.

\section{Tribe $1 \mathrm{X}$.}

SILERI'NEA (this section contains plants agreeing with Siler in important characters,) or Orthospérmæ multijugàtæe lenticulàres, Koch, umb. 84. D.C. prod. 4. p. 199. Fruit lenticularly compressed from the back. Mericarps with 5 primary ribs, having the lateral ones of these marginating; and 4 secondary less prominent ones, these last are rarely wanting; all filiform and wingless. Seed flattish in front.

CXVI. KRUBERA (named after John Julius Kruber, M.D., a promoter of botany). Hoffm. umb. 1. p. 103. and 202. t. 1. $\beta$, f. 14. Koch, umb. 86. f. 32, 33. D. C. prod. 4. p. 199.-Capnoplıýllum spec. Lag. but not of Gærtn.-Ulospérmum, Link, hort, berol. 1. p. 267.-Tordýlium species, Lin.-Càchrys species, Spreng.-Cònium species, Desf.

Lin. syst. Pentándria, Digýnia. Margin of calyx 5-toothed. Petals obovate, emarginate, with an inflexed point. Fruit lenticularly compressed from the back. Mericarps with thick plicately crenated ribs; the 3 intermediate ones elevated, blunt, and keeled: the 2 lateral ones marginating, roundish, keeled near the raphe. Vittæ none. Carpophore bifid. Seed flattish in front.-An herb, with multifid leaves, and short linear leaflets. Umbels not rayed, with very few male flowers. Involucra of $2-5$ leaves; involucels of 4-5 leaves. Flowers white.

1 K. Leptopir'lla (Hoffm. umb. p. 104. t. 3.) ○. H. Native of the Canary Islands, Mauritania, Spain, Portugal, Sicily, Greece, and the Levant. Caúcalus Hispánica, Cam, hort. p. 37. t. 11. Tordýlium peregrìnum, Lin. mant. p. 55. Cònium dichótomum, Desf. atl. 1. p. 245. t. 66. Capnojhýllum dichótomum, Lag. gen. et spec. 13. Cảchrys dichótoma and C. peregrìna, Spreng. umb. spec. p. 2I. Ulospérmum dichótomum, Link, enum. hort. berol. 1. p. 267. Tordýlium Lusitánicum cicutæ folio semine striato, Tourn. herb.

Fine-leaved Krubera. Fl. June, July. Clt. I596. Pl. 1 to $1 \frac{1}{2}$ foot.

Cult. See Tordýlium above for culture and propagation.

CXVII. PACHYPLEU'RUM (from $\pi a \chi v s$, pachys, thick, and $\pi \lambda \varepsilon v \rho o v$, pleuron, a rib; the ribs of the fruit are thick and corky). Led. fl. ross. alt. ill. and fl, alt. 1. p. 296.

Lin. syst, Pentándria, Digýnia. Margin of calyx obsolete or minutely denticulated. Petals permanent; those of the disk flowers obovate-oblong, and emarginate with an acute inflexed point ; those of the margins difformed: the 3 inner petals ovate, hardly emarginate, gradually attenuated into an acute inflexed point. Fruit lenticularly compressed from the back. Mericarps with 5 elevated thick corky ribs; the lateral ones marginating, and a little broader than the rest. Seed flattish in front. Vittæ wanting. Involucra and involucels of many leaves. This genus differs from Krubera, to which it is very nearly allied, by the ribs of the fruit being equal, not plicately undulated; and in the very different habit. $-\mathbf{A}$ perennial herb, with a thick branched root. Stems solitary, rarely 2 or 3 from the same root, straight, about a foot high. Radical leaves on long petioles, bipinnate or tripinnate; leaflets oblong-linear, tapering at both ends, entire, glabrous, pale green. Cauline leaves for the most part only one, on a short petiole, very like the radical ones. Umbels of many rays. Leaves of involucra and involucels oblong or oblong-linear, with white margins.
1 P. Alpínum (Led. f. ross, alt, ill, with a figure, fl. alt. 1. p. 297.) 4. H. Native in alpine or subalpine places, about the metal mines near Riddersk, and on Alp Aigulac.

Alpine Pacliypleurum. Fl. May, July. Pl. 1 foot.

Cult. The plant will grow in any kind of soil; and can only be increased by seed.

CXVIII. AGASY LLIS (the Greek name of the Ammoniac plant). Hoffm. umb. 176. Koch, in litt. D. C. prod. 4. p. 199.-Agasýllis species, Spreng.-Càchrys species, Bieb.

Lin. srst. Pentándria, Digynia. Margin of calyx obsolete. Petals lanceolate, incurved. Fruit oval, compressed from the back; mericarps with 5 primary obtuse ribs: the 2 lateral ones of these more humble than the rest, and placed in front of the slort accessory margin: the secondary ones sometimes absent. Seed a free nucleus, which is flat on one side, and rather convex on the other, covered with many vittæ, $8-10$ on the back, and 5-6 in the commissure.-A perennial herb, with the habit of Càchrys. Stem succulent. Leaves pubescent, ternately decompound; leaflets decurrent, lanceolate, serrated, a little lobed. Involucra wanting. Umbels of many rays. Leaves of involucels numerous, setacenus. Flowers white.

1 A. Cauca'sica (Spreng. umb. prod. p. 22. f. 4.) భ. H. Native of Caucasus, in subalpine places near Nartzana. Càclirys latifòlia, Bieb. fl. taur. and suppl. no. 549. Sìler Cancásicum, Spreng. umb. spec. 90. Cachrys decursiva, Horn. hort. hafn. add. p. 960 . Spondýlium Armènium foliis ammi perennis, Tourn. herb.

Cancasian Agasyllis, Fl. July, Aug. Clt. 1818. Pl. 2 to $3 \mathrm{ft}$. Cult. See Pachypleurum above for culture and propagation.

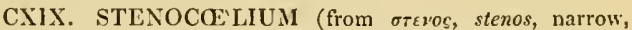
and sou of the fruit). Ledeb. fl. ross, alt. ill. t. 175. f. alt. 1. p. 298.

Lun. sysr. Pentándria, Digýnia. Margin of calyx 5-toothed. Petals obovate-orbicular, somewhat emarginate, with an inflexed point. Fruit compressed from the back. Mericarps with 5 elevated roundish thick equal ribs; the lateral ribs marginating. Vittæ one in each furrow, and 2 in the commissure. Seed flat in front. Involucra and involucels of many lanceolate-linear leaves, with membranous margins. - A perennial herb, liaving a fuscescent root, nearly a foot long. Stem solitary, $2-3$ inches high, leafy at top: but with numerous axillary elongated branches, which are furnished with leaves beneath tlue middle. Pctals dilated into sheatlss. Leaves pinnate; leaflets pinnatifid. Cauline leaves tripinnate; leaflets oblong, acute, entire or bifid. Umbels of many rays. Umbellules when bearing the fruit nearly globose. Flowers white. The whole plant is pubescent, and powdery towards the apex. Stems, petioles, peduncles, and rays of umbels violaceous.

1 S. athamantoi des (Led. 1. c.) - 24. H. Native of Altaia. in stony alpine places at the river 'T schuja, against the mouth of the river Tschegan. Càclırys athamantoìdes, Bieb. Al. taur. 3. p. 217. Sclunltes, syst. 6. p. 445 .

Athamanta-like Stenocolium. Fl. July. Clt. 1818. Pl. I ft. Cult. See Pachypleùrum above for culture and propagation.

CXX. SILER (siler, withy, from salio, to spring; from the quick growth of the plant). Scop. carn. 1. p. 217. Gartn. fruct. 1. p. 92, t. 21. Lag, am. nat. 2. p. 101 . Koch, umb. 84. f. 34. and 35. but not of Moencl. I). C. prod. 4. p. 200. - Siler species, Spreng.-Laserpítium species, Lin.-Angélica species. Lam.-Bradlæia species, Neck. elem. no. 280. but not of $\mathrm{Lin}$.

LuN. syst. Pentándria, Digýnia. Margin of calyx 5 -toothed. Petals obovate, emarginate, with an inflexed segment. Fruit y y 2 
lenticularly compressed from the back; mericarps with elevated obtuse filiform ribs, having 5 primary ones: the lateral ones of these marginating; and 4 less prominent secondary ones. Vittæ one in each furrow, under the secondary ribs. Seed flattish in front.-Perennial glabrous herbs. Leaves triternate; petioles trifid, slieathing at the base; branches of petioles bearing 3 roundish, coarsely and bluntly crenated, or bluntly 3 -lobed leaflets. Umbels large, of many rays. Involuera wanting or of few leaves, cadncous. Flowers white.

1 S. Trílobum (Scop. carn. 1. p. 217.) 24. H. Native of Europe and Asia, from Spain to Kamtschatka; but the habitats given are doubtful, the plant being often confused with Laserpítium aquilegif òlium. Laserpítium trílobum, Lin. spec. p. 357. exclusive of some of the synonymes. Angélica aquilegifòlia, Lam. dict. 1. p. 173. D. C. fl. fr. p. 306. ed. 5. p. 508. Siler aquilegifòlium, Gærtn. I. c.-Mor. ox. sect. 9. t. 13. no. 3. Libanòtis vi. C. Bauh. pin. 157.

Thre-lobed-leaved Siler. Fl. May, July. Clt, 1796. P], 3 to 4 feet.

Cult. See Laserpitium, p. 351. for culture and propagation.

CXXI. GALBANUM (galb or galban, in Celtic, means fat, oily; in reference to the gum). D. Don, in Lin. trans. 16. p. 603.

Lin. srst. Pentándria, Digýnia. Fruit compressed from the back, elliptic, unguicular; raplse narrow, open, not closed. Mericarps with 5 elevated compressed bluntly keeled ribs, not winged : lateral ones distinct, marginal ; furrows broadish, concave, without any vittæ. Commissure flat, dilated, furnished with 2 vittæ; vittæe broad, a little arched. The seeds from which the foregoing description has been drawn were picked from the gum. The rest of the plant remains unknown.

1 G. officina'le (D. Don, l. c.) 4. H. The plant, according to Dioscorides, is a native of Syria; but it must be in some remote inaccessible part of it, as it bas not been observed by any of the numerous travellers who have visited that country. As the gum-galbanum is partly imported from Smyrna and partly from India, it is very probable that the plant is also a native of Persia. The Bubon Gálbanum of Linnæus possesses neither the smell nor the taste of Gálbanum, but in these particulars agrees best with Fennel, and the fruit has no resemblance whatever to that found in the gum. How a plant differing so essentially from Gálbanum slould yet have been retained so long in the Pharmacopocia may well be subject of surprise, especially as the Bùbon Gálbanum, being so frequent in gardens, afforded abundant opportunitics of settling the question.

Galbanum agrees in virtue with gum-ammoniac, but is generally accounted less proper in asthmas, and more so in hysterical complaints. It is exhibited in the form of pills or emulsions, to the extent of about a drachm. Applied externally, it is supposed to resolve and discuss tumours, and to promote suppuration. The best sort of galbanum consists of pale coloured pieces, about the size of a hazel nut, which, on being broken, appear to be composed of clear white tears, of a bitterisl acrid taste, and a strong pcculiar smell. But it most commonly occurs in agglutinated masses, composed of yellowish or reddish, and clear white tears, which may be easily torn asunder, of the consistence of firm wax, softening by heat, and becoming brittle by cold, mixed with seeds and leaves. Galbanum is generally obtained by cutting the plant across some inches above the root. The juice which fiows from the wound soon hardens, and is the galbanum brought to us from Syria and the Levant.

Officinal Galbanum. Pl. 4 to 5 feet.

Cult. See Thápsia, p. 350 . for culture and propagation.

$$
\text { Tribe X. }
$$

CUMI'NEE (this tribe contains plants agreeing with Cumi- num in important characters), or Orthospermæ multijugatæ contractæ, Koch, umb. 81. D. C. prod. 4. p. 200. Fruit contracted from the sides. Mericarps with 5 primary filiform ribs: the lateral ones of these marginating, and 4 secondary more prominent ones; all wingless. Seed straight, flattish in front.

CXXII. CUMI'NUM (qamoun is the Arabic name of Cumin). C. Bauh. pin. p. 116. Lin. gen. no. 351. Gærtn. fr. 1. t. 2:3. Lag. am. nat. 2. p. 95. Spreng. unsb. prod. p. 25. Hoflin. umb. ed. 2. p. 194. D. C. prod. 4. p. 201.

Lrs. syst. Pentándria, Digýnia. Teeth of calyx 5, lanceolate, setaceous, unequal, permanent. Petals oblong, emarginate, with an inflexed point, erectly spreading. Fruit contracted from the sides. Mericarps with 5 wingless ribs; the 5 primary ones filiform, and minutely muriculated, the lateral ones of these marginating : the 4 secondary ones more prominent and prickly. Vittæ one in eacl furrow, under the secondary ribs. Carpopliore bipartite. Seed ratler concave in front and convex on the back.Herbs, with multifid leaves; linear setaceous leaflets. Involucra of 2-4 simple or divided leaves; involucels dimidiate, of 2-4 leaves, which are at length reflexed. Flowers white or reddish.

1 C. Hispa' Nicum (Merat, herb. D. C. prod. 4. p. 201.) seginents of leaves linear-setaceous, acute; unbels bifid; unbelJules bearing 3-4. fruit; involucels about equal in length to the fruit, which are bearded by bristles. $\odot . H$. Native of Spain, in corn-fields in Valle de la Manca. Habit of C. Cyminum, but differs in the fruit not being glabrous or puberulous, but bearded by long stiff spreading pili. Flowers reddish.

Spanish Cumin. PI. 1 foot.

2' C. MiNu'rum (D'Urv. enum. 32. t. 272.) segments of leaves linear, obtuse ; involucels about equal in length to the fruit, which is glabrous, $\odot . H$. Native of the island of Cos, in shady places frequent. Stem slender, branched, hardly 2-3 inches high. Every part of the plant is smaller than in the other species. In the specimens received from D'Urville, the segments of the leaves are acute, and the involucels are rather shorter than the fruit.

Ninute Cumin. Pl. 2 to 3 inches.

3 C. Cүміхим (Lin. spec. p. 365.) segments of leaves linearsetaceous, acute; umbels 3-5-cleft; involucels exceeding the fruit, which is pubescent. $\odot$. H. Native of Upper Egypt. and Ethiopia. Cuminum, Riv. pent. t. 40. Cam. epit. 518 Schkulır, handb. no. 714. t. 80 . Woodv. med. bot. t. 190. Nees, off. pflanz. 13. t. 7. Hayn. arz. gew. 7.t. 11. P'lench. icon. 192. Cav. icon. 4. t, 360.-Mor. hist. p. 271. sect. 9. t. 2. There are varieties of Cumin with white, red, or purple flowers. Coat of fruit aromatic; albumen insipid. The plant is cultivated in the south of Europe and all Lesser Asia. In the islands of Malta and Sicily, where it is much cultivated for sale, it is called Cumino aigro or hot cumin, to distinguish it from Cumino dolce, sweet cumin. Cumin seeds have a bitterish warm taste, accompanied with an aromatic flavour, not of the most agreeable kind, residing in a volatile oil.

Var. a, scábridum (D. C. prod. 4. p. 201.) fruit clothed with short down; but roughish on the ribs. $\odot$. H. C. Egyptiacum, Merat, in lierb. This is the wild plant.

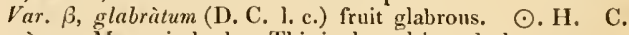
Cyminum, IIerat, in herb. This is the cultivated plant.

Cyminum or Officinal Cumin. Fl. June, July. Clt. 1594. Pl. $\frac{1}{2}$ foot.

Cult. The seed should be sown in spring in a warm sheltered situation, where the plants will flower in summer, and produce seed in autumn.

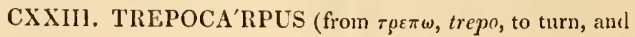


$\kappa a \rho \pi \circ$, , $k \operatorname{arp} s$, a fruit; application not evident). Nutt. in litt. 1825. D. C. coll. diss, v. p. 50. t. 14. prod. 4. p. 201.

Lin. syst. Pentándria, Digýnia. Calyx 5-toothed; teeth subulate, falling off but slowly after flowering. Petals obcordate, inflexedly emarginate. Fruit pyramidally angular or nearly terete, contracted from the sides. Mericarps convex on the back, with 5 primary, filiform, hardly prominent ribs, marginerl each by a brown vittaform line on both sides; and 4 secondary elevated ribs, bearing one vittæ at the lower part of each. Commissure thick, furrowed in the middle, and furnished with vittæ inside. Seed somewhat compressed on the back, straight. -Glabrous branched herbs, with the habit of Athùsa. Leaves multifid, with linear segments. Umbels opposite the leaves, of 5 rays. Involucra linear, of 1-3 leaves. Umbellules 5-8flowered; involucels linear, unequal, 4-5-leaved, dimidiate. Flowers white. This genus is more nearly allied to Cuminum than Athùsa; it differs from the first in the commissure being spongy, and in the mericarps having accessory margins.

1 T. EтиU's.e (Nutt. I. c. ex D. C. l. c.) umbels of 5 rays ; fruit 5 times longer than its breadth. $\odot . H$. Native of North America, in the Arkansa territory, ex Nutt. The primordial leaves are nearly as in Cynàpium, with short acutish lobes; cauline leaves with long linear acute lobes. Involucra of $2-3$ leaves; involucels of 4-5 leaves.

Aithusa-like Trepocarpus. Pl. 1 foot.

2 T. вRAchyca'rpus (D. C. prod. 4. p. 202.) umbellules of

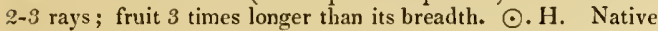
of Louisiana. Perhaps only a variety of the first. It differs from it in the involucra and involucels being of fewer leaves; in the lower umbels being on shorter peduncles; and in the fruit being thicker, and less angular.

Short-fruited Trepocarpus. Pl. 1 foot.

Cult. See Cuminum above for culture and propagation.

\section{Tribe XI.}

THAPSIE: $\approx$ (this section contains plants agreeing with Thápsia in important characters), or Orthospermæ multijugatæ alate, Kocl, umb. p. 73. D. C. prod. 4. p. 202. Fruit compressed from the back, or the transverse section is nearly terete. Mericarps with 5 filiform bristly primary ribs : the lateral ones of these placed in the commissure, which is flat; and 4 secondary ones: interior ones of these filiform, and the exterior ones or all are winged; wings undivided; hence the fruit has 8 wings, or only 2 wings on each side. Seed somewhat complanate or teretely convex, but flat in front.

CXXIV. THA'PSIA (the first species was discovered"in the island of Thapsus). Tourn. inst. 321. t. 171. Lin. gen, no. 361. Spreng. prod. 17. Lag. am. nat. 2. p. 90. Koch, uinb. p. 74. f. 3-5. D. C. prod. 4. p. 202.

Lix. syst. Pentándria, Digýnia. Margin of calyx 5-toothed. Petals elliptic, entire, with an inflexed or involute point. Fruit compressed from the back. Mericarps with 5 primary filiform ribs, 3 of which are dorsal, and the 2 lateral ones are placed in the commissure, which is flat; and 4 secondary ribs, the 2 dorsal ones are filiform, and the 2 lateral ones are inembranous and winged; wings entire. Vitta one in each furrow, under the secondary ribs. Carpophore bipartite. Seed complanate.Perennial herbs. Leaves pinnate, bipinnate, and tripinnate, or decompound; petioles sheathing; the upper leaves usually reduced to the petioles. Umbels large, compound, of many rays. Involucra and involucels wanting, or of a few deciduous leaves. Flowers yellow. This genus differs from Laserpitium, in the wings of the mericarps being only 2 , not 4 ; and from Melanosclinum and Artèdia, in the wings being entire; and from Lepidosciàdium, in the backs of the mericarps not being scaly.
* Involucra nanting or of 1-2 lcates.

1 'T. GARGA'Nica (Lin. mant. 57.) stem terete, glabrous; leaves bi-tripinnate, shining; segments linear, acute, elongated, quite entire along the margins, decurrent or confluent; involucra of few leaves; fruit cordate at the base, with a very open recess. 4. H. Native of Calabria, Mauritania, Greece, Sicily, Sardinia, Spain, \&c. in open places and on hills. Magn. bot. inonsp. p. 286. with a bad figure.-Gouan, obs. p. 18. t. 10. Desf. alt. 1. p. 262. Sibth, et Smith, fi. græc. t. 287. There are varieties of this with glabrous or hairy petioles. To this the Férula Neapolitàna, Ten. fl. med. p. 316 . append. 4th. p. 12. is referred by Sprengei, which is said by the author to be nearly allicd to F. glauica. The bruised root is said to be good for resolving tumours.

Var. $\beta$, decussita (D. C. prod. 4. p. 202.) petioles and nerves of leaves hispid beneath; involucra wanting. $4 . \mathrm{H}$. Native of Spain and of Mauritania. T. decussàta, Lag. gen. ct spec. p. 12.

Garganian Deadly-carrot. Fl. July, Aug. Clt. 1683. Pl. 2 to 4 feet.

2 T. Sílphiv (Viv. fl. lyb. p. 17.) stem terete, furrowed, glabrous; leaves pinnate; leaflets many-parted; segments simple or trifid, all linear, elongated, hairy on both surfaces, with revolute margins; fruit cordate at the base, having the recess constricted. 24. H. Native of the north of Africa, on the mountains of Cyrenaica. This is supposed to be the plant which yielded the juice called silphium, a medicine held in such high estimation among the ancients, as to have imparted to the region where it grew (the vicinity of Cyrene, now included in the paslialic of Tripoli,) the appellation of "Silphifera!"

Silphium Deadly-carrot. Fl. July, Aug. Clt. 1824. Pl. 2 to 4 feet.

3 T. viclòs a (Lin. spec. p. 375 .) stem terete, glabrous; leaves tripinnate, and are, as well as the petioles, villous: leaflets oblong, sinuately pinnatifid: lower ones deflexed; involucra and involucels almost wanting. $4 . \mathrm{H}$. Native of Portugal, Spain, south of France, and Mauritania, on hills and in bushy places. Lam. ill. t. 206. D. C. fl. fr. 4. p. 342.-Moris, ox. sect. 9. t. 18. f. 3. Plench. icon. 219. Parkins. 878. 2. t. 877. f. 2. Ger. emac. 1030. Flowers yellow, as in the rest of the species. Aspect of plant lioary. Root carrot-shaped, black on the outside.

Villous Deadly-carrot. Fl. June, July. Clt. 1710. Pl. 3 to 4 fcet.

4. 'T. Ascle'pium (Lin. spec. p. 375.) stem terete, glabrous; leaves tripinnate; leaflets digitately multifid, capillary, short; petioles glabrous; involucra and involucels wanting. $\psi . \mathrm{H} . \mathrm{Na}$ tive of Apulia, Sicily, Rhodes, and about Constantinople. Sibth. fi. græc. t. 286. ex Simith, prod. 1. p. 201. Guss. prod. fl. sic. 1. p. 370. T. Apùlia, Mill. dict. no. 4.-Col. ecphr. 1. t. 86 . Mor. hist. 3. p. 319. sect. 9. t. 18, f. 9. Fruit one-half smaller than those of $T$. Gargánicum, having the wings rather truncate at both ends. Habit of Elceoselinum meoides. The root is about the thickness of a man's thumb; the bark is yellow and wrinkled; the inside white, abounding in a bitter milky juice.

Snallow-nort Deadly-carrot. Fl. July, Aug. Pl. 2 to 3 feet.

5 T. FG'TIDA (Lin. spec. p. 375.) stem and petioles villous; leaves tripinnate; leaflets much spreading, pinnatifid, attenuated at the base: segments short, lanceolate, toothed; involucra wanting. 4. H. Native of Spain, Zante, Cyprus, Sc. Blackw. t. 459. Lob. icon. t. 780. ex Smith. Moris. hist. sect. 9. t. 18. f. 7. ex Lin. Lobel's figure is more probably referrible to Laserpítium gummíferum. T. tenuifòlia, Lag. gen. et spec. 12. is referrible to the figure of Morison, but differs in the stem being glabrous. It is probably only a variety of this species. The leaves are rough and hairy.

Fetid Deadly-carrot. Fl. July, A ug. Clt. 1596. Pl. 2 to $3 \mathrm{ft}$. 


\section{* * Involucra of $5-7$ leaves.}

6 T. poly'gama (Desf. fl. atl. 1. p. 261. t. 75.) stem terete, glabrous, sparingly branched; leaves glabrous, bipinnate; leaflets multifid : lobes linear, acute, divaricately trifid; involucra of 5-7 leaves; central flowers malc. \%. H. Native of Mauritania, abont Bone, Lacalle, and Tangiers. Spreng. in Schultes, syst, 6. p. 614. exclusive of the synonyme of Lam, and therefore the description. Flowers pale yellow. Stylopodium thick. Styles diverging, at length reflexed.-Barrel. icon. 356. appears to be intended for this plant, but the flowers are said to be white.

\section{Polygamous Deadly-carrot. Pl. 1 to 2 feet.}

\section{$\uparrow$ Spccies not sufficicntly known.}

7 T. PREA'LtA (D'Urv. enum. p. 32.) stem branched above; radical leaves quadrifariously decompound, shining; leaflets oblong, cut, almost pimatifid ; umbels numerous : central one much the shortest: lateral ones on peduncles, which are furrs nished each with a lanceolate twin bractea at the base. 24. H. Native of the island of Cos, among broken rocks at the height of 900 feet. Stem 6-S feet high. Fruit unknown.

Tall Deadly-carrot. PI. 6 to 8 feet.

8 T. Transtaga'na (Brot. fl. lus. 1. p. 468.) leaves bipinnate; leaflets pinnatifid: segments linear-lanceolate, hairy. $\psi$. H. Native of Portugal, near Montemor and Serpa. Habit of T. Gargánica, but more hairy.

Transtagus Deadly-carrot. Pl. 2 to 4 feet.

9 T. ma'xıa (Mill. dict. no. 2.) leaves pinnate; leaflets very broad, pinnatifid, villous beneath; petioles decurrent. 2 . H. Native of Spain, all over Old Castile quite to the Pyrenees. Perhaps not different from $T$. villosa. Root said to be of a dark colour on the outside, and the leaves very thick.

Largest Deadly-carrot. Fl. June, July. Cit.? Pl. 4 to $5 \mathrm{ft}$. 10 T. alti'ssima (Mill. dict. no. 6.) leaves decompound; leaflets large, shining; umbels large. \%. H. Native of Apulia. Perhaps the same as T. prafiltu.

Tallest Deadly-carrot. Pl. 8 feet.

Cult. The species of Thápsia will grow in any common garden soil. They are only to be increased by seeds, which should be sown in autumn as soon as ripe.

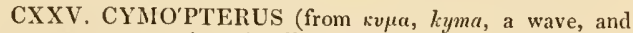
tregov, ptcron, a wing; in allusion to the undulated wings of the mericarps). Rafin. journ. phys. 1819. aug. p. 100. but not of Schultes, syst. 6. p. 34.-Thápsia, Nutt. gen. amer. 1.p. 184.

Lin. syst. Pentándria, Digýnia. Calyx minutely 5 -toothed. Petals roundish-oval, with an inflexed point. Fruit nearly elliptic, compressed, 7-8-winged: the perfect mericarps are therefore 4-winged, and the imperfect ones 3 -winged: wings undulated; furrows of fruit flat, 1-nerved; commissure naked, but with 3 stripes. Carpophore not separable from the mericarps.-A smooth humble herb, with tuberous roots, rather decumbent, nearly naked stems; biternate leaves : with short obtuse decussate lobes, and long petioles. Umbels 4-6-rayed; involucra wanting; involucels 5-7-parted, dimidiate. Flowers polygamous ; female ones nearly sessile and white; central ones male, pedicellate.-This genus is truly distinct from Thápsia, but perhaps may be joined with Laserpitium.

1 C. glomera'tus (D. C. prod. 4. p. 204.) 24. H. Native of North America, in the open plains of the Missouri. Selinum acaúle, Pursh, fl. bor. amer. 2. suppl. 732. Thápsia glomeràta, Nutt. gen. amer. 1. p. 184.

Glomeratc-flowered Cymopterus. Pl. decumbent.

Cult. See Thápsia above for culture and propagation.
CXXVI, LASERPI'TIUM (from laser, its gum, and pix, pitch; the name of the ancient Silphitum). Tourn. inst. 324. t. 17\%. Lin. gen. 344. Spreng. umb. prod. 17. Lag. atn. nat. 2. p. 90 . D. C. prod. 4. p. 204.

Lin. syst. Pentándria, Digýnia. Margin of calyx 5-toothed. Petals obovate, emarginate, with an inflexed point. Fruit compressed from the back, or nearly terete, 8 -winged; the 5 primary nerves of the mericarps being filiform: and the 4 secondary ones being winged. Vittæ 1 in each furrow, under the secondary ribs. Carpophore free, bipartite.-Herbs with bipinnate or tripinnate leaves; leaflets entire, toothed or cut. Umbels showy, of many rays. Involucra and involucels of many leaves. Flowers white, rarely yellow. This genus is easily distinguished from the others by the 8 wings to the fruit.

* Fruit glabrous, or the primary ribs are clothed with adpressel, very short down.

1 L. A'sperum (Crantz, austr. 3. p. 54.) leaves bipinnate, covered with rough hairs beneath and on the petioles; leaflets ovate, rather cordate, mucronately toothed: ultimate ones usually confluent; leaves of involucra linear-setaceous; wings of fruit curled. 24. H. Native of Europe, on dry lills, and by the margins of woods. D. C. fl. fr, suppl. p. 509. L. latifólium, Lam. Jict. 3. p. 423. L. pubéscens, Lag. gen. et spec. 12. L. Cervària, Gmel. bad. 1. p. 657. L. Libanòtis, Spreng. in Scliultes, syst. 6. p. 617. exchusive of many of the synonymes. - Lob. icon. 704. f. 2 . Flowers white.

Rough Laserwort. Pl. 1 to 2 feet.

2 L. GLA'Brum (Crantz, aust. 3. p. 5 4.) leaves bipinnate, quite glabrous in every part, and shining; leaflets obliquely cordate, mucronately toothed: but those of the superior leaves are quite entire: leaves of involucra setaceous; wings of fruit equal, rather curled. 24. H. Native of Europe, on the mountains, in dry and stony places. D.C. fl. fr. suppl. p. 509. L. latifỏlium, Lin. spec. 356. Jacq. fl. aust. t. 146. Schkuhr, handb. t. 67. Fl. dan. t. 1513. L. Libanòtis, Lam. dict. S. p. 423.Dod. pempt. 312, f. 2 . Clus. list. 2. p. 194. f. 2.-Riv. pent. t. 21.-Plench. icon. 179.-Mor, hist. sect. 9. t. 17.-Mor. hist. 3. p. 320. t. 19. f, 1-6. Stem and under side of leaves rather glaucous. Flowers white. In the Alps this plant is only a foot or 2 feet in height, while in cultivation it grows much larger. The plant is acrid and aromatic, with something of bitterness, and seems to merit a place amongst the aromatic stimulants, emmenagogues, and aperient sudorifics. It is used by the peasants for themselves, and by farriers for horses, in some countries. The root is the hottest part of the plant.

Var. $\beta$, crispum (Turra, fl. ital. prod. p. 65. no. 14) wings of fruit very much curled. 4 . H. Native of Mount Baldo.

Glabrous Laserwort. Fl. June, Jul. Clt. 1640. PI. 2 to $4 \mathrm{ft}$. 3 L. Aquilegifo'lium (Murr. syst. p. 228.) leaves biternate or triternate; leaflets ovate, rather cordate at the base, slightly lobed, glabrous, but puberulous on the nerves beneath; involucra and involucels deciduons, of few leaves; wings of fruit equal, flat. 2\%. H. Native of France, Austria, Hungary, \&c. on the mountains. D. C. fl. fr. 5. p. 510 . Jacq. aust. 22, $\imath$. 147. L. trílobum, Jacq. vind. 48. Crantz, austr. p. 187. but not of Lin. L. alpinum, Waldst. et Kit. pl. hung. t. 253. Bess. prim. 2. p. 393. Stem glabrous, glaucous, green. This plant is usually confused with Siler trilobum, from the shape of the leaves; but it is easily distinguished from that plant in the 8 winged fruit.

Columbine-leaved Laserwort. Fl. May, July. Clt. 1640. Pl. 4 to 6 feet.

4 I. Gaudrinir (Moretti, in Com. (1824.) A. com. no. 344. and in bot. ital. (1825.) no. 3. p. 33.) leaves somewhat tripinnate: leaflets roundly 2-3-lobed, acutely and deeply serrated: 
upper cauline ones tripartite; lobes linear-lanceolate; involucra and involucels of few leaves : wings of fruit flat, unequal : the dorsal ones a little smaller than the lateral ones. 4. H. Native of Switzerland and Italy, in subalpine places. L. lutèolum, Gaudin, f. helv. 2. (1828.) p. 348. L. trílobum, Sut. fl. helv. but not of Lin.-Hall. hist. no. 352. exclusive of the synonyme. Allied to L. aquilegifolium and $L$. glàbrum, but differs from them in the flowers being yellow.

Gaudin's Laserwort. Pl. 3 to 4 feet.

5 L. margina'tum (Waldst, et Kit. pl, rar, hung. 2. p. 210. t. 192.) leaves biternate, shining, and are as well as the stems glabrous; petioles and nerves of leaves rather pilose beneath ; leaflets ovate, sessile, somewhat 3-lobed, serrated; upper stem leaves reduced to the petioles; involucra and involucels of $2-5$ linear-lanceolate leaves; wings of fruit unequal : the 2 lateral ones the broadest. 4 . H. Native of Croatia, in woods. Petals incurvedly obcordate at the apex, greenish yellow, margined with purple.

Margined-petalled Laserwort. Fl. Jul. Aug. Clt. 1823. Pl. 2 to 3 feet.

6 L. Sículum (Spreng.syst. 1. p. 918.) stem terete, branched, few-leaved; leaves bipinnate ; leaflets elliptic or obovate, glaucous, mucronate, vciny; involucra and involucels of many awned leaves; wings of fruit coloured, emarginate. 24. H. Native of Sicily, among rocks, on the Nebrode mountains. Guss. prod. fi. sic. 1. 1. 317. L. Nebrodénse, Jan, herb. 260. spec. 15. Allied to $L$. Siler, but the wings of the fruit are very different.

Sicilian Iaserwort. Pl. 3 to 4 feet.

7 L. Siler (Lin. spec. 357.) lcaves bipinnate, quite glabrous; leaflets lanceolate or oval, quite entire, mucronate, sometimes confluent and 3-lobed; leaves of involucra and involucels linearlanceolate, awnedly acuminated; wings of fruit narrow. 4 . H. Native of middle and south Europe, on the mountains. Jacq. fl. aust. 2. t. 145 . D. C. fi. fr. 4. p. 313. Hayne, arz. gew. 7. t. 7. Plench. icon. 178. Blackw. 426. Ligústicum Gargánicum, Till, pis. t. 30. Ten. in herb. Balb. and Mor. Siler lancifòlium, Mœench. L. montànum, Lam. fl. fr. L. trifoliàtum, Sieb. and Schultes, syst. 6. p. 619. Siler montànum, Mor. oxon. sect, 9. t. 3. f. 1. Plant quite glabrous, growing from 1-2 feet high in subalpine places. Stem green or purplish. Flowers white. The root is extremely bitter, and might be useful in fevers, loss of appetite, $\delta$ c. An infusion of it in wine has been given with success in disorders of the stomach. It yiclds an aromatic resinous oil on being wounded, and being made into a syrup, is recommended in disorders of the breast. Vill. dauph. 2. p. 627. Allion. pedem. no. 1316.

Wilhy or Mountain Laserwort. Fl. May, July, Clt. 1640. Pl. 1 to 6 feet.

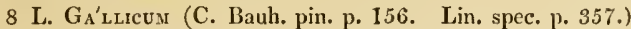
leaves supra-decompound, glabrous, shining; leaflets cuneated, 3-5-cleft, mucronate; leaves of involucra linear-lanceolate, acuminated; wings of fruit equal, flat. 24. H. Native of the south of France; and of Upper Italy. D. C. fl. fr. 4. p. 312. Spreng. in Schultes, syst. 6. p. 624. Gaud. aix. t. 58. Park. theat. 938. f. 1. L. trifurcàtum, Lam. A. fr. 3. p. 415. L. cuneàtum, Mœnch. meth. 79 . There is a variety with broader segments (in Mor. hist. sect. 9. t. 19. f. 8.) and with the lobes very much divaricate and short (Pluk. alm. t. 199. f. I. L. formòsum, Willd. spec. 1. p. 1518.) ; segments of leaves oblong-linear (Mor. hist. sect. 9. t. 19. f. 9. and therefore L. angustifòlium, Lin. spec. p. 357.); segments of leaves very narrow (J. Bauh. hist. 3. p. 137. and therefore L, angustif òlium, Willd. l. c.) segments of leaves cut into many lobes (L. Gállicum laciniatum, Hortul, \&c.). The most of the varieties have glabrous stems; very few lave them hispid from scattered bris- tles. I. tenuifolium, Riv. pent. irr. 22. is also a variety of this sprecies. Flowers white.

French Laserwort. Fl, Ju, Jul. Clt. 1686, Pl. 1 to $2 \mathrm{ft}$.

9 L. peucedanoioes (Lin. spec. p. 358.) leaves triternate, quite glabrous; leaflets quite entire, oblong, mucronate; leaves of involucra, and involucels setaceous ; pistils elongated; wings of fruit unequal, flattish. 4. 11. Native of Carniola, Croatia, and Upper Italy, in mountain woorls. 'There are varieties of this with oval-oblong leaflets (Hoppe, pl. exsic.); oblong leaflets (Jacq. icon. rar. 2, t. 250.); oblong-lincar leaflets (Seg. ver. 3. p. 227. t. 7.); and linear leaflets (Pluk. alm. t. 198. f. 4.) but all these varicties differ from any of those of $L$. Gállicum in the segments of the leaves not being cuncated nor lobed. Flowers white.

Sulphur-wort-like Laserwort. Fl. June. Clt. 1816. Pl. 1 to 3 feet.

10 1. gummíferum (Desf. fl. atl. 1. p. 254. t. 72.) leaves ternately decompound, glabrous ; leaflets pinnatifid; lobes lanceolate, sliort, acute, stiffish ; involucra and involucels of few leaves. 4 . H. Native of Portugal, Spain, and Mauritania, in sandy and barren fields. L. thapsiæéórme, Brot. phyt. lus. p. 77. t. 35. L. polýgamum, Lam. dict. 3. p. 425. Thápsia gummifera, Spreng. umb. spec. p. 31. Flowers white. Petals inflexedly emarginate. Fruit 8-winged (ex Brot.); and therefore this plant if referrible to Laserpitium and not to Thipsia. Lobes of leaves, when dry, usually channelled. Petioles sometimes pilose, usually glabrous as well as the lobes.

Gum-bcaring Laserwort. P]. 2 to 3 feet.

11 L. Irrsu'tum (Lam. fl. fr. 3. p. 648.) leaves supra-decompound, laairy; leaflets narrow, pimatifid: lobes short, linear, cuspidate; leaves of involucra and involucels membranous, rather trifid at the apex, ciliated; wings of fruit thin, flat. $\mathcal{4}$. H. Native of France, Switzerland, Piedmont, on the Alps, in meadows; and of Kotzebue's Sound. D. C. fl. fr. 4. p. 313. I. Pànax, Gouan. ill. 13. L. Hallèri, All. pedem. no. 1315. -Hall. helv. no. 795. t. 19. exclusive of the synonyme of Gmel. ant Seg.-Mor. hist. sect. 9. t. 15. f. 16. Flowers white.

Hairy Laserwort. Fl. June. Clt. 1759. Pl. 1 to 2 feet.

12 L. scA'вrum (Cav. icon. 2. p. 72. t. 190.) leaves bipinnate, scabrous ; leaflets oblong, cut, acute, and are as well as the stems glaucous; leaves of involucra and involucels lanceolate, tapering into a bristle; fruit tomentose while young: adult ones 8 . winged. §. H. Native of Spain, near Cati and Vallefames, on dry exposed hills. Referrible to $L$. hirsùtum, but truly distinct. Petals white, with a violaceous border, villous beneath. Stem scabrous.

Scabrous Laserwort. Fl. Ju. Jul. Clt. 1800 . Pl. 2 to $3 \mathrm{ft}$.

13 L. Nírinum (Zanted, comm. brix. 1813. ex Poll. fl. ver. p. 351.) lcaves bipinnate, beset with setose bristles, as well as on the stem and petioles; sheaths of petioles glabrous; leaflets ovate, serrated: ultimate ones confluent; leaves of involucra and involucels lanceolate, with membranous margins, deeply serrated at the apex; wings of fruit nearly equal. 5 . or $4 . \mathrm{H}$. Native of Upper Italy, among rocks on the mountains. L. pilosum, Com. fl. comp. p. 53. but not of Willd. Fruit glabrous. Flowers white.

Nitid-leaved Laserwort. Pl. 2 to 3 feet?

14 I. Archangélica (Jacq. icon. rar. 1. t. 58. Wulf. in Jacq. coll. 1. p. 214.) leaves ternately divided; stem and petioles hispid; leaflets ovate, cuncated at the base, serrated, extreme one 3-lobed: and the lateral ones 2-lobed; leaves of involucra and involucels linear-lanceolate, hairy, 2-3-cleft at the apex; wings of fruit flat, broader than the mericarps. $\% . \mathrm{H} . \mathrm{Na}$ tive of Carniola, Croatia, Silesia, Carpathian mountains, among rocks. L. Chirònium, Scop. carn. no. 324. Archangélica, 
Clus. hist. 2. p. 195. Lob. icon. 701. Petioles large, saccate, very villous. Stem 5 feet high, furrowed. Flowers white, purplish when young. Fruic glabrous, or clothed with adpressed pubescence according to Koch.

Archangel Laserwort. Fl. Ju. Aug. Clt. 1800. Pl. 4 to $5 \mathrm{ft}$.

\section{* Primary ribs of fruit hispid from sprcading bristles.}

15 L. u'́spivum (Bieb. A. taur. 1. p. 221. suppl. p. 222.) leaves ternately bipinnate; petioles, nerves on the under sides of the leaves, stem and umbels hispid; leaflets cuneiformovate, deeply serrated; stem terete, furrowed: leaves of involucra and involucels oblong, acuminated at the apex, or cut; wings of fruit unequal: 2 lateral ones the largest. 4 . H. Native of Tauria and Caucasus, in gravelly places. L. pilòsum, Wiljd. enum. p. 310 . L. Archangélica, Hortul. but not of Jacq. Caícalis líspida, Desf. hort. par. Petals white.

Hispid Laserwort. Fl. June, Jul. Clt. 1817. Pl. 2 to $3 \mathrm{ft}$.

16 L. Pruténicum (Lin. spec. p. 357.) leaves decompound, rather hairy on the nerves and petioles; leaflets ovate-lanceolate, pinnatifid: lobes lanceolate, cuspidate: outer ones confluent; stem angular, beset with retrograde bristles; leaves of involucra and involucels linear, with entire byaline margins: wings of fruit unequal : 2 lateral ones the largest. $\delta$. H. Native of Hungary, Camiola, Germany, Switzerland, east of France, on hills. Jacq. f. aust. t. 153. L. selinoìdes, Crantz, aust. 182. L. Gállicum, Scop. carn. 321. Jacq. vind. 48.Breyn. cent, t. 84.-Riv, pent, irr, 23. Flowers white.

Var. $\beta$, glabràtum (D. C. prod. 4. p. 206.) leaves and stems glabrous. \&. H. Native of Piedmont, Pyrenees, \&c. L. daucoides, Dufour, in litt. L. Pruténicum, Lapeyr. suppl. p. 48. Balb. Al. taur. 49. Fruit pilose on the primary ribs, as in var. $a$. The wings of the fruit are very unequal: the 2 lateral ones are large: and the 2 dorsal ones very small, or nearly wanting, hence this species falls in almost to Thápsia, but differs in the petals being emarginate.

Prussian Laserwort. Fl. Jul. Aug. Clt. 1759. Pl. 3 to $4 \mathrm{ft}$. 17 L. Atriama'Nтæ (Spreng. in Schultes, syst. 6. p. 624.) plant hispid; stem furrowed, much branched; leaves ternately decompound, rough on both surfaces, stiffish ; leaflets oblong, pinnatifid; segments broadly lanceolate, mucronate; leaves of involucra and involucels oblong, reflexed. $\delta$. H. Native of Siberia. Perhaps the same as $L$. lispidum or a variety of $L$. Pruténicun.

Alhananta-like Laserpitium. Fl. June, July. Clt. 1817. Pl. 3 feet.

\section{$\uparrow$ Species not sufficiently known.}

18 L. CAPE'NSE (Thunb. prod. p. 50. fl. cap. 2. p. 201.) stem terete, glabrous; leaves bipinnate; leaflets oval, mucronate, margined, quite entire; sheatls large, petiolar.-Native of the Cape of Good Hope. Fruit ovate, striated, and therefore the genus is doubtful.

Cape Laserwort. Pl. 1 to $1 \frac{1}{2}$ font.

19 L. AU'REUM (Willd. spec. 1416.) stem tercte, nearly simple; leaves ternately decompound; leaflets ovate-lanceolate, pinnatifid : segments lanceolate, bluntish, mucronate; leaves of involucra and involucels filiform. 4. H. Native of the Levant. Spreng. in Schultes, syst. 6. p. 626.-Buxb. cent. 1. t. 43. ex Spreng. but the description hardly agrees with it. L. élegans, Clark, in Spreng. neue. entd. 3. p. 160 , is related to it according to Spreng. syst. 1. p. 918. Flowers golden yellow. Fruit unknown. Perhaps a species of Thápsia.

Golden-flowered Laserwort. Fl. June, July. Clt. 1820. Pl. 2 to 3 feet.

20 L. FERULA'CEUM (Lapeyr. abr. pyr. p. 152. but not of Lin.) stem naked, simple, furrowed; leaves decompound : leaf- lets capillary, simple in the lower part, and more decompound at the apex; mericarps of fruit 4-winged. 24. H. Native of the Pyrenees, in a place called Pic du Gard. This is a very obscure species.

Fennel-like Laserwort. Pl. 2 to 3 feet?

Cult. All the species grow well in common soil, but it must be rather dry. They are only to be increased by sced, which should be sown in the autumn or spring.

CXXVII. LOPHOSCIA'DIUM ( $\lambda$ oфos, lophos, a crest ; and $\sigma$ tiaciov, sciadion, an umbel; in reference to the crested wings of the mericarps). D. C. coll. mem. 5. p. 57. t. 3. f. 6 . prod. 4. p. 207.

Lin. syst. Pcntándria, Digýnia. Margin of calyx 5-tootlued. Petals elliptic, entire, acuminated, somewhat involute at the apex. Fruit compressed from the back. The primary ribs of the mericarps are mknown: but the 4 secondary ones are winged: the 2 lateral of which are expanded into a somewhat serrated wing each : and the 2 dorsal ones are expanded into interrupted wings, which at first sight appear like retrograde scales. Seed unknown.-Herb glabrons. Stem terete, erect. Lower leaves like those of Achillè millef òlia, pinnate; leaflets short, innumerable, divided into linear-subulate lobes; upper leaves sessile, pinnate from the base, usually rising from the axils of the sheaths. Umbels compound, sometimes proliferous. Leaves of involucra 5-7, ovate-lanceolate, cuspidate; of the involucels 5-7, but narrower, and about equal in length to the umbellules. Flowers yellow. Allied to Thápsia, but differs in the ribs of the fruit being scaly; but the fruit examined being immature and incomplete, it is therefore doubtful in what part of the order the genus should be placed. Perhaps it should lave been placed near Càchrys.

1 L. MEIfo'lium (D. C. l. c.) 4. H. Native of the Levant. Férula meoides, Lin. spec, 356. Lam. dict. 2. p. 455 . Laserpítium orientàle folio mei, Tourn. cor. p. 23. L. Pónticum meifolio flore luteo, Tourn. lierb. without fruit. Laserpítium meifölium, Vent. in herb. mus. par. Radical leaves long, pinnate; leaflets dense, opposite, pinnate-parted; partitions multifid: lobes short, setaceous.

Meum-leaced Lophosciadium. Fl. July, Aug. Clt. 1810. P!. 3 feet.

Cult. See Lascrpitium above for culture and propagation.

CXXVIII. MELANOSELI'NUM (from $\mu \varepsilon \lambda r s$ $\mu \varepsilon \lambda \alpha v o s$, melas melanos, black, and $\sigma \varepsilon \lambda \iota r o v$, selinon, parsley; black parsley). Hoffm. umb. ed. 2. vol. 1. p. 156. Koch, umb. p. 75. f. 6-8. D. C. prod. 4. p. 208. - Selinum species, Wendl. and Spreng.

Lin. syst. Pcntándria, Digýnia. Margin of calyx 5-toothed. Petals obovate, emarginate, with an inflexed point. Fruit flatly compressed from the back. Mericarps with 5 filiform, primary ribs: the 3 intermediate ones on the back: and the 2 lateral ones placed in the commissure, which is flat; and 4 secondary ones: the inner ones of these fliform and very slender, but the onter 2 are expanded into membranous serrated wings; under all the ribs there are oleiferous canals. Carpophore bipartite. Seed flat.-A shrub with a terete simple stem, which is naked below. Leaves tripinnate; leaflets ovate, acuminated, serrated : ultimate ones usually confluent; petioles sheathing. Umbels composed of many rays. Involucra of many cut leaves; and the involucels of many entire leaves. Flowers white.

1 M. Decíliens (Hoffm. umb. l. c.). 々. G. Native of Madeira? Selinum decipiens, Schrad. and Wendl, sert. hann. 3. p. 23. t. 13. Willd. spec. 1. p. 1400 . enum. 1. p. 307. Horn. hort. hafn. 1. p. 274 . Schultes, syst. 6. p. 562. This 
plant is called by gardeners Dübon Gúlbanum, to which it is very similar in habit, hence it has the name of decipiens.

Deceiving Black-parsley. Fl. Ju. Jul. Clt. 1785. Shrub.

Cult. Any light soil will suit this plant; and it is only to be increased by secd.

\section{Tribe XII.}

DAUCI'NEE (this section contains plants agreeing with Daúcus in important characters) or ORTnosPe'rM⿻ MULTIJUGA'TE ARMA'tx. Koch, umb. p. 76. D. C. prod. 4. p. 208. Fruit lenticularly compressed from the back, or the transverse section is nearly terete. Mericarps with 5 primary, filiform, bristly ribs: the latcral ones placed in the commissure, which is flat, as in Thapsiece; and with 4 secondary ones, which are more prominent and prickly than the primary ones: the prickles free, or joined into a wing. Seed complanate or somewhat semi-teretely convex, flattish in front.

CXXIX. ARTEDIA (leter Artedi, a student of medicine in Sweden. He arranged umbelliferous plants from the calyx; died in 1735.). Lin. gen. no. 332. Lam. ill. t. 173. Spreng. umb. prod. 18. Lam. am. nat. 2. p. 90 . Koch, umb. 76. f. 9-10. D. C. prod. p. 208.

Lin. syst. Penlándria, Digýnia. Margin of calyx obsolete. Petals obovatc, emarginate, with an inflexed point; those in the outer ray of the umbels with uncqual lobes: the outer lobe very large. Fruit compressed from the back. Mericarps with 5 primary, fliform ribs: the 3 intermediate dorsal, and the 2 lateral ones placed in the commissure; and 4 secondary ribs: the 2 inner ones of these filiform: and the 2 outer ones winged; the wings decply and sinuately lobed. Carpophore bipartite. Vitta none. Seed flat.-An annual, glabrous herb. Leaves, as well as those of the involucra and involucels divided into linear lobes. Umbels compound. Flowers white. Herb with the habit of Nigélla Damascèna; and the inflorescence like tliat of Orlìya grandiflòra.

1 A. squama'ta (Lin. spec. p. 3.7..). $\odot$. H. Native of the Levant, on Mount Lebanon (Lin.); between Bagdad and Kermancha (Olivier), on the banks of the Euphrates (C. Rostan); in Syria and Asia Minor (Schr.); in the Morea, and Lycia (Smith); Cyprus (Sibth.). Gingídium Rauwólfiz, Cam. hort. 16. but not of Dioscorides, ex Sibth. and Smith, fl. græc. 268. Thápsia orientàlis, Toum. cor. 22. 1. Mor. ox. scet.9. t. 18. f. 11. Flowers white. There is a pencil-like brown brush in the centre of the umbels. Cotyledons long, linear. Compare D. C. mem. umb. t. 19. t. 7.

Scaly Artedia. Fl. Jul. Clt. 1740 . Pl. 1 to $1 \frac{1}{2}$ foot.

Cult. The seeds should be sown as soon as they are ripe, in a warm border, as if sown in spring, the plant rarely produces seed.

CXXX. ORLA'YA (in honour of Joln Orlay, M.D. secretary to the Medico-Chirurgical Society of Moscow). Hoftm. umb. 1. p. 58. Koch, umb. p. 78. f. 12-13.-Caúcalis species, Lin. Spreng. Lag. Platyspérmum, Koch, in litt. 1828. but not of Hoffm. D. C. prod. 4. p. 209.

Lin. syst. Pentándria, Digýnia. Margin of calyx 5-toothed. Petals obovate, emarginate, with an inflexed point: those in the outer rays of the umbel radiant and profoundly bifid. Fruit lenticularly compressed from the back. Mericarps with 5, filiform, prinary, setiferous ribs : the 3 intermediate ones dorsal : and the 2 lateral ones placed in the commissure, which is flat: and with 4 secondary ones, bearing $2-3$ series of prickles each : the outer ones more prominent, or a little winged; prickles hooked, or rayed at the apex. Vittæ 1 in each furrow, under the secondary ribs. Carpophore bifid or undivided. Seed VOL. III. flat, convex helind.-Annual herbs. Leaves multifid; lobes linear. Involucra variable; involuccls of many leaves. Flowers white: those in the rays of the umbels hermaplurodite, with short styles: those in the disk nale: the rest fomale, and fertile, with long styles.

1 O. grandifloora (1 Ioffin, umb. 1. p. 58.) plant erect, dichotomous, glabrous ; leaves bipinnate ; lcaflets pimnatifid: segments linear, short; leaves of involucra 5 , with scarious mar-

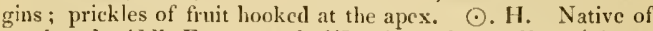
south and middle Europe, and of 'Tauria, in fields. Echinóphora, Col. cephr. 1.91. t. 94.f. 1. Rivin. pent. t. 25. Caúcalis grandiflòra, Lin. spec. p. 316. Lam. ill. t. 192. f. 1. Jacq. aust. 1. t. 54. Daúcus grandiflòrus, Scop. carn. 1. p. 189.-Lob. icon. 728. f. 1.-Mor. hist. sect. 9. t. 14. f. 3. There is a varicty of this with smaller flowers, a native of the south of France.

Great-flonered Orlava. Fl. Jul. Ang. Clt. 164.9. Pl. 1 to $2 \mathrm{ft}$.

2 O. Platycánpos (Koch, umb. p. 79.) plant erect, divaricately branched, roulh, or rather pilose; leaves bipinnate; scgments lanceolate, remotish; peduncles stiff, opposite the leaves; leaves of involucrum 3 , short; prickles of fruit coloured and hooked. $\odot$. II. Native from the south of France to 'l'auria, in the region of Olives, in fields. Echinophora platycárpos, Col. ecphr. 1. p. 94. Caúcalis platycárpos, Lin. spec. p. 347. C. latifolia, I.am. fl. fr. 3. p. 426 . exclusive of the synonymes.-J. Bauh. hist. 3. p. 2. p. 80. f. 1.

Broad-fruited Orlaya. Fl. Jul. Aug. Clt. 1800 . Pl. $1 \mathrm{ft.}$

3 O. Marítiua (Koch, l. c.) plant diffusely procumbent, velvety from villi; leaves bipinnate: segments bluntish, mucronate; peduncles elongated; leaves of involucra 3, short, undivided; prickles of fruit radiately glochidate at the apex. $\odot . H$. Native of Mauritania, Spain, and the south of France, Corsica, west of Italy, and Candia. Caúcalis marítimus, Gouan. hort. monsp. p. 135 . D. C. A. fr. 4. p. 335 . C. pùmila, Gouan. flor. 285. Dańcus marítimus, Gærtn. fruct. t. 20 f. 4. but not of Lam. Daúcus marítimus $\beta$, Lin. maut. p. 352.-Moris. hist. sect. 9. t. 14. f. 7 . There is a variety of this baving a bifil umbel (Gerard. gallo-prov. p. 2:7. t. 10.) or 3-4-cleft, and the lower ones 5 -cleft.

Sea-side Orlaya. Fl. May, Jul. Clt. 1S10. Pl. proc.

Cult. Sow the seeds in spring, in the open ground.

CXXXI. DAU'CUS ( from incw, daio, to make hot; from its supposed effect in medicine). Tourn. inst. p. 30\%. t. 161 . Lill. gen. no. 333 Gærtn. fruct. 1. t. 20. Duby, bot. gall. 1. p. 215. Koch in litt. 1828. D. C. prod. 4. p. 209:-Caúcalis species, Lag. Daúcus and Platyspérmum, Hoffm, umb. 1. p. 62. and 64. Koch, umb. p. 76 and 78 .

Lin. syst. Pentándria, Digýnia. Margin of calyx 5toothed. Petals obovate, emarginate, with an inflexed point: outer ones usually radiating, and profoundly bifid. Fruit somewhat compressed from the back, ovate or oblong. Mericarps with 5 primary, filiform, bristly ribs: the 3 intermediate ones lorsal: and the 2 lateral ones placed in the commissure, which is flat; and with 4 more secondary, prominent, equal, winged ribs, which are divided into a simple series of prickles. Vittæ 1 in each furrow, under the secondary ribs. Seed flattish in front.Herbs, usually biennial. Leaves bipinnate. Leaves of involucra many, trifid, or pinnatifid; involucels of many entire or trifid leaves. Flowers white or yellow: the central ones usually fleshy, dark purple, and sterile. The species of this genus are badly known, and are extremely difficult to extricate from confusion.

Sect. I. Platyspe'rmum (from $\pi$ hatuc, platys, broad, and

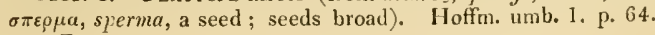
$\mathrm{Z}$ z 
Koch, umb. 78. D. C. prod. 4. p. 210 . Prickles of the secondary ribs evidently coliering and broader at the base. Involucra wanting, or very small: having the leaves divided a little.

1 D. murica'tus (Lin. mant. p. 392.) plant hispid; leaves tripinnate; leaflets multifidly cut; leaves of involucrum $5-7$, many of which, or all, are trifid or pinnatifid ; prickles of fruit longer than the breadtl of the seed, peltately glochidate at the apex. $\odot$. H. Native of Mauritania, Numidia, Calabria, and China, in fields.-Mor. hist. sect. 9. t. 14. f. 4. Herm. par. 111. Artèdia muricàta, Lin. spec. ed. 1. p. 242. D. muricàtus, Desf. atl. 1. p. 243. Spreng. in Sclultes, syst. 6. p. 477. exclusive of the synonyme of Poir. Piatyspérmum muricàtuin, Hotfin. and Koch, l. c. and perhaps Caúcalis Mauritánica is referrible to this. The hairs on the lower part of the stem are bent back.-Col. ecplir. 1. p. 95. t. 94. Flowers pink.

Muricatcd-fruited Carrot. Fl. Ju. Jul. Clt. 1683 . Pl. $1 \mathrm{ft}$.

2 D. LitTorA'Lis (Sibth. and Smith, fl. græe. t. 272. prod. 1. p. 185.) stem decumbent, hispid from defiexed hairs; leaves bipinnate, hisjid; leaflets short, multifid, cuneiform; leaves of involucrum 3 -cleft, shorter than the umbel; fruit ovate, beset with glochidate prickles. $\odot$. H. Native of the island of Cyprus, by the sea-side; and of Spain. Leaves of the involucrum usually 5 ; of the involucels membramous. Flowers white. Fruit angular, beset with strong prickles.

Sea-shore Carrot. Fl. Ju. Jul. Clt. 1820. Pl. dec.

3 D. PULCIE'RRIMUs (Koch, in litt. ex D. C. prod. 4. p. 210.) plant glabrous; leaves ternately supra-decomponud; segments linear, very narrow, short; umbels of many rays ; involucrum wanting; prickles of fruit longer than the breadth of the seed; when young covered with rough pubescence. $\odot$. H. Native of Tauria, Caucasus, lberia, Persia, on the sea-slore, in sand. Caúcalis orientàlis, Bieb. fl. taur. 1. p. 208. exclusive of the synonyme. Spreng. in Schultes, syst. 6. p. 469. exclusive of the synonyme. Caúcalis pulchérrima, Willd, enum, p. 301. Platyspérmum pulchérrimum, Koch, umb. p. 78.-Buxb. cent. 3. p. 16. t. 29. Flowers white.

Most-beautiful Carrot. Fl. Ju, Jul. Clt. 1816. Pl. 2 to $4 \mathrm{ft}$.

4 D. Bessarábicus (D. C, prod. 4. p. 210.) glabrous ; leaves ternately supra-decompound; segments linear-setaceous; umbels of many rays; involucrum wanting; prickles of fruit length of seeds, when young scabrous. \$.11. Native on the shores of the Black Sea, about Odessa; and of the south of Bessarabia. Caúcalis littoràlis, Bieb. fl. taur. 1. p. 208. Càclirys littoràlis, Spreng. umb. prod. 20. no. 5. Platyspérmum littoràle, Koch, l. c. This is very different from Daúcus littoràlis of Sibth., but it nearly agrees with D. pulchérrimus, especially in the leaves of the involucels being ciliated, but differs from it in the segments of the leaves being fewer and longer ; in the rays of the umbels and umbellules being fewer; and in the prickles of the fruit being shorter. Flowers white.

Bessarabian Carrot. Fl. May, June. Clt, 1819. Pl. I ft.

5 D. Laserpitioides (D. C. prod. 4. p. 210.) plant glabrous; leaves pinnate and bipinnate: with linear, elongated segments; umbets of 6-8 rays; leaves of involucrum $5-6$, linear, undivided; prickles of fruit joined at the base, neither scabrous nor glochidate. 4 . H. Native of Mauritania, in sand by the sea-side, near Bone. Laserpitium daucoides, Desf. fl. alt. 1. p. 253 . t. 70. Caúcalis virgàta, Poir. voy. 2. p. 133. suppl. 2. p. 136.

Lascrwort-like Carrot. P1. 2 to 3 feet.

6 D. PUBE'scens (Koch, umb. p. 77.) stem rough, branched; leaves pinnate, rather hispid; leaflets pinnatiff, with linear or trifid segments; leaves of involucrum usually trifid or undivided; prickles glochidate at the apex, longer than the breadth of the fruit, which is oblong. $\odot$. H. Native of Egypt, at
Alexandria. Caúcalis glàbra, Forsk. descript. p. 206. Dclile, fl. ægypt. 64, t. 23. f. 2 and 3 .

Var. $a$; smaller, sea-side plant; stems humble, diffuse. Delile, l. c. f. 2.

I ar. $\beta$; a larger plant, native of sandy places, with taller, erect stems, and more slender and more acutely divided leaves.

Pubescent Carrot. Fl. May, Ju. Clt. 1820 . Pl. $\frac{1}{2}$ to $1 \mathrm{ft}$.

7 D. setulo'sus (Guss. act. soc. borb. ex D. C. prod. 4. p. 211.) stem branched, bristly ; leaves pinnate; leaflets multifid; segments linear; leaves of involucra multifid; prickles of fruit longer than broad, glochidately capitate at the apex. $\odot . H$. Native of Calabria, and-at Naples. D. scabrosus, Bert. ex Guss.

Bristly-stemmed Carrot. PI. 1 to 2 fect.

Sect. Il. Caro'ta (from car, celt, red; colour of root). D. C. prod. 4. p. 211 . Prickles of secondary ribs slender, separate, even to the base. Rays of umbel nearly equal, or gradually shorter to the centre.

8 D. Parviflòus (Desf. fl. atl. 1. p. 241. t. 60.) stem tubercular, rather hairy; leaves bipinnate; leaflets of lower leaves ovate-oblong: of the superior ones linear-lanccolate, cut; leaves of involucra trifid, subulate, short; of the involucels simple; flowers equal, small; prickles shorter than the breadth of the fruit, which is ovate, peltately glochidate at the apex. $\odot . H$. Native of Mauritania, about Arzeau (Desf.). Flowers yellowish, according to the dried specimens.

Small-flowered Carrot. Fl. June, Jul. Clt. 1824. PI. $3 \mathrm{ft}$.

9 D. involucra'tus (Sibth. and Smith, fi. græc. t. 271. Smith, prod. 1. p. 184.) stem hispid from spreading hairs; leaves bipinnate; leaflets multifid; leaves of involucrum pinnatifid, longer than the umbel; umbellules few-flowered, uniform; leaves of involncels narrow. $\odot$. H. Native of Cyprus, by the sea-side. Perbaps the same as $D$. Crétiens, Mill. dict. no. 5.? Fruit small, scabrous from silvery prickles, which are hooked and glochidate at the apex.

Involucrated Carrot. Fl. June, July. Clt. ? Pl. $\frac{1}{2}$ to $1 \mathrm{ft}$.

10 D. CAro't ta (Lin. spec. 348.) stem hispid; leaves bipinnate, and tripinnate; leaflets pinnatifid, with linear-lanceolate acute segments ; umbels with a solitary, coloured, abortive flower; when in seed concave; bristles of fruit slender; leaves of involucra pinnatifid, not so long as the umbels; umbellules few-flowered, equal; leaves of involucels undivided or trifid. \&. H. $\mathrm{Na}$ tive of Europe, Tauria, Caucasus, and now introduced to South America, China, Cochin-china, Sc. in pastures and the borders of fields, in a gravelly soil ; common is Britain, in like situations. Smith, engl. bot, 1174. Mart. rust. t. 82. Fl. dan. 723. Plench. off. t. 176 . Hayn. arz. gew. 7. t. 2. D. vulgàris, Neck. D. polýgamus, Jacq. vind. 3. p. 43. t. 78. Caúcalis Caròta, Crantz. Huds. ang. p. 114. Staphylìnus, Riv. pentap. irr. t. 28. Pastinàca sylvéstris, Matlı. valgr. vol. 2. p. 107. f. 1.-Ger. cmac. 1098 .-Fuchs. list. p. 681 . Root slender, aromatic, and sweetish, resembling the garden carrot, which is only a cultivated variety. Leaves rather luairy. Umbels white, except the one central neutral flower, which is blood red. Seeds small, protected by the incurvation of all the flowerstalks, by which the umbels are rendered hollow, like a bird's nest. There are several varieties of the wild carrot, besides the cultivated kinds.

l'ar. $\beta$, satìca (D. C. prod. 4. p. 211.) root spindle-shaped, thick, succulent. This is the cultivated carrot, of which there are varieties witl white, red, but usually yellow or copper-coloured roots.

The root of the plant, in its wild state, is small, dry, sticky, of a white colour, and strong flavoured; but the root of the 
cultivated variety is large, succulent, and of a red, yellow, or pale straw colour.

Use.-It is used in soups and stews, and as a regetable dish. Parkinson informs us that, in his day, ladies wore carrot leaves instead of feathers. In winter, an elegant chimney ornament is sometimes formed by cutting off' a section from the head or thick end of a carrot, containing the bud, and placing it in a shallow vessel with water. Young and delicate leaves unfold themselves, forming a radiated tuft, of a very handsome appearance, and heightened by contrast with the season of the year.

faricties.-Those in common cultivation are :

I Large red or field carrol, grows to a large size, and is chiefly cultivated in fields, and in farmers' gardens, for colouring butter.

2 Orange carrot. The root is long and large, of an orange colour, and is the best sort for the main crop.

3 Early horn. Root short, smaller. It is the best kind for a small, early crop; also for shallow soils.

4 Late horn. With the same characteristics as the preceding, but suited for a late crop.

William Christie enumerates the following sorts of horn carrots :-Early red, common carly, long horn. Of long carrots :White, ycllon, long yellow, long orange, long red, and the $\mathrm{Al}$ tringham, or superb, originally from Cheshire.

Soil.-The carrot requires a light mellow soil, mixed with sand, which should be dug or trenched one or two spades deep, breaking well all the lumpy parts, so as to form a porous bed, and an even surface. The orange and red sorts, on account of their longer roots, require a soil proportionally deeper than the horns.

Seed estimate and sowing.-The seeds have numerous forked hairs on their ribs, by which they adhere together, and therefore should, previously to sowing, be rubbed between the hands, and mixed with dry sand, in order to separate them as much as possible. They are also very light, and therefore a calm day must be chosen for sowing; and the seeds should be disseminated equally, and trod in before raking. Previously to sowing, if convenient, the seed should be proven, by sowing a few in a pot, and placing it in a hot-bed, or hot-house, as it is more frequently bad than most garden seeds. For a bed $4 \frac{1}{2}$ feet by 30 , one ounce will be requisite, and the same for 150 feet of drill rows.

Times of soning.-To have early summer carrots, sow on a warm border in the beginning of February, or, to have them still more forward, sow in a moderate hot-bed, giving copious admission of air. In the open garden, begin with the early horn, in the last fortnight of February, or first week of March, as dry, fine, and open weather may occur. The first sown beds should be assigned a favourable situation, and covered for a time with haulm. Follow with the orange, in the first fortnight of March, and make successive sowings thence to the 20th of April for main crops. Add smaller sowings twice in May, for plants to draw young late in summer; also sow a few at the commencement of $\mathrm{July}$, for a later succession of young carrots in summer and autumn. Lastly, in the beginning of August, two separate small sowings may be made for plants to stand the winter, and afford young roots early in spring, March and April.

Insccts.-Carrots, when they come up, are apt to be attacked by insects, like the turnip; the most approved remedies for which are thick sowing, in order to afford both a supply for the insects and the crop; and late sowing, especially in light soils, thus permitting the grubs to attain their fly state before the seed comes up.

Culturc. - When the plants are up 2 or 3 inclies in growth, in May and June, they will require thinning and clearing from weeds, either by liand or small hoeing. 'Thin from 3 to 5 inches' distance, such as are designed for drawing in young and mis]dling growth. But the main crop, intended for larger and fullsized roots, thin to 6 or 8 inches' distance. Keep the whole clean from weeds in their advancing young growth. Some of small and middling growth will be fit for drawing in June and July ; large sizeable roots, in August and September; and those of full growth, by the end of October.

Prescrving in ninter.-Carrots are taken up at the approach of winter, cleaned, and stored among sand. They may be built very firm, by laying them heads and tails alternately, and packing with sand. In this way, if frost be excluded from the storehouse, they keep perfectly well till March or April of the following year. Some persons insist that the tops should be entircly cut off at the time of storing, so as effectually to prevent their growing; while others wish to preserve the capability of vegetation, though certainly not to encourage the tendency to grow.

To save seed.-Plant some of the largest best roots in October, November, or the last fortnight of February, 2 feet apart ; insert them a few inches over the crowns. They will yield ripe seed in autumn, of which gather only from the principal umbel, which is likely not only to afford the ripest and largest seed, but the most vigorous plants. A considerable quantity of carrotseed, for the supply of the London seedsmen, is raised near Weatherfield in Essex; and much is imported from Holland.

Ficld culture of the carrot.-It is observed, by a judicious writer, that the carrot has been too much neglected on lands, where it would have yielded a more valuable product in agriculture perhaps than any bulbous or tap-rooted plant whatever. Several contradictory experiments in its culture have been detailed in a number of publications, from which the practical husbandman will be at a loss to draw any definite conclusion. But in a communication to the board of agriculture from Robert Burrows, an intelligent Norfolk farmer, who has cultivated earrots on a large scale, and with great success, for several years, so accurate an account is presented of the culture, application, and extraordinary value of this root, that carrots will probably soon enter more largely into the rotation of crops on suitable soils.

$I^{\prime}$ arieties.-The only sort adapted for field culture is the long red or ficld carrot. New seed is most essential, as it will not vegetate the second year.

The best soil for the carrot is a deep rich sandy loam; such a soil ought at least to be a foot deep, and all equally good from top to bottom; on any other the field culture of the carrot will not answer.

In preparing the soil for the carrot, it is essential to plough it before winter, that it may be pulverized by frost, and to work it well in the spring to at least the depth of a foot. This deep tillage may be perfectly accomplished by means of the trench plough, following the common one, or even by the common one alone with a good strength of team; but the former method is to be preferred, wherever the lands are inclined to be stiff or heavy. Three ploughings are mostly found sufficient where the land has been previously in a state of tillage, but more may in other cases be necessary. As soon as the last ploughing bas been made in March, the land should be harrowed, and the sur face made as fine as possible. In Suffolk the farmers sow carrots after turnips, barley, and peas, set upon a rye-grass ley; the crops upon the first have generally been most productive ; next to that they prefer the latter. In the first place, they feed off the turnips by the beginning of February, and then lay the land up in small bulks or furrows, in which state it remains till the second week in March, when it is harrowed down, double furrowed to the depth of about a foot, and the seed sown.

The climate most suitable to the carrot is the same as for the turnip; but they will thrive better than the turnip in a dry and z $\quad$ z $\quad 2$ 
warm climate, and are consequently of better growth in the south of England and France, in proportion to their size in moist climates, as Holland and lreland, than the turnip.

Manure, according to some, should not be given to carrots the year they are sown, as it is alleged when the roots meet with it they become forked and wormy. This, however, is only applicable to cases in which recent unfermented manure has been given, or where other manure has not been properly broken in pieces, and spread over the soil, or in the drills. The Suffolk and Norfolk farmers, who are the best carrot growers, always use dung; a suitable proportion of well-rotted farm-yard dung being constantly turned into the soil at the last plonghing in Mareh, as it has been fully shown by various trials detailed in the Annals of $\Lambda$ griculture, and other books on husbandry, that though good crops of carrots may be occasionally grown without the aid of manure, it is only by the liberal application of that substance that the greatest produce possibly can be obtained, as they are in general found to bear a relative proportion to the quantity that may have been employed. Mr. Burrows prepares the land with a good dressing of about 16 cart loads per acre of rotten farm-yard manure, or cottagers' ashes, - the load about as much as three horses can draw. He usually sows wheat stubbles after clover, ploughing the first time in autumn, and once more in the early part of the month of February, if the weather permits; setting on the manure at the time of sowing, which is about the last week in March, or sometimes as late as the second week in April. In Suffolk, when carrots are intended to be sown after peas, they usually plough the stubble as soon as the barvest is over, in order that the land may clear itself of weeds; in December, it is laid up in small bulks to receive the benefit of the frosts; in February, it is harrowed down, and manured at the rate of 15 loals per acre; the manure ploughed in to the depth of about 4 inches, and in the month of March the land is double-furrowed, and the seed sown. By pursuing this method, they say, the manure lies in the centre of the soil, and not only affords nouri.hment and support to the carrot in its perpendicular progress, but renders it easy to be turned up by a single plonghing, and greatly promotes the growth of the succeeding crop of barley. In Norfolk, it is the practice to sow carrots after a crop of turnips. The manure, after being put on the land in the beginning of March, is furst ploughed in with a common plough, and afterwards trench ploughed about 14 or 15 inches deep; it is then harrowed very fine, and the seed sown about the beginning of March.

The season for soning the carrot, preferred by Mr. Burrows, is the last week in March or first of Apri]; but he prefers the tirst period, having generally found early crops the most productive.

The asual preparation of the seed for sowing, is by mixing it with earth or sand, to cause it to separate more freely; but Burrow's adds water, turns over the mixtmre of seeds and moist earth several times, and thus brings it to a point of vegetation before he sows it. "Haxing then weighed the quantity of seed to be sown, and collected sand or fine mould in the proportion of 2 bushels to an acre, I mix the seed with the sand or mould 8 or 10 pounds to every 2 bushels, and this is done about a fortnight or 3 weeks before the time I intend sowing; taking care to have the heaps tumed over every day, sprinkling the outside of them with water each time of turning over, that every part of the sand heaps may be equally moist, and that vegetation may take place alike throughout. I have great aclvantage in preparing the seed so long beforehand; it is by this means in a state of forward regetation, therefore lies but a short time in the ground, and by quichly appearing above ground, is more able to contend with those numerous tribes of weeds in the soil, whose seeds are of quicker vegetation." Suppl. \&c.

The quantity of sccd, when carrots are sown in rows, is 2 pounds per acre, and for broad-cast sowing 5 pounds. Burrows sows 10 pounds per acre in the broad-cast manner.

The usual mole of sowing the carrot is broad-cast, but perhaps the better mode would be to sow them in rows at 12 or 14 inches asunder; drawing the drills, and hoeing the intervals by any suitable hoe. 'The most common practice, however, where carrots are best cultivated, is the hand or broad-cast method, the seed being dispersed as evenly as possible over the land, after the surface lias been reduced to a very fine state of pulverization by harrowing, in order to provide a suitable bed for it to regetate in, being then covered in by means of a light harrow. As the seed is not of a nature to be deposited with much regularity by the drill, and as the young plants can be easily set out to proper distances in the operation of hoeing, this is probably the most appropriate method of putting such sort of seed into the ground. And an additional proof of it is indeed found in its being that which is almost universally adopted in those districts where carrot-husbandry is practised to the greatest extent. The drill method, however, would save much hand labour. The seed may either be deposited by the drill-machine, or by furrows made with a hoe or other implements, burying the seed about an inch in depth, and harrowing once.

The after culture given to the carrot consists entirely of hoeing and weeding. In suffolk they are hoed generally 3 times in the season. The first time, as soon as the plants can be distinguished from the weeds, which sh uld be done with a 3 -inch hoe. It is an operation that requires to be performed with great attention, as it is extremely difficult to distinguish the young carrots from the weeds. The second hoeing should be given in 3 or 4 weeks afterwards, according to the forwardness of the crop; it may be perforıned with common hoes, care being taken to set out the plants at proper distances. From 8 to 15 inches each way is the common distance, at which they are allowed to stand; and it has been proved by experience, that carrots which grow at such distances always prove at more abundant crop than when the plants are allowed to stand closer together. 'T'he third hoeing is commonly made about the middle or end of June, and in this, beside's destroying the weeds, another material circumstance to be attended to, is to set the carrots at proper distances, and also wherever any have been left double at the former hoeings, to take the worst of the two plants away.

Carrots som according to the plan of Burrows, are ready to hoe within about 5 or 6 weeks. He hoes 3 , and sometimes 4 times, or until the crop is perfectly clean. The first hoeing is with hoes 4 inches long, and $2 \frac{x}{4}$ inches wide. The second hoeing invariably takes place as soon as the first is completed, and is performed with 6 -inch hoes, by $2 \frac{1}{4}$ inches wide. By this time the plants are set; the first time of hoeing nothing was cut but the weeds. He leaves the plants 9 inches apart from each other, sometimes they will be a foot or even farther asunder.

Carrots are generally taken up in the last week of October. The operation is performed by 3-pronged forks. "I take up in autumn a sufficient quantity to have a store to last me out any considerable frost or snow that may happen in the winter months. 'Whe rest of the crop I leave in the yround, preferring them fresh out of the earth for both horses and bullocks. The carrots keep best in the ground, nor can the severest frosts do them any material injury; the first week in March it is necessiry to have the remaining part of the crop taken up, and the lanil cleared for barley; the carrots can either be laid in a heap, with a small quantity of straw covered over them, or they may be laid into some empty outhouse or barn, in heaps of many hundred bushels, provided they are put together dry. This latter circumstance it is indispensable to attend to; for if laid together in large heaps when wet, they will certainly sustain 
much injury. Such as I want to keep for the use of my horses until the months of May and June, in drawing over the heaps (which is necessary to be clone the latter end of April, when the carrots begin to sprout at the crown very fast,) I throw aside healthy and most perfect roots, and have their crown cut completely off, and laid by themselves; by this means carrots may be kept the month of June ont in a high state of perfection." Burrows' Conmunications to the Board of Agriculture, vol. vii. p. 72 .

The storing of the whole crop of carrots, may be a desirable practice when winter wheat is to follow them, in which case the same mode may be adopted as for turnips or potatoes, but with fewer precautions against the fiost, as the carrot if perfectly dry is very little injured by that description of weather.

The produce of an acre of carrots in Suffolk, according to Arthur Young, is at an average 350 bushels ; but Burrows' crop averaged upwards of $\$ 00$ bushels per acre, which considerably exceeds the largest crop of potatoes.

The uses to which the carrot is applied in Suffolk are various. Large quantities are sent to the London markets, and also used as food to different kinds of live stock. Horses are remarkably fond of carrots, and it is even said when oats and carrots are given together, the horses leave the oats and eat the carrots. The ordinary allowance is about 40 or 50 pounds a day to each horse. Carrots, when mixed with chaff, that is, cut straw, and a little hay, keep horses in excellent condition for performing all kinds of ordinary labour. The farmers begin to feed their loorses with carrots in December, and continue to give them chiefly that kind of provender till the beginning or middle of Nay ; to which period, with proper care, carrots may be preserved. As many of the farmers in that country are of opinion, that carrots are not so good for horses in winter as in spring, they give only half the above allowance of carrots at first, and add a little corn for a few weeks after they begin to use carrots.

The application of the currot to the feeding of working catle and hogs, is thus detailed by Burrows: "I begin to take up the carrot crop in the last week of October, as at that time I generally finish soiling my horses with lucern, and now solely depend upon my carrots, with a proper allowance of hay, as winter food for my horses, until about the first week of $J$ une following, when the lucern is again ready for soiling. By reducing this practice to a system, I have been enabled to feed 10 cart horses throughout the winter months for these last 6 years, without giving them any corn whatever, and have at the same time effected a considerable saving in hay. I give them to my carthorses in the proportion of 70 pounds weight of carrots a horse per day, upon an average, not allowing them quite so many in the very short days, and sometimes more than that quantity in the spring months, or to the amount I withheld in the short winter days. The men who tend the horses slice some of the carrots in the cut chaff of hay, and barn door refuse; the rest of the carrots they give whole to the horses at night, with a small quantity of hay in their racks, and with this food my horses generally enjoy uninterrupted health. I mention this, as I believe that some persons think that carrots only, given as food to horses, are injurious to their constitutions; but most of the prejudices of mankind have no better foundation, and are taken up at random, or inherited from their forefathers. So successful have I been with carrots, as a winter food for horses, that with the assistance of lucern for soiling in summer, I lave been enabled to prove by experiments, conducted under iny own personal inspection, that an able Norfolk team-horse, fully worked two journeys a day, winter and summer, may be kept the entire year round upon the produce of one statute acre of land. I have likewise applied carrots with great profit to the feeding of hogs in winter, and by that means have made my straw into a most excellent manure, without the aid of neat cattle. The hog: so fed are sold on Norfolk-hill to the London dealers as porkers." The profits of carrots so applied, he slows in a subsequent statement, togetlıer with an experiment of feeding four Galloway bullocks with carrots, arainst four others fed in the common way with turnips and hay.--Burrows' Communications, \&c.

In comparing the carrot with the potatoe, an additional circumstance greatly in favour of the former is, that it does not require to be steamed or boiled, and it is not more difficult to wash than the potatoe. 'These, and other circumstances considered, it appears to be the most valuable of all roots for working horses.

The use of the carrot in domestic cconomy is well known. 'Their produce of nutritive matter, as ascertained by Sir H. Davy, is 98 parts in 1000 , of which 3 are starch, and 95 smar. 'They are used in the dairy in winter and spring to give colour and flavour to butter. In the distillery, owing to the great proportion of sugar in their composition, they yield more spirit than the potatoe; the usual quantity is 12 gallons per ton. They are excellent in soups, stews, and haricots, and boiled whole with salt beef.

Medical qualities.-The seeds, especially of the wild variety, have a moderately warm pungent taste, and an agreeable smell. They are carminative, and are said to be diuretic. The roots, especially of the eultivated variety, contain much mucilaginous and saccharine matter, and are therefore highly nutritious and emollient. When beaten to a pulp, they form an excellent application to carcinomatous and ill-conditioned ulcers, allaying the pain, checking the suppuration and fetid smell, and softening the callous edges.

Common Carrot. FI. Ju. Jul. Britain. PI. 2 to 3 feet.

11 D. marítimus (Lam. dict. 1. p. 634. but not of With.) stem elongated, smooth, and glabrous at the base, but seabrous from tubercles above; leaves glabrous: lower ones bipinnate; leaflets jagged : segments linear, acuminated; leaves of involucra pinnatifid, linear, acute; of the involucels undivided; prickles about equal in length to the diameter of the fruit, which is ovate. 8 .H. Native of France, in sand, along the sea-shore; as well as along the shores of the Mediterranean Sea, where it is generally mixed with $D$. Carota, but from which it is easily distinguished. D. C. fl. fr. 4. p. 329 bot gall. 1. p. 215.

Sca-side Carrot. Fl. Jume, Jul. Clt.? PI. 1 to 2 feet.

12 D. GLABE'RRimus (Desf. fl. atl. 1. p. $24 \%$ t. $6 \%$ ) stem glabrous, or rather scabrous from small down; leaves pinnate; leaflets cuneated, bluntly 3-5-lobed, glabrous; leaves of involucra pinnatifid, acute, one half shorter than the umbels; involucels trificl or simple; prickles about equal in length to the breadth of the fruit, which is ovate. $\odot$. H]. Native of the north of Africa, near Tozzer, in woods of palm trees. Flowers small, white.

Quite-glabrous Carrot. Pl. 1 to 2 feet.

13 D. Gisaŕdium (Lin. spec. 34.8.) stem and petioles seabrous from scattered bristles; leaves bipinnate; leaflets deeply toothed, ovate: segments obtuse, mucronate; leaves of involucra striated, pinnatifid, about equal in length to the umbels; prickles bristle-formed, equal in length to the breadth of the fruit, capitately glochidate at the apex. $\delta$. H. Native of Corsica, on rocks by the sea-side, and probably of Sicily. D. Mauritánicus, Salzm. exsic.-Gingídium, Math. ed. Valgr. 373. f. 1. D. lucidus, Lin. fil. suppl. 179. ex Smith, in Lin. trans. 9. p. 133.-Boce. mus. t. 20. Habit of D. Hispánicus, but

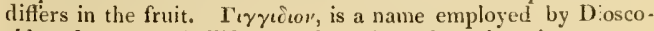
rides for an umbelliferous plant, but what plant is now unknown.

Chervil-like or Shining-leaved Carrot. Fl, June, July. Clt. 1722. l'l. 2 to 3 feet. 
14. D. Hispásicus (D. C. prod. 4. p. 212.) stem hispid at the base, branched, smoothisl above; leaves bipinnate; leallets smoothish, ovate, deeply toothed, thick, obtuse, somewhat mucronate; leaves of involuera striated, pinnatifid, or trifid, shorter than the umbels; prickles stiffish, comb-formed, acute, and entire at the apex, shorter than the diameter of the fruit. $\delta$. H. Native of Sicily, Italy, France, on rocks by the sea-side. In the south of England, on the sea-coast, near Dover; and in Cornwall. D. gúmmifer, Lam. dict. 1. p. 634 . D. C. fl. fr. 4. p. 328. 5. p. 512. Bert. amœen. ital. p. 136. D. marítimus, With, brit. 290. Sowerb. engl. bot. t. 2560. but not of Lam. D. Caròta $\gamma$, Smith, fl. brit. 300 . D. Hispánicus, Gouan. ill. 1. 9. Leaflets dilated, with rounded segments, whose elges and ribs are hairy. Bristles of fruit more flattened than in $D$. Caròta. Umbels convex when in sced, as in most of the species.

Spanish Carrot. Fl. Ju. Aug. England. Pl. 1 to 2 feet.

15 D. Pectina'ceus (D. C. prod. 4. p. 212.) stem smoothish, striated, rather scabrous at the apex; leaves bipinnate, glabrous ; leaflets ovate-lanceolate, pinnatifid : segments ovate-lanceolate, acute; leaves of involucra pinnatifid, ahout equal in length to the umbels, which are many-rayed; prickles simple, regularly pectinated, shorter than the breadth of the fruit, which is ovate. §. H. Native country unknown. This species differs from all the rest in the fruit.

Pectinated-fruited Carrot. Fl. Ju. Jul. Clt. ? Pl. 2 to $2 \mathrm{ft}$.

16 D. Mauritánicus (All, pedem. no. 1381. t. 61. f. 1.) stem scabrous from retrograde bristles; leaves bipinnate, glabrons; leaflets of the lower leaves lanceolate, deeply toothed: of the superior leaves linear, acute; leaves of involucra striated, pinnatificl, slorter than the umbels; prickles simple, acute, exceeding the breadth of the fruit, which is ovate. of. H. Native in fields about Nice, and in the south of France, and of Mauritania. D. C. fl. fr. 5. p. 512, and probably of Lin. spec. 848 .

Iar. 3 , pteroclcenus (D. C. prod. 4. p. 212.) leaves of the involucels variable, some of them undivided; and some, as the outer ones, pinnatifid. of. H. Native of 'Tauria, on the banks of rivers.

Mauritanian Carrot. Fl. June, July. Clt. 1768. Pl. $3 \mathrm{ft}$.

17 D. MA'xures (Desf. fl. atl. 1. p. 241.) stem scabrous, striated ; leaves bipinnate or tripinnate : leaflets of the lower leaves ovate, equally cut, with obtuse mucronate segments: of the upper leaves linear, acute; leaves of involucra pinnatifid, about equal in length to the umbels; prickles glochidate at the apex, equal in length to the breadth of the fruit, which is ovate. $\odot$. H. Native of Mauritania, Sardinia, south of France, on the borders of fields. Umbels large, radiating : having the central flower abortive.

Largest Carrot. Pl. 2 to 4 feet.

18 D. gutra'tus (Sibth. et Smitl, fl. græc. t. 269. Smith, prod. 1. p. 184.) stem hairy from spreading pili; leaves bipinnate; lower leaflets cuneated, pinnatifid, mucronate: superior ones lanceolate, finely serrulated; involucra shorter than the umbels; leaves of involıcels membranous; central flowers of umbels abortive, and of a different colour from the rest. $\odot$. H. Native of the Grecian islands, and of Asia Minor.

Spotted Carrot. Pl. 1 foot.

19 D. poly'Gamus (Gouan. ill. p. 9.) stem terete, nearly scabruus; leaves bipinnate, smoothish, but pilose beneath on the nerves, as well as on the petioles; leaflets pinnatifid: segments lanceolate-linear, acute ; leaves of involucra trifid or pinnatifid: outer flowers of umbel abortive; prickles acute, about equal in length to the fruit, which is ovate. $\hat{0}$. H. Native of Spain, and probably of Sicily, if the figure in Boce. sic. t. 40, f. 3. appertain to this species. D. Caròta $\beta$, Pers, ench. exclusive of the synonyme of Jacq. Fruit larger than those of D. Caròta, and the prickles are twice the length. Perhaps sufficiently distinct from $D$. Caròta.

Polygamous Carrot. Fl. Ju. Jul. Clt. 1817. Pl. 2 feet.

20 D. H'́spidus (Desf. atl. 1. p. 243. t. 63.) stem hispid from spreading or deflexed hairs; leaves bipinnate, rather villous; leaflets ovate, lobately toothed; leaves of involucra pinnatifid, shorter than the umbels; prickles about equal in length to the breadth of the fruit, incurved and glochidate at the apex. $\delta$. H. Native of the north of Africa, and the north of France, near Dieppe and Treport, by the sea-side on rocks. D. C. fl. fr. 4. p. 328. Bouch, H. abb. p. 20. Spreng. in Schultes, syst. 6. p. 480 . exclusive of the synonymes. 'T he French plant is probably the same as the Mauritanian one. Flowers reddish.

Hispid Carrot. Fl, June, July. Clt. 1804. Pl. 1 to 2 feet.

2I D. grandiflo'rus (Desf. fl. atl. 1. p. 24.0. t. 59.) stem pilose ; leaves tripinnate and quadripinnate ; leaflets trifid, linear, cuspidate ; leaves of involucra pinnatifid, with subulate segments, about equal in length to the radiating umbels; prickles peltately glochidate at the apex, exceeding the breadth of the fruit, whicl is ovate. $\odot$. H. Native of Algiers, among corn. Flowers like those of Orlàya grandiflora, and the leaves like those of $D$. Mauritánicus, but difiers in the prickles of the fruit being gloclidate at the apex.

Great-flowered Carrot. Pl. 2 to 3 feet.

22 D. Pusíluus (Miehx. f. bor. amer. 1. p. 164.) stem hispid from retrograde pili at the base, and rather scabrous at top; leaves bipinnate, rather scabrous; leaflets cut into linear segments; leaves of involucra pinnatifid, about equal in length to the umbels, which are small; prickles distinctly glochidate at the apex, about equal in length to the breadth of the fruit, which is ovate. 8. H. Native of Carolina, at St. Jolın's and Savannah, in dry places (Ell. sketch. 1. p. 349.); at the Red River (Nutt. in litt.); in Pennsylvania, at Reading (Herb. Koch.). Truly distinct from $D$. Caròta.

Small Carrot. Pl. 1 foot.

23 D. Microphy'llus (P'resl. in herb. Hænke, ex D. C. prod. 4. p. 2I3.) stem villons from soft retrograde hairs, especially at the bottom; leaves bipinnate, villous; leaflets cut into linear segments ; leaves of involucra pinnatifid, about equal in length to the umbels, which are small and crowded; prickles distinctly glochidate at the apex, about equal in length to the breadth of the fruit, which is ovate. $\odot . ? \delta . ? H$. Native of the northwest coast of America, at Nootka Sound; Straits of De Fuca ; Rocky places of the Grand Rapids of the Columbia; and on the plains of the Mulnomak River. Very nearly allied to $D$. musillum, but the hairs on the stem are more numerous, longer, soft, and not tubercular at the base; and the fruit is a little larger.

Small-leaved Carrot. PI. 1 foot.

24. D. Setifólius (Desf. fl. atl. 1. p. 244. t. 65.) stem smooth, erect; leaves decompound, pubescent; leaflets matyparted, opposite, somewhat verticillate : segments elongated, filiform, very narrow; leaves of involucra multifid ; fruit cylindrical, pubescent, ciliately echinated at the angles; prickles short. 2. H. Native of Mauritania, near Mlascar, on uncultivated hills. Central Howers abortive. Perhaps the same as D. verticillatus, Horn. hort. hafn. 1. p. 272 .

Bristle-lcaved Carrot. Pl. 3 feet.

25 D. Au'revs (Desf. fl. atl. 1. p. 242. t. 61.) stem bispid from spreading pili ; leaves glabrous, supra-decompound; leaflets multifid: segments linear-lanceolate, acute, with rather revolute edges; leaves of involucra and involucels decompound, reflexed; prickles stiff, peltately glochidate at the apex, longer than the diameter of the fruit, which is oblong. $\odot$. H. Native of Mauritania, in corn-fields near Mascar; and of Sicily and Calabria, in argillaceons soil; and of Lycia. Flowers white, 
but becoming yellowish on drying. Umbels of many rays. Fruit yellow.

Golden-flowered Carrot, Fl. July. Clt. 1823. Pl. 2 to $3 \mathrm{ft}$.

26 D. crinitus (Desf. fl. atl. 1. p. 242. t. 62.) stem rather roughish from small, retrograde down; leaves glabrous, pinnate; leaflets multifid, somewhat verticillate: segments setaceous, stifish; leaves of involucra many-parted at the apex; prickles bristle-formed, acute, and a little cleft at the apex, double the length of the cliameter of the fruit. 4. H. Native of Mauritania, near Tangiers, Mascar, Tlemsen, and on Miount Atlas. Bristles of fruit purplish in Desfontaine's specimens, but yellowish in those of Salzmann. Torilis crinita, Spreng. umb. spec. 141. D. meifolius, Brot. phyt. t. 36 . is not distinct from the present species.

Long-haired Carrot. Fl. June, Jul. Clt. 1804. Pl. 2 to $3 \mathrm{ft}$.

27 D. Hirsu'tus (Sibth. and Smith, fl. grac. t. 269 . prod. 1. p. 184.) stem hairy from spreading pili; leaves bipinnate; leaflets lanceolate, finely serrulated; leaves of involucra entire, trifid, or pinnatifid, shorter than the umbels; prickles of fruit elongated, glochidate, and coloured. $\odot$. H. Native in the islands of the Archipelago and Asia Minor, frequent. Spreng. umb. 143. Leaves of involucels membranous. Flowers white: central ones abortive. Prickles of fruit golden yellow.

Hairy Carrot. Pl. 2 feet.

28 D. Bícolor (Sibth. et Smith, fl. grac. t. 270. prod. 1. p. 1S4.) stem beset with spreading hairs; leaves pubcrulous, bipinnate; leaflets multifid, with linear lobes; leaves of involucra trifid, longer than the umbels; involucels membranous, on one side; central flower discoloured. $\odot$. H. Native of Asia Minor.

\section{Tho-coloured-flowered Carrot. Pl, 1 to $1 \frac{1}{2}$ foot.}

Sect. 11I. Anisa'ctis (from avroos, anisos, unequal, and aktı, aktin, a ray; in allusion to the unequal rays of umbels). D. C. prod. 4. p. 214. Carpophore undivided, or hardly bifidly emarginate at the very top. Rays of umbels very unequal.

29 D. вRAchí' tus (Sieb. exsic. nov. holl. no. 115.) stem glabrous; leaves bipinnate, smoothish : leaflets divided into linear lobes; leaves of involucra multifid, much shorter than the rays of the umbel, which are unequal; leaves of involucels simple, much shorter than the pedicels; prickles glochidate at the apex, about equal in length to the breadth of the fruit, which is oblong. $\odot . ? H$. Native of New Holland. Stem 2 or 3 from the same root, about a foot high. Rays of umbels diverging much.

Brachiate-umbelled Carrot. Pl. 1 foot.

30 D. Toriloi'des (D. C. prod. 4. p. 2[4.) stem lispid from deflexel hairs; leaves bipinnate, scabrous; leaflets diviled into linear lobes; leaves of involucra multifid, much shorter than the rays of the umbels, which are unequal and scabrous from bristles; leaves of involucra simple, much shorter than the pedicels ; prickles stellately hooked at the apex, about equal in length to the breadth of the fruit, which is oval-obleng.-Native of Peru, on the mountains; and of Mexico at Tolucco, and the Cordileras de Guchilaque; and probably of Chili and Caraccas. D. montànus, Willd. rel. in Schultes, syst. 6. p. 482.? Torìlis Peruviàna, Presl. in herb. Hænke. Habit of Torilis ; but differs from that genus in the albumen not being involute. Rays of umbels shorter and less diverging than in the preceding species.

Torilis-like Carrot. Pl. 1 foot.

31 D. Montevide'nsis (Hort. berol. ex Bernh. in herb. Balb. D. C. prod. 4. p. 214.) stem, petioles, and under side of leaves hispid from long, soft villi; leaves bipinnatifid; segments divided into linear-subulate lobes; terminal umbels 5-7-rayed: axillary ones 3-5-rayed; rays unequal; prickles of fruit glochidate at the apex. $\odot$. H. Native of Monte Video. Leaves of involucrum multifid, about equal in length to the umbel. Petals obcordate.

Monte-Iideo Carrot. Fl. June, Aug. Clt. 1827. Pl. $1 \mathrm{ft}$.

32 D. Austra' Lis (Poeppig. pl. exsic. no. 97. diar. no. 330.) stem simple, hispid; hairs on the lower part of the stem deflexed; leaves bipinnate, hispid; leaflets multifid, with short acute lobes; leaves of involucra multifid, almost excecding the umbels, which are crowded, and composed of few rays; prickles of fruit glochidate at the apex. $\odot$. H. Native of Chili. Flowers small, golden yellow in the dried state. The whole herb yellowish.

\section{Southern Carrot. Pl. 1 to 2 feet?}

\section{+ Specics not sufficiently known.}

33 D.? cuminoides (Lam. ill. t. 192. f. 2. Poir. suppl. 2. p. 118.) stem glabrous, flexuous; leaves tripartite; segments linear, very long, glabrous ; leaves of involucrum ternate, shorter than the umbel, which is composed of few rays; prickles shorter than the breadth of the fruit, which is oblong. - Native comntry unknown. Perhaps a species of Anthriscus.

Cumin-like Carrot. Pl. $\frac{1}{2}$ foot.

34 D. Sı'culus (Tineo, pug. sic. 1. p. 6.) stem erect, striated, hispid; leaves pinnate; leaflets ovate, deeply toothed; teeth obtuse, mucronate; petioles hairy; leaves of involncrum pinnatifid, larger than the umbel. $\odot$. H. Native of Sicily. Schultes, syst. 6. p. 628. Schrank, in H. 1819. p. 383. Outer flowers of umbels yellow : inner ones reddisb. Fruit unknown.

Sicilian Carrot. Pl. 1 to 2 feet.

35 D. próliér (Presl, del. prag. 130.) stem erect, rather dichotomous, furrowed, covered with retrograde hairs; leaves bipinnate; leaflets cordate, pinnatifid, toothed; leaves of involucrum entire, or deeply toothed; primary umbel proliferous; pedicels and fruit very hairy. $\odot$. H. Native country unknown, according to Gussone, prod. 1l. sic. 1. p. 324.; but according to Presl, it is a native of Sicily, between Syracuse and Catana, in sand by the sea-side. Perhaps the same as $I$. Siculus.

Proliferous-umbelled Carrot. Pl. 1 to 2 feet.

36 D.? a LA'tus (Poir. suppl. 2. p. 118.) stem erect, furrowed, hairy; leaves glabrous, somewhat pinnate; leaflets broadly cut: segments bluntish; petioles pilose; leaves of involucra pinnatifid at the apex, with linear segments; rays of umbel crowded, hispid; ribs of fruit membranously winged, spiny-toothed. 4. H. Native of Barbary, in uncultivated stony places by the sea-side.

Winged-fiuited Carrot. Pl. 2 feet?

37 D. FE'Tudus (Rafin. f. lud. 81.).-Native of Louisiana, in pastures. Plant stinking. Roots white, ex Rob. voy. p. 461 . Fetid Carrot. Pl.?

38 D. Rígidus (Hort. par.) These 2 species have not 39 D. Macroca'rpus (Hort. erf.) $\}$ been described.

Cult. All the species grow well in any common garden soil. The seeds of them should be sown in spring.

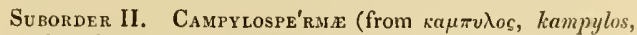
curved, and $\sigma \pi \varepsilon \rho \mu \alpha$, spcrma, a seed). D. C. prod. 4. p. 215. Albumen involute, or marked hy a longitudinal furrow or channel on the inner side.

\section{Tribe XIII.}

ELEOSELINEF (this tribe contains plants agreeing with the genus Elcosclinum in important claracters) or CAMPrLo-

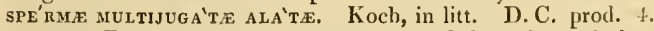
p. 215. Fruit cylindrical, more compressed from the back than from the sides. Mericarps with 5 filiform, primary ribs; and $t$ secondary ribs : the 2 dorsal ones of these last nerve-formed: 
and the 2 lateral ones expanded into wings: having the margins nerve or wing-formed Seed involute, semi-lunar.

CXXXII. ELLOSELINUM] (from exrta, elaia, an olive tree, and $\sigma \varepsilon \lambda w^{\prime} v$, sclinon, parsley). Koch, in litt. D. C. prod. 4. p. 215.-Laserpítium species, Desf. Thápsia species, Guss.

LrN. sist. Pentándria, Digýnia. Margin of calyx hardly 5-toothed. Petals obovate, entire, with an inflexed point. Fruit somewhat compressed from the back, nearly terete, 1 -winged. Mericarps with 5 filiform primary ribs: the 3 intermediate ones dorsal, and the 2 lateral ones placed within the wings and the nerve-formed margins: and 4 secondary ribs, the inner ones of thes $e$ last obtuse, and the 2 outer ones expanded into membranous wings. Vitta under all the ribs abounding in oil, those under the primary ribs slenderer and narrower than those under the secondary ones; and 4 in the commissure. Sced involutePerennial herbs. Stems terete, glabrous. Leaves decompound from the branched petioles. Umbels and umbellules of many rays. Involucra and involucels of many linear-cuspidate leaves. Flowers yellow. Carpophore undivided in E. mecides, but bipartite in $E$. thapsoides.

1 E. meol'Des (Koch, in litt. D. C. pred. 4. p. 215.) leaves bipinnate, hispid on the petioles and nerves; leaflets divided into sctacens lobes. 2. H. Native of Mauritania, about Algiers Tangiers; and on grassy hills and valleys in Sicily. Laserpitium meoìdes, Desf. fl. atl. 1. p. 250. t. 69. Thápsia meoìdes, Guss. prod. fl. sic. 1. p. 370 . Peucídanum Siciliae folis hirsutis Horibus huteis, J. Bauls. hist. 3. pt. 2. p. 37. ex Vaill. herb. There are simple leaves at the base of the flow ering branches.

Mcum-like Olive-parsley. Fl. July, Ang. Clt. 1818. Pl. 2 to 3 feet.

2 H. thapsordes (D. C. prod. 4. p. 215.) leaves pinnate, hardly velvety on the petioles and nerves; leaflets pinnateparted, cuneated at the base : lobes oblong-oval, toothed: ultimate one trifid. 4. H. Native of Mexico, about St. Angela. Herb 6-7 feet high, with the habit of Thápsia Gargánica. Teeth of calyx nearly obsolete. Fruit a little smaller than in E. mcoides, but the rest of the plant is similar.

Thapsia-like Olive-parsley. Fl. July, Aug. Clt. 1683. Pl. 6 to 7 feet.

Cult. The plants will grow in any common garden soil; and are only to be increased by seed.

\section{Tribe XIV.}

CAUCALI'NEE (this tribe contains plants agreeing with Calicalis in important characters), or Campylospérmæ multijugàtæ armàtæ, Koch, umb. p. 79. D. C. prod. 4. p. 216. Fruit contracted from the sides or nearly terete. Mericarps with 5 filiform primary bristly or prickly ribs : the lateral ones placed in the commissure, which is flat ; and 4 secondary more prominent, prickly ribs, or they are obliterated from the copious prickles covering the whole furrows. Seed involute or inflexed on the margin. Cancalinece is allied on one hand to Daucince, and on the other to Scandicinece.

CXXXIII. CAU'CALIS (a named used by Hippocrates and T'licophrastes for an umbelliferous plant). [Hotfin. umb. 54. t. 1. f. 14. Koch, unıb. p. 79. f. 14. D. C. prod 4. p. 216. Lin. Spreng. Lag.

Lin. syst. Pentándria, Digynia. Teeth of calyx 5, ovatelanceolate. Petals obovate, emarginate, with an inflexed point: outer ones radiating, profoundly bifid. Fruit somewhat compressed from the sides. Mericarps with 5 filiform primary bristly or prickly ribs : the 3 intermediate ones on the back and the 2 lateral ones placed in the commissure, which is flat; and 4 secondary more prominent ones, which are deejly cleft into a simple series of prickles. Vitta one in each furrow, under the secondary ribs, and 2 in the commissure, which is flat. Carpo- phore stiff, cleft at the apex. Seed involute or inflexed on the margin.-Herbs, with multifid leaves. Involucrum wanting, or of 1 or 2 leaves. Leaves of involucels 3-8, lanceolate, spreading. Flowers white; those in the disk of the umbels male and sterile.

I C. DAccoides (Lin. syst. nat. ed. 12. vol. 2. 1. 204. mant. 351. but not of his species,) plant nearly smooth ; stem hairy at the joints; leaves repeatedly subdivided, with narrow deep green segments; umbels of 3 rays; involucrum none; involucels 3-leaved; umbellules ripening about 3 fruits; prickles of fruit hooked at the apex. $\odot . H$. Native of Mliddle and South Europe, even to Tauria, Cancasus, and Persia, in corn fields on a chalky soil. In England at Marham, Norfolk; Carlby, between Stamford and Bourn, Lincolnshire; Thorp Arch, Yorkshire. Frequent in the counties of Oxford and Cambridge. J acq. fl. austr. t. 157. Sinith, engl. bot. t. 197. Cònium Royèni, Lin. spec. 350. C. leptophýlla, Huds. ed. 1. p. 99. Lam. dict. 1. p. 657. Schkuhr. handb. t. 61. Daúcus leptophýllus, Scop. carn. 1. p. 190. Echinóphora, Riv. pent. irr. t. 24.-Caúcalis, no. v. Baul. pin. 132. Stem deeply furrowed. Leaves on short membranous edged footstalks, 8-cleft at the base, then thrice compounded. Petals generally reddish, but slightly radiant.

Carrot-like Bur-parsley. Fl. June. Britain. Pl. $1 \frac{1}{2}$ foot.

2 C. Leftophy'LLA (Lin. spec. p. 347.) stem glabrous or rough from scattered retrograde liairs; leaves decompound, with linear-lanceolate acute segments; umbels 2-3-cleft; involucrum wanting; prickles of fruit scabrous, hooked at the apex. $\odot$. H. Native of Middle and South Europe, and of Mauritania and the Levant, as well as of Caucasıs. C. humilis, Jacq. hort. vind. 2. t. 195. C. parviflòra, Larn. dict 1. p. 657 . Involucels of 5 leaves. Peduncles stiff. Flowers pinkish.

Slender-lcaced Bur-parsley. Fl. Jul, Aug. Clt. 1739. Pl.1 ft.

3 C. GLocmidi'ta (Poir. suppl. 2. p. 137) stem glabrous above, but rough from retrograde bristles at the base; leaves pilose, decompotind, with short linear segments : involucra of 2 leaves; rays of umbel unequal, few ; prickles of fruit glochidate at the apex. $\odot$. H. Native of Van Diemen's Land. Scándix glochidiàta, Labill. nov. holl. 1.p. 75. t. 102. Caúcalis glochidiàta, Spreng. umb. prod. p. 24. Schultes, syst. 6. p. 471 . Fruit ovate. The petals are said to be pilose on the outside.

Glochidate-prickled Bur-parsley. Pl. I foot.

4 C. TENE'LLA (Delil. fl. eg. p. 58. t. 21. f. 3.) stem hispid from adpressed retrograde hairs; leaves decompound, hispid, with linear-subulate setaceously-acute segments; umbels 5-7rayed; involucra wanting or of one leaf; prickles shorter than the length of the fruit, which is oblong; furrows of fruit smooth. $\odot$. H. Native about Alexandria, in stony places.

Slender Bur-parsley. PI. 1 foot.

\section{+ Species not sufficiently known.}

5 C. Maurita'sica (Lin. spec. p. 347.) stem stiff, rougl, spreadingly branched; leaves bipinnatifid, with linear-lanceolate strigose segments; peduncles bifid; involucrum wanting; involucels usually of 3 leaves; umbellules 6 -flowered. ๑. Н. Native of Mauritania. Spreng. umb. spec. 143. Fruit somewlit prismatic, having the 3 dorsal ribs prickly. Tlse fruit under this name in Willd. herb. does not differ from that of Daucus muricàtus, but the description given by Linnæus does not agree with that plant.

Maurilanian Bur-parsley. Fl. June, July. Clt. 1818. Pl. $\frac{1}{2} \mathrm{ft}$.

6 C. strigòsa (Russ. beschr. alepp. ex Schultes, syst. 6. p. 4.73.) leaves pinnate, cut, pilose; umbel of many rays; leaves of involucra and involucels membranous ; fruit glabrous, and the bristles are lanceolate-subulate, $\odot$. H. Native about Aleppo.

Strigose Bur-parsley. Pl. 1 foot?

7 C. Angustifòlia (Forsk, ægypt. deser. suppl. p. 206.) 
lcaves multifid, narrow ; involucra and involucels hispid, as well as the fruit. - Native of Arabia, at Hadie.

Narrow-leaved Bur-parsley. Pl.?

Cult. The seeds may be sown either in autumn or spring.

CXXXIV. TURGENIA (from turgeo, to swell; fruit). Hoffm. umb. p. 59 . Koch, umb. 80. t. 16 . D. C. prod. 4. p. 217.-Caúcalis species, Lam. Lag. Spreng.-Tordýlium species, Lin.-Torilis species, Adans.

Lin. syst. Pentándria, Digýnia. Teetl of calyx 5, setaceous. Petals obovate, emarginate, with an inflexed point: outer ones radiating, bifid. Fruit contracted from the sides, rather didymous. Mericarps with 5 primary ribs, and 4 secondary ones: the lateral primary ones placed in the commissure, which is flat, furnished with a simple series of muricæ or prickles; not as in the rest of the ribs, which are furnished with 2 or 3 rows of prickles each; prickles all equal. Furrows under the secondary ribs 1 -vittate from both sides of the raphe. Carpophore setaceous, bifid. Seed involute.-Erect scabrous herbs. Leaves pinnate; leaflets oblong, toothed. Umbels of few rays. Leaves of involucra and involucels $3-5$, ovate, concave, equal, with membranous margins. Flowers white or rose coloured; those in the disk of the umbellules male and sterile.

1 T. zatrò̀lia (Hoffm. l. c.) leaves pinnate; leaflets deeply pinnatifid or strongly serrated, the upper ones decurrent; umbels of $2-4$, but usually of 3 long firm rays; umbellules having the flowers in the circumference alone fertile; ribs of fruit beset witl double rows of straight purplish bristles; the ribs in the commissure bear acute tubercles, not bristles. $\odot$. H. Native of Middle and South Europe, Mauritania, Greece, Caucasus, and Persia, in corn fields. In England in fields on a chalky soil, but rare; in Cambridgeshire not uncommon. Caúcalis latif olia, Liı. syst. nat. ed. 12. vol. 2. p. 276. Smith, engl. bot. t. 198. Jacq. hort. vind. t. 128.-Mill. fig. t. 85. Garid, prov, t. 22. Tordýliun latifòlium, Lin. spec. 345. Reich. spec. 1. p. 666.-Colum. ecphr. 98. t. 97. f. 1. Broad Bur.-parsley, Petiv. lierb. brit. t. 27. f. 6. Broad-jagged Bur-parsley, Petiv, herb. brit. t. 27. f. 7. Herbage rough, rather glaucous. Stem beset with minute ascending prickles. Teeth of calyx broad, sliort, spreading. Petals bright pink; those in the circumference of the umbellules twice as large as the rest. The plant varies much in stature, in the leaves, and in the colour of the flowers, which are sometimes white. This is one of the most striking and handsome of our native umbelliferous plants.

Broad-lcaecd Turgenia. Fl. July. Britain. Pl. 8 to 3 feet.

2 T. multiflòra (D. C. prod. 4. p. 218.) leaves teınate above the slieath; leaflets pinnatifid; umbels of 4 or 5 rays; ribs of fruit in the commissure bearing true prickles. $\odot$. H. Native of fields about Constantinople. Fruit more orate than in the preceding species, $6-8$, not $2-3$ in each umbellule; and all parts of the plant are much more robust.

Many-flonercd Turgenia. Fl. July. Pl. 3 feet.

3 T. Heteroca'rPA (D. C. prod. 4. p. 218.) leaves pinnate; leaflets oblong, deeply toothed; umbels of $6-10$ rays; mericarps of fruit dissimilar, having the secondary ribs in both toothless. $\odot .11$. Native of Persia, in the district of Khoi, in corn fields; and of the Levant, between Bagdad and Kermancha. Habit and flowers very similar to those of $T$. latifolia. Outer mericarp of fruit having the 3 dorsal primary ribs ornamented with $2-4$ broad prickles each, and the lateral ribs filiform and tootliless : the secondary ones hardly distinct, or a little toothed; the inner mericarp has the primary ribs all toothless, but the dorsal 3 are larger than the lateral ones: and the secondary rilos are hardly distinet. Albumen involu te

I'ariable-fruited Turgenia. Pl. 2 to 3 feet.

Cult. See Caúcalis above for culture and propagation. vol. 111 .
CXXXV. TORILIS (a name employed by Adanson, and maintained by Gærtner. It probably, like many of Adanson's words, has no meaning). Sprcng. umb. prod. p. 24. Hoffm, umb. 49. t. 1. f. 18. Lag. am, nat. p. 95 . Koch, $14 \mathrm{mb}$. p. 80 . t. 15. D. C. prorl. 4. p. 2I8.-Torilis species, Allans, Gæertı. Mocnch. —Tordýlium, Caúcalis, and Scándix species of autlıors.

Lis. syst. Pentándria, Digýnia. T'eeth of calyx 5, triangular-lanceolate, acute, permanent. Petals obovate, emarginate, with an inflexed point: outer ones of the umbellules larger than the central ones and bifid. Fruit contracted from the sides. Mericarps with 5 bristly primary ribs: the 3 intermediate ones on the back, and the 2 lateral ones placed in the commissure, which is flat; the secondary ribs beset with copious prickles, which occupy the whole furrows, having one vitta under each secondary rib below the prickles. Carpophore setaceous, bifid. Seed with an inflexed margin.-Herbs, with multifid leaves, beset with short adpressed hairs, which are retrograde on the stems, and erect on the rays of the umbels. Umbels opposite the leaves. Involucra of 1-5 leaves; involucels of 5-8 lanceolate ciliated leaves. Flowers white, those in the disk of the unbellules male and sterile. Prickles of fruit hair-formed, usually hooked at the apex.

Sect. I, Eutori'us (from $\varepsilon v, e u$, well, and Torilis; this section is considered to contain the true species of the genus). D.C. prod. 4. p. 218. Fruit covered with stiff prickles, which are usually looked at the apex.

1 'I'. Microca'rpa (Bess. cont. enum. no. 1362.) stem branclıed ; leaflets linear-cut, onter ones not elongated; umbels on long peduncles, 7-10-rayed; leaves of involucra and involucels setaceous; fruit ovate; prickles much shorter than the fruit, incurved. $\odot$. H. Native of the Ukraine and the south of Podolia. Torilis Ukránica, Spreng. in Schultes, syst. 6. p. 485 . Involucels as in T. Anthriscus, equal in length to the unbellules.

Small-fruited Hedge-parsley. Pl. 2 to 3 feet.

2 T'. Anthríscus (Gmel. 1]. bad. 1. p. 613.) nmbels on long peduncles of from 5 to 10 close rays; leaves of involucra and involucels several, aw-shaped; fruit covered with incurved bristles. $\odot$. H. Native of Europe and Caucasus, in hedges and on the borders of fields, very common; plentiful in Britain in like situations. Caúcalis Antliríscus, Scop. A. carn. no. 311. Huds. angl, p. 114. Smith, engl. bot. t. 987 . Fl. dan. t. 919. Curt. lond. fasc. 6. t. 22. Tordýlium Anthríseus, Lin. spec. 346. Jacq. fl. austr. t. 261. Torilis rubélla, Moench, meth. p. 103. Caúcalis áspera $a$, Lam. dict. 1. p. 656.-Riv. pent. irr. t. 32. -Baul. pin. 153. prod. 80. with a figure. Stem rough from deffexed hairs. Leaves bipinnate, pinnatifid, and sharply cut, rather soft than harsh to the touch; the lowermost one much more compound than the others. Flowers small, either white or flesh-coloured; the exterior ones only a little irregular or radiant.

Anthriscus or Upright Hedge-parsley. Fl. July, Aug. Britain. l'l. 2 to 3 feet.

3 T. NECLE'ctA (Schultes, syst. 6. p. 484.) stem and branches erect; leaflets ovate-lanceolate, cut; the terminal one hardly longer than the rest; umbels on long peduncles of from 7 to 10 rays; involucrum wanting. $\odot$. H. Native of Sardinia, Germany, Sc. in fields and on the margins of woods. Scandix infésta, Jacq. A. austr. 1. 46. Caúcalis infésta, V'est. ench. p. 495. ex Schultes. Peduncles longer and the fruit larger than in $T$. infésta. Flowers white.

Neglccted Hedge-parsley. Fl. July, Aug. Clt. 1817. Pl. $1 \frac{1}{2}$ foot.

4 T. Infe'sta (Hoffm. umb. p. 89. Spreng. prod. 24.) stem erect, much branched; leaves pinnatifid, cleeply cut, and sometimes almost bipinnate: the terminal leaflets elongated; umbels $3 \mathrm{~A}$ 
on long peduncles, of from 3 to 5 or 7 rather close rays; involucra wanting or of one leaf, which, like the leaves of the involucels, which are numerous, is lanceolate and acute; prickles exceeding the breadth of the fruit. $\odot . H$. Native of Europe, in fields, and by way sides; plentiful in Britain in like situations. $T$. Helvética, Gmel. Al. bad. 1. p. 617. D. C. prod. 4. p. 219. Caúcalis Helvética, Jacq. hort. vind. 3. t. 16. Caúcalis arvénsis, Huds. aug. 113. Caúcalis infésta, Curt. f. lond. fasc. 6. t. 23. Smith, engl. bot. 1314. Scándix infésta, Lin. syst. nat. ed. 12. vol. 2. p. 73\%. Caúcalis ségetum, Thuill. par. ed. 2. p. 136. Caúcalis áspera $\beta$, Lam. dict. 1. p. 656 . Caúcalis hùmilis, Riv. pent. irr. t. 33.-Hall. hist. 1. p. 325, no. 742. Flowers creamcoloured or pure white. A very distinct species, well marked by the deficiency of the involucra, and by the spreading branches.

Var, a, divaricata (D. C. prod. 4, p. 219.) stem branched, divaricate. ๑. H.

l'ar. $\beta$, anthriscoides (D. C. prod. 4. p, 219.) stem sparingly branched, or almost simple, tall; branches erect. $\odot . H$. This appears to be a variety intermediate between $T$. infésta and $T$. anthriscus, and is probably the T. Anthriscus, Spreng. exclusive of the synonymes.

Var. $\beta$, purpùrea (D. C. 1. c.) leaflets hardly clongated. $\odot$. H. Native of the south of Europe. Torilis purpurea, Ten. append. 4. p. 12. Guss. prod. fl. sic. 1. p. 325. In the specimens examined of this variety, the flowers are white, and the prickles of the fruit are more or less coloured. Perhaps a proper species.

Troublesome or Spreading Hedge-parsley. Fl. July. Britain. Pl. $\frac{1}{2}$ to $1 \frac{1}{2}$ foot.

5 T'Me'TerophY'LlA (Guss. prod.fl. sic. 1. p. 326.) stem erect, sparingly branclied: segments of leaves linear-lanceolate, cut; outer or terminal one not elongated: upper ones linear, entire; umbels on long peduncles of $2-3$ rays; involucra almost wanting; prickles equal in length to the breadth of the fruit. $\odot . H$. Native of Sicily, Corsica, and south of France. Caúcalis linearifolia, Requien, in litt. 1815. The fruit in this species is very variable in form and size, as in $T$, nodòsa.

Iariable-leaved Hedge-parsley. Fl. June, July. Pl. 1 foot. 6 T. Africa'na (Spreng. in Schultes, syst. 6. p. 486.) umbels on long peduncles, bifid; involucrum wanting; prickles shorter than the breadth of the fruit. $\odot . H$. Native of the Cape of Good Hope. Cańcalis Capénsis, Lam. dict. 1. p. 651. C. Africàna, Thunb. A. cap. p. 256. Athamántha Capénsis, Burm. fl. cap. prod. 7. Habit of $C$. Anthriseus.

\section{African Hedge-parsley. Pl. $1 \frac{1}{2}$ foot.}

7 'T. CHLORoca' RPA (Spreng. syst. 1. p. 898.) stem branched, rather puberulous; leaves bipinnate; leaflets or segments lanceolate, pimnatifidly serrated; umbels on long peduncles, 7-8.. rayed; involucra usually of only one leaf; bristles coloured, rather soft, scabrous, glochidate at the apex, rather longer than the diameter of the fruit. $\odot$. H. Native of the Canary Islands.

Grcen-fruited Hedge-parsley. Pl. 1 to 2 feet.

8 T'. Nodòs A Gærtn. fruct. 1. p. 82. t. 20. f. 6.) umbels ncarly sessile, glomerate, lateral, simple; stems prostrate; involucra of several linear hairy leaves; the outer mericarps of each external fruit thickly clothed with long, straight, pale, rough bristles, minutely hooked at the tops; the inner, as well as the interior fruits covered with dense, whitish, shining, tuber-

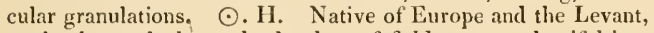
on banks, and about the borders of fields; most plentiful in a gravelly or chalky soil; plentiful in Britain. 'The plant is also to be met with in Chili and Peru, but has probably been transported thither. Caúcalis nodòsa, Huds. angl. 114. Smith, engl. bot. t. 199. but not of All. Tordýlium nodòsum, Lin. spec. 346. Jacq. aust, append. t. 24. Caúcalis nodiflòra, Lam. dict. 1. p.
656.-Kiv. pent. irr. t. $36 .-$ Mor, oxon. sect. 9. t. 14. f. 10. Stem rough from rcflexed bristles. Leaves a deep glaucous grcen, hairy, bijinnate, and sharply cut, with very narrow tolerably uniform segments. Petals white or reddish, hardly at all radiating or unequal. This plant is very different from Charophýllum nodosum, of which it is said to be a synonyme by Sprengel in Schultes, syst. 6. p. 485. The Caúcalis Hispánica, Lam. 1. p. 658. appears to be referrible to this from the description; and Caúcalis lappulàcea, Poppig. diar. no. 356. pl. exsic. p. 96. does not differ from this.

Knotted Hedge-parsley. Fl. May, June. Brit. Pl. prostrate.

9 T. JArónica (D.C. prod. 4. p. 219.) stem smoothish, terete, branched; leaves pubescent, bipinnate; leaflets oblong, pinnatifid; umbels pedunculate, axillary, and terminal, 5-7-rayed ; involucra and involucels of a few short subulate leaves; mericarps oblong; bristles of fruit stiff, hooked at the apex. $\odot . H$. Native of Japan. Caúcalis Japónica, Houtt. pfl. syst. 8. p. 42. t. 45. f. 1 . Upper branches and rays of umbel angular, beset with upright hairs.

Japan Hedge-parsley. Pl. 1 to 2 feet.

10 T. sca'bra (D. C. prod. 4. p. 219.) stem smoothish, terete, branclied; leaves pubescent, pinnate; leaflets oblong, pinnatifid, much acuminated; umbels terminal, and opposite the leaves, 5-7-rayed, sometimes without an involucrum; leaves of involucels subulate; mericarps oblong, covered with stiff bristles, which are hooked at the apex.-Native of Japan. Chærophýllum scabrum, Thumb. fl. jap. 119.

Scabrous Hedge-prarsley. PI. 1 to 2 feet.

11 T. tubercula'ta (Spreng. in Schultes, syst. 6. p. 486.) plant glabrous; branches twiggy; leaves pinnate; leaflets linear, quite entire; involucra and involucels wanting; hairs of fruit hardly hooked.- Native of Syria. Caúcalis tuberculàta, Poir. suppl. 2. p. 137. Styles tubercular at the base; hence the name. Fruit the size of that of $T$. microcárpa.

Tubercular-fruited Hedge-parsley. Fl. June, JuJy. Clt. 1817. Pl. 1 foot.

12 T. ela'ta; lispid, erect, branched; involucrum of many leaves; fruit ovate, very hispid from stiff bristles; leaves supradecompound; leaflets Janceolate, deeply pinnatifid: outer ones elongated. $\odot$. H. Native of Nipaul, on the mountains. Caúcalis elàta, D. Don, prod. fl. nep. p. 183. Caúcalis coniifòlia, Wall. cat. mss. Umbels of 8-10 rays. Involucrum of 6-8 linear-subulate leares.

\section{Tall Hedge-parsley. Pl. 2 to 3 feet.}

Sect. II. Trichocarfe'a (from $\theta \rho t \xi$ rotxos, thrix trichos, a

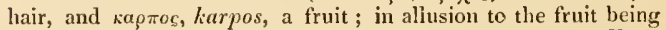
covered with long soft hairs). D. C. prod. 4. p. 220. Fruit covered with very long, soft, setaceous, crowded, spreading, coloured hairs, which are not hooked at the apex.

13 'T. TRICHospe'rMA (Spreng. umb. spec. 142.) stem nearly erect; branches smoothish; leaves bipinnate, rough from adpressed hairs; leaflets pinnatifid, acute; umbels on long peduncles, 3-6-raycd; involucrum wanting; involucels of 2-3subulate leaves. $\odot$. H. Native of Egypt, ex Lin.; and of Syria, at Tripoli. Scándix trichospérma, Lin. mant. 57. Chærophýllum trichospérmum, Lam. dict. 1. p. 685. but not of Schultes. Anthríscus trichospérma, Pers. ench. 1. p. 685. but not of Schultes. Bristles of fruit painted with rufous or violet colour.

IIair-seedcd Hedge-parsley. Fl. Jıne, July. Clt. 1824. Pl. 1 foot.

Cult. Sow the seeds in the open ground.

$$
\text { Tribe XV. }
$$

SCANDICl'NEA (this tribe contains plants agreeing with 
Scádix in many important characters), or Campylosperma paucijugatæ, elongatæ, Koch, umb. p. 130. Sprengel in Schultes, syst. 6. p. 42 . D. C. prod, 4. p. 220 . Fruit evidently compressed or contracted from the sides, usually beaked. Mericarps with 5 filiform ribs, now and then winged: lateral ones marginating; all equal ; and sometimes all are obliterated at the base, and only cvident at the tops. Seed teretcly convex, having a profound furrow in front, or with the margins somewhat involute.

CXXXVI. SCA'NDIX (Greek name of an eatable plant, but what plant is unknown). Gartn. fruct. 2. p. 33. t. 85. D. C. f. fr. 4. p. 291. Lag. am. nat. 2. p. 37. Koch, umb. p. 132. Spreng. syst. 1. p. 201. D. C. prod. 4. p. 220.-Scándix and IV ýlia, Hoffm.-Scándix species, Lin.

Lin. sxst. Pcntándria, Digýnia. Margin of calyx obsolete, or somewhat 5-toothed. Petals obovate, truncate or emarginate, usually furnished with an inflexed point. Fruit somewhat compressed from the sides, having a very long beak; mericarps with 5 blunt equal ribs: lateral ribs marginating; furrows without vittæ, or with obsolete ones. Carpophore undivided, or forked at the apex. Seed teretely convex, with a deep furrow in front. -Annual herbs, with terete, rather striated stems, and bi-pinnate leaves, having the leaflets divided into linear lobes. Umbels of few rays. Involucra wanting, or of one leaf. Umbellules of ferv rays; involucels of $5-7$ leaves. Flowers white.

Sect. I. Pécten (from pecten, a comb; beaks of fruit like the teeth of a comb). Duby in D.C. bot. gall. 1. p. 240. D.C. prod. 4. p. 221.-Scándix, Hoffm. umb. 1. p. 23. Beak of fruit compressed from the back. Petals nearly equal. Carpophore setaceous, undivided.

l S. Pinnatífida (Vent. hort. cels. t. 14.) leaves of invoJucels divided into linear lobes; umbels of few rays, fasciculate; fruit scabrous in the seminiferous part. $\odot . H$. Native of the Levant, between Bagdad and Kermancha; and of Persia, in the province of Aderbeicljan, between Amadan and Telieran; also of Tauria and lheria. Bieb. fl. taur. 1. p. 229. suppl. 235. Schultes, syst. 6. p. 505. S. stélla, Russ, alep. Stem and leaves glabrous, or hardly pilose. Leaves multifid, with slender segments. Perhaps S. parviflòra, Retz, jug. 12. Schultes, syst. p. 502. is referrible to this species.

Pinnatifid-leaved Shepherd's-needle. Fl. June, July. Clt. 1805. Pl. 1 foot.

2 S. PÉcten-VE'NERIs (Lin. spec. 368.) leaves of involucels jagged; fruit nearly smooth, with a bristly edged beak. $\odot$. H. Native of Europe, Levant, north of Africa and Teneriffe, in cultivated fields, common; plentiful in Britain. Smitl, engl. bot. t. 1397. Curt. lond. 5. t. 21. Mart. rust. t. 38 . Fl. dan. 844 . Jacq. austr. t. 263. S. Pécten, Hoffm. umb. 1. p. 24. t. 1. f. 22. Schultes, syst. 6. p. 501. Chærophýllum P'cten-Véneris, Crantz, austr. p. 189. Chærophýllum rostràtum $a$, Lam. dict. 1. p. 685. Mýrrlis Pécten-Véneris, All. pedem, no. 1376.Riv. pent. irr. t. 38 . Pécten-Véneris, Matth. valgr. 1. p. 481. with a figure. Cam. epit. 304. with a figure. Stem furrowed, smooth, or rather hairy, often purplish. Leaves pale green, triply pinnatifid: with linear acute smooth segments. Umbels simple, solitary or in pairs, over-topped by the broad jagged leaves of the involucels. Flowers in some degree radiant. Petals inflexed at the point. This is sometimes a troublesome weed, to which, thongh slightly aromatic and acrid, no particular use is attributed. Dioscorides, indeed, mentions it as eatable, but his

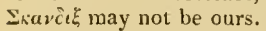

Common Shepherd's-needle, J'enus's-comb, or Needle Cliervil. Fl. June, Sept. Britain. Pl. 1 foot.

3 S. mRachycárpa (Guss. ind. sem. 1825. prod. sic. 1. p. 350.) involucrum wanting; leaves of involucels cntire; umbels of feiv rays ; fruit glabrous in the seminiferous part ; beak hardly twice the length of the seed. ○. H. Native of Sicily, on the Nebrodes; and of Syria. This is an intermediate plant hetween the two sections of the genus from habit; but the beak of the fruit is compressed from the lack, not from the sides. Leaves ternately decompound, glabrous: lobes short. Stem hardly a liand ligigh. Fruit 10 lines long.

Short-fruited Shepherd's-needle. P1. $\frac{1}{2}$ to $\frac{3}{4}$ foot.

Sect. II. WY'LIA (named in memory of Sir James Wylie, M.D. president of the Medico-Chirurgical Academy of l'etersburgl, and first plyysician to the emperor of Russia). Duby in D.C. bot. gall. 1. p. 240. D. C. prod. 1. c. Wýlia, Hoffm. umb. 1. p. 3. t. 2. Beak of fruit compressed from the sides. Carpophore bifid at the apex. Petals radiant.

4. S. AUstra'Lis (Lin. spec. 569.) leaves of involucels ovate, acute, a little toothed, erect, somewliat convolute around the pedicels; radiant petals obovate, entire, exceeding the others a little; fruit scabrous in every part; stem glabrous below. $\odot$. H. Native of the south of Europe, in corn fields and sterile places. D. C. fl. fr. 4. p. 202. Sibth and Sınith, fi. graec. t. 285. Mýrrhis austràlis, All. pedem. no. 1877. Chærophýllum, austràle, Crantz. umb. 76. Chæroplýllum rostràtum $\beta$, Lam. dict. 1. p. 685 . Wy'lia austràlis, Hoffm. umb. 1. p. 5. t. 2. f. 1. Col. ecphr. 1. t. 90 . Sheaths of leaves and petioles usually pilose.

Southern Shepherd's-necdle. Fl. May, June. Clt. 1713. Pl. 1 foot.

5 S. FALCA'TA (Lond. journ. mosc. 1. p. 87. t. 5. ex Hoffm.) leaves of involucels obovate, bluntly bidentate, ciliated, with membranous margins; radiant petals obovate, somewhat emarginate; fruit rather falcate, scabrous from bristles; stem and petioles pilose; umbels glabrous. $\odot$. H. Native of 'Tauria, frequent. S. austràlis $\beta$, Bieb. suppl. 424. Wy'lia ràdians, Schultes, syst. 6. p. 504 .?

Falcate-fruited Shepherd's-needle. Fl. May, Ju. Clt. 1817. Pl. $\frac{1}{2}$ foot.

6 S. APICULA'TA (D. C. prod. 4. p. 221.) leaves of involucels oval, acutely mucronate or bidentate, with membranous ciliaterl margins; radiant petals oblong-obovate, entire or bifid, with an acute recess; fruit scabrous from bristles; stem and petioles pilose; umbels glabrous. $\odot . H$. Native of the Levant. Very like $S$. falcata, but differs in the involucels being mucronate and acute; in the styles being long, and at length diverging; in the lower leaves being on longer petioles, and in the plant being smaller.

\section{Apiculated-fruited Shepherd's-needle. Pl. $\frac{1}{2}$ foot.}

7 S. GraNdif Lòra (Lin. spec. 369.) leaves of involucels ovate, obtuse, somewhat denticulated, with membranous ciliated margins; radiant petals somewhat olcordate, with an obtuse recess;

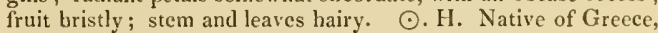
Tauria, and Iberia, in fields; also of Dalmatia, if S. hirsùta of Biasoletto, collected at Lossin-Piccolo, he the same. Scándix orientalis fiore maximo, Tourn. cor. p. 23. Chæe ropliy'llım grandifiorum, Lam. dict. 1. p. 686 . Wy'lia grandiflora, Iloffm. umb. 1. p. 15. t. 2. f. 3.

Far. 3 , glabrita (D. C. prod. 4. p. 222.) stem and leaves glabrous. $\odot$. H. Native of the Levant, about Bagdad. lays of umbel forming almost a straight angle: lateral ones bearing 12 15 fruit, and the terminal ones 5-6, the rest abortive. Involucels spreadingly deflexed, rather ciliated. Perhaps a proper specics, or a variety of $S$. falcàta.

Great-flowercd Shepherd's-needle. FI. May, June. Clt. 181 s. P]. 1 foot.

8 S. lBE'rica (Bieb. fl. taur. 1. p. 230.) leaves of involucels ovate, somewhat bidentate, with rather membranous ciliated margins; radiant petals obcordate, with an acute recess; fruit 3 A 2 
scabrous from bristles; sten furnished with one row of hairs umbels glabrous. $\odot . H$. Native of Iberia, in corn fields, and in gravelly places; and of Persia, in the province of Aderbeidjan, at Seidkhodzi and Badalan. Wy'lia Ibérica, Hoffim. umb. 1. p. i9. t. . f. 4. Fruit nearly 2 inches long, scabrous in the seminiferous part, having the beak compressed and scabrous at the angles; the rest smooth.

Iberian Shepherd's-needle. Fl. June, Jul. Clt. 1\$23. Pl. $1 \mathrm{ft}$.

\section{+ Spccies not sufficiently knonn.}

9 S. Gila' Nica (S. G. Gmel. itin. 3. p. 304. t. 31. f. 2.) stems branched, striated; fruit smooth.-Native of the north of Persia. Gmel. syst. veg. 486 .

Gilan Shepherd's-needle. Pl. 1 foot.

Cult. Sow the seeds in the open ground.

CXXXVII. ANTHRI'SCUS (a name given by Pliny to a plant resembling Scándix). Hoffm. umb. 1. p. 38. Koch, umb. 131. f. 57-60. D. C. prod. 4. p. 222.-Charophy'llum, Lag. am. nat. 2. p. 98, but not of Hoffin.-Cerefòlium, Hall.Scándix and Chærophy'llum species, Lin.-Chærophy'llum, My'rrhis, and Anthriscus species, Spreng.

Lin. syst. Pentándria, Digýnia. Margin of calyx obsolete. Petals obovate, truncate or emarginate, with an inflexed point, which is usually very short. Fruit contracted from the sides, beaked; the beak shorter than the seed. Mericarps nearly terete, without any ribs, the beak alone 5-ribued. Carpophore bifid at the apex. Seed teretely convex, having a deep furrow in front.-Perennial, biennial or annual herbs. Stems terete, striated or furrowed. Leaves decompound, witl usually linear slender segments. Umbels opposite the leaves or terminal. Involucrum wanting. Involncels of many leaves. Flowers white. The fruit varying in many of the species, either naked or furnished with a whorl of hairs at the base, resembling a collar. (Koch, in litt.)

\section{* Percnnial species.}

1 A. morous'ta (Duby, in D. C. bot. gall. 1. p. 239.) glabrous; stem rather striated; leaves bipinnate; leaflets ovatelanceolate, coarsely and decply toothed; leaves of involucels deflexed, lasceolate, acuminated, ciliated; umbels terminal ; rays glabrous; outer petals radiant ; fruit shining, girded by a series of small bristles at the base. $4 . H$. Native of the Alps of the south of Provence and Piedmont. Chreply'llum torquàtum, D. C. fl. fr. suppl. 505. My'rrhis bulbòsa, All, pedem. no. 1373. exclusive of the symonymes. My'rrhis torquàta, Schultes, syst, 6. p. 511 .

Collarcd-fruited Rough Chervil. Fl. May, June. Clt. 1819. Pl. 2 to 3 feet.

2 A. Sícula (D. C. prod. 4. p. 223.) stem glabrous, striated; leaves ternately decompound; sheaths and involucra ciliated; lcaflets ovate, pinnatifid: lobes oblong, deeply toothed, bluntish; fruit oblong, glabrous, smooth, girded by a series of bristles or hairs at the base. 4 . H. Native of Sicily, in woods and shady groves. Chacrophy'llum Siculum, Guss. prod. 1. p. 352.

Íar. $\beta$, scàbra (i. C. l. c.) fruit scabrons from tubercles, particularly on one side. 4 . H. Native of Sicily.

Sicilian Riongh Chervil. Pl. 2 to 3 feet.

3 A. cicuta'ria (Duby, in D. C. bot. gall. 1. p. 239.) plant smoothish; leaves ternate, then pinnate; leaflets pinnatifid, unequal at the base; segments lanceolate, bluntly toothed; umbels opposite the leaves and terminal; rays numerous, glabrous; petals hardly emarginate, outer ones rachant ; fruit ovate-oblong, smooth, naked at the base. 4. H. Native of the $A l p s$ of Dauphiny and Switzerland, \&.c. in humid places; also of $\mathrm{V}$ olhynia and Podolia, in woods. Chæerophy'llum cicutària, Vill. dauph. 2. 1. 6\$4. D. C. A. fr. suppl. p. 506 . Anthríscus hù- milis, Bess. enum. p. 13. no. 358. Chærophy'llum daucifolium, Desf. cat. hort. par. 1828. Leaves membranous, glabrous; leaflets broad. Involucels of 5 deflexed leaves, with ciliated margins. Flowers either white or red.

Cicuta-like Rough Chervil. Fl. May, Ju. Clt. 1810. Pl. $1 \frac{1}{2} \mathrm{ft}$.

4 A. Sylve'stris (Hoffin. umb. 40-46, t. 1. f. 19. 13. 210. t. 1. B, f. 17.) stem branched, striated, the lower part downy; leaves triply pinnate; leaflets ovate, pinnatifid, rough edged: extreme ones elongated; umbels smooth, terminal; inrolucels of 5 ovate fringed deflexed leaves; styles short, hardly diverging ; fruit lanceolate, with a deep channel on each side, smooth. 4. H. Native throughout the whole of Europe, even to Cancasus, in hedges and the borders of pistures and fields, in a rather fertile soil, very common; plentiful in Britain. Chærophy'llum sylvéstre, Lin. spec. 369. Smith, engl. bot. t. 752. Curt. lond. fase. 4. p. 25. Nart. rust. t. 96. Jacq. anstr. t. 149. Riv. pent irr. t. 44. Hayn. arz. gew. 1. t. 33. Cerefölium, no. 748. Hall. helv. 1. p. 328.-Moris. hist. 3. p. 303. sect. 9. t. 11. f. 5. Cicutària vulgàris, Raii. syn. p. 207. My'rrhis, Fuch's hist. 524. t. 525. Flowers white. Petals unequal in the marginal flowers, which alone are prolific. Perhaps A. prócerus, Bess. enum. pl. volh. 13. no. 359 . is referrible to this species. The whole herb having the flavour of carrots, is eaten by domestic cattle, and is reported to be very grateful to rabbits. The snow white flowers, some of the earliest of their tribe, plentifully adorn the hedges and bushy margins of fields in spring, and announce the approach of summer. J. Bauhm mentions instances of two families being poisoned by eating small quantities of the root.

Var. $\beta$, tenuifòlia (D. C. prod. 4. p. 223.) plant glabrous; leaves finely cut. $\quad$. H. Native of the Alps of Dauphiny. Chærophy'llum alpinnm, Vill. dauph. 2. p. 462.

I ar. $\gamma$, pilossula (D. C. mem. soc. gen. vol. 4.) petioles and nerves of leaves hispid from hairs beneath. \%. H. Native country unknown, but grown in gardens under the name of Chærophy'llum angústum.

Tar. ¿, scábrida (Spreng. umb. prod. 4. p. 223.) fruit rather scabrous. 4. H. Native of Germany and Italy. Chærophy'llum Magellénse var. $a$, Tenore, prod. fl. neap. append. 4. p. 15. exclusive of variety $\beta$, which is a synonyme of $A$. nemoròsa, according to Koch.

IFild Chervil or Smooth Cow-parsley. Fl. April, May. Britain. Pl. 3 feet.

5 A. Nemoròsı (Spreng. umb. prod. 27.) stem striated, branched, glabrous; leaves triply pinnate: leaflets pinnatifid : segments broad-lanceolate, acute; petioles pilose; umbels terminal, and opposite the leaves; leaves of involucel ciliated; fruit ovate, short, muricated, and girded by a circle of hairs at the base. 2. H. Native of Cancasus and Kamtschatka. Chærophyllum nemoròsum, Hoffin. umb. 45 and 210, t. 1. $\beta$, f. 19. Cham. et Schlecht. in Linnaea. 2. p. 390 . The whole herb is very like $A$. syliéstris, but the fruit is more ovate and shorter, and alway's more or less echinated.

Tar. $\beta$, lùcida (D. C. prod. 4. p. 22y.) fruit somewhat muricated on one side; lobes of lower leaves blunter. 4 . H. Chærophy'llum lùcictum, Desf. cat. hort. par. 1828 .

Grove Chervil. Fl. May, Jume. Clt. 1810 . P]. 2 to 3 feet.

$$
\text { * Annual spccies. }
$$

6 A. cerefòlum (Hoffim. umb. 41, 47. t. 1. f. 21. p. $210 . \mathrm{t}$. 1. $\beta$, f. 26 .) herb pale green, shining, delicate, and tender; stem a little hairy at the joints, only striated; leaves twice pinnate, cut, with channelled footstalks; umbels either axillary or opposite the leaves, sessile, of $3-5$ pubeseent rays; fruit somewhat furrowed, not ribbed, oblong-linear, smooth. $\odot$. H. Native of the south of Europe. In Britain, near Worcester ; in great 
plenty on a bank near Halesworth, Suffolk; frequent near Glasgow ; but probably an outcast of gardens. Scándix cerefollium, Lin. spec. p. 368. Smith, engl. hot. t. 1268. Jacq. austr. 390. Hayn. arz. gew. 7. t. 14. Berg. act. nov. soc. dronth. 1788. vol. 2. p. 496. Cerefolium sativum, Bess. gall. 1. p. 218. Chærophy'llum cerefòlium, Crantz. austr. 191. Chærophy'llum sativum, Bauh. pin. 152. Gærtn. fr. 1. p. 107. Lam, dict. 1. p. 684 . Schultes, syst. 6. p. 520. Snith, engl. fl. 1. p. 48. Chærofòlium sativum, Trag. list, 471, with a figure. Cerefölium, Riv. pent. irr. t. 43. Cam. epit. p. 302. with a figure. Gingídium, Fuschs, hist. 217.t. 216. Flowers slightly radiant. This herb is much used in France for salads, and is mentioned as a pot-herb by Gerarde, though now little regarded. The leaves are frequently used in soups, especially by the Dutch. Geoffroi relates, that he has found it from experience of remarkable service in dropsy. Haller, who is copious on the properties of chervil, has no opinion of it in dropsy; but thinks it may be of service in obstructions of the bowels, in external liæmorrhoides, \&c. Chervil is not admitted in our practice, and has almost disappeared from our kitchens and tables.

I ar. $\beta$, trichospérma (Koch, in litt. ex D. C. prod. 4. p. 224.) stem weak, glabrous; leaves ternately decompound or triply pinnate; leaflets coarsely 5-7-toothed : segments bluntish ; umbels opposite the leaves, pedunculate; rays few, glabrous; fruit oblong-linear, muricated from short down; styles short, erect. $\odot$. H. Native of Pannonia. Chærophy'llum trichospérmum, Schultes, oestr. fl. 2. 1. p. 504. but not of Lam Anthriscus trichospérma, Schultes, syst. 6. p. 525. but not of Pers. Chæroply'llum trichospérmum, Bess. in litt. Allied to $A$.cerefòlium, but very different from Torilis trichospérma. Perhaps a variety of Scándix cerefolium, with scabrous fruit, ex Jacq. and Bieb, and therefore Chærophy'llum nemorosum, Jacq. appertains to this plant.

Garden Chercil. Fl. June. Britain. PI. $1 \frac{\mathfrak{l}}{2}$ foot.

7 A. FUMARIOldes (Spreng. umb. prod. 27.) plant quite glabrous; stem striated, branched; leaves ternately supra-decompound; leatlets pinnatifid : segments linear, remote, cut, ciliated; umbels terminal; leaves of involucels reflexed, not ciliated; fruit ublong-linear, scabrous. \$ै.H. Native of Croatia, on calcareous mountains. Sclıultes, syst. 6. p. 525. Scándix fumarioides, Waldst. et Kit. pl. rar. lung. 3. p. 249. t. 224. Petals white, oblong, cuneated. Fruit oblong, echinated with stiff short hairs. Styles short, parallel, erect. l'erluaps the same as Chrerophy'llım divaricàtum, P'oir. suppl. 4. p. 343. and Chærophy'llum tuberculòsum, Poir. suppl. 4. p. 34\%. or Anthríscus tuberculàta, Scluultes, syst. 6. p. 527.?

Fumitory-like Chervil. Fl. May, June. Clt.1810. Pl. 1 to $2 \mathrm{ft}$.

8 A. vulga'ris (Pers. ench. 1. p. 320.) stems smooth and polished; leaves triply pinnate; leaflets pinnatifid; segments short, obtuse, their edges, ribs, and stalks a little hairy; sheaths ciliated; umbels on rather short stalks, opposite the leaves, smooth ; fruit ovate, covered with numerous short ascending incurved bristles, and tipped with a smooth pyramidal angular beak, scarcely half its own length. $\odot . H$. Native throughout Europe, even to Tauria, in cultivated grounds. In Britain, on banks and waste grounds, chiefly near large towns. Scándix Anthríscus, Lin. spec. 368. Sinith, engl. bot.t. 818. Curt. lond. fasc. 1. t. 19. Mart. rust. t. 75. Jacq. austr. t. 154. Cańcalis Ścándix, Scop. carn. no. 312. Caúcalis scandicina, Rotl, ff. germ. 1. p. 121. D. C. H. fr. 4. p. 334. Fl. dan. 863. Chærophy'llum Anthríseus, Lam. dict. 1. p. 685. Anthríscus Caúcalis, Bieb. fl. taur. no. 574. Anthríscus vulgàris, Hoffin. umb. 43. 47. t. 1. f. 24 . p. 211 . t. 1. 3. f. 27 . Koch, umb. 132. f. 59 , 60.-Riv. pent. irr. t. $35 .-$ Column. ecplur. 110, t. 112. Involucra wanting; involucels of 5-6 ovate-lanecolate leaves, with fringed margins. Flowers small, white, all uniform. Leaves of a most beantiful light green when young. The whole herb has a swcetish aromatic flavour, approaching to the garden chervil, to which it is in habit very nearly allied. Stem swelled under each joint.

Common Beaked-parsley. Fl. May. Britain. Pl. 2 to 3 feet.

Cult. All the species are of the most easy culture, and will grow in any soil and situation.

CXXXVIII. CHEROPHY'LLUM (from Xatow, chairo, to rejoice, and $\phi v \lambda \lambda \omega \nu$, phyllon, a leaf; in reference to the smell of the leaves). Hotfm. umb. 1. p. 33. Koch, umb. 130. f. 61-63. D. C. prod. 4. p. 224.-Chæropliy'llum species, Lin.-Chærophy'llum and My'rrhis species, Spreng. - My'rrhis species, Lag.

Lin. syst. Pentandria, Digýnia. Margin of calyx obsolete. Petals obovate, emarginate, with an inflexed point. Fruit without a beak, compressed or contracted from the sides. Mericarps with 5 obtuse equal ribs : lateral ribs marginating. Commissure with a deep furrow. Vittre one in each furrow of the mericarps between the ribs. Carpophore bifid. Seed teretely convex, the transverse section semilunar.-Perennial, biennial, or annual herbs. Leaves decompound ; leaflets toothed or multifid. Involucra none, or of few leaves. Involucels of many leaves. Flowers white, sometimes rose colour.

Sect. I. Physocaúlis (from $\phi v \sigma a$, physa, a bladier, ani $\kappa a v \lambda \iota c, k a u l i s$, a stem; in allusion to the stems being tumil at the joints). D. C. coll. diss. 5. p. 59. prod. 4. p. 225 . Fruit subcylindrical, somewhat attenuated at the apex, covered by stiff, compressed, angular bristles : having the ribs obtuse and much depressed. Styles short, straight.-Annual.

1 C. Nopòsum (Lam. dict. 1. p. 685.) stem fistular, tumid at the joints, scabrous; leaves triternate; leaflets cut ; fruit hispid. $\odot$. H. Native from France to Tauria, in hedges. Scándix nodòsa, Lin. spec. p. 369. Jacq. lort. vind. 3. t. 25. Anthríscus nodòsa, Spreng. umb. prod. 27. Schultes, syst. 6. p. 526. Torilis macrocárpa, Gærtn. fruct. 1. p. 83. t. 25. Torilis tìmida, Møench, meth._Moris. oxon. sect. 9. t. 10. f. 4. Flowers white.

Knotted-stemmed Cicely. Fl. May, June. Clt. 1656. P'. 1 to $1 \frac{1}{2}$ foot.

Sect. II. Brachy'stylis (from Goaxvc, brachys, short, and $\sigma \tau v \lambda o s$, stylos, a style; in reference to the short styles). D. C. coll. diss. 5. p. 59. prod. 4. p. 225 . Fruit glabrous, and evidently ribbed. Styles very short, straight. Annual. Umbels of few rays.

2 C. Procu'mbens (Lam. diet. 1. p. 685.) stems smoothish, decumbent; sheatls of petioles and leaves of involucels ciliated; leaves bipinnate; leaflets lanceolate, pinnatifid, with bluntislı lobes; umbels bifid, few-flowered, without involucra. $\odot$. H. Native of Virginia, Pennsylvania, and Maryland, in humid shady places. Scándix procúmbens, Lin. spec. 369. Mýrrhis procúmbens and M. bífida, Spreng. prod. 2. p. 25. Schultes, syst. 6. p. 516. Chærophýllum bífidum, Willd. herb.-Morr. oxon. sect. 9. t. 11. ultimate figure. Flowers small, white. Fruit 3 lines long. Herb slender, smoothish.

Var. $\beta$, Bóscii (D. C. prod. 4. p. 225.) stem ratler hairy, erectish; leaves tripinnate; leaflets pinnatifid; segments short bluntish; umbels of $2-3$ rays. $\odot$. H. Native of Carolina. Stem a foot or a font and a half high, contracted at the nodi in the dried state. Involucra of 1 or 2 multifid leaves; involucels of 5 ovate entire leaves. Fruit 3 lines long, without any beak. Mericarps with 5 ribs, and one vitta in each furrow. Styles 2 , very short. Charophýllum articulàtum, Bosc, in herb. Vent.

Procumbent Cicely. Pl, procumbent.

3 C. villòsus (Wall. cat. no. 558.) stem erect, the base beset 
with retrograde hairs, and the top with spreading ones; leaves rather pilose, pinnate; leatlets bipinnatifid: lobules short, acut-

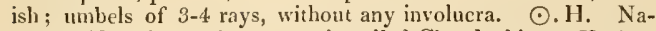
tive of Nipaul, on the mountain called Chandaghiry. Herb 2 feet high, branched, very hispid at the base. Involucels of 3.4 linear acute leaves. Fruit a little shorter than the pedicels. Styles short, straight.

$$
\text { Yillous Cicely. Pl. a feet. }
$$

Sect. III. Eucherorny'luum (from $\varepsilon v, e u$, well, and cherophyllum; this section is supposed to contain the true species of the genus). D. C. prod. 4. p. 225. Fruit glabrous, evidently ribbed. Styles more or less diverging.-Perennial or biennial plants.

\section{* Biennial plants.}

4. C. colora'tum (Lin. mant. p. 57.) root simple, fusiform; stem terete, and is as well as the petioles pilose; leaves ternately decompound: leaflets pinnatifid, divaricate; involucels glabrou: yellow. §. H. Native of Dalmatia. Jacq. hort. vind. 1. t. 51. Mýrrlis coloràta, Spreng, in Schultes, syst. 6 . p. 515.-Pluk. aln. t. 100. f. 5.-Moris, oxon. sect. 9. t. 10. f. 6. Root yellowish. Flowers yellow. Styles short, diverging. Hairs on the stem usually deflexed.

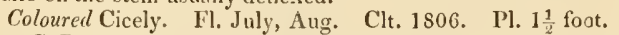

5 C. Prescóttı (D. C. prod. 4. p. 225.) root unknown; stem heset with retrograde hairs below, but glabrous above; leaves supra-decompound, the lower ones pilose at the petioles: superior ones glabrous : leaflets multifid: lobes linear; leaves of involucels cuspidate and glabrous; styles hardly diverging ; fruit cylindrical.- Native of Altaia. Very like $C$. bulbosum, but the styles are hardly diverging, and erectish on the fruit, which is much slenderer and longer.

\section{Prescott's Cicely. Pl. $1 \frac{1}{2}$ foot.}

6 C. sulbòsum (Lin. spec. p. 370.) root turbinate; stem beset with retrograde hairs at the bottom, and glabrous at the top; leaves supra-decompound; lawer ones pilose at the petioles: superior ones glabrous; segments multifid, linear; leaves of involucels glabrous, cuspidate; styles short, divaricate. $\delta^{\jmath}$. II. Native of Alsatia, Germany, Siberia, Dahuria, even to Persia, in humid parts of woods. Jacq. f. austr. t. 63. Hayn. arz. gew. 1. t. 32. Scándix bulbòsa, Roth, germ. 1. p. 123. Mýrrhis bulbòsa, Spreng. in Schultes, syst. 6. p. 513 . Horn. A. dan. t. 1768.-J. Bauh. hist. 3. p. 183, with a figure.-Plench. icon. t. 207. Perlaps the same as C. verticillàtum, hort, paris, ex Pers. Root not bulbous, but tuberous and turnip-formed. Stem usually tumich at the nodi, spotted at the base. Leaves triply pinnate, finely cleft. Flowers white. The roots taken up early in the spring are eaten boiled, with oil and vinegar. Gmelin affirms both these and the seeds to occasion vertigoes; but certainly this is not true, at least of the fresh root, many persons having eaten of that with impunity.

Bulbous-rooted Cicely. Fl. Ju. July. Clt. 1726. Pl. 3 to $6 \mathrm{ft}$.

7 C. Tenule'ntum (Lin. spee. 370 .) root spindle shaped, subdivided; stem solid, striated, rough with short defexed hairs, and spotted with dark purple, swelled under each leaf like most of the other species; leares dark green, hairy, twice pinnate; leaflets pinnatifid or lobed; umbels of many unequal hairy seeds; involucra wanting, of one leaf, rarely of several; involucels of several ovate pointed leaves, which are finely fringed at the margins and keel, occasionally confluent at the base; seeds furrowed, nearly smooth. §. H. Native of Enrope, in bushy places, and under hedges, common; plentiful in Britain. Jacq. austr. t. 65. Fl. dan. 918. Smith, engl. bot. 1521. Curt. lond. fasc. 6. t. 24. Hayn. arz. gew. t. 34.-Scándix témula, Roth, fi. germ. 1. p. 22. C. témulum, D. C. prod. 4. p. 12G. Scándix nùtans, Moench, meth. p. 101. Mýrrhis témula, Gærtn. fruct. 1. p. 23. t. 10. Schultes, syst. 6. p. 514. Mýrrluis temuléntum, Smith, engl. f. 1. p. 51. C. aúreum, Lin. mant. p. 356 . but not of his spec. according to Smith in Lin. trans. 10. p. 339.Mýrrhis, Riv. pent. irr. t. 49.-Noris. hist. 9. p. 308. sect. 9. t. 10. f. 7. Cerefòlium sylvéstre, Raii. syn. 207. Anthríscus Plinii, Dalesch. hist. 791. with a fgure. Wild Chervil, Petiv. herb. brit. t. 25. f. 3 . Flowers white, numerous, very slightly irregular, partly barren; those of the circumference principally fertile. Fruit linear, crowned with the short recurved styles. The whole plant is sweetish and aromatic, acceptable to domestic cattle, nor is any intoxicating quality recorded, notwithstanding the specific name. The herbage is often mildewed. Linnæus asserts that all the flowers are perfect, which does not accord with Haller's account, nor with our English specimens.

Intoxicating or Rough Cicely, or Rough Cow-parsley. Fl. June, July. Britain. Pl. 3 feet.

\section{* Perennial species.}

8 C. Moxógrnum (Kit. ex Link, enum. 1. p. 281.) stem quite glabrous; leaves decompound; leaflets lanceolate, deeply serrated, having the middle nerve and margins hairy; leaves of involucra and involucels ciliated. 4 . H. Native of Hungary. C. angulàtum, Kit. According to Link and Koch, this is a very distinct plant from Anthriscus syliéstris, although it has been joined to it by Sprengrel. Perhaps C. ciliàtum, Kit. in Schultes, syst. is the same, and probably C. nítidum, Wahl. fl. carp. p. 85. It is perhaps only a variety of $C$. aureum.

Monogynous Cicely. Fl. May, June. Clt. 18I0, Pl. 3 feet.

9 C. AU'REUM (Lin. spec, p. 370. but not of his mant.) stem solid, branched, angular, striated, downy, with copious short deflexed hairs, intermixed with more or less numerous coarser bristles; leaves decompound: the stem ones remarkable for their tapering leaflets, with numerous fine sharp parallel segments, their surfaces hairy or smooth; fruit in the early state club-shaped, when ripe linear, crowned with the lengthened spreading styles; seeds linear, of a tawny yellow, each with 3 prominent obtuse permanent ribs, which are often roughish upwards, as well as the furrows; involucra wanting, or of very few leaves; leaves of involncels ovate-lanceolate, pointed, reflexed, coloured. 2. H. Native of Middle Europe, among the mountains. In Scotland between Arbroath and Montrose; and at Corstorphine near Edinburgh, on the borders of fields. Smith, engl. bot. 2103. Jacq. austr. t. 64. Mýrrhis aúrea, Spreng. prod. 29. and in Schultes, syst. 6. p. 511. Smith, engl. fi. 1. p. 52. exclusive of the synonymes of Willd. Scándix aúrea, Roth, germ. 1. p. 123.-Lob. icon. t. 734. Ger. emac. 1039.-Moris. hist. 3. p. 301 . sect. 9. t. 10. f. 2.-Rupp. gen. ed. Hall. 282. t. 5. Joints of stem more densely hairy than the other parts, and a little swclled, crowised by the narrow annular base of each petiole. Flowers cream coloured, slightly irregular, the barren ones numerous, with only globose rudiments of styles. Stylopodia somewliat depressed, and considerably wrinkled.

Golden-secded Cicely. Fl. June, July. Scotland. Pl. $3 \mathrm{ft}$.

10 C. macula'tum (Willd. enum. suppl. 15.) stems smoothish, angular, spotted; leaves supra-decompound, pilose; leaflets lanceolate, deeply serrated, attenuated at the apex; fruit mutic, colourcd, 6 times longer than broad. 24. H. Native of the south of Lurope, but the particular places are not known. It differs from $C$. anreum, to which it has been joined by Sprengel, in the stem heing spotted and smooth, and in the fruit being twice the length.

Spotted-stemmed Cicely. Fl. May, Ju. Clt. 1810. Pl. $3 \mathrm{ft}$.

11 C. milféòium (D. C. prod. 4. p. 226.) stem and petioles hispid from pili ; leaves many-parted; leaflets linear-filiform, glabrous, distant; iuvolucrum of one leaf; leaves of invo. 
lucels deflexed, subulate at the apex, and ciliated with wool at the base, longer than the umbellules. 4. H. Native of Cancasus, at the base of the mountains. C. tenuifòlium, Stev. in Hoffm. umb. p. 180, and 212. t. 1. f. 33. but not of Poir. Mýrrhis millefơlia, Spreng. in Schultes, syst. 6. p.519. Scándix millef òlia, Willd, herb. C. ròseum var. $\beta$, Bieb. suppl. 239. Mýrrlis orientalis mei folio semine brevi, Tourn. cor. 22. Chærophýllum brachycárpum, Bicb. in Hoffm. umb. 212.? Fruit ovate, short. Styles short, diverging. Flowers white. Leaves as fine as Caraway leaves.

Millefoil-leared Cicely. Fl. May, June. Clt. 1818. Pl. 1 to $1 \frac{1}{2}$ foot.

12 C. RòseuM (Stev. mem. mosc. 3. p. 260. Bieb. fi. taur. no. 582.) stem and petioles lispid, and rather pilose; leaves manyparted : leaflets pinnatifid, glabrons; segments linear, approximate; involucra generally of one leaf; leaves of involucels numerous, deflexed, subulate at the apex, ciliated at the base, woolly, longer than the umbellules. 4 . H. Native of Caucasus and Iberia, in mountain meadows. Leaves as finely cut as those of the carrot. Petals of a fine rose colour, not ciliated as in $C$. hirsuitum. Mýrrlis ròsea, Spreng. in Schultes, syst. 6. p. 519. Fruit not seen.

Rose-coloured-flowered Cicely. Fl. May, June. Clt. 1817. Pl. 1 to $1 \frac{1}{2}$ foot.

13 C. Iú'sine (Bieb. suppl. 240.) stems aggregate, declinate, equal, pubescent ; leaves decompound; leaflets pinnatifid; segments oblong, very short; involucra of 1 or 2 leaves; involucels usually of 5 leaves, which are ciliated and margined with white. 4. H. Native of lberia, at the river Ksani. Mýrrhis humilis, Schultes, syst. 6. p. 519 . Flowers white.

Humble Cicely. Fl. May, June. Clt. 1823. Pl. 1 foot.

14. С. ну'ввіDUm (Ten. fl. neap. prod. 66.) stem glabrous, striated, rather scabrous; leaves tripinnate ; leaflets lanceolateoblong, deeply serrulated; segments acuminated, smoothish above, rather hispid beneath ; leaves of involucra and involucels ovate, acuminated, ciliated with long hairs; petals glabrous; styles divaricate. $\psi$. H. Natire of the kingdom of Naples, in the woods of Magella. Flowers white.

Hybrid Cicely. Fl. May, June. Clt. 1822. Pl. 3 feet.

15 C. ніrsu'rum (Lin. spec. 371.) stem fistular, beset with deflexed hairs; leaves ternately decompound, nearly naked; leaflets ovate-cordate, acute, pinnatifid: segments deeply serrated; petals usually ciliated; styles stiff, diverging, straight, permanent. 4 . H. Native of the temperate parts of Europe, as in Switzerland, Germany, Austria, Carniola, in mountain groves. Jacq. th. austr. t. 14S. Scándix hirsùta, Scop. carn. no. 350. Mýrrhis lirsùta, Spreng. in Schultes, syst. 6. p. 510. -Riv. pent. irr. t. 51.-J. Bauh. hist. 3. pt. 2. p. 182. f. 2.Moris, hist. p. 30 \% sect. 9. t. 10. f. 6. Petals white, with the ciliæ sometimes deciduous or almost wanting. Involucels of 5 lanceolate acuminated leaves. Leaves sometimes hairy on the veins beneath.

Var. $\beta$, glabràtum (Lam. dict. 1. p. 683.) stem and leaves smooth. $4 . H$. Native of more humid places than the species. C. cicutària, Murr. bot. 60. but not of Vill. C. palléscens, Presl, in helv. Balb. Petals ciliated.

Íar. $\gamma$, élegans (Schleich. cat. 1821.) stem hairy; leaves pubescent; leaflets and segments elongated. 4 . H. Native of the Alps of Switzcrland. Ch, élegans, Gaudin, fl. helv. 2. fr. 564. Ch. hirsùtum subverticillàtum, Schleich. cat. and exsic. no. 40 .

Iar. ¿, rubriflòrum (D. C. prod. 4. p. 227.) flowers of a rusy purplish colour. 4. H. Native of Switzerland, Savoy, Germany, Carniola, \&c. in meadows on the higher mountains.

Hairy Cicely. Fl. June, July. Clt. 1759 . Pl. $\mathrm{I} \frac{1}{2}$ foot.

16 C. MAGelle'NSE (Tenor. prod. fl. neap. append. 4. p. 15. var. $\beta$, exclusire of variety $\alpha$, ) stem beset with retrograde hairs, especially at the base; leaves pubescent, many-parted; leaflets oblong, pinnatifid; lobes acute, deeply toothed, lanceolate; petals a little ciliated; fruit cylindrical; styles stiff, permanent, diverging. 4. H. Native of the kingdom of Naples, on Mount Magella. The specimen received froin Tenore under this name is nothing but Antleriscus sylvéstris var. $\gamma$; but another specimen has been sent by him to Moricand in flower and fruit, which differs from $C$. hirsutum in the fruit being longer and thicker.

Magella Cicely. Fl. May, June. Pl. 3 feet.

17 C. Calábricun (Guss, in act. reg. soc, borb. ex litt. 1828.) stem finely pubescent ; leaves doubly dissected; leaflets broad, ovate, somewhat cordate, acute, deeply toothed, puberulous along the nerves, the rest glabrous; sheaths of leaves and leaves of involucels glabrous, hardly ciliated; petals subciliated; styles erect. 2\%. H. Native of Calabria, on the mountains about springs and rivulets. In habit the plant is intermediate between $C$. hirsitum and $C$. aromáticum.

Calabrian Cicely. Pl. 1 to 2 feet.

is C. Aromáticum (Lin. spec. 37 I. Jacq. fl. austr. t. 150.) stem striated, round, and hairy in the lower part, but smooth upwards, slightly tumid and angular below each joint; leaves biternate, large, on narrow-winged footstalks; leaflets stalked, broad, orate or elliptic-oblong, acute, sharply and finely serrated, both sides nearly smooth, the serratures minutely fringed; umbels smooth; involucra occasionally of a few lanceolate pointed leaves; involucels of several; fruit linear, smooth, crowned by the long, slender, spreading styles. $\mathcal{\imath}$. H. Native of Greece, Turkey, Hungary, Poland, Silesia, Austria, \&c. In Scotland, near Guthrie, by the road lenling from Forfar to Arbroath. Scándix tinctòria, Scop. carn. no. 351. Mýrrhis aromática, Spreng. prod. 28. Smith, engl. fl. 1.p. 52. Schultes, syst. 6. p. 509.-Kiv. pent. irr. t. 53.-Boce. mus. 29. t. 19. Herb when bruised somcwhat aromatic ; but the seeds, according to Jacquin, have scarcely any flavour. Scopoli says, they stain the fingers when rubbed with a brownish red. Flowers numerous, white, the external ones fertile.

Aromatic Cicely. Fl. June. Scotland. Pl. 3 fect.

19 C. Angelicaròlius (Bieb. suppl. 1. p. 240.) stem and petioles pubescent; leaves ternately divided, somewhat bipinnate; leaflets ovate-cordate, coarsely serrated. $4 . H$. Native of the Levant and Iberia. Mýrrhis aromática, Scliultes, syst. 6. p. 509. Nýrrhis orientàlis, Scc. Tour. cor. 22. Ch. aromáticum, Lin. spec. 371 . ? C. aromáticum, $\beta$, Pers. ench. no. 12. Ch. orientàle, iVilld. herb. ex Stev, obs. mss. Very like $C$. aromalicum, but differs in the lower leaflets being cordate-ovate, in the upper ones being lanceolate, and in the uppermost ones being linear-subulate. The root is said to be tuberous by 'Tournefort. Angelica-leaved Cicely. Fl. May, June. Clt. 1820. Pl. 2 ft.

\section{† Spccies not sufficiently known.}

20 C. ARBoréscens (Lin. spec. 1. p. 371. ) stem frutescent; leaves supra-decompound, smooth; involucels present only; flowers all fertile. $々$. H. Native of Virginia. This species is very doubtful.

\section{Arborescont Cicely. Shrub.}

21 C. CAPE'NSE (Thunb. prod. p. 51. f. cap. 2. p. 204.) stem terete, glabrous; leaves triternate, rather hairy; leaflets rather remote, linear-lanceolate, somewhat trifid, cuspidate ; involucels glabrous: fruit obversely pyramidal, a little beaked, acutely 5ribbed; styles permanent, reflexed.-Native of the Cape of Good Hope. Mýrrhis Capénsis, Spreng. umb. spec. p. 182. Schultes, syst. 6. p. 513.

Cape Cicely. Fl. May, June. Clt. 1810. Pl. $1 \frac{1}{2}$ foot. 22 C.? Anjsta'tum (Thunb. fl. jap. 119.) stem terete, gla- 
brous ; leaves ternately decompound, rather hispid on both surfaces; leaflets ovate, acuminated, pinnatifidly cut; fruit rather strigose; styles permanent, divaricate.-Native of Japan. Jýrrhis aristàta, Spreng. umb. spec. 133. Schultes, syst. 6. p. 512. Said to be allied to Urósporum dílcc, and probably a species of that genus.

Arned Cicely. Pl. 2 to 3 feet.

23 C. minusu (Vand, in Rom, script. p. 56.) stems numerous, hairy; radical leaves flat on the ground, biternate, hairy ; leaflets somewhat 3-lobed, cut; involucra wanting; involucels usually of about 7 leaves.-On the mountains about Milan. Vittm. suppl. p. 369. Schultes, syst, 6. p. 524. Moretti suspects this to be nothing but a variety of $C$. hirsutum.

\section{Least Cicely. Pl. $\frac{1}{2}$ foot.}

24. C. Tenuifòliun (Poir. suppl, 4. p. 342. but not of Stev.) plant glabrous; leaves decompound; leafiets finely cut, acute; fruit nearly glabrous, profoundly ribbed.-Native of the kingdom of Morocco. Mýrrlis tenuifòlia, Scbultes, syst. 6. p. 520 .

Fine-leated Cicely. Pl. 1 to 2 feet?

Cult. All the species are of the most easy culture, and will grow in any soil.

CXXXIX. CALDA'SIA (in honour of J. Caldas, a naturalist of Santa Fe de Bogota). Lag. am. nat. 1821, no. 2. p. 98. obs. apar. p. 26, and diss, in litt. D. C. coll. diss. 5. p. 60. t. 2. f. 1. but not of Willd. nor Mutis.-Mýrrhis, Kunth, nov. gen. amer. 5. p. 13. t. 419 . but not of Koch.

Lin. syst. Pentándria, Digýnia. Margin of calyx obsolete. Petals oval, with an entire subinvolute point, pilose on the outside. Fruit somewhat compressed from the sides, ovateoblong, crowned by the short diverging styles. Mericarps with 5 obtuse prominent rilss, 3 dorsal, and 2 marginating; vittæ one in each furrow, which are broad, flat, and striated. Commissure furrowed in the middle. Carpophore bipartite. Seed teretely convex, somewhat convolute at the commissure.-Puberulous or hairy tufted herbs, not above 2 or 4 inches ligh. Leaves tripinnately multifid; segments lanceolate-linear, acute. Scapes erect, pubescent. Umbels simple, containing about 20 flowers, surrounded by involucra composed of about 20 leaves each, which are oblong-lanceolate. Flowers white, some male, and others female.-This genus, from the seed and fruit, is allied to Scandix; but differs from Chceropliyllum in the umbels being simple, in the ribs of the mcricarps being distant, and in the furrows being broad.

1 C. Andicola (Lag. in litt. D. C. coll mem. 5, t. 2. f. j. 1-3.) the plant is either wholly glabrous or puberulous; pedicels smoothish, a little longer than the involucrum. 24. F. Native of South America, in grassy plains at Antisana, at the height of 6000 to 7000 feet. Mýrrlis Andicola, H. B. et Kunth, nov. gen. amer. 5. p. 13. t. 419 . Plant dwarf, tufted, deep green, but becoming blackish on drying. Umbels 10-12-flowered. Scapes hardly twice the length of the leaves. Kunth's specimen is less than that of Dombey's, and more glabrous; but the hairs of the scapes in both are deflexed. Pedicels glabrous.

Andes Caldasia. Pl. 2 to 3 inches.

2 C. entóroda (D. C. l. c. f. j. 4-5.) the whole plant is clothed with hoary pubescence; pedicels tomentose or hairy, much longer than the involucrum. $4 . F$. Native of New Holland, where it was collected by D'Urville. Scape 4t times longer than the leaves. Leaves of involucrum oval-oblong. Fruit quite glabrous, seated on very hairy pedicels.

Woolly-pedicelled Caldasia. Pl. 2 to 3 inches.

\section{$\dagger$ Species not sufficiently knomn.}

3 C. cmanopHyläi (Lag. am. nat. 2. p. 98, and in litt. ined.) stems covered with retrograde hairs; segments of invo- luerum entire, or cut, about equal in length to the flowering umbel. 24. F. Native of Peru.

I ar. a, glabriúscula (D. C. prod. 4. p. 229.) leaves pubcrulous, especially above, as well as the outside of the involucra : petals almost glabrous; peduncles dichotomous, twin. 4 . F. Native of Peru, at the town of Chinchin, in the province of Chancay, where it was collected by Ruiz et Pav.

Var. $\beta$, hirsuta (D. C. l. c.) leaves pubescently hairy on both surfaces, as well as the outside of the involucels and petals; forks of umbels 3-4-rayed.

Charvil-like Caldasia. Pl. 2 to 3 inches.

4. C. Laslope'tala (Lag, in litt. ex D. C. prod. 4. p. 229.) stem and leaves rather tomentose, greyish; segments of involucels cut and pinnatifid, longer than the umbels; petals pubescent on the outside. 24. F. Native on the Andes, in the tract called Cordillera del Peru.

Hairy-petalled Caldasia. Pl, 2 to 3 inches.

Cult. See l'ragosa, p. 259. for culture and propagation.

CXL. SPHALLEROCA'RPUS ( $\sigma \phi a \lambda \lambda \omega$, sphallo, to deceive, and kaproc, harpos, fruit ; from the fruit being liable to be mistaken for cumin seed). Bess, in litt. 182S. D. C. coll. mem. 5. p. 64. t. 2. f. N. prod. 4. p. 230.

Lin. syst. Pentándria, Digynia. Teeth of calyx 5, subulate. Petals obovate-cuneated, emarginate, with an inflexed point; outer ones of the umbel radiant. Styles short, at length reflexed. Stylopodium rather urceolate, toothed. Fruit ellipticoblong, contracted from the sides, without a beak. Mericarps with 5 subalate ribs: lateral ribs marginating. Vitta $2-3$ in each furrow, which are convex; and 4-6 in the commissure. Carpophore bipartite. Seed having a furrow inside.-Herbs. Stems terete, and are as well as the petioles hairy. Leaves bipimnate; leaflets pinnatifid: lobes linear, acute. Involucrum wanting. Unbels 6-7-rayed. Involucels of 5 lanceolate leaves. Flowers white, nearly all hermaphrodite in the terminal umbels, and male in the lateral ones.

1 S. Crminum (Bess. l. c.) \&. Native of Dahuria, about Nerschinski Sawod. ex Fisch.; and of Volhynia, ex Bess. Chærophýllum Cymìnum, Fisch. in litt. 1819. Cat. hort. Vratisl. 1821. Chær. gràcile, Bess, hort. crem. 1822. Trev. nov. act. nat. bonn. 1826. vol. 13. p. 172. Mýrrhis gràcilis, Spreng. syst. 4. pt. 2.p. 120. Fruit thickish, elliptic-oblong, with acute angles, very aromatic according to the testimony of Fisch. Leaves almost like those of Cher. aromáticum, triplicately pinnatifit, with linear segments. Stem smooth.

Cumin-like Sphallerocarpus. Fl. June, July. Clt. 1822. Pl. 2 to 3 feet.

Cult. The seeds of this plant only require to be sown in the open border.

CXLI. MOLOPOSPE'RMUM (from $\mu \omega \lambda \omega \psi$, molops, a stripe, and $\sigma \pi \varepsilon \rho \mu a$, spcrma, a seed; the fruit is yellowish, and the vitte chestmut coloured, giving the fruit the appearance of being striped). Koch, umb. p. 108. diss. ined. in litt. 18\%8. D. C. prod. 4. p. 230.-Ligústicum species, Lin. and Spreng.

Lin. syst. Pentándria, Digýnia. Calyx 5-toothed, foliaceous. Petals lanceolate, entire, ending in a long ascending acumen each. Fruit contracted from the sides; mericarps with 5 membranous winged ribs, the 2 lateral ones marginating, and onehalf shorter than the rest, and the 3 dorsal ones are very sharp. Seed bluntly tetragonal or angular; angle of commissure opposite, engraven by a profound furrow; the canals empty between the seed and commissure of the pericarp. Vittie broad, brown, solitary in the furrows; but none in the commissure, which is very narrow. Carpophore bipartite. $-\Lambda$ peremnial glabrous herb. Leaves ternatcly decompound; leaflets lanceo- 
late, elongated, shining, or decurrently pinnate-parted; segments slarply pinnatifid. Leaves of involucrum ammerous, elongated, rather membranous, sometimes multifid. Involucels of many leaves. Flowers white, on short pedicels. Terminal umbels, large, fertile: lateral ones smaller, male. Fruit often deformed, having the lateral ribs almost wanting, and the vittæ of the literal furrows. Perlaps this genus comes nearer to Plcurospérmum and Hymenola'na than to I'cle' $\alpha$.

1 M. Cicuta'rium (D. C. prod. 4. p. 230.) 4. H. Native of the Pyrenees, Cevenues, Alps of Provence, Daupliny, Piedmont, and Carniola. Séseli Peloponénse, Mattl. ed. Valg. 502. f. 4. but not of Dioseorides. Ligústicum Peloponesiacum, Lin. spec. 360. Jacq. fl. austr. append. t. 13. Lig. Peloponénse, Lam. dict. 3. p. 576. Lig. Cicutàrium, Lam. fl. fr. 3. p. 453. Molopospérmum Peloponesiacum, Koch. l. c. Séseli Peloponénse, Diose. lib. 3. cap. 62. is Angélica sylvéstris, which grows frequently in the Morea, ex Smith, prod. fi. grae. 1. p. 193.

Cicuta-like Molopospermum. Fl. May, July. Clt. I596. Pl. 3 to 5 feet.

Cult. This plant will grow in any soil, and is easily inereased either by dividing at the root or by seed.

CXLII. VELE'A (named after Seb. Eug. Vela, who illustrated umbelliferous plants under the auspices of Lagasca). D. C. coll. mem. v. p. 61. t. 2. f. H. prod. 4. p. 230.-Ligístieum species of H. B. et Kunth.

L1s. syst. Pentándria, Digýnia. Margin of calyx obliterated. Petals unknown. Stylopodium conically depressed, sliort. Styles erect, filiform. Fruit orate, without a beak; mericarps somewhat compressed from the sides, having the transverse section nearly terete; ribs 5 , the 2 lateral ones marginating, and nearly filiform, the 3 dorsal ones winged; vittæ usually 3 in the furrows, but sonetimes only 2 , probably from 2 of them being joined in one; and 4 in the commissure. Albumen involute. Carpophore bipartite from the base.-A branched glabrous lierb. Stem sulcately striated. Leaves ternately decompound ; leaflets nearly sessile, trifid, or pimmatifid, serrated, cuneated at the base. Umbels terminal, of about 20 rays. Involucra and involucels none. Fruit almost like that of Cnidium, but differs in the albumen being involute; of Molopospermum, hut the calys is toothless, the commissure less contracted, and the furrows marked with many stripes; of My'rrhis, but the vittæ are more numerous, and the earpophore is bipartite to the base.

I V. Toluccéxsis (D. C. prod. 4. p. 231.) 4. H. Native of Mexico, in the mountains near Tolucea. Ligústicum Toluecénse, H. B. et Kunth, nov. gen. amer. 5. p. 19. t. 422. Cnídium Toluccénse, Spreng. syst. 1. p. 388.

Tolucca Velæa, Pl. \& feet.

Cult. This plant will require some shelter in severe winters. It will be easily increased by seed or by dividing at the root.

CXLIII. MY'RRHIS (from $\mu v p o n$, myron, perfume, or

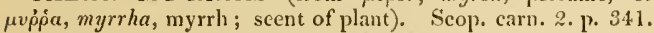
Hoffm. umb. 1. p. 27. t. 1. f. 23. Koch, umb. 123. D. C. prod. 4. p. 231.-Chærophýllum species, Lam.-Scándix species, Lin.-Mýrrhis species, Spreng.

Lin. syst. P'entándria, Digýnia. Margin of calyx obsolete. Petals obovate, emarginate, witls an inflexed point. Fruit compressed from the sides. Seed involute, covered by a double membrane; the outer membrane acutely lieeled by 5 equal sharp ribs, which are hollow inside: the inner membrane closely adnate to the seed. Vittæ wanting. Carpoplore cleft at the apex.-Perennial villous herbs, having a strong scent of anise. Roots fusiform. Leaves ternately decompound; leaflets pinnatifid. Involucrum wanting. Involucels of many lanceolate ciliated leaves. Central flowers of umbel male. Petals white.

1 M. odora'ta (Scop. I. c.) leaves rather villous beneath; voL. III. leaves of involucels lanceolate, finely fringed. 24. H. Native of Middle and South Europe, from Spain to Asia Minor; Germany, Switzerland, $\Lambda$ ustria, the sonth of France, and the north of Italy. In Britain, in Yorkshire, Cumberland, and Lancashire, and in the lowlands of 'Scotland, in mountain pastures. It is also to be found in Chili, but it has probably been introduced thither. Mýrrhis, Dod. pempt. 701. with a figure. Odoràta, Riv, pent. irr. with a figure. Scándix odoràta, Lin. spee. 368. Snith, engl. bot. t. 697. Jaer. austr. 5. append. t. 37. Blackw, t. 243. Plench. icon. 206. Clıærophýllum odoràtum, Lam. dict. 1. p. 683. Scándix odoràta of Burm. H. eap. p. 8. is our plinne. 'This was one of the old medicinal plants, but it is now disused. Formerly the young leaves and sceds were put into salads, and the roots were boiled or eaten, cold or in tarts, and in a variety of sauces. "Sweet Chervil gathered while it is young," says Parkinson, "and put among other lierbs in a sallet, addeth a marvellous good relish to all the rest." In Germany, it is said to be still used in soups. It no longer appears at the table with us. In the north of England the seeds were formerly employed in polishing and perfuming oak floors and furniture.

Sincet Cicely or Great Chervil. Fl. May, June. Britain. Pl. 2 to 3 feet.

2 M. surca'ta (Lag. gen. et spec. p. 13.) leaves hoary from tomentum beneath; leaves of involucels oblong, concave, setaceously mucronate. 4 . 11. Native of Spain. Fruit deeply furrowed.

Furrowch-fruited Cicely or Great Chervil. Pl. \& feet.

Cuil. These plants will grow in any common garden soil, and are easily increased by seed or dividing at the root.

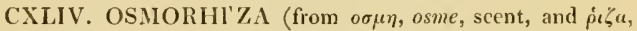
rhiza, a root; roots sweet scented). Rafin. journ. phys. 1821, D. C. prod. 4. p. 232.-Uraspérmum, Nutt. gen. amer. 1. p. 192. but not of Juss. - Spermatura. Reichenb. consp. 1827. 1. p. 141.-MÝrrlis species, Michx. 'Torr. Spreng.

Lis. srsx. Pcntándria, Digýnia. Margin of ealyx obsolete. Petals obovate, hardly emarginate, but with a short inflexed point each. Fruit elongated, tapering into a tail at the base, solid, acutely angled: having the transverse section nearly terete; mericarps with the angles rather furrowed and hispid: having 5 acute ribs each; commissure furrowell; rittæ none. Seed terete, involute, much shorter than the tube of the calyx. Carpophore semibifid.-American perennial herbs. Roots fusiform, sweet-scented. Stems branched, 2 feet high. Leaves biternate; leaflets broadly ovate-lanceolate, deeply-toothed. Involncra of 2-3 leaves; involucels usually of 5 leaves; leaves of both the involucra and involucels lanceolate, ciliated. Flowers white, the central ones of the umbellules male, the outer ones alone fertile.

\section{$\$ 1$. Involucra and involucels of 3 or 5 leares.}

1 O. Longístylus (D. C. prod. 4. p. 232.) styles filiform, somewhat diverging, equal in length to the breadth of the fruit, or rather longer. 4 . H. Native of North America, about Albany and New York, \&e. ex Torrey; in moist parts of woods about Boston, ex Bivel, \&e. Througlout Canada, from Lake Huron to the Saskatchawan, and on the banks of the Columbia in shady places, ex Hook. fl. bor. amer. 1.p. 271. t. 96. Mýrrhis longístylis, Torr. fl. un. st. 1. p. 310 . Uraspérmum Claytónii, Nutt. gen. amer. 1. p. 193. Bigel. fl. bost. ed. 2. p. 11 2. Seándix dúlcis, Muhl. ex spec. Nutt. Sehrad. in litt, My'rrhis Claytònii, Spreng. spec. umb. 129. t. 3. f. 6. Chæ̣rophy'llum Claytònii, Pers. There are varieties of this having the stem and leaves more or less villous or smooth. Umbels usually of 5 rays. Leaves of involucra and involucels oval-lanceolate. Lioot smelling of anise according to Bigelow. Fruit clavate. Involucra permanent.

$3 \mathrm{~B}$ 
Long-styled Osmorhiza. Fl. July, Aug. Clt. 1806. Pl. 1 foot. 2 O. BREvi'styuis (D. C. prod. 4. p. 232.) styles short, conical, tapering at the base and apex, one-half shorter than the breadth of the fruit. 24. H. Native of North America, in the United States and Canada, and in woody places on the west side of the Rocky Mountains; and from the mouth of the Columbia to Observatory lnlet, in lat. $55^{\circ}$ on the north-west coast. Hook. f. amer. bor. 1. p. 272, t. 97. My'rrhis Claytonii, 'Torr. f. un. st. 1. p. 310 . exclusive of many synonymes. Uraspérmum lirsùtum, Big. f. bost. ed. 2. p. 112. Umbels usually of 3-4 rays. Leaves of involucra linear-lanceolate, deciduous. The root, according to Bigelow, has an ungrateful scent, similar to that of Arùlia nudicaúlis; but according to Torrey it has a sweet anise scent. Short-styled Osmorbiza. Pl. 2 feet.

\section{§. Involucra and involucels nantiug.}

3 O. Berte'ru (D. C. prod. 4. p. 232.) plant hairy; leaves decompound; leaflets pinnatifil ; styles very short, diverging; fruit villous, especially at the base. 4. H. Native of Chili, near Tagua-tagua, and about Conception, in shady woods. Herb nearly like that of $O$. brevistylis. O. Chilénsis, Hook. et Arn. in Beech. bot. p. 26. Scándix Cluilénsis, Molina, chil. p. 125. cd. gall. p. 331. Leaves bipinnate; leaflets cuneate-ovate, pinnatifid; segments subdivided, acute. Flowers some of them male. Bertero's Osmorhiza. Pl. 2 feet.

Cult. Sce My'rrhis, p. 369. for culture and propagation.

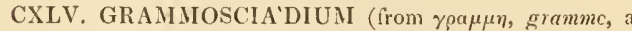
line, and okcaioov, sciadion, an umbel; fruit lined). D. C. coll. mem. v. p. 62. t. 3. f. K. prod. 4. p. 232.

Lis. syst. Pentándria, Digýnia. Tecth of calyx 5, stiff, permanent. Petals obcordate, with an inflexed point. Styles short, conical, diverging, permanent, stiff. Fruit cylindrical, without a beak; mericarps with 5 primary flattish white ribs; furrows flat, having one vitta in each; and the commissure lıving 2. Seed unknown.-Quite glabrous herbs, natives of the Levant. Stems branched. Leaves pinnate; leaflets multifid: lobes linear-setaceous. Unbels compound, of from 5 to 16 rays. Leaves of involucra $5-7$, multifid ; of the involucels linearsubulate, rarely cut. Pedicels stiff, thickening after flowering. This is a very distinct genus, but from the structure of the seed being unknown, the place which it should occupy in the order is doubtful.

1 G. DAucoides (D. C. l. c. t. 3. f. K.) leaves of involucra multifid; most of the flowers in each umbellule are fertile; fruit terete, crowned by the calycine teeth, which are conical and elongated.- Native of Armenia, ex herb. Tourn. about Amadan in Persia, ex herb. Oliv. et Brug. My'rrhis Armena foliis Mei seu foniculi semine brevi. Tourn, herb. Herb quite glabrous, erect. Root terete, nearly simple. Stem furrowed, a foot high. Leaves nearly like those of Daúcus setifolius, having the petioles dilated at the base. Central umbel of 15-16 rays, lateral ones of $10-12$.

Carrot-like Grammosciadium. Pl. 1 foot.

2 G. MEoides (D.C.l. c.) leaves of involucra hardly cut ; the central flower in each umbellule alone fertile; fruit rather clubshaped; calycine teeth small.--Native of Armenia. My'rrlis orientalis Mei folio semine longissimo, Tourn. cor. 22. My'rrhis orientalis semine unciam longo, 'Tourn. herb. Scándix macrospérnna, Willd. herb. ex Scluiltes, syst. 6. p. 507 . Scándix clavata, Spreng. syst. 1. 1. 903 . Stem branched, terete. Leaves none in the specimen. Involucrum wanting, or of one usually nndivided leaf. Umbels of 5-7 rays. Umbellules each containing 7.8 sterile flowers, and one fertile one. Fruit in Tournefort's specimen shorter than in the preceding.

Meum-like Grammosciadium. Pl. 1 foot.
Cult. The species will grow in any common soil, and will be easily increased by seed.

\section{Tribe XVI.}

SMY'RNE $E$ (this tribe contains plants agreeing with the genus Smy'rnium in character), or Campylospermæ pancijugata turgidæ, Koch, umb. 133. D. C. prod.4.p. 233. Fruit turgid, usually compressed or contracted from the sides; mericarps with 5 ribs: the lateral ribs marginating, or situated in the front of the margin; the ribs sometimes nearly obliterated. Seed involute, or with a furrow inside, semilunar or complicate. - Habit of plants and inflorescence variable; the genus Exoacántha and Echinóphora agree in labit with Ery'ngium, in consequence of having spinose leaves; Laga'cia agrees with Actinòtus in the one-sceded fruit; Pleurospérmum with Astrántia in the utricular fruit.

CXLV1. LAGEECIA (from $\lambda a \gamma \omega s$, lagos, a hare, and owos, oikos, a house; the place where a hare lies; the seeds envelloped in the hairy involucrum lave been likened to young leverets in a hare's form). Lin. gen. no. 285. Gartn. fruct. 1. p. 103. t. 23. f. 3. Lag. ans. nat. 2. p. 106. D. C. prod. 4. p. 233.-Cuminoìdes, Tourn. inst. t. 155.

Liv. syst. Pentándria, Digýnia. Lobes of calyx large, pectinated. Petals obcordately bifid, shorter than the calyx; lobes awned. Ovarium bilocular, one of the cells abortive; the fruit is therefore ovate, and crowned by the calyx, hence there is a furrow on one side indicating the place of the abortive cell. Secd marked with a furrow on one side, and therefore appearing involute.-An annual erect herb. Leaves pinnate; leaflets ovate, uniform, altermate, coarsely toothed: teeth awned. Peduncles opposite the leaves. Umbels compound, of many rays. Umbellules 1-flowered. Leaves of involucra 8-10, pectinated, of the involucels 4 , also pectinated. Flowers pedicellate, within the involucel, white. Fruit downy.

1 L. cuniroìds (Lin. spec. 294.) ๑. H. Native of Galatia, Persia, Greece, Candia, Lybia, Spain, Sc. in corn fields and vineyards. Smitl, fl. græc. t. 243. prod. 1. p. 162. Schkuhr, handb. 1. t. 48. Lans. ill. t. 142. Sabb. hort. 4. t. 55. Plench. icon. t. 153.-Mor. hist. 3. sect. 9. t. 13. umb. t. 1. f. 13. Umbels nodding before flowering, but at length becoming nearly globose. The seeds are mostly all abortive in the plants cultivated in gardens.

Cumin-like Lagoecia or Wild Cumin. Fl. June, July. Clt. 1640. Pl. $\frac{1}{2}$ foot.

Cult. The seeds should be sown in autumn, soon after they are ripe; otherwise if this is deferred till spring, they commonly remain a year, and sometimes two or three years before they grow.

CXLVII. OLIVERIA (in honour of M. G. A. Olivier, author of a history of insects, and formerly one of the editors of the Encyclopédie Methodique, and who was sent with M. Brugniere by the French government into the Levant, for the purpose of collecting objects of natural history). Vent. hort. cels. t. 21 . Lag. am. nat. 2. p. 105. D. C. prod. 4. p. 234.

Lin. syst. Pentándria, Digýnia. Margin of calyx 5-toothed. Petals profoundly obcordate, nearly bipartite: lobes involute on the margin at the base, and excavated on the side, undulated and reflexed above. Fruit obovate-ovate, hairy; mericarps nearly terete, bluntly 5 -ribbed. Carpophore bifil at the apex. Seed marked with a furrow on the inside, therefore the albumen is probably involute.-A branched herb, native of the Levant. Stems erect, white. Leaves pinnate, having the scent of thyme when bruised; leaflets many-parted: segments trifil, acute. Umbels of 3-4-rays. Umbellules dense, many-flowered. Leaves of involucrum 3-4, trifid: lobes usually tridentate. Leaves of 
involucels numerous, cuneiform, trifid. Flowers equal, hermaphrodite, white.

1 O. orientalus (D. C. prod. 4. p. 234.) ๑. H. Native about Bagdad, on the banks of the Euplirates, where it was detected by Olivier and Bruguiere. Olivèria decúmbens, Vent. hort. cels. t. 21. Stems white, decumbent in Ventenat's figure, but stiff and erect in the spontancous specimens. Lower and floral leaves clothed with soft velvety villi.

Eastcrn Oliveria. Fl. May, July. Clt. 1816. Pl. 1 foot.

Cult. The seeds of this plant only require to be sown in the open border in spring or autumn, in a warm sheltered situation.

CXLVIII. ANISOSCIA'DIUM (from avıoos, anisos, unequal, and oricacov, sciadion, an umbel; in reference to the lobes of the calyx and petals being unequal in the outer and inner flowers of the umbel). D. C. coll. mem. v. p. 63. t. 15. prod. 4. p. 234.

Lin. sxst. Pentándria, Digýnia. Lobes of calyx in the outer Howers of the umbels, large, ovate, and foliaceous; in the outer central flowers stiff, hooked, and mucrone-formed; in the inner ones all wanting or tooth-formed. Petals very unequal, outer ones large, obcordately bifid; inner ones small. Fruit rather pubescent, oblong-cylindrical, crowned by the calyx, and 2 stiff conical erect styles. Mericarps semi-terete, one of which is usually abortive; ribs 5 , very blunt; vittæ one in each furrow, brown, but none in the commissure. Albumen involute.-An herb, native of the Levant. Root simple. Stems diffuse, stiff, dichotomously branched, puberulous when examined by a lens. Leaves petiolate, pinnate; leaflets deeply pinnatifid: lobules short, hardly acute. Branches opposite the leaves. Involucra of 4-5 leaves, which are unequal, oblong, acute, and at length rather spinescent. Rays of umbel 4-5, stiff, a little longer than the involucrum. Leaves of involucels $4-5$, oval, spreading, permanent, unequal. Flowers white, $7-10$, sessile, stiff.

1 A. orienta'LE (D. C. 1. c. t. 15.) ๑. H. Native of the Levant, between Bagdad and Aleppo, where it was collected by Olivier and Bruguiere.

Eastcrn Anisosciadium. Pl. spreading.

Cult. See Oliveria above for culture and propagation.

CXLIX. ECHINO'PHORA (from Exivos, eclinos, a hedgehog, and $\phi \varepsilon \rho \omega$, phero, to bear; in allusion to the strong stiff spines of the involucrum). Tourn. inst. $656 . \mathrm{t} .423$. Lin. gren. no. 329. Lam. ill. t. 190. Lag. am. nat. 2. p. 106. Koch, umb. 135. D. C. coll. mem. v. p. 64. t. 16 . prod. 4. p. 234.

Lin. sxst. Pentándria, Digy'nia. Margin of calyx 5-toothed. Petals obovate, emarginate, with an inflexed point; or the outer ones are larger and bifid. Styles in the female flowers elongated (f. $65 . h$.), filiform, 2 , rarely 3 . Fruit ovate, nearly terete (f. $65 . f$.$) , inclosed in a hollow receptacle, furnished with a short$ emersed beak. Mericarps with 5 depressed equal undulated ribs. Vitta one in each furrow, covered by a cobwebbed membrane. Albumen deeply involute (f, $65 . j$. ).-Perennial herbs. Leaves bipinnatifid; segments cut. Umbels terminal; the flowers of the ray male, and joined together at the base before flowering, having the receptacle girding them; the female flowers solitary and central. Involucra and involucels constantly of many leaves.

Sect. 1. Leucópioria (from $\lambda \varepsilon v \kappa o s, ~ l e u c o s$, white, and $\phi \varepsilon \rho \omega$, phero, to bear; in reference to the white flowers of the species). D. C. prod. 4. p. 235. Flowers white. Petals obcordate, glabrous, nearly equal. Lobes of leaves pungent, terete or conical.

1 E. spinòsa (Lin. spec. 344.) plant glaucous, finely downy ; leares pinnate; leaflets subulate, trifid, stiff; leaves of involucrum and involucels spinose. 4. $\mathbf{H}$. Native along the Mediterranean, in the sand by the sea side. Said to have been found by Ray on the sea coast of Lancashire, and by Mr. Blackstone between Feversham and Sca Salter; between Whitstable and the Isle of Thanet, by Sandwich, and near West Chester by Gerarde; but it has been since searched for without success; it was therefore nothing but the common samplire that was found in the above mentioned habitats. Cav. icon, 2, t. 127. Smith, fl. grac. t. 265. eng. bot. 2413. D. C. coll. mem. v. t. 16.-Mor, ox. sect. 9. t. 1. f. 1. Root fusiform, cdible. Flowers white. (f. 65 .)

Var. $\beta$, pubéscens (Guss. prod. f. sic. 1. p. 309.) stem pubescent, deeply furrowed; leaves scabrous; rays of umbels pilosely pubescent. $4 . \mathrm{H}, \mathrm{Na}$ tive of the Levant.

Prickly Sea-parsnip. Fl. Jul. Pl. 2 to 3 feet.

2 E. PLATY'LOBa (D. C. prod. 4. p. 235.) plant smoothish or pubescent in the upper part; leaves petiolate, pinnate: leaf-

lets $3-4$-cleft: lobes lanceolate, flattish, divaricate, spinescent: leaves of involucra lanceolate, spiny. 24. F. Native of Persia, about Teheran. Stems angular, flexuous. Umbels small, when young, pubescent. Flowers white.

Broad-lobed Sea-parsnip. PI. $\frac{1}{2}$ to 1 foot.

$3 \mathrm{~S}$. TRIснорну' LLA (Smith, in Rees' cycl. vol, 12. no. 3.) leaves bitriternate; segments filiform, channelled, acute, unarmed. 4 . F. Native of the Levant, in stony places at the foot of Mount Ararat; and of Persia, in the province of Aderbeidjan, where it was gathered by Szowits. Umbels turgidly muricated, about the size of those of $E$. spinòsa, of a deep purple while young ; petals white. Perhaps this plant is the same as E. orientalis peucedanifolio, Vaill. herb. The plant has a strong smell of galbanum according to Szowits.

Hair-leaved Sea-parsnip. Fl. July, Clt. 1820. Pl. 1 foot.

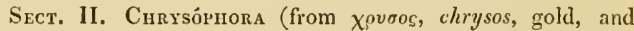
фepw, pincro, to bear; in reference to the yellow flowers). D. C. prod. 4. p. 235. Flowers yellow. Petals ovate, barbately ciliated; the outer ones of the umbel rather radiant. Lobes of leaves flat, foliaceous, toothed at the apex. According to Fischer it is probably a distinct genus.

4. E. TEnuifòlia (Lin. spec. 344.) plant pubescent; leaves bipinnate; leaflets pinnatifid or cut, cuneated, unarmerl at the apex. 24. F. Native of Apulia, Sicily, Greece, Tauria, and about Smyrna and Constantinople, in fields; and of Persia, in the province of Erivan, in dry saltish places. Sibtl. and Smith, fl. græc. 266. prod. 1.p. 179. Ster. mem. soc. mosc. 3. p. 249 and 258. D'Urv. enum. 29.-Moris. oxon. sect. 9. t. 1. f. 2. Pluk, alm. t. 11. f. 1. The fruit is similar to the rest of the species. A much branched glaucous plant.

Fine-lcaved Sea-parsnip. Fl. July, Aug. Clt. 1731. Pl. $1 \frac{1}{2} \mathrm{ft}$.

Cult. These plants not producing seeds in this country are increased by cuttings of the roots or stems. Place them in a warm situation and a dry soil, or else cover them in winter, to prevent the frost from destroying them.

CL. EXOACA'NTHA (from $\varepsilon_{i}^{2} \omega, e x o$, without, and axar $\theta a$, akantha, a spine; in allusion to the leaves of the involucels being spinose, and situated on the outside of the umbellules). Labill. pl. syr. dec. 1. p. 10. t. 2. Lag. am. nat. 2. p. 106. D.C. prod. 4. p. 235.

3 в 2 
L1n. syst. Pentándria, Digýnia. Flowers polygamous, central ones fertile, the rest sterile. Calyx in the sterile flowers, with obsolete margins. Petals obcordate, inflexed, equal. Young fruit of the sterile flowers obovate, and striated; those of the central flowers much larger, ovate, and somewhat papillose, erowned by 15 elongated stiff bristles. Seed unknown.-An herb, native of the Levant. Leaves pinnate: leaflets of the radical leaves ovate, toothed, rather cut; of the cauline leaves lanceolate-linear, acute. Umbels terminal, compound; umbellules on short peduncles. Leaves of involucra 10-12, large, cliannelled, spinose, longer than the rays, spreading; leaves of involucels $7-11$, spinose, situated on the outer side of the umbellules, and longer than them, very unequal, 1 of which is very long, 2-4 are middle-sized, and 2-t are bristle-formed. Flowers white.-This very singular genus is allied to Echinóphora and Arctopus from the inflorescence, but the fruit is scarcely known. Perhaps the truit is said to be crowned by 15 bristles, because the caly $\mathrm{x}$ is 5-parted, and each of these parts again trifid.

1 E. heterophíla (Labill. l. c.) of. F, Native of the Levant, at Nazareth.

lariable-leaved Exoacantlia. P1. 2 feet.

Cull. The seed of this plant ought to be sown in a pot, and the plants when of sufficient size to be potted separately; and in the second year, about the month of May, they may be planted out into the open border, where they will flower and seed freely.

CLI. ARCTO'PUS (from aok'тos, arlitos, a bear, and $\pi$ ovs, pous, a foot; this singular plant is beset with spines, which have been compared to the claws of a bear). Lin. hort clift. 495 . gen. no. 1165. Lam. ill. t. 865 . Gæertn. fil. carp. 3. p. 14. 1. 182. f. 4. D. C. prod. 4. p. 936.-A pràdus, Adans, fam. 2. p. 182.

Lis. syst. Pentándria, Digýnia. Flowers polygamo-dioecious. Margin of calyx 5 -toothed. Petals lanceolate, with an incurred acute entire acumen. Stamens in the male flowers twice the length of the corolla, antheriferous. Stylopodium flat. Styles 2, very short, deciduous. Ovarium abortive. Stamens in the female tlowers none. Styles 2, thickened at the base, and divaricate at the apes. Fruit ovate, beaked, crowned by the calyx, and conferruminated with it from the base to the middle, having one side depressed and naked, with a furrow, not separable into two parts, but bilocular, with one of the cells abortive; the fruit is therefore 1 -seeded from abortion, roundish, convex on one side, and concave with a furrow on the other.-A perennial herb, native of the Cape of Good Hope. Radical leaves pressed close to the ground in a stellate manner, with flat petioles, and roundish trifid limbs: the lobes toothed and spiny-ciliated. Male umbels compoumd, pedunculate, sterile, but mixed with a few female flowers; umbellules nearly globose; involucrum usually of 5 leaves, which are joined together after flowering. Female umbels sessile, fertile, surrouncled by the 1 concrete leaves of the involucrum, which are coriaceous, reticulated, and spiny toothed, girding the fruit. Petals white.

1 A. ecunsa'tus (Lin. spec. ed. 2. vol. 2. p. 1512.) 24.G. Native of the Cape of Good Hope, on hills about Cape Tiown, \&c. Thunb. fl. cap. 255. Ker, bot. reg. t. 705.-Burm. afr. 1. t. 1.-Pluk. mant. t. 271. f. 5. The roots are used with success at the Cape in cases of siphilis; but upon trial here some years since they were found to be less efficient than sarsaparilla.

Rough Arctopus. Fl. May, June. Clt. 1774. Pl. 1 foot.

Cult. This plant should be grown in a mixture of peat, sand, and loan ; and it may either be increased by dividing the plant or by seed.

CLII. CA'CHRYS (one of the names given by the Romans to the Rosemary. According to Morison, the name was derived from kretw, kaio, to burn, on account of the carminative qualities of the plants). Tourn. inst. t. 172. Lin. gen. no. 342. D. C. coll. mem. v. p. 65. prod. 4. p. 236.-Càchrys and Hippomáratlırum, Link. hort. berol. 1. p. 271. Koch, umb. 196. f. 36, 37.-Càchrys species, Spreng.

Lin. syst. Pentándria, Digýnia. Margin of calyx 5-toothed, or rarely obsolete. l'etals ovate, entire, involute or inflexed at the apex. Stylopodium depressed, short, hardly distinct in the mature fruit. Fruit turgid, the transverse section nearly terete, or somewhat didymous; mericarps with 5 thick ribs, variable in the different sections. Commissure nearly equal to the breadth of the mericarps. Seed constituting a free nucleus, covered with copious vittæ, deeply involute. Cotyledons of embryo diverging.-Perennial berbs. Leaves decompound. Umbels numerons. Involucra and involucels of many leaves. Flowers yellow.

Sect. I. Euca'cirrs (from eu, well, and cachrys; this section contains what are supposed to be the true species of the genus). D. C. prod. 4. p. 236. Càchrys, Koch, umb. 1. c. Margin of calyx obsolete. Ribs of fruit broad, thick, obtuse, sometimes so very broad at the base as bardly to be distinct. Prickles, bristles, or tubercles none.

1 C. LEVIGA'TA (Lam. dict. 1. (1783) 256.) plant glabrous: leaves decompound; leaflets multifid, linear-setaceous, divaricate; leaves of involucra and involucels few, entire; fruit globose, with very blunt, hardly distinct, smooth ribs. 24. H. Native of the south of France, in dry open places.-Moris. umb. $t$. 3. superior figure.-C. Libanòtis, Gouan. ill. p. 12. but not of Lin. C. Morisònii, All. pedem. auct. (1789) p. 23. Schultes, syst. 6. p. 441. exclusive of the synonyme of Desf. The oldest name is here admitted. Flowers yellow.

Simoolh-fruited Cachrys. Fl. July, Aug. Clt. 1710. Pl. $\frac{1}{2}$ to 1 foot.

2 C. macrocárpa (Ledeb. A. ross, alt. ill. t. 31 . A. alt. 1. p. 365.$)$ radical leaves ternate : leaflets bipinnate or tripinnate: pinnula ternate or palmate: segments entire or 3-parted : lobes linear or oblong; involucra and involucels of many leaves; fruit oval; mericarps glabrous, 11 -angled. 2.H. Native of Siberia, on hills in the Kirghisean steppe, at Ustkamenogorsk, and between Bucktorminsk and Lake Noor-Saisan. Root rather woody, stupose. Stems many from the same root, striately furrowed, pubescent, branched at top. Leaves a foot long and more than a foot broad. Umbels of 5-10-rays, but usually of 8 . Leaves of involucra ovate or lanceolate, short, membranous ; of the involucels of unequal size. Flowers yellow, all hermaphrodite in the primordial umbels; but in the lateral ones they are polygamous, the outer ones fertile, and the inner ones for the most part sterile. Calyx very minute. Petals yellow, oblong, concave, reflexed, hardly keeled on the inside. Stylopodium pulvinate. Fruit large, compressed from the sides; mericarps with 5 thick keeled ribs. Carpophore bipartite, free.

Large-fruited Cachrys. PI. 1 to 2 feet.

3 C. odontál Lgica (Pall. itin. 3. p. 720. t. g. f. 1, 2, 3. ed. germ. 3. append. no. 75. t. 9. ed. gall. in 8vo. append. no. 309. t. 78. f. 1.) leaves decompound, clothed with hoary pubescence; leaflets linear, short, rather trifid; stem naked; leaves of involucra and involucels few, undivided; fruit oblong, laving the mericarps somewhat compressed from the back, and hardly furrowed. 24. H. Native of Siberia, Tauria, and Caucasus, in very arid muddy places. Bieb. fl. taur. 1. p. 217. suppl. 216. Hoflm. umb. 1. p. 176. t. 3. f. 2. and f. 4. d. e. f. Càchrys callospérma, ]'all, itin. 3. p. 663. Involucrum none, ex Hoffin. 1-leaved, ex Vest.; few-leaved, ex Pall. Fruit oblong, smooth, and ribless on the outside, as in $C$. lcevigata, but cylindrical, not 
nearly globose. The Cossacks of the Jaik chew the seeds for pain in the teeth, and obtain relief by the copious salivation which follows their use.

Tooth-ache Cachrys. Pl. 1 foot.

4. C. Peucedanoides (Desf. fl. alt. 1. p. 250.) leaves decompound; leaflets filiform, stiflish, rather pubescent ; leaves of involuera pinnatifid; of the involucels undivided; fiuit oval, with smooth obsolete ribs. 24. H. Native of Algiers, in corn fields. This species differs from $C$. lavigata in the leaves of the involucra being multifid, and in the leaves being pubescent.

Pcucedanum-like Cachrys. Pl. 1 foot.

5 C. VAgina'ta (Led. fl. ross. alt. ill. t. 9. f. alt. 1. p. 366.) radical leaves bipinnate: leaflets pinnate-parted: segments oblong-linear, acute; lower leaflets and segments approximating the rachis ; sheaths of cauline leaves, ventricose ; involucrum almost wanting; involucels of many leaves; fruit didymous; mericarps nearly globose. \%. H. Native of Siberia, on the mountains of Dolenkara, in the Kirghisean steppe. Stems rather flexuous, sulcately striated. Umbels of 10-20, tunequal, spreading rays. Leaves of involucels linear-lanceolate, with membranous margins. Margin of caly $x$ obsoletely denticulated. Petals whitish, nearly orbicular, eniarginate, with an inflexed acumen, keeled inside.

Sheathed-petioled Cachrys. P1. $1 \frac{1}{2}$ foot.

6 C. A lpìn (Bieb. fl. taur. 1. p. 217 . suppl. 216.) plant glabrous; leaves decompound; leaflets linear, elongated; leaves of involucra and involucels very short, undivided; fruit oval, having the mericarps a little furrowed and striated, the striæ crenulated. 4 . H. Native of Tauria, on the tops of mountains. Hoffin. umb. 1. p. 176. C. Libanòtis, Pall. ind. taur. Allied to $C$. Libanotis and $C$. lavigàta, but differs in the fruit not being perfectly smooth in $C$. lavigàta, nor deeply furrowed as in $C$. Libanotis. Perhaps this and the two preceding plants belong to the following section.

Alpine Cachrys. Fl. July. Clt. 1S26. Pl. 1 foot.

Sect. II. Egomá ratirum (from ať alyọ, aix aigos, a goat,

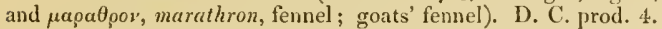
p. 237.- Hippomárathrum, Link, 1. c. and Koch, diss. but not of Riv.- Egomárathrum, Koch, in litt. Margin of ealyx 5toothed. Ribs of fruit very thick, obtuse, almost filling the furrows, more or less tubercular, papillose, wrinkled, or tomentose, rarely smooth.

7 C. Libanòtis ( $L$ in. spec. p. 355.) plant glabrous; leaves decompound; leaflets trifid, linear, rather pungent: superior ones opposite: upper ones trifid; leaves of involucra and involucels numerous, undivided; fruit ovate; mericarps very bluntly 5-ribbed. $\quad$ \%. H. Native of Mauritania, Sicily, but not in France. Schkuhr, handb. t. 65. good. Hippomárathrum Libanòtis, Koch, in litt. Hippom. Sículum, Boce. sic. t. 18.-Mor. ox. sect. 9. t. 1. f. G. umb. t. 3. lower figure. C. vèrior, Lob. icon. t. 783. f. 2. C. Sícula $\gamma$, Guss. prod. 1. p. 359. and perhaps C. sphærospérma, Ten. prod. xix. syn. 120. is also referrible to this plant.

Libanotis or Smooth-seeded Goat's-fennel. Fl. July, Aug. Clt. 1570. Pl. 2 to 3 feet.

8 C. PTERochlèxa (D. C. prod. 4. p. 237.) plant glabrous; leaves decompound: leaflets trifid, keeled, stiff, divaricate, with the margins and keel scabrous; central umbels furnished with divided leaves of involucra, and the lateral ones with undivided leaves of involucra; leaves of involucels all undivided; fruit nearly globose; mericarps with 5 thick blunt ribs, which are granularly muricated on every side, having the furrows between the ribs deep and very narrow. 4 . H. Native of Barbary, Italy, and Greece, ex Vahl. Salzm; of Sicily, Spain, and the island of Cyrus, ex Sibthorp. C. Sicula, Lin. spec. p. 355. exclusive of Boce. syn. Desf. A. atl. 1. p. 240. Sibth. et Smith, A. graec. t. 278. Hippomáratlırum Sículum, Link. enum. 1. p. 271. Koch, l. c. Flowers yellow, as in the rest of the species.

IVing-corered Goat's-fennel. Fl. July, Aug. Clt. 1604. Pl. 2 to 3 feet.

9 C. Críspa (Pers, ench. 1. p. 311.) plant glabrous, or nearly so; leaves multifid, trichotomous: ultimate segments sliort, nearly conical; leaves of involucra and involucels linear, very short; fruit nearly globose, granular from papillæ; ribs of fruit thick, almost closing the furrows. 24. H. Native of Palestine and of Eastern Cancasus. C. críspa, Spreng. in Schultes, syst. 6. p. 443. Hippomárathrum críspum, Koch, umb. 136. C. microcảıpa, Stev. in litt. 1819. but not of Bieb. C. nudicaúlis, Godet, in litt. 18:9. Perhaps the Caucasian plant and the Palestine one are distinct. Flowers yellow.

Curled-fruted Goat's-fennel. Fl.July. Clt. 1810 . Pl. $1 \frac{1}{2} \mathrm{ft}$.

$10 \mathrm{C}$. Amplifòlı ; leaves scabrous; petioles 6 times divided, furrowed; leaflets tripartite: segments stiff, subulate, trigonal, or somewhat pentagonal, chamelled above; involucra and involucels of 5 short lanceolate leaves; mericarps granular, with rather prominent ribs, and distinct furrows. 4. H. Native of Cancasus, by the sea side, in the province of Baku, near Kaljari. Hippomárathrum amplifòlium, Ledeb. in litt. Meyer, verz. pfl. p. 131. Echinóphora? Caspia, D. C. prod. 4. p. 235. Segments of leaves short, hardly 2 lines long, thick, and stiff, by which it is easily distinguished fiom C. crispa.

Ample-nleaved Goat's-fennel. Pl. 2 to 3 feet?

11 C. Longílobs (D. C. prod. 4. p. 237.) plant smoothish; leaves multifiel, trichotomous; leaflets linear, stiflish, elongated ; leaves of involucra and involucels linear, short; firuit nearly globose, gramular from papillæ: with thick ribs: which almost close the furrows. \%. H. Native of Persia, among rocks on the mountains about Seidkhodzi, where it was collected by Szowits. Flowers and fruit like the Caucasian variety of $C$. crispa, but the ultimate lobes of the leaves are very slencler, about 2 inches long, not 2 lines as in that plant.

Long-lobe-leaved Goat's-fennel. Pl. $1 \frac{1}{2}$ foot.

12 C. involecra'ta (Pall, in Willd, herb. ex Schultes, syst. 6. 1) $44 \pi$.) plant glabrous ; leaves ternately tripinnate: leaflets cumeiforn, jagged, acute; leaves of involucra and involucels lanceolate, membranous; fruit spongy, tubereular from papillæ all over. 4 . H. Native of Persia. This species is hardly known, but from the character given it is nearly allied to the preceding species. Stem branched at the base. Leaves three times tripinnate.

Involucrated Goat's-fennel. Pl. 2 feet.

13 C. eruántha (D. C. prod. 1. p. 238.) leaves maltifid, and are, as well as the stems, quite glabrous; lobes or leaflets trichotomous: segments linear-subulate, stiffish; rays of umbel puberulous; umbellules crowded with flowers; calyx and fruit tomentose. 2. H. Native of Persia, in gravelly places at Badalan. This is a very distinct species, from the fruit being nearly an inch long, and tomentose, with thick obtuse ribs, and very narrow furrows.

IIairy-flowercd Goat's-fennel. Pl. $1 \frac{1}{2}$ foot.

14 C.? ACAU'LIS (D. C. prod. 4. p. 238.) radical leaves bipinnate; petioles and scapes clothed with short white hairs; leaflets multifid, smoothish: lobes linear, soft, short; rays of umbel $4-5$, puberulous, sometimes proliferous; leaves of involucra and involucels linear, with membranous margins; umbellules crowded with flowers; calyxes glabrous. 24.H. Native of Persia, on arid hills at the Lake Ormiah, in the province of Alerbeidjan, where it was collected by Szowits. Herb small, with a fibrons neck. This is a very distinct species, allied to the preceding, but the fruit is unknown.

Stemless Goat's-fennel. Pl. $\frac{1}{2}$ foot. 
15 C. Hu'mlis (Schousb. maroc. p. 118.) plant glabrous ; leaves supra-decompound, fleshy; leaflets linear, trifid, mucronate; leaves of involucra and involucels numerous, lanceolate, undivided; fruit furrowed, smoothish. 24.H. Native of Barbary, near Cape Spartel, mixed with Crithum maritimum. Perhaps belonging to a different section.

Humble Goat's-fennel. Pl, $\frac{1}{2}$ foot.

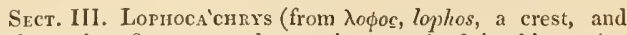
cachrys; in reference to the species contained in this section having crested or winged fruit). Gen. propr. Koch, umb. in litt. D. C. prod. 4. p. 238 . Margin of calyx 5-toothed. Ribs of fruit sharply winged: wings cleft into mucrone-formed teeth : the furrows broad and open.

16 C. crista'ta (D. C. prod. 4. p. 238.) plant glabrous; leaves decompound; leaflets trifid: lobes linear, blunt, short, divarjcate; leaves of involucra and involucels linear ; fruit ovate; mericarps with 5 , rather winged crested ribs, and broad concave furrows. 24. H. Native of the Grecian Archipelago, as in the islands of Melos, Samos, and Astypalæa. C. Sícula, D'Urvil. enum. pl. 31 . but not of Lin. C. semine fungosa sulcato aspero minore foliis peucedani, Mor. ox. 3. p. 267 . sect. 9. t. 1. f. 3. Stem much branched. Teeth of calyx 5 , elongated, permanent. Crestcd-fruited Goat's-fennel. Pl. 2 feet.

17 C. PU'Ngexs (Jan. pl. exsic. Guss. prod. 1. append. p. 7.) plant glabrous; leaves decompound; segments or leaflets filiform, linear, acute, somewhat pungent, elongated; leaves of jnrolucra and involucels linear; fruit ovate, with distant somewhat winged crested ribs, and broad concave furrows. 4 . H. Native of Calabria and Sicily, in the sand on the sea shore. C. Sícula $\beta$ longifòlia, Guss. prod. fl. sic. 1. p. 360 . Segments of the leaves elongated, 1-3 inches long.

I'ar. $\beta$, echinóphora (D. C. prod. 4. p. 238.) leaves decompound; leaflets trifid, lanceolate-linear, acute, rather scabrous from short scattered down, especially on the margins; leaves of involucra and involucels lanceolate-linear, acuminated, entire, of the involucra defiexed, of the involucels equal in length to the umbellules; fruit obscurely ribbed; ribs tubercular, somewliat echirately crested. 2\%. H. Native of Sicily, and in fields about Naples, and probably of Greece and Spain. C. Sícula, Ten. fl. neap. prod. 19. C. Sícula var. a, Guss. prod. fl. sic. 1. p. 359. There is sometimes a one branched leaf at the base of the rays of the umbel, which may be taken for an involucrum. It is perfectly distinct from $C$. peterochla'na; the upper leaves are opposite as in it, but the segments are broader, and striated beneath by elevated nerves. Leaves of involucra broadest at the base.

Pungent Groat's-fennel. Pl. 1 to 3 feet.

Cult. The species of Cachrys are only to be increased by seeds, which shoukl be sown in autumn. A deep light soil suits them best.

CLIII. PRANGOS (the native name of $P$. pabuliria). Lindl. in journ. sc. lond. 1825 . no. 37. p. 7 . Lag. obs. apar. 1826. p. I 5. D. C. coll. mem. 5. p. 67.-Pteromárathrum, Koch. in litt.-Càchrys spec. of authors.

Lin. syst. Pentándria, Digýnia. Margin of calyx 5-toothed. Petals ovate, entire, involute at the apex. Stylopodium depressed, hardly prominent in the fruit. Transverse section of fruit nearly terete ; commissure broad. Mericarps compressed from the back, with 5 smooth ribs, which are thick at the base, and ending each in a vertical membranous wing on the back. Seed girded by copious vitte. Albumen involute-Perennial herbs, with terete stems. Leaves decompound; leaflets or segments linear. Úmbels numerous. Flowers yellow.

1 P. pabulária (Lindl. l. e. Wall. pl. rar. asiat. 3. t. 212.) plant glabrous; leaves supra-decompound; segments linear ; leaves of involucra and involucels simple; fruit corky; mericarps with 5 ribs, which are expanded into crenated wings. 4. H. Native of the temperate parts of the East Indies, about Imfal and Droz. This plant is called prangos at Imfal and Droz. It is employed in the form of hay as winter fodder for sheep and goats, and frequently for neat cattle, but its seed, when eaten by horses, is said to produce inflammation in the eyes, and temporary blindness. The properties of prangos, as a food, appear to be heating, producing fatness in a space of time singularly short, and also destruetive to the Fasciola hepática, or liver flake, which in Britain, after a wet autumn, destroys some thousands of sheep by the rot, a disease which has hitherto proved incurable. The last-mentioned properties of the plant, if they be retained in Britain, would render it especially valuable to our country. But this, taken along with its highly nutritious qualities, its vast yield, its easy culture, its great duration, its capability of flourishing on lands of the most inferior quality and wholly unadapted to tillage, impart to it a general character of probable utility unrivalled in the history of agricultural productions. When once in possession of the ground, for which the preparation is easy, it requires no subsequent culture, save that of cutting and converting the foliage into hay. Of the duration of the plant there are several facts. Seeds having been transported westward along with those of yellow lucern above 40 years ago, and sown on the eastern frontier of Kashmeer, where they vegetated, and of which the plants of the first growth still remain in a flourishing condition. In another instance, the seeds were transported eastward, and sown upon rocks near Molbee, where the plants flourisherl for about 40 years, but in consequence of a long period of drought the prangos perished along with the crops of that disstrict in general. From various facts it is conceived not unreasonable to presume, that by the cultivation of this plant moors and wastes, hitherto uncultivated, and a source of disgrace to Britisls agriculture, may be made to produce large quantities of winter fodder, and that the yield of the higlilands, and of downs enjoying a considerable depth of soil, may be trebled. As the prangos has hitherto been of spontaneous grow th alone, practices better adapted to the nature of the plant or of the country may be adopted at a future time; but from a view of its habitudes, Mr. Moorcroft ventures to suggest that the seeds should be dibbled into holes singly, at an inch deep and a foot apart. Yellow lucern, which is also a spontaneous production of the country of the prangos, is of a constitution more hardy than that of the lucern of Europe, and requires no other culture than that necessary for sowing it, and lasts in vigour for a long series of years. It is submitted that, as it naturally grows along with the prangos, it would be well to imitate this habitude. The joint yield is vastly greater than that of the richest meadow land, and is produced on a surface of the most sterile nature, in regard to other herbage.

Fudder Prangos. Pl. 2 to 3 feet.

2 P. TERULA'cea (Lindl, journ. sc. lond. 1825. no. 37. p. 7.) leaves supra-decompound, hairy; leaflets or segments linearsubulate, divaricate; leaves of involucra and involucels short, undivided; fruit ovate: ribs expanded into subundulate, entire, membranous wings ; mericarps 3 times longer than their diameter. 24. H. Native of Persia, on hills, Asia Minor, Iberia, Eastern Caucasus, Italy, and Sicily. Càchrys orientallis ferulæ folio, Tourn. voy. 2. p. 186. with a figure. Laserpítium ferulàceum, Lin. spec. 358. Càclırys alàta, Hoffm. 1. p. 186 . Bieb. fl. taur. 1. p. 217. supp]. 215. Càchrys Libanòtis, Guss. prod. 1. p. 358. but not of Lin. Thápsia laserpitii, Spreng. umb. spec. 32. exclusive of the synonymes? Calyx obsolete. There is a variety with glabrous leaves. The Italian specimen has larger 
fruit than the Asiatic ones, but they are probably hardly varieties. Flowers yellow, as in the rest of the species.

Giant-fennel-like Prangos. Clt. 1752. Pl. 1 to 2 feet.

3 P. Cylindra'cea (D. C. prod. 4. p. 239.) leaves supradecompound, rather hairy; segments or leaflets linear, divaricate; leaves of involucra and involucels undivided, linear ; fruit eylindrical, expanded into membranous, entire, subundulated wings; mericarps 5 times longer than their diameter. $\mathcal{\psi}$. H. Native of Calabria. Càclırys eylindrica, Guss, in litt. 1829. Fruit an inch long; the section of the mericarps are not semicircular, as in $P$. ferulacea, but somewhat depressed on the back.

Cylindrical-fruited Prangos. Pl. 1 to 2 feet.

4 P. ulóptera (D. C. prod. 4. p. 239.) leaves decompound, glabrous, with the petioles trichotomous; segments or leaflets linear; leaves of involucra and involucels linear, spreading; fruit ovate, with very curled membranous wings. 4 . H. Native of Persia, on rocks at Seidhodzi, in the province of Aderbeidjan, where it was collected by Szowits. Allied to P.ferulàcca, but evidently distinct from it in the fruit being one-half smaller ; in the wings being much more curled and white, and in the umbellules being more dense.

Curlch-ninged-fruited Prangos. Pl. 1 to 2 feet.

5 P. thapsioides (D. C. prod. 4. p. 340.) leaves supra-decompound, glabrous : leaflets or segments subulate, stiffish, shining; leaves of involuera and involucels 5-7, undivided, deflexed; fruit ovate: having the ribs expanded into thick wings. $2 . \mathrm{H}$. Native of Mount Atlas. Laserpitium thapsioides, Desf. fl.alt. I. p. 252. t. 68 . Laserpítium Atlánticum, Poir. suppl. 3. p. 304. Thápsia Laserpítii, Spreng. in Schultes, syst. 6. p. 613 . It differs from Laserpitium in the petals being yellow, not white, oblong, not emarginate. Ribs of fruit few.

Thapsia-formed Prangos. Pl. 2 to 3 feet.

6 P. Anisopét tala (D. C. prod. 4. p. 240.) plant glabrous ; leaves decompound: lobes or segments linear, short; stem nearly naked; leaves of involucra and involucels ovate-lanceolate, acute, entire ; mericarps of fruit compressed from the back, oblong: with the ribs expanded into wings, the 3 dorsal ribs attenuated at the base, and somewhat concrete, the $\stackrel{\sim}{\sim}$ lateral ones marginating and broader than the rest. 4 . H. Native of Syria, near Nazareth. It is allied to Càchrys odontálgica, but differs in being glabrous, and in the fruit being winged. Calyx with 5 short teeth.

Unequal-pelalled Prangos. Pl. 2 to 3 feet.

7 P. Fonicula'cea (Meyer, verz. pflanz. p. 131.) plant quite glabrous; leaves supra-decompound; segments setaceous ; leaves of involucra and involucels lanceolate; wings of mericarps flat: furrows naked. 4. H. Native of Caucasus, among rocks or in stony places, on the higher mountains of Talusch, at the elevation of 2000 or 3000 feet.

Fennel-like Prangos. Pl. 2 to 3 feet.

Cult. The species of Pringos are of easy culture, but grow best in a dry soil. They are only to be increased by seeds, which should be sown in the autumn.

CLIV. COLLADO'NIA (dedicated in honour of F. Colladon, M. D. author of a monagrapl of Cássia). D. C. prod. 4. p. 240. but not of Spreng.-Perlèbia, D. C. coll. mem. v. p. 67. but not of Mart.-Laserpítium species, Vent.-Càchrys species, Spreng.

Lin. sצst. Pcntándria, Digýnia. Margin of calyx entire. Petals oval, entire, involute at the apex. Stylopodium depressed, hardly prominent in the fruit. Transverse section of fruit oval; mericarps compressed from the sides; commissure narrow, furnished with 2 vittæ. Mericarps expanded into 5 vertical membranous wings on the back, with the furrows between the wings broadish, and furmislied with one vitta each. Albumen
involute.-Perennial glabrous herbs. Stems acutely triquetrous, at length somewliat spirally twisted. Leaves pinnatifid; lobes broadly oblong, toothed. Umbels and umbellules of many rays. Leaves of involucra and involucels many, undivided. Flowers golden yellow. This genus, according to Lagasca, in obs. apar. P. 26. is easily distinguished by its character and habit. Perlèbia is a name given to a genus by Martius, and is therefore already preoccupied. Colladonia of Sprengel is a species of Palicoúrea.

I C. tríquetra (D. C. prod. 4. p. 240.) 4. H. Native in the neiglibourhood of Constantinople, near the eanal. Laserpitium tríquetrum, Vent. cels. t. 97. Càchrys tríquetra, Spreng. in Schultes, syst. 6. p. 443 .

I'riquetrous-stemmed Colladonia. Fl. June, July. Clt. 1816. Pl. 3 to 4 feet.

Cull. See Prángos above for culture and propagation.

CLV. LECO'KIA (named after Henry Lecoq, author of an elementary work on the natural history of A uvergne). D. C. coll. mem. v. p. 67. t. 2. f. L. prod. 4. p. 240.-Càchrys species, Tourn. Lam.-Scándix species, Sibth. et Smitl.

Lis. sist. Pentándria, Digýnia. Margin of calyx with 5 very short teeth. Petals ovate, with an inflexed acumen. Stylopodiun 2, distinct, conical, permanent, exserted; styles subulate, diverging. Fruit ovate, didymous; commissure narrow. Mericarps semi-terete, with 5 obtuse fungous ribs, which are muricated with prickles. Seed girded by copious vittæ. Albumen involute, with the central area empty and orbieular.-A perennial herb, with the appearance of a species of Angélica. Root a fascicle of tubers. Leaves glabrous, triternate; leaflets ovate, coarsely toothed. Umbels of many rays, without involucra; rays unequal, angular. Umbellules of 10.15 flowers ; involucels of $5-8$ subulate leaves. Flowers white, some of them in each umbellule sterile.

1 I. CRE'tica (D. C. l. e.) \%. H. Native of Candia and Cyprus. Càchrys Crética Angelicæ folio et asphodeli radice, Tourn. inst. 23. Càchrys Crética, Lam. dict. 1. p. 259. Desf. ann. mus. 11 . p. 274. t. 29. pl. cor. t. 42. Sieb. pl. exsic. cret. Scándix latifòlia, Sibth. et Smith, fl. græc. t. 284. Smith in Rees' cycl. no. 31. Plant dark green, glabrous. Stem furrowed.

Crctan Lecokia. Fl. July, Ang. Clt. 1823. Pl. 3 to 4 feet.

Cult. See Prangos above for culture and propagation.

CLVI. MAGYDA'RIS (the Latin name of the herb Laserwort). Koch, in litt. 1828. D. C. coll. diss. v. t. 68. prod. 4. p. 241.-Erioedchrys, D. C. in litt.-Càchrys species of authors. - Athamánta species, Spreng.

Lin. syst. Pentándria, Digýnia. Margin of calyx obsolete. Petals obcordate, with an inflexed point. Fruit ovate, villously tomentose; mericarps with 5 thick, very blunt ribs, and narrow furrows. Seed covered all over with numerous very fine vittæ, convex on the outside, and with a deep involute furrow on the inside.--Perennial herbs, hoary from villous tomentum in every part ; referrible to Hérmas or IIcraclèum in habit. Leaves pinnate; leaflets lobed: lobes ovate, toothed, decurrent. Umbels and unbellules many-flowered, involucrate. Flowers white. This genus is easily distinguished at once from Càchrys, in the petals being white and obcordate.

I M. Tomentósa (Koch, in litt. 1828. D. C. prod. 4. p. 241.) leaves pinnate, with $3-5$ large, broadly ovate, toothed, cut leaflets: ultimate leaflets confluent; all tomentose beneath, and nearly glabrous above; leaves of involuera and involucels numerous, elongated, linear, undivided; fruit ovate; meriearps bluntly 5 -ribbed, tomentose all over. 4 . H. Native of Barbary and Sicily. Càchrys tomentòsa, Desf. atl. 1. p. 249. 
Càehrys Pastinàca, Lam. diet. 1. p. 260. C. I'ànax Sículum Ueria. C. panacif olia, Vahl, symb. 1. p. 25.? Guss. prod. A. sie. 1. p. 327. Athamánta panacifolia var. Spreng. umb. spec. 140.-Boee. sie. t. 1. Moris. ox. sect. 9. t. 1. f. 4. Leaves like those of Heraclèum spondy'lium.

Tomentosc Magydaris. Fl. June, July. Clt. 1823. Pl. $3 \mathrm{ft}$. 2 M. ambígua (D. C. prod. 4. p. 24. .) leaves pinnate, with 5 oval-oblong crenulated leaflets, which are glabrous above, and seabrous on the nerves beneath, as well as on the petioles: ultimate ones distinet; leaves of involuera and involucels numerous, lanceolate-linear, undivided; fruit ovate, woolly. 24. $\mathrm{H} . \mathrm{Na}-$ tive of Mauritania, near Tangiers. Càclırys anbigua, Salzm. pl. exsic. 1825. This species is intermediate between the preceding and following; to the first in the fruit, and to the last in the analogy of the leaves.

Ambiguous Magydaris. Pl. 3 feet.

3 M. yANA'cina (D.C. prod. 4.p. 241.) leaves on long petioles, some of them undivided, oval-oblong, and toothed: others are pinnate, with the ultimate segments confluent, all seabrous beneath on the nerves, and on the petioles; leaves of involucra and involucels numerous, deflexed, undivided; fruit oblong, beset with spreading villi, hardly furrowed. 4. H. Native of Spain. Càchrys panacif òlia, Vahl, symb. 1. p. 25. Brot. fl. lus. 1. p. 434. Athamánta panacifòlia, Spreng. nmb. spee. 1. p. 140.- I'uero, Clus. hist. 2. 13. 192.

Panax-leaved Magydaris, Fl. June, July. Clt. 1823. Pl. 3 feet.

Cull. See Perángos, p. 375, for eulture and propagation.

CLVII. HE'RMAS (a name the meaning of whieh is wholly unknown). Lin. gen. no. 1332. 'Thunb. nov. act. petrop. 14. p. 531. Gartn. fruet. 2. p. 30. t. 85. Lam. ill. t. 851. Lag. am. nat. 2. p. 102. D. C. prod. 4. p. 241.

Lin. syst. Pentándria, Digýnia. Margin of ealyx 5-parted, foliaceous, permanent. Petals oval-oblong, acnte, keeled, entire, equal. Fruit ovate; mericarps rather inflated, compressed from the baek, 5-ribbed, the dorsal rib exserted, the two middle ones larger, and the 2 marginating ones small, and placed under the commissure; vittæ many in the furrows, which are broad. Seed elliptic, somewhat concave on the inside, and probably revolute, not adnate to the tegument.-Cape herbs, having the leaves elothed with soft white tomentum. Leaves undivided, hardly toothed. Umbels componnd, nearly globose, of many rays. Involuerum of many leaves; involncels of 3 leaves. Rays of umbellules many; outer ones bearing sterile male flowers: the inner one or three bearing hermaphrodite flowers; the pedicels of the sterile or abortive flowers setaeeous and permanent after the inflorescence, forming as it were an involucel to the fertile flowers. Lateral umbels sterile, male. Flowers white or purple.

1 II. Gigante'A (Lin. fii. suppl. 435.) radical leaves on long petioles, oval or oblong, somewhat serrated, clothed with dense soft tomentum on botls surfaces. 4. G. Native of the Cape of Good Hope. Thunb. nov. aet. petrop. 14. p. 529. t. 11. fl. cap. 249. Bupleùrum gigantèum, Thunb. prod. 50. Leaves from the dense tomentum usually entire. The upper part of the plant and umbels glabrous. Petals purple, ex Thumb. The wool seraped from the leaves is used for tinder at the Cape of Good Hope, as that from Artemisia is in Clima and Japan.

Gigantic Hermas. Fl. June, July. Clt. 1794. Pl. 4 feet.

2 11. villòsa (Tluunb. nov. act. petrop. 14. p. 531. A. cap. 249.) leaves ovate-oblong, acute, somewhat cordate at the base, stem-clasping, toothed, glabrous above, and elothed with white tomentum beneath. $\%$. G. Native of the Cape of Good Hope, on the Table Mountain. Burm. afr, t. 71. f. 2. Bupleùrum villòsum, Lin. spee. 343. Burm. A. cap. p. 7. H. depauperàta, Lam. dict. 3. p. 121. ill. t. 351. f. 1. Sten tomentose between the leaves, and glabrous above. There is also tomentum under the bracteas and involucra. Stems purple.

lar. $\beta$, depauperàta (D. C. prod. 4. p. 242.) leaves on sliort petioles, velvety beneath from short rufous tomentum; involuera and bracteas glabrous at the base. 24. G. Native of the Cape of Good Hope. Hérmas depauperàta, Lin. mant. 299. Perluaps a proper speeies.

Iillous Hermas. Fl. June, July. Clt. 1795. PI. 1 to $3 \mathrm{ft}$.

3 H. capita'ta (Lin. fil. suppl. 435.) radical leaves petiolate, ovate-cordate, obtuse, erenately toothed, glabrous above, but clothed with white tomentum beneath; stem glabrous at the apex. 4. G. Native of the Cape of Good Hope, on the Table Mountain. Thumb. nov. act. petrop. 14. p. 532. t. 12. 月. eap. 248. Lam. dict. 3. p. 122. ill. 851. f. 2. Leaves of involucra 3-nerved. Perliaps sufficiently distinet from the following. Umbels capitate. Seape biumbellate.

Capitate-flowered Hermas. Pl. $1 \frac{1}{2}$ foot.

4. H. QUINQUEDENTA'TA (Lin. fil. suppl.p. 436.) leaves almost radical, petiolate, ovate, cuneated at the base, few-toothed, naked above, but elothed with white tomentum beneath; stem subtomentose even to the apex. 4. G. Native of the Cape of Good Hope, on the Table Mountain. Bupleùrum quinquedentàtum, Thunb. prod. 3. 50. H. quinquedentàta, Thumb. nor. act. petrop. 14. p. 533. t. 12. f. eap. 249. Leaves of involucra striated with 3 longitndinal nerves. Corolla white. Stem filiform. Umbels nearly slobose.

Five-toothcd-leaved Hermas. PI. 1 foot.

5 H. cılí'тA (Lin. fil. suppl. 4. p. 436.) leaves radical, petiolate, ovate or obovate, obtuse, ciliated, naked above, and clothed with white tomentum beneath; umbels few, densely eapitate; male flowers on long peduncles, exserted. $4 . \mathrm{G}$. Native of the Cape of Good Ilope, on the Mountains. Burm. afr. t. 72. f. 1. Bupleùrum ciliatum, Thunb. prod. 50. H. ciliàta, Thunb. nov. aet. petrop. 14. p. 531 . f. eap. 248. Stem glabrous, leafless. Petioles length of the limbs. Corolla white.

Cilialed-leared Hermas. Fl. June, July. Clt. 18I6. PI. $1 \frac{1}{2}$ foot.

Cull. A mixture of peat, sand, and loam is the best soil for the species of Ilermas, and they may be either inereased by seed or euttings.

CLVIII. CO'NIUM (said by Linnæus to be from kov's, or ros'a, lonis, or lonia, dust or powder ; but the application of the term is not evident). Lin. gen. no. 469 . Hoflm. umb. p. 99. t. 1. f. 3. Lag. am. nat. 2. p. 103 . Koels, umb. p. 135. f. 40.-Cicùta, Tourn. inst. t. 160. Gartn. fruet. 1. t. 22. Iram. lict. 2. p. 3 .

Lin. syst. Penlándria, Digýnia. Margin of ealyx obsolete. Petals obcordate, somewhat emarginate, with a short inflexed point. Fruit ovate, compressed from the sides; meriearps witl 5 prominent equal undulately-erenulated ribs : lateral ones marginating; furrows with many striæ, but without vittæ. Carpophore bifid at the apex. Seed with a deep narrow furrow, and as if it were complicate.-Biennial poisonons herbs, natives of Europe. Root fusiform. Stem terete, branched. Leaves decompound. Involuera of $3-5$ leaves; involueels dimidiate. Flowers white, all fertile.

1 C. macula'tum (Lin. spec. 349.) leaves of involueels lanceolate, shorter than the umbellules. \&. H. Native throughout the whole of Europe, in cultivated ground, among rubbish, and on dung hills; also of the eastern parts of A sia, North America, and Clili, where it has been introduced; plentiful in some parts of Britain. Schkuhr, handb. t. 62. Bull. herb. t. 63. 
Hayn. arz. gew, 1. t. S1. Sowerb. engl. bot. t. 1191. Jacq. austr, 2. t. 156. Woodv. med. bot. t. 22. Plench, icon. t. 183. Cicùta maculàta, Lam. fl. fr. 3. p. 104. Cicùta màjor, Lam. dict. 2. p. 3. Coriándrum Cicùta, Crantz, austr. 24. Coriándrum maculàtum, Roth, f. germ. 1. p. 130. Cicùta, Hall. helv. no. 766. Riv, pent. irr. 75. Blackw, t. 451. Iob. icon. 782. f. 1. Cicùta doméstica, Mor. umb. 18. c. b. sect. 9. t. 6. f. 1. Cònium tenuifolium, Mill. dict. no. 2. Stem hollow, green, but often of a livid colour, marked with dark spots. Hemlock is obviously distinguished from all other umbelliferons plants by its spotted stem, by the lark and shining grcen colour of the bottom leaves, and particularly by their disagreeable smell when bruised. According to Linnæus, sheep eat the leaves, and horses, cows, and goats refuse it. Ray informs us, that the thrush will feed upon the seeds even when corn is to be had. Hemlock has been stigmatised as one of the most noxious of vegetable poisons, has for many years been considered as a highly useful and powerful article of the Materia Medica, and it has been proved that though highly deleterious when imprudently used, yet in small doses it has been productive of considerable benefit in cases which have resisted the usual methods. The first plyysician who endeavoured to bring hemlock into repute as a medicine was Baron Stoerck, of Vienna, who announced its extraordinary effects in the most inveterate chronic disorders in 1760. The whole plant is a virulent poison, but varying very much in strength, according to circumstances. When taken in an over-dose, it produces vertigo, dimness of sight, difficulty of speech, nausea, fetid eructations, anxiety, tremors, and paralysis of the limbs. But Dr. Stoerck found that in small doses it may be taken in great safety, and that, without at all disordering the constitution, or even producing any sensible operation, it sometimes proves a powerful remedy in many obstinate disorders. In scirrhus, the internal and external use of hemlock has been found useful, but mercury has been generally used at the same time. In open cancer it often abates the pain, and is free from the constipating effects of opium. It is likewise used in scrofulous tumours, and in other ill-conditioned ulcers. It is also recommended by some in chin-cough, and various other diseases. Its most common and best form is that of the powdered leaves, in the dose at first of 2 or 3 grains a day, which in some cases has been gradually increased to upwards of 2 ounces a day. An extract from the seeds is said to produce giddliness sooner than that from the leaves.

Hemlock should not be gathered unless its peculiar smell be strong. The leaves should be collected in the month of June, when the plant is in flower. The leaflets should be picked off, and the footstalks thrown away. The leaflets are then to be dried quickly in a hot sun, or rather on tin plates before a fire, and preserved in bags of strong brown paper, or powdered and kept in close vessels, excluded from the light; for the light soon dissipates their green colour, and with it the virtues of the medicine. The narcotic seeds are most active and uniform when perfectly ripe. When the fresh root is wounded, it yields a bitter and acrid juice, which Stoerck found to excite in the tongue swelling, stiffiness, violent pain, and transient paralysis. Pfaff is of opinion, that the virtues of the hemlock reside in a volatile principle, which, however, he was not able to obtain separate. Dr. Paris says, that the medicinal activity of the plant resides in a resinous clement, which may be obtained in an insulated form by evaporating an etherial tincture made with the leaves on the surface of water. It has a rich dark green colour, and tastes of hemlock in perfection. A dose of half a grain will produce vertigo and headache.

I ar. $\beta$, striàtum (Tratt. arch. 1. t. 24.) stem diffuse, much branched, very straight; umbels and umbellules proliferous. roL. III. f. II. Native of Hungary, at the river Leitha, Schultes, syst. 6. p. 655 .

Spolted-stemmed or Common Hemlock. Fl. June, July. Brit. Pl. 4 to 6 feet.

2 C. Croa'ticum (Waldst. et Kit. in Willd. enum. p. 305.) leaves of involucels linear, equal in length to the umbellules or exceeding them. o. H. Native of Croatia. According to Kittabail and Willd. this is a distinct species; but it is only a variety of the preceding according to Scliultes, Koch, and Host. The cultivated plant is hardly to be distinguished from the common species, mnless in its more glaucous hue.

Croatian Hemlock. Fl. June, July. Clt. $1818 . \quad \mathrm{Pl} .5$ to 6 feet.

Cull. The seeds only require to be sown in the open ground in autumn.

CLIX. VICA'TIA (named after M. Vicat, who has wrote upon poisonous plants). D. C. prod. 4. p. 243.-Sìson species, Wall.

Lus, syst. Pentándria, Digýnia. Margin of calyx entire.

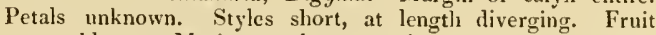
ovate-oblong. Mericarps almost semi-tercte, with 5 filiform ribs: and broad flat furrows containing many small vittac each ; commissure narrow. Carpophore thick, rather bifid at the apex. Albumen furnished with a furrow in the commissure, convex on the ontside.- $\boldsymbol{A}$ glabrous erect herb, native of $\mathrm{Nipaul.} \mathrm{Leaves}$ petiolate, bipinnate; leaflets bipinnatifid: lobes linear, acute, slender. Stems sparingly leafy at the base; the rest naked. Umbels terminal, without any involucrum, of many rays; rays unequal, umbellules of the shorter ones sterile. Involucels wanting, or very small, and of few leaves. Habit of Conium, but the character is near that of Arracácha. Fruit almost like that of the genus Pimpinélla, but differs in the seed being curved.

1 V. conirfolia (D. C. prod. 4. p. 243.) 24.?H. Native of Nipaul, at Kamaon. Sison? conifólium, Wall. mss. Herb $1 \frac{1}{2}$ foot high. Leaves a foot long, of a thin menibranous consistence.

Hemlock-lcaved Vicatia. Pl. $1 \frac{1}{2}$ foot.

Cult. This plant will grow in any soil or situation, and will bc easily propagated by seed.

CLX. ARRACA'CHA (the name of the plant by the Spaniards of South America). Bancr. in gart. dir. p. 382. ex Linnrea. litt. 1829 . p. 13. D. C. in bibl. univ. 1829. jan. p. 74. prod. 4. p. 243.-Cònium species of authors.

Lin. syst. Penlándria, Digýnia. Margin of calyx obsolete. Petals lanceolate or ovate, entire, with an inflexed point, curved above the midale nerve. Stylopodium conical, thick; styles diverging, at length reflexed. Fruit ovate-oblong, somewhat compressed from the siles; mericarps with 5 equal, not crenulated ribs: lateral ribs marginating; vitta many in the furrows. Albumen nearly semi-terete, furnished with a furrow in the commissure.-Perennial South American herbs, of a salubrious quality. Roots tuberous, thick, edible. Leaves pinnate or bipinnate: leaflets deeply toothed, lower ones tripartite. Umbels opposite the leaves or terminal. Involucrum wanting or of one leaf; involucels of 3 leaves. Flowers polygamous; those of the rays hermaplrodite, and those of the disk male or imperfect. Petals white. This genus is nearly allied to Conium, but differs in the form of the petals, and in the ribs of the fruit being entire, not undulately crenulated.

1 A. Escule'NTA (D. C. prod. 4. p. 244.) leaves pinnate: leaflets 5 , broadly ovate, acuminated, deeply pinnatifid, profoundly serrated : the $\underset{\sim}{ }$ lower leaflets petiolate, subternate; involucrum wanting; ribs of fruit obtuse. 4 . F. Native of $3 \mathrm{C}$ 
South America, at Santa Fe de Bogota, and of the Caraccas, where it is cultivated for culinary purposes under the name of Arracaclia. Cònium Arracácha, Hook. exot. fl. bot. t. 152. Arracácha xanthorhiza, Bancroft, 1. c. who first published the history and uses of the plant in Alced, dict. geogr. amer. ex Vargas, in Koen. ann. 1. p. 400. Bancr. in rev. brit. 1826. Root forming large oblong tubers in cultivation. Stem $1 \frac{1}{2}$ foot high. Petioles tubular.

The first account which reached our country of this interesting and raluable plant was published in the first volume of the Annals of Botany, about the year 1805, from a communication made to the editors of that excellent work by Mr. Vargas, a native of Santa Fe de Bogota, who at that period was residing in London. The arracacha is one of the most useful vegetables in that part of South America ; in some parts of the country it is called apio, from its resemblance to celery. The rnots immediately divide into 4 or 5 branches, and each of these, if the soil be light, and the scasoj favourable, will grow to the size of a cow's horn. This root yields a food, which is prepared in the same nunner as potatoes, is grateful to the palate, and so easy of digestion, that it constitutes the chief aliment of the sick; starch and pastry are made from its fecula; and the roots, reduced to a pulp enter into the composition of certain fermented liquors, supposed to be efficacious as tonics. In the city of Santa Fe, and indeed wherever it can be procured, the arracacha is as universally used as the potatoe is with us. The cultivation of this plant requires a deep black soil, that will easily yield to the descent of the large vertical roots. It is propagated by planting pieces of the root, in each of which is an eye or shoot; these acquire in 3 or 4 montlis a size sufficient for culinary purposes, though if pernitted to continue 6 months in the ground, they attain to immense dimensions, withont any injury to their flavour. The colour of the root is white, yellow, or purple, but all the varieties have the same quality. Like the potatoe, the arracacha does not thrive in the hotter regions of America, for in such parts the roots acquire no size, and are indifferent in flavour, and sometimes run altogether to stems. In the countries which are there called temperate, being less hot than those at the foot of the Cordilleras, this vegetable sometimes succeeds; but never so well as in the elevated region of those mountains, where the medium heat is between $58^{\circ}$ and $60^{\circ}$ of Fahrenheit. Here it is that these roots grow the most luxuriant, and acquire the most delicious taste. Before Vargas this plant was not mentioned by any other American writer, except by Alcedo, who notices it in a few words, at the end of his "Diccionario Geographico-historico de las Indias Occidentales O America." According to the late Baron de Schack, the arracacha is an essential article of food, not only to the poor, but to the rich, throughout Santa Fe and New Granada, and is every where cultivated as carrots are with us. It is also cultivated abundantly in the Caraccas and the adjacent mountainous country.

Plants of the arracacha have been introduced to this country, but have not succedid, although every situation, temperature, and soil have been tried; they have only produced at best a few leaves, and at the end of the year or less have perisherl altogether. Mr. Sliepherd of Liverpool alone has been so fortunate as to have a few plants flowering in his garlen.

Esculent Arracacha. F]. Ju. Jul. Clt. 1823 . Pl. 1 to $2 \mathrm{ft}$. 2 A. Moscira'tA (1). C. prod. 4. p. 244.) leaves bipinnate, or tripinnate; leaflets pinnatifid: lobes ovate, acutish, serrated; involucrum of 1-3 jagged leaves; ribs of fruit acute. 24. F. Native of South $\Lambda$ merica, in the province of de los Pastos, near Teinclela, where it is called by the inhabitants Sacharachaca. Herb smelling of musk. Cònium moschàtum, H. B. et Kunth, nov. cren, amer, 5. p. 14. t. 420 .
Musk Arracacha. Fl. June, July. Clt. 1824. Pl. 2 feet.

Cult. These plants are of easy culture if kept from the frost; they may be either increased by seed or dividing at the root.

CLXI. PLEUROSPE'RMUM (from $\pi \lambda \varepsilon v \rho o \nu$, pleuron, a rib, and $\sigma \pi \varepsilon \rho \mu a$, sperma, a seel ; in allusion to the mericarps being furnished with a double membrane, both having ribs). Hoffm. umb. in præf. p. 9. lit. f. 16. 22. Koch, umb. 6. p. 457. Spreng. in Schultes, syst. 6. p. 39. D. C. prod. 4. p. 944.-Ligústicum species, Lin.- l'hyssospérmum, Vela et Lag. am. nat. 2. p. 75. and 9\%. but not of Cuss.-Enymonospérmum, Spreng.

Lin. syst. Pentándria, Digýnia. Margin of calyx 5-toothed. Petals obovate, entire, flat, or somewhat attentuately inflexed at the apex. Fruit ovate, somewhat compressed from the sides; mericaps furnished with a double membrane, outer membrane inflated into 5 hollow winged ribs; interior one closely adnate to the seed, elevated into 5 smaller ribs, situated under the exterior ones; furrows of the inner membrane furnished with $1-2$ vitta each. Commissure furnished with 2 vitta. Carpophore filiform, bipartite. Seed semi-lunar.-Perennial glabrous herbs. Leaves bipinnate; leaflets pinnatifid, cut: lobes acute. Stem fistular. Involucra and involucels of many foliaceous leaves. Flowers white.

1 P. Austríacum (Hoffm. l. c.) vittæ one in each furrow of the fruit; ribs bhutish. 4. H. Native of the Alps of Daupliny, Provence, Switzerland, Silesia, Austria, and of the Carpathian Mountains. Schultes, syst. 6. p. 457. Ligústicum Austriacum, Lin. spec. 36. Jacq. austr, 151. All. pedem. t. 43. Ligusticum Gmelini, Vill. dauph. 2. p. 610. t. 13. exclusive of the synonyme of Gmel. Ligústicum Archangélica, Geners. el scept. no. 252. ex Schultes. Ligust. Sprengèlii, Sieb. in Spreng. umb. spec. 124. Physospérmum Cussòni, Lag. am. nat. 2. p. 97. Ligust. Hacquètii, Guss. pl. rar. p. 132. Athamánta Golàkı, Hacq. pl, carn. t. 5. Athamánta Galátta, Gmel. Plant glabrous. Leaves ternately pinnate; leafiets pinnatifid, decurrent at the base; segments cumeiform, oblong, deeply toothed. Leaves of involucra oval-lanceolate, entire, permanent. Umbels all fertile. Fruit oval, glabrous. Stems furrowed.

Austrian Pleurospermum. Fl. June, July. Clt. 1597. Pl. 2 to 3 feet.

2 P. URALE'NSIS (Hoffin. 1. c.) vittæ one in each furrow of the fruit; ribs very acute. 24. 11. Native of Siberia, on the Ural Mountains. Ligústicum, Gmel. sib. 1. t. 45. This plant differs from Plcurosjérmum Austriacum in the rays of the umbel being evidently velvety when examined by a lens; the colour of the leaves is more glaucous; the petals more obtuse at the apex, and flat.

Tral Pleurospermum. Pl. 2 to 3 feet.

3 P. Kamtsciáticum (Hoffin. 1. c.) vitte 2 in the furrows of the fruit; ribs somewhat denticulated; membranes ahost cohering between themselves. $\psi$. H. Native of Kamtschatka. Petals obovate, with somewhat undulated margins, a little inflexed at the apex. A plant agreeing with this was found about lrkutsk in Siberia, but differs in the leaves of the involucra being sometimes multifid, as is sometimes the case in $P$. Austriacum.

Kamtschatka Pleurospermum. P1. 2 to 3 feet.

4 P. Archangélics (I.ed. fl. alt. 1. p. 369.) 24.H. Native of Sibcria. This plant is not well known. It has the habit exactly of Archangélica officinalis, and grows in the same places with it. 'The fruit is grey or dirty yellow.

Archangelica-like Pleurospermum. Pl. 4 to 6 feet.

Cult. Any common soil will suit these plants; and they may either be inereased by dividing at the root or by seed.

CLXII. HYMENOLE $\mathbb{E}^{\prime} \mathrm{N}$ (from $i\langle\eta v$, hymen, a membrane, and $\chi^{\lambda a u} a$, chlaina, a cloak; in reference to the ribs of the fruit 
being winged and membranous). D. C. prod. 4. p. 214.-Ligústicum spec. Wall, mss.

Lis. syst. Pentándria, Digýnia. Margin of calyx obsolete. Petals oborate, entire, flat or attenuately inflexed at the apex. Fruit ovate or oblong; mericarps with 5 exserted nearly equal winged ribs; vittæ 2 in the commissure, which is flat, and onc in each furrow. Seed with a furrow in front, convex on the outside. Carpophore bipartite.-Perennial glabrous herbs, natives of the monntains of Nipaul. Leaves decompound. Umbels terminal, of many rays. Involucra and involucels of many leaves, which are membranous, and are usually toothed or cut. This genus is allied to Molopospérmum on the one hand, and Pleurospérmum on the other; it differs from the first in the commissure being tlat, in the ribs being equally winged, and in there being no empty canal before the commissure, Sc.; and from the last in the fruit having the membranes joined together, and from both in the obsolete margin of the calyx. Perhays this genus should be divided into two, from the oblong or ovate fruit of the species, and from the seeds being angular or convex on the outer side; but in most of the species the fruit is not sufficiently known.

1 H. AxGeLicoi'des (D. C. prod. 4. p. 245.) leaves ternate; leaflets tripartite: lobes oval-lanceolate, acuminated, toothed: teeth ovate, mucronate; leaves of involucra and involucels lanceolate-linear, acuminated, entire, with membranous margins. 4. H. Native of Nipaul, on the highest mountains at Kamaon and Gosaingsthan. Ligústicun) angelicoìdes, Wall. mss. Habit, when dried, almost of Ligústicum Scóticum. Fruit oblong, 5 lines long, somewhat compressed from the sides. Sced with very prominent angles, as in Molopospérmum, but the commissure is flat and bivittate. Leaves of involucels 6-8 lines long, membranous.

Angelica-like Hymenolæna. Pl. 1 to 2 feet.

2 H. notunda'ta (D. C. prod. 4. p. 245.) leaves ternate, rarely triternate; leaflets ovate-roundish, obtuse, toothed : teeth roundish, hardly mucronate ; leaves of involucra $1-2$, of the involucels $4 \cdot 7$, linear-lanceolate, acute, membranous, entire. $\psi$. H. Native of Nipaul, on Gosaingsthan and Himalaya. Ligústicum rotundatum, Wall. mss. Petioles broadly dilated at the base, many-nerved, those of the radical leaves very long, and those of the cauline ones gradually shorter, till at length the uppermost ones are very short. Leaves sometimes tripartite.

Roundish-leaved Hymenolæna. Pl. 2 to 3 fect.

3 H. PU' Mila (D. C. prod. 4. p. 245.) leaves pinnate; leaflets 5 , orate, deeply pinnatifid : lobes equally toothed: teeth roundish, mucronate; stems scape-formed, nearly naked; leaves of involucra 2-3, of the involucels 4-5, lanceolate, acute, membranous, entire. 4. H. Native of Nipaul, at Gosaingsthan. Ligústicum pùmilum, Wall. mss. Herb a foot high when in flower. Leaves radical, or 1-2 rising from the base of the stem. Umbels of 7-8 rays. Leaves of involucra sometimes drawn out into a small cut leaf.

\section{Dwarf Hymenolæna. Pl. 1 foot.}

4. H. deNtA'TA (D. C. l. c.) radical leaves ternate, with trifid petioles; leaflets bipinnatifid ; eaulinc leaves bipinnate : leaflets ovate, acute, serrated; leaves of involucra 1-8, of the involucels $7-8$, lanceolate, acuminated, membranous, undulatelyserrulated. 4. H. Native of Nipaul, at Kamaon and Gosaingsthan. Ligústicum dentàtum, Wall, mss. Leaves membranous. Rays of umbel 5-8, angular, somewhat puberulous. Leaves of involucels exceeding the flowers.

$V^{\prime} a r . \beta$, eròsa (D. C. 1. c.) cauline leaves pinnate: leaflets tripartite : lobes ovate-oblong, irregularly and deeply toothed; umbels of 15-18 rays : rays scabrous; leaves of involucra 5-6, lanceolate, serrated, of the insolucels $7-8$, obovate, eroselyserrated, tipped by a mucrone. $4 . H$. Native of Nipaul.
Toothed-leaved Hymenolana. Pl. 1 to 2 feet.

5 H. CAN DólüI (D.C. l. c.) leaves pinnate: leafets petiolate, ovate, decply pinnatifid: lobes deeply serrated at the ajex; peduncles in fascicles; umbels and umbellules crowded; leaves of involuera and involucels many, obovate, obtuse, membranous, large, entire. $4 . \mathrm{H}$. Native of Nipaul, on the Himalaya, at the temple of Buddrinath. Iigústicum Candóllii, Wall. mss. Herb hardly a foot high, agreeing with Plcurospérmum in habit. Upper leaves membranous, emulating the leaves of the involncra. Leaves of involucrum nearly an inch long.

De Candolle's Hymenolana, Pl. 1 foot.

6 H. Brunònis (D. C. 1. c.) leaves eapillaceously mulcifid ; segments linear, acutc ; leaves of involucra 5-6, membranaceously dilated, multifid at the apex : of the involucels $6-8$, membranous, some of which are undivided, with the middle nerve simple: and others are trifid, with the middle nerve trifurcate. 4.1H. Native of the mountains of Nipaul, on the Himulaya, Kamaon, and Gosaingsthan. Ligústicum Brunònis, Wall. mss. There are varieties of this having the leaves of the involucels smaller, length of the flowers, and larger exceeding the flowers.

Bron's's Hymenolena. Pl. 1 to 2 feet.

7 H. Govania'Na (D. C. prod. 4. p. 246.) leaves pinnate: leaflets decply pinnatifid: lobes oblong-linear, acute; leaves of involucra $5-7$, multifid, much shorter than the rays of the umbels; lcaves of involucels membranous at the base and margin, multifid at the apex, and exceeding the flowers. 2.11. Native of the Snowy Mountains of Sirmore. Ligústicum Govaniànum, Wall. mss. Leaves like those of $A$ pium. Rays of umbel 7-8, unequal. Stem striated.

Govan's Hymenolæna. Pl. 1 foot.

8 11. Benthi'm (D.C. l. c.) leaves pinnate: leaflets 5-7, ovate, cuneated at the base, coarsely toothed, trifid or tripartite: teeth mucronate; leaves of involuera foliaceous, oblong, deeply toothed, much shorter than the rays of the umbels; involucels about the length of the flowers. 21.H. Native of Nipaul, at Gosaingsthan. Ligústicum Benthàmi, Wall. mss. Fruit ovate; mericarps somewhat compressed from the back, with broad furrows and narrow winged ribs. Sced convex on the back.

Bentham's Hymenolæna. Pl. 1 foot.

9 H. obtusiu'scula (D. C. l. c.) leaves pinnate: Jeaflets 5-7, ovate, decply pinnatifid, bluntly toothed: leaves of involucra foliaceous, dilated at the base, and multifid at the apex, a little shorter than the rays of the umbel; leaves of involucels oblong, foliaceous, deeply toothed. 24. H. Native of Nipraul, at Gosaingsthan. Ligústicum obtusiưsculum, Wall. mss. Fruit ovate; mericarps semi-ovate, with broad furrows, and undulately-toothed narrow-winged ribs. Carpophore thick, bipartite. Sced scmi-ovate, obtuse on the back.

Bluntish-secded Hymenolana. Pl. 1 foot.

Cult. See Pleurospérmum, p. 378, for culture and propagation.

CLXIII. PHYSOSPE'RMUM (from $\phi v \sigma a, p h y s a$, a bladder, and $\sigma \pi \varepsilon \rho \mu a$, sperma, a seed; in reference to the tegument not adhering to the seed in the young state). Cusson, mem. soc. med. par. 1782. p. 279. Spreng. mem. soc. mose. 5. p. 1. t. 1. f. 1-3. Koch, umb. 134. D. C. prod. 4. p. 246.-Danda, All. pedem. no. 1392. D. C. fl. fr. 4. p. 311. Lag. am. nat. 2. p. 97. but not of Smith.-Hænselèra, Lag. gen. et spcc. p). 13.Vèla, in Lag. am. nat. 2. p. 75 .

Lin. syst. Pentándria, Digýnia. Margin of calyx 5-toothed. Petals obovate, somewhat emarginate, with an inflexed point. Fruit contracted from the sides, didyınous ; mericarps reniformly globose, with 5 filiform, slender, equal ribs: the lateral ribs placed in front of the margins; vitte broad, one in cach furrow. Seed involutely semi-lunar--Perennial herbs. Lower leaves triternately cut; upper ones often reduced to the scale-formed 3 c 2 
sheaths. Leaves of involucra and involucels many. Flowers white. The tegument does not adhere to the fruit in the young state, but when ripe it does, whence the name is incongruous when the fruit is mature.

1 P. Aquilegrfòluu (Koch, 1. c.) lower leaves triternate, glabrous; leaflets cuneated, deeply toothed ; upper leaves many, reduced to the quite entire stipula-formed sheaths. 24. H. Native of Taur ia, Italy, Spain, and Portugal, in woods and shady places. Danàa aquilegifòlia, All. pedem. no. 1392. t. 63. Hænselèra damæcórnis, Lag. l. e. Ligústicum aquilegifòlium, Willd. spec. 1. p. 1425. Balb. mem. acad. taur. 1804. p. 333. Sison sylváticum, Brot. A. Jus. 37. Danàa sylvática, Lag. am. nat. 2. p. 97. Oreoselinum Lusitánicum, Tourn. herb. Smýrnium medicaúle, Bieb. f. taur. 1. p. 238. Spreng. umb. spec. t. 4. f. 7. Pimpinélla Danàa, Bieb. casp. p. 163 .

Columbine-leaved Physospcrmum. Fl. May, June. Clt. 1817. Pl. 3 feet.

2 P. Connubiénse (D. C. prod. 4. p. 246, ) lower leaves triternate, glabrous; leaflets cuneate-lanceolate, deeply toothed: uppermost ones reduced to the sheaths, each sheath bearing 3 linear, nearly entire leaflets. 4 . H. Native only of Cornwall, in thickets, among bushes, and in hedges; in great plenty in the neighbourhood of Bodmin. Ligústicum Cornubiénse, Lin. spec. p. 359. Smith, engl. bot. t. 683. Smitl, icon. pict. t. 11 . Physospérmum commutàtum, Spreng. umb. spec. t. 4. f. 8. exclusje of many synonymes. Danàa aquilegifòlia, Lag. am. nat. 2. p. 97.? ex synonyme of Spreng. Cornwall Saxifrage, Petiv. herb. brit. t. 26. f. 9 . Cattle are so fond of the plant that they eat it down to the ground. The root contains a yellow resinous juice.

Cornish Physospermum. Fl. Jul. Aug. Fngl. Pl. 2 to $3 \mathrm{ft}$.

3 P. cicuta'rium (Spreng. umb. spec. 23.) lower leaves supradecompound : cauline ones decompound: upper ones ternate; leaflets 3-lobed, toothed, acute; stem leafy, furrowed. 24. H. Natice of Eastern Caucasus. Smýrnium cicutàrium, Bieb. fl. taur. 1. p. 239. suppl. 249. Ligústicum Caucásicum, Willd. herb. ex Schultes, syst. 6. p. 457. Uinbels lateral and terminal.

Cicuta-like Physospermum. Fl. June, July. Clt. 1827. Pl. 2 to 3 feet.

4 P. Angelic fòlium (Guss. ind. sem. 1825. prod. A. sic. 1. p. 356.) stem furrowed, nearly naked; radical leaves biternate, with the ramifications not divaricate: leaflets of the lower leaves ovate, of the superior ones oval-oblong, 2-3-parted, dentately serrated, glabrous above, and pubescent beneath. $\psi$. H. Native of Sicily, on shady gravelly parts of mountains. Leaves like those of Angélica syliéstris.

Angelica-lcaved Physospermum. Pl. 2 to 3 feet. tion.

Cult. See Pleurospérmum, p. 378. for culture and propaga-

CLXIV. SMY'RNIUM (from opvova, smyrna, a synonyme of $\mu v \rho \rho a$; the odour of myrrh is common to many umbelliferous plants, anong others the My'rrhis odoràta, for which reason it is so named). Lag. am. nat. 2. p. 101. Koch, umb. p. 133. f. 38, 39. D. C. prod. 4. 1. 247.-Smýrnium species, Lin. and Spreng,

Lin. syst. Pentándria, Digýnia. Margin of calyx obsolete. Petals lanceolate or clliptic, entire, acuminated, with an inflexed point. Fruit contracted from the sides, didymous from the mericarps being reniformly globose; mericarps with 3 dorsal, rather prominent sharp ribs, and 2 lateral, nearly obliterated marginal ones; vittæ many in the furrows. Carpoplore bipartite. Seed involute-Erect, biennial, glabrous herbs. Roots fleshy. Leaves variable. Umbels terminal. Involucra variable. Flowers yellow or greenisli-yellow, usually polygamous.
1 S. olusa'trum (Lin. spec. 376.) stem terete; cauline leaves ternate; leaflets ovate, serrated; involucels very short. $\delta . \mathbf{H}$. Native of Middle and South Europe, in humid places; as in France, Spain, Italy, Belgium, and Britain. It is rather a maritime plant, and is found near cur coast in various places, as about Scarborough Castle, and about Dover; it is common in Anglesea and in all the western counties, and in the flat parts of Gloucestershire, as also in many places of Dorsetshire. It occurs also about many inland towns, as Nottinglian, York, Bury, Newmarket, and about Mackerell's Tower, Norwich. In several places of Cambridgeshire, Worcesterslire, Kent, and Middlesex. In Scotland upon the coast of Dunglass, on the edge of Berwickshire. Lam. ill. 204. Smith, engl. bot. t. 230. S. Mathioli, Tourn. inst. 316.-Lob. icon. 708. f. 2. Moris. sect. 9. t. 4. The whole herb is of a pale bright green, in flavour something like celery. Lower leaves biternate: upper ones ternate. Petioles inflated. Umbels globular. Flowers greenish white. The plant was formerly eaten in various parts of Europe, either as a salad or potherb, whence, and from its blackness, the name olusatrum, from olus and atcr. Ray says it was called Alexanders, because in Italy and Germany it had long been denominated herba alexandrina; having been supposed to have been brought from Alexandria. It flowers in $\mathrm{May}$, and by the middle of July the stalks are dried up, but remain laden with large black sceds.

Olusalrum or Common Alexanders. Fl. May. Britain. Pl. 2 to + feet.

2 S. Apufòlium (Willd. spec. 1. p. 1468.) stem terete; cauline leaves cuneiform, obtuse, trifid, toothed: involucra and involucels wanting. $\delta$. H. Native of Candia. Schultes, syst. 6. p. 440. S. Créticum palıdapifòlio, Tourn. cor. 23. S. Créticum, Mill. dict. no. 4. Perhaps only a variety of the preceding. Stem angular, glabrous. The lower leaves of this plant are much smaller than those of the preceding, and more like those of smallage; the umbels are also smaller, and the sceds are less.

Smallage-leaved Alexanders. Fl. May. Clt. 1731. Pl. 2 to 3 feet.

3 S. Rotundifòlum (Mill. dict. no. 2.) stem terete; canline leaves stem-clasping, orbicular, quite entire, or hardly toothed. §. H. Native of the islands in the Mediterranean, as in Corsica, Sicily, Cos, Sce, on the mountains. Moretti, pl, ital. dec. 2. p. 9. S. Dodonæ'i, Spreng. umb. spec. 24. exclusive of many of the synonymes. S. Créticum, Math. ed. Valgr. 1570. p. 515. f. 2. S. Mathioli, Presl. del. prag. p. 127. but not of Tourn. S. ramòsum, D'Urv, enum. no. 278. S. perfoliàtum $a, \mathrm{Lam}$. dict. 3. p. 266. S. Egyptiacum, Lin. amon. 4. p. 270. probably belongs to this species, which has often 2 single cordate, quite entire leaves on the floral branches, as in it. Root tuberously fusiform, black on the outside, with a sweet taste. Leaves pale green: lower ones ternately decompound; leaflets ovate, deeply serrated, for the most part attenuated at the base. Lower cauline leaf 3 -lobed.

Round-leaved Alexanders. Fl. May, June. Clt. 1700. Pl. $3 \mathrm{ft}$. 4 S. PERfolis'tum (Mill. dict. no. 3.) stem angularly winged above; cauline leaves stem-clasping, ovate-cordate, denticulated. of. H. Native of Spain, Provence, Italy, Dalmatia, Balearic Islands, Greece, Sc. Lin. spec. 376. Moretti, pl. ital. dec. 2. p. 10. S. Dioscóridis, Spreng. umb. spec. p. 25. Smith, fl. græc. 2S9. exelusive of the synonymes of Matl. and Dalech,-Dodon. pempt. p. 698. f. 2. Lob. icon. 709 . Lower leaves ternately decomponnd, and the leaflets 3-lobed, ovate, and toothed. Flowers yellow.

lar. $\beta$, Kittabèlii (D. C. prod. 4. p. 247.) superior leaves coarsely toothed. $\delta$. H. Native of Hungary. S. perfoliàtum, Waldst. et Kit. hung. 1. p. 22. t. 23. 
Perfoliate-leaved Alexanders. Fl. May, June. Clt. J $\frac{1}{2}$ foot.

5 S. Egopodioides (H. B. et Kunth, nov. gen. amer. 5 . p. 16.) leaves somewhat biternate; leaflets oblong, sharply serrated; umbels of 10-12 rays; involucra and involucels of one leaf. $\$$. H. Native of Mexico, near Moran, at the height of about 4.000 feet; and on the Cordilleras de Qualıilapa. Sison agopodioides, Spreng. syst. I. p. 886. Flowers yellow. Fruit didymous, hardly compressed; vittæ small; ribs filiform; furrows broad, reticulated; albumen involute.

Gout-need-like Alexanders. Pl. 1 foot.

\section{$\uparrow A$ doubtful species.}

6 S.? LATEra'Le (Thunb. fl. cap. 2. p. 206.) leaves pinnate and ternate; leaflets obovate, deeply lobed, mucronately toothed; umbels lateral, nearly sessile; involucels few-leaved. §. G. Native of the Cape of Good Hope. Petals white, inflexed. Fruit globose, pubescent. This plant evidently does not belong to the present genus, but to what genus it belongs is unknown.

Lateral-umbelled Alexanders. Pl. 1 foot.

Cult. The species will grow in any kind of soil in which the seeds may be sown.

CLXV. EU'LOPHUS (from $\varepsilon v$, eu, well, and $\lambda \circ \phi o c$, lophos, a crest; in reference to the stripes as well as the ribs of the fruit being rather prominent). Nutt. in litt. 1825. D. C. coll. mem. v. p. 69. t. 2. f. M. prod. 4. p. 248.

Lis. sxst. Pentándria, Digýnia. Margin of calyx 5-toothed, at last falling off after flowering. Petals unknown. Fruit somewhat contracted from the sides, rather didymous; mericarps ovate, with 5 hardly prominent ribs: the furrows between the ribs furnished with 3 convex stripes each, which are more prominent than the ribs, they are hollow inside, and replete with oil, from sustaining oleiferous canals; commissure bearing 4 similar stripes or vittæ. Seed semilunar, filling the mericarp; carpophore bipartite--Glabrous herbs. Leaves multifid; lobes linear, elongated. Terminal umbels large, of 10 rays, fertile; the lateral ones opposite, and sterile. Involucra and involucels of many linear acute leaves. Flowers many, abortive. This genus is very nearly allied to Physospérmum, but differs in the fruit being covered with many vittæ, as in Smýrnium.

1 E. Auerica'nus (Nutt. in litt.) - Native of North America, in the Arkansa territory. Root composed of fascicles of oblong tubers. Stem terete, fistular.

Ameriean Euloplus. Pl.

Cult. See Smyrnium above for culture and propagation.

CLXVI. SCALIGE'RIA (in honour of J. C. Scaliger, conmentator on Theophrastus). D. C. coll. mem. v. 1. 70. t. 1. f. B. prod. 4. p. 248.

Lis. srst. Pentándria, Digýnia. Margin of calyx entire. Petals obcordate, with a slort, inflexed, obtuse point. Stylopodium thick, conically cylindrical, parallel; styles filiform, bent ontwards. Fruit somewhat didymous; mericarps ovate, contracted at the raphe, scarcely compressed from the sides, with 5 filiform ribs, and flattisl-convex furrows, each furrow containing $2-3$ vittæ. Commissure flattish, containing 4-6 vittæ. Albumen furnished with a furrow inside.-Herb glabrous. Radical leaves on long petioles, which are hardly dilated at the base, ternate ; leaflets pinnate: segments pinnatifid : lobes diverging, lanceolate, acute. Stem branched, rather dichotomous, terete. Upper leases reduced to quite entire, or unidentate, elongated ligula. Umbels terminal, without involucra, of 9-10 rays; umbellules 12-15-flowered; involucels of a few small, linear leaves. Flowers white.-This genus is allied to Fúlophus and Plıssospérmum from habit and character, but differs from both in the ealyx being toothless, in the form of the stylopodium, and in the want of involucra. From habit and the somewhat didymous fruit it comes also very near A'stoma.

1 S. merocárpa (D. C. l. c.). Native of the Levant, near Seyde, at the foot of Mount Lebanon. Fruit small, blackish. Small-fruited Scaligeria. Pl. 1 foot?

Cult. Sow the seeds in autumn, in the open ground; they will grow in any common soil.

Suborder 1II. COELOSPE'RME (from rot toc, koilos, hollow, and $\sigma \pi \varepsilon \rho \mu a$, sperma, a seed; from the seeds being involutely curved from the base to the apex, and therefore forming a hollow on the inner side). D. C. prod. 4. p. 249. Albumen involutely curved from the base to the apex, excavated in front.

\section{Tribe XVII.}

CORIA'NDREE (this tribe contains plants agreeing with Coriándrum in important claracters). Koch, umb.p. 82. D. C. prod. 4. p. 249. Fruit globose or clidymous, with 2 subglobose mericarps. Mericarps with 5 primary, depressed, or flexuous ribs; the lateral ribs placed before the accessory margin; the 4 secondary ribs are more prominent than the primary ones; all wingless. Seeds involute, or curved from the base to the apex, hence they are excavated in front.

CLXVII. BI'FORA (bis, twice, and foris, a door; in reference to the commissure being furnished with 2 holes). Hoffm. umb. 191. f. 2. in tit. Kocli, unıb. 83. D. C. prod. 4. p. 249. -Bíforis, Spreng. in Schultes, syst. 6. p. 38, and p. 448.Còrion, Hoffin. et Link, fl. port. 2. p. 457.-Coriándrum species, C. Bauh. Tourn. Lin.-Anidrum, Neck. elem. no. 319.

Lıs. syst. Pentándria, Digýnia. Margin of calyx obsolete. Petals obovate, emarginate, with an inflexed point ; outer petals nearly equal, or radiating and bifid. Fruit didymous : mericarps somewhat globosely rentricose, granularly wrinkled, marked with 5 impressed obsolete stripes: the 2 lateral stripes semicircular, and placed before the accessory margin. Vittæ none. Commissure furnished with 2 holes. Seed involute from the base to the apex. Carpophore bipartite, adnate on both sides.-Fetid herbs, with sulcately angular stems; and decompound leaves; having five segments. Umbels of $2-3$ rays. Involucra and involucels wanting, or of one leaf. Flowers white.

1 B. Testicula'ta (Spreng. 1. c.) umbels of $2-3$ rays; involucra and involucels of one leaf; flowers nearly equal; styles very short. $\odot . H$. Native of Europe, especially in the south of France, Italy, Greece, Spain, and of Barbary. Coriándrum testiculàtum, Lin. spec. p. 367. f. fr. 4. p. 293. Bífora dicócca. Hoffin. umb. 192. Bífora flosculòsa, Bieb. suppl. 232. -Lob. icon. t. 706. f. 1.-Pluk. alm. t. 196. f. 2.-Riv. pent. 72. Baul. hist. 91-92, f. 1. Herb fetid when bruised. Petals white; anthers red.

Twin-fruited Bifora. Fl. June, Jul. Clt. 1640. Pl. 1 to $2 \mathrm{ft}$.

2 B. RA'Dians (Bieb. suppl. 233.) umbels of 5 rays; involucra and involucels of 1-2 leaves; outer flowers radiant; styles elongated after flowering. $\odot$. H. Native of Tauria, frequent among corn. Coriándrum testiculàtum, Bieb. fl. taur. 1. p. 228. exclusive of the synonymes. Coriándrum orientàle, chamæmeli folio, Tourn. cor. 22,? Herb fetid. Petals white; anthers red.

Radiant Bifora. Fl, Ju. Jul. Clt. 1817. Pl. $1 \frac{1}{2}$ foot.

Cult. The seeds only require to be sown in the open border.

CLXVIII. A'STOMA (from a priv. and $\sigma \tau o \mu a$, stoma, a mouth; this genus differs from Bifora in the want of the 2 holes in the commissure; hence the name). D. C. coll. mem. $v$. p. 71. t. 17. prod. 4. p. 249. but not of Gray.

Lis. syst. Pentándria, Digýnia. All as in Bifora, but the 
fruit is more evidently didymous ; the commissure narrow, neither perforated nor dilated at the apex; and the styles rather divergent. - A glabrous herb, at first sight appearing like a species of Sćseli. Stem terete, striated, erect, branched. Superior leaves bipinnatifid: with a few linear, nearly subulate, elongated, quite entire segments. Umbels by threes, pedunculate at the tops of the branches: the 2 lateral ones axillary and opposite, 6-8-rayed: but the central umbel is 10-12-rayed. Leaves of involucrum 5-6, lanceolate, entire, acuminated. Umbellules of 10-12 flowers; involucels of 4-5 leaves. Flowers white, all lermaphrodite. This is an intermediate genus between Bifora and Alrèma; from the first it diflers in the commissure being imperforated, in the fruit being smaller, and in the involucra and involucels being of many leaves; and from the last in the margin of the calyx being obsolete, in the fruit being without ribs, and exactly didymous.

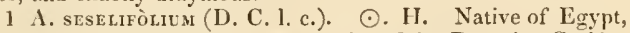
or rather of Syria, where it was gathered by Donati. Coriándrum seselifolium, D. C. The fruit of this plant is 5 times smaller than in all the other genera of Coriándrce, and exactly didymous. Mericarps nearly globose.

Sescli-leaved Astoma. Fl. June, Jul. Pl. 1 foot.

Cult. See Bifora, p. 381. for culture and propagation.

CLXIX. ATRE'MA (from $a$ priv, and r $\rho \mu \alpha$, trema, a hole; there are no holes in the commissure, as in the genus Bifora). D. C. coll. mem. v. p. 71. t. 18. prod. 4. p. 250.

Lin. syst. Pentándria, Digynia. Teeth of calyx 5, acute, small, permanent. Petals obovate, emarginate, nearly equal, with an inflexed segment. Frnit nearly didymous; mericarps nearly globose, ventricose: marked with 5 rather prominent small ribs. Vittæ none. Commissure narrow, closed. Seed involute from the base to the apex.-An herb with a furrowed stem, having the angles acute and dentately muricated under the umbels. Leaves multifid, with linear segments. Umbels and umbellules of 5.8 rays. lnvolucra and involucels of many linear-setaceous, undivided leaves. This genus is intermediate between Coriándrum and Bifora. The flowers are equal and the fruit is didymous as in Bifora, and the fruit is sapid, 5ribbed, and the calyx 5-toothed, as in Coriándrum sativum.

1 A. Anericanum (D.C. l. c.), ๑. H. Native of North America, in the southern provinces at the Red River. Coriándrum Americànum, Nutt, in litt.

American Atrema. Pl. 1 to 2 feet.

Cult. See Bifora, p. 381. for culture and propagation.

CLXX. CORIA'NDRUM (a name used by Pliny, derived from kopec, coris, a bug; in reference to the fetid smell of the leaves). Hoftin. umb. p. 186 . f. $14-15$. in tit. D. C. prod. 4. p. 250. Spreng. in Schultes, syst. 6. p. 448. Koch, umb. p. 82. f. 72-73.-Coriándrum species, C. Bauh. Tourn. and Lin.

Lun. sist. Pentándria, Digýnia. Teeth of calyx 5, acute, unequal, permanent. l'etals obovate, emarginate, with an inflexed point; onter petals radiant and bifid. Fruit globose, 10 -ribbed, hardly separable; mericarps with 5 primary depressed flexuous ribs: and 4 secondary more prominent keeled ones. Vitte none in the furrows, but 2 in the commissure. Carpophore free in the middle, semi-bifid, adnate at the base and apex. Seed excavated in front, covered by a loose membrane.-Herb glabrous. Stems terete. Leaves decompound: the superior ones most so. Umbels of 3-4 rays, without any involucra; involucels of 3 dimidiate leaves. Flower-buds sometimes rosecoloured. Flowers white. Stylopodium conical.

1 C. sativem (Lin. spec. p. 367.). ๑. H. but in gardens sometimes 8 . Native of corn-fields in the Levant, Tartary, Greece,
Italy, and the south of France. The plant, although found wild in Essex, where it has been long culcivated, is not a native of this country. Smith, engl, bot. t. 67. fl. græc. t. 283. Blackw. herb. t. 176 . Hayne, arz. gew. 7. t. 13. Brunf. hist. 1. p. 203. Mart. rust. t. 141. Rivin. pent. irr. t. 71 . Woodv. med. bot. 492 . t. 181 . Plench, icon. t. 204. Moris. hist. 3. p. 269. sect. 9. t. 11.f. 1. The culture and management of the coriander consists in sowing the seeds on a light rich soil in September. Twenty pounds of seed will sow an acre. When the plants come up, thin them to 6 or 8 inches distance every way, and next spring stir the soil with a pronged hoe. In Angust the seed will be ripe, and if great care be not used, the largest and best part of the seed will be lost. To prevent this, women and children are employed to cut plant by plant, and to put it immediately into cloths, in which it is carried to some convenient part of the field, and there threshed upon a sail cloth. A few strokes of the flail get the seeds clean out, and the threshers are ready for another bundle in a few minutes. In Essex it is sometimes cultivated with caraway and teazle. See Càrum cárvi. The produce of coriander is from 10 to $14 \mathrm{cwt}$. on an acre. It is used by the distillers for flavouring spirits; by the confectioner for incrusting with sugar; and by the druggist $s$ for various purposes, for all of which it is said to have a ready sale. Coriander seeds are strong and disagreeable when fresh; but by drying become sufficiently grateful. They are recommended as carminative and stomachic; they are also used to cover the taste of senna, and in spices as currie powder, and seasoning for black puddings: formerly they were steeped in wine, and then dried to render them milder.

Yar. $\beta$ ? microcárpum (D. C. prod. 4. p. 250.) fruit one half smaller than that of the species; segments of the leaves very slender and short. $\odot$. H. Native of Mexico, at Tampico. Perhaps a proper species.

Cultiruted Coriander. Fl. Ju. Jul. England. Pl. $1 \frac{1}{2}$ foot.

Cult. Sow the seeds in the autumn or spring in the open ground.

CLXXI. CYMBOCA'RPUM (from kv $\mu$ /3os, kymbos, a hollow,

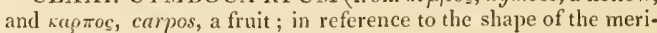
carps, which are hollow in front). D. C. ex Meyer, verz. pflanz. p. 132 .

Lin. srst. Pentándria, Digýuia. Margin of calyx obsolete. Petals equal, obcordate; with an inflexed point. Stylopodium depressed; styles reflexed. Fruit nearly globose; mericarps solid, hemispherical: with 5 primary, filiform ribs, which are often obliterated: the lateral ones of these marginating; secondary ribs none. Vittee wanting. Carpophore bipartite, free in the middle, but adnate at the base and apex. Seed excavated in front. - A small, annual fetid plant. Leaves decompound, with short, linear segments. Umbels opposite the leaves. Lcaves of involucra and involucels linear. Flowers white.

1 C. Anethoides (D. C. ex Meyer, verz. pflanz. p. 132.) $\odot$. H. Native of Caucasus, in stony places on the mountains of Talusch, near Swant, about 2000 feet above the level of the sea.

Fennel-like Cymbocarpum. PI. 1 foot.

Cult. For culture and propagation see Bifora, p. 381 .

N.B. The two species of Coritindrum cultivated in China and Cochin-china, are mentioned by Loreiro in his fl. coch. p. 225. under the names of $C$. sativum and $C$. testiculatum; but the first differs from the true $C$. satirum in the involucels being of one leaf; and the second differs from the true $C$. testiculatum or Bifora, from the involucra and inrolucels being multifid, and in the fruit being sweet scented. 
ORDER CXIIV. ARALIACEA (this order contains only plants agreeing with the genus Aràlia in important characters). Juss. diet. 2. p. 348. D. C. prop. med. ed. 2. p. 163. D. Don, prod. fl. nep. 186 . D. C. prod. 4. p. 251.-Aráliæ, Juss. gen. p. 247 .

Tube of ealyx adnate to the ovarium: with the limb entire or toothed. Petals 5-10, alternating with the ealyeine teeth, valvate in estivation, rarely wanting altogether. Stamens equal in number to the petals, rarely double that number, inserted beneath the margin of a large epigynous disk; anthers bilocular, peltate. Ovarium adnate to the calyx: with 2 or more cells, containing each only one ovulum. Styles many, simple, sometimes distinct and diverging, sometimes joined in one, rarely wanting; stigmas simple. Berry 2-15-celled, crowned by the entire or toothed limb of the ealyx; having as many 1 -seeded cells as there are styles. Seels angular, erect, with a crustaceous testa, and a membranous endopleura. Embryo small, inverted, surrounded by copious flesliy albumen : having a superior radicle, which is twice the length of the cotyledons.Trees or shrubs, rarely herbs. Stems frutescent, often scandent, adhering by root-formed fibres to other substances, as in ivy. Leaves alternate, exstipulate, petiolate, simple or compound. Petioles long, always dilated and thickened at the base. Flowers axillary or terminal, umbellate or eapitate; the umbels or heads often disposed in a racemose or paniculate manner : having involucels usually present.

The order Araliàcece approximates Umbellifera, but differs from it in the inflorescence being often imperfectly umbellate; in the styles bcing usually many ; in the fruit being baceate, and usually plurilocular, always without vitte; and in the parts of the fruit not being separable; in the albumen being fleshy, and in the embryo being nearly the length of the albumen. It also comes near $A$ mpelidece, but differs in the stamens in $A$ raliàcece alternating with the petals, not as in Ampelidece opposite them, in the leaves being exstipulate, and in the inflorescence never being opposite the leaves, as well as in the calyx adhering to the ovarium, not free from it. The genus Hédcra has often been confused with Caprifolideec, but agrees best with the present order, in the free petals and strueture of the fruit.

The flowers have no beauty, but the foliage of many is extremely fine. The medicinal properties are much the same as those of $U$ mbelliferce, except the fruit, which differs in virtues, as it does in botanical strueture. The bark of many of the species exudes an aromatic gum-resin, as in Aràlia umbellifera and others. The roots are tonic, with, in some cases, the flavour of parsnip. The famous Ginseng, which is produced by a species of Pànax, is reputed to have powerful tonic, restorative, and even aphrodisiacal qualities; but it is probable that these have been greatly exaggerated. The plant has perhaps some really invigorating power when fresh, which after the statements made by Father Jartoux cannot reasonably be doubted.

$$
\text { Synopsis of the genera. }
$$

1 Adóxa. Calyx 2-3-cleft. Corolla rotate, 4 (f. 66. a.) -5- cleft. Stamens 8-10. Styles 4-5 (f. 66. b.). Berry 4-celled 4-seeded. Seed girded by a membranous border.

2 PA'NAx. Flowers polygamous. Margin of ealyx obsoletely 5-toothed. Petals 5. Stamens 5. Styles 2-3, short. Fruit fleshy, compressed, orbicular, or didymous, 2-celled.

3 Cussònia. Margin of ealyx entire, or with 5-7 acute teeth. Petals 5-7. Stamens equal in number to the petals. Ovarium crowned by a broad disk. Styles 2-3, short. Fruit 2-3-celled, roundish, nearly dry.

4. Mara'Lia. Margin of calyx small. Petals and stamens 5. Styles 3. Berry cylindrieal, 3-celled, 3-seeded.

5 Ginibe'rtia. Margin of calyx entire, drawn out beyond the ovarium. Petals 5-10. Stamens 5-10. Ovarium 5-10eelled, crowned by a broad disk. Style short, composed of 5-10 eoncrete ones, which at lengt! diverge a litcle at the apex. Fruit flesby, 5-10-celled.

6 Gastonia. Margin of calyx entire, drawn out beyond the ovarium. Petals 5-16. Stamens double the number of the petals, 2 in front of each petal. Styles $8-12$, short, rather conerete at the base. Fruit 8-12-eelled, 8-12-ribbed, nearly dry.

7 Poly'scias. Margin of calyx short, denticulated. Petals $5-7$, but usually 8 . Stamens $5-7$, but usually 8 . Style none. Stigmas 3-5, short, spreading. Berry globose, 4-celled, 4seeded.

8 Toricéllua. Margin of calyx acutely 5-toothed. Petals 5, uncinately incurved at the apex. Stamens 5, very short. Styles 4, short. Berry nearly dry, 4-celled.

9 ArÁlia. Margin of ealyx rery short, entire or toothed Petals 5, free at the apex. Stamens 5. Styles 5. Berry 5celled, usually torose. Seed chartaceous.

10 Scrodapux zlum. All as in Aralia, but the petals are joined together into the form of a calyptra at the apex.

11 Hédera. Margin of ealyx elevated or toothed. Petals 5-10, not colsering at the apex. Stamens 5-10. Styles 5-10, conniving, or joined in one. Berry 5-10-celled.

12 Panatro'pra. All as in Arùlia or Hédera, but differs in the stigmas being sessile, at first approximate, and immersed in the epigynous disk.

13 Arturophy'llum. Margin of ealyx short, obsoletely 5-toothed. Petals 5. Stamens 5. Style short, or almost wanting; stigma obtuse. Fruit baccate, crowned, containing a oneseeded nucleus.

I. ADO'XA (from a pris, and coša, dloxa, glory ; without any appearance. 'This plant covers the places where it grows, but the flowers are hardly to be seen, being of the same colour as the leaves). Liu. gen. no. 501. Gartn. fruct. 2. p. 141 . t. 112. f. 9. Lam. ill. t. 320. D. C. prod. 4. p. 251.-Moschatellina, Tourn. inst. t. 68 .

LiN. syst. Oclándria, Tetrasǵnia. Tube of calyx adnate to the ovarium, with $2-3$ deep segrments. Corolla of one petal, whecl-shaped, in 4-5 (f. 66. a.) deep ovate, acute, spreading segments, longer than the ealyx. Stamens $S$ or 10 ; antbers roundish. Ovarium half superior. Styles 4-5 (f. 66. b.), short, united at their base, which is permanent. Berry globose, its lower half invested with the permanent calyx, whose segments surround the middle part, of one cell, pulpy insidc. Seeds 4, ranged round t]ic 
central pulp, compressed, surrounded by a vertical membranous border. The terminal flower is only 4 -cleft, with $S$ stamens: the rest 5 -cleft; hence according to the rule assumed by Linnæus, this genus is placed in Octandria.-A smooth herb of humble growth, with twice ternate leaves, and terminal capitate green flowers. (f. 66, a.)

1 A. moschatellina (Lin. spec. p. 527.) 4. H. Native of Europe and Siberia, even to Dahuria, in groves, thickets, and under hedges; plentiful in Britain in like situations; in North America in the woods between lat. $54^{\circ}$ and $64^{\circ}$, and the Rocky Mountains between lat. $42^{\circ}$ and $46^{\circ}$. Smith, engl. bot. t. 453. Curt. fl. lond. t. 26. Fl. dan. 94. Moschatellìna tetragòna, Mœnch. meth. 478.-Lob. icon. 674. f. 2.-Cord. hist. 1722. f. Gerard. emac. 1091. Root of

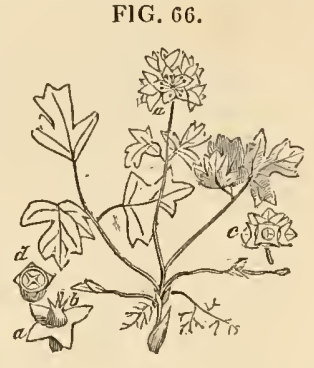
several white imbricated concave scales, producing fibres and runners from their interstices. Stem angular. Radical leaves twice ternate, on long stalks; cauline ones ternate, on long stalks. Flowers with a musk scent, when moist, forming a round head. (f. 66.a.)

Tuberous Moschatcll. Fl. April, May. Britain. Pl. $\frac{1}{3}$ foot.

Cult. The plant will grow freely under the shade of trees; and will be easily increased by the offsets.

II. PA'NAX (from $\pi \alpha v, p a n$, all, and $a$ kos, akos, a remedy ; that is to say, a remedy for all diseases; in allusion to the miraculous virtues which is attributed to $P$.quinquef olium, the ginseng of the shops). Lin. gen. no. 1166. Lam. ill, t. 860. D. C. prod. 4. p. 252.

Lin. syst. Polygàmia, Dix'cia. Flowers polygamous. Margin of calyx very short, obsoletely 5 -toothed. Petals 5 (f. 67 . a.). Stamens 5 , inserted along with the petals under the margin of the disk, alternating with them. Styles 2-3, short. Fruit fleshy, compressed, orbicular, or didymous (f. 67. c.), 2-celled: cells coriaccously chartaceous, 1-seeded.-Herbs, shrubs, and trees, having the leaves and inflorescence variable. The habit of the species is heterogeneous, but the characters of those that are perfectly known agree.

§ 1. Herbaceous plants, with tubcrous roots; and verticillate, petiolate, palmately-compound leaves.-Aureliàna, Cat. car. append. . 16.-Araliástrum, I'aill. serm. p. 43.

1 P. QUINQUeFòlum (Lin. spec. 1512.) root fusiform, a little branched; leaves with 5 leaflets, which are stalked from the top of the common petiole; peduncle of umbel shorter than the petioles; styles and seeds 2. 4 . 1]. Native of North America, in shady mountain woods, from Canada to Carolina; and of the north of Asia, as in Tauria; and the north of China. Sims, bot. mag. 1333. Bigel. med. bot. 2. t. 29. Woodv. med. bot. t. 99 . Blackw. 513 . -Lafit. gins. 51. t. 1. Catesb. ear. 16.-Trew, eluret. t. 6. f. 1. Jartoux, in plil. trans. 20. p. 237. Herb larger than the following species. Flowers yellowish. Berry globose, depressed, red. This plant is a native of Chinese Tartary, and also of North America. In the former country it has been gathered as an invaluable drug from time immemorial. In 1709 the Emperor of China gave orders to 10,000 Tartars to go in quest of the root, and to bring as much as they could find; every one was to give two pounds of the best to the emperor, and to sell the rest for the same weight of fine silver. The roots, which are said to bear some resemblance to the human form, are gathered and dried, and enter into almost every medicine used by the Tartars and Chinese. Osbeck says that he never looked into the apothecaries' shops but they were always selling ginseng, that both poor people and those of the highest rank made use of it, and that they boil half an ounce in their tea or soup every morning, as a remedy for consumption and other diseases. Jartoux relates that the most eminent physicians of China have written volumes on the medicinal powers of this plant, asserting that it gives immediate relief in extreme fatigue, either of body or mind, that it dissolves petuitous humours, and renders respiration easy, strengthens the stomach, promotes appetite, stops vomiting, removes hysterical, hypochondriacal, and all nervous affections, giving a vigorous tone of body, even in extreme old age. The French in Canada use the root for curing the asthma, and as a stomachic. After all, our physicians say that we have no proof of the efficacy of ginseng in Europe, and that from its sensible qualities it seems to possess very little power as a medicine. The Chinese name of yansam or yanson, and the American one garangtonges or garangtoging are both derived from the fancied resemblance in the root.

Five-lcaved Panax. or Ginseng. Fl. Ju. Clt. 1740 Pl. $1 \frac{1}{2} \mathrm{ft}$. 2 P. trifoldum (Lin. spec. 1512.) root globose; leaves of 3 , rarely of 5 leaflets, which are sessile on the top of the common petiole; peduncle of umbel longer than the petioles; styles and seeds 3. 2. H. Native of North America, in low shady woods, from Canada to Georgia. Michx. f. bor. amer. 2. p. 256. Bigel. f. bost. ed. 2. p. 376 . P. pusílla, Sims, bot. mag. 1334. Aràlia triphýlla, Poir. suppl. 1. p. 418.-Pluk. mant. t. 435. f. 7.-Trew. ehret. t. 6. f. 2. A small herb, with the habit of Ancmone nemoròsa. Flowers greenish. Berry greenish, bluntly trigonal.

Three-leaved Ginseng. Fl. May, June. Clt. 1759. Pl. $\frac{1}{2} \mathrm{ft}$.

3 P. pseu'do-gínseng (Wall. in act. soc. med. et phys. calc. 4. p. 117 . pl. rar. asiat. 2. p. 30. t. 137.) tubers of roots in fascicles; leaves in threes or fours, quinate or ternate; leaflets lanceolate, ending in a long taper point, petiolate, much attenuated at both ends, doubly and cuspidately serrated, sometimes deeply serrated, beset with hoary bristles along the nerves and midrib; peduncles terminal, usually trifid, about equal in length to the petioles; flowers hermaphrodite; berries 2-3-seeded. 4. H. Native of Nipaul, on the top of Mount Sheopore. Flowers whitish. Styles 2-3, Berry 2-3-celled, red. 'This species comes very near to $P$. quinquefolium or Ginseng, but is not known to possess any medicinal qualities.

False Ginscng. Fl. June. Pl. 1 to 2 feet.

4. P. tripinna'tum (Wall. cat. no. 4934.) herbaceous, unarmed; leaves triternate; leaflets ovate, acuminated, mucronately serrated, pale beneath, rather downy; panicle long, pubescent; umbellules many-flowered. 4. H. Native of Nipaul, at Gosaingsthan. P. decompósitum, Wall. but not of D. C.

Tripinnate-leaved Panax. P]. 2 to 3 feet.

\$2. Pricklyshrubs. Leaves iernate, or palmately lobed.

5 P. aculea'tum (Ait. hort. kew. 3. p. 448.) stem shrubby; 
branches and petioles prickly; leaves of 3 ovate, or nearly lanceolate, glabrous leaflets; umbels terminal, usually simple, rarely compound, on short peduncles; petals 5. h.G. Native of China. Jacq. coll. 4. p. 175. icon. rar. t. 634. Zanthóxylum trifoliàtum, Lin. spec. 1455. Lam. dict. 2. p. 40. Umbels exinvolucrate. Pedicels purplish. Flowers white, polygamous. Calyx exactly 5-toothed. Styles 2-3, short. Prickles hooked.

Prickly Panax. Fl, Nov. Clt. 1773. Shrub 3 to 5 feet.

6 P. Lovreiria'vum (D. C. prod. 4. p. 252.) stem shrubby; branches prickly: leaves of 3 broad, lanceolate leaflets; umbels terminal, densc; petals 4 . h. G. Native of China, in the province of Canton. Plectrònia Chinénsis, Lour. coch. p. 16i2. This is a true species of Pànax, and probably nothing but $P$. aculcitum. Flowers white. Stamens 5. Berry 2-seeded.

Loureiro's Panax. Slirub 5 feet.

7 P. Ió'rRidum (Smith, in Rees' cycl. 26, no. 10.) slirub bushy and very prickly; leaves simple, palmately lobed, deeply serrated, cordate: with prickly veins; umbels capitate, racemose; styles and seeds $2 . \quad$..

H. Native of the west coast of North America, at Nootka Sound. Abundant on the west side of the Rocky Mountains, from the head-springs of the Columbia to the coast; and of North California, ex Smith ; and of the islands of Kadiak and Sitka, according to Steven. Styles 2, short. Fruit orbicular, pulpy. Racemes hispid. Flowers polygamous. Aràlia occidentàlis, Willd. herb. ex Stev. The entangled stems of this remarkable plant are described as a

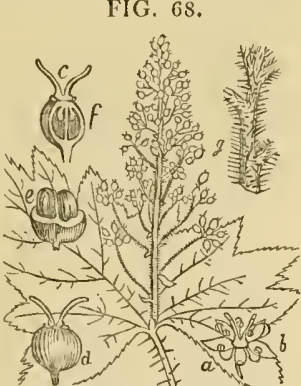
great impediment to travellers in the woods of North America. Hook. fl. bor. amer. 1. p. 273. t. 98. (f. 68.)

Ilorrid Panax. Shrub straggling.

8 P.? Hainla (D. C. prod. 4. p. 253.) stem arboreous, prickly; leaves cordate, 5 -lobed, toothed, coriaceous, glabrous; umbels globose, tomentose, disposed in racemose panicles. h. F. Native of Nipaul, at Narain-hetty. Hédera Haínla, Iamilt. in D. Don, prod. nep. 187 .

Mainla Panax. Tree.

\section{§3. Shrubby, unarmed. Leavcs simple, undivided.}

9 P. cocmlen'tum (D. C. prod. 4. p. 253.) stem thick, frutescent, unarmed; leaves petiolate, cordate, ovate-roundisl, concave, cochleate, spiny-ciliated, and somewhat toothed; nmbels densely capitate, disposed in a panicle. $\zeta_{c}$. S. Native of the Moluccas and Java. Aràlia cochleàta, Iam. dict. 1. p. 224. Schultes, syst. 6. p. 697 . P. scutellarioitles, Reinw. in Blum. bijdr. ned. ind. 880 . P. conchifòlia, Roxb.-Scutellària, Rumph. amb. 4. p. 75 . t. 91

Shell-leaved Panax. Clt. 1820. Shrub 10 to 12 feet.

10 P. Heynea'Num (Wall. cat. no. 4927.) shrubby, unarmed; leaves broad, roundish-cordate, petiolate, quite entire, coriaceous, glabrous; branches of panicle in clusters; umbellules fewHowered, h. S. Native of the East Indies.

Heyne's Panax. Tree.

11 P. símplex (Forst. prod. no. 399.) stem fruticose; leaves lanceolate, serrated; umbels compound. $\eta_{\text {. G }}$. Native of New Zealand. Perhaps the same as $P$. simplicifolium, Dietr. gærtn. lex, 6. p. 633.

Simple-leaved Panax. Shrub.

voL. III.

\section{§4. Unarmed shrubs, with digitate leavcs.}

12 P. Attenua'tum (Swartz, prod. p. 54. fl. ind. occ. 1. p. 562.) stem shrubby, unarmed; leaves petiolate, digitate; stipulas intrapetiolar, nembranous : leaflets 5 , rarely 3 , petiolate, ovate, narrowly acuminated, crenated, glabrous; umbels terminal; branches racemiferous. h. S. Native of Guadaloupe and St. Christopher. Racemes shorter than the leaves. liruit compressed, indchiscent, obtuse, hardish, 2-seeded, rarely 3-seeded. Flowers hermaphrodite, all fertile. Style bifid, rarely trifid.

Ailemuated-leafletted Panax. Clt. 1823. Shrub 10 to $12 \mathrm{ft}$.

13 P. arbòrevm (Forst. prod. 398.) stem arborcous, unarmed; leaves digitate, petiolate; leaflets 5 , obovate, serratetoothed; umbels compound; rays of umbel elongated. $h . \mathrm{G}$. Native of New Zealand. Lin. fil. suppl. 441.

Arboreous Panax. Tree.

14 P.? Gavdiciaúdi (D. C. prod. 4. p. 253. Hook. and Arn. in Beech. voy. pt. bot. 1. p. 84.) stem arboreous, glabrous, unarmed; leaves digitate, petiolate: superior ones opposite; leaflets 5, on long petioles, oval-elliptic, obtuse, remotely and sharply serrated, coriaceous; peduncles terminal, bearing umbels which are disposed in panicles; pedicels very short ; styles 3 ; fruit globosely-trigonal, 3-seeded. $\zeta$. G. Native of the Sandwich Islands, in temperate places. Aràlia trígyna, Gaud. voy. p. 474 . t. 98. This species is very nearly allied to $P$. Lcssonii, and will perhaps, along with it, form a separate genus.

Gaudichaud's Panax. Tree.

15 P.? Lessònis (D. C. prod, 4. p. 253.) shrub glabrous, unarmed; leaves digitate, petiolate; leaflets $3-5$, obovate-lanceolate, cuneated at the base, acute, and quite entire at the apex, or bluntly somewhat toothed; umbels panicled, rising from the upper axils of the leaves, length of leaves. 々. G. Native of New Zealand, where it was gathered by Lesson. Petioles not dilated at the base. Peduncles having the branches umbellately disposed at the apex, the rest scattered. Leaves scattered along the branches. Styles 3, very short, ahmost concrete.

Lesson's Panax. Shrub.

16 P.? ova'tum (Hook. et Arn. in Beech, voy. pt. bot. 1. p. 84.) stem arboreons, glabrous, nnarmed; leaves petiolate: superior ones opposite ; leaflets 3 , on long petiolules, ovate, quite entire, coriaceous. h. F. Native of the Sandwich Islands. Flowers and fruit unknown.

Ovate-leaved Panax. Trec.

17 P. ? platypuýludu (Hook. et Arn. in Beech. voy. pt. bot. 1. p. 84.) stem arboreous, glabrous, unarmed; leaves petiolate : upper ones opposite; leaflets 3 , on long petiolules, transversely oblong, twice as broad as long, apiculated at the apex, coriaceous, quite entire; peduncles terminal, bearing umbels of flowers, which are disposed in panicles. $\mathfrak{h}$. S. Native of Oahu, one of the Sandwich Islands.

Broad-leaved Panax. Tree.

is l'. glabra'tum (H. B. et Kunth, nov. gen. amer. 5. p. 10.) stem arboreous, unarmed; leaves petiolate, digitate; leaflets 5 , petiolulatc, elliptic-oblong, acute at the base, quite entire, glabrous; panicle terminal; umbellules few-flowered. $\eta_{2} . \mathrm{S}$. Native of South America, near La Vente Grande de Caraccas.

Smooth Panax. Tree 20 feet.

19 P. Longi-pethola'tum (Pohl, in litt. ex D. C. prod. 4. p. 253.) stem arboreous, unarmed; leaves on long petioles, digitate, glabrous; leaflets 5-9, oblong, acuminated, acute at the base, entire, or acutely toothed, membranous, on long petioles: adult oncs glabrous, but when young clothed with rusty tomentum beneath. h.S. Native of Brazil.

Long-petioled Panax. Tree. $3 \mathrm{D}$ 
20 P. SPLE'XDENS (H. B. et Kunth, l. c. p. 11.) stem arboreous, unarmed; leaves digitate, on long petioles; leaflets 9 , petiolulate, somewhat oblong, cuspidately acuminated, rounded at the base, or somewhat cordate, sharply and doubly toothed, rather hispid above and silky beneath. $h_{2}$. S. Natire of South America, in the temperate parts of Popayan. Aràlia micans, Willd. mss. in Schultes, syst. 6. p. 701. Flowers and fruit unknown.

Splcndent-leaved Panax. Tree 20 feet?

21 P. serra'tum (Wall. in herb. Moricand. ex D. C. prod. 4, p. 253.) stem shrubby, unarmed; leaves on long petioles, digitate; leaflets 7 , petiolulate, oblong-lanceolate, acuminated, rather bluntish at the base, somewhat serrated, pale beneath, glabrous on both surfaces in the adult state. $々$. G. Native of Nipaul. Umbels many, disposed in a racemose manner.

Scrrated-leaved Panax. Shrub.

22 P. tomentòsum (Wall, in herb. Moricand, ex D. C. prod. 4. p. 254.) stem shrubby, unarmed; leaves on long petioles, digitate; leaflets 5 ? petiolulate, oblong-lanceolate, quite entire, acuminated, somewhat attenuated at the base, glabrous abore, and tomentose beneath. $F_{\imath}$. G. Native of Nipaul. Flowers like those of $P$. serratum, and perhaps, with that species, ought to be excluded from Pànax.

Tomentose Panax. Slirub.

23 P. specròsum (Willd. spec. 4. p. 1126.) stem arboreons, unarmed; leaves petiolate, digitate ; leaflets $7-10$, petiolulate, ovate-oblong, rounded at the base, acute and quite entire at the apex, flat, clothed with silky tomentum beneath; panicles terminal, crowded; umbels of 12-15 flowers. h. S. Native of Caraceas and Porto-Rico, on sterile lills. I'. spinòsa, Poir. suppl. 2. p. 778 . P. undulàtum, H. B. et Kunth, nov. gen. amer. 5. p. 11. t. 417. f. 2. Panicle very showy, rather silky. Petioles 3 feet long; leaflets nearly a foot long.

Shoxy Panax. Tree large.

21 P. Моготото̀n (Aubl. guian. 2. p. 949. t. 360.) stem arboreous, unarmed; leaves petiolate, digitate; leaflets $\bar{\tau}-9$, oblong-lanceolate, attenuated at both ends, quite entire, undulated, elothed with golden tomentum beneath; panicle terminal, diffuse ; umbellules of 8-13 rays. h.S. Native of Cayenne, and the Island of Trinidad. P. elirysophýllum, Vahl. eclog. I. p. 33. P. undulata, Pers, ench. 1. p. 298. but not of Kunth. Fruit compressed, pubescent. Leaflets like the leaves of Chrysophíllum Cainito. Mrototòn is the Guiana name of the tree.

Morotoloni Panax. Clt. 1822. Tree 100 feet.

25 P. seríceun (Pohl, in litt. ex D. C. prod. 4. p. 254.) stem arboreous, unarmed; leaves digitate; leaflets $6-7$, nearly sessile, oblong, obtuse, cuneated, with a revolute entire margin, coriaceous, silky from very fine rusty down beneath; racemes umbelliferous, panicled, elothed with silky rusty do:nn. h. S. Native of Brazil. P. vinòsus, Schlecht, ex Polıl.

Silly Panax. Tree.

\$. Shrubby or herbaccous plants. Leaves pinnate, bipinnate, and pinnately decomponend.

26 P.? Axisum (D. C. prod. 4. p. 254.) stem shrubby, unarmed; branches very hispid; leaves impari-pinnate: with 5-7 oval, quite entire leaflets, which are acute at both ends; umbels terminal, compound. $\zeta$. S. Native of the Moluceas, and other Indian islands. Anìsum Moluceànum, Rumph. amb. 2. p. 132. t. 42. Fruit rather didymons, with the scent of anise-seed.

Anise-scented-seeded Panax. Shrub 10 feet.

27 P. L.eschenau'Ltil (D. C. prod. 4. p. 254 .) stem shrubby, unarmed; leaves pinnate: with 5 petiolulate, broadly ovate, narrowly acuminated, acutely serrated, glabrous leaflets; umbels compound, bracteate. $\zeta_{\imath}$. F. Native of the East Indies, on the Nellighery mountains, where it was gathered under the name of Solé maliquet. Calyx bluntly 5 -toothed.

Leschenaull's Panax. Tree.

28 P. вísugum (Wall. eat. 4987.) unarmed; leaves pinnate; leaflets 5 , broad-ovate, acuminated, smooth, spinulosely serrated, rather oblique at the base; panicle umbellate, compound, spreading; umbellules of many flowers. $h$. G. Native of Nipaul.

Two-paired-leafletted Panax. Tree.

29 P. pinnA'tum (Lam. dict. 2. p. 715.) stem slırubby, unarmed; leaves impari-pinnate; leaflets oval-lanceolate, acuminated, nearly entire, glabrous; paniele terminal ; umbels fewflowered. $h_{2}$. S. Native of the Molnecas. Scutellària seeúnda, Rumph. amb. 4.p. 76 t. 32. Pànax secúnda, Schultes, syst. 6. p. 215 . Berry somewhat compressed.

Pinnate-leaved Panax. Shrub 10 to 12 feet.

30 P. ARMA'Tum (Wall. eat. no. 4933.) stem shrubly, prickly ; rachis of leares jointed, furnished with hooked prickles, particularly at the joints; leaflets ovate, acuminated, serrated, beset with bri-tly hairs on both surfaces, but particularly on the nerves; panicle long, downy; umbellules many-flowered. $\mathbf{I}_{2} . \mathrm{S}$. $\mathrm{Na}$ tive of the East Indies.

Armed Panax. Shrub.

31 P. Findaysoninum (Wall. cat. no. 4936.) shrub furnisbed with hooked prickles on the stems, and rachis of leaves; leaves pinnate and bipinnate; leaflets ovate, acuminated, membranous, coarsely serrated, beset with bristly hairs on both surfaces; panicle large; umbellules many-flowered. $\zeta_{\text {. }}$. S. Native of the East Indies.

Finlayson's Panax. Shrub.

32 P. Fra'grans (Roxb. hort. beng. p. 21.) stem shrubby, unarmed; leaves decompound, having the petiole many times oppositely branched: the ultimate branches of the petiole trifoliate; leaflets ovate, acuminated, entire, petiolulate, the middle one the longest ; panicles loose : ultimate branches short, bearing few-flowered umbellules. 々. G. Native of Nipaul. Hédera fràgrans, D. Don, prod. fl. nep. 187.? but the leaves are not truly ternate, nor the margins setaceously serrated, nor any ways glancous beneath.

Fragrant Panax. Clt. 1816. Shrub.

33 P. rruticosum (Lin. spec. 1513.) stem shrubby, unarmed; leaves pinnately decompound; leaflets petiolate, oval-oblong, acuminated, coarsely and dentately serrated: ultimate ones deeply trifid; panicle corymbose: with the branches umbelliferous at the apex. $T_{2}$. S. Native of the islands of Ternatea, Java, and Amboyna. Andr. bot. rep. t. 595. Blum. bijdr. p. 850 . Scutellària tértia, Rumph. amb. 4. p. 78. t. 33. Styles 3. Berry 2-3-seeded. Leaves bipinnate or tripinnate.

Shrubby Panax. Fl. Aug. Sept. Clt. 1800. Shrub 6 feet.

31. P. oвтu'sum (Blum. bijdr. p. 880.) stem shrubby, unarmed; leaves supra-decompound; leaflets obovate-roundish, entire, or deeply parted, repandly and cuspidately serrated: umbels compound, terminal. $T_{2}$. S. Native of Java, where it is called Kodong-dong.

Obtusc-leafletted l'anax. Shrub.

35 P. sambucrfòlitu (Sieb. pl. exsic. nov. holl. 2. no. 256.) stem shrubby, unarmed; leaves pinnate, and somewhat bipinnate; leaflets petiolulate, distant, oblong, acuminated, remotely serrated; paniele terminal; umbels 10-12-flowered. $\digamma_{\text {. }} G$. Native of New Holland. Styles 2 , acute.

Elder-leaved Panax. Shrub.

36 P. Decompósitum (Wall. in herb. Moricand. ex D. C. prod. 4. p. 255.) stem herbaceons? unarmed; leaves imparipinnate, of $2-4$ pairs of petiolulate, ovate, acuminated, slarply serrated, glabrous, or rather scabrous leaflets; 1 mbels decompound.-Native of Nipaul. Umbellules many-flowered; pedicels $\{-5$ lines long. 
Deeompound-umbelled Panax. Pl. 2 to 3 feet.

Cult. The liardy species of this genus grow best in peat, and are increased by dividing at the root. The other species grow well in a mixture of loam and sand: and are increased by euttings which shonld be planted in sand, with a laand-glass placed over them.

III. CUSSO'NIA (in honour of Peter Cusson, once Professor of Botany in the University of Montpelier: his writings are principally on umbelliferous plants). Thunb. nov. act. ups. 3. p. 212. nov, gen. 1. p. 11 . Lin. fil. suppl. 182. Juss, gen. p. 217. Lam. ill. t. 187. Scluultes, syst. 6. p. 22. D. C. prod, 4. p. 255.

Lin. syst. Pent-IIcptándria, Di-Trigýnia. Margin of caly'x short, entire or with $5-7$ acute teeth. Petals 5-7. Stamens $5-7$, alternating with the petals. Ovarium turbinate, crowned by a broad disk. Styles $2-3$, short, erect, distinct, approximate. Fruit 2-3-celled, roundish, nearly dry.-Caje slirubs; with rather succulent, thick trunks. Leaves glabrons, petiolate, palmate; leaflets 5.7 , 1-nerved, entire, or lobed. Flowers greenisl.

1 C. sptcA'TA (Thunb. nov, act. ups. 3. p. 212. t. 13.) leaves palmate; leaflets petiolate, variously and acutely cut, often trifid at the apex; flowers spicate, exactly sessile along the rachis. h. G. Native of the Cape of Good Hope. Thunb. fl. cap. 247. Ait. hort. kew. 2. p. 115. Shrub glabrous, 8-10 feet ligh. Leaflets usually 7 , rarely 5, lower ones 3 , variously pinnate-parted, ternate at the apex; lobes angularly toothed, very acute. Calyx entire. Flower bud globose. Styles 2-3. Flowers spirally lisposed along the rachis of the spike in 5-6 series.

Spilied-flowered Cussonia. Clt. 1789. Shrub 6 to 10 feet.

2 C. Thyrsiflòra (Thunb. act. nov. ups. 3. t. 12.) leaves palmate; leaflets sessile, cuneiform, obtuse, truncate, tridentate ; flowers racenıse, pedicellate along the rachis. $h_{\text {. }}$ G. Native of the Cape of Good Hope. Jacq. fil. eclog. 1. p. 89. t. 61 . C. thyrsoídea, Thunb. nov. gen. 1. p. 11. Pers. ench. 1. p. 298. Leaflets some of them entire, and a little toothed : others are ternate, varying in number from 3 to 5 . Calyx acutely 5 toothed. Styles 3. There is a variety of this with jointed leaflets, the lowest joints dilated at end into smaller lobes.

Thyrse-flonered Cussonia. Clt. 1795. 'Tree 6 to 12 feet.

3 C. Trí Ptera (Colla, hort. ripul. 43. t. 26.) leaves palmate, leafiets sessile, variously and deeply pinnatifid, trifid at the apex. h. G. Native of the Cape of Good Hope. The leaflets are the number and form of those of $C$. spicata, but they are sessile, as in C. thyrsiflora. Flowers unknown.

Three-ninged Cussonia. Shrub.

Cult. A mixture of peat, loam, and sand is a good soil for the species; and cuttings root readily if planted under a handglass.

IV. MARA'LIA (altered from Aràlia). Pet. Th. nov, gen. mad. p. 13. no. 43. D. C. prod. 4. p. 255. Aràlia species of Schultes.

Lin. sxst. Pentándria, Trigýnia. Margin of calyx small. Petals and stamens 5. Styles 3. Ovarium cylindrical. Berry cylindrical, 3-celled, 3-seeded.-A small shrub, native of Madagascar. Leaves pinnate. Racemes hanging. Umbellules on long peduncles. Berries blackish.-This genus differs from all others in the present order, particularly in the ovarium and fruit being cylindrical, not turbinate nor obovate.

1 M. M adagascariénsis (D. C. prod. 4. p. 255.). দ. S. Native of Madagascar. Aràlia Maràlia, Schultes, syst: 6. p. 704.

Madagasear Maralia. Shrub.

Cult. See Cussomia above for culture and propagation.
V. GILIBE'TitA (named after J. E. Gilibert, a French botanist, author of Chloris de Iyon). Ruiz et Pav. fl. per. prod. p. 50. t. 8. D. C. prod. 4. 1) 255.-Gastònia species, Lam.

Lin. syst. Pent-Decindria, Monogýnia. Margin of calyx entire, drawn out beyond the ovarium. Petals 5-10. Stamens the same number as there are petals, and alternating with them. Ovarim 5-10-celled, crowned by a broad disk above. Stylc short, thick, conical or pyramidal, composed of $5-10$ joined ones, which are erectly conuiving at the apex at first, but at lengt diverging a little. Fruit fleshy.-Shrubs or small trees. Leaves variable. Flowers umbellate, disposed in racemose panicles. This genus differs from Gastomia in the stamens being equal in number to the petals, not double that number as in that genus ; and in the style being thick and pyramidal, hardly divided at the apex, not parted to the base, and stellate.

I G. umbella'ta (Ruiz et Pav. fl. per. 3. p. 75. t. 312.) leaves simple; petioles unarmed; limb oval-oblong, obsoletely denticulated, glabrous; umbels terminal, componnd. $h_{\text {. G. }}$ Native of Peru, in the groves of Munna. Calyx 7-toothed. Petals 7. Style thick, conical; stigınas 7, at length spreading a little. Fruit 7 -celled. Wangenheimia umbellàta and Ginámuia umbellàta, Dietr. ex Stend.

Umbcllalc-flowered Gilibertia. Tree.

2 G. рлLma'ta (D. C. prou. 4. p. 256.) leaves simple, glabrous above, and clothed with rusty pubescence beneatl, cordate, palmately lobed: lobes lanceolate, acute, serrated; petioles long, prickly; flowers umbellate. 々. G. Native of the East Indies, at Chittagong. Gastònia palıàta, Roxb. hort. beng. 33. Lindl. bot. reg. 894. Calys plicate. Petals white, nearly ovate, 5-9. Perliaps G. palmàta, Mess. sc. 1825. in Feruss, bull. 1825. oct. 220. From the description the leaves are said to be nearly peltate; the leaflets petiolate, and the petals wanting. Flowers whitish.

Palmate-leaved Gilibertia. Fl. Feb. Mareh. Clt, 1818. Slirub is to 6 feet.

3 G. REPA'NDA (D. C. l. c.) leaves or leaflets broadly ovate, feather-nerved, coriaceous, glabrous on botlı surfaces, bluntly somewhat attenuated at the base, on short petioles, with repandtoothed margins; Howers umbellate. $\eta^{2}$. S. Native of the Mauritius. Margin of calyx short, entire. Ovarium sulcate, conical in the superior part. Style lardly any; stigmas $5-7$, very short, nearly stellate. The leaves or leaflets being detached from the specimen examined, it is doubtful whether the leaves are simple or compound; but from analogy we would rather consider them as compound.

Ricpand-toothed-leaved Gilibertia. Shrub.

4. G. NaLu'Gu (D. C. l. c.) leaves impari-pinnate: with 5 ovate, acuminated, feather-nerved, coarsely and irregularly-toothed, coriaceons, glabrous leaflets; flowers corymbose. $I_{2}, \mathrm{~S}$. Native of Malabar. Naligu, Rheed. mal. 2. p. 43. t. 26. Gastònia Nalùgn, Lam. dict,2. p. 611. Smith, in Rees' cycl. vol. 15. Petals 5. Stamens unknown. Fruit nearly globose, depressed, blueish black, 8-9-seeded. Flowers whitish or green. Nalug $u$ is the Bralimin name of the tree.

Nalugu Gilibertia. Shrub 8 to 10 feet.

5 G. PANicula'ta (D. C. l. c.) leaves or leaflets broadly obovate, obtuse, feather-nerved, quite entire, coriaceous, glabrous ; flowers panicled, disposed in racemes along the branches of the panicle. 々. S. Native of the Mauritius and Bourbon. The leaves or the leaflets, whichever they may be, are about a foot long, and 6 inches broad. Panicle 6-8 inclies long. Flowers on short pedicels. Margin of calyx entire; flower-bud conical, obtuse, 10-angled. Petals 10, valvate. Stamens 10, alternating with the petals. Style thick, conical, hardly 8-10-lobed at the apex. Ovarium 8, rarely 9-10-celled.

Panicled Gilibertia. Tree. $3 \mathrm{D} 2$ 


\section{+ A species not described.}

6 G. Saururoìdes (D. C. l. c.) h. S. Native of the Moluccas. Gastònica saururoìdes, Roxb. hort. beng. p. 90.

Saururus-like Gilibertia. Tree.

Cult. Shrubs and trees, having handsome foliage. The soil best adapted to grow these is a mixture of sand, loam, and peat; and cuttings are readily rooted, if planted in sand under a handglass in heat.

VI. GASTO' NIA (Commerson instituted this genus in honour of Gaston de Bourbon, son of Henry IV. of France; a promoter of botany). Comm. in Juss. gen. 217. Lam. dict. 2. p. 610 . D. C. prod. 4. p. 256.

Lis. syst. Pcntándria, Digýnia. Margin of calyx éntire, drawn ont beyond the ovarium. Petals $5-16$. Stamens double the number of the petals, 2 of which are opposite each petal. Ovarium 8-12-celled. Styles 8-12, short, concrete at the very base. Fruit 8-12-celled, 8-12-ribbed, nearly dry, ex Juss. capsular.-A tree, native of the Mauritius. Leaves impari-pinnate. Flowers umbellate; umbels exinvolucrate, disposed in panicles.

1 G. cutisfóngla (Lam. dict. 2. p. 610.) h. S. Native of Bourbon, where it is called by the inhabitants bois d' éponge or sponge-nood. G. spongiòsa, Pers. ench. 2. p. 20. Araliaceæ, sieb. f. maur. exsic. 2. p. 197. A tall smooth tree, covered with spongy bark. Leaves at the tops of the branches imparipinnate: with 5 coriacenus, ovate, obtuse, quite entire leaflets. Racemes rising under the leaves, bearing umbels, containing about 20 fiowers each.

Spongy-barked Gastonia. Tree tall.

Cult. See Gastonia above for culture and propagation.

VIl. POLY'SCIAS (from $\pi o \lambda v$, poly, many, and oxu, skia, a shadow; in reference to the numerous umbels). Forst. gen. p. 63. t. 32. Lam. dict. 5. p. 559. ill. t. 320. with a figure. D. C. prod. 4. p. 257.

Lin. syst. Pent-Octándria, Tri-Pentagýnia. Margin of calyx short, denticulated. Petals 5-7, but usually 8 , lanceolate, spreading. Stamens equal in number to the petals, and alternating with them. Style wanting; stigmas $3-5$, short, erectly spreading. Berry globose, crowned by the margin of the calyx and stigmas, 4-celled, 4-seeded Leaves pinnate. Umbels compound or verticillately proliferous; umbellules of many rays, tlat. The rest unknown. A very doubtful genus, but probably only a species of Aràlia.

i 1. PINNA'TA (Forst. J.c.) h.G. Native of the islands in the Southern ocean. P. umbellata, Spreng. ex Steud. nom. 516. A plant has been sent by La Billardicre from New Zealand, under the name of Polýscias, which rather clisagrees with the description given by Forster of his plant, in the branches of the panicle being verticillate, and in the umbellules being 5-7flowered. Margin of calyx nearly entire. Disk fleshy, covering the ovarium. Styles 2-3, erect, approximate, acute. Leaflets oblong, obtuse at the base, and acuminated at the apex, with somewhat denticulated margins.

Pinnate-leaved Polyscias. Tree or slirub.

Cult. See C'ussona, p. 387. for culture and propagation.

VIII. 'TORICE'LLIA (in honour of Dr. Toricelli, who prepared a barometer for the measurement of mountains, and therefore has done something towards tle geography of botany). D. C. prot. 4. p. 257.

Lin. syst. Pentándria, Tetragýnia. Margin of calys acutely 5-toothed. l'etals 5, oblong, attenuated at the base, and uncinately incursed at the apex. Stamens 5 ; filaments very slort ; anthers ovate. Styles 4, straight, short. Berry nearly dry, ovate, crowned by the calyx, 4-celled. Seed unknown.-A small mountain shrub: with terete white glabrous branches, ringed with cicatrices. Leaves alternate, exstipulate, simple, corclate, roundish, membranous, palmately 5-nerved, coarsely and acutely toothed, somewhat 5-lobed, pubescent along the nerves and nervules; petioles rather dilated at the base. Panicle terminal, many flowered. Flowers abortive or polygamous, or the number of parts are rather variable. This genus is nearly allied to Polyscias.

1 T. TILiefòlia (D. C. prod. 4. p. 257.) 々. H. Native of Nipaul, on the highest mountains. Sambùcus? tiliæf òlia, Wall. mss. Leaves $5-6$ inclies in diameter, on petioles 3 inches long.

Lime-tree-leaved Toricellia. Shrub 1 to 2 feet.

Cult. This shrub will grow very well in the open ground, and it may be increased by cuttings or seeds.

IX. ARA'LIA (a name of unknown meaning, under which one species was sent to Fagon from Quebec, in 1764, by one Sarrazin, a French pliysician). D. Don, prod. A. nep. 185. in a note. Kunth, nov. gen. amer. 5. p. 8. in a note. D. C. prod. 4. p. 257.-Aràlia species of Lin. and other authors.-Aràlia veræ, Blum. bijdr. 869 .

Lin. syst. Pentándria, Pentagýnia. Margin of calyx very short, entire or toothed. Petals 5, free, and expanded at the apex. Stamens 5. Styles 5, expanded, spreading divaricately. Berry 5-celled, usually torose. Pyrenæe chartaceous.-Herbs and shrubs, indigenous to North America, with compound Jeaves; and umbellate white flowers, which are usually disposed in panicles.

\section{\$1. Unarmid species.}

1 A. Nudicsu'L1s (Lin. spec. 393.) plant stenuless; radical leaf one, with a trifid petiole : impari-pinnate divisions, bearing each 5 ovate acute serrated leaflets; scape trifid at the apes, shorter than the leaf: each division bearing a many-flowered umbel, without any involucrum. \%. H. Native of North America, from Canada to Carolina, and from Lake Huron tliroughout the woody country to Jat $61^{\circ}$, and the Rocky Mountains; and of Newfoundland. Lam. dict. 1. p. 224. Torr. fl. un. st. 1. p. 327. Big. fl. bost. ed. 2. p. 122. Rafin. med. bot. 1. t. 8.-Pluk. alm. t. 238. f. 5. Petals white, reflexed. Stamens exserted. Styles 3-5, short, erect, distinct. The Crees use the root of this plant as a remedy against the venereal disease, under the name of nanpoosootchepeh, i. e. rabbit-root; and also they apply the bruised bark of its root to recent wounds.-Richardson. The roots were for. merly brought over and sold for sarsaparilla, and some of the inhabitants of Canada make nse of it as such, but it is very different from the true sort. A. nuclicaúlis, Blum. bijdr. p. s70. introduced into Java from Japan, is tistinct from our plant.

Naled-stemmed Aralia. Hl. June, July. Clt. 1731. P1. $\frac{1}{2}$ to 1 foot.

2 A. RAcemòsa (Lin. spec. 393.) stem herbaceous, smootl, divaricately branched; petioles tripartite, the partitions bearing each $3-5$, ovate or cordate, acuminated, serrated, smoothish leaflets; peduncles axillary, and disposed in a terminal raceme, umbelliferous; involıcrum small, of few leaves. $\%$.H. Native of North America, from Canalla to Virginia, in rocky slady situations; throughout Canada, S.c. from Lake Huron to the Saskatchawan. Schkuhr, liandb. 1. t. 86. Hayn. term. bot. t. 38. f. 5.-Corn. can. t. 75.-Moris. luist, sect. 1. t. 2. f. 9. Petals greenish-white, spreading. Styles 5, short, erect, hardly recurved at the apex. Fruit 5-ribbed. Stamens equal in lengt to the petals. The plant is called spikenurd in North America, and is highly csteemed as a medicine. Axillary branclies leafy. 
Racemose-flowered Aralia. Fl. June, Sept. Clt. 1658. Pl. 3 to 4 feet.

3 A. nu'suls (Cav, icon. 4. p. 7. t. 313.) stem herbaceous, glabrous, a little branched; leaves impari-pinnate, pubescent : leaflets cordate, acute, serrated; umbels disposed in terminal racemes; involucra very short, of many leaves. 4. G. Native of New Spain. The fruit, aecording to Cav. icon. is nearly globose. Styles 5, erect, rather distant. Stem variegated with hrown tubercles. Petals green.

IIumble Aralia. Pl. $1 \frac{1}{2}$ foot.

4 A. Pube'scens (D. C. eat. hort. monsp. 1813. p. 80.) stem woody, unarmed, glabrous, branched; leaves impari-pinnate, pubescent; leaflets ovate-lanceolate, serrated, attenuated at the base, and acuminated at the apex; umbels numerous, disposed in a terminal raceme; involuera very short, of few leaves. $h . G$. Native of New Spain. A. seàbra, Presl, in herb. Hænke. Petioles not dilated into auricles at the base. Styles 5, divaricately recurved. Fruit globose, dark purple.

Pubescent Aralia. Clt. 1818. Shrub.

5 A. Híspida (Miclix. fl. bor. amer. 1. p. 185.) stem suffrnticose, very hispid at the base from bristles; leaves bipinnate; leaflets ovate, acute, deeply serrated, glabrous ; petioles hispid ; umbels on long peduncles; involuera of many short setaceous leaves. $\zeta .11$. Native of North America; in stony woods in New England, \&c.; on high mountains in Pennsylvania and Virginia; Canada, from Lake Huron to the Saskatehawan; Hudson's Bay, and of Newfoundland. Vent. hort. cels. t. 41. Sims, bot. mag. t. I0S5. Lodd. bot. eab. 1306 . A. Muhlenbergiàna, Scluttes, syst. 6. p. $70 \%$. does not differ from this species. The shrub is called $W_{\text {ild }}$-clder. Stem panieulately branched at top.

Hispid Aralia. Fl. June, July. Clt. 1799." Shrub 1 foot.

\section{+ Unarmed species, which are not suffeiently known.}

6 A. corda'ta (Thunb. jap. p. 127.) stem almost herbaceons, angular, unarmed, a little branched ; leaves cordate-ovate, serrate-toothed, seabrous on both surfaces; perlicels of umbels tomentose. 4. H. Native of Japan. Dos Jen, Kœmpf. amon. 5. p. 8\%6. Styles 5, divaricate, ex Thunb.

Cordate-leaved Aralia. Pl. ?

7 A. Jarónica (Thunb. fl. jap. I28.) stem slırubby, inarmed; leaves petiolate, $\gamma$-nerved, $\gamma$-lobed: lobes ovate, scrrated at the apex; panicles terminal; peduneles umbelliferous. 々. $H_{\text {. }}$ Native of Japan, near Nagasaki. Banks, icon. Kampf. t. 10. Styles 5, diverging. Berry striated. Petals ovate, acute, reflexed (Thunb.). Leaves coriaceous, glabrous in the adult state, but when young woolly on both surfaces. (Blum. bijjlr. p. 37 I.) Petals white.

Japan Aralia. Shrub 5 to 6 feet.

8 A. Scheffe'ra (Spreng. pug. 1. p, 28.) stem shrubby, smooth; leaves on long petioles, digitate ; leaflets 5 , petiolulate, lanceolate, attenuated at the base, serrulated, glabrous on both surfaces. 々. G. Native of New Zealand. Scheftlèra digitàta, Forst. gen. t. 23. Lam. ill. t, 221. Petals 5, nearly spatulate, erect, not as in the genus Sciadophy'llum, cohering into a calyptra at the apex. Styles 8-10, diverging, not erect, as in Hédera. Berry 8-10 angled.

Scheffler's Aralia. Shrub.

9 A.? остонну'Lla (Lour. coch, p. 187.) stem almost arboreous, unarmed; leaves petiolate, digitate: leaflets $S$, oblong, obtuse, quite entire, glabrous; panicle umbellate. 々.G. Native of Cochin-china. Flowers yellow, of 5 petals. Stigmas 5, sessile. Berry ovate, 5 -sceded. Perhaps a species of $\mathrm{Po}$ ly'scias. Panicle large, ending in umbels, which are without involucra.

Eight-leafletted Aralia. Slurub 10 feet.

10 A.? P.ALAA'tA (Lam. dict. 1. p. 224. but not of Lour.) stem shrubby, unarned; leaves petiolate, pinnately 9-nerved, 9-cleft: lobes laneeolate, serrated; berry sulcately angular, 6-8celled. h.S. Native of the Moluceas.-Rumpl, amb. 4. t. 43. Perhaps a species of Poly'scias or IIédera. Umbels crowded, terminal.

I'almate-leaved Aralia. Slırub.

11 A. ? m'cans (Willd. herb. ex Spreng. syst. 1. p. 953.) leaves digitate; leaflets or lobes $[0$, subcordate, ob]ong, acuminated, mucronately toothed, hispid above, and silky beneath ; heads disposed in racemes, $h$. S. Native country unknown. Perlaps a species of IIédera.

Glitering Aralia. Tree or shrub.

\section{§2. Prickly species.}

12 A. syınòsa (Lin. spec. p. 392.) stem arboreons, and are, as well as the petioles, prickly; leaves doubly and triply pinnate; leaflets ovate, acuminated, deeply serrated ; panicle much branched, beset with velvety stellate down; umbels numerous; involucra small, of few leaves. h. H. Native of North Ameriea, in fertile low woods; of Carolina and Virginia; likewise in the Illinois country. Wats. dend. brit. t. 116 . Comm. lort. amst. I. t. 47. Plik. alm. t. 20. Selımidt, arb. 102 and 103. A tree about 8-12 feet ligh, with a simple stem. Petals white, reflexed. Styles 5, divaricate, arched. Fruit 5-ribbed. Known under the name of angelica-trce. The berries used in an infusion of wine or spirits are a remarkable medicine for relieving rheumatic pains.

I ar. ß3, inérmis (Pursh, fl. amer. sept. 1. p. 209.) stem spinose, glaucous; petioles unarmed. h. H. Native of South Carolina, near Charlestown.

Spiny Aralia or Angelica-tree. Fl. Aug. Sept. Clt. 1688. Tree 8 to $12 \mathrm{feet}$.

13 A. Monta'ina (Blum. bijdr. p. 870.) stem arboreseent, and are, as well as the petioles and base of the leaves, prickly; leaves decompound; leaflets ovate, acuminated, oblirpuely subeordate at the base, doubly serrated, hairy on both surfaces; panicle branched; flowers umbellate. $\zeta$.S. Native of Java, on the mountains of Seribu, where it is called Kibohoya.

Mountain Aralia. Shrub 8 to 10 feet?

14 A. Chinénsis (Lin. spec. 393.? Blum. bijdr. p. 8i0.) stem arborescent, and is, as well as the petioles, prickly; leaves bipinnate, decompound: leaflets ovate-oblong, acuminated, unequally rounded at the base, sharply serrated, villous; panicle branched; flowers glomerate. $\zeta$. S. Native of Java, on the mountains (Blum.), China (Lin.), Lour. eoch. 187. Styles diverging, revolute. Petioles villous, bearing a few straight prickles. The figure in Rumph. amb. 4. t. 44. cited by limnaus for this plant, is a species of Lec̀a. Lourciro describes the plant as very troublesome to travellers, with its numerons crooked prickles, as it elimbs in the herlges. According to him the eorolla is white. Styles scarcely any.

China Aralia. Tree 10 to 12 feet.

15 A. rrina'cea (Hook. in Brewst. edinb. jouru, sc. 1827. p. 6 k.) stem very spiny; leaves nearly palmate, very acute: lobes cut; petioles and nerves of leaves spiny; umbellules glohose, disposed in racemes. h. H. Native of the west coast of Nortl America, in Queen Charlotte's islands.

lirinaccous Aralia. Shrub.

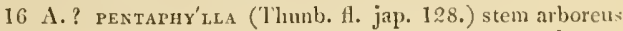
prichly; leaves digitate: leaflets 5 , ovate, acute, somewhat petiolate, serrated at the top; tumbels simple, pedunculate. h. II. Native of Japan. Pànax spinòsa, Lin. fil. suppl. 4t1, ex Lan. dict. 2. p. 715 .

Five-lcaved Aralia. Tree.

Cult. The hardy herbaceous species of Aràlia grow hest in peat or vegetable mould, and are increased by dividing at the 
root, or by seed. The hardy shrubby kinds also grow best in peat-earth, and are very ornamental and curious; they are increased by seeds brought from the places of their natural growth, which do not vegetate until the second year; or by slips of the roots. The other species being either green-liouse or stove plants, require to be grown in pots, in a mixture of loam, peat, and sand; and cuttings of them root readily under a handglass.

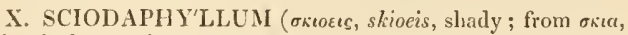
skia, shadow, and $\phi v \lambda \mathrm{Nov}$, phyllon, a leaf; the leaves are large, and usually digitate, and afford much shade). P. Browne, jam. p. 190. Poir. dict. 6. p. 745. Spreng. syst. 1. no. 1189 . Bhum. bijdr. p. 874 . D. C. prod. 4. p. $259 .-$ Actinophýllum, R. et Pav, fl. per. prod.-Arâlia species, Blume, in liti, Se.

Lin. srist. Pentándria, Pentagýnia. All as in Aràlia, but the petals cohere in the form of a calyptra at the apex, notwithstanding it ought perliaps still to be joined with Arália.

\section{\$1. Leaves simple, undivided.}

I S. Hu'Mue (Blum. bijdr. p. 875.) shrub parasitical, diffuse ; leaves simple, ovate-oblong, acuminated, distantly serrated, coriaceous, glabrous; racemes terminal ; flowers umbellate, tetrandrous. $h_{\text {. }} \mathrm{s}$. Native of Java, in woods on Mount Salak.

Humble Sciodaphyllum. Shrub diffuse.

\section{\$. Leaves simple, palmate-lobed.}

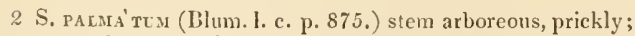
lcaves membranous, glabrous, palmately 5-9-parted: segments lanceolate, serrated from the middle to the apex; racemes axillary; flowers umbellate, with $8-12$ stamens. h. S. Native of Java, in humid parts of woods on the mountains, where it is called tjanluran by the natives. Fruit hemispherical, 6 lines in diameter.

Palmatc-leaved Sciodaphyllum. Tree.

\section{\& 3. Leaves trifoliate.}

3 S. sca'ndens (Blum. bijdr. p. 878.) stem shrubby, scandent; leaves trifoliate; leaflets lanceolate, much acuminated, quitc entirc, coriaceous, glabrous: the middle one on a long petiole; racemes crowded, terminal, divaricate; flowers umbellate, pentandrous. $h \cdot \cup \cdot \mathrm{S}$. Native of Java, in woods on Mount Tjerimai.

Seandent Seiodaphyllum. Shrub cl.

4. S. PARAsíticua (Bhm. bijdr. p. 877.) stem shrubby, parasitical; leaves ternate: leaflets oblong, acuminated, obtuse at the base, remotely serrated, coriaceous, glabrous, nearly veinless; racemes axillary and terminal, solitary or twin; flowers umbellate, hexandrous. r. S. Native of Java, at the foot of Mount Salak, where it is called Ramo giling huntjc.

Parasitic Sciodaphyllum. Shrub parasitical.

\section{\$4. Lcaves digitate. \\ * East Indian species.}

5 S. subave'Ne (B]um. bijdr. p. 876.) stem frutescent; leaves digitate: leaflets $3-5$, oblong, acuminated at both ends, coriaceous, nearly veinless; raccmes crowded, terminal, diverging; flowers umbellate, pentandrous. $h$. S. Native of Java, on Mount Salak, in woods, where it is called Ramo-huntje by the natives.

Nearly-2cinless-leaved Sciodaphyllum. Shrub.

6 S. Tomentòsum (Blum. bijdr. p. 877.) stem pubescent ; leaves digitate; leaflets $5-7$, oblong, acuminated, rounded at the base, shining above, but clothed with stellate tomentum beneath; racemes panicled, axillary, and terminal; flowers umbellate, pentandrous. $h_{2} . \mathrm{S}$. Native of Java, in woods on Mount Burangrang.

lar. $\beta$, farinòsum (Blum. bijdr. p. 875.) leaflets 7 , ending in a long taper-point each. $h_{\text {. }} \dot{S}$. Native of the west of Java, in mountain woods, where it is called Pangany tapols. Actinophýllum farinosum, Blum. cat. hort. buit. p. 4\%.

Tomentose Sciodaphyllum. Shrub.

7 S. ellípticum (Blum. bijdr. p. 878.) stem shrubby, scandent; leaves digitate; leaflets $5-7$, rarely 3 , elliptic, acutish at both ends, coriaceous, glabrous; panicle terminal, divaricate; flowers umbellate, pentandrous. $h$. $\cup$. S. Native of Java, at the foot of Mount Salak, where it is called Ramo-gunti by the natives. Petals purplish.

Elliptical-leafletted Sciodaphyllum. Shrub cl.

8 S. Divarica'tum (Blum. bijdr. p. 876.) stem arborescent, sometimes scandent; leaves digitate: leaflets $5-9$, petiolulate, oblong, bluntish at both ends, glabrous; racemes panicled, terminal; flowers umbellate, pentandrous. $h . S$. Native of Java, on the moumtains in humid woods, in the province of Buitinzorg, where it is called Ramo-giling or Sanga-boanah. Actinophyllum divaricàtum, Blum. cat. hort. buit. p. 42. and in flora 1825. p. 147 .

Divaricate Scioctaphyllum. Shrub cl.?

9 S. LU'сנDUм (Blum. bijdr. p. 877.) stem arborescent; leaves digitate: leaflets 11-12, oblong, acuminated, rounled at the base, coriaceous, glabrous; racemes crowded, terminal, divaricate, glabrous; flowers umbellate, pentandrous. $\zeta$.S. Native of Java, on the top of Mount Salak.

Shining Sciodaphyllum. Tree.

\section{* American species.}

10 S. Brótvall (Spreng. syst. 1. p. 953.) stem arboreous; leaves digitate; leaflets $7-11$, nearly umbellate, petiolulate, oblong-lanceolate, glabrous, unequal; racemes compound, very long, nutant; flowers nearly capitate, pentandrous; corollas hemispherical. $h_{2}$. S. Native of Jamaica, on the mountains in woods. Sciodaphy'llum, Browne, jam. 195. t. 19. f. 1. Aràlia Sciodaphy'llum, Swartz, prod. 55. Hédera Sciodaphy'llum, Swartz, fl. ind. occ. 1. p. 519. Schules, syst. 5. p. 510 . Vitis heptaphy'lla, Lin. mant. p. 210. ex Smith, exclusive of the country. The central leaflets of the leaves are smallest. Anthers purple.

Bron'ne's Sciodaphyllum. Clt. 1793. 'Tree 10 to 15 feet.

11 S. cónicum (loir. dict. 6. p. 746.) stem shrubby; leaves digitate: leaflets $7-13$, petiolulate, oblong, abruptly acuminated, coriaceous, glabrous, reticulately veined ; racemes $2-3$, rather velvety; flowers capitate, with 7-8-9-10-11 stamens; corollas conical. $\hbar_{2}$. S. Native of Peru, in groves. Actinophy'llum cónicum, Ruiz et Pav. fl. per. 3. p. 7\%. t. 309 . Heads of Howers about the size of a pea. Corollas of a whitish-red colour. Branches violaceous.

Conical-flowered Sciodaphyllum. Slurub 10 to 12 feet.

12 S. pentándrua (Poir. dict. 6. p. 7 \%.) stem shrubby, somewhat arboreous ; lcaves digitate : leaflets $7-11$, petiolulate, oblong, acuminated at the apex, coriaceous, glabrous above, but beset with stellate pili bencath; racemes 1-3, woolly; flowers capitate, pentandrous; corollas conical, obtuse. $々$. S. Native of Peru. Actinoply'llum pentándrum, Ruiz et Pav. fi. per. 3. p. 75. t. 311 . Corollas of a whitish purple colour; anthers yellow. Berry whitish, about the size of a cherry. Leaflets darkbrown beneath. Racemes pale-reddish.

Pcntandrous Sciodaphyllum. Clt. 1820 . Tree 18 to $20 \mathrm{ft}$.

13 S. ANGULA'TUm (Poir. dict. 6. p.745. exclusive of Browne's synonyme, stem arboreous ; leaves digitate: leaflets $7-11$, petiolulate, oblong, acuminated, concave at the base, shining above, 
but clothed with powdery velvety rusty down beneath; racemes elongated, granular; flowers eapitate, with $7-9$ stamens; corollas obovate, angular, and truncate. $\zeta_{2}$. G. Native of Peru and New Granada, on shady hills. Actinopliy'llum angulàtum, Ruiz et Pav. A. 5. p. 73. t. 307 . H. B. et Kunth, nov. gen. amer. 5 . p. 9. Heads of flowers about the size of a walnut, yellowish. Berry dark purple, cuneiform, angular. Styles 4-6.

Angular Sciodaphyllum. Tree 20 to 30 feet.

14. S. PLdicela'tum (Poir. dict. 6. p. 746.) stem scandent ; leaves digitate: leaflets $9-13$, petiolulate, oblong, acuminated, somewliat sinuately undulated, and concave at the base, glabrous; racemes many; flowers pedicellate, umbellate on the branches; corollas hemisplerieal. $\mathbf{b}$. G. Native of Perı, in groves at Munna. Actinophy'llum pedicellàtum, Ruiz et Pav. f. per. 3. p. 73. t. 308 . Stem rooting, filled with medulla; branches purplish. Racemes purplish, a foot long. Stamens 6-7. Berries angularly globose, greenish purple.

Pedicellate-flowered Seiodaphyllum. Shrub el.

15 S. acumina'tum (Poir. dict. 6. p. 746.) stems scandent; leaves digitate: leaflets $7-11$, petiolulate, oblong, obliquely acuminated, coriaceous, glabrous, reticulately veined; racemes $2-5$, tomentose; Howers pentandrous and octandrous, capitate; corollas hemisplerical, apiculated. $\zeta_{2} . \mathrm{G}$. Native of Peru, in groves. Actinophy'llum acuminàtun, Ruiz et Pav. fl. per. 3. p. 74. t. 310 . Corollas yellow, disposed in heads, which are a little larger than a pea. Styles 5 .

Acuminatcd-leaved Sciodaphyllum. Shrub el.

16 S. anómalum (G. Don, in Loud. hort. brit. p. 112.) arboreus; leaves digitate : leaflets $5-7$, oblong-lanceolate, acuminated at the apex, green and smooth on both surfaces: onter ones the smallest ; umbels eapitate, panicled; branches green and smootl. h. S. Native of 'Trinidad, in woods. Carolinea insignis, Hortul. Flowers whitish yellow. Largest leafiets 1 foot long.

Anomalous Sciodaphyllum. Clt. 1817. Tree 20 feet.

17 S. Quindue'nse (D. C. prod. 4. p. 261.) stem shrubby, scandent; leaves digitate : leaflets 7 , oblong, acuminated, quite entire, glabrous; umbels 4-flowered, racemose; flowers with 8-10 stamens. $h . \cup$. G. Native of the Andes, abont Quindiu, at the height of 3300 feet above the level of the sea. Aràlia Quinduénsis, H. B. et Kunth, nov. gen. amer. 5. p. S. t. 417 . f. 1. Styles 3-10, spreading. Petals cohering at the apex. Fruit 8-10-ribbed. Perhaps a species of Aràlia.

Quindiu Sciodaphyllum. Shrub el.

Cult. All the species are wortl cultivating in gardens for the sake of their fine handsome large foliage. A mixture of loam, peat, and sand is a good soil for them; and they are easily increased by cuttings under a hand-glass in sand, placed in a moderate heat.

XI. HE'DERA (a name for wlich many etymologies have been offered. The best explanation is, that it has been derived from hedra, cord in Celtic, lierre in French. The English name of ivy is derived from the Celtic word i $\mathrm{w}$, green, from its being always green. The word $i w$ is given to Táxus by the French, hence also the English name of the genus $Y^{(e w)}$. Swartz, fl. ind. occ. p. 518. D. Don, prod. nep. p. 186. Gærtn. fruct. 1. t. 26. D. C. prod. 4. p. 261.-Aràlia sect. Gymuapteina, Blum. bijdr. p. 871 . - Hédera and Aràlia species Lin. and all other authors.

Lin. syst. Pent-Decándria, Pcnt-Decagýnia. Margin of calyx elevated or toothed. P'etals $5-10$, not coliering at the apex in the form of a calyptra. Stamens 5-10. Styles 5-10, conniving, or joined in one. Berry 5-10-celled.-Climbing or erect shrubs. Leaves simple or compound. Flowers umbellate or capitate.

\section{\$1. Leaves simple, undivided, or lobed.}

1 H. HÉLIX (Lin. spec. 292.) stems climbing, throwing out roots from the side by which it is placed to any substance; leaves coriaceous, glabrous, shining, with 5 angular lobes; those on the old upright branches, which form the tops of the plants, ovate, acute, quite entire; umbels simple, pubescent. $h_{2}$. $\checkmark$. H. Native of Europe. Common ivy is a valuable ornamental evergreen climbing shrub. It is useful for covering walls and sides of houses, or training into fanciful shapes, as of human figures, \&r. on skeletons of wire-work, or trained up to a stake, so as to form a standard; but when ivy has reached to the top of any support, the branches shorten, and become woody, forming themselves into large bushy heads, and the leaves become entire and more of an oval shape, and not divided into lobes like the lower ones, and in this state they produce flowers at the end of every shoot. 'The berries aje black at maturity. The flowers are yellowish, and appear late in the season, and in consequence is much resorted to by bees and flies, when little other food is to be liad. The berries increase during the winter, are full formed in February, and ripen in April; furnishing food for wild pigeons, blackbircls, thrushes, Sic. in the spring. Blackbirds, and several other birds, build their nests in the stumps of ivy tufts. Sheep are fond of the leaves, especially during severe weather. The ancients held ivy in great esteem, and Bacehus is represented erowned with it to prevent intoxication; and Homer describes his heroes as drinking out of a cup made of the wood. Haller says, that the leaves are given in Germany as a specific in atropus in children. Common people apply them to issues and corns. The berries are aperient and emetic. The wood is soft and porous, so as to transmit liquids if turned of a sufficient degree of thinness. The roots are used by leather-cutters to whet their knives upon. The whole plant is rather aromatic; and a very fragrant resin exucles from the old stems when bruised. The specific name Hìlix is clerived from $\varepsilon \iota \lambda \varepsilon \omega$, eilco, to encompass or turn round; in reference to the twining stems.

I'ar, a, vulgàris (D. C. prod.4. p. 261.) pedicels elothed with stellate down; floral leaves ovate; fruit black; leaves of the rooting branches 5 -lobed, with white veins. $\zeta . \cup$. H. Native of Europe, in woods, hedges, and on old buildings. Hédera Hèlix, Lin. spec. 292. Smith, engl. bot. t. 1267. Curt. lond. fasc. 1. t. 16. Fl. dan. t. 1027. Bull. fr. t. 183. Drev, and Hayne, pl. europ. t. 66. There is a variegated-leaved varicty of this in the gardens.

Far. B, Canariónsis (D. C. prod. 4. p. 261.) pedicels beset with lepidotted pubescence; floral leaves subcordate: those of the ereeping branches 5 -lobed, larger than those of the common ivy; fruit red. 5.4 . H. Native of the Canary Islands. Hédera Canariénsis, Willd. in berl. mag. 2. p. 170. t. 5. f. 1 Schultes, syst. 5. p. 508. In the gardens this is ealled Irish Ivy.

Var. $\gamma$, chrysocárpa (D. C. prod. 4. p. 261.) pedicels lepidotted ; floral leaves elliptic, usually cuneated at the base ; fruit yellow. $h$. H. Native of the north of India. H. Helix, Wall. in Roxb. fl. ind. 2. p. 515 . D. Don, prod. A. nep. 187. It differs from var. $a$, vulgàris in the stature being more gigantic, in the leaves being much more cuneated at the base, in the pedicels being lepidotted, in the berries being yellow and ustally 5-sceded. H. Poética, C. Baul. pin. p. 305. H. chrysocárıos, Dalech. lugd. H. Dionýsias, J. Bauh, hist. with a figure.

Ilelix or Common Ivy. Fl. Oct. Britain. Shrub cl.

2 H. corymbòsa (Choisy, mss. in herb. D. C. ex prod. 4. p. 262.) stem arboreous, bushy; learcs cordate, acute, bluntly 5-angled, when young velpety on the nerves beneath, but in the adult state glabrous on botli surfaces; flowers corym- 
bose. 2. . H. Native of the Canary Islands, where it has been probably introduced, and is called Pcpila de St. Augustin. Ihis is probably nothing but the Irish ivy of the gardens.

Corymbose-flowered lvy. Slurub el.

3 H. Polyacáxтна (Wall. cat. no. 4907.) stem beset with short, conical prickles; leaves glabrons, 5-lobed, cordate at the base: lobes serrated; panicle large, pubescent; umbellules many-flowered, furnished with woolly scales at the hase of the pedicels; Hower buds white from pubescence. $々$.H. Native of Nipaul.

\section{Many-spined lvy. Tree.}

4. I1. ARBòrea (Swartz, fl. ind. occ. p. 518.) stem arboreous, usarmed; leaves oval, acuminated; racemes terminal; umbels pedunculate; pedicels longer than the flowers. h.S. Native of Jamaica and Porto Rico. Aràlia arborea, Lin. amon. acad. 5. p. 369. Jacq. hort. schoenbr. t. 51. Leaves feather-nerved at the base, not 3-nerved, as in $I I$. capitata. Flowers almost umbellate; umbellules girded by short scarious involucels. Berry hexagonal.

Trce Ivy. Tree 10 to 12 feet.

5 H. PE'NDElA (Swartz, H. ind. occ. 1. p. 512. icon. t. 9.) stem arboreous, unarmed ; leaves ovate, lanceolate, entire; unbels almost capitate; peduncles very long, drooping. h. S. Native of Jamaica, on the higher mountains. Willd. spec. 1179. Schultes, syst. 5. p. 509. Petals oblong, spreading. Style short. Berry 5 -sceded.

Pendulous-umbelled lvy. Clt. 1824 . T'ree 12 to 15 feet.

6 11. umbellífera (D. C. prod. 4. p. 262.) stem frutescent, unarmed; leaves on long petioles, lanceolate, acuminated, rarely serrated; peduncles umbellate, trifid; umbellules capitate, nearly globose, $\eta_{2}$.S. Native of Amboyna, on the mountains. Pscùdo-sántalum Amboinénse, Rumph. amb. 2. p. 54. t. 12. Aràlia umbellífera, I،am. dict. 1. p. 225 . Schultes, syst. 6. p. 697. There is a yellow gum issues from this tree, which becomes blackish on drying, and is swcet scented, which is called Saruru in Amboyna. Flowers whitish.

Lmbelliferous Ivy. Tree.

7 H. cunca'ta (D. C. prod. 4. p. 262.) stem arboreous, unarmed; leaves petiolate, broadly oblong, acute, quite entire, cuneated at the base, membranous, glabrous, with pinnate nerves: the 2 lower nerves parallel with the margins, rising from an acute angle; umbels terminal, of many rays; heads half globose. r. S. Native of Brazil, where it was collected by Schott. Aràlia umbellàta, Pohl, in litt. but not of Lam.

Cuncate-leared lvy. 'Tree small.

8 H. NU'Tans (Swartz, fl. ind. oce. 1. p. 514.) stem arboreous, unarmed; leaves elliptic, acutish, coriaceous, entire; umbels nodding, hemisplerical; peduncles erectish. $h_{2} . \mathrm{S}$. Native of the south of Jamaica, on the tops of the Blue Mlomntains. Very like $I I$. péndula, but the perlmucles are shorter, the petioles terete, and the petals reflexed. Style short, 5 -angled.

Drooping-mbelled lvy. Tree 10 to 15 feet.

9 H. ramizlòra (D. C. prod, 4. p. 26\%.) stem arboreous, unarmed; leaves petiolate, acute, quite entire, membranous, glabrous, hardly cuneated at the base, with pinnate nerves: the 2 lower nerves parallel to the margin, and rising from an acute angle; racemes few, rising from the old branches; umbels semiglobose. $\eta$. S. Native of Brazil, where it was collected by Sichott. Aràlia ramiftòra, Pohl, in litt. Flowers $15-16$ in each umbel, pedicellate.

Branch-flowcred lvy. Tree 10 to 15 feet.

10 11. capita'ta (Smitl, icon. pict. rar. 1. t. 4.) stem arboreous, unarmed; leaves elliptic, acnminated, entire, with pinnate nerves: the 2 lower nerves rising from an acute angle; raceme terminal, compound; umbels capitate, on long peduncles; flowers sessile. $々$. S. Native of Jamaica, Guadaloupe, and the province of Caraccas, in subalpine places. Swarts, fl. ind. occ. p. 546 . H. B. et Kuntl, nov. gen. amer. 5. p. 2. Sclultes, syst. 5. p. 510 . Aràlia capitàta, Jacq. amer. 89. t. 61. Petioles long, terete. Leaves cuneated at the base, 3-nerved. (Horn. add. 125.) Flowers as if they were in a calyculate receptacle. Petals oblong, acute, white. Berry globose, 5-celled. Styles 3-5, contiguous, joined at the base, at length reflexed.

Capitale-flowered Ivy. Fl. Oct. Nov. Clt. 1823. Tree 50 to 60 feet.

11 H. multiflòra (D. C. prod. 4. p. 262.) stem arboreous, unarmed; leaves on long petioles, oblong-elliptic, acuminated, somewhat cuneated at the base, quite entire, nembranous, glabrous, with pinnate nerves: the 2 lower nerves remote from the rest, parallel with the margin, and rising from an acute angle; racemes panicled, diverging: heads globose. $\zeta$. S. Native of Brazil, where it was collected by Schott. Aràlia multiflòra, Pohl, in litt.

Many-flowered Ivy. Tree 10 to 12 feet.

12 H. Mutisin'na (D. C. prod. 4. p. 262.) stem arboreous? unarmed; leaves oblong, somewhat serrulated at the apex, acute, rounded at the base, coriaceous, glabrous, shining; ra-

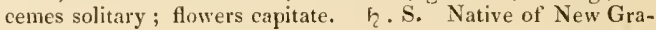
nada, at the altitude of from 8000 to 4000 feet. A ràlia Mutisiàna, H. B. et Kunth, nov. gen. amer. 5. p. 1. Aràlia heterophylla, Mut. but not of Willd. Styles 5, short, conniving.

Mutis's Ivy. 'Tree or shrub.

13 H. ovA'TA (Wall. cat. no. 4911.) stem unarmed; leaves ovate, elliptic, quite entire, coriaceous, ending in a short blunt point, rusty beneath ; peduncles axillary, solitary, and terminal, umbellate; umbellules many-flowered. $h$. S. Native of Madras.

Ovate-leaved Ivy. Shrub.

14 H. acutiròla (D. C. prod. 4. p. 263.) stem arboreous; leaves roundish-ovate, acuminated; nmbels corymbose. h. S. Native of South America. Humb. and Bonpl. Aràlia acutifòlia, Willd. in Schultes, syst. 6. p. 697.

Acute-lcated lvy. Tree or shrub.

15 H. AViceñiffòlia (D. C. prod. 4. p. 263.) arboreous, tmarmed; leaves oblong-lanceolate, acute at the apex, and acutish at the base, quite entire, coriaceous, glabrous above, but clothed with white tomentm beneath; corymbs branched; flowers capitate. $々$.S. Native of South America, in the province of Quito, between Tambo de Burgay and Delay, at the altitude of 4000 to 5000 feet. Aràlia avicemniæfólia, H. B. et Kunth, nov. gen. amer. 5. p. 2. t. 2. Aràlia tarchonanthif òlia, Willd. in Schultes, syst. 6 . p. 698. Styles 4-5, short, connivent. Aricennia-leaved Iry. Tree.

16 H. Cumanénsis (D. C. l. c.) stem arboreous, unarmed; leaves ovate, acuminated, cuneated at the base, quite entire, somewhat 3-nerved, membranous, glabrous, shining. Natice of Cumana, in shady places at Mount Cocollar, at the elevation of 1200 feet. Aràlia Cumanénsis, H. B. et Kunth, nov. gen. amer. 5. p. 3. Flowers and fruit unknown.

Cumana lvy. T'ree.

17 H. сатадpefòlia (D. C. 1. c.) stem arboreous; leaves ovate, subcordate, acuminated, quite entire, glabrous; racemes short, bracteate at the base; heads of flowers globose. T.S. Native of South America. Humb. et Bonpl. Aràlia catalpæfòlia, Willd. in Schultes, syst. 6. p. 697.

Catalpa-leaved lvy. 'Iree or shrub.

18 H. septemnérvia (D. C. l. c.) stem arboreous? unarmed; leaves ovate, acuminated, rounded at the base, 7 -nerved, rather coriaceous, glabrous; racemes panicled; heads globose. h.S. Native of New Granada, at the altitude of 4000 feet. Aràlia septemnérvia, H. B. et Kunth, nov. gen. amer. 5. p. 3. Said to be hardly distinet from $H$. capitàta. Style 1 . 
Seen-nerved-leaved Ivy. Tree or shrub.

19 H. TukbacE' Nsis (D. C. 1. c.) stem arboreous; leaves on long petioles, acute at the base, membranous, glabrous, of one colour; sone of them are unclivided, and otlers are trifid at the apex: with the lobes or segments entire and acuminated : laving the recesses betwcen the lobes rounded. $\eta_{2}$. S. Native of Nesv Granada, in lot places near Turbaco, where it is called Arbol de Guaco. Aràlia Turbacénsis, H. B. et Kunth, nov. gen. amer. 5. p. 3. Flower and fruit unknown.

Turbaco Ivy. Tree 40 to 50 feet.

20 H. Díscolor (D. (.. l. c.) stem arhoreous? leaves petiolate, rather coriaceous, glabrous, rounded at the base, shining above, and of a rusty-purplish colour bencath: some of them undivided and 1-nerved, and others are 3-nerved and trifid at the apex: having the lobes somewhat acuminated, the intermediate one the longest; racemes panicled; heads globose. $h$. S. Native of New Granada? Aràlia díscolor, I1. B. et Kuntl, nov, gen. aner. 5. p. 4. Flowers and fruit not suffieiently known.

Discoloured-leaved Ivy. Tree or shrub.

21 H. ARGENTA'TA (D. C. 1. C.) stem arboreous, unarmed; leaves petiolate, coriaceous, glabrous and shining above: but marked by silvery dots beneath; some of which are undivided and 1 -nerved, and others are 3-nervel and trifid at the apex : having the lobes or segments somewhat acuminated: the intermediate lobe remotely serrated; racemes panicled; heads of flowers glo-

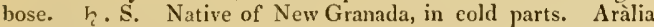
lieterophýlla, Willd. in Scluutes, syst. 6. p. 698. Aràlia argentàta, H. B. et Kunth, nov. gen. amer. 5. p. 4. t. 414. Styles 3, conniving. Petals white.

Silvery-dotted Ivy. Tree 15 to 20 feet.

22 H. crassine'rvia (D. C. l. c.) stem arborcous? leaves petiolate, acute at the base, coriaceous, glabrous above and shining, densely beset with rusty dots beneath: some entire, ovate-oblong, and others 3 -lubed and somewhat aeuminated; racemes panicled; heads globose. h. G. Native of Sonth America, along with 11 . argentàta. Aràlia crassinérvia, H. B. et Kunth, nov, gen. amer. 5. p. 5. Styles 5-6, conniving.

Thick-nervel-leaved Ivy. 'Tree.

$28 \mathrm{H}$. овтusíloba (D. C. l. e.) stem arboreous? leaves petiolate, truncately rounded at the base, 5-nerved, coriaceous, glabrous and shining above, but beset with fusceseent dots beneath, 5-cleft: segments obtuse, ovate-oblong; racemes panicled; heads of flowers elliptic-globose. h.s. Native in tem. perate places towards Loxa, at the altitude of 3300 feet. Aràlia obtusiloba, H. B. et Kunth, nov. gen. amer. 5. p. 5. Willd. in Schultes, syst. 6. p. 699. Petals white, glabrous. Styles 4, conniving.

Blunt-lobed-leaved Ivy. Tree or shrub.

24. H. ANGLLA'Ris (D. C. prod. 4. p. 263.) stem arboreous; leaves 5 -angled, obtuse, tomentose bencath; flowers capitate. h.S. Native of South America, Humb, et Bonpl. Aràlia angulàris, Wil]d. in Schultes, syst. 6. p. 698.

Angular-leaved Ivy. 'Tree.

25 A. Platanifòla (D. C. l. e.) stem arboreous; leaves petiolate, coriaceous, glabrous above and shining, but clothed with rusty tomentum beneath, truncate at the base, 7-nerved, 7-cleft at the apex : lobes or segments oblong, acuminated, quite entire; racemes panicled; heads of flowers globose. $h$. G. Native of Peru, on the western declivity of the Andes. Aràlia platanifòlia, H. B. et Kuntl, nov, gen. amer, 5. p. 6. t. 415. Willd. in Schultes, syst. 6. p. 699. T'ree 15-20 feet. Styles 4-5. Petals white, tomentose on the outside.

Platanus-leaved Ivy. Tree 15 to 20 feet.

26 H. ACERifòlia (D. C. prod. 4. p. 264.) stem arboreous; leaves 5 -lobed, acuminated, quite entire, glabrous, shining lepidotted and of a different colour beneath. $\zeta . S$. Native of VOL. III.
Soutl America, IIumb. and Bonpl. Aràlia aeerif òlia, Willd. in Scliultes, syst. 6. p. 699 . The rest unknown. This is the same as $I I$. argentita, according to Sprengel.

Maple-leaved Ivy. Trec.

27 H. Jatropneiolia (D. C. l. c.) stem arboreous; leaves petiolate, coriaceous, glabrous above, but clothed with fuscescent tomentum bcneath, cordate at the base, 7-nerved, deeply 7 cleft : segments or lobes lanceolate-oblong, acuminated, narrowed at the base and quite entire. $\zeta$. S. Native of New Granada. Aràlia jatrophafòlia, H. B. et Kunth, nov. gen. amer. 5. p. 6 , Leaves almost like those of Mánihot. This species approaches very near 11 . platanifolia.

Jatropha-lecued Ivy. Tree.

28 H. reticula'ta (D. C. l. c.) stem arboreous: lcaves palmately 7 -lobed, hoary beneath, and reticulately wrinkled: lobes

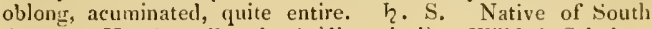
America, Humb. et Bonpl. Aràlia retieulàta, Willd. in Schultes, syst. 6. 1) 699 .

Retieulatcd-leaved Ivy. Tree.

29 H. cheiropuýlla (D. C. l. c.) stem unknown; leaves palmately 5 -cleft, cream-coloured beneath: lobes or segments acuninated, toothed; hearls of flowers disposed in racemes, clothed with villous tomentum. $h$. S. Native of South Anerica. Aràlia palnàta, Willd. herb. Aràlia cheirophýlla, Spreng. syst. 1. p. 953 .

Hand-leaved Ivy. Tree or slirub.

30 H. FLORIEU'NDA (D. C. 1. c.) stem arboreous; leaves petiolate, glabrous above, but clothed with cancscent tomentum beneath, 7-9-parted: segments or lobes acuminate, remotely and sharply toothed; racemes panicled; heads elliptically globose. h.S. Native of New Granada, in temperate parts, at the altitude of 3600 feet. Aralia floribinda, H. B. et Kuntl, nov. gen. amer. 5. p. 6. t. 416 . Aràlia Humboldtiàna, and A. incisa, Willd. in Schultes, syst. 6. p. 699. ex Kunth. Styles slort, connivent, somewhat diverging after flowering. Leaves so deeply parted as nearly to be compound.

Bundle-flonered Ivy. Tree 15 to 20 feet.

31 H. sca'ndens (D. C. prod. 4. p. 264.) stem shrublyy, prickly; leaves 5 -lobed, on long petioles; umbels simple, lateral. $h . \cup$ G. Native of China, Aràlia palmàta, Lour. coch. p. 187. but not of Lam. Aràlia scándens, Poir. suppl. 1. p. 419. Prickles on the stem bent backwards. Flowers white. The bark is used in dropsy and cutaneous disorders.

\section{Climbing Ivy. Shrub cl.}

$\$ 2$ Leaves compound; leaflets divided to the top of the pitiole, digitately or palmatcly disposed.

32 H. Ferrugínea (D. C. l. e.) stem arborcous; leaves on long petioles, digitate ; leaflets 7 , petiolate, oblong, acuminately cuspidate, rounded at the hase, quite en:ire, coriaceous, glabron: above, but clothed with fine tomentum beneath: when young clothed with rusty wool; raeemes panicled; heads somewhat elliptically globose. $h$. S. Native of South Anerica, in the province of Quito, between Paramo de Saraguru and Ona, at the altitude of 3600 feet. Aràlia ferruginea, H. B. et Kunth, nov. gen. amer. 5. p. 7. Willd in Schultes, syst. 6. p. 701 .

Rusty-leaved Ivy. Clt. 1826. Tree.

33 H. X Xlape' Nsis (D. C. l. c) stem arboreous; leaves on long petioles, digitate ; leaflets $5-7$, glabrous, shining above, but dotted beneath, lanceolate-oblong, aeute, narrowed at the base, and quite entire, rather coriaceous; racemes panicled; heads of flowers nearly globose. $h_{i}$. G. Native of Mexico, on the mountains near Xalapa, at the altitude of 2000 feet. Aràlia Xalapénsis, H. B. et Kunth, nov. gen. amer. 5. p. 8. Aralia digitàta, Willd. in Schultes, syst. 6. p. 701. ex Kunth. Petals glabrous. Styles joined in one. $3 \mathbf{E}$ 
Xalapa Ivy. Tree.

34 H. Echí 174. under Aràlia) leaves membranous, smoothish above, except on the middle nerve, but clothed with lax stellate tomentum beneath; floral leaves entire and lobed: lower leaves compound, of 5 nearly cuneate-obovate, acuminated leaflets ; heads of flowers globose. $\zeta_{2} \cdot G$. Native of Mexico, in woods near Hacienda de la Laguna. Middle leaflet a foot long and $5 \frac{1}{2}$ inches broad.

Globe-thistle-like Ivy. Shrub.

35 H. ela'ta (Hamilt. in D. Don, prod. fl. nep. p. 187.) stem arboreous, unarmed; leaves digitate; leaflets 7 , radiant, petiolate, elliptic-oblong, acminated, coriaceous, quite entire, glabrous, glaucous beneath, rounded at the base: umbels glabrous, racemosely panicled. $\zeta$. G. Native of Nipaul, at $\mathrm{Na}$ rain-lietty, where it is called Cailushi by the natives.

Tall lvy. Tree.

36 H. undula'tum (Wall. cat. no. 4916.) stem shrubby ; leaves on long petioles, digitate ; leaflets $3-5$, petiolulate, smooth, oblong-lanceolate, acuminated, undulated; panicle diffuse ; umbellules few-flowered : lateral ones opposite: terminal ones umbellate. h. G. Native of Silhet. Fruit oblong. Style 1, crowned by a capitate stigma.

Undulate-leaved lvy. Slirub or tree.

37 H. xsculifòlia (Wall. cat. no. 4913.) stem shrubby ; leaves digitate; leaflets 7 , obovate-oblong, acuminated, clothed with rusty pubescence beneath: outer ones the smallest, all serrated; racemes lateral; umbellules pedunculate, many-flowered. h. H. Native of Nipaul.

Horse-chestnut-leaved Ivy. Shrub or tree.

38 H. tonentòsa (Hamilt. in D. Don, prod. fl. nep. p. 187.) stem arboreous, unarmed; leaves digitate ; leaflets $7-9$, petiolulate, oblong-lanceolate, acuminated, coriaceous, quite entire, acute at the base, densely clothed with tomentum beneath, as well as the peduncles, petioles, and younger stems; umbellules rising in clusters, pedunctulate. $\quad$. F. Native of Nipaul.

Tomentose Ivy. Tree.

39 H. sUbcorda'ta (Wall. cat. no. 4917.) stem shrubby; leaves on long petioles, trifoliate; leaflets petiolate, membranous, ovate, somewhat cordate at the base and acuminated at the apex; panicles numerous; flowers disposed in long slender racemes. 々. G. Native of Silhet. Flowers small, spreading.

Subcordate-leafletted lvy. Shrub or tree.

40 H. FLoribu'NDA (Wall. cat. no. 4912.) stem beset with short, conical prickles; leaves digitate; leaflets $\tau$, on long petiolules, elliptic, acuminated, clothed with rusty tomentum beneath while young; racemes long; umbellules on long peduncles, rusty as well as the rachis. h.G. Native of Silhet.

Bundle-flowerd Iry. Shrub or tree.

4.1 H. Aculea'ta (Hamilt. in D. Don, prod. A. nep. p. 187.) stem arboreous, prickly; leaves digitate; leafiets 7 , radiant, elliptic-oblong, acuminated, serrated, puberulous beneath, acute at the base; umbellules tomentose, racemose. h. G. Native of Nipaul, at Narain-Hetty. Tree tall and thick. Flowers wlite. Prickly Ivy. Clt. I8ะ0. Tree.

4.2 H. terebintha'cea (Vahl. symb. 3. p. 42.) stem arboreous ; leaves petiolate, digitate ; leaflets $5-7$, radiant, petiolate, elliptic, quite entire; panicle difluse, terminal; umbellules disposed in racemes. $\quad$ b. S. Native of Ceylon, Penang, Silhet, and Nipaul, in groves and woods. Aràlia digitàta, Roxl. Petals 6. Style 1. Fruit angular. Allied to Unjàla of Rheed. hort. inal. 7. t. 28 .

Turpentinc Ivy. Tree.

43 H. Rugòsa (D. C. prod. 4. p. 265.) stem shrublyy, parasitical; leaves digitate; leaflets $5 \cdot 7$, ovate, or oval-oblong, acuminated, obliquely attenuated at the base, quite entire, rugged, clothed with brown stellate tomentum beneatls; panicle terminal, very long; flowers racemose. $h$.S. Native of Java, in woods on Mount Gede. Aràlia rugòsa, Blum. bijdr. 871.

Wrinkled-leaved Ivy. Shrub.

44 H. sıм'́lima (D. C. 1. c.) stem shrubby; leaves digitate; leaflets 5-6, elliptic-oblong, acuminated, rounded at the base, remotely serrulated, reticulate, wrinkled and rather downy from stellate pili beneath; panicle terminal, divaricate ; flowers race-

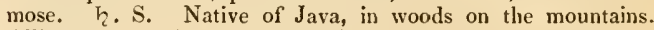
Allied to $H$. rugòsa. Aràlia simíllima, Blum. bijdr. p. 171 .

Jery similar lvy. Shrub.

4.5 H. авома' 'ica (D.C. 1. с.) stem shrubby; leaves digitate; leaflets 57 , elliptic-oblong, acuminated, for the most part obliquely rounded at the base, glabrous; panicles corymbose, lateral; flowers umbellate. $h$.S. Native of Java, on Mounts Salak and Gede, Sc. where it is called Pangang-pugu. Aràlia aromática, Blum. l. c. p. 871 .

Var. $\beta$; leafless, longer, serrated. $\zeta_{2}$. S. Native of Java, on Mount Salak, where it is called Kirengdong. Blum. 1. c.

Aromatic Ivy. Shrub.

46 H. LUTE'SCENs (D. C. 1. c.) stem shrubby; leaves digitate; leaflets $7-9$, oblong-lanceolate, long-acuminated, nearly veinless, shining above ; racemes crowded, terminal; flowers umbellate. . . S. Native of Java, in woods in the province of Bantam. Aràlia lutéscens, Blum. bijdr. p. 872.

Yellowish Ivy. Shrub.

47 H. DISPÉ RMA (D. C. prod. 4. p. 256.) stems shrubby, climbing; leaves digitate; leaflets 5-7, oblong, acuminated, rounded at the base, sharply serrated, glabrous; raceme terminal, scurfy; flowers umbellate; fruit 2 -seeded. $\mathbf{b} . \mathrm{S}$. Native of Java, in the higher woods, on the mountains of Barangrang and Tjerimai. Aràlia dispérma, Blum. l. c. p. 872. Perhaps a species of Pànax.

Tro-secded Iry. Shrub cl.

48 H. GLOMLRUL'TA (D. C. l. c.) stem arboreous, spinescent; leaves digitate; leaflets $5-7$, rarely 3 , oblong, acuminated, acutish at the base, serrulated towards the apex, smoothish; panicle terminal, very long; flowers glomerate; ovaries 2 -seeded. $\downarrow$. S. Native of Java, on Mount Gede, where it is called Pangang. Aràlia glomerulata, Blum. bijdr. p. $87 \%$. Perlıaps a species of Pànax.

Glomerate-flowered lvy. Tree.

49 H. HetEROPHY'LLA (Wall. cat. no. 4919.) stem shrubby ; leaves digitately compound, with the divisions quinate or ternate; leaflets oval-oblong, acuminated, glabrous; umbellules disposed in racemes, many-flowered, with a woolly bractea at the base of each peduncle; rachis woolly. $r$. S. Native of Penang. Fruit angular.

I ariable-leated Ivy. Tree or shrub.

\section{\$3. Leaves compound, pinnate.}

50 HI. Parasítica (D. Don, prod. fl. nep. p. 188.) stems rooting, parasitical ; leaves pinnate : with 5 , elliptic, acute, quite entire, nearly sessile, coriaceous, glabrous leaflets, which are glaucous beneath; umbels glabrous, racemose. h. G. Native of Nipaul, at Narain-Hetty. Aràlia parasítica, Hamilt. mss.

Parasitical Ivy. Slrub climbing and rooting.

51 H. GLAU'CA (Wall. cat. no. 4921.) stem shrubby, much branched; leaves pinnate; leaflets 5 , elliptic-lanceolate, acuminated, glaucous beneath, glabrous ; umbellules terminal, solitary or twin, many-flowered. 々. G. Native of Nipaul, at Kamaon. Style simple.

Glaucous-leaved lvy. Shrub.

52 H. JАCKiA'xA; leaves pinnate : with many pairs of opposite, oblong-lanceolate, petiolulate, quite entire, smooth leaflets, which are oblique at the base; rachis jointed; umbels con- 
pound; umbellules few-flowered; fruit oblong. $h$. S. Native of Singapore. Panax Heyneàna, Wall. cat. no. 4901. Mormorà phis Sumatràna, Jack, mss.

Jack's Ivy. Tree.

Cult. All the species of Ivy are of easy culture. The common ivy and its varieties only require to lave slips of them planted where they are intended to remain; or to be grown in pots until they are the size required, and then finally planted out : the other hardy species should be treated in a similar manner. The greenhouse and stove kinds will grow in almost any kind of soil, but the lighter the better; and cuttings of them are easily rooted under a hand-glass.

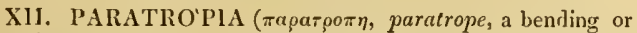
crooking; the petioles are kneed and bent). D. C. prod. 4. p. 265.-Aràlia, sect. 3. Paratròpia, Blum. bijdr. p. 875.

Lin. syst. Pentándria, Monogýnia. All as in Aràlia or Hedera, but differs in the stigmas being sessile, at first approximate, and immersed in an epigynous disk.-Slırubs or trees. Leaves compound. Flowers panicled or racemose.

1 P. Nodòsa (D. C. prod. 4. p. 265.) stem arboreous: leaves impari-pinnate : with many pairs of leaflets; leaflets on short petioles, crenated, glabrous : lower ones roundish-ovate, the rest oblong; panicle terminal, very long. $々$. S. Native of Java, in woods on the mountains in the western provinces, where it is called Kilangit. Aràlia nodòsa, Blum. 1. c. Common petioles 5-6 feet long, bent, articulated when dried. Panicle 4-5 feet long. Flowers pentandrous.

Nodose-petioled Paratropia. Tree.

2 P. pergana'cea (D. C. prod. 4. p. 266.) stem shrubby, parasitical; leaves digitate: leaflets $6-12$, oval, acute, rounded at the base, in substance like parchment, glabrous; racemes crowded, terminal, scurfy ; flowers subfasciculate. $\boldsymbol{h}$. S. Native of Java, on the ligher declivities of Mounc Gede. Aràlia pergamàcea, Blum. bijdr. 875 .

Parchment-leaved Paratropia. Shrub.

3 P. Rígrda (D. C. I. c.) stem arborescent; leaves digitate: leaflets 6-12, oblong, acute, bluntish at the base, and acutish at the apex, in substance like parchment, glabrous; racemes crowded, terminal, divaricate, rather scurfy ; flowers umbellate, octandrous. $\zeta$. S. Native of the western parts of Java, in woods on the mountains, where it is called Songo-Poana. Aràlia rígida, Blum. l. c.

$\operatorname{lar} \beta$; racemes incurved, densely clothed with scurf. $h$. S. Native of Jara, in the province of Bantam, where it is called Tulak-Tangol. Blum. 1. c.

Stiff Paratropia. Tree.

4 P. Longifòlia (D. C. l. c.) stem arborescent, scandent; leaves digitate: leaflets 9-11, rather large, oblong, acute, rounded at the base, glabrous; racemes crowded, densely clothed with tomentum, teminal, straight; flowers umbellate, with 7-9 stamens. $h$. S. Native of Java, in mountain woods, where it is called, along with many other Araliaceous plants, Ramo-giling. Sciodaphýllum longif òlium, Blum. bijdr. p. 876 .

Long-leaved Paratropia. Shrub cl.

5 P. Cantonénsis (Hook. et Arn. in Beech. voy. pt. bot. 189.) stem arboreous; leaves on long petioles, digitate: leaflets $5-9$, elliptic, acutish at the base, acuminated at the apex, rather coriaceous, glabrous; racemes terminal, furfuraceous; flowers in fascicles, decandrous; stigma sessile, 10-cleft. $\eta . \mathrm{G}$. $\mathrm{Na}$ tive of China, about Canton. Aràlia octophýlla var. Cantonénsis, Lour. coch. p. 187. This species comes very near $P$. pergamàcea. Canton Paratropia. Tree 10 feet.

Cult. Any light soil will suit the species of Paratròia; and cuttings of them will be easily rooted under a band-glass in heat.
XIIl. ARTHROPHY'LLUM (from a $\rho 0 \rho o v$, arthron, a joint, and $\phi v \lambda \lambda \circ \nu$, pliyllon, a leaf; in reference to the jointed petioles). Blum. bijdr. p. 878 . D. C, prod. 4. p. 266.

Lin. syst. Pentándria, Monogýnia. Margin of calyx short, obsoletely 5-toothed. Petals 5. Stamens 5, alternating with the petals. Ovarium 1-ovulate. Style short, or nearly wanting : stigma obtuse. Fruit baccate, crowned, containing a oneseeded nucleus. Albumen somewhat corneous. Embryo inverted.-Unarmed Java shrubs. Leaves glabrous, variable, usually bipinnate. Umbels petiolar, compound. Perhajss referrible to the monospermous $A$ raliaceous unarmed genus, incompletely described in l'et. Th. gen. nov. mad. p. 13, under no. 42.

1 A. Java' nicum (Blum. 1. c.) leaves bipinnate: leaflets cuneate-obovate, bluntish at the apex, or the upper leaflets are rounded and coriaceous. $\zeta$. S. Native of Java, in mountain woods at Parang.

Java Arthrophyllum. Shrub or tree.

2 A. Diversifòlium (Blum. l. c.) leaves impari-pinnate, ternate or bipinnate; leaflets oblong, somew hat acuminated, oblique at the base, membranous. $\zeta$. S. Native of Java, in woods, on Mount Salak.

Diversc-leavcd Arthrophyllum. Tree.

3 A. ellípticum (Blum. l. c.) leaves bipinnate: leaflets elliptic-oblong, acute, oblique at the base, coriaceous. h.S. Native of Java, in mountain woods.

Elliptic-leafletted Arthrophyllum. Shrub or tree.

Cult. See Paratròpia above for culture and propagation.

OrDER CXXV. HAMAMELI'DEE (plants agreeing with Hamamèlis in important characters). R. Br. descr. pl. chin. 1815. p. 3. Adr. Juss, dict. class 8, p. 28. Sweet. hort. brit. 371. D. C. prod. 4. p. 267.-Pet. Th. veg. afr, austr. ed. 2. p. 31.

Tube of calyx adhering to the ovarium more or less, 4-lobed (f. 69. a. g.) or repandly tootlied. Petals 4 (f. 69. e. i.), linear, elongated, inserted in the calyx, alternating with the calycine lobes, involutely valvate in rstivation: rarely wanting, but probably sometimes changed into stamina. Stamens inserted with the petals, and double their number (f. $69 . b$.) ; those alternating with the petals are fertile, and those opposite the petals are sterile and destitute of anthers (f. $69 . \mathrm{g}$.); filaments all short. Fertile anthers inserted by the base, 2-celled, deliscing in various ways. Ovarium adnate at the base, 2-celled: cells 1scedecl; ovula pendulous. Styles 2 (f. 69.l.), very rarely 3. Capsule adnate at the base to the permanent tube of the calyx, 2-celled, 2-valved; ralves bifid at the apex. Seed pendulous, with a superior hylum. Albumen corneous. Embryo straight, slender, with a superior radicle; and foliaceous flat cotyledons, or having their margins rather involute.-Shrubs. Leaves alternate, bistipulate, petiolate, feather-nerved, entire or sinuately toothed. Flowers axillary, nearly sessile, in fascicles, usually bracteate, sometimes dioecious or polygamous.

Many of the genera of this order were formerly placed among the Berberidea and Amementàcea, but were constituted a distinct order by R. Brown in 1818 ; but the place which it slould hold in the natural system is still doubtful. According to $\mathrm{R}$. Brown, it is intermediate between Bruniàcee and Márlea*, (a genus which should have been placed in Alangièa, vol. ii. p. 806 . But according to Pet. Thouars, it comes nearest to Rhlimnea, and according to Juss. to Haloragièce. But afterwards it was 8 E 2 
placed by R. Brown and Pet. Thouars near Araliàcece and Córnece. The order differs from Alangièce in the fruit being capsular, not baccate; and from Bruniàceee in the parts of the flowers being quaternary, in the stamens being double the number of the petals, in the insertion and dehiscence of the anthers, and in the cells of the ovarium being $]$-seeded, $\delta \cdot c$; it differs from Araliàcee and C'órnece in the fruit being capsular, in the number of the parts of the flower, and in the structure of the anthers; and from Amenticece in the flowers of most of the genera being complete; but the genus Fothergilla agrees with Amentìcea in habit, and in the want of petals; but perlaps in this genus the outer series of the stamens represent the petals.

* MA'RleA (the name of the tree in Silliet). Roxb. cor. 3. p. 283. D. C. prod. 4. p. 267. - Stylídium, Lour. coclı. p. 221. but not of Swartz.-Pautsaùria, Juss. dict. sc. nat. p. 51. p. 158.-Stỳlis, Poir. suppl. 5. p. 260.

Lin. syst. Octándria, Monogýnia. Tube of calyx adnate to the ovarium: limb short, bluntly 6-8-toothed. Petals 6-8, linear, alternating with the teeth of the calyx. Stamens 8 , adnate to the epigynous disk, and inserted at the top of the calyx ; anthers long, linear. Ovarium 2-celled, biovulate. Style short : stigma 4-toothed. Drupe oval, rather fleshy, umbilicate from the tecth of the calyx : containing a 2 -celled nucleus. Seed compressed. Albumen fleshy. Embryo with a superior radicle and flat cotyledons. - A small A siatic tree. Leaves alternate, exstipulate, petiolate, unequally cordate, acuminated, entire, glabrous, except the nerves on the under side. Flowers on axillary peduncles, somewhat corymbose, whitish or yellowish.

1 II. negonifòlia (Roxb. l. c.) h. G. Native of the East Indics, in Silhet and Nipaul; and of China, near Canton, where it is called Pautsau. Stylidium Chinénse, Lour. I. c. Stýlis Chinénsis, Poir. l. c. Leaves sometimes acutely bifid, or a little tootlied.

Begonia-leaved Marlea. Fl. June, July. Clt. 1824. Shrub 5 to 6 feet.

Cult. This shrub is easily increased by cuttings in sand under a hand-glass. The soil best adapted for it is a mixture of sand, loam, and peat.

\section{Synopsis of the genera. \\ Tribe I.}

Hamame'zeze. Petals 4 (f. 69. c.). Stamens 8,4 fertile (f. 69. b.), and 4 sterile (f. 69. g.). Anthers dehiscing by a valve.

1 Hamame'zis. Calyx 4-lobed, furnished with $3-4$ scales on the outside. Ovarium ending in 2-3 styles at the apex ( $f .69$. l.). Capsule coriaccous, g-celled (f. 69. c.).

2 Dicory'pire. Calyx 4-lobed. Styles 2. Fruit inclosed in the circumcised calyx, umbilicate at the apex, 2-horned, 2-seeded.

3 Trichócladus. Flowers dioecious, intermixed with chafly seales. Petal 1, convolute. Stamen 1. Female flowers : ovarium villous. Style 1. Capsule 4-celled, 4-valved. Arillus of seed 2-valed.

\section{TRIBE II.}

Fotuergíleex. Petals wanting. Stamens 24, all fortile. Anthers opening by a semicircular chink at the margin.

4 Fotnergíla. Calyx campanulate, 5-7-toothed. Anthers form of a horse-shoe. Styles 2. Capsule 2-lobed, 2-celled: cell $\approx$ - -valved at the apex, 1 -seeded.

\section{Tribe $\mathbf{I}$.}

HAMAMELER (shrubs agreeing with the genus Hamamilis in important characters). D. C. prod. 4. p. 268 . Petals 4. Stamens 8,4 of which are sterile. Anthers dehiscing by a valve.

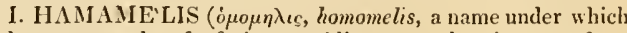
Athenæus speaks of a fruit resembling an apple; it comes from opvc, omos, like, and $\mu \eta \lambda \varepsilon a$, melea, an apple-tree; but the present genus is not in any way analogous to the apple). Lin. gen. no. 169. Juss. gen. p. 288. Lam. ill. t. 88. f. 1. D. C. prod. 4. p. 268.-Trílopus, Mith. act. acad. nat. cur. 8. appendix.

LıN. syst. Tetrándria, Digy'nia. Calyx 4-lobed, adhering to the ovarium at the base, furnished with $2-3$ scales on the outside. Petals 4 (f. 69.a.), long, tongue-shaped, alternating with the teeth of the calyx (f. 69.e.). The 4 stamens alternating with the petals, fertile (f. 69. b.), with very short filaments: adnate 2-celled authers; the cells opening by a vertical valve. The 4 sterile stamens $(f .69, g$. ) with very thick filaments and round anthers, one in front of each petal. Ovarium free at the apex, ending in 2 (f. 69. l.), rarely in 3 short styles. Capsule coriaceons, half free, 2 -celled, 2-valved at the apex; valves bifid. Arils 2 in each capsule, coriaceous, 1 -seeded, opening by 2 elastic valves above. Seed oblong, shining, with a superior hylum; albumen fleshy. Embryo with a superior radicle and flat cotyledons.-Small American or Asiatic trees. Leaves alternate, on short petioles, bistipulate, ovate or cuneated, feather-nerved, nearly entire. llowers nearly sessile, disposed in clusters in the axils of the leaves, girded by a 3-leaved involucrum. Pctals yellow.

1 H. VirGínica (Lin. syst. nat. p. 333.) leaves obovate, acutely toothed, with a small cordate recess at the base. $\zeta$. H. Native of North America, from Canada to Florida, in stony and dry situations, but frequently near water. Mill. ill. t. 10. Duulam. arb. 1.t. 114. Schkulır, handb. t. 27. Lodd. bot. cab. 598. Guimp. abb. holzart. t. 75. Rafin. med. hot. 1. t. 45.-Catesb. car. 3. t. 2. This singular shrub, which grows about 10 or 12 feet high, begins to show its yellow flowers in autumn, when all others lave dropped their leaves, continues to flower all winter, and forms its fruit the spring following. The flowers are either polygamous, varying to dioecious, monoecious, and androgynous; hence the names of Hamamèlis dioíca, monoíca, and andrógyna, Walt. car. 255. The lndians consider this tree as a valuable article in their Materia Medica. They apply the bark, which is sedative and discutient, to painful tumours and external inflammations. A cataplasm of the inner rind is found to be very efficacious in removing painful inflammations of the eyes.

lar. B, parvifolia (Nutt. gen. amer. 1. p. 107.) leaves smaller, oblong-obovate, upper part undulately and grossly crenated : the under side pubescent, rather hairy; segments of the calyx oblong; stamens and perigynous filaments often nearly equal. $h$. H. From the mountains of Pennsylvania.

Vinginian Witch-hazel. Fl. Oct. Feb. Clt. 1796. Shrub 8 to 12 feet.

2 H. масиорит'tra (Pursh. f. sept. amer. 1. p. 116.) leaves nearly orbicular, cordate, coarsely and bluntly toothed, scabrous from dots beneath. $h_{2}$. H. Native of North America, in the 
western part of Georgia ; and of North Carolina, on the Catabaw Mountains. The large leaves punctated on their under side, with rough tubercles and other marks, give sufficient reason for considering it a distinct species.

Large-leaved Witch-hazel. Fl. May, Nov. Clt. 1812. Shrub 10 to 12 feet.

3 H. PE'rsica (D. C. prod. 4. p. 268.) leaves oval, acuminated, repandly toothed above, cuneated at the base, equal. $h_{\text {. }}$ H. Native of Persia, in the province of Lenkeran, where it was collected by Hansen. Adult leaves rather scabrous on the nerves and petioles; the rest glabrous. Flowers unknown. Fruit a little smaller than that of $I I$. Jirginica, but similar.

Persian Witch-liazel. Shrub 10 to 12 feet.

4 H. CHiNe'nsis (R. Br. descr. pl. chin. 181s. p. 4. with a figure,) leaves ovate, quite entire, unequal at the base, grey on hotl surfaces from stellate down. h. H. Native of China, near Nankin, and in the island of Cheusan.-Pluk. amalth. 32. t. 368, f. 2. Petals linear, 3-nersed, very much elongated. Anthers with deciduous valves; hence it is proposed by $\mathrm{R}$. Br. to form it into a distinct section under the name of Loropétalum.

China Witch-hazel. Shrub 6 to 10 feet.

Cult. The species of Witch-hazel are well adapted for shrubberies; they will grow in any common soil, and are increased by layers or suckers.

1I. DICORY'PHE (from $\delta \iota s$, dis, twice, and кo $\rho v \phi \eta$, coryphe, a vertex; in reference to the two horns on the top of the fruit). Pet. Th. hist. veg. afr. austr. 1. p. 31. t. 7. ed. 2. p. 15. t. 4. and p. 31. nov. gen. mad. p. 12. D. C. prod. 4. p. 269.Dicory'pha, Spreng. syst. 1. p. 54.6 .

Iin. syst. Telrándria, Digýnia. Tube of calyx oblong, hairy, adhering to the ovarium: limb 4-lobed, circumcised after flowering. Petals 4, inserted in the upper part of the tube of the calyx, joined to the filaments at the base. Stamens 4 , fertile, alternating with the petals : filaments broad at the base: anthers oblong, aclnate, erect, dehiscing at the sides; and 4 sterile smaller stamens alternating with the first named ones. Styles 2 . Pericarp inclosed in the circumcised calyx, umbilicate at the apex, and 2 -horned, inclosing 21 -seeded coriaceous coccula, which open at the apex. Seed ovate, hanging from the top. Albumen fleshy. Embryo with a superior radicle: and flat cotyledons, having revolute edges.-A small slurub, with twiggy weak branches. Leaves alternate, on short petioles, oblong, feather-nerved, entire, furnished with 2 unequal broad foliaceous stipulas at the base. Corymbs terminal, somewhat fasciculate, 7-8-flowered.

1 D. stipula'ta (Jaum. exp. fam. 2. p. 318.) h. S. Native of Madagascar, near Foulpointe. Pet. 'Th. 1. c. D. Thouársii, Rom. et Schultes, syst. 3. p. 4.85 .

Stipulate-leaved Dicoryphe. Shrub.

Cult. A mixture of sand, loam, and peat will be a good soil for this plant; and young cuttings will strike root in sand under a hand-glass, in heat.

III. TRICHO'CLADUS (from $\theta \rho \iota \xi$ r $\rho \iota \chi^{\circ} s$, thrix trichos, a hair, and kiaios, klados, a branclı; the branches are clothed with stellate hairs). Fers. ench. 2. p. 597. D. C. prod. 4. p. 269.-Dáhlia, Thunb. diss. ( 792 ) and in edit. goett. 1. p. 108. act. soc. hist. nat. hafn. 2. vol. 1. p. 133. t. 4. hut not of Cav. 1791 .

Lin. syst. Dioéciu, Monándria. Flowers dioecious. Scales paleaceous, distinguished from the capitate flowers. Male flowers. Calyx unknown. Petal 1, convolute. Stamen 1, near the scale and the petal; anthers ovate, double celled from the connate filaments (Thunb.), valves dehiscent (Burch.). Female flowers. Calyx unknown. Petals wanting. Ovarium villous.
Style 1. Capsule ovate, 4-valved, 4-celled. Arillus (seed, Thunb.) ovate, glabrous, villous from stellate dots. Leaves opposite, petiolate, oval, acuminated, entire. Flowers in terminal heads, crowded on a common receptacle. The character is taken from the deseription of the tree by Thunberg.

1 T. crivitus (Pers. l. c.) h. G. Native of the Cape of Good Hope, in the woods of Houtniquas. Dálilia crinita, Thunb. 11. ce. and fl. cap. 1. The shrub lias the resemblance of a spccies of Cròton.

Hairy Trichocladus. Clt. 1823. Shrub 4 to 8 feet.

Cult. A mixture of loam and sand is a good soil for this shrub; and young cuttings will root readily in sand under a liand-glass.

\section{Tribe II.}

FOTHERGI'LLE $E$ (this tribe only contains the genus $F_{0}$ thergilla). D. C. prod. 4. p. 269. Petals wanting. Stamens 24, all fertile; anthers dehiscing by a chink. 'This tribe is intermediate between IIamamèlece and Amentàcea from hahit.

IV. FOTHERGl'LLA (in memory of John Fothergill, M.D. an eminent physician, and patron of botany; who cultivated a variety of most curious plants in his garden near London). Lin. fil. suppl. p. 4\%. Iam ill. t. 480. Juss. gen. 408. but not of Aublet. D. C. prod. 4. p. 269.

LıN. syst. Icosándria, Digýnia. Calyx campanulate, adhering to the ovarium at the base, somewhat truncate, with 5.7 callous subrepand teetl. Petals wanting. Stamens about 25, inserted in the calyx, club-shaped, exserted; anthers terminal, of the form of a horse shoe, opening by a semi-circular chink at the margin. Ovarium 2-celled, 2-ovulate. Styles 2, filiform. Capsule adnate to the base of the calyx, 2-lobed, 2-celled ; cells 2-valved at the apex, I-seeded. Seed bony, pendulous, with a superior hylum.-A shrub, with alternate, obovate, feathernerved, bistipulate leaves, clothed with soft starry down; and terminal ovate spikes of flowers, having a solitary bractea under each flower; those bracteas at the base of the spike are trific?, and those at its apex are nearly entire. Flowers white, sweetscented, sessile. Anthers yellow.

1 F. AlNifòlia (Lin, fil. suppl. 267.) $h$. II. Native of North America, from Virginia to Carolina, in sliady woorls on the sides of hills. Duham. arb. ed. nov. 4. t. 26. Guimp. arb. holzart. t. 16. F. Gardèni, Michx. fl. bor. amer. 1. p. 313. Hamamèlis monoíca, Lin. ex Smith, in Rees' cycl. vol. 17. Flowers appearing before the leaves.

I ar. a, obtùsu (Sims, bot. mag. 1341. Mill. fig. t. 1.) leaves obovate, crenate at the top, when young clothed with fascicles of down beneath. F. major, Lodd. bot. cab. t. 1520 . (f. 70 .)

Vur. $\beta$, acùta (Sims, l. c.) leaves narrow, ovate, acute, nearly entire, white from down beneath. T. Gardèni, Jacq. icon. rar. t. 100 .

Var. $\gamma$, màjor (Sims, bot. mag. t. 1342.) leaves ovate-oblong, somewhat cordate at the base, very blunt and serrated at the apex, sometimes with an acumen; when young tomentose beneath.

l'ar. c̀, serótina (Sims, l. c.) leaves oblong, acute, crenately toothed at the top, green beneath.

Alder-leaved Fothersilla. Fl. April, May. Clt. 1765. Shrub 3 to 6 feet. 
Cult. All the varieties of this shrub are very handsome while in flower and leaf, and are therefore proper for shrubberies. A peat or vegetable soil answers them best; and they may either be increased by layers put down in spring or autumn, or by seed, which is anuually received from America.

ORder CXXVI. CO'RNEA (this order contains plants agreeing with Córnus in important characters). D. C. prod. 4. p. 271. -Caprifoliàcea Córneæ, Kunth, nov. gen. amer. 3. p. 430.Genera of Caprifoliàceæ, Juss.

Calyx having the tube adnate to the ovarium; and the limb superior and 4-lobed (f. 71.c.). Petals 4, oblong, broad at the base, inserted in the upper part of the tube of the calyx, regular, valvate in æestivation. Stamens 4 , inserted with the petals, and alternating with them; anthers ovate-oblong, 2celled. Style filiform; stigma simple. Drupe baccate, crowned by the vestiges of the calyx, containing a 2 -celled nucleus. Seed pendulous, solitary in the cells. Albumen fleshy. Embryo with a superior radicle, which is shorter than the two oblong cotyledons.-Trees and shrubs, rarely herbs. Leaves of all opposite, except in one species of the genus Cormus, entire or toothed, feather-nervet. Flowers capitate, umbellate or corymbose, naked or invohucrated, rarely dioecious from abortion. Flesh or pulp of finit edible.

This order agrees with Hamamelidea, and Caprifolidece, tribe Sambucee; but differs from the first in the astivation of the petals being truly valvate; in the stamens not being double the number of the petals; in the style being simple, not double; in the fruit being drupaceous, not capsular; and in the albumen being fleshy, not horny, Sc. From Sambucea it differs in the corolla being polypetalous, not gamopetalous; in the parts of the flower being quaternary, not quinary; in the style being exserted, not wanting; in the stigmas being 2 , not 3 , and in the fruit being drupaceous, not baccate, Sc. Córnece differs from Loranthacce in the stamens alternating with the petals, not opposite them.

All the genera of this order have more or less astringent bark ; that of Córnus flórida is used in North America in intermittent fevers, as is also that of Cómus sericea, which, according to Barton, is scarcely inferior to quinquina.

\section{Synopsis of the genera.}

1 Cónnus. Limb of calyx 4-toothed (f. 71. c.). Drupe baccate, marked by the vestiges of the calyx, containing a 2 -celled, rarely 3 -celled nucleus.

2 Voтомiтs. Tube of calyx turbinate; limb 4-toothed. Anthers approximating into a tube, and terminated by a thin membrane. Stigmas 4, oblong. Drupe crowned by the calyx, 1-celled.

3 Mastíxia. Limb of calyx 4-5-toothed. Stamens 4-5; anthers didymous. Style short, girded by a disk; stigma obtuse. Drupe umbilicate, containing a 1 -seeded nucleus.

4. Polxósma. Limb of calyx 4-tootlued. Petals sometimes joined at the base. Anthers 2-celled. Stigma truncate. Drupe containing a 1 -seeded nucleus.
I. CO'RNUS (from cornu, a liorn; the wood being thought to be as hard and as durable as horn. Its value as a material for warlike instruments has been celebrated by Virgil.-Bona bello cornus). Tourn. inst. 641. t. 410. Lin. gen. no. 149. Gærtn. fruct. t. 26. D. C. prod. 4. p. 271.

Lin. sysr. Tetrándria, Monogýnia. Tube of calyx adhering to the ovarium; limb small, 4-toothed (f. 71.c.). Petals 4, oblong, sessile; valvate in restivation. Stamens 4. Style 1. Drupe baccate, marked by the vestiges of the calyx, containing a 2 -celled, rarely 3 -celled nucleus. Seed solitary, pendulous. Albumen fleshy. Radicle of embryo shorter than the cotyledons.-Trees and shrubs, sometimes low herbs. Leaves all opposite, except in the first species, entire, feathernerved. Flowers sometimes capitate and umbellate, involucrated; sometimes corymbose and panicled, without involucra. Petals white, rarely yellow.

\$ 1. Nudiftorce (from nudus, naked, and flos, a flower; in allusion to the flowers being exinvolucrate). D. C. prod. 4. p. 271. Flowers corymbose or panicled, exinvolucrate.

\section{* Leaves alternate.}

1 C. Alternifòlia (Lin. fil. suppl. p. 125.) leaves alternate, ovate, acute, hoary beneath; corymbs depressed, spreading; branches warted. $\eta$. H. Native of North America, from Canada to Carolina, in shady woods on river banks. Lher. corn. no. 11. Guimp. abb. holz. t. 43. Schmidt, arb. 2. t. 70 . C. altérna, Marsh. Berries purple, globose, about the size of a grain of pepper. Leaves on long petioles. Branches green or reddish-brown.

Alternate-leaved Dogwood. Fl. May, July. Clt. 1760. Tree 15 to 20 feet.

$$
\text { * Lcaves opposite. }
$$

2 C. Panicula'ta (Lher, corn. no, 10. t. 5.) branches erect ; leaves ovate, acuminated, glabrous, hoary beneath; corymbs thyrsoid; ovarium silky. h. H. Native of North America, from Canada to Carolina, rare, in swamps and near rivulets among other bushes. Schmilt, arb. 2. t. 68. C. racemòsa, Lam. dict. 2. p. 116. C. fémina, Mill. dict. no. 4. C. citrifòlia, Hort. par. Branches pale-purplish. Berries roundish, depressed, watery, white, 3 lines in diameter. The dots on the under side of the leaves, which are only seen through a lens, bear bicuspidate short adpressed hairs. Tube of calyx pubescent.

I'ar. $\beta$, álbida (Ehrh. beitr. 4. p. 16.) leaves elliptic-lanceolate.

Var. $\gamma$, radiàta (Pursh. fl. amer. sept. 1. p. 100.) racemes sterile, foliiferous.

Panicled-flowered Dogwood. Fl. July, Aug. Clt. 1758. Shrub 4 to 6 feet.

3 C. Toluccénsis (H. B. et Kuntb, nov, gen. amer. 3. p. 430.) branches dichotomous, spreading; leaves ovate-oblong, narrowly acuminated, puberulous on both surfaces, paler beneath; cymes lateral, naked. 々. H. Native of Mexico, on the higher plains about the city of Tolucca. Very like C. paniculàta. Compare Cham. et Schlecht, in Linnaa. 5. p. 171. in which place there is a species described which was found abont Jalapa, and which is probably referrible to the present plant.

Tolucca Dogwood. Tree or slirub.

4 C. oвlónga (Wall, in Roxb. fl. ind. 1. p. 432.) leaves oblong, acuminated, acute at the base, glaucous and rather scabrous beneath, with many excavated glands along the axils of the ribs and nerves; corymbs spreading, panicled. $々$. H. Native of Nipaul, about Narainhetty, Katmandu, and the valley of Dhoon. C. paniculàta, Hamilt. ex D. Don, prod. Al. nep. p. 140. Young shoots clothed with short adpressed hair. Leaves 4-6 inches 
long, and 1 to $1 \frac{1}{2}$ inch broad; petioles about an inch long. Flowers white or pale-purplish, fragrant. Calyx clothed with adpressed silvery hairs, as well as the pedicels and petals. Drupe ovate-oblong. Ovarium 3-cel]ed.

Oblong-leaved Dogwood. Clt. 1818. Tree 10 to 15 feet.

5 C. strícta (Lam. dict. 3. p. 116.) branches straight, fastigiate ; leaves ovate, acuminated, glabrous, green on both surfaces, when young hardly pubescent beneath; corymbs convex, somewhat panicled. $々 \cdot H$. Native of North America, from Carolina to Canada, on the banks of rivers, frequent; also of Mexico, between Tampico and Real del Monte. Lher, corn. no. 9. t. 4. Schmidt, arb. 2. t. 67 . C. fastigiàta, Michx. fl. bor. amer. 1. p. 92. C. sanguínea, Walt. but not of Lin. C. cyanocárpos, Gmel. syst. veg. 1. p. 257. C. Canadénsis, Hort. par. C. cærùlea, Meerb. icon. 3. but not of Lam. Branches reddishbrown. Anthers blue. Berries globose, soft, blue on the outside, but white inside.

Var. $\beta$, variegàta; leaves variegated with white or yellow.

Straight-branched Dogwood. Fl. June, July. Clt. 1758. Shrub 6 to 10 feet.

6 C. sanguínea (Lin. spec. p. 171.) branches straight; leaves ovate, acute, smooth and green on both surfaces; corymbs flat. $\zeta$. H. Native of Europe and the north of Africa, in hedges and thickets, especially on a chalk and limestone soi], common; plentiful in Britain in like situations. It is also said to grow in North America near the Lakes of Canada and New York, but has probably been introduced there. Smith, engl. bot. t. 249. Fl. dan. $481 .-$ Duham. arb. 1. t. 75.-C. fémina, Raii, syn. 460. Ger. emac. 1467. witlı a figure. Virga sanguínea, Matth. valgr. 1. p. 236. with a figure. Cam. epit. 159. with a figure. Branches of a dark-red when full grown. Leaves 2-3 inches long. Flowers greenish-white, unpleasantly scented; petals revolute at the sides. Fruit dark-purple, very bitter. Matthiolus records that an oil is obtained from the berries by pressure, after they have first been boiled, which is used for lamps in the country near Trent. The shrub, after a smothered combustion, affords a charcoal, esteemed the best for entering into the composition of gunpowder. It has a variety of names in different parts of the kingdom, as female cornel, dogberry-tree, hound's-tree, prickwood, from its use in making skewers, gaten or gaten-tree, gatcr or gater-tree. The wood was formerly made use of for cart timber and rustic instruments, \&c. Mr. Miller informs us, that in his time the fruit was often brouglit to the markets, and sold for those of buclithorn.

Bloody-branched Dogwood or Wild Cornel-tree. Fl. June, Britain. Shrub 4 to 5 feet.

7 C. Pu'rsirir; branches straight; leaves ovate, green on both surfaces, and pubescent; corymbs spreading. $\eta . \mathrm{H}$. Native of North America, near the lakes of Canada and New York. C. sanguínea, Pursl, fl. amer. sept. 1. p. 109. Schmidt, arb. 2. t. 66. Flowers with yellow anthers. Berries dark-brown. This differs from the $C$. sanguinea of Europe in the leaves being pubescent, and in stature.

Pursh's Dogwood or Cornel. Fl. June, July. Sh. 8 to $12 \mathrm{ft}$.

8 C. $\operatorname{ExCE}{ }^{\prime} L S A$ (H. B. et Kunth, nov. gen. amer. 3. p. 430.) branches spreading; branchlets pubescent ; leaves ovate, acuminated, pubescent and paler beneath, and with minute scattered pili above; cymes naked, spreading. Ћ.H. Native about the city of Mexico. Allied to C. sanguinea.

Tall Dogwood. Tree.

9 C. A'LB (Lin. mant. p. 40.) branches recurved ; branchlets glabrous; leaves ovate, acute, pubescent, hoary beneath; corymbs depressed. $\quad$. H. Native of Siberia, at the rivers Oby and Irtysch, among bushes, \&.c.; North America, from Virginia to Canada, on the banks of rivers and lakes; and of North California. Pall. f. ross. 1. t. 34. C. stolonífera, Michx.
A. bor, amer. 1. p. 109. C. Sibírica, Lodd. C. Tatárica, Mill. fig. 104.-Amm. ruth. t. 32. Branches of a fine red colour. Berries white or bluish-white.

$\operatorname{lar} . \beta$, circinnàta; leaves larger, more lıairy beneatl. $々 . H$. Native throughout Canala, and from Lake Huron to north lat. $69^{\circ}$, Newfoundland, and the north-west coast of America. C. circinnàta, Cham. et Schlecht. in Linnæa. 3. p. 139. The berries are lead-coloured according to Dr. Richardson, who further says, they are named by the Crees musquamena, because the bears fatten upon them, and methquan-pecmecnattick and mecnisan (red stick berry), and that pigeons are fond of them.

White-berried Dogwood. Fl, May, July. Clt. 1741. Shrub 4 to 10 feet.

10 C. Serícea (L'Her. corn. no. 6. t. 2.) branches spreading ; branchlets waolly; leaves ovate, acuminated, clothed with rusty pubescence beneath ; corymbs depressed, woolly ; nucleus compressed. $々$. H. Native of North America, from Canada to Carolina, in swampy woods and on river banks. Sclımidt, arb. 2. t. 6.4. C. lanuginòsa, Michx. fl. bor. amer. 1. p. 92. C. álba, Walt. fl. car. 88. but not of Lin. C. cærùlea, Lam. dict. 2. p. 116. C. amòmum, Duroi, larbk. 1. p. 165. C. rubiginòsa, Ehrh. beitr. 4. p. 15 . C. ferrugínea, Hort. par. C. candidissima, Mill. C. cyanocárpos, Moench, but not of Gmel. Berries bright blue, globose.

Var. $\beta$, ablongifòlia (D. C. prod. 4. p. 272.) leaves oblong, glabrous above. h. H. C. oblongifòlia, Rafin. in litt.

Var. $\gamma$, asperifolia (D. C. prod. 4. p. 272.) leaves oval, acuminated, rough above from minute stiff pubescence, and rather tomentose beneath. $h$. H. Native of Lower Carolina, in shady woods. C. asperifòlia, Michx. fl. bor. amer. 1. p. 93.

Silky Dogwood. Fl. June, July. Clt. 1683. Shrub 5 to 8 feet.

11 C. circinsa'ta (L'Her. corn. p. 7. no. 8. t. 3.) branches warted; leaves broadly oval, acuminated, clothed with hoary tomentum beneath; corymbs depressed, spreading. $\zeta . \mathrm{H}$. Native of North America, from Canada to Virginia, on the banks of rivers, and probably of California, ex Cham, and Schlecht. in Linnæa. 3. p. 139. Schmidt, arb. 2. t. 69. C. tomentòsula, Michx. fl. bor. amer. 1. p.9l. C. rugòsa, Lam. dict. 2. p. 115 . C. Virginiàna, Hort. par. Branches slightly tinged with red. Leaves broad, waved on their edges. Flowers white as in most of the species. Berries globose, at first blue, but at length becoming white.

Rounded-leaved Dogwood. Fl. June, July. Clt, 1784. Shrub 5 to 10 feet.

12 C. Macrophy'lla (Wal]. in Roxb. fl. ind. 1. p. 433.) branches smootl?; leaves broad-ovate, acuminated, rounded at the base, smooth, glaucous and soft beneath, with the axils slightly glandular; corymbs umbellate; flowers racemose along the branches of the corymb, and secund. $\boldsymbol{~}$. H. Native of Nipaul, near Saharumpore and Sirinagur, and at Kamaon. Leaves with adpressed bristles, 6 inches Jong, and 4 inches broad, pale beneath; the bristles fixed by the centre, and therefore bicuspidate, but are only to be seen through a lens. Ovarium hairy. Berries round, smooth, about the size of a grain of black pepper.

Long-leaved Dogwood. Shrub.

\$2. Involucràte (from involucra, an involucrum; the heads of flowers are surrounded by an involucrum). D. C. prod. 4. p. 273. Floners disposed in heads (f. 71.b.) or umbels, surrounded by coloured involucra, which are usually composed of 4 lcaces (f. 71. a.).

* Trees, with nhite capitate floners.

13 C. capita'ta (Wall. in Roxb. fl. ind. 1. p. 4.34.) branclies 
spreading, smooth; leaves lanceolate, acuminated at both ends, on short petioles, rather rough from small adpressed down; flowers sessile, densely aggregate, forming a ronnd head, girded by a 4-leaved scabrous involucrum. h.H. Native of Nipaul, in Gosaingsthan, where the tree is called chung' $\alpha^{\text {; }}$ and about Serampore, where it is called Bhunonro; and between Sutley and Jumna. D. Don, prod. fl, nep. 14I. Leaves coriaceous, 2 inches long, glaucous and pale beneatls: with sometimes pinkcoloured nerves, having each a minute gland in their axils. Heads of flowers about the size of a moderate-sized cherry, supported by a club-shaped peduncle, which widens at the upper end into a convex ligneous receptacle for the reception of the flowers. Involucrum yellow, of 4 obovate leaves.

Capilate-flowered Dogwood. Tree 10 to 15 feet.

14 C. Disciflòra (Moc. et Sesse, fl. mex. icon. ined. D. C. prod. 4. p. 273.) branches smoot 3 ; leaves Ianceolate, acuminated at both ends, on short petioles; flowers nearly sessile, disposed in capitate umbels; leaves of involucrum joined together into a roundish 4-lobed disk. h. H. Native of Mexico, near Jalapa, where it was collected by Berlandier, Deppe, and Schiede. C. grándis, Clıan. et Schlecht. in Linnæa. 5. p. 171. Flowers white, many sterile. Fruit ovate. Perhaps C. polýgama, Rafin. f. lud. p. 78. ?

Disk-flonered Dogwood. Tree.

15 C. JAFónica (Thunb. f. jap. p. 63.) arboreous; branches striated; leaves ovate, acuminated, entire at the base, pale beneath ; umbels decompound, of 3-5 rays; involucrum of 4 leaves. ז. H. Native of Japan, near Nagasaki. Vibúrnum Japónicum, Spreng. syst. 1. p. $93 \%$. Rom. et Schultes, syst. 3. p. 320. Stamens 4. Flowers white. Fruit crowned by the very short permanent style, and the trigonal acute stigma, compressed, red, smooth, rather acid, ex Thumb. I. c.

Japan Dogwood. Shrub 5 to 6 feet.

\section{* Trees, with yellow umbellate flowers.}

16 C. MA's (Lin. spec. 171.) branches smoothish; leaves oval, acuminated, rather pubescent on both surfaces; flowers rising before the leaves; umbels about equal in length to the $1-$ leaved involucra; fruit elliptic. $\zeta$. H. Native throughout Europe, Britain excepted, and in the north of $\mathrm{Asia}$, in hedges, and among buslses; as in France, Russia, Germany, Switzerland, Austria, Carniola, Piedmont, \&c. Blackw. t. 121. Plench. icon. 1. 64. C. máscula, L’Her. corn, no. 4. Guimp. abb. t. 2. Hayne, term. bot. t. 35. Fl. græe. t. 151. Schmidt, arb. 2. t. 63. Lam. ill. t. 74. f. 1. Kinip, cent. 1. t. 18. Flowers yellow. Fruit elliptic, of a high shining scarlet colour, the size and form of a small olive or acorn, very styptic in its immature state. 'The Cornelian cherry is very common in plantations of shrubs. If the season be mild, the flowers will come out in the beginning of February; and thongh there be no great beauty in them, yet they are produced in plenty at a season when few other flowers appear. Formerly it was cultivated for the fruit, which was used to make tarts, and a rob de cornis was liept in the shops. The fruit is gratefully acid, and is called sorbet by the Turks. Cornel, says Erelyn, grows with us of a good bulk and stature, and is exceedingly commended for its durableness in wheelwork, pins, and wedges, in which it lasts like the bardest iron.

Var. $\beta$; fruit yellow or yellowish. Dulam. arb. 1. p. 182. This variety is to be found but very rare in the gardens.

Var. $\gamma$, variegàta; leaves edged with white or yellow.

Male Cornel or Cornelian-cherry. Fl. Feb. April. CIt. 1596. Shrub 10 to 15 feet.

17 C. Flókida (Lin. spec. 1661.) branches shining; leaves ovate, acuminated, pale beneath, beset with adpressed pili on both surfaces; flowers umbellate, rising after the leaves; leaves of involucrum large, roundish, retuse or nearly obcordate; drupes ovate. $\eta_{\text {. }}$ H. Native of North America, from Carolina to Canada, in woods, common; aud on the banks of the Columbia near its confluence with the sea. L'Hher. corn. no. 3. Curt. bot. mag. t. 526. Catesb. car. t. 27. Bigel. med. bot. 2. t. 28. Guimp. abb. hol\%. t. 19. Rafin. med. bot. t. 28. Sclınidt, arb. 2. 1. 52. Wang. beytr. 1. t. 17. f. 41. This is a beautiful small trec. Leaves of involucrum white. Flowers greenislyellow. Berries scarlet, about half the size of those of C. máscula, ripe in $\Lambda$ ugust. 'The wood is extremely hard, and of a very fine texture. The bark is extremely bitter, and is used in North America for the cure of remittent and intermittent fevers; and is considered not inferior to Peruvian bark. The young branches stripped of their bark, and rubbed with their ends against the teeth, render them extremely white. (Barton, 1. p. 51.) From the bark of the more fibrous roots the Indians obtain a good scarlet colour.

Flowering Dogwood. FI. April, May. Clt, 1781. Tree 20 to 30 feet.

** Herbaceous plants, with subtcrranecus creeping roots. Stems simple, herbaccous. Flowers white, in umbels.

18 C. Canadénsis (Lin.spec. 172.) stems simple, herbaceous; upper leaves in whorles, ovate, acuminated, veiny, on sliort petioles; flowers umbellate, much shorter than the leaves of the involncrum, which are ovate, and acuminated; drupes globose. 4. H. Native of North America, on the high mountains, in boggy gromd, from New England to Carolina; also of Newfoundland, and the island of Unalasclıka; throughout Canada nearly to the Arctic coast, every where as far as pine woods extend, \&c. L'Her. corn. no.?. t. 1. Curt. bot. mag. 8s0. Begel. f. bost. ed. 1. p. 37. Cham. and Schlecht. in Linnæa. 3. p. 139. Kerner, t. 636 . ex Rom. et Schultes, syst. 3. p. 319. Flowers purplish-white; involucra white. Berries red, ripe in July. Habit of Pàris quadrifòtia.

Canadian Dogwood. Fl. May, June. Clt. 1774. PI. $\frac{1}{2} \mathrm{ft}$. 19 C. Suécrea (Lin. sprec. 172.). stem lierbaceous; umbel betwcen two branclies, stalked, surrounded by 4 unequal white involucral leaves, tinged with red; leaves opposite, sessile, ovate, almost nerved from the base; drupe globose. 4 . H. Native of Europe and the north of Asia, Kamtschatka, Aleutian Islands, Greenland, Lapland, Canada, Newfoundlind, and Labrador, in moist alpine pastures. In Britain in like situations; on the Cheviot hills of Northmberland, abundantly. In the highlands of Scotland, frequent in boggy spots about rivulets. In the llole of Horcum, near Scarborough. Lin. fi. lapp. ed. 2. p. 38. t. 5. f. 3. Svensk. bot. t. 201. Penn. tour. scotl. p. 39. Smith, engl, bot. t. 310.-Eder, fl. dan. t. 5. Sturm. deutschl. f. with a figure. C. herbacea, Huds. angl. 71.-Dill. elth. 108 . t. 91.-Raii, syn. 261. Park. theatr. 14.61. f. 1 . The involucral leaves finally turn green. Flowers dark purple. The berries are red and sweetish, containing a 2-celled nucleus, having the dissepiment between the cells furnished with a large bole; they are supposed by the Highlanders to create an appetite, and hence the Gaclic name, Lus-a-ehrasis, plant of gluttony.

I ar. $\beta$; nearly twice the size of the species. 4 . H. Native of North America, at Fort Vancouver, on the Columbia. 
Swedish Dogwood or Dwarf-cornel. Fl. June, July. Britain. Pl. $\frac{1}{4}$ to $\frac{1}{2}$ foot.

\section{† Species not sufficiently knonn.}

20 C. Ferula'cea (Jacq. ex Steud. nom. 227.) or C. ferulæfölia, Nocca, syn. pl. p. 38 . but is undescribed. Compare Rœm. et Schultes, syst. 3. p. 323.

Fennel-likc Dogwood. Shrub.

21 C. Latifòlia (Bray. in Steud. nom. pluan. 227.) this species is undescribed as far as we know.

Broad-leated Dogwood. Shrub.

22 C. polýgama (Rafin. f. lnd. p. 78.) branches straight, smooth, glabrous; leaves opposite, sessile, oblong, entire, obliquely acuminated, hoary beneath; flowers polygamous. h. H. Native of Louisiana. Cómus, no. 2. Rob. voy. 456. Shrub 15 feet high. Branches red. Calyx entire. Petals white, acute. Styles shorter than the stamens. Fruit black, edible.

Polygamous Dogwood. Shrub 15 feet.

Cult. All the woody species are desirable for shrubberies; and many of the kinds will grow under the drip of trees, which renders them valuable for thickening strips of plantations which have become naked below. They are easily increased by cuttings, layering, or by suckers. The $C$. Suécica and $C$. Canadénsis should be grown in a border of peat, in a rather shady situation; they are to be increased by dividing when the plants have run considerably at the roots; or they may be planted in pots filled with peat earch, and treated as alpines.

II. VOTOMI'TA (Votomit is the name of the tree in Guiana). Aubl, guian. 1. p. 90. t. 35. D. C. prod. 4. p. 275.-Glóssoma, Schreb. gen. no. 1728.-Guillemínia, Neck. elem. no. 813. but not of Kunth.

Lin. syst. Pentandria, Monogýnia. Tube of calyx turbinate, adnate to the ovarium; limb 4-toothed. Petals 4, oblong, acuminated, spreadingly reflexed. Stamens 4 , with very slıort filaments; anthers oblong, approximate into a tube, terminated by a thin membrane. Style filiform, perforating the tube of the anthers; stigmas 4, oblong. Drupe crowned by the calyx, 1celled. Seed one striated. - A glabrous shrub, having the branches somewhat quadrangular at the apes. Leaves opposite, sessile, ovate, acuminated, stiff, quite entire, furnished within the base of the petioles with 2 deciduons stipulas. Flowers corymbose; corymbs axillary, few-flowered. Corolla white. This genus is not sufliciently known, but is allicd to Córnus from the description.

1 V. Guianésisis (Aubl. l, c.) h. S. Native of French Guiana, near the river Sinemari. Poir. dict. 8. p. 698. Glóssoma Votómita, Rœm. et Schultes, syst. 3.p. 318 . Glóssoma arboréscens, Willd. spee. 1. p. 664.

Guiana Votomita. Shrub 5 to 6 feet.

Cult. A mixture of loam, peat, and sand will suit this shrub; and cuttings will root readily in sand under a liand-glass in heat.

III. MASTIXIA (meaning unknown to us). Blum. bijdr. p. 654. D. C. prod. 4. p. 275.

Lin. syst. Tetra-Pentándria, Monogýnia. Tube of calyx adnate to the ovarium : limb superior, 4-5-toothed. Petals 4-5, ovate, broadest at the base. Stamens $4-5$, opposite the calycine teeth. Anthers didymous, bursting inwards. Ovarium containing a pendulous ovulum. Style short, girded by a disk; stigma obtusc. Drupe baccate, umbilicate, containing a 1 -seeded nut. Embryo inverted in the albumen.- Tall trees, natives of Java, with oblong acuminated leaves, and corymbose flowers.

1 M. PENTA'NDRA (Blum. l.c.) leaves alternate, oblong, quite glabrous; corymbs terminal; flowers pentandrous. $h . S$. Native of Java, on the more elevated woods on Mounts Salak and Burangrang, where it is called by the natives Huru-Lilin. vol. III.
Pentandrous Mastixia. Fl. July, Dec. Tree 30 to 50 feet.

2 M. тrichótona (Blum. l. c.) leaves opposite, oblong, puberulous on the under side, as well as the petioles, and the corymbs which are terminal and trichotomous; flewers with a 4 -toothed calyx, 4 petals, and 4 stamens. h.S. Native of Java, in woods on the mountains along with the preceding species, where it is called Palaglar burriet or Tenjoh.

Trichotomous-corsmbed Mastixia. Tree 50 to 60 feet.

Cult. For culture and propagation sec Votómita above.

IV. POLYO'SIIA (from $\pi \sigma \lambda v$, poly, much, and $o \sigma \mu \eta$, osme, smell ; flowers). Blum. bijdr. p. 658. D. C. prodl. 4. p. 275.

Lin. syst. Tetrándria, Monogýnia. Tube of calyx adnate to the ovarium : limb superior, 4-toothed, permanent. Petals 4, sometimes joined at the base. Stamens 4 , free, alternating with the petals ; filaments linear, rather membranous ; anthers bursting lengthwise inwardly, adnate, 2-celled. Ovarium incompietely 2-celled, many-seeded. Style filiform; stigma truncate, simple. Druye somewhat baccate, containing a 1 -seeded nucleus. Albumen rather horny. Embryo inverted.-.Trees and shrubs, native of Java, with opposite exstipulate leaves; and axillary terminal racemes of whitish, very sweet-scented flowers, furnished with o bracteoles under each.

1 P. ilictròlium (Blum. l. c.) stem arborescent ; leaves oblong, coarsely and deeply serrated at the top. $h^{2}$.S. Native of $J_{\text {ava, }}$ on the tops of the higher mountains.

IIolly-leaved Polyosma. Tree 20 to 30 feet.

2 P. serrula'tum (Blum. l. c.) stem slirubby; leaves oblong, slightly serrulated. $h$. S. Native of Java, in woods on IIounts Gede and Pangurango.

Serrulated-leaved Polyosma. Shrub 5 to 6 feet.

3 P. Integrifòlium (Blım. l. e.) stem arboreous; leaves oblong, quite entire. $\eta_{\text {. }} \mathrm{S}$. Native of Java, in the higher woods on Dlount Burangrang.

Entire-leaved Polyosma. Tree 60 feet.

Cult. See Votómita above for culture and propagation.

Order CXXVII. LORANTHA CEÆ (plants agreeing with Loránthus in important characters). D. Don, prod. fi. nep. 142. D. C. coll. mem. vi. with 12 figures, prod. 4 . 1. $27 \pi$.. Lorántheæ, Rich. and Juss. in ann. mus. 12. p. 292. exclusise of Rhizophòreæ, Clorântheæ, and some genera of Loranthàceæ. Loranthídeæ, Gray, brit. arr. 2. p. 492.

Flowers hermaphrodite, or of different sexes (f. 73. u. d.). Tube of caly $x$ girded at the base by a calyculous, which is adnate to the ovarium; limb short, entire, or lobed. Petals 4-8 (f. 73 . e.), sometimes distinct from each other, sometimes cohering more or less together, valvate in æstivation. Stamens equal in number to the petals, and opposite them; filaments adrate to the corolla, more or les;, or wanting; anthers oscillatory, or erect on the tops of the filaments; or when the filaments are deficient or wanting, they are adnate to the lobes of the corolla. Ovarium ovate or turbinate, adnate to the calyx. Style filiforn or wanting; stigma capitate. Berry 1-celled (f. 73. a.f.), 1 -seeded (f. 73.c.), crowned or umbilicate by the calyx (f. 73.b.). Tegument membranous, involving the seed. Albumen fleshy. Embryo with a superior radicle, which is thickened or truncate at the apex.-The shrubs contained in this order are almost all parasitical, that is, growing on and deriving their nourishment from other trees : very few of them grow in earth. Leaves opposite, rarely alternate or wanting, coriaceous or more or less fleshy, and always entire. The disposition of the flowers and $3 \mathrm{~F}$ 
the habit of the plants are very variable.-Very few of the plants belonging to this order are cultivatable; they being nearly all genuine parasites, fixed in the bark and wood of trees, on which they grow, and deriving from their juices the whole of their nutriment. The Viscums have little or no beauty, but the other parasitical genera are among the most lovely of plants, hanging in clusters of rich scarlet flowers from the trunks and branches of trees in the tropics, which they often clothe with a beauty not their own. The Mistletoe of the Druids is supposed to have been the Loránthus Europa'ns, the common I iscum never having been seen upon the oak, while the Loránthus Europa'us inhabits no other tree. If this be correct, the latter must have once existed in this country, although now extinct. It has been suggested, that all vestiges of their religion were extirpated with the Druids, which will perhaps account for the Loránthus having disappeared wherever that religion formerly held its sway.

This order is very nearly allied to Caprifoliacece, from which it is easily distinguished by the anthers being opposite the lobes of the corolla. A comnection is established between this order and Araliàcea by means of Aúcuba. Mr. Brown suggests their relation to Protencea. The germination of $I_{\text {iscum }}$ is exceedingly remarkable; it has afforded a subject of some curious experiments upon the vital energies of vegetables. See Du Trochet sur la Motilité, p. 114.

\section{Synopsis of the gcnera.}

Tribe I. Parasitical shrubs.

1 V'scum. Flowers dioecious (f. 73. b.e.), or monoecious. Margin of calyx obsolete, but in the male flowers wanting. Petals usually 4 (f. 73. e.), connected at the base in the male flowers, but free in the female. Stamens 4. Stigma obtuse, sessile.

\& Arceutho'buum. Flowers dioecious. Male flowers sessile, without a calyx, but with a monopetalous 2-3-4.parted corolla, and the same number of sessile 1-celled anthers, and a gland in place of an ovarium. Female flowers pedicellate, with an ovate, fieshy, bidentate calyx, adnate to the ovarium, without any corolla, stamens, or style, but with a small obscurely-lobed stigma. Berry obovate.

3 Misode'ndron. Flowers dioecious: male ones unknown: female ones having a small truncate limb. Capsule oblong, trigonal.

4 Lona'ntuus. Flowers dioecious or hermaplırodite. Margin of calyx entire. Petals 5-6, linear, reflexed. Stamens inserted into the middle of the petals; filaments very short. Berry globose, umbilicate by the calyx, immersed in the rachis.

5 Sтrutha'nthus. Flowers hermaphrodite, nearly all hexamerous. Margin of calyx truncate. Petals linear, at length revolute. Anthers ovate, fixed near the base or heneath the middle of the petals; filaments very short. Berry ovate-elliptic.

6 Psitraca'ntuus. Flowers liermaphrodite, for the most part hexamerous. Margin of calyx entire, obsoletely 5-6-toothed or repand. Pctals linear-spatulate, erect, spreading, for the most part free to the niddle. Filaments filiform from the middle of the petals; anthers fixed by the base or back. Berry ovate.
7 Trísterix. Flowers hermaphrodite; each furnished with 3 bracteas. Margin of calyx entire. Petals linear-spatulate, or linear, bearing the stamens in the middle; anthers fixed by the back, incumbent. Berry ovate or elliptic.

8 DEndroptho'e. Flowers hermaphrodite; each furnished with 1 bractea. Margin of calyx entire or toothed. Petals linear-spatulate, bearing the stamens in the middle; anthers fixed by the base. Berry ovate or elliptic.

9 Phturnu'sa. Flowers hermaphrodite, perhaps always 4parted; each furnished with 3 or more bracteas. Anthers fixed by the back, ovate. Berry ovate.

10 Scu'rrula. Flowers hermaphrodite, tubular, divided into 4-5 short lobes, usually gibbous at the base, and bursting by a longitudinal fissure as in Lobelia. Filaments 4-5, adhering a long way to the corolla; anthers fixed by the base, erect. Style filiform ; stigma capitate.

11 Elytra'nthe. Flowers hermaphrodite; petals 4-6-8, joined to the middle, forming a regular 4-6-8-cleft limb. Filaments adnate to the petals at the base, but free at the apex; anthers fixed by the base, erect. Style filiform. Stigma capitate.

12 Notanthe'ra. Flowers hermaphrodite. Petals 5-6-8, but usually 6 , sometimes almost free, and sometimes joined at the base. Filaments adnate to the petals at the base, but free at the apex; anthers fixed by the back, versatile or incumbent. Bracteas concave, 1 under each ovarium, but often wanting.

13 Loxanthe'ra. Flowers hermaphrodite. Tube of corolla elongated, kneed at the base, but somewhat clavate and obliquc at the apex, and 6-lobed; the lobes somewhat spirally twisted. Filaments stiff and curved at the apex, not attenuated but rather dilated, and the anthers are fixed by the back. Style filiform. Stigma clavate.

\section{TriBe II. Terrestrial shrubs.}

14. Sснок'́pia. Flowers hermaphrodite. Margin of calyx entire. Limb of corolla 5-cleft, rarely 4-6-cleft. Filaments adnate to the tube; anthers ovate-roundisl. Drupe containing a 3-celled, 3-seeded nucleus.

15 Aúcuba. Flowers dioecious. Calyx 5-toothed. Petals 4 , ovate-lanceolate. Stamens 4, alternating with the petals? Stigma concrete. Fruit 1 -seeded.

\section{Tribe I. Parasitical shrubs.}

I. VI'SCUMI (viseus, birdlime, on account of the sticky nature of the berries; called gui, in French; mistl in German; visco in Italian; and mistletoe in English). Tourn. inst. p. 609. t. fruct. 1. p. 131. t. 27. Lam. ill. t. 807. D. C. prod. 4. p. 277. 380. Lil. gen. no. 1105. D. C. coll. mem. 6. no. 1. Gartn. Lin. syst. Monoècia or Dioćcia, Teträdria. Flowers monoecious or dioecious. Calyx a slight border in the male flowers, but rather a more evident border in the female flowers. Corolla in the male flowers gamopetalous, in 4 deep, ovate, acute equal divisions; in the female flower of 4 ovate, equal, deciduous petals, which are dilated at the base. Anthers in the female flowers none, but in the male flower there are 4 compressed, sessile ones, one on the base of each corolline segment, all over pitted or cellular. Ovarium in the female flower inferior, ovate, adnate to the calyx, and crowned by its border. Stigma sessile, obtuse, undivided. Berry globular, smooth, juicy, viscid, of 
1 cell. Seed solitary, heart-shaped, compressed, sometimes with a double embryo.-Parasitical on trees, shrubby, branched, all smooth except one species, pale green. Branches terete, tetragonal, or compressed, usually jointed. Leaves opposite, very rarely alternate, simple, undivided, entire, rigid, sometimes wanting or reduced to scales. Flowers in fascicles or spikes, greenish. Berries of various colours. Concerning the very

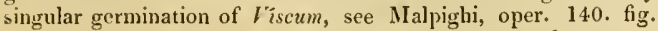
105. Dulam. phys, arb. vol. 2. p. 220. liv. 5. t. 1. f. 2-10.

\section{\$1. Plants with true leaves. Floners in fascicles or unbels.}

1 V. A'LBUm (Lin. spec. 1451.) stem much brancherl, forked: with sessile, intermediate lieads, of about 5 flowers; branches terete; leaves obovate-lanceolate, obtuse, nerveless. $々$.P.H. Native of Europe, parasitical on trees, especially on the appletree and hawthorn; but it is said also to have been found growing on the lime-tree, oak, American locust-tree, elm, fir, pear-tree, service, almond, white willow, walnut, \&c. Smith, engl. bot. t. 1470. Mill. fig. 87. Woodv. suppl. t, $270 .-$

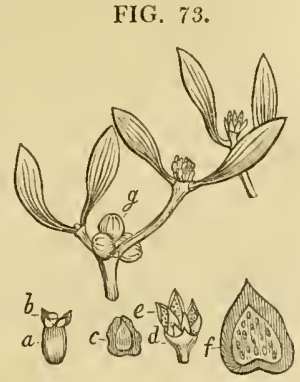
Duham. arb. 2. t. 104 . Rich. ann. mus. 12. t. 27.-Fuschs. hist. 329. t. 1817 . Cam. epit. 555. with a figure. V. álhum of Thunb. and Walt. are distinct from this. Root hard, incorporated deep with the wood of the tree on which it grows, without any radicles, as in all the other species of this genus, as well as of Loránthus and the allied genera. Leaves permanent, stiff, with parallel ribs. Flowers yellowish. Berries white, pellucid, the size of a currant, sweet, very glutinous internally, serving to make the best bird-lime, when boiled with a small portion of vegetable oil. Loránthus Europa'us seems to be the original and most common mistletoe, $\theta$ to os of the Greeks, which grows usually on some kind of fir-tree. But our $V$, album is sometimes found in Greece, thongh rarely, growing on the oak; and ilis has been preferred from the most remote antiquity. Hence, when the superstitions of the East travelled westward, our Druids adopted a notion of the mistletoe of the oak being more holy or efficacious in conjurations or medicine, than what any otlier tree afforded, the Lorknthus or ordinary mistletoe not being known here. This superstition actually remains, and a plant of liscum from an oak is preferred by those who rely on virtues, which perhaps never existed in any mistletoe whatever. The Druids sent round their attendant youths with branches of mistletoe to announce the entrance of the new year; and something like the same custom is still continued in France. In England branches of it are hung up in most houses at Christmas, along with other evergreens. The berries are devoured by several birds of the thrush kind, and especially by the inistletoe thrush. The common mistletoe is not difficult to propagate by sticking the berries on thorn or apple trees, after a little of the outer bark has been cut off, and tying a shred of mat over them, to protect them from the birds.

White-berried or Common Mistletoe. Fl. May. Britain. Shrub par.

2 V. stella'tum (Hamilt, in D. Don, prod. f. nep. 142.) much branched; branches whorled, terete; leaves oblong, obtuse, attenuated at the base, 5 -nerved beneath ; flowers terminal, sessile, 3-5-together in a cluster. h. P. H. Native of Upper Nipaul, at Suembu, parasitical on trees. Habit of $\boldsymbol{V}$. álbum. Nerves of leaves acutely prominent on the under surface, but line-formed on the upper surface. The branches are more likely dichotomous or trichotomous than verticillate.

Starry Mistletoe. Slurub parasitical.

3 V. ORIENTA'LE (Willd. spec. 4. p. 737.) branches terete; leaves oblong, obtuse, attentwated at the base, 3-nerved; peduncles axillary, usually 3 -flowered. h. P. S. Native of the East Indies (ex Wall.), and of Java, on the mountains (ex Blum. bijdr. 666.), and of Palestine upon olive trees, ex Sieb. pl. exsic. pal. Leaves 15-18 lines long, but in the Palestine specimen. 20-23 lines long. Berries purple, ex Wall. Perhaps the Indian plant is the same as the l'alestine one.

Eastern Mistletoe. Shrub parasitical.

4. V. HEYNEA'NUM (D. C. prod. 4. p. 278.) branches terete; branchlets rather compressed ; leaves ovate, acute at both ends, quintuple-nerved; peduncles axillary, aggregate, 3-flowered. h. P. S. Native of the East Indies, where it was collected by Heyne. V. orientàle, Heyne, herb. ex Wall, and probably of Willd. The form of the leaves is truly different from the $\mathrm{Pa}_{\mathrm{a}}$ lestine form of $V$. orientile, but more of the figure of those of V. monoicum.

Heyne's Mistletoe. Shrub parasitical.

5 V. monoícum (Roxb. hort. beng. p. 105.) branches terete, jointed: branchlets striated; leaves elliptic-oblong, acuminated at both ends, 5 -nerved: the 2 lateral nerves hardly conspicnous; fascicles axillary, very short, few-flowered, somewhat spicate. h.P. S. Native of the East Indies, at Sunderbund.

Monoccious Mistletoe. Shrub parasitical.

6 V. FAlca'tum (Wall. cat. no. 492.) branches terete; leaves elliptic-oblong, acuminated, rather falcate, acute at the base, 5nerved; fascicles of flowers axillary, aggregate, sessile, usually with only 3 flowers in each cluster, 5 . P. S. Native of the East Indies, on the Pundua mountains. Leaves 24-27 lines long, and $9-10$ broad. Flowers very small.

Falcate-leaved Mistletoe. Shrub parasitical.

7 V. ovalifòlum (Wall. cat. no. 489.) branches terete; leaves oval, obtuse, 5 -nerved, narrowed into the short petioles at the base; flowers some of them in axillary sessile fascicles, and others are opposite, and somewhat verticillate, along an axillary rachis, disposed in an interrupted spike. h.P.S. Native of the East Indies, in the island of Penang. Leaves 3 inches long, and $1 \frac{1}{2}$ broad. Rachis not articulated. Berry oval.

Oval-leaved Mistletoe. Shrub parasitical.

8 V. овтияa'тuм (Wall. cat. no. 494.) branches terete; leaves oval, obtuse, somewhat cuneated, 5-nerved; flowers axillary, 1-3-together, almost sessile. $h$. P. S. Native of the East Indies, in the kingdom of Ava, on Mount 'Taong-Dong. Leaves 30 lines long, and 15 lines broad. Flowers small. Berries oval. Lateral nerves of leaves slender.

Bluntish-leaved Mistletoe. Shrub parasitical.

9 V. hetera'́thum (Wall. cat. no. 488.) branches angular, at lengtlı terete; leaves elliptic, obtuse, cuneated at the base, 5 -nerred beneath; peduncles axillary, 2-5-together, equal in length to the petioles, capitate at the apex, 5-6-flowered, bearing 3-5 involucrate bracteas. h. P. S. Native of Nipaul. Berries ovate-globose, solitary in each head, surrounded by the small permanent bracteas. Flowers 5 -cleft, one central, the rest disposed in a whorl around the central one, all sessile on the top of the common peduncle.

Variable-flowered Mistletoe. Shrub parasitical.

10 V. PLATYPHY'LLUM (Spreng. cur. post. 47.) branches alternate, angular; leaves alternate, ovate or obovate, petiolate, attenuated at the base, nerved beneath; umbellules usually of 4 flowers, dispersed, pedunculate, solitary or agıregate : involucels 5-cleft, permanent. h. P.G. Native of Nipaul, at Bimpedi. V. latifölium, Hamilt. in D. Don, prod. fi. nep. p. 142. but not of others. 
Broad-leaved Mistletoe. Shrub parasitical.

11 V. имвецLA'тuм (Blum. bijdr. p. 666.) branches alternate, angular while young; leaves obovate, 3-nerved: lateral nerves bifid; umbellules pedunculate, axillary, crowded; male flowers pentandrous. h.P. S. Native of Java, on trees on Mount Salak.

Umbellatc-flowered Mistletoe. Shrub parasitical.

12 V. capitella'tum (Smith, in Rees' cycl. 37. no. 18.) stem branched, rougl to the tonch; leaves concave, obtuse; pechuncles axillary; berries capitate, oval. $\zeta$. P. S. Native of Ceylon. Stems 3 inches high. Leaves an inch long, smooth, thick, fleshy. Heads 4-5-flowered, and under each head there are two thick bracteas.

Capitellate-flowered Mistletoe. Shrub parasitical.

13 V. TRiflòrum (D. C. prod. 4. p. 279.) branches angular from numerous stripes; leaves oval, bluntish, somewhat undulated, and rather attenuated at the base, 3-nerred beneath; peduncles axillary, 3 times shorter than the leaves, about the length of the berries, 3 -flowered, and furnished with 3 bracteas at the apex; flowers 4-cleft, sessile among the bracteas; berries globose. $h_{2}$. P. S. Native of the Mauritius. Leaves 6-7 lines long, and 5 lines broad. Peduncles hardly 2 lines long. Flowers 1-2-together, sometimes sessile in the axils of the upper leaves. This species is designated V. rotundifolium in Bory, voy. 1. p. 320 .

Three-flonercd Mistletoe. Shrub parasitical.

14 V. venòsum (D. C. l. c.) branches angularly striated ; leaves ovate or oval, obtuse, attenuated at the base, on short petioles, 5-veined; veins branched; peduncles axillary, very short, 2-3-flowered; berries glohose. $h$. P. S. Native of the Mauritius. V. Capénse, Bory, voy. 1. p. 320.? Plant becoming blackish on drying.

Var. 3 , lanceolatum (D. C. l. c.) leaves ovate-lanceolate, somewhat acuminated. $h$. P.S. Native along with the species.

l'ciny-leaved Mistletoe. Shrub parasitical.

$15 \mathrm{~V}$ Rotundfòlium (Lin. fil. suppl. p. 426.) stem and branches hexagonal, articulated; leaves sessile, roundish, acute; peduncles 3-flowered, short; bracteas minute, opposite. $h$. P. G. Native of the Cape of Good Hope, on trees. Thunb. f. cap. 154 .

Round-leaced Mistletoe. Shrub parasitical.

\$2. Plants with true leaves. Flowers disposcd in articulated spikes; the jints sheathed.-American species.

$$
\text { * Branches terete. }
$$

16 V. torulòsum (D. C. prod. 4. p. 279.) much branched; branches terete; leaves roundish-ovate or elliptic, oblique, rounded at the apex; spikes axillary, of $2-3$ joints; flowers immersed, in 4 rows. h.P.S. Native of Quito, on trees near Guayaquil. V. buxif òlium, from South America, Spreng. syst. 1. p. 488. Loránthus torulòsus, H. B. et Kunth, nov. gen. amer. 3. p. 443. Schultes, syst. 7. p. 156. Leaves 30-33 lines long, and 16-20 broad, on petioles, which are 2-3 lines long. Fructiferous spikes $1 \frac{1}{2}$ inch long. Flowers unknown

Torulose-spil:ed Mistletoe. Shrub parasitical.

17 V. TRiNé Rvium (Lam. dict. 3. p. 57.) branches terete, articulated, trichotomous; leaves obovat, obtuse, narrowed at Ihe base, 3-nerved; spikes dense, short, lateral; berries round. দ. P. S. Native of St. Domingo and Martinico. Plum. ed. Burm. t. 258. f. 2. V. verticillàtum, Lin. exclusive of the syn. Browne, and Sloane. Berry copper-coloured, size of a grain of pepper.

Thee-nerved-leaved Mistletoe. Shrub parasitical.

18 V. вuxifòdum (Lam. dict. 3. p. 56.) branches terete, articulated : joints short, thickish; leaves obovate, obtuse, 1-nerved, sessile; spikes axillary, solitary or twin, length of the leaves. ${ }$. P.S. Native of St. Domingo, in the district of Leogane.
Willd, spec. 4. p. 738.-Plum. ed. Burm. t. 258. f. 3. There are varieties with both white and purple berries.

Box-leaved Mistletoe. Shrub parasitical.

19 V. saururoides (D.C. prod. 4. p. 36.) branches terete; leaves ovate, acute or acuminated, on very sbort petioles, beset with dot-like tubercles beneath, having the middle nerve rather prominent, and the lateral veins hardly perspicuous; spikes axillary, twin, shorter than the leaves, very slender. $h_{\text {. }}$. P. S. Native of Cayenne. V. latifolium, Lam. dict. 3. p. 57. but not of Swartz, Don, nor Plum. V. racemòsum, Aubl. guian. 2. p. 895.? Leaves 4 inches long, and $2 \frac{1}{2}$ broad, on petioles which are a line long. Spikes an inch long, with bifid sheaths. Flowers in 4, 3-flowered whorls between the sheaths.

Saururus-like Mistletoe. Shrub parasitical.

20 V. tereticau'Le (D. C. l. c.) branches terete, smooth ; leaves ovate, acute, nerveless, veinless, on very short petioles; spikes axillary, tw in or solitary, shorter than the leaves; female flowers trifid. $\zeta$. P. S. Native of Jamaica, on trees. V. latifòlium, Swartz, fl. ind. occ. 1798. but not of Lam. nor Don.

Iar. 3 , Cubcrnse (D. C. l. c.) leaves having the middle nerve rather prominent, but with few vcins in the dried state; the margins rather undulated. $h$. P.S. Native of Cuba. Lower spikes 2-3. Perhaps the same as the Jamaica plant.

Tercte-stcmmed Mistletoe. Shrub parasitical.

21 V. Martinic '́nse (D. C. 1. c.) plant glabrous; branches terete; leaves ovate-lanceolate, acuminated, 3-nerved, on very short petioles, thick; spikes axillary, solitary, 3 times shorter than the leaves; flowers 4 in a whorl, between the sheaths in each joint of the rachis of the spike. $\zeta$. P.S. Native of Martinico. Sieb. fl. mart. no. 227 . Leaves 3 inches long, and an inch broad, having the micldle nerve rather prominent.

Martinico Mistletoe. Shrub parasitical.

22 V. Flave'scens (Pursh, f. amer. sept. 1. p. 114.) branches terete, opposite, and verticillate; leaves cuneate-obovate or lanceolate, obtuse, 3-nerved: spikes axillary, solitary, a little shorter than the leaves, interrupted. Ђ. P. H. Native of North America, from Pennsylvania to Carolina, and probably of Louisiana, on oak trees. V. álbum, Walt. car. 241. Muhl. cat. no. 91. V. verticillatum, Nutt. gen. amer. 2. p. 235 . Ell. sketch. 2. p. 677. V. leucocárpum, Rafin. H. lud. 79. Berries white, diaphanous. Male flowers mostly trifid.

Vellowish Mistletoe. Shrub parasitical.

23 V. crassiròlom (Pohl. in litt. ex D. C. prod. 4. p. 280.) branches terete; leaves broad-oval, attenuated at both ends, nerveless, on short petioles ; spikes axillary, twin or tern, 4-6 in a whorl, 7 times shorter than the leaves, articulated: with truncate sheaths, and short joints; flowers disposed in 4 rows; berry ovate-globose. 12. P. S. Native of Brazil, where it was collected by Pohl. Leaves 4 inches long, and $2 \frac{1}{2}$ broad. Spikes 6-8 lines long.

Thick-leaved Mistletoe. Shrub parasitical.

24. V. Leptosta'chyum (D. C. prod. 4. p. 280.) branches terete ; leaves oblong-lanceolate, acute at both ends, 3-nerved; spikes trichotomous, elongated, somewhat panicled, s?ender, jointed: with cushion-shaped sheaths; berries ovate-roundish, not immersed. Ђ. P. S. Native of St. Domingo, where it was collected by Bertero. V. macrostàchyum, ex Hispaniola, Spreng. syst. 1. p. 487. V. aplyyllum baccis aureis, Pinn. ed. Burm. t. 258. f. 1 . and therefore $V$. opuntioides var. $\beta$, Lam. dict. 3. p. 56 .

Slender-spiked Mistletoe. Shrub parasitical.

25 V. Perrotte'ti (D. C. prod. 4. p. 280.) branclses terete; leaves lanceolate, obliquely falcate, bluntish at the apex, cuneated at the base, 5-7-nerved: nerves branched a little; spikes axil. lary, solitary, opposite, one-half shorter than the leaves, jointed: with bifid slieatlis. h. P. S. Native of French Guiana. Lcaves 
5-6 inclies long and $1 \frac{1}{2}$ broad. Spikes 2 inches long, erect, constantly of 5 joints. Flowers in 6 rows, many of which are abortive. Immature berries nearly glohose, half immersed.

Perrottet's Mistletoe. Shrub parasitical.

26 V. вRаснуsта'cuyum (D. C. I. с.) branehes terete; leaves oblong, obtuse, attenuated at the base, finely 5-nerved; spikes axillary, solitary, opposite, sessile, ovate, few-flowered ; herries ovate-globose. $h$.P.S. Native of Mexico, between Tampico and Real del Monte, where it was collected by Berlandier. Leaves 12-15 lines long, and $y-4$ broad. Spikes 3-4 lines long. Shorl-spiked Mistletoe. Shrub parasitical.

27 V. rc'brum (Lin. spec. 1451.) stems terete, simple; leaves oblong, obtuse, tapering into the petiole at the base; spikes axillary, one-half shorter than the leaves, somewhat interrupted; flowers tripartite; berries globose. h. l'. S. Native of the Bahama Islands, parasitical upon malogany and other trees. Berries red. Leaves opposite, of a shining green colour.

Red-berried Mistletoe. Slırub parasitical.

28 V. Berteria'num (D. C. prod. 4. p. 281.) branelies terete, dichotomous ; leaves oblong-lanceolate, attenuated at both ends, acute at the base, on very short petioles, having the middle nerve rather distinct, and with 2 rather oblique veins rising from the middle; spikes axillary, solitary, opposite, one-half shorter than the leaves, jointed, with bifid sheaths. h. P. S. Native of St. Domingo. V. dichótomum, Spreng. syst. 1. p. 4.18. exelusive of the synonymes, but not of $D$. Don. Leaves 3 inclies long, and an inch broad. Spikes 1-2 inclies long. Berries globose. Flowers disposed in 4 rows on the spikes.

Bertero's Mistletoe. Shrub parasitical.

«9 V. Serótтı (Pohl, in litt. ex D. C. prod. 4. p. 281.) branches terete; leaves oblong-laneeolate, attenuated at both ends, and somewhat acuminated, having the middle nerve rather distinct, but the rest of the leaf veinless ; raeemes axillary, solitary or twin, opposite or vertieillate, 2 or 3 times shorter than the leaves, artienlated : with trifid sheaths; berries ovate; flowers trifid. দ. P. S. Native of Brazil, where it was collected by Schott. Leaves $2-3$ inches long, and 8-9 lines broad. Spikes 9-12 lines long. Allied to $V$. Berteriànum.

Schott's Mistletoe. Shrub parasitical.

30 V. maerosta'ehyum (Jacq. eoll. 2. p. 109. t. 5. f. 3.) branches terete; leaves linear-lanceolate, nearly sessile, obtuse, veinless; spikes axillary, solitary, filiform, much longer than the leares, artieulated : with bowl-shaped sheaths; corolla tripartite. h.P. S. Native of Martinico and Trinidad, on trees. Sieb. f. trin. no. 357 . Spikes 3-6 inehes long: uhtimate ones subpanicled. Flowers small. Leaves an ineh long, and 3 lines broad.

Long-spiked Mistletoe. Slurub parasitieal.

31 V. FA'lcifrons (Hook. et Arn. in bot. misc. 3. p. 356.) branelies terete, but when young compressed; leaves narrow. lanceolate, bluntish, reeurvedly falcate, tapering into the petiole at the base, obseurely 3-5 veined; spikes axillary, solitary, opposite, almost one-half shorter than the leaves; sheaths of spikes truneate. 々. P. S. Native of Brazil, upon laurels by the river Uraguay. The slieatlis of the spikes are here formed of 2 opposite and equal portions, whicl are truneate at the apex. In $\boldsymbol{I}^{\prime}$. Liga they are keeled on the back, and acute at the extremity.

Sickle-leaved Mistletoe. Shrub parasitical.

32 V. Piperojides (D. C. prod. 4. p. 281.) plant pendulous, dichotomous, much branched; branches terete, articulated: joints bidentate at the apex; leaves cblong, narrowed at the apex, and olstuse, somewhat ensiform; spikes $2-3$, axillary, articulated; flowers in 4 series, somewhat immersed in the rachis. F. P. S. Native of South America, near Carthagena and Po- payan. V. diehótomum, var. ex Amer. austr. Spreng. syst. 1. p. 488. Loránthus piperoides, H. B. et Kunth, nov. gen. amer. 3. p. 443. Sebultes, syst. 7. p. 156. Leaves 3 inebes long, 12-14 lines broad, on petioles 2 lines long. Fruit bearing spikes an ineh long. Flowers unknown.

Pepper-like Mistletoe. Slirub parasitical.

33 V. Angustifòluum (1). C. prod, 4.p. 281.) much branched; branches terete, in whorles; leaves jetiolate, linear-lanceolate, somewhat ensiform, narrowed at the apex and obtuse; spikes 1-3-together, axillary, articulated ; flowers in \& series, immersed in the raehis. $3 . P$. S. Native of Peru, in the temperate regions of the Andes, between Ollera and Mount Aipate. Leaves 4-5 inelies long, and lialf an inch broad; petioles 3-4 lines long. Spikes 12-18 inches long. Flowers unknown. V. stenoplyýllum, Spreng. syst. 1. p. 487. Loránthus piperoìdes, H. B. et Kuntl, nov. gen. amer. 3. p. 4.9. Schultes, syst. 7. p. 155.

Narrow-leaved Mistletoe. Shrub parasitical.

34 V. affine (Pohl, in litt. ex D. C. prod. 4. p. 281.) branchlets rather tetragonal; branches terete ; leaves linear-lanceolate, obtuse, attenuated at the base, finely 5-1,erved; spikes axillary, solitary or twin, twice or thrice longer than the leaves, articulated: with small sheaths; berries ovate, exserted. 々. P. S. Native of Brazil, where it was eolleeted by l'oh]. Leaves nearly 2 inches long, and $3-4$ lines broad. Spikes $9-10$ lines long.

Allicd Mistletoe. Shrub parasitical.

35 V. Liga (Gill. mss. ex Hook. bot. mise. 3. p. 355.) branehes terete, while young compressed ; leaves straight, linearoblong, obtuse, hardly apiculated, attennated at the base, $3-$ nerved, somewhat feather-veined in the middle; spikes solitary, axillary, opposite, 2 or 3 times shorter than the leaves; sheaths of spikes keeled, acute; berries ovate, exserted. Native of Chili, on trees near Los Cerillos de San Juan, where it is ealled Liga by the natives. This species seems very nearly allied to V. affine, Pohl.

Liga Mistletne. Shrub parasitical.

36 V. ensifoldum (Pohl, in litt. ex D. C. prod. 4. p. 281.) branches terete; leaves linear-oblong, acuminated at both ends, petiolate, finely 3-5-nerved at the base; spikes axillary or terminal, many, verticillate, articulated, length of the petioles: with the sheaths bifid; flowers in 6 rows; berries globose. h. P.S. Native of Brazil, where it was eollected by Pohl. Leaves eoriaceous, 6-7 inches long, and $8-9$ lines broad; petioles 8 lines long.

Snord-leaced Mistletoe. Shrub parasitical.

37 V. velutinum (D.C. prod. 4. p. 281.) branches terete, velvety fron short down; leaves linear-oblong, attenuated at both ends and aeute, 3-5-nerved at the base, rather velvety when young, but glabrous in the adult state; spikes axillary, solitary or twin, 3 times shorter than the leaves, artieulated with bificl ciliated slieaths; berries in 4 ? rows. 々. P. G. Native of Mexico, in the valley of Tolucea, where it was collected hy Berlandier. Leaves 4 inehes long, and 6 lines broad. Spikes 9-15 lines long. The plate in Catesb. car. t. \$1. lower figure, agrees pretty well with the present species.

lelvety Mistletoe. Shrub parasitieal.

38 V. tomentòsum (D. C. prod. 4. p. 670.) branches terete, while young rather compressed ; leaves obovate, obtuse, a little attenuated at the base, elothed with velvety, somewhat deciduous tomentum on both surfaees, as well as the branchlets; spikes axillary, interruptedly articulated, solitary or twin, rather shorter than the leaves: with small nearly entire sheaths. $h . l$. $\mathrm{S}$. Native of Mexico, in the plains at Real de Ratone, beyond the range of Mimosas, where it was eolleeted by Berlandier.

Tomentose Mistletoe. Shrub parasitical. 
* Branchlets 2-edged or compressed, but at length becoming terete.

39 V. INTERRU'PTUM (D. C. prod. 4. p. 282.) branches compressed while young, but at length becoming terete; leaves oblong-lanceolate, obtuse, attenuated at the base, petiolate, almost nerveless, with $3-5$ fine veins; spikes axillary, 1-2: with the sheaths rather truncate at the apex : joints naked at the base, and fructiferous at the apex. $\quad$. P. S. Native of Brazil, where it was collected by Pohl. V. lanceolato-ellipticum, Pohl, in litt. Leaves 4 inches long, and 8-10 lines broad. Petioles 4 lines long. Spikes $1 \frac{1}{2}$ inch long, interrupted, constantly of $3-4$ joints. Perhaps sufficiently distinct from $I^{*}$, rùbrum.

Interrupted-spiked Mistletoe. Shrub parasitical.

40 V. A'NCEPs (Spreng. syst. 1. p. 457.) branches 2-edged, but in the adult state they are nearly terete; leaves oblong-lanceolate, obtuse, attenuated at the base, having 3 veins rising from the base; spikes axillary, opposite, one-half or more shorter than the leaves. $h$. P. S. Native of Porto-Rico and Hispaniola, where it was collected by Bertero. Leaves 3-4. inches long, and 9 lines broad; petioles 4 lines long. Spikes an inch long or a little more.

Two-edged-branched Mistletoe. Shrub parasitical.

4 I V. Hexa'sticuum (D. C. prod. 4. p. 282.) branches 2edged, but at length becoming nearly terete; leaves elliptic, tapering at both ends, bluntish at the apex, and acute at the base, petiolate, feather-nerved; spikes axillary, solitary, opposite, articulated: with the sheaths truncate; berries globosely depressed, disposed in 6 rows. h. P. S. Native of the island of Cuba, near Havannah. Leaves coriaceous, 3 inches long, and about 15-16 lines broad; petioles 4 lines long. This species is very like $r$. Pcrrottètii.

Six-ranked Mistletoe. Shrub parasitical.

4.2 V. undula'tum (Pohl, in litt. ex D. C. prod. 4. p. 282.) branchlets 2-edged; branches terete; leaves oral or oblong, tapering at the base, and bluntish at the apex, undulated, thickish, having the middle nerve rather tumid, and the rest of the leaf veinless; spikes axillary, twin, articulated, 3 times shorter than the leaves: having the sheaths rather truncate, and the joints short. h. P.S. Native of Brazil, where it was collected by Pohl.

Undulated-leaved Mistletoe. Shrub parasitical.

43 V. MACRopury LLUM (Spreng. syst. 1. p. 488.) branches nearly terete; branchlets compressed at the apex; leaves broadly ovate or oval, petiolate, with the middle nerve rather thick, and the lateral veins perspicuous; spikes $2-4$ from each axil, one-half shorter than the leaves, somewhat tetragonal; berries ovate, half immersed. $h$. P.S. Native of the West India Islands, as of St. Domingo (Plum. ed. Burm. t. 258. f. 4.), and Porto-Rico (Bertero). Leaves 6 inches long, and $3 \frac{1}{2}$ broad; petioles 6-8 lines long. Spikes $2 \frac{1}{2}$ inches long, interrupted. Fruit disposed in 4 rows on the spike, and each row composed of 4 berries. Sheaths of spike truncate.

Long-leaverl Mistletoe. Shrub parasitical.

44. V. SchiedeA'Num (D. C. prod. 4. p. 670.) trunk terete; branches 2-edged, clilated under the forks; leaves fleshy, 3-5nerved, falcate, obtuse: female spikes 1-3-together, axillary ; flowers 6 in a whorl. $\eta_{\text {. }}$ P. G. Native of Mexico, on trees near Jalapa. Fruit a little smaller than hemp seel. Y. falcàtum, Cham. et Schlecht. in Linnæa. 5. p. 172. but not of Wall.

Schicde's Mistletoe. Shrub parasitical.

45 V. FlA'vess (Swartz, fi. ind. occ. p. 266.) branches 2-erlged, at length terete; leaves ovate, somewhat attenuated at the apex, obtuse, 5-nerved at the base, on very short petioles; spikes axillary, twin or tern, 3 times shorter than the leaves, articulated; berries ovate. そ.P.S. Native of Jamaica (Swartz), and Porto-Rico (Bertero), on the branches of trees. The figure of Plumier, cited for this plant by several authors, has here been omitted in consequence of the leaves in the figure being feathernerved, and not 5 -nerved at the base, as in this species.

Yellowish Mistletoe. Shrub parasitical.

\section{* * * Branches and branchlets tetragonal.}

46 V. tetragònum (D. C. prod. 4. p. 282.) branches opposite, and are, as well as the brancblets, tetragonal; leaves elliptic-lanceolate, attenuated at the base, and obtuse at the apex, 3 -nerved or 5 -nerved, the 2 lateral nerves being hardly evident; spikes axillary, solitary, 3 or 4 times shorter than the leaves. 々. P. S. Native of Porto-Rico and Guadaloupe, on trees by the sea side. V. angustifolium, Spreng. syst. 1. p. 487. ? myrtilloìdes and Loránthus séssilis, Spreng. in herb. Balb. Leaves 12-16 lines long, and 5-8 lines broad; petioles a line long. Spikes 2-3 lines long. Perhaps the same as V. myrtilloides, Willd. spec. 4. p. 739.?

Tetragonal-branched Mistletoe. Shrub parasitical.

47 V. mucrons'tum (D. C. l. c.) branches tetragonal, 2-edged while young, but nearly terete in the adult state; leaves oblonglanceolate, attenuated at the base, obtuse, and mucronate at the apex, having the middle nerve and one on eacb side of it distinct; spikes axillary, solitary, 4 times sborter than the leaves. そ.P.S. Native of St. Domingo. V. myrtilloides, Spreng. in lierb. Balb., and hence it is the V. myrtilloides from Hispaniola of Spreng. syst. 1. p. 488 . Leaves nearly an inch long, and 4 lines broad; petioles $1-2$ lines long. Spikes $2-3$ lines long.

Mueronate-leaved Mistletoe. Shrub parasitical.

49 V. PENNive'NiUm (D. C. l. c.) branches tetragonal, nearly terete; leaves somewhat alternate, oval on short petioles, obtuse : having the middle nerve rather prominent beneath, and with the lateral veins pinnate and branched, hardly perspicuous above; spikes axillary, solitary, one half shorter than the leaves; herries oblong. $\quad$. P. S. Native of French Guiana.

Feather-veined Mistletoe. Shrub par.

$49 \mathrm{~V}$. Kuntma'xum (D. C. prod. 4. p. 283.) plant much branched; branches tetragonal, articulated; leaves nearly sessile, obliquely oblong, 3-5-nerved, rounded at the apex and cuneated at the base; spikes axillary, $2-3$ together, articulated; berries globose, immersed in the rachis. h. P. S. Native of Quito, near Guayaquil, on trees. Leaves 18-24 lines long, and 7-9 lines broad. Spikes nearly an inch long. V. trinérvium, Spreng. syst. 1. p. 488 . exclusive of the syn. of Lam. Loránthus viscifolius, H. B. et Kunth, nov. gen. amer. 3. p. 443. Schultes, syst. 7. p. 156 .

Kunth's Mistletoe. Shrub par.

50 V. Quadrangula're (D.C. prod. 4. p. 283.) plant much branched; branches tetragonal, almost winged; leaves lanceolate-oblong, obtuse, almost ensiform, 5-nerved; spikes axillary, twin? articulated; berries globose, disposed in 4 series, sessile. 々. P. S. Native of the temperate parts of New Granada, parasitical on Guazùma. V. rubrum, var. from New Granada. Spreng. syst. 1. p. 488 . Loránthus quadrangulàris, H. B. et Kunth, nov, gen. amer. 3. p. 444. Schultes, syst. 7. p. 156. Leaves 24-27 lines long, and 6-7 broad; petioles a line long. Fruit bearing spikes an inch and a half long.

Quadrangular-stemmed Mistletoe. Shrub parasitical.

$51 \mathrm{~V}$. oblongifòlium (D. C. prod. 4. p. 283.) branches tetragonal; leaves oblong, obtuse, attenuated at the base, nearly nerveless, or somewhat 1-nerved at the base; spikes axillary, solitary, 2 or 3 times shorter than the leaves. h. P.S. Native of Guadalospe, on the mountains. Allied to $\boldsymbol{V}$. tetragònum and $V$. mucronatum, but differs in the leaves being longer and nerveless. Leaves 12-14 lines long and 3-4 broad. Fruit bearing spikes an inch and a half long. 
Oblong-leaved Mistletoe. Shrub par.

52 V. microphy' Llum (Pohl, in litt. ex D. C. prod. 4. p. 283.) branches tetragonal, when young rather compressed, but in the adult state nearly terete; leaves linear-oblong, obtuse, attenuated at the base, nerveless; spikes axillary, solitary, much shorter than the leaves, articulated: with small sheaths, and short, usually t-flowered joints. h.P.S. Native of Brazil, where it was collected by Schott. Leaves an inch long and 2 lines broad. Spikes 3 lines long, constantly of 3-4 joints.

Small-leaved Mistletoe. Shrub parasitical.

\section{§3. Plants without leaves. Branches articulated.}

53 V. CAPE'NSE (Lin. fil, suppl. p. 426.) plant leafless; stems bluntly tetragonal, much branched, articulated; branches decussate; flowers usually 6 in a whorl, sessile: female ones 4parted; berry globose. h. P. G. Native of the Cape of Good Hope, parasitical on some species of Rhuis. Male flowers 2-4cleft. Thunb. prod. p. 31. fl. cap. p. 154. Razomówskia Capénsis, hort. mosc. In the racemes of a plant under this name, collected by Mr. Burcliell, the branches are terete, it is therefore perhaps a distinct species.

Cape Mistletoe. Shrub parasitical.

54 V. angula'tum (Heyne, herb. ex Wall. cat. no. 497. D. C. prod. 4. p. $28 s$.$) plant leafless; branclies angular, tetragonal,$ articulated; flowers unknown. $\eta$. P. S. Native of the East Indies, where it was collected by Heyne. From the imperfect specimens examined, it appears to be very distinct from the other species of this genus, but it is hardly known.

Angular-branched Mistletoe. Shrub parasitical.

55 V. Ambíguum (Hook. et Arn. in bot. misc. 3. p. 356.) plant leafless; branches terete, without joints and without sheaths; spikes alternate towards the tops of the branches, oblong-linear, without sheaths; flowers sessile, a little longer than the concave obtuse scales. $\zeta$. P. G. Native of Brazil, upon myrtles by the river Uraguay. The two lateral petals are carinate, and the dorsal one nearly plain. In I'iscum the margin of the calyx in the female flowers is usually conspicuous, but in this species it is so entirely wanting, as almost to induce a belief that the 3 petals, which are apparently of the same texture as the tube of the calyx, form its limb; and if this really were so, it ought to form a genus next to Tupèia, Cham. et Schleclst. in Linnaea. 3. p. 203., which seems in the same predicament.

Ambiguous Mistletoe. Shrub parasitical.

56 V. Tentcídes (Comm. ex Pet. 'Th. mel. obs. p. 43.) plant leafless, much branched; stem and branches compressed, articulated, linear-oblong; sheatlis truncate; flowers sessile, 2 opposite or 4 in a whorl, situated in the axils of the sheaths. $\mathfrak{b}$. P.S. Native of the Mauritius and Bourbon. Joints 3 lines long, and a line broad, but not striated. Flowers snuall. Plant becoming wholly black in drying. Habit almost of Salicórnia.

Wreath Mistletoe. Slirub parasitical.

57 V. Japónicum (Thunb. ex Steud. D. C. prod. 4. p. 283.) plant leafless; stem proliferous, branched, compressed. h.P.G. Native of Japan. V. opúntia, Thunb. fl. jap. p. 64. V.opuntioìdes, var. Spreng. syst. 1. p. 487. Perhaps the same as $V$. diehótomum. Japan Mistletoe. Shrub par.

$58 \mathrm{~V}$. Dicnотомсм (Hamilt. D. Don, prod. fl. nep. 14.7. but not of Spreng.) plant leafless ; branches compressed, articulated ; joints oval-oblong, striated lengthwise, 5 times longer than its breadth; flowers by threes, sessile at the tops of the joints or branches. 々. P. G. Native of Nipaul, about Narain-hetty. V. Nepalénse, spreng. cur. post. Bractea membranous, cupular, under the fruit, which is oval. Branches usually opposite, hence dichotomous.

Dichotomous Mlistletoe. Slurub parasitical.
59 V. elonga'tum (Wall. cat. no. 495. D. C. prod. 4. p. 284.) plant leafless; branches compressed, articulated: joints linear-oblong, somewhat attenuated at the base, 7 times longer than their breadth; fascicles of flowers somewhat verticillate, sessile, containing 1-3 flowers each, placed at the tops of the joints. $\zeta$. P.S. Native of the East Indies, on the Pandua mountains, in Silhet. Joints 20-22 lines long, and 3 lines broad. Branchlets usually opposite.

Elongatcd Mistletoc. Shrub parasitical.

60 V. Fra'GlLe (Wall. cat. no. 498. D. C. prod. 4. p. 284.) plant leafless; branches compressed, articulated; joints linearoblong, striated a little, thickisly in the middle, six times longer than their breadth; fascicles of flowers opposite, sessile, containing 1-3 flowers, placed at the tops of the branches. h. P.s. Native of the East Indies, at Martaban and Tavoy. Branchlets isually opposite. Perhaps sufficiently distinct from $l$. dichócomum.

Brittle Mistletoe. Slurub parasitical.

61 V. attenua'tum (D. C. prod. 4. p. 281 .) plant leafless ; branches compressed, articulated; joints gradually attenuated both at the base and apex, linear-cuneated, somewhat striated, sometimes longer than their breadth; fascicles of flowers at the tops of the joints opposite, sessile, containing each 3-5 flowers. h.P. S. Native of the East Indies, where it was collected by Heyne. V. opuntiò̀les, Heyne, herb. Branches usually in whorles, or somewhat dichotomous.

Attcnuated-jointed Mistletoe. Shrub parasitical.

62 V. articula'tum (Burm. A. ind. p. 311.) plant leafless; branches compressed, articulated; joints elongated, striated a little, 10 times longer than broad; fascicles of flowers at the tops of the branches opposite, sessile, containing 1-3 flowers. そ. P.S. Native of Java, parasitical upon some species of $A n$ nòna. Joints of branches an inch long, and a line or a little more in breadth. Stems nearly terete at the base.

Var. $\beta$, Timoriénse (D. C. prod. 4. p. 28\%) branches nearly herbaceous; ultimate joints of branches acute at the apex. I? P. S. Native of Timor. Perliaps the same as V. compréssum, Poir. suppl. 2. p. 861 ., which was collected in Amboyna. The berry, according to Poir, is small and yellow.

Jointed Mistletoe. Shrub parasitical.

$63 \mathrm{~V}$. мonilı́órme (Blım. bijdr. p. 667.) plant leafless ; stems terete at the base; branches 2 -edged, articulated; joints naked; Howers in whorles, sessile. Һ.P. S. Native of Java, on trees about Buitenzorg, very common, and is called by the natives Mengando along with other species.

Neclilace-formed Misseltoe. Shrub parasitical.

64 V. tuñfórme (D. C. prod. 4. p. 284.) plant leafless ; branches compressed, articulated, trichotomous, elongated; joints of branches 4 times longer than broad, striated lengthwise; flowers nearly sessile, by threes at the tops of the joints. $r_{2}$. S. Native of Brazil, where it was collected by Pohl. I?. articulàtum, Pohl, in litt. but not of Burm. Allied to $Y$. dichótomum, but differs in the joints being longer, branches much less branched, branchlets elongated, and the flowers not in whorles.

Tuna-formed Mistletoe. Shrub parasitical.

$65 \mathrm{~V}$. opustioloes (Lin. spec. 1452.) plant leafless; branches compressed, articulated ; joints broadly ovate; spikes jointed, at the tops of the branches or articulations, bearing 2 rows of opposite flowers, and margined by a membrane. $h$. P. S. Native of Jamaica. Sloane, hist. jam. 2. p. 93. t. 201. f. I. $\mathrm{V}$. monstròsum, Bertero, ined. V. opuntioides, Willd. spec. 4. p. 74.0. exclusive of the synonyme of Plumier. Spreng. syst. 1. p. $48 \%$. exclusive of the Japan plant. Berries like those of the common misseltoe.

Yar. $\beta$. angústius (D. C. prod. 4. p. 284.) joints oblong, somewhat attenuated at the base. 5. P.S. Native of Jamaica 
Berries oval-oblong; flowers 3-cleft. Perhaps the present variety is the female plant, and that called the specics the malc. Indian-fig-like Mistletoe. Shrub parasitical.

66 V. vaginatum (Humb. et Bonpl. in Willd. spec. 4. p. 740.) plant leafless; stem tetragonal; branches teretely compressed; joints hearing sheaths, which are bidentate at the apex; flowers 2, opposite, sessile in the recess of the sheatl. h. P.S. Native of Mexico, in pine woods, on the high mountain called Cofie de Perote. H. B. et Kunth, nov, gen, amer. 3. p. $\$ 45$.

Sheathcd Mistleioc. Slirub parasitical.

67 V. cupula'tum (D. C. prod. 4. p. 285.) plant leafless; stem tetragonal; branches compressed; sterile joints elongated : fertile ones very short, usually bearing 2 fruit each; sheatlis very slıort; flowers spicate, sessile, opposite; bractea cupulate, membranous, orbicular under each berry; berries ovate. $\vdash$. P. S. Native of St. Domingo, where it was collected by Bertero. V. vaginatum ex Hispaniola, Spreng. syst. 1. p. 4i7.

C'upulate-bractead Mistletoe. Shrub parasitical.

68 V. Dowringe'vsis (Spreng. syst. 1. p. 487.) plant leafless; stem and brasches terete; sheaths large, bowl-shaped, bifid, with white rather scarious margins. 々.P.S. Native of St. Domingo. Spikes opposite, flexuous.

Si. Domingo Mistletoe. Shrub parasitical.

69 V. GRA'cile (D. C. prod. 4. p. 285.) stem terete : branches rather compressed, articulated; joints linear, clongated, J2 times longer than broad; spikes terminal, compressed, articulated, with the flowers disposed along the margins on both sides in distant rows. b. P. S. Native of the West Indies, but in what island is unknown.

Slender Mistletoe. Shrub parasitical.

to V. Chule'nse (Hook. et Arn. in Beech. bot. p. 25.) stem terete, branched; branches and branchlets opposite, articulated, leafless ; flowers 2-3-together, sessile at the knees of the branclses. h. P. G. Native of Chili, at Conception.

Chili Mistletoe. Shrub parasitical.

$$
\dagger \text { Species not sufficiently known. }
$$

71 V.? PURP'reum (Lin. spec. 1451.) branclies terete; leaves obovate, obtuse, petiolate; racemes axillary, a little longer than the leaves; flowers opposite, distant, 3-6 pairs ; berries obovate, on sloort pedicels, terminated by the long style.

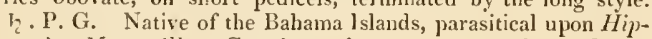
pomàne Mancenilla. Catesb. carol. ‥p. 95. t. 95. lower figure. Perhaps a species of Loránthus.

\section{Purple Mistletoe. Shrub par.}

$72 \mathrm{~V}$. verticula'tum (Lam. dict. 3. p. 57.) stem terete, striated; branches verticillate, terete. $h, P$. S. Native of Jamaica, parasitical on the branches of trces. Sloane, jans. hist. 2. p. 93. t. 201. f. 2. Perhaps a species of Rhipsalis.

Whorled-branched Mistletoe. Shrub par.

73 V. paucielòum (Lin. fil. suppl. 246.) stem striated; branches alternate; leaves alternate, sessile, oblong; flowers scattered, solitary, on sliort peduncles. 々. P. G. Native of the Cape of Good Hope. From the leaves being alternate, this is perhaps a true species of I'iscum.

Fcn flowered Mistletoe. Shrub.

74. V. овscu'rum (Thunb. prod. p. 31. fl, cap. p. 154.) stem erect, wrinkled; branches alternate; leaves opposite, elliptic, veinless, unequal. ?.P. G. Native of the Cape of Good Hope. Flowers and fruit unknown.

Obscure Mistletoe. Shrub.

75 V. Anta'rcticum (Forst, prod. no. 370.) branclies unknown; leaves oblong or ovate, narrowed at both ends, obtuse, nerveless; racemes terminal, articulated, usually containing 5 flowers. h. P. G. Native of New Zealand, parasitical on trees. Willd. spec. 4. p. 39.
Antarctic Mistletoe. Shrub par.

76 V. Kompfe'ri (D. C. prod. 4. p. 285.) h. P. G. Native of Japan, at Mikawaksei, Kompf. am. ex. 785. where it is called Gami Maatz. V. álbum, Thunb. jap. p. 64. but it differs from $r$. álbum in the spikes being axillary, in the berries being reddish, and in the leaves being 1 -nerved.

Koenipfer's Mistletoe. Shrub par.

N. B. V. RU'BRU⿻, Burm. fl. ind. 311. is certainly not a species of l'iscum, but perhaps one of Hédera. V. capilla're and V. Ligula'tum, Blum. bijdr. 667. are species of Psilotis. V. TERRE'TRE, Lin. spec. 1452. is Lysinàchia stricta. V. FLA$\mathrm{vE}^{\prime}$ Scens, Comm. is Misodéndron punctulìtum.

Cult. None of the species of Mistletoe are cultivable in gardens, except the common Mistletoe, whose culture and propagation are treated of under that species.

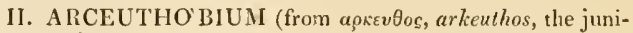
per, and $\beta$ sow, bioo, to live; in reference to the plant being parasitical on Juniperus Oxycèdrus). Bieb. fl. taur. suppl. p. 629. Hook. H. bor. amer. 1. p. 277.- Víscum species, D. C. f. fr. ed. 3. no. 34.00 .

Lin. syst. Dioécia, Di-Tetrándria. Flowers dioecious. Male ones sessile; calyx none; corolla monopetalous, 2-3, rarely 4-parted, tough, and fleshy : segments ovate, concave, spreading ; stamens 2-3-4; anthers sessile, fixed in the middle of the segments, free, nearly globose, 1-celled, membranous, deliscing transversely; ovarium none, but in its stead there is a small 2-3-4-lobed gland. Female flowers on short pedicels; calyx oval, compressed, fleslyy, bidentate, almost covering the ovarium, which is one ovulate, and adnate to it ; corolla, style, and stamens none; stigma small, obscurely lobed. Berries narrow, obovate, terete, 1 -seeded, on short pedicels. Seed immersed in viscid pellucid pulp, fixed to the npper part of the cell, pendant, obovately cylindrical, acuminated at the base ; integument thin; abbumen flesliy. Enbryo immersed, slender, cylindrical, placed towards the base of the seed; radical turned to the hilum of the seed.-A snull, leafless, rather fleshy, proliferous branched shrub, parasitical on resiniferous trees, in Middle Europe and North America; branches opposite, bluntly tetragonal, articulated in the manner of Salicórnia; joints sheathing above, and somewhat pelviform. Flowers terminal and lateral, ustally by threes, small, and conspicuous.

1 A. Oxrce'dri (Bieb. fl. taur. suppl. p. 629. Hook. fl. bor. amer. 1. p. 27 S. t. 29.) h. P. H. Native from Spain, near Lescurial, to lberia, near 'Tiflis and Gandscha, on Juniperus Oxycèdrus; and of North America, on the west side of the Rocky Mountains, on Pinus ponderòsa; and from the Spoken River to the west side of the Rocky Mountains, on Pinus Banksiana, in lat. $47^{\circ}$, to the liocky Mountains and thence to Hudson's Bay on the east, in lat. $57^{\circ}$. In America the female plants grow on Pinus Bankisiana, and the male ones on Pinus ponderòsa. Razoumówskia Caucásica, Hoffin. hort. mosq. 1808 . intr. no. 1. f. 1. Víscum Oxycèdri, D. C. fl. fr. ed. 3. no. 3400. Stev. soc. mosq. 4. p. T1. Bieb. fl. taur. 2. p. 406.-Víscum in Oxycèdro, Clus. hist. 1. p. 39. Lob. icon. 2. p. 2?3. f. 2. This is a very singular parasitical plant. The American plants become yellowish when dried, and the European ones become blackish-green.

Red-cedar Arcenthobium. Shrub par.

Cult. This curious plant is not cultivable, unless the trees or shrubs on which it grows could be imported with the plant growing upon them.

III. MISODE'NDRUM (from $\mu$ oos, misos, disdain, and iEvíov, dcndron, a tree; trees with neither appearance nor beauty). Banks, ined. D. C. coll. mem. 6. no. 2. t. 11 and 12. prod. 4. p. 285. 
Lin. syst. Dioècia, Tetrándria? Flowers dioecious; male ones unknown; female ones baving the tube of the calyx adnate to the ovarium, and furnished with 3 long plumose bristles on the outside, altermating witl 3 bracteas, which are adnate to the calyx; limb of calyx minute, truncate. Fruit an oblong triquetrous indehiscent utriculus, erowned by the permanent limb of the calyx. Seed one; albumen fleshy.-Small smooth parasitical shrubs, with the habit of $l$ iscum.

\section{$\S 1$. Plant leafless.}

1 M. punctula'tum (Banks, mss. ex D. C. prod. 4. p. 286.) plant leafless; branches terete, rugged from dots; bracteas alternate along the branches, half stem-clasping, ovate, obtuse ; flowers 1-2, sessile in the axils of the bracteas. h.P.S. $\mathrm{Na}$ tive of America, on trees. D. C. coll. mem. vi. t. 11.

Iar, a, Magellanicum. $\quad$. P. H. Native of the Straits of Magellan. Víscum flavéscens, Comm. herb.

Var. $\beta$, subumbellatum. h. P. G. Native of the north-west coast of America, in Statenland. It differs from var. $a$ in the branches being thicker and somewhat umbellate.

Dotted-branched Misodendron. Shrub par.

2. Plants furnished with leaves. Branches alternatc, bearing cach one articulatcd lcaf at the apex.

2 M. brachysta'chyum (D. C. coll. mem. vi. t. 12. f. 1.) branches alternate, bearing each an obovate or oval obtuse leaf at the apex; spiklets few-flowered, bractless, rising from the branchlets beneath the leaves; fruit ovate. $\zeta$. P. H. Native of the north-west coast of America, in Statenland. Leaves 3-5 lines long, and 2-S broad, flat, nerveless. Flowers and fruit not sufficiently known, and therefore the genus is doubtful.

Short-spiked Misodendron. Shrub par.

3 M.? Quadriflòrum (D. C. coll. mem. iv. t. 12. f. 2.) branchlcts alternate, each bearing an oblong-obovate subserrulated leaf at the apex, and 4 sessile unilateral flowers on the upper side. 々. P. H. Native of North America, in Statenland. This is very like the preceding species in habit, but differs in the flowers and fruit being unilateral. Calyx triquetrous, dehiscing at the sides.

Four-flowered Misodendron. Shrub par.

\$ 3. Plants furnishcd with leaves. Leaves alternate. Branchcs floriferous at the apcx.

4. M. oblongryòluu (D. C. prod. 4. p. 671.) branches clothed with fine velvety down; leaves oblong-lanceolate, cuneated at the base, 3-nerved, glabrous; spikes bearing each one leaf at the base, conforming to the others. h. P. G. Native of Chili (Bertero), and of Chiloe (Cuming). Genus novum, no. 1. Popp. pl. exsic. no. 813 . Flowers bractless, with 8-10 distant ones in each spike.

Oblong-leaved Misodendron. Shrub par.

5 M. linearifòlium (D. C. prod. 4. p. 671.) plant glabrous; leaves linear, acute; flowers sessile, solitary at the axils of the leaves in the flowering branches. h.P. G. Native of Chili, where it was collected by Poeppig. Genus novum, no. 2. Poepp. pl. exsic. no. 800 .

Linear-leaved Misodendron. Shrub par.

6 M. Micropiy Llum (Hook. et Arn. in bot. misc. 3. p. 357.) leaves minute, linear; Howers sessile, solitary at the axils of the leaves; branches pubescent. $\zeta_{c}$. P. G. Native of Chili, in the province of Maule. Closely allied, but apparently quite distinct from the preceding spccies.

Small-leaved Misodendron. Shrub par.

Cult. These are singular shrubs, similar to the Mistletoe, but are not cultivable in gardens.

VOL. III.
IV. LOR A'NTHUS (from lorum, a lash made of teather, and av $\theta 0 \mathrm{~s}$, anthos, a flower; alluding to the long linear shape and leathery sutsstance of the petals). Mart. in D. C. prod. 4. p. 671.-Loránthus species of Lim. and others.

Lin. syst. Penta-llexándria, Monogýnia. Flowers dioecious or hermaphrodite. Calyx cup-shaped, adnate, with an entire border. Petals 5-6 (f. 74. $a . d$.), linear, reflexed. Stamens insered into the middle of the petals ; filaments short ; anthers globose, didymous, having the cells dehiscing in front towards the connecting part. Style thickish; stigma simple. Berry globose (f. 74.e.), umbilicate by the caly $x, 1$-celled, 1 -seeded as in the rest of the genera, broken off from the present.-Parasitical shrubs. Spikes axillary and terminal, simple. Flowers immersed in the fleshy raclis, each propped by a somew hat orbicular bractea at the base.

1 L. Europe us (Lin. spec. 1672.) plant glabrous, much branched; branches terete; leaves opposite, petiolate, oval-oblong, obtuse, somewhat attenuated at the base; racemes terminal, simple; flowers dioecious, of 6 petals; anthers adnate in the male flowers. 々. P. H. Native of Austria, Hungary, Italy, and Upper Siberia, parasitical on oak and sweet-chestnut trees. Jacq. f. austr. t. 30. Schkuhr, handb. t. 94. Sturm, fl. germ. with a figure. Plench. icon. t. 248. Habit of Viscum álbum. Flowers greenish. Berries oval, white or yellowish. This is the Víscum or Mistletoe of the ancients.

European Loranthus. Shrub par.

2 L. onora'tus (Wall. in Roxb. f. ind. 2. p. 215.) glabrous; branches terete; leaves nearly opposite, ovate-lanceolate, fleshy : spikes axillary, subfascicled, with a foveolate fleshy rachis, and jointed sessile subimmersed spreading 6-petalled hexandrous flowers; anthers ovate, inserted by the base; style shorter than the petals. h. P. G. Native of Nipaul, on the mountains of Chancigiri and Sheopore, parasitical on trees. D. Don, prod. ff. nep. p. 143. Schultes, syst. 7. p. 101. D. C. prod. 4. p. 294. Leaves pale green, at length becoming yellowish, from 4 to 6 inches long. Spikes shorter than the leaves, many flowered, almost sessile. Flowers small, nearly white, very sweet-scented, at first clavate, but at length spreading; petals cuneate, slightly concave at the apex. Ovarium supported by no other bractea than the acute margin of the foveola of the rachis.

Sneet-scented-flowered Loranthus. Shrub par.

3 L. Lambertianus (Schultes, syst. 7. p. 118.) glabrous, dichotomously branched; leaves opposite, on very short petioles, ovate-lanceolate, narrowed at both ends, acute, nerved; spikes terminal, solitary; flowers half immersed in the foveolate rachis, 5 -petalled; anthers fixed by the back. $\{$. P. G. Native of Nipaul. Habit of L. Europe'us.

Lambert's Loranthus. Shrub par.

Cult. The species have the habit of common mistletoe, but are not cultivable in gardens on account of their being parasitical.

V. STRUTHA'NTHUS (from oroovtos, strouthos, a sparrow, and avos, anthos, a flower; some of the species are called Erva de Passerinho and Herba dos Passeros, i. e. Sparrowplant, in South America). Mart. in D. C. prod. 4. p.671.Loránthus species of authors.

Liv. syst. Hcxándria, Monogýnia. Flowers hermaphrodite, almost always 6-parted (except in one species, which is 4-parted $3 \mathrm{G}$ 
and dioccious, and in another 5-parted). Calyx angular, small, hemispherical, with an extenuated truncate margiu. Petals linear, distinct from each other a long way at the base, and at length revolute at the apex; anthers ovate, fixed by the back near the base or beneath the middle; filaments short, inserted beneath the middle of the petals. Ovarium ovate-globose. Style subclavate. Berry ovate-elliptic.-Parasitical slurubs. Racemes terminal or lateral, solitary or aggregate in the axils, having the rachis for the most part angular or 2-edged. To this genus belongs the greater part of the sections Stachyánthus and Protostelides of Lorántlus, D. C. prod, 4. p. 287 and 289. particularly the Brazilian species.

Sect. I. Stachya'sthus (from $\sigma \tau a \chi v c$, stachys, a spike, and av0os, anthos, a flower; flowers sessile, clisposed in spikes). Flowers sessile along the rachis, and sometimes immersed in pits on it, spicate, solitary or by threes, usually furnished with 3 bracteas each.

1 S. AlveouA'tus; plant glabrous, much branched; branches terete ; leaves petiolate, romndish-ovate, rather oblique, obtuse, somewhat coriaceous; spikes axillary, 1-3-together, without joints, somewhat tetragonal; flowers disposed in 4 rows on the spikes, immersed in pits in the rachis; petals linear-lanceolate. b. P. S. Native of South America, near Popayan and Carthagena, parasitical on Crescéntia Cujètc. Loránthus alveolàtus, H. B. et Kunth, nov. gen. amer. 3. p. 444. Loránthus rotundifölius, Bonpl. herb. Schultes, syst. 7. p. 154. Leaves 2 inches long, and $1 \frac{1}{2}$ broad, on petioles 2 lines long. Spikes an inch or an inch and a half long. Corolla greenish white. Perliaps a true species of Lorínthus.

Alveolate-spiked Struthanthus. Shrub par.

$\approx$ S. PTERI'GoPUs; plant glabrous; branches compressed at the apex; leaves opposite, on short petioles, ovate, acuminated, coriaceous; spikes axillary, solitary, longer than the leaves; peduncles compressed, winged ; flowers by threes, sessile; petals 6 , linear-lanceolate. h.P.S. Native of Brazil, in the provinces of Minas Geraes and Bahia, on trees in tlıe woods. Loránthus pterýgopus, Mart. in Schultes, syst. 7. p. 153. Flowers seni-linear. Anthers roundish-ovate.

\section{IIing-stalked Struthantlus. Shrub par.}

3 S. URAGUE'NSIS; plant glabrous, erect; branches terete; leaves alternate, oblong-lanceolate, cuspidate by a point at the apex, attenuated into the petiole at the base; peduncles 1-2, axillary, equal in length to the leaves, forked above the middle; pedicels furnished with 3 bracteas and 3 flowers at the apex; flowers sessile; petals 6 , linear, nearly free; filaments shorter than the petals; anthers ovate, erect; stigma capitate; berries egg-slaped. 々. P. G. Native of South America, upon laurels and myrtles, on the banks of the Uraguay. Loranthus Uraguénsis, Hook. et Arn. in bot. misc. 3. p. 358. In many points it resembles Loránthus flagellàris, Cham. et Schlecht.

Uraguay Struthanthus. Shrub par.

4. S. PODo'pterus; plant glabrous, erect; branches terete, when young angularly compressed; leaves elliptic, attenuated at both ends, feather-nerved, reticulated above; spikes axillary and terminal, flexuous, pedunculate; flowers by threes, immersed in the rachis, which is winged; corolla 6-parted, with linear lobes; anthers inserted by the base; stigma capitate. h.P.S. Native of Brazil. Loránthus podópterus, Cham. et Schlecht. in Linnæa. 3. p. 218. Loránthus acùtus, Pohl, in litt. Leaves $3 \frac{1}{2}$ inches long, and $1 \frac{1}{2}$ broad, on petioles 2 lines long. Corolla a line Jong.

Winged-peduncled Struthanthus. Shrub par.

5 S. овLóngus; plant glabrous; branches terete; branchlets compressed; leaves oblong, nearly elliptic, obtuse, cuneated at the base, and 3-5-nerved : nerves slender, reticulately branched; spikes axillary, very short, few-flowered. $\boldsymbol{h}_{2}$. P. S. Native of Brazil. Loránthus oblóngus, Schott. and Pohl, in litt. ex D. C. prod. 4 . p. 287. Leaves 2 inches long, and 8 lines broad; petioles and spikes about 2-3 lines long. The nervation of the leaves is very distinct from the other species, but the young flowers are not described. It is probably a speciès of $I$ iscum.

Oblong-leaved Struthanthus. Shrub par.

6 S. occidentA'LIs; branches terete, scabrous; leaves ovateroundish or elliptic, marginate, glabrous, feather-nerved at the base, on very short petioles; spikes axillary, simple, shorter than the leaves, nearly terete; flowers almost sessile, furnished with a small very blunt bractea each ; petals 6 , rather connate at the base; stamens 6, 3 fertile and 3 sterile. h. l'.S. Native of Jamaica, on trees, and of many other of the IVest Indian Islands. Loránthus occidentàlis, Lin. amœen, 5. p. 396. Swartz, obs. 138. Schultes, syst. 7. p. 146. Sloan. jam. 2.t. 100. f. 2. Scúrrula 2. Brown, jam. 197. Leaves 15-16 lines long, and 8-9 broad. Spikes an inch long. Flowers 2 lines long. Berries roundish.

Hestern Struthanthus. Shrub par.

7 S. Polysta'curus ; plant glabrous ; branches terete, but compressed at the articulations; leaves petiolate, ovate-lanceolate, acute, thick, veiny; spikes axillary, by threes, one-half shorter than the leaves, diverging; flowers by threes, sessile, opposite; petals 6. h. P. G. Native of Peru, in groves on the Andes 11pon trces and shrubs. Loránthus polystàchyus, Ruiz et Pav. f per. 3. p. 50. Schultes, syst. 7. p. 155. Leaves as in many other species about 2 hands long. Flowers small, purple. Bracteas semianular, hardly conspicuous. Berries oval, brownislyellow.

Many-spiked Struthanthus. Shrub par.

8 S. PAtri'sir; plant glabrous; branches terete, but when young compressed ; leaves opposite, petiolate, oval-oblong, obtuse at the base, acuminated at the apex, of the consistence of parclıment, feather-nerved; spikes axillary, simple, shorter than the leaves: nltimate ones disposed in a terminal panicle ; flowers distant along the rachis, sessile, bractless ; fruit oblong, spreading, truncate at the apex. h. P.S. Native of French Guiana, where it was collected by Patris. Loránthus Patrìii, D. C. prod. 4. p. 288. Leaves 4-5 inches long, and 1-2 broad, rather glaucous above, and rufescent beneath, on petioles 2 lines long. Berries tetragonally compressed while young, 3 lines long. Flowers unknown, therefore it is doubtful whether it belongs to this genus or not.

Patris's Struthanthus. Shrub par.

9 S. Amplexicaúlis ; plant glabrous; branches terete; leaves sessile, stem-clasping, reniform, coriaceous; spikes axillary, twin, not jointed, nearly sessile; berries half immersed in the

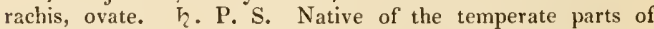
Caraccas. Loránthus amplexicaúlis, H. B. et Kunth, nov. gen. amer. 3. p. 445. Schultes, syst. 7. p. 154. Flowers mknown. Said to be nearly allied to $S$, alveolatus. Perhaps a true species of Loránthus.

Stem-clasping-leaved Struthanthus. Shrub par.

10 S. eMARGiNa'tus; plant glabrous, somewhat scandent ; branches terete, when young compressed; leaves ovate-cuneated, emarginate, on very short petioles, without any lateral nerves ; spikes axillary and terminal, tetragonal, rather shorter than the leaves; flowers opposite, hractless, nearly sessile ; petals 6, lanceolate, distinct; anthers 6,3 of which are acuninated and sterile, and the 3 fertile ones roundish. h. P. S. Native of Hispaniola, Porto-Rico, and Guadaloupe, on the mountains, parasitical on trees. Loránthus emarginàtıs, Swartz, prod. $\mathrm{p}$. 58. fl. ind. occ. p. 625. Schultes, syst. 7. p. 152. Berries black, elongated.

Emarginate-leaved Struthantluus. Shrub par.

11 S. spica'rus; plant glabrous; branches terete; leaves ob- 
ovate or oval, attenuated at the base, somewhat palmately veined, obtuse; spikes axillary, thick, tctragonal, shorter than the leaves, bcaring flowers almost from the base; flowers decussate; petals 6 , concrete at the very base: berry ovate-oblong. $\eta$. P. S. Native of South America, amongst the bushes and woods of Carthagena. Loránthus spicàtus, Jacq. amer. p. 97. t. 68 . Flowers small, red. Berries green, red at the apex. Schultes, syst. 7 . p. 151 .

I ar. $\hat{\beta}$, athroánthus (E. Meyer, nov. act. bonn. 12. p. 788.) lower spikes axillary, superior ones crowded in racemes, leafless. h. P. S.

Spiked-flowered Struthanthus. Shrub par.

12 S. Leptosta'chyus; plant glabrous; branches somewhat tetragonal; leaves petiolate, ovate-elliptic, acuminated, rounded at the base, ratlier coriaceous; spikes axillary, twin or tern, 2 or 3 times shorter than the leaves ; flowers sessile, scattered, distant; rachis compressed, ratler quadrangular; petals 6 , lanceolate-linear, spreading. . P. S. Native of the Andes of Quindiu, between Carthagena and Buga, Loránthus leptóstàcliyus, H. B. et Kunth, nov. gen. amer. 3. p. 440 . Schultes, syst. 7. p. 154. Leaves 5 inches long, and $2 \frac{1}{2}$ broad. Spikes $1 \frac{1}{2}$ to $2 \frac{1}{2}$ inches long. Flowers hardly 2 lines long.

Slender-spiked Struthanthus. Slirub par.

13 S. ovalıfòlıus; plant glabrous, herbaceous ; stem terete, quite simple, erect; leaves oval, thick, nearly veinless, on short petioles, obtuse or emarginate; spikes axillary, 1-2, twice the length of the petioles; flowers sessile, bractless; petals 6 , linear, retroflexed at the apex. 4.P. S. Native of Peru, on the Audes in groves, upon trees and shrubs. Loránthus ovalifòlius, Ruiz et Pav. fl. per. 3. p. 50. t. 277. f. b. Schultes, syst. 7. p. 151. Herb a foot high. Flowers much crowded, small, purple. Berry oval, of an obscure purple colour.

Oval-leaved Struthanthus. Shrub par.

14 S. margina'tus (Lam. dict. 3. p. 596.) plant glabrous ; branches terete; leaves ovate-lanceolate, acuminated, petiolate, with scarious margins, having the middle nerve rather prominent, and the lateral ones wanting; spikes axillary, solitary, opposite, shorter than the leaves; flowers by threes in a fascicle along the rachis, bracteolate; corolla 6-parted, with linear segments ; anthers very caducous; stigma capitate. 々. P. S. Native of Brazil. Loránthus marginàtus, Lam. dict. 3. p. 596. Schultes, syst. 7. p. 137. L. àvium, Pohl, in litt. Leaves 2 inches long, and 9-10 lines broad; petioles 2-3 lines long. Corolla 2-3 lines long.

Marginate-leaved Struthanthus. Shrub par.

15 S. concínsus; plant glabrous; branches slender, terete ; leaves opposite, lanceolate, acuminated, membranous, shining above; spikes axillary and terminal, solitary, interrupted, shorter than the leaves; flowers by threes, opposite, sessile, somewhat verticillate, bracteate; petals 6 , linear, reflexed. $h$. P.S. Native of Brazil, in the province of Rio Negro, in woods at Ega. Loránthus concínnus, Mart. in Schultes, syst. 7. p. 150. Flowers a line and a half long, clavate in the unexpanded state. Anthers ovate.

Neat Struthanthus. Shrub par.

$16 \mathrm{~S}$. Nítens; plant glabrous; branches terete, rooting on one side; leaves alternate, ovate-lanceolate, acuminated, shining, membranous; spikes racemose, interrupted, lower ones axillary, solitary : superior ones panicled ; flowers by threes, sessile, bracteate; petals 6, linear-lanceolate. $\boldsymbol{~}$. P. S. Native of Brazil, in the province of Rio Negro, in woods. Loránthus nitens, Mart. in Schultes, syst. 7. p. 150. Flowers a line long, ovate-club-shaped in the unexpanded state. Anthers ovate, excavated at the side of the filaments.

Shining Struthanthus. Slırub par.

17 S. suвсамре'sтris; branclies terete, beset witl rusty dots at the apex, compressed ; leaves opposite, ovate-elliptic, obtuse, coriaceous, nerved, glabrous; spikes 1-2, axillary, interrupted, one-half shorter than the leaves; flowers nearly opposite, by threes, sessile, bracteate, small ; petals 6 , linear-lanceolate. $\zeta_{c}$. P. S. Native of Brazil, in the province of Minas Geraes. Flowers half a line long. Anthers ovate. Lorânthus subcampéstris, Mart. in Schultes, syst. 7. p. 151.

Field Struthanthus. Shrub par.

18 S. Afrinis; branches terete, compressed at the apex, and beset with rusty dots; leaves nearly opposite, ovateelliptic, acuminated, coriaceous, nerved, glabrous; spikes axillary, solitary, interrupted, not half so long as the leaves; flowers by threes, sessile, retroflexed, bracteate, small. h. P. S. Native of Brazil, in the woods of Japura, in the province of Rio Negro. Loránthus af'ìnis, Mart. in Sclıultes, syst. 7. p. 151. Very like the preceding species.

Allied Struthanthus. Shrub par.

19 S. A'xcePs; branches compressed, 2-edged, green; leaves on short petioles, elongated, ovate-obtuse; spikes on short peduncles, solitary, axillary, much shorter than the leaves; flowers small, somewhat imbricate. $\boldsymbol{h}$. P. S. Native of Guiana. Lorảntlus ánceps, Desv. in Hamilt. prod. p. 33. Schultes, syst. 7. p. 153. The rest unknown.

Two-cdged-branched Struthanthus.

Sect. II. Protostelides (meaning unknown to us). Loránthus, sect. 3. Protostelides, D. C. prod. 4. p. 289 . Flowers of 6 petals, racemose or panicled; the branches of the panicles or racemes usually bearing 3 flowers and 3 bracteas at the apex. - Species all natives of South America.

$20 \mathrm{~S}$. RU'FUs; branches terete; leaves nearly opposite, on short petioles, ovate-oblong, long-acuminated, coriaceons; spikes terminal, panicled; rachis beset with rufous dots; pedicels very short, bearing 3 flowers and 3 bracteas each; petals 6 , linear ; anthers roundish-ovate. $h$. P. S. N Native of Brazil. in the province of Rio Negro, in the woods of Japura. Lorántlıus rùfus, Mart. in Schultes, syst. 7. p. 130. Flowers a line and it half long, white.

Rufous-branched Struthanthus. Slurub par.

21 S. Avicula'rius; plant glabrous; young branches tetragonal; leaves nearly opposite, ovate, rather acuminated, coriaceous; panicles axillary and terminal, solitary, diffuse, longer than the leaves; peduncles opposite, bracteate at the base; flowers by threes, sessile, 3 bracteated; petals 6 , linear-lanceolate. $\quad$. P. S. Native of Brazil, frequent, where it is called Erva de Passerinho. Loránthus aviculàrius, Mart. in Schultes, syst. 7. p. 132. Flowers a line and a half long. Filaments of stamens excavated on the side at the apex.

Knot-grass-like Struthanthus. Shrub par.

$22 \mathrm{~S}$. Thеовоммж; branches tetragonal, but at length becoming terete, rather radicant; leaves ovate, acuminated, on short petioles; panicles axillary and terminal, longer than the leaves; pedicels very short, 3 -flowered at the apex. $h_{2}$. P. S. Native of Brazil, at Para, upon trees of Theobròma Cacìo, where it is called Herva dos Passeros. Loránthus Theobròmæ, Willd. rel. ex Schultes, syst. 7. p. 132. According to Schultes, this is probably the same as the preceding species.

Cacao Struthanthus. Shrub par.

$23 \mathrm{~S}$. virgA'Tus; plant glabrous; branches radicant, tetragonal at the apex; leaves opposite, ovate, acuminated, complicate, rather coriaceous; panicles axillary, solitary, twiggy, 3 times longer than the leaves : laving the branches tetragonal, and bracteate at the base, and the branchlets short and bearing 3 flowers at the apex, and 3 bracteas; petals 6 , linear-lanceolate. ?.P.S. Native of Brazil, in the province of Rio Negro, in woods about Japura. Loránthus virgàtus, Mart. in Schultes, $3 \mathrm{G}$ ? 
syst. 7. p. 132. Flowers half a line long. Filaments of stamens excavated at the side at the apex.

Triggy Struthanthus. Shrub par.

24. S. DEPPEA'Nus; glabrous: branches rather radicant; leaves almost opposite, petiolate, ovate-lanceolate, acuminated, somewhat 3-nerved; racemes 1-2, axillary; peduncles 3-flowered, bractless; flowers pedicellate; anthers linear, fixed by the base. 々. P. S. Native of Nexico, near Jalapa. Lorántlus Deppeànus, Cham. et Schlecht. in Linnæa. 5. p. 172. Style twisted in a circinate manner at the apex.

Deppe's Struthantluus. Shrub par.

25 S. ERYThrocárpus; plant glabrous; branches terete; leaves nearly opposite, ovate-lanceolate, acuminated, attenuated at the base, coriaceous, veiny; racemes 1-3 together, rather spicate, interrupted, axillary, and terminal : having very short branchlets, which bear 3 flowers and 3 bracteas at the apex; petals 6 , linear. $h$. P.S. Native of Brazil, in the province of Rio Negro, on trees. Loránthus erythrocárpus, Mart. in Scliultes, syst. 7. p. 138. Anthers ovate. Berries orangecoloured.

Red-fruited Struthanthus. Shrub par.

26 S. crtrícola; plant glabrous; branches terete; leaves rather alternate, ovate, somewhat acuminated, and obtuse, subemarginate, veiny ; racemes axillary and terminal, shorter than the leaves: superior ones solitary, but the lower ones are somewhat verticillate; branches of racemes short, opposite, bearing each 3 flowers at the apex and 3 bracteas. $F_{\text {? }}$. P. S. Native of Brazil, near Rio Janeiro, on trees of the orange tribe, where it is called Herva de Passerinho. Loránthus citrícola, Mart. in Schultes, syst. 7. p. 137. Perhaps the same as S. marginàlus.

Orange Struthanthus. Shrub par.

27 S. FLEXICAU'Lrs; plant glabrous; branches sarmentose, radicant ; leaves almost alternate, oblong, obtuse, with a mucrone, tapering at the base, flat, reflexed; racemes $1-2$ together, axillary, erect, shorter than the leaves: having short, opposite, 3flowered, tribracteate branchlets; petals 6 , linear, spreading above the middle. h.P.S. Native of Brazil, in the fields of Taboleira, in the province of Mınas Geraes. Loránthus flexicaúlis, Mart. in Schultes, syst. 7. p. 139. Flowers yellowish, a line long, clavate in the unexpanded state.

Bent-stemmed Struthanthus. Shrub par.

28 S. Polyruizos; plant glabrous; branches scandent, rooting; leaves subalternate, obovate, emarginate, flat, veiny; racemes axillary, solitary, compound, erect, one-half shorter than the leaves: having the branchlets tetragonal, and bearing 3 flowers at the apex and 3 bracteas; petals 6 , reflexed from the middle. In. P. S. Native of Brazil, in the province of Bahia, in the woods. Loránthus polyrhizos, Mart. in Schultes, syst. 7. p. 139. Flowers 2 lines long, green. Anthers ovate.

Many-rooted Struthanthus. Shrub par.

29 S. TETRA'QUETER ; plant glalıous; branches compressedly tetragonal, scandent, rooting; leaves nearly opposite, ovate, obtuse, reflexed, rather coriaceous; racemes $2-3$, axillary : having very short, nearly opposite 3 -flowered tribracteate branchlets ; petals 6 , linear, hardly reflexed, spreading. $\zeta_{c}$. P. S. Native of Brazil, in the province of Minas Geraes, on trees. Loránthus tetráqueter, Mart. in Schultes, syst. 7. p. 140. Flowers hardly a line long, roundish in the unexpanded state.

Four-sided-branched Struthanthus. Shrub par.

30 S. staPyYl'nus; plant glabrons; branches compressed at the apex; leaves nearly opposite, obovate or emarginate, attenuated at the base, flat, coriaceous, nerved; racemes axillary, solitary, longer than the leaves: having short bent branchlets, each bearing 3 flowers and 3 bracteas at the apex; petals 6 , linear, reflexedly spreading. $\oiiint_{\text {. }}$ P.S. Native of Brazil, in the pro- vince of Rio Negro. Loránthus staphylinus, Mart. in Schultes, syst. 7. p. 290. Flowers a line long. Anthers roundish-ovate. Staphylea-like Struthanthus. Shrub par.

31 S. cuspida'Tus; plant glabrous; branches rooting, terete ; leaves nearly opposite, obovate, attenuated at the base, cuspidate at the apex, coriaceous, glaucous; racemes axillary, solitary, about equal in length to the leaves, few-flowered: having the branchlets 3 -flowered at the apex, and tribracteate; petals 6 , linear, reflexed from the middle. h. P.S. Native of Brazil, in the woods about Pianhia. Loránthus cuspidàtus, Mart. in Schultes, syst. 7. p. 140 . Flowers 2 lines long, clavate in the unexpanded state. Anthers ovate.

Cuspidate-leaved Struthanthus. Shrub par.

32 S. LONGIPEDUNCULA'tus; plant glabrous; branches terete; leaves opposite, oblong-ovate, acuminated, attenuated at the base, rather coriaceous, nerved; racemes axillary, solitary, longer than the leaves: with few branchlets, bearing each 3 flowers at the apex and 3 bracteas; petals 6 , linear, spreading above the middle. $\quad$. P.S. Native of Brazil, in the province of Bahia. Flowers 4 lines long, of a pale greenish colour. Anthers ovate. Loránthus longipedunculàtus, Mart. in Schultes, syst. 7. p. 141.

Long-peduncled Struthanthus, Shrub par.

33 S. SYRINGæFòlıUs; plant glabrous; branches unknown; leaves opposite, petiolate, ovate, rather coriaceous, ending in a long taper point; racemes axillary, solitary, panicled, shorter than the leaves; peduncles compressedly tetragonal: with the branchlets short, thick, and bearing 3 flowers at the apex and 3 bracteas; petals 6 , linear. h. P.S. Native of Brazil, in the province of Rio Negro, in the woods. Loránthus syringæfolius, Mart. in Schultes, syst. 7. p. 141. Racemes $1 \frac{1}{2}$ to 2 inches long. The unexpanded flowers dilated into a somewhat liexagonal club. Anthers erect, hastate at the base.

Syringa-leaved Struthantlus. Shrub par.

34 S. PA'TENs; plant glabrous; branches terete ; leaves opposite, lanceolate, thin, ending in a long taper point; racemes axillary, solitary, spreading, exceeding the leaves a little: pedicels 3-flowered; flowers pedicellate; bracteas very minute, orbicular; petals 6 , nearly linear, reflexed above the

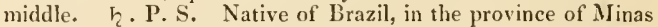
Geraes. Loránthus pàtens, Mart. in Schultes, syst. 7. p. 142. Flowers $4 \frac{1}{2}$ lines long, tubularly club-shaped in the unexpanded state. Anthers ovate.

Spreading Stuthauthus. Shrub par.

85 S. E'LEGANS; plant glabrous; branches terete at the base, but compressed at the apex; leaves nearly opposite, somewhat ovate, rather coriaceous, terminating in a short reflexed acumen; racemes axillary, solitary, twice the length of the leaves: having the branchlets opposite, and bearing 3 flowers at the apex, without any bracteas; petals 6 , linear-lanceolate. $\eta_{2}$. P.S. Native of Brazil. Loránthus élegans, Mart. in Schultes, syst. 7. p. 14.4. Hlowers white, a line and a half long, of a roundish chubshaped form at the apex in the unexpanded state. Anthers ovate.

Elegant Struthanthus. Shrub par.

36 S. Ru'BENS; plant glabrous; branches terete, radicant; leaves opposite, somewhat reflexed, lanceolate, . attenuated at both ends, nerved, somewhat undulated; racemes shorter than the leaves: and the peduncles are trifid: branchlets short, nearly opposite, bearing 3 flowers at the apex, and 3 bracteas. 2. P. S. Native of Brazil, in the province of Rio Negro, in the woods of Japura. Loránthus rubens, Mart. in Schultes, syst. 7. p. 144. Flowers unknown. Berries ovate-oblong, unbilicate, 3-4 lines long.

Reddish Struthanthus. Shrub par.

37 S. POLYA'NTHos; plant glabrous; branches terete; leaves opposite, lanceolate, mucronatcly acuminated, flat, coriaceous ; 
racemes axillary, many-flowered, about equal in length to the leaves: branchlets 3 -Howered at the apex, and tribracteate; bracteas ovate, acute; petals linear, reflexed from the middle. h. P. S. Native of Brazil, in the province of Bahia, in the woods called Catingas. Lorảnthus polyảntlıos, Mart. in Schultes, syst. 7. p. 145. Flowers yellowish, 2 lines long. Antluers ovate.

Many-flowercd Struthanthus. Shrub par.

SS S. PANicula'tus; plant glabrous; branches terete; floriferous branches tetragonal; leaves petiolate, ovate-elliptic, acute at hoth ends, rather coriaceous; panicles terminal, branched, diffuse : branchlets very short, bearing 3 flowers and 3 bracteas at the apex. h. P.S. Native of South America, on trees near Cumana, where it is called Paxarito. Loránthus paniculàtus, H. B. et Kunth, nov. gen. amer. 3. p. 442. Flowers unknown. Berries oblong. Lorántlus tetragònns, Willd. rel. in Schultes, syst. 7. 13. 131. Perhaps the same as S. Orinocénsis.

Paniclcd Struthanthus. Shrub par.

39 S. Orinoce'ssis; plant glalrous; branches somewhat tetragonal; leaves petiolate, ovate-elliptic, acuminated, rounded at the base, and somewhat complicate, rather coriaceous; racemes axillary and terminal, exceeding the leaves, paniculately disposed, diffuse: branchlets short, bearing 3 bracteas and 3 flowers; flowers sessile; petals 6 , linear-lanceolate, 3 of which are cohering; filaments broad; anthers adnate. $々$. P. S. Native on the banks of the Orinoco, parasitical on trees. Loránthus Orinocénsis, Spreng. syst. 1. p. 129. Sehultes, syst. 7. p. 136. Loránthus marginàtus, H. 13. et Kunth, nov. gen. amer. 3. p. 442. t. 299. exclusive of the syn. of Lam. Leaves $2 \frac{1}{2}$ inches long and $1 \frac{1}{2}$ broad; on petioles about 5 lines long. Flowers hardly 3 lines long.

Orinoco Struthanthus. Shrub par.

40 S. PIYLLiRsoìnes; plant glabrous; branclies elongated, filiform; leaves oblong, acute, rather coriaceous, running into the short petiole at the base, veinless, with the middle nerve rather prominent beneath; peduncles axillary, rather dichotomons, 2-3 times shorter than the leaves; flowers sessile, ustally by threes, tribracteate ; petals 6 , linear, spreading; anthers adnate, mueronate. 々. P. S. Native of South Ameriea, parasitical on trees, near Cumana, where it is called by the natives Guate-Paxarito. Loránthus phylliræoides, H. B. et Kunth, nov. gen. amer. 3. p. 439 . Sehuites, syst. 7. p. 122. Leaves 9-10 lines long, and $2-3$ broad. Flowers small.

Phyllirca-like Struthanthus. Shrub par.

41 S. Microphy'LLUs; plant elothed with hairy pubeseence; branches terete; branchlets very short, bearing leaves and flowers at the apex : leaves oblong, obtuse, rather mucronate, sessile, thickish, eanescent ; flowers sessile, crowded, axillary, and terminal; petals $6-7$, lanceolate-linear, rather concrete at the base; filaments adnate to the petals, nearly to the apex; anthers adnate, mucronate. $\eta$. P. S. Native of Mexico, near Gucrnacava, on the mountains. Loránthus mieroplyýllus, H. B. Kunth, nov. gen. amer. 4. p. 291. Leaves 4 lines long and $1 \frac{1}{2}$ broad. Flowers hardly 2 lines long, pubescent on the outside.

Small-leaved Struthanthus. Shrub par.

42 S. PARvifòlus; plant glabrous; branches terete, while young angularly compressed; leaves attenuated at the base, on short petioles, obtuse at the apex, nerveless; peduncles axillary, opposite, trifid, 3-flowered, 3 times shorter than the leaves; petals 6, lanceolate, acute; stamens shorter than the petals; $h_{2}$. P. S. Native of the higher mountains of Jamaica, upon the branches of trees. Loránthus parvifolius, Swartz, prod. p. 58. A. ind. oec. p. 628 . Schultes, syst. 7. p. 120 . Leaves 6 lines long, and 3 broad. Corolla 2 lines long. Berry oblong, black.
Small-leaved Struthanthus. Shrub par.

$43 \mathrm{~S}$. rotundifòlıus; stems diffuse; leaves roundish, glabrous; flowers axillary, crowded, braeteate, hexandrous; peduncles slıort, many-Howered. h. P. S. Native of Brazil, among bushes about Rio Janeiro. Loránthus rotundifolius, St. Hil. pl. rem. bras. intr. p. 21. Schultes, syst. 7. p. 121.

Round-leaved Struthanthus. Shrub par.

$44 \mathrm{~S}$. PYRıfòlıus ; glabrous, pendulous; branches terete, compressed at the nodi; leaves petiolate, oblong, obtuse, acute at the base, rather membranous, complicated; racemes axillary and terminal: branchlets very short, nearly opposite, tribracteate, 3-flowered; flowers sessile; petals 6, lanceolate. h.P.S. Native of South America, near Carthagena, growing on Crescéntia Cujète. Lorảnthus pyrifòlius, H. B. et Kunth, nov. gen. amer. 3. p. 441. Schultes, syst. 7. p. 139 . Leaves 2-8 inches long, and 13-15 lines broad, on petioles 3 lines long. Racemes 3 inches long. Flowers small. Berries ovate.

Pear-leaved Struthanthus. Shrub par

45 S. suвrotu'Ndus; plant glabrous, twining; branches terete; leaves alternate or opposite, petiolate, ovate-orbicular, ending in a short mucronate acumen, feather-nerved, shining above, coriaceous; racemes axillary, solitary, about equal in length to the leaves, or twin one shorter than the other : branclilets opposite, bearing 3 sessile flowers and 3 bracteas at the apex; petals 6 , linear, somewhat concrete at the base; filaments a little shorter than the petals, anthers ovate, erect. h. $\frown$ S. Native of Brazil, where it was collected by Schott. Loránthus subrotúndus, Pohl, in litt. ex D. C. prod. 4. p. 292. Leaves 15-18 lines Jong, and 10-12 broad; petioles 5-6 lines long. Corolla 3 lines long. Style filiform; stigma simple, not capitate.

Roundish-leaved Struthanthus. Shrub par.

46 S. GlorerA'rus : plant glabrous; branches terete, radicant; leaves opposite, on short petioles, ovate, ending in a short acumen, glaucous, coriaceous; peduncles very short, axillary, glomerate, bifid; flowers by threes, sessile, tribracteate; petals 6 , linear, reflexed from the middlle; anthers ovate; style equal in length to the petals. $h$. P. S. Native of Brazil, in the provinees of the Mlines. Loránthus glomeràtus, Mart. in Schultes, syst. 7. p. 121. Flowers yellowish green, 2 lines long. Glomeratc-flowered Struthanthus. Shrub par.

47 S. confértus; plant glabrous ; branches radicant, terete ; leaves opposite, ovate or romdish, obtuse, with a short acumen, coriaceous, nerved: peduneles axillary, erowded, dichotomous, simple; flowers by threes, sessile, tribracteate; petals 6 , spreadingly reflexed, linear; anthers ovate; style one lalf shorter than the petals. h. P. S. Native of Brazil, on trees of the orange tribe. Loránthus confértus, Mart. in Sehultes, syst. 7. p. 121 .

Crowded-peduncled Struthanthus. Shrub par.

48 S. Perrotte'ti:; plant glabrous; branches terete, but rather compressed in the young state : leaves petiolate, ovate, or oval, obtuse, coriaceous, feather-nerved; racemes twin, unequal, simple, axillary: with the branchlets bearing each 3 small concrete bracteas, and 3 sessile flowers; flower-buds ovate, small; berry oval. h.P.S. Native of French Guiana. Lorántlus Perrottètii, D. C. prod. 4. p. 292. Racemes, petioles, and rachi of racemes rufous, appearing velvety at first sight. Flowers small. Leaves $2-3$ inches long and $1 \frac{1}{2}$ broad. Racemes sometimes equal in length to the leaves, but sometimes $t$ ice the length

Perrottet's Struthanthus. Shrub par.

4.9 S. interru'Ptus; glabrous, pendulous; branches terete; leaves oblong, acute, running into the petiole at the base, rather coriaceous; racemes axillary and terminal: with short, nearly opposite, distant branches, bearing each 3 sessile flowers at the apex, witlout bracteas. 々. P. S. Native of Mexico, near 
Ario, on trees of Annòna Humbóldtii. Lorántlus interıúptus, H. B. et Kunth, nov. gen. amer. 3. p. 440 . Schultes, syst. 7 . p. 138. Flowers and fruit not sufficiently known. Leaves nearly 2 inches long and 9 lines broad; petioles $3-4$ lines long.

\section{Interrupted-spiked Struthanthus. Slirub par.}

50 S. ADU'Ncus; plant glabrous; branches terete, knotted, scandent ; branchlets angular ; lcaves opposite, oblong-roundish, apiculated by a hooked point, veiny, petiolate; racemes axil. lary, trichotomous, or simple; flowers sessile, 3-6 together, propped by a subtriangular bractea; petals 6 , linear; anthers oblong. $F_{c}$. P. S. Native of Guiana, on trees. Loránthus adúncus, Meyer. prim. esseq. p. 149. Schultes, syst. 7. p. 147. Perhaps the racemes ought to be called spikes; or perhaps the flowers are sessile on the tops of the branchlcts, not on a rachis.

Hookcd-leaved Struthanthus. Shrub par.

51 S. MAGDALE'NE; plant glabrous; branches terete, rather sarmentose ; leaves petiolate, ovate, acute, complicate, feathernerved, rather coriaceous; panicles axillary, longer than the leaves, spreadingly branched; peduncles distant, bearing 3 flowers and 3 bracteas at the apex; petals 6 , linear; anthers erect, inserted by the base, 3 of which are drawn out in a horn? h. P. S. Native of South America, on the banks of the river Magdalena, where it was collected by Bertero. Loránthus Magdalènæ, Cham. et Schlecht. in Linnaa 3. p. 219. Wéihea Magdalènæ, Spreng. in herb. Balb. but not of his syst. Leaves 20-22 lines long and 12-15 lines broad; petioles 4-5 lines long. Corolla 2 lines long.

Magdalena Struthanthus. Shrub par.

52 S. SE'SS1L1s; glabrous; leaves ovate; spikes sinple, solitary; flowers sessile, by threes; pedicels thick, 3 -flowered at the top. $\zeta$. P.S. Native of South America, in the woods of Carthagena. Loránthus séssilis, Jacq. amer. 99. Berries of reddish dirty green colour. Perhaps Loránthus séssilis, Meyer. prim. esseq. 4. p. 149. is the same as that of Jacquin.

Sessile-flowered Struthanthus. Shrub par.

$53 \mathrm{~S}$. STE'LIS; glabrous; branches spreading; leaves ovate or oblong, coriaceous, nearly sessile; peduncles numerous, axillary, spreading, trigonal, bifid: having the branchlets bearing 3 equal, sessile, hexandrous flowers. $r_{c}$. P. S. Native of Cumana, upon trees. Loránthus Stèlis, Lin. spec. 331. Scluıltes, syst. 7. p. 147. Stèlis, no. 1. Lofl. itin. 187. Plant not sufficiently known, and Stèlis, no. 2. Lœefl. is still more obscure. Mistletoe Struthanthus. Shrub par.

54. S. PENUNCula'tus; glabrous; branches shining; leaves cordate-ovate, ending each in a short taper point, coriaceous, shining, petiolate, feather-veined; racemes axillary, solitary, shorter than the leaves: having the rachis compressed and the branchlets 3-flowered, and the flowers pedicellate; petals 6 , obtuse; stamens some of them sterile. h. P. S. Native of South America, in the woods of Carthagena, especially on the sea coast. Lorínthus pedunculàtus. Jacq. amer. p. 98. Schultes, syst. 7. p. 145. Leaves 2 inches long. Flowers small, white.

Pedunculate-flowered Struthanthus. Shrub par.

55 S. PSILobótrys; glabrous; branches terete; branchjets angularly compressed ; leaves oblong, acutish, attenuated at the base, on short petioles, nerveless, except the middle nerve; racemes axillary, 4 times longer than the leaves, 2-edged, especially at the base; pedicels nearly opposite, l-flowered; bracteas 3, concrete, resembling a 3-cleft cupula under each flower. h.P. S. Native of St. Domingo, wliere it was collected by Bertero. Loránthus psilobótrys, D. C. prod. 4. p. 293. Loránthus uniftòrus, Spreng. in herb. Balb. but it is very different from the true L. uniflòrus. Alabastra oval, a line long. Racemes 6-7 inches long. Leaves I5 lines long and 4 broad.
Naked-racemed Struthanthus. Shrub par.

$56 \mathrm{~S}$. Domingénsis; branches 2 edged, green ; leaves obovate-oblong, mucronulate, fleshy, running down the petiole at the base; racemes simple or tern; flowers remote. h. P. S. Native of St. Domingo. Loránthus Domingénsis, Desf. in Hamilt. prod. p. 33. Schultes, syst. 7. p. 147. The rest unknown.

St. Domingo Struthanthus. Shrub par.

57 S. LAXiFlònus; branches terete, brownish; leaves roundish-ovate, finely marginated, running into the petiole at the base; racemes for the most part solitary, greyish, on long peduncles; flowers remote; pedicels elongated. $\zeta$. P. S. Native of Hispaniola. Loránthus laxiflòrus, Desf. in Hamilt. prod. p. 33. The rest unknown.

Lax. flowered Struthanthus. Shrub par.

58 S. unir Lòus; glabrous; branches terete; leaves obovate or oval, on short petioles, obtuse at the apex, emarginate, and rather mucronate, feather-veined, rather membranous; racemes axillary, solitary or twin, simple; pedicels 1 -flowered, a little longer than the flowers, girded by a trifid involucrum; petals 6 , obtuse; alternate anthers sterile. mingo, upon trees and bushes in the woods. Loránthus uniflòrus, Jacq. amer. 98. t. 69 . Schultes, syst. 7. p. 146. Loránthus parvifòrus, Lam. dict. 3. p. 595. Leaves 1-2 inches long. Flowers purple, 2 lines long. Berries cylindrical, dark.

One-floncred Struthanthus. Shrub par.

59 S. Portorice'nsis ; glabrous; stem terete, rooting, dichotomous; branchlets compressed; leaves petiolate, lanceolate, acute, glancous, veinless, except the middle nerve, which is conspicuous at the base but hardly evident at the apex; corymbs dichotomous, few-flowered, terminal, one half slorter than the leaves; fruit oval, crowned by the teeth of the calyx. 々. P. S. Native of Porto Rico, parasitical upon trees, where it was collected by Bertero. Lorânthus Portoricénsis, D. C. prod. 4. p. 293. Loránthus Braziliénsis, Spreng. in herb. Balb. Flowers smaller than in the rest of the species. Leaves 8 lines long and 3 lines broad.

Porto Rico Struthanthus. Shrub par.

60 S. PAucılònus; glabrous; branches terete, spreading ; leaves obovate-roundish, veiny, on very short petioles; racemes axillary, solitary, tripartite, shorter than the leaves; flowers nearly sessile, decussate; bractea concave; petals 6 , lanceolate, contiguous at the base; anthers 6 , ovate. $h$. P. S. Native of the interior of Jamaica, and of Cayenne, parasitical on trees. Loránthus pauciflòrus, Swartz, prod. p. 58. fl. ind. occ. $67 \%$. Schultes, syst. 7. p. 147. Loránthus occidentàlis, Aubl. guian. p. 310. ex Swartz. Allied to $S$. occidentalis, but differs in the raceme or spike being tripartite, not simple.

Few-flowered Struthanthus. Shrub par.

61 S. Guadalupe'nsis; glabrous; branches terete; leaves ovate, rather cordate at the base, acuminated at the apex, on very short petioles, veinless except the middle nerve; peduncles terminal, trichotomous and corymbose at the apex, about the length of the leaves; bracteas small ; calyx denticulated ; berry oval. h. P. S. Native of Guadaloupe, where it was collected by Bertero. Loránthus Guadalupénsis, D. C. prod. 4. p. 294. Lorânthus pedunculàtus, Spreng. in herb. Balb.

Guadaloupe Struthanthus. Shrub par.

62 S. QUERCICOLA; glabrous; branches terete ; leaves almost opposite, petiolate, ovatc, acuminated, papery, reticulately veined; racemes 1-2, axillary; flowers almost sessile, by threes, opposite: anthers orbicular, fixed by the base. h. P. S. Native of Mexico, near Jalapa, parasitical on oak and other trees. Flowers minutely bracteolate. Corolla a line and a half long. Loránthus quercicola, Cliam, et Schlecht. in Linnæa. 5. p. 173. Oak Strutlianthus. Shrub par. 
63 S. RETROFLE'xus; glabrous; branches terete; leaves ovate, acute, deflexed, rather coriaceous, on short petioles; panicles axillary and terminal: with an angular rachis: and retroflexed branchlets, bearing ovate, concave, deciduous bracteas, and 2-4 flowers, which stand on short pedicels ; petals 6 , linear, reflexed at the apex. $\zeta$. P. S. Native of Peru, in groves on the Andes, upon trees. Loránthus retrofléxus, Ruiz, et Pav. fl. per. 3. p. 49. t. 279. f. a. Schultes, syst. 7. p. 138. Leaves usually an inch and a half long and 2 inches broad; on petioles 2-3 lines long. Flowers small, purple. Berries oval, of a yellowish glancous colour.

Retroffexed-petalled Struthanthus. Slirub par.

Cull. All the species of this beautiful genus being parasitical, they are consequently not cultivable in gardens. They have something of the aspect of Lonicèra or honeysuckle.

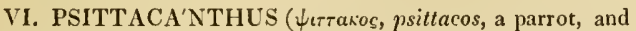
av $\theta 0 s$, anthos, a flower; perhaps from the bright colour of the flowers). Mart. in D. C. prod. 4. p. 671. Loránthus section Oscillatòriæ Callánthæe. D. C. prod. 4. p. 308.-Loránthus species of authors.

Lin. syst. Hexándria, Monogýnia. Flowers hermaphrodite, for the most part hexamerous. Calyx cup-shaped, hemispherically cyathiform, with a contracted mouth : having the border sometimes entire, and sometimes obsoletely 5-6-tootlied or repand. Petals 6, linear-spatulate, in most of the species distinct to the middle, erect, spreading, often furnished with a linear scale in the middle. Filaments filiform, rising from the middle of the petals; anthers linear or oblong, fixed by the base, therefore erect : or by the back, then they are incumbent. Ovarium ovate. Style filiform; stigma capitate. Berry ovate-Panicles dichotomous or trichotomous, expanded or corymbose; peduncles articulately inserted, bracteate; pedicels extended into a cup-shaped bracteole each. Flowers large, thick, deeply coloured.

1 P. rasiflònus; glabrous; branches terete; branchlets angular ; leaves ovate, bluntish, attenuated at the base ; peduncles opposite, trifid, 6-flowered, spreadingly deflexed, rising beneath the leaf-bearing branches; alabastra conical ; petals lanceolatelinear, acuminated; anthers versatile. h. P. G. Native of Mexico, parasitical on trees, on the mountains of Mahuitzola. Loránthus ramiflòrus. Moc. et Sesse, f. mex. icon. ined. ex D. C. prod. 4. p. 308. Leaves $1 \frac{1}{2}$ inch long, and 6-7 lines broad; on very short petioles. Corolla 10 lines long, conical.

Branch-flonered Psittacanthus. Shrub par.

2 P. calycula'tus; glabrous; branches nearly terete; leaves opposite, ovate, or lanceolate, hardly petiolate, coriaceous, veinless; corymbs terminal, trichotomous, shorter than the leaves: having a cup-shaped bractea under each flower, as in all the rest of the species; petals 6 , linear, acute; anthers versatile. h. P. S. Native of Mexico, about Cuarcavara, where it was collected by Berlandier. Loránthus calyculàtus, D. C. coll. mem. vi. t. 101 . Larger leaves 2 inches long and $1 \frac{1}{2}$ broad, the rest rather smaller. Flowers of a yellowish scarlet colour, almost 2 inches long. 'There are 2 oblong foral leaves under each lateral branch of the corymb. Limb of calyx truncate. Allied to $P$. ca'sus. Perlaps the same as Loránthus Quauchitli of Moc. et Sesse, fl. mex.

Calyculate Psittacantlius. Shrub par.

3 P. JAcour'NI; glabrous; branches terete; leaves obovate or oval, coriaceous, shining, on short petioles, veinless; peduncles axillary and terminal, cymose, shorter than the leaves: ultimate ones trifid : having an urceolate, small bractea under each flower; petals 6 , contiguous at the base, linear, revolute at the apex; alabastra curved a little; anthers oblong, versatile. $h$.
P. S. Native of Jamaica, Martinico, and Brazil, parasitical on trees. Lorảnthus Jacquìni, D. C. prod. 4. p. 308. L. Americànus, Jacq. amer. 1. 97. t, 67 . exclusive of the synonymes. Lin. spec. 331. exclusive of the synonyme of Cham. and Schlecht. in Linnæa. 3. p. 210. but not of Lin. amon. nor Swartz.

I'ar. $\beta$, longifòlius (D. C. prod. 4. p. 308.) leaves oblique, lanceolate, attenuated at the base. $\zeta$. P. S. Native of Jamaica. Calyx cup-shaped. Flowers sometimes of 4 petals.

Jacquin's Psittacanthus. Shrub par.

4 P. Brasilie'ssis; glabrous; branches terete, compressed while young; leaves petiolate, lanceolate-ovate, obliquely nerved, thickish, shining above; peduncles trichotomous, terminal, and in the upper axils: branchlets 5-flowered; alabastra clubshaped; petals 6 , linear; anthers versatile. 々.P.S. Native of Brazil. Lorántluus Brasiliénsis, Desr. in Lam. dict. 3. p. 596. Schultes, syst. 7. p. 127. Habit of Avicénnia tomentòsa, but is perfectly glabrous. Leaves 3 or $3 \frac{1}{2}$ inches long, and $12-$ 15 lines broad, on petioles 3-4 lines long. Corolla an inch and a half long.

Brazilian Psittacanthus. Shrub par.

5 P. crínctus; branches terete; leaves opposite and alternate, on very short petioles, oblong-ovate, obtuse, thick, marginated; racemes axillary and terninal, compound: peduncles nearly opposite, 2-flowered; bracteas cup-shaped; flowers tomentose on the outside, clavate at the apex in the mexpanded state; petals 6 , nearly linear, glandular at the base. $\zeta$. P. S. Native of Brazil, in the province of Rio Negro, in the wools of Japura. Lorảnthus cínctus, Mart. in Schultes, syst. 7. p. I34. Corolla 1 or $1 \frac{1}{2}$ inch long, densely clothed with coloured tomentum. Anthers oblong. Style equal in length to the petals. Stigma capitate.

Girded Psitticanthus. Shrub par.

6 P. specıosus; glabrous; leaves oblong-elliptic, or lanceolate, bluntish, cuneated at the base, coriaceous : having the middle nerve hardly couspicuous, and the lateral veins wanting; racemes unknown; alabastra cylindrical ; petals 6 , linear, hardly concrete at the base; anthers versatile; stigma not capitate. h. P. S. Native of Brazil. Loránthus speciòsus, Polıl, in litt. but not Dietr. nor Wall. Leaves 3 iuches long and an inch broad; petioles hardly any. Corolla 3 inches long. It differs from $P$. Brasiliénsis, Lam. in the alabastra not being clavate.

Showy Psiticanthus. Shrub par.

7 P. Dichno'os; glabrous ; branches terete ; leaves opposite, obovate, emarginate, coriaceous, hardly veined; peduncles solitary, axillary, dichotomous : the branches $2-3$-flowered ; bractea cup-shaped, shorter than the ovarium, 1-toothed; petals 6 , linear, spreadingly reflexed from the middle; anthers linearoblong. $\eta$. P. S. Native of Brazil, in the province of Rio Janeiro. Loránthus dichròos, Mart. in Schultes, syst. 7. p. 122. Flowers 18-20 lines long, scarlet, but green at the apex.

Two-colourcd-flowered Psittacanthus. Shrub par.

$8 \mathrm{P}$. crandiplòres; branches terete; leaves opposite, on short petioles, ovate-lanceolate, acuminated, thick; peduncles dichotomous : terminal ones $3-4$ : axillary ones solitary; flowers pedicellate by threes, tomentose ; bractea cup-shaped, unidentate; petals 6 , linear, bearing each a scale on the inside at the base. $h$. P. S. Native of Brazil, in the province of Rio Negro, in the woods about Japura. Loránthus grandiflòrus, Mart. in Schultes, syst. 7. p. 124 . Corolla $1 \frac{1}{2}$ to 2 inches long, purplish? Stigma globose-capitate.

Great-flowered Psittacanthus. Shrub par.

9 P. Biterna'tus; branches terete, rather velvety; leaves nearly opposite, petiolate, elliptic, obtuse, thick, glancous; peduncles axillary and terminal : lower ones solitary, dichotomous: superior ones sub-panicled; flowers pedicellate, pubescent; 
bracteas ovate; petals 6 , lincar, bearing each a scale on the

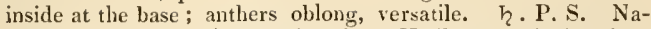
tive of Brazil. Loránthus biternàtus, Hoffmanseg, in Schultes, syst. 7. p. 124. Corolla 12-18 lines long. Three of the stamens are shorter than the rest. Style bent, with 2 knees; stigma capitate.

Biternate I'sittacanthus. Shrub par.

10 P. ROBu'stus; glabrous; branches tetragonal; leaves opposite, decussate, on short petioles, oblong-obovate, obtuse, thick; peduncles terminal, and corymbosely crowded in the axils of the upper leaves, 3-flowered ; flowers erect, angular; bracteas nearly orbicular, short. h. P S. Native of Brazil, in the province of Rio Negro, in woods about Japura. Loránthus robústus, Mart. in Schultes, syst. 7. p. 125. Corolla yellow, 2-3 inches long, glabrous on the outside. Style filiform; stigma capitate. Anthers linear.

Robust Psittacanthus. Shrub par.

11 P. Furca'Tus; glabrous; branches tetragonal at the apex; leaves opposite, obovate, emarginate or obuse, coriaceous, almost nerveless; peduncles axillary and terminal, 1-3 together, those in the forks bearing 2-6 flowers; bracteas ovate, acutish ; petals 6 , cohering at the base, but spreadingly reflexed at the apex. h. P. S. Native of Brazil, in woods, at the river St. Francisco. Loránthus furcàtus, Mart. in Schultes, syst. 7. p 126. Corolla 1 or $1 \frac{1}{2}$ inch long, scarlet at the base, but paler towards the apex, and yellow inside. Anthers oblong, probably versatile.

Forked-peduncled Psittacanthus. Shrub par.

12 P. picalycula'tus; branches terete ; leaves opposite, ovate-cordate, obtuse, somewhat stem-clasping, thick, glaucous ; panicle terminal, dichotomous, bracteate; peduncles 2-3-flowered, tomentose; bracteas cup-shaped, girding the ovarium; calyx 6-toothed; petals linear. h. P. S. Native of Brazil, in the province of Bahia, in woods. Loranthus bicalyculàtus, Mart. in Schultes, syst. 7. p. 128. Corolla 14 lines long, tomentose on the outside, scarlet. Style longer than the stamens ; stigma capitate.

Bicalyculatc-flowered Psittacanthus. Shrub par.

13 P. condA'rus; glabrous; branches terete; leaves opposite, cordate at the base, stem-clasping, coriaceons, ending in a long acumen, triple or quintuple-nerved; flowers racemosely panicled on the tops of the branches, and in the axils of the upper leaves; peduncles 2-flowered; rather tomentose ; bracteas cup-shaped; petals 6 , linear, spreading above the middle. $h_{\imath}$. P. S. Native of Brazil. Loránthus cordàtus, Hoffmanseg in Schultes, syst. 7. p. 128. Corolla 12-16 lines long. Anther's oblong. Stigma capitate.

Cordatc-leaved Psittacanthus. Slurub par.

14 P. Falcifróns; glabrous; branches terete; leaves opposite, sessile, oblong-lanceolate, rather falcate, triple or quintuple-nerved, coriaceous; panicles terminal and axillary, somewhat dichotomous; flowers by threes, glabrous; pedicels equal in length to the bracteas, which are drawn out into a cup, around the ovaria, and much longer than them; petals 6 , linear. $\quad$. P. S. Native of Brazil, in the province of Rio Negro, in woods about Japura. Loránthus falcifróns, Mart. in Seluultes, syst. 7. p. 129. Corolla golden-yellow, 14-18 lines long. Anthers oblong, yellow.-There is a variety of this species having shorter, ovate. oblong, hardly falcate leaves,

Siclile-leaced Psittacantluus. Shrub par.

15 P. Acina'ruus; glabrous; leaves lanceolate, acuminated, oblique, rather falcate, thick, hardly veined; cymes 5 -parted, with the branchlets 3 -flowered; flowers pedicellate; bracteas cup-shaped, large, truncate, nearly entire; calyx 6-toothed; petals 6 , linear. h. P. S. Native of Brazil, in woods in the province of Piauhia. Loránthus acinòrius, Mart. in Schultes, syst. 7. p. 130. Corolla $1 \frac{1}{2}$ inch long, club-shaped at the apex in the unexpanded state. Anthers oblong. Stigma xather oblique.

Acinarious Psittacanthus. Shrub par.

$16 \mathrm{P}$. cuculda'ris; glabrous; branches terete, nodose at the joints ; leaves broad-lanceolate, falcate, 5-nerved, opposite, on short petioles; peduncles axillary and terminal, bifid or subpaniculate, nearly one-half shorter than the leaves: with 1-3flowered branches ; bracteas large, concave, cordate, acuminated ; flowers sessile; petals 6 , linear; anthers versatile. $\eta$. P. S. Native of French Guiana. Loránthus cucullàris, Lam. journ. hist. nat. 1. p. 1.4. t. 23. Schultes, syst. 7. p. 130.

Cucullar-bracted Psittacanthus. Shrub par.

17 P. MExica'nus; glabrous; leaves ovate-lanceolate, rather falcate, running down the short petiole in a cuneate manner at the base, 5-7-nerved, rather coriaceous; panicles axillary and terminal : with thick branchlets, bearing 3 flowers at the apex; pedicels shorter than the bracteas, which are drawn out into ovate cupula, much exceeding the ovaria; petals 6 , linear, acute, velvety on the outside; anthers oblong. $h$. P.S. Native of Mexico, where it was collected by Hanke. Loránthus Mexicànus, Presl, in herb. Hænke, and in Schultes, syst. 7. p. 129. Leaves 5 inches long and $1 \frac{1}{2}$ broad. Flowers 18-20 lines long, golden yellow in the dried state. The leaves are very similar to those of $P$. cucullaris, but differs in the bracteas being much smaller.

Mexican Psittacantlus. Slırub par.

18 P.? DESTRU'croR; glabrous; branches tetragonal, warted; leaves petiolate, oblong, acute, coriaceous, having the middle nerve rather prominent beneath, the rest of the leaf veinless; racemes terminal, having the branchlets 3 -flowered, approximate, secund, and bractless; flowers pedicellate; petals 6 , linear ; anthers incumbent. $\quad$. P. S. Native of Quito, on trees near Villa de lbarra, where it is called Matapalo. Loránthus destrúctor, H. B. et Kunth, nov. gen. amer. 3. p. 485 . Scluultes, syst. 7. p. 135. Leaves 2 inches long and 8-9 lines broad; petioles 3 lines long. Flowers about an inch long, orangecoloured. Berries globose, black. It is very doubtful whether this is a species of the present genus from the want of bracteas.

Destructive Psittacanthus. Slirub par.

19 P. Formòsus; quite glabrous; branches compressedly angular at the nodi; leaves elliptic-lanceolate, obtuse, on short petioles, coriaceous, feather-veined; umbels 3,1 terminal, and 2 axillary, pedunculate; bracteas irregular; calyx repandly truncate; corolla 6 -parted, with linear lobes; anthers versatile. দ.P. S. Native of Brazil. Lotánthus formòsus, Cham. et Schlecht. in Linnæa. 3. p. 211. An intermediate species between $P$. Jacquini and $P$. Mutisii. Leaves almost alternate or opposite, 3-4 inches long, and 1-2 broad. Corolla 4 inches long, showy.

Beautiful Psittacanthus. Shrub.

20 P. cuneı́ò̀ıus; glabrous; branches terete; leaves nearly sessile, cuneiform, small, ending in a short acumen, fleshy, shining; peduncles 1-3 together, axillary, 1-fiowered, 3 times sliorter than the leaves; bracteas cup-shaped, one under each flower; petals 6 , linear-spatulate, concrete at the base; anthers versatile. 5. P. S. Native of Brazil and Peru, on trees and shrubs ; of Chili, in valleys in the Andes of Mendoza, Cordillera of Chili, on Accàcia Cavènia at Llayllay, and upon willows at Banda Oriental. Loránthus cuneifòlius, Ruiz et Pav. fl. par. 3. p. 46. t. 276. f. b. Cham. et Schlecht. in Linnæa. 3. p. 212. Schultes, syst. 7. p. 118. Loránthus Montevidénsis, Spreng. syst. 2. p. 128. Leaves hardly an inch long, some of them emarginately retuse at the apex. Corolla scarlet, an inch and a half long. Berries roundish, black, crowned by the urceolate calyx.

$$
\text { Cuneiform-leaved Psittacanthus. Slrub par. }
$$


21 P. cUPU'L1FER; glabrous; branches tercte; leaves nearly sessile, obliquely ovate-oblong, narrowed at the apex and obtuse, reticulately many veined, somewhat membranous; peduncles axillary, 2-3-flowercl, unibracteate; pedicels furnished with a large cup-shaped bractea under the flower; petals 6 , linear, spreading, revolute at the apex; anthers incumbent. r. l'. S. Native of Peru, near Loxa. Loránthus cupúlifer, H. B. et Kunth, nov. gen. amer. 3. p. 438. Schultes, syst. 7. p. 120. Leaves 5 inches long and 2 inches broad, on very short petioles. Flowers 1 or $1 \frac{1}{2}$ inch long, on very short pedicels. Berry elliptic, about the length of the cup-shaped bractea.

Cup-bearing Psittacanthus. Shrub par.

22 P. Plume'ri; glabrous; branches terete; leaves ovate (3-nerved ex Lam.) 5-7-nerved at the base, coriaceous; peduncles axillary, trichotomously corymbose, shorter than the leaves; petals 5 , linear, contiguous at the base; alabastra a little curved; anthers versatile. h. P.S. Native of the West India Islands, parasitical on trees. Loránthus Plumièri, Cham. et Schlecht. in Linnæa. 3. p. 311 . Lonicèra, Plım. nov. gen. 17. t. 37. pl. amer. cd. Burm. t. 166. f. 1. Loränthus, Vaill. act. acad. par. 1722. p. 201. Plumier says the flowers of his plant are composed of 6 petals, but the number of the parts of the flower is unknown.

Plumier's Psittacanthus. Shrub par.

23 P. Eucalyptifòlius; glabrous; branches terete; leaves petiolate, ovate, rounded at the apex, coriaceous, almost veinless; peduncles axillary, 3-flowered, shorter than the leaves; pedicels furnished with a cup-shaped bractea each under the flower; petals 6 , linear, a little dilated at the apex, hardly cohering at the base; anthers incumbent. 2. P.S. Native of Sonth America, in the province of Caraccas, at Villa de Cura. Loránthus eucalyntifòlius, H. B. et Kunth, nov. gen. amer. 3. p. 433. Leaves 3 inches long, and nearly 2 broad. Flowers yellow, glabrous, abont $1 \frac{1}{2}$ inch long. Schultes, syst. 7. p. 120 .

Eucalyptus-leaved Psittacanthus. Shrub par.

24 P. crassifólios; branches terete, dotted with brown at the apcx; leaves opposite, broad-ovate, obtuse, with subrevolute margins, coriaceous; peduncles axillary, 1-3-together, dichotomous ; flowers twin or tern, pedicellate, tubular: the tube velltricose above the middle, and spreacling at the apex, and having the throat constricted; bracteas cup-shaped, one under each

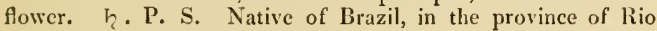
Grande, in woods abont Japura. Loránthus crassifòlius, Mart. in Scliultes, syst. 7. p. 123 . Corolla purplish, 2 and $2 \frac{1}{2}$ inches long. Anthers linear.

Thick-leaved Psittacanthus. Shrub par.

25 P. Dicnótonus; glabrous; branches terete, dichotomous, 3 or 4 in a whorl; leaves usually in whorles, ovate-elliptic, rounded at the apex, coriaceous ; peduncles axillary, twin, bifurcate, pendulous in the flower-bearing state, but erect in the fruit-bearing state; limb of calyx truncate; bracteas cupshaped, one under each flower; petals 6 , linear, concrete at the base, revolutely spreading at the apex; anthers incumbent. $h$. P. S. Native of Peru, on the Andes, in troves about Muna. Loránthus dichótomus, Ruiz et Pav. f. per. 3. p. 45. t. 274. f. a. Schultes, syst. 7. p. 123. Loránthus clusiæfòlius, Willd. rel. ex Schultes, syst. 1. c. Leaves 2 hands long, and a hand and a half broad. Corolla about a hand and a half long, scarlet at the base, and yellow at the top. Petioles very short.

I'ar. $\beta$, Balthasìreus (D. C. prod. 4. p. 311.) petioles 8-9 lines long; margins of leaves somewhat revolute, shining above, and rather glaucescent; flowers red, 3 inches long; petals a little dilated at the apex. $\quad$. P. S. Native of South America, on the banks of the Orinoco, near Balthasar. Loránthus dichótomus, H. B. et Kunth, nov. gen. amer. 3. p. 433. Perhaps sufficiently distinct from the species.

voL. III.
Dichotomous-peduncled Psittacanthus. Shrub par.

26 P. Nonòsus; glabrous; branclies terete, dichotomous, articulated at the nodi; leaves opposite, petiolate, ovate-roundish, coriaceous, somewhat 7 -nerved at the base; peduncles axillary, and in the forks of the branches, in fascicles, 1-2-flowered, ncarly the length of the petioles; bracteas semicircular; alabastra tercte, acute; petals 6 , linear-lanceolate; filaments adnate a long way to the petals. 々. P. S. Native of Peru. Loránthus nodòsus, Desr. in Lam. dict. 2. p. 601. Schultes, syst. 7. p. 119. Leaves $3 \frac{1}{2}$ to 4 inches long, and $2 \frac{1}{2}$ to 3 inches broad. Corolla 3 or $3 \frac{1}{2}$ inches long.

Knottcd-branclied Psittacanthus. Slırub par.

27 P. Murísn; glalorous; branches terete; leaves 3 in a whorl, sessile, somewhat obliquely elliptic-oblong, or obovate, rounded at the apex, coriaceous ; peduncles axillary, few-flowered, bractless; petals 6 , lincar, glabrous, concrete at the base? h. P.S. Native of South America, near Santa Fe de Bogota. Loránthus Mutisii, H. B. et Kunth, nov. gen. amer. 3. p. 439. Schultes, syst. 7. p. 124. Loránthus longif òlus, Mutis, ined. ex Bonpl. Lcaves $2 \frac{1}{2}$ to 3 inclses long, and $1 \frac{1}{2}$ broad. Flowers half a foot long.

Mutis's Psittacanthus. Shrub par.

28 P. Divarica'tus; glabrous; branches terete, divaricate; leaves petiolate, oblong or elliptic, rounded at the apex, coriaccous, glaucescent; peduncles panicled on the tops of the branches, 3-flowered, bractless; pedicels expanded into an entire cupula under each flower; petals 6, linear, glabrous; anthers incumbent. h. P. S. Native of South America, on the banks of the Orinoco. Loránthus divaricàtus, H. B. et Kunth, nov. gen. amer. 3. p. 433. Schultes, syst. 7. p. 127. Flowers more than an inch long. Leaves 10-15 lines long, and 5-9 broad. Peduncles axillary and terminal.

Divaricate Psittacanthus. Shrub par.

29 P. Acurifòlıus; glabrous; branches terete; leares petiolate, lanceolate, very acutc; racemes axillary, one-half shorter than the leaves, having the branchlets 1-3-flowered; flowers pedicellate, furnished with a common acute bractea each ; petals 6 , linear, somewhat spatulate, erect to the middle, and conniving. h.P.S. Native of Peru, parasitical on trees, and in hedges at Huanaco. Loránthus acutifòlius, Ruiz et Pav. fl. per. 3. p. 48. t. 274. f. b. Schultes, syst. 7. p. 142. Leaves 2-3 inches long, and nearly an inch broad; petioles 2-3 lines long. Corolla white, 4-5 lines long. Berry oval, blackish.

I ar. $\beta$, Chilénsis (D. C. prod. 4. p. 314.) racemes denseflowered, almost bractless; petals erect beneath the middle, and conniving, linear and acute at the apex. h.P. G. Native of Chili, where it was collected by Hanke. Loranthus acutifòlius, Presl, in herb. Hænke. Perhaps a distinct species.

Acule-leaved Psittacanthus. Shrub par.

30 P.? EschscholziA'nus; branches terete, or a little angular, rough; leaves subalternate, on very short petioles, rough, ovate or roundish, obtuse, glabrous, coriaceous; peduncles corymbosely racemose, terminal and axillary, erect, for the most part 3-flowered: the middle flower scssile; bracteas ovate, fringed at the apex, equal in length to the ovaria; corolla 5cleft, clavate; anthers fixed by the back. 々. P. G. Native of Chili. Loránthus Eschscholziànus, Mart. in Schultes, syst. 7. p. 117. Ovarium oblong. Corolla 3 lines long.

\section{Eschscholz's Psittacanthus. Shrub par.}

31 ? P. Thy Rsiflòrus; glabrous; branches dichotomous or trichotomous; leaves broad-lanceolate, acutish or acuminated, with pellucid cartilaginous margins; racemes terminal and axitlary: flowers 2-3, sessile at the tops of the branchlets; bracteas ovate, acute, one under each flower; corolla 6-parted, with linear lobes; anthers versatile. $\quad$. P.S. Native of Brazil. Loránthus thyrsiflorus, Cham. et Schlecht, in Linnæa. 3. p. 214. $3 \mathrm{H}$ 
Leaves 2 inches long, and 8-9 lines broad; petioles 6-9 lines long. Flowers 5 lines long. Limb of calyx very narrow, truncate.

\section{Thyrse-flonered Psittacanthus. Slurub par.}

32 P.? FLAGELLA'RIS ; glabrous, sarmentose; branches terete; leaves sessile, linear, acute, coriaceous, with the middle nerve hardly conspicuous ; racemes terminal, naked, erect ; lower pedicels 3-flowered, superior ones 1-flowered; bracteas deciduous, one under each flower; calyx lacerated, truncate; corolla 5-6-parted, having the lobes linear and dilated at the apex; anthers versatile. $\quad$. P. S. Native of Brazil; of Chili, near La Punta de San Luis, at El Aquadita, and on the banks of El Rio Chorillo. Loránthus flagellàris, Cham. et Schlecht. in Linnæa. 3. p. 213. Like Loránthus cuneifòlius and sarmentòsus, Ruiz et Pav. in fl. per. Corolla fine red, 6 lines long. Style attenuated at the apex. Leaves 20 lines long and $1 \frac{1}{y}$ broad.

\section{Whip Psittacanthus. Shrub par.}

33 P. BERTERò̀; glabrous; branches terete; leaves alternate, broad, elliptic, obtuse, tapering into the short petioles at the base, coriaceous, witl somewhat revolute margins; peduncles terminal, in dense corymbose racemes; the partial peduncles 2-5-flowered; flowers tubular, with 6 linear-spatulate, nearly free segments; filaments equal in length to the petals; anthers linear-oblong, oscillatory ; style filiform, angular; stigma hardly capitate; ovarium roundish, exceeding the unilateral bractea, which is roundish and denticulated at the apex. $\eta$ P. G. Native at Juan Fernandez, growing on Mýrtus Fernandesiàmus. Hook. et Arn. Loránthus Berteròi, Hook. et Arn. in bot. misc. 3. p.358. Loránthus venètus, Bertero, but not of Kunth. The partial peduncles are simple, and bear 2 flowers, or are forked, and then bear 3 or 5 flowers. The flowers are about an incli long. It is probably a species of Struthánthus.

Bertcro's Psittacanthus. Shrub par.

34 P. Scinedea'nus; plant glabrous; branches subalately tetragonal, dilated at the nodi; leaves nearly opposite, on short petioles, ovate-lanceolate, obliquely falcate, feather-veined, and somewhat triple-nerved; corymbs terminal ; bracteas cup-shaped, one under eacl flower; limb of calys truncate. h. P. S. Native of Mexico, near Jalapa. Loránthus Schiedeànus, Cham. et Sclılecht. in Linnæa. 5. p. 17\%. Allied to P. Jacquini, but differs in the flowers being more s!ender, and about 2 inches long. Schiede's Psittacanthus. Shrub par.

Cult. The flowers of all the species of this genus are very showy, and comparatively large. The habit is that of honeysuckle. Being all parasitical shrubs, they are not cultivable.

VII. TRI'STERIX (from rogtc, treis, three, and $\pi \tau \varepsilon \rho t_{n}^{\xi}$, pterix, a wing; in reference to the 3 bracteas to the flowers). Mart. in D. C. prod. 4. p. 671 ..-Loránthus species of autlıors.

Lun. syst. Tetra-Hexándria, Monogínia. Flowers hermaphrodite, each propped by 3 bracteas. Calys cup-shaped or cylindrical, with an entire border. Petals linear-spatulate, or linear, bearing the stamens in the middle; anthers fixed by the back, incumbent, linear-oblong or ovate. Style filiform; stigma capitate. Berry ovate or elliptic. Racemes brachiate, lateral or terminal.

1 T. VIRIDIFLònus; glabrous; primary branches subverticillate, rather compressed when young; leaves opposite, on short jetioles, lanceolate, attenuated at both ends; racemes axillary, $2-4$ in a fascicle, shorter than the leaves; pedicels remote, 1flowered ; bracteas 3 under each flower, rather concrete; corolla 6-cleft, liaving the middle of the tube angular, and the lobes spreadingly reflexel ; stamens 6 . 々. P.S. Native of Nipaul, upon trees. Loránthus viridiflòrus, Wall, in Roxb. $\mathrm{A}$. ind. 2. p. 219. Corolla green, 3-4 lines long. Anthers adnate, ex Wall.
Green-flowered Tristerix. Slırub par.

2 T. Tetrándrus; branches terete, and are, as well as the petioles and nerves of leaves, pubescent; leaves ovate, bluntish, rather cordate, coriaceous, glabrous in the adult state; corymbs nearly sessile, dense, many flowered; pedicels very short, pubescent, having 3 bracteas under each flower; corolla glabrous, 4-parted: lobes shell-formed at the apex and acute; stamens 4; anthers versatile. h. P. G. Native of Chili, about Talcaquano, Conception, El Valle del Rio Tingririca, and Valparaiso, parasitical on Guevina and other trees, along with Loránthus buxif òlius, Cham. et Schlecht. in Linnæa. 3. j. 206. Schultes, syst. 7. p. 103. Loránthus tetrándrus, Ruiz et Pav. fl. per. 3. p. 48. t. 275. The vernacular name of this species is Quintral ex Bertero.

Tetrandrous Tristerix. Slurub par.

3 'T. APHY'LLUs; mucl branched; branches nearly terete, glabrous, short, leafless; flowers pedicellate, somewhat corymbose; bracteas 3 under each flower, somewhat concrete; corolla glabrous, 4-parted: lobes linearly cochleate at the apex; stamens 4 ; anthers versatile. h. P. G. Native of Chili, parasitical upon Cèreus Peruviànus at Rancagua, Coquimbo, Guardia del Maypu, Villavicenzio in the Andes of Mendoza, Cordillera of Chili, \&c. Lorántluss apluýllus, Miers, ex Bert. in litt. 829. Loránthus cactòrum, Hook. et Arn. in Beech. voy. part. bot. 1. p. 25. Flowers like those of the prcceding species. The vernacular name of this plant is Quintral de Quisco.

Leafless Tristerix. Shrub par.

4 'T'. Reinwardtia'nus; leaves opposite, oblong, attenuated at botlı ends, coriaceous, veinless beneath; peduncles crowded, axillary, 1-flowered; flowers pentandrous or tetrandrous; tube of corolla very long, curved : lobes linear, secund, at length circinnately revolute at the top. $\eta_{2}$. P. S. Native of Java, in woods on the mountains. Lorántlus Reinwardtiànus, Scluultes, syst. 7.p. 105. Loránthus coccíneus, Reinw. in Blum. bijdr. p. 664. but not of Jack.

Reinwardt's Tristerix. Slırub par.

Cult. The species of this genus, like the rest of the genera of this order, are not cultivable in gardens. Their habit is that of Lonicèra.

VIII. DENDROPHTHO'E (from iहvêon', dendron, a tree, and $\phi \theta 0 \eta$, phthoe, corruption; the plants kill the trees upon which they grow). Mart. in D. C. prod. 4. p. 671.-Loránthus species of authors.

Lin. syst. Tetra-Pentándria, Monogýnia. Flowers hermaphrodite, each furnished with one bractea; bracteas sometimes lateral, and sometimes cupular and oblique. Calyx cup-shaped or campanulate, with an entire or toothed border. Petals linearspatulate, bearing the stamens in the middle. Anthers fixed by the base, erect, linear. Style filiform ; stigma capitate. Berry ovate or elliptic.-Racemes for the most part lateral, subcorymbose.

$\$ 1$. Flowers of 4-5 petals, having a cucullate bractea under each floner.

1 D. ugustri'nus; branches terete, when young, as well as the new leaves, peduncles, bracteas, and flowers pubescent; leaves petiolate, lanceolate, acuminated, coriaceous, at lengtl glabrous ; peduncles many, axillary, cymosely corymbose; bractea lateral, cucullate under each flower : limb of calyx almost entire; corolla tetragonal ; petals 4 , linear, at length spreading; flowers pentandrous. $\zeta . P . G$. Native of Nipaul, in woods in the great valley. Loránthus ligustrinus, Wall. in Rioxb. $\mathrm{fl}$. ind. 2. p. 219. D. Don, prod. fl. nep. p. 143. Schultes, syst. 7. p. 101. Leaves 2 inches long, and 6-9 lines broad; petioles 2 lines long. Corolla 4-6 lines loug, reddisl. 
Privet-likc Dendrophthoe. Slırub par.

2 D. WaLLicina'nus; glabrous; branches terete; leaves rather alternate, ovate, obtuse, acute at the base; racemes axillary, 1-3-together, one-half shorter than the leaves, simple, in fascicles round the base of the branches; flowers small, pedicellate; bracteas lateral cucullate, one under each flower; petals 4, linear-cuneated: alabastra nearly terete ; berry subglobose, reflexed; flowers tetrandrous. $\zeta$. P. S. Native of the East Indies, where it was detected by Heyne. Loránthus Wallichiànus, Schultes, syst. 7. p. 100. Loránthus polystàchyus, Wall. in Roxb. A. ind, 2. p. 217. but not of Ruiz et Pav. Corolla deep purple, 4 lines long.

Wallich's Dendrophthoe. Shrub par.

3 D. Pu'LCHER; glabrous; branches terete; leaves nearly opposite, on short petioles, ovate-clliptic, acuminated, coriaceons, glaucous; racemes axillary, simple, many flowered, length of the leaves; bracteas cucullate, lateral, one under each flower; alabastra cylindrically pentagonal; petals 5 , free to the base, linear; flowers pentandrous. $\zeta$.P.S. Native of Penang. Loránthus púlcher, D. C. prod. 4. p. 295 . Loránthus speciòsus, Wall. mss. but not of Pohl, nor Perr. nor Dietr. Leaves 4 inches long, and 2 broad. Corolla 2 lines long. Style filiform; stigma simple. Calyx truncate.

Fair Dendrophthoe. Shrub par.

4 D. PÉ$^{\prime}$ NDuLus; glabrous; branches terete; leaves opposite, petiolate, long-linear, acutish, coriaceous, with 5 subparallel veins, which are hardly conspicuous; corymbs axillary, 1-2together, pedunculate, trifid; branches 3 -flowered; bracteas ovate-roundish, lateral, one at the outer side of each flower; limb of calyx truncate; alahastra terete, clavate; petals 5 , linear, somewhat dilated at the apex; flowers pentandrous; anthers oblong, erect. 々. P. G. Native of New Holland. Loránthus péndulus, Sieb. f. nov. holl. no. 241. Schultes, syst. 7. p. 157. D. C. coll. mem. vi. t. 1. Leaves 6-8 inches long, and 5 lines broad; petioles 10 lines long. Corolla 15 lines long. Berry ovate. Style filiform.

Pendulous Dendrophthoc. Shrub par.

5 D. CONGE'NER; glabrous; branches terete; leaves oblong, obtuse, attenuated at the base, on short petioles, coriaceous, veinless; racemes axillary, shorter than the leaves, subcorymbose; peduncles 3 -flowered ; flowers pedicellate; bracteas ovate, acute, lateral, one under each flower; limb of calyx truncate; alabastra terete, somewhat club-shaped; petals 5 , linear, acute; flowers pentandrous; anthers linear, inserted by the base. $h$. P. G. Native of New Holland. Loránthus congèner, Sieb. nov. holl. no. 243 . Schultes, syst. 7. p. 114. D. C. coll. mem. vi. t. 2. Leaves 2 inches long, and 4-5 lines broad. Corolla nearly an inch long. Style filiform.

Congener Dendrophthoe. Shrub par.

$6 \mathrm{D}$. Forsteria'nus; glabrous; branches terete; leaves opposite, petiolate, ovate, obtuse, veiny, thin ; cymes axillary, solitary, shorter than the leaves; peduncles 3 -flowered; bracteas ovate, obtuse, lateral, one under each flower; calyx truncate; corolla pentagonal, subclavate in the young state. $h$. P. G. Native of the Socicty lslands. Loránthus Forsteriànus, Schultes, syst. 7. p. 114. Loránthus stèlis, Forst. prod. ex specimen in herb. Screb. from Schultes obs. Perhaps this species does not belong to the present genus.

Forster's Dendrophthoe. Shrub par.

7 D. GAUDicha'UD1; glabrous; branches tercte; leaves opposite, linear, obtuse, thickish, attenuated at the basc; peduncles axillary, much shorter than the leaves, divaricately bifid at the apex, 2-4-flowered; parts of flowers equal; flowers tetrandrous; petals spatulate; anthers ovate, inserted by the base. দ. P. G. Native of New Holland, where it was collected by Gaudichaud. Loránthus Gaudichàıdi, D. C. prod. 4. p. 295.
Leaves 10-12 lines long, and 2 lines broad. Flowers 5-6 lines long. Style filiform.

Gaudichaud's Dendrophthoe. Shrub par.

8 D. tetrapétalus; leaves opposite, ncarly sessile, oblong, or elliptic, coriaceous; flowers tetrandrous, one on each side of each leaf, and therefore there are 4 at each joint, disposed in a whorl; petals 4, linear. h. P. G. Native of New Zealand. Loránthus tetrapêtalus, Lin. fil. suppl. 211. Forst. prod. no. 156. Schultes, syst. 7. p. 96 . Calyx nearly entirc. Style a little longer than the petals, filiform; stigma capitatc. Bracteas probably wanting.

Four-petalled Dendrophthoe. Shrub par.

9 D. Luzons'ssis; glabrous; branches terete, dichotomous or whorled, knotted at the joints; leaves opposite or verticillate, oval-oblong, coriaceous, sessile, almost veinless; peduncles terminal, cymosely corymbose at the apex, pubescent; bracteas ovate, acute, lateral, rather concave, one under each flower; limb of calyx truncate; corolla of 4 linear acute petals, which are somewhat concrete at the base (sometimes joined by pairs); style filiform. h.P.S. Native of Luzon, one of the Philippines. Loránthıs Luzonênsis, Presl, in herb. Hænke, and in Schultes, syst. 7. p. 104. Leaves 11-15 lines long, and 6-7 broad. Corolla 15 lines long, hardly pubescent on the outside.

Lu an Dendrophthoe. Shrub par.

10 D. PENTAPE'TALUS; glabrous, much branched; leaves opposite, petiolate, lanceolate-ovate or oval-corlate, obliquely attenuated, smooth; racemes $1-2$, axillary, simple, stiff, length of the leaves; flowers very numerous, on short pedicels; bractea oblique, oval, adpressed to the ovarium ; limb of calyx nearly entire; petals 5 , swelled out at the base into a fleshy triquetrous body, recurved at the apex; stamens 5 ; anthers obovate; style angular; berry oblong. $\zeta$. P. S. Native of the East Indies. parasitical on trees, in Silhet. Loránthus pentaphýllus, Roxb. fl. ind. 2. p. 211. Schultes, syst. 7. p. 109. Wall. pl. rar. asiat. 3. t. 225. Flowers regular, small, red. Berry greenish yellow. Leaves 3-4 inches long; petioles 6 lines long. Racemes 6-8 inches long, red. Anthers inserted by the base.

Five-petalled Dendrophthoe. Shrub par.

11 D.? RACEMI'FERUs; branches terete, glabrous, clothed with rufous villi in the young state, as well as the peduncles; leaves opposite or alternate, on short petioles, oblong-lanceolate, bluntish at the base, and acutish at the apex, glabrous; racemes axillary, spicate, simple, length of leaves; bracteas cucullate, lateral, one under each flower; petals 4, triquetrous at the base. h.P.S. Native of the East Indies, in the Burman empire, at Amherst and Tavoy. Lorânthus racemíferus. Wall. mss. Very like D. pentapétalus, but differs in the flowers being tetrandrons.

Racemc-bearing Dendrophthoe. Shrub par.

12 D. coccínets; glabrous; branches elongated; leaves alternate, on short petioles, oblong-ovate, obtuse, somewhat cordate at the base; spikes axillary, 1-2-together, erect, longer than the leaves; flowers sessile, with one bractea under each; limb of calyx nearly entire; corolla tubular; petals 4, linear, dilated at the base; anthers adnate; flowers tetrandrous.

1. S. Native of the East Indies, in Singapore. Loránthus coccíneus, Jack, mal. misc. 1. p. 8. and in Roxb. fl. ind. 2. p. 215. Schultes, syst. 7. p. 102. Corolla scarlet. Berry ovate. Said to be allied to D. pentapétalus.

Scarlet-flowered Dendrophthoe. Shrub par.

\$2. Flowers tubular, slender, 4-cleft, disposed in racemes, with one bractea under each flower. Many of the plants in this section are probably species of Scúrrula.

13 D. овтE'́ctus; branches terete; branchlets compressed, velvety, as well as the young leaves; leaves opposite, on short $3 \mathrm{H} \approx$ 
petioles, elliptic-lanceolate, at length glabrous ; flowers in fascicles from the axils of the leaves, velvety from dense rufous pubescence, as well as the racemules and peduncles; bracteas lateral, ovate, one under each flower; limb of ealyx hardly any ; corolla tubular, arched : lobes 4 , oblong ; anthers erect. $\digamma_{c} . P . S$. Native of the Burmese Empire, on Mount T'aong-Dong, near Ava. Lorántbus obtéctus, Wall. mss. Leaves \& inches long and an inch broad; petioles $1 \frac{1}{2}$ inch long. Corolla 4-cleft, 1011 lines long. Stigna hardly capitate.

Covered Dendrophthoe. Shrub par.

14 D. REcu'rvus; branches terete, adult ones glabrous ; leaves alternate, petiolate, elliptic, obtuse, acute at the base, smoothish; peduncles axillary and lateral, branched, 2-8flowered, and are, as well as the flowers, velvety; flowers recurved; bracteas broad, obliquely cupulate, one under cach flower; limb of calyx cup-shaped, toothed; alabastra terete; lobes 5, oblong; flowers tetrandrous. h. P. G. Native of the East Indies, on the Nelligherry mountains, where it was collected by Noton. Loránthus recúrvus, Wall. mss, Leaves 2 inches long and 15 lines broad; petioles 3-4 lines long. Alabastra 6 lines long. Anthers oblong, inserted by the base. Style filiform. Stigna hardly capitate.

Recurved-tlowered Dendrophthoe. Shrub par.

15 D. LEPTA'NTHUs; hranches terete, while young as well as the leaves white from velvety down; leaves opposite, or rather alternate, petiolate, oval, obtuse at both ends, at length glabrous; racemes short, axillary, and are, as well as the flowers, velvety from white tomentum; tube of corolla long, terete, somewhat incurved : lobes 4 , nearly equal, spreading; flowers tetrandrous. 々. P.S. Native of the Burmese empire, at the river Irrawaddy, near Yenangenn. Loránthus leptánthus, Wall. mss. var. rotundifòlia, D. C. coll. mem. vi t. 5. Corolla 4-cleft, 15-17 lines long. Anthers linear, erect. The species is allied to $D$. pulveruléntus.

\section{Delieate-flonered Dendrophthoe. Slurub par.}

16 D. FERRUGíneus; branches long, pendulous, densely clothed witlı ferruginous down when young, as well as the under side of leaves, pedicels, calyxes, and corollas; leaves opposite, on short petioles, elliptic, obtuse, coriaceous, glabrous above; peduncles 1-4 together in the axils of the leaves, 2-6-flowered; bracteas small, adpressed to the ovaria, one to each; corolla tubular, deeply 4-parted; berry ovate; flowers tetrandrous. $\eta$. P. S. Native of the East Indies, in Pulo-Penang, Singapore. and Sumatra. Loránthus ferrugíneus, Roxb. fl. ind. 2. p. 207, Jacq. mal. misc. 1. p. 9. Schultes, syst. 7. p. 98 . Corolla densely clothed with rusty hairs, 7 lines long.

Rusty Dendrophthoe. Shrub par.

17 D. Gracilizlòrus; branches compressed, at length terete, glabrous; leaves opposite, on short petioles, elliptic-oblong, acute at both ends, at length glabrous ; racemules axillary, 5-7flowered, somewhat umbellate; bracteas lateral, small, acute, one under each flower; corolla whitish from velvety down, slender, 4-lobed: lobes linear. $h_{2}$.P. S. Native of the East Indies, in Silhet. Lorántlııs graciliflòrus, Wall. mss. Loránthus gracilifòlius, Schultes, syst. 7. p. 99. Leaves an incl and a half long, and 6-9 lines broad. Corolla 5 lines long, 4-cleft, with the tube tetragonal at the base. Anthers inserted by the base. Allied to D. ligustrinus.

Slender-flowered Dendrophthoe. Shrub par.

$18 \mathrm{D} . \mathrm{HE}_{Y}^{\prime} \mathrm{NEI}_{\text {; }}$ branches terete, glabrous in the adult state; leaves opposite, on short petioles, oval, bluntish, rather velvety beneath from rufescent down; peduncles axilary, in fascicles, or branched, much shorter than the leaves, and are, as well as the flowers, clothed with rufous velvety down; bracteas Jateral, small, one under each flower; corolla very slender, tubular, terete, 4-lobed : lobes oblong, short. Ђ.P.S. Native of the East Indies. Loránthus Héynei, Wall. mss.
Heyne's Dendrophthoe. Shrub par.

19 D. atropurpu'reus: branches nearly terete, somewhat canescent; leaves nearly opposite, oval, obtuse at both ends, rather oblique at the base, obsoletely and undulately repand, white from scurf beneatl ; racemes crowded, axillary; limb of calyx quite entire, very short; flowers 4-parted; fruit subconical. $\quad$. P.S. Native of Java, upon trees. Loránthus atropurpùreus, Blum. bijd. p. 669. f. jav. 2. t. I. exclusive of var. $\beta$, batav, verhandl. 1823. p 186. ex litt. 1829. Flowers small, clothed with white scurf on the outside, but dark purple inside.

Dark-purple Dendrophthoe. Shrub par.

20 D. REPA'NDUs ; branchlets somewhat compressed, clothed with rusty lepiclotted down; leaves nearly opposite, oval or obovate, obtuse, equal at the base, repand, clothed with leprous fuscescent down bencath; racemules crowded, axillary ; corolla slender, 4-toothed, covered with brown scurf on the outside: Jobes or teeth short, equal. h. P. S. Native of Java, about Batavia, on trees. Loránthus repándus, Blım. in litt. 1829. Blum. fl. jav. 2. t. 3. This species comes very near $D$. atropurpüreus, but differs in the leaves being more attenuated at the base, and in the flowers being smaller.

Repand-leaved Dendrophthoe. Shrub par.

21 D. Scuulte'su; branches terete, clothed with lepidotted rusty down at the top; leaves nearly opposite, obtuse at both ends, or rather cordate at the base, pale, and ochraceously lepidotted beneath ; racemes crowded, axillary ; flowers 4-parted, rusty on the outside. 々. P.S. Native of the interior of Java, in temperate places. Lorántlus lepidòtus, Schultes, syst. 7. p. 100. but not of Blume. Loránthus melanostèmon, Reinw. ined. ex Schultes, syst. 7. p. 100 . Loránthus Schultèsii, Blume, in J.tt. 1899. fl. jav. 2. t. 2. Hlowers brownish. Anthers black.

Sehultes's Dendrophthoe. Shrub par.

22 D. SPIIENoíDES; branches terete, glabrous; leaves nearly opposite, cuneiform, roundly obtuse, when young covered with rusty scurf, at length glabrous on both surfaces; peduncles crowded, axillary, bearing $3-5$ flowers, in fascicles; alabastra terete, globose at the apex, hardly 4-toothed. $々$. P. S. Native of Java, in the province of Bantam, on trees. Loránthus sphenoides, Blum. in litt. 1829. f. jav. 2. t. 4. Loránthus atropurpùreus var. cuneàtus, Blum. bijdr. p. 660 . Very nearly allied to $D$. atropurpurcus, but differs in the figure of the leaves, and in the shorter more crowded peduncles.

Splenoid-flowered Dendrophthoe. Shrub par.

23 D. cinnanòmus; branches terete, when young velsety from rufous down, as well as the peduncles and flowers; leaves opposite, on short petioles, lanceolate, acute, glabrous; flowers $3-5$ in a fascicle in the axils of the leaves, on short pedicels; corolla clavate, truncate at the apex; style clavate. h. P.S. Native of the East Indies, in Silhet. Lorántlus cinnamòmeus, Wall. mss. D. C. coll. mem, vi. t. 6. Leaves 27 lines long and 10-11 broad. Corolla 6-7 lines long.

Cinnamon-coloured Dendrophthoe. Shrub par.

24 D. curysántuus; branches terete, glabrous, compressed when young; leaves oval, on short petioles, blunt at both ends, or rather cordate at the base, covered with fuscous scurf; but when young clothed with dense ferruginous tomentum, as well as the branches and flowers; peduncles solitary or crowded, axillary, bearing $乡-5$ flowers; corolla cylindrical, truncate anthers 4. h. P. S. Native of Java, on the mountains in the province of Bantam. Loranthus chrysánthus, Blum. in litt. 1829. ex D. C. prod. 4. p. 300 . Allied to D. cinnamomeus, but the flowers are shorter.

Golden-flowered Dendrophthoe. Slirub par.

25 D. cunca'tus; branches terete, velvety from rufous down while young, as well as the leaves and flowers; leaves opposite or alternate, obovate-cuneated, very blunt, at length glabrous; 
peduncles axillary, 3-5-flowered; bracteas lateral, cucnllate, one to each flower; corolla cylindrical, truncate at the apex; style clavate. h. P'. S. Native of the East Indies, at Martaban, on the banks of the lrrawaddy. Loránthus cuneàtus, Wall. mss. Heyne, ex Roth, nov. spec. p. 193. Anthers probably 5 , but in the younger Howers they are glued together, and with the stigma. Corolla 6 lines long, velvety on the outside. This, with the preceding species, may hereafter form a distinct genus, or at least a separate section.

Cuncated-leaved Dendrophthoe. Shrub par.

Cult. Like the rest of the genera of this order, the species are not cultivable in gardens. They are showy plants, with the habit of honeysuckle.

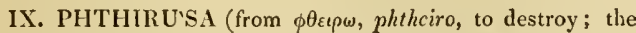
species destroy the trees on which they grow), Mart. in D. C. prod. 4. p. 672. Loránthus, sect. Clandestini, D. C. prod. 4. p. 287.

Lin. syst. Tetrándria, Monogýnia. Flowers hermaphrodite, 1-parted, furnished with 3 jagged bracteas each, some of them crowded in the axils of the leaves. Anthers fixed by the back, ovate. Styles short; stigma capitate. Berry ovate. Flowers small, axillary, sessile, or in axillary racemes.

1 P. CLANDESTiNa; glabrous; branches compressedly tetragonal while young; leaves opposite, obovate, coriaceous; flowers axillary, solitary, sessile, small; petals 4, concave; anthers ovate; berries oblong. $\quad$. P.S. Native of Brazil, in the province of Para, in woods. Loránthus clandestinus, Mart. in Schultes, syst. 7. p. 96. Flowers hardly half a line long. Bracteas suborbicular, jagged, one under each flower. Stamens shorter than the petals, but equal in length to the style. The anthers are said to be almost sessile.

Clandestine-flowered Phthirusa. Shrub par.

2 P.? salıcı́òlia; branches compressedly tetragonal above ; leaves opposite, lanceolate, acuminated, glaucous, coriaceous ; racemes solitary, axillary, 3 times shorter than the leaves; pedicels 3 -flowered, short, bearing 3 bracteas at the apex; petals 4 , linear-lanceolate; anthers roundish-ovate. h. P.S. Native of Brazil, in the province of Minas Geraes. Loranthus salicif òlius, Mart. in Schultes, syst. 7. p. 102. Flowers small, probably dioecious.

Willow-leaved Phthirusa. Shrub par.

3 P.? Lucarque'Nsis; plant glabrous, much branched; branches terete; leaves petiolate, roundish-elliptic, acute, rounded at the base, somewhat membranous, veiny, with the middle nerve rather prominent; racemes axillary and terminal, fewflowercd; flowers almost sessile, scattered, bractless; petals 4, oblong, rather concave; anthers unknown. h. P. S. Native of Peru, in temperate parts near Lucarque. Loránthus Lucarquênsis, H. B. et Kunth, nov. gen. amer. 3. p. 440. Schultes, syst. 7. p. 102. Leaves an inch long, and 9-10 lines broad; petioles 4-5 lines long. Racemes 3 lines long. Flowers minute, of a whitish yellow colour.

Lucarque Plithirusa. Shrub par.

Cult. The species of this genus do not possess any beauty, and are not cultivable in the gardens.

X. SCU'RRUIA (a diminutive of Scuira, a parasite; plants parasitical on trees). Loránthus, sect. iii. Scürrula, D. C. prod. 4. p. 301 .

Lin. syst. Tetra-Pentándria, Monogýnia. Flowers hermaphrodite. Petals 4-5, joined together into a long tube, which is divided at the apex into 4 or 5 short unilateral lobes, usually gibbous at the base, opening by a longitudinal fissure as in Lobelia. Stamens 4-5; filaments adhering a long way to the corolla, but free at the apex; anthers fixed by the base, seldom by the back, to the top of the filaments, oblong, erect. Style filiform or clavate; stigma capitate. Peduncles axillary, few-flowered, or racemose, having a solitary bractea under each flower, which is ustally pressed to the ovarium.

\section{\$ 1. Flowers tetrandrous. Corolla 4-parted.}

1 S. Roxвu'rghr ; branches terete, glabrous; leaves opposite, ovate, subcordate, whitc from soft down beneath; peduncles crowded in the axils of the leaves, very short, simple or branched, 1 or few-Howered; bractea adpressed to the ovarium, which is turbinate; alabastra cylindrical, 4-lobed at the apex, and having the tube cleft longitudinally. দ. P. S. Native of Malabar, and probably of China, if the synonyme of Limme does not appertain to S. Clinénsis. Lorânthus Scûrrula, Lin. spec. 47\%. Roxb. cor. 2. t. 140. Corolla of a rusty grey colour and mealy on the outside, but dark purple inside.

Roxburgh's Scurrula. Shrub par.

$2 \mathrm{~S}$. CuIne'nsis; branchlets and young leaves clothed with rusty villi : the rest glabrous; leaves opposite, ovate, on short petioles, coriaceous, obtuse, cuneated at the base; peduncles axillary, very short, bearing $2-5$ umbellate pedicellate flowers; bractea ovate, small, under the ovarium; limb of calyx truncate; corolla clavate, and curved in the bud, cleft longitudinally on one side; lobes of corolla 4, linear, short, reflexed. h. P. G. Native of China, where it was collected by Sir George Staunton. Loránthus Chinénsis, D. C. coll. mem. vi. t. 7.

Chinese Scurrula. Sturub par.

3 S. PULVERULE' NTA ; the younger parts of the plant are clothed with mealy stellate tomentum; branches terete; leaves opposite, petiolate, broad-ovate, acute, at length glabrous; racemes lateral, tomentose, in fascicles; flowers pedicellate; tube of corolla long, terete, curved, cleft at the apex into 4 short unilateral reflexed lobes. h. P. G. Native of Nipaut, on trees at Hetounra, and along the banks of the river Rapti. Loránthus pulveruléntus, Wall. in Roxb. fl. ind. 2. p. 221. Schultes, syst. 7. p. 99. Petioles an inch long. Leaves 5-7 inches long. Corolla more than an inch long, mealy outside. Berry large, club-shaped, mealy.

Pondered Scurrula. Shrub par.

4. S. FAscicula'ta; glabrous; branches terete; leaves opposite, or somewhat verticillate, obovate, veiny above, but veinless beneath, coriaceous; fascicles lateral, few-flowered; lobes of corolla 4, reflexed, secund; style longcr than the exserted stamens. $\quad$. P. S. Native of Java, near Linga Jattie, in the province of Cheribon, on trees. Loránthus fasciculàtus, Blum. bijdr. p. 661. Loránthus odoràtus, Blum. bijdr. p. 663. does not differ from this species according to the author.

Fascieled-flowered Scurrula. Shrub par.

5 S. FU'scA; glabrous; branches terete, rather angular in the young state; leaves opposite, on short petioles, obovate, and oval, acute at the base, coriaceous, beset with rusty dots beneath while young; peduncles axillary, 1-2-flowered; corolla cleft on one side, having 4 erect lobes. $h_{c}$. P. S. Native of Java, on Mounts Salak and Gede, on trees. Loránthus fuiscus, Blum. bijdr. p. 660. Genitals dark purple. Stigma capitate. See Blum. bat. verhandl. 1823. p. 190.

Fuscous Scurrula. Shrub par.

6 S. unвÉLlfEer; glabrons; branches terete; leaves opposite, oblong-lanceolate, on short petioles, acute at the base; peduncles in fascicles, axillary, and lateral, pubescent, 3-flowered, subumbellate; corolla very long, slender, cleft into 4 linear reflexed segments at the apex; stigma clavate. h.P. S. Native of Nipaul, on Mount Sheopore. Loránthus umbéllifer, Schultes, syst. 7. p. 97. Loránthus umbellàtus, Wall. in Roxb. Al. ind. 2. p. 222. but not of Roth. Corolla of a bright red colour, curved, pubescent. Peduncles clothed with ferruginous tomentum.

Umbel-bearing Scurrula. Shrub par.

7 S. cordifòis ; branches terete, villous, mealy while young; 
lcaves opposite, ovate-cordate, obtuse, villous on both surfaces, petiolate; racemes fascicled, villous, axillary; corolla tubular, clavate, villous, cleft at the apex into 4 short lanceolate lobes. そ. P. G. Native of the East Indies, at Shreenagur. Loránthus cordif ölus, Wall. in Roxb. f. ind. 2. p. 222. Schultes, syst. 7.p. 100. D. Don, prod. fl. nip. p. 148. New shoots, as well as all the tender parts of the plant, covered with pale or white stellate tomentum. Petioles an inch long. Corolla an inch long.

Cordate-leaved Scurrula. Shrub par.

8 S. BUDLEioides; branches terete, velvety when young; leaves usually opposite, ovate, on short petioles, glabrous above, and clothed with fine velvety down beneath; fascicles of flowers axillary, on short peduncles, hardly longer than the petioles; bracteas ovate, small, one under each flower; tube of corolla arched, clothed with rusty velvety down, cleft into 4 linear-cuneated unequal lobes. 5. P. S. Native of the East Indies. S. budleioides, Desr. in Lam. dict. 3. p. 600. Schultes, syst. 7. p. 97 .

Bulleia-like Scurrula. Shrub par.

9 S. BIFLòra; glabrous; branches terete; leaves petiolate, ovate-roundish, thickish; peduncles axillary, 1-2, bifid, a little shorter than the petioles; bractea ovate, girding the base of the ovarium; bud of corolla slender, somewhat clavate at the apex, arched, clothed with rufous velvety down. $\zeta$. P. S. Native of the East Indies, Loránthus biflòrus, Desr. in Lam. dict. 3. p. 600. Schultes, syst. 7. p. 119 . Corolla 4-lobed.

Tno-flonered Scurrula. Shrub par.

10 S. Philipé'nsis; branches terete, velvety from short down when young, as well as the peduncles, bracteas, calyxes, and corollas; leaves on short petioles, oval, rather pubescent, obtuse at both ends ; flowers few, in fascicles, axillary, on short pediccls; bractea ovate, concave, small, under the ovarium; limb of calyx truncate; corolla cylindrical, cleft into 4 linear nearly equal lobes at the apex; style filiform. h. P. S. Native of the Plilippine Islands. Loránthus Philippénsis, Cham. et Schlecht. in Linnæa. 3. p. 204. Leaves 3 inches long and an inch broad. Corolla 7-S lines long. Stigma small, capitate. Anthers linear, erect.

Philippine Scurrula. Shrub par.

11 S. vesti'ta; branches terete; branclulets, petioles, under side of leaves, peduncles, bracteas, and flowers, clothed with rusty, mealy, velvety, stellate tomentum; leaves oblong-lanceolate, acute, shining above, and glabrous; fascicles of flowers numerous, on short peduncles in the axils of the fallen leaves; bractca concave, small under the ovarium ; limb of calyx somewhat 4-toothed; corolla cylindrical, 4-cleft; lobes of corolla 4, linear, unilateral, reflexed. h. P. G. Native of Nipaul, on the mountains of Chandagiri and Sheopore. Loránthus vestìtus, Wall. in Roxb. fl. ind. 2. p. 218 . D. Don, prod. fl. nep. p. 143. Wall. pl. rar. asiat. 3. t. 280. Plant stout. Fascicles numerous, few-flowered, in the axils of the fallen leaves. $\mathrm{Co}$ rolla cylindrical, with a subglobular apex before expansion, afterwards its limb bursts into 4 limear reflexed segments. On the outside the flower is rust or cinnamon coloured, and within purple and smooth. Berry oblong, tomentose.

Clothed Scurrula. Slirub par.

12 S. I.EVIGA'TA; branclies terete, glabrous, when young compressed; leaves petiolate, opposite, elliptic-oblong, obtuse, glabrous, smooth; peduncles axillary, branched, 7-8-flowered, 4 times shorter than the leaves, and are, as well as the flowers, rather velvety from rusty down; bractea lateral, small; tube of corolla terete, cleft on one side: lobes 4 , oblong. h. P. S. Native of the East Indies, at Tavoy, in the Burmese Empire. Loránthus lavigàtus, Wall. mss. Flowerbud $7-8$ lines long, regular while young. Anthers erect. Stigma rather capitate.

Smootle Scurrula. Shrub par.
13 S. RUFídurA; branches terete, glabrous in the adult state, but when young angularly subcompressed; leaves opposite, petiolate, elliptic-oblong, acutish, glabrous, or clothed with rufous velvety down on the nerves beneath ; bractea lateral, small, concave; corolla with a terete tube, and 4 oblong lobes. h.P.S. Native of the East Indies, at Tavoy, in the Burmese Empire. Loránthus rigidulus, Wall. mss. This is hardly distinct from S. lavigàta .

Small-rufous Scurrula. Shrub par.

14. S. LEPIDòTA; branches terete, compressed while young, beset with velvety dots at first, but at length glabrous; leaves nearly opposite, oval, beset with rusty dots beneath; corolla 4cleft, curved, elongated, covered with rusty dots : lobes reflexed, unilateral. 々. P.S. Native of the western parts of Java, on the higher ranges of mountains. Loránthus lepidòtus, Blum. bijdr. p. 660. bat. verh. 1823. p. 192. but not of Schultes.

Lepidoted Scurrula. Shrub par.

15 S. RugulòsA; glabrous ; branchlets rather compressed, but at length terete; leaves opposite or alternate, on very short petioles, oblong-lanceolate, obtuse, glaucous, reticulately wrinkled, with smooth cartilaginous margins; racemes axillary, opposite, simple, shorter than the leaves; bracteas concave, one at the side of each ovarimm; corolla tubular, arched: limb of 4 lanceolate lobes. $\quad$. P. S. Native of the East Indies, Lorántlıus rugulosus, hoth, nov. spec. p. 194. Schultes, syst. 7. p. 101. Corolla nearly an inch and a half long.

Wrinkled-leaved scurrula. Shrub par.

J 6 S. conynitis ; leaves opposite, broad-lanceolate; flowers axillary, few, aggregate, tetrandrous ; corolla irregular, 4-cleft ; berry clavate. h.P.S. Native of the East lndies, in Silhet, parasitical on Averrhòa Carambòla. Loránthus corynitis, Spreng. cur. post. p. 140. Lorảntlıus clavàtus, Roxb. 月. ind. 2. p. 210. but not of Lam. The rest unknown.

Club-flowered Scurrula. Shrub par.

17 S. ? овоvA'тus; leaves nearly opposite, obovate, glabrous ; racemules crowded, axillary ; flowers tetrandrous ; tube of corolla elongated. $\quad$. P. S. Native of Java, about Linga Jattie, on trees. Lorántlıtıs obovàtıs, Blım. bijdr. p. 663.

Obovate-leaved Scurrula. Slirub par.

\section{$\S 2$. Floners pentandrous. Corolla 5-lobed. * Species natives of Africa.}

$18 \mathrm{~S}$. Thonningri ; branches terete, compressed at the apex; leaves petiolate, ovate, somewhat acuminated, coriaceous, glabrous and dark green above, somewhat canescent beneath from almost imperceptible down, as well as the branchlets; peduncles 1-3, axillary, short, bearing each $3-4$ umbellate flowers on short pedicels ; bracteas small, ovate, lateral, one under each pedicel; fruit ovate. h. P. S. Native of Guinea, where it was collected by Thonning. Loránthus Thonníngii, D. C. prod. 4. p. 303. Loránthus clavàtus, Thonn. mss. but not of Lain. Flowers unknown.

Thonning's Scurrula. Shrub par.

19 S. RUFE'ScENs; branches terete, rather compressed at the apex; young leaves, peduncles, and flowers clothed with rusty down; leaves petiolate, oval, obtuse at both ends, coriaceous ; peduncles 1-3 together, shorter than the petioles, bearing 2-31flowered pedicels; bracteas lateral, oblong, 1 under each pedicel; flower-bud pentagonal at the apex; fruit ovate. h.P.S. Native of Senegambia, near Nghianga, on trees. Loránthus ruféscens, D. C. prod. 4. p. 303 . Alabastra 3 lines long. Calyx truncately urccolate. Very nearly allied to $S$. Thonningii.

Rufescent Scurrula. Shrub par.

20 S. sEssiLifòlia ; glabrous ; branches terete, simple; leaves sessile, opposite, ovate-roundish, cordate at the base; flowers 
many in the axils, fascicled, sessile, deflexed; corolla tumid at the base, narrowed above, cleft longitudinally, hence it is expanded into a 5 -lobed ligula on one side. $\zeta$. P. S. Native of Africa, at Koto or Keta. Lorántlus sessilifòlius, Beauv, fl. d'ow. 2. p. 8. t. 23. Schultes, syst. 7. p. 108 . The anthers are lelineated in the figure versatile.

Sessile-leaved Scurrula. Shrub par.

21 S. BELvisII; glabrous; branches simple, terete; leaves on short petioles, nearly opposite and alternate, broad ovatelanceolate, acute; peduncles very short, axillary, numerous, fascicled, 1-flowered, deflexed; corolla tumid at the base, narrowed above, cleft laterally, expanded into a 5-lobed ligula at the apex; anthers somewhat versatile. $h$. P.S. Native of Africa, in the kingdom of Waree, at Chama or Sama. Loránthus Belvisii, D. C. prod. 4. p. 303 . Loránthus lanceolàtus, Beauv. fl. d'ow. 2. 1. 8.t. 64. Schultes, syst. 7. p. 108. but not of Ruiz et Pav.

Belvis's Scurrula. Shrub par.

$22 \mathrm{~S}$. PENTAgònia; glabrous; branches terete; leaves on short petioles, ovate or lanceolate, coriaceous, almost veinless, glancous; flowers 4.5 , in the axils of the leaves, sessile, crowded; bractea calyciform under the ovarium; corolla tumid at the base, and contracted under the middle, clavate, and pentagonal at the apex before expansion, but at length expanded into a 5 -lobed ligula; flaments inflexed; style tumid and pentagonal under the apex; stigma capitate. h. P.S. Native of Senegal, on trees. Loránthus pentagònia, D. C. coll. mem. vi. t. 8. This species is easily distinguished from the rest in the form of the style and flower-bud. It is very like $S$. Belvisii.

Pentagonal-flowered Scurrula. Shrub par.

23 S. DoDonexfòlia; glabrous; branclies terete; leaves on short petioles, elongated, oblong-linear, obtuse, attenuated at the base, thick and coriaceous, glaucous, almost nerveless; flowers 2-3 together, sessile, crowded ; bracteas cup-shaped, one under each ovarium; alabastra cylindrical; corolla tumid at the base, but somewhat constricted above, expanded into a 5 -lobed ligula at the apex; filaments inflexed; style tumid at the apex and pentagonal; stigma capitate. h.P.S. Native of Senegal, on the trunks of tamarind trees. Loránthus dodoneafòlius, D. C. coll. mem. vi. t. 9 . Allied to $S$. pentagònia.

Dodoncea-leaced Scurrula. Shrub par.

24. S. GLAU'CA; glabrous; branches terete; leaves alternate, opposite, and 3 in a whorl, oblong or ovate-oblong, obtuse, covered with a glaucous bloom; peduncles axillary, erect, bearing each 3 flowers at the apex, on short pedicels; corolla rather tumid at the base, constricted in the middle, and divided at the apex into 5 linear revolute lobes; anthers linear, erect. $\zeta . P$. $G$. Native of the Cape of Good Hope. Loránthus glaúcus, Thunb. fl. cap. p. 295. but not Ruiz et Pav. Schultes, syst. 7. p. 104. Moquínia rìbra, Spreng. ex Zeyl., in herb. Moricand. Habit almost of $S$. olecefolia, but differs in the anthers being long and linear, not oval, and in the stamens being free, not concrete.

l'ar. $\beta$, Burchéllii (D. C. prod. 4. p. 303.) leaves more remote and narrower, and less glaucous in the dried state. $\zeta . \mathrm{P}$. G. Native of the Cape of Good Hope. Burch. cat. pl. afr. austr. no. 2887.

Glaucous Scurrula. Shrub par.

25 S. OLEFFòlIA; branches terete; leaves opposite, oblong, silky, bluntish, feather-nerved; peduncles axillary, very short, bearing each 3 almost sessile flowers at the apex; corolla tumid at the base, and narrowed above, tubular, 5 -lobed : lobes short, deflexed; stamens monadelphous; anthers oblong, fixed by the base. h. P. G. Native of the Cape of Good Hope. Loránthus oleæfòlius, Cham. et Schlecht. in Linnæa. 3. p. 209. Lichtensteinia oleæfỏlia, Wendl. coll. 2. p. 4. t. 39 . Loránthus speciòsus, Dietr. Corolla red. Ovarium 1-celled; cell pentagonal, 1-seeded, ex Cham. et Schlecht. not 5-seeded.

\section{Olive-leaved Scurrula. Shrub par.}

$26 \mathrm{~S}$. CANE'scens; every part of the plant is cancscent; leaves oval, obtuse, small. $\eta$. P.S. Native of the Cape of Good Hope, in arid places on the branches of Lycium. Loránthus canéscens, Burch. cat. geogr. 1119. trav. afr. 2. p. 90.

Cancscent Scurrula. Slirub par.

27 S. CLAvA'TA; glabrous; branches terete; leaves opposite, on short petioles, oval, obtuse, coriaceous, almost veinless, rusty beneath; peduncles many, crowded, very short, in the axils of the leaves, dilated under the apex into a somewhat discoid bractea; limb of calyx 5-toothed; alabastra cylindrical, clavate; corolla at length cleft laterally, 5-lobed; style striately angular. h. P. S. Native of Madagascar. Lorántlus clavàtus, Lam. dict. 3. p. 598. but not of Roxb. Schultes, syst. 7. p. 106. Filaments of stamens adnate a long way to the corolla; anthers oblong, erect, terminal.

Clarate-flowered Scurrula. Shrub par.

\section{* Species nutives of Asia.}

$28 \mathrm{~S}$. HænкEA'va; glabrous; branches terete; leaves petiolate, lanceolate-oblong, obtuse or acuminated, coriaccous, obsoletely veined; peduncles from the forks of the branches erect, bearing 3 -flowered pedicels; bractcas ovate, concave, one under each ovarium; calyx pubescent, entire; corolla tubular, cleft laterally on one side : lobes 5, linear, reflexed. ᄃ.P. S. Native of the island of I,uzon. Loránthus Hænkeànus, Presl, in herb. Hænke, ex D. C. prod. 4. p. 304. Schultes, syst. 7. p. 113. Leaves 3-6 inches long, and $1 \frac{1}{2}$ to 2 inches broad, on petioles $8-10$ lines long. Corolla $3-4$ lines long, glabrous. Calyx reddish.

Hanke's Scurrula. Shrub par.

29 S. MALıғòLı; glabrous; branches terete; leaves ovate, acute, petiolate, coriaceous, obsoletely veined; peduncles axillary, solitary, reflexed, bearing a dense umbel of flowers; pedicels and calyxes clothed with rusty pubescence; limb of calyx nearly entire; corolla 5 -cleft beyond the middle, and somewhat laterally cleft; lobes linear, reflexed. h. P. S. Native of the island of Luzon. Loránthus malifòlius, Presl, in herb. Hæenke, ex D. C. prod. 4. p. 304. Schultes, syst. 7. p. 113. Perlıaps sufficiently distinct from $S$. Hacnkcàna.

Apple-leaved Scurrula. Shrub par.

30 S. Longrflòra; glabrous; leaves oval-oblong, obtuse, veiny, coriaceous : upper ones rather cordate at the base; racemes axillary, simple, short, subcorymbose; bracteas concave, one under each ovarium ; limb of calyx entire: corolla long, clavate, contracted beneath the limb: Jobes 5 , unequal, cuneated. $5 . P$. S. Native of Malabar and Pondicherry. Loránthus longiflòrus, Desr. in Lam. dict. 3. p. 498. Wall. in Roxb. fl. ind. 2. p. 217. Schultes, syst. 7. p. 112. Walli-lti-canni, Rheed. mal. 10. p. 5. t. 4. Flowers purple, curved, 20 lines long. Anthers linear, inserted by the base.

\section{Long flowered Scurrula. Slirub par.}

31 S. IncARnA'Ta; plant while young beset with deciduous stellate down; leaves alternate, on short petioles, broad-ovate, acute, nerved; racemes rising beneath the leaves, hoary from wool; flowers nearly sessile, each furnished with 1 bractea; limb of calyx 5 -toothed; tube of corolla gibbous at the base, but constricted a little above the base: linib 5-parted : lobes reflexed; stigma clavate. h. P.S. Native of the East Indies, in the island of Pulo Nias. Loránthus incarnàtus, Jack, in Roxb. $\mathrm{A}$. ind. 2. p. 213. Schultes, syst. 7. p. 111. Leaves 9 inches long. Corolla above 2 inclies long, slightly tomentose without, pale rosy, with a greenish limb; tube gibbous below, contracted a little above the base, then widening upwards till it suffers a 
second contraction before expansion into the limb, which is about a fourth the length of the tube, 5-parted, with reflexed segments. Berry mealy, ovate, 1 -seeded. This is a beautiful species.

Flesh-coloured-flowered Scurrula. Shrub par.

$92 \mathrm{~S}$. E'LEGANs; glabrous; branches terete; leaves opposite, or nearly alternate, oblong, obtuse, somewhat cuneated at the base, with undulated margins, almost veinless, coriaceous ; racemes axillary, short, twin or tern, erect, 5-7-flowered; corolla terete, somewliat incurved, 5 -loled: lobes linear, spreadingly reflexed, nearly equal; style exserted beyond the anthers. P. S. Native of the East Indies, near Yenangenn. Loránthus élegans, Wall. cat. no. 530 . Leaves 2 inches long, and 9 lines broad. Corolla glabrons, an inch and a half long, red. Anthers linear, erect. Calyx truncate. Bracteas lateral, small, one under each ovarium.

Elegant Seurrula. Shrub par.

33 S. CyLíndrica; glabrous; leaves alternate, petiolate, lanceolate, acute at both ends, smooth, nerved; racemes axillary, stiff, length of the leaves; flowers pedicellate, rather distant from each other, each girded at the base by a bractea on the outer side; limb of calyx almost entire; limb of corolla much longer than the tube, which is eylindrical, with reflexed segments. $?$. P. S. Native of Sumatra. Lorántbus cyĺndricus, Jack, in Roxb. fl. ind. 2. p. 213. Schultes, syst. 7. p. 110. D. C. prod. 4. p. 305. Leaves $4-5$ inches long; petioles about an inch long. Corolla red, perfectly cylindrical, before expansion, 5-petalled; limb reflexed, 3 times as long as the tube; petals linear, separating almost to the base. Ovarium cylindrical, 1-seeded. Flowers sometimes tetrandrous.

Cylindrieal-flowered Scurrula. Shrub par.

34. S. I'NDica; glabrous; branches terete; leaves nearly opposite, ovate-oblong, on short petioles, bluntish, feather-nerved; racemes axillary, or nearly terminal, solitary, simple, shorter than the leaves; flowers on short peduncles, each peduncle bearing 1-3 sessile flowers at the top, each flower propped by an ovate bractea ; petals 5 , linear, acute, luardly concrete at the base: the border reflexed; anthers linear, erect. $\eta$. P.S. Native of the island of Timor, and probably elsewhere in India. Loránthus I'ndicus, Desr. in Lam. dict. 3. p. 601. Schultes, syst. 7. p. 149. D. C. prod. 4. p. 305 . Lonicèra Zeylánica, Gærtn. fruct. 1. p. 137. t. 27.? Corolla purple, glabrous, 7-8 lines long. Leaves 3 inches long, 1 or $1 \frac{1}{2}$ broad, on petioles, which are 2.3 lines long. Berry ovate.

Indian Scurrula. Shrub par.

$35 \mathrm{~S}$. TUREINA'TA; glabrous; branches terete; leaves subalternate, on short petioles, oval or oblong, obtuse or acutish, thick; peduncles axillary, 2-3-cleft, much shorter than the leaves; bracteas ovate, one under each ovarium, which is turbinate; limb of ealyx unequally and bluntly 5 -toothed. $\zeta$. P.S. Native of the East Indies, on the Nelligherry mountains, where it is called Mandjil, along with other species, by the natives. Loránthus turbinàtus, D. C. prod. 4. p. 305 . Leaves 3 inches long, and i2-16 lines broad; petioles 3-6 lines long. Corolla unknown, and is only judged to belong to the present section of the genus in the calyx being said to be 5 -parted.

Turbinate-fruited Scurnla. Shrub par.

36 S. Bícolor; glabrous; leaves nearly opposite, on short petioles, from oral to lanceolate, thick, undulated, hardly veined; racemes axillary, simple, solitary, many flowered; bracteas concave, cordate, small, one adpressed to each ovarium on the outer side; calyx cup-shaped, with an entire border; corolla long, tubular, a little curved, swelling from the bottom to within a third of the mouth, then contracting a little, with a 5-parted border: upper fissure much the deepest ; lobes linear, reflexed towards one side; stigma clavate; berry oblong, smooth, 1-celled, 1-seeded. . P. S. Native of the East
Indies, frequent on trees. Loránthus bícolor, Roxb. cor. 2. p. 19. t. 139 . fl. ind. 2. p. 205. Schultes, syst. 7. p. 109 . D. C. prod. 4. p. 305 . Flowers the size and appearance, and much like those of a honeysuckle, red at the base, and grcen at the apex, nearly $1 \frac{1}{2}$ inch long. Anthers exserted, linear, fixed by the base. Leaves from $3-5$ inches long, and from $\frac{1}{2}$ to 1 inch in breadth.

Two-coloured-flowered Scurrula. Shrub par.

37 S. rALcA'TA; glabrous; branches terete; leaves opposite, on short petioles, linear, glaucous, coriaceous, obtuse, laterally falcate; racemes axillary, few-flowered ; bracteas short, one under each ovarium on one side; alabastra falcate, cylindrical, pentagonal at the apex: lobes of corolla 5 ; anthers linearoblong, inserted by the base. h. P. S. Native of Madras. Loranthus falcàtus, Lin. fil. suppl. 211. Schultes, syst. 7. p. 150. The flowers are fulvous according to Linnaus.

Falcate-flowered Scurrula. Shrub par.

38 S. venòsa; glabrous; branches terete; leaves subalternate or opposite, oval, attenuated at both ends, coriaceous, having the veins blood coloured beneath; racemes axillary, much shorter than the leaves, rather canescent ; limb of calys somewhat 5-toothed; tube of corolla more or less cleft on one side: lobes 5 , reflexed, unilateral; berries oblong-conical. h. P. S. Native of Java, at Buitenzorg, upon trees. Loránthus venòsus, Blum. bijdr. p. 668 . bat. verhandl. 1823. p. 188 . Corolla 4-5 lines long. Leaves variable in form. Style a little longer than the stamens; stigma capitate. Anthers linear, adnate. Blum. l. c.

Veiny Scurrula. Slırub par.

39 S. PENTA'NDRA (Lin. mant. p. 63.) glabrous; branclies terete; leaves alternate, on short petioles, oblong, bluntish, thickish; racemes axillary, solitary, few-flowered, and are, as well as the flowers, covered with velvety mealy down; bracteas ovate, one inder each ovarium; limb of calyx bluntly 5-toothed; bud of corolla cylindrical; petals 5 , linear. $h$. P.S. Native of Java, on trees. Loránthus pentándrus, Lin. mant. p. 63. Blum. bijdr. p. 661 . Schultes, syst. 7. p. 110 . D. C. prod. 4. p. 305. Leaves 4 inches long, and an inch broad. Corolla 7 lines long, purplish inside. Anthers erect.

I ar. F, flàvus (Blum. bijdr. p. 661. under Loránthus) racemes crowded; tube of corolla inflated. . P. S. Native of Java, on trees, about Buitenzorg.

Pentandrous Scurrula. Shrub par.

40 S. Amplexifòlia; glabrous; branches terete; leaves sessile, opposite, cordate at the base, orbicular, coriaceous, marginate; flowers racemose; bracteas rather concave, orbicular, one under each ovarium on one side; corolla cylindrical, contracted under the apex; lobes oblong. h. P. S. Native of the East Indies, on the Nelligherry mountains, where it was collected by Noton. Loránthus amplexifolius, D. C. prod. 4. p. 305. Loránthus amplexicaúlis, Wall. mss. but not of $\mathbf{K}$ unth. Corolla 15 lines long, of a brownish purple colour. Anthers linear, erect. Calyx truncate. Upper leaves 2 inches in diameter.

Clasping-leaved Scurrula. Shrub par.

41 S. MEtera'ntua; glabrous; branches terete, angular while young; leaves alternate, on short petioles, elliptic or lanceolate, somewhat attenuated at both ends, thick, and coriaceous; racemes axillary, length of the leaves; pedicels twice the length of the calyx ; bracteas convex, short, one under each ovarium on the outside ; bud of corolla nearly straiglt, somewhat pentagonal: with 5 linear lobes; anthers erect, linear, twice the lengtl of the filaments. 2. P. S. Native of the Last Indies, at Martaban. Loránthus heteránthus, Wall. cat. no. 537 . Leaves 4 inclies long, and 15-18 lines broad. Flowers 8-10 lines long. Calyx truncate. 
Variable-flowerel Scurrula. Shrub par.

42 S. PKÆLO'XGA; leaves alternate, oval, obtuse, tapering a little at the base, glabrous, of the consistence of parchment; racemes axillary; flowers sccund; tube of corolla very long, clavate, angular. $h_{c}$. P. S. Native of Java, near Tjiradjas. Loránthus prælóngus, Blum. bijdr. p. 664. Schultes, syst. 7. p. 112. Allied to $S$. clavata and S. longiftora. Tube of corolla yellow, nearly 3 inches long : lobes linear, clannelled inside, greenish.

Longest-flowered Scurrula. Shrub par.

43 S. cuRva'TA; leaves opposite or alternate, oblong, bluntish, acute at the base, coriaceous, rather veiny, glabrous; racemes axillary, solitary; tube of corolla elongated, curved: lobes reflexed. $\zeta$.P. S. Native of Java, on Mount Salak, parasitical on trees. Loránthus curvàtus, Blum. bijdr. p. 665. Sehultes, syst. 7. p. 110. 'Tube of corolla nearly $1 \frac{\pi}{2}$ inch long, yellow, but having the limb of a pale orange colour. Anthers adnate, elongated.

Curved-flowered Scurrula. Shrub par.

44 S. BRACTEA'TA; every part of the plant clothed with grey starry tomentum; branches terete; leaves small, alternate, obovate, cbtuse, tapering to the base, on rather long petioles; umbels axillary, 5 -flowered; bracteas ollong, tongue-shaped, one under each ovarium; corolla long, slender, cylindrical at the base, but wilening at the apex, with the throat contracted: lobes linear, unilateral, much shorter than the tube. h.P.S. Native of the East Indies. Loránthus bracteàtus, Heyne, in Roxb. fl. ind. 2. p. 220. Loránthus Heyneànus and $\mathrm{L}$. tomentòsus, Schultes, syst. 7. p. 105 and 106. Loránthus tomentosus, Roth, nov. spec. p. 191. Umbels densely villous; pedicels one-tlird of an inch long.

Bracteate Scurrula. Shrub par.

45 S. Goodenıæfòlı; branches terete, glabrous; leaves alternate, obovate-cuneated, obtuse, somewhat emarginate, tapering into the petioles at the base, rather veiny, glabrous in the adult state, but canescent in the young state from stellate deciduous down; peduncles axillary, 2-3-flowered; bracteas orate, acute, one under each ovarium; tube of calyx pubescent, with 5 rather ciliated teeth; corolla cylindrical, cleft on one side: lobes 5, linear, reflexed, unilateral; style filiform. 々. P. S. Native of the East Indies, on the Nelligherry mountains, where it is called Mandjil, and where it was collected by Lesclienault. Loránthus goodeniæ folius, D. C. prod. 4. p. 306 . Very nearly allied to $S$. lobelicefiora.

Goodenia-flomered Scurrula. Shrub par.

46 S. LOBELIfFLòra; glabrous; branches terete; leaves obovate-cuneated, obtuse, tapering into the pctioles, sparingly veined; pedicels 1-2, axillary, I-flowered, very short, spreading; bracteas ovate, acute, one under each ovarium; tube of calyx cylindrical, cleft on the inner side: lobes 5 , linear, reflexed, unilateral; style filiform. $h$. P. S. Native of the south of India, where it is called Ira-narum and pile-rivi by the natives, and where it was collected by Leschenault. Loránthus lobeliæflòrus, D. C. prod. 4. p. 306. Leaves an inch long, and 4 lines broad. Corolla an inch long, red in the dry state. Loránthus cuneàtus, Roth, nov. spec. p. 193.?

Lobelia-flonered Scurrula, Shrub par.

47 S. ELA'STICA ; glabrous; branches strong, columnar: internodes short; leaves sessile, thick, orate, acutish, obscurely 5-nerved; flowers almost sessile, in fascicles about the joints; tube of corolla cylindrical: having the limb beaked before expansion : segments linear, short, separating from the base upwards, revolute. $५$. P. S. Native of Malabar. Loránthus elasticus, Desr. in Lam. dict. 3. p. 599. Wall. in Roxb. f. ind. 2. p. 217. Schultes, syst. 7. p. 107. Behtta-Itti-cani, Rheed. mal. 10.p. 7. t. 3. The leaves are renrarkably thick, and appear both trinerved and triple-nerved.

voL. III.
Elastic-flowered Scurrula. Shrub par.

48 S. Reiniwardia'ina; leaves opposite, oblong, attenuated at both ends, coriaceous, veinless beneath; peduncles crowded, axillary, 1-flowered; tube of corolla very long, curved: lobes linear, unilateral, at length circinnately revolute. $h . P . S$. Native of Java, on the mountains. I,oránthus lieinwardtiànus, Schultes, syst. 7. p. 105. Lorántluts coccíneus, Reinw. in Blum. bijdr. p. 66\%. but not of Jack.

Reinnardi's Scurrula. Shrub par.

49 S. Konigia'vus; glabrous; leaves nearly opposite, on short petioles, elliptic, veiny; racemes axillary; pedicels deflexed; ealyx rather truncate; corolla 5 -cleft, clavate. h. P. S. Native of the East Indies. Loránthus Konigiànus, Agardh, in Schultes, syst. 7. p. 108.

Koenig's Scurrula. Shrub par.

Cult. The species of this gents are easily distinguished from the rest that are broken off from the old genus Loranthus in the tube of the corolla being curved, and bulged at the base on one side, as in Lobèlia, cleft longitudinally on the upper side, and the segments all leaning to the lower side, and reflexed. The plants have the habit of honeysuckle, but are not cultivable.

XI. ELYTRA'NTHE (from $\varepsilon \lambda \nu \tau \rho o v$, elytron, a case or sheath,

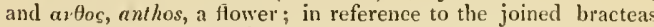
forming a slieath under the flower). Lepeostegères and Elytránthe species of Blum. in litt. 1829. Loranthus species of authors. Loránthus, sect. iii. Symphyánthus, $\S 1-3-4$ and 5 . D. C. prod. 4. p. $296 \longrightarrow 299$.

Lin. syst. Penta-Hexándria, Monogýnia. Flowers hermaphrodite, pentamerous or hexamerous. Petals 5.6, joined together into a tube to the middle, and therefore divided to the middle into a 5-6 cleft regular limb. Stamens 5-6: filaments arlnate to the petals at the base, and free at the apex; anthers fixed by the base, erect. Style filiform; stigma obtuse. Raccmes axillary: flowers bracteate. - This genus differs from Struthánthus in the corolla being gamopetalous, and from $D$ endrophthèe, to which it comes nearest, in the flowers being racemose, not corymbose, and in each flower being usually furnished with more bracteas than one, which are not cup-shaped nor oblique, as in that genus : it also diflers from Scrirrula in the limb of the corolla being regular, not as in that genus unilateral; and from Loxunthera in the anthers not being oscillatory.

\$ 1. Angulifturi (fiom angulus, an angle, and flos, a flower ; the flowers are more or less hexagonal from crests at the base). Flowers tubular, usually tumid at the base, and more or less hexagonal from crests, dividing into 6 lobes to the middle; anthers erect. Bracteoles 3, joined together under each flower.

1 E. RETu'sA ; glabrous; leaves opposite, on short petioles, obovate-oblong, coriaceous, retuse, or emarginate, with the lateral nerves indistinct; racemes short, usually solitary, rising from the axils of the fallen leaves; flowers pedicellate, each furnished with $1-2$ bracteas at the base; limb of calyx entire; tube of corolla clarate, gibbous, and angular, contracted at the limb: lobes 5-6, lanceolate, reflexed. h. P. 5. Native of the Island of Singapore. Loránthus retùsus, Jack, in Roxb. fl. ind. 2. p. 212. Schultes, syst. 7. p. 112. The plant fastens itself by long runners to trees. Leaves smootl, about 8 inches long. Margin of calyx entire. Tube of corolla clavate, gibbous, and angled above, rosy, suddenly contracted at the limb, which is yellowish green, having the lobes or segments shorter than the tube.

Retuse-leaved Elytranthe. Slırub par.

2 E. AMPULLA'CEA; glabrous; lcaves opposite, on sliort petioles, oblong, polished; racemes axillary, solitary or in pairs, much shorter than the leaves; flowers opposite, on short pedi3 I 
cels; bracteas ovate, one at the base of each pedicel, and 2 others pressing the base of the germ, like an inferior bilabiate calyx; limb of calyx entire, rotate ; corolla with a gibbous tube, and a 6 -cleft regular border, the divisions revolute, and rather spatulate; anthers ovate; style longer than the corolla: stigma large; berry long, oval. h. P.S. Native of the East Indies, in the forests of Silhet, but seems to prefer the Mango trees to all others. Loránthus ampullàceus, Roxb. H. ind. 2. p. 209. Sehultes, syst. 7. p. 149. Leaves 3-4 inches long, and rather less than 2 inches broal. Flowers pretty large, greenish yellow. Berry yellow, size of a currant.

Ampullaceous Elytranthe. Shrub par.

3 E. carinátula; glabrous; leaves opposite, petiolate, elliptic, somewhat acuminated; racemes spiked, 7 -flowered, 3 times longer than the petioles; bracteas 2 , subeoncrete under each flower; limb of calyx hardly any ; tube of corolla inflated, hexagonal: lobes 6 , oblong; style shorter than the corolla. $h$. P.S. Native of the East Indies, at Martaban, and at Cheppedon. Loránthus carinátulıs, Wall. mss. D. C. coll. mem. vi. t. 3. Very like E. ampullìcca.

Little-kecled EIytranthe. Shrub par.

4 E. viridifLòra; glabrous; primary branches somewhat verticillate, rather compressed while young ; leaves opposite, on short petioles, lanceolate, tapering at both ends; racemes axillary, and from the cieatrices of the fallen leaves, 2-3-together, sessile, one-third shorter than the leaves; pedicels 1 -flowered, remote; bracteas 3 , rather conerete under each ovarium; tube of corolla slightly ventricose, bluntly 6-cornered: having the limb divided regularly into 6 , rarely into 5 linear-clavate reflexed segments, which are nearly as long as the tube, their inside rugose, their extremity broadish, concave, acute. h. P.S. Native on trees in the forest of Gonkurrun, in the valley of Nipaul. Lorántluus viridiflòrus, Wall. in Rosb. fl. ind. 2. p. 219. Leaves smooth, about 3 inches long, rather conspicuously reticulated, less coriaceous than in most other species. Flowers green, rather remote, with the tube an inch and a half long. Filaments attached to the segments of the corolla, running down to their base. Style filiform; stigma rugose. Berry small, ovate.

Green-flowered Elytranthe. Shrub par.

5 E. SUBG Lobòsa ; glabrous; branches terete; leaves opposite, linear-oblong, on very short petioles, attenuated at both ends; peduncles axillary, simple, 4 times shorter than the leaves; bracteas trifid, or 3 conerete ones under each flower : tube of corolla inflated, ovate, hexagonal : the limb divided into 6 linearoblong ereet segments. h. P. S. Native of the East Indies, on the banks of the Irawaddy, parasitical on trees. Loránthus subglòbosus, D. C. prod. 4. p. 297 . Leaves 3 inclies long, and 8 lines broad. Corolla 8 lines long, and the tube 8 lines in diameter. Antliers erect. Stigma small, capitate.

Subglobose-flowered Elytranthe. Shrub par.

6 E. FA'LLENS; glabrous; branches terete, compressed while young ; leaves opposite, on short petioles, ovate, ending in a short blunt acumen, coriaceous, rather glaucous; racemes axillary, short, few-flowered; bracteas lateral, ovate, small, one unler each ovarium; flower-bud hexagonal at the base, having the tube at length broadly obconical: lobes 6 , reflexed from the

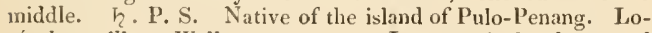
rántlus pállens, Wall. cat. no. 523. Leaves 3 inches long, and usually about 2 incles broad.

\section{Pale Elytranthe. Shrub par.}

7 E. oLEoines; glabrons; branches terete, when young rather compressed; leaves oblong, attenuated at both ends, opposite, on short petioles, stiff, rather glaucous; peduncles axillary, short, few-flowered ; flowers unknown ; bracteas lateral, roundish, one under each ovarium; berries ovate. $々 . l$ ?. S. Native of the island of Pulo-Penang. Loránthus oleoldes, D. C. prod. 4. p. 297. Lorânthus oleifòlius, Wall. mss. but not of Cham. et Schlecht. Allied to E. pállens, ex Wall.

Olive-like Elytranthe. Shrub par.

8 E. GLobòs ; plant glabrous, branched; leaves opposite, though sometimes alternate, and 3 in a whorl, oblong, coriaceous, smooth, almost veinless; racemes or spikes axillary, or between the leaves, or from the axils of the fallen leaves, generally solitary, but sometimes 2-3 together, much shorter than the leaves; flowers sessile, opposite, from 3-6 pairs on each spike; bracteas no other than the perianth of the fruit, but according to D. C. they are cordate; limb of calyx truncate; tube of corolla gibbous, 6 -sided : limb 6-parted: segments regular, reflexed ; berry round-oval, size of a pea. $\zeta$. P. S. Native of the East Indies, throughout Bengal on trees. Loránthus globòsus, Roxb. fl. ind. 2. p. 206. Leaves $2-3$ inches long. Flowers small, of a greenish orange colour. Perianth of the fruit inferior, 2-leaved, the under and exterior cordate, the inner bidentate: that of the flower no other than the circular margin of the pit, which receives the flower. Filaments inserted at the base of the segments of the corolla. Berry smooth, size of a pea, when ripe the pulp is yellow, clammy, and elastic.

Globose-flowered Elytranthe. Shrub par.

9 E. Foruòss; glabrous; branches terete; leaves nearly opposite, ovate-oblong, coriaceons, almost veinless; racemules crowded, lateral; tube of corolla very long, clavate, angular. h. P. S. Native of Java, upon trees on Mount Salak. Loránthus formòsus, Blum. bijdr. p. 664. Sehultes, syst. 7. p. 149 . Flowers scarlet, showy : segments of corolla revolute, somewhat secund, with dark purple margins. Anthers linear, adnate. Stigma obtuse. Corolla nearly 2 inches long. Perhaps a species of Scúrrula.

Shon'y Elytranthe. Shrub par.

10 E. SPHEROCA'RPA; glabrous; branches terete; leaves on short petioles, opposite, ovate-oblong, coriaceous, veinless beneath; racemes axillary, solitary or twin; flowers angular. $h$. P. S. Native of Java, about Buitenzorg, Batavia, Se. on trees, where it is called Mengando, as well as many other species, by the natives. Loránthus sphærocárpus, Blum. bijdr. p. 661. and bat. verhandI. 1823 . p. 189 . Schultes, syst. 7. p. 149. Tube of corolla angular : flower-bud 5 lines long.

Round-fruited Elytranthe. Slurub par.

11 E. PA'TULA ; glabrous; leaves opposite, petiolate, elliptic-ovate, coriaceous, smooth, acutish; panicles axillary, or rising beneath the leaves, shorter than the leaves; bracteas 2 or 3 , embracing the ovarium; limb of ealyx entire; tube of corolla acutely 6 -angled, equal in length to the segments of the limb, which are 6, narrow, and revolute. 5. P. S. Native of the interior of Bencoolen, on trees. Lorânthus pátulus, Jack, in Roxb. f1. ind. 2. 1. 214. Schultes, syst. 7. p. 135. Leaves about 3 inches long. Corolla green, tipped with light red, and with a purplish tinge towards the base: having the tube clavate and dilated upwards. Stigma capitate. Berry subglobose.

Syreading-panieled Elytranthe. Slurub par.

12 E. Cocunnchinénsis; glabrous, much branched; leaves opposite, ovate-lanceolate, acute; peduncles axillary, manyflowered, crowded, furnished with 3 conerete bracteas nnder each Hower; tube of corolla hexagronal, with 6 linear-lanceolate lobes, which burst clastically, and become revolute; stigma capitate; berries ovate. $々$. P. G. Native of Cochin-china, on trces in gardens. Lorânthus Cochinchinénsis, Lour. coch. p. 195. Flowers greenish yellow. Berry yellowish red.

Cochin-china Elytranthe. Slirub par.

13 E. AVE'Nrs; glabrous; branches terete; leaves opposite, narrow-lanceolate, coriaceous, glabrous, veinless: peduncles crowded, axillary, usually 2-flowered; flowers angular, hexan- 
drous. $h$. P.S. Native of Java, on Mounts Salak and Gede, Sc. Loránthus avènis, Bhum. bijdr. p. 663. and bat. verhandl. 1823. p. 191. Loránthus Blumeànus, Schultes, syst. 7. p. 119. V cinless-leaved Elytranthe. Shrub par.

14. E. tetragona; glabrous; branches tetragonal; leaves opposite, sessile, oval, acute or obtuse, of the consistence of parchment, glabrous; raccmes crowded, axillary; flowers angrular, hexandrous. h. P. S. Native of Java, on trees about Tjiradjas, in the province of Krawang. Loránthus tetragònus. Blum. bijdr. 663. Schultes, syst. 7.p. 149. Corolla 3 lines long. Tetragonal-branched Elytrinthe. Shrub par.

15 E. subunberra'ta; leaves opposite, oblong-lanceolate, long-acuminated, coriaceous, glabrous ; racemes crowded, axillary; ultimate pedicels subumbellate; flowers hexandrous. $h_{c}$. P.S. Native of Jasa, on trees near Tjiradjas, in the province of Krawang. Loránthus subumbellàtus, Blın. bijdr. p. 669. Schultes. syst. 7. p. 14s. Allied to E. spharocárpa, and is, as well as it, called Mengando by the natives of Java.

Subumbellate-flowered Elytranthe. Shrub par.

§ 2. Rigidiflòra (from rigidus, stiff, and flos, a flower; flowers stiff). Flowers pentandrous, tubular, clefi into 5 parts beyond the middle, having the lobes reflexed from the middle; tube obconical, hardly pentagonal. Anthers ercet. Bractcas one under each floner.

16 E. RI'GIDA; glabrous; branches terete, rather compressed when young; leaves opposite, petiolate, clliptic-lanceolate, acuminated; racemes axillary, simple, 7 -flowered; flowers on short pedicels; bracteas ovate, lateral, one under each ovarium; calyx repand, somewhat denticulated; tube of corolla ovate at the base: lobes linear-oblong, reflexed from the middle. $\zeta$. P. S. Native of the East Indies, at Amherst. Loranthus rígilus, Wall. cat. no. 531. Leaves 2-3 inches long, and 12-18 lines broad. Corolla 9 lines long, finely velvety, as well as ovarinm. Anthers linear. Flower-bud pentagonal at the apex.

Stiff Elytranthe. Shrub par.

17 E. FAnı⿰òsA ; glabrous; branches terete; leaves alternate, smooth, coriaceous, ovate, obtuse, on thick short petioles ; racemes in axillary fascicles, clothed with much mealy stellate whitish tomentum; tube of corolla ventricose, divided twothirds of its length into 5 linear semi-recurved segments; berry large, ovate, slightly tomentose. h. P. S. Native of the East Indies, at Singapore. Loránthus farinòsus, Desr. in Lam. dict. 3. p. 597. Wall. in Roxb. fl. ind. 2. p. 221. Schultes, syst. 7. p. 111. D. C. coll. mem. vi. t. 4. Leaves nearly as large as a hand, with unequal margins, having the nerves remote and a little elevated. Flowers of a bright red colour, densely clothed with stellate tomentum, which is easily rubbed off; they are about an inch long, having the tube wide.

Mealy Elytranthe. Shrub par.

\$3. Cupulati (from cupula, an acorn cup; in reference to the shape of the bractea, which surrounds the ovarium). Floners small; bud of corolla equal at the base, terete, but globose and pentagonal at the apex; limb of 5 equal regular lobes. Anthers ovate, truncate, inserted by the base, dchiscing laterally. Stigma capitate. Bracteas cup-shaped, one girding or surrounding each orarium.

18 E. cupula'ta; branches terete, somewhat compressed at the apex ; young petioles, leaves, peduncles, and flowers clothed with rusty down; leaves petiolate, ovate or oblong, acutish, coriaceous, more or less cordate at the base; peduncles very short, branched, umbellately many-flowered; bracteas cupshaped, one girding each ovarium. h.P. S. Native of Casamania, on the trunks of trees. Loránthus cupulàtus, D. C. prod. 4. p. 298. Flowers 2-3 lines long. Branches clothed with rusty villi. Leaves variable in size and form. Berry obovate-glotose. Lower part of the tube of the corolla cylindrical.

Cupular-bractead Elytranthe. Shrub par.

\$. Involucrati (the flowers are involucrated with bracteas). Flowers tubular, 5-6-cleft. Anthers ercet. Bractcas many, cronded, constituting an intolucrum around the flowers, which are subcapitate.

19 E. involucra'ta; glabrous; branches shining; leaves opposite, on short petioles, ovate-cordate, smooth ; umbels axillary, nearly sessile, much shorter than the leaves, 4-flowered, involucrated by 4 bracteas; bracteas ovate-Janceolate, smooth, entire; calyx villous, with a 5 -toothed border; tube of corolla villous, widening towards the mouth: limb regular, 5-parted, with linear-revolute segments; anthers oval; stigma 2-lobed. h. P. S. Native of the East Indies, on the eastern border of Bengal: parasitical on trees. Loránthus involucràtus, Roxb. fl. ind. 2. p. 209. Schultes, syst. 7. p. 106. Leaves 3-4 inches long. Flowers pentandrous. Stamens equalling the segments of the corolla, and inserted on them below the middle. Ovarium silky. Style rather longer than the corolla.

Iar. $\beta$, hebéclada (D. C. prod. 4. p. 298. under Loránthus) branchlets angular, velvety from pale rusty down. দ. P. S. Native of Silhet. Wall. in fl. ind. p. 209. Corolla 6 lines long, villous on the outside, not gibbous at the base; lobes 5 , equal. Anthers oval, inserted by the base.

Involucrate-flowered Elytranthe. Shrub par.

20 E. GEMMIFLòra; glabrous; branches tetragonal; leaves opposite, broad-ovate, or oval, obtuse, coriaceous ; buds (imbricated involucra) axillary, solitary, sessile, many-flowered. ${ }_{2}$. P.S. Native of Java, in woods on the mountains. Lorânthus gemmifòrus, Blum. bijdr. p. 665 . Schultes, syst. 7 . p. 159. Lepeostégeres gemmiflòrus, Blum. in litt. This species is called Menganlo by the Javanese. Flowers in capitate heads, sessile, densely crowded upon the dilated tops of the peduncles. Anthers subulatc, ex Blum. and the berries are pedicellate.

Bud-flowcred Elytranthe. Shrub par.

21 E. LoNiceroides; glabrous; leaves almost sessile, ovate to lanceolate, attenuated, obtuse, rounded at the base; peduncles opposite, longer than the pctioles, bearing each a head of a few sessile, hexandrous flowers, and each head supported by 4 broad-ovate, acute, concave bracteas; corollas long, tubular, slender, having the limb irregularly cleft into 5 cuneated spread-

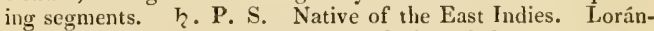
thus loniceroides, Lin. spec. 473. exclusive of the synonyme of Plukenet. Wall. in Roxb. fl. ind. 2. p. 216. Loránthus coriàceus and loniceroldes, Schultes, syst. 7. pp. 107 and 108. Loránthus coriàceus, Desr. in Lam. dict. 3. p. 597. The flowers, according to Wallich, are hexandrous, but according to Lamarck pentandrous. It is perhaps a species of Scurrula, on account of the irregular flowers.

Honey-suckle-like Elytranthe. Shrub par.

22 E.? unBeLLa'tus; leaves opposite, ovate-lanceolate; umbels axillary, opposite, on short peduncles, few-flowered; bracteas opposite, orbicular under each flower; limb of calyx truncate; corolla tubular: with 6 linear obtuse segments; anthers linear. 5. P. S. Native of the East Indies. Loránthus umbellàtus, Roth. nov. spec. p. 192. but not of Wall. Schultes, syst. 7. p. 158. Flowers deep purple, glabrous, coriaceous. Berry ovate.

Umbellate-flowered Elytranthe. Shrub par.

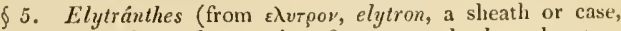
and av $\theta 0 s$, anthos, a flower; in reference to the large bracteas 312 
forming a sheath to the flowers). Flowers tubular, 6-cleft, hexandrous; lobes of limb lincar, acute. Flower-buds nearly terete. Anthers erect. Flowers scssile, and decussale along the rachis of the spikes, furnished cach with 3 bracteas, onc under the flower and two opposite lateral combined ones; all large, concave, and decidllous.

23 E. A'LEIDA (Blum, in litt. 1329.) glabrous; branches compressed; leaves opposite, oval-oblong, acute, coriaceous; spikes axillary, on short peduncles, sub-capitate, each bearing 4 decussate, tribracteate flowers. $h_{\text {. }}$ P. S. Native of Java, in wools on the mountains. Loranthus álbidus, Blum. bijdr. p. 665.

IThitish Elytranthe. Shrub par.

24 E. ? oвмuvìtus; branches terete, straight; leaves spatulately linear, thickened at the apex; peduncles nutant, somewhat secund. 々. P. S. Native of Brazil, on the banks of the Rio Grande. Loránthus obmunitus, Spreng. cur. port. 139. Each ovarium is supported by a cup-shaped bractea, or by 3 concrete ones.

Clothed Elytranthe. Shrub par.

Cull. Like the rest of the genera of the present order, the species are not cultivable. The plants have much the habit of Lonicèra.

XII. NOTAN'THE'RA (from $\nu^{\prime}$ tos, notos, the back, and av $\theta$ mo, anthera, an anther; the anthers are fixed by the back to the filaments; lience they are oscillatory). Loránthus, sect. iv. Notanthèra, exclusive of $\$ 1$. Tetrámera and $\$ 3$. Calântha, D. C. prod. 4. p. 307.-Loránthus species of authors.

Lin. syst. Pcnta-Ilexindria, Monogýnia. Flowers hermaphrodite. Petals $5-6-7-8$, but usually 6 , sometimes almost distinct to the base, and sometimes equally joined together at the base, linear or lanceolate. Stamens equal in number to the petals ; filaments adnate to the corolla at the base, but free at the apex; anthers fixed by the back, oscillatory or incunbent. Style filiform. Stigma clavate. Berries ovate.-Parasitical slırubs, natives of South America, except one from Asia. Peduncles coryubose or racemose; branchlets usually bearing 3 flowers and 3 bracteas; sometimes the pedicels are 1 -flowered, and with a bractea under each flower.

\$1. Pentúmerce (from $\pi \varepsilon v \tau \varepsilon$, pente, five, and $\mu \varepsilon \rho \iota$, meris, a part; the flowers are pentamerous or divided into 5 prarts). Flomers pentamerous and pentandrous, large, from 1.8 inches ling.

1 N. GRANDiflòrus; shrub glabrous, dependent; stems terete; leaves on short petioles, oval, thick; racemes terminal, subcorymbose, few-flowered; pedicels bearing each 1 flower and 1 bractea; bracteas ovate, concave, length of fruit; petals 5, linear, joined to the middle; anthers versatile. $h$. P. G. Native of Peru, parasitical on trees, where it is called Hatun Mccmá. Loránthus grandiflòrus, Ruiz, et Pav. fl. per. 3. p. 45. t. 273. f, a. Schultes, syst. 7.p. 115. Corolla very long. Berry blue, size of an olive.

Great-flomered Notanthera. Shrub par.

2 N. Losglbractea'tus; glabrous; branches terete; leaves scattered, lanceolate, or ovate-lanceolate, acute, sessile, coriaceous, veinless; spikes terminal; bracteas foliaceous, linearlanceolate; flowers adhering to the bracteas at the base; flowerbud clavate; petals 5 , linear; anthers versatile. h. P. G. Native of Peru. Loránthụs longibracteatus, Desr. in Lam. dict. 3. p. 599. Schultes, syst. 7. p. 117. Leaves 18-24 lines long, and 8-9 lines broad. Corolla $2 \frac{1}{2}$ inches long.

Long-bractead Notanthera. Shrub par.

3 N. verticilla'tus; branches terete, 3 in a whorl ; leaves also usually 3 in a whorl, lanceolate, nerveless, glaucons, usually secund ; flowers terminal, secund, crowded into heads; bracteas ovate, concave, 1 under each flower; petals 5 , joined at the base, spatulately-lanceolate and revolute at the apex; anthers oblong. . P. G. Native of Chili, upon trees and shrubs on the banks of the river Andalien. Lorántlus verticillàtus, Ruiz, et Pav. fl. per. 3. p. 47. Sclıultes, syst. 7. p. 117. Berry oval, blackish purple.

thorled Notanthera. Shrub par.

4 N. cæ'sıus; glabrous; branches terete; leaves on short petioles, ovate-lanceolate, or lanceolate, thickish, veinless; peduncles 1 -flowered, disposed in terminal racemes, bearing under each flower an oblong bractea, which is 3 times longer than the ovarium; petals 5 , joined to the middle, and spreading at the apex, linear; anthers incumbent. $々 . P . G$. Native of the Andes of Peru, upon trees. Loránthus ca'sius, Spreng syst. I. p. 132. Loránthus glaúcus, Ruiz, et Pav. fl. per. 3. p. 45. t. 275 . f. b. H. B. et Kunth, nov. gen. amer. 3. p. 438. but not of Thunb. Loránthus corymbòsus, Dietr. gart. lex. 4. p. 468. Schultes, syst. 7. p. 115. Leaves an inch or more long, and half an incls broad; petioles 2 lines long. Flowers an inch long, red at base and apex, but yellow in the middle. Berry oval, dark purple. This species is nearly allied to $N$. longebracteàtus.

Grey Notanthera. Shrub par.

5 N. Poeppígir ; glabrous ; branches terete, rather glancous; leaves opposite, on short petioles, lanceolate, thickish, veinless; peduncles 1-flowered, disposed in a terminal raceme, bearing an ovate, acute bractea under each flower, which is one-lialf shorter than the ovarium; limb of calyx truncate; petals 5 , joined together a little beyond the middle; anthers fixed by the back to the filaments. $h$. P. G. Native of Chili, where it was collected by Poeppig. Leaves an inch long. Flowers 2 inches long.

Poeppig's Notantliera. Shrub par.

6 N. Sternbergia'vus; glabrous; branches terete; leaves ovate or oval, obtuse, coriaceous, veinless above; peduncles many, short, 1-flowered, crowded, corymbose, rising from the axils of the upper leaves and the tops of the branches: bracteas ovate, one under each ovarium, and shorter than it; petals 5 , linear, hardly concrete at the base; anthers versatile. h. P. G. Native of Chili, near La Guardia, and Aconcagua, and on the Cordillera of Chili, Loránthus Sternbergiànus, Scluultes, fil. in herb. Hænke, and syst. 7. p. 116. Loránthus glaúcus, Gill, but not of Ruiz and Pav. nor Thunb. Leaves 12-15 lines long, and 8-10 broad; petioles $1 \frac{\mathrm{t}}{2}$ line long. Allied to $N$. ce'sius, but differs in the bracteas being one half shorter than the ovaries, not 3 times longer.

Sternberg's Notanthera. Shrub par.

7 N.? PónLı; glabrous; branches terete; leaves oval, obtuse at both ends, on short petioles, thick, coriaceous, glaucous; the middle nerve hardly distinct at the base, the rest of it obsolete; peduncles axillary, solitary, shorter than the leaves, opposite, dichotomously corymbose, few-flowered; petals 5 , liuear, thick, alnost distinct, bearing each a ligula beneath the stamens; anthers versatile. h. P. S, Native of Brazil, where it was detected by Pohl. Loránthus glaúcus, Pohl. in litt. but not of others. Lorántluus Póhlii, D. C. prod. 4. p. 308 . Leaves 1215 inches long, and $8-9$ broad. Corolla an inch long. Bracteas small, very blunt, one under each flower. Perhaps a species of Psittacánthus.

Pohl's Notanthera. Slirub par.

§ 2. Micránthae (from $\mu$ koos, micros, small, and avtos, anthos, a flower; flowers of the species small). Flowers small, usually hexamerous or clixided into 6 parts, but in a very $f \mathrm{c} w$ they are divided into 4-5-7 parts, disposed in racemes; the branches of the raceme usually bearing 3 flomers and 3 bracteas cach.specics all natives of America. 


\section{* Racemes axillary.}

$8 \mathrm{~N}$. SARMExTòsus; glabrous, ratlier scandent, hence the branches throw out roots on one side; branches angular; leaves petiolate, oblong-lanceolate, acute, somewhat complicate and keeled: having the middle nerve rather prominent; racemes axillary, about equal in length to the leaves: having their branchlets short and angular, and bearing 3 bracteas and 3 sessile flowers each at the apex; petals 6 , linear-spatulate; anthers ovate, incumbent. $\zeta$. P. G. Native of Peru, at Munna: parasitical on trees. Lorántlıus sarmentòsus, Ruiz et Pav. $\mathrm{f}$. per. 3. p. 49. t. 278. f. a. Schultes, syst, 7. p. 145. Corolla yellowish, $3-4$ lines long. Berry oblong, greyish. Leaves $1 \frac{1}{2}$ inch long, and an inch broad; petioles 2 lines long.

Sarmentose Notanthera. Shrub par.

$9 \mathrm{~N}$. Acunisa'tus; glabrous; branches angular, somewhat sarmentose; leaves petiolate, remote, ovate, long-acuminated ; racemes axillary, one half shorter than the leaves: having the hranchlets bracliate, and bearing each 3 ovate, concave, acute bracteas, and 3 sessile flowers; petals 6, linear; anthers ovate. h.P. G. Native of the Andes of Peru, in groves. Loránthus acuminàtus, Ruiz et Pav. fl. per. 3. p. 49. Schultes, syst. 7. p. 144. Very nearly allied to $N$. sarmentòsus, but differs in the leaves being flat, in the stigma being peltate, and the berries being brownish yellow.

Acuminated-leaved Notanthera, Shrub par.

\section{* Racemes terminal and axillary.}

10 N. Sellowtinus; glabrous; branches tetragonally terete, radicant ; leaves obovate, retuse, or emarginate, ending in a recurved mucrone, cartilaginous, feather-nerved, tapering into the short petioles; racemes axillary and terminal, naked, shorter than the leaves: having the branchlets bearing 3 flowers and 3 bracteas; limb of calyx lax; corolla 6-parted: with linear lobes; anthers versatile. $々$. P. S. Native of Brazil. Loránthus Sellowiànus, D. C. prod. 4. p. 312. Loránthus retùsus, Cham. et Schlecht. in Linnæa. 3. p. 215. but not of Jack. Leaves 20 lines long, and 15-16 lines broad; petioles 4 lines long. Corolla 3 lines long. Stigma thickish.

\section{Sello's Notanthera. Shrub par.}

11 N. RADi'cans; glabrous; branches terete, elongated, radicant ; leaves ovate, oblong, or lanceolate, acuminated, ending in a subulate point, feather-veined, with cartilaginous margins, running down the petioles at the base ; spikes axillary and terminal ; flowers and bracteas by threes; corolla 6-parted, with linear lobes; anthers versatile. h. P. S. Native of Brazil. Loránthus radicans, Cham. et Schlecht. in Linnæa. 3. p. 207. Leaves 5 inches long and $1 \frac{1}{2}$ broad; petioles hardly 5 lines long. Corolla 3 lines long. Flowers disposed in something like whorls of fives.

Rooting Notanthera. Slurub par.

$12 \mathrm{~N}$. Buxı́òııus; branchlets rather angular, and rather hispid from stiff short hairs; branches terete, and are as well as the petioles and leaves glabrous; leaves oval, coriaceous; racemes terminal and axillary, erect; pedicels bearing each 3 flowers and 3 bracteas; corolla tubular, 4-5-6-parted: having the lobes dilated and concave at the apex; anthers versatile. h. P. G. Native of Chili, near Talcahuano: parasitical on various trees. Loránthus buxif òlius, Cham. et Schlecht. in Linnæa. 3. p. 207. Lorảnthus Eschscholziànus, Mart. in Schultes, syst. 7. p. 117. Leaves rough in the young state. Bracteas fringed at the apex. The root, according to Chamisso, creeps under the bark of the trees on which the plant grows. Style acute at the apex. Corolla 3-4 lines long. 'This comes very near to $N$. heteropliyllus; and appears only to difler in the branches being covered with short rigid hairs.
Box-leaved Notanthera. Shrub par.

13 N. neteropir'tuds; branches terete, slender, scabrous, rusty; leaves scattered, on short petioles, cordate or oval, mucronate, coriaceous, glabrous; racemes terminal and axillary, angular; pedicels short, bearing each 3 bracteas and 3 flowers ; the : lateral flowers stalked: and the middle one sessile; bracteas sınall; petals 6 , linear-spatulate; anthers incumbent. $h$. P. G. Native of Chili : parasitical upon trees, especially myrtaceous trees. Loránthus heterophýllus, Ruiz et Pav. A. per. 3. p. 48. t. 273. f. b. Scliultes, syst. 7. p. I35. The old branches are smooth: the younger ones are angled, glabrous, or sometimes roughish from minute rust-coloured tubercles. Petals 4-5, concave, and dilated at the apex. Leaves 6-12 lines long, and 4-9 lines broad: petioles 2 lines long. Corolla purplish white, 4i-5 lines long.

Variable-leaved Notanthera. Shrub par.

14 N. ELLípticus; glabrous; branches terete, slender, angular; leaves petiolate, elliptic, somewhat acuminated, thickcoriaceous, veinless, shining above; peduncles axillary and terminal, racemose; pedicels short, bearing each 3 bracteas and 3 sessile flowers at the apex; petals 7 , linear-spatulate, joined together to the middle; anthers versatile. $\Gamma_{2}$. P. S. Native of Peru, in groves, in high frigid places on the Andes near Pozuzo. Loránthus ellípticus, Ruiz et Pav. A. per. 3. p. 4.7. t. 276. f. a. Schultes, syst. 7. p. 159. Leaves an inch long, and half an inch broad; petioles 2 lines long. Corolla yellow, 4. lines long. Perhaps a species of Gaiadéndron.

Elliptic-leaved Notanthera. Shrub par.

I5 N. Ligustrifòliús; glabrous; branches terete; leares oblong-lanceolate, acuminated, coriaceous ; corymbs axillary and terminal, one half shorter than the leaves, solitary; pedicels crowded, bractless, bearing 2-3 flowers ; petals 6 , linear, somewhat dilated and concave at the apex; anthers ovate, versatile. h. P. G. Native of Peru, or Chili, where it was collected by Hænke. Loránthus ligustrif òlius, Schnltes, fil. in herb. Hænke, and in syst. 7. p. 135. Loránthus ligustrìnus, Willd. herb. ex Schultes, but not of Wall. Leaves 2 inches long, and 9-10 lines broad; petioles 2 lines long. Corolla 4-5 lines long, black in the dried state.

Privet-leaced Notantlera. Shrub par.

16 N. VE'GETUS; glabrous; branches scandent, terete ; leaves elliptic-oblong, obovate, rounded at the apex, thick-coriaceous, glaucescent, ou short petioles; racemes axillary, solitary ; pedicels short, bractless, bearing each 3 sessile flowers at the apex, drooping in the fructiferous state. $h$. l'. G. Native of Mexico, near Cuernavaca. Iorainthus végetus, D. C. prod. 4. p. 313. H. B. et Kunth, nov, gen. amer. 3. p. 434 . Leaves 2 inches long, and 10-12 lines broad. Flowers unknown. Berries ovate-oblong.

Lively Notantliera. Shrub par.

17 N. orbicura'ks; glabrous; branches tetragonal ; leaves petiolate, orbicular, acutish, thick-coriaceous, obsoletely reined; racemes axillary, solitary; perlicels short, bearing each 3 sessile flowers at the apex; petals 6 , glabrous; anthers ovate. 々.P. S. Native of Quito, near Guayaquil, on trees. Loránthus orbiculàris, H. B. et Kunth, nov. gen. amer. 3. p. 434. Schultes, syst. 7. p. 143. Leaves 18 lines long and 16-17 broad; petioles 3-4 lines long. Flowers 4 lines long, green on the outside, and white on the inside.

Orbicular-leaved Notanthera. Shrub par.

18 N. salicifòlius; plant glabrous, pruinose? branches terete, compressed at the nodi; leaves oblong-lanceolate, acuminated, marginate, petiolate; racemes axillary, solitary or twin, erect, sessile; pedicels very short, bearing each 3 flowers and 3 bracteas; corolla 4-parted, with linear lobes, which are shellformed at the apex; anthers versatile; stigma capitate. Һ. P.S. 
Native of Brazil. Loránthus salicif òlius, Cham. et Schlecht. in Linnæa. 3. p. 216 . Leaves $4 \frac{1}{2}$ inches long and $\frac{1}{2}$ inch broad; petioles 6 lines long. Flowers a line long.

IVillon-leaved Notanthera. Shrub par.

19 N. LANceola'tus; glabrous; branches terete, slender, rather angular; leaves on short petioles, lanceolate-oblong; peduncles racemose, axillary, and terminal; pedicels short, bearing each 3 bracteas and 3 sessile flowers at the apex; petals $7-9$, linear-spatulate, joined at the base; anthers incumbent. Ћ.. P. G. Native of Peru, on the Andes at Pillao. Loránthus lanceolàtus, Ruiz et Pav. fl. per. 3. p. 47. t. 278. f. b. but not of Beauv. Loránthus lancifólius, Poir. ex Schultes, syst. 7 . p. 142. Leaves 2 inclies long and an inch broad; petioles $2-3$ lines long. Corolla yellow, half an inch long. Berries oblong. Lanccolate-leaved Notanthera. Shrub par.

20 N. oxypur'Llus; glabrous; branches terete, but somewhat compressed at the apex; leaves lanceolate-oblong, tapering into the petioles at the base, and much acuminated at the apex, feather-nerved: having the middle nerve rather prominent; racemes axillary, solitary, shorter than the leaves; pedicels opposite, bearing each 3 bracteas and 3 sessile flowers at the apex; petals 6 , linear, acute, hardly joined together at the base, longer than the filaments; antluers ovate, erect, incumbent. ?. P. S. Native of Brazil, where it was collected by Pohl. Loránthus oxyphýllus, Pohl. ex D.C. prod. 4. p. 314 . Loránthus acuminàtus, Pohl. in litt. Leaves 2 inches long. Flowerbud sub-clavate. Style thickish; stigma truncate.

Sharp-lcaved Notanthera. Slurub par.

21 N. SUAVE'olens; glabrous; branches terete; leaves petiolate, ovate-oblong, acuminated, rounded at the base, coriaceous; racemes $2-4$ together; pedicels short, approximate, bractless, bearing each 3 stalked flowers at the apex; petals 6 , linear, spreading; anthers incumbent. $h$. P. S. Native of Peru, in groves near Gonzanama. Loránthus suavèolens, H. B. et Kunth, nov. gen. amer. 3. p. 435 . Schultes, syst. 7. p. 143. Leaves 26-27 lines long and an inch broad; petioles 2-3 lines long. Flowers 3 lines long, white, glabrous.

Sncet-scented Notanthera. Shrub par.

22 N. conduplica'tus; glabrous; branches tetragonal ; leaves petiolate, ovate, acuminated, acute at the base, rather coriaceous, conduplicately recurved; panicle terminal, much branched, leafy: having the branches twin, and are as well as the rachis tetragonal; pedicels very short, bearing 3 flowers and 3 bracteas at the apex; petals 6 , linear. $h$. P. S. Native of Cumana and Cumanocoa, on trees. Loránthus conduplicàtus, $H$. B. et Kunth, nov. gen. amer. 3. p. 441. Lorántlus ánceps, Will. rel. in Schultes, syst. 7. p. 131. Leaves 24-27 lines long, and 14-17 lines broad: petioles 4-5 lines long. Flowers hardly 2 lines long.

Conduplieate-leaved Notanthera. Shrub par.

23 N. attenua'tus; plant glabrous, twining; branches terete; leaves rather alternate, obovate-oblong, cuneated at the base, and tapering into the petioles, and mucronate at the apex; mucrone deciduous; racemes axillary, twin or tern, sloorter than the leaves: pedicels short, bearing each $2-3$ bracteas and $2-3$ sessile flowers at the apex; petals 6 , linear, hardly connected at the base, longer than the filaments; anthers ovate-roundish, fixed by the base. Ћ. P. S. Native of Brazil. Lorántluus attenuàtus, Pohl. in litt. ex D. C. prod. 4. p. 315 . Leaves 12-15 lines long and 6-7 broad. Corolla $1 \frac{1}{2}$ line long. Stigma not capitate.

Atteniated-leaved Notanthera. Shrub par.

24. N. A'NCEPs; glabrous; branches terete; branchlets and peduncles compressed and 2-edged; leaves alternate or opposite, oblong-elliptic, petiolate, ending in very sliort mucrones, feather-nerved; racemes axillary, solitary, or twis, and terminal, subcorymbose, unequal ; pedicels short, bearing each 3 bracteas and 3 sessile flowers at the apex; anthers ovate, erect. $\supsetneq$.P.S. Native of Brazil, where it was detected by Polll. Loránthus ánceps, D. C. prod. 4. p. 315 . Loránthus oblóngo-ellípticus, Polil. in litt. Leaves an inch long and $5-6$ lines broad; petioles 3 lines long. Corolla 2 lines long. Allied to Loránthus pancifòlius.

Two-edged-branclıed Notanthera. Shrub par.

$25 \mathrm{~N}$. ova'tus; glabrous; branches unknown; leaves ovate, acute, somewhat acuminated, petiolate, coriaccous: having the middle nerve rather prominent, and the lateral ones hardly conspicuous; racemes a little shorter than the leaves; pedicels short, bearing 3 bracteas and 3 sessile flowers at the apex; petals 6 , linear, distinct, acutish, a little longer than the filaments; anthers erect, fixed by the base. Ћ. P. S. Native of Brazil. Loránthus ovàtus, Polıl. in litt. ex D.C. prod. 4. p. 315 . Leaves $2 \frac{1}{2}$ inches long and $1 \frac{1}{2}$ broad; petioles 2.3 lines long. Branchlets racemose, 2 lines long. Ovarium glancescent. Petals 2 lines long. Style thickish, equal at the apex. Perliaps this and the preceding belong to Struthánthus.

Ovate-leaved Notanthera. Shrub par.

Cult. The species are not cultivable, and have the habit of those of the other parasitical genera of the order.

XHI. LOXANTHERA (from $\lambda_{0} \xi_{0}$, loxos, oblique, and

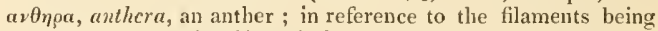
curved at the apex). Blum. in litt. Loránthus, sect. ij. Loxanthèra, D. C. prod. 4. p. 316.

Lin. sxsт. Hexándria, Monogýnia. Flowers hermaphrodite. Tube of corolla geniculated at the basc, but clavate, and rather oblique at the apex, with a 6 -lobed limb; lobes oblong, attenuated at the base, and somewhat spirally twisted. Filaments stiflly curved at the apex, not attenuated, but somewhat dilated; anthers inserted by the back. Style longer than the stamens. Stigma clavate.-Parasitical shrubs.

1 L. speciòs (Blum. in litt. 1829.) glabrous; leaves oblong, obtuse or bluntly acuminated, coriaceous, 1-nerved, veinless; peduncles axillary, few-flowered; tube of corolla elongated. $\zeta$. P. S. Native of Java, in woods. Loránthus loxanthèra, D. C. prod. 4. p. 316 . Bud of corolla 4 inches long, scarlet, but yellowish inside. Stigma blood-coloured.

Shon'y Loxanthera. Shrub par.

2 L.? spino'stris ; glabrous; branches terete, tetragonally compressed at the apex; leaves somewhat alternate, petiolate, oblong-lanceolate, coriaceous, having the middle nerve rather prominent, the rest veinless; racemes solitary or twin, axillary, shorter than the leaves; rachis angular; petals 6 , linear; anthers fixed by the back to the filaments; style spirally twisted. $h$. P.S. Native of Mexico, at Acapulco. Loránthus spiróstylis, D. C. prod. 4. p. 315 . Spiróstylis Hænkeàna, Presl, ex Schultes, syst. 7. p. 164. Flowers 2 lines long. This is perhaps a distinct genus, as it differs from all the others in the twisted style; and from the present in the filaments not being curved at the apex, and in the petals not being spirally twisted.

Screv-styled Loxanthera. Shrub par.

Cult. The species of this genus have the habit of the other parasitical genera of the order, and are not cultivable like them.

+ Plants referred to the old genus Lorínthus by authors, but the number of the parts of the floners and their structure bcing unknown, it is impossible to refor them to any of the genera broken off from that gemus; thercforc they must stand under the names origimally gic

1. I. Forule' N'Tus (Rich. act. soc. hist. nat. par. p. 107.) branclies opposite, spreading, quadrangular; leaves oblongovate, very blunt; peduncles solitary and sessile in all the axils. 
h. P. S. Native of Cayenne. Schultes, syst. 7. p. 157. The rest unknown.

Flowering Loranthus. Shrub par.

2 L. вRActea'tus (Rich. l. c.) leaves oblong, rather falcate, nerved; peduncles bifid; bractea terminal, cordate, 3-flowered. h.P.S. Native of Cayenne. Schultes, syst. 7. p.161. The rest unknown.

Bracteate-flowered Loranthus. Shrub par.

3 L. Terniflòus (Willd. rel. ex Sclıultes, syst. 7. p. 161.) branches terete; leaves oblong, petiolate, acute; racemes axillary; pednncles 8 -flowered. $h_{2}$. P. S. Native of Caraccas.

Thrce-flowered Loranthus. Shrub par.

4. L. Laurinus (Willd. rel. ex Schultes, syst. 7. p. 162.) leaves coriaceous, oblong, acute, tapering into the petioles; Howers terminal, aggregate. $h$. P. S. Native of South America.

Lourel-like Loranthus. Shrub par.

5 L. cardiphy' LuUs (Willd. rel. ex Schultes, syst. 7. p. 162.) leaves ovate-cordate, stem-clasping, obtuse; flowers terminal, spicately aggregate. h. P. S. Native of South America.

IIcart-lcaved Lorantlius. Shrub par.

6 L. tubucòsus (Willd. rel. ex Schultes, syst. 7. p. 162.) leaves lanceolate, acute; Howers tubular, somewhat spicate, terminal. h. P. S. Native of South America.

Tubular Loranthus. Shrub par.

7 L. GNeoror'des (Willd, rel. ex Schultes, syst. 7. p. 162.) leares lanceolate, attenuated at the base, obtuse, glaucous, much longer than the spikes; spikes axillary and terminal. $\zeta_{2}$. P. S. Native of Sonth America.

Gneorum-like Loranthus. Slırub par.

8 L. Multiflònus (Willd. rel. ex Schultes, syst. 7. p. 162.) leaves ovate, acuminated, longer than the racemes; racemes axillary; peduricles 3-flowered. 々. P. S. Native of South America.

Many-flowered Loranthus. Shrub par.

9 L. Alterna'tus (Willd. rel. ex Schultes, syst. 7. p. 162.) leares oblong, attenuately acuminated at the apex; flowers axillary and terminal, panicled. America.

Alicrnate-leaved Loranthus. Shrub par.

10 L. obvalda'tus (Schultes, syst. 7. p. 162.) leaves oblong, obtuse, coriaceous; flowers terminal, racemosely panicled; pedicels 3 -flowered; bracteas ovate, longer than the calyx. h. P. S. Native of South America. Loránthus bracteàtus, Willd. rel. but not of Roxb.

Environcd Loranthus. Shrub par.

11 L. macróstacurs (Willd. rel. ex Schultes, syst. 7. p. 162.) leaves elliptic-roundish, petiolate; racemes cymose, axillary, 4 times smaller than the leaves. h. P. S. Native of South America. The rest muknown.

Small-spiked Loranthus. Shrub par.

12 L. Macro'stachis (Willd, rel. ex Schultes, syst. 7. p. 162.) leaves oblong, attenuated at both ends, bluntish, coriaceous; spikes sessile, longer than the leares, verticillate. $h . P$. S. Native of South America. The rest unknown.

Long-spiked Loranthus. Shrub par.

13 L. membrana'ceus (Willd. rel. ex Schultes, syst. $7 . p$. 162.) leaves ovate, drawn ont at the apex, attenuated, membranous, nerved; flowers $t$ win, 2 inches long. $h_{2}$. P. S. Native of South America. The rest unknown.

Mcmbranous-leared Loranthus. Shrub par.

14 L. celtidifòlius (Willd. rel. ex Schultes, syst. 7. p. 161.) leaves ovate, oblique, glaucous beneath; peduncles axillary, aggregate. h. P. S. Native of Guinea. The rest unknown.

Celtis-lcaved Loranthus. Shrub par.

15 L. macula'tus (Blum. bijdr. p. 662.) leaves opposite or alternate, elliptic-oblong, obtuse, acute at the base, spotted with black, coriaceous, glabrous; flowers unknown. h.P.S. Native of Java, in the province of Bamtam.

Spottcd-leaved Loranthus. Shrub par.

16 L. eucalyptoìdes (D. C. prod. 4. p. 318.) glabrous; branches terete, dichotomous; leaves opposite, petiolate, lanceolate-linear, acutish, thick-coriaceous, almost veinless. h.P. G. Native of New Holland. L. encalyptifolius, Sieb. fl, nov. holl. no. 242. but not of Kunth. Leaves 3-4 inches long, and 6-7 lines broad. Petioles 6 lines long. Flowers and fruit unknown. Schnltes, syst. 7.p. 163.

Eucalyptus-like Loranthus. Shrub par.

17 L. Hoffuanseggia'vus (Willd. in Schultes, syst. 7. p. 113.) leaves ovate-oblong, acute; racemes axillary, usually twin; flowers verticillate. $h$. P. S. Native of Brazil, at Para. Lor. verticillàtus, Hoffimansegg in herb. Willd. Flowers pentandrous.

Hoffmansegg's Loranthus. Shrub par.

\section{++ Species only linown by name.}

1 L. acàcia-Nilólice, Oudh. in Brown, append. $2.2 \mathrm{~L}$. calycinus, R. Brown, in Salt, abyss. 3 L. congéslus, R. Br. l. c. 4. L. le'tus, R. Br. l. c. 5 L. serrulàtus, Roxb. ex Stend.

N. B. Asclèpias lactifcra, Burm. A. ind. p. 61. is a species of Loránthus not known.

\section{Tribe II.-Terrestrial shrubs.}

XIII. $a$ GAIADE'NDRON (from yaı, gaia, the earth, and $\delta \varepsilon v \delta \rho o v$, dendron, a tree; these trees grow in eartl and not parasitical, like other genera broken off from Loránthus). Lorántlus species of authors.

Lin. syst. Hexa-Octándria, Monogýnia. Calyx 6-8-toothed. Petals 6-8, narrow, sometimes free and sometimes joined at the base. Stamens 6-8, inserted in the petals. Style filiform; stigma simple. Ovarium oblong-cylindrical.-'Terrestrial trees, with obovate leaves and racemes of yellow flowers.

1 G. evgenioìns; arboreous; branches terete; leaves ovate-oblong, acuminated, running down the petioles at the base, rather coriaceous; racemes axillary and terminal, solitary or twin ; pedicels short, approximate, 3 -flowered, bractless ; flowers pedicellate; corolla 5-6-parted; lobes linear-acute; anthers incumbent. 3. G. Native of Peru, on the Andes, near Guamcabamba; and of Brazil. Loránthus eugenioìdes, H. B. et Kunth, nov. gen. amer. 3. p. 435. Schultes, syst. 7. p. 135. Cham. et Schlecht. in Linnæa. 3. p. $21 \%$ Loránthus attenuàtus, Willd. herb. but not of Pohl. Flowers about half an inch long, white, sweet-scented. Racemes $1 \frac{1}{3}$ to 3 inches long.

Eugenia-like Gaiadendron. Tree 15 to 20 feet.

2 G. TA'GUA; arboreous; branches terete; leaves oblong, acute, running down the petioles at the base, coriaceous, shining above and dotted beneath; racemes axillary, solitary; pedicels short, usually 3 together, approximate, bearing eacli 3 bracteas and 3 flowers; flowers on short pedicels; petals 7, spreading, linear, acute. 々. G. Native about Santa Fe de Bogota. Loránthus Tàgua, H. B. et Kunth, nov. gen. amer. 3. p. 436. Schultes, syst. 7. p. I59. Loránthus arbòreus, Mutis mss. Leaves $3 \frac{1}{2}$ incloes long, and 14-1 8 lines broad; petioles 6 lines long. Flowers 9 lines long. Berry ovate-oblong. Very like N. punctàtus.

Tagua Gaiadendron. Tree 15 to 20 feet.

3 G. LAURifòlium; arboreous ; glabrous; branchlets angu= lar; leaves elliptic-oblong, bluntish, running into thc petioles at the base, coriaceous, shining above; racemes axillary and solitary, terminal, and panicled; pedicels short, usually by threes, approximate, bearing each 3 bracteas and 3 sessile flowers; 
petals $7-8$, linear, rather dilated at the apex; anthers incumbent. そ. G. Native about Santa Fe de Bogota. Loránthus laurifòlius, H. B. et Kunth, nov, gen. amer. 3. p. 436. Schultes, syst. 7. p. 160. Leares $2 \frac{1}{2}-3$ inches long, and 12-15 lines broad; petioles 3 lines long. Flowers 9 lines long, glabrous.

Laurel-leaved Gaiadenclron. Tree 15 to 20 feet.

4. G. NíTiDum; arborcous, glabrous; branches terete; leaves petiolate, oblong, obtuse at both ends, coriaceous, shining above, veinless, having the middle nerve obsolete; corymbs terminal; peduncles bearing each $2-3$ flowers and 3 bracteas; flowers sessile; petals 8, linear; anthers incumbent. 々. G. Native of the Andes of Quito, in Paramo de Saraguru, in temperate parts. Loránthus nítidus, H. B. et Kunth, nov. gen. amer. 3. p. 437. Schultes, syst. 7. p. 160 . Leaves 2 inches long, and 10 lines broad; petioles 4 lines long. Flowers sweet-scented, about an inch long, yellow, glabrous. Berries ovate.

Shining-leaved Gaiadendron. Tree 15 to 20 feet.

5 G. Puracénse; arboreous, glabrous; brancles terete; leaves lanceolate-oblong, acutish, running into the petioles at the base, coriaceous, shining above, and beset with black spots beneatl; racemes terminal; peduncles short, 3-5-together, approximate, eacl bearing 3 bracteas, and from 1-3 flowers; petals 6-8, linear. $h$. G. Native on the Andes, about Popayan, in Paramo de Purace. Loránthus Puracénsis, H. B. et Kunth, nov. gen. amer. 3. p. 437 . Schultes, syst. 7. p. 160 . Leares 22-27 lincs long, and 9-10 broad: petioles 4 lines long. Racemes 4-6 inches long. Corolla yellow. Perliaps sufficiently distinct from $N$. 'T'àgua.

Purace Gaiadendron. Tree 10 to 15 feet.

6 G. PUNCTA'TUM; arboreous, glabrous; branches terete: leaves obovate or oval, somewhat attenuated at the base into the short petioles, coriaceous, beset with black dots beneath, having the middle nerve rather prominent ; racemes long, terminal, and from the axils of the superior leaves; peduncles somewhat verticillate, bearing each 3 bracteas and 3 sessile flowers at the apex; petals 6 , linear-spatulate; anthers incumbent, fixed by the back near the base to the filaments. h. G. Native of the Andes of Peru, in cold places in groves. Loránthus punctàtus, Ruiz et Pav. f. par. 3. 1. 47. t. 177. f. a. Presl, in herb. Hænke, Schultes, syst. 7. p. 134. Leaves 2 inches long, and 1 broad; petioles $2-3$ lines long. Corolla yellow, almost an inch long before expansion. Berry ovate-roundish, crowned by the limb of the calyx, which is truncate.

Dotted-leaved Notanthera, Tree par.

Cult. For culture and propagation see Nuytsia.

XIII. $b$ NUY'TSIA (named after Peter Nuyts, a celebrated Dutch navigator, and discoverer of that part of New Holland called Nuytsland). R. Br. in geogr. soc. trans. vol. 1.

Lin. syst. Hexándria, Monogýnia. Teeth of calyx 3-5, unequal. Petals 6-7, linear, distinct. Stamens 6-7, inserted towards the middle of the petals; anthers versatile, sub-hastate, 2 -celled. Ovarium turbinate, rather trigonal. Style subulate : stigma acute. Fruit 1 -seeded, covered by pulp or glutin, and of a different texture from the rest of the Loranthaceous genera. - A terrestrial tree, native of New Holland.

I N. FLORIBU'NDA; arboreous, glabrous; branches terete ; leaves alternate, linear, obtuse, thick ; racemes elongated, simple; peduncles longer than the flowers, bearing each 3 bracteas and 3 flowers at the apex. h. G. Native of New Holland, in Van Lewin's Land. Loránthus floribúndus, Labill. nov. holl. 1. p. 87. t. 113. Schultes, syst. 7. p. 133. Loránthus celastroides, Sieb. fl. nov, holl. exsic. no. 244. Leaves $2-3$ inches long, and 4-5 lines broad. Racemes 6-8 inches long, crowded at the tops of the branches. Corolla 9-10 lines long, sulphurcoloured.
Bundle-flowered Nuytsia. Clt. 1831. Tree 15 to 25 feet.

Cult. A mixture of sand, loam, and peat will be a good soil for this singular tree. Cuttings will probably root if planted in sand under a hand-glass.

XIV. SCHO'EPFIA (named after John Schœpf, a German botanist, who has written upon the plants in the neighbourhood of Ulm). Schreb. gen. no. 323. D. Don, prod. fl. nep. 145. Wall. in Roxb. fl. ind. 2. p. 188. D. C. coll, mem. vi.-Corlònium, Vahl, act. soc. hist. nat. hafn. 1. p. 206. t. 6.-Hæ'nkea, Ruiz et Pav. fl. per. 3. p. 8. but not of their prod.

Lin. syst. Pentándria, Monogýnia. Flowers hermaphrodite. Margin of calyx entire; tube adnate to the ovarium, very narrow, calyculate at the base. Corolla gamopetalous, tubular, with a 5-cleft limb, rarely with a 4-6 cleft limb; lobes valvate in astivation. Stamens equal in number to the lobes of the corolla, and situated in front of them, and having the filaments adnate to the tube ; antluers ovate or roundish, dehiscing laterally by a double chink. Style erect, truncate; stigma capitate or 3-lobed. Ovarium 3-celled, with a solitary ovulum in each cell. Drupe containing a 3-celled 3-seeded nucleus, or only 1 -seeded from abortion. Embryo minute, placed in the vertex of the albumen, which is amygdatine: with a turbinate radicle.Small smooth terrestrial trees. Leaves alternate, petiolate, entire, feather-nerved. Peduncles axillary, usually many flowered. -This genus comes near to Caprifoliacece from the gamopetalous corolla and 3-celled fruit; but differs from it, and agrees with Loranthacea, in the stamens being in front of the lobes of the corollit, and in the flowers being calyculate. It also agrees with the order Symplocinece in the 3-celled fruit.

* Tube of corolla ovate, with a naked throat.-American species.

1 S. ARBoréscens (Rœm. et Schultes, syst. 5. p. 160.) leaves ovate; peduncles axillary, usually twin, 1-3-flowered. $h_{2}$. S. Native of the islands of Santa Cruz, Montserrat, ex Rohr; and of Guadaloupe, ex Bertero; but in Rohr's specimen the leaves are obtuse, while in that of Vall's they are acuminated: they are therefore probably distinct species. Codònium arboréscens, Vahl. act. soc. hafin. 2. pt. 1. p. 206. t. 6. symb. bot. 3. p. 36. S. Schrebèri, Lam. ili. 2. p. 51. S. Americàna, Willd. spec. 1. p. 996. Flowers yellow.

Arborescent Schopfia. Tree 8 to 10 feet.

2 S. Flexuòsa (Roem. et Schultes, syst. 5. p. 160.) leaves ovate-lanceolate, acute; racemes axillary, solitary, 4-5-flowered; tube of corolla ovate: lobes acute: throat naked. h. G. Native of Peru, on the Andes, on the mountains at Pillao and St. Antonio de Playa Grande. Hæ'nkea flexuosa, Ruiz et Pav. fl. per. 3. p. 8. t. 231. Leaves $3-1$ inches long. Branches flexuous, diffuse. Corolla yellow.

Flexuous-branched Schopfia. Tree 10 to 12 feet.

* Tube of corolla tercte, having the throat furnished with fascicles of hairs at the origin of the stamens.-Species natives of Asia.

3 S. Fra'grans (Wall. in Roxb. fl. ind. 2, p. 188.) leaves lanceolate or elliptic-oblong, attenuated at both ends; racemes axillary, solitary, many-flowered; corolla infundibuliform, with a long cylindrical tube : segments of corolla lanceolate, acute. h. G. Native of Nipaul, in less elevated situations from Becheako as far as the valley, where it is rather common; it has also been found in more northern situations. Wall, tent. ff. nep. 1. p. 18. t. 9. D. Don, prod. fl. nep. 145. Symphoricárpos? orloràta, Ham, ex D. Don, l. c. Bark of tree thick and spongy, yellowish. Leaves deep green above. Flowers yellow, 
exquisitely fragrant, even after being dried, disposed in racemes, which are about half the length of the leaves. Ovarium supported by a calycitorm bractea like the rest of the species, which is divided into 2 or 3 unequal acute segments. Corolla rather fleshy; tube nearly an inch long. Drupe pale yellow, almost white, about the size of an olive, 1 -seeded from abortion. The perfume of the flowers is of a most delightful kind, and may be perceived on steeping them in warm water even long after they lave been dried.

Fragrant Schœpfia. Tree 10 to 15 feet.

4. S. Acumina'ta (IVall. cat. no. 486.) leaves ovate, acuminated, obtuse at the base; racemes axillary, many flowered; tube of corolla terete: lobes bluntish. h.G. Native of Nipaul, on the Pundua mountains. Flowers yellow?

Acuminated-leaved Schocpfia. 'Tree 10 to 12 feet.

Cult. A mixture of loam, peat, and sand will suit these trees; and young cuttings of them will be easily rooted if planted in sand, and placed under a hand-glass.

XV. $\Lambda U^{\prime} C U B A$ (the Japanese name of the shrub). Thunb. A. jap. p. 4. Lam. ill. t. 759 . D. C. prod. 4. p. 274.-Aúkuba, Kompf. amœen. 5. p. 775 .-Eubàsis, Salisb. prod. p. 68.

Lın. syst. Dioc̀cia, Tetrúndria. Flowers dioecious. Calyx closely adhering, with the margin a little elevated and 4-toothed: teeth obtuse, very short. Petals 4 , deciduous, alternating with the calycine teeth, inserted in the margin of the elevated flesh, t-angled disk ovate, acuminated, fleshy, with the margin truncate on one side, and minutely papillose on both surfaces, valvate in astivation, induplicate at the apex. Stamens 4 , opposite the petals? Ovarium cylindrical, adhering closely to the tube of the calyx, 1-celled, containing one ovulum. Style very short, thick, terete : stigma capitate, thick, fleshy, viscid, obsoletely 2-lobed. Berry fleshy, 1-seeded, crowned by the permanent style. The rest unknown.-A small evergreen tree, native of Japan; branches diclıotomous or verticillate in the manner of Loránthus and $I$ 'iscum. Leaves opposite, petiolate, broad, oratelanceolate, acuminated, to thed, coriaceous, glabrous, shining, pale green, beautifully spotted with yellow, having the mid-rib rather prominent, the rest of the lcaf reticulately veined. Petioles cylindrical. Flowers small, panicled. Panicles many, spike-formed, pedunculate; peduncles rather villous. Bracteas lanceolate, membranous, pale, caducous. Calyx beset with adpressed villi. Petals dark blood coloured. The buds are large, angular, imbricated from conduplicate stipulas; the leaves are large, toothed, and veiny, and the petioles are articulated with the branches and dilated at the base; hence there is some analogy in the genus to Fráxinus. This genus was included by Jussien in the order Rlarmni; but from its having no affinity whatever to either of the families into which that order has been since divided, its place in the natural system has remained undetermined; and perhaps also from its want of novelty, the plant has been despised by botanists, and its characters and affinities consequently overlooked. Like the Salix Babylónica, or weeping-willow, too, we possess only one sex of the tree in Europe, and that the female, which circumstance has likewise prevented its being accurately examined. 'The structure of the female

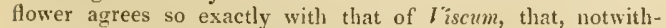
standing the different mode of growth of the two genera, and the absence of more accurate details respecting the male blossoms, and the ripe fruit, its arrangement among the Loranliàcece appears fully justified. It will nltimately be found the connecting link between the Araliàcea and the present family.

1 d. Japónica (Thunb. fi. jap. p. 64.) h. H. Native of Japan. Banks, icon. Kœmpf. t. 6. Thunb. icon. fl. jap. t. 12 and 13. Sims, bot. mag. 1197. Eubasis dichótomus, Salisb. prod. p. 68. The Aúcuba is a wcll known laurel-like evergrcen vol. III. shrub, having tlie leaves mottled with yellow; but in Japan the leaves are said to be sometimes green by 'f'lumberg. According to Kocmpfer, the fruit is a red oblong drupe, like a laurel-berry, with a white sweetish pulp, and a kemel with a bitter taste. The shrub is called in the gardens aucuba or spotted-leaved laurcl.

Japan Aucuba. Fl. May, July. Clt. 1783. Slurub 6 to 10 feet.

Cull. This is a showy evergreen shrub, well adapted for shrubberies and small gardens. It is easily increased by cuttings from the young wood planted in antumn under a handglass or by layers. The shrub will grow in any soil.

Order CXXVIII. CHLORA'NTHEE (plants agreeing with Chloránthus in particular characters). R. Br. in bot. mag. 2190. (1821) and in Parry, voy. 1824. Lindl. coll. bot. 17. (1521). Blum. fl. jav. (1829) vol. 1.

Flowers disposed in spikes, hermaphrodite or unisexual ; with a supporting tridentate calyx. Stamens lateral; if more than one connate definite; anthers 2-4-celled, bursting lengthwise, each adnate to a fleshy connective, which coheres laterally in various degrees; flaments slightly adhering to the ovarium, which is 1-celled; stigma simple, sessile; ovulum pendulous. Fruit drupaceous, indehiscent. Seed pendulous. Embryo minute, placed at the apex of a fleshy albumen; having the radicle inferior, and consequently remote from the hilum; cotyledons divaricate.-Herbaceous plants or under shrubs, with an aromatic taste. Stems jointed, tumid under the articulations. Leaves opposite, simple, with sheathing petioles, and minute intervening stipulas. Flowers disposed in terminal loose slender spikes.

This order is nearly allied to Loranthicce, from which it differs in the tridentate calys, in the want of petals, in the fewer stamens, in the structure of the anthers, and in the inferior radicle, \&c. It is said to be nearly allied to Sarivece and $P_{i-}$ peràcece, from both of which it differs in the want of a sack to the embryo, and in the pendulous ovulum, and opposite leares with intermediate stipulas. The anthers consist of a fleshy mass, upon the face of which the cell lies that bears the pollen; whether their anthers are 1 or 2 -celled is a matter of doubt, one botanist considering those that have 2 cells to be double anthers, another understanding those with 1 cell to be half anthers. This order comes nearest in aftinity to Rubiàcea, tribe Opercularinea.

The whole plant of Chloranthus officinalis has an aromatic fragrant smell, which is gradually dissipated in lrying; but its roots retain a fragrant camphorated smell, and an aromatic somewhat bitter flavour. They are found to possess very nearly the properties of Aristolochia serpentiria, and in a high degree. There seems to be no doubt but that it is a stimulant of the lighest order.

\section{Synopsis of the genera.}

1 Chloránturs. Flowers hermaphrodite. Anther seated on the side of the ovarium, undivided and 2-celled, or trilobed and 4-celled. Ovarium 1-ovulate. Drupe 1-seeded.

2 Ascarina. Spikes dioecious. Filament short; anther oblong, 4-furrowed, and probably 4-celled. Stigma 3-lobed. Drupe 1-seeded.

$3 \mathrm{~K}$ 
3 Hediósuum. Flowers monoecious. Male aments oblong, naked; anthers numerous, closely imbricated. Female flowers in racemes, witla a tridentate calyx. Drupe trigonal, 1-seeded, clothed by the baccate calyx.

1. CHLORA'NTHUS (from $\chi^{\lambda \omega \rho o s, ~ c h l o r o s, ~ g r e e n, ~ a n d ~} a r-$ Oos, anthos, a flower; tlie flowers are green). Swartz, in phil. trans. 77. p. 859 . Lher. sert. angl. 1. p. 35. R. Brown, in bot. mag. 2190 . Blum. fi. jav. 1. p. 7.-Nigrina, Thunb. nov gen. j. 58. fl. jap. p. 65.-Crèodus, Lour. coch. p. 89 . Ascarina species, Blum. enum. pl. jar. 1. p. 79.-Crypluæa, Hamilt. in edint. plit. journ. 1825 . vol. 2. p. 9.

Lin. syst. Monándria, Monogýnia, R. Br. Gynándria, Triandria, Spreng. Calyx tridentate or wanting. Corolla wanting. Anther seated on the side of the ovarium, undivitled, and 2 celled, or trilobed and 4-celled: in the latter case the middle lobe alone is perfect and 2 -celled, while the 2 lateral lobes are imperfect and only I-celled. Ovarium 1-seeded: ovulum pendulous; stigma capitate. Drupe I-seeded.-Dmall sublierbaceous slirubs: with opjosite toothed leaves, and slender spikes of inconspicuous flowers.

1 C. OFficina'us (Blum. enum. pl. jav. 1. p. 79. H. jav. 1. p. 10. t. 1.) stem suffruticose; leaves oval-oblong, or lanceolate, the superior ones more acuminated than the rest; spikes branclied, termiual; anther 3-lobed: mildle lobe perfect and 2-celled: lateral ones imperfect and 1-celled. $h_{c}$. G. Native of Java, in hish moumtain woods. Straopha Noronha, ined. Berries white. The plant has an aromatic and fragrant smell, and is a stimulant of the highest order. It is used in medicine by the Javanese.

Officinal Chloranthus or Chu-Lan. Shrub 3 to 4 feet.

2 C. Bracnu'stacuss (Blum. f. jav. 1. p. 13. t. 2.) stem suffruticose ; leaves oblong-lanceolate, acuminated at both ends, serrated; spikes branclied, terminal; anther undivided, 2called. $\eta$. G. Native of Java, in the provinces of Bamtam and Krawang, in wools on the higher mountains. Ascarina serràta, Blum. enum. jl. jav. I. p. 180.

Short-spilkal Chloranthus or Chu-Lan. Shrub 2 to 3 feet.

3 C. Mono'stacurs (R. Br. in bot. mag. t. 2190. Lindl, coll. t. 171.) stem sufliticose; leaves elliptic, serrated, acmminated; spikes solitary, simple; flowers alternate; anther incurved, 3lobed: the midklle lobe 2-celled and perfect, and the lateral lobes 1-celied and imperfect. h. G. Native of China. Flowers yellowisl.

One-spiled Chloranthus or Clu-Lan. Fl. Feb. May. Clt. 1819 . Slurub 1 to 2 feet.

4. C. inconsrícuus (Swartz, in phil. trans. vol. 77. p. 359. t. 15.) suffruticose; leaves ovate-oblong, obtuse, serrated, pale beneatlı; spikes axillary, branched : branches alternate; flowers opposite; anther 3.lobed: middle lobe perfect and 2-celled, the lateral ones imperfect and 1-celled. h. G. Native of China and Japan. Nigrina spicàta, Thunb. fl. jap. p. 65.

Inconspicuous Chloranthus or Chu-Lan. Fl. April, Sept. Clt. 1781. Shrub 1 foot.

5 C. MONA'NDER (R. Br. in bot. mag. under no. 2190.) spikes brachiate; flowers opposite? antlier individcal, 2-celled, perfect. I. G. Native of Clina.

Monandrous Chloranthus or Chu-Lan. Fl. Junc. Clt. 1817. Shruli 1 to $1 \frac{1}{2}$ foot.

6 C. ELA'Tion (R. Br. l. c.) shrubby ; leaves oblong-lanceolate, serrated, petiolate: spikes slender, long, refiexed, crowded, nearly terminal; antlacr 3 -lobed, the middle lobe perfect, 2celled, the lateral lobes imperfect and 1-celled. h. G. Native of China ansl Cochinchina. Crèolus odorifer, Lour. coch. p. 89. Flowers small, yellow, sweet-scented. Branches long, somewhat scandent. In Cochinchina this plant is grown in gardens for the sake of the scent of the flowers.

Taller Chloranthus or Chu-Lan. Shrub 6 feet.

7 C. Serra'rus (Rœm. et Schultes, syst. 3, p. 461.) leaves ovate-oblong, acute, doubly serrated; spikes bracliate, axillary. h. G. Native of Japan, in the interior of the islands. Nigrina serràta, Thunb, act, ups. t. 7. p. 142. t. 5. f. 1. Stem simple, about a foot high. Leaves a hand long, having the serratures acute.

Serrated-leaved Chloranthus or Chu-Lan. Pl. 1 foot.

Cult. A mixture of loam, sand, and a little peat, is a good soil for the species of Chloranthus; and they are easily increased by cuttings under a hand-g]ass, or by suckers.

II. ASCARINA (from arkapts, ascaris, ascarides, or small round worms; the name is applied to this genus because the anthers are formed like small worms). Forst. char. gen. 1. 59.

Lin. syst. Monlindria, Monogýnia. Spikes filitorm, dioeciusis. Perianthium a very short scale. Filanent short; anther oblong, 4-furrowed, and probably 4-celled. Style wanting: stigma somewhat 3-lobed, adnate to the ovarimm.-A tree, with oblong-serrated stalked leaves, and sheathing stipulas at the base of the petioles.

1 A. rolrsta'cura (Forst. l. c.) $\eta_{\text {. }}$ G. Native of the Society Islands.

Many-spited Ascarina. Tree.

Cull. See Chloranthus above for culture and propagation.

III. HEDYO'SMUM (from ijôv, hedy, sweetness, and $\sigma \sigma \mu \eta$, osme, a smell; thie jlants are sweet-scented). Humb. et lionpl. nov, gen. 7. p. 634, 635. Swartz, fl. ind. 2. p. 957. t. 8. Schreb. gen. 2. p. 1453.-'Iafálla, Ruiz et Pav. A. per.

LiN. syst. Polyándria, Monogýnia. Flowers monoecious. Male aments oblong, naked, without scales and perianthia. Filaments none; anthers numerous, closely imbricated, oblong, a-celled, furnislied with a mucronate process. Female flowers with a monophyllous tridentate calyx. Style very short, triquetrous: stigna sim]le, obtuse. Drupe trigonal, 1-seeded, covered by the baccate calyx. - Small shrubs, with opposite branches and leaves. Leaves serratel. Flowers monoccious, male ones disposed in anents, and the female ones in racemes.

1 H. NU'TANS (Swartz, fi. ind. occid. 2. p. 959. prod. p. 84.) frutescent; branches lax; leaves lanceolate, acuminated: petioles sliort, connate on both sides from stipulaceous membranous sheaths at the base, which are retuse and ciliated on the margins. h. G. Native of Jamaica, in woods, on the highest mountains. Shrub brancherl. Branchlets tetragonal, jointed, rising from the axils of the sheaths of the petioles. Leaves serrated, pale green. Male aments pedunculate, oblong, nutant, filiform, rising from the sheaths of the petioles. Female racemes terminal and axillary from the same axils as the male ones, usually tripartite. Calyx tridentate. Drupe triquetrous, hard, shining, brown, clotlied by the roundish, scarlet, fleshy calyx. The whole plant has a grateful smell, and an aromatic hot taste.

Nodding-spiked Hedyosmum. Slirub 1 to 4 feet.

2 H. RACEMòsa ; leaves oblong, serrated, short-acuminated; female peduncles twin, racemose, fiexuous. $h$. G. Native of Peru, at Cuchero and Pillao, where it is called Carpales and Aytacupi. 'Tafálla racemòsa, Ruiz et Pav. f. per. syst. p. 271. There is a white pellucid sweet-scented resin issues from this plant, which has the scent of gum-anime.

Racemose-flowered IIedyosmum. Tree 15 feet.

3 H. Areore'scens (Swartz, f. ind. occ. 2. p. 961. prod. p. 84.) arborescent ; branches straight, erect; leares ovate-lanceolate; sheaths of petioles cucullate, bidlentate; male aments oblong, usually twin; female racemes tripartite. $h . G$. Native 
of Jamaica and Martinico, on the ligher mountains. Branches angular near the sheaths of the petioles, kneed, rather fleshy. Leaves serrated, attenuated and obtuse at the apex, brownish green, shining. Stipulaceous sheaths large, cucullate, bidentate at both sides. Female flowers crowded on the racemes by threes, sessile. Scales 3.4 under the flowers. Ovarium trigonal. Strle triquetrous: stigma obtuse. Fruit white, rather diaphanous. Calyx baccate, like that of the first species.

Arborescent Hedyosmum. Shrub 12 to 16 feet.

4 H. нinsu'tum (H. B. et Kunth, nov. gen. amer. 7. p. 164.) sheaths and leaves oblong, serrated, hairy beneath. 々. S. Native of New Granada.

Hairy-leaved Hedyosmum. Shrub.

5 H. glabra'tum (H. B. et Kuntb, nov, gen, amer. 7. p. 165. t. 635.) leaves oblong-lanceolate, serrated, rough; aments and strobiles tern. $々$.S. Native of Peru, in Pati and Muna, where it is called Aytacupi; and New Granada. Tafálla scàbra, Ruiz et Pav. fl. per. syst. p. 270 .

Smooth Hedyosmum. Tree 20 feet.

6 H. Bonplandia'num (H. B. et Kunth, nov. gen. 7. p. 164. t. 634-635.) leaves oblong, acuminated, glabrous, serrated; male peduncles twin, 3-spiked: those of the fermale branched. 々. S. Native of Peru, in the mountains of Cuchero and Acomago, where it is called Ayacupi and Almacijas; and New Granada, Tafálla glaúca, Ruiz et Pav. A. per. syst. p. 271.

Bonpland's Hedyosmum. Tree 25 feet.

Cult. For culture and propagation see Chloránthus, p. 434. with the exception that the species require more heat. They are shrubs of no beauty.

Order CXXIX. CAPRIFOLIA'CEE (this order agrees with Caprifolium or Honeysuckle). Juss. gen. p. 110. (exclusive of sects. 2 and 4.) Ricl, dict. class. 3. p. 172. D. C. prod. 4. p. 321.

Calyx haviog the tube adhering to the ovarium (f. 77.c.): and the limb free and 5-lobed (f. 77. $d$. f. 78 . a.). Corolla gamopetalous (f. $7 \%, b . f .78 . b$. f. 79.6 .), inserted in the calyx, with the tube short (f. 77, b.), or long (f. 78, b.), and the limb 5 -lobed $($ f. $77, b$.$) , and sometimes irregular (f. 78. b. f. 79. b.),$ not valvate in æstivation. Stamens inserted in the calyx, and adnate to the corolla at the base (f. $82 . f . f .79 . c$.$) , and alternating$ with its lobes, and equal in number to them (one of which is sometimes ahortive), sometimes exserted (f. 79. c. f. 78. c.), sometimes inclosed (f. 8\%. f. f. 81. b.); filaments subulate; anthers ovate, 2 -celled. Ovarium adnate to the calyx, while young 3-celled (f. 77.e.). Style exserted (f. 78, c.) or wanting; stigmas 3, sometimes distinct, sometimes combined into a head. Berry crowned by the limb of the calyx (f. 77, $d$. f. 81. g.), usually pulpy, rarely almost dry, many-celled in the adult state, but often 1-celled from the dissepiments, which are very thin, having vanished. Seeds inverted, solitary, twin, or numerous in the cells, but sometimes many of them are abortive; spermaderm crustaceous. Embryo in the centre of a fleshy albumen; with a superior radicle, and 2 ovate-oblong cotyledons. -Shrubs, rarely herbs or trees. Leaves opposite, exstipulate (rarely furnished with 2 small stipulas at the base of each petiole) simple, undivided, toother, rarely pinnate, feather-nerved. Flowers terminal, corymbose, or axillary.

Taking Lomicèra for the type of the order, there will be found a striking affinity with Rubiàcea, Tribe Cinchonàcece in the monopetalous tubular corolla, definite stamens, inferior orarium, and opposite lenves, an aftinity which is confirmed by the corolla of the latter being occasionally regular or irregular. With Apocynce it has an intimate alliance for the same reasons, diflering chiefly in their qualities, with the non-connivance of the anthers, the æstivation of the corolld, and the structure of the fruit. To Loranthicece they also approach, in the structure of the flowers and berries. Besides these points of affinity, Caprifoliacese probably tends towards Umbellifcrae through Sambùcus, from the fetid divided leaves and half herbaceous habit. The genus Triostcum appears to be a link between this order and Rubiàcece. The fragrance and beanty of the honeysuckle tribe have been the theme of nany a poet's song. They consist either of twining or erect shrubs, with clusters of trumpet-shaped, fragrant, white, scarlet, or yellow flowers; or of fine bushes: having cymes of white blossoms. The honeysuckle is the representative of the former and the clder of the latter. Here too is found the modest and delicate Limnc'a boreàlis, which, however inferior its attractions for the rulgar eye may be to those of its more ostentatious neighbours, yields to none of them in elegance or interest for the botanist; but independently of such recommendations, they possess properties of considerable interest. Their bark is generally astringent; that of Lonicèra corymbòsa is used for dying black in Chili. The flowers of the elder are fragrant, soporific, and sudorific, its leaves and inner bark fetid, emetic, and a drastic purgative, qualities which are also possessed by the honeysuckle. The fruit of İburnum is destitute of these properties, but has instead an austere, astringent pulp, which becomes eatable after fermentation, and is made into a sort of cake by the American Indians. Triosteum perfoliàtum is a mild cathartic; in large doses it produces vomiting; and its dried or roasted berries have been used as coffee. All caprifoliaceous plants love shady and cool places in both hemispheres, but few have been found in such as endure a very severe climate.

\section{Synopsis of the gencra.}

TrIBE I.

SAMBU'CEE, Corolla gamopetalous, regular, rotate (f. 74. " f. 75. a.) ; petals 5 , only connccted a little at the base, rarely tubular. Style nanting. Stigmas 3, sessile.

1 Sambu'cus. Limb of calyx 5-cleft. Corolla rotate (f. 74 . a.), urceolate. Berry roundish, pulpy, 1-celled, 3-4-seeded (f. 74. b.), hardly crowned (f. $74 . e_{\text {. }}$ ).

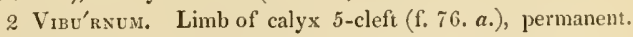
Corolla rotate (f. 75. $a$, f. 76. b.), sub-campanulate or tubular. Berry ovate or globose, 1 -seeded from abortion, crowned by the calycine teeth.

\section{Tribe II.}

Lonice're.e. Corolla gamopctalous (f. 77.b. f. 7S. b.) more (f. 78, b.) or less (f. 77. b.) tubular, usually irregular (f. $78 . b$. f. 79. b.). Style filiform (f. 78. c.), cronned by 3 distinct or concrcte stigmas.

$3 \times 2$ 
3 Triósteun. Calyx with an ovate tube and a 5 -parted permanent linb (f. 77 . a.). Corolla gibbous at the base, almost equally 5 -lobed (f. 77. b.). Stamens inclosed. Stigmas oblong, thick. Berry coriaceous, obovately triquetrous (f. 77 . c.), crowned by the calyx (f. 77. d.), 3-celled (f. 77.e.), 3-seeded.

4. Diervílla. Calyx bibracteate at the base, with an oblong tube and a 5-parted limb. Corolla funnel-shaped, 3-cleft. Stigma capitate. Cansule oblong, not crowned, 1-celled, manyseeded. Seeds minute.

5 Lonice'ra. Tube of calyx 5-toothed (f. 78, a.). Corolla tubular (f. 78. b. f. 79. b.), funnel-shaped (f. 79. b.), or campanulate (f. So. a.), with a 5-parted, usually irregular limb (f. 78. b. f. 79. b.). Stigma capitate (f. 7S. c.). Berry 3-celled; cells few-seeded.

6 Leyceste'ria. Calyx with an ovate tube, and a 5-parted irregular limb, ciliated with glands. Corolla funnel-shaped, with the tube gibbous at the base, and the limb 5-parted and campanulate. Stigma capitate. Berry roundish, 5-celled, crowned by the calyx; cells many-seeded.

7 Sxmphoricárpos. Calyx with a globose tube (f. $81 . c$.$) ,$ and a small 4-5-toothed limb. Corolla funnel-shaped (f. 81.e.), with an almost regular 4-5-lobed limb. Stigma semi-globose. Berry crowned by the calyx (f. 81. g.), 4-celled, 2 of them empty, and the other 2 containing 1 seed each.

S Aes'ria. Calyx with oblong tube; and a 2-5-parted foliaceous limb. Corolla funnel-shaped, 5 -lobed, regular. Stamens 4, somewhat didynamons. Stigma capitate. Ovarium 2-celled; cells 2 -seeded. Fruit 1 -seeded, crowned by the limb of the calyx.

9 Linnes'A. Calyx with an orate tube (f. 82. a.), and a 5 jarted limb (f. 82. b.). Corolla turbinate (f. 82. d.), somewhat campanulate, 5-lobed (f. 82. d.). Stamens 4, 2 long and 2 short, inclosed. Stigma globose (f. 82.e.). Berry almost dry, small, ovate-globose, 3-celled.

$\dagger$ Genera allied to the present order, but not sufficiently known.

I0 AŕD1A. Limb of calyx 5-toothed. Corolla hypocrateriform,- with a woolly throat and a 5-parted limb. Anthers 5, linear, inserted into the incisures of the corolla. Style equal to the corolla; stigma ovate-oblong. Berry ovate, umbilicate, 1 -seeded.

11 Valentiana. Limb of calyx 8-cleft. Corolla tubular, with a 5-cleft, nearly cqual limb. Stamens 4 , epipetalous. Style filiform; stigma 2-lobed. Fruit 2-celled.

12 Karpa'ton. Limb of calyx 4-tootlied. Corolla tubular, 4-cleft, bilabiate. Stamens 2 ; anthers 2-lobed. Style under the superior lip of the corollat ; stigma simple. Capsule crowned by the calyx, 1-celled, t-seeded.

\section{Tribe $\mathrm{I}$.}

SAMBUCEE (containing shrubs agreeing with Sambùeus in the want of the style). H. B. et Kunth, nov. gen. amer. 3. p. 487. D. C. prod. 4. p. 321.-Sambucíneæ, Batsch, tab. aff. p. 238. A. Rich. dict. class. 3. p. 173 . Corolla garnopetalous, regular, rotate, 5 -lobed, or the petals are 5 , and concrete at the base, rarely tubular. Style wanting; stigmas 3 , sessile.
I. SAMBU'CUS (from $\sigma \alpha \mu \beta v \kappa \eta$, which the Latins have changed to sambuca, a musical instrument, which is believed to have been made of elder-wood: this wood has always been renowned for its hardness). Tourn. inst. 376. Lin. gen, no. 372. Gærtn. fruct, t. 27. Lam. ill. t. 211. Scbkubr, handb. t. 83. D. C. prod. 4. p. 321.-Phyteùma, Lour. coch. p. 138. but not of Lin.

Lin. srst. Pentándria, Trigýnia. Calyx small, but divided into 5 deep segments, permanent. Corolla rotate (f. 74. a.), urceolar, 5-lobed; lobes obtuse. Stamens 5 (f. 74. b.), about the length of the corolla ; filaments awl-shaped; anthers roundish, beart-shaped. Style none ; stigmas 3, obtusc. Berry globular (f. 74.e.), pulpy, of I cell, containing 3-5 seeds (f. 74. b.), which are convex on the outside and angular inside. -Shrubs, rarely herbaceous; having a strong disagreeable scent ; stems with a solid spongy pith. Leaves opposite, stalked, pinnate; leaflets toothed, pinnate, or jagged, bi-stipellate or bi-glandular at the base. Flowers white or purplish, disposed in terminal cymes, which are in some flat and in others thyrsoicl. Berries purplish, cathartic. Those plants of the genus which have pinnate or jagged leaflets are not true species but only varieties, all the true species having only toothed leaflets.

\section{* Leaves pinnate. Flowers cymose or eorymbosc.}

1 S. E'bulus (Iin. spec. p. 385.) root fleshy, crecping ; stems herbaceous, simple, deeply and unequally furrowed; leaflets ovate-lanceolate, acute, sharply serrated, unequal at their base; stipulas foliaceons, cut; cymes of 3 main branches; flowers all hermaphrodite. $4 . \mathrm{H}$. $\mathrm{Na}$ tive of Europe, even to Caucasus, in waste ground about hedges. In Britain, in like situations, but not common either in England or Scotland. Smith, engl. bot. t. 475. Curt. lond. 3. t. 18. Woodv. med. bot.

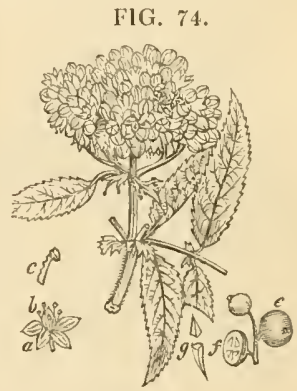
stippl. t. 260. Oed. fl. dan. t. 1156.-Mill. ill. t. 226. S. hùmilis, Lam. fl. fr. 3. p. 370.-E'bulus, Math. valgr. 2. p. 608. with a figure. Cam. epit. 979. with a figure. Leaflets 4-5 inches long, nearly smooth. Flowers all stalked, of a dull purplish hue, with thick white filaments, whose anthers are reddish. Berries globose, black, not always perfected, 3-4-seeded.

Our ancestors evinced a just hatred of their brutal enemies the Danes, in supposing this nauseous, fetid, and noxious plant to have sprung from their blood; hence it was formerly called Dane-wort. Its qualities are violently purgative, sometimes emetic; yet a rob of the fruit is said to have been taken with safety, as far as an ounce. The foliage is not caten ly cattle, nor will moles come where these leaves, or those of any of the species are laid. They also drive away mice from granaries, and the Silesians strew them where their pigs lie, under the persuasion that they prevent some of the diseases to which swine are liable. The specific name is from $\varepsilon v / 3 o \lambda \eta$, cubole, an eruption.

Var. $\beta$, himilis (Mill. dict. no. 5.). Mr. Miller makes this a distinct species. He says that the roots do not crecp so much; that the stems do not rise so high; that the leaves have seldom more than 7 leaflets, and towards the top only 5 , longer and narrower than in the common dwarf elder, deeply eut on their edges, and ending with winged acute points. $4 . \mathrm{H}$. Savi collected this variety about Pisa. 
Dwarf-clder or Dane-wort. Fl. July. Brit. Pl. 4 to 5 feet. 2 S. Chine'ssis (Lindl. hort. trans, 6. p. 297.) root crecping; stems herbaccous, warted, with dark furrows; leaves pinnate; leaflets $7-9$, oblong-lanceolate, crenately serrated, naked on both surfaces; flowers monoecious: female ones cup-shaped, apetalous and fleshy. 4. H. Native of China. A strong, rough herbaceous plant, very like $S$. E'bulus. The male flowers are white and numcrous, with brownish-purple anthers.

China Dwarf-elder. Fl. Sept. Clt. 1822. Pl. 5 to 6 feet.

3 S. Palue'xsis (Link. in Buch. can. p. 151.) stems unknown; leaves pinnate; leaflets lanceolate, serrated; petioles, nerves of leaves, and peduncles, densely hairy. h.? H. Native of the island of Palma, one of the Canaries, near Sauces.

Palma Elder. Slirub?

4 S. ADNA'TA (Wall. cat. no. 452.) stems suffruticose; leaves pinnate; lcaflets $5 \cdot 7$, oblong-lanceolate, sharply serrated, pubescent along the nerves, mequal at the base: the lower side decurrent ; cymes trichotomous ; berries ovate, striated, almost dry. 々. H. Native of Nipaul, at Gosaingsthan. Flowers white?

Adnatc-leafletted Elder. Shrub.

5 S. JAVA'xica (Reinw, in Blum. bijdr, p. 657.) stem suffruticose ; stipulas foliaceous ; leaves pinnate ; leaflets oblong-lanceolate, acuminated, oblique at the base, sharply and glandularly serrulated; corymbs with 3-5 main branches. h. G. Native of Javi, frequent on the mountains, where it is called Kitespon.

Java Elder. Shrub.

6 S. Gaudichaudia'na (D. C. prod. 4. p. 322.) stem suffiuticose ; leaves pinnate, glabrous; leaflets ovate-lanceolate, acuminated, equal at the base, sharply serrated; stipulas ovate, foliaceous, serrated; corymb pedunculate, umbellate, of 5 main rays or branches. 5 . H. Native of New Holland, at Port Jackson, where it was collected by Gaudichaud. According to the description this appears to be ncarly allied to S. Javánica. Berries ovate-globose, sinall.

Gaudichaud's Elder. Shrub 8 to 10 feet.

7 S. Mexica'na (Presl. in lierb. Hæenke, ex D. C. prod. 4. p. 322.) stem suffruticose? leaves pinnate ; leaflets 7 , ovate or oblong-lanceolate, acute, serrated, rather hairy beneath as well as on the petioles and branches; corymb of 5 principal rays or branches. $\hbar_{\text {. }}$ H. Native of Mexico. S. subalpina, Cham. et Schlecht. in Linnæa. 5. p. 171.

Mexican Elder. Shrub 5 to 8 feet.

8 S. Canadénsis (Lin. spec. 385.) frutescent, glabrous; leaves pinnate or sub-pinnate: leaflets about 4 pairs, oblongoval, stiffish, acuminated, more or less pubescent beneath, sometimes appendiculated at the base; cymes of 5 main branches. 々. H. Native of North America, from Carolina to Canada, in swamps and near hedges, and throughout Canada, as far as the Saskatchawan. Schmidt, arb. 2. t. 142. Flowers said to be almost inodorous. Berries deep bluisli-black.

Canadian Elder. Fl. Ju. Aug. Clt. 1761. Sh. 6 to $10 \mathrm{ft}$.

9 S. Nìra (Lin. spec. 385.) arboreous; leaves pinnate; leaflets usually 5 , smooth, deep grecn, ovate or oblong-oval, acuminated, the lower leaflets sometines ternate; cymes with 5 main branches. $h_{2}$. H. Native thronghout the whole of Europe, Caucasus, Siberia, and probably of Japan, in hedges, coppices, and woods, common; plentiful in Britain, in like situations; the varieties rare, except in gardens. Dnham. arb. 2. t. 65. cd. nov. 1. t. 55. Hayn. term. bot. t. 32. f. 2. Smitl, engl. bot. t. 476 . Woodv. med. bot. t. 78 . FI. dan. t. 545 . Branches, after a year's growth, clothed with smooth grey bark, and filled with a light spongy pith. Flowers cream-coloured, with a sweet but faint smell. Berries globular, purplish black ; their stalks reddish. It may be remarked that our uncertain summer is establislsed by the time the elder is in full flower, and entirely gone when its berries are ripe. The tree is, as it were, a whole magazine of physic to rustic practitioners, nor is it quite neglected by more regular ones. The berries make a useful and agreeable rob, of a slightly purgative quality, and very good for catarrlis, sore throats, \&c. 'The inner balk is more actively cathartic, and is thought beneficial in rustic ointments and cataplasms for burns. The dried flowers scrve for fomentations, and make a fragrant but debilitating tea, useful perhaps in acute inflammations, but not to be persisted in habitually. An infusion of the leaves proves fatal to the various insects which thrive on blighted or delicate plants ; nor do many of this tribe, in the caterpillar state, fecd upon them: cattle scarcely touch them, and the mole is driven away by their scent. $A$ wine is made from the berries, to be taken warm, with spices and sugar ; and they are said to frequently enter into the composition of a less innocent beverage-artificial or adulterated port. An infusion of the mner green bark of the trunk in wine, or the expressed juice of the berries, in the dose of half an ounce, is said to purge moderately, and in small doses to prove deobstruent. The expressed juice of the berries, inspissated to tise consistence of a rob, proves an useful aperient medicine, and if continued for a suflicient length of time, is of considerable service in various chronical disorders. The young leaf-buds are strongly purgative, and act with so much violence as to be accounted unsafe. The flowers have an agreeable aromatic flarour, like that of Frontignac wine, which they yield in distillation to water, and impart, by infusion, to vinous and spirituous liquors and oils. Sydenham recommends as an effectual hydragogue diuretic 3 handfuls boiled in a quart of milk and water till only a pint remains, of which one half is to be taken night and morning, and repeated several days. Boerhaave gave its expressed juice in doses from a drachm to half an ounce. It is said also that if sheep who have the rot can get the bark they will soon cure themselves, An infision of the leaves is useful for gardeners to sprinkle over the buds of such flowers as they wish to preserve from minute caterpillars, for few insects can bear the elder. In Scotland the tree is called Bountry.

Iar. 3 , virćscens (D. C. prod. 4. p. 322.) fruit green. h. H. S. viréscens, Desr. arb. fr. 1. p. 34.8 .

Iar. $\gamma$, leucocárpa; fruit white. 々. H.

Y ar. ó, laciniàta; leaflets cut into fine segments. $h . H . S$. laciniàta, Mill. dict. no. 2.-Lob. icon. 2. t. 164. f. 2. Called Parslcy-lcaved clder.

I'ar. $\varepsilon$, rolundifolia; leaves ternate ; leaflets petiolate, roundish, serrated; corymbs few-flowered. $\zeta$. H. Cultivated in Chelsca garden.

Var. ל, monstròsa; branches striped; flowers of from $5 \cdot 15$ parts, and with from 5-15 stamens ; stigmas 5-12 ; berries irrcgular. Ђ.H. S. monstròsa, Hort.

Iar. c, varicgàta; leaves variegated with yellow or white. h. H.

Common or Black-berried Elder. Fl. June. Britain. Shrub) 10 to 15 fect.

10 S. Peruvia'na (H. B. et Kunth, nov. gen. amer. 3. p. 429.) arboreous ; leaves pinnate ; leaflets 7 , oblong, acuninated. obtuse at the base, nearly equal; petioles glabrous; corymbs somewhat trichotomous; berries usually 5 -seeded. $I_{?}$. H. Native of Peru, on the Andes, in cultivated places, at the elevation of 4000 feet. S. suavèolens, Willd. in schultes, syst. (i. p. 441. Flowers white. Berries black.

Pcrmian Elder. Shrub 1: to 20 feet.

11 S. Austra'us (Cham. et Schlecht. in Linnæa. 3. p. 140.) shrubby; leaves pinnate; stipulas glabrous; leaflets 11-18, ovate-lanceolate, usually unequal at the base; corymbs brac- 
teate: stigmas 5, sessile; berries 5-celled. $\eta$. H. Native of Brazil, and cultivated at Talcahuano in Chili. Flowers creamcoloured? There is a variety of this having 4 stigmas and a 4.-celled berry.

Southern Elder. Shrub 5 to 10 feet.

\section{* Leaves pinnate. Flowers panicled.}

12 S. racemòsa (Lin. spec. 386.) shrubby ; leaves pinnate: Jeaflets 5 , membranous, oblong, acuminated, serrated, unequal at the base; petioles glabrous; panicle ovate. $\zeta_{2}$. H. Native of middle and south Europe, and Siberia on the mountains. Jacq. icon. rar. 1. p. 59 . Duham. arb. t. 66 . and ed. nov. I. t. 56. S. montàna, Cam. epit. 976 . S. cervini, Tabern. t. 1029. -Lob. icon. t. 163. Leaves pale green, pretty smooth. Flowers of a whitish green colour. Fruit red or scarlet when ripe.

I ar. $\beta$, laciniata (Koch, in D. C. fl. fr. suppl. p. 500.) leaflets jagged. $\zeta_{\text {. }}$ H. Native of the Palatinate of the Rhine.

Racemose-flowered Elder. Fl. April, May. Clt. 1596. Shrub 10 to 12 feet.

13 S. Pu'bens (Michx. fl. bor. amer. 1. p. 181.) shrubby ; leaves pinnate; leaflets 5 , membranous, ovate-lanceolate or oblong, acuminated, serrated, pubescent, but chiefly on the under side; panicle thyrsoid. $\eta_{2}$. H. Native from Carolina to Canada, on the highest mountains, as far as the Saskatchawan. S. racemòsa, Hook, fl. bor. amer. 1. p. 279. but not of Lin. Berries red. Flowers whitish. Resembles S. racemòsa very much.

Iar. $\beta$, heptaphýlla; leaves larger than those of the species; leaflets 7. $\quad$. H. Native of North America, on the east side of the Rocky Mountains: and shores of the Columbia, near Fort Vancouver, and at its confluence with the sea. The Rocky Mountain specimens, and, more especially those from the $\mathrm{Pa}-$ cific, are remarkable for the great size and length of their leaflets, and there being almost constantly seven upon eac hrachis.

Donny Elder. Fl. May, June. Clt. 1812. Sh. 6 to $10 \mathrm{ft}$.

$$
\text { *** Leaves bipinnate. }
$$

14 S. ebuloìdes (Desv. in herb. mus. par.) suffruticose ; leaves bipinnate; leaflets lanceolate, serrated ; panicle composed of racemes. $h$. H. Native of China, in the suburbs of Canton. Phyteùma bipinnàta, Lour. coch. 138. Branches angular and furrowed. Flowers white. Fruit perforated, 3-celled, many-seeded.

Danenort-like Elder. Shrub 5 to 6 feet.

15 S. Phyteumoìnes (D. C. prod. 4. p. 323.) suffiuticose ; leaves bipinnate; leaflets lanceolate, serrated, wrinkled; peduncles many-flowered, divaricate. $\zeta$. H. Native of Cochinchina, on the mountains. Phyteuma Cochinchinénsis, Lour. coch. 139. Flowers white. Berry roundish, pertuse, small, 1-celled, many-seeded. Very nearly allied to $S$. ebuloides.

Phyteuma-like Elder. Shrub 5 feet.

+ Doubtful species, to be inquired into or excluded from the order.

16 S. ? Loureiria'xa (D. C. prod. 4. p. 323.) arboreous; leaves pinnate; leaflets 5 , broad-lanceolate, quite entire, glabrous. $h$. H. Native of China, on the mountains. S. nigra, Lour. coch. p. 181. but not of Lin. Cymes 5-parted and 8parted; peduncles long, nearly equal. Fruit a round, small, reddish-brown, 3-seeded inferior berry. The berries are used by the Chinese in coldness of the extremities, as they are of a heating nature, from which quality, and the quite entire leaflets, it is not likely to be a species of Sambucus, but probably a species of Turpinia.

Loureiro's Elder. Shrub s feet.
17 S.? Jafónıc a (Thunb. f. jap. p. 125.) shrubby ; leares impari-pinnate, with $3-7$ pairs of leaflets and an odd one; leaflets ovate, acute, cartilaginously serrated, glabrous; flowers disposed in pranicled, trichotomous cymes. $h$. H. Native of Japan. Ovarium superior and style filiform, for which reason it ought evidently to be excluded from the genus : it is probably also a species of Turpinia. Stipulas none. Stigmas capitate, white.

Japan Elder. Shrub.

18 S.? 'Tiunbe'rgil; shrubby ; cymes 5-parted; leaves somewhat bipinnate. $\zeta_{c}$. H. Native of Japan, near Nagasaki and elsewhere, where it is called by the $\mathbf{J}$ apanese Sokusoso and Sali-Teki. Shrub perishing just above the earth every year. S. Canadénsis, Thumb. f. jap. p. 126. This plant is hardly known as well as the S. nigra, Tlunb. I. c.

Thunberg's Elder. Slurub.

Cult. All the species of elder are of the most easy culture, and will thrive in any soil or situation. The perennial herbaceous species creep much at the root, and are difficult to extirpate, having once got loold in the ground. The shrubby and arboreous kinds are easily increased by cuttings, stuck in the ground in autumn or spring. Those species, natives of warmer climates, will require a little protection in severe weather in winter.

II. VIBU'RNUM (this name is derived, according to Vaillant, from the Latin word vico, to tie; on account of the plia. bility of the branches of some species). Lin. gen. p. 370. Gærtn. fruct. 1. t. 27. Adans. fam. 2. p. 501. Schkulhr, handb. t. 81 . D. C. prod. 4. p. 323.-O' Oulus, Vibúrnum, and Tìnus, Tourn. inst. p. 607 . t. 376 and $377 .-$ Vibúrnum and O'pulus, Mœnch. meth. p. 505.

LiN. syst. I'cntándria, Trigýnia. Limb of calyx small, 5-cleft (f. 76.a.), permanent. Corolla rotate (f. 75. $a$. f. 76. b.), somew luat campanulate, or tubular, with a 5 -lobed limb (f. 76. b.). Stamens 5, equal (f. 75. b.). Stigmas 3, sessile. Berry ovate or globose, 1 seeded from abortion, crowned by the calycine teeth. Seeds compressed.-Shrubs. Leaves opposite, petiolate. Corymbs of flowers terminal. Flowers isually white, but sometimes verging to a rose colour.

Sect. I. Lenta'go (from lento, to make pliant; in reference to the pliability of the branclıes of some species). D. C. prod. 4. p. 324.-Vibúrnum, Monch. meth. p. 505.-Vibúrnum and Tìnus, Tourn. 1. c. Borkh. in Rœm. arch. 1. p. 20. Corymbs not radiant, laving the flower's all fertile, and equal in shape and size. Corolla rotate, or hardly somewhat bell-shaped. Seed oval.

$\$ 1$. Lcaves quite entire or toothed. Style almost nanting; stigmas 3 , sessilc.

1 V. Tinus (Lin. spec. 383.) leaves ovate-nblong, quite entire, permanent: having the ramifications of the veins beneath, as well as the branchlets, furnished with glandular hairs. $h_{2}$. H. Native of the south of Europe, in the region of the olives, and of the north of Africa, as of Portugal, Spain, Italy, the south of France, and Algiers. Duh. arb. ed. nov. 2. t. 37. Curt. bot. mag. t. 38 . V. laurifơrme, Lam. fl. fr. 3. p. 363. Timus, Tourn. inst. p. 607. t. 377. Tìnus laurifòlius, Borkh.
FIG, 75 .

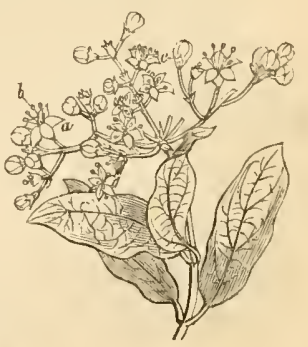


in Rœm. arch. 1. pt. 2. p. 20. Corymbs flat. Flowers white, but rose-coloured before expansion, and sometimes afterwards for a little time. Berries dark blue. The Luturestine or Laurestinus is one of the most ornamental of evergreen shrubs, with shining leaves and showy white fowers, which appear during the winter months. The name of Laurestinus was given to the shrub by old authors, they supprsing it to be a kind of bay or laurel. The berries are very liot, and inflame the fauces violently, like those of Mizereon; and they are also violently purgative, according to l'arkinson; but some kinds of birds are said to eat them greedily.

Var. a, hirlum (Ait. hort. kew. 2. p. 166.) leaves oval-oblong, hairy beneath and on the margins. $\zeta$. H. Native of Portugal and Spain, and the country of Nice. V. Tinus, Mill. dict. no. 4.-Clus. hist. 1. p. 49. no. 1. The flowers of this variety appear in autumn and continue all the winter. It is the most hardy and most common sort, called Hairy Laurestinc. V. lùcidun, Mill. Pers. and Schultes._Clus. hist. 1. p. 49. no. ii.

Var. $\beta$, lùcidum (Ait. l. c.) leaves ovate-oblong, glabrous on both surfaces, shining. $\zeta_{2}$. H. Native about Algiers and on Mount Atlas. The cimes as well as the flowers are larger than the common sort; these seldom appear till the spring, and when the winters are sharp the flowers are killed, and never open unless they are sheltered. Called Shining Laurestine.

I ar. $\gamma$, virgàtum (Ait. I. c.) leaves oblong-lanceolate, pilose on the margins as well as on the veins beneath. I. $I_{2} \mathrm{Ha}$. tive of Italy, about Rome and 'Tivoli, \&c.-Clus. hist. no. iii. with a figure. Called Common Laurestine.

Laurestine. Fl. Dec. Mar. Clt. 1596. Shrub to to 6 feet.

2 V. Rugòsum (Pers. ench. 1. p. 326. exchusive of the syn. of Ait.) leaves broad, ovate, wrinkled, hairy, permanent ; universal involucrum 7-leaved; berries ovate-oblong. $h_{2} . F$. Native of the Canary Jslands, in woods. Ker, bot. reg. t. 376. Lodd. bot. cab. t. 859 . Sims, bot. mag. t. 2082. V. Tinus $\delta$, stríctum, Ait. hort. kew. ed. 2. vol. 2. 1. 167. V. rígidum, Vent. malm. t. 9s. Desf. arb. 1. p. 34\%. V. strictım, Link. enum. 1. p. 288. Very like $\boldsymbol{l}$. Timus, but differs in the leaves being larger, and hairy all over. Flowers white.

Wrinkled or Large-leaved Laurestine. Fl. Dec. March. Shrub 4 to 6 feet.

3 V. trxoides (Lin. fil. suppl. p. 184.) leares elliptic-glabrous, quite entire; branches terete, and are as well as the corymbs hairy. 2. G. Native of Soutl America, where it was collected by Mutis.

Tinus-like Laurestine. Fl.? Clt. 1820. Sl. 4 to 6 feet.

4 V. GLABra'tum (H. B. et Kunth, nov, gen. amer. 3. p. 428.) leaves ovate-oblong, acuminated, rounded at the base, quite entire, and very glabrous; petioles naked ; branches canescent and powdery; corymbs involucrated. $h . F$. Native of South Anerica, in woods on the Andes, about Popayan, at the altitude of 3000 or 4.000 feet. V. glàbrum, Willd. in Schultes, syst. 6. p. 639. Calyx bluntly 5 -toothed. Flowers white.

Smooth Laurestine. Tree 15 to 20 feet.

$5 \mathrm{~V}$. Ayayacénse (H. B. et Kunth, nov. gen. amer. 3. p. 428.) leaves ovate, acute, cordate, quite entire, glabrous, shining above, but with the axils of the veins beneath furnished with stellate hairs, as well as the branchlets and corymbs; petioles naked. $々$. G. Native of Peru, near Ayavaca, in temperate places, at the elevation of 4000 or 5000 feet. Teeth of calyx roundish-ovate, acute, ciliated. Flowers white? Perhaps the same as $V$. linoides.

Ayataca Laurestine. Shrub 4 to 6 feet.

6 V. INTEge'rrimum (Wall. cat. no. 157. D. C. prod. 4. p. 324.) leaves oval, acute at the base, acuminated, quite entire, glabrous, rather coriaceous, dotless; petioles, branchlets, and peduncles hairy ; corymbs loose, terminal ; fruit oval, compressed. ऑ. S. Native of the island of Pulo-Penang. This species agrees with $V$. Tinus on the one hand and $V$. punctitum on the other. Calycine teeth crect, exceeding the berries.

Quite-entirc-leaved Laurestine. Shrub 4 to 6 feet?

7 V. Chine'sse (Hook. et Arn. in Becch. voy. pt. bot. p. 190.) leaves membranous, broad-elliptic, acute, coarsely and unequally toothed, glabrous above while young, puberulous and

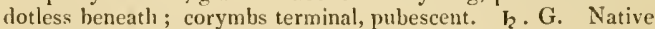
of China.

China Laurestine. Shrub.

8 V. puncta'tum (Hamilt. in D. Don, prod. ff. nep. p. 142.) leaves oval-oblong, quite entire, mucronulate, glabrous on both surfaces, beset with clots beneath; corymbs terminal, smooth, spreading, sessile. h. H. Native of Nipaul, at Suemba, where it is called Itemu-swa by the Nawar people. Teeth of ealyx obtuse. Flowers white.

Dottcd-leaved Iaturestine. Shrub.

9 V. Acuminstum (Wall. cat. no. 465. D. C. prod. 4. p. 325.) leaves elliptic, acuminated at both ends, glabrous, coriaceous, dotted beneath ; branchlets, petioles, and peduncles beset with scurfy lots; corymbs terminal, trichotomous, shorter than the leaves; berries oval-oblong. . . H. Native of the East Indies, on the Nellighery Mountains, where it was collected by Notan. Very nearly allied to $V$. punctàtum.

Acuminated-leaved Laurestine. Shrub.

10 V. PREMns'ceum (Wall. cat. no, 461. D. C. prod. 4. p. 325.) leaves elliptic-oblong, acuminated, glabrous above and dotless beneath, and downy along the nerves, having $\mathbf{I}-3$ coarse serratures on each side; petioles short, and are as well as the branchlets and peduncles clothed with villous tomentum; corymbs terminal, with 5 main branches, involucrated by 5 elliptic leaves, h. G. Native of the East Indies, on the Pundua mountains. Leaves $3-3 \frac{1}{2}$ inclies long, and $1 \frac{1}{2}$ inch broad, feathernerved; but the 2 lower lateral nerves rise from the base and give the leaf the appearance of being 3 -nerved.

Premna-like Laurestine. Slurub 5 to 7 feet.

$11 \mathrm{~V}$. Nervòsum (Hook. et Arn. in Beech. voy. pt. bot. p. 190.) evergreen; leaves elliptic-lanceolate, glabrous, acute at the base and apex, dotless beneath, with a few serratures towards the apex on both sides; nerves impressed above, but prominent beneath, glabrous in the axils, and with numerous transverse conspicuous veins between them; peduncles and petioles short and glabrous; corymbs terminal. $h . \mathrm{G}$. $\mathrm{Na}$ tive of China. This is closely allied to $V$. premniceum, Wall. in which plant is observed, besides the character given by D. C. that the axils of the leaves are furnished with a tuft of short hairs, which is totally alssent from the present species.

Nered-leared Viburnum. Shrub.

12 V. Colebrookea'nuy (Wall. cat. no. 460. D. C. prod. 4. p. 325.) leaves elliptic, acuminated, hardly obtuse at the base. regularly serrate-toothed, glabrous, dotless: petioles, branches, and peduncles scurfy from stellate down; corymbs axillary, pedunculate, without any involucra. $ъ$. G. Native of the East Inclies, on the Pundua Momitains. Tlie corymbs are not truly axillary, but are borne on short leafless, axillary branchlets or peduncles, which are furnished with 2 leares at the base. Flowers white.

Colebrooke's Laurestine. Shrub to to 6 feet.

13 V. FE'TIDUM (Wall. cat. no. 466. D. C. prod. 4. p. 325.) leaves elliptic-oblong, cuneated at the base, coarsely and sintately toothed, glabrous above, but villous along the nerves beneath; petioles, branchlets, and peduncles villous; corymbs terminal, pedmiculate, of 6 main branches, without any involucra; fruit almost sessile, oval. $\zeta_{\text {. }}$ S. Native of the Burman Empire, on Mount Taong-Dong, near Ava. Leaves 2 
inches long, and half an inch broad, on petioles $2-3$ lines long. Flowers white.

Fetid Viburnum. Shrub 4 to 6 feet.

14. V. sambu'cixum (Reinw, in Blum. bijdr. p. 656.) leaves elliptic-oblong, attenuated at botb ends, almost quite entire, puberulous on the ribs beneath; corymbs terminal, divaricate, puberulous. h. S. Native of Java, among bushes on the mountains. Flowers white.

Iar. $\beta$; leaves oval, acute at both ends, smootlish, serrated at the top. $h_{\text {. }}$.S. Native of Java, at the foot of Mount Salak. Elder-scented Viburnum. Shrub 4 to 6 feet.

15 V. LUTE'scens (Blum. bijdr. p. 655.) leaves oblong, bluntly acuminated, acutely and coarsely serrated at the base, coriaceous, shining, paler beneath; corymbs terminal, divaricate, puberulous. $h$. S. Native of Java, in the provinces of Krawang and Tjanjor, among other bushes on the mountains.

Yellowish Viburnum. Shrub 4 to 6 feet.

16 V. prunifòlum (Lin. spec. 383.) leaves roundish-obovate and oval, glabrous, rather membranous, crenately serrated, ending in a short acumen; petioles marginate, glabrous; cymes sessile; berries ovate or roundish. h.H. Native of North America, from New England to Carolina, in hedges and fields; also of Canarla about Lake Huron. Wats. dendr. t. 23.--Pluk. alm. 46. f. 2.-Duham. 2. t. 38. Flowers white as the rest of the species. Berries dark blue. This species appears to be very nearly allied to $I^{r}$. nidum, but the leaves are broader and more membranous.

Plum-leated Viburnum. Fl. May, June. Clt. 1731. Shrub 8 to 10 feet.

17 V. pYrifòlium (Poir. dict. 5. p. 658.) leaves ovate, acutish, glabrous, subserrated; petioles smooth; corymbs somewhat pedunculate; fruit ovate-oblong. h.H. Native of Pennsylvania, New Jersey, \&c. on the banks of rivers. Flowers white. Berries black. Resembles the preceding species, but is not so straggling in its growth.

Pear-leaved Viburnum. Fl. May, June. Shrub 5 to 8 feet. is V. Lenta'go (Lin. spec. p. 384.) leaves broad-ovate, acuminated, sharply serrated, glabrous; petioles with narrow eurled margins; corymbs terminal, sessile. দ. H. Native of Nortl America, from New England to Carolina, among liedges, and on the borders of woods. Throughout Canada to the Saskatchawan. Wats. dend. brit. t. 21. Schmidt, arb. 3. Ł. 176. ex Rom. et Schultes, syst. 6. p. 637. Flowers white. Fruit black. Serratures of leaves hooked a little, and somewhat cartilaginous. This species is more inclined to grow to a tree than any of the rest. The specific name is from lento, to make pliant, on account of the pliable propendent branches.

Lentago or Pliant-branched Viburnum. Fl. July. Clt. 1761. Shrub 10 feet.

19 V. NU'DUn (Lin. spec. 383.) leaves oval-oblong, angular at the base, bluntish, with revolute obsoletely crenulated margins, quite glabrous; petioles beset witì scale-like scurf or down; corymbs pedunculate, exinvolucrate. ケ. H. Native from Canada to Georgia, in swamps, particularly on a saudy soil; about Quebec, and on the banks of the Saskatchawan; and of Newfoundland. Wats. dend. t. 20. Mill. fig. 274. V. squamàtum, Wilh. enum. 1. p. 337. ex Torrey, fi. un. st. p. 319. Wats. dend. t. 24. Flowers whitish. Berries globose, black, or dark blue. In the southern states this shrub becomes evergreen; the young branclies are ferruginous, and sometimes the under side of the leaves. According to Richard. in Boot's herb. this is the same as $\mathbf{V}$. pyrifolium, Poir.

Naked-cymed Viburnum. Fl. May, Jıne. Clt. 1752. Shrub 6 to 10 feet.

$20 \mathrm{~V}$. oвova'tum (Walt. car. p. 116.) glabrous; leaves obovate, erenately toothed, or quite entire, obtuse, but acute at the base, on short petioles; corymbs sessile; berries ovate-roundish. 2. H. Natise of Carolina and Georgia, in sluady woods. Lodd. bot. cab. 1476 . V. cassinoides. Miclix. fl. bor. amer. 1 . p. 179. but us of Lin. Flowers white. Fruit black, shining.

$V_{a r} \beta$, punicifólium (Desf. arb. 1. p. 345.) leaves oblong-obovate, obtuse, entire or loosely crenated at the ajex. $h . H$. Growing along with the species.

Oborate leaved Viburnum. Fl. Hay, June. Clt. 1S12. Sh. 3 to 6 feet.

21 V. cassinoìns (Lin. spec. p. 384.) leaves ovate-lanceolate, acnte at both ends, crenated, glabrous above, witlı subrevolute edges; under side of leaves, as well as the petioles, which are keeled, and branches, which are tetragonal, covered with scurfy dots; corymbs sessile; fruit ovate. h. H. Native from New York to Carolina, in swamps. V. punctàtum, Rafin. in litt. Flowers white. Berries bluish-black.

Cassine-like Viburnum, Fl. June, July, Clt. 1761. Shrub 3 to 5 feet.

22 V. Leviga'tum (Willd. spec. 1. p. 1491.) leaves lanceolate or oblong-lanceolate, smooth, remotely and unequally serrated, cuneated at the base and quite entire, glabrous; branches tetragonally 2 -edged, glabrous; corymbs sessile. $५ . H$. Native of Virginia and Carolina, near the sea coast. Cassine Parágua, Lin. mant. 220. Cassine corymbòsa, Mill. icon. t. 83. f. 1 . ${ }^{\text {t}}$. cassinoides, Duroi, larbk. 2. p. 486. V. lanceolàtum, Hill, hort. kew. t. 19. Flowers white. Berries black.

Smooth Viburnum. Fl. June, July. Clt. 1724. Slurub 10 to 14 feet.

23 V. Nítidum (Ait. hort. kew. 1. p. 371.) quite glabrous; leaves linear-lanceolate, shining above, obsoletely serrated or entire; branches tetragonal. $h$. H. Native of Carolina and Georgia, in sandy barren woods. A low shrub, with small leaves. Flowers white.

Shining-leaved Viburnum, Fl. May, June. Clt. 1758. Shrub 2 to 4 feet.

24 V. odoratíssimum (Ker, bot. reg. t. 456.) evergreen, glabrous; leaves coriaceous, elliptic-oblong, almost entire, with revolute margins; branclses of thyrse opposite, having the peduncles of the branches trichotomously pedicellate; style simple, short ; berries oblong. h. G. Native of China. V. Sinénse, Zeyh. in Coll. hort. ripul. 145. app. 2. p. 330. t. 16. V. Chinénse, Zeyl. ex Stend. nom. p. 850. Cóflea monospérma, Hook. et Arn. Berries red, but at length becoming blackish, shining, 1seeded, crowned by the lobes of the calyx, which are erect.

Flowers white, with the scent of those of O'lea fràgrans, or sweet olive. This shrub has scarcely at all the appearance of a I aburmum, from which genus the presence of a style essentially distinguishes it. (f. 76.)

Sweet-scented-flowered Viburnum. Fl. Feb. Clt. 1818. Shrub 4 to 8 feet.

25 V. Lanta'na (Lin. spec. p. 384.) leaves cordate, rounded, finely serrated, reiny, clothed beneath, but more sparingly on the upper side, with starry mealy pubescence, like that on the branches, petioles, and peduncles; cymes pedunculate, broad, flat, of numerous crowded white flowers; bracteas several, small, acute. $h_{2}$. H. Native throughout Europe, even to Caucasus, in hedges. In Britain in woods and hedges, especially on 
a clialky or limestone soil. Smith, engl. bot. t. 33I. Jacq. austr. t. 341.-V. tomentòsum, Lam. fl. fr. 3. p. 363.-Cam. epit. 122. with a figure.-Duham. arb. 2. t. 103.-Lob. icon. 2. t. 106. A small tree, with copious, opposite, round, pliant, mealy branches. Under side of leaves and branches white from mealy dow $n$. Berrics compressed in an early state, red on the outer side, yellow on the inner, finally black, with a little mealy astringent pulp. Seed large, that, and furrowed. The leaves turn of a dark red in autumn. This shrub is hardly worth cultivating for ornament, nor is it of any particular use, except that the bark serves to make bird-lime; but that of the holly is much better. It is supposed to be the viburnum of Virgil. The name lantàna is from lento to make pliant, on account of the pliant branches.

Fay-faring Tree, Fl, May, June. Britain. Shrub 6 to 15 feet.

26 V. Lantanoìes (Michx. A. bor. amer. 1. p. 179.) leaves roundish-cordate, abruptly acuminated, mequally serrated : serratures awnless ; branchlets, petioles, and nerves of leaves clothed with powdery tomentum; corymbs terminal, almost sessile; fruit ovate. $\zeta$. H. Native of North America, from Canada to Carolina, principally in the forests called Beech-woods; about Quebec and Lake Huron. V. Lantàna $\beta$, grandifolium, Ait. hort. kew. ed. 1. vol. 1. p. 392. V. grandifòlium, Smith, in Rees' cycl. no. 14. V. Lantàna $\beta$, Canadénse, Pers, ench. 1. p. $32 \pi$. The outer flowers of the corymbs are abortive and radiant, a circumstance noticed by few botanists. Berries at first red, but at length becoming black. In North America it is known by the name of hobble-bush. Very like $V$. Lantàna, but of more humble growth, and the leaves larger and tomentose.

Lantana-like Viburnum or American Wayfaring Tree. Jume, July. Shrub.

27 V. Dемта'тuм (Lin. spec. p. 384.) partly glabrous; leaves ovate, and nearly orbicular, plicate, coarsely and dentately serrated, with the nerves thick and feathered, glabrous on both surfaces; cymes or corymbs pedunculate; fruit nearly globose. h. H. Native of North America, from New York to Carolina, in mountain woods, and of Mexico. Jacq. hort. vind. 1. t. 36. Wats. dend. t. 25. V. dentàtum lùcidum, Ait. hort. kew. 1. 1. 372. V. dentàtum glabéllum, Michx. fl. bor. amer. 1. p. 179. Flowers white. Berries small, dark blue, crowned by the calyx. In North America the shrub is known by the name of arron-nood.

Toothcd-leaved Viburnum. Fl. June, Julv. Clt. 1763. Shrub 4. to 6 feet.

28 V. Pubéscens (Pursh, fi. amer. sept. 1. p. 202.) pubescent ; leaves ovate, acuminated, on short petioles, coarsely serrate-toothed, villous beneath, with the nerves feathered and prominent ; corymbs pedunculate; fruit small, ovate. $\zeta . \mathbf{H}$. Native of North America, in the lower parts of Virginia and Carolina, and New York; and of Canada about Lake Winnepeg. V. dentàtum $\beta$, jubéscens, Ait. hort. kew. 1. p. 168 . V. dentàtum semi-tomentòsum, Miehx. fl. bor. amer. 1. p. 179 . V. tomentòsum, Rafin. med. rep. 11. p. 360 . V. villòsum, Rafin. in Desv. journ. 1.p. 228. V. Rafinesquiànum, Scbultes, syst. 6. p. 630 . Flowers white. The shrub is smaller in every part than $r$. dentàtum.

Downy Viburnum. Fl. June, July. Clt. 1736. Shrub 3 feet.

29 V. ellípticum (Hook. fl. bor. amer. 1. p. 280.) leaves elliptic, obtuse, on short petioles, coarsely serrated at the top, very hairy beneath, but most so on the veins, which are parallel ; corymbs dense, pedunculate; ovaries very hairy ; betries oval-globose, deep black. $\zeta$. H. Native of North America, common on the branches of the Columbia, near its confluence with the Pacific. Bark of branches pale brown. Leaves about 2 inclies long.

voL. 111 .
Yar. $\beta$; ovaries glabrous. $h$. H. Growing along with the species.

Elliptic-leaved Viburnum. Shrub 2 to 4 feet.

$30 \mathrm{~V}$. villòsum (Swartz, prod. p. 54. fl. ind. occ, 1. p. 564.) leaves ovate, acuminated, quite entire, glabrous above in the adult state, but tomentose beneath from stellate down, as well as the petioles and branchlets; corymbs terminal, pedunculate; fruit ovate-oblong. $h_{\imath}$. S. Native of the south of Jamaica, on the mountains. Peduncles and calyxes rather villous. Corollas white. This species agrees with $\vec{L}$. Tinus in the leaves being entire, and from the tomentum with $V$. Lantina. Petioles quadrangular and channelled.

Yillous Viburnum. Clt. 1824. Shrub 5 to 6 feet.

31 V. сотı́ifòluum (D. Don, prod. fl. nep. p. 14l.) leaves roundish-oval, quite entire, clothed with stellate tomentum on both surfaces, grey beneath, as well as the branches; corymbs

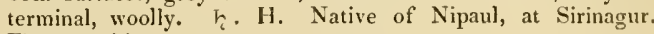
Flowers white.

Cotinus-lcaved Viburnum. Shrub.

32 V. nervòsum (D. Don, prod. fl. nep. p. 141.) leaves cordate, acuminated, nerved, serrated, clothed witl deciduous stellate tomentum beneath, as well as on the branches; peduncles terminal, tern, cymose, few-flowered. h.H. Native of Nipaul, at Sirinagur, where it is called Pheelaroo by the natives. V. Lantàna, Wall. mss.

Nerved-leaved Viburnum. Shrub 4 to 6 feet.

$33 \mathrm{~V}$. cordifòliva (Wall. cat. no. 462. D. C. prod. 4. p. 327.) leaves heart-shajed, acuminated, dentately serrated, membranous, glabrous above, clothed with stellate down on the petioles and nerves, which is at first dense, but at length scattered; corymbs terminal, sessile, with 5-7 long main branches or rays ; berries elliptic. 々. H. Native of Nipaul, in Kamaon and Gosaingsthan. Leaves 4 inches long, and $2 \frac{1}{2}$ broad. Petioles 12-15 lines long. There are 4-6 nerres at the base of the limb of the leaf on each side, rising from the midrib.

Heart-leaved Viburnum. Shrub 5 to 6 feet.

34. V. Mulda'ua (Hamilt. in D. Don, prod. A. nep. p. 141.) leaves ovate, acuminated, distantly serrated, rouncled at the base, densely clothed with tomentum beneath, as well as on the branches; corymbs terminal, compound, spreading, tomentose ; teeth of calyx short. h. Il. Native of Nipaul, at Suembu. Nearly allied to $V$. tomentòsum. Flowers white.

Mullaha Viburnum. Shrub.

35 V. stelleta'tum (Wall. cat. no. 463, D. C. prod. 4. p. 327.) leaves ovate, cordate, acuminated, glabrous above, except on the middle nerve, densely clothed witl stellate down beneath, as well as the branchlets and peduncles; the margin serrated: serratures distant, small, callous; corymbs terminal, with $5-7$ main branches, exinvolucrate. h. H. Native of Nipaul, in the valley, and at Kamaon. Wall. pl. rar. asiat. 2. p. 54. t. 169. Flowers white. Leaves roundish-cordate. Berries scarlet.

Starry-haired Viburmum. Shrub 12 to 20 feet.

36 V. involucra'tum (Wall. cat. no. 458. D. C. prod. 4. p. 327.) leaves ovate, acuminated, somewhat cordate at the base, villous from simple hairs while young, as well as the branchlets; corymbs terminal, decompound; bracteas and bracteoles foliaceous, oval, attenuated at the base, acuminated, nearly entire, exceeding the flowers. $々$. H. Native of Nijaul. Brancbes of corymb and calyxes villous. Flowers white.

Involucrated Viburnum. Shrub 4 to 6 feet.

\$2. Leaves serrated and denticulated. Floners monogynous from the style being a little elongated, and the stigmas being concrete.

37 V. Ekòsum (Thunb. A. jap. p. 124.) leaves broad-ovate, acuminated, erosely serrated, rather villous on both surfaces; $3 \mathrm{~L}$ 
petioles tomentose; umbels decomponnd, pilose; style simple. h. H. Native of Japan. Branches grey, glabrous.

Erose-toothed Viburmum. Shrub 4 to 6 feet.

$38 \mathrm{~V}$. MoNógYNum (Blum. bijdr. p. 655.) leaves elliptic-oblong, nttenuated at both ends, glandularly denticulated above the base, paler beneath; corymbs divaricate, terminal, downy; flowers monogynous. $\zeta . G$. Native of Java, in woods on the mountains. Said to be nearly allied to $V$. eròsum.

Monogynous Viburnum. Shrub.

\section{§ 3. Leaves 3-lobed.}

39 V. AcERsfòluus (Lin. spec. 383.) branchlets and petioles pilose ; leaves ovate-cordate, usually 3 -lobed, acuminated, sharply and loosely serrated, downy beneath; petioles glandless, when young stipulaceous at the base, and rather tomentose; corymbs terminal, pedunculate, not radiant. h. H. Native of North America, from New England to Carolina, and of Newfoundland, in rocky mountainous situations. Throughout Canada from Lake Huron to the Saskatchawan; and about Fort Vancouver on the Columbia. Vent. hort. cels. t. 72. Wats, dend. brit, t. 118. Flowers white. Berries black, oval, compressed.

Maple-leaved Guelder-rose. Fl. May, June. Clt. 1736. Shrub 4 to 6 feet.

40 V. orienta'le (Pall. f. ross. t. 58. f. H.) leaves 3-lobed, acuminated, coarsely and bluntly toothed; petioles glandless, glabrous; corymbs terminal, not radiant; fruit oblong, compressed. $\zeta$. H. Native of Iberia, in woods, on the mountains, Sc. Bieb. fl. taur. 1. p. 245. O'pulıs orientàlis folio amplissimo tridentato, Tourn. cor. p. 42. Flowers white. Seed oval, furnished witl 2 channels on both sides, as in $V$. Lantàna. Very like the preceding species.

\section{Oriental Guelder-rose. Fl.July. Shrub 6 to 10 feet.}

Sect. II. O'pulus (a name altered from populus, the poplar: the leaves resembling those of the poplar). Tourn. inst. t. 376. Monch, meth. p. 605 . Outer flowers of the corymbs radiant and sterile, much larger than the rest, which are fertile. Seed obcordate.

41 V. O'pucus (Lin, spec. 384.) quite glabrous in every part; leaves broad, 3-lobed, acuminated, unequally serrated, veiny ; petioles beset with glands towards the top, and several oblong leafy appendages lower down; cymes pedumculate, white, with linear bracteas: with several of the marginal flowers dilated flat, radiant, and without stamens or pistils; berries elliptical, bright red, very juicy, but bitter and nauseous; seed compressed. $々 . \mathbf{H}$. Native throughout Europe to Caucasus, in watery hedges and swampy thickets. In Britain in like situations. Smith, engl. bot. t. 332 . Fl. dan. 661 . Hayn, term. t. 32. f. 4 . V. lobàtum, Lam. fl. fr. 3. p. 363. O'pulus glandulòsus, Mœench, metl. p. 505. Opulus, Raii, syn. 460. Dulam. arb. 2. t. 16. Sambùcus aquática, Baul. pin. 456. Trag. hist. 1002. with a figure. Math. valgr. 2. p. 607 , with a figure. Branches smooth, green. Leaves bright green in summer, but in autumn assuming a beatiful pink or crimson hue, like other European species of the genera, that are principally American, as Cornus, Rhus, Sc. Flowers white. Berry crowned by the limb of the calyx. There is to be found in the gardens a varie. gated leaved variefy.

I'ar. $\left\{3\right.$, stérilis (D. C. prod. 4. p. 328) $\hbar_{2}$. H. Cultivated in gardens. 'T'his variety is called snow-ball-trce or guelder-rose. It is commonly planted in slrubberies along with the lilac and liburnum, grouping elegantly with the various purple hues of the former, and the golden chain of the latter, but they are all mere summer beauties; nor does any thing profitable or ornamental follow. The several marginal flowers of the corymb in the species are dilated, flat, and radiant, without stamens or pistils. In this variety the whole cyme nearly consists of radiant sterile flowers, and becomes globular. V.O'pulus ròseum, Rœm. et Schultes, syst. 6. p. 635.-Knor, del. 2. t. 5 and 6 . The snow-ball has been raised from seed by accident, and has been multiplied by cuttings.

Guelder-rose. Fl. May, June. Britain. Shrub 6 to 14 feet. 42 V. EDU'LE (Pursh, fl. bor. amer. 1. p. 203.) leaves 3-lobed, bluntish behind, and 3-nerved: lobes very short, denticulately serrated: serratures acuminated; petioles glandular; outer flowers of corymbs radiant. $\zeta$. H. Native of North America, from Canada to New York, on the banks of rivers. In Canada from the Saskatchawan to Slave Lake, in lat. $66^{\circ}$. V. O'pulus edìle, Michx. f. bor. amer. 1.p. 180. A smaller and more upright shrub than the preceding species. The berries of the same colour and size, but when completely ripe more agreeable to eat, and sometimes employed as a substitute for cranberries. It does not seem to differ much from $V$. oxycóccos except in the broader base of the leaf.

Edible-fruited Guelder-rose. Fl. July. Clt. 1812. Shrub 5 to 10 feet.

43 V. oxycóccos (Pursh, fl. amer. sept. 1. p. 203.) leaves 8-lobed, acute behind, 3-nerved; lobes divaricate, acuminated, coarsely and distantly serrated; petioles glandular; cymes radiant. $\eta_{\text {. H. Native of North America; on the mountains }}$ of New York and New Jersey; and throughout Canada to the Arctic circle, and from Hudson's Bay to the Rocky Mountains, in swamps and shady woods. V. opuloides, Muhl. cat. $32 . \mathrm{V}$. trílobum, Marsh. arb. p. I62. V. O'pulus Pimina, Michx. fl. 1. p. 180. V. O'pulus Americàna, Ait. hort. kew. 1. p. 373. Flowers white. Berries subglobose, red, of an agreeable acid, resembling that of cranberries, for which they are a very good substitute. Very like the $V$. O'pulus of Europe.

Var. $\beta$, subintegrifòlia (Hook. fl. bor. amer. 1. p. 281.) leaves but little cut, very pubescent beneath. $\zeta$. H. Native on the banks of the Columbia.

\section{Cranberry Guelder-rose. Fl. July. Shrub 6 to 12 feet.}

44 V. Mólde (Michix. fl. bor. amer. 1. p. 1S0.) leaves nearly orbicular, cordate, plicate, toothed, rather tomentose beneath from very soft down; petioles rather glandular; corymbs ra-

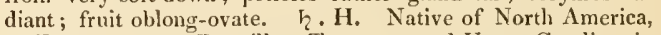
in Kentucky, near Danville; Tennessee and Upper Carolina, in hedges. V. alnifolium, Marsh. arb. p. 162. Flowers white. Berries red. Bark deciduous. Very like $V$. oxyeóceos, and perhaps only a variety of it.

Sofi Guelder-rose. Fl. June, July. Shrub 6 to 12 feet.

4.5 V. microca'rpu (Cham. et Sichlecht. in Linnæa. 5. p. 170.) leaves subcordate, orbicular, or obovate, short-acuminated, remotely and sinuately toothed, pubescent above, and clothed with hoary tomentum beneath; petioles short, without glands; rays of cyme almost sessile. h. H. Native of Mexico, near Jalapa and San Meguel del Soldado. Leaves like those of the flbert. Fruit black.

Small-fruited Guelder-rose. Shrub 6 to 8 feet.

Sect. III. Solenoti'nus (from $\sigma \omega \lambda \eta v^{\prime}$, solcn, a tube, and tinus, the laurestine; in reference to the corollas being tubular). D. C. prod. 4. p. 328. Corymbs not radiant. Corolla obconical or cylindrical. Seeds oval-oblong. This section agrees with the tribe Lonicèrce in the corollas being tubular.

46 V. Dahu'ricum (Pall. f. ross, ed. 8vo. p. 52.) leaves ovate, somewhat cordate at the base, crenately serrated, beset with stellate down, as well as the branchlets; corymbs dichotomous, few-flowered; corollas tubular, somewhat funnel-shaped,

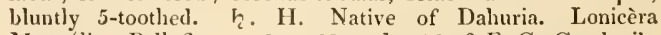
Mongólica, Pall. f. ross. 1. t. 38. and t. 58. f. F. G. Gmel. sib. 3. t. 25. Córnus Daúrica, Laxm. Berry 5-7 seeded, ex Pall. 
ed. 1., 1-seedecl, at first red, but at length becoming black and sweet, ex Pall, ed. 2. Allied to $V$. Laniàna. Flowers yellow. ish white.

Dahurian Viburnum. Shrub 6 to 8 feet.

47 V. polyca'rpus (Wall. cat. no. 455.) leaves cordate, ovate, somewhat acuminated, glabrous above, and tomentose from dense stellate white down beneath, but at length rather naked; corymbs terminal, 5 -rayed, on short peduncles; corollas obconically tubular; berry elliptic, glabrous. Ћ..H. Native of Nipaul, at Kamaon and Sirmore. Leaves $4-5$ inches long, and 3 inches broad; petioles 4 lines long.

Many-fruitcd Viburnum. Shrub 6 to 8 feet.

$48 \mathrm{~V}$. crul'Ndricus (Ham. in D. Don, prod. fl. nep. p. 14.2.) leaves oval-oblong, acuminated, coriaceous, quite entire, pubescent bencath, and on the branches; corymbs compound, erect, tomentose ; corolla oblong, tubular, with a short 5-toothed limb. h. H. Native of Nipaul, at Narainhetty. This species has the habit of $V$. nùdum. Flowers white, tubular, very like those of $V$. Dahùricum.

Cylindrical-flowered Viburnum. Shrub.

49 V. grandiflòrum (Wall. cat. no. 464. D. C. prod. 4. p. 829.) leaves elliptic, acuminated, dentately serrated, pubescent along the nerves beneath, when young ornamented wish pencilled hairs in the axils of the serratures above; corymbs terminal, bracteate; corollas cylindrical. $h_{2}$. H. Native of Nipaul, at Kamaon. Very nearly allied to $V$. erubéscens, but differs in the singular hairs on the leaves. Bracteas villous, foliaceous, 4-5 lines long. Flowers white.

Great-flowered Viburnum. Shrub 5 to 8 feet.

50 V. erube'scens (Wall. pl. rar. asiat. 2. t. 134. D. C. prod. 4. p. 329.) leaves elliptic, acuminated, serrated, glabrous ; branchlets, petioles, and peduncles rather hairy ; corymbs terminal; bracteas linear-subulate, small; corollas cylindrical. $h . H$. Native of Nipaul, at Kamaon. Leaves while young downy and ciliated. Flowers white. Berries ollong, red, 1-seeded, crowned.

Erubescent Viburnum. Shrub 10 to 12 feet.

51 V. coria'ceum (Blum. bijdr. p. 656.) leaves ovate or ovaloblong, acuminated, denticulated, coriaceous, glabrous : corymbs terminal, fastigiate; tube of corolla cylindrical. $r_{2} . H$. Native of Java, in woods on the bigher mountains.

Coriaccous-leaved Viburnum. Shrub 6 to 7 feet.

\section{$\dagger$ Species natives of Japan, but are not sufficicntly known.}

52 V.? cuspida'tum (Thunb. f. jap. p. 125.) leaves ovate, cuspidate, serrated, villous ; umbels supra-decompound, terminal, radiant. $h_{2}$. H. Native of Japan. Flowers white.

Cuspidate-leaved Viburnum. Shrub.

53 V.? dilata'tum (Thunb. fl. jap. p. 124.) leaves ovate, acuminated, unequal, toothed; petioles and peduncles villous; panicle axillary, dccompound, but not radiant; style simple, very short. $\xi_{c}$. H. Native of Japan.

Dilated Viburnum. Shrub.

54 V.? томеntòsia (Thunb. f. jap. 123.) leaves ovate, acuminated, serrated, veiny, tomentose beneath and on the petioles; umbels lateral, radiant. Ћ. H. Native of Japan, in woods. Sijo vulgo Adsai, Koempf. amcen. ex p. 854. Branches glabrous, reddish. Flowers blue, disposed on a dense large round head like the Snow-ball Guelder-rose; some are radiant and sterile, and others are small and pentandrous.

Tomentose Viburnum. Shrub 5 to 6 feet.

Cult. The species of I iburnum are all beantiful shrubs, and the hardy species are well adapted for ornamental shrubberies. They are either increased by laying in the shoots, or by cuttings under a hand-glass in a shady situation. The greenhouse and hardy kinds are early flowerers, which render them very desirable.

\section{Tribe II.}

LONICEREE (plants agreeing with Lonicèra in important characters). R. Br. char. et descr. (1818) p. 4. D. C. prod. 4. p. 329.-Caprifolièæe A. Rich. dict. class. 3. p. 173.-Caprifòlia, Batsch, tabl. aff. p. 239. Corolla gamopetalons, more or less tubular, often irregular. Style filiform; stigmas 3 , free, or combined in one.

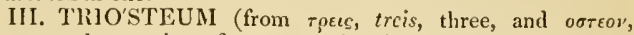
ostcon, a bone; in reference to the three bony seeds in each berry). Lin. gen. no. 234. Gærtn. fr. 1. t. 26. Lam. ill. t. 150. D. C. prod. 4. p. 329 .

Lin. syst. Pentándria, Monogýnia. Tube of calyx ovate; limb 5-parted (f. 77. a.): lobes linear-lanceolate, permanent. Corolla tubular (f. $77 . b$.), almost equally 5-lobed, gibbous at the base, a little longer than the calyx. Stamens 5 , inclosed. Stigma thick, oblong. Berry coriaceous (f. 77. c.), obovately triquetrous, crowned by the calyx (f. $77 . d$.$) , 3-celled (f. 77.e.),$ but sometimes only 1 -celled at maturity. Seeds 3 in each capsule, rarely 5 , bony, elliptic.-Perennial herbs, rarely suffruticose. Leaves tapering into the petioles, and somewhat connate at the base. Flowers axillary, sessile, or on very short pedicels.

1 T. perfolia'tum (Lin. spec. 250.) leaves oval, acuminated, abruptly narrowed at the base, and connate; flowers sessile, appearing verticillate. $4 . \mathrm{H}$. Native of North America, in the states of New Jersey, New England, Upper Carolina, and Virginia, in rich rocky grounds, principally in a lime stone soil. Schkuhr, handb. 1.t. 41. Bigel. med. bot. 90. t. 9 . T. måjus, Michx. fl. bor. amer. 1. p. 107.-Dill, elth. p. 394. t. 293 . f. 378 . Flowers and berries deep purple. Leaves sometimes subsinuated. There are glabrous and pubescent varieties of this species. The roots of this species, as well as those of the following, are used in North America as an emetic for ipecacuanha. It was first brought into notice by Dr. Tinkar, and hence it has been called 'Tinkar's root.

Perfoliate-leaved Fever-wort. Fl. June, Aug. Clt. 1730. Pl. 2 to 3 feet.

2 'T. Angustifòluum (Vahl. symb. 3. p. 37.) leaves oval-lanceolate, rather connate at the basc; pedicels axillary, solitary, 1-flowered; stem hispid. 4.H. Native of Virginia and Carolina, on the borders of woods in sandy soil. T. minus, Michx. f. bor. amer. 1. p. 107.-Pluk. alm. t. 104. f. 2. Stem hairy, rather quadrangular. Leaves quite entire. Flowers yellow. Berries yellow.

Narrow-lcaved Fever-wort. Fl. June, July. Clt. 1699. Pl. 1 to 2 feet,

3 T. Himalaya'vum (Wall. in Roxb. fl. ind. 2. p. 180.) plant covered with long hairs; leaves obovate, acute, connate at the base: lowermost ones free; racemes terminal, bearing the flowers in whorls. 2. H. Native of Nipaul, on the Himalaya at Gosaingsthan, where it grows on very high and exposed rocks. Stems terete. Leaves membranons, rounded at the end, with a short acumen, $6-8$ inches long, about 4 fingers broad, somewhat narrow towards the base. Berries oval, about the size of a small gooseberry, 3-furrowed, 1-celled, 3-seeded, liairy, yellow.

Himalaya Fever-wort. Pl. 2 to 3 feet. 3 เ 2 
4 T. misu'tum (Roxb. fl. ind. 2. p. 180.) plant suffruticose, hairy; leaves on short petioles, lanceolate, entire, acuminated; flowers axillary, sessile, much shorter than their numerous lanceolate bracteas; berries 5 -seeded. 24. H. Native of Chittagong, where it flowers during the hot season.

Hairy Fever-wort. Pl. 2 to 3 feet?

Cult. These species of Triósteum will grow in almost any kind of soil, although they prefer a peat or vegetable mould; and they are easily increased by dividing at the root, or by seed, which generally ripen in abundance.

IV. DIERVI'LLA (named by Tournefort in compliment to M. Dierville, a French surgeon, who was the first to introduce D. Canadénsis into Europe). Tourn. act. ac. par. 1706. t. 7. f. ]. Lin. hort. cliff. p. 63. t. 7 . Juss, gen. 211. D. C. prod. 4. p. 330.-Lonicèra species, Lin. gen.-Weigèla, Thunb. fl. jaj. p. 6. Lam. ill. 105, and Weigèlia, Pers. ench. 1. p. 176. ex R. Br. in Wall. pl. asiat. 1. p. 15.

Lin. syst. Pentándria, Monogýnia. Tube of calyx oblong, bibracteate at the base: limb 5 -cleft. Corolla funnel-shaped, 3-cleft, spreading twice the length of the calyx. Stamens 5, somewhat exserted. Stigma capitate. Capsule oblong, acute, 1-celled, not crowned by the limb of the calyx, as in most of the other genera of the present order. Seeds numerous, minute-Erect shrubs. Leaves ovate, acuminated, serrated. Peduncles axillary, bibracteate, usually dichotomous, 2-3 or 4Howered.

1 D. Canade'nsis (Willd, enum. 1. p. 222.) leaves on short petioles, ovate, acuminated, serrated, and are, as well as the petioles, glabrous. $\quad$. H. Native of Carolina, New England, Newfoundland, on rocks and the highest mountains; throughout Canala to the Saskatchawan; and from Hudson's Bay to the Rocky Mlountains. Lonicèra Diervilla, Lin. mat. med. p. 62. Sims, bot. mag. 1796. D. Tournefórtii, Michx. fl. bor. amer. 1. p. 107. D. hùmilis, Pers. ench. 1. p. 214. D. lùtea, Pursh, fl. amer. sept. 1. p. 162. D. trífida, Monch, metl. 492. D. Arcadiénsis, Duham. arb. 1. t. 87.-Smiclth, arb. t. 116. Hlowers yellow. Fruit a brown dry capsule. There are a number of varieties of this plant in respect to size of flowers, and leaves, Root creeping, throwing up suckers.

Canadian Diervilla. Fl. June, July. Clt. 1739. Shrub 3 to 4 feet.

2 D. JAPó́nicA (D. C. prod. 4. p. 330.) leaves on short petioles, ovate, acuminated, having the veins and petioles hairy above. 々. H. Native of Japan, near Jedo ; and of Faconia. Weigèla Japónica, Thumb. fl. jap. p, 90. t. 16. and in Lin. trans. 2. p. 381 . nov. gen. 1. p. 5. act. holm. 1780 . p. 137. t. 5.Sima Utsùgi, Koempf. amon. 5. p. 855. Corolla purple.

Japan Diervilla. Shrub.

3 D. Corae'nsis (D. C. prod. 4. p. 330.) leaves petiolate, obovate, serrated, acuminated, glabrous ; petioles stem-clasping, ciliated. h. H. Native of Japan. Weigèla Coræénsis, Thunb. in Lin. trans. 2. p. 331 . Weigc̀la Coræensis, Pers. ench, 1. p. 176.-Sòrei Utsùgi, Kœempf. icon. sel. ed. Banks, t. 45. Flowers large campanulate. Perhaps a congener of the preceding.

Corae Diervilla. Shrub.

Cult. The species of Diervilla are well fitted for the front of slrubberies; and they are easily increased by cuttings put into the ground in autumn and spring; or by suckers, which rise from the roots in plenty.

V. LONICE'RA (named after Adam Lonicer, a German who was born in 1528, and died in 1586 . There was another Lonicer, Jolm, who wrote comments on Dioscorides). Desf. $\mathrm{fl}$. atl. 1. p. 183. Lam. ill. t. 150. D. C. prod. 4. p. 330.-Lonicèra species, Lin. and many other authors.-Caprifòlium and Xylós. teum, Juss. gen. p: 212.-Xylósteum, Caprifòlium, Chamæcérasus, and Periclýmenum, Tourn. inst. t. 378 and $379 .-$ Caprifòlium and Lonicèra, Rœm. et Schultes, syst.-Lonicèra and Xylósteum, Torrey, fi. un. st.

Lin. sqst. Pentándria, Monogýnia. Tube of calyx 5-toothed (f. 78. a.). Corolla tubular (f. 78. b. f. 79. b.), campanulate, or finnel-shaped: with a 5 -cleft, usually irregular limb (f. 78 . b. f. 79. 6.). Stamens 5. Style filiform; stigma capitate (f. 78. c.). Berry 3-celled; cells few-seeded. Seeds crustaceous. -Erect or climbing shrubs. Leaves opposite, sometimes connate, entire, but sometimes somewhat runcinate (f. 79.e.) in the same species. Flowers axillary, variously disposed.

Sect. I. Caprifòlium (caper, a goat, and folium a leaf; in reference to the climbing habit of the species). D. C. fl. fr. 4. p. 270 . D. C. prod. 4. p. 331.-Caprifòlium, Juss. gen. 212. Rœm. et Schultes, syst. 5. p. 19. Lonicèra, Torr. $f$. un. st. 1. p. 242. but not of Sclınltes. Berries solitary, while young 3-celled, but when mature usually 1-celled, crowned by the tube of the calyx, which is permanent. Flowers disposed in capitate whorls.-Climbing shrubs.

\section{* Flowers ringcnt.-Caprifölium, Tourn. inst.p. 608.}

1 L. Caprifo'luu (Lin. spec. p. 246.) branches twining; leaves deciduous, obovate, acutish, glaucous: uppermost ones broader and connate; flowers ringent, teminal, disposed in capitate whorls. h. ?. Il. Native of middle and sonth Eurupe, even to the Terek, in woods, hedges, and thickets. In England in like situations; in a wood near E.lsfield, Oxfordshire, plentiful ; in Chalkpit Close, Ilinton, Cambridgeshire, certainly wild; also in another coppice in the same parish. In several woods in the south of Scotland. Smith, engl. bot. t. 799. Jacq. austr. t. 357. Engl. gard. cat. 14. t. 5.-Dodon. pempt. 411, with a figure.-Math. valgr. vol. 2. p. 321. with a figure. Cam. epit. 713. with a figure.-Rivin. irr. t. 123. Periclýmenum perfoliàtum, Ger. emac. p. 891 . with a figure. Stem twining from left to right. Buds acute, glaucous. The lower leaves are distinct and somewliat stalked; 2 or 3 of the upper pairs united : the uppermost of all forming a concave cup. Flowers in one or more axillary whorls: the uppermost whorl terminal: with a central bud, 6 in each whorl, highly fragrant, 2 inches long, yellowish, with a bluish-coloured tube. Berries elliptical, of a tawny orange colour, each crowned by an almost entire calyx.

Goat's-lcaf or Pale-perfoliate Honeysuckle. Fl. May, June. Britain. Shrub tw.

2 L. Eтru'sca (Santi, viagg. 1. p. 113. t. 1.) branches twining ; leaves decidnous, obovate, obtuse, pubescent : lower ones on short petioles: upper ones connately perfoliate, acute, glabrous; flowers disposed in verticillate lreads: with usually about 3 heads on the top of each branch. h. ก. H. Native of the south of France, Sicily, Vallais, Carniola, Dalmatia, on lills. Savi, fl. pis. 8. p. 236. D. C. H. fr. suppl. 500. L. Etrúsca, Host, H. aust. 1. p. 298. Caprif òlium Etrúscum, Rœem. et Schultes, syst. 5. p. 261. I. I'ericlýmenum, Gouan, hort. p. 101. Caprifòlium Itálicım perfoliàtum præ'cox, Tourn. inst. p. 608. Flowers glabrous, sweet-scented, purplish on the outside, and yellow inside.

Etruscan Honeysuckle. Fl. May, June. Clt.? Shrub tw.

3 L. IMLE'XA (Ait. hort. kew. 1. p. 231.) quite ghabrous; branches twining; leaves permanent, evergreen, glaucescent: lower ones oblong, distinct : middle ones perfoliate : uppermost ones connate, forming a hollow roundish cup; flowers alisposed in capitate "horls, ringent. $\boldsymbol{2} . \frown$. H. Native of the Balearic Islands and Sicily. Sims, bot. mag. t. 640 . Viv. fl. cors. p. 4. exclusive of the Guss. syn. Camb. bal. p. 84. et Guss. 
sic. 1.p. 257. Caprif òlium impléxum, Rœm. et Schultes, syst. 5. p. 261. Flowers purplish before expansion, becoming paler on the outside as they expand; white on the inside; but finally changing to yellow, as in the common woodbine. The leaves in Curtis's figure appear to be ovate and acute.

Iar. $\beta$, Baleárica (Viv. Camb. et Guss. l. c.) lower leaves somewhat cordate: upper ones connate, obovate, glaucous beneath. h. ก. H. Native of Corsica, South of France, Italy, Sicily, and Mauritania, \&e. Caprifòlium Baleáricum, Dum. Cours. bot. cult. ed. 2. vol. 4. p. 358. Rœm. et Schultes, syst. 5. p. 261. L. Baleárica, D. C. fl. fr. suppl. 499. L. Caprifòlium, Desf. fl. atl. 1. p. 183. Evergrcen. Bark of branehes violaceous, clothed with glancous bloon. Flowers 4-6 in a head, large, cream-coloured, 15-18 inches long.

Internoven or Minorea Honeysuckle. Fl. June, Sept.

Clt. 1772. Shrub tw.

4. L. Cyrenaica (Viv. fl. lib. spec. 12. t. 8. f. 1.) quite glabrous ; branches twining; leaves elliptic, glaucous beneath : lower ones sessile, distinet: upper ones truncate at the base, and confluent; flowers disposed in whorled heads. $\zeta_{-} \cap . \mathrm{H}$. Native of Lybia, in the vieinity of Cyren, on hills. Said to be allied to $L$. Caprifolium, but differs in the upper leaves being much smaller, almost as in L. Periclýmenum.

Cyron Honeysuckle. Slurub tw.

5 L. Periclímenum (Lin. spec. p. 247.) branches elimbing; leaves all separate, deciduous, sometimes downy, glaucous beneath, ovate, obtuse, attenuated at the base: upper ones the smallest; heads of flowers all terminal, ovate, imbricated; flowers ringent. $々 . \cap$. H. Native of middle Europe, in hedges, groves, and thickets, common; plentiful in Britain, in like situations. Smith, engl, bot. t. 800 . Curt. fl. lond. fasc. 1. t. 15. Oed. fl. dan. t. 908. Sehmidt. arb. t. 107. Svensk, bot. t. 140. Caprif òlium Germánicum, Raii, syn. p. 458, engl. gard. eat. t. 5. Periclýmenum, Ger. emae, p. 891 , with a figure. Periclýmenum Germẩicum, Riv. mon. irr. t. 122. P. horténse, Gesı. icon. piet. fase. 1. 38. t. 7. f. 49 . Caprifòlium Periclýmenum, Roem, et Schultes, syst. 5. p. 262. Caprif òlium sylváticum, Lam. A. fr. 3. p. 365. There are varieties of this species with either snooth, pubescent, or variegated leaves; and when the plant grows by the sea-side they are occasionally more glaucous and rather succulent. Corollas externally deep red, or in the earlier flowering varieties all over buff coloured; in the maritime plant smaller and greenish. Berries nearly globular, deep red, bitter and nauseous, accompanied by permanent bracteas. The early writers attribute virtues to this shrub which are now quite given up, but the beauty and exquisite fragrance of the flowers make it a favourite plant in gardens and shrubberies. I'his is the true woodbine of poets, though likewise the " twisted eglantine" of Milton. Notwithstanding Curtis's imperfect quotation, Shakspeare is guiltless of this blunder. He says,

\section{"So dotls the woodbine, the sweet honcysuckle, Gently entwist the maple."}

Irar. $\beta$, scrótinum (Ait. hort. kew. 1. p. 378.) branches glabrous; flowers late, reddish. $々 . \frown$. H. Hort. angl. 14. no. 4. t. 7. Mill. fig. t. 79. Riv, mon, irr. t. 122. Periclýmenum Germánicum, Mill. diet. no. 4. This, the late red honeysuckle, produces a greater number of flowers together than either the Italian or Duteh honeysuckle, so that it makes a finer appearance than either of them, during the time of flowering. It has not been such a long inhabitant of our gardens as the Dutch honeysuckle, for about the year 1715 it was considered a great curiosity, when it was called the Flemish honeysuckle, and was probably brought over by the Flemish florists.

lar. $\gamma$, Bélgica; branches smooth, purplish ; leaves oblong- oval, of a lucid green above, but pale beneatli, on long petioles; flowers in terminal, verticillate heads, each flower arising out of a scaly cover, reddish on the outside, and yellowish within, of a very agreeab!e odour. h. . II. Periclýmenum Germánicum, Mijl. dict. no. 4.-Hort. angl. 15. no. 5. t. 6. This, the Dutch honeysuckle, may be trained with stems, and formed into heads, which the wild sort cannot, the branches being too weak and trailing for that purpose.

Var. $\delta$, qucreifolium (Ait. hort. kew. 1. p. 378.) leaves sinuated like those of an oak. h. . H. This variety is to be found in England in a wood near Kimberly, Norfolk; and near Oxford. There is also a kind of this with variegated leaves. The flowers are like those of the species. 'l'his is ealled the Oak-learcl honeysuckle.

Woodbine or Common Honeysuckle. Fl. June, July, Oct. Britain. Slırub tw.

6 L. FLA'va (Sims, bot. mag. t. 1318.) quite glabrous; branches twining a little ; leaves ovate, sometimes glaueous beneath, with cartilaginous margins ; upper leaves connately perfoliate; flowers in terminal verticillate heads; corollas rather ringent: with oblong, obtuse lobes. $\zeta . \frown$. H. Native of the Paris Mountains, South Carolina; on the Catskill Mountains, New York. Torrey, fl. un. st. 1. p. 243. Caprifỏlium flàvum, Ell. sketch. 1. p. 271. Caprif òlium Erasèri, Pursh, fl. amer. sept. 1. p. 160. Flowers bright yellow, but as they fade becoming orange-coloured, very fragrant.

Yellow-flowered Honeysuckle. Fl. June, July. Clt. 1810. Shrub tw.

7 L. PUBE'scens (Sweet, hort. brit, p. 194.) branches twining; leaves broad-ovate-elliptic, on short petioles, pubescent and ciliated, glaucous beneath : upper ones connately perfoliate; spikes or racemes composed of verticillate heads of flowers; corollas beset with glandular pubescence. $h . \frown$. H. Native of North America, in Massaehuset, Vermont, New York, and Canada, in many places. Caprifölium pubéseens, Goldie, in edinb. phil. journ. 1822. april, p. 323. Hook, exot. fl. t. 27. L. hirsuta, Eaton, man. bot. ed. 3. p. 341. ex Torrey, fl. un. st. 1. p. 242. L. Góldii, Spreng. syst. 1. p. 758. Flowers yellow. This appears to hold the place in the more northern parts which L. flava does in the sonth; of which indeed Dr. Torrey suspects it to be a variety.

Pubescent Honeysuckle. Fl. June, Jul. Clt. 1822. Sl. tw.

8 L. parviflòra (Lam. dict. 1. p. 728.) quite glabrous; branches twining; leaves elliptic, sessile : lower ones somewhat connate: upper ones connately perfoliate, glabrous, very glaucous beneath; flowers disposed in verticillate hearls; corollas glabrous; with the tube gibbous at the base on one side; filaments hairy. $\digamma_{2} \cap$. H. Native of North Ameriea, from New England to Carolina, in rocky shady situations; frequent in Canada, and as far north as the Saskatchawan; and from Hudson's Bay to the Rocky Mountains. Caprif òlium parviflòrum, Pursh, f. amer. sept. 1. p. 161. Lonicèra dióca, Lin. syst. veg. ed. 13. p. 181. L. mèdia, Murr. nov, comm. gœett. 1776. p. 28. t. 3. Caprifòlium bracteòsum, Michx. fl. bor. amer. 1. p. 105. Caprifòlium dioícum, Roem. et Schultes, syst. 5. p. 260. Caprif òlium glaúcum, Monch. Flowers yellow, smaller than in any of the foregoing species; but it varies exeecdingly in the colour of the flowers, for there is a variety mentioned by Michaux having purplish flowers.

Lar. $\beta$; leaves pubescent or tomentose beneath. $\eta$. H. Native of Canada, along with the species.

Small-flowered Honeysuckle. Fl. June, July. Shrub tw.

9 I. Dovgla'sı (D. C. prod. 4. p. 332.) branches twining; leaves oval, acute at both ends, petiolate, glabrons, ciliated, tomentose on the outside : upper ones connate; flowers disposed in capitate whorls ; stigma exserted; stamens inclosed. 々. . H. 
Native of the western coast of North America, on the banks of the Saskatchawan. Caprif òlium Douglàsii, Lindl. hort. trans. 7. p. 244. Corollas pubescent, bilabiate, deep orange red. Leaves 4-6 inclies long, deep green. Hooker in his fl. amer. bor. 1. p. 282. considers this nothing but a variety of $L$. parviflòra.

Douglas's Honeysuckle. Fl. Jul. Sept. Clt. 1824. Sh. tw.

10 L.? MicrophýlLA (Hook. fl. bor. amer. 1. p. 283.) branches twining ; leaves small, on short petioles, cordate, obtuse, stiff, hispid from pili as well as the branches, pale and glaucous beneath. $h . \frown$. H. Native of north-west America, on the subalpine range of Mount Hood, in rocky, partially shady places, abundant; sparingly at the Grand Rapids, and on steep rocks near Oak Point, on the Columbia. The specimens examined have no flowers, but judging from the habit of the plant it may perhaps safely be referred to this genus, and to the present division of it. The leaves are hardly 6 lines long, uniform, exactly cordate, very villous as well as the stems with brown hairs.

Small-leaved Honeysuckle. Shrub tw.

11 L. GRA'TA (Ait. hort. kew. 1. p. 231.) branches twining; leaves permanent, obovate, rather mucronate, glaucous beneath and reticulately veined, glabrous : upper ones connately perfoliate; spikes composed of approximate whorles of flowers; corollas ringent. h. . H. Native of North America, from Carolina to New York, on the mountains, rambling among rocks in shady moist situations, but rare. Hort. angl. p. 15. no. 10.t. 8. Caprifỏium gràtum, Pursh, fl. amer. sept. 1. p. 161. Roem. et Schultes, syst. 5. p. 262. L. Virginiàna, Marsh, arb. 136. ? Periclýmenum Americànum, Mill. dict. no. 7. Branches reddish brown. Flowers inclining to scarlet on the outside, according to Pursh. Corolla ringent, reddish on the outside, and yellow inside. Berries red.

Pleasant Honeysuckle. Fl. Ju. Sept. Clt. 1730. Sl. tw.

* Limb of corolla nearly equal.-Periclýmenum, Tourn.

12 L. SEMPERvirexs (Ait. hort. kew. 1. p. 230.) quite glabrous; leaves permanent, evergreen, obovate or ovate, glaucous beneath, glabrous: upper ones comnately perfoliate; spikes nearly naked, composed of whorls of flowers; tube of corolla ventricose on the upper side; limb nearly regular, with 5 roundish lobes. $\hbar_{2} \curvearrowleft \mathrm{H}$. Native of North America, from New York to Carolina, in stony dry woods. Hort. angl. t. 7. Knor, del. 1. t. 53 . Caprifòlium sempervìrens, Miclıx. f. bor. amer. 1. p. 105. Periclýmenum sempervirens, Mill, dict. no. 1. Alatérnus sempervirens, Rohl. ex Steud. Periclýmenum Virginiàcum, Riv. mon. 116. Branches brown. Leaves deep green above, 2 inches long and an inch broad. Whorls of flowers usually 3 , at the top of each branch. Flowers of a beautiful scarlet outside and yellow inside, about 1 inch long, inodorous. There are several varieties of this species, particularly one with an almost upright stem.

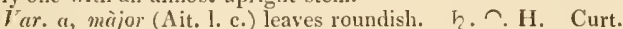
bot. mag. 781. Schmidt, arb. t. 104. Great Trumpet Honeysuckle.

V ar. $\beta$, minor (Ait. l. c.) leaves oblong, acute at both ends : upper ones obtuse, perfoliate. h. $ᄃ$. H. Sims, bot. mag. 1753. Ker. bot. reg. t. 556. L. connàta, Meerb. icon. t. 11.? Small Trumpet Honeysuckle. According to the figure in bot. mag. the flowers are scarlet both outside and inside.

Evergreen or Trumpet Honeysuckle. Fl. May, June. Clt. 1656." Shrub tw.

13 L. cruòsa (Poir. supp]. 5. p. 612.) plant twining; upper part of the branches hairy on one side; leaves coriaceous, reticulated, ovate, on short petioles, glaucous beneath, and ciliated on the margins : upper ones connately perfoliate : spikes composed of approximate verticillate heads of nearly sessile flowers; tube of corolla hairy, ventricose in the middle: limb nearly equal. h. $\cap$ H. Native of North America, on the banks of the Kooskoosky, Caprifòliun ciliòsum, Pursh, fl. amer. sept. 1. p. 160. L. ciliàta, Dietr. lex. suppl. 4. p. 263. Flowers deep yellow. Peduncles beset with glandular hairs.

Ciliatcd-leaved Honeysuckle, Fl. Ju. Clt. 1825. Sh. tw.

14. L. occidenta'L1s (Hook, f. bor. amer. 1. p. 282.) twining; leaves oval, almost sessile, glabrous, ciliated, glaucous beneath: upper ones connately perfoliate; flowers disposed in verticillate heads; corolla glabrous, with an elongated tube, which is gibbous above the base: the limb nearly equal; stamens almost inclosed. $々 . \frown$. H. Native about Fort Vancouver, on the Columbia. Caprif òlium occidentàle, Lindl. bot. reg. t. 1457. Caprifòlium ciliòsum, Dougl. mss. The flowers are longer than any other British North American species, and of a full orange red. Branches and peduncles glabrous.

Hestern Honeysuckle. Fl. Ju. Jul. Clt. 1824. Shrub tw.

15 L. pitosa (Willd. mss. ex Kunth, D. C. prod. 4. p. 333.) leares orate-oblong, ending in an acute, cuspidate point, ciliated, pilose on the nerves beneath: upper ones connately perfoliate flowers disposed in a verticillate terminal head; heads sessile : tube of corolla long: limb nearly equal. $\hbar_{c} . \frown$. H. Native of New Spain, in frigid places. Caprifollium pilosum, H. B. et Kunth, nov. gen. amer. 3. p. 427. t. 29s. Flowers purple.

Pilose Honeysuckle. Shrubtw.

Sect. 11. Xylósteun ( $\xi v \lambda o v, x y l o n$, wood, and ootzor, osteon, a bone; the woad of $L$. xylósteum is as hard as bone). D. C. fl. fr. ed. 3. vol. 4. p. 271. D. C. prod. 4. p. 333.-Xylósteon, Juss. gen. 212.-Lonicèra, Rom. et Schultes, syst. 5. p. 19. -Xylósteon and Chamæcérasus, Tourn. inst. p. 609.-Xylósteum and Isìka, Adans, fam. 2. p. 501.-Cobe'a, Neck. elem. no. 219. Pedicels axillary, 2-flowered, bibracteate at the apex. Berries twin, distinct, or joined together more or less, 3-celled in the young state, rarely 2 -celled in the adult state; the limb of the calyx is generally deciduous, thercfore the fruit is usually not crowned.-Climbing or erect shrubs. Leares never connate.

\$ 1. Nintòoa ( $\mathrm{Nin}$-too or Sin-too is the name of L. Japónica in China). D.C. prod. 4. p. 333. Ovaria and berries altogether distinct. Stems scandent. Flon'ers irregular.

16 L. macra'ntha (D. C. prod. 4. p. 333.) branches twining, hispid; leaves ovate or oblong, rather cordate at the base, and acuminated at the apex, of an ash-grey colour and villous beneath, glabrous above, except along the nerves; peduncles axillary and terminal, 2-flowered, longer than the petioles, the whole forming an ample leafy raceme; calycine segments subulate, lispid; corolla very long. $h$. $\frown$. I1. Native of Nipatl, at Suembu, and of Silhet. Caprifòlium macrånthum, D. Don, fl. nep. p. 140. Xylósteon scándens, Ham. mss. Lon. Japónica, Wall. in litt. and in Roxb. fl. ind. 2. p. 174. Leaves 3-5 incles long, shining above, and villous along the nerres and margins: beautifully reticulated, glaucous, villous, and hairy beneath. The flowers are at first snow-white and gradually changing into a beautiful yellow, acquiring thereby a peculiarly varied appearance. Berries nearly globular, smooth, deep purple, covered slightly with a pale bloom, crowned by the permanent villous calyx, 3-cellcd; cells 4-seeded. In Nipaul this species embellishes most of the forests, both in the valley and on the surrounding hills.

Large-flowered Honeysuckle. Fl. A pril, June. Shrub tw.

17 L. confu'sa (D. C. prod. 4. p. 333.) branches twining, pubescent ; leaves ovate, acute, rounded at the base, downy on both surfaces as well as on the peduncles; peduncles axillary, longer than the petioles, 2-flowered, opposite, disposed in some- 
hing like a tlyyrse at the tops of the branches; calycine segments ovate, and are as well as the corollas pubescent. H. Native of Japan and China. Nintoòa confùsa, Sweet, hort. brit. ed. 2. Lonicèra Japónica, Andr. bot. rep. t. 583. Ker. bot. reg. t. 70. Delaun, herb. amat. t. 132, but not of Thunb. Nin-too Sin-too, Kæmpf. amœen. 5. p. 785. The flowers are snow-white at first, but gradually change to a golden ycllow colour, hence it is called Sui-Kadsura and Kinginqua, i. e. gold and silver flowers, by the Japanese. Corolla about an inch long, bilabiate.

Confused Honeysuckle. Fl. July. Clt. 1805. Shrub tw.

18 L. LongifLora (D. C. prod. 4. p. 333.) glabrous in every part; brancles twining; leaves petiolate, oblong-lanceolate, shining above and pale beneath; peduncles short, 2-flowered, about the length of the petioles; tube of corolla very long and filiform : limb bilabiate..$\bumpeq$. H. Native of China and Nipaul. Caprifölium longiflòrum, Sabine, ex Lindl. bot. reg. 1232. Nintòoa longiflòra, Sweet, hort. brit. ed. 2. Caprif òlium Japónicum, D. Don, prod. fl. nep. 140 . Caprifòlium Nepalénse, G. Don, in Loud. hort. brit. 79. Flowers several inches long, at first snow white, but finally changing to a golden yellow colour.

Long-flonercd Honeysuckle. Fl. July, Sept. Clt. 1826. Sh. tw.

19 L. J APónica (Thunb. fl. jap. p. 89.) stems twining, flexuous, hairy; branchlets opposite, very hairy, hearing 2 leaves and 2 sessile flowers at the top of each; leaves petiolate, ovate, acutish, villous, pale beneath: uppermost ones the smallest; corolla tubular, irregular, villous. h. ก. H. Native of China and Japan. Nintoòa Japónica, Sweet, hort. brit. ed. 2. L. Chinénsis, Wats, dend. brit. t. 117. L. flexuòsa, Lodd. bot. cab. 1037. Ker, bot. reg. 712 . but not of Thunb. Leaves about an inch long. Corolla about an inch long, red, and villous on the outside and white inside, sweet-scented, equal in length to the stamens.

Japan Honeysuckle. FI. July, Sept. Clt. 1806. Sh. $t w$.

20 L. JAVA'NicA (D. C. prod. 4. p. 334.) stem twining; leaves ovate or oval-oblong, acuminated, rounded at the base, ciliated, glabrous above, glaucous and tomentose beneath; peduncles 2 -flowered, axillary, solitary, but so much crowded at the tops of the branches as to appear somewhat corymbose. h. . G. Native of Java, in woods on Mount Tjerimai. Caprifòlium Javánicum, Blum. bïjdr. p. 653.

Java Honeysuckle. Shrub tw.

21 L. Loureirr (D. C. prod. 4. p. 334.) climbing or twining; leaves ovate-oblong, acuminated, subcordate at the base, rather pilose on both surfices; peduncles 2-flowercd, axillary, solitary: those at the tops of the branches disposed in dense lieads. $h$. $\frown$ G. Native of Java, on the tops of Mounts Gede and Tjerimai. Caprifòlium Loureìri, Blum. bijdr. p. 653. Flowers white?
Loureiro's Honcysuckle. Shrub tw.

22 L. Cocnincuine'Nsis; climbing or twining, much branched; leaves ovate, pubescent, small; peduncles 2-flowered, axillary; berries distinct, roundish. $h . \cap$. H. Native of Cochin-china, among bushes and in hedges. L. Xylósteum, Lour. coch. p. 150. Tube of corolla very long; limb bilabiate: one of the lips 4-cleft and the other entire. Berry red. Flowers white.

Cochin-china Honeysuckle. Shrub tw.

23 L. Telfat'rn (Hook. et Arn. in Beech. voy, pt. bot. p. 190.) branches twining, pubescent; leaves petiolate, oblong, acute, obtuse at the base or cordate, glabrous above in the adult state, and densely clothed with velvety pubescence beneath ; peduncles bibracteate at the apex, 2-flowered, axillary, solitary, one half shorter than the petioles: the terminal ones forming a kind of head; calyx villons: with minute, ovate, acute teeth ; tube of corolla elongated, equal, villous. $\eta$. . H. Native of China. Lonicèra Periclýmenum, Lour. coch. p. 150. Closely allied on the one hand to $L$. confusum, D. C. from which it differs in the leaves being smooth above, and in the shorter peduncles, and on the other to L. Leschenaúltii, Wall. which, however, is said to have ovate-subcordate ciliated leaves; and villous branches.

Telfair's Honeysuckle. Shrub tw.

24 L. Leschenaúltii (Wall. in Roxb. A. ind. 2. p. 173.) branches twining; leaves ovate, subcordate, acute, quite entire, smooth above, hoary and villous beneath: with the margins ciliated; peduncles 2 -flowered, axillary, solitary, or in terminal fascicles. h. . H. Native of the East Indies, on the Nellighery Mountains, where it is called Moulle Gueda by the natives. Leaves 1-2 inches long; petioles villous. At the apex of each peduncle there is an involucrum, consisting of six unequal villous bracteas, which stipport the two flowers. Calycine teeth linear, villous. Corolla large, probably yellow; with a villous slender tube, about an inch in length; and a bilabiate limb, which is nearly as long as the tube; the upper lip consisting of 4 ovate, obtuse lobes; under lip deeply divided; throat villous. Ovarium ovate, villous. Stamens long.

Leschenault's Honeysuckle. Shrub tw.

25 L. GLABRA'ta (Wall. in Roxb. fl. ind. 2. p. 175.) glabrous in every part; branches twining; leaves ovate, acuminated, glaucous beneath, glabrous except on the nerves beneath, which are pubescent; peduncles axillary and terminal, short, villous, bearing towards the apex several opposite, approximate, very short, 2 -flowered pedicels; tube of corolla rather short, cylindrical, widening at the apex; bracteas ovate. $\eta_{\text {. }} \cap$. H. Native of Nipaul, on the top of Sheopore, and from Kabelas in the valley. L. nìgra, Thunb. jap. $\mathrm{p}, 8 \%$, and in Lin. trans. 11. p. 330.? Bark of branches shining, brownish. Leaves 3-5 inches long, seldom obtuse at the base; the upper surfaces polished; petioles about lialf an inch long, surrounding the stem and branches with an elevated margin, as in L. acuminata. Flowers yellow, smooth, with a purplish bloom on the outside, supported by a common involucrum, consisting of 6 very small, ovate, ciliated bracteas. Calycine segments subulate, ciliated. Tube of corolla about an inch long, widening at the apex into a bilabiate limb, which as well as the filaments and style are rather hairy: upper lip trifid, obtuse, the intermediate lobe retuse : the under lip oblong. Berries distinct, almost black, 3 -celled; cells 4 - seeded.

Smoolh Honeysuckle. Shrubtw.

26 L. Acumina'TA (Wall. in Roxb. fl. ind. 2. p. 177.) branches twining, villous; leaves ovate to olslong, cordate, acuminated, slightly hairy, membranous; peduncles axillary, longer than the petioles, villous, 2-flowered; bracteas linear, acuminated, ciliated, longer than the ovaries; corolla not gibbons, funnelshaped. $\eta \cap$. H. Native of the Himalaya, at Gosaingsthan. 
Leaves 3-5 inches long: petioles half an inch long. At the apex of the peduncles there is usually an involucrum of 6 small bracteas, which are hairy. Flowers like those of $L$. Xylósteum, and about the same size; they are yellow, tinged with pale purple, slightly hairy on the outside. Calycine segments lanceolate, ciliated, bluntish. Style and filaments hairy.

Acuminate-leaved Honeysuckle. Shrubtw.

27 L. Diversifòla (Wall. in Roxb. fi. ind. 2. p. 178.) branches twining; leaves ovate, cuspidate, acute, or acuminated, rounded or subcordate at the base, pubescent above, villous beneath; peduncles axillary, shorter than the petioles, 2-flowered; calyx cup-shaped, acutely 5 -lobed; corolla gibbous, funnel-shaped, villous; ovaries villous. $h . \curvearrowleft$. H. Native of the East Indies, on Mount Gurval. Branches villous. Leaves 3 inches long, on very short petioles. Peduncles smooth. Bracteas ciliated with long hairs. Flowers resembling those of L. Xylósteum both in size and colour.

lar. $\beta$, Royleina (W all. cat. no. 487. D. C. prod. 4. p. 334.) leaves oval; peduncles length of petioles. h. $\mathrm{h}$. Native of Nipaul, on Sirmore and Kamaon.

Diverse-leaved Honeysuchle. Shrub tw.

28 L. Ligustrixa (Wall. in Roxb. fi. ind. 2. p. 179.) branches slender, twining, covered with ash-grey, shining, smooth bark; young shoots villous; leaves ovate-lanceolate, hardly petiolate, slining, ciliated, obtuse at the base, acute at the apex; peduncles villous, axillary, very short, 2-flowered; limb of calyx truncate; berries distinct, and are as well as the ovaries covered by a common membrane. $\zeta$. $\frown$. H. Native of Nipaul, on the mountains, in woods. Sylosteum ligustrìnum, D. Don, prod. f. nep. p. 140. X. Naisoca, Hamilt. mss. ex D. Don, l. c. Young shoots surrounded at the base with some lanceolate, acute, quadrifariously imbricated bud-scales. Leaves dark green above, pale and reticulated beneath; petioles villous. Bracteas 2 at the apex of each peduncle. Corollas yellowish-white, funnel-shaped, half an inch long; tube gibbous and pubescent at the base, villous within: limb nearly equal, spreading, divided into 5 ovate, obtuse, ciliated segments. Filaments smooth, about the length of the limb of the corolla. Ovaries distinct, 3 celled; cells 3 -seeded.

Privet-leaved Honeysuckle. Shrub tw.

29 L. LANCEola'ta ( $W$ all. in Roxb. f. ind. 2. p. 177.) stems almost erect, bushy? leaves lanceolate, acuminated, hairy, acute at the base and glaucous beneath; peduncles axillary, longer than the petioles, and like them villous; berries distinct, globose, smootl, ; bracteas 2 linear and 4 ovate. $r$. H. Native of Nipaul, at Gosaingsthan. Stem covered with fibrous epidermis, probably erect. Branches slender, pubescent. Leaves pubescent above and shining, glaucous and hairy beneath, with somewhat repand margins, Petioles short. Berries the size and colour of black currants, smooth, crowned, 3-celled, supported by 2 linear and 4 ovate bracteas, the latter recurved and shorter.

Lanccolate-leaved Honeysuckle. Shrub erect?

SO L. CANE'SCENs (Schousb. mar. 1. p. 88.) branches twining, and are as well as the leaves canescent from down; leaves petiolate, ovate, cordate, bluntish; peduncles 2-flowered, longer than the petioles; bracteas and lobes of calyx oblong. h. $\bumpeq$. H. Native of hedges about Mogodor, and on Mount Trara in Mauritania; and of Sicily at Palermo. ex Guss. fl. sic. 1. p. 250. L. bifòra, Desti. fi. atl. J. p. 184. t. 52. Corolla bilabiate, attenuated at the base, velvety on the outside. Berries nearly distinct.

Canescent Honeysuckle. Shrub tw.

\$2. Chamacérasi (The name signifies a kind of false clierry; the fruit of some of the species resemble cherries). D.C. prod.
4. p. 335. Berries distinct, but usually connected together at the base, and diverging at the apex. Corolla hardly gibbous at the base or equal. Ereet bushy shrubs.

31 L. TAтA'R1CA (Lin. spec. 1. p. 247.) quite glabrous, erect; leaves cordate-ovate, hardly acute; peduncles shorter than the leaves; berries distinct while young, and nearly globose, but at length connate at the base. $h$. H. Native of Tartary. Pall. fl. ross. t. 36. Jacq. icon, rar. t. 37. Ker, bot. reg. t. 31. Guimp. abb. holz. t. 87. Xylósteum cordàtum, Moench, meth. p. 502. X. 'Tatáricum, Dum. Cours. Flowers rosecoloured, short, somewhat gibbous at the base. Fruit black, with one of the berries usually abortive. Bracteas 2, linearsetaceous. Peduncles 2-flowered.

I'ar. $\beta$, albiftora (D. C. prod. 4. p. 335.) Alowers white. L. Pyrenàica, Willd. baumz. p. 181.

Iar. $\gamma$, rubifiora (D. C. 1. c.) flowers red. L. Sibírica, Hortul. ex Pers. ench.

Tartarian Honeysuckle. Fl. April, May. Clt. 1752. Sh. 4. to 6 feet.

32 L. c1L1A'xA (Muhl. cat. p. 22.) erect; leares ovate or oblong, cordate, thin, ciliated, villous beneath in the young state; peduncles elongated; bracteas 2, ovate, 3 times shorter than the ovaries, which are distinct; corolla bluntly spurred at the base: with short, nearly equal lobes; berries distinct, red, divaricate. $h_{c}$. H. Native of North America, on mountains among rocks, in rich soil ; from Canada to Virginia, and throughout Canada to the Saskatchawan, frequent. Xylósteum ciliàtum, Pursh, fl. sept. amer. 1. p. 161. L. Tatárica, Michx. fl. amer. 1. p. 166. but not of Lin. L. Canadénsis, Rom. et Schultes 5. p. 260. Flowers white, with a tinge of red or yellow; tube ventricose above; limb with short, acute segments. Style exserted. The variety $\beta$ of Pursh is I'accinium álbum.

Ciliated-leaved Honeysuckle. Fl. June, July. Clt. 1824. Shrub 4 to 6 feet.

33 L. Pyrena'ica (Lin. spec. p. 248.) glabrous, crect; leaves obovate-lanceolate, acute, glaucons beneath; peduncles 2flowered, shorter than the leaves; bracteas oblong-linear, foliaccous; flowcrs almost regular; berries globose, distinct. $h_{\text {. }}$ H. Native of the Pyrenees, on calcareous rocks, in exposed situations. Duham. arb. 2. t. 110. ed. 2. vol. 1. t. 15. Magn. hart. p. 209. with a figure-Caprifölium Pyrenàicum, Lam. fl. fr. 3. p. 366.-Xylósteum, Tourn. inst. 609. Corolla white, twice the size of those of $L$. Xylosteum, funnel-shaped; limb 5 -cleft, flat: with equal, ovate, obtuse segments.

Pyrenean Honeysuckle. Fl. May. Clt. 1739 . Sh. 4 to $5 \mathrm{ft}$.

3. L. PUNíceA (Sims, bot. mag. t. 2469.) erect; leaves ovate, subcordate at the base, of the same colour on both surfaces: peduncles axillary and almost terminal, 2-flowered, sliorter than the leaves; tube of corolla rather gibbous at the base ; segments of corolla nearly equal, irregularly arranged, 3 one way and 2 another; berries distinct? h. H. Native country unknown. Symplioricárpos puníceus, Sweet. Flowers deep red or crimson. Leaves sometimes 3 in a whorl on the young shoots.

Crimson-flowered Honeysuckle. Shrub 2 to 4 fcet. 35 L. Xylósteum (Lin. spec. 248.) erect, downy; leaves
FIG.so.

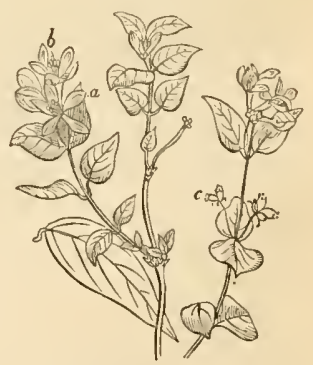

Fl. April, May. Clt. 1 \$21. 
ovate, acute, petiolate, soft; peduncles 2 -flowered, shorter than the leares; bracteas hairy, double: the 2 outer ones lanceolate, spreading: inner a small coneave seale under each germ; berries oval, distinct, 1-celled, 6-seeded. h. H. Native nearly throughont the whole of Europe, even to Caucasus, in thickets, liedges, and rocky places, and by the sides of woods. In Britain in like situations; in the fissures of rocks under the Roman wall near Shewing-Reels, or rather Sewen-Rele, in Northumberland, plentiful; and certainly wild, in a coppice called the Hacketts, to the east of Houghton Bridge, 4 miles from Arundel, Sussex. Smith, engl. bot. t. 916. fl. græc. t. 223. Oed. f. dau. t. 80 S. -Duh. arb. 1. p. 153. t. 59.-Riv, mon. irr. t. 120.-Mill. fig. 167. f. 1. Caprif òlium dunetòrum, Lam. f. fr. 3. p. 367. Xylósteum dumetòrum, Monch. meth. p. 502. Flowers small, cream-coloured, downy. Calyx of 5 obtuse lobes. Berries scarlet. A shrub of little beauty and no known utility, thangh common in plantations. Stamens and styles villous. The wood is extremely hard.

I ar. $\beta$, leucocárpa (D. C. prod. 4. p. 335.) berries white.Dul. arb. ed. 2. vol. 1. p. 52.

I'ar. $\gamma$, xanthocúrpa (D. C. l. c.) berries yellow.-D Duham. l.c. I'ar. $\hat{c}$, melanocírpa (D. C. l. c.) berries black.-Bauh. pin. 451 .

Bony-nooded or Upright Fly Honeysuckle. Fl. July. Brit. $\mathrm{Sh} .4$ to $5 \mathrm{ft}$.

36 L. Nigra (Lin. spec. 247.) erect; leaves oval-oblong or elliptic, on short petioles, rather villous while young, but nearly glabrous in the adult state; peduncles 2-flowered, elongated, shorter than the leaves. $\{$. H. Native of middle Europe, in subalpine woods, as in France, Switzerland, Austria, Silesia, Piedmont, \&c. Jacq. aust. t. 314. Schmidt, arb. t. $110 . \mathrm{Ca}-$ prifòlium ròseum, Lam. fl. fr. 3. p. 368. Chamæcérasus nìgra, Delarb. f. atw. ed. 2. p. 130.-Gesn. fase. 37. t. 8. f. 48 . Corolla reddish and pubescent on the outside, but whitish on the inside. Bracteas 4 under the ovaries: the 2 outer ones lanceolate : and the inner quadrifid. Berries black, globose, joined together at the side.

Black-fruited Honeysuckle. Fl. March, May. Clt. 1597. Shrub 3 to 4 feet.

37 L. In'spida (Pall, ex Willd. mss. Led. fl. ross. alt. ill. t. 212.) branches hispid; leaves ovate, ciliated, petiolate, glabrous on looth surfaces; peduncles 2-flowered; bracteas ovate-elliptic, exceeding the berries. $\zeta .11$. Native of Siberia, on the Altaian mountains. Branches opposite, glabrous or bristly, brownish. Leares 2 inches or $1 \frac{1}{2}$ inch long, aud an inch broad, glabrous on both surfaces, cordate at the base. Flowers greenish white, pendulous. Berries distinet, purple.

Hispid Honeysuckle. Shrub 2 to 3 feet.

38 L. Flexvo'sa (Thunb. in Lin. trans. 2. p. 330. but not of Lodd. nor Ker.) erect, branched; branches very villous at the apex ; leaves ovate-oblong, acute, on short petioles, glabrous ; petioles villous; nerves of leaves puberulous ; flowers axillary, few, almost sessile; berries globose, glabrous. h. H. Native of Japan, L. nigra, Thunb. fl. jap. p. 89. but not of Lin. L. brachýpoda, D. C. prod. 4. p. 335. Stems flexuous. Leaves about an inch long: upper ones the smallest. Peduncles hardly a line long. Berries distinct, ovate, acuminated, black.

Flexuous-stemmed Honeysuckle. Fl. June, July. Clt. 1806. Shrub 4 to 5 feet.

\$ 3. Cuphanthe (from кuфos, kuphos, a curve, and av0os, anthos, a flower; in reference to the flowers being gibbous on one side at the base). D.C. prod. 4. p. 336. Eerries cither distinct or joined together. Corollas very gibbous on one side at the base. Erect bushy shrubs.

89 L. grввo'sa (Willd. mss, in Schultes, syst. 5. p. 257.) VOL. III. erect; leaves on very short petioles, uvate-oblong, acuminated, rounded at the base, pubescent beneatls; peduncles 2 -flowered, shorter than the leaves; bracteas linear, shorter than the ovaria: tube of corolla giblous on the outer side at the base; berries almost globose, joined at the side. $h_{2} \cdot \hat{\text {. }}$. Native of Mexicn, at heal del Monte, in woods. Xylósteum Mexicànum, II. B. et Kunth, nov, gen. amer. 3. p. 426, t. 297. Corolla scarlet; with the limb oblique and bluntly 5 -lobed.

Gibbaus-flowered Honeysuckle. Shrub 3 feet.

40 I. Mociniana (D. C. prod. 4. p. 336. ) erect; leaves petiolate, elliptic-oblong, acuminated, obtuse at the base, pubescent beneath ; pedumcles 2 -flowered, shorter than the leaves ; bracteas oblong, acuminated, longer than the ovaria; tube of corolla gibbous above at the base; berries globose, joined together a little on the inner side. 々. H. Native of Mexieo. I.. gibbòsa, Moc. et Sesse, fl. mex. ieon. ined. Very nearly allied to $L$. gibbòsa, but differs in the corolla being yellowish : but when decayed of a blood colour, permanent, and jagged, with the bracteas spreading. Berries globose, dark purple.

Mocino's Honeysuckle. Shrub.

41 I. 1 involucra'ta (Banks, herb. ex Spreng. syst. 1. p. 759.) erect; branclies acutely tetragonal; leaves orate or oval, petiolate, membranous, beset with adpressed hairs beneath; peduncles axillary, 2-3-flowered; bracteas 4:2 outer ones ovate: 2 inner broad, obcordate, at length widening, clothed with glandular pubescence; corollas pubescent, gibbous at the base on the outsile; style exserted. in. H. Native of North-rest America, between lat. $54^{\circ}$ and $64^{\circ}$ (but probably confined to the vicinity of the Saskatchawan), thence to the Rocky Mosmtains. Lindl. bot. reg. 1179. Xylósteum involucràtum, líehards. in Frankl. 1. journ. ed. 2. append. p. 6. Corolla yellowish, tinged with red.

Involucrated Honeysuckle. Fl. May. Clt. 18:4. Sh. 2 to $3 \mathrm{ft}$.

4.2 L. LEDEBov'ril (Eschsch. mem. act. soc. petersb. 10. p. 28. Hook, et Art. in Beech. voy. pt. p. 145.) erect : branches elongated, acutely tetragonal; leaves ovate or oblong, somewhat acuminated, stiff; pubescent, tomentose on the nerves; peduncles axillary, 2-3-flowered; bracteas $4: 2$ onter oncs ovate: 2 inner broad-obcordate, pubeseent, at length increasing in size; corollas gibbous at the base on the outside; berrics distinct. 々. H. Native of California. Cliam. et Schlecht. in Linnea. 4. p. 138 . Very nearly allied to $L$. involucreita ant hardly to be distinguished from it. Flowers yellow, tingeil with red.

Ledcbour's Honeysuckle. Slirub 2 to 3 feet.

$\$$ 4. Isike (a name employed by Adanson for this tribe of the genus Lonicèra, and is probably without a meaning). D. C. prod. 4. p. 356. Berries 2 on each peduncle, joined logether in one, which is biumbiticate at the apex.-Lirect bushy shrubs.-Isika, Adans. fam. 2. p. 501.-1sica, Mench. meth. p. 504 .

43 J. Alpi'GeNa (Lin. spec. 248.) erect; leaves oval-lanccolate or elliptic, acute, glabrous, or pubescent, on very short petioles, rather eiliated; peduncles 2 -flowered, shorter than the leaves; corollas gibbous at the base. 12. H. Native of middle and south Europe, in subalpine places of mountains. Jacq. fl. aust. t. 274.-Duh, arb. ed. 2. vol. 1. t. 16.-Mill fig. t. 167. f. 2. Caprifòlium alpinum, Lam. fl. fr. Caprifölium Alpigenum, Gærtn. fr. 1. p. 136. Isika Alpigrena, Börck, Isica lùcida, Moench. Chamæcérasus Alpígena, Delarb.-Lob. icon. 173. Corolla greenish yellow, tinged with red or purple. Berries red, size and appearance of those of a cherry; hence it is called Cherry moodlbine by Jonstone. Leaves large.

Tar. \$, Sibirica (D. C. prod. 1. p. 336.) lower leaves ratlic $3 \mathrm{MI}$ 
cordate; peduncles thickened a little under the flowers. Native of Siberia. L. Sibírica, Vest. in Roem. et Schultes, syst. 5. p. 259 ,

Alpine Honeysuckle. Fl. April, May. Clt. 1596. Shrub 3 to 5 feet.

44 L. merophy'Lla (Willd. rel. in Rom. et Scluultes, syst. 5. p. 258.) leaves elliptic, acute at both ends, glaucous beneath ; peduncles 2-flowered. h. H. Native of Eastern Siberia. Led. fl. ross. alt. ill. t. 213. L. Alpigena, Sievers. The epidermis falls from the branclies. Leaves rather villous on both surfaces, sometimes rounded at the base. Peduncles shorter than the leaves. Corollas greenish, yellow. Berries joined, of a reddish orange colour.

Small-leaved Honeysuckle. Clt. 1818. Shrub 3 to 4 feet.

45 L. WEBBIA'NA (Wall, cat. no. 476 . D. C. prod. 4. p. 336.) erect; leaves ovate-oblong, acuminated, obtuse at the base, on very short petioles, pilose along the nerves, and ciliated on the margins; peduncles 2 -flowered, 3 times shorter than the leaves; berries semi-concrete. $h . H$. Native of the East Indies, in Sirinagur. Habit almost of $L$. Alpigena, but differs in the leaves being pilose and ciliated, in the peduncles being equal in length to the internodes, not longer than them, Sc. Corolla unknown.

II'ebl's Honeysuckle. Shrub is to 4 feet.

46 L. Guvania'sa (Wall. cat. no. 481. D. C. prod. 4. p. 337.) erect; leaves elliptic or lanceolate, acute at both ends, membranous, glabrous; peduncles 2 -flowered, 3 times longer than the petioles, but 1 times shorter than the leaves; bracteas linear, length of ovarium; corollas gibbous at the base; berries joined. h. H. Native of the East Indies, in Sirnore, where it was collected by Mr. Govan. Allied to L. Alyigrena, but the leaves are much thinner, the petioles longer, the flowers smaller and sometimes solitary by abortion.

Govan's Honeysuckle. Slirub 3 to 4 feet.

47 L. angustifo'la (Wall, cat. no. 480 . D. C. prod. 4. p. 33\%.) erect; leaves oblong-lanceolate, acuminated, glabrous; peduncles 2-flowered, a little shorter than the leaves; bracteas linear, twice the length of the ovaria ; berries joined together completely; corollas nearly equal, pubescent on the outside. h. H. Native of Nipaul, in Kamaon, and of Sirmore. Branches numerous, smooth. Leaves 15 lines long and 4. lines broad, pale and glaucous beneath; petioles 2-3 lines long. Corolla pale, 4 lines long.

Narron-leared Honcysuckle. Shrub 3 to 4 feet.

48 L. oblowgifo'lia (Hook, fl. bor, amer, 1. p. 284. t. 100.) erect; lcaves oblong or oval, clothed with velvety pubeseence beneath; peduncles elongated, erect; bracteas obsolete; tube of corolla hairy, gibbous at the base on one side; limb unequal, deeply bilabiate: the upper lip 4-toothed, and the lower one nearly entire; berries joined in one, which is biumbilicate at the top, bluish black in the dried state. $h$. H. Native of North America, in the island of Montreal, in the St. Lawrence ; about Montreal, Lake Winnipeg, and of the western parts of the state of New York. Xylostenm oblongifolium, Goldie, in edinb. phil. journ. 6. p. 323. Corolla hairy, yellow? Berries bluish black, size of a pea.

Oulong-leaved Honeysuckle. Fl. April, May. Clt. 1823. Shrub 4 feet.

49 L. C.ERU'LEA (Lin. spec. 2\$9.) erect; leaves oval-oblong, ciliated, stiffish, densely clothed with pubescence while young ; peduncles short, 2-flowered, reflexed in the fructiferous state; bracteas 2, subulate, longer than the ovaria; tube of corolla glabrous, short, gibbous on one side at the base: lobes of limb short, nearly equal; berries closely joined in one which is bimmbilicate at the apex. $h . H$. Native of Europe, in France, Switzerland, and Austria, \&c, on the mountains. Throughout the woody country of British North America, and as far as lat. $66^{\circ}$ to the mountains in the west, Labrador and New foundland, Hudson's Bay ; in the states of New York, Massachusets, New Hampshire; and of Siberia, and Kamtschatka. Jacr. fl, aust. 5. append. t. 17. Sims, bot. mag. t. 1965. L. villòsa, Mull. cat. p. 22. Hook. et Arn. in Beech. voy. pt. bot. 1. p. 115 . Xylósteon villosım, Michx. fl. bor. amer. 1. p. 106. Richards, in Frankl. 1st journ. ed. 2. append. p. 6. X. Solònis, Eaton. man. bot. p. 518 . L. velutina, D. C. prod. 4. p. 337. L. Altàica, Pall. A. ross. t. 37. Xylósteum cærùleum Canadénse, Lam, dict. 1. p. 731. X. Canadénse, Duham. arb. 2. p. 373. Caprifòlium cærùleum, Lam. fl. fr. Chamæcérasus cærùlea, Delarb. fl. auv. L. Pyrenàica, Pall. fl. ross. p. 58 . L. P’allàsii, Led. fl. ross. alt. ill. t. 131. Flowers greenish yellow, tubular. Berries elliptic or globose, dark blue, and covered with a kind of bloom. Bark of young branches purplish. 'There is no difference between the American and European plants of this species.

Blue-berried Honeysuckle. Fl. Mar. April. Clt. 1629. Slirub 8 to 5 feet.

50 L. orienta'Lis (I Iam. dict. 1. p. 731.) erect; leaves on very sliort petioles, ovate-lanceolate, acute, quite entire, smoothish ; peduncles 2 -flowered, shorter than the leaves; bracteas 2 , setaceous; berries joined in one, somewhat didymous and biumbilicate at the apex, 10 -seeded. h.H. Native of Iberia and Asia Minor, in woods. Bieb. fl. taur. et suppl. no. 396. L. Caucásica, Pall. fl. ross. 1. p. 57. L. carùlea, Güld. itin. 1. p. 423. ex Pall. Chamæecérasus orientàlis laurifòlio, Tourn. cor. j. 42. Berries black (Lam. Bieb.), dark blue (Pall.). Leaves stiffish, reiny, larger than in L. ccerùlea. Flowers greenish yellow. This is perhaps nothing more than L. ecerulea.

Oricntal Honeysuckle. Fl. April, June. Clt. 1825. Shrub 3 to 5 feet.

51 L. IBE'rica (Bieb. fl. taur. and suppl. 395.) erect; leaves petiolate, cordate, roundish, tomentose or jubescent ; peduncles 2 -flowered, shorter than the leaves; bracteas oblong, ciliated; berries joined together to the middle, globose. h. H. Native of Iberia, about Tiflis and at the Derwent. Stev. mem. soc. mose. 3. p. 257. Xylósteon Ibéricum, Bieb. cent. pl. rar. 1. t. 13. ex suppl. Corollas lurid, form of those of L. Alpigena, Ovarium tomentose. Berries blood-coloured. Leaves like those of Cotoncúster vulgàris.

Iberian Honeysuckle. Fl. April, May. Clt. 1824. Shrub 3 to 4 feet.

\section{+ Species not suffieiently known.}

52 L. QUineuelocula'ris (Hardw. asiat. res, 6. p. 351 . ex f. ind. 2. p. 17\%) shrub bushy; leaves petiolate, elliptic, acute, quite entire; peduncles short, 2-flowered; berries 5-celled. h. H. Native of the East Indies, in valleys about Shreenagur. Very like L. ligustrina, Wall. but differs in the 5-celled fruit, and is therefore probably a species of Leyeestèria.

Five-celled-fruited Honeysuckle. Shrub.

53 L. corruno's ( Lin. spec. p. 249.) leaves ovate, acute; corymbs terminal. $\zeta$. F. Native of Chili, near Conception, where it is called Itiu. Itiu. Feuill. obs. 2. p. 760. t. 45. Loránthus Utùi, Molina, sagg. chil. p. 139. ex Schultes, syst. 7. p. 161. Froelíchia violàcea, Spreng. syst. 1. p. 406. hut the plant does not belong to Rubiñeca, according to Bertero, in merc. chil. 1829. may. p. 611 . nor Loranthice a, in consequence of the fruit being many-seeded. But from the flowers being 4 -cleft, it is probably a genus of the present order. Leaves an inch broad, fine green. Corolla blood-coloured; and calyx 4cleft to the middle. Stamens 4. Style yellow. Fruit form and colour of an olive; with sweetish flesh.

Corymbose-flowered Honeysuckle. Shrub 12 feet.

54. L. QuAdrifo'lia (Willd, spec. 1. p. 986.) stem unknown; 
leaves 4 in a whorl, ovate-lanceolate, glabrous, bluntish ; peduncles twin, 2-flowered, length of leaves; lracteas 2, linear; berries distinct. $\vdash$. H. Native country unknown. Corollas like those of $L$. Xylósteum, but having the tube natrower.

Four-leaved Honeysuckle. Slirub.

Cult. All the species of honeysuckle are truly ornamental, particularly the climbing and twining species, which are well adapted for training on trellis work or arbours, or against walls. The greenhouse twining kinds have a fine appearance, trained on the rafters. The upright hardy species are well fitted for decorating shrubberies. They all grow well in any common garden soil, and are easily increased by cuttings taken off in autumn, and planted in a sheltered situation: those of the tenderer kinds under a hand-glass.

VI. LEYCESTE'RIA (named by Dr. Wallich after lis friend William Leycester, formerly Clief Judge of the principal native court under the Bengal liresidency, who during a long series of years and in various distant parts of Hindoostan, has pursued every brancl of horticulture with a munificence and zeal and success, which abundantly entitle him to that distinction). Wall. in Roxb. f. ind. 2. p. 181. pl. rar. asiat. 2. p. 21. t. 120.

Lis. srst. Pentándria, Monogijnia. Calyx with an ovate tube and an unequally 5-parted, permanent limb; segments unequal, small, linear, glandularly ciliated. Corolla funnelshaped, having the tube gibbous above the base, and the limb campanulate, and divided into 5 ovate, nearly equal lobes. Stamens 5 ; filaments exserted. Stigna capitate. Berry roundish, crowned by the calyx, 5-celled; cells many-seeded. Seeds smooth, shining, ovate. Albumen fleshy. Embryo minute, terete, centripetal.-A beautiful large rambling shrub, with elongated fistular branches, which rise from scaly buds. Leaves opposite, ovate-lanceolate, acuminated, petiolate, smooth, entire, membranous, glaucous, with an obtuse, subcordate base; petioles pilose. Flowers white, with a tinge of purple, middlesized and sessile, in fascicles, disposed in approximate whorls of fives and sixes, the whole forming short leafy drooping racemes, which tcrminate the branches and branchlets. Bracteas large, foliaceous, purplish, pubescent, and ciliated, lanceolate, acuminated, surrounding the rachis with their concave hases; there are generally 6 under each whorl of flowers, of which the 2 outer owes are 2 or 3 inclues long, rounded, and generally connate at the base: the inner ones much smaller; those at the base of the racemes considerably larger than the rest. Berries deep purple, approaching to black, as large as a common-sized gooseberry; pulp very soft; cells 8-10-seeded.-This genus appears to be intermediate between the present order and Rubiàcece, but from the last it is distinguished in the want of stipulas.

1 L. Formo'sa (Wall, in Roxb. fl, ind. 2. p. 182.). h. H. Native on the highest mountains, surrounding the valley of Nipaul; and of the much more northerly situations towards Gosaingsthan. It is also found at an elevation of seldom less than 8000 feet above the plains, among the pine and oak forests of Bishupur, as at Huttoo and Desoo in the Thakooraee of Kioonthul, blossoming from June to August, and ealled by the natives Nulkuroo. Hamèlia connàta, Puerari, mss. Dr. Govan remarks, with great propriety, that this is a most beautiful shrub when in blossom, from the contrast of the deep green hue of its stem and leaves with the purple colour of the large bracteas and the berries.

Shony Leycesteria. Fl. June, Aug. Clt. 1824. Sh. rambl.

Cult. This elegant shrub grows best in a light soil; and it is easily increased by cuttings planted in autumn or spring, or by seeds which ripen in abundance. It is well fitted for decorating the front of shrubberies; but being rather tender, should be protected in winter by a mat, or the haulm of herbaceous plants.
VII. SYMPHORICA'RPOS (from $\sigma u \mu \phi o p \varepsilon \omega$, symphoreo, to accumulate, and kapros, karpos, a fruit ; the shrubs bear clusters of united fruit). 1)ill. elth. p. 371. Juss. gen. 211. Moench, meth. 502. D. C. prod. 4. p. 338.-Symphoricárpa, Neck. elem. p. 220.-Symphòria, Pers. ench. 1. p. 214.-Anisántlous, Willd. rel.-Lonicèra species Linnæus.

Lin. syst. I'entundria, Monogýnia. Tube of calyx globose (f. S1.c.); limb small, 4-5-toothed. Corolla funnel-shaped (f. 81. e.), almost equally 4-5-lobed. Stamens 5, hardly exserted. Stigma semi-globose. Ovarium adnate, 4-celled; fertile cells contaiuing only one ovulum each; and the sterile ones few ovula. Berry 4-celled, crowned by the calyx (f. 81, $\epsilon_{*}$ ), having 2 of the cells empty, and the other 2 containing one seed eacli. - Erect elegant busliy oppositely brancher shrubs. Leaves oval, quite entire. Peduncles short, axillary, one or many flowered. Flowers bibracteate, small, white or rose-coloured, on short pedicels.

1 S. vulga'ris (Michx. A. bor. amer. 1. p. 100.) flowers disposed in axillary capitate clusters, composed of nearly sessile racemules. $\quad$. H. Native of Virginia, Carolina, and Pennsylvania, in sandy dry fields. Lonicèra symphoricárpos, Lin. spec. 249. S. prarviflòra, Desf. cat. Symphòria conglomeràta, Pers. ench. 1. p. 214. Symphòria glomeràta, Pursh, fl. amer. sept. 1. p. 162.-Schmidt. arb. t. 115 .-Dill. elth. t. 278 . f. $360 .-$ Hort. ang. 85. t. 20. Corolla white. Berries red, size of liemp seed; but according to Pursh the flowers are small, red, and yellow; and the berries purple. Branches brown, smooth. Leaves elliptic, ovate, obtuse, glaucous, and pubescent beneath. The berries are cup-shaped, and ripen in winter.

Common St. Peter's-wort. Fl. Aug. Sept. Clt. 1780. Shrub 3 to 6 feet.

2 S. RAcEmòsus (Mich. A. bor. amer. 1. p. 107.) flowers disposed in nearly terminal loose interrupted racemes, which are often leafy; corolla densely bearded inside; style and stamens inclosed. h. H. Native of North America; on mountains near Lake Mistassins; on the banks of the Missouri; of Upper Canada; abundant about the Saskatchawan; on the banks of the Columbia, and at Puget's Sound, and Nootka Sound, north-west coast. Symphoria racemòsa, Pursh, fl. amer. sept. 1. p. 162. Sims, bot. mag. 2211.

Lodd. bot. cab. t. 230. S. leucocárpa, Hort. Leaves glancous beneath. Corolla rose-coloured. Berries large, white. This is a fine shrub, very common in our gardens, easily known by its large white berrics, and small red flowers. The S. elongata and S. heterophýlla, Presl, in herb. Hæake, which were collected about Nootka Sound, do not differ from this species, in which the lower leaves are sometimes deeply sinuated.

Racemose-flowered St. Peter's-wort or Snow-berry. Fl. July, Sept. Clt. 1817. Shrub 4 to 8 feet.

$3 \mathrm{~S}$. occinenta'lis (Richards, in Frankl. 1st journ. ed. 2. append. p. 6.) spikes dense, terminal, and axillary, drooping ; corolla and segments densely bearded inside; style and stamens a little exserted. そ. H. Native of British North America, in the woody country, between lat. $54^{\circ}$ and $64^{\circ}$, and known under the name of wolf-berry; abundant about the Saskatchawan and Red River; and about Fort Vancouver, on the Columbia. According to Dr. Richardson this species comes very near $S$. racemosus, but is distinguished by the larger, less glaucous, $3 \$ 2$ 
more rigid, and denser foliage, and by the flowers being arranged in dense drooping spikes, larger than in $S$. racemòsus, and by the prominent style and stamens.

Western St. Peter's-wort. Shrub \& to 6 feet.

4. S. meropux'llus (H. B. et Kunth, nov, gen. amer. 3. p. 4.4.) fowers axillary, solitary ; leaves roundish-ovate, bluntish, pulescent. $h$. F. Native of Mexico, in the temperate parts near Moran, at the altitude of 4000 feet. Symplooria microphýlla, Willł. in Schultes, syst. 1. p. 757. Anisanthus microphyllus, Willd, in Schultes, syst. 5. p. 223. Corolla white.

Small-lcaved St. Peter's-wort. Shrub 4 to 6 feet.

5 S. Glauce'scens (H. B. et Kunth, 1. c. p. 4.24. t. 295.) fowers axillary, solitary ; leaves elliptic, acute, somewhat mucronate, smoothish. h. F. Native of Mlexico, on the mountains near Santa Rosa, at the elevation of 4000 feet. Symplioria montàna, Spreng. syst. 1. p. 757. Leaves glancescent beneath.

Glaucescont St. Peter's-wort. Shrub 3 to 4 feet.

Cult. Symphoricárpos is a genus of very beautiful and delicate shrubs, well adapted for shrubberies or borders. They grow in any common garden soil ; and are easily increased by cuttings, which should be planted either in autımn or spring.

VIII. ABELIA (named by Mr. Brown after Clarke Abel, M. D. physician to the embassy to China under Lord Amherst ; he collected and brought home many interesting plants). R. Br. car, and descript. pl. Abel, 1818. in 4to, p. 5. with a figure. D. C. prod. 4. p. 339.

Lin. syst. Tetrándria, Monogýmia. Calyx with an oblong tube, and a 2 or 5 -parted foliaceous limb: the segments oblong. Corolla tubular, fumnel-shaped, 5-lohed: lobes ovate, nearly equal. Stamens 4 , didynamous or nearly equal. Stigma capitate. Ovarium 3-celled; 2 of the cells contain many ovula, but all become abortive, and the third contains only one ovulum, which comes to perfection. Pericarp 1-seeded, indehiscent, crowned by the foliaceons limb of the calyx. - Decumbent or weak glalrous shrubs. Leaves petiolate, dentately crenated. Peduncles axillary, trichotomous or trifid, or terminal and undivided. Involucrum 2 or many flowered, composed of 6 or more leaves.

1 A. Cunne'nsis (R. Br. 1. c.) involucrum 2-flowered; pedincles trichotomous; stamens exserted. $\zeta$. G. Native of China, in the province of Kiang-si at the Lake Po-Yang, where it was collected by Dr. Clarke Abel. Tube of corolla 5-nerved: 4 of the nerves approximate, and the fifth remote. Ovarium laving one nerve on one side, and 4 on the other. Leaves ovate, finely pubescent.

C'bine Abelia. Slirub 2 to 3 feet?

¿ A. triflòra (R. Br. in Wall. pl. asiat. rar. 1.p. 14.t. 15.) flowers by threes, forming terminal corymbs: lateral flowers firnished with 3 bracteas: middle one sessile, naked; calyx 5 parted: the segments foliaceous, linear, and ciliated; leaves ovate-lanceolate, acuminated, quite entire, ciliated with hyaline laairs. h.G. Native of the East Indies, on the highest mountains of Northern and Western Kamaon towards the Himalaya, where it is called Kumlit. Flowers pale red, delightfully fragrant.

Three-flonered Abelia. 'Tree small.

3 A. Uniflòra (R. Br. in Wall. pl. asiat. rar. p. 15.) peduncles 1-flowered, tribracteate. h. G. Native of Clina.

One-flowered Abelia. Shrub.

Cull. A mixture of loam, peat, and sand will be a good soil for the species of Abelia; and they may be easily increased by cuttings planted in any light soil, with a hand-glass placed over them.

1X. LINNE'A (this little nortliern plant, long overlooked, depressed, abject, flowering early, Linnæus selected to transmit his own name to posterity). Gron. in Lin. gen. no. 774. Juss. gen. 211. D. C. prod. 4. p. 340._Oholària, Sieg. prim. p. 79. - Campánula spec. C. Bauh. Tourn. \&c.

Lin.syst. Didlynàmia, Angiospérma. Calyx double, superior one of one leaf; in 5 deep, erect, lanceolate, acute, equal segments (f. 8. b.). Corolla bell-shaped (f. 82. d.); tube cylindrical, gradually dilated upwards, about twice the length of the superior calyx; limb divided into 5 deep, nearly equal, slightly spreading segments (f. 82. d.). Stamens 4, inclosed, didynamons (f. $82 . f$. ) : the 2 uppermost ones the shortest. Ovarium globular, of 3 cells. Style cylindrical, gently swelling upwards, declining longer than the corolla (f. 8\%.e.); stigma obtuse. Berry dry, ovate-oblong, of 1-cell, membranous, closely invested with the inferior calyx, and crowned with the superior one. Seed solitary, filling the cavity.-A trailing, somewhat shrubby plant, of an elegant aspect, and rendered most interesting to a botanist on account of the name given, with the concurrence of Linnæus, by his friend Dr. J. F. Gronovius.

1 L. Borea'lis (Lin. spec. 8s0.) h. H. Native of Lapland, Sweden, Norway, Russia, Germany, Switzerland, Savoy, Siberia, \&c., in dry, stony, shady, mossy, fir woods, on the mountains. In Scotland the plant was first found in an old fir wood at Inglismaldie, on the borders of Mearnshire in 1795; it has since been found in several similar situations in the highlands of Scotland. In North America in several parts, as in the states of New England, New Hampshire, Vermont, but more particularly in Canada throughout the woody country from Lake Huron to the Arctic circle; and from Newfoundland and Labrador on the east to the Columbia, Unalaschka, and Kotzebue's Sound on the west. Lin. fl. snec. p. 219. t. 1. fl. lapp. ed. 2. p. 214. t. 12. f. 4. Smith, engl. bot. t. 433 . Wahl. fl. lapp. 170 . t. 9. f. 3. Oed. fl. dan. t. 3.-A trailing, subshrubby, creeping, and evergreen plant, forming broad leafy patches; the young shoots hairy and leafy. Leaves roundish or ovate, firm, crenate in the fore part, sliglitly hairy, and of a full green above, paler beneath. Peduncles axillary, about a finger in length, bearing each 2 elegant, pendulous, flesh-coloured flowers at the apes, which are said to be very fragrant at night. A pair of very small leaves stand at the origin of the partial flower-stalks, or pedicels, and there is often a larger pair or two at the lower part of each peduncle. Corolla variegated internally with rose colour and yellow. The American plants are generally stronger than the European ones.

Northern Linnza. Fl. May, June. Scotland. Pl. trailing.

Cult. This elegant little trailing evergreen slurub will not grow in cultivation unless in a peat border, where it will thrive and Hower freely; and most so if the border is in a shady situation. It is sometimes grown in large pots or pans, filled with peat earth, and grows luxuriantly. It is easily increased by separating the creeping stems when rooted.

\section{$\uparrow$ Genera allied to Caprifoliàcea, but are not sufficiently} known.

X. Al'DIA (from aiôtos, aidios, perpetual; in reference to the durability of the wood of this tree). Lour, coch. p. 143. D. C. prod. 4. p. 340 .

LiN. syst. Pentándria, Monogýnia. Tube of calyx adnate 
to the ovarium; limb 5-tootled, erect. Corolla superior, salvershaped, with a woolly throat and a 5-parted limb: the segments lanceolate. Anthers 5, linear, inserted in the recesses between the segments of the corolla. Style equal in length to the stamens; stigma ovate-oblong. Berry ovate, umbilicate, I-seeded.-A large tree, with very durable wood and spreading branches. Leaves opposite, lanceolate, quite entire, glabrous. Racemes axillary, short, loose. Flowers white.

1 A. Cochincurve'nsis (Lour. l.c.) h.G. Native of Cochinchina. The wood of this tree is white and heavy, composed of thick fibres; and is used for the purpose of forming the foundation of bridges, being imperishable either by being under water or under ground.

Cochinchina Aidia. Tree large.

Cult. Any common soil will suit this tree ; and cuttings will be easily rooted if planted under a hand-glass.

XI. VALENTIA'NA (meaning unknown to us). Rafin. specch. 1. p. S7. D. C. prod. 4. p. 340 .

Lun. syst. Tetrándria, Monogínia. Tube of calyx adnate to the ovarium; limb 8-cleft. Corolla tubular: with a 5-cleft nearly equal limb. Stamens 4, epipctalous, nearly equal. Style filiform: stigma 2-lobed. Fruit 2-celled?-A twining slirub. Leaves opposite, petiolate, somewhat sagittate, a little serrated, acute. Flowers axillary, solitary, bibracteate; bracteas cordate, winged on the outside. - This genus is said by Rafinesque to be allied to Linnce' $a$, but the plant is wholly unknown to other botanists.

I V. volu'Bluss (Rafin. l. c.) $\eta$. 。 G. Native of Abyssinia.

Trining Valentiana. Slurub tw.

Cult. See Aidia, p. 452. for culture and propagation. The plant is well fitted for training up the rafter in a green-house.

XII. KARPA'TON (meaning unknown to us). Rafin. fl. lud. p. 78. D. C. prod. 4. p. 340 .

LiN. syst. Diándria, Monogýnia. Tube of calyx adhering to the ovarium; limb 4-toothed. Corolla tubular, 4-cleft, bilabiate. Stamens 2; anthers 2-lobed: lobes remote. Style under the upper lip of the corolla; stigma simple. Capsule crowned by the calyx, 1-celled? 4-seeded. Stem herbaceous? angular; branches fastigiate. Leaves opposite, sessile, oblong, hastate, unequally toothed at the base, acuminated, glabrous. Flowers small, sessile, disposed in whorls. According to the author it is allied to Dicrvilla, but the genus is entirely unknown to any other author.

1 K. hasta'tum (Rafin. l. c.) 4. H. Native of Louisiana. Anónyma, Rob. voy. p. 457 .

Hastate-leaved Karpaton. Pl.?

Cult. This plant will grow best in a border of peat earth, and may probably be increased by dividing at the root.

Order CXXX. RUBIA'CEA (this order contains plants agrceing with Rùbia in important characters). Juss. gen. p. 196. D. C. ann. mus. 9. p. 216. prod. 4. p. 341. prop. med. ed. 2. p. 168. Juss. mem. mus. 6. p. 365. Cham. et Schlecht. in S. F. 220. and 810 . and vol. 4. p. 1. 30. and 179.-Aparines, Adaus. fam. 2. p. 140.-Stellàtæ and Contórtæ genera of Lin.

Tube of calyx adlering to the ovarium (f. $94 . e$. f. $97 . g$.); limb variable, truncate (f. 93. a.), or of many lobes, usually regular; the sepals or lobes equal in number to the petals ( $f .84$. c.), very rarely intermixed with accessory teetl. Corolla gamopetalous, inserted in the upper part of the tube of the calyx, usually with a 4.5 lobed $\operatorname{limb}$ (f. 93.b. f. 84.c.), rarely with a 3 or 9 -parted limb (f. 101.b.); the tube cither short (f. 8. b.) or long (f. 92.c.); the lobes or segments twisted or valvate in æstivation. Stamens equal in number to the segments of the corolla, alternating with them, and more or less adnate to its tube (f. 83. g. f. 91. b.). Anthers oval, 2-celled (f. 111.c.), bursting inwardly. Ovarium situated within the calyx, and adhering to it (f. 94.e. f. 103.g.f.), usually 2 (f. 94. c.) or many celled (f. 103. g.), rarely 1 -celled by abortion : always crowned by a fleshy urceolus, or the limb of the calyx (f. 103. $f$.). Style one, rising from the urceolus (f. 83. $d$.); stigmas usually 2 , distinct (f. 105.c.), or more or less combined (f. 83. e.), rarely more than 2. Fruit baccate (f. 107. $h_{\text {. }}$ ), eapsular (f. 95. k.), or drupaceous (f.103. g.), 2 (f. 94.c.) or many celled (f. 103. g.); cells 1-2 or many seeded. The secds, where they are solitary in the cells, are sometimes fixed by the apex, but usually by the base; but where they are numerous in the cells, they are fixed to a central placenta, and are usually horizontal. Albumen large, horny or fleshy. Embryo straight, or a little curved, inclosed in the middle of the albumen; with a terete radicle turned towards the hilum; and foliaceous cotyledons.-Trees, shrubs, and herbs, with terete or tetragonal branches. Leaves simple, girded by a marginal nerve, and therefore quite entire, opposite or verticillate, always bistipulate. Stipulas variable in cohesion and form, interpetiolar or intrafoliaceous. Flowers arranged in various ways, but usually in panicles or corymbs, rarely unisexual by abortion.

This well marked order is nearly allied to Compósita, from which its distinct stamens, bilocular, and plurilocular ovarium and inflorescence, distinguish it, and consequently it participates in all the relation of that extensive order. From Apocynece in the astivation of the corolla, the presence of stipulas, and the inferior ovarium distinguish it, yet, according to Mr. R. Brown, there exists a genus in equinoxial Africa which has the interpetiolar stipulas and seeds of Rubiàcece and the superior ovarium of Apocynca, thus connecting these two orders, Congo, $\mathrm{p}$. 44.8. There is a striking affinity between Rubiàcece and Caprifoliàcece in the monopetalous tubular corolla, definite stamens, inferior ovarium, and opposite leaves, which is confirmed by the corolla of the latter being occasionally regular or irregulir. The tribe Opercularièce, referred to this order by Mr. R. Brown (Congo, p. 447.) and others (A. Rich. elem. ed. 4. p. 483.), is remarkable for having but $\mathrm{I}$-seed, and the number of stamens unequal to the lobes of the corolla, and therefore occupies an intermediate station between the Rubiàcece and Dipsàcece. The tribe Stellatce is distinguished from the rest of the order in the stipulas being as large as the leaves, and of the same form and consistence, having from 1-3 between each leaf on both sides, forming with them a kind of star or whorl, from which circumstance the name stellate is applied. The leaves in this tribe can only be distinguished from the stipulas by the axillary buds.

Powerful febrifugal or emetic qualities are the grand features of this order, the most eflicient products of which in these two respects are Quinquina and Ipecacuanta. The febrifugal properties depend upon the presence of a bitter tonic astringent 
principle, which exists in great abundance in the bark; those of Cinchòna are known to depend upon the presence of two alkalies, called cinchonine and quinine, both of which are combined with kinic acid; two principles which, though very analogous, are distinctly different, standing in the same relation to each other as potass and soda. Turner, p. 648. Dr. Sertürner has obrained some other vegato-alkalies from Cinchòna, one of which he calls chinioidia. Brande, journ. 12. p. 417. new series. The existence of this is denied by M. M. Neury and Delondre, ibid, July, 1830, p. 442. A detailed account of the qualities, synonymes, and commercial names of the species of Cinchiona is given in Mr. Lambert's work on the genus Cinchòna, 4to. London, 1821. In the same work is the translation of Baron Humboldt's account of the Cinchòna forests of South America. Three species of Cinchona, the C. forruginca, C. Vellosii, and C. Remijiana, are found in Brazil, where they are used for the same purposes as the Peruvian bark, to which, however, they are altogether inferior. St. Hil. pl. usuel. bras. no. 2. The French Guiana bark possesses properties analogous to those of Cinchòna, and is obtained from Portlándia hexándra the Coutàrea spcciòsa, Aublet. Humb. cinch. forest. p. 43. The Quinquina Pitou and Quinquina des Antilles are produced by species of the genus Exostémma, and are remarkable for possessing properties similar to those of the true Quinquina, but without any trace of either cinchonine or quinine. St. Hil. pl. usuel. bras, no. 3. $A$ kind of fever-bark is obtained at Sierra Leone from Rondeletia febrifuga. Besides, there are a great number of other species possess barks more or less valuable. Pinclknèya pùbens is the fever-bark of Carolina; Condaninca corymbòsa, Isértia coccinca, Antirlec'a, and Morinda Ròyoc, are all of the same description. A lightish brown, bitter, and powerfully astringent extract, called Gambier, is obtained at Malacea by boiling the leaves of Naiclea Gambir; it is sometimes substituted for gum-kino, Ainslie, 2. p. 106. A decoction of the leaves, as well as the root, of Canthium parviflorum, is prescribed in India in certain kinds of flux, and the last is supposed to have anthelmintic properties, though neither has much sensible taste or smell. The bark and young shoots are also used in dysentery. Ainslie, 2. p. 63. Among the emetics, Ipecacuanha holds the first rank; it is the root of Cephaelis Ipecacuànlıa, a little creeping-rooted half-herbaceous plant, found in damp shady forests of Brazil. Similar properties are found in the roots of other $R u$ biaccous plants of the same country, as in Richardsònia ròsen and $R$. scìbra, Borriria ferrugínea and $B$. Por̀ya, Sc. A peculiar alkaline principle, called emetia, is found in Ipecacuanha, which contains 16 per cent, of it. Turner, p. 653. The Raiz Preta, which is celebrated for its power in curing dropsy, and in destroying the dangerous consequences of bites of serpents, is said to be related to Ipecacuanha. Edinb. phil. journ. 1. p. 218. Several species of Psychótria, as P. emética, \&c. and Gcóplila rcnifórmis, are substitutes for I pecacuanha. The spurious barks called Quinquina Pitou, are capable of exciting vomiting. The powdered fruit of Rándia dumctòrum, is a powerful emetic. An infusion of the bark of the root is administered to nauseate in bowel complaints. Ainslie, 2.p. 186. According to Roxburg, the root bruised and thrown into ponds where there are fish, intoxicates them, as Cócculus I'ndicus. Ainslie, 2. p. 186. Psychótria Nóxa and Palicoùrea Maregràvii, both called Erva de rata, are accounted poisonous in Brazil; but nothing very certain seems to be known of their properties. Edinb. phil, journ. 14. p. 267. The root of Morinda umbellàta in the Moluccas, and that of $M$. citrifolia in India, is used for dyeing red and brown; and the bark of $M$. Róyoc for ink. The leaves of Oldenlandia umbellàta are considered by the native doctors of India as expectorant; and the root is employed in India for staining nankeens. Ainslie, 2. p. 101. Coffee is the roasted seeds of a plant of this order, Coffèa Arábica, and is supposed to owe its characters to a peculiar chemical principle called coffein. Turner, p. 699. The part roasted is the albumen, which is of a hard horny consistence; and it is probable that the seeds of most of the plants of the present order, whose albumen is of the same texture, would serve as a substitute. This would not be the case with those with fleshy albumen. The fruit of some Gardènias Génipa and of Vanquèria, the Voa Vanga of Madagascar, and Sarcocéplialus esculéntus, are succulent and eatable. The root of Rùbia tinctoria, the madder, is one of the most important dyes with which we are acquainted; a quality in which the roots of many other plants belonging to the tribe Stellate participate in a greater or less degree. The roots of Rùbia Munjista yield the madder of Bengal. Ainslie, I. p. 203. The torrefied grains of Galium are said to be a good substitute for coffee. The flowers of Gàliun vèrum are used to curdle milk. An infusion of Aspérula cynánchica has a little astringency, and has been used as a gargle. Aspérula odoràta, or Hoodruff, is remarkable for its fragrance when dried; it passes for a diuretic. Rübit Nóxa is said to be poisonous.

Opposite leaves, with intervening stipulas, a monopetalous corolla, with a definite number of stamens, are the great cliaracteristics of Rubiàcce; an order of such extent, that it embraces a very large proportion of the whole phenogamous plants, including within its limits bumble weeds and lofty trees. Among them the plants of beauty or value are innumerable; of the former description the genera Ixòra, Bouvárdia, Catesbe'a, Portlándia,Cardènia, Hamètia,Cephè'lis, Augústea, and many others, are notable examples.

\section{Synopsis of the genert.}

\section{A. Cells of fruit many-sceded. \\ Tribe I.}

Cinchona'cex. Fruit eapsular, 2-eclled; eells many sceácd. Sceds ninged.-.Trecs or slirubs. Stipulas interpetiolar.

Subtribe I. Naucle'es. Flowers capitate, scssilc, upon a globose receptacle (f. $83, e$, f. $84 . k$.).

1 Naúclea. Tube of calyx oblong; limb truncate or 5toothed (f. 83. b.), with linear lobes. Corolla funnel-sliaped ( $\mathrm{f}$. 83. c.), with a slender tube and naked throat. Stigma tumid, undivided (f. 83, d.). Capsules sessile, not attenuated at the base.

2 Unca'ria. All as in Naúclea, but differs in the flowers being scattered on the receptacle. Calyx urceolately $5 \cdot$ cleft. Capsules pedicellate, clavate, attenuated at the base. 
3 Adind. Tube of calyx oblong ; limb campanulate, 5 -parted (f. 84. a.), permanent. Corolla funnel-shaped, 5-lobed (f. (f. 84. b. c.), with a naked throat and valvate lobes. Anthers almost sessile (f. 84. c.), inclosed. Stigma capitate (f. 84. b.). Capsules membranous, 4-valved (f. 84. g.), pyramidal. Seeds 2-4 in each cell.

4. Breo'nia. Limb of calyx 5-parted. Corolla with a terete tube, and a flat, 5-lobed, spreading limb. Stamens inserted in the throat, half-exserted. Style very long: stigma bipartite. Ovarium 2-celled; cells 7-8-ovulate: ovula fixed to membranous placentas, and langing from the axis.

5 Lecanántrus. Limb of calyx campanulate, coloured, irregularly divided. Corolla with a short tube, and a 5-lobed limb. Antliers large, inserted in the tube. Style bifid; stigmas linear. Ovarium 2-celled; cells many seeded. Placentas semicylindrical.

Subtribe II. Cincho'nes. Floners morc or less pedicellate, never scatcd on a globose receptacle.

6 Steve'xsia. Calyx girded by a 4-lobed involucel; limb bipartite, deciduous. Corolla salver-shaped, with a short tube, and a bluntly 6-7-parted limb. Anthers 6-7, sessile in the throat. Capsule globose, areolate at the apex. Seeds a little winged, pubescent at the top.

7 Couta'rea. Limb of calyx 6-parted. Corolla funnelshaped, with a short tube, and a bluntly 6-lobed limb. Stamens inserted in the bottom of the throat; anthers linear, exserted. Capsule obovate, compressed; valves bifid at the apex. Wings of seeds membranous.

8 Híllia. Calyx girded by a 4-leaved involucel; limb 2-4parted, permanent. Corolla with a long tube (f. 85.6 .), and a 4-6-parted limb (f. 85. b.). Stamens 4-6, inclosed, sessile beneath the throat (f. 85.e.). Capsule elongated, crowned. Seed ending in a pencil-formed tail (f, 85.e.).

9 Hymenópogon. Limb of calyx 5-parted, permanent. Corolla salver-shaped, with a very long tube, and a 5 -parted limb. Stamens 5, inclosed, inserted in the top of the tube, which is inflated. Capsule oblong, clavate, 10-nerved, crowned. Seeds appendiculated at both ends.

10 Cincho'na. Calyx 5-toothed (f. 86, a.). Corolla with a terete tube, and a 5 -parted limb (f. $86 . b$.), which is valvate in astivation. Anthers linear, inserted in the middle of the tube (f. 86. a.), a little exserted. Capsules dehiscing at the valves, crowned. Seeds girded by a membranous lacerated wing.

11 Cosmbue'na. Calyx 5-toothed. Corolla with a long tube, and a 5 -lobed limb, which is valvate in astivation. Anthers oblong, exserted. Stigma bipartite. Capsule somewhat 4-valved, dehiscing from the apex. Seeds girded by a lacerated wing.

12 Lastone'ia. Calyx 5-toothed. Corolla tubular, with a 5 -lobed limb, which is imbricate in restivation. Stamens exserted; filaments bearded in the middle. Anthers roundish, peltate. Stigma 2-lobed. Capsule 2-celled, dehiscing in the middle of the cells, many-seeded. Seeds small, sameroid.

13 Lucu'sı. Calyx 5-toothed (f. 87, c.), deciduous: lobes foliaceous. Corolla with a longish tube, and a 5-lobed expanded limb, which is imbricate in astivation. Stamens almost inclosed (f. 87. a.); anthers linear. Stigma 2-parted (f. 87. b.). Capsule dehiscing at the dissepiment from the apex. Wings of seed jagged.

14. Hyanony'ction. Calyx 5-tuothed. Corolla tubular, with a 5 -cleft limb, which is valvate in estivation. Stamens exserted; anthers pcltate. Capsule not crowned, dehiscing at the dissepiment. Wing of seeds bifid at the base.

15 Exoste'ma. Calyx 5-toothed. Corolla with a terete tube, and a 5-parted limb, which is plicate in æestivation. Anthers linear, exserted. Capsules crowned, dehiscing at the cells. Seeds girded by a membranous entire border.

16 Dana's. Flowers dioecious from abortion. Limb of calyx 5-toothed. Corolla funnel-shaped, with a slender tube, a villous throat, and a spreading 5 -parted limb. Stamens exserted in the male flowers, and in the female inclosed and abortive. Style bifid at the apex. Capsule globose. Seed girded by a membranous border.

17 Mane'ttia. Limb of calyx 4-5-lobed (f. 88. d.). Corolla funnel-shaped (f. 88. b.), with a terete tube, a hairy throat, and a 4. (f. 88, b.) -5-lobed limb. Anthers sessile in the throat. Capsule ovate, compressed (f. 88. d.), crowned. Seeds peltate, girded by a usually toothed border.

18 Bouva'rdia. Limb of calyx 4-parted (f. 89. $a . b$. ). Corolla funnel-shaped, tubular (f. 89.c.), with a 4-parted (f. 89. a.) spreading short limb. Stamens adnate at the base to the tube, but free above the middle. Anthers linear, inclosed. Capsule membranous, globose, compressed. Seeds girded (f. 89. a.) by a membranous border.

19 Pinckne'ya. Calyx 5-parted; the fifth lobe expanded into a coloured leaf. Corolla with a cylindrical tube, and a 5-cleft limb, which is valvate in æstivation. Stamens inserted at the base of the tube, exserted; anthers peltate. Capsule compressed, 2-celled, dehiscing at the dissepiment. Seeds surrounded by a wing, which is emarginate at the base.

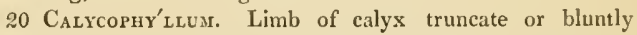
toothed; one of the teeth expanded into a membranous stalked coloured leaf. Corolla campanulate or funnel-shaped; limb 5parted. Stamens rising from the throat; anthers oval, exserted. Style ending in 2 reflexed stigmas. Capsule oblong. Seed fixed to the linear placentas, girded by a narrow wing.

\section{Tribe II.}

Gardenia'cere. Fruit indehiscent (f. 94. b.), fleshy, usually 2-celled, rarely 1-celled by abortion. Sceds not winged. Albumen fleshy. - Trees or shrubs, with oppositc leuves, and interpetiolar stipulas.

Subtribe I. Sarcocepha'les. Flomers sessile, collected into a head (f. 90. a. b.) upon the receptacle. The fruit combined together into one (f. 90. b.c.).

21 Sarcoce'puarus. The calyxes are closely joined together into a globose fleshy head (f. 90. 6.); limb of calyx with a very sliort margin. Corolla funnel-shaped, 5-cleft. Anthers 
sessile in the throat. Stigma undivided. Berries many seeded. Seed small, somewhat reniform.

22 Zuccarínia. Limb of calyx 5-toothed. Corolla tubular: limb 5-lobed, erect. 'Anthers 5, linear, inclosed, adnate between the lobes of the corolla. Stigma bifid. Berries owal, stipitate, crowned by the calyx. Seed compressed, 2 rows in each cell.

23 Lucines'a. Flowers combined into a dense head. Margin of calyx entire. Corolla funnel-shaped, 4-parted, densely villous inside. Stamens shorter than the corolla; anthers linear. Stigma bifid. Berries joined together, many seeded. Seeds angular.

24. Canépilora. Limb of calyx 5-6 toothed. Corolla with a somewhat campanulate tube, and a 5-6-lobed limb. Anthers 5-6, oblong, almost sessile, inclosed. Stigma bifid. Fruit baccate? 2-celled, many seeded. Ovula imbricate, inserted in spongy axillary placentas; but according to Rich the fruit is peashaped, 2-seeded, and crowned by the calyx.

Subtribe II. Gardenie's. Floners distinct, not joined together into a head.

25 Burchéclia, Limb of calyx drawn out beyond the ovavium, 5-cleft (f. 91, a.) beyond the middle. Corolla clavately funnel-shaped (f. 91.b.); throat naked: lobes imbricated, and twisted in æstivation. Filaments adnate to the tube (f. 91.b.) at the base; anthers inclosed. Stigma bearing 5 convex crests on the outside, and tufts of hairs. Berry crowned by the calyx, turbinately globose. Placentas adnate to the dissepiment. Seeds angular. Flowers capitate.

26 Anaiou'A. Limb of calyx 6-toothed. Corolla salvershaped, with a terete tube, which is longer than the calyx, and a 6-parted spreading limb. Anthers 6, inclosed, linear. Stigma clavate. Berry obovate-oblong, 2-3-celled. Seeds disposed in 2 rows in each cell, nearly orbicular, separated by the horizontal dissepiments.

27 MussiénDA. Limb of calys 5-parted, deciduous, one of the outer lobes usually drawn out into a large petiolate coloured leaf. Corolla funnel-shaped, with a 5 -parted limb and a villous throat. Anthers 5, sessile, linear. Stigma bifid. Fruit ovoid, fleshy, indehiscent, many seeded. Sceds scabrons. Placentas rising from the middle of the dissepiment, pedunculate, bifid at the apex. Flowers corymbose.

28 Котсниве'А. Limb of calyx truncate. Corolla with a cylindrical tube, much longer than the calyx, a villous throat, and an 8-parted limb: lobes twisted in æstivation. Anthers 8, oblong-acute, almost sessile among the villi in the throat. Stigma clavate, hairy on the outside. Flowers subcorymbose.

29 Cassu'Pa. Limb of calyx short, entire. Corolla tubular, rugged on the outside, with a villous throat, and a 6-parted limb. Anthers 6, oblong, nearly sessile, inserted among the hairs in the throat. Stigma bifid. Berry globose, crowned, many seeded. Placentas fixed to the middle of the dissepiment.

30 Grnopa'chys. Limb of calyx urceolate, entire, deciduous. Corolla with a short tube, a 5-parted spreading limb, and a bristly throat. Stamens 5 , inserted in the mouth of the tube; anthers linear, exserted. Berry globose, umbonate, many seeded. Placentas stipitate, rather fleshy. Seeds compressed.

31 Tocoy E's A. Limb of calyx very short, 5 -toothed. Corolla with a very long tube, a naked dilated throat, and a spreading 5-parted limb. Anthers linear-sagittate, rising from the throat, exserted. Style fusiform at the apex. Berry rather fleshy, crowned. Seeds numerous, imbedded in soft pulp.

32 Posoquéria. Limb of calyx short, 5-toothed. Corolla funnel-shaped, with a very long terete tube, a villous hardly dilated throat, and a 5 -parted spreading limb. Stamens 5 , rising from the throat, free, a little exserted. Style filiform, bifid at the apex. Berry ovate, crowned, succulent, many seeded.

33 Oxy A'ntuus. Limb of calyx acutely 5-toothed (f. 92.a.). Corolla with a very long slender tube (f. 92. c.), a glabrous throat, and a regular 5-parted limb (f. 92.d.). Stamens 5, exserted (f. 92. $f$.), free at the throat; anthers acute. Style clavate at the apex (f. 92. $c$.). Fruit baccate.

34. Struocory'na. Limb of calyx 5-toothed Corolla salver-shaped or funnel-shaped, with a cylindrical tube, and a 5 -parted limb. Stamens 5, inserted in the mouth of the corolla; anthers linear, very long. Stigma clavate (f. 92. g.). Berry globose, crowned by the calyx, almost dry. Placentas spongy, adnate to the middle of the dissepiment on both sides. Seeds angular.

$35 \mathrm{GE}^{\prime}$ Nipa. Limb of calyx truncate or subdentate. Corolla salver-shaped, the tube not exceeding the calys, and the limb large and 5-parted. Anthers linear, exserted, sessile in the throat. Stigma clavate. Berry corticate, somewhat 4-celled, attenuated at both ends, crowned by the tubular calyx. Seeds many, horizontal, imbedded in pulp.

36 Garde'nia. Limb of calyx truncate or toothed (f. 93. $a$.). Corolla funnel or salver-shaped (f. 93. b.), having the tube much longer than the calyx; limb twisted in restivation (f. 93. c.), 5-9-parted, spreading. Anthers 5-9, linear, nearly sessile in the throat. Stigma clavate, bifid. Berry fleshy, crowned by the calys, incompletely $2-5$-celled. Seeds minute, immersed in the fleshy parietal placentas.

37 RÁnDIA. Limb of calyx 5-lobed. Corolla salver-shaped, with a slort tube, and a 5 -parted limb. Anthers inclosed, sessile, within the throat. Stigmas 2. Berry nearly dry, crowned by the calyx, many seeded. Seeds fixed to the central placenta, imbedded in the pulp.

38 Chapelie'ria. Limb of calyx 5-parted, permanent. Corolla with a slender tube, a 5 -parted limb, and a villous throat. Stamens 5, nearly sessile, inclosed, inserted in the middle of the tube. Stigma bipartite. Fruit ovoid, rather flesliy, crowned by the erect, large, spreading limb of the calyx, many seeded. Seeds angular, and clothed with adpressed golken silky down.

39 Heíssia, Limb of calyx 5-parted, permanent. Corolla salver-shaped: tube terete, longer than the calycine lobes, very hairy in the upper part inside: limb 5-lobed: lobes undulated. Anthers 5, linear, sessile towards the top of the tube. Stigma: 
2, linear. Fruit globose, crowned, dry, hard. Placentas 2, thick, adnate to the dissepiment. Seed nestling on the superfices of the placentas.

40 Menestòria. Limb of calyx 5-parted. Corolla with a long terete tube, an almost naked throat, and a 5 -lobed limb. Anthers 5, oblong, sessile within the tube. Stigma bifid, incloserl. Fruit baccate, nearly dry, not crowned. Placentas adnate to the dissepiment, many sceded.

41 Helóspora. Limb of calyx campanulate, 4-toothed. Corolla with a longish tube, a naked throat, and a 4-jobed spreading limb. Antliers 4, linear, inclosed. Style 4-cleft at the apex. Berry crowned, tetragonal, not divided into cells, but liaving the seeds immersed in the pulp, and disposed crosswise in a double series.

42 Hipro'tis. Limb of calyx sheath-formed, cleft on one side, and drawn out into a mucronate auricle on the other. Corolla funnel-shaped, with the tube a little incurved, and the limb blunt and 5-lobed. Stamens inserted in the middle of the tube; anthers ovate, inclosed. Ovarium girded by a 5 -crenate urceolus. Stigma of 2 adpressed lobes. Berry ovate, crowned. Seeds numerous, minute.

4.9 Poma'tiun. Limb of calyx bluntly 5 -toothed : the teeth deciduous. Corolla small, with a terete tube and a 5-parted limb. Anthers ovate, sessile in the throat, inclosed. Stigma bifil. Berry nearly dry, globose, subrlidymous, crowned by the remains of the calyx, many seeded. Placentas rather tumid. Seed angular.

44 Bertiéra. Limb of calyx short, 5-toothed, permanent. Corolla funnel-shaped, with a terete tube and a 5-parted spreading limb. Anthers 5, sessile within the throat. Stigma bifid. Berry nearly dry, crowned, roundish, many seeded. Seeds fixed to the central placentas, angular, muricated.

45 Pouche'tia. Limb of calyx small, 5-toothed. Corolla with a short obconical tube and a 5 -lobed limb, which is twisted in astivation. Anthers 5, linear, sessile in the tube. Stigmas 2, exserted a little. Berry dry, obovate, crowned. Seeds 4-6 in each cell, deformed, clothed with silky down.

4.6 Cu'pia. Limb of calyx 5-parted, permanent. Corolla funnel-shaped, with a terete tube, which is a little longer than the calyx, and gradually widening to the throat; and a 5-parted recurved limb. Filaments very short; anthers oblong. Style 2-lobed at the apex, or 10-angled. Berry globose, crowned. Placentas spongy, central, few-seeded at maturity. Seed angular, wrinkled at the hilum.

47 TARE'NNA. Limb of calyx 5-parted, permanent, reflexed. Corolla unknown. Berry globose, $\delta$-striped, crowned. Placentas central, spongy. Seed $\$-6$ in each cell, horizontal, semilunate, rugged.

48 Pete'sia. Limb of calyx short, 4-5-toothed. Corolla funnel-shaped, with a 4-5-cleft equal limb. Stamens $4-5$ within the tube. Berry nearly globose, naked at the apex, many seerled. Seeds ratlier angular.

49 Coccocy'pselum. Limb of calyx 4-parted (f. 94. d. a.), permanent. Corolla funnel-shaped, with a 4-parted limb and a glabrous throat. Stamens 4. (f. 94, b.), inserted in the tube; vol. III. anthers oblon:, heart-sliaped, inclosed. Stigma bifid. Berry ovate, crowned (f. 94. d.), many seeded. Seeds angular.Creeping herbs.

50 Ferne'lia. Limb of calyx 4-cleft. Corolla small, with a short tube and a 4-lobed spreading limb. Stamens 4, inserted in the tube, almost inclosed. Stigma bifid. Berry crowned, having the dissepiment incomplete. Seeds numerous, rather compressed.

51 Petu'nga. Limb of calyx 4-toothed, permanent. Corolla funnel-shaped, with a short obconical tube, a 4-parted limb, and a villous throat. Stamens 4 , a little exserted. Style villous ; stigma bidentate. Berry globose, umbilicate. Seeds $2-4$ in each cell, fixed to the upper part of the dissepiment, ex Rosb. ; but according to Blume scale-formed, and imbricated downwards.

52 Higgr'nsia. Limb of calyx 4-toothed, permanent. Corolla funnel-shaped, somewhat campanulate, with a short tube, a $t$ parted spreading limb, and a naked throat. Stamens inserted in the middle of the tube; anthers ovate, inclosed. Stigmas:, exserted. Berry oblong, somewhat tetragonal, crowned, many seeded. Placentas adnate to the dissepiment.

53 Hofmánnia. Limb of calyx 4-toothed: tube tetragona!. Corolla salver-shaped, with a very short tube and a 4 parted limb. Anthers 4, linear, acute, sessile on the upper part of the tube, conniving. Stigma obtuse, hardly emarginate. Capsule baccate, indehiscent, crowned. Placentas ovate, distinct in each cell. Seeds minute, numerous.

54. Cатеsвż́A. Limb of calyx 4-toothed or 4-parted. Corolla funnel-shaped, with a very long tube, which is gradually dilated to the throat; and a 4-lobed limb. Stamens 4, inserted in the bottom of the corolla; anthers linear, exserted. Stigma bidentate. Berry globose or oblong, crowned. Placentas spongy, fixed to the top of the dissepiment. Seeds numerous, scale-formed, collected into two fascicles in each cell.

\section{Tribe III.}

Hedyotíne.e. Fruit capsular (f. 95.k.), 2-celled, dehiscing at the cclls; and rather membranous and indehiscent; cells manyseeded. Seeds not ninged._-Shrubs or herbs, nith opposite leaves. Stipulas interpetiolar.

Subtube I. Rondeletie's. Stipulas trin on both sides, combincl or distinct, but neither sheathed nor divided into many bristlcs. - Trecs or shrubs.

55 Condaninea. Calyx campanulate (f. 95. a.), 5 crenate or 5-toothed; limb deciduous. Corolla funnel-shaped (f. 95.6.), with a somewhat curved tube, which is a little longer than the calyx, a dilated throat, and a 5 -parted $\operatorname{limb}($ f. 95 . b.). Stamens inserted above the middle of the tube (f. $95, e$.), or near the throat; anthers oblong-linear, bifid at the base (f. $95 . f$. ), length of corolla. Stigma 2-lobed (f, 95.e.). Capsule turbinate, truncate, opening in the middle of the cells (f. $95 . k$.). Seeds wedgeshaped (f. 95.l.).

56 Alse'is, Limb of calyx superior, 5-parted. Corolla cup$3 \mathrm{~N}$ 
shaped, with a 5-lobed limb and a bearded throat. Stamens 5 , free to the base of the corolla, exserted. Stigma divided. Ovarium 2 -celled, many ovulate.

57 Macrocne'mum. Limb of calyx minute, 5-toothed, permanent. Corolla tubular, with a widened throat and a 5-lobed limb; tube pentagonal at first. Stamens 5 , free from the corolla, except at the very base, hairy above the midule; anthers oblong, inclosed. Stigma obtuse, 2-lobed. Capsule 2-valved ; valves dehiscing at the sides. Seeds acute, imbricated.

58 Chimárлus. Limb of calyx almost wanting, entire. Corolla with a short tube and a 5 -cleft spreading limb: lohes hairy in the middle outside. Stamens 5 , inserted at the top of the tube, hairy at the base; anthers oval. Capsule obovate or turbinate, crowned; valves semibificl. Seeds many.

59 Augu'stea. Limb of calyx 5-parted. Corolla funnelshaped, much longer than the limb of the calyx; tube widened at the apex, a little incurved; limb 5-parted, spreading. Anthers 5 , sessile in the sinuses of the corolla, and shorter than its lobes. Style hairy at the base; stigma bifid. Capsule oblong, separable from the calyx, and naked at maturity, but crowned. Seeds many, tetragonal.

60 Portiándia. Limb of calyx 5-parted; tube 5-nerved. Corolla large, funnel-shaped, with a short tube, a wide throat, and a bluntly 5 -lobed limb. Stamens 5 , inserted in the bottom of the throat; anthers long, a little exserted. Stigma undivided. Capsule obovate, crowned, and retuse at the apex; valves dehiscing at the apex. Placentas coriaceous, central. Seeds scabrous.

61 Ві́кла. Calyx with an 8-ribbed tube, and a 4-parted limb. Corolla clavate, tetragonal, with a 4 -cleft limb. Anthers 4, linear, not exceeding the limb. Capsule ovate, at length separating from the calyx, 2-celled or nearly 4-celled; valves bifid at the apex. Placentas narrow. Seeds small, crested on the margins.

62 Isino'rea. Limb of calyx 5-parted. Corolla tubular, pentagonal, with a naked throat, and a 5 -cleft limb. Stamens inserted in the very base of the corolla, and equal in length to it, monadelphous and hairy at the base; anthers oblong, obtuse. Stigma bilamellate. Capsule nearly globose, pentagonal, truncate at the apex, crowned. Coccula dehiscent, many seeded. Seeds angular, furnished with a cup-formed membrane at the base.

63 Sinllanza'nia. Limb of calyx 5-parted, permanent, longer than the tube of the corolla. Corolla with a slender tube, a naked throat, and a 5 -lobed limb. Stamens 5 , free from the throat, exserted; anthers oblong. Stigmas 2, slender. Capsule ovate-globose, ribbed, crowned; valves semibifid. Placentas adnate to the dissepiment. Seeds tubercular.

64. Rondelétia. Limb of calyx 4-5-parted, permanent. Corolla with a cylindrical tube and a 1-5-lobed spreading limb. Anthers 4-5, sessile on the top of the tube, inclosed. Stigma bifid. Capsule globose, crowned; valves cleft in the middle. Placentas central. Seed angular, few in the cells at maturity.

65 WENDLA'NDIA. Limb of calyx very slort, permanent, 4-j-toothed. Corolla with a terete tube, which is longer than the calyx, and a 4-5-loberl spreading limb. Stamens 4-5, ris- ing from the top of the tube; anthers oblong, exserted. Stigma bifid. Capsule ovate-globose, crowned; debiscing at the cells at top, many seeded.

66 Халтhорну'тum. Limb of calyx 4-5-cleft. Corolla funnel-shaped, with a short tube, a villous throat, and a 4-5cleft spreading limb. Stamens 4-5, exserted, inserted in the throat, connivent. Style perforating the disk of the ovarium. Stigma 2-lobed, gaping. Drupe didymous, crowned, divided into 2 many seeded cells. Placentas prominent, fixed by the middle on both sides. Seeds angular, minute.

67 Carpha'lea. Limb of calyx 4-parted, permanent. Corolla with a long filiform tube, a ventricose hairy throat, and a 4-parted limb. Anthers oblong, almost sessile, inclosed. Stigma bifid. Capsule crowned, dehiscing at the cells; valves semiseptiferous; cells many seeded.

68 Sipa'nea. Limb of calyx 5-parted, permanent. Corolla with a long terete tube, a bearded throat, and a 5-parted limb. Anthers 5, sessile, inclosed. Stigma bifid. Capsule subglobose, crowned, dehiscing at the cells. Placentas central, fleshy. Seeds numerons, minutely tubercular. Annual herbs.

69 VIRE'cta. Limb of calyx divided into 5 setaceous lobes. Corolla funnel-shaped, with an obconical tube, a naked throat, and having the limb divided into 5 linear-oblong ciliated lobes. Stamens 5, much exserted; anthers linear, oscillatory, bifid at the base. Stigma undivided. Capsule globose, deliscing at the cells, at first crowned. Seeds numerous, 4-5-sided, a little muricated. Hairy half herbaceous plants.

70 Ophioriiza. Limb of calyx 5-cleft, permanent. Corolla tubular, funnel-shaped, 3 times longer than the limb of the calyx, hairy inside: with a 5-lobed limb. Stamens 5, inclosed. Style girded by an urceolus at the base. Stigma 2-lobed. Capsule compressed, 2-lobed, crowned, dehiscing by a transverse chink at the apex. Placentas exserted from the dissepiment. Seeds numerous, hexagonal.-Herbs.

71 Argostémina. Limb of calyx 3-4-5-toothed. Corolla rotate, spreading, 3-5, rarely 3-4-parted. Stamens alternating with the lobes of the corolla. Anthers large, exserted, cohering at the apex. Style perforating the fleshy disk; stigma globose. Capsule crowned, dehiscing radiately at the apex. Placentas convex, adnate to the dissejiment. Seeds numerons, angular.Herbs.

72 Spiradiclis. Limb of calyx 5-toothed. Corolla with a short tube and a 5-parted spreading limb. Stamens 5, inclosed. Style girded by 4 glands. Stigma 2-lobed, gaping. Capsule oblong, crowned; valves bipartite. Seeds numerous, angular. An herb.

73 Tu's. Limb of calyx 5-toothed. Corolla with an oblong tube, and a 5-cleft toothed curled limb. Anthers inclosed. Capsule many seeded.-A procumbent herb.

74. Dentélla. Limb of calyx 5-cleft. Corolla funnelshaped, 5-cleft, with a hairy throat; lobes furnished with one tooth on each side. Anthers 5, inclosed, nearly sessile. Stigmas 2. Capsule or berry dry, almost indehiscent, nearly globose, crowned. Placentas fleshy, prominent on both sides within the cells. Seeds small, ovate.-Creeping herbs. 
75 Dé PPEA. Teeth of calyx 4, short, triangular. Corolla rotate, glabrous. Anthers 4, linear, exserted. Style exserted. Capsule membranous, ellipsoid, crowned, 2-celled, and dehiscing at the cells; cells 1 -sceded.-A shrub. Stipulas triangular, deciduous. Flowers cymose.

Subtribe II. Hedyo'tex. Stipulas formed into a sheath on cach side, adnate to the petioles, and ending in many bristles at the anex.-Hcrbaceous or suffrutescent plants.

76 Hedyo'trs. Limb of calyx 4-toothed, permanent. Corolla tubular, with a bearded throat, and a 4 -cleft limb. Stamens exserted a little; anthers ovate-roundish, small. Capsule ovate, crowned, dehiscing at the cells. Seed numerous, minute, angular.

77 Oldenlándia, Limb of calyx 4-toothed, permanent. Corolla with a sloort tube, a 4-cleft limb, and a villous or glabrous throat. Stamens a little exserted; anthers ovate or orbicular. Stigma undivided or bifid. Capsule nearly globose, crowned, dehiscing at the vertex by a loculocudal chink. Seeds numerous, small, half immersed in a globose placentas.

78 Gonothe'cs. Limb of calyx short, truncate, somewhat 4-toothed. Corolla laving the tube inflated at the base, the throat villous, and the lobes keeled. Stamens inclosed. Stigmas 2, obtuse, sessile. Capsule compressed, furnished with a double wing on each side, which also runs down along the pedicel, crowned, dehiscing between the stigmas. Seeds numerous, small, serobiculate.

79 Конау'тін. Limb of calyx 4-toothed. Corolla with a long terete tube, and a 4-lobed limb: lobes cuspidate. Anthers sessile within the tube, inclosed. Style bifid at the apex. Capsule globose, crowned, dehiscing at the cells. Seeds numerous, small, half immersed in pits on the globose pedicellate placentas.

$80 \mathrm{KA}$ 'vua. Limb of calyx 4-cleft or 4-toothed. Corolla salver-shaped, with a long tube and a 4 -cleft linb. Anthers linear or oblong, nearly sessile within the throat. Style bifid at the apex. Capsule globose, crowned, dehiscing at the apex at the cells. Seeds numerous, small, angular, inserted on fungous placentas, which are fixed to the middle dissepiment.

81 A so'ts. Limb of calyx 4 -toothed (f. 96. a.), permanent. Corolla salver-shaped (f. 96. b.), with a 4-lohed limb, and an almost glabrous throat. Anthers inclosed or exserted (f. 96.c.). Stigma somewhat 2-lobed (f. 96.e.). Capsule ovate, crowned, dehiscing at the cells at the apex. Seeds 4-8 in each cell, rather angular.

82 Racilca'Llis. Limb of calyx 4-lobed, furnished with 1-3 teeth between each of the lobes. Corolla with a long terete tube, a slort spreading 4 -lobed limb, and a beardless throat. Anthers at the throat inclosed. Stigma 2-lobed. Capsule subdidymous, dehiscing at the cells, crowned. Seeds angular, 8-20 in each cell.

83 Lu'cra. Limb of calyx divided into 4 bifid teeth, permanent. Corolla with a very short tube and a 4-lobed limb. Stamens sliorter than the corolla. Style short, bifid. Capsule globose, didymous, dehiscing at the cells and near the dissepiment; hence it is somewhat 8 -valved at the top. Seed 2 in each cell, ex Spreng., 5-6, ex Rich.

84 ? Poxyre'mus. Limb of calyx 4-parted. Corolla with a very short tube, a bearded throat, and a 4 -lobed limb. Stamens 4, inclosed. Style undivided. Capsule orate, compressed, dehiscing at the cells. Placentas oblong, adnate to the bottom of the dissepiment. Seeds numerous, very minute, angular.

\section{Trlbe IV.}

Isertie'æ. Fruit drupaceous (f. 97.g.), composcd of from 2 to 6 many sceded pyrence or coccula (f. 97.f.). Albumen feshy. -Shrubs or herbs. Leaces opposite. Stipulas interpetiolar.

85 Metábolos. Limb of calyx 4, rarely 5-cleft. Corolla funnel-shaped, with a 4, rarely 5-parted limb. Stamens 4-5, inserted in the throat of the corolla. Stigma bifid or quadrifid. Berry dry, crowned, divisible into $2-4$ coccula. Sceds angular, fixed to the prominent placentas. - Suffrutescent herbs.

86 Gonza'lea. Limb of calyx 4-lobed. Corolla funnelshaped or salver-shaped, villous outside; with a long cylindrical tube, and a hairy or downy throat. Stamens 4, inclosed. Stigmas usually 4, adpressed to each other. Berry of 3-4 pyrenæ. Seeds angular, dotted, minute.

87 Isértia. Limb of calyx 4-6-toothed (f. 97. a.). Corolla with a long tube (f. 97.b.), 6-lobed at the apex (f. 97.c.), woolly iuside, having the recesses betwcen the lobes drawn ont into crests. Stamens 6, inclosed (f. 97. d.). Stigmas stellate. Berry globose (f. $97, g$. ), crowned (f. $97, h_{.}$), composed of 6 triquetrous pyrenæ $(\mathrm{f} .97 . f$.$) .$

\section{Tribe $V$.}

HАMеLiе'Æ. Fruit baccate, many celled (f. 98.f.h.); eclls many sceded. Albumenfleshy.-Shrubs or trees, with opposite or verticillate leaves, and interpetiolar stipulas.

88 TFPE'sia. Limb of calyx 5-toothed: teeth unequal. Corolla unknown. Berry oblong, crowned, 4-celled. Seeds numerous, imbedded in the pulp.

89 Evo'sura. Limb of calyx very slort, 4 -toothed (f. 98. a.). Corolla subrotate (f. 98. c.), 4-cleft. Stamens 4, inserted in the throat (f. 98 . b.) ; anthers ovate, inclosed, or nearly so. Stigma thick or 4-lobed. Fruit crowned (f. 98. g.), 4-celled (f. 98. h.)

$90 \mathrm{Sabi}$ 'cea. Limb of calyx 4-5-parted. Corolla salvershaped, with a long slender tube, a 4-5-parted limb, and a laairy throat. Stamens 4-5, inclosed, or nearly so. Style 4-5-lobed at the apex. Berry globose, crowned, 4-5-celled.

9 I Ozóstyla. Limb of calyx very short, 5-toothed. Corolla subrotate, with a short tube, which is pilose inside, and 4 reflexed lobes. Stamens 5, inserted in the throat; anthers linear, exserted. Style undivided. Berry crowned, 4-celled.

92 Axa'nthes. Flowers usually dioecious. Calyx with a quite entire border. Corolla rotate, with a short cylindrical tube, having 5 fascicles of hairs in the throat; lobes spreading. Stamens 5, inserted in the throat, hardly exserted. Stigma 5lobed. Berry globose, crowned, 5-celled. Placentas fleshy. $3 \times 2$ 
93 Urophy'zlum. Limb of calyx 5-cleft. Corolla funnelshaped, with a bearded throat and a 5 -parted limb. Stamens 5 , shorter than the limb; anthers linear. Stigma 5-lobed? Ovarium crowned by a glandular disk. Berry globose, 5 -celled.

94 HaME'L1A. Limb of calyx 5 -lobed (f. 99. a.). Corolla with a somewhat pentagonal tube, and a small 5-lobed hardly spreading limb (f. 99. c.). Stamens 5 , inserted in the tube (f. 99.b.); anthers oblong-linear (f. 99.f.), inclosed. Stigma pentagonal (f. 99,e.). Berry oval, 5-celled (f. 99. d.).

95 AluBe'rtia. Flowers unisexual. Calyx tubular, 5-toothed. Corolla tubular, with a 5 -parted spreading limb. Stamens 5 , nearly sessile, inserted in the tube; anthers linear, inclosed. Style undivided in the male flowers, but crowned by a 5 -lobed stigma in the female flowers. Berry globose, depressed, crowned, 5 -celled. Seeds wrapped in thin pulp.

96 Schrade'ra. Limb of calyx truncate or subdenticulated. Corolla funnel-shaped, with a terete tube, a dilated pilose throat, and a 5-8-lobed spreading limb, each lobe usually furnished on the inside with a retrograde callous tooth. Anther's 5-8, linear, nearly sessile, inserted in the throat, hardly exserted. Stigma bifid or quadrifid. Berry pea-formed, 3-4-sided, crowned, 2-4-celled. Seeds imbedded in the pulp.

97 Brigno'zia. Limb of calyx 4-toothed; teeth unequal. Corolla with a short tube, and a 6-lobed limb, which is very hairy inside as well as the throat. Stamens 6, inserted in the tube; anthers linear. Stigma capitate, undivided. Fruit globose, fleshy, crowned.

98 РАтімA. Limb of calyx tubular, with a sinuated, very short, 5-toothed border. Corolla tubular, 5-parted, densely clothed with silky down inside. Stamens 5 , inserted in the tube ; anthers oblong-cordate, inclosed. Style undivided. Berry roundish, crowned, 4.-6, but usually 5 -celled. Seeds fixed to a fleshy, 2-loberl placenta.

99 Polyphrágmon. Limb of calyx entire or 5 -toother. Corolla salver-shaped, bristly, with a terete tube, and a 10 parted limb. Stamens 10 , inserted in the middle of the tube; anthers linear, inclosed. Stigmas numerous. Berry globose, 10-20-celled, with 1 series of seeds in each cell.

100 MoRE'L1A. Limb of calyx erect, nearly entire. Corolla short, tubular, with a 5 -parted limb, which is imbricate in astivation. Stamens 5 , inserted in the throat, exserted; anthers linear. Style fusiform towards the apex; stigma bifid. Fruit fleshy, 4-5-celled: cells 2-3-seeded.

\section{B. Cells of fruit usually 1-secded, rarcly 2-seeded.}

\section{Tribe VI.}

Cordi'nex. Fruit baccate, of many cells; cells 1-sceded. Differs from the neighbouring tribes in the cclls being 1-secded. Shrubs with opposite lcaves, and broal interpctiolar stipulas.

101 Tricaly'sia. Flowers liermaphrodite.

102 Cordèra. Flowers unisexual.

\section{Tribe VIl.}

Guettand'cex. Fruit drupaccous (f. 101. d. f. 103.f.) composed of 2-5 1-seeded pyrence or nuts (f. 103. g.). Seeds terete, elongated, usually erect. Albumen fleshy.-Shrubs ar small trees. Leaves usually opposite, rarely 3 in a whorl, with interpetiolar stipulas.

Subtribe I. Moríndex. Floners and fruit congregated, or joined togcther into a hcad.

103 Morínda. Character the same as that of the subtribe.

Subtribe II. Guettárdex. Flowers distinct, not concrete. 104. Mrrmeco'dia. Limb of calyx tubular: with an entire border. Corolla funnel-shaped, 4-cleft, the throat closed fiom arched scales or hairs. Stigma simple (Jack.), or quadrifid (Blum.). Drupe baccate, composed of 4 triquetrous pyrenæ.

105 Hydorнy'тum. Limb of calyx entire. Corolla with a short tube, hairy inside, and a flat, 4-lobed limb. Stamens 4, inserted in the throat. Stigma 2-]obed. Drupe succulent, containing 2-pyrenæ.

106 HYpoba'thrum. Limb of calyx 4-toothed. Corolla small, subcampanulate, with a villous throat, and a 4-cleft spreading limb. Stamens 4, inserted in the mouth of the tube. Stigma bifid. Drupe crowned, a-celled; cells containing ? pyrena.

107 Nekte'ra. Limb of calyx small, 4-toothed. Corolla funnel-shaped, sub-campanulate, 4-lobed (f. 100. b.) glabrous inside. Stamens rising from the bottom of the corolla (f. 100 . c.), adnate to the tube; anthers roundish, liardly exserted. Stigmas 2 (f. 100 d.), hairy. Berry roundish, umbilicate, containing 2.4 pyrenæ. Herbs creeping.

108 Miтенés LA. Limb of calyx large, 4-toothed. Corolla funnel-shaped, with a terete tube: having the throat as well as the lobes hairy inside. Stamens adhering to the tube almost to the throat; anthers ovate, hardly exserted. Stigmas 4, inclosed. Berry nearly globose, crowned, containing 4 pyrenæ. Creeping herbs.

109 Mephitidia. Limb of calyx 3-6-parted or toothed. Corolla funnel-shaped, 4-6-cleft, usually hairy. Stamens 4-6, inserted towards the throat; anthers linear, exserted, or inclosed. Stigmas 4-9. Drupe baccate, crowned, containing 4-9 pyrenæ.

110 VAxque'ria. Limb of calyx spreading, 5-toothed, deciduous. Corolla campanulate, 5 -cleft, hairy in the throat; lobes reflexed. Stamens 5; anthers oblong, hardly exserted. Stigma capitate. Berry apple-formed, containing 5 pyrenæ.

111 Guettánda. Limb of calyx permanent or decidıous, truncate or irregularly toothed (f, 101, a.). Corolla salvershaped, with a cylindrical tube (f. 101.c.), and a 4-9-lobed limb (f. 101.b.). Anthers 4-9, inserted in the throat, sessile, inclosed. Stigma capitate, rarely 2-lobed, Drupe crowned

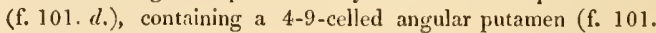
e.); cells 1 -seeded.

112 MaLA'Nea. Limb of calyx 4-toothed. Corolla small, nearly rotate, with a very short tube, and a 4-lobed spreading limb. Stamens exserted; anthers roundish. Drupe dry, crowned, containing a 2-celled putamen; cells 1 -seeded. 
113 Antiriac'A. Limb of calyx campanulate, 4-toothed. Corolla tubular, 4-cleft. Anthers nearly sessile in the throat, not exserted. Stigma bifid. Drupe sub-baccate, crowned, containing a 2-celled putimen; cells 1 -seeded.

114 Stenóstomum. Limb of calyx small, 5-toothed. Corolla funnel-shaped, having the tube widened at the throat, and a 5-lobed limb. Anthers 5, oblong, hardly exserted. Stigma 2lobed. Drupe ovate-oblong, crowned, containing a 2-celled putamen; cells 1 -seeded.

115 Chro'ne. Limb of calyx repandly 5 -toothed. Corolla tubular, short, 5-lobed. Stamens inserted in the top of the tube. Stigma 2-lobed. Fruit olive-formed, rather fleshy, containing a 2-celled bony nut; cells 1 -seeded.

116 Truo'nus. Limb of calyx ubular, trunoate, 2-6-toothed. Corolla tubular, salver-shaped, with a 4-6-parted spreading limb, and a naked throat Stamens 4, almost sessile, inserted in the upper part of the tube; anthers 4 , oblong-heart-shaped. Stigmas 2, digitately 5-cleft. Drupe globose, crowned, containing $7-25$ bony 1 -seeded nuts.

117 Haniltónia. Limb of calyx 5-parted. Corolla funnelshaped, with a long tube (f. 102. b.), and a 5 -lobed limb (f. 102 . c.). Stamens 5, inserted in the throat, inclosed. Stigma 5cleft. Capsule crowned, deliscing at the apex, containing 5 1-seeded pyrenæ.

118 LEPTODÉrits. Calyx inclosed by a 2 -leaved calyciform involucrum; limb 5-lobed. Corolla funnel-sliaped, scabrous, with a terete tube, which is pilose inside, and a 5 -lobed cuspidate limb. Stamens 5 , very short, inclosed. Stigma 5 -cleft. Fruit 5 -celled, 5 -seeded?

119 Psatun'ra. Limb of calyx campanulate, 5-6-toothed. Corolla bearded inside, with a short tube, and a 5-6-lobed spreading limb. Anthers 5-6, nearly sessile in the throat. Stigma 5-6-lobed. Berry globose, crowned, containing 6 pyrenæ.

120 Mronima. Limb of calyx small, bluntly S-toothed. Corolla with a short tube, and a 4-parted limb. Stamens 4 ; anthers oblong, exserted. Stigmas 4, approximate. Berry globose, not crowned, containing 4 pyrenæ.

121 Pyróstria. Limb of calyx 4-5-toothed. Corolla subcampanulate, 4-5-cleft; throat tomentose. Stamens 4-5, hardly exserted. Stigma capitate, bifid. Fruit pear-shaped, not crowned, containing 4-8 bony nuts.

122 Octa'via. Linb of calyx hardly any, truncate. Corolla unknown. Ovarium crowned by a fieshy disk, which is perforated in the middle. Drupe fleshy, globose, not crowned, containing 8 pyrenæ.

123 Litosa'xthes. Limb of calyx small, 4-tootled. Corolla globose, with a villous throat, and a short, spreading 4cleft limb. Stamens 4, inclosed; anthers linear. Stigma 4tootlied. Drupe succulent, obovate, umbonate, containing 4 nuts.

124 ERI'thals, Limb of calyx short, with a 5-10-toothed border. Corolla rotate, without a tube, 5-10-parted. Stamens $5-10$, hardly adnate to the corolla at the base; anthers linear. Stigma bilamellate. Drupe globose, crowned, containing 5-10 pyrenæ.
I25 Retiniphy'tuu. Limb of calyx 5.cleft. Corolla salvershaped, with a terete tube and a 5 -lobed spreading limb. Stamens 5, exserted; anthers oblong. Stigma undivided. Drupe globose, crowned, containing 5 nuts.

126 Nonate'lia. Limb of calyx 5-toothed, Corolla funnelshaped, with a somewhat gibbous tube, and a 5 -lobed limb. Stamens 5, almost inclosed. Stigmas 2. Drupe globose, crowned, containing 5 nuts.

127 Grnóchtodes. Limb of calyx short, quite entire. Corolla 4-5-parted, villous inside; lobes connivent below and spreading above, each furnished with an inflexed point at the apex. Stamens 4-5, inclosed, inserted in the base of the corollat. Stigma bilid, warted. Drupe globose, umbilicate, containing 4 pyrena.

128 Canospérmum. Limb of calyx quite entire, deciduous. Corolla with a short tube, and a 4-6-cleft, spreading limb. Stamens 4-5, exserted, inserted in the throat; anthers linear, incumbent. Stigma bifid. Drupe globose, umbilicate, containing 4 pyrenæ.

129 Ancyla'nthus. Limb of calyx 5 -parted (f. 103. a.). Corolla tubular (f. 103. b.), incurved; limb regular, 5-cleft (f. 103. c.); lobes cuspidate. Anthers 5, sessile in the throat (f. 103.e.). Stigma 5-lobed (f. 103. d.). Fruit 5-celled (f. 103. g.) ; cells 1-seeded.

130 Phalla'ria. Calyx with a globose tube, and an acutely 5 -toothed limb. Corolla tubular, 5-cleft; lobes spreading or reflexed. Anthers 5, ovate, at the throat. Style filiform, crowned by an elongated thick stigma. Ovarium 2-seeded.

131 Hyca'cium. Limb of calyx 5-toothed. Corolla funuelsloped, with a long tube and 5 roundish reflexed lobes. Anthers 5 , almost sessile in the throat. Style thick at the base, 5-furrowed. Stigma cylindrical, 5-furrowed. Drupe dry, containing a 2-celled rugged nut: one of the cells usually abortive.

132 Cuvie'ra. Limb of calyx 5-parted. Corolla campanulate, 5-cleft, spinescent at the apex. Anthers 5, at the throat, inclosed. Stigma clilated, with a reflexed margin. Fruit baccate, 5-celled; cells 1 -seeded.

133 Doslosia. Limb of calyx very short, hardly 5 -toothed. Corolla with a short broad tube, beset with a row of stiff retrograde hairs inside, and a 5 -lobed limb. Style tumid in the middle, and hispid. Ovarium I-celled ? many seeded.

134. Stigmántuus. Limb of calyx 5 -parted. Corolla with a long tube and a 5 -lohed limb. Stamens 5; anthers reflexed. Stigma large. Berry dry, tubercular, compressed, 1-celled. Seeds numerous, bony.

135 Stru'mpria. Limb of calyx campanulate, 5-cleft beyond the middle. Corolla somewhat campanulate, profomndly 5-cleft, with hardly any tube. Stamens 5 , inserted in the base of the tube of the corolla, connate. Stigma bifid. Drupe pea-formed, umbilicate, containing a 2-celled globose nut, rarely 1 -celled.

136 Bisliótia. Limb of caly $\times 5-7$-parted. Corolla salvershaped, with a 5-7-parted limb, and the throat bearded by bristles inside. Stamens 5-7, adnate to the tube. Ovarium covered by a nectariferous urceolus at the apex. Style 1, crowned by 4 stigmas. Drupe 1 -seeded by abortion. 
Tribe VIII.

PeDERIE'E. Fruit 2-celled, indehiscent, hardly fleshy, the rind easily separated from the seeds or carpels. Carpels compressed, 1-sceded (f. 104. f.), hanging from a filiform axis. Albumen fleshy.-Climbing shrubs, with opposite leaves, and interpetiolar stipulas.

137 Lygodyso'dea. Limb of calyx 5-tootled (f. 104.a.). Corolla having the tube much longer than the teeth of the calyx (f. 104. b.), with a hairy throat and a 5 -lobed limb (f. 104.c.); lobes revolute. Anthers sessile within the tube (f. 104.e.). Stigmas 2, slender (f. 104.d.). Fruit indehiscent, crowned (f. $104 . \mathrm{g}$.$) , containing 2$ carpella.

138 Leco'ntea. Limb of calyx 5-parted. Corolla with a longish terete tube, a 5-parted limb, and a naked throat. Anthers almost sessile in the throat, exserted. Stigmas 2 , linear. Fruit containing 2 winged carpella.

139 PEDE'ria. Limb of calyx small, 5-toothed. Corolla funnel-shaped, hairy inside, 5-lobed, plicate in astivation. Anthers 5 , almost sessile in the middle of the tube. Stigma bifid. Berry 2-celled, 2-seeded, with the bark at length brittle.

\section{Tribe IX.}

Cofrea'ces. Fruil 2-celltd (f. 105. k. f. 107.c.), baccate, containing 21 -seeded bony nuts (f. 107.d.), which are flat inside, and usually marked by a furrow on the outside; rarely only containing 1 nut from abortion. Albumen horny.-Trees or shrubs, with opposite leaves. Stipulas interpctiolar, 2 on cach side, combined or distinct.

Suetribe I. Coffee'e. Flowers distinet, nol joined together.

140 Amaracárpus. Limb of calyx 4-cleft, unequal. Corolla funnel-shaped, with a villous throat, and a deeply 4-cleft limb. Stamens 4, inserted in the throat. Stigma 2-lobed. Drupe crowned.

141. Damacánthus. Limb of calyx 5-toothed. Corolla unknown. Berry globose, crowned.

14.2 CA'NThum. Limb of calyx 4-5-toothed. Corolla with a short tube, a bearded throat, and a 4-5-lobed spreading limb. Stigma undivided, globose or mitre-formed. Berry globose or didymous, crowned.

143 Plectro'sia. Limb of calyx 5-toothed. Corolla short, funnel-shaped, with a 5 -parted limb and a bearded throat: lobes reflexed. Stamens 5 , inserted in the throat, a little exserted. Stigma bilamellate, subcapitate. Berry nearly dry, naked at the apex, emarginate, compressed, didymous.

144 Psy'drax. Limb of calyx 5-toothed, deciduous. Corolla with a short tube, a hairy throat, and a 5-lobed reflesed limb. Stamens inclosed. Style exserted; stigma bilamellate. Berry fleshy, obovate, areolate at the apex.

145 Marquisia. Limb of calyx short, acutely 5-parted. Corolla with a short tube, a glabrous throat, and a 5 -lobed spreading limb. Anthers 5, ovate, sessile at the throat. Stigmas 4-6. Berry ovate, fleshy, crowned.

146 Nescídia. Limb of calyx hardly any, quite entire. Corolla with a short tube, a 5 -cleft limb, and a naked throat.
Stamens 5, inclosed, nearly sessile, inserted in the throat; anthers linear, acute. Stigmas 2, face to face. Ovarium 2-celled.

147 Diplóspora. Limb of calyx subcampanulate, 4-toothed. Corolla with a broad tube, a pilose throat, and a 4-lobed spreading limb. Stigma bifid. Ovarium 2-celled. Fruit unknown.

148 Epıтнínia. Limb of calyx cylindrical, hardly 4-toothed. Corolla tubular, with a spreading 4-parted acute limb, and a villous throat. Stamens 4, exserted; anthers linear. Style exserted: stigma bifid. Berry 8-furrowed.

149 Siderodéndron. Limb of calyx hardly any, somewhat 4-toothed. Corolla with a long terete tube, a 4-lobed obtuse limb, and a glabrous throat. Anthers 4, oblong, sessile at the throat. Style bifid at the apex. Berry dry, subgtobose, not crowned.

150 Euma'chia. Limb of calyx 4-toothed, deciduous. Corolla funnel-shaped, with a short tube, a naked throat, and a 4-parted spreading limb. Stamens 4 , inserted at the bottom of the tube; anthers oblong, inclosed. Stigma bifid. Berry globose, not crowned.

151 Declieu'xia. Limb of calyx 4-parted (f. 105. b.). Corolla funnel-shaped (f. $105 . g$. ), with a terete tube (f. 105.f.), a bearded throat, and a 4 -lobed reflexed limb. Stamens 4 , inserted in the throat; anthers linear, incumbent, exserted (f. 105. e.). Stigma bifid (f. 105. c.). Berry nearly dry, somewhat didymous, compressed (f. 105. k.), crowned (f. 105.b.).

152 Tertre's. Limb of calyx 4-parted. Corolla short, funnel-slaped, 4-cleft; lobes spreading; throat beset with long hairs. Stamens inserted in the upper part of the tube, exserted. Style inclosed: stigmas 2. Drupe oblong, compressed, crowned.

153 Chroco'cca. Limb of calyx 5-toothed. Corolla funnelshaped, with an obconical tube or throat, and a 5 -lobed acute limb. Stamens 5, downy, hardly adnate at the bottom of the corolla; anthers linear, inclosed. Style clavate or 2-lobed at the apex. Berry somewhat didymous, compressed, crowned.

154 Marga'ris. Limb of calyx somewhat turbinate, semiquinquifid. Corolla fumnel-shaped, with an obconical tube, which is bhuntly 5 -toothed or 5 -lobed at the apex. Stamens inserted into the middle of the tube, inclosed; anthers ovate. Stigma undivided or somewhat 2-lobed. Berry globose, crowned.

155 Saldín1A. Limb of calyx somewhat campanulate, obsoletely repand. Corolla with a short tube, an acute 4-parted limb, and a hairy throat. Stamens 4 , inserted in the throat, hardly exserted; anthers oblong, nearly sessile. Fruit ovoid, compressed, crowned, drupaceous, 1-celled and 1-seeded by abortion, small.

156 Scolosánthus. Lobes of calyx 4, linear-lanceolate. Corolla tubular, tetragonal before expansion. Stamens adnate to the lower part of the tube, downy, not exserted; anthers linear. Stigmas 2. Drupe nearly globose, crowned, containing a 2 -celled 2 -seeded nut.

157 Сноме'цia. Limb of calyx 4-toothed. Corolla salvershaped, with a long slender tube, a glabrous throat, and a 4lobed linb. Anthers 4, almost sessile in the throat. Style bifid at the apex, situated among the anthers. Drupe ovate, crowned, containing a 2-celled 2-sceded nut.

158 Bacònia. Limb of calyx bluntly 4-cleft. Corolla fun- 
nel-shaped, with a short terete tube, a bearded throat, and 4 oblong lobes, which are longer than the tube, and twisted in æstivation. Anthers 6, linear, almost sessile, exserted. Style exserted. Stigma undivided. Berry dry, 2-celled, 2-seeded.

159 Ixòra, Limb of calyx small, 4 -toothed (f. 106. a.). Corolla salver-shaped (f. 106. b.), with a slender terete tube (f. 106. d.), and a 4-parted spreading $\operatorname{limb}$ (f. 106. b.). Anthers 4, almost sessile in the throat. Style bifid (f. 106. e.) at the apex, equal in length to the corolla or a little longer. Berry drupaceous, crowned, nearly globose.

160 Pavétrta. All as in Ixòra, but differs in the style being exserted beyond the corolla, and clavate, undivided, or hardly bifid at tlie apex.

161 Sapro'sma. Limb of calyx small, 4-toothed. Corolla 4-cleft, with a hairy throat. Stamens 4 , inserted in the throat. Stigma bifid. Berry oval, smooth, umbilicate, crowned, 1-seeder.

162 Coussa'rea. Iimb of calyx tubular, sinuately 4-toothed. Corolla with an elongated terete tube, which is hardly subtumid under the apex, and a glabrous throat. Stamens 4 , inserted in the upper part of the tube, inclosed; anthers oblong-linear. Stigma bipartite, hardly exserted. Berry ovate-globose, bardly fleshy, crowned, 1-celled, 1-seeded.

163 Polvòzus. Limb of calyx obsoletely denticulated, deciduous. Corolla with a cylindrical tube, which is shorter than the 4.5 lobes of the limb, and a villous throat. Anthers hardly exserted. Style short; stigma bifid. Berry drupaceous, nearly globose, not crowned.

164 Grumílea. Limb of calyx 5-toothed. Corolla and stamens unknown. Berry crowned, ovate-globose, rather coriaceous, 2 rarely 3 -celled.

165 Rutidea. Limb of calyx small, 5-parted. Corolla funnel-shaper, with a terete tube and a 5 -lobed spreading limb. Anthers oblong, sessile in the throat, exserted. Style clavate at the apex; stigmas 2, adnate. Berry nearly dry, globose, crowned, 1-celled, 1-seeded by abortion.

166 Fara'mea. Limb of calyx very short, 4-toothed, or entire. Corolla with a short terete tube, a naked throat, and 4 spreading oblong or linear lobes. Anthers 4, sessile, inclosed. Style short, bifid at the apex. Berry dry, marked by 8 crenæ at the apes, 1-celled by abortion at maturity.

167 STREMPE'Lia. Limb of calyx campanulately tubular, 45-toothed. Corolla tubular, with a 4-5-parted spreading limb, and a naked throat. Stamens inserted in the middle of the tube, pilose in the free part; anthers linear, inclosed. Fruit ovoid, crowned.

168 CoffE'A. Limb of calyx small, 4-5-toothed (f. 107. $a$.). Corolla tubular, funnel-shaped, with a 4-5-parted spreading limb (f. 107. b.). Stamens $4-5$, inserted in the middle of the upper part of the tube, exserted or inclosed. Style bifid at the apex. Berry umbilicate (f. 107. h.), not crowned.

169 Antherv'ra. All as in Psychótria, but differs in the corolla being rotate and 5 -parted; in the anthers being sagittate at the base and caudate at the apex; in the style being subulate, and longer than the corolla, and in the stigma being simple.

170 Rona'bia. Limb of calyx small, 5-toothed. Corolla olblong, somewhat funnel-shaped, with 5 spreading acute lobes, and a naked throat. Anthers 5, oblong, inclosed. Stigma bilamellate. Berry ovate, umbilicate.

171 Psychótria. Limb of calyx 5-lobed or 5-toothed. Corolla funnel-shaped, short, 5-cleft; limb spreading or recurved; throat bearded or glabrous. Stamens 5 : anthers exserted or inclosed. Stigma bifid. Berry drupaceous, crowned.

172 Antònı. Calyx having the tube clothed with imbricate scales and a 5-cleft limb. Corolla funnel-shaped, with a bearded throat and a 5-parted limb. Stigma ovate, bifid. Berry 2-celled.

173 Palicov'rea. All as in Psychótria, except the corolla, which is tubular and cylindrical, and a little gibbous at the base or curved, 5-cleft, bearded beneath the middle inside. The teeth of the calyx, and the lohes of the corolla, sometimes rather unequal.

174. Chasa'tia. Limb of calyx urceolate, rather tubular, entire or 5-toothed at the apex. Corolla with an elongated equal tube, and 5 short acutish erect or spreading lobes. Anthers 5 , inserted in the mouth or top of the tube, inclosed or a little exserted. Stigmas 2. Berry ovate, crowned, hardly dry.

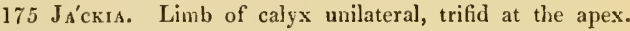
Corolla funnel-shaped, with a filiform tube and a campanulate 5parted limb. Anthers a little exserted, filiform, sessile at the throat. Style exserted, pilose in the middle ; stigma ovate, globose, longitudinally furrowed.

Subtribe II. Cephelídee. Flowers disposed in heads, involucrated by bractcas.

176 CEPHE'LIS. Limb of calyx very short, 5-toothed. Corolla fumel-shaped, with 5 small lobes. Anthers inclosed. Stigma bifid, usually exserted. Berry obovate-oblong, crowned, 2 celled, 2-sceded. Shrubs and luerbs.

177 Carapícuea. All as in Cepheelis, but the anthers and stigmas are a little exserted. Berry dry, salcate, divisible into two parts, crowned. The nuts are smooth on the outside, not as in Cepha'lis striated on the outside.

178 Sute'ria. Limb of calyx tubular, angular, 5 times longer than the ovarium, with an unequally 5-toothed border. Corolla salver-shaped, with a terete tube and a naked throat. Anthers sessile, inclosed. Stigma bilamellate. Fruit 2-celled, 2-seeded.

179 Geóphila. Limb of calyx 5-parted. Corolla tubular, with a pilose throat, and 5 rather recurved lobes. Anthers 5 , inclosed. Stigma bifid. Berry ovoid, angular, crowned, 2celled, 2-seeded.-Herbs.

180 Pata'bea. Limb of calyx very short, entire, or 4-toothed, rarely 5-6-toothed. Corolla with a short, nearly terete tube, and 4-6 spreading lobes. Anthers 4-6, sessile witlin the throat. Stigma bluntly bifid. Berry globose, crowned, smooth, 2-celled, 2-seeded.

181 SaLzmánn1a. Limb of calyx bluntly 4-toothed or sinuated. Corolla witl a short tube and a t-lobed limb. Stamens with very short filaments, and very long linear anthers. style undivicled. Berry dry, crowned, compressed, 1-celled and 1sceded from abortion. 


\section{Tribe X.}

SPermacòceÆ. Stigma bilamellate (f. 189. b.). Fruit dry, and rather feshy, usually composed of 2 1-seeded meriearps; rarely of 3-4, which are sometimes joined together and sometimes separating, indehiscent, but somctimes dehiscing in various ways. Albumen between flcshy and horny.-Shrubs or herbs. Leares opposite. Stipulas membranous at the base, and usually divided into many bristles at the apex.

Subtribe I. Cephalánthes. Floners and fruit sessile, denscly aggregate, seated on a globose receptacle. Fruit divisible into two parts. Shrubs.

182 Cephalántuus. Limb of calyx angular, 4-toothed. Corolla tubular, slender, with a 4 -cleft limb. Stamens 4, slıort, inserted in the tube, hardly exserted. Style exserted; stigma capitate. Fruit crowned.

Subtribe II. Euspermacòcee. Flowers distinct, Fruit dry, usually divisible into 2 parts, and sometimes in 3 or 4 parts.Usually herbs, rarcly shrubs.

183 Democrítea. Lobes of calyx 5, lanceolate, acute, stiff. Corolla, stamens, and style unknown. Fruit 2-celled, 2-seeded when young, but becoming 1 -celled from the dissepiment having vanished at maturity. Seeds free within the pericarp.-A slirub.

184 O'ctodon. Limb of calyx with 8 very short teeth. Corolla campanulate, 4-cleft, beset with adpressed hairs inside, which are tipped with glands. Stamens inserted in the bottom of the tube. Stigma globular. Capsule turbinate, obsoletely tetragonal, 2-celled, 2-valved, debiscing at the dissepiment.

185 Borréria. Limb of calyx 2-4-toothed. Corolla salverslıaped or fumnel-shaped, 4-lobed. Stamens 4, exserted or inclosed. Stigna bifid or undivided. Capsule crowned, 2-cellerl, dehiscing at the dissepiment when mature; coccula bursting by a longitudinal chink inside.

186 Spermacòce. Limb of calyx 2-4-tootlied (f. 108. a.), with sometimes accessory teeth. Corolla salver-shaped or funnel-shaped, 4-lobed (f. 108. c.). Stigma bifid or undivided (f. 109. e.). Capsule crowned (f. 108.f.), 2-celled: nuts divisible into two parts from the apex, one open and the other closed.

187 Hexasépalum. Limb of calyx 6-parted. Corolla campamulately funnel-shaped, with an obconical tube and 4 lanceolate lobes. Stamens 4 , shorter than the lobes of the corolla. Fruit oblong, dry, divisible into two parts at the dissepiment; the dissepiment being double the nuts are both closed.

188 Diòdia. Calyx with a 2-4-toothed limb, rarely more. Corolla fumel-shaped, with a 4-Jobed limb. Stamens 4 , exserted or inclosed. Style bıfid or undivided. Fruit crowned, divisible into two parts : the parts indehiscent.

189 Triodon. Limb of calyx 2-4-toothed, with sometimes other accessory teeth. Corolla slort, funnel-sliaped, 4-cleft. Stigma bifid. Capsule papery, crowned, 2-celled: nuts 2, indehiscent, having the axis tridentate and remaining after the nuts have fallen.
190 Cru'sea. Limb of calyx constricted above the ovarium, profoundly cleft into 4 linear lobes, and 4 accessory small ones. Corolla salver-shaped, with a long tube, a glabrous throat, and 4-lobed limb. Stamens exserted. Style exserted, bifid at the apex. Fruit of 2 indehiscent nuts, adhering to a flat membranous permanent axis, but at length separating from it.

191 Richardsònia. Limb of calyx of 4-7 unequal teetl. Corolla funnel-shaped, with an obconical tube, and a 3-5-lobed spreading limb. Stamens 3-5, exserted. Style 3-4 cleft at the apex. Capsule crowned at first, containing 3-4 1-seeded membranous indehiscent nuts. Seeds peltate.

192 KNo'xia. Teeth of calyx 4, unequal. Corolla salvershaped, with a terete tube, a usually bearded throat, and a 4lobed limb. Anthers at the throat. Stigma 2-lobed. Fruit 2-celled: the 2 nuts usually separating from the base to the apex at the dissepiment. Seed ovate-triquetrous.

193 Psyllocáryus. Limb of calyx 8-toothed, unequal. Corolla funnel-sliaped, having the tube bearded at the tliroat, and an acutish 4-lobed limb. Anthers 4, inclosed. Stigma 2lobed. Capsule crowned, compressed from the back of the carpels, 2-celled: dissepiment parallel with the valves.-Sinall shrubs.

194 Mitracárpum. Limb of calyx 4-toothed; teeth unequal. Corolla salver-shaped, with a terete tube, having a circular line of hairs near the base inside, a glabrous throat, and a 4-Jobed limb. Anthers exserted or inclosed. Stigma bifid. Capsule membranous, crowned, 2-celled, circumcised about the middle.

195 Crucksha'nksia. Limb of calyx 4-tootlued: teeth usually having an accessory tooth on each side, 1 or 2 of which are usually expanded into roundish wings. Corolla salversliaped, with an elongated tube, a 5 -cleft spreading limb, and a glabrous throat. Stamens 5, exserted, inserted in the mouth of the corolla. Anthers linear-oblong, fixed by the base. Stigma bifid, pilose. Capsule globose, subdidymous, crowned, 2celled, 4-valved : cells 2-seeded. Seed obovate, tubercular.

I 96 STE'L1A. Teeth of calyx 2, subulate. Corolla funnelshaped, with a slender tube, and a 4 -lobed acute limb. Stamens 4, exserted. Stigma 2-lobed. Capsule crowned, membranous, 2celled, 2-valved : dissepiment entire, permanent.

197 Tessie'ra. Limb of calyx 4-]obed: Jobes unequal. Corolla funnel-shaped, with a glabrous throat, and a 4-lobed Jimb. Stamens exserted a little. Stigma 2-Jobed? Capsule crowned, 2-celled, 2-valved; dissepiment entire, deciduous.

198 Gallzònia. Limb of calyx 5-7-toothed; teeth unequal. Corolla funnel-shaped, with a terete tube, and a 5-7-lobed limb. Stamens 5-7, exserted from the throat. Style filiform; stigma 2 -lobed. Fruit ovoid, containing 2 separable indehiscent nuts.

199 Macilaònia. Limb of calyx small, 5-parted. Corolla funnel-shaped, 5-cleft, with a short tube, and a villous throat. Stamens 5, inserted in the throat ; anthers subcordate, exserted. Stigma bipartite. Capsule somewhat tetragonal, crowned, containing 2 1-seeded indehiscent nuts, which are fixed to the top of a linear axis.-Slirubs or trees. 
Subtribe III. Putorie'e. Fruit rather fleshy, not divisible. -Shrubs and herbs.

200 Seríssa. Limb of calyx 5, rarely 4-cleft, with sometimes accessory teetl. Corolla funnel-shaped, having the tube hairy inside, and the limb 5, rarcly 4-parted; lobes induplicate in astivation, hence somewhat trifid at the apex. Stamens 5, rarely 4; anthers linear, exserted. Style inclosed, bifid at the apex. Berry nearly globose, 2 -celled, 2-secded.

201 Ernònea. Limb of calyx 4-6-parted, permanent. Corolla salver-shaped, with a terete subtetragonal tube, a naked throat, and 4-6 lanceolate revolute lobes. Stamens longer than the corolla; anthers acute. Style exserted; stigma emarginate. Berry roundish, crowned, 2-celled, 2-seeded.

202 Cu'ncea. Limb of calyx small, 4-toothed. Corolla with a short tube and a 4.ecleft limb, having the throat closed with villi. Anthers 4, linear, sessile, inclosed. Stigma bifid, exserted. Berry 2-celled, 2-seeded, crowned.

203 Hydropm'LAx. Limb of calyx 4-parted (f. 109. a.), permanent. Corolla campanulately funnel-shaped, 4-lobed (f. 109.f.). Anthers 4, linear-oblong, sessile, inserted at the throat (f. 109.f.), exserted. Stigma roundish, 2-lobed (f. 109. b.). Berry dry, angular, lanceolate, crowned, 2-celled (f. 109. $c$.). Seed bisulcate inside.

20.4 Scyphí PIora. Limb of calyx tubular, trumcate, nearly entire. Corolla funnel-shaped, with a spreading limb, having the tube hairy inside. Stamens 4, exserted; anthers incumbent, Stigma bifid. Drupe baccate, crowned, \&-furrowed, containing 21 -seeded nuts.

205 Plócama. Limb of calyx lardly any, sinuately 5-cleft. Corolla campanulately funnel-shaped, 5-cleft, rarely 6 -cleft. Anthers linear, inserted between the lobes of the corolla, sessile. Stigma thickish. Fruit subbaccate, areolate at the apex, crowned, 2-3-celled.

206 Putòria. Limb of calyx short, tubular, sinuately 5toothed. Corolla salver-shaped, with a long terete tube, a glabrous throat, and 4 spreading acutish lobes. Stamens short, rising from the top of the tube, hardly exserted ; anthers oblonglinear. Stigma bifid. Berry almost dry, umbilicate, 2-celled.

\section{Tribe XI.}

Anthospérmez. Floners sometimes dioecious. Corolla rotate (f. 110.b.). Styles 2, separate to the base, ending each in an elongatcd plumose stigma (f. 110.c.). Fruit constantly composed of 2 indchiscent 1 -scedcd mericarps at maturity (f. 110. g.f.), which are casily separatcd. Albumen fleshy.-Horbs or subshrubs. Leaves opposite or in whorles. Stipulas small, 1-3-toothed, rather adnate to both sides of the petioles.

207 Caprósia. Limb of calyx 4-7-toothed, short. Corolla campanulately turbinate, with a short broad tube, a naked throat, and 4-7 acute lobes. Stamens 4-7. Style nearly bipartite to the base, pilose, exserted. Berry obovate, pulpy, containing 2.3 bony indeliscent nuts.

208 Phy'Lls. Limb of calyx obsolete. Corolla tubular, with a 5-lobed spreading limb. Stamens 5. Style almost wantvoL. III. ing; stigmas 2. Capsule obovate, compressed, naked at the apex, divisible into two parts; mericarps hanging from the central axis.

209 Galopina. Flowers hermaphrodite. Limb of calyx very minute, lardly any. Corolla subrotate, 4-parted. Stamens inserted in the bottom of the corolla. Styles 2, ending in very long pilose stigmas. Fruit didymous; nuts separable, indehiscent, warted.

$210 \Lambda$ nтhospéruum. Flowers dioecious, rarely polygamons or hermaphrodite. Limb of calyx small, 4-5-toothed (f. 110, $a$.), decichous. Corolla with a short tube, and a 4-5-parted limb ( $f$. 110. b.), which is longer than the tube. Stamens $4-5$, inserted at the base of the tube (f. 110. d.); anthers oblong, terete. Stigmas 2 , very long (f. 110. c.), hairy. Fruit constantly of 2 easily separated nuts (f. $110 . f$. g.).

211 Ambia'ria. Flowers dioecious, with the same structure as Anthospermum, but the fruit is falsely 3-4-celled; mericarps joined by a concave commissure, hence the central cell is empty; and the 2 lateral ones filled.

Tribe XII.

Stelld'tж. Floners hermaphrodite, rarely unisexual. Corolla rotate or funnel-shaped; lobes valcate in cestivation. Styles 2, distinct from the base, or joined together more or less; stigmas capitate. Fruit constantly of 2 indchiscent 1-sccded mericarps. Seed hardly distinct from the calyx and pericarp. Albumen horny. - Sometimes subshrubs, but usually herbs. Leaves opposite, bcaring buds in the axils, having 1-2 or 3 leaf-formed stipulas, on cach side, forming whorls along with them. The leaves are only to be distinguished from the stipulas by being furnishod with axillary buds.

212 Sherárda. Limb of calyx 4-6-toothed, permanent. Corolla funnel-shaped, with a terete tube, and a 4-lobed limb. Stamens 4. Style one, 2-lobed. Fruit crowned, dry, bipartite.

213 Aspérula. Limb rery short, 4-toothed, deciduous, or obsolete. Corolla funnel-shaped, rarely campanulate, 1-cleft, rarely 3 -cleft. Styles 2, joined at the base, and sometimes nearly to the apex. Fruit didymous, not crowned, almost dry.

214 Cructanétra. Limb of calyx none. Corolla tubular, elongated, funnel-shaped, 4-5-lobed: lobes usually drawn out into a bristle-like inflexed appendage. Stamens 4-5, inclosed. Style 2-lobed at the apex. Fruit bipartite, not crowned.

215 Ru'BIA. Limb of calyx hardly any. Corolla rotate, 5parted. Stamens 5, short. Styles 2, short. Fruit dilymous, globose, baccate, juicy.

216 GA'Lium. Linıb of calyx hardly any. Corolla 4-parted (f. 111. b.), rotate, rarely 3-parted. Stamens 4, short (f. 111.c.). Styles 2 , short. Fruit didymous, roundish, dry.

217 Callipe'ztis. Limb of calyx not perspicuous. Corolla 4-parted, campanulate. Stamens 4, very short. Stigmas 2. Fruit oblong, somewhat incurved, 1-seeded from one of the mericarps being abortive.

218 Valllántia. Flowers by threes: the middle one hermaphrodite and fertile, the 2 lateral ones male, and joined to the middle one. Limb of calyx denticulated, pernanent: 30 
teeth many, irregular, stiff. Corolla of the male flowers trifid, of the hermaphrodite one quadrifid. Stamens 3-4. Styles in the female flower 2. Fruit $\%$-horned.

\section{Tribe XIII.}

Opercularie's. Fruit 1-celled, 1-sceded, joined together laterally into a head (f. 112. b.), and at lcngth opening by 2 valves at the apex.-Herbs or subshrubs, with opposite lcaves. Stipulas twin on each sidc, distinet or conerete.

219 Pòrax. Limb of calyx wanting. Corolla 3-4-cleft. Stamens 1-4. Style short; stigmas 2, slender. Seeds wrinkled from tubercles.- Suffrutescent herbs.

220 Opercula'ria. Limb of calyx 3-4-lobed. Corolla 3-4 cleft. Stamens 1-5. Style short; stigmas 2, slender. Seeds nearly smooth.-Herbs suffruticose at the base (f. 112.).

221 Lipo'stoma. Limb of calyx 4-parted. Corolla with a tubular base, a ventricose throat, and a 4-lobed limb; tube hairy inside, bearded at the top. Stamens 4 , inserted in the throat. Stigmas 2. Capsule globose, 2-celled, but usually only 1-celled from the rupturing of the dissepiment, many seeded, crowned by a deciduous operculum.

\section{$\dagger$ Rubiaceous genera not sufficiently known.}

222 Psilo'erum. Limb of calyx spreading, 5-parted. Corolla with a short tube and a 5-parted limb. Stamens 5, fixed to the base of the corolla. Stigma clavate, 10-winged, exserted. Fruit cylindrical, silique-formed, crowned, 2-celled, many-seeded. Seeds fixed to the central axis, 2 series in each cell... Shrubs.

223 Peatrme'rium. Limb of calyx rotate, 5-parted, rarely 4-parted. Corolla coriaceous, funnel-shaped, with a short tube, which is woolly inside, and a 5, rarely 4-parted limb, which is twisted in astivation. Anthers sessile in the tube. Style clavate, spirally 10 -ribbed. Ovarium 2 -celled, crowned by an epigynous disk.-Shrub, very nearly allied to Psilobium.

224 Stripula'ris. Calyx small, tubular, with a 5 -toothed border. Corolla tubular, slender. Stamens 5? Heads of flowers axillary, nearly sessile, surrounded by a large calyciform 5 -toothed villous involucrum.

225 Benzo'nia. Limb of calyx small, 5-toothed. Corolla tubular, coriaceous, 5-cleft. Anthers triquetrous, sessile in the throat. Stigma ovate-globose, furrowed longitudinally. Fruit unknown. - A sbrub, with corymbose flowers.

226 Himatánthus. Calyx with a turbinate tube, and a loose permanent 5 -parted unequal limb. Corolla funnel-shaped, having the tube much longer than the calyx, and a 5 -cleft limb. Stamens 5, capillary, very short, inserted in the tube. Style clavate: stigma subulate. Orarium 2-celled, 2-sceded.-A tree. Flowers spicate, sessile, involucrated by a large deciduous bractea before expansion. Perhaps belonging to Rubiàcce.

227 Sickíngia. Calyx 5-toothed, permanent. Corolla campanulate, 5-toothed. Filaments inserted in the middle of the tube. Anthers exserted. Stigma 1. Capsule woody, z-valved. Seeds winged.-A tree, with panicles of sweet-scented flowers. Perhaps belonging to Rubiàcece.

\section{Tribe 1.}

CINCHONA'CEE (this tribe contains plants agreeing with Cinchòna in important characters). D. C. prod. 4. p. 343. Cinchòneæ, Rich. diss. p. 108. Fruit capsular, 2-celled; cells many-seeded. Seeds winged. Albumen fleshy.-Trees or shrubs. Leaves opposite. Stipulas interpetiolar.

Subtribe I. Naucre'ex (shrubs agreeing with the genus Naúclea in the globose flowers). D. C. prod. 4. p. 343. Flowers capitate, sessile upon a globose receptacle (f. $83 . e$. f. 84.l.)

I. NAU'CLEA (from vavs, naus, a ship, and $k \lambda \varepsilon \iota \omega$, kleio, to inclose; in reference to the hull-shaped half capsule). Lin. gen. no. 223. Gærtn. fruct. 1. p. 151. t. 30. Lam. ill. t. 153. Roxb. fl. ind. 2. p. 117 . D. C. prod. 4. p. 343.-Naíclea species, Juss. Kunth, Blume.-Cephalánthus species. Lin. ed. 1. Lam. Rejch.

Lin. syst, Pentándria, Monogýnia. Calyx with an oblong tube (f. 83. a.), and a short, truncate, or 5-toothed limb (f. 83. b.); lobes linear. Corolla funnel-shaped (f. 83. $c$.), with a slender tube, a naked throat, and 5 spreading, oval-oblong lobes (f. 83. c.). Anthers inclosed (f. 83. g.), or exserted, always shorter than the lobes of the corolla. Style filiform (f. 83. e.), exserted; stigma oblong (f. 8. d.), or ovate, tumid, undivided. Capsules 2 -celled (f. $83 . h$. $i$.), sessile upon the receptacle, not gradually attenuated to the base. Seeds numerous, imbricate, winged, fixed to oblong placentax, which are adnate to the dissepiment. Embryo inverted in a Heshy albumen.-Unarmed trees, rarely shrubs, natives of India and Africa. Leaves opposite, or 3-4 in a whorl, petiolate or sessile. Stipulas interpetiolar, deciduons. Peduncles terminal and axillary, each bearing a globose head of flowers. Bracteas wanting at the base of the head of flowers, but with linear palea among the flowers. Flowers crowded, sessile. This genus differs from Cephalánthus in the parts of the flowers being quinary, and in the cells of the capsules being many-seeded; and from Sarcocéphalus in the fruit being capsular, not baccate; and from Lncària in the capsules being sessile, not attenuated at the base.

Sect. I. Nauclea'ria (altered from Naúelca). Lobes of calyx short, acute, or wanting.

\section{\$1. Capsules growing together in the head.}

1 N. undula'ta (Roxb. fi. ind. 2. p. 117.) arboreous; branches brachiate; leaves petiolate, ovate-oblong, obtuse, undulated, shining; stipulas elliptic, obtuse, almost the length of petioles; peduncles terminal, solitary; capsules united. h.S. Native of the Moluccas. Peduncles drooping, each bearing a large globular head of numerons, small, most beantiful yellow fracrant flowers. Anthers seated in the 5 fissures of the corolla, with hardly any filaments.

Undulated-leaved Nauclea. Fl. May, June. Clt.1820. Tree 20 feet.

2 N. GLabérrima (Bartl. in herb. Hænke ex D. C. prod. 4. p. 344.) branches tetragonal; leaves ovate, glabrous, flat; stipulas oval, length of petioles; peduncles solitary, terminal; capsules united. h.S. Native of the island of Luzon. This species differs from $N$. undulàta in the leaves not being undulated or shining, in the petioles being 1 inch long, not 2 inches. The heads are referrible to the fruit of Platanus, but are smooth. Quite-glabrus Nauclea. Tree 12 to 15 feet.

3 N. 'Walichína (R. Br. in Wall. cat. 6098.) branches quadrangular; leaves broad, roundish-elliptic, obtuse at both ends, but sometimes cuneated at the base, glabrous : peduncles terminal, solitary ; stipulas elliptic, obtuse; stamens exserted; 
fruit combined. I. S. Native of the East Indies, on the banks of rivers.

Wallich's Nauclea. Slırub.

4 N. coaduna'ta (Roxb. in Rees' cycl. vol. 24. no. 6.) arborescent; leaves petiolate, broad-ovate, cordate, obtuse, coriaceous, smooth ; stipulas obovate; peduucles terminal, solitary ; capsules united. h. S. Native of Ceylon. N. cordàta, Roxb. fl. ind. 2. p. 118. Peduncles drooping, each bearing a large beautiful globular head of very fragrant bright yellow flowers. Bractea a small irregularly 4 -toothed withering ring, round the peduncles near the base, within the stipulas. Anthers cordate, on very short filaments, from the mouth of the tube just under the fissures of its border.

Coadunate-capsuled Nauclea. II. May, June. Cit. 1820. Tree 20 to 30 fect.

5 N. SERÍcEA (Wall. cat. no. 6095.) branches tetragonal; leaves elliptic, obtuse at both ends, almost sessile, smooth; heads terminal by threes : middle one on the shortest peduncle; corollas clothed with silky villi. h.S. Native of the Burman empire, on the banks of the Irrawaddi at Henzrava; and at Chittagong. Capsules combined.

Silky Nauclea. Slirub.

6 N. Brunòxis (Wall. cat. no. 6097.) branches obscurely tetragonal ; leaves broad, roundish, cordate at the base, smooth above and pubescent beneath, as well as on the petioles; peduncles terminal, trichotomously panicled : the middle ones shortest ; stamens exserted; fruit combined; stipulas elliptic, obtuse, pubescent. h. S. Native of the East Indies, at Plavong.

Bronn's Nauclea. Shrub.

7 N. Bartlíngil (D. C. prod. 4. p. 344.) branches from compressed to terete; leaves nearly sessile, cordate at the base, oblong, acute, shining above, at length glabrous, pubescent beneath as well as the branchlets; stipulas ovate, obtuse, pubescent on the outside, deciduous, longer than the petioles; peduncles terminal, solitary; fruit united, rather tomentose. $\zeta$. S. Native of Luzon, near Sorzogon. N. móllis, Bartl. in herb. Hænke, but not of Blume. Heads size and form of the fruit of Plátanus.

Bartling's Nauclea. Tree 20 feet.

8 N. Diversifòli (Wall. cat. no 6096.) branclilets tetragonal; leaves of various sizes and shapes, but usually elliptic, obtuse at the apex, and somewhat cordate at the base, smooth, on longish petioles : perluncles terminal, trichotomously panicled: the middle one always short; heads globose; fruit combined; stamens exserted. h. S. Native of the East Indies, in various parts of the Burmese empire.

Diverse-leaved Nauclea. Shrub.

9 N. polycéphala (Wall. cat. no. 6100.) leaves oblong-lanceolate, long-acuminated, glabrous; peduncles forming a terminal panicle; lieads small; fruit combined. h. S. Native of the East Indies, on the mountains of Silhet.

Many-headed Nauclea. Shrub.

\section{Capsules distinct in the heads.}

10 N. MacropHy'LLA (Roxb. fi. ind. 2. p. 120.) arboreous ; leaves stem-clasping, very broad, oval, obtuse, villous on the nerves beneath; stipulas linear-lanceolate; peduncles terminal, solitary, recurved; capsules distinct. $\zeta$. S. Native of Amboyna. Trunk of tree straight, like that of a pine or fir. Branches decussate. Leaves 8-24 inches long, and 6-8 inches broad. Peduncles length of the stipulas; each supporting a heart of numerous, short, beantiful pale yellow sweet-smelling flowers, which is 3 inches in diameter. Stigmas exserted, pure white. Placentas to which the seeds are attached linear.

Long-leaved Nauclea. Tree 30 to 40 feet.

11 N. sessilifòlia (Roxb. fl. ind. 2. p. 124.) arboreous; leaves oblong, sessile, rather cordate at the base and clasping the stem, rounded at the apex; heads terminal, solitary; capsules distinct, 4-valved. h.S. Native of the East Indies, in the forests of Clittagong. The rest unknown.

Sessile-leated Nauclea. Tree.

12 N. ovalifòla (Roxb. f. ind. 2. p. 124.) arboreous; leaves sessile, oval, or elliptic; heads of flowers terminal, solitary. h.s. Native of the East Indies, in the forests of Sillet, where it is called Shal by the natives. The rest unknown.

Oral-leaved Nauclea. Tree.

13 N. CADAmba (Roxb. fl, ind. 2. p. 121.) arboreous, glabrous; branches brachiate; leaves petiolate, coriaceous, ovate, obtuse at the base, and acuminated at the apex; stipulas triangular; peduncles terminal, solitary, usually shorter than the heads, which are globose; lobes of calyx linear; stamens exserted, shorter than the lobes of the corolla. h. S. Native of the East Indies, about Calcutta ; and of Malabar. Katon-jaka, Rheed. mal. 3. t. 33. and therefore Cephalánthus orientàlis, Lin. spec. erl. 1. p. 95. N. citrifòlia, Poir. dict. 4. p. 435. Flowers orange-coloured, collected into heads about the size of a small apple (Roxb.). Style white, exserted; stigma thickish, oblong. Capsules distinct, 4-celled at top. Seeds not winged. Leaves 5-10 inches long. Kudumba is the native name of the tree. It is common about Calcutta, where it grows to be a large tree, and is not only highly ormamental, but very useful from the extensive close shade it yields.

Cadamba Nauclea. Clt.? Tree 30 to 40 feet.

14 N. Parvifo'lia (Roxb. cor. 1. p. 40. t. 52 . fl. ind. 2 . p. 122.) arboreous, glabrous ; branches brachiate; leaves petiolate, obovate, obtuse, or short acuminated; stipulas oval; peduncles terminal, solitary, or by threes, when 3 the middle one is shortest; heads globose, bibracteate ; limb of calyx truncate. $\eta$. S. Native of the East Indies, almost every where; and is a native of all the coast of Coromandel, but cliefly in the mountains and in the Philippines. Ham. in Lin, trans. 15. p. 94. N. parviflòra, Pers. ench, 1. p. 202. Wall. in litt. N, orientàlis, Gærtn. fruct. 1. p. 151. t. 30 , exclusive of the synonymes, ex Ham. Branches numerous, spreading, forming a large oval shady head. Heads of flowers light yellow, globular, size of a plum. Anthers on short filaments. Style much exserted. The wood is of a light chestnut colour, firm and close grained; is used for varions purposes, where it can be kept dry, but exposed to wet it soon rots. (f. 83.)

Small-leared Nauclea. Tree 30 to 40 feet.

15 N. gla'bra (lioxb. fl. ind. 2. p. 121.) leaves elliptic, smooth; stipulas linear; peduncles terminal by threes; lobes of calyx triangular; stigma globose; cells of capsule 3-4seeded. $h$.S. Native of the Molnccas. The leaves, according to Blum. bijdr. p. 1009, are oval, bluntish, attenuated at the base; and the peduncles are trifid from the falling of the leaves.

Glabrous Nanclea. Tree.

16 N. Missio'nis (Wall. cat. no. 6099.) leaves lanceolate, glabrous; peduncles terminal, solitary, bracteate at the base; fruit distinct. $\hbar_{\varepsilon} . S$. Native of the East Indies. N. orientalis, Herb. Madras. Stipulas lanceolate, acute.

Mission Nauclea. Shrub.

I7 N. exce'LsA (Blum, bijdr. 1009.) leaves oval, acute, rounded at the base, coriaceous, glabrous; stipulas oblong, obtuse, pubescent; peduncles terminal by threes (or trifid from So: 
the leaves having fallen). $h_{\text {. S. Native of }} \mathbf{J}_{\text {ava, }}$ in the mountain woods of Seribu and Panang. Said to be allied to $N$. glàbra. Heads of flowers globose. Fruit sometimes sessile and sometimes pedicellate, but probably from abortion.

Tall Nauclea. Tree 30 to 40 feet.

18 N. oвтu'sa (Blum. bijdr. p. 1009.) leaves obovate-oblong, obtuse, coriaceous, glabrous, downy in the axils of the veins beneath; stipulas oblong, obtuse; peduncles solitary or by threes, terminal, length of petioles. $h . S$. Native of Java, in the woods on Mount Tjerimai.

Obtuse-leaved Nauclea. Tree.

19 N. Stella'ta (Wall. cat. no. 6102.) branches terete, smooth; leaves lanceolate, glabrous; peduncles solitary, terminal, bearing each a globose crowded head of flowers. Ђ. G. Native of Cochin-china. Cephalánthus stellàtus, Lour. coch. Flowers apparently red.

Stellate Nauclea. Shrub.

20 N. rotundfòlia (Roxb. f. ind. 2. p. 124.) arboreous; leaves petiolate, roundish-oval, obtuse; stipulas oblong, obtuse, many-nerved; heads terminal, on short peduncles; capsules distinct. b.S. Native of the Fast Indies, in Chittagong; and of the Society Islands. The rest unknown.

Round-lcaved Nauclea. Tree.

21 N. Africa'sa (Willd. spec. 1. p. 929.) shrubhy, smoothish; leaves oval, acute, petiolate; stipulas oblong, acute; peduncles short, terminal, solitary, rarely by threes; bearing eacl a globose head of flowers; tube of calyx short, truncate; anthers exserted, reflexed. h. S. Native of Guinea, at Cape Cuast, and Senegal, and ali along the western coast of Africa. Uncùria inérmis, Willd. in Ust. del. 2. p. 199. t. 3. N. Africàna, Schum. pl. guin. p. 104. Cephalánthus A fricànus, Reichb. in Sieb. fl. exsic. seneg. no. 20. Flowers red.

Var. $\beta$, Luzoniénsis (D. C. prod. 4. p. 345.) pubescent; leaves pubescent beneath, but less so above; throat of corolla densely bearded. $b_{2}$. S. Native of the island of Luzon, one of the Philippines. N. Africāna, Cham. et Schlecht, in Linnæa. 4. p. 140. Perliaps a proper species.

African. Nauclea. Shrub 6 to 10 feet.

22 N. Cixcióne (D. C. prod. 4. p. 345.) leaves ovate, obtuse at the base, and acutish at the apex, glabrous above, pale beneath and rather pilose on the nerves; panicle terminal, elongated: having the branchlets opposite, and each bearing a globose head of flowers, 3-5 in number; bracteas ovate-oblong, deflexed, under the branchlets of the panicle $h$. S. Native of South America, probably in Peru. Cínchona globifera, Pav. quinol. ined. N. polycéphala, A. Rich. mem. soc. hist. nat. par. 5. p. 289. Heads dense, many-flowered. Flowers velvety on the outside. Fruit unknown. Perlaps a species of Cophalánthus, but differs from that genus in the flowers being pentamerous.

Cinchona Nauclea. Shrub.

23 N. microcé phala (Delile, in Caill. pl. afr. p. 67. no. 54.) shrubby, glabrous; leares 4 in a whorl, lanceolate, tapering into the petioles; stipulas united into a 4-toothed ring; peduncles axillary, smooth, slender, longer than the petioles; heads of flowers globose; calyxes and corollas small, pubescent. 々. S. Native of the north of $A$ frica, at Singue.

Small-headed Nauclea. Shrub.

24 N. Lancela'ta (Blum. bijdr, p. 1009.) leaves on short petioles, oblong-lanceolate, acuminated at both ends, coriaceous, glabrous; stipulas oblong, obtuse; peduncles terminal, solitary. h. S. Native of the west of Java, in motintain woods. Cephalânthus orientàlis, Blun, cat. hort. buitenz. p. 38. Flowers varying to tetrandrous.

Lanccolate-leaved Nauclea Shrub.

25 N. Grandifòlia (D. C. prod. 4. p. 345.) leaves rather large, obovate or ovate-oblong, obtuse, acute at the base, rather undulated, glabrous; stipulas oval, about equal in length to the petioles; peduncles terminal, solitary, length of petioles. 々. S. Native of Java. N. macrophýlla, Blum. bijdr. p. 1010. but not of Roxb. There is a variety of this species in the province of Bantam, having the leaves all obovate and undulated, and another in the province of Rembang having larger and more undulated leaves.

Great-leaved Nauclea, Tree or shrub.

26 N. corda'ta (Blum. bijdr. p. 1011. but not of Roxb.) leaves roundish-cordate, retuse at the apex, glabrous; stipulas oblong-roundish, united at the base, length of petioles; peduncles terminal, solitary. $々$. S. Native of Java, on Mount Salak.

Cordate-leaved Nauclea. Shrub or tree.

27 N. orienta'Lis (Lam. ill. 153. f. 1.) arboreous, glabrous ; leaves oval-oblong, on short petioles, smooth; stipulas oblong; peduncles axillary, opposite: upper ones solitary, 3 times longer than the heads of flowers, which are globose. $\zeta_{2} . S$. Native of the East Indies, Java, and China. Poir. dict. 4. p. 435. Blum. bijdr. p. 1006. Ham. in Lin. trans. 15. p. 94.-Bancàlus, Rumph. amb. 3. t. 55. f. 1. Anthers inclosed. Style much exserted; stigma ovate.

Eastern Nanclea. Tree 35 to 20 feet.

¿8 N. canéscexs (Bartl. in herb. Hænke, ex D. C. prod. 4. p. 34.6.) branches tetrigonal, velvety; leaves on short petioles, elliptic, short-acuminated, glabrous above and canescent beneath; peduncles compressed: lower ones axillary, opposite : the upper ones from the falling of the leaves appear racemose, and are as well as the heads tomentose; lobes of calyx linear, obtuse. $\eta_{2}$. S. Native of the Island of Luzon. Stipulas decidnous, at the sides of the leaves, oblong-linear, twin, on both sides in the upper part of the racemes.

Canescent Nauclea. Shrub or tree.

$29 \mathrm{~N}$. вотundifòia (Bartl. in herb. Hænke, ex D. C. prod. 4. p. 340.) glabrous; branchlets tetragonal; leaves petiolate, roundish-cordate, short-acuminated, paler beneath; peduncles axillary, opposite, solitary, compressed, articulated in the middle; heads globose, tomentose; segments of the calyx ovate, obtuse. $h_{2}$.S. Native of the Island of Luzon. Corolla hoary from tomentum; with an elongated tube; and roundish lobes. The sterile peduncles become hardened and hooked, as in the genus Uncìria.

\section{Round-leaved Nauclea. Tree or shrub.}

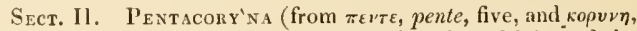
corync, a club; in reference to the 5 club-shaped lobes of the calyx). D. C. prod. 4. p. 346 . Segments of calyx (or bracteoles) elongated and club-shaped.

30 N. condifòlra (Roxb. cor. 1. p. 40. t. 53. fl. ined. 2. p. 122.) arboreous; leaves petiolate, roundish-cordate, villous beneath ; stipulas oval, peduncles 1-3 together, axillary; bearing each a giobose head of flowers; lobes of calyx and stigmas clavate. $々$. S. Native of Coromandel and Cottala, on the mountains, in the southern peninsula of India. Petioles terete, rather villous, equal in length to the peduncles. Flowers yellowish. Seed 6 in each cell of the capsule, membranaceously winged, never imbricated, but bifid at the apex. Leaves 4-12 inches each way, on petioles from 2-3 inches long. Peduncles downy, from 1-4. 'The wood is exceedingly beautiful, its colour is like that of box-wood, but much lighter, and at the same time very close-grained. It is to be had of a large size, from 1-2 feet or more in diameter, and is used for almost every purpose, where it can be kept dry. For furniture it answers exceedingly well, being light and durable. 'This is probably the N. sterculiæfòlia, A. Rich. mem. soc. hist. nat. par. 5. p. 289.

Hcart-lcaved Nauclea. Tree 40 to 50 fcet. 
31 N. purpu'rea (Roxb. cor. 1. p. 11. t. 54. fl. ind. 2. p. 123.) sub-arboreous, glabrous; leaves petiolate, oval-oblong, acmminated, smooth; stipulas oval, obtuse, large, deciduous ; peduncles terminal, solitary, or by threes, bracteate in the middle; lobes of calyx 5 , clavate. $h$. S. Native of the East Indies, in the moist valleys up amongst the Circar mountains. Cephalánthus Chinénsis, Lam. dict. 1. p. 678 . exclusive of the syn. of Rumpl. Branches decussate. Leaves shining. Ileads of flowers large, purple. Capsules turbinate, dehiscing from the base. Seeds imbricate, winged.

Purplc-flowered Nauclea. T'ree 20 feet.

32 N. Roxвu'ran ; slirub glabrous; leaves roundish, obtuse, cordate at the base, on long petioles; stipulas large, oblong, obtuse. $\boldsymbol{~}$. S. Native of the East Indies. N. stipulàcea, Roxb. herb.

Roxburgh's Nauclea. Shrub.

33 N. Peduxcula'ris (Wall. cat. no. 6091.) arborescent, smooth; Jeaves ovate-elliptic, coriaceous, acuminated, smooth; peduncles terminal by threes, not so long as the upper pair of leaves; heads of flowers globose. h. S. Native of Pulo Penang. N. purpùrea, Roxb. herb. Flowers purplish?

Pcduncular Nanelea. Shrub.

34 N. calricina (Bartl. in Hrenke herb. ex D. C. prod. 4. p. S46.) glabrous; leares petiolate, oblong, attenuated at both ends; stipulas deciduous; peduncles terminal, solitary, or by threes, bearing eaducous bracteas under the apex; lobes of calyx 5, elavate; style not exserted. h. S. Native of the lsland of Luzon, one of the Philippmes. Very nearly allied to $N$. purpurca, and is probably the same, but the calyx is pale, not purple, and the branches are tetragonally compressed, not terete.

Large-calyxed Nanclea. Tree 15 to 20 feet.

35 N. stipula'cea (D. C. prod. 4. p. 346.) arboreous; leaves broad-obovate, glabrous, downy on the nerves on the under surface, as well as on the petioles and branchlets; stipulas ovate, large, leafy; heads of flowers globose; corolla villous on the outside; calyx quite entire, truneate; bracteoles or lobes of calyx 5, club-shaped. $\zeta$. S. Native of $A$ frica, on the banks of the Gambia near Albreda. N. macroplıýlla, Perr. et Leprieur. mss. but not of Roxb. nor Blum. The dehiscence of the capsule exhibits distinct carpella within the calycine tube, which is cleft lengthwise ; the segments coliering at the apex, and propped by 5 claviform bracteoles on the outside.

\section{Stipulaccous Nauclea. Tree 20 to 40 feet?}

\section{$\uparrow$ Spccies not sufficiently knon'n.}

36 N. Morindefòla (Blum. bijdr. p. 1011.) arboreous: leaves oval, acute, rounded at the base, ribbed, glabrous, bearing depressed glands in the axils of the ribs on the under surface; stipulas spatulate, coloured, viscid, one half shorter than the petioles. 5. S. Native of Java, on Mount Salak. Flowers unknown.

Morinda-leaced Nauclea. Tree.

37 N. Mo'́lis (Blum. bijdr. p. 1010.) leaves rather large, oval, acute, rounded at the base, sometimes subcordate, glabrous above but rather villous beneath and on the branches; stipulas oval, obtuse, rather villous beneath. $h_{2}$. S. Native of Java, on Mount Salak. Flowers unknown. Allied to N. macrophýlla, Roxb.

Soft Nanclea. Tree.

Cult. All the species of this genus are of the most easy culture. A mixture of loam, sand, and peat is the best soil for them; and euttings root readily in the same kind of earth under a hand-glass, in heat.

1I. UNCA'RIA (from uncus, a look; the old or inferior peduncles are converted into hooked axillary spines). Schreb. gen. no. 311. Roxb, and Wall, in A. ind. 2. p. 125. but not of Burch. D. C. prod. 4. p. 3+7.-Naúclea, sect. ii. Blım. bijdr. p. 1011.-Ouroupària, Aubl. guian. 1. p. 177. Agylóphora, Neck, elem. no. 254.-Naúclea species, Lam. Willd. Juss. and hunth.

LiN. syst. Pentándria, Monogýnia. All as in Naúclca, but differs in the flowers being less erowded on the receptacle. Calyx tubularly urceolate, 5-cleft. Capsules pedicellate, clavate, attenuated at the base.-Scandent shrubs, hanging to other trees by the old peduncles, which are hooked for the purpose. T'he greater portion are natives of India, but a few are natives of America. The old or lower peduncles are converted into compressed, hooked, axillary spines. Perhaps only a section of the genus Naúclea.

$1 \mathrm{U}, \mathrm{GA}_{\mathrm{A}}^{\prime} \mathrm{mir}$ (Roxb. fl. ind. 2. p. 126.) branches terete; leaves ovate-oblong, acute, on short petioles, smooth on both surfaces; stipulas ovate; peduncles axillary, solitary, opposite, bracteolate in the middle: the lower ones sterile, and converted into hooked spines. $h . \cup$. S. Native of Pulo-Penang, Sumatra, Malacca, Sc. Naúclea Gámbir, Hunt. in Lin. trans. 9. p. 218 . t. 92. Fleming in asiat. res. 11 . p. 187 . Smith, in Rees' cyel. vol. 24. no. 7. Hayn. getr, gew. 10. t. 3. U. jasminifòlia, Wall, herb. Fùnis uncàtus angustifòlius, Rumph. amb. 5. p. 63. t. 34. f. 2. and 3. The upper peduncles bear each a solitary, globular head of beautiful green and pink flowers. Bracteas forming a 3 or 4-cleft annular, periantli-like cup, about the middle of each peduncle. Calyx silky on the outside. Corollas villous on the ontside, and hairy in the center of the inside. Capsules pedicellate, clavate, grooved longitudinally. Seeds imbricate, winged. Gambicr is the Malay name of an extract prepared from the leaves of this plant, and one of the drugs, if not the only one, formerly called Terra Japonica in Europe. For the following account of the tree we are indebted to Dr. Charles Campbell of Bencoolen, who says, "This material is called by the Malays gambicr. It is chewed by the natives, mingled with betel-leaf and areea, after the manner in which the cutch is used on the continent of lndia. With some sweetness it has a more highly concentrated astringent principle than terra Japonica. I am solicitons that a trial should also be made of its power in tanning. In regard to the natural history of the gambicr, it is procured from a elimber. It is the Funis uncàtus, or Daun gatta gambier of Rumph. amb. 5. t. 3t. The variety from which it is chiefly made is that denominated by Rumphius the Fùnis uncòtus angustifolius. The preparation is simple; the young shoot and leaves are shred, and bruised in water for some hours, until a feculum is deposited ; this, inspissated in the sun to the consistence of paste, is thrown into moulds of a circular form, and in this state the gambier is brouglit to market. Rumpluius has fallen into error in asserting that gambier is not made from this plant ; for in my journey to $\mathrm{Co}$ chin-china I had an opportunity of inspecting the whole process, having resided some days at a small village near the foot of the mountains, where the Sultan of Moco lias established a colony for the purpose of carrying on the manufacture to a considerable extent. The price at which it can be procured from the northern parts of this coast I lave ascertained to be nearly 10 dollars per hundred weight; it can be supplied in any quantity desired, for the plant abounds in these districts, and the mode of eliciting the astringent matter is such as requires neither much attention nor labour." But Dr. Walieh has learned that in other parts to the eastward of the Bay of Bengal, the process is carried on by boiling the leaves and young shoots, evaporating the decoction by fire, and the heat of the sun. When sufficiently inspissated, it is spread out thin, and cut into little square cakes and dried. The same substance is mentioned by Mlarsden in his history of Sumatra at pp. 242 and 243, who 
refers for a particular detail of the cultivation of the plant and manufacture of gambier to the $2 \mathrm{~d}$ volume of the Transactions of the Batavian Society. Mr. Hunter (Lin. trans. 9. p. 220.) says, that in Prince of Wales's Island the substance is preparcd by boiling the leaves for an hour and a half, adding more water as the first wastes, till towards the end of the process, when it is inspissated to the consistence of thin syrup, and when taken off the fire and allowed to cool it becomes solid. It is then cut into little square pieces, which are dried in the sun, turning them frequently. The gambier, prepared according to this process, is of a brown colour; but prepared in the way described by Dr. Campbell above, it is perfectly wlite. In medicine it is found beneficial in anguina and aphthæ, as well as diarrhoea and dysentery. The drug is infused in water, to which it gives the colour of black tea. By the Malays it is mixed with lime, and applied externally to cuts, burns, boils, \&c. The finest is alone selected to chew along with leaves of betel, in the same manner as cutch or kut, the catechu in other parts of India. The brown being strong tasted and rank is exported to China and Batavia, to be used in dyeing and tanning.

For the cultivation of the shrub a rich soil is preferred. It gives the most luxuriant crop when the rains are frequent, but does not thrive in grounds that are apt to be flooded. On this account the side of a hill is esteemed better than any other situation. The plants are propagated from seed; and when they are about 9 inches ligh they may be finally removed to the field, and planted at distances of 8 or 9 feet. At the end of one year from the time when they are planted in the field, a small crop of leaves is obtained. A larger is got in eighteen months, and the third at the end of two years, when the plants are at their full growth. They continue in their prime, and admit of being cut twice a-year, for the space of 20 or 30 years, provided care be taken to keep the ground clean, and the roots free from weeds. Their tops must be cut to prevent them growing to a greater height than 5 or 6 feet. It is said that the young leaves produce the whitest substance. In Prince of WVales's Island, gambier, if good, is sold for $8 \frac{1}{2}$ dollars per pecul, while in the same island sago is sold for 3 dollars per pecul; lience the manufacturer is tempted to adulterate the gambier with this article, which mixes intimately, but may be easily detected by solution with water.

Gambier. Clt. 1825. Shrub cl.

2 U. A'cida (Roxb. fl. ind. 2. p. 129.) branches tetragonal, smooth; leaves ovatc, acuminated, smooth on both surfaces; stipulas acuminated, twin on both sides; peduncles axillary, solitary, bearing each a single head of flowers, bracteolate in the middle, but after flowering becoming recurved and spinescent. $\zeta$. $\smile$. S. Native of the Island of Pulo-Penang, at Soongey Clooan, ex Hunter ; of Java, ex Blum. bijdr. 1011.; also of the Moluccas, ex Rumph. Naúclea ácida, Hunter, in Lin. trans. 9. p. 223. Fùnis uncatus latif olius, Rumph. amb. 5. p. 63. t. 34. f. 1. Naúclea longiflòra, Poir. suppl. p. 63.Cinchòna Kattu-Kambar, Kœen. in Retz. obs. 4. p. 6. to which it is nearly allied. The leaves have an acid taste.

Acid Uncaria. Slirub cl.

3 U. sclerophy'Lla (Roxb. fl. ind. 2. p. 130.) branches tetragonal, pubescent ; leaves elliptic, short-pointed, stiff, rugged beneatl $;$; stipulas lateral, lunate, 2-lobed; peduncles axillary, solitary, simple, jointed, bracteolate above the middle, bearing each one head of flowers, after flowering becoming recurved and spinescent. $h . \cup$.S. Native of Pulo-Penang, on the sop of the mountain called Soongey Clooan. Naúclea sclerophýlla, Hunter, in Lin. trans. 9. p. 223. Leaves pubescent beneath. Bracteas 6 in a whorl, at the joint of the peduncle. Calyx pubescent outside. Corolla villous on the outside. Flowers on long pedicels.
Hard-leaved Uncaria. Shrub cl.

4. U. ovalifo'lia (Roxb. fl. ind. 2. p. 128.) leaves oval, petiolate, acute, smooth on both surfaces; peduncles axillary and terminal, compound; receptacle of flowers as well as the capsules villous. $h$. ᄂ. S. Native of Pulo-Penang. Leaves somctimes obovate, from 3-6 inches long. Peduncles bearing from $1-3$ heads of flowers, on pedicels which are as long as the common peduncle, and furnished with a sheathing 4-6-cleft bractea in the middle of each. Petioles short, recurved, channelled.

Oval-leaved Uncaria. Shrub cl.

5 U. Pilòsa (Roxb. et Wall. in fl. ind. 2. p. 130.) branches villous, obscurely tetragonal; leaves oval, acuminated, sometimes subcordate, hairy on both surfaces, on very short petioles; stipulas bipartite or twin : segments lanceolate, acute, longer than the petioles; peduncles axillary, opposite, villous, divaricate, at length recurved and spinescent. $h . \cup$. S. Native of Nipaul, in the valley in the forest of Sankoo, and at Bheempedi; and of Chittagong and Java. Wall. pl. rar. asiat. 2. p. 55. t. 170. Naúclea scándens, Smith, in Rees's cycl. vol. 24. no. 9. Naúclea pilòsa, Blum. bijdr. p. 1013.? Branches clothed with rusty hairs; young shoots silky. Leaves from 5-7 inches long. Peduncles jointed, and bear a whorl of about 6 small linear-lanceolate bracteas, which are hairy without and smooth within. Flowers hairy, whitish, forming round dense heads of 2 inches in diameter. In the Java plant there are 4-6 ovate-lanccolate, acuminated, pilose, rather membranous bracteas in a whorl at the top of each peduncle, under the head of flowers. Perlaps distinct from the plant of Roxburgh.

Pilose Uncaria. Shrub cl.

6 U. LANòsa (Wall. in Roxb. fl. ind. 2. p. 131.) every part of the plant is clothed with long rust-coloured hairs; leaves ovate-lanceolate, acuminated, smooth above, on short petioles; stipulas twin, on both sides, ovate, membranous, recurved; peduncles axillary, opposite, short, at length converted into spinose hooks; corollas almost smooth; capsules on long pedicels. $h_{\text {. }}$. S. Native of P'ulo-Penang and Sumatra, and other East Indian islands. Naúclea lanòsa, Poir suppl. 4. p. 54. Naúclea setigera, Blum. bijdr. 1013. . Branches rather quadrangular. Leaves 3-4 inches long. Stipulas hairy without, permanent. Peduncles about an inch long, surrounded by a whorl of 4 lanceolate bracteas. Capsules smooth, ash-coloured. In the Java plant, the branches are almost smooth, hardly hispid; and the upper surfaces of the leaves are glabrous, or scarcely hispid, but villous beneath from long adpressed hairs; fruit oblong, glabrous, shorter than the pedicels; lobes of caly $\mathrm{x}$ oblong, ciliated. Hoolly Uncaria. Shrub cl.

7 U. LeVIGA'TA (Wall. cat. no. 6111.) branches quadrangular, smooth; leaves ovate-elliptic, acuminated, smooth; peduncles axillary, solitary, opposite, divaricate, bracteolate above the middle, some of which are converted into hooked spines. $\mathrm{F}_{\mathrm{i}}$. S. S. Native of the Burnan empire at Amherst. Fruit sessile.

Smooth Uncaria. Shrub cl.

8 U. Macrophy'Lla (Wall. in Roxb. fl. ind. 2. p. 132.) branches tetragonal, pubescent, with 2 opposite furrows; leaves petiolate, broad-ovate, acuminated, smooth and shining above, villous beneath, coarscly nerved and reticulated; stipulas caducous; lieads of flowers axillary, solitary, opposite, tomentose. I. . S. Native of the East Indies, from Silhet. Lcaves from 6-7 inches long. Peduncles opposite, axillary, and terminal, 2 inches long, covered with rusty hairs, about 5 lines under the apex they are jointed and surrounded by a ring of 5-6 lanceolate, spreading, villous bracteas. Flowers covered with ashcoloured dense pubescence.

Long-leaved Uncaria. Shrub cl. 
9 U. INsígnis (D. C. prod. 4. p. 348.) branches acutely tetragonal; leaves on short petioles, having a narrow cordate recess at the base, roundisl-clliptic, short-acuminated, shining above, reticulately veined beneath, and canescent from down between the veins; peduncles axillary, solitary, recurved, compressed; flowers on long pedicels. $h . \cup$. S. Native of the island of Luzon, one of the Philippines. Calyx tubular, 5-cleft. Corolla large, clothed with silky tomentum inside. Style exserted. Ovarium containing 2 bodies, perhaps seeds or placentas.

Famous Uncaria. Slurub cl.

10 U. eLL'PTICA (R. Br. in Wall, cat. no. 6104.) branches rather tetragonal; leaves elliptic, acuminated, tapering at the base, on longish petioles, glabrous except on the nerves beneatl while young; peduncles axillary, solitary, opposite, shorter than the leaves, usually not longer than the petioles: the lowermost ones converted into sterilc hooked spines. $h$. . S. Native of Pulo-Penang. Naúclea ovalifòlia, Roxb. herb. Corolla downy outside.

Elliptic-leaved Uncaria. Shrub cl.

11 U. cirrhiflòra (Roxb. fl. ind. 2. p. 120.) leaves ovateoblong, smooth; stipulas bifid; peduncles recurved, floriferous at the apex, $\zeta$. $\cup$. S. Native of the Malay Islands. The rest unknown.

Tcndril-flowered Uncaria. Shrub cl.

12 U. GLABRA'ta (D. C. prod. 4. p. 348.) leaves oblong-lanccolate, acuminated, glabrous as well as the branches, which are tetragonal; stipulas bifid; peduncles solitary, spreading, articulated above the middle, at length hooked. $h_{2} \cup . S$. Native of Java, on the mountains of Seribu. Naúclea glabràta, Blum. bijdr. p. 1012. Allied to $U$. cirrhiftora, Roxb. ex Blume.

Glabrous Uncaria. Shrub cl.

13 U. Pedicella'ta (Roxb. f1. ind. 2. p. 119.) leaves oval, acutish, rounded or subcordate at the base, shining above, reticulated beneath and clothed with rusty tomentum, as well as the branches, which are tetragonal; stipulas bifid; peduncles axillary, solitary, bearing each a single head of flowers, spreading, articulated above the middle; flowers on long pedicels. $h$. U. S. Native of the Molucca islands, and probably of PuloPenang and Java. Naúclea pedicellàta, Blum. bijdr. p. 1012. Flowers forming round heads of about an inch and a half in diameter, covered with rusty tomentum.

Pedicellate-flowered Uncaria. Shrub cl.

14 U. Speciòsa (Wall. cat. no. 6106.) branclies tetragonal, clothed with brown villi, as well as the under side of the leaves and nerves on the upper side, petioles, peduncles, and calyxes; leaves pilose on both surfaces, ovate-elliptic, cordate at the base, and short-acuminated at the apex, on very short petioles; peduncles axillary, solitary, opposite. $\zeta . u$. S. Native of PuloPenang and Singapore. Naúclea cordifòlia, herb. Findl. Heads of flowers large. Calyx and fruit clothed with brown villi, and the corolla with white. Flowers pedicellate. Lower peduncles converted into spinose recurved hooks.

Shony Uncaria. Shrub cl.

15 U. FerRugínea (D. C. prod. 4. p. 348.) leaves ovate. acuminated, rounded at the base, shining above, reticulated beneath and clothed with rusty tomentum as well as the branches, which are tetragonal; stipulas bipartite; peduncles solitary, spreading, articulated in the middle. $h_{\text {. }} \cup$. S. Native of Java, on the mountains. Naúclea ferrugínen, Blum. bijdr. p. 1013. Very like $U$. pedicellata, but differs in the flowers and the capsules being 3 times smaller.

Rusty Uncaria. Shrub cl.

16 U. FE'RREA (D. C. l. c.) leaves on very short petioles, ovate-oblong, acuminated, rounded and subcordate at the base, pubescent above, densely tomentose beneath, as well as on the branches, which are obscurcly tetragonal; stipulas bifid; pe- duncles solitary, spreading, articulated in the middle. $\zeta_{2} \cdot \mathrm{s}$. Native of Java, on the mountains of Seribu. Naúclea férrea, Blum. bjjdr. p. 1014 .

Iron Uncaria. Shrub cl.

17 U. sessilafru'crus (Roxb. f. ind. 2. p. 180.) Jeaves elliptic, smooth, acuminated; peduncles axillary, bearing from 1-3 heads of flowers: also terminal, bearing many heads of flowers ; capsules sessile. $h$.. . G. Native of the East Indies, in the forests of Chittagong. The slirub supports itself by strong spiral axillary looks. The terminal peduncles form themselves into a kind of racemose panicle.

Sessile-fruited Uncaria. Clt. 1829. Shrub cl.

$18 \mathrm{U}$. AFRICA'NA; leaves ovate-lanceolate, acuminated, on short petioles; Howers disposed in a loose globular liead; heads terminal; calyx and corolla villous on the outside; hooks axillary, twisted, or reflexed. $h \cdot \cup$. S. Native of Sierra Leone, on the banks of rivulets. Corolla greenish yellow.

A frican Uncaria. Shrub to to 6 feet, cl.

19 U. Guian Énsis (Gmel. syst. 1. p. 370.) branclilets tetragonal ; leaves petiolate, ovate, acute, glabrous; stipulas solitary, on both sides, triangular; peduncles solitary, bracteolate in the middle, axillary, opposite, and terminal: lower ones sterile and converted into tlat, hooked spines. $h_{2}$. S. Native of Guiana, on the banks of rivers and rivulets. Ouroupària Guianénsis, Aubl. guian. 1. p. 177. t. 68. Naúclea aculeàta, Lam. ill. t. 153. f. 2. Poir. dict. 4. p. 436. Hayn. term. bot. t. 29. f. 5. U. aculeàta, Willd. in Ust. del. opusc. 2. p. 200. The flowers in the same head are variable in colour, yellow, white, green, red, rufous, and blackish : they are very fragrant.

Guiana Uncaria. Shrub cl.

20 U. tomentòsa (D. C. prod. 4. p. 349.) arboreous; branches somewhat quadrangular, downy ; leaves ovate-elliptic, acute, clothed with fine pubescent tomentum bencath, and shining above with the nerves downy; stipulas broad ovate; peduncles villons, disposed in a terminal panicle: and the lowermost ones converted into axillary hooks. $h_{\text {. }} \cup$. S. Native of New Granada, on the banks of the river Magdalena: near Naers. Naúclea tomentòsa, Willd. in Rom. et Schultes, syst. 5. p. 221. N. aculeàta, H. B. et Kunth, nov, gen, amer. 3. p. 282. Corolla clothed with silky pubescence on the outside. Peduncles also axillary, bearing 1-3 stalked heads.

Tomentose Uncaria. 'Tree.

Cult. See Naúclea, p. 469. for culture and propagation.

1II. ADINA (from achoc, adinos, crowded; in reference to the flowers being disposed in heads). Salisb. par. lond. t. 115. Juss. mem. mus. 6. p. 403 . D. C. prod. 4. p. 3.19.-Naúclea species of some.

Lin. syst. Pentándria, Monogýnia. Calyx with an oblong tube, and a campanulate 5-parted, permanent limb (f. 84.a.). Corolla funnel-shaped, 5-lobed (f. 84 . b. c.); throat glabrous; lobes valvate in astivation. Anthers almost sessile (f. 8\%.e.), at the recesses between the lobes, inclosed. Style exserted (f. 84 . d.) ; stigma capitate-ovate, Capsule membranous, ob-pyramidal, 2 -celled; valves 4 (f. 8 t.g.), dehiscing from the apex; central axis permanent, bearing the calyx at the apex. Seeds $2-4$ in each cell, oblong, marginate (f. $84 . h_{\text {. }}$ ), inserted near the top of the cell, hanging by spongy funicles.-Glabrous shrubs, natives of China. Branches terete, opposite. Stipulas twin, on both sides, joined at the basc, yellowish, lanceolate. Leaves lanceolate, glabrous. Peduncles axillary, rarcly terminal, solitary. Heads of flowers globose, without any involucra, yellowish. Flowers sessile, crowded, intermixed with palea. Receptacle pilose.-This genıs is intermediate between Naúclea and Cephalántlus, arel probably not distinct from the first. 
1 A. globiflòra (Salisb. par. lond. t. 115.) leaves lanceolate; peduncles shorter than the leaves. h. G. Native of China. Naúclea Adina, Smith, in Rees's cycl. vol. 21. Lindl. bot. reg. t. 895 . Sims, bot. mag. 2613 . Lodd. bot. cab. 1284. (f. 84.) Globe-fonered Adina. Fl. July, Aug. Clt. 1804. Shrub 3 to 4 feet.

2 A. PEDUNCLLA'ris (D. C. prod. 4. p. 349.) Jeaves obovatelanceolate; peduncles twice the length of the leaves. h. G. Native of China. Naúclea adinoides, Lindl. bot. reg. p. 895 .

Pcduncular Adina. Fl. July, Aug. Clt.? Shrub.

Cult. The culture and propagation of the species of Adina are the same as those of Naúclea, p. 469 , but do not require so much heat.

IV. BREO'NlA (this name is not explained, but is perhaps so called after some botanist of the name of Breon). A. Rich. mem. soc. hist. nat. par. 5. p. 290. D. C. prod. 4. p. 620.

Lin. sist. Pentándria, Monogínia. Calyx with a 5-parted limb, and truncate sub-cuneated lobes. Corolla with a terete tube, and a flat, spreading, 5 -lobed limb: laving the lobes ovallanceolate. Stamens half exserted, inserted in the throat of the corolla. Style very long, exserted; stigma bipartite, with the lobes approximate. Ovarium 2-celled; cells 7-8-ovulate; ovulas fixed to the membranous placentas, which ha:1g from the axis. Fruit somewhat crustaceous, indehiscent.-A tree. Leaves opposite, very large. Stipulas connate. Flowers disposed in axillary, solitary, globose heads, which stand on long peduncles; each peduncle girded by a beaked involucrum, which at length bursts on one side and falls off.-This genus is nearly allied to Nauclea, but probably referrible to Sarcocephalea, by the fruit being indehiscent.

1 B. Madagascarie'nsis (A. Rich. l.c.). h. S. Native of Madagascar.

Madagascar Breonia. Tree.

Cult. See Naúclea, p. 469. for culture and propagation.

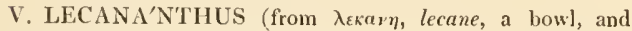
$\alpha y \theta$, anthos, a flower; in reference to the cup-like involucrum under the head of flowers). Jack, mal. misc. vol. 2. ex Wall. in Roxb. fl. ind. 2. p. 319 . A. Rich. menn. soc. hist. nat. par. 5. p. 293. D. C. prod. 4. p. 620 .

Lin. syst. Pentándria, Monogýnia. Limb of calyx campanulate, dilated, coloured, divided irregularly. Corolla with a short tube, and a 5-lobed limb, which is valvate in astivation. Anthers large, inserted in the tube of the corolla. Style bifid; stigmas linear, thick. Ovarium 2ncelled; cells many-seeded; placentas semi-cylindrical or convex, centra]. The rest unknown.-A radicant shrub, witl tetragonal stems, with 2 of the angles more prominent than the other 2. Leaves opposite, on short petioles. Stipulas ligulate. Flowers pale red, disposed in terminal, dense, globular heads; each head involucrated by a salver-shaped involucrum.-This genus is nearly allied to Naúclea.

1 L. erubéscens (Jack, l. c.). h. S. Native of Singapore. Leaves on short petioles, ovate-lanceolate, acute at both cnds, about 8 inches long. The involucrum which surrounds each head of flowers is entire and cup-shaped. Flowers sessile. Ovarium crowned by a prominent nectareal ring.

Reddish-flowered Lecananthus. Sbrub.

Cult. See Naúclca, p. 469. for culture and propagation.

Subtribe II. CINCHO'NEF (shrubs and trees agreeing with Cinchòn in important characters). D. C. prod. 4. p. 349 . -Cinchònex and Manettièæ, Cham. et Schlecht. in Linnæa. 4. p. 178. Flowers on longer or shorter pedicels, not seated on a globose receptacle, as in those of the first subtribe. (f. 86 . f. 88. f. 89 .)

VI. STEVE'NSIA (in honour of Edward Stevens, who rendered important services to St. Domingo, while he was consul of the United States there). Poit, ann. mus. 4. p. 235. t. 60 . Gartn. fruct. 3. p. 99 . t. 197 . Juss. mem. mus. 6. p. 389. but not of Neck.

LiN. syst. Pentándria, Monogýnia. Calyx with a subglobose tube, girded at the base by an unequally 4-lobed involucel; limb biparted, deciduous : having acute lobes. Corolla salver-shaped, with a short tube and a spreading bluntly 6-7parted limb. Anthers 6-7, sessile in the throat of the tube. Stigma bilamellate. Capsule globose, areolate at the apex, and pubescent in the areolæ, 2-celled, containing 2 cocculi, which are separable from the calyx : one of them only dehiscent. Placentas central, connecting the margins of the valves. Seeds minute, numerous, oval, winged a little, rather pubescent at the apex. Embryo straight in the fleshy albumen: having the radicle turned towards the hylum.--A much branched shrub, native of St. Domingo; having the branches clothed with resin. Leaves oval, white beneath, finely reticulated. Stipulas joined into a short sheatly. Flowers axillary, solitary, white, on short pedicels, girded by 4 concrete bracteas, forming a kind of involucel to each flower.

1 S. Buxjfo'lta (Poit. 1. c.). h. S. Native of St. Domingo, near La Vigie du Cap Francais.

Box-leaved Stevensia. Shrub 10 to 12 feet.

Cult. See Nauclea, p. 469. for culture and propagation.

VII. COUTA'REA (this name is not explained by Aublet). Aubl. guian. 1. p. 314 . t. 122 . Juss. gen. 202. mem. mus. 6 . p. 38s. Gartn. fr. 3. p. 79. t. 194. D. C. prod. 4. p. 350. -Portlándia species, Schreb.

Lin. sxst. Ilexándria, Monogýnia. Calyx with a turbinately oblong tube, and a 6 -parted limb: having the segments subulate. Corolla large, funnel-shaped, with a short tube, an obconical ventricose throat, and a bluntly 6-lobed limb. Stamens inserted at the bottom of the throat; anthers linear, much exserted. Stigma furrowed. Capsule coriaceously chartaceous, obovate, compressed, 2-celled; valves bifid at the apex. Placentas spongy, at length nearly free. Seeds compressed, erect, girded by a membranous margin. Embryo long, in fleshy albumen: having a centripetal radicle, and flat cotyledons. South American trees. Leaves ovate, acuminated, on short petioles; stipulas broad, short, acute. Peduncles usially trifid, axillary, and terminal. Flowers white, sometimes septamerous. This genus comes very near to Portlándia.

1 C. speciòsa (Aubl. gurian. 1. p. 30\%. t. 122.) leaves glabrous on both surfaces; peduncles trifid, 3-flowered; corolla broad, fumnel-shaped. $\zeta$. S. Native of Guiana, Cayenne, Island of Triniclad, and Carthagena, and between Caraceas and La Guayra, among bushes. Lam. jll. t. 15\%. Portlándia hexándra, Jacq. amer. 63. t. 182. f. 20. Swartz, f. ind. occid. 1. p. 385 . The tree is much branched at the top. Corolla large, purple. ex Aubl.

Showy Coutaria. Clt. 1803. Tree 25 feet. 
2 C. campanílza (D. C. prod. 4. p. 350.) leaves glabrous above, but villous bencath as well as the calyxes and peduncles; peduncles trifid, 3-flowered. $h$. S. Native of South America, about the Caraccas, where it was collected by Vargas, who says it is called Cam anilla by the natives. Flowers and fruit one half smaller than those of $C$. speciosa, and the capsule is less compressed, and ribless.

Campanilla Coutarea. Shrub 3 to 4 feet.

3 C. Mexica'na (Zuce. et Mart. in litt. 1829. ex D. C. prod. 4. p. 350.) leaves glabrous on both surfaces; peduncles 1flowered, bibracteolate at the base; corolla funnel-shaped, with very blunt lobes. $h$. S. Native of Mexico.

Mexican Coutarea. Shrub or trec.

\section{+ Specics hardly known.}

4 C. latiflo'ra (Moc. et Sesse, f. mex, icon. ined. ex D. C. prod. 4. p. 350.) pedicels 1-flowered, bractless; the diameter of the flower equal to its length. h. S. Native of Mexico, where it is called Copalchi by the natives. Leaves oval, attenuated at the base. Pedicels axillary, usually twin. Corolla white. Stigma bilamellate. Capsule less compressed, ornamented with 6 ribs and scattered tubercles.

Broad-flonered Coutarea. Shrub or tree.

5 C. Flave'scens (Moc. et Sesse, I. c. ex D. C. I. c.) pedicels numerous, bractless; the diameter of the flower almost one half smaller than its length. h. S. Native of Mexico. Superior leaves sometimes by threes, oval, attenuated at the base. Peduncles 3 in a whorl, twice bifid, only bracteate under the ramifications. Flowers yellowish, smaller and narrower than in the preceding species.

Iellowish-flowered Contarea. Shrub or tree.

Cult. For culture and propagation see Naúclca, p. 469.

VIII. HI'LLIA (named after Sir John Hill, a voluminous botanical author). Jacq. amer. p. 96, t. 66. Lin. gen. no. 444. Lam. ill. t. 257. Gærtn. fruct. 3. p. 97. t. 197. Juss. mem. mus. 6. p. 388 . D. C. prod. 4. p. $350 .-$ Fereiria, Vand. in Rom. script. p. 98. t. 6. ex icon.

Lix. syst. Tetra-Hexándria, Monogýnia. Calyx with an obovate tube, girded by a 2-4-leaved involucel at the base; limb 2-4-parted: segments narrow, acute, permanent. Corolla with a long terete tube, a short ventricose throat, and a 4-6-parted limb (f. 85 . b.), with spreading flat oval lobes. Stamens 4-6, sessile beneath the mouth of the tube, inclosed (f. 85. c.). Stigma thick, bifid (f. $85 . d$. .). Capsule elongated, 2-celled, crowned by the limb of the calyx; cells dehiscing from the top inside. Placentas 2, central. Seeds imbricated downwards, rather compressech, ending each in a pencil-formed tail (f. 85.e.). Embryo straight, in sparing fleshy albumen; having the radicle turned towards the hylum.- Small glabrous shrubs or subshrubs. Leares obovate, green, rather Heshy. Stipulas oval, membranous, foliaceous, deciduous, the 2 upper ones constituting an involucel. Flowers terminal, solitary, elongated, white. Fruit follicle-formed.

I H. LONGIFLòra (Swartz, obs. p. 135. t. 5. f. 1.) flowers hexandrous; corollas 6-cleft, with linear-lanceolate, rather revolute segments. $\boldsymbol{~}$. S. Native of $\mathrm{Ja}_{\mathrm{a}}$ maica, Guadaloupe, Martinico, Cuba, the hot ter parts of Mexico, on the decayed parts of old trees, and among moss. H. parasítica, VOL. 111.
Jacq. amer, p. 96, t. 66. Perbaps there are two species confused under this name. Lobes of calyx, ex Jacq. 6, but according to Swartz 2-4, and in the specimens examined only 2. The involncel, according to Swartz, is 6-leaved, but according to Jacquin and the specimen examined only 2-leaved, constantly composed of the 2 superior stipulas. 'The branches, according to Swartz and Jacquin, are terete, but according to the figure in the fl. mex. and the specimen examined tetragonal. In the figure of bot. mag. t. 721. the branches are round, the leaves ovate, smooth; the involucel of 2 leaves, limb of the corolla of 6 twisted segments, and the limb of the calyx apparently 6 -cleft. 'The flowers are whitc and very fragrant.

Long-flomered Hillia. Fl. Feb. March. Clt. 1789. Slirub 2 feet.

2 H. Brasilie'Nsis (Cham. et Schlecht. in Yinnæa. 4. p. 201.) corollas 6-cleft, hexandrous : segments ovate-lanceolate, obtuse. そ.S. Native of Brasil. Leaves oval, acuminated. Tube of corolla 3 inches long.

Brasilian Hillia.' Shrub.

3 H. TETRA'NdRA (Swartz, fl. ind. occ. 1. p. 630. icon. t. 11.) flowers 4-cleft, tetrandrous: segments ovatc. $\eta$. S. Native of Jamaica, on the high mountains among the roots of bushes. Leaves obovate, pale green. Roots creeping, tuberous. Lobes of calyx 4, cuncate-oblong, 2 of which are decilluous. Leaves of involucel 4, 2 of them snaller than the other two. Flowers yellowish-white, having the tube nearly an inch long and tetragonal. Seeds pappose at the apex.-Perhaps II. Tuxtlénsis, Moc. et Sesse, fi. mex. ined., which was collected about Tuxtla in Mexico, is distinct from this species, in consequence of the calyx being 2 -lobed, and the involucel 2 -leaved.

Tctrandrous Hillia. Fl. Jume, July. Clt. 1793. Shrub 3 to 4 feet.

Cult. The species of this genus delight in a mixture of turfy loam, peat, and sand; and cuttings will soon strike root in the same kind of soil, or in sand under a hand-glass, in heat.

IX. HYMENO'POGON (from $\dot{\nu} \mu \nu$, hymen, a membrane, and $\pi \omega \gamma \omega x$, pogon, a beard; the seeds are furnished with a membranous appendage at each end). Wall. in Roxb. fl. ind. 2. p. 156. D. C. prod. 4. p. 351 , but not of Beatu.

Lin. syst. Pentándria, Monogýnia. Calyx with an obovate tube, and a 5-parted permanent limb. Corolla salver-shaped, with a very long tube, and a 5 -parted limb. Stamens 5 , iriserted in the inflated apex of the tube, inclosed. Stigma oblong, ?lobed : lobes linear. Capsule oblong-clavate, 10 -nerved, crowned, 2-celled; carpels dehiscing at the apex, cleft in the middle, hence the capsule appears f..valved. Placentas very narrow. Seeds imbricated, linear, furnished with a membranous appendage at both ends. - A small crooked shrub, with compressed branchlets. Leaves approximate, acuminated, membranous, pubescent above, and villous beneath. Stipulas permanent, membranous, ovate, acute, ciliated. Corymbs nearly terninal, trichotomous, bracteate. Flowers very long, white, inodorons, pubescent.

1 H. Parasíticus (Wall. l. c.) h. S. Native of the East Indies, growing on trees, and sometimes on rocks, on Sheopore, Chandagiri, near Hetounra, and between that place and Chitlong. Stems rooting, as well as the branches, covered with pale ash-coloured bark. Leaves 5-7 inches long. Seeds linear, smooth, terminated by a long linear membranous, sometimes bifid appendage, measuring altogether 3 lines in length.

Parasitic Hymenopogon. Shrub.

Cult. See Hillia above for culture and propagation.

X. CINCHO'NA (said to be named in honour of the Countess de Chinchon, vice queen of Peru, who was cured of a fever $3 \mathrm{P}$ 
in 1638 by this remedy). Lamb. cinch. D. Don, in Lin. trans. vol. 17. D. C. 1806 . bibl, univ, 1829, scienc. 2. p. 144. Humb. et Bonpl. pl. equin. 2. t. 10. Rom. et Schultes, syst, no. 861. -Cinchòna, sect. 1. Pers, ench. 1. p. 196.-Cinchòna species, Lin. Gartn. Lam. Vahl, Juss._Kinkina, Adans. fam. 2. p. 147.

Lin.syst. Pentándria, Monogínia. Calyx 5 -toothed (f. 86,a.). Corolla tubular : with a 5 -lobed limb (f. 86.6 .), which is valvate in æstivation. Anthers linear, semi-exserted (f. 86. c.). Stigma 2-lobed (f. 86. d.). Capsule 2-celled, deliscing at the dissepiment (f. 86. g.), many seeded. Seeds samaroid, girded by a membranous lacerated margin (f. $86 . h$. .).-Trees, natives of South America, from which the various kinds of Peruvian bark are obtained. Leaves on short petioles, with flat margins. Stipulas ovate or oblong, foliaceous, free, deciduous. Inflorescence panicled. Flowers white or reddish. For the properties of Cinchòna see La Cordamine in act. acad. sc. par. 1738. Vahl. in act. soc. hist. nat. hafn, vol. 1. Lamb. cinch. in tto. Lond. 1797. Rhod. mon. cinch. Ruiz et Pav. th. per. vol, 2, et 3. Ruiz, quin. in 4to. Madr. 179\%. et def. quin. 1802. Humb. diss. in magaz. fr. nat. berl. 1507. Humb. et Bonpl. pl. equin. vol. 1. Alibert, trait. fievr. pern. 8vo. 1799. ed. 2. 1800. ed. 3. 1801. Fee, hist. nat. pharm. 2. p. 240.

\section{§1. Capsule dehiscing at the base--Normal spccies.}

1 C. LANCEOLA'ta (Ruiz et Pav. fl. per. 3. p. I. t. 223.) leaves oval - lanceolate, acute, naked on both surfaces, as well as the branches, shining; panicle brachiate, much branched, smooth; calycine teetl ovate, acuminated; segments of corolla linear-lanceolate; stigma emarginate; capsule ovatc, ribbed. h. S. Natise of Peru, in the mountains of Loxa, and other cold mountainous regions; as well as of New Granada, between Guaduas and Santa Fe de Bogota, where it was collected by Mutis. C. lancifòlia, Mutis, FIG. 86 .

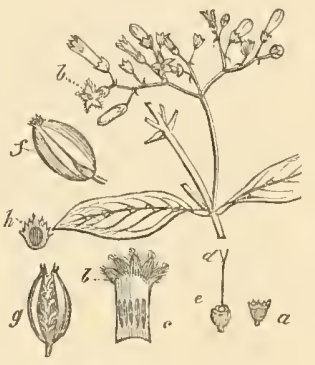
period. de Santa Fé, p. 465. Humb. in mag, der, gisell. nat. fr. berl. 1807. p. 116. Alib. tract. des fievers, p. 374 . C. nítida, Kuiz et Pav. A. per. 2. p. 50. t. 191. C. angustif òlia, Ruiz et Pav. quin. suppl. p. 14. with a figure. C. glàbra, Fuiz, quin. 2. p. 64. C. Cucumafólia, Pavon, mss. Quinquina orange, Mutis, quin. Cascarilla officinal. Ruiz, quin. p. 56. Cascarilla Lampino, Ruiz, quin. 2. p. 64. Cincliòna Condanínea, Humb, et Bonpl. pl. equin. 1. p. 33. t. 10. Humb. in mag. der, gesell. uat. fr. berl. 1807. p. 112. nov. gen. amer. 3. p. 400 . C. offcinàlis, Lin. syst. veg. ed. 10. p. 929. Condamine in mem. de l'Academie de Paris, 1738. p. 114. Lam. ill. t. 164. f. 1. Vahl, skrivt, af. natur. selfkab 1. t. 1. Lamb. mon. t. 1. C. stùpea, Pav, mss. Cascarilla fina de Uritusinga of the Spaniards. 'I'his species varies extremely in the form of the leaves. The celebrated Mutis has, with great propriety, considered his C. lancifolia the quina Naranganda or Quinquina orange of Santa Fé, as identical with the Quina fina de Uritucinga of Humb. et Bonpl. C. Condaminea. Although it is probable that sereral species of this important genus afford the Peruvian bark of the shops, of these three only are admitted into our national pharmacopoeias, to which the names of $C$. laneifolia, $C$. oblongifölia, and $C$. cordifolia have been applied, designating respectively the pale, the red, and the yellow bark. The present species was first described and figured by the astronomer Con- damine in 1738 , in the mem. de l'Acadamie. It is described by Humboldt as a handsome tree of from 30 to 40 feet in height, and exuding whenever it is wounded a yellow astringent juice. The stipulas are acute and silky. The flowers are of a very pale rose-colour, supported on pedicels, which are powdered and silky, as well as the calyx. The tube of the corolla is silky, and the border white and woolly above. This is the pale bark of the shops.

Lanceolatc-leaved Cinchona or Pale Pcruvian-bark. Tree 30 to 4.0 feet.

2 C. cordifòlia (Mutis, mss. Humb, in mag. \&c. p. 117. nov. gen. amer. 3. p. 401.) leaves roundish-ovate, cordate at the base or attenuated, rather pilose beneath and on the branchlets, naked and shining above; panicle brachiate, diffuse, pubescent; teeth of calyx roundish-mucronulate; corolla silky on the outside : limb bearled; stigma 2-lobed; capsule oblong-ovate, cylindrical, ribless. 5 . S. Native of Peru, on the mountains of Loxa, in the kingdiom of Quito; and of New Granada. Rhode, mon. p. 58. Steph. and Church, med. bot. 3. t. 175. Quina amarilla. Genitals inclosed. Flowers pale red. This species is totally listinct from Cinchòna purpurea, hirsùta, and ovata of Fl. peruv., whicl Humboldt and Bonpl. in their beforementioned work have given as synonymes of Mutis's plant. It differs from C. ovàta, Ruiz et Pav, the C. pubéscens of Vahl, with which it has the greatest affinity in the shorter petioles, by the broader round teeth of the calyx, by the filaments being twice longer, and, lastly, by its capsules being smooth, and without ribs. The bark of this tree is known to the natires by the name of Quina amarilla, Cascarilla de Loxa, and Casearilla amarilla, and is the yellow or orange bark of the shops. It is described as a middle-sized tree, with a trunk of modlerate thickness, and covered with smooth brownish bark; the younger branches are quadrangular. All the species of Cinchona vary very much in the shape and smoothness of their leaves, according to the altitude in which they grow, to the severity or mildness of the climate, to the trees standing single, or being closely surrounded by other plants, to the luxuriance of growth, and the greater and less humidity of the soil. Cordate leaves occur but seldom in the present species; however, almost every branch exhibits some of them.

Cinchona bark appears to have been long known as a medicine in Peru; but we liave not a satisfactory account at what period, nor by what means, the febrifugal virtues of this valuable remedy were first discovered. Some say a patient had been cured of an intermittent fever by having drank the water of a lake, which had acquired a bitter taste from Cinchona trees which had lain in it; others that a lion had cured himself of the agne by instinctively chewing Cinchona bark, and had directed the attention of the Indians to this tree. "That animals," observes Humboldt in his Dissertation on the Cinchona forests of Soutl America, " have taught men is a very common form of the traditions of nations. The valuable antidote Bijuco del Guaco, a plant described by Mutis, which is probably a species of Miliamia, and has been erroneously confounded with Ayajina of Brasil, is also said to have attracted the notice of the Indians, as is affirmed of the Falco serpentarius, by the Falco Guaco of New Granada figliting with serpents. However, that the great American lion without mane (Felis cóncolor) should be subject to the ague is just as bold an hypothesis as the assertion of rhe inhabitants of the pestilential valley, Gualla Bamba, near the town of Quito, that even the vultures (I íltur aúra) in their neighbourhood were subject to that disorder. Indeed in the regions of the Cinchona forests there is not a Fèlis cóncolor, so fond of warmth, to be found; but at the most the cat Puma, not yet properly described, and which we have met with in heights of 2,500 toises. 'The story so often copied 
respecting the Countess Chinchon, vice-queen of Peru, is probably still more douhtful than it is generally supposed to be. There certainly was a Count Clinchon, Don Geronimo Fernandez de Cabrera Bobadella y Mendoza, who was Viceroy of Lima from 1629 to 1639 . It is very probable that his wife, after her return to Spain in 16.0 , was the first to introduce the Cinchòna bark to Europe. The name of Pulvis Committissa appears even more ancient than that of Pulvis Jesuiticus or Pulvis patrum. But I do not believe that the Corregidor of Loxa, Don Juan Lopez de Cannizares, who is said to have cured the Countess of ague, received this remedy from the Indians. In Loxa there is no tradition whatever of this kind, nor is it probable that the discovery of the medicinal power of the Cinchona belongs to the primitive natives of America ; if it is also considered that these natives (like the Hindoos) adhere with unalterable pertinacity to their customs, to their food, and to their nostrums; and that notwithstanding all this the use of the Cinchona bark is entirely unknown to them in Loxa, Guamcabamba, and far around. In the deep and hot valleys of the mountains of Catamango, liio Calvas, and Macara, agues are extremely common. But the natives there, as well as in Loxa, of whatever cast, would die rather than have recourse to Cinchona bark, which, together with opiates, they place in the class of poisons, exciting mortification. The Indians cure themselves by lemonades, by the oleaginous aromatic peel of the small green wild lemon, by infusions of Scoparia dúlcis, and by strong coffee. In Malacatis only, where many bark-peelers live, they begin to put confidence in the Cinchona bark. In Loxa, there is no document to be found which can elucidate the listory of the discovery of the Cinchona ; an old tradition, however, is current there, that the Jesuits, at the felling of the wood, had distinguished, according to the custom of the country, the different kind of trees by chewing their barks; and that on such occasions they had taken notice of the considerable bitterness of that of the Cinchona. There being always medical practitioners among the missionaries, it is said they had tried an infusion of the Cinchona in the tertian agne, a complaint which is very common in that part of the country. This tradition is less improbable than the assertion of European authors, and among them the late writers Ruiz and Pavor, who ascribe the discovery to the Indians. The mcdicinal powers of the Cinchona was likewise entirely unknown to the inhabitants of the kingdom of New Granada."

Cinchona bark is stripped from the trunk and brancles in the dry season, from September to November; it is dried by exposure to the sun, and after being inported into Europe is sorted for sale. It is brouglt to this country in chests, each of which contains from 100 to 200 pounds weight of bark, mixed with dust and other impuritics. According to Humboldt, the quantity of this drug annually exported from America is from 12,000 to 14,000 quintals. The kingdom of Santa Fe furnishes 2000 of these, which are sent from Carthagena; 110 are furnished by Loxa, and the provinces of Huamanga, Cuenca, and Jean de Bracamoros, and the thick forests of Guamcabamba and Ayaraca, furnish the rest, which is slipped from Lima, Guayaquil, Payta, and other ports on the South Sea.

The pale bark of the shops, the Quina Naranjada, and Cascarilla fina de Critusinga of the Spaniards, which is obtained from $C$. lanceolita, is preferred in South America to all the other kinds of bark. It is in pieces, 5 or 6 inches long, singly or doubly convoluted, externally of a greyish brown colour, to which crusts of lichens often adhere, and is internally when fresh broken of a bright cinnamon bue. There are often intermixed with this others of a coarser texture, thicker, and nearly flat, which appears to be obtained from the trunk and larger branches. The fracture is smooth and eren; its powder is of a pale colour; its taste is bitter and astringent ; its smell peculiar and aromatic.

The ycllow bark, named Quina amarilla, Cascarilla de Loxa, and Cascarilla amarilla, is less rolled than the pale bark, and the pieces are larger and thicker. Externally it is of a greyish brown, and covered with lichens; internally of a much deeper orange than the pale bark. It las a more bitter taste, with a less aromatic odour, and with scarcely any sensible degree of astringency.

The rad bark is sometimes rolled, but more commonly in flat thick pieces, covered with rough entire reddish brown epidermis. It has a smooth fracture. It is composed of three layers; the inner one being of a dark ferruginous colour, it is more bitter and astringent than the pale and yellow bark.

These three kinds of bark are only distinguished in Britain; but M. Von Bergen, a drug broker of Hamburgh, who has written a valuable monograph on the Cinchonas, enumerates eight kinds as distinguished in commerce; and the drug merchants of Spain enumerate about 50 different kinds of bark: these are probably obtained from as many species of Cinchòna, or several of them may be obtained from the same species-the difference depending upon the age, state, and habitats of the trees.

Qualitics and chemical propcrties.-Few vegetable substances have undergone so many analyses, by the most eminent chemists, as the different varieties of Peruvian bark. The basis of all of them is woody fibre, combined with which are various principles capable of heing abstracted by different solvents. The taste of all is more or less bitter and astringent. Boiling water extracts all their active principles, affording a solution of a pale brown colour; this infusion is transparent when hot, but on cooling becomes turbid, and a precipitate is deposited, which is soluble in alcohol. The decoction has a very astringent taste, and a deep brown colour. By long boiling the virtues are nearly destroyed, owing to the chemical change and precipitation of its active matter. Alcohol, in all its modifications, is a powerful solvent of the active principles of Cinchona. A saturated solution of ammonia is also a solvent of them, but acetate acid acts less imperfectly than even water. Vauquelin found that an infusion of the pale bark reddened litmus paper; was copionsly precipitated by solution of galls, and in a smaller degree in yellowish flocculent flakes by solution of isinglass. A solution of tartar emetic was rendered turbid, and slowly precipitated by it; solution of superacetate of lead produces quickly a copious precipitate. The addition of a solution of the sulphate of iron to the infusion changed the colour to a bright olive green, but was scarcely precipitated. The powder macerated in sulphuric acid afforded a golden yellow tincture, which reddened litmus paper, and left a pellicle of bitter resin when evaporated on the surface of water, to which it gave the colour of the tincture. This coloured water did not precipitate the solution of galls and of tartar emetic, and occasioned no precipitate on the addition of the solution of sulphate of iron. With alcohol it produced a deep orange coloured tincture, which precipitated sulphate of iron, tartarized antimony, and tannin. The agency of the different menstrua on the red and yellow varieties of the Cinchona produce nearly the same results as on the common or pale bark. The filtered solution of yellow bark has a pale golden hue, with a shade of red; it is bitter, reddens litmus paper, and precipitates solution of galls. On adding a solution of isinglass, a pinkish yellow precipitate is produced; superacetate throws down a precipitate; tartarised antimony gives a precipitate in pale yellowish flakes. A solution of the sulphate of iron changes its colour to a bluish green, and slowly lets fall a precipitate of the same colour. The alcoholic tincture appears to be in every respect the same as that afforded by the pale bark. The red bark lias a more nauseous taste than the barks of the other species. 3 P 2 
The aqueous infusion is of a pale ruby colour; its action on the solutions of galls and of isinglass is nearly the same as those of the two former species, but it is not altered by tartarised antimony, nor by the superacetate of lead; and the solution of iron occasions a dirty yellow colour only, little being precipitated. The alcoholic tincture is of a deep brownish red colour, and precipitates the solution of the sulphates of iron and of tartarised antimony; the former of a black colour, and the latter red. From the experiments of Vauquelin, Fabroni, and others, it appears that the active principles of Cinchonas consist chiefly of cinchonine, resin, extractive gluten, a very small portion of volatile oil, and tannin. Vauquelin has determined the presence of a peculiar acid, to which he gives the name of kinic acid, in some varieties of the bark. The following are the most important results that have been oltained by $\mathbf{M} M$. P'elletier and Caventou, respecting the composition of the three officinal species. - 1st, In pale bark they found acidulous kinate of cinchonine, a green fatty matter, which they term red cinchonine; tannin, a yellow colouring matter, kinate of lime, gum, starch, and woody fibre. 2nd, In yellow bark they found that the alkaline base differs from cinchonine in being uncrystallizable, very soluble in ether, and forming salts with the acids very different from those of cinchonine. The chemical constituents of the yellow bark are an acidulous kinate of this salt, which they have named quinine, a deep yellow fatty matter, red cinchonine, tamin, yellow colouring matter, kinate of lime, starch, and woorly fibre. 3rd, Red bark contains acidulous kinate of cinchonine, kinate of quinine, reddish fatty matter, red cinclsonine, tannin, kinate of lime, yellow colouring matter, starch, and woody fibre. The difference between the pale, the red, and the yellow barks, depends principally on the quantity of the two alkaline bodies, cinchonine and quinine, found in them. The pale bark contains cinchonine, but a very small portion of quinine; the alkali, again, which predominates in the yellow bark, is quinine; while in the red bark, and some spurious kinds, there is a combination of both these substances. The presence of cinchonine, as a distinct vegetable principle, was first discovered in Peruvian bark by Dr. Duncan, of Edinburgh.

The separation of cinchonine from the pale bark, and of quinine from the yellow bark, is a rery simple operation. It consists in digesting the bark, coarsely powdered, in weak sulphuric acid, and then to repeat this digestion with about half the quantity of liquid, till all the soluble matter is extracted. To this decoction a small quantity of powdered slacked lime is added, somewhat greater than is necessary to saturate the acid; the precipitate that ensues (a mixture of cinchonine and the sulphate of lime,) is collected, dried, and boiled for a few minutes in alcohol, which takes up the cinchonine, but will not dissolve the sulphate of lime; the solution is decanted off while still hot, and fresh portions successively added for the repetition of the same operation, until it ceases to act on the residuum, which is then merely sulphate of lime. The different alcoholic solutions are then put into a retort, and considerably evaporated, during which and on cooling acicular crystals of cinchonine are deposited. By repeating the solution once or twice, in boiling alcolol, and again crystallizing, the cinchonine wilt be obtained in at perfectly pure state. Its erystals are semi-transparent, have a pearly lustre, and are usually obtained in the form of small needles. It has but little taste, and requires 700 parts of water for its solution, but boiling alcohol dissolves it much more abundantly; it is sparingly soluble in oils and sulphuric ether. At a moderate heat it is partly volatilized, and partly decomposed. It combines with different acids, forming neutral salts. Mr. Brande found that it contained no oxygen, 100 parts consisting of about 80 parts of carbon, 13 of nitrogen, and 7 hydrogen. It has an intensely bitter taste, and excrts the same action on the animal economy as the bark itself, but it is less generally used in medicine than the other active principle of the bark, quinine, because the yellow bark from which it is procured is more plentiful; the quinine, therefore, is cheaper than cinchonine, and equally efficacious. Quinine may be obtained from the yellow bark in the same manner as cinchonine is prepared from the pale bark, or by adding an alkali to the solution of the sulphate of quinine. Quinine is not crystallizable like cinchonine, but on the application of heat it melts into a kind of paste. It has a much more bitter taste than the other, and is very sparingly soluble in water. They differ also remarkably in their chemical composition, cinchonine containing no oxygen, while in quinine there is a notable proportion of this element. According to Mr. Brande, it consists of about 5.55 parts of oxygen, 7.65 hydrogen, 13 nitrogen, 73.80 carbon. By digesting quinine in a wcak solution of sulphuric acid, the sulphate of quinine is obtained, which is the salt now generally used for medicinal purposes. The most approved process for preparing this salt was pointed out by Mr. Henry. A kilogramme of bark (2 lbs, $3 \mathrm{oz} .5 \mathrm{dr}$.) is reduced to a coarse powder, and boiled twice for about a quarter of an hour in 14 or 15 pints of water, 2 ounces of sulphuric acid being arlded to it each time. The decoctions containing the sulphate of quinine are of a reddish colour, which gradually acquire a yellow tint, and have a very strong bitter taste. They are to be filtered through a linen cloth, and about half a pound of powdered quicklime added to the solution. The sulphate of quinine is decomposed in this manner, the alkali being precipitated along with the sulphate of lime. This is digested repeatedly in alcohol, till it no longer imparts any bitter taste to this fluid; the alcoholic solutions are then evaporated till a very bitter viscid substance is obtained, which becomes brittle as it cools. This is the quinine separated from almost all the other ingredients of the bark, and by digesting it in dilute sulphuric acid a solution of sulphate of quinine is obtained, which crystallizes on evaporation. It is a white pulverulent substance; it crystallizes in small white 4-sided prisms, which are distinguished by their pearly lustre. It is not very soluble, therefore not affording a very bitter taste; but by adding a drop or two of acid to the solution, its solubility is increased, and then it becomes intensely bitter. It is decomposed by the alkalies and earths; it volatilizes at a moderate heat, and it can unite with an excess of acid, forming a bisulphate of quinine. The sulphate of quinine is frequently adulterated with starch, pipe-clay, and various other substances. To determine its purity, the simple process of heating it is sufficient; if it evaporate entirely without charring and melting, it is pure; but if it should turn black or smell sweetish, it is probable that sugar or starch is present. Pure quinine is seldoun used in medicine, but the sulphate possesses in a very eminent degree the medicinal properties of Peruvian bark, one grain, or one grain and a half, being equivalent to a drachm of the bark in substance. In Paris it has superseded, in a great measure, the Peruvian bark, and is now extensively used in this country in all cases where that valuable medicine is indicated, in doses of from 2 to 5 grains.

Medical properties and uses.-Peruvian hark has been long known as one of the most powerful and valuable tonics we possess, and may be administered with great freedom in all cases where that class of remedies are indicated. 'The only effects of an overdose are headache and nausea. It also possesses antiseptic and astringent powers in a very eminent degree, and is universally employed as a febrifuge in the cure of intermittent and remittent fever, in diseases of debility, such as typhus, cynanche maligna, in passive hæmorrhages, confluent small pox, in dysentery, in some cutaneous diseases, as lichen agrius, and livida, in purpurea, in some varieties of erysipelas, in gangrene, in dyspepsia, and even in acute rheumatism and gout. The 
decoction of yellow cinchona bark, given in large quantities, is the best antidote to the poison of tartar-emetic.

Cordatc-leaved Cinchona or YellowPeruvian-bark. Tr. 30 to $40 \mathrm{ft}$.

3 C. notundifòla (I'avon, mss. Lamb. cinch. p. 5.) leaves roundish, naked above and shining, pilose beneath and on the branchlets; panicle brachiate, pubescent; calycine teeth very short; corolla clothed by silky tomentum outside, with a bearded limb; style exserted; stigma bipartite ; capsule linear, terete. h.S. Native of Peru, in the forests of Loxa, in the province of Quito. Segments of corolla ovate. Anthers sliorter than the filaments. Lobes of stigma linear, flat, and obtuse. This is a very distinct species, being easily distinguished from all its congeners by its narrow cylindrical capsules, and by the narrow linear divisions of the stigma.

Round-leaved Cinchona. Tree 30 to 40 feet.

4. C. ovalifòlia (Humb. et Bompl. pl. equin. 1. p. 65. t. 19. nov. gen. 3. p. 403 .) leaves oval or obovate, naked above and shining, but pilose on the veins beneath; calycine teeth ovate, acute; corolla clothed by silky tomentum outsicle, with a bearded limb; anthers twice longer than the filaments; stigma bipartite; capsules oval, constricted at the apex. h.S. Native of Peru, in the forests of Loxa, in the kingdom of Quito; Pavon; and on the Andes of Peru, near Cuenca; Humboldt and Bonpland. Panicle brachiate, pubescent. Flowers white. Segments of corolla linear. Lobes of stigma linear, obtuse. This species must not be confounded with the C. ovalifolia of Mutis, the C. macrocárpa of Vahl, or Quinquina blanc of New Granada, which are totally diflerent.

Oval-leaved Cincliona. Tree 15 to 20 feet.

5 C. purpu'rea (Ruiz et Pav. fl. per. 2. p. 52. t. 193) leaves oval or ovate, acute at the apex, and attenuated at the base, at length naked on both surfaces and shining; panicle corymbose, pubescent; anthers shorter than the filaments, but exceeding the throat; corolla clothed by silky tomentum outside, with a bearded limb; stigma 2-lobed, inclosed; capsules narrow, ovate-oblong, attenuated at the apex. $\eta$. S. Native of the lower mountains of the Andes, in forests, at Chincluao, Pati, Muna, Casape, Casapillo, Sc. (Pavon); and of the Andes of Peru, near the city of Jaen de Bracamoros. C. scrobiculàris, Humb. et Bonpl. pl. equin. 1. p. 165 . t. 47. nov. gen. amer. 3. p. 402. Cascarilla fina Bracamorensium and Cascarilla morada, Ruiz, quinol. p. 67 . Cascarilla bobo de liogamorada. Corolla rose coloured. Capsule bisulcate, pubescent when young, but glabrous in the adult state. This is distinguished from the preceding species by its more acute smoother leaves; by its corymbose panicles; by its filaments being longer than the anthers, and their surpassing the throat of the corolla; by the capsules, which are ovate-oblong, narrowed, and without ribs; and, lastly, by the shorter and broader lobes of the stigma.

\section{Purple-flowered Cinchona. Tree 40 feet.}

6 C. Pube'scens (Vahl, in act. havn. 1. p. 19. t. 2. Lamb. mon. t. 2.) leaves broad-ovate, or roundish-ovate, acute, on long petioles, rounded at the base or acutish, naked and shining above, but clothed with pilose tomentum beneath, as well as the branchlets; panicle brachiate, diffuse, clothed with rusty tomentum; corolla clothed by silky down on the outside, with a bearded limb; anthers almost sessile; stigna 2-lobed; capsule oval-oblong, obsoletely ribbed, tomentose. $h$. S. Native of Pcru, in forests on the lower mountains of the Andes, towards Puzuzo and Panao; and also of the forests of Huanuco, Ruiz et Pavon. C. ovàta, Ruiz et Pav. fl. per. 2. p. 52. t. 195. Cascarílla pállida, Ruiz, quinol. p. i4. Cascarillo de Pato de Gallareta. Petioles 2 inches long. Teeth of calyx very short, acute. Corolla purplish ontside and white inside, with ovate obtuse segnents. Genitals inclosed. Style exceeding the anthers. Lobes of stigma ovate.
Pubescent Cinchona. Tree 30 to 40 feet.

7 C. micrántua (Ruiz et Pav. fl. per. 2. p. 52. t. 194.) leaves broad, oval or obovate, naked and shining above, but pilose in the axils of the veins beneath; panicle crowded, pubescent; anthers shorter than the filaments, hardly exserted; style very short; stigma 2 -lobed; capsule elliptic, attenuated at the apex. h.S. Native of the Andes of Peru, in cold clevated forests towards St. Antonio de Playa Grande, where it was first observed by John Tafalla. Corolla clothed with silky down on the outside, with a bearded limb, and ovate segments. Calycine teeth very short, acute. Lobes of stigma ovate. Capsule bisulcate, ribless. This species has some affinity with $C$. Condaminea, but its small flowers, and elliptical ribless capsules, together with its very short style, and other marks, readily distinguish it.

Simall-flowered Cinchona. Tree 20 to 30 feet.

8 C. Humbozdin'sa (Lamb, cinch. p. 7.) leaves lanceolate, acute at both ends, naked above, but villous beneath, as well as on the branchlets; panicle glomerate, villous; calycine teeth very short, acute; corolla clothed by silky down outside, with a bearded limb; anthers sessile, inclosed; stigma exserted, emarginate; capsules ovate, hairy, glomerate. $h . S$. Native of Peru, in the kingdom of Quito, in forests near the town of Jaen de Bracamoros. Paron. This is a strongly marked and very distinct species; there is none with which it can be confounded; it is the C. villòsa, Pavon, mss.

Humbold's Cinchona. Tree.

9 C. glandurífera (Ruiz et Pav. fl. per. s. t. 224.) leaves oval, acutish at both ends, naked and shining above, very pilose beneath, as well as on the branchlets, with undulated rather revolute margins; panicle bracliate, very pilose; corolla pilose outside, with a bearded limb; calycine teeth very short, mucronulate; segments of corolla ovate; stigma emarginate; capsules ovate, drooping. $\quad$. S. Native of Peru, in the kingdom of Quito, at Losa. Pavon. C. microphýlla, Mlutis, mss. C. quercifòlia, Pavon, R̂ss. C. Mutìii, Lamb. cinch. p. 9. Anthers exserted, shorter than the filaments. Corolla white.

Far. $\beta$; leaves oval, obtuse, rounded at the base, and rather corłate. $\vdash$. S. C. quercifòlia, var. críspa, Pavon, mss.

Gland-bcaring Cinchona. Tree 10 to 12 feet.

10 C. hirsu'ta (Ruiz et Pav. fl. per. 2. p. 51. t. 192.) leaves oval, acute at the base, beset with bristly hairs, as well as the branchlets, veiny above, and at lengtls naked; flowers glomerate, beset with bristly hairs; calycine segments lanceolate, acuminated; corolla pilose outside, with a bearded limb ; stigma 2-lobed; capsule ovate. h.S. Native of Peru, on the Andes, in forests in cold clevated places, towards Pillao and Acomayo. Ruiz et Pavon. Cascarílla delgado, Ruiz, quinol. p. 60. Flowers red. Humboldt and Bonpland have confounded this with the $\mathrm{C}$. cordif òlia of Mutis, with which it has not the least resemblance.

Hicairy Cinchona. T'ree 20 to 30 feet.

11 C. STEnocáRPA (Lamb. cinch. p. 18.) leaves lanceolate, acute at both ends, naked above, but pilose on the veins beneath; teeth of calyx ovate, acute; corolla clothed by silky tomentum outside, with a glabrous limb; anthers sessile; style very short; stigma emarginate; capsule linear, terete. h. S. Native of Peru, in forests in the kingdom of Quito, near the city of Jaen de Bracamoros. Pavon. C. species nova, Pavon, mss. Panicle diffusely branched, pubescent. Segments of the corolla linear, obtuse. Very like $C$. Condaminea, but very distinct.

Narrow-fruilcd Cinchona. Tree.

12 C. caduciflòra (Bonpl. in pl. equin. 1. p. 167. H. B. et Kunth, nov gen. amer.3. p. 411.) leaves broad-obovate, acute at the base, naked and shining above, but pilose in the axils of the veins beneath; panicle brachiate, pubescent; calycine tceth ovate, obtuse; corolla clothed with silky down outside, having the limb glabrous above, and the segments linear-oblong; an- 
thers a little exserted; style very short ; stigma bipartite ; capsules oval-oblong. h. S. Native of Peru, on the Andes, near the city of Jaen de Bracamoros. Humboldt and Bonpland. C. magnifòlia, Humb, et Bonpl. pl. equin. 1. p. 139. t. 39. exclusive of the synonyme of Flora Peruviana. Cascarilla bova of the Peruvians. Segments of corolla shorter than the tube. Lobes of stigma linear, flat.

\section{Caducous-fowered Cinchona. Tree 100 feet.}

\section{\$2. Capsule dehiscing at the apex.-Aberrant species.}

13 C. Macroca'rPa (Vahl, in act. havn. 1. p. 20. t. 3. exclusive of the synonymes. Lamb. mon. p. 22. t. 3.) leaves broadelliptic, very blunt, densely clothed with rough tomentum beneath, as well as on the branches; calyx entire, with rather prominent teeth; corolla large, clothed by silky down outside, with a bearded limb, and lanceolate segments, which are recurved at the apex; genitals inclosed; stigma emarginate; capsule pear-shaped, tomentose. $\quad \zeta$.S. Native of Peru, in the forests of Loxa, Guayaquil, and Cuenca ; and of New Granada. C. ovalifòlia, Mutis, mss. Humh. in mag. S.c. p.118. Cosmibuèna species nov. Pavon, mss. Called Quina blanca, and Quinquina blanc de santa Fe. Corymbs few-flowered. Calyx urceolate, entire. Style furrowed. This species ought not to be confounded with the C. ovalifolia of Humb., to which it has not the least resemblance.

Large-fruited Cinchona. Tree 30 to 40 feet.

14 C. obloxglfòli (Mutis, mss. Humb. in mag. Sc. p. 118. Rhode, mon. p. 57. exclusive of the synonymes,) leaves oblong or cordate, densely clothed with scabrous hairs on both surfaces, as well as the branchlets; panicle brachiate, corymbose, scabrous from hairs; segments of corolla pilose outside, but glibrous inside, linear; genitals inclosed; anthers 3 times longer than the filaments; stigma bipartite; capsules ovate. $\zeta_{\imath}$. S. Native of Peru, in forests in the mountains of Loxa; and of New Granada, near Maraquita. H. B. Kunth, nov. gen. amer. 3. p. 401. exclusive of syn. of fl. per. and Ruiz, quinol. Called Quina roga and Cinchona vulgo Azahar. Flowers white. This is a very distinct plant from C. magnifolia of Ruiz et Pav. It is distinguished from it by its leaves being rounded at the base, often cordate, covered on both sides with rough pilose tomentum, sometimes the older leaves, however, become nearly naked above; the corolla is covered on the ontside with bristly pilose hairs, while that of $\mathbf{C}$. magnifolia has short down, and in the sliape of the capsules.

Oblong-lcaved Cinchona. Tree 12 to 20 feet.

15 C. Magnifòlia (Ruiz et Pav. fl. per. 2. p. 52. t. 196. but not of Humb. et Bonpl.) leaves broad-roundish-oval, naked and shining above, and densely clothed with tomentum beneath; panicle brachiate, corymbose, tomentose; calycine teeth short, acute ; corolla clothed with silky tomentum outside, but laving the limb glabrous above, and the segments lanceolate; anthers inclosed; style exserted ; stigma bipartite ; capsules linear, terete. h. S. Native of Peru, on the Andes, in very hot places in forests, on the banks of mountain streams, at Chinchao, Cuchero, and Chacalıassi. Ruiz et Pavon. C. oblongifölia, Steph. and Churchill, med. bot. 4. t. 184. Cascarilla amarilla, Ruiz, quinol. p. 71. This species of Cinchiona is regarded as yielding the red bark of the shops. Flowers white, sweet-scented.

Large-leard Cinchona or Red Peruvian-bark. Tree $40 \mathrm{ft}$.

16 C. Pavòni (Lamb. cinch. p. 8.) leaves orbicular or cordate, naked above, but clothed with rusty tomentum beneath, as well as the branchlets; corymbs clothed with rusty tomentum; calyx urceolate, entire, obsoletely denticulated ; tube of corolla very long, clothed by silky tomentum outside, with a bearded limb; anthers sessile; stigma deeply bipartite; capsules very long, terete. $h$. S. Native of Peru, in the king- dom of Quito, in groves at Loxa. C. càva, Paron, mss. Called Canela. Corymbs crowded with flowers. Corollas large, with ovate-oblong obtuse segments; anthers hardly exserted above the throat. Style inclosed; lobes of stigma linear, obtuse, with revolute edges. Capsule length and thickness of a finger. This species has considerable affinity with $C$.macrocárpa. The form of its leaves, the deeply bipartite stigma, its very long cylindrical capsules, however, widely separate it.

Pavon's Cinchona. Tree.

17 C. Acutifòlia (Ruiz et Pav. Al. per. 2. p. 51. t. 225.) leaves lanceolate, acuminated, naked and shining above, but pilose at the veins beneath; segments of the calyx linear-oblong, obtuse ; corolla clothed with silky tomentum on the outside, having the limb glabrous above, and the segments linear, acute; genitals inclosed; stigma bipartite; capsule pear-shaped, hairy, attenuated at the base. $h$. S. Native of Peru, on the Andes in groves at the river Chilcoplaya. Cascarilla detropa aguda, Ruiz et Pav. suppl. quinol. p. 8. Panicle brachiate, densely clothed with pili. Lobes of stigma linear, obtuse.

Acute-leaved Cinchona. Tree 20 feet.

18 C. HEXA'xDRa; leaves large, oval, obtuse, clothed with ochraceous villi beneath, as well as on the branchlets and flowers; corollas 5-6-cleft; stamens 5-6. h. S. Native of Brazil, in mountain woods, in the provinces of Rio Janeiro and Minas Geraes. Buèna hexándra, Pohl. pl. bras. 1. p. 10. t. 8. China, Eschwege, journ. bras. 2. p. 86. Quino do Rio de Janeiro, mem. acad. Lisb. 3. pt. 2. p. 96 . The bark is thin, of a bay colour on the outside, but blood-coloured within, very bitter, and is used by the Brazilians as a febrifuge, in place of Peruvian bark. Corolla purple.

Hexandrous Cinchona. Tree.

\$3. Floners disposed in interrupted clongated axillary racemes. Corollas villous on the outside. Capsules dehiseing from the apex. Seeds peltate, girded by a membranous wing.-Rcmijia, D.C. bibl. univ. 1829. scienc. vol. 2. p. 185. prod. 4. p. 357. The spceies are called Quina de Serra or Quina de Remijo throughout Brazil.

19 C. merrugínea (St. Hil. append. voy. p. 8. pl. usuel, bras. 1. t. 3.) leaves oblong-lanceolate, rather narrow, coriaceous, clothed with rusty villi beneath, as well as the branches, with revolute margins; racemes interrupted, hardly branched; corolla tomentose outside. h.S. Kative of Brazil, in the province of Minas Geraes, on arid mountains. Remíjia ferrugínea, D. C. prod. 4. p. 357.-Macrocnèmum no. 1. Velloz. in Vand. f. p. 14. Leaves usually 3 in a whorl. The fascicles of flowers on the raceme are opposite. The bark is bitter and astringent, and is used in place of Peruvian bark in Brazil, under the names of Quina de Remijo and Quina de Serra.

Rusty Cinchona. Slurub 4 to 5 feet.

20 C. VELLO'ziI (St. Hil. pl. usuel, bras. p. 1. no. 2.) leaves ovate, coriaceous, acuminated at both ends, clothed with rusty villi beneath as well as on the branchlets; racemes interrupted, hardly branched; corolla tomentose ontside. $h . S$. Native along with the preceding. Remíjia Vellòzii, D. C. prod. 4. p. 357.- Macrocnèmum, no. 2. Vell. in Vand. f. p. 14. This differs fiom the preceding species in the flowers being on shorter pedicels, in the bracteas being less linear, and in the flowers being longer and more numerous. Fascicles of flowers on the racemes? opposite. The bark of the species is used in Brazil in place of Peruvian bark, under the name of Quina de Serra.

Icllozi's Circhona. Slirub 4 to 5 feet.

21 C. Remijia'na (St. Hil. pl. usuel. bras. p. 1. no. 2. in a note) leaves broad-elliptic, obtuse, cuspidate: the upper ones decurrent at the base, clothed with rusty villi beneath, as well as the branchlets; racemes interrupted, hardly branched; corolla 
villous on the outside. $h$. S. Native of Brazil, along with the two preceding species, C. Remyana, Spreng. syst. 1. p. 705. Remijia Ililàrii, D. C. prod. 4. p. 357. Clusters of flowers opposite, on the raceme. The bark of this species is also used in place of Peruvian bark, under the name of Quina de Remijo.

Remijo's Cinchona. Shrub.

22 C. Candóldiı ; leaves oblong, acute, attenuated at the base, undulated, coriaceous ; panicles axillary, verticillately branched: the branches interruptedly racemose; corolla villous on the outside. $\quad$. S. Native of Brazil. Remíjia paniculàta, D. C. prod. 4.p. 357. Branches trigonal. Branches and branchlets of panicle angular. Leaves clothed with rusty down beneath, as well as the branchlets and panicle. Fruit unknown.

De Candolle's Cinchona. Shrub.

\section{+ Species not sufficiently knorn.}

23 C. Pelátba (Pav. quinol. ined. D. C. bibl. univ. 1829. \&c.) leaves roundish, hardly apiculated, membranous, beset with velvety hairs on the petioles and on the nerves beneath, and velvety between the nerves, but puberulous above; stipulas oval, obtuse, equal in length to the petioles; panicle glabrous, much branched; fruit oblong-terete, crowned by the calyx, glabrous. 5. S. Native of South America, and probably of Peru. This is a very distinct species. Fruit 6-7 lines long. Stipulas an inch long.

\section{Pelalba Cinchona. Tree.}

24 C. Muzone'ssis (Goudot, in plill. mag. 1828, febr, p. 132.) leares ovate-oblong, acute, attenuated at the base; stipulas revolute; panicle brachiate ; corolla white, with a bearded limb. h. S. Native of Columbia, in the extensive forests about the town of Muzo.

Muzo Cincliona. Tree.

25 C. Lambertia'sa (Mart. in bot. zeitumg, no. 7. p. 119. 1831.) leaves petiolate, oval, rather cordate, bluntish, glabrous abore and slining, soft and opaque beneath, and pilose on the nerves; cymes compound, terminal; fruit cylindrical, ribbed, glabrous, dehiscing on one side; seeds girded by a narrow jagged margin. $h_{2}$. S. Native of South America, on the banks of the Amazon.

Lambert's Cinchona. Tree.

26 C. Bergiana (Mart. in bot. zeit. no. 7. p. 119. 1831.) branches and all the younger parts of the tree clothed with rusty hairs; leaves oblong-lanceolate, tapering into the short petioles, flat; thyrse axillary, interrupted, brachiate at the base; capsule oblong-cylindrical. $Ћ$. S. Native of South America, on the banks of the Amazon.

Bcrgius's Cinchona. Tree.

Cult. All the species of this very interesting genus are grown with great difficulty in the stoves of our gardens. The best soil for them is a misture of turfy loam and sandy peat. Cuttings should be taken off when ripe, and planted in a pot of sand, which should be plunged under a hand-glass in a moist heat.

XI. COSMIBUE'NA (named by Ruiz and Pavon after Cosimi Bueno, a Spanish physician, who has written on the natural history of Peru). Ruiz et Pav. H. per. 3. p. 3. but not of their prod. D. Don, in Lin. trans. vol. 17. ined.-Buèna, Pohl. fl. bras. 1. p. 8. D. C. prod. 4. p. 356. but not of Cav.Cinchòna species of authors.

Lin. syst. Pentándria, Monogýnia. Calyx 5-toothed. Corolla tubular, with a 5 -lobed limb, which is imbricate in x'stvation. Anthers oblong, exserted. Stigma bipartite. Capsule somewhat 4-celled, many-seeded, dehiscing from the apex. Dissepiment semiferous, double from the revolute margins of the valves. Seeds narrow, ramentaceous, fibrous at the extremities.-Smoothish trees, natives of South America, with ovate, coriaceous leaves, on short petioles; oval, large, obtuse stipulas, and cymose inflorescence. The bark of these trees is used like those of Cinchòna.

1 C. овтusmo'lia (Ruiz et Pav. fl. per. 3. p. 3.t. 198.) leaves obovate, very obtuse, naked, and shining on both surfaces; corymlss few-flowered, glabrous; calycine teeth ovate, acute; corolla glabrous, with a large tube; anthers sessile, inclosed; stigma 2-lobed; capsules elongated, terete. $々$. S. Native of Peru, in forests towards Pozozo, on the banks of streams; also at Pucblo Nuevo de St. Antonio de Chicoplaya. Cinchòna grandiflòra, Ruiz et Pav. ff. per. 2. p. 54. t. 198. Cinchòna Chìna, Lop. Ruiz, in fl. per. 3. p. 4. Buèna obtusif òlia, D. C. prod. 4. p. 356. Segments of corolla broad, ovate, flat, fleshy. Anthers linear. Style exserted. Lobes of stigma ovate, obtuse, thick. Capsule naked. The flowers are of a brilliant white, and large, which, together with its green shining leaves form a striking contrast in its native forests. It delights in the warmest regions of Peru.

Blunt-leaved Cosmibuena. Tree 20 feet.

2 C. Acumna'ta (Ruiz et Pav. fl. per. 3. p. 4. t. 226.) leaves ovate, short-acuminated, naked and shining on both surfaces; flowers terminal, almost solitary, glabrous; calycine teeth oblong-ovate, bluntisls; tube of corolla very long, and narrow; genitals hardly exserted; stigma 2 -lobed; capsule oblong, cylindrical. 2. S. Native of Peru, in forests on the lower Andes, at Chicoplaya, where it was gathered by Joln Tafalla. Buèna acuminàta, D. C. prorl. 4. p. 356 . Cinchòna acuminàta, Poir. and Spreng. Flowers large, white. Segments of corolla broad-ovate. Anthers linear, sessile. Lobes of stigma oblong, thick, and blunt.

Acuminated-leaved Cosmibuena. Tree 20 feet.

3 C. Dichótoma: leaves elliptic, short-acuminated, at length naked on both surfaces, acute at the base, when young silky; perluncles terminal, dichotomous, few-flowered; calycine teeth very short; capsules linear, very long, terete. h.S. Native of Peru, in forests towards Pueblo-Nuevo, in the tract of the Chicoplaya, where it was first detected by Joln Tafalla. Cinchòna dichótoma, Ruiz et Pav. fl. per. 2. p. 53. t. 197 . All the specimens collected by Tafalla, now in the collection of Mr. Lambert, are in a fruit-bearing state, so that the flowers still remain unknown; they are, however, probably white and glabrous, like the other species.

Diehotomous-peduncled Cosmilmena. 'Tree 20 feet.

Cult. See Cinchòna above, for culture and propagation.

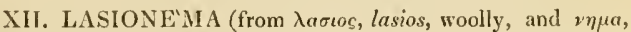
nema, a filament ; in reference to the filaments, which are bearded in the midule). D. Don, in Lin. trans, vol. 17. ined.-Cinchòn: species of authors.

Lis. syst. Pentándria, Monogýnia. Calyx 5-toothed. Corolla tubular, with a 5 -lobed limb, which is imbricate in aestivation. Stamens exserted; filaments bearded in the middle; anthers roundish, peltate: cells loosened at the base. Stigma 2-lobed. Capsule Q-celled, dehiscing in the middle of the cells, many-seeded: having the dissepimcnt complete. Seeds small and narrow. - A tree, native of Peru, with panicled inflorescence.

1 L. Ro'sea (D. Don, in Lin. trans, vol. 17. ined.). $h_{\text {. }}$ S. Native of Peru, on the Andes at Puzuzo, and in the tract of St. Antonio de Playa Grande. Cinchòna ròsea, Ruiz et Pav. f. per. 2. p. 54. t. 199. Cinchòna Tarantàrum, Paron. mss. Cascarílla Pardo, Ruiz, quinol. p. 77. Leaves lanccolate-ovate, acute at both ends, naked, and shining on both surfaces. l'anicle crowded. Corolla tubular, rose-coloured : segments broad- 
ovate. Capsules ovate, bisulcate, glabrons. Humboldt, on the authority of Zea, lias joined this with Cinchòna lancifolia of Mutis, with which it has not the least affinity. Called Asmonich in Peru.

Rose-coloured-flowered Lasionema. Tree.

Cult. See Cinchòna, p. 479. for culture and propagation.

XIII. LUCULIA (Luculi swa is the name given to the tree by the Nipaulese). Sweet, brit. fl. gard. t. 145. D. C. prod. 4. p. 357. D. Don, in Lin. trans. vol. 17. ined.

Lan. syst. Pcntándria, Monogýnia. Calyx 5-parted (f. 87. c.) ; segments foliaceous. Corolla tubular, with a 5-lobed limb, which is imbricate in restivation. Stamens almost inclosed (f. 87. a.). Anthers linear. Stigma bipartite (f. 87. b.) Capsule 2-celled (f. 87. b.), dehiscing at the dissepiment from the apex, many-seeded, crowned by the calyx. Seeds samaroid, surrounded by a jagged membranous inargin.-A tree, native of Nipaul : having cymose bracteate inflorescence.

1 L. Gratíssima (Sweet, l. c.). h. F. Native of Silhet and Nipaul, on the mountains. Cinchòna gratíssima, Wall. in Roxb. f. ind. 2. p. 154. tent. fl. nep. 1. p. 30. t. 21. Mussæénda Lucùlia, Hamilt. in D. Don, prod. fl. nep. p. 139. A small branching tree, with terete pubescent branches; elliptic, actlminated leaves, which are glabrous above and villous on the veins beneath, on short petioles. Cymes terminal, many-flowered. Flowers rose-coloured, rather fleshy, sweet-scented. Stipulas solitary on each side, broad at the base and cuspidate at the apex, longer than the petioles. Segments of calyx deciduons. It is impossible to conceive any thing more beautiful than this tree, when covered with its numerous cymes of pink-coloured very fragrant flowers.

I ery-grateful-scented Luculia. Fl. Aug. Sept. Clt. 1823. Tree 16 to 20 feet.

Cult. A very good rich light soil will suit this tree; and cuttings may be rooted in sand under a liand-glass, but with great difficulty.

XIV. HXMENODI'CTYON (from $i \mu \eta \nu$, hymen, a membrane, and iørvov, dictyon, a net; in reference to the seeds being girded by a reticulated membrane). Wall. in lioxb. fl. ind. 2. p. 148. tent. H. nep. 1. p. 31. D. C. prod. 4. p. 385. D. Don, in Lin. trans. vol. $1 \%$ ined.-Cinchòna species of authors.

Lin. syst. Pentandria, Monogýnia. Calyx 5-toothed. Corolla tubular, with a 5 -cleft limb, which is plicate in astivation. Anthers linear, exserted. Stigma 2-lobed. Capsule 2-celled, dehiscing at the cells, many-seeded; valves ventricose, membranous. Dissepiment complete. Seeds girded by a nembranous, reticulated border, which is bifid at the base.-Trees, natives of the East Indies, with compressed branches: coriaceous, petiolate leaves; deciduous, glandularly ciliated stipulas; and small, inconspicuous, greenish, pubescent flowers, disposed in fascicles, the whole forming racemose panicles. Floral leaves one under each branch of the panicle, lanceolate, convex, veiny, on long petioles, similar to the large calycine teeth of Musce'nda, but placed in a different situation.

1 H. exce'tsum (Wall. in Roxb. A. ind. 2. p. 358.) leaves oblong, downy: floral ones coloured and blistered; stipulas cordate, serrated; panicles axillary and terminal; anthers almost sessile in the month of the tube; partition of capsule contrary. $h$. S. Native of the East Indies, in the mountainous parts of the Circars, and chiefly of the valleys, where it grows to be a large tree. It is called Bundaroo in the 'Telinga language. Cinchòna excélsa, Roxb. cor. 2. p. 3. t. 106 . Tratt. tab. t. 170. The lower pair, or two of the ramifications of the panicle, are ornamented each with a pair of coloured floral leaves. Panicles terminal, large. Flowers fascicled, small, greenish white. The infusion of one fresh leaf in water all niglit had little taste, but struck quickly a deep purplish blue with a chalybeate. The two inner coats of the bark (the onter light spongy stratum is tasteless) possess both the bitterness and astringency of Peruvian bark, and when fresh in a stronger degree; the bitterness is not so quickly communicated to the taste on chewing the bark, as that of the former, but is much more durable, and chiefly about the upper part of the fauces. The wood is firm, close-grained, of a pale malogany colour, and very useful for many purposes.

Tall Hymenodyction. Fl. July, Ang. Clt. 1820. Tree 30 to 50 feet.

2 H. тhy rsiflo'rum (Wall. in Roxb. fl. ind. 2. p. 151.) leaves ovate, downy, pale beneath: the floral ones coloured and reticulated; thyrse terminal and axillary, drooping; stipulas oblong, fringed with coloured glands; limb of corolla urceolate ; partition of capsule contrary, $々$. S. Native of the East Indies, in the interior parts of Bengal. Cinchòna thyrsittòra, Roxb. Branches forming a large ovate head to the tree. Leaves from 2.8 or 10 inches long. Thyrse very dense. Flowers small, greenish yellow, fascicled. The floral pair or two of leaves are on longer petioles than the rest.

Thyrse-floncred Hymenodyction. Fl. June, July. Clt. 1819. Tree 20 to 30 feet.

3 H. Fla'ccidum (Wall. in Roxb. A. ind. 2. p. 152.) leaves ovate-elliptic, smooth, and shining above; stipulas oblong-spatulate, ciliated; racemes axillary, slender, pendulous; capsules oblong. $h_{\text {. }}$ S. Native of the East Indies, on the north side of Sheopore, towards the bottom; and in the valley of Noakote. Leaves from 6-10 inches long: laving the margins slightly waved. Common peduncle pubescent, bearing a hardly coloured, lanceolate-oblong, pubescent, reticulated floral leaf, which is convex on the upper side, and concave on the under. It comes very near the preceding species, but differs, however, in having broader, elliptic, downy leaves, and much thicker both terminal and axillary subcompround racemes $;$ its capsules too are much broader.

Flaccid Hymenadyction. Tree 20 to 30 feet.

4 H. овола'тum (Wall. in Roxb. f. ind. 2. p. 153.) leaves obovate, acuminated, smooth : floral ones lanceolate, acuminated, reticulated, convex, glaucous ; stipulas ovate, acute, glandularly ciliated; racemes axillary and terminal, a little branched, erect. b. S. Native of the Last Indies, and perhaps of Wynaad. Young shoots green, much compressed. Rachis of peduncles villous. At the apex of each peduncle there is a floral pallid leaf, 2 inches long, convex and a little rugose above: glaucous and concave, beautifully veined, and rather pubescent beneath.

Obocate-leaved Hymenodyction. Tree.

Cult. See Cincliona, p. 479. for culture and propagation.

XV. EXOSTE'MMA (from $\varepsilon \xi \omega, e x o$, without, and $\sigma \tau \varepsilon \mu \mu \tau$, stemma, a crown; in reference to the exserted stamens). D. C. diss. 1806 . Rœm. tt Schultes, syst. 5. p. 111. Spreng. syst. 1. p. 705. D. C. prod. 4. p. 358. D. Don, Lin. trans. vol. 17. ined.-Exostèma, Rich. in Humb. et Bonpl. pl. æquin. 1. p. 151.-Cinchòna, section Exostèma, Pers. ench. 1. p. 196.

Lin. syst. Pentándria, Monogýnia. Calyx 5-toothed. Corolla tubular, with a 5-parted limb: having linear, elongated 
segments, which are induplicate in rstivation. Stamens exserted; anthers narrow-linear, having the cells adnate at the base. Stigma undivided. Capsule 2-cellcd, dehiscing at the dissepiment from the apex, many-secded. Seeds girded by an entire membranous border.-C'Trees or shrubs, usually glitbrous. Leaves oval or lanceolate, on short petioles. Stipulas solitary on cach side. Peduncles axillary and terminal. Flowers white or reddish. 'The barks of all the species are destitute of quinine and cinchonine, according to St. Hilaire.

Sect. I. Pito'nia (the bark of some of the species is called Quinquina Piton in the Antilles). I). C. prod. 4. p. 359. Limb of calyx parted almost to the base into tecth of various lengths. Corolla glabrous: having the tube longer than the segments. Stigma undivided. - Species all natives of the Caribbee Islands. The bark is febrifugal, somewhat emetic, and is sold in the shops under the name of Quinquina Piton of the Antilles.

] E. Caribèum (Rocm. et Schultes, syst. 5. p. 18.) leaves ovate-lanceolate, acuminated, glabrous; pedicels axillary, 1fowered, rather shorter than the petioles; calyx bluntly 5 toothed; style and stamens about equal in length to the corolla. r. S. Native of the Caribbee Islands, Guadaloupe, St. Domingo, Jamaica, Santa Cruz, Sc.; and of Mexico. Cinchona Caribæa, Jacq. amer. t. 179. f. 65. obs. 2. t. 17. Lamb. mon. t. 4. Gærtn. fiuct. 1. t. 33. f. 4. Cinchòna Jamaicénsis, Wright, in roy. soc. trans. lond. p. 67. p. 504. t. 10 . Andr. bot. rep.t. 481 . Flowers white, sweet-scented, about the length of the leaves; but according to Jacquin they are pale fleshcoloured. Stanens, according to Andrews's figure, shorter than the segments of the corolla. Dr. Wright says that the jesuits' bark of Jamaica rises only to 20 fect, with leaves of a rusty green colour; ant the young buds of a bluish green hue. The bark is generally smooth and grey on the outside, though in some rough and scabrous, when well dried, and the inside of a dark brown colour. Its flavour is at first sweet, with a mixture of the taste of horse radish and of the aromatics of the East, but when swallowed of that very bitterness and astringency which characterises the Peruvian bark. It grows near the sea shore, and is called in Jamaica Sca-side beech.

Caribhacan Exostemma. Fl. Ju. Jul. Clt. 1780 . Tr. $20 \mathrm{ft}$.

2 E. longirlórum (licm. et Schultes, syst. 5. p. 18.) Jeaves linear-lanceolate, attenuated at both ends, glabrous; pedicels axillary, very short; teeth of calyx long, linear-lanceolate, glabrous; corollas 3 or 4 times longer than the leaves. $h . \mathrm{S}$. Native of St. Domingo. Cinchòna longiflòra, Lamb. mon. p. 38. t. 12. exclusive of the synonymes. Flowers white, 5 inches long before expansion; segments linear; tube very long.

Long-flowered Exostemma. Fl. June, July. Clt. 1820. Tree 20 feet?

3 E. cane'scens (Bartl, in herb. Hænke, ex D. C. prod. 4. p. 359.) leaves ovate-oblong, acuminated, canescent from rilli on both surfaces as weil as on the branchlets; peduncles axillary, 1-flowered. $h_{2}$. S. Native of Mexico. The canescent down on the leaves, branches, pedicels, and young fruit distinguishes it from all the other specics. Flowers unknown. Capsule naked at the apex, not crowned by the calyx. Pedieels length of fruit.

Canescent Exostemma. 'T'ree.

4 E. Angustifo'lium (Rocm. et Schultes, syst. 5. p. 19.) leaves linear-lanceolate, pubescent beneath, as well as on the calyxes; peduncles terminal, corymbose; calycine teeth linearsubulate. $h_{c}$. S. Native of St. Domingo, on the rocky banks of rivers. Cinchòna angustifòlia, Swartz, prod. p. 42. fl. ind. occid. p. 3S0. act, holm. 1787. p. 117. t. 3. Lamb. cinch. 29. t. 9. Capsule oblong, pentagonal. Branches and pedicels rather downy. Peduncles forming a terminal corymbose panicle. CoVOL. III. rolla glabrous, white? about the size of those of $E$. Caribce'um, sweet-scented.

Narrom-leaved Exostemma. Tree 10 to 15 feet.

5 E. coria'ceum (Roem. et Schultes, syst. 5. p. 20.) leaves ovate, scarcely acute, coriaccous, glabrous on both surfaces, slining; branches and flowers glabrous; peduncles axillary, 2-3-flowered; tceth of calyx short, acutc; corollas about the length of the leaves; capsules ovate, smooth. h. S. Native of St. Domingo. Cinchòna coriàcea, Poir. dict. 6. p. 38. Peduncles $\approx$ or 3 times shorter than the leaves. Seed girded by a membranous wing. Corolla glabrous, 2 inches long, with a terete tube and narrow reflexed segments. Branches of panicle dichotomous.

Coriaceous-leaved Exostemma. Tree.

6 E. Linfa'tum (Rcm. et Schultes, syst. 5. 1. 18.) leaves ovate, acuminated, aud are as well as the branches and flowers glabrous; peduncles terminal, corymbose; calycine segments linear; capsule pentagonal. $h$. S. Native of St. Domingo. Cinchòna lineàta, Vahl, symb. 2. p. 27. act. soc. hist. nat. hafn. 1. p. 20. t. 4. Lamb. mon. p. 26. t. 6. Panicle corymbose, terminal, trichotomous. Leaves marked with lines on the ujyrer surface. Flowers an inch long, white.

Lined-leaved Exostenma. T'ree 20 to 30 feet.

7 E. parviflo'rum (Rich. in Humb. et Bonpl. pl. equin. I. p. 132.) leaves oval, mutic, furnished with porose glands in the axils of the nerves; petioles, branches, and pedumcles pubescent; fascicles of flowers axillary and terminal, crowded; teath of calyx short. $\zeta$. S. Native of the Caribbee Islands.

Small-flowercd Exostemma. Tree.

8 E. Brachycárpun (Rom. et Schultes, syst. 5. p. 19.) leaves elliptic, obtuse, and are as well as the branches and flowers glabrous; peduncles terminal, corymbose; teeth of calyx short, acutish; capsules ovate or obovate, ribbed. $々$. S. Native of the eastern parts of Jamaica, in shady parts of mountains. Cinchòna brachycárpa, Swartz, prod. p. 42. $\mathrm{f}$. ind. occid. 378. Lindsay, roy. soc. trans. edinb. 1794. p. 214. t. 5. Vahl, act. soc. hist. nat. hafn. 1. p. 22. Lamb, cinch. p. 18. t. 8. Panicle terminal, corymbose, trichotomous. Corolla $3 \frac{1}{2}$ inches long before expansion, pale red or flesh-coloured. Leaves 5-6 inches long, decp green. The bark, when wounded, emits a whitish juice; which becomes of a brownish purple colour on drying, and is easily reduced into a greyish purple powder, which is at first sweet, but afterwards very bitter and astringent.

Short-fruited Exostemma. Tree 20 feet.

9 E. TRIF Lo' RUM; leaves lanceolate, obtuse, attenuated at the base, quite glabrous, and shining on both surfaces; branches glabrous; corymbs compound ; pecluncles 2-3-flowered; calycine teeth subulate; corolla with a very long filiform tube, and long, narrow, linear, dependent segments; capsule obovate. h.S. Native of Jamaica. Cinchòna triflòn, Wright, in edinb. med. journ. p. 210. Lamb. cinch. p. 15. It comes nearest to $E$. floribundun, but differs from it in the lcaves being ovateelliptic, acuminated, not attenuated at the base; the corymbs of flowers are also much larger and closer; the tceth of the calyx are sliorter and broader; the tube of the corolla is much shorter and wider; and the capsules oblong-cylindrical.

Three-flowered Exostemma. Tree 20 feet.

I0 E. Floribu'NDA (Røm. et Schultes, syst. 5. p. 19.) leaves elliptic, acuminated, and are as well as the branches and flowers glabrous; peduncles terminal, corymbose; teeth of calyx short, acute; capsules turbinate, smooth. $\eta$. S. Native of the Caribbee Islands, Jamaica, Guadaloupe, St. Domingo, St. Lucia, and Trinidad, in woods on the banks of mountain streams. Cinchòna floribúnda, Swartz, prod. 1. 4.1. f. ind. occid. p. 375. Lamb. mon. p. 17. t. 7. Cinchòna montàna, Badier. in jouru. phys, 1789 . febr, p. 129. t. 1. Cinchòna, St. Lùciæ, David, phil. $3 \mathrm{Q}$ 
trans, vol. 74. Cinchòna Luciàna, Vittm. summ. suppl. 1. p. 264. Kinkina Piton. Act. nat. cur. 1787. Rozier, journ. de phys. 1781. p. 169-179. and 1789. p. 129-132. t. I. Murr. append. med. vol. 1. p. 94.1. Panicle large, corymbose, terminal. Leaves like those of Coffèa Arábica, 5-6 inches long. Corolla 2 inches long before expansion, of a whitish purple colour. The Quinquina Piton is of a cinnamon colour, and is used as a succedaneum for Peruvian bark, but is somewhat drastic.

Bundle-flowered Exostemma. Clt. 1794. Tree 20 to $80 \mathrm{ft}$.

11 F. сан1тA'tum (Spreng. new. entd. 2. p. 143.) Jeaves ovate, coriaceons, glabrous; flowers capitate ; calyx small, 5-toothed ; corolla with a long tube, and revolute segments. h.S. Native of South America. Perhaps only a variety of $E$. floribindum. Specimens of this tree were received under the name of St. Lucia bark.

\section{Capitate-flowered Exostemma. Tree.}

Sect. II. Brachyántuum (from ßoazvs, brachys, short, and av0oc, anthos, a flower; in reference to the tube of the flower being shorter than the segments). 1). C. prod. 4. p. 360. Limb of calyx divided even to the base into teetl. Corolla having the tube shorter than the segments of the limb, or at the longest hardly equal in length to them. Stigma sometimes undivided, and sometimes somewhat 2-lubed. Corolla glabrous, or pubescent on the outside.

12 E. Puníppicum (Rom. et Schultes, syst. 5. p. 366.) leaves oval, acute, crowded, and are as well as the branches and flowers glabrous; peduncles terminal, corymbose; teetl of calyx short, acute; tube of corolla rather shorter than the segments of the limb; filaments hairy. $r_{c}$. S. Native of the Philippine Islands, at Manilla : and in Santa Cruz de la Laguna. Cinchona Philippica, Cav. icon. 4. t. 329. Peduncles axillary, trichotomous, corymbose, bearing 2 leaves at the origin of the branches, about the length of the leaves. Corolla 9 lines long before expansion. Stigma clavate, marked by a furrow on each side, probably from the colsesion of the lobes. Capsule turbinate, 5 lines Jong, crowned by the calycine limb. Bark bitter and astringent.

Philipine Exostemma. Tree 10 to 15 feet.

13 E. corymbíferua (Rom. et Schultes, syst. 5. p. 20.) leaves oblong, acute, and are as well as the branches and flowers glabrous; peduncles axillary, corymbose, bearing 2 leaves just below the ramifications; teeth of calyx short, acute; segments of corolla hardly shorter than the tube. $h_{2}$. S. Native of the islands of 'T'ongatabu and Eaove, in the Pacific Ocean, where it is cultivated for the elegance and odour of its flowers. Cinchòna corymbifera, Forst. act. nov. ups. 3. p. 176. Lin. fil. sippl]. p. 144. Lamb. cincl. p. 25. t. 5. Leaves deep green, size of those of Coffêa Arábica: having the nerve purplish beneath. Corymbs trichotomous. The bark is very bitter and subastringent, and very like Jesuits' bark. Flowers white, but reddish on the outside.

Corymb-bearing Exostemma. Tree 10 to 15 feet.

14. E. Perunin'nu (Humb. et Bonpl, pl. equin. 1. p. 183. t. 38.) leaves ovate or oblong, acute, rounded at the base : the superior ones sessile and cordate; corymbs terminal, sessile; peduncles and calyxes pubescent; corolla silky outside. Һ. S. Native of Peru, on the declivities of the Andes, in cold places by the sides of streams, at the altitude of 3000 feet. H. B. et Kunth, nov. get), amer, 3, p. 404. Cinchòna Peruviàna, Poir. suppl. 4. p. 640. Flowers rose-coloured. Leaves smooth, deep grcen above. Segments of corolla hardly sliorter than the tube. Filaments glabrous, adnate to the throat of the corolla. Stigma obsoletely 2-lobed. Teeth of calyx acute.

Peruvian Exostemma. Tree 10 to 12 feet.
15 E. coryubo'sum (Spreng. syst, 1. p. 706.) leaves oblonglanceolate, acute, and are as well as the branches and flowers glabrous; corymbs terminal, brachiate; teeth of calyx almost linear, acute, spreading; segments of corolla about equal in length to the tube. $h$. S. Native of Peru, in hot places between Chaclla and Muna. Portlándia corymbòsa, Ruiz et Pav. fl. per. 2. p. 49. t. 190. f. a. Leaves shining above, 2-3 inches long. Corolla white: having the limb reflexed. Capsule fuscous, turbinate. Seeds girded by a membranous wing, lience it is not a species of Portlandia.

Corymbose-flowered Exostemma. Tree 15 to 18 feet.

16 E. dissimlliflo'rum (Rom. et Schultes, syst. 5. p. 17.) leaves cordate-oblong, quite glabrous; limb of corolla longer than the tube; capsules almost linear, very narrow. $\eta_{2}$. S. Native of South America, at the altitude of 6000 or 7000 feet. Cinchòna dissimilifòrum, Mutis, in Humb. berl. mag. nat. 1 . p. 120.

\section{Dissimilar-flowered Exostemma. Tree.}

Sect. III. Pseudoste'man. Limb of calyx campanulate, sub-tubular, truncate, or somewhat 5-toothed. Corolla usually villous on the outside: having the tube shorter than the segments of the limb. Stigma usually 2-lobed. Fruit unknown. Flowers clisposed in panicles. Species natives of Brazil. Perhaps a proper genus.

17 E. cuspida'tum (St. Hil. pl. usuel. bras, 1. t. 3. f. A.) leaves ovate-lanceolate, cuspidate, nerved, villous beneath; panicle terminal; limb of calyx campanulately tubular, obscurely 5 -toothed, Jonger than the ovarim; corolla villous on the ontside: with the segments longer than the tube; filaments villous in the middle; stigma bifid. $h$. S. Native of Brazil, in woods. Leaves 9.15 lines long. Corolla white, 2-4 lines long. Fruit unknown. It is called Quino do mato, and the bark is used as a substitute for Peruvian bark.

Cuspidate-leaved Exostemma. Tree 8 to 10 feet.

18 E. Austra'le (St. Hil, pl. usuel. bras. 1. t. 3. f. B.) leaves ovate, nerved, rather villous beneath; panicle terminal, sessile, tripartite; limb of calyx campanulate, shorter than the ovarium, bluntly 5-toothed; corolla rather pubescent on the outside: with the segments longer than the tube; filaments glabrous; stigma undivided. T2.S. Native of Brazil, in woods. Leaves 12-15 inches long, and 7-8 broad. Style villous. The bark of this and the preceding species is employed by the Brazilians in the cure of intermittent fevers, from the want of more efficacious remedies. It is bitter and a little astringent.

Southern Exostemma. Tree 8 to 10 feet.

19 E. vormo'sum (Cham. et Schlecht. in Linnaa. 4. p. 179.) leaves oborate-elliptic, acute at both ends, rather granular when examined under a lens; panicle trichotomous, loosely pyramidal; limb of calyx quite entire; corolla glabrous on the outside, but the throat is villous, and the segments are rather pilose on the inside, and a little longer than the tube; stigma 2 -lobed. $\eta$. S. Native of Brazil, within the tropics.

V́ar. $\alpha$, lepròsum (D. C. prod. 4. p. 361.) leaves large; tube of corolla shorter than the segments of the limb.

Iar. B, lae've (D. C. I. c.) leaves lanceolate; tube of corolla longer than the segments of the limb.

Showy Exost'mma. Tree.

20 E. Souza'num (Mart. reis, ex Linnæa. 5. p. 45.) leaves obovate or ovate, acute, glabrous; corymbs few-flowered, terminal; capsules hardly an inch long, obovate, compressed; valves usually 4-nerved; seeds transversely oblong, with a broad margin. . S. Native of Brazil.

Souza's Exostemma. Tree.

2 I E. macrocne'mia; branches naked; leaves oblong-spatulate, acuminated, tapering into the short petioles, smooth on both 
surfaces, shining; stipulas connate at the base, and running sound the petioles, and forming a callous semicircular margin to them; thyrse axillary, panicled, loose ; flowers minute, tetramerous; fruit cylindrical; seeds furnished with a quite entire

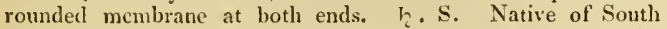
America, on the banks of the Amazon. Cinchona macrocnèmia, Mart. in bot. zeit. no. 7. p. 119.1881.

Long-stamened Exostemma. Tree.

Cult. See Cinchòna, ]) 4.79., for culture and propagation. T'he species are of frecr growtl than those of Cinchiona; and the cuttings sliould not be too ripe when taken off.

XVI. DANA'IS (iazay, danac, the laurel of Alexandria; similarity). Comm. herb. Vent. tabl. 2. p. 584. Pers. ench. 1. p. 198. Juss. mem. mus. 6. p. 385. D. C. prod. 4. p. 361 . -Predèria species, Juss. gen. p. 204. Lam. ill. t. 166. f. 2.Danàis, spec. Poir. Cinchona species, Pet. Th.

Lin. syst. Pentándria, Monogínia. Flowers dioecious from abortion. Calyx with a short obovate tube, and a snall limb, which is 5 -toothed to the base. Corolla funnel-shaped, with a slender tube, a villous throat, and a 5 -parted limb. Stamens exserted in the male flowers, but abortive and inclosed in the female flowers. Style exserted in the female flowers, and bifid at the apex, but abortive in the male flowers. Capsule globose, coriaceously chartaceous, marked by an areola at the apex from the fallen calyx, 2 -celled, debiscing at the cells, 2 -valved. Seeds small, fixed to central placentas, imbricated lownwards, girded by a membranous wing; albumen fleshy.-Smooth, climbing, or straggling shrubs, natives of the Mauritius. Roots exuding a yellow juice when bruised. Leaves oblong or roundish. Stipulas solitary on each side, broad, very short. Peduncles axillary, many-flowered, corymbose, with opposite branchlets. Flowers fragrant, orange-coloured, sometimes hexamerous.

I D. rra'grans (Comm. ex Lam. ill. t. 166. f. 2.) leaves oblong; corymbs crowded; capsule not furrowed, crowned by the permanent, spreading, calycine teeth. $h$. u. S. Native of the Mauritius. Gartn. fil. carp. 3. p. s3. t. 195. D. fràgrans 3, coronàta, Pers. enclı. 1. p. 19s. Pæedèria fràgrans, Lam. dict. 2. p. 260. Cinchona A'fro-I'nda, Willem. herb. maur. p. 16. Petioles 3-4 lines long. Corymbs crowded, many-flowered, twice longer than the petioles. Segments of corolla narrow, spreading. Flowers small, red, swelling like those of Narcissus.

\section{Fragrant Danais. Shrub cl.}

2 D. LAXiFLo'ra (D. C. prod. 4. p. 361.) leaves obovate, obtuse, and cuspidate; corymbs loose, sub-panicled; capsule not furrowed, crowned by the erect permanent calycine teeth. h. . S. Native of Madagascar and Bourbon. Petioles 4 lines long. Panicle of female flowers $2-3$ inches long, but that of the males is unknown.

Loose-flonered Danais. Shrub cl.

S D. Rotundfo'lia (Poir. sippl. 2. p. 450.) leaves ovateroundish, acutish at the apex; corymbs crowded; capsule not furrowed, crowned by the toothless truncate limb of the calyx. h. $\checkmark$. S. Native of the Mauritius, where it is called Liane de bois jaune. Cinchòna chlorrhiza, Bory, in litt. Malànea verticillata, Sieb. fl. maur. exsic. 2. p. 264. exclusive of the synonymes. Petioles 7-8 lines long. Corymbs hardly an inch, mucl shorter than the leaves. Flowers small. Leaves 2-3 inches long.

Round-leaved Danais. Shrub cl.

4. D. sulca'ta (Pers. ench. 1. p. 198.) leaves ovate; capsule furrowed, crowned by the calycine segments, which are foliaceous. $h_{2} \cup$. S. Native of the Mauritius, where it climbs over the highest trees.

Furrowed-fruited Danais. Shrub climbing.
Cult. A mixture of loam, peat, and sand will be a good soil for the species of Danuis; and cuttings will be easily rooted under a hand-glass, in heat. 'They are well fitted for training up the rafters in a stove.

XVII. MANE'TTIA (named after Xavier Manetti, prefect of the botanic Garden at Florence, and secretary of the botanic society there. Author of Viridarium Florentinum 1751: and Regnum Vegetabile, 1756). Mutis, in Lin. Mant. (1771.) p. 556. gen. ed. vii. no, 171. Schreb. gen. 181. H. B. et Kuntl, nov. gen. amer. 3. p. 387. D. C. prod. 4. p. 361 . but not of Adans.-Nacíbea, Aubl. (1775.) guian. 1. p. 96. t. 37. Juss. mem. mus, 6. p. 384 , exclusive of Forsk. syn, and the syn. in fl, per.

Lin. syst. Tetra-Pentándria, Monogýnia. Calyx with a turbinate tube, and the limb parted into as many lobes as there are corolline segments, or double that number (f. 88. a.), and often furnished with lobules in the recesses between the segments. Corolla funnel-shaped, with a terete tube, a hairy throat (f. S8. $c$.) and a 4 (f. $88 . b$.), rarely 5 -parted limb. Anther sessile in the throat. Capsule ovate, compressed, crowned by the calycine lobes (f. 88 . d.), dehiscing from the apex to the base at the dissepiment (f. $88 . d$.): the divisions boat-shaped. Placentas somewhat exserted from the dissepiment. Seeds imbricate, ahnost sessile, peltate, surrounded by a winged membranous border, which is usually toothed. Embryo erect, in fleshy albumen; cotyledons foliaceous, lanceolate,-Perennial, herbaceous, or suffruticose plants : having the stems and branches twining and slender. Leaves ovate-oblong, or subcordate. Stipulas broad, short, acute, usually adhering to the petioles at the base. Peduncles axillary, 1 or many-flowered.

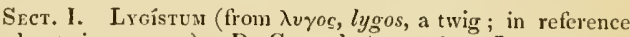
to the twiggy stems). D. C. prod. 4. p. 362.-Lygistum, P. Browne.-Manéttia, Mutis, Lin. and Sclureb. Lobes of calyx twice the number of those of the segments of the corolla, usually $\mathrm{S}$ (f. $8 \mathrm{~s}$, a.), rarely 10 ; besides the accessory lobules.

1 M. RECLINA'TA (Lin. mant. p. 553.) stem herbaceous, reclinate, weak, branched; leaves ovate, acute, pubescent beneath ; peduncles axillary, many-flowered, shorter than the leaves; pedicels opposite, hairy. $\odot \cdot \cup$. G. Native of Mexico. Corolla white. Calyx 8-lobed; lobes linear, concave, hairy. Nacíbea reclinàta, Poir. in Lam. dict. 4. p. 416.

Reclinate-branched Manettia. Pl. tw.

2 M. raceno'sa (Ruiz et Pav. fl. per. 1. p. 58. t. 89.) stems twining; branches tetragonal; leaves ovate or oblong, acuminated ; stipulas semi-circular, acuminated, ciliated ; racemes axillary, few-flowered, longer than the leaves; corollas hairy. $h_{2}$. $\therefore$ S. Native of Peru, in groves at Cuchero and Chinchao. M. mutábilis, Pers. ench. 1. p. 134. Nacíbea mutábilis, Poir. suppl. 4. p. 55 . Lobes of calyx 8 , but in the ultimate flowers 10 , according to the figure; and sometimes 4-5, according to the description. Corolla purplish.

Racemose-flowered Manettia. Slirub tw.

3 M. coccínea (Willd. spec. 1. p. 625.) stems twining; branches tetragonal; leaves ovate, acuminated, glabrous, shining; stipulas oblong, acute ; peduncles axillary, racemose, few-flowered, shorter than the leaves. $\mathbf{k}$. $\mathrm{C}$. S. Native of

French Guiana. Ker. bot. reg. 693. Nacíbea coccínea, Aubl. 3 \& 2
FIG. 88 .

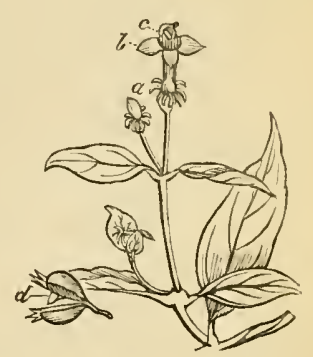


guian. 1. p. 96. t. 37. f. 1. Calyx oblong, compressed : having 4 furrows on each side, and 8-lobed at the apex; lobes narrow, acute, fleshy. Corolla having a white tube, spotted with red, a throat closed by yellow hairs: and 4 oval, acute lobes, which are scarlet and villous above.

Scarlet-flowered Manettia. Fl. May, July. Clt. I 806. Shrub tw.

4. M. Lygístum (Swartz, prod. 4. p. 362. fl. ind. occ, p. 323.) stem suffruticose, flexuous, scandent; branches filiform; leaves ovate, acute, veiny, roughish on the nerves beneath; stipulas subulate, very short; peduncles axillary, longer than the leaves, many-flowered. $h$. ?. S. Native of the south of Jamaica, on the higher mountains. Spreng. syst. 1. p. 4.13. exclusive of the syn. of Kunth. Lygístum, Browne, jam. p. 142. t. 3. f. 2. but the calyx is said to be 4-lobed and the fruit baccate and 4celled, and is therefore the Petèsia Lygistum, Lin. spec. 160. the Lygístum axillàre, Lam. ill. 1. p. 286.t. 67. f. 2., in which the caly $x$ is also delineated with 4 lobes, and therefore also the Coccocýpsilum biflòrum, Willd. spec. 1. p. 618.; the Fernèlia biflòra, Riom. et Schultes, syst. 3. p. 187. Perhaps 2 species are here confused, one with a 4-lobed calyx and the other with an 8-lobed calyx: having 4 of the lobes lanceolate, and 4 of them tooth-formed and smaller.

Twiggy Manettia. Fl. Feb. April. Clt. 1822. Sh. cl.

5 M. Havanne'ssis (H. B. et Kunth, nov. gen. amer. 3. p. 388.) stems twining; branches angular; foriferous branchlets by threes; 1-3-flowered: leaves orate-oblong, acuminated,

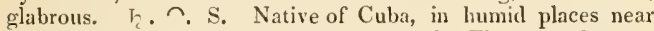
the Havannah. Leaves usually 3 in a whorl. Flowers unknown. Capsule roundish, crowned by the 8 linear lobes of the calyx. Seerls girded by a jagged wing.

Havamah Manettia. Shrub tw.

6 M. cuspida'ta (Bert. in Spreng. syst. 1. p. 415.) plant glabrous; stems twining; branches filiform, rather tetragonal; leaves oval-oblong, acuminated; stipulas broad, very short; pedıncles axillary, bipartite; pedicels elongated, 1-flowered. I. $\cap . S$. Native of Jamaica, Trinidad, and Mexico. Calyx roughish, turbinate, with 8 linear elongated subulate lobes. Corolla smoothish. Capsule oval, compressed, glabrous, with 8 nerves, which remain after the seeds have fallen. Seeds girded by a tootlied wing.

Cuspidate-leaved Manettia. Shrub tw.

7 M. Unielo'ra (H. B. et Kunth, nov. gen. amer. 3. p. 387.) stems suflitescent, scandent; branehes tetragonal, rather hispid ; leaves ovate-oblong, ending in a narrow acumen, rather pilose above and glabrous beneath; peduncles terminal and lateral, ]-flowered. $h \cdot \cup$. S. Native of New Andalusia, in temperate places near Caripe. Stipulas short, ovate, ciliated. Corolla red. Lobes of calyx 8, linear. Capsule pear-shaped, s-ribbed. Wings of seeds laciniately toothed. According to Kuntll this is very ncarly allied to $M$, racemòsa.

One-flowered IIanettia. Shrub cl.

Sect. I1. NAcíbea (Aublet does not gire the meaning of this word). D. C. prod. 4. p. 363 . Lobes of calyx equal in number to the lobes of the corolla, usually 4, without any accessory lobules.

8 M. condro'us (Mart. spec. mat. med. bras. 1. p. 19. t. 7.) stcms herbaceous, twining, terete, rouglish; leaves ovate, cordate at the base, acute at the apex, finely pubescent on both surfaces; peduncles axillary, 1-flowered. $4 . \frown$ G. Native of Brazil, in the province of Minas Geraes, at Villa Ricca, in hedges and on the margins of woods. Roots woody, brown, and are an excellent remedy in dropsy and dysentery. Lobes of calyx i, ovate-lanceolate, downy. Corolla scarlet, an inch long, glabrous ontside, and villous inside.
Hearl-leaved Manettia. Fl. Aug. Oct. Clt. 1832. Pl. tw. 9 M. GLA'Bra (Cham, et Schlecht, in Linnæa. 4. p. 159.) plant quite glabrous; stems twining; leaves cordate, acuminated; peduncles axillary, 1-flowered. $4 . \cap$. G. Native of the South of Brazil, among bushes, on the banks of rivers and rivulets, as on the Uraquay. Corolla scarlet, glabrous on the outside, but clothed with white villi above the base inside. Stigma club-shaped. Stipulas with a subulate point in the middle. Segments of calyx narrower than in $M$. cordif òlia, which plant is very similar, and which Hook. and Arnott consider identical.

Glabrous Manettia. Pl. tw.

10 M. GRA'cilis (Cham. et Schlecht. in Linnæa. 4. p. 169.) plant puberulous, twining; leaves petiolate, ovate-lanceolate, acuminated; peduncles axillary, 1-flowered; calyx glabrous. 4. $\frown$. S. Native of the south of Brazil. Very like M. glabra, but is distinguished by the characters given, in the flowers being smaller and slenderer, also scarlet; in the calycine lobes being narrower, and in the anthers being linear.

Slender Manettia. H. tw.

11 I. PUBE'scens (Cham. et Schlecht. l. c. p. 170.) plant cinereous from down; stems twining; leaves petiolate, ovate, obtuse at the base, and acuminated at the apex; stipulas furnished with a short acumen; peduncles axillary, 1-flowered; calycine segments longer than the tube, but at length equal with it. 4 . $\sim$. S. Native of the south of Brazil. Very like the two preceding species. Corolla scarlet, 3 times longer than the limb of the calyx.

Pubescent Manettia. Pl. tw.

12 M. villo'sa (Cham, et Schlecht. l. c. p. 172.) plant twining; branches cinereously tomentose from rouglish flown; leaves petiolate, ovate, somewhat acuminated, acutish at the base ; stipulas triangular; peduncles axillary, 1-flowered; segments of the calyx linear, one half shorter than the tube of the corolla; corolla pubescent on the outside; capsule ovate, rather villous. $4 . \cap$. S. Native of the south of Brazil.

Villous Manettia. Pl. tw.

13 M. Atrenuata (Nees. et Mart. in nov, act. bonn. 12. p. 14.) stem scandent, almost terete, roughish; leaves ovatelanceolate, attenuated at both ends, clothed with pubescent tomentum beneath; peduucles axillary, 1-flowered. $\eta_{2} \cap \mathrm{S}$. Native of Brazil, on the road to Felisbert, and in fields at the mountain called Grao-major, in the province of the Mines. Lobes of calyx 4, lanceolate, acuminated, erect, pubescent. Corolla glabrous, 2 inches long, crimson, with ovate acutish reflexed lobes. Upper leaves 3 in a whorl.

Attcnuatcd-leaved Manettia. Shrub tw.

14 M. acutifòla (Ruiz et Pav. f. per. 1. p. 58. t. 89. f. b.) plant glabrous; stems twining, terete; leaves lanceolate, very acute, petiolate; stipulas acuminated, adpressed, broad at the base; peduncles axillary, 1-3-fluwered; tube of corolla hardly longer than the calyx. $4 . \frown$. S. Native of Peru, in groves, in the province of Panatahua. M. acutiflòra, Rom. et Schultes, syst. 3. p. 203. Nacíbea acutiflòra, Poir. suppl. 4. p. 55. Lobes of calyx 4 , lanceolate-linear, acute. Corolla purple, villous outside, as well as in the throat.

Aeute-flowered Manettia. Shrub tw.

15 M. Unbella'ta (Ruiz et Pav. f. per. 1. p. 58, t. 90. f. a.) plant glabrous; stems scandent, terete; leaves ovate and rather cordate, acute; stipulas broad at the base, acuminated, adpressed; peduncles axillary, many flowered, umbellate. $h$. . S. Native of Peru, in groves, at Muna. Nacíbea umbellàta, Poir. suppl. 4. p. 55. Bracteas 2-4, surrounding the flower in the manner of an involucrum. Lobes of calyx 4, lanceolate. Corolla blue, with a bearded throat.

Umbellate-flowered Manettia. Slorub cl. 
16 M. rósea (Pohl, in litt. ex D. C. prod. 4. p. 364.) stems ratler twining, compressedly angular, rather pubescent; leaves oblong, acuminated, glabrous; stipulas broad, short, acuminated; peduncles axillary, bifid, 2-flowered, shorter than the leaves. h. $\frown$. S. Native of Brazil. Lobes of calyx 4, lanceolate, longer than the tube of the calyx. Corollas rose-coloured, larger than in any other species of the genus, pubescent outside, with oblong ciliated segments.

liose-colourcd-flowcred Manettia. Shrub tw.

17 M. Pícta (Willd. spec. 1. p. 625.) stems suffruticose, twining; leaves ovate, acute, on short petioles; perluncles somewhat corymbose at the apex, longer than the leaves. $h . \cap . S$. Native of Cayenne. Nacíbea álba, Aubl. guian. 1. p. 96. t. 37. f. 1. Conotrichia álba, A. Rich. diss. with a figure. Coccocípsilum virgàtum, Lam. ill, no. 1457.? Spreng. syst. 1. p. 417. ex synonymes. Leaves variegated with yellow, Calyx t-tooth. ed. Corolla white, having the hairs in the throat erect, and forming an exserted truncate cone, ex A. Rich., with the lobes villous on the upper side. Flowers varying from 4 to 5 -parted, according to Aublet's figure.

Paintcl-leaved Manettia. Shrub tw.

18 M. Fimbria'ta (Cham. et Sclileclit. in Linnæa. 4. p. 173.) plant twining and quite glabrous ; leaves petiolate, elliptic, acuminated, acute at the base; peduncles lateral, 1-3-flowered; lobes of calyx ovate-lanceolate, a little shorter than the tube of the corolla; lobes of corolla fringed with long hairs; stigma 4lobed. $4 . \cap$. S. Native of the south of Brazil.

liringed-flowered Mancttia. Pl. $t$ w.

19 M. PSEv'Do-Diòdia (Chım, et Schlecht. l. c. p. 174.) stems twining, obscurely tetragonal, glabrous, marked by a ciliated line at the apex; leaves petiolate, broad-oval, acuminated, acute at the base; stipulas triangular, ciliated; peduncles lateral, 1-3flowered; segments of calyx lanceolate, acuminated, ciliated; corolla clothed with grumose tomentum outside; capsule tetragonal, pear-shaped. $\%$..$S$. Native of the south of Brazil. Diòdia pedunculàta, Spreng. syst. 1. p. 405.

False-Diodia Manettia. Pl. tw.

20 M. cilia'ta (Cham. et Schlecht. 1. c. p. 176.) stems twiniıg, tetragonal; angles winged, ciliated; leaves on short petioles, lanceolate, acuminated, ciliated, rather coriaceous ; stipulas ciliated, ending each in a reflexed acumen; peduncles 1-3flowered, pubescent; segments of calyx lanceolate, acuminated, ciliated; corolla clothed with rusty tomentum on the outside;

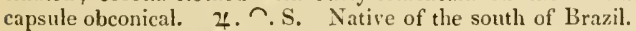

Ciliated-stemmed Manettia. Pl. tw.

21 M. Albiflòra (Schott, mss. ex Pohl, in litt. D. C. prod. 4. p. 364.) stems herbaceous; branches tetragonal, rather pilose; leaves oblong, acuminated at hotl ends, pubescent on both surfaces; stipulas broad, short, cuneated; pedicels numerous, Ifowcred, rising umbellately from the axils of the leaves. $4 . \cap$. S. Native of Brazil. Calyx with a turbinate, rather tetragonal tube, and 4 lanceolate lobes. Corolla white. Fruit unknown.

White-flonered Manettia. Pl. tw.

\section{$\uparrow$ Spccics not sufficiently knomn.}

22 M. Gertne'ri (D. C. prod. 4. p. 364.) stems and leaves unknown; capsule ovate, compressed a little, bisulcate, crowned by the 4-parted limb of the calyx.-The rest unknown. Nacibea glabra, Gærtn. fil. carp. 3. p. 102. t. 197. f. 5 .

Gartner's Manettia, Pl. tw.

23 M. secundiflóa (D. C. prod. 4. p. 364.) plint herbaceous, scaudent; leaves ovate-lanccolate-linear; racemes axillary, subsecund, few-flowered; flowers on short pedicels, bracteate. $\not . ? \cap . S$. Native of St. Domingo. Pæù̀ria secundi- flòra, Poir. suppl. 2. p. 450. Nacíbca species, ex A. Rich. Nacíbea angustifòlia, Vahı, inced, ex Rich.

Secund-flowered Manettia. Pl. cl.

Cult. All the species of Manétia are worth cultivating for the beanty and elegance of their flowers. A mixture of loam peat and sand is the best soil for them. They are easily propagated by young cuttings in the same kind of soil under a handglass, in a moderate heat.

XVIII. BOUVA'RDIA (named after Dr. Charles Bouvard, formerly superintendent of the Jardin du Roi at Paris). Saljsb. parad. lond. 2. no. 88. Ait. hort. kew. ed. 2. vol. 1. p. 245. Kunth, nov. gen. amer. 3. p. 383 . Juss. mem. mus, 6. p. 383. exclusive of the tetrandious species of Rondelètia.-Aginètia, Cav. icon. 6. p. 51. but not of Lin. nor Roxb.-Houstònia species, Andr.-Houstònia, section Christimia, Rafin. ann. gen. sc. phys. 5. p. 2224.

LiN. syst. Tetrándria, Monogýnia. Calyx with a subglobose tube (f. 89. a.), and a 4-parted limb (f. 89. b.); lobes linearsubulate (f. 89.6 .), sometimes with a tooth between each lobe. Corolla funnel-shaped (f. $89 . e$. ), tubular, elongated, beset with velvety papillæ outside, with a naked throat, and a 4-parted spreading short limb (f. 89. d.). Stamens having the filaments artnate to the tube at the base, and free from about the mictdle (f. 89.e.); anthers linear, incloscd. Stigina bilamellate (f. 89. g.), exserted. Superior part of the ovarium naked. Capsule membranaceous, glohose, a little compressed, 2-celled, and deliscing at the cells above; valves semi-septiferous. Placentas orbicular. Seeds many in each cell, compressed, imbricated downwards according to the figure of Salisbury, but upwards according to the figure in $f$. mex., girded by a membranous wing.-Shrubs, natives of Mexico. Leaves opposite or in whorles. Stipulas narrow, acute, adnate to the petioles on botl sides. Peduncles terminal, 3-flowered or trichotomous and corymbose.-'This genus is very nearly allied to IIIancttia.

$\$ 1$. Leaves disposed in nhorles. Corollas flesh-coloured or pale red, having the tube bearded inside.

1 B. Linca'ris (H. B. et Kunth, nov, gen, amer. 3. p. 383. ) branches terete, when young pubescent; leaves 3 in a whorl, linear, with revolute edges, scabrous above, but canescent from hairs beneath; corymbs trichotomous; lobes of calyx 5 times shorter than the tube of the corolla, which is hairy. $h . G$. Native of the temperate parts of Mexico, near St. Augustin de Las Cuevas, Moran, \&c. Corolla 8 lines long, pale red.

Linear-leaved Bouvardia. Slirub 5 feet.

2 B. Angustifòlia (H. B. et Kunth, l. c. p. 384.) branches terete, smoothish; leaves 3 in a whorl, lanceolate, with revolute edges, glabrous above, but beset with fine hairs beneath; corymbs somewhat trichotomous; lobes of calyx $\underset{\sim}{\sim}$ or 3 times shorter than the tube of the corolla, which is hairy. h. G. Native of temperate parts of Mexico, along with the preceding. 'There is a variety of this species with 5 -cleft flowers. Flowers pale red.

Narrow-leaved Bouvardia. Shrub.

3 B. HiRtélia (H. B. et Kunth, l, c.) branches terete ; branchlets and leaves hairy on both surfaces, lanceolate, with revolute edges; flowers corymbose; lobes of calyx 5-6 times shorter than the tube of the corolla, which is hairy. $h . G$. Native about the city of Mexico. Flowers pale red or fleshcoloured.

Ilairy Bonvardia. Shrub.

4 B. QuATERNifòlia (D. C. prod. 4. p. 365.) branches striated, rather downy; leaves 4 in a whorl, lanceolate, acuminated, rather scabrous above, and pubescent beneath; corymbs trichotomous; lobes of calyx 6 times shorter than the tube of the 
corolla, which is pilose. ?. G. Native about the city of Mexico. Carphàlea? pubiflòra, Moc. et Sesse, fl. mex. icon. ined. Flowers scarlet, 12-14 lines long. Perhaps only a variety of B. lirtélla.

Four-leaved Bouvardia. Shrub.

5 B. JACQuín (H. B. et Kuntl, l. c. p. 385 .) branchlets trigonal, and are, as well as the under side of the leaves, hairy ; leaves smoothish above, 3 in a whorl, oblong; corymbs somewhat trichotomous; lobes of calyx 5 times shorter than the tube of the corolla, which is hairy. h.G. Native near the city of Mexico. Ixòra Americàna, Jacq. hort. schœubr. 3. p. 9. t. $25 \%$ Ixòra ternifòlia, Cav. icon. 4. p. 3. t. 305 . exclusive of the description of the seeds. Houstonia coccínea, Andr. bot. rep. 106. Delaun. herb. amat.

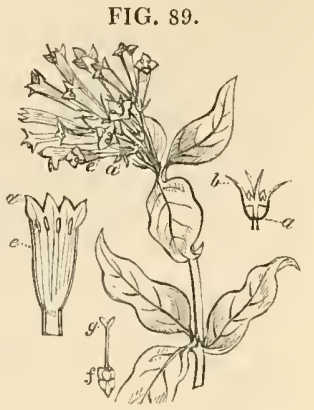

t. 116. Bouvárdia trip̧býlla, var, $\alpha$, Salisb. parad. no. 88. Ker, bot. reg. 107. Ixòra Americana and Hedyotis fruticòsa, Noc. et Sesse, fl. mex. icon. ined. Tlacoxochilt jasminiflòra, Hern. mex. p. 231. with a figure. Corolla scarlet, with the tube about 9 lines long. There are varieties of this species with either pubescent or glabrous leaves.

I ar. $\beta$, exógyna (D. C. prod. 4. p. 365.) leaves oblong-lan-

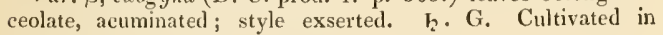
gardens.

I ar. $\gamma$, orcita (D. C. l. c.) leaves ovate, acnte. h. G. Bouvárdia triphýlla, var. $\beta$, Salisb. parad. t. 88 .

Jacquin's Bouvardia. Fl. April, Nov. Clt. 1794. Shrub? to 3 feet.

6 B.? овоva'ta (H. B. et Kunth, 1. c. p. 385.) branclies tetragonal, striated, and are, as well as the leaves, smoothish; leaves 4 in a whorl, obovate; corymbs trichotomous. 24. G. Native of Mexico, hetween Chapoltepec and Tezcuco. Herb 1-3 feet high, ex Bonpland. Perhaps this is a true species of Bouvárdia, ex Kunth.

Obovate-leaved Bouvardia. Pl. 1 to 3 feet.

\section{§2. Leaves opposite. Corolla with a bearlless tube.}

7 B. versícolor (Ker, bot. reg. t. 254.) branches terete, glabrous, velvety while young; leaves opposite, lanceolate, ciliated; corymbs 3-flowered, trichotomous, dreoping; lobes of calyx 8 times shorter than the tube of the corolla, which is glabrous both inside and outside, h.G. Native of South America, but in what place is unknown. Corolla witl a scarlet tube, which is 9 lines long, but having the limb yellowish inside.

Party-eoloured-flowered Bouvardia. Fl. July, Sept. Clt. 1814. Slurub 2 to 3 feet.

8 B. Triflòra (H. B. et Kunth, nov. gen. amer. 3. p. 386. t. 288.) branches terete, glabrous; branchlets rather hairy; leaves opposite, lanceolatc-oblong, acute, rounded at the base, beset with fine hair's; peduncles terminal, 3-flowered; lobes of calyx 3 or 4 times shorter than the tube of the corolla, which is glabrous. h. G. Native of the temperate parts of Mexico. Céstrum spermacocifòlium, Willd, rel. mss, in Roem. et Schultes, syst. 4. p. 808. Corolla white, with the tube 5-6 lines long.

Three-flowered Bouvardia. Shrub.

9 B. Longtrióna (H. B. et Kunth, l. c. p. 386 ) branches compressedly tetragonal, glabrous; leaves opposite, oblong, acute, cuneated at the base, glabrous; fowers terminal, solitary, sessile; lobes of calyx 3 or 4 times shorter than the tube of the corolla, which is glabrous. $\zeta$. G. Native of temperate parts of Mexico, near Santa Anita, where it is called by the natives Flor de San Juan; also near Queretaro and Huanajuato, ex Cav.; and at Pascuaro, ex Cervantes, in herb. Hanke. Eginètia longiflòra, Cav. icon. 6. p. 51. t. 572. f. 1. Corolla white, with the tube 2 or 3 inches long. Stipulas usually cleft into 2 awns at the arex.

Long-flowered Bouvardia. Clt. 3827. Shrub 2 to 3 feet.

10 B. Cavanille'sin (D. C. prod. 4. p. 366.) suffruticose; leaves opposite, ovate-lanceolate, acuminated, rather villous beneath; peduncles terminal, trifid, 3-flowered; capsule transversely ovate, somewhat didymous. $\zeta . G$. Native of Mexico. Eginètia multiflòra, Cav. icon. 6. p. 52. t. 572. f. 2. without flowers.

Cavanilles's Bouvardia. Shrub.

11 B. condro'lia (D. C. prod. 4. p. 366.) suffruticose; leaves opposite, on very short petioles, cordate, acute ; corymbs terminal, sessile, 8-10-flowered. h.G. Native of Mexico. Ixòra cordifòlia, Moc. et Sesse, A. mex. icon. ined. Corolla from dirty yellow to scarlet, 6- 7 lines long.

Heart-leaved Bouvardia. Slırub.

Cult. The species of this gemus usually bear red or searlet flowers, and are therefore worth cultivating in gardens. The readiest way of increasing them is by pieces of the roots, planted in a pot of good mould, and placed in a warm situation; or they may be increased by young cuttings, which root readily under a hand-glass, in a mixture of sand, peat, and loam, in heat.

XIX. PINCKNE'YA (named after an American gentleman of the name of Pinckney, who is now forgotten). Michx. H. bor. amer. 1. p. 103. t. 13. Gærtn. fil. carp. 3. p. 80. t. 194. D. C. prod. 4. p. 366 . D. Don, in Lin. trans, yol. 17. ined.-Pinknèa, Pers. ench. 1. p. 397.-M Issæe'nda species, Juss.-Cinchòna species, Poir.

Lis. syst. Pentándria, Monogýnia. Calyx 5-parted, having one of the segments large, coriaceous, and coloured. Corolla tubular, with a 5 -cleft limb, which is valvate in restivation. Stamens 5 , exserted, inserted in the base of the tube; anthers peltate. Stigma emarginate. Capsule 2-celled, dehiscing at the dissepiment. Seeds compressed, surrounded by a winged membranous margin, which is emarginate at the base.-A tree, native of North America. Branches opposite. Leaves oval, acute at both ends, tomentose beneath, as well as the branches. Stipulas deciduous. Flowers rather large, pubescent, pale red, bracteolate, disposed in cymes; the cymes rising from the axils of the upper leaves. Large calycine leaves, white, tinged with red.

1 P. pu'bens (Mich. l. c.) h. F. Native of Nortl America, in Georgia, on the banks of the river St. Maria, in muddy places; and on the banks of the New river in Sonth Carolina. Pursh, fl. amer. sept. 1. p. 158. Ell. sketch. 1. p. 268. Cinchòna Caroliniàna, Poir. dict. 6. p. 40. Pinknèya pubéscens, Pers. ench. 1. p. 197. The bark of this tree is used in place of Peruvian bark in Georgia and Carolina, under the name of fever bark.

Domny Pinckneya. Il. June, July. Clt. 1786 . Tree $20 \mathrm{ft}$. Cult. This tree is usually treated as a greenlonse plant in Britain; but thrives much better against a south wall, with the protection of a mat in severe weather. A mixture of sand and peat is the best soil for it; and cuttings planted in sand, with a liand-glass placed over them, will strike root.

XX. CALICOPHY'LLUM (from $\kappa a \lambda v \xi$, calyx, a calyx, and $\phi v \lambda \lambda o v$, phyllon, a leaf; in allusion to one of the teeth of the calys being expanded into a large petiolate coloured leaf.) D. C. prod. 1. p. 367 .-Macrocnèmum, Vahl, symb. 2. p. 38. but not of Browne.-Mussánda species, Poir. 
Lin. syst. Pentandria, Monogýnia. Limb of calyx truncate, or bluntly 5 -toothed; one of the teeth expanded into a petiolate coloured inembranous leaf. Corolla campanulate or funnelshaped, with a 5 -parted limb. Stamens 5 ; filaments rising from the throat, free, length of corolla ; anthers oval, exserted. Style ending in 2 reflexed stigmas. Capsule dehiscing at the apex, oblong, 2-celled, many seeded. Seeds fixed to the linear placentas, imbricate, oblong, girded by a very narrow membranous wing. - Small smoothish trees, natives of the West Indies. Leaves opposite, petiolate, membranous, glabrous above, but villots on the veins beneath. Stipulas short, broad, deciduous. Flowers disposed in axillary and terminal trichotomous corymbs; peduncles compressed. Habit of Mussa'nda.

1 C. candidíssinum (D. C. prod. 4. p. 367.) leaves ovate, bluntly acuminated; corymbs terminal ; limb of calyx truncate, except the petiolate leaf; corolla campanulate, with a bearded throat. $\boldsymbol{~} 2$. S. Native of St. Martha, Vahl, and near St. Fernando de Atabapo, on the banks of the Orinoco, H. B. et Kunth; and of Cuba, about the Havannal.. Macrocnènum candidíssimum, Vahl, symb. 2. p. 38. t. 30. Mussæínda candidíssima, Rœm. et Schultes, syst. 5. p. 251. M. cándicla, Poir. dict. 4. p. 395 . The peduncles of the corymbs are 2 -edged. Calyxes villons. Flowers 3 together, the middle one bearing a petiolate leaf, but the 2 lateral ones are naked. Leaves 2-3 inches long. Leaf of calyx hardly an inch long, white, sometimes ovate, and sometimes subcordate.

Very-white-leaved Calycophyllum. Tree 20 feet.

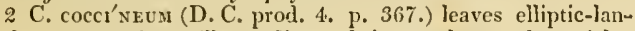
ceolate; corymbs axillary, disposed in an elongated panicle; limb of calyx bluntly 5-toothed; corolla somewhat funnclshaped, glabrous. $\zeta$. S. Native of the island of Trinidad. Macrocnènum coccíneum, Valıl, symb. 2. p. 38. t. 29. Mussa'nda coccínea, Poir. dict. 4. p. 395. Leaves a foot long and a hand broad. Flowers crowded, few, bearing each an ovaloblong, purple or scarlet calycine leaf, which is about 6 inclies long.

Scarlet-leaved Calycophyllum. Clt. 1823. Tree 20 feet.

3 C. тubulòsum (D. C. prod. 4. p. 367.) leaves oval, acute at the base, acuminated at the apex, clothed with fine velvety down on both surfaces; panicles terminal; limb of calyx bluntly 5-toothed; corolla tubular, pubescent on the outside; large lobe of calyx petiolate, orbicular and pubescent on the nerves and veins. $\zeta$. S. Native of Brazil. Macrocnèmum tulıulosum, A. Richard, in herb. mus. par. Capsule ovate, truncate, dehiscing from the apex to the base at the dissepiment. Anthers exserted. Filaments joined together beyond the middle in to a tube.

Tubular-stamened Calycophyllum. Tree.

Cult. Like Musscé $u d a$ this genus is remarkable for the large coloured segment of the calyx, which see for culture and propagation, p. 492 .

\section{Tribe II.}

GARDENIACEE (this tribe agrees with the genus Gardènia in important eharacters). A. Rich. diss. p.108. D. C. prod. 4. p. 367.-Gardenièr and Coccocysèlea, Cham. et Schlecht. in Linnaca. 4. p. J38. and 197. Fruit baccate, 2-celled, or from abortion only 1-celled; cells many seeded. Albumen fleshy, Seeds not winged.-Trees or shrubs, with opposite leaves, and interpetiolar stipulas.

Subtribe I. Sarcocepha'les (agreeing with Sarcocéphalus in the fruit being combined and flesliy). 1). C. prod. 4. p. 367. Flowers collected into a bracteated head (f. $90 . a$.), sessile upon the receptacle. Fruit combined (f. 90. b.).

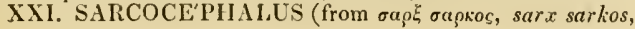

fleshy, and $\kappa \& \phi \alpha \lambda \eta$, kcphale, a head; in allusion to the fruit being combined into a fleshy head). Afz. in lierb. Banks, Sabin. hort. trans. 5. p. 442. t. 18 . D. C. prod. 4. p. 367.-Cephalina, Thonn. in Schum. pl. guin. p. 105.

Lin. sysr. Pentándria, Monogýnia. Flowers 5-6-parted, sessile upon the globose receptacle (f. 90. $a$.), which with the calyxes are combined into a globose fleshy mass. Limb of calyx with a very short margin. Corolla funnel-shaped, 5 -cleft : lobes erect, obtuse. Anthers sessile in the throat of the corolla. Style exserted ; stigma oblong, capitate, undivided. Berries I-celled? many seeded, the whole combined into one mass (f. 90. b.), which is areolate from the margins of the calyxes. Seeds small, somewhat kidney-shaped.-A spreading branchy shrub. Leaves opposite, on short petioles, roundish-oval, acute, shining above, and pubescent in the axils of the veins beneath. Stipulas solitary on each side, triangular, undivided, almost concrete at the base. Heads terminal, on slort pechuncles or sessile, about the size of a peach. Flowers rose coloured or yellowish.

1 S. esculéntus (Sabin. in hort. trans. 5. t. 18.) Native of Guinea, in many parts, as of Sierra Leone and Gambia. Lindl. bot. reg. t. 1827. Cephalina scándens, Thonn. in Schum. pl. guin. 105. Naúclea latifòlia, Smith in Rees' cycl. 24, no, 5. The heads of fruit are edible, and by the negroes of Sierra Leone called peach; they are brown when ripe. Cephalina scándens of Schum. is probably a distinct species, as the Sierra Leone plant does not climb at all. (f. 90.)

Edible-fruited Sarcoceplialus.
FIG, 90

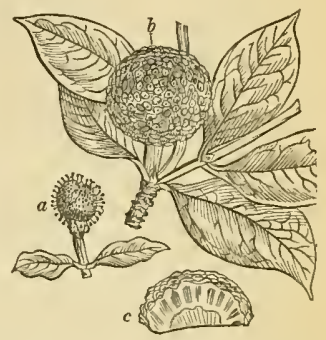

Fl. July. Clt. 1822. Shrub 4 to 6 feet.

Cult. A mixture of loam and peat is the best soil for this plant; and cuttings are easily rooted in the same kind of soil under a liand-glass, in heat. The shrub requires to be kept in a strong beat, or it will neither flower nor fruit.

XXII. ZUCCARI'NIA (J. G. Zuccarini, a professor in the academy at Monach; author of some papers in the transactions of that academy). Blum. bijdr. (1826.) p. 1006. but not of Spreng. (1827.)

Lis. syst. Pentándria, Monogýnia. Calyx with an oval tube and a 5 -tootlied limb. Corolla with a short tube, and an erect 5-lobed limb. Anthers 5, linear, inclosed, adnate to the tube between the segments. Stigma bifid, lardly exserted. Ovarium covered by a depressed disk. Berries oval, stipitate, crowned by the calyx, 2-celled. Seeds compressed, 2 rows in each cell. Embryo albuminous, centripetal.-A fine tree, having the nltimate branches compressed. Leaves elliptic-oblong, acuminated, undulated, glabrous. Stipulas twin, keeled, semi-concrete on both sides. Heads of flowers pedunculate, axillary, solitary. Receptacle hemispherical. Flowers aggregate, sessile, bracteate.

1 Z. Macropirylla (Blum. l. c.) h. S. Native of the west of Java, in woods on the mountains, where it is called Kibara. Leaves more than a foot long.

Long-leaved Zucearinia. T'ree.

Cult. See Sareocéphalus above for culture and propagation.

XXIII. LUCIN E'A (Lucina is one of the names of Juno or Diana). D. C. prod. 4. p. 368.

Lin. syst. Tetrándria, Monogínia. Flowers combined into a dense head. Margin of calyx entire. Corolla fumel-shaped, 
4-parted, densely villous inside. Stamens 4, shorter than the corolla; filaments short; anthers linear. Stigma bifit. Berries combined, a-celled, many-seeded. Seeds numerous, angular. -A glabrous somewhat dichotomous shrub. Leaves petiolate, ovate, acuminated, smooth, coriaceous. Stipulas short, interpetiolar. Axillary peduncles opposite, but the terminal ones are subumbellate. Heads few-flowered. This genus differs from Morinda in the fruit being many seeded, not 1 -seeded.

1 L. Morinde (D. C. prod. 4. p. 368.) h. S. Native of the island of Singapore. Morínda polyspérma, Jacq. in mal. misc. 1. no. 2. p. I4. f1. ind. 2. p. 204. Leaves about 3 inclies long.

\section{Morinda-like Lucinæa. Shrub cl.}

Cult. See Sarcocéphalus, p. 487. for culture and propagation.

XXIV. CANE'PHORA (from ka'ys, kanes, a basket, and $\phi \varepsilon \rho \omega$, pliero, to bear; in reference to the involucrum under the head of the flowers). Juss, gen. mem. mus. 6. p. 401. Lam. ill, t. 151. f. 1. A. Rich. mem, soc. hist. nat. par. 5. p. 261. D. C. prod. 4. p. 617.

Lin. syst. P'enta-IIexándria, Monogýnia. C'alyx with an obovate tube, a 5-6-toothed limb: and triangular, lanceolate, bluntish, rather concave teeth. Corolla with a campanulate tube, and a 5-6-loled spreading limb. Anthers 5-6, oblong, almost sessile, not exserted. Stigma bifid. Fruit baecate? 2-celled : cells many seeded. Seeds compressed, imbricated, inserted in an axillary spongy receptacle. The fruit, according to A. Rich. I. c., is pea-formed, crowned, and 2 -seeded. $-\Lambda$ glabrous shrub, native of Madagascar. Leaves elliptic, coriaceous. Stipulas solitary on both sides, triangular, acute. Flowers on the top of dilated peduncles, or sessile on the tops of the branclses, intermixed with distinct scales, giruled by a tubular toothed involucrum. This genus appears to be intermediate between the subtribes Sarcocephìlece and Gardenièce.

I C. Axilla'ris (Lam. ill. t. 151. f. 1.) leaves elliptic, acute, on short petioles; peduncles axillary, thickened from the base to the apex, ending in a 5-6-lobel cupula at the apex, which bears the flowcrs. $h$. S. Native of Madagascar, where it is called Allou-gala-lay by the natives. Poir. suppl. 2. p. 77. exclusive of the diarnosis.

Axillary-flowered Canephora. Shrub.

Cull. See Sarcocéphalus, p. 487. for culture and propagation.

Subtribe II. Gardenie's (containing slirubs agreeing with the genus Gardènia in having distinet flowers). D. C. prod. 4. 1. 368. Flowers distinct, never combined into a head.

XXV. BURCHE'LIA (named in honotr of William Burchell, F.R.S. F.L.S., who collected many thousand plants in bis travels at the Cape of Good Hope, and in Brazil). li. Brown, in bot. reg. no. 466 . D. C. prod. 4. p. 368.-Bubalina, Rafin. ann. gen. sc. phys. 6. p. 86.-Patàbea species, Juss. Lonicèra species, Lin.

Lin. sist. Pentándria, Monogýnia. Calyx with an obovate tube, having the limb 5-cleft beyond the mildle (f. 91.a.), and drawn out above the ovarium. Corolla of a clavate funnelshape (f. 91. b.), with a naked throat, and 5 sliort lobes (f. 91 . c.), which are imbricated and twisted in æstivation. Stamens 5; flaments adnate to the tube, but free above the iniddle; anthers almost sessile, inclosed (f. 91.b.). Stigma oblong-clavate (f. 91 . e.), and appearing as if it were composed of 2 concrete ones, bearing five convex crests, and a series of tufts of hairs. Berry crowned by the calyx, 2-celled, turbinately globose. Placentas adnate to the dissepiment. Embryo slender.-Shrubs, native of the Cape of Good Hope. Leaves ovate, acute, a little cordate at the base, petiolate. Stipulas interpetiolar, broad, cuspidate at the apex, deciduous. Flowers scarlet, disposed in heats at the tops of the branches, sessile upon a villous receptacle, intermixed with small distinct bracteoles; and each head is propped by the nltimate pair of leaves.

I B. Capénsis (R. Brown, in Ker, bot. reg. t. 466.) leaves ovate, acute, clothed with hispid pubescence; stipulas very broad, and very sliort, cuspidate at the apex; anthers adnate to the upper part of the tube of the corolla. $\zeta . G$. Native of the Cape of Good Hope, where it is called from the hardness of the wood buffel-horn. Cham. et Schlecht, in Linnæa. 4. p. 146. Lonicèra Bubalina, Lin. fil. suppl. p. 146. Thunb. fl. cap. 187. Cephæ'lis Bubalina, Pers. ench. 1. p. 20\%. Flowers 9-10 lines long, of a deep scarlet colour. (f. 91.)

Cape Burchellia. Fl. March. Clt.? Shrub 3 to 5 feet.

2 B. PARYiflòra (Lindl, bot. reg. t, 891.) leaves oval-lanceolate, smoothish ; stipulas ovate, eacl ending in a short point ; anthers inserted in the inidlle of the tube of the corolla. $5 . G$. Native of the Cape of Good Hope. Cinchòna Capénsis, Burm. herb. B. Iubalina, Sims, bot. mag. t. 2339.? Canéphora capitàta, Lam. ill, t. 151. f. 2.? Poir. suppl. 2. p. 77.? exclusive of the country. Flowers $\tau-8$ lines long, orange co!oured.

Small-flowered Burchellia. Fl. Mlay, June. Clt. 1818. Shrub 3 to 4 feet.

Cult. The species of Burchéllia thrive well either in the warm part of a green-house, or the cold parts of a stove, and therefore may be termed hardy stove plants. Their heads, of beautiful scarlet and orange coloured flowers, make them desirable for collections. They grow well in a rich light soil, or a mixture of turfy loam, turfy peat, and sand; and cuttings taken off not too ripe strike root readily, if planted in sand and placed under a hand-glass, in a moderate heat.

XXVI. AMAIOUA (Amaioua and Graine a Tatou are the Guiana names of the first species). Aubl. guian. suppl. 13. t. 375. D. C. ann. mus. 9. p. 218 . Schultes, syst. 7. p. 90. D. C. prod. 4. p. 369.-Amaioùa, Desf. mem. mus. 6. p. 11. t. 4-6. Juss. mem. mus. 6. p. 391.-Amajoùa, Spreng. syst. 2. p. 126. exclusive of some species.-Hexactìna, Willd. rel.-Haméllia species, Lam.

Liv. syst. Hexándria, Monogínia. Limb of calyx tubular, terete, 6 -toothed, falling off very slowly. Corolla salver-shaped, with a terete tube, which is longer than the calyx, and a 6 parted spreading limb; lobes oblong. Anthers 6, inclosed, linear. Stigma clavate. Berry obovate-oblong, corticate, areolate at the apex, 2-3-celled. Seeds disposed in 2 rows in each cell, flat, depressed, nearly orbicular, separated from each otler by small horizontal dissepiments.-Trees or shrubs, natives of South America. Leaves opposite or 3 in a whorl, on short petioles, nerved, glabrous. Stipulas oblong, deciduous. Flowers almost sessile, disposed in corymbs at the tops of the branches. -Perhaps the fruit is at length 1-celled, from the dissepiment having vanished, ex Aubl.

1 A. Guianénsis (Aub]. guian. suppl, p. 13. t. 375.) hranchlets triquetrous, furrowed, clothed with adpressed pubescence; leaves usually 3 in a whorl, broad-elliptic, acuminated, nerved; flowers crowded, almost sessile; limb of calyx tubular,

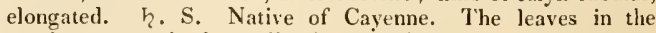
specimens examined are all 3 in a whorl, but are sometimes op- 
posite according to Desfontaines, mem. mus. 6. p. 12. t. 4 . Hamèlia sessiliflòta, Willd. spec. 1. p. 981. Hamèlia glàbra, Lam. dict. 3. p. 65. Duhamèlia glàbra, Pers. ench. 1. p. 203. Berry obovate, areolate at the ajex, from the calyx having fallen off, 2 -3-celled; cells bearing each 2 rows of seeds, and distinct septa; lience the fruit appears 4-6-celled at first sight in the dry state.

Guiana Amaioua. Shrub 4 to 6 feet.

2 A. Fagifólia (Desf. mem. mus. 6. p. 14. t. 5.) branchlets nearly terete, smonthish; leaves opposite, obovate, acuminated, nerved; corymbs of flowers on short peduncles; flowers crowded, almost sessile; limb of calyx tubular, short. $\zeta$. S. Native of Cayenne. Fruit unknown.

Beach-lcaved Amaioua. Shrub 4 to 6 feet.

3 A. 1NTERuE'dia (Mart. in Schultes, syst.7. p, 90.) branches terete, glabrous; leaves opposite, oblong, attenuated at both ends, ciliated ; flowers crowded, almost sessile, silky; upper 2 stipulas forming an involucrum to the head of flowers. $h . \mathrm{S}$. Native of Brazil, in the province of Bahia, in woods.

Intermediate Amainua. Shrub 4 to 6 feet.

4 A. coryuròsa (H. B. et Kunth, nov. gen. amer. 3. p. 419. t. 294.) branchlets almost terete, smoothish; leaves opposite, ovate-elliptic, nerved, acuminated ; corymbs panicled, pedunculate; limb of calyx tubular, short. $\eta_{2}$. S. Native of New Andalusia, near Cumanacoa, in bushy shady places. Desf. mem. mus. 6. p. 15 . Hexáctina corymbòsa, Willd. rel. ex Schlecht. in Schultes, syst. 1. c. Petioles 6-10 lines long. Fruit unknown. Flowers by threes.

Corymbose-flowered Amaioua. Shrub 8 to 9 feet.

5 A. Pertvia'na (Desf. mem. mus. 6. p. 16. t. 4. f. B.) leaves opposite, elliptic, nerved, acuminated, shining on the upper surface; flowers aggregate, corymbose. $\hbar_{c} . S$. Native of Peru. Said to be nearly allied to the preceding.

Pcrucian Amaioua. Shrub 4 to 6 feet.

6 A. ? saccífera (Mart. in Schultes, syst. 7. p. 91.) branches angular and bristly at the apex; leaves 3 in a whorl, obovatelanceolate, attenuated at the base, saccately scrobiform, hairy, costately nerved; flowers terminal, crowded, on short peduncles; calyxes elongated. $h_{c}$. S. Native of. Brazil, in woods, at Barra do Rio Negro, where it is called by the natives Folho dc Comminao and Coa-Jusara.

Sack-bearing Amaioua. Shrub 4 to 6 feet.

7 A. Brasilia'na (A. Rich. diss. ex D. C. prod. 4. p. 370 .) plant suffrutescent, creeping; branches assurgent ; leaves elliptic, acuminated ; flowers small, disposed in crowded corymbs; segments of corolla very sliort. $h$.S. Native of Brazil.

Brazilian Amaioua. Shrub creeping.

Culi. See Mussa'nda, p. 492. for culture and propagation.

XXVII. MUSSE'NDA (the vernacular name of $M$. frondosa in Ceylon). Lin. gen. no. 241. Gærtn. fruct, 1. p. 140. t. 28. Lam. ill. t. 15\%. Juss. mem. mus. 6. p. 386. Ham. in Lin. trans. 14. p. 198. and 203. D. C. prod. 4. p. 870.-Belílla, Rheed. and Adans.

Lin. syst. Pentándria, Monogýnia. Calyx with an oblongturbinate tube, a 5-parted limb, and deciduous erect acute lobes, one of which is usually drawn out into a large petiolate, reticulately nerved, coloured leaf. Corolla funnel-shaped, with a 5parted limb, and a villous throat. Anthers 5, sessile within the tube, linear, inclosed, and sometimes a little exserted. Stigma bifid. Fruit ovoid, fleshy, naked at the apex from the limb of the calyx being deciduous, indehiscent, 2-celled; cells many seeded. Placentas pedunculate, bifid at the apex, rising from the dissepiment, and appearing like a Burgundian cross. Seeds very numerous, small, lenticularly compressed, scabrous. Embryo in fleshy albumen, with the radicle thick, and turned towards the VOL. III.
hylum.-Small trees or shrubs. Leaves ovate, petiolate, villous or glabrous. Stipulas twin on both sides, free or combined at the base, acuminated. Flowers corymbose, terminal. Bracteas small under the pediccls or branches of the corymb, and ouglit to be cautiously distinguished from the large coloured calycine lobes.

Sect. 1. Beríl La (the name of one of the species in Malabar). Rheed. mal. and Adans. One of the calycine lobes is always drawn out into a large coloured reticulately veined bracteaformed leaf, which has been throngh want of proper caution taken for and called bracteas. Anthers sessile within the tube of the corolla, inclosed. Capsule ovate.

1 II, speciosa (Poir. suppl. 4. p. 37.) leaves broad-oval, acute, rather villous at the nerves and veins above, pubescent beneath ; teeth of calyx obtuse, one of which is usually petiolate, large, and coloured; corolla tubular, with obtuse lobes. $h_{2} . \mathrm{S}$. Native of South America, in Caraccas. Macrocnèmum speciòsum, Jacq. hort. schonbr. 1. p. 19. t. 43. The bractea-formed calycine leaves are rose coloured. Corymbs fastigiate, rather villous ; bracteas subulate. Style exserted. Anthers inclosed. Corolli villous on the outside, an inch long, with a rose-coloured limb.

Shomy Mussænda. Fl. Aug. Sept. Clt. 1820. Slırub 3 to 6 feet.

2 M. Acutiflo'ra (Bartl. in Hænke, herb. ex D. C. prod. 4. p. 370.) leaves oval, acuminated, acute at the base, glabrous, except the nerves and veins, which are pubescent on the under surface; corymbs trichotomous pubescent ; teeth of calyx acute, one of which is usually large, petiolate, ovate, and coloured; corolla tubular, with acute lobes. $h$. S. Native of Mexico. Stipulas villous on the outside, bifid, acuminate, and deciduous. The large calycine leaf is 5 -nerved and acuminated. Perhaps only a variety of $M$. speciosa.

Acute-flowercd Mussienda. Shrub 5 to $6 \mathrm{f}$.et.

3 M. Frosdo'sa (Lin. spec. 251.) leaves oblong, acuminated, villous; branchlets and corymbs downy; stipulas subulate; corymbs terminal, dichotomous, somewhat panicled; lobes of calyx elongated, subulate, one of which is petiolate, ovate, acuminated, inembranous and puberulous. $\eta$. S. Native of the East Indies, Java, Malabar, \&c. Belilla, Rheed. mal. 2. p. $2 \%$. t. 17. M. Zeylánica, Burm. zeyl. 165. t. 76. M. formòsa, Lin. mant. p. 338. M. frondòsa, Roxb. et Wall. in f. ind. 2. p. 227. Lam. ill. t. 157. f. 1. Flowers of a deep golden colour The bractea-formed leaf of the calyx is 2 inches long and white.

Frondose Mussanda. Fl. Ju. Sept. Clt. 1824. Slı. 5 to $6 \mathrm{ft}$.

4 M. GLA'BRA (Vahl. symb. 3. p. 38.) leaves oval, acuminated at both ends, glabrous on both surfaces, as, well as the branches; corymbs terminal, smoothish; segments of calyx broad-lanceolate, acute, one of which is large, petiolate, glabrous, and acute. $h$. S. Native of the East lndies. Lodd. bot. cab. t. 1269. Fòlium Principíssa, Rumpl. amb. 4. t. 51. Flowers yellow. The bractea-formed leaf of the caly $\mathrm{x}$ is about 4-5 inches long, white.

Glabrous MI ussænda. Fl. Ju. Sept. Clt. 1820. Sh. 5 to $6 \mathrm{ft}$.

5 M. calycisa (Wall. cat. no. 6253.) leaves ovate or oblong, acuminated, tapering to both ends, almost glabrous, except on the nerves; stipulas villous, cuspidate at the apex; calyxes downy : segments large, ovate, cuspidate; the large foliaceous segment petiolate, ovate, elliptic, acuminated, yellow; young branches and peduncles villous; peduncles terninal and axillary, corymbose, or trichotomous, bearing a single flower in each fork ; fruit turbinate. $\zeta_{2}$. S. Native of the East Indies, in the Burmese empire, on Mount Taong Dong, and at Prome. Flowers yellow.

Large-calyxed Mussanda. Shrub 5 to 6 feet.

6 MI. villo'sa (Wall. cat, no. 6254.) leaves oblong, acumin$3 \mathbf{R}$ 
ated, tapering at the base, on short petioles, hispid from villi on both surfaces; petioles, young branches, and peduncles very villous; stipulas linear-lanceolate, cuspidate, very villous ; corymbs trichotomous, terminal: calyx villous : segments linear: the large, foliaceous segment petiolate, elliptic, yellow. $\zeta$. S. Native of Penang. Flowers yellow.

Villous Mussanda. Shrub 4 to 6 feet.

7 M. Sumatre'nsis (Roth, nov. gen. et spec. p. 152.) leaves elliptic, tomentose on the under surface, as well as the petioles and branches; corymbs terminal ; bractea-formed leaf of calyx roundish, pubescent, reticulately veined. $\eta_{2} . S$. Native of the East Indies.

Sumatra Mussæenda. Shrub 5 to 6 fect.

8 M. nсumina'ta (Blum. bijdr. p, 986.) leaves lanceolate, acuminated at both ends, pubescent on the mid-rib on both sides; corymbs terminal, trichotomous, pubescent; lobes of calyx linear, acuminated: one of which is drawn out into an elliptic-oblong leaf. $h$. S. Native of Java, at the head of the river Tjikiundal, on Mount Gede.

Acuminated-leaved Mussanda. Shrub 5 to 6 feet.

9 M. ríspida (D. Don, prod. fl. nep. p. 139.) leaves oval, acuminated, pilose; branchlets hispid; pedicels and calyxes very bristly; stipulas lanceolate; segments of calyx ovate, acute: one of which is petiolate, ovate, acuminated, hispid on the petiole and villous on the nerves. $\mathbf{b}$. G. Native of Nipaul, at Narainhetty. The lobes of the corolla are rounded and mucronate. It comes near to $M$. frondosa, but the leaves of that species are canescent from tomentum beneath, and the segments of the calyx are linear and elongated.

IIispid Mussanda. Shrub 5 to 6 feet.

10 M. eryturophýlia (Schum. pl. guin. p. 116.) branches velvety from short soft down; leaves ovate, cuspidatc, pubescent above, and villously tomentose beneath; stipulas villouts, deciduous; corymlus terminal, trichotomous, villous; calycine segments subulate: one of which is large, petiolate, ovateacuminated, and very villous; tube of calyx hispid. h.S. Native of Guinea, where it was collected by Thonning. The bractea-formed calycine segments are 4-5 inches long, and 2 inches broad, 5-nerved, and of a reddish colour. Corolla hardly twice the length of the calyx. Habit of $M$. frondosa, under which name it was received from Puerari.

Red-lcaed Mussæenda. Shrub 5 to 6 feet.

11 M. uvtéola (Delil. in Caill. pl. afr. p. 65. t. 1. f. 1. Caill. voy. t. 62.) leaves alnost sessile, ovate-lanceolate, acute, nerved, and tomentose beneath; stipulas twin on each side, lanceolate-subulate; corymbs terminal, trichotomous; calycine teeth subulate: one of which is often petiolate, oval, and acute. f. G. Native of Arabia, on the mountains of Hadie and - Isewhere; and about Singue in Nubia. Ophiorhiza lanceolata, lorsk. œgypt. arab. p. 42. Manéttia lanccolàta, Vahl, symb. 1. p. 12. MIussæénda lanceolàta, Spreng. syst. 1. p. 705. but not of Poir. The bractea-formed calycine leaf is yellowish, as well as the flowers. Corolla an inch long, slender.

Yellow-bractead Mussænda. Shrub 5 to 6 feet.

12 M. Isertia'na (D. C. prod. 4. p. 371.) leaves elliptic, on short petioles, and are as well as the branches glabrous; flowers disposed in corymbose panicles; peduncles and corollas clothed with canescent villi; bractea-formed calycine lobes large, roundish, and glabrous. h.S. Native of Guinea, where it was collected by Isert. M. macrophýlla, Schum. pl. guin. 118. bit not of Wall.

Iscrt's Mussæenda. Shrub 5 to 6 feet.

13 N. Arze'LII ; every part of the shrub is villous; leaves ovate-lanceolate: having the veins clothed with rusty hairs beneatl, as well as the petioles; corymbs panicled, crowded; bractea-formed calycine segment large, white, and villous; cap- sules villous. $々$. S. Native of Sierra Leone, by the sides of rivulets, among other bushes. Flowers yellow.

Afzelius's Mussanda. Shrub 4 to 6 feet.

14. M. PUbe'scens (Ait. hort. kew. ed. 2. vol. 1. p. 372.) leaves ovate-oblong, acuminated, pubescent on the nerves; stipulas $t$ win on each side, subulate; corymbs terminal; calycine lobes subulate: one of which is petiolate, ovate, and acute; corolla with a slender tube, and acute lobes. $h_{2} . G$. Native of China, where it is called Cum mun fa. M. pubéscens, Sims, bot. mag. 2099. Lodd. bot. cab. t. 4.51. but not of Humb. et Bonpl. Corollas small, yellow, elothed with adpressed down on the outside. The branches are rather scandent, and the bracteaformed calycine scgments are white.

Donny Mussenda. Fl. May, Sept. Clt. 1805 . Sh. 3 to $4 \mathrm{ft}$.

15 M. VARTolòsa (Wall. cat. no. 6259.) branches and peduncles hispid and warted; leaves elliptic-lanceolate, hispid from stiff hairs on both surfaces, as well as on the petioles; corymbs trichotomous, terminal; the large foliaceous segments of the calyx roundish, mucronate, triple-nerved, somewhat cordate and somewhat cuneated at the base, white; fruit roundish, not crowned, warted; calycine teeth short. $\zeta$. S. Native of the East Indies, at Amherst, Cliappedong, and 'Tavoy.

Hartcd-fruited Mussaenda. Shrub 5 to 6 feet.

16 M. conyubo'sa (Roxb. f. ind. 2. p. 226.) leaves oblong, pointed, and are as well as the branches smooth; corymbs terminal, smootls; stipulas cordate at the base, and cuspidatc at the apex; calycine scgments setaceous : the bractea-formed one ovate-lanceolate; lobes of corolla ovate, acute. $\boldsymbol{I}_{2} . \mathrm{S}$. Native of Ceylon, Malabar, and other parts of the East Indies. The bractea-formed calycine scgment is white, and the border of the corolla orange-coloured, but greenish underneath. In some parts of India the white floral leaves are brought to table as an esculent herb.

Corymbose-flowered Mussæenda. Shrub 5 to 6 feet.

17 M. macrophy'Lla (Wall. in Roxb. fl. ind. 2. p. 228.) branchlets beset with soft silky hairs; leaves ovate, acuminated, pubescent ; stipulas broad-ovate, bifid, acuminated and recurved at the apex; corymbs terminal, trichotomous, very pilose, on short peduncles; calycine segments foliaceous, broad, oblonglanceolate; bracteas large, very hairy. $h . \mathrm{S}$. Native of $\mathrm{Ni}$ paul, on the mountains of Chundugiri and Nagarjoon. Branches tetragonal, brown. Leaves green above and pale villous beneath. Stipulas nearly twice as long as the petioles. Corymbs shorter than the uppermost pair of leaves. There are generally 3 floral leaves in each coryıb, which are snow white, and 2-3 inches long. Bracteas large under each division of the inflorescence. Flowers large, orange-coloured, hairy outside. Berries dark purple, hairy, sizc of a marrowfat pea.

Long-learcd Mussaenda. Shrub 5 to 6 feet.

$18 \mathrm{M}$. WALlícum; leaves long, elliptic, tapering much to both ends, acuminated, quite glabrous; corymbs glabrous, trichotomous, terminal; the large petiolate calycine leaflets glabrous, triple-nerved, white, acuminated; fruit roundish, crowned by the calycine segments, which are linear. $I_{2}$. S. Native of the East Indies, at Tavoy and Rangoon. M. longif òlia, Wall. cat. no. 6258. but not of Lam.

Wallich's Mussanda. Shrub 6 to 8 feet.

19 M. inca'na (Wall, in Roxb. f. ind. 2. p. 229.) shrub hoary in every part from adpressed soft hairs; lcaves ovateoblong, ahost sessile, white beneath; stipulas broad at the base, lanceolate at tlic apex, adpressed; corymbs tcrminal, sessile, faciculate, few-flowered; bractcas linear-subulate; bracteaformed segment of the calyx large, ovate, petiolate, and acuminated. h. G. Native of Nipaul, towards Gosaingsthan. Root simple, slender. Stem about the thickness of a goose quill, undivided, though seldom with 1 or 2 slender alternate 
branches. Leaves rather longer than the interstices, which are pretty equal, about 5-6 inclies long, villous above. Stipulas about the length of the petioles, furnished with a number of glands inside on the lower part. Corymbs very hairy. Floral leaves subcordate, milk white, downy. Tube of corolla very long, hairy.

Hoary Mussanda. Slirub 2 to 3 feet.

20 M. cuneroo'sia (D. Don, prod. fl. nep. p. 139.) leares cuneate-oblong, acuminated, downy on both surfaces as well as on the branches; stipulas lanceolate, acuminated; corymbs terminal; bracteas lanceolate; calycine segments linear, acute, 5 times shorter than the corolla : one of which is bractea-formed, petiolate, oval, acuminated; tube of corolla villous. 々. G. Native of Nipanl. The large calycine scgment is probably white, and the flowers are probably yellow.

Wedge-lcaced Mussanda. Shrub to to 6 feet.

Sect. II. LA' Ndia (M. De la Land, a correspondent of the Museum of Natural History at Paris). Comm. herb. D. C. prod. 4. p. 372. Lobes of calyx equal or nearly so: laving none of the segments expanded into bractea-formed leaves. Capsule naked at the apex, not crowned by the calyx. Leaves opposite.

21 M. LA' Ndia (Lam. ill. t. 157. f. 2. Poir. dict. 4. p. 392.) leaves ovate, acuminated, clothed with villous pubescence on both surfaces; branches, petioles, corymbs and corollas villous; lobes of calyx equal, triangularly lanceolate, 12 times shorter than the tube of the corolla. $h$.S. Native of the Mauritius, where it is called Quinquina indigc̀ne, or Indigenous Peruvian bark, and is used in the cure of fevers. M. latifolia, Poir. sujpl. 4. p. 36. dict. scienc. nat. 33. p. 452. Rodelètia Lándia, Spreng. syst. l. p. 707. M. holoserícea, Smith, in Rees' cycl. vol. 24. no. 6. Bracteas linear, acute. Corolla an inch long, hairy outside.

De La Land's Mussænda. Fl. Ju.Scpt. Clt. 18\%4. Sh. 4 to $5 \mathrm{ft}$. 22 M. UNifLo'RA (Wall. cat. no. 6264.) young branches, tube of corolla, calyxes, and fruit villous; leaves small, rather villous, roundish, acute, running down the petioles at the base; stipulas villous, narrow; calycine segments subulate; corolla with a long tube and a spreading limb; flowers solitary, terminal. $\quad$. S. Native of the East Indies, at Tavoy. Flowers as large as those of the common jasmine, probably white.

One-flowered Mussænda. Shrub 1 to 2 fect.

23 M. Stadiánis (Michx. med, ex Bory in litt. D. C. prod. 4. p. 372.) leaves oval, ending in short cuspidatc points, hardly pubescent, unless on the nerves; branchlets, corymbs, and corollas pubescent; lobes of calyx equal, elongated, lanceolate, 6 times shorter than the tube of the corolla. $h$. S. Native of the Mauritius. Oxyánthus cymòsus, Reiclıb. in Sieb. fl. maur. exsic. 2. no. 78. M. Lándia, Smith, in Rces' cycl. vol. 24. no. 5. Tube of corolla $1 \frac{1}{2}$ incl long, as in $M$. Landia. The lobes of the calyx are 3 lines long in the present plant, while in that of $M$. Lándia they are hardly a line and a half long.

Stadmann's Mussænda. Shrub 4 to 6 feet.

24 M. Arcua'ta (Lam. dict. 4. p. 392.) leares oval-oblong, acuminated, rather pilose on the nerves beneatlı; branchlets, corymbs, and corollas glabrous on the outside; lobes of calyx linear-subulate, a little unequal; tube of corolla very villous inside. $h$. S. Native of the Mauritius. Sicb. fl. maur. exsic. 2. no. 78. Lándia stelligera, and Lảndia astrogràpha, Comm. ex herb. mus. Paris. The flowers are yellow, and when inmersed in water tinge it with the same colour. Limb of corolla glabrous ontside. Branches archerl.

Arch-branched Mussænla. Clt. 1822. Shrub 4 to 5 feet.

25 M. томектo'sa (Wall. cat. no. 6265.) branclies downy ; leaves elliptic or ovate-elliptic, acute, clothed with white woolly down on both surfaces; calyx downy, with subulate segments stipulas subulate, twin on both sides; tube of corolla long, slender, hairy, with a broad, spreading border; berries roundisl, crowned by the calycine teeth; corymbs terminal, trichotomous. h. S. Native of the East Indies, on the Gingee mountains. Flowers apparently white, as large as tlose of jasmine.

I'omentose Mussænda. Slirub 4 to 6 feet.

26 M. E'LEGANs (Schum. pl. guin. p. 117.) leaves oval, encling in short cuspidate points, and are as well as the branches glabrous ; corymbs terminal, trichotomous, pubescent ; segments of calyx linear, spreading a little; tube of corolla very hispicl, but the lobes are glabrous. $h$. S. Native of Guinea, where it was collected by Thonning. M. díscolor, Thonn. in herl). Vahl, ex Puerari. Very distinet from $M$. discolor, Willd.

Elegant Mussænda. Shrub 4 to 6 feet.

27 M. CORDIFo'lia (Wall. cat. no. 6260.) glabrous in every part; leaves ovate-oblong, acuminated at the apcx and cordate at the base, glabrous, coriaceous, on short petioles; corymbs trichotomous, terminal; berries turbinate, not crowned. $\zeta . S$. Native of Pulo Penang.

Heart-lcarcd Mussænda. Shrub 5 to 6 feet?

28 M. PA'Rva (Wall. cat. no. 6261.) branches and leaves rather hispid from scattered hairs ; leaves ovate-lanceolate, acuminated, tapering to both ends; stipulas subulate; corymbs terminal, crowded; tube of corolla very long, slender, rather swollen near the top; calycine segments linear. $h$. S. Native of the East Indies, at Tavoy. M. angustifòlia, Wall. mss. Apparently a rambling, small shrub.

Small Mussænda. Shrub rambling.

29 M. serícea (Blum. bijdr. p. 986.) leaves ovate-oblong, acuminated, attenuated at the base, glabrous, except on the reins underneath; branches silky ; corymbs terminal, trichotomous, silky. $h$. S. Native of the Moluceas. Segments of calyx linear-lanceolate, silky, all equal. Tube of corolla elon-. gated, densely tomentose.

Silky Mussanda. Shrub 4 to 6 feet.

30 M. RE'PENS (Wall. cat. no. 6263.) root creeping; leares elliptic, acuminated, rather bispid; petioles, young branches, and corymbs clotlsed with brown villi ; stipulas subulate, villous ; corymbs terminal ; calyx downy, with linear-subulate segments ; corolla long, slender, swelling a little near the top. $h$.S. Native of Silhet. The leaves opposite each other are unequal in size.

$$
\text { Crecping Mussænda. Pl. } \frac{1}{2} \text { to } 2 \text { feet. }
$$

E Sect. III. CÁasthe (from kalw, kaio, to burn or nip, and av $\theta 0 s$, anthos, a flower; the flowers of the species are deprived of the large calycine leaves). D. C. prod. 4. p. 372. Lobes of caly $\mathrm{x}$ equal, all linear or setaceous, permanent, therefore the fruit is crowned. Leaves 3 in a whorl. Stipulas broad at the base, acute at the apex, adpressed, coriaceous. - Species natives of Madagascar. Perhaps a proper genus.

31 M. ? citrifo'lia (Lam. in Poir. dict. 4. p. 393.) leaves 3 in a whorl, ovate, almost sessile, coriaceous, and are as well as the branches glabrous; stipulas broad at the base, acute, short corymbs terminal; lobes of calyx linear. $r_{c} . S$. Native of Madagascar. Habit of Raunólfic. Corolla small, yellow.

Citron-lcaved Mussanda. Shrub 5 to 6 feet.

32 M.? Longrfo'lia (Lam. in Poir. dict. 4. p. 393.) leares 3 in a whorl, lanceolate-oblong, rather tomentose from short down; stipulas broad at the base, acute; corymbs terminal; lobes of calyx sctaceous; capsule ribbed. $\zeta_{\text {. }}$ S. Native of Madagascar. Very similar to the preceding species. Leaves green above and whitish beneath. Fruit pyriform, with 8 or 10 longritudinal ribs.

Long-leared MIussanda. Shrub 5 to 6 feet. $3 \mathrm{R} \approx$ 


\section{+ Species not sufficiently known.}

33 M.? glomerula'ta (Lam. in Poir. dict. 4. p. 393.) leaves ovate, acute, smoothish beneath, but clothed with fuscous velvety down above and on the petioles; branehes rather villous; flowers terminal, glomerate; calyx campanulate, with a 5-6-toothed limb. 々. S. Native of French Guiana. Rodelètia glomerulàta, Spreng. syst. 1. p. 707. Peduncles and calyxes beset with white silvery hairs. Corolla tubular, white, rather villous outside. Stamens 5-6.

Glomerate-flowered Missænda. Slurub 5 to 6 feet.

34. M. Díscolor (Pet. Th. in Willd. rel. ex Schultes, syst. 5. p. 254.) hairy; leaves scabrous, strigose above, and clothed with eanescent pili beneath; flowers corymbose, permanent. h.S. Native country unknown, as well as flowers.

Two-coloured-leaved Mussæenda. Shrub.

35 M.? CHine'Nsis (Lour. coeh. p. 152.) leaves in fascicles, lanceolate, glabrous; flowers solitary, terminal; berries 4-celled, many-seeded. h. G. Native of China, in the suburbs of Canton. Calyx 5-parted, with lanceolate segments. Seeds bony, almost kidney-shaped. This is certainly not a speeies of Mussánda.

\section{China Mussæenda. Shrub 5 to 6 feet.}

36 M. echitoldes (Willd. rel. in Sebultes, syst. 5. p. 254.) leaves oblong, acute, glabrous; flowers eorymbose. $h \cdot \cup \cdot S$. Native country unknown. A climbing shrub.

\section{Eclitus-like Mussaenda. Shrub el.}

37 M. tetra'ndra (Schultes, syst. 5. p. 254 .) leaves smooth, glabrous, acute; corymbs tripartite; flowers tetrandrous. $h_{\text {. }}$ S. Native country unknown. Maeroenèmum tetrándrum, Cav. ann. sc, ex Schultes.

Tetrandrous-flowered Mussanda. Shrub.

Cult. Some of the species of this genus are very pretty, and worth cultivating in eollections. $A$ mixture of loam and peat is the best soil for them; and cuttings are easily rooted in the same kind of mould under a hand-glass, in heat.

XXVIII. KUTCHUBE'A (named after - Koutchouba, minister of the home department of Russia; a promoter of the sciences). Fiseh. in litt. ex D. C. prod. 4. p. 373.

Lin. sist. Octándria, Monogýnia. Calyx with a turbinate tube, and a tubular truncate limb, which is longer than the ovarium. Corolla with a cylindrical tube, much longer than the calys, a villous throat, and an 8-parted limb, which is twisted in astivation; segments of corolla laneeolate, acu. minated. Anthers 8, almost sessile, oblong, acute, inserted in the throat of the corolla among the hairs. Style filiform; stigma large, clavate, with 2 lobes, which are applied to each other, hairy and convex on the outside, but flat and smooth on the inside. Fruit unknown.-A glabrous tree, native of Guiana. Branehes terete. Leaves obovate, bluntish, on short petioles. Stipulas ovate, broad, short, combined, permanent, sometimes bifid. Flowers terminal, somewhat corymbose, pedicellate, large, bractless. Corolla purple at the base and pale at the apex.This genus comes very near Génipa and C'assùpa; from the first it differs in the tube of the corolla being much longer than the calyx; and from the second in the ealyx being tubular, and in the stigma being clavate; and from both in the greater number of the parts of the flower.

1 K. insignis (Fisch. l. e, with a figure). h. S. Native of French Guiana, where it was collected by Martin. A tall elegant tree. 'l'ube of corolla 3 inches long, coriaceous.

Famous kutclubaa. Tree.

Cult. For culture and propagation see Musscinda above.

XXIX. CASSUPA (called Cassupo by the natives on the banks of the Rio Negro, in Brazil). Humb. et Bonpl. pl. equin. 1. p. 43. t. 12. Juss. mem. mus. 6. p. 38\%. D. C. prod. 4. p. 373.

Lin. syst. Hexándria, Monogýnia. Calyx with a globose tube and a short entire hardly perspicuous limb. Corolla much longer than the calyx, tubular, wrinkled on the outside, with a villous throat, and a 6-parted short limb; lobes acutish and spreading a little. Antliers 6, almost sessile, inserted in the throat of the corolla among the villi. Stigma bifid, slender, inclosed. Berry almost globose, crowned, 2-celled, manyseeded; placentas fixed to the middle dissepiment. Seeds minute.-An American tree. Leaves obovate-oblong, on long petioles, coriaceous, rather tomentose, about a foot long. Thyrse panicled, terminal, with opposite flowers. Bracteoles 2-3 under each flower, sometimes adnate to the calyx. Corolla I-2 inehes long, pale red.

l C. verruco'sa (Humb, et Bonpl. l.c.). $h_{2}$. S. Native of South America, in shady places on the banks of the Rio Negro, near San Carlos. H. B. et Kunth, nov. gen. amer. 3. p. 412.

Wartcd Cassupa. Tree 30 to 40 feet.

Cult. See Mussánda above for culture and propagation.

XXX. GYNOPACHYS (from $\gamma v u^{\prime} \eta$, gyne, a female, and $\pi a \chi^{v}$, packys, thick; in reference to the thick 2 -lobed stigma). Blum. in flora, 1825. p. 13\%. bijdr. p. 933. D. C. prod. 4. p. 374 .

Lin. syst. Pentándria, Monogýnia. Limb of ealyx turbinate, urceolate, almost quite entire, deciduous. Corolla with a short tube, a 5 -parted spreading limb, and a bristly tliroat. Stamens 5 , seated in the mouth of the tube; filaments short; anthers linear, rather incumbent, exserted. Style short; stigma thick, 2-lobed, exserted. Berry globose, umbonate, crowned by the circular base of the calyx, 2-celled, manyseeded; piacentas membranous, stipitate, rather fleshy, transversely lamellate. Seeds compressed.-Climbing shrubs, natives of Java. Leaves distich. Stipulas interpetiolar, undivided, or twin and rather eonerete. Flowers rising from the axils of the leaves in dense corymbs, unilateral.-This genus comes near to C'ánthium and Bertièra, but difiers from them in the undivided limb of the ealyx, and in the short tube of the corolla.

1 G. Acumina'ta (Blum. 1. e.) leaves ovate or elliptic-oblong, acuminated, almost sessile, glabrous; cymes short, interfoliaceous; pedicels numerous, 1 -flowered. $h \cdot \cup$. S. Native of Java, on the west side, on the mountains. Leaves $7-8$ inches long.

Aeuminated-leaved Gynopacliys. Shrub el.

2 G. тоmеnto'sa (Blum. l. c.) leaves sessile, rather cordateoblong, acuminated, shining above, but clothed with deciduous rufous tomentum on the veins beneath and on the corymbs, which are dichotomons and interfoliaceous. $h . \cup$. S. Native of Java, on Mount Burangrang, in woods.

Tomentose Gynopachys. Slirub el.

3 G. corrmbòsa (Blum. l. c.) leaves almost sessile, ellipticoblong, bluntish, glabrous; corymbs trichotomous, interfoliaceous, divarieate. $\zeta$ ? $\cup$. S. Native of Java, on Mount Salak, in woods. Throat of corolla beset with yellowish rufous bristles. Fruit globose, size of a pea.

Corymbose-fiowered Gynopachys. Shrub el.

Cult. See Mussa'nda above for culture and propagation.

XXXI. TOCOYE'NA (the name of the first species in Guiana). Aubl. guian. 1. p 131. t. 53. Lam. ill. t. 163. Juss. mem. mus. 6. p. 390 . H. B. et Kunth, nov. gen. amer. 3. p. 4.11. D. C. prod. 4. p. 374.-Ucriàna, Willd. spec. 1. p. 961 .

Lin. syst. Pentándria, Monogýnia. Calyx with a turbinate tube, and a very short 5 -toothed limb. Corolla with a very 
long tube, a naked dilated throat, and a 5-parted spreading limb; the lobes obtuse. Anthers rising from the throat of the corolla, exserted, linear-sagittate, furnished each with a blunt appendage at the base? Style filiform, fusiform at the apex; stigma clavate, bilamellate. Berry rather flesliy, 2-celled, crowned. Sceds numerous, roundish-ovate, imbedded in soft pulp.- Unarmed shrubs or undershrubs. Leaves opposite, on short petioles. Stipulas triangular or ovate. FJowers terminal, corymbose.

] T. LoNguro'ra (Aubl. guian. 1. p. 131. t. 50.) stem tetragonal, quite simple; leaves lanceolate-oblong, acuminated at both ends, glabrous; flowers almost sessile, aggregate. $h . \mathrm{S}$. Native of French Guiana, at Araura. Lam. ill. t. 163. f. 1. Ueriàna speciòsa, Willd. spec. I. p. 961. Tocoyèna longifòlia, Poir. diet. 7. p. 602. but not of Kunth. Leaves a foot long, and 4-5 inelres broad. Corolla 8-9 lines long, with the tube yellow, and the limb white. Stipulas triangular.

Long-flonered 'Tocoyena. Clt. 1\$26. Shrub 3 to 6 feet.

2 T. MAcrophy'Lla (H. B. et Kunth, nov, gen. amer. 3. p. 412.) branches tetragonal; leaves broad-ovate, slort-acuminated, glabrous; stipulas roundish, coriaceous; flowers terminal, racemose. $\downarrow$. S. Native of South America, on the banks of the river Magdalena, between Monpox and El-Penon, and near Honda. Ucriàna insígnis, Willd. rel. Spreng. syst. 1. p. $76 \mathrm{I}$. exclusive of the synonyme of Lam. T. insignis, lioem. et Schultes, syst. 5 . p. 229.

Large-leaved Tocoyena. Shrub.

3 T. Loxarfo'Lia (H. B. et Kunth, nov. gen. amer. 3. p. 411. but not of Poir.) branches terete; leaves ovate-oblong, acute, glabrous, shining, with revolute margius; stipulas ovate, acuminated; flowers racemose; teeth of calyx short, acute. h.S. Native of New Granada, in hot places. Ueriàna Humbóldtii, Spreng. syst. 1. p. 761.

Long-leaved Tocoyena. Shrub.

4 T. Mutísil (H. B. et Kunth, nov, gen. amer. 3. p. 411.) branches terete; leaves oblong, acutish, glabrous, shining, witl somewhat revolute margins; stipulas ovate, acuminated ; flowers terminal, corymbose; teeth of calyx short. 々. S. Native of New Granada, in hot places. Ucriàna Mutísii, Spreng. syst. 1. p. 761 .

Mutis's Tocoyena. Shrub.

5 T. Mrsu'ta (Moricand, herb. ex D. C. prod. 4. p. 375.) leaves elliptic, ending each in a short cuspidate point, clother? with villous down above, and with soft velvety hairs beneath. Һ.S. Native of Brazil. Tube of calyx 4 inches long.

Hairy Tocoyena. Shrub.

Cult. See Oxyánthus, p. 494., for culture and propagation.

XXXII. POSOQUERIA (Aymara-posoqueri is the name of the first species by the natives of Guiana). Aubl. guian. 1 . p. 184. t. 51. Lam. ill. t. 163 . Juss. mem. mus. 6. p. 369. D. C. prod. 4. p. 375. but not of Roxb. Blume, nor Gartn.Tocoyèna species, Rich.-Kyrtánthus, Gmel. syst. 1. p. 362.Cyrtánthus, Schreb. gen. no. 30\%. but not of Ait.-Solèna, Willd. spec. 1. p. 961. but not of Lour. nor Hoffin. nor Agardh. -Posòria, Rafin, ann. gen. sc. ph. 6. p. 80.

Lin. syst. Pentándria, Monogynia. Calyx with an obovate tube, and a short 5-toothed limb. Corolla funnel-shaped, with a very long terete tube, a villous hardly dilated throat, and a 5 -parted limb; the segments spreading, obtuse, and nearly equal; the alabastra gibbous on one side. Stamens 5 , rising from the throat of the corolla, free, unequal, a little exserted. Style filiform, slender, and bifid at the apex: with the lobes unequal, rather papillose and acute. Berry ovate, crowned by the calyx, succulent, 2 -celled, many-seeded. Seeds unknown.
-Glabrous shrubs or small trees, natives of Guiana. Branches terete. Leaves opposite, on short petioles, coriaceous. Stipulas oblong-triangular, at length falling off. Flowers white, very long, disposed in terminal corymbs.

1 P. Longiflóra (Aubl. guian. 1. p. 134. t. 5I.) leaves oblong, acuminated, acute at the base; stipulas oblong; ealyx bluntly 5-toothed; tube of corolla very much incurved, and nutant at the apex. $h$. S. Native of Frenclu Gujana, on the banks of rivers. Lam. ill. 163. Solèna langiflòra, Willd. spec. 1. p. 961. Kyrtánthus longifiòrus, Gmel. syst. 1. p. 162. Corolla white, witl the tube very loug, and green at the base; and the hairs in the throat are very long. Berry yellow, about the size of a hen's egg. Seeds 12 , imbedded in the red pulp, according to Aublet. The limb of the corolla is said to be regular. Corymbs composed of about 6 flowers; and the flowers are pedicellate and scaly at the base from bracteas.

Long flowered Posoqueria. Clt, 1820. Shrub 5 to 6 feet.

2 P. Latifo'lia (Roem. et Schultes, syst. 5. p. 227.) leaves ovate, acuminated, obtuse at the base, or a little cordate; stipulas broad, triangular ; calyx bluntly 5 -tootlied; tube of corolla straight: and the limb irregular; alabastra gibbous on one side. h. S. Native of French Guiana and Brazil. Solèna latifòlia, Rudge, guian. 1. p. 26. t. 40. Tocoyèna latifỏlia, Lam. ill. t. 163 . f. 2. Poir. dict. 7. p. 692. Corolla white, with the tube 4 inches long.

Broad-leaved Posoqueria. Clt.? Shrub 5 to 6 feet.

3 P. Deco'ra (D. C. prod. 4. p. 375.) leaves ovate, ending eacl in a short cuspidate point, obtuse and rather cordate at the base ; stipulas oval, obtuse, large, foliaceous, and coriaceous ; calyx bluntly 5 -toothed; tube of corolla straiglit; alabastra rather gibbous on one side. $h$. S. Native of French Guiana. Allied to $P$. latifolin, but differs from all the species in the form of the stipulas. Tube of corolla $3-4$ inches long. Flowers terminal, corymbose.

Neat Posoqueria. Slirub.

4 P. 'Trinita'tis (D. C. prod. 4. p. 375.) leaves ovate, on short petioles, ending in short cuspidate points, obtuse at the base and subcordate; stipulas oblong, bluntish, membranous and foliaceous, and sheatling a little; calyx bluntly 5 toothed. $\zeta$. S. Native of the Island of Triniclad. Sieb. ff. trin. exsic. no. 215. without a name. Tube of corolla slender, $4 \frac{1}{2}$ inches long. Corollas white.

Trinidad Posoqueria. Shrub 5 to 6 feet.

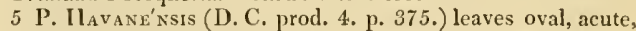
membranous, bluntish at the base; stipulas laneeolate, acute; calyx bluntly 5-toothed; tube of corolla straight; alabastra gibbous on one side. $々$. S. Native of Cuba, about the Havaunah. Tube of corolla slender, $4 \frac{1}{2}$ inches long. Petioles 6 lines long.

Hacannah Posoqueria. Shrub 5 to 6 feet.

6 P. Gracilis (Roem. et Schultes, syst. 5. p. 277.) leaves oval-lanceolate; stipulas oblong; calyx acutely 5-toothed; tube of corolla curved, and the limb irregular. h. S. Native of French Guiana, in remote woods, from the river Darapa to Kaw. Solèna grìcilis, Rudge, pl. guian. p. 27. t. 41. It differ's from $P$. longiflora in the character given, and in the slender nerves of the leaves. Flowers white, 4-5 in a corymb.

Slender-flowered Posoqueria. Clt. 1825. Shrub 5 to $6 \mathrm{ft}$.

7 P. Reyolu'ta (Nees, in flora, 1821. p. 328. Selirad. goett. anz. 1821. p. 714.) leaves elliptic-ovate, each ending in a short cuspidate point, with revolute margins; stipulas deciduous; corymbs dense; tube of corolla straight: throat villous, and limb irregular. $h_{2}$. S. Native of Brazil. P. insignis, Neuw. in flora. 1821 . p. 301 . in reis, bras. with a figure. Flowers white,

Revolute-leaved Posoqueria. Shrub 5 to 6 feet. 
Cult. For culture and propagation see Oxyánthus below. All the species are very pretty when in flower.

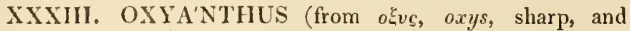
artos, anthos, a flower; in reference to the acute teeth of the calyx and acuminated segments of the corolla). D. C. ann. mus. 9. p. 218. Juss. mem. mus. 6. p. 390. D. C. prod. 4. p. 376. Lindl. coll. p. 13.

Lin. sxst. Pentándria, Monogýnia. Calyx with an obovate tube (f. 92, a.), and a short, acutely 5-toothed limb (f. 92. a.). Corolla with a very long tube (f. 92. c.), a glabrous thiroat, and a 5-parted regular limb (f. 92. $d$.) : having the segments oblong and acuminated. Stamens 5, rising from the throat of the corolla, free, exserted (f. 92. b.). Anthers very acute. Style filiform, clavate at the apex (f. 92.e.), protruding beyond the asthers. Fruit 2-celled, and probably baccate-Shrubs, natives of Guinea. Leaves elliptic, acuminated, on short petioles. Stipulas oblong-triangular, falling off but slowly. Peduncles axillary, racemosely corymbose.-This genus comes very near Posoquerria, but differs from that genus in the limb of the corolla being regular, in the throat being glabrous, and its parts being acute, and in the clavate stigma.

] O. speciòsus (D. C. l. c. and in diss. ined. with a figure) branchlets, leaves, and calyxes quite glabrous; calycine teeth very much acumiuated; racemes many-flowered; tube of corolla one half shorter than the leaves. $h$.S. Native of Sierra Leone on the mountains, where it was collected by Smeathmann. Flowers about 20 in eacl raceme, apparently red, according to the dried specimens, but are probably white or milk-coloured in their recent state.

Shony Oxyanthus. Shrub 3 to 4 feet.

2 O. Tubiflo'rus (D. C. prod. 4. p. 376.) branchlets, leaves, and calyxes glabrous; calycine teeth bluntish; racemes very short, 3-flowered; tube of corolla longer than the leaves. $h$. S. Native of Sierra Leone on the mountains. Gardènia tubiflòra, Andr. bot. rep. t. 183 . O. speciòsus, Ait. hort. kew. ed. 2. vol. 1. p. 371 . but not of D. C. Flowers by threes, white, 6 inches long, sweet scented.

Tube-flonered Oxyanthus. Fl. July. Clt. 1789 . Sh. 3 to $4 \mathrm{ft}$. 3 O. Hirsu'tus (D. C. prod.

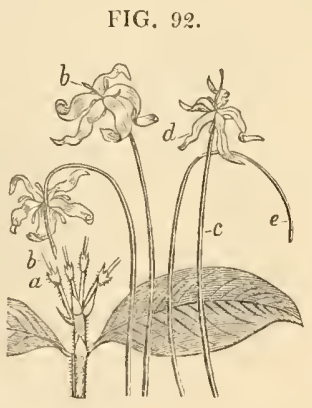
4. p. 376. ) branchlets, petioles, and nerves of leaves on the under side as well as the calyxes beset with hairy down; calycine teeth acute; racemes few-flowered; tube of corolla much longer than the leaves. $h_{c}$. S. Native of Sierra Leone, on the mountains. O. speciòsus, Sims bot. mag. t. 1992. Lindl. coll. t. 13. but the synonymes given are extremely doubtful, and ought probably to be excluded. Ucriàna racemòsa, Schum. pl. guin. p. 107. Tube of corolla 6 inches long. Flowers white, swcet-scented. (fig. 92.)

Hairy Oxyanthus. Fl. July. Clt. 1789. Shrub 2 to $3 \mathrm{ft}$.

4 O. villo'sus; villous all over; leaves petiolate, obovate, acute ; fiowers subcapitate, terminal; tube of corolla very long; style much exserted; stigma clavate. $\zeta$. S. Native of Sierra Leone. Flowers cream-coloured, very fragrant. Calyx 5-cleft. Iillous Oxyanthus. Shrub 2 to 3 feet.

Cult. This genus is easily distinguished by its very long, slender, sweet-scented flowers. All the species thrive well in a mixture of loam, sand, and peat; and cuttings are easily rooted by planting them in a pot of sand, and placing it under a hand-glass, in heat.

XXXIV. STYLOCORY'NA (from $\sigma \tau v \lambda o c$, stylos, a style, and $\kappa o \rho v \eta$, coryne, a club; in allusion to the stigma, which is clavate). Cav. icon. 4. p. 45. t. 368. Gærtn. fil. carp. 3. 1). 100. t. 197. Blum. bijdr. p. 982. D. C. prod. 4. p. 377.Wahlenbérgia, Blum. cat. hort. buit. p. 14. but not of Schrad. nor Schum.-Ceríscus, Nees in flora, 1826, p. 116. and perhaps of Gartn.

Lin. syst. Pentándria, Monogýnia. Calyx with an ovateglobose tube, and a short, tubular, 5-toothed limb. Corolla salver-shaped, with a cylindrical tube, and a 5 -parted limb. Stamens 5, inserted in the mouth of the tube of the corolla; anthers linear, very long. Style exserted; stigma clavate, undivided, or the lobes are closely conferruminated. Berry globose, crowned by the calyx, dry, 2-celled; placentas spongy, adnate to the middle dissepiment. Seeds numerous, wingless, angular. Albumen rather cartilaginous. Embryo long.- T'rees or unarmed shrubs. I,eaves opposite, oval, or oblong, petiolate. Stipulas solitary on both sides, 1-nerved in the middle, broad at the base and acuminated at the apex. Peduncles axillary, and almost terminal, bearing many flowers disposed in corymbs or cymes.

1 S. racemòsa (Cav. l. c. t. 368.) leaves elliptic-oblong, acute at the base, acuminated at the apex, glabrous; panicles axillary, dichotomous, loose, one-half shorter than the leaves; corolla salver-shaped, laving the lobes longer than the tube. $h$. S. Native of the Philippines. Corolla whitish-yellow. Berry spherical, about the size of a pea. Seeds nestling in pulp, ex Cav. but not according to Gærtn., nor in the fruit examined. Cymes of fruit large, spreading. Segments of corolla ovate, obtuse.

Racemose-flowered Stylocoryna. Shrub 10 to 12 feet.

2 S. Fra'grans (Blum. bijdr. p. 982.) leaves elliptic-oblong, acute at both ends, glabrous, beset with minute strigæ on the veins beneath; corymbs terminal, fastigiate, dense-Howered; corolla salver-shaped, with the segments shorter than the tube. $\eta$. S. Native of Java, in shady parts of woods. Walılenbérgia fràgrans, Blum. cat. liort. buit. p. 13. Ceríscus fràgrans, Nees, in flora, 1825. p. 116. Style very long.

Fragrant Stylocoryna. Shrub 5 to 6 feet.

3 S. Laxıflòra (Blum. bijdr. p. 983.) leaves oblong, acuminated at both ends, strigose on the veins beneath; corymbs terminal, trichotomous, divaricate, loose-flowered; corolla salvershaped. h. S. Native of Java, on the mountains of Parang, in the province of Tjangor. The flowers are smaller, and the styles less elongated than those of the preceding species.

Loose-flonered Stylocoryna. Tree 10 to 15 feet.

4 S. томеxròs (Blum. bijdr. 983.) branchlets, petioles, and peduncles densely clothed with tomentunı; leaves oval, acute, pubescent on the veins beneath; cymes pedunculate, axillary, and terminal, dense-flowered: corolla funnel-shaped, 5-parted. 7. S. Native of Java, in the province of Bantam, on the mountains.

Tomentose Stylocoryna. Tree 10 to 12 feet.

5 S. PUBE'scins (Bartl, in herb. Hanke, ex D. C. prod. 4. p. 377.) leaves oblong, acuminated, downy on both surfaces, as well as on the branchlets; cymes terminal, pedunculate, of 5 rays. $h$. S. Native of the island of Luzon. Branches compressedly tetragonal, opposite. Stipulas triangular, acuminated. Calyx minutely 5-toothed. Lobes of corolla linear. Style filiform, undivided, exserted.

Pubeseent Stylocoryna. Shrub.

6 S. мaсторну' LLA (Bartl. in herb. Hænke, ex D. C. prod. 4. p. 37\%.) leaves elliptic-oblong, acuninated at both ends, and 
are, as well as the branches, glabrous; panicle terminal, fastigiate; flowers and pedicels pubescent on the outside. $\zeta$. S. Native of the island of Manilla, near Sorzogon.

Long-leaved Stylocoryna. Shrub or tree.

7 S.? PANDA'k (D.C. prod. 4. p. 377.) glabrous; spines scattered; leaves oblong, minutely apiculated at the apex; racemes axillary, short; pedicels in fascicles, 1-flowered; tube of corolla shorter than the lobes. $h$.S. Native of the East Indies. Gardènia Pandàki, Vahl, herb. ex Puer. Rándia Malabárica, Lam. Branches spinescent on one side. Leaves coriaceous, an inch long, and 4 lines broad. Peduncles axillary, very short, bearing the pedicels in an umbel. Stigma oblong, undivided. Fruit unknown. Perhaps sulficiently distinct from the following.

Pandaki Stylocoryna. Shrub.

8 S. Malaba'rica (D. C. prod. 4. p. 377.) spines opposite, 3 times shorter than the leaves; leaves oblong-obovate, obtuse, cuneated at the base, glabrous, beset with glandular pili in the axils of the veins beneath; umbels $\mathrm{S}-\mathrm{l} 0$-flowered, almost terminating the branches; flowers on short pedicels; limb of calyx 5-toothed. b. S. Native of Coromandel and Malabar near Cochin, in arid places. Gardènia fràgrans, Roxb. corom. t. 197. Posoquèria fràgrans, Roxb. fl. ind. 2. p. 167. Flowers small, white, sweet-scented. Berry globose, size of a cherry, red, 2. celled. Seeds orange coloured. Perhaps G. fràgrans, Roth, nov. spec. 150 . is the same. The Benkàra of Rheed. mal. cited by Lam. for this species, is a distinct plant, from the flowers being said to be purple. The shrub is well adapted for making hedges, being nell armed with thorns.

Malabar Stylocoryna. Clt. 1820. Slirub 4 to 5 feet.

Cult. For culture and propagation see Oxyánthus, p. 494.

XXXV. GE'NIPA (Genipapo is the Guiana name of the first species). Plum. cat. no. 20. Tourn. inst. 1. 436, 437. Lin. gen. no. 240. Juss. gen. 201. mem. mus. 6. p. 391. Gærtn. fil. carp. 3. p. 55. t. 190 . D. C. prod. 4. p. 378.-Gardènia species, Swartz, Lam.-Duròia, Lin. fil. suppl. p. 30.

Lin. syst. Pentándria, Monogýnia. Calyx with an ovate tube, and a tubular truncate or subdentate limb. Corolla salver-shaped, not excceding the tube of the calyx; limb large, 5parted: segments ovate, acute. Anthers linear, sessile in the throat of the corolla, exserted. Stigma clavate, obtuse, undivided. Berry corticate, somewhat 4 -celled, crowned by the tube of the calyx, attenuated at both ends. Seeds numerous, horizontal, nestling in the pulp. Albumen cartilaginons. Embryo with a common radicle, and foliaceous cotyledons.--Trees. Leaves opposite, oval or oblong. Stipulas interpetiolar, ovate, acuminated, deciduous. Flowers axillary or terminal, solitary or few, white, at length yellow. Fruit when young yielding a black juice. Génipa agrees with Stylocorima in the undivided stigma, and with Gardenia in labit: but from both it is easily distinguished by the truncate limb of the calyx and fruit.

1 G. Arerica'sa (Lin. spec. 251.) leaves oblong-lanceolate, quite glabrous on both surfaces; peduncles axillary, dichotomous, corymbose. h.S. Native of the Caribbce islands, as in St. Domingo, \&.c., and now cultivated in many parts for the sake of the fruit, especially in Brazil and Guiana. Phum. ed. Burm. t. 136. Gærtn. fil. carp. t. 190. Garcènia Génipa, Swartz, obs. p. 84.-Janipàba, Marcgr. bras. p. 92. with a figure. Pis. bras. 159. with a figure. Flowers small, white. Fruit large, greenish-white, full of dark purple juice; pulp edible, rather acid.

American or Common Genipa. Clt. 1779. Tree 20 to $30 \mathrm{ft}$.

2 G. CAru'to (H. B. et Kiunth, nov. gen. amer. 3. p. 407.) leaves obovate, obtuse, glabrous above, clothed with velvety tomentum beneath; peduncles terminal, 2-3-flowered; pediceIs longer than the peduncle. $h_{2} . S$. Native on the banks of the Orinoco and Rio Negro, and near Caraccas and Carthagena, where it is called Carulo by the natives. Corolla white, having the tube silky both insicle and outside.

Caruto Genipa. 'Tree 20 feet.

3 G. PUBE'Scens (D. C. prod. 4. p. 378.) leaves obovate, obtuse, glabrous above, and clothed with velvety pubescence beneath ; flowers by threes, almost terminal, on very short pedicels. h. S. Native of Cuba, about the Havannah. Flowers very like those of $G$. Amcricina, but are on shorter pedicels, and fewer in number; and the leaves are broader and blunter.

Donny Genipa. Tree 20 feet.

4 G. oblongifo'lia (Ruiz et Pav. fl. per. 2. p. 67. t. 220. f. a.) leaves oblong-ovate, obtuse, shining above, and downy on the nerves beneath, with rather revolute margins; flowers crowder at the tops of the branches, on short perlicels, and disposed somewhat racemosely. $\zeta$. S. Native of Peru, on the Andes, in groves in hot places, and at Guayaquil. The corolla is said to be yellow, but is probably white in the recent state as in the rest of the species. Fruit size of a peach. The seeds and pulp of the fruit are used by the Indians to dye their face and hands of a permanent black colour.

Oblong-leaved Genipa. Clt. 1821. Tree 20 feet.

5 G.? struflèra (D. C. prod. 4. p. 378.) leaves elliptic, membranous, acuminated at both ends, glabrous, on short petioles; stipulas small, deciduous; pedicels axillary, short, 1flowered; limb of calyx broadly truncate, ciliated, short; tube of corolla broad, conical, striated, borny on the inside at the base, and closed in the middle inside by a circle of hairs; stigma thick, 2-lobed. 2 . S. Native of Brazil. Perhaps a proper genus. Leaves somewhat sinuated from some cause.

Striped-flowered Genipa. Tree.

$$
\begin{gathered}
+ \text { Species not sufficiently knomn. } \\
* \text { American. }
\end{gathered}
$$

6 G. Merta'ne (Rich, act. soc. hist. nat. par. p. 107.) hairy; leaves oblong-obovate; flowers crowded at the tops of the branches; fruit globose, very villous, crowned by the tube of the calyx. F. S. Native of Cayenne and Surinam. Poir. suppl. 2. p. 70 S. Duròia eriópila, Lin. fil. suppl. p. 30. and p. 209.-Merian, sur. t. 43. 'The tree bas the habit of Isértia coccinca. Flowers hexamerous and hexandirous, nearly sessile, very like those of Jasminum Sambac. Berry hairy, about the size of the clenched fist, umbilicate. Seeds imbedded in the pulp, which is grateful and edible.

\section{Merian's Genipa. Clt.' 1800 . Tree 20 feet.}

$$
\text { * Asiatic. }
$$

T G.? Buffalina (Lour, coch. p. 149.) prickles long, straight, opposite; leaves ovate, glabrous, in fascicles; flowers solitary ; calyx bluntly 5 -cleft; berry almost dry, roundish. $\eta$. G. Native of Cochinchina. Flowers greenish-white. Berry brownish. Perhaps a species of Rándia or Gardènia, but the berry is said to be 2 -celled. Corolla rotate, 5 -cleft.

\section{Buffalo's Genipa. Shrub 9 feet.}

8 G. ? escule'nta (Lour. l. c.) stem quite simple; spines long, straight, opposite; leaves opposite, laairy, in fascicles: flowers lateral, in faseicles ; calyx acutely 5 -cleft; berry fleshy, roundish, 1-celled. Һ. G. Native of Cochinchina. Flowers greenish-white. Segments of corolla oblong, acuminated. Berry size of a cherry, edible.

Ėsculent Genipa. Clt. 1823. Shub 6 feet.

9 G.? FLA'va (Lour. l. c.) prickles few, scattered, straight; leaves broad-lanceolate, glabrous; flowers solitary, terminal; corolla rather hairy. Ћ., G. Native of China, about Canton. Corolla yellow, rotate. Fruit unknown.

Ycllon-flowered Genipa, Slırub 5 feet. 
Cult. For culture and propagation see Gardènia, p. 499.

XXXVI. GARDE'NIA (so named after Alexander Garden, M.D. of Charlestown, Carolina, one of the correspondents of Ellis and Linnæus). Ellis, in Lin. gen. no. 296. Gærtn. fruct. t. 23. 177. 193. and 194. Blum. bijdr. j. 1014. Roxb. fl. ind. 2. p. 549. D. C. prod. 4. p. 379.-Gardènia and Rothmánnia, 'Thunb._Gardènia and Pirínga, Juss._-Gardènia and Salı]bérgia, Neck.

Lis. syst. Pentandria, Monogýnia Calyx with an ovate, usually ribbed tube, and a tubular truncate, toothed (f. 93. a.), cleft, or parted limb. Corolla funnel-shaped (f. 93. b.), or salvershaped, having the tube much longer than the calyx, and the limb twisted in restivation (f. 93. e.), but afterwards spreading, from 5-9-parted. Antbers 5-9, linear, almost sessile in the throat of the corolla or exserted (f. 93. c.). Stigma clavate, bifid or bidentate: Jobes thick, erect. Orarium 1-celled, half divided by $2-5$ incomplete dissepiments. Berry fleshy, crowned by the calyx, chartaceous or nucleate inside, incompletely 2.5 celled. Seeds minute, immersed in the fleshy parietal placentas. Embryo albuminous.-Unarmed or spinescent trees or shrubs. Leaves oppositc, and sometimes, thongh rarely, in whorls, oval or ovate. Flowers axillary or terminal, usually solitary, white, and generally sweet-scented. The fruit of the greater number of the species not being sufficiently known, they cannot be divided into proper sections.

$\$ 1$. Shrubs mithout prickles. Tube of calyx or ovarium ribbed. Tabe of corolla cylindrical.

1 G. FLo'RIDA (Lin. spec. p. 305.) shrubby, unarmed, erect; leaves elliptic, acute at both ends; flowers solitary, almost terminal, sessile, salver-shaped; calycine segments vertical, lanceolate-subulate, equalling the tube of the corolla in length; berry elongated, turbinate, ribbed. $\digamma_{2}$. G. Native of China, and cultivated in Japan, East Indies, the Cape of Good Hope, Sc. Ker, bot. reg. t. 449. G. jasminoides, Sol. phil. trans. 52. t. 20.-Pluk, amalth. t. 448. f. 4. Jasminum Capénse, Mill. dict. no. 7. fig. t. 180. Ehret. pict. t. 15. Flowers white, sweetscented, 5-9-parted. Berry 5-6-angled, 5-6-celled at the base, and 1-celled at the apex, orange coloured, size of a pigeon's egg, and the pulp is used for dyeing yellow in China and Japan.

Tar. $\beta$, flòre plèno; flowers double white, when fully blown about the size of the middling rose. $h$. G. This variety is very frequent in gardens. G. jasminoides, Ellis in phil. trans. vol. 51. t. 23. Jasminum Capénse, Mill. fig. t. 180.-Rumph. amb. 7. t. 1 1. f. 2.

Flonering Gardenia or Cape Jasmine. Fl. July, Ang. Clt. 1754. Shrub 2 to 6 feet.

2 G. RAdicans (Thumb. diss. gard. no. 1. t. 1. f. J.) shrubby, unarmed; stems radicant; leaves lanceolate; flowers solitary, almost terminal, and nearly sessile, salver-shaped; segments of the calyx vertical, linear-subulate, equal in lengt ts to the tube of the corolla. h. G. Natise of Japan, and cultivated in the East Indies, and at the Cape of Good Hope. Tlumb. A. jap. t. 20. Ker, bot, reg. t. 73. Andr. bot. rep. t. 491 . Flowers white, very fragrant.

Rooting Gardenia or Cape Jasmine. Fl. March, June. Clt. 1804. Pl. 1 to 2 feet.

3 G. angustifo'zia (Lodd. bot. cab. 512.) very like $G$. flòrida, from which it chiefly differs in being smaller, with narrower leaves. $\zeta$. S. Native country unknown. Flowers white, sweet-scented.

Narrow-lcaved Gardenia. Fl. July. Clt. 1823. Shrub $3 \mathrm{ft}$.

4. G, tomentòsa (Blum. mss. ex D. C. prod. 4. p. 379.) unarmed; branchlets, leaves, and calyxes clothed with velvety tomentum; leaves obovate-cuneated; flowers terminal, sessile, solitary; tube of calyx angularly ribbed: calycine teeth 10 , subulate, short. $\xi_{c}$.S. Native of the island of Java. Lobes of corolla 10 , obovate-oblong; tube hardly longer than the calyx. Flowers white, sweet-scented. Fruit unknown.

Tomentose Gardenia. Slrub.

5 G. Calycula'ta (Roxb. fl. ind. 2. p. 550.) arboreous, unarmed; leares ovate, petiolate, acuminated, smooth ; flowers terminal, solitary, sessile, involucrated; calycine segments ensiform; anthers inclosed within the tube of the corolla. Native of the East Indies. Flowers large, white, fragrant, 5-parted.

Calyculate Gardenia. Tree.

6 G. costa'TA (Roxb. fl. ind. 2. p. 550.) arboreous, unarmed; leaves cunciform-oblong, smootli, ribbed; flowers terminal, salver-shaped; calycine segments resiniferous, caducous; berry drupaceous, oval, 5-ribbed, 1-celled, containing a 2-valved shell; placentas 2 , opposite. $h$.S. Native of the mountainous parts of India; from those of Chittagong it has been introduced to the botanic garden of Calcutta. G. coronària, Hamilt. in Symes. emb. to Ava, p. 474. with a figure. Flowers large, white, sweet-scented, the tube being above 3 inches long, and the border above 4 in diameter; limb 5-parted. Berry yellow, containing a soft and rather fetid pulp.

Ribled-fruited Gardenia. Tree 20 feet.

7 G. carina'ta (Wall. in Roxb. fi. ind. 2. p. 560.) arboreous, unarmed, resinous on the younger parts; leaves ellipticobovate, ribbed, villous beneath; flowers terminal, solitary; limb of calyx truncate, broad, obscurely 5 -lobed, and 5 -keeled; tube of corolla very long: limb 6-s-lobed. h. S. Native of Penang, where it grows on the hills. Flowers smaller than those of $G$. costata, at first snow white, but afterwards yellow, becoming when dry of a beautiful orange colour. Fruit precisely as in G. costàta.

Keclcd-calysed Gardenia. Tree.

8 G. GRANOIFLòra (Lour. coch. p. 14\%.) arboreous, unarmed; leaves lanceolate, shining; flowers solitary, lateral, and terminal, hexamerous; segments of the calyx reflexedly-falcate; corolla salver-shaped, 6-parted; berry oblong, acute at both ends. $\zeta$. G. Native of Cochinchina, on the banks of rivers. Blum. bijdr. p. 1013. Flowers large, white, sweet-scented. Berry bexagonal, 1-celled, glabrous, yellow. Seeds nestling in red pulp. Anthers 6 , rarely $5-7$.

Great-flowered Gardenia. Tree middle-sized.

9 G. 'TAITE'NSIS (D. C. prod. 4. p. 380.) unarmed, glabrous, resinous at the tops of the branches; leaves obovate, almost sessile; stipulas broad, connate, permanent, short-acuminated; flowers solitary, in the axils of the upper leaves, pedicellate; tube of calyx angular: limb 3-4-parted, with vertical-oblong foliaceous lobes; corolla with a long terete tube, and a $5-7$ parted limb. h. G. Native of the island of Tabiti, where it was collected by D'Urville. Lobes of calyx fewer by abortion than the lobes of the corolla. Stigma bifid, the lobes long, and acute. Fruit unknown.

Tahiti Gardenia. Slurub.

10 G. MARU'BA (Siebold, in Blum. bijdr. p. 1013.) unarmed; leaves opposite, or 3 in a whorl, obovate, coriaceous, glabrous; calyx angular, 5 -cleft : segments subulate, spreading. $\zeta$. G. Native of Japan. The rest unknown.

Maruba Gardenia. Tree.

11 G. stLCA'TA (Gærtı. fil. carp. 3. p. 79. t. 194.) berry obovate or elliptic, attenuated at the base, angular from obtuse furrows, 1-celled; seeds imbedded in the pulp. h. G. Native country unknown. Perlaps allied to G. flórida.

Furrowcd-fruited Gardenia. Slirub.

\$2. Unarmed slrubs or trees. Tube of calyx or ovarium not 
ribbel; having the limb equally toothed or parted, rarely truncate. Tubc of corolla cylindrical.

12 G. MUta' вiLis (Reinw. in Blum. bijdr. p. 1016.) unarmed? leaves oblong, acuminated, glabrous, but pubescent in the axils of tlue ribs on the under surface ; flowers axillary, solitary; limb of calyx rather truncate; corolla with an elongated glabrous tube, and a 5 -cleft limb. $h$. S. Native of the island of $\mathrm{Ce}$ lebes. Said to be allied to $G$. carinata and $G$. tubiflora.

Changeable-flowered Gardenia. Tree.

13 G. cacrina ; leaves oblong-lanceolate, rather coriaceous, glabrous, on short petioles; flowers axillary, solitary, almost sessile; corolla with a long tube, and a 5 -cleft equal border; calyx 5-cleft. $\quad \zeta$.S. Native of Sierra Leone, on the edges of woods. Flowers pale red, pentandrous.

Large-calyxed Gardenia. Shrub.

14. G. Reinwardin'na (Blum. bijur. p. "1913.) unarmed? leaves oblong, attenuated at both ends, bluntish at the apex, coriaceous, glabrous; corymbs axiliary, trifid, shorter than the leaves; limb of calyx obsoletely 5 -toothed, rather truncate; corolla with an elongated glabrous tube, and a 5-cleft limb. Ђ. S. Native of the Mloluccas. Ignàtia, Reinw. herb. ex Blum. Ovarium half 2-celled, many seeded.

Reinrardt's Gardenia. Shrub.

15 G. Latifòcia (Ait. hort. kew. 1. p. 294.) arboreous, unarmed; leaves almost sessile, ovate or obovate : in the axils of the veins beneath are hollow glands with hairy margins; flowers terminal, 1-4-together, almost sessile, salver-shaped, 7-11-parted; limb of calyx short, subdentate; berry drupaceous, round, 1-celled, 5-valved. h.S. Native of the East Indies, on barren rocky hills, in the Circars and Carnatic. Roxb. cor. 2. p. 18. t. 13\%. ff. ind. 2. p. 552. G. enneándra, Koen. inss. ex Roxb. Flowers very large and very fragrant, when they first open in the morning white, gradually growing yellow before night. Berry size of a pullet's egg, crowned by a small part only of the tube of the calyx. Leares opposite or 3 in a whorl. - G. latifòlia, Gartn. fr. 3. p. 78. t. 193. is a distinct species from the fruit being crowned by the whole of the calyx, not with part of it.

Broad-leatcd Gardenia. Clt. 1787. Tree 10 feet.

16 G. LU'cıdA (Roxb. f. ind. 2. p. 553.) subarboreous, unarmed, with resinous buds; leaves oblong, smooth, shining, witl lateral simple parallel veins; flowers almost terminal, solitary, on short pedicels: lobes of calyx 5 , subulate, 3 times shorter than the tube of the corolla; berry drupaceous, containing a 2 valved shell. $々$. S. Native of Chittagong, and various other parts of India; and of the island of Luzon. Leaves about 6 inclies long and 3 broad. Peduncles clavate, 1 to $1 \frac{1}{2}$ inch long. Flowers large, pure white, fragrant, 5-parted.

Shining-leaved Gardenia. Clt. 1819. Shrub or tree.

17 G. ARBòrea (Roxb. ff. ind. 2. p. 55\%) arboreous, unarmed; leaves ovate-oblong: flowers terminal, almost sessile, usually by threes; corolla with a filiform tube, and a 5-parted limb; berry drupaceous, snooth, containing a 4-5-valved shell. $\eta$. S. Native of the East Indies, among the Circars. The leaves are deciduous during the cold season, and the shrub continues naked till the hot season is pretty far advanced. From the buds and wounds made in the bark there exudes a very beautiful yellow resin, like that from $G$. gummifcra. The size, number, fragrance, mutability, and beauty of the flowers of this species render it more deserving of a place in the garden than any other species. The natives eat the fruit when ripe.

Arboreous Gardenia. Tree.

18 G. gumM'fera (Lin. fil. suppl. 1. p. 164.) shrubby, unarmed, witl resinous buds; leaves oblong, bluntly acuminated, (hairy, ex Lin.) ; flowers sessile, solitary, almost terminal ; segvoL. III. ments of the calyx ovate, acute, very short ; tube of corolla equal in length to the limb. $h_{2}$. S. Native of Ceylon and Coromandel. T'hunb. diss, gard. no, 4. t. 2. f. 3. Rottl. and Willd. in act. bonn. 4. (1803) p. 198. G. inérmis, Dietr. lex. 4. p. 285. Allied to $G$. arborrca. Flowers white, sweet-scented. From the bark of this tree exudes a yellow resin, similar to gum elemi.

Gum-bearing Gardenia. Shrub 3 to 4 feet.

I9 G. clusiefòcia (Jacq. coll. append. 37. t. 4. f. 3.) slirubby, unarmed, glabrous; leaves obovate, retuse, and somewhat cmarginate, coriaceous, on short petioles; peduncles almost terminal, racemose; flowers on long pediccls; limb of calyx short, 5toothed; corolla salver-shaped, with 5 linear acute segments, which are about the length of the tube. I2. G. Native of the Bahama islands, where it is called by the inhabitants seven ycars apple, ex Catesb. car. 1. p. 59. t. 59. Flowers wbite, sweetscented, with a greenish tube. Berry large, oval. Seeds imbedded in the pulp. The internal structure of the berry is unknown. It differs from Gardenia in the shape of the stigma and disposition of the flowers.

Clusia-lcavcd Gardenia. Shrub 5 feet.

20 G. ? тетraspérua (Roxb. fl. ind. 2. p. 555.) shrubby, unarmed; leaves obovate-cuneated, smooth; flowers axillary, solitary, on short pedicels, pentandrous; calycine segments 5 . subulate; limb of corolla 5-parted; berry round, 4-seeded. h.S. Native of the East Indies, on the mountains near Shreenugur. Gardènia, no. 3. Hardw, in asiat. res. 6. p. 354. Leaves on short petioles. Flowers greenish yellow, sweet-scented, with a long tube, which widens upwards, and partly closed about the middle by a ring of silky down.

Four-seeded Garderia. Sbrub 2 feet.

21 G. tubírera (Wall. in Roxb. f. ind. 2. p. 562.) subarboreous, unarmed; leaves cuneate-oblong, petiolate, slightly scabrous above, and pubescent beneath; drupe round, uneven, crowned by the very long truncate calycine tube, $\zeta$. S. Native of the East Indies, in Singapore. All the young parts of the tree are resinous. Leaves $5-6$ inches long. Drupe containing a putamen, which is divisible into 8 valves. Flowers unknown.

Tube-bearing Gardenia. Tree or shrub.

22 G.? ANisorhy'Lla (Jack, in Roxb. fl. ind. 2. p. 561.) arboreous, unarmed; lcaves elliptic, those opposite each other unequal, densely clothed with villi; stipulas concrete at the base, bearded inside; corymbs axillary, villous; limb of calyx 5 -toothed; tube of corolla short; drupe oval, villous. $h_{\text {. }}$ S. Native of the islands of Pulo-Penang and Singaporc, on the litls. Leaves tapering to the basc, 6-12 inches long. Flowers rather small, white, by threes, villous outside: limb 5-parted. Stigma clavate, 2-lobed. Drupe size of a walnut, containing a 2-valved putamen. Perbaps a species of Génipa or Posoquèria.

Unequal-leaved Gardenia. Tree.

23 G. Forsòsa (Cham. ct Schlecht. in Linnæa. 4. p. 200.) unarmed; leaves on short petioles, nearly orbicular, terminating in a very short acumen each, clothed with canescent tomentum along the reins on the upper surface, but clothed with hoary tomentum underneath, as well as the petioles, cymes, and flowers: calyx 5-toothed; stigma bilamellate. $\zeta_{6} . S$. Native of Brazil. Corolla white, having the tube about 4 incbes long, and the throat an inch in diameter; $\operatorname{limb} 5$-parted. Fruit unknown.

Beautiful Gardenia. Slirub.

24 G. Selcowia'sa (Cham. et Schlecht. 1. є. p. 198.) unarmed, glabrous; leaves broad-lanceolate, on short petioles, shining above; stipulas connate between the petioles; cymes 3 5-flowered; calyx 5-toothed; stigna bilamellate. $h_{c} . S$. Native of Equinoxial Brazil. Corolla wlite, hairy; the tube about 3 inches long and coriaceous, and the limb 5-parted. Fruit spberical, smootli. 


\section{Sello's Gardenia. Slurub.}

25 G. HEXA'NDRA (Willd, rel, in Rœm. et Schultes, syst. 5. p. 243.) unarmed ; leaves obovate, pubescent beneath; Howers usually hexandrous; corollas hairy both inside and ontside, with the tube very short. $h$.S. Native of South America, where it was collected by Humboldt and Bonpland. The rest unknown.

Hexandrous-flowered Gardenia. Shrub.

\$ 3. Unarmed slirubs. Tube of calyx or oxarium not ribbed; but the limb is tubular and ribbed, 5-6-cleft, as well as being cleft latcrally. Tube of corolla cylindrical._Piringa, Juss.

26 G. Thunbérgi (Lin. fil. suppl. p. 162.) shrubby, unarmed; leaves elliptic, acute, glabrous ; flowers terminal, solitary, sessile, 8-parted; limb of calyx tubular, cleft laterally : with the segments dilated at the apex; berry ovate. h. G. Native of the Cape of Good Hope, and the island of Manilla. Thunb. diss. gard. no. 3. Sims, bot. mag. t. 1004. Thunbérgia Capénsis, Montin, in act. holm. 1773. t. 11. G. verticillàta, Lam. dict. 2. p. 607. G. crassicaúlis, Salisb. par. lond. t. 46. Bẻrgkias, Sonner. voy. nov. guin. t. 17-18. Journ. plıys. 3. p. 299. t. 3. Caquepíria Bérgkia, Gmel. syst. 651. Pirínga, Juss. mem. mus. 6. p. 399 . Flowers large, white, fragrant. Berry 1-celled; placentas parietal, 4, exserted. Leaves opposite, or 3-4 in a whorl.

Thunberg's Gardenia. Fl, Jan. March. Clt. 1774. Shrub 4 to 5 feet.

\$4. Unarmed slirubs. Tube of calyx ribbed or angular from the decurrent scgments. Tubc of corolla with a dilatcd obconical (ti)'out. Berry 2-cclled.-Rotlimánnia, Thunb.

27 G. Rothun'svia (Lin. fil. suppl. p. 165.) arboreous, unarmed; leaves oblong, acute, glabrous, on very short petioles, having glandular lairs in the axils of the veins underneath; Howers axillary, and almost terminal, solitary, sessile, 5-parted, and pentandrous; calyx ribbed, laving the segments subulate, terete, and erect; corolla with an obconical tube, a campanulate throat, and spreading acute segments. h. G. Native of the Cape of Good Hope. 'Thunb. diss. gard. no. 6. Sims, hot. mag. 690. Rothmánnia Capénsis, Thunb. act. holm. 1776. 1) 65. f. 2. Flowers white, spotted with red, sweet-scented; tube of corolla glabrous. Young branches downy.

Rothmann's Gardenia. Fl. July. Clt. 1774. Shrub 5 to 10 feet.

\section{§5. Unarmed or spinose shmubs. Lcaves 3 in a whorl.}

28 G. TERNifòla (Thonn. in Schum. pl. guin. p. 147.) unarmed, glabrous; leaves 3 in a whorl, obovate, cuneated at the base, almost sessile; flowers solitary, almost terminal, girded at the base by a short truncate involucel; calyx with a smooth tube, and a tubular short toothed limb; corolla with a long terete tube, and a 6-7-parted limb. $h . S$. Native of Guinea. Flowers 3 inches long, white; lobes of corolla oval-oblong, acutish.

Tern-lcavcd Gardenia. Shrub 1 to 5 feet.

29 G. triacántha (D. C. prod. 4. p. 382.) glabrous ; branches 3 in a whorl, spinescent; leaves 3 in a whorl, obovate, cuneated at the base, almost sessile; flowers solitary, terminal, sessile; calyx with a smooth tube, and a tubular semi- $\overline{-}$-cleft limb : lobes acute; corolla with a long almost terete tube, and a 5 -parted limb: lobes thick, obovate. $\eta$. S. Native of the Gambia, in woods. Leaves hardly an inch long. Corolla 2 inches long. Berry ovate-globose. Fruit size of a walnut. Spines thick, short, conical, spreading.

Three-spined Gardenia. Shrub 4 to 5 feet.

30 G. uedicina'Lls (Vahl, in Schum. pl. guin. p. 148.) gla- brous ; spines tern, stiff, leafy at the apex; leaves elliptic, glabrous; flowers terminal, sessile, solitary; limb of calyx bifid, with roundish recesses, and trifid segments; corolla with the tube dilated upwards, and the lobes obovate. $h$. S. Native of Guinea.

Medicinal Gardenia. Shrub 4 to 5 feet.

$$
\text { \$6. Spiny shrubs. }
$$

31 G. anc'na (Sims, bot. mag. t. 1904.) shrubby; spines axillary, short, straight ; leaves oval, acute, glabrous, on short petioles; flowers almost terminal, solitary, sessile, 5-parted, and pentandrous; tube of calyx with short teeth; corolla salvershaped, with a long terete tube. h.G. Native of Clina. Flowers white, having the lobes purple on the outside in that part, which is exposed to the air, while the corolla is in restivation; the tube greenish.

Plcasing Gardenia. Fl. June, Aug. Slirub 3 to 5 fect.

32 G. TU'RGIDA (Roxb. f. ind. 2. p. 557.) arboreous, with swollen mealy bark, and brachiate branclics; spines opposite and terminal; leaves obovate, tapering into the petioles at the base, smooth; flowers lateral, usually solitary; limb of calyx tubular, 5-toothed; corolla smooth, salver-sliaped; anthers almost inclosed. h.S. Native of the East Indies, at Botham. Leaves 1.4 inches long, and 1-3 broad. Stipulas broad at the base, and subulate at the apex. Flowers 5-6-parted. Berry oval, scabrous outside, coutaining a hard 5-valved putamen. Seeds imbedded in the pulp. Stigma clavate, 5 -grooved.

Swollen-barked Gardenia. Tree.

33 G. monta'sa (Roxb. A. ind. 2. p. 556.) arboreous; spines opposite, slıort, acute, stiff; leaves oblong, obtuse, almost sessile, downy beneath, with rerolute edges; flowers rising 3-5 in a fascicle from the buds, on short pedicels; limb of calyx usually 5 -toothed; corolla 5-7-cleft; stamens inclosed; berry drupaceous, roundish, containing a 5-6-valved putamen. h.S. Native of the East Indies, among the Circar mountains. Bark white, soft, and spongy. Leaves deciduous in December, 3 inches long, and 2 broad, smooth and shining above. Flowers pretty large, fragrant, when first open white, but soon becoming more or less yellow. Corolla with a somewhat gibbous tube, and a smooth throat. Nectary a moniliform fleshy ring, surrounding the insertion of the style. Berry the size of a pullet's egg, ash coloured, and yellow mixed. Seeds imbedded in the pulp.

Mountain Gardenia. Clt. 1819. Tree or slurub.

34 G. caupanula'ta (Roxb. fi. ind. 2. p. 557.) slirubby; branches short, spiny at the apex; spines solitary; leaves lanceolate, smooth, acuminated at both ends ; flowers on short pedicels, in terminal and lateral fascicles; limb of calyx campanulate, with a short acutely 5 -toothed border ; corolla subcampanulate, 5-lobed; berry roundish-ovate. $\eta$. S. Native of the East Indies, in the forests of Chittagong. Thorns generally terminating the little lateral opposite branchlets. Leaves 2-5 inclies long. Stipulas triangular, acute. Flowers small, of a pale yellow colour, crowded at the extremities of short stiff lateral spinose branchlets. Stigma somewhat 5-grooved. Anthers inclosed. Berry round, the size of a golden pippin apple, smooth, 1-celled; placentas 5, parietal. Seeds inıbedded in the yellow pulp.

Campanulate-calyxed Gardenia. Clt. 1S15. Sh. 5 to $10 \mathrm{ft}$. 
35 G. Blumea'sa (D. C. prod. 4. p. 383.) shrubby, spinose; leares lanceolate, glabrous ; flowers axillary, and almost terminal, usually solitary ; calycine segments ovate, bluntish ; corolla somewhat campanulate. h.S. Native of Java, among bushes on the mountains. G. campanulàta, Blum. bijdr. p. 1017. This difters from G. campanulata, Roxb. in the figure of the calyx.

Blume's Gardenia. Shrub 5 to 6 feet.

\section{$\uparrow$ Species not sufficiently known. \\ * Unarmcd shrubs.}

36 G.? vout'BtLIs (Lour. coch. p. 148.) slrubby, unarmed, twining; leaves lanceolate, acuminated, glabrous, on short petioles; peduncles long, axillary, many flowered; calycine segments 5, acute, erect; corolla funnel-shaped, with a dilated throat; berry roundish, 2-celled. h. G. Native of China beyond the suburbs of Canton. Flowers pale. Stigma thick, warted, subulate at the apex. Seeds round. This shrub should be excluded from Gardenia. Segments of corolla, long, repand.

Twining Gardenia. Slirub tw.

37 G.? PUBE'scens (Roth, nov. spec. 151.) unarmed; leaves roundish-oval, acuminated at both ends, clothed with brown tomentum beneath while young, as well as on the branchlets; corymbs axillary, dichotomous, divaricate; calyx minutely 5 toothed; corolla funnel-shaped, tomentose. $h$.S. Native of the East Indies. Flowers the size of those of Rhamnus frángula. Berry the size of a cherry, rugged from dots, glabrous.

Pubescent Gardenia. Clt. 1824. Shrub 4 to 6 feet.

38 G.? acumna'ta ; shrubby, branched, unarmed; leaves broad-oval, lanceolate, long, sessile ; flowers terminal and axillary, small; fruit oval, acuminated. $\zeta . S$. Native of Sierra Leone, on the mountains in the woods. Perhaps a species of Pomàtium.

Acuminatcd-fruited Gardenia. Shrub 6 to 8 feet.

39 G.? Brasille' Nsis (Spreng. syst. 1. p. 763.) unarmed; leaves oblong, coriaceous, opaque; branchlets hairy; peduncles axillary, 3-4-flowered, shorter than the leaves; calycine segments subulate, shorter than the tube of the corolla. h.S. Native of Brazil.

Brazilian Gardenia. Shrub.

40 G.? Longifòlia ; shrubby, branched, unarmed; leaves long, broad-lanceolate, acuminated, entire, membranous, petiolate; flowers terminal, solitary, sessile; fruit large, roundish, smooth. $h . S$. Native of Sierra Leone, in the woods on the mountains.

Long-leaved Gardenia. Shrub 5 to 6 feet.

$$
\text { * Spinose shrubs. }
$$

4.1 G. ? DE'NSA (Wall. in Roxb. fl. ind. 2. p. 559.) slurubby, stiff; branches numerous, decussate, spinose at the apex; leaves in fascicles, obovate, almost sessile, smooth; flowers solitary, sessile, terminal ; limb of calyx tubular, 5 -toothed : teeth subulate; corolla with a 5-parted limb, and lanceolate acuminated lobes. 5 . G. Native of Nipaul, on the southern face of Sheopore, above Thoka. Branches obscurely 4-cornered. While young the thorns are pubescent, and covered by a pair of approximate stipula-like scales. Flowers small, of a yellowish white colour, fragrant. Corolla pubescent within, and closed by a circle of silky hairs about the middle. Stigma obscurely 2lobed. Very nearly allied to G. tetraspérma. Cells of ovarium S-seeded.

Dense Gardenia. Shrub 4 to 5 feet.

42 G. sca'NDENS (Thunb. diss. gard. no. 9. t. 2. f. 5.) shrubby, climbing; spines straight, very short, decussate; leaves ovate, glabrous ; peduncles axillary, solitary, 1-flowered; corolla with a terete tube, and lanceolate segments; calyx 5toothed. h. . G. Native of China. G. jasminoìles, Retz, obs. 2. p. 14. Perhaps a species of Rándia. Corolla white, glabrous. Stigma clavate.

Climbing Gardenia. Slırub cl.

43 G.? Pa'tula (Horsf. ex Wilk. in Rœm. et Schultes, syst. 5. p. 244.) spines looked, shorter than the petioles; leaves ovate, acute; corymbs axillary. $々$. S. Native of Java. The rest unknown.

Spreading Gardenia. Shrub.

44 G. ? stipula'ris (Rottl. et Willd. in act. bonn. 4. (1803.) p. 182.) shrubby; spines setaceous; leaves elliptic, acute at both ends, short; flowers sessile, solitary, terminal; calycine segments obtuse, and are as well as the tube glabrous. $\zeta . s$. Native of the East Indies. Spines very short. Leaves like those of $G$. spinòsa. Corolla with a long slender tube. The spines, accorcling to Rottler, are stipular; hence the name.

Stipular-spined Gardenia. Shrub.

45 G. ? ragifòlı (Willd. rel. ex Rœm. et Sclııltes, sysţ. 5. p. 243.) branchlets terminated by 4 spines; flowers solitary ; leaves roundish-ovate, downy beneath, stiff, plicately veined. h. S. Native of South America, where it was collected by Humboldt and Bonpland. Willdenow says the leaves are acuteangled, but this is probably a mistake.

Beach-leaved Gardenia. Shrub 5 to 6 feet.

46 G.? cornifòcia (D. C. prod. 4. p. 384.) shrubby, spinose; branches glabrous; leaves acuminated, ovate, rather coriaceous, and are, as well as the branches, downy ; flowers 6-8together at the tops of the branches, sessile, subcorymbose, eacl furnished with a bifid involucel; calyx 4-toothed; corolla villous on the outside, with a terete tube, and a spreading 4-parted limb. h. G. Native of the temperate parts of New Granada, near Guadua. Gardènia parviflòra, H. B. et Kunth, nov. gen. amer. 3. p. 408. t. 293. but not of Poir. Flowers white, sweetscented. The ovarium and fruit being unknown, it is doubtful whether it belongs to the genus.

Dogmood-leaved Gardenia. Slirub 5 feet.

47 G. ? MICroca'rPA (Bartl. in herb. Hænke ex D.C. prod. 4. p. 384.) spines few, short, straight; leaves oblong, coriaceous, shining above, quite glabrous on botli surfaces, as well as the branchlets; stipulas subulately acuminated; flowers 1.3torether, terminal, pedicellate; limb of calyx short, tubular, with subulate teeth, which are much shorter than the corolla,

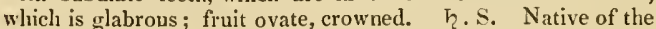
Philippine islands, as in Luzon, \&c. Perhaps a species of Rándia.

Small-fruited Gardenia. Shrub 5 to 6 feet.

Cult. All the species of Gardènia bear elegant swcet-scented flowers, which in most of the species are large. They are generally free flowerers. The soil best suited for them is a mixture of loam, peat, and sand. The stove species thrive best in a moist heat; and cuttings of all root readily if taken off while not too ripe, planted in a pot of sand, which should be plunged in a moist heat under a hand-glass. The doubleflowered varieties of $G$. flirida and $G$. radicans are cultivated to a considerable extent, under the name of Cape jasmine, for the beauty and fragrance of their flowers; the best manner of getting these to bloom freely is to set them in a close frame, on a little bottom heat, in spring, but the pots should not be plunged; and in winter they may be set in the green-house.

XXXVII. RA'NDIA (named after Isaac Rand, M.D. once a demonstrator of botany at the Chclsea botanic garden). Houst. in Lin. hort. cliff. (1797.) p. 485 . gen. no. 211 . Juss. mem. mus. 6. p. 392 . Lam. ill. t. 156 . D. C. prod. 4. p. $384-\mathrm{O} x \dot{y}-$ 3 s 2 
ceros, Lour. coch. p. 151.-Posoquèria and Rándia species, Roxb. A. ind.

Lin. syst. Pentándria, Monogýnia. Calyx with an obovate tube, and a 5-lobed limb. Corolla salver-shaped, with a short tube, which is hardly longer than the calycine lobes in the first section, but in the second section 2 or 3 times longer, always with a 5 -parted limb, which is twisted in astivation. Anthers sessile within the tube of the corolla, inclosed. Stigmas 2, thick. Berry nearly dry, crowned by the calyx, corticate, 2-celled. Seeds many in each cell, fixed to a central placenta, wingless, imbedded in the pulp, or imbricated downwards. Albumen cartilaginous. Embryo straight, with a terete radicle, and orbicular flat cotyledons.-Much branched small trees or shrubs, with axillary opposite or subverticillate thorns. Leaves sessile or on very short petioles. Stipulas solitary on each side, sometimes evidently formed from 2 being combined. Flowers almost sessile, usually solitary, rising from the axils of the leaves.This genus is nearly allied to Posoquèria, but differs in the dry fruit, and in its being truly 2-celled.

Sect. I. Oxy'ceros (from o६vc, oxys, sharp, and kepac, keras, a horn; in reference to the shrubs being furnished with sharp, thorns). D. C. prod. 4. p. 385. 'Thorny shrubs. Throat of corolla not dilated.

\section{\$. Floners axillary, solitary, on short prdicels.}

1 R. LATIFòlı (Lam, dict. 3. p. 24. ill. t. 156. f. 1.) branchlets glabrous; leaves obovate, quite glabrous, almost sessile, cuneated at the base; flowers axillary, sessile, solitary, salvershaped; tube of corolla twice the length of the calycine teeth, with a pilose throat. $h$. S. Native of the West India jslands, in arid places among bushes; and probably of Mexico. Rándia aculeàta, Lin. spec. p. 214. Gardènia aculeàta, Ait. lort. kew. Gard. Rándia, Swartz, $\mathrm{A}$. ind. occ. p. 526.-Browne, jam. t. 8. f. 1. Sloan. hist. t. 2. f. 4. Spines axillary, opposite, spreading, forming a straight angle, 4-5 lines long. Corolla white, with the tube 1-5 lines long, and green. Berry the size of a small cherry, white or yellow. Seeds $6-8$ in each cell, surrounded by pulp. Browne called this species Indigo berry, because the pulp of the fruit stains paper and linen of a fine fixed blue colour. The spines at the tops of the branchlets are usually solitary.

lar. $\beta$, milis (D. C. prod. 4. p. 385.) the larger leaves are nearly oval; the thorns are few or wanting altogether, and the Howers are fewer and larger than in the species. $\zeta_{2} . S$. Native along with the species, but in more moist situations. Rándia mitis, Lin. spec. 213. Gardènia Rándia $\beta$ mitis, Swartz, fl.ind. occ. p. 528. Gard. Rándia, Sins, bot. mag. t. 1841.-Sloane, hist. t. 161. f. 1. Flowers white. The juice of the fruit is deep biue.

Broad-leared Randia. Fl. May, Sept. Clt. 1733. Slurub 5 to 10 feet.

2 R. овогл'та (H. B. et Kuntl, nov. gen. amer. 3. p. 4.09. but not of Ruiz and Pav.) branchlets clothed with hairy tomentum; leaves obovate, glabrous ; thorns straight, spreading ; flowers solitary, sessile, almost terminal; tube of corolla twice the length of the calyx, with a silky throat? h.S. Native of New Granada, at the mouth of the river Sinu. Flowers small, white. Very like $R$. latifòlia, but differs in the branches being tomentose, and in the flowers being smaller.

Oboratc-leaved Randia. Shrub 5 to 8 feet.

3 R. pubéscens (liuiz et Pav. fl. per. 2. t. 120. f. b.) leaves obovate, acute, downy ; thorns opposite, axillary, spreading, much shorter than the leaves; flowers solitary, sessile, girled at the base by numerous short adpressed bracteas; tube of corolla rqual in length to the calycine lobes. $\zeta$. S. Native of Peru, on the Andes, in hot places among broken rocks. R. obovita, Ruiz et Pav. fl. per. syst. 2. p. 68. Rom. et Schultes, syst. 5. p. 246. but not of Kunth. Gardènia obovàta, Dietr. Spreng. Floriferous branches spinose, the rest unarmed, spreading, and somewhat tetragonal; stipulas subulate. Leaves $4-5$ inches long. Corolla white, twice the length of the calyx. Berry pubescent, of a greyish yellow colour, crowned by the lobes of the calyx, which are acminated.

Downy Randia. Fl. June, Aug. Clt. 1820. Slırub 5 to $6 \mathrm{ft}$.

4. R. Rotundifòlia (Ruiz et Pav. fl. per. 2. p. 68.) thorns and branches somewhat verticillate; leaves roundish and ovate, downy on both surfaces, wrinkled; flowers solitary, sessile; corolla twice as long as the calyx. $h$.S. Native of Peru, in groves about Huassa-Huassi. Gardènia rotundifòlia, Dietr. ex Rocm. et Schultes, syst. 5. p. 246. Stipulas ovate, acute. Flowers solitary in the centre of the leaves. Corolla white. Berry yellowish, l-celled, size of a filbert, when young villons, crowned by the lobes of the calyx, which are elongated and linear. Seeds compressed, imbedded in the black pulp.

Round-lcaved Randia. F]. June, Aug. Clt. 1820. Shrub 6 feet.

5 R. ecinnoca'rpa (Moc. et Sesse, fl. mex. icon. ined. ex D. C. prod. 4. p. 385 .) thorns 4 in a whorl, spreading; leaves ovate, acuminated, rather villous, crowded at the tops of the branches; flowers solitary, sessile, almost terminal; fruit glohose, echinated. $々$. S. Native of Mexico. Flowers white. Limb of calyx 5 -lobed; lobes linear-subulate. Allied to $R$. tetracintha, but differs in the calyx being 5 -parted, not tubular and 5 -toothed, and in the tube of the corolla being one-half shorter,

Hedgchog-fruitcd Randia. Shrub 4 to 6 feet.

6 R. Dumetòrum (Lam. ill. t. 156. f. 4.) thorns opposite; leaves oval, bluntish, cuneated at the base, glabrous; flowers sessile, solitary, almost terminal; limb of calyx 5-parted, with oblong lobes, which are a little shorter than the corolla, which is

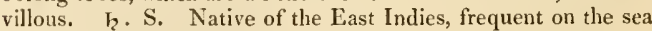
shore. Cánthium coronàtum, Lam, dict. 1. p. 602. Gardènia dunetòrum, Retz, obs. 2. p. 14. Roxb. cor, t. 136. Gardènia spinòsa, Lin. fil. suppl. 164. Rándia spinòsa, Blum. bijdr. p. 981. Posoquèria dumetòrum, Roxb. fl. ind. 2. p. 564. Gardènia spinòsa, Thunb. diss, gard. no. 7 . t. 2. f. 4 . Ceríscus Malabáricus, Gærtn. fr. 1.t. 25.-Pluk. t. 98. f. 6. Flowers white, clothed on the outside with adpressed villi, sweet-scented. Branches downy while young, but afterwards glabrous. Berry almost globose, yellow, about the size of a small apple, 2-celled, and crowned; cells many seeded. This shrub is employed for fences in the places of its natural growth. The fruit bruised and thrown into ponds where fish are, they are soon intoxicated, and seen floating. Fishermen sometimes follow this mode to enable them to take the fish with more ease. They are not deemed less wholesome from the effects of the fruit. Cócculus I'ndicus does not grow in those parts, nor is it known or used there for this purpose.

Bush Randia. Fl. July, Sept. Clt. 1777 . Shrub 6 to 10 feet.

7 R. ? uliginòs (D. C. prod. 4. p. 386.) thorns almost terminal, opposite; branches tetragonal; leaves oblong, somewhat cuneated, glabrous; flowers solitary, sessile, almost terminal ; limb of calyx tubular, almost entire, a little shorter than the tube of the corolla, which is villous in the throat. $\zeta$. S. Native of the East Indies, delighting in moist places, such as tle banks of rivers, low lands, $S c$. Gardènia uliginòsa, Retz, obs. 2. p. 14. Roxb. cor. t. 135. Posoquèria uliyinòsa, Roxb. f. ind. 2. p. 563. Thorns $1-2-3$ or 4 at the extremities of the branchlets. Leaves $2-3$ inches long, and $1 \frac{1}{2}$ broad. Flowers $1-2$ or 3 at the tops of the branclilets, large, white, and fragrant. Berry size and sliape of a pullet's egg, ash coloured, or olive grey, 2-celled. 
Seeds flattish, nestling in the pulp. The flowers of this species render it deserving of a conspicuous place in a lot-house. The uncommon appearance of the plant is also in its favour.

Bog Randia. Fl. July, Sept. Clt. 1802 . Slurub 5 to 8 feet.

8 R. Longispina (1. C. prod. 4. p. 386.) thorns opposite or alternate, horizontal; branclies long, dependent ; leaves obovatecuneated, smooth; flowers axillary, and almost terminal, solitary on short pedicels; tube of calyx cylindrical, 5-lobed: lobes ovate-cordate, permanent ; corolla villous on the outside ; berry obovate, smooth. h. S. Native of the coast of Coromandel. Posoquèria longispìna, Roxb. fl. ind. 2. p. 566. Link, enum. hort. berol. 225.? Thorns sharp, from 1 to 2 inches long. Leaves on the young shoots opposite, on the old ones in fascicles. Stipulas subulate. Flowers pretty large, pure white, and fragrant. 'Tube of corolla as long as the calyx, with a villous throat. Berry size of a nutmeg. Seeds immersed in the pulp.

Long-spined Randia. Fl. June, Aug. Clt. 1812. Slirub 5 to 6 feet.

9 R. Nu'rans (D. C. prod. 4. p. 386.) thorns slender, opposite, spreading; branches long, dependent, pubescent while young; leaves narrow-obovate-oblong; flowers asillary, solitary, on short peduncles; corolla silky on the outside; berry globose, crowned by the tube of the calys, which is entire. h.S. $\mathrm{Na}$ tire of the East Indies. Posoquèria nùtans, Roxb. fl. ind. 2. p. 565. Ceríscus Malabáricus, Gærtn. fr. 1. t. 28. ? Leaves on short petioles, opposite on the young shoots, but fascicled on the old ones, from 1 to 2 inches long, by about 1 broad. Flowers solitary, under the spines, middle-sized, white, and fragrant; throat of corolla villous. Berry size of a nutmeg, 2-celled.

Nodding-branched Randia. Fl. June, Aug. Clt. 1820. Shrub 3 to 4 feet.

\$2. Floners in fascicles or raccmes, in the axils of the laves, or cxtrcmitics of the branches.

10 R.? PARviflòra (Lam. dict. 3. p. 25.) thorns opposite, very short ; leaves ovate, petiolate, glabrous ; racemes villous ; flowers axillary, disposed in fascicles, on short pedicels; limb of calyx with 5 short teeth. h. S. Native of the East Indies. The thorns, according to Lamarck, are arched. Gardènia Sonneráttii, Spreng. syst. 1. p. 762. Perlaps Gardènia macrántha, Thunb, diss. gard. no. S. t. 1. f. 2 . is referrible to this species, but the spines are said to be straight; but the fruit in both are unknown, therefore the genus to which they belong is doubtful. Flowers small, 3-together.

Small-flowercd Randia. Fl. April, June. Clt. 1818. Shrub 4 to 5 feet.

11 R. FloRiBu'xDA (D. C. prod. 4. p. 386.) thorns axillary, stiff; leaves opposite and in fascicles, obovate-cuneated, smooth; flowers disposed in lateral fascicles, on short pedicels; tube of calyx longer than the lobes, which are lanceolate; corolla silky outside; berry ovate, cordate, polished. $\eta$.S. Native of the coast of Coromandel. Posoquèria floribunda, Roxb. fl. ind. 2. p. 569. A large stiff branched shrub, in a good soil growing to a small tree. Flowers middle-sized, white at first, but soon becoming yellow, and fragrant, produced in fascicles, from short scaly spurs. Segments of corolla obovate. Berry size of a prune, 2-celled, many seeded, crowned.

Bundle-flowered Randia. Shrub or small tree.

12 R. Longiflòra (Lam. dict. 3, p. 26. ill. t. 156. f., 3. but not of Salisb.) arboreous; tliorns opposite, recurved; leaves lanccolate-oblong, smooth; corymbs terminal and axillary, 11-13 flowered; limb of calyx tubular, 5-lobed: lobes semilunar; tube of corolla long and slender. $h$. S. Native of Chittagong, in the East Indies, where it grows to a pretty large tree. Posoquèria longitiòra, Wall. in Roxb. fl. ind. 2. p. 568. Gardènia multiflòra, Willd. spec. 1. p. 1231. Posoquèria multiflòra, Blım. bijdr. p. 9S0. Branches terete, smooth. Leaves 6 inches long, and $1 \frac{1}{2}$ or 2 broal. Flowers large, pale, or nearly white when they first expand, lsecoming yellow by the second day, fragrant. Berry the size of the cherry, yellow when ripe, smooth, fleshy.

Long-fonered Randia. Fl. Aug. Sept. Clt. 1818. Tree small.

13 R. Fascicula'ta (D. C. prod. 4. p. 386.) thorns axillary, spreading ; Ieaves ovate-oblong, almost sessile, smooth; fascicles of flowers nearly sessile, axillary, and in the forks of the branches : calyx hairy, with 5 subulate lobes. $\zeta$. G. Native of Silhet, in the East Indies. Posoquèria fasciculata, Roxb. fl. ind. 2. p. 568. A much branched slurub. Thorns straight. Flowers middle-sized, at first white, but in the course of a day changing to a pale yellow colour. Segments of corolla oblong. Ovaritum 2-celled, many seeded.

Fasciclcd-flowered Randia. Shrub 4 to 5 feet.

14 R. RígidA (D. C. prod. 4. p. 386.) thorns opposite, supraaxillary, each having an annular joint, rarely 2 above the middle, the lower half downy, the upper smooth and shining; branches tetragonal, and are, as well as the calyxes, villous; leaves ovate, smooth, on short petioles; flowers by threes, axillary, and almost terminal; tube of corolla long, slender; berry downy. $h_{c} . S$. Native of the valley of Nipaul, and the surrounding mountains; and also at Noakote. Posoquèria rígida, Roxb. H. ind. 2. p. 570. A strong rigid branchy shrub. Leaves in approximate fascicles, ending each in a cuspidate point. Flowers white and fragrant. Leaves slining above, but with a few short hairs along the nerves beneath. Corolla smootl on the outside. Berry purple, 2-celled, many seeded. Perhaps a true species of Posoqueria. Said to be allied to R. fasciculata.

\section{Stiff Randia. Shrub 6 feet.}

15 R. strícta (Roxb. fl. ind. 2. p. 145.) branches stiff, decussate; leaves smooth, oblong, acute, on short petioles ; fascicles of flowers sessile, dense, globose, axillary, bracteate; tube of corolla short, hairy inside; berry globose. $h_{2} . S$. Native of the East Indies, on the mountains north of Bengal. Macrocnèmum stríctum, Willd. rel. in Rœem. et Schultes, syst. 5 . p. 6. Smith, in Rees's cycl. vol. 22. no. 5. Rodelètia strícta, Roth, nov. spec. p. 140 . Flowers small, white. Berry size of a pea, 2 -celled, smooth. Seeds imbricated in 2 rows in each cell, attached to the partition above its middle. Perhaps a distinct genus.

Straight Randia. Slurub 5 to 10 feet.

16 R. sca'ndens (D. C. prod. 4. p. 387.) stem scandent prickly ; prickles recurved; leaves oval, acuminated, coriaceous, glabrous; peduncles almost terminal, usually 3 -flowered at the apex; tube of corolla slort; limb of calyx tubular, rather truncate. $\zeta$. S. Native of $\mathbf{J}$ ava, on the mountains of Parang and Salak. 'I'ocoyèna scándens, Blum. bijdr. p. 980. Flowers white.

Climbing Randia. Slirub cl.

17 G. TEtra'NdRA (D. C. J. c.) thorns scattered, straight ; leaves ovate, acuminated, narrowed at the base, rather coriaceous, and are as well as the branclilets downy; stipulas ovate, acuminated; flowers $6-8$ in a fascicle at the tops of the branches, sessile, tetrandrous; bracteas connate; teetl of calyx 4, subulate; corolla clothed with silky hairs outside. $\eta_{2}$. S. Native of New Granada, in temperate places near Guadua. Gardènia parviflòra, H. B. et Kunth, nov. gen. amer. 3. p. 408 . t. 293. Flowers small, white.

Tetrandrous-flowered Randia. Shrub 5 feet.

is R. AnмA'тA (D. C. prod. 4, p. 387.) thorns 4 together at the tops of the branchlets, short, spreading; leaves ovate, acute at both ends ; flowers usually 4 on the tops of the branchlets, on short pedicels; lobes of calyx linear-cuneiform; tube of corolla long, cylindrical, glabrous. ..S. Native of Cartha- 
gena, Martinico, St. Lucia, Sc. in woods. Mussæ'nda spinòsa, Lin. mant. p. 45. Jacq. amer. t. 49. Gardènia armàta, Swartz, f. ind. occ. p. 524. Gardènia tetracántha, Lam. dict. 2. p. 609. Leaves glabrous or downy, cuneated at the base. Tube of corolla an inch long. Flowers pure white, sweet-scented. Berry oval, corticate, 2-celled, crowned by the calyx. Seeds numerous, enveloped in pulp. It differs from $R$. tetracántha in the flowers being one half smaller.

Armed Randia. Clt. 1813. Slirub 5 to 10 feet.

19 R. FE'RoX (D. C. l. c.) thorns decussate, spreading, acnte; leaves ovate, or oval, glabrous above and pubescent beneath; stipulas pellucid; flowers disposed in cymose fascicles; tube of calyx turbinate, but the limb is acute and 5-cleft beyond the middle; segments of corolla almost orbicular. $h$. S. Native of Brazil, at Rio Padre. Gardènia fèrox, Cham. et Schleclit. in Linnæa. 4. p. 198. Flowers white, sweet-scented.

Fieree Randia. Shrub 4 to 5 feet.

20 R. capita'ta (D.C. l. c.) thorns stiff, short, 4 at the top of each branchlet; leaves ovate, acute, hairy on botl surfaces as well as on the branchlets; flowers sessile, 6-8 in a capitate fascicle at the tops of the branchlets; limb of calyx tubular, with stiff, subulate teeth; tube of corolla 3 times longer than the segments, villons on the outside. $\zeta \cdot G$. Native of Mexico. Flowers white, sweet-scented.

Capitatc-flowered Randia. Shrub 4 to 6 feet.

21 R. TETraca'́ntha (D. C. l. c.) branches opposite, horizontal, bearing each 4 thorns at the apex; leaves lanceolate, acuminated, tomentose ; flowers sessile, 4 at the top of each branch; limb of calyx tubular, terminating in 5 subulate teeth; tube of corolla long, villous. $h$. S. Native of Mlexico, about Acapulco and Regiomonti. Mussæénda tetracántha, Cav, icon. 5. p. 20. t. 435. Gardènia armàta. Bartl. but not of Swartz. Corolla pale yellow. Berry size of a pigeon's egg, not crowned by the calyx.

Four-spined Randia. Fl. Ju. Aug. Clt. 1820. Sl. 5 to $10 \mathrm{ft}$. 22 R. PropíneUA; branches slightly downy, armed with 4 spines at the apex, placed crosswise; leaves ovate, cordate, nndulated, acuminated, downy, petiolate; flowers in terminal fascicles. $\zeta_{2}$. S. Native country unknown. Garòènia propínqua, Lindl. bot. reg. t. 975 . Thorns straight, infra-axillary. Leaves clustered at the ends of the branches, rather longer than the flowers. Corolla with a long cylindrical tube, and a 5parted, spreading limb, with cordate, ovate, acute, flat segments, which are rather longer than the tube. Anthers semi-exserted, Flowers large, white.

Allied Randia. Fl. July. Clt. 1823. Shrub 6 to 8 feet.

23 R. Humoldtia'sa (D. C. l. c.) branclies nearly terete, glabrous, furnished each with 2 spines at the apex; leaves elliptic, short-acuminated, pubescent, membranous; flowers 3-5 together, terminal, pedunculate; corollas pubescent. $\eta_{2}$ S. Native on the shores of the Pacific near Guayaquil. Mussæ'nda pubéscens, H. B. et Kunth, nov, gen. amer. 3. p. 410. Gardènia Humboldtiàna, Røm. et Schultes, syst. 5. p. 243. Mussæ'nda Ilumboldtiàna, Steud. nom. Gardènia pubéscens, Bartl. in herb. Hanke, but not of Roth. Flowers white, sweetscented. Allied to R. armata. Fruit unknown.

IIumboldt's Randia. Shrub 5 to 10 feet.

24 R. NíTidA (D. C. l. c.) branchlets ratier angular, furnished with 2 spines at the apex; leaves ovate-elliptic, acute, glabrous, shining; flowers terminal, twin, or by threes or fours, sessile; corollas glabrous. $\eta$. S. Native of New Granada, near Turbaco. Mussæ'nda nítida, H. B. et Kunth, nov. gen. amer. 3. p. 410. Flowers white, sweet-scented. Fruit unknown.

Shining-leaved Randia. Shrub 5 to 8 feet.

25 R. triflo'ra (Hamilt. in D. Don, fl. nep. p. 138.) thorns opposite, subulate, adnate to the branches above the petioles; petioles and branchlets hairy; stipulas ovate, cuspidate; leaves ovate; peduncles axillary, 3 -flowered; calyx campanulate: having the lobes ovate at the base, and linear-subulate at the apex. Ђ. G. Native of Nipaul, at Hetlaura. Peduncles solitary, very short, usually 3 , sometimes 4 -flowered. Flowers usually 6-cleft and hexandrous. Anthers semi-exserted.

Three-flowered Randia. Slirub.

26 R. HórRida (Rom. et Schultes, syst. 5. p. 248.) branches reclinate; branchlets decussate; thorns opposite, horn-formed; leaves ovate-lanceolate, glabrous ; racemes trichotomous, almost terminal. $h$. G. Native of Cochin-china, in woods. Oxýceros hórrida, Lour. coch. p. 151. Spines large, acute. Flowers white. Berry black.

Horrid Randia. Slurub 8 feet.

27 R. Sine'Nsis (Roem. et Scluultes, l. c.) thorns short, opposite, rather recurved; leaves lanceolate (Lour.): superior ones ovate, nerved, glabrous; corymbs small, terminal, few-Hlowered; limb of calyx tubular, 5-lobed ; tube of corolla long, glabrous : having the throat hardly inflated; anthers linear, exserted, about equal in length to the lobes, which are spreading. h.G. Native of China, about Canton. Oxýceros Sinénsis, Lour. coch. p. 151. Rándia Chinénsis, Spreng. syst. 1.p.768. R. longifiòra, Lam. ill. 156. f. 3.? Flowers white, salver-shaped, with a very long tube. Berry small, roundish, 2-celled, manyseeded.

China Randia. FI. Ju. Aug. Clt. 1818. Shrub 5 feet.

28 R. Africa'na; shrub spinose; fruit woody, oblong, or roundish. h. S. Native of Sierra Leone. Flowers small, greenish yellow.

African Randia. Shrub 3 to 4 feet.

Sect. II. Euclínia (from $\varepsilon v, c u$, well, and $\kappa \lambda \iota v \omega$, klino, to bend; the segments of the corolla are well bent over each other before expansion). D. C. prod. 4. p. 388. Unarmed shrubs. Tube of corolla usually dilated and obconical at the throat. Perhaps a proper genus.

29 R. macula'тA (I. C. prod. 4. p. 388.) shrubby, unarmed; branclilets rather downy; leaves oval, smooth, glandular in the axils of the nerves beneath, not pilose; flowers terminal, solitary from the axils on the ultimate leaves; tube of corolla very long, dilated at the apex. $h$. S. Native of Guinea. Rotbmánnia longiflòra, Salisb par. t. 65. Limb of calyx rather villous, 5 -toothed. Corolla 5 inches long, white, spotted with purple at the throat; segments ovate, spreading. Ovarium 2celled.

Spotled-flowered Randia. Fl. Jul. Sept. Clt. 1696. Shrub 5 to 6 feet.

30 R. SPecio'sa (D. C. prod. 4. p. 388.) shrubby, unarmed, glabrous; leaves elliptic-oblong, shining above; flowers from the tops of the branchlets, solitary in the axils of the ultimate leaves; tube of corolla very long, clothed with adpressed down on the outside : the segments acuminated. $h$. S. Native of Cayenne, where it was collected by Patris. Tube of corolla 9 inches long, hardly dilated at the apex. Genitals inclosed. Berry ovate. Tube of calyx cylindrical, semi-quinquefid; lobes subulate, erect.

Elegant Randia. Shrub.

31 R. Mussźnda (D. C. l. c.) shrubby, umarmed; leaves ovate or lanceolate, acute, downy on the veins underneath; flowers solitary, sessile, terminating the branchlets ; tube of caly $\mathrm{x}$ semi-quinquefid : the lobes subulate; corolla villous on the outside, with a long tube, and acuminated segments. $\eta$.S. Native of Carthagena in woods (Jacquin.); on the banks of the river Magdalena, near Honda (H. B. et Kunth, nov. gen. amer. 3. p. 408.); Dutch Guiana (Meyer, esseq. p. 128.); Mexico, Demerara, French Guiana, and probably of Tobago. Mussæénda formòsa, 
Jacq. amer. p. 70. t. 48. Gardènia marítima, Vahl, herb. Gardènia Mussaénda, Thunb. diss. no. 5. Perhaps 2 or $\$$ allied species are here confused. 'The branches are glabrous in Jacquin's and De Candolle's specimens, but bairy in those of Kunth and Thunberg. Corolla with an incurved or straight tube, villous and green on the outside (ex Jacq.), but the seginents are white within. Berry corticate, ovate, crowned by the calyx, 2-celled. Stigmas 2, acute, revolute.

Musscenda-like Randia. Clt. 1820. Shrub 5 to 6 feet?

32 R. Ruizin'Na (D. C. prod. 4. p. 388.) shrubby, unarmed; leaves lanceolate, acute, on short petioles, glabrous above, rather hairy on the veins underneath; flowers terminal, solitary, sessile; calyx hairy, with subulate, erect segments ; corolla hairy on the outside, with a very long tube, an obconical villous throat, and spreading acute segments. $\zeta$. S. Native of Peru, on the Andes, in groves at Pozuzo. Gardènia longittòn, Ruiz et Pav. f. per. 2. t. 219. but not of Ait. Branches very long, when young rather tetragonal. Berry cylindrical, large, yellowish, striated longitudinally by 10 brown nerves, 2 -celled, containing a sweet edible pulp. Flowers white. Stigmas 2, thick, reflexed.

Ruiz's Randia. Shrub 10 to 12 feet.

33 R. Macra' Nтна (D. C. l. c.) shrubby, unarmed; leaves oval-oblong, acuminated, rather ciliated ; flowers sessile, almost terminal, 5-parted; lobes of calyx subulate, spreading; corolla with a long tube, which is dilated at the apex, and revolute segments. $h_{\varepsilon} . S$. Native of Sierra Leone. Rándia longiflòra, Salisb. par. t. 93 . but not of Lam. Gardènia longiflora, Ait. hort. kew. ed. 2. vol. 1. p. 368 . but not. fi. per. Gardènia macrántlia, Rœm. et Schultes, syst. 5. p. 235. Flowers 6-7 inches long, cream-coloured, fragrant. Stigmas 2, thick, obtuse, flat inside and convex outside. Ovarium 2-celled. According to Salisbury, this with others he proposes to separate into a distinct genus to be called Euclinia.

Long-flonered Randia. Fl. July, Sept. Clt. 1696. Shrub 5 to 6 feet.

34 R. Longístrua (D. C. l. c.) shrubby, unarmed; leaves oval, villous above, but villously tomentose beneath, as well as the petioles; stipulas ovate, glabrous, scarious, deciduous ; flowers almost terminal, disposed in corymbose fascicles; lobes of calyx parted to the base of the limb, erect, lanceolate, cili-

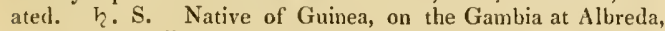
where it was collected by Leprieur and Perrottet. Flowers black, in the dried state, but probably white when recent, $1 \frac{1}{2}$ inch long. Style much exserted; stigma thick, bipartite. Fruit nearly globose, about an inch in diameter. Seeds compressed, separated by gluten and partitions.

Long-slyled Randia. Shrub 5 to 6 feet.

35 R. Mladagascarie'nsis (D. C. prod. 4. p. 389.) shrubby, unarmed; leaves ovate, acute, on short petioles, glabrous, coriaceous; flowers axillary, sessile, bibracteate at the base; limb of calyx 5-lobed, obtuse; corolla velvety outside from tomentum, with a terete tube, and 5 oblong obtuse lobes; genitals inclosed. $\zeta$. S. Native of Madagascar. Gardènia Madagascariénsis. Lam. dict. 2. p. 608. Flowers about 3 inches long. (ex Lam.) Tube of corolla 15 lines long. (ex D. C.)

Madagascar Randia. Shrub 5 to 18 feet.

36 R. GENIPAFLO'RA (D. C. l. c.) shrubby, unarmed; leaves oval-oblong, acuminated at both ends, coriaceous, glabrous, on short petioles; stipulas lanceolate; peduncles axillary, very short, divided at top into many 1 -flowered pedicels, which are disposed in a corymb; limb of calyx tubular, permanent, 5toothed, a little shorter than the corolla. h. S. Native of Sierra Leone, where it was collected by Smeathmann. Tube of corolla cylindrical, hardly longer than its lobes. Anthers long, linear. Stigmas 2, slender, acute. Berry dry, 2-celled, crowned by the tubular limb of the calyx; placentas scarcely exserted. Seeds horizontal.

Genipa-flowered Randia. Shrub 5 to 8 feet.

37 R. Thangninis (D. C. l. c.) leaves oval-oblong, acute at the base, obtuse at the apex, coriaceous, glabrous; stipulas short, undivided: flowers axillary, solitary, a little shorter than the leaves; calyx long and tubular beyond the ovarium, with 5 short, acute teeth at the apex; corolla with a long terete tube, and is as well as the segments clothed with velvety hairs on the outside. $\eta$. S. Native of Madagascar, on the east coast, where it was collected by Cliapelier, and called by him Talangninia. Berry dry, ovate, rather acuminated.

Talangnin's Randia. Shrub.

\section{+ Doubtful species.}

38 R. ? DRUPA'CEA (D. C. l. c.) berry ovate, drupaceous, containing a bony putamen. $\zeta$.S. Native of Java. Posoquèria drupàcea, Gartn. fil. carp. 3. p. 77. t. 195. f. 1. The rest unknown.

Drupaceous-fruited Randia. Tree or shrub.

39 R. ? polyspérma (Roxb. fl. ind. 2. p. 146.) shrub bushy and much branched; leaves oblong, acuminated, smooth; stipulas subulate; spikes panicled, axillary. $\zeta$. S. Native of the East Indies, about Chittagong.

Many-seeded Randia. Shrub 5 to 6 feet.

Cult. For culture and propagation see Gardènia, p. 499. All the species being very showy, usually bearing large, white, fragrant flowers, are therefore worth cultivating in every collection of stove plants.

XXXVIII. CHAPELIE'RIA (named after M. Chapelier, who collected many plants in Madagascar, during his travels in that island). A. Rich. mem. soc. hist. nat. par. vol. 5. p. 25\%. D. C. prod. 4. p. 389.

Lin. syst. Pentándria, Monogýnia. Calyx with a 5-parted limb, and erect, acute, permanent lobes. Corolla with a slender tube and a 5-parted limb: rather oblique, spreading, lanceolate, acute segments, and a villous throat. Stamens 5, almost sessile, inclosed, inserted in the middle of the tube. Style short, inclosed; stiuma oblong, bipartite, with the lobes approximate. Fruit egg-shaped, fleshy, coriaceous, 2-celled, crowned by the large erect limb of the calyx; cells many-seeded. Seeds distinct, many-sided, of a golden yellow colour, and clothed with adpressed, silky down. Embryo linear, terete, in the center of a horny albumen.-A shrub. Leaves opposite, coriaceous, elliptic, acute, quite glabrous. Stipulas entire, caducous, interpetiolar. Flowers on short pedicels, crowded in the axils of the leaves. Habit almost of an apocyneous plant.

1 C. Madagascariénsis (A. Rich. l. c.). そ. S. Native of Madagascar.

Madagascar Chapelieria. Shrub 2 to 4 feet.

Cult. For culture and propagation see Gardènia, p. 499.

XXXIX. HEI'NSIA (named in memory of the famous philologist Heinsius, the translator of 'Theophrastus's works). D. C. prod. 4 . p. 390 .

Lin. sxst. Pentúndria, Monogýnia. Calyx with an obovate tube and a 5-parted limb; and oblong, foliaceous, permanent lobes. Corolla salver-shaped, with a terete tube, which is longer than the calycine lobes, very hairy inside in the upper part, and 5, oval, acute undulated lobes. Anthers 5, linear, acnte, sessile towards the top of the tube, inclosed and hidden among the hairs. Style filiform, shorter than the tube of the corolla; stigmas 2, linear. Fruit globose, crowned by the calyx, dry, hard, indehiscent, 2-celled; placentas 2, thick, adnate to the 
dissepiment. Seeds numerous, wingless, nestling on the superficies of the placentas. - A much-branched, unarmed, glabrous shrub or small tree, but there are small permanent spurs, which look like spines. Leaves opposite, oval-oblong or ovate, acuminated, on short petioles. Stipulas twin on each side, small, acute. Flowers 3-4 together at the tops of the branchlcts, pedicellate, and disposed in something like racemes, white, about the size of those of l'inca ròsea, and very similar to those of Gardènia and Rándia.

1 H. jasuiniflòra (D. C. prod. 4. p. 390.). Ђ. S. Native of Sierra Leone, where it was collected by Smeathmann, Afzelius, and G. Don. The plant we have seen at Sierra Leone has numerous I-flowered, terminal, and axillary pedicels; the tube of the corolla clothed with yellow hairs; and the segments of the corolla hispid. The shrub bears nothing like spurs or spines that we recolleet.

Jasmine-flowered Heinsia. Fl. Feb. Clt. 1824. Sh. 5 to $8 \mathrm{ft}$. Cult. See Gardènia, p. 499. for culture and propagation. A beautiful shrub, clothed with numereus white flowers.

XL. MENESTORIA (Menestor was a plyysiologist cited by Theophrastus). D. C. prod. 4. p. 390.

Lin. srst. Pcntándria, Monogýnia. Calyx with a globose tube, a 5-parted limb : and linear, almost subulate, acute, distant segments. Corolla with a long terete tube, 5 oval acute short lobes, and an almost naked throat. Anthers 5, oblong, sessile within the tube of the corolla. Style filiform; stigma bifid, inclosed: lobes linear. Ovarium 2-celled; placentas manyseeded, adnate to the dissepiment. Fruit baccate, almost dry, areolate at the apex, never crowned, from the lobes of the calyx being deciduous. Seeds very small, wingless.-Unarmed shrubs, natives of Nipaul. Leaves opposite. Stipulas solitary on each side, at length deciduous. Corymbs of flowers terminal. This is rather a doubtful genus, differing from Mussa'nda in the tube of the calyx or ovarium being globose, not turbinate, and in the stipulas being solitary on each side, not twin; and from Tocoyèna in the limb of the caly $\mathrm{x}$ being parted to the base.

I M. Tocoxe'NA (D. C. prod. 4. p. 390.) leaves obovate, obtuse, cuneated at the base, almost sessile, glabrous above, pale beneath, and beset with adpressed villi along the nerves. $h$. G. Native of Nipaul. Branches terete. Stipulas broad, slort, very blunt, membranous. Corymbs terminal, trichotomous, on short peduncles; pedicels puberulous. Corolla 15 lines long, puberulous on the outside; segments ciliated, apiculated, clothed with adpressed down on the outside, as well as the tube. Style about equal in length to the tube of the corolla; stigmas 2 , linear, applied to each other in the dried state.

Tocoycna-like Menestoria. Shrub 5 to 6 feet.

2 M. HAME'Llis (D. C. l. c.) leaves oval, acuminated at both ends, on long petioles, rather scabrous from scattered hairs ahove, and along the nerves underneath. $h$. G. Native of Nipaul. Branchlets compressed. Leaves along witl the petioles an inch and more in length. Stipulas ovate, broad, sliort, acutish. Peduncles numerous, spreading, disposed in loose cymes, rising from the top of the stem and forks of the branches. Corolla 6 lines long, scarcely puberulous. Style very short, inclosed, hardly attaining the height of the anthers.

Hamellia-like Menestoria. Shrub 5 to 6 feet.

3 M. Muss $e^{\prime}$ DE (D. C. l. c.) leaves ovate, acute, on short petioles, pale beneath, and downy on both surfaces; petioles, stipulas and middle nerve of the leares clothed with rufous hairs. $h$. G. Native of Nipaul. Branches rather hispid and rufous. Stipulas ovate. Corymbs dichotomous, with some of the flowers sessile and solitary in the forks, and others terminal. Calyx hispid; lobes deciduous. Berry ovate-globose, smoothisl.

Musscenda-like Menestoria. Slumb 5 to 6 feet.
4 M.? rígida (D. C. 1. c.) leaves cuneated, retuse, and mucronulate, glabrous; stipulas ovate, acute. h. G. Native of Nipaul, at Suembu. Gardènia rígida, Hamilt. ex D. Don, prod. f. nep. p. 138. A much-branclied depressed rigid shrub. Segments of the calyx subulate. Limb of corolla 5 -lobed; lobes attenuated at the apex.

Stiff Menestoria. Shrub 3 to 4 feet.

Cult. For culture and propagation see Gardènia, p. 499.

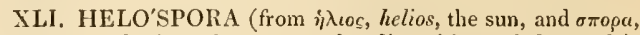
spora, a seed; in reference to the disposition of the seeds). Jack, in Lin. trans. 14. p. 127. t. 4. f. 3. D. C. prod. 4. p. 391 .

Lin. syst, Tetrándria, Monogýnia. Calyx with a globose tetragonal tube, and a somewhat campanulate 4 -toothed, erect, pernanent limb. Corolla tubular, much longer than the calycine limb, with a naked throat, and 4 oblong spreading lobes, which are valvate in restivation. Anthers 4, linear, inclosed. Style 4-furrowed, and 4-cleft at the apex; stigmas short, spreading. Berry crowned by the calyx, tetragonal, not divided into cells inside, but bearing the sceds disposed crosswise, in 4 double series, immersed in pulp. Seeds linear, curved a little.-A smoothish shrub. Leaves opposite, on short petioles, ovatelanceolate. Stipulas deciduons, bearing a row of ciliæ inside. Peduncles axillary, 1-flowered, shorter than the leaves. Bracteoles 2 , under each ovarium.-This genus is perliaps allied to Guettárda or Gardènia.

I H. Flave'scens (Jack, l, c.). h. S. Native of Sumatra. Leaves 3-5 inches long. Corolla yellowish, 3-4 lines long.

Yellonish-flowered Helospora. Tree small.

Cult. For culture and propagation see Gardènia, p. 499.

XLII. HIPPO'TIS (from i $\pi$ ro hippos, a horse, and ove wros, ous otos, an ear; the form of the calyx has been compared to the ear of a horse). liniz et Pav. prod. p. 33. fl. per. 2. p. 55. t. 201 . Juss. mem. mus. 6. p. 396. A. Rich, mem. soc. hist. nat. par. 5. p. 255.

Lin. srst. Pentándria, Monogýnia. Calyx with an obovate tube and a spath-formed limb, which is cleft on one side, and drawn out into a mucronate auricle on the other. Corolla a little longer than the calyx, funnel-shaped, with a somewhat incurved tube, and a bluntly 5 -lobed limb. Stamens 5 , inserted in the middle of the tube; anthers ovate, inclosed. Urceolus 5 -crenate, seated on the ovarium. Stigma of 2 adpressed lobes. Berry ovate, crowned by the calyx, 2-celled. Seeds numerous, minute-An unarmed villous slirub. Leaves obovate-oblong, acuminated, petiolate. Stipulas ovate, acute, caducous, villous on the ontside and solitary on each side. Peduncles axillary, hardly one half shorter than the leaves, 3-flowered at the apex. Corolla and berries villous, purplish red.

I H. triflóna (Ruiz et Pav. l.c.). h. S. Native of Peru, in forests about Cuchero, Macora, and Marimarchahua. Peduncles furnished with small, subulate, decidnous bracteas. Calyx reddish purple. Corolla crimson, greenish at the base: having the tube yellowish inside.

Threc-flowered Hippotis. Shrub 10 to 12 feet.

Cult. For culture and propagation see Gardènia, p. 499.

XLIII. POMA'TIUM (from fomum, an apple; sliape of fruit). Gærtn. fil. carp. 3. p. 252. t. 225. f. 10 . D. C. prod. 4. p. 391 .

Lux. syst. Pentándria, Monogýnia. Calyx with a subglobose tube, and a 5 -toothed limb; teeth short, obtuse, deciduous, leaving only a membranous circle belind. Corolla small, with a terete tube and a 5 -parted limb. Anthers ovate, sessile in the throat of the corolla, inclosed. Stigma bifid, with oblong 
lobes. Berry almost dry, globose, somewhat didymous, crowned by an areola formed by the falling of the calyx, 2-celled, manyseeded. Placentas rather tumid. Seeds angular. Embryo straight, in fleshy albumen, with a centripetal radicle, and flat ovate-roundish cotyledons. - African shrub. Branches terete, hispid in the young state, and glabrons in the adult state. Leaves opposite, almost sessile, oblong-lanccolate, acuminated. Stipulas foliaceous, solitary on each side, oblong, acuminated, almost an inch long. Thyrse spike-formed, terminal.-Habit of Bertiera.

1 P. spica'tum (Gartn. l. c. D. C. diss. ined. with a figure). 々. S. Native of Sierra Leone, where it was collected by Smeathnuann and G. Don; and in the woods of Casamancia at l tou by Perrottet and Leprieur. Génipa labiàta, Smeathm. in herh. Lher. Flowers small, white.

Spicate-flowered Pomatium. Slurub 6 to 8 feet.

2 P. DU'Bıx ; leaves broad-lanceolate, long-acuminated, rather cordate at the base, sessile; flowers panicled, axillary, and terminal. $h$. S. Native of Sierra Leone, on the mountains, in woods. Flowers small, white.

Doubtful Pomatium. Slirub 6 to 8 feet.

Cult. See Gardènia, p. 499. for culture and propagation.

XLIV. BERTIE'RA (named by Aublet after a Madam Berthier, who was of great assistance to him while he was collecting plants in Guiana). Aubl. guian. 1. p. 180. t. 69. Lam. ill. t. 165 . D. C. diss. ined. 1806. with a figure. prod. 4. p. 391. Gærtn. fil. carp. 3. t. 192 . Juss. mem. mus, 6. p. 390. Rich. niem. soc. hist. par. 5. p. 253.

Lin. syst. Pentándria, Monogýnia. Calyx with a subglobose tube, and a very short permanent 5 -toothed limb. Corolla funnel-shaped, with a terete tube, and a 5 -parted spreading limb; segments oval, very acute. Anthers 5, sessile within the throat of the corolla. Stigma bifid; the lobes acute. Berry almost dry, crowned by the calyx, umbilicate, roundisl, 2celled, many-seeded. Seeds fixed to the central placentas, angular, muricated. -Shrubs. Leaves oral-oblong, acuminated, petiolate, villous. Stipulas solitary on both sides, combined at the base, acuminated. Thyrse terminal, racemosely panicled, bracteolate. Flowers small, white, and sometimes red.-Habit of Lygistum, but differs in the flowers being 5-parted.-This genus is probably divisible into several.

Sect. 1. Bertie'ra (see genus for derivation). D. C. prod. 4. 1. 392.-Bertièra, Aubl. Fruit usually striated, crowned by the calycine teeth, which are erectly comnivent and subulate. Inflorescence terminal.

1 B. Guianénsis (Aub]. guian. 1. p. 180. t. 69.) leaves ovate-oblong or elliptic, acute, with distant villous nerves; stipulas undivided on both sides, acuminated; flowers disposed in a racemose thyrse; fruit sessile, striated, hairy, disposed along the branches of the panicle, crowned by the erect subulate calycine teeth. $h_{\text {. }}$. S. Native of French Guiana, in woods; and of Cayenne. Vahl, symb. 3. p. 35. Lam. ill. t. 165. Spreng. syst. 1. p. 708. exclusive of some synonymes. Branches villous. Stipulas broad at the base, and rather connate. Leaves $3-4$ inches long. Flowers small, white.

Guiana Bertiera. Shrub 6 to 7 feet.

2 B. mucrona'ta (Gærtn. fil. carp. 3. p. 74. t. 192. f. 7.) leaves and flowers unknown; fruit striated, crowned by the erectly connivent calycine teeth, pedicellate, disposed along the branches of the panicle. $h$. S. Native country unknown. Perhaps the same as $B$. Guianénsis.

Mucronate Bertiera. Shrub.

3 B. PALu'stris (A. Rich, in mem. soc. hist. nat. par. 5. p. 245.) leaves elliptic-oblong, acute, hairy, with approximate vol. 11 . nerves; stipulas bifid on both sides; flowers almost cymose ; fruit not striated, hairy, crowned by the subulate teeth of the calyx. 々. S. Native of Guiana, in marshy parts of woods. A small sub-herbaceous erect shrub, clothed with rusty down. Leaves soft, usually tapering gradually to the base.

\section{Marsh Bertiera. Shrub 1 to 2 feet?}

Sect. 1I. Zaluza'nia (altered from Zaluzianski, an obsculc l'olish hotanist). D. C. prod. 4. p. 392.-Zaluzània, Comm. mss. Fruit smootl, crowned by the calycine teeth, which are spreading or erect, but not connivent. Embryo transverse, ovatecylindrical, in the albumen.--Inflorescence terminal, racemose? thyrsoid.

4 B. Bonвónica (A. Rich, l. с.) smoothish; leaves ellipticlanceolate, acuminated, petiolate; stipulas undivided, drawn out into a setaceous point each, length of petioles; racemes thyrsoid, terminal; fruit glabrous, not striated, crowned by the teeth of the calyx, which are permanent, acute, and straight, but not connivent. h. S. Native of the Island of Bourbon. Peduncles angular. Bracteas subulate.

Bourbon Bertiera. Shrub 3 to 4 feet.

5 B. RU'FA (A. Rich, l. c.) leaves elliptic, acute, on very short petioles, clothed with rufous silky down; stipulas broad, connate, acute, silky inside, and smoothish on the outside; racemes elongated; pedicels silky; fruit globose and villous, crowned by the erect calycine teeth. $h .5$. Native of the lsland of Bourbon.

Rufous Bertiera. Shrub.

6 B. Zaluza'sia (Gærtn. fil. carp. 3. p. 74. t. 192.) smoothish ; leaves rather coriaceous, lanceolate-elliptic, acuminated, on slıort petioles, ciliated on the edges; stipulas undivided, drawn out into an acumen, length of petioles; racemes thyrsoid, terminal, and are as well as the flowers downy; branches of racemes dichotomous, with a sessile flower in each fork; fruit crowned by the limb of the calyx, wlich is hardly toothed; teeth spreading. $h$. S. Native of the Matritius. Mussánda racemosa, Sieb. fl. maur. 3. no. 362. Stipulas short, broad, concrete. Racemes apparently drooping. Bracteas small, acute. Flowers sessile. Anthers mucronate. Calyx truncate. Corolla widening from the base, with acute segments.

Zaluzianski's Bertiera. Shrub 3 to 4 feet.

Sect. III. MYcE'TIA (aplrarently after some botanist of the name of Mycet). Reinwardt. mss. D. C. prod. 4. p. 392. -Bertièra, Blum. bijdr. p. 987. Tube of calyx obovate or turbinate. Berry crustaceous inside, crowned by the calycine teeth, which are spreading. Racemules axillary, somewhat corrmbose.

7 B. JAvA' Nic A (Blum. bijdr. p. 987.) stem simple; leaves petiolate, cuneate-oblong, acuminated, with a few scatterel hairs above, and more so on the nerves beneath; corymbs divaricate, axillary, and terminal, trichotomous, solitary, drooping; tube of corolla short. $\quad$. S. Native of Java, in shady parts of woods.

Jar a Berticra. Shrub 2 to 3 feet.

8 B. FAscicula'ta (B]um. bijdr. p. 987.) stem a little branched; leaves cuneate-oblong, acuminated, glabrous above, but somewhat strigose on the veins beneath; corymbs short, axillary, trichotomous, erect; pedicels in fascicles; tube of corolla elongated. $々$. S. Native of Java, on Mount Salak, in humid places. Corymbs often lateral, lardly longer than the petioles. Throat of corolla velvety.

Íar. $\beta$, macrophýlla (Blum. l. c.) leaves obovate, acute. $\hbar$. S. Native of Javi, on Mount Bonkok, in the province of Bantam.

Fascicled-pedicelled Bertiera. Shrub. $3 \mathrm{~T}$ 
9 B. lateriflòra (Blum. bijdr. p. 987.) stem branched; leaves almost sessile, cuneate-oblong, acuminated, glabrous above and puberulous beneath on the veins; corymbs terminal and axillary, solitary or crowded, trichotomous, at length pendulous ; tube of corolla elongated. $\xi$. S. Native of Java, on the momntains. Mycètia, Reinwardt. ex Blım. Corymbs often lateral. Corolla reddish, tubular, with a velvety throat. Berry globose. Teeth of calyx acuminated, separated to the base of the limb. Stipulas triangular, acuminated.

Lateral-flowered Bertiera. Shrub 4 to 5 feet?

\section{$+A$ species not sufficicntly known.}

10 B. coccínea; shrub rambling, villous; leaves opposite, ovate, acuminated, quite entire, petiolate; corymbs panicled, terminal; calyx 5-cleft, hairy, with linear segments; corolla tubular, sajver-shaped, with a spreading 5 -cleft border, and a villous throat; stamens 5 , inclosed. 5. S. Native of Sierra Leone, among bushes, in the lowlands about Freetown. Flowers about the size and form of those of linca ròsea, of a deep scarlet colour, and very showy.

Scarlet Bertiera. Shrub rambling.

Cult. Sce Mussénda, p. 492. for culture and propagation.

XLV. POUCHE'TIA (named after M. F. Pouchet, professor of botany in the Jardin des Plantes at Roven; author of Histoire Naturelle et Medicale de la Famille des Solanees). A. Rich, soc. hist, nat. par, vol. 5. j. 251 . D. C. prod. 4. p. 393.

Lin. syst. Pentándria, Monogynia. Calyx with an ovate tube, and a small 5 -toothed limb. Corolla witl a short obconical tube, a glabrous throat, and a 5 -lobed limb; lobes ovaloblong, twisted in astivation. Anthers 5, linear, sessile in the throat of the corolla. Style filiform. Stigmas 2, linear, acute, diverging a little at the apex, hardly exserted. Berry dry, closely crowned by the connivent teeth of the calyx, obovate, 2-celled. Seeds 4-6 in each cell, oblong, deformed from being pressed against each other, and clothed with adpressed silky villi. Albumen Aesliy. Enbryo unknown.-A glabrous African shrub, with roundish branches. Leaves ovate, acuminated, on short petioles. Stipulas solitary on both sides, ovate, ending each in a short cuspidate point. Peduncles opposite, panicled, few-flowered, asillary: but the ujper ones are disposed in a terminal panicle from the leaves being gradually diminished and changed into bracteas. Flowers small, glabrous, white?-This genus differs from Gardenia in habit, in the 5toothed calyx, in the dry 2 -celled fruit, and in the cells being few-seeded; in these last characters it agrees with Cùpia, but differs from it in the connivent calyx, and in the velvety seeds, and in habit.

1 P. Africa'na (D. C. prod. 4. p. 393.). h. S. Native of Sierra Leone, where it was collected by Sineathmann; and in the woods of the Gambia, Casamancia, and Cayor, where it was collected by Leprieur and Perrottet. Gardènia parviflòra, Smeatlumans, but not of Poir. dict. suppl, 2. p. 708. which is according to A. Rich. Psydrax dicóccos.

African Pouchetia. Shrub 5 to 6 feet.

C'ult. For culture and propagation see Mussánda, p. 492.

XLVI. CU'PIA (Cupi is the Malabar name of one of the species). D. C. prod. 4. p. 393.-Cùpi, Rheed. mal. 2. p. 37. Adans, fam. 2. p. 158.-Chomelia, Lin. gen. ed. 1737. no. 167. but not of Jacq.-Rondelètia species, Lin. spec.- Webèra, Schreb. gen. 1791. no. 1733 . Willd. spec. 1. p. 1224. exclusive of the characters and species no. 3. Gærtn. fil. carp. 3. p. 7l. t. 102. Roxb. f. ind. 2. p. 533. but not of Hedw. (1782.)-Cánthium species, Pers.-Stylocorỳna species, Rich.
XlV. Pouchetia. XLVI. Cupia.

Cánthium, sect. Cùpia, Rœm. et Schuites, syst. 4. p. 306.Zamària, Rafiı. ann. gen. sc. phys. 6. p. 85.?

Lin. syst. Pentándria, Monogýnia. Calyx with a turbinate tube, and a 5-parted limb; lobes erect, acute, permanent. Corolla funnel shaped, with a terete tube, which is longer than the calyx, a gradually widened throat, and a 5 -parted limb; segments ovate-oblong, recurved. Filaments very short. Anthers oblong, dehiscing at the side in the upper part of the cells. Style clavate, 10-angled or 2-lobed. Berry globose, crowned by the calyx, 2-celled. Placentas spongy, central. Secds wrinkled at the hylum. Albumen cheesy. Embryo centripetal.-Asiatic glabrous shrubs. Leaves oblong-lanceolate. Stipulas intrafoliaceous, broad, ending each in a short acumen. Corymbs or panicles trichotomous, terminal, axillary, or opposite the leaves. Flowers white, fragrant.

\section{\$1. Stigma undivided.}

1 C. corrubòsa (D. C. prod. 4. p. 394.) shrubby ; leaves lanceolate-oblong, with revolute margins, shining; corymbs terminal; inbes of calyx 5 , about equal in length to the tube of the corolla; mature capsule 4-seeded. h. S. Native of the coast of Coromandel, frequent; Malabar; Pulo Penang, on hills; Ceylon, China, sc. Cùpi, Rheed. mal. 2. p. 37. t. 23. Rondelètia Asiática, Iin. spec. 244. Webèra corymbòsa, Willd. spec. 1. p. 1224. Ker. bot. reg. t. 126 . Cáuthium corymbòsum, Pers. ench. 1. p. 200. Roxb. H. ind. 2. p. 533. Stylocorỳna Webèra, A. Rich. mem, soc. hist. nat. par. 5. p. 248. Leaves 6-7 inches long and $2 \frac{1}{2}$ broad: having hairy glands in the axils of the large veins. Corymbs terminal. Flowers small, very numerons, at first white, but finally yellowish, faintly fragrant. Berry size of a large pea, black when ripe. Seeds $4 \cdot 8$ in each cell. The extremities of the young sloots are often found covered with a white resinous matter, like that on the germs of most species of Gardinia.

Corymbose-flowered Cipua. Clt. 1759. Slır. 5 to $6 \mathrm{ft}$.

2 C. Macropiry'Lla (1. C. prod. 4. p. 394.) leaves broadlanceolate, acuminated : panicle terminal, villons; tube of corolla long, slender, villous; herries 5-12-seeded. h. S. Native of the Prince of Wales Island. Webèra macrophýlla, Wall. in Roxb. fl. ind. 2. p. 534. Young sloots villous. Leaves 6-8 inches long, and from 4-5 broad. Panicle large. Flowers large, white. Anthers as long as the segments of the corolla.

Long-leaved Cupia. Shrub.

3 C. densiflo'ra (D. C. prod. 1. c.) sub-arborescent; leaves oblong-lanceolate, acute at the base; panicle rounded, lateral, almost sessile, occupying the place of a leaf or branch, trichotomous, dense-flowered; throat of corolla bearded; ovarium many-seeded. h.S. Native of Pulo-Penang, on bills. Webèra densiflòra, Wall. in Roxb. fl. ind. 2. p. 636 . Leaves coraceous, acuminated, shining above, 5-6 inches long. Flowers numerous, by threes, white. Bracteas lanceolate, ciliated. Anthers very long.

Dense-flonered Cupia. Shrub large.

4. C. Molzíssima (Hook. et Arn. in Beech. bot. p. 192.) Jeaves lanceolate, clothed with soft dense hairs on botl surfaces; lobes of calyx short, very blunt; fruit pubescent, many-seeded. $h$. G. Native of China. The hairs, which clothe every part of the plant are of a rusty colour. Stigma unknown.

I'ery-soft Cupia. Shrub.

5 C. oppositifo'lia (D. C. l. c.) shrubby ; leaves lanceolateoblong, firm, and glossy; panicles opposite the leaves, composed of a few stiff, jointed, sub-recurved spikes; corolla with a short tube and a woolly throat; stigma clavate. $h . S . \mathrm{Na}$ tive of Chittagong. Webèra oppositif òlia, Roxb. A. ind. 2. p. 535. Flowers white.

Opposite-leaved Cupia. Slirub. 
6 C. odora'ta (D. C. I. c.) shrubby; leaves lanceolate, acuminated, polished; corymbs terminal, and are as well as the bracteas villous; calyx 5 -toothed: teeth one half shorter than the tube of the corolla; cells of berries $3-4$-seeded. h.S. Native of Sillset, where it is called Palugrooja. Webèra odoràta, Roxb. A. ind. 2. p. 535. Leaves 4-6 inches long and I-2 broad. Stipulas triangular. Flowers numerous, middle-sized, white,very fragrant. Anthers about as long as the segments of the corolla.

Sweet-scented-flowered Cupia. Shrub large.

\section{\$ 2. Stigma 2-lobed.}

7 C. AURicula'ta (D. C. I. c.) arborescent, smootl?; leaves ovate-oblong, emarginate, and unequally 2 -lobed at the base, acuminated, almost sessile, the axils of the veins glandular beneath; panicles terminal and lateral, brachiate, on flattened peduncles; throat of corolla swelled, elevated, and bearled; ovarium many-seeded. $々$. S. Native of Pulo-Penang. Webèra auriculàta, Wall. in Roxb. fl. inct. 2. j. 537. Leaves contracted towards the cordate base, 7 inches long. Flowers white, fragrant.

Auricled-leaved Cupia. Shrub large.

S C. TRUNCA'ta (D. C. l. c.) shrub twining; leaves ovate, acute; panicles terminal, on flattened peduncles : corolla with a naked throat; ovarium 4-ovulate. h. $\cap$. S. Native of Pulo-Penang, on hills. Webèra truncàta, Wall. in Roxb. fl. ind. 2. p. 538. Leaves 3-4 inches long, acute at the base, dark and shining above, coriaceous. Bracteas lanceolate, deciduous. Flowers white, fragrant, on short pedicels by threes, or in fascicles. Anthers very long.

Truncate Cupia. Shrub tw.

9 C. sca'NDENs (D. C. l. c.) shrubby, scandent, glossy ; leaves oblong, acuminated; cymes axillary; stigma of $\underset{\sim}{\sim}$ oval plates. $r_{2}$. S. Native of Silhet, where it is called Gujer-lcota by the natives. Webèra scándens, Roxb. fl. ind. 2. p. 534. Leaves 6 inches long and 2-3 inches broad. Divisions of cymes generally biternate. Flowers large, funnel-shaped, fragrant when they first open, white, but like Gardènias become yellow by the second day. Anthers linear, sessile.

Climbing Cupia. Shrub cl.

\section{+ Species not sufficiently known.}

10 C. cYmo'sA (D.C. I. c.) arborescent ; brauches pubescent ; leaves ovate, acute, shining; cymes axillary, pedunculate, manyflowered; stigma capitate, 2 -lobed. $h_{c}$. S. Native of the East Indies. Webèra cymòsa, Willd. spec. 1. p. 1224. Rondelètia cymòsa, Poir. dict. 6. p. 256. Cánthium cymòsum, Pers. ench. 1. p. 200. Flowers white, fragrant. Berries about the size of jumiper berries, but their internal structure has not been noticed.

Cymose-flowered Cupia. Clt. 1811. Tree.

II C. Thyrsoidea (D. C. l. c.) branches woody, clothed with brown pubescence; leaves oblong-ovate, acuminated at both ends; thyrse dense, terminal; corolla glabrous outside and pilose inside; stigma bifid. h. S. Native of the East Indies. Webèra thyrsoidea, Roth. nov. spec. p. 149. Cánthium thyrsoídeum, Rom. et Schultes, syst. 6. p. 207. Flowers white. Fruit unknown.

Thyrse-flowered Cupia. Slrub.

Cult. For culture and propagation see Rondelètia, p. 5 I7. All the species are very elegant when in blossom, and the flowers are very fragrant.

XLVII. TARE'NNA (Tarenna is the Ceylonese name of the shrub). Gartn. fruct. 1. p. 139. t. 28. f. 3. D.C. prod. 4. p. 395 .
Lin. syst. Pentándria, Monogýnia. Calyx with a globose tube, and a 5 -parted limb; lobes linear-oblong, reflexed, permanent. Corolla, stamens, and stigma unknown. Berry globose, with 8 stripes, crowned by the limb of the calyx, 2-celled; pulp thin. Placentas central, sjongy. Seeds 4-6 in each cell, horizontal, semi-lunate, cuneated, compressed, wrinkled. $\Lambda \mathrm{lbu}$ men Aeshy. Embryo dorsal, with the radicle directed to the periphery, and foliaceous cotyledons. This genus appears to be allied to Cùpia, but the flowers and all other particulars besides those mentioned are unknown.

1 T. ZEYLÁnica (Gærtn. l. c.). দ..S. Native of Ceylon. Ceylon Tarenna. Tree or shrub.

Cult. For culture and propagation, see Rondeletia, p. 517.

XLVIII. PETE'SIA (the author does not give the derivation of the name). P. Browne, jam. p. 144. Jacq, amer. p. 18. ? Swartz, fl. ind. occ. 3. p. 194.5.? Bart]. in lierb. Hænke, mss. but not of Gartn. D. C. prod. 4. p. 395.-Petèsia species, Juss.

Lis. syst. Tetra-Pentándria, Monogýnia. Calyx with a roundisl tube, and a short, 4-5-toothed limb. Corolla funnelshaped, with an equal 4-5-cleft limb. Stamens 4-5, within the tube. Berry almost globose, naked at the apex, 2-celled, many-seeded. Seeds numerous, rather angular, crustaccous.Trees and shrubs. Leaves opposite, or 3 in a whorl, on short petioles, often coriaceous. Stipulas intrapetiolar, undivided, solitary, on both sides. Peduncles axillary, shorter than the leaves, bearing each a few-flowered corymb or cyme; rarely terminal, except in the more doubtful species.-Petèsia of Grertn. is Eumàchia, D. C. a genus among the tribe Coffeàcere. The character given by $\mathbf{P}$. Browne agrees with this genus, but the species given are probahly true species of Rondelctia. $\mathrm{Pe}_{e}$ tésia of Jacq. and Swartz is very doubtful, and will probably constitute a new genus, according to Bartling.

\section{* Floners axillary.}

1 P. GRA'NDIs (Bartl. in lierb. Hanke, ex D. C. prod. 4. p. 395.) leaves opposite, rbomboid-ovate, acuminated at both ends, villous on both surfaces while young, but in the adult state they are beset with a little scattered down above, and rather villous on the nerve and veins beneath, reticulated and radiately striated between the veins; corymbs few-flowered. $々$. S. Native of Mexico. Limb of calyx 5 -cleft, deciduous. Seeds scrobiculate. Greal Petesia. Tree.

2 P. xítida (Bartl. in herb. Hænke, ex D. C. 1. c.) leaves opposite, oblong, attenuated at both ends, glabrous, reticulately veined beneath, and radiately striated between the veins; peduncles axillary, 3-5-flowered, but only bearing one fruit each. h.S. Native of the Philippine Islands and Mariane Island. Calyx sinuately 4-toothed. Corolla tomentose, small. Berry globose, hardly the size of a pea. Seed sub-cylindrical. The leaves are striated, almost like those of the first species.

Shining-leaved Petesia. Tree.

3 P. Terxifòlia (Bartl. in herb. Hanke, ex D. C. 1. c.) leaves 3 in a whorl, obovate-oblong and oblong, acute at both ends; peduncles axillary, bifid, 5-7-flowered, but bearing only 1 fruit each. . S. Native of the Island of Luzon.

Thre-leaved Petesia. Tree.

4 P. carno'sa (Hook et Arn. in Beech, voy. pt. bot. p. 64.) leaves opposite, oblong-obovate, obtuse, attenuated at the base, glabrous, fleshy; peduncles axillary, 1 -flowered. ?. S. Native of the Society Islands. Corolla funnel-slaped, 4-lobed: having the anthers sessile in the throat. It differs from most Rubiaceous plants in the fleshy leaves.

Flcshy-leaved Petesia. Tree or shrub. 3 T 2 


\section{* Floners terminal.}

5 P.? Hi'spida (Bartl. in herb. Hænke. ex D. C. l. c.) leaves opposite, membranous, obovate-oblong, acuminated at both ends, having the middle ncrve on both surfaces, and the veins beneath hispid from bristles; corymbs terminal, short. $\eta$. S. Native of the island of Luzon.

Hispid-leaved Petesia. Tree or shrub.

6 P.? tonentòsa (Jacq. amer. p. 18.) leaves oblong, attenuated at both ends, very soft on both surfaces from hardly conspicuous tomentum; corymbs lateral and terminal. $\zeta$. S. Native of New Spain, in woods about Cartlagena. Flowers tetramerous. Fruit unknown. Perhaps a species of Rondelètia.

Tomrntose Petesia. Tree.

7 P.? spica'ta (Swartz. fl. ind. occ. 3. p. 1945.) leaves elliptic, attenuated, glabrous, pubescent on the nerves beneath; petioles hairy; racemes terminal, spicate. $\hbar_{\imath} . S$. Native of the south of Jamaica, among bushes. Flowers small, white, 4-parted. Berry crowned by the very minute calyx.

Spicale-flowered Petesia. Shrub 5 to 6 feet.

8 P.? simplicíssima (Lour. coch. p. 77.) stem herbaceous, quite simple, tetragonal; leaves lanceolate-linear, glabrous; racemes erect, almost terminal; calyx 5 -toothed. 4 . G. Native of Cochinchina. 'The fruit is said to be baccate, 2-celled, and many seeded. Flowers white.

Quite-simp! $\boldsymbol{e}$-stemmed Petesia. Pl. 1 foot.

9 P.? TERMina'lis (Hook, et Am. in Beech. voy. pt. bot. p. S5.) leaves oblong, obtuse at the base, acutish at the apex, membranous, glabrous; panicles terminal, racemose, one-half shorter than the leaves; cololla salver-shaped, having the lobes shorter than the tube. $\zeta$.S. Native of the Sandwich Islands. Stem dichotomously branched. Leaves 4 inches long, and 1 and $1 \frac{1}{2}$ inch broad. Corolla funnel-shaped, 4-lobed, inclosing the anthers. Much the habit of Stylocoryna racemòsa, Cav.

Terminal-flowered Petesia. Tree or shrub.

10 P.? conia'ceA (Hook. et Arn. in Beech. voy. pt. bot. p. 85.) leaves oblong, acute at the base, and obtuse at the apex, coriaceous, glabrous; corymbs terminal, dense, few-flowered, much shorter than the leaves. $h_{c} . S$. Native of the Sandwich Islainds.

Coriaceous-leaved Petesia. Tree or shrub.

Cult. For culture and propagation see Rondclètia, p. 517.

XLIX. COCCOCY'PSELUM (from koknoc, koktos, a berry, and $\kappa v \psi \varepsilon \lambda \eta$, liypsele, a vase; in allusion to the form of the fruit). Swartz, fl. ind occid. 1. p. 245. H. B. et Kunth, nov. gen. amer. 3. p. 403. Chan. et Schlecht. in Linnæa. 4. p. 138. D. C. prod. 4. p. 396, Coccocýpsilum and Sicèlium, P. Browne, jam. 144.-Coccocýpsilum and Tontànea, Juss. mem. mus. G. p. 394.-Coccocýpselum and Bellárdia, Schreb. gen. no. 1721. and 1723.-Condália, Ruiz et Pav. fl. per. prod. p. 11. t. 2. but not of Cav.

Jin. syst. Tetrándria, Monogýnia. Calyx with an ovate tube, and a 4-parted permanent limb (f. 94. $a$.); lobes narrow. Corolla funnel-shaped (f. 94. b.), with a 4-parted limb (f. 94. b.), and a glabrous throat. Stamens 4 , inserted in the tube of the corolla, inclosed (f. 94. b.); anthers oblong-heart-shaped. Stigma bifid. Bcrry ovate, crowned (f. 94. d. e.), 2-celled (f. 9 H. c.) ; cells many-sceded. Seerls lenticularly angular, wingless.-Creeping herbs. Leaves opposite, on short petioles. Stipulas subulate, solitary on both sides. Peduncles axillary, solitary, and in the alternate axils, bearing each a few-flowered head, surrounded by a sliort involucrum. Corollas and berries blue or purple.
1 C. RE'PENS (Swartz, fl. ind. occ. 1. p. 24.5.) plant prostrate, creeping ; leaves ovate, pubescent on both surfaces; peduncles very short while bearing the flowers, but afterwards becoming more elongated; heads few-flowered ; bracteas subulate. $\odot$. S. Native of Jamaica and St. Domingo, in temperate parts on the mountains. Browne, jam. 14. t. 6. f. 2. C. herbaceum, Lam. dict. 2. p. 56. ill. t. 64. Flowers almost sessile, collected in the axils of the leaves, blue. Fruit seated on peduncles, 4-5 lines long, blue, inflated. (f. 94.)

Creeping Coccocypselum. Fl. May. Clt. 1793. Pl. cr.

2 C. unbelca'tum (Poir. suppl. 2. p. 307.) leaves ovate, acute, shining, pubescent ; pedumcles one-half shorter than the leaves; bracteas of the heads of flowers subulatc.-Native of Peru, at Pillao, Cuchero, and Chinchao, in woods. Condàlia rèpens, Ruiz et $\mathrm{Pav}$. fl. per. 1. p. 54. t. 84 . f. a. C. Condàlia, Pers. ench. 1. p. 132. Cham. et Schlecht. in Linnæa, vol. 4. p. 139. C. capitàtum, Willd. herb. There are glabrous and downy varieties of this plant. Corolla purplish. Berries blue.

Umbellate-flowered Coccocypselum. Pl. creeping.

3 C. ova'tum (Clam. et Schlecht. in Limnæa, 4. p. 141.) plant ascending, rooting at the base ; leaves ovate, very blunt at the base, and acute at the apex, heset with minute adpressed down; peduncles alternate, shorter than the leaves, clothed with strigose hairs; heads 8-10-flowered. 24. S. Native of Brazil. Allied to $C$. umbellàtum and $C$. lanccolatum.

Ovate-leaved Coccocypselum. Pl. cr.

4 C. lanceola'tum (Pers. ench. 1. p. 132.) plant densely clothed with down; leaves lanceolate, acute; heads many flowered, pedunculate; bracteas lanceolate; berries ovate-oblong. 2. S. Native of Peru, in shady groves at Cuchero and Chinchao, ex Ruiz ct Par.; and on the mountains about the Orinoco, ex Hæenke; and at Caraccas, ex Vargas. Condàlia lanceolàta, Ruiz et Pav. A. per. 1.p. 54. Corolla of a pale violaceous colour. Berries blue.

Lanceolatc-leaved Coccocypselum. Pl. cr.

5 C. Hrisc'tum (Bartl. in herb. Hanke, ex D. C. prod. 4. p. 396.) plant ascending, very hairy in every part; leaves broadovate, acute; heads axillary when in flower, almost sessile; peduncles a little elongated when in fruit, and recurved. 4.S. Native country unknown.

Hairy Coccoctpsclum. Pl. ascending.

6 C. CANE'scens (Willd. herb. ex Cham. et Schlecht. in Linnæa. 4. p. 139.) plant prostrate, creeping; leaves ovate, clothed with silky yellow down on both surfaces; heads axillary, and almost terminal, on long pe:Iuncles; bracteas of heads 5-6, oblong, acute. 24 .? S. Native of South America, in temperate shady places, near Buenavista, Caraccas, Popayan, and of tropical and extratropical Brazil. C. rèpens, H. B. et Kunth, nov. gen. amer. 3. p. 405. exclusive of the synonymes. Schwenkféldia áspera, Spreng. neu. entd. 1. p. 2so. but not of Willd. Bellárdia móllis, Willd. herb. ex Cham. et Schlecht. in Linnæa. vol. 4. Corolla bluish or red. Berries blue.

Canescent Coccocypselum. Pl. cr.

7 C. Au'revm (Cham. et Schlecht. in Linnæa. 4. p. 139.) leaves oblong, acute, with parallel veins, clothed with golden silky down; heads axillary, sessile, few-flowered; bracteas 4-j, narrow, acute. $4 . \mathrm{S}$. Native of tropical Brazil. Schwenkféldia aúrea, Spreng. neu. entd. 1. p. 280. syst. 1. p. $76 t$. 
Allied to $C$. canéscens, but differs in the above characters, and in the flowers being larger and slenderer, and less hairy; and in the lobes being more acute and longer.

Golden Coccocypsclum. P1. cr.

8 C. numularifònum (Cham. et Schlecht, in Linnæa. 4. p. 397.) plant very hairy, prostrate, crecping ; leaves ovate-roundish, very blunt at the base, obtuse at the apex, and somewliat mucronulate; heads on short peduncles; bracteas linear. $4 . \mathrm{S}$. Native of equinoxial Brazil. Corolla violaceous, beset with spreading pili at the tops of the lobes. Allied to C. campanuliftorum and $C$. cordifölium.

Moncy-nort-leaced Coccocypselum. Pl. cr.

9 C. condifòlium (Nees et Mart. in nov, act. bonn. 12. p. 14.) plant creeping; leaves cordate, obtuse, hairy; peduncles at length equal in length to the petioles; heads of flowers almost globose; calyxes and petioles very villous. 4. S. Native of Brazil, on the road to Felisbert and of St. Catharine. Corolla white, pubescent. Berries globosc, blue. Habit of Gcóphila.

IIcart-leated Coccocypselum. Pl. cr.

10 C. ? ERythroce'PHalum (Cham. et Schlecht. in Linnæa. 4. p. 144.) branches or stems simple, hairy; leaves ovate, acute, obtuse at the base, hairy on both surfaces, often purplish beneath ; heads on short peduncles, beset with purplish hairs. \%. S. Native of equinoxial Brazil. Flowers and fruit unknown.

lied-hcaded Coccocypselum. Pl. cr.?

11 C. Peduncula're (Cham, et Schlecht. in Linnaa. 4. p. 142.) plant ascending, clothed with adpressed strigose hairs; leaves lanceolate-oblong, with revolute edges ; peduncles alternate, longer than the leaves, usually reflexed after flowering; heads 10-12-flowered. 4.S. Native of equinoxial Brazil.

Peduncular Coceocypsehum. Pl. cr.

12 C. Tonta'ne (H. B. et Kunth, nov, gen. amer. \&. p. 406.) leaves ovate, acutish, clothed with hairy down on both surfaces; heads axillary, pedunculate, 3-5-flowered; bracteas subulate; anthers a little exserted. 24. S. Native of Cayenne, Guiana, Caraccas, Popayan, and of Jamaica, if C. Sicèlitum, P. Browne, jam. 144. be the same. Tontanea Guianénsis, Aubl. guian, 1. p. 108. t. 408. Tontànea rèpens, Pers. Bellárdia rèpens. Willd. sjec. 1. p. 626 . Bellârclia T'ontànea, Rœm. et Schultes, syst. 3. p. 205. Corolla either white or blue, ex Aubl. Berries blue. Tontance is the Guiana name of the plant.

Tontanca Coccocypselum. Pl. cr.

13 C. Glíbun (Bartl. in herb. Hanke, ex D. C. prod. 4. p. 397.) plant creeping, quite glabrous; leaves ovate, subcordate, acutish; heads few-flowered, axillary, when bearing the fruit on longer peduncles, which are deflexed. 24. S. Native of Panama. Very nearly allied to $C$. Tontìnea, and probably only a glabrous variety of that species, but the flowers are unknown.

Glabrous Coccocypselum. Pl. cr.

14. C. cinis'tum (Cham. et Schlecht. in Linnæa. 6. p. 414.) leaves roundish-ovate, ciliated, as well as the petioles, having the nerves furnished with long hairs on the upper surface; heads of flowers equal to about half the length of the leaves. h. S. Native of Mexico, between Huilamalco and Cuapa. Very like $C$. umbellàta. Leaves an inch and a lialf long and 14 lines broad.

Ciliated Coccocypselum. Pl. creeping.

+ The generic character of the two folloning species is doubtful, and according to Kunth, syn. should probably be excluded from the present genus.-Ercct suffruticosc glabrous plan!s.

15 C. овоva'tum (Pers. ench. 1. p. 132.) stcm erect, suffruticose; leaves obovate, acuminated ; peduncles axillary, aggregate, unequal, racemose. $h_{2}$. S. Native of l'eru, at Chinchao, on mountains. Condàlia obovàta, Ruiz et Pav, fl, per. 1. p. 54 . Corolla greenish white. Berries purple.
Obocatc-leaved Coccocypselum. Shrub 3 feet.

16 C. se'sstLe (Pers. 1. c.) stem erect, suflituticose; leaves oblong, acute; flowers sessile, crowded, axillary. h.S. Native of Pert, on the mountains about Chinchao. Conclàlia séssilis, Ruiz et Pav. A. per. 1. p. 54. Corolla purplish. Berries ovate, purplish.

Sessilc-flowered Coccocypselum. Shrub 2 to 8 feet.

Cult. A mixture of peat and sand is the best soil for the species; and they will be easily increased by separating the creeping stems from the main plant.

L. FERNELIA (named after J. Fernel, M. D. pliysician to Henry II. of France; he died in 1558). Comm. in Itlss. gen. p. 196. mem. mus, 6. p. 393. Lam. ill. t. 67. f. 1. Gærtn, fil, carp. 3. 1. 61. . Rich. mem. soc. hist. nat. par. 5. p. 275 . D, C. prod. 4. p. 398.-Coccocýpsilum species, Willd. and Spreng.

Lis. syst. Tetrándria, Monogýnia. Calyx with an obovate tube, and a 4-cleft limb; lobes subulate at the apex. Corolla small, with a short tube, and a 4-lobed spreading limb. Stamens 4 , inserted in the tube of the corolla, inclosed, or a little exserted. Stigma bifid. Berry crowned by the limb of the calyx, 2-celled, having the dissepiment incomplete and semilunar, and elliptic. Seeds numerous, somewhat compressed. Albumen cartilaginous. Embryo almost dorsal, with a centripetal radicle, and flat roundish cotyledons. - Small glabrous branched trees, having much the habit of box. Leaves obovate, stiffish. Stipulas short, acute, solitary on each side. Pedicels axillary, very short, bracteolate, 1 -flowered.

1 F. Buxifòlia (Lam, ill. no. 1478. but not of Gartn.) lobes of corolla obtuse ; berry obovate, crowned by the subulate lobes of the calyx. দ. S. Native of the Mauritius, where it is called bois de buis. F. obovàta, Gartn. fil. carp. 3. p. 62. t. 191. but not of Lam. Coccocýpselum buxifòliun, Spreng. syst. 1. p. 416. Leaves 5-6 lines long, and 3-4 broad.

Box-lcaved Fernelia. Clt. 1816. Shrub.

2 F. oвova'ta (Lam. ill. t. 67. f. l.) lobes of corolla acuminated; berries nearly globose, crowned by the lobes of the calyx, which are bluntish and velvety inside. $\eta_{c}$. S. Native of the Mauritius, where it is called bois Malabare and bois de rondc. F. buxifòlia, Gartn. fil. carp. 3. p. 63. t. 197. f. 6. Coccocýpsilum uniflòrum, Willd. snec. 1. p. 618 . Sieb. fl. maur. exsic. 2. no. 100. Leaves 8-10 lines long, and 6i-7 broad.

Oborate-leaved Fernelia. Clt. I816. Shrub.

3 F. peduncula'ta (Gærtn. fil. carp. 3. p. 191. f. 3.) lobes of corolla unknown; berry ohovate, tapering a long way into the stipe at the base, crowned by the lobes of the calyx, which are bluntish. 々. S. Native of the Mauritius. Shrub and flowers unknown.

Pedunculatc-fruited Fernelia. Shrub.

Cult. For culture and propagation, see Rondelètia, p. 517.

LI. PETU'NGA (Peetunga is the name of $P$. Roxbúrghii in the Bengalee language). D. C. prod. 4. p. 398.-Rándia species, Roxb.-Higginsia, Blum. bijdr. p. 988. but not of Pers.

LıN. syst. Tetrándria, Monogýnia. Calyx with an ovate tube, and a permanent 4 -toothed limb. Corolla funnel-shaped, with a short obconical tube, a 4 -parted limb, and a very villows throat. Stamens 4; anthers a little exserted. Style filiform, villous : stigma bidentate, a little exserted. Berry globose, de. pressed and umbilicate at the apex, 2-celled. Seets $2-4$ in each cell, fixed to the upper part of the dissepiment, ex Roxb. scale-formed, and imbricated downwards, ex Blum. Albumen cartilaginous. Embryo iuverted, with linear cotyledons.-Unarmed erect glabrous shrubs, with decussate horizontal branclies. Leaves opposite, oblong, attenuated at loth ends. Stipulas long-acuminated, deciduous. Spikes axillary, solitary or twin, 
simple, many flowered, 3 times shorter than the leaves. Bracteas short, 1-flowered. Flowers disposed in 2 or 4 rows, sessile along the rachis of the spike, small, greenish white. This genus differs from Rándia in the flowers being tetramerous, and very mucb bearded in the throat, and in the spicate inflorescence and whole habit; and from Higginsia in the throat of the corolla being bearded, in the genitals being a little exserted, and in the globose depressed fruit, \&c.

1 P. Roxbu'rgur (D. C. prod. 4. p. 399.) leaves elliptic-oblong, glabrous, acuminated at both ends; spikes axillary; bracteas and calyxes glabrous. $h . S$. Native of the East Indies, about Luksmeeapoora, where it is called Peetung $a$ by the natives. Rándia raccmòsa, Roxb. f. ind. 2. p. 144. Branches almost horizontal. Leaves drooping, 3-4 inches long, and about 1 broad. Stipulas large, caducous. Spikes about one-half or onethird shorter than the leaves. Flowers small, pale, greenish white. Berries round, smooth, shining, straw coloured, size of a pea.

Roxburgh's Petunga. Clt. 1820. Shrub 3 to 4 feet.

z P. Longrfòlia (D. C. l. c.) leaves elliptic-ohlong, acuminated at both ends; branches terete; bracteas and calyxes downy. 々. S. Native of Java. Higgínsia longifòlia, Blum. bijdr. p. 988. Leaves 6.7 inches long, and 2 broad. Spikes about 2 inches long. Flowers small, greenish white.

Lonm-leaced Petunga. Shrub 8 to 4 feet.

3 P. microcárpa (D. C. l. c.) leaves oblong-lanceolate, acuminated, finely veined; spikes short, quadrifariously imbricated; tube of corolla very short. $h$. S. Native of Java, where it is called $K i-A$ piet by the natives. Higginsia microcárpa, Blum. bijdr. p. 988 . Leaves 3 incles long, and 9 lines broad. Spikes 5-6 lines long. Flowers small, greenish white.

Small-fruited Petunga. Shruh 3 to 4 fect.

4 P. glomerula'ta (D. C. prod. 4. p. 399.) leaves oblonglanceolate, veiny; spikes densely glomerulated. h. S. Native of Java, on mount Salak, and in woods on the island of NusaKambanga.

Glomerulated-spiked Petuna. Shrub.

Cult. For culture and propagation see Catesba'a, p. 511 .

LII. HJGGI'NSIA (named after General O-Higgins, sometime Governor of Chili). Pers. ench. 1. p. 133. D. C. prod. 4. p. 399.-O-Higgínsia, Ruiz et Pav. f. per. 1. p. 55. Rœm. et Schultes, syst. 3. p. 10. (exclusive of all the species with 4celled fruit). Evósmia species, Spreng.-Nacíbea species, Juss.

Lin. syst. Tetrándria, Monogýmia. Calyx with a short obovate tube, and a permanent limb, which is 4-tootbed to the base. Corolla funnel-shaped, and somewhat campanulate, with a short tube, a 4-parted spreading limb, and a naked throat. Stamens inserted into the middle of the tube; filaments short; anthers ovate, inclosed. Stignas 2, exserted. Berry oblong, somewhat tetragonal, bisuleate, 2-celled, erowned by the calyx. Placentas adnate to the dissepiment. Sceds many in each cell, small, wingless.-Shrubs about 3 or 4 feet bigh, with bluntly tetragonal branches. Leaves opposite or in whorles, obovate or oblong, acute. Stipulas solitary on both sides, small, acute, deciduous. Peduncles axillary, racemose, bearing short unilateral pedicels. Corollas reddish.

1 H. verticilla'ta (Pers. ench. 1. p. 133.) leaves 3 in a whorl, lanceolate, downy beneath; peluneles solitary, dependent, bearing about 4 flowers. h. S. Native of Peru, at Muna, where it is called Carpales. O.Higgínsia verticillàta, Ruiz et Pav. fl. per. 1. p. 55. t. 85. f. a. Erósmia verticillàta, Spreng. Corolla scarlet. Berries purplish wlite.

Whorled-leaved Higginsia. Shmb 3 to 4 feet.

2 H. Angustifòlı (Bartl. in lierb. Hænke, ex D. C. prod. 4. p. 399.) leaves opposite, narrow-oblong-lanceolate, glabrous, tapering much at both ends; fruit axillary, usually twin, oblong, opposite, on short pedicels. $h_{\text {. S }}$. Native of Peru, on mountains about tbe Guanocco. Flowers red.

Narron-leaved Higginsia. Shrub 3 to 4 feet.

3 H. Latrfolia (Bartl. in herb. Hanke, ex D. C. prod. 4. p. 399.) leaves opposite, obovate, acuminated, attenuately cuneated at the base, glabrous, having the nerves and veins clothed with rusty tomentum beneath; flowers axillary, in fascicles, pedicellate, nutant. h. S. Native of Peru, on mountains about the Guanocco. Fruit membranous, somewhat tetragonal.

Broad-leaved Higrinsia. Shrub 3 to 4 feet.

4. H. овоva'ta (Pers. ench. 1. p. 133.) leaves opposite, obovate, short-acuminated, glabrous ; peduncles aggregate, unequal, spreading, many flowered. h. S. Native of Peru, in shady places at Muna. O-Higgínsia obovàta, Ruiz et Pav. fl. per. 1 . p. 56. r. 85. f. b. Evósmia obovàta, Spreng. Corolla flesh coloured. Berries purple.

Obovate-leaved Higginsia. Shrub 3 to 4 feet.

Cult. See Catesba'a, p. 511. for culture and propagation.

LIII. HOFFMA'NNIA (named by Swartz, in memory of Maurice Hoffimann, professor of botany at Altorff, autlior of Florilegium Altorfinum, 1660). Swartz, prod. p. 30. fl. ind. occ. 1. p. 241. t. 5. Schreb. gen. no. 1719 . Juss. mem. mus. 6. p. 383. but not of Loefl, nor Willd.

LıN. syst. Tetrándria, Monogýnia. Calyx with an oblong somewhat tetragonal tube, and a 4 -toothed limb: teeth erect, acute. Corolla salver-shaped, with a very short tube, and a 4-parted spreading limb; segments lanceolate. Anthers 4, ses. sile upon the tube, erectly connivent, linear, acute. Stigma obtuse, hardly emarginate. Capsule baccate, indehiscent, crowned by the calyx, 2-celled, slightly tetragonal. Placentas ovate, distinct in the cells of the fruit. Sceds numerous, minute, roundish.-A herb, which is suffruticose, and branched at the base, having the branches hairy. Leaves ovate, acuminate, rough from dots ahove, and hairy beneath. Stipulas very short, acute. Peduncles axillary, longer than the petioles, many flowered.

1 H. Pedunculatia (Swartz, l. c.) h. S. Native of the higher mountains of Jamaica, in rather humid shady places. $H$. Jamaicénsis, Spreng. syst. 1. p. 416. Corolla with a red tube, and the segments of the limb striped with blood-colour at the base, but they are yellow at the apes. Berries searlet.

Peduneulate Hoffmannia. Shrub 2 to 3 feet.

Cult. See Catesbce'a, p. 511 . for culture and propagation.

LIV. CATESBA'A (named by Gronovius after Mark Catesby, author of the natural history of Carolina). Gron. in Lin. gen. no. 130. Juss. gen. 199. mem. mus. 6. p. 393. Lam. ill. t. 67. Gærtn. fil. earp. 3. p. 67. t. 192. A. Rieb. mem. soc. hist. nat. Par. 5. p. 256. D. C. prod. 4. p. 400.

Lin. syst. Tetrándria, Monogýmia. Calyx with an obovate tube, and a 4-toothed or 4-parted limb. Corolla funnel-shaped, with a very long tube, gradually widening and dilated to the throat, and a 4 -parted limb. Stamens 4 ; filaments inserted at the base of the tube of the corolla; anthers linear, exserted. Stigma bidentate, from the lamellæ being combined. Berry globose or oblong, 2-celled, crowned by the limb of the calyx; having the dissepiment perforated according to Jussieu, but according to Gartner, it is entire. Placentas spongy, fixed to the upper part of the dissepiment on botb sides. Seeds numerous, scale-formed, inverted, imbricated downwards, collected in 2 bundles in each cell. Albumen fleshy. Embryo minute, inverted.-Glabrous shrubs, bearing supra-axillary simple spines. Leaves small, oval, usually in fascicles. Stipulas solitary on each side, deciduous. Pedicels axillary. Flowers whitish, elongated, 
bractless.- This genus comes very near to Seolosánthus, but differs in the cells of the fruit being many seeded.

\$1. Recurviflòra (from rccurvus, recurved, and flos, a flower ; in allusion to the flowers being pendulous from the pedicels being recurved). D. C. prod. 4. p. 400 . Pedicels 1-flomered, recured. Flowers pendulous. Corollas glabrous. Slamens exserted.

1 C. Latifòla (Lindl. bot. reg. 858.) leaves obovate, shining, convex, rather shorter than the spines; teeth of calyx subulate; tube of corolla very long, obconical at the apex. h.S. Native of the West Indies, particularly in Cuba near the Harannah. Corolla pale yellow, 4 inches long. Fruit ovate, crowned by the 4 subulate calycine teeth.

Broad-leaved Lily-thorn. Fl. June, July. Clt. 1823. Shrub 4 to 5 feet.

2 C. spinòs (Lin. spec. p. 159.) leaves ovate, acutish at both ends, rather longer than the spines; teeth of calyx short, acute; berry oval; tube of corolla very long, cylindrical, widening at the apex. h. S. Native of the Bahama Islands, but particularly of Providence, near Nasma. Lam. ill. 67. f. 1. Curt. bot. mag. t. 131. Tratt. tab. t. 259. C. longitlòra, Swartz, prod. p. 30.-Catesb. car. 2. t. 100. Corolla pale yellow, 3-6 inches long. Leaves like those of box, roundish, rising in fascicles. Berry about the size of a middling plum, yellowish, with rather tart pulp.

Spinose Lily-thorn. Fl. May, Sept. Clt. 1726. Shrub 10 to 14 feet.

3 C.? Vavassòril (Spreng, syst, 1. p. 416.) leaves ellipticoblong, obtuse, shining above, and are, as well as the spinescent branches, glabrous; pedicels 1 -flowered. $h_{\text {. }}$ S. Native of St. Domingo. Cinchòna spinòsa, Vavass. journ. phys. oct. 1790 . p. 243. t. 2. Iamb. cinch. p. 38. t. 13. C. elliptica, Spreng. in litt. The fruit is said to be capsular and dehiscent at the apex, and the seeds are said to be edged with a wing, but should this be the case it is certainly not a species of Catesbce'a.

Vavasseur's Lily-thorn. Shrub 4 to 6 feet.

\$2. Ercetiftorce (from ercctus, erect, and flos, a flower ; the flowers are erect, not drooping as in the first section). D. C. prod. 4. p. 401. Pedicels axillary, 1-flowered. Flowers erect, glabrous. Stamens incloscd.-Perhaps all are species of the genus Rándia.

4 C. Parviflòra (Swartz, prod. 30. fi. ind. occ. 1. p. 236.) leaves ovate, stiff, with revolute margins, mucronate, and are, as well as the brancbes, glabrous; teeth of calyx short, acute; flowers sessile among the leaves; tube of corolla short, tetragonal; berries roundish. $h$. S. Native of the north of Jamaica, among bushes by the sea side. Vahl, symb. 2. p. 31. eclog. 1. p. 12. t. 10. f. 1. but not of Lam. Gærtn. fil. carp. t. 192. f. 3. C. parviflòra, ex Jamaica, Spreng. syst. 1. p. 416. exclusive of the diagnosis and synonymes.-Sloan. hist. t. 207. f. 1. Corolla white, with a tetragonal tube, about 4 lines long.

Small-flowered Lily-thorn. Fl. June, July. Clt. 1810. Shrub 4 to 5 feet.

5 C. campanula'ta (La Sagra, in litt. ex D. C. prod. 4. p. 401.) leaves ovate-roundish, coriaceous, and are, as well as the branchlets, quite glabrous; spines opposite, longer than the leaves; flowers erect, short, sessile in the axils of the leaves. h.S. Native of Cuba, near the Havannah, where it was collected by Ramon de la Sagra. Perhaps sufficiently distinct from C. parvifiòra.

C'ampanulate-flowered Lily-thorn. Shrub 4 to 5 feet.

6 C. Parvifòlia (D. C. prod. 4. p. 401.) leaves ovate-roundish, mucronate, glabrous ; spines axillary, subulate, a little longer than the leaves; branchlets hairy; flowers short, usually twin, axillary, on very short pedicels. $\zeta$. S. Native of st. Domingo. Catesbie'a parviftòra var. Domingénsis, spreng. syst. 1. 1. 4.16. Gardènia parvifòlia, Dietr. suppl. gart. lex. 3. p. +1.1. ex Rem. et Sehultes, syst. 5. p. 247. Rándia parvifòlia, Lam. dict. 3. p. 25. (exclusive of the syn. of Sloane,) ill. t. 156. f. 2. but the flowers in the figure are drawn 5 -cleft. Spines opposite, straight, about 5 lines long. Leaves like those of box, in fascicles. Berries globose, almost sessile. Flowers white, changing to yellowish.

Small-lcaved Lily-thorn. Fl. July, Sept. Clt. 1818. Shrub 4 to 5 feet.

7 C. erécta (Moc. et Sesse, f. mex. icon. ined. ex D. C. prod. 4. p. 401.) leaves oval-oblong, acute; branchlets opposite, spreading, unarmed; flowers'almost termiual, nearly sessile, solitary, erect; tube of corolla very long. h. S. Native of Mexico. Flowers white, almost like those of C. spinòsa, but erect. Spines none in the figure given.

Ercel Lily-thorn. Slirub 4 to 5 feet.

Cull. All the species of Catcsbe'a are very ornamental while in bloom. They grow best in a mixture of light turfy loam and peat; and cuttings will root if planted in sand plunged in heat, with a bell-g'ass placed over them. The plants being apt to be infested with insects, they should be kept clean or they will not thrive.

\section{Tribe III.}

HEDYOTI'DEE (this tribe contains plants agreeing with the genus Hedyotis in particular characters). Cham. et Schlecht. in Linnæa. 4. p. 150. D. C. prod. 4. p. 401. Fruit capsular, 2-celled, dehiscing in the middle of the cells: or rather membranous and indehiscent; cells many seeded. Seeds not winged. Albumen fleshy.-Slurubs and herbs, with opposite leaves, and interpetiolar stipulas.

Subtribe I. Ronneletie'se (plants agreeing with the grenus Rondelètia in important cliaracters). D. C. prod. 4. p. 4.01. Stipulas twin on both sides, combined or distinct, neither sheathed nor ending in bristles.

LV. CONDAIIINA (in honour of - La Condamine, a famous astronomer, and traveller in South America, and who was the first who described and figured Cinchona lanceolala). D. C. prod. 4. p. 402.-Macrocnèmum, Ruiz et Pav. f. per. 2. p. 48. but not of Browne.-Macrocnèmum, sect. 2. Kunth, and A. Rich.

Lin. syst. Pentándria, Monogýnia. Calyx with a cup-shaped tube, and a 5 -crenated or 5 -toothed limb (f. 95 . a.), which at length becomes circumcised at the base, and falls off. Corolla funnel-shaped, with a somewhat curved tube (f. 95. b.), which is a little longer than the calyx, a dilated throat, and a 5 -parted limb (f. 95 . e.); the segments ovate, acute, spreading, and thickened at the apex (f. 95 . c.). Stamens 5, inserted above the middle of the corolline tube (f. 95. b.), or near its thoat ; filaments shorter than the corolla; anthers oblong-linear, bifid at the base, length of corolla. Stigma 2-lobed (f. 95. $f$.). Capsule turbinate (f. 95. g.), rather compressed, truncate, umbilicate, 2celled, dehiscing in the middle of the cells (f. $95 . k$.). Seeds small, numerous, cuneiform, not winged.-South American shrubs. Leaves large, opposite, on short petioles. Stipulas intrafoliaceous, bipartite, acuminated, adpressed, usually connate. Corymbs or racemes terminal, many flowered.-This genus differs from Macrocnemum in the form of the calyx, in the stamens being inserted above the middle of the corolline tube, not at its base, as in that genus, and in the seeds being wingless; and from Sickingia in the stigma being double, not simple, and in the seeds not being winged, \&c.

1 C. coRymbòsa (I). C. prod. 4. p. 402.) leaves ovate-oblong, 
acuminated, cordate at the base, sessile, plicate, coriaceous; corymbs large, brachiate, trichotomous; teeth of calyx broad, short, blunt. $\zeta$. S. Native of Peru, on hills towards Chinchao, Acomayo, Pillao, and Muna, \&c. ex Ruiz et Pav.; and on mountains about the Guanocco river, ex Hanke; as well as of New Granada about Mariquita, and Santa Anna, ex H. B. et Kunth. Macrocnèmum corymbòsum, Ruiz et Pav. fl. per. 2. p. 48. t. 189. H. B. et Kunth, nov. gen. amer. 3. p. 399 . Leaves a foot long. Calyx purplish, fleshy. Corolla

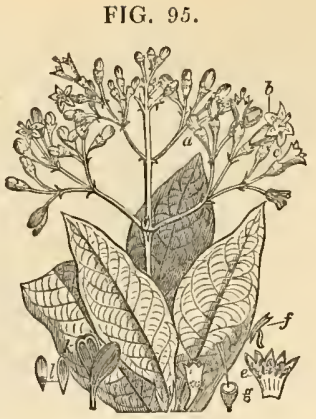
white inside and purplish on the outside, with a naked throat. Capsule at first purplish, but at lengt! almost black. Seeds yellow.

Corymbose-flowered Condaminea. Tree 40 to 50 feet.

2 C. tinctòria (D. C. prod. 4. p. 40\%.) leaves elliptic-oblong, acute, rounded at the base, petiolate, glabrous on both surfaces; corymbs sessile, tripartite; flowers crowded into heads; segments of corolla acute. h. S. Native of South America, at the Missions of the Orinoco, between Encaramada and Carichana. Nacrocnèmum tinctòrium, H. B. et Kunth, nov. gen. amer. 3. p. 399. Willd, rel. in Rœem. et Schultes, syst. 5. p. 6. Corolla white. Corymbs terminal.

Dyers' Condaminea. Fl. Sept. Oct. Clt. 1820. Tree 20 to 30 feet.

3 C. microcárpa (D. C. prod. 4. p. 402.) leaves oblong, bluntly acuminated, jubescent beneath; racemes terminal; flowers crowded, sessile; tecth of calyx minute. h.S. Native of Peru, in hot shady forests near Chinchao and Cuchero. Macrocnèmum microcárpum, Ruiz et Pav. fl. per. 2. p. 48. t. 188. f. a. Leaves shining above. Racemcs 8.9 inches long. Corolla white, with reflexed segments, 4 times longer than the calyx. Capsule small, turbinate. Seeds yellow.

Small-fruited Condaminea. Tree 25 feet.

4 C. venòsa (D. C. l. c.) leaves oval-oblong, acuminated, lined with numerous veins; the nerves and veins downy; stipulas connate, with the lobes acuminated; racemes terminal; Howers sessile; teeth of calyx minute. h. S. Native of Peru, in groves in hot places towards Acomayo and Pati. Macrocnèmum venòsum, Ruiz et Pav. fl. per. 2. p. 49. t. 190. f. b. Branches tetragonal. Leaves 9 inches long. Stipulas reddish. Racemes downy. Flowers small, white.

F ciny-leaved Condaminea. Slirub 10 feet.

5 C. GLABRA'TA (D. C. l. c.) leaves obovate, short-acuminated, attenuately cuneated at the base, quite glabrous, lined with the veins; stipulas 2-lobed, shorter than the petioles: lobes rounded; panicle terminal, glabrous ; flowers glomerate ; teeth of calyx minute. h.S. Native of Peru, on mountains about Huanocco. Macrocnèmum glabràtum, Bartl, in herb. Hornke. Very like C.venòsa, but differs in the smoothness and shape of the leaves.

Glabrous Condaminea. Shrub 10 feet?

Cult. See Catesba'a, p. 511. for culture and propagation.

LV1. ALSE'IS (from $a \lambda \sigma o s$, alsos, a grove; the tree grows in groves). Schott, in Spreng. syst. append. p. 40\%. D. C. prod. 4. p. 620 .

Lin. syst. Pcntándria, Monogýnia. Limb of calyx superior, 5-parted. Corolla cup-shaped, with a 5-parted limb, and a bearded throat. Stamens 5, almost distinct to the base of the corolla, exserted. Stigma parted. Ovarium 2-celled, many-
ovulate.-A middle-sized tree. Leaves oblong, acuminated, rather pilose on both surfaces. Spikes branched, terminal. Flowers small, cream-coloured.-This genus is allied to Macrocrèmum and Machaonia according to the author.

I A. Floribu'nda (Schott, l. c.) h. S. Native of Brazil, in groves.

Bundle-flonercd Alseis. Tree.

Cult. For culture and propagation see Rondelètia, p. 517.

LVII. MACROCNEMIUM (from $\mu$ aroos, makros, long, and

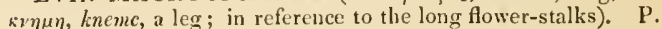
Browne, jam. p. 165. Lin. amœen. 5. p. 413 . Swartz, obs. p. 68. t. 3. f. 1. Juss. mem. mus. 6. p. 386. D. C. prod. 4. p. 402. - Macrocnèmım species of authors.

Lin. syst. Pentándria, Monogýnia. Calyx with a turbinate tube, and a small 5-toothed permanent limb. Corolla tubular, with a wide throat; the tube pentagonal before expansion: and the segments 5 , acute, and erectish. Stamens 5 , almost free from the corolla, but sometimes adnate to the base of the tube; filaments very hairy above the middle; anthers oblong, inclosed. Style length of the stamens; stigma obtuse, 2--lobed. Capsule 2-celled, 2-valved; valves dehiscing at the sides (ex Swartz). Seeds numerous, imbricated, acute.-Small glabrous trees. Leaves approximate, oblong, short-acuminated. Stipulas solitary on both sides. Peduncles terminal and subaxillary, solitary, trichotomously corymbose above. Flowers rather large, yellowish green.

1 M. JAMAICE'NSE (Lin. amœn. 5. p. 413.) arboreous; leaves oblong-oval, petiolate, polished; stipulas ovate-triangular, much shorter than the petioles; corymbs on long peduncles. $h . S$. Native of the south of Jamaica, in shady places on the banks of rivulets. Swartz, obs. p. 68. t. 3. f. 1. Lam. dict. 3. p. 670. ; and of Guadaloupe at a place called Grand Brandaube, where it was collected by l'Herminier. Brancles warted. Corollas rather large, of a yellowish green colour.

Jamaica Macrocnemum. Clt. 1806. Tree 12 to 14 feet.

+ Species not sufficiently knon'n, and do not probably belong to the prescnt genus.

2 M. ? stipula'ceum (Roxb. fl. ind. 2. p. 14.4.) leaves almost sessile, lanceolate, smooth; stipulas oval, very large; corymbs terminal, supradecompound. $h$. S. Native of the Molnccas. The mouth of the corolla is uncommonly woolly, almost liding the stamens.

Stipulaceous Macrocnemum. Tree.

3 M.? PARvirlòrum (Roxh. fi. ind. 2. p. 144.) slırubby ; leaves on short petioles, lanceolate, entire, smooth; stipulas annular, truncate; peduncles axillary, many-flowered; corolla acetabuliform. h. S. Native of the Moluccas.

Small-flowercd Macrocnemum. Shrub.

4 M.? tetrándum (A. Kich. mem. soc. hist. nat. Par. 5. p. 279.) Jeaves elliptic-lanceolate, acute at both ends, discoloured, tomentose beneath; flowers subracemose, terminal, small, tetramerous; calyx woolly; corolla short; stamens exserted; capsule dehiscing at the dissepiment. h.S. Native of Brazil.

Tetrandrous Macrocnemum. Shrub or tree.

5 M.? тubuzosum (A. Rich. l. c.) Jeaves broad-ovate, acuminated at the apex, dimidiate at the base, petiolate, downy; flowers subcymose, terminal; one of the teetl of the calyx is expanded into a large, broad, somewhat heart-shaped petiolate leaf; corolla with a long tube, and a 5 -lobed limb; stamens exserted; capsule dehiscing in the middle of the cells. $h . \mathrm{S}$. Native of Brazil. This is probably a species of Calycophýllum.

T'ubular-flowered Macrocnemum. Tree or slırub.

Cult. For culture and propagation see Catesbe'a, p. 511. 


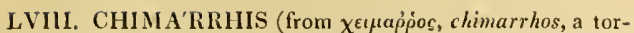
rent; the tree grows on the banks of torrents). Jacq. amer. p. 61. Juss. gen. p. 204. mem. mus. 6. p. 381.-Macrocnèmum species, A. Rich.

Lin. syst. Pentíndria, Monogy'nia. Calyx with an obovate or turbinate tube, and an almost obsolete entire limb. Corolla with a short tubc, and a 5-cleft spreading limb; segments hairy in the middle outside. Stamens 5 , inserted in the upper part of the corolline tube; filaments hairy at the base; anthers oval. Capsule obovate or turbinate, ligneous, coriaceous, crowned by the marginal limb of the calyx, 2-celled; cells dehiscing from the apex to the base, ex Jacquin, 1-seeded, ex A. Richard, manyseeded; valves semibificl. Seeds pendulous.-American glabrous trees. Leaves opposite, on short petioles. Stipulas ihterpetiolar, solitary on both sides. Corymbs or cymes terminal. Flowers white.-This genus is nearly allied to Machaònia.

1 C. cysòsa (Jacq. amer. p. 61.) leaves ovate, acuminated at both ends; branches of corymb alternate; capsules obovate, very short. $\zeta$. S. Native of Martinico, along the sides of mountain streams or torrents, where it is conmonly called bois de rivière, or river wood. Macrocnèmum longifölium, $\mathrm{A}$. Rich. mem. soc. hist. nat. Par. 5. p. 279. A lofiy tree, with a handsome head. Leaves a foot long, shining, commonly 8 or 10 at the top of each branch. Flowers small, disposed in racemose corymbs, white. Capsules small. 'The wood is white, and used for beams and rafters.

Cymose-flowered River-wood. Tree lofty.

2 C. turbixa'ta (D. C. prod. 4. p. 404.) leaves oval, oltuse at the apex, and acute at the base; branches of corymbs opposite; capsules turbinate. $\zeta . S$. Native of Cayenne, where it was collected by Patris. Upper leares 3 inches long and $1 \frac{1}{2}$ broad, on short petioles. Stipulas triangular, acuminated. $\mathrm{Pe}$ duncles and capsules downy.

Turbinate-fruited River-wood. Tree.

Cult. For culture and propagation see Rondclètia, p. 51\%.

LIX. AUGU'STEA (named in compliment to the present en. press of Austria, princess Caroline Augusta of Bavaria). D. C. prod. 4. p. 404.-Augústa, Polıl, A. bras. 2. p. 1. but not of Leand.

Lin. syst. Pcntándria, Monogýnia. Calyx 5 -cleft, with foliaceous permanent scgments. Corolla very long, tubular, incurved, 10-striated, with a spreading limb, which is valvate in astivation. Anthers sessile, exserted. Stigma cloven. Capsule 2-celled, dehiscing at the apex, 4-cleft. Seeds angular, marginated, truncate at the apex, fixed to a transverse receptacle.Middle-sized trees. Leaves on short petioles, simple, decussate, entire, oblong, stipulate. Flowers slowy, bracteate, in terminal fascicles, deep red or crimson. This genus differs from Exostémma by the funnel-shaped corolla, with broad short segments, by the foliaccous calycine lobes, and by the angular seeds.

1 A. lanceola'ta (Pohl, fl. bras. 2. p. 2. t. 101.) leaves lanceolate, and are, as well as the stipulas, glabrons; flowers terminal, 3 in a fascicle; bracteas lanceolate, flat, ciliated. $h . S$. Native of Brazil, in the province of Goyaz, in shady places, on the banks of rivers and ditches, in Serra de Cristaes. Flowers crimson or deep red. Stem bluish red.

Lanceolate-leaved Augustea. Shrub.

2 A. Pakvifòlia (Pohl, fl. bras. 2. p. 3. t. 102.) leaves lanccolate, equal at the base and apex, acutish ; stipulas and bracteas glabrous ; flowers terminal, $t$ win; calycine segments oblong, bluntish, retuse at the base, and pilose inside. b. S. Native of Brazil, in the province of Rio Janeiro, in shady places on the banks of rivers and rivulets on the road from Engenlo da Varge to Agoa de Serra. Stem of a greyish brown colour. Flowers bluish red.

Small-lcaved Augustea. Slirub.

voL. I11.
3 A. oblongifòlia (Pohl, fl. bras. 2. p. 4. t. 103.) leaves oblong, acuminated at the base and apes, glabrous above, and rather pilose beneath ; stipulis, bracteas, and peduncles pilosely tomentose; fascicles first ternate, then bificl. $\eta$. S. Native of Brazil, in the province of Goyaz, on the mountains among bushes on the banks of rivers and rivulets. Stcm greyish black. Flowers deep red or crimson. Panicles terminal, trifid, then bifit, each ultimate division bearing 1 flower.

Oblong-leaved Augusta. Shrub.

4. A. attenua'ta ('ohl, pl. bras. 2. p. 6. t. 104.) leaves oblong, tapering into the petioles at the base, ciliated when examined by a lens, glabrous; stipulas glabrous on the outside, and pilose inside; fascicles of flowers terminal, first ternatc, then bifid; bracteas lanceolate, channelled, villous inside. $h$. S. Native of Brazil, in the province of lio Janeiro, on the margin of rivers and rivulets, in Serra Tingua. Stem greyish brown. Corolla bluish red. Panicles of flowers divided like that of the last.

Altenuated-leaved Augusta. Shrub.

5 A. grauce'scens (P'ohl, fl. uras. 2. p. 7. t. 105.) leaves crowded, oblong, tapering to both ends, therefore acute, quitc glabrous; stipulas triangular, cuspidate, glabrous; fascicles of flowers terminal, trifurcate; bracteas lanceolate, acuminated, pilose inside. h. S. Native of Brazil, in the province of Goyaz, in shady places on the banks of rivers and rivulets at Riveirao Bateiro. Stem bluish black. Corolla deep red or crimson. Glaucescent Augusta. Shrub.

Cult. The species of Augustea are very ornamental; the flowers being long and tubular, of a deep red or crimson colour. Their culture and propagation is the same as that recommended for Catesbce'a, p. 511.

LX, PORTLA'NDIA (so named after the Duchess of Portland, who was a great lover of botany, and well acquainted with English plants). P. Browne, jam. p. 164. Lin. spec. $22 \%$. Gærtn. fruct. 1. p. 153. t. 31. D. C. prod. 4. p. 404.-Portlándia species, Sclireb. and Swartz.

Lin. syst. Pentándria, Monogýnia. Calyx with an ohovate, 5-nerved tube, and a 5 -parted limb: lobes large, foliaceous. Corolla large, funnel-shaped, with a short tube, a wide obconical throat, and a bluntly 5 -lobed limb. Stamens 5 , inserted at the bottom of the throat; anthers long, semi-exserted. Stigma undivided. Capsule obovate, or nearly oblong, ribbed from nerves, crowned by the calyx, retuse, 2-celled; valves dehiscing at the apex. Placentas coriaceous, central. Sceds numerous, elliptic, much compressed, scabrous from elevated dots.-Small glabrous trees, natives of South America. Leaves shining, on short petioles. Stipnlas broad, triangular. Peduncles axillary, short, 1-3-flowered. Flowers large, whitish.

1 P. grandirlóra (Lin. spec. 244.) leaves elliptic-lanceolate; flowers axillary, pedicellate, solitary, 4 times the length of the breadtl. h. S. Native of Jamaica, St. Thomas, \&c. among rocks at the foot of the mountains. Smith, icon. pict. 1. t. 6 . Curt. bot. mag. 286. Jacq. amer. t. 44. pict. t. 64 . Flowers almost like those of Brugmánsia arbòrea, white, reddish inside at the throat, 5 inches long and $1 \frac{1}{2}$ broad, very fragrant at night; but in the bud state they are yellowish, tipped with red. Tube witl 5 hairy angles.

$\operatorname{Var} . \beta$; leaves ovate, acute. $\eta_{\text {. }}$ S. Growing along with the species.

Great-flowered Portlandia. Fl. June, Ang. Clt. 1775. Shrub 10 to 14. feet.

2 P. coccínea (Swartz, f. ind. occ. 1. p. 384.) leaves ovateroundish, coriaceous; flowers axillary, pedicellate, solitary, hardly twice the length of the breadth. $h_{\text {c. }} \mathrm{S}$. Native of the west of Jamaica, on the precipices of mountains, but rare. P. $3 \mathrm{U}$ 
coriàcea, Spreng. syst. 1. p. 708. Leaves 3 inches long and 2 broad. Corolla scarlet, 3 inches long, with a 5 -sided tube. Anthers yellow. Capsules roundish.

Scarlel-flowered Portlandia. Clt. 181\%. Shrub 2 to 3 feet.

\section{+ A spccies hardly known.}

3 P. Acuminatia (Willd. rel, in Rom. et Schultes, syst. 5. p. 23.) leaves ovate, acuminated. $h$. S. Native of New Spain, at Caraccas. Perhaps the same as $P$. grandifiora $\beta$.

Acuminated-leaved Portlandia. Shrub.

Cult. The species of Portlandia are deserving of a place in every collection of stove plants, for their large showy flowers. They thrive best in a mixture of sandy loam and peat; and cuttings, not having their leaves shortened, will root freely if planted in a pot of sand, plunged in heat, with a hand-glass over them. A strong heat is necessary for flowering the species, and without it they will not even grow freely.

LXI. BI'KKIA (meaning unknown to us; but is probably named after some person). Reinw. in Blum. bijdr. p. 1017. D. C. mem. omb. 1. 10. A. Rich, mem. soc. hist. nat. Par. 5. p. 230. D. C. prod. 4. p. 405 -Portlándia species, Forst-Cormigònus of Rafin. ann. gen. sc. ph. 6. p. 83.

Lin. syst. Tetrándria, Monogýnia. Calyx with a turbinately oblong tube, which is angular from 8 filiform ribs, 4 of which are carinal, and 4 sutural: and a 4 -parted limb; lobes linear-lanceolate. Corolla clavate, tetragonal, with a 4-parted limb. Antlers 4, linear, not exceeding the limb of the corolla. Stigma unknown. Capsule ovate, dehiscing at the apes, separable from the calyx, and therefore at length becoming naked, 2 -celled, but almosi 4-celled from the margins of the valves being involute; values bifid at the apex. Placentas narrow, rather prominent. Seeds innumerable, small, compressed, not winged, but echiwated along the margins from membranous crests. Albumen fleshy. - A glabrous shrub. Leaves opposite, obovate, bluntish, cuncated at the base, petiolate, veinless, with the exception of the middle nerve. Stipulas short, truncate, combined. Pedicels axillary, solitary, 1-flowered, naked. Flowers white.

1 B. austra'tis (D. C. prod. 4. p. 405.) * h. S. Native of the islands in the Pacific. Portlandia tetrándra, Forst. prod. no. 86. Lin. fil. suppl. 143. Willd. spec. 1. p. 935. Poir. dict. 5. p. 575. Hoffinánnia Amicòrum, Spreng. syst. 1. p. 416. Bikkia grandiflora, Reinw. in Blum. bijdr, p. 1017. Leaves approximate at the tops of the branches. Corolla white.

I'ar. $\alpha$, Forstcriana. $\eta$. S. Native of Savage Island and Weggio in the Pacific. Leaves oborate, coriaceous, obtuse, cuneated at the base, on short petioles, 2 inclses long. Corolla tubular, rather dilated at the apex; with 4 short triangular lobes, which are each terminated by a mucrone. Anthers a little longer than the corolla. Perliaps the flowers are monstrous.

lar. $\beta$, Commersoniàna. 5 . S. Native at Port Praslin. Leaves broad-obovate, very blunt, hardly coriaceous, cuneated at the base, on short petioles, $3-4$ inches long and 2 or more broad. Corolla more than 2 inches long, with an obconical tube, and ovate lobes, which are apiculated by a mucrone at the apex. Anthers shorter than the lobes of the corolla.

Var. $\gamma$, Gaudichaudiana. $\nvdash$. S. Native of the Island of Rawak. Intermediate between the two preceding varieties. Lobes of corolla triangular, acute, with the recesses broad and obtuse. Anthers equal in length to the corolla.

Southern Bikkia. 'Tree or shrub.

Cult. For culture and propagation see Portlándia above.

LXII. ISIDO'REA (isidos is the Latin name of a shrub like coral; the name has been applied to this genus because it is stiff and dry, and grows by the sea side). A. Rich. in mem. soc. hist. nat. par. 5. p. 284. t. 25. f. 1. D. C. prod. 4. p. 405.

Lis. syst. Pcntándria, Monogýnia. Calyx with a turbinate pentagonal tube, and a 5 -parted limb; lobes erect, keeled, lanceolate-subulate. Corolla tubular, pentagonal, with a naked throat, and a 5-cleft limb; segments triangular, acute, short. Stamens inserted in the bottom of the tube of the corolla, and about its length; filaments capillary, villous at the base, and combined together in a monadelphous nanner; anthers oblong; obtuse at the apex. Style slender, length of corolla; stigma bilamellate; lamellæ oblong, obtuse. Capsule almost globose, pentagonal, truncate at the apex, crowned by the segments of the calyx, 2-celled; cells debiscent, many-seeded. Seed angled, from being pressed against each other, girded by a cup-shaped membrane at the base.-A stiff slurub, with the habit of Ernodea. Leaves opposite, linear, stiff, with revolute margins. Stipulas on the younger branches entire and subulate, but those on the older branches are bipartite. Flowers ahmost terminal, solitary, nearly sessile, often bexamerous.

1 I. Ame'na (Rich. l.c.). h. S. Native of the West India Islands. Ernòdea pedunculàta, Poir. suppl. 2. p. 581.? and Ernòdea púngens, Lam. ill. 1. p. 276.? ex Rich. but the descriptions given do not agree.

Pleasant Isidorea. Shrub.

Cult. See Rondelètia, p. 517. for culture and propagation.

LXIII. SPALLANZANIA (named in honour of Abbe Spallanzani, an Italian celebrated for his researches in natural history, particularly in zoology). D C. prod. 4. p. 406. but not of Neck, nor Pall.

Lin. syst. Pcntándria, Monogýnia. Calyx with an obversely pyramidal tube, a 5-parted limb, and foliaceous, linear, distant, acute, erect, permanent lobes, which are longer than the tube. Corolla with a slender, terete tube, which is longer than the segments of the limb, a naked throat, and 5 oval spreading segments. Stamens 5 ; filaments free from the throat, exserted; anthers oblong. Stylc filiform; stigmas 2, slender, elongated. Capsule ovate-globose, ribbed by nerves, and crowned by the calycine lobes, 2 -celled, obscurely dehiscent : having semi-bifid carpels. Placentas adnate to the dissepiment. Seeds ovate, tubercular.-A smooth shrub. Branches terete, but compressed at the apex. Leaves obovate or oval, rather coriaceous. Stipulas solitary on both sides, ovate, bifid at the apex. Corymbs terminal, many-flowered, with angular branclies, which are bracteate at the base.-Very nearly allied to Landia a section of Musscénda.

1 S. conymbo'sa (D. C. l. c.). h. S. Native of Madagascar, where it is called Tambaracha by the natives.

Corymbose-flowered Sprallanzania. Slurub.

Cult. For culcure and propagation see Rondeletia, p. 517.

IXIV. RONDELETIA (so naned by Plumier, in memory of William Rondelet, a famous physician and natural historian of Montpelier). Plum. gen. p. 15. t. 12. Lam. ill. t. 162. Gartn. fil. carp. 3. t. 1S\%. Kuntl, nov. gen. amer. 3. p. 393. A. Ricl. mem. soc. hist, nat. par. 5. 1\% 271 . but not of Roxb.Rondelètia species, Lin. gen. no. 220.-Petèsia, P. Browne, but not of others.-Arachnimórpha, Desv. in Hamilt. prod. p. 28. -Lightfòotia, Schreb. gen. no. 303. but not of L'Her.-Willdenòvia, Gmel. syst. 1. p. 362. but not of Thumb.

Lin. sysr. Tetra-Pentandria, Monogynia. Calyx with a subglobose tube, and a 4-5-parted limb; lobes oblong-linear, acute, permanent. Corolla with a cylindrical tube, which is hardly ventricose at the apex, and a $4-5$-lobed spreading limb; lobes roundisl. Anthers 4-5, sessile at the top of the tube, inclosed. Stigma bifid. Capsule globose, crowned by the calyx, 2-celled, dehiscing from the apex into 2 valves, which 
are usually cleft at the apex, whence it sometimes appears 4valved; but usually dehiscing at the cells, rarely at the dissepiment. Placentas central. Sceds mumerous, sinall, ovate, angular, usually only 2 in each cell at maturity.-Small trees or shrubs, mostly natives of America. Leaves almost sessile, or more or less petiolate. Stipulas deltoid, or linear-lanceolate, solitary on both sides, undivided, sometimes lairy inside. Peduncles axillary, usually trichotomous, sometimes disposed in a terminal corymbose panicle, rarely 3 or 1 -flowered.-All the Asiatic plants referred to this genus are species of $/$ cndlandia.

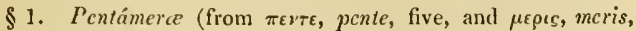
apart; in reference to the flowers being pentamerous). D. C. grod. 4. p. 407. Calyx 5-lobed. Corolla 5-lobcd. Stamens 5. -Rondclètia, Juss. mem. mus. 6. p. 384.

\section{* Tube of corolla hardly longer than the calyx.}

1 R. LAvrifo'lia (Swartz, fl. ind. occ, p. 363.) leaves lanceolate-oblong, acute, glabrous on both surfaces; stipulas deltoid, glabrous on the outside, with ciliated margins, and villous at top; racemes compound, axillary, erect; tube of corulla very short, clothed with adpressed villi. $\zeta$. S. Native of Jamaica and Guadaloupe, anong bushes. Petèsia, no. 2. P. Browne, jam. p. 143. t. 2. f. 2. Tube of calys turbinate, clothed with adpressed down; limb 5-parted, smoothish: lobes acute, about equal in length to the tube of the corolla. Flowers small, dusky yellow. Capsules about the size of hemp-seed. Leaves 3-4 inches long, on petioles about an inch long.

Laurel-leaved Rondeletia. Fl. July, Aug. Clt. 1824. Sli. 4 to 6 feet.

2 R. Racemósa (Swartz, fl. ind. occ. p. 360.) leaves lanceolate-ovate, acuminated, petiolate, glabrous on both surfaces; stipulas almost deltoid, with somewhat ciliated margins; racemes axillary, trichotomous, spreading. $\zeta_{2}$. S. Native of Jamaica, in woods on the mountains. Petèsia, P. Browne, jam. p. 143. t. 2. f. 3. Leaves opposite and 3 in a whorl. Tube of corolla short, clothed with silky hairy down on the outside, a little longer than the calycine teeth, which are very short. Very nearly allied to $R$. laurifolia, but the petioles are longer, the racemes shorter, the calycine teeth shorter, and probably the stigma is undivided, as mentioned by Swartz. Branches covered with hoary bark; branchlets tetragonal. Corolla hoary.

Racemose-flowered Rondeletia. Fl. July, Aug. Clt. 1820. Shrub 4 to 6 feet.

* Tube of corolla cylindrical, 2-3 or 4 times longer than the calycine lobcs.

3 R. thyrsoídea (Swartz, prod. p. 41. fi. ind. occ. 1. p. 358.) leaves oblong, acute, petiolate, membranous, glabrous on the upper surface as well as the branches, but downy beneath; stipulas broad ovate, acute, glabrous, stiff; thyrses axillary, shorter than the leaves. h. S. Native of Jamaica, on the driest hills in the western parts of the island. Branches bluntly tetragonal. Leaves 3 inches long. Calyx minute, 5 -toothed. Flowers small, dull whitish yellow or rust-coloured, with an elongated tube, which swells below the limb, and clothed with silky pubescence on the outside. Capsules roundish, size of coriander seeds. Seeds 2 in each cell at maturity.

Thyrsoid-tlowered Rondeletia. Fl. July, Aug. Clt. 1819. Shrub 4 to 6 feet.

4 R. umbellula'ta (Swartz, prod. p. 41. fl. ind. oce. 1. p. 367.) leaves lanceolate-ovate, acute, rather hairy, petiolate; stipulas lairy, ending each in a bristly acumen; peduncles axillary, trichotomous at the apex, somewhat umbelliferous, shorter than the leaves. $々$. S. Native of Jamaica, on rocks near streams. Petèsia, no. 3. P. Browne, jam. p. 144.? and there- fore Petèsia villòsa, Smitl, in Rees's cycl. no. 4. Calyx very villous, with linear teetls. Corolla larger than in the rest of the species, downy, of a dusky yellow colour; tube elongated. Capsule roundish: having 2 sceds in each cell at maturity.

Umbcllate-flowered liondeletia. Slırub \& feet.

5 R. томеntòsa (Swartz, prod. p. 4.1. A. ind. oce. 1. p. 365 .) leaves ovate, aemminated, petiolate, membranous, hairy above, but clothed with hoary villous tomentum beneath; peduncles axillary, tripartite, short. $h$. S. Native of Jamaica, near Spanish Town, on rocky hills. Petèsia stipularis, Lin. spee. p. 160.? ex Swartz. Stipulas ovate, downy, with a short point. Branchlets villous at the ends. Flowers small, whitish, or dusky yellow, villous outside. Capsules roundish, size of eorianter seeds, containing 1 secd in cach cell at maturity.

Jar. $\beta$, Domingénsis (D. C. prod. 4. p. 407.) leaves ovaloblong, cuneated at the base, downy or villous above, but clothed with soft hoary tomentum beneath. $\zeta_{2}$. S. Native of St. Domingo, where it was collected by Bertero. R. tomentosa, ex Hispaniola, Spreng. syst. 1. p. 708. This plant is probably referrible to Petèsia tomentòsa.

Toncntose Rondeletia. Fl. July, Aug. Clt. 1819. Sh. $3 \mathrm{ft}$.

6 R. INeA'Na (Swartz, prod. p. 41. A. ind. oce. 1. p. 369.) leaves ovate-lanceolate, petiolate, glabrous above, hairy beneatl, and hoary ; stipulas very short, truneate, eiliated, white on the margins; peduncles axillary, simple, 3 -flowered. $々$. S. Native of Jamaica, on rocky ealcareous mountains, but rare. Arachnimórpha incàna, Hamilt. prod. fl. ind. oce. p. 28. R. incàna, ex Hispaniola, Spreng. syst. 1. p. 707. ex herb. Balb. is not different from this plant. Branches rugged. Petioles tomentose. Lobes of calyx ovate, acute, thick, hoary from silky down. Corolla rather large, silky outside. Capsule oblong, ripening 2 seeds in each cell.

Hoary Rondeletia. Shrub 2 to 3 feet.

7 R. Hírta (Swartz. prod. p. 41. 11. ind. oce. 1. p. 373 . but not of $\mathrm{A}$ it.) leaves oblong, acuminated, on short petioles, hairy, stiff, nerved beneath; peduncles axillary, trichotomous, erect ; lobes of calyx linear. $\eta$. S. Native of Janaica, among bushes on the mountains. Gærtn. fil. carp. p. 33. t. 184. Lodd. bot. cab. t. 350 . Stipulas broad, acuminated, hairy. Branchlets pilose. Flowers yellowish. Mature capsule perfecting 2-4seeds. Peduncles tripartite to the base; the branches bearing 3 flowers at the apex.

I ar. $\beta$, Aitòiz (D. C. prod. 4. p. 408.) leaves ovate-oblong, acute, pilose; capsules many-seeded. $\zeta$. S. Native of $\mathbf{J}_{\mathrm{a}}$ maica. Rondeletia hírta, Ait. hort. kew. 1. p. 227. This differs from the plant of Swartz, in the leaves being shorter, broader, and less acuminated, and in the fruit being dehiscent, and containing a great number of small seeds.

Hairy Rondeletia. Fl. Ju, Aug. Clt. 1776. Sh. 5 to $6 \mathrm{ft}$.

8 R. Panane'ssis (D. C. prod. 4. p. 408.) leaves ovaloblong, acuminated at both ends, glabrous above, white beneath, and villous on the nerves and veins; stipulas triangular, acute, villous outside; peduncles axillary, opposite, shorter than the leaves, trifid and densely corymbose at the apex : ultimate ones collected into a short thyrse; calyx villous, with lanceolate segments. h. S. Native of Panama. R. hírta, Bartl. in herb. Hænke. Tube of corolla villous; limb of 5 roundish lobes. Capsules almost globose. Seeds numerous, and of 2 forms, appendiculate.

Panama Rondeletia. Slorub 4 to 5 feet.

9 R. minsu'ta (Swartz, prod. p. 41. fl. ind. occ. 1. p. 371.) leaves oblong, acuminated, hairy on both surfaces, pale beneath, on short petioles: stipulas ovate-lanceolate, hairy; branchlets. peduncles, and flowers hairy; peduncles axillary, trichotomous. loose, about the length of tlie leaves. h.S. Native of the south of Jamaica, among bushes on the mountains near Bath. $3 \cup 2$ 
Petioles clothed with rufescent villi. Calyx villous. Corolla yellowish, tomentose outside, with a narrow throat. Seeds girded by a wing, according to A. Rich: if this be the case it is referrible to the genus Boucírdia.

IIirsute Rondeletia. Fl. July, Aug. Clt. 1820. Sh. 5 to $6 \mathrm{ft}$.

10 R. TRIFOLIA'TA (Jacq. amer. p. 60. t. 43. pict. t. 62.) leaves oblong - lanceolate, 3 in a whorl, on short petioles, glabrous above but tomentose beneath; petioles and branches hairy; panicles axillary, shorter than the leaves, $々$. S. Native of Jamaica, at the foot of the mountains. Flowers reddish, small. Leaves 3 inches long. 'Teeth of calyx acuminated. Corolla with a very long tube. Capsulc many-seeded.

Trifoliate Rondeletia. Tree 12 to 14 feet.

11 li. Leviga'ta (Ait. hort. kew. ed. 2. vol. 1. p. 366.) leaves oblong or elliptic, acuminated at both ends, glabrous, paler beneath, petiolate; stipulas deltoid, glabrous on the outside, but bearded inside; peduncles axillary, trichotomous, rather panicled, 3 times longer than the petioles, but one half shorter than the leaves. $h$. S. Native of Cuba, about the Havana; and of Trinidad. Anónyma, Sieb. fl. trin. no. 374. Tube of calyx downy ; limb of 3-5 linear lobes, which are $3-$ tinies shorter than the tube of the corolla. Capsule downy, smaller than a pea.

Smooth Rondeletia. Fl. Jul. Aug. Clt. 1793. Sh. 5 to $6 \mathrm{ft}$.

12 R. Anerjcaiva (Lin. spec. 243.) leaves lanceolate or clliptic, acuminated at both ends, glabrous, hardly petiolate, paler beneath; stipulas deltoid, downy outside; peduncles opposite, axillary, a little longer than the leaves, dichotomously cymose at the apex. h.S. Native of Cuba, near the Havana; Jamaica, and many other West India islands, ex Plum. od. Burm. t. 242. f. 1. Flowers white, bibractcolate, with a little scent. Tube of calyx clothed with adpressed villi; lobes of limb oblong-linear, \& times shorter than the tube of the corolla. Capsule many-seeded.

American Rondeletia. Fl. Aug. Clt. 1752. Sh. 8 to $10 \mathrm{ft}$.

13 R. Cumane'nsis (H. B. et Kunth, nov. gen. amer. 3. p. 394.) leaves oblong, acuminate, almost sessile, glabrous, paler beneath; stipulas rather deltoid, with ciliated silky margins; panicles terminal, sessile. $h$. S. Native of New Andalusia, near Cumanacoa. Panicle sessile, and the peduncles opposite, dichotomons, and 3-5-flowered, ex Kunth. Lobes of calyx ovate-oblong. Flowers white.

Cumana Rondeletia. Shrub 8 to 10 feet.

14. R. mícrodon (D. C. prod. 4. p. 4.08.) glabrous; leaves oval or oblong, acute at both ends, on very short petioles; stipulas bipartite, obtuse, permanent ; corymbs pedunculate, rising from the forks of the branches; calyx truncate, with 5 very short teeth. I2. S. Native of Cuba, about the Havana, where it was collected by De la Ossa. Flowers white in the dried state, form of those of the other pentamerous species of Rondelètia, but the calyx is hardly 5 -toothed.

Small-toothed-calyxed Rondeletia. Shrub.

15 R. odora'ta (Jacq. amer. p. 59. t. 42. pict. t. 61.) leaves hardly petiolate, ovate, or subcordate, acutish, scabrous above, paler beneath and rather scabrous on the nerves ; corymbs terminal. $h_{2}$.S. Native of Cuba, on rocks by the sea-side, at the Havana; and of Mexico. Lin. spec. 1671. H. B. et Kunth, nov. gen. amer. 3. p. 394. R. coccínea, Moc. et Sesse, H. mex. icon. ined. R, obovàta, Lin. syst, veg. Branchlets villous. Stipulas wide, acute. Peduncles trichotomons. Flowers haudsome scarlet, with the projecting rim of the tube orangecoloured, having the scent of violets, downy on the outside, either pentamerous or hexamerous. Lobes of calyx linear, erect, one half shorter than the tube of the corolla. Capsule containing many angular seeds.

Sncet-scented Rondeletia. Slirub 5 to 6 feet.
* * African species, with pentamerous floners.

16 R. Febrífuas (Afz.) leaves oval coriaceous, deep green, glabrous, petiolate; corymbs terminal. $\zeta$. S. Native of Sierra Leone, in the low lands about Freetown. A branched spreading shrub, with the habit of Lauristinus. Flowers pale red. Stamens 5 , a little longer than the tube of the corolla. Calyx 5-cleft.

Febrifugal Rondeletia. Shrub 4 to 5 feet.

17 R. FLORIBU'NDA; leaves ovate, acuminated, membranous, petiolate; corymbs lateral and terminal, numerous; stamens 5 , exserted. $h$. S. Native of Sierra Leone, in woods on the mountains. Corolla tubular, 5-cleft, white. Calyx 5 -cleft.

Bundle-flowered Rondeletia. Shrub 5 to 6 fect.

18 R. LONICERoìnes; shrub twining; leaves roundish, ovate, coriaceous, glabrous, peticlate; corymbs panicled ; corolla with a long tube and a 5 -cleft border; stamens 5 , longer than the tube. $h$. S. Native of Sierra Leone, among bushes in the low lands. A branched twining slorub.

IIoneysuckle-like Rondeletia. Shrub tw.

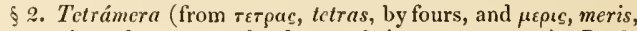
a part; in reference to the flowers being tetramerous). $D . C$. prod. 4. p. 409. Calyx 4-lobed. Corolla 4-lubed. Stamens 4. Bouvárdia species of Juss. - Hedyòtis species of Spreng.

\section{- Unarmed. Panicles terminal.}

19 R. viRga'ta (Swartz, prod. p. 41. fl. ind. occ. 1. p. 354.) leaves roundish-cordate, on very short petioles, quite glabrous, paler beneath; stipulas minute, acute; branches filiform, spreading; peduncles elongated, trifid; flowers crowded by threes. h. S. Native of the north of Hispaniola, among bushes by the sea-side. Hedyòtis cordifòlia, Spreng. pug. 2. p. 26. Flowers of a dusky purple colour, clothed with silky down outside. Lobes of calyx linear. Capsule pubescent, subdidymous, many-seeded.

Triggy Rondeletia. Shrub 5 to 6 feet.

20 R. Díscolor (H. B. et Kunth, nov. gen. amer. 3. p. 396. t. 291.) leaves ovate-oblong, acuminated, petiolate, with revolute edges, glabrous above and on the lranches, but clothed with white tomentum beneath ; stipulas linear-subulate; panicles terminal, sessile. h. S. Native of New Granada, between Maraquita and Ionda. Hedyòtis líscolor, Spreng. syst. 1. p. 411. Flowers pedicellate, sweet-scented, red on the outside. Lobes of calyx ovate-lanceolate. Capsule dehiscing at the dissepiment; valves bifid at the apex.

Discoloured-leaved Rondeletia. Shrub 4 to 6 feet.

21 R. PUBE'scens (H. B. et Kunth, nov, gen. amer. 3. p. 396. t. 291.) leaves oblong, acute, petiolate, clothed with fine down above, and with canescent pubescence beneath, as well as on the branchlets; stipulas lanceolate-subulate; panicles terminal, sessile, tripartite. h. S, Native of New Granada, between Maraquita and Honda. Lobes of calyx lanceolate, 5times shorter than the tube of the corolla. Corolla tomentose, outside. Fruit unkuown.

Donny Rodeletia. Slirub 4 to 6 feet.

22 R. elonga'ta (Bartl. in herb. Hanke, ex D. C. prod. 4. p. 409.) leaves elliptic-oblong, acuminated at both ends, pubescent above, but clothed with white tomentum beneath, but they at length become glabrous from the down being deciduous; stipulas lanceolate, equal in length to the petioles; panicles terminal, on long peduncles; flowers crowded ; lobes of calyx linear, 3 times shorter than the tube of the corolla. $h . S$. Native of Mexico, about Acapulco. An intermediate species, between $R$. pubéscens and R. leucophýllum.

Elongated Rondeletia. Shrub.

23 R. Levcorhy'lium (H. B. et Kunth, nov, gen. amer. 3. 
p. 395. t. 290.) leaves linear-lanceolate, acuminated, almost sessile, pubescent above, white from woolly tomentum beneath as well as the branches; panicles terminal, on long peduncles, usually formed into a kind of capitulum. $\eta$. S. Native of Mexico, between Alto del Peregrino, and the river Papagallo. Hedyòtis leucophýlla, Spreng. syst. 1. p. 411. Flowers red, sessile, or on short pedicels. Lobes of calyx linear-lanceolate, 3 times shorter than the tube of the corolla.

White-lcaecd Rondeletia. Slirub 3 to 4 feet.

* Unarmed. Peduncles axillary, trichotomously raccmose or 3-fonered.

24 R. Berteriana (D. C. prod. 4. p. 409.) Jeaves oval, acute, somewhat cuneated at the base, petiolate, clothed with villous pubescence above, but hoary from soft villous tomentum beneath; branches clothed with velvety tomentum; stipulas lanceolate, acuminated, villous; racemes axillary, shorter than the leaves, many-flowered. $h$. S. Native of St. Domingo, where it was collected by Bertero. R. hirsùta, Spreng. in herb. Balb. but not of Swartz. Calyx villous ; lobes linear, 3 times shorter than the tube of the corolla, which is clothed with adpressed villi on the outside.

Bertero's Rondeletia. Shrub 4 to 6 feet.

25 R. Pılòsa (Swartz, prod. p. 41. fl. ind. occ. 1. p. 356.) leaves ovate-lanceolate, or oblong, almost sessile, veiny, roughish above, pale and villous beneath; stipulas deltoid, broad, villous; peduncles axillary, 3-flowered, almost the length of the leaves, and are as well as the calyxes pilose. $\eta$.S. Native of the West India islands, as in Santa Cruz, Montserrat, and Martinico. R. triftòra, $\mathrm{Vah}$, symb. 3. p. 34. t. 54. Oldenlándia longiflòra, Lam. dict. 4. p. 534. Hedyòtis longiflòra, Spreng. pug. 2. p. 27. Branches hairy towards the top, terete or tetragonal. Leaves 2-3 inches long. Lobes of calyx length of the tube of the corolla. Capsule many-seeded. Tube of corolla silky outside.

Pilose Rondeletia, Slurub 4 to 6 feet.

\section{* Unarmed. Pediccls axillary, 1-flowercd.}

26 R. Buxifòlı (Vahl. ecl. amer. 2. p. 11. t. 12.) leaves obovate-oblong, on very short petioles, mucronulate at the apex, glibrous on both surfaces, and shining above; stipulas small, deltoid; pedicels axillary, very short, l-tlowered. $h . \mathrm{S}$. $\mathrm{Na}$ tive of the islands of Montserrat and Porto-Rico. Poir. dict. 6. p. 253. Catesbæ'a inérmis, Spreng. syst. 1. p. 416. Catesbæ'a parviflòra, Spreng. in herb. Balb. Ixòra buxif òlia, Spreng. syst. 1. p. 409. ex syn. The leaves, in the specimens from Porto-Rico, are 8 lines long and 3 lines broad, striated with the nerves, which are oblique. Ovarium globose, pubescent outside. Lobes of calyx sliort, linear, acute. Tube of corolla $2 \frac{1}{2}$ lines long, downy outside. Capsules size of a black pepper, 2-seeded.

Box-leaved Rondeletia. Shrub 2 to 3 feet?

27 R. Roy Eneròlia (D. C. prod. 4. p. 410.) leaves obovateoblong, obtuse, on very short petioles, somewhat mucronate, hoary on both surfaces from short down; stipulas laneeolate, acute; pedicels axillary, vcry short, l-flowered. $h . \mathrm{S}$. $\mathrm{Na}$ tive of St. Domingo, where it was collected by Bertero. R. incàna, ex Hispaniola, Spreng. syst. 1. p. 707. ex herb. Balb. Allied to $R$. buxif òlia, but quite distinct from $R$. incàna.

Royena-leaved Rondeletia. Shrub.

* * Shrubs nith axillary thorns. Perhaps the spines are cither rameal or peduncular. Fruit unknown, and therefore the genus to which they properly bclong.

28 R. Leptacántha (D. C. prod. 4. p. 410.) spines opposite; leaves broad-oval, acutish, glabrous on both surfaces, but rather pilose when young as well as the branches; peduncles slender, equal in length to the leaves, or longer than them, bcaring 3-5 flowers at the apex. $\zeta$. S. Native of Cuba, about the Havana, where it was collected by De la Ossa. Branches slender, glabrous. Spines axillary, long, bearing rudiments of leaves on one side. Pcduncles an inch long. Segments of the calyx subulate. Corolla 5 lines long.

Slcnder-spined Rondeletia. Slirub.

29 R. brachyacántia (D. C. J. c.) spines opposite; leaves elliptic-oblong, acute at the base, and acmminated at the apex, glabrous above, but villous beneath, as well as the branchlets, peduncles, and flowers; peduncles one half shorter than the leaves, 3-4-flowered at the apex. $々$. S. Native of Brazil. Branches dotted by linear-oblong crowded warts. Spines conical, stiff, forming a straight angle, spreading, 4-5 lines long. Segments of the ealyx subulate. Anthers inserted at the throat.

Short-spined Rondeletia. Shrub.

\section{$\uparrow$ Species not sufficiently known.}

30 R. PARYiflo'ra (Poir. dict. 6. p. 252.) leaves oblong, cumeated at the base, obtuse and acuminated at the apex, petiolate, quite glabrous, coriaceous, paler beneatl, ; peduncles axillary, opposite, corymbose, many-flowered. $h_{2}$. S. Native of Martinico. Veins of leaves black. Leaves 4 inches long and 2 broad. Stipulas ovate, acute, short. Bracteas glabrous outside and lairy inside. Capsule globose. R. parviflòra, Spreng. syst. ex lierb. Balb. appears to be a distinct plant from the present.

Small-flonered Rondeletia. Shrub.

31 R. rнy nсhóspora (H. B. et Kunth, nov. gen. amer. 3. p. 395.) leaves oblong-elliptic, acute, on short petioles, pubescent above and on the branches, but clothed with canescent tomentum beneath; panicles terminal; seeds beaked at both ends. 々.S. Native of New Granada, near Honda. The flowers are unknown.

Beaked-seeded Rondeletia. Shrub 4 to 6 feet.

32 R.? dispérma (Jacq. amer. p. 59.) leaves oval, obtuse, petiolate, glabrous; racemes axillary, compound, loose, trifid; fruit somewhat baccate, 2 -seeded. $h$. S. Native of South America, in the woods of Carthagena, in rocky places; very frequent in the islands of Baru and Tierra Bomba. This plant should probably be removed from the genus as well as from the present tribe. Flowers sweet-scented, purplish white. Perliaps a species of Cánthium.

Two-seedcd Rondeletia. 'I'ree 15 feet.

33 R.? CORIA'CEA (Spreng. syst. 1. p. 707. but not of Wall.) leaves oval-oblong, coriaceous, shining above, but clothed with very short velvety down beneath as well as on the branchlets; stipulas semi-orbicular, furnished with a pungent tooth in the middle; cymes terminal; calyxes and corollas 5-parted, rather hispid; stamens exserted. h.S. Native of equinoxial Brazil. Mussæ'nda coriàcea, Spreng. neu. entd. 2. p. 145. It is probable that the plant is neither a Musscenda nor a Roulcletia, according to Cham. et Schlecht. in Linnæa. vol. 4. p. 165 ., but the structure of the fruit is entirely unknown.

Coriaccous-leaved Rondeletia. Shrub.

Cult. The species thrive well in a mixture of sand, loanr, and peat; and cuttings of them are easily rooted if planted in a pot of sand, plunged in heat under a hand-glass. All are slurubs of very little beauty or interest.

LXV. WENDLA'NDIA (Henry Ludov. Wendland, Curator of the botanic garden at Hanover, and author of Commentatio de Acaciis Aplyyllis). Bartl. ined. ex D. C. prod. 4. p. 411 . but 
not of Willd. Rondelètia, Roxb. and Wall. fl. ind. 2. p. 133. but not of Plumier.

Lin. syst. Tetra-Pentándria, Monogýnia. Calyx with an almost globose tube, which is often striated, and a very sloort permanent limb, which is 4-5-toothed to the base. Corolla with a terete tube, which is longer than the calyx, and a spreading 4-5-lobed limb; lobes orate, acutislı. Stamens 4-5; filaments rising from the top of the tube; anthers oblong, exsertest. Style exserted; stigma bifil, with the lohes thickish. Capsule ovate-globose, 2-celled, crowned by the calyx, dehiscing at the cells into 2 valves at the apex. Seeds small, numerous in each cell.- Trees and shrubs, all natives of the East Indies. Leaves opposite, coriaccous, oval, petiolate. Stipulas broad at the base, acuminated. Panicles axillary and terminal, many-flowered. Flowers small.-This genus differs from Rondelêtia as Exostémma does from Cinehòna.

§ 1. Pentámerce (from $\pi \varepsilon \nu_{\tau} \varepsilon$, pente, five, and $\mu \varepsilon \rho \iota$, meris, a part; in allusion to the flowers being pentamerous). D. C. prod. 4. p. 411. Calyx and eorolla with 5-lobed limbs. Stamens 5 .

\section{* Indian species.}

1 W. PANicula'ta (D. C. prod. 4. p. 411.) arboreous; leaves almost sessile, oval-oblong, acuminated, smooth ; stipulas reniform, sometimes apiculated, at length recurved; panicles terminal and sub-axillary. $h_{\xi} . S$. Native of the Malay islands. Rondelèria paniculàta, Roxb. f1. ind. 2. p. 133. Flowers small, white, very numerous. Bracteas of various forms and sizes, all hairy. Calyx villous. Corolla glabrous, with revolute segments. Panicled-flowered Wendlandia. Fl. Ju. Aug. Clt. 1820. Tr.

2 W. тілсто'ria (D. C. l. c.) arboreous; leaves petiolate, oblong-lanccolate, smooth above, but pubescent on the nerves beneath, as well as on the branches, petioles, peduncles, and calyxes; stipulas triangular, cuspidate; panicles terminal, decussate; flowers by threes. $々$. S. Native of Bengal, about Burdwan and Midnapoor. Rondelètia tinctoria, Roxb. fl. ind. 2. p. 134. Leaves 4-6 inches long and 1-2 broad. Branches of panicle 4-sided, hairy. Bracteas numerous, hairy, those of the ultimate divisions of the panicle ensiform, with a hastate base. Flowers numerous, small, white, almost sessile, fascicled. Segments of corolla spreading. The bark is employed as a mordant by the natives in some of their dyes, and is called by them Toola-lodh.

Dyers' Wendlandia. Tree.

3 W. Notonis'va (Wall. cat. no. 2673.) shrub downy in every part, except the corollas; leaves elliptic or obovate-oblong, acuminated, pale beneath; peduncles axillary and terminal, disposed in terminal racemose thyrsoid panicles; corolla with a slender tube, much longer than the calyx, which is woolly; stipulas broad, rounded at the apex. $\quad \boldsymbol{z}$. S. Native of the East Indies, on the Nellighery mountains, where it was collected by Noton. Ixòra congésta, Roxb. Flowers white, in clusters? Leaves usually 3 in a whorl.

Noton's Wendlandia. Shrub or tree.

4. W. glabra'ta (D. C. l. c.) arboreous; leaves petiolate, oblong-lanceolate, glabrous on both surfaces, as well as the petioles, branchlets, peduncles, and calyxes ; stipulas triangular, cuspidate; panicles terminal, decussate; flowers by threes. $\zeta$.S. Native of Java, on the mountains in woods. Rondelètia tinctòria, Blum. bijdr. p. 974. but differs from the plant under the same name by Roxburgh, in its smoothness, and by the flowers being distinctly pedicellate.

Glabrous Wendlandia. Tree.

5 W. NI'TENS (Wall, cat. no. 627l.) branchlets downy ; leaves glabrous, elliptic-lanceolate, tapering to both ends, pale beneath; stipulas broad at the base, and cuspidate at the apex; panicles terminal, downy; flowers almost sessile, in fascicles. $h$. S. Native of Martaban, on the banks of the Atram. Flowers very small.

Shining Wendlandia. Shrub or tree.

6 W. EXSE'RTA (D. C. prod. 4. p. 4.11.) arboreous; leaves petiolate, broad-lanceolate, glabrous or downy above, pubescent, or tomentose beneath; stipulas semi-lunate, reflexed; panicles terminal, with spreading downy branches ; corolla subcampanulate. h. S. Native of the interior parts of Bengal, and particularly over the ruins of the ancient city of Gour ; and of Nipaul. Rondelètia exsérta, Roxb. fl. ind. 2. p. 135. Rond. thyrsiflòra, Roth. nov. spec. 141. Rond. Héynei, Roem. et Schultes, syst. 5. p. 234. and Rond. Oryssénsis, Roth. nov. spec. p. 142. ex Wall, fl. ind. 2. p. 135. Branchlets villous. Leaves 4-6 inches long. Bracteas somewhat ensiform, varying much in size. Flowers numerous, small, pure white, fragrant. Calyx hoary. Scgments of corolla recurved.

Exserted-stamened Wendlandia. Tree 20 to 30 feet.

7 W. Pnóxıma (D.C. I. c.) arboreous ; leaves elliptic, acuminated, clothed with tomentum beneath, as well as on the branchlets; panicles very hairy; flowers very much crowded; limb of corolla one half shorter than the tube; calycine teeth obtuse, pilose. $\quad h$. S. Native of the east of Bengal, in Silhet. Rondelètia próxima, D. Don, prod. fl. nep. p. 139. Nearly allied to $W$. exservta, but in that species the leaves are silky beneath, and the branchlets are more canescent; the limb of the corolla is about equal in length to the tube; the stigma is bipartite, and the calycine teeth are ovate and acute.

Allied Wendlandia. Tree.

8 W. Ligustrina (Wall. eat. no. 6272.) slirub glabrous in every part ; leaves elliptic, tapering to both ends, shining above; stipulas broad at the base, and cuspidate at the apex; teeth of calys subulate, much slorter than the tube, which is terete and slender; bracteas to the flowers linear. $h$. S. Native of the Burmese empire, on Mount Taong-Dong. Flowers pedicellate, white, disposed in terminal racemose panicles; pedicels solitary. Capsules hardly the size of coriander seeds.

Privet-like Wendlandia. Tree.

9 W. DENTIFLo'ra (D. C. prod. 4. p. 412.) arboreous; leaves petiolate, ovate-oblong, acuminate, acutish at the base, coriaceous, pubescent on the veins beneath ; panicle terminal, decussate, densely clothed with tomentum; flowers much crowded. $\eta$. S. Native of $\mathbf{J} a v a$, in the province of Cheribon, in woods on the mountains of 'Tjerimai, where it is called Kissampanggunung. Rondelètia densiflòra, Blum. bijdr. p. 974 .

Tooth-flowered Wendlandia. Tree.

10 W. cine'rea (D. C. prod. 4. p. 412.) arboreous; the upper parts clothed with ash-coloured dense tomentum; leaves lanceolate, petiolate, villous above and tomentose beneath; stipulas recurved at the apex; panicles terminal, much branched, tomentose; flowers in dense fascicles; corolla with a very short tube. h.S. Native of the valley of Nipaul, at Bunipa, and at Bheempedi ; as also from Noakote and Shreenagur; and is called in the Newar language Gothina. Rondelètia cinèrea, Wall. in Roxb. fl. ind. 2. p. 141. Branches quadrangular, with rounded corners. Leaves 4-6 inches long, smooth above, glaucous beneath. Stipulas reniform, emarginate. Bracteas oblong, caducous, sometimes lobed or sub-hastate at the base. the lowermost ones very long, linear. Flowers numerous, small, white. Teeth of calyx small, triangular. Segments of corolla spreading; throat furnished with 5 tubercles. Capsule globular, villous. The wood is brownish, close-grained, and seems well adapted for furniture.

Grey Wendlandia. Tree 12 to 14 feet.

11 W. Luzonie nsis (D. C. l. c.) branches, petioles, and 
nerves of leaves hairy; leaves oval-oblong, acuminated at both ends; stipulas semi-orbicular, obtuse, permanent, coriaceous; panicle much branched, many-flowered, rather villous; anthers hardly exserted; stigma bificl. $h . S$. Native of the island of Luzon. Wendlándia multiflòra, Bartl. in herb. Hæenke. Allied to $R$. pubérula. Fruit hardly larger than turnip seed. Flowers small, white.

Luzon Wendlandia. Tree.

12 W. coriA'CEA (D. C. l. c.) arboreous, smooth in every part; leaves oblong-lanceolate, acuminated, tapering at the base, petiolate, coriaceous, shining; stipulas broad, short, rounded, ending each in a cuspidate point : panicles dense, terminal, manyflowered; flowers opposite, very numerous. $h$. S. Native of Nipaul, in the valley, very common in the forest of Thoka, and other places: and from Noakote. The tree is called Kongeea in the Parbuteeyan language, and Julsi in that of Newar. Siondelètia coriàcea, Wall. in Roxb. fl. ind. 2. p. 142. D. Don, fi. nep. p. 138. Leaves $5 \cdot 7$ inches long. Flowers white, fragrant. Bracteas lanceolate, coriaceous, those of the flowers capillary. Corolla with a cylindrical tube, and a spreading border. The inhabitants of Nipaul use the wood of this tree for various purjoses, such as rafters, tools, S.c.: it is close grained, and becomes of a brownish colour soon after being cut, not unlike mahogany. A red dye is likewise prepared from it. The leaves and flowers attain sometimes a bhish colour on being dried.

Coriaceous-leavel Wendlandia. Tree 10 to 12 feet.

13 W. PUBE'RULA (D. C. l. c.) branchlets, petioles, nerves of leaves underneath, and panicles hairy; leaves petiolate, ovaloblong, acute at both ends, glabrous above; stipulas adpressed, broad at the base, cuspidate at the apex; panicle terminal, branched, many-flowered; corollas glabrous; stigma clavate. 々. S. Native of Nipaul. Allied to $\boldsymbol{W}$. péndula, but differs in the stipules being 4 times shorter, in the corolla being glabrous, \&c.

Puberulous Wendlandia. Tree.

14 W. PE'NDULA (D. C. l. c.) fruticose ; branches pendulous; leaves lanceolate-ovate, acuminated, smooth above and rough underneath; stipulas lanceolate, adpressed, deciduous, rather sliorter than the petioles; corymbs terminal, oblong, panicled; tube of corolla filiform, smooth without and pubescent within; segments of corolla recurved. $h$. S. Native of Nipaul, between Hetaunra and Rheempedi, also on Sheopore. Rondelètia péndula, Wall. in Roxb. A. ind. 2. p. 140. A very elegant slurub. Branches obscurely quadrangular; new shoots downy. Leaves 3-5 inches long, and disposed 3 in a whort on the robust shoots. Peduncles villous. Flowers fascicled, green, fragrant. Stigma clavate.

Pendulous-branclied Wendlandia. Shrub 5 to 6 feet.

$15 \mathrm{~W}$. Malaya'na; branches somewhat tetragonal; leaves elliptic-lanceolate, acuminated, downy on the nerves, tapering to the base, membranous; stipulas broad; calyx with a roundish tube and a 5-cleft border; corolla with a very slender tube, and a spreading border; panicles terminal, corymbose, hardly longer than the petioles, $h$. S. Native of the Malay islands. Anderosácme Malayàna, Wall. cat. no. 6282.

Malay Wendlandia. Shrub or tree.

16 W. LONGifo'lia (D. C. 1. c.) fruticose : epidermis falling from the branches; leaves elliptic-oblong, acuminated, tapering at the base, villous underneath; stipulas lanceolate, erect, acute, often bidentate, furnished within their broad base with a series of subulate glands; panicle many times trichotomous, downy; calyx downy, with a yellow gland on each margin of the segments, and sometimes at the points; bracteas villous, glandular. $\quad$. S. Native of Silhet; and of Nipaul, on Chundagiri, Nagurjoon, and at the foot of Slieopore near Thoka. The
Bengalee name of the plant is Soopari. Rondelètia longif olia Wall. in Roxb. fl. ind. 2. p. 137. D. Don, prod. fi. nep. p. 138. Anderosácme longrifòlia, Wall. cat. no. 6280. Leaves 6-14 inches long, dark green above. Bracteas with an entire or S-lobed base, their margins marked with yellow subulate fleshy glands. Flowers large, fleshy, yellow, scentless, with a valvate ostivation. Segments of corolla spreading. Stamens inserted in the bottom of the tube. Capsules round, smooth. All the species of this genus vary considerably in the size of the leaves, the degree of their pubescence, and in their inflorescence, which renclers their specific discrimination difficult.

Long-leaved Wendlandia. Shrub.

$$
\text { * African specics, not sufficicntly know'u. }
$$

17 W. succs'тA; leaves oblong-lanceolate, acuminated, glabrous, on short petioles; stipulas sheath-formed, supra-foliaccous; racemes panicled, terminal; capsule round, sulcate. h. S. Native of Sierra Leone, in woods on the margins of rivers. Slurub branched.

Furroned-fruited Wendlandia. Shrub 5 to 6 feet.

18 W. PrLo'sA; leaves broad, ovate-lanceolate, acuminated, cordate at the base, almost sessile; stipulas large, sheathformed, supra-foliaceous, and are as well as the leaves piluse ; racemes panicled, terminal; capsules round. $々 . S$. Native of Sierra Leone, in woods on the banks of rivulets.

\section{IIairy Wendlandia. Shrub 5 to 6 feet.}

19 W. RACEMo'sA; glabrous in every part; leaves elliptic, very long, acuminated, coriaceous, on short petioles; stipulas large, sheath-formed, supra-foliaceous ; racemes panicled, terminal; capsules ovate. $h$. S. Native of Sierra Leone, in woods on the banks of rivulets.

Raccnose-flowered Wendlandia. Shrub.

20 W. VIRGA'TA : leaves oval, acuminated, petiolate; panicles axillary and terminal. $\zeta$.S. Native of Sierra Leone, on the edges of woods. A branched twiggy shrub. Stamens 5, longer than the corolla. Capsule 1-celled, many-seeded. Corolla funnel-shaped.

Twiggy Wendlandia. Shrub.

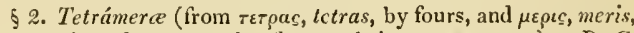
a part; in reference to the flowers being tetramerous). $D . C$. prod. 4. p. 412. Limb of calyx and corolla 4-lobed. Stamens 4.-Doublful species.

21 W. SPica'ta (D. C. prod. 4. p. 412.) leaves elliptic, tapering downwards, villous, as also the panicle ; stipulas oblong, acute, smooth, except the elevated rib, which is villous; panicle large, terninal, almost sessile, with opposite compressed peduncles: the secondary divisions of the peduncle dichotomous, terminating in cylindrical slender, twin, or ternate spikes, which are 2 inches long; Howers disposed in one row along one side of the rachis of the spike; corolla pubescent, with a slender tube, widening at the apex; stigma of 2 recurved lobes. $々$. S. Native of Pulo-Penang. Rondelètia spicàta, Wall. in Roxb. fl. ind. 2. p. 139. Leaves 6-12 inches long. Bracteas lanceolate, subhastate, acute. Flowers small. Capsule small, round, villous. Seeds angular. Inflorescence like that of Tournefórtia. Perhaps a proper genus.

Spicate-flowered Wendlandia. Shrub or tree.

22 V. Tetra'ndra (D. C. l. c.) slurubby; branches tetragonal, smootlı; leaves lanceolate, sessile, smooth ; stipulas pinnatifid, ending each in a subulate point ; flowers axillary, glomerate. $h$. S. Native of Pulo-Penang. Rondelètia tetrándra, Roxb. fl. ind. 2. p. 136. Flowers mixed with many lanceolate-ciliated bracteas. Capsule small, black, angular. Seeds numerous, immersed in pits in the placentas. Perhaps a proper genus.

Tetrandrous-flowered Wendlandia. Shrub. 
23 W.? corymвo'sa (D. C. prod. 4. p. 413.) leaves obovatelanceolate; peduncles for the most part terminal, dichotomously corymbose; flowers unilateral, tetrandrous. $h$. S. Native of Pulo-Penang. Rondelètia corymbòsa, Jack, in mal. misc. 1. no. 1. p. 4. Corolla white, tinged with red. Perhaps a separate genus.

Corymbose-flowered Wendlandlia. Tree.

$24 \mathrm{~W}$. WIGHTIA'NA (Wall. cat. no. 6277.) young branches downy ; leaves obovate-oblong, rather acuminate at the apex, tapering much to the base, glabrous; panicle trichotomous; flowers small, sessile, tetrandrous, clisposed in a single row, on the upper side of the branches of the panicle. h. S. Native of the East Indies. Tournefortia, herb. Wiglit. Leaves 1 to $1 \frac{1}{2}$ foot long. Stipulas broad, membranous. Very like $I$. corymbòsa.

IF'ight's Wendlandia. Shrub or tree.

25 W.? Lawso'nie (D. C. l. c.) sub-arboreous; branchlets quadrangular; leaves lanceolate, acuminated, glabrous; corymbs terminal, trichotomous; fruit oblong. $T_{2}$. S. Native of Malabar. Poutaletsje, Rheed. mal. 4. t. $5 \%$. Petèsia species, ex Juss. Ligústrum species, ex Comm. Lawsònia purpürea, Lam. dict. 3. p. 10\%. Barsoti, anc. enclycl,, where the fruit is said to be baccate, but in the figure the fruit is drawn capsular and many-seeded, it is therefore more likely to be a species of Wendlándia than Petésia.

Lan'son's Wendlandia. Tree.

\section{$+A$ species hardly known.}

26 W.? Sca'NDENs; shrubby, scandent, smooth; leaves opposite, petiolate, oblong, entire; panicles axillary, small, brachiate; capsules globular; seeds small, numerous. $\zeta . S$. Native of the Mauritius. Rondelètia scándens, Roxb. fl. ind. 2. p. 137 .

Clembing Wendlandia. Slirub cl.

Cull. See Rondelètia, p. 517, for culture and propagation.

LXVI. XANTHOPIYYTUM (from $\xi \alpha \theta 0 s$, xanthos, yellow, and $\phi v \tau o v$, phyton, a plant ; so called from the first species being clothed with rufous villi). Blum. bijdr. p. 989 . A. Rich. mem. soc. hist. nat. par. 5. p. 275 . D. C. prod. 4. p. 413.

Lin. syst. Tetra-Pentándria, Monngýnia. Calyx witl an ovate tube and a 4-5-cleft limb. Corolla funnel-shaped, with a short tube, a villous throat, and a 4-5-cleft limb. Stamens $4-5$, exscrted; filaments inserted in the throat, connivent. Style sub-clavate, perforating the disk of the ovarium; stigma thick, 2-lobed, in the throat. Drupe didymons, crowned by the calyx, divisible into 2 many-seeded parts or cells. Placentas prominent, fixed to the middle dissepiment on both sides. Seeds minute, angular, wingless.-This genus is nearly allied to Wendlándia, but differs in the fruit not being dehiscent.

1 X. Fruticulo'sum (Reinw. in Blum. bijdr. p. 989.) suffruticose, clothed with rufous villi; leaves oblong-lanceolate; stipulas bifid; peduncles axillary, trichotomous, many-flowered. $h_{2}$. S. Native of the islands of Java and Nusa-Kambanga, on the mountains, among bushes. Branches, peduncles, calyxes, and lower surfaces of leaves clothed with adpresscd rufous silky villi. Stipulas large, deciduous.

Shrubby Xanthophytum. Shrub.

2 X. spica'tum (Blum. in litt. ex D. C. prod. 4. p. 413.) suffruticose, glabrous, erect; leaves oblong, acuminated at both ends ; spikes axillary and terminal, nutant; flowers in heaps. h. S. Native of Java, especially on calcareous mountains. Chiocócca spicàta, Blum. bijdr. p. 958 . Berries small, indehiscent, dry, didymous, striated. Seeds small, not winged. Stipulas twin on both sides, subulate at the apex, combined into a short sheath at the base. Spikes slender, elongated.
Spicate-flowered Xanthophytum. Shrub.

Cult. For culture and propagation see Rondelètia, p. 517.

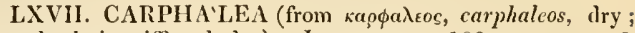
the shrub is stiff and dry). Juss. gen. p. 198 . mem. mus. 6. ). 383. Lam. ill. t. 59. A. Rich. mem. soc. list. nat. par. 5 . p. 274. D. C. prod. 4. p. 413.

Lin. sys'r. Tetríndria, Monogýnia. Calyx with a turbinate tube, and a 4.parted limb ; lobes large, oval-oblong, rather spatulate, scarious, permanent. Corolla with a long filiform tube, a ventricose throat, which is hairy inside, and a 4-parted limb; lobes oblong, acute. Anthers almost sessile, inclosed, oblong. Stigma 1 (ex Juss.), but slender and bifid according to Lamarck's figure. Capsule crowned by the calyx, 2-celled, dehiscing at the cells: valves semi-septiferous. Seeds many in each cell.-A dry stiff shrub, with the labit of Scrissa, and leaves like those of hyssop. Leaves sessile, linear, acute. Stipulas unknown. Flowers terminal (ex Lam.); capitate (ex Juss.); corymbose.-It is doubtful which place this genus should occupy in the order, both the seeds and stipulas being unknown.

I C. Madagascarie'ssis (Lam. ill. 1. p. 258. t. 59.). h. S. Native of Mladagascar. Poir. suppl. 2. p. 119. C. corymbòsa, Willd. spec. 1. p. 585.

Madagascar Carphalea. Shrub.

Cult. For culture and propagation see Rondelètia, p. 517.

LXVIII. SIPA'NEA (Aublet does not give the meaning of this name). Aubl. guian. (1775.) 1. p. 147. t. 56 . H. B. et Kunth, nov, gen. amer. 3. p. 397. A. Rich. mem. soc. hist. nat. par. 5. p. 275 . D. C. prod. 4. p. 414.-Virécta, Lin. fil. suppl. (1781.) p. 17. Vahl, eclog. 2. p. 211. Gærtn. fil. carp. 3. 1. 31. t. 184 . Juss, mem. mus. 6. p. 385.-Sipànea and Virécta, Pers. ench. 1. p. 205.-Rœm. et Schultes, syst. 5. p. 2. no. 853-856.

Lun. syst. Pentándria, Monogýnia. Calyx with a turbinate tube, and a 5 -parted limb; lobes lanceolate-subulate, permanent. Corolla with a terete tube, about 3 times longer than the lobes of the calyx, a bearded throat, and a 5 -parted limb; segments ovate. Anthers 5 , sessile, inclosed. Stigma bifid, acute. Capsule almost globose, crowned by the calyx, 2 -celled, dehiscing at the cells into 2 valves. Placentas central, rather fleshy. Sceds very numerous, wingless, very minutely tuberculated.-Annual green herbs. Leaves ovate. Stipulas lincar, acuminated, solitary on both sides. Flowers axillary and terminal.-This genus is nearly allied to Rondeletia.

1 S. praténsis (Aubl. guian. 1. p. 147. t. 56.) stems creeping at the base; leaves ovate-lanceolate, rather scabrous, ciliated at the base; flowers sessile, almost terminal, sub-corymbose. ๑. S. Native of Cayenne. Poir. dict. 7. p. 199. Cham. et Schlecht. ex Linnæa. 4. p. 166. with a good description. Virécta praténsis, Vahl. eclog. amer. 2. p. 11 . Corolla rosecoloured, with a bearded throat. Stem rather villous. The plant is used in Guiana in astringent ptisans, and in the cure of gonorrhoea; and a decoction of it is used to wash ulcers and other sores.

Field Sipanea. Pl. creeping, 2 feet.

2 S. рісно́тома (H. B. et Kunth, nov. gen. amer. 3. p. 397.) stem tetragonal; leaves lanceolate, clothed with silky villi on both surfaces; panicle terminal, dichotomous. $\odot$. H. Native of South Anerica, in humid places near Atures, at the cataract of the Orinoco. Corolla rose coloured, pilose on the ontside, with a bearded throat. Virécts dichótoma, Spreng. syst. 1. p. 702. Ptychódea dichótoma. Willd. herb. ex Cham. et Schlect. in Linnæa. 4. p. 166 . Stem villous, branched.

Dichotomous Sipanea. Pl. 2 to 3 feet. 
3 S. gromera'ta (H. B. et Kunth, nov. gen. anner. 3. p. 398.) stems unknown; leaves oblong-lanceolate, clothed with silky tomentum on both surfaces, with undulated margins; flowers glomerate, terminal, and axillary. $4 . \mathrm{S}$. Native on the banks of the Orinoco, between Atures and Carichana, in inmolated places. Virécta glomeràta, Spreng. syst. 1.p. 70 2. Ptychòdea sessilifiòra, Willd. herb. ex Cham. et Schlecht. 1. c. Corolla yellow, with a silky tube, which is 4 times longer than the ealyx.

Glomeratc-flowered Sipanea. Pl. creeping?

4. S. Biflòra (Lin. fil. suppl. p. 134.) stem ereeping ; leaves ovate, obtuse; peduncles terminal, rising from the forks of the branches, 2-flowered. $\odot$. S. Native of Surinam and Brazil, in humid places. Cham. et Schlecht, in Linnaea. 4. p. 168. Rondelètia biflòra, Rottb. pl. sur. 7. t. 2. f. 2. A. Rich. mem. soc. hist. nat. par. 5. p. 271 . Virécta virens, Vahl. symb. 2. p. 38. Gærtn. fil. carp. t. 184. There is a tooth between each of the calycine lobes, accorling to Lin. fil., but according to Gartn. there are none; but in the sjecimens examined there are 5 subulate teeth, and 5 minute ones between these.

Two-flowered Sipanea. Pl. creeping.

Cull. The specics of this genus possess no beauty, and are therefore only worth cultivating in botanical gardens. The seeds should be sown in spring, on a hot-bed, and the plants, when of sufficient size, should be planted into separate pots, and shifted from size to size of pots as they grow.

LXIX. VIRE'C'TA (from viréctum, a green place; from the agreeable greenness of the leaves). D. C. prod. 4. p. 414.Virécta species, Smith, but not of Lin. fil.--Sipànea species, A. Rich.?-Phyteumoldes, Smeathmann, in herb. L'Her.

Lin. syst. Pentándria, Monogýnia. Calyx witl an ovate short tube, and 5 linear-setaceous lobes. Corolla funnel-shaped, with an obconical tube, about equal in length to the lobes of the calyx, a naked throat, and 5 linear-oblong ciliated lobes. Stamens 5: having the filaments much exserted beyond the throat; anthers linear, oscillatory, bifid at the base. Style filiform, equal in length to the stamens. Stigma hardly thickened, undivided. Capsule globose, crowned by the calycine lobes in the young state, but almost naked in the adult state, 2 -celled, and at length dehiscing at the cells. Seeds innumerable, 4-5sided, and a little muricated.-Hairy herbs, with opposite branches. Leaves opposite, oval-oblong. Stipulas twin on each side, lanceolate. Flowers white or yellow, disposed in dense cymose corymbs : branchlets of cyme elongated after flowering.This genus is nearly allied to Sipanca, but differs in the genitals being exserted; it differs also from Hedyotis in the quinary number of the floral parts, and in the exserted stamens, \&c.

1 V. mutiflòra (Smith, in Rees's cycl. no. 4.) stem erect; leaves ovate-lanceolate, almost sessile.-Native of Sierra Leone, where it was collected by Smeathmann. Phyteumoìdes hirsùta, Smeathm. in herb. L'Her. Perhaps Sipànea angustifòlia, A. Rich. mem. soc. hist. nat. par. 5. p. 276. is the same as the present plant. Flowers white.

Many-flonered Virecta. Pl. 2 to 3 feet.

2 V. Procu'mbens (Smith, 1. e. no. 2.) stem procumbent; leaves ovate, 3 times longer than the petioles. 4 . S. Native of Sierra Leone.

Procumbent Virecta. Pl. procumbent.

$3 \mathrm{~V}$. LU'TEA; leaves ovate-lanceolate, acuminated, hairy; pedicels aggregate, axillary; calyx 5 -toothed ; corolla tubular, 5 -cleft, hairy. 4 . S. Native of Sierra Leone, in cultivated places. Flowers yellow. Habit of Lilhospérmum. Perhaps the same as $I$. procumbens.

Yellow-flowered Virecta. Pl. rambling.

4 V. elA'tior (D. C. prod. 4. p. 415.) leaves oval-lanceolate, VoL. III. rounded at the base and abruptly petiolate, acute at the apex, smoothish; flowers terminal, almost aggregate; calycine segments very unequal, smoothish; tube of corolla very long. 4. S. Native of Angola, in south-western Africa. Sipanea elàtior, A. Rich. mem, soc. hist, nat. par. 5. p. 276.

Taller Virecta. P'l.

5 V.? PANicura'ta; suffruticose, branched, clothed with brown or copper-coloured hairs; leaves oval-lanceolate; corymbs panicled, axillary, and terminal. 5 . S. Native of Sierra Leone, on the mountains. Flowers small, greenish.

Paniclel-flowered Virecta. Shrub.

Cull. For culture and propagation see Sipànca above.

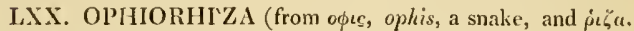
rhiza, a root; used for the cure of the bite of the riband snake). Lin. fl. zeyl. no. 402 . Gertn. fruct. 1. p. 264. t. 55 . R. Br. prod. 1. p. 450 . A. Rich. mem. soc. hist. nat. par. 1823. vol. 1. p. 67. Rioxb. fl. ind. 2. p. 554. Blum. bijdr. p. 976. D. Don, prod. f. nep.p. 135 . D. C. prod. 4. p. 415.-Ophiorhiza species, Lin. gen. no. 210 . and others.

Lin. syst. Pentindria, Monogýnia. Calyx with a short turbinate tube, which is adnate to the ovarium at the base, and a 5-cleft permanent limb. Corolla tubularly funnel-shaped, 3times longer than the limb of the calyx, laairy inside; with 5 ovate segments. Stamens 5, inclosed. Style filiform, girded by an urceolus at the base; stigma 2 -lobed, shorter than the corolla. Capsule broad, compressed, 2-lobed, almost mitreformed, crowned by the calycine teeth, internally divided into 2 cells by a transverse partition, opening between the remains of the 2 fleshy nectareal lips, or by a transverse chink round the apex. Seeds numerous, small, hexagonal. Embryo straight, slender, in fleshy or rather horny albumen.-Dwarf perennial herbs, natives of the East Indies. Leaves opposite, petiolate, membranous, those opposite each other often unequal in size. Stipulas twin on each side, small. Peduncles axillary and terminal, solitary, cymose at the apex, with sub-umbellate branches. Flowers disposed along the branches of the peduncles in a single unilateral row.

1 O. Múngos (Lin. amœn. 2. p. 11\%. spec. 213. mat. med. 27. with a bad figure, but not of Burm.) suffruticose; leaves elliptic-lanceolate, acuminated at both ends, glabrous, papery ; stipulas small, truncate; cymes pedunculate, terminal, branched ; tube of corolla short, funnel-shaped. 4 . S. Native of Java, Ceylon, Sumatra, Pulo Penang, \&c. Blum. bijdr. p. 976. Roxb. f. ind. 2. p. 544 Gærtn. fr. 1. t. 55.? A. Ricl. 1. c. t. 2. Radix. Mungo. Kœmpf. amœe. 573. and 57\%. Stipulas a slight connecting membrane. Nectary a 2-lipped termiual body, surrounding the base of the style. Flowers white. The root is very bitter, and is celebrated as an alexiteric, the trunk of which is horizontal, and the fibres perpendicular. The plant is called in Ceylon Elanerya and Naghawalli, from nagha, the ribandsnake, for the bite of which it is accounted a specific.

Mungos' Snake-root. Fl. May, Dec. Clt. 1820. Pl. 1 to $2 \mathrm{ft}$.

2 O. BRActeola'tA (Wall. cat. no. 6228.) stem ascending, villous above, simple, or a little branched; leaves unequal in size in each pair, as is the case in most of the species; stipnlas ensiform, pubescent; common peduncles slender, villous, from 3.5 inches long. 4.S. Native of the valley of Nipanl, in dark moist situations.

Bracteolate Snake-root. Pl. 1 foot.

3 O. oblonglfòlia (D. C. prod. 4. p. 415.) suffruticose, downy at the apex as well as on the peduncles; leaves oblong, bluntish, attenuated at the base, glabrous above, pale and rather velvety beneath; stipulas small, triangular, acute; cymes pedunculate, branched; tube of corolla short. ᄂ.? 4. ? S. $3 \mathrm{X}$ 
Native of the Island of Luzon, one of the Philippines. O. Múngos, Bartl. in herb. Hærnke. Herb hardly a hand high, erect, suffruticose at the base, and throwing out a few roots from the lower part.

Oblong-leaved Snake-root. Slirub $\frac{1}{2}$ foot.

4 O. V1llo'sa (Roxb. fl. ind. 2. p. 546.) stem suffruticose, erect, villous; leaves ovate-oblong or lanceolate, villous on the veins beneath; stipulas ensiform, villous; cyınes or corymbs terminal, on long peduncles, villous; corolla funnel-shaped. 4. S. Native of Chittagong and Silhet, on the hills in shaded moist places. O. Mlúngos, Gærtn. fruct. 1. p. 264. t. 55.? ex lioxb. Corymbs almost globular, with numerous white almost sessile flowers, and recurved branclies. Urceolus bilabiate, surrounding the base of the style. Capsule opening round the apex.

Villous Snake-root. Pl. $\frac{1}{2}$ foot.

5 O. ARgE' NTEA (Wall. cat. no. 6229.) suffruticose; stem hispid; leaves ovate, acuminated, tapering at the base, glabrons, green above and white beneath; peduncles axillary and terminal, trichotomous at the apex; tube of corolla longer than in O. villosa. h. S. Native of Silhet and Chittagong. O. villòsa, Wall. but not of Roxb. Peduncles downy.

Silvery Snake-root. P], $\frac{1}{2}$ to 1 foot.

6 O. MARGina'ta (Blum. bijdr. p. 9i6.) stem suffruticose, crect; leaves lanceolate, acuminated at botll ends, glabruus, except the margins, which are scabrous; stipulas semi-lanceolate, small, acuminated; cymes or corymbs pedunculate, terminal, almost trifid; corolla funnel-shaped, with an angular tube. 4 . S. Native of Java, on Mount Tjerimai. Allied to O. Múngos, but differs in the flowers being larger and in the stipulas being subulate at the apex.

Marginate-leaved Snake-root. Pl. $\frac{1}{2}$ to 1 foot.

7 O. Fascicula'ta (D. Don, prod. fl. nep. p. 136.) stem suffruticose, erect, branched; leaves elliptic, acuminated, glabrous above and downy beneatly; flowers in terminal fascicles; calycine scgments ovate, acute. h.S. Native of Nipaul, in moist shaded places, near Suembu. Virécta fasciculàta, and $O$. suffruticosa, Hamilt. mss. Differs from O. Mungos in the leaves being downy beneath, and in the flowers being in terminal fascicles.

Fascicled-flowered Snake-root. Pl. $\frac{1}{2}$ foot.

8 O. Rugòsa (Wall. in Roxb. fl. ind. 2. p. 547.) stems herbaceous, creeping at the base, and ascending at the apex, villous; leaves elliptic-lanceolate, attenuated at both ends, shining, rugose and rather scabrous above, paler beneath and rather flowny along the veins; stipulas semi-lanceolate, acuminated; cymes or terminal corymbs pedunculate, bifid or trifid, equalling the uppermost pair of leaves. 4.S. Native of Nipaul, in forests, on Shivapoor and other high mountains near the valley; and of Java, on Mount Gede in woods. Blum. bijdr.p. 976. lioot consisting of a number of long pink-coloured fibres. Petioles villous. Peduncles furnished with 2 subulate bracteas about the middle, villous. Flowers white, downy, twin, the one sessile, and the otber pedicellate. Urceolus 2-lobed.

Urinkled-leaved Ophiorhiza. Pl. $\frac{1}{2}$ to 2 feet.

9 O. Díscolor (R. Br. in W'all. cat. na. 6232.) leaves elliptic-oblong, much acuminated, tapering to the base, glabrous, green above, and reddish beneatb; stems and peduncles downy; perluncles terminal, corymbose, trichotomously branched. h.S. Native of Penang. O. Mungos, Wall. in Roxb. fl. ind. 2. p. 547. O. corymbòsa, Hamilt. herb.

Discoloured-leaved Snake-root. Shrub 1 to 2 feet.

10 O. cane'scens (Bluin. bijdr. p. 977.) stems herbaceous ; leaves oblong-lanccolate, attenuated at both ends, whitish beneath, and rather downy along the veins ; stipulas broad, short, subulate at the apex; cymes on short peduncles, terminal, and axillary, naked, usually quadrifid; stamens about equal in length to the tube of the corolla. 24. S. Native of Java, on the mountains of Seribu, in shady places. Allied to O. rugòsa, but is distinguished from it in the cymes being naked.

Canescent Snake-root. Pl. $\frac{1}{2}$ to 1 foot.

11 O. твлсноса' вPA (Blum. bijdr. p. 97\%.) stems herbaceous, tomentose; leaves on short petioles, ovate-lanceolate, acutish, rather downy on the veins beneath; capsules downy; stipulas subulate; cymes pedunculate, axillary, and terminal, dicliotomous. 24. H. Native of the islands of Java and Nusa-Kambanga. Said to he nearly allied to $O$. villosa.

Ilairy-fruited Snake-root. Pl. $\frac{1}{2}$ to 1 foot.

12 O. Longrflòra (Blum. bijdr. p. 977.) stem suffruticose; leaves oblong-lanceolate, acuminated at both ends, hairy beneath ; stipulas semi-lanceolate, acuminated; cymes pedunculate, terminal, loose-flowered; tube of corolla very long, velvety. $\zeta_{2}$. S. Native of Java, on Mount Gede, in woods near the top.

Long-flonered Snake-root. Shrub $\frac{1}{2}$ to 1 foot.

13 O. sanguinea (Blum. bijdr. p. 977.) stem herbaceous; leaves ovate or elliptic-lanceolate, acuminated, rather oblique at the base, glabrous; stipulas foliaceous, ovate-oblong, bifid; cymes pedunculate, terminal. $4 . \mathrm{S}$. Native of Java, on the mountains in shady places. Leaves reticulately veined in the dry state; the veins blood coloured.

Bloody-reined Snake-root. Pl. $\frac{1}{2}$ to 1 foot.

14. O. Neglécta (Bhum. herb. ex D. C. prod. 4. p. 416.) stem herbaceous, erect, dark purple, glabrous; leaves oblong-lanceolate, acuminated, pite beneath; peduncles axillary, clothed with rusty down; cymes bifid or quadrifid, having the branchlets elongated. 4.? S. Native of Java. Nerves of leaves purplish beneath. Stipulas deciduous.

Neglected Snake-root. Pl. $\frac{1}{2}$ to 1 foot.

15 O. QUADRÍFIDA (Blum. bijdr. p. 977.) stem herbaceous; leaves ovate or oblong, acute at both ends, smooth, with simple veins; stipulas linear, obtuse ; cymes pedunculate, axillary, and terminal, usually quadrifid. 24.S. Native of Java, in shady mountain woods.

Quadrifid-cymed Snake-root. Pl. $\frac{x}{2}$ to 1 foot.

16 O. JAPÓNıcA (Blum. bijdr. 977.) stem herbaceous, radicant; leaves ovate or oblong-lanceolate, roughish above, and downy on the veins beneath; corymbs terminal, pedunculate, dichotomous; corolla funnel-shaped, with a very long tube, and having the segments hairy inside. 2 . G. Native of Japan, where it was collected by Sicbold.

Japan Snake-root. Pl. $\frac{1}{2}$ foot.

17 O. Prostra'ta (D. Don, prod. fl. nep. p. 136.) stem prostrate, radicant, downy; leaves ovate or elliptic, rough above, and downy beneath; calycine segments oblong. 4. G. Native of Nipaul, at Narainhetty. Virécta? prostrà ta, Hamilt. miss. Differs from $O$. Mlúngos in the plant being smaller, and more pubescent, and in the stems being radicant.

Prostrate Snake-root. Pl. prostrate.

I 8 O. томеntòs (Jack, in Roxb. fl. ind. 2. p. 546.) the whole plant is clothed with very soft villi; stem herbaceous, erect, branched; leaves lanceolate-oblong, finely acuminated, on longish petioles, villous and hoary underneath, with reddish veins; stipulas subulate; cymes pedunculate, terminal. b. S. Native of the islands of Pulo-Penang and Sumatra, on the hills. Stem reddish. Petioles villous. Flowers almost sessile. Peduncles and calyxes tomentose. Corollas white. Urceolus bilabiate, glandular. Very like $O$. bracteolàta.

Tomentose Snake-root. Pl. 1 foot.

19 O. ERUBE'scens (Wall. cat. no. 6233.) stem clothed with rusty down at the top; leaves elliptic-lanceolate, acuminated, tapering at the base, glabrous above, and downy beneath; stipulas broad at the base, and cuspidate at the apex; flowers ter- 
minal, corymbose. $\quad$ h. S. Native of the East Indies, at Cheppadong.

Reddish Snake-root. Shrub 1 foot.

20 O. Hispídura (Wall. cat. no. 6234.) stem and petioles lowny: leaves elliptic, tapering to both ends; peduncles terminal, downy, corymbose, dichotomously branched; capsules downy. 5.S. Native of the East Indies, at Tavoy.

\section{Hispid Snake-root. Shrub $\frac{1}{2}$ to $\frac{3}{4}$ foot.}

21 O. heterophy'Lla (Jack, mal. misc. 2. no. 7. p. 85. Wall. in Roxb. f. ind. 2. p. 547.) stem crect, tomentose; leaves roundish-ovate, those opposite each other very unequal in size; cymes small, terminal, h.S. Native of Sumatra, in the interior of the island. Leaves with a bluntish acumen, smooth, pale, and whitish beneath. Capsules compressed, obcordate.

lariable-leated Snake-root. PI. $\frac{1}{2}$ to 1 foot.

22 O. Acumina'ta (D. C. prod. 4. p. 416.) stem suffruticose, clothed with rufous velvety down above, as well as the petioles; leaves lanceolate, acuminated, glabrous, velvety on the nerves beneath; stipulas broad at the base, and awned by a bristle at the apex: cymes pedunculate, of 5 velvety branches. $h$. S. Native of the island of Luzon, at Sorzogon. O. subumbellàta, Bartl. in herb. Hænke. Perhaps the same as $\mathbf{O}$. subumbellàta, Forst.

Acuminated-leaved Snake-root. Shrub.

23 O. Richardia'na (Gaud. in Freyc. voy. p. 473. t. 97.) plant suffruticose, quite glabrous ; leaves oblong, much acuminated at both ends, petiolate, with smooth margins; corymbs terminal, on short peduncles, trifid or quadrifid; tube of corolla short; calycine teeth very short. $h$.S. Native of the Moluccas.

Richard's Snake-root. Shrub $\frac{1}{2}$ to 1 foot.

24. O. Perpusílza (Blum. herb. ex D. C. prod. 4. p. 417.) stem erect, dwarf, simple ; leaves elliptic, glabrous; flower terminal, solitary, nutant, on a short pedicel ; corolla funnel-shaped, glabrous; calycine teeth obtuse. 4. S. Native of Java. Herb hardly an inch long. Fruit unknown.

Smallest Snake-root. Pl. 1 incl.

25 O. Harrisòxiı (Heyne, ex Wall. cat. no. 6236.) stem, petioles, peduncles, and nerves of leaves on the under side downy; leaves ovate or roundish-ovate, acutish, glabrous and green above, and pale beneath ; peduncles terminal, corymbose, and dichotomously branched at the apex. 4. S. Native of the East Indies. Root creeping much.

\section{Harrison's Snake-root. Pl. $\frac{1}{3}$ to 1 foot.}

26 O.? gemina'ta (Wall. cat. no. 6237.) stem, petioles, peduncles, and nerves on the under surface of the leaves, downy; leaves large, obovate-oblong, tapering much at the base, and running down the petioles, and acute at the apex, glabrous and green above, but pale or reddish beneath; peduncles long, terminal, racemose. $\quad$. S. Native of the East Indies, in Silhet and Gualpara. Dentélla? geminàta, Herb. Ham. Root creeping. Stem dwarf. Racemes numerous, crowded, secund, alternate, short, recurvel, on each peduncle. Perhaps a proper genus.

Twin Snake-root. $\mathrm{Pl} . \frac{1}{2}$ to 1 foot.

$$
+A \text { doublful species. }
$$

27 O. ? subumbella'ta (Forst. prod. no. 66.) stem shrubby; leaves lanceolate, acute; umbels axillaıy, trifid. $h$.S. Native of the island of Otahiti.

Subumbellate-flowered Snake-root. Shrub.

Cult. The species of Snake-root will grow in a mixture of loam, sand, and peat; and they may either be increased by cuttings under a hand-glass in heat, or by seeds.

LXXI. ARGOSTE'MMA (from apros, argos; white, and $\sigma \tau \varepsilon \mu \mu a$, stemma, a crown; in reference to the terminal racemes or umbels of snow white flowers). Wall. in Roxb. fl. ind. 2. p. 32.4. Blum. mss. ex D. C. prod. 4. p. 417.-Pomángium, Reinw. ex Blum.

LiN. syst. Tri-Pentándria, Monogýmia. Calyx witl a short obconical tube, and a 3-4-5-cleft limb: lobes acute, valvate in astivation. Corolla rotate, spreading, with a $3-5$, rarely with a 3-4-parted limb. Stamens alternating with the lobes of the corolla. Anthers large, exserted, cohering at the apex. Style perforating a flesliy disk; stigma globose. Capsule crowned by the calyx and an opercular disk, 2 -celled, dehiscing in a radiant manner at the apex; receptacles convex, adnate to the dissepiment. Seeds numerous, angular.-Herbs, for the most part hairy from short lown. Leaves quite entire, opposite, one usually smaller than the other, rarely verticillate. Stipulas foliaceous, ovate, solitary on both sides. Peduncles terminal, and almost axillary, bearing fascicled umbels of flowers at the apex, very rarely only one flower. Flowers white. The species of this genus have the habit of those of Ophiorhiza.

I A. sarmento'sum (Wall. in Roxb. fl. ind. 2. p. 324.) plant rather villous, creeping at the base, and stoloniferous, the upper part of the stem erect; leaves ovate, obtuse, almost sessile, downy above, and villous on the nerves beneath, in two approximate pairs ; flowers 3 or 4-parted, disposed in a terminal umbel or corymb-formed raceme. $h$.S. Native of the East Indies, on rocks on the hills at Schukragiri, near Rujmaluul; and of Nipaul, on the mountains to the northward of the valley on the route to Gosaingstlan. Stem and leaves rather pubescent. Flowers snow white. Corolla 5 times longer than the calyx. Leaves at end of stem.

Sarmentose Argostemma. Pl. $\frac{1}{2}$ foot.

2 A. verticilla'tum (Wall. 1. c. p. 325.) plant erect, downy, and tufted; leaves 4 in a whorl, linear-lanceolate, rather falcate ; peduncles $2-3$, rarely solitary, bearing a few umbellate tlowers each; flowers 4-5-parted. 4. S. Native of Nipaul, on rocks at Moreko in the valley. Root fleshy, and almost tuberous. Stems furnished with a pair or two of lanceolate connate scales. Leaves ciliated. Flowers snow white, rather smaller than those of the preceding species. The mouth of the corolla is marked with 10 minute tubercles, alternately receiving the basis of the filaments. Ovarium smooth. Wall. pl. rar. asiat. 2. p. 80.t. 185.

Whorled-leaved Argostemma. Pl. 4 inches.

3 A. rostra'tum (Wall. l. c. p. 326.) plant erect, smooth ; leaves in 2-4 approximate pairs, narrow-lanceolate, acuminated, petiolate; stipulas ovate, recurved, permanent; umbels pedunculate, terminal, many flowered; segments of corolla and tube of the anthers acuminated. $\%$. S. Native of the East Indies, on the Pundua mountains near Silhet. Stem furnished with several remote pairs of lanceolate-ciliated stipulas : the upper ones becoming enlarged and foliaceous. Pedicels an inch long, clavate, a little ventricose above the middle. Corollas white, nearly an inch in diameter. Habit of Trientàlis Europa'a.

Beaked-anthered Argostemma. Pl. $\frac{1}{2}$ to $\frac{3}{4}$ foot.

4 A. Pı́ctum (Wall. 1. c. p. 327.) plant glabrous; stem short; leaves smooth, ovate, subcordate, painted with reticulated white nerves, on very short petioles; umbels terminal, pedunculate, many fowered; flowers pentandrous. 4.S. Native of PuloPenang, growing on rocks near the water-fall. Leaves only 2 , or in 2 remote pairs, slightly ciliated. Peduncle simple, or having 2 opposite branches, each bearing a round umbel of many small flowers. Unripe berry as large as a coriander sced, smooth.

Painted-leaved Argostemma. Pl. I to 2 inches.

5 A. Borragíneum (Blum. mss. ex D. C. prod. 4. p. 417.) stem creeping at the base, but erect above, and scabrous at the apex; leaves elliptic, acute at both ends, petiolate, with a few $3 \times 2$ 
scattered hairs above, but more crowded on the nerves beneath, and on the petioles; umbels pedunculate, terminal, subtrifid; flowers pentamerous, at length secund. $\odot$. S. Native of Java, in mountain woods in humid places. Stem 4-6 inches long. Leaves 4-6 along each stem.

Borrage-like Argostemma. Pl. $\frac{1}{2}$ foot.

6 A. Monta'nun (Blum. mss. ex D. C. prod. 4. p. 418.) stem tomentosely hairy, ascending ; leaves ovate, acuminated, ciliated, petiolate, beset with scattered hairs above, and with bristlelike liairs on the nerves beneath; umbel terminal, pedunculate, bracteated, 5-6-flowered.-Native of Java. Pomángium montànum, Blum. mss. Stem branched a little, 3-4 inches long. Leaves 10-1 2 on each stem, disposed in nearly equal distant pairs. Peduncles hardly longer than the leaves.

Mountain Argostemma. Pl. $\frac{1}{4}$ foot.

7 A. Pauchelo'rum (Blum. miss. ex D. C. prod. 4. p. 418.) stem creeping at the bottom, but branched, and rather scabrous above; leaves petiolate, ovate, acute, tapering a little at the base, hairy; umbels pedunculate, shorter than the leaves, terminal, subtrifid, few-flowered. $\zeta$. S. Native of Java, on Mount Salak in shady places. Leaves $16-20$ on each plant, membranous, pale beneath. Flowers white, smaller than those of the preceding species.

Fon-flonered Argostemma. Pl. $\frac{1}{2}$ foot.

S A. uniflòrux (Blum. mss. ex D. C. prod. 4. p. 418.) stem creeping below, clothed with hairy pubescence; leaves opposite, very unequal, one of which in each pair hardly exceeds a stipula in size, the otler is lanceolate, with an unequal base, rather pilose; peduncle terminal, 1-flowered. $\odot$. S. Native of Java, in woods on the higher mountains.

One-flonercd Argostemma. Pl. creeping.

Cult. For culture and propagation, see Ophiorhiza, p. 523. The species are all remarkable in their appearance.

LXXII. SPIRADI'CLIS (from $\sigma \pi \varepsilon \iota r$, speira, a spire, and is $\lambda \iota c$, diclis, valves with folding doors; in allusion to the valves being divided into 2 parts, and also twisted at the apex). Blum. bijdr. p. 975. D. C. prod. 4. p. 418.

Liv. syst. Pentándria, Monogýnia. Calyx with an oblong turbinate tube, and a 5-toothed limb. Corolla with a short tube, and a 5-parted spreading limb. Stamens 5, inclosed. Style girded by 4 glands; stigma 2 -lobed in the throat. Capsule oblong, crowned by the calyx, 2-celled, 2-valved; valves bipartite, at length twisted. Seeds numerous, angular.-This genus is nearly allied to Tüla, with the tufted habit of Nertèra. Leaves opposite, ovate, rather undulated, glabrons. Spikes terminal and lateral, few-flowered. Flowers small, secund, each furnished with one bractea.

l S. c.espitòs A (Blum. l. c.)-Native of Java, at the foot of Mount Salak in humid places.

Tuftcd Spiradiclis. Pl. tufted.

Cult. For culture and propagation see Tùla below.

LXXIII. TULA (like the rest of Adanson's names this is also probably without a meaning). Adans. fam. 2. p. 500. Juss. mem. mus. 6. p. 385 . Røem. et Schultes, syst. 4. p. 25. D. C. prod. 4 . p. 418.

Lin. syst. Pentándria, Monogýnia. Limb of calyx 5-toothed. Corolla with an oblong tube, and a 5 -cleft blunt toothed curled limb. Anthers inclos.d. Capsule 2-celled; cells many seeded. -A small procumbent branched tufted herb. Leaves reniform, petiolate. Pedicels asillary, short, 1-flowered. 'This genus was alone known to Feuillee, and is therefore very doubtful. Habit of Nertera, but differing in the flowers being pentamerous, and in the cells of the fruit being many seeded; it is perhaps, however, or ly that genus badly described.
I T. Agunsònı (Roem. et Schultes, syst. 4. p. 355.) భ. G. Native of Peru, on rocks by the sea-side. Soldanclla facie, Feuill. obs. 3. pt. 2. p. 63 . t. 44.

Adanson's Tula. Pl. tufted.

Cult. A mixture of loam, peat, and sand will be a good soil for this little plant; and it may either be increased by cuttings planted in sand under a hand-glass, or by seeds. The pot in which it is grown sliould be half filled with sherds.

LXXIV. DENTE'LLA (a dim. of dens, a tooth; the lobes or segments of the corolla are furnished with a small tooth on each side). Forst. gen. p. 26. t. 13. Lam. ill. t. 118. D. C. prod. 4. p. 418. Juss. mem. mus. 6. p. 385.-Oldenlándia species, Lin. -Hedyòtis species, Lam.

Lin. syst. Penlándria, Monogýnia. Calyx with an ovateglobose tube, and a 5 -cleft limb. Corolla funnel-shaped, 5-cleft ; lobes furnished witl a small tooth on each side; throat hairy. Anthers 5, inclosed, almost sessile. Style short; stigmas 2, thick. Capsule almost indehiscent, nearly globular, 2-celled, crowned by the limb of the calyx. Placentas fleshy, prominent on both sides within the cells. Seeds small, ovate.-A creeping tufted marsh annual herb. Stems filiform, glabrous. Leaves oblong, glabrous, ciliated at the base, as well as the petioles. Stipulas small, acute. Pedicels axillary, alternate, 1-flowered, short. Fruit hispid. Flowers small, white.

1 D. RE'PENS (Forst. 1. c.) $\odot$. F. Native of the East Indies, as in Java, Coromandel, Timor, Luconia, New Caledonia, \&c., in humid sharly places along the banks of rivers, and on the margins of rice fields. Blum. bijdr. p. 990. Roth. nov. spec. 139 . Roxb. H. ind. 2. p. 159. Cham. et Schlecht. in Linnæa. 4. p. 150. Hedyòtis rèpens, Lam. ill. no. 1424. Oldenlándia rèpens, Lin. mant. p. 4.0. but $\mathrm{O}$. rèpens of Burm. $\mathrm{A}$. ind. according to his herbarium is nothing but Péplis Pórtula.-Rumph. amb. 6 . t. $170 . \mathrm{f} .4$. Flowers small, in the divisions of the branchlets.

Creeping Dentella. Fl.July. Clt, 1802. Pl. creeping.

Cull. The seeds require to be sown on a gentle lot-bed in spring; and the plants when of sufficient size may be planted out into a moist sluady situation in the open ground.

LXXV. DE'PPEA (named after M. Deppe, who has collected and sent home many plants from Mexico). Cham. et Schleclit. in Linnæa. 5. p. 167. D. C. prod. 4. p. $61 \mathrm{~S}$.

Lis. syst. Tetrándriu, Monogýnia. Teeth of calyx 4, triangular. Corolla somewhat rotate, quite glabrous; lobes elliptic. Anthers 4, linear, exserted; filaments very short. Style longer than the stamens; stigma thicker than the style. Capsule membranous, elliptic, crowned by the calycine teeth beneath the vertex, 2-celled; cells 1 -seeded, with a loculicidal dehiscence. Seeds fixed to the middle dissepiment.- $\boldsymbol{A}$ small shrubby plant, with a woody root, and reddish inner bark. Leaves petiolate, elliptic, acuminated at both ends, rather pilose above and on the margins. Stipulas triangular, deciduous. Cymes terminal and axillary, pedunculate, of 3 or 4 branches. Flowers yellow. Habit, fruit, and capsule of Hcdyo'is, but the cells are 1 -seeded as in the tribe Spermacòcea.

1 D. enyтuronuiza (Cham. et Schlecht. l. c. p. 168.)-Native of Mexico, in shady places near the Hacienda de la Laguna. D. hydyotídea, D. C. prod. 4, 13. 618 .

Red-rooted Deppea. Shrub 1 to 2 feet.

Cult. For culture and propagation see Dentélla above.

Subtribe 1I. HEDYO'TEE (this tribe contains plants agreeing with lledyòtis in important characters). D. C. prod. 4. p. 419. Stipulas resembling a sheath on both sides, and ending in many bristles at the apex.

LXXVI. HEDYO'I'IS (from ičvs, hedys, sweet, and ovs wros, ous olos, an ear ; the leaves are oval, soft, and firm, from 
which circumatance they have been compared to ears). Roxh. f. ind. 1. p. 368 . Cham. et Schlecht. in Limmea. 4. p. 153. D. C. prod. 4. p. 419.-Hedyotis species of Lin. and all authors. Lin. sist. Tetrándria, Monogynia. Calyx with an ovate tube, and a 4-toothed limb : teetli erect, permanent, also separated on the fruit by acute narrow recesses. Corolla with a short tube, a bearded throat, and a 4 -lobed limb. Stamens exserted a little; anthers ovate or roundish, small. Cajsule ovate, somewhat attenuated at the apex, crowned by the calycine tecth, which arc connivent, but separate, 2 -celled, and dehiscing in the middle of the cells. Secds minute, angular, many in cacli cell. - Herbs, soinetimes suffruticose at the base, with a habit like that of Spermacòce. Stems tetragonal or nearly terete. Leaves opposite. Stipulas adhering to the petioles on both sides, ending in many bristles. Flowers axillary, usually glomerate.This genus differs from Houstonia, to which St. Hil. pl. rem. bras. p. sxi. has joined it, in the calyx being adnate to the fruit the whole length. It diflers from Oldenlándia in the teeth of the calyx being separated on the fruit by narrow recesses, not by broad ones.

\section{- Pedicels axillary, 1-flomered, solitary, and sometimes twin.}

1 H. gra'cilis (D. C. prod. 4. p. 419.) plant decumbent and elongated, scabrous from hairs; leaves linear, acute; stipulas cleft into many bristles; pedicels axillary, 1-flowered; solitary, equal in length to the leaves; corolla hardly longer than the calycine teeth.- Native of New Caledonia. Capsule downy, ovate, rather compressed: lobes of calyx lanceolate, separated by narrow recesses.

\section{Slender Hedyotis. Pl. decumbent.}

2 H. Adscé Nsionis (D. C. l. c.) stem suffiruticose, branched, glabrous; leaves linear, acute, with revolute margins, and are, as well as the calyses, rather scabrous; pedicels axillary, solitary, 1 -flowered, shorter than the flowers. $h$. S. Native of the island of Ascension, where it was collected by Lesson, G. Don, \&c. Herb becoming black on drying. Capsule compressed. Seeds very minute. Corolla white. Lobes of calyx long, linear. Ascension Hedyotis. Pl. $\frac{1}{2}$ foot.

3 H. Pauciflóra (Bartl. in herb. Hæenke, ex D. C. prod. 4. p. 4.19.) plant suffruticose, glabrous; branches tetragonal, smooth; leaves linear, very acute, with revolute margins; stipulas with many stiff erect bristles; flowers solitary, axillary, hardly pedicellate. $h_{2}$. S. Native of the island of Luzon, one of the Philippines. Leaves 1 or $1 \frac{1}{2}$ inch long, and a line broad. Fruit unknown, but the lobes of the calyx are separated by narrow recesses, indicating it to belong to this genus.

Fen-flonered Hedyotis. Pl.

* Floners axillary, almost sessile, disposed in glomerale whorles.

4. H. tenelliflòra (Blum. bijdr. p. 971.) stems suffruticose, kneed, procumbent; leaves on short petioles, lanceolate, veinless beneath, with scabrous margins; bristles of stipulas long and setaceous; flowers usually twin, axillary, sessile. দq. S. Native of the island of Nusa Kambanga, near Java.

Slender-flonered Hedyotis. Shrub procumbent.

5 H. Asigustifòzia (Cham. et Schlecht. in Linnaca. 4. p). 153.) stems branched a little, tetragonal, when young the angles are luairy; leaves linear, very narrow, acute, with revolute scabrous margins; stipulas hairy, membranaceously fringed; flowers 3-6-together, axillary, almost sessile, glomerate. $\odot . F$. Native of the island of Luzon, one of the Philippines.

\section{Narrow-leaved Hedyotis. Pl. $\frac{1}{2}$ foot.}

6 H. Bóscu (D. C. prod. 4. p. 420.) plant glabrouss; stems herbaceous, ascending, branched, slender, tetragonal; leaves lincar; bristles of stipulas shorter than the fruit ; flowers few, axillary, somewhat verticillate; fruit ovate, crowned by the

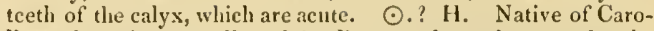
lina, where it was collected by bose, and sent home under the name of Diodlia. Leaves almost an inch long, and a line broad. Secds vervininute.

Bose's Herlyotis. Pl, ascending.

千 H. auricula'ma (Iin. spec. 147.) stem almost simple, tetragonal, rather hairy at the apex; leaves lanceolate-ovate, nerve:l ; stipulas ciliated with bristles; flowers glomeratc, axillary, somewhat verticillate. $\%$. S. Native of Ceylon, Malabar, also of Silhet and Nipaul, ex Roxb. fl. ind. 1. p. 369 . Kheed.mal. 10. t. 32.-Burm. f. zeyl. t. 108. f. 1.? H. nervòsa, Lam. dict. 3. p. 79.? Flowers white, sessile.

Auricled Hedyotis. Pl. $\frac{1}{2}$ foot, procumbent.

8 H. genicula'ta (Roxb. fl. ind. 1. p. 368.) plant weak, decumbent; stems nodose, terete, smooth; leaves almost sessile, lanceolate, smooth; flowers on short peduncles, disposed in whorles.-Native of the Malay Islands. 'The rest unknown.

Kneed-stemmed Hedyotis. Pl. decumbent.

9 H. LAPEYrou'si (D. C. prod. 4. p. 420.) stem erect, glabrous, terete, rather angular at the apex, and harchy branched ; leaves oblong-lanceolate, acuminated at both ends, glabrous; stipulas of many bristles; flowers few, axillary, almost sessile, verticillate; capsules globose. $\odot$. F. Native of the island of Vanikoro, where it was collected by Lesson. Stem $1 \frac{1}{2}$ foot high. Leaves 4 inches long, and 8-10 lines broad, lined with 5-6 oblique nerves on each side.

La Peyrouse's Hedyotis. Pl. $1 \frac{1}{2}$ Coot.

10 H. crassifòlia (Blum. bijdr. p. 971.) stems diffuse, rather hairy; leaves lanceolate, cuspidate, almost veinless, except the middle nerve, scabrous beneath and on the nargins, on very short petioles; stipulas setigerous; flowers disposed in clense whorles; filanents exserted.-Native of the west of Java, in humid slıady places. Said to be allied to $H$. hispida. Bristles. of the stipulas long. Teeth of calyx very acute. Perhaps the same as $H$. cralceogònum.

Thick-leaved Hedyotis. PI. 2 to 3 feet.

11 H. cratæogònum (Spreng. pug. 2. p. 35.) stems terete, glabrous, articulated; leaves lanceolate, acuminated, veiny, scabrous ; stipulas setaceously jagged ; fiowers sessile, disposed in glomerate whorles.- Native of Amboyna, ex Rumph. amb. 6. p. 25. t. 10.; and of Java, ex Lin. not in Jamaica, as said by Roem. et Schultes, syst. 3. p. 199. Oldenlándia verticillàta, Lin. mant. 40 .

Strong-joinled Hedyotis. Pl. 1 foot.

12 H. H'srida (Retz, obs. 4. p. 23. but not of Roth,) stems diffuse, branched, tetragonal, rooting at the nodi ; leaves ses rile, lanceolate, with hispid margins; stipulas with many bristles; flowers axillary, almost sessile, disposed in glomerate whorles; filaments inclosed.-Native of China, ex Retz; of the Moluccas, ex Roxb. ft. ind. 1. p. 368.; of Java, Blum. bijdr. p. 971. Oldenlándia hí pida, Poir. dict. 4. p. 536 . Stamens shorter than the style, which is clavate, ex Retz. Capsule hispid, ex Spreng. pug. 2. p. 32.

IIispid Hedyolis. Pl. $\frac{1}{2}$ foot, decumbent.

13 H. uncinétia (Hook. et Ain. in Beech. voy. pt. bot. p. 192.) plant suffruticose, glabrous ; branclıes simple; leaves petiolate, oblong-lanceolate, with almost simple longitudiual veins ; flowers axillary and terminal, numerous, almost sessile, disposed in glomerate whorles; capsules turbinate, glabruus, crowned, bipartite at the dissepiment; tube of calyx contracted, and the lobes subulate and recurvedly uncinate, long, and ciliated. $\zeta$. G. Native of China. This may be the type of a new genus, and is probably the $H$. cephalophora, R. Br. in Wall. cat. no. $84 \%$.

Ilooked-calyxed IJedyotis. Shrub. 
14 H. Rotundifólia (Spreng. pug. 3. p. 197.) plant decumbent, branched a little; leaves petiolate, broad-ovate, somewhat 3-nerved; stipulas scarious, ciliated; flowers axillary, almost sessile, disposed in whorles; capsules hispid.-Native of the East Indies, in humid places. Oldenlándia trinérvia, Retz, obs. 4. 1) 23.

Round-leaved Hedyotis. Pl. decumbent.

15 H. perpusílla (Hook. et Arn. in bot. misc. 3. p. 259.) glabrous; stems tufted, diffuse, branched, weak ; leaves oblong; stipulas ininute, not setigerous; pedicels terminal, and from the forks of the branches, 1-flowered, about equal in lengtlı to the leaves; tube of calyx globose, hispid from bristles; teeth of calyx erect, ovate, obtuse.-Occasionally found in inundated places by the shores of La Plata, near Buenos Ayres. Stem 1 to 2 inches long, branched; the branches are furnished with several short lateral ramuli, from the axils of which springs a peduncle, which after flowering becomes reflexed. Very closely allied to $I I$. uniflora, but seems to differ from the genus by the stipulas not being furnished with bristles.

Lcast Hedyotis. Pl. tufted.

16 H. NODIF Lòra (Wall. cat. no. 855.) glabrous ; stems quadrangular; petioles downy; leaves ovate-elliptic, acuminated, veined; flowers much crowded, axillary, subverticillate, sessile. ४. S. Native of the East Indies, in Tavoy.

Knot-flon'ered Hedyotis. Pl. 1 to 2 feet.

17 H. ARGE'NTEA (Wall. cat. no. 858 ) glabrous; stem quadrangular; leaves broad-ovate, acuminated, whitish above, and rusty beneath; flowers in axillary heaps. 4. S. Native of the Burmese Empire, on the banks of the Irrawaddy.

Silvery Hedyotis. Pl. 2 to 3 feet.

18 H. costa'ta (R. Br. in Wall. cat. no. 849.) stem downy, quadrangular; leaves lanceolate, tapering to both ends, glabrous, with many parallel veins; flowers disposed in crowded axillary heaps, subverticillate; teeth of calyx separated by distant reces. ses. 2. S. Native of Pulo-Penang and Silhet.

Ribbed Hedyotis. Pl. 2 to 3 feet.

19 H. PINıFOLIA (Wall. cat. no. 850.) plant much branched. branches quadrangular; leaves linear, with revolute edges; flowers disposed in axillary and terminal verticillate heaps. $\odot$. S. Native of Pulo-Penang, and of the Burmese Empire, at Prome and Amherst. Perhaps a species of Oldenlandia.

Pine-leaved Hedyotis. Pl. $\frac{1}{2}$ to 1 foot.

20 H. conge'sta (R. Br. in Wall. cat. 844.) herbaceous, glabrous; stem and branches quadrangular; leaves ovate-lanceolate, acuminated, pale beneath ; flowers crowded, axillary; stipulas somewhat pinnatifid; lobes of calyx rounded, separated by narrow blunt recesses. 4 . F. Native of Pulo-Penang.

Cronded-flowered Hedyotis. Pl. 3 to 4 feet.

21 H. macrophy'Lla (Wall, cat. no. 841.) stem and branches quadrangular; leaves large, roughish, veined, tapering to both ends; stipulas pinnatifid ; flowers much crowded, axillary, forming glomerate whorles. $\psi$. S. Native of Pulo-Penang. Calyx downy, with the lobes separated by narrow recesses.

Large-leaved Hedyotis. Pl. 2 to 3 feet.

\section{* * Peduncles axillary, many-flowered: flowers crowded.}

22 H. сарітA'та (Lam. dict. 3. p. 80.) stem terete, almost simple, downy ; leaves almost petiolate, ovate-lanceolate, acute, nerved, glabrous above, velvety on the nerves beneath; stipulas setaceously jagged; peduncles axillary, solitary, much shorter than the leaves, bearing each a dense head of flowers.-Native of the East Indies, particularly in Java, in moist parts of mountains. Blum. bijdr. p. 973. Habit of Euphórbia capitàta.

Capitate-flowered Hedyotis. Pl. $\frac{1}{2}$ foot.

23 H. LiNeA'ta (Roxb. fl. ind. 1. p. 369.) plant diffuse, pilose; leaves sessile, orate-lanceolate, with longitudinal simple parallel veins; peduncles axillary, many flowered, rather long, 2-3-together; capsules rousd, pilose. $\odot$. F. Native of the East Indies, in Chittagong. The rest unknown.

Lined-leaved Hedyotis. Pl. diffuse.

24 H. ulmifòrs (Wall. in Roxb. A. ind. 1. p. 370.) plant ascending, clothed with soft hairs; leaves oval-lanceolate, acute, nerved, very villous on the nerves on both surfaces; stipulas cup-shaped, acuminated at both ends, joined to both sides of the petioles; peduncles axillary, much shorter than the leaves, bearing many subcorymbose flowers; flowers usually by threes; calyx villous, with acute lobes. 24. G. Native of Nipaul. H. lineàta, D. Don, fl. nep. p. 134. but not of Roxb. Spermacòce lineàta, Hamilt. mss. Stipulas coriaceous, acuminated in the middle. Stems many from the same root, woody, simple. Calycine segments lanceolate, spreading.

Elm-leaved Hedyotis. Pl. 1 to 2 feet.

25 H. vesti'ta (R. Br. in Wall. cat. no. 847.) stems, peduncles, and petioles villous; stem quadrangular; leaves ovate-lanceolate, much acuminated, tapering at the base, downy, particularly on the veins beneath; stipulas villous, bearing 3 long bristles each ; peduncles axillary, trichotomous, each division bearing a head of flowers. 4. S. Native of Pulo-Penang and Silhet. Leaves with parallel veins.

Clothed Hedyotis. Pl. 2 to 3 feet.

26 H. macrosténon (Hook. et Arn. in Beech. voy. pt. bot. p. 192.) plant suffruticose, branched; branches pubescent ; leaves on short petioles, ovate-lanceolate, clothed with soft down beneath, rather scabrous and shining above, with longitudinal simple parallel veins; peduncles axillary, solitary, shorter than the leaves, many flowercd; flowers capitate; stamens mucl exserted; capsules hairy, free at the apex. h.G. Native of China. Closely allied to the two preceding species.

Long-stamened Hedyotis. Pl. $\frac{1}{2}$ foot.

27 H. serPyLLifòla (Poir. suppl. 3. p. 14.) stem herbaceous, branclied, rather angular; leaves ovate, acuminately mucronate, somewhat ciliated; stipulas bipartite, acuminated; flowers $2-4$ in each heap, axillary and terminal, on short peduncles; tube of calyx downy.-Native of the island of Bourbon, where it was collected by Bory de St. Vincent. Corolla white, shorter than the calyx. Seeds innumerable, very minute. Stem hispid.

Hild Thyme-leaved Hedyotis. Pl. $\frac{1}{2}$ to $\frac{3}{4}$ foot.

28 H. RE'PENs; stem creeping, filiform, branched, rooting at every joint; leaves small, oval or obovate, linear-lanceolate, ex Lour, smooth; flowers axillary, solitary, on very short pedicels ; capsule nearly globular, covered with hollow pellucid laairs. 4 . S. Native of the East Indies and China. Oldenlándia rèpens, Burm. fl. ind. 38. t. 15. f. 2. Lour, coch. p. 78 . Corolla bellshaped, white.

Creeping Hedyotis. Pl. crecping.

29 H. Uniflòra (D. C. prod. 4. p. 421.) plant glabrous; stems creeping, branched, weak ; leaves ovate-roundish, obtuse ; stipulas small; pedicels terminal, 1-flowered, longer than the leaves; tube of calyx rather hispid. $\odot$. F. Native of Chili, in sandy places along the banks of streams. Oldenlándia uniflora, Ruiz et Pav. fl. per. 1. p. 57. Corolla with a broad tube, which is bearded inside. Lobes of calyx ovate, acutish.

One-flowered Hedyotis. Pl. creeping.

30 H. GLOMERA'TA (Ell. sketch. 1.p. 185.) stem nearly ereet, herbaceous, downy, branched; leaves lanceolate, attenuated at the base, downy ; stjpulas acutely bidentate ; flowers almost sessile, capitate, axillary and terminal, rarely almost solitary; tube of calyx hispid. $\odot$. ex Torrey, $\%$. ex Ell. H. Native of North America, in humid places, from Carolina to New York. Torr. f. un. st. 1. p. 171. Oldeulândia glomeràta, Michx. fl. bor. amer. 1. p. 83. H. auriculàta, Walt. car. p. 85. but not of Lin. Oldenlándia uniflòra, Lin. ex Willd. spec. 1. p. 674. H. 
uniflòra, Lam. ill. p. 271.? H. Virgínica and H. glomeràta, Spreng. syst. 1. p 412,413 . Lobes of calyx 4, ovate, acuminated. Corolla subrotate, shorter than the calyx; with the lobes rather spinose. Stamens short, opposite the lobes of the corolla, ex Torrey. Style almost wanting; stigma thick, undivided. Sceds innumerable, very minute, as in the genus Oldenlandir.

Glomeratc-flowered Hedyotis. Pl. $\frac{1}{2}$ creeping.

81 II. Golte'ssis (D. C. prod. 4. p. 421.) plant diflise, many stemmed; stems rather angular, glabrous, except at the nodi, where they are downy; leaves lanceolate, acute, glabrous; peduncles axillary and on the tops of the branches, disposed in umbellate heaps, a little shorter than the fruit ; fruit downy, crowned by the calycine teeth, which are subulate, and somewhat involutely uncinate at the apex. $\odot$. F. Native of the coast of Africa, in the island of Goree. Habit of Chickweed. Leaves oval-oblong or lanceolate. Capsule dehiscing but slowly. Seeds very minute. Corolla not seen.

I ar. $\beta$, ćrecta (D. C. J. c.) stems erect, much shorter than those of the species; heads of flowers solitary, terminal, umbellate. $\odot$. S. Native in humid parts of woods.

Gorce Hedyotis. Pl. diffuse.

* * Panicles or corymbs tcrminal, loose, rarcly axillary. The spccies are very different from each other, and from the rest of the genus.

32 H.? LA'XA (D. Don, prod. fl. nep. p. 195.) stem herbaceous, weak, dichotomously branched, angular, glabrous; leaves ovate, acute, rather hairy on both surfaces, ciliated; stipulas divided into bristles; peduncles axillary, dichotomous; flowers usually by threes. 24. G. Native of Nipaul. Habit of a species of Ophiorhiza. Anthers in some specimens examined exserted, and in others almost inclosed. T'eetl of calyx acutely mucronate, 3 times shorter than the corolla. Capsule somewhat didymous, free at top, and dehiscing in the middle of the cells. Seeds ovate-roundisl.

Loose-flowered Hedyotis. Pl. $1 \frac{1}{2}$ foot.

S3 H. POLYCA'RPA (Wall. cat. 838.) branches tetragonal; leaves elliptic-lanceolate, acuminated, tapering to the base; stipulas joined to the petioles, and forming a sheath with them, firnished with a tooth on each sicle; panicle terminal, corymbose, trichotomons; lobes of calyx separated by broad recesses. 4. S. Native of Silhet. Perhaps a species of Oldenlándia.

Many-fruited Hedyotis. PI. 2 to 3 feet.

34 H. Mólus (Wall. cat. no. 859.) plant clothed with soft white down in every part, but particularly so on the under side of the leaves; peduncles axillary and terminal, panicled ; pedicels corymbose; stipulas with 3 bristles. 4 . S. Native of Pulo-Penang.

Soft Hedyotis. Pl. 1 to 2 feet.

35 H. vagina'ta (Blum. herb. and mss. ex D. C. prod. 4. p. 421.) plant suffruticose, glabrous; leaves lanceolate, much acuminated, nerved; stipulas long, sheathing, drawn out on both sicles into one puberulous bristle; corymbs terminal, trichotomous; throat of corolla bearded; stamens exserted. h. S. Native of the island of Ternate, one of the Moluccas.

Sheathed-stipuled Hedrotis. Shrub.

36 H. eloxga'ta (R. Br. in Wall. cat. no. 865.) plant puberulous; leaves lanceolate or linear: stipulas jagged; peduncles terminal, elongated, dichotomously branched; flowers distant on the branches of the peduncle, usually by twos, and one in each fork, almost sessile. $\odot$. S. Native of the East Indies. Perhaps a species of Oldenlándia.

Elongated-peduncled Hedyotis. Pl. 1 to $\approx$ feet.

37 H.? scándens (Roxb. fl. ind. 1. p. 369.) stem terete, scandent, glabrous; leaves on short petioles, broad-lanceolate, acuminated, glabrous, shining; stipulas entire, joined to the pe- tioles, furnished with a short mucrone on both sides; corymbs panicled, axillary, and terminal, with the branchlets rather villous; lobes of corolla and throat hairy inside; style villous at the apex; stigma bilamellate. $4 . \cup . S$. Native of Nipaul and Silhet, where it is called Gujec. I'cetesia Hita, Hamilt. mss. cx D. Don, Al. nep. p. 134.

Climbing Hedyotis. ऐl. el.

\&8 H. cApıteLLA'TA (Wall. cat. 837.) glabrous; leaves elliptic, acuminatel, tapering at the base; stipulas joined to the petioles, furnished with a tooth on both sides; panicle terminal, composed of round heads of flowers. 4 . $\checkmark$. S. Native of Pulo-Penang, and 'Tavoy.

Headed-flowered Herlyotis. Slirub cl.

39 H.? Lescuenau'tisin (D. C. prod. 4. p. 4.2.) suffruticose ; branches glabrous, tetragonal at the apex; leaves lanceolate, pilose bencath ; stipulas combined with the petioles, forming a kind of cupula, and furnished with 3 bristles on both sides; panicle terminal, with glabrous branches; limb of calyx with 4 short teeth; lobes of corolla liairy above: style shorter than the corolla. দ. S. Native of the East Indies, on the Nebligherry mountains, where it was collected by Leschenault. Allied to II. scándens, and with it will probably form a distinct genus.

Var. $\beta$, Wallichii (D. C. prod. 4. p. 422.) branches compressedly angular; leaves acuminated; limb of calyx 4-cleft to the midale: lobes oblong-linear; limb of corolla very hairy above. h.G. Native of Nipaul, at Katmandu. Perhaps the same as H. scándens, Roxb. ex Wall. fl. ind. 1. p. 369, but it does not exactly agree with the description given of that plant by Roxburgh.

Leschcrault's Hedyotis. Shrub cl.?

40 H. Articula'ris (R. Br. in Wall. cat. no. 854.) plant dense and dwarf; leaves much crowded, lanceolate, veiny ; stipulas jagged; peduncles terminal and axillary, forming panicles. 4. G. Native of the Nelligherry mountains.

Jointed Hedyotis. Pl. $\frac{1}{2}$ foot.

41 H.? ARBorea (Roxb. in Beats. voy. append. p. S10.) arboreous; leaves on short petioles, oblong, acuminated, shining, recurved at the apex; stipular sheath cylindrical, furnished with 1-3 unequal teetl ; coryubs terminal, brachiate, almost globular; capsules globose. $h_{2}$. S. Native of the island of St. Helena, in woods towards the tops of the mountains, where it is called $d o g n o o d$ by the inhabitants. Lobes of calyx oval. Corolla short, glabrous. Perlaps a proper genus.

Tree Hedyotis. Shrub.

4.2 H. struòsa (R. Br. in Wall. cat. no. 853.) stems quadrangular; leaves glabrous, elliptic-lanccolate, tapering to both ends, coriaceous; stipulas pinnatifid; peduncles axillary and terminal, trichutomous, forming panicled corymbs; corolla very bairy inside. $h$. G. Native of the Nellighlierry mountains.

Long-s'yled Hedyotis. Slirub 1 to 2 feet.

\section{+ Doubtful species.}

43 H. crassifo'lia and H. ro'sea, Rafin. f. lud. 77. are very doubtful plants, and are probably species of Anòtis.

Cult. None of the species of this genus are worth cultivating except in botanic gardens. Any light soil will suit them ; and cuttings of the shrubby and herbaceous perennial species will root in the same kind of soil, with a hand-glass over them, in a little heat. 'The annual kinds require the same treatment as other tencler annuals. All are easily increased by seeds.

LXXVII. OLDENLA'NDIA (named by Plumier in memory of Henry Bernh. Oklenland, a Dane, who collected plants at the Cape of Good Hope in 1695 . They came into the possession of Burmann, and there is an account of them in the 6th volume of Linnæus's Amœnitates Academicæ). Lin. gen. no. 15 t. 
Roxb. $\mathrm{A}$. ind. 1. p. 444. D. C. prod. 4. p. 424. but not of Smith.-Gerontògea, Cham. et Schlecht. in Linnæa. 4. p. 154. -Hedyòtis species, Spreng. Smith, and Blume.-Hedyotis and Oldenlándia, Gærtn. fr. 1. t. 30.-Oldenlándia and Listèria, Neck. elem. no. 345 and 346.-Listèria, Rafin. ann. gen. sc. pliys, 6. p. 81, but not of R. Br.

Lin. syst. Tetrándria, Monogynia. Calyx with a subglobose tube, and 4 sub-approximate teeth, which remain on the fruit and are separated by very wide recesses. Corolla with a short tube, a 4-cleft limb, and a villous or glabrous throat. Stamens a little exserted ; anthers ovate or orbicular. Stigma undivided or bifid. Capsnle almost globose, crowned by the small distant teeth of the calyx, 2-celled, dehiscing at top by a loculacidal chink. Seed small, innumerable, fixed to sub-globose placentas, and as if they were half immersed in them.-Small, herbaceous, or suffruticose plants, with the habit of chickweed. Leaves opposite, with the stipulas adhering to both sides of the petioles. Peduncles axillary and terminal, bearing 1-2 or many flowers, usually elongated and slender. Flowers usually white. This genus hardly diflers from Hedyotis, except in the teeth of calyx being separated by wide recesses on the fruit instead of narrow ones, which character we think would scarcely constitute a sectional distinction. The species, however, have a different habit, and are more readily distinguished by it, than by any other character.

* Pedicels axillary, ]-flonered, usually solitary, rarcly by tros or tirces.

1 O. BRAchY' PODA (D. C. prod. 4. p. 424.) plant glabrous and decumbent; leaves linear ; stipulas fumished with 2 bristles on both sides; pedicels axillary, 1-flowered, shorter than the flowers, solitary or twin; corolla tubular; anthers exserted to the lengti of the lobes of the corolla. $\odot$. F. Native of Java, Philippine Islands, and Nipaul. Hedyòtis berbácea, var. $\alpha$. Blum. bijdr. p. 970 . H. radicans, Bartl. in herb. Hænke. Allied to $O$. herbacca but distinct, and it is probably the same as O. ramosissima or $O$. diffùsa.

Short-pedicelled Oddenlandia. Pl. $\frac{1}{2}$ foot.

2 O. Raxosíssina (Fisch. mss. in Spreng. mant. 1. p. 35.) stems herbaceous, diffuse ; leaves Janceolate, bluntish; stipulas toothed; fruit almost solitary, axillary, sessile. 4. F. Native country unknown. Hedyòtis ramosíssima, Spreng. pug. 2. p. 31. Flowers white. Probably distinct from O. brachypoda.

Much-branchcd Oldenlandia. Fl. June, Aug. Clt. 1819. Pl. $\frac{1}{8}$ foot.

3 O. sabulòsa (D. C. prod. 4. p. 424.) an herbaceous, tufted, diffuse, much-branched plant, which is roughish from short scattered hairs in every part; leaves linear, acute; stipulas membranous, furnished with many bristles; pedicels $2-3$ together, axillary, 1-flowered, much shorter than the leaves, deflexed in the fructiferous state; corolla length of the lobes of the calyx. $\odot$. F. Native of Senegal, in sandy places at Walo, where it was collected by Perrottet and Leprieur. Flowers white. Perhaps only a luxuriant variety of $O$. ripària.

Sand Oldenlandia. Pl. $\frac{1}{2}$ foot.

4. O. RIPA'RIA (D. C. prod. 4. p. 4.24.) stem branched, erectish, tetragonal, smoothish ; leaves lincar, acute, rather scabrous ; pedicels axillary, l-flowered, twin, 3 times shorter than the leaves; corolla tubular, about the length of the calyx. $\odot . F$. Native of Senegal, in humid sandy places, on the banks of the river, where it was collected by Perrottet and Leprieur. Very nearly allied to $O$. scábrida, but is easily distinguished from it in the pedicels being much shorter, and the lobes of the calyx being longer.

River-side Oldenlandia. Pl, $\frac{1}{2}$ foot.

5 O. CAPE'xsis (Thunb. prod. p. 29. fl. cap. 1. p. 537.) stem decumbent, branched, villous; leaves linear, acute, glabrous ; pedicels numerous, 1-fowered, shorter than the leaves; lobes of calyx ciliated; throat of corolla villons. $\odot$. F. Native of the Cape of Good Hope, in sandy places by the margins of rivers. Hedyòtis Capénsis, Lam. ill. no. 1425. Stigma clavate (ex Thunb.). Capsule ovate, didymous.

Cape Oldenlandia. Pl. decumbent.

6 O. LiNea'ris (D. C. prod. 4. p. 425.) plant glabrous, erect, branched; stem tctragonal; leaves linear, acute; stipulas cupulate, furnished with many bristles; pedicels axillary, twin, 1-flowered, about the length of the leaves: but the uppermost ones are longer than them; capsule globose; teeth of calyx acute, very short. $\odot$. F. Native of Senegal, in sandy places, at St. Louis, where it was collected by Leprieur and Perrottet.

Linear-leaved Oldenlandia. Pl. $\frac{1}{2}$ foot.

7 O. LANCiFo'L1A (D. C. l. c.) stem simple, weak, somewhat dichotomous, creeping, glabrous; Jeaves linear-lanceolate, glabrous, with rather scabrous margins; bristles of the stipulas distant; peduncles axillary, solitary, rarely twin. $\odot . ? \mathrm{~F}$. Native of Guinea. Hedyotis lancifólia, Schum. pl. guin. p. 72. Lancc-leaved Oldenlandia. Pl. $\frac{1}{2}$ foot.

8 O. herba'cea (D. C. l. c.) plant glabrous, decumbent; leaves linear or linear-Janceolate; stipules of many bristles; pedicels axillary, 1-flowered, solitary or twin, shorter than the leaves, but 2-3 times longer than the flowers; tube of corolla cylindrical; anthers hardly cxserted from the throat. $\odot$. F. Native of the East Indies, Madagascar, Senegal, St. Domingo, Mexico, \&c. O. Madagascariénsis, Desf. cat. hort. par. 1815. -Rheed. mal. 10. t. 23. and 35. Hedyòtis herbàcea, Lin. f. zeyl. p. 65 . H. herbàcea, var. $\beta$, Blum. bijdr. p. 970 . Flowers white.

Herlaceous Oldenlandia. Fl. Ju. Aug. Clt. 1819. Pl. $\frac{3}{2} \mathrm{ft}$.

9 O. TENuifo'lia (Forst. prod. no. 57. but not of Burm. ex D. C. prod. 4. p. 425.) stem erect, tetragonal, branched; leaves linear, attenuated at both ends: stipulas ciliated a little, rather scarious; peduncles axillary, 1 -flowered, shorter than the leaves, reflexed while in flower, and erect when bearing the fruit. $\odot$.? F. Native of the lsland of 'Tanna. Hedyotis tenuif òlia, Smith, in Rees's cycl. 17. no. 19. Spreng. pug. 2. p. 30, where it is confused with $O$. Capénsis and $O$.herbàcea. O. tenuifòlia, Burm. A. ind. 38. t. 14. f. 1 . is probably distinct from this but is not sufficiently known. Flowers white.

Fine-learcd Oldenlandia. Pl. $\frac{1}{2}$ foot.

10 O. scábrida (D. C. prod. 4. p. 425.) stem erectish, branched; tetragonal, scabrous along the angles; leaves linear, acute; pedicels axillary, 1-flowered, a little shorter than the Jeaves; corolla tubular, hardly longer than the calyx. $\odot$. F. Native of Nipaul. Oldenlándia tenuif òlia, Burm. fl. ind. t. 14. $f$. 1 . is referrible to this species, as the figure given agrees very well with it.

Scabrous Oldenlandia. Pl. $\frac{1}{2}$ foot.

11 O. graninifo'lia (D. C. 1. c.) plant decumbent, much branched, smoothish; leaves linear; stipulas of 2-3 setaceous divisions; pedicels axillary, 1 -flowered, about equal in length to the leaves, twin or crowded; corolla hardly longer than the calyx. $\odot$. F. Native of the East Indies and Arabia. Hedyòtis graminifòlia, Lin. fil. suppl. p. 119. Vahl. symb. 2. p. 27. Spreng. pug. 2. p. 29, exclusive of the syn. of Pluk. which is referrible to Mollùgo Cerveàna. Hedyòtis herbàcea, Forsk. cat. arab. no. 88. Old. strícta, Lin. mant. 200. ex Vahl. Corolla and anthers blue.

Grass-leaved Oldenlandia. Pl. decumbent.

12 O. PU'MiLA (D. C. l. c.) stems decumbent, tetragonal, scabrous; leaves almost sessile, elliptic, acute at both ends, with scabrous margins; stipulas laving 2-3 setaceous divisions; peduncles axillary, solitary, 1-flowered, about equal in length 
to the leaves. $\odot$. F. Native of Tranquebar and Java. Hedyòtis pumila, Lin. fil. suppl. 119. Spreng. pug. 2. p. 34. bijdr. p. 97 I. Flowers white.

Drarf Oldenlandia. Pl. decumbent.

13 O. LNifo'ma (D. C. l. c.) leaves linear, attenuated at both ends; peduncles 1-flowered, longer than the leaves. $\odot . ? \mathrm{~F}$. Native of the East Indies. Medyòtis linifòlia, Willd. mss. in Rocm. et Schultes, syst. 3. p. 526. The rest unknown.

Flax-leaved Oldenlandia. P. decumbent.

14 O. virga'ta (D. C. l. c.) plant very slender, galabrous ; stems tetragonal; leaves linear; stipulas furnished with very short bristles, at length truncate; peduncles twin, 1-flowered, elongated : the ultimate ones disposed into a kind of terminal panicle; pedicels opposite, from the axils of the bracteas, longer than them, and about equal in length to the internodes. $\odot . F$. Native of Guinca (ex Willd.), in the rice-fields of Casamancia and Gambia (ex Perrottet and Leprieur), and Sierra Leone (ex Smeathmann). Hedyòtis virgàta, Willd. spec. 1. p. 167. Schum. pl. guin. p. 69.? Flowers and fruit very small. Leaves 8-9 inches long. Stamens a little exserted.

Twiggy Olienlandia. Pl. $\frac{1}{2}$ foot.

15 O. ASPE'RULE (D. C. l. c.) plant glabrous; stem erect, branched, tetragonal; leaves distant, linear, ciliated at the base; stipulas entire, cupular, truncate; pedicels straight, 1-flowered, rising from the axils of the upper leaves, which are almost abortive. $\odot . ?$ F. Native of Ceylon, where it was collected by Leschenault. Habit almost of the species of Aspérula. Corolla greenish in the dried state, also glabrous in the throat, 4-cleft. Anthers pedicellate, shorter than the lobes of the corolla. Stigmas 2, elongated. Capsule oblong. Seeds minute. Lobes of calyx short, distant. Perhaps this plant ought to be removed from the genus.

Woodroof-like Oldenlandia, PJ. $\frac{1}{2}$ foot.

16 O. DIFFu'sa (Roxb. fl. ind. 1. p. 444.) stem terete, flaccid, spreading, scabrous; leaves linear-lanceolate, acute, smooth ; stipulas at length of many bristles; peduncles axillary, 1-flowered, 4-times shorter than the leaves. $\odot$.F. Native of the East Indies, at Banda. Corolla smooth, white. Stigma profoundly bifid. Capsule roundish. Perhaps only a variety of $O$. bifiora.

Diffuse Oldenlandia. Fl. Ju. Aug. Clt. 1821. Pl. diffuse.

\section{* Peduncles 2-3 or many-fonercd.}

17 O. Biflòra (Lin. spec. 174.) stems erect, weak, scabrous; leaves linear-lanceolate, rather scabrous while young; stipulas membranous, lanceolate, with ciliated fringed edges; peduncles axillary, shorter than the leaves, 2-3-flowered: corolla glabrous inside; anthers length of the lobes of the corolla. $\odot . F$. Native of the East lndies, Philippine Islands; and of Guinea, at Cape Coast, plentiful in the rainy season. Roxb. fl. ind. 1. p. 445. Hedyòtis biflòra, Smith, in Rees's cycl. 17. no. 15. Spreng. pug. 2. p. 31. Horn. hort. hafn. 1. p. 130. Gerontògea biflòra, Cham. et Schlecht. in Linnæa. 4. p. 155. Hedyòtis diffùsa, Willd. spec. I. p. 566 . Old. dichótoma, Willd. herb. ex Cham. et Schlecht. Burm. fl. zeyl.t.11. Flowers small, white.

Tno-flomercd Oldenlandia. Fl. Ju. Aug. Clt.1821. Pl. $\frac{1}{2} \mathrm{ft}$.

18 O. Alsinifòia ; glabrous; leaves membranous, lanceolate, tapering to both encls; peduncles axillary, few-flowered; stipulas bristly at top; teeth of calyx distant. $\odot$. F. Native of Pulo-Penang. Hedyòtis alsinifòlia, R. Br. in Wall. cat. no. 873. Plant diffuse.

Chicknecd-lcaved Oldenlandia. Pl. $\frac{1}{4}$ to $\frac{1}{2}$ foot.

19 O. вRAсну' PODA; plant glabrous, diffusely branched; leaves linear, with revolute edges; peduncles short, axillary, bearing at the top an umbel of short pedicellate flowers, or the VOL. III. pedicels solitary and axillary. ๑. F. Native of the Island of singaprore. Hedyòtis brachýpoda, R, Br. in Wall. cat. no. 874 . Short-pcduncled Oldenlandia. 1'l. cliffuse, $\frac{1}{b}$ foot.

$20 \mathrm{O}$ lieamanna'sa; plant glabrous, diffuse; stems quadrangular; leaves linear; pediccls short, axillary, twin, or solitary. ๑. F. Native of the East Indies. Hedyòtis Burmanniàna, R. Hr. in Wall. eat. no. 868 . Old. biflòra, lioxb. but not of Lin. Burmann's Oldenlandia. Pl, $\frac{1}{2}$ to 1 foot.

21 O. longifòlia (D. C. prod. 4. p. 4 6.) plant procumbent, glabrous, branched; branches diverging; leaves lincar, rather prapillose: upper ones with scabrous margins; stipulas ciliated a little; peduncles clongated, axilliry, 2-flowered: but the terminal ones are 3-flowercd. $\odot$. F. Native of Guinea. Hedyòtis longifolia, schum. pl. guin. p. 70. Flowers small, white.

Long-lcaved Oldenlandia. Pl. procumbent.

22 O. crystálina (Roxb. fl. ind. 1. p. 44.9.) plant diffuse, much branched; stems tetragonal; leaves sessile, lanceolateoblong, marked with crystalline dots beneatli; stipulas joined to the petioles, many-toothed; peduncles axillary, 2-flowered, one half shorter than the leaves; throat of corolla pilose. $\odot$. F. Native of Bengal. 'This plant is very distinct from $O$. pùmilu and $O$. biflòra.

Crystalline-dotted Oldenlandia. Pl. diffuse.

23 O. conyubo'sa (Lin. spec. p. 174.) plant glabrous, erect, or diffuse ; stems tetragonal, smooth; leaves linear-lanceolate; stipulas joined to the petioles, membranous, each furnished with 3 bristles; peduncles axillary, 2-5-flowered; flowers disposed in umbellate corymbs; throat of corolla hearded; anthers a little exserted; stigma sub-capitate. $\odot . F$. Native of Gniana, and elsewhere in South America; also of the west coast of Africa, at Cape Verd, near Kounoun, and of the Molnccas. Cham. et Schleclst. in Linnæa. 4. p. 156.-Plum. ed. Burm. t. 212 f. 1 . Flowers small, white. There are varieties of this species, having the peduncles either longer or shorter than the leaves. Hedyòtis corymbòsa, Spreng. is rery different from this plant.

Corymbose-flowered Oldenlandia. Fl. Ju. Aug. Clt. 1739. Pl. diffuse or $\frac{1}{2}$ foot high.

24. O. ramo'sa (Roxb. fl. ind. 1. p. 445.) plant diffuse, glabrous, branched; stems tetragonal; leaves sessile, linear-lanccolate, paler beneath; stipulas membranous, joined to the petioles, furnished with $3-4$ bristles cach; pedmoles axillary, 3-5-flowered; corolla roundish, with a bearded throat. $\odot . F$. Native of Pegu and the west of Java. Hedyotis ramòsa, Blım. bijd̈. p. 973. Flowers small, white; anthers blue (ex Roxb.). Branched Oldenlandia Pl. diffuse.

25 O. unibela'ta (Lin. spec. 174.) stem diffuse, tetragonal, smoothish; leaves narrow-linear, acute, with revolute margins, rather scabrous above and paler beneath ; stipulas joined to the petioles, ciliated by bristles; peduncles axillary, umbelliferous. §. S. Native of Java and Coromandel, in sandy places; and probably on the west coast of Africa, at Joal; and of Mexico. Burm. fl. ind. p. 37. Roxb. fl. cor. 1. t. 3. Root long, orangecoloured; in the cultivated sort it is longish with few fibres. Stem in the cultivated plant erect and terete, from $\frac{1}{2}$ to 1 foot high, and branched: in the wild hind there is liardly any stem, but many scraggy branches. Flowers small, white; the whole forming a panicle composed of small 3-cleft umbellets. This plant is cultivated on the coast of Coromandel, where its roots descend to a great depth in the sand. It is used in dying red, purple, a deep clear brown orange, and to paint the red figures on clintz, of all which Dr. Roxburgh has given a full account in his pl. cor. 1. p. 2. t. 3. and also Dr. Anderson, in trans. roy. soc. edinb. 1792. p. 16.

The woody part of the Chay or Che root, as it is callcd, is $3 \mathrm{Y}$ 
white and tasteless; it is the bark only that is possessed of the colouring principle; when fresh it is orange-coloured, tinges the spittle yellow, and leaves a slight degree of acrimony on the point of the tongue, for some hours after chewing; to apjearance it loses its yellow colour on drying, but still retains the above property on being chewed. It impregnates cold water or spirits with a straw-colour, and to boiling water it gives a brownish porter colour. The watery infusions and spirituous tinctures are changed into a bright and deep red by alkaline substances, and are rendered paler or nearly destroyed by acids. The colouring powers of this root are sail to improve by keeping 3 or 4 years. When the wild sort can be had in any quantity, it is esteemed one-third or fourth stronger, and yields a better colour; and when these roots can be had of two years' growth they are reckoned still better. This plant is the Tsherivello of the Telingas; and the Saya-ver or Imburel of the Tamuls. The Telinga physicians do not give any part of the plant a place in their Materia Medica; but the Malabar ploysicians say that the roots cure poisonons bites, colds, and cutaneous disorders, and warm the constitution.

Umbel-flowered Oldenlandia or Indian Madder. Fl. July, Aug. Clt. 1792. Pl. $\frac{1}{2}$ to 1 foot.

26 O. PUBÉRULA ; downy in every part; leaves linear-lanccolate, mucronate; peduncles axillary or from the forks of the stems, bearing each a simple umbel of flowers, or 3 pedunculate umbels of flowers, rising from 2 leaves. $\odot$. H. Native of the East Indies. O. pubérula, R. Br. in Wall. cat. no. 884 .

Donny Oldenlandia. Pl. $\frac{1}{2}$ foot.

27 O. capllla'rss (D. C. prod. 4. p. 426.) stem ascending, teretely tetragonal, and rather scabrous along the angles, much hranched; leaves linear-lanceolate, rather scabrous; stipulas sinall, with setaceous bristles; peduncles axillary and terminal, loosely panicled, longer than the leaves, very slender, 2-4-6flowered; flowers opposite, on long pedicels. $\odot$. F. Native of Madras. Corolla small, tubular. Capsule globose, glabrous.

Capillary Oldenlandia. PI. $\frac{1}{2}$ foot.

28 O. PANicula'ta (Lin. spec, p. 1667.) plant glabrous, erectish, branched; branches tetragonal; leaves ovate-lanceolate; stipulas small, undivided; racemes axillary and terminal, almost naked; pedicels longer than the leaves; corolla with a gibbous tube and a villous throat. $\delta$. S. Native of the East Indies, Moluccas, and Pliilippines.-Burm. A. ind. 38. t. 15. f. 1. Hedyòtis racemòsa, Lam. dict. 3. p. 76. ill. t. 62. f. 2. Leaves smooth. Flowers small. Hedyòtis dichótoma, Cav. icon. 6. p. 573, f. 2. and H. mèdia, Cav. icon. 6. p. 574. f. 1. according to Bartling is probably distinct from this. Flowers small, red, on long pedicels.

I'ar. $\beta$, arenaioides (D. C. prod. 4. p. 427.) leaves lanceolate, acuminated, stiffish. §. S. Native of the coral island Radak. Gerontògea racemòsa, Cham. et Schlecht. in Linnæa. 4. j. 155. Habit of Arenàra trinérvia.

Panicled Otdenlandia. Pl. creeping.

29 O. PEnTÁndRA (D. C. prod. 4. p. 427.) plant procumbent, glabrous; leaves lanceolate, cordate at the base, or ovateoblong, sessile, discoloured ; racemes axillary, naked; flowers pentamerous.-Native of Guinea. Hedyòtis pentándra, Sclıum. pl. guin. j. 71 .

Pentandrous Oldenlandia. Pl. procumbent.

30 O. multiflo'ra (Cav. icon. 6. p.53. t. 574. f. 2.) glabrous; stem branched, furrowed, ascending; leaves sessile, ovate-oblong; stipulas small, undivided; panicles axillary, opposite, and terminal, many-flowered: peduncles 3-flowered, elongated.-Native of the Philippine Islands, about Manilla, not of the Friendly Islands, as said by Poiret and Romer. Very nearly allied to $O$. paniculata.
Many-flowered Oldenlandia. Pl. $1 \frac{1}{2}$ foot.

31 O. crassifo'lia (Bartl. in herb. Hænke, under Hedyòtis) plant glabrous, suffruticose, diffuse; branches tetragonal; leaves ovate or oblong, obtuse, fleshy; peduncles axillary and terminal, 3-flowered, usually shorter than the leaves; pedicels shorter than the flowers; segments of calyx lanceolate, short. -Native of the Island of Luzon, one of the Philippines.

Thick-lcaved Oldenlandia. Pl. diffuse.

32 O. strigulo'sa (Bartl. in herb. Hænke, under Hedyòtis, ex D. C. l. c.) plant herbaceous, branched, erectish ; leaves obovate-oblong, beset with very minute callous dots above, and with adpressed strigæ beneath ; stipulas undivided, linear-subulate; peduncles axillary and terminal, longer than the leaves, 3-flowered; pedicels hardly any; calycine segments ovatetriangular.-Native of the Island of Mariane.

Strigulose OJdenlandia. Pl. $\frac{1}{2}$ foot.

33 G. ovatifo'lia (D. C. prod. 4. p. 427.) plant almost stemless, villous; stem short, simple; leaves ovate, ciliated, on short petioles, white beneath; peduncles 3-4 together, rising from the top of the stem, trichotomous, slender, twice the length of the leaves. $\odot$. F. Native of the Philippine Islands at Manilla. Hedyòtis ovalifòlia, Cav. icon. 6. p. 52. t. 573. f. 1. Spreng. syst. 1. p. 4.14. Corolla pale red, hardly a line long. Stamens exserted.

Ovate-leaved Oldenlandia. Pl. $\frac{1}{4}$ foot.

34 O. ALA'ta (Kon. in Roxb. t. ind, 1. p. 442.) plant glabrous, erect ; stem tetragonal, branched; leaves almost sessile, elliptic-oblong, smooth, rather fleshy; stipulas broad, erosely tootled, obtuse; panicle terminal, leafy; corolla ventricose, with the throat closed by villi; capsule somewhat compressed, furnished witl a somewhat winged nerve on both sides. $\odot$. F. Native of the East Indies, Java, Timor, Scc. on the edges of rice-fields. Old. alata, Wall. in herb. Puer. Hedyòtis ramosíssima, Blum. bijdr. p. 972, but not of Fisch. Perliaps Hedyòtis paniculàta, Lam. ill. 1412. but the figure in Burm. ind. t. 71. f. 2. cited for this plant has 5-cleft flowers, and is consequently not it. From the capsules being furnished with a somewhat winged nerve on each side, it comes very near to the genus Gonothèca. Flowers small, white.

Winged-nerved-capsuled Oldenlandia. $\mathrm{Pl} . \frac{1}{2}$ foot.

35 O. Macropity'lla (Lepr. et Perr. mss. under Hedyòtis, ex D. C. prod. 4. p. 427.) plant glabrous, erect, branched; leaves sessile, lanceolate, acuminated: stipulas undivided; peduncles axillary, racemose, longer than the leaves; pedicels in 4-5 opposite pairs. - Native of the Gambia, in rice-fields at Albreda, where it was collected by Leprieur and Perrottet. Allied to $O$. alàta. Capsule somewhat turbinate, and probably furnished with a nerved wing on each side.

Long-lcavcul Oldenlandia. Pl. $\frac{1}{2}$ foot.

36 O. LA'ctea (Cham. et Schlecht. in Linnæa. 4. p. 159. under Gerontògea) stem terete, pubescent; leaves linear-lanceolate, acute at both ends, flat; stipulas bidentate, scarious; peduncles terminal; corollas villous inside; anthers oblong, exserted. $\odot$.F. Native of the East Indies. Hedyòtis láctea, Willd. enum. hort. berol. 1. p. 149. H. cymòsa, Spreng. syst. 1. p. 413.? Flowers cream-coloured.

Milk-coloured-flowered Oldenlandia. Pl. $\frac{1}{2}$ foot.

37 O. FE'TIDA (Forst. prod. p. 55.) plant suffruticose; leaves spatulate; stipulas almost cntire; corymbs trichotomous. h. S. Native of the Island of Tongatabu. Hedyòtis fétida, Spreng. pug. 2. p. 28. Gerontògea foétida, Cham. et Schlecht. in Linnæa. 4. p. 154. The leaves in Forster's specimen are elliptic and acute.

Fetid Oldenlandia. Pl. $\frac{1}{2}$ foot.

38 O. Miскотне'ca (Cham. et Schlecht. in Linnæa. 4. p. 169. under Gerontògea) plant herbaceous, erect, much branched; 
leaves petiolate, orate-lanceolate, acuminated, scabrous above ; stipulas small, downy, dentately ciliated; flowers disposed in loose cymose terminal panicles. $\odot$. F. Native of Mexico, at Baranca de Tioselos, in shady places, where it was collected by Deppe and Schiede.-Chichia-tzonpatonic de Ocopetlaycic. Hern. mex. p. 366.? Corolla funnel-slıped, a line or more long. Capsules small. A larger variety of this is found about Tampico, ex Cham, et Schlccht, in Linnæa. 6. p. 414.

Small-sheathed Oldenlandia. PI. 1 to $1 \frac{1}{2}$ foot.

39 O. Deprea'va (Cliam. et Schlecht. in Linnæa. 5. p. 169. under Gerontògea) plant shrubby, much branched, erecı, glabrous; leaves petiolate, ovate-lanceolate, tapering into the petioles, firm, much acuminated, rather revolute, and scabrous on the margins; stipulas white, beset with glandular down, setosely jagged: the bristles thickened and glandular at the apex; flowers disposed in loose panicles at the ends of the branches. h. S. Native of Mexico, at San Andres, where it was collected by Schiede and Deppe. Gerontògea Deppeana, Link and Otto, neu abhild. t. 36. Leaves large, but bardly an inch long. Corolla about 3 lines long. Anthers blueish. Flowers sometimes only 3-parted.

Deppe's Oldenlandia. Shrub 1 foot.

40 O. spergula'cea (D. C. prod. 4. p. 428.) plant erect, aimost simple, bairy; leaves oval-oblong; stipulas cupulate, mucronate; peduncles almost terminal, elongated, many-flowered, naked; calyx glabrous; corolla tubular; anthers sessile; style at length bipartite to the base. $\odot . H$. Native of Nipaul. Herb a finger in height, with the habit of Spérgula. Upper leaves usually 4 in a whorl. Peduncles glabrous. From the dehiscence of the capsule it agrees with $O$. conóstyla; but is very different in habit.

Spurrey-like Oldenlandia. Pl. $\frac{1}{6}$ foot.

41 O. rotundifo'lia (Ham. ex Wall. cat. no. 6190. under Hedyòtis) leaves elliptic-ovate, rounded at the apes, downy, but most particularly so on the veins beneath, close together; peduncles long, axillary, and terminal, panicled. ๑. H. Native of the East Indies, at Goalpara. Hedyotis scapígera, R. Br. in Wall. cat. no. 881 .

\section{Rund-leaved Oldenlandia. Pl. $\frac{1}{4}$ to $\frac{1}{2}$ foot.}

42 O. Marítina; plant glabrous; stems erect; leaves linear or lanceolate, acute, with revolute edges; panicles terminal, erect; peduncles swelling toward the top, angular, erect; teeth of calyx distant. $\psi$. S. Native of the East Indies, by the sea-side. Hedyòtis marítima, Wall. cat. no. 6192. Old. gramminifòlia, $\mathrm{Vahl}$.? Old. strícta, herb. Russ.

Sea-side Oldenlandia. Pl. 1 foot.

43 O. oxyPuÝLLA; glabrous ; leaves linear-lanceolate, tapering to both ends; peduncles terminal and axillary, dichotomous, panicled; pedicels short, bracteate; teeth of calyx distant. 4. S. Native of the mountains of Silhet. Hedyotis oxyphýlla, Wall. cat. no. 6193. Leaves like those of the weeping willow. Stipulas broad at the base, ending in 2 subulate points at the apex, and a small tooth on each sicle.

Sharp-leaved Oldenlandia. Pl. 2 to 3 feet.

$44 \mathrm{O}$. HE'YNu; glabrous; leaves linear; stems diffusely branched, panicled; pedicels slender, $2-6$ together; stipulas bifid, short; teeth of calyx distant. $\odot$. F. Native of the East Indies. Hedyòtis Héynii, R. Br. in Wall. cat. no. 867 . Oldenlándia herbàcea, Heyne and Roxb. but not of Lin. Flowers white.

Heyne's Oldenlandia. Pl. 1 foot, diffuse.

4.5 O. тubuso'sa ; glabrous, erect : leaves ovate, acute ; peduncles terminal and axillary, umbellate or capitate; flowers crowded, almost sessile; tube of corolla long, slender. $\odot$. F. Native of the East Indies. Hedyòtis tubulàris, $\mathrm{R}$. Br. in Wall. cat. no. 876 . Hedyòtis míniuna, Heyne, in Wall. cat. no. 857.
Tubular-flowered Oldenlandia. P'. $\frac{1}{4}$ to $\frac{1}{2}$ foot.

46 O.' Mrsorénsis ; lowny; stems quadrangular; leaves ovate, acute, clothed with rusty down on the nerve and veins beneath, and on the petioles, ciliated on the margins; peduncles terminal and axillary, racemose, branched; flowers almost sessile. $\odot$. F. Native of Mysore. Hedyòtis Mysorénsis, Heyne ex Wall. cat. no. 882 .

Mysore Oldenlandia. Pl. 1 foot. ?

\section{† Spccies not sufficiently known.}

47 O. ? uÍspida (Roth, nov. spec. p. 95. under Hedyòtis) the whole plant is hispid from bristles; stem ascending, diclion tomous, terete; leaves petiolate, ovate-lanceolate; stipulas setosely toothed; peduncles axillary, bearing few-flowered umbels; corolla twice the length of the calycine lobes.- Native of the East Indies. Anthers linear, length of corolla. Hedyòtis I'ndica. Rom. et Schultes, syst. 3. p. 195.

Hispid Oldenlandia. Pl, $\frac{1}{2}$ foot, procumbent.

4.8 O. a'spera (Roth, nov. spec. p. 94. under Hedyòtis) the whole plant is roughish from papillic ; stem straight, filiform, terete; leaves linear-subulate; stipulas linear-subulate, a little toothed; raceme terminal, pedunculate, sub-fastigiate, naked; teeth of calyx linear, 4 -times shorter than the tube of the corolla.-Native of the East Indies. Hedyòtis áspera, Spreng. syst. 1. p. 415. The stamens being inclosed, it is very doubtful whether it belongs to this genus.

Rough Oldenlandia. Pl. $\frac{1}{2}$ foot.

49 O. Afrisis (Røm. et Schultes. syst. 3. p. 194. under Hedyòtis) plant erect, much branched; branches rather tetragonal, scabrous at the angles; leaves linear, acuminated, finely ciliated ; stipulas tridentate; peduncles disposed in a loose, divaricate, dichotomous panicle; corolla twice the length of the calyx.-Native of the East Indies. Hedyòtis dichótoma, Roth. nov. spec. p. 93. but the Oldenlándia dichótoma of Spreng, now called Vàhlia dichótoma, is a very distinct plant. Corolla blue. Anthers inclosed, and therefore it ought to be excluded from the present genus, but it is said to be nearly allied to $O$. biflòra and 0 . herbicen.

Allied Oldenlandia. Pl. $\frac{1}{2}$ foot.

50 O. Hinsu'ta (Lin. fil. suppl. p. 127.) stem herbaceous, diffuse, and are as well as the calyxes hispid; leaves ovate, acute, petiolate, veiny; peluncles axillary, bearing few-flowered umbels.-Native of Java. Hedyòtis hirsùta, Spreng. pug. 2. p. 35.

Hairy Oldenlandia. Pl. diffuse.

51 O. Jusílea (Roth, in Willed. act. amœen. nat. cur. berol. 4. p. 216.) stem branched, tetragonal, rough; leaves linear, acuminated; racemes axillary, simple, few-flowered.-Native of the East Indies. Hedyòtis attenuàta, Willd. I, c. Said to be allied to $O$. graminifolia.

Small Oldenlandia. Pl. $\frac{1}{2}$ foot.

52 O. DE'BILIs (Forst. prod. no. 56.) leaves ovate, sessile; umbels axillary, pedunculate, few-flowered.-Native of the Island of Tongatabu. The rest unknown.

Weak Oldenlandia. Pl.?

53 O. Zanqueba'rle (Lour. coch. p. 78.) stem herbaceous, much branched; leaves linear, glabrous; peduncles terminal, few-flowered, erect; stigmas lanceolate. $\odot$. F. Native of Zanquebar, on the east coast of Africa. Hedyòtis Zanquebárica, Rom. et Schultes, syst. 3. p. 192. Corolla purple, salvershaped. Capsule didymous.

Zanquebar Oldenlandia. Pl. $\frac{3}{4}$ foot.

54 O. DEPRE'sSA (Willd. spec. 1. p. 6r5.) stem diffuse; leaves elliptic, petiolate, glabrons; peduncles axillary, twin, 1-flowered,-Native of the East Indies. Hedyòtis depréssa, 3 × 2 
Roem. et Schultes, syst. 3. p. 200. A very obscure species, and syn. in Rheed. mal. 10. t. 31 . cited for this species is referrible to Portulácca Meridiàna.

Depressed Oldenlandia. Pl. prostrate.

N. B. Oldenlándia nudicaúlis, Roth, nov. spec. p. 96. and Old. maritima, exclusive perhaps of the synonyme of Lin., differs from this genus in the flowers being of 4 distinct petals, and in the want of stipulas; they therefore even do not belong to Rubiàcece, but are probably Caryophyllaceous plants.

Cult. The species are not worth cultivating, unless in botanic gardens. A very sandy soil suits them best, and cuttings of the shrubby kinds will root in sand, under a hand-glass, or by seeds. The annual kinds should be treated like other tender annuals, by being raised on a hot-bed, and afterwards planted our. All the species require a considerable degree of moisture.

LXXVIII. GONOTHE'CA (from $\gamma \omega v t a$, gonia, an angle, and $\theta \eta k^{\circ} \eta$, theke, a sheath; in reference to the capsule, which is furnished with a double wing on each side). Blum. mss. ex D. C. prod. 4. p. 429. but not of Rafin.-Hedyòtis species, Blum. bijdr.

Lin. sYst. Tetrúndria, Monogýnia. Calyx with a somewhat compressed tube, and a short truneate somewhat 4-toothed limb. Corolla having the tube inflated at the base, the throat villons, and the lobes keeled. Stamens inclosed. Style wanting; stigmas 2, obtuse. Capsule compressed, margined by a double wing on both sides, which runs down the pedicel, erowned by the tube and short limb of the calyx, and dehiseing between the stigmas, membranous, 2-celled. Seeds numerous, ovate, small, scrobicnlate.-A glabrous, erect herb, with the habit of Oldenlándia. Stem divaricate, quadrangular. Leaves lanceolate, almost sessile. Stipulas toothed. Cymes pedunculate, axillary, and terminal, few-flowered.

1 G. Blume't (D. C. prod. 4. p. 429.). ○.? F. Native of the islands of Timor and Java, in the latter island on calcareous hills at Kuripan. Hedyòtis pterìta, Blum. bijdr. ps. 972. Conyza Chinénsis, N. L. Burm. A. ind. p. 179. exclusive of the synonyme Oldenlándia alàta, herb. mus. par.

Blume's Gonotheca. Pl. ${ }_{2}^{2}$ foot.

Cult. See Kàdua, p. 533 . for culture and propagation.

LXXIX. KOHAU'TIA (in memory of Francis Kohaut, who collected many plants and other objects of natural history in Senegal). Cham. et Schlecht, in Linna:a. 4. p. 156. D. C. prod. 4. p. 429.-Knóxia and Hedyòtis species of anthors.

Lin. syst. Tetrándria, Monogýnia. Calyx with an obovate tube; teeth acnte, separated by acnte recesses while in flower, but at last by very broad ones. Corolla with a long terete tube, and oval-lanceolate lobes, which are usually cuspidate by a mucrone. Anthers sessile, within the tube, inclosed under the throat. Style shorter than the anthers, bifid at the apex. Capsule globose, membranous, crowned by the teeth of the calyx, 2-celled, dehiseing at the cells. Seeds innumerable, small, half immersed in pits on the placentas, which are globose and stand on short pedicels.-Erect, twiggy, glabrous, branched herbs, with the lıabit of Aspérula. Leaves opposite, linear, or linear-lanceolate. Stipulas joined to the petioles, furnished with one or few bristles. Cymes terminal, corymbose, or loosely spieate.

1 K. GRANDiflóra (D. C. prod. 4. p. 490.) leaves linear, lower ones the broadest, and nearly lanceolate : uppermost ones very slender and subulate; stipulas membranous, comnecting the petioles: lower ones cuspidate in the middle, the rest furnished with 2 bristles on both silles; flower's trichotomously corym- bose; lobes of corolla oval, mucronate. $\zeta$. S. Native of Senegal, from which place it $w$ as sent by Bacle, under the name of IIcdyotis herbaicen; and in sandy places at Kounoun, where it was collected by Perrottet and Leprieur. Tube of corolla 6 lines long, and the lobes 3 lines long and $1 \frac{1}{2}$ broad.

Great-floncred Kohautia. Shrub $\frac{1}{2}$ to 1 foot.

2 K. Senegalénsis (Cham. et Schlecht. in Linnaa. 4. p. 156.) leaves linear: floral ones subulate; stipulas with very narrow margins, joining the petioles, furnished with 2 bristles; flowers on short pedicels along the branches and at their tops, distant; lobes of corolla lanceolate. $b$. S. Native of Senegal. Knóxia Senegalénsis, Reichb, in Sieb. fl. seneg. exsic, no. 9. Tube of corolla $4 \frac{1}{2}$ lines long; and the lobes $2 \frac{1}{2}$ lines long.

Senegal Kohautia. Shrub $\frac{1}{2}$ to 1 foot.

3 K. strícta (D. C. prod. 4. p. 430.) leaves linear, with sub-revolute margins ; stipulas joined to the petioles by a very narrow margin, furnished each with 2 short bristles; flowers trichotomonsly corymbose; lobes of corolla oblong-linear. $\odot$. S. Native of Senegal at $\mathrm{Walo}$ and Lampsar, where it was collected by Leprieur and Perrottet; and at Sierra Leone by Afzelius. Hedyòtis strícta, Smith, in Rees's cycl. vol. 17. no. 21. but not of Wall. Root simple, perpendicular, white. Tube of corolla 5 lines long; and the lobes $2 \frac{1}{2}$ lines long and hardly a line broad.

Straight Kohautia. Pl. $\frac{1}{2}$ foot.

4 K. LONGIFlo'RA (D. C. prod. 4. p. 430.) leaves linear, hardly acute; stipulas short, with many bristles : bristles spreading a little, length of membrane; flowers pedicellate along the branches on one side; corolla with a very long tube, and linear, hardly acute lobes. $h$. G. Native of the south of Africa, where it was collected by Burchell, ex cat. geogr. no. 1987. Tube of corolla 7 lines long; and the lobes 3 lines long, and searcely a line in breadth. Teeth of calyx short. Pedicels $2-4$ lines long.

\section{Long-flowered Kolbautia. Pl. $\frac{1}{2}$ foot.}

5 K. crnánemea (D. C. prod. 4. p. 430.) leaves linear, acute; stipulas membranous, joining the petioles: bristles reflexed, twin on both sides, at last deciduous; corymbs fewflowered; lobes of corolla linear, hardly acute, $h . \mathrm{G} . \mathrm{Na}$ tive of the south of Africa, where it was collected by Burchell, ex cat. geogr. no. 77\%. Capsule turbinate. Teeth of calyx short. Tube of corolla 3 lines long; with tlie lobes a little shorter than the tube.

Cynanchica-like Koluautia. Shrub $\frac{1}{2}$ to 1 foot.

6 K. setífera (D. C. prod. 4. p. 430.) leaves linear, cuspidately mucronate, with somewhat revolute edges; stipulas membranous, joining the petioles, cleft into 4 spreading bristles on both sides, which are longer than the membrane; corymbs few-flowered; lobes of corolla short, oval. h. G. Native of the south of $A$ frica, where it was collected by Burchell, ex cat. geogr. no. 2322. Plant hardly a hand high. Bracteas stipulaceous, membranous, multifid. Tube of corolla lardly 2 lines long.

\section{Bristle-bearing Kohautia. Pl. $\frac{1}{2}$ foot.}

7 K. Gra'ersis (D. C. I. c.) leaves linear ; branches and peduncles compressed ; stipulas truncate, fringed, at length naked; flowers on long peduncles, rising from the forks and from the tops of the branches; lobes of corolla linear-lanceolate, bluntisl, a little shorter than the tube. $\odot$. F. Native of Nipaul. Hedyòtis strícta, Wall. act. soc. asiat. 13. p. 369. but not of Sinith. Hedyòtis gràcilis, Wall. in Roxb. f. ind. 1. p. 377. Hed. fúsca, Hamilt. ex D. Don, prod. fl. nep. p. 134. Tube of corolla 4 lines long; and the lobes 3 lines long, and hardly a line broad.

Slender Kohautia. Pl. $\frac{1}{2}$ to 1 foot.

Cult. For culture and propagation see Oldenlándia above. 
LXXX. KA'DUA (named in memory of M. Kadu, a native of Ulea, who sailed with Kotzebue, for the purpose of collecting plants). Cham, et Selilecht. in Linıæa. 4. p. 157. D. C. prod. 4. p. 490 .

Lin. syst. Tetrándria, Monogrinia. Calyx with a hemispherical tube, and a 4-cleft or 4-toothed limb. Corolla coriaceous, glabrous inside, salver-shaped: witl a long tube and a 4-cleft limb. Genitals inclosed. Anthers linear or oblong, almost sessile within the tube. Style filiform, thickest at the apex and bifid: lobes bearing papillæe inside. Capsule globose or elliptic, 2-celled, half adnate to the calyx, which is sometimes dry and sometimes fleshy, usually crowned by the segments of the calyx, dehiscing at the cells at the apex. Seeds innumerable, small, angular, inserted in the placentas, which are spongy, and fixed to the middle dissepiment.-Smooth Australian subshrubs. Leaves opposite. Stipulas solitary on each side, acute, entire. Flowers in terminal cymes or solitary and axillary, pedunculate.

1 K. Cоокin'sa (Cham. et Schlecht, in Linnæa. 4. p. 158.) branches opposite, terete; leaves linear, acute, witl revolute margins; flowers few, terminal ; capsule beaked at the apex. h. G. Native of the Island of $\mathrm{O}-\mathrm{Wal}$. The beak of the capsule having both a loculicidal and septicidal deliscence at the same time, hence the capsule is at length apparently 4beaked.

Cook's Kadua. Shrub $\frac{1}{2}$ to 1 foot.

2 K. condA'TA (Cham. et Schlecht. I. c. p. 160.) branclilets almost terete; leaves sessile: upper ones cordate, acuminated, coriaceous; cymes dichotomous and trichotomous, leafy; capsule turbinately hemispherical, beakless. h. G. Native of the Island of O-Wahu. Lower leaves oblong-lanceolate.

Cordate-leaved Kadua. Shrub $\frac{1}{2}$ to 1 foot.

3 K. Glomera'ta (Hook. et Ârn. in Beech, voy, pt. bot. p. 85.) lower parts of branches almost terete, upper part compressed; leaves oblong-lanceolate, suddenly contracted at the base into a very short petiole; panicle terminal, with elongated opposite branches, bearing each 2 foliaceons braeteas at the apex, and glomerate flowers; calyx and corolla downy. h.G. Native of the Sandwich Islands. 'The flowers may be said to be axillary, pedunculate, capitate, if the axils of the panicle be viewed as a continuation of the branch. Teeth of calyx linear, stiff.

Glomerated-flowered Kadua. Slirub $\frac{1}{2}$ to 1 foot.

4 K. Arnótriı; plant erect, glabrons, branched; leaves oblong, on slıort petioles; stipulas undivided, triangular; flowers disposed in fascicles in the axils of the superior leaves, the whole forming interrupted racemes; calyxes downy; tube of corolla very long, terete : lobes obtuse, revolute; style bipartite to the base. $\boldsymbol{h}$. G. Native of the Sandwich Islands, where it is called by tlie natives Kiore. Hedyòtis conóstyla, Gaud. in Freyc. voy. pt. bot. p. 471. t. 9 . Oldenlándia conóstyla, D. C. prod. 4. p. 428. Nearly allied to the preceding species, according to Arnott.

Arnott's Kadua. Shrub $\frac{1}{2}$ to 1 foot.

5 K. Menziesia'na (Cham. et Schlecht. l.c. p. 160.) branches tetragonal ; leaves elliptic, petiolate, bluntly acuminated, downy beneath at the base; stipulas glandular, truncute; cymes terminal, few-flowered; peluncles compressed, downy; drupe rather convex at the apex. 々. G. Native of the Island of O.Wahu.

Menzies's Kadua. Shrub $\frac{1}{2}$ to 1 foot.

6 K. Smítun (Hook. et Arn. in Beech. voy. pt. bot. p. 86.) branches terete, but compressed towards the tops; leaves coriaceous, ovate-elliptic, glabrous, petiolate; stipulas triangular, bluntly apienlated; paniele terninal, trichotomous, dense; calyxes and corollas downy. $h$. G. Native of the Sandwich
Islands. Hedyòtis coriàcea, Simith, in Rees's eycl. vol. 17. no. 11. The tube of the corolla is long, and the segments of the limb are deflexed, with long-acuminated reeurved points.

Smith's Kadua. Shrub $\frac{1}{2}$ to 1 foot.

$7 \mathrm{~K}$. centranthoìde (IIook, et Arn. in Beech, voy, pt. bot. p. 85.) branclilets terete at the base, and compressed at the apex; leaves cordate-lanceolate, almost sessile; panicle terminal, with short opposite branches, bearing naked heaps of flowers at their tops; calyx and corolla glabrous. $h_{c} . \mathrm{G}$. $\mathrm{Na}$ tive of the Sandwich Islands.

Centranthus-like Kadua. Shrub $\frac{1}{2}$ to 1 foot.

8 K. Romanzofrie'ssis (Cham. et Schlecht. in Linnæa. 4. p. 162.) branches tetragonal, densely leafy; leaves obovate, obtuse, or somewhat acuminated, on short petioles, rather coriaceous ; stipulas furnished with a sub-glandular mucrone; flowers terminal, 1-3 together, pedicellate; drupe obovate. h. G. Native on the coral island, called Romanzoff's Island.

Romanzoff-island Kadua. Slirub $\frac{1}{2}$ to 1 foot.

9 K. acumins'ta (Cham, et Sehlecht. 1. c. p. 163.) branches terete, compressed towards the tops; leaves lanceolate, longacuminated, distinctly petiolate, rather coriaceous; stipulas triangular, acuminated; flowers axillary, usually twin, pedicellate; teeth of calyx narrow-lanceolate, equal in length to the tube of the corolla; capsule globose. 々. G. Native of the Sandwich islands, particularly of $\mathrm{O}-\mathrm{W}$ ahu.

Acuminated-leaved Kadua. Shrub $\frac{1}{2}$ to 1 foot.

$10 \mathrm{~K}$. ? Afrisis (Cham. et Sehlecht. l. c. p. 16\%) branches tetragonal, wrinkled transversely; leaves elliptic-lanceolate, acute, obtuse at the base, on short petioles; stipulas membranous, deciduous, toothed a little on both sides ; cyme thyrsoid, terminal; drupe nearly globose, crowned by the remaining part of the calyx, indeluiscent. h. G. Native of the Island of O-Wahu. Flowers unknown.

Allied Kadua, Shrub $\frac{1}{2}$ to 1 foot.

Cult. None of the species are worth cultivating, except in botanic gardens. They will grow in any light soil; and will be easily increased by euttings planted under a hand-glass, or by seed, which latter mode will be preferable.

LXXXI. ANO'TIS (from a priv. ovs wros, ous otos, an ear; there are no accessory teeth to the calyx). D. C. jurod. 4. p. 431. - Hedyòtis species, Ruiz et Pav. and Cav.-Houstònia species, Lin. and others.

Lin. syst. Tetrándria, Monogýnia. Calyx with an obovate tube, and a 4-toothed limb (f. 96. a.); teeth acute, separated by acute recesses, with no accessory ones. Corolla salver-shaped (f. 96.6 .), having the tube a little longer than the lobes; limb 4 -cleft; throat almost glabrous. Anthers inclosed or a little exserted (f. 96. c.). Stigma somewhat 2-lobed (f. 96.e.). Capsule ovate, crowned by the calyx, 2-celled, with a loculicidal debiscence at the apex. Seeds 4-8 in each cell, ovate, and rather angular.--Subshrubs and herbs, natives of Anerica. Leaves opposite, linear, mucronate or oval. Stipulas undivided or toothed. Flowers terminal, solitary or corymbose. This genus is nearly allied to Rachicállis, but differs from that genus in the want of accessory teeth to the calyx, whence the generic name. The genus probably contains the types of 3 different genera, which it may hereafter be necessary to separate.

Sect. 1. Ericiòts (this name has been given to this seetion on account of the plants contained in it having the habit of heaths). D. C. prod. 4.p. 431. Heath-like small shrubs, rarely herbs. Leaves linear, mucronate. Corolla salver-shaped, having the tube longer than the lobes $\left(\mathrm{f} .96^{\circ} \mathrm{d}\right.$.) Tube of calyx almost adnate with the ovarium to the apex. 
1 A. Filifórais D. C. prod. 4. p. 431.) stems herbaceous, creeping, much branched, tetragoual, glabrous; leaves sessile, linear, apiculated, rather ciliated; stipulas small, ciliated; flowers solitary, terminal, almost sessile; anthers exserted. 4 . F. Native of Peru, on the Andes, in frigid places. Hedyòtis filifórmis, Ruiz et Pav. fl. per. 1. p. 67. t. 87 . f. b. Habit of a species of Gálium. Corolla white; limb spreading at first, but reflexed at last. Lobes of calyx lanceolate, acute. Capsule ovate. (f. 96.)

Filiform Anotis. Pl. proc.

2 A. CONFE'RTA (D. C. prod. 4. p. 431.) stem creeping, much branched; branches ascending, tetragonal; leaves linear, apiculated, flat, glabrous; stipulas subulate; flowers terminal, solitary; anthers at the throat. 4. F. Native of Peru, on the Andes of Tarma and Cantua. Hedyòtis conférta, Ruiz et Pav. fl. per. 1. p. 57. t. 87. f. it. Leaves 2-s lines long. Corolla white. Capsule glabrous, emarginate.

Cron'ted Anotis. Pl. creeping.

3 A. HYrNoldes (D. C. prod. 4. p. 432.) stems suffruticose, creeping, tufted; branches tetragonal; leaves sessile, linear-lanceolate, glabrous, piliferous at the apex: stipulas subulate at the apex; flowers terminal, solitary, sessile; anthers exserted. $\mathcal{4}$. F. Native of the province of Quito, in very cold places of the Andes, about Assuaya. Houstònia bryoides, Willd. herb. ex Kunth. Hedyòtis liypnoìdes, H. B. et Kunth, nov, gen. amer. 3. p. 389. Leaves hardly a line long. Corollas white.

\section{Hypnum-like Anotis. Pl. creeping.}

4 A. JUnilerifo'ila (D. C. prod. 4. p. 432.) plant suffruticose, procumbent, much branched; branchlets tetragonal; leaves linear, apiculated, sessile, with revolute edges; stipulas ovate, acute; flowers terminal, tern, pedicellate. h. F. Native of Peru, in high frigid places of the Andes, of Tarma, and Cantua. Hedyòtis jumiperifòlia, Ruiz et Pav. A. per. 1. p. 57. t. 87. f. c. Corollas unknown.

\section{Juniper-leaved Anotis. Pl. proc.}

5 A. micropuy'Lla (D. C. l. c.) stems suffruticose, creeping; branchlets nearly terete; leaves oblong, glabrous on short petioles, piliferous at the apex; stipulas tridentate at the apex; flowers solitary, sessile, terminal, but at length lateral; anthers exserted; cells of capsule 4-5-seeded. h.F. Native of Peru, near the mines of Gualyagoc, and the city of Micuipampa. Hedyòt is microphÿlla, H. B. et Kunth, nov, gen. amer. 3. p. 389. Wilkl. in Schultes, syst. 3. p. 526.

\section{Small.learcd Anotis. Pl. creeping.}

6 A. Cervante'sis (D. C. I. c.) stems tufted, diffuse, quadrangular, rather scabrous, corymbose at the apex; leaves sessile, linear, acute, flat, glabrous; stipulas ovate, toothed; flowers pedunculate, 2-3-together, terminal, rarely axillary ; anthers exserted. h. F. Native of Mexico. Hedyòtis pygma'a, Rœm. et Schultes, syst. 3. p. 526 . Hed. pùmila, Willd. herb. Hed. Cervantèsii, H. B. et Kuntl, nov. gen. amer. 3. p. 390. Cham. et Schlecht. in Linnæa. 5. p. 168. Corolla funnel-shaped, violaceous? glabrous, size of those of Aspérula cyuánchica. Capsule subglobose, didymous; cells 4-8-seeded.

Cerrantes's Anotis. Shrub diffuse and tufted.

7 A. титмға' la (D. C. l. c.) plant shrubby, erect, much branched; branchlets hairy; leaves sessile, linear, glabrous, with revolute margins ; stipulas acutely bifid ; corymbs terminal, trichotomous; cells of capsule 8-seeded. $\zeta$. F. Native of Peru, on ligh hills in the provinces of Tarma and Caxatambo. Hedyòtis thymifòlia, Ruiz et Pav. 1. p. 56. t. 88. f. a. Leaves 5-6 lines long. Corollas white. Capsule obcordate. Branchlets subtetragonal.

Var. $\beta$, thesioides (D. C. prod. 4. p. 432.) plant erect; branchlets terete; flowers lateral and terminal, usually by threes, on very short peduncles; cells of capsule 9-12-seeded. $\boldsymbol{h} . \mathbf{F}$. Native near Pasto and Quito. Hedyòtis thymifòlia, H. B. et Kunth, nov. gen. amer. 3. p. 391. Hed. thesioides and Hed. coarctàta, Willd, herb. ex Kunth, nov. gen. amer. 3. p. 391. Hed. thuyoìles and Hcd. coarctàta, Willd. in Schultes, syst. 3. p. 527. Leaves 5-6 lines long. Corolla funnel-shaped : with the lobes one-half shorter than the tube. Capsule subgloboseelliptic. Anthers exserted.

Var. $\gamma$, hyssopifòlia (D. C. I. c.) plant suffruticose; leaves an inch long; corymbs terminal, trichotomous. $h_{2}$. F. Native of Chili, near Coquimbo; and of Peru, at Guamantanga and St. Bonaventura, Hedyòtis hyssopifòlia, Cav. icon. 6. p. 54. t. 575. f. 2. Corolla as in var. $\beta$. Branches bluntly tetragonal. Seeds larger than in any of its congeners, and is perhaps a proper species.

Thyme-leaved Anotis. Shrub 1 to 2 feet.

8 A. laricifo'lia (D. C. l. c.) plant suffruticose, erect, branched, glabrous ; leaves sessile, linear, acute, with hardly revolute margins; stipulas acute; peduncles $3-5$-flowered, rising from the forks of the branches; anthers exserted. h.F. $\mathrm{Na}$ tive of the Cordillera of Chili, on the highest mountains. Hed. laricifòlia, Cav. icon. 6. p. 54. t. 575 . f. 1. Corolla of a reddish brown colour, funnel-shaped. Capsule ovate, truncate.

Larch-leaved Anotis. Shrub $\frac{1}{2}$ to 1 foot.

9 A. Seto'sA (D. C. l.c.) plant shrubby, erect, much branched; leaves on short petioles, ovate, acute, ciliately serrulated, glabrous; stipulas connate, ovate, furnished with many bristles at the apex; Howers terminal, usually by threes. $\eta$. F. Native of Peru, on the Andes at Churupallana and Huassa-Huassi. Hed, setòsa, Ruiz et Pav. H. per. 1. p. 56. t. 88. f. a. Corolla large, purple, with a broad terete tube, and having the lobes almost one-half shorter than the tube. Habit of Rachicallis nitida, but differs from it in the calyx being 4 -lobed, without any accessory teeth. Anthers inclosed.

Bristly Anotis. Shrub 2 to 4 feet.

10 A. ERicoìdes (D. C. prod. 4. p. 433.) leaves linear, in fascicles, furrowed; flowers terminal, subcorymbose. $h_{\text {. F }}$. Native of Peru, ex Roem. ex Schultes; and of New Granada, in icy places on the Andes, between Ona and Paramo de Saraguru, ex Kunth. The rest unknown. Hed. ericoides, Willd. herb. in Schultes, syst. 3. p. 527. and in Kunth, nov. gen. amer. 3. p. 393.

Ileath-like Anotis. Shrub $\frac{1}{4}$ to $\frac{1}{2}$ foot.

Sect. 11. Ahrнio'tis (a wros, ous otos, an ear). D. C. prod. 4. p. 433. Herbs erect. Leaves ovate, or lanceolate. Corymbs trichotomous. Corolla salver-shaped. Calyx drawn out to half the length of the ovarium only; the capsule is therefore naked at the apex.

11 A. LANCEola'ta (D. C. diss, ined, with a figure, ex prod. 4. p. 433.) plant glabrous; stem erect, tetragonal, with the angles a little winged; leaves sessile, lanceolate, acute, glabrous; stipulas lanceolate, membranous; corymbs trichotomous, terminal; corolla funnel-shaped ; anthers exserted ; capsule globose, halfadnate to the calyx. $\odot . F$. Native of the south of Carolina, where it was detected by Bosc. Hed. lanceolàta, Poir. suppl. 3. p. 14. Genus novum, Fraser, mss. in herb. L'Her. Seeds nearly globose, 4-5 in each cell. Lobes of calyx linear, permanent, excceding the capsule a little. Corolla purplish. 
Lanceolate-leaved Anotis. Pl. $\frac{1}{4}$ to $\frac{1}{2}$ foot.

12 A. LONGIFo'LIA; stems erect, branched, tetragonal, very downy at the joints; leaves linear-oblong: radical ones attenuated at tlye base; stipulas broad, ovate, entire, bidentate or tridentate, membranous, white; corolla funnel-shaped. $4 . \mathbf{H}$. Native of Florida, in exposed places by the sea side; of Canada, about Lake Huron, and abundant about Lake Winepeg and the Saskatchawan. Houstònia longifòlia, Gartn. fruct. 1. p. 2266. t. 49. f. 8. Hook. in bot. mag. 3099. Houstònia angustif òlia, Michx. A. amer. bor. 1. p. 160. Iledyòtis longifolia, Hook. A. amer. bor. 1. p. 286. Flowers scarlet, terminal, almost sessile, 3 in a fascicle. Capsules subturbinate.

Long-learcd Anotis. Fl. May, July. Pl. $\frac{1}{3}$ foot.

$13 \mathrm{~A}$. ciliolo's $\mathrm{A}$; radical leaves ovate, obtuse, attenuated at the base, with ciliated edges: cauline ones ovate-spatulate, sessile; flowers corymbose, terminal, perlicellate; peduncles trichotomous; calycine segments linear-lanceolate; stem glabrous, branched at the top. 4 . H. Native of North America, in Goat Island, and at the Falls of Niagara. Houstònia ciliolòsa, Torrey, f. un. st. 1. p. 174. Hedyòtis ciliolòsa, Hook. fl. amer. bor. 1. p. 286.

Ciliated-leaved Anotis. Pl. 1 foot?

14 A. PURPU'rea; stems erect, branclied at the top, and downy at the joints; leaves ovate-lanceolate or linear-lanceolate, sessile; corymbs terminal. 24. H. Native from Pennsylvania to Carolina, in dry woods. Knóxia purpùrea, Lam. ill. p. 259. Houstònia purpùrea, Lam. ill. 251, Hedyòtis umbellàta, Walt. fl. car. 85 . Hed, vàrians, Michx, fl, amer. bor, 1.p. 80. Flowers purple.

Purple-flowered Anotis. Fl. May, Aug. Clt. 1800 . Pl. $1 \mathrm{ft}$.

Sect. III. Pane'tos (the plants flower all the year round). Rafin. in ann. gen. sc. phys. 5. p. 227. D. C. prod. 4. p. 433. Prostrate or creeping plants, witl the habit of Anagallis. Leaves ovate-roundish. Flowers axillary and terminal, solitary. Calyx not adnate to the ovarium at the apex, and therefore the capsule is naked at the top.

15 A. rotundifo'lia (D. C. prod. 4. p. 433.) stems herbaceous, prostrate, branched; branches tetragonal; leaves nearly orbicular, on short petioles, glabrous, hardly ciliated; stipulas small ; tlowers axillary, solitary, on short pedicels; corolla salver-slaped, having the tube 3 times longer than the calyx; capsule half-adnate to the calyx. $4 . F$. Native of Carolina and Florida, in dry exposed places by the sea side. Houstonia rotundifòlia, Michx. fl. bor. amer. I. p. 85. Ell. sketch. 1. p. 193. Anónymos procúmbens, WValt. car. p. 86 . Poirètia procúmbens, Gmel. syst. 263. Habit of Verónica numnularifòlia. Flowers white.

Round-leaved Anotis. Pl. prostrate.

16 A. Salzanini (D. C. l. c.) stems herbaceous, prostrate, branched; leaves nearly orbicular, on short petioles, glabrous, hardly ciliated; stipulas hardly any; flowers axillary, solitary, having the pedicels exceeding the leaves; corolla campanulate, twice the length of the lobes of the calyx, which are oval. 4 . S. Native of Brazi], about Bahia frequent. Intermediate between the preceding and following species. Corollas pale red.

Sulzmann's Anotis. Pl. prostrate.

17 A. SE'RPENS (D. C. prod. 4. p. 433.) stems suffruticose, creeping, much branched; branches tetragonal; leaves roundish-ovate or elliptic, petiolate, acutish, glabrous, with spinulosely ciliated edges; stipulas dentately ciliated ; flowers axillary, solitary, pedunculate; corolla subrotate, ciliated a little; anthers a little exserted. 々.? F. Native of Quito, on the burning Mount Antisana. Hedyòtis sérpens, H. B. et Kunth, nov. gen. amer. 3. p. 390. t. 289 . Hed. microplýlla, Willd. herb.? in
Rom. et Schultes, syst. 3. p. 527. Houstònia microphýlla, Willd. herb.? Corolla white, with a very short tube, and the lobes of the calyx distant as in Oidenlandia. Seeds usually 5 in cach cell.

Creeping Anotis. Pl. creeping.

$18 \Lambda$. ceervilen; plant tufted; stems erect, dichotomous; leaves ovate-lanceolate, attenuated at the base: radical ones spatulate, and a little hairy; peduncles elongated, 1-flowered; corollas salver-shaped, with acute lobes. 24. H. Native of Virginia; and of Canada, about Quebec. IIoustònia coerulea, Lin. spec. p. 152. Pursh. fl. amer. sept. 1. p. 106. Sims, bot. mag. t. 370 . Houstònia Linnæ'i $\boldsymbol{a}$, Michx. fl. bor. amer. 1. p. 8. Hedyòtis cœrùlea, Hook. fl. bor. amer. 1. p. 286 . A small tufted plant, with the habit of Anagállis tcrélla, with liglıt blue flowers. The first peduncles are 2 -flowered. 'There is also a variety of this with white flowers.

Blue-flowered Anotis, Fl. May, Aug. Clt. 1785. Pl. $\frac{1}{4}$ foot

19 A. Serpyllifo'lia; plant tufted; stems very short; leaves oval, attenuated at the base; peduncles terminal, very long, solitary, divaricate; corolla salver-shaped, with acute lobes. 24. H. Native of Carolina, on the banks of rivulets in the mountains; and of Canada, about Lake William and Lake Superior. Houstònia serpyllifòlia, Michx. f. bor. amer. 1. p. 85. Pursh, fl. amer. sept. 1. p. 106. Grabam, in bot. inag. 2822. Houstònia cœrulea $\beta$ minor, Pursh, fl. amer. sept. 1. p. 10E. Houstònia Linnæ'i $\beta$, Michx. ff. amer. bor. 1. p. 85 . Houstònia pàtens, Elliott. fl. carol. 1. p. 191. Hedyòtis coerùlea $\beta$, Hook. $f$. bor. amer. 1. p. 286. Flowers white. A small tufted plant, very like the last.

Wild-thyme-leaved Anotis. F]. June, Aug. Clt. 1826. Pl. $\frac{1}{4} \mathrm{ft}$.

20 A. TENE'LLA ; stems creeping, filiform ; leaves orbicular, acute, nerved; pechuncles terminal, one-flowered, very long. 4. F. Native of North Carolina, on high mountains, Houstònia tenélla, Pursh, fl. amer. sept. 1. p. 106. Flowers purple. Very like $A$. serpyllifòlia.

Slcnder Anotis. Pl. creeping.

Cult. This is a genus of pretty little plants. All the species require to be grown in small pots, well drained with sherds, in a mixture of peat and sand. They are increased by dividing at the root. Those natives of warm elimates require protection in winter, by placing them in a frame or green-house.

LXXXII. RACHICA'LLIS (from $\rho \alpha \chi \iota$, rachia, a crag by the sea side, and $\kappa a \lambda \lambda o s$, kallos, beauty; because the plants ornament the rocks by the sea side). D. C. prod. 4. p. 433.Hedyòtis species, Swartz, Kunth, \&c.

Lin. syst. Tetrándria, Monogynia. Calyx with a hemispherical tube, and a 4-lobed limb, furnished with from 1-3 accessory teetl between each of the lobes. Corolla with a long terete tube, a short spreading bluntly 4 -lobed limb, and a beardless throat. Anthers at the throat, inclosed. Stigma 2-lobed. Capsule rather didymous, dehiscing by 2 valves at the cells, and crowned by the teeth of the calyx. Seeds $8-20$ in each cell. - Small shrubby South American plants, inhabitants of rocks by the sea side, with the habit of Passerina. Leaves oblong, fleshy, with revolute edges, sessile. Stipulas connate, undivideil or tridentate. Flowers solitary, sessile.

I R. NI'TIDA (D. C. prod. 4. p. 433.) plant shrubby, much branclued; branches crowded, densely leafy; leaves linear, acute, fleshy, with revolute margins, glabrous, and shining on both surfaces; stipulas connate, short, trifid at the apex; flowers solitary, terminal, sessile; corolla glabrous. 々. S. Native near Santa Fe de Bogota, Hedyotis nítida, H. B. et Kunth, nor. gen. amer. 3. p. 392. Lobes of caly $\times$ 4, linear-lanceolate, fir. 
nished with 2-3 linear accessory teeth between each. Anthers exserted. Capsule globose, turbinate at the base. Seeds ovate, angular, 8-9 in each cell.

Shining Rachicallis. Slurub 2 to 3 feet.

2 K. RUPE'stris (D. C. prod. 4. p. 434.) plant shrubby, mucl brancled; branches twisted, corky; leaves crowded in stellate fascicles, oblong, fleshy, with revolute edges, shining above; stipulas connate, pubescent inside; flowers axillary, solitary, sessile; corollas villous, with a curved tube. $h$. S. Native of the Caribbee Islands, on rocks by the sea side; as of Cuba, Jamaica, Sc. Hedyòtis rupéstris, Swartz, prod. p. 29. H. B. et Kuntl, nov, gen. aıner. 3. p. 391. Hed. Americàna, Jacq. amer. p. 20. Oldenlándia rupéstris, Lam. dict. 4. p. 535. -Sloane, jam. t. 202. f. 1. Habit of Passerina. Corolla yellow. Calyx 4-cleft; lobes woolly inside, with 4 accessory teeth between each. Seeds orate, angular, about 20 in each cell. This plant has been incautiously referred to the genus Buclinèra by Smith in Rees's cycl. vol. 17.

Rock Rachicallis. Shrub 2 to 3 feet.

3 R. Caracasa'sa (D. C. l. c.) plant suffruticose, much branclied; branclies leafy at top; leaves oblong, acure, fleshy, with revolute margins, spreading, glabrous, and shining; flowers terminal and axillary, solitary, sessile. h. S. Native of South America, on the southern declivities of the mountains called Silla de Caraccas. Hedyòtis Caracasàna, H. B. et Kunth, nov. gen. amer. 4. p. 393. Corolla violaceous.

Caraccas Rachicallis. Slurub 8 feet.

Cult. Elegant shrubby plants of difficult culture. A mix. ture of peat and sand will probably be the best soil for them, and they should be grown in pots half filled with pot-sherds. They may either be increased by seeds or by cuttings planted in sand, with a bell-glass over them. They should be placed on shelves in a green-house.

LXXXIII. LUCYA (named by De Candolle after the late Lucy Dunal, who made many observations upon the Rubiaceous plants growing in the neighbourhood of Montpelier, as may be seen by comparing the $\mathrm{A}$. fr. ed. 3. vol. 5 . p. 499 , sister to Michel Felix Dunal, professor of botany at Montpelier). D. C. prod. 4. p. 434.-Dunàlia, Spreng. but not of Kunth.-Hedyòtis species, Swartz and A. Rich.-Pèplis species, Lin.

Lin. syst. Tetrándria, Monogínia. Calyx with a bemispherical tube, and the limb of 8 twin teeth or of 4 bifid ones, permanent. Corolla with a very short tube, and a 4-lobed limb; lobes obtuse. Stamens shorter than the corolla. Style short, bifid. Capsule globose, didymous, 2-celled, with a loculicidal and half septicidal dehiscence; hence the capsule appears $S$. valved at the apex. Seed 2 in each cell, ex Spreng., 5-6, ex Rich.-A small herb, with the habit of Péplis. lioots fibrous and tuberous. Stens short, glabrous. Leaves almost sessile, cordate-ovate, downy beneath: upper ones usually by fours. Flowers axillary, and nearly terminal, solitary on very short pedicels, small, white.

1 I. tubero'sa (D. C. prod. 4. p. 434.) $\odot$. F. Native of the West India Islands, in shady dry places at the bottom of the mountains, and on the roots of trees; as of Jamaica, St. Domingo, \&c. Ammánnia hírta, P. Browne, jam. p. 145. Péplis tetrándra, Lin. spec. 474. Jacq. amer. p. 100. t. 180. f. 29. Oldenlándia tuberòsa, Lam. dict. 4. p. 535. Hedyòtis tuberòsa, Swartz, obs, bot. p. 136. t. 1. f. 2. Dunàlia tuberòsa, Spreng. pug. 1. p. 25 .

Tuberous-rooted Lucya. Herb small.

Cult. This plant should be treated like other tender annuals. It is not worth growing except in botanic gardens.
LXXXIV. POLYPREMUM (from $\pi o \lambda v c$, polys, much, and

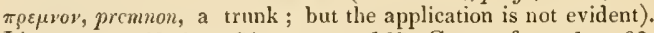
Lin. act, ups. 1711 . p. 78 . gen. no. 137. Gærtn. fruct. 1. t. 62. Lam. ill. t. 71 . Juss. ann. mus. 5. p. 255. mem. mus. 6. p. 382. D. C. prod. 4. p. 434 .

Lix. syst. Tetrándria, Monogýnia. Calyx with a very short tube, adnate to the bottom of the ovarimm, and a 4-parted limb; lobes subulate. Corolla with a very short tube, a bearded throat, and a 4-parted limb; lobes or segments oval. Stamens 4, with very short filaments, and inclosed anthers. Style 1, undivided. Capsule ovate, compressed, 2-celled, with a loculicidal dehiscence. Placentas oblong, ascending, adnate to the bottom of the dissepiment. Seeds numerous, very minute, angular, diaplanous. Embryo straight, slender, in fleshy albumen.- $\Lambda$ glabrons herb, with the habit of Gàlium or Buffónia. Leaves opposite, linear-subulate, having their bases connate from the almost entire stipular sheaths. Corymbs terminal, dichotomous, cymose, with small sessile flowers in the forks and tops of the branchlets, each flower propped by $2-4$ bracteas. Corollas white.

1 P. Procu'melans (Lin. act. ups. 1741. p. 78.) భ. F. ex Ell. sketch. 1. p. 200. ค. ex Pursh, fi. amer. sept. 1. p. 99. Native of Carolina and Virginia, in barren places. P. Linnæ' $i$, Michx. fl. amer. bor. 1. p. 83. Linum Caroliniànum, Petiv. gaz. 9. t. 5. f. 6 .

Procumbent Polypremum. Pl. procumbent.

Cult. This plant should be treated as other tender annuals.

\section{Tribe IV.}

ISERTIE' $\mathrm{E}$ (this tribe contains plants agreeing with the genus Isértia, in liaving a drupaceous fruit, containing many seeded pyrenæe or nuts). A. Rich, mem. soc. hist. nat. Par. 5. p. 108. and 235. 1). C. prod. 4. p. 435. Fruit drupaceous (f. 97.g.), composed of numerous many seeded pyrenæ (f. 97. c.). Albumen of seeds fleshy.-Shrubs or herbs. Leaves opposite. Stipulas interpetiolar.

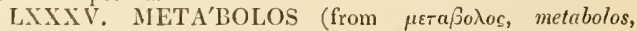
changeable; but the application is not evident). Blum. bijdr. p. 990. D. C. prod. 4. p. 435.-Sclerocúccus, Bartl. in herb. Hrake.

Lin. sust. Tetra-Pentándria, Monogýnia. Calyx with an obovate roundish tube, and a 4, rarely 5-parted limb. Corolla funnel-shaped, with a 4 , rarely 5 -cleft or parted limb. Stamens $4-5$, inserted in the throat of the corolla. Style filiform; stigma thickencd, 2-4-parted. Berry dry, crowned by the calyx, divisible into 2-4 many-seeded pyrenæe or nuts. Seeds angular, fised to prominent placentas. - Suffruticose herbs. Stems tetragonal. Leaves oppositc, with parallel veins. Stipulas twin on both sides, cut. Flowers disposed in whorles or axillary heads. This genus is evidently very distinct from Hedyòtis in the fruit being indehiscent (ex Blum), and in the cells being usually 4 or 5 .

1 M. vano'sus (Blum. bijdr. p. 991.) stem suffruticose, prostrate; leaves on short petioles, ovate-lanceolate, acuminated, lined with veins, rather scabrous; whorles of flowers glomerate, axillary. $\eta_{2} . S$. Natire of Jara, in the province of Buitenzorg, in sliady places.

I'einy-leaved Metabolos. Shrub prostrate.

2 M. LATIFo'Lius (Blum. l. c.) stem suffruticose, divaricate; leaves on longish petioles, elliptic-lanceolate, acuminated at both ends, rather scabrous; flowers disposed in dense axillary glomerate whorles. $\zeta_{2}$. S. Native of Java, on the mountains.

Broad-leaved Metabolos. Shrub diffuse.

3 M. Rtgo'sus (Blum. l. c.) stem slurubby, decumbent; leaves 
oblong-lanceolate, acuminated, wrinkled, a little ciliated, downy beneath; flowers in dense axillary heaps; fruit containing 4 pyrena. $r_{c}$. S. Native, of Java, on the top of Mount Gede. Stigma exserted, 4-cleft.

Wrinkled Metabolos. Shrub procumbent.

4. M. prostra'tus (Blum. 1. c.) stem suffruticose, prostrate; leaves oblong-lanceolate, glabrous; hearls of flowers axillary, sessile or pedunculate. $h$.S. Native of Java, in woods on the mountains.

Prostrate Metabolos. Slirub prostrate.

5 M. Rigidus (Blum. 1. e.) stem suffruticose, erect; leaves elliptic-oblong, acuminated at both ends, stiff, glabrous; heaps of Howers axillary, bibracteate; calyx campanulate, quadrifid. 々. S. Native of Java, on Mount Seribu, and on Mount Bonkok, in the province of Bantam. Leaves 6 inches long.

Stiff Mletabolos. Shrub.

6 M. unea'tus (Bartl. in herb. Hænke, ex D. C. prod. 4. p. 495. under the name of Sclcrocóccus) stem herbaceous, erectish, and are, as well as the branches, beset with hairs; leaves on short petioles, ovate-lanceolate, acuminated, downy, lined with veins; heads of flowers somewhat corymbose, axillary, on short peduncles. $h . S$. Native of Mexico, according to Hanke, herb.; but probably of the Philippine Islands. Very like the following species, and probably only a variety of it. Stipulas membranous, and connate at the base, ending in long subulate bristles, as in $M$. coerùlca. Flowers small. Stamens a little exserted.

Lined-leaved Metabolos. Pl. ereet.

7 M. Carv'le A (Blum. bijdr. p. 991.) stem suffruticose, procumbent, and is, as well as the branches, beset with soft hairs; leaves lanceolate, on short petioles, acuminated, downy, lined with veins; heads of flowers subcorymbose, axillary. $h_{c} . \mathrm{S}$. Native of Java, about Buitenzorg, in lumid shady places.

Blue-flowered Metabolos. Slirub procumbent.

8 M, RADicass (Bart, in herb. Hanke, under the name of Sclerocóccus,) stem herbaceous, radicant at the base, glabrous, having 2 downy lines at the apex; leaves lanceolate, petiolate, glabrous, pale beneath; teeth of stipulas setaceous; pedicels axillary, very short, disposed in a kind of half whorles, very short. - Native of the island of Luzon, one of the Philippines.

Rooling Mletabolos. Pl. creeping.

$9 \mathrm{M}$. Angustifo'zius (Bartl, in Hank. herb. under the generic name of Sclerocáccus,) stems shrubby; leaves linear-lanceolate, almost sessile, lined with veins, downy on the nerves beneath, as well as the branchlets; stipulas ovate-lanceolate, cuspidate, downy, a little toothed at the apex; flowers on short pedicels, disposed in axillary and terminal heaps. h. S. Native of the island of Manilla, near Sorzogon.

Narrow-leared Metabolos. Shrub.

10 M. Ferkugíneus (Bartl, in herb. Hænke, under the generic name Sclcricóccus, ex D. C. prod. 4. p. 436.) plant shrubby; leaves linear-oblong, attenuated at the base, glabrous above in the adult state, and clothed with rusty wool beneath, particularly on the nerves, as well as the branchlets; stipulas ovate, acutc, quite entire ; flowers axillary, glomerate, almost sessile. 2 . S. Native of Luzon, one of the Philippines, at Sorzogon. Some of the fruit examined have 3 cells only.

Rusty Metabolos. Shrub.

11 I. L.EvigA'tus (Bart]. in herb. Hænke, under the generic name of Siclerocóccus, ex D. C. l. c.) plant slurubby, smoothish ; leaves ovate-lanceolate, petiolate, glabrous above, rather scabrous on the nerves beneath, as well as on the petioles and branchlets; stipulas lanceolate, pectinately ciliated ; flowers axillary, glomerate, almost sessile. $h . S$. Native of the island of Luzon, one of the Philippines.

Smooth Metabolos. Shrub.

Cult. For culture and propagation see Hamèlia, p. 542. voL. IIt.
LXXXV1. GONZA'LEA (this genus is dedicated by Ruiz and Pavon to F. Gonzaler Laguna, a Spanish botanist). Pers. ench. no. 265. Juss. mem. mus. 6. p. 400. Roem. et Schultes, syst. no. 466. D). C. prod. 4. 13. 436.

Lin. syst. Tetrándria, Monogýnia. Calyx with a subglobosc tube, and a 4-lobed limb. Corolla funnel-sliaped or salvershaped, villous outside : with a long cylindrical tube, ovate lobes or segments, and a downy or hairy tlıroat. Stamens 4 , inclosed. Style filiform; stigma usually 4, somewlut pressed together into a head. Berry containing 4 pyrena, rärely 3-2-celled; cclls or pyrenæ many seeded. Seeds minute, angular, dotted.South American shrubs, with terete villous branches. Leares oval-lanceolate, acuminated. Spikes terminal, or from the axils of the upper leaves, very long. Flowers disposed in fascicles on one side of the spikes, and sessile along its axis.-I'his genus is possibly divisible into two or three.

Sect. I. Gonzalagu'nia (see genus for derivation). Ruiz et Pav, fl. per. prod, p. 12. t. 3. Berries fleshy, containing 4 bony pyrenæ. Stijulas $t$ win on both sides.

1 G. PE'NDUla (Pers. ench. 1.p. 132.) Jeaves ovate, acute, bullately crenated; flowering branches pendulous; teeth of calyx bluntish; stipulas twin on both sides, subulate. h.S. Native of Peru, in groves in the province of Chinchao. Gonzalagunia depéndens, Ruiz et Pav. fl. per. 1. p. 56. t. 86. quinol. suppl. p. 84. t. 1. f, a. Corolla of a purplish rose-colour, woolly, with a bearded throat and acutish lobes. Berries black, woolly.

Pendulous-branched Gonzalea. Shrub 10 to 12 feet.

2 G. PARVifLòra; young parts of plant and inflorescence canescent from down, but the olcler parts are smoothish; Jeaves elliptic-lanceolate, acuminated at both ends; stipulas triangular acute, keeled; cymes 3-7-flowered, on short peduncles, the whole disposed in a terminal, elongated raceme. $h$. S. Native of Mexico, at Cuesta Grande de Jalacingo. Gonzalagùnia? parvifiòra, Cliam. et Schlecht. in Linnæa. 6, p. 415 . Leaves half a foot long, feather-nerved, and reticulately reined. Tube of calyx tomentose outside. Corolla smoothish outside, and segments downy, and tube hairy inside. Stigma 2-lobed.

Small-floncred Gonzalea. Shrub.

Sect. II. Lygistoìnes (from lygistum and idea, similar; the plants contained in this section resemble species of Lygistum). 1). C. prod. 4. p. 436.-Buèna, Cav. icon. 6. p. 50. t. 57 l. anal. hist. nat. hisp. 2. p. 279. but not of Poh.-Lygístum spec. Lam. Kunth.-Cuccocýpselum species, Kunth. Berry almost dry, containing 4 , rarely 3 or 2 chartaceous pyrenæ. Stipulas solitary on each side.

3 G. tonentòsa (Humb. et Bonpl. pl, equin. 1. p. 225.t. 64.) leares oblong, petiolate, acuminated, glabrous and bullate above, and clothed with white tomentum beneath, and on the branchlets; stipulas short, ovate, acute. h.S. Native of Peru, in hot places between Loxa and Gonzanama. H. B. et Kunth, nov. gen. amer. 3. p. 416 . Corolla white, tomentose on the outside, with a hairy throat, and obtuse lobes.

Tomentose Gonzalea. Shrub 8 to 9 feet.

4. G. NiveA (Bartl. in herb. Hænke, ex D. C. prod, 4. p. 436.) leaves oval-oblong, cuneated at the base, and acuminated at the apex, smoothish and flat above, and clothed with white tomentum beneath, as well as the branchlets and racemes; stipulas subulate. $h$. S. Native of Mexico. Very nearly allied to G. tomentòsa.

Snowy Gonzalea. Shrub 6 to 8 feet.

5 G. pulverulénta (Humb, et Bonpl. pl. equin. 1. p. 228.) leaves lanceolate, obtuse at the base, clothed with powdery pubescence beneath, as well as the branches; stipulas subulate. h.S. Native of Peru, in hot places near Gonzanama. Curolla white. The rest unknown. $3 \mathrm{Z}$ 
Pomdery Gonzalea. Shrub 8 to 9 feet.

6 G. Panane'nsis (Pers. ench. 1. p. 132.) leaves oblong, acuminated, acute at the base, petiolate, hairy from very short down above, and whitish from short tomentum beneath; stipulas broad at the base, and subulate at the apex, length of the petioles. $h$. S. Native of Panama and Mexico. Buèna Panaménsis, Cav, icon. 6. p. 571 . Branches sub-tetragonal. Corolla reddisb yellow.

Panama Gonzalea. Shrub 5 to 7 ieet.

7 G. conNifòlia (H. B. et Kunth, nov. gen. amer. 3. p. 416.) leaves oblong or ovate-oblong, acuminated, acute at the base, petiolate, glabrous above, and downy on the nerves and vcins beneath, as well as the branchlets; stipulas ovate-subulate, lengtl of the petioles. h.S. Native of New Granada, in rocky places near Honda. Perhaps only a variety of G. Panaménsis.

Dognood-leaved Gonzalea. Shrub.

8 G. spica'ta (D. C. prod. 4. p. 437.) leaves oblong, acuminated, downy on both surfaces; stipulas subulate at the apex; spikes terminal, elongated; calycine lobes linear; fruit almost always 2-celled. h. S. Native of Cuba, near Havannah, Porto-Rico, and Guadaloupe. Lygístum spicatum, Lam. ill. no. 1477. Gonzàlea Panaménsis, ex Guadalupa, Spreng. syst. 1. p. 417. ex herb. Balb. Barlèria hirsùta, Jacq. obs. with a good figure.

Iar. B, arbòrca (D. C. prod. 4. p. 437.) stem arboreous. 々. S. Native of Cumana, near Santa Cruz, in lumid shady places; and of New Granada. Coccocýpselum spicàtum, H. B. et Kunth, nov. gen. amer. 3. p. 406 . Spreng. syst. 1. p. 416.

lar. $\gamma$, glabràta (D. C. l. e.) leaves smoothish; branchlets downy. h. S. Native of Porto-Rico. Hedyòtis seeúnda, Spreng. in herb. Balb.

Spriked-flowered Gonzalea. Shrub 8 to 10 feet.

9 G. incane'scens (D. C. prod. 4. p. 437.) leaves pubescent above, and camescent from adpressed silky villi beneath; lobes of ealyx oblong. দ.S. Native of Tobago?

IIoary Gonzalea. Slirub.

Cult. For culture and propagation see Hamèlia, p. $5+2$.

LXXXVII. ISE'RTIA (named after P. E. Isert, a German, in the Danish service as a surgeon at Danish Acera, on the coast of Guinea; who rendered valuable services to botany during his residence there). Sehreb. gen. no. 602. Vahl, eclog. 27. Juss. men. mus. 6. p. 399. D. C. prod. 4. p. 437. Phosánthus, Rafin. ann. gen. se. phys. 6 , p. 82.

Lin. syst. Hexándria, Monogýnia. Calyx with a subglobose tube, and a short permanent 4-6-toothed limb (f. 97. a.), ex Rich. Corolla with a long tube (f. 97.6 .), which is more slender in the middle than any where else (f. 97.b.); and with 6 short obtuse erect lobes at the apex (f. $97 . c$.), which appear a little twisted before expansion, densely elothed with yellow down inside, having the recesses or sinuses between the lobes drawn out into little erests. Stamens 6, inclosed (f. 97. d.). Stigmas linear, ereetly stellate (f. $97 . e$.). Berries globose (f. $97 . g$.), crowned by the ealyx (f. 97. h.), containing 6 brittle many seeded triquetrous pyrenæ (f. 97.c.), which are furrowed inside. Seeds subglobose, truncate at the base. Albumen fleshy.- South American trees or shrubs, with striated or quadrangular branches. Leaves oval, acuminated at both ends, on short petioles, elothed witls short down beneath. Stipulas twin on each side, lanceolate-subulate. Thyrse terminal, many-flowered, spike-formed or panicle-formed; peduncles opposite. Flowers scarlet

1 1. spic жfórsis (D. C. prod. 4. p. 487.) leaves oval-oblong, acuminated, acute at the base ; thyrse spike-formed; flowers on very long pedicels along the axis. $々$. S. Native of Guiana or Cayenne, where it was collected by Patris. Leaves and flowers like those of $I$. coccinea, but diflering in the inflorescence.
Spike cylindrical, having the flowers on the lower part remote and opposite, and those at the top crowded. Corollas scarlet.

Spike-formed Isertia. Slrub 10 to 12 feet.

2 I. coecíneA (Vahl. eclog. amer. 2. p.27.) leaves oval, acuminated, acute at the base; tliyrse oblong, panieled. h.S. Native of Guiana, Cayenne, and Maranham, as also on the banks of the Magdalena, among bushes. Guettárda coceínea, Aubl. guian. 1. p. 317. t. 123. Lam. ill. t. 259. Corolla an inch long, velvety on the outside, scarlet. Berries red. There is a variety of this plant, according to Kunth, having the leaves disposed 3 in a whorl. The wood is bitter. A decoction of the leaves is used by the Creoles in fomentations.

Scarlet-flowered Isertia. Fl. July, Aug. Clt, 1820. Shrub 8 to 12 feet.

3 I. HENKEA'NA (D. C. prod. 4. p. 437.) leaves oval, acuminated at botl ends; thyrse ovate, panicle-formed, with verticillate branches. 々. S. Native of Mexico. Isértia coccínea, Bartl. in herb. Hænke, ex D. C. l. c. Calyxes as in I. parviflòra. Corollas searlet, a little smaller than those of the preceding, but one-half larger than those of the following, clothed with fine velvety down on the outside.

Hanke's Isertia. Shrub 8 to 10 feet.

4. 1. parviflòra (Vahl, ecl. amer. 2. p. 28. t. 15.) upper leaves oblong: lower ones cordate at the base; thyrse ovate, paniele-formed, with opposite branehes. h. S. Native of Trinidad. Leaves almost glabrous, except on the nerves. Teeth of calyx 4 , and 2 of these are larger than the rest, and are probably formed of 2 combined ones each. Corolla scarlet, unguicular, glabrous on the outside. Fruit unknown.

Small-flowered lsertia. Shrub 8 to 10 feet.

Cull. The species are worth eultivating in every collection of stove plants, for the sake of their leaves and panicles of showy scarlet blossoms; their culture and propagation are the same as that recommended for Hamèlia, p. 542.

\section{Tribc V.}

HAMELIE' E (this tribe agrees with the genus Hamèlia in the many-celled many-seeded fruit). D.C. prod. 4. p. 438.Hameliàceæ, A. Rich. mem. soc. hist. nat. par. 5. p. 108.Hameliàceæ genera, Kunth, syn. 3. p. 63.-Rubiàceæ, sect. v. Juss, mem. mus. 6. p. 398 . Fruit baccate, many eelled (f. 98. f. h.); cells many seeded. Albumen of seeds fleshy.-Trees and shrubs, with opposite or verticillate leaves, and interpetiolar stipulas.

LXXXVIII. TEPE'SIA (meaning unknown to us). Gærtn. fil. carp. 3. p. 72 . t. 192 . D.C. prod. 4. p. 438.

Lin. sx'st. Pentándria, Monogýnia. Calyx with an oblong tube, and a 5 -toothed limb, 2 of the teeth opposite each other, larger than the rest, outer ones erect, incurved, the 2 smaller teeth connivent. Corolla and stamens unknown. Berry oblong, crowned by the limb of the calyx, 4-celled. Seeds many, nestling in the pulp. Albumen fleshy.-Perhaps this genus is dis tinet from Gonzàlea or Evósmia, but it is hardly known.

1 T. DU'BlA (Gærtn. l. e.) h. G. Native of Chili. Nothing is known of this plant except the fruit.

Doubtful Tepesia. Shrub.

Cult. For culture and propagation see Hamèlia, p. 542.

LXXXIX. EVO'SMIA (from $\varepsilon v, e u$, well, and $o \sigma \mu \eta$, 
osme, a smell; the young fruit of $E$. Caripensis is sweetscented). Humb. et Bonpl. pl. equin. 2. p. 165. t. 134. Juss. mem. ınus. 6. p. 398. D. C. prod. 4. p. 438.-Euósmia, H. B. et Kunth, nov. gen. aner. 3. p. 418.-Evósma, Steud.-Euósma, Willd. but not of Andr.-Evósmia species, Spreng.

LiN. srst. Tetrándria, Monogýnia. Calyx with an ovate tube, and a very short 4-toothed limb (f. 98. a.). Corolla subrotate, 4-cleft beyond the middle(f. 9s.e.b.). Stamens 4 , inserted in the throat (f. 9S. b.), a little exserted or inclosed ; anthers ovate. Style filiform; stigma thick or 4 -lobed. Fruit ovate (f. 9s. $f$.), crowned by the calyx (f. 98. g.), 4-celled (f. 98. h.); cells many seeded.-Glabrous shrubs or small trees, with terete branches, natives of South America. Leaves petiolate, oval, acute at both ends, membranous. Stipulas ovate, acute, short, deciduous. Racemes short, by twos or threes from the axils of the lower leaves; pedicels clongated, capillary. Flowers red. The young fruit in $E$. Caripénsis is sweet-scented; hence the generic name.

1 E. Caripénsis (Humb. et Bonpl. 1. c.) leaves oval, acuminated at both ends; racemes loose, a little longer than the petioles; pedicels slender, elongated. $\xi_{i} . S$. Native of South America, in the province of Cumana, near Caripe. Flowers red (f. 98.).

Caripe Evosmia. Tree $20 \mathrm{ft}$.

2 E. Aggrega'ta (Spreng. syst. 1. p. 417.) leaves lanceolate, acuminated; flowers in fascicles; pedicels shorter than the calyx. h.S. Native of Peru, in groves on the Andes at Cuchero, Chinchao, and Muma.

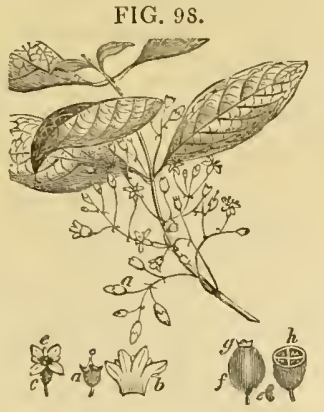
O-Higgínsia aggregàta, Ruiz et Pav. A. per. 1. p. 55. t. 83. f. b. Higgínsia aggregàta, Pers. ench. 1. p. 133. According to Jussieu, this plant is referrible to Sabicea, but according to Kunti to Gonzalea. But it certainly differs from all the other species of $\mathrm{O}$-Higginsia of the $\mathrm{fl}$. per. in the fruit being 4-celled and many-seeded. Flowers red.

Aggregate-flowered Evosmia. Shrub.

Cult. For culture and propagation see IIamèlia, p. 542.

XC. SABICEA (altered from Sabisabi, the name of $S$. áspera in Guiana). Aubl. guian. 1. p. 192. Lam. ill. t. 165. Juss. mem. mus. 6. p. 400 . D. C. prod. 4. p. 439.-Schwenkfélda, Schreb. gen. no. 306.-Schwenkféldia, Willd. spec. 1. p. 982.

Lin. syst. Tetra-Pentándria, Monogýnia. Calyx with an oblong or turbinate tube, and a 4.5-parted permanent limb. Corolla salver-shaped, with a long slender tube, a bairy throat, and a 4-5-parted limb: with the lobes acute. Stamens 4-5, inclosed or hardly exserted. Style filiform, clavate at the apex, 4-5lobed. Berry almost globose, crowned by the calyx, 4-5-celled; cells many seeded. Seeds minute, angular.-Climbing shrubs or subshrubs. Leaves oval, acute, on short petioles. Stipulas solitary on both sides. Flowers white, axillary, in sessile fascicles, or corymbose and pedunculate. Corollas pilose.

\section{$\S 1$. Parts of flowers quinary.}

1 S. cINE'rea (Aubl. guian. 1. p. 192. t. 75.) leaves orate, acutish, villous above in the young state, but at length becoming glabrous, and clothed with dense white tomentum beneath; stipulas broad-ovate, acutish; flowers bracteate, disposed in axillary fascicles. $h \cdot \cup$. S. Native of Guiana and Cayenne, in hedges and among buslıes. Schwenkféldia cinèrea, Swartz, f. ind. occ. 1. p. 452. Willd. spec. 1. p. 492. Flowers white. Berries villous, red, ex $\Lambda$ ubl. Branches hispid. Branchlets villous.

Grey Sabicea. Shrub cl.

2 S. n'rta (Swartz, prod. 1. p. 46.) leaves ovate-lanceolate, acuminated, hairy on both surfaces; stipulas corlate-ovate, large, membranous; umbels 3-flowered, on short peduncles; involucrum of 4 leaves. 5 . U. S. Native of Jamaica, and probably of Trinidad, if the specimen in Sieb. fl. trin. no. 327. be the same; of Porto-Rico, according to specimens from Bertero; and of Mexico, ex icon. fl. mex. ined. Flowers white. Berries snow white when ripe, ex Swartz; but in the figure in fl. mex. they are painted reddish, and is therefore probably a distinct species. Branches striated, hairy.

Hairy Sabicea. Shrub el.

3 S. Hirsu'ta (H. B. et Kunth, nov. gen. amer. 3. p. 417.) leaves elliptic-oblong, acuminated, pilose above, and hairy beneath ; stipulas roundish-ovate, acute, reflexed; flowers disposed in verticillate fascicles, sessile. $h \cdot \cup$. S. Native of South America, on the banks of the Orinoco; of Mexico, ex Hanke, and probably of Peru. S. villosa, Roem. et Schultes, syst. 5. p. 265. Schwenkféldia villòsa, Willd. rel. mss. Schwenféldia hirsùta, Spreng. syst. 1. p. 765. Flowers white.

Hirsute Sabicea. Shrub cl.

4. S. Eriántua (D. C. prod. 4. p. 439.) leaves elliptic-oblong, acuminated, pilose above, and clothed with hoary tomentum beneath; branches very hairy; stipulas ovate, acute, glabrous inside; flowers numerous, axillary, sessile; lobes of calyx linear; tube of corolla very pilose on the outside. $r . \cup . S$. Native of Brazil, at Bahia, in hedges, where it was collected by Salzmann, G. Don, Sc.

Hoolly-flowered Sabicea. Shrub cl.

5 S. ? triflòra (D. C. prod. 4. p. 439.) stems twiggy, velvety; leaves on short petioles, oblong-lanceolate, acuminated, pale and villous beneath; stipulas lanceolate-subulate, undivided; flowers axillary, 1-3-together, rising from a short peduncle; bracteoles ciliated; ovarium long, glabrous, crowned by the elongated linear-subulate calycine teeth. $h \cdot \cup$.S. Native of Madagascar. Triósteum trifiòrum, Vahl, symb. 3. p. 37.

Thirec-flowered Sabicea. Shrub cl. ?

6 S.? niversifólia (Pers. ench. 1. p. 203.) under side of leaves and branchlets hoary: the opposite leaves very unequal among themselves, the larger one broad, elliptic or ovate, obtuse, glabrous above, and hoary beneath; the smaller one bractea-formed; flowers almost sessile, glomerate in the axils of the smaller leaves. $h$. S. Native of Madagascar and the Mauritius. Stamens lalf exserted. Berry pea-formed, 5-celled, crowned by 5 bristles, ex $\mathrm{A}$. Rich. Schwenkféldia diversif òlia, Spreng. syst. 1. p. 765. The rest unknown. Perhaps this plant is properly referred to the present genus.

Diverse-leaved Sabicca. Shrub cl.

\section{\$2. Parts of flowers usually or always quaternary.}

7 S. A'spera (Aubl. guian. 1. p. 194. t. 76.) leaves elliptic, acuminated, rough above, and villons beneath; stipulas oval-oblong, acute; flowers sessile, disposed in subverticillate fascicles. $h$. $v$. S. Native of Guiana, on the banks of the river Sinemari. Lam. ill. t. 165. Schwenkféldia áspera, Willd. spec. 1. p. 982. Flowers white. Berries red. Parts of flowers and fruit varying from quaternary to quinary, ex Aubl.

Rough Sabicea. Shrub cl.

8 S. Umbelia'ta (Pers. ench. 1. p. 203.) leaves oval, acuminated, acute at the base, scabrous on both surfaces from adpressed down, pale beneath; stipulas ovate, spreading; corymbs many-flowered, pedunculate. $h \cup$. S. Native of Peru, in groves on the Andes at Cuchero, Macora, and Chinchao. $3 \mathrm{z} 2$ 


\section{RUbiacea. XC. Sabicea. XCi. Olostyla. XC11. Axanthes. XCili. Urophyllum. XCiV. Hamelia.}

Scbwenkféldia umbellàta, Ruiz et Pav. fl. per. 2. p. 55. t. 200. f. 2. Flowers white. Berries white, roundish.

Umbellate-flowered Sabicea. Shrub cl.

9 S. PU'mil. (Bartl. in herb. Hanke, ex D. C. prod. 4. p. 440.) stem herbaceous, glabrous; leaves oblong-lanceolate, glabrous, ciliated with silky down; stipulas subulate; heads pedunculate, axillary, few-flowered, glabrous.-Native of Peru, on the mountains about the Guanocco.

Dnarf Sabicea. Pl. cl. ?

Cult. For culture and propagation see Olóstyla below.

XCI. OI.O'STYLA (from ìos, holos, entire, and $\sigma \tau v \lambda o c$, stylos, a style; the style is undivided). D. C. prod. 4. p. 440. - Stylocorina, Labill. sert. caled. p. 47. but not of Cav.

Lin. syst. Pentándria, Monogínia. Calyx with an ovate tube, and a very short 5 -toothed limb. Corolla sub-rotate, with a short tube, which is pilose inside, and a 5 -lobed limb; lobes valvate in rstivation, linear-lanccolate, with inflexed edges. Stamens 5, inserted in the throat of the corolla; anthers linear, exserted. Style clavate, undivided. Berry glabrous, crowned by the teeth of the calyx and urceolus, 4-celled; cells manyseec'ed. Seeds minute, elliptic, nestling in the pulp.-A glabrous unarmed shrub. Leaves opposite, obovate-oblong, coriaceous, on short petioles. Stipulas broad, short, apiculated. llowers disposed in a terminal somewhat thyrsoid corymb.This genus differs from Stylocoryna in the fruit being 4-celled, not 2-celled as in that genus.

1 O. corymbòsa (D. C. prod. 4. p. 410.). h. G. Native of New Caledonia. Stylocorìna corymbòsa, Labill. sert. cal. p. 1.8. Perhaps the same as Gardènia corymbòsa of Rchb. icon. cxot. 2. p. 103 . t. 106.

Corymbose-flowered Olostyla. Shrub 5 to 6 feet.

Cult. A mixture of loam, peat, and sand will suit this slurub; and cuttings will root in sand under a hand-glass. It is a very pretty shrub, and therefore worth cultivating.

XCII. AXA'NTHES (from $\alpha_{\xi}^{\xi} \omega \nu, a x o n$, an axle-tree, and $\alpha \nu$ Oos, anthos, a flower; the flowers are disposed in axillary heads or corymbs). Blum. bijdr. p. 1002 . D. C. prod. 4. p. 440.Wallichia, Reiow. cat, hort. buit. ex flora. 1825 . p. 107. but not of lioxb. nor D. C.-Maschalánthe, Blum. herb. ex D. C. 1. c.

Lin. syst. Pentándria, Monogýnia. Flowers liermaphrodite, or dioecious by abortion. Caly $x$ with an urceolate tube and almost entire limb. Corolla rotate, with a short cylindrical tube, which is furnished with 5 fascicles of hairs in the throat, and spreading lobes. Stamens 5 in the hermaphrodite flowers, inserted in the throat of the corolla, hardly exserted. Ovarium and style wanting in the male flowers, but the ovarium in the female flowers is covered by a sulcate disk. Style short ; stigma 5 -lobed: lobes at first connivent. Berry globose, crowned by the permanent calyx, 5-celled, many-seerled; placentas fleshy. Seeds minute, beset with depressed dots.-Shrubs or trees. Leaves opposite. Flowers disposed in axillary heads or cymes, rarely in corymbs.

\section{* Flowers dioecious by abortion.}

I A. Macrophy'LiA (Blum. bijdr. p. 1002.) stem slirubby ; ultimate branches rather tetragonal; leaves oblong, much acuminated, acutish at the base, shining above, but clothed with ailpressed silky down beneath; heads of flowers axillary, sessile, involucrated. $h_{2}$. S. Native of Java, in mountain woods.

Long-learcd Axanthes. Shrub.

2 A. romentòsa (Blum. herb. and mss. ex D. C. prod. 4. p. 440.) stem unknown; branches geniculated, clothed with velvety tomentum; leaves oblong, much acuminated, glabrous above, but clothed with velvety tomentum on the nerves beneath as well as on the petioles; cymes pedunculate, axillary. $\eta_{c} . S$. Native of l'ulo Penang.

T'omentose Axanthes. Shrub.

8 A. strigòs (Blum. bijdr. j) 1002.) stem arborescent; ultimate branches geniculated, strigose ; leaves oblong, attenuated at both ends, glabrous above, but rather strigose on the veins beneath; flowers on short peduncles, crowded, axillary. $h$.S. Native of Java, on the mountains of Seribu.

Strigose Axanthes. Tree small.

4. A. AR Bòrea (Bhım. l. c.) stem arborescent ; branches terete, glabrous; leaves oblong-lanceolate, acuminated at both ends, glabrous; cymes pedunculate, axillary. h. S. Native of Java, on the higher mountains, in woods. Wallichia arbòrea, Reinw, cat, hort. buit, p. 11, ex Blume.

Arborcous Axanthes. Tree.

5 A. TiMorie'nsis (D. C. prod. 4. p. 441.) stem unknown; branchlets terete, and are as well as the petioles villous; leaves oblong, acuminated at both ends, glabrous above, but clothed with adpressed villi beneath on the veins; cymes axillary, pedunculate, bifid. $\eta$. S. Native of the Island of Timor. Calyx downy. Corolla clothed with strigose villi on the outsicle.

Timor Axanthes. Tree.

$$
\text { * Flowers hermaphrodite. }
$$

6 A. corymbòsa (Blum. l. c.) stem arborescent; ultimate branchlets somewhat tetragonal, puberulons; leaves glaucous, oblong-lanceolate, much acuminated at both ends, shining above, but downy beneath as well as the corymbs, which are axillary. $\eta$. S. Native of Java, on the top of Mount Burangrang.

Corymbose-flowered Axanthes. Tree.

Cult. See Hamclia, p. 542. for culture and propagation.

XCIII. UROPHY'LLUM (from ovoa, oura, a tail, and $\phi v \lambda \lambda o v, p h y l l o n$, a leaf; the leaves terminate in very long taper points). Jack and Wall. in Roxb. A. ind. 2. p. 184. D. C. prod. 4. p. $141 .-$ Wallichia, Roxb. ined. but not of others.

Lin. syst. Pentándria, Monogýnia. Calyx with an ovate tube, and a short, campanulate rather 5 -cleft limb. Corolla funnel-sliaped, with a bearded throat and a 5 -parted limb; the lobes ovate, and valvate in estivation. Stamens 5 , shorter than the limb; anthers linear. Stigma thick, 5-lobed. Ovarium crowned by a glandular disk. Berry globose, 5-celled; cells many-seeded. Seeds minute, shining, marked by pentagonal pores, as in Pomatium.-Erect shrubs. Leaves on short petioles, oblong-lanceolate, ending each in a very long taper point. Stipulas oblong, acute, deciduons. Peduncles axillary, short, bearing verticillate heads of flowers. Bracteas numerous, acute, surrounding the heads of flowers. Corollas greenish.

] U. vis.òsun (Jack and Wall. 1. c.) shrub villous; branches terete; calyx 5-lobed. h. S. Native of Pulo Penang. Branches as well as the veins of the leaves densely clothed with soft hairs. Lcaves shining above and villous beneath, 10 inches long.

lillous Urophyllum. Shrub.

2 U. GLA'BRUM (Jack and Wall. l.c.) shrub glabrous; branches

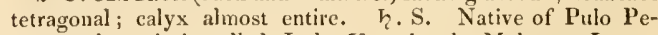
nang, where it is called Lodu Utan by the Malays. Leaves about 6 inches long.

Glabrous Urophyllım. Shrub.

Cult. See Ilamelia, p. 54\%. for culture and propagation.

XCIV. HAME'LIA (so named in honour of Henry Lonis du Hamel dı Monceau, the celebrated author of several valuable 
works on trees). Jacr. amer. p. 71. Lin. gen. no. 232. Juss. gen. 207. mem. mus. 6. p. 398. Lam. ill. t. 155. Gærtn. fil. carp. p. 68 . D. C. prod. 4. p. 441.-Duhamèlia, Pers. ench. no. 454. Røem. et Schultes, syst. 5. p. xx.-Lonicèra species, Plum. gen. 17. t. 33.-'Jangáraca, Adans. fam. 2. p. 147.

Lin. syst. Pentándria, Monogínia. Calyx with an oval tube, and a 5-toothed linib (f. 99. a.); teeth erect, short, acute, permanent. Corolla with a somcwhat pentagonal tube (f. 99 . b.), and a small, 5-lobed equal limb (f. 99. c.), which hardly spreads at all. Stamens 5, inserted in the middle of the tube ( $f$. 99. b.) of the corolla, inclosed ; anthers oblong-linear (f. $99 . f$.) Stigma obtuse, somewhat pentagonal (f. 99. c.). Berry oval, 5 -furrowed, 5-celled (f. $99, d$.), crowned by the calyx; cells membranous, many-seeded. Seeds small, compressed. Albumen fleshy.-American slurubs. Leaves opposite, or 3 or 4 in a whorl, petiolate, oval-oblong, acute at both encls. Stipulas lanceolate-subulate, solitary on botls sides. Cymes dichotomous or trichotomous, disposed usually in terminal panicles or curymbs. Bracteas small. Flowers of a croccous red colour.

\section{* Leaves verticillate.}

1 H. PA'TENs (Jacq. amer. p. 72. t. 50. pict. t. 72.) leaves 3 in a whorl, oval-oblong, acuminated at both ends, clothed with villous pubescence; cymes di-trichotomous, coloured, dispused in a terminal pedunculate umbel; corollas cylindrical. $\eta$. S. Native of St. Domingo, Cuba, Mexico, Brazil, Peru, \&c. in hedges on the mountains. Lin. spec. 246. Smith, exot. bot. t. 24. Gærtı. fil. carp. 3. p. 196. f. 3. H. coccínea, Swartz, prod. p. 46. Duhamèlia pàtens, P'ers. ench. 1. p. 203. H. patens, Ruiz et $P a v$. fl. per. 2. p. 221. f. a.? Flowers almost scarlet. Berries black. Branches villous at top. There are varicties of this species with velvety, villous, or downy leaves, always most so on the under surface.

I'ar. $\beta$, erécta (Lam, dict. 3. p. 68.) racemes erect. $f_{2} . \mathrm{S}$, Native of Carthagena, in woods; and of Mango Island. H. erécta, Jacq. amer. p. ill.

Iar. $\gamma$, quinifolia: leaves and branches of cymes 5 in a whorl. $h . S$. Native of Mexico, on the mountains of Maliatlano. H. pàtens, Moc. et Sesse, fl. mex. icon. ined. H. verticillàta, fi. mex. mss, ined. Perhaps a proper species.

Sprcading Hamelia. Fl. Jul. Aug. Clt. 1752. Sh, 5 to $10 \mathrm{ft}$.

2 H. Xorulle'sis (H. B. et Kunth, nov. gen. amer. 3. p. 414) leaves 3 in a whorl, elliptic-oblong, acuminated, acute at the base, glabrous above and downy beneath; cymes composed of 5-6 spikes, terminal; corollas campanulately ventricose. h. S. Native of Mexico, on the burning Mount Xorullo. Flowers of a yellowish red colour.

Torullo Hamelia. Shrub 4 to 5 feet.

3 H. SPhÆrocárpa (Ruiz et Pav, fl. per. 2. p. 69. t. 221. f. b.) leaves 3 in a whorl, oblong, hairy on both surfaces; cymes coloured, disposed in a terminal panicle; corollas cylindrically pentagonal. $h$. S. Native of Perı, in groves. Duhamèlia sphæerocárpa, Pers. Petioles and peduncles red. Flowers unilateral, pedicellate. Corollas of a reddish coppery colour. Berry dark purple, globose, hispid.

Round-fruited Hamelia. Fl. July, Ang. Clt. 1811. Slırub 8 to 10 feet.
4. H. Latifo'la (Rich, in Sieb. A. trin, no. 32.) leaves 3 in a whorl, ovate-lanccolate, acuminated, acute at the base, glabrous on both surfaces; cymes dichotomous, few-flowered, disposed in a terminal pedunculate umbel; corollas cylindrical. h.S. Native of Trinidad. Flowers smaller than those of $\|$. pàtens, but similar in colour.

Broad-lcated Ilamelia. Fl. July, Aug. C'lt. 1819. Slirub 4. to 6 feet.

5 H. ventricosa (Swartz, prod. p. 46. f. ind. occ. 1. p. 44.5.) leaves 3 in a whorl, quite glabrous, oval-oblong, acuminated; racemes terminal (rarcly axillary); flowers on long pedicels: corollas tubularly campanulate, ventricose. h. S. Native of Jamaica, on hills, and among bushes in arid places, where we have seen it in great abundance from Kingston to the bottom of the Port Royal mountains, by the road side, and about Spanish Town ; and of Mexico, alout Real del Monte. Lindl. bot. reg. t. 1195. Sims, bot. mag. t. 1894. H. grandiflòra, L'Iler. sert. angl. 4. t. 7. Salisb. par. t. 55. Duhamèlia ventricòsa, Pers. ench. 1. p. 203.-Sloane, hist. jam. 2. no. 63. t. 183. f. 2. Margins of leaves at length becoming reddish. Flowers ycllow, almost an inch long. Berries oblong, scarlet. This species grows to a considerable sized tree, aftording boards for tables and cabinets, of the softness and grain of elm, whence its name Spanish elm. The cabinet makers, who use it much, call it Prince-wood. Perbaps H. pauciflòra, Willd. rel. in Roem. et Schultes, syst. 5 . p. 207 . is the same.

I'entricose-flowered Hamelia. Fl. Sept. Nov, Clt. 1778. A large shrub or small tree.

6 H. suavéolens (H. B. et Kunth, nov, gen. amer. S. p. 414.) leaves $3-4$ in a whorl, oblong, acuminated, glabrous ; cymes branched, of 5-6 rays; flowers almost sessile; corolla tubular, ventricose at the base. h. S. Native of New Granada, on the banks of the Magdalena, near Carapata and Badilla. Duhamèlia odoràta, Roem. et Schultes, syst. 5. p. 267. Stipulas linear-subulate, not pinnatifid, as said by Willdenow. Corollas glabrous, purple. 'There is a variety of this species having a 6 -cleft corolla and 6 stamens.

Sneet-scentcl Hamelia. F1. Jul. Aug. Clt. 1824. Sh. 4 to $6 \mathrm{ft}$.

\section{* Leaves opposite.}

7 H. chrYsántila (Swartz, prod. p. 46. A. ind. occ. 1. p. 444.) leaves opposite, oval-oblong, cuneated, acuminated, quite glabrous; racemes terminal ; flowers pedicellate; corollas cylindrical. $h_{2}$. S. Native of Jamaica, on the mountains among bushes; and according to Hærike, herb. of Mexico; and at Caraccas, according to Vargas.-Browne, jam. 166. t. 14. f. 1. -Plım, amer. ed Burm. t. 218, f. 1.-Duhamèlia chrysántha, Pers. ench. 1. p. 203. exclusive of the syn. of Jacq. H. pàtens, West. St. Croix. p. 200. Flowers yellow, almost an inch long, inflated in the middle.

Golden-flonercd Hamelia. Fl. Oct. Dec. Clt. 182?. Shrub 4 to 5 feet.

8 H. Lu'TEA (Rohr, ex Smith, in Rees's cycl. vol, 17. no. 4.) leaves opposite, oval, acuminated, acute at the base, glabrous; cymes terminal; flowers almost sessile; corollas short, with a ventricose throat. h.S. Native of Santa Cruz, and at Caraccas. H. clırysántha, Jacq. coll. 3. p. 204. icon. rar. 2. t. 335. but not of Swartz. Hamèlia species, no. 2 without a name. West. St. Cr. p. 273. Corollas yellow, 4-5 lines long.

Yellow-flowered Hamelia. Shrub 4 to 5 feet.

9 H. AXILLA'Ris (Swartz, prod. p. 46. fl. ind. occ. 1. p. 443.) leaves opposite, ovate-lanceolate, glabrous; stem suffiutescent; cymes bifid or trifid, pedunculate, rising from the forks of the branches; flowers secund, sessile; corollas tubular, pentagonal; berry oval-oblong, crowned by the 5 distant subulate teeth of the calyx. $T_{2} . S$. Native of Jamaica, in rocky places among 
bushes; and of St. Domingo near rivers. Branches sub-herbaccous. Flowers pale yellow. Berries small.

Var. $\beta$, appendiculata (D. C. prod. 4. p. 442.) leaves on longer petioles, and more distinctly acuminated. $\eta$. S. Native of Porto Rico. H. appendiculàta, Gærtn. fil. carp. 3. p. 64. t. 91. f. 1. H. lùcida, Desf.

Axillary Hamelia. Fl. Aug. Sept. Clt. 1822. Sh. 2 to $3 \mathrm{ft}$.

10 H. Rostra'ta (Bartl. in herb. Hænke, ex D. C. prod. 4. p. 442 .) leaves usually opposite, rarely 3 in a whorl, ovate, acuminated, downy beneath, as well as the petioles and branchlets; cymes terminal, 3-4-parted, downy; corollas glabrous ; berries ovate-globose, glabrous, beaked. $h$. S. Native of Mexico, at Acapulco. Branches terete or trigonal.

Bealied-berried Hamelia. Shrub 4 to 5 feet.

Cult. All the species of this genus are very ornamental while in blossom. They are free flowerers and of easy culture. A mixture of loam and peat is the best soil for them; cuttings strike root freely in the same hind of soil, under a hand-glass, in a moist heat.

XCV. ALIBE'RTIA (named after M. Alibert, a celebrated French chemist, author of 'Traite des Fievres attaxique; in which work he mentions the effects of Peruvian bark). A. Rich. mem. soc. hist. nat. par. 5. p. 234. t. 21. f. 1. D. C. prod. 4. p. 443.-Genipélla, L. C. Rich. ined.-Melanopsídium, Poit. ined. herb. mus. par.

LiN. syst. Pentándria, Monogýnia. Flowers incompletely unisexual by abortion. Limb of calyx tubular, 5-toothed. Corolla tubular, longer than the calyx ; limb spreading, 5-parted : segments oval, acute. Stamens 5 , almost sessile, inserted in the tube; anthers linear, inclosed. Style simple, in the male flower it is clavate, striated, and terminated by an acute simple stigma; in the female and hermaphrodite fowers the anthers are shorter than in the males, and the stigmas are 5 and linear. Berry somewhat corticate, globose, depressed, crowned by the tubular limb of the calyx, 5-celled; cells many-seeded. Seeds wrapped in thin pulp.-A small tree. Leaves opposite, coriaceous, oblong, acuminated. Stipulas rather connate, entire, acute. Flowers solitary or in fascicles, terminating the branches, cream-coloured, almost sessile.-Habit of Génipa.

1 A. EDU'L1S (A. Rich, l. c.). h. S. Native of French Guiana, where it is called Goiace noire. Génipa edùlis, Rich. act. soc. hist. nat. par. p. 107. Gardènia edùlis, Poir. suppl. 2. p. 708. Melanopsídium nìgrum, Coll, hort. rip. t. 35. Leaves shining above and bearded in the axils of the veins beneath. Fruit edible.

Edible-fruited Alibertia. Clt. 1\$23. Tree 12 feet.

Cult. See IIamilia above for culture and propagation.

XCVI. SCHRADERA (so named by Vahl, in bonour of Henry Adolph. Schrader, author of Spicelegium Flora Germanice, Hanover 1794.). Vahl. eclog. 1. p. 35. Juss. mein. mus. 6. p. 403. D. C. prod. 4. p. 443.-Füclssia, Swartz, but not of Lin.-Urceolaria Willd. in Coth. disp. p. 10. Gmel. syst. 1. p. 390. but not of Molino nor others.

Lin. sist. Penta-Octándria, Monogýnia. Calyx with an obovate tube, and a short truncate or sub-denticulated limb. Corolla funnel-sliaped, with a terete tube, and a rather dilated pilose throat; lobes or segments $5-8$, spreading, thickened inside, and sometimes furnished with a retrograde callous toothlet. Anthers 5-8, sessile, linear, inserted in the throat of the corolla, hardly exserted. Style short; stigma bifid (ex Vahl and Rich), quadrificl (ex Swartz). Berries pea-formed, 3-4-sided, crowned by the limb of the calyx, 2-4-celled; cells many-seeded. Seeds very minute, nestling in the pulp.-Glabrous radicant slırubs, growing on trees. Leaves petiolate, oval or lanceolate, coriaccous. Stipulas oval-oblong, falling off at length, but those at the base of the peduncles are more permanent, and may be called hracteas. Peduncles solitary or numerous, longer than the petioles. Flowers 4-12 together, sessile, capitate, girded by an orbicular, entire, or rather lobed involucrum, which is formed from two coinbined bracteas.

1 S. CAPita'ta (Vahl, ecl. 1.p. 35. t. 5. exclusive of the syn. of Swartz) leaves elliptic, bluntish, but more acute at the base; peduncles solitary, terminal; head of flowers girded by a subJobate involucrum; limb of calyx truncate, quite entire; corolla 5-6-lobed. h. S. Native of Mont-Serrat, on the higher mountains. Urceolària exótica, Gmel. syst. 2, p. 390. Branches square. A climbing sub-parasitical shrub.

Capitate-flowered Schradera. Shrub cl.

2 S. Brasille' Nsis (Mart. in Schultes, syst. 7. p. 164.) leaves elliptic, obtuse; peduncle terminal, solitary; head of Howers surrounded by an entire involucrum; limb of calyx quite entire; corolla 5-6-lobed : the segments reflexed. Native of Brazil, in woods at Lake d'Almada, in the province of Bahia.

Erazilian Schradera. Shrub cl.

3 S. cepinalòtes (Willd. spec. 2. p. 238.) leaves oblong, acuminated; peduncle terminal, solitary, short; head of flowers surrounded by an entire involucrum; limb of calyx somewhat denticulated; corolla 7-8-lobed. $h . S$. Native of the interior of Jamaica, in woods on the mountains. Fúchsia involucrata, Swartz, prod. p. 62. Al. ind. occ. 2. p. 674. Flowers 4-8, within the involucrum, white. Stignta quadrifid. Berry 4-celled, ex Swartz.

IIcaded Schradera. Fl. July, Aug. Clt. 1820. Shrub cl.

4. S. polycéphata (D. C. prod. 4. p. 444.) leaves oval, acutish; peduncles numerous, terminal ; heads surrounded by entire involucra; limb of calyx quite entire; corolla 5-lobed. h. S. Native of French Guiana, where it was collected by Patris. Berries ovate, crowned by the entire limb of the calyx, 2-3-celled; cells many-seeded.

Many-headed Schradera. Shrub cl.

Cult. The species of this genus are elegant when in flower. Vegetable mould is the best soil for them; and they will be easily increased by separating the rooted branches.

XCVII. BRIGNO'LIA (in honour of J. L. Brignoli, a professor of Verona, author of Fasciculus rariorum plantarum Forajuliensium, 4to. Urbina, 1810). D. C. diss. ined. with a figure, prod. 4. p. 444. but not of Bertol.

Lin. sist. Hexándria, Monogýnia. Calyx with a short roundish tube, and a 4 -toothed limb; 2 of the teeth larger than the other 2 , and probably made up of 2 combined ones each. Corolla with a short tube, and a 6-lobed limb; lobes linearoblong, bluntisb, longer than the tube, very hairy inside as well as the throat. Stamens 6 , inserted in the tube, alternating with the lobes ; filaments very short; anthers linear. Style filiform; stigma capitate, undivided. Frnit globose, fleshy, many-seeded, crowned by the calyx. The rest not sufficiently known. A shrub or tree. Branches terete, villous. Leaves opposite, petiolate, oval-oblong, obtuse at the base, acuminated at the apex, downy on the petioles and nerves, the rest glabrous. Stipulas twin on both sides, lanceolate, acuminated, but when young combined into an inter-petiolar stipula, but at length separating from the basc to the apex into 2 parts each. Corymbs terminal, pedunculate, with a short hairy rachis, and downy crowded, trichotomous branches. Bracteas ciliated. Flowers sessile in the forks of the corymb, and at the tops of the pedicels.-This genus is nearly allied to Isértia, but from the fruit not being sufficiently known, its place in the order is very doubtful.

1 B. acumina'ta (D. C. prod. 4. p. 444.). h. S. Native of Trinidad, where it was collected by Lockbart. Leaves almost 
a foot long and 3 inches broad, pale beneath. Petioles 8-12 lines long, a little longer than the stipulas. Corymbs much shorter than the leaves.

Acuminated-leaved Brignolia. Shrub.

Cult. For culture and propagation see Hamèlia, p. 542.

XCV1II. PATIMA (altered from Patima-Rana, the name of the first species). Aubl. guian. 1. p. 196. t. 77. Juss. mem. mus. 6. p. 401 . A. Rich. mem. soc. hist. nat. par. 5. p. 25. f. 2. D. C. prod. 4. p. 444.

Lin. syst. Pentándria, Monogýnia. Calyx with an ovate tube, and a loose, entire, urceolate, tubular, somewhat pentagonal limb, with a very short 5 -toothed sinuated border. Corolla tubular, hardly dilated towards the apex, with a 5 -parted linb: having the segments long-acuminated, and the inner surfaces clothed with dense silky down. Stamens 5 , inserted in the tube; filaments short; anthers cordate-oblong, inclosed. Style simple. Berry roundish, erowned by the limb of the calyx, $4-6$ but usually 5 -celled; cells many-seeded. Seed very minute, fixed to a rather fleshy, 2-lobed, prominent trophosperm.Small perennial, glabrous subshrubs. Stems straight, terete, simple. Leaves opposite, petiolate, ovate-oblong, acute at both ends. Stipulas solitary, short, broad, acute, permanent. Peduncles axillary, short, 1 or few-flowered.

1 P. Guiane' Nsis (Aubl. guian. 1. p. 196. t. 77.) leaves on long petioles; pedicels numerous, 1-flowered, shorter than the petioles. 2 . S. Native of Guiana, in marshes. Leaves a foot long and 4 inches broad. Berries green.

Guiana Patima. Shrub 2 to 3 feet.

2 P. Forsy'tни (D. C. prod. 4. p. 444.) leaves hardly petiolate; racemes few-flowered, longer than the petioles. $h_{\text {. }}$ S. Native country as well as the flowers unknown. This plant was received from Mr. Forsyth under the name of Patima Guianénsis of Aubl. but differs from the plant of Aubl. in the characters indicated.

Forsyth's Patima. Shrub 2 to 3 feet.

Cult. For culture and propagation see IIamèlia, p. 542.

XCIX. POLYPHRA'GMON (from $\pi 0 \lambda v$, poly, many, and фoaypos, phragmos, a dissepiment; there is a small transverse septum separating each seed). Desf. mem. mus. 6. p. 5. t. 2. Juss. men. mus. 6. p. 399 . D. C. prod. 4. p. 445.

Lin. syst. Decándria, Monogýnia. Calyx with an ovate tube, and a short, permanent, entire, or 5-toothed limb. Corolla salver-shaped, bristly, with a terete tube, and a 10-parted limb : lobes elliptic-oblong. Stamens 10 , inserted in the middle of the tube of the corolla; anthers linear, inclosed. Style 1 , thickened, furrowed lengthwise; stigmas 6-7 or more. Berry globose, 10-20-celled. Seeds oblong, disposed in 1 row in each cell, and as if they were imbricated, separated by small trans. verse dissepiments.-Shrubs. Leaves opposite, oval, lanceolate, acuminated at both ends, clotlsed with adpressed silky down beneath. Stipulas deciduous. Peduncles short, axillary, 1-flowered.

1 P. Seríceum (Desf. mem. mus. 6. p. 6. t. 2.) calyx quite entire. $h . S$. Native of the Island of 'Timor.

Silky Polyphragmon. Shrub.

2 P.? nixus (A. Rich, diss. ex D. C. prod. 4. p. 445.) calyx 5 -toothed. $\eta$. S. Native country unknown. Eríthalis uniflora, Gærtn. fil. carp. 3. p. 93. t. 196. f. 4. Perhaps this plant is referrible to Timonius.

Smaller Polyphragmon. Shrub.

Cult. For culture and propagation see Iamèlia, p. 542.

C. MORE'LIA (evidently called after some person of the name of $\mathrm{M}$ orel, of whom we know nothing). A. Rich. mem. soc. hist. nat. par. 5. p. 23 . D. C. prod. 4. p. 617.
LiN. syst. Pentándria, Monogínia. Limb of calyx marginal, ereet, nearly entire. Corolla short, tubular, with a 5parted limb; segments lanceolate, spreading, imbricate in $x s-$ tivation. Stamens 5 , inserted in the throat, exserted; anthers linear. Style simple, thickened and fusiform towards the apex; stigma bifid: lobes approximate. Ovarium 4-5-celled; cells 3-5-ovulate; ovnla fixed to the inuer angle of the cell. Fruit rather fleshy, 4-5-celled; cells 2-3-seeded, crowned by the short neck of calyx. $-A$ small glabrous tree, native of Senegal, with the habit of Baconia. Branches terete, cinereous, glabrons. Leaves opposite, elliptic, coriaceous, glabrous. Stipulas interpetiolar, deciduous. Flowers axillary, racemose; racemes somewhat trichotomous.

1 M. Senegale'nsis (A. Rich. I. c.). h. S. Native of Senegal, where it was collected by Leprieur and Perrottet. Senegal Morelia. Shrub.

Cult. For culture and propagation see Hamètia, p. 542.

\section{Tribe VI.}

CORDIEREE (this tribe contains plants agreeing with the genus Cordiera in having baccate many-celled fruit, and in the cells being 1 -seeded). A. Rich. mem. soc. hist. nat. par. 5. p. 107. and 222. D. C. prod. 4. p. 445. Fruit baccate, of many 1-seeded cells. This differs from Tribe Guettardacece in the fruit not containing pyrenæ, but true cells ; and from Tribe $\mathrm{Ha}$ mclièce in the cells being 1 -seeded, not many-seeded.

CI. 'TRICALY'SIA (meaning unknown to us). A. Rich, mem. soc. list. nat. par. 5. p. 224 . D. C. prod. 4. p. 445.

Lun. syst. Penta-Hexándria, Monogýnia. Limb of calyx 5-6-toothed, wide. Corolla with a shortish tube, a naked throat, and a 5-6-parted limb; segments narrow, spreading. Stamens $5-6$, inserted in the throat of the corolla, exserted ; filaments short; anthers linear. Stigmas 2, linear, shorter, somewhat recurved, exserted. Ovarium 2-celled; cells biovulate; ovula collateral._Shrub. Leaves opposite, linear-lanceolate, gradually tapering at the base, and joined by the broad, acuminated, entire stipulas. Flowers downy, almost sessile, crowded in the axils of the leaves.

1 'J. A sGole'ssis (A. Rich, l. c.). h. S. Native of Angola.

Angola Tricalysia. Slirub.

Cult. For culture and propagation see Hamclia, p. 542.

CI1. CORDIE'RA (in lionour of Niccolo Cordieri, a celebrated French seulptor). A. Rich, mem. soc. list. nat. par. 5. p. 230. t. 10. f. 2 . D. C. prodl 4. p. 445.

Lın. syst. Monoècia, Pentándria. Flowers unisexual. with the sexes on different branches. Male flower. Calyx cupshaped, solid, with an entire limb. Corolla salver-slıaped, with a long tube, which gradually tapers to the apex, and is a little incurved, coriaceous, shining, and as if it were lorny ; with a 5-parted limb: having oblong acute lobes, and a very narrow naked throat. Stamens 4-5, inclosed, inserted in the middle of the tube; anthers rising from the bottom of the calyx. Styles only vestiges. - Female flower. Calyx sub-globose, adnate to the ovarium, with an entire marginal limb. Corolla straight, less attenuated at the apex than in the male flowers, with a 4-5parted limb. Stamens small, abortive. Disk depressed in the middle. Stigmas 4-5, subulate. Berry globose, depressed, unbilicate, fleshy, 4-8-celled; cells 1-seeded. Seeds black, smooth. Albumen fleshy. Embryo parallel with the hylum, having a terete radicle, and subcordate cotyledons, which are the length of the radicle.-Bushy shrubs, 4-5 feet high. Leaves opposite, elliptic, acuminated, glabrous; stipulas very acute, conbined at the base. Flowers white, occupying the tops of the branches: male ones by threes, sessile, girded by 4 scalc-formed brac- 
teas: the female ones solitary, and furnished with 4 bracteas each.

1 C. TRIFLòra (D. C. prod. 4. p. 445.). \%2. S. Native of Guiana, on the banks of the river Kourou.

Three-flonercd Cordiera. Shrub 4 to 5 feet.

Cult. For culture and propagation see Hamèlia, p. 542.

\section{Tribe VII.}

GUETTARDACEÆ (this tribe contains shrubs and trees agreeing with Guettárda in the fruit containing many 1-seeded pyrenæ). Kunth, nov, gen. 3. p. 419. Cham. et Schlecht. in Liunzea. 4. p. 181. A. Rich, mem. soc. hist. nat. par. 5. p. 107. D. C. prod. 4. p. \$46. Rubiàceæ, sect. vi. Juss. mem. mus. 6. p. 395. Fruit drupaceous (f. 101.d. f. 103.f.), containing from 2.51 -seeded pyrenæe (f. 103.g.). Seeds terete, elongated, usually erect. Albumen fleshy. - Shrubs or smali trees. Leaves opposite, rarely by threes, with interpetiolar stipulas.

Sub-tribe 1. Moníndex (this sub-trihe only contains the genus Morinda). D. C. prod, 4. p. 446. Flowers and fruit collected into heads and combined.

CIII. MORI'NDA (altered from Morus Indica, or Indian mulberry; so named by Vaillant, from the shape of its fruit and country). Vaill. act. acad. par. 1722. p. 275 . Lin, gen. no. 235. Juss, mem. mus, 6. p. 402. Lam. ill. t. 153. Gærtn. fr. 1. t. 29. A. Rich, mem. soc. hist. nat. par. 5. p. 211. D. C. prod. 4. p. 446.-Rö̀òc. Phum. gen. p. 11. t. 26.

LiN. syst. Pentándria, Monogýnia. Tube of calyx obovate, usually combined with those nearest it : limb short, hardly toothed. Corolla funnel-shaped, with a nearly terete tube, and a spreacling, 5-lobed, rarely 4 -lobed limb. Stamens 5, rarely 4 ; filaments short; anthers inclosed, except in one species. Sityle filiform, usually exserted ; stigma bifid, except in one or two species, in which it is entire. Berries containing 2-4 1-seeded pyrenæ each, usually combined, compressed or angular from being so close together, areolate from the vestiges of the calyx. Embryo terete, in fleshy albumen.-Shrubs or small trees, natives within the tropies. Leaves opposite, rarely $3-4$ in a whorl. Stipulas intrapetiolar, usually obtuse and membranous. Peduncles solitary or numerous, axillary or terminal, sometimes combined at the base, when this is the case they are said to be branched. Flowers aggregate, sessile, upon a sub-globose naked receptacle, forming dense, globose, or ovate heads : having the berries at length combined into a spurious fruit or compound berry. 'The bark of the roots is styptic, and is used by dyers.

Sect. I. Rolòc (Royoc is the American name of $M$. Royoc). Plum. gen. 11. t. 26. D. C. prod. 4. p. 446.-Morínda of most authors. Flowers pentamerous, pentandrous. Stigma bifid. Berries containing 2-4 1-sceded pyrenæ cach.

* Pcduncles terminal, inin, or lateral and opposite the leaves, in the latter case one of the opposite leaves is deficient or half abortive.

1 M. cıтrıfòlıa (Lin. spcc. 250.) plant glabrous, almost arboreous; branchlets tetragonal; leaves oblong, attenuated at both ends, shining; stipulas semi-lunar, membranous, obtuse ; heads on short peduncles, opposite the leares, bractless; berries combined into an ovate mass. $h$. S. Native of the East Indies, as in Malabar and Pegu, \&.c. as well as of the Society Islands. Gærtn. fruct. 1. p. 144. t. 29. Roxb. fl. ind. 2. p. 196. Ham. in Lin. trans. 13. p. 533. Lour, coch. p. 140,Rheed. mal. 1. p. 97. t. 52.--Rumph. amb. 3. p. 158. t. 99. Peduncles opposite to a solitary leaf, on the upper side of the branchlets, each supporting a small head of small white flowers. Anthers half hid in the tube of the corolla. Berries combined in the head, white and polished. The root of this species is employed by the natives of India to dye red.

I ar. 3 , papyràcea (D. C. prod. 4. p. 446.) leaves oblong, acuminated at both ends, on long petioles, papery; stipulas triangular. 5. S. Native of the East Indies, where it was collected by Labillardiere.

Íar. $\gamma$, latifolia (D. C. l. c.) leaves ovate, blunt at the base, hardly acute; stipulas broad, membranous, very blunt. $\mathbf{2} \cdot \mathbf{G}$. Native of the Islands of O-Wahu and Radak, where it was collected by Chaınisso. M. citrifòlia, Cham. et Schlecht. in Linnea. 4. p. 149 .

Citron-leaved Indian-mulberry. Clt. 1793. Tree small.

2 M. TINCTòria (Roxb. f. ind. 2. p. 197.) glabrous and somewhat arboreous; leaves oblong, almost sessile, smooth, but not shining; peduncles opposite the leaves, solitary, much longer than the petioles; heads ovate; stamens inclosed. $h$. S. Native of the East Indies, almost every where. M. citrifolia, Hunt. in asiat res. 4. p. 35 . Trunk seldom above a few feet in height, but supporting a pretty large shady head of branches. Leaves pale beneath, from 6-10 inches long. Peduncles supporting each an oval head of pure white jasmine-like sweet-scented flowers. Fruit like that of $M$. citrifolia. The bark of the root is used to dye red; the colour is fixed with alum, but it is neither bright nor durable. In some parts of India it is cultivated for the sake of its roots. In the Circars the dyers use the bark of the fresh roots bruised and gently boiled in water for a slıort time. The cloth or yarn is prepared in a cold infusion of the powdered galls of Terminatia Chebula, in milk and water; it is then dried and moistened with alum water, and again dried, and receives from the above decoction a pretty bright but fugitive red. The green fruit are picked by the Hindoos, and eaten with their curries. The wood is lard and very durable, variegated with red and white, and is employed for gun-stocks in preference to all other kinds.

Dyers' Indian-mulberry. Tree small.

3 M. BRActea'ta (Roxb. f. ind. 2. p. 198.) glabrous and sub-arborescent, stiff; leaves oblong, shining, on short petioles; stipulas large, semi-circular at the apex; peduncles solitary, opposite the leaves, bracteate. $\eta_{\imath}$. S. Native of the East Indies, in the Gamjam district; also of the Moluceas and Philippines. Cham, et Schlecht. in Linnæa. 4. p. 149. Ham. in Lii. trans 13. p. 534. Blum. bijdr. p. 1006.-Rumpl, amb. 3. p. 157. t. 98. Leaves deep green and polished on both sides. The crown of the germ has frequently a small portion of it growing to be a long linear-lanceolate leaf. The anthers are inclosed, and the stigmas exserted, as in most of the other species of the genus. Peduncles supporting each a small head of small pure white flowers. Berries combined, 4-seeded. Corolla with a very villous throat.

Bracteate Indian-mulberry. Tree small.

4 M. EXSE'Rta (loxb. fl. ind. 2. p. 199.) arboreous; branches somewhat tetragonal, sometimes villous; leaves on short petioles, oval, acute, smooth, or downy beneatin; stipulas emarginate; peduncles opposite the leaves, generally solitary, but sometimes rising by tw os or threes; heads roundish; stigma inclosed; stamens exserted. h.S. Native of Bengal. Branches spreading in every direction. Peduncles supporting each a head of many pure white jasmine-like flowers. Berries 4-seeded, combined.

Exscrtcd-stamened Indian-mulberry. Shrub 6 to 12 feet.

5 M. GEMINA'TA (D. C. prod. 4. p. 447.) branches tetragonal, puberulous ; leaves obovate or oval, cuneated at the base, hardly petiolate, rather downy beneath; peduncles twin, opposite the leaves; stigma and anthers at the throat. $h$. S. Native of 
Gambia and Casamanca, among bushes, where it was collected by Leprieur and Perrottet. Flowers white.

Tnin-peduncled Indian-mulberry. Shrub.

6 M. Multifldra (lioxb. fl. ind. 2. p. 200.) sub-arboreous; leaves oval-oblong, acute, with undulated margins, downy on both sicles, but particularly so beneath; pcduncles terminal and opposite the leaves, solitary or twin or tern, villous, usually compound; heads nearly globose, many-flowered. h. S. Native of the East Indies, in Berar. Stamens inclosed. Style exserted. Berries combined in a head, about the size of a mulberry, each containing 4 seeds This plant is cultivated about Nagpore for the sake of its roots, as the other species are in various other parts of India, and for the same purpose.

Many-flonered Indian Mulberry. Tree small.

7 M. PUBE'scens (Smith, in Rees's cylc. vol. 24. no. 3.) young branches tomentose; leares elliptic-lanceolate, acuminated at both ends, scabrous, but witlı villous veins; peduncles hairy, opposite the leaves, and terminal; heads globose, fewflowered ; corollas elongated, almost glabrous. h. S. Native of the Mauritius.

Don'ny Indian-mulberry. Tree or shrub.

8 M. squarròsa (Ham. in Lin. trans. 13. p. 535.) shrubby, erect, glabrous; leaves elliptic or lanceolate, undulated; peduncles naked, opposite the leaves, solitary, twice the length of the petioles; lieads ovate, nodose in the fructiferous state from the berries being prominent. $h$. S. Native of the East Indies, among bushes at Camprura. Berries of a livid whitish colour : having the pulp white and diaphanous, each containing 4 seeds never combined or conferruminated, many of them abortive.

Squarrose Indian-mulberry. Shrub.

9 M. angustifòlia (Roxb. fl. ind. 2. p. 201. but not of Roth.) shrubby, erect, glabrous ; leaves elliptic or lanceolate, blistered, almost sessile; stipulas somewhat corclate, united into a ring; peduncles short, solitary, almost terminal, but usually opposite the leaves; heads globose, many-flowered; berries distinct in the head. $々$. S. Native of the East Indies, at Chittagong. Roxb. cor. 3. t 237. I'eduncles seemingly-terminal when they begin to blossom, but soon afterwards a branch shoots out from between each peduncle and its respective opposite leaf, which marks their proper situation to be opposite the leaves, supporting each a head of pure white jasmine-like flowers. Anthers hid in the middle of the tube. Berries succulent, of a deep shining black, with very dark-coloured pulp, containing 4 seeds each. The root of this species is used by the natives of India for dyeing, where the plant is in plenty.

Narron-leaved Indian-mulberry. Fl. April, July. Clt. 1816. Shrub 4 to 5 feet.

10 M. PERsiciefòlia (Ham. in Lin. trans. 13. p. 535.) suffiuticose, diffuse, glabrous; branches tetragonal ; leaves elliptic, acute, on short petioles; stipulas subulate, longer than the petioles; heads sessile, solitary, opposite the leaves, usually containing about 10 flowers, and sometimes bracteated by a leaf. $h_{i}$. S. Native of Pegir and Ava, in woods. Corolla incurved, much longer than the head.

Peach-leaved Indian-mulberry. Shrub 1 to 2 feet.

11 M. 'Turbace' nsis (H. B. et Kunth, nov, gen. amer. 3. p. 380.) slirub downy, twining; leaves obovate-oblong, acute ; stipulas connate at the base, acute, downy; heads terminal and opposite the leaves, on very short peduncles; corollas villous on the outside. $h$. S. Native of New Granada, between Turbaco and Carthagena. Flowers white.

Turbaco Indian-mulberry. Shrub cl.

\section{* Terminal peduncles twin, but the lateral and axillary ones are solitary.}

12 M. Roto'c (Lin. spec. 250.) glabrous, procumbent at the vol. III. base; leaves lanceolate, acuminated at both ends, on short petioles; stipulas broal, very slort, mucronate; heads small, axillary, and nearly terminal, on short peduncles. $h .5 . \mathrm{Na}$ tive of St. Domingo, Cuba, and Mexico. Jacq. hort. vind. t. 16. Lin. hort. cliff. p. 73. Roiòc humifùsum fructu Cupressino. Plum. gen. p. I1. t. 26. Pluk. alm. t. 212, f. 4. Flowers white. Berries 1 -seeded, ex Plum., but 2-seeded, ex Lin., combined into a globose head. 'T'he roots dye linen of a dark colour.

Roioc Indian-mulberry. Fl. July, Oct. Clt. 1793. Slırub procumbent.

13 M. Longtrlòra; a branched rather climbing shrub; leaves elliptic-lanceolate, acuminated; peduncles short, axillary; bearing each a head of $6-7$ flowers. $h_{2}$. S. Native of Sierra Leone, among bushes. Corolla white, with a very long tube.

Long-flowered Morinda. Shrub cl.

14 II. QUADRANGULA'ris; shrubby; branches rather quadrangular; leaves broad, oblong, acute, membranous, veiny ; peduncles axillary, bearing each a head of 9-10 flowers. $h . S$. Native of Sierra Leone, among bushes on the mountains, and in the lowlands. (V. S. in herb. Lamb.).

Quadrangular-branched Indian-mulberry. Shrub \& to $4 \mathrm{ft}$.

15 M. PEduncula'ris (H. B. et Kunth, nov. gen. amer. 3. p. 380.) glabrous, erect ; leaves elliptic-oblong, acuminated, shining; stipulas short, connate, acuminated; heads axillary, on long peduncles; bracteas ovate, acuminated. দ. S. Native of South America, in woods on the banks of the Orinoco, near San Borja. Branchlets tetragonal. Corollas white, glabrous. Tube of calyx downy.

Peduncular-flowered Indian-mulberry. Shrub 4 to 5 feet.

16 M. Retu'sa (Lam. and Poir. dict. 4. p. 316. ) arboreous, glabrous; leaves oborate, obtuse, attenuated at the base, on short petioles, shining above; stipulas connate, membranous, obtuse; heads globose, on short peduncles, terminal? $h_{\text {? }} \mathrm{S}$. Native of Madagascar, where it is called Lingo. Poiret says, in his diagnosis of this species, that the leads are lateral, but in his description he says they are exactly terminal.

Retuse-jeaved Indian-mulberry. Tree.

17 M. palmetòrum (D. C. prod. 4. p. 448.) shrubby, glabrous ; leaves oval-lanceolate, acuminated, on short petioles ; stipulas broad-ovate, cuspidate, membranous, foliaceous; heads almost terminal, solitary, globose, on peduncles, which are shorter than the leaves. $h$. S. Native of Africa, in Cayor and Gambia at the roots of palm-trees, where it was collected by Leprieur and Perrottet. Peduncles variable in length, from $\frac{1}{2}$ an inch to 3 inches long. Limb of calyx campanulate, hardly 5 -toothed. Corolla villous on the outside. Style short. Anthers almost exserted.

Palm Indian-mulberry. Slirub.

18 M. Stenophýti.A (Spreng. syst. 1. p. 749.) branches nearly terete, glabrous, but when young rather tetragonal, and clotherl with grey tomentum ; leaves elliptic-lanceolate, acuminated at both ends, on short petioles, grey from very short tomentum; stipulas lanceolate, at length reflexed; peduncles axillary. solitary, tomentose. $々$. S. Native of the East Indies, near Beddir, where it is cultivated for its roots, which are used for dyeing. M. angustifòlia, Roth, nov. spec. p. 147. but not of Roxb. The figure in Rumph. amb. 3. t. 98 . is sometimes referred to for this species, but is probably distinct.

Narrow leaved Indian-mulberry. Shrub or tree.

19 M. TOMENTòsa (Heyn, in lioth, nov. spec. 147.) branchlets angular, glabrous; leaves sub-cordate, ovate, acuminated, clothed with grey tomentum beneath, and on the veins above; petioles long, channelled; peduncles axillary, solitary. $h . S$. Native of the East Indies. Perhaps the same as the following, but it differs in the glabrous branches and long petioles.

4 A 
Tomentose Indian-mulberry. Shrub.

20 M. Mu'dis (Ham. in Lin. trans. 13. p. 536.) sub-arboreous ; branchlets tetragonal, tomentose ; leaves cordate-elliptic, acuminated, tomentose on both surfaces, on very short petioles; stipulas usually bifid; peduncles axillary, solitary, bractless, shorter than the petioles. $h_{c} . S$. Native of the coast of Coromandel, in the woods of Carnata, where it is called Mudi. Each head contains 5.6 flowers.

Mudi Indian-mulberry. Tree small.

21 M. Chachu'ca (Ham. l. c.) sub-arboreous; branches hexagonal; leaves elliptic, acute, often 3 in a whorl, scabrous above, pubescent beneath, and bearded at the axils of the ribs; stipulas semi-circular, often 2 -lobed; peduncles axillary, solitary, naked, a little longer than the petioles. $h$. S. Native of Bengal, in woods at Matsia and Magadha, where it is called Chakluca, i. e. six eyes, from the heads containing only 6 flowers. The bark of the root is used in dyeing red, like others of the species.

Chachuka Indian-nulberry. Shrub.

22 M. Novòsa (Ham. J. c.) sub-arboreous; branches obtuseangled; leaves opposite, or $3-4$ in a whorl, glabrous, elliptic, acute, on very short petioles; stipulas marcescent; heads axillary and terminal, pedunculate, egg-shaped, nodose from many of the berries being abortive. $h_{2} . S$. Native of the East Indies, in the woods of Magadha. Very like $M$. Corèia.

Nodose-headed Indian-mulberry. Tree.

23 M. Core'ta (Ham. l. c.) arboreous; branches with obtuse angles, glabrous; leaves elliptic, acute, undulated, glabrous, on very short petioles; stipulas marcescent; peduncles axillary, and terminal, much longer than the petioles, glabrous, bracteate at the apex; heads roundish. $々$. S. Native of the East Indies, in the woods of Mithila, where it is called by the natives Koreia. Flowers white, large, sweet-scented, 10-12 in each head.

Korcia Indian-mulberry. Tree.

$$
\text { * * Peduncles cronded, umbellate. }
$$

24 M. vмведц'та (Lin. spec. 250.) arboreous, erect: leaves petiolate, lanceolate-ovate; peduncles crowded, terminating the branches. $\eta$. S. Native of Ceylon. This plant is unknown at the present day, and probably the same as M. microcéphala.

Umbellate-flowered Indian-mulberry. Clt. 1809. Tr. or sh.

25 M. Microce'priala (Bartl. in herb. Hænke, ex D. C. prod. 4. p. 449.) shrub glabrous, climbing a little; branches terete; leaves ovate-oblong, acute; stipulas ovate-triangular, acuminated, 3 times shorter than the petioles; heads pedunculate, 4 together, forming umbels at the tops of the branches. $h_{\text {. }}$ S. Native of the Island of Luzon. Flowers white.

Small-headed Indian-mulberry. Shrub cl.

26 M. Cochinchine'nsis (D.C. prod. 4. p. 449.) arboreous; branches spreading; leaves lanceolate, hispid; peduncles crowded, lateraJ. h. S. Native of Cochin-china, in woods. M. umbellàta, Lour. coch. p. 140. Fruit-bearing heads round, small, yellowish, composed of many berries. Flowers white.

Cochin-china Indian-mulberry. Tree.

27 M. sca'Ndens (Roxb. fi. ind. 2. p. 202.) shrublyy, climbing; leaves oblong-lanceolate, acuminated at both ends, on short petioles; stipulas membranous, obtuse ; peduncles numerous, umbellate, terminal. $h \cup$. S. Native of the East Indies, on the east side of Point de Galle Bay. Leaves 3 inches long, and an inch broad. Petioles hardly longer than the stipulas. Peduncles 7-8, short. Fruit-bearing beads globose, about the size of a pea. Flowers white, few in each head.

Scaudent Indian-mulberry. Shrub cl.

28 M. saRMENTòsa (Blum. bijdr. p. 1006.) climbing; leaves oblong-lanceolate, acuminated, glabrous; peduncles terminal by twos or threes, and twin and axillary, concrete at the base, or they may be said to be solitary and bifid; heads usually containing only 4 flowers. $h \cdot \cup$. S. Native of Java, on Mount Burangrang in the province of Krawang. Allied to $M$. scándens.

Triggy Indian-mulberry. Shrub cl.

29 M. LA'xa (Bartl. in herb. Hænke, ex D. C. prod. 4. p. 449.) leaves oblong, acuminated at both ends, membranous, downy beneath as well as on the branchlets; stipulas semi-circular, cuspidate; floriferous branchlets rising from the axils of the superior leaves, opposite, bearing each 2 leaves, and numerous snall peduncled heads, which are disposed in an umbellate manner. $h$.S. Native of Mexico.

Loose Indian-mulberry. Shrub.

Sect. II. Panava'sa (Pada-vara is the Malabar name of M. tetrándra). D. C. prod. 4. p. 449. Flowers tetramerous, tetrandrous. Style bifid at the apex. Berries containing each 4 1-seeded pyrenæ. Perhaps a proper genus.

30 M. TETRA'NDRA (Jack, in mal. misc. 1. no. 2. p. 13. and in fl. ind. 2. p. 203.) shrubby, diffise, glabrous; leaves lanceolate, ciliated with glands in the axils of the veius beneath; stipulas truncate; peduncles terminal, umbellate. $\eta_{\text {q }} . \mathrm{S} . \mathrm{Na}$ tive of the Malay Islands. Pada-vara, Rheed. mal. 7. p. 51 . t. 27. M. Padavàra, Juss. in Røem. et Schultes, syst. 5. p. 216. II. Royòc, Lour. coch. p. 140. but not of Lin. Peduncles 5-10 together. Segments of corolla bearded inside. Berries yellow, combined into heads. Anthers 4, inclosed. A small diffuse shrub.

Tetrandrous Indian-mulberry. Shrub diffuse.

31 M. parvifòlia (Bartl. in herb. Hænke, ex D. C. prod. 4. p. 449.) shrubby, glabrous; sterile branches twining; leaves linear-oblong, cuspidate, glabrous, as well as in the axils of the veins ; stipulas combined into a truncate sheath; heads terminal, 4-5 together in an umbel, pedunculate. h. S. Native of the Island of Luzon. Very like the last species, but the number of the parts of the flower is unknown.

Small-lcaved Indian-mulberry. Shrub.

Sect. 111. Phyllirea'strum (from Phyllira'a and astrum, an affixed signification, like; the shrub contained in this section has much the habit of Phyllirce'a). D. C. prod. 4. p. 449. Flowers tetramerous, tetrandrous. Style clavate, undivided. Berries containing each 4 1-seeded pyrenæ. Perhaps a proper genus.

32 M.? phyllireoides (Labill. nov. caled. p. 49. t. 49.) shrubby, glabrous, erect; leaves elliptic-oblong, acute, on short petioles; stipulas short, membranous, marcescent; heads axilJary, opposite, almost sessile, few-flowered. h. S. Native of New Caledonia. Leaves rather sulphur-coloured beneath when dry. Heads smaller than a pea. Calyx nearly entire. Corolla 4. cleft, short. Style clavate. Berry 4-celled; celts 1-secded.

Phylliratike Indian-mulberry. Shrub 5 feet.

Sect. IV. Cir rysorhiza (from xpvoos, chrysos, gold, and plלa, rhiza, a root; the roots are yellow). D. C. prod. 4. p. 450 . Flowers pentamerous, pentandrous. Berries 2-celled, 2-seeded, Heads of flowers opposite the leaves. Habit of the other species of Morinda, but probably a proper genus.

39 M. chrysorhiza (D. C. prod. 1. p. 450.) shrub much branched; branchlets glabrous, bluntly tetragonal; leaves oblong-elliptic, on short petioles, pubescent in the axils of the veins beneath; stipulas roundish, foliaceous, entire; heads pedunculate, opposite the leaves. h. S. Native of Guinea, where it is called by the natives Boj-tegi-tjo. Psychótria? chrysorhiza, Schum. pl. guin. p. 111. Corolla salver-shaped, white. Stigma bipartite.

Golden-rooted Indian-mulberry. Shrub. 
$+A$ species not sufficicntly known.

34. M. Macroply'LLA (Desf. cat. hort. par. ed. 3. p. 404.) stem erect; branches quadrangular; leaves broad-elliptic, acute, glabrous, on short petioles; stipulas twin, ovate, sprealing. $\zeta$. S. Native country unknown. Cultivated in the stove of the Jardin du Roi, Paris, but has never flowered.

Long-leaved Indian-mulberry. Shrub.

Cult. For culture and propagation see IFamièlia, p. 542.

Subtribe II. Guetra'rdee (this sub-tribe contains shrubs agreeing with Guettárda in the flowers being distinct). D. C. prod. 4. p. 450 . Flowers distinct, never combined.

CIV. MYRMECO'DIA (from $\mu v \rho \mu \eta \xi \xi \nu \rho \mu \eta \kappa o s, ~ m y r m e x ~ m y r-$ mckos, an ant or emmet; ants form nests in the tubers of the roots). Jack, in Lin. trans. 14. p. 122. Blum. bijdr. p. 1001. D. C. prod. 4. p. 450.-Lasióstoma species, Spreng.

Lin. syst. Tetrándria, Monogýnia. Limb of calyx tubular, with an entire border. Corolla funnel-shaped, 4-cleft, having the throat closed by arched scales or hairs. Stamens 4, inclosed. Ovarium covered by a fleshy disk. Style 1. Stigma simple (ex Jack.), quadrifid (ex Blum.). Drupe baccate, crowned by the anmular base of the calyx, containing each 4 triquetrous, 1 -seeded, chartaceously arillate pyrenæ. Embryo erect.-Half parasitical suffruticose plants, tuberous at the base. Leaves opposite, crowded, petiolate, glabrous. Stipulas petiolar, ciliated. Flowers sessile. The germinating plant has a tumid base (ex Blum.).

1 M. INE'RMIS (Gaud. in Freyc. voy. p. 472. t. 95.) tubers unarıned; leaves obovate-oblong; limb of calyx alınost entire; tube of corolla pilose inside; stigma simple, tomentose. $\zeta . S$. Native of the Moluccas and Pulo Nias, parasitical upon trees. M. tuberòsa, Jack. in Lin. trans. 14. p. 122. Lasióstoma tuberòsum, Spreng. syst. 1. p. 423. Nidus gérminans, Rumph. amb. 6. p. 119. t. 55. f. 2 .

Unarmed Myrmecodia. Shrub.

2 M. ARMA'TA (D. C. prod. 4. p. 450.) tubers covered with rows of prickles; leaves oblong-cuneated ; limb of calyx quite entire; throat of corolla closed with arched scales; stigma quadrifid. $h$. S. Native of the western provinces of Java, in the mountains, upon trees, where it is called by the natives Tankurah. M. tuberòsa, Blum. bijdr. p. 1001.-M. echinàta, Gaud. in Freyc. voy. pt. bot. t. 96. has the stem beset with rows of prickles; stipulas twin on both sides, connected by their bases within the petioles into a bifid limb; leaves petiolate, elliptic, acute at both ends; but perhaps both plants are the same.

Armed Myrmecodia. Slirub.

Cult. For culture and propagation see Schradcra, p. 542.

CV. HYDNOPHYTUM (from ivirov, hydnon, a tuber,

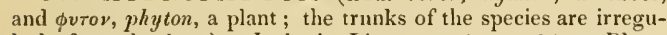
larly formed tubers). Jack, in Lin. trans. 14. p. 124. Blum. bijdr. p. 955. D. C. prod. 4. p. 450.-Lasióstoma species, Spreng.-Myrmecòdia species, Gaud. A. Rich. mem. soc. hist. nat. par. 5. p. 224.

Lin. syst. Tetrándria, Monogýnia. Limb of calyx short, entire. Corolla with a short tube, which is lairy inside, and a flat, 4-lobed limb. Stamens 4, inserted in the throat; filaments short. Style filiform; stigma 2-lobed. Drupe juicy, containing 21 -seeded pyrenæ, which are flat inside, and convex on the back, coriaceous. Embryo erect, in the center of the albumen. -Falsely parasitical shrubs, growing upon trees, tuberous at the base. Leaves oval, on sliort petioles. Stipulas small, linear. Flowers axillary, sessile, white.-Habit of the Myrmecòdia.

1 H. Fornica'rum (Jack. l. c. Blum. l. c.) leaves almost sessile, oval, rounded at the apex. $\zeta_{c} . S$. Native of the Moluccas, Sumatra, and Nusa-Kambanga, upon trees in the woods. Lasióstoma formicàrum, Spreng. syst. 1. p. 428. Nìdus gér- minans formicarum nigrarum. Rumph. amb. 6. p. 119 . t. 55 . The trunk of this plant is an irregular tuber, fixed to trces by fibres like the stems of ivy; it is hollow inside, and becomes the nest of black ants.

Ants' Hydnopliytum. Shrub parasitical.

2 H. Monta'Num (Blum. bijdr. p. 956.) leaves on short petioles, oblong, obtuse. h. S. Native of Java, on the mountains, in the province of Buitenzorg, upon trees. The base of the stem is swollen, as in the first species.

Mountain Hydnophytum. Shrub parasitical.

Cult. For culture and propagation sec Schradera, p. 542.

CVI. HYPOBA'THRUNI (from iño, hupo, upon, and $\beta a \theta \rho o \nu$, bathron, a seat; flowers seated on Hat axillary recep-

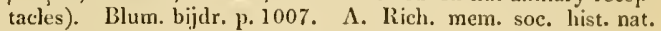
par. 5. p. 198. D. C. prod. 4. p. 451.

Lin. syst. Tetrándria, Monogýnia. Limb of calyx small, 4-toothed. Corolla small, sub-campanulate, with a villous throat, and a 4-cleft spreading limb. Stamens 4, inserted in the mouth of the tube; filaments very short. Style short, perforating the disk; stigma bifid in the throat. Drupe crowned by the calyx, 2-celled; cells containing each 2 I-seeded pyrenæ. Embryo inverted in the albumen.-A shrub, having the habit of Coffèa, with divaricate branches. Leaves distich. Flowers densely crowded on sessile hemispherical, axillary receptacles, sessile, bracteate, umbellate; but the fruit is pedicellate.

1 H. FrUte'scens (Blum. l. c.). $h_{2} . S$. Native of Java, in woods on Mount Burangrang.

Shrubby Hypobathrum. Shrub 4 to 5 feet.

Cult. For culture and propagation see Hamelia, p. 542.

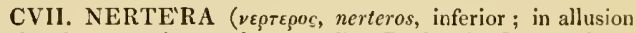
to the plant creeping on the ground). Banks, in Gertn. fr. 1 . p. 124. t. 26. Juss. mem. mus. 6. p. 376. A. Rich, mem. soc. hist. nat. par. 5. p. 219. $\quad$ D. C. prod. 4. p. 451.-Nertèria, Smith, icon. ined. 2. p. 28. t. 28.-Gomòzia, Mutis, in Lin. fil. suppl, p. 17.-Erythrodànum, Pet. Th. A. trist. d'ac. p. 41 .

Lin. syst. Tetrándria, Monogýnia. Calyx witl an ovate tube and a small 4-toothed limb. Corolla funnel-shaped, subcampanulate, 4-cleft (f. 100. b.), glabrous inside. Filaments rising from the bottom of the corolla (f. $100 . c$.), but not adnate to its tube; anthers roundish, hardly exserted. Style filiform ; stigmas 2 , bairy $\left(f_{0} 100 . d_{0}\right)$. Berry roundisl $\left(f_{0} 100 . f_{\text {. }}\right)$, umbilicate, containing 2-4 1-seeded, coriaceous pyrenæ. Seeds semi-ovate, convex on the outside, flat and furrowed inside. Albumen horny. Embryo dorsal, straight, inverted (ex Gærtn.), erect (ex Pet. Th. and Blum.).-Creeping lierbs, with the habit of Michélia. Leaves opposite, rather Hesliy, oval. Stipulas small. Flowers terminal, sessile, solitary, white. Berries red._Perliaps this genus is sufficiently distinct from Michélla.

1 N. DEPRE'sSA (Banks, in Gartn. l. c.) stems low, creeping ; leaves petiolate, flat, subacuminated. 4. G. Native of New Granada on Silla de Caraccas, Peru, Chili, Falkland Islands, 'Tristan d'Acunha, Java, \&.c. in humid or marsliy places. N. depréssa, Smith, icon. ined. 2. t. 28. Tratt. arch. 3. p. 129. D'Urv. A. mal. p. 45. Gaud. A. mal. p. 16. Erythrodànum alsinefórme, Pet. Th. fl. trist. p. 42. t. 10. Gomòzia Granaténsis, Mut. in Lin. fil. suppl.

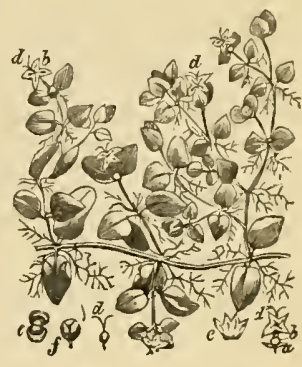


p. 49. N. rènens, Ruiz et Pav. fl. per. 1. p. 60. t. 90 . The figure in Smitl's icon. ined. exhibits much exserted anthers, and the figure of $\mathrm{fl}$. per. a long exserted style, but the figure in Pet. Th. trist. has neither the anthers nor style exserted. There are therefore two distinct species confounded under this name. The specimens from Madagascar have pentamerous flowers (ex Rich.), and those from Java have acuter leaves, on longer petioles than any other; these are probably specifically distinct.

Depressed Nertera. Pl. creeping on the ground.

2 N. Adsu'rgens (Pet. 'T'h. fl. trist. d'ac. t. 11.) stems rooting at the base, but at length ascending at the points; leaves almost sessile, oval, undulated, with callous edges. 4 . F. Native of the Island of Tristan d'Acunha. Carm. in Lin. trans. vol. 12. p. 505. Erythrodànum màjus, Pet. Th. fl. trist. d'ac. p. 42. A larger plant than the preceding.

Rising Nertera. Pl. creeping.

3 N. ? Alsinoìdes (Cliam. et Schlecht. in Linnæa. 6. p. 413.) leaves pubescent, and ciliated at first, but at length becoming glabrous; peduncles axillary, deflexed when in fruit, about equal in length to the leaves; drupes juicy, globose. $\boldsymbol{L}$. F. Native of Mexico, at Cuesta Grande de Jalacingo. Herb beset with a few stiffish white hairs. Drupe bluish-black, containing 2 coriaceous 1-seeded pyrenæ.

Chickneed-like Nertera. Pl. creeping.

Cult. The species of Nertèra are small creeping suffruticose evergreen plants, of little beauty even when in flower; they grow best in a mixture of turfy peat and sand; and are increased easily by separating the rooted creeping stems. They may be placed among the alpine plants in summer, but in winter they will require the protection of a green-house. They should be grown in pots well drained with sherds, placed in pans of water.

CVII1. MITCHE'LLA (so named by Linnæus in honour of John Mitchell, M.D. a physician in Virginia, who described many genera of Virginian plants, which were published in act. nat. cur. for. 1748). Lin. gen. no. 134. Juss. gen. 205. mem. mus. 6. p. 373. Lam. ill. t. 63. Gærtn. fil, carp. 3. p. 70, t. 192. A. Rich. mem. soc. hist. nat. Par, 5. p. 220. D. C. prod. 4. p. 45\%.-Chamædảplıne, Mitch. gen. p. 17. but not of Buxb.

Lin. syst. Tetrándria, Monogýnia. Calyx with an ovateglobose tube, and a large 4-toothed limb. Corolla funnelshaped, with a terete tube, and a 4-lobed spreading limb, having the throat and lobes of the limb hairy inside. Filaments adnate to the tube, almost to the throat; anthers ovate, hardly exserted. Style filiform; stigmas 4, inclosed. Berries almost globose, crowned by the teeth of the calyx, containing 4 horny 1 -seeded pyrenæ each ; and somctimes containing 8 , when 2 berries are combined. Albumen somewhat cartilaginous. Embryo minute, erect, with very short cotyledons.-American glabrous creeping evergreen lıerbs, with the habit of Linna'a or Nertèra. Leaves roundish or ovate. Stipulas small, solitary on eacl side. Flowers axillary and terminal, sometimes combined by twos at the tops of the peduncle, and sometimes solitary and sessile.

1 M. RE'PENS (Lin. spec. p. 161.) leaves roundish; flowers 2 on the top of each peduncle, combined; berries combined. 4 . H. Native of Nortl America, from Boston to Carolina; Upper Canada; and of Mexico between Pueblow Viejo and Real del Monte, in shady woods at the roots of trees, and among moss. -Pluk. alm. t. 444. f. 2.-Cat. car. t. 20,-['etiv. gaz. t. 1. f. 13. Corollas white, tinged with purple, usually $\approx$ together on the top of each peduncle, and seated on two combined ovaries; the flowers are sometimes also combined, and therefore 8 -cleft, according to the obs. of Torrey. Berries red, insipid.

Creeping Mitchella. Fl. June. Clt. 1761. Pl. cr.

2 M. ova'TA (D. C. prod. 4. p. 4.52.) leaves ovate, acutish; flowers solitary, sessile. 2 F. Fative of South America, in humid places at the foot of the burning mount Tunguragua, in the kingdom of Quito. Flowers white, solitary, not by twos. Nertèra tetraspérma, H. B. et Kunth, nov. gen. amer. 3. p. 379. Spreng. syst. 1. p. 492 . exclusive of the synonymes.

Ovate-leaved Mitchella. Pl. cr.

Cult. These are small creeping evergreen plants of very little beauty; they will grow very well in a peat border, or in pots filled with a mixture of peat and sand, placed among other alpine plants; they are easily increased by separating the creeping stems.

CIX. MEPHITI'DIA (from mephitis, a damp of the earth; in reference to the ungrateful smell of the shrubs). Reinw. in Blım. bijdr. D. C. prod. 4. p. 452.-Lasiánthus, Jack, in Lin. trans. 14. p. 125. Blum. bijdr. p. 995. A. Rich, mem. soc. hist. nat. par. 5. p. 210 . but not of Lin.

Lin. syst. Tetra-Hexándria, Monogýnia. Limb of calyx 3-6-parted or toothed. Corolla funnel-shaped, regular, 4-6cleft, for the most part hairy. Stamens 4-6, inserted towards the throat; filaments very short; anthers linear, exserted or inclosed. Stigmas 4-9, linear, thick. Drupe baccate, crowned by the permanent calyx, containing $\$-9$ triquetrous coriaceously arillate 1-seeded pyrenæ.-Shrubs or subshrubs, natives of India, usually with an ungrateful smell. Flowers crowded or in dense heads, axillary and terminal, bracteate. Drupes usually blue.-This genus, according to Blume, is nearly allied to $A n$ cylánthus and Psathùra.

\section{* Limb of ealyx 3-6-parted.}

I M. CYANOCA'RPA (Jack, in Lin. trans. 14. p. 125. under Lasiánthus,) plant suffruticose, hairy ; leaves oblong, acuminated, attenuated at the base; flowers usually by threes, involucrated by bracteas. $々$. S. Native of Sumatra and Java, in shady places on tlie mountains. Blum. bijdr. p. 996. Bracteas cordate. Corollas yellow, ex Jack, whitish, ex Blume. Berry blue, pilose, size of a gooseberry.

Blue-fruited Mephitidia. Shrub.

2 M. ATTENUA'TA (Jack, 1. c. p. 126. under Lasilinthus, plant suffruticose, villous; leaves oblong, attenuated at the apex, but roundly cordate at the base, glabrous above; flowers axillary, 3-4-together, almost sessile, involucrated by lanceolate bracteas. h. S. Native of the intcrior of Bencoolen. Calyx 4-parted. Corolla yellow, pilose. Berries deep blue, smaller than thosc of the preceding species.

Atlenuated-leaved Mephitidia. Shrub.

3 M. INEQUA'Lis (Blum. bijdr. p. 996. under Lasiánthus, as well as all the following species,) slirubby, hairy ; leaves oblong, acuminated, unequally rounded at the base; flowers axillary, crowded, involucrated by bracteas. h. S. Native of Java, on mounts Salak and Seribu. Corolla white.

Unequal-leaved Mephitidia. Shrub.

4 Il. RHiNoceròtis (Blum. bijdr. p. 996.) shrubby ; leaves oblong, acuminated, rounded at the base, glabrous above, but hairy beneath, as well as the branches and calyxes; flowers crowded, axillary. $h$.S. Native of Java, in the higher woods on mounts Salak, Gede, Sc. Corollas white.

Horn-snouted Mephitidia. Shrub.

5 M. cartTA'TA (Blum. bijdr. p. 996.) shrubby; leaves oblong-lanceolate, acuminated, attenuated at the base, glabrous above, and hairy beneath, as well as the branches, peduncles, and calyxes; heads of flowers pedunculate, axillary. $h$. S. Native of Java, in woods on the mountains. Flowers white.

Capitate-flowered Mephitidia. Shrub.

6 M. томеnтo'sa (Blum. bijdr. p. 997.) shrubby; leaves oblong, long-acuminated, acute at the base, glabrous above, but 
tomentose on the veins beneath, as well as on the branches; flowers axillary, solitary or twin, sessile. $h$. S. Native of Java, in woods on mounts Salak, Gede, \&c. Corollas white.

\section{Tomentose Mephitidia. Shrub.}

7 M. onscu'ra (Blum. mss, ex D. C. prod. 4. p. 4.53.) shrubby; leaves oblong, acuminated, rather obliquely attenuated at the base, clothed with tomentum beneatl, as well as on the rib above and the branches; heads of flowers axillary, almost sessile. h. S. Native of Java, in the westeru parts on the mountains. Corolla white. This species differs from $M$. tonentosa in the stipulas being larecr, and in the flowers being more numerous, $\mathrm{Sic}_{\mathrm{c}}$.

Obscure Mcphitidia. Shrub.

8 M. LU'cida (Blum. bijdr. p. 997.) slurubby ; branches glabrous; leaves ovate-oblong or lanceolate, cuspidate, shining above, rather pubescent beneath at the margins, and on the veins; flowers crowded, axillary, rarely solitary. h. S. Native of Java, in the more elevated woods. Flowers white.

Shining-leaved Mephitidia. Shrub.

9 M. stipula'ris (Blum. bijdr. p. 997.) shrubby; branches glabrous; leaves oblong, acuminated, attenuated at the base, and are as well as the branches glabrous, but ciliated at the apex; stipulas large, roundish, rather membranous; flowers crowded, axillary; calyxes hairy. h. S. Native of Java, on mount Salak. Corollas white.

\section{Stipular Mephitidia. Shrub.}

10 M. LEVIGA'TA (Blım. bijdr. p. 998.) shrubby; leaves oblong, acuminated, acutish at the base, and are as well as the branches glabrous; fascicles of flowers axillary ; caly $\times 3$-parted. h. S. Native of Java, in mountain woods. Flowers white. There is a variety of this with lanceolate leaves.

Smooth Mephitidia. Shrub.

11 M. Latifòlia (Blum. mss. ex D. C. prod. 4. p. 453.) shrubby; leaves oval, acute at both ends, reticulately veined, and are as well as the branches glabrous; flowers crowded, axillary, on short peduncles. $\zeta$. S. Native of Java, on mount Salak in shady parts of woods. Corollas white. Fruit globose, orange coloured. Lobes of calyx lanceolate, parted to the base, at lengtl becoming connivent.

Broad-leaved Mephitidia. Shrub.

$$
\text { * * Limb of calyx with short lobes. }
$$

12 M. INODo'RA (Blum. bijdr. p. 998.) shrubby; branches glabrous; leaves oblong or oblong-lanceolate, acuminated at both ends, glabrous, downy on the veins beneath; flowers crowded, axillary, girded by blunt bracteas. h.S. Native of Java, in woods at mount Gerle. The leaves of this species are without any ungrateful smell.

Scentless Mephitidia. Shrub.

13 M. HEXÁNDRA (Blum. bijdr. p. 998.) shrubby; leaves lanceolate, long-acuminated, clothed with strigose down on the rib above, and on the veins beneath, as well as the branchlets; flowers axillary, usually solitary, hexandrous. 々. S. Native of Java, in the more elevated woods on mount Salak. Corollas white.

Hexandrous Mephitidia. Shrub.

\section{* * Limb of calyx with short teeth.}

14 M. vexòsa (Blum. bijdr. p. 999.) shrubby; leaves on short petioles, oblong, acuminated, obliquely attenuated at the base, very reiny, glabrous above, downy on the veins beneath, as well as on the branchlets; flowers crowded, axillary, sessile. h. S. Native of Java, in woods on the Seribu mountains. Corollas white.

Veiny Mephitidia. Shrub.

I 5 M. syLVE'stris (Blum. bijdr. p. 999.) shrubby; leaves on short petioles, oblong-lanceolatc, acuminated at both ends, glabrous, veiny, clothed with adpressed down on the veins beneath, as well as on the branchlets; flowers crowded, axillary, sessile; fruit containing 4-5 pyremae. $\zeta$. S. Native of Java, along with the preceding, from which it differs in the smaller leaves, which are unequally narrowed at the base, in the fewer and remoter veins, and in the more obsoletely toothed calyx.

IVild Mephitidia. Shrub.

16 M. Reticula'ta (Blum. bijdr. p. 1000.) shrubby; leaves large, on short petioles, oblong, acuminated, acute at the base, glabrous above, and reticulately veined, rather tomentose on the veins and branches; flowers crowded, axillary, almost sessile. h. S. Native of Java, on the Seribu mountains. Flowers white.

Reticulatcd-Jeared Meplitidia. Shrub.

17 M. purfu'rea (Blum. bijdr. p. 1000.) shrubby; leaves lanceolate, long-acuminated, and are as well as the branches glabrous; peduncles crowded, I-flowered, axillary, or lateral from the leaves having fallen. $\eta$. S. Native of Java, on mounts Salik, Gede, Sc, in shady places. Flowers purple.

Purple-flowered Mejluitidia. Shrub.

18 M. stercora'ria (Blum. bijdr. p. 1000.) shrubby; leaves lanceolate, long-acuminated, acute at the base, glabrous except the veins beneath, which are clothed with adpressed down, as well as the branches; flowers crowded, axillary, sessile; fruit globose, containing 7-9 pyrenæ. $h_{\text {. }}$ S. Native of Java, on the mountains. Allied to M. sylvéstris; but the fruit is evidently distinct. Flowers white.

Stinking Mephiticlia. Shrub.

Cult. See Hamelia, p. 542 . for culture and propagation.

CX. VANGUERIA (altered from Voa-Ianguer, the Madagascar name of the first species). Comm. in Juss. gen. p. 266. mem. mus. 6. p. 396 . A. Rich. mem. soc. list. nat. Par. 5. p. 217. D. C. prod. 4. p. 454 . -Vanguièra, Pers. ench. 1. p. 459. —Vavánga, Rohr, in act. soc. hist. nat. hafn. 2. pt. 1. p. 208. t. 7.-Mèynia, Link.

Lin. syst, Pentándria, Monogýnia. Calyx with a short obovate tube, and a small spreading 5-toothed deciduous limb. Corolla campanulately globose, 5-cleft, hairy inside at the throat: lobes lanceolate, acute, reflexed. Stamens 5, with very short filaments, and oblong hardly exserted anthers. Stigma capitate, (bilamellate, ex Vahl.) 4-5-lobed (ex Roxb.). Berry applesliaped, not crowned at the apex by the calyx, but marked by a sinuated areola, indicating the place from which the limb of the calyx had fallen off, containing 5 bony 1 -seeded pyrenæ, which are obtuse at the base, and acute at the apex. Seed oblong, fixed to the inner angle of the cell, near the middle. Albumen fleshy. Embryo large, inverted, with long plano-convex cotyledons, and a bluntly cordate compressed superior radicle.Small trees. Leaves petiolate, ovate. Stipulas solitary on both sides, lanceolate. Cymes branched, subpanicled, axillary, or rising beneath the leaves from the cicatrices, occasioned by the folling of the old leaves. Flowers white.-This genus is anomalous in the order, from the structure and situation of the seeds; it is allied to Cánthium, but diflers from that genus in the ovarium being 5 -celled, not 2 -celled.

1 V. cDu'LIs (Vahl, symb. 3. p. 36.) unarmed; leaves ovate, membranous, glabrous; cymes rising beneath the leares. Native of Madagascar, from whence it has been introduced to China and the Mauritius. Lam. ill. t. 159. Sieb. A. maur. exs. 2. no. $7 \%$, and no. $13 \mathrm{~S}$. V. cymò $:$, Giertn. fil. carp. 3. p. 75. t. 193. V. Madagascariénsis, Gmel. syst. 1. p. 367. V. Commersònii, Desf. ex Steud. Jacq. hort. vind. 1. t. 44. V'avánga Chinénsis, Rolır, and Vavánga edùlis, Vahl, act. soc. hist. nat. hafn. 2. pt. 1. p. 20\% and p. 208. t. \%. The habit of the tree 
is much like that of Callicarpa. The fruit is eaten by the natives of Madagascar and the Mauritius under the names of I'oa-vanga and loa-vanguer. Flowers white.

Edible-fruited Vangueria. Clt. 1809 . Tree 10 to 15 feet.

2 V. spino'sa (Roxb. fl. ind. 2. p. 172.) spines decussate ; leaves ovate-oblong, smooth; cymes axillary, in fascicles. $h . S$. Native of Bengal and China; in Bengal it is called Mayna. Mèynea spinòsa, Link, jahrb. 1-3. H. p. 32. Roem. et Schultes, mant. 1. p. 67, and 84. Leaves opposite or three in a whorl, 3-4 inches long. Flowers axillary, fascicled on a short peduncle, with proper longer pedicels, small, of a pale greenish colour. Anthers small, cordate. Stigma 4-5-lobed. Berry size of a cherry, turbinate, smooth, yellow when ripe, succulent, and edible. The flowers and habit of the wloole plant are exceedingly like Cánthium parviflòrum.

Spinose Vangueria. Fl. June, July. Clt. 1816. Shrub large. 3 V. Infau'sta (Burch. cat. geogr. pl. afr. austr. no. 2629. trav. 2. p. 258. and 259. with a figure,) unarmed; leaves tomentose, roundish-ovate, usually acuminated; cymes axillary. $\eta$. S. Native of the south of Africa, without the tropic, in the territory of Bachapin, where it is considered unlucky by the inhabitants. Fruit round, an inch in diameter, but not edible.

Unlucky Vangueria. Shrub 5 to 10 feet.

N. B. Vanguèria verrucòsa, Sieb, fl. maur, does not belong to the present order, but is probably a species of Loganea or Solìnum.

Cult. For culture and propagation see Hamèlia, p. 542.

CXI. GUETTA'RDA (so named by Linnæus in honour of John Etienne Guettard, member of the academy of sciences at Paris, who published, in $\mathbf{1 7 4 7}$, a catalogue of the plants growing in the vicinity of Estampes). Vent, choix. no. 1. A. Rich. mem. soc. hist. nat. par. 5. p.20I. D. C. prod. 4. p. 455.-Guettárda species and Matthiola, Lin. gen.-Guettárda species and Laugèria, Jacq. Juss.-Guettárda spec. Lam. Pers.-Halèsia, P. Browne, jam. but not of Lin.-Viviàia, Rafin. spech. 1. p. 117. but not of Cav. nor Colla, nor Raddi.

Lin. syst. Tetra-Enneándria, Monogýnia. Calyx with ovate or globose tube; and a tubular permanent or deciduous limb, which is either truncate or irregularly toothed (f. I01.a.). Corolla salver-shaped, with a cylindrical tube (f. 101.c.), and from 4-9 oval-oblong lobes (f. $101 . b$.). Anthers 4-9, sessile in the throat of the corolla, inclosed. Stigma capitate, rarely 2 -lobed. Drupe roundish or ovate, crowned by the tube of the calyx (f. $101 . d$.$) , containing a bluntly angled 4-9-celled putamen (f. 101$. $c$.$) , having the cells straight or curved, 1-seeded. Seeds erect,$ nearly terete.-Small trees or shrubs, natives of South America, and a few of India. Leaves ovate or lanceolate, rarely cordate. Stipulas lanceolate, deciduons, except in one species in which they are sheathing and truncate. Peduncles axillary, bifid, rarely twice bifid. Flowers sessile and milateral along the branches of the peduncles, and solitary in the forks.

Sect. I. C $A$ Ad $^{\prime}$ MBA (vernacular name of $G$. speciòsa). D. C. prod. 4. p. 455.—Cadámba, Sonner. trav. 2. p. 228. t. 128. Limb of calyx soon falling off. Cells of drupe curved at top.

1 G. speciòsa (Lin. spec. 1408.) leaves broad, ovate or obovate, usually subcordate at the base, obtuse and apiculated at the apex, downy beneath; stipulas ovate or lanceolate, acuminated, deciduous; cymes pedunculate, velvety, much shorter than the leaves; flowers of from 4 to 9 parts; fruit depressed, marked by an areola at the apex. $h$. S. Native of the East India islands; coast of Coromandel and Malabar, \&c. Lam. ill. 1. 154. f. 2. Roxb. fl. ind. 2. p. 521. Lindl. bot. reg. t. 1393. Cadámba jasminiflora, Sonn. trav. 2. p. 128. Rava-Pou, Rheed. mal. 4, p. 47. and 4.8. Leaves canescent from villi in the young state, but the adult ones only along the nerves. Branches horizontal, forming a large shady head. Peduncles twice bifid. Flowers unisexual, large, white, exquisitely fragrant, partaking much of the scent of cloves. Seeds much curved, with the concave part of the curve outwards. Leaves sometimes downy on both surfaces. (f. 101.)

I Tar. $\beta$, glabràta (D. C. prod. 4. p. 455.) young leaves downy along the nerves and veins, but the adult ones are glabrous. $\eta$. S. Native of Mexico, but probably only cultivated in gardens. Thcre are varieties of this with the leaves either subcordate or subattenuated at the base.

Showy Guettarda. Fl. June, July. Clt. 1771. Tree $30 \mathrm{ft}$.

Sect. 11. Guettarda'ria (altered from the generic name). D. C. prod. 4. p. 455 . Limb of calyx usually permanent, truncate or irregularly subdentate. Corolla silky on the outside, with the lobes flat. Drupe having the cells of the putamen straight.

\section{\$ 1. Tube of corolla silky, villous or downy. Drupe containing} a 4-7-celled putamen.

2 G. Argéntea (Lam, dict. 3. p. 54. ill. t. 154. f. 1.) leaves ovate, acuminated, on short petioles, glabrous and smooth above, but clothed with silky velvety down beneath, with the transverse nerves parallel; stipulas villous on the outside, ovate, terminating in a subulate point; cymes pedunculate, bifid, velvety; flowers hexamerous, with a villous tube, which is 10 times longer than the ovarium. $\zeta$. S. Native of Cayenne. G. speciòsa, Aubl. guian. 1. p. 320. bnt not of Lin. Peduncles about the length of the leaves. Leaves 5 inches long and 3 broad. Petioles 5 lines long. Corolla 15 lines long, white. Ovarium 6-celled, 6-ovulate.

Silvery Guettarda. Tree 20 feet.

3 G. Havane'ssis (D. C. prod. 4. p. 455.) leaves obovate, acutish at the base, and.mucronate at the apex, scabrous above, and tomentose beneath; stipulas acuminated, 3 times shorter than the petioles; peduncles hairy, about the length of the leaves; cymes trifid; tube of corolla 4 times longer than the ovarium, and the limb 5-6-cleft. h. S. Native of Cuba, about the Havannah. Allied to $G$. ambigua. Flowers white?

Hacannah Guettarda. Tree.

4 G. MIssiònıs (Wall, cat. no. 6221.) leaves oblong, acuminated, paler beneath, glabrous in every part, except on the mid-rib beneath; cymes pedunculate, axillary, dichotomous; calyx 5-parted, permanent; corolla villous on the outside; fruit roundish, crowned by the calyx. h.S. Native of the East Indics. Stipulas ovate. Flowers white, not so large as those of $G$. speciòsa.

Mission Guettarda. Shrub or tree.

5 G. ambígua (D.C. prod. 4. p. 455.) leaves ovate or obovate, cordate at the base, and rather mucronate at the apex, scabrous above, but clothed with downlike tomentum beneath; stipulas acuminated, one-half shorter than the petioles; peduncles hairy, about the length of the leaves; cymes bifid; fruit globose, reticulated, crowned by the tubular calyx. $\zeta . \mathrm{S}$. $\mathrm{Na}-$ tive of Guadaloupe, and also of Jamaica, if, as is suspected, this be the Halèsia, P. Browne, jam. p. 205. t. 20. f. 1. Flowers white?

Ambiguous Guettarda. Shrub 8 to 10 feet.

6 G. conda't A (H. B. et Kunth, nov. gen. amer. 3. p. 420.) leaves ovate-elliptic, deeply cordate, rounded at the apex, rather pilose above, and clothed with white tomentum beneath; stipulas ovate, acute, length of petioles; peduncles 3 or 4 times longer than the petioles; cymes 3-flowered; flowers bexamerous, with a downy tube, which is 4 times longer than the ovarium. h. S. 
Native of New Granada, near Ibague and Cuesta de Tolina, in hot places. Said to be nearly allied to $G$. scàbra.

Cordate-leaved Guettarda. Tree or shrub.

7 G. Rugo'sa (Swartz, prod. p. 59. f. ind. occ. 1. p. 632.) leaves ovate-subcordate, mucronate, scabrous above, and tomentose beneath; peduncles 3 or 4 times longer than the leaves, compressed, villous; cymes bifid: flowers hexamerous, with a villous tube, which is 9 times longer than the ovarium. $h . S$. Native of the Caribbee islands, as of Santa Cruz, Antigua, and Dominica. Vahl, symb. 3. p. 50. Tube of corolla an inch and a half long, silky. Very nearly allied to $G$. scàbra, but differs in the nervules of the leaves being less prominent and straight, not reticulated. Drupe purplish, containing a 6 -seeded putamen. Wrinkled Guettarda, Clt. 1793. Tree.

8 G. sca'bra (Lam. ill. t. 154. f. 3.) leaves obovate, mucronate, coriaceous, scabrous above, reticulated and pubescent beneath; stipulas lanceolate, acuminated, caducous ; peduncles compressed, villous, almost 4 times longer than the petioles; cymes bifid; limb of corolla 6-7-parted; stamens 6-7; tube of corolla villous, 3 times longer than the ovarium. $h$. S. Native of the West Indies, as of Porto-Rico. Vent. choix. t. 1. Mathiola scàbra, Lin. spec. 1661. Mathiola, Plum. ed. Burm. t. 179. f. 2. Flowers white. Drupe containing an angular 4-7 celled putamen, and crowned by the somewhat crenate limb of the calyx.

Scabrous Guettarda. Clt. 1818. Tree.

9 G. viburnoides (Cham. et Schlecht. in Linnæa. 4. p. 182.) leaves ovate, acute, on long petioles, smoothish above, but not scabrous, and clothed with silky tomentum beneath, as well as the branchlets and inflorescence; stipulas elongated, triangular, very soon falling off; peduncles sliorter than the leaves, twice bifid, with the branches expanded; limb of calyx very short, somewhat truncate; drupe globose, depressed. h. S. Native of Brazil within the tropie. Leaves 4 inches long and $2 \frac{1}{2}$ broad, on petioles about 15 lines long. Corolla densely elothed with silky down, having the tube almost an inch long, and the limb 4-6-parted.

Iiburnum-like Guettarda. Shrub 10 feet.

10 G. Peduncula'ris (Wall. cat. no. 6222.) leaves ovateoblong, acuminated, glabrous ; peduncles axillary, solitary, 1flowered, girded by a ring just under the fruit, which is extended into 2 opposite subulate points; fruit oblong, crowned by the 4 perinanent teeth of the calyx. $\zeta$. S. Native of Sirinagur.

Peduncular-flowered Guettarda. Shrub or tree.

11 G. PLATY' PodA (D. C. prod. 4. p. 456.) leaves oval, mucronulate, acute at the base, on short petioles, glabrous and smooth above, but hoary beneath; stipulas triangular, acute; peduncles compressed, smoothish, length of the leaves, cymose at the apex, and bearing 5-7 flowers; limb of calyx short, tubular, a little toothed: fruit globose, depressed. $h$. S. Native of Brazil, in the sand by the sea side at Bahia, where it was collected by Salzman.

Broad-peduncled Guettarda. Shrub.

12 G. Móllis (D. C. prod. 4. p. 456.) leaves elliptie, somewhat mucronate, downy above and villous beneath; peduncles 5 times longer than the petioles; cymes capitate, villous; flowers hexamerous, with a villous tube, which is 2 or 3 times longer than the ovarium. h.S. Native of St. Domingo. G. elliptica, ex Hispaniola, Spreng. syst. 1. p. 789.

Soft Guettarda. Tree or shrub.

13 G. XyLosteoides (H. B. et Kunth, nov.gen. amer.3.p. 420.) leaves oblong, acute, rounded at the base, glabrous above, and downy beneath, but hairy on the veins, as well as on the branchlets; stipulas lanceolate, length of the petioles; peduncles 6 times longer than the petioles; cymes 3-7-flowered; flowers hexamerous, having the tube 8 times longer tlan the ovarium.
Native on the banks of the Orinoco, between Angustura and Ferreras. Dierobótryum divaricàtum, Willd. in Schultes, syst. 5. p. 221. Flowers white. Fruit globose, downy, containing a 5-6-celled putamen.

Fly-IIoneysuckle-like Guettarda. Tree 20 feet.

14. G. PArviflòra (Vahl, ecl. amer. 2. p. 26.) leaves oblong, polished, and glabrous on both surfaces, but laving the middle nerve rather downy ; stipulas sinall, subulate ; peduncles crowderl at the tops of the branches, rather shorter than the leaves, 9flowered, rarely bifid, each branch bearing 3 flowers; flowers small, either pentamerous or hexamerous; ovarium striated; tube of calyx often obseurely bifid; tube of corolla villous, $h$. S. Native of Santa Cruz, Montserrat; and of Mexico, at Acapulco. Edechi, Loefl. trav. 259. and p. 271. ex Rohr. Ixòra pentándra, West. mss. Fruit globose, about the size of a pea, not crowned.

Small-flonered Guettarda. Shrub 6 to 8 feet.

15 G. odora'ta (Lam. ill. t. 154. f. 4.) leaves oval, acute at both ends, glabrous above, but rather villous on the nerve beneath, as well as on the petioles and branchlets; stipulas subulate, deciduous; peduncles almost one-half shorter than the leaves, villous, as well as the cymes, which are bifid; flowers pentamerous ; tube of calyx unequal, 7 times longer than the ovarium. h. S. Native about Carthagena and Havannah, among bushes by the sea side. Laugèria odoràta, Jacq. amer. p. 64 . t. 177. f. 21 . pict. t. 259 .

f. 16. Drupe containing a roundish 5-furrowed 5 -celled putamen. Flowers of a dirty reddish colour, 9-10 lines long, villous on the outside, very sweet-scented at night. Fruit black, size of a pea. There is a spinescent variety of this species according to Jacquin.

Swcct-scentcd-flowered Guettarda. Clt. 18I8. Sh. 6 to $10 \mathrm{ft}$.

16 G. membrana'cea (Swartz, prod. p. 59. f. ind. occ. 1. p. 685.) leaves ovate, acuminated, membranaceous, rather hispid on both surfaces; down very minute, curved; peduncles length of the petioles, dichotomous; flowers secund, tetramerous; limb of calyx rather bifid, truncate; tube of corolla downy, h.S. Native of Hispaniola, among bushes on the mountains. Corolla white, half an inch long. Drupe oblong, 4-seeded.

Membranous Guettarda. Shrub.

17 G. Elli' PTICA (Swartz, prod. p. 59. A. ind. occ. 1. p. 634.) leaves elliptic, obtuse, smoothish above, and downy beneath, as well as on the branches; peduncles shorter than the leaves; cymes bifid; flowers tetramerous, with a silky tube, which is 3 times longer than the calyx. 5 . S. Native of Jamaica, in dry ficlds. Drupe roundish, 4-seeded. Stigmas 2, blunt. Flowers small. This species is easily distinguished from $G$. móllis, with which it has been confused by Sprengel in lis syst.

Elliptic-leaved Guettarda. Tree 20 feet.

18 G. microphy'Lla (Bartl. in herb. Hænke, ex D. C. prod. 4. p. 457.) leaves ovate-oblong and oblong, smoothish above, and rather downy beneath; peduncles 3 or 4 times shorter than the leaves, 3-flowered; ealyx quadrifid, with acute segments ; corolla silky on the outside, with rounded lobes. h.S. Native of Luzon, one of the Philippines. Very like $G$. parrifiòra.

Small-leaved Guettarda. Shrub.

19 G. URUGUE'Nsis (Cham. et Schlecht. in Linnæa. 4. p. 183.) leaves elliptic-oblong, acuminated, rather pilose above, and 
canescent from tomentum beneath, as well as the petioles, branchlets, and inflorescence; stipulas lanceolate, triangular, caducous; peduncles twice bific, shorter than the leaves; limb of calyx very short, somewhat truncate; corolla silky; drupe oblong, 3-4-seederl. $h$. S. Native of the south of Brazil, on the banks of the Uruguay. Leaves 2 inches long, and an inch broad, on petioles 1-2 lines long. Tube of corolla 2-3 lines long; lobes 5 , roundish.

Iruguay Gucttarda. Shrub 10 feet.

20 G. Fingaysonia'na (Wall. cat. no. 6223.) leaves obovateoblong, obtuse at the apex; calyx truncate; pedicels solitary, axillary, l-flowered, much shorter than the leaves ; corolla villous outside. h. S. Native of the East Indies.

Finlayson's Guettarda. Shrub.

21 G. WALLICHIA'NA; leaves oblong, acuminated, glabrous ; pedicels 1-flowered, rising in numbers from short axillary peduncles; calyx truncate; corolla glabrous, apparently purple,

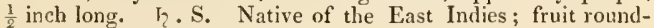
ish, not crowned. Perlaps belonging to the first section.

Wallich's Guettarda. Shrub.

\$2. Doubtful spccies, having 4-cleft silky corollas, and the drupes containing a 2-3-colled putamen. Perhaps specics of the grenus Stcnóstomum.

22 G. ? protra'cta (Bartl, in herb. Hænke, ex D. C. prod. 4. p. 457.) leaves ovate or ovate-lanceolate, acuminated, rather villous on botli surfaces, silky on the nerves and veins beneath; peduncles cymose, bifid, having the branches recurved. $\zeta . S$. Native of Mexico. Perhaps a species of Stenóstomum.

I ar. a, brévipes (D. C. prod. 4. p. 457.) leaves ovate, with 9 very prominent nerves on each side of the mid-rib; peduncles twice the length of the petioles; limb of calyx truncate, irregularly sublobate; corolla 4-cleft? clothed with silky tomentum outside. $h$. S. Native of Mexico.

Y ar. $\beta$, lóngipes (D. C. I. c.) leaves ovate-lanceolate, with 7-8 rather prominent nerves on each side of the mid-rib; peduncles 4 times longer than the petioles; drupes ovate-oblong, acute, 2, sometimes 3-celled. $h$. S. Native of Mexico, at Acaptulco.

Protracted Guettarda. Shrub.

23 G.? ARMA'ta (Bartl. in herb. Hænke, ex D. C. prod. 4. p. 457.) armed with opposite spines; leaves ovate, acuminated, smoothish above, but clothed with hoary tomentum on the nerve and reins beneath, as well as on the branchlets; peduncles cymosely bifid, 3 or 4 times longer than the petioles; segments of calyx 4, narrow-lanccolate, acutc; corolla silky, with acute lobes; drupe ovate-oblong, (ex Bartl.) 2-3-celled. $h . \mathrm{S}$. $\mathrm{Na}$ tive of Mexico. Very nearly allied to $G$. protrúcta.

Armed Guettarda. Shrub 6 to 8 feet.

24 G.? panicula'ta (Bartl. in herb. Hænke, ex D. C. l. c.) leaves ovate, acuminated, glabrous above, clothed with silky tomentum on the nerve and veins beneath, as well as on the brauchlets; cymes dichotomous, many-flowered, on long peduncles, axillary, but the ultimate ones are disposed in a panicle; corolla clothed with silky tomentum outside, with ovate-oblong lobes. h.S. Native of Peru, on the mountains. Corolla 6 lines long. Teeth of calyx acute, smoothish. Fruit unknown.

Panicled-flowered Guettarla. Shrub 6 to 8 feet.

SEct. 11I. ULO'LOBUS (from ov $\lambda o s, o u l o s$, curled, and $\lambda o-$ fos, lobos, a lobe ; in reference to the curled lobes of corolla). D. C. prod. 4. p. 457.-Laugèria, Ruiz et Pav. f. per. 2. p. 22. but not of Jacq. Limb of calyx short, 5-parted almost to the base, permanent. Corolla silky on the outside, with 5 lobes, which are curled on the margins.

25 G. crispirlòra (Vahl, cclog. 1. p. 36. t. 6.) leaves broad- ovate, acuminated, obtuse at the base, laving the lower lateral nerves approximate. h. S. Native of the Island of Montserrat, towards the tops of the mountains, ex $\mathrm{Vah}$; and of St. Vincent, on the edges of mountains, in inundated places, ex Forsyth; and about Santa Fe de Bogota, ex Mutis, in H. B. et Kunth, nov. gen. amer. 3. p. 420. G. crispiftòra var. $a$, Pers. Ricm. et Schultes. Stipulas large, undulated, foliaceous, ovate, acuminated. Guettárda membranàcea, Sieb. pl. exsic. mart. no. 57. from Martinico, is the same, or a very nearly allied species.

Curled-flowcred Guettarda. Tree or shrub.

26 G. Hursu'ta (Pers. ench. 1. p. 200.) leaves ovate-oblong, acuminated, acute at the base; stipulas longer than the petioles; drupes ovate. b. S. Native of Peru, and in the hot parts of New Granada. Langèria hirsùta, Ruiz et Pav. fl. per. 2. p. 22. t. 145. f. a. Guettárda hirsùta, H. B. et Kuntl, nov. gen. amer. 3. p. 420. Peduncles equal to the petioles, even to the bifurcation, having the branches subrevolute and many flowered.

Hairy Guettarda. Clt. 1820. Tree 20 feet.

27 G. DEPE'NDENS (D. C. prod. 4. p. 458.) laves oval-oblong, acuminated, acute at the base; stipulas shorter than the petioles; drupes oblong, 3-4-celled. $\zeta$. S. Native of Peru, ii) groves about Muna. Laugèria depéndens, Ruiz et $\mathbf{P a v}$. ff. per.2. p. 23. t. 145. f. b. Branches of cyme spreading, usually dependent. G. crispifiòra var. $\beta$, Pers. and $\mathrm{R}$ œem. et Schultes, but is more nearly allied to hirsùta than to $G$. erispiflòra.

Dependent-cymed Guettarda. Tree 20 feet.

Sect. IV. LaUge'ria (named after Albert Laugier, professor of botany and chemistry at Vienna). D. C. prod. 4. p. 458.Laugèria, Jacq. Juss. but not of Ruiz et Pav. Limb of calyx truncate or toothed. Corolla glabrous, 4-5-lobed. Stamens 4-5.

28 G. Coria'cea (Pers. ench. 1. p. 200.) quite glabrous ; leaves elliptic-ovate, rather coriaceous, bluntish, almost nerveless, rather paler beneath ; stipulas acuminated, decidusous ; peduncles about equal in length to the leaves, compressed, bifid or twice bifid; flowers tetramerous, glabrous, unilateral, and distant along the branches of the peduncle; tube of calyx bluntly 4-toothed. h.S. Native of the Island of Montserrat, ex Vahl; and Guadaloupe, at Pointe-a-Pitre. Laugèria coriàcea, Vahl, eclog. 1. p. 26. Laugèria tubulòsa, Fors. in herb. L'Her. Drupe oblong, ex $\mathrm{Vahl}$, containing a 4-celled putamen. Corolla 6-7 lines long. Perhaps Viviània Domingénsis, Rafin. specch. 1. p. 117.

Coriaceous-leaved Guettarda. Tree or shrub.

29 G. REsinòsa (Pers, ench, 2. p. 200.) leaves lanceolate, attenuated at both ends, glabrous, glaucous beneath; stipulas combined into a somewhat truncate ciliated sheath; branchlets and cymes clothed with clammy resin; peduncles a little shorter than the leaves; cymes bifid, crowded with flowers; flowers pentamerous, glabrous; limb of calyx short, truncate, or hardly 5-toothed. $\quad$ 2. S. Native of Montserrat, on the mountains, ex Vahl ; of Guadaloupe, where it was collected by Perrottet; of Porto Rico, Riedley; of 'Trinidad, ex Sieber, fl. trin. no. 112 ; and of Mexico, ex herb. Puerari. Laugèria resinòsa, Vahl, ec]. 1. p. 27. t. 10. f. 6, with a figure. Terebrària, Sesse, fl. mex. icon. ined. Drupe oblong, containing a 4-celled, 4seeded putamen, ex Vahl, but in the specimen examined the drupe contains a 4-5-celled 4-5-seeded putamen; there are therefore 2 species confused under this name.

Resinous Guettarda. Shrub 8 to 10 feet.

30 G. ? Brunònis (Wall, cat. no. 6220.) leaves elliptic, acuminated, coriaceous, quite glabrous; peduncles axillary, solitary, or twin; cymes dichotomous; stipulas ovate, acuminated. h.S. Native of the East Indies, in Sirinagur. Flowers small. Calyx a little twisted.

Brown's Guettarda. Shrub. 


\section{+ Species not sufficiently linonn.}

31 G. Fontane'sir (D. C. prod. 4. p. 458.) stem arboreseent; leaves broad-ovate, acuminated, and are, as well as the divaricate branches, villous; stipulas ovate, acute, deciduous. †. S. Native country unknown. G, hirsùta, Desf, cat. hort. par. ed. 3. p. 404. but not of Pers. Habit of $G$. argéntea.

Desfontaincs's Guettarda. Slirub.

32 G. ? umbelia'ta (Spreng. neu entd. 3. p. 48.) leaves oblong, quite glabrous on both surfaces; branches tubercular, compressed, dilated at the top; peduncles axillary, aggregate; flowers pentamerous, glabrous. $r_{\text {. }}$. S. Native of Brazil. The calyx is said to be 5 -toothed, and the drupe 6 -celled. This plant ought probably to be excluded from the order.

L'mbcllate-flowered Guettarda. Shrub or tree.

Cult. For culture and propagation see IIamiltonia, p. 555 . The species bear very fine leaves and flowers, and are therefore worth cultivating.

CXII. MALA'NEA (Aublet does not mention the meaning of this word). Aubl. guian. 1. p. 106.t. 41. Juss. mem. mus. 6 , p. 376 . D. C. prod. 4. p. 459.-Malànea species, Lam. A. Rich. -Cunningbàmia species, Schreb. Willd.-Chomèlia species, Spreng. Scop.

Lin. syst. Tetrándria, Monogýnia. Calyx with a very short tube, and a 4-toothed limb. Corolla small, almost rotate, with a very short tube, and a 4 -lobed spreading limb. Stamens 4 , with exserted filaments, which are about equal in length to the limb of the corolla, and roundish anthers. Drupe dry, thin, ovate, crowned by the calyx, containing a 2 -celled nut; cells 1-seeded.-A sarmentose slirub, native of Guiana, climbing among bushes. Leaves opposite, petiolate, ovate, acute, Stipulas oval, obtuse, deciduous, interpetiolar. Peduncles axillary, 3 times shorter than the leaves, racemosely panicled : having the branches opposite, the lower ones the longest. Flowers small, sessile along the branches, bluish.

1 M. Saraientòsa (Aubl. guian. 1. p. 106. t. 41.?) ケ. S. Native of French Guiana, upon trees on the banks of rivers. Lam. ill. t. 66. f. 2. Cunninghàmia sarmentòsa, Willd. spec. 1 . p. 615 . Stipulas acute, ex Aubl., and the leaves tomentose beneath; but in the specimens examined the stipulas are obtuse, and the leaves are rather villous boneath, and at length glabrous. Perhaps there are two distinct species, Aublet's and Patris's.

Sarmcntose Mlanea. Shrub el.

Cult. See Pcedèria, p. 561. for culture and propagation.

CXIII. ANTIRHE'A (from $a v \tau \iota$, anti, against, and $\dot{\rho} \varepsilon \omega$, rco, to flow; the plant is used to stop bæmorrhage in Bourbon). Comın. mss. Juss. gen. p. 204. mem. mus. 6. p. 377. D. C. prod. 4. p. 459.-Malànea species, Lam. A. Rich.-Cunninghàmia species, Schreb.-Guettárda species, Sieb.

Lin. syst, Tetrándria, Monogýnia.. Calyx with an ovate or oblong tube, and a short campanulate 4-toothed limb. Corolla tubular, 4-cleft, with acutish lobes, which are shorter than the tube. Anthers oblong, almnst sessile in the throat, not exserted. Stigma bifid. Drupe somewhat baccate, ovate or oblong, crowned, containing a 2-celled putamen: cells 1 -seeded. Seeds terete.-Small trees, natives of the Mauritius. Leaves petiolate, opposite, or 3 in a whorl, oblong or obovate, glabrous, usually beset with glandular hairs in the axils of the veins. Stipulas interpetiolar, acute, deciduous. Peduncles axillary, shorter than the leaves, bifid. Flowers small, whitish, sometimes dioecious from abortion, unilateral, and sessile along the branches of the peduncles. This genus bas the inflorescence of Stenóstomum, but differs in the parts of the flowers being quaternary, not quinary. The flowers are nearly like those of Malà voL. III. nca, but the inflorescence is different; the tube of the corolla is longer, and the anthers almost sessile.

1 A. verticilla'ta (D. C. prod. 4. p. 459.) leaves 3 in a whorl, obovate-oblong, cuneated at the base, acuminated at the apex, glabrous on both surfaces; flowers hermaplurodite; drupes oblong. h.S. Native of the island of Bourbon, and probably of the Mauritius, where it is called bois de Losteau. A. Lostæàna, Comm. in herb. Juss. Malànea verticillàta, Lam, ill. t. 66. f. 1. Desr. in Lam. diet. 3. p. 688. Antirhoc'a Borbónica, Gmel. syst. 1. p. 24\%. Cunninghàmia verticillàta, Willd. spec. 1. p. 615 . Drupe the size of a grain of wheat. Flowers small, white.

Whorled-leaved Antirhoea. Tree 20 feet?

2 A. Diol'c. (Bory, in litt. ex D. C. prod. 4. p. 459.) leaves opposite, and 3 in a whorl, obovate, cuneated at the base, shortacuminated, smoothish, beset with glandular pili in the axils of the veins; flowers dioecious from abortion; drupes oblong. $h$. S. Native of the Mauritius. Pet. Th. mel. obs. p. 56 . Malànca neurópora, Comm. in herb. Thouin. Flowers small, whitisl.

I $a r . \beta$, barbinérvis (D. C. prod. 4. p. 466.) nerves of young leaves bearded, and very hairy in the axils. $々$. S. Native of the Mauritius. Guettárda barbinérvis, Sieb. fl. maur, 1. no. 61. Cham. et Schleclut. in Linnea. 4. p. 190.

Var. $\gamma$, acuninaita (D. C. I. c.) leaves almost smootl, longacuminated. 々.S. Native of the Mauritius. Guettárda acuminàta. Sieb. fl. maur. 1. no. 60 .

Dioecious Antirlicea. Tree 20 feet?

3 A. Frangula'cea (D. C. prod. 4. p. 460.) leaves opposite, ovate, acutish at the base, and rather acuminated at the apex, smoothish, with the axils of the veins glandless; flowers hermaphrodite; drupes ovate. h. S. Native of the Mauritius. Guettárda frangulàcea, Sieb. fl. maur. exsic. 2. no. 59. Drupe onchalf shorter than in the first species, sometimes 3-celled and 3seeded, which shows its affinity with Guettárda. Flowers small, whitish.

Frangula-like Antirhoea. Tree.

Cult. For culture and propagation see IIamiltonia, p. 555 .

CXIV. STENO'STOMUM (from $\sigma \tau \varepsilon y^{\circ}$, slenos, narrow, and

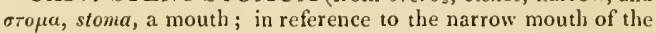
corolla). Gærtn. fil. carp. 3. p. 69. t. 192. under Stúrmia. D. C. prod. 4. p. 460.-Stenostènum, Juss. mem. mus. 6. p. $37 \%$. Malànca species, A. Rich. mem. soc. hist. nat. par. 5. p. 202.Laugèria species, Swartz.

Lix. syst. Pentíndria, Monogínia. Calyx with an ovate tube, and a small 5-toothed limb; teeth permanent, connivent, rather unequal. Corolla fummel-shaped, having the tube a little wider at the throat, and a 5 -lobed limb: lobes lanceolate, bluntish. Anthers 5, oblong, hardly exserted. Stigma 2-lobed. Drupe ovate-oblong, crowned, containing a 2-celled putamen. Seeds terete, solitary in the cells, inverted. Embryo central, in the fleshy albumen.-West Indian trees. Leaves opposite, oval or oblong, on short petioles. Stipulas at length deciduous. Peduncles axillary, divided into a bifid cyme. Flowers small, white, sessile and unilateral along the branches of the cyme, and one in each fork.-Inflorescence of Antirhce $\alpha$, but difters fron that genus in the parts of the flowers being quinary; and from Guetiarda in the putamen of the fruit being 2 -celled, not many celled.

\section{\$1. Corollas glabrous.}

1 S. Lu'cidum (Gærtn. fil. carp. 3. p. 69.) leaves oblong, obtuse, shining above, glabrous on both surfaces; teeth of ca!y. short, obtuse. h.S. Native of the West lndies, as in Jamaica, Santa Cruz, St. Lucia, Porto-Rico, Trinidad, Sc. Stúrmia lù4. B 
cida, Gærtn. fil. carp. 3. p. 199. Guettárda lùcida, Pers. ench. 1. p. 201. Laugèria lùcida, Swartz. fl. ind. 1. p. 475. Vahl, symb. 3. p. 40. t. 57. Flowers small, white.

Lucid-leaved Stenostomum. Clt. 1818. Tree 20 feet.

2 S.? AситA'тum (D. C. prod. 4. p. 460.) leaves oblong, acute at the base, and acuminated at the apex, glabrous on both surfaces, reticulately veined above; lobes of calyx linear-subulate, very acute, almost equal in length to the tube. $h$. S. Native of Guadaloupe. Stipulas triangular, acuminated, deciduous. Peduncles bifid, each of the branches bearing 4-5 flowers. Perhaps this species is nearly allied to Guettârda resinosa, but the number of the cells of the ovarium is not riglitly known. Flowers small, white.

Acute-calyxed Stenostomum. Shrub.

$$
\text { §2. Corollas clothed with silky tomentum. }
$$

3 S. тomen tósum (D. C. prod. 4. p. 460.) leaves ovate, acute, tomentose beneatb; drupes oblong, acuminated, glabrous. $\zeta$. S. Native of Jamaica, on the west side amons bushes. Laugèria tomentòsa, Swartz, fl. ind. 1. p. 477. Guettárda tomentosa, Pers. ench. 1. p. 20I. Flowers small, white. The specimens collected by Bertero in Jamaica differ from the description of Swartz, in the limb of the calyx being truncate and entire, not 5 -toothed, and therefore there are probably two nearly allied species, natives of Jamaica.

Tomentose Stcnostomun. Clt. 1820. Tree 20 feet.

\section{+ Species not sufficiently knonn.}

4. S. ? вifurca'tum (D. C. prod. 4. p. 460.) leaves ovate, acute at hoth ends, glabrous, beset with glandular pili in the axils of the veins beneath; peduncles bifurcate. $h$.S. Native of the West India islands. Malànea bifurcàta, Desr. in Lam. dict. 3. p. 688. The inflorescence is the same as that of the other species, but the number of the parts of the flower is not de. scribed.

Bifurcate-peduncled Stenostomum. T'ree.

5 S. ? N'TIDUm (D. C. prod. 4. p. 461.) leaves ovate, shining, quite glabrous, except in the axils of the veins beneath, which are beset with glandular hairs; peduncles dichotomous. $\zeta . \mathrm{S}$. Native of the West India islands. Malànea nitida, Desr. in Lam. dict. 3. p. 685. The number of the parts of the flowers being undescribed, the genus to which it belongs is rather doubtful.

Shining Stenostomum. Tree.

6 S.? рiсно'томим (D. C. prod. 4. p. 461.) leaves ellipticoblong, obtuse, rather coriaceous, glabrous on both surfaces ; peduncles dichotomous: flowers tetrandrous. $々 . S$. Native of Mexico. Laugèria dichótoma, Moc. et Sesse, icon. ined. Corolla of a dirty cream colour, with blunt lobes. Perlaps a genuine species of Stenóstomum, or a species of Antirhce'a.

Dichotomous-peduncled Stenostomum. Tree.

Cult. For culture and propagation see Hamiltònia, p. 555 .

CXY. CHIO'NE (a mythological name, the danghter of Deucalion, or from $\chi^{t o v \varepsilon o s, ~ c h i o n e o s, ~ s n o w y, ~ w h i t e ~ a s ~ s n o w ~ ; ~ i n ~ r e f e r-~}$ ence to the cymes of white flowers). D. C. prod. 4. p. 461.Crùsea, A. Rich. mem. soc. hist. nat. Par. 5. p. 204. t. 19. f. 1. but not of Schiede and Deppe, nor Bartl. nor D. C.

Lis. syst. P'entlindria, Monogynia. Calyx with an obovate tube, and a marginal repandly 5 -toothed limb. Corolla tubular, short, with a 5 -lobed limb; lobes flattish, obtuse. Stamens inserted above the tube. Style simple; stigma 2-lobed: lobes short, obtuse. Fruit olive-formed, rather fleshy, much furrowed when dried, crowned by the limb of the calyx, containing a 2 -celled putamen. Seeds solitary, almost terete-A glabrous tree. Lcaves opposite, coriaceous, joined together by an entire stipular sheath. Flowers white, cymose; cymes terminal, pedunculate. Allied to Malìnca.
I C. GLA'bra (Rich. 1. c. under Crùsea, ) h. S. Native of Tortoise island. Psychótria megalospérma, Vahl, eclog. amer. 3. p. 3. t. 21. ex lierb. Juss. but neither the description nor the figure agree well with it, and it is therefore Jacquínia venòsa, Swartz, prod. p. 47. Rom. et Schultes, syst. 4. p. 491.

Glabrous Chione. Clt. 1824. Tree 40 feet?

Cult. For culture and propagation see Hamiltònia, p. 555 .

CXVI. TIMO'NIUS (Timon or Aytimon is the name of the first species in Amboyna). Rumph. amb. 3. p. 216. t. 140. D. C. prod. 4. p. 461.--Bòbea, Gand. voy. uran. t. 93.Bobæa, A. Rich. mem. soc. hist. nat. Par. 5. p. 215.-Burnèya, Clıam. et Schlecht. in Linnæa. 4. p. 188.-Eríthalis, Forst. but not of Lin.

Lis. sysr. Tetrándria, Monogýnia. Calyx with an ovate tube, and a tubular truncate 2-6-toothed limb. Corolla tubular, salver-shaped, with a 4-6-parted spreading limb, a naked throat, and oval obtuse lobes. Stamens 4, almost sessile, inserted in the upper part of the tube of the corolla. Anthers oblong-heart-shaped, sessile in the throat. Stigmas 2, exserted, digitately 5 -cleft, with the lobes linear. Drupe globose, smooth, crowned by the limb of the calyx, containing from 7-25 bony distinct 1 -seeded indehiscent pyrenæ. Seeds inverted, linear. Albumen fleshy. Embryo terete.-Glabrous trees. Leaves opposite. Stipulas interpetiolar, acute, entire. Peduncles axillary, shorter than the leaves, bearing each 3 flowers at the apex, the middle flower sessile, and the lateral ones pedicellate, each girded by a cup-shaped 2 -lobed permanent bractea at the base.Allied to Guettarda, but differs in the pyrenæ being distinct, not combined.

1 T. Ru'mpнn (D. C. prod. 4. p. 461.) leaves lanceolate ; peduncles bearing 3 flowers, but only 1 fruit; fruit smooth, ovate-globose. h. S. Native of the Island of A mboyna, in open places and on hills. T'imònius, Rumph. amb. 3. p. 216. t.14.0. Eríthalis Tìmon, Spreng. pug. 1. p. 18. Pyróstria hexaspérma, Roxb. E. polýgama (j̉, Willd. spec. 1. p. 997.

Rumplius's Timonius. Tree.

2 T. Forste'ri (Cliam. et Schlecht. in Linnæa. 4. p. 189. under Burnèya) leaves opposite; flowers axillary: male ones disposed in cynes: hermaphrodite ones solitary; berries roundish. $\quad$. S. Native of the Society Islands ; and in Romanzofl's Island. Erithalis polýurama, var. $a$. Forst. prod. 1. p. 101. Eritl. cymòsa, Spreng. pug. 1. p. 17. Erith. polýgama a. Willd. spec. 1. p. 997. Fruit containing usually 25 pyrenæ. The flowers are described by Chamisso and Schlecht. as quaternary and quinary, but they are also sometimes senary.

Forster's T'imonius. 'Tree.

3 T. Gaudena'udu (Cham. et Schlecht. in Linnæa. 4. p. 190. under Burnèya) leaves elliptic, bluntish, acute at the base; cymes on long peduncles: fertile ones 3-flowered: but the sterile ones are twice bifid and 7 -flowered. $\zeta$.S. Native of the lsland of O-Wahu, and of a number of the Sandwich Islands. Bòbea elàtior, Gaud. in Freyc. voy. p. 473. t. 93 . Fruit containing usually 1 ? bony pyrene.

Gaudichaud's Timonius. Tree.

Cult. For culture and propagation see Hamiltònia, p. 555.

CXVII. HAMILTO'NIA (so named after William Hamilton of Woodlands, near Philadelpluia, in Nortl America, an eminent botanist, and the first who was at the expence of erecting a conservatory in that country for the preservation of plants of hot climates). Roxb. bort. beng. (1814.) p. 15. fl. ind. 2. p. 228. but not of Muhl. nor Willd.-Spermadictyon, Roxb. cor. 3. (1S I\%.) p. 92.

Lin. syst. Pentándria, Monogýnia. Calyx with an ovate tube, a 5-parted limb, and subulate permanent segments. 
Corolla funnel-shaped, with a long straight tube (f. 102. b.), and 5 oblong lobes (f. 102. c.). Stamens 5 , inserted in the throat of the corolla, inclosed. Stigma 5-cleft. Capsule crowned by the calyx, dehiscing at the apex, 1-celled, containing 5 triquetrous 1 -seeded pyrena. Seeds inserted by the base, erect, covered by a dry reticulated membrane or epidermis. Albumen very sparing. Embryo erect, with an oblong radicle, and cordate foliaceous cotyledons.-East Indian shrubs. Leaves lanceolate, on short petioles. Stipulas short, acute, broad and adpressed at the base. Flowers disposed in fascicles or umbels, sweet-scented.-This genus has been joined with Ancylanthus by Jussieu, but is sufficiently distinct from that genus.

1 H. Suave'olexs (Rosb. liort. beng. p. 15. Al. ind. 2. p. 223.) glabrous; leaves broadlanceolate; heads of flowers densely umbellate, pedunculate, terminal ; calyx beset with glandular hairs. $々$. S. Native of the East Indies, on the Rajmuhal hills. Spermadictyon suavèolens, Roxb. cor. 3. p. 32. t. 236. R. Br. in bot. reg. $t$. 348 . Lasiánthus tubiflòrus, Blum. bijdr. p. 990 . Leaves $3-6$ inches long. Stipulas broad, ensiform. Flowers sessile, in terminal corymb-formed heads, on short trichotomous branclılets, numerous, pure white, delightfully fragrant.

Sweet-scented Hamiltonia. Fl. Oct. Clt. 1818 . Sh. 4 to $6 \mathrm{ft}$.

2 H. sca'bra (D. Don, prod. fl. nep. p. 197.) leaves ovatelanceolate, short-acuminated, scabrous on both surfaces, rounded at the base; calycine segments linear, villous. h. S. Native of Nipaul, at Narainhetty, and between Hetounra and Bhempedi, chiefly between Bhinsadoban, and the last-mentioned village, forming the most extensive thickets. Dr. Wallich has also met with it about the village near Cheesnagurree, and on several mountains in the valley. Hamiltonia Dulìna and Nonatèlia filamentòsa, Hamilt. mss. Hamilt, azùreum, Wall. in Roxb. fl. ind. 2. p. 225. Spermadictyon azùreum, Lindl. bot. reg. 1235. Flowers azure blue, perfuming the air by their delicious fragrance from November until March, during which time they are very beantiful. Infiorescence ample, densely villous, especially the corollas. The tender parts of the plant emit a fetid smell, like those of Padèria and Serissa.

Scabrous Hamiltonia. Fl. Jan. Clt. 1828.? Sh. 4 to $6 \mathrm{ft}$.

3 H. pulosa (Roxb. fl. ind. 2. p. 226.) shrub stiff, very pilose : leaves lanceolate; fascicles of flowers axillary, intermixed with hairy bracteas. $h$. S. Native of the Moluccas.

Pilose Hamiltonia. Slirub 4 to 6 feet.

Cult. The species are desirable for every collection of stove plants, being free flowerers, very fragrant, and of easy culture. They succeed best in a mixture of loam and peat; and cuttings strike root readily in sand, with a hand-glass over them, in a moist heat.

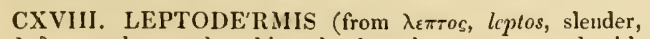
and $\delta \varepsilon \rho \mu a$, derma, the skin; the branches are covered with separating fibrous bark). Wall. in Roxb. fl. ind. 2. p. 191. A. Rich, mem. soc. hist. nat. par. 5. p. 221. D. C. prod. 4. p. 462.-Hamiltònia species, D. Don, prod. fl. nep. p. 137.

Lin. syst. Pentándria, Monogýnia. Involncrum calyciform, of 2 leaves, closely girding the ovarium. Tube of calyx inclosed within the involucrum; limb of calyx short, permanent, 5-lobed; lobes roundish, adpressed. Corolla funnel-shaped, scabrous from minute pap. Ilae, with a terete tude, which is hairy inside, and 5 ovate cuspidate lobes which are involutely valvate in astivation. Stamens 5, with very short filaments aud inclosed anthers. Ovarium 5-celled; cells 1-sceded. Style filiform; stigma quadrifid. Fruit oblong, 5-celled? 5-valved? 5-seeded.-Shrubs, with decussate, tetragonal branches. Leaves lanceolate or oblong, on short petioles, membranous. Stipulas length of petioles, adpressed, permanent, acute. Flowers sessile, scentless, white--Perhaps sufticiently distinct from $I l a-$ miltònia.

1 L. Laxceora'ta (Wall. in Roxb. A. ind. 2. p. 191.) leaves lanceolate, attenuated, acute, membranous, villous; flowers ses. sile by threes at the ends of the branches; stipulas triangular, villous; branches quadrangular, downy while young. $々 . G$. Native of Nipaul, on the mountains, though it is among the less common plants. Hamiltònia fruticòsa, D. Dou, prod. fl. nep. p. 137. Flowers white, scentless. According to the description in fl. nep. the flowers are said to be hexamerous and hesandrous.

Lanceolatc-leaved Leptodermis. Shrub 3 to 4 feet.

2 L. овLónga (Bunge, in mem. acad. sc. Petersb. 2. p. 108.) leaves oblong, glabrous; flowers terminal, aggregate. $h_{\text {. }} \mathrm{G}$. Native of China, on the mountains.

Oblong-leaved Leptodermis. Shrul).

Cult. See Hamiltònia above for culture and propagation.

CXIX. PSATHU'RA (from $\psi a \theta v o o s, p s a t h u r o s$, fragile or brittle; the branches are brittle). Comm. in Juss. gen. p. 206. mem. mus. 6. p. 396. Lam. ill. t. 260. Gærtn. fil. carp. 3. p. 82. t. 194. f. 4. A. Rich, mem. soc. hist. nat. par. 5. p. 214. D. C. prod. 4. p. 462.-Chicoinæ'a, Comm.-Psatùra, Poir. dict. 6. p. 587.--Psatliỳra, Spreng. syst. 2. p. 127. but not of Fries.

Lin. sist. Penta-Hexándria, Monogýnia. Calyx with an ovate tube, and a campanulate 5-6-toothed permanent limb. Corolla bearded inside, with a short tube, and a 5-6-lobed spreading limb; lobes acute, rather longer than the tube, valvate in restivation. Anthers 5-6, almost sessile at the throat. Stigmas 5-6-lamellate. Berry globose, furrowed, crowned by the limb of the calyx, containing 4-6 1-seeded pyrenæ. Seeds erect. Albumen fleshy. Embryo erect.-Small glabrous trees, witl knotted fragile branches. Leaves lanceolate, acute at both ends, petiolate, smooth. Stipulas ovate, caducous, with an elevated zone, which is joined to the petioles. Peluncles rising from the axils of the upper leaves, loosely panicled, shorter than the leaves.

1 P. Borbónıca (Gmel. syst. 1. p. 577.) leaves oblong-lanceolate; peduncles $7-8$-flowered. $h$.S. Native of the Island of Bourbon, on the mountains, where it is called Bois cassant. P. corymbòsa, Gærtn. fil. carp. 3. p. 8\%. P. Borbónica, Roxb. f1. ind. 2. p. 158 . Flowers minute, pentandrous, disposed in axillary and terminal trichotomous corymbs. Stigma 2-lobed. Drupe containing 5 pyrenæ.

Bourbon Psathura. Tree small.

2 P. Mrrtiròlia (A. Rich, diss. l. c.) leaves oblong. bluntish; peduncle. usually 3-flowered, lateral flowers sterile and deciluous; limb of calyx 5 -parted; Johes lanceolate. $h . S$. Native of the Mauritius. Perliaps sufficiently distinct from the preceding.

Myrtle-lcaved Psathura. Tree small.

3 P. terniflòra (A. Rich, diss. 1. c.) leaves elliptic-lanceolate, acute; peduncles at the tops of the branchlets, usually by threes, 1-flowered; limb of calyx wide, obsoletely 5-7-toothed. h.S. Native of the Mauritius.

I'hree-flonered Psathura. Tree small.

Cult. For culture and propagation see Hamilionia above. $4 \mathrm{~B} 2$ 
CXX. MYONIMA ( $\mu v s \mu v o s, m y s m y o s$, a rat, and $o v \eta \mu$, onemi, to succonr; rats are very fond of the fruit, and eat it with great avidity). Comm, in Juss. gen. p. 206. mem. mus. 6. p. 997. Lam. ill. t. 68. Gartn. fil. carp. 3. p. 86. t. 195 . A. Rich, mem.osoc. hist. nat. par. 5. p. 211. D.C. prod. 4. p. 463 .

Lın. syst. Telrándria, Manogýnia. Calyx with a globose tube, and a small bluntly 8-toothed limb. Corolla with a short tube, and a bluntly 5 -parted limb. Stamens 4 ; filaments very short; anthers oblong, exserted. Stigmas 4, linear, short, thickish, approximate, almost concrete. Berry globose, not crowned, containing 4 l-seeded pyrena, which adliere to the flesh of the fruit. Seeds umbilicate, fixed by the middle. Albumen flesliy. Embryo dorsal, erect, with an inferior, nearly terete radicle, and cordate blunt cotyledons. - Small glabrous trees or shrubs, natives of the Mauritius. Leaves coriaceous. Stipulas small, very acute, deciduons. Pedicels axillary and terminal, shorter than the leaves. Perhaps not distinct from Polyòzus.

\section{\$1. Fruit containing 4 pyrena. Myonime vìra.}

1 M. obova'ta (Lam. ill. no. 1482. t. 68. f. 1. dict. 4. p. 397.) leaves obovate, obtuse, on short petioles; peduncles 1-3flowered; berries bluntly tetragonal. $\eta_{2}$. S. Native of the Island of Bourbon, where it is called Bois de rat, from the fruit being grateful to mice and rats. M. Borbónica, Ræuch, nom. Berries red, size of grapes.

Obovate-leaved Myonima. Shrub 4 to 6 feet.

2 M. MYrtifòlia (Lam. ill. no. 1483, t. 58. f. 2. dict. 4. p. 398.) leaves ovate-lanceolate, acute, on short petioles; peduncles 1-3-florered; berries spherical. $\zeta . S$. Native of the Island of Bourbon. M. lanceolàta, Willd. spec. 1. p. 614. Rubiàcea, no. 103. Sieb. fl. maur. fasc. 2.

Myrlle-leaved Myonima. Shrub 4 to 5 feet.

3 M. multiflòra (A. Rich, diss. p. 132.) leaves nearly sessile, rather cordate at the base, ovate-oblong, acute, shining above, reticulately nerved, veiny beneath; corymbs terminal. 々. S. Native of the Mauritius. Ixòra parviflòra, Lam. ill. no. 1473. t. 66. f. 2. exclusive of the syn. of Rheed. lxòra micrántlıa, Roem. et Schultes, syst. 3. p. 179. Faràmea corymbòsa, Sieb. f. manr. 2, no. 62. but not of Aubl.

I ar. $\beta$, oblongifòlia (D. C. prod. 4. p. 463.) leaves oblong, obtuse ; corymbs more crowded.

Tar. $\gamma$, ovìta (D. C. l. e.) leaves ovate. $h . S$. Ixòra parviflòra, Poir. suppl. 3. p. 207. Engènia vinlàcea, Lam. dict. 3. p. 200. Mýrtus androsæmoides, Poir. dict. 4. p. 409. Faràmea, Sieb. fl. maur. 2. no. 63. Perbaps a proper species.

Many-flowered Myonima. Shrub 4 to 5 feet.

§2. Fruit containing 2 pyrena. Nyanima dùbia. Perhaps a proper genus.

4 M.? umbelatita (Bartl. in herb. Hanke, ex D. C. prod. 4. p. 468.) leaves obovate or obovate-oblong, coriaceous; peduncles axillary, many-flowered at the apex; pedicels $7-8,11 \mathrm{~m}-$ bellate; berries roundish; calycine teeth very sl.ort, acutish. h.S. Native of the Island of Luzon, one of the Philippines. Segments of corolla valvate in restivation. Genitals rot exserted. Seeds narrow, cylindrical, as in Guettárda, ex Bartl. Perhaps a section of Myonima, as Laugèria is of Guctlárda.

Umbellate-flowered Myonima. Tree small or shrub.

Cult. For culture and propagation see IIamiltonia, p. 555.

CXXI. PYRO'STRIA (from pyrus and striatus; in allusion to the fruit being shaped like a pear, and striated). Comm. in Juss. gen. 206. mem. mus, 6. p. 397. Lam, ill. t. 65. A.
Rich, in mem. soc. hist. nat. par. 5. p. 216. D. C. prod. 4. p. 4.64 .

Lis. syst. Tetra-Pentándria, Monogýnia. Calyx with an obovate tube, and a small 4-5-toothed limb. Corolla subcampanulate, spreading, 4-5-cleft, with lanceolate acute lobes, and a tomentose throat. Stamens 4-5, hardly exserted. Stigma capitate, bifid: having the lohes approximate (ex Rich.). Fruit pear-shaped, 6-8-striped, but not crowned, containing 4-5 1seeded, bony, combined pyrena. Embryo inverted. Albumen fleshy. - Small glabrous trees, natives of the Mauritius. Leaves on short petioles. Stipulas lanceolate, acuminated, rather longer than the petioles. Peduncles axillary, 1-3-fiowered. The number of the cells of the fruit is variable.

1 P. oleoides (Lam. ill. no. 1484, t. 65. f. 3.) leaves oblong, obtuse; stipulas glabrous; peduneles 1-3-flowered; drupes 8seeded. 5 . S. Native of the Island of Bourbon, where it is called Bois Mussard. P. Commersòni, Gmel. syst. 1. p. 247. P. salicifòlia, Willd. spec. 1. p. 614 .

Otive-like Pyrostria. Tree 20 feet.

2 P. Hexaspérixa (Roxb. fl. ind. 1. p. 403.) leaves oblong, acute; stipulas pilose; corymbs axillary, dichotomons, with recurved branches; drupes 6 -seeded. $h$. S. Native of the East Indies in the Island of Hominoa.

Six-seeded Pyrostria. Tree.

3 P. orbicula'ris (A. Rich, 1. c.) leaves oval-orbicular, sessile at the base and rather cordate, obtuse at the apex; stipulas glabrous : peduncles 1 -flowered, furnished each with an involucel composed of 2 keeled leaves, which girds the flower. $\boldsymbol{h}$. S. Native of the Island of Bourbon.

Orbicular-leaved Pyrostria. Shrub.

4 P. cordifo'la (A. Rich, l. c.) leaves oval, acute, rather cordate at the base, on very short petioles; stipulas combined, sheath-formed, obtuse, and permanent; flowers pedicellate, solitary, girded by scales, which are combined into the form of an involucel; lobes of corolla oval, acute. 々.S. Native of the Nauritius.

Hearl-leaved Pyrostria. Tree small.

5 P. Polynórpila (A. Rich, l. c.) leaves sometimes linearlanceolate, sessile, variegated: sometimes orbicular and obtuse, petiolate: sometimes oblong-cordate, acute: stipulas acute, hardly combined at the base, caducous ; flowers solitary, girded each by a 3-4-toothed tomentose involucel; lobes of corolla lanceolate, $\quad$.S. Native of the Mauritius.

Iariable Pyrostria. Tree small.

6 P. Macrophy'Lla (A. Rich, 1. c.) leaves oval-oblong, somewhat cordate, on short petioles, scrobiculate in the axils of the veins beneath; stipulas glabrons; flowers sessile, solitary, axillary, girded each by a 2-leaved involucel. h. S. Native of the Manritius. Fruit egg-shaped, ribbed, erowned by the calyx.

Long-leaved Pyrostria. Tree small.

Cult. For culture and propagation see Hamiltonia, p. 555 .

CXXII. OCTA'VIA (from Octavus, the eighth; in reference to the drupe containing 8 pyrenæ). D. C. prod. 4. p. 464.

Lin. syst. Pentándria, Monogýnia? Calyx with a globose tube, and a truncate hardly conspicuous limb. Corolla, stamens, and style unknown. Ovarium crowned by a fleshy shining permanent disk, which is perforated in the middle. Drupe fleshy, globose, smooth, not crowned by the calyx, containing 81 -seeded pyrena, which are disposed in a whorl. Albumen Heshy. Embryo unknown.-A glabrous shrub, native of Guiana. Leaves petiolate, oval, long-acuminated, membranous, shining above. Bracteas ovate-oblong, acuminated, erect, much shorter than the petioles, falling off very slowly. Flowers sessile, solitary, bractless, in the axils of the superior leaves, or on the tops of the branchlets. -This gents is not sufficiently known from the want 
of the flowers; but it appears to come nearest to Pyróstria, but differs from that genus in the truncate calyx and inflorescence.

1 O. sessiliflòra (D.C. l. c.) h.S. Native of French Guiana, where it was collected by Patris.

Sessile-flonered Octavia. Shrub.

Cult. See Hamiltòia, p. 555. for culture and propagation.

CXXII. LITOSA'NTHES (from $\lambda \iota \tau o s$, litos, small, and av $\theta 0 s$, anthos, a flower; the flowers are small). Blum. in flora, 1825 , p. 189 . bijdr. p. 991 . D. C. prod. 4. p. 465 .-Litosánthes, A. Rich. mem. soc. hist. nat. par. 5. p. 213.

Lıx. syst. Tetrándriu, Monogýnia. Limb of calyx small, 4-toothed. Corolla globose, with a villous throat, and a short spreading 4-cleft limb. Stamens 4, inclosed; filaments very short, inserted beneath the throat; anthers linear. Style inclosed, perforating the fleshy disk; stigma subclavate, 4 -toothed at the apex. Drupe succulent, obovate, umbonate, inflated, when young 4-celled, but in the adult state usually 1 -celled, containing generally 4 1-seeded pyrenæ, which are furnished with papery aril at the base, and fixed to the central axis, which is incomplete. Embryo incurved. $-\Lambda$ shrub, with the habit of Fernèlia. Leaves small, trapeziform, almost sessile. Peduncles axillary, filiform, usually bearing 2 flowers at the apex.-This genus is nearly allied to Pyróstria.

1 L. Biflo'ra (Blum. l. c.) h. S. Native of the western parts of Java, on the mountains in woods.

Tno-flowered Litosanthes. Shrub 4 to 6 feet.

Cult. For culture and propagation see Hamiltònia, p. 555.

CXXIV. ERI'THALIS (from $\varepsilon \rho$, eri, and $\theta a \lambda \lambda \omega$, thallo, to grow green; in allusion to the leaves being of a deep shining green). P. Browne, jam. p. 165. t. 17. f. 3. Lin. gen. no. 238. Juss. gen. p. 206. mem. mus. 6. p. 396. Lam. ill. t. 159. Gærtn. fruct. 1. t. 26. A. Rich. mem. soc. hist. nat. Par. 5. p. 213. D. C. prod. 4. p. 465.-Herrèra, Adans, fam. 2. p. 158. but not of Ruiz et Pav.

Lin. syst. Peta-Declindria, Monogýnia. Calyx with an ovate tube, a short permanent subtruncate limb, having its borler hardly 5-10-toothed. Corolla rotate, almost without a tube, 5-10-parted; lobes linear-oblong, spreading. Stamens 5-10, scarcely adnate at the bottom of the corolla; filaments subulate; anthers linear. Stigma appearing simple at first sight, but on more close examination it will be found to be bilamellate. Drupe globose, furrowed, crowned by the calyx, containing 5-10 1seeded pyrenæ. Seeds pendulous. Albumen fleshy.-Glabrous shrubs. Leaves petiolate, having the lateral nerves hardly evident. Stipulas broad, short, mucronate, sheathing, permanent. Peduncles axillary, panicled, rather longer than the leaves. Flowers small, white.

1 E. FRuticòsa (Lin. spec. 251.) leaves obovate; panicles pedunculate; berries 8-10-furrowed, crowned by the truncate limb of the calyx. 5 . S. Native of Martinico, Guadaloupe, Jamaica, St. Thomas, Porto-Rico, Cuba, Se. in woods on the mountains. Swartz, obs, p. 80.-Prowne, jam. t. 17. f. 3.Plum. ed. Burm. t. 249. f. 2,-Erithalis odorifera, Jacq. amer. 72. t. 173. f. 23. Flowers white, sweet-scented, usually hexandrous. Berries purple.

Var. $\beta$, inodòra (Jacq amer. p. T2.) shrubby; branclies procumbent; flowers inodorous; herries white. h.S. Native of Curacoa, on rocks by the sea side. E. inodora, Rom. et Schultes, syst. 5. p. 268 . This is a shrub about 2 feet high.

Shrubby Erithalis. Fl. July, Aug. Clt. 1793. Tree 10 to $15 \mathrm{ft}$. 2 E. Angustiròlia (D. C. prod. 4. p. 465.) leaves oblonglanceolate, acuminated at both ends; panicles pedunculate, fewflowered; berry 5-9-furrowed, crowed by the 5 -toothed $\operatorname{limb}$ of the calyx. I. . S. Native of Culia, about the Havannah.
Teeth of calyx 5-6, more conspicuous than those of the first species, and the tube of the corolla is a little longer. Berry nearly dry, containing 5.7 pyrenae.

Narrow-leaved Erithalis. Shrub.

3 E.? pentagovia (D. C. prod. 4. p. 465.) leaves oval-lanceolate, acute; panicles terminal ; fruit deeply 5 -furrowed, not crowned by the calyx; style very short, crowned by 5 reflexed stigmas. h. S. Native of Cuba. Fruit the size of a pea, containing 5 chartaceous compressed narrow pyrena. Style permanent. Corolla and stamens unknown. Ilabit of the other species of Erithalis, hut is probably a distinct genus.

Five-angled-fruited Erithalis. Shrub 4 to 6 feet.

Cult. For culture and propagation sce IIamiltònia, p. 555.

CXXV. RETINIPIIY'LLUM (from $\rho \eta \pi, \eta$, retine, resin, and $\phi v \lambda$ inor, phyllon, a leaf; the leaves are covered with resin). IItumb. et Bonpl. pl. equin. 1. p. 86. t. 25. H. B. et Kunth, nov. gen. amer. 3. p. 4.21. A. Rich. mem. soc. list. nat. Par. 5. p. 20S. D. C. prod. 1. p. 366.-Nonatèlia species, Juss. Spreng.

LiN. syst. Pentándria, Monogýnia. Calyx with a subulobose tube, a 5-cleft limb, and acute lobes. Corolla salver-shaped, with a terete tube, and 5 spreading linear obtuse lobes. Stamens 5 ; filaments exserted from the throat of the corolla; anthers oblong. Stigma thick, undivided. Drupe globose, crowned by the calyx, furrowed, containing 5 bony 1 -seedcd pyrenx. - Small glabrous trees. Leaves obovate, obtuse or emarginate at the apex, cuneated at the base, coriaceous, downy beneath. Stipulas sheathing. Spikes of flowers axillary, at the tops of the branches, pedunculate. Flowers secund, $2-4$ in a cluster, fleshcoloured, propped by $3-5$ coloured bracteas.

1 R. secundiflòrum (Humb. et Bonpl. l. c.) দุ. S. Native of South America, on the shady banks of the Orinoco and Atabapo, near St. Balthazar. Nonatèlia secundiflòra, Spreng. syst. 1. p. 751. The leaves and branches are covered by a kind of yellow resinous matter. Berries size of a pea, brownish.

Secund-flonercl Retiniphyllum. Shrub 10 to 12 feet.

Cult. For culture and propagation sec Hamiliònia, p. 555.

CXXVI. NONATELIA (the Guiana name of one of the species). Aubl. guian. 1. p. 182. Lam. ill. t. 155. Juss. gen. p. 205. H. B. et Kunth, nov, gen. amer. 3. p. 422. A. Rich. mem. scc. hist. nat. Par. 5. p. 206, t. 19. f. 2. D. C. prod. 4. p. 466.-Oribàsia, Schreb. gen. no. 307.-Psychótria species, Willd.-Nonatèlia species, Juss. mem.

Lin. syst. Pentándria, Monogýnia. Calyx with an ovate tube, and a 5 -toothed permanest limb. Corolla tubular, funnel-shaped, having the tube as if it was yibbous, and a 5 -lobed limb. Stamens 5, almost inclosed. Stigmas 2? obtuse. Drupe globose, furrowed, containing 5 coriaceous 1 -seeded pyrenæ. Albumen lorny.-Shrubs or small trees. Leaves glabrous or downy, oval-oblong. Stipulas combined together more or less, or free. Thyrse terminal, panicle-tormed or corymb-formet. Flowers often bracteolate, white.

] N. RACEno'sa (Aubl, guian. 1. p. 187.t. 72.) !eaves elliptic-oblong, acuminated at both ends, petiolate; stipulas twin on both sides, 3 times shorter than the petioles; tlyyrse pranicled, a little longer than the petioles; flowers bracteolate at the base. $\hbar$. S. Native of Guiana, in the woods of Orapu. Psychótria racemòsa, Willd. spec. 1. p. 966 . Oribàsia racemòsa, Gmel. syst. 1. p. 367. Flowers small, white. Bracteas t, deciduons. Fruit globose, 5 -angled, 5 -celled. Perhaps $\mathrm{N}$. racemòsa, A. Rich. act. soc. hist. nat. Par. 1792. p. 107. is the same.

Racemose-flowered Nonatelia. lil. June, July. C'lt. 1 sis. Shrub 2 to 3 feet.

2 N. Paname' xsis (D. C. prod, 4. p. 466.) leaves oblong, acuminated at both ends, petiolate; stipulas twin on both sides, 
connected at the base by a ligula, linear-subulate, longer than the petioles; thyrse terminal, panicled, divaricate, sessile, short. h. S. Native of Panama. N. divaricàta, Bartl. in herb. Hanke, but not of A. Rich. Drupe roundish, depressed, containing 5 pyrenx. Allied to $N$. racemòsa.

Panama Nonatelia. Shrub 3 to 4 feet.

3 N. viola'ceA (Aubl. guian. 1. p. 189. t. 73.) leaves elliptic, acuminated, tapering into the short petioles at the base; stipulas solitary on both sides, ovate, obtuse, deciduous; thyrse manyflowered, about half the length of the leaves; flowers bracteate. h. S. Native of Guiana, in woods. Rœm. et Schultes, syst. 5. p. 221. exclusive of the observations. Psychótria violàcea, Willd. spec. 1. p. 966 . but not of Aubl. Oribàsia violàcea, Gmel. Bracteas permanent. Corollas white. Berries ovate, 5 -celled, of a violaceous colour, about the size of currants.

İolaccous-berried Nonatelia. Fl. June, July. Clt. 1824. Shrub 4 to 5 feet.

4 N. ofricina'zis (Aub]. guian. 1. p. 18\%. t. 73.) leaves ovate, acute, glabrous; stipulas combined into a 4 -toothed sheath; panicles corymbose; involucrum small, 3-leaved under each Hower. h.S. Native of Cayenne, in sterile places. Lam. dict. 1. p. 342. Stems nodose. Flowers white. Berry 5-celled and 5-seeded, according to Aublet. Psychótria involucràta, Swartz, fl. ind. occ. p. 413 . a native of Jamaica, is certainly distinct from the plant of Aubl. in the fruit being 2-celled and ¿-seeded.

Officinal Nonatelia. Fl. June, July. Clt. 1827. Shrub 2 to 3 feet.

5 N. Lv'TEA (Aubl. guian. 1. p. 190. t. 74.) leaves broadovate, acuminated; stipulas bluntly 2-lobed; panicles erect; tube of corolla narrow at the base, long, and with the segments of the Jimb acute. h. S. Native of French Guiana, at the foot of Mount Couron. Psychótria lùtea, Willd. spec. 1. p. 971. but not of Sieb. Flowers yellow. Young fruit 5 -celled, ex Anbl.

Ycllcm-flowered Nonatelia. Fl. June, July. Clt. 1823. Shrub 1 foot.

6 N. longiflo'ra (Aubl. guian. 1. p. 185. t. 71.) leaves lancolate, acuminated, acute at the base, glabrous; stipulas combined into a slieath, furnished with 2 acute lobes on eacl side; thyrse panicled, few-flowered, pedunculate, one-half shorter than the leaves; tube of corolla incurved, and with the segments of the limb bluntish. $h$. S. Native of French Guiana, in woods. Psychótria longiflòra, Willd. spec. 1. P. 971. but not of Poir. Leaves greenish yellow. Berry globose, brownish purple, 10 striped, 5-celled, ex Aubl. Habit of Palicurea Paréttce.

Long-floncred Nonatelia. Shrub 2 to 3 feet.

i N. GRANdiflo'ra (H. B. et Kunth, nov. gen. amer, 3. p. 42..) leaves elliptic-oblong, acuminated, acute at the base, glabrous; stipulas connate, bifid; corymbs pedunculate, terminal. h. S. Native of South America, on the banks of the Orinoco and the Tuamini, near Javita. Flowers rose-coloured. Fruit oval, furrowed, 5-celled, ex Bonpl.

Great-flonered Nonatelia. Shrub.

8 N.? macrophy'Lla (H. B. et Kunth, 1. c. p. 423.) leaves ovate, acuminated, membranous, glabrous above, and clothed with fine down beneath; panicles terninal, pedunculate. $\zeta . S$. Native of South America, in the woods of the Orinoco near Javita. Schwenkféldia macrophýlla, Spreng. syst. 1. p. 765 . Stamens probably 5. Flowers yellow. Drupe globose, 10-furrowed, 4-5-celled, ex Kunth.

Long-leaved Nonatelia. Shrul.

9 N. Formo'sa (A. Rich. in mem. soc. hist. nat. Par. 5. p. 207.) leaves elliptic, long-acuminated, abruptly petiolate, glabrous above, and rugged from tomentum beneath; spikes terminal, simple, erect, length of leaves; flowers tetramerous ; fruit 4-celled; corolla with a long tube, which is very villous inside. h. S. Native of French Guiana. Allied to $N$. longiflòra.

Beautiful Nonatelia. Shrub.

10 N. divarica'ta (A. Rich. l. c.) leaves elliptic, acuminated, tapering into the petioles at the base; flowers 5-6-together, on the top of a common peduncle; fruit globose, 4-furrowed, containing 4 pyrenæ. 5. S. Native of French Guiana, in woods. Flowers unknown.

Divarieate Nonatelia. Slırub.

11 N.? In'spida (Wall. in Roxb. fl. ind. 2. p. 18\%.) leaves oblong, acuminated, oblique at the base, villous beneath; stipulas linear-lanceolate, broad at the base; flowers sessile, axillary, verticillate, with hispid bracteas; stigma 5 -lobed. $\zeta$. S. Native of the East Indies, in Silhet. Corolla funnel-shaped, white. Ovarium hairy, 5-celled. Habit of Sabicea. Perhaps a proper genus.

Hispid Nonatelia. Slırub 3 to 4 feet.

Cult. For culture and propagation see Hamilionia, p. 555.

CXXVII. GYNOCHTHODES (from $\gamma v v \eta$, gyne, a female, and $o x \theta$ winc, ochthodes, warted; in reference to the warted stigma). Bhum. bijdr. p. 993 . A. Rich. mem. soc. list. nat. Par. 5. p. 208. D. C. prod. 4. p. 467.

Lin. syst. Tetra-Pentándria, Monogýnia. Limb of calyx short, quite entire. Corolla 4-5-parted, villous inside, with the segments of the limb comniving at the base, and spreading at the apex, each tipped by a short inflexed claw. Stamens 4-5, inclosed, inserted in the base of the corolla. Stigma bifid, warted. Drupe globose, baccate, umbilicate, containing 4 1-seeded triquetrous pyrena, which are furmished with papery aril. Embryo albuminous, erect.-A climbing glabrous shrub. Leaves opposite, oblong-oval, acute, coriaceous, glabrous. Stipulas permanent, twin on both sides, approximate, erect, at length marcescent. Flowers crowded, axillary. This genus is nearly allied to Nonatielia according to the author.

1 G. coria'cea (Blum. 1. c.) $\eta$. U. S. Native of Java, among bushes between Rompien and Kuripan.

Coriaceons-leaved Gynochthodes. Shrub cl.

Cult. For culture and propagation see Padèria, p. 561.

CXXVIII. CELOSPE'RMUM (from kot low, and $\sigma \pi \varepsilon \rho \mu a$, spcrma, a seed; the seeds are concave inside). Blum. bijdr. p. 994. A. Rich. mem. soc. hist. nat. Par. 5. p. 209. D. C. prod. 4. p. 468.

Lin. syst. Tetra-Pentándria, Monogýnia. Limb of calyx urceolate, quite entire, decidıous. Corolla with a short tube, and a spreading 4-5 cleft limb; lobes oblong-linear. Stamens 4-5, exserted; flaments inserted in the throat; anthers long, linear, incumbent. Style perforating the disk. Stigma bifid, exserted. Drupe globose, umbilicate, containing 4 1-seeded chartaceously arillate pyrenæ, which are hollow inside, and gibbous on the outside. Embryo albuminose, erect._Glabrous climbing shrubs, with terete branches. Leaves opposite, petiolate. Stipulas broad, short, trumcate. Corymbs or umbels axillary and terminal, simple or compound. This genus is nearly allied to Gynochthòdes, but differs from it in the stamens being exserted.

1 C. sca'NDENS (Blum. bijdr. p. 468.) leaves oval, acute; flowers subumbellate, exceeding the upper leaves. $\zeta \cdot \cup . \mathrm{S}$. Native of Java and the island of Nusa-Kambanga, on the mountains, climbing upon trees, where it is called Sambon and Tjunkankan.

Climbing Cœlospermum. Shrub cl.

2 C. соRумво'sum (Blum. herb. ex D. C. prod. 4. p. 468.) leaves oblong, acuminated at both ends; flowers subumbellate, 3 times shorter than the upper leaves. $I_{?} . \cup$. S. Native of Java. 
Corymbose-flowered Colospermum. Shrub cl.

Cult. See Poderia, p. 561 . for culture and propagation.

CXXIX. ANCYLA'NTHUS (from a ${ }^{\prime} v \mathbf{v}$ 'os, ankylos, curved, and $a v \theta 0 s$, anthos, a flower ; the corolla is incurved). Desf. mem. mus, 4. p. 5. t. 2. Juss. mem. mus. 6. p. 396. A. Rich. mem. soc. hist. nat. Par. 5. p. 209. D. C. prod. 4. p. 468.

Lin. syst. Pentlundria, Monogýnia. Calyx with an ovate tube, and a 5-parted limb (f. 103.d.); lobes acute. Corolla tubular, incurved (f. 103. b.), with the tube widened at the apex, and an irregular 5-lobed limb (f. 103.e.): the 2 superior lobes the longest, all ending in callous points. Anthers 5 , sessile at the throat (f. 103, e. ). Stigma thick, terete, 5-lobed at the apex $\left(f .103 . d_{\text {. e. }}\right)$. Ovarium 5 -celled (f. 103. g.); cells 1 -seeded. -A shrub, with villous branchlets. Leaves elliptic, obtuse, puberulous, on short petioles, reticulated beneatl. Stipulas coriaceous, acute, sheathing at the base. Flowers 1-3 together, on short pedicels, axillary, spreading, bracteolate, hairy.-From the stigma and lobes of the corolla this genus agrees with $\mathrm{C} u$ vièra.

1 A. rubigino'sa (Desf. l.c.) $h_{2}$. S. Native of Angola, on the western coast of Africa. (f. ] 03.)

Rusty Ancylanthus. Shurb $\approx$ to 3 feet.

Cult. For culture and propagation see Hamiltònia, p. 555 .

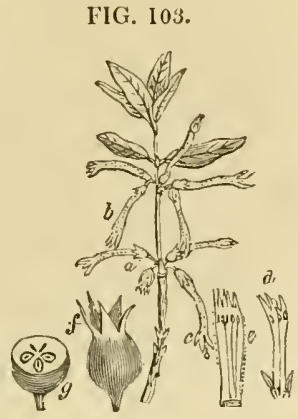

CXXX. PHALLA'RIA (from Phallus, in reference to the form of the stigna). Schum. pl. guin. p.112. D. C. prod. 4. p. 619 .

Lin. srst. Pentándria, Monogýnia. Calyx with a globose or turbinate tube, and an acutely 5 -toothed limb. Corolla tubular, 5-cleft: segments acute, spreading or reflexed. Anthers 5, oval, inserted at the throat. Style filiform ; stigma phalliform. Ovarium 2-seeded?-Glabrous shrubs, natives of Guiana. Branches terete. Leaves opposite, ovate-elliptic, on short petioles. Stipulas interpetiolar, acuminated. Peduncles axillary. -Nearly allied to Cucièra.

1 P. horizonta'Lis (Schum. pl. guin. p. 112.) branches horizontal, unarmed; peduncles umbellate. $\zeta$. S. Native of Guiana. Stigma conical, and as if it was furnished with a reflexed membrane from the very loose margin, truncate at the apex.

Horizontal-branched Phallaria. Shrub.

2 P. spino'sA (Schum. pl. guin. p. 113.) branches spinose ; peduncles racemose. $\quad$. S. Native of Guiana. Stigma of a capitate conical form, bifid at the apex, ex Schum.

Spinose Phallaria. Shrub.

Cult. See Hamiltònia, p. 555. for culture and propagation.

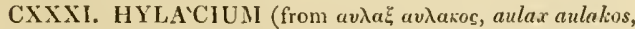
a furrow ; in reference to the style and stigma being furrowed). Beauv. A. d'ow. 2. p. 83. t. 113. D. C. prod. 4. p. 619.-Psychótria species, Juss. mem. mus, 6. p. 379.

Lin. syst. Pentándrin, Monogýnia. Calyx with a short hemispherical tube, and a 5-toothed limb. Corolla funnelshaped, with a long tube, and 5 roundish reflexed lobes. Anthers 5 , almost sessile in the threat. Style thick at the base, 5 -furrowed ; stigma cylindrical, truncate at the base and apex, 5 -furrowed. Drupe dry, containing a 2 -celled rugged nucleus; cells I-seeded, bnt one of them is usually abortive. - A shrub. Leaves opposite, on short petioles, ovate-oblong, attenuated at both ends, glabrous. Stipulas unknown. Corymbs terminal; pedicels 2-3-flowered. Flowers white. This genus is nearly allied to Palicùrca, if the fruit be 2 -celled, but if it be 5 -celled it is more nearly allied to Nonatelia; but in the form of the stigma it agrees with Cuvièra.

1 H. Owarie'nse (Beauv, l. c.) h.S. Native of Western Africa, in the kingdom of $\mathrm{W}$ aree in deserts.

Waree IIylacium. Shrub.

Cull. For culture and propagation see IIaniltònia, p. 555 .

CXXXII. CUVIEIRA (in honour of M. Frederick Cuvier, the celebrated French zoologist). D. C. ann. mus. 9. p. 222. t. 15 . Juss. mein. mus, 6. p. 396. D. C. prod. 4. p. 168 . A. Rich. mem. soc, hist. nat. Par. 5. p. 210. but not of Koel.

LiN. syst. Pentándria, Monogýnia. Calyx with a short tube, and a 5-parted limb: lobes linear, acute, foliaceous, spreading, 3 times longer than broad. Corolla campanulate, 5-cleft; lobes linear, very acute, hardened, and therefore spinescent? Anthers 5, irclosed in the throat; filaments very short. Stigma large, dilated, cup-formed, obtuse, and somewhat pentagonal, with reflexed edges. Fruit baccate, 5-celled; cells 1-sceded.-A glabrous shrub, with diverging branches. Leaves oval-oblong, acute, almost sessile. Stipulas combined into a short bidentate sheath. Panicles terminal, corymbose. The corolla has a membrane on the inside, which is separable from it, and this membrane is probably furnished with the stamens. Ovarium destitute of the urccolus at the apex.

1 C. Acutiflo'ra (D. C. l. c.) 々. S. Native of Sicrra Leone, where it was collected by Smeathmann. Cuvièra Africàna, Spreng. syst. 1. p. 760.

Aeule-flowered Cuviera. Shrub 3 to 4 fcet.

Cult. For culture and propagation see IIamiltònia, p. 555.

CXXXIII. DONDI'SIA (named after James de Dondis, who was among the first who illustrated the descriptions of plants by figures). D. C. prod. 4. p. 469 . but not of Adans. nor Scop. nor Relib.

Lin. syst. Pentándria, Monogýnia. Calyx with a turbinate tube, which is adnate to the ovarimm, and a very short hardly 5-toothed limb. Corolla with a short broad tube, furnished with one series of retrograde scarious stiff hairs inside, which is perhaps the loose jagged part of a membrane inside the tube; lobes 5 , acuminated, valvate in restivation, but at length spreading. Stamens 5 , inserted in the throat of the corolla between the lobes; filaments short, slender. Style filiform, tumid in the middle, and hispid. Stigma ovate, truncate at the base, almost cup-shaped. Ovarium 1-celled? many seeded? Fruit unknown. - A glabrous shrub, native of India, with slender branches. Leaves oblong, acuminated, acute at the base, on very short petioles. Stipulas acute, short, deciduous. Racemules 3-4-flowered, short, axillary or rising from very slort branchlets, bracteolate, much shorter than the leaves.-This genus is nearly allied to Cuvièra and Stigmainthus, but differs: from both in the truncate ealyx, which is 5 -parted in those genera; from Cuviera in the limb of the corolla being unarmed, in the tube being pilose inside, not clothed by a membrane, in the form of the stigma, and perlaps of the fruit; and from Stigmanthus in the tube of the corolla being short, not long, in the style being tumid in the middle, and in the ovarium being turbinate, not roundish.

1 D. Leschexaúlis (D. C. prod. 4. p. 469.) $\eta$. S. Native of the East Indies, on mountains, where it was collected by Leschenault.

Leschonault's Dondisia. Shrub 4 to 5 feet.

Cult. For culture and propagation see Hamiltonia, p. 555. 
CXXXIV. STIGMA'NTHUS (from $\sigma \tau \imath \gamma \mu a$, stigma, a stigma, and $\alpha$ for, anthos, a flower; in allusion to the large stigma). Lour, coch. p. 146. Juss. mem. mus. 6. p. 390. D. C. prod. 4. p. 469.-Stigmatánthus, Røm. et Schultes, syst. 5. p. xv.

IıN. sצss. Pentándria, Monogýnia. Calyx with a short tube, a 5-parted limb, and filiform segments. Corolla funnel-shaped, with a long tube, and 5 ovate-oblong spreading lobes. Stamens 5 ; filaments very short; anthers reflexed. Style filiform, longer than the corolla; stigma ovate, furrowed, large. Berry dry, tubercular, compressed, 1-celled. Seeds many, bony. - A climbing shrub, with glabrous lanceolate leaves. Cymes large, axillary, and terminal. Flowers white.-This genus is not sufficiently known: it differs from Curièra in the 1-celled fruit; and from Dondisia in the 5-parted calyx. Perhaps both this genus and Dondisia are referrible to Tribe Gardeniàcere, subtribe Gardenière.

l S. cymòsus (Lour. l. c.). দ. G. Native of Cochin-china, in woods on the mountains. Cuvièra Asiática, Spreng, syst. 1 . p. 760 .

Cymose-flowered Stigmanthus. Shrub climbing.

Cult. See Hamiltònia, p. 555. for culture and propagation.

CXXXV. STRU'MPFIA (named by Jacquin after Christopher Charles Strumpf, professor of cliemistry and botany at Hall, in Magdeburg, editor of Linnæus's Genera Plantarum in 1752). Jacq. amer. p. 218. Lam. ill. t. 731. A. Rich, mem. soc. hist. nat. par. 5. p. 218 . t. 19. f. 3. D. C. prod. 4. p. 469. -Strúmphia, Pers. ench. 2. p. 211.

Lin. syst. Pentándria, Digy'nia. Limb of calyx campanulate, cleft in 5 parts beyond the middle; lobes acuminated. Corolla sub-campanulate, deeply 5 -parted, with hardly any tube, but with erectish lanceolate lobes or segments, which are somewhat reflexed at the apex. Stamens 5 ; filaments very short, inserted in the bottom of the corolla, connate; anthers combined into an ovate-oblong somewhat pentagonal tube, which is 5 -celled inside; cells regularly disposed, 3 external and 2 internal. Style length of stamens. Stigma bifid; with the lobes erect and obtuse. Ovarium 2-celled; cells 1-ovulate. Drupe pea-formed, umbilicate, containing a 2-celled globose nucleus, rarely 1-celled from abortion.-A small shrub with a short stem. Leaves fleshy, 3 in a whorl, linear, obtuse, with revolute margins. stipulas interpetiolar. Flowers small, disposed in short, nearly simple axillary racemes: having 2 opposite scale-formed bracteas under cach flower.

1 S. marítima (Jacq. 1. c.). h.S. Native of Curacoa, on rocks by the coast. The leaves resemble those of rosemary, and the stipulas are blackish. Flowers small. The whole plant has a disagreeable smell.

Sea-side Strumpfia. Slurub 3 feet.

Cult. For culture and propagation see Hamiltònia, p. 555.

CXXXVI. BILLIO'TIA (named by Aloysia Colla, of Turin, after his daughter, Madame Tecofila Billioti, a famous botanical artist). D. C. prod. 4. p. 618. but not of Colla.-Viviània, Colla. ann. soc. lin. par. 1825. but not of Cav. nor Raddi nor Rafin.-Melanopsídium, Cels. hort. but not of Poit.

Lin. syst. Penta-Hcptándria, Monogýnia. Calyx with the tube adhering to the ovarium, and a 5-7-parted limb. Corolla salver-shaped: having the tube bearded with bristles inside, and a 5-7-parted limb. Stamens 5-7, adnate to the tube. Ovarium crowned by a nectariferous urccolus. Style 1 ; stigmas 4. Drupe 1-seeded by abortion. - A smoothish shrub. Lcaves opposite, petiolate, elliptic, acutish, villous on the petioles, margins, and the nerres on the under side of the leaves, the rest glabrous. Stipulas solitary at each of the nodi, probably formed of 4 , which are combined into a sheath, which is cleft on one side, and denticulated at the apex, downy when young, brow $\mathrm{n}$ in the adult state, falling off at length in a circular manner at the base.

1 B. psycnotrioides (D. C. l. c.). h. S. Native country unknown. Viviània psychotriò̀des, Colla, l. c. Melanopsídium nìgrum, Cels. hort. Colla, hort. rip. t. 35 . I,eaves 3 inches long and 15 lines broad, on petioles 3-4 lines long. Stipulas 6-7 lines long. Flowers white, disposed in terminal heads.

Psychotria-like Billiotia. Clt.? Shrub.

Cult. See Ilamiltonia, p. 555. for culture and propagation.

\section{Tribe VIII.}

PEDERIE: $Æ$ (this tribe agrees with Paderia in important characters). D. C. prod. 4. p. 470.-Lygodysodeàceæ, Bartl. in herb. Hanke, ex D. C. prod. 4. p. 470. Fruit 2-celled, indehiscent, hardly fleslyy, and the rind is easily separated from the carpels or nuts, which are compressed, I-seeded (f. 104. f.), and hanging from the central filiform axis. Albumen fleshy.Climbing shrubs, with opposite leaves and interpetiolar stipulas.

CXXXXVI1. LYGODYSODEA (from $\lambda v \gamma o s$, lygos, a twig,

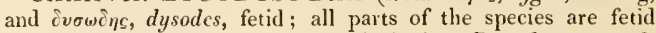
when bruised, like those of P(ederia). Ruiz et Pav. fl. per. prod. p. 32. t. 5. Bartl. in herb. Hænke. D. C. prod. 4. p. 470.Disòdea, Pers. ench. 1. p. 210.

Lin. syst. P'entándria, Monogýnia. Caly $\mathrm{x}$ with an ovate globose tubc, and a 5 -toothed acute, permanent $\operatorname{limb}\left(\mathrm{f}, 104 . a_{\text {. }}\right.$ ). Corolla having the tube nuch longer than the teeth of the calyx (f. 104.6.$)$, with a hairy throat, and 5 somewhat revolute lobes (f. 104. c.). Anthers oblong, sessile within the tube (f. 104. c.). Style equal in length to the tube; stigmas 2 , slender (f. 104. d.), exserted. Fruit indehiscent, oval, somewhat compressed, shining, crowned by the calycine teeth (f. 104.g.); the rind is crustaceous, and at length becomes brittle and breaks irregularly, and therefore is easily separated from the carpels or seeds. Carpels or seeds 2 in each fruit, indehiscent, oval, applied together, girded by a nerve-formed winged margin, hanging by a thread from the base of the fruit, and when the rind has been separated from them appear pendulous. Albumen a thin fleshy membrane, combined with the tegument of the carpella or wanting altogether. Embryo straight, with an inferior terete radicle, cordate foliaceous flat cotyledons, and an inconspicuons plumule.-Smoothish twining shrubs, holding the same station in America as the genus Paderia does in Asia. Stems terete or compressed. Leaves opposite, petiolate, cordate or ovate, acuminated. Stipulas very short, rather truncate, combined with the petioles. Panicles few-flowered, loose, terminating in fewleaved, axillary branchlets, or axillary and lcafy.-This genus comes very near Paderia, and might probably form a distinct order with it from the distinct calyx and carpels.

] L. F⿱宀'tids (Ruiz et Pav. fl. per. 2. p. 48. t. 188.) stems alternately compressed and furrowed ; corymbs axillary, leafless, one half shorter than the leaves; leaves all more or less cordate. h. ..S. Native of Peru, in groves at Muna and Pozuzo. Dysodea foe'tida, Pers. ench. 1. p. 210 . Petioles 4 lines long. Flowers purplish white. This plant has been confused with Paderia foe'tida by Sprengel.

Fetid Lygodysodea. Slı. tw. 2 L. ciliA'ta (Bartl. in herb. Hænke, ex D. C. prod. 4. p.

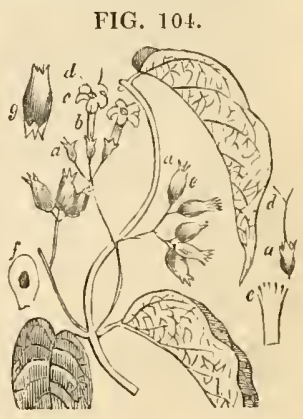


4;0.) stcms terete; corymbs axillary, bearing $2-4$ leaves, length of leaves; leaves some of them cordate and others ovate at the base, $h, \bumpeq$. S. Native of Mexico, where it was collected by Hanke. Rondelètia volùbilis, Sesse et Moc. A. mex. icon. ined. L. Mexicàna, 1). C. annot. fl. mex. ined. Petioles, nerves of leaves on the under side, and margins ciliated with hairs. Petioles 12-15 lines long, villous ahove.

Ciliated-leaved Lygodysodea. Shrub tw.

Cult. See Poderia, p, 562. for culture and propagation.

CXXXV111. LECO'NTEA (named after John Leconte, F.L.S. of Savannah, in Georgia ; a celebrated American botanist). A Rich, mem. soc. hist. nat. par. 5. p. 105. t. 20, f, 1-2. D. C. prod. 4. p. 470 .

Lin. syst. Pentándria, Monogýnia. Limb of calyx 5parted; lobes subulate, spreading. Corolla with a longish terete tube, and a 5-parted limb. Stamens 5, inserted in the throat, which is naked, almost sessile; anthers oblong, exserted. Style simple; stigmas 2, linear, recurved. Ovarium 2-celled, 2-seeded. Fruit compressed, crowned, a little striated : rind coriaceonsly membranous, bursting from the carpels or seeds at the base. Carpels compressed, 1-seeded, with winged margins, hanging each from the top of a thread, which rises from tlie base of the fruit. Seeds erect. Embryo straight, in fleshy albumen, with a short radicle, and longer obtuse cotyledons. Small climbing shrubs, natives of Madagascar. Leaves opposite, petiolate, tomentose. Stipulas undivided. Flowers almost sessile, disposed in spikes; spikes in fascicles, ereet, or incurved, rising from the top of a common axillary peduncle.

1 L. ARGE'NTEA (A. Rich, l.c.) leaves oval, abruptly acuminated, obtuse at the base, clothed with silvery tomentun beneath; spikes erect, in fascicles, elongated; flowers distant; fruit oblong-oval. $h_{c} \cup$. S. Native of Madagasear.

Silvery-leaved Lecontea. Slurub el.

2 L. Bojeria'sa (A. Rich, l. c.) leaves heart-shaped, tomentose, abruptly acuminated at the apex; spikes in fascicles, very short, recurved; flowers approximate; fruit nearly orbicular. 々: ᄂ. S. Native of Madagascar. Lygodysodea Lingun, Bojer?

Bojer's Lecontea, Clt. 18³. Shrub cl.

Cult. For culture and propagation see Padèria, p. 562.

CXXXIX. PEDE'RIA (from paderos, an opal; in reference to the transparent berries). Lin. mant. p. 7. no. 1252. Juss. gen. p. 205. (exclusive of Danàis) mem. mus. 6. p. 381. Lam. ill. 166. f. 1. Gærtn. fil. carp. 3. p. 84. t. 195. A. Ricl,, mem. soc. hist. nat. par. 5. p. 194. D. C. prod. 4. p. 471.

Lin. syst, Pentándria, Monogýnia. Calyx with an ovate tube, and a small 5 -toothed permanent limb. Corolla funnelshaped, hairy inside, 5 -lobed, plicate in æstivation. Stamens 5 , sometimes abortive; anthers oblong, almost sessile in the middle of the tube. Style not exserted; stigma bifict. Berry small, ovate-globose, 2-celled, 2-sceded: the rind at length becoming brittle, and easily separated. Albumen fleshy. Embryo straight, with a terete inferior radicle; flat, foliaceous, large cotyledons, and an inconspicuous plumule.-Sarmentose slirubs, rarely erect. Leaves opposite, petiolate, lanceolate, ovate or cordate, acute. Stipulas solitary on both sides. Peduncles terminal and axillary, branclied, somewhat corymbose. Flowers small, white, usually unisexual.

\section{* Climbing shrubs.}

1 P. F®' TIDA (Lin, mant. p. 52.) leaves oblong or lanceolate, cordate at the base, glabrous; panicles axillary, opposite, short, few-flowered, rarely terminal ; bracteoles minute; anthers inclosed; berry ovate, a little compressed. $h . \cup$ S. Native of the East Indies, very common in many places, as well as of VOL. III.
Japan, and the Moluceas, among bushes. Lam. dict. 2. p. 257. ill. t. 166, f. 1. Thunb. jap. 107. Roxb. in Wall. fl. ind. 2. p. 517. Sieb. fl. maur. 2. no. 82. A pócynum fo'tidum, Burn. fl. ind. p. 71 . - Rumph. amb. 5. p. 160.-Koempf, icon. sel. t. 9.-Somarìji, asiat. res. 4. $\mathrm{p}, 261$. Stijulas broad, cordate. Panieles axillary, brachiate. Flowers numerous, of a deep pink colour. Seeds compressed, bordered by a membranous wing. The leaves vary much in form. The whole herb has a fetid smell, when bruised. The roots are used as an cmetic by the Hindoos.

Fetid Paderia. Clt. 1806 . Slorub el.

2 P. Recu'rva (Roxb. A. ind. 2. p. 518.) leaves lanceolate, acuminated, glabrous; corymbs terminal, recurved, villous ; anthers inclosed; berries globose, dry, striated a little. $h . \cup$. S. Native of the East Indies, at Chittagong. Leaves 6 inches long and from 2-3 broad. Stipulas with a subulate hairy point. Stigma simple, linear, elavate. Berry size and colour of a black currant.

Recurved-corymbed Paderia. Slirub cl.

3 P. мaсrocár pa (Wall. eat. no. 7292.) leares broad, cordate, acuminated, downy above and woolly beneath; racemes long, axillary, panicled, downy ; fruit oblong, compressed, witl a polished rind. $h \cdot \cup$. S. Native of the Burmese Empire, at Rangoon.

Large-fruited Prederia. Shrub tw.

4. B. LANuginòsA (Wall. pl. asiat. rar. 2. p. 52. t. 165.) leaves broad-ovate, and ovate-lanceolate, acuminated, sagittately cordate at the base, downy above and woolly beneath; racemes long, axillary and terminal, panicled, downy or pilose as well as the petioles; fruit roundish, compressed. $\eta_{.} \smile$. S. Native of the Burman Empire, on the banks of the river Abran. Flowers green and purple.

Woolly-leaved Pæderia. Slirub tw.

5 P. tomentòsa (Blum. bijdr. p. 968.) leaves ovate-cordate, acute, tomentose beneath; panicles axillary and terminal, elongated, leafy. $h \cdot \cup . S$. Native of Java, among bushes on the mountains, common.

Tomentose-leaved Paderia. Shrub tw.

6 P. verticilla'ta (Blum. bijdr. p. 968.) leaves 3 in a whorl, elliptic-oblong, acuminated, glabrous ; panic!es axillary and terminal, elongated, leafy. $\quad \zeta_{\cdot} \cup$. S. Native of Java, on Mount Salak.

Whorled-leaved Pæderia. Shrub tw.

* Erect shrubs, which probably do not rightly belong to the genus.

7 P. erécta (Roxb. fl. ind. 2. p. 519. but not of Spreng.) ereet ; leaves almost sessile, broad-lanceolate, smooth; panicles terminal, erect, in the forks of the branches; stamens exserted a little. $h$.S. Native of the East Indies, in Silhet. Leaves 4 inches long and $1 \frac{1}{2}$ broad. Flowers numerous, small, white, inodorous. Berries the size of a pea, when ripe bighly polished, black, sinooth.

Erect Paderia. Shrub 2 to 3 feet.

8 P. TERnA'ta (Wall. in Roxb. f. ind. 2. p. 520.) erect, trichotomous, smooth: with triangular branchlets; leaves 3 in a whorl, oblong-lanceolate; corymbs axillary, trichotomous, erect, shorter than the leaves; limb of calyx campanulate, obscurely 5-toothed. $\boldsymbol{z}$. S. Native of the East Indies, on the Juyuntyapoora mountains bordering on Silhet. Flowers rather large, funnel-slaped, white, on long filiform pedicels, each pedicel having a pair of linear ciliated bracteas above the middle. The flowers are said to be fragrant when quite fresh, but they emit a very offensive smell on being steeped in water after they have been dried. Corolla fleshy, half an inch long, with a 5-cleft, rarely 4-cleft border. Fruit unknown.

$$
4 \mathrm{C}
$$


Ternate-leaved Pæederia. Tree small.

\section{+ Species not sufficiently known.}

9 P.? VA'LLI-KA'RA (Juss. men. mus. 6. p. 381.) climbing; branches terete, villously tomentose; leaves broad-ovate, acute, somewhat cordate, rather pilose above, and rather woolly beneath ; corymbs axillary, many-flowered. h.u. S. Native of Malabar. Rheed. mal. 7. p. 35. t. 18. Hondbessen, Adans, fam. 2. p. 158. Berry globose, green, probably 1-seeded. Flowers 5-cleft, according to the figure, but tetrandrous according to the description.

Ialli-kara Paderia. Shrub cl.

10 P.? sessilirlòra (Poir. suppl. 2. p. 449.) stems ascending; leaves lanceolate, glabrous; petioles geniculated at the base; racemes rather longer than the leaves, brachiate, panicled; flowers sessile, sub-secund. $\zeta$. S. Native of the Mauritius. Said to be allied to $P$. frétida, but is probably a species of Laugèria.

Sessile-flowered Pæderia. Shrub ascending.

11 P. Brazilis'na (D. C. prod. 4. p. 472.) leaves cordateoblong, pilose beneath and on the branches; panicles terminal, much branched; flowers pedunculate. h. S. Native of Brazil, in the province of Minas Geraes. Anthers inclosed. Berry dry, containing 2 pyrenæ. Padèria erécta, Spreng. neu. entd. 3. p. 34. but not of Roxb.

Brazilian Prederia. Shrub 3 to 4 feet?

Cult. The species of Padèria are free growers, and will thrive in any kind of rich light soil; and cuttings strike root readily in the same kind of soil, under a hand-glass.

\section{Tribe IX.}

COFFEA'CE $A$ (this tribe agrees with the genus Coffer in the fruit being baccate, and in containing 2 hard 1 -seeded nuts). D. C. diss. 1806 . H. B. et Kunth, nov. gen. amer. 3. p. 352 . exclusive of some genera. A. Rich, ex D.C. prod. 4. p. 472. -Psychotriàceæ and Cephalideæ, Cham. et Schlecht. in Linnæa. 4. p. 4. and p. 133. Fruit 2-celled (f. 105.h. f. 107. c.), baccate, containing 21 -seeded bony or crustaceous nuts (f. 107 . d.), which are flat inside and usually marked by a furrow on the outside; rarely containing only 1 nut from abortion. Nuts adhering by the inner sides. Albumen horny,-Trees or shrubs. Leaves opposite. Stipulas inter-petiolar, with 2 on each side, which are either combined or distinct.

Sub-tribe I, Coffee'无 (this sub-tribe contains shrubs agreeing with the genus Coffer in having distinct flowers). D. C. prod. 4. p. 472-Psychotriàceæ, Cham. et Schlecht. 4. p. 4. Flowers distinct, not combined.

CXL. AMARACA'RPUS (from apcos, amara, leading

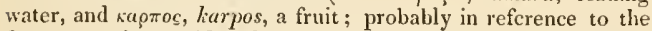
furrow on the outside of the pyrenæ or nuts). Blum. bijdr. 1. 954. A. Rich, mem. soc. hist. nat. par. 5. p. 198. D. C. prod. 4. p. 472.

Lin. syst. Tetríndria, Monogýnia. Calyx with an ova] tube and a 4-cleft unequal limb. Corolla finnel-shaped, with a villous throat and a deeply 4 -cleft limb. Stamens 4 , inserted in the throat of the corolla. Style 1; stigma 2-lobed. Drupe baccate, crowned by the calyx, containing 2 bony 1 -seeded pyrenre, which are furrowed a little on the back.-A small shrub, with downy branchlets. Leaves opposite, on short petioles, lanceolate, glabrous above, paler beneath, and rather downy on the veins. Stipulas connate at the base, bifid at the apex, deciduous. Flowers small, solitary, in the axils of the leaves, rarely terminal, sessile, bracteolate at the base.-Habit and axillary inflorescence of this genus disagree with Psycliótria.
1 A. Pubéscens (Blum. bijdr. p. 954.), 々. S. Native of Java, and the Island of Nusa-Kambanga.

Pubescent Amaracarpus. Slurub.

Cult. See Coffèa, p. 584. for culture and propagation.

CXLI. DAMNACA'NTHUS (from $\delta a \mu v a w$, damnao, to conquer, axas $\theta 0$, acanthos, a spine; in reference to the strong opposite thorns). Gærtn. fil. carp. 3. p. 18. t. 182. D. C. prod. 4. p. 473.-Cảnthium species, ex Juss. Rich.

Lin. systr. Pentúndria, Monogýnia. Calyx with a globose tube, and a small 5-toothed permanent limb. Corolla, stamens, and style unknown. Berry globose, 2-celled, crowned by the calyx. Seeds solitary in the cells, and fixed to the bottom of the cells. Albumen cartilaginously fleshy. Embryo very minute, seated in the base of the albumen, with a short inferior radicle.-An Indian slirub, furnished with opposite spines, but the leaves and flowers are hardly known.-This genus is nearly allied to Canthium, but differs in the seeds being fixed to the bottom of the cells, not to their tops, and in the embryo being small. The Spina spinàrum of Rumph. amb. cited by Gærtner, for this plant has nothing to do with Rubiàcece, in the leaves being alternate and serrated, and is therefore referrible to Stigmarota Janghomas; but perhaps the Oxycántha Javánica, Rumph. amb. 7. t. 19. f. 3 . is a species of Daminacánthus or Cánthium.

1 D. I'ndicus (Gærtn. fil. 1. c.). $h_{2}$. S. Native of the East Indies. Caríssa spinàrum, Thunb. in litt. to Gærtn.

Indian Damnacanthus. Shrub.

Cult. For culture and propagation, see Chiocócca, p. 569.

CXLII. CAN'THIUM (Canti is the Malabar name of one of the species). Lam. dict. 1. p. 602. Juss. gen. p. 204. mem. mus. 6. p. 380. Gærtn. fil. carp. 3. p. 93. t. 196. Roxb. fl. ind. 2. p. 169. Blum. bijdr. p. 966. D. C. prod. 4. p. 473. but not of Labill. nor Lindl._Cánthium species, A. Rich, mem. soc. hist. nat. par. 5. p. 187.-Gardènia species, Lin. fil.Webèra species, Schreb.

Lin. syst. Tetra-l'entándria, Monogýnia. Calyx with an ovate tube, and a short 4-5-toothed limb. Corolla with a short tube, a bearded throat, and 4-5 spreading lobes. Anthers 4-5, inserted at the throat, hardly exserted. Style filiform, exserted ; stigma undivided, thick, ovate-globose, or mitre-formed. Berry globose, or didymous, flesly, crowned by the calycine teeth, 2-celled. Seeds solitary in each cell, inserted towards the apex, inverted, incurved. Albumen flesby. Embryo central, with a long superior radicle--Asiatic or African shrubs, with spinose or unarmed branches. Leaves opposite, rather coriaceous. Stipulas interpetiolar, solitary on botli sides. Peduncles axillary, short, many-flowered.

Sect. I. Evca'nthuum (from $e u$, well or good, and cánthium; this section is supposed to contain the true species of the genus). D. C. prod. 4. p. 473. Mature fruit 2-celled, terminated by an umbilicus.

\section{* Unarmed shrubs, with pentandrous flowers..}

1 C. Conne'lia (Cham. et Schlecht. in Linnæa 4. p. 14.) branches unarmed; peduncles, calyxes, and petioles villous ; leaves oval, obtuse at the base, acute at the apex, rather villous on both surfaces; peduncles bifid; cymes dense, many-flowered. h.S. Native of Senegal. Pavétta Cornèlia, Reichb. in Sieb. fl. seneg. exsic. no. 21. Fruit unknown. Flowers white.

Cornelia Canthium. Shrub 4 to 5 feet.

2 C. subcorda'tum (D. C. prod. 4. p. 473.) unarmed; leaves ovate, rather cordate, acutish, downy beneath, as well as on the branches; peduncles bifid, cymose, many-flowered; fruit a little compressed and rather cordate. $々 . S$. Native of Senegal, in 
lumid places; and of Gambia, near Albreda, where it was collected by Leprieur and Perrottet. Flowers smaller than in any other species of the genus. Stigma ovate. Fruit almost like that of the following.

Subcordate-leaved Canthium. Tree.

3 C. Dídxulu (Gartn. fil. carp. 3. p. 94. t. 196. exelusive of the syn. of lihecd.) shrubby, unarmed, glabrous, and smooth ; leaves on short petioles, obtuse, and oval, glandular in the axils of the veins beneath; cymes axillary, on slort peduneles; fruit didymons. $h$.S. Native of Coromandel, on the mountains.

Didlymous-fruited Canthium. Shrub.

4. C. Moldcca'num (Roxb. fl. ind. 2. p. 172.) shrubby, unarmed; leaves oblong; tube of corolla gibbons, lengtl of style; stigma turbinate. $\zeta$. S. Native of the Moluccas. The rest unknown.

Molucca Canthium. Shrub.

5 C. Fascicula'tum (Blum. bijdr. p. 967.) arboreous, unarmed; leaves elliptic-lanceolate, glabrous ; flowers in axillary fascicles. h. S. Native of the west of Java, in mountain woods. Said to be allied to C. didymum.

Fascicled-flowered Canthium. 'Tree.

6 C. Gla'brum (Blum. bijdr. p. 967.) arboreous, -unarmed; leaves ovate, or elliptic-oblong, obtuse, acutish at the base, glabrous ; cymes axillary, branclied, many-flowered. $I_{\imath} . S_{\text {. }}$ Native of Java, in woods on the mountains.

lar. $\beta$, pubérulum (Blum. l. c.) leaves roughish above and puberulous beneath, $h_{\imath}$. S. Native of Java, at the foot of Mount Salak.

Glabrous Canthium. Tree.

7 C. vìte (Bartl. in herb. Hænke, ex D. C. prod. 4. p. 474.) unarmed, glabrous; leaves petiolate, ovate, acuminated, glandular in the axils of the veins beneath; cymes axillary, loose,

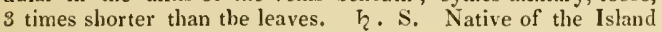
of Luzon, one of the Philippines. Stipulas acuminated. Cymes bipartite, with diverging branches, and many-flowered branchlets. Calyx with 5 short, acute tecth.

Mild Canthium. Shrub.

8 C. Lu'cidus (Hook, et Arn, in Beech, voy. pt. bot. p. 65.) branches unarmed; leaves on short petioles, elliptic, obtuse, attenuated a little at the base, coriaceous, shining above, pale beneath; cymes pedunculate, axillary, nearly globose. $\eta_{\text {. S. }}$. Native of the Society Islands. Calyx 4-5-toothed. Corolla 4-5-lobed. Stamens 4-5. Closely allied to $C$. glàbrum and C. nìtens.

Lucid-leaved Cantlium. Shrub.

\section{* Unarmed shrubs, with tetrandrous flowers.}

9 C. Nítens (D. C. prod. 4. p. 474.) unarmed, glabrous ; leaves petiolate, broad-ovate, bluntish, shining and glossy above; racemes compound, axillary, many-flowered, a little longer than the petioles. h.S. Native of the East Indies, where it was collected by Leschenault. Petioles 8 lines long. Stipulas triangular, deciduous. Peduncles disposed in dense panicles. Tube of corolla a little longer than the lobes, which are oral and obtuse. Stigma thick, ovate, much exserted.

Shining-leaved Canthiunı. Slırub.

$$
\text { * * Spinose shrubs, with tetrandrous flowers. }
$$

10 C. Parviflòrum (Lam. diet. 1. p. 602.) shrubby ; branchlets glabrous; spines opposite, horizontal, supra-axillary; leaves ovate, on short petioles, smooth, longer than the spines, usually in fascicles; racemes rising beneath the spines at the axils; berries nearly globose. $\zeta$. S. Native of Coromandel, frequent. Roxb. cor. 1. p. 39. t. 51. fl. ind. 2. p. 170. Gartn. fil. carp. 2. p. 196. f. 3.? Webèra tetrándra, Willd. spec. 1. p. 1224. Kanden-kara, Rheed. mal. 5. p. 71. t. 36 . When the plant is in luxuriance, the spines are sometimes threefold. lilowers small, yellow. Berries yellow, obcordate, compressed laterally, size of a cherry. 'The bush makes excellent fences. 'The leares are universally eaten in curries; on this account the plant has the nane of Balusoo-kura, which latter word means esculent.

Small-flonered Canthium. Shrub 5 to 6 feet.

11 C. Hebécladum (D. C. prod. 4. p. 474.) shrubby ; branchlets velvety ; spines opposite, rising from an acute angle; leaves obovate, glabrous, hardly longer than the spines ; pecticels numerous, 1-flowered, axillary. h. S. Native of the Island of Luzon, one of the Philippines. C. parviflòrum, Bartl. in herb. Hanke. but not of Lam.

Don'ny-branched Canthium. Shrub 5 to 6 feet.

$$
\text { **** Spinose shrubs, with pentandrous floners. }
$$

12 C. Mundra'sum (Cham, et Schlecht. in Linnæa. 4. p. 131.) a small erect shrub: with opposite spinescent branches; leaves ovate-oblong, of the same colour on both surfaces, membranous; petioles downy inside; cymes axillary, pedunculate. h. G. Native of the Cape of Good Hope, at Plittenberg's Bay. Habit of Plectrònia ventòsa, but the cymes are on longer peduncles; the flowers are smaller, and the stipulas are glabrous inside, not leaving a margin of white wool on falling, as in that plant.

Var. $\beta$, pubéscens (D. C. prod. 4. p. 474.) leaves downy on both surfaces. h. G. Growing along with the species.

Mundi's Canthium. Shrub 4 to 5 feet.

J 3 C. hórridium (Blum. bijdr. p. 966.) shrubby, erect ; spines spreading, straight; lcaves small, almost sessile, ovateoblong, acutish, downy on both surfaces, as well as the branches and stipulas; flowers twin or tern, axillary, on very short peduncles, h.S. Native of Java, among bushes about Buitenzorg. Branches spreading, opposite.

Horrid Cantlium. Shrub 5 to 6 feet.

14. C. PARvifòlum (Roxb. fl. ind. 2. p. 170.) shrub thorny and hairy ; leaves oval, hairy beneath ; flowers axillary, crowded; tube of corolla globose. $h$. S. Native of the East Indies. The inside of the tube of the corolla is surrounded by a circle of straight white bristles of its own length, inserted round its mouth, and pointing to its bottom. The figure in Pluk, alm 27. t. 133. f. 3. so often referred to as this plant, has nothing to do with it; consequently it is neither Manètia diacántha, Willd. spec. 1. p. 670, nor Azlma diacántha, Lam. dict. 1. p. 343 .

Small-lcaved Canthium. Shrub 5 to 6 feet.

15 C. angustifòlium (Roxb. fl. ind. 2. p. 169.) shrub thorny; leaves lanceolate, glabrous, and shining, on short petioles; flowers numerous, axillary, on short pedicels; berries roundish, retuse. h. S. Native of the East lndies, on hills, in the vicinity of Chittagong, Silhet, and the whole eastern frontier of Bengal. Branches glabrous. Flowers small, greenish-yellow. Corolla with a short gibbous tube, and 5 lanceolate segments. Drupe roundish, when ripe yellow.

Narrow-leared Canthium. Shrub.

16 C. RnEE'nir (D. C. prod. 4. p. 474.) shrub thorny; leaves oval-lanceolate, acuminated, on very short petioles, shining; flowers numerous, axillary, on short pedicels; berries roundishovate, compressed. $h$. S. Native of Malabar, where the Braclimans called it Canti, hence the generic name. Tsjeronkara, Rheed. mal. 5. p. 73. t. 37. Root reddish, bitter. Flowers small, greenish. Berries green. It differs from $C$. parviflorum in the flowers being 5 -cleft and pentandrous.

Rheede's Canthium. Slirub.

17 C. Peduncula're (Cav. icon. 5. p. 21. t. 436.) slirub thorny; leaves ovate, acute, almost sessile, downy; peduncles 4 c 2 
axillary, solitary, longer than the leaves. $\zeta$. S. Native of the Island of Luzon, one of the Philippines. Teeth of calyx subulate. Corolla pale purple, with a woolly throat, anl 5 lanceolate, very acute segments. Filaments shorter than the corolla. Berry ovate, sub-compressed. This shrub is perhaps generically distinct from Cânthium.

Peduncular Canthium. Shrub 8 to 10 feet.

18 C. Lycioides (A. Rich, diss. p. 108.) spines supra-axillary, simple; leaves small, oblong-oval, acuminated, rather hairy; stipulas broad, ending in a long abrupt point at the apcx; flowers axillary, pedunculate, solitary. $h$. S. Native of Manilla. Habit of a species of Lýcium. The rest unknown.

Lycium-like Canthium. Shrub.

19 C. Chine'nse (Pers. ench. 1. p. 200.) shrub thorny ; leaves obovate; flowers sessile, hairy. h. G. Native of China, at Macao; and of Madras. Gardènia spinòsa, Thunb. diss. gard. no. 7. t. 2. f. 4. exclusive of the synonymes. Willd. spec. 1. p. 1229. Rándia spinòsa, Poir. dict. 2. p. 829. Leaves many from the buds under the spines, glabrous, Corolla white, a little longer than the calyx, with ovate, obtuse, spreading segments. Stigma clarate. This plant does not probably belong to Cánthium.

China Canthium. Fl. Ju. Aug. Clt. 1800. Sh. 5 to $8 \mathrm{ft}$.

20 C. scándens (Blum. bijdr. p. 966.) climbing; spines divaricate or recurved; leaves on short petioles, oblong, acu-minated, downy beneath as well as on the branclses; flowers disposed in axillary fascicles; fruit didymous. $\zeta_{\text {. }}$. S. Native of the Island of Nusa-Kambanga, near Java, among bushes. Thorns much shorter than the leaves, straight, or a little recurved, but sometimes wanting on the branchlets. Fruit rather rugged, like that of Psydrax.

Climbing Canthium. Shrub cl.

Sect. 11. Pleuroga'ster (from $\pi \lambda \varepsilon v \rho o \nu$, pleuron, a side,

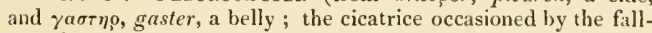
ing of the flower is left at one side of the fruit). D. C. diss. ined. acad. sc. par. 1806. prod. 4. p. 475. Mature fruit 1. celled, furnished with the floral cicatrice on one side at the base.

21 C. аломоса' врum (D. C. prod. 4. p. 475.) glabrous; branches divaricate, and probably at length becoming spinescent; leaves oval, acuminated, on short petioles: pedicels slender, elongated, 1-flowered, corymbose, usually deflexed, rising from the axils of the superior leaves. $h$.S. Native of Sierra Leone, where it was collected by Sineathmann; and of the Gambia, at Albreda. This plant comes near to Plectrònia centòsa, from the singularity of the fruit.

Anomalous-fruited Canthium. Shrub.

Cult. For culture and propagation see Chiocócca, p. 569.

CXLIH. PLECTRO'NIA (from $\pi \lambda \eta \kappa$ \%on, plccktron, a whip ; in reference to the square branclies). Lin. mant. p. 6. no. 1249 . Lam. ill. t. 146. A. Rich, mem. soc. hist. nat. par. 5. p. 189. but not of Burm. nor Lour.-Rhámnus species, Burm.

Lin. syst. Tetrándria, Monogýmia. Calyx with an obovate or oblong tube, and a 5 -toothed limb. Teeth very short, acutish. Corolla short, rather funnel-shaped, with a 5-parted $\operatorname{limb}$, and a bearded throat; segments acute, reflexed. Stamens 5 , inserted in the throat, a little exserted. Style short; stigma sub-capitate, of 2 approximate lamella. Berry dry, naked at the apex, emarginate, obovate-oblong, compressed, didymous, containing 2 chartaceously coriaceous, 1-seeded, indeliscent pyrenæ, which are flat inside.-Small A frican trees, with opposite, sub-spinose branches. Leares opposite, petiolate, elliptic, acute at both ends, rather coriaceous, pale beneath. Stipulas solitary on each side, apiculated. Peduncles axillary, short, solitary, racemose, or corymbose; pedicels about equal in length to the fruit, slender.-This genus, along with Damnacánthus, Psýdrax, and Cánthium ought probably to be united.

1 P. vento'sa (Lin. mant. p. 52.) branchlets glabrous, tetragonal; stipulas 8 times shorter than the petioles; peduncles many-flowered, corymbose. $\zeta$. S. Native of the Cape of Good Hope, in woods much exposed to the wind. Seríssa Capénsis, 'Thunb. fl. cap. p. 193. exclusive of the syn. of Willd. Cruse, rub. cap. p. 21. 24. t. 2. Cánthium Thunbergiànum, Cham. et Schlecht. in Linnæa. 4. p. 130. Plectrònia corymbòsa, A. Rich. 1. c.-Burm. afr. p. 257. t. 94. Flowers greenish white.

Windy Plectronia. Clt. 1816. Tree.

2 P. Madagascariénsis (A. Rich, in mem. soc. hist. nat. Par. 5. p. 189.) branchlets glabrous, compressed; pedicels axillary, 1 -flowered. h.S. Native of Marlagascar, where it was collected by M. Chapelier. The whole shrub is glabrous. Leaves oval, attenuated at the base, petiolate. Stipulas short, acuminated, deciduous. Flowers unknown. Fruit obovate, emarginate at the apex, and probably obcordate and compressed, usually 1-celled by abortion.

Madagascar Plectronia. Shrub or tree.

3 P. Hinsu'ta (D. C. prod. 4. p. 476.) branchlets villons; leaves villous beneath; stipulas length of petioles. F. S. Native of Senegal, by the sides of woods near Dagana, where it was collected by Leprieur and Perrottet. Cánthium Senegalénse, A. Ricl. l. c. p. 188 . Branches terete, divaricate, spreading, forming straight angles. Peduncles axillary, villous, compressed, corymbose at the apex. Berry 2-celled, emarginate at the apex; but one of the cells is usually abortive, in this case the fruit becones 1-celled, and the umbilicus lateral, which is indicated by the permanent 5 -toothed calyx.

Ifairy Plectronia. Shrub 4 to 6 feet.

Cult. See Chiocócca, p. 569 . for culture and propagation.

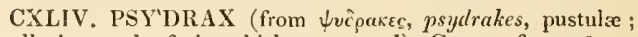
in allusion to the fruit, which are warted). Gærtn. fruct. 1. p. 125. t. 26. f. 2. A. Rich. mem. soc. hist. nat. Par. 5. p. 190. D. C. prod. 4. p. 476 .

Lis. syst. Pentándria, Monogýnia. Calyx with an obovate tube, and a 5 -toothed deciduous limb. Corolla with a short tube, a hairy throat, and 5 oval acute reflexed lobes. Stamens inclosed, inserted at the throat. Style much exserted; stigma bilamellate. Berries fleshy, areolate at the apex, obovate, compressed, wrinkled from tubercles, marked by a furrow on both sides, 2-celled, containing usually 2 , rarely 3 pyrenæ; pyrenæ oblong, scabrous from wrinkles, 1 -seeded, marked by a linear furrow, and an umbilicus in the middle. Seeds bony, filling the pyrenæ. Albumen amygdalaceous, scrobiculate. Embryo inverted, filiform, curved into the form of a Greek sigma, with linear cotyledons. - Shrubs, with opposite ovate leaves, and axillary racemes of snall flowers. 'This genus, from the hard fruit being often 3-celled; and from the form of the embryo, almo t agrees with the tribe Guettardacea.

1 P. Dico'́ccos (Gaertn. fruct. 1. p. 125. t. 26. f. 2.) leaves elliptic, long-acuminated, gradually tapering into the short petioles at the base; stipulas lanccolate, acute, permanent ; cymes pednnculate, branched; fruit rather heart-shaped. h. S. Native of Ceylon.

Tno-seeded Psydrax. Shrub.

2 P. mAjor (A. Rich. 1. c. p. 191.) leaves elliptic, on short petioles, short-acuminated; stipulas semi-oval, bluntish; cymes pedunculate, simple; fruit heart-shaped. $\downarrow$. $\lesssim$. Native of Madagascar. Very like the preceding species, but differs in the broader leaves with shorter points, caducous stipulas, simple cymes, and larger fruit.

Larger Psydrax. Shrub. 
3 P. ME'DI (A. Rich. I. c.) leaves oval, very blunt, gradually attenuated at the base; stipulas ending in long points, caducous; cymes hardly pedunculate, simple, few-flowered; fruit deeply emarginate, didymous. h.S. Native of Madagascar.

Intermediate Psydrax. Shrub.

4 P. Angustifólia (A. Rich. l. c.) leaves linear, acutish at the apex, gradually attenuated at the base; stipulas lanceolate, caducous ; cymes hardly perlunculate, 3-5-flowered; fruit small, heart-shaped, didymous. h.S. Native of Madagascar.

Narrow-laced Psydrax. Shrub.

Cult. For culture and propagation see Chiocócca, p. 569.

CXLV. MARQUISIA (evidently called so after some person of the name of Marquis, who is unknown to us). A. Rich. mem. soc. hist. nat. Par. 5. p. 192. D. C. prod. 4. P. 477.-Cánthitum species, Labill.

Lin. syst. Pentandria, Monogy'nia. Calyx with an ovate tube, and a short acutely 5 -parted limb. Corolla with a short tube, a glabrous throat, and 5 oblong spreading bluntish lobes, which are longer than the tube. Anthers 5 , ovate, sessile at the throat of the corolla. Style filiform, length of tube ; stigmas 4-6. Berry ovate, fleshy, 2-celled, crowned by the calyx. Seed or pyrenæ solitary in the cells, erect, convex on the outside, but flat and furrowed inside.-A glabrous shrub, with spinose branches. Leaves on short petioles, opposite, lanceolate, small, attenuated at both ends. Stipulas small, solitary on both sides, adhering to the petioles. Pedicels axillary, solitary, 1-flowered, deflexed, calyculated by 4 small combined bracteas under the flower. Flowers small. This genus differs from Cánthium in the stigma being divided into many lobes, and in the seeds rising from the bottom of the cells, not from the top.

1 M. Billarde'tui (A. Rich. l. c.) h. G. Native of Van Diemen's Land. Cânthium quadrífidum, Labill, nov. holl. 1. p. 69. t. 94. A very spimose slirub, very variable in habit, luaving the branches sometimes loose and elongated, and sometines short and crowded. Pedicels rising each from a slieath.

La Billardier's NIarquisia. Shrub 5 to 6 feet.

Cult. For culture and propagation see Chiocócca, p. 569.

CXLVI. NESCl'DIA (from ncscio, to be ignorant; the fruit being unknown the genus is very doubtful). A. Rich. mem. soc. hist. nat. Par, 5. p. 192. D. C. prod. 4. p. 477.

Lis. syst. Pentándria, Minogýnia. Limb of calyx hardly any, quite entire. Corolla with a short tube, a naked throat, and a 5 -cleft limb; segments incumbent, bluntish. Stamens 5 , inserted in the throat, almost sessile, inclosed. Anthers linear, acute. Style short; stigmas 2, linear, acute, joined face to face. Ovarium 2-celled; ovula solitary in the colls, fixed to the middle dissepiment. Seeds unknown.-A glabrous shrub, native of the Mauritius. Leaves opposite, petiolate, like those of a myrtle, coriaceous, scarcely acute. Stipulas short, interpetiolar. Flowers axillary, solitary, girded by a bidentate calyculous at the base.-This is a doubtful genus from the fruit being unknown, but it has the habit of Mlyonima.

I N. myrtifolia (A. Rich. l. c.) $\zeta$. S. Native of the Mauritius.

Myrtle-leaved Nescidia. Shrub 5 to 6 feet.

Cult. See Chiocócca, p. 569. for culture and propagation.

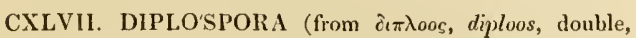
and $\sigma \pi \circ$ o, spora, a seed; in reference to the cells of the fruit being 2 -seeded). D. C. prod. 4. p. 477.-Cánthium species, Lindl.

LiN. syst. Tetrándria, Monogy'nia. Calyx with an obovate tube, a very short subcampanulate 4-toothed limb. Corolla with a wide tube, which is shorter than the lobes, a pilose throat, and 4 ovate fleshy spreading lobes. Anthers 4, sessile at the throat, semi-exserted. Style length of the tube; stigma bifid. Ovarium 2-celled; cells 2-seeded; ovula collateral, ascending. Fruit and seeds unknown. $-\Lambda$ glabrous shrub, native of China, with tetragonal branches. Leaves opposite, petiolate, oblonglanceolate, acuminated at both ends. Stipulas solitary on both sides, ovatc, acuminates, permanent. Flowers axillary, crowded, almost sessile, yellowish-green, calyculate by combined bracteas at the base. This genus agrees witl Epithinia in the cells of the ovarium being biovulate, but differs in the ovula being collateral, not one on the top of the other.

1 D. viridif Lo'RA (D. C. prod. 4. p. 477.) h. G. Native of China. Cánthium dùbium, Lindl. in bot. rẹ. t. 1026.

Green-flowerel Diplospora. Fl. July. Clt. 1824. Shrub? to 4 feet.

Cult. See Chiocócca, p. 569. for culture and propagation.

CXLVIII. EPITHI'NIA (from $\varepsilon \pi \iota, e p i$, upon, and $\theta \iota v, t h i n$, the seashore; the shrub grows among mangroves on the seashore). Jack, in mal. misc. 1. no. 2. p. 12. D. C. prod. 4. p. 477 .

LiN. syst. Tctrandria, Monogy'nia. Limb of calyx cylindrical, scarcely 4-toothed, permanent. Corolla tubular, with a 4-parted spreading acute limb, and a villous throat. Stamens 4, exscrted; anthers linear. Style exserted; stigma bifid. Berry 8 -furrowed, containing 2 oblong 2 -seeded pyrenæ. Seet. placed one above another.-An Indian shrub. Leaves opposite, petiolate, obovate, smooth, almost veinless. Stipulas wanting? Peduncles axillary, dichotomous, many flowered, with a solitary flower in the fork. Flowers white.-This genus is said to be allied to Malànca, but differs in the cells of the fruit being 2 -seederl, and from all other Rubiaceous plants in the want of stipulas.

1 E. MaLAYA'Na (Jack, l.c.) h. S. Native of the islands of Malacca, Singapore, in marshes among mangroves.

Malay Epithinia. Shrub.

Cill. For culture and propagation see Chiocócca, p. 569.

CXLIX. SIDERODE'NDRON (from aîngos, sideros, iron, and $\delta$ ericoov, dendron, a tree; in reference to the hardness of the wood of the trees). Sclurcb. gen. no. 691. Vahl, ecl, amer. 1. p. 10. Juss. mem. mus, 6. p. 374 . A. Rich. mem. soc. hist. nat. Par. 5. p. 183 . t. 16. f. 3. D. C. prod. 4. p. 478.-Sideroxyloides, Jacq. amer. p. 19.

Lin. sxst. Tetrándria, lionogýnia. Calyx with a subglobose tetragonal tube, and a very sinall 4-toothed limb. Corolla with a long terete tube, which is hardly widened at the apex, a glabrous throat, and 4 oval roundish bluntish spreading lobes. Anthers 4, sessile in the throat of the corolla, oblong, hardly exserted, one-half shorter than the lobes of the corolla. Style bifid at the apex, leugtis of the corolla. Berry dry, nearly globose, naked at the apex, 2-celletl, 2-seederl. Seeds convex on the outside, concave inside, and furnished with a circular areola as in Bacinia. Albumen cartilaginous. Embryo unknown.Glabrous liard-wooded trees, natives of South America. Branches terete, but tetragonal when young: as wcll as the pedicels. Leaves opposite, oval-oblong, acute, rather coriaceous, petiolate. Stipulas solitary on both sides, apiculated by a short point. Peduncles axillary, trifid or trichotomous. Flowers rose coloured on the outsile, and white inside. This genus is nearly allied to Coffica.

I S. TRIFLo'REM (Vabl, ccl. 1. p. 10.) peduncles twin, axillary, 3-flowered. $\quad$ h.S. Native of the islands of Mlontserrat and Martinico, where it is called bois de fer or iron-wood. S. férreum, Lam. ill. p. 282. Sidcroxyloides fërreum, Jaç, amer. 
p. 19. t. 175. f. 9.-Pluk, alm. t. 224. f. 2. Petioles slort, and the leaves are acute at the base, ex Vahl.

Three-flonercd Ironwood-tree. Clt. 1793. Tree tall.

2 S. nultiflo'rum (A. Rich. 1. c.) peduncles axillary, tripartite, having the lateral branches trifid, and the middle one twice trifid. $々$. S. Native of French Guiana. Petioles 2-3 lines long. Peduncles 3 or 4 lines longer than the petioles. Leaves acuminated at the apex, but bardly acute at the base.

Iar. $\beta$, angustifòlium (D. C. prod. 4. p. 478.) leaves oblong, acuminated. $\eta$.S. Native along with the species.

Many-flowered Ironwood-tree. Tree.

\section{$+A$ doubtful species.}

3 S. Panicula'tum (Willd. herb. no, 2811, ex Cham. et Schlecht. in Linnæa. 4. p. 26.) panicles axillary, pedunculate, hairy, with subdichotomous branches; leaves ovate-cordate, acutely mucronate, nearly sessile. $\zeta_{2}$. S. Native of South America, on the banks of the river Atabapo, near San-Balthazar. Psychótria cordifòlia, H. B. et Kuntl, nov. gen. amer. 3. p. 365. but not of Dietr. The fruit is unknown, but the tree agrees better with Siderodéadron than with Psychótria in the tetrandrous flowers and axillary panicles. Flowers blue, glabrous, with a villous throat.

Panicled-flowered Ironwood-tree. Shrub.

Cult. See Chiocócca, p. 569. for culture and propagation.

CL. EUMA'CHIA (Eumachus, an author cited by Theophrastus). D. C. prod. 4. p. 478.-Petèsia, Gartn. fil. carp. 3. p. 66. t. 192. but not of P. Browne, nor Lin.--Petèsia species, Juss. and Spreng.

Lin. syst. Telrandria, Monogýnia. Calyx with an obovate tube, and a 4-toothed deciduous limb. Corolla funnel-shaped, with a short tube, a naked throat, and a 4 -parted limb; lobes roundish, spreadingly reflexed. Stamens inserted in the bottom of the tube; filaments short; anthers oblong in the throat. Stigma bifid, having the lobes long and acute. Berry globose, naked at the apex, 2-celled; cells 1 -seeded. Seeds convex on the back, and flattish in front, with a moon-shaped umbilicus. Albumen cartilaginous. Embryo unknown.-A glabrous Australian tree. Branches terete. Leaves opposite, petiolate, smooth, oblong-lanceolate. Cymes terminal and axillary, trifid. Corolla flesh coloured.

1 E. cárnea (D.C. prod. 4. p. 479.) h. S. Native of the island of Namoka, one of the Friendly Islands. Petèsia cànea, Forst. 2, no. 51.

Flesh-coloured-flowered Eumachia. Tree.

Cult. For culture and propagation see Chiocócca, p. 569.

CLI. DECLIEU'XIA (named after M. Declieux, a French gardener, who carried the coffee plants first into Martinico). H. B. et Kuntl, nov. gen. amer. 3. p. 352. Mart. et Zucc. in Rœm. et Schultes, mant. 3. p. 111. Cham. et Schlecht. in Linnæa. 4. p. 4. A. Rich. mem, soc. list. nat. Par. 5. p. 193. D. C. prod. 4. p. 479.-Psyllocárpus, Poll, in litt. but not of Mart.

Lin, syst. Tetrandria, Monogýnia. Calyx with an obovate tube, and a 4-parted limb (f. 105. b.). Corolla funnel-shaped (f. 105. g.), with a terete tube (f. 105.f.), a bearded throat, and 4 spreadingly reflexed lobes. Stamens 4 , inserted in the throat; filaments filiform; anthers linear, fixed by the middle, exserted (f. 105. e.); stigma bifid (f. 105. c.). Berry nearly dry, 2-celled, subdidymous, compressed (f. 105. h.), crowned by the permanent calyx (f. 105 . b.), containing 2 chartaceously coriaceous 1-seeded pyrenæ. Albumen borny. Embryo unknown.Shrubs, rarely herbs, natives of America. Stems erect, tetragonal when young. Leaves opposite or in whorlcs, nearly ses- sile. Stipulas small, interpetiolar. Corymbs terminal, tripartite, bracteate, with dichotomous branches. Flowers white, lateral and sessile, or terminal and pedunculate, bibracteate.

1 D. chrococcoides (H. B. et Kunth, nov. gen. amer. 3. p. 353. t. 281.) shrubby, glabrous; leaves opposite, sessile, oblonglanceolate, acute, cuneated at the base, with rather revolute edges ; corymbs sessile, tripartite; stamens about equal in length to the lobes of the corolla. $\zeta . S$. Native of New Andalusia, on the banks of the Orinoco, near the monastery of Caripe : and of Rio Janciro, ex Cham. et Schlecht. in Linnaca. 4. p. 4. Røum. et Schultes, mant. 3. p. 112. Houstònia fruticòsa, Willd. mss, in Røm. et Schultes, syst. 3. p. 527. Shrub 4 feet high. Flowers white. (f. 105.)

Chiococea-like Declieuxia. Sh. 4 feet.

2 D. Mexica'na (D. C. prod. 4. p. 479.) suffruticose, gla brous; leaves opposite or 3 in a whorl, sessile, oblong-lanceolate, obtuse at the base, acute at the apex; corymbs pedunculate, 4-5-parted; stamens about equal in length to the lobes of the corolla. h. S. Native of Mexico, D. chiococcoides, Bartl. in herb. Hanke. Flowers white.

Mexican Declieuxia. Slirub $1 \frac{1}{2}$ foot.

3 D. Thy urroides (Mart. et Zucc. in Roem. et Schultes, mant. 3. p. 111.) slirub much branched; leaves disposed in verticillate fascicles, sessile, linear, acute, attenuated at both ends, and are, as well as the branches, roughish; flowers solitary or few together on the tops of the branches. $\eta$. S. Native of Brazil.

Thymbra-like Declieuxia. Shrub.

4 D. satureioides (Mart. et Zucc. in Rem. et Schultes, mant. 3. p. 111.) shrub inuch branched; leaves linear-lanceolate, attenuated at the hasc, sessile, opposite or 6 in a whorl, and are, as well as the branches, scabrous from hairs; flowers axillary, solitary. $\zeta$. S. Native of Brazil. The rest unknown.

Savory-like Declieuxia. Slırub.

5 D. Galioides (Polıl, in litt. under the name of Psyllocárpus,) plant sublierbaceous, glabrous; branches terete; leaves 3 in a whorl, linear; whorles distant; panicles terminal, having the branches disposed 3 in a whorl, cymose. $h$. S. Native of Brazil, where it was collected by Pohl.

Galium-like Declieuxia. Shrub 1 foot.

6 D. SPERgulifòlia (Mart. et Zucc. l. c.) shrubby, glabrous ; leaves linear-subulate, opposite, sessile; racemes dichotomous ; terminal. h. S. Native of the south of Brazil. Cham. et Schlecht. in Linnæa. 4. p. 6. Panicle terminal, dichotomously compound from cymes: having the branchlets capillary, elongated, and erect, with alternate flowers. Flowers twin, one of each pair sessile. Stamens inclosed. Cham. et Schleclit.

Spurry-leaved Declieuxia. Shrub.

7 D. Marioides (Mart. et Zucc. I. c.) shrubby; stem and branches clothed with soft down; leaves 3 in a whorl, rarely 4 , ovate-lanceolate, almost sessile, glabrous, with revolute edges; flowers axillary, almost terminal. h.S. Native of Brazil.

Cal-thyme-like Declieuxia. Shrub.

8 D. Enantioides (Mart. et Zucc. l. c.) plant herbaceous, glabrous; stem nearly simple; leaves 4 in a whorl, sessile, remote, linear-lanceolate, acute; racemes bifid, forming a terminal

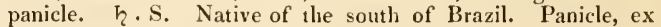
Cham. et Sclileclit. in Linnæa. 4. p. 5. terminal, from whorles 
of branches, ustally twin, and forming a terminal umbel, with a central flower. Flowers sessile.

Enanthe-like Declieuxia. Shrub.

9 D. Folio'sa (Pohl, in litt. under the Psyllocárpus,) shrubby, scabrous in every part; branclies tetragonal; leaves opposite, linear-oblong, acuminated at both ends, revolute at the margins while young; cymes terminal, few-flowered. $h$.S. Native of Brazil, where it was collected by Pohl. In the axils of the leaves there are two young leaves, and therefore at first sight appear 6 in a whorl.

Lcrfy Declieuxia. Shrub.

10 D. cordígera (Mart. et Zucc. l. c.) suffruticose, nearly simple, clothed with roughish pubescence; leaves opposite, decussate, approximate, sessile, ovate-cordate, acute, concave on the back; racemes bifid, terminal, crowded into a dense panicle. 々. S. Native of Brazil within the tropic. Cham. et Schlecht. in Linnæa. 4. p. 7. Psyllocárpus cordifollius, Pohl, in litt. Leaves rarely 3 in a whorl. Panicle terminal, erect, many flowered, nearly globose, with angular flexuous branches, dichotomous, hence bearing sessile flowers.

Heart-bearing Declieuxia. Slrub.

11 D. Glav'ea (Mart. et Schlecht. in Linnæa. 4. p. 8.) shrubby, glabrous, pruinosely glaucescent; lcaves opposite, sessile, ovate, very acute, erectly adpresscd, coriaceous; panicle terminal, erect, nearly globose, dense. $h_{\text {. }} S$. Native of Brazil within the tropic. Very nearly allied to the preceding species.

Glaucous Declieuxia. Shrub.

12 D. Passeri'na (Mart, et Zucc. in Rœm. et Schultes, mant. 3. p. 112.) slirubby, glabrous ; leaves opposite, decussate, sessile, adpressed, imbricating in 4 rows, ovate, acute, 3-5-nerved beneath ; flowers axillary, sessile, covered each by a leaf. $!$. S. Native of Brazil.

Passcrina-like Declieuxia. Shrub.

13 D. Daphroides (Mart. et Zucc. 1. c.) shrubby; branches twiggy; leaves opposite, decussate, somewhat imbricating in 4 rows, sessile, ovate-cordate, acute, rather concave above, scabrous from hairs beneath, 7-9-nerved ; peduncles axillary, fewflowered. $h$.S. Native of Brazil. The rest unknown.

Daphne-like Declieuxia. Shrub.

14. D. гзвкіса'та (Pohl, in litt. under the name of Psyllocárpus,) sbrubby, glabrous; branches terete; leaves opposite, decussate, crect, ovate, hardly subcordate, cuspidate, stiff, having 4 small ribs on each side of the midrib; peduncles axillary, fewflowered. h. S. Native of Brazil.

Imbricated-leaved Declieuxia. Shrub.

15 D. RHexioìes (Mart. et Zuce. 1. c.) shrubby, glabrous; young branches subumbellate, twiggy; leaves opposite, decus sate, sessile, erectly spreading, imbricating in 4 rows, orbicularly ovate, acute, 5-nerved ; flowers axillary, almost solitary. b.S. Native of Brazil.

Rhexia-like Declieuxia. Shrub.

16 D. origanoides (Zucc. 1. c.) shrubby, clothed with roughish hairs; branches dichotomous, terete; leaves opposite, rather remote, on short petioles, nearly orbicular, acute, many nerved; flowers terminal, thyrsoid. $\zeta$. S. Native of Brazil. Leaves like those of Origanum Dictímmes.

Origanum-likc Declieuxia. Slirub.

17 D. Mól.rs (Zucc. I. c.) slirubby ; leaves opposite, ovatelanceolate, somewhat rhomboid, acute, tapering into the short petioles at the base, with ribbed veins, clothed with villi; flowers terminal, disposed in dichotomous panicles. $h_{2}$. S. Native of Brazil.

Soft Declieuxia. Shrub.

18 D. Lysimacinoides (Zuce. 1. c.) plant herbaccous or suffruticose, downy; branches simple, erect; leaves 3 in a whorl, ovate, attenuated at both ends, acute ; flowers terminal, dichotomously panicled. $\hbar$. S. Natise of Brazil.

Lysimachia-lele Declieuxia. Shrub.

19 D. Rubroìns (Zucc. l. c.) slırubby, glabrous; leaves opposite, decussate, ovate, acute, rounded and cordate at the base, shining above; Howers terminal, disposed in dichotomous panicles. h. S. Native of Brazil.

Rubia-like Declicuxia. Shruh.

20 D. A'LBa ('/ucc. 1. c.) slirubby, scabrous; leaves opposite, decussate, ovate, acute, sessile, rounded at the base; racemes terminal, bifid, disposed in dichotomous cymes, $h$. S. Native of Brazil.

White Declieuxia. Shrub.

21 D. Divergentiflòra (Pohl, in litt. under Psyllocárpus,) suffruticose ; branches terete, clothed with velvety hairs; leaves opposite, sessile, ovate, acutish, nerved, clothed with fine velvety down on both surfaces ; cyme terminal, on short peduncles, of 6

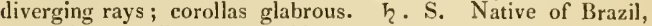
where it was collected by Poli].

Diverging-flowered Declieuxia. Shrub.

22 D. Pulverulénta (Mart. Cham. et Schlecht, in Linnaa. 4. p. 9.) suffruticose, clothed with short dense hairs in every part except the corollas; leaves usually 3 in a whorl, rarely opposite, sessile, ovate, acute or acuminated ; cymes terminal, of many rays, subfastigiate. $h$.S. Native of Brazil within the tropic.

Pondery Declieuxia. Shrub.

23 D. Polygaloides (Zucc. in Schultes, mant. 3. p. 113.) suffruticose; branches twiggy, erect; leaves 3 or 4 in a whorl, sessile, lanceolate, acute, erect, smoothish; flowers terminal,

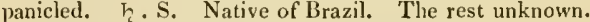

Polygala-like Declieuxia. Shrub.

24. D. vincoides (Mart. et Zucc. I. c.) shrubby, glabrous; leaves opposite or 3 in a whorl, ovate, attenuated at both ends, acute, sessile, shining; flowers terminal, disposed in dichotomous panicles. h.S. Native of Brazil.

I inca-like Declieuxia. Shrub.

25 D. Pruinòsa (Polıl, in litt. under Psyllocárpus, D). C. prod. 4. p. 481.) suffruticose, glabrous, glaucous; branches terete; leaves opposite, sessile, orbicularly ovate, mucronate; cymes terminal, trichotomous, on short peduncles, fastigiate. $h$. S. Native of Brazil.

Frostcd Declieuxia. Slırub.

26 D. mucronula'ta (Mart. Cham. et Schlecht. in Linnæa. 4. p. 10.) suffruticose, quite glabrous; leaves opposite, sessile, elliptic or obovate, cuneated at the base, mucronate at the apex : the mucrone usually reflexed; cymes terminal, on short petluncles, somewhat fastigiate. $\eta$. S. Native of Brazil within the tropic. Stem and branches terete, furnished with 2 slight wings. Psyllocárpus trichótomus, Pohl, in litt. may be referrible to this, but the mucrones of the leaves are not reflexed in the specimens of that plant collected by Pohl.

Mucronate-leaved Declieuxia. Shrub.

27 D. GLA'Bra (D. C. prod. 4. p. 481.) plant suffruticose, glabrous; stem somewhat tetragonal; leaves opposite, petiolate, elliptic-oblong, acuminated at both ends, but not mucronate; cymes terminal, of many rays, subumbellate. $h$. S. Native of Brazil, Pohl; about Caraccas, Vargas. Psyllocárpus glàber, Pohl. in litt. Very like the preceding.

Glabrous Declieuxia. Shrub.

28 D. ? psychotrioìdes (D. C. prod. 4. p. 4SI.) suffruticose, glabrous ; leaves opposite, on short petioles, elliptic, long-acuminated, acute at the base; cymes terminal, on short peduncles, trichotomous, onc-half sborter than the leaves. h.? 4 .? S. Native of Cayenne, where it was collected by Patris; and of Panama and Mexico, according to Hanke. herb. Coffèa didy- 
ınocárpa, Bartl. in herb. Hænke. Flowers unknown. Stipulas twin on both sides, subulate.

Psychotria-like Declieusia. Shrub.

29 D. herba'cea (Cham. et Schlecht. in Linnæa. 4. p. 11.) plant herbaceous, glabrous; branches straight, glabrous, terete, a little winged: leaves opposite, petiolate, ovate-lanceolate, attenuated, acute; cymes axillary, on long peduncles, of 5 spreading rays. 4 . S. Native of Brazil, about Rio Janeiro. Knóxia Brasiliénsis, Spreng. syst. 1. p. 406. Habit of Borrèria láxa. Corolla a line long. Fruit nearly dry. This plant ought probably to be excluded from the present genus, according to Martius in Linnæa. 1. c.

Herbaceous Declieuxia. Shrub.

Cult. For culture and propagation see Chiocócca, p. 569.

CL1l. TERTRE'A (named after J.B. du Tertre, a traveller in the French West Indian Islands, and who has written a general history of them). D. C. prod. 4. p. 481.-Schièdea, A. Rich. mem. soc. hist, nat. Par. 5. pt. 1. p. 186. (1830) but not of Schlecht. in 1826 .

Lin. syst. Pentándria, Monogýnia. Limb of calyx 4-parted: lobes erect, oval, obtuse, ciliated. Corolla short, funnelshaped, 4-cleft; lobes short, obtuse, rather spreading: throat beset with hairs. Stamens exserted, inserted in the upper part of the tube. Style shorter than the corolla. Stigmas 2, short, obtuse. Drupe oblong, compressed, crowned by the calyx, with 2 opposite furrows, containing 2 chartaceous 1 -seeded pyrenæ. Seed oblong, compressed, pendulous.-A shrub, native of Martinico, having the branchlets usually spinescent at the apex. Leaves opposite, oval, acute, on short petioles, membranous, glabrous. Stipulas interpetiolar, acuminaterl. Flowers small, disposed in a terminal oppositely branched raceme.

1 T. Martinicénsis (A. Rich. l. c.) h. S. Native of Mar.. tinico.

Martinico Tertrea. Shrub 1 to 2 feet.

Cult. For culture and propagation see Chiocócca, p. 569.

CLIII. CIIIOCO'CCA (from $\chi \imath \omega v$, chion, snow, and кok'кos, kokkos, a berry; the berries of $C$. racemosa are white, hence it is called snow-berry). P. Browne, jam, p. 174. Lin. gen. no. 231. Jacq. amer. p. 68. Juss. mem. mus. 6. p. 378 . Lam. ill. t. 160. Gærtn. fruct. 1. p. 125. t. 26. A. Rich. mem. soc. hist. nat. Par. 5. p. 186. D. C. prod. 4. p. 482.-Lonicèra species, Lin. hort. cliff. et spec. ed. 1st._Chiocócca species, Spreng.

Lin. syst. Pentándria, Monogýnia. Calyx with an ovate tube, and an acutely 5 -tootlied permanent limb. Corolla funnelshaped, with an obconical tube or throat, and 5 acute lobes. Stamens with the filaments hardly adnate to the bottom of the corolla, downy, and shorter than the anthers, which are inclosed and linear. Style rather clavate at the apex, entire or slightly 2-lobed. Berry somewhat didymous, compressed, crowned by the teeth of the calyx, containing 2 chartaceous 1 -seeded pyrene. Secds pendulous. Embryo with a long superior radicle. Albumen cartilaginous.- Shrubs generally with a some what climbing habit. Leaves opposite, ovate or oblong, acute, glabrous. Stipulas broarl at the base, permanent, more or less apiculated. Racemes axillary, opposite, simple or panicled. Flowers pedicellate, of a yellowish white colour. Roots emetic and alexiteric.

1 C. racemòsa (Jacq. amer. p. 68. Lin. spec. 246.) leaves oval, acuminated at both ends, smooth; stipulas broad at the base, and apiculated by a long point at the apex; racemes many flowered; corolla much longer than the teeth of the calyx; filaments of stamens downy. $h$. S. Native of the West India islands, Mexico, and Carthagena, on hills. Swartz, obs. p. 76 . Andr. bot. rep. t. 284. Tratt, tab. t. 631. Hook. fl. exot. t.
93.-Sloane, hist. t. 188. f. 3.-Dill. hort. elth. t. 228. f. 295. and therefore the Lonicèra álba, Lin. spec. ed. 1. p. 175. A very variable shrub. Corollas at first white and scentless, but at length becoming yellowish and sweet-scented. Leaves shining on the upper surface. Berries snow white, hence the English name snow-berry, and the Greek one chiococca. The stamens are glabrous in the figure given by Hooker, and the stigma is trifid in that given by Andrews, variations which have never been seen in nature. The root has much the same acrid bitter taste as snake-root, and has been long used as a strong resolntive or attentant ; it is administered with great success in obstinate rheumatisms, and old syphilitic taints. It is best given in decoction; it is also an excellent emetic, and may be used as ipecacuanha.

I ar. $\beta$, scandcns (Pers. ench. 1. p. 209.) branches very slender, and evidently climbing; leaves oblong; racemes shorter than the leaves, simple. 5 . S. Native of Jamaica, and the island of Santa Cruz.-Browne, jam. p. 164. no. 2. Swartz, obs. 76. var. $\beta$.

I ar. $\gamma$, laxiflòra (D. C. prod. 4. p. 482.) climbing; leaves oblong; racemes panicled, longer than the leaves. $h . S . H$. Cultivated in the botanic garden at Calcutta.

Var. \&, longiflòra (D. C. prod. 4. p. 482.) leaves oblong, longacuminated; racemes simple, equal in length to the leaves. h. S. Native of Guadaloupe, where it was collected by Badier.

Var. E, Floridìnum (D. C. l. c.) leaves elliptic, Jardly acuminated; racemes simple, a little longer than the leaves. $h$. S. Native of Florida and Mexico by the sea side. Chiocócca racemòsa, Michx. fl. bor. amer. 1. p. 103.

Racemose-flowercd Snow-berry. Fl. Feb. Clt. 1729. Shrub 4 to 6 feet.

2 C. Densiflòra (Mart. spec. med. bras. p. 17. t. 6.) leaves ovate, rather coriaceous; stipulas broad at the base, apiculated by a longish point; racemes many flowered; corolla much longer than the teeth of the calyx; filaments densely bearded. $h$. S. Native of Brazil, in woods at Almadas and Ferradas, on the mountains of Bahia; and at the Port of St. Catharine, ex Cham. et Schlecht. in Linnæa. 4. p. 13. Racemes simple. Flowers white, sweet-scented. This species grows plentiful about Bahia, where we have seen it either with loose or crowded branches and leaves.

I ar. $\beta$, Cubénsis (D. C. prod. 4. p. 482.) leaves ovate, subcordate; racemes rather compoind; flaments bearded. h.S. Native of Cuba.

Dense-flonercd Snow-berry. Shrub 3 to 4 feet.

3 C. ANGUi'fuga (Mart. spec. mat. med. bras. p. 17. t. 5.) leaves ovate, acuminated; stipulas rery broad, short, each ending in a short point; racemes panicled; corolla hardly 3 times longer than the calycine teeth. h.S. Native of Brazil, in woods, French Guiana, Trinidad, Peru, Cuba, and about $\mathrm{Cu}$ mana, on the Spanish Main. Cham. et Schlecht. in Linnæea. 4. p. 13. C. brachiàta, Ruiz et Pav. fl. per. 2. p. 67. t. 219. f. b. C. racemòsa, H. 13. et Kunth, nov. gen. amer. 3. p. 352. Sieb. fl. trin. exsic. no. 38 . C. parviflòra and $\mathrm{C}$. paniculàta, Willd. in Rom. et Scliultes, syst. 5. p. 203. Pedicels and branchlets glabrous. Flowers white. Root diuretic, and is called by the Brazilians Cainca.

Vur. $\beta$, pubéscens (D. C. prod. 4. p. 483.) pedicels and branchlets downy. h.S. C. pubéscens, Willd. in Rœem. et Schultes, syst. 5. p. 202 .

Anguifugal Snow-berry. Fl. June, Aug. Clt. 1824. Shrub 3 to $\Psi$ feet.

4 C. odora't (Hook. et Arn. in Beech. voy. pt. bot. p. 65.) leaves broad-oval, rather coriaceous, very blunt, acute at the base, and running down the short petioles; peduncles axillary, solitary, 3-4-flowered; corolla with a bearded throat. $h$. S. 
Native of Elizabeth Island, one of the Society Islands. Coffèa odoràta, Forst. prod. 1. p. 94.? The flowers are described as fragrant, and smelling like cowslips.

Sncet-scentcd Snow-berry. Slurub.

5 C. BARBA'TA (Forst. jrod. 1. p. 96. Hook. et Arn. in Beech. voy. pt. bot. p. 65. t. 14.) erect; leaves oval, acute at the base, and tapering into the short petioles, acuminated and obtuse at the apex; peduncles axillary, solitary, 1-3-flowered; corolla with a bearded throat, 5-eleft. $h$. S. Native of the Society and Friendly Islands. Flowers white. Drupe size of a filbert.

Bearded-flowered Snow-berry. Shrub.

6 C.? Java'Na (Blum. bijdr. p. 968.) slırub parasitical; leaves oblong-lanceolate, acuminated at both ends, glabrous, velvety' and shining above; corymbs terminal, trichotomous. $h$. S. Native of Java, in woods on the mountains upon trees. Coffèa Javánica, Blum. eat, hort. buit. p. 46. Perhaps a species of Psychótria.

Jaca Snow-berry. Shrub parasitical.

Cult. A mixture of loam, peat, and sand is the hest soil for the species of Chiocócca; and cuttings strike root frcely in sand under a hand-glass in heat.

CLIV. MARGA'RIS (from $\mu$ arapov, margaron, a pearl; the berries are white and shining in $\boldsymbol{M}$. nudiflor $a$, and are called perlitas, or pearls, by the Mexicans). D. C. prod. 4. p. 483.Descliæ'a, Moc, ct Sesse, fl. mex, icon. ined. ex D. C. l. c.

Lin. syst. Pentándria, Monogýnia. Calyx with a globose tube, and a somewhat turbinate semi-5-cleft limb; teet! acutish, permanent. Corolla funnel-shaped, with an obconical tube, which is 5 -toothed or with 5 short lobes at the apex. Stamens 5 , inserted in the middle of the tube ; filaments a little shorter than the corolla; anthers ovate. Stigma capitate, undivided or slightly 2-lobed. Berry globose, crowned by the ealyx, 2celled, 2 -seeded. Seeds semi-ovate, acute at one end.-Shrubs, with slender branches. Leaves opposite, ovate, glabrous, about the size of those of the common myrtle. Stipulas small, solitary on both sides. Pedicels axillary, opposite, short, 1-flowered. Flowers white, usually secund, bibracteolate inder the calyx. Berries white.

1 M. BARBícera (D. C. prod. 4. p. 483.) leaves acute; corollas bearded inside. $\nvdash$. S. Native of Mexico. Desclia'a leucocárpa, Moc, et Sesse, $\mathrm{fl}$. mex. icon. ined. Berries size of a pea.

Bcard-bcaring Pearl-berry. Shrub.

2 M. NUDiflóna (D. C. prod. 4. p. 483.) leaves mucronate ; corolla glabrous inside. $々$. S. Native of Mexico, about Tapelpa. Chiocócea axillàris, Moc. et Sesse, fl. mex. icon. ined. Descliæ'a margaritària, Moc. et Sesse, fl. mex. icon. ined. Slırub 8 feet high. Berries ovate, globose, a little smaller than a pea, white and shining, hence they are called perlitas by the Mexicans.

Naked-flowered Pearl-berry. Shrub 8 feet.

Cull. See Chiocócca above for culture and propagation.

CLV. SALDI'NIA (meaning unknown to us). A. Rich. in mem. soc. hist. nat. Par. 5. p. 206. D. C. prod. 4. p. 483.Morínda species, Poir.

Lis, syst. Tetrándria, Monogýnia. Limb of calyx sloort, subcampanulate, obsoletely repand. Corolla with a short tube, a 4-parted limb, and a pilose throat; lobes oblong, acute, spreading. Stamens 4, inserted in the throat, liardly exserted; anthers oblong, almost sessile. Fruit small, egg-shaped, compressed, umbilicated by the limb of the calyx, drupaceous, usually 1-celled, and 1 -seeded by abortion. Seed erect, oblong. Embryo nearly terete, slender. Albumen fleshy. - Shrub. Leaves opposite, elliptic, acuminated, coriaceous, glabrous on short petioles. Stivol. 111 . pulas subulate, acute. Flowers small, almost sessile, 4-5-together in the axils of the leaves.

1 S. PSEU'DO-MORíNDA (A. Ricl. l. c.) h.S. Native of Madagascar. Morinda axillàris, Poir. in Lam. dict. 4. p. 315. Ronàbea species, Juss.

False-Morinda Shrub.

Cult. Sce Chiocócca above for culture and propagation.

CIVI. SCOLOSA'NTHUS (from $\sigma \kappa^{\prime} \omega \lambda$ tos, skolos, a thorn, and artos, anthos, a flower; the peduncles are sometimes hardencd into thorns, which sometimes, though rarely, bear the flowers). Vahl, ecl. 1. p. 11. t. 10. Juss. mem. mus. 6. p. 377. A. Rich. mem. soc. hist. nat. Par. 5. p. 205. D. C. prod. 4. p. 484.-Antacánthus, L. C. Rich. mss.

Lix. syst. Tctrándria, Monogýnia. Calyx with a short ovate tube, and 4 linear-lanceolate acute lobes. Corolla tubular, somewhat tetragonal before expansion; the tube somewhat quadrangular at the apex; lobes 4 , ovate, acute, revolute. Stamens having the filaments downy and adnate to the tube at the base; anthers linear, not exserted. Stigmas 2, obtuse, hardly longer than the tube. Drupe nearly globose, crowned by the calyx, containing a 2-celled 2 -seeded nucleus, ex Rich., or very often 1 -celled and 1 -seeded by abortion.-West Indian shrubs, with the habit of Catesbe'a or Justicia spinòst. Leaves small, almost sessile, oblong or obovate, coriaceous, opposite, usually disposed in fascicles in the axils. Stipulas small, interpetiolar. Peduncles 1-flowered, axillary, 1-4-together, and sometimes they are hardened into simple bifid or trifid spines, which are usually naked, rarely floriferous. Flowers small, purple or saf. fron coloured.

l S. versícolor ( $\mathrm{Vahl}$, eel. amer. 1. p. 11. t. 10.) leaves olovate, shining above; spines simple, bipartite or twin. $々 . S$. Native of Santa Cruz and Porto Rico. Chomèlia versícolor, Spreng. syst. I. p. 110. Catesbæ'a parviflòra, Lam. ill. t. 67. f. 2. Leaves 3 lines long. Spines commonly in pairs from each alternate axil, combined at the base, for the most part a little longer than the leaves, stiff, purplish, often bearing a flower at one of the points; they are the peduncles which have hardened, and keep growing on after the flowers have fallen. Flowers on short peduncles; those from the tops of the spines solitary, usually drooping, purple, and abortive ; others are axillary, solitary, or more rarely 2-4-together, erect, saffron coloured, and fertile. Fruit snow white.

Party-coloured-flowered Scolosanthus. Shrub 3 to 4 feet.

2 S. TRlaca'nthus (D. C. prod. 4. p. 484.) leaves oblong, rather glaucescent; spines for the most part trifid. $h_{i} . S$. Native of St. Domingo, where it was collected by Bertero. Catesbæ'a triacántha, Spreng. syst. 1. p. 416. Leaves 4-5 lines long. Flowers and fruit not sufficiently known, but the habit is that of Catesbie' $a$.

Three-spined Scolosanthus. Shrub.

Cult. See Ixòra, p. 574, for culture and propagation.

CLVII. CHOME LIA (named by Jacquin after J. B. Clomel, M.D. physician to Louis XV.; author of Abrégé de L'Histoire des plantes usuelles, edition 1st, $12 \mathrm{mo}$. Paris, 1712.) Jacq. amer. p. 18. t. 13. Juss, mem, mus. 6. p. 375. Cham. et Schlecht. in Linnrea. 4. p. 185 . A. Ricl, mem. soc, hist, nat. Par. 5. p. 182. but not of Lin.-Ixòra species, Lam.

Lix. syst. Tetrandria, Monogýnia. Calyx with a turbinate tube, and a permanent limb, which is 4-toothed to the middle. Corolla salver-shaped, with a long slender tube, a glabrous throat, and 4 spreading lobes, which are shorter than the tube. Anthers 4, sessile, or on short filaments, inserted at the throat of the corolla. Style bifid at the apex, situated among the anthers. Drupe ovate, crowned, containing a 2-celled for 1- 
celled from abortion) nucleus; cells 1 -seeded. Seeds pendulous in the cells, oblong.-American shrubs, usually spinescent, glabrous or downy. Leaves opposite on short petioles, stiff, coriaceous. Stipulas short, interpetiolar. Peduncles axillary, one or few-flowered, short.-This genus differs from Ixora in habit and inflorescence, but more particularly in the fruit containing a hard nut; and from this it is more nearly allied to $S \mathrm{So}-$ losánthus than to Ixòra.

1 C. spino'si (Jacq. amer. 18. t. 13.) leaves uvate, acuminated, almost sessile, glabrous; peduncles axillary, usually 3flowered; lobes of calyx and corolla acute. $々$. S. Native of Carthagena, in woods; and probably of St. Domingo. Ixòra spinòsa, Lam. dict. 3. p. ü44. Flowers white, fragrant at night, $1 \frac{1}{2}$ inch lorig.

Spiny Chomelia. Clt. 1793. Shrub 8 to 12 feet.

2 C. Fascicula'ta (Swartz, fl. ind. occ. 1. p. 238.) leaves ovate, acute, glabrous, on short petioles ; pedicels 2-3-together, axillary, I-flowered; lobes of calyx rather spatulate, unequal ; lobes of corolla oblong. $\quad$. S. Native of Grenada, in hedges. Ixòra fasciculàta, Swartz, prod. p. 30. Willd. spec. 1. p. 610. Flower's white. Fruit unknown.

Fascicled-flowered Chomelia. Clt. 1825. Shrub 5 feet.

3 C. овтu'sa (Cham. et Schlecht. in Linnæa. 4. p. 185.) leaves clliptic, acutish at the base, glabrous, on short petioles; peduncles axillary, 1-3-flowered; lobes of calyx and corolla obtuse. h. S. Native of the south of Brazil. Flowers white.

Blunt-calyxed Chomelia. Shrub 4 to 5 feet.

4. C. Puse'scens (Cham, et Schlecht. in Linnæa. 4. p. 187.) leaves ovate, acute, on short petioles, pilose on the nerves above, and silky beneatl; peduncles axillary, 1-flowered. h. S. Native of Brazil within the tropic. Perhaps the same as C. Brasiliàna, A. Rich. mem. soc. hist. nat. Par. 5. p. I 83.

Donny Chomelia. Shrub.

Cult. See Ixòra, p. 574. for culture and propagation.

CLVHII. BACO'NIA (in memory of Bacon, baron of Verulam. Lord Bacon's speculations in natural knowledge may allow us to claim lim as a botanist). D. C. ann. mus. list. nat. par. 9. p. 219. Juss. mem. mus. 6. p. 374. A. Rich. mem. soc. hist. nat. Par. 5. p. 184 . D. C. prod. 4. p. $485-$-Verulàmia, D. C. mem. niss. Poir. dict. 8. p. 543. Smith, in Rees' cycl. vol. 37.

Lin. syst. Tetrándria, Monogýnia. Calyx with a very short tube, adnate to the ovarium at the base, and a bluntly 4 -cleft limb. Corolla funnel-shaped, with a short terete tube, a bearded throat, and 4 oblong acute lobes, which are longer than the tube, and twisted in astivation. Anthers 4, linear, almost sessile, erect, situated at the throat between the lobes, and a little shorter than them, at length twisted spirally. Style filiform, exserted; stigma undivided, or hardly 2 -lobed. Disk thick, crowning the ovarium. Berry dry, 2-celled, 2-seeded. Seeds semi-globose. Albumen cartilaginous. Embryo erect, nearly terete- - A glabıous African shrub. Leaves opposite, petiolate, oval, acuminated at both ends. Stipulas connate, sheathing, short. Corymbs terminal, trichotomous. Flowers white.This genus is nearly allied to Ixòra, but differs in the tube of the corolla being shorter; and to Polyozus, but liflers in the stigma being undirided.

1 B. corrmbòsa (D. C. diss. ined. t. 1. ann. mus. 9. p. 219.) h. S. Native of Sierra Leone, where it was collected by Smeathmann. Verulàmia corymbòsa, Poir. dict. 8. p. 543 . Ixòra nítida, Schum. pl. guin. p. 77.

Var. $\beta$, angustifólia (D. C. jrod. 4. p. 485.) leaves narrower than in the species, and more acuminated at both ends. $h . \mathrm{S}$. Native of Gambia and Cayor, in humid places, where it was collected by Leprieur and Perrottet.
Corymbose-flowered Baconia. Shrub 4 to 5 feet.

Cult. See Ixòra, p. 574. for culture and propagation.

CLIX. IXO'RA (the name of a Malabar idol, to which the flowers of some of the species are offered). Lin. gen. no. I31. Juss, gen, p. 203. mem. mus. 6. p. 375. Gærtn. fruct. 1.p. 117. t. 25. D. C. prod. 4. p. 485.-Pavétta sect. Ixòra, Blum. bijdr.- Ixòra species of Lam. and Roxb.-Pavétta species, A. Rich.

Lin. srst. Tetrándria, Monogýnia. Calyx with an ovate tube, and a small 4-tootlied limb (f. I06. $a$.). Corolla salvershaped (f. 106. b.), with a slender terete tube (f. 106. d.), and a 4-parted spreading limb (f, 106. b.); tube longer than the lobes. Anthers 4, ahmost sessile in the throat, exserted a little. Style equal in length to the tube of the corolla, or a little longer, but sliorter than the corolline lobes, bifid at the apex (f. 106.e.); lobes of stigma diverging or revolute. Berry drupaceous, nearly globose, crowned by the permanent calyx, 2-celled, containing 2 chartaceous 1 -seeded pyrenæ, which are flat or hollow inside, and gibbous on the back. Albumen cartilaginous. Embryo dorsal, erect, incurved, with foliaceous cotyledons, and a long radicle.Shrubs, sometimes rising to the height of small trees, natives of Asia, rarely of Africa. Leaves opposite. Stipulas broad at the base, acute at the apex, or ending in a bristle-like awn. Corymbs terminal, usually trichotomous. Flowers scarlet, rose-coloured, flame-coloured or white, usually fragrant.

\section{* Flowers scarlet, flame-coloured, rose-coloured, or flesh-co- loured.}

1 I. Grandiflòra (Ker. bot. reg. t. 154.) leaves sessile, cordate, oblong, acute, shining; lobes of calyx acute; lobes of corolla ovate-lanceolate, acute; corymbs umbellate; style hardly exserted; berry crowned by the lobes of the calyx. $h$. S. Native of the East Indies, at Tanjore; and of China and Ceylon. -Burm. fl. zeyl. t. 57.-Pluk. alm. t. 59. f. 2. I. coccínea, Lin. spec. 159. exclusive of the synonymes. Roxb. fl. ind. 1.p. 385. Smith in Rees' cycl. no. 1. Pavétta coccínea, ex Blum. bijdr. 950. An elegant shrub. Flowers scarlet, disposed in ample corymbs. Tube of corolla almost 2 inclies long.

Great-flonered Ixora. Fl. Aug. Clt. 1S14. Sh. 3 to 4 feet.

2 I. BandHu'ca (Roxb. fi. ind. 1. p. 386.) leaves sessile, cordate, stem-clasping, oval-oblong, obtuse ; coryinbs coaretate; lobes of calyx acutish ; lobes of corolla orate, acutish; style exserted; berry crowned by the spreading calyx. $h$. S. Native of the East Indies, where it is often celebrated by the Hindoo poets. Ker. bot, reg. t. 5 I3. Bandhuica, Jones in asiat, res. 4. p. 250. Schétti, Rheed. mal. 2 . p. 13. t. I2. ex Ham. in Lin. trans. 14. j. 190. I. arbòrea, Lodd. bot. cab. t. 609 ? but not of Roxb. I. obovàta, Roth, nov. spec. p. 90.? A slrub, with spreading branches. Flowers of a deep scarlet colour. Tube of corolla 15 lines long. (f. 106.)

Bandhuca Ixora. Fl. July. Clt. 1815. Shrub 2 to 4 feet.

3 I. PropíneuA (R. Br. in Wall. cat. 6119.) leaves almost sessile, ovate or oblong, cordate at the base, coriaceous, glabrous, mucronate or acuminated; corymbs compound, sessile, 
many flowered; calycine teeth acute; lobes of corolla oblong, acuminated; style exserted, bifid, smooth. h.S. Native of Madras, Ceylon, and Martaban. I. coccinea Ceylonénsis, Roxb. Flower's scarlet. Very nearly allied to I. Bandhùca.

Allicd Ixora. Shrub.

4. I. strícta (Roxb. f. ind. 1. p. 388.) leaves almost sessile, lanceolate-oblong or oblong; corymbs dense, compound; lobes of calyx acutish ; lobes of cornlla obovate, very blunt; stigma a little exserted; anthers apiculated. h. S. Native of China, about Canton, Manilla, the Moluceas, and Plilippines, and now cultivated in Java. I. coccínea, Curt. bot. mag. t. 169. Schnev. icon. t. 1. Lour, cocl?. p. 75. Osb. res. p. 220. but not of Lin. I. stricta, Roxb, hort. beng. p. 10. I. flámmea, Sałisb. prod. p. 62. I. speciòsa, Willd. enum. 1. 1. 157. I. incarnàta, Roxb. ex Smitl, in Rees' cycl. no. 4. Rom. et Schultes, syst. 3. p. 179. exclusive of the synonymes. Pavétta stricta, Blum. bijdr. p. 950. Fláınma sylvàrum peregrìna, Rumplı. amb. 4. t. 47. Branches straight. Flowers of an orange scarlet colour, much crowded. Tube of corolla 9-10 lines long. Berries red.

Straight-branched Ixora. Fl. July, Aug. Clt. 1690. Shrub 1 to 3 feet.

5 I. croca'ta (Lindl, bot. reg. 782.) leaves firm, rather coriaceous, oval-lanceolate, much attenuated; corymbs manyflowered, decompound, crowded, fastigiate; teeth of calyx ovate, acute, short ; lobes of corolla obovate-cuneated, 3 times or more shorter than the tube; style a little exserted, rather hairy in the middle. $h$. S. Native of China, 1. Chinénsis, Lam. dict. 3. p. 344. Flowers orange coloured. Tube of corolla 15 lines long. The species is very nearly allied to $I$. stricta; hut differs in the leaves being stiffer, and in the tube of the corolla being twice the length.

Saffron-coloured-flowered Ixora. Fl. Aug. Sept. Clt. 1822. Shrub 2 to 3 feet.

6 I. incarna'ta (D. C. prod. 4. p. 486. but not of Roxb. ex Smith,) leaves almost sessile, oblong, obtuse and rather cordate at the base, and bluntish at the apex; corymbs on short peduncles; lobes of calyx acute; lobes of corolla oval-oblong, acute. Java. Lodd. bot. cab. t. 1048. Pavétta incarnàta, Blum. bijdr. p. 950 . The flowers are either pale rose-colonred, flesh-coloured or white; but in the British gardens there is only the pale red flowered variety to be found. Tube of corolla 10-11 lines long.

Flesh-coloured-flowered Ixora. Shrub 2 to 3 feet.

7 I. AME'Na (Wall. cat. no. 6121.) leaves oblong-lanceolate, glabrous, petiolate; stipulas cuspidate at the apex; corymbs compound, pedunculate; lobes of calyx obtuse; lobes of corolla bluntish; style and anthers exserted. $h$. S. Native of the East Indies, at Amherst, Chappedong, Tavoy, Pulo-l'enang, \&c. Flowers apparently pale, scarlet.

Pleasing Ixora. Shrub.

8 1. Fu'Lgens (Roxb. fl. ind. 1. p. 387.) leaves almost sessile, lanceolate, acute ; corymbs terminal, compound; lobes of calyx cordate; tube of corolla with a contracted mouth; lobes of corolla lanceolate, acute; berry 2-lobed. $\zeta$. S. Native of the Moluccas. I. lanceolàta, Lam. dict. 3. p. 343 . I. longifòlia, Curt. bot. mag.-Rumph. amb. 4. t. 46.? and therefore I. longifòlia, Smith in Rees' cycl. no. 3.? Branches weak. Flowers deep scarlet. Berries deep purple. Perhajs the BemSchetti, Rheed. mal. 2. t. 57. is a paler variety of this or a nearly allied species.

Fulgent Ixora. Fl. June, Aug. Clt. 1823. Shrub 2 to $5 \mathrm{ft}$. 9 1. Notonis'sa (Wall. cat. no. 6132.) leaves ovate-oblong or oblong, acuminated, coriaceous, glabrous ; panicles terminal, with the branches corymbose and dense; lobes of corolla obtuse; stigma exserted, mndivided; stipulas much acuminated. 々. S. Natives of the East lndies, on the Nellighery mountains. Flowers apparently red or scarlet.

Noton's Ixora. Shrub.

10 1. TENuiflòra (Roxb. fl. ind. 1. p. 397.) leaves on short petioles, oblong, obtuse, smootlı ; panicles terminal, corymbose, contracted; lobes of calyx cordate, obtuse; corolla with a long slender tube, and oblong obtuse lobes, which are longer than the erect style or stamens. $\eta_{2}$.S. Native of the Moluccas. Flowers scarlet. Allied to I. filgens.

Slender-flowered Ixora. Shrub 2 to 4 feet.

11 I. conge'sta (Roxb. H. ind. 1. p. 397.) leaves on short petioles, oblong, coriaceous, acuminated, with coarse parallel veins ; corymbs terminal, short, dense ; flowers almost sessile; teeth of calyx bluntish; lobes of corolla oblong, obtuse; stigma exserted. $\zeta$. S. Native of the Moluccas. Flowers scarlet. Allied to I. fülgens.

Cronded-flowered Ixora. Shrub 2 to 4 feet.

12 I. PE'N DULA (Jack, mal. misc. no. 2. p. 11.) leaves broadelliptic, quite glabrous, pale beneath; branches compressed; corymbs on long trichotomous peduncles, pendulous; lobes of calyx small, acutish; lobes of corolla narrow; stigma exserted. $\zeta$. S. Native of Pulo-Penang, where the most of the Malay Ixoras are called Bunga-yarum. Flowers red.

Pendulous Ixora. Shrub 2 to 4 feet.

13 I. elonga'ta (Heyne, ex Wall. cat. no. 6131.) leaves petiolate, broad-ovate, tapering mucl to the base, glabrous ; floral ones ovate, sessile, cordate at the base, and clasping the stem; peduncles terminal, trichotomous, with the branches corymbose; corymbs hairy ; corolla with a smooth tube, but the segments are downy on the outside, particularly in restivation; Jobes of corolla acute; stigma exserted. $\zeta$. S. Native of the East Indies. Flowers apparently red or scarlet.

Elongated-peduncled 1xora. Shrub.

14. I. ro'sed (Wall. in Roxb. fl. ind. 1. p. 398.) leaves almost sessile, oblong, acute, acuminated, contracted at the base and somewhat emarginate, rather downy on the nerves beneath, as well as the branchlets; corymbs terminal, decompound, large, loose; lobes of calyx acute, rather ciliated; lobes of corolla oblong-cuneated, acute; stigma exserted. Ђ. S. Native of Bengal, on the hills of Silhet. Ker, bot. reg. t. 540 . Sims, bot. mag. 2428. Lodd, bot. cab. t. 729. Flowers rose coloured. Tube of corolla about an inch long. There is a variety of this plant having the leaves glabrous beneath.

Rose-coloured-flowered Ixora. Fl. July. Clt. 1819. Shrub 2 to 4 feet.

15 I. Parviflòra ( $\mathrm{V}$ ahl, symb. 3. p. 11. t. 52. but not of Lam.) leaves on short petioles, coriaceous, lanceolate-oblong, obtuse, cordate at the base, glabrous; stipulas triangular, acute; corymbs panicled, terminal; teeth of calyx short, bluntish; lobes of corolla oblong, 3 times shorter than the tube ; stigma a little exserted. $\zeta$. S. Native of the East Indies. Flowers scarlet.

Small-flowered I xora. Shrub.

16 I. A мвoínica (D. C. prod. 4. p. 487.) leaves on short petioles, ovate-ohlong, acuminated, undulated, glabrous; corymbs compound, trichotomous, divaricate; lobes of calyx and corolla acute. $\zeta$. S. Native of Amboyna. Pavétta Amboínica, Blum. bijdr. p. 949 . Leaves larger than any other of the genus.

\section{Amboyna Ixora. Shrub 4 feet.}

17 I. ERUBE'SCENS (Wall. cat. no. 6143.) leaves oblong, blunt at both ends, glabrous, on short petioles : upper ones sessile ; corymbs downy; lobes of corolla linear ; stigna exserted. $\zeta$. $\mathrm{S}$. Native of the Burmese empire, on the banks of the Atram. Flowers reddish. 1, affinis, Wall, cat. no. 6144. does not ap4 D 2 
pear to differ from this species, except in the more acuminated leaves.

Reddish-flowered Ixora. Shrub.

18 I. JAVA'Nica (D. C. prod. 4. p. 487.) leaves on short petioles, ovate-oblong, acuminated, glabrous; corymbs on long peduncles, trichotomous, divaricate; segments of the calyx obtuse, of the corolla oval and rounded. $\xi_{c}$. S. Native of Java, on the mountains in woods. Pavétta Javánica, Blum. bijdr. p. 949. Flowers of a deep vermilion colour. Habit of $I$. coccinea and 1. incarnàta.

Jaca Ixora. Shrub 3 to 4 feet.

19 I. paucifióra (D. C. l. c.) leaves on short petioles, oblong, acuminated, acute at the base, glabrous; cymes on short peduncles, tripartite, few-flowered; teeth of calyx acute; lobes of corolla oval, acutish. h. S. Native of the west of Java, on Mount Pangarangha, in woods. Pavétta pauciflòra, Blum. Flowers of a vermilion colour. Allied to I.Javanica, but differs in the cymes being fewer-flowered, and on sliorter peduncles; and in the teeth of the calyx being acute.

Fen-flowered Ixora. Shrub.

a0 1. salicifólia (D. C. prod. 4. p. 487.) leaves on short petioles, linear-lanceolate, acuminated, glabrous ; corymbs bracteate; calycine segments acute ; segments of corolla lanceolate, acuminated. h.S. Native of Java, on the mountains. Paıétta salicifòlia, Blum. bijdr. p. 951. Flowers scarlet. A very beautiful spccies. Leaves $9-10$ inches long, and 6 lines broad. Willon-leaved Ixora. Shrub 3 to 4 feet.

21 I. Finlaysonia'na (Wall. cat. no. 6166.) leaves obovatelanceolate, glabrous, tapering much to the base, obtuse, and mucronate at the apex, petiolate; corymbs terminal, compound; lobes of calyx membranous; lobes of corolla obtuse; stigma exserted. h. S. Native of the East Indies. Flowers apparently red.

Finlayson's Ixora. Shrub.

\section{* Flowers white.}

22 I. BLA'NDA (Ker. bot. reg. t. 100.) Jeaves oval or ovatelanceolate, almost sessile; cymes trichotomous, compound, contracted, many-flowered; teeth of calyx short, bluntish; lobes of corolla obovate, reflexed; style a little exserted. $h$. S. Native of the East Indies. I. álbit, Roxb. fl. ind. 1. p. 389. but not of Lin. Nearly allied to I. stricla, but differs in the corolla being white. Peduncles and calyses red. Stigma exserted, but shorter than the lobes of the corolla. Tube of corolla 10 lines long. Flowers at first white, but becoming yellow as they fade. Stipulas broad at the base, and ending in an awn. Bland-flowered Ixora. Fl. Aug. Clt. 1768. Sh. 3 to $4 \mathrm{ft}$.

23 I. Macropliy' LLA (Bartl. in herb. Hænke, ex D. C. prod. 4. p. 487.) glabrous; leaves cuneate-obovate, or oblong-obovate, acute, on short petioles; peduncles elongated, bracteolate at the base, and trichotomously corymbose at the apex; teeth of caly $x$ acute, hardly perspicuous ; stigma exserted, with revolute lobes; fruit nearly globose. $r_{\varsigma}$. S. Native of the Island of Manilla. Allied to I. cuneifolia. Flowers blackish in the dried state, but probably white in the recent state.

Large-leaved Ixora. Shrub.

24. 1. SuBSE'SsiLis (Wall. cat. no. 6139.) leaves oblong, tapering to both ends, petiolate, glabrous; corymbs almost sessile, dense; lobes of calyx subulate; lobes of corolla acute; stigma exserted, $h_{\imath} . S$. Native of Silhet, on the mountains, Stipulas subulate at the apex. Flowers apparently white.

Almost-sessile-corymbed Ixora. Shrub.

25 I. cunenòlis (Roxb. fl. ind. 1. p. 390.) leaves broadcuneated, lanceolate or oblong-lanceolate, acuminated, glabrous ; corymbs terminal, on long peduncles, panicled ; flowers crowded; lobes of calyx oblong, conical; lobes of corolla oblong, obtuse; stigma exserted. $\eta_{\text {. }}$ S. Native of the East Indies, about Dacca and Serampore. Ker. bot. reg. 648. Lodd. bot. cab. t. 1215. Corolla white, with the tube about 6-7 lines long. Berries turbinate, red. Down very minute on the peduncles, branchlets, and usually on the nerves of the leaves underneatls.

Wedge-leaved Ixora. Fl. Ju. Jul. Clt. 1822. Sh. 2 to $4 \mathrm{ft}$.

26 1. ваRвA'TA (Roxb. f. ind. 1. p. 394.) leaves oblong, on short petioles, shining : upper ones almost sessile, and roundly cordate at the base; panicle spreading, loose, sub-corymbose; lobes of calyx acutish ; lobes of corolla oblong, bearded with long white hairs at the throat; stigma exserted. $々 . S$. Native of the East Indies. Smith, in Rees' cycl. no. 6. Sims, bot. mag. 2505. Bem.-Schetti, Rheed. mal. 2. t. 13.? Flowers white. Stigma, according to Roxb. almost at the throat, but in the specimens examined it is exserted. Berries red.

Bearded Ixora. Fl. June, July. Clt. 1823 . Sh. 8 to $12 \mathrm{ft}$.

27 I. oxyPhy'LuA (Wall. cat. no. 6159.) leaves elliptic-lanceolate, long-acuminated, glabrous, on short petioles; stipulas subulate at the apex; Jobes of calyx subulate; stigma exserted. b. S. Native of Silhet, on the mountains. Flowers apparently white.

Sharp-leaved Ixora. Shrub.

28 I. undula'ta (Roxb. fl. ind. 1. p. 395.) leaves broadlanceolate, acuminated, undulated, glabrous; panicle terminal, compound, having its brauches corymbose at the apex; lobes of calyx acute ; segments of corolla linear, bluntish ; stigma exserted; berry transversely oval, somewhat didymous. $h . \mathrm{S}$. Native of Bengal, in woods. Smith, in Rees' cycl. no. 7. Roth, nov. spec. p. 91. Rom. et Schultes, syst. 3. p. 190. Lindl. hort. trans. 7. p. 50 . Ixòra Cània. Ham. ex Wall. cat. no. 6130 . Flowers white. Tube of corolla, 5 lines long; lobes reflexed.

Haved-leaved Ixora. Fl. June, Aug. Clt. 1820. Shrub 3 to 4 feet.

29 I. sPECTA'B1L1s (Wall. cat. no. 6133.) leaves broad, ellipticlanceolate, petiolate, glabrous: upper ones oblong, cordate at the base and stem clasping; peduncles elongated, trichotomous, having the branches corymbose; teeth of calyx small, acute: lobes of corolla narrow. $\zeta$ S. Native of the Burmese Empire, near Martaban. Flowers apparently white.

Showy lxora. Shrub.

30 I. lanceora'ria (Colebr. in Roxb. fl. ind. 1. p. 397.) leaves approximate, very long, ovate-lanceolate, acuminated, on short petioles, glabrous; corymbs terminal, alnost sessile, small; bracteoles coloured; corolla with a filiform tube, and linear-oblong lobes; anthers linear, bifid at the base; style exserted. F. S. Native of the East Indies, in Travancore. Branches twiggy, pendulous, somewhat dichotomous. Stipulas subulate at the apex, rather longer than the petioles. Corolla white, having the tube 9 lines long. Berries red, globose.

Lanceolar-leaved Ixora. Shrub 4 to 6 feet.

31 I. Levca'́nтia (Wall. cat. no. 6148.) leaves ovate-lanceolate, acuminated on sloort petioles; peduncles and corymbs downy; stipulas subulate at the apex; lobes of calyx, and bracteas subulate; lobes of corolla long and narrow; stigma much exserted; corymbs loose. $h$. S. Native of the East Indies, near Travancore. Flowers white.

White-flowered Ixora. Shrub.

32 I. ARBòre A (Roxb. mss, ex Smith, in Rees' cycl. no. 5. but not of Lodd.) leaves elliptic-oblong, obtuse, on short petioles, rather undulated, smooth; corymbs triclıotomous, divaricate, sessile, many-flowered; teeth of calyx acutish; lobes of corolla oblong, obtuse, one-half shorter than the tube; stigma hardly exserted. $r_{\imath}$.S. Native of the East Indies. I. Pavétta, Andr. bot. rep, t. 78. Pers. ench. 1. p. 130. but not of Roxb. Corolla white, 5 lines long. Stigmas 2, thickish, greenish at the throat. 
Arboreous Ixora. Fl. June, Aug. Clt. 1800. Shrub 4 to 12 feet.

S3 I. BRACHY'PODA (D. C. prod. 4. p. 488.) glabrous leaves, on very short petioles, elliptic-oblong, bluntly acuminated; stipulas intrapetiolar, combined, truncate, and mucronated on both sides; corymbs terminal, pedunculate, shorter than the leaves; limb of calyx very short, bluntly 5 -toothed. $h_{c} . S$. Native of equinoctial A frica, in the woods of Casamancia, where it was collected by Leprieur and Perrottet. Leaves 6 inches long, and 2 broad, and the petioles about 2 lines long. Tube of corolla, almost an inch long. Bracteas small. Flowers pale in the dried specimens, but are probably white in the recent state.

Short-pctioled Ixora. Shrub 4 to 5 feet.

34 I. Acunina'ta (Roxb. fi. ind. 1. p. 393.) leaves petiolate, broad-lanceolate, acuminated, smooth, glaucous : floral leaves stem+clasping, and broader; corymbs supra-decompound, crowded, almost sessile ; lobes of calyx ensiform ; lobes of corolla ovateoblong, obtuse; stigma exserted, undivided. $々$. S. Native of the East Indies, in the province of Silhet, in woods. Flowers large, white, with the tube $1 \frac{1}{2}$ inch long. Calyxes white.

Acuminated-leaved Ixora. Shrub 3 to 5 feet.

85 I. Sinue'nsis (Wall. cat. no. 6162.) leaves orate-oblong, mucronate, cordate at the base : upper ones attenuated at both ends; corymbs terminal; lobes of corolla acute; stigma exserted. $\mathbf{b}$. S. Native of Siam, in the East Indies. Flowers white?

Siam Ixora. Shrub.

36 I. opA'cA (R. Br. in Wall. cat. no. 6141.) leaves long-lanceolate, acuminated, petiolate, glabrous; corymbs downy; tecth of calyx small; lobes of corolla obtuse; stigma exserted. h.S. Native of Pulo-Penang. Flowers apparently white.

Opaque-leaved Ixora. Shrub.

37 I. вRAchia'ta (Roxb. fl. ind. 1. p. 39l.) leaves on short petioles, broad-lanceolate, obtuse, glabrotis; panicle brachiate, with remote diverging corymbose branches; tube of corolla filiform, and the lobes are obovate and emarginate; anthers sessile at the throat; stigma exserted. $h$. S. Native of Bengal, in woods. Flowers small, white. Nearly allied to I. parviflòra, Valll, but differs in the flowers being white. Berries deep purple, rather larger than peas. Petioles about half an inch long.

Brachiate-panicled Ixora. Clt. 182.3. Shrub 2 to 4 feet.

38 I. Decíplens (D. C. prod. 4. p. 488.) glabrous; leaves on short petioles, oblong-lanceolate, acutish at the base, acute or obcordate at the apex; stipulas broad at the base, and ending in a subulate awn at the apex; corymbs terminal, tripartite at the base, sessile, with panicled branches; lobes of calyx short, bluntish; corolla with a slender tube, and oval, bluntish lobes; style pilose. $h_{c}$. S. Native of Coromandel, on the mountains. I. parvifiora, Roxb. fl. ind. 1. p. 393. but not of Vahl, nor Lam. Flowers white, sweet-scented. Tube of the corolla 4 lines long, twice the length of the lobes. Berries roundish, black.

Deceiving Ixora. Fl. Aug. Oct. Clt. 1806. Tree 20 feet.

39 I. Brunònis (Wall. cat. no. 6136.) leaves obovate-lanceolate, sessile, cordate at the base, acuminated at the apex, downy beneath, but villous on the nerves; peduncles and corymbs villous, as well as the calyxes and corollas outside; bracteas and teeth of calyx subulate; lobes of the corolla narrow, acute; stigma exserted. $\zeta$. S. Native of Pulo-Penang. Flowers apparently white. Allied to $I$, villosa.

Bronn's Ixora. Shrub.

40 I. villòsa (Roxb. fl. ind. 1.p. 39\%.) leaves broad-cuneatedlanceolate, acuminated, villous beneath, on short petioles; corymbs trichotomous, or 6 to 7 times divided, with the branches trichotomous and villous; lobes of calyx oblong, ciliated; corolla with a very long slender tube, and oblong obtuse lobes. h.S. Native of the East Indies, in Silhet. Flowers white, fragrant. Stipulas and branches villous.

Villous Ixora. Shrub 4 to 5 feet.

41 pubiruòra (I). C. prod. 4. p. 489.) leaves scssile, obovateoblong, cuneated, and somewhat cordate at the base, acuminated at the apex, downy on the nerves on both surfaces, as well as the branchlets, corymbs, and corollas ; stipulas long, subulate at the apex; corymbs terminal, dense, sessile; teetl of calyx and alabastra, very acute. $々$. S. Native of the East Indies. A very distinct species. Leaves 8 inches long and 8 broad. Corollat having the tube about 9 to 10 lines long, and the lobes linear and acute, about 3 lines long.

Downy-flowered Ixora. Shrub.

42 I. LONGIFòlta; leaves broad, elliptic-lanceolate, tapering to both ends, glabrons above, and villous beneath, particularly on the nerves, as well as the branches, petioles, peduncles, panicles and fruit; segments of the calyx subulate. $h_{2} . S$. Native of Pulo-Penang. I. macrophýlla, R. Br. in Wall. cat. no. 6165.

Long-leaved Ixora. Slirub.

\section{$\dagger$ Species not sufficiently known.}

43 I. A'LBA (Lin. spec, 160. but not of Roxb.) leaves ovatelanceolate: flowers fasciculate. h. S. Native of the East Indies, but is a very obscure species, and probably fictitious; the description taken from the figure in Pluk. alm. t. 109. f. o. and Bem.-Schetti Rheed, mal. 2. t. 14. Plukenet's plant belongs to I. incarnata, and Rheede's probably to $I$. fúlgens. 'The flowers are said to be terminating in small clusters, white, and without scent.

White-flowered Ixora. Shrub 6 to 7 feet.

44 I. Lovreírı; leaves ovate-oblong, acute, smooth, nearly sessile; cymes or corymbs fasciculate. h. G. Native of Cochin China. I. álba, Lour. coch. 76. Flowers white. Berries red.

Loureiro's Ixora. Slirub 3 to 4 feet.

45 1. Monta'na (Lour. coch. p. 76.) leaves oblong, broadest at the apex, obtuse, cmeated and cordate at the base, nearly sessile, glabrous; corymbs terminal, fastigiate. 々.G. Native of Cochin China, on the mountains. Flowers scarlet.

Mountain Ixora. Shrub 3 to 4 feet.

46 I. Novemne'rvia (Lour. coch. p. 76.) climbing; leaves ovatelanceolate, almost sessile, 9-nerved, rough; cymes terminal, hemispherical. $\quad \xi . \cup$. G. Native of Cochin Clina, in uncultivated places. Flowers white, terminating in hemispherical cymes. Tube of the corolla very long and slender. Stigma ovate, bifid. Berry 1 -seeded.

Nine-nerved-leaved Ixora. Shrub cl.

47 I.? viola'cea (Lour. coch. p. 76.) climbing; leaves lanceolate, almost sessile, pilose, 9-nerved; cymes axillary. h. G. Native of Cochin China, in uncultivated places, climbing over trees. Flowers violaceous. Berry 1 -seeded. Seed ovate, rough.

Fiolaccous.flowered Ixora. Shrub cl.

48 I. Thy rsiflòra (Poir. suppl. 3. p. 208.) leaves almost sessile, ovate-cuneated, obtuse, glabrous on both surfaces, hoary beneath ; stipulas ovate, acute; thyrse terminal, crowded; teetl of calyx acute, somewliat setaceous ; corolla with a slender tube, and oval obtuse lobes, which are shorter than the tube. h. G. Native of the Cape of Good Hope.

Thyrse-fowered Ixora. Shrub.

49 I. Laxir Lòra (Smith, in Rees' cycl, vol. 19. no. 8.) leaves elliptic-oblong, acute, tapering into the petioles at the base: upper ones rounded at the base, almost sessile; panicles corymbose, loose, longer than the leaves; lobes of the corolla convex, spreading, bearded in the disk above: style nearly the length of 
the limb. $h$. S. Native of Sierra Leone. This plant does not probably belong to the genus.

Loose-flonered Ixora. Shrub.

N. B. C. multiflòra (Swartz, prod. 30. fl. ind. oce. p. 240.) should be excluded from the order altogether, from the leaves being alternate, and crowded into fascieles; in the want of stipulas; in the flowers rising from the same bud as the faseicles of leaves; in the tube of the eorolla being funnel-shapred, and in the stamens being inserted in the receptaele.

Cult. Most of the species of this genus are truly beautiful when in blossom, and are therefore worth cultivating in every collection. They require to be kept in a moist heat, but the pots should never be plunged in tan. A mixture of turfy loam, turfy peat, and sand in equal portions, is the best soil for them; and euttings strike root readily if planted in sand or even mould, placed in heat, with a hand-glass over them.

CLX. PAVE'TTA (the vernacular name of $P$. I'ndica in Malabar). Lin. gen. no. 132. Juss, gen. p. 203. mem. mus. 6. 12. 375 . Gartn. fruct. 1. p. 116. t. 25. D. C. prod. 4. p. 490. -Pavéttæ veræ, Blum. bijdr. p. 951.-Ixòra species of Lam. and Roxb.-Pavétta speeies, A. Rich.-Pavàte, Ray.

I.1N. syst. Tetrándria, Monogýnia. All as in Jxòra, but differs from that genus in the style being mueh exserted beyond the mouth of the tube of the corolla, even execeding the seyments of its limb, elavate at the apex, nearly entire, or the lobes of the stigma are so close as scareely to be distinguished. Flowers white.-All the species are either natives of Afriea or Asia.

\section{* Asiatic species, especially from India and Arabia.}

1 P. I'NDiea (Lin. spec. 160.) leaves oval-oblong, acuminated at both ends, petiolate; stipulas broad, aeute, somewhat concrete; paniele terminal, subeorymbose, with opposite branches; teeth of ealyx acute; lobes of corolla one-half shorter than the tube; style very long. $\zeta$. S. Native of the East Indies, frequent in hedges, and among bushes. Gærtn. fr. 1. t. 25. P. álba, Vah], symb. 3. p. 11.? Ixòra paniculàta, Lam. diet. 3. p. 34 1. Ixòra Pavétta, Roxb. f. ind. 1. p. 395. Pavétta polyántha, Wall. cat. no. 6176. Pavétta, Rlıeed. mal. 5. p. 10. - Burm. ind. t. 13. f. 3. Pavàte, Raii, list. 1581. Flowers white. There are varieties of this species with either glabrous branches and leaves, or the branches and under surfaees of the leaves are downy.

Indian Pavetta. Fl. Aug. Oet. Clt. 1791. Sh. 3 to 4 feet.

2 P. ARtòsa (Lour. coeh. p. 73.) branches braehiate; leaves lanceolate, tubereular, shining; flowers terminal, fastigiate; calyx baecate, 5 -toothed; corolla salver-shaped, 5 -cleft ; anthers 4 , sessile at the throat; berry ovate, 1 -seeded, $h . G$. Native of China, about Canton. P. l'ndica, Ker, bot. reg. 190. The leaves appear as if they were sprinkled over with sand, hence the Chinese name of the shrub Tasa or sand plant. Elowers white.

Sandy-leaved Pavetta. Fl. March, Oct. Clt. 1799. Shrub 3 to 4 feet.

3 P. томемто'sa (Roxb. ex Smith in Rees' eyel. vol. 26. but not of Rich.) leaves petiolate, oblong, villous on botl surfaees, but partieularly beneath; panicles terminal, broad, tomentose, with trifid branches. $\zeta$. S. Native of the East Indies, Ixòra tomentòsa, Roxb. fl. ind. 1. p. 396. Pavétta tomentòsa, Rotl, nov. spee. p. 89. Pavétta velutina, Wall. cat. no. 6174 . Flowers ummerous, white, fragrant. Style twice the length of the tube of the eorolla; stigma clavate, undivided. Berry globose.

Tomentose Pavetta. Shrub.
4. P. monta'na (Reinw, in Blum. bijdr. p. 95.) leaves on long petioles, oblong-lanceolate, mueh acnminated at both ends, downy, as well as the corymbs, which are terminal, trichotomous, and braehiate; ealveine teeth acute; segments of eorolla acutish. $h$. S. Native of Java, in woods on the mountains. Very nearly allied to $P$. I'ndica. Flowers white, having the segments tipped with green.

\section{Marutain Pavetta. Shrub 4 to 5 feet.}

5 P. odora'ta (Blum. bijdr. p. 952.) arboreous; leaves on short petioles, oblong, acute at both ends, but usually bluntish at the apex, coriaceous, glabrous ; eorymbs terminal, trichotomous, divarieate, downy; limb of ealyx bluntly toothed; segments of corolla obtuse. h. S. Native of Java, on the mountains in woods. Flowers white, very sweet scented.

Sneet-scented-flowered Pavetta. Shrub 4 to 5 feet.

6 P. waerophy'Lla (Blum. bijdr. p. 953.) Jeaves on short petioles, oblong, very blunt, attenuated at the base, coriaceous, glabrous ; corymbs axillary and terminal, downy, trichotomously fastigiate; segments of calyx and corolla blunt. $\zeta$. S. Native of Java, in mountain woods. Flowers white.

Long-leated Pavetta. Shrub 4 to 5 feet.

7 P. Reticula'ta (Blum. bijdr. p. 953.) leaves oblong, aeuminated at both ends, eoriaceous, glabrous, reticulated beneath; corymbs terminal, trichotomous, loose, on long peduncles ; segments of calyx aente; segments of eorolla lanceolate, acuminated. $\zeta$. S. Native of Java, on Mount Salak. Flowers white. Stem 4 feet high, Young branches compressed. Fruit didymously globose.

Reticulatcd-leaved Pavetta. Shrub 4 feet.

8 P. Lóngires (D. C. prod. 4. p. 490.) leaves oval-oblong, aeuminated, petiolate, glabrons; stipulas short, acuminated; peduncles terminal, longer than the leaves, eorymbose at the apex, few-flowered; fruit ovate, didymons, naked at the apex. h.S. Native of the island of Timor. Upper leaves 4-5 inches long, $1 \frac{1}{2}$ to 2 broad. Peduncles slender, 6 inches long. Corolla with a slender tube, and 4 oblong spreadingly reflexed lobes. Anthers linear. Style a little exserted; stigma thick, bipartite.

Long-peduncled Pavetta. Shrub 4 to 5 feet.

9 P. PALudo'sa (Blum. bijdr. p. 954.) leaves on short petioles, oblong, bluntisl, membranous, glabrous: the upper ones oblong-eordate, sessile; corymbs terminal, on long peduncles, triehotomous, eoloured; teeth of calyx obtuse ; segments of corolla oblong, acute. $\boldsymbol{h} . \mathrm{S}$. Native about Batavia, in marshes. Flowers white. Allied to Ixòra barbàta.

Marsh Pavetta. Shrub 4 to 5 feet.

10 P. sylva'tiea (Blum. bijdr. p. 953.) leaves oblong-lanceolate, acuminated at both ends, membranous, glabrous, downy in the axils of the veins beneath; corymbs terminal, peduneulate, loosely trichotomous; limb of calyx obsoletely denticulated; segments of corolla oblong, obtuse. $h$. S. Native of Java, in woods on the Seribu mountains. Flowers small, white.

IIood Pavetta. Shrub + to 5 feet.

11 P. breviflóra (D. C. prod. 4. p. 491.) Jeaves aval, acute, acuminated at the base, on short petioles, rather membranous, glabrous; paniele eorymbose, many-flowered, with opposite branches and branchlets, and are as well as the flowers glabrous; tube of eorolla hardly longer than the lohes. $h$. S. Native of the East Indies, on the Nellighery mountains, where it was colleeted by Leschenault. Tube of corolla 3 lines long. Style 4 lines long, elavate at the apex. Stipulas broad, rather membranous. Plant becoming blaekish on drying.

Short-flowered Pavetta. Shrub 3 to 4 feet.

12 P. Rotmin (D. C. prod. 4. p. 491.) branchlets and ealyxes elothed with hoary villi ; leaves elliptic, petiolate, rather hairy, but while young clothed with hoary tomentum; stipulas 
triangular, glabrous inside; flowers disposed in panicled co. rymbs, bearded; corolla with a long terete tube, which is bearded at the throat, and oblong obtuse lobes; style setaccous, glabrous. $\quad$. S. Native of the East Indies. P. villòsa, Roth, nov. spec. p. 88 . but not of Vahl.

Roth's Pavetta. Shrub 3 to 4 feet.

13 P. navelexfo'ra (R. Br. in Wall, eat. no. 6171.) villous in every part; leaves oblong-lanceolate, acuminated; corymbs terminal; teeth of calyx short, acute; lobes of eorolla obtuse. h.S. Native of Pulo l'enang. Fruit round.

Nauclea-flonered Pavetta. Shrub.

14 P. Buvxònss (Wall. cat. no. 6172.) soft and villous all over; leaves obovate; stipulas and bracteas broad, membranous; peduncles trichotomous, having the branches dense and corymbose; lobes of calyx subulate. h. S. Native of the East Indies, on the Nellighery mountains. Pavétta móllis, Wall. eat. no. 6179. Leaves smoothish above in the adult state.

Brom's Pavetta. Shrub.

15 P. Weberefòlia (Wall. eat. no, 6182.) leaves broadlanceolate, glabrous, tapering to both ends; corymbs downy; fruit spherical, $\zeta_{c}$. S. Native of Pulo-Penang and Chittagong.

II ebcra-leaved Pavetta. Shrub.

16 P. Sumatre'xsis (Roth, nov. spec. p. 88. and in Rom. et Schultes, syst. 3. p. 176.) leaves petiolate, oblong-elliptic, glabrous, strigose on the ribs beneath; corymbs trichotomous; flowers pentandrous, clothed with white tomentum; corolla with a filiform tube, and oblong obtuse lobes; style much exserted; stigma oblong, glabrous. h.S. Native of Sumatra. Flowers white.

Sumatra Pavetta. Shrub 5 to 4 feet.

17 P. Longiflòra (Vahl, symb. 3. p. 12.) leaves lanceolateelliptic, and are as well as the branches glabrous; stipulas pilose inside; flowers disposed in fascicles; teeth of calyx rather long, acute. h.S. Native of Arabia Felix. Ixora occidentàlis, Forsk. cat. p. ev. Ixòra longiflòra, Poir. suppl. 3. p. 208. Flowers white. Berries black. Corolla an inch and a half in diameter.

I'ar. $\beta$, Javàna (D. C. prod. 4. p. 491.) leaves on short petioles, oblong, acute at both ends, coriaccous; corymbs terminal, fastigiate, trichotomous, downy ; tube of corolla very long; lobes of ealyx and corolla acute. $h_{c} . S$. Native of Java, in woods on the mountains. Pavétta longiflòra, Blum. bijdr. p. 152. Long-flowered Pavetta. Shrub.

18 P. vılcòsa (Vahl, symb. 3. p. 12.) branches and calyxes villous, hoary; leaves on short petioles, elliptie-lanceolate, clothed with canescent villi while young; flowers in fascicles. そ. G. Native of Arabia Felix. Ixòra villòsa, Poir. suppl. 3. p. 208. Leaves smooth on the upper surface in the adult state. Branches 4-cornered. Flowers white. Stipulas, style, and stigma as in P. I'ndica.

Tillous Pavetta. Shrub.

\section{* African species.}

19 P. Owarie'Nsis (Beauv. f. d'ow, 1. p. 87.t. 52.) leaves on long petioles, ovate-oblong, attenuated at both ends, membranous, glabrous ; corymbs terminal ; lobes of calyx oval, acutish; lobes of corolla linear, obtuse, almost the length of the tube; style twice as long as the tubc, clavate at the apex. $\zeta . \mathrm{S}$. Native of the west coast of A frica, between Waree and Buonopozo. Ixòra Owariénsis, Poir. suppl. 3. p. 207. Flowers white. Throat of corolla very villous. Stipulas short, stem-clasping, apiculated by a short point at the apex.

Warce Pavetta. Shrub 4 to 5 feet.

20 P. CA'FFRA (Thunb. prod. p. 29. Al. cap. 1. p. 535.) leaves obovate, almost sessile, glabrous; stipulas membranous, connate; flowers subumbellate; teeth of calyx setaeeous; lobes of corolla oblong, acute, shorter than the tube. h. G. Native of the Cape of Good Hope, in the woods of Krakokamma. Ixòra Cáftra, Poir. suppl. S. p. 209. Pavétta eorymbòsa, Houtt. ed. 1. p. 11. t. 40. and Crinita Capénsis, Houtt. pfl. syst. 5. p. 357. t. 40 . f. 1. ex 'Thunb. and Roem. syst. 3. p. 175. Ixòra álba, Burm. herb. Pav. thyrsitlora, Thumb. herb. Corymbs of flowers terminating in shorter branches. Flowers white. Style much exserted, clavate at the apex. This is a beautiful shrub when in flower.

Caffrarian Pavetta. Fl. June, Aug. Clt. 1823. Shrub 3 to 4 feet.

21 P. parviflòra ( $\mathrm{Afz}$, rem. guin. p. 47.) leaves oblong, attenuated at hoth ends; stipulas aeute; peduncles diclotomously umbellate; calyxes and corollas villous. $々$. S. Native of Guiana. Flowers white.

Small-flowered Pavetta. Shrub \& to 5 feet.

22 P.? Smeatuna'nni (D. C. prod. 4. p. 492.) leaves oval, short-acuminated, coriaceous, smooth, on short petioles; corymbs axillary, on short peduncles; teeth of calyx oblong, ciliated; corolla with a terete tube, and the limb globose before ex. pansion. h.S. Native of Sierra Leone. Pavétta parviflòra, Smeathm. herb. Perhaps this plant belongs to a difierent genus. Smeathmann's Pavetta. Shrub 3 to 4 feet.

23 P. subgra'bra (Schum. pl. guin. p. 78.) branches terete, nearly glabrous; leaves ovate, acuminated, rather ciliated at the base; petioles ratlier hairy ; stipulas ciliated on the inside, ovate, mucronate; corymbs festigiate, terminal; lobes of calyx lanceolate, acute. $\zeta$. S. Native of Guinea. Flowers white. Stigma globose.

Nearly-glabrous Pavetta. Shrub 4 to 5 feet.

24. P. GENIPEfòlia (Schum. pl. guin. p. 78.) branches terete, downy ; leaves oblong-lanceolate, acuminated, shining, glabrous, downy beneath and on the petioles; stipulas setaceously acuminated; corymbs terminal, globose; peduncles and calyxes hairy. h.S. Native of Guinea. Flowers white.

Genipa-leaved Pavetta. Slirub 4 to 5 feet.

25 P. Lateriflòra; leaves oblong-lanceolate, coriaceous, acuminated, almost sessile, disposed in 2 rows; peduncles axillary, subcorymbose. h.S. Native of Sierra Leone. Flowers white. Berry roundish, containing a 1 -seeded nut. Cotyledons long, twisted. Perhaps the same as P. Smeathmánni.

Side-flowered Pavetta. Shrub 4 to 6 feet.

26 P. CANE'scens (D. C. prod. 4. p. 492.) branchlets clothed with white hairs; leaves elliptic, attenuated at the base, on short petioles, reticulately veined, downy above, and clothed with canescent villi beneath; corymbs lateral, many-flowered, almost sessile; pelicels and calyxes hairy; corolla with a downy tube, and a glabrous limb; style much exserted, rather clavate at the apex. $h$.S. Native of the South Western Coast of Africa, in Angola. Pavétta tomentòsa, A. Rich. mem. soc. hist. nat. par. 5. p. 181. but not of Roxb. Flowers white.

Canescent Pavetta. Shrub.

\section{*** Specics natives of Madagasear.}

27 P.? ANTHophy'LLA (A. Rich. in mem. soc. list. nat. par. 5. p. 181.) quite glabrous; leaves short, oval, acute, rather fleshy; stipulas broad, short, acuminated, permanent ; flowers cymose, terminal, pentamerous; one of the ealycine lobes is drawn out into a leaf; anthers inclosed; style much exserted. 々. S. Native of Madagascar. Perhaps a proper genus.

Leaf-flowered Pavetta. Shrub.

28 P. cine'reA (A. Rich. l. e.) shrub clothed with grey tomentum; leaves rather oval, acute, gradually narrowed at the base, clothed with cinereous tomentum, especially beneatls; stipulas connate, lanceolate, permanent ; cymes terminal, peduncu- 
late, branched; flowers tomentose. $\zeta$. S. Native of Madagascar.

Cinereous Pavetta. Shrub.

29 P. grA'CILIs (A. Rich. l. c.) quite glabrous; leaves cllipticoblong, very acute, almost sessile; stipulas connate, narrowlanceolate; cymes few-flowered, terminal; flowers very long, slender; stamens exserted; style hardly exserted beyond the tube. h.S. Native of Madagascar. Perhaps a proper genus. Slender-flowered Pavetta. Shrub.

\section{*** Species natives of the South Sca Islands.}

30 P. opulina (D. C. prod. 4. p. 492.) leaves ovate-lanceolate; corymbs coarctate, globase, terminal. $\zeta$. S. Native of New Caledonia. Coffèa Opulina, Forst. prod. 1. no. 93. Chiocócca Opulina, Spreng. syst. 1. p. 756 . I ròra species, A. Rich. Bracteas roundish, scarious. Pedicels rather hispid. Lobes of the corolla 4, linear, revolute, obtuse. Style simple, clavate, twice longer than the corolla. Flowers white.

Guelder-rose-like Pavetta. Shrub.

31 P. sanbu'cina (D. C. prod. 4. p. 492.) leaves oblonglanceolate, acute, glabrous; cymes corymbose, terminal. $\downarrow_{2} . \mathrm{S}$. Native of the Friendly Islands. Coffèa Sambùcina, Forst. prod. 1. no. 92. Branchlets tetragonal. Leaves a span long. Branches of the panicle verticillate. Lobes of the corolla 5, spreading, bluntish. Style simple, clavate, much longer than the stamens, ex Spreng. pug. l.p. 16. Chiocócca sambùcina, Spreng. syst. 1. p. 756. Ixòra species, ex A. Rich. Flowers white.

Elder-like Pavetta. Slurub.

32 P. triflòra (D. C. prod. 4. p. 492.) leaves ovate-lanceolate, acuminated; peduncles terminal, by threes, 3-flowered. $r_{i}$. S. Native of Otaheite. Chiocócca triflòra, Spreng. syst. 1. p. 756. Coffèa triflòra, Forst. prod. 1. no. 95. Flowers white.

\section{Three-flomered Pavetta. Shrub.}

\section{+ Specics not sufficicntly known.}

33 P. Angustifòdia (Rœem. et Schultes, syst. 3. p. 175.) leaves linear-lanceolate, attenuated at both ends; cymes terminal, trichotomons, subumbellate; teeth of calyx acute; corolla with a slender tube, and oblong acute lobes. $h . S$. Native of the East Indies. Pavétta I'ndica, Burm. fl. ind. p. 35. t. 13. f. 3. exclusive of the synonymes. Ixòra angustifòlia, Lam. dict. 3. p. 45. Flowers white. Stigma nearly entire as in Pavétta, and about equal in length to the lobes of the corolla, as in Ixora.

Narrom-leaved Pavettat. Shrub 3 to 4 feet.

34. P. amplexicau'irs (Pers. ench. 1. p. 131.) glabrous; leaves stem-clasping, oval; segments of corolla acute, lanceolate. $\eta$.S. Native of the East Indies; and is often mixed with $P$. I'ndica according to Persoon.

Stem-clasping-leaved Pavetta. Slirub 3 to 4 feet.

35 P.? PARAsítica (Lour. coch. p. 73.) stem parasitical, much branched; leaves verticillate, ovate, tomentose ; clusters of flowers axillary; calyx tetragonal, truncate, villous; corolla with a long tube, and 4 oblong inflexed lobes; style equal in length to the corolla; berry I-seeded. $\eta_{2}$. G. Native of Cochin-china, in gardens, growing upon trees. Flowers small, dusky yellow. This plant should probably be removed from the genus.

Parasitical Pavetta. Shrub 1 foot.

Cult. For culture and propagation see Ixòra, p. 574.

CLXI. SAPRO'SMA (from oaroos, sapros, rancid, and $o \sigma \mu \eta, o s m e$, a smell; the wood and berries are very fetid). Blum. bijdr. p. 956. A. Rich. mem. soc. hist. nat. Par. 5. p. 178. D. C. prod. 4. p. 493.-Brùchia, Scliwagr.
Lin. syst. Tetrándria, Monogýnia. Calyx with an oval tube, and a small 4-toothed permanent limb. Corolla 4-cleft, with a hairy throat. Stamens 4, inserted in the throat of the corolla; filaments short; stigma bifid. Berry oval, smooth, umbilicate, 1 -seeded, crowned by the permanent calyx. Embryo erect, in fleshy albumen.- Trees or shrubs, natives of Java. Leaves opposite, glabrous, acuminated at both ends. Flowers crowded, terminal, rarely axillary, sessile. Berry and wood very fetid.This genus comes very near the following.

1 S. авво'rеvм (Blum. bijdr. p. 956.) arboreous; leaves petiolate, elliptic-oblong; flowers crowded, terminal, and sometimes axillary. $\zeta$.S. Native of Java, in mountain woods.

Tree Saprosma. Tree.

2 S. Frutrco'sum (Blum. bijdr. p. 956.) shrubby; leaves almost sessile, oblong-lanceolate; flowers crowded, terminal. $\boldsymbol{h}$. S. Native of Java, on Mount Parang.

Shrubby Saprosma. Shrub.

Cult. See Ixòr $\alpha$, p. 574. for culture and propagation.

CLXIJ. COUSSA'REA (Aublet does not give the meaning of this word). Aubl. guian. 1. p. 98. t. 38. Lam. ill. 1. p. 281. t. 65. A. Rich. mem. soc. hist. nat. Par, 5. p. 177. t. 18. f. 1 . and 2. D. C. prod. 4. p. 493.-Coussàrea and Frolíchia, Juss. mem. mus. 6. p. 376.-Froelichia, Vahl. ecl. praf. 3. but not of Mlench, nor Wulf.-Billardièra, Vahl, ecl. 1. p. 13. t. I0. f. 3. but not of Smith, nor Mcench.-Pechèya, Scop. intr. p. 143. no. 530 .

Lin. syst. Tetrándria, Monogýnia. Calyx with an ovate tube, and a short tubular sinuately 4 -toothed limb. Corolla with an elongated terete tube, which is hardly tumid at the apex, and a glabrous throat. Stamens 4, inserted in the upper part of the tube, inclosed ; anthers oblong-linear. Style filiform; stigma bipartite, with the lobes linear, and hardly exserted. Berry ovate-globose, hardly fleshy, crowned by the tubular limb of the calyx, 1-celled, 1-seeded. Seed rather globose, fixed to the sides of the parietes. Embryo small, in a pit at the bottom of the albumen, which is horny, with a thick coriaceous radicle, which is longer than the small cotyledons.-Glabrous shrubs, natives of America. Leaves opposite, coriaceous, on short petioles. Stipulas solitary on both sides, acute. Flowers terminal, few, rather crowded, on short pedicels, white.

1 C. viola'cea (Aubl. guian. 1. p. 98. t. 38.) leaves ovate, acuminated; flowers terminal, almost sessile. $\zeta_{\text {. }}$. S. Native of French Guiana, in the woods called Caux woods. Flowers white. Berries violaceous.

Violaccous-berried Coussarea. Shrub 7 to 8 feet.

2 C. raceno'sa (A. Rich. in mem. soc. hist. nat. Par. 5. p. 177.) leaves elliptic, acuminated; stipulas caducous; flowers small, disposed in terminal pedunculate racemes; fruit ovoid, compressed, white, $\eta$. S. Native of French Guiana.

Racemose-flowered Conssarea. Shrub.

3 C. macrocárpa (A. Rich. l. c.) leaves elliptic, acuminated; stipulas caducous; flowers disposed in terminal and axillary, hardly pedunculate racemes; fruit ovoid, black. h.S. Native of French Guiana. Very like the preceding species. Long-fruitcd Coussarea. Shrub.

4 C.? squano'sa (Lam. ill. p. 2S1. no. 1462.) leaves ovateoblong; cymes scaly, axillary; limb of calyx cylindrical. $h . S$. Native of the Caribbee islands.

Scaly-cymed Conssarea. Shrub.

5 C. Frefícina (A. Ricl. 1. c.) leaves oblong-lanccolate, acuminated at both ends; panicle corymbose, terminal, pedunculate; peduncles compressedly angular. $h$. S. Native of the island of Trinidad, ex Valsl; and of Porto Rico, where it was collected by Ryan. Frœlichia paniculàta, Vahl, ecl. præf. p. 3. Billardièra paniculàta, Vahl, ecl. 1. p. 13. t. 10. f. 3 . 
RUBIACEE. CLAHI. Polrozus.

Stipulas very short, rounded, acuminated on botlı sides, ex Vahl; but in the specimen collected at l'orto-Rico by Ryan, the stipulas are connate a little way at the basc, and bidentate at the apex; both are, however, probably the same species.

Freelich's Coussarea. Shrub.

Cult. For culture and propagation see Ixòra, p. 574 .

CrXIII. POLYO'ZUS (from $\pi 0 \lambda v$, poly, many, and $o$ לoc, $0 z o s$, a branch; in reference to the shrub, which is much branched). Lour. coch. p. 74. exclusive of the first species. D. C. prcd. 4. p. 494. Blum. bijdr. p. 947.-Polyòzus, A. Rich. mem. soc. hist. nat. Par. 5. p. 183.-Ixòra species, Poir.

Lin. syst. Tetra-Pcnlándria, Monogýnia. Calyx with a turbinate tube, and an obsoletcly denticulated deciduous limb. Corolla with a cylindrical tube, a villous throat, and $4-5$ spreadingly reflexed lobes, which are longer than the tube. Anthers 4-5, alternating with the-lobes of the corolla, hardly exserted. Style short; stigma bifid. Ovarium crowned by the disk. Berry drupaceous, nearly globose, 2-celled, naked at the apex; cells containing 1 pyrena each. Pyrenæ excavated on the inside, and gibbous on the back, coriaceous, 1-seeded. Albumen cartilaginous. Embryo minute, erect.--Sinall glabrous trees, natives of Asia and the Mauritius. Leaves opposite. Stipulas interpetiolar. Cymes trichotomous, axillary, and terminal.-This genus is nearly allied to Ixòra, but differs in the tube being shorter than the corolline lobes, and in the limb of the caly $\mathrm{x}$ being deciduous. It is also nearly allied to Baconia, but differs in the stigma being bifid.

1 P. Lanceola'ta (Lour. coch. p. 75.) leaves lanceolate, petiolate; racemes terminal, compound ; flowers tetramerous and tetrandrous. h. G. Native of China, about Canton. Branches diffise. Flowers reddlish.

Lanceolatc-leaved Polyozus. Shrub 4 feet.

2 P. Aсuмina'ta (Blum. bijdr. p. 948.) leaves oblong-lanceolate, very much acuminated; racemes axillary; flowers tetramerous and tetrandrous. $h$. S. Native of the western part of Java, on the mountains. Branchlets compressed. Stipulas broad, short. Flowers small, corymbose; corymbs in the axils of the superior leaves on short peduncles.

Acuminated-leaved Polyozus. Shrub.

3 P. Latifo'lia (Blum. bijdr. p. 948.) leaves elliptic-oblong, acute at both ends; flowers pentamerous and pentandrous. $h$. S. Native of the island of Nusa-Kambanga, near Java.

Broad-leaved Polyozus. Shrub.

\section{+ Doublful species.}

4 P. ? Maderaspata'na (D. C. protl. 4. p. 495.) leaves petiolate, oblong-lanceolate, hardly acute at the base, and rather acuminated at the apex; corymbs terminal, trichotomons; flowers pentamerous and pentandrous. $h$. S. Native of the East Indies, about Madras. Stipulas broad, short, acuminated, adpressed. Leaves coriaceous, those of the flowering branches 4 inches long and $1 \frac{1}{2}$ broad, standing on petioles about half an inch long.

Madras Polyozus. Shrub.

5 P.? Barba'ta (Smitl, in Rees' cycl, vol, 26. under Pavétla,) leaves lanceolate-oblong, acute, smooth ; panicles brachiate, divaricate, smooth; tube of corolla one-half shorter than the lobes, which are 5 , and beset with bristles in the mouth. 5. S. Native of the island of Hominoa, in the East Indies. Leaves coriaceous, a foot long, and 2 inches broad. Stigma cylindrical, acute. From the tube of the corolla being shorter than the lobes, and the flowers being pentamerous and pentandrous, it is probably a true species of Polyòzus.

Bearded Polyozus. Shrub.

voL. III.
Clisiv. Gremiesa. Cliv, Rutidea.

N. B. P. bipimnàtus (Lour, coch. p. 75.) should be excluded from the present order altogether, from the bipinnate leaves, but its true place is unknown.

Cult. For culture and propagation sce Ixòra, p. 574.

CLXIV. GRUMILEA (from grumula, a little heap; in reference to the albumen, which is grumose). Gærtn. fruct. 1. p. 138. t. 28. f. 2. D. C. prod. 4. p. 495.-Grunilea, Poir. suppl. 2. p. 857.-Grumilia, Du Theis, Gloss. bot. p. 210.

Lin. syst. Pentándria, Monogýnia. Calyx with an ovate tube, and a 5-toothed limb. Corollia, stamens, and style unknown. Berry crowned by the calyx, ovate-globose, rather coriaceous, 2-celled, rarely 3 -celled. Seeds solitary in each cell, plano-convex or angular. Albumen rather cartilaginous, grumose from chinks and fissures. Embryo erect, small, rather curved, and nearly dorsal, with lanceolate cotyledons.-This genus is hardly known, but from the albumen it comes very near to Rutidea; and to Psychótria from the form of the fruit.

1 G. Nigra (Gærtn. fruct. 1. p. 138. t. 28. f. 2.) berry smooth; teeth of calyx on the top of the fruit, comniving and rounded. h.S. Native of Ceylon, where it is called Hoglala. Berries black.

Black-berried Grumilea. Shrub.

2 G. Psychotrioìns (D. C. prod. 4. p. 495.) berry striated lengthwise, crowned by the short tubular truncate limb of the calyx. $h . S$. Native of the western coast of $\Lambda$ frica, in Casamancia at Itou, where it was collected by Leprieur and Perrottet. Shrub glabrous. I Leaves petiolate, elliptic, cuneated at the base, acute at the apex, shining. Stipulas solitary on both sides, lanceolate, deciduous. Flowers unknown. Fruit 5-6 together at the tops of the branches, sessile, almost capitate, black, ovate, 2-celled. Seeds ruminated as in Annòna.

Psychotria-like Grumilea. Shrub 4 to 5 feet.

Cult. For culture and propagation see Ixòra, p. 574.

CLXV. RUTI'DEA (from pviec, rutis, a wrinkle; in allusion to the wrinkled albumen). D. C. diss. 1807. ined. with a figure, ann. mus. hist. nat. Par. 9. p. 219. prod. 4. p. 497. Juss. mem. mus. 6. p. 378. A. Rich. mem. soc. hist. nat. Par, 5. p. 179.Rytídea, Spreng.

Lis. syst. Pentándria, Monogýnia. Calyx with a globose tube, and a small 5-parted limb: lobes ovate. Corolla funnelshaped, with a terete tube, which is dilated at the apex, and 5 spreading oval lobes. Anthers 5, sessile in the throat of the corolla, exserted, oblong, but shorter than the lobes of the corolla. Style clavate at the apex ; stigmas 2, combined, indicated only by a furrow. Berry nearly dry, globose, crowned by the vestiges of the calyx, 1-celled, 1-seeded. Seed globose, umbilicate at the base, wrinkled on the outside. Albumen large, grumose, cartilaginous. Embryo oblique, terete.-Shrubs, natives of India and Africa. Branches terete, hispid while young. Leaves opposite, on short petioles, hispid on the nerves and petioles. Stipulas twin on both sides, combined to the middle, subulate at the apex. Spikes racemose, interrupted, terminal; flowers disposed in almost sessile opposite fascicles. Bracteas and calyxes hispid. Corollas glabrous, beconing black on drying, but probably white in the recent state.

1 R. PARViflo'ra (D. C. l. c.) branches, petioles, and nerves of leaves on the under surface, rather hispid; leaves elliptic-oblong; spikes terminal, formed of interrupted fascicles of tlowers; fruit glabrous. $\eta$.S. Native of Sierra Leone, where it was collected by Smeathmann; and of Casamancia near Itou, where it was collected by Leprieur and Perrottet.

Small-flowered Rutidea. Shrub 3 to 4 feet.

2 R.? Mó LLIS (Blum, ex D. C. prod. 4. p. 495.) every part of the plant is clothed with soft hiry tomentum; leaves elliptic$4 \mathrm{E}$ 
oblong, clothed with soft hairs on both surfaces, but most so beneath; corymbs terminal, dichotomous; fruit rather villous, globose, 1-seerled. $\eta$. S. Native of the island of PuloPenang. The fabric of the seed is unknown.

Soft Rutidea. Shrub.

Cult. For culture and propagation see Ixòra, p. 574.

CLXVI. FARA'MEA (Aublet does not give the meaning of this name). A. Rich. mem. soc. hist. nat. Par. 5. p. 175. t.17. f. 1 and 2. D. C. prod. 4. p. 496.-Faràmea and Tetramèrium, Juss. mem. mus. 6. p. 376 .

Lin. srst. Tetrándria, Monogýnia. Calyx with a turbinately globose tube, and a very short 4-toothed or entire limb. Corolla with a short terete tube, a naked throat, and 4 spreading oblong or linear acute lobes, which are longer than the tube. Anthers 4, sessile, inclosed. Style short, bifid at the apex. Berry dry, 2-celled while young, but in the adult state it is globose, depressed, 1-celled, and 1-seeded, marked by 8 crenulations at the cicatrice. Sceds fixed to the bottom of the cell, umbilicate at the base, globosely depressed. Albumen horny. Embryo lateral, small, horizontal.-Glabrous, dichotomously branched shrubs, natives of America. Leaves petiolate, oval or oblong, acuminated. Stipulas interpetiolar, solitary on each side, broad at the base, and setaceously cuspidate at the apex. Flowers corymbose or umbellate, on the tops of the branches or peduncles. Corollas white.

Sect. I. Eufaratyea (this section is supposed to contain the true species of the genus). D. C. prod. 4. P. 496.-Faramea, Aubl. guian. 1. p. 102 . t. 40 . Lam. dict. 2. p. 460 . ill. t. 63.Famàrea, Vittm. summ. pl. 1. p. 357. Peduncles terminal, 1-3 together, bearing each a simple umbel of flowers at the apex. Flowers involucrated by caducous bracteas. Stipulas ending in an awh.

1 F. Sessiliflo'ra (Aubl. guian. 1. p. 104.t. 40. f. 2.) umbels terminal, solitary, simple, sessile; calyx 4 -toothed. h.S. Native of Guiana, in the woods called Cauxwoods. Leaves obovate. Flowers white.

Sessile-flowerd Faramea. Shrub 7 to 8 feet.

2 F. sertulífera (D. C. prod. 4. p. 496.) peduncles terminal, solitary, nearly terete, bearing a simple umbel of flowers at the apex; calyx truncate. $\zeta$. S. Native of Cuba, about the Havannah. Branches slender, dichotomous. Leaves oblong, acuminated at both ends.

Garland-bearing Faramea. Shrub.

3 F. trunca'ta (D. C. prod. 4. p. 496.) peduncles terminal by threes, compressed at the apex, bearing each a simple umbel of flowers; calyx truncate. 7 . S. Native of French Guiana. Very like the following species, but differs in the calyx being truncate. Corolla marcescent. Fruit pale, but exactly like those of $F$. odoratissima.

Truncate-calyxed Faramea. Shrub 4 to 5 feet.

4. F. coryabòsa (Aubl. guian. 1. p. 102. t. 40. f. 1.) peduncles terminal by threes, compressed at the apes, each bearing a simple umbel of flowers; calyx 4-tootled. $h$.S. Native of French Guiana, in the woods called Cauxwoods. Lam. ill. t. 63. Flowers white.

Corymbose-flowered Faramea. Shrub 7 to 8 fect.

Sect. 11. Tetrane'rium (from retpuc, tetras, fourfold, and $\mu \varepsilon \rho \iota$, meris, a part; in reference to the flowers being tetramerous). D. C. prod. 4. p. 496 .-Tetramèrium, Grertn. fil, carp. 3. p. 90. t. 196. H. B. et Kunth, nov. gen. amer. 3. p. $373 .-$ Coftèa section Potima, Pers. ench. 1. p. 209.-Darlùca, Rafin. ann. gen. sc, phys, 6. p. 87.? Coffèa and Ixòra species, Lin. Corymbs terminal, tricliotomous. Flowers naked.

\section{* Stipulas ending in an ann.}

5 F. odoratíssima (D. C. prod, 4. p. 496.) leaves oval-oblong, acutish at the base, and abruptly acuminated at the apex; stipulas broad, ending in a subdorsal awn; corymbs terminal; limb of calyx very short, truncate, ten times shorter than the tube of the corolla; berry crowned by the very short bluntly 4-toothed limb of the calyx. h. S. Native of the West Indian islands, as in St. Domingo, Jamaica, Porto-Rico, Guadaloupe, Cayeme, Panama, and probably of Mexico. Plum. ed. Burm. t. 156. f. 2. P. Browne, jam. t. 6. f. 1. but not fig. 2.-Coffèa occidentàlis, Jacq. amer. t. 47. Lin. spec. p. 246. Ixòra Americàna, Lin. amœn. acad. 5. p. 393. ex Swartz. Tetramèrium odoratíssimum, Gartn. fil. carp. 3. p. 90. t. 196. Tetramèrium occilentàle, Nees and Mart. nov. act. nat. cur. 12. p. 13. Flowers white, sweet-scented, about the size of those of the jasmine; lience it is called jasmine in Jamaica.

I'ery-sweet-scented-flowered Faramea. Clt. 1793. Sh. $6 \mathrm{ft}$.

6 F. Latifo'lia (D. C. prod. 4. p. 497.) leaves oval, abruptly acuminated ; stipulas broad, ending in a subdorsal awn; corymbs terminal; tube of calyx slightly tetragonal, somewhat 4toothed, 5 times shorter than the tube of the corolla. $b . \mathrm{S}$. Native of Brazil, in tlse province of Rio Janeiro. Tetramèrium latifòlium, Clıam. et Schlecht. in Linnæa. 4. p. 30. It differs from the preceding species in the flowers being one-half smaller. This plant is probably also a native of 'Trinidad and Santa Cruz.

Broad-leaved Faramea. Shrub 6 feet.

7 F. Montevide'nsis (D. C. prod. 4. p. 497.) leaves oblong, acuminated at both ends; stipulas broadish at the basc, ending in a subdorsal awn at the apex; corymbs terminal; berries crowned by the limb of the calyx, which is tubularly cup-shaped

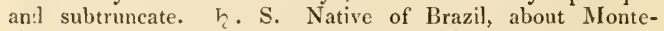
Video; and of Porto-Rico. Tetramèrium Montevislénse, Cham. et Schlecht. in Linnæa. 4. p. 29. Flowers white. Leaves and inflorescence almost like those of $F$. odoratissima; but the limb of the calyx on the fruit is very different.

Montc-lideo Faramea. Slurub 4 to 6 feet.

8 F. stipula'cea D. C. prod, 4. p. 497.) leaves oblong, attenuated at the base, and acute at the apex; stipulas broad at the base, and ending in a dorsal awn at the apex; corymbs terminal; limb of calyx acutely 4 -toothed; berry globose, crowned by the short limb of the calyx. $\zeta$.S. Native of Brazil, within the tropic. Tetramèrium stipulàceum, Cham. et Schlecht. in Linnaa. 4. p. 31. Flowers white. Habit of $F$. jasminoides, but differs in the dorsal awn to the stipulas.

Stipulaceous Faramea. Slirub 4 to 6 feet.

9 F. ceru'LeA (D. C. l. c.) leaves ovate-elliptic, acute at both ends; stipulas dilated at the base, and ending in a short awn at the apex; peduncles axillary, usually 3-flowered; limb of calyx acutely 5-toothed, 6 times shorter than the tube of the corolla. 々. S. Native of Brazil. T'etramèrium corùleum, Nees et Mart. nov, act. bonn. 12. p. 12. Peduncles and branches 2edged. Corolla of an amethyst colour, with lanceolate segments. Blue-flowered Faramea. Shrub 5 to 6 feet.

10 F. Axillariflo'ra (D. C. prod. 4. p. 673.) leaves sessile, ovate-oblong, cordate at the base, acuminated at the apex; stipulas ending in a long-awned acumen; branches much compressed; flowers on short pedicels, in fascicled corymbs from the axils of the leaves. $\xi$. S. Native of Brazil, about Bahia, where it was collected by Salzmann, G. Don, \&c. Flowers white. Fruit exactly like that of $F$. odoratissima. Leaves $7-8$ inches long, and about 3 broad.

Axillary-flonered Faramea. Shrub to to 6 feet.

11 F. Guayaquilénsis (D. C. 1. c.) leaves oblong, acuminated, almost sessile; stipulas oblong, acuminated, and a little awned, permanent : upper ones bifid on both sides; panicle ter- 
minal, trichotomous, divaricate. h. S. Native of Guayaquil. Tetramèrium multiflòm, Bartl. in herb. Hanke. Flowers white? Stipulas different in form from any other species.

Guayaquil Faramca. Slirub 4 to 6 feet.

* Stipulas never ending in an awn.

12 F. JAsminoìdes (D. C. prod. 4. p. 497.) leaves ellipticoblong, acuminated at both ends; stipulas ovate, large, acutish ; corymbs terminal ; calyx urceolate, with 4 long teeth ; berry globose, crowned by the short limb of the calyx. 24.? S. Native of New Granada, near Ibague. Tetramèrium jasminoides, H. B. et Kunth, nos. gen. amer. 3. p. 373, t. 287. Cofl'ea flavicans, Willd. mss, in Roem. et Schultes, syst. 5. p. 201. Branches tetragonal. Lcaves pale green, yellowish beneath. Lobes of corolla one-half shorter than the tube. Flowers white.

\section{Jasmine-like Faramea. Slirub.}

13 F.? sessilifo'lia (D. C. l. c.) leaves oblong, acuminated, cordate, sessile; stipulas ovate, acuminately subulate; corymbs terminal, trichotomous; limb of calyx urceolate, 4-toothed. $h$. S. Native in woods on the banks of the Orinoco, between Maypure and St. Fernando de Atabapo. Tetramèrium sessilifolium, H. B. et Kunth, nov. gen. amer. 3. 1\%. 374. Ixòra sessilifölia, Spreng. syst. 1. p. 409 . Flowers white. Anthers probably exserted. From the fruit being unknown, it is doubtful whether it belongs to the present genus.

Sessile-lcaved Faramea. Shrub.

14. F. multiflo'ra (A. Rich. in mem. soc. hist. nat. Par. 5. p. 1 76.$)$ leaves oval-elliptic, acuminated, abruptly petiolace; stipulas interpetiolar, connate, sheath-formed, acuminated; fowers corymbose, terminal. $h_{\text {. }}$.S. Native of French Guiana.

\section{Iany-flowered Faramea. Shrub.}

15 F. calyciflo'ra (A. Rich. \}.c.) leaves elliptic, acuminated; stipulas interpetiolar, acuminated; flowers spiked; spikes terminal, pedunculate; limb of calyx tubular, large, permanent. h. S. Native of French Guiana. From the caly'x being permanent, it does not probably belong to the present genus.

Calyx-flowered Faramea. Shrub.

Sect. III. Farameoìes (from faramea, and idea, like; but is meant only as an alteration of the generic name). D. C. prod. 4. p. 498. Panicles thyrsoid, terminal.

16 F. Alé'scens (D. C. prod. 4. p. 498.) panicle terminal, pedunculate, having its branches bearing umbels of flowers at the apex; calyx trumcate. $h$. S. Native of French Guiana. Branchlets compressedly angular. Leaves oblong, acuminated at both ends, shining on both surfaces, pale green. Stipulas acute, deciduous while young. Peduncles 2-edged, furnished with 3-4 pairs of branches. Panicles white, one-lialf shorter than the leaves. Corollas elongated, very like those of $F$. truncàta.

Whitish-panicled Faramea. Shrub 4 to 6 feet.

17 F. MARTiNi (D. C. l. c.) panicles terminal, on short peduncles, shorter than the leaves; branches corymbose at the apex; calyx hardly toothed: leaves large, oval; anthers exserted at the throat. $h_{2}$. S. Native of Guiana, at Mount Kaw, where it was collected by Martin. Branchlets compressed. Stipulas broad, short, permanent. Leaves glabrous, membranous, attenuated at the base. Lobes of corolla 4 , a little longer than the tube. Calyx urceolate. Fruit unknown.

Martin's Faramea. Shrub 4 to 6 feet.

Cult. For culture and propagation see Coffèa, p. 584.

CLXVII. STREMPELIA (named after Charles Frederick Strempel, author of Filicum Berolinensium Synopsis, Berlin, 1822-1828). A. Rich. mem. soc. hist. nat. Par. 5. p. 180. D. C. prod. 4. p. 498.

Lin. syst. Tetra-Pentándria, Monogýnia. Calyx with an obovate-globose tube, and a campanulately tubular 1-5-toothed limb. Corolla tubular, terete, with a $1-5$-parted spreading limb, lanceolate acute segments, and a naked tluroat. Staniens inserted in the middle of the tube; filaments beset with short laairs in the free part; anthers linear, inclosed. Fruit ovoid, striated, fleshy, crowned by the tubular limb of the calyx, containing 2 bony 1 -seeded indehiscent nuts, which are flat on the inside, and furrowed in the middle. Seed erect. Einbryo nearly terete.-A Guiana slirub. Leaves opposite, elliptic. Stipulas fringed. Flowers sessile, umbellate on the tops of the peduncles.

1 S. Guiane'nsis (A. Rich. l. c.) h. S. Native of French Guiana.

Guiana Strempelia. Shrub.

Cult. For culture and propagation see Coffé $a$, p. 584.

CLXVIII. COFFE'A (so named from Caffee, a province of Narea in Africa, where the common coffee grows in abundance). Lin. gen. no. 230. exclusive of some species. Gærtn. fr. 1. p. 118. t. 25. Lam. ill. t. 160 . Juss. mem. mus. 6 . p. 379. D. C. prod. 4 . p. 498.

IıN. sxst. Tetra-Pentándria, Monogynia. Calyx with an ovate, globose or turbinate tube, and a small 4-5-tootled limb (f. 107. a.). Corolla tubular, funnel-shaped, with a spreading 4-5-parted limb (f. 107. b.), and oblong lobes. Stamens 4-5, rising from the middle of the tube of the corolla, or from its apex, exserted or inclosed. Style bifid at the apex, having the lobes rarely combined. Berry umbilicate (f. 107.h.), naked or crowned, containing 21 -seeded nuts of the consistence of parchment, which are convex on the outside, and flat inside, and marked by a longitudinal furrow. Embryo erect, in horny albumen, with a terete obtuse radicle, and foliaceous cotyledons.Trees and shrubs. Leaves opposite. Stipulas interpetiolar. This genus is probably divisible into several genera, but that has not been attempted on account of specimens of the greater number of the species being rare in European collcctions.

Sect. I. Coffe (altered from the generic name). Rai. hist. pl. Juss. act. acad. sc. Par. 1713. D. C. prod. 4. p. 498. Coffèa, A. Rich. mem. soc. hist. nat. Par. 5. p. 168. t. 16. f. 2. Tube of calyx very short, not increasing after flowering, but always vanishing. Throat of corolla usually naked. Berry ovate or globose. Stigma bifid.-Trees and shrubs. Stipulas solitary on both sides, undivided, neither toothed nor ciliated. Inflorescence axillary in the genuine species. Flowers from 4 to $7 \mathrm{cleft}$, but usually 5 cleft.

\section{* Peduneles axillary. Floners 5-7-eleft, pentandrous or hep- tandrous.}

1 C. Arábica (Lin. spec. p. 24.5.) leaves oval-oblong, acuminated, glabrous, shining on the upper surface; peduncles axillary, short, aggregate; corolla 5-cleft : anthers exserted; berries ovate. h.S. Native of Arabia Felix and Etbiopia, from whence it has been carried to almost all parts of the world within the tropics. Gærtn. fruct. 1. t. 25. Sims, bot. mag. 1303. Tratt. tab. t. 400 . Tuss. ant. t. 18. Delaun. herb. amat. t. 285. Church. ad Steph. med. bot. 4. t. 182. C. laurifòlia, Salisb. prod. p. 62. - Juss. act. ac. par. 1713. t. 7. Ellis, mon. 1774. in 4to. Till. pis. t. 32. Pluk. alm. t. 272. f. 1. Alp. egypt. t. 36. Blackw. 4. E 2 
herb. t. 337. Plench. icon. t. 130. Stipulas awl-shaped, undivided. Leaves wavy, dark-green and shining above, paler beneath. Flowers white, sweet-scented, disposed in axillary clusters of 4-5. Berries red, cherry-formed. The secds or nuts are involved in a thin elastic pellucid aril. The coffee-tree is frequently cultivated in the trot-houses of our gardens for ornament, where it both flowers and ripens its fruit. It is propagated by the berries, which must be sown soon after they are gathered, or they will not vegetate. Cotylcdons transversely ovate, 3-nerved at the base, and emarginate at the apex.

Few vegetable substances have been more generally esteemed for their medicinal and dietetic properties than the berries of the coffee-tree. The plant is fully described by Ellis and several other writers. The coffee-tree is generally regarded as a native of Arabia, but Bruce says it derives its name from Caffee, a province of Narea, in Africa, where it grows spontaneously in great abundance. The plant does not appear to have been known by the Greeks or Romans, nor are there any facts respecting its origin in the East. It has been well ascertained, however, that the berries were imported into every part of Europe, and used as a favourite beverage, long before it was known of what plant they were the product. Prosper $A$ lpinus has seen the coffeetree, without fructification, in some gardens in Egypt; but the first intelligible botanical account was publisheal by Ant. de Jussieu, in the Mem. Acad. Scienc. Paris, in 1713. We are informed by Boerhaave, in his Index to the Leyden Garden, that it was first introduced into Europe by Nicholas W'isten, a burgomaster of Amsterdam, and chairman of the Dutch East India Company, who gave directions to the governor of Batavia to procure seed from Mocha, in Arabia Felix. These being sown in the Island of Java, several plants were procured, and one was transmitted by Wisten, about the year 1610 , to the botanic garden at $A$ msterdam. From the progeny of this plant, not only the principal botanic gardens in Europe, but also the West India Islands, were supplied with this valuable tree. Soon after its introduction into Holland, it was cultivated by Bishop Compton, at Fulham.

In Arabia the fruit is dried in the sun upon mats, and the outer coat is separated by means of a large stone cylinder. It is again placed in the sun, winnowed, and packed up in bales. In the West India Islands, as snon as the fruit is of a deep red colour, it is reckoned to be ready for being gathered. Large linen bags, kept open by means of hoops round their mouths, is suspended by the negroes from their necks, who pull the berries with their hands, and, after filling the bags, empty them into a large basket. $\Lambda$ single negro can easily collect three bushels in a day. As the berries do not ripen together, they are collected at three different gatherings. One thousand pounds of good coffee are produced from one lundred bushels of the berries just from the tree. The coffee-berries may now be dried in two different ways. The first method is to place them in the sum, in layers of four inches thick, on inclined planes. In a few days the pulp is discharged by fermentation, and in about three weeks the cotfee is completely dry. The skin of the berries, already broken, is removed by mills, or in wooden mortars. The second method is to separate the grain from the pulp at once, by means of a mill, and the grains are then left to soak in water for twenty-four hours. They are afterwards dried, and then stripped of the pellicle, or parchment, as it is called, by means of appropriate inills. The grains of coffee are afterwards winnowed, and mingled with the grindings and dust of the parchment, in which state they are put up into bags for sale.

Cullure.-The coffee-tree is less cultivated in Jamaica than in Barhadoes, St. Domingo, and some other islands in the West Indies. Richness of soil lessens the flavour of the seeds; on this account, coffee produced in the dry, hot, arid climate of
Arabia is always hetter than that from the West India Islands. In cultivating the coffee in the West Indies, the berries are sown inmediately after being gathered, as they are found to retain their vegetative quality only a few weeks. In three montlıs the seeds so sown produce plants fit for transplanting to the final plantation. In the low lands they are planted five feet apart, and in the mountains ten feet or more. In three years the plants will produce a crop, and continue bearing a number of years. The berries are gathered when they are just about to drop.

Qualities and chemical properlies.-When the seeds of coffee are roasted, a portion is converted into tannin by the action of heat, and an agreeable aromatic substance is developed, the nature of which has not been ascertained. 'The same principle is also developed by roasting barley, beans, and many other vegetables, which, on that account, are occasionally employed as substitutes for coffec, and suit some stomachs better. The infusion of unroasted coffee in boiling water is of a yellowish green colour; but the decoction, by continuing the boiling, becomes brown, and turbid on cooling. From experiments made cliefly by Cadet, it appears that coffee contains an aromatic principle, a little oil, gallic acid, mucilage, extractive and bitter principle. Other analyses have been made by chemists. M. Grindel found it to contain kinic acid, and M. Paysse has discovered what he has endeavoured to show as a peculiar acid, to which he has given the name of coffee acid. More recently, M. Robiquet is said to have demonstrated another principle, which he names Cafeine. It is in silk-like acicular crystals, bearing a resemblance to Benzoic acid. It liquefies by the aid of a gentle lieat; in close vessels it volatilizes, and sublimes in needles. Cafeine is neither acid nor alkaline; it furnishes a great quantity of azote; it dissolves with difficulty in ether, but quickly in water and alcohol.

Medieal properties and uses. - It is evident that we are indebted to the Arabians for our use of this pleasant beverage, as the first rite of Eastern hospitality is the presentation of a bowl of coffee. In Europe it is said to have been first used in Italy, in the year 1650 ; and, according to Dulaine, was introduced at the court of Paris, in 1669 , by Soliman $\mathrm{Aga}$, ambassarlor from the Porte. An Armenian, named Pascal, opened the first Café, and Procope the second, in "Rue des Fossés, Saint Germain des Près." Nearly at tlie same time coffee was introduced into London.

By some, coffee is supposed to be best suited to the aged; and its abuse, as when taken too strong, is said to impair digestion, instead of promoting it ; and it stimulates, heats, and produces watchfulness in certain constitutions. The Mahometans of India, who use a great deal of coffee in the same way as we do, with the exception of combining milk with it, believe it to have the effect of soothing and allaying nervous irritations, and prescribe it to stop the vomiting in cholera mo:bus. Dr. Ainslie also states, that it is often employed for the same purposes by the Spaniards at Manilla. It is said that Sir John Floyer, during his residence in Lichfield, found great benefit in his own person by the use of coffee in asthma. Sir John confirms its success in a letter to Dr. Percival; "On reading the section of coffee," says he, "in the second volume of your essays, one quality occurred to me which I had observed of that liquor, confirming what you had said of its sedative powers. It is the best abater of periodic asthma that I have seen. The coffee ought to be the best Mocha, newly burnt, and male very strong immediately after grinding it. I have cosmmonly ordered an ounce for one dish, which is to be repeated afresh after the interval of a quarter of an hour, without nilk or sugar." Percival's Essays, vol. iii.

As a general palliative, strong coffee is often serviceable in various linds of head-ache; and where its own sedative power 
is unavailing, it forms one of the best velicles for the administration of laudanum. It diminislies in some degree the liypnotic power of the latter, but counteracts its distressing secondary effects. Whien laudanum is intermised with strong coffee for the cure of many nodifications of head-ache, tranquillity and ease are produced, though there may be no sleep; when laurlanum, on the contrary, is taken alonc, slcep will, perlsaps, follow, but is mostly succected by nausea and a return of pain. Hence the Turks and Arabians make strong coffee their common vehicle for opium, from its tendency to counteract the narcotic principle of the latter; and on the same account it is plentifully administered after the stomach has bcen evacuated of its contents, in cases of poisoning by opium.

For common purposes, infusion of coffee is the most agreeable method of preparing it, as the aromatic and volatile principles are dissipated by boil ing.

Coffee is named by the Persians Cohwa and Coho; by the Turks, Chaube and Caluey; by the Arabians, Cachua, Caoua, Caffaye, and Cahouah; and by the Egyptians, Elcavc. In Germany it is called Arabischc Kafferbaum ; in Cochin China, Caycaphe.

The Galla, a wandering nation of Africa, in their incursions in Abyssinia, being obliged to traverse immense deserts, and being also desirous of falling on the Abyssinians without warning, that they may be encumbered as little as possible with baggage, carry nothing with them to eat, but coffee roasted till it can be pulverized, and then mixed with butter into balls, and put into a leathern bag: one of these, about the size of a billiard-ball, keeps them, they say, in strength and spirits during a whole day's fatigue, better than a loaf of bread, or a meal of meat.

Arabian or Common Coffee-tree. Fl. Aug. Nov. Clt. 1696. Shrub 5 to 15 feet.

2 C. Mauritia'na (Lam. dict. 1. p. 550. ill. t. 160. f. 2.) leaves oval, acute at both ends, reticulately veined; peduncles axillary, solitary, 1-flowered, very short; berries oblong, acute at the base. h. S. Native of the Island of Bourbon, in the

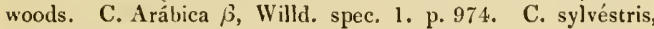
Willd. mss. in Rocm. et Schultes, syst. 5. p. 201 . Flowers white. This species is known in the Island of Bourbon under the name of Café-Marron, but should not be confounded with the variety of $C$. Arábica, known in commerce under the name of Café Bourbon, or Bourbon Coffee.

Mauritian Coffee-tree. Slurub 4 to 5 feet.

3 C. Benghalénsis (Roxb. hort. beng. p. 15. fl. ind. 2. p. 194.) leaves oval-oblong, acuminated at both ends; flowers axillary, rather aggregate, sessile; stipulas undivided, subulate, much acuminated; corolla 5 -cleft, with oblong lobes; anthers inclosed. $h_{c}$. S. Native of Bengal, but chiefly about Silhet; and of Nipaul. Roth. nov. spec. 148. Rœm, et Schultes, syst. 5. p. 200. Branches so placed as to form a bush of a pyramidal form. Leaves from ovate to oblong, glabrous. Flowers 1-3 together or more, axillary, white, sweet-scented. Berry black, size of a small cherry. It was for some time much cultivated in Bengal, under the idea of its heing the Arabian Coffee; it is now neglected, being of inferior quality, and not productive; however, the number of its flowers entitle it to a conspicuous place in the flower-garden.

Bengal Coffee-trce. Shrub 4 to 6 feet.

4 C. Stenophy'LLA; leaves oblong-lariceolate, acuminated; peduncles almost sessile, axillary, 2-3-flowered. h.S. Native of Sierra Leone, where it is cultivated. Flowers white. Berries oblong, black. 'The seeds of this species are roasted and used as the common coffce, and are even considered superior to it.

Narrow-leaced Coffie-tree. Shrub 4 to 6 feet.
5 C. InRsu'tus; leaves ovate, acuminated, on short petioles; young branches, petioles, and veins of leaves hairy; peduncles axillary, 3 -flowered. $々$.S. Native of Sicrra Leone, inthe low lands. Flowers white.

Hairy Coffee-tree. Shrub 4 to 5 feet.

6 C.? microcárpa (D. C. prod. 4. p. 499.) leaves ellipticoblong, short-acuminatcd, and are, as well as the branches, quite glabrous; flowers in fascicles along the branches, after the falling of the leaves, and therefore they appear as if they were disposed in interrupted raccmes, but in fact the flowers are merely in fascicles from the axils of the fallen leaves; fruit elliptic, 3 times longer than their pedicels, and crowned by the cup-shaped limb of the calyx. $\eta$. S. Native of Africa in Casamancia, in woods, at Cape Roure, where it was collected by Perrottet and Leprieur. Leaves $2 \frac{1}{2}$ inches long, and 8-9 lines broad. Stipulas solitary, undivided, acuminately subulate, deciduous.

Flowers white.

Small-fruited Coffee-tree. Shrub 4 to 5 lieet.

7 C. Laurina (Smeathm. in herb. L'Her. et D. C. prod. 4. p. 4.99.) leaves oblong-lanceolate, mucronate, cuneated at the base, coriaceous, quite glabrous; racemes axillary, crowded with flowers, much shorter than the leaves; corolla 5 -cleft, with a villous throat; anthers exserted, but rather shorter than the lobes of the corolla; berries globose. T. S. Native of Sierra Leone. Poir. suppl. 2. p. 14. Leaves yellowish in the dried state. Calyx truncate. Corollas white.

Laurel-like Coffee-tree. Shrub 4 to 5 feet.

8 C.? stipula'cea (D. C. prod. 4. p. 492.) leaves elliptic or oblong, petiolate, acuminated at both ends; stipulas foliaceous, oblong, acute, striated lengthwise, deciduous; peduncles axillary, very long, corymbose at the apex, trichotomous. h. S. Native of French Guiana, where it was collected by Patris. Limb of calyx obscurely but acutely 5 -toothed. Flowers unknown. Berries ovate, not crowned. Peduncles 6 inches long.

Stipulaceous Coffee-tree. Shrub 4 to 6 feet.

9 C. PEDUncula'ta (Roxb. A. ind. 2. p. 195.) leaves clliptic, almost sessile, smooth; peduncles terminal and axillary, in fascicles, lone, 1-fiowered; tube of the corolla slender, smooth; stamens inclosed. $h$. S. Native of the Moluceas.

Pedunculated Coffee-tree. Shrub.

* Pcduncles axillary. Flowers tetramerous and titrandrous. -Ixòra species, Spreng.

10 C. Guiane'ssis (Aubl, guian. 1. p. 150. t. 57.) leaves ovate-oblong, bluntly acuminated, quite glabrous; peduncles axillary, aggregate, very short, 1-flowered; corollas 4 -cleft, with acute lobes; anthers inclosed; berries globose, small. $\mathfrak{h}_{2} . \mathrm{S}$. Native of French Guiana, and of the Island of Trinidad, ex Sieb. fl. trin. no. 44. Ixòra Guianénsis, Spreng. syst. 1. p. 409. Flowers small, white. Berries violaceous.

Guiana Coffee-tree. Shrub I to 3 fect.

11 C. Ròsea (Hoc. et Sesse. f. mex. icon. ind. ex D. C. prod. 4. p. 499.) leaves oval-oblong, acuminated at both ends, glabrous; peduncles axillary, 5 -flowered, much shorter than the leaves; corollas 4-cleft, with rerolute lobes; anthers exserted; berries globose. $h \mathrm{~S}$. Native of Mexico. Corollas rosecoloured. Berries reddish, size of a pea.

Rose-coloured-flowered Coffee-trec. Shrub 4 to 6 feet.

12 C. овоун'тA (Cham. et Schlecht. in Linnæa, 6. p. 412.) glabrous; leaves obovate, cuneated, acuminated, acute, featherveined; cymes axillary, almost sessile, aggregate, short, manyflowered; stipulas ovate-triangular, caducous. $h_{\text {. }}$ S. Native of Mexico, in shady places, near Masantla. Leaves half a foot long. Tube of the calyx ovate, witls short acute tecth. Corolla with a short tube and a naked throat. Anthers linear, exserted. 
Obovate-leaved Coffec-tree. Shrub.

13 C. LANCEona'ta (Cham. et Schlecht, in Linnæa. 6. p. 412.) stems, petioles, nerves, and primary veins of leaves underneath downy; leaves lanceolate, glaucescent beneath, featherveined; cymes axillary, usually solitary, few-flowered, on short peduncles; stipulas small, ovate-triangular, carlucous. $\zeta$. S. Native of Mexico, near Jalapa. Leaves 2-3 inclies long, acuminated. Calyx with a clavate tube, and small acute teeth. Anthers linear, exserted.

Lanceolate-leaved Coffee-tree. Shrub.

14. C. Tetrásdra (Roxb. fl. ind. 2 p. 193.) leaves broadlanceolate, acute, shining; stipulas bifid; peduncles axillary and terminal, in fascicles, long, s!ender, 1-flowered; corollas usually 4-cleft, with a long slenter tube; anthers inclosed; berries globose. $\quad \zeta$. S. Native of Silhet and Chittagong, and the whole east border of Bengal. Leaves 4-5 inches long, and lardly 2 broad. Corolla with a 4-5-cleft border. Stamens 4-5. Berries size of a small cherry, blackish-purple when ripe, 1 or 2-celled. An erect slender-branched Shrub.

Tetrandrous-flowered Coffee-tree. Shrub.

15 C. DEnstrlòra (Bhum. bijdr. p. 965.) leaves oval-oblong, acuminated, clothed with fine down on the reins beneath; flowers crowded, axillary; corollas 5-cleft. $\eta_{\text {. }}$ S. Native of Java, on Mount Salak. There are varieties of this with smaller and larger flowers.

Dense-flow cred Coffee-tree. Shrub.

16 C. angustifo'lia (Roxb. fl. ind. 2. p. 195.) leaves lanceolate, stiff, slining; panicles axillary ; throat of corolla bearded; lobes of corolla linear, longer than the tube, but equal to the an-

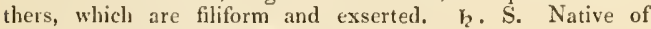
Pigeon Island, one of the Malay Archipelago.

Narrow-liaced Coffee-tree. Slirub.

17 C. Racemòsa (Ruiz et Pav. A. per. 2. p. 64. t. 214. f. a. but not of Lour.) leaves oblong-oval, acuminated, glabrous ; stipulas bifid; racemes axillary and terminal, drooping while in flower, but erect in the fruit-bearing state; flowers almost sessile, 5 -cleft; anthers exserted; berry oval. $h$. S. Native of Peru, in groves at Pati and Macora, where it is called Café. Rúdgea racenòsa, Spreng. syst. 1. p. 755. Flowers white.

Raccmose Coffee-tree. Slirub 4 to 6 feet.

1 C. Zaneueba'ria (Lour. coch. p. 145.) leaves ovate-lanceolate, glabrous; peduncles axillary, many-together, short, 1-flowered ; corollas 6-7-cleft; berries oblong-ovate, angularly nerved. h.S. Native of Africa, on the coast of Zanquebar, in woods. Anajoùa Africàna, Spreng. syst. 2. p. 126. Flowers white. Berries red. This species is cultivated near Mozambique in gardens along with $C$. Arábica, and where the seeds are used as a substitute for the common coffee.

Zanquebar Coffee-tree. Slirub 5 to 6 feet.

19 C. l'xica (Poir. suppl. 2. p. 14.) leaves ovate-oblong, acuminated, glabrous ; stipulas very short, undivided; panicles short, divaricate, terminal; pedicels elongated; fruit small, obobovate, not crowned by the calyx. h. S. Native of Java. Flowers unknown.

Indian Coflee-tree. Slurub.

\section{* * Panicles terminal. Flowers 4-5-parted, tetrandrous or pentandrous.}

20 C. Panicula'ta (Aubl. guian, 1. p. 152. t. 58.) leaves orate-oblong, acuminated, shining; branches tetragonal; stipulas acute, caducous ; panicles terminal, divaricate; flowers 4-cleft ; anthers inclosed. h.S. Native of Guiana, in woods. Tetramèrium paniculàtum, Spreng. syst. 1. p. 409. Flowers white, sweet-scented. Berries ovate-globose, bluish, containing 2 seeds or nuts, one of which is usually abortive.

Panicled-flowered Coffee-tree. Clt. 1822. Sh. 6 to 8 feet.
21 C. Mozambica'na (D. C. prod. 4. p. 500.) leaves ovatelanceolate, scabrous from tubercles; racemes terminal, erect, brachiate; peduncles tetragosal. $\eta$.S. Native of the eastern coast of Africa, in the island in Mozambique Channel. C. ramòsa, Rocm. et Schultes, syst. 5. p. 198. C. racemòsa, Lour. coch. p. 145. but not of Ruiz et Pav. The flowers are unlsnown, but are probably tetrandrous. Berries small, red, watery, roundish, 1-celled, 2-seeded. Seeds truncate, marked by a furrow inside. Mozambique Coffee-tree. Shrub + feet.

22 C. SEMiexsérta (Colebr, in Roxb. fl. ind. 2. p. 195.) leaves oblong-lanceolate, acuminated; corymbs terminal. h.S. Native of Bengal, in Sithet. Berries purple, size of large peas. Habit of Ixòra.

IIalf-exserted-stamened Coffee-tree. Shrub.

Sect. II. Ho'rnia (named after M. Van Horn, who, in the year 1690 , carried coffee from Arabia to Batavia, and in the year 1710 to the gardens of Amsterdam). D. C. prod. 4. p. 500 . Tube of calyx increasing after the flowers have fallen, and crowning the berry by a neck, having the teeth almost obsolete. Flowers 5-cleft. Stigma bifid. Throat of corolla glabrous. Berry ovate or globose, usually 1 -seeded from abortion. - Shrubs, natives of Peru. Inflorescence axillary or terminal. Stipulas solitary on both sides, undivided, never toothed nor ciliated.

23 C. subse'ssilis (Ruiz et Pav. fl. per. 2. p. 64. t. 215. lower figure, ) leaves glabrous, coriaceous, sessile, oblong-lanceolate, acuminated, excavated at the base; stipulas ovate; racemes axillary, trichotomous, shorter than the leaves. $\zeta$. S. Native of Peru, on the Andes in forests at Chinchao, Quebrada, and Pati. Coffèa macrophýlla, Dietr. nachtr. 2. p. 544. Leaves a foot long, shining above. Peduncles quatrangular. Berries ovate, at first red, but at last becoming purplish, ovate, 1 -seeded, size of cherries. Probably a species of Faràmea.

Sessile-leaved Coffee-tree. Shrub 5 to 6 feet.

24. C. umbella'ta (Ruiz et Pav. fi. per. 2. p. 64. t. 215. upper figure, leaves glabrous, coriaceous, petiolate, oblong, acuminated, nerved by transverse veins; stipulas roundish; peduncles terminal, usually by threes; flowers crowded, umbellate, involucrated. $々$. S. Native of Peru, on the Andes in forests. Branches dichotomous, rather tetragonal. Involucrum 4-leaved, and involucels 7-leaved. Berries red, ovate.

Umbcllate-flowered Coffee-tree. Shrub 10 to 12 feet.

25 C.? Acumina'ta (Ruiz et Pav, fl. per, 2. p. 64. t. 214. f. b.) leaves petiolate, oval, aenminated, glabrous, villous in the axils of the veins; stipulas ovate, deciduous ; raeemes terminal, few-flowered; flowers crowded. $h_{c}$. S. Native of Pertu, on the Andes in forests. Branches tetragonal, a little compressed. Corollas white, 5 -cleft (ex descript.), with revolute segments. Berries oval, red, 1-seeded, size of cherries, blunt at the apex, crowned by the tubular limb of the ealyx.

\section{Acuminatcd-leaved Coffee-tree. Shrub 5 to 6 feet.}

Sect. III. Pancra'sia (named after M. Pancras, who first transmitted the coffee-tree from the gardens of Amsterdam to those of Paris, in the year 1713). D. C. prod. 4. p. 501. 'Throat of corolla bearded. Berries crowned by the vestiges of the calyx. Racemes or corymbs terminal. Stipulas usually fringed or eiliately toothed, as in Rudgca, but differs from that genus in the calyx not being parted, and in the lobes of the corolla not being horned. Flowers 5-cleft.-Glabrous Peruvian shrubs.

\section{* Stipulas ciliatcd.}

26 C. cilia'ta (Ruiz et Pav. A. per. 2. p. 65. t. 216. f. a.) leaves oblong, acuminated; stipulas truncate, ciliated : racemes subpanicled, terminal; flowers aggregate, sessile, 4-5-cleft; 
anthers exserted. h. S. Native of Peru, in forests on the Andes. Rüdgea ciliàta, Spreng. syst. 1. p. 755 . Branches thickened at the notli. Bracteas small, subulate, at the ramifications of the panicle. Corollas white, with reficxed segments. Berries ied, globose. Perhaps the same as $C$. ciliàta of Brazil, which was collected on the road to Felisbert, by the Prince de Neuwied, but according to Nees and Martius, in nov. act. bonn. 12. p. 13., it diflers from the Peruvian plant in the racemes being shorter.

Ciliated-bractead Coffee-tree. Slurub 4 to 6 feet.

27 C. Foveolitia (Ruiz et J'av, fl. per. 2. p. 65. t. 216. f. b.) leaves oblong*oval, acuminated, with pits in the axils of the reins beneatly; stipulas ovate, ciliated with glands while young ; panicles terminal; anthers exserted. $々$. S. Native of Peru, in forests on the Andes. Psychótria foveolàta, sipreng. syst. 1. p. 746. but not of Ruiz et Pav. Psychótria scrobiculata, Spreng. fil. ind. P. 572. Bracteas small, subulate. Corollas white, but pale purple on the outsicle. lerries reddish, depressed at both ends.

Pittcd-leaved Coffee-trec. Slurub.

2S C. Mexica'va (I. C. prod. 4. p. 501.) leaves oblong, acuminated, reticulately reined bencath; stipulas crested; corymbs terminal, trifid; limb of calyx truncate, ohtuse. h.S. Native of Mexico. Rúdgea Mexicàna, Bartl. in herb. Hænke. Branches dichotomous. Fruit dry, indehiscent, chartaceous, tice nuts separating at length from each other. Seeds hemispherical, having a very narrow furrow in front. It differs from Riulge $a$ in the limb of the calyx not being 5 -parted, but quite entire.

Mexican Coffee-tree. Shrub.

29 C. Nítida (Ruiz et Pav. ff. per. 2. p. 65. t. 217. f. a.) leaves oblong, bluntly acuminated, shining; stipulas truncate, ciliated; panicles terminal; flowers sessile; anthers inclosed. 々. S. Native of Peru, on the Andes in forests. Rúdgea nitida, Spreng. syst. 1. p. 755 . exclusive of the synonymes of Kunth. Branches compressed. Stipulas covered with white linear glands on the outside. Corollas white. Berries red, globose, size of peas.

Shining-leaved Coffee-tree. Shrub 5 to 6 feet.

30 C. Laurifo'lia (H. B. et Kunth, nov. gen. amer. 3. p. 372. but not of Salisb.) leaves oblong, somewhat acuminated, coriaceous, shining; stipulas ciliately multifid; corymbs terminal; berries clliptic. $h$. S. Native of South Anerica, in shady humid places at the Missions of the Orinoco. Coffè coriàcea, Willd. mss. in Roem. et Scluultes, syst. 5. p. 201. ex Kunth. Corolla and stamens unknown. Perhaps a species of Psychótria, ex A. Rich.?

Laurel-lcaved Cuffee-tree. Shrub 12 to 20 feet.

31 C. verticilla'ta (Ruiz et Pav, fl. per, 2. p. 66. t. 217. f. b.) leaves oblong-lanceolate and obovate, acuminated; stipulas ovate, ciliated; panicles terminal; branches of panicle in whorles of fours; anthers exserted. $\zeta$. S. Native of Peru, in forests on the Andes. Rúdgea verticillàta, Spreng. syst. 1. p. 755 . Bracteas small, setaceous. Calyx small, ciliated. Flowers sessile, white, on the tops of the ramifications of the panicle.

Whorled-panicled Coffee-tree. Shrub 4 to 6 feet.

\section{* * Stipulas undivided or bidcntate. but necer ciliatcd.}

32 C. Loxgifo'la (Ruiz et Pav. f. per. 2. p. 66. t. 218. f. a.) leaves oblong-lanceolate, repandly undulated; stipulas ovate, undivided; panicles terminal; anthers exserted. 5. S. Native of Peru, in forests on the Andes. Leaves shining above, a foot long. Corolla white with reflexed segments. Berries globose, red.

Long-leaved Coffee-tree. Shrub.

33 C. microcárpa (Ruiz et Pav. fl. per. 2. p. 66. t. 218. f. b.) leaves lanceolate, acute; stipulas bidentate on both sides; cymes axillary and terminal, spreading; anthers hardly exserted. h.S. Native of Peru, on the Andes in forests. Branches a little compressed at the apex. Bracteas subulate. Corollas white, downy on the outside. Berries redilish, globose, size of black pepper. Perhaps belonging to a diflerent section.

Small-fruited Coffee-tree. Shrub.

34. C. spics'ta (H. B. et Kunth, nov, gren. amer. 3. p. 371. t. 286.) leaves elliptic-oblong, acute, coriaceous, shining; stipulas connate, hidentate on hoth sides; spikes terminal ; flowers sessile, disposed in whorles; lobes of coroll $i$ ending each in a callous horn. h. S. Native of New Granada, Riudgrea spicàta, Spreng. syst. 1. 1. 755 . 'Tube of corolla villous inside. Fruit unknown. Perhaps a species of P'sychótria.

\section{Spiked-flowered Coflee-tree. Shrub.}

35 C. oleifo'lia (H. B. et Kuntl, nov. gen. amer. 3. p. 372.) leaves oblong, somewhat acuminated, coriaceous, shining; stipum las truncate; corymbs terminal. $h$. S. Native of South America, near Santa $\mathrm{Fe}$ de Bogota. Tetramèrium oleæfòlium, Spreng. syst. 1. p. 409 . Branches slightly 5 -angled. Corolla 5-cleft, ex Kunth, 4-cleft, ex Mutis. Fruit unknown. Perhaps a species of Mapouria according to A. Rich.

Olive-leaved Coffec-trec. Shrub.

Sect. IV. Straússia (named after Laurence Strauss, who was the first, in 1666 , to recommend coffee as a beverage). D. C. prod. 4. p. 502. Berries turbinate or acuminated at the base. Stipulas ovate, deciduous, ciliated on the lower maryin of the cicatrices. Flowers 4-6-cleft. Stamens 4-6. Scigma bifid. Berries globose or oval.- Slrubs, natives of the islands in the South sea. Cymes terininal.

56 C. Luzonie'sisis (Cham. et Sehlecht. 4. p. 32.) leaves lanceolate, acute at both ends, with rather reflexed margins; stipulas ovate-oblong, rather scarious, decidnous, with the cicatrices rather ciliated at the margins; cymes terminal, sessile, contracted while young ; flowers $4_{2}-6$-cleft ; throat of corolla bearded. $I_{2}$. S. Native of the Island of Luzon. Corolla white, glabrous. Anthers exserted a little. The central flower is 5-cleft, and the rest either $t$ or 5 -cleft. Berries almost globose, acute at the base, sometimes 1 -seeded by abortion. Branches fistular.

Luzon Coffee-tree. Shrub 4 to 6 feet.

37 C. Kanua'na (Cham. et Schlecht. in Linnaa. 4. p. 33.) leaves cuneate-obovate, somewhat scrobiculate in the axils of the veins, with reflexed margins, usually elothed with rufescent down beneath ; stipulas ovate, acute, caducous, the inner margins of the cicatrices ciliated; cymes terminal, on long peduncles, of 5 rays, 4 of which are disposed in a whorl around the other, which is central; corolla 5 -cleft, with a naked throat. Native of the Sandwich Islands, particularly in O-IVahu. Berry elliptic, attenuated at the base, rarely 1 -sceded by abortion. Branches compressed. Mr. Arnott remarked, that the segments of the calyx are not ciliated as stated by the authors, although the bracteas are.

Kadu's Coffee-tree. Shrub 4 to 5 feet.

38 C. Chammssònis (Hook. et Arn. in Beech. voy. pt. bot. p. 86.) leaves elliptic-oblong, scrobiculate in the axils of the veins, with reflexed margins, quite glabrous on hoth surfaces: stipulas orate, caducous, having the inner margins of the cicatrices ghabrous; eymes on long peduncles of 5 rays, which are disposed in a whorl; corolla 5 -cleft, with a naked throat. $h$.s. Native of the Sandwich Islands. Very like the preceding.

Chammisso's Coflee-tree. Slirub 4 to 6 feet.

39 C. Marinia'na (Cham. et Schlecht. in Linnæa. \%. p. 85.) leaves elliptic, acute at boll ends, scrobiculate in the axils of the veins; stipulas ovate, deciluous, with the inner marmins of the cicatrices ciliated; cymes terminal, pedunculate, with the branchlets decussate; corolla 5 -eleft, with a bearded throat. $h$. S. 
Native of the Island of O. Wahu, in forests on the mountains. Branches and branchlets of panicle compressed.

Marin's Coffee-tree. Shrub 4 to 6 feet.

Cult. All the species of Coffera thrive well in a mixture of turfy loam, turfy peat, and sand. They require to be watered a good deal, and to have plenty of pot-room to thrive well. Ripe cuttings strike root freely in sand under a hand-glass in a moist heat; and the young plants so raised, produce flowers and fruit more readily than those raised from seed. As the plants are apt to be infested by insects, particularly the mealy bug, they should be examined often, and the insects rubbed off with a brush, otherwise the plants will look unsightly.

CLXVIII (A). RU'DGEA (named by Salisbury after Edward Rudge, F. R. and L. S., author of Plantarum Guianæ Rariorum, Icones et Descriptiones, 2 vol. fol. London, 1805). Salisb. in Lin. trans. 8. p. 327 . Juss. mem. mus. 6. p. 381 . D. C. prod. 4. p. 503 .

Lis. syst. Pentándria, Monogýnia. Calyx with an ovateglobose tube, and a 5-parted limb; lobes acute. Corolla with a long slender terete tube, 5 linear spreadingly recurved segments, which are hooked on the back and acute, and a naked throat. Anthers sessile, within the throat, inclosed. Stigma bilamellate. Fruit 2-celled, 2-seeded.-Trees or shrubs, natives of Guiana. Branchlets and petioles clothed with cinereous down. Leaves opposite, large, smoothish. Stipulas interpetiolar, large, ovate, fringed, deciduous. Panicles terminal, dense, bracteolate, with the branches opposite. Flowers blackish in the dried state, but most probably white in the recent state. Fruit not sufficiently known.

l R. LANCEAfo'lia (Salisb. 1. c. t. 18.) leaves lanceolate, acuminated; tube of corolla 10 times longer than the lobes of the calyx. $\quad$. S. Native of French Guiana. Leaves 10 inclies long, and about 3 broad. Corolla downy outside.

Lance-leaved Rudgea. Shrub or tree.

2 R, ovaL1Fòlı (Salisb. l. c. t. 19.) leaves oval, acuminated; tube of corolla 6 times longer than the lobes of the calyx. h. S. Native of French Guiana. Leaves 4-5 inches broad, and 7-8 long. Corolla downy outside.

Oval-lcaved Rudgea. Shrub or tree.

Cult. See Cofféa above for culture and propagation.

CLXIX. ANTHERURA (from a $v \eta \eta \alpha$, anthera, an anther, and ovpa, oura, a tail; the anthers end in a long tail cach). Lour, coch. p. 144. D. C. prod. 4. p. 503.-Psychótria species, Willd. Poir.

LıN. syst. Pentándria, Monogýnia. All as in Psychótria, but the corolla is rotate and 5-parted; the anthers sagittate at the base, and furnished with a long reflexed tail at the apex; the style subulate, and longer than the corolla, and the stigma simple.-A glabrous shrub, with reddish diffuse branches. Leaves opposite, ovate-lanceolate, on short petioles. Panicles terminal, erect, loose, racemose. Flowers white, with red filaments. Berries ovate, brownish red. Stipulas unknown.

1 A. RU'Bra (Lour. coch. p. 14.4.) 々. G. Native of Cochinchina and the Moluccas. Caryophyllaster riber, and probably C. álbus, Rumph. amb. 3. p. 136. Psychótria rùbra, Poir. suppl. 4. t. 597. Psychótria Antherùra, Rœm. et Schultes, syst. 5. p. 188. Leaves 2-3 inches long.

Red-branched Antherura. Shrub 5 feet.

Cult. For culture and propagation see Coffè̃ above.

CLXX. RONA'BEA (Aublet does not give the meaning of this word). Aubl. guian. 1. p. 154. Lam. ill. t. 166. Juss. gen. p. 205. mem. mus, 6. p. 380 . A. Rich. mem. soc. hist. nat. Par. 5. p. 270. D. C. prod. 4. p. 503.--P'syclótria species, Willd.

Lin. syst. Pentándria, Munogýnia. Calyx with an ovate tube, and a small 5 -toothed limb. Corolla oblong, rather funnelshaped, with 5 spreading acute lobes, and a naked throat. Anthers 5 , oblong, inclosed. Stigma bilamellate. Perry ovate, umbilicate, containing 21 -seeded nuts, which are flat inside, and convex outside.-Glabrous shrubs, natives of Guiana. Leaves oval, acute, on short petioles. Stipulas solitary on both sides. Peduncles axillary, 2-6-flowered, shorter than the petioles. Flowers small, white. Bracteoles 2 under each flower.-Allied to Psychótria, but differs in the berries not being ribbed. Perhaps the species of Psychótria with axillary peduncles ought to be joined to this genus

1 R. LAtifòlı (Aubl.guian. 1. p. 155.t. 59.) stems flexuous; leaves ovate, ending in a short point, variegated with green and blue above. h.S. Native of Guiana, in woods at Oyac-Orapu and Sinemari. Psycliótria axillàris var. $\alpha$, Willd. spec. 1. p. 962. Stems simple, nodose, twisted. Stipulas broad, acute. Flowers white. Lobes of corolla pilose. Berries black.

Broad-leaved Ronabea. Shrub 2 to 3 feet.

2 R. erécta (Aubl. guian. 1. p. 156.) stems erect; leaves ovate, acute, thin, greenish-yellow. h.S. Native of Guiana, in woods along with the preceding. R. latifolia $\beta$, Gmel. syst. 1. p. 365. Psychótria axillàris $\beta$, Willd. spec. 1. p. 962. Leaves 4. inches long and $1 \frac{1}{2}$ broad. Flowers white. Berries black.

Erect Ronabea. Shrub 1 to 2 feet.

3 R. ? MYOdE'NdRoN (A. Rich. in mem. soc. hist. nat. 5. p. 270.) leaves linear-lanceolate, very acute, petiolate; flowers disposed in few-flowered terminal corymbs; fruit didymous, hardly umbilicate. h. S. Native of Brazil, where it is called Herbo do rato. Flowers white.

Rat-tree Ronabea. Shrub.

4 R.? morindoides (A. Rich. l. c.) leaves elliptic, acuminated, petiolate; flowers small, crowded into many terminal pedunculate pea-formed heads ; fruit pea-formed, rather umbilicate at the apex; seeds chinky outside. h. S. Native of French Guiana. Flowers white.

Morinda-like Ronabea. Shrub.

5? R.? didyocár pos (A. Rich. 1, c.) leaves elliptic, acuminated, on short petioles; stipulas connate intrapetiolar truncate, furnished each with 2 bristles; flowers disposed in a terminal cyme; fruit didymous, umbilicated by a terminal dot. $\zeta$. S. Native of French Guiana. This and the two preceding are very doubtful species of Ronabea, from the flowers being terminal, and ouglit perhaps on that account to be joined with Psychótria.

Twin-fruited Ronabea. Shrub.

Cult. For culture and propagation see Coffèa above.

CLXXI. PSYCHO'TRIA (said to he from $\psi v \chi \eta$, psyche, life; in allusion to the powerful medicinal qualities of $P$. emética, or as others say from $\psi v \chi^{\circ} \rho \circ \phi_{0}$, psychotrophon, an ancient name for an herb loving shade). Lin. gen. no. 229. H. B. et Kunth, nov. gen. amer. 3. p. 354 . D. C. prod. 4. p. 504.-Psychótrophum, P. Browne, jam.--Psychótria species, Juss. Lam. Willd.-Psychótria and Mapoúria, A. Rich.-Psychótria Simira and Mapoúria, Anbl.

Lin. syst. Pentándria, Monogýnia. Calyx with an ovate tube, and a short 5-lobed 5 -toothed or nearly entire limb. Corolla short, funnel-shaped, 5-cleft, regular; limb spreading or reflexed ; throat bearded or glabrous. Stamens 5 ; anthers exserted or inclosed in the tliroat. Stigma bifid. Berry drupaceous, crowned by the limb of the calyx, furnished with 10 blunt ribs in the dried state, containing 21 -seeded chartaceouslycoriaceous ribbed pyrenæ. Sced erect, witl cartilaginous albumen, and a small basilar embryo.-Small trees or shrubs, rarely 
lerbs, natives within the tropies. Leaves opposite, petiolate. Stipulas variable. l'eduneles sometimes axillary, but usually terminal. Flowers disposed in panicles or corymbs, rarely tetramerous, but almost alway's pentamerous; sometimes, however, there are tetramerous and pentamerous flowers to be found at the same time, and on the same plant. The species are very numerous and truly intricate, therefore diffieult to define.

\$1. Peduncles axillary.-Perhaps all the species belonging to the present scction belong to the genus Rionabea.

\section{* Spceies natives of South America.}

] P.? ExeE'LSA (H. B. et Kunth, nov. gen. amer. 3. p. 355. t. 281.) arboreous; branchlets terete, downy; leaves oblong, acuminated, narrowed at the base, membranous, glabrous ; stipulas deciduous; peduneles axillary, few-flowered; flowers tetramerous and tetrandrous. h. S. Native of Mexico, near Xalappa. Corolla white, glabrous: with the lobes oblong, and longer than the tube. Drupe globose, red, 2-celled; cells I-seeded; ovula erect.

Tall Psychotria. Tree tall.

2 P.? EME'TICA (Mutis, in Lin. fil, suppl. p. 144. exclusive of the synonymes of Marcgrave and Piso,) plant suffruticose, erect, simple, pilosely tomentose; leaves oblong, acuminated, narrowed at the base, membranous, ciliated, rather pilose beneath; stipulas ovate, acuminated, very short; peduncles axillary, fewflowered, subracemose. $h$. S. Native of New Granada, near Nares on the banks of the Magdaiena, and in the province of Girone. H. B. et Kunth, nov, gels. amer. 3. p. 355. Humb. et Bonpl. pl. equin. 2. p. 1.12. t. 126. Cephæ'lis emética, Pers. ench. I. p. 208. I peeacuánha noir, Rich. diet. sc. med. 26. p. 4. with a figure. Ipecacuánha, f. med. 4. f. 201. Flowers white. Berries bluish, ovate-globose, smooth, not furrowed; hence it is probably a speeies of Ronabea. Throat of corolla closed by villi. Root perpendicular, knotted, branehed, emetie, with a slender axis and thick friable bark; and is the ipeeacuanha supplied by Spanish America, but not that supplied by Brazil, which is Cephe'lis Ipecacuánha.

Emetic Psyelotria or Spanish Ameriean Ipeeaeuanha. Sl. 1 to $1_{1}^{1}$ foot.

3 P. н'rta (Willd. in Roem. et Scbultes, syst. 5. p. 191.) branches, peduneles, petioles, and under side of leaves hairy; leares obovate-oblong, acuminated at both ends; stipulas ovate, obtuse ; peduncles axillary, 3-flowered. $h_{\text {. }}$ S. Native of New Granada, on Mount Quindiu. The rest unknown. Perhaps a variety of $P$.ruféscens.

Hairy Psychotria. Sbrub.

4. P. macrophýlid (Ruiz et Pav. f. per. 2. p. 56. t. 202. f. a.) plant herbaceous, glabrous; branches terete; leaves ovallanceolate, acuminated, large, membranous; stipulas broad-ovate, unidentate, short-acuminated; panicles axillary, on short peduncles, with opposite dichotomous branches; fruit oval. $4 . \mathrm{S}$. Native of Peru, in forests on the Audes. Flowers small, sessile, white. Fruit of an obseure violaceous colour. Leaves a foot long. Stipulas beset with glands inside at the base.

Long-lcaved Psychotria. P'. 7 to 8 feet.

$5 \mathrm{P}$. Willdenòwu ( $\mathrm{D}$. C. prod. 4. p. 505.) leaves oblong, attenuated at the base and apex, petiolate, coriaceous, shining, downy beneath; stipulas 2-lobed; panicles axillary, very short, sessile. $\quad$. S. Native of South America. P. magnoliæf òlia, Rœm. et Selultes, syst. 5. p. 190. P. floribúnda var. Spreng.

IIilldenow's I'syehotria. Shrub.

6 P. uligixosa (Swartz, prod. p. 43. fl. ind. oce. p. 421.) plant subherbaceous, simple, ereet, glabrous; leaves laneeolateoblong, acuminated, shining; stipulas connate, acute, convex; cymes pedunculate, tripartite, opposite in the axils of the upper YOL. 111. leaves; flowers sessile; corolla with a villous throat; berries spherieal; seeds crested on the outside. $\boldsymbol{z}_{2} . \mathrm{S}$. Native of $\mathrm{Ja}_{\mathrm{a}}$ maica, in low rather humid parts of the mountains. P'. Browne, jam. p. 160. no. 1.? Root long, ereeping. Berries scarlet, compressed in the dried state. Flowers pale red.

Bog Psychotria. Pl. 2 to 3 feet.

7 P. L.E'vis (D.C. prod. 4. p. 505.) glabrous; leaves ovai, acute at the base, and ending in a short cuspidate point at the apex, smooth above, almost nerveless; stipulas thiek, with a reflexed acumen; peduncles axillary, compressed, shorter than the leaves, trifid at the apex, and each of the branchlets bearing erowded sessile flowers; fruit nearly globose, not erowned. h.S. Native of l'orto-Rico, where it was colleeted by Bertero. P. Phytolácea, Spreng. in herb. Balb, and probably of Poir. Seeds compressed. Ribs of fruit thick, distant.

Smooth Psychotria. Shrub.

S P. Hooke'rı; slurubby, glabrous; branches tetragonal; leaves lanceolate, tapering into the short petioles, coriaceous.ly membranous, with finely reflexed margins, pale and reticulated beneath ; stipulas oval, acute, deciduous ; pedincles axillary, short; flowers on short pedicels, bracteate at the base; bracteas small, convolute, toothed ; flowers dioecious ; fruit oval, erowned by the limb of the calyx, which is tubular, and minutely 5 -toothed at the apex. $\eta$. G. Native of Juan Fernandez. Hippòtis triflòra, Bertero, in ann. des seiene, nat. 21. p. 348. but not of R. and Pav. P.? triflòra, Hook. et Arn. in hot. misc. 3. p. 359. but not of Schum. Fruit a drupaceous berry, nearly half an inch long, inclosing 2 ehartaceous pyrena.

Ilooker's Psychotria. Shrub 3 to 5 feet.

9 P.? PYRrotina (Hook. et Arn. in bot. mise. 3. p. 360.) arboreous, glabrous; branches obscurely tetragonal; leaves broad-ovate or oblong, on long petioles, with erosely sinnated finely reflexed margins, coriaceously membranous, paler beneath and reticulated; stipulas broad-ovate, acute, deciduous; peduncles axillary, 3-fiowered; drupe turbinate, crowned by the erect acuminated teeth of the ealyx. $h$. G. Native of Juan Fernandez, where it is called Pcralillo according to Bertero. Hippòtis pyrifòlia, Bertero, mss. Bertero thinks it may only be a variety of the preeeding species, but it is much larger; he did not meet with the flower; but if its structure prove to be the same as the other, both merit being raised to the rank of a genus according to Arnott.

Pear-leaved Psychotria. Shrub 4 to 6 feet.

10 P. AGNA'TA (D. C. prod. 4. p. 505.) leaves narrow, oblong, attenuated at both ends, shining above, hairy beneath, and bearded on the mid-rib on both surfaces; stipulas acutely bidentate: peduncles axillary, corymbose at the apex, downy; flowers crowded on the tops of the branches of the peduncles; fruit nearly globose. $h$. S. Native of St. Domingo. Nerves of leaves yellowish. Leaves and branchlets erowded. Flowers downy outside when young. Berries glabrous. Perhaps suffieiently distinet from the next species.

hindred Psychotria. Shrub.

11 P. neurótriena (D.C. 1.e.) leaves elliptie-oblong, acuminated at both ends, glabrous, except the middle nerve, which is beset with a series of hairs on both surfaces; stipulas acutely bidentate, permanent; panicles axillary, rather deflexed, raccmose, and rather pilose; flowers sessile, crowded on the tops of the lateral short branches of the paniele; fruit subobovate. $h . S$. Native of Porto-Rico. Bracteas broad, ovate, permanent, under the flowers. Berries glabrous. Flowers unknown.

IIairy-ncred-leaved Psychotria. Shrub.

$$
\text { * Species natires of Africa. }
$$

12 P. TRiflòra (Schum. pl. guin. p. 108.) shrubby; branches brachiate; branchlets rather tetragonal, pilose; leaves ovate, $4 \mathrm{~F}$ 
bluntly acuminated, downy beneath; stipulas reniformly cordate, acute, entire; peduncles very short, axillary, 3 -flowered. $\zeta . S$. Native of Guinea. Flowers white.

Thrce-flonered Psychotria. Shrub \& to 4 feet.

13 P. multiflóra (Schum. pl. guin. p. 108.) plant slirubby, decumbent or scandent, quite glabrous; branchlets rather tetragonal; leaves oblong-ovate, attenuated at the apex, on short petioles; stipulas entire, acuminated; panicles axillary, subcapitate; peduncles length of the petioles. $\zeta$. S. Native of Guinea, at Asiama. Corolla white, downy inside.

Many-flowered Psychotria. Shrub decumbent.

14 P. umbella'ta (Schum. pl. guin. p. 108.) shrub much branched, glabrous; brancblets alternately compressed; leaves hardly petiolate, lanceolate; stipulas acuminated, cleft at the apex, deciduous; peduncles axillary, angular, trifid at the apex, umbelliferous; berries globose, umbilicate at the apex. h. S. Native of Guinea. Leaves $2-4$ inches long. Peduncles 2 inches long. Corolla white.

Umbellate-flowered Psychotria. Shrub 3 to 4 feet.

15 P. KótLy (Sclum. pl. guin. p. 110.) shrubby, glabrous; branchlets compressed; leaves petiolate, ovate-elliptic, acutish, of a different colour beneath; stipulas ovate, acutish ; corymbs axillary and terminal, fastigiate; tube of corolla cylindrical. i. S. Native of Guinea, where it is called Kolly-Tjo by the natives.

Kolly-Tjo Psychotria. Shrub 3 to 4 feet.

16 P. obvalna'ta (Schum. pl. guin. p. I1I.) plant herbaceous, creeping; petioles elongated, rather hairy at the apex; leaves ooblong, cordate, obtuse, glabrous; stipulas ovate, acutish ; peduncles almost axillary, usually 5 -flowered; flowers girded by a foliaceous 4-leaved involucrum. 4 . S. Native of Guinea, at Aquapim.

\section{Environcd Psychotria. Pl, creeping.}

\section{* * * Species natives of Asia.}

17 P. Prilippe' nsis (Cham. et Schlecht. in Limnæa. 4. p. 21.) glabrous and resinous; branchlets tetragonal; leaves obovate, very blunt, petiolate, coriaceous; stipulas very short, intrafoliaceous, permanent; cymes opposite, axillary or supra-axillary, 3 times shorter than the leaves, dichotomous; ovarium cylindrical, crowned by the truncate limb of the calyx. $々$.S. Native of the Island of Luzon, about Tierra Alta by the sea side.

Philippine Psychotria. Slırub.

\section{\$2. Peluncles terminal. \\ * Species natives of Peru.}

18 P. Reticula'ta (Ruiz et Pav. 2. p. 56. t. 212. f. b.) plant herbaceous, downy; branches tetragonal, glabrous; leaves ovatelanceolate, acuminated, reticulately veined, rather coriaceous ; stipulas subconcrete at the base, bifid beyond the middle, with the lobes linear-lanceolate and acuminated; panicles terminal, longer than the leaves, with opposite spreading hairy-velvety branches, and crowded flowers. 24. S. Native of Peru, on the Andes in groves. Leaves a foot long, downy beneath, and having the nerves purplish. Corolla small, yellow, downy outside, with a villous throat.

Reticulated-leaved Psychotria. Pl. 7 to 8 feet.

19 P. Acutiflòra (1. C. prod. 4. p. 506.) leaves oblong, acuminatcd, ciliated, downy beneath, rather scabrous above, clothed with hairy tomentum on the mid-rib on both surfaces, as well as the branchlets; panicles terminal, erect, rather hairy, longer than the leaves, with cymosely bifid branches; segments of corolla mucronately cuspidate. $h_{\text {. }}$ S. Native of Guayaquil, where it was collected by Hanke. Guettárda acutiflòra, Bartl. in herb. Hænke. Nearly allied to $P$. deftéxa. Stipulas connate, sheathing, ending each in a sublanceolate acumen.
Acute-flowered Psychotria. Shrub.

20 P. picòsa (Ruiz et Pav. fl. per. 2. p. 60. t. 208. f. a.) suffruticose, pilose ; branches tetragonal; leaves oblong, acuminated at both ends; stipulas bifid, with lanceolate acute lobes, which are about the length of the petioles; panicles short, terminal, on short peduncles, with opposite branches; bracteas lanceolate, acute, ciliated; teeth of calyx acute. h. S. Native of Peru, on the Andes in humid prarts of forests. Leaves 4 inches long. Inflorescence as in Aspérula. Bracteas bluish. Peduncles hairy. Berries blue, about the size of peas.

Pilose Psychotria. Shrub 2 feet.

21 P. crmòsa (Ruiz et Pav. f. per. 2. p. 59. t. 206. f. b.) suffruticose, glabrous; branches compressedly tetragonal ; leaves oblong-lanccolate, acute, shining above; stipulas bipartite, with the lobes linear-subulate and distant; cymes terminal, on short peduncles, of 5 rays; segments of the calyx long, subulate; tube of corolla villous at the base; berries oval. $\boldsymbol{h}$. S. Native of Peru, in groves on the Andes. Leaves 6 inches long. Peduncles compressed. Corolla purplish. Berries violaceous. Calyx almost as in Geóphila.

Cymose-flowered Psychotria. Shrub 3 to 4 feet.

22 P. magnoliefo'lia (H. B, et Kunth, nov, gen. amer. 3. p. 360. but not of Willd.) glabrous; branchlets compressed; leaves elliptic, bluntish at both ends, rather membranous; stipulas oblong, obtuse, length of the petioles; cymes pedunculate, of 4 spreading rays ; flowers sessile, usually by threes. $\zeta$. S. Native about Quito. Fruit unknown. Said to be allied to $P$. ardisicefòlia. Leaves 7.8 inches long and $4-5$ broad, on petioles 8-9 lines long.

\section{Magnolia-leaved Psychotria. Shrub 4 to 6 feet.}

23 P. glomera'ta (H. B. et Kunth, nov. gen. amer. 3. p. 362.) glabrous; branchlets compressed; leaves oblong or obovate-oblong, acute, narrowed at the base, membranous; stipulas lanceolate, acuminated, ciliated; panicles pedunculate, very simple, spreading; flowers disposed in verticillate heaps, sessile; fruit nearly globose. $\quad$. S. S. Native of Peru. Said to be allied to $P$. ardisicefolia, but the inflorescence is different. Sprengel asserts this species to be a native of New Granada and Brazil, but without giving any authority for so stating.

Heaped-flowered Psychotria. Shrub.

24 P. Rugulòs A (H. B. et Kunth, nov. gen. amer. 3. p. 556.) glabrous ; branches compressed ; leaves lanceolate, long-acuminated, rather coriaceous, narrowed at the base, a little wrinkled, foreulate in the axils of the veins beneath; stipulas lanceolate, acuminated; panicles pedunculate, having the lower branches 4 in a whorl, and spreading; fruit nearly globose, didymous. $\zeta$. S. Native of the temperate parts of Peru.

Wrinkled-leaved Psychotria. Shrub.

25 P. vínivis (Ruiz et Pav. fl. per. 2. p. 61. t. 210. f. b.) glabrous; branchlets somewlut tetragonal; leaves oblong, acuminated, foveolate in the axils of the veins beneath at the base; stipulas comnate, lanceolate, caducous, one-half longer than the petioles; panicles pedunculate, terminal, with opposite branches ; flowers crowded, sessile; berry globose. $\zeta$. S. Native of Peru, in groves on the Andes. Palicurea víridis, Rom. et Schultes, syst. 5. p. 195 . Corollas small, green, with a hairy throat. Anthers inclosed. This has nothing to do with Palicùrea tinctoria, with which it has been confounded by Sprengel. Leaves 3-4 inches long.

Grecn-flowered Psychotria. Shrub 6 to 7 feet.

26 P. RePa'nna (Kuiz et Pav. fl. per. 2. p. 6I.) glabrous; branches somewhat tetragonal, leafy at the top; leaves lanceolate-oblong, repand; stipulas connate at the base, lanceolate, ciliated on the back and margins, caducous ; panicles terminal, with brachiate compressed branches; bracteoles ovate, acnte; flowers sessile, on the tops of the branches of the panicle. 
々.S. Native of Reru, on the Andes in groves. Corolla small, yellow, with a villous throat. Berries size of pepper-corns, purple.

Repand-leaved Psychotria. Shrub 4 to 6 feet.

27 P. Foveola'ts (liuiz et Pav, fl. per. 2. p. 59. t. 207. f. b.) leaves narrow-lanceolate, acuminated at both ends, hardly petiolate, with the axils of the upper veins often glandularly foveolate, but downy on the veins bencath, as well as the branchlets and peduncles; stipulas oval, deciduous; pasicles pedunculate, having the branchlets drooping while bearing the fruit; flowers $3-5$, sessile at the top of each branch of the panicle. h. S. Native of Peru, on the Andes in groves, at Chinchao and Cuchero, cx Ruiz et Pav.; and on the mountains about the Guanocco, ex herb. Hanke. P. foveolàta, Spreng. syst, 1. p. 743. no. 39. exclusive of the synonymes. Branches rather tetragonal. Corolla small, cream-coloured. Berries ovate, purplisli-green, ex Bartl, globose and rufous, and about the size of pepper berries.

Forcolate-leaved Psychotria. Tree 18 feet.

28 P. nivarica'ta (H. B. et Kunth, nov. gen. amer. 3. p. 362. but not of Willd.) glabrons; branchlets terete; leaves lanccolate-oblong, acute, narrowed at the base, membranous, foveolate in the axils of the veins beneath; panicles pedunculate, rather ovate, with opposite spreading branches; flowers pedicel-

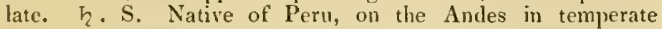
places about Quito. Very nearly allied to $P$. forcolàta. There is a variety of this with tetramerous tetrandrous flowers.

Divarieate Psychotria. Shrub.

29 P. virga'ta (Ruiz et Pav. fl. per. 2. p. 60. t. 209. f. a.) glabrous; leaves oblong or elliptic, acuminated, coriaceous, reticulately-veined beneath; stipulas bluntly bifid, length of the petioles; cymes on short peduncles, trichotomous, crowded with Howers; flowers almost sessile, on the tops of the branches of the cyme; fruit oval. $५ . S$. Native of Peru, on the Andes in cold mountain forests. Leaves 4 inches long, with red nerves, and reflexecl margins, bitter, and supplying a yellow colour when dried. Corollas sulphur-coloured, with a villous throat. Berries ovate, deep blue, size of peas. P. virgàta Jamaicénsis, Spreng. syst. 1. 1. 742 . is perlaps a very distinct species from the present.

Triggy Psychotria. Shrub 9 to 10 feet.

30 P. cunetròlia (D. C. prod. 4. p. 507.) glabrous; leaves obovate, cumeated at the base, and ending in a short cuspidate point at the apex; stipulas small, deciduous; panicles erect, shorter than the leaves, with opposite branches. $h_{2} . S$. Native of Peru, at Guayaquil. P. glabràta, Bartl. in herb. Hænke, but not of Swartz. Flowers unknown. Berries ovate-globose, 10striped in the dried state. Seeds semi-ovate.

Wedge-leaved Psychotria. Shrub.

31 P. H.eNKEA'NA (D. C. prod. 4. p. 507.) glabrous; leares oval-oblong, acuminated at both ends; stipulas bifid on both sides, acuminated; peduncles a little shorter than the leaves; cymes contracted. $h$.S. Native of Guayaquil, and probably of Mexico. P. pedunculàta, Bartl, in herb. Hænke. Allied to P. pedunculàta, Swartz, but differs in the stipulas being much more acuminated, in the leares being narrower, and more acuminated at both ends. Cymes obconical. Flowers and fruit unknawn.

Hoenke's Psychotria. Shrub.

32 P. trífida (Ruiz et Pav. f. per. 2. p. 60. t. 209. f. b.) smoothish; branchlets bluntly tetragonal; leaves lanceolate, acuminated, shining above, but downy along the nerves and veins beneath; stipulas comnate at the base, acutely bifid at the apex; cymes scssile, tripartite, with the branches again trifid; flowers sessile, by threes at the tops of the branchlets of the cyme; corollas downy; berries roundish-turbinate. $\eta_{2} . \mathrm{S}$. Na- tive of the Andes of Peru, in mountain groves. Leaves 3 inches long. Throat of corolla villous. Berries black.

Trifid-cymed Psyclotria. Tree 18 feet.

33 P. capita'ta (Ruiz et Pav. fl. per. 2. p. 59. t. 206. f. a.) smoothish ; branchlets slightly tetragonal; leaves oblong, acuminated, very veiny, downy beneath; stipulas bifid, obtuse; panicles shorter than the leaves, ovate, terminal, on short peduncles; peduncles bracteate, opposite; flowers crowded. h.S. Native of Peru, on the Andes in groves. Ceplra'lis Peruviàna, Spreng. syst. 1. p. 749. Stipulas hispid, glandular on the inner side at the base. Bractcas lanceolate; bractcoles ovate, acute. Berries ovate, blackish, umbilicate.

Capitate-flowered Psychotria. Shrub 9 to 10 fect.

34 P. villòsa (Ruiz et Pav. fl. per. 2. p. 59. t. 207. f. a.) branchlets, peduncles, petioles, and nerves of leaves clothed with rufons villi; leaves attenuated at both ends, glabrous above in the adult state, downy on the nerves beneath; stipulas ovateoblong, acute, caducous; panicles pedunculate, with the branches and branchlets opposite; flowers by threes, glabrous. h. S. Native of the Andes of Peru, in mountain groves. Bartl. in herb. Hænke. Knots of branches pilose. Leaves 4-5 inches long. Bracteas small, acuminated. Berries red, globose, rather compressed, size of small peas. Allied to $P$. micrántha and $P$. hirsüta.

Villous Psychotria. Shrub 9 to 10 feet.

S5 P. мicrántha (H. B. et Kunth, nov. gen. amer. 3. p. 363. t. 284.) hairy from rufescent villi; branchlets terete; leaves obovate-elliptic, acuminated, cuneated at the base, rather coriaceous; stipulas oblong, awnedly bidentate; cymes pedunculate, of 6 rays, diftuse; flowers glomerate; corollas hairy on the outside; fruit globosely elliptic, hairy. $\zeta$. S. Native of Peru, ex Kunth; or at the river Magdalena, ex Willd. P. ruféscens, Willd. in Roem. ct Schultes, syst. 5. p. 192. but not of Kunth.

Small-flonered Psychotria. Slirub.

36 P. subtomentòsa (Ruiz et Pav, fl. per. 2. p. 61. t. 210. f. a.) clothed with downy tomentum; branchlets bluntly terragonal; leaves lanceolate-oblong, acute; stipulas comnate at the base, acutely bifid at the apex; corymbs pedunculate, trifid, bearing almost sessile crowded flowers at the tops of the branchlets ; corollas hairy. S. Native of the Andes of Peru, in mountain groves. Leaves 3 inches long, white beneath. Stipulas glandular. Calyx and corclla blue. Bracteas subulate. Cephæ'lis subtomentòsa, Spreng. syst. 1. p. 749.

Subtomentose Psychotria. Shrub 4 to 6 feet.

\section{* Species natives of Brazil.}

S7 P. ÁLba (Ruiz, et Pav. fl. per. 2. p. 58. t. 205. f. a.) smoothish; branchlets compressed ; leaves elliptic-oblong, acute at both ends, beset with rows of hairs along the nerves beneath, and often forcolate in the axils of the nerves; stipulas ovateoblong, undivided, rather concrete ; panicles pedunculate, terminal, shorter than the leaves, with the branches opposite; calyx short, truncate; herrics orate. $h$. S. Native of Sonth America, especially in tropical Brazil, Guayaquil, and Andes of Peru. Cham. et Schlecht, in Limnæa. 4. p. 19. P. ardisiæfolia, H. B. et Kunth, nov. gen. amer. 3. p. 359. Bartl. in herb. Hzenke. P. densifiòra, Willk. in Riom. et Schultes, syst. 5. p. 189 . P. patula, Willd. in Rœm. et Schultes, syst. 5. p. 189. P. ardisiæfòlia, P. pàtula, and $\mathbf{P}$. álba, Spreng. Leaves $6-8$ inches long. Stipulas obovate, hairy at the base. Bracteas conniving, ovate, acute. Flowers and herries white.

lar. $\beta$, tónsa (Cham. et Schleclit. in Linnea. 4. p. 19.) leaves glabrous, nearly obovate, few-reined. h.S. Native of Brazil, near Rio Janeiro.

I'lite-herried Psychotria. Shrub 12 feet.

38 P. LEIOCA'RIA (Cham. ct Schlecht. in Linnæa. 4. p. 22 ) 1. E ? 
smoothish; leaves narrow-lanceolate, acuminated at both ends, membranous; stipulas rather concrete, bidentate on botb sides; cymes pedunculate, terminal: with the branchlets slender, opposite or verticillate, downy; flowers tetrandrous, rarely pentandrous; calyx 5 -lobed; fruit globose, ribless. $\eta$. S. Native of tropical Brazil.

$V_{a}$. $\beta$, extratrópica (Cham. et Schlecht. in Linnæa. 4. p. 22.) cymes quite glabrous; flowers triandrous or tetrandrous; calycine teeth inequal. $h_{c}$. S. Native of the south of Brazil, without the tropic. Perhaps a proper species.

Smooth-fruited Psychotria. Shrub 4 to 6 feet.

39 P. Nitidula (Cham. et Schlecht. in Linnæa. 4. p. 25.) quite glabrous; leaves lanceolate, acuminated, on very sliort petioles; stipulas triangular, acute, at length bifid, permanent; cymes terminal, pedunculate, length of leaves of 5 compressed rays, 4 of them in a whorl, and the other in the centre of these 4. ; calyx acutely 5-toothed. $\zeta$. S. Native of tropical Brazil. Leaves 3-4 inclies long, and 10-18 lines broad. Flowers small, pedicellate. Fruit unknown.

Shining-leaved Psychotria. Shrub 4 to 6 feet.

40 P. Foryos a (Cham. et Schlecht, in Linnæa. 4. p. 24.) leaves glabrous, obovate or elliptic, short-acuminated, cuneated at the base, of the consistence of parchment ; stipulas ovate, acute, small, deciduous; panicles terminal, pedunculate, loose, longer than the leaves, downy or hairy; lobes of the corolla acute, bearded at the apex. $h$. S. Native of tropical Brazil. Very like $P$. álba, and the cicatrices of the stipulas are beset with rufous villi, as in it.

Beautiful Psychotria. Shrub 6 to 8 feet.

4.1 P. cuspida'ta (Bred. ex Willd. in Rœm. et Schultes, syst. 5. p. 192.) smooth and glabrous; leaves oval, cuneated at the base, acuminated at the apex, scrobiculately villous in the axils when old; stipulas bidentate, truncate; panicles terminal, pedunculate, 3 times shorter than the leaves, with compressed hranches, which are dilated at the ramifications. $h$. S. Native of tropical Brazil, and at Caraccas. Allied to P.nonateloides and $P$. cormifolia.

Cuspidated-leaved Psychotria. Shrub 5 to 6 feet.

42 P. nonatelioldes (Cham. et Sclılecht, in Linnæa. 4. p. 26.) smooth and glabrous ; branchlets compressed; leaves lanceolate, acute at the base, and long-acuminated at the apex, membranous; stipulas 2-lobed, permanent; cymes racemose, terminal, one-half shorter than the leaves; pedicels 3-flowered: middle Hower and one of the lateral ones tribracteate. 5.S. Native of tropical Brazil, and at Caraccas. P. involucràta, Willd. herb. Fruit unknown. Habit of $P$. cornifolia.

Nonatelia-like Psychotria. Shrub.

43 P. Nóxia (St. Hil. pl, rem. bras. p. 234, t. 21, f. a.) branchlets compressed, furnished with 2 rows of hairs; leaves lanceolate, acuminated, on short petioles, approximate, glabrous; stipulas short, bipartite; flowers $2-4$ in a fascicle, sessile, bracteate, terminal, and axillary; bracteas acuminated, ciliated ; fruit elliptic. $h$. S. Native of Brazil, in the province of Minas Geraes. This species is supposed to be hurtful to animals who eat it,

Hurtful Psychotria. Slirub 5 to 6 feet.

44 P. eleiptica (Ker. bot. reg. t. 607. but not of Willd.) glabrous; leares elliptic, attenuated at both ends, shining, membranous; stipulas sheathing, ovate, rather erosely fringed, deciduous; cymes terminal, sessile, tripartite, with trichotomously panicled branches, shorter than the leaves. h. S. Native of Brazil. Flowers slort, white. Calyx cup-shaped, slightly toothed.

Elliptic-leaved Psychotria. Fl. May, June. Clt. 1821. Sh. 3-4 feet.

45 P. chenótricha (D. C. prod. 4. p. 509.) quite glabrous; branchlets compressed; leaves elliptic, acuminated at both ends, smooth; stipulas short, bifid at both sides; corymbs terminal, sessile, with umbellate branches, much shorter than the leaves, each branch bearing 4-5 flowers at the apex; corollas glabrous on the outside, but villous in the throat. $h$. S. Native of Brazil, at Bahia, in sand by the sea-side, where it was collected by Salzmann. Flowers cream-coloured. Anthers copper-coloured, sessile in the throat of the corolla among the villi. Style a little exserted.

Gaping-haired Psychotria. Shrub.

46 P. BARbiflòra (D. C. prod. 1. p. 509.) quite glabrous ; branchlets compressed; leaves oval-ovate, acute at the base, acuminated at the apex, shining above ; stipulas combined at the base, biaristate ; peduncles terminal, very short, densely corymbose at the apex, bracteate under the flowers; corolla glabrous outside, witls the lobes of the limb hairy above. $\hbar_{2} . S$. Native of Brazil, on hills about Bahia, where it was collected by Salz. mann. Style cxserted. Anthers inclosed. Fruit black, globose, a little furrowed.

Bearded-flowered Psychotria. Shrub 4 to 6 feet.

47 P. Baniénsis (D. C. prod. 4. p. 509.) quite glabrous; leaves elliptic, attenuated at the base, acuminated at the apex, shining above; stipulas rather concrete at the base, and furnished with 2 ligulæ on both sides, lanceolate, acuminated; peduncles terminal, one-half shorter than the leaves, racemosely corymbose at the apex; corollas beardless. $h_{c}$. S. Native of Brazil, about Bahia, where it was collected by Salzmann. Slirub 3 feet high. Flowers white, probably dioecious. Branches compressed.

Var. $a$, stylòsa (D. C. l. c.) style exserted; anthers inclosed; fruit globose, sub-didymous, hardly furrowed.

Var. $\beta$, staminca (D. C. l. c.) style inclosed; anthers exserted. Perhaps a proper species, or the male variety of the preceding.

Bahia Psycliotria. Slurub 3 feet.

48 P.? sambu'cixa (Link, in Roem. et Schultes, syst. 5. p. 188.) glabrous : leaves ovate-lanceolate, acuminated, petiolate; stipulas deciduous; branches of the panicle glabrous, verticillate, 3 times shorter than the leaves. h. S. Native of Brazil. Leaves a span long, and 3-4 inches broad, of a livid black colour in the dried state.

Elder-like Psychotria. Slirub.

49 P. Longifolia (Hoffnans, ex Willd. in Røem. et Schultes, syst. 5. p. 190.) leaves ovate-oblong, acuminated, cuneately attenuated at the base; stipulas bifid; panicles terminal. $\zeta . \mathrm{S}$. Native of Brazil. Leaves a foot long. Perhaps the same as $P$. racemòsa.

Long-leaved Psychotria. Shrub.

50 P. grandiólia (Hoffmans. ex Willd. in Roem. et Schultes, syst. 5. p. 190.) leaves ovate, acute; stipulas bifid, obtuse; flowers panicled. h.S. Native of Brazil. Leaves half a foot long. Corollas yellow. Very like $P$. latifólia, but differs in the form of the stipulas.

Great-leaved Psychotria. Shrub.

\section{* * Species natives of Guiana.}

51 P. Mapu'ria (Rœm. et Schultes, syst. 5. p. 187.) glabrous; leaves obovate, each ending in a short blunt acumen, cuneated at the base; stipulas ovate-roundish, deciduous; panicles terminal, shorter than the leares; fruit ovate-globose, striated. 5.S. Native of French Guiana, on the banks of rivers. Mapoùria Guianéusis, Aubl. guian. 1. p. 175. t. 67. Simìa nítida, Poir. dict. 7. p. 196 . P. nítida, Willd. spec. 1. p. 963. Leaves 8 inches long, and $4-5$ broad. Corollas white, having the limb longer than the tube. Stamens filiform, exserted. Stigma bilamellate.

Mapuria Psychotria. Shrub 7 to 8 feet. 
52 P. Mapovrioldes (D. C. prod. 4. p. 509.) glabrous; leaves elliptic, cuneated at the base, short-acuminated at the apex; stipulas obovate, foliaceous, deciduous, length of the petioles; panicles rising from the forks of the branches, pedunculate, hardly shorter than the leaves; fruit ovate, striated. $\zeta$. S. Native of French Guiana, where it was collected by Patris. Very nearly allied to $P$. Mapouria, but differs from that species in the above characters, besides in the longer leaves, larger stipulas, and in the peduncle of the fructiferous panicle being 4 inches long.

Mapouria-like Psychotria. Slirub 5 to 6 feet.

53 l. Sruira (lion. et Scluultes, syst. 5. p. 187.) glabrouts ; leaves elliptic-ovate, abruptly acuminated, with parallel veins, paler beneath ; stipulas ovate, acuminated, deciduous; panicles erect, on short peduncles, one-half shorter than the leaves; ber-

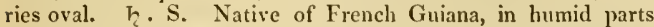
of woods. Sinìra tinctòria, Aub]. guian. 1. p. 170. t. 65. l'. parviflòra, Willd. spec. 1. p. 96\%. Bark red on the inside. Leaves 14 inches long, and 6 broad, with the nerves red beneath. Branches of the panicle short. Corolla white, with rounded segments, ex Aubl., but acute segments, ex Rich., shorter than the stanens. The bark of this shrub is used to dye silk and cotton of a red colour. Simira is the Guiana name of the tree.

Simira Psychotria. Slirub 10 to 12 feet.

54 P. Patrísir (D. C. prod. 4. p. 510.) glabrous; leaves elliptic-oblong, acuminated at both ends; stipulas elliptic, actitish, deciduous; panicles pedunculate, a little slıorter than the leaves, having the branches and branchlets opposite; frnit ovate, striated, terminated by a short conical horn. h. S. Native of French Guiana, where it was collected by Patris, along with many other species. Branches terete. Leaves 5-6 inches long, and 2 or $2 \frac{1}{2}$ broad. From the stipulas and habit, this species comes near to $P$. Mapuria.

Patris's Psychotria. Shrub 6 to 8 feet.

55 P. soròris (D. C. l. c.) glabrous; leaves elliptic-oblong, acuminated at both ends; stipulas triangularly-elliptic, acute, deciduous; panicles terminal, pedunculate, hardly shorter than the leaves, with the branches and branchlets opposite; fruit nearly globose, striated, truncate at the apex. $々$. S. Native of French Guiana, where it was collected by Patris. Very nearly allied to $P$. Patrisii, but the berries are fewer, and larger round, without horns, and crowned by the 5 small teeth of the calyx.

Sister Psychotria. Shrub 6 to 8 feet.

56 P. Ficigésina (D. C. prod. 4. p. 510 .) glabrous; leaves oval, acuminated at both ends; stipulas oblong, acuminated, deciduous; panicles pedunculate, longer than the leaves, having the branches and branchlets opposite; fruit ovate, striated. h. S. Native of French Guiana, where it was collected by Patris. The buds and stipulas are oblong and acute, and very much like those of the fig-tree. Peduncle of the panicle 3 inches long. Fruit small. Allied to P. Simira.

Fig-budded Psychotria. Shrub 5 to 6 feet.

57 P. RACEMòsA (A. Rich. act. soc, hist. nat. par. 1792. p. 107.) glabrous ; leaves elliptic-oblong, acuminated at both ends, shining beneath; stipulas bifid, with the lobes acuminated; racemes terminal, pedunculate, straight, one half shorter than the leaves; rachis of the raceme angular, downy; fruit compressed, coarsely ribbed. $々$. S. Native of French Guiana, Leaves 10 inclies long, and 3 broad, on petioles which are nearly an inch long. Flowers unknown.

Racemose-flowered Paychotria. Slurub.

58 P. Flexiòsa (Willd. spec. 1. p. 966.) glabrous, subherbaceous ; branches compressed ; leaves oval, acuminated, on short petioles, membranous ; stipulas bipartite, acuminated, equal in length to the petioles; panicles terminal, racemose, pedunculate, shorter than the leaves; berries globose, compressed, rather didymous. $々$. S. Native of Caycnne, in sterile places. Nonatèlia paniculàta, $A$ ubl. guian. 1. p. 181. t. 70. f. 2. Flowers white. Berries violaceous.

Flexuous l'sychotria. Slirul, 2 feet.

59 P. DEFLE'XA (D. C. prod. 4. p. 5 I0.) glabrous; branches and peduncles compressed; leaves ovate-lanceolate, or ovallanceolate, acuminated at the apex, and acute at the base, membranous; stipulas twin on both sides, lancelate, lrardly joined at the base; panicles pedunculate, shorter than the leaves, with reflexed compressed branchlets, which are bearded in the axils; flowers small, tetramerous. $\zeta$. S. Native of French Guiana, where it was collected by Patris. Very nearly allied to $P$. flexuosa, but differs in the flowers being tetramerous and tetrandrous.

Deflexed-peduncled Psychotria. Shrub 1 to 2 feet.

60 P. Panicula'ta (WVilld. spec. 1. p. 970.) glabrous; leaves ovate, acuminated at both ends, veiny; stipulas connate, bidentate; panicles terminal, erect ; berries globose, compressed, subdidymous. h. S. Native of Surinam and other parts of South Anierica.

Var. $\beta$, oblongàta (D. C. prod. 4. p. 510.) leaves oblong ; panicles weak. $\zeta$. S. Native of French Guiana, where it was collected by Patris. Nerves of the leaves and peduncles yellowish. Panicles the length of the leaves.

Panicled-flowered Psychotria. Trec, tall.

61 P. BRActen'ta (D. C. prod. 4. p. 510 .) glabrous; leaves oblong, acuminated, almost sessile, stiff, shining above, with revolute margins; stipulas twin on both sides, linear, acuminated, longer than the petioles, which are very short; cymes trichotomous, on short peduncles; bracteas oblong, many, under the flowers; fruit nearly globose, striated. $\eta$. S. Native of French Guiana, where it was collected by Patris. This is a very distinct species. Leaves 3 inches long, and 8-9 lines broad. Petioles 1-2 lines long. Peduncle of the cyme compressed, 9-10 lines long.

Bracteate-flowered Psychotria. Shrub 4 to 6 feet.

62 P. Platy'yoda (D. C. l. c.) glabrous; leaves oval or ol)long, acuminated, with parallel nerves; stipulas connate, short, bidentate on both sides; cymes terminal, 4 parted, on very short peduncles, girded by 4 large ovate bracteas, having the branches compressed so much as to be 2-edged, the secondary branches bearing the flowers at their tops; fruit round, depressed, coarsely ribbed. . S. Native of French Guiana, where it was collected by Patris. The leaves and peduncles become yellowish on drying. Leaves 5-6 inches long, and 2-3 broad. Petioles 4-6 lines long.

Broad-pcduncled Psychotria. Shrub 6 to $S$ feet.

63 P. BRE'vipes (D. C. prod. 1. p. 51 1.) glabrous; branchlets compressed; leaves elliptic, acuminated at both ends, shining above; stipulas twin on both sides, linear, acuminated, hardly joined at the base; cymes irregularly branched, on short peduncles, rather bracteate; fruit roundish, compressed, profoundly ribbed. h. S. Native of French Guiana. Fructiferous cymes equal in length to the attenuated part of the base of the leaves. Leaves 5 inches long, and 2 broad. Petioles I-3 lines long.

Short-peduncled Psychotria. Shrub.

$$
\text { *** Specics natives of Colimbia. }
$$

64. P. Cartuagene'nsis (Jacq. amer. p. 65. t. 17t. f. 22.) glabrous; leaves obovate or elliptic, rather coriaceous, attenuated at both ends; stipulas ovate, rather membranous, rufous, deciduons; peduncles elongated, corymbose, trichotomous, rising from the forks of the branches; throat of the corolla villous; 
berries ovate. $h$. S. Native of Carthagena, among bushes, cx Jacq. ; and of St. Domingo, ex Bertero. P. Cartlagenénsis, Spreng. ex Balb. Corollas white, having the tube much exceeding the limb, which is said to be 6-7-cleft, and the stamens are $6-7$, according to Jacquin. Berries red, crowned by the calyx, which is of the same colour. Willdenow says that the stipulas are emarginate; but they are probably entire and obtuse.

Carthagena Psychotria. Shrub 5 to 6 feet.

65 P.? calycina (H. B. et Kunth, nov. gen. amer. 3. p. 356.) glabrous; branchlets compressed; leaves lanccolate or oblong, long-acuminated, narrow at the base, membranous; stipulas oblong, obtuse ; corymbs pedunculate, tricliotomous, spreading; calyses cucullately spathaceous, cleft on one side. $\eta$. S. Native of New Granada. Calyx campanulate, 5-toothed, one half shorter than the corolla. On account of the form of the calyx, this plant does not agree witls the present genus, but the fruit is unknown.

Large-calyxed Psychotria. Shrub.

66 P. salicifólia (H. B. et Kunth, nov. gen. amer. 3. p. 360. but not of Willd.) glabrous; branchlets compressed; leaves lanceolate, acuminated at both ends, membranous; stipulas oblong, acute, fascescent; panicles pellunculate, with opposite, muchspreading branches; fruit spherical. 々. S. Native of New Granada.

Iillon-leaved Psychotria. Shrub.

67 P. Ánceps (H. B. et Kunth, nov. gen. amer. 5. p. 360.) glabrous; branches 2 -edged; leaves oblong, acuminated at both ends, shining above, scrobiculate in the axils of the voins beneath; stipulas ovate, acutisls; cymes pedunculate, trichotomous, spreading; flowers sessile, usually by threes; fruit ovate. ?. S. Native of New Granada, in temperate places, near the cataract of Tequendama.

Tro-edged-branched Psychotria. Shrub.

68 P. Lu'cida (H. B. et Kunth, nov. gen. amer. 3. p. 361. t. 288. but not of Willd.) glabrous; branches 2-edged; leaves lanceolate-oblong, acuminated at both ends, coriaceous, slining above; stipulas ovate, acute, deciduous; corymbs pedunculate, dichotomous, spreading; bracteoles and teetlis of the calyx ciliated; fruit nearly globose. $h$. S. Nativc of New Granada, on the banks of the river Magdalena, near Honda. P. viburnoides, in Roem, et Schultes, syst. 5. p. 189. but not of Kunth. Flowers usually by threes, sessile, about the size of those of the privet.

Shining-leaved Psychotria. Tree 20 feet.

69 P. connifòlia (H. B. et Kunth, nov. gen. amer. 3. p. 362.) glabrous ; branchlets terete ; leaves almost sessile, ovate-rluomboid, acuminated, cuneated at the base, membranous ; corymbs pedunculate, terminal, bifid, divaricate ; fruit rounlish, compressed. $々$. S. Native on the banks of the Orinoco, near Maypures. Stipulas and flowers unknown. Perhaps a distinct genus.

Dognood-leaved Psychotria. Shrub.

70 P. viburnoides (H. B. et Kunth, nov, gen. amer. 3. p. 361. but not of Willd.) glabrous ; branchlets compressed; leaves oblong, acuminated at both ends, coriaceous, slining above; stipulas ovate, acute, deciduous; cymes pedusculate, of 4 rays, spreading; bracteoles and teeth of the calys ciliated. $r_{c} . S$. Native on the banks of the Orinoco, near the cataract of Atures. Very like $P$. licida.

l'iburnum-like Psychotria. Shrub.

1 P. BorJE'nsis (H. B. et Kunth, nov, gen, amer. 3. p. 557.) smoothish; branchlets compressed; leaves lanceolate, acuminated at both ends, membranous, with undulated margins, shin. ing a little; stipulas ovate, acute; cymes pedunculate of 5 rays, spreading, the rays clothed with powdery down. h.s. Na- tive in woods, on the banks of the Orinoco, near San-Borja. P. ligustrìna, Willd. in Roem. et Schultes, syst. 5.p. 188. Nearly allied to $P$. rugulòsa, but the flowers are smaller, \&c. Leaves glabrous on both surfaces according to Kunth, but according to Willdenow the leaves are downy underneath.

San-Borja Psychotria. Shrub.

72 P. Glaucé'scens (H. B. et Kunth, nov. gen. amer. 3. p. 558.) branchlets tercte, hairy; leaves oblong or lanceolate-oblong, acuminated, acute at the base, with sub-undulated margins, rather coriaceous, glabrous, glaucescent beneath, foveolate in the axils of the vcins beneath, and downy on the veins; stipulas ovate, acuminated; cymes pedunculate of 5 spreading rays; pedicels hairy; fruit nearly globose-elliptic. $\zeta$. S. Native on the banks of the Orinoco, and near the city of Angostura. P. divaricàta, Willd. in Rom. et Schultes, syst. 3. p. 191.

Glaucescent Psychotria. Slırub 10 to 15 feet.

73 P. RUfE'scens (Spreng. syst, 1. p. 741.) branclilets, stipulas, peduucles, petioles, and nerves of the leaves clothed with rusty hairs; leaves obovate-oblong, acuminated, narrow at the base; stipulas oval, obtuse; cymes sessile, of 3-4 rays or branches, the rays bearing almost sessile, crowded flowers at their tops. h. S. Native of South America.

Irar. $a$, ferruginca (D. C. prod. 4. p. 512.) branches subtrigonal; flowers conglomerate; stipulas acutish, half an incl long. 々. S. Native of New Andalusia, near Caripe. The corolla is said to be white, with a villous throat and reflexed lobes. Fruit unknown. P. ruféscens, H. B. et Kunth, nov. gen. amer. 3. p. $36 \%$. but not of Willd. Bertic̀ra ferruginca, Willd. in Roem. ct Schultes, syst. 5. p. 227.

tar. $\beta$, hïrta (D. C. l. c.) branchlets compressed; flowers usually by thrces; stipulas obtuse. $々$. S. Native of New Granada, on the Andes, about Quindiu. P. hírta, H. B. et Kuntl, nov. gen. amer. 3. p. 364. but not of Willd. Corolla hairy outside. Berry oblong.

l'ar. $\gamma$, Hankeàna (D. C. l. c.) branchlets compressed; stipulas obtuse, hairy in the young state, and glabrous in the adult state; flowers conglomerate; corollas hairy outside; berries ovate-oblong. h. S. Native of Mexico. P. ruféscens, Bartl.

Rufesccnt Psychotria. Shrub.

74. P. diervilloides (H. B, et Kunth, nov. gen. amer. 3. p. 358.) clothed with fine hairy tonentum; branchlets compressed ; leaves ovate-acuminated, rounded at the base, membranous, glabrous above; stipulas oblong, obtuse; cymes pedunculate of 4 spreading rays; pedicels and calyxes hairy. $\eta$. S. Native of South America, near Angostura. Petioles glabrous. Stipulas equal. Lobes of the corolla revolutely reflexed. Fruit unknown.

Diervilla-like Psychotria. Shrub.

75 P. Oninocénsis (D. C. prod. 4. p. 512.) leaves on short petioles, roundish-ovate, acute, shining; stipulas 2 -lobed; corymbs divaricate. $\eta$. S. Native on the banks of the Orinoco. P. cornifolia, Willd. in Røem. et Schultes, syst. 5. p. 191. but not of Kunth.

Orinoco Psychotria. Shrub.

76. P. Latifolia (Willd. in Rem. et Schultes, syst. 5. p. 189.) leaves ovate, acute at both ends, ribbed; stipulas acutely bidentate; panicles terminal, elongated. $I_{2}, S$. Native on the banks of the Orinoco, in shady places. Humb, et Bonpl, Leaves a foot long, very broad, shining on both surfaces, downy on the vcins beneatl. Branclies of the panicle crowded, erect, ex Spreng. syst. 1. p. 745 .

Broad-lcaced Psyclotria. Shrub.

i7 P. L.triga'ta (Willd. in Rocm. et Schultes, syst. 5. p. 190.) leaves oblong-ovate, petiolate, tapering at the base, glabrous; stipulas bidentate; panicle terminal. $h$. S. Native of South 
America, at the river Atabapo. Humb. et Bonpl. This is said to be the same as Palicoùrca speciòsa, by Spreng.

Smooth Psychotria. Shrub.

78 P. Hunde'ssis (Willd. in Roem. et Schultes, syst. 5. p. 189.) leaves oblong, acuminated at both ends, rather membranous; stipulas oblong, obtuse; panicle trichotomously corymbose. h. S. Native of New Granada, on the banks of the Magdalena, near Honda, or Hunda. Palicoùrea mitis is joined with this by Spreng. but for what reason we know not.

Hondu Psychotria. Shrub.

79 Cumanénsis (Willd. in Roem. et Sclultes, syst. 5. p. 191.) leaves oblong; stipulas ovate, acute; cymes few-flowcred. h.S. Native of Cumana, Humb. et Bonpl; and Trinidad, G. Don. Flowers yellow.

Cumana Psychotria. Clt. 182t. Shrub 10 feet.

80 P. sessiliflòra (Willd. in Roem. et Schultes, syst. 5. p. 191.) herbaceous ; leaves oblong, acuminated at both ends; stipulas emarginately bidentate ; flowers terminal, crowded, sessilc. 4. S. Native on the banks of the Orinoco, Humb. et Bonpl. Herb half a foot higl. Flowers white.

Sessile-flowercd Psychotria. I'l. half a foot.

\section{*****A species native of Panama.}

8I P. Furca'ta (D. C. prod. 4. p. 512.) smoothish; branches bifurcate, terete; branchlets compressed; peduncles, petioles, and nerves of the leaves roughish; leaves ovatc-oblong, acuminated; stipulas bidentate, small, acute; heads on short peduncles; pedicels thick, very short; bracteas 4, linear, spreading. h. S. Native of Panama, where it was collected by Hænke. Cephæ'lis furcàta, Bart]. in herb. Hænke. Fruit ovate-globose, compressed, furrowed. Flowers unknown. Habit of Cephe'lis oblong $a$, but the inflorescence and fruit are like that of $P$.platypoda.

Forked-branched Psychotria. Shrub.

$$
\text { ****** Spccics natives of Mexico. }
$$

82 P. Biarista'ta (Bartl. in herb. Hænke, ex D. C. prod. 4. p. 513.) glabrous; branchlets a little conıpressed; leaves oblong, or obovate-oblong, attenuated at both ends, coriaceous; stipulas short, broadly ovate, biaristate, deciduous; cymes on short peduncles of 3-4 rays, much shorter than the lcaves ; fruit nearly globose. $h$. S. Native of Mexico. Leares 2 inclies long, and 9 lines broad. Petioles 1-2 lines long.

Tno-anned-stipulated Psychotria. Shrub 1 to 2 feet.

83 P. Mo'llıs (Poir. dict. 5. p. 702. ? Bartl. in herb. Hænke, ex D.C. prod. 4. p. 513.) branclslets nearly terete; peduncles and nerves of leaves downy ; leaves elliptic-oblong, acuminated at botls ends, membranous, when young downy, but in the adult state glabrous above; stipulas ovate, acutely bidentate; panicle corymbose, crowded, pedunculate, shorter than the leaves; corolla with a short tube, blunt erect lobes, and a hairy throat. h. S. Native of Mexico. Allied to P. horizontàlis var. $\beta$. P. móllis, Spreng. in herb. Balb. should be excluded from the present order. The plant of Poirett is probably distinct from that of Bartl.

Soft Psychotria. Shrub.

84 P. IEBE'CLADA (D. C. prod. 4. p. 513.) branchlets, petioles, panicles, and nerves of leaves downy ; leaves elliptic-oblong, acuminated at both ends; stipulas acutely bifid; panicles erect, ovate, with the rachi compressed, and the brancles opposite. h. S. Native of Mexico. P. pubéscens, Bartl. in herb. Hænke. It differs from $P$. pubéscens in the stipulas being more acute, in the panicles not being corymbose, in the rachi of the panicles being compressed, and in the bracteoles being shorter. Flowers unknown. Berries globose, compressed, downy, crowned, striated in the dry state.
IHairy-branched Psychotria. Shrub.

85 P. auréola (Bartl. in herb. Hanke, ex D. C. prod. 4. p. 513.) clothed with velvety down; branchlets from compressed to terete; leaves oblong-lanceolate, attenuated at both ends : veins parallel, and are as well as the nerve yellowish ; stipulas broad, ovate, drawn out each into a setaceons acumen at the apex, which is sometimes undivided, and sometimes biaristate; corymbs pedunculate, trichotomons; calyx 5-toothed, and are, as well as the corollas, downy. $h$. S. Native of Mexico. Branches and leaves yellowish in the dried state. Leaves 2 or $2 \frac{1}{2}$ inches long, and 9-10 lines broad. Petioles a line long.

Golden Psychotria. Shrub.

86 P. scabriu'scula (Bartl. in herb. Hanke, ex D. C. prod. 4. p. 513.) branchlets a little compressed; young leaves and peduncles clothed with very fine down; leaves oblong-lanceolate, attenuated at both ends, at length glabrous on the upper surface ; stipulas ovate, biaristate, shorter than the petioles; corymbs trichotomous, pedunculate, shorter than the leaves; fruit globosely didymous. $\quad$. S. Native of Mexico, about Acapulco. Allied to $P$. aurèla. Peduncles often clanged into lateral elongated pseudo-axillary branches.

Roughish Psychotria. Shrub.

87 P. Mexica'sa (Willd. in Rom. et Schultes, syst. 5. p. 192.) leaves oblong, acuminated at both ends, rather membranous; stipulas bipartite, acute; panicles narrow, terminal. $h$. S. Native of Mexico. Humb. et Bonpl. This plant is referred to Palicourea fastigiàta by Sprengel, who is probably correct.

Mexican Psychotria. Shrub.

88 P. Padifo'lia (Willd. in Roem. et Scluultes, syst. 5. p. 189.) leaves oblong, acuminated, pilose on the veins beneath; stipulas bipartite, linear-subulate; panicles corymbose, terminal. $h . S$. Native of Mexico, about Xalappa. Humb. et Bonpl.

Bird-cherry-leaved Psychotria. Shrub.

\section{$* * * * * A$ specics native of Florida.}

89 P. Lanceola'ta (Nutt. in Sill. amer. journ. 5. p. 290.) branches and under sides of leaves clothed with rusty down; leaves lanceolate, acuminated at both ends ; stipulas stem-clasping, roundish, deciduous, sphacelate; corymbs terminal, trichotomous from the base. $h$. S. Native of Eastern Florida. Leaves 2-3 inches long. Berries ovate, red.

Lanceolate-leaved Psychotria. Shrub.

$$
\text { *******A species native of the Bahamas. }
$$

90 P. UNDA'TA (Jacq. hort. schoenbr. 3. p. 5. t. 260. fragm. 101.) glabrous; leaves oval-lanccolate or oblong, acuminated at both ends, undulated; stipulas connate, ovate, deciduous, a little shorter than the petioles ; cymes terminal, sessile, tripartite, with trichotomous branches; corolla with a naked throat, but the tube is villous at the origin of the filaments. $々$. S. Native of the Bahama Islands. Leaves acute at both ends, wavy, shining above, 3-4 inclies lang. Corollas white, with reflexcd segments. Berries small, roundish, red.

Wravy-leaved Psychotria. Fl. May, June. Clt. 1823. Shrub 3 to 4 feet.

\section{******** Species natives of the Wcst India Islands.}

91 P. Floribu'nda (H. B. et Kunth, nov. gen. amer. 3. p. 359.) glabrous ; branchlets compressed; leaves elliptic-nblong, acuminated at bath ends, coriaceous; stipulas oblong, obtuse ; cymes pedunculate, of 6 rays, much branched, diffuse: the rays again divided into $4-5$ rays; bracteas and calycine teeth hairy; stamens length of the lobes of the corolla. $h_{2}$. S. Native of South America, in the province of Carthagena near Turbaco? ex 
liunth; in the Island of Martinico, ex Sieb, ; and of Guadaloupe, ex Perrottet.

Bundle-flowered Psychotria. Shrub.

92 P. tenulfolla (Swartz, prod. p. 4. f. ind. oce. 1. p. 402.) glabrous ; leaves oblong, acuminated at both ends, memhranous ; stipulas ovate, deciduous, bifid, with acuminated lobes; panicles erect, almost sessile, shorter than the leaves; throat of corolla villous. $\boldsymbol{h}$. S. Native of Hispraniola, among bushes. Leaves with an obtuse acumen, ex Swartz. Panicles trichotomous. Flowers small, white. Berries oblang, glabrous.-P. glabràta, Sieb. A. mart. no. 73. does not differ from the plant of Swartz, unless in the leaves being acutely acuminated. P. laurifolia, Bertero, collected in Hispaniola, has the leaves acute at the apex, and the nerves of the leaves beset with rusty down underneath. In both, however, there are rufous cilia in the axils of the leaves and stipulas.

Thin-leaved Psychotria. Slurub 3 to 4 feet.

93 P. Nertòsa (Swartz, prod. p. 43. fl. ind. oce. 1. p. 403.) glabrous; leaves ovate, acute at the base, and acuminated at the apex, veined, a little undulated; stipulas oblong, acuminated, emarginate, deciduous; corymbs tripartite, with trichotomously panicled branclies; throat of corolla villous; berries oblong. 々. S. Native of Jamaica, among hushes. P. stipulàcea, Swartz, in herb. L'Her. Branches a little compressed. Panicles terminal and axillary, shorter than the leaves. Stipulas large, rusty.

Nered-leaved Psychotria. Slirub 5 to 6 feet.

94. P. LA'XA (Swartz, fl. ind. oee. P. 407. but not of Ruiz et P'av.) glabrous; leaves ovate, acuminated, hardly nerved, on very short petioles; stipulas ovate, acuminated, deciduous; corymbs terminal, tripartite from the base, triehotomous, baving the branches and pedicels rather eapillary and loose; berries oblong. $h_{2}$.S. Native of Jamaica, among bushes on the mountains. Stipulas small, subciliated. Fruit oblong, acuminated at both ends. Branches terete. Leaves 1-2 inclies long.

Loose-corymbed P'sychotria. Shrub 4 to 6 feet.

95 P. oligó́tricha (D. C. prod. 4. p. 514.) glabrous ; leaves elliptie, acuminated at both ends, membranous, hairy in the axils of the veins; stipulas ovate, membranous, rufons, deciduous; corymbs sessile, tripartite, having the branehes trichotomous; throat of corolla bearded. h.S. Native of Jamaica, PortoRico, Martinique, \&c. P. horizontàlis, Spreng, in herb. Balb. It differs from $P$. horizontalis in the nerves of the leaves being glabrous, in the throat of the corolla being bearded, not nalied; and in the corymbs being sessile, not pedunculate. Very nearly allied to $P$. undata and $P$. chimarrhoides.

\section{Few-haired Psyehotria. Slirub 4 to 6 feet.}

96 P. chinarmoldes (D. C. prod. 4. p. 514.) glabrous; leaves oblong-lanceolate, acuminated at both ends, membranous ; stipulas ovate, obtuse, rusty, deciduous, length of the petioles; cymes terminal, sessile, tripartite: with the branchlets 3 times shorter than the leaves. $々$. S. Native of Guadalonpe and? Trinidad, ex Sieb. fl. trin. no. 256; and of Cuba. Fruit oval, striated, crowned by the 5 -toothed calyx. Leaves 3 or $3 \frac{1}{2}$ inches long, and 7-9 lines broad. Very nearly allied to $P$. undàta, but differs in the leaves being flat, and one-lalf narrowcr ; and in the fruit being oval, not sphierical.

Chimarrhis-lile Psychotria. Shrub 5 to 6 feet.

97 P. capitella'ta (D. C. prod. 4. p. 514.) branchlets compressed, glabrous; leaves elliptic, a little euneated at the base, and acuninated at the apex, membranous, glabrous; stipulas drawn out into 2 setaceous ligulæ; peduncles terminal, hairy, bearing three nearly sessile downy bracteate lieads of flowers, one-half shorter than the leaves. h. S. Native of 'Trinidad. Sieb. fl. trin. no. 236. Habit different from any other species
Capitellate-flowered Psychotria. Shrub.

98 P. oliga'ntha (D. C. l. c.) leaves oblong, cuneated the base, nerved: nerves prominent beneath, rather roughish; stipulas bifid, with triangular acute lobes; peduncles terminal, shorter than the leaves, 2 -fiowered at the apex; fruit ovate. h. S. Native of St. Domingo. P. lineàta, Spreng, in herb. Balb.; and in syst. 1. p. 746. exclusive of the synonymes. Leaves 2-3 inches long, and 9-10 lines broad. Pedicels $1 \frac{1}{2}$ incl $_{1}$ long. Flowers unknown. Berry striated a little.

Fen-flowered Psychotria. Shrub 4 to 6 feet.

99 P. Portorté'nsis (D. C. prod. 4. p. 515.) branches, petioles, nerves of leaves, and peduneles clothed with rusty hairs; leaves elliptie, acuminated at both ends, and clothed with velvety down on both surfaces; stipulas ovate, large, membranous, rufous, deciduous; cymes terminal, sessile, tripartite, with the brauclses trichotomous; throat of corolla villous. $\zeta_{c} . S$. Native of Porto-Rico, in woods by the sea-side, where it was collected by Bertero. P. hirsita from Porto-Rico, Spreng. syst. 1. p. 744. It differs from $P$. villosa and $P$. hirsùta in the inflorescence being a sessile cyme, not a pedunculate panicle.

Porto-Rico Psyclıotria. Shrub 5 to 6 feet.

100 P. Berteria'na (D. C. prod. 4. p. 515.) leaves ovateoblong, acuminated at both ends, glabrous above, downy on the nerves beneath, and branches of the panicle; stipulas twin on both sides, ovate, acute, hardly joined at the base; branches and branchlets of panicle opposite; tube of corolla short. h. S. Native of St. Domingo and Porto-Rico. Nonatèlia pubéscens, Spreng. syst. 1. p. 751. Leaves membranous, 7 inches long, and 3 inches broad. Petioles 9-10 lines long; axils of leares somewhat ciliated. Fruit globose, furrowed.

Bertero's Psychotria. Shrub.

101 P. вRAchi'TA (Swartz, prod. p. 4.5. f. ind. oce. p. 415.) leaves oral-oblong, acuminated at both ends, glabrous; stipulas oval-oblong, bluntly bidentate; branches tetragonal; branches and branchlets of panicle opposite, spreadingly divaricate, downy : ultimate flowers by threes, girded by a double bractea. $h_{i}$. S. Native of the south of Jamaica, on high mountains, ex Swartz; and of St. Domingo, ex 13ertero. Nonatèlia officinàlis, Spreng. in herb. Balb. Leaves downy on the veins heneath. Flowers dirty white. Fruit deep blue, oblong.

Brachiate-panicled Psyclotria, Clt. 1793. Sh. 6 to 7 feet.

102 P. pube'scens (Swartz, prod. p. 44. f. ind. oce. 1. p. 424.) branches, petioles, leaves (especially underneath), and panicles downy; leaves ovate, acuminated at both ends; stipulas with $\approx$ short acute teeth; panicles cymose, spreading, lengtls of leaves. $h_{\varepsilon}$. S. Native of Jamaica and St. Domingo, in hedges and waste places. Psychotròphum, P. Browne, jam. 161. no. 5. Panicles trichotomons, with usually a sessile flower in each fork. Pedicels furnished with linear opposite bracteas. Flowers greenish yellow, downy outside; throat of eorolla villous. Berries downy, roundish, didymous, black, containing bluish juice.

Donny Psychotria. Clt. 1812. Shrub 5 to 6 feet.

103 P. Horizonta'lis (Swartz, prod. p. 44. f. ind. oce. p. 410.) branches terete, lorizontal, smooth; leaves ovate-lanceolate, acute, downy beneatly on the nerves, as well as the petioles and panicles; stipulas small, ovate, deciduous, minute; peduncles shorter than the leaves; panicles erect, with the branches horizontal, and tripartite at the apex; throat of corolla naked. $\zeta_{\text {. }}$ S. Native of St. Domingo, in ehalky dry places. The leaves are said by Swartz to be downy beneath, and villous on the petioles and nerves. Flowers small, dirty white: antliers white. Berries oblong.

Iar. $\beta$, euspidàta (D. C. prod. 4. p. 515.) stipulas broad, short, cuspidate, marcescent ; throat of corolla hairy. h. S. 
Native of St. Domingo, where it was collected by Bertero. Perliaps a proper species.

Horizontal-leaved Psychotria. Shrub 3 to 4 feet.

104. P. conYmbósa (Swartz, prod. p. 44. f. ind. occ. 1. p. 423.) glabrous; leaves ovate-lanceolate, acuminated, shining; stipulas bidentate: teeth lanceolate; corymbs trichotomous, erect, shorter than the leaves; peduncles and pedicels coloured; throat of corolla naked. $h$. S. Native of Jamaica, on the mountains, ex Swartz; Iispaniola, ex Spreng ; and Guadaloupe, ex herb. Balb. Branches terete. Peduncles purple, as well as the bracteas, which are subulate. Corolla purplish, tubular, with a naked white tliroat. Berries globose, reddish. Perhaps a species of Palicourra. In the specimen collected by Bertero the tube of the corolla is 4 lines long, and the berries are roundish, didymous, and rather compressed, and crowned by the acute teeth of the calyx.

Corymbose-flowered Psychotria. Shrub 6 to 7 feet.

105 P. NU'TANS (Swartz, prod. 4. p. 515.) glabrous; leaves lanceolate, acute, nerved; stipulas bidentate, marcescent, deciduons, acute ; corymbs terminal, pedunculate, trichotomous, shorter than the leaves, erect when bearing the flowers, but nutant when bearing the fruit. $\zeta$. S. Native of Hispaniola, on arid cretaceous hills. Corollas small, white, with acute segments; anthers yellow. Berries round, scarlet, size of red currants.

Nodding-corymbed Psychotria. Shrub.

106 P. conge'sta (Spreng. in lierb. Balb. ex D. C. prod. 4. p. 515.) glabrous; leaves lanceolate, acute at the base, and acuminated at the apex; stipulas deciduous; panicles pedunculate, trichotomous, loose; ultimate branches of the panicle bearing 3-4 flowers in a heap; throat of the corolla bearded; anthers inclosed. $h$. S. Native of Jamaica. Leaves $2 \frac{1}{3}$ inches long, and 9-10 lines broad. Petioles 2 lines long. In the axils of the leaves and stipulas there are rufous ciliz. Panicles longer than the leaves. Flowers small.

\section{Cronded Psychotria. Shrub.}

107 P. PA'TEns (Swartz, prod. p. 45. fl. ind. oce. 1. p. 419.) glabrous ; leaves ovate-lanceolate, acuminated, roughish, membranous, distich; stipulas bidentate; peduncles slsorter than the leaves; panicles secund, with spreading branches; throat of the corolla naked. $h$. S. Native of Jamaica, on the higher mountains, and probably of St. Domingo, ex Spreng. syst. 1. p. 746. Young branches compressed. Flowers small, white, with a reflexed limb. Berries roundish, black.

Sprcading-panicled Psychotria. Shrub 4 to 5 feet.

108 P. MYRTIPHýlLua (Swartz, prod. p. 44. f. ind. occ. 1. 405.) glabrous ; leaves lanceolate-ovate, nerveless, shining, stiff; stipulas ovate, deciduous; branches secund; racemes compound, terminal : throat of the corolla villous; berries oblong. $h$. S. Native of the north of Jamaica, in logwood forests. Myrtiphýllum, P. Browne, jam. p. 152._Sloane, jam. hist. 2. p. 102. t. 109. f. 2. The shrub has a habit like the myrtle. Leaves an inch long, deep green, grey beneath from numerous small dots. Branches of racemes trifid. Flowers white. Berries scarlet, with the dissepiment usually ranished at maturity.

Myrtle-leared Psychotria. Clt. 1826. Shrub 3 feet.

109 P. Parasítica (Swartz, prod. p. 41. fl. ind. occ. 1. p. 408.) plant sarmentose, radicant, and glabrous; leaves ovate, acuminated, veinless, rather succulent; stipulas stem-clasping, retuse, permanent; cymes terminal and axillary, pedunculate; throat of the corolla downy; berries nearly globose. $h_{c} . \mathrm{S}$. Native of Martinique, Montserrat, St. Christopher, Dominica, Guadaloupe, Sic., parasitical upon trees. Viscoides péndulum, Jacq. amer. p. 73. t. 51. f. 1. Branches pendulous. Cymes trichotomous. Flowers small, white, pedicellate. Berries round, scarlet.

VOL. III.
Parasitical Psychotria, Fl. May, Aug. Clt. 1802. Shrub parasitical.

110 P. marginatta (Swartz, prod. p. 43. fl. ind. occ. p. 400.) glabrous; leaves lanceolate-ovate, acute, margined with cartilaginous bristles; stipulas ovate, acuminated, entire, deciduous, length of petioles; panicles loose, pedunculate; anthers inclosed; berries ovate. h.S. Native of the south of Jamaica, in woods; and of Panama and Mexico. Bartl. in herb. Hienke. Psychotr. P. Browne, jam. I6I, no. 6. Leaves shining above, and glaucescent beneatl. Branches of panicle opposite, slender, 3-6flowered. Corollas small, whitc, glabrous, with a reflexed limb. Berries black.

Marginate-leaved Psychotria. Fl. May, June. Clt. 1816. Slurnb 3 to 4 feet.

111 P. nursv'ta (Swartz, prod. p. 4.3. fl. ind. occ. 1. p. 396.) branches, panicles, petioles, and leaves clothed with rusty hairs; leaves lanceolate-ovate, acute; stipulas lanceolate, undivided, deciduous ; panicles pedunculate, spreading; throat of corolla villous; berries ovate, downy. $\zeta$. S. Native of the south of Jamaica, in woods of long standing. Branclies of panicles trichotomous. Flowers white. Berries red.

Hairy Psychotria. Clt. 1826. Shrub 5 to 6 feet.

112 P. FG'Tens (Swartz, prod. p. 43. A. ind. occ. 1. p. 396.) glabrous; leaves lanceolate-ovate, acute ; stipulas ovate, acuminated, deciduous, entire; panicles pedunculate, much spreading, with reflexed filiform divisions; throat of corolla villous; anthers oblong, among the villi in the throat; berries oblong. $h$. S. Native of the south of Jamaica, in woods on the mountains. Panicle of 4 main branches, the ultimate branchlets bearing 3 flowers. Flowers small, white. Berries small, oblong, scarlet.

Stinking Psychotria. Shrub.

113 P. WE'stir (D. C. prod. 4. p. 516.) glabrous; branches terete; leaves oblong-elliptic, attenuated at both ends, membranous: stipulas deciduous ; corymbs pedunculate, trichotomous, loose, diverging, having the ultimate branchlets 3-flowered; throat of corolla naked; corolla oblong; anthers linear; fruit nearly globose, crowned by the calyx. $h$. S. Native of PortoRico, where it was collected by West. Leaves 4-5 inches long, and 1-2 broad. Petioles 7-8 lines long. Branches of corymb 2 inches long, but the first branches are diverging, and about an inch long. Calyx 5-tootlied. Lobes of corolla acute.

II'cst's Psychotria. Shrub.

114 P. polyántia (D. C. prod. 4. p. 516.) glabrous; stipulas ovate, acuminated; leaves elliptic, acuminated at both ends, stiff, membranous; panicles on long peduncles, trichotomously branched; throat of corolla bearded; stamens glabrous; anthers exserted. h. S. Native of St. Domingo, where it was collected by Bertero. P. laurifòlia, Spreng. in herb. Balb. Superior leaves 10 inclies long, and 4 broad, pale beneath. Petioles an inch long. Common pcduncle of panicle 6 inches long. Flowers very numerous, glabrous, except in the throat. Fruit unknown.

\section{Many-flonered Psychotria. Shrub.}

115 P. citrifòlia (Swartz, prod. p. 43. fl. ind. occ. 1. p. 398.) glabrous; leaves elliptic, acuminated, rather coriaceous; stijulas ovate, acuminated, permanent; peduncles short ; branches of panicle opposite, trichotomous ; throat of corolla villous ; berries oblung. h. S. Native of the West India Islands. Branches compressed a little. Leaves coloured like those of the orange, 3-6 inches long. Corolla white, having the throat and segments villous. Berries large, ribbed, P. brachiàta, Spreng. in herb. Balb.

Citron-lcaved Psychotria. Clt. 1793. Shrub.

116 P. Laurifòlia (Swartz, prod. p. 43. H. ind. occ. 1. p. \%92.) glabrous; leaves lanceolate-ovate, thickish, shining; stipulas ovate, acuminated, deciduous; panicles cymose, erect, $4 \mathrm{G}$ 
trichotomous ; filaments ciliated ; anthers inclosed in the bearded throat; berries roundish. h.S. Native of Jamaica and Hispaniola. Corolla white, with acute lobes. Stipulas downy. Berries red, slining. Said to be allied to $P$. glabrata.

Laurcl-lcaved Psychotria. Fl. June, July. Clt. 1818. Shrub 4 to 5 feet.

117 P. Bró'WNEI (Spreng. syst. 1. p. 742.) glabrous; leaves elliptic, attenuated at both ends, rather coriaceous, paler beneath stipulas ovate, harlly mucronate, caducous, length of petioles ; panicles pedunculate, trichotomous, rising from the forks of the branches; berries ovate. h. S. Native of Porto-Rico, St. 'l'homas, and Jamaica. Browne, jam. p. 160. no. 2. t. 17. f. 2. P. Asiática, Lam. ill. t. 161. f. 1. Allied to P. Carthaginénsis, but differs from it in the fruit being ovate, not oblong, and in the stamens being inclosed, and in the throat of the corolla being glabrous, ex icon. Browne.

Browne's Psychotria, Fl. July. Clt. 1806 . Sh. 4 to 5 feet.

118 P. BaLbisia'na (D. C. prod. 4. p. 517 .) glabrous; leares elliptic, acute at both ends, rather acuminated, stiflish; stipulas ovate, deciduous; peduncles rising from the forks of the branches or from their tops, equal in length to the leaves, corymbiferous and trichotomous at the apex; corolla with a villous throat, and having the lobes shorter than the tube. $h$.S. Native of $\mathbf{J a}$ maica, where it was collected by Bertero. P. lucida, Spreng. in herb. Balb. Leaves 3 inches long and $1 \frac{1}{2}$ broad. Corolla glabrous, except the throat, which is villous, 3 lines long. Berries ovate.

Ballis's Psychotria. Shrub 4 to 6 feet.

119 P. ReVolu'ta (D. C. prod. 4. p. 517. ) glabrous; leaves elliptic, tapering to both ends, coriaceous, witl revolute margins; stipulas oblong, rufous and membranous, deciduous; corymbs terminal, pedunculate, trichotomous, hardly longer than the leaves; corolla with a subvillous throat, and having the lobes shorter than the tube. $h$.S. Native of St. Domingo, where it was collected by Bertero. P. glabràta, ex Hispaniola, Spreng. syst. I. p. 745. no. 63 . Leaves 2 or $2 \frac{1}{2}$ inches long, and $12-15$ lines broad. Petioles 3-4 lines long. Berries ovate.

licvolute-leaved Psychotria. Shrub 4 to 6 feet.

120 P. Glabra'ta (Swartz, prod. p. 43. fl. ind. occ. 1. p. 390.) glabrous; leaves ovate, obtuse, shining; stipulas small, ovate, and acute, rusty, deciduous; panicle erect, with opposite branches; margin of calyx almost entire. $h . S$. Native of the interior of Jamaica, among rocks on the mountains. P. glabràta ex Jamaica, Spreng. P. Asiática a, Poir. dict. 5. p. 696. but not of Lin. Allied to $P$. Asilitica, but is distinct according to Swartz. Corolla small, white, with a villous throat. Berries oblong.

Glabrous Psychotria. Fl. June, July. Clt. 1810. Shrub 4 to 6 feet.

121 P. exsérta (D. C. prod. 4. p. 517.) glabrous; leaves oblong, bluntish, cuneated at the base, coriaceous, shining above; stipulas lanceolate, acute, rather connate at the base, deciduous; corymbs pedunculate, trichotomous, longer than the leaves; corollas glabrous; anthers exserted. $h$. S. Native of St. Domingo, where it was collected by Bertero. $\mathrm{P}$. coriàcea ex Hispaniola, Spreng. syst. 1. p. 742. exclusive of the synonymes. Corolla tubular, 3 lines long, with very short bluntish lobes.

Exsertcl-stamened Psychotria. Shrub 3 to 4 feet.

122 P. platyphy'lla (D. C. prod. 4. p. 517.) glabrous; stipulas bipartite, with triangular acute lobes; leaves elliptic, acuminated at both ends, membranous; branchlets tetragonal; panicles racemose, rather downy, one-half shorter than the leaves, with opposite branches; throat of corolla glabrous. h.S. Native of Porto-Rico. P. macrophýlla, Vent. in herb. Deless. Leaves 8 inches long and 3 broad. Petioles 15-18 lines long. Flowers white.
Broad-leaved Psychotria. Shrub.

123 P. GRA'NDis (Swartz, prod. p. 43. fl. ind. occ. 1. p. 417.) glabrous; leaves obovate, short-acuminated, cuneated at the base; stipulas deltoid, with revolute margins, subulate at the apex, permanent; branches angular; panicles large, pedunculate, with subverticillate branches. $h$.S. Native of Jamaica, in the interior and western parts of the island, anong bushes on the mountains; and of Mexico, ex herb. Hanke. Leaves a foot and more long, and 3 inches broad. Branches of panicle compressed, usually temately verticillate. Flowers numerous, small, white. Throat of corolla villous. Berries ovate.

Great Psychotria. Shrub 12 to 15 feet.

124. P. Peduncula'ta (Swartz, prod. p. 44. fi. ind. occ. p. 427.) glabrous; leaves ovate-lanceolate, acute at the base, and acuminated at the apex, rather wrinkled; stipulas shorter than the petioles, bidentate on both sides, permanent; peduncles longer than the leaves, cymose at the apex, dense-flowered. $h$. $\mathrm{S}$. Native of the interior of Jamaica, in mountain woods. P. attenuata, Willd. Psychotròphum, P. Browne, jam. p. 160, no. 4. Branches rather angular. Branclies of panicle trichotomous, approximate. Corolla large, cylindrical, yellowish, witls a naked throat. Berries roundish.

Pedunculate Psychotria. Clt. 1818. Tree 16 to 20 feet.

125 P. Angustifòlia (Poir. dict. 5. p. 703.) glahrous; leaves narrow-lanceolate, usually obtuse at the base, and acuminated at the apex; stipulas bidentate, acuminated; panicles erect, trichotomous at the apex, shorter than the leaves; berries globose. $\eta$. S. Native of St. Domingo. Flowers unknown. Nerves of leaves and pedicels yellow. Leaves 2-3 inclies long, and an inch broad. Border of calyx hardly toothed. Berries globose, dark purple.

Narrow-leaved Psychotria. Shrub 4 to 6 feet.

126 P. Barba'ta (Poir. dict. 5. p. 704.) plant sublerbaceous, glabrous; leaves ovate, acuminated, membranous; branches compressed, rather angular; panicles pedunculate, spreading; lobes of corolla obtuse; throat of corolla villous; anthers exserted. 々. S. Native of Martinico. Leaves 2 inches long. Ramifications of panicle tern or dichotomous. Fruit unknown.

Bearded-flowered Psychotria. Shrub.

127 P. bícolor (Bredem. ex Willd. mss. in Rœm. et Schultes, syst. 5. p. 191.) glabrous; leaves oblong-lanceolate, on short petioles; stipulas bidentate, setose ; flowers panicled; peduncles copper-coloured. $\quad$. S. Native of Martinico, on the banks of mountain streams. Perhaps the same as Palicoùrea cròcea.

\section{Two-coloured Psychotria. Shrub.}

*********** Spccies natives of South America, but in what particular localities is unlcnown.

128 P. рнутода'cca (Poir. dict. 5. p. 704.) glabrous; leaves ovate, short-acuminated, petiolate, rather fleshy; panicles short, cymose; flowers crowded; fruit globose. h. S. Native of South America, ex Poir., St. Domingo, ex herb. Desf. Leaves like those of Phytolácca. Flowers numerous, disposed in an irregular order.

Phytolacca-leaved Psychotria. Shrub.

129 P. coria'cea (Poir. dict. 5. p. 703.) glabrous; leaves ovate-lanceolate, very coriaceous, slining; panicles few-flowered, much shorter than the leaves, dichotomous; corolla tubular; teeth of calyx and lobes of corolla obtuse. $h$. S. Native of South America. Stems blackish. Leaves 3-4 inches long, and 2 broad. Panicles yellowish, divided into 3-4 compressed branches, which are bifurcate at the apex. Perhaps a species of Palicoùrea.

Coriaceous-leaved Psychotria. Fl. June, Aug. Clt. 1810. Shrub 4 to 6 feet.

130 P. arista'ta (Willd, in Røem. et Schultes, syst. 5. p. 
191.) leaves oblong, acuminated at both ends, shining above, but downy on the veins beneath ; stipulas connate, aristately bidentate; panicles terminal, elongated; peduncles and pedicels hairy. $\zeta$. S. Native of South America, where it was collected by Humb. and Bonpl., but is unknown to Kunth.

An'ned-stipuled Psychotria. Shrub.

131 P. spléndens (Spreng. syst. 1. p. 747.) leaves lanceolate, narrowed at the base, bluntish, shining; stipulas deciduous; corymbs few-flowered, pedunculate, terminal. 万. S. $\mathrm{Na}$ tive of South America, at the Rio Negro, where it was collected by Humb. and Bonpl., but is unknown to Kunth. P. lùcida, Willd. in Rom. et Schultes, syst. 5. p. 189.

Glittering-leaved Psychotria. Shrub.

132 P. LAMPropux'Lla (Spreng. syst. 1. p. 747.) leaves narrow-lanceolate, elongated, tapering to both ends, coriaceous, shining above, quite glabrous and veinless beneath; stipulas short, caducous; panicles terminal, tripartite. $h$. S. Native of South America. P. salicifolia, Willd. in Rœm. et Schultes, syst. 5. p. 190. The rest unknown.

Shining-leaved Psychotria. Shrub.

183 P. attenua'ta (Willd, in Roem. et Schultes, syst. 5. p. 192.) leaves ovate-elliptic, long-acuminated, membranous; stipulas bidentate; cymes terminal. $h_{2}$. S. Native of South America, where it was collected by Humb. and Bonpl., but is unknown to Kunth. It is joined with $P$. pedunculàta by Sprengel, who is probably right.

Attenuated-leaved Psychotria. Shrub.

134 P.? рісно'тома (Willd. in Rcem. et Schultes, syst. 5. p. 518 .) leaves ovate-oblong, acute; stipulas bifid; spikes dichotomous. $\zeta$. S. Native of South America, where it was collected by Humb. and Bonpl.

Dichotomous-spiked Psychotria. Shrub.

135 P. commuta'ta (D. C. prod. 4. p. 518.) leaves elliptic, acute at both ends, rather membranous; stipulas oblong, obtuse, stem-clasping; panicle corymbose, terminal. $h . s$. Native of South America. Humb. and Bonpl. P. efliptica, Willd. in Roem. et Sehultes, syst. 5. p. 189. but not of Ker.

Changed Psychotria. Shrub.

136 P. membrana'cea (Willd. in Rom. et Schultes, syst. 5 . p. 189.) leaves obovate-oblong, acuminated, membranous; stipulas ovate, acute. h. S. Native of South America, where it was collected by Humb. and Bonpl.

Membranaceous-leaved Psychotria. Shrub.

\section{$* * * * * * * * * *$ Species natives of Africa.}

137 P. Nu'bica (Caill. et Delil. pl. afr. p. 66.) leaves elliptic, glabrous above, acutish at both ends, with the nerves on the under surface prominent and downy; stipulas triangular; cymes terminal, with trifid crowcled branches, which are downy, as well as the corollas; style much exserted. $h$. S. Native of the north of Africa, in Nubia, at Singie. Teeth of calyx 5, obtuse, very short. Stigna turbinate, bifid. Tube of corolla campanulate. Fruit unknown.

Nubian Psychotria. Shrub.

138 P.? PSAthuroldes (D. C. prod. 4. p. 518.) glabrous; leaves oblong, acute at both ends, coriaceous, petiolate; stipulas ovate, obtuse, deciduous, 4 times shorter than the petioles; panicles terminal, shorter than the leaves, with opposite branclies; calyx truncate; corolla divided beyond the middle. $\zeta$. S. Native of the Mauritius, where it was collected by Bory de St. Vincent. The flowers are not well known; and the fruit is perfectly unknown.

Psalhura-like Psychotria. Shrub.

139 P.? oвtusifòlia (Lam. ill. t. 161. f. 4. Poir. dict. 5. p. 67.) glabrous; leaves obovate, cuneated, very blunt, tapering into the very short petioles; stipulas twin on both sides, some- what concrete at the base, cnding in linear points ; corymbs trifid, pedunculate, much shorter than the leaves, with the branchlets bearing crowded sessile flowers at the apex. $2 . S$. Native of Madagascar, where it is called Maron-Pouton. Leaves 4-5 inches long and 2 broad. Berries ovate, striated.

Blunt-lcaved Psychotria. Shrub.

140 P. Angustiròlia ; shrub erect, nearly simple ; leaves ovallanceolate, entire, acuminated; flowers panicled, terminal. h.S. Native of Sierra Leone, on the banks of rivulets. Flowers pale red. Narron-leaced Psychotria. Shrub.

$$
\text { ************ Species natives of A sia. }
$$

141 P. SE'RPENS (Lin. mant. p. 204.) plant suffruticose, much branched, twisted, glabrous; branchlets rather compressed, but at length becoming terete; leaves ovate, acute at both ends, coriaceous ; stipulas ovate, obtuse, undivided, brown, deciduous ; corymbs pedunculate, trichotomous, terminal, having the peduncles and branchlets 2 -edged; berries ovate. $h$. G. Native of China and the East Indies.

Serpentine-branched Psychotria. Shrub 2 to 6 feet.

142 P. Roxbo'rgui (D. C. prod. 4. p. 519.) branchlets opposite, complanate, downy, but becoming smooth at length; leaves elliptic, acuminated at both ends, membranous, shining above, downy on the nerves beneath, which are parallel ; stipulas oval, about equal in length to the petioles, recurved at the apex, acutely bifid; panicles terminal, on slort peduncles; pedicels downy, compressed, umbellate; lobes of calyx ciliated. そ. S. Native of the Moluceas. P. Asiática, Lin. spec.? exclusive of the synonymes. Roxb. fi. ind. 2. p. 160. Leaves 8-10 inches long. Flowers very small, greenish. Bracteas small, lanceolate. Throat of corolla villous; anthers inclosed. Berries oval, 10-nerved (conforming to that in the figures of Gartn. fruct. 1. t. 25. and Browne, jam. t. 17. f. 2.), deep red.

Roxburgh's Psychotria. Shrub.

14.3 P. SPHERoca'rPA (Wall. in Roxb. Al. ind. 2. p. 161.) glabrous; branchlets compressed; leaves ovate-elliptic, acuminated, coriaceous, with parallel veins; stipulas ovate, about equal in length to the petioles, recurved at the apex, and acutely bifid; corymbs pedunculate, compact, villous; teeth of calyx subulate; berries globose, smooth. $\quad$. S. Native of the East Indies, on the hills near Silhet. Leaves 8-12 inches long, shining above. Flowers very small, crowded. Corolla densely bearded at the throat. Berries pale red, without ribs.

Round-fruitcd Psyehotria. Shrub.

144 P. truncata (Wall. in Roxb. fl. ind. 2. p. 16?.) glabrous; axils of petioles pilose; branchlets somewhat compressed ; leaves elliptic-ovate, acnte, attenuated at the base, coriaceous, foveolate in the axils of the veins beneath; stipulas broadcrate, undivided, coriaceous, deciduous; corymbs terminal, small, pedunculate, fleshy, bracteolate; limb of calyx truncate ; throat of corolla bearded. $h$. S. Native of the East Indies. Leaves 6-8 inches long and 4 broad. Petioles submarginate. Backs of stipulas depressed. Elowers rather large, by threes, intermediate ones sessile.

Truncate-calyxed Psychotria. Shrub.

145 P. conNA'TA (Wall. in Roxb. A. ind. 2. p. 163.) glabrous; branchlets compressed; leaves lanceolate, acuninated, tapering much at the base, almost sessile, coriaceous; stipulas ovate, acutely cuspiclate, longer than the petioles, rather recurved at the apex; corymbs terminal, ovate, on long peduncles, with the first ramifications umbellate, the rest trichotomous; bracteas connate at the base, ciliated, slightly lobed; flowers by threes, sessile; throat of corolla bearded. $h$. S. Native of the East Indies. Leaves foveolate in the axils of the nerves beneath. Peduncles rather compressed. Berries ovate, almost black, anular when dried.

$$
4 \text { G } 2
$$


Connate-bractead Psychotria. Shrub.

146 P. stipula'cea (Wall. in Roxb. fl. ind. 2. p. 164.) glabrous ; leaves oblong-lanceolate, acuminated, coriaceous, nerved, tapering at the base, almost sessile, smooth; stipulas broad, triangular, expanded into foliaceous lamina at the apex; panicles terminal, trichotomous, shorter than the leaves; pedicels compressed; flowers by threes, sessile; lobes of calyx obtuse. そ. S. Native of Pulo-Penang. Leaves 7-10 inclies long, somewbat glandular in the axils of the veins beneath. On the inside of the base of the stipulas there is a tuft of hairs, which remains some time after the stipulas have fallen. Corolla with a very short tube, and a bearded throat. Stamens exserted.

Large-stipuled Psychotria. Shrub.

$14 i$ P. Reeve'si (Wall. in Roxb. fl. ind. 2. p. 164.) glabrous; leaves oblong-lanceolate, acute at both ends, smooth, glaucous, coriaceous; stipulas broad-ovate, adpressed, with a rounded apex; panicles terminal, oval, small, with decussate branches; limb of calyx truncate; corolla short, with a densely bearded throat. $h$. G. Native of China, from which place it was sent to the botanic garden at Calcutta by Mr. Reeves. Branches beset with copious small whitish dots, having the upper extremities slightly compressed. Leaves 6-7 inches long, a little wrinkled, foveolate in the axils of the veins beneath. Panicles almost sessile. Bracteas deciduous. Flowers small, by threes, pea-green. Stamens concealed among the hairs in the throat of the corolla.

Reeves's Psychotria. Shrub.

148 P. aurantiaca (Wall. in Roxb. fl. ind. 2. p. 165.) glabrous; branches flattened; leaves lanceolate, acuminated, smooth, on short petioles; stipulas ovate, acuminated, deciduous; panicles terminal, pedunculate, erect, with whorled branches; flowers by threes, middle ones sessile; limb of calyx truncate; corolla with a long tube, and a villous throat. $h$.S. Native of PuloPenang, Java, and Nusa-Kambanga. Blum. bijdr. p. 962. Leaves $5-7$ inches long, dotted beneath. Stipulas ending in a long subulate acumen each. Peduncles compressed. Stamens exserted. Berries obovate, as large as a cherry stone, orange-coloured, ex Wall, but ovate, and 10 -ribbed according to specimens from Java.

Orange-coloured-fruited Psychotria. Shrub.

149 P. Denticula'ta (Wall. in Roxb. fl. ind. 2. p. 520.) stem ascending, with a creeping base, compressed at the apex; leaves ovate, short-acuminated, coriaceous, shining; stipulas ovate, subcordate, with a toothed apex, downy outside, about equal in length to the petioles; panicles cymose, many flowered, downy; teeth of calyx subulate; corolla rather rotate. h.S. Native of Nipaul, in the forest of Sanko. Stem purplish, undivided, or sparingly dichotomous. Leaves from 6-9 inches long, upper surface dark green, under pallid. Stipulas villous within at the base. Panicles cymose, downy. Throat of corolla slightly hairy. Teeth of calyx subulate. Berries globular, purple, size of currants.

Denticulated-stipuled Psychotria. Shrub creeping.

150 P. adenophix'Lea (Wall. in Roxb. fl. ind. 2. p. 166.) glabrous; leaves lanceolate, acuminated, shining, with parallel nerres, which are glandular in the axils; stipulas ovate, blunt, connate at the base, deciduous; racemes terminal, cylindrical, a little branched at the base; peduncles compressed; bracteas aristatcly acuminated. h. S. Native of the East Inclies, in Silhet. The uppermost branches dichotomous, and a little conpressed. Leaves 3-4 inches long, pallid beneath. Peduncles flattened. Flowers greenish, in heaps, almost sessile. Corolla with a short tube, a villous throat, and acute segments.

Glandular-leaved Psychotria. Shrub.

151 P.? curwiplòra (Wall. in Roxb. fl. ind. 2. p. 167.) glabrous; branchlets terete; leaves lanceolate-oblong, long- acuminated, tapering much to the base, on long petioles, membranous, shining above, and pubescent on the nerves beneath, and glandular in the axils; stipulas ovate, obtuse, connate at the base, sometimes furnished with 1-2 teeth at the apex, with a series of adpressed hairs within their insertion, deciduous; racemes small, terminal, oval, compact, on short peduncles, much shorter than the leaves; corolla long, slender, tubular, with an incurved border. $\zeta$. S. Native of Pulo-Penang. Petioles long. Racemes smooth, consisting of opposite approximate more or less compound fascicles of long sessile flowers. Corollas nearly an inch long, with lanceolate acute lobes, and a naked throat. Anthers exserted. Filaments inserted near the middle of the corolline tube. P'erhaps a species of Chasalia or Palicoùrea.

Curved-flonered Psychotria. Shrub.

152 P. ophioxyloìes (Wall. in Roxb. f. ind. 2. 1) 168.) smooth, climbing, dichotomous; leaves lanceolate, on short petioles, acuminated; stipulas ovate, drawn out at the apex into an acumen, which is often bifid; corymbs small, terminal; corollas long, slender, tubular, with incurved lobes. h. S. Native of Silhet, in the East Indies. Leaves smooth, acute at the base, about 5 inches long. Perhaps a species of Chasàlia or Palicoùrea.

Snake-wood-like Psychotria. Shrub cl.

153 P. polyneu'ra (D. C. prod, 4. p. 520.) glabrous; branchlets and peduncles compressed; leaves elliptic-ovate, short-acuminated, coriaceous, with usually 20 pairs of opposite lateral nerves; stipulas ovate, drawn out into a long setaceous acumen, deciduous; corymbs terminal, pedunculate, one half shorter than the leaves; limb of the calyx with 5 short teeth; corolla short, with a smoothish throat. h. S. Native of Nipaul, where it was collected by Wallich. It agrees with $P$. aurantiaca in the stipulas, but differs from that plant in the short corollas, \&.c.; and from $P$. nervosa in the teeth of the calyx being acute, not obtuse, nor membranous.

Many-nerved-leaved Psychotria. Shrub.

154 P. Waldichia'ina (Spreng. cur. post. p. 79.) leaves oval, acuminated, serrulated, nerved, glabrous; stipulas simple; teeth of the calyx roundish, membranous; panicles terminal, glomerate. 々. S. Native of Nipaul, Wallich. P. nervòsa, D. Don, prod. f. nep. p. 137. but not of Swartz.

Hallich's Psychotria. Shrub.

155 P. vagina'lis (D. C. prod. 4. p. 520.) glabrous; leaves ovate-oblong, cuspidate at the apex, attenuated at the base; stipulas entire, foliaceous, combined into a sheath-like tube, which is bifid at the apex, laving the lobes bidentate at the apex, in front of the leaves; panicles terminal, pedunculate, downy, with the rachis compressed, and the branchlets opposite; limb of the calyx broadly campanulate, truncate. h. S. Native of Ceylon. Ophióxylon arbòreum, Kœn. in herb. Royen. Bracteas short, acuminated, spreading. Fruit unknown. 'Perlraps a species of Chiocócca.

Sheathed-stipuled Psychotria. Shrub.

156 P. MIALAYA'Na (Jack, in mal. misc. 1. no. 1. p. 3.) leaves broad-lanceolate; stipulas undivided; panicles terminal, corymbose; throat of the corolla bearded. $h$. S. Native of PuloPenang, where it is called Byumbaba by the Malays. Corolla white, witl a greenish limb.

Malay Psyclıotria. Shrub.

157 P. токті̀ (Blum. bijdr. p. 958.) stem herbaceous, creeping at the base; leaves ovate-oblong, attenuated, smooth above, reticulated beneath, and rather tomentose; stipulas ovate, bifid; cymes compound, pedunculate, axillary, rarely terminal; flowers secund; pyrena l-ribbed. h. $\psi$. S. Native of Java, on the mountairs, in humid places. Berries globose, ribbed. Perhaps belonging to the first section of the genus. 
Tnistel-stemmed Psychotria. Pl. creeping.

158 P. DIVE'roens (Blum. bijdr. p. 959.) leaves oblong-lanceolate, acuminated at both ends, coriaceous, glabrous above, pallid beneath, and downy on the veins; stipulas bifid, ciliated, hardly shorter than the petioles; corymbs terminal, trichotomous; corollas funnel-shajed; drupes oval, dry, ribbed. Ђ.S. Native of Java, on the higher mountains, in woods. P. divaricàta, Blum. cat. hort. buit. p. 53. but not of Swartz.

Diverging Psychotria. Shrub.

159 P. LU'RIDA (Blum. bijdr. p. 959.) leaves lanceolate-oblong, acuminated, rather membranous, glabrous; stipulas broadovate, short, bidentate, adpressed; corymbs terminal, trichotomous; flowers densely crowded, sessile; calyxes obsoletcly 5 toothed, and are, as well as the peduncles, coloured; tube of the corolla elongated; drupes globose. h.S. Native of the West of Java, frequent in humid, shady places. Peduncles thickened at length. Pyrenæ l-ribbed on the back, and fenestrate inside. Nearly allied to $P$. corymbòsa and $P$. sphcerocárpa.-There is a variety of this with oblong-lanceolate leaves.

Lurid Psychotria. Shrub.

160 P. candarussarólıa (Blum. bijdr. p. 960.) leaves on short petioles, linear-lanceolate, acuminated at both ends, membranous, glabrous; stipulas ovate, acute, bidentate; cymes terminal and axillary, dense, trifid. $h$. S. Native of the Jsland of Java, in the province of Bantam, among bushes. Leaves 5 inches long, and 6-7 lines broad.

Gandarussa-leaved Psychotria. Shrub.

J61 P. Monta'sa (Blum. bijdr. p. 960.) leaves oblong, acuminated at both ends, membranous, glabrous ; stipulas intraaxillary, membranous, clasping the petioles; flowers terminal, umbellately corymbose; limb of the calyx urceolate, obsoletely 5-toothed; corolla with a short sub-cylindrical tube; drupes elliptic globose; pyrence wrinkled, with one furrow on the back. $\quad \zeta . S$. Native of Java, on the mountains.

Mountain Psychotria. Shrub.

162 P. rostra'ta (Blum. bijdr. p. 961.) leaves on short petioles, oblong-lanceolate, much acuminated, membranous, glabrous; stipulas short, rather connate; corymbs pedınculate, lichotomous, or trichotomous; calyxes obsoletely 5 -toothed ; corolla with a short cylindrical tube ; drupes nearly globose ; pyrenæe smooth, obsoletely l-ribbed, h. S. Native of Java, in shady places, on Mount Salak. Allied to P. montàna and $P$. tetrándra.

\section{Bealicd Psychotria. Shrub.}

163 P. TETRA'NDRA (Blum. bijdr. p. 961.) leaves on short petioles, oblong, acuminated at both ends, menbranous, glabrous, reticulated beneath; stipulas short, acute; corymbs pedunculate, terminal ; flowers tetrandrous; drupes nearly globose, ribbed in the dry state. $h$. S. Native of Java, in woods on Mounts Salak and Seribu, \&c. Sides of the leaves unequal.

Tetrandrous-flowered Psychotria. Shrub.

164 P. Rнiкосе ro'ts (Reinw. in Blum. bijdr. p. 961.) leaves cuneate-oblong, acute, coriaceous, glabrous above, tomentose beneatlı; corymbs terminal, tomentose; stipulas bifid, or trifid; llowers capitate; tube of the corolla sub-campanulate; drupes ovate-globose, furrowed in the dried state. $h_{2} . S$. Native of Java and Nusa-Kambanga, in humid parts of woods.

Rhinoceros Psychotria. Shrub.

165 P. Rовu'sta (Blum. bijdr. p. 962.) leaves obovatc, or cuneate-oblong, acuminated, coriaceous, glabrous; stipulas intraaxillary, acuminated, connate at the base, and clasping the petioles; panicles terminal, with whorled branches; limb of the calyx urceolate, obsoletely 5 -toothed; tube of the corolla short, cylindrical. $\boldsymbol{h}$.S. Native of Java, on the mountains. P. latifölia, Blum. cat. lort. buit. p. 5t. but not of Willd.

Robust l'sychotria. Shrub.
166 P. virtdrflòrı (Reinw. in Blum. bijdr. p. 963.) leaves oblong-lanceolate, acuminated at both ends, membranous, glabrous; stipulas ovate, obtuse, with membranous margins, ciliated at the base; corymbs terminal, divaricately trichotomous; calyxes downy; tube of the corolla short, cylindrical; drupes nearly globose, somewhat 10 -ribbed in the dry state. $\eta$. S. Native of Java, in humid places among bushes. Allied to $P$. stipulìcca, WVall.

Green-flowered Psychotria. Shrub.

167 P. SYLVA'tica (Blum. bijdr. p. 963.) leaves on long petioles, oblong-lanceolate, acuminated, glabrous; stipulas ovate, bluntish, membranous at the top, clasping the petioles; corymbs terminal, trichotomous, glabrous; tube of the corolla short, cylindrical; drupes elliptic-globose, ribbed when dry, $々$. S. Native of Java, in mountain woods. Allied to $P$. viridiflor

Wood Psychotria. Shrub.

168 P. Expa'xsa (Blum. bijdr. p. 963.) leaves elliptic-oblong, acuminated at both ends, membranous, connate at the base; cymes pedunculate, terminal, 3-5-parted ; flowers sub-umbellate; calyx obsoletely 5 -toothed; tube of the corolla slort, cylindrical. 々. S. Native of Java, at the foot of Mount Salak. Leaves rather large.

Expanded Psychotria. Shrub.

I69 P. Laxiflòra (Blum. bijdr. j. 964.) stem radicant and climbing; leaves on short petioles, elliptic-oblong, attenuated at both ends, membranous, glabrous; stipulas connate; corymbs tripartite, loose; tube of the corolla somewhat campanulate; drupes nearly globose, furrowed when dry. $々$. S. Native of Java, in mountain woods.

Lax-flowered Psychotria. Shrub.

170 P. sarmentòsa (Blum. bijdr. p. 964.) stem radicant and climbing; leaves on short petioles, lanceolate, acuminated at both ends, finely veined, coriaceous, glabrous; stipulas connate ; corymbs terminal, divaricate, trichotomous; tube of the corolla funnel-shaped; drupes clliptic-globose, furrowed when dry. 7.S. Native of the west of Java, in woods on the higher mountains. Allied to $P$. parasitica, Swartz.

Sarmentose Psychotria. Shrub.

171 P. Leucocárea (Blum. bijdr. p. 964.) stem radicant and climbing; leaves on short petioles, oblong-lanceolate, acuminated at both ends, coriaceous, glabrons, terminal ones verticillately approximate; stipulas connate ; corymbs terminal, trifid; flowers capitate; drupes globose; pyrena smooth on the back. $\zeta$. S. Native of Java, in woods on the mountains of Seribu. Allied to $P$. sarmentòsa.

White-fruited Psychotria. Shrub.

172 P. Paucielòra (Bartl, in herb. Hænke, ex D. C. prod. 4. p. 522.) glabrous; branchlets compressed; leaves narrow-oblong, acute, tapering much at the basc, rather coriaceous, glancescent; stipulas lanceolate, elongated, deciduous; corymbs terminal, trifid to the base, having the branches bearing from 1 to 3 flowers; calyx truncate; fruit obovate. h. S. Native of the Island of Luzon. Colour of the leaves and habit almost of $P$. álba. Fen-flowered Psychotria. Shrub.

173 P. ixoroides (Bart). in herb. Hænke, ex D. C. prod. 4. p. 522.) glabrous; branchlets compressed ; leaves oblong, tapering much at the base, short-acuminated at the apex, glaucescent, hardly veined beneath; stipulas triangularly ovate, acute, Jeciduous ; corymbs terminal, downy, pedunculate, trifid, with compact many-flowered branches; limb of the calyx with 5 short acute teeth; fruit globose. h.S. Native of the Island of Luzon.

Ixora-like Psychotria. Shrub.

174 P. MARIA'Na (Bartl, in herb. Hanke, ex D. C. prod. 4. p. 522.) glabrons; branches and peduncles compressed; leaves oval-oblong or ohovate, bluntish, attenuated at the base, rather coriaceous; stipulas caducous; cymos pedunculate, terminal, 
shorter than the leaves, twice trifid; flowers sessile in the forks, and on the tops of the branchlets of the cyme; limb of the calyx campanulate, truncate, or bluntly toothed, and at length cleft irregularly. h. S. Native of Marianne Island. Corolla short, campanulate, but obovate in the bud state. Fruit unknown.

II rianne Psychotria. Shrub.

175 P. membranifòlia (Bartl. in herb. Hænke, ex D. C. prod. 4. p. 522.) glabrous; leaves ovate-oblong and oval, shortacuminated, membranous, veiny beneath ; stipulas membranous, acutely bidentate, erose; panicles terminal, contracted, corymbformed, almost sessile, much shorter than the leaves; anthers exserted. 々. S. Native of the Islands of Luzon and Sozogon, in the Philippine Archipelago. The leaves in the specimens from the Island of Luzon are more oblong and more acuminated at both ends than those from Sozogon.

Membrane-leaved Psychotria. Shrub.

176 P. Linea'ris (Bartl. in herb. Hanke, ex D. C. prod. 4. p. 522.) branches terete, and are, as well as the panicles, petioles, and leaves, especially on the nerves on the under surfaces, beset with rusty hairs; leaves long-linear, glabrous above; stipulas membranous, ovate, acuminated, caducous ; flowers crowded in terminal fascicles, on short pedicels; calyx rather truncate; corolla villous; fruit obovate. $\bar{h}$. S. Native of the Island of Manilla, near Sozogon.

Linear-leaved Psychotria. Shrub.

177 P. Manillénsis (Bartl. in herb. Hanke, ex D.C. prod. 4. p. 522.) glabrous ; branchlets rather compressed ; leaves ellipticoblong, acuminated, attenuated at the base, rather coriaceous, of a different colour beneath; stipulas ovate, acute, combined into a short ring at the base, deciduous; corymbs tripartite, hardly pedunculate, with elongated branches, which are twice trifid at the apex; fruit ovate-oblong. h. S. Native of the Island of Manilla, near Sozogon.

Manilla Psychotria. Shrub.

*

178 P. colnìn (Labill. sert. caled. p. 47. t. 47.) glabrous ; branches nearly terete; leaves lanceolate-oblong, attenuated at both ends; stipulas ovate, caducous ; corymbs terminal, on short peduncles, shorter than the leaves, trichotomous; peduncles compressed; style bifid beyond the middle; berries roundish. 々. S. Native of New Caledonia.

Hill Psychotria. Shrub.

179 P. Loniceroìdes (Sieb. nov. holl. exsic. no. 263.) every part of the plant is clothed with rusty hairs; leaves elliptic or oblong, acutish at both ends; stipulas lanceolate, acuminated, deciduous; panicles terminal, a little sliorter than the leaves, with opposite distant branches, which are trifid, or twice trifid at the apex, with a sessile flower in each fork; bracteas ovate, acute; berries ovate, crowned by the 5-toothed calyx. $h_{\text {. }}$ S. Native of New Holland. It is very like $P$. hirsuila of Swartz, with which it is joined by Sprengel, in his cur. post., but is still very distinct.

Honeysuckle-like Psychotria. Shrub.

180 P. speciosa (Forst. prod. no. 89.) arboreous; leaves oblong-lanccolate; involucrum terminal, usually 3-flowered. $々$.S. Native of Otaheite. Cepliæ'lis speciòsa, Spreng. syst. 1. p. 749. Showy Psychotria. Slirub.

181 P. DAPHNoides (Cunningh. in bot. mag. 3228.) shrub dichotonous, glabrous; branches very leafy at ends; leaves obovate; stipulas nearly orbicular, bidentate, small ; corymbs terminal, few-flowered; mouth of corolla villous. h.G. Native of New Holland. Flowers pure white.

Daplane-lile Psychotria. Fl. A pril. Clt. 1829. Shrub.

Cult. All the species of Psychotria are of the most easy culture and propagation. They grow best in a mixture of loam, peat and sand; and cuttings will strike root readily, if planted in sand, with a hand-glass over them. Some of them bear handsome foliage, but the flowers of all are insignificant.

CLXX1I. ANTO'NIA (named in compliment to the Archduke Antony of Austria, a promoter of botany). Pohl, pl. bras. 2. p. 13. t. 109.

Lin. sxst. Pentándria, Monogynia. Calyx with an oblongcylindrical tube, which is covered by scales, and a 5 -parted limb. Corolla funnel-shaped, with a bearded throat, and a 5 -parted limb; segments lanceolate, acute, at length reflexed. Stamens 5 , exserted, bearded at the base. Style long, filiform, thickened towards the apex; stigma bifid, obtuse. Berries oblong, 2celled.-Shrub middle-sized. Leaves decussately opposite. Stipulas interpetiolar. Cymes terminal, many-flowered. Flowers by threes, white.

1 A. ova'ta (Pohl, l.c. 2. p. 14.t. 109.) leaves ovate-elliptic, quite glabrous, as well as the branches. h. S. Native of Brazil, among bushes in dry places, about Joze de Tocantins, in the province of Goyaz.

Ovale-leaved Antonia. Shrub 5 feet.

Cull. For culture and propagation see Psychotria above.

CLXXIII. PALICOUREA (Aublet does not give the meaning of this word). Aubl. guian. 1. p. 173. t. 66 . H. B. et Kuntl, nov. gen. amer. 3 p. 365 . St. Hil. pl. rem. bras. p. 230. D. C. prod. 4. p. 5 24.-.Palicùrea ad Galvània, Røm. et Schultes, syst. 5. p. 11.-Galvània, Vell. et Vand. fl. bras. et Roem. script. p. 89. t. 6. f. 7.-Stephànium, Schreb. gen. no. 308.-Psychótria species, Juss. Willd.-Psychótria species, Galvània, and Colladònia, Spreng.

Lin. syst. Pentándria, Monogýnia. All as in Psychótria, but differing in the corolla being tubular, nearly cylindrical, curved or gibbous on one side at the base, shortly 5-cleft at the apex, and bearded beneath the middle inside. 'Teeth of the calyx and lobes of the corolla sometimes rather unequal.-Glabrous slirubs, all natives of America. Leaves opposite, rarely verticillate, usually large. Stipulas connected in varions ways. Panicles terminal, sometimes elongated, sometimes thyrsoid, and sometimes cymose, sessile, but usually pedunculate. Corollas yellow or white. Anthers exserted or inclosed, either inserted in the bottom, middle, or upper part of the tube of the corolla. Flowers variable, rarely with a 3 -celled ovarium and 3 -lobed stigma.

\section{$\S 1$. Flowers corymbose or cymose.}

1 P. Sellowia'na (D. C. prod. 4. p. 525.) glabrous; branches terete; leaves elliptic, acute at both ends, with undulated margins, on long petioles; stipulas bluntly bidentate, with a large blunt recess; panicles cymose, fastigiate, with angularly compressed branches; corollas glabrous; stamens inclosed; fruit roundish-ovate. h. S. Native of Brazil, about Rio Janeiro, where it was collected by Sello. P. fastigiàta, Cham. et. Schlecht. in Linnæa. 4. p. 16. but not of Kunth.

Sello's Palicourea. Shrub 6 to 8 feet.

2 P. fastigia'ta (H. B. et Kuntl, nov. gen. amer. 3. p. 368. but not of St. I-Iil.) glabrous; branchlets rather tetragonal; leaves elliptic, or ovate-oblong, acuminated, acute at the base, membranous; stipulas bidentate; corymbs pedunculate; flowers on long pedicels, somewhat fastigiate, glabrous; fruit ovate, nearly globose. $\eta$. S. Native on the banks of the Orinoco, near Atures. Psychótria fastigiàta, Spreng. syst. 1. p. 742. exclusive of the synonyme of Willd.

Fastigiate-flowered Palicourea. Shrub 6 to 8 feet.

3 P. tabernefólia (D. C. prod. 4. p. 525.) glabrous; branches terete; leaves large, soft, lanceolate, acuminated, petiolate; stipulas unknown; panicles almost cymose, short; segments of the calyx subulate; tube of the corolla slender, with 
lanceolate lobes. $\eta_{\imath}$. S. Native of St. Domingo. Psychótria tabernafòlia, Poir. dict. 5. p. 704. Flowers cream-coloured, hardly half an inch long.

Tent-leaved Palicourea. Slirub 4 to 6 feet.

4. P. hebeá́лtha (D. C. I. c.) glabrous; branches terete ; leaves elliptic-oblong, acuminated, acute at the base; stipulas twin on both sides, acute, small, hardly joined by a ligula ; panicles pedunculate, terminal; peluncles trichotomous, compressed; corollas bluntly 4-cleft, clothed with powdery tomentum. h.S. Native of Brazil.

\section{Hairy-flonered Walicourea, Shrub.}

5 P. Marcgràiu (St. Hil. pl. rem. bras. p. 281. t. 22. f. A.) branchlets somewhat tetragonal ; leaves oblong, acuminated, bluntish at the base, on short petioles; stipulas trifid?; cymes pedunculate, downy; rachis and branclies angular; corollas cylindrical, with 5 very short blunt teeth, clothed with papillose

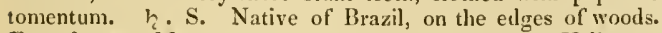
Erva do rato, Marcg. bras. 60. f. 2. Galvània, no. 2. Vell. mss. ex St. Hil. Galvània Vellòsii, Roem. et Schultes, syst. 5. p. 193. Peduncles of a coppery scarlet colour. Corollas of a yellowish copper colour at the base, and purple at the apex.

Íar. $\beta$, pubéscens (D. C. prod. 4. p. 525.) leaves downy beneath. $\zeta$. S. Native along with the species. St. Hil. l. c. and Cham. et Schlecht. in Linnæa. vol. 4.

Marcgrave's Palicourea. Shrub 2 to 3 feet.

$6 \mathrm{P}$. Apics'ta (H. B. et Kunth, nov. gen. amer. 3. p. 367. t. 285.) glabrous; branches terete; leaves oblong, short-acuminated, narrow at the base, coriaceous ; stipulas connate, bidentate, longer than the petioles; panicles cymose, sessile; corolla glabrous; fruit rather turbinate, crowned by a permanent urceolus. h.S. Native of Caraccas, on Mount Silla de Caraccas. Psychótria lineàta, Willd. in Rœm. et Schultes, syst. 5. p. 191. Corolla evidently ventricose at the base. Fruit sometimes 3celled, and the stigma trifid.

Cronned-fruited Palicourea. Fl. Ju. Aug: Cit. 1824. Shrub 4 to 6 feet.

7 P. Pave'tta (D. C. prod. 4. p. 525.) glabrous; branches terete; leaves ovate-lanceolate, acuminated, thin, nerved; stipulas menibranous, bidentate; corymbs terminal, pedunculate, with brachiate trichotomous branches; corolla funnel-shaped, curved a little; anthers inclosed; fruit roundish, diclymous. $々$. S. Native of Jamaica, on the mountains in woods. Psychótria Pavétta, Swartz, prod. 45. Lam. ill. t. 161. f. 3 . l'avétta pentándra, Swartz, f. ind. occ. 1. p. 233. Céstrum nervòsum, Mill. dict.—Sloane, hist. jam. 2. t. 202. f. 2.-Plum. ed. Burm. t. 156. f. 1. Flowers white, very sweet-scented, with spreading acute lobes. This is certainly not a species of Pacétta, from the style not being exserted, nor a Psychotria, from the tube of the corolla being elongated and a little curved.

Pavetta-like Palicourea. Shrub 2 to 3 feet.

8 P. Tincròria (Roem. et Schultes, syst. 5. p. 194.) glabrous; leaves oblong, acuminated, coriaceous, foveolate in the axils of the veins beneath; stipulas lanceolate, connate at the base; panicles on short peduncles, sub-corymbose, brachiate; throat of the corolla bearded; filaments hairy; fruit roundish. $\zeta . S$. Native of Peru, in forests on the Andes, ex Ruiz et Pav,; and at Guayaquil, ex Hænke. Psychótria tinctòria, Ruiz. et Pav. A. per. 2.p. 62. t. 211 . f. a. Spreng. syst. 1. p. 745. exclusive of the synonyme of Bartl. in herb. Hænke. Stipulas glandular at the base. Peduncles rather tetragonal. Bracteas small, acute. Flowers sessile, usually by threes. Calyx yellowish. Corollas white or cream-coloured, with a reflexed limb. Fruit globose, rufescent. This species yields a red dye.

$\operatorname{Var} \beta$; leaves ovate. $\zeta$. S. Native about Guayaquil, ex Hænke.

Dyers' Palicourea. Tree 18 to 28 feet.
9 P. xantuins (D. C. prod. 4. p. 525.) glabrous; branclics terete; leaves ovate or oval-lanceolate, acute at the base, acuminated at the apex, membranous, on short petioles; stipulas very short, somewhat bidentate; corymbs pedunculate, terminal, rarely axillary, trichotomons, bractless; corollas downy on the outside, curved; anthers a little exserted. $々$. S. Native of French Guiana, where it was collected by Patris. Branches and peduncles yellow. Berries nearly globose, ditymous, ribbed.

Yellow Paliconrea. Shrub 5 to 6 feet.

10 P. PuníceA (D. C. prod. 4. p. 526.) glabrous; branchlets nearly terete, rufescent; leaves oblong-lanceolate, acute, shining on both surfaces; stipulas twin on both sides, subulate, connected by a short ligula; panicles corymbose, pedunculate, of a scarlet colour; corollas urceolate; berries roundish, didymous. h. S. Native of Peru, in forests on the Andes. Psychótria punícea, Ruiz et Pav. f. per. 2. p. 62. t. 42. f. a. Leaves 9 inches long, undulated. Bracteas subulate. Flowers glomerate. Corolla of a purplish scarlet colour, with a short tubc, and ovate acute segments.

Searlet-corymbed Palicourea. Shrub 6 feet.

11 P. crócra (Rom. et Schultes. syst. 5. p. 193.) glabrous ; leaves ovate or oval-lanceolate, acuminated, stiffish; stipulas connected by a short ligula, twin on both sides, line:ur, acuminated, one half shorter than the petioles; panicles corymbose, terminal; corollas obconically tubular; anthers exserted from the tube, but shorter than the limb; berries rather didymous. h. S. Native of Porto-Rico, Trinidad, Cuba, Guadaloupe, Sc. Psyclótria crocea, Swartz, fl. ind. occ. p. 429. Sieb. ff. trin. no. 28. Meyer, esseq. 1. p. 105.?-Browne, jam. t. 13. f. 1. Leaves with prominent veins. Panicles and peduncles saffron coloured.

Saffron-coloured-panicled Palicourea. Fl. June, July. Clt. 1823. Shrub 4 to 6 feet.

12 P. Pedunculòsa (D. C. prod. 4. p. 526.) glabrous; leaves elliptic-oblong, acuminated at both ends, and somewhat cuspidate at the apex, stiffish; stipulas oval, decichous; panicles corymbose, on long peduncles, with opposite branches; corolla funnel-shaped, glabrous, with revolute lobes; fruit ovate-globose. $h_{2}$. S. Native of French Guiana, where it was collected by Patris. Psychótria pedunculòsa, Rich, act. soc. hist. nat. par. 1792. p. 107.? Palicùrea Cayennénsis, Desv. in Ham. prod. f1. ind. occ. p. 29.?

Long-peduncled Palicourea. Shrub 4 to 6 feet.

13 P. снionántha (D. C. 1. c.) glabrous; leaves ovate, ending in a short point at the apex, hardly acute at the base, stiflish; stipulas oval, at length deciduous; panicles corymbose, pedunculate, shorter than the leaves, with opposite branches; corolla funnel-shaped, glabrous on the outside; anthers exserted; fruit obovate, pear-shaped, ribbed. $\zeta$. S. Native of Brazil, about Bahia, where it was gathered by Salzmann, G. Don, \&c. Corollas snow-white, tubular, with linear-lanceolate lobes, and a villous throat. Stigma bifid. Lobes compressed.

Snow-flowered Palicourea. Shrub 4 to 6 feet.

11. P. unBeLla'ta (D. C. l. c.) glabrous; branches trigonal or tetragonal ; leaves elliptic-oblong, acuminated, attenuated at the base, stiff, nerved, on short petioles; stipulas connected, sheathing, short, coriaceous, with 2 short teeth on botb sides; corymbs pedunculate, sub-umbellate, composed of 5-7 branches, which rise almost from the same point, and are corymbosely brancherl at their tops; calyx acutely 5 -toothed. tive of French Guiana, where it was collected by l'atris. On the same branch there is often opposite leaves, or $3-4$ in a whorl. Stigma 3-cleft in many of the flowers.

Umbellate-corymbed Palicourca. Slorub 4 to 6 fect. 


\section{$\S 2$. Flowers panicled. \\ - Leaves disposed in whorles.}

15 P. tripny'Lla (D. C. prod. 4. p. 526.) glabrous; leaves 3 in a whorl, elliptic-oblong, acuminated at both ends, hardly petiolate; stipulas twin on both sides, linear-subulate, hardly joined at the base, longer than the petioles; racemes terminal, pedunculate, downy, somew hat paniculate, longer than the leaves. h. S. Native of French Guiana, where it was collected by Patris. Leaves 4-5 inches long, and $1 \frac{1}{2}$ broad. Raceme, along with the peduncle, 6 inches long. Fruit rather compressed, coarsely ribbed. Corolla unkuown, hence the genus is doubtful.

Three-leaved Palicourea. Shrub.

16 P. verticilla'ta (D. C. l. c.) branchlets tetragonal, glabrous; leaves 4 in a whorl, lanceolate-oblong, quite glabrous, on short petioles; stipulas bifid; panicles pedunculate, downy; rachis of the panicle triquetrous, and the branchlets are angularly compressed; corollas glabrous; fruit orbicularly ovate. $\eta_{2}$. S. Native of the south of Brazil, in woods. P. longifolia, St. Hil. pl, rem. bras. p. 232. t. 22. f. в. Corollas yellow. Stamens inclosed.

Whorled-leaved Palicourea. Shrub 4 to 6 feet.

17 P. QUADRıFòlıa (Rudge, pl. guian. p. 27. t. 42.) stem tetragonal; leaves 4 in a whor], oblong-lanceolate, acuminated ; stipulas intrafoliaceous, sheathing; corymbs many-flowered; peduncles a little shorter than the leares. French Guiana.

Four-lcaved Palicourea. Shrub.

18 P. Tetraphy'Lla (Cham. et Schlecht. in Linnæa. 1. p. 17.) branchlets bluntly tetragonal, smooth; leaves 4 in a whorl, ovate, or lanceolate-oblong, attenuated at both ends, stiffish, on short petioles, glabrous above, and downy beneath; stipulas bifid, with the lobes lanceolate, acute, and ciliated; panicles terminal, pyramidal, large, pedunculate, downy; corollas glabrous on the outside. h. S. Native of tropical Brazil.

Tetraphyllous Palicourea. Slirub 4 to 6 feet.

$$
\text { * Leares opposite, more or less petiolate. }
$$

19 P. Macróвotuys (D. C. prod. 4. p. 527.) branchlets terete, glabrous; leaves long-lanceolate, acuminated, clothed with velvety down beneath; stipulas twin on both sides, hardly connected at the base, ovate-lanceolate; panicles elongated, much longer than the leaves, clothed with velvety down; rachi somewhat tetragonal. h. S. Natice of Peru, on the Andes, in forests at Cuchero and Chinchao, et Ruiz et Pav.; and on the mountains about the Guanocco, ex herb. Hanlic. Psychótria macróbotrys, Ruiz ct Pav. fl. per. 2. p. 57. t. 203. f. a. Bartl. in herb. Hanke. Spreng. syst. 1. p. 714. Rom. et Schultes, syst. 5. p. 184. Leaves 6 inches long. Stipulas glandular at the base. Panicles purplish, a foot long. Bracteas small, subulate. Corollas small, yellow, villous inside at the insertion of the stamens, and having the segments edged with purple. Berries ovate, dark blue, a little compressed.

Long-racemed Palicourea. Shrub 10 to 12 feet.

20 P. macrocárpa (H. B. et Kunth, nov. gen. amer. 3. p. 369.) branches terete, glabrous; leaves obovate-oblong, shortacuminated, cuncated at the base, rather coriaceous, glabrous above, and hairy on the veins beneath ; stipulas bifid, glabrous; panicles pedunculate, spreading; corollas glabrous; fruit nearly

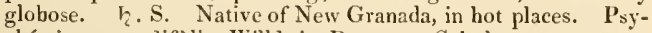
chótria anacardifòlia, Willd. in Rcem. et Schultes, syst. 5. p. 190. Distinct from $P$. macróbotrys, with which it is joined by Sprengel.

Long-fruited Palicourea. Shrub 6 to 7 feet.

21 P. Amethy'stina (D. C. prod. 4. p. 527.) branchlets somewhat tetragonal, rather hairy; leaves oblong-lanceolate, acuminated, glabrous above, and villous on the nerves and veins beneath; stipulas connected together almost to the middle into a sheath, and drawn out into 2 subulate teeth on each side; panicles hairy, a little longer than the leaves; bracteoles subulate; fruit oval. $々$. S. Native of Peru, in forests on the Andes at Pillao and Huassa-Huassi. Psychótria amcthýstina, Ruiz et Pav. f. per. 2. p. 57. t. 203 . f. b. Glands 7 in the axils of each stipula. Corollas tubular, blue. Berries ovate, blue.

Bluc-berried Palicourea. Shrub 10 to 12 feet.

22 P. Longibractea'ta (D. C. prod. 4. p. 527.) branchlets slightly tetragonal, smoothish; leaves oblong, acuminated, on short petioles, clothed with villous down on both surfaces; stipulas connate at the base a little way, twin on both sides, linear, acuminated; panicles longer than the leaves, hairy; bracteoles elongated, rather foliaceous; berries roundish, compressed. $h$. S. Native of Panama. P. amethýstina $\beta$ longibracteàta, Bartl. in herb. Hænke. Very like P. amethy'stina, but differs in the petioles being 1-2 lines long, not 11-12; and in the stipulas not being glandular at the base, and connected only a very short way. Berries globose, blue. Corollas blue?

Long-bractead Palicourea. Shrub 6 to 8 feet.

29 P. onova'TA (D. C. l. c.) branchlets bluntly tetragonal ; leaves obovate, acuminated, large, veiny, downy on the nerves and reins beneath; stipulas connected, ovate, with 2 short blunt lobes on each side; panicles thyrsoid, downy, brachiate, longer than the leaves; calyx ciliated ; corolla tubular; berries globose. h.S. Native of Peru, on the Andes in forests at Chinchao and Pillao. Psychótria obovàta, Ruiz et Pav. f. per. 2. p. 58 . t. 204. f. a. Leaves a foot long. Stipulas glandular at the base. Corollas purple, villous inside. Berries purple, almost globular.

Obovate-leaved Palicourea. Shrub 8 to 10 feet.

24. P. Miris (D. C. l. c.) branchlets bluntly tetragonal; leaves lanceolate, acute at both ends, very soft and probably velvety above, and glabrous beneath; stipulas connate at the base, ovate, emarginate, with very blunt teeth; panicles divaricate, hardly longer than the leaves; corollas funnel-shaped. $h_{2} . \mathrm{S}$. Native of Peru, in forests on the Andes at Pillao and Chacahuassi. Psychótria mìtis, Ruiz et Pav. fl. per. 2. p. 60. t. 208. f. b. Leaves $4-10$ inches long. Peduncles tetragonal. Flowers sessile. Bracteas subulate. Corolla yellow, with a hairy throat. Anthers linear, shorter than the corolla.

Mild-leaved Palicourea. Shrub.

25 P. LA'xA (Røem. et Scliultes, syst. 5. p. 195.) glabrous; branchlets tetragonal; leaves oblong, acuminated, shining above; stipulas smooth, bifid, with ovate obtuse Jobules; panicles long, loose, when in flower erect, but when bearing the fruit pendulous; bracteas long, reflexed. $h$. S. Native of Peru, on the Andes in forests. Psychótria láxa, Ruiz et Pav. f. per. 2. p. 61. t. 212. f. b. but not of Swartz. Psychótria lùteo-viréscens, Pers. ench. 1. p. 20s. Psychótria brachiàta, Dietr. Leaves 9 inches long. Peduncles compressed, Corolla greenish-yellow. Berries ovate, didymous, purplish-green.

Loosc-flowered Palicourea. Shrub 8 to 10 feet.

26 P. hyacinthiflòra (Røem. et Schultes, syst. 5. p. 194.) glabrous; branchlets bluntly tetragonal; leaves large, obovate, acuminated; stipulas bifid, with the lobes ovate, obtuse ; panicles length of leaves; peduncles brachiate; bracteas small, ovate; corolla funnel-shaped, with long revolute lobes. 5.5 . Native of Peru, on the Andes in forests. Psychótria hyacinthiflòra, Ruiz et Pav. fl. per. 2. p. 62. t. 213. f. a. Psych. hyacintholdes, Pers. ench. 1. p. 208. Panicles purple. Corolla violaceous. Stamens inclosed in the middle of the tube. Berries roundish, ovate, of a bluish violet colour.

Hyacintl-flowered Palicourea. Shrub 10 to 12 feet.

27 P. CERU'LEA (Rœen. et Schultes, syst 5.p. 194.) glabrous; 
leaves lanceolate, acuminatud, spreadingly deflexed; stipulas ovate, undivided, one-lialf shorter than the petioles; branches of panicle opposite, lower and ultimate ones rising from the axils; flowers crowded at the tops of the branches of the panicle; corolla funnel-shaped, with revolute lobes; berries turbinate. h.S. Native of l'erit, on the Andes in forests at Vitoc. Psy. corùlca, Ruiz et Pav. fl. per. 2. p. 62. t. 213. f. b. Branchlets terete. Leaves 8.9 inclıes long. Corollas yellowislı. Stamens inserted below in the middle of the tube. Berries blne, pearsliaped, size of peas.

Blue-berried Palicourea. Shrub 9 to 10 feet.

28 P. sulpnu'rea (D. C. prod. 4. p. 528.) glabrous ; branchlets bluntly tetragonal; leaves obovate-cuneated, terminating in a short blunt point, coriaccous, nerved, shining above; stipulas bluntly 2-Jobed, somewhat connected at the base ; paricle loose, rather longer than the leaves; corollas funnel-slaped; fruit roundish. $\eta_{\text {. }}$ S. Native of Peru, on the Andes in forests. Psychótria sulphùrea, Ruiz et Pav. A. per. 2. 1. 58. t. 203. f. a. Leaves yellowish, 6 inches long. Bracteas subulate. Corolla sulphur-coloured, having the tube villous inside below the throat. The shrub is very villous, and affords a yellow dye, which is used by the natives in the places of its natural growth.

Sulphur-colourcd-flowered Palicoure?. Shrub 10 to 12 feet.

29 P. Fiave'scens (H. B. et Kuntl, nov, gen, amer. 3. p. 366.) branchlets rather tetragonal, villous; leaves oblong, acuuninated, narrowed at the base, rather coriaceous, downy or hairy above, and elothed with golden yellow hairy tomentum beneath, and particularly so on the nerves; stipulas villous, combined, bidentate: teeth subulate; panicles sessile : corollas hairy. $I_{2}$. S. Native of Peru, in temperate places. Psychótria flavéscens, Spreng. syst. 1. p. 74 .

Yellonish Palicourea. Shrub 8 to 10 feet.

30 P. тuYrsif zòra (D. C. prod. 4. p. 52S.) glabrous; branchlets bluntly tetragonal; leaves lanceolate, acute; stipulas twin on both siles, short, tooth-formed, connected by a ligula; panicles thyrsoid, brachiate, longer than the leaves; berries ovate. h.S. Native of Peru, on the Andes in forests at Cuchero. Psychótria thyrsiflòra, Ruiz et Pav. fl. per. 2. p. 57. t. 204. f. b. Leaves 5 inches long. Stipulas triclentate, the middle tooth ovate ciliated, and the lateral ones subulate. Calyxes yellowish. Corollas yellow, villous inside. Berries ovate, dark purple.

\section{Thyrse-flowercd Palicourea. Shrub 10 to 12 feet.}

31 P. ALPina (D. C prod. 4. p. 528.) branchlets tetragonal; leaves ovate-lanceolate, nembranous, reticulated, a little ciliated; petioles duwny; stipulas twin on both sides, linear, rather ciliated, connected by a short ligula ; panicles terminal, ereet, usually shorter tlan the leaves; corollas terete, elongated, diaphanous; anthers inclosed in the throat. 々. S. Native of Jamaica, on the Bhe Mlountains. Psychótria alpina, Swartz, prod. p. 44. fl. ind. occ. p. 431. The leaves and branches are said to be glabrous. Peduncles rufescent. Corolla rather ventricose at the base, yellow, red, purple, and white. Berries nearly globose.

Alpine Palicourea. Slirub.

32 P. eriántia (D. C. prod. 4. p. 528.) branclilets terete; leaves elliptic, acute at the base, acuminated at the apex, glabrous above, hairy on the petioles and nerves beneath; stipulas twin on both sides, subulate, joined by a membrane; panicles terminal; calyx acutely 5 -toothed, glabrous; corolla tubular, very hairy outside. $h$. S. Native of St, Domingo. Psychótria alplna, Poir. dict. 5. p. 702. exclusive of the synonyme of Desf.

Hoolly-finered Palicourea. Shrub 8 to 10 feet.

38 P. specjòs A (H. B. et Kunth, nov, gen. amer. 3. p. 368.) branches glabrous, terete ; leaves oblong, acuminated, acute at the base, membranous, roughish, shining; stipulas glabrous; panicles pedunculate, with angular branches, which are as well vol. III. as the corollas downy. $\zeta_{2}$. S. Native of New Granada, near Santa Anna. Form of stipulas and fruit unknown. According to Aprengel, this is the same as Pychótria levigàta, Willd. but not of $K u n t h$.

Shon'y Palicomrea. Shrub 6 to 8 fect.

3.1. P. vilíl'tica (II. B. et Kunth, nov. gen. amer. 3. p. 369.) branchlets tetragonal, smoothish; leaves roundish-elliptic, acute, rounded at the base, coriaceous, stiff, glabrous above, and hairy or downy beneath; panicles on short perluncles, with short dichotomous smoothish branches; corollas glabrous, h.S. Native on the banks of the Orinoco. Psychótria circinàta, Willd. in Rom. et Schultes, syst. 5. p. 190. ex Spreng. syst. 1. p. T.14.? Distinct from Psychótria elliptica of Ker. and Willd.

Elliptic-leaved Palieourea. Shrub.

35 P. Longirlòra (D. C. prod. 4. p. 528.) branches terete, smeoth ; leaves ovite-lanceolate, acuminated, large, coriaccous, rather dlowny beneatl, on short petioles; panicles one-lialf shorter than the leaves, with alternate horizontal branches; corolla with a very long tube, which is attenuated at the base, and short straightish lobes. $\zeta$. S. Native of Cayenne. Psychótria longiflòra, Poir. diet. 5. p. 104. but not of Willd. Nerves of leaves and branches of panicle yellowish. Stipulas unknown. In the specimens of the plant preserved in the royal museum at Paris, the leaves appear to be quite glabrous on both surfaees. Leaves 6-8 inclies long.

\section{long-flomered Palicourea. Shrub.}

36 P. Domingénsis (D. C. prod. 4. p. 529.) glabrous ; branches terete; leaves ovate-lanceolate, acute, shining, petiolate; panicles terminal, usually twin; flowers sessile, cylindrical, incurred; berries shining. 々. S. Native of St. Domingo, on the banks of mountain streams in shady humid places. Psy chótria Domingénsis, Jacq. amer. p. 66. Leaves 5 inches long. Corollas white. Berries dark, shining, with a watery pulp.

St. Domingo Palicourea. Shrub 5 to 6 feet.

37 P. Tinifólia (D. C. prod. 4. p. 529.) glabrous; branches terete; leaves obovate-oblong, acute, reticulately veined beneatl, rather coriaceous, shining; stipulas bifid, obtuse ; panicles stiff, with angular thickened branches; corollas salver-shaped; stamens inclosed. h. S. Native of South America. Psychótria tinifòlia, Willd. in Røeın. et Schultes, syst. 5. p. 190. Colladònia tinifòlia, Spreng. syst. 1. p. 516. and 757. Berries 3.celled, 3seeded, probably from the same cause as those of Paliccurrea apicàla.

Laurestinc-leaved Palicourea. Shrub.

$38 \mathrm{P}$. croceoides (Desf. in Ham. prod. fi. ind. occ. p. 29.) leaves broad-ovate, acuminated, attenuated at the basc, shining, quite glabrous; panicles on long peduncles. $h$. S. Native of the Antilles. Branches saffron-coloured, as in $P$. cròcea, to which it is very nearly allied, but differs in the flowers being smaller and fewer, and in the nerves of the leaves being common, not parallel. The stipulas, flowers, and fruit remain undescribed.

Crocea-like Palicourea. Shrub 4 to 6 feet.

39 P. coccínea (D. C. prod. 4. p. 529.) glabrous; leaves elliptic-oblong, acuminated at both ends, rather membranous ; stipulas twin on both sides, setaceons, connected by a short ligula ; panicles elongated, contracted; corolla with a short cylindrical tube, and an crect limb; anthers inclosed; berries roundish. h. S. Native of St. Domingo and Porto-Rico. Psychótria coccínea, Poir. pl. exsic. Very nearly allied to $P$. cròcea, and is probably often confused with it, but differs in the corollas and fruit being smaller, in the branches of the panicle being crect and spreading, and usually alternate, in the stipulas being shorter and thinner, sc.

Scarlet Palicourea. Shrub 4 to 6 feet.

40 P. longleozia (H. B, et Kunth, nov. gen, amer. 3. p. 369.) 4. $\mathrm{H}$ 
glabrous; branches terete; leaves lanceolate-oblong, acuminated, acute at the base, membranous, shining; stipulas caducous; panicles sessile; corollas smoothish. h. S. Native of New Granada, near Santa Anna. This is a very distinct plant from Psychótria longiflora, Willd., with which it has been confounded by Sprengel in his syst. 1. p. 744 .

Long-leared Psychotria. Slirub.

41 P. angustifòdia (H. B, et Kunrh, nov. gen. amer. 3. p. 367.) branchlets hairy; leaves oblong-lanceolate, acuminated, acute at the base, membranous, stiff, discoloured, glabrous, rather hairy on the nerves and veins; stipulas glabrous, bidentate: tecth subulate; panicles pedunculate, hairy; corollas hairy ; fruit nearly globose, didymous. h. S. Native of South America, on the lanks of the Orinoco or Rio Negro. Psychótria stenophýlla, Spreng. syst. 1. p. 714.

Narrow-leaced Palicourea. Shrub.

42 P. Nicotianafòlia (Cham. et Schlecht. in Linnæa. 4. p. 18.) branchlets, panicles, stipulas, and under surfaces of leaves clothed with minute down; leaves ovate-lanceolate, acuminated at both ends, membranous, glabrous above; stipulas truncate, drawn out into 2 lanceolate-linear teetl each; panicles elongated, contracted; corollas tubular, downy on the outside while young. $r_{2}$. S. Native of equinoxial Brazil. Segments of the corolla rather unequal, pilose at the apex. There are also 5 fascicles of hairs in the tuive of the corolla. Berries nearly orbicular, flattened.

Tobacco-leaved Palicourea. Shrub 6 to 8 feet.

43 P. calophy'lla (D. C. prod. 4. p. 529.) glabrous; branches terete; leaves oblong, acute at the base, acuminated at the apex, on short petioles; stipulas combined at the base, twin on both sides, lanceolate, acuminated; panicles erect, contracted, shorter than the leaves, with very short few-flowered downy branchlets; corollas clothed with powdery tomentum. h. S. Native of French Guiana, where it was collected by Patris. Leaves 6-8 inches long, and 2 or $2 \frac{1}{2}$ broad. Nearly allied to $P$. nicotianafolia, but differs in the leaves being glabrous beneath, in the different form of the stipulas. The lobes of the stipulas appear as if they were verticillate, 2 being axillary, and the other 2 between the petioles.

Beautiful-leaved Palicourea. Shrub 5 to 6 feet.

44. P. PEtrola'ris (H. B. et Kunth, nov. gen. amer. 3. p. 370.) glabrous; leaves elliptic-oblong, acuminated, cuneated at the base, membranous, on long petioles : stipulas connate, acutely bifid at the apex; panicles erect, clotbed witl very minute down; calyx glabrous, with acutish lobes. h. S. Native of New Andalusia, on Mount Tumiriquiri. Psychótria petiolàris, Spreng. syst. 1. p. 745 . Corolla unknown. Leaves 6-7 inches long. Petioles 1 or $1 \frac{1}{2}$ inch long. Panicles $3-4$ inches long. Said to be nearly allied to $P$. Guianénsis.

Petiolar Paliconrea. Tree 60 feet.

45 P. Guiant'́nsis (Aubl. guian. 1. p. 173. t. 66.) glabrous; leaves oval, short-acuminated, hardly acute at the base, membranous, petiolate; stipulas bluntly bifid, rather connate, at length distinct, intrafoliaceous; panicles much-branched, erect ; corollas cylindrical, mealy outside. $\zeta$. S. Native of French Guiana, in woods. Psychótria Palicurea, Swartz, f. ind. occ. p. 433. Stephànium Guianénse, Gmel. syst. veg. p. 36s. Semira Palicùrea, Poir. dict. 7. p. 196. Leaves a foot long, and 5-6 inches broad. Flowers sweet-scented, scarlet. Tube of corolla a little inflated, and curved.

Guiana Palicourea. Slorub 7 to 8 feet.

46 P. HaNKEA'Na (D. C. prod. 4. p. 530.) branchlets bluntly tetragonal; leaves petiolate, elliptic, acute at the base, and very blunt at the apex, or hardly cuspidate, glabrous, velvety beneath on the middle nerve and veins; stipulas triangular, acute; paniçles terminal, pedunculate, much branched, equal in length to the leaves, with opposite or alternate spreading branches; corollas glabrous. $\eta$. S. Native of Peru, on the mountains about the Guanocco, where it was collected by Hænke. Cinchona Hænkeàna, Bartl. in herb. Hæuke. Corollas purplish, 4 lines long. Fruit unknown. Habit very like that of $P$. Guianénsis.

Hanke's Palicourea. Shrub 6 to 8 feet.

47 P. BARBinérvia (D. C. prod. 4. p. 530.) branches terete, glabrous; leaves oval, acute at the base, cuspidate at the apex, stiffish, glabrous, with the nerves rather prominent beneath, and bearded on both sides; stipulas intrafoliaceous, adpressed, very blunt, somewliat 2-lobed; panicles pedunculate, rather longer than the leaves, large, much branched, having the rachis angular, and the branchlets somewhat verticillate, spreading, and manyflowered; corollas clothed with powdery tomentım. $h$. S. Native of Porto-Rico, and probably of St. Domingo. Psychótria macrophýlla and Psych. lìtea, Spreng. in herb. Balb. A very beautiful species, nearly allied to $P$. Guianénsis, but very distinct. The nerves of the leaves become naked at length.

Bearded-nerved Palicourea. Shrub 6 to 7 feet.

48 P. costa'ta (H. B. et Kunth, nov. gen. amer. 3. p. 366.) branchlets villons; leaves oblong, acuminated, acute at the base, membranous, glabrous, discoloured beneath, and hairy on the nerves and veins; stipulas hairy, bifid, with the segments linear, and about equal in length to the petioles; panicles pedunculate, hairy ; corollas hairy on the outside, and bearded inside. $\eta_{\text {. }} \mathrm{S}$. Native of Sonth America, on the banks of the Orinoco and Rio Negro. Said to be nearly allied to Psychótria reticulata. Perhaps the same as Psychótria aristàta, Villd. in Røm. et Schultes, syst. vol. 5. to which it is referred by Sprengel.

Ribbed-leaved Palicourea. Shrub.

49 P. No'xı (Mart. reis. ex Linuæa. 5. p. 39.) glabrous; leaves membranous, oblong, acuminated, rounded at the base on short petioles; panicles divaricate; pedicels usually trifid; corollas velvety. Ђ.S. Native of Brazil. The rest unknown, as in the following species.

Poisonous Palicourea. Shrub.

50 P. sònans (Mart. l. c.) glalırous; leaves coriaceous, oblong, attenuated at both ends, acuminated or retuse; racemes subcorymbose, disposed into a large pyramidal panicle. $h . S$. Native of Brazil. Corollas velvety.

Sounding Palicourea. Shrub.

51 P. DiURE'Tica (Mart. l. c.) leaves with thickened revolute margins, velvety beneath between the ribs and veins; racemes disposed into a subcorymbose panicle; flowers clothed with fine velvety down. $h$.S. Native of Brazil.

Diuretic Palicourea. Shrub.

52 P. officisa'tis (Mart. l. c.) shrub clothed with harsh yellow down in every part; leaves narrow-elliptic, on short petioles, acute or rounded at the apex, with a mucrone, tapering a little at the base; corymbs disposed into a coarctate panicle. h. S. Native of Brazil.

Officinal Palicourea. Shrub.

53 P. Aura'ta (Mart. 1. c. p. 40.) leaves 4 in a whorl, membranous, stiffish, oblong or obovate, on long petioles, bluntish, glabrous, of a golden yellow colour beneath; racemes disposed in a coarctate panicle; corollas clothed witl fine velvety down. h.S. Native of Brazil.

Eared Palicourea. Slurub.

54 P. strépens (Mart. l. c.) bark corky ; leaves coriaceous, stiff, glabrous on both surfaces, almost sessile, broad-ovate, obtuse at both ends, with thickened revolute margins, yellowish beneath; corymbs disposed into a pyramidal panicle; corollas clothed with fine velvety down. 々. S. Native of Brazil. Perhaps the same as $P$. rigida?

Rattling Palicourea. Sluub. 


\section{* Leares opposite, sessile.}

55 P. RígIDA (I. B. et Kunth, nov. gen. amer. 3. p. 370. ) glabrous; branches bluntly tetragonal; leaves elliptic, acutish, rounded at the base, almost sessile, coriaceons, shining: stipulas twin on both sides, connected by a short ligula, almost linear, acute; panicles on long peduncles, spreading; corollas clothed with very fine down; stamens exserted. h.S. Native of New Andalusia, on arid mountains, tropical Brazil, and at Caraccas. Cham. et Schlecht. in Linnaea. 4. p. 15. Psychótria rígida, Willd. in Rom. ct Schultes, syst. 5. p. 192. P'sych. byrsophýlla and P'sych. rígida, Spreng. syst. 1. p. 747. and 745. and perhaps P. strépens, Mart. Flowers yellow, varying from pentamerous to hexamerous.

Stiff Palicourea. Fl. Aug. Sept. Clt. 1820. Shrub 3 feet.

Cult. For culture and propargation see Psycliótria, p. 599.

CLXXIV. CHASA'LIA (in honour of D. Chasal, once governor of the Mauritius, a great lover of naturul history). Comm. mss. Juss. mem. mus. 6. p. 379. A. Rich. mem. soc. hist. nat. par. 5. p. 166. t. 16. f. 1. D. C. prod. 4. p. 531.Psychótria, Coffèa, and Nonatèlea species, Sieb.

Lin. syst. Pentándria, Monogýnia. Calyx with an ovate tube, and an urceolate rather tubular limb, with an entire or 5 toothed border ; lobes or teeth joined together at length. Corolla with an elongated terete equal tube, and 5 short acutish erect or spreading lobes, which are usually callous at the apex, and valvate in astivation. Anthers 5, inserted in the middle or top of the tube of the corolla, inclosed or sometimes a little exserted. Stigmas 2, linear. Berries ovate, crowned by the limb of the calyx, containing 2 pyrenæ, hardly ribbed even in the dry state; pyrenæe coriaceously-chartaccous or horny, oblong, marked by a furrow inside, convex on the outside, and furnished by a longitudinal crest in the middle, which is extended beyond the basc, I-seeded. Seed erect, with the tranisverse section arched, lunate, and compressed. Embryo at the base of a horny albumen.-Glabrous shrubs, all natives of the Mauritius. Leaves opposite or 3 in a whorl. Stipulas ovate, undivided or combined into a 4 -cleft sheath. Flowers tubular, crowded and sessile on the tops of the branches, or disposed in terminal panicled corymbs. This genus differs from Psychótria in the corolla being elongated, and from Palicourea in the corolla not being gibbous at the base, and from both in the urceolate or campanulate calyx. The habit is that of Gertnèra, but the characters are very different.

* Flowers sessile, and cronded on the tops of the branches. Leaves opposite.-Chasàlia, Juss.

1 C. capita'ta (D. C. prod. 4. p. 531.) leaves opposite, oval, or obovate, terminating in a very short point; stipulas ovate, acuminated, permanent, longer than the petioles; flowers disposed in spicate heads at the tops of the branches, fascicled, sessile. $\zeta$. S. Native of the Mauritius. Psychótria capitàta, Sieb. f. maur. no. 56. Corolla tubular, 8-10 lines long, with acute hardly open lobes. Leaves 2 inches long, and 12-15 lines broad. Stipulas 8-9 lines long. Fruit unknown. Perlaps the same as Chasàlia Commersònii described by Jussieu.

Capitate-flowered Chasalia. Shrub. posite.

* Floners disposed in terminal panicled corymbs. Lcaics op-

2 C. psycriotrioìdes (D. C. prod. 4. p. 531.) leaves opposite, obovate-oblong, bluntish, coriaceous, cuneated at the base, on very short petioles; stipulas ovate, obtuse, about equal in length to the petioles; panicles corymbose, pedunculate: rachis and branches compressed, opposite. $\zeta$. S. Native of the Mauri- tius. Psychótria? Sieb. fl. maur. 2. no. 57. Internodes lıalf an inch long. Leaves $2 \frac{1}{2}$ to 3 inches long, and 15 lines broad. Corolla in the unexpanded state $\gamma$ lines long. Calyx bluntly 5-toothed.

\section{Psychotria-like Chasalia. Shrub.}

3 C. coffeoldes (D. C. l.c.) leaves opposite, oblong, bluntish, cuneated at the base ; stipulas ovate, acute, a little longer than the petioles; panicles terminal, pedunculate, somewhat corymbose, with the rachi and peduncles compressed, ard the branches opjosite. $h_{\text {. }}$ S. Native of the Mauritius. Cofl'ca capitata. Sieb. fl. maur. exsic. no. 335 . Leaves $3 \frac{1}{2}$ to $\frac{1}{1}$ inches long, and 12-15 lines broad. Stipulas 5 lines long. Calyx with 5 acute short teeth. Corolla in the unexpanded state 5 lines long.

Coffee-like Chasalia. Shrub.

4 C. Fontane'si (D. C. l. c.) leaves opposite, obovate-oblong, bluntish, attenuated at the base; stipulas oval, obtuse, deciduous, shorter than the petioles; panicles terminal, pedunculate, rather corymbose, with the rachi and branches compressed. h.S. Native of the Mauritius, and probably of the island of Bourbon. Coffèa cymòsa, Willd. in Roem. et Schultes, syst. 5. p. 201.? Very nearly allied to $C$. coffeoùdes, but the stipulas are different. Petioles 4.6 lines long. Fruit ovate, crowned by the calyx. Flowers unknown.

Dcsfontaines's Chasalia. Shrub.

5 C. stipula'cea (D. C. prod. 4. p. 532.) Jeaves opposite, obovate, acutish, cuneated at the base; stipulas combined in the middle into a 4-cleft sheath, equal in length to the petioles or longer than them: Jobes acuminated, 2 of which are within the leaves, and 2 between the leaves; corymbs terminal, trichotomous, with elongated branches, which bear a head of the flowers each at their tops. h.S. Native of the Mauritius. Psychótria, Sieb. fl. maur. 2. no. 271 . Leaves 6 inches long. Corolla 6-i lines long. Limb of calyx short, 5 -toothed.

Largc-stipuled Chasalia. Shrub.

6 C. oivarica'ta (D. C. l. c.) leaves opposite, obovate-oblong, acutish, cuneated a long way at the base, and petiolate; stipulas ovate, obtuse, membranous, deciduous, 2 or 3 times shorter than the leaves; panicles corymbose, one-half shorter than the leaves; lobes of corolla short, acute, straight. h. S. Native of the Mauritius. Coflèa divaricàta, Tansch. ex Sich, fl. maur. 2. p. 271. in herb. Dunant. Mussa'nda lanceolàta, Poir. dict. 4. p. 392.? and hence the Chasàlia Bourbonia, Comm.? Leaves 5-6 inches long, and 15 lines broad. Petioles about an incl long. Calyx urceolate, bluntly and shortly 5-toothed. Corolla 6 lines long.

Divaricate Chasalia. Shrub.

** * Flowers disposed in terminal panicled corymbs. Leaves 3 in a whorl.

7 C. Borxa'na (D. C. prod. 4. p. 532.) leaves 3 in a whorl, elliptic, acute at both ends, on long petioles; stipulas deciduous ; panicles trichotomous, a little shorter than the leaves; Jobes of corolla short, ovate, spreading; anthers exserted a little from the throat; calyx subtruncate. $h$. S. Native of the Matritius and the Island of Bourbon, where it was collected by Bory de St. Vincent. Sieb. fl. maur. 2. no. 253. Petioles 12-16 lines long. Leaves 4 inches long and 2 broad, with the nerves often white. Corolla 6 lines long.

Bory dc St. I'incent's Chasalia. Shrub.

8 C. grandifòlia (D. C. 1. c.) leaves 3 in a whorl, elliptic, acuminated at both ends, rather membranous, on long petioles; stipulas ovate, acuminated, rather longer than the petioles; panicles thyrsoid, terminal, on short peduncles. $\zeta_{\text {? }} . S$. Native of the Mauritius. Psychótria grandifòlia, Sieb. fl. maur. 2. no. 55. but not of Roem. et Schultes. Branchlets bluntly trigonal. Petioles $7-10$ lines long. Leaves 5 inches long and $1 \frac{1}{2}$ broad. 4 н 2 
Limb of calyx short, hardly 5-toothed. Corolla 10-12 lines long. Anthers at the throat.

Grcat-leaved Chasalia. Shrub.

9 C. chusıaròla (D. C. 1. e.) leaves 3 in a whorl, obovateoblong, obtuse, coriaceous, attenuated at the base ; stipulas twin on both sides, ovate, obtuse, adpressed, shorter than the petioles; peduncles rising by threes from the tops of the branches, angularly compressed, and densely corymbose at the apex; bracteas numerous, short. h. S. Native of the Mauritius. Nonatèlia? clusiaf òlia, Reich. in Sieb. f. maur. no. 89. Branchlets angular. Leaves 2-3 inclies long and 1 or $1 \frac{1}{2}$ broad. Petioles 6 lines long. Bracteas one at the base of each pedicel, and $\approx$ on each. Corolla 5 lincs long in the unexpanded state.

$\operatorname{Var} \beta$; leaves opposite. $h$. S. Growing along with the species.

Clusia-leaved Chasalia. Shrub.

Cult. For culture and propagation see Psychótria, p. 599.

CLXXV. JA'CKIA (named in memory of the late William Jack, a surgeon in the service of the East India Company, whose well known indefatigable labours in natural history have long ago entitled him to the highest respect). Wall, in Roxb. A. ind. 2. p. 321. D. C. prod. 4. p. 621.

lin. syst. Pentándria, Monogýnia. Limb of calyx unilateral, trifid. Corolla funnel-shaped, with a filiform tube, and a campanulate 5 -cleft border; segments lanccolate, valvatc in æstivation. Anthers filiform, scssile in the throat of the corolla, semi-exserted. Style long, hairy in the middle; stigma 2-lobed. Capsule? crowned by 3 large uniliteral wings, 1-celled, and 1 -seeded? - Tree tall. Leaves large, opposite, on short petioles, elliptic-obovate, cuspidate, clothed with rusty hairs beneath, as well as the branches, which are obscurely quadrangular. Stipulas combined, sheathing, fringed, interpetiolar. Panicles large, axillary, opposite, pendulous, on very long peduncles, hairy, and villous, with spreading opposite slender branches, each terminated by a corymb of crowded subdichotomous spikes. Peduncles slender, compressed, partial ones each supported by a pair of ample fringed connate bracteas, which sometimes grow out at the margins into opposite small floral leaves. Flowers whitc, inodorous, sessile, alternatc, disposed in short unilateral spikes, and each flower is supported by an oval densely villous toothed permanent biactea, and these bractcas are soniewhat imbricated on the back of the spikes.

1 J. ornA'TA (Wall. in Roxb. fl. ind. 2. p. 321. pl. asiac. rar. 3. p. 68. t. 293.) h. S. Native of the East Indies, in several of the small islands in the immediate vicinity of Singapore. A very large branching umbrageous tree. Leaves 6 to 10 or even 14 inches long, crowled at the tops of the branches.

Decked Jackia. Tree large.

Cult. See Psychótria, p. 599. for culture and propagation.

Subtribe 11. Cepheletioes (the plants contained in this subtribe agree with the genus Cepha'lis in the flowers being disposed in involucrated heads). D. C. prod. 4. p. 532.-Cephælídea, Cham, et Schlecht, in Linnaea. 4. p. 133 . Flowers disposed in fasciculate heads; the heads involucrated by bracteas.

CLXXVI. CEPHA'LIS (from $\kappa^{\circ} \phi a \lambda \eta$, kephale, a head; in reference to the disposition of the flowers in heads). Swartz, prod. p. 45. f. ind. occ. p. 435. t. 10. A. Ricl. mem. soc. list. nat. Par. 5. p. 172. D. C. prod. 4. p. 532.-Cepha'lis and Evea, Juss. mem. mus. 6. p. $40 \%$. exclusive of syn. 2. and 5.Tapagòmea and Evèa, Aubl. guian. 1. p. 157. and 100. Juss. gen. 258. Poir. dict. 7. p. 515.-Callicócca, Schreb. gen. no. 316.-Ceplı'leis, Vahl, eclog. 1. p. 19.

Lin. srst. Penlándria, Monogýnia. Calyx with an oborate tube, and a very short 5 -toothed limb. Corolla funnel-shaped, with 5 small bluntish lobes. Anthers inclosed. Stigma bifid, usually exserted. Berries obovate, oblong, 2-celled, 2-seeded, crowned by the vestiges of the calyx.-Shrubs and herbs, natives of America. Leaves ovate, acute, petiolate. Stipulas twin on both sides, free or combined, and sometimes bidentate or bipartite. Heads of flowers terminal or axillary, sessile or pedunculate, involucrated by 2-8 bracteas, which are disposed in a cruciately opposite manner; there are also bracteoles or palea among the flowers. - Perhaps the species with dry berries, and those with fleshy berries, ought to be separated into distinct genera. Perhaps $E^{\prime \prime}$ rea is properly joined with this genus, notwithstanding its tetrandrous flowers. Probably Carapíchea might be joined with this genus, but for its exserted stamens.

Sect. 1. Tapogomea (Tapogomo is the Guiana name of the first species). D. C. prod. 4. p. 533. Heads of flowers involucrated by 2 large spreading connate coloured bracteas.

l C. томentòs (Willd. spec. 1. p. 977.) branches, petioles, peduncles, leaves, and involucra hairy; stipulas acuminated, villous; heads of flowers on long peduncles; leaves of involucrum broad, ovate-cordate, wide at the apex. $\zeta$.S. Native of Guiana, Trinidad, and probably of Mexico (if C. cyanocárpa, Moc. et Sesse, f. mex. icon. ined. be the same,) in open spaces of woods, and about way sides. Tapogòmea tomentòsa, Aubl. guian. 1. p. 160.t. 61. Cephæ'leis tomentòsa, Vahl, eclog. 1. p. 19. Callicócca tomentòsa, Gmel. syst. 1. p. 371. Peduncles axillary and terminal. Bracteas or involucrum scarlet, or of a vermilion-colour, large, sometimes long-acuminated, and sometimes only cuspidate. Branches obscurely tetragonal. Berries striated, ex Aubl, but blue and smooth according to the fig. in fl. mex. There are therefore 2 species probably confused. In Trinidad we have seen this shrub growing in great abundance, and where it makes a very elegant appearance from its scarlet bracteas; the flowers, as far as we can remember, are brownish, and the berries bluish.

Woolly Cephalis. Fl. June, Sept. Clt. 1825. Sh. 4 feet.

2 C. PuníceA (Willd. spec. 1. p. 977.) quite glabrous; stipulas obtuse; lieads of Howers on long peduncles; leaves of involucrum obtuse, longer than the heads. $\eta$. S. Native of Jamaica. Cepha'lis punícea, Vahl, eclog. 1. p. 19. 'Tapogòmea punicea, Poir. dict. 7. p. 585 . Leaves oblong or elliptic, acuminated at both ends, 3-5 inches long. Branches roddish. Petioles villous at the base while young. Stipulas twin on both sides, joined to the middle. Peduncles rising between 2 branchlets, furrowed, reddish. I.eaves of involucrum scarlet, cordate, ovate.

Scarlet-involucred Cephælis. Fl. June, Sept. Clt. 1820. Shrub 4 to 6 feet.

3 C. elA'ta (Swartz, prod. p. 45. fl. ind. occ. p. 437.) quite glabrous; stipulas obtuse; heads of flowers globose, on long jeduncles; leaves of involucrum obtuse, hardly equal in length to the heads. $r$. S. Native of the south of Jamaica, on the high mountains ; and of Guadaloupe. Callicócca elàta, Gmel. syst. 1. p. 372. Tapogòmea elàta, Poir. dict. 7. p. 585. Branchlets tetragonal. Leaves oblong, 6 inches long. Stipulas bidentate. Leaves of involucrum large, roundish, cordate, concave, purplish red. Paleæ anong the flowers small, stiff, and coloured. Corolla with a villous throat.

Tall Cephalis. Clt. 1793 . Shrub 12 to 15 fcet.

4. C. Ruellizfòlia (Cham. et Schlecht. in Linnæa. 4. p. 134.) every part of the plant is clothed with slıort hairs; leaves broadlanceolate, acute, attenuated at both ends, on short petioles, membranous; stipulas triangular, bifid at the apex; heads of flowers terminal, almost sessile, solitary or by threes; floral leavcs connate and dilated; bracteas reticulately nerved, lancco- 
late, longer than the calyx. ?. S. Native of equinoxial Brazil.

Rucllia leaved Cephalis. Shrub 4 to 5 feet.

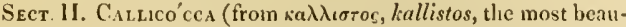
tiful, and nokwos, kokkos, a berry; the berries are blue or purplish). D. C. prod. 4. p. 533. Heads of flowers involucrated by distinct ovate or oblong erectly adpressed bracteas.

\section{* Shrubs. Heads of floners pcdunculate.}

5 C. justiciefòlia (Rudge, pl. guian. 1. p. 28. t. 43.) glabrous; branches dependent, knotted; leaves oval-lanceolate; stipulas truncate, hidentate; heads on long peduncles, involıcrated by broad-lanccolate bracteas; calyx nearly entire. $h . S$. Native of Guiana, on the banks of rivers. Peduneles downy. Bracteas fulvous. Corolla with a bearded throat. Flowers sessile on a disk formed by the bases of the bracteas.

Justicia-lcaurd Cephalis. Shrub 6 to 8 feet.

6 C. sripula'cea (Blım. bijdr. p. 1005.) stem suffiuticose, nearly simple; leaves cuncate-oblong, acuminated, glabrous; stipulas scmiorhicular; heads on very shore peduncles, axillary, and terminal, involucrated by roundish bracteas. h.s. Native of Java, on the mountains. Stipulas large, membranous. Margin of calyx truncate, entire. Berries dry, 2-celled, compressed, the commissure drawn out into a prominent angle on both sides.

Stipulaccous Cephælis. Shrub 1 to 2 fcet.

7 C. rigula'ris (Rich. mss, ex 1). C. prod. 4. p. 533.) glabrous ; leaves peciolate, oval, acutish ; stipulas broad, emarginate; peduncles compressed, solitary, involucrated by $9-10$ ligular bracteas; calyx hardly 5 -toothed. h. S. Native of French Guiana. Schradèra ligulàris, Rudge, pl. guian. 1. p. 29. t. 815. Tratt. tab. t. 84. According to Richard, the ovarium is 2-celled, and the cells 1 -secded, and therefore it is a true species of Cephe'lis.

Ligular-bractead Cephrelis. Shrub.

8 C. salicifòlia (H. B. et Kunth, nov, gen. aner, 3. p. 376.) glabrous ; leaves almost scssile, lanceolate, acuminated. shining; stipulas subulate, combined at the base; heads of flowers pedunculate, terminal, involucrated by 4 ovate-cordate leaves or bracteas. $h . S$. Native of New Andalusia, in arid places on Mount Cocollar. Involucrum green. Branches compressed while young.

Willow-lcaced Cephælis. Tree 20 feet.

9 C. GrA'BRA (Willd. spec. 1. p. 979.) branches terete, clothed with rufous villi while young; leaves ovatc-oblong, acute, glabrous, downy on the veins beneatls; stipulas bipartite, acute; heads pedunculate, terminal, rather liairy. $々$. S. Native of French Guiana, in open places. Tapogòmea glàbra, Aubl. guian. 1. p. 168. t. 63. Callicócca glàbra, Gmel. syst. 1. p. 379. Corollas and berries blue.

Glabrous Cephælis. Shrub 2 to 3 feet.

10 C. Bracteocárdia (D. C. prod. 4. p. 534.) branclies terete, clothed with velvety down while young, but glabrous in the aclult state; leaves elliptic-oblong, tapering to both ends, downy on the veins beneath; stipulas twin on both sides, subulate, joined a little way at the base; heads of flowers peduncu. late, terminal, downy, involucrated by $4-6$ acute bracteas, which are cordate at the base. h.S. Native of French Guiana, where it was collected by Patris; and of Brazil, in the province of Bithia by Salzmann.

Var. $a$; bracteas acuminated, purplish.-Native of Guiana.

I ar. $\beta$; bractcas pale, less acuminated. Native of Brazil, at Bahia. Corollas flesh-coloured.

Var. $\gamma$; bracteas pale, hardly acuminated, rather ovate at the buse,-Native of Guiana.
Heart-bractead Cephælis, Shrub 2 to 8 feet.

11 C. амвіgita (I). C. prod. 4. p. 534.) branches terete, downy, compressed while young; leaves elliptic-oblong, tapering to both ends, downy on the veins beneath; stipulas twin on both sides, subulate, joined together a little way at the base; heals pedunculate, terminal, smoothish, involucrated by $4-6$ bracteas, which are hardly cordate at the base, and very blunt at the apex. $\quad$. s. Native of Brazil, near Malia, in shady valleys, where it was collected by Salzmann. Involucrum violaceous.

Ambiguous Cephaelis. Shrub 2 to 3 fect.

12 C. cròcé (Meyer, esseq. p. 107.) glabrous; branches rather tetragonal; leaves ovate, short-acuminated at both ends ; stipulas linear, twin; heads terminal, globose, on short peduncles, involucrated by $S$ oblong-linear bracteas, and without any palex among the flowers. $h$.S. Native of Dutch Guiana, at Essequebo. Corolla saffron-coloured, villous outsicle. Ireaves of involucrum ciliated, yellowisl.

Saffion-coloured-flowered Cephrlis. Shrub.

13 C. Humbordtina (Chain. et Schlecht. in Linnea. 4. 1. 136.) glabrous ; leaves elliptic-lanceolate, tapering to both ends, on short petioles, firm and shining; stipulas tooth-formed on both sides at the base of the petioles; heads terminal, pedunculate, nearly globose, loose; bracteas inembranous, nerved : outer ones roundish-ovate: inner ones more acute. $\zeta$. S. Native of South America, at Javita, in shady places.

IIumbold's Cephælis. Shrub.

1.4 C. рiсно'томa (Rudge, pl. guian. 1. p. 29. t. 44.) glabrous; branches dichotomous; leaves on short petioles, ovatelanceolate; stipulas bidentate; heads terminal, on short peduncles, involucrated by nearly orbicular bracteas. $h . \mathrm{S}$. Native of French Guiana, and of Brazil, near the river Ilheos, if C. dichótoma, Nees et Mart. nov, act. bonn. 12. p. 17. be the same. Bracteas fulvous. Calyx obsoletely 5-cleft. Fruit furrowed, as in the genus Psychótria.

Dichotomous Cephalis. Shrub 6 to 8 feet.

15 C. Swártzis (D. C. prod. 4. p. 534.) glabrous; branchlets rather tetragonal; leaves ovate-lanceolate, acuminated, nerred, petiolate; stipulas broad, combined, acuminated, at length ciliated; heads terminal, globose, pcdunculate, involıcrated by 5 ovate concave bracteas; palex among the fiowers obtuse. 2 . S. Native of the West India Islands, and of st. Lucia, Sc. C. violàcea, Swartz, prod. p. 45 . fl. ind. oce. 439. exclusive of the synonymes. Peduncles an inch long, quadrangular. Corollas bluish. Berries blue. Bracteas violaceous. It differs from the true $C$. violacea in the heads of the flowers being pedunculated, in the stipulas being ciliated, and in the paleæ among the flowers being obtuse.

Swartz's Cephalis. Shrub 4 to 6 feet ?

16 C. Maranilaménsis; leaves broad-oblong, acuminated, membranous, glabrous; heads of flowers terminal and axillary. $h$. S. Native of Maranhain, on the banks of rivulets. Shrub branched. Flowers violaceous.

Maranham Cephalis. Slirub 4 feet.

17 C. FERrugínea; climbing, villous; leaves oblong-lanccolate, acuminated, rusty beneati, petiolate; peduncles axillary, elongated, villous; heads involucrated by many leaves. $h$. S. Native of Sierra Leone, on the banks of rivulets.

Rusty Cephatis. Slırub d.

18 C. PEDUNCula'ta (Salinb. par. lond. 2. t. 99.) stem terete, swelled below the joints: leaves oblong-lanceolate, glabrous, tapering to both ends; stipulas twin on both sides, combined almost to the top, keeled; heads of flowers pedunculate, terminal, or in the forks of the hranches; onter bracteas repandly toothed; calyx bearded; segments of calyx horned on the back. h. S. Native of Sierra Leone. Flowers white.

Pedunclad Cephælis. Fl. Feb. Clt.? Shrub \& feet. 
19 C. conı'cea; leaves oblong, coriaceous, dark green; heads on long peduncles, involucrated by many leaves. Native of Sierra Leone, on the edges of woods.

Coriaceous-leaved Cephælis. Shrub 2 to 3 feet.

\section{* Shrubs. Heads of floncrs sessile.}

20 C. viola'cea (Willd. spec. 1. p. 977. exclusive of the synonyme of Swartz.) glabrous; branches nearly terete; leaves oval, acuminated, on short petioles; stipulas broad, somewhat concrete, obtuse, rather scarious at the apex; heads of flowers terminal, globose, sessile, declinate, involucrated by 5 ovateroundish bracteas; palea among the flowers acute. h. S. Native of French Guiana, in woods, in humid places. Tapogòmea violàcea, Aubl. guian. 1. p. 157. t. 60 . Leaves $3-5$ inches long. Bracteas and corollas violaceous. Berries blue, angular.

I iolaceous-flowered Cephaiis. Shrub.

21 C. NU'DA (Cham. et Schlecht. in Linnæa. 4. p. 135.) glabrous; leaves elliptic-lanceolate, sub-acuminated, membranous, on short petioles; stipulas small, twin, on both sides acute; heads terminal, sessile, few-flowered, involucrated by pellucid, membranous bracteas, $\zeta$. S. Native of Brazil, near Rio Janeiro.

Naked Cephalis. Shrub 4 to 6 feet.

22 C. muscòs a (Swartz, prod. p. 46. fl. ind. oce. p. 442.) glabrous; leaves ovate-oblong, attenuated at both ends, on short petioles; stipulas sheathing, bidentate on both sides; heads terminal, almost sessile, involucrated by numerous oblong bracteas; palex among the flowers toothed. $\zeta$. S. Native of Martinique, in mountain woods, and by river sides. The same plant has been found in French Guiana, Trinidad, about the Havannah, in Cuba, \&c. Morínda muscòsa, Jacq. amer p. 65. t. 35 . Tapogòmea muscòsa, Poir. dict. 7. p. 587. Leaves 3.4 inches long. Stipulas rusty. Corollas white. T'le branches are always covered with moss.

Mossy Cephrelis. Tree 15 feet.

23 C. Axilla'ris (Swartz, prod. p. 45. A. ind. occ. p. 441.) glabrous; leaves petiolate, oblong, acuminated at both ends; stipulas ovate, combined, membranous, obtuse; heads axillary, sessile, globose, involucrated by $4-6$ bracteas; palex among the Howers ovate, obtuse. h.S. Native of the West India Islands, as of St. Christopher, Guadaloupe, Sc. Tapogòmea axillàris, Poir. dict. 7. p. 585.

Axillary-flowered Cephrlis. Fl. April, May. Clt. 1816. Shrub 4, feet.

24. С. овц́́NGA (D. C. prod. 4. p. 535.) glabrous; branches dichotomons, terete; leaves oblong, tapering to both ends, on short petioles; stipulas acuminated at length, truncate, ciliated ; heads terminal, sessile, involucrated by 4 oblong bracteas. $h$. S. Native of French Guiana. Branches purplish. Leaves painted with white above, as in $C$. purpurea, $2-3$ inches long, and an inch broad. Berries almost dry, striated, much smaller than peas.

Oblong-leaved Ceplicelis. Shrub.

25 C. pruvifòmis (H. B. et Kunth, nov. gen. amer. 3. p. 377.) bracteas terete, downy ; leaves oblong, acute, mucronate, glabrous, shining; stipulas bidentate: teeth furrowed; heads terminal, sessile, involucrated by 4 spatulate ciliated bracteas. $T_{\imath}$. S. Native of South America, in shady places on the banks of the Orinoco, near the cataract of Maypures. Involucrum green. Corollas blue. There is a variety of this species with tetramerous flowers, hence the genus $E$ vè $a$ has been joined with Ceplæ’lis.

Plum-leaved Cephalis. Shrub.

26 C. FRA'Grans (Hook. et Arn. in Beech. voy. pt. bot. p. 64. t. 13.) flowers tetrandrous; branchlets compressed; leaves broad-oval, obtuse, coriaceous, glabrous, reticulately reined, on short petioles; stipulas ovate, acuminated; peduncles bibracteolate at the base; bracteas heart-shaped ; flowers by threes, sessile. 々. G. Native of Elizabeth Island, one of the Society Islands. It seems to approach $C$. speciòsa, Sprengel, from Otahiti. Corollas red.

Fragrant Cephalis. Tree 20 fect.

27 C. EvE'A (D. C. prod. 4. p. 535.) glabrous; branchlets rather tetragonal; leaves oval-oblong, on short petioles; stipulas oblong, undivided; heads axillary, sessile, involucrated by 4 ovate, obtuse bracteas; flowers tetramerous and tetrandrous. h. S. Native of French Guiana, in woods, where it is called Eve by the natives. Evèa Guianénsis, Aubl. guian. 1. p. 100. t. 39. Lam. ill. t. 59. dict. 2. p. 392. Cephælis tetrándra, Willd, spec. 1. p. 979 . Paleæ among the flowers acute. Corollas white.

Evea Cephrlis. Slirub.

$$
\text { * * Herbaceous plants. }
$$

28 C. Furpu'rea (Willd. spec. 1. p. 978.) stems creeping, ascending, hispid from rufescent hairs at the tops; leaves oblong, acuminated, hispid on the nerves beneath, and ciliated on the edges; stipulas twin, hispid; heads terminal, almost sessile, involucrated by 2 oblong bracteas, which are, as well as the paleæ among the flowers, ciliated. 24. H. S. Native of French Guiana, in woods, and of Maranham. Tapogòmea purpùrea, Aubl. guian. 1. p. 162. t. 63. f. 3. Callicócca purpùrea, Gmel. syst. 1. p. 371. Leaves painted with a white line above. Corollas and berries purple.

Purple-flowered Cephalis. Fl. A pril, June. Pl. creeping.

29 C. A'LBA (Willd. spec. 1. p. 978.) stems creeping, hairy; leaves broal-ovate, acute, petiolate, villous ; stipulas lanceolate; heads terminal, sessile, involucrated by 5 ciliated bracteas. $\mathcal{4}$. S. Native of French and Dutch Guiana, in woods, Meyer, esseq. p. 106. Tapogòmea álba, Aubl, guian. 1. p. 164. t. 62. f. 4. Callicócca álba, Gmel. syst. 1. p. 371. Leaves of involucra rufescent. Corolla reddish on first expanding, but almost immediately afterwards becoming white. Berries red.

I'thite-flowered Cephælis. Pl. creeping.

30 C. Ipecacuánila (A. Rich, bull. fac. med. 1818, pol. 4. p. 92. dict. sc. med. vol. 26. with a figure) stems ascending at first, but at length becoming erect, rather downy at the apex; leaves oblong-ovate, scabrous above, and clothed with fine down beneath; stipulas setaceonsly cleft; heads terminal, pedunculate, erect at first, but at length becoming pendulous, involucrated by 4 subcordate bracteas. 4 . S. Native of Brazil, in woods and valleys on the mountains. Tuss, in Desv. journ. bot. 4. p. 247. Mart. mat. med, bras. 1. p. 4. t. 1. St. Hil. pl. usuel. bras. t. 6. Steph, et Church. 2. t. 62. C. emética, Pers. ench. 1. p. 203. exclusive of the synonymes Callicócca Ipecacuánha, Brot. in Lin. trans. 6. p. 137. t. 11. I pecacuánla officinàlis, Arrud. disc. p. 44. ex. St. Hil.-Pis, bras. 231.-Marcgr. bras. 17. Root creeping, annular, brown or greyish, and is the Ipecacuanha of the shops of Europe, and the Poyas of those of Brazil. Leaves crowded at the tops of the stems, which are simple, and obscurely tetragonal. Flowers white, downy outside.

Although the root of ipecacuanha has been long employed as a valuable article of the Materia Medica, yet the botanical characters of the plant which produced it remained unknown till Professor Brotero, of Coimbra, determined the genus to which it onght to be referred, with the assistance of observations made in Brazil, on living plants, by Bernardo Gomez, a resident medical botanist. The plant is a native of moist woods near Pernambuco, Bahia, Rio Janeiro, and other provinces of Brazil. It is called Ipccacuanha by the natives of some parts of Brazil; 
Poaia do. Matto by those of the southern provinces; and Cijo by others, which is the name often given to it by the Portuguese settlers. The root is simple, or a little branched, and furnished with a few short radicles, irregularly bent, externally brown, wrinkled from rings.

It appears that a native of Brazil, whose name was Michacl Tristan, was the first who brought ipeeacuanla into use. He speaks of it as a remedy for dysentery. Piso afterwards describes it, and speaks of two sorts (hist. nat. bras. p. 101.), the white and brown, which he says were given for fluxes, and as vomits. But we are indebted to Hclvetius for bringing it into general use, under the patronage of Louis XIV., from whom he received a thousand pounds, to reveal the secret medicine with which he so successfully treated dysentery. Besides the hrown ipecacuanha, there is another sort, brought from Brazil, which varies in appearance from the former; and some have supposed that these differences are owing to accidcntal circumstances, such as the place of growth, the kind of soil, \&.c.; but, on the althority of M. Gomez, the common brown ipecacuanha of the shops, is yielded to be Ccpha'lis ipecacuánha, while the white is the root of Richardsònia scàbra and $R$. ròsea, which is exported largely to Portugal. Besides these, the name of ipecacuanha, which, in the language of South America, means vomiting root, is given to various species of Cynánchum, Asclèpias, Euphórbia, D. rstènia, and Ruéllia; and with regard to their comparative power, De Candolle says that vomiting is produced by 22 grains of Cynánchum; by 24 of Psychítria emética; by from 60 to 72 of I'iola calccolaria; and by from 1 to $S$ draclims of $C$. ipecacuánha. Linnæus, in a paper published in the third volume of "Amonitates Academica," gave ipecacuanha, as a trivial name, to a species of Euphórbia, a native of Virginia and Carolina, the root of which is there used as an emetic. But this was soon discovered not to be real ipecacuanha. In his second "Mantissa" lie gave the trivial name to a species of Iiola, a native of Brazil, the rcot of which he supposed to be the white ipecacuanla of the shops. De Candollc, in a paper published in the "Bulletin des Sciences par la Société Philomatique," and republished entire in the "Noureau Dictionnaire d' Histoire Naturelle," says there are three species of $I$ iola which produce the white ipecacuanha; the $V$. calccolaria, a native of Guiana and the Antilles; the $I$. ipecacuánha, and the $\boldsymbol{V}$. partiftion, both natives of Brazil. The roots of these, and especially the last, are sometimes mingled in common with the true, or brown, ipecacuanha; but they are a fraudulent adulteration, and do not possess its active properties. They may be distinguished by their colour, but most certainly by the size of the woody part, which in these is always considerably thicker than the bark; whereas in the true ipecacuanha it is much less, and, as described by Brotero, is only a fibre.

The black or striatcd Ipecacuanha (Psychótria emética) is exported from Carthagena to Cadiz, and is also said to be the Peruvian grey ipccacuanha. The root is black within and without, fusiform, articulated, striated, and not annulated. The white incracuanha is described by Gomez to be the root of Richardsonia scàbra; it is of a dirty white, and turns brown by drying; it is simple, or a little branched, often 5 or 6 lines thick, 3 inclies long and upwards, variously twisted, and tapering at its extremities, with transverse annular rugosities, larger than those of the brown ipecacuanha. The common brown ipecacuanha is exported from Rio Janeiro to Portugal. Its colour varies from different degrees of grey and brown; but it is characterized by being contorted, wrinkled, and unequal in thickness; having a thick brittle bark, deeply fissured transversely, covering a central, very small white wood, so as to give the idea of a number of rings strung upon a thread.

Qualities and chemical properties.-Powdered ipecacuanha has a sickly odour, and a bitterish acid taste; and on those who pulverize it, sometimes excites such powerful cffects as to produce nutusea, faintings, and spitting of blool. It has been subjected to various chemical investigations, and Dr. Irvine ascertained that it contains a gum resin. MM. Pellitier and Magendie, while pursuing their investigation on ipccacuanha, discovered that the power of the various kinds of ipecacuanha depended on a peculiar principle, to which the name emetine has been given; and they think that it might upon all occasions be substituted with advantage, bcing much more active than ipecacuanha itself, without possessing its disagreeable taste and smell. The latter quality resides in a greasy substance, quite distinct from its emetine virtue; for $M$. Caventon swallowed it with impunity to the extent of 6 grains.-All vegetable astringents, as infusion of galls and regetable acids, weaken or destroy the power of ipecacuanha; and Dr. Irvine found that lialf a drachm, administered in 2 ounces of vinegar, had little effect.

Medical properties and uses.-The utility of ipecacuanla is generally known, and properly appreciated. As an emetic, it operates in doses of from 5 to 30 grains, surely and efficiently, without depressing the system at large, like many other emetics, or injuring the mucous membrane of the stomach; it is therefore to be preferred as a mere evacuant of that organ; and it can be given in the fullest doses with perfect safety, and without exciting much nausea. Its power as an emctic has been rather undervalued in one particular view; for if opium be taken, recourse is generally had to violent remedies, whicl, by simple contact with the stomach, when in a torpict condition, cannot fail to produce injurious results. Iprecacuanlia is sometimes employed in a full dose after the accession of a paroxysm of intermittent fever ; and, by destroying the link which held the chain of diseased sympathies together, it has often succeeded in cutting slort the disease. Paroxysms of spasmodic asthnia also often yield to the same treatment; and in the more chronic form of that disease, small doses advantageously produce both expectoration and perspiration. In cluronic dysentery and diarrhoea, it is a most useful medicine in small doses. Given in doses of half a grain, it promotes secretion in the lining membrane of the bowels, wherehy a healthy condition is eventually re-established, and is, therefore, frequently prescribed in cases of dyspepsia, attended by a foul tonguc. Small nauseating doses are advantageously given to subdue uterine and pulmonary hæmorrhages: and combined with opium, the effects of both appear to be modified; so that under the name of Dover's powders, doses of from 5 to 10 grains form one of the most powerful and useful sudorifies that can be employed for acute or chronic rheumatism, and for eruptive diseases that are disposed to recede. Nauseating doses of ipecacuanha are also useful for hooping-cough, epilepsy and aneurosis. Two kinds of emetine are obtained from ipecacuanha-the coloured emetine and pure emetine; the latter is white and powdery, not acted on by the air, whereas coloured emetine is deliquescent. The cases in which emetine may be given, are the same as those in which ipecacuanha is indicated. Pure emetine is much more powerful than the coloured. Two grains are sufficient to kill a large dog. 'The officinal preparations are Pulvis ipecacuanhe, Compositu and Vinum ipecacuanha. Pectoral lozenges of cmetine are useful in chronic pnlmonary catarrls, hooping-cotsgl, obstinate diarrhneas, \&c.

Ipecacuanha Cephælis. Pl. $\frac{1}{2}$ to 1 foot.

3† C. ru'bra (Hoffim. ex Willd. mss, in Rom. et Schultes, syst. 5. p. 214.) stem dichotomous, knced; leaves ovate, acuminated, petiolate, glabrous above, and downy beneath; stipulas sheathing, bidentate; heads terminal, on short peduncles, involucrated by 6 unequal bracteas. 4. H. S. Native of Brazil. Roots creeping. Veins of leaves purple. Stems flexuous, tumid at the joints. 
Rcd-veined-leaved Cephælis. P]. 1 foot.

32 C. colora'ta (Hofin. ex Willd. mss. in Røem. et Schultes, syst. 5. p. 213.) stems herbaceous, simple, glabrous; leaves oblong, tapering at both ends, roughish beneath; stipulas furnished with 2 bristles on each side; heads terıninal, on short peduncles. 2. S. Natice of Brazil. Stems thickened at the joints.

Colourd Cephrlis. Pl. 1 fuot.

33 C. PUBE'scens (Hoffm. 1. c.) stem simple, herbaceous, downy; leaves elliptic, acute at both ends, downy at the veins; lheads pedunculate, terminal, involucrated by many leaves. 4 . S. Native of Brazil, at Bahia.

Downy Cephrelis. P]. $\frac{1}{2}$ to 1 foot.

34. C. Hofranseggia'va (Rom. et Schultes, syst. 5. p. 214.) stem herbaceous, branched ; branches dichotomous or trichotomous; leaves oblong, narrowed at both ends, acuminated ; heads terminal, surrounded by a 4 -leaved involucrum. 24. S. Native of Brazil. C. dichótoma, Willd. rel. but not of Rudge. Nearly allied to $C$. rùbra, but the stems are much taller.

Hoffnansegg's Cephælis. 1'. 2 feet.

\section{+ Species not sufficicntly knonn.}

35 C. gemujflòra (Willd. rel. and Scliultes, syst. 5. p. 213.) leaves obovate, tapering at both ends, glabrous; heads globose, twin, on long peduncles, involucrated. $\zeta$. S. Native country unknown.

Bud-flomered Cephælis. Slirub.

36 C. ? midenta'ta (Humb. ex Willd. rel. in Roem. et Schultes, syst. 5. p. 21.) leaves oblong, acuminated, glabrous ; heads globose, terminal; involucrum 2-leaved, bidentate. 4. S. Native of Sierra Leone.

Bidcntate-involucred Cephælis. Pl.?

Cult. See Psychòtria, p. 599. for the culture and propagation of the slmubby species; and Geophila, p. 609. for those of the herbaceous kinds.

CLXXVII. CARAPICHEA (Carapiche is the Caribbean uame of the first species). Aubl. guian. 1. p. 16\%. t. 68. D. C. prod. 4. p. 536. Cepha'lis species, Willd. Juss. Euròthia, Neck. elem,

Lin. sxst. Pentándria, Monogýnia. All as in Cephàlis, except in the anthers and stigmas, which are a little exserted. Berries dry, bipartible, angularly furrowed, crowned by the small limb of the calyx; nuts or pyrenæ 1-sceded, smootl on the outside, not striated, as in Cephaclis.-Glabrous shrubs, with rather nodose branches. Leaves petiolate, oval, acuminated. Stipulas twin on both sides, combined at the base, and therefore bidentate. Heads of the flowers rising from the axils of the upper leaves, on short peduncles, deflexed, girded by 4 acute bracteas. Corollas white. According to Willdenow, Jussieu, and Richard, this genus should only form a section of $\mathrm{Ce}$. phe'lis.

1 C. Auble'tu (D. C. prod. 4. p. 536.) stipulas almost distinct, biglandular at the base; the 2 exterior bracteas of the heads elongated and acuninated, and the 2 interior ones short and mucrcnate. $\zeta$. S. Native of French Guiana, in woods, where it is called Carapiche by the natives. C. Guianéusis, Aubl. guian. 1. p. 168. t. 68. Callicócea Guianénsis, Gmel. syst. 1. p. 372. Cepha'lis involucràta, Willd. spec. 1.p. 979. Tapogomea Carapichea, Poir, dict. 7. p. 587. Leaves lanceolate, glabrous. Flowers small, white. Berries small, capsular.

Aublct's Carapichea. Fl. Jıne, Sept. Clt. 1826. Shrub 5 to 7 feet.

2 C. Patrísis (D. C. prod. 4. p. 536.) stipulas combined, bidentate at the apex; bracteas of the heads of the flowers nearly equal, ovate, acute. $h$. S. Native of French Guiana, where it was collected by Patris. Stems terete, dichotomous. leaves oval-lanceolate, acute at the base, and acuminated at the apex. Heads on very short peduncles, hardly larger than peas. Corolla white, hairy on the inner part of the limb. Anthers linear, exserted.

Patris's Carapichea. Shrub 5 to 6 feet.

Cult. See Psychótria, p. 599. for culture and propagation.

CLXXVIII. SUTERIA (named after John Rudolpl Suter, a professor at Bern in Switzerland; author of Flora Helvetica, Sc.). D. C. prod. 4. p. 536.-Cepha' lis species of Lindl.

Lin. sxsr. Pcntándria, Monogýnia. Calyx with an ovate tube, and a tubular angular limb, which is 5 times longer than the ovarium, having an unequally 5 -toothed border. Corolla salver-shaped, with a terete tube, a naked throat, and 5 ovaloblong lobes. Anthers sessile, inclosed. Stigma bilamellate. Fruit 2-celled, 2 -seeded.- $\Lambda$ glabrous shining shrub, with terete branches. Leaves almost sessile, oblong-lanceolate. Stipulas ovate, deciduous. Heads of flowers axillary, almost sessile, ustrally 6 -flowered, surrounded by ovate-foliaccous bracteas. Paleæ among the flowers linear. Corollas white, almost like those of jasmine, sweet-scented.-This genus differs from $C c$ pha'lis in the form of the calyx.

1 S. calycina (D. C. prod.4. p. 536.) h. S. Native of Brazi]. Cephr'lis calycina, Lindl. coll. t. 21.

Large-calyxed Suteria. Fl. April, May. Clt. 1816. Shrub 3 to 4 feet.

Cult. For culture and propagation see Psychótria, p. 599.

CLXXIX. GEOPHILA (from $\gamma \eta$, ge, the earth, and $\phi i \lambda \varepsilon \omega$, phileo, to love; the species creep on the surface of the earth, and the stems never rise beyond it). D. Don, prod. fl. nep. p. 136. but not of Berg. D. C. prod. 4. p. 537.-Psycliótria species, Lin.-Ceplı' 'lis species, Kunth.

Lis. sxst. Pentándria, Monngýnia. Calyx with an obovate tubc, and a 5 -parted limb; segments linear, spreadingly recurved. Corolla tubular, with a pilose throat, and 5 oval somewhat recurved lobes. Anthers 5, inclosed. Stigna bifid. Berry ovoid, angularly ribbed, crowned by the calyx, 2-celled, 2-seeded.Perennial depressed creeping lierbs. Leaves petiolate, cordate, similar to those of some species of $t$ iola. Stipulas solitary on both sides, undivided. Peduncles rising from the axils of the ultinate leaves, terminal, solitary, bearing many flowers at the apex. Flowers almost sessile, umbellate, involucrated by bracteas, which are shorter than the flowers.

1 G. Renifórmis (Cham. et Schlecht, in Linnæa, 4. p. 137.) petioles hairy above; leaves reniform, obtuse, with the lobes at the base approximate; bracteas linear; peduncles 4-6-flowered, shorter than the leaves. 4 . S. Native of South America, in shady places; as of Jamaica, Porto-Rico, Cuba, about the Orinoco, Brazil, Guiana, Society Islands, \&c. Psychótria herbàcea, Lin. spec. p. 245. Jacq. amer. t. 46. Tuss. ant. t. 8. Psychótrophum herbàceum, Browne, jam. p. 161. Cephæ'lis renifórmis, H. B. et Kunth, nov. gen. amer. 3. p. 377. Flowers white. Berries red. There are varieties of this with downy or glabrous stems and leaves. Leaves a]ways glabrous beneath.

Kidncy-shaped-leaved Geophila. Fl. April, June. Clt. 1793. P]. creeping.

2 G. viola'cea (D. C. prod. 4. p. 537.) petioles hairy above; leaves cordate-reniform, obtuse, glabrous, with the lobes approximate at the base; umbels few-flowered, almost sessile between the ultimate pair of leaves; bracteas linear-lanceolate. 24. S. Native of Cayenne and Guiana, in wools (Aub].); and of the Istlımus of Panama (Hæoke). Psychótria violàcea, Aubl. guian. 
1. p. 145. t. 55. Bartl. in herb. Hanke, but not of Willd. Very nearly allied to $G$. reniformis, but the petioles are shorter, the umbels are hardly pedunculate, the corollas violaceous, and the berries blue.

Violaceous-flowered Gcophila. Pl. creeping.

\& G. diversifòla (D. C. prod. 4. p. 537.) petioles anil peduncles clothed with short hairs or down; leaves reniformly cordate, rounded or acute, glabrous on both surfaces, paler beneath, with the lubes at the base approximate; lieads 2 or fowflowered; bracteas linear-lancenlite, downy. 4.S. Native of Java, on the mountains; and probably of Malabar and Silhet, \&c. if the Karinta-Tali, Rliced. mal, 10, t. 21 . be the same. Psychótria herbàcea, Roxb. A. ind. 2. p. 161. ant therefore G. reniformis, D. Don, prod. A. nep. p. 136. Ceplie'lis diversifòlia, Blum. bijdr. p. 1004. Flowers white? Berries red?

Diverse-leaved Geophila. Pl. ereeping.

4 G. violefòlı (D. C. I. c.) petioles hairy above; leares roundish-cordate, acutish, glabrous on both surfaces, with the lobes at the base divaricate; peduncles about equal in length to the petioles; bracteas lanceolate; umbels 6-9-flowered. 24. S. Native of New Granada, on the hanks of the river Magdalena, in humid places. Cepliæ'lis violafolia, H. B. et Kunih, nov. gen. amer. 3. p. 379. P'sychótria hederàcea, Willd. in Roem. et Schultes, syst. 5. p. 191. Corolla white, glabrous, 4 times longer than the calyx.

Fiolet-leared Geophila. Pl. creeping.

5 G. mackópoda (D. Don, prod. fi. nep. p. 136.) peioles roughish; leaves cordate, acute, glabrous; peduncles length of leaves; bracteas linear-lanceolate; umbellules 3-6-flowered. 4. S. Native of Peru, in groves, along the traet of Pillao to Izcutuna. Psychótria macrópoda, Ruiz et Pav. fl. per. 2. p. 63. t. 211. f. b. Psych, cordifolia, Dietr. gærtn. lex. 1. p. 618. Berries dark purple. Seeds smooth.

Long-peduncled Geophila. Pl. creeping.

6 G. GrÁcilis (D. Don, l. c.) petioles striated, beset witl retrograde hairs at top; leaves cordate, acute, rather pilose above; peduncles length of petioles; bracteas subulate; umbels 6-9-flowered. 4 . S. Native of Peru, in forests at Pillao and Pueblo-Nuevo. Psychótria grácilis, Ruiz et Pav. fl. per. 2. p. 63. t. 211 : f. c. Corollas pale-violaceous, glabrous inside. Berries ovate, blackish. Seeds trisuleate.

Slcnder Geophila. Pl. creeping.

Cull. A mixture of vegetable mould and sand, or peat and sand, is the best soil for the species of Geóplita; and they are easily increased by detaching their creeping stems.

CLXXX. PATA'BEA (the Guiana name of the first species). Aubl. guian. 1. p. 111. t. 45. Juss. gen. p. 208. men. mus. 6. p. 401. exclusive of the synonymes, Lam. ill. t. 65. H. B, et Kunth, nov. gen. amer. 3. p. 375.-Cephæ'lis species, Willd. Spreng.

LiN. syst. Tetra-Hexándria, Monogýnia. Calyx with an obovate-globose tube, and a very short entire or 4-toothed limb, rarely 5-6-toothed. Corolla with a short nearly terete tube, and 4-6 oblong spreading lobes. Stamens 4-6; anthers sessile within the throat. Stigma bluntly bifid. Berries globose, crowned by the nearly closed calyx, smooth, 2-celled, 2-seeded. -Glabrous shrubs, natives of South America. Leaves on short petioles, oval or ovate, acuminated at the apex. Stipulas broad at the base, and subulate at the apex. Flowers sessile, crowded into heads in the axils of the leaves or tops of the branches. Heads propped by 4 small binately opposite bracteas. This genus differs from Psychotria in the capitate inflorescence, in the smooth berries, and in the number of the floral parts being usually quaternary.

1 P. coceínea (Aubl. l. c.) stipulas undivided; leaves oval, YOL. 111. acute at the hase; heads of flowcrs sessile; flowers tetramcrous ; throat of corolla naked. $\eta$. S. Native of French Guiana, in the woods of Orapu. Lam. ill. no. 1464. t. 65. Cephae'lis sessilifiòra, Willd. spec. 1. p. $979 . \quad$ Flowers red.

Searlet Patabca. Shrub 4 to 5 feet.

2 P.? tenulfòra (D. C. prod. 4. p. 538.) leaves oblong, acute at both ends, membranous; stipulas 4 , lanceolate-linear, connate at the base; heads of flowers some sessile, and others pedunculate; corolla with a naked throat, linear lobes, and a slender tube; limb of ealyx truncate. 2.S. Native of French Guiana, where it was collected by Patris. Leaves 5-6 inches long and $1 \frac{1}{2}$ broad. Bracteas small. Fruit unknown.

Slcnder-flowercl Patabea. Shrub t to 5 feet.

3 P.? A'LBA (H. B. et Kuntl, wov. gen. amer. 3. p. 375.) leaves ovate, rounded at the base; stipulas bifid at the apex; cymes pedunculate; flowers pentamerous and hexamerous: throat of corolla villous. h. S. Native of South America, on the banks of the Orinoco, near Maypures, and Sin Fernando. Cephæ'lis cymòsa, Spreng. syst. 1. p. 749. P'sychótria Maypurénsis, Willd. rel. in Roem. et Schultes, syst. 5. p. 190.? ex Spreng. Calyx violaceous. Corollas white.

IThite-flowered Patabea. Shrub.

Cult. See Psychotria, p. 599. for culture and propagation.

CLXXXI. SALZMA'NNIA (named after M. Salzmann, a colleetor of plants in Mauritania, and afterwards in Brazil). D. C. prod. 4. p. 617.

LiN. sysx. Tetrándria, Monogínia. Calyx with an oval tube, and a cupular very bluntly 4 -toothed or sinuated permanent limb. Corolla with a short tube, and 4 oblong lobes. Alabastra tetragonal. Stamens with very short filaments, and very long anthers. Style 1, undivided, or the lobes are combined. Berry dry, crowned by the limb of the calyx, 1-celled in the adult state by abortion, compressed, oval, l-seeded. Sced compressed.-A glabrous Brazilian slirub. Branches at first tetragonal, but terete in the adult state. Stipulas truncate, very short. Leaves opposite, ovate, on short petioles, shining above, and as if they were varnished. Peduncles axillary, opposite, very short, bearing dense hearls composed of 10-12 flowers, girded by 2-4 ovate foliaceous bracteas. Flowers sessile within the bracteas, white. This genus appears to come nearest to Cepha'lis, from which it diflers in the very long anthers, in the compressed fruit, and in habit.

1 S. NíTIDA (D. C. prod. 4. p. 617.) Ћq. S. Native of Brazil, about Bahia on arid hills. Corolla a line and a half long. Leaves $1 \frac{1}{2}$ inch long and 1 broad, obtuse.

Shining-leaved Salzmannia. Shrub 5 to 6 feet.

Cull. See Psychótria, p. 599. for culture and propagation.

\section{Tribe $\mathrm{X}$.}

SPERMACOCEÆ (this tribe contains plants agreeing with the genus Spermacòce in particular charaeters). Cliam. et Schlecht. in Linnæa. 3. p. 309. A. Rich. mem. soc. hist. nat. Par. 5. p. 147. D. C. prod. 4. p. 538. Stigma bilamellate (f. 109.6 .). Fruit dry or hardly fleshy, usually of 2 , rarely of 3-4 1-seeded mericarps or nuts, which are sometimes combined, and sometimes separating from each other, indehiscent or dehiscing in various ways. Albumen between fleshy and horny. -Shrubs or herbs. Leaves opposite. Stipulas membranous ar the base, and usually of many bristles at the apex.

Subtribe I. CEPHALA'NTHEE (this subtribe only contains the genus Cephalanthus). D. C. prod. 4. p. 538. Flowers and fruit erowded and sessile, upon globose receptacles. Fruit divisible into 2 parts. 
CLXXXII. CEPHALA'NTHUS (from $\kappa \varepsilon \phi a \lambda \eta$, kephale, a hearl, and avoos, anthos, a flower; in allusion to the flowers being disposed in globular heads). Lin. gen. no. 113. Gartn. fruct. 2. t. 86. Lam. ill. t. 59. Juss. mem. nuss. 6. p. 402. Rich. diss, with a figure. D. C. prod. 4. p. 538.

Lin. sysx. Tetrándria, Monogýnia. Calyx with an obversely pyramidal tube, and an angular 4 -toothed limb. Corolla with a slender tube, and a 4-cleft limb; lobes erectish. Stamens 4, short, inserted in the upper part of the tube, hardly exserted. Style much exserted; stigma capitate. Fruit inversely pyramidal, crowned by the limb of the calyx, 2.4 ? celled, and separating into $2-4$ ? parts ; cells or parts 1 -seeded, indehiscent, and sometimes empty by abortion. Seeds oblong, terminating in a little callous bladder. Albumen somewhat cartilaginous. Embryo inverted in the albumen, with a superior radicle.--Slurubs, with terete branches. Leaves opposite or 3 in a whorl. Stipulas short, distinct, or a little combined. Peduncles naked, rising from the axils of the upper leaves, or from the tops of the branches. Heads globose, in consequence of the flowers being sessile, and seated on a spherical piliferous receptacle.-This genus is badly defined, and should probably be reduced to the American species, which have the fruit 2-celled and 2-seeded, and the rest should probably be thrown back into the genus Spermacòce.

Sect. I. Platanocéphalus (from miataros, platanos, the plane-tree, and $\kappa \varepsilon \phi a \lambda \eta$, kephale, a head; the heads of flowers resemble those of the plane-tree). D. C. prod. 4. p. 538.Platanocéphalus, Vaill. act. acad. par. 1722. Glands none in the calyx nor corolla.-American species.

1 C. occidenta'lis (Lin. spec. 138.) leaves opposite or 3 in a whorl, ovate or oval, acuminated ; peduncles much longer than the lieads, usually by threes at the tops of the branches. $\downarrow$. S. Native of Nortl America, from Canada to Florida, in marshy places. Duham. arb. 1. t. 54 . Schkuls, handb. t. 21. and t. 5 . b. fruit. Lois. lierb. amat. t. 272.-Pluk. alm. 336. t. 77. f. 4 . C. oppositifolius, Monch. meth. p. 487. Petioles reddislı next the branches. Heads of flowers globular, size of a marble. Flowers whitish-yellow. There are varieties of this species having the branchlets and young leaves either glabrous or downy.

Var. B, brachýpodus (D. C. prod. 4. p. 539.) leaves ellipticoblong, 3 in a whorl, on short petioles. $\zeta . G$. Native of the North of Mexico, near Rio rle la Trinitè and Bejar, where it was collected by Berlandier. Petioles 3-4 lines long. There are varieties of this with either glabrous or downy branches.

Western Button-wood. Fl. July, Aug. Clt. 1735. Shrub 6 to 8 feet.

2 C. SARA'NDI (Cham. et Schlecht, in Linnæa. 2. p. 610. and 4. p. 147.) leaves opposite or 3 in a whorl, oblong, acuminated, on very short petioles; peduncles hardly longer than the heads, 3-5-together at the tops of the branches. $\eta$. S. Native of the south of Brazil, where it is called Sarandi by the natives, and where it was collected by Sello; common on the coasts of La Plata and Caraccas; and of Peru, ex Hæenke. Búddlea glabràta, Spreng. syst. 1. p. 431. ex Cham. et Schlecht, in Linnæa. Glabrous. Leaves lanceolate or ovate-lanceolate, red beneath while young, and hairy in the axils of the secondary veins. Heads of flowers verticillate in the axils of the upper leaves, and umbellate at the tops of the branches, mucls smaller than those of the first species.

Sarandi Button-wood. Shrub 10 to 15 feet.

3 C. salicifòlıús (Humb. et Bonjl. pl. equin. 2. p. 63. t. 98.) leaves opposite or 3 in a whorl, linear-lanceolate, on very short petioles; heads of flowers on long peduncles, terminal, solitary. h.S. Native of Mexico, near Acapulco. Stipulas linear-subulate, permanent, twin on both sides. Heads of flowers white. IVillow-leaved Button-wood. Shrub 10 feet.
Sect. II. Naucleoides (from Nauclea and idea, like; the species resemble species of the genus Nauclèa). D. C. prod. 4. p. 539. Glands in the recesses between the lobes of the calyx and corolla.-Indian species.

4. C. Naucleoìnes (D. C. prod. 4. p. 539.) leaves opposite or 3-4 in a whorl, ovate-lanceolate, acuminated, on short petioles, villous beneath, and on the branchlets; stipulas intrafoliaceous, acuminated; heads terminal, subverticillate. h.S. Native of the East Indies, in Silhet. Nanclèa tetrándra, Roxb. fl. ind. 2. p. 125. Peduncles terminal, from 3 to 4 in whorled panicles. Flowers yellow, intermixed with filiform clavate scales. Capsules turbinate, 2-celled, 2-seeded; the cells 2-valved. According to Cham. et Schlecht. in Linnæa. 4. p. 147. this species is more nearly allied to Cephalanthus than to Nauclea, from the tetramerous flowers, and single seeded cells of the fruit.

Nauclea-like Button-wood. Tree 10 to 20 feet.

$\dagger$ Asiatic species not sufficiently known, and probably ought to be cxcluded from the genus altogether.

5 C.? pllu'lifer (Lam. dict. 1. p. 679.) leaves opposite, approximate, ovate, bluntly acuminated, smooth on very short petioles; peduncles axillary, leafy, a little shorter than the leaves. h.S. Native of the East Indies. Fruit and number of the parts of the flowers unknown. Leaves hardly 2 inches long. Heads of flowers hardly the size of peas.

Pill-bearing Button-wood. Shrub.

6 C. ? piluliflòrus (Willd. mss. in Rœem. et Schultes, syst. 3. p. 525.) leaves elliptic, tapering to both ends, bluntish; heads of flowers terminal and axillary, numerous. h.S. Native of Asia. The rest unknown.

Pill-flowered Button-wood. Shrub.

7 C. ? orienta'is (Rom. et Schultes, syst. 3. p. 105. but not of Lin.) arboreous; leaves opposite or 3 in a whorl, ovate, acuminated, reflexed, glabrous; peduncles terminal, divided; fruit baccate. h. S. Native of China. C. occidentàlis, Lour. coch. p. 67. but not of Lin. Acródryon orientàle, Spreng. syst. 1. p. 386. A large tree. Flowers white, tetramerous, and tetrandrous. Berries 1-seeded, red, edible. Perhaps a species of Morinda. According to Sprengel, this with the following species will constitute a distinct genus, which be has called deródryon.

Eastern Button-wood. Tree large.

8 C.? Angustifòlius (Lour. coch. p. 67.) arboreous; leaves opposite, lanceolate-linear; heads of flowers terminal; lobes of calyx subulate, beset with glandular hairs; fruit baccate. h. G. Native of Cochin-china. Acródryon angustifòlium, Spreng. syst. I. p. 386. Receptacle of flowers villous. Flowers pale, tetramerous and tetrandrous. Berries roundish, crowned, 2-celled, 1-seeded, aggregate into a globose bead. Perhaps a species of Morinda, or perhaps will form a distinct genus along with the preceding species.

Narrow-leaved Button-wood. Tree.

+ The two following species should be romoved from the order altogether.

9 C. ? PROCu'MBENS (Lour. coch. p. 67.) stem procumbent ; leaves alternate, ovate-lanceolate, tomentose ; racemes terminal, interrupted; flowers 5-cleft, dioecious. \%. G. Native of Cochinchina. Stílbe procúmbens, Spreng. syst. 1. p. 418. Flowers violaceous. The female flowers on a naked globular receptacle. Flowers numerous, on long peduncles, forming a ball or head. Stigma simple. This plant ouglit evidently to be excluded from the order, but it is hardly a species of Stilbe.

Procumbent Button-wood. Shrub procumbent. 
RUBIACEE. CLIXXIII. Democritea.

10 C.? monta'sus (Lour. coch. 67.) arboreous; leaves alternate, ovate, acuminatch, rougl above, and tomentose bencath ; peduncles axillary, solitary ; flowers apctalous, dioecious, 4-clelt ; seeds or fruit pappose. h. G. Native of China. Flowers green, on solitary axillary pcduncles, forming round heads, on naked globular receptacles.

Mountain Button-wood. Tree large.

Cult. The first species, $C$. occidentatis, being hardy, is a very proper plant for the fronts of slurubberies. It thrives best in a peat soil; and is readily increased by laycring, or by ripened cuttings under a hand-glass. The rest of the species being tender, their culture and propagation are the same as that recommended for Psychótria, p. 599.

Subtribe II. EUSPERMACO'CE $Æ$ (the genera contained in this subtribe agree witl Spermacòce in the distinct flowers, and divisible fruit). D. C. prod. 4. p. 540.-Spermacòceæ, H. B. et Kunth, nov, gen. aner. 3. p. 341. Flowers distinct. Fruit dry, usually separable into 2 parts, rarely into 3 or 4 parts.

CLXXXIII. DEMOCRI"TEA (so named from Democritis, an ancient philosopher). D. C. prod 4. p. 540.

LrN. syst, Pentándria, Monogýnia. Calyx with a turbinate rather angular tube, and 5 lanccolate acute stiff lobes. Corolla, stamens, and stigma unknown. Fruit adnate to the tube of the calyx and inembranous pericarp at first, but at length becoming ruptured, \&-seeded, 2-celled while young, but at length only 1-celled from the dissepiment having vanished. Seeds free within the pericarp, flat inside, and convex outside. Albumen fleshy. Embryo erect, central.-A Chinese shrub, with the habit of Serissa. Flowers unknown; but the calyx and fruit are very different from those of Serissa. Branches terete, white, when young rather downy. Leaves opposite. Sheaths short, combined with the petioles a little, and bearing each 3 stiff bristles. Flowers in fascicles at the tops of the branches.

1 D. Serissoides (D. C. prod. 4. p. 540.) h. G. Native of China, where it was collected by Sir George Staunton.

Serissa-like Democritea. Shrub 1 to 2 feet.

Cult. A mixture of loam, peat, and sand will be the best soil for this little shrub; and cuttings will be easily rooted in sand under a hand-glass.

CLXXXIV. O'CTODON (from oxiw, octo, eight, and ocous voovtos, odous odontos, a tooth; in allusion to the limb of the calyx, which is 8-toothed). Thonn. in Schum. pl. guin. p. 74 . D C. prod. 4. p. 540 .

LiN. syst. Tétrándria, Monogýnia. Calyx with a clavately obovate tube, and an 8-toothed limb; teeth very short, obtuse. Corolla campanulate, 4 -cleft ; lobes acute, beset with a few glandular hairs inside. Stamens inserted in the bottom of the tube of the corolla. Stigna globose, obsoletely bifid. Capsule turbinate, obsoletely tetragonal, 2-celled, 2-valved, dehiscing at the dissepiment; cells l-seeded; valves semi-bifid inside. Sceds oblong.-An ereet branched glabrous herb, about a foot high. Stems tetragonal. Leaves filiform, elongated, acute. Stipulas sheathing, furnisled with $3-4$ bristles on each side, which are shorter than the sheath. Heads of flowers verticillate, terminal and axillary ones nearly equal, roundish.-Very nearly allied to Borrèria; but differs from it in the calyx being 8-toothed, and in the other charaeters indicated above.

1 O. Filifdlium (Thonn. 1. c.)-Native of Guinea, where it was collected by Thonning, and in the waters of the Senegambia and Gala by Leprieur and Perrottet. Spermacòce filifolia, Perr. et Lepr. mss.

Thread-leaved Octodon. Pl. 1 foot.

\section{Cult. See Spermacòce for culture and propagation.}

CLXXXV. BORRE'RIA (named after William Borrer, F.I.S. Sc. one of our first British botanists). Mcyer, esseq. p. 79. Cham. et Sehlecht in Limasa. 3. p. 310 . Spreng. neue entd. 2. p. 141 . but not of Ach.-l bigelowia, Spreng. syst. 1. p. 394 . but not of lis neue entd. nor of others.-Chlorophytum and Spermacòcc, P'ohl, in litt.-Spermacòce speeies, Lin. Lam. Spreng. A. Rich,-Grulhanánnia, Neck. elem. no. 388.?

Lin. srst. Tetrúndria, Monogýnia. Calyx witl an ovate tube, and a permanent limb, which is parted into 2-4 teetl. Corolla salver-shaped or funnel-shaped, 4-lobed. Stamens 4 , exserted or inclosed. Stigma bifid or undivided. Capsule crowned by the limb of the calyx, 2 -cclled, opening from the apex at the disscpiment when mature, but without any free disscpiment; cocce or nuts 1 -sceded, opening by a longitudinal clink inside. Seeds ovate-oblong, marked in front by a longitudinal furrow.-Herbs or subshrubs, nearly all natives of the hotter parts of America. Stems and branches usually tetragonal. Leaves opposite, or the young ones are disposed in fascicles in the axils of the old ones, and therefore appearing verticillate. Stipulas joined with the petioles, more or less sheathing, fringed by many bristles. Flowers disposed in verticillate heads in the axils of the leaves, or on the tops of the branches, rarely cymose or corymbose, small, white, rarely blue.

\$ 1. Floners disposed in axillary and terminal verticillate heads: the terminal heads are girded by floral leares, wlich are longer than them.

$$
\text { * Tectle of calyx only } 2 .
$$

1 B. GLobularioides (Cham. et Schlecht, in Linnæa. 3. p. 3 12.) plant shrubby, ereet, glabrous; branches somewhat tctragonal ; leaves narrow-lanceolate, acuminated, with scabrous margins, paler beneath; bristles of stipulas longer than the sheath; heads of flowers globose, terminal or lateral; calyx bidentate; genitals exserted. $\zeta$. S. Native of equinoxial Brazil. Spermacòce fruticòsa, Pohl, in litt. Heads of flowers a little larger than peas. Flowers 3 times the size of those of $B$. verticillata, white. Capsule glabrous; nuts opening but slowly.

Globularia-leaved Borreria. Shrub 1 to $1 \frac{1}{2}$ foot.

2 B. verticilla'ta (Meyer, esseq. p. 83.) plant suffruticose, glabrous; brancllets tetragonal; leaves linear-lanceolate, acuminated, opposite, but appearing verticillate from the fascicles of young leaves in the axils ; bristles of stipulas length of sheath ; whorles of flowers globose, terminal, and axillary; capsule glabrous, oval, small, crowned by the bidentate calyx. $h . S$. $\mathrm{Na}$ tive of Jamaica, Guiana, Brazil, Caraceas, Trinidad, Sc. Spermacòce verticillàta var. Americàna, Lin. spec. p. 148. exclusive of the synonymes. Bigelowia verticillata and B. commutàta Spreng. syst. 1. p. 404. Spcrmacóce mucronàta, Nees, hor. berl. p. 49. and Spermacòce stellàta, Willd. herb. ex Cham. et Schlecht. in Linnæa. 3. p. 311 . Spermacòce verticillàta, Swartz, Pohl, Nees, and Willd,, but not of Burm. Flowers white. Calyx sometimes furnished with accessory teeth. Seeds granular.

I ar. $\beta$; leaves more crowded, and much shorter. $h_{2} .5$. Native of Brazil, in dry places at Rio Janeiro.

Whorled-flowered Borreria. Fl. June, July. Clt. 1792. Sh. 2 to 3 feet.

3 B. Kohautra'va (Cham. et Schlecht. in Linnæa. 3. p. 311. ) plant suftruticose, glabrous; branclilets tetragonal; leaves oblong-lineas, bluntish, mucronate, opposite, but appearing verticillate from clusters of young ones in their axils; bristles of stipulas shorter than the sheath; whorles of flowers globose, terminal, and axillary ; capsule downy, erowned by the bidentate calyx. $\zeta$.S. Native of Senegal and Gambia; and probably 4. 12 
of Madagascar and the East Indies. B. verticillàta, Sieb. seneg. 110. 10. Spermacóce verticillàta, Lin. spec. 148. var. Africàna, Apermacòce globòsa, Schum. pl. guin. p. 73. Dill. hort. elth. 2. f. 348. Flowers white. Nearly allied to $B$. verticillata.

Kohaut's Borreria. Fl. Ju. Aug. Clt. 1732. Shrub 1 to $2 \mathrm{ft}$.

4. В. sтиі́ста (Meyer, esseq. p. 83. t. 1. f. 1-3. fr.) stems lierbaceous, suffruticose at the base, twiggy, glabrous, smooth, tetragonal at the apex; leaves linear, acute, petiolate, opposite or falsely verticillate; bristles of stipulas shorter than the sheath, which is downy; whorls of flowers globose, terminal, and axillary ; capsule glabrous, oblong, crowned by the 2 subulate teeth of the calyx. h.S. Native of Porto-Rico, where it was collected by Ledru and Wydler. Flowers white. Nearly allied to $B$. verticilluta, but differs in the capsule being twice longer. lower leaves almost lanceolate-linear, rather scabrous on the margins at the top: upper ones usually with revolute margins.

Straight Borreria. Slırub $\frac{1}{4}$ to 1 foot.

5 B. Dichót том (Cham. et Schlecht. in Linnæa. 3. p. 348.) stem suffruticose, rather compressed, tetragonal; branchlets dichotomous; leaves lanceolate, acutely inucronate, glabrous, with serrulated margins; stipulas hairy, ciliated, with bristles at the apex; heads or whorles of flowers terminal and axillary; capsule scabrous from dots, glabrous, obovate, crowned by the 2 ovate-lanceolate teeth of the calyx. $\zeta$. S. Native of Peru, near Ayavaca, (Diòdia glàbra, Willd. herb.), and on Mount T’anqueragua (Knóxia dichótoma, Willd. herb.). Spernacòce dichótoma, H. B. et Kunth, nov. gen. amer. 3. p. 348. Flowers white.

Dichotomous-branched Borreria. Shrub 1 to 2 feet.

6 B. PODOCE'PHALA (D. C. prod. 4. p. 542.) stem branched, tetragonal, glabrous, rather downy at the nodi; leaves linear, glabrous, opposite, or falsely verticillate, almost veinless, with revolute nıargins; bristles of stipulas $5-7$, longer than the sheath, which is downy; lieads of flowers globose, and as if they were pedumculate, in consequence of the lateral branchos being naked, except the 4 floral leaves surrounding each head ; capsule oblong, glabrous, crowned by the 2 subulate calycine teetl. 4 . S. Native of Mexico or of Cuba. This species differs from all the others in the heads of flowers being on long tetragonal peduncles, which are 1-2 inches long, naked and glabrous, sometimes rising from the forks of the branches, then solitary, and sometimes from the axils of the leaves, then opposite.

Slalkcl-healcd Borreria. Pl. 1 foot.

7 B. Dístans (Cham. ft Schlecht. in Linnæa. 3. p. 340.) stems herbaceous, erect, tetragonal, having the angles beset with retrograde prickles; leaves lanceolate, glabrous, with serrulately scabrous margins; stipulas hairy, ciliated with lıristles; whorles of flowers capitate, remote; capsule oblong, villous at the top, erowned by the 2 subulate teeth of the calyx. 24. S. Native of Mexico. Spermacòce dístans, H. B. et Kunth, nov. gen. amer. p. 344. Spermacòce apiculàta, Willd. herb. Spermacòce aculeàta, Schlecht. in Schultes, syst. 3. p. 531. Flowers white. Very nearly allied to $B$. verticillata. Corolla funnelshaped, a little longer than the calys.

Distant-whorled Borreria. Pl. 1 foot.

\& B. Dexsiflòra (D. C. prod. 4. p. 542.) stem erect, tetragonal, glabrous; leaves linear, with revolute margins, l-nerved, glabrous; bristles of stipulas 7-9, longer than the sheath; whorles of flowers dense, sessile, 2-3 axillary, and the terminal one globose, and larger than the axillary ones; floral leaves 1.6 , reHexed; capsule linear-oblong, villous at the apex, crowned by the 3 subulate calycine teeth. $h$. S. Native of Jamaica. Spermacòce longif òlia, L'Her. herb. but not of Aubl. Superior leaves 2 inches long, and 1-2 lines broad. Corollas small, glahrous.

Dense-flowercd Borreria. Slirub 1 to 2 feet.

9 B. sprinòsa (Cham, et Schlecht. in Linnæa. 3. p. 340.) stem erect, herbaceous, simple, glabrous, somewhat tetragonal, with the angles a little muricated; leaves lanceolate-linear, acuminated, attenuated at the base, glabrous, with roughish margins: the mid-rib drawn out into a prickle-formed tubercle at the apex; stipulas membranous, bristly; whorles of flowers capitate, axillary ones 2-3, and the terminal one surrounded by an 8-leaved involucrum; capsule oblong, downy at the a pex, crowned by the 2 subulate teeth of the calyx. $h$. S. Native of the south of Jamaiea, in ficlls; and of Martinique and Mexico. Spermacòce spinosa, Lin. spec. 148. exclusive of the syn. of Jacq. Swartz, obs. p. 45. Flowers white.

Spiny-leaved Borreria. Pl. $1 \mathrm{ft}$.

10 B. Neesia'ina (D. C. prod. 4. p. 542.) glabrous, erect; stems herbaceous, tetragonal; leaves lanceolate, acute, scabrous on the mid-rib and margins; bristles of the stipulas 5 , ciliated; whorles of flowers twin, one of them terminal; calyeine teeth 2, setaceous; throat of the corolla closed with hairs. 4 . S. Native of Brazil. Spermacòce linifòlia, Nees. hor. berl. p. 49. but not of Vahl. Spermacòce Neesiàna, Schultes, mant. 3. p. 209. Flowers white. The same as B. Bogoténsis, according to Sprengel, but doubtful according to Cham. et Schlecht. in Linmæa. 3. p. 311.

Nees's Borreria. Pl. 1 foot.

11 B. RE'PENS (D. C. prod. 4. p. 542.) stems herbaceous, crecping, dichotomous, low, tetragonal, with the angles winged and pilose, and the sides striated; leaves oblong, acute, attenuated at the base, ulabrous; bristles of stipulas shorter than the sheath, which is villous; heads of flowers roundish, sessile in the forks, and at the tops of the branches, and nearly in the axils of all the leaves; capsule ovate, rather villous, crowned by the 2 acute teeth of the calyx. 4. S. Native of the Mauritius. Bigelòwia parviflòra, Sieb. fl. maur. exsic. no. 144. but not of Spreng. Flowers white.

Creeping Borreria. Pl. creeping.

12 B. mínima (D.C. prod. 4. p. 542.) plant glabrous, herbaceous, small, sparingly branclied ; stems tetragonal ; leaves oblonglinear, acuminatcd at both ends; bristles of the stipulas rather shorter than the sheath; heads of flowers terminal, involucrated by 4 leaves; calycine teeth 2 , subulate. $\odot$. S. Native of Brazil, where it was collected by Pohl. Herb a finger high, erect, or ascending. Corolla and mature fruit unknown.

Least Borreria. Pl. $\frac{1}{4}$ foot.

$$
\text { * T'eeth of the calyx } 4 .
$$

13 B. RAOIA'TA (D. C. prod. 4. p. 542.) stem herbaceous, erect, branched, terete, hispid from spreading hairs; leaves oblong-linear, acuminated, glabrous, glaucous, smooth, margined by a vein, 1-nerved; bristles of the stipulas longer than the sheath, which is villous; heads of flowers terminal, depressed, girded by 12-16 radiant floral leaves; capsule oblong, downy at the apex, crowned by the 4 short, linear-subulate teeth of the calyx. $\odot$. S. Native of Senegal, in sandy places, at Gala and Walo. Spermacòce radiàta, Sieb. pl. sen. exsic. no. 8. Flowers white. A very distinet species, agreeing in habit with B. spinòsa. Keel or mid-rib of the leaves smooth, and much exserted.

Ray-involucred Borreria. Pl. 1 foot.

14. B. Aspe'rula (D. C. prod. 4. p. 543.) stem herbaceous, erect, glabrous, rather tetragonal; leares oblong-linear, acute, glabrous, having the keel rather prickly from small stiff teeth; bristles of the stipulas longer than the sheath, which is membranous; heads of flowers many: verticillate; calycine teeth 4,1 or 2 of which are often deciduous, shorter than the ovarium, which is rather pilose. $\odot . \mathrm{S}$. Native of Brazil, about Bahia, in dry pastures, where it was collected by Salzmann.

Ri ughish Borreria. Pl. 1 foot.

15 B. subuta'ta (D. C. prod. 4. p. 543.) plant herbaceous, 
glabrous, crect, sparingly branched; stem tetragonal; leaves linear-subulate, with rather scabrous margins; bristles of the stipulas the length of the sheath; heads of flowers terminal, girded each by an erect 8 -leaved involucrum; corolla tubular, glabrous ; anthers exserted ; teeth of the calyx 4 , lanceolate, unequal, 2 of which are one lialf smaller than the other $2 . \odot . S$. Native of Mexico. Spermacòce subulàta, Pav. ined. Flowers white.

Subulate-leaved Borreria. Pl. 1 foot.

16 B. gracíllima (D. C. prod. 4. p. 543.) plant glabrous, herbaceous, slender, sparingly branclsed; branches rather tetragonal; leaves linear-subulate; stipulas lanceolate, undivided, or furnished with $S$ bristles; heads of flowers terminal, on long peduncles, girded by 2-leaved involucra. $\odot . S$. $\mathrm{Na}$ tive of Brazil, where it was collected by Pohl. Flowers and fruit hardly known. Habit very much like that of $B$. subulata.

Very slender Borreria. Pl. $\frac{1}{2}$ to 1 foot.

17 B. pusílla (D. C. prod. 4. p. 54.3.) stem herbaceous, slender, simple or branclsed, tetragonal, hispid under the nodi, the rest glabrous; leaves linear-lanceolate, acute, glabrous, pale beneath; bristles of the stipulas exceeding the whorles; heads of flowers small, $2-3$ of them axillary, and one terminal; involucra 4-6-leaved; capsule oval, hairy, crowned by the 3-4 linear-subulate teeth of the calyx. $\odot$. S. Native of Nipati, in the valley. Spermacòce pusílla, Wall. f. ind. 1. p. 379. Bigełòwia pusílla, Spreng. syst. 1. p. 405 . Spermacòce triándra, Ham. ex D. Don, prod. II. nep. p. 131. Flowers white. Very like $B$. téner $a$ and $B$. pùmila, but differs from them in the calycine teetlı being usually $y$.

Small Borreria. Pl. $\frac{1}{4}$ to $\frac{1}{2}$ foot.

18 B. TE'SERÁ (D. C. l. c.) stem herbaceous, erect, branched, tetragonal, slender, hardly scabrous; leaves linear, acute, glabrous; bristles of stipulas shorter than the sheath, which is glabrous; whorles of flowers dense, 3 of them axillary, and 1 terminal, the latter larger, sessile, and involucrated by 4-6 leaves; capsule oval, smoothish, crowned by the 3-4 linear-subulate caly-

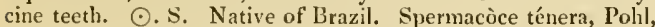
in litt. Flowers white. Very nearly allied to $B$. pumila, but differs in its smoothness, and in the axils of the leaves being nearly all floriferous, and in the leaves being almost always 3 times shorter.

Tender Borreria. Pl. $\frac{1}{4}$ foot.

19 B. pu'mua (D. C. l. c.) stem herbaceous, slender, tetragonal, beset with retrograde pili; leaves linear, acuminated, with revolute margins, scabrous above, and glabrous beneath, 1nerved; bristles of the stipulas longer than the sheath, which is scabrous; heads of flowers terminating the stem and axillary branches, rarely axillary; involucra 6-8-leaved; capsule oval, downy at the apes, crowned by the glabrous, subulate teeth. $\odot$. H. Native of Brazil, where it was collected by Pohl. Herb with a slender root, and a stem 6 inclies high. Superior leaves 15 lines long, and a line broad.

Dnarf Borreria. Pl. $\frac{1}{2}$ foot.

20 B.? TE' NuIs (D. C. I. c.) stem slender, tetragonal, erect, sparingly branched, downy, especially on the angles; leaves lan. ceolate-linear, acute, downy on both surfaces, scabrous; bristles of the stipulas stiff, a little longer than the sheath, which is villous; whorles of flowers capitate, 1-2 of them axillary, and 1 terminal; involucrum 2-leaved; calycine teeth 4, glabrous, unequal; anthers inclosed. $\odot$. F. Native of Brazil, where it was collected by Pohl. Spermacòce ténuis, Pohl, in litt. Herb 6-7 inches high, indurated at the base. Fruit unknown, but from habit it is judiged to be a species of Borrèria.

Slender-stemmed Borreria. 1'], $\frac{1}{2}$ foot.

21 B. cupUla'ris (D. C. I. c.) stem herbaceous, erect, simple, rather angular, downy, and rather scabrous; leaves oval-oblong, acuminated, petiolate, glabrous; upper stipulas broad-connate, cup-shaped, furnished with $9-10$ bristles on each side, which are slorter than the sheath; heads of flowers 2, 1 axillary, and 1 terminal and larger: capsule oval, downy at the apex, crowned by the 4 oblong teeth of the calyx. $\odot$. F. Native of Brazil, where it was collected by Pohl. Spermacòce pusilla, Pohl, in litt. but not of Wall. Herb 5-6 inches ligh. Flowers densely crowded in the cups formed by the stipulas, whitc.

Cupular-stipuled Borreria. Pl. $\frac{1}{2}$ foot.

22 B. ocrmoides (D. C. prod. 4. p. 54t) stem herbaceous, branched, tetragonal, with the angles hairy and winged; leaves ovate, tapering into the petioles at the base, acutish, glabrous : bristles of the stipulas few, rather shorter than the shearlı; whorles of flowers axillary, sessile, dense; capsule small, ovate, crowned by the $2-4$ small teeth of the calyx. $\odot . H$. Native of the East Indies. Spermacòce ocymoldes, Burm. fl. ind. 34. t. 13. f. 1. but the angles of the stems are said to be glabrous.

Basil-like Borreria. Pl. $\frac{1}{2}$ foot.

23 B. RaMispa'rsa (D. C. prod. 4. p. 514.) smoothish ; stem herbaceous, dichotomous, tetragonal ; leaves oval-oblong, acute at both ends; bristles of the stipulas membranous, pale, longer than the slieath; whorles of flowers capitate in nearly all the axils, and on the tops of the branches, equal in sizc, sessile, girded by $2-4$ leaves; capsule small-ovate, smoothish, crowned by the teeth of the calyx, of which 2 are larger and subulate, and 2 small. $\odot$ ? F. Native of Brazil, where it was collected by Pohl. Angles of the stems, nerves of the leaves, and the base of the calyxes downy, the rest of the herb glabrous. Flowers white.

Scattercd-branched Borreria. Pl. $\frac{1}{2}$ to $\frac{3}{4}$ foot.

24. B. PARviflòra (Meyer, esseq. p. 83. t. 1.) stem herbaceoús, erect, tetragonal, with the angles usually hairy, and a little winged below; leaves oval-oblong, tapering to both ends, rather hairy beneath while young, and at length scabrous on the margins ; bristles of the stipulas longer than the sheath; whorles of flowers axillary and terminal, dense, small, involucrated by 2-4 leaves; capsule ovate, crowned by the 4 short subulate calycine teeth. $\odot$. F. Native of the West lndies, as of Porto Rico, Guadaloupe, St. Domingo, \&c.; and of Peru. Spermacòce áspera, Valll, ecl. p. 10. but not of Aublet. Spermacòce la'vis from Gualaloupe, and Sperm. áspera from Hispaniola, Spreng. syst. 1. p. 401 . ex herb. Balb. Perhaps Spermacòce laevis, Lam. is identical with this plant. This species, with many others, is very intricate, but is nearly allied to $B$. ramispársa. It differs from $B$. áspera, Aublet, in the much less scabrous stem, in the shorter leaves, and in the smaller whorles of flowers. Flowers white. Bigclònia áspera, Sieb. is a distinct plant from this. Bristles of the stipulas pilose.

Small-flowered Borreria. Pl. 1 to 2 fcet.

25 B.? ala'ta (D. C. prod. 4. p. 544.) stems herbaceous, diffuse, radicant, branched, glabrous, tetragonal, with winged angles; leaves smooth oval, acuminated; bristles of the stipulas longer than the sheath; heads of flowers terminal, girded by 4 leaves; style bifid to the middle. $\odot$. F. Native of French Guiana, at the river Aroura. Spermacòce alàta, Aubl. guian. 1. p. 60. t. 22. f. 7 . Flowers white. Fruit divisible into 2,1 -seeded, dehiscent nuts. It is nearly allied to $B$. Bartlingiùna, but the structure of the fruit and flowers is doubtful. Superior leaves sessile, rather cordate at the base. Stamens didlymous, 2 of which are shorter than the corolla. Corollas rather large, blue.

Winged-stemmed Borreria. Pl. creeping.

26 B. Bartlingia'sa (D. C. prod. 4. p. 514.) stem herbaceous, diffuse, radicant, tetragonal, with winged pilose angles, 
and the sides between the wings are lined with parallel veins; leaves oval, acutish, beset with bristle-like hairs on both surfaces; whorles of flowers sessile, glomerate, axillary ones nnmerous, and one terminal, girded by 4 leaves; capsule nearly globose, pilose, crowned by the 4 lanceolate teeth of the calyx. ๑. F. Native of Mexico. Bigelòwia alàta, Bartl. in herb. Hænke, but differs from $B$. alàta in the wings of the stem being hispic, in the leaves being hispid and much less acute, in the axillary whorles, \&c.

Bartling's Borreria. Pl. creeping.

27 B. 'Taupica'sa (D. C. l. c.) plant glabrous, diffuse, branclied, herbaceous; branches tetragonal, with smooth angles; leaves oblong-linear, acute, l-nerved, scabrous on the mid-rib, but not on the margins; whorles of flowers capitate from nearly all the axils, and from the tops of the stens, sessile, involucrated by 4-8 leaves; capsules small, ovate, glabrous, crowned by the 4 sloort subulate teeth of the calyx. 4 . G. Native of Mexico, at Tampico de Tamaulipas, where it was collected by Berlandier. Very nearly allied to $B$. parvifiora, but the nuts of the fruit are dissimilar, one of them bearing 3 of the calycine teeth, and the other 1 .

Tampico Borreria. PI. 1 foot.?

28 B. Diffu'sa (D. C. 1. c.) glabrous ; stem diffuse, dichotomous, rather tetragonal; leaves linear, with revolute margins ; stipulas setiferous; whorles of flowers capitate, axillary, and terminal, globose, rather compound; foral leaves $4-8$, reflexed; capsule oval, smoothish, crowned by the 4 short, subulate teeth of the calyx.-Native of Brazil, where it was collected by Polıl. Spermacòce diffùsa, Pohl, in litt. but not of Kunth. Corollas small, smoothish, white.? Capsale small, membranous, whitish.

Diffuse Borreria. Pl. diffuse.

29 B. Renotifòlia (D. C. l. c.) stem slender, tetragonal, rather hairy; leaves oblong-linear, almost sessile, acute, scabrous above and on the margins, but downy beneath; bristles of the stipulas downy, a little longer than the sheath, which is villous; whorles of flowers capitate, terminal ones on long peduncles, a very few axillary; lobes of the calyx 4, narrow, acute, unequal, glabrous.- Native of Brazil, where it was collected by Pohl, in litt. but not of Ruiz et Pav.

\section{Remote-leaved Borreria. Pl. $\frac{1}{2}$ to $\frac{3}{4}$ foot.}

30 B. díscolor (Bartl. in herb. Hænke, under Bigelònia, exD. C. prod. 1. p. 545.) stem herbaceous, branched, quite glabrous, tetragonal, having the angles winged a little; leaves ovaloblong, or oblong-lanceolate, acute, scabrous above, and clotlicd with yellowish down beneath; bristles of the stipulas many, longer than the leaves; whorles of flowers axillary, and terminal, small, girded by 2 leaves; capsule nearly globose, rather downy, crowned by the 4 lanceolate teeth of the calyx.Native of the Island of Manilla, near Sorzogon, where it was collected by Hænke.

Discoloured-leaved Borreria. Pl. I to 2 feet.?

31 B.? cornifolla (D. C. prod. 4. p. 545.) stem herbaceous, erect, tetragonal, tomentose ; leaves petiolate, oblong, acute, with scabrous margins, and having the veins downy beneath; stipulas villous, of many bristles; whorles of Howers dense, l axillary, and 1 terminal, the latter girded by 4 leaves; calyx villous, with 4 equal teeth; anthers exserted. $\odot$. F. Native of Brazil. Spcrmacòce cornifòlia, Fisch. in Nees. hor. berl. p. 50 . Link. enum. hort. berl. 1. p. 132. Cham. et Schlecht. Linnæa. 3. p. 813. Allied to $B$. brachystemonoides, but the fruit is unknown.

Dognood-leaved Borreria. F]. May, Ju. Clt. 1819. Pl. I ft. 32 B.? WYDLERIA'NA (D. C. l. c.) stem herbaceous, ascending, elongated, rather tetragonal, with the angles rather hairy; leaves elliptic-oblong, attenuated at both ends, glabrous above, and downy on the nerves beneath; bristles of the stipulas 7 , shorter than the sheath; whorles of flowers 2-3, axillary, distant, almost immersed in the stipular sheaths, and terminal, pedunculate, larger than the axillary ones; involucrum of 4 spreading leaves.-Native of Porto Rico, where it was collected by Wydler. Flowers while young densely crowded, intermixed with a number of bristles. Very like the following and preceding.

Wydler's Borreria. Pl. ascending.

33 BRACHYsTemonoines (Cham. et Schlecht. in Linnæa. 3. p. 314.) stems suffruticose at the base, erect, tetragonal, scabrous from retrograde hairs; leaves elliptic-lanceolate, acute, scabrous on both surfaces, and on the margins while young, but glabrous above in the adult state; bristles of the stipulas longer than the sheath, which is villons; heads of flowers terminal, girded by 4 leaves; capsule oblong-conical, villous upwards, crowned by the 2 acute teeth of the calyx, and $1-2$ accessory ones. $h . S$. Native of the south of Brazil. Flowers white?

Brachystemon-like Borreria. Shrub 1 to 2 feet.

34. B. capitella'x (Cham. et Schlecht. in Linnæa. 3. p. 319.) stems fistular; leaves petiolate, ovate, lined, acuminated, rather pilose on both surfaces; bristles of the stipulas 5.7 ; whorles of flowers axillary and terminal; capsules oblong, elliptic, hairy at the top, crowned by the teeth of the calyx, which are 3 times shorter than it. - Native of New Granada, near Santa Fe de Bogota. Spermacòce capitellàta, Willd. in Roem. et Schultes, syst. 8. p. 530 . H. B. et Kunth, nov. gen. amer. 3. p. 349. but not of Sprengel. Flowers white.? Said to be allied to $B$. scabiosoides. Involucrum clothed with pili.

Small-headed Borreria. Pl. 1 foot.

y5 B. scabiosoìes (Cham. et Schlecht. in Linnæa. 3. p. 318.) stems fistular, terete, glabrous; leaves lanceolate, acute, on short petioles, with a few oblique veins, and scabrous margins; teeth of the stipulas $3-5$, ending in a bristle each, shorter than sheath; heads of the flowers terminal, hemispherical, involucrated by 2-6 leaves; capsule glabrotis, oblong, crowned by the 2-4 hairy teeth of the calyx.-Native of equinoctial Brazil. The part of the involucrum girding the flowers is pilose both inside and outside.

Scabious-like Borreria. Pl, $\frac{1}{2}$ foot.

36 B. capita'ta (D. C. prod. 4. p. 545.) stems shrubby at the base, prostrate; branches ascending, rather tetragonal, villous; leaves lanceolate, with scabrous margins, smoothish on both surfaces; bristles of the stipulas longer than the sheath; heads of flowers 2 , one axillary, and the other terminal and larger, involucrated by 4 leaves; corolla glabrous, tubular; anthers exserted ; capsule glabrous, turbinate, crowncd by the 4 lanceolate teeth of the calyx. $h$. S. Native of Peru, on the declivities of the mountains. Spermacòce capitàta, Ruiz et Pav. f. per. 1. p. 61. t. 91 . f. b. Branches purplish. Leaves sessile. Flowers white; anthers reddish.

Capitate-flowered Borreria. Shrub I foot.

37 B. A ture'nsis (Cham. et Schlecht. in Linnæa. 3. p. 34.5.) plant shrubby, erect; branchlets tetragonal, roughish; leaves narrow-linear, glabrous, with serrulated margins; stipulas hairy, ciliated with bristles; heads of Howers terminal, rarely lateral; capsule hairy, oblong, crowned by the 4 linear-subulate, ciliated teeth of the calyx. h. S. Native on the banks of the Orinoco, near Atures. Spermacòce Aturénsis, H. B. et Kunth, nov. gen. amer. 3. p. 345 . Flowers white. Allied to B. verticillata. Corolla funnel-shaped, a little longer than the calyx.

Alures Borreria. Shrub 1 to 2 feet.

38 B. ERYNgoìns (Cham. et Schleclit. in Limnæa. 3. p. 316.) glabrous; stems herbaceous, erect, tetragonal, almost simple; leaves linear, acute, with revolute margins; bristles of the stipulas 5 , longer than the sheath; whorles of flowers nearly globose, terminal and axillary; capsule downy, elliptic, crowned 
by the 4 nearly equal teeth of the calyx, and with a small accessory tooth betwcen each of these. 4 . S. Native of the south of Brazil and Buenos Ayres. Heads small. Leaves an inch long, and a line broad. Seed oblong, granular.

\section{Eryngo-like Borreria. Pl. 1 foot.}

39 13. satureiafòla (Cham. et Sclileclıt. in Linuze. 3. p. 313.) stem shrubby, crect, snoothish; branchlets tetragonal; leaves linear-laneeolate, acute, glabrous, with somewhat revolute edges; bristles of the stipulas rather downy, longer than the sheath; whorles of flowers semi-globose, axillary, and terminal, the latter the largest; capsule glabrous, crowned by the 4 elongated calycine teeth, which are furnished with short pili in the recesses. $\zeta$. S. Native of equinoctial Brazil. Said to be allied to $B$. suaveolens, but the flowers are smaller, the involucral leaves are larger, and the stature is smaller, \&c.

Satory-leaved Borreria. Shrub 1 foot.

40 B. suave'olens (Meyer, esseq. p. 81. t. 1.) glabrous; stem shrubby, erect, much branched; branchlets slightly tetra* gonal; leares linear, pungent, opposite, and falsely verticillate ; bristles of the stipulas stiff, rather shorter than the sheath; whorles of flowers globose, a few axillary, and a larger terminal one, which is involucrated by 8 leaves; corolla glabrous, with acuminated lobes; capsule ovate, glabrous, crowned by the 4 teeth of the calyx, and 4 small accessory ones in the recesses between the others. h. S. Native of Dutch Guiana, in shady places, at Arrowabichkreck. Bigelòwia suavèolens, Spreng. syst. 1. p. 404. exclusive of the variety from Porto Rico, and probably that from Brazil. Corolla funnelshaped, ex Meyer. Stamens exserted.

Sweet-scented Borreria. Shrub 1 to 2 feet.

41 siveritis (Cham, et Schlecht. in Linnæa. 3. p. 201.) plant scabrous from hairs; stem tetragonal, having the angles a little winged; leaves ovate-oblong, sessile, marked by 4 nerves on both sides; bristles of the stipulas shorter than the sheath, which is pilose; whorles of flowers axillary, at length globose; lobes of the corolla bearded outside; capsule pilose, ovate, crowned by the 4 teeth of the ealyx. 24. S. Native of equinoctial Brazil. Plant probably procumbent.

Sideritis-like Borreria. Pl, procumbent.

42 B. sea'NDENS (D. C. prod. 4. p. 546 .) stem shrubby at the base, ascending, weak, rather scandent, branched; branches tetragonal, striated, rather scabrous along the angles; leaves ovate, glabrous, tapering into the petioles a little; bristles of the stipulas few, shorter than the sheath; heads of flowers small, terminal, girded by 4 leaves; capsule oval, glabrous, crowned by the 4 teeth of the calyx. 24. S. Native of Guadaloupe, where it was collected by Bertero. Diòdia sarmentòsa, from Guadaloupe, Spreng. syst. 1. p. 405. Spermacòce scándens, Gmel. syst. 235.-S Sloan. jam. hist. 1. t. 28. f. 4. A. It differs from Diòdia sarmentosa, in the leaves being glabrous and more ovate, in the heads being terminal, and in the fruit being dehiscent.

Climbing Borreria. Shrub cl.

43 B. AfFinis (D. C. prod. 4. p. 516.) stems herbaceous, tetragonal, having the angles scabrous from pili; leaves oblonglanceolate, acuminated, tapering to the base, scabrous from seattered pili above, and more so along the veins beneath; bristles of the stipulas yellow, $7-9$, longer than the sheath; whorles of flowers sessile, axillary, and terminal, the latter involuerated by $2-4$ leaves; capsule oval, glabrous, crowned by the 4 subulate teeth of the calyx, and 4 smaller subulate accessory ones in the recesses between the others.-Native of Brazil, where it was colleeted by Pohl. Spermacòce affinis, Pohl, in litt.

Allied Borreria. P1. 1 foot.

44 B. MicrophýlLa (D. C. prod. 4. p. 456.) glabrous ; stems herbaceous, ascending, tetragonal; leaves lanceolate-linear, acute; bristles of the stipulas $7-9$, longer than the sheath; whorles $10-$ 12-flowered in nearly all the axils, and at the tops of the stem and branches, all equal in size, the latter girded by 4-6 leaves ; capsule oval, downy, crowned by the 4 subulate teeth of the calyx.-Native of Brazil, where it was collected by Pohl. Spermacòce microphýlla, Pohl, in litt. Leaves 7-8 inches long, and $1 \frac{1}{2}$ to 2 broad.

Small-leaved Borreria. Pl. ascending.

45 B. rubro-stipula'ta (D. C. I. c.) stem herbaceous, straight, almost simple, tetraigonal, having the angles beset with retrograde villi; leaves oblong-linear, acute at both ends, opposite, or falsely verticillate; bristles of the stipulas $7-9$, stiffisl, coloured, glabrous, longer than the sheath, which is downy; whorles of flowers eapitate, 3-4 axillary, and one terminal, the latter the largest, and girded by 4 leaves; teeth of the calyx 4 ; anthers exserted. $\odot$. S. Native of Brazil, where it was collected by Pohl. Spermacòce rubro-stipulata, and Sperm. fasciculàta, Pohl, in litt. Spermacòce Brasiliénsis, Spreng. syst. 1. p. 402 . Fruit unknown.

\section{Red-stipuled Borreria. Pl. $\frac{1}{2}$ to 1 foot.}

46 B. ELONGA'TA (D. C. prod. 4. p. 547.) stem herbaceous, branched; branches elongated, hairy, terete; leaves oblonglanceolate, acuminated, downy on both surfaces; bristles of the stipulas longer than the sheath, which is villons; whorles of flowers capitate, 1-2 axillary, and a nearly globose terminal one, which is involucrated by 5-6 leaves; teeth of the calyx 4, acute, short.-Native of Brazil, where it was collected by Pohl. Spermacòce verticillàta, Pohl, in litt. Branches a foot high. Leaves usually in fascicles in the axils. Fruit unknown, and therefore the plant is referred to Borrèria from habit only.

\section{Elongated-branched Borreria. Pl. 1 to 2 feet.}

47 B. FERRuginea (D. C. prod. 4. p. 547.) stem herbaceous, hard, ereet, branched; branches tetragonal, hairy; leaves oblong, acute, obliquely 3-4-nerved, scabrous above, and pale beneath and seabrous on the nerves from hairs; bristles of the stipulas the length of the sheath; whorles of flowers globose, terminal, and axillary; capsule downy, crowned by the 4 subulate teeth of the calyx. $h$. S. Native of Brazil, in elevated pastures in the provinces of Minas Geraes and St. Paul. Spermacòce furrugínea, St. Hil. pl. usuel. bras. no. 13. t. 13. Spermaeòce globòsa, Pohl, in litt. The hairs on the branches and nerves of the leaves are rust coloured. Corollas rose-coloured, violaceous, or white, with the lobes pilose at the apex. Heads of flowers one half Jarger than those of $B$. verticillàta, which it is very like. The plant is ealled Paaya and Poaya do praya at Cape Frio. The roots are of a brown colour, and are used as Ipccacuanha.

Rusty Borreria. Pl. 1 to 2 feet.

48 B. spile'rica (D. C. l. c.) stem suffruticose at the base? branched, tercte, glabrous; leaves oblong-linear, acute, scabrous above, pale and villous beneath; bristles of the stipulas longer than the sheath, which is villous; heads of flowers globose, terminal, and axillary; capsule oblong, glabrous, crowned by the 4 subulate eiliated teeth of the calyx. $\{$. S. Native of Cayenne. Very like $B$. ferruginea, but differs from it in the branches being smoothish, in the leaves being less nerved, in the involucral leaves being 4, larger and reflexed, and in the capsules being twice the length.

Spherical-headed Borreria. Shrub 1 to 2 feet.

49 B. Lute'scens (D. C. prod. 4. p. 547.) stem terete, simple, clothed with dense soft hairs, but with retrograde down at the apex ; leaves sessile, lanceolate, acuminated, villous on both surfaces, furnished with 4 oblique nerves on each side; bristles of the stipulas stiffish, rufous, much longer than the sheath, which is alnost obsolete; whorles of flowers dense, sessile, 
1-2 axillary, and a terminal globose one, which is involucrated lyy reflexed bracteas; capsule oblong, villous at the apex, crowned by the 4 subulate, glabrous teeth of the calyx.Native of Brazil, where it was collected by Pohl. Spermacoce lutéscens, Pohl, in litt. Allied to B. ferruginea.

\section{Luteseent Borreria. Pl. 1 foot.}

50 B. HÆNKea'va (D. C. l. c.) stem erect, sub-herbaceous, straight, branched, tetragonal, with the angles hairy at the apex; leares linear, acute, rather scabrous, with rather revolute edges; bristles of the stipulas longer than the sheath; heads of flowers globose, terminal, girded by 4 -leaved reflexed involucra; capsule obovate, roughish, crowned by the 4 lanceolate teeth of the calyx.-Native of Mexico and Peru. Bigelòwia psyllioìdes, Bartl. in herb. Hænke. Spermacòce tenùior, Pav. ined. but not of Lin. It differs from B. psyllioides in the involucrum being reflexed, in the lieads being one half larger, in the limb of the calyx being divided into 4 lobes to the base, not to the middle.

\section{Hanke's Borreria. Pl. 1 foot.}

51 B. structíssima (D. C. J. c.) stem and branches straight, tetragonal, clothed with powdery down under the nodi; leaves linear, acute, glabrous, almost veinless, opposite, and in axillary fascicles; bristles of the stipulas $5-7$, stiff, longer than the sheath; whorles of flowers capitate, sessile, 1-\% of which are axillary, and a larger terminal globose one, which is girded by 2-4 leaves; capsule oblong, glabrous, crowned by the 4 shost subulate teeth of the calyx. - Native of Brazil, where it was collected by Polıl. Spermacòce strictíssima, Polıl, in litt. Allied to $B$. suarèlens, but differs from that species in the calyx being without accessory teetl. Corolla unknown.

Very straight Borreria. Pl. 1 to 2 feet.

52 B. Tenélla (Clam. et Schlecht. in Linnæa. 3. p. 317.) stem suffruticose at the base, erect, searly terete, clothed with retrograde adpressed villi; leaves oblong-linear, acuminated, clothed with small down above, and scabrous on the nerves and margins, having a few oblique nerves on both sides; bristles of the stipulas longer than the slieath, which is downy; heads of flowers globose, terminal, surrounded by 4 . reflexed leaves; capsules oblong, hairy at top, crowned by the hairy 4-tootlied calyx. $h_{2}$. S. Native of equinoctial Brazil.

lar. $\beta$, angustifòlia (D. C. prod. 4. p. 547.) plant weak; leaves narrow-linear; heads size of peas; floral leaves spreading. $\zeta$. S. Native of Brazil, where it was collected by Polll; and along the banks of the Orinoco, by Humboldt and Bonpland. Spermacòce longisèta, Pohl, in litt. Spermacòce tenélla, H. B. et Kunth, nov. gen. amer. 3. p. 345. Sperm. capitàta, Willd. herb. Sperm. Orinocénsis, Willd. in Roem. et Schultes, syst. 3. p. 531 .

I'ar. $\gamma$, lavandulafolia (D. C. prod. 4. p. 548.) stem at first clothed with fine velvety down, but at length becoming glabrous; leaves linear, with rather revolute margins; bristles of the stipulas very long; heads of the flowers hemispherical, depressec, involucrated by 4 spreading leaves. 5 . S. Native of Brazil, where it was collected by Polıl. Spermacòce lavandulafolia, Poll, in litt.

\section{Heak Borreria. Shrub $\frac{1}{2}$ to 1 foot.}

53 Linoìnes (D. C. prod. 4. p. 458.) quite glabrous; stem suffruticose at the base, erect; branches tetragonal; leaves linear, acutish, with revolute edges; stipulas ending in 1-3 stif;, setaceous points; axillary lieads few, or wanting, and 1 terminal and sub-glolose, the latter involucrated by $2-4$ reflexed floral leaves; corolla glabrous; capsule oval, glabrous, crowned by the 4 short teeth of the calyx. $\zeta$. S. Native of Brazil, where it was collected by Polıl. Spermacòce linoides, Pohl, in litt. Anthers exserted.

Flax-like Borreria. Shrub 1 foot.
54 B. ? Psyluioìes (H. B. et Kunth, nov. gen. amer. 3. p. 346. t. 278. under Spermacòce) stem suffruticose, erect, tetragonal, branched, scabrons from retrograde bristles; leaves linearlanceolate, hairy on both surfaces, with serrulately scabrous edges; bristles of stipulas longer than the sheath; heads of flowers terminal, involucrated by $6-8$ radiant floral leaves; calyx funnel-shaped, 4-cleft to the middle. h. S. Native of Mexico, near Ario. Fruit unknown, but from liabit it is evidently a species of Borrèria. V'ery nearly allied to $B$. strictissima and $B$. Hankeana. It differs from all the rest of the species in the caly $\mathrm{x}$ being divided to the middle.

Fleawort-lilic Borreria. Shrub 1 to 2 feet.

55 B. Flavéscens (D. C. prod. 4. p. 548.) plant diffise, quite glabrous, suffruticose at the base ; branchlets tetragonal; leaves oblong, acute, attenuated at the base; bristles of stipulas 3-5, longer than the sheath; axillary whorles of flowers few, and one terminal and larger than the axillary ones, the latter involucrated by $2-4$ floral leaves; capsule oval, crowned by the lanceolate teeth of the calyx. দ.S. Native of Brazil, where it was collected by Pohl. Spermacòce flavéscens, Pohl, in litt. The whole herb is yellowish. The nuts of the inmature fruit appear almost indeliscent; it is, therefore, perhaps a species of Diòdia, with the habit of Borrèria.

Jellowish Borreria. Slirub diffuse.

56 B. sca'BRIDA (D. C. l. c.) stem erect, tetragonal, scabrous on the angles; leaves lanceolate, acute, with 4 oblique nerves on both sides, scabrous above, and pilose on the nerves beneath; bristles of stipulas 5 , stiflish, longer than the sheath; whorles of flowers capitate, sessile, terminal, and axillary, approximate; corolla glabrous; capsule oblong, glabrous, crowned by the 4 subulate teeth of the calyx.-Native of Brazil, where it was collected by Pohl. Spermacòce scábrida, Pohl, in litt. Corollas one half smaller than in $B$. asclepiàdea.

Seabrous Borreria. Pl. 1 to 2 feet.?

57 B. Ascreria'dea (Chan, et Schlecht. in Linnæa. 3. p. 320. under Bigelowia) plant smoothish, suffruticose at the base; stems erect, tetragonal, glabrous, but downy at the apex, having the angles winged; leaves lanceolate, acute, glabrous, obliquely 4 nerved on both sides; bristles of stipulas 3 , Jonger than the sheath, the middle one the longest; whorles of flowers loosely capitate, terminal, and axillary; lobes of corolla lanceolate, bearded a little; capsule elliptic, crowned by the 4. elongated, acuminated teeth of the calyx. $h_{2}$. S. Native of the south of Brazil Stipulas 2 , revolute.

Var. 3 , glabérrima (D. C. prod. 4. p. 548.) stems and corollas glabrous; stipulas furnished with one bristle each. $\zeta_{\imath} . \mathrm{S}$. Native of equinoctial Brazil.

Asclepias-like Borreria. Shrub 1 to 2 feet.

58 B. Perrotte'til (D. C. l. c.) sten herbaceons, tetragonal, with rather rough angles; leaves oblong-lanceolate, acuminated at both ends, scabrous above, and downy beneath, obliquely nerved; bristles of stipulas 9, hispid, longer than the sheath; flowers axillary, verticillate, sessile; capsule oblong, compressed, crowned by the 4 lanceolate acute connivent teeth of the calyx. -Native of French Guiana, where it was collected by Perrottet. Perhaps Sperm. áspera, Aubl. guian. 1. p. 59. t. 22. f. 6. not of Vahl, but in the present plant the branches are nearly glabrous.

Perrottet's Borreria. Pl. 1 foot.?

59 B. Nervòsa (Pohl, in litt. under Chlorophýtum, ex D. C. prod. 4. p. 548.) the whole plant clothed with scabrous pubescence; stems erect, tetragonal, striated; leares lanceolate, or oval-lanceolate, acute, obliquely 4-5-nerved on both sides; stipulas cleft into 3-5 linear, acute ligule; whorles of flowers axillary and terminal, sessile; lobes of calyx 3-4, longer than the ovarium, lanceolate, acuminated, scabrous, a little toothed at 
the apex. 24. S. Native of Brazil, where it was collected by Polıl. Perliaps the same as Spermacòce Poàya, var. pubéscens, St. Hil. Sc.

\section{Nereed-leaved Borreria. Pl. I foot.}

60 B. praténsis (Pohl. in litt. under Chlorophỳtum, ex D. C. prod. 4. p. 548.) quite glabrous; stem tetragonal, erect, almost simple, with the angles a little winged; leaves sessile, oblong, acute, with 6-7 prominent veins on eacl side; stipulas triangular, 3-4-toothed at the apes: teeth acute, middle one the largest; heads of flowers axillary and terminal: lower ones on short peduncles, the rest sessile; lobes of calyx 4, lanceolate-linear; lobes of corolla smoothish; stamens exserted. \%.S. Native of Brazil, where it was collected by Pohl. Corolla very like that of $B$. Poàya when dry. Perluaps the same as Spermacòce gentianoides, St. Hil. pl. us. bras. no. 12. in a note.

Mcadow Borreria. Pl. 1 foot.

61 B. PoA'y (D. C. prod. 4. p. 549.) quite glabrous; stem herbaceous, simple, tetragonal; leaves sessile, oblong-elliptic, acute, obliquely 6-nerved on both sides of the mid-rib; stipulas cleft into many long bristles; whorles of flowers capitate, sessile, few axillary, and a larger terminal one; lobes of caly $x$, lanceolate-linear, acute, longer than the ovarium; corolla smoothish ; anthers exserted. $\%$. S. Native of Brazil, in elevated pastures, in the mine provinces frequent. Spermacòce Poàya, var. a, St. Hil. pl. us. bras. no. 12. t. 12. Corolla blue, with the lobes rather hairy above. The roots are white, and are substituted with success in place of Ipccacuanha. The leaves are at first sweet, but afterwards acid, and a decoction of them is used in the cure of cholic.

Poaya Borreria. Pl. $\frac{1}{2}$ to 1 foot.

62 B. Platriny'Lea (D. C. prod. 4. p. 549.) the whole plant is scabrous from stiff hairs; stem herbaceous, erect, simple, tetragonal, having the angles a little winged; leaves lanceolate, acute, attenuated at the base, obliquely 4-5-nerved on both sides; stipulas ending in $5-7$ very long scabrous bristles; whorles of flowers sessile, capitate, many axillary, and one terminal, which is hardly larger than the rest; lobes of calyx 4 , lanceolate-linear, subulate, scabrous, longer than the ovarium. 4. S. Native of Brazil, where it was collected by Pohl. Spermacòce latifòlia, Pohl, in litt. but not of Aubl. Bristles of stipulas 6 lines long. Very nearly allied to $B$. Poòya, but differs in being hispid. Corolla unknown.

Broad-leaced Borreria. PI. $\frac{1}{2}$ to 1 foot.

63 B.? gYMNoce'PliALA (D. C. prod. 4. p. 549.) stem branclied, tetragonal, striated, furrowed, and glabrous between the angles: and the angles are winged a little, and rough from being serrulated; leaves ovate, acute, attenuated at the base, glabrous, obliquely nerved; bristles of stipulas 7-9, Jonger than the sheath ; whorles of flowers nearly globose, many axillary, and one terminal, which is naked from the abortion of the floral leaves; teeth of calyx 2-3, conically subulate.-Native of Brazil. This plant is probably generically distinct from Borrèria. Stem tetragonal and smootl between the heads. Corollas small. Anthers inclosed.

Naked-headed Borreria. Pl. 1 foot.?

64 B. cyuòsa (Cham. et Schlecht. in Linnæa. 3. p. 323.) shrubby, glabrous; branches flexuous, tetragonal; leaves elliptic-lanceolate, acuminated, coriaceous, on short petioles; stipulas interpetiolar, connate, drawn out on both sides into 5 linear segments, the middle segment the longest; heads of flowers 3 at the top of each stem, and the lateral ones pedunculated and almost leafless; capsule smoothish, crowned by the 4 lanceolate-linear teeth of the calyx. $\zeta$. S. Native of Brazil, in the province of Rio Janeiro. Spermacòce cymòsa, Spreng. syst. 1. p. 403. Leaves 3 inches long, and one broal. Corollas hairy outside. Inflorescence rather panicled.

VOL. IHE.

\section{Cymose-headed Borreria. Shrub 2 to 3 feet.}

\section{\$2. Floners solitary, or in axillury fascicles.}

65 B. virga'ta (Cham. et Schlecht, in Linnaa. 3. p. 324.) branches fistular, tetragonal, with downy angles; leaves lanceolate, tapering to both ends, glabrous on the margins, and scabrous at the nerves beneath; upper stipulas undivided, the rest downy, and furnished with 5-9 bristles; flowers glomerate in every other axil ; capsules downy, elliptic, crowned by the irregularly 2-6-toothed calyx. 24.S. Native of Brazil, about liio Janeiro.

Troiggy Borreria. Pl. $1 \frac{1}{2}$ foot.

66 B. saponariefòlia (Cham. et Schlecht. in Linnæa. 3. p. 325.) glabrous; stem prostrate, tetragonal, fistular, branched : leaves sessile, acuminated, with scabrous margins; lower ones obovate, upper ones lanceolate: bristles of stipulas 1-3, hairy, the middle one the largest ; flowers solitary in every axil; capsule glabrous, oblong-elliptic, crowned by the 2 primary and the 2 accessory teeth of the calyx.-Native of Brazil.

Soap-nort-leaeed Borreria. 1'l. prostrate.

67 B. A'ridA (D. C. prod. 4. p. 549.) stems simple, erectish, tetragonal, downy, glabrous at the apex; leaves linear, acute, scabrous on the nerve beneath at the apex, with revolute serrately scabrous edges; bristles of stipulas $5-7$, stiflish, longer than the sheatlı; flowers 2-3 together, axillary, sessile; capsule oval-oblong, rather downy, crowned by the 2 subulate teeth of the calyx. - Native of Porto Rico, in arid places by the sea side, where it was collected by Bertero. Bigelòwia suavèolens, from Porto Rico, Spreng. syst. 1.p. 416. but is very distinct from the true $B$. suacèolens.

\section{Arid Borreria. Pl. 1 foot.}

$\$ 3$. Flowers disposed in cymes, or corymbose-cymes. Floral leaves small. Corollas campanulately funnel-shaped. Sceds marked by a crest inside, probably in all. Perhaps a proper gcnus.

68 B. entcoìns (Cham. et Schlecht. in Linnæa. 3. p. 326.) shrubby, erect, glabrous ; branchlets tetragonal ; leaves linear, bluntisl, l-nerved, opposite, or in whorled fascicles: bristles of stipulas 3-5, shorter than the sheath; cymes terminal, 3-4forked; floral leaves small; capsule cylindrically turbinate, crowned by the 4 elliptic teetls of the calyx. 2.S. Native of equinoctial Brazil. Corolla short, funnel-shaped, glabrous outside, and villous in the throat. Habit of a heatl.

Heath-like Borreria. Shrub $\frac{1}{2}$ to 1 foot.

69 B. Anthosfermoides (D. C. prod. 4. p. 550 .) glabrous ; branches twiggy, tetragonal; leaves linear, acutish, nerveless; bristles of stipulas many, stiff, longer than the sheath; corymbs small, terminal, crowded; lobes of calyx 4, narrow, acute. $h$. S. Native of South America, near Santa Fe de Bogota. Habit of $B$. stipulata, with the inflorescence of $B$. ericoidcs. Mature fruit unknown.

Anthospermum-like Borreria. Pl. 1 foot.

70 B. Eupatorioìdes (Cham. et Schlecht. in Linnæa. 3. p. 327.) shrubby, downy; branches bluntly tetragonal; leaves ovate-oblong, acute, lined; bristles of stipulas equal in length to the sheath; cymes terminal, compact, trichotomous; floral leaves small; capsule oblong, downy, crowned by the 4 ovate teeth of the calyx. $\quad$. S. Native of Equinoctial Brazil. Corolla campanulately funnel-sliaped, downy outside.

Eupatorium-like Borreria. Shrub 1 foot.

71 B. centranthoides (Cham. et Schlecht. in Linnæa. 3. p. 328.) plant lierbaceous, smoothish; stem ascending, fistular, bluntly tetragonal; leaves elliptic-lanceolate, attenuated at both ends, rather scabrous; bristles of stipulas $5-7$, hardly longer than the sheath; cymes terminal, fastigiate, pedunculate; Horal leaves small; capsule hairy, obconically cylindrical, crowned by

$$
4 \mathrm{~K}
$$


the 4 ovate teeth of the calyx. 4 . S. Native of the south of Brazil.

I ar. $\beta$, angustifolia (Cham. et Schlecht. 1. c.) the whole plant canescent from hairs; leaves oblong-lanceolate, much more nerved than those of the species. 4. S. Native of the south of Brazil.

Centranthus-like Borreria. Pl. 1 to 2 feet.

i2 B. Pohlia'na (D. C. prod. 4. p. 550.) branches hairy, compressed; leaves lanceolate, acuminated, lined, downy above, and rather hairy on the nerves beneath; bristles of stipulas length of sheath, which is villous; corymbs trichotomous, terminal, crowded; tube of calyx canescent from loairs; lobes of calyx 4, lanceolate; corolla hairy inside.-Native of Brazil, where it was collected by Pohl. Hydrophylax pusillum, Pohl, in litt. Fruit unknown, but the plant has a habit very different from Hydrophylax, and appears to be nearly allied to $B$. eupatorioides and $B$. centranthoides.

Pohl's Borreria. Pl. 1 foot.

73 B. ANgustifòla (Cham. et Schlecht. in Linnaea. 3. p. 330.) plant herbaceous, erect, glabrous; stem tetragonal; leaves lanceolate-linear, with revolute edges, having $2-3$ veins on each side of the mid-rib; bristles of stipulas twice the length of the sheath, which is downy; cymes trichotomous, contracted; floral leaves small ; capsule oblong-cylindrical, glabrous, crowned by the 4 lanceolate teeth of the calyx. 4. S. Native of Equinoctial Brazil. Corolla short, glabrous outside.

Narrow-leaved Borreria. Shrub 1 foot.

74. B. coryмвòsa (Bartl. in herb. Hænke, under Bigelòwia, ex D. C. prod. 4. p. 550.) glabrous; stem suffruticose, terete, erect; leaves lanceolate, acuminated, lined with veins, which are smooth, as well as the margins; bristles of stipulas longer than the sheath; corymbs terminal, trichotomous ; capsule obovateoblong, glabrons, crowned by the 4 lanceolate teeth of the calyx. h.S. Native of Peru, on the mountains. Spermacòce corymbòsa, Ruiz et Pav. f. per. 1. p. 60. t. 91. f. a. but not of Lin. Spermacòce Peruviàna, Pers, ench. 1. p. 124. Hedyòtis Spermacòcea, Domb. herb. The leaves of the figure in $\mathrm{H}$. per, are one half broader than those of the specimens collected by Paron and Hanke.

Corynbose-flowered Borreria. Shrub 1 to \& feet.

75 B. verbenoides (Cham. et Schlecht. in Linnæa. 4. p. 550 .) plant herbaceous, erect, smoothish; stem tetragonal at bottom; leaves narrow-lanceolate, very acute, scabrous on the margins above; bristles of stipulas longer than the sheath; cymes terminal, di-trichotomous, with a lateral flower; floral leaves small; capsule alinost cylindrical, glabrous, crowned by the 4 . lanceolate teeth of the calyx. 4 . S. Native of the south of Brazil. Herb very variable in habit, sometimes glabrous, and sometimes downy. Leaves linear, or lanceolate; lower ones usually ovate, petiolate. Corolla short, tubular, clothed with pruinose down outside.

\section{Vervain-like Borreria. Pl. 4 feet.}

76 B. Valerianoides (Cham. et Schlecht, in Linnæa. 3. p. 335.) plant lierbaceous, erect; stem tetragonal, fistular, glabrous at the base, but scabrous from retrograde bristles at the apex; leaves lanceolate, acute: lower ones somewhat spatulate, with the nerves all scabrous from hairs: bristles of stipulas longer than the sheath, which is rather scabrous; cymes terminal, large, trichotomous: floral leaves small; capsule nearly cylintrical, roughish, crowned by the 4 narrow-linear teeth of the calyx. 24. S. Native of Equinoctial Brazil. Corolla glabrous; Jobes acute, bearded with stiff hairs at the apex.

Valerian-like Borreria. Pl. 3 to 4 feet.

77 B. LA'Xa (Cham. et Schlecht. 1. c. p. 337.) plant herbaceous, erect; stem fistular, tetragonal, with opposite, spreading branches; leaves lanceolate, attenuated at both the ends, loose, membranous, with scabrous edges ; bristles of stipulas glabrous, length of the sheath, which is downy; cymes terminal, somewhat trichotomous; floral leaves small; capsule elliptic, rather truncate, crowned by the 4 narrow, acute teeth of the calyx. 4. S. Native of the south of Brazil.

Loose-leaved Borreria. Pl. 2 feet.

78 B.? EQuisetoides (Cham. et Schlecht. 1. c. p. 338.) glabrous; root woody; stems berbaceous, erect, contracted at the nodi, bluntly tetragonal? leaves narrow-linear, straight, almost filiform, with revolute, scabrous edges; stipulas fuscescent, ciliated with bristles; cymes terminal and axillary, crowded. 24.S. Native of the south of Brazil. Habit of the plant elegant ; but the fruit being unknown, it is very doubtful whether it belongs to the present genus.

\section{Horse-tail-like Borreria. Pl. 3 feet.}

\section{$\S 4$. Flowers umbellate; umbels cymose or capitate.}

79 B. undelda'ta (Spreng. neu, entd. 2. p. 144.) stem herbaceous, branched, somewhat tetragonal, shining; leaves lanceolate, tapering to both ends, glabrous; stipulas setose, connate at the base ; umbels pedunculate, semi-globose, axillary, and terminal ; capsule obconical, downy, crowned by the 4 acute teeth of the calyx. 4. S. Native of Brazil, within the tropic. Cham. et Schlecht, in Linnæea. 3. p. 338. Bigelòwia umbellàta, Spreng. syst. 1. p. 405. Corolla small, white. Herb clothed with very fine down while young.

Umbellate-flowered Borreria. Pl.

80 B.? aralioìes (Cham, et Schlecht, in Linnaa, 3. p. 339.) glabrous ; stem herbaceous, erect, fistular, tetragonal, branched at the top; leaves lanceolate, acuminated, on short petioles, rather coriaceous; bristles of stipulas few, shorter than the sheath; cynes umbellate, terminal, downy, with tetragonal branchlets; calyx glabrous, acutely 4-toothed; anthers exserted.-Native of Equinoctial Brazil. Allied to $B$. umbellàta, but is twice the size in all its parts. Fruit unknown, therefore the genus is doubtful.

\section{Aralia-like Borreria. Pl. 2 feet.}

\section{+ Species not sufficiently knon'n.}

8I B. Adsce'NDENS (Cham. et Schlecht. in Linnæa. 3. p. 340.) glabrous; stems ascending; leaves linear-lanceolate, acute; stipulas toothed : teeth bristly.-Native of Madagascar. Spermacòce adscéndens, Willd. in Rœem. et Schultes, syst. 3. p. 523.

Ascending Borreria. Pl. ascending.

82 B. vagina'ta (Cham. et Schlecht. l. c. p. 340.) stem suffruticose, and is as well as the branches, terete and glabrous ; leaves lanceolate: stipulas connate; lower ones sheathed: fruit hispid.-Native of St. Domingo. Spermacòce vaginàta, Willd. in Rom. et Schultes, syst. 3. p. 531. Bigelòtwia vaginàta, Spreng. syst. 1. p. 405 .

Sheathed Borreria, Shrub 1 foot. ?

83 B. LINifòlia (D. C. prod. 4. p. 551.) stem herbaceous, tetragonal, rather villous on the angles; leaves linear-lanceolate, acute, on short petioles, villous, with scabrous margins ; bristles of stipulas rather shorter than the flowers: whorles of flowers axillary and terminal; the latter globose, and girded by 4 leaves: anthers exserted; calyxes clothed with cinereous villi. --Native of Cayenne. Spermacòce linifòlia, Vahl, ecl. 1. p. 8. but not of Nees. Bigelòwia linifòlia, Spreng. syst. 1. p. 404. Fruit unknown. Anthers blue.

Flax-lcatcd Borreria. Pl. 1 foot.

Cult. The species of Borrèria are of most easy culture. A light soil suits them best; and cuttings of the perennial and shrubby kinds strike root readily in the same kind of soil, in heat. The annual kinds require the treatment of other tender anuuals. 
CLXXXVI. SPERMACOCE (from $\sigma \pi \varepsilon \rho \mu a$, sperma, a

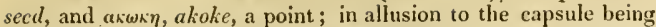
crowned by the calycine points). Meyer, $\mathrm{fl}$. esseq. p. 79. Cham. et Schlecht, in Linnæa. 3. p. 355 . D. C. prod. 4. p. 552.Spermacòce species, Lin. Lam. Spreng. \&c.-Spermacòce, Covèlia, and Chenocárpus, Neck. elem. no. 336, 337 ? and $\$ 39$.

Lin. sist. Tetrándria, Monogýnia. Calyx with an ovate or turbinate tube, and a 2-4-lobed limb (f. 108. a. b.), and sometimes accessory teeth in the recesses of the primary lobes. Corolla salver-shaped, or funnel-shaped, 4-lobed (f. 108. c.). Stigma bifid or undivided. Capsule crowned by the limb of the calyx (f. 108. $f$ ), which is often obliterated, 2-celled; nuts 1 -seeded, dividing into 2 parts from the apex : the one part closed by the adnate dissepiment, and the other open. Seed oval-oblong, marked inside by a longitudinal furrow.-Herbs or subshrubs. Branches or stems usually tetragonal. Leaves opposite. Stipulas combined with the petioles, sheathing, fringed by numerous bristles. Flowers axillary, sessile, crowded, verticillate, or semi-verticillate, white, red, or blue.-The fruit of this genus is drawn witl great character in Gærtn. fruct. 1. t. 25.The fruit of a great number of the plants still preserved in this genus being unknown, many of them will yet be expelled, when proper specimens can be procured.

\section{Spccies natives of America.}

1 S. TENu'Ior (Lin. spec. p. 147.) stems herbaceous, branched; branches tetragonal, with the angles smooth or scabrous; leaves lanceolate, on very short petioles, rather scabrous above and on the margins; bristles of stipulas hardly longer than the sheath; flowers disposed in sessile axillary fascicles, semi-verticillate; stamens inclosed; capsule oval, usually hairy, crowned hy the 4 short, acute calycine teeth. $\odot$. F. Native of the West India Islands, as of Jamaica, Martinico, Porto-Rico, Cuba, St. Domingo, \&c., as well as of Peru, Panama, Carolina, very frequent. S. lanceolàta and S. dichótoma, Willd. in herb. S. parvifiora, Salisb. prod. p. 60.-Dill. elth. p. 370 . t. 359. Lain. ill. t. 62. f. 1. There are varieties of this species (ex Swartz, obs. p. 43.) with smooth, pubescent, and straight or ascending stems; narrow and broader leaves; whorled or solitary flowers; smooth or hispid fruit, having one of the parts or nuts bearing 3 of the calycine teeth, and the other bearing only one. The varieties are so numerous, and run so gradually into each other, as hardly to be distinguished, many specimens of which are to be found in herbaria, under various names, from their different habits ; as $P$. assírgens, Spreng. syst. 1. p. 402. a native of Porto-Rico, but not of the $\mathrm{Al}$. per.; and Sperm. longifolia, Bartl. in herb. Hanke, Sc. Some specimens are suffruticose at the base, and others are herbaceons. Perhaps the whole form a congeries of species, of which some may be ultimately distinguished from each other. The flowers in most of the varieties are of a white or pink colour, and one is said to have yellow flowers.

Slender Spermacoce. Fl. June, Aug. Clt. 1792. Pl. 1 to $3 \mathrm{ft}$. 2 S. Portorice'ssis (Balb. in herb. Bert. ex D. C. prod. 4. p. 552.) stem herbaceous, glabrous, tetragonal; leaves ellipticoblong, acuminated at both ends, on very short petioles, glabrous; stipulas rather downy, having the bristles longer than the sheath ; flowers axillary, sessile, crowded, semi-verticillate; fruit oval, rather downy, somewhat truncate at the apex.Native of Porto-Rico, where it was collected by Bcrtero. Perhaps sufficiently distinct from $S$. tenùior.

Porto-Rico Button-weed. P]. 1 to 2 feet.

3 S. Loxifíòla (Aubl. guian. 1. p. 59. t. 21.) stem herbaceous, glabrous, dichotomous, and are, as well as the branches, acutely tetragonal; leaves oval-oblong, tapering to both ends, on short petioles, scabrous above between the nerves and on the margins, and pilose on the nerves beneath; stipulas downy, bearing each 5-7 bristles, and short hairs between these bristles; whorles axillary, few-flowered; fruit ovate, downy, crowned by the 4 short teeth of the calyx. $h . S$. Native of French Guiana. S. fruticosa, Poir. Flowers white. Stems reddish.

Long-lcaved Button-weed. Shrub.

4 S. c.eru'lea (Pohl, in litt. ex D. C. prod. 4. p. 552.) stem herbaceous, almost tetragonal, downy; leaves elliptic-oblong, acute, petiolate, glabrous, downy on the nerves beneath; stipulas downy, bearing $5-7$ bristles, which are a little longer than the sheath; flowers axillary, sessile, crowded, semi-verticillate; fruit oval, downy, truncate at the apex.-Native of Brazil, where it was collected by Pohl. Flowers blue. Very nearly allied to $S$. tenuior, but is very distinct.

Blue-flowered Button-weed. Pl. ] to 2 feet?

5 S. RIPA'RIA (Cham. et Schlecht. in Linnæa. 3. p. 355.) quite glabrous; stems loose, fistular, tetragonal, suftrutescent at the base; leaves lanceolate, acute, with scabrous margins; bristles of stipulas 5, longer than the sheath; flowers terminal in the upper axils, disposed in whorled heads; stamens almost inclosed; capsule ovate, glabrous; teeth of calyx 6-7, acute, at length obliterated. $2 /$. S. Native of Brazil, on the banks of the Rio Negro.

River-side Button-weed. Pl. 1 foot.

6 S. HeBecárPA (D. C. prod. 4. p. 553.) stem herbaccous, tetragonal, nearly naked, downy; the rest of the plant smoothish: leaves ovate, acute, tapering to the base, glabrous above, but downy on the nerves beneath while young; bristles of stipulas many, rather shorter than the sheath, which is downy: heads of flowers verticillate, 1-2 axillary, and one terminal; the latter girded by 4 very unequal leaves: fruit downy, truncate at the apex.- Native of South America, about Caraccas, where it was collected by Vargas. Both the nuts of the fruit being dehiscent, it is therefore rather an ambiguous spccies.

I ar. $\beta$, angústior (D. C. prod, 4. p. 553.) leaves lanceolate, and are, as well as the stems, glabrous.-Native of St. Domingo, where it was collected by Bertero.

Don'ny-fruitcd Button-weed. PI. 1 foot?

7 S. DIFFu's A (H. B. et Kunth, nov, gen. amer. 3. p. 343.) stems suffruticose, procumbent, terete, hairy; leaves lanceolate, scabrous from retrograde hairs on both surfaces, with the margins serrately scabrous; stipulas hairy, ciliated with bristles : whorles of flowers axillary, sessile, and one larger terminal; the latter girded by 4 leaves : capsule smoothish, globose, crowded by the 4 teeth of the calyx, 2 of which arc linear-subulate, and longer than the other 2. $\zeta$. S. Native of South America, in the province of Varino, at the river Atures. Flowers white. Said to be allied to $S$. tenuitor, and therefore it is probably a true species of Spermacòce.

Diffuse Button-weed. Shrub procumbent.

$S$ S. SUFFRUte'scens (Jacq. schoenbr. t. 322.) stem suffrutescent at the base, rather diffuse, branched, tetragonal, glabrous; leaves ovate-lanceolate, acuminated, lined, with scabrous margins; stipulas furnished with bristles: whorles of flowers dense, sessile, axillary, and terminal; the latter girded by 4 leaves: lobes of corolla villous at the apex; genitals exserted; stigma capitate; fruit turbinate, lispid, crowned by the 4-cleft calyx. $\eta_{2}$.S. Native country unknown. S. suffruticòsa, Spreng. syst. 1. 4. ${ }^{2} 2$
FIG. 108.

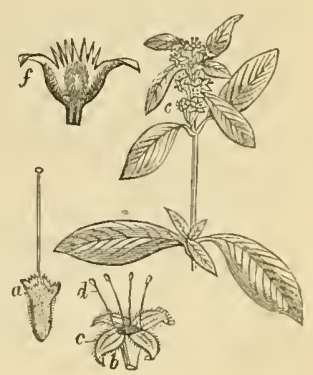


400. S. tetragòn, hort. berol. Leaves pilose above? Flowers pale red.

Suffrutescent Button-weed. Fl. June, Aug. Clt. 1824. Pl. $\frac{1}{2}$ foot.

9 S. LiNeA'Ris (H. B. et Kunth, nov. gen. amer. 3. p. 343. ) stem suffruticose, obsoletely tetragonal, clothed with hairy down; leaves linear, scabrous above and on the margins, hairy beneath; stipulas hairy, ciliated with bristles; whorles many-flowererl, sessile, axillary; corollas glabrous; stigma rather capitate, exserted; capsule oblong, hispid at top; teeth of calyx 4, ovatelanceolate. $h$. S. Native on the banks of the Orinoco. Corollas white. Bigelòwia lineàris, Spreng. syst. 1. p. 405 .

Linear-leaved Button-weed. Shrub 1 foot.?

\section{* Species natives of Africa.}

10 S. palmeto'rum (D.C. prod. 4. p. 553.) plant lierbaceous, ascending, branched ; stem tetragonal, hairy ; branchlets compressed; leaves oval-lanceolate, scabrous above and lined, hairy beneath and nerved; stipulas villous, with the bristles shorter than the sheath; flowers 5-6 together on both sides, sessile, axillary, verticillate; fruit ratlier hairy, obovate; teeth of calyx, 4, short, subulate, at length deciduous.- Native every where about the Gambia, at the roots of palm-trees, in humid places, where it was collected by Leprieur and Perrottet. Allied to S. tenùior. Perhaps Diòdia scàbra, S'chum. pl. guin. p. 76. ?

Palm-tree Button-weed. Pl. 1 foot.

11 S.? Pilo's A (D. C. prod. 4. p. 553.) stem herbaceous, tetragonal, with blunt, pilose angles; leaves ovate, acute, scabrous on both surfaces; bristles of stipulas distant, longer than the sheaths; whorles sessile, nany-flowered; fruit ovate, crowned by the 4 reflexed, acute lobes of the calyx.-Native of Guinea. Diòdia pilòsa, Schum. pl. guin. p. 76 .

Pilose Button-weed. Pl. 1 foot.

12 S. Phyllocéphala (D. C. 1. c.) plant erect, glabrous, sparingly branched; stems tetragonal; leaves linear, 1-nerved: Horal ones dilated at the base; bristles of stipulas 3-5 on each side, longer than the slieath; heads of flowers axillary, verticillate, very few, and a large terminal one, the latter surrounded by long, squarrose leaves; fruit solitary in the axils of the floral leaves, crowded from the floral leaves being clustered; seeds large, shining. $\odot . S$. Native of the west coast of Africa, at Kouma and Walo, where it was collected by Perrottet and Leprieur. Seeds 2 lines long, alnost like those of Psýllium.

Leaf-lecadcd Button-weed. PI. 1 foot.

13 S. stacur'deA (D. C. prod. 4. p. 554.) plant erect, nearly simple, villous; stem tetragonal; branchlets compressed; leaves linear, acute, floral ones chilated at the base; bristles of stipulas $5-7$, longer than the sheath, which is velvety; heads of flowers verticillate, numerous, surrounded by 6-8 aggregate, squarrose leaves; flowers solitary in the axils of the leaves, and aggregate only from the leaves being crowded; lubes of calyx linear subulate, nearly the length of the fruit; seeds large, slining. $\odot$. S. Native of the west coast of Africa, among stones, at Bakel, where it was collected by Leprieur. Plant about a foot high. Leaves 3 inches long, and nearly 4 lines broad. Bristles of stipulas blackish. Seed 2 or $2 \frac{1}{2}$ lines long, larger than any other of the genus.

Stacliys-like Button-weed. Pl. 1 foot.

14 S. gaLeo'psinis (D. C. prod. 4. p. 554.) erect, branched; stem tetragonal, hairy; leaves lanceolate-linear, rather scabrous on both surfaces; bristles of stipulas longer than the sheath, which is velvety; flowers axillary, few, sub-verticillate; fruit large, velvety, longer than the subulate, calycine lobes. $\odot$. S. Native of Senegambia, at Dagana, in sandy places. Allied to S. Ruéllia, but very distinct. Herb about a foot high. Leaves
15-16 lines long, and 3 broad, pale beneath. Stipulas yellowish. Fruit larger than in any other species of the genus, almost like that of a species of Diòdia, but is membranous and dehiscent. Seeds large.

Galcopsis-like Button-weed. Pl, 1 foot.

15 S. Ruélule (D. C. I. c.) erect, branched; stem tetragonal, hispid ; leaves lanceolate-linear, acuminated, clothed with rough doun on both surfaces; heads many, verticillate, axillary; bristles of stipulas many, 3 times longer than the sheath, which is downy; valves of fruit at length opening widely at the apex; lobes of calyx subulate, rather longer than the fruit. $\odot$. S. Natise of Equinoctial Africa, in sandy places at Bakel, where it was collected by Leprieur. Stem a foot high. Leaves 3 inches long, and 5-6 lines broad. Mature fruit nearly as in the genus Rućllice. Seed a line and a half long.

Ruellia-like Button-weed. Pl. 1 foot.

16 S. сu.tocépiala (D. C. l. c.) stem erect, simple, terete at the base and glabrous, and tetragonal at the apex, with the angles scabrous; leaves linear-elongated, acuminated, glabrous; bristles of stipulas 5-7, subulate, longer than the sheath, which is villous; heads verticillate, surrounded by many leaves, and the many bristles of the stipulas; fruit pale, membranous, downy at the apex; lobes of calyx subulate, shorter than the frut. ๑. S. Native of Equinoctial Africa, in Gala, among rocks at Bakel, where it was collected by Leprieur. Plant $1 \frac{1}{2}$ foot high. Leaves 3 inches long, and 3 lines broad. Bristles of stipulas rufous. Capsules whitish. Seeds a line long.

Bristly-headed Button-weed. PI. $1 \frac{1}{2}$ foot.

\section{* * Species natives of the Mauritius and Madagascar.}

17 S. FLAGellifórmis (Poir. dict. 7. p. 314.) stem herbaceous, terete, glabrons, simple, erectish ; leaves glabrous, oblong-lanceolate, acute, revolute on the margins at the base, and therefore petiole-formed; stipulas broad-cupshaped, having the bristles rather shorter than the sheath; flowers axillary, few, sessile, verticillate; capsule ovate, puberulous, crowned by the 4 slender acute teeth of the calyx. ○. S. Native of the Manritius and Bourbon. S. flagellàris, Willd. in Rœm. et Schultes, syst. 3. p. 532. ex Cham. et Schlecht. in Linnæa. 3. p. 357. Hedyòtis verticillàta, Lam. ill. no. 1423. exclusive of the synonymes of Desf.

Whip-formed Button-weed. Pl. 1 foot.

18 S. muricula'ta (D. C. prod. 4. p. 554.) glabrous; stem herbaceous, tetragonal, having the angles just under the nodi rough from small tubercles; leaves elliptic-lanceolate, acuminated at both ends, scabrous above; bristles of stipulas longer than the sleath, which is very short; Howers disposed in sessile, glomerate whorles in the axils of the leaves; fruit ovate, downy, crowned by the 2.4 very short, acute, calycine teeth, but is at length nearly naked.- Native of the Mauritius and Bourbon. Allied to $S$.tenutior; but the angles of the stem are not downy, but scabrous from tubercles.

Murienlated-stemmed Button-weed. Pl. 1 to $1 \frac{1}{2}$ foot.

19 S. serpyllifòlia (Willd. in Roem. et Schultes, syst. 3. p. 532.) plant diffuse, scabrous; leaves elliptic, with revolute margins; whorles few-flowered.-Native of Madagascar. A true species of Spermacòce ex Cham. et Schlecht. in Linnæa. 3. p. 357 . but the rest is unknown.

Hild-thyme-leaved Button-weed. Pl.

$$
\text { **** Species natives of India. }
$$

20 S. Strícta (Lin. fil. supp]. p. 120.) stem herbaceous, straight, erect, scabrous at the angles; leaves linear-lanceolate, lined, scabrous; stipulas ciliately fringed; whorles of flowers axillary, remote, globose; fruit obovate-globose, rather membranous at the base, and hispid at the apex, crowned by the 4 
lobes of the calyx. $\odot$. S. Native of the East Indies. S. strícta, Roxb. H. ind. 1. p. 376 . S. lasiocárpa, R. Br. in Wall. cat. no. 832. Bigelòwia strícta, Spreng. syst. 1.p. 404. Flowers white.

I'ar. $\beta$, latifòlia (D. C. prod. 4. p. 555.) leaves ovate-lanccolate, rather scabrous above.-Native of Java, about Tugu. Bigelowia stricta, Blum. bijdr. p. 945.

Straight Button-wced. Fl. June, July. Clt. 1820. Pl. $\frac{1}{2}$ to 1 foot.

21 S. Burmánel (D. C. prod. 4. p. 555.) stem tetragonal, branched, slender, rather pilose on the angles; leaves oblonglincar, acuminated at both ends, scabrous above, and on the margins; bristles of stipulas glabrous, about the lengtlı of the sheath, which is villous; flowers axillary, sessile, few, somewhat verticillate, almost inclosed in the stipular sheaths; fruit ovate, rather hairy, crowned by the 4 acute teeth of the calyx.Native of the East Indies. S. corymbòsa, Burm. fl. ind. p. 34. but not of Lin. Allied to S. flagcllifórmis. Flowers white.

Burmann's Button-weed. ]1.

22 S. SCABE'RRMA (Blum. bijdr. p. 946.) stem herbaceous, branched, climbing; branches quadrangular, having the angles beset with retrograde down; leaves oval-lanceolate, rough above, and on the veins beneath; stipulas pubescent, furnished with bristles, which are a little longer than the sheath; stamens exserted; fruit glabrous, crowned by the 4 lobes of the calyx.Native of Java, in htmid places about Buitenzorg. Habit of $S$. tenùior.

Very-scabrous Button-weed. Pl. climbing.

23 S. H'sPIDA (Lin. mant. p. 558.) plant herbaceous, erect, hoary ; stem tetragonal, hispid; leaves obovate, a little mucronate, hispid on both surfaces, and on the margins; bristles of stipulas length or longer than the sheath; flowers 1-8-together, axillary, sessile, opposite or somewhat verticillate; stamens length of corolla; capsule ellipsoid, laairy, crowned by the 4 teeth of the calyx. $\odot$. S. Native of the East Indies.-Murr. comm. goett. 3. p. 77. t. 5. Cham. et Schlecht. in Linnæa. 3. p. 355. S. rígida, Salisb. prod. p. 60.-Burm. zeyl. t. 20. f. 3. Corollas turbinate, violaceous. Stamens purplish.

IIispid Button-weed. Fl. Aug. Sept. Clt. 1781. P1. I $\frac{1}{2}$ foot. 24 S. SCA'BRA (Willd, spec. 1. p. 572.) stem herbaceous, diffuse, terete, or slightly tetragonal, scabrous from pili; leaves obovate, obtuse or acute, undulated, scabrous on both surfaces, and on the margins; bristles of stipulas rather longer than the sheath, which is downy ; flowers few, axillary, verticillate; stamens exserted; capsule ovate, rather hairy, crowned by the 4 lanceolate teeth of the calyx. $\odot . F$. Native of Coromandel, ex Roxb. ; of Malabar, ex Rheed. mal. 9. t. 76.; and of the Island of Timor. Roxb. f. ind. 1. p. 377. S. hírta, Rottl. in nov. act. nat. cur. berl. 1803. p. 95. Flowers small, purple.

Rough Button-weed. Fl. June, July. Clt. 1818. Pl. diffuse. 25 S. Articula'ris (Lin. fil. suppl. p. 119. exchusive of the synonymes,) plant herbaceous, diffise ; stems tetragonal, pilose above at the angles; leaves elliptic-lanceolate, hardly acute, clothed with rough pubescence on both surfaces, and on the margins; bristles of stipulas longer than the sheath, which is downy; flowers 2-4, axillary, sessile; capsule oval, downy, crowned by the 4 teeth of the calyx. $\odot$. F. Native in sandy places on the shores of Coromandel. Roxb. fi. ind. 1. p. 378 . Allied to $S$. hispida. Stem reddish. Flowers white. Branches procumbent.

Jointed-branched Button-weed. Pl. procumbent.

26 S. Brunònis (Wall. cat. no. 822.) stems herbaceous, erect, tetragonal, glabrous; leaves lanceolate, acute, sessile, glabrous, with serrulated scabrous edges; stipulas bifid and trifid, or multifid; heads of flowers terminal, rarely axillary : the former involucrated by 2 long leaves, and sometimes also 2 small ones. 24. S. Native of Kamaon. Flowers white, Perhaps a species of Borrìria.

Bron'n's Button-weed. Pl. 1 to 2 feet.

27 S. Longicau'tis (R. Br. in Wall. cat. no. 826.) plant scabrous; stem elongated, tetragonal, with scabrous angles; leaves oblong and obovate-oblong, opposite, and falsely verticillate, scabrous; bristles of stipulas longer than the sheath; flowers axillary, few, verticillate. $4 . \mathrm{S}$. Native of the Burmese Empire, at Prome; and of Singapore.

Long-stemmed Button-weed. PI. 2 to 3 feet, diffuse.

28 S. Ava'na (R. Br. in Wall. cat. no. 828.) stems tetragonal, scabrous on the angles; leaves elliptic or obovate-elliptic, acute, attenuated at the base, rather scabrous, serrulated on the margins; bristles of stipulas longer than the sheath; flowers axillary, sessile, somewhat verticillate. 2 . S. Native of the Burmese Empire, at Ava. Very nearly allied to the preceding.

Ava Button-weed. Pl. 1 to 2 feet.

29 S. TE'NERA (R. Br. in Wall. cat. no. 833.) plant glabrous, diffuse; leaves lanceolate, tapering to both ends, petiolate, smooth; flowers axillary, verticillate; bristles of stipulas longer than the sheath. $\odot$. F. Native of the East Indies. S. ocymoides, Hcyne, but not of Burm.

Pliant Button-weed. Pl. diffuse.

30 S. compre'ss. (Wall. cat. no. 6187.) plant diffuse, densely clothed in every part with woolly scabrous hairs; leaves ovate or oblong, acute; stipulas bristly; heads of flowers axillary and terminal, verticillate; fruit compressed, crowned by the teeth of the calyx. $4 . \mathrm{S}$. Native of Silhet, in the East Indies.

Compressed-fruited Button-weed. Pl. procumbent.

\section{+ Species not sufficiently known.}

\section{* Species natives of Asia.}

31 S. Flexuòsa (Lour. coch. p. 79.) stem shrubby, flexuons, nearly terete, procumbent; leaves ovate-lanceolate, obliquclynerved, thick; stipulas bristly; whorles of flowers globose; capsule of 22 -horned nuts. $\zeta$. G. Native of Cochin-china, in hedges and among bushes. Corollas white, with revolute segments.

F'lexuous Button-weed. Shrub procumbent.

32 S.? hedyotídea (D. C. prod. 4. p. 555.) stem tetragonal, glabrous ; leaves lanceolate ; stipulas rhomboid ; thyrse brachiate; bracteas subulate; corolla tomentose inside; anthers linear; stigma capitate; capsule ovate, crowned by the 4 -toothed calyx; cells 1-seeded. $h$. S. Native of the East Indies. Hedyòtis fruticosa, Retz, obs. 2. p. 8. and probably also of Lin. If the cells of the fruit are truly 1 -seeded, it is a true Spermacòce. All the synonymes cited by authors for this plant are very doubtful.

Hedyotis-like Button-weed. Pl.

33 S. Procu'mbens (Lin. syst. veg. p. 124.) stems herbaceous, procumbent, angular; leaves linear; corymbs lateral, opposite, pedunculate, surrounded by many-leaved involucra; stamens exserted.-Native of the East Indies. S. corymbòsa, Lin. spec. p. 149. but not of others. Stamens longer than the corolla.

Procumbent Button-weed. Pl. procumbent.

34. S.? seMIERE'cta (Roxb. H. ind. 1. p. 377.) stems tetragonal, ascending, bent in various ways, with rather hispid angles ; branches brachiate, alternately smaller; leaves ovate, acuminated, on short petioles, scabrous; stipulas of many bristles ; whorles of flowers small, compact; genitals inclosed; capsule turbinate, pilose.-Flowers small, white. Native of Sumatra. S. Roxburghiàna, Wall. cat, no. 6186. Fruit not sufficiently known.

Half-erect Button-wced. P]. $\frac{1}{2}$ foot.

35 S. ? costa'ts (Roxb. fl. ind. 1. p. 376.) plant diffuse, very villous; leaves broad-lanceolate or oblong, nerved; stipulas 
usually furnished with 3 bristles; flowers axillary, disposed in small proliferous crowded umbels; stamens protruding beyond the corolline tube. \&. S. Native of the Moluccas. Perhaps the same as S. cristàta, Willd. in Rœm, et Schultes, syst. 3. p. 530.? Flowers pale, pink.

Ribled-leaved Button-weed. Pl. diffuse.

36 S. ? NA'NA (Roxb. f. ind. 1. p. 375.) stem erect, simple, nearly terete, smooth; leaves petiolate, lanceolate, smooth; flowers axillary or terminal, sessile, crowded.-Native of the Island of Hominoa. Plant hardly half a foot high.

Dnarf Button-weed. Pl. $\frac{1}{2}$ foot.

37 S. ? LiNeA'ta (Roxb. fl, ind. 1. p. 375. but not of Blume, plant erect, branched, pilose ; leaves on short petioles, lanceolate-linear, acuminated, lined; stipulas triangular, furnished with bristles; peduncles axillary, trichotomous: flowers capitate; stamens exserted.--Native of the Moluccas. The rest unknown.

Lined-leaved Button-weed. Pl. 1 foot.

38 S.? PHiLipie'nsis (Spreng. syst. 1. p. 401.) stem erect, and is as well as the leaves rongh; stipulas toothed; stamens exserted; fruit glabrous.-Native of the Plilippines. The rest unknown.

Philippine Button-weed. Pl. 1 foot?

\section{* * Species natives of the IFest India Islands.}

39 S. Lex'vis (Lam. ill. no. 14.35. Poir, dict. 7. R. 313. but not of Roxb.) glabrous; stem erect, nearly terete, with opposite spreading branches; leaves lanceolate, acuminated, on slort petioles; flowers sessile, somewhat verticillate; capsules smooth, obtuse.-Native of St. Domingo, where it was collected by Martin. Sloane, hist. 1. p. 94 . f. 2. Said to be nearly allied to S.tenuitor. Flowers numerous.

Smooth Button-weed. Fl. May, July. Clt. 1820. Pl. 1 foot. 40 S. ? stella'ta (Rœm. et Schultes, syst. 3. p. 530.) flowers terminal, capitate; leaves linear, verticillate. - Native of St. Domingo, where it was collected by Poiteau. The rest unknown.

\section{Stellate-leaved Button-weed. Pl. 1 foot?}

41 S.? rота'та (Poit. in Rœm, et Schultes, syst. 3. p. 275.) glabrous; stems diffuse, ascending, quadrangular; leaves ovate, mucronate; bristles of stipulas few, naked, short; flowers in capitate whorles; teeth of calyx villous.-Native of St. Domingo, where it was collected by Martin. Poir. dict. 7. p. 312. Whorles of flowers the size of a pea.

Rotate Button-weed. Pl. diffuse.

42 S. ? Rемо̀т A (Lam. ill. 1. no. 1436.) stems straight, rather tetragonal, and downy; leaves linear-lanceolate, very rough, canescent beneath, shorter than the internodes; whorles of flowers dense, distant ; capsules obtuse, villous.-Native of St. Domingo, where it was collected by Martin. Poir. dict. 7. p. 312. Leaves more than an inch long.

\section{Remote-whorled Button-weed. Pl. 1 foot?}

$43 \mathrm{~S}$. ? ocYmifòia (Willd. in Rom. et Schultes, syst. 3. p. 530.) branchlets and under sides of leaves downy: bristles of stipulas longer than the whorles of flowers; stamens inclosed.Native of the West Indies. S. decídua, Bosc. The rest unknown.

Basil-lcaved Button-weed. Pl. 1 foot.

44 S.? oвscu'ka (D. C. prod. 4. p. 556.) glabrous; stem herhaceous, tetragonal; leaves ovate-oblong, attenuated at both ends, lined; stipulas connate, ciliated with bristles; whorles of flowers globose; corollas villous inside; stamens exserted.Native of Cuba and Hispaniola. S. capitellàta, Spreng. neu. entd. 3. p. 46. exclusive of the synonymes. Fruit unknown.

Obscurc Button-weed. Pl. 1 foot.?

\section{*** Species nutives of Brazil.}

45 S.? strigòsa (Thunb. et Otto, pl. bras. no. 23. ex flora, 1821. ]. 602. but not of Sims, stem branched, pilose; leaves ovate, hairy ; flowers verticillate.-Native of Brazil.

Strigose Button-weed. Pl. 1 foot.

46 S.? ELLí PTica ('Thunb. et Otto, pl. bras. no. 22. ex flora, 1821. p. 602.) stem simple, glabrous; leaves elliptic, glabrous; flowers axillary.- Native of Brazil.

Elliptic-leaved Button-weed. Pl. 1 foot.

47 S.? cephalòtes (Willd. in Rœm. et Schultes, syst. 3. p. 531.) stem herbaceous, scabrous, branched; leaves lanceolate, acuminated, tapering to the base, veiny ; heads of flowers terminal, involucrated, hairy ; stamens exserted.-Native of Brazil. Leaves quite glabrous, ex Spreng. neu. entd. 2. p. 144. but rough, ex Spreng. syst. 1. p. 402. Fruit unknown.

Iycaded Button-weed. Pl. 1 foot?

48 S. Assu'rgens (Ruiz et Pav. fl. per. 1. p. 60.t. 92.) stem ascending, branched, tetragonal, liaving the angles rough; leaves lanceolate, lined, with rough margins; stipulas sheathing, ciliated; whorlcs of flowers axillary, small, sessile and terminal : the latter about equal in size to the axillary ones, and girded by a 2-leaved involucrum. 24. S. Native of Peru, about Lima and Huanaco, in waste places, ex Ruiz et Pav.; and of Brazil, on the road to Felisbert, ex Nees et Mart. nov. act. bonn. 12. p. 11. Stem purplish. Leaves ovate, lanceolate. Calyx purplish. Corollas white or reddish. Said to be allied to $S$. Portoricénsis. -Compare Feuill. per. 3. p. 23. t. 40.

Assurgent Button-weed. Pl. 1 to $1 \frac{1}{2}$ foot.

$$
\text { **** Species natives of Peru, Bogota, and Chili. }
$$

49 S.? inconseícua (Bartl. in herb. Hænke, ex D. C. prod. 4. p. 557.) plant suffrutescent; branches ascending, somewhat hexagonal, glabrous at bottom, but clothed with powdery down at top; leaves linear-oblong, acuminated at both ends, glabrous, with scabrous elges; bristles of stipulas longer than the sheath; heads of flowers terminal, girded by 4 -leaved involucra; teeth of calyx 4, nearly equal, acuminated. h.S. Native of Peru, on the mountains. Branches truly tetragonal, but 2 of the sides are very narrow, and the other 2 are broader, convex, and almost keeled in the centre of the convex part; therefore they are said to be somewhat lexagonal. The habit is that of Borrèria, but the fruit is unknown.

Inconspicuous Button-weed. Shrub ascending.

50 S.? Gra'cilis (Ruiz et Pav. fl. per. 1. p.61. t. 92. f. a.) plant herbaceous, glabrous; stem erect, tetragonal, slender branched; leaves lanceolate, acuminated, with scabrous margins; stipulas sheathing, ciliated by bristles; whorles of flowers axillary and terminal, small, sessile; fruit hispid. $\odot$.H. Native of Peru, on the mountains. Flowers white. It is probably a spccies of Borreria from the fruit being crowned by the 4 teeth of the calyx; but the habit is almost that of $S$. tenüior.

Slender-branched Button-wood. Pl. $\frac{1}{2}$ foot.

51 S.? Oldenlándi玉 (D. C. prod. 4. p. 557.) plant glabrous; stem herbaceous, much branched, creeping, filiform; branches opposite; leaves ovate, on very short petioles, shining; peduncles 1-flowered, solitary; fruit hispid.-Native of Chili, in humid places and about springs. Oldenlándia uniflòra, Ruiz et Pav. fl. per. 1. p. 57. but not of Lin. Perhaps a true species of Spermacoce from the cells of fruit being 1 -seeded.

Oldenlandia-like Button-weed. Pl. creeping.

52 S. ? HUмifu's. (Willd. in Rœm. et Schultes, syst. 3. p. 530. H. B, et Kunth, nov. gen. amer. 3. p. 349.) stem suffruticose, procumbent, tetragonal, glabrous, with ciliately-serrulated margins; stipulas downy, ciliated by bristles; heads of flowers lateral and axillary, pedunculate; limb of calyx tetragonally- 
urceolate, sinuately-quadrifid. $\hbar$. S. Native near Santa Fe de Bogota. Corolla, genitals, and fruit unknown.

Trailing Button-weed. Slirub procumbent.

53 S.? ERIócladA (D. C. prod. 4. p. 557.) plant suffruticose, ascending; branches rather angular, clothed with hairy tomentum; leaves oblong, acuminated, very scabrous on both surfaces, alnost veinless, with serrately scabrous edges, and sometimes mucronate at the apex; bristles of stipulas glabrous, length of sheath, which is villous; heads of flowers terminal, girled by 4 leaves; tceth of calyx 4, equal; stamens exserted. h. S. Native of Peru. S. scabérrima, Bartl. in herb. Hanke, but not of Blume. Fruit unknown, and therefore the genus is doubtful. The habit is that of Borrèria.

Var. $\beta$, linearifolia (D. C. prod. 4. p. 557.) leaves linear, distinctly mucronate. h.S. Native of Peru.

Woolly-branched Button-weed. Shrub ascending.

\section{***** Species natives of Guiana.}

54 S.? sexangula'ris (Aubl. guian. 1. p. 61. t. 22. f. 8.) plant glabrous, prostrate; stem flexuous, prostrate, hexagonal; leaves ovate, acute, petiolate; heads of flowers terminal ; anthers in the throat.- Native of Guiana, on the banks of rivers. S. hexagòna, Willd. spec. 1. p. 569. Flowers small, blue. Perhaps a species of Borrèria nearly allied to $B$. alàta.

Six-angled-stemmed Button-weed. Pl. prostrate.

55 S.? prostra'ta (Aubl. guian. 1. p. 58. t. 20. f. 3.) glabrous; stem herbaceous, prostrate, oppositely branched, tetragonal; leaves almost sessile, elliptic, acute, smooth; flowers verticillate.-Native of Guiana, on the banks of rivers. Flowers small. Leaves pale green.

Prostrate Button-weed. Pl. prostrate.

56 S.? Radicans (Aubl, guian. 1. p. 58. t. 20. f. 4.) gla. brous; stem lierbaceous, alternately branched, prostrate, radicant; leaves almost sessile, lanceolate, acute; flowers verticillate. 4. 8. Native of Guiana, on the banks of the river Orapu. The rest unknown.

Rooting Button-weed. Fl. July. Clt. 1803. Pl. creeping.

57 S.? CERUle'scens (Aubl. guian. 1. p. 57. t. 19. f. 2.) stem simple, straight, tetragonal; leaves ovate, acute, rather hairy, snooth; bristles of stipulas about equal in length to the flowers; flowers verticillate; stamens exserted.-Native of Guiana and Cayenne, on the edges of fields. Vahl. eclog. 1. p. 9. Corollas blue. Fruit unknown.

Bluish-flowered Button-weed. Pl. 1 to 2 feet.

58 S. zatı́òlı (Aubl. guian. 1. p. 56. t. 19. f. 1.) glabrous; stem, erect, herbaceous, tetragonal ; leaves ovate, acuminated, petiolate, rough; bristles of stipulas hispid, a little longer than the sheath; flowers axillary, verticillate; limb of calyx 4 -toothed, rather villous, as well as the capsules, which are ovate.Native of Guiana and Cayenne by way sides. Lam. ill. t. 62. f. 2. Probably a species of Borrèria or Mitracárpum. Flowers white.

Broad-lcaved Button-weed. Fl. July. Clt. 1803. Pl. 2 to 3 feet.

\section{***** Spccies natives of Mexico.}

59 S. polycéphala (Bartl. in herb. Hænke, ex D. C. prod. 4. p. 558.) stem herbaceous, erect, branched, quadrangular, villous ; leaves ovate-lanceolate, acuminated, pilose on both surfaces, lined with veins beneath; bristles of stipulas longer than the sheath, hairy; heads of flowers terminal, nearly globose, girded by 4-leaved involucra; teeth of calyx subulate, nearly equal ; stamens exserted.-Native of Mexico. Perhaps a species of Borrèria.

Many-headed Button-weed. Pl. 2 to 3 feet.

60 S.? Ecmoldes (H. B. et Kunth, nov. gen. amer, 3. p.
344.) stem herbaceous, tetragonal, erect, hispid ; leaves lanceolate, acuminated, petiolate, hispid on both surfaces; stipulas hispid, ciliated by bristles; whorles of flowers nearly globose, axillary and terminal. 4 . S. Native of Mexico, near Campeche. There is a variety of this with glabrous stems, and narrower less hispid leaves.

Buglos-like Button-weed. [’].

61 S.? Diverisifòlia (H. B.et Kunth, nov. gen. amer. 3. p. 34.1.) plant herbaceous, erect, with tetragonal branches, which are scabrous from retrograde bristles; leaves linear, with remotely scabrously serrulated margins : the lower oncs minnte and oblongelliptic ; stipulas smoothish, fringed by bristles; heads of flowers

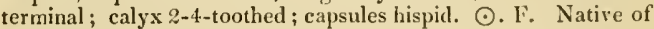
Mexico. Knóxia símplex, Willd. in Rœm, et Schultes, syst. 3. p. 532. Perhaps a species of Borríria. Elowers white.

Diverse-leaved Button-weed. Pl.

62 S.? REcLina'ta (Nees, lor. berl. p. 50.) plant glabrous, ascending, herbaceous; leaves lanceolate, acute, smooth, veinless; stipulas downy, furnislied with 5 bristles each; heads terminal, dense, hemispherical, supported by 2 leaves; calyx and fruit glabrous. 4 . S. Native of Mexico. Fruit unknown.

Reclinate Button-weed. Pl. ascending.

$$
\text { ******** Species natires of North America. }
$$

63 S.? Lasiáxtha (Rafin. H. lud. p. 76.) stem weak; branches diffuse; leaves sessile, oblong, acute, nerved: nerves scabrous ; flowers verticillate ; corolla woolly inside.-Native of Louisiana.

Woolly-fowered Button-weed. Pl. diffuse.

64 S.? GLA'Bra (Michx. fl. bor. amer. 1. p. 8\%.) plant glabrous, procumbent; leaves ovate-lanceolate; whorles manyflowered. $\odot$. H. Native of North America, on the banks of the Ohio and Mississippi. Diòdia glàbra, Pers. ench. 1. p. 124. Flowers white, longer than those of $S$, tenuior. Fruit unknown.

Glabrous Button-weed. Fl. July, Aug. Clt. 1823. Pl. procumbent.

65 S.? involvera'xa (Pursh, fl. amer. sept. 1. p. 105.) plant very hispid, herbaceous, erect; stem alternately branched; leaves ovate-lanceolate, acuminated, hairy on both surfaces; stipulas of many bristles; heads terminal, involucrated ; tube of corolla very long; stamens exserted.-Native of Carolina. Flowers white. Leaves rather broad. According to Sprengel this is a variety of Crùsea rùbra. Fruit unknown.

Involucrated-flowered Button-weed. Pl. 1 foot.

Cult. See Borrèria, p. 618. for culture and propagation.

CLXXXVI1. HEXASE'PALUM (from $\varepsilon_{h}^{\natural}, h e x$, six, and $\sigma \varepsilon \pi u-$ $\lambda o v$, sepalon, an alteration of $\pi \varepsilon \tau \alpha \lambda o v$, a sepal; in reference to the limb of the calyx being 6 -parted, indicating its being composed of six sepals). Bartl. in herb. Hæenke, ex D. C. prod. 4. p. 561.

Lin. syst. Tetrandria, Monogy'nia. Calyx with an oblong obpyramidal tube, and a 6-parted limb; lobes narrow, nearly equal, acute, permanent. Corolla campanulately funnel-shaped, with an obconical tube, and 4 lanceolate acute lobes, which are valvate in rstivation. Stamens 4, shorter than the lobes of the corolla. Fruit oblong, dry, ribbed, divisible into 2 parts at the dissepiments : the dissepiment being double, both the parts of the fruit or nuts are closed, and 1-seeded.-A small ascending much branched glabrous shrub, with diffuse flexuous compressed branches. Leaves opposite, long-linear, acute, with the margins hardly scabrous. Stipulas sheathing, furnished with many bristles, which are equal in length to the sheath, intermixed with very short ciliæ. Flowers axillary, solitary, sessile, larger than in any other genus belonging to the tribe Spermacòcece.

1 H. Angustifòlum (Bartl. l. c.) h. S. Native of Mexico, 
in Real del Monte, where it was collected by Hænke. Leaves $1 \frac{1}{2}$ to 2 inches long, and a line broad. Corolla 6 lines long. Ovarium 3 lines long.

Narron-leaved Hexasepalum. Shrub 2 to 3 feet.

Cult. See Borrèria, p. 618. for culture and propagation.

CLXXXVIII. DIO'DIA (from swosos, diodos, a passage; the greater part of the species grow by way sides, hence the name). Lin. gen, no. 122. Gærtn. fruct. 1. p. 121. t. 25. Meyer, esseq. p. 81. Cham. et Schlecht, in Linnæa. 3. p. 341. D. C. prod. 4. p. 561.-Diòdia and Spermacòce species of authors.

Lun. syst. Tetrándria, Monogy'nia. Calyx with an obovate or ovate tube, which is usually 8 -nerved; limb dentately parted; teeth sometimes 2, sometimes 4 , equal or unequal, cruciately disposed, rarely more than 4. Corolla funnel-shaped, with a 4lobed limb. Stamens 4, exserted or inclosed. Style bifid or undivided. Fruit 2-celled, crowned by the calyx, divisible into $2 \mathrm{I}$-seeded indehiscent parts or mits. Seeds erect in the cells, furrowed in the front. - Herbs or subshrubs, all natives of America except one species. Branches terete or tetragonal. Leaves opposite, or falsely verticillate from axillary fascicles. Flowers small, white, disposed in various ways in the different sections.

Sect. J. Evdioda (from eu, well, and Diodia; this section is considered to contain the true species of the genus). D. C. prod. 4. p. 561. Capsules crustaceous or somewhat fleshy; having the mericarps or nuts separate, without any dissepiment between them.-Flowers axillary, sessile, opposite ; or 2 or more on each side verticillate.

\section{* Calyx bidentate.-Diòdia, Gron. Lin. Michx, Pursh.}

1 D. VIRGI'NICA (Lin. spec. 151.) glabrous in every part; stems procumbent, nearly terete; leaves lanceolate; lobes of stipulas linear-subulate; corollas rather hairy inside; fruit ovateoblong, glabrous, crowned by the 2 lanceolate lobes of the calyx. 4. F. Native from Virginia to Carolina, in humid sandy places. Jacq. icon. rar. 1. t. 29. Lam. ill. t. 63. Pursh, fl. sept. aner. 1. p. 105. Stems reddish, smooth. Flowers white.

Iirginian Diodia. FI. June, July. Clt. 1820. Pl. proc.

2 D. TETrAgòna (Walt. fl. virg. p. 87. Ell, sketch. 1. p. 190.) stems procumbent, rather angular, smoothish; leaves ovate-cordate; lobes of stipulas linear-subulate; corollas hairy inside; fruit rather hairy, crowned by the 2 lobes of the calyx. $4 . \mathrm{F}$. Native of Carolina, frequent in humid places. D. Virgínica, Michx. fl. 1. p. 81. ex Eill. Flowers white.

Tetragonal-stemmed Diodia. Pl. procumbent.

3 D. innsu'ta (Pursh, fl. amer. sept. 1. p. 106.) plant very hairy; stems procumbent, tetragonal; leaves linear-lanceolate; lobes of stipulas setaceous ; corolla densely bearded inside ; fruit ovate, hairy, crowned by the 2 linear-subulate lobes of the calyx. 4. F. Native of Georgia, Lonisiana, and Carolina, in sandy fields. Ell. sketch. 1. p. 191. D. híspida, MIuhl, cat. ex Eli. D. oblónga, Rafin. fl. lud. p. 80.? Flowers white. Stem much branched.

Hairy Diodia. Pl, procumbent.

4 D. sí iplex (Swartz, f. ind, occ. 1. p. 226.) stems herbaceous, erectish, smooth, simple; leaves oblong-lanceolate, glabrous; lobes of stipulas linear-subulate; fruit ovate-oblong ; limb of calyx bidentate: teeth linear. 4 .? F. Native of Jamaica, on the higher mountains. Jeaves ciliated on the margins while young. Flowers sessile, solitary, axillary, white.

Simple-stenmed Diodia. Pl. 1 to $1 \frac{1}{2}$ foot.

5 D. Verticilla'ta (Vahl, symb. 2, p. 28.) glabrous; stem herbaceous, simple, erect, smooth; leaves lanceolate, attenuated at both ends, with scabrous margins; stipulas ciliated; fowers verticillate; fruit linear, crowned by the 2 calycine teeth.-
Native of the Island of Santa Cruz. The leaves are said to be in whorles within the stipulas, hence they are probably in axillary fascicles. Flowers white, in axillary and terminal whorles: the latter the largest. It is probably a species of Borrèria from the terminal whorl of flowers being larger than the axillary ones.

Whorled-flowered Diodia. Fl. June, July. Clt. 1821. Pl. 1 foot.

6 D. villòsa (Moc. et Sesse, fl. mex. icon. ined. ex D. C. prod. 4. p. 562.) stem herbaceous, declinate, tetragonal, villous ; leaves lanceolate, acnminated, scabrous above and on the margins, hairy beneath, and obliquely nerved; bristles of stipulas scabrous, longer than the sheath; whorles axillary, sessile, 10 12-flowered; fruit ovate, easily separated into 2 parts, crowned by the 2 teeth of the calyx.-Native of New Spain. Spermacòce declinàta, Pavon, ined. Habit of Spermaèce tenùior, but the fruit is composed of 2 indehiscent nuts, each crowned by one calycine tooth.

Iillous Diodia. Pl. declinate.

$$
\text { * Calyx 4-toothed. }
$$

7 D. TE'REs (Walt. car. p. 87.) stem terete, velvety, procumbent; leaves linear-lanceolate, clothed with velvety down; lobes of stipulas setaceons, longer than the fruit ; corolla bearded inside; fruit orate, downy, crowned by the 4 lanceolate calycine lobes. $\odot$.H. Spermacòce diodìna, Michx. f. amer. bor. 1. p. 82. Torr. fl. un. st. 1. p. 170 . Leaves with scabrous edges and keel. Flowers white, solitary, sessile.

Terete-stemmed Diodia. Pl, procumbent.

8 D. Hyssopifòlta (Cham. et Schlecht. in Linnæa. 3. p. 342.) plant suffruticose, branched; branches nearly terete, bairy; leaves linear, acute, glabrous, glancescent; bristles of stipulas equal in length to the fruit; whorles usually 6-flowered; fruit obovately turbinate, downy. I. S. Native on the banks of the Orinoco, near San Borja in hot places. Spermacòce hyssopifòlia, H. B. et Kunth, nov, gen. amer. 3. p. 342. Willd. in Rocm. et Schultes, syst. 3. p. 532. Said to be allied to $D$. tères. Flowers white.

Hyssop-leaved Diodia. Shrub.

9 D. prostra'ta (Swartz, f. ind. occ. 1. p. 228.) stem suffruticose, subdivided; branches prostrate, tetragonal, filiform, rather hairy at the apex; leaves linear, rather hairy, with revolute edges; lobes of stipulas setaceous, intermixed with pili, which rise from the sheath; fruit ovate, downy, crowned by the 4 short lobes of the calyx. h. S. Native of Jamaica. D. procúmbens, Swartz in herb. L'Her. D. prostràta, Spreng. exchusive of the species from Hispaniola. Flowers white.

Var. $\beta$, longisèta (D. C. prod. 4. p. 562.) bristles of stipulas longer than the sheath; branches hispid. $\boldsymbol{h}_{2}$. S. Native of Mexico. D. prostràta, Bartl. in herb. Hænke, ex D. C. I. c.

Prostrate Diodia. Fl. June, July. Clt. 1818. Sh. prostrate.

10 D. Dominge'nsis (D. C. prod. 4. p. 563.) glabrous; branches and stems procumbent, tetragonal, filiform; leaves linear, with revolute margins; bristles of stipulas stiff.-Native of St. Domingo, where it was collected by Bertero. Diòdia prostràta, ex Hispaniola, Spreng. syst. 1. p. 4.06. Flowers and fruit unknown, and therefore the genus to which it belongs is donbtful. Nearly allied to $D$. prostrita.

St. Domingo Diodia. Shrub procumbent.

11 D. sca'ndens (Swartz, fl. ind. 1. p. 230.) stem suffruticose, climbing; branches very long, tetragonal, smoothish; leaves ovate-lanceolate, scabrous, at length rather muricated above; bristles of stipulas stiffish; fruit ovate-oblong, crowned by the 4 lanceolate calycine teeth. $h_{2}$. S. Native of St. Domingo. Leaves muricated above, almost as in boragineous plants. Flowers white, sessile, 4-6-together, axillary.

Climbing Diodia. Shrub cl. 8 to 10 feet. 
12 D. SARMentòsa (Swartz, f. ind. occ. 1. p. 231.) stem climbing, suffruticulose, tetragonal, villous, particularly on the angles; leaves oval-oblong, acute, scabrous from muricæ, rugosely nerved in the adult state; bristles of stipulas stiflish; fruit oval, rather tetragonal, crowned by the 4 . lanceolate teeth of the calyx. h. S. Native of Jamaica, Porto-Rico, St. Thomas, S.c. Spermacòce ràdula, Spreng. neu. entd. 2. p. 144. Schultes, mant. 3. p. 207. but not of Willd.-Diòdia sarmentòsa c̀ Guadalıpa, Spreng. syst. 1. p. 405. is a species of Borrèria. Flowers solitary, axillary, white. Corolla with a tetragonal tube.

Twiggy Diodia. Fl. June, Aug. Clt. 1821. Shrub cl.

13 D. Latílòra (D. C. prod. 4. p. 563.) stems suffuticose; branches nearly terete, clothed with velvety down; leaves lanceolate, acutely awned, rather downy above, and scabrous beneath from hispid down; bristles of stipulas numerous, long; corolla campanulately funnel-shaped, with a broad glabrous throat, and acute rather ciliated lobes; fruit obovate-globose, crowned by the 4 linear teeth of the calyx. $\eta$. S. Native of St. Domingo. Spermacòce barbàta, Spreng. in herb. Balb. but not of Lam. D. scándens, Vahl, herb. ex Puer. Very nearly allied to $D$. scándens, and probably only a variety of it. Corolla 5 lines long, obconical, white.

Broad-flonered Diodia. Shrub cl.

14 D. grandiflòra (D. C. prod. 4. p. 563.) stems twiggy, flexuous, sparingly branched, tetragonal, glabrous, hardly pilose at top; leaves linear, cuspidate, glabrous on both surfaces, with serrulately scabrous margins, ciliated at the base; bristles of stipulas equal in length to the fruit; flowers axillary, sessile, opposite ; corolla glabrous; fruit obovate-globose, rather hairy, crowned by the 4 lanceolate, acuminated, unequal calycine teeth. $h$. S. Native of St. Domingo, where it was collected by Bertero. Spermacòce grandiflòra, Spreng. neu. entd. 3. p. 4.5. syst. 1. p. 400. Flowers white. Nuts of fruit truly indehiscent. Allied to $D$. scándens and $D$. latiflòra.

Great-flonered Diodia. Shrub.

15 D. CONFE'RTA (D. C. prod. 4. p. 563.) stem ascending; branches hairy, almost tetragonal; leaves ovate, acuminated, terminated by a long hair each, sessile, with serrulately scabrous edges, hairy beneath ; bristles of stipulas numerous, stifl, longer than the sheath. $\zeta . S$. Native of Brazil, where it was collected by Schott. Spernacòce conférta, Schott. ex Polıl, in litt. Fruit not seen, but from its analogy with $D$. polysèta it has been placed in this genus.

Cronded-flowered Diodia. Shrub 3 to 4 feet.

16 D. seti'GERA (D. C. prod. 4. p. 563.) stem ascending, suffruticose at the base, somewhat tetragonal, hairy; leaves sessile, ovate-lanceolate, subcordate at the base, and terminating in a bristle at the apex, ciliated on the nerve and margins: the ciliæ largest towards the base; bristles of stipulas longer than the sheath, which is smoothish; fruit nearly globose, ribbed, glabrous, crowned by the 4 teeth of the calyx. $h$. S. Native of Brazil, about Bahia, in arid places, where it was collected by Salzmann. Corolla blue, with acuminated lobes.

Bristle-bearing Diodia. Shrub ascending.

17 D. ? вавва'та (D. C. l. c.) plant procumbent, scabrous; branches tetragonal, downy; leaves lanceolate, villous; bristles of stipulas long ; flowers few, axillary.-Native of St. Domingo. Spermacòce barbàta, Lam. ill. no. 1437. Poir. dict. 7. p. 314 . Allied to $D$. longifiora and $D$. longisèta, but the fruit is unknown. The flowers are said to be small. Leaves hardly an inch long: superior ones lisposed in fascicles.

Bearded Diodia. Pl. procumbent.

18 D. Polyse'ta (D. C. 1. c.) branches or stems simple, twiggy, rather tetragonal, hispid from long spreading stiff bairs; leaves lanceolate, acute, hispid from long spreading pili; bristles of stipulas numerous, long, stiffish; fruit 2-3-together, axillary, VOL. III. roundish, crowned by the 4 small teeth of the calyx. h. S. Native of Porto-Rico.

Many-bristled Diodia. Shrub.

19 1. MARítima (Schum. pl. guin. p. 75.) stems prostrate, tetragonal, with furrowed sides, and scabrous angles; leaves oval or oblong, having the margins scabrous from serrulations, rather downy or hairy on both surfaces; bristles of stipulas stiffish; fruit oval-oblong, crowned by the 4 lanceolate teeth of the calyx. $4 . \mathrm{S}$. Native of Guinea, along the coast in the sand. Flowers white.

Var. $\beta$, commutàta (D. C. prod. 4. p. 564.) leaves glabrous on both surfaces. 24. S. Native of Porto-Rico, in the sand by the sea side, where it was collected by Bertero and Wydler. Spermacòce commutàta, Schultes, mant. 3. p. 208. There are varieties of this plant witls either elongated or tufted branches, and having the axils of the leaves naked, or bearing fascicles of leaves or branches, and with the leaves flat, or nervosely furrowed.

Íar. serrulata (D. C. prod. 4. p. 564.) stem erectish ; margins of leaves evidently serrulated. 4 . H. Native of equinoxial Africa, in the kingdom of Waree. Spermacòce serrulàta, Beauv. fl. d'ow. 1. p. 39. t. 23. Nerves of leaves reddish. Flowers axillary, sessile, verticillate.

Sea-side Diodia. PI. prostrate.

20 D. nígida (Cham. et Schleclit. in Linnæa. 3. p. 341.) stem suffruticose, creeping, quadrangular, hairy ; leaves lanceolate, piliferous at the apex, stiff, with serrulated margins, hairy beneatl ; stipulas hairy, ciliated at the apex; fruit obovate, glabrous, crowned by the 4 linear-subulate teeth of the calyx. S. Native of the Spanish Main, near Caraccas ; of St. Domingo ; Brazil, in the province of Para, and of the Society Islands. Spermacòce rígida, H. B. et Kunth, nov. gen. amer. 3. p. 342. Sperm. apiculàta and Sperm. rígida, Willd. in Schultes, syst. 3. p. 531. Sperm. setòsa, Willd. herb. but not of Schultes. Flowers white.

Stiff Diodia. Shrub creeping.

21 D. articula'ta (D. C. prod. 4. p. 564.) glabrous; stem shrubby, terete, nodose ; leaves linear, acute at both ends, with rather revolute edges, also smooth on the margin and mid-rib; bristles of stipulas stiff, shorter than the sheath; whorles 6-8flowered; fruit obovate-oblong, crowned by the 4 calycine teeth. b. S. Native of Brazil, where it was collected by Pohl. Spermacòce articulàta, Pohl, in litt. Leaves in axillary fascicles, hence they appear in whorles, very like those of Hippuris.

Jointed-stemmed Diodia. Shrub.

22 D. rosmarinifòla (Pohl, in litt. ex D.C. prod. 4. p. 564 .) stem herbaceous, erect, simple, terete, hairy ; leaves linear, ending in a long hair each, with rather revolute edges, glabrous, but scabrous from serrulations on the margins and nerve below; bristles of stipulas very long; fruit oval, crowned by the 4 calycine tecth. $\odot$. F. Native of Brazil, where it was collected by Pohl. This is a very distinct species, having the ciliæe of the stipulas half an inch long, about half the length of the leaves.

Rosemary-leaved Diodia. Pl. $\frac{1}{2}$ to I foot?

23 D. ARExo'sa (D. C. prod. 4. p. 564.) stem decumbent, branclied, tetragonal, rather scabrous above ; leaves lanceolatelinear, sessile, acuminated, with revolute edges, rather scabrous on both surfaces; bristles or ciliæ of stipulas longer than the sheatlı; whorles 8-10-flowered; fruit obovate-globose, scabrous from down, crowned by the 4 calycine teeth. h. 4 . S. Native of Brazil. Spermacòce arenòsa, Pohl, in litt. Nuts of fruit indehiscent. If Spermacòce ciliàris, $\mathrm{Pav}$. in herb. Moric, be the same it is also a native of New Spain.

Sand Diodia. Pl, decumbent.

24 D. multiflo'ra (D. C. prod. 4. p. 564.) stem and branches long and twiggy, compressedly tetragonal, hairy; leaves lanceolate, sessile, acute, lined, beset with stiff villi on both sur$4 \mathrm{~L}$ 
faces; bristles of stipulas longer than the sheath, reflexed under the beads of flowers; whorles 15-20-flowered, nearly in all the axils; fruit obovate, rather downy, crowned by the 4 calycine teeth.-Native of Brazil. Fruit easily separated into 2 parts; the parts or nuts closed.

Many-flowcred Diodia. Pl.

25. D. muricula'ta (D. C. prod. 4. p. 564.) stem ascending; branches tetragonal, hairy; leaves sessile, ovate, cuspidate, reflexed below the whorles of flowers, beset with strigæ above, and villi on the nerves beneath; bristles of stipulas longer than the sheath; fruit nearly globose, downy, crowned by the 4 calycine teeth. 4.5 . S. Native of Brazil, about Bahia, in dry places. Allied to $D$. multiftiona.

Muriculated Diodia. Pl. ascending.

26 D. Díscolor (D. C. 1. c.) stem suffruticose, downy, rather ascending, tetragonal; leaves lanceolate, acuminated at both ends, glabrous, rough, canescent beneath; bristles of stipulas 711 , ciliated ; fruit hairy, brittle, crowned by the 4-5 hispid teeth of the calyx. $\eta$. S. Native of Surinam. Spermacòce díscolor, E. Meyer, nov, act. bonn. 12. p. 786 . Flowers white. Allied to D. ràdula, but distinct, ex Cham. et Schlecht. in Linnæa. 3. p. 342.

Discoloured-leaved Diodia. Shrub 1 to $1 \frac{1}{2}$ foot.

27 D. mispídula (A. Rich. in herb. mus. Par. ex D. C. prod. 4. p. 565.) stem erect, tetragonal, glabrous ; leaves oblong-lanceolate, acute, glabrous; bristles of stipulas 7 , stiff, straight, longer than the sheath; spikes many, interrupted, at the tops of the branches, with hardly any leaves; flowers $2-4$ in a kind of whorl, sessile at the stipulas; tube of calyx scabrous from bristles; lobes of calyx 4,2 of them longer than the other 2 ; nuts or mericarps rather membranous, closed, one of which bears 3 of the calycine lobes, and the other only one.-Native of Brazil.

Hispid Diodia. Pl. 1 to 2 feet?

o8 D. radicans (Cham. et Schlecht, in Linnæa. 3. p. 350.) stem radicant, oppositely branched, tetragonal, glabrous; leaves lanceolate, acute, obliquely nerved, smoothish, pale beneath ; fruit ovate, sessile, crowned by the 4 lanceolate lobes of the calyx. h.S. Native of St. Domingo, where it was collected by Poiteau. Spermacòce radicans, Willd. lierb. but not of Aubl. Flowers large, axillary, solitary, white?

Rooting Diodia. Shrub crecping.

$$
\text { *** Calyx 5-10-toothed. }
$$

29 D. RA'dula (Cham. et. Schlecht. in Linnea. 3. p. 342.) stem herbaceous, weak, tetragonal, smoothish; leaves ovatelanceolate, acute, lined, scabrous above, and downy on the nerves beneath; stipulas downy, ciliated; whorles 6-10-flowered; calyx unequally 5-10-toothed, ciliated; fruit didymous. 4. S. Native of Brazil, in the provinces of Para and Rio Janeiro. Spermacòce ràdula, Willd. in Roem. et Schultes, syst. 3. p. 531. This probably belongs to a different genus from the calyx.

\section{Rasp-leaved Diodia. Pl. 3 feet.}

Sест. Il. Dasycépiala (from $\delta \alpha \sigma v \varsigma$, dasys, thick, and $\kappa^{*} \phi \alpha \lambda \eta$, kephale, a head; the flowers are disposed in dense thick heads). D. C. prod. 4. p. 565 . Capsules membranous, having the mericarps or nuts probably subdehiscent inside at length. Flowers disposed in heads.--This is probably a section of the genus Borrèria, or a proper genus.

30 D. Palu'stris (Cham. et Schlecht. in Linnæa. 3. p. 347.) stem herbaceous, glabrous, ercet, simple, tetragonal, with winged scabrous angles; leaves elliptic, rather cuneated, obtuse, but apiculated ; bristles of stipulas 7-9, long; heads of flowers axillary, rather pedunculate; limb of calyx 4-toothed. 2. S. $\mathrm{Na}$ tive of Brazil. Flowers white.
Marsh Diodia. Pl. 1 to 2 feet.

31 D. DAsYce'rnala (Cham. et Schlecht. l. c. p. 348.) plant glabrous, herbaceous, ascending, rather woody at the base; branches tetragonal; leaves lanceolate, on short petioles, rather glaucescent, with scabrous margins; bristles of stipulas $5-7$, hardly longer than the sheath; heads terminal, globose, girded by 4 leaves; calyx hairy, bidentate. $\psi$. S. Native of the south of Brazil. Flowers white.

Thick-headed Diodia. . Pl. $\frac{1}{2}$ to 1 foot.

32 D. ALA'ta (Nees et Mart. nov, act. bonn. 12. p. 11.) stem erect, glabrous, dichotomous at the base, tetragonal; angles membranous, spinulose ; leaves ovate, cuspidate, glabrous, with scabrous edges; bristles of stipulas 7-8, long; wliorles of flowers terminal, naked, globose; fruit obovate, crowned by the $2 \mathrm{ob}$ long-lanceolate teeth of the calyx. $\odot . S$. Native of Brazil, about the river Ilheos. Probably a species of Borrèria.

$H^{\text {Tinged }}$-stemmed Diodia. Pl. $1 \frac{1}{2}$ foot.

33 D. Bogoténsis (Clan. et Schlecht. in Linnza. 3. p. 347.) plant suffruticose; branches quadrangular, scabrous; leaves oblong-lanceolate, glabrous, serrulated on the margins, and on the midcle nerve beneath; heads of flower's terminal, rarely nearly axillary; fruit glabrous, obovate, crowned by the 4 scabrous teeth of the calyx. h.S. Native near the town of Santa Fe de Bogota. Spermacòce Bogoténsis, H. B. et Kunth, nov. gen. amer. 3. p. 347. Willd. in Rom. et Schultes, syst. 3. p. 530. Corolla white, having the throat, and upper part of the tube bearded.

Bogota Diodia. Shrub procumbent.

34 D. indeco'ra (D. C. prod. 4. p. 565.) plant decumbent or ascending, much branched, glabrous; stem tetragonal, scabrous along the angles; leaves oblong-linear, acuminated, glabrous, opposite, or falsely verticillate; bristles of stipulas longer than the sheath; heads of flowers terminal, girded by 4 leaves; fruit oval-oblong, glabrous, crowned by the 4 teeth of the calyx. - Native of Mexico, at the Cordillera de Cuchilagua, where it was collected by Berlandier. Perhaps the immature fruit is indehiscent. Perhaps a species of Borrèria.

Indccorous Diodia. Pl. decumbent.

Cult. For culture and propagation see Borrèria, p. 618.

CLXXX]X. TRIODON (from rosıs, treis, three, and ocous ofovtos, odous odontos, a tooth; the axis remains after the nuts of the fruit have fallen, and is tridentate at top). D. C. prod. 4. p. 566.-Diòdia species, Cham. et Schlecht, in Linnæa. 3. p. 343 .

Lin. syst. Tetríndria, Monogýnia. Calyx with a turbinate tube, and a 2 -1-toothed limb, and sometimes with accessory teeth. Corolla short, funnel-shaped, 4-cleft. Stigma bifid. Capsule chartaceons, 2 -celled, crowned by the calyx, containing 2 indehiscent 1 -seeded nuts; having the axis, along with the lateral nerves, remaining after the nuts have fallen, and therefore the axis appears tridentate.-Much branched glabrous shrubs, natives of Brazil, with acutely tetragonal branches. Leaves opposite and falsely verticillate, oblong or linear; floral ones small. Flowers axillary or terminal at the tops of the branches, small, disposed in spikes or fascicles. It differs from Diodia in the axis of fruit being permanent and tridentate; and in habit.

1 T. Anthospermoides (Cham. et Schlecht, in Linnæa. 3. p. 343. under Diodia) slırubby, much branched, glabrous, downy at top while young; branches acutely tetragonal; leaves sessile, linear, acute, opposite, or falsely verticillate; bristles of stipulas longer than the sheath; flowers usually by threes in the axils of the upper leaves, and appear almost spicate from the upper leaves being nearly abortive; calyx hairy, with many teeth. $\eta$. S. Native of Equinoctial Brazil.

Anthospermum-like Triodon. Shrub. 
2 T. glomera'tus (D. C. prod. 4, p. 566.) shrubby, much branched, glabrous; branchlets acutely tetragonal; leaves oblong-linear, opposite, and falsely verticillate; bristles of stipulas short ; flowers disposed in fascicles at the tops of the branches; teeth of calyx 4 , on the top of the fruit, 2 large, and 2 nearly obliterated. h. S. Native of Brazil. Diôdia Brasiliensis, Spreng. syst. 1. p. 406. Rùbia glomeràta, Pohl, in litc. Nearly allied to $T$. polymórpha, var. $a$, but differs in the bristles of the stipulas being one-half shorter, in the branchlets being glabrous, and in the flowers being in terminal fascicles.

Glomerate-flowered 'Triodon. Shrub.

3 T. polymónpin (Cham, et Schlecht, in Linnæa. 3. p. 34t. under Diòdia) shrubby, much branched, glabrous; branches tetragonal; leaves petiolate, oblong-linear, opposite, and falsely verticillate; bristles of stipulas rather longer than the sheath; flowers axillary and terminal, few; calyx bidentate, and sometimes with 2 accessory teeth. $h$. S. Native of Brazil. Fruit as in $T$. anthospermoides, to which it is very nearly allied.

Iar. a, microphýllus (Cham. et Schlecht, l. c.) tops of plant downy; leaves smaller and firmer; calyx hairy, 4-toothed. $h_{2}$. $\mathrm{S}$. Native of Brazil, in the province of Rio Janeiro, in dry, exposed places.

Var. $\beta$, intermèdius (Cham. et Schlecht. 1. c.) smoothish ; leaves flat, softish; calyx glabrous, 4 -toothed. $h$.S. Native of the south of Brazil.

Var. $\gamma$, macrophýllus (Cham. et Schlecht. l. c.) glabrous; internodes elongated; leaves flat, thinner and larger; calyx glabrous, bidentate. $\eta$.S. Native of the south of Brazil.

Polymorphous Triodon. Shrub $1 \frac{1}{2}$ foot.

Cult. The species of Triodon will grow in any good, light soil; and cuttings of them will strike root readily in the same kind of soil, under a hand-glass in heat.

CXC. CRU'SEA (in honour of G. Cruse, M.D., who has written on the rubiaceous plants of the Cape of Good Hope). Cham. et Schlecht. in Linnæa. 5. p. 165. D. C. prod. 4. p. 566. but not of Rich.

Lin. sxsт. Tetrándria, Monogýnia. Calyx with a didymous, ovate tube, and with the limb contracted at the base, and profoundly cleft at the apex, but not parted; lobes 4, linear-subulate, clongated, hairy, and 4 small accessory ones between these. Corolla salver-shaped, with a long tube, which is obconical at the apex; a naked throat, and a 4 -lobed limb. Stamens exserted. Style longer than the stamens, bifid at the apex. Fruit composed of 2 indehiscent, 1 -seeded nuts, which at length separate from the axis, which is permanent, flat, membranous, and retaining the calyx at its apex.-Herbs which are sometimes suffruticose at the base, erect or ascending. Leaves opposite, ovate-lanceolate. Stipulas sheathing, ciliated with bristles. Flowers red, disposed in capitate, terminal umbels, which are girded by involucra.

1 C. calocé phala (D. C. prod. 4. p. 567.) stem terete, herbaceous, villous ; leaves oblong-lanceolate, acuminated, with rather oblique nerves, of which 2 rise near the base on both sides; bristles of stipulas 7-9, hispid. $\odot$. H. Native of Mexico. Spermacòce capitàta, Moc. et Sesse. fl. mex. icon. ined. but not of $\mathrm{fl}$. per. Spermacòce hírta, Pav. ined. but not of Lin. Stamens longer than the lobes of the corolla. Corolla 4 lines long, red.

\section{Beautiful-headed Crusea. Pl. 2 feet.}

2 C. Ru'bra (Cham. et Schlecht. in Linnaa. 5. p. 165.) stem tetragonal, herbaceous, hispid; branches opposite; leaves ovate, acuminated, hairy, with the nerves oblique on both sides of the mid-rib; bristles of stipulas 7-9, hispid. $\odot$. H. Native of Vera Cruz and Cuba. Crucianélla híspida, Mill. dict. no. 4. Spermacòce rùbra, J $\mathrm{acq}$.hort. schoenbr. 3. p. 8. t. 256. Spermacòce longiflòra, H. B. et Kunth, nov. gen. amer. 3. p. 271.
Spermacòce strigosa, Sims, bot. mag. t. 1558. but not of Thunb. Spermacòce rìbra and S. strigòsa, Poir. Schultes. Flowers red! or purple.

Red-flowered Crusea. Fl. July, Aug. Clt. 1766. Pl. 2 to 3 feet.

3 C. coccínea (I. C. prod. 4. p. 567.) stem tetragonal, suffruticose at the base, glabrous; leaves ovate-lanceolate, acuminated, petiolate, glabrous, with 3 nerves on both sides of the mid-rib; bristles of stipulas 8 , glabrous, the middle one the longest. $々$. S. Native of New Spain. Spermacòce coccínea, Pavon, in herb. Dunant. Corollas scarlet, larger than in any other plant belonging to the tribe Spermacòce; it is even an inch long. Alabastra and lobes of the corolla beset with bristles on the outside; the rest of the corolla glabrous. Style exserted beyond the tube of the corolla. Fruit unknown; but the plant agrees in habit with the other species of the genus.

Scarlet-flowered Crusea. Pl. 1 to 2 feet.

4. C. BRachypix'Lla (Cham. et Schlecht. in Linnaa. 5. p. 165.) stem nearly terete, fistular, clothed with rather retrograde hairs; leaves broad-ovate, on short petioles, of a lifferent colour beneath, beset with scattered hairs above, and along the nerves beneath; heads of flowers terminal, involucrated by leaves: lobes of calyx triangular.-Native of Mexico, on Serra Colorado, where it was collected by Schiede and Deppe. Nearly allied to $C$. rubra, but differs in the characters indicated above, and in the fruit being much smaller, and nearly terete, not globose. Flowers red, smaller and shorter than in $C$, nùbra.

Short-leavcd Crusea. Pl. 2 feet.

Cult. The annual species should be treated as other tender annuals, by being raised in a frame, and afterwards planted out in the open ground in May. The shrubby species should be treated in the manner recommended for Triodon above.

CXC1. RICHARDSO'NIA (named by Kunth, in memory of Richard Richardson, an English botanist of the 16th century). Kunth, in mem. mus. 4. p. 430 , nov. gen. amer. 3. p. 350 . D. C. prod. 4. p. 567. but not of Neck.-Richárdia, Lin. gen. no. 439. Gærtn. fruct. 1. t. 25. A. Rich. mem. soc. hist. nat. Par. 5. p. 154.t. 14. f. 5. Schultes, syst. 7. p. 85. but not of Kunth. - Schièdea, Bartl. in herb. Hænke, but not of Cham. et Schlecht. nor of A. Ricl.

Lrn. sxsr. Tri-Mexándria, Monogýnia. Calyx with a subglabose tube, and a 6-7-parted limb; teeth or lobes unequal, without any accessory ones. Corolla funnel-shapel, with an obconical tube, and a spreading, 3-6-lobed limb; lobes valvate in restivation. Stamens equal in number to the lobes of the corolla; filaments exserted. Style 3-4-cleft at the apex. Stigmas rather capitate. Capsule containing 3-4 indehiscent, membranous, 1 seeded nuts, crowned by the permanent calyx, which at length becomes circumcised at the base, and falls off; leaving the nuts naked. Seeds peltate. Albumen between fleshy and horny. -Diffuse, decumbent herbs, natives of America. Roots almost simple, rather woody, with thick bark, which is wrinkled transversely; those of many of the species are used in various parts of the world as substitutes for I pecacuanha. Leaves opposite, ovate. Stipulas of many bristles. Flowers capitate at the tops of the branches, each head involucrated by the 4 uppermost leaves.

\section{Calyx 6-7-lobcd.}

1 R. SCA'Bra (St. Hil. pl. us. bras. 8, t. 8. Mart. spec. mat. med. bras. p. 10 . t. 9. f. 13 . root.) stems luairy; leaves ovate, or ovate-lanceolate, rarely oblong, acutish, with scabrotis margins; bristles of stipulas shorter than the sheath; heads many-flowered; lobes of calyx triangular, ciliated; segments of 4. 2 
corolla pilose at the apex. $4 . \mathrm{S}$. Native of Brazil, at Rio Janeiro, in sandy, cultivated fields, and by way sides; also of New Granada, in dry, sandy places near Ibague, and at VeraCruz; as well as of P'eru, about Lima and Cercado, Sc., Sweet, fl. gard. t. 91. Richárdia scàbra, Lin. spec. 470. Richárdia pilòsa, Ruiz et Pav. fl. per. 3. p. 50. R. scàbra and R. pilòsa, Pers. ench. 1. p. 392. R. pilòsa, H. B. et Kunth, nov. gen. amer. 3. p. 350. t. 279. Spermacòce hexándra, A. Rich. hist. nat. spec. p. 13. and 31. R. Brasiliénsis, Gom. mem. ipec. p. 31. t. 2. Virey, journ. pharm. 1820. p. 257. with a figure. Hayn. arzı. 8. t. 21, Spermacòce hirsùta, Rœm. et Schultes, syst. 7. p. 85. Corolla white, twice the length of the calyx. The roots are horizontal, and white, and are used as a substitute for Ipecacuanha, in the province of Rio Janeiro, where it grows in great plenty, under the name of Porya do Campo. It is the Ipecacuánha amylàce ou blanc, Nerat. dict. med. 26. p. 13. and therefore the white Ipecacuanha of the shops.

Scabrous Richardsonia, or White Ipecacuanha. Fl. Sept. Clt. 1814. Pl. procumbent.

2 R. ko'sra (St. Hil. pl. us. bras, no. 7. t. 7.) stems hispill, very hairy at the tops; leaves ovate-lanceolate, mucronately acute, with scabrous margins; bristles of stipulas longer than the sheath; heads few-flowered; lobes of calyx 6 , linear, rather hispid; corolla ventricose, having the segments pilose on the outside. 4. S. Native of Brazil, in dry, sandy places. R. emética, Mart. spec. mat. med. bras. p. 11.t.9. f. 19. Cham. et Schlecht. in Linnaa. 3. p. 35l. R. ròsea and R. emética, Schultes, syst. 7. p. 87 . Corolla rose-coloured, 3 times longer than the lobes of the calyx. Roots black, twisted, and are used as a sub-titute for Ipecacuanha in the neighbourlood of Joao del Rey, in Brazil, where it is cultivated in great quantities for that purpose, under the name of Poaya do Campo, and are, along with the roots of R. scabra, imported into Europe.

Rose-flowered Richardsonia. Pl. procumbent.

3 R. grandiflo'ra (Cham. et Schlecht. in Linnæa. 3. p. 351.) plant ascending; stems hispid from bristles; leaves lanceolate, acute, scabrous from bristles; bristles of stipulas rather longer than the sheath; heads few-flowered; segments of the calyx lanceolate, acuminated; corolla glabrous. 4. S. Native of the south of Brazil. Roots like that of $R$. ròsea. Curolla white, tipped with red. Stamens 6 .

Great-flowered Richardsonia. PI. decumbent.

4 R. r.itera'sis (D. C. prod. 1. p. 568.) erect, stem hispid from spreading hairs; leaves oblong-lanceolate, muriculated above, and pilose beneath; bristles of stipulas longer than the sheath; heads of flowers small, 3 times shorter than the bracteas, which are ovate-lanceolate, and hispid beneath at the base; lobes of calyx 6 , subulate, longer than the tube. 4 . S. Native of Brazil, where it was collected by Polll. Spermacòce lateràlis, Pohl, in litt. Very nearly allied to $R$. divérgens, but the fruit is unknown, and is therefore a doubtful species of the genus.

Latcral Richardsonia. Pl. 1 to 2 feet.

5 R. Dive'rgeNs (D. C. prod. 4. p. 568.) plant erect, hispid from bristles in every part; leaves linear-lanceolate, acuminated; bristles of stipulas longer than the sheath; heads small, 3 times shorter than the bracteas, which are lanceolate; limb of calyx very hispid, 6-cleft; fruit of 4 tubercularly muricated nuts. 4. S. Native of Brazil, Pohl ; and near Bahia, in cultivated places, Salzmann. Spernacòce divérgens, Polıl, in litt. Corolla white.

Diverging Richardsonia. Pl. 1 to 2 feet.

6 R. SPA'rSA (D. C. prod. 4. p. 568.) the whole plant hispid from bristles; branches trichotomous; leaves linear-lanceolate, acuminated; bristles of stipulas equal in length to the sheath: heads cither from the forks of the branches or from their tops; the latter one-half shorter than the bracteas, which are lanceolate; limb of calyx very hispid, 6-cleft ; fruit of 4 tubercularly muricated nuts. $\%$. S. Native of Brazil, Pohl; at Bahia, in dry pastures, Salzmann. Spermacòce spársa, Pohl, is litt. Flowers white.

Scattercd Richardsonia. Pl. 1 to 2 feet.

\section{§ 2. Calyx 4-lobed, very rarely 3-5-lobed.}

7 R. stella'ris (Cham. et Schlecht. in Linnæa. 3. p. 352.) plant decumbent, twisted; stem hairy; leaves lanceolate, acuminated, hairy; bristles of stipulas 5 , much longer than the sheath; heads hemispherical; segments of the calyx 4, oblong; corolla glabrous, about equal in length to the calycine teeth. $\odot . \mathrm{F}$. Native of Brazil, in the province of Cisplatine. Flowers 3-4parted, white?

Starry Richardsonia. Pl. decumbent.

8 R. mumisira'ta (Cham. et Schlecht. 1. c. 3. p. 354.) plant trailing, flexuous; stems clothed with canescent hairs; leaves ovate-lanceolate, acute, clothed also with canescent hairs; bristles of stipulas 3-6, equal in length to the sheath; heads hemispherical ; segments of calyx 4, oval ; corolla glabrous, rather longer than the lobes of the calyx. 4. S. Native of Brazil, in the province of Monte Video. Flowers small, tetramerous and pentamerous.

Trailing Richardsonia. Pl. trailing.

9 R. ADSCE'NDENS (D. C. prod. 4. p. 549.) stems ascending, villous; leaves oblong, attenuated at both ends, scabrous from pubescence on bath surfaces; heads terminal, on long peduncles; leaves of involucrum ovate, hardly exceeding the flowers ; calycine segments 5, acute; corolla tubular, downy outside at the tops of the lobes, the rest glabrous. 4. S. Native of Mexico. Spermacòce adscéndens, Pav. in herb. Moric. Richárdia villòsa, Moc. et Sesse, fl. mex. icon. ined., in which the corolla is more coloured.

Asccnding Richardsonia. Pl. ascending.

10 R. HeNkEA'Na (D. C. prod. 4. p. 569.) stems trailing, tufted, twisted, creeping, suffruticose, hairy; leaves oblong, villous; bristles of stipulas shorter than the sheath; heads of flowers flattish; lohes of calyx 4, ovate, acutish ; corolla subrotate. 4.? S. Native of Mexico, where it was collected by Hænke. Schièdea Mexicana, Bartl. in herb. Hænke.

Hanke's Richardsonia. Pl. trailing.

Cult. The species of this genus wil] thrive in any lights soil; and cuttings of them strike root readily in the same kind of soil, under a hand-glass, in a little heat.

CXCII. KNOXIA (named after Robert Knox, who lived many years in Ceylon, and published a relation of it in 1781). Lin. gen. no. 123. Gartn. fruet. 1. p. 121. t. 25. Lam. ill. t. 59. A. Rich. mem. soc. hist. nat. Par. 5. p. 152 . t. 15. f. 1. but not of P. Browne.-Spermacòce species, Roxb. Willd, and others.

LiN. syst. Tetrándria, Monogýnia. Calyx with an ovate, rather ribbed tube, and 4 small unequal teeth, which are permanent, and erectly connivent on the fruit. Corolla salvershaped, with a terete tube, a usually bearded throat, and a 4lobed limb. Anthers at the throat. Stigma 2-lobed. Fruit 2 -celled, usually separated from the base to the apex at the dissepiment into 2 indeliscent, 1 -seeded nuts, which are sometimes, however, combined at the base, and separating slowly, having the axis filiform, and remaining as in umbelliferous plants. Seeds ovate, triquetrons, erect. Albumen fleshy. Embryo erect.Herbs or sub-shrubs, natives of the East Indies. Stems terete or tetragonal. Leaves opposite, and falsely verticillate from axillary fascicles. Stipulas undivided, or of few bristles, joined with the base of the petioles. Cymes as in the plants belonging 
to the order Faleriànece, terminal, sessile, or pedunculate, having their branches becoming elongated and spike-formed, after flowering.

1 K. ZEYLÁnica (Lin. spec, p. 151.) stem erect, glabrous, nearly terete; leaves lanceolate, almost sessile, glabrous; branches of cyme 1-3, very long, spicate, erect; tube of corolla much longer than the calycine teeth; throat of corolla bearded; stigma exserted.-Native of Ceylon. Burm. fl. ind. 34. t. 13. f. 2. Lam. ill. t. 59. f. 1. Corolla 6 lines long. Fruit easily separated into 2 parts from the base.

Ceylon Knoxia. Fl. July, Aug. Clt. 1826. Pl. I foot.

2 K. Sumatrénsis (D. C. prod. 4. p. 569.) stem sufluticose, erect, tetragonal, tomentose; leaves lanceolate, remote, villous, on short petioles; corymbs terminal, compound ; tube of corolla gibbous, short. $h$. S. Native of the East Indies, among the Circars, and probably of Sumatra and Velore, as well as of Nipaul and Kamaon. Spermacòce Sumatrénsis, Retz, obs. 4. p. 23. Roxb. H. ind. 1. p. 372. Knóxia strícta, Gærtn. fruct. 1. p. 122. t. 25. Knóxia corymbòsa, Willd. spec. 1. p. $582 . ?$ but the fruit is not separable into 2 parts as in the following. Knòxia móllis, R. Br. in Wall, cat. no. 820. Flowers small, white.

Sumatra Knoxia. Fl. July, Aug. Clt. 1818 . Sh. 2 to $3 \mathrm{ft}$.

3 K. TE'res (D. C. l. c.) stem suffruticose, erect, branched, terete, villous; leaves lanceolate, villous; corymb terminal, compound, with opposite branches, which at length become spike-formed; tube of corolla terete, straight, with the throat very villous, and hiding the anthers; style twice the length of the corolla. $\xi$. S. Native of the East Indies, in woods at Koorg. Spermacòce tères, Roxb. fl, ind. 1. p. 373 . K. umbellàta, Banks, herb. ex Roxb.

Terete-stemmed Knoxia. F. June, Ang. Clt, 1820. Shrub $\approx$ to 3 feet.

4 K. EXse'ктA (D. C. 1. c.) stem suffruticose, stiff, villous in the younger parts; leaves lanceolate, petiolate, remote; corymbs terminal, compound; stamens exserted; style bifid, exserted; fruit ovate, hardly separable into 2 parts. $h$. S. Native of the East Indies, on the Circars, and of Nipaul. Spermacòce exsérta, Roxb. fl. ind. 1. p. 374. This is only, perliaps, a var. of $\mathbf{K}$. tères, according to Roxb.

Exserted-stamened Knoxia. Shrub 1 foot.

5 K. GLA'BRA (D. C. 1 c.) stem suffruticose, terete, glabrous; erect ; leaves linear-lanceolate, smooth ; corymbs axillary, compound ; style pilose ; stigma clavate; capsule globular, smooth. $h$. S. Native of Pulo-Penang. Habit almost of a grass, or Bamboo. Spermacòce glàbra, Roxb. fl. ind. 1. p. 374, but not of Mich. Spermacòce insulàris, Spreng. syst. 1. p. 4.0. Corolla campanulate, crean-coloured.

Glabrous Knoxia. Shrub 1 foot.

6 K. LE'VIS (D. C. prod. 4. p. 5\%0.) stem herbaceous, stifl; terete, smooth; leaves almost sessile, lanceolate, glabrous; corymbs terminal; corolla funnel-shaped, with a bearded throat and hidden anthers; stigma bifid. $\delta$. ex Roxb. ; $\odot$. ex Lesch. S. Native of Bengal, Spermacòce la'vis, Roxb. f. ind. 1. p. 374. Sperm. Roxburghiana, Schultes, mant. 3. p. 199. Sperm. Roxbúrghii, Spreng. syst. 1.p. 404. Leaves 3 inclıes long, and 6 lines broad. Flowers large, pink.

Smooth Knoxia. Fl. July, Aug. Clt. 1818. I']. 1 foot.

7 K. Heynea'na (D. C. prod. 4. p. 570.) stem obsoletely tetragonal, rather roughish; leaves lanceolate, ribbed, with scabrous margins, rough from dots on both surfaces; corymbs terminal, trichotomous.-Native of the East Indies. Knóxia species, Heyne. Spermacòce corymbòsa, Roth, nov. spec. p. 98. Rom. et Schultes, syst. 3. p. 278. but not of Lim. nor Burm. Very nearly allied to K. Sumatrénsis.

Heyne's Knoxia. Pl. 1 foot.
8 K. LINEA'TA (D. C. l.c.) downy; stem herbaceous, branched a little, erect, villous; leaves ovate-lancenlate, with parallel veins; bristles of stipulas pilose; cymes corymbose, pedunculate, tripartite, axillary, and terminal; stamens inclosed. $\odot . ? \mathrm{~S}$. Native of Java, among grass, ahout Rompien. Spermacoce lineàta, Blum. bijdr. p. 947. but not of Roxb.

Lined-leaved Knoxia. Pl. I foot.

9 K. Wigutia'na (Wall. cat. no. 6184.) plant glabrous ; stem and branclies slightly tetragonal; leaves lanceolate, mucronate, almost sessile ; corymbs terminal, compound, with spike-formed branches. দ. S. Native of the East Indies. Śpermacòce, Wight, herb.

Wiglt's Knoxia. Shrub 2 to 3 feet.

10 K. PLANTAGínea (Wall. pl. rar. asiat. 1. t. 92.) stems herbaceous, almost simple, rising in numbers from the root, which is fusiform: radical leaves long-lanceolate, pilose; cauline ones distant, narrower; flowers terminal, sub-capitate : one or two of the calycine teeth are elongated ; tube of corolla very long. 24. S. Native of the Burmese Empire, on the mountains. Flowers blue.

Plantain-like Knoxia. P!. 1 to 2 feet.

Cult. For culture and propagation sec Crùsea, p. 627.

CXCIII. PSYLLOCA'RPUS (from $\psi v \lambda \lambda \lambda^{\prime} s$, psyllos, a flea, and карлос, karpos, a fruit; in allusion to the colour and shape of the seeds). Mart. nov. gen, et spec. bras. 1. p. 14. t. 28. D. C. prod. 4. p. 570 , but not of Pohl.

Lin. syst. Tetrándria, Monogýnia. Calyx with a turbinate tube, and an 8-toothed limb; teeth subulate, 6 of which are very short, and the other 2 opposite, linear, and elongated. Corolla funnel-sbaped, with a bearded throat, and a 4-lobed acutish limb. Anthers 4, inclosed. Stigma emarginately 2-lobed. Capsule crowned by the teeth of the calyx, compressed from the back of the carpels, 2-celled, having the dissepiment parallel with the valves; cells 1-seeded. Seeds oval, or orbicular, winged, much compressed, fixed to the centre of the dissepiment. Enbryo straight, in the axis of thin albumen.-Snall Brazilian shrubs, with twiggy, tetragonal branches. Leaves opposite, and often fasciculately verticillate from clusters of the leaves in the axils of the opposite ones. Stipulas joined with the petioles, forming a sheath, ciliated with bristles. Flowers axillary or terminal.

1 P. ERIcoìes (Mart. 1. c. p. 45. t. 28. f. 1.) suffruticose, almost simple at the bottom, glabrous; leaves $8-12$, verticillate, shorter than the internodes; florvers terminal, sub-capitate. $\zeta$. S. Native of Brazil, in the province of Minas Geraes, at Bandeinha, near Tejuco. Branches slender, twiggy. Corollas pale blue. Calyx glabrous.

Heath-like Psyllocarpus. Slumb 1 to 2 feet.

2 P. Laricoides (Mart. l. c. p. 45. t. 28 . f. 2.) a muchbranched, glabrous shrub; leaves opposite, approximate, setaceous, clustered in the axils, and therefore falsely verticillate; flowers terminal, disposed in something like spikes. $h_{\imath} . S$. Native of Brazil, in the provinces of Minas Geraes and Bahia, in dry mountainous places. Cham. et Sclilecht. in Limas. 3. p. 357. P. larícinus, Spreng. cur. post. p. 39. Branches erectly spreading. Corollas pale blue, Calyx glabrous.

$\operatorname{Var}, \hat{\beta}$, densifolius (Mart. 1. c.). 々. S. Native of Brazil, os Serra de I tambe.

Lareh-like Psyllocarpus. Shrub $1 \frac{1}{2}$ to 2 feet.

3 P. asparagoides (Mart. 1. c. p. 46.) a glabrous shrub, with twiggy branches; leaves disposed in verticillate fascicles, very slender, and setaceous; peduncles terminal, elongated, naked; flowers capitate, $h$. S. Native of Brazil, in the province of Minas Geraes, near Piedade. Branches twiggy. Corollas small, white. Calyx glabrous. 
Asparagus-like Psyllocarpus. Shrnb 1 to 2 feet.

4 P. THYMBroldes (Mart. 1. c. p. 46.) shrub much branched; branches squarrose, downy; leaves downy, in fascicles; flowers terminal, somewhat spicate: calyxes hairy. $\zeta . S$. Native of Brazil, in the province of Minas Geraes, on Serra de Gran Mogol. Flowers azure blue.

Thymbra-like Psyllocarpus. Shrub 1 to 2 feet.

Cult. See Richardsonia, p. 628. for culture and propagation.

CXCIV. MITRACA'RPUMI (from $\mu$ roa, mitra, a girdle, or

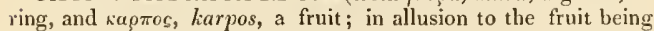
cut round about in the middle). Zuccar. in Roen. et Schultes, syst. 3. p. 210. (1827.). Cliam, et Schlecht. in Linnaa. 3. p. 358. A. Rich. mem. soc. hist. nat. par. 5. p. 151. t. 14. f. 4. D. C. prod. 4. p. 571.-Crùsea, Cham. in litt. 1829.-Schizángium, Bartl. in herb. Hænke.-Staurospérmum, Thoun. in Schum. pl. guin. (1827.) p. 73.-Spermacòce species of authors.

LiN. syst. Tetrándria, Monogýnia. Calyx with an ovate tube, and a 4-toothed, permanent limb; 2 of the teeth are usually larger than the other 2, which are always small, or nearly obsolete. Corolla salver-shaped, with a terete tube, which is furnished near the base inside with a circular line of hairs, a glabrous throat, and a 4-lobed limb. Anthers exserted, or inclosed. Stigma bifid. Capsule membranous, crowned by the calyx, 2-celled, circumcised round the middle. Seeds solitary in the cells, basilar, partly fixed to the dissepiment.- Herbs or sub-shrubs, witl the habit of Spermacòce, all natives of America, except one species from Africa. Leaves opposite. Stipulas combined with the petioles a little way, and ending in many bristles. Flowers in dense, verticillate, axillary and terminal heads, the latter always involucrated by 4 leaves. Corollas white.

\section{\$1. Tno of the calycine teeth are large, and tno small. * Suffruticose and herbaceous perennial plants.}

1 M. Humboldia'num (Cham. et Schlecht. in Linnæa. 3. p. 358. t. 3. f. 1.) erect; branches nearly terete, downy while young, but glabrous in the adult state; leaves linear-oblong, or lanceolate, pubescent or hairy on both surfaces; stipulas with .5 stiff bristles on each side, naked at the apex; flowers disposed in dense verticillate lieads; heads numerous, distant, terminal and axillary ones alike; the two large teeth of the calyx are subulate, and ciliated. $\eta$. S. Native of New Spain, on Silla de Caraccas; and of Brazil, in sand by the sea-side, at Rio Janeiro. The specimens from Caraccas are more hairy than the Brazil plant, which is trailing. Spermacoce frigida, Willd. in Roem. et Schultes, 3. p. 531. Kunth, nov. gen. 3. p. 349. Flowers white.

IIumboldt's Mitracarpum. Pl. 2 to 3 feet.

2 M. Sellowinum (Cham. et Schlecht. in Linnæa. 3, p. 361.) stem diffuse, much branched, clothed more or less with white hairs; leaves oblong or lanceolate, sessile, cuspidate, scabrous on both surfaces; stipulas cleft into many stiff bristles, membranous and villous at the base ; heads terminal, dense, involucrated by 4 leaves, which are 2 or 3 times longer than the head. -Native of Brazil, abont Rio Grande do Sul, Monte Video, Sc. ; in the Pampas of Buenos Ayres and Cordova. Capsule glabrous. The 2 larger teeth of the calyx are scabrous, erect, and subulate, with a very few additional denticulations. Flowers white. Leaves varying from 2 to 4 lines broad. Stem usually very villous, but sometimes almost glabrous, as well as the leaves.

Sello's Mitracarpum. Pl. diffuse.

3 M. Salzmannia'num (D. C. prod. 4. p. 57 1.) stems diffuse, much branched, hispid from spreading stiffish hairs; leaves ovate-lanceolate, scabrous on both surfaces, setigerous at the apex; stipulas villous, membranous at the base, cleft into many stiffish bristles; flowers disposed in dense, verticillate heads, the ultimate or terminal head round, and involucrated by 2.4 leaves, which are bardly longer than the head. 4. S. Native of Brazil, in sand by the sea-side, at Bahia, where it was collected by Salzmann. Very like $M$. Sellowianum, but differs in the characters indicated, as well as in the seeds being paler and onebalf smaller. Flowers white.

Salzmann's Mitracarpum. Pl. diffuse.

4 M. scinzá Naivm (D. C. prod. 4. p. 572.) suffruticose ; branches sub-tetragonal, downy ; leaves oblong-lanceolate, acuminated, scabrous on both surfaces, and on the margins; stipulas villous and membranous at the base, cleft in many stiff bristles: heads of flowers terminal and axillary, verticillate; the former involucrated by 4 leaves. $\zeta$. S. Native of Mexico, where it was collected by Hænke. Schizangium dùrum, Bartl. in herb. Hænke. Leaves $24-27$ lines long, and 4 broad. Teeth of calyx acuminated, scabrous. Flowers white.

Cut-capsuled Mitracarpum. Shrub diffuse.

5 M. cuspida'tum (D. C. prod. 4. p. 572.) stems ascending, branched, downy; leaves linear, cuspidate by a straight mucrone, almost veinless, glabrous; bristles of stipulas $3-5$, stiff, longer than the sheath; heads of flowers hemispherical, terminal, 3-4 times shorter than the bracteas; calyx with 2 cuspidate teeth, and 3-4 nearly abortive ones. 24. S. Native of Monte Video; and of Chili, at Maldanado, in the Banda Oriental. Stem hardly a hand high, suffruticose at the base. Heads of flowers 4 lines in diameter. Floral leaves 9 lines long, and a line broad. 'Tube of the corolla almost double the length of the calycine teetl. Flowers white.

\section{Cuspidate-leaved Mitracarpum. Pl. ascending.}

6 M. virga'tum (Cham. et Schlecht. in Linnæa. 3. p. 363.) stem suffruticose, erect, and are, as well as the branches, terete and glabrous : leaves linear, very narrow, flaccid; stipulas of two colours, ciliated; corollas long, tubular; stamens exserted. $\eta$. S. Native of Brazil. Spermacòce virgàta, Willd. in Roem. et Scliultes, syst. 3. p. 281. and 531. mant. 3. p. 205. Spreng. syst. 1. p. 401. Flowers white. Leaves $6-8$ in a whorl, according to Link, but are probably only in axillary fascicles.

Tniggy Mitracarpum. Shrub 1 foot.

7 M. Diffu'sum (Cham. et Schlecht. in Linnæa. 3. p. 363.) stems suffruticose, procumbent, terete, hairy; leaves lanceolate, beset with retrograde asperities on both surfaces, and serrulately ciliated on the margins; flowers capitate and verticillate; the 2 larger lobes of the calyx exceeding the corolla, which is salvershaped; capsule smoothish. দ. S. Native of South America, in woods about the Orinoco and Apure. Flowers white; stamens exserted; seeds oblong.

Diffuse Mitracarpum. Shrub diffuse.

8 II. Sagrea'Num (D. C. prod. 4. p. 572.) plant suffruticose, twisted and tufted, clothed with fine down; leaves oblong: heads of flowers axillary and terminal, the latter girded by 4 leaves: lobes of calyx 4,2 large concave and blunt, and 2 small. $h_{2}$. S. Native of Cuba, near the Havannah, where it was collected by Ramon de La Sagra. Flowers white. Seeds brown, lollow in front, and marked by 4 small rays.

Ramon de La Sagra's Mitracarpum. Shrub tufted.

9 M. SFNegale' NSE (D.C. prod. 4. p. 572.) glabrous; stem erect, suffruticose at the base, rather tetragonal; leaves oblong, acuminated at both ends: stipulas furnished with $2-3$ teeth on both sides; flowers disposed in capitate whorles; calyx with 4 teeth, 2 long and acute, and 2 small. $h . ? \odot . ?$ F. Native of Senegal, on the banks of the river at Walo, where it was collected by Bacle, Perrottet, and Leprieur; and in other parts of Guinea, hy Thonning. Oldenlándia verticillàta, Bacle, in litt. Staurospérmum verticillàtum, Thonn. in Schum. pl. guin. p. 73. Flowers white. Seeds small, nearly globose, pale, umbilicate in 
front, and marked by 4 rays. Perhaps the same as M. scàbrum, Zuccar. in Rœm. et Schultes, syst. 3. p. 210, which was found about Fort Louis.

Senegal Mitracarpum. Shrub.

$$
\text { * Annual plants. }
$$

10 M. Torresia'xum (Cham. et Schlecht. in Linnæa. 3. p. 360. t. 3. f. 2.) stem erect, simple, somewhat tetragonal, rather pilose on the angles; leaves elliptic-lanceolate, attenuated at the base, membranous, rather downy on both surfaces; stipulas membranous, with white villous bristles; flowers disposed in capitate whorles, the terminal one usually formed of 2 combined heads, and girded by 4 leaves. $\odot$. F. Native of Guajan and Marianne lslands. Flowers white.

Torres's Mitracarpum. Pl. $2 \frac{1}{2}$ foot.

11 M. viluòsus (Cham. et Schlecht. in Linnæa. 3. p. 363.) stem erectish, sparingly branched, slightly tetragonal, villous; leaves oval.-lanceolate, downy; stipulas membranous, cleft into many bristles; heads of flowers axillary, verticillate, and terminal, the latter girded by 4 leaves; anthers inclosed. $\odot$. F. Native of Jamaica. Spermacòce hírta, Jacq. icon. rar. t. 308. and probably of Lin. Spermacoce villosa, Swartz, obs. p. 45. Corolla white. Anthers yellow. Secds pale, somewhat tubercular on the back, and marked by a cruciate furrow in front.

Villous Mitracarpum. Fl. June, July. Clt. 1816 . J'. $\frac{1}{2}$ to 1 foot.

12 M. нírtum (D. C. prod. 4. p. 572.) stem erect, branched, scabrous, tetragonal; leaves ovate-lanceolate, clothed with hairy pubescence; stipulas membranous, with many bristles: axillary heads of flowers verticillate ; terminal ones girded by 4 leaves; anthers exserted. $\odot$. F. Native of Jamaica, in dry, grassy places; and of the Society Islands. Spermacòce lírta, Swartz, obs. p. 45. Very like M. villòsa, but diflers in being more branched, in the anthers being exserted and blue, and in the seeds being smaller, blacker, and concave in front, not with 4 rays.

Hairy Mitracarpum. Fl. June, July. Clt. 1818 . Pl. $\frac{1}{2}$ to 1 foot.

13 M. Fische'ri (Cham. et Schlecht. 3. p. 363.) stem erect, hairy, tetragonal ; leaves oblong, attenuated at the base, acute, downy from very short hairs ; stipulas ciliated ; flowers densely capitate, terminal; teeth of calyx 4 , lanceolate, acute, a little

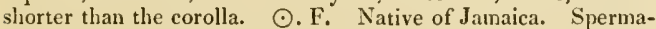
còce Fischèri, Link. enum. 1. p. 132. Spermacòce adscéndens, Fisch. ined. Corollas white. Habit of Spermacoce áspera, Aubl.

Fischer's Mitracarpum. Fl. May, June. Clt. 1821. Pl. 1 foot.

14 M. struòsum (Cham. et Schlecht. in Linnæa. 3. p. 363.) stem decumbent, terete, glabrous; leaves oblong-lanceolate, attenuated at the base; bristles of stipulas long ; flowers disposed in clense whorles; the two large teeth of the calyx are subulate at the apex; style exserted. $\odot$. F. Native of Manilla. Spermacòce stylòsa, Link. enım. 1. p. 132. Spermacòce crassifòlia, Hortul. Capsule membranous, glabrous. Corollas white. Seed orbicular, with a mark like the letter $\mathbf{x}$ engraven on the front, somewhat 4-lobed, of a pale, dirty colour.

Long-styled Mitracarpum. Fl. May, June. Clt. 1819. Pl. 1 foot.

\section{\$2. Calyx nith 4 nearly equal acuish tceth.}

15 M. Negle'ctum (D. C. prod. 4. p. 57 3.) plant glabrous, dichotomous; leaves oblong-linear, acute, almost veinless; bristles of stipulas 3 , stiff, longer than the sheath; heads of flowers terminal, 3 times shorter than the bracteas ; calyx glabrous, with 4, hardly acute teeth, which are a little shorter than the corolla. -Native of Brazil, where it was collected by Pohl. Spermacòce neglécta, Schott ex Pohl, in litt. Heads of flowers 5 lines in diameter. Floral leaves about an inch long, and 2 lines broad.

Neglected Mitracarpum. Pl.?

\section{$\uparrow$ Species not sufficiently linown.}

16 M. Seuarro'sum (Cham. et Schlecht. in Linnaea. 3. p. 363.) - Native of Cuba, on rocks about Havannah. Spermacòce squarròsa, Poepp. Nearly allied to $\mathbf{M}$. Sellowiànum, but differs in its smoothness.

Squarrose Mitracarpum. Pl.

Cult. See Borreria, p. 618. for culture and propagation.

CXCV. CRUCKSHA'NKSIA (named after Mr. Cruckslianks, the original discoverer of the plant, and a particular friend of both Hooker and Arnott). Hook. et Arn. in bot. misc. 3. p. 361. but not of Hook. in bot. misc. vol. 2. t. 90 .

Lis. Syst. Pentándria, Monogýnia. Calyx with a globose subdidymous tube, and a 5 -toothed limb; teeth usually furnished with an accessory small subulate tooth on each side; one or two of the teeth are usually expanded into large reticulated pedunculate roundish membranous wings. Corolla salver-shaped, with an elongated tube, a 5-cleft spreading limb, and a glabrous throat. Stamens 5, exserted, inserted in the mouth of the corolla. Filaments club-shaped, acute; antbers linear-oblong, fixed by the base. Style filiform, a little longer than the tube of the corolla; stigma bifid, pilose: the divisions linear and acute. Capsule nembranous, globose, subdidymous, crowned by the more or less widened calycine segments, 2-celled, 4valved; cells 2-seeded; valves ovate, very concave, boatshaped, 1 -nerved in the middle, separable from the thin membranous white dissepiment. Seeds large, obovate, black, tubercled, very deeply furrowed on the inside at the hylum. Albumen horny. Embryo central, very much curved; cotyledons flat; radicle nearly terete, inferior, elongated.-The whole plant is more or less pubescent. Root perennial, dividing into many stems at the neck. Stems herbaceous, terete, ascending, flexuous, branched. Leaves obovate-lanceolate, acute, tapering into the petiole, stipulate; stipulas interpetiolar, broad-subulate, free, or joined more or less. Bracteas involucra-formed, simple or tripartite, furnished with small subulately toothed stipulas at the base on both sides. Peduncles terminal and axillary. Flowers disposed into a rather large depressed cyme: having the corolla and calycine wings yellow.

1 C. HYuénodon (Hook. et Arn. l. c.) - Native of Chili, about Coquimbo. There are varieties with hoary or less pubescent leaves. This most extraordinary plant has little of the general appearance of any of the Rubiàcea, although in its most striking peculiarities, the dilatation of some of the calycine teeth into disproportionably large orbicular, or somewhat reniform petiolate wings, it has an aftinity with Musscénda. Its place in the order is, however, near Spcrmacòce and Mitracárpunt.

Membrane-toothed Cruckshanksia. Pl.

Cull. See Richardsomia, p. 628, for culture and propagation.

CXCVI. STAE'L1A (this genus is dedicated to the illustrious Baron Augustus de Stael Holstein). Cham, et Schlecht. 3. p. 364 . t. 3. f. 3. D. C. prod. 4. p. 573.

LiN. syst. Tetrandria, Monogýnia. Calyx with an ovate tube, and only 2 subulate teeth, with hardly any accessory ones. Corolla funnel-shaped, with a slender tube, and a 4-lobed acute limb. Stamens 4, exserted. Stigma 2-lobed. Capsule membranous, 2-celled, 2-valved, with an entire permanent dissepiment; valves concave, crowned each by a calycine tooth, cut at the 
base by a line from the dissepiment, and therefore falling asunder. Seed solitary, fixed to the dissepiment.-Brazilian herbs, with terete stems. Leaves glabrous, linear, opposite, and in axillary fascicles. Stipulas membranous, narrow, of many bristles, or acutely 3-lobed. Axillary heads of flowers verticillate, and the terminal ones globose. Allied to Mitracárpum.

1 S. THYmoìnes (Cham. l. c.) stem much branched, ascending, puberulous; stipulas acutely 3-lolsed; whorles of flowers few. 2. S. Native of the south of Brazil. Leaves 5 lines long, and hardly a line broad. Corolla purple. Heads of flowers size of small peas.

Thyme-like Staelia. Pl. $\frac{1}{4}$ to $\frac{3}{4}$ foot.

2 S. Galiojdes (D. C. prod. 4. p. 573.) stems glabrous, sparingly branched, twiggy, elongated; stipulas of many bristles ; whorles of flowers few.- Native of Brazil, where it was collected by Pohl. Spermacòce galioìdes, ex Pohl, in litt. Leaves an inch long, and half a line broad. Whorles of flowers distant at the top of the stem.

Galium. like Staelia. Pl. $\frac{\mathrm{T}}{2}$ foot.

3 S. REFLE'XA (D. C. l.c.) stems smoothish, much branched; branches twiggy; leaves linear, with rather revolute margins; stipulas tridentate; whorles in nearly all the axils; floral leaves reflexed.-Native of Brazil, where it was collected by Pohl. Spermacòce refléxa, Pohl, in litt. Whorles 20-30 on each branch. Leaves 4 lines long.

Reflexed-leaved Staelia. Pl. $\frac{1}{2}$ to 1 foot.

Cult. See Richardsònia, p. 628 . for culture and propagation.

CXCVII. TESSIERA (named after M. Tessier, who has witten on the diseases of wheat, and the effects of light upon plants, \&c.). D. C. prod. 4. p. 574.

Lix. syst. Tetrándria, Monogýnia. Calyx with an ovate tube, and a 4-lobed limb; lobes nearly equal, without any accessory ones. Corolla funnel-shaped, with a glabrous throat, and a 4-lobed limb. Stamens hardly exserted. Stigma 2-lobed. Capsule 2-celled, 2-valved, with an entire oval deciduous dissepiment; valves concave, crowned by the teeth of the calys, falling asunder from being cut vertically along the dissepiment. Seeds solitary in the cells, fixed to the middle dissepiment.-American lierbs, clothed in every part, except the corollas, with tomentum or wool. Leaves opposite, sessile, lined by the nerves. Stipulas cleft into many bristles. Flowers axillary, sessile, few, verticillate, bracteolate.-This genus is nearly allied to Staelia from the structure of the fruit, but to Borrèria or Diodia from habit.

1 T. LANífera (D. C. prod. 4. p. 574.) plant clothed with long white wool; stem or branches twigey, terete-Native of Brazil, where it was collected by Pohl. Diòdia or Spermacòce lanifera, Polkl, in litt.

Wool-bearing Tessiera. Pl.

2 T. zituospermoides (D. C. prod. 4. p. 574.) plant suffruticose, erectish, branched, grey in every part from crowded short velvety down; fruit at length glabrous. $\zeta_{2}$ ? $24 . ?$ S. Native of Mexico, where it was collected by Hænke. Spermacoce lithospermoìdes, Bartl. in herb. Hænke.

Lithospermum-like Tessiera. Pl. 1 foot.?

Cult. For culture and propagation, see Richardsònia, p. 628.

CXCVIII. GAILLO'NIA (evidently named after some person of the name of Gaillon, of whom we know nothing). A. Rich. mem. soc. hist. nat. par. 5. p. 153. t. 15. f. 34. D. C. prod. 4. p. 574 .

Lin. syst. Pent-Heptándria, Monogýnia. Calyx witlı an ovate tube, and a 5-7-lobed permanent limb; teeth unequal. Corolla funnel-shaped, with a terete tube, and a 5-7-lobed linb; lobes oblong. Stamens 5-7, exserted from the throat, but shorter than the corolline lobes. Style filiform, thickened at the apex; stigma 2-lobed. Fruit egg-shaped, almost naked at the apex, containing 2 scparable, 1-sceded, indeliscent nuts.Hard, oppositely-branched herbs, velvety from fine down in every part, as also on the corollas. Leaves linear, ending in a callous mucrone, opposite, bearing $t w i n$ stipulas on both sides, which are sometimes short and truly stipula-formed, and sometimes long and foliaceous, and in the latter case appearing like those of Galium. Flowers some in the forks of the branches, sessile, solitary, and naked, and others sessile at the tops of the branches, between the 2 superior leaves.- Habit of $A$ spérula. with a velvety aspect. This genus ought probably to be placed among Rubiàcece, sect. Stellàta.

1 G. OLnE'kI (Rich. J. c.) stem multiple, brachiate, and as if it was articulated; branches opposite; leaves distinct at the base, linear-subulate, spinescent at the apex; stipulas leafformed, distinct from the leaves. h.? 24.? F. Native of Persia, between Teheran and Ispaban, where it was collected by Olivier and Brugniere.

Olivier's Gaillonia. Pl. $\frac{1}{2}$ foot.?

2 G. BRUGUE'rir (A. Rich. l. c.) stem multiple; leaves linearlanceolate. $h . ? 2$.? S. Native along with the preceding, and probably only a broad-leaved variety of it.

Bruguiere's Gaillonia. Pl. $\frac{2}{2}$ foot.?

3 G. Szowítzir (D. C. prod. 4. p. 574.) stem branched at top; branches erect: leaves subulate; upper ones connate at the base, and adhering to the stipulas, and therefore appearing trifurcate and trispinose at the apex. 4 . F. Native of Persia, in very arid, stony places near Nekhitcheven, where it was collected by Szowitz. - A very distinct species.

Szonitz's Gaillonia. Pl, $\frac{1}{2}$ foot.

Cult. The species of Gaillonia should be grown in pots, half filled with pot-sherds, in a mixture of sand and peat, and placed anong other alpine plants. They may be increased either by cuttings or seeds.

CXCIX. MACHAO'NIA (named after Machaon, an eminent hero and physician, who, with his brother Podalyriıs, accompanied the Grecian army in the expedition against Troy, and performed great services among the troops). Humb. et. Bonpl. pl. equin. 1. p. 101. t. 29. H. B. et Kunth, nov. gen. amer. 3. p. 350. Juss. mem. mus. 6. p. 382. Cham. et Schlecht. in Linnæa. 4. p. 2. A. Rich. mem. soc. hist. nat. par. 5. p. 161. D. C. prod. 4. p. 574 .

J.1N. syst. Pentándria, Monogýnia. Calyx with an obovate tube, and a small 5-parted limb. Corolla funnel-shaped, 5-cleft, with a short tube, and a villous throat. Stamens 4 , inserted in the throat, exserted; anthers rather cordate. Stigma bipartite. Capsule oblong-cuneated, rather tetragonal, crowned by the limb of the calyx, 2-celled, separable into 2 , 1 -seeded, indebiscent, ligneous-coriaceous, trigonal nuts, which are fixed internally to the linear axis beneath its apex. Seeds solitary in the cells, pendulous. Radicle superior. Albumen fleshy.-Shrubs or trees natives of South America. Leaves opposite, petiolate, acuminated. Stipulas interpetiolar, solitary on both sides. Panicles sub-corymbose, terminal. Flowers white, hardly larger than those of Aspérula.

1 M. Acumixa'ta (Humb. et Bonpl. pl. equin, t. 29.) unarmed; leaves ovate-elliptic, slıort-acuminated, downy on both surfaces. $\zeta$. S. Native in the town of Guayaquil, by way sides, where it is called Ceiba-blanea by the natives. H. B. et Kunth, nov. gen. amer. 3. p. 350. Flowers white.

Aeuminated-leaved Machaonia. Tree 25 feet.

2 M. Brasilie'ssis (Cham. et Schlecht, in Linnæa. 4. p. 2.) unarmed; leaves oblong-lanceolate, acuminated, having the veins downy beneath. $h$. S. Native at the mouth of the Amazon, about Gran-Para. Cinchòna Brasiliénsis, Hoffmanseg. ex Willd. mss. in Humb. berl. mag. p. 119. Rœm. et Schultes, 
RUBIACER. CXCIX. Machaonia, CC. Serissa.

syst. 5. p. 13. Flowers white. Salzmann collected a plant which is, perhaps, referrible to the present species, on the hills about Balia, in Brazil, in which the stem is scandent; the branches tetragonal, and villous on the angles; the panicles terninal; the flowers small, white; and the throat of the corolla villous.

Brazilian Machaonia. Shrub cl.?

3 M. spixòs A (Cham, et Schlecht. in Linnæa. 4. p. 2.) branchlets spinescent; leaves elliptic-lanceolate, acuminated at both

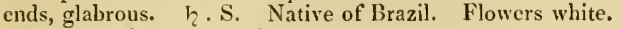

Spinose Machaonia. Slurub or trec.

Cult. See Richardsonia, p. 628. for culture and propagation.

Subtribe III. PUTORIE"E (the plants contained in this tribe agree with the genus Putoria in having flesliy, indivisible fruit). D. C. prod. 4. p. 575. Fruit rather fleshy, not separable into parts.

CC. SERI'SSA (a name given by Dioscorides, but the meaning is unknown). Comm. in Juss. gen. (1789.) p. 209. men. mus. 6. p. 395. Lam. ill. t. 151. f. 3. Blım. bijdr. p. 969. A. Rich. mem. soc. hist. nat. Par. 5. p. 161. D. C. prod. 4. p. 575. - Dysòda, Lour. (1790.) coch.-Buchòzia, L'Her. diss. with a figure.-Lýcium species, Lin. fil. and Thunb.

Lin. sist. Tctra-Pentándria, Monogýnia. Calyx with an obovate tube, and a 5, rarely 4-cleft limb; lobes short, and sometimes with a few accessory teeth between them. Corolla funnel-shaped, with the tube hairy inside, and a 5, rarely 4.parted limb; lobes induplicate in rstivation: hence they are somewhat trifid at the apex. Stamens 5 , rarely 4 . Anthers exserted, lincar. Style inclosed; stigma bifid. Berry nearly globose, 2-celled, 2-seeded, crowned by the limb of the calyx, ex Rich.-A small shrub, glabrous in every part except the young branches, which are whitish. Leaves small, almost sessile, opposite, and generally in axillary fascicles, having an ungrateful scent when bruised. Stipulas combined with the petioles, and ciliately fringed on the margins. Flowers terminal, in fascicles, almost sessile, white.-The fruit is described by Blume and Jussieu as many-seeded.

1 S. FE'TIDA (Comm. l. c.). 々 . G. Native of China, Japan, Cochin-china, and other places of the East. Lýcium Japónicum, Thunb. fl. jap. p. 93. t. 17. Curt. bot. mag. 361. Lýcium foe'tidum, Lin. fil. suppl. 150. Lýcium I'ndicum, Retz, obs. 2. p. 12. Dysòda fasciculàta, Lour. coch. p. 146. Buchòzia caprosmoides, L'Her. diss. with a figure. Dysòda fœ'tida, Salisb. prod. p. 60. Spermacòce fruticòsa, Desf. hort. Par. A small bushy shrub, with small dark-green, shining, myrtle-like leaves, and white single or double flowers, which are reddish outside. I'he plant from Japan differs from that of Clina, according to Blume, in the hairs on the inside of the throat of the corolla being geniculated, not clavate. feet.

Fetid Serissa. Fl. May, Sept. Clt. 1787. Shrub 2 to 3

Cult. This little shrub grows well in a mixture of loam, peat, and sand; and cuttings root readily in sand, with a handglass over them.

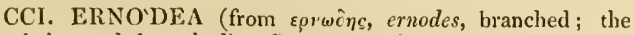
shrub is much branched). Swartz, prod. p. 29. fl. ind. occ. 1. p. 223. t. 4. Schreb. gen. no. 1718. Juss. mem. mus. 6. p. 373. Gærtn. fil. carp. 3. p. 94. t. 196. A. Rich. mem. soc. hist. nat. Par. 5. p. 156 t. 15 . f. 2 D. C. prod. 4. p. 575.

Lin. syst. Tetra-Hexándria, Monogýnia. Calyx with an ovate tube, and a 4-6-parted limb; lobes oblong-linear, acute, erect, permanent. Corolla salver-shaped, with a terete, somewhat tetragonal tube, a naked throat, and 4-6 lanceolate, revolute lobes, ex Riclı; but circinnately convolute according to VOL. III. others. Stamens with the filaments free from the upper part of the tubc, longer than the corolla; anthers acute, erect. Style longer than the stamens; stigma emarginate. Berry ronndish, crowned by the calyx, bisulcate, 2-celled, containing two 1seeded pyrena, or muts. Sceds peltate, ex Rich, fixed by a longitudinal chink in the middle. Albumen cartilaginous. Embryo erect, with foliaccous cotyledons.-A decumbent shrub, native of America. Leaves opposite, almost sessile, lanceolate or elliptic. Flowers axillary, pale yellow, sessile.

1 E. littora'lis (Swartz, l. c.). $\zeta$. S. Native of Jamaica, Porto Rico, Guadaloupe, and others of the West India Islands, on the sea shore, Vahl, symb. 2. p. 28.-Knoxia, Browne, jam. 140. no. 1. Thymelæa, Sloane, hist. jam. 2. p. 93. t. 169. f. 1-2. Berries yellow. In $\mathrm{H}$. mex. the flowers are painted white, and the berries reddish; it is, therefore, perhaps a distinct specics. Stipulas surrounding the branch ciliated.

Sea-shore Ernodea. Shrub decumbent.

Cult. See Richardsònia, p. 628. for culture and propagation.

CCII. CU'NCEA (meaning unknown to us). Ham. in D. Don, prod. fl. nep. p. 135. A. Rich. menı. soc. hist. nat. Par, 5. p. 157. D. C. prod. 4. p. 576.

Lin. syst. Tetrádria, Monogýnia. Limb of calyx small, 4-toothed. Corolla with a sloort tube, a 4-cleft limb, and a throat closed by villi; lobes or segments of the limb roundish. Anthers 4, linear, sessile, inclosed. Stigma bifid, exserted. Berry 2-celled, 2-seeded, crowned by the calyx.-Herb perennial. Stem erect, branclied, terete, tomentose. Leaves opposite, petiolate, nerved downy on both surfaces, 2-3 inches long; lower ones elliptic; upper ones lanceolate, mucronate. Stipulas twin, tripartite, with the lobes setaceous. Cymes terminal, compound, trichotomously branched, many-flowered. Flowers small, yellow.

1 C. Trífida (Hamil. l. c.). 4. F. Native of Nipaul.

Trifid-bractead Cuncea. Pl. $1 \frac{1}{2}$ foot.

Cull. For culture and propagation, see Richardsònia, p. 628.

CCIII. HYDROPHILAX (from icwo, hydor, water, and $\phi v \lambda a \xi, p h y l a x$, a keeper, or guardian; the plant always grows by the sea-side). Lin. fil. suppl. p. 126. Lam. ill. 76. f. 1. A. Rich. mem. soc. hist. nat. Par. p. 158. D. C. prod. 4. p. 576.Seríssus, Gært. fruct. 1. p. 118 . t. 25.

LiN. syst. Tetrándria, Monogýnia. Calyx with an ovate, angular tube, and a 4-parted, permanent limb (f. 109. a.); teeth acute, erect. Corolla campanulately funnel-shaped, 4-lobed (f. 109. a.). Anthers 4, sessile in the throat, exserted, linearoblong (f. 109.f.). Stigma roundly 2-lobed (f. 109. b.). Berry dry, corky, angular, lanceolate, crowned by the calyx, 2-celled (f. 109. c.). Seeds solitary in the cells, oblong, bisulcate inside, with hard albumen, and a straight embryo.-Glabrous, crecping herbs. Stems terete. Leaves opposite, ovate-oblong, fleshy, joined with the stipulas into a cupular toothed sheath at the base. Flowers axillary sessile, usually by twos, pale lilac. -This genus is very nearly allied to Liòdia, but differs in the fruit not being divisible into 2 parts, and in the stipulas not being cut into many bristles.

1 H. MARítima (Lin. fil. suppl. p. 126.). 4. S. Native of Malabar and Coromandel, in the sand by the sea side, Roxb. 4 II
FIG. 109.

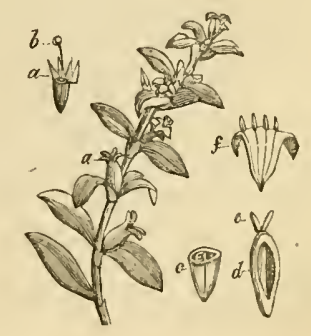


634 rubiace,e. CCili. Hydrophilax. CCiv. Scyphiphora, CCV. Plocama. CCVi. Putoria. CCVit. Caprosma.

corom. 3. p. 30. t. 233. f. ind. 1. p. 380. Seríssus ánceps. Gærtn. 1. c. Flowers of a lilac colour. Habit of Arenaria peploìdes, but larger (f. 109.).

Sea-side Hydrophilax. Pl. creeping.

\section{$\uparrow A$ species not sufficiently knon'n.}

2 H. Madagascarie'nsis (Willd. herb. ex Rom. et Schultes, syst. 3. p. 527.) leaves lanceolate, acute, sessile, closely imbricated, sheathed; flowers terminal.-Native of Madagascar, where it was collected by Commerson.

Madagascar Hydrophilax. Pl. creeping.

Cult. This plant should be grown in a pot filled with small gravel, and watered from time to time with salted water. It will be easily increased by separating the rooted stems, or by seeds.

CCIV. SCYPHI'PHIORA (fiom $\sigma \kappa v \phi o s, ~ s k y p h o s$, a bowl or cup, and $\phi \varepsilon \rho \omega$, phero, to bear; application not evident). Gartn. fil. carp. 3. p. 91 . t. 196 . Blum. bijdr. p. 955 . A. Rich. mem. soc. hist. nat. par. 5. p. 159. t. 14. f. 1. D. C. prod. 4. p. 577.Hydrophi'lax species, Juss.

Lin. syst. Tetrándria, Monogýnia. Calyx with an ovate tube, and a short tubular truncate nearly entire limb. Corolla funnel-shaped, laving the tube hairy iuside, and the limb with $\mathrm{A}$ lanceolate spreading segments. Stanens 4, exserted; filaments short; anthers incumbent inwardly. Stigma bifid, with approximate lobes. Drupe baccate, crowned, 8-furrowed, containing 2 bony oblong 1-seeded pyrenæ or nuts, which are flat inside, and furrowed on the back. Albumen flesliy. Embryo central, erect, with oblong cotyledons, and a somewhat incurved radicle. -A shrub native of the Moluccas. Leaves opposite, veinless. Flowers subcorymbose, axillary.

1 S. hydropjila'cea (Gærtn. and Blum. l. c.). 々. S. Native of the Moluccas, by the sea side. Hydrophi'lax, Banks, herb.

Hydrophilax-like Scyphiphora. Slurub.

Cult. For culture and propagation see Hydrophilax above.

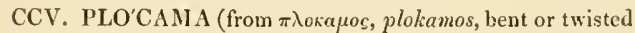
hairs; in reference to the numerous slender, pendulous branches). Ait. hort. kew. ed. 1. p. 292. Gærtn. fil. carp. 3. p. 196. Juss mem. 6. p. 371. A. Rich. mem. soc. hist. nat. Par. 5. p. 161. D. C. prod. 4. p. 577.-Plácoma, Pers. ench. 1.p. 210.Bartlíngia, Rehb. in flora 1824. p. 241. icon. exot. 1. t. 11. but not of Brongn.-Plócoma and Bartlíngia, Spreng. syst.-Plócoma and Plácoma, Gmel. syst.

Lin. sxst. Penta-Hexandria, Monogynia. Calyx with an ovate-globose tube, and a small sinuately toothed limb. Cololla campanulately funnel-shaped, 5-cleft, rarely 6-cleft. Anthers inserted between the lobes of the corolla, sessile at the throat, linear. Stigma thickisl, slightly 2 -lobed, or undivided. Fruit almost baccate, areolate at the apex, and crowned by the small inflexed calyx, 2-3-celled. Endocarp membranous. Seeds solitary in the cells, erect, with thin albumen. Embryo with a terete radicle, and flat cotyledons. - A small, glabrous, much-branched shrub, with the branches terete, slender, and pendulous. Leaves linear-filiform, opposite. Stipulas combined, with the petioles short, bluntly toothed, membranous. Flowers solitary or by threes in the axils of the upper leaves, and on the tops of the branclies, white, on short peduncles.

1 P. PE'ndura (Ait. l. c.). দ. G. Native of the Canary Islands. Plácoma péndula, Poir. suppl. 4. p. 441. Bartlíngia scopària, Rehb. icon. exot. t. 11. and Plácoma péndula, Rchb. p. 9. with a good description and figure. Habit of Gàlium. Leaves 2 inches long.
Pendulous Plocama. Clt. 1772. Shrub 2 feet.

Cult. See Seríssa, p. 633. for culture and propagation.

CCVI. PUTO'RIA (from putor, rankness; in reference to the smell of the leaves when bruised). Pers. ench. 1. p. 524. A. Rich. mem. soc. hist. nat. Par. 5. p. 160 . D. C. prod. 4. p. 577. Aspérula species, Lin. fil.- Sherárdia species, Cyr.-Pavétta species, Cyr.-Ernòdea species, Smith.

Lin. syst. Pentándria, Monogýnia. Calyx with an ovate tube, and a short tubular, 5-toothed limb. Corolla salvershaped, with a long terete tube, a glabrous throat, and 4 spreading, acutish lobes. Filaments of stamens short, rising from the top of the tube of the corolla, hardly exserted. Antliers oblonglinear, ex Rich. Stigma bifid. Berry nearly dry, ovate-oblong, umbilicate, 2-celled. Seeds oblong, solitary in the cells.-Shrubs stiff. Leaves opposite, fetid when bruised, oblong-linear, obtuse. Stipulas solitary on both sides. Flowers sessile on the tops of the branches, in fascicles. Habit of Dáphne Gneòrum.

1 P. CaLA'brica (Pers. l. c.) stem shrubby, much branclied; branches clothed with velvety down; leaves oblong, obtuse, smoothish; stipulas solitary on both sides. দ. F. Native of Calabria, Candia, Syria, Atlas, Sicily, \&c. on calcareous rocks. Aspérula Calábrica, Lin. fil. suppl. p. 120. L'Her. stirp. nov. 1. p. 65. t. 32. Sherárdia fótida, Lam. dict. 4. p. 326. Pavétta foetidíssima, Cyr. pl. neap. 1. p. S. t. 1. Ernòdea montàna, Sibth. and Smith, fl. græc. t. 143. Guss. fl. sic. 1. p. 169. Lonicèra Sícula, Ucria, pl. add. p. 249. ex Guss. Sherárdia foetidíssima, Cyr. char. 69. t. 3. f. 7. Pavétta foetidíssima, Cyr. neap. fasc. 1. t. 1. Flowers red. Habit of Aspérula. Leaves pale beneath, scabrous on the edges and keel.

Calabrian Putoria. Fl. July. Clt. 1820. Shrub $\frac{1}{2}$ to 1 foot.

2 P.? I'NDicA (D. C. prod. 4. p. 577.) stem herbaceous, sparingly branched, rather radicant at the base; branches hispid from villi; leaves ovate, acute, villous; stipulas twin on both sides, subulate. 4. F. Native of the East Indies, on the Nellighery mountains, in humid places, where it was collected by Leschenault, who has called it Aspérula from liabit, in his herbarium. Style exserted, divided at the apex into 2 thickish, hispid, short stigmas. The flowers are much like those of the first species, but the fruit being unknown, the genus to which it properly belongs is still doubtful.

Indian Putoria. Pl. $\frac{1}{2}$ to 1 foot.

Cult. A mixture of chalk, sand, and peat will be the best soil for the species of Putoria; and they may be readily increased by cuttings or seeds.

\section{Tribc XI.}

ANTHOSPE'RMEE (the plants contained in this tribe agree with the genus Anthospérmum in particular cliaracters). Cham. et Schlecht. in Linnæa. 3. p. 309. A. Rich. mem. soc. list. nat. Par. 5. p. 136. D. C. prod. 4. p. 578. Flowers dioecious, or hermaphrodite. Corolla rotate (f. 110.b). Styles separate to the base, ending in an elongated, hispid, or plumose stigma each (f. $110 . c$.). Frnit constantly of 2 indebiscent, 1 -seeded mericarps or nuts (f. $110 . g . f$. ), which are easily separated at maturity. Albumen fleshy.-Small shrubs or herbs. Leaves opposite or verticillate. Stipulas small, 1-3-toothed, adnate to both sides of the petioles.

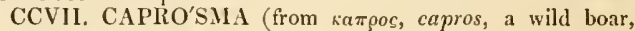
and $o \sigma \mu \eta$, osme, a smell; in allusion to the species having a fetid smell). Forst. gen. t. 69. Lam. ill. t. 186. and S54. Juss. mem. mus. 6. p. 381. A. Rich. mem. soc. hist. nat. Par. 5. p. 137. D. C. prod. 4. p. 578 .

Lin. syst. Tetra-Heptándria, Digýnia. Calyx with an ovate tube, and a 5.7-lobed short limb (f. 110 . a.). Corolla cam- 
panulately turbinate, with a short broad tube, a naked throat, and 4-7 acute lobes (f. 110. b. e.). Stamens 4-7 (f. 110.k.). Style almost divided to the base into 2 parts; the divisions filiform, very long, pilose (f. $110 . c_{\text {. }}$ ), and exserted. Berry nearly ovate, pulpy, containing $2-3$ indehiscent, bony nuts (f. 110 . f.). Seeds flat on one side, and convex on the other: one in each nut. Albumen hard, fleshy. Embryo with an inferior radicle, and foliaceous cotyledons.-Glabrous shrubs, natives of A ustralia. Leaves opposite, oval-oblong. Stipulas interpetiolar, solitary on both sicles, permanent. Flowers axillary and terminal, solitary or few together on the same peduncle, bibracteolate at the base, sometimes male by abortion. Fruit of Coffèa. Stigma of Anthospérmum.

1 C. HIRTÉLla (I Jabill. nov. holl. 1. p. 70. t. 95.) leaves oblong, cuspidate; peduncles simple; flowers 3-5 together, axillary or terminal, hermaphrodite; anthers inclosed; styles very long, hairy. $h_{\imath}$. G. Native at Cape V Tan Dieman. (F. 110.)

Hairy Caprosma. Sh. 8 feet.

2 C. Foctidíssina (Forst. prod. no. 138.) peduncles simple; flowers solitary; anthers exserted. . G. Native of New Zealand. Leaves opaque. Herb very fetid.

Very-fctid Caprosma. Shrub.
FIG. 110

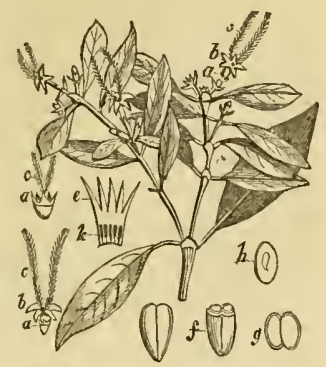

3 C. LU'Cida (Forst. prod. no.

138.) leaves ovatc, acuminated at both ends; peduncles axillary, compound; flowers sub-capitate; anthers exserted. Ћ.G. Native of New Zealand.-C. lùcida, Gærtn. fil. carp. 3. p. 17. t. 182. is probably distinct from Forster's plant, and even appears to belong to a different genus, as the fruit is said to be a unilocular, 8-seeded berry.

Shining-leaved Caprosma. Shrub.

4 C. cuspidifòlia (D. C. prod. 4. p. 578.) leaves oval, attenuated at the base, and ending in a spine-formed point at the apex; flowers axillary, few, fasciculate, almost sessile. $\boldsymbol{h}$. G. Native of Australia, at the Strait d'Entrecastcaux. The flowers are probably dioecious, as in a specimen we examined they were all female. Limb of calyx nearly entire. Lobes of corolla 4-7, linear, striated by 3 parallel nerves. Anthers 1-3 at the top of the tube. Style solitary? very hairy, elongated. Berry ovate, 2-celled, crowned by the calyx. Stipulas triangular, acuminated.

Cusp-leaved Caprosma. Shrub.

Cult. For culture and propagation, see Phýllis.

CCVIII. PHY'LLIS ( $\phi v \lambda \lambda o v$, phyllon, a leaf; the leaves are the chief beauty of the shrub). Lin. gen. no. 323. Gærtn. fruct. 1. p. 123. t. 25. Juss, mem. mus. 6. p. 370 . A. Rich. mem. soc. hist. nat. Par. 5. p. 140. t. 12. f. 3. D. C. prod. p. 578.-Nóbula, Adans. fam. 2. p. 145.-Bupleuroides, Boerb. -Valerianélla, spec. Dill.

LIN. syst. Pentándria, Digýnia. Calyx with an obovate, compressed tube, and an obsolete limb. Corolla with a short tube, and a 5 -lobed spreading limb. Stamens 5. Anthers sessile at the throat. Style almost wanting. Stigmas 2. Capsule obovate, compressed, narrow at the apex, divisible into twol-seeded parts, or nuts, ex Gærtn. which hang from the central filiform axis, as in the genus Knóxia, or as in umbelliferous plants, ex Rich; but according to others there is no central axis. Seeds erect, conforming to the mericarps. Albumen fleshy. Embryo erect, dorsal, with a filiform radicle, and cordate foliaceous cotyledons.
-Glabrous shrubs, with terete branches. Leaves opposite, or 3-4 in a whorl, acuminated. Stipulas membranous, adnate to the petioles, and cleft into many filiform bristles. Panicles terminal, compound. Flowers small, greenish white, but changing to brownish as they fade. According to Cruse, ex Linnæa. 6. p. 20. the fruit is shining, and the nuts are fixed by the base, not hanging from a central filiform axis.

1 P. Nóbla (Lin. spec. p. 333.). 々. G. Native of the Canary Islands.-Dill. elth. p. 405. t. 299. f. 386. Panicles manyflowered. Leaves large.

Var. $\beta$, pauciflora (D. C. prod. 4. p. 579.) peduncles 1-3flowered, shorter than the leaves. $h$. G. Native of the Canary Islands. P. pauciflora, A. Rich. mem. soc. hist. nat. par. 5. p. 141 .

Noble Bastard Hare's-ear. Fl. June, July. Clt. 1699. Shrub 2 to 3 feet.

Cult. A mixture of loam, peat, and sand is a good soil for this shrub; and cuttings root freely, if planted in a pot of sand, with a hand-glass over them.

CCIX. GALOPINA (the meaning of this word is not given by the author). Thunb. diss. nov. gen. 1. p. 3. Juss. mem. mus. 6. p. 371 . Cruse, rub. cap. p. 18. A. Ricb. mem. soc. hist. nat. par. 5. p. 140. D. C. prod. 4. p. 579.-Asthospérmum, spec. Thunb. prod.-Plıýlis, spec. Schlecht. and Cruse.

Lin. syst. Tetrándria, Digýnia. Flowers hermaphrodite. Calyx with an obovate tube, and a very minute, nearly equal limb. Corolla subrotate, 4-parted, almost cleft to the base. Stamens 4, inserted in the bottom of the corolla. Anthers oblong. Styles 2, very slort, each ending in a long hairy stigma. Fruit obovate, rather didymous, somewhat compressed from the back, and elegantly and gyrosely warted on the back, composed of two 1-seeded, indehiscent mericarps, joined by a concave commissure, but at length separating from each other.-A glabrous herb, with the habit of Circa'a. Stem rather angular from 2 elevated lines which run from the stipulas, branched. Leaves opposite, 1 to 3 inches long, ovate-lanceolate, acuminated, tapering into the petioles, paler beneath, with serrulately-scabrous margins. Stipulas trifurcate. Peduncles terminal and axillary, the whole forming a large terminal, trichotomous panicle, which is nearly a foot in diameter. Flowers small. Fruit dark brown.

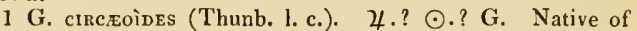
the Cape of Good Hope. Anthospérmum Galopina, Thunb. prod. p. 32. Phýllis Galopina, Schlecht. and Cruse, in Linnæa. 6. p. 20 .

Enchantress's Nightshade-like Galopina. Pl. 2 feet.

Cult. See Phýllis above for culture and propagation.

CCX. ANTHOSPE'RMUM (from ar ${ }^{\prime}$ os, anthos, a flower, and $\sigma \pi \varepsilon \rho \mu \alpha$, sperma, a seed). Lin. gen. no. 1164 . Juss. gen. 178. Gærtn. fil. carp. 3. p. 87. t. 195. Crus. rub. cap. p. 1. A. Rich. mem. soc. hist. nat. par. 5. p. 138. D. C. prod. 4. p. 579. Schlecht. and Cruse, in Linnæa. 6. p. 7.-Tournefórtia, Ponted. epist. 11. ex Gærtn.-Ambrària, Heist. but not of Cruse.

Lin. syst. Tetra-Pentándria, Digy'nia, or Dicécia Tetra-Pentándria. Flowers dioecious or hermaphrodite. Calyx with an obovate tube, and a 4-5-toothed deciduous limb (f. 110, a.). Corolla funnel-shaped, with a short tube, and a 4-5-parted limb (f. 110.6. ); lobes linear or ovate-lanceolate, revolute, valvate in rstivation. Stamens $4-5$, inserted in the base of the tube of the corolla (f. 110.c.). Anthers oblong, sub-tetragonal, exserted. Styles 2, very short, conuate? ending each in a long 4. 12 
hairy stigma (f. 110. f.g.). Fruit composed of 2 easily-separated, indehiscent, 1 -seeded mericarps, which are a little compressed at the raphe, and joined together by a flatish commissure. Albumen sub-cartilaginous. Embryo dorsal, erect.Small slirubs or herbs, natives of the Cape of Good Hope. Stems branched. Leaves linear or lanceolate, small, opposite or verticillate. Stipulas adhering to the petioles at the base, drawn out into a tooth in the middle. Flowers axillary, sessile, verti. cillate or opposite, rarely panicled, small, furnished each with $2-3$ bracteas at the base, usually dioecious. The male flowers are always smaller than the female ones.

\section{* Floners dioccious, sessilc in the axils of the leaves.}

1 A. Berghainum (Cruse, rub. cap. p. 8.) leaves linear-lanceolate, 3 in a whorl, imbricated, and connately perfoliate, ciliated; flowers pentandrous, disposed in a verticillate spike. $h_{c} \cdot G$. Native of the Cape of Good Hope. Stem branched, terete or obsoletely angular, glabrous at the base, but clothed with long white hairs above. Leaves pale green, having the margins and keel ciliated with long white hairs, half an inch long. Whorles 3. flowered.

Bergius's Amber-tree. Shrub I foot.

2 A. Етно́pıcum (Lin. spec. 1511.) leaves linear-lanceolate, 3 in a whorl, glabrous; stipulas simple, short, acute; flowers tetrandrous, disposed in verticillate spikes; mericarps elliptic, clothed with white tubercles, crowned by the calycine teeth. $h$. G. Native of the Cape of Good Hope, Crus. rub. cap. p. 10. Gærtı. fruct. 3. p. 195. Lin. hort. cliff. t. 27.-Pluk. alm. t. 183. f. 1.-Ambrària Heistèri, Walth. hort. t. 9. Stem much branched, downy above. Leaves shining above, and whitish beneath, 2-3 lines long. Male flowers brownish, and the female ones green.

Ethiopian Amber-tree. Fl. June, July. Clt. 1692. Shrub 2 to 3 feet.

3 A. spatula'tum (Spreng. neu. entd. 3. p. 45. syst. 1. p. 399.) leaves opposite, linear-spatulate, bluntish ; Howers axillary, sub-verticillate; nericarps oblong, warted; branches twiggy, crectly spreading, downy. $h \cdot G$. Native of the Cape of Grood Hope, Cruse, rub. cap. p. 9. and p. 13. A. Ethiópicum, var. $\beta$, oppositifolium, Schlecht. and Cruse, in Linnæa. 6. p. 10. It differs from $A$. Ethiópicum in the opposite, linearspatulate leaves, and in the more loose habit. A. Aithiópicum, var. $\gamma$, Eckloniànum, Schlecht, and Cruse, in Linnæa, 6. p. 10. does not appear to differ much from this species.

Spatulate-ieaved Anthospermum. Shrub 2 feet.

4 A. cilis're (Lin. spec. 1521.) leaves opposite, lanceolate, acute, ciliated; stipulas short, simple; flowers axillary, tetrandrous ; mericarps obovate, glabrous, shining, destitute of the calycine limb. b. G. Native of the Cape of Good Hope, Gartn. fil. carp. 3. p. 195. Cruse, rub. cap. p. 9. and p. 13. A. galioides, Rchb. in Spreng. syst. 4. p. 398.-Plık. mant. t. 344. f. 5. Stem usually decumbent, much branched; branches angular, downy. Leaves glabrous, and green above, but white beneath, connate at the base. Lobes of the corolla hairy outside. Anthers white.-The A. galioides, Rchb. differs from this in the leaves being rusty beneath.

Ciliated-leaved Amber-tree. Shrub decumbent.

5 A. lanceola'tum (Thunb. prod. 32. f. cap, p. 15\%.) leaves opposite, lanceolate, acute, glabrous, spreading; stipulas profoundly bifid; flowers axillary, sub-verticillate, tetrandrous, and often pentandrous ; mericarps ovate-oblong, glabrous. h. G. Native of the Cape of Good Hope, Cruse, rub. cap. p. 12. A. herbiceum, Lin. fil. suppl. p. 44.0. Stem procumbent, glabrous, brownish purple. Branches sub-tetragonal, purplisb, downy at the apex. Leaves an inch long, comate at the base, paler beneatl, and whitish. Habit of Galium.
Lanceolate-leaved Amber-tree. Shrub procumbent.

6 A. Hírtum (Cruse, rub. cap. p. 11.) leaves opposite, lanceolate, acute, ciliated while young, hairy at the base; stipulas simple, subulate, hairy ; flowers axillary, pentandrous; mericarps unknown. Ђ. G. Native of the Cape of Good Hope, on mountains. A. rubiàceum, Rehb. in Spreng. syst. 4. j. 338. A. lanceolàtum, Sieb. fl. cap. no. 90 . A. hirsutum, D. C. prod. 4. p. 580. Stem purplish brown, branched, beset with white hairs about the axils of the leaves. Branches purple, hairy. Leaves an inch long, connate at the base. Stipulas hairy, of a shining green colour above, but whitish beneath.

Hairy Amber-tree. Shrub 1 foot.

7 A. sca'brom (Thunb. prod. 32. fl. cap. p. 158.) leaves opposite, linear, somewhat trigonal, acuminated, having the margins and keel scabrous; stipulas simple, very sliort; flowers axillary, pentandrous. h. G. Native of the Cape of Good Hope, on the mountains. Stem decumbent at the base, branched a little. Branches aggregate, twiggy, cinereous at the base, and rather scabrous at the apex, leafy. Leaves $\frac{1}{2}$ to 1 inch long, connate at the base.

Scabrous Amber-tree. Shrub $\frac{1}{2}$ decumbent.

\section{* Flomers dioccious, panieled.}

8 A. Panicula'tum (Cruse, rub. cap. p. 9. and p. 15. t. 1. f. 2.) leaves opposite, linear-subspatulate; stipulas short, simple; flowers panicled, tetrandrous; mericarps glabrous, with 3

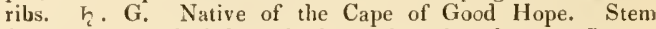
fuscescent, branched from the base; branches downy. Leaves glabrous, bluntish, pale on the lower surface, hardly ${ }_{2}^{1}$ an inch long. Panicle terminal, narrow, elongated. Fruit crowned by the calycine teeth.

Paniclcd-flowered Amber-tree. Shrub 1 to $I \frac{1}{2}$ foot.

\section{*** Flowers hermaphrodite.}

9 A. Licutensteinin (Crus, rub. cap. p. 15.) leaves opposite, linear, keeled, glabrous, ciliated; stipulas simple, ciliated; flowers axillary, verticillate; mericarps hairy. I2. G. Native of the Cape of Good Hope. Spermacòce ericafolia, Licht. in Rom. et Scluultes, syst. 3. p. 281. Stem branched, glabrous at bottom, and downy at top. Branches naked at the base. Leaves connate at the base, mucronate. Flowers tetrandrous.

\section{Lichtcnstcin's Amber-tree. Shrub 1 to 2 feet.}

10 A. spermacóceum (Rchb. in Spreng, syst. 4. p. 338. ) leaves opposite, oblong-lanceolate, with scabrous margins; stipulas entire ; flowers axillary, solitary, pedicellate, pentandrous ; calyx 5-toothed. 2f. G. Native of the Cape of Good Hope. Stem herbaceous, flexuous, rather angular, branched, glabrous, but downy at the apex. Leaves connate at the base. Stipulas pilose, cleft into bristles.

Spermacoce-like Amber-tree. Pl. 1 foot.

Cull. See Phyllis, p. 635. for culture and propagation.

CCXI. AMBRA'RIA (a name formerly applied to the genus Anthospérmum by Heister, and is probabiy derived from Cape Ambra, in Madagascar). Cruse, rub. cap. p. 16. t. 1. f. 3-4. D. C. prod. 4. p. 580 . but not of Heister. A. Rich. men. soc. list. nat. Par. 5. p. 139 . t. 12. f. 2.

Lin. syst. Dioécia, Tetrándria. Flowers dioecious, of the same structure as those of Anthospérmum, but differs from that genus in the capsule being 3-celled, the intermediate cell vacant, and the lateral ones 1 -seeded. The rest as in Anthospcrmum.

$1 \Lambda$. п'кта (Cruse, rub. cap. p. 17. t. 1. f. 2.) leaves 3 in a whorl, connately perfoliate; fruit tomentosely hairy. $\zeta$. G. Native of the Cape of Good Hope. Shrub much branched from the base, hairy at the top. Leaves linear, subtriquetrous, glabrous, connate at the base, with the margins and keel ciliated, 
at length imbricated and deciduous. Stipulas hardly prominent, ciliated. Flowers axillary, verticillate. According to Cham. et Schlecht. Clifłórtia cinérea, Lin. is a synonyme of this.

Hairy Ambraria. Slirub $\frac{1}{2}$ to $\frac{3}{4}$ foot.

2 A. olA'Bra (Cruse, rub. cap. p. 17.t. 1. f. 3.) leaves 3 in a whorl, connately perfoliate; fruit obovately subglobose, glabrous. h. G. Native of the Cape of Good Hope. Nènax aceròsa, Grertn. fruct. t. 32. f. 7. Young branches reddish. Leaves linear, subtriquetrous, glabrous, serrulately ciliated on the margin and keel, 3-6 lines long, and $\frac{1}{5}$ to 1 broad. Flowers axillary, subverticillate.

Glabrous Ambraria. Slirub $\frac{1}{2}$ to $\frac{3}{4}$ foot.

Cult. See Phýllis, p. 635. for culture and propagation.

\section{Tribe XII.}

STELLA'T $Æ$ (from stellatus, starry; the leaves and stipulas form whorles, resembling the rays of a star). Ray, syn. p. 223. Cham. et Schlecht. in Linnæa. 3. p. 220. D. C. prod. 4. p. 580.-A parineæ, Link, (1809).-Gàleæ, Kunth, nov. gen. amer. (1815) 3. p. 335.-Asperùleæ, A. Rich. mem. soc. hist. nat. Par. (1830) 5. p. 126. Flowers hermaphrodite, rarely of different sexes. Corolla rotate or funnel-shaped; lobes valvate in æstivation. Styles 2, almost distinct from the base, or more or less combined in one. Stigmas capitate. Fruit constantly of 2 indehiscent 1 -seeded mericarps. Seeds liardly distinct from the pericarp and calyx. Albumen horny.-Usually herbs, rarely small shrubs. Leaves opposite, bearing each a bud in the axils, furnished witl 1-2 or 3 leaf-formed stipulas between the leaves on both sides, which are destitute of buds, and form whorles along with them. Roots usually red, furnishing a red dye, as the madder.-The leaves are only to be distinguished from the stipulas in having buds in their axils.

CCXII. SHERA'RDIA (named by Dillenius after his patron IVilliam Sherard, LL.D., consul at Smyrna). Dill, gen. 3. Lin. gen. no. 120. Gærtn. fruct. 1. p. 110. t. 24. A. Rich. mem. soc. hist. nat. Par. 5. p. 129. D. C. prod. 4. p. 581.-Dillènia, Heister.-Aparines spec. T'ourn.

Lin. sysr. Tetrándria, Monogýnia. Calyx with an ovate tube, and a 4-6-toothed permanent limb. Corolla funnel-shaped, with a terete tube, and a 4-lobed limb. Stamens 4 . Style 1, 2-lobed at the apex; stigmas capitellate. Fruit dry, erowned by the calyx, divisible into two mericarps; mericarps 1-seeded, indeliscent, flat on one side, and convex on the other.-An annual herb, native of Europe. Leaves opposite, with 1-2 stipulas on each side, obovate, acute, scabrous, forming whorles. Flowers small, red, capitate, almost sessile, girded or involucrated by the uppermost whorl of leaves.

1 S. ARVE' Nsis (Lin. spee. p. 149.) ๑. H. Native of Europe and Tauria, very common in fields in sandy soil; plentiful in many parts of Britain in fallow fields and among corn. Fl. dan. t. 439. Curt. lond. 5. t. 13. Smith, engl. bot. t. 891 . Sehkuhr, lıandb. t. 22.-Barrel. icon. t. 541. Root with many reddish brown fibres. The whole plant rough and hairy. Leaves rough along the edges and keel, 4-6 in a whorl.

Corn Field-madder. Fl. April, Sept. Britain. Pl. $\frac{1}{4}$ to $\frac{1}{2} \mathrm{ft}$.

N. B. Sherürdia fruticòsa (Lin. spec. 149.) stem shrubby ; leaves 4 in a whorl, equal; flowers axillary. h. G. Native of the island of Ascension. Stipulas very short, subulate, interfoliaceous. Corolla white. Fruit unknown. This plant appears to be intermediate between Diódia and Spermacòce.

Cult. The seeds only require to be sown in the open ground in a dry situation.

CCXIII. ASPE'RULA (a dim. of asper, rough; leaves). Lin. gen. no. 121. Juss, gen. 196. Lam. ill, t. 61. Gærtn, fil. earp. 3. p. 89. t. 195. A. Rich. mem. soc. hist. nat. Par, 5. p. 130. t. 11. f. 1. D. C. prod. 4. p. 581 .

Lin. syst. Tetrándria, Monogýnia. Calyx with an ovate dirlymous tube, and a very short 4-toothed deciduous or obsolete limb. Corolla funnel-shaped, rarely campanulate, 4cleft, rarely 3-cleft. Styles 2, joined together at the base, and nearly to the apex. Fruit didymous, not crowned by the calyx, dry, or hardly fleshy; mericarps easily separated, indehiscent, 1 -seeded.-Herbs, rarely small shrubs. Stems and branches usually tetragonal. Leaves opposite, with 1-2-3 stipulas on each side; they are therefore called 4 to 8 in a whorl, but between the uppermost leaves there are no stipulas. Flowers terminal and axillary, in fascicles.

$\$ 1$. Sherardiana (this section only contains plants with the habit of Sherárdia). D. C. prod. 4. p. 581. Annual plants. Corollas tubularly funnel-shaped.

1 A. ARve'Nsis (Lin. spec. p. 149.) plant erect, smoothish; leaves 6-10 in a whorl, lanceolate-linear, a little ciliated; lower ones obovate: floral ones ciliated with long hairs; corymbs fas. cicled, terminal, many flowered; flowers sessile; fruit glabrous. $\odot$. H. Native of Europe and Caucasus, in fields and arid stony places. A. coerulea, Dorl. pempt. p. 355 . Lob. icon. t. 801. f. 2. A. ciliàta, Mœench. meth. 1) 484. A. dùbia, Willd. herb. ex Spreng. Roots yellow. Under surface of leaves whitish from adpressed hairs. This differs from all the other species of Aspérula in the flowers being blue. It difters from Sherárdia in the capsule not being crowned by the calyx, in the blunter leaves, and in the floral leaves being ciliated. Anthers yellow.

Cornfield Woodroof. Fl. July. Clt. 1596 . Pl. $\frac{1}{2}$ to 1 foot.

2 A. cilia'ris (D. C. prod. 4. p. 582.) stens ascending, angular, glabrous; leaves 6-9 in a whorl, lanceolate-linear, acute, and are as well as the bracteas, serrated by stiff ciliz; flowers almost sessile, disposed in a terminal subumbellate corymb, pen. tandrous; style exserted.-Native of Persia, where it was collected by Gmelin. Corollas glabrous, 5-6 lines long. Stanens 5. Ciliated-leaved Woodroof. Pl. ascending.

3 A. Tricho'oes (Gay, in litt. 1829: ex D. C. prod. 4. p. 582.) stens erect, simple at the base, branched at the apex, glabrous ; leares glabrous, subulately filiform, equal in length to the internodes: cauline ones $10-16$ in a whorl, and the rameal ones 2.6 in a whorl; pedicels solitary, almost axillary; corollas small, downy ontside, trifid; fruit obovate, clothed with very short down. $\odot$. H. Native of the north of Persia. Stem very smooth, white, 7-10 inches high. Leaves an inch long, scabrous. Corolla greenish-white, with a slender terete tube, and oblong: awnless lobes. Stamens 3.

Hairy Woodroof. Pl. $\frac{1}{2}$ to 1 foot.

\$2. Cynánehica (this section agrees with $A$. cynánchica in the corollas being funnel-shaped). D. C. prod. 4. p. 582. Plants perennial. Corollas tubularly funncl-shaped.

4 d. Taurina (Lin. spec. 150.) plant smoothish, erect; leaves 4 in a whorl, ovate-lanceolate, 3-nerved, with finely ciliated margins; corymbs pedunculate, axillary, fasciculately umbellate, involucrated ; bracteas ciliated ; fruit glabrous, and rather scabrous. 4 . H. Native of Dauphiny, l'iedmont, Switzerland, Carniola, Iberia, \&e. on hills in shady places. A. trinérvia, Lam. f. fr. 3. p. 376 . Gàlium Taurinum, Scop. carn. no. 148.-Lob. icon. t. 800 . f. 1.-Moris, hist. sect. 9. t. 21 . f. 1.-Hall, helv. no. 732. Leaves broad. Corollas white, elongated. Anthers violaceons, exserted.

Bill Woodroof. Fl. April, July. Clt. 1739. Pl. 1 foot.

5 A. LEvigA'TA (Lin. mant. p. 38.) plant glabrous, ascending; leaves 4 in a whorl, elliptic, nerved, with finely scabrous nargins ; cymes corymbose, pedunculate, axillary or nearly terminal; corolla with a short tube ; fruit glabrous, scabrous from elevated 
dots. 4. H. Native of the south of Europe, in rugged places and in woods, from Narbonne to Constantinople. Willd. spec. 1. p. 579. exclusive of Barrel. syn. D. C. fl. fr. no. 3344. A. rotund ifòlia, Lam. diet. 1. p. 298.-Moris, oxon. 3. sect. 9. t. 21. f. 4.-Bocc. sic. p. 10. t. 11. f. 5. Flowers white.

Smooth Woodroof. Fl. June. Clt. 1775. P]. $\frac{1}{2}$ to 1 foot ascending.

6 A. Hexaphy'Lla (All. ped. no. 48. t. 77. f. 3.) plant ascending, glabrous; leaves 6 in a whorl, linear, spreading, acute, with rerolute scabrous margins; cymes terminal; flowers aggregate, umbellate; bracteas glabrous, actite, shorter than the flowers. 24. H. Native of Piedmont, on the lower Alps abont Tende and Saorgio. A. Alliòni, Baumg. enum, trans. 1. p. 80. Corolla purple outside, but white within.

Var. 3, rigídula (D. C. prod. 4. p. 582.) leaves stiffer and blunter than those of the species, and the floral ones are obovate. 4. I1. Native of Sicily, in the fissures of calcareous rocks by the sea side. A. hexaphýlla, Guss. prod. A. sic. 1. j) 166. There are glabrous and downy variations of this plant.

Six-leaved Woodroof. Pl. $\frac{1}{2}$ foot.

7 A. Gru'cruss (Meyer, verz. pfl. p. 52.) plant perennial, smooth, glabrous; stems filiform, much branched, diffuse; leaves 4 in a whorl, equal, elliptic, bluntish, with rather seabrous margins : upper ones opposite; umbels terminal, few-flowered ; corolla 4 -5-cleft, almost glabrous, with obtuse segments; style semibifid; mericarps smooth, glabrous. 24. H. Native of Caucasus, in alpine places at the river Malka.

Slcnder Woodroof. Pl. diffuse.

8 A. in'rta (Ramond, bull. phil. no. $4 \mathrm{I}$, p. 131. t. 9. f. 1. 2-3.) plant tufted, erectish; leaves 6 in a whorl, linear, acute, hairy, longer than the internodes; flowers aggregately umbellate, terminal, sessile, exceeding the bracteas; fruit glabrous. 4. H. Native of the central Pyrenees, on the higher ranges on dry banks. A. nov. spec. St. Amans, trav. pyr. 194. Corollas white, purplish outside. In cultivation the plant becomes smooth, and is then referrible to $A$. hexaphýlla.

Hairy Woodroof. Fl. June, July. Clt. 1817. Pl. $\frac{1}{2}$ foot.

9 A. тілетòria (Lin. spec. 150.) plant erectisl, glabrous ; leaves linear: lower ones 6 in a whorl : middle ones 4 , and the uppermost ones opposite; floral leaves ovate; flowers usually trifid. 24. H. Native of Europe, on hills in arid stony places. A. rubèola 3 , Lam. f. fr. 3. p. 375 . Gàlium tinctòrium, Scop. carn. no. 149. - Tabern. icon. t. 733. f. 2. Roots large, creeping, reddish, and are used in Gothland instead of madder for dyeimg red. Plant procumbent, unless supported. Stem 1-2 feet long, purplish. Flowers usually by threes. Corollas white, reddish on the outside. Very like $A$. cynánclica.

Dyers' Woodroof. Fl. June, July. Clt. 1764. Pl. 1 to 2 feet.

10 A. сrNánchica (Lin. spec. p. 151.) plant glabrous, erectish; leaves 4 in a whorl, linear: lower ones small, oblong, upper ones opjosite; floral ones lanceolate-linear, acuminately awned; flowers terminal, quadrifid; fruit granulated. $4 . H$. Native of Europe, in dry gravelly places; abundant in many parts of England on chalky downs. Smith, engl. bot. t. 33. Berg. phyt. t. 81. Rùbia cynánchica, J. Bauh. hist. 3.p. 723. with a figure. Asp. rubèola $a$, Lam. ft. fr. 3. p. 375 . A. tinctòria var. $\beta$, Lam. dict. 1. p. 298. Gàlium cynánchicum, Scop. carn. no. 147. Herb variable in habit. Stems prostrate, dichotomously branched. The flowers grow on ereet branches, forming a fastigiate corymb, white or blush-coloured, elegantly marked with red lines, and sometimes they are pure white. Dalechamp seems to be the chief authority for the reputation this plant formerly acquired in the cure of quinsies. He says it should be applied externally, as well as taken internally, but it is now entirely ont of use.

Var. $\beta$, heterophyilla (D. C. prod. 4. p. 583.) decumbent; leaves of the sterile branches ovate, and of the flowering ones linear. 4. H. Native of the Pyrenees, in sandy places. A. Pyrenàica, Lin. herb. A. cynánchica $\beta$ and $\gamma$, D. C. suppl. fl. fr. p. 493. A. rubèola, Gratel, in bull. soc. hist. nat. bord. 1. p. $311 . ?$

V́ar. $\beta$, saxátilis (D. C. suppl. p. 495. var. $\delta$,) plant tufted, erect; leaves linear, length of internodes. 24. H. Native of the Pyrenees, among stones and on rocks. A. Pyrenàica, Lin. spec. 151.? A. saxátilis, Lam. ill. no. 139. A. multiflòra, Lapeyr. abr. p. 62, ex Benth.

Var. 8, elongaita (Stev. in litt. ex D. C. prod. 4. p. 583.) plant elongated, erect; leaves linear, shorter than the internodes. 24 . H. Native of Tauria and Caucasus. A. cynánchica, Bieb. $A$. talir.

Quinsy Woodronf. Fl. July. England. Pl. $\frac{3}{4}$ to 1 foot.

11 A. supina (Bieb. fl. taur. 1. p. 101.) glabrous; stem much branched at the base, procumbent; leaves 4 in a whorl, linear, acute : lower ones imbricately crowded; peduncles 3 flowered, axillary and terminal, rather panicled; corolla with a terete tube, and 4 oblong lobes; fruit glabrous. 4 . H. Native of Tauria and Caucasus, in the fissures of calcareous rocks, and in gravelly places. A. cynánchica $\beta$, Meyer, verz. pfl. p. 406 . Very nearly allied to $A$. cynánchica, but the flowers are white, not as in it, blush-coloured. Internodes of the stem short.

Supine Woodroof. Fl. June, July. Clt. 1821. Pl. pr.

$12 \Lambda$. Longlf lòra (Waldst. et Kit. pl. rar. hung. 2. t. 150) stems numerous from the same neck, erectish, glabrous; leaves 4 in a whorl, linear: lower ones small, obovate: upper ones opposite; fascicles of flowers terminal, pedunculate; bracteas small, subulate; tube of corolla elongated; frnit glabrous, smooth. 4. H. Native of Croatia, Carniola, and Carinthia, in mountainous places, and on rocks. A. suavèolens, Schrad. in litt. 1815. Corolla whitish, yellowish inside, and reddish outside. Stems weak.

Long-flonercd Woodroof. Fl. July, Aug. Clt. 1821. Pl. $\frac{1}{2} \mathrm{ft}$. 13 A. BREvifòlia (Vent. hort. cels. p. 63. t. 63.) plant glabrous, decumbent ; leaves 4 in a whorl, very short, distant : uppermost ones opposite ; flowers axillary, solitary on short pedicels, and in terminal fascicles; corolla 4-cleft; style bipartite to the base. $4 . H$. Native of Caramania, near Cylindre on mountains. Stem much branched. Corollas at first yellowishgreen, but at length becoming purplish.

Short-leaved Woodroof. Fl. July, Aug, Clt. 1824. Pl. dec.

14 A. LD'TEA (Smith, f. græc. t. 120.) stems erect; leaves 4 in a whor], linear, glabrous, mucronate; flowers in fascicles, downy, awned. 2. H. Native of Mount Parnassus. Kubèola Crética saxatilis frutescens flore luteo, Tourn. cor. p. 5. Flowers yellow. Fascicles of flowers spicate.

Yellow-flowered Woodroof. Pl. 1 foot.

15 A. ARista'ta (Lin. fil. suppl. 120.) plant erect, glabrous; leaves 4 in a whorl, linear, acute: upper ones opposite: the floral ones like the rest, but smaller; flowers in terminal fascicles; lobes of corolla bluntly awned. 4. H. Native of the south of Europe, Sicily, \&c. Flowers usually by threes, pale yellow.

Var. $\beta$, fláccida (D. C. prod. 4. p. 583.) plant diffuse; branches divaricate, pendulous; pedicels usually 2-flowered. 4. H. Native of the kingdom of Naples, in rocky places. A. fláccida, Tenore, append. 4. prod. p. 8. A. cynánchica $a$, Tenore, prod. xii. A. longiflòra, Tenore, fi. med. p. 89.

Anned-flowered Woodroof. Fl. July, Aug. Clt. 1823. Pl. $\frac{1}{2}$ to 1 foot.

16 A. Monta'sa (Willd. enum. p. 151.) glabrous; stem flaccid; leaves linear: lower ones 6 in a whorl: middle ones 4 , upper ones opposite; floral leaves linear ; flowers in fascicles; corollas 4-cleft, scabrous externally. 4. H. Native of Hun- 
gary, on hills in woods. Link, enum. 1. p. 134. Corolla blush. Perhaps sufficiently distinct from $A$. tinctòria.

Mountain Woodroof. Fl. June, July. Clt. 1801. Pl. $\frac{1}{2}$ to to $\frac{3}{4}$ foot.

17 A. urnsu'ra (Desf. A. atl. 1. p. 127.) plant erect or ascending; leaves 6 in a whorl, linear, acute, with revolute margins : lower ones and tops of stems glabrous; flowers in fascicled umbels, rising from the tops of the stem or branclies; bracteas hardly exceeding the ovaries; fruit glabrous. 24. H. Native of Algiers and Algarves, on chalky and sandy bills. Rubèola Lusitånica, Sc. Tourn. inst. p, 130. A. rèpens, Brot. phyt. lus. 1. no. 10. t. 10 . A. Algérica, Pers. ench. 1. p. 124. Rùbia rèpens, \&.c. Grisl. vir. no. 1244. Stem hairy at bottom. Leaves glaucous. Flowers subcapitate, red. In cultivation this plant becomes smooth.

Hairy Woodroof. Fl. May, June. Clt. 1S19. Pl. 1 to $2 \mathrm{ft}$.

18 A. том entòs (Ten. prod. xii. fl. neap. t. 9.) plant ascending or diffuse, clothed with velvety tomentum; leaves 4 in a whorl, linear, with revolute margins: lower ones obovate; fowers terminal or axillary, $8-10$ in a fascicle; bracteas rather shorter than the flowers. 24. H. Native of Goats' Island, near Naples, in arid places. Herb branched from the base. Stem tetragonal. Stipular leaves the longest. Tube of corolla longish. Corolla red. A crassifölia, Lin. mant. p. 37. does not seem to differ from the present plant. Perhaps A. scàbra, Link, enum. 1. p. 134. is also the same.

Var. $\beta$, semiglàbra (D. C. prod. 4. p. 584.) lower part of herb velvety; upper part and flowers glabrous. 4. H. Native along with the species, and probably of Sicily at Cafalu. $A$. commutàta, Presl, fl. sic. prod. p. 62.? Rœm. et Schultes, syst. 3. p. 267.?

Tomentose Woodroof. Fl. June, July. Clt. 1795. Pl. $\frac{1}{8}$ to $\frac{3}{4}$ foot.

19 A. INCA'NA (Smith, fl. græc. t. 119.) stems villous at the base, and smoothish at top; leaves 6 in a whorl, linear, hoary ; flowers downy, in terminal fascicles. 24. H. Native of Candia, on the Sphaceotic mountains. Flowers pale red.

Hoary Woodroof. P]. $\frac{1}{2}$ to $\frac{3}{4}$ foot.

20 A. Arcadie'nsis (Sims, bot. mag. t. 2146.) plant hoary, decumbent ; leaves 6 in a whorl, oblong-ovate, acute, with revolute edges; flowers terminal and axillary, aggregate, sessile ; style bifid at top. $\psi$. F. Native of Arcadia, on Mount Tyria. A small hoary plant, with rose-coloured flowers. Gàlium Græ'cum, Hort.

Arcadian Woodroof. Fl. May. Clt. 1819. Pl. 2 to 3 incbes.

21 A. DE'Bilts (Led. hort. dorp. suppl. 1824. p. 2.) plant bispid from pili ; leaves 6 in a whorl: upper 4 in a whorl, linearlanceolate, scabrous above, and keel smooth; umbels lateral, pedunculate, 3-flowered; corolla funnel-shaped; fruit granular. 4. H. Native of Tauria, near Bachtschisarai.

H'cak Woodroof. P!. $\frac{1}{a}$ foot.

22 A. Nítida (Smith, fi. græc. t. 12\%) glabrous; stems diffuse, densely tufted, as well as the leaves; leaves 4 in a whorl, shining, glaucescent: lower ones oval, the rest linear, acute, awned, revolute; fascicles terminal, 3-4-flowered, length of leaves; lobes of corolla awned; tube terete, wide; fruit glabrous, rather rugged. 24. H. Native of Sicily, on rocky and gravelly mountains, and on Mount Olympus, in Bithynia. Guss, prod. fl. sic. 1. p. 168. Flowers purplish. Very like $A$. hexaphyllum.

Nitid Woodroof. Pl. tufted, $\frac{1}{4}$ foot.

23 A. SCA'BRA (Presl. del. prag. p. 124. but not of Link.) stem scabrous, diffuse, kneed; leaves 4 in a whorl: lower ones oblong downy: upper ones glabrous, linear, unequal, opposite, small, awned; flowers in fascicles; corollas scabrous, with the lobes mucronate; style bipartite to the base. 4. H. Native of Sicily, on dry mountains ; of Spain, in arid places; and of Portugal, on the banks of the Tagus and Douro. Guss. prod. f. sic. 1. p. 167. A. dígyna, Dufour, ann. gen. sc. phys. 7. p. 295. A. macrorhiza, Link. A. port. 2. p. 41. t. 84. Stems exactly quadrangular. Flowers purplish whitc. Habit of $A$. longiflòra, but differs from it in the lower leaves and flowers being downy.

Scabrous Woodroof. Pl. 1 to 2 feet.

24 A. Alpina (Bieb. fl. taur. suppl. p. 103.) the whole plant, as well as the corollas and ovaries are downy; stems procumbent, much branched, tetragonal; leaves 4 in a whorl, linear, acute: upper ones nearly equal, spreading; cymes terminal, crowled, 5-7-flowered; lobes of corolla 4. 2\%. H. Native of Eastern Caucasus, on the Alps. A. cynánchica, var. $\gamma$, Stev. in mem. soc. mosc. 3. p. 253. Meyer, verz. pfl. p. 406. Flowers white, or tinged with red. Leaves shorter and broader than in A. cynánchica, and the lower ones blunter.

Alpine Woodroof. Fl. June, July. Clt. 1S20. Pl. $\frac{1}{2}$ foot.

25 A. creta'cea (Willd. in Roem. et. Scluules, syst. 3. p. 529.) stems tufted, prostrate ; leaves 6 in a whorl, lanceolate : the whorles so close as to be imbricated; flowers terminal, aggregate. $\psi$. H. Native of Siberia, in chalky places.

Cretaccous Woodroof. Pl. prostrate.

26 A. L1t torA'L1s (Smith, fl. græc. t. 122.) stem downy; leaves linear, 4 in a whorl, scabrous on the margins and stem (almost hoary, according to D'Urv.): floral ones opposite ; flowers quadrifid, pilose; fruit hispid. 4 . H. Native on the shores of the Euxine Sea, on hills. Flowers pale red. Fascicles of flowers disposed in terminal panicles.

Sca-shore Woodroof. Pl. procumbent.

27 A. Neglécta (Guss. pl. rar. 69. t. 13. f. 1.) stems numerous, hairy, ascending; leaves 4 in a whor\}, hairy, acute, longer than the internodes: lower ones obtuse; flowers in terminal fascicles; mericarps globose, hispid. $\mathbf{4}$. H. Native of Abruzzo and Sardinia, in ajpine places. Corolla white inside, and reddish outside, and downy. Bracteas ovate. Said to be allied to $A$. littorìlis.

Neglected Woodroof. P]. decumbent.

28 A. nírens (Guss. pl. rar. 70. t. 13. f. 2.) plant smooth ; stems tufted, decumbent; leaves 4 in a whorl, awned, longer than the internodes, shining, quite glabrous: lower ones the broadest; flowers in terminal fascicles; lobes of corolla awned ; mericarps tubercularly muricated. 24. H. Native of Abruzzo, in arid, alpine situations. Flowers white inside, and purplish ontside. Very like $A$. neglécta, and probably only a variety of it.

Shining Woodroof. Pl. decumbent.

29 A. RíGida (Sibth. et Smitl, fl. græc. t. 121.) stems diffuse, downy; leaves linear, 4 in a whorl, superior ones opposite; Howers scattered; fruit glabrous. 24. H. Native of Candia, on hills and in fields, Rom. et Schultes, syst. 3. p. 270. exclusive of the syn. of Lois. Leaves rather scabrous. Flowers pale red, disposed in terminal and lateral few-flowered fascicles.

Stiff Woodroof. Pl. $\frac{1}{2}$ to 1 foot.

30 A. suberòsa (Smith, fl. græe. t. 123.) stems tufted, ascending; root corky; leaves 4 in a whorl, linear, rather hoary; lobes of the corolla awnless. 24. H. Native of Greece, on high rocks. Stems downy. Flowers rose-coloured, disposed in subspicate fascicles.

Corky-rooted Woodroof. P!. $\frac{1}{4}$ to $\frac{1}{2}$ foot.

$\$ 3$. Galioidca (the plants contained in this section agree with Gàlium, in having campanulate flowers). D. C. prod. 4. p. 585. Pcrennial plants. Corollas campanulate.

81 A. Longifòlia (Smith, fl. græc. t, 118.) stems smooth; 
leaves $\mathrm{S}$ in a whorl, linear-lanceolate, deflexed, with rather scabrous margins ; panicles capillary, many-flowered; fruit smooth. 4. H. Native of Turkey, about Constantinople. Flowers white, campanulately funnel-shaped. Habit of a species of Gàlium.

Long-leaved Woodroof. Fl. June, Aug. Clt. 1820. Pl. 3 feet, diffuse.

32 A. Odora't a (Dod. pempt. p. 355.) plant glabrous, erect, or ascending; stems simple; leaves 8 in a whorl, lanceolate, smooth, with serrulately scabrous edges; corymbs terminal, pedunculate; fruit hispid. 4. H. Native of Europe, Siberia, and Caucasus, in shady places and woods; plentiful in Britain. Cd. fl. dan. t. 562. Lam. ill. t. 61. Mill. fig. t. 55. Smith, eng. bot. t. 755. Blackw. t. 60. Gàlium odoràtum, scop. carn. no. 158. Root creeping a little below the surface of the soil. Stems tetragonal. Corymbs usually trifid, each division benring abont 4 flowers. Flowers snowy white. The plant is without scent when fresh, but when dried diffuses an odour like that of vernal grass. It is said to give a grateful flavour to wine; and when kept among clothes, not only to impart an agreeable perfume to them, but to preserve them from insects. Turner calls the plant Wood-rose, or Wood-rovel. Gerard, Hoodrowe, Hoodrowell, and Noodrooffe; and Parkinson, Woodroofe. In modern times it is called Woodroof, or IIoodruff. These names are derived from the place of its natural growth, in woods, and from the whorles, ruffs, or rowels of leaves.

Sneet-scenlcal or common Woodroof. Fl. May, June, Britain. Pl. $\frac{1}{2}$ to $\frac{3}{4}$ foot.

S3 A. Apakine (Bieb. fi. taur. p. 102. and suppl, 105. Bess. 11. gall. 1. p. 114.) branches diffuse, straggling, with scabrous angles; leaves $6-8$ in a whorl, oblong or lanccolate, scabrous, having the keel and margins beset with small retrograde prickles ; peduncles axillary, branched, disposed in a loose fasciculate panicle; corolla short, tubular; fruit granular. 24. H. Native of Galicia, Tauria, Cancasus, Volhynia, Russia at Moscow, Siberia, and Greece, in boggy, grassy places. Rchb. pl. crit. 1. t. 93. f. 198. Gàlium uliginosum, Pall. ind. taur. Asp. rivàlis, Sibth. and Smith, ff. græc. t. 117. Angles of stems scabrous from retrograde prickles. Flowers white, canpanulately funnel-shaped. Very much the habit of Gàlizm aparine, but stronger. Herb scabrous all over.

Cleaters' Woodroof. Fl. July, Aug. Clt. 1818. Pl. straggling.

31 A. panicula'ta (Bunge in Ledeb. fi. alt. ill. t. 301. fl. alt. 1. p. 140.) stems tetragonal, glabrous; lower leaves 4 in a whorl: the rest 6 , oblong-lanceolate, acuminated, with scabrous margins; flowers terminal and axillary, panicled; panicle diffuse; corollas campanulate; fruit smooth. 4 . H. Native of Siberia, in grassy parts of mountains at the rivers Tscharysch and Sentelek, and in sandy places at the river Katunja. Leaves rather glaucous beneath. Corollas white, with obtuse segments.

Paniclcd-flowered Woodroof. Pl. 1 foot.

35 A. subvelutina (D. C. prod. 4. p. 585.) stems many, branched, erect, velvety from small down; leaves $5-8$ in a whorl, broad-linear, obtuse, rather velvety; flowers verticillate, and capitate at the tops of the branches; floral leaves small; corollas campanulate; fruit glabrous. 24. H. Native of Persia, on Mount Elwend, where it was collected by Olivier and Brugniere. Old stems permanent, white, and glabrous. Leaves 6 lines long, and a line broad.

Ralher-velvety Woodroof. Pl. $\frac{1}{2}$ to 1 foot.

36 A. Galioines (Bieb. f. taur. 1, p. 101, and suppl. p. 104.) plant glabrous; stems terete, ascending; leaves $6-8$ in a whorl, linear, glaucous; peduncles dichotomous, terminal, corymbose ; corollas campanulate; fruit glabrous, smooth. $4 . \mathrm{H}$. Native of Middle and South Europe, even to Tauria and Caucasus, in stony places. Gàlium glaúcum, and probably Gàlium montànum, var. Lin. spec. 156. Asp. glaúca, Bess. Galium Hal. lèri, Sut. fl. helv. 1. p. 88. Gàlium campanulàtum, Vill. dauph. 2. p. 326. Gàlium grandiflòrum, Clairv. man. p. 41. Flowers white. Plant glaucous.-This is a very variable plant, and is intermediate between Gàlium and Aspérula. Stems either terete or bluntly sub-tetragonal, erectish or diffuse, smooth or scabrous at the base. Leaves with revolute or flat margins, obtuse or mucronulate.-See Jacq. f, austr. t. 84. Vill. dauph. t. 7. Bocc. mus. 2, t. 116.

l'ar. $\beta$, Tyràica (D. C. prod. 4. p. 585.) stems erect, hispid at the base; lower leaves rather hispid. 4. H. Native about Tyra and elsewhere, in stony places. Aspérula Tyràica, Bess. enum. cont. p. 42. Gàlium glaúcum, var. Requien, in. herb. D. C.

Galium-like Woodroof. Fl. Ju. Aug. Clt. 1710. Pl. $\frac{1}{2}$ to $\frac{5}{4} \mathrm{ft}$. 87 A. нumifu'sa (Bieb. fl. taur. suppl. p. 105.) stems prostrate, much branched, hispid, tetragonal; leaves 6 in a whorl, linear, spreadingly reflexed, with scabrous edges: lowermost ones 8 in a whorl; pedicels axillary, usually by threes, 1 flowered; corolla sub-campanulate, with a short tube; fruit glabrous. $\%$. H. Native of Tauria, Caucasus, at the $D_{\text {on }}$ and on Mount Besclitau, Podolia, and about Theodosia, ex D'Urv. enum. p. 15. Gảlium humifùsum, Bieb. fl. taur. 1. p. 104. Ledeb. in Schrad. neu. journ. 4. t. 1. p. 59 . Flowers white.

Trailing Woodroof. F1. Ju. Aug. Clt.1818. Pl. prostrate.

$$
\dagger \text { Species not sufficiently known. }
$$

38 A. Tourxefórtil (Sieb, ex Spreng. syst. 1. p. 395.) stems suffruticose; leaves obovate-oblong, quite glabrous, glaucous ; whorles of flowers approximate; Howers sub-fasciculate, hispid. 4. H. Native of Candia.

Tourneforl's Woodroof. Pl. suffruticose.

39 A. unbella'ta (Willd. herb. ex D. C. prod. 4. p. 586.) 4. H. Native of Hungary. This is the same as $A$. hexaphylla, ex Spreng. syst. but according to Stevens, obs. mss. it differs in the flowers being shorter.

Umbellate-flowered Woodroof. PI.

$40 \mathrm{~A}$. involucra'ta (Bergr. et Wahl. in isis. 1828. vol. 21. p. 971.) leaves 4 in a whorl, obovate, elongated, obtuse, glabrous; stems decumbent; peduncles lateral and terminal ; flowers umbellate; leaves of involucrum obtuse, glabrous. $\mathcal{\psi}$. H. Native of the Levant, among bushes on the sides of hills. Leaves like those of Gàlium palistre.

Involucrated Woodroof. Pl. decumbent.

Cult. Most of the species of Woodroof are very pretty when in flower, and are therefore well adapted for decorating flowerborders or rock-work. They will grow in any common gardensoil, and are easily increased by parting at the root. $A$. odorita will thrive under the slade of trees, where hardly any thing else will grow. The seeds of annual species only require to be sown where the plants are intended to remain.

CCXIV. CRUCIANE'LLA (a dim. of erux, a cross : in allusion to the leaves being placed crosswise). Lin. gen. no. 126. Gærtn. fruct. 1. p. 111 . t. 24. Lam. ill. t. 61. Juss. mem. mus. 6. p. 370 . A. Rich. mem. soc. hist. nat. par. 5. p. 131, D. C. prod. 4. p. 586 .

Lix. syst. Tetra-Pentándria, Monogýnia. Calyx with an ovate tube, and a hardly distinct limb. Corolla tubular, elongated, funnel-shaped, 4-5-lobed; lobes usually drawn out into a setaceous, inflexed appendage each. Stamens 4-5, inclosed; anthers linear. Style 2 -lobed at the apex, shorter than the tube of the corolla. Fruit divisible into 2 parts, but not crowned by 
the calyx ; mericarps semi-ovate or oblong, indehiscent.-Herbs, sometimes suffrutescent at the base, but usually annual. Leaves truly opposite, furnished with from 1 to 3 stipulas on each side. Flowers furnished with 3 bracteas each, the exterior bractea representing a cauline leaf, and the 2 lateral ones opposite, all longer than the ovarium, and appearing like a calyx. Spikes sometimes elongated and continuous, sometimes capitate, and sometimes interrupted from being formed of pedunculate faseicles of flowers.

\section{\$1. Flowers disposed in continuous spikes.}

1 C. LAtifòra (Lin. spec. 157.) plant erect, with ascending branches; leaves 4 in a whorl, elliptic-lanceolate, acute: lower ones usually ovate, and mueronated, with scabrous margins; spikes filiform, tetragonal ; flowers quadrifid, solitary, imbricated in 4 rows. $\odot$. H. Native in the region of the Mediterranean, in sandy places from Spain and Mauritania to Tauria. Guss. prod. Al. sic. 181. Smith, fl. græe. t. 139. C. spicàta, $\beta$, Lam. fl. fr. 3. p. 372. Sclsmied. icon. t. 83. f. 84.-Barrel. icon. t. 520. and 549. Corollas slender, pale yellow: lobes awned.

I ar. $\beta$, erectiúscula, (D. C. prod. 4. p. 586.) stem erectisl. C. latifolia, Bieb. A. taur. 1. p. 106.

B lar. $\gamma$, Monspeliaca,(D.C. l. c.) lower leaves ovate: upper ones 5-6 in a whorl, linear. $\odot$. H. Native of France, Mediterranean, Dalmatia, Greece, Palestine. Bentl. cat. no. 73. C. Monspeliaca, Lin. spec. 158. D. C. fl. fr. no. 3347. Smith, fl. græe. t. 140. C. spicàta, $\gamma$, Lam. A. fr. 3. p. 372. C. valgàris, Gat. f. mont. 44. Rubèola heterophýlla, Moenelı. meth. p. 526. Lobes of corolla 5, ending in a twisted awn each.

Broad-leaved Crosswort. FI. June, July. Clt. 1633. Pl. 1 foot, ascending.

2 C. ANGUStifòla (Lin. spec. p. 157.) erect; leaves 6 in a whorl, linear, acute, scabrous on the margins, and on the angles of the stem; spikes linear, imbricated in 4 rows, somewhat interrupted at the base; flowers tetramerous, twin: one of them bibracteolate. $\odot$. H. Native of arid, stony places from Spain and Mauritania to Tauria and Caucasus. Sinith, exot. bot. t. 109. Guss. prod. fl. sic. p. 181. C. spicàta, $a$, Lam. A. fr. 3. p. 37\%. Rubèola linearifòlia, Mœench, meth. p. 525.-Barrel. icon. t. 550.-Sabb. hort. rom. 2. t. 12. Corolla slender, yellowisli-green.

Var. $\beta$, monostàchya (D. C. fl. fr. no. 3345.) stem simp̣le, bearing only one spike at the apex.

Var. $\gamma$, mucrouita, (Rotl, cat. 1. p. 27.) leaves 4 in a whorl, mucronate.

Narrow-lcaved Crosswort. Fl. June, July. Clt. 1658. Pl. 1 foot.

3 C. GLAU'CA (A. Ricl. in mem. soc. hist. nat. par. 5. p. 131.) plant suffruticose at the base, erect, glaucous; leaves 6 in a whorl, linear, witl revolute edges; spikes slender, pedunculate, somewhat interrupted at the base; bracteas ciliated; flowers pentamerous. 4. H. Native of Persia.

I'ar. a, Bruguièri (D. C. prod. 4. p. 587.) leaves rough ; branchlets and bracteoles ratler velvety from fine down. 4. H. Native of Persia, between Kermancha and Amadan, where it was collected by Olivier and Bruguiere.

Var. $\beta$, Michaúxii (D. C. 1. c.) stem glabrous; leaves smoothish; bracteas a little smaller. 24. H. Native of Persia, where it was collected by Michaux.

Glaucous Crosswort. Pl. 1 foot.

4 C. cilı't A (Lam. dict. 2. p. 21\%.) plant diffuse; leaves 4 in a whorl, or opposite; spikes bardly interrupted at the base; bracteas ciliated, unequal, rather loose; flowers tetramerous; fruit beset with blınt tubercles. $\odot . H$. Native of the Levant, about Aleppo, where it was collected by Michaux. C. diffùsa, Roth, in Ust. neu. ann. 4. p. 40. cat. 1. p. 26. C. tuberculòsa, voL. III.
Cav, descript. p. 319. Flowers yellowish. Nearly allicd to $C$. pàtula.

Ciliated-bractead Crosswort. Fl. June, July. Clt. 1805. Pl. diffuse $\frac{1}{2}$ foot.

5 C. PA'TULA (Lin. spec. p. 602.) erect; branches spreading ; leaves 6 in a whorl, linear, rather scabrous; flowers $1-2$ in the axils of the bracteas, on short pedicels, pentanerous; fruit smoothisl.. $\odot$. II. Native of Spain, on rocks at $\Delta$ ranjuez, Tudela, and Navarre, and in the kingdom of Valentia. I,ocfl. itin. p. 68. C. pentándra, Dufour, in Rom. et Śchultes, syst. 3. p. 532. Corolla yellowish.

Sprcading Crosswort. Fl. June, July. Clt. 1798. Pl. $\frac{1}{2}$ to $\frac{3}{4}$ foot.

6 C. suave'olens (Meyer, verz. pil. p. 4.06.) plant perennial, glabrous; stem herbaceous, erect, branched; leaves linear, mucronate, with prickly, revolute edges, 8 in a whorl, but the upper ones are 6 in a whorl; flowers opposite, disposed in dense spikes: floral leaves and bracteas lanceolate, ciliated, a little shorter than the corollas, which are glabrous, and 5 -cleft ; stamens inclosed; meriearps glabrous, smoeth. 24. H. Native of Cancasus, in dry, stony places on the Talusch mountains.

Sneet-scented Crosswort. PI. 1 foot.

7 C. Egyptiaca (Lin. mant. p. 38.) plant diffuse; leaves 4 in a whorl, linear, with revolute edges, glabrous above, and on the margins: lower ones ovate; spikes terminal; bracteas lanceolate, with the keel and margins rather scabrous. $\odot . ~ H$. Native about Alexandria, in Egypt. C. herbàcea, Forsk. A. egyp. p. 30. Flowers pentamerous, pale yellow, awned.

Egyptian Crosswort. Fl. June, July. Clt. 1800 . Pl. $\frac{1}{2}$ foot.

8 C. Gila'xica (T'rin. in mem. act. petersb. 1818. p. 493. t. 12.) stems erectish, branched; leaves 4 in a whorl, linear, mucronate, with prickly revolute edges; flowers remotely spicate; bracteas and floral leaves ovate, ciliated, 4 times slorter than the corolla, which is glabrous. 4 . H. Native of Persia, in the province of Ghilan, on the mountains; and of Caucasus, in dry, stony places on the Talusch mountains. Root slender, creeping. Flowers pentamerous. Lobes of the corolla mucronate. Fruit and stamens glabrous. Style inclosed.

Ghilan Crosswort. Pl. procumbent.

\section{\$2. Flowers capitate.}

9 G. marítrma (Lin. spec. 158.) plant suffruticose, procumbent, much branched, glaucous, glabrous; leaves 4 in a whorl, lanceolate, stiff, marginated, mucronate; flowers axillary, disposed in interrupted spikes, pentamerous. 々. F. Native along the Mediterranean, in the sand by the sea side. Desf. fl. atl. I. p. I 32. D. C. f. fr. no. 3348.-- Rubèola marítima, Monch. meth. p. 526.-Barrel. icon. t. 355. Flowers cream-coloured. Styles sometimes 3, but usually 2.-Rubia marítima, Bauh. pin. 334. Rùbia marina, Clus, hist. 2. p. 176.

Sca-side Crosswort. Fl. July, Aug. Clt. 1640. Pl. proc.

10 C. capita'ta (Labill. pl. syr. dec. 1. p. 12. t. 3.) plant suf. fruticose, procumbent, branched, glaucous, glabrous ; leaves 6 in a whorl, almost linear; spikes capitate, ovate; bracteas membranous, lanceolate, longer than the leaves, trifid, girding 2 flowers each; corollas 5-parted. $\eta$. F. Native on the top of Mount Lebanon. Corolla blackish in the dried state. Bracteas trifid. Bracteoles linear.

Capitate-flowered Crosswort. Shrub procumbent.

11 C. styuòsa (T'rin. mem. act. petersb. 1818. p. 485. no. 3. t. 11. ex Spreng. net. entd. 1. p.99.) plant procumbent; leaves $8-9$ in a whorl, and are, as well as the stems, hispid; hcads terminal, pedunculate; flowers pentamerous; style clavate, much exserted, bifid at the apex.-Native of Persia, in the province of Ghilan, among rocks; and of Caucasus, among bushes in the province of Lenkeran, from the Caspian Sea even to the Talusch $4 \mathrm{~N}$ 
mountains. Laxmannia fasciculàta, S. G. Gmel. Said to be nearly allied to $C$. molluginoides.

Long-styled Crosswort. Pl. procumbent.

12 C. Pube'scens (Willd. spec. 1.p. 602.) plant erect; leaves 6 in a whorl, linear, downy ; heads of flowers pedunculate, axillary, and terminal; corollas pentamerous. $\odot$. H. Native of Candia. Rubèola Crética incana floribus purpurascentibus, Tourn. cor. 5. Stem downy. Corollas purplish, downy.

Downy Crosswort. Fl. July, Aug. Clt, 1799. Pl. 1 foot.

\$. Flowers in fascicles; fascicles opposite, on short peduncles: the whole forming an interrupted raceme.

13 C. molluginoides (Bieb. cent. 2. t. 65. ex fl. taur. 1. p. 106. suppl. 110.) erect; leaves $8-12$ in a whorl; linear-lanceolate, with revolute, scabrous edges, and a villous keel; fascicles of flowers opposite, disposed in an interrupted spike; bracteas ovate-lanccolate, acuminate!, villous, much shorter than the flowers; fruit glabrous, smoothish; corollas pentamerous. $\mathcal{\psi}$. H. Native of Caucasus, in subalpine places, Armenia, and Hungary. C. anómala, Balb. herb. taur. Aspérula tubiflòra, Hortul.-Buxb. cent. 2. t. 30. f. 1. Corollas greenish ycllow. Stamens 5. Mericarps nearly globose. Angles of the stem scabrous. foot.

Mollugo-like Crosswort. Fl. July, Aug. Clt, 1800. Pl. 1

14. C. A'SPERA (Bieb. fl. taur. 1. p. 107.) plant procumbent or ascending; leaves usually 6 in a whorl, linear, bluntisb, with revolute edges, and are, as well as the stem, scabrous; fascictes of flowers opposite, pedınculate, dispozed in interrupted spikes ; bracteas ovate, acute, ciliated, much shorter than the flowers; Howers pentamerous; fruit glabrous. 24. H. Native of Iberia, about Tiflis. C. prostràta, Adams. in Web. et Molır. cat. 1. p. 46. Flowers greenish yellow.

Rough Crosswort. Pl. procumbent.

15 C. glomera'ta (Bieb. fl. taur. 1. p. 107.) stems ascending . sterile ones hairy, and floriferons ones smoothish ; leaves 6 in a whorl, linear, with revolute margins, scabrous, rather glaucous; heads of flowers opposite, pedunculate, disposed in an interrupted raceme; bracteas ovate, acute, ciliated, much shorter than the flowers; flowers pentamerons. 4 . H. Native of Iberia and Caucasus, on stony hills. Rubeola orientàlis foliis Galii, flore multiplici, Tourn. cor. 5. Flowers greenish yellow.

Glomerate-flowered Crosswort. Fl. July, Aug. Clt. 1824. PI. $\frac{3}{4}$ foot.

+ Plants referred to the genus which ought to be excluded from it.

16 C.? America'na (Mill. dict. no. 5.) stem erect, villous ; leaves opposite, linear-laneeolate, hairy ; flowers solitary, axillary. $\hbar_{\imath}$. S. Native of Vera Cruz. Flowers pale blue. Fruit didymons. Probably a species of Spermacòce.

American Crosswort. Fl. July, Aug. Clt. 1780. Shrub 3 feet.

17 C.? níspida (Mill. dict. no. 4.) stem hispid; leaves opposite, lanceolate, hairy; flowers umbellate, terminal. $h$. S. Native of Vera Cruz. Stems quadrangular, rough, prickly. Flowers blue, tetramerous. Fruit didymous.

II ispid Crosswort. Shrub 2 feet.

Cult. The seeds of annual species should be sown in the open ground where the plants are intended to remain. The perennial, herbaceous, and shrubby species being rather tender, should be grown in pots, in a mixture of peat, sand, and a little loam ; and they will be easily increased by dividing at the root, or by cuttings.

CCXV. RUBIA (from ruber, red; in allusion to the red colour of the roots). 'Tourn. inst. 113. t. 38. Lin. gen. no. 127.
Lam. ill. t. 60. Gartn. fil. carp. 3. p. 85. t. 195. D. C. prod. 4. p. 588 .

Lin. syst. Pentándria, Digýnia. Calyx with an ovate-globose tube, and a 4-toothed limb. Corolla 4-5-parted, rotate. Stamens 4, short. Styles 2, short. Fruit didymous, nearly globose, baccate, juicy.-Herbs or sub-shrubs. Stems diffuse, much branched, tetragonal. Leaves opposite, usually furnished with $1-2$, rarely with $3-4$ stipulas on both sides, which are very like the leaves, constituting 4-10-leaved whorles. Flowers small, greenish white, or pale yellow. Berries black, rarely red or white.

\& 1. Exinvolucrita (the flowers of the plants contained in this section are withont involucra). D. C. prod. 4. p. 588 . Peduncles axillary, dichotomous or trichotomous; bracteas wanting, or very snall, and opposite, but never constituting an involucrum. Flowers usually pentamerous. - Species all natives of the old morld.

* Cordifolia (from cor, the heart, and folium, a leaf: the leaves are heart-shaped). D. C. prod. 4. p.588. Stems herbaceous. Lcaves on long petioles, all cordate, or only the lower ones.

1 R. cordifòlia (Lin. mant. p. 197.) leaves 4 in a whorl, petiolate, oblong, cordate at the base, 3-5-nerved, beset with prickles on the middle nerve, margins, petioles, and angles of stems; flowers tetramerous or pentamerous. $4 . H$. Native of Siberia, on the banks of the Salenga, \&c.-There are varieties of this plant with glabrous, hairy, narrower and broader leaves, which are disposed 8 in a whorl. (Pall. itin. 3. t. L. f. 1. and gall. t. 92.). Flowers whitish. Berries red or black. Perhaps 2 species are confused under this name.

Heart-lcaved Madder. Fl. July. Clt. 1783. Pl. straggling.

2 R. J Ava'NA (D. C. prod. 4. p. 588.) leaves 4 in a whorl, petiolate, ovate-lanceolate, not cordate at the base, 5 -nerved, scabrous on the middle nerve, petioles, and angles of stems ; flowers tetramerous and pentamerous. $\psi$. S. Native of Java, on the mountains. R. cordifòlia, Blum. bijdr. p. 944. An intermediate plant between $R$. cordifolia, $R$. Sibirica, and $R$. MIunjista.

Java Madder. P'l. stragghing.

3 R. Munjísta (Roxb. fl. ind. 1. p. 383.) leaves 4 in a whorl, petiolate, cordate, acuminated, 5-nerved, and are, as well as the stems, hispid; flowers all pentamerous. 24. H. Native of Nipaul and Bengal, on the mountains; and of Japan. R. cordàta, Thunb. f. jap. p. 60 . R. Manjith, Roxb. ex Flem. cat. in Desv, journ. bot. 1814. pt. 2. p. 207. There does not appear much difference between this and R. cordifòlia, Lin. This kind of madder is nsed by the dyers and calico-printers in the same manner as the common madder.

Munjith or Indian Madder. PI. straggling.

4. R. ala'ta (Wall. in Roxb. fl. ind. 1. p. 384 .) leaves 4 in a whorl, petiolate, ovate-lanceolate, and linear, 3-nerved, acuminated at the apex, scabrous; angles of stem winged, scabrous from recurved denticulations; flowers pentamerous, hispid; corymbs trichotomous, elongated. 4 . H. Native of Nipaul. Limb of leaf 3 times the length of the petiole. Very like a species of Gòlium.

Winged-stemmed Madder. Pl. straggling.

5 R. petiola'ris (D. C. prod. 4. p. 588.) leaves 4 in a whorl, petiolate, oblong-lanceolate, acuminated, l-nerved, having the nerve, margins, petioles, and angles of the stem scabrous from prickles. 4. G. Native of the Cape of Good Hope. R. cordifolia, Thunb. fl. cap. p. 151. but not of Lin. Petioles the length of leaves, tetragonal; perhaps the lower leaves are cordate. Flowers not sufficiently known.

Petiolar-leaved Madder. Pl. straggling. 
6 R. ANgustissima (Wall, cat. no. 6207.) stems quadrangular, almost winged, serrated from retrograde prickles; leaves 4 in a whorl, long, linear, with scabrous edges, sessile; peduneles dichotomously divided. 4. S. Native of the Burmese Empire, on Mount Taong Dong, near Ava. Root like that of R. Munjista.

l'ery-narrow-leaved Madder. Pl. straggling.

7 R. cirarefo'Lia (Wall. cat. no. 6210.) stems quadrangular, angles beset with retrograde, prickly denticulations; leaves 8-10 in a whorl, linear, sessile, scabrous on the margins and keel; corymbs terminal. 4 . F. Native of Nipaul.

Chara-lcaved Madder. Pl. straggling.

* Suffruticòse. Stems shrubby. Leaves on short petioles, oblong or lanecolate.

8 R. rRuticòsA (Ait. hort. kew. 1. p. 147.) stem slirubly, smooth; leaves $2-6$ in a whorl: the uppermost ones opposite, elliptic, on short petioles, having the margins and keel scabrous from prickles; flowers pentamerous; corymbs axillary, short, few-flowered. h. G. Native of Teneriffe, among bushes, Jacq. icon. rar. t. 25. R. fruticòsa, and R. Canariénsis, Poir. suppl. 2. p. 707. Leaves varying from oval to oblong-lanceolate, with distant retrograde prickles on the margins. Corollas yellowish. Peduncles usually 3 -flowered.

I ar. $\beta$, galivides (D. C. prod. 4. p. 589.) stem shrubby, terete, smooth; leaves 6 in a whorl, petiolate, ovate-lanceolate, with rough margins; peduncles axillary, 3-4-flowered, mueh shorter than the leaves. $\eta$. G. Native of the Canary Islands. R. galioides, Poir. suppl. 2. p. 705.

Shrubby Madder. Fl. Sept. Clt. 1779. Shrub 4 to 5 feet.

9 R. ACALYculA'TA (Cav, icon. 2. p. 75. t. 195.) stems rather herbaceous, smooth, hexagonal ; leaves petiolate, ovate-lanceolate, having the nerve beneath and the margins furnished with retrograde prickles; corymbs axillary, trichotomous, bibracteate; flowers pentamerous. 4 . $\eta$. G. Native of Madras, where it is ealled Tasaygo. Leaves 7-9 in a whorl, but on the branches only 3 in a whorl. Flowers yellowish. Teeth of calyx not perspicuous, as in many other species of the genus. Very nearly allied to $R$. fruticòsa.

Ecalyeulate-flowered Madder. Shrub 2 feet.

10 R. LE'Vis (Poir. voy. 2. p. 111. suppl. 2. p. 706. but not of Thunb.) stem shrubby, smooth ; leaves 8 in a whorl, linear-lan. ceolate, mucronate, smooth; peduncles axillary, simple, or bifurcate, diverging. $\quad$. S. Native of Barbary, on the sea-shore near Lacalle. Perhaps a species of Gàlium. Flowers white, tetramerous.

\section{Smooth Madder. Shrub.}

* Tinctoria (from tinctorius, for dying; the roots of most of the species are used for dying). D. C. prod. 4. p. 589 . Stems herbaceous. Leaves sessile, or on short petioles, never cordate.

11 R. Angustiròlia (Lin. mant. p. 39.) plant herbaceous; leaves 4 in a whorl, linear, scabrous above, and also along the margins and nerve ; angles of stems prickly ; corymbs axillary, 3-flowered; lobes of corolla bluntish, apiculated. 2. F. Native of Gibraltar, Portugal, and Balearic lslands. Lam. ill. t. 60. f. 2. Leaves evergreen. Flowers pale yellow. Perhaps this and the 6 following are only variations of $R$. tinctoria.

Narron-leaved Madder. Fi. June, Aug. Clt. 1772. Pl. straggling.

12 R. Longifolla (Poir. suppl. 2. p. 703. ?) herbaceous; leaves 4-6 in a whorl, linear-lanceolate, elongated, acuminated, almost sessile, smooth above, but with the margins and nerve scabrous from prickles, as well as the angles of the stem; peduncles trichotomous; lobes of corolla acutish, acuminated, not abruptly cuspidate. 4 . H. Native of Corsica and at Mogo- dor: R. Requiènii, Duby, bot. gall. 1. p. 247. Flowers yellowish. Berries black.

Long-leaved Madder. Pl. straggling.

18 R. тілсто̀rum (Lin. spec. p. 158.) herbaceous; leaves 4-6 in a whorl, on short petioles, lanceolate, smooth above, scabrous from prickles on the margins and keel, and along the angles of the stem; peduneles axillary, trichotomous; lohes of corolla gradually acuminated, not euspidate. 4 . H. Native of the Levant and south of Europe; and also of Caucasus, on Mount Beschbarmak, and plentiful near Dervent, and in the province of Baku; but cultivated in many parts for the sake of its routs. Lam. ill. t. 60. f. 1. Heyne, arzn. gew. xi. t. 5. Selikuhr. handb. t. 2s. Mill. fig. t. 1. Woodv. med. bot. t. 68. Smith, f. græc. t. 141. Sabb. hort. 1. t. 77. Blackw. t. 26. R. peregrina, Murr. bot. val. p. 91. ex Gaudin. R. sylvéstris and R. tinctorum, Mill. dict. no. 1-2. Roots long, thick, and red. Leaves and stems fading in autumn. Flowers yellow, pentamerous. Berries dark purple.

The root of the dyer's madder is composed of many long, thick, succulent fibres, almost as large as a man's little finger; these are joined at the top in a head, like the roots of asparagus, and strike very deep into the ground, being sometimes more than three feet in length. From the upper part come out many side-roots, which extend just under the surface of the ground to a great distance, whereby it propagates very fast ; for these send up a number of shoots, which, if carefully taken off in spring, soon after they are above ground, become so many plants. It is a native of the south of Europe, flowers in June, and seeds soon afterwards; but by them it is never propagated. Madder is mentioned by the Greeks as a medical plant; but when it was first used in dying is uncertain. It has been cultivated in $\mathrm{Hol}-$ land and Flanders, and other parts of the continent for that purpose, for many years, and has been tried in this country; but unless the importation of the root from the continent were entirely prevented, it will not answer. Its culture has been attempted at different times, when our commerce with the Dutch was interrupted, or when they raised the price of the article exorbitantly high. At present it may be imported not only from Holland, but from France, 1taly, and Turkey.

The soils most suited to the cultivation of madder are those of the deep, fertile, sandy loams, that are not retentive of moisture, and which have a considerable portion of vegetable matter in their composition. It may also be grown on the more light deseription of soils, that have sufficient deptl, and which are in a proper state of fertility.

The preparation of the soil may either consist in trenchploughing, lengthway's and across, with pronged stirrings, so as to bring it to a fine tilth; or, what will often be found preferable, by one trenching 2 feet deep by manual labour.

The sets of plants are best obtained from the runners, or surface shoots of the old plants. These being taken up, are to be eut into lengths of from 6 to 12 inches, according to the scarcity or abundanee of runners. Sets of one inch will grow, if they have an eye, or hud, and some fibres; but their progress will be slow, for want of maternal nourishment. Sets may also be procured by sowing the seeds in fine light earth, a year before they are wanted, and then transplanting them; or sets an incl, long may be planted for one year in a garden, and then removed to the field plantation.

The season of planting is commonly May or June, and the manner is generally in rows, 9 or 10 inches asunder, and 5 or 6 inches apart in the rows. Some plant promiseuously in beds, with intervals between; but this is unnecessary, as it is not the surface, but the descending roots, which are used by the dyer.

The operation of planting is generally done by the dibber, but some plant them by the aid of the plough. By this mode, the $4 \times 2$ 
ground is ploughed over wish a shallow furrow, and in the course of the operation the sets are deposited in each furrow, leaning on and pressed against the furrow-slice. This, however, is a bad mode, as there is no opportunity of firning the plants at the roots, and as some of the sets are apt to be buried, and others not sufficiently covered.

The after cullure consists in hoeing and weeding, with stirring by pronged hoes, either of the horse or hand kind. Some earth up, but this is unnecessary, and even injurious, as tearing the surface roots.

The Madder crop is taken at the end of the third autumn after planting, and generally in the month of Octoher. By far the best mocle is that of trenching over the ground, which not only clears it effectually, but fits it at once for another crop. But where madder has been grown on land prepared by the plongh, that implement may be used in removing it. Previously to trenching, the haulm may be removed with an old scythe, and carted to the farmery, to be used as litter to spread in the straw-yards.

Drying the rools is the next process, which, in very fine seasons, may sometimes be effected on the soil, by simply laying the plants on it as they are taken up; but in most seasons they require to be dried on a kiln, like that used for malt or hops. They are dried till they become brittle, and then packed up in bags for sale to the dyer.

The produce from the root of this plant is different according to the difference of the soil, but mostly from 10 to 15 or 20 hundred weight, where it is suitable to its cultivation.

In judging of the quality of Madder roots, the best is that which, on being broken in two, has a brightish red or purplish appearance, without any yellow east being exhibited.

The usc of the Madder roots is chiefly in dyeing and calico printing. The haulm which accumulates on the surface of the field in the course of 3 years, may be carted to the farm-yard, and fermented along with horse-dung. It has the singular property of dyeing the horns of the animals who eat it of a red colour.

Madder seed in abundance may be collected from the plants in September of the second and third years, but it is never so propagated.-Madder is sometimes blighted, but in general it has but few diseases.

Madder is cultivated in Holland only on the very best soils, and with plenty of inanure. At the end of May or April, according as the young plants are large enougl to be transplanted, the land inust be ploughed in beds of 2 feet, and $2 \frac{1}{2}$ feet wide; the beds are then harrowed and raked, and the young suckers of the roots or plants are to be put down in rows, at intervals of a foot or a foot and a lialf, and at 6 or 8 inehes distant in the row. During the entire summer the land should be frequently stirred, and kept fiee from weeds. In the month of November, when the leaves are faded, the plants are covered with 2 inches of earth, by a plough, having the point of the coulter a little raised or rounded, so as not to injure the young plants. In the following spring, when the young roots are 4 or 5 inches long, they are gathered or torn off, and planted in new berts, in the same manuer as above stated; and then, in the month of September or October, after the faded leaves have been removed, the old roots are taken up. The madder thus taken up should be deposited under cover, to protect it from the rain, and after 10 or 12 days, llaced in an oven moderately heated. When dried sufficiently it is gently beaten with a flail, to get rid of the clay that may adhere to the plasts; and by means of a small wind-mill, is ground and sifterl, to separate it from any remaining earth or dirt. It is then replaced in the oven for a short time, and when taken out, is spread upon a hair cloth to cool; after which it is ground and cleaned once more. It is then carried to a bruising mill, and reduced to fine powder, and then packed in casks or barrels for the market.

I ar. $\beta$, Ibérica (Fisch. in litt. ex D.C. prod. 4. p. 589.) leaves on longer petioles, downy on the veins and nerves beneath. 24. H. Native of Iberia. The roots of this variety are said to be better for the purposes of dyeing than those of the species.

Dycr's Madder. Fl. June. Clt. 1596. Pl. straggling.

14 R. peregrina (Lin. spec. p. 158.) herbaceous; leaves 4-6 in a whorl, sessile, lanceolate, shining above, smooth, but scabrous from looked prickles on the margins and keel, and along the angles of the stem; peduncles axillary, dicliotomous; lobes of corolla ovate, cuspidately arvned. 4 . H. Native of south and middle Europe, in rough places; in the west of Britain in thickets, and on stony or sandy grouncl. D. C. H. fr. 1. no. 3389. Smith, engl. bot. t. 851 . R. A'nglica, Huds. angl. 1. p. 54. R. tinctòrum, With. brit. p. 193. R. tinctòrum $a$, Lam. f. fr. 2. p. 605. R. lùcida, D'Urv. cat. p. 17.-Petiv. brit. t. 30. f. 3. - Moris, hist. sect. 9. t. 21. f. 2. Flowers dusky yellow, pentamerous. Root creeping, Heshy, tawny red. Berries black.

Forcign Madder. Fl. July. England. Pl. straggling.

15 R. Lu'cida (Lin. syst. veg. xij. p. 732.) herbaceous; leaves 4-6 in a wborl, elliptic, shining, with a smooth keel, but scabrous from prickles along the margins and angles of the stem; peduncles axillary, trichotomous, short; lobes of corolla lanceolate, acuminated, inflesed at the points. 4. H. Native of south and middle Europe, in rugged places. Smith, fl. graec. 142. D. C. A. fr. 4. p. 265 . R. tenuifòlia, D'Urv. eat. p. 17. R. rotundifölia, Poir. suppl. 2. p. 106 . Leaves permanent. Flowers dusky yellow, pentamerous.

I ar. $\beta$, angustifolia (Guss. prod. fi. sic. 1. p. 183.) stem smoothish; leaves elliptic-oblong or lanceolate. 4. H. Native of Sicily and the south of France.

Shining-leaved Madder. Fl.July. Clt. 1762. Pl. straggling.

16 R. Boccòn (Petagn. inst. bot. 2. p. 255.) herbaceous; leaves 4 in a whorl, ovate, shining above, scabrous on the keel and margins, and angles of the stem; peduncles axillary, trichotomous; lobes of corolla 4-5, acute. $4 . H$. Native of Naples and Sicily, anong calcareous rocks. Ten. A. neap. t. I0. Guss. prod. sic. 1. p. 1s2.-Boce. mus. t. 75.-Barrel. icon. t. 547. Flowers greenish-white, sweet-scented. Habit of $R$. lucida. Root yellow. Leaves permanent. Angles of stems prickly. Stamens 4-5.

Bocconi's Madder. Fl. June, Aug. Clt. 1823. Pl. straggling.

17 R. spléndens (Hoffms. et Link, H. port. 2. p. 67. t. 85.) herbaceous; leaves $4-6$ in a whorl, obversely oblong, acute, having the nerve on both surfaces and margins scabrous from prickles, as well as the angles of the stems; panicles axillary; lobes of corolla prickly. 4 . H. Native of Portugal, in hedges about Lisbon. R. sylvéstris, Brot. A. lus. 1. p. 153. but not of Mill. Flowers yellow, pentamerous.

Glittering-leaved Madder. Fl. June, Aug. Clt. 1812. Pl. straggling.

$18 \mathrm{R}$. intricata (Hook, et Arn. in bot. mise. 3. p. 36\%.) glabrous, smoothish; stems diffuse, herbaceous, divaricately branched, intricate, acutely 4-angled; leaves small, oblonglinear, hardly acute, almost nerveless; branches of panicle divaricate; Howers peduneulate, bractless; berries globose.Native of Chili, among hedges of Cacti at San Isedro.

Intricate-bratched liubia. P'l, diffuse.

19 R. Oliveirn (A. Rich, in mem. soc. hist. nat. Par. 5. p. 132.) stems suffiticose, rather hexagonal, scabrous from retrograde prickles or bristles; branches powdery, downy; leaves usually 6 in a whorl, oboval, mucronate at the apex, with hispid margins; peduncles axillary, usually by threes, tripartite, and 3-flowered at the apex; corolla subcampanulate, 5-parted. 4 . H. Native of the island of Scio, where it was collected by Oliveir and Bruguiere. 
Oliveir's Madder. PI. straggling.

20 R. TuUnbe'Ran (D. C. prod. 4. p. 590.) plant glabrous in every part; leaves usually 4 in a whorl. - Native of the Cape of Good Hope. R. lævis, 'Thunb. fl, cap. 151. but not of Poir. The rest unknown.

Thunberg's Madder. Pl. straggling.

\$2. Involucratce (the flowers of the plants contained in this section are involucrated by bracteas). D. C. prod. 4. p. 590 . Peduncles a.rillary, bearing each 4 bracteas in a nhorl, mhich constitute an incolucrum to the flowers. Flowers 1-3, rising from cach involucrum, sessile, or pediccllatc, usially tetramerous.Diffuse prostrate plants, all natives of America, which probably should be joined with Gàlium according to A. Richard.

\section{* Berries glabrous. Leaves 1-nerved.}

21 R. WALte'RI (D. C. prod. 4. p. 590.) stems tetragonal, smooth on the angles, and pilose on the sides; leaves ovate, membranous, rather pilose on both surfaces while young, but having the keel and margins scabrous in the adult state; bracteas ovate, acute; flowers solitary from the involucra; fruit glabrous, petlicellate. 24. H. Native of Carolina and Florida, in shady places. R. peregrina, Walt. car. p. 86 . but not of Lin. R. Brównei, Michx. fl. bor. amer. 1. p. 81. exclusive of the syn. of Browne. R. Techénsis, Rafin. fl. lud. p. 76.? Flowers small, yellow, tetramerous. Fruit blackish.

Walter's Madder. Pl. straggling.

22 R. Guadalupe'xsis (Sprcug. syst. 1.*p. 397.) stems tetragonal, rough along the angles at the base; leaves oblong, mucronate, attenuated at the base, having the margins and keel prickly; peduncles axillary, shorter than the leaves, 1 -flowered; flower sessile among the bracteas, which are oblong; berries scabrous. 4. S. Native of Guadaloupe, where it was collected by Badier and Bertero.

Guadaloupe Madder. Pl. straggling.

23 R. ixdeco'ra (Cham. et Schlecht, in Linnæa. 3. p. 229.) stems tetragonal, scabrous from pili; leaves oblong, somewhat cuneated, obtuse, mucronate, membranous, remotely pilose on the nerve beneath and margins; peduncles axillary, solitary, opposite, 1-flowered; bracteas lanceolate; ovarium pilose; berries egg-shaped, glabrous, sessile within the involucra. $4 . \mathbf{F}$. Native of the south of Brazil.

Indecorous Madder. Pl. straggling.

24. R. CunL' Nsis (11ol. chil. 118. ed. gall. p. 330. but not of Willd.) stems smooth, tetragonal while young, but at length becoming terete and erectish; leaves oblong-linear, mucronate, pilose on the nerve and margins; peduncles axillary, opposite, 1 -flowered, a little longer than the leaves, hairy at top, as well as the bracteas. 24. F. Native of Chili, near Rancagua and Valparaiso, where it was collected by Bertero, who asserts that it is the Relbun of the natives. Nearly allied to $R$. indecora.

Chili Madder, Pl, straggling.

25 R. ramosíssima (Pohl, in litt. ex D. C. prod. 4. p. 591.) stems tetragonal, rather hairy along the angles; leaves oblong, obtuse, rather cuneated at the base, l-nervel, rather pilose beneath and glabrous above, and shining; peduncles axillary, length of leaves, 1-flowered; bracteas oval, glabrous; berry sessile, within the involucrum, glabrous. \%. G. Native of Brazil, where it was collected by Polsl. Herb becoming black on drying.

Much-branched Madder. Pl, straggling.

26 R. VAldistoldes (Cham. et Schlecht. in Linnæa. 3. p. 231.) stems tetragonal, pilose along the angles; leaves sessile, ovate, acute, membranous, 3-nerved, pilose on the margins and nerves; peduncles axillary, verticillate, shorter than the leaves, 1-flowered; bracteas ovate-oblong; flower sessile within the involucrum. 4,F. Native of Brazil. Stem seabrous from the bases of the hairs remaining. Corolla pilose. Berries glabrous. Valantia-like Madder. Pl. straggling.

27 R. Nı'TıA (H. B. et Kunth, nov. gen. 3. p. 339. t. 280) stems tetragonal, beset with reflexed hairs along the angles; leaves elliptic, bluntish, with revolute edges, glabrous above and slining, and rather hairy beneath; peduncles axillary, 1-flowered, opposite, twice the length of the leaves; flower sessile, within the involucrum; berries glabrous. 24.F. Native at the foot of the burning mount Pichincha, near Quito. Allierl to $R$. Waltèri.

Nitid-leaved Madder. Pl. straggling.

28 R. vìls (Cham. et Schlecht, in Limnae. 3. p. 230.) glabrous; stems tetragonal, scabrous from retrograde bristles on the angles, and on the nerves and margins of the leaves; leaves oblong, obtuse, hardly attenuated at the base, rather mucronate, membranous; peduncles axillary, verticillate, 3-flowered, length of leaves: the middle flower sessile; bracteas oblong, acute. 4. F. Native of the south of Brazil. Berries globose.

Vile Madder. Pl. straggling.

29 R. cilia'ta (D. C. prod. 4. p. 591.) stems procumbent, mucl branched, tetragonal, glabrous; leaves 4 in a whorl, on short petioles, linear-lanceolate, ciliated, reflexed ; peduncles axillary, solitary, filiform, 1 -flowered, length of leaves, bearing 4 verticillate leaves at the apex; Hower sessile, within the involucrum; fruit glabrous. 4 . F. Native of Pert, on arid hills. Gàlium ciliàtum, Ruiz et Pav, fl. per. 1. p. 59. Gàlium involucràtum, H. B. et Kunth, nov, gen. amer. 3. p. 334. Flowers purple. Fruit nutant. Perhaps a species of liubia.

Ciliated-leaved Madder, Pl. procumbent.

30 R. MONÁNTila (D. C. prod. 4. p. 591.) stems procumbent, much branched, tetragonal, smoothish; leares oval or ovate-oblong, acutish, ciliated with long hairs, hispid above; peduncles axillary, solitary, 1-flowered, bearing each 4 leaves or bracteas just under the flower; flower sessile, within the involucrum; fruit glabrons, smooth. 2 . F. Native of Peru, where it was collected by Hænke. Gảlium monánthon, Bartl. in herb. Hænke. This species is nearly allied to $R$. ciliata.

One-flowered Madder. Pl. procumbent.

31 K. ova'Lss (D. C. l. c.) stems climbing a little, tetragonal, hairy; leaves 4 in a whorl, oblong-oval, acuminated, equal, at length reflexed; peduncles axillary, 1-flowered, a little shorter than the leaves, bearing 4 oval acute bracteas at top inder the flower; fruit glabrous. 24. F. Native of Peru, among rubbish. Gàlium ovà'e, Ruiz et Pav. fl. per. 1. p. 59.

Oval-leaved Madder. Pl. climbing.

32 R. cro'cea (D. C. I. c.) stems procumbent, branched; branches tetragonal; leaves 4 in a wlorl, linear, ciliatel, rather scabrous beneath; peduncles axillary, short, 1 -flowered, bearing 4 leaves at the apex ; fruit glabrous.-Native of Peru, at Tarma and Huanaco, on arid declivities. Gàlıum cròceum, Ruiz et Pav. fl. per. p. 126. Flowers 3-4-cleft. Fruit of a reddish copper-colour.

Saffron-coloured-fruited Madder. 1'l. procumbent.

33 R. LEVIGA'TA (D. C. l. c.) plant gute glabrous; stems tufted, much branched, diflise; leaves 4 in a whorl, ovate-oblong or ovate-lanceolate; peduncles axillary, l-flowered, bearing 4 leaves at the apex; flower sessile, within the involucrum; fruit glabrous, smooth. $\odot . ? H$. Native of Mexico, where it was collected by Hænke. Gàlium levigàtum, Bartl. mss.

Smootl Madder. Pl. diffuse.

34 R.? conymbòsa (D. C. prod. 4. p. 591.) stems creeping, filiform; branches alternate, erect, corymbosely dichotomons, tetragonal; leaves 4 in a whorl, sessile, approximate, oblonglanceolate, rather ciliated, glabrous; peduncles 1-flowered, bearing each 4 bracteas : fruit glabrous.-Native of Peru, on the 
high mountains of Tarma, at Bombom. Gàlium corynıbòsum, Ruiz et Par. fl. per. 1. p. 59. The roots dye a red colour. Corymbose-flowered Madder. Pl, creeping.

\section{* Berries hairy or scabrous. Leaves 1-nerved.}

35 R. нYросA'RPIA (D. C. prod. 4. p. 591.) stems tetragonal, hispid from long villi along the angles; leaves oval-oblong, hairy on both surfaces; peduncles axillary, 1-flowercd, hardly shorter than the leaves; bracteas oblong, rather hairy; flower as well as the fruit almost sessile within the involucrum; berries rather lairy.-Native of Jamaica. P. Browne, jam. p. 141. Valántia liypocárpia, Lin. spec. 1491. Swártz, obs. p. 385. R. Brównci, Spreng. syst. 1. p. 397. Berries blackish.

Under-fruited Madder. Pl, straggling.

36 R. KE' LbUN (Cham. et Schlecht. in Linnæa. 3. p. 229.) the whole plant is scabrous, and clothed with short pili; stems acutely tetragonal; leaves obovate-elliptic, obtuse, mucronate, rather membranous, with ciliated margins, scabrous from hairs on both surfaces; peduncles axillary, l-flowered, opposite or verticillate; bracteas broad-lanceolate; flower sessile; berry sessile, globose, rather pilose. ४. F. Native of Chili, Brazil, and Caraccas. Poep. pl. exsic. chil. no. 705. Feuill, obs. 3. p. 60. t. 45. R. Chilénsis, Willd. spec. 1. p. 60\%. but not of Mol. The plant is called Fclbun in Chili, as well as other species; and the roots are red, and used for dyeing like the common madder.

Relbun Madder. Pl. straggling.

37 F. Richardia'sa (Gill, mss. ex Hook. et Arn. in bot. misc. 3. p. 362.) plant glabrous, scabrous, shining; stems erectish, teretely quadrangular; leaves 4 in a whorl, linear-ohlong, acute, 1-nerved, one-half shorter than the internodes; peduncles opposite or in whorles, equal in length to the leaves, bearing 4 bracteas and 3 flowers at the apex; fruit tubercular in the immature state.-Andes of Mendoza.

Richardson's Rubia. Pl. straggling.

38 R. HeNKeA'Na (Gill, mss. ex Hook, bot. misc. 3. p. 363.) plant hairy, hoary; stems procumbent, terete; leaves 4 in a whorl, linear, acute, deflexed, one-nerved, broader at the base ; peduncles in whorles much longer than the leaves, bearing 3 flowers and 4 bracteas at the apex; fruit tubercular, scabrous. 4. F. Native of Chili, about Mendoza.

\section{Hanke's Rubia. Pl. procumbent.}

39 R. Pusíxla (Gill. mss. ex Hook. et Arn. in bot. misc. 3. p. 863.) plant tufted, glabrous, branched, shining ; stems smooth, terete, furrowed; leaves 4 in a whorl, oblong-linear, mucronate, with smoothish margins; peduncles equal in length to the leaves, bearing 3 flowers and 3 bracteas at the apex; fruit minutely tubercular when immature. 4. F. Native of Chili, in the province of San Louis. This has quite the appcarance of some states of Gàlium pùmilum.

Small Rubia. Pl, straggling.

40 R. Orinoce'nsis (H. B. et Kunth, nov. gen. amer. 3. p. 239.) stems tetragonal, glabrous, scabrous on the angles; branches pilose; leaves on short petioles, oblong, acute, pilose, one-half shorter than the internodes; peduncles axillary, l-flowered, solitary; flower almost sessile, within the involucrum; berries pilose. 4 . F. Native on the banks of the Orinoco, in liot places, and of the south of Brazil, ex Cham. et Schlecht. in Limnæa. 4. p. 228. R. Brównei, Spreng. syst. 1. p. 397. Gàlimm pauciflòrum, Willd. herb.

Orinoco Madder. Pl. straggling.

41 R. mucroma'ta (Hook. et Arn. in bot. misc. 3. p. 363.) stems prostrate, glabrous, terete, 4 -furrowed, branched; leaves 4 in a whorl, linear-oblong, glabrous, shining, with revolute edges, 3 times shorter than the internodes; common peduncles axillary, longer than the leaves; flowers cymose. 4. F. Native of
Chili, about Conception and Tarma ; and of Peru, in arid places. Gàlium leucocárpum, D. C. prod. 4. p. 612. Gàlium Tarménse, Spreng. syst. p. 27. G. mucronàtum. Ruiz et Pav. f. per. 1. p. 66 . G. apiculatum, Rœm, et Schultes, syst. 3. p. 222. Fruit milk coloured.

Mucronate Madder. Pl. prostrate.

42 R. inea'sa (H. B. et Kunth, nov. gen. amer. 3. p. 338.) stems tetragonal, hoary from villi; leaves 4 in a whorl, ovate, short-acuminated, mucronate, with revolute margins, which are as well as the middle nerve hispid from pili ; peduncles axillary, 1-flowered, length of leaves; flower sessile, within the involucrum; berries rather pilose. 4 . F. Native on the Andes about Quindiu, near El Moral. Corolla rather hairy outside.

Hoary Madder. Pl. straggling.

43 R. Hírta (H. B. et Kunth, nov. gen. amer. 3. p. 338.) stems tetragonal, hairy ; leaves 4 in a whorl, on short petioles, oblong, acute, mucronate, hairy; peduncles axillary, opposite, 1-flowered, hardly slorter than the leaves; flower sessile, within the involucrum; berries scabrous. 4 . F. Native near the town of Quito.

Hairy Madder. Pl. straggling.

\section{* Lcaves 3-nerved. Berries glabrous.}

44 R. NóxıA (St. Hil. pl. rem. bras. p. 229.) stems tetragonal, beset with retrograde bristles along the angles below, and hairy at top ; leaves sessile, elliptic, obtuse, ending in a very short point, 3-nerved, membranous, rather pellucid, scabrous from pili above, and on the nerves beneath ; peduncles axillary, solitary, 1 -flowered, pilose; bracteas 4, ovate; berries glabrous.-Native of Brazil, in woods in the province of Minas Geraes. Corollas greenish, hardly pilose. Flowers either sessile or pedicellate within the involucrum. Berries white.

Hurtful Madder. Pl. straggling.

45 R. A'spera (Pohl, in litt. ex D. C. prod. 4. p. 592.) stems tetragonal, glabrous, scabrous along the angles from retrograde bristles; leaves sessile, ovate, mucronulate, membranous, 3 nerved, rather scabrous along the margins and nerves, especially beneath, glabrous; peduncles axillary, tetragonal, rather longer than the leaves; bracteas oval, glabrous ; berries glabrous, sessile, within the involucrum. 4 . F. Native of Brazil, where it was collected by Pohl. Nodi of stems scabrous from short crowded hairs. Bracteas greenish-yellow. Berries blackish.

Rough Madder. Pl, straggling.

46 R. diffu'sa (Pohl, in litt. ex D. C. prod. 4. p. 592.) stems tetragonal, hispid ; leaves sessile, oval, acute, membranous, 3nerved, hispid along the margins and nerves, especially beneath ; peduncles axillary, 1 -flowered, Jonger than the lcaves; bracteas 4 , ovate, acute, rather hispid; berry glabrous, sessile within the involucrum. 2.F. Native of Brazil, where it was collected by Pohl. Upper leaves smoothish. Peduncles 5-6 lines long. Berries blackish.

Diffuse Madder. Pl. straggling.

\$3. Galioidece (this section contains plants having the habit of species of Gälium). D. C. prod. 4. p. 492. American species witl tetrandrous flowers, which are disposed in dichotomous cymes, ncver girded by any involucra.

47 R. equisetoìnes (Cham. et Schlecht, in Linnæa. 3. p. 232.) branches compresscdly tetragonal, scabrous from retrograde bristles; leaves small, erectly adpressed, somewhat triangular, acute; cymes divaricate, dichotomous or trichotomous; flowers sessile in the forks; bracteas 4, under the branches; berries glabrous. 4. F. Native of the south of Brazil.

Hor se-tail-like Madder. Pl. straggling.

48 R. EPHedroidrs (Cham. et Schlecht. in Linnæa. 3. p. 231.) glabrous; stem nearly terete; branches acutely tetragonal, roughish; leaves narrow-elliptic or linear, acute, smooth; cymes 
dichotomous or trichotomous; bracteas conforming to the leaves under the branches; flowers pedicellate; berries glabrous. $\psi$. F. Native of Brazil. Leaves deciduous, smootl.

Ephedra like Madder. Pl. straggling.

49 R. sca'bra (H. B. et Kunth, nov. gen. amer. 3. p. 340 ) stems tetragonal, beset with retrograde prickles along the angles; leaves 6 in a whorl, and the upper ones 4 in a whorl, sessile, oblong-lanceolate, acutish, with rather revolute and serrulated edges, 3 times shorter than the internodes; peduncles terminal, usually by tlirees; bracteas $1-3$; berries glabrous. $\odot$. H. Native of the Andes about Quindiu, between Carthage and lbague. Perhaps a species of Galium nearly allied to $G$. Claytòni.

Scabrous Madder. Pl, straggling.

50 R. DE'BıLıs (H. B. et Kunth, nov. gen. amer. 3. p. 340.) stems tetragonal, beset with retrograde prickles along the angles; leaves oblong, acute, mucronate, flat, having the margins and keel beset with retrograde prickles; peduncles 2-3 together, terminal, 1-flowered, naked; berries glabrous. 4. F. Native of Quito, in high places near Chillo and Ichubamba. Perhaps a species of Gâlium nearly allied to $G$. ciliàtum. Mature fruit unknown.

Weak Madder. Pl. trailing.

Cult. The species will grow in any common soil, and are all easily increased by dividing at the root or by seeds. Those species natives of warm climates require to be placed in the green-house in winter.

CCXVI. GA'LIUM (from $\gamma a \lambda a$, gala, milk; some species are used for curdling milk). Scop. carn. ed. 2. vol. 1. p. 94. D. C. fl. fr. ed. 3. vol. 4. p. 248. Rœm. et Scluultes, syst. 3. p. 481. D. C. prod. 4. 1). 593.-Gàlium and Valántia species, Lin. -Gàlium, Aparìne, and A'spera, Mœench. meth._Gàlium, Eysèlia, Aparine, Neck. elem. no. 332. 333. and 335.-Gàlium and A parine, Tourn. inst. t. 39. Møench. meth. 484. and 640.Gâlium species, A. Rich. mem. soc, hist. nat. Par. 5. p. 133.

LıN. sysr. Tetrándria, Digýnia. Calyx with an ovate-globose or oblong tube, and hardly any limb. Corolla 4-parted (f. 111. b.), rotate, rarely 3 -parted. Stamens 4 , short (f. 111.c.). Styles 2, short. Fruit didymous, roundish, rarely oblong, dry, composed of 2 indehiscent 1 -seeded mericarps. - Branched herbs. Leaves forming whorles along with the stipulas. Inflorescence variable.

Secr. I. Euga'luum. Perennial plants.

1. Lciogàlia (from $\lambda \varepsilon \iota$ c, lcios, smooth, and galium; in reference to the smooth fruit of the species). Percnnial plants. Leaves 6 to 10 in a whorl, rarely only 4-5. Flowers disposed in cymose panicles, hermaphrodite, white. Fruit glabrous.

1 G. sylváricum (Lin. spec. p. 155.) stems erect, smooth, terete, much branched; leaves 8 in a whorl, elliptic, obtuse, mucronate, smooth, scábrous beneath, and rather glaucous; floral leaves opposite ; peduncles capillary, disposed in a terminal panicle; lobes of corolla obtuse; fruit glabrous. $\boldsymbol{\varkappa}$. H. Native throughout Europe (Britain and Sicily excepted), in woods. D.C. fl. fr. no. 3356.-Baul. hist. 3. pt. 2. p. 716 . f. 4. Flowers white.

$V$ ar. $\beta$, pubéscens (D. C. fi. fr. vol. 4. p. 24.8.) stem, branches, and nerves on the under side of leaves downy. 4. H. Native of Moguntia and elsewhere.

Wood Bed-straw. Fl. July, Aug. Clt. 1658. Pl. 1 to $2 \mathrm{ft}$.

2 G. Linıòlıu (Lam. dict. 2. p. 578.) stems erect, terete, smooth; leaves 4-8 in a whorl, lanceolate-linear, acuminated, quite glabrous, membranous, glaucous beneath, with smoothish margins; peduncles capillary, panicled; lohes of corolla acute ; fruit glabrous, smoorh. 24. H. Native of Dauphiny, Provence, Italy, \&.c. in shady places as in woods. D. C. fl. fr. 4. p. 252. G. àtro-vírens, Lapeyr. abr. ex Benth. G. lævigàtum, Vill. dauph. 2. p. 229. Leaves rather rough at the tops from a very few bristles or prickles. Flowers white.

lar. B, scrulatum (D. C. prod. 4. p. 593.) leaves membranous, serrulated by prickles round the margins. $4 . \mathrm{H}$. Native about Naples, where it was collected by l'assy.

Var. $\gamma$ ? rigidulum (D. C. prod. 4. p. 593.) leaves stiffish, subserrated round the margin. $\psi$. H. Native of the Pyrences and Corsica, \&c. G. aristatum, Gaud. fl. helv. and perhaps of Lin. G. glaúcum, Sut. $A$. helv.? G. intermèdium, Schultes, obs. bot. no. 153.? G. sylváticum, Bess. fl. gal. 1. p. 219. G. glaúcum, Oed. fl. dan. t. 609. G. mutábile, Bess. cont. fl. Volh. no. 1336 . is probably referrible to this. Pcrhaps a proper species.

Flax-leaved Becl-straw. Fl. June, July. Clt. 1759. P!. 1 to 2 feet, var. $\gamma, 3$ to 4 feet.

3 G. Pascira'le (Forsk. descrip. p. 203.) stems weak, glabrous, smooth ; leaves $8-9$ in a whorl, linear-lanceolate, with scabrous margins, glabrous, mucronate; peduncles axillary, opposite, twice longer than the leaves, trichotomous at the apex; fruit glabrous, minute. 2 . H. Native about Constantinople. G. Hierosolymitànum is probably not distinct from this, ex Vall, symb. 2. p. 29. but that plant is joined to $G$. laeve by Sclurader, and to $G$. scabrum by Persoon. Flowers white.

Paschale Bed-straw. Pl. $1 \frac{1}{2}$ foot.

4. G. Ixcu'Rvum (Sibth and Sinith, fl. græc. t. 132.) stems panicled; leaves 8 in a whorl, linear, glabrous, awned, incurved; lobes of corolla obtuse, awnless; fruit glabrous. $\because$. H. Native of Crete, on the splaceotic mountains. Flower: yellow.-Perhaps the same as G. incúrvum, D'Urv. enum. p. 1j. which was collected on rocky hills in the island of Samos. Sten. often pubescent. Peduncles axillary and terminal, trichotomous.

Incurved Bed-straiv. Pl.

5 G. subrrífidum (Reinw. ex Blum. bijdr. p. 944.) stems twiggy, obversely scabrous; leaves usually 6 in a whorl, short, narrow, linear-spatulate, acutish, rather scabrous; peduncles terminal, few-flowered. 24. F. Native of Java, on the mountains. Said to be nearly allied to $G$. spatulàtum and $G$. pùmilum.

Subtrifid Bed-straw. Pl. 1 foot?

6 G. apicula'tum (Sibth et Smith, fl. græc. t. 129.) stems hoary; leaves 6 in a whorl, lanceolate, rather scabrous; peduncles trichotomous, leafy; lobes of corolla apiculated; fruit glabrous. 4 . H. Native of Mounts Parnassus and Athos. Rœm. et Schultes, syst. p. 229. but not p. 222. Flowers greenish-purple Peduncles axillary and terminal, forming a leafy panicled raceme. Apiculated-flowered Bed-straw. Pl. $\frac{1}{2}$ to 1 foot.

7 G. Inca'num (Sibth et Smith, f. græc. t. 130.) leaves 6 in a whorl, linear, and are as well as the stems hoary; peduncles 3flowered; lobes of corolla awned; fruit glabrous. 21. H. Native on Mount Parnassus. Flowers white. (f. 111 .)

Hoary Bed-straw. Pl. tufted, $\frac{1}{4}$ to $\frac{1}{2}$ foot.

8 G. oblievum (Vill. dauph. 2. p. 324.t. 8.) stems ascending, tetragonal, villous at the bottom; leaves 8 in a whorl: lower ones obovate, villous: upper ones linear-lanceolate, glabrous; peduncles twice trifid, glabrous ; lobes of corolla ending in a setaceous acumen each; fruit glabrous. 2. H. Native of Dauphiny, Piedmont, Etruria, and Austria, in rugged places, and in hedges among the mountains. G. mucronatum, Lam. dict. 2. p. 581 . D. C. f. fr. 4. p. 258. Flowers white. Habit of $G$. Bocconi, but differs in the lobes of the corolla ending in a setaceous point. 
Obluque Bed-straw. Pl. 1 foot, ascending.

9 G. Pusíl cum (Lin. spec. 154. Smith, engl. bot. 74.) stems diffuse, ascending or decumbent, smootl, glabrous; leaves 8 in a whorl, linear-lanceolate, acute, mucronate, glabrous : lower ones almost obovate; umbels terminal, trichotomous; lobes of corolla acute, not awned; fruit glabrous. 4. H. Native of Europe, in dry pastures and in hedges frequent. In Britain on limestone hills near Kendal; about Matlock bath, Derbyshire; in Scotland; and in lreland, near the lake of Killarney. D. C. fl. fr. no. 3366 . var. a. This is a very variable plant, and to it belong G. Austriacum, Jacq. fl. austr. t. 80. G, læ've, Thuill. fl. par. ed. 2. vol. 1. p. 7\%. G. sylvéstre vulgàtum, Gaudin, $f$. helv. 1. p. 248. G. glàbrum, Sut. fl. helv. p. 90. G. papillòsum, Lapeyr, abr. p. 66. G. pállens, Thuill.fl. par. G. umbellàtum a, Lam, dict. 2. p. 579. and G. multicaúle oxyphýltum, Wallr. sched. p. 53. Flowers white. Plants forming tufts. Lower leaves and stems sometimes slightly hairy.

Small Bed-straw. Fl. June, Aug. England. Pl. $\frac{1}{2}$ to $1 \mathrm{ft}$.

10 G. Alpe'stre (Gaud. in Rom, et Scbultes, syst. 3. p. 225.) plant tufted, glabrous, aseending, erectish, stiff; stems smooth, glabrous; leares 8 in a whor], obrersely lanceolate, with smoothish margins; umbels trichotomous, fastigiate; lobes of corolla acute, not awned; fruit smooth, glabrous. 4. H. Native of France, Switzerland, Germany, Carniola, and Upper Italy, among the mountains and alps. G, læye var, $a, \beta$, and $\gamma$, D. C. fl. fr. 4. p. 256 . G. sylvéstre alpéstre, Gaud. fl. helv, 1. p. 429. G. anisophýllum, pusíllum, montànum, and argénteum, Vill. dauph. 2. p. 318-324, t. 78. G. la've, Schleich. G. Jussia'i, Vill. dauph. 2. p. 323. t. 7. Flowers white. There are varieties of this species with stems from a finger to a hand high, quite glabrous or rather hairy. It is intermediate between $G$. la've, $G$. Bocconi, and $G$. supinum, which probably should be all combined under one name.

Alp Bed-straw. Fl. June, July. Clt. 1819. Pl. $\frac{1}{2}$ foot.

11 G. Boccònr (All. ped. no. 24.) stems ascending, tetragonal, downy below; leaves $6-8$ in a whorl, obversely lanceolate, smoothish, mucronate : lower ones broadest and downy; umbels trichotomous; lobes of corolla acute, not awned; fruit glabrous, smooth. 4. H. Native of France, Italy, Germany, in dry sterile places, and in hedges. D. C. fl. fr. no. 3367. G. sylvéstre Boccòni, Gaud. fl. helv. 1. p. 430 . G. sylvéstre hirsùtum, Mert. et Koch. deutsch. fi. G. umbellàtum, $\beta$, Lam. G. scàbrum, Pers. ench. 1. p. 127. Schleich. exsic. G. sylı́stre, Poll. no. 151. G. nitídulum, Thuill. A. par. 1. p. 86. G. ásperum, Schreb. spic. p. 5. G. hirsùtum, Sut. fl. helv. G. Marchándi, Lapeyr, abr. p. 25. G. Jussiæ'i, Lapeyr. ex Arnott. G. multicaúle eriophýllum, Wallr. sched. p. 54.-Boce. mus. t. 101. Barrel. icon. t. 57. Flowers white, tinged with red outside. Probably only a variety of $G$. le've.

Bocconi's Bed-straw. Fi. May, July. Clt. 1801. PI. 1 foot, ascending.

12 G. ru'milum (Lam. dict. 2. p. 580, ill. no. 1368. t. 60. f. 2.) plant tufted; leaves $6-8$ in a 1 horl, linear, smooth, bisulcate beneath, very acute, tumid at the base; flowers almost terminal, subumbellate; peduncles longer than the leaves; fruit glabrous. 4. H. Native of the Pyrenees, in rugged places, sc. D. C. fl. fr. no. 3374. Req. diss. mss. G. trichophýlhum, All. ped. auct. p. 1. Flowers white. Lobes of the corolla obtuse.

Iar. a, hypnoides (Vill, dauph. 2. p. 323.) plant tufted, erectish; peduncles 2-3-flowered. 24. H. Native of Dauphiny, frequent on the mountains.

Íar. $\beta$, caspitòsum (Req. diss. mss.) stems decumbent, much branched; pedicels 1-flowered. 24. H. Native of the Pyrenees, in high pastures. G. cæspitòstim, Ramond, act. acad. sc. par. 1826. p. 155. Lam. ill. no. 1369.? G. Jussią, Vill, ex Gaud. in litt.
Var. $\gamma$, réctum (Req. diss. mss.) stems erectish, branched above; peduncles divided, 2-4-flowered. 14. H. Native of Provence, \&c. among rocks.

Var. $\delta$, pubéscens (D. C. A. fr. suppl. p. 496.) stems tufted, erectish, and are, as well as the leaves, downy. 24. H. Native of Provence, in exposed, rocky places. G. pubéscens, Req. in litt. 1813. G. pusíllum, Lin. spec. 154. G. pùmilum hirtéllum, Gaud. fl. helv. 1. p. 433.

Inarf Bed-straw. Fl. June, July. Clt. 1820. Pl. tufted.

13 G. Littora'Le (Guss. fl. sic. prod. 1. p. 172.) stems stiff, tetragonal; branches approximate ; leaves usually 8 in a whorl, oblong-lanceolate, dilated at the apex, mucronate, a little serrated on the margin, spreading or reflexed; branches of panicle trichotomons, erect; corolla downy outside, with ovate-lanceolate, awned lobes. 4. H. Native of Sicily, in sandy, bushy places by the sea side. Flowers white. Nearly allied to $\dot{G}$. Mollùgo and $G$. apiculàtum.

Iar. $\beta$, pubéscens (Guss. l. c.) stems and peduncles downy or villous at top.

Sea-shore Bed-straw. Pl. 1 to 2 feet.

14 G. surinum (Lam. dict. 2. p. 579.) stems procumbent, filiform, branched, smooth : leaves 5 in a whorl, obovate-linear, with prickly or scabrous edges; umbels trichotomous; lobes of corolla awnless; fruit glabrous. 4. H. Native of the temperate parts of Europe, in hedges. D. C. A. fr. no. 3372. Req. diss. mss. G. sylvéstre pùmilum, Mert. et Koch. deutsch. A. I. p. 789. Gaud. f. helv. 1. p. 431. G. Jussiæ'i, Vill. dauph. 2. p. ย23.? G. multicaúle polyphýllum, Wallr. sched. p. 59. Juss. act. acad. par. 1714. p. 378 . t. 15. f. 2. but the plant, in Jussieu's herbarium, has the margins of the leaves smooth and revolute. Flowers white.

Supine Bed-straw, Fl. June, July. Clt. 1819. Pl. proc.

15 G. Tyrolénse (Willd. enum. 1. p. 153.) stems flaccid, tetragonal, equal, smooth; leaves $6-8$ in a whorl, obovate-lanceolate, mucronate, with scabrous margins; floriferous branches panicled; peduncles trifid; lobes of corolla awned; fruit smooth, glabrous. 4. H. Native about Tyrol, on the monntains, \&c. Req. diss. mss. G. spléndens, llorn. suppl. 17.? G. Mollingo, var. Link. Flowers white. Probably a mere variety of $G$. Mullùgo.

Tyrolcse Bed-straw. F1. June, July. Clt. 1801 . P1. 1 to $2 \mathrm{ft}$.

16 G. cine'reum (All. ped. no. 22. t. 77. f. 4.) stems erect, woody at the base, much branched, panicled at top, tetragonal and smooth; leaves $6-8$ in a whorl, linear, glaucous beneath, stiff, mucronate, with hardly scabrous margins, usually reflexed; branches of panicle trichotomous; lobes of corolla ending in a setaceous mucrone each: fruit glabrous, smooth. 4. H. Native of the south of France, in exposed places; and Upper 1 taly and Vallais. In the lowlands of Scotland, on the banks of the river Leith near Slateford, 3 miles from Edinburgh. D. C. f. fr. no. 3364 . G. diffùsum, Hook. scot. p. 52. Bristles on the edyes of the leaves pointing forward. Flowers white.

I ar. $\beta$, tenuifólium (D. C. prod. 4. p. 595.) leaves linear, and stifler than those of the species. 4. H. Native of Piedmont and Daupliny. G. temifolium, All. ped. no. 23. D. C. fl fr. no. 3365 . G. corrudæfòlium. Vill. dauph. 2. p. 320. G. pállidum, Presl. A. sic. pr. 60 .

Var. $\gamma$, pubéscens (D. C. A. fr. no. 3364.) lower part of the stems and lower leaves downy. ४. H. Native of dry, exposed places.

Grey Bed-straw. Fl. June, July. Scotland. Pl. 1 to $2 \mathrm{ft}$.

17 G. Hyrcánicum (Neyer, verz. pf. p. 53.) plant glaucescent, downy; stems erectish, branched a little, tetragonal, smooth; leaves 6 in a whorl, nearly linear, mucronately acuminated, 1-nerred, smooth; mobels trichotomons, terminal; corolla glabrous, laving the lobes terminated by a deciduous, inflexed point; fructiferous pedicels erectly spreading, liardly 
twice the length of the fruit. 4. H. Native of Caucasus, among rocks, and in stony, dry places, on the Talusch mountains.

Hyrcanian Bed-straw. Pl. 1 foot.

18 G. ERE'CTUM (Huils, angl. p. 68. Snitl, engl. bot. 2067.) stems erect, branclied at the top, tetragonal, smooth, equal; leaves $6-8$ in a whorl, linear-lanceolate, mucronate, stiff, having the margins serrulated with prickles; panicles trichotomous, lobes of corolla acuminated; fruit glabrous, smooth. $4 . \mathrm{H}$. Native of Europe, in hedges and pastures. In England, on the busliy part of Heydon Common; and in dry liedges at Port-Slade. D. C. f. fr. 110. 3362 . Req. diss. mss. G, provinciallis, Lam. dict. 2. p. 581. Stem slightly hairy under each joint. Marginal bristles of leaves pointing forwards. Flowers white. Perhaps a mere variety of $G$. Mollùgo.

Jar. $\beta$, lùcidum (D. C. I. c.) lobes of corolla setaceously acuminated. $\psi$. H. Natıve of hills in Piedmont and Dauphiny. G. lùcilum, All, ped. no. 21. t. 77. f. 2. G. rígidum, Vill. dauph. 2. p. 319.

Var. y, scábridum (D. C. prod. 4. p. 596.) lower part of stem and lower leaves clothed with scabrous pubescence. 4 . H. Native of Switzerland and Austria, on dry hills. G. pubéscens, Schleich. exsic. G. scàbrum, Jacq. fl. aust. t. 422. G. lùcidum, 3 , Gaud. fl. helv. 1. p. 419.

Iar. $\hat{c}$, approximàtum (D. C. prod. 4. p. 596.) whorles of leaves closer together. $\psi$ H. H. G.lùcidum, Hort. par.

Erect Bed-straw, Fl. June, July. Britain. Pl. 1 to 2 feet.

19 G. Mollu'go (Lin. spec. p. 155.) stems flaccid, tetragonal, thickened above the nodi, glabrous, spreadingly branched; leaves $6-8$ in a whorl, elliptic-obovate, mucronate, spreading, serrated a little; peduncles mucl, branched, disposed in panicles; Jobes of corolla acuminated; fruit glabrous, smooth. $\psi$. H. Native almost throughout Europe and Caucasus, in hedges ; plentiful in Britain. EEder. fl. dan. t. 455. Bull, herb. t. 283. Smith, engl. bot. t. 1673. Lob. icon. t. 802. f. 12. G. horeàle, Lapeyr. ex Bentl.--Petiv, herb. brit. t. 30. f. 4. Flowers white, and sometimes yellowish. Herb very variable in height and breadth of leaves. Leaves hairy on the margins and keel, but never rongh to the touch. The plant is called Hild Madder, and Great Bastard Madder. The roots are creeping, and yield a red dye like the true Ma!der, but of a brighter colour: like that also they dye the bones of animals red that feed on them.

Iau. 3 , aristàtum (Dub. bot. gall. p. 249.) lobes of corolla nucronate. $4 . H$. G. aristàtum, Lin. spec. 152. D. C. fl. fr. 4. p. 255 .

Jar. $\gamma$, scàbrum (D. C. fl. fr. no. 3361. 3.) lower parts of stems and lower leaves scabrous from hairs. $\psi$. H. Native of cxposed places. G. scàbrum, With. brit. 190.

Iar. $\delta$, elàtum (D. C. prod. 4. p. 596.) stems taller and more tumid at the joints. 24. H. Native of moist places, as bogs. G. elàtum, Thuill. fl. par, ed. 2. vol. 1. p. 76.

Mollugo, or Great-hedge Bed-straw. Fl. July, Aug. Britain. Pl. 2 to 4 feet.

20 G. FRUTicòsum (Willd. spec. 1. p. 585.) stems suffrutescent, glabrous, tetragonal; leaves 4 in a whorl, linear, very blunt, glabrous; flowers densely panicled at the tops of the branches; lobes of corolla acuminated; fruit glabrous. $4 . \mathrm{H}$ Native of Candia. Cruciàta Crética fruticosa, flore albo, Tourn. cor. p. 4. Very nearly allied to $G$. Mollùgo.

Shrubby Bed-straw, Fl. June, July. Clt. 1819 . Slı. $1 \mathrm{ft}$.

21 G. Mediterra'neum (D. C. prod. 4. p. 596.) stems ascending, tetragonal, smooth; lower leaves 4 in a whorl, obovate, mucronulate: upper leaves 6 in a whorl, linear-lanceolate, mucronate, with rather scabrous margins; peduncles di-trichotomous; lobes of corolla ending in an awn; fruit glabrous. $4 . \mathrm{H}$. Native of Corsica, on Mount Reston, where it was collected by XI. Thomas; and on the mountains of Liguria, by Badaro. G. voL. Jus. campéstre, Dub. bot. gall. 1.p. 248. but not of Willd. Flowers white or yellowislı. It diflers from $G$. campéstre in the sten being smooth, not scabrous on the angles, in the form of the leaves, and in the awned lobes of the corolla.

Mediterranean Bed-straw. Pl. ascending.

22 G. ma'ximus (Moris, elench. sart. 1. p. 55.) plant glabrous; stems smoothish, much branched, erect; leaves 6 in a whorl, oblong-linear, obtuse, with scabrous edges; branches 4 in a whorl; peduncles trichotomous; lobes of corolla acutish ; fruit glabrous. $2 /$ H. Native of Sardinia, among bushes, and in wet pastures by the sea side.

Largest Bed-straw. Pl. 2 to 3 feet.?

23 G. Insu'bricus (Gaud. fi. lielv. 1. p. 421.) plant glabrous; stems decumbent, much branched; leaves obovate, apiculated, serrated with prickles : cauline ones $(i$ in a whorl: rameal ones 4 in a whorl; umbels trifid, few-flowered; bracteas oblong, solitary; lobes of corolla drawn out into a thread each ; fruit glabrous. 4. H. Native of Switzerland and Insubria, in rocky, stony places. Flowers very small, white. Allick to G. Mollùgo.

Insubrian Bed-straw. PI, decumbent.

24 G. Pyrena'icum (Gouan. ill. p. 5. t. 1. f. 4.) plant tufted, quite glabrous, greenish-glaucous, shining; stems striated, smooth; leaves 6 in a wholl, linear, aristate, erect, approximate, "rather tumid at the base; pedicels axillary, solitary, 3 times shorter than the leaves, 1-flowered; fruit glabrous. 24. H. Native of the Pyrenees, especially on the eastern and central ranges ; and on the top of Mount Olympus, in Bithynia. Lin. fil. suppl. p. 121. D. C. fl. fr. no. 3373. exclusive of the syn. of Vill. Sibth. et Smith, fl. græc. t. 131. G. muscoldes, Lam. dict. 2. p. 580. Flowers pure white. Leaves keeled, with revolute edges.

Pyrencean Bed-straw. Pl. $\frac{1}{4}$ foot, tufted.

25 G. Villa'rsil (Req. in Guer. in vaucl. ed. 2. p. 250.) stems flaccid, filiform, glabrous, much branched ; leaves 4-fi in a whorl, oblong-linear, soft, mucronate, with smoothish margins ; peduncles by threes, trifid, subumbellate : lobes of corolla awnless ; fruit smooth, glabrous. 2. H. Native of the Alps of Europe and the Pyrenees, on rocks, or in stony pastures. D. C. fl. fr. suppl. p. 497. Gaud. in Rom. et Schultes, syst. 3. p. 220. Benth. cat. p. 80 . G. megalospérma, All. ped. no. 55 . t. 79. f. 4. ? Vill. dauph. 2. p. 517. t. 7. but not of Iam. G. sylvéstre vírens, Gaud. fl. lielv. 1. p. 432. G. megalospérmum, suavèolens, and cometerhizon, Lapeyr. abrig. and suppl. ex Bentl. Herb blackish in the dried state. Fruit larger than in the allies. Flowers small, white.

Iillars's Bed-straw. Fl. June, July. Clt. 1823. Pl. dec.

26 G. uliginòsum (Lin. spec. I53.) stems weak, erectisl, scabrous along the angles; leaves 6 in a whorl, obovate-lanceolate, serrulated on the margins and nerve, with retrograde prickles, mucronate, stiff; peduncles almost terminal, trichotomous; lobes of corolla acute; fruit glabrous, dotted. 4 . H Native of Europe and Siberia, in bogs, wet meadows, and ditches, among reeds; plentiful in Britain. D. C. fl. fr. no. 3971 . Req. diss. Smith, engl, bot. t. 1972. Schrad. spic. 17. t. 1. f. 1. Hook. fl. lond. fasc. 1. t. 21. G. spinulosum, Merat, ex Lejeun. fl spa. p. 33.? G. supinum, $\beta$, Lam. dict. 2. p. 579. G. spùrium, $\beta$, Sut. fl. helv. no. 175. Corollas white; anthers purplish. Root and lateral shoots creeping.

Var. a, Withcringii (D. C. prod. 4. p. 597.) leaves lanceolate lower ones 5-6 in a whorl: upper 4 in a whorl, beset with hooked prickles on the margins: the serratures often tumid towards the apex. 4. H. Native of Scotland, in bogs. G. montanum, Witl. arr. p. 187. t. 2S. G. Witheríngii, Snith, fl. brit. p. 17t. engl. bot. t. 2206 . The prickles on the edges of the leaves are sometimes retrograde, sometimes straight, and sometimes forward

Bog Bed-straw. Fl. July, Aug. Britain. Pl. 1 foot, 4. $\mathrm{O}$ 
27 G. Helòdes (Hoffm. et Link. f. port. 2. p. 47.) stems weak, diffuse, scabrous ; leaves $5-6$ in a whorl, lanceolatelinear, mucronulate, scabrous above and on the margins ; panicles capillary. 4. H. Native of Portugal, in marshes about Torres Vedras. G. uliginòsum, Brot. f. lus. 1. p. 150. It is very like G. uliginosum, and probably only a variety of it.

Marsh Bed-straw. Fl. July. Clt. 1325. Pl. decumbent.

28 G. PALu'stre (Lin. spec.p. 153.) stems diffuse, tetragonal, rather scabrous; leaves $4-6$ in a whorl, obovate, obtuse, unequal, glabrous, with scabrous edges: superior ones lanceolate; peduncles nearly terminal, trichotomous; lobes of corolla ovate, awnless; fruit smooth, glabrous. 2. H. Native of Europe and Siberia, on the banks of rivers and ditches, and in moist meadows; frequent in Britain. QEd. fl, dan. t. 423. Smith, engl. bot. t. 1857 . Hook. A. lond. fasc. 1. t. 20.-Petiv brit. t. 30 . f: 5. Roots creeping. Flowers numerous, white. Plant tall when supported by other herbage.

I ar. $\beta$, constrictum (Dub. bot. gall. 1. p. 260.) leaves linear. 4. H. G. constrictum, Chaub. in St. Amans, H. agr. bouq. t. 2. G. elongàtum, Presl. A. sic. prod. p. 59.

l'ar. $\gamma$, dèbile (D. C. prod. 4. p. 597.) leaves 5-6 in a whorl; stem roughish. 4. H. G. dèbile, Desv. obs. fl. par. 134. G. uliginosum, Mer. f. par. 2. p. 220.

Fen Becl-straw. Fl. July, Aug. Britain. Pl. 3 to 4 feet.

29 G. suberòsum (Sibth. et Smith, fl. græec. t. 128.) stems diffuse, much branched, smooth; leaves 4 in a whorl, lanceolate, acute, glabrous: flowers terminal and axillary, by threes; fruit glabrous. 24. H. Native of Candia, on the mountains, Leaves with roughish margins. Flowers greenish-purple, bracteolate. Bracteas ciliated, ovate, acute.

Corky-fruited Bed-straw. Pl. diffuse.

30 G. satureizfòlum (Trev. mag. nat. amic. ber]. 1815. vol. 7. p. 146.) stems flaccid, scabrous along the angles; lower leaves 6 in a whorl, rameal ones 4 in a whorl, linear-elliptic, unequal; branclies of panicle dichotomous, panicled; fruit glabrous, spherical, emarginate. 4 . H. Native of Tauria, among reeds about Astrachan; and of Caucasus, in humid places near I.enkeran, mixed with G. palústre, Bieb. suppl. 106. G. palústre, Bieb. fl. taur. 1. p. 103. Corolla wlite.

Sacory-leaved Bed-straw. Fl. June, Aug. Clt. 1817. PI. $1 \mathrm{ft}$.

31 G. TRíridum (Lin. spec. p. 153.) stems ascending or procumbent, scabrous below; leaves 4-6 in a whorl, linear, obtuse, scabrous on the margins and nerve beneath; peduncles slender, spreading, trifid; lobes of corolla 3-4, obtuse; fruit glabrous, smooth. 24. H. Native of Sweden, Norway, Lapland, Island of Unalaska, and Falkland lskands, in humid places; and of the Island of Sitka. Ed. fl. dan. t. 48. Cham, et Schlecht. in linnæa. 3. p. 221. Torr. fi. un. st. 1. p. 165 . G. Claytoni, Michx. fl. bor, amer. 1. p. 7S. G. trifidum and G. Claytòni, Rom. et Schultes, syst. G. tinctòrium, Richards. in Frankl. journ. append. 752 . Corollas white. This species varies in size from an inch to a foot in lengtl.

Iar. 3 , latifölium (Torr. Al. un. st. 1. p. 165.) leaves obovatecuneated. 2f. H. Native of North America.

Trifid-peduncled Bed-straw. Fl.Ju. July. Clt.1826. Pl. proc.

32 G. Tinctòrum (Lin. spec. p. 153.) stems decumbent, smonth; leaves 4-6 in a whorl, linear, obtuse, scabrous on the margins and keel; peduncles axillary and terminal, elongated, subcorymbose, many-flowered; lobes of corolla 4 , obtuse ; fruit glabrous, smooth. 2 2 . H. Native of North America, in low marshy places, as in Canada, United States, Newfoundland; Straits of De Fùca, on the North-west Coast. Very nearly allied to the preceding, but differs from it in the stems being smooth, in the peduncles being longer, and in the flowers being always 4parted. It is saicl that from the roots of this species the Indians prepare the red dye with which they colour the feathers and other ornaments of their dress. Some states of $G$. palustre, in our country, when they have more numerous leaves than usual, are scarcely distinguislable from the $G$. tinctorium.

Dyers' Bed-straw. Pl. decumbent.

33 G. овту'sum (Torr. fl. bost. ed. 2. p. 55.) stems smooth; procumbent, tetragonal; leaves 4 in a whorl, oblanceolate, obtuse, roughish on the margins and nerve; peduncles 3 -flowered; lobes of corolla acute; fruit smooth, globose. 24. H. Native about Boston, on the banks of rivers and rivulets. Corollas white.

Blunt-leaved Bed-straw. Pl. procumbent.

34. G. Asprélecm (Michx. f1. bor. amer. 1.p. 178.) stems diffuse, much branched, tetragonal, rough from retrograde prickles along the angles; cauline leaves 6 in a whorl, rameal ones 4, lanceolate, acuminated, prickly on the nerve and margins; floriferous branches divaricate, many-flowered; pedicels short; lobes of corolla awnless; fruit glabrous. 2. H. Native of North America, from Canada to Virginia. Pursl.. ff. amer. sept. 1. p. 103. Flowers white. Perhaps the same as G. Claytoni or $G$. trifilum.

\section{Rouglt Bed-straw. Pl. decumbent.}

35 G. HeLve'ticun (Weig. obs. p. 24.) stems weak, tufted, glabrous; leaves $4-6$ in a whorl, oblong-linear, mucronate, attenuated at the base, with scabrous margins; peduncles shorter than the leaves, nearly terminal, few-flowered; fruit glabrous, smooth; lobes of corolla obtuse. 2. II. Native of Dauphiny, Piedmont, Spain, Pyrences, Switzerland, on rocks. Gaud. fl. helv. 1. p. 434. Sc. Lam. dict. 2. p, 584. Req. diss. mss. G. Baldénse, Spreng. pug. 1. p. 10. ex Jan. et Gaud. Plant becoming black on drying. Flowers white.-Juss. mem. de l'acad. de Par. 1714, t. 15. f. 1.

Swiss Bed-straw. Fl. June, July. Clt. 1819. Pl, $\frac{1}{4}$ foot.

36 G. saxa'tule (Lin. spec. 15\%. Smith, engl. bot, 1815.) stems procumbent or straggling, glabrous ; leaves 6 in a whorl, obovate, obtuse, mucronate, roughish on the edges; flowers in forked lateral and terminal panicles ; fruit didymous, granulated. 2. H. Native of Sweden, Germany, France; plentiful in Britain, on heaths and hilly ground. G. Hercýnicum, Weig. obs. p. 25. D. C. icon. rar. t. 25. G. montànum, Huds. angl. p. 67. G. procúmbens, With. 187.- Petiv, herb. brit. t. 30. f. 8 . G. multicaúle, var. Wallr. in litt. Root creeping. Plant becoming blackish on drying. Flowers white, copious.

Hercynian Bed-straw. Fl. Ju. Aug. Britain. Pl. procumb. 37 G. Asperifòitum (Wall. in Roxb. fl. ind. 1. p. 381.) stems branched, weak, tetragonal, scabrous from recurved hairs along the angles; leaves 6 in a whorl, oblong-linear, somewhat cuneated, mucronate, rather scabrous above, but beset with recurved hairs on the nerve beneath and margins; peduncles axillary, many-flowered, disposed in a kind of leafy panicle; fruit glabrous.-Native of Nipaul. Req. diss. mss. G. parviflòrum, D. Don, prod. A. nep. 133. Flowers white, but blackislı when dried. Lower leaves 8 in a whorl. The stem and branches are soft, while the leaves are harsh.

Rough-leaved Bed-straw. Pl, diffuse.

38 G. E'тuNıси (Biv. man. 4. p. 21.) root creeping; stems tetragonal, smooth; leaves 6 in a whorl, mucronate, with prickly serrated margins: lower ones spatulate, upper ones linear; peduncles trichotomous, disposed in a short panicle; lobes of corolla awned. 4. H. Native of Mount Etna, above the woody region. Guss. prod. 1. p. 1\% 4. fl. sic. ined. t. 63. f. 1. G. trinácrium, Røem. et Schultes, syst. 3. p. 238. G. Ethnénse, Presl. f. sic. p. 60. Flowers white. Very nearly allied to $G$. cinèreum. Root long, red, Leaves 8-9 in a whorl, ex Roem. et Schultes.

Etna Bed-straw. Pl, tufted.

39 G. Frutice'scens (Cav. icon. 3. p. 3. t. 206. f. 1.) stems suffrutescent at the base, erect; branches tetragonal, glabrous; leaves 6 in a whorl, linear, mucronate, subrevolute; peduncles 
usually 2-3-flowered; lobes of corolla acute; fruit glabrous. $h$. F. Native of Spain, in great plenty on the mountains of $\mathrm{Val}$ digna and Enguera, $\delta$. . G. Capénse, $\beta$, Pers. ench. Flowers white, racemose.

Frutescent Bed-straw. Slirub 1 foot.

40 G. DE'BILE (Hoftinans. et Link. fl. port. 2. p. 48.) stems weak, tetragonal, branched, rather scabrous ; leaves 6 in a whorl, linear, ending in a short nucrone, with roughish margins: the prickles bending forward, not backwards, as in most of the species; panicles erect. 4 . H. Native of Portugal, in humid meadows. Corollas white. Nearly allied to $G$. palustre and $G$. helodes, and probably only a mere variety of one of them.

Weak Bed-straw, Fl. June, July. Clt. 1824. Pl. dec.

41 G. arista'tum (Lin. spec. 152. Smith, engl. fi. 1. p. 204.) stem erect, much branched, spreading, smooth; leaves 6 in a whorl, petiolate, lanceolate, flat, bristly pointed, with minute marginal prickles, which point forward; lobes of corolla acuminated; seeds smooth, kidney-shaped, separated. 4. H. Native of many parts of Europe; in Scotland, on hilly ground, in Angusshire, but not common.-Barrel. icon. 1. t. 356.-Bocc. mus. 1.t. 75. Flowers white, in terminal forked compound panicles. The upper leaves are sometimes 4-5 in a whorl.

Anned Bed-straw. Fl. July, Aug. Scotland. Pl. 1 foot.

42 G. Ju'nceum (Sibth. et Smith, fl. grac. t. 127.) stems erect, smooth; leaves 4 in a whorl, obovate-linear, obtuse, glabrous; flowers crowded, panicled; fruit glabrous. $\psi$. H. Native of Candia, in hedges, and on the margins of fields. Flowers cream-coloured. Root creeping.

Rushy Bed-straw. Pl. 1 to 2 feet.

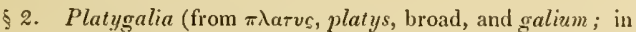
reference to the leaves of the species being broad). D. C. prod. 4. p. 598. Perennial, herbaccous plants. Leaves broad, 4 in a nhorl. Floners disposed in cymose panicles, hermaphrodite, white, very rarely purple or cream-coloured. Fruit glabrous.

43 Tata'ricum (Trev, mag. am. nat. cur. berl. 1815. p. 146.) stems quadrangular, scabrous from retrograde prickles along the angles; leaves 4 in a whorl, lanceolate, equal, acuminated, 1nerved, scabrous along the margins above, and on the nerves beneath; peduncles axillary, shorter than the leaves, trichotomous, few-flowered; fruit glabrous. 24. H. Native of Tartary, on the Ural mountains, ex Fisch; and frequent about Astrachan, ex Trev. Stem purplish at the base. Corollas white, with obtuse lobes.

Tarlarian Bed-straw. Pl. 1 foot.

44 G. Latifòlua (Michx. fl. bor. amer. 1. p. 70. but not of D. Don.) stems erect, smooth; leaves 4 in a whorl, oval-lanceolate, acuminated, 3-nerved, membranous, having the margins and nerves hispid from very minute bristles; peduncles axillary, opposite, or terminal, divaricate, trichotomous, loosely manyflowered; fruit glabrous. 24. H. Native of Carolina, on the mountains. Ell. sketch. 1. p. 194. Flowers dark purple. One of the mericarps of the fruit is abortive, and therefore the fruit is 1 -seeded. Leaves 1-2 inches long.

Broad-leaved Bed-straw. PI. 1 foot.?

45 G. Rubroides (Lin. spec. p. 152.) stems erect, straight, tetragonal, simple, smoothish; leaves 4 in a whorl, lanceolate, 4 or 5 times longer than broad, 3-nerved, often scabrous on the nerves beneath and margins; peduncles axillary, trichotomous, much longer than the leares, disposed in a terminal panicle; bracteas ovate-oblong; fruit glabrous. $\%$. H. Native of Europe, in meadows and woods, especially in the temperate parts; and of Siberia and Caucasus, even to Kamtschatka. G. rubioides, var. $\boldsymbol{a}$, Lam. dict. 2. p. 576 . Røem. et Schultes, syst. 3. p. 214. Buxb. cent. 2. t. 29. G. diffìsum, Schrad. Link, enum. 1. p. 134. ex Cham. et Schlecht. in Linnæa, 4. p. 220. G. hyssopifolium,
Hoffm. germ. 1. p. 71. Root creeping, red. Flowers pale yellow, or cream-coloured. Very like $G$. boreàle, but larger, with broader leaves. There is a variety of this species with hispid fruit, according to Steven, obs. p. 70 .

I'ar. $\beta$, angustifolium; leaves narrower and longer; flowers fewer. 24. H. Native of Kotzebue's Sound; abundant in dry elevated soils, under the shade of solitary pines, in the valley of Columbia, North-west America. The leaves are alınost as narrow as those of $G$. boreàle, but the inflorescence and fruit are very different. G. rubioides, Hook, et Arn. in Beech. voy. pt. bot. p. 115. and 125. This variety has been received by Dr. Hooker from the United States, under the name of $G$. Bermudiànum.

Madder-like Bed-straw. Fl. July. Clt. 1775. PI. 1 foot.

46 G. articula'tum (Lam. dict. 1. p. 260.) stems ascending, nodose at the joints, tetragonal, smoothish ; leaves ovate-lanceolate, 3 times longer than broad, 3-nerved, with scabrous edges; peduncles trichotomous, disposed in a crowded corymbose panicle: bracteas ovate; fruit glabrous. 2. H. Native of Tauria, Caucasus, and the Levant, in meadows, and along the margins of paths in woods. Req. diss. mss. ex herb. D. C. Valántia articulàta, Lam. ill. t. 843. f. 3. G. rubioìdes, Bieb. fl. taur. 1 . p. 102. ex spec. Stev. G. articulatum and G. geniculàtum, Roem. et Sclultes, syst. 3. p. 215. and 250. G. rubioiles, $\beta$, Lam. dict. 2. p. 576. Flowers cream-coloured, sometimes small. Jointed Bed-straw. Fl. July, Aug. Clt. 1752. Pl. 1 foot.

47 valantioides (Bieb. f. taur. 1. p. 102.) stems erectish, branched at the base, glabrous, smooth along the angles; leaves 4 in a whorl, rhomboid-lanceolate, twice longer than broad, ob. tuse, 3-nerved, rather scabrous on both surfaces; panicle trichotomous, much branched; fruit glabrous, smooth. $4 . \mathrm{H} . \mathrm{Na}-$ tive of Caucasus, among subalpine rocks. Req. diss. mss. ex herb. D. C. Roem. et Schultes, syst. 3. p. 215 . Very nearly allied to $G$. rubioides and $G$. articulatum. Flowers creamcoloured.? There is a variety of this with hispid fruit, according to Stev. obs. p. 70.

I ralantia-like Bed-straw. Fl. June, July. Clt.1819. Pl. $1 \mathrm{ft}$.

§3. Trichogàlia (from $9 \rho t_{n}^{\xi} \tau \tau^{\prime} \mathrm{us}_{\text {s }}$ thrix trichos, a hair, and galium; in reference to the fruit being hispid). D. C. prod. 4. p. 599. Perennial herbaccous plants. Leaves 4.10 in a whorl. Floners hermaphrodite, usually nhite, disposed in eymose panieles. Fruit hispid.

48 G. CA'spicun (Stev. obs, pl. ross. p. 70.) whole plant villous; stems obsoletely tetragonal; lower leaves 8 in a whorl, lanceolate-oblong, mucronate, upper ones opposite; floriferous branches panicled, and are, as well as the fruit, villous. $2 . \mathrm{H}$. Native of the north of Persia, in the province of Ghilan. Flowers white. Stature and leaves of $G$. sylváticum, but the panicle is dense, like that of $G$. mollùgo.

Caspian Bed-straw. Pl. 1 to 2 feet.

49 G. Rotundifòluu (Lin. spec. p. 156. exclusive of var. $\beta$.) stems diffuse, glabrous; leaves 4 in a whorl, roundish-ovate, 3-nerved, ciliated; peduncles axillary and terminal, loose, elongated, naked, trichotomous at the apex; fruit nearly globose, beset with bristles, which are hooked at the apex. $4 . \mathrm{H}$. Native nearly throughout the whole of Europe, in mountain woods; and on the Talusch mountains in Caucasus. Lam. dict. 2. p. 577. D. C. fl. fr. no. 3386 . G. decípiens, Ehrh. herb. p. 63. Aspérula lævigàta, $\beta$, Lam. dict. 1. p. 298.-Boce. sic. t. 6, f. 1 . - Moris. hist. 9. t. 21. f. 5.-Barrel. icon. t. 323. Flowers white. Stems procumbent.

Round-leaved Bed-straw, Fl. Ju. Aug. Clt. 1821. Pl. proc. 50 G. elsípticum (Willd, enum, suppl, 1813. Horn. cat. hort. hafn. suppl. 1819. p. 17.) stems erectish, hairy; leaves 4 in a whorl; panicles axillary and terminal, trichotomous, capil- 
lary ; fruit nearly globose, hispid from bristles, which are looked at the apex. 24. H. Native of Corsica, Sardinia, Sicily, on hills and in woods. Guss. prod. 1. p. 176. Presl. del. prag. 1822. p. 122. G. Barrelièri, Salzm. in flora, 1820. p. 107. Duby, bot. gall. 1. 1. 251. Lois. fl. gall. ed. 2. p. 114.-Barrel. icon. t. 324.-Bocc. sic. t. 6. f. 1.-G. rotundifòlium, var. 3, Rom. et Schultes, syst. 3. p. 254. G. ovalifolium, Schott. isis. 1818. p. 821. Flowers white; but there is a variety also with reddish flowers, according to Soleir, in litt.

Elliptic-lestved Bed-straw. Fl. Ju. July. Clt. 1819. Pl. $1 \mathrm{ft}$.

51 G. oвova'tum (H. B. et Kunth, nov. gen. amer. 3. p. 336. t. 2i8.) stems almost simple, pilose; leaves 4 in a whorl, on short petioles, obovate, acute, flat, smoothish, ciliated, 4 times shorter than the internodes ; flowers terminal, by threes, peduneulate; fruit covered with hooked bristles.-Native of South Anerica, in temperate parts of the kingdom of Quito, about Chillo and Guancabamba. Corolla of a whitish violaceons colour. Nearly allied to $G$. rotundifolium.

Obovate-leaved Bed-straw. Pl. $1 \frac{1}{2}$ foot.

52 G. JAVA' Nicus (Blum. bijdr. p. 943.) branches tetragonal, hairy; leaves 4 in a whorl, roundish obovate, 3-nerved, with the margins and veins downy beneath; cymes pedunculate, trichotomous, leafy.-Native of the East of Java, on the mountains. Siaid to be allied to $G$. Élegans.

Juva Bed-straw. Pl.

53 G. Neesia'num (Req. diss. mss. ex D. C. prod. 4. p. 600.) stems ascending, ercctish, branched, tetragonal, beset with soft liairs; leaves 4 in a whorl, roundish-ovate, ending each in a very short cusp, 3-nerved, hairy; peduncles axillary and terminal, longer than the leaves, trichotomous, hairy ; fruit nearly globose, beset with hooked bristles. 24. F. Native of Tenerifle, in the Chestnut woods. G. hirsùtum, Nees, in Buch. in hor. berl. p. 113. t. 22. but not of Ruiz et Pavon. G. ovalifòlium, Schott, Spix, and Mart. 1. p. 55. ex Link. in Buch. can. p. 151. Flowers white. Said to be nearly allied to $G$. rotundifolium.

Necs's Bed-straw. Pl. ascending.

54 G. E'Legans (Wall. in Roxb. fl. ind. 1. p. 382.) stems diffuse, ascending, tetragonal, hairy; leaves 4 in a whorl, elliptic, obtuse, sessile, 3-nerved, rather hairy above, and villous along the nerves and margins beneatl ; peduncles axillary and terminal, trichotomous, hardly pilose, disposed in a panicle; fruit roundish, hispid from bristles, which are hooked at the apex. 4. F. Native of Nipanl. G. Punduàmun, Wall. cat no. 6212. Roots creeping. Fruit small. Flowers white. Habit of $G$. cruciàtum.

Iar. 3, glabriúsculum (Req. diss. mss. ex D. C. l. c.) stens and leaves smoothish. $4 . H$. Native of Nipaul.

Elegant Bed-straw. Pl. diffuse, $1 \frac{1}{2}$ foot.

55 G. Hanhtònu (Spreng. cur. post. p. 39.) stems erect, branched, pilose; leaves 4 in a whorl, oblong, acute, rather pilose on both surfaces; peduncles terminal, trichotomous, looseHowered; fruit hispid. 4. F. Native of Upper Nipaul, at Mereba. G. latifòlium, Ham. in D. Don, prod. A. nep. 133.

\section{llamilton's Bed-straw. Pl.1 $\frac{1}{2}$ foot.}

56 G. hirtiflòrum (Req. diss. mss. ex D. C. prod. 4. p. 600.) stems weak, branched, rather seabrous; leaves 4-6 in a whorl, linear, bluntiol, glabrous above, and scabrous from pili on the keel and margins beneatl; peduncles axillary and terminal, bifid, disposed in a kind of panicle; pedicels divarieate; corollas bristly outside; fruit roundish, hispid from bristles, which are hooked at the tops. 24. F. Native of Nipaul, at Narainhetty. G. ciliàtum, D. Don, prod. A. nep. p. 133. but not of Ruiz et Pav. G. Aparine, Roxb. fl. ind. 1. p. 382.? Stenis sather hispid. Flowers small, milk-coloured.

llairy-flowered Bed-straw. Pl. $\frac{1}{2}$ to 1 foot.

57 G. uncinula'tum (D. C. prod. 4. p. 600.) stems weak, diffuse, branched, tetraconal, hispid at the base, and glabrous at the apex; leaves 4 in a whorl, oval, acutish, hispid on both surfaces, liardly 3-nerved at the base; peduncles dichotomously corymbose, few-flowered; fruit beset with bristles, which are hooked at the apex, and about equal in length to the diameter of the fruit. 2. F. Native of Mexico, between Tampico and Real del Monte, where it was collected by Berlandier.

Small-hooked Bed-straw. Pl. diffuse.

58 G. Chamissònis (Hook. et Mrn. in bot. mise. 3. p. 363.) plant quite glabrous, perennial; stems erectish, acutely tetragonal: angles smoothish ; leaves deflexed, oblong, acute, with revolute margins; panicles axillary and terminal, trifid, bifid, or trichotomous; pedicels very much divaricate; fruit roundish, hispid from compressed bristles, which are acute at the apex, but not hooked. 24. F. Native of Chili, about Valparaiso. This approaches somewhat in habit to Aspćrula galioides.

Chamisso's Bed-straw. Pl. 1 foot.

59 G. Glulie'su (Hook. et Arn. in bot. misc. 3. p. 364.) perennial; stems herbaceous, diffuse, almost simple, acutely 4 -angled; leaves 4 in a whorl, oval, obsoletely 1 -nerved, with spinulose margins; peduncles axillary and terminal, 3-flowered, equal in length to the leaves ; flowers pedicellate ; fruit hispid; bristles longer than the friut, not hooked at the apex.

Var. $\boldsymbol{a}$; stem and leaves glabrous. 24.F. Native of Chili, in El Valle de Las Caigas, Andes of Mendozo, Cordillera of Chili.

Var. $\beta$; stem and leaves hairy. 4. F. Native of Cliili, at El Malpaso and Los Palomares, Andes of Mendozo.

Gillies's Bed-straw. Pl. diffuse.

60 G. suffrutico'sum (Hook, et Aru. in bot. misc. 3. p. 363.) suffruticose, hairy, canescent; stems erectish, simple, terete; leaves oblong-linear, mucronate, laairy: the nerves as well as the recurved margins pilose; peduncles alternate, longer than the leaves, divaricately panicled. 4. F. Native of Chili, in Vina de La Mar, near Valparaiso. The hairs forming the pubescence point downwards. Suffruticose Bed-straw. Pl. 1 foot.

61 G. erioca' RPUM (Bartl. in herb. Hænke, ex D. C. prod. 4. p. 600.) plant suffruticose, glabrous, ereet; leaves 4 in a whorl, oblong, 1-nerved ; flowers trichotomously panicled; fruit beset with bristles, which are as long as it, but are not hooked at the apex. 24. F. Native of Cordillera of Chili. This is very distinct from all other species.

Woolly-fruited Bed-straw. Pl. 1 foot.?

62 G. Trichocárpun (D. C. prod. 4. p. 600.) stems dichotomous, much branched, glabrous, tetragonal, having the angles scabrous from retrograde bristles, the rest glabrous; corymbs trichotomous, few-flowered; fruit beset with bristles, which are a little shorter than it, but not hooked at the apex.-Native of Chili, about Rancagua, among bushes. Allied to G. eriocárpum, but differs in the bristles of the fruit being shorter and fewer.

Mairy-fruitcd Bed-straw. Pl, diffuse.

63 G. BOREA LE (D. C. A. fr. suppl. p. 4.98.) stems erect, straight, tetragonal, smoothish; leaves 4 in a whorl, linear-lanceolate, 3-nerved, glabrous; peduncles axillary, trichotomous, much longer than the leaves, disposed in a terminal panicle; bracteas obovately orbicular. 4. H. Native throughout the whole of Europe, in moist rocky shady places, by rivers and lakes; plentiful in some parts of Britain, as in the north of England and Scotland. Root creeping, brownish. Leaves with scabrots margins. Flowers milk-coloured.

Var, a, hyssopifolium (D. C. prod. 4. p. 600.) fruit quite glabrous. Hoffim. germ. 3. p. T1. G. rubioìdes, Poll. pall. no. 148. G. boreàle $a$, Lan. dict. 2. p. 576. G. rubioìles $\beta$, Lam. fl. fr, 4. p. 258. Nearly allied to $G$. rubioides, but differs in the leaves being narrower, and in the bracteas being roundish.

Var. $\beta$, intermédium (D. C. prod. 4. p. 601.) fruit rather scabrous from somewhat adpressed bristles.-G. boreàle, Koch, in litt. D. C. suppl. p. 498. 
l'ar. $\gamma$. scàbrum (D. C. prod. 4, p. 601.) fruit hispid from crowded bristles, which are hooked at the apex. G. boreale $\beta$, Lam. G. bortäle, Lin. spec, 156. D. C. fl. no. 3s85. but not of Lapeyr. Oed. fl, dan. t. 1024. Smith, eng. bot. t. 105. Svensk. bot, t. 122. G. nervòsum a, Lam. fl. fr.

Northern Bed-straw, Fl. July. Britain. Pl. 1 foot.

64 G. septentrtonile (Rom, et Schultes, syst. 8. p. 253.) stems erect, straight, tetragonal, smoothish, downy at the nodi ; leaves 4 in a whorl, oblong-lanceolate, 3-nerved, ciliated at the base; peduncles axillary, much longer than the leaves, trichotomons, disposed into a terminal panicle; bracteas oblong, acute. 24. H. Native of North America, about lakes in Canada and the State of New York. Bigel. fl. bost. ed. 2. p. 54. G. bortàle, Pursh, fl. amer, sept. 1.p. 104. Torr. fl. un. st. 1. p. 169. Hook. fl. bor. amer. 1. p. 289. G. stríctum, Torr, cat. new York, 23. Flowers milk-coloured, very numerous. Fruit beset with hooked bristles. Like the European $G$. boreate this is liable to considerable variation, and generally passes into the usual state of G. boreàle. The Cree women dye red with the roots of this and G. Claytònii indiscriminately, ex Richardson.

Northern Bed-straw. Pl. $1 \frac{1}{2}$ foot.

65 G. CORiA'Ceum (Bunge in Ledeb. At. ross. alt. ill. t. 216.) stems branched, tetragonal, scabrous at the base; leaves coriaceous, shining, with revolute scabrous edges: lower ones 4 in a whorl, obovate-oblong: upper ones opposite, oval, rather scabrous, as well as the stems; peduncles axillary, 2-4-flowered; fruit hispid from hooked pili at the base, much shorter than the pedicels. 24. H. Native of Siberia, in the fissures of rocks at the river Katunga, at a place called Boom, and at the river Tschuja. Peduncles slender, bifid, trifid, rarely twice trifid, rather hispid. Flowers yellowish-white.

Coriaceous-leaved Bed-straw, PI. $\frac{1}{4}$ to 1 foot.

66 G. CIRCE'zans (Michx. fl. bor. amer, 1. p. 30.) stems erect, smooth; leaves 4 in a whorl, oval, obtuse, smooth, 3nerred, ciliately scabrous along the nerves and margins; pe. duncles axillary ant termiral, divaricate, few-flowered, longer than the leaves; fruit drooping, beset with hooked bristles. 4. H. Native of North America, from Carolina to New England and Boston, in rocky inountain wools. Torr, fl. un. st. 1. p. 168 . Bigel. fl. bost. ed. 2. p. 55 . G. boreàle, Walt. car. p. 87 . G. brachiàtum, Muhl. cat. 1. p. 15. G. circacoides, Rœm. et Schultes, syst. 3. p. 256. Flowers milk-coloured.

Circcea-like Bed-straw. Pl. 1 to $1 \frac{1}{2}$ foot.

67 G. Lanceola'tum (Torr. fl. un. st. 1. p. 163.) stems erect, glabrous; leaves 4 in a whorl, ovate-lanccolate, acute, with ciliately scabrous edges, 3-nerved at the base; peduncles terminal, dichotomous, divaricate, longer than the leaves; flowers lateral, sessile, deflexed; corollas very acute; fruit beset with hooked bristles. 24. H. Native of North America, in the states of New York, Massachusetts, and Boston; and of Canada about Quebec. $G$. circæ'zans $\beta$ lanceolàtım, Torr. cat. new york, p. 23. G. Torrèyi, Bigel. fl. bost. ed. 2. p. 56 . G. circa'zans var. Nutt. Flowers milk-coloured.

Lanccolate-leaved Bed-straw. Pl. 1 to $1 \frac{1}{2}$ foot.

68 G. Brachia'tum (Pursh, fl. amer. sept. I. p. 103.) stems flaccid, elongated, brachiately branched, hispid; branches short; leaves 6 in a whorl, oblong-lanceolate, acuminated, glabrous, having the margins and keel ciliated by bristles; floriferous branches verticillate, longer than the leaves, divaricately dichotomous; perlicels 2-Howered; fruit beset with hooked hristles. 4. H. Native of North America, from New England to Virginia, in meadows, and on the margins of woods, frequent. G. longicaúle, Rafin. fl. lud. p. 75.? Flowers white.

Brachiate Bed-straw. 1'. 1 to $1 \frac{1}{2}$ foot.

69 G. cuspida'tum (Muhl, cat. ex Ell. sketch. carol 1.p. 197.) stems prostrate, glabrous; leaves usually 6 in a whorl, lanceolate, acuminated, a little ciliated; pcduncles trifid; lobes of corolla acuminated; fruit pilose. $\Psi$. H. Native of Carolina and Georgia. Flowers white. Fruit beset with long white pili. Cuspidate-flowered Bed-straw. l']. prostrate.

70 G. Hispídulum (Michx. fl. bor. amer. 1. p. 79.) stems procumbent, much branched, hispid; leaves 4 in a whorl, ovallanceolate, acuminated, with revolute edges, wrinkled, hispid on both surfaces; flowers nearly solitary, terminal; fruit hispirl. 4. H. Native of Lower Carolina. lerhaps the same as G. lappàceum, H. per. 1. p. $59 . ?$ ex Pursh, fl. sept. amer. 1. p. $10 \mathrm{H}$ Flowers white.

Small-hispid Bed-straw. Pl. procumbent.

71 G. Densıflòrum (Led. Al. alt. ill. t. 194. H. alt. I. p. 137.) stems many from the same root, erect or ascending, glabrous ; leaves 8 in a whorl, oblong-linear, cuspidate, glabrous with scabrous margins; panicles coarctate; segments of corolla mucronulate; ovarium villous. 4 . H. Native of Siberia, near Smejow. Rameal leaves sometimes 6-7 in a whorl, pale green. Panicles from the tops of the stem and branches. Corollas greenish-yellow.

Dense-flowered Bed-straw, Pl. 1 foot.

72 G. Puncticulòsum (Michx. H. bor. amer. 1. p. 80.) stems erect, branched, smoothish ; leaves 4 in a whorl, ovate, obtuse, glabrous, but rather downy on the margins and nerves, full of pellucid dots ; floriferous branches elongated, trifid at the apex ; flowers pedicellate; fruit beset with hooked bristles. భ. H. Native of South Carolina, in humid places. Req. diss. ined. ex lierb. D. C. G. punctàtum, Pers, ench. 1. p. 128. G. Bermudiànum, Pursh, fl. sept. amer. 1. p. 104. and probably of Lin. spec. 153. G. purpùreum, Walt. carol.-Pluk. alnı. t. 248. f. 6. Flowers purple. Fruit purple.

Var. 13, pilosum (D. C. prod. 4. p. 601.) stems hispid ; leaves villous on both surfaces, and full of pellucid dots. \%. H. Native of the states of New York and Boston, in dry pastures and woorls. G. pilòsum, Ait. hort. kew. p. 145. T'orr. fl. um. st. I. p. 167. The dots on the leaves less pellucid, and villi more conspicuous than in var. $a$, but very like it.

Small-dotted-leaved Bed-straw. Fl. June, July. Clt. 1778. PI. 1 foot.

73 G. Triflòrum (Miclıx. fl. amer, bor. 1. p. 80.) stens procumbent, tetragonal, hisyid or smoothish; leaves 6 in a whorl, oblong, cuspidate, glabrous, scabrous along the nerves and edges, 1-nerved; peduncles axillary and terminal, 3-flowered, longer than the whorles of leaves ; flowers pedicellate; fruit beset with bristles, which are hooked at the apex. 4 . H. Native of Carolina, Pennsylvania, New York, Canada, Unalaschka, Sitcha, and Norland, in rather humid shady places. It is common from Quebec to the Rocky Mountains, and as far north as lat. $55^{\circ}$, and from the west side of the Rocky Mountains to the Pacific. Clian. et Schlecht. in Linnæa. 3. p. 222. Torrey, $t$. un. stat. 1. p. 167. Willd. hort. berol. $t$. 66 . G. cuspidătum, Mulıl. cat. p. 15. G. suavèolens, Wahl. fl. lapp. p. 18. Reø. diss, mss. ex herb. D. C. There are varieties of this with either rough stems, as in $G$. aparine, or glabrous stems. Flowers small, white. Habit and scent of Aspérula odorìta.

l'ar. $\beta$, ciridiflòrum (D. C. prod. 4. p. 602.) stems smooth; corollas green. 4 . H. Native about Moscow, in mossy woods. G. hyssopif òlium, Goldb. in litt. 18\%1. Req. diss. mss, in herb. D. C.

Thrce-flonicred Bed-straw. Fl. June, July. Clt. 1821. PI. procumbent.

74 G. Marítimum (Lin. mant. p. 38. but not of Thunb. prod. 3.) plant villous all over; stems much branched, tetragonal; leaves $4-6$ in a whorl, but the ultimate ones are opposite, all lanceolate-linear, acute; peduncles axillary, 1-flowered; corollas and fruit villous or hispid outside. 4.H. Native of Nice and 
the Levant, in exposed rocky places. Corollas reddish. Stems creeping at the base.

Var. $\beta$, villossum (D. C. prod. 4. p. 602.) plant more crowded; leaves $4-8$ in a whorl. 4 . H. Native of the south of Europe, and at the bottom of the Pyrenees. G. villosum, Lam. dict. 2. p. 582. G. marítimum, Gouan. ill. p. 5. D. C. fl. fr. no. 3384. - Barrel. icon. p. 81.-Bocc. mus. 2. p. 110 . t. 86. Fruit clothed with white hairs.

Sca-side Bed-straw. Fl. June, July. Clt. 1826. Pl. $\frac{1}{2}$ to 1 foot.

75 G. BRAchypny'llum (Schultes, mant. 3. p. 180.) plant smoothish, much branched, procumbent; leaves 4-6 in a whorl, but the upper ones are opposite, all lanceolate, mucronate, and reflexed; pedicels 2-3-together, axillary, 1-flowered; fruit scabrous from pubescence. $\%$. H. Native of Caucasus, about Buduch, in the calcareous range, \&c. G. brevifolium, Stev. mem. mosc. 3. p. 253. but not of Smith et Sibth. G. alpéstre, Stev. cat. hort. gor. 1812. p. 43. G. brachyphýllum, Bieb. $\mathrm{A}$. taur. suppl. p. 107. Flowers white. This is an intermediate plant between the granular and villous fruited species.

Short-leated Bed-straw. Pl. procumbent.

76 G. GRE'CUM (Lin. mant. p. 38.) stems suffruticose, branched at the base; branches erect, hispid; leaves 6 in a whorl, linear, hairy, erect; peduncles axillary and terminal, fewflowered, a little longer than the leaves; fruit beset with long white bristles, 24. H. Native of Greece, on Mount Parnassus, and the islands of Cois and Candia, on exposed rocks. Sibth et Smith, A. græc. t. 136. D'Urv. cat. no. 129. Req. diss. mss. Lam. dict. 2. p. 584 . Lodd. bot. cab. t. 1573.-P. Alp. exot. t. 166. Peduncles forming a racemose or thyrsoid panicle. Flowers small, yellowish-brown.

Grecian Bed-straw. F]. June, July. Clt. 1798, Pl. $\frac{1}{2}$ foot.

77 G. ca'Num (Req. diss. mss. ex D.C. prod. 4. p. 602.) stems suffruticose, tufted; branches very hairy and hoary; leaves lanceolate, with revolute margins, hairy on both surfaces, hoary beneath; peduncles cymose, few-flowered, 2-3 times longer than the leaves; fruit hispid. 2. H. Native of Syria, where it was collected by Donati and Labillardiere. Flowers small, purplish. Perhaps only a variety of $G$. grècum.

Hoary Bed-straw. Pl. $\frac{1}{4}$ foot.

78 G. micra'nthum (Pursh, fl. amer. sept. 1. p. 103.) stems much branched, divaricate, beset with retrograde prickles; leaves short, lanceolate, mucronate, glabrous, having the margins and keel prickly; floriferous branches divaricately branched; pedicels usually 2 -flowered; fruit hispid. 21. H. Native of North America, from Canada to New York, in mountain bogs. Said to resemble $G$. uliginòsum very much.

Small-flowered Bed-straw. Pl. divaricate.

\$4. Coccogàlia (from kokxos, kokkos, a grain, and galium; in reference to the granular fruit). D.C. prod. 4. p. 602. Percnnial plants. Leaves 4 in a whorl. Floners on long peduncles, hermaphrodite. Fruit granular.

79 G. сотіn oides (Cham. et Schlecht. in Linnaa. 3. p. 227.) stems diffuse, weak, tetragonal, beset with retrograde bristles along the angles; whorles of leaves distant; leaves 4 in a whorl, sessile, lanceolate, acute, with the nerve and margins scabrous; panicles trichotomous, few-flowered, terminal; pedicels capillary, very long; fruit glabrous, minutely tubercular. 24. F. Native of Chili, in hedges near Talcaguana, and about Conception. This is a very showy species, with the habit of $G$. uliginosum.

Cotinus-likc Bed-straw. Pl. diffise.

80 G. Lanuginòsum (Lam. ill. no. 1360.) stems, branches, and peduncles clothed with long soft dense hairs; leaves 4 in a whorl, lanceolate, acute, glabrous, with scabrous margins; pedicels axillary and terminal, simple and bifid, very long, 1-flower- ed ; corolla glabrous, with acutish lobes; fruit glabrous, minutely tubercular.-Native of the East Indies, ex herb. Lam.

Woolly Bed-straw. Pl. diffuse.

81 G. томеNтòsum (Thunb. fl. cap. 151.) stems scandent, glabrous, much branched, tetragonal: with the angles denticulated; branches densely clothed with white hairs; leaves 4 in a whorl, oblong, roughly serrated; peduncles dichotomous, capi]lary, villous. - Native of the Cape of Good Hope. G. maritimum, Thunb. prod. p. 30. but not of Lin.

\section{Tomentose Bed-straw. Pl. climbing.}

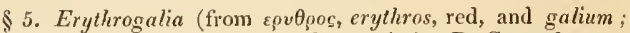
in allusion to the red flowers of the species). D. C. prod. 4. p. 603. Perennial plants. Lcaves 6 in a whorl. Flowers hermaphrodite, cymosely panicled, purple or red. Fruit glabrous.

82 G. PURPU'REUM (Lin. spec. p. 156.) stem erect, suffruticose, much branched, glabrous; leaves $5-6$ in a whorl, linearsetaceous; preduncles capillary, longer than the leaves; lobes of corolla apiculated ; fruit glabrous. h. G. Native from Provence to Genoa, on dry hills ; and in Greece, Carniola, Croatia. Req. diss. mss. Host. fl. aust. 1. p. 202. Nocc. et Balb. fl. tic. 1. p. 73. t. 3. G. rùbrum, Scop. carn. no. 154. D. C. f. fr. no. 3354. exclusive of the synonymes. G. purpùreum and $G$. rùbrum, Wulf. ex Hort. G. sylvéstre, Schleich. pl. exsic.-J. Baul. hist. 3. p. 721, f. 2. Gàlium rubro flòre, C. Bauh. hist. 335. no. 2. Flowers small, deep purple.

Purple-flowered Bed-straw. Fl. Ju. July. Clt. 1731 . Pl. $1 \mathrm{ft}$. 83 G. RU'BRUM (Lin. spec. 156.) stems herbaceous, weak, glabrous ; leaves 6 in a whorl, linear, spreading, glabrous ; peduncles axillary, many flowered; pedicels short; lobes of corolla apiculated; fruit glabrous. 24. H. Native of the south of Europe, as of Nice and Piedmont. Nocc. et Balb. fl. tic. 1. p. 74. G. purpùreum, Schleich. pl. exsic. D. C. fl. fr. 4. p. 251.-Clus. hist. 2. p. 174. lower figure. Flowers dirty purple, larger than those of $G$. purpureum.

I'ar. $\beta$, pilosum (Duby, ench. 1. p. 248.) stem pilose at the base. 4. H. Native of the meadows of Lozera, about Meldas. G. purpureum var. $\beta, D . C$. fl. fr. 5. p. 446 .

Red-flowered Bed-straw, Fl. June, July. Clt. 1597. Pl. procumbent.

\$ 6. Tanthogàlia (from ¿aves, xanthos, yellow, and galium; in reference to the yellow flowers of the species). D. C. prod. 4. p. 603. Plants perennial. Leaves 6-10 in a whorl. Flowers yellow, all hermaphrodite. Inflorescence panicled.

84. G. RUPE'stre (V'isiani, ex Biasol. in litt. 1829. ex D. C. prod. 4. p. 603.) stems erect, tetragonal, velvety, glabrous at the apex; leaves 6 in a whorl, upper 4 in a whorl, and the uppermost ones opposite, linear-lanceolate, a little cuneated, mucronate, glabrous, with rather scabrous edges; floriferous branches panicled; lobes of corolla acuminated; fruit glabrous. \& $\mathbf{H}$. Native of Dalmatia, on rocks, Flowers small, deep yellow.

Rock Ladies' Bed-straw. PI. 1 foot.

85 G. VE'Run (Lin. spec. 155.) stems erectish, tetragonal, almost simple; leaves 8 in a whorl, linear, sulcate, with rather revolute edges, smooth; floriferous branches panicled, almost all terminal; pedicels crowded, leafy, about equal in length to the flowers. 24. H. Native of Europe and Siberia, in meadows, way sides, margins of fields and woods, and among bushes frequent; very common in Britain, in dry soil. G. lùteum, Monch, meth. 456. Root creeping, tawny. Flowers yellow. Leaves each tipped by a hair.

Far. a, leiophýllum (Wallr. sched. crit. p. 56.) stem and leaves quite glabrous, smooth; flowers pale yellow. $\boldsymbol{\psi}$. $\mathbf{H}$. Native in rather humid shady places. G. vèrum $\beta$ glàbrum, Req. diss. mss. 
Var. $\beta$, trachyphyllum (Wallr. l. c.) stems and leaves rather scabrous ; fruit glabrous; flowers deep yellow. 4. H. Native of Europe and Caucasus, in open places. Mill. fig. t. 129. Oed. fl. dan, t. 1146 . Mart. f. rust. t. 54. Curt. fl. lond. 6. t. 13. Smich, engl. bot. t. 660 . G. vèrum pubéscens, Guss. prod. 171. G. tuberculàtum, Presl, dcl. prag. p. 120.

lar. $\beta$, trachychrpum (D. C. prod. 4. p. 603.) stems and leares rather scabrous; fruit hairy. 24. H. Native of Eastern Cancasus, on the I,ower Volga, Sc. G. vèrum var. Gold. in litt. G. verosímile, Schultes, syst. 3. p. 254.? Perhaps G. Caucásicum, Lag. cat. hort. madr. p. 95.

Far. $\delta$, maritimum (D. C. fl. fr. 4. p. 248.) stems low, much branched, glabrous at the base, villous at the apex; ovaries glabrous. 24. H. Native of Armoracia, in sand by the sea side.

I'ar. $\varepsilon$, tomentòsum (Meyer, verz. pfl. p. 5..) stems and fruit densely clothed with tomentum. 24. H. Native of Caucasus, on the tops of the Talusch mountains near Drych.

The common name Bed-straw given to all the species is from the verb to strew, anciently written straw. Before the invention of feather-beds a variety of herbs were used to strew beds with; among these doubtless this was one. In Johnson's edition of Gerard, it is called our Ladies' Bed-straw (p. 1127.). From the notion of its curdling milk, Dioscorides has named it $\gamma a \lambda\llcorner o v$; and it is said to have been used in many parts for this purpose, but from later experiments it has not sticceded in coagulating milk. It has probably been put into milk destined to make cheese, not so much for the purpose of curdling it, as of giving it a flavour, or as Matthiolus expresses it, to make it eat the sweeter. The French formerly prescribed the flowers in liysteric and epileptic cases. Boiled in alum-water the flowering stems dye a good yellow colour. The roots dye a very fine red, not inferior to madkler.

True Ladies' Bed-straw or Cheese-rennet. Fl. July, Aug. Britain. Pl. 1 to 2 feet.

86 G. Rutuénicum (Willd. spec. 1. p. 596.) leaves 8 in a whorl, linear-filiform, cuspidate, with revolute scabrous margins; stems also scabrous; flowers panicled; peduncles puhescent; fruit hispid from villi. 24. H. Native of siberia and Caucasus, growing along with $G$. vèrum. Flowers deep yellow.

Var. $\beta$, rosmarinifòlium (Ledeb. fl. alt. 1. p. 138.) leaves 8-10 in a whorl, linear, slining above and pubescent, and clothed with hoary tomentum beneath, with revolute edges; stems tomentose suffruticose at the base; panicle coarctate; fruit villous. 24. H. Native of Siberia, at the river Tschuja, in the Karaic desert in dry exposed places.

Ruthian Lady's Bed-straw. I'l. 1 foot.

87 G. VÈro-Mollu'go (IVallr. in Schiede, pl, lyybr. p. 6.4.) stems tetragonal, rather downy; leaves sublanccolate-linear, rather scabrous, with revolute scabrous edges, downy beneath; panicles rather divaricate; flowers rather distant ; corollas cream coloured, with acutisls segments. 24. H. Native of Germany. This is a hybrid raised from the seed of $G$. virntm, impregnated by $G$. Mollùgo. G. vèrum $\beta$, Rom. et Schultes, syst. 3. p. 233. $\mathrm{G}$. Mollùgo var. ochreoleùca of authors.

Vcro-MIollugo or Hybrid Ladies' Bed-straw, Pl. 1 to 2 feet.

88 G. 'Funeta'num (Lam. dict. 2. p. 583.) stems erect, terete, canescent; leaves $8-10$ in a whorl, linear, downy, with rough revolute edges; peduncles many flowered, disposed in a panicle; fruit hispid. 4 . F. Native of Tunis, about Algiers in hedlges. Desf. f. atl. 1. p. 129. Poir. voy. 2. p. 110. Stems villous. Flowers yellow. Resembles $G$. vèrum.

Tunis Bed-straw. Pl. 1 to 2 feet.

89 G. man'тum (Lin. spec. p. 154.) stems decumbent, smooth; leaves 8 in a whorl, lanceolate, mucronate, serrated from prickles, glabrous, incurved; peduncles reflexed; fruit fleslıy. 24. H. Native of Russia. Gmel. sib. 3. p. 169. no. 45. Flowers yellow. The plant resembles $G$. vèrum very much, and is probably only a variety of it.

Minutc Bed-straw. Pl. decumbent.

90 G. momfu'sum (Bieb. fl. taur. 1.p. 104 .) stems prostrate, much branched, villous; leaves 6 in a whorl, linear, sprealing much, villous ; floriferous branches axillary, aggregate ; lobes of corolla acutish; fruit downy. 4. H. Native of Caucasus, Tauria, on the lower Volga, in exposed places, and by way sides common. Corollas cream-coloured; anthers yellow. Habit and inflorescence like that of $G$. vèrum.

Trailing Bed-straw. Pl. trailing.

91 G. arena'rium (Lois. fl. gall. p. 85.) plant glabrous ; stems prostrate, much branched; leaves $6-10$ in a whorl, linear-oblong, short-apiculated, thick, with revolıte rather scabrous edges; corymbs small, on short peduncles, crowded into a panicle; fruit glabrous, rather fleshy. 4 . H. Native of the west of France, from Bayonne even to Armoracea on the south, in the sand by the sea side. D. C. fl. fr. suppl. p. 495. G. hierosolymitànum, Thor. chl. land. 40. but not of Lin. G. megalospérmum var. $\beta, D$. C. A. fr. ed. 3. no. 3350 . exclusive of var, $a$. G. minutum, Aubr. morb. p. 16. Flowers yellow, varying from 3-5-cleft. Distincs from the sea side variety of $G$. vèrum.

\section{Sand Bed-straw. Pl. prostrate.}

$\$ 7$. Ericogalia (from erica, a heath, and galium; the habit of the species is that of E'rica). D. C. prod. 4.p. 604. Perenniat or suffruticose plants. Leaces 4-6 in a whorl. Inflorescence axillary. Flowers hermaphrodite.

92 G. ericoìns (Lam. dict. 2. p. 583.) stems suffruticose, much branched, downy; leaves approximate, 4-5 in a whorl, linear-lanceolate, with revolute margins, apiculated, stiff, smoothish ; flowers axillary, nearly sessile, solitary, bibracteate; corolla pilose outside; fruit covered with stiff short hairs. h.G. Native of Monte-Video and Clili. Cham. et Sclslecht. in Linnæa. 3. p. 225. Larger leaves 2-3 lines long, and the smaller ones only half a line. Flowers minute, cream-coloured. Fascicles of leaves sessile, hence the plant has the habit of a heath. Stems decumbent.

I'ar. $\beta$, intermèdium (Cham. et Schlecht. in Linnæa. 3. p. 225.) plant shrubby, clothed with short down; leaves linear, quite glabrous, ending in a long cusp each. I I $_{2}$ G. Native of Brazil, in Campo d'Utna.

l"ar. $\gamma$, atheròdes (Cham. et Schlecht. in Linnaa. 3. p. 295.) quite glabrous in every part, as also the fruit; leaves linear, with revolute edges. $\zeta$. G. Native of Brazil, in Estrella do Campo Aguda. G. atheròdes, Spreng. cur. post. p. 39.

Heath-likc Bed-straw. Pl. decumbent.

93 G. H'́ntum (Lam. diet. 2. p. 583.) root woody; stems herbaceous, branched, tetragonal, very leafy, hispid; leaves $1-5$ in a whorl, sessile, lanceolate, more or less hairy on both surfaces; flowers axillary, verticillate, nearly sessile, bibracteate; lobes of corolla acute ; fruit glabrous, tubercular. 24. G. Native of the south of Brazil and Monte-Video. Cham, et Schlecht. in Linnæa. 3. p. 224. Req. diss. mss. G. refléxum, Pohl, in litt. G. megapotámicum, Spreng. cur. post. p. 39. ex Cliam. et Schlecht, in Linnæa. Stems decumbent or erect. Flowers yellow. Inflorescence of $G$. verticillàtum.

\section{Hairy Bed-straw. Pl. decumbent or erect.}

94 G. campònu (Pohl, in litt. ex D.C. prod. 4. p. 604.) plant quite glabrous; stems erect, tetragonal; leaves 4 in a whorl, sessile, linear, acutish, spreading, will revolute edges, more or less ciliated; flowers axillary, almost sessile; fruit finely granulated.-Native of Brazil, where it was collected by Pohl. Flowers small. Fruit almost like that of $G$. spurrium, but differs in being almost sessile. Leaves 4 lines long. Allied 
to $G$. hirtum, but differs in the angles of the stem being glabrous.

\section{Field Bed-straw. Pl. I foot.}

95 G. нu'mle (Cham. et Schleclut. in Linnæa. 3. p. 226.) stems diffise, tetragonal, filiform, beset with stiff hairs or glabrous; leaves 4 in a whorl, petiolulate, elliptic, acute at both ends, flat, cuspidate, ciliated; flowers axillary, solitary, opposite, on short pedicels, bibracteate; lobes of corolla acute, rather pilose at the apex; fruit globose, didymous, downy.-Native of the south of Brazil.

\section{Humble led-straw. P]. procumbent.}

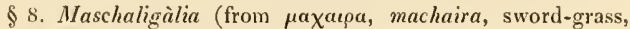
and galium). D. C. prod. 4. p. 605. Perennial plants. Leaves 4. in a whorl. Inflorescence axillary. Flowers polygamous, cream-colourcd.

96 G. corona'tum (Sibth et Smith, fl. græc. t. 125.) stems ascending, branched from the base, smooth; leaves 4 in a whor], elliptic, obtuse, nearly veinless, with the margins and base ciliated ; peduncles quinquefid, glabrous, bibracteate; flowers polygamous; fruit glabrous. $4 . H$. Native of Bithynia, on Mount Olympus; and of Tauria and Caucasus. Valántia Taúrica, J3ieb. fl. taur. 2. p. 437.-Buxb. cent. 5. p. 47. f. 39. There is a variety of this with rather hispid stems. Flowers pale yellow.

Var. $\beta$, glabérimum (D. C. prod. 4. p. 605.) stems and lower leaves quite glabrous on the nerve and margins. 24. H. Native of A rmenia and Cappadocia, on the mountains. Valántia humifùsa, Willd. spec. 4.p. 949. Bieb. fl. taur. 2. p. 436. Cruciata orientalis glabra humifusa, Tourn. cor. p. 4 .

Crowned Bed-straw. Fl. June, July. Clt. 1816. Pl. procumbent.

97 G. Tau'ricum (Rœem. et Schultes, syst. 3. p. 250.) stems decumbent, branched, hispid ; leaves 4 in a whorl, elliptic, reticulated, hispid; peduncles branched, ciliated, bracteated, deflexed; bracteas oblong; flowers polygamous ; fruit hispid from sliort down. 4. H. Native of Tauria, in rongh places. Valảntia Taúrica, Pall. in Willd. spec. 4. p. 95]. act. petr. nov. 10. p. 315 . Bieb. suppl. p. 640. D'Urv. cat. no. 138 . Valántia redevira, Hoffm. ex sieb. Flowers yellow.

Taurian Bed-straw, Fl. Jume, Aug. Clt. 1819. Pl. dec.

98 G. vE'RNum (Scop. carn. ed. 2. no. 14. t. 2.) stems erect, simple or branched from the base; leaves 1 in a whorl, 3-nerved, ciliated; peduncles dichotomous, bractless, shorter than the leaves; flowers polygamous; fruit glabrous. 4. H. Native of France and Switzerland, Upper Italy, Germany, Hungary, Gallicia, Siberia, \&c. in grassy places. Stems and leaves glabrous or hicpid, with the exception of the cilia. Flowers yellow or cream-coloured. D. C. fl. fr. ed. 3. no. 3353 . Very like $G$. cruciàtum. Valántia vérua, G. Don, in Loud. lıort. brit. p. 411. Iar. a, Bauhinii (D. C. prod. 4. p. 605.) leaves oval or elliptic. 4. H. Valántia glàbra, Lin. spec. 1491. Valántia glàbra, Waldst. et Kit. hung. t. 32 . Valántia crebrifò̀ia, St. Am. fl. agr. p. 424. G. Bauhinii, Roem. et Schultes, syst. 3. p. 218.-J. Bauh. hist. 3. p. 717. Flowers yellow.

I'ar. $\beta$, IIallèri (D. C. prod. 4. p. 605.) leaves oblong ; flowers paler and smaller. 24. H. Valántia glàbra, Vill. dauph. 2. p. 354. G. Scopòlii, Vill. dauph. 1. p.304. G. rubioìdes, Sut. fl. helv. 1. p. 88. G. Hallèri, Roem. et Schultes, syst. 3. p. 218. -Hall. nom. no. 720. Flowers cream-coloured.

Spring Bed-straw. Fl. May, June. Clt. 1371. Pl. trailing, 1 font.

99 G. PÉrsicun (D. C. prod. 4. p. 605.) plant quite glabrous, smooth, erect, of many stems; leaves 4 in a whorl, oblang, not ciliated; pedumcles axillary, many-flowered, 3 times slorter than the leaves, bracteate; liruit glabrous. 24. $\mathbf{H}$. Native of Persia, near Amadan, where it was collected by Ulivier and Bruguiere. Flowers yellow in the dried state. Nearly allied to $G$. vérnum, but differs in the plant being perfectly glabrous.

Persian Bed-straw. Pl. $\frac{1}{2}$ to 1 foot.

100 G. crucia'tum (Scop. carn. 1. P. 100.) stems erect ; branclied from the base, simple at the apex, pilose; leaves 4 in a whorl, elliptic-oblong or ovate, hairy, 3-nerved; peduncles hispid, branched; bracteas 2, oblong, ciliated; flowers polygamous ; fruit glabrous. 2. H. Native of Eurnpe, in hedges, road-sides, and shady places frequent; plentiful in Britain; and of Siberia. D. C. f. fr. no. 3351. Req. diss. mss. G. cruciàtum, Smith, engl. bot. 143. G. Vaillántia, fl. Wett. G. Valántia, Baumg. trans. Valántia cruciàta, Lin. spec. 1491. Lam. ill. t. 843. f. 1. A parìne latifòlia, M @enclı. metlı. 640 . Valántia ciliàta, Presl. fl. cecl. p. 34. but not of Russ. Root creeping. Flowers yellow, and some are 3-cleft.

lar. $\beta$, angustifôlum (D. C. prod. 4. p. 606.) leaves linearoblong, very scabrous along the edges. 4 . H. Cultivated in gardens, according to Req. diss. mss. ex D. C.

Crossnort Bed-straw. Fl, May, June. Britain. P]. 1 font.

10 I G. Chersonénse (Rom. et Schultes, syst. 3. p. 250.) stems branched, ascending, with hispid angles; leaves 4 in a whorl, oblong, ciliated, somewhat 3-nerved: nerves hispid beneath; peduncles branched, hispid, deflexed, bracteated ; bracteas oblong, ciliated; fruit glabrous. 2.H. Native of 'Tauria and Caucasus. Valántia Chersonénsis, Willd. spec. 4. p. 951. Bieb. fl. taur. suppl. 197\%. G. cruciàtum, $\beta$, Chersonénse, D. C. prod. 4. p. 606. Root creeping. Flowers yellow. Very like G. cruciàtum.

Cherson Bed-straw. Fl. May, July. Clt. 1817. Pl. $1 \mathrm{ft}$.

\section{Sect. 1I. Annual species.-Aparine.}

\$ 9. Cruciata (from crux, a cross; in reference to the disposition of the t leaves in each whorl). D. C. prod 4. p. 605 . -Cruciàta, Tourn. inst. p. 115 .-Valántia species, Lin. Plants annual. Flowers polygamous; some male, and some hermaphrodite, intermixed, yellow. Leaves 4 in a rhorl. Fruit glabrous or pilose.

102 G. retrórsum (D. C. prod, 4. p. 605.) stem erect, simple, beset with retrograde prickles along the angles; leaves 4 in a whor], oblong, villously ciliated; peduncles axillary, pilose, nearly simple, reflexed while in fruit; flowers polygamous, 3-4cleft; fruit glabrous. $\odot$. H. Native of Sicily, Pannonia, and Caucasus, on liills, and in woods on the mountains. G. Pedemontànum, Bieb. fl. taur. 2. p. 436. Guss. prod. 1.p. 170. but not of All. Vaillántia Pedemontàna, Waldst, et Kit. pl. rar. lrung. 1. t. 33. but not of Bellardi. Flowers yellow.

Retrogradc-prickled Bed-straw. Pl, $\frac{1}{2}$ to 1 foot.

103 G. Pedenonta'sa (All. auct. p. 2.) stem erect, simple, slender, loosely villous; leaves 4 in a whorl, oval-oblong, hispid; peduncles bractless, 3-4-flowered, shorter than the leaves, deflexed after flowering; flowers polygamous; fruit glabrous, globose, didymous. $\odot$. H. Native of the soutll of Europe, is of Portugal, Spain, Vallais, Piedmont, \&.c. in sterile dry places. D. C. fl. fr. ed. 3. no. 3352. Req. diss. mss. Valántia Pedemontàna, Bel]. append. 46. t. 5. act. taur. 5. t. 7. but not of Kit. G. chlorántluum, Brot. fl. lus. 1. p. 149. Fruit sometimes truly globose, from one of the cells being abortive. Flowers yellow, very like those of $G$. cruciàtum.

I'ar. $\beta$, refléxum (Presl. fl. sic. prod. p. 123.) fruit rough from stiff pili. $\odot$. H. Native of Sicily, among grass on the mountains and in groves. Perhaps a proper species.

Piedmont Bed-straw. Fl. July. Clt. 1799. Pl, $\frac{1}{2}$ to 1 foot. 104 G. Gibraltáricum (Schott, in isis, 1828. p. 821.) stems 
pilose, muricated along tle angles; lower leaves ovace: cauline ones 8 in a whorl: "ppermost ones opposite, all with revolute hispid edges; panicles decompound; lobes of corolla cuspidate ; fruit glabrous. $\odot$. H. Native of Gibraltar, on the mountains. Flowers yellow.

Gibrallar Bed-straw. Pl. $\frac{1}{9}$ to 1 foot.

105 G. Schulte'sil; leaves cordate, glabrous, rather ciliated, with seabrous margins; peduncles dichotomous, leafless. $\odot . H$. Native of Caucasus, in dry stony places on the Talusch mountains, near Swant. G. articulitum, Rom. et Schultes, syst. 3. p. 250. but not of Lam. nor D. C. ex Meyer, pfl. syst. p. 55 .

Schulles's Bed-straw. PI. $\frac{1}{2}$ foot.

106 G. PYGME'Um (D. C. prod. 4. p. 606.) plant quite glabrous, branched from the luase; leaves 4 in a whorl, roundish; peduncles axiliary, hort, 3-6-flowered, bractless; fruit globose, drooping, glabrous. $\odot$. H. Native of Iberia. Valántia muràlis, Bieb. A. taur. 2. p. 435. exclusive of the synonyme. Vaillántia pusílla, Stev. in litt. 1825. Herb very minute. Flowers yellow.

Pigmy Bed-straw. Pl. small.

107 G. conda'tum (Rom. et Schultes, syst. 3. p. 259.) plant glabrous, erectisl, branched from the base; leaves 4 in a whorl, oborate, unequal: floral ones sessile, ovate-cordate, deflexed, and covering the flowers and lower parts of the nodi; peduncles branched, short, few-flowered; fruit glabrous. ○. H. Native of the Levant, at the foot of Mount Lebanon, where it was collected by Labillardiere, Sxc. 'The flowers are probably yellow. This plant is often to be found in gardens under the name of Callipéltis cucullària. Nearly allied to $G$. articulàtum.

Cordate-leaved Bed-straw. Pl. $\frac{1}{2}$ foot.

$\$ 10$. Vanthaparines (from ¿avos, xanthos, yellow, and a $\pi$ apur , aparine, the Greek name of eleavers or goose-grass; in reference to the yellow flowers of the species). I. C. prod. 4. p. 600. Plants annual. Leaves 4-8 in a whorl. Inflorescence cymosely panicled. Floners ycllow, hermaphrodite. Fruit glabrous.

108 G. campe'stre (Schousb. ex Willd. enum. 1. p. 152.) stem erect, tetragonal, laving the roughness on the angles turned upwards, not retrograde; lower leaves 4 in a whorl, the rest 6 , elliptic, mucronate, with scabrous margins; peduncles dichotomous; lobes of corolla lanceolate, bluntish. $\odot . H$. Native of Barbary. Rœm. et Schultes, syst. 3. p. 224. Link, enum. 1. p. 135 . Corollas crean-coloured. Leaves 4 lines long, and 2 lines broad. Stems decumbent at the base. Leaves on the upper part of the branches sometimes oppnsite.

Var. 3 , Iahlii (D. C. prod. 4. p. 606.) stem smoothish; leaves oblong. $\odot$.H. Native of Barbary, where it was collected by Vahl and Lamarck, \&c. See Lam. dict. 3. p. 584. observations under G. megalospérmum. The leaves are almost like those of var. a, but the margins are more scabrous. Lobes of corolla not armed. Fruit granular.

Field Bed-straw. Fl. Jume, July. Clt. 1820. Pl. $\frac{1}{2}$ foot.

109 G. glomera'tum (Desf. fl. atl. 1. p. 128. t. 40.) stem erect, branched, panicled, tetragonal : angles rough; leaves 6 8 in a whorl, linear-lanceolate, mucronately acute, serrulately scabrous on the margins; panicles trichotomous; lobes of corolla very acute, a little awned; fruit glabrous. $\odot . H$. Native of Barbary, in corn-fields. Flowers pale yellow. Said to be allicd to G. compéstre.

Glomeratc-flowered Bed-straw. Pl. $\frac{1}{2}$ to $\frac{3}{4}$ foot.

110 G. visco'sust (Vahl, symb. 2. p. 29.) stems ascending, tetragonal, smooth, brauched; lower leaves 4 in a whorl: upper ones 6, linear-lanceolate, with serrated margins and a smooth keel; the serratures directed upwards; peduncles filiform, by threes; pedicels 2-flowered; fruit clammy. ○. II. Native of the kingdom of Tunis, on the mountains. Corolla pale yellow, almost white.

FOL. III.
Clammy-fruited Bed-straw. Pl. $\frac{1}{4}$ foot.

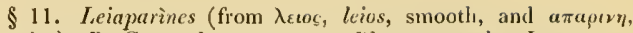
aparine). D. C. prod. 4. p. 607. I'lants annual. Leuves 4-8 in a whorl. Inflorescence eymoscly panicled. Flowers white, hermaphliroditc. Fruil glabrous.

111 G. URvíllei (Req. diss. mss. ex D. C. prod. 4. p. 607.) stem erect, brinched at the base, glabrous; leaves 6-8 in a whorl, linear, erect, glabrous, with revolute edges: peduncles axillary and terminal, trifil; pedicels 3 times longer than the flowers; fruit glabrous. $\odot$. H. Native of the islands in the Grecian Archipelago, in arid places. G. floribundum, D'Urv. cat. no. 130. but not of Smith. llowers purplish in the dried state. Habit of $G$. setìcum, but differs in the fruit being quite glabrous.

D'C'rille's Bed-straw. Pl. $\frac{1}{2}$ foot.

112 G. mivarica'tum (Lam. dict. 2. p. 580.) stem ascending or erect, branched at top, slender, smoothish; leaves 6-8 in a whorl, linear, acute, hispid; peduncles axillary and terminal, slender, elongated, divaricate, trificl at the apex; pedicels twice the length of the flowers; fruit glabrous. $\odot$. H. Native of the south and middle of France; Liguria and Sicily, in arid sandy places. D. C. fl. fr. no. 3370, icon. rar. t. 21. Req. diss. mss. G, tènue, Vill, dauph. 2. p. \$ I2, t. 7. Flowers greenish.

Divaricate Bed-straw. F1. June, July. Clt. 1818. Pl. $\frac{1}{4} \mathrm{ft}$.

113 G. TENu'ssimum (Bieb. f taur. 1. p. 10\%.) stems weak, ascending, much branched, rather scabrous along the angles; leaves $6-8$ in a whol, linear, acute, scabrous, hispid; peduncles axillary and terminal, trichotomous, divaricate; pedicels length

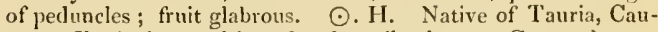
casus, Iberia, in uncultivated and sterile places. G. purpùreum, Pall. ind. taur. but not of Lin. Flowers small, greenish-white. Very nearly allied to $G$. divaricalum, and probably only a variety of it according to Steven, but differs in the pedicels being 3 or 4 times longer.

Most-slender Bed-straw. Fl. June, July. Clt. 1818. Pl. $\frac{1}{4} \mathrm{ft}$.

114 G. A'nglicum (Huds. fl. angl. p. 69.) stems decumbent, much branclied, rather scabrous; leaves 6 in a whorl, linearlanceolate, mucronate, with scabrous edges; peduncles 2-3cleft, a litcle longer than the leaves, axillary, disposed in a kind of panicle ; fruit glabrous, granular. $\odot$. H. Native of England, on walls and in sandy places; north and middle of France, palatinate of the Rline, Vallais, Sicily, and Caucasus. Smith, $\mathrm{fl}$. brit. 1. p. 179 . D. C. f. fr. 3369 . Smith, engl, bot. 384 . G. Parisiénse, Lam. dict. 2 p. 584 . G. Parisiénse ß̂, Bertol. dec. 3. p. 15. G. rùbrum, Poll. pal. no. 156. exclusive of the syn. G. gràcile, Wallr. sched. p. 57. Presl, f. sic. prod. p. 60. ex Guss. prod. p. 173. Ray. syn. t. 9. f. 1. Corollas of a greenish cream-colour, almost white, small. It differs from $G$. litigiòsum in the fruit being glabrous, and from $G$. divaricatum in the peduncles being shorter.

Iar. $\beta$, parvifölinm (Gaud. 11. helv. 1. p. 439.) stems erect, short; floriferous branches short; fruit gramlar. ๑. H. Native in fields about Geneva. G. parvifòlium, Roem. et Schultes, syst. 3. p. 246.

English Bed-straw. Fl. June, July. Wales. Pl. decumbent.

115 G. Apricum (Sibth et Smith, fl. græc. t. 126.) stems pilose, diffuse; leaves 4 in a whorl, obovate, uniform, with scabrous edges; peduncles trifid, leafless; fruit glabrous. $\odot . \mathrm{H}$. Narive of Candia and other islands in the archipelago, frequent. Peduncles 3-flowered; middle flower hermaphrodite and quadrifid; lateral ones male and trifid. Certainly a species of I aillántia.

Sumny Bed-straw. Pl. difluse.

116 G. Gaudichau'di (D. C. prod. 4. p. 607.) stems weak, decumbent, tetragonal, rather hispicl; leaves 4 in a whorl, ob$4 \mathrm{P}$ 
long-linear, with hairy revolute edges; floriferous branches short, axillary, few-flowered; lobes of corolla hardly acutish ; fruit glabrons.-Native of New Holland, at Port Jackson, where it was collected by Guudichaud. Stems S-10 inches long. Leaves 2-3 lines long, shorter than the internodes. Flowers white.

Gaudichand's Bed-straw. Pl. decumbent.

\$12. Euaparines (from eu, well, and aparine, cleavers; the section is supposed to contain the true kinds of cleavers). D. C. prod. 4. p. 607. Plants annual. Stems scabrous. Leaves 4-8 in a whorl. Inflorescence axillary. Flowers usually hermaphrodite. Fruit gramular or hispid, didymously globose.

117 G. sacchara'tur (All. pedem. no. 39.) stems weak, branched, with retrograde roughness along the angles; leaves 6 in a whorl, linear-lanceolate, scabrous from prickles along the margins; prickles not retrograde; peduncles axillary, 3-4Howered, recurved when bearing the fruit, and length of leaves; fruit didymosely globose, warted. $\odot$. H. Native of Europe, in corn fields; Scotland, in the Carse of Gowrie, and near Forfar; and near Malton, in Yorkshire. D. C. fl. fr. cd 3. no. 3379 . Wallr. anı. bot. 2\%. Req. diss. mss. G. verrucosum, Smith, in engl. bot. t. 2173. fl. greec. t. 133 . Valántia saccharàta, Gmel. fl. bad. 3. p. 781. Valántia aparìne, Lin, spec. 1491. Schrad. spic. 55 . t. 1. f. 3. V. aparine a, Lam. fl. fr. 3. p. 383. A parìne verrucòsa, Moench. meth. p. 640.Vaill. bot. t. 4. f. 3. b. Perhaps G. granulatum, Rom. et Schultes, syst. 3. p. 249. or Valántia granulâris, Spreng. in Schrad. journ. 1800. 2. p. 200. Peduncles 3-flowered, lateral ones male, and middle one hermaplirodite.

Sugary Cleavers or Goosegrass. Fl. Ju. Aug. Britain. Pl. dif.

118 G. Tricórne (With. brit. ed. 2. p. 153.) stems weak, simple, roun from retrograde prickles along the angles; leaves 8 in a whorl, lanceolate, scabrous from retrograde prickles along the margins and keel; peduncles axillary, 3-flowered, recurved when in fruit, not exceeding the leaves; fruit didymously gloloose, gramular. $\odot$. H. Native throughout the whole of Europe, in corn-fields; also of Caucasus; in many parts of England, in ehalky fields, but not common. D. C. fl. fr, ed. 3. no. 3378. Smith, engl. bot. t. 1641. Wallr. ann, bot. t. 23. Req. diss. mss. G. spùrium, Huds. angl. p. 68. G. Valántia, Wigg. prim. p. 12. Valántia triflòra, Lam. fl. fr. 3. p. 384. exchusive of the synonymes. Valántia aparine, Mart. f. rust. 1. t. 122. Valántia tricốnis, Roth, neu. beytr. 1. p. 142.-Vaill, bot. $t$. 4. f. 3. a, a. Flowers greenish-white.

Three-horned Goosegrass. Fl. Ju. Aug. Britain. Pl. $\frac{1}{2}$ to $1 \mathrm{ft}$. 119 G. spu'rium (Lin. spec. p. 154.) stems decumbent, scabrous from retrograde prickles along the angles, but glabrous at the knces; leaves 6-9 in a whorl, lanceolate, mueronate, keeled, scabrous from retrograde prickles along the keel and edges; peduncles many-flowered, hardly recurved, while in the fruit longer than the leaves; fruit glabrous, smooth. ค. H. Native of Europe and Siheria, in fields and all cultivated ground: in Scotland, in corn-fields about Forfar, but rare. D. C. f. fr. ed. 3. no. 3377 . Smith, eng. bot. t. 1571. G. agréste leiospérmum, Wallr. sched. p 59 . G. líspidum, Hoftim. germ. 1.p. 74. G. adhæ'rens, Jacq. hort. vind. ex Jan. herb. G. aparine var. Spreng. Flowers green. Perhaps two species are confused under this name, differing much in the size of the fruit.

Spurious Goosegrass. Fl. June, July. Britain. Pl. decumb.

$120 \mathrm{G}$ scabe'rrinum (Vahl, in Horn. hort. hafu. 1. p. 135.) stem angular, scabrous from retrograde prickles; leaves 8 in a whorl, linear, spreadingly reflexed, longer than the internodes, mucronate, very scabrois above, and scabrous from prickles along the keel and margins; peduncles axillary, few-flowered, subcorymbose; fruit globose, didymous, hispid from bristles, which are hooked at the apex. $\odot$.H. Native of Egypt. G. híspidum, Willd. enum. hort, berol. 1. p. 150. Corollas yellowish. Stem simple.

l'ery-rough Goosegrass. Fl. Ju. July. Clt. 1821. Pl. $\frac{1}{2}$ foot.

121 G. Aparine (Lin. spec. p. 157.) stems weak, branched, rougl from retrograde prickles, villous at the nodi; leaves 8 in a whorl, lanceolate-linear, apiculated, scabrous from retrograde prickles along the margins and keel; pecluncles simple and bifid, scabrous ; fruit didymously globose, very hispid from bristles, that are hooked at top. $\odot . H$. Native throughout the whole of Europe, north of Asia, and North America, in hedges, fiekls, and in most cultivated places; plentiful in Britain. Oed. fl. dan. t. 495. Smith, engl. bot. t. 816. Bull. herb. fr. t. 215. Heyne, term. bot. t. 13. f. 6. Mart. f. rust. t. 104 . Woodv. med. bot. suppl. 269. Valántia A parìne $\beta$, Lam. fl. fr. 3. p. 383. Aparìne híspida, Moench. meth. p. 640. Rubia tinctòrum, Lapeyr. ex Benth. A parine, Dod. pempt. 353. Petiv. brit. t. 30. f.11. Flowers small, pale buff-coloured. Fruit rather large. Stems climbing. T'he well known property of this plant of adhering to whatever it comes in contact with, acquired it the names of Cleavers or Clivers, and Catchweed or Scratchweed; and from being a favourite food or medicine of geese, Goosegrass, Gooseshare, and Gostingweed. The stalks, according to Linnæus, are used in Sweden as a filtre to strain milk througls. Dioscorides relates that the shepherds made the same use of it in his time. It is reckoned to purify the blood, and for that purpose the tops are an ingredient in spring broth. The expressed juice of the herb taken to the amount of 4 ounces or a quarter of a pint night and morning, during several wecks, is very efficacions in removing many cutaneous disorders. It has been most celebrated in scrofulous and cancerous sores, but the experiments made has not turned out in its favour. The seeds are a good substitute for coffce. The roots, like most of the genus, will dye red, and caten by birds have tinged their bones of that colour.

Tar. 3 , minor (Req. diss. mss. ex D.C. prod. 4.p. 608.) stem dwarf; leaves usually 6 in a whorl, and smaller. $\odot$. H. Native of the island of St. Lucia, near Narbonme.

Conmon Cleavers or Goosegrass. Fl. May, Aug. Britain. Pl. climbing.

122 G, Villántil (D. C. fl. fr. 1805. no. 8381.) stems weak, nearty simple, glabrous at the nodi, but scabrous from retrograde prickles along the angles; leaves 8 in a whorl, linear, having the keel and margins scabrous from retrograde prickles; peduncles simple or bifid; fruit globosely didymous, rather hispid from a few bristles, which are hooked at their tops. $\odot$. H. Native of Europe, in cultivated fields; plentiful in some parts of Britain. G. inféstum, Waldst. et Kit. pl. rar. hung. 3. p. 202. (1808) Bess. gall. 121. G. agréstc echinospérmum, Wallr. sched. p. 59. G. Aparìne $\beta$, Lam. Flowers small, yellowish. Fruit about half the size of those of G. aparine, and not so hispid.

I'aillant's Goosegrass. Fl. June, July. Clt. 1817. Pl. 2 to 3 feet.

123 G. aparinoides (Forsk. descrip. p. 30.) stems weak, prickly along the angles, but the prickles are not retrograde as in most of the species, but lean forward, and the knees or joints are equal and glabrous; leaves 6 in a whorl, oblong, scabrous from retrograde prickles along the margins and keel; peduncles 3 from the top of each branch, bifid; fruit hispid from bristles, which are hooked at the tops. $\odot$. H. Native of Arabia, in shady places. Vahl, symb. 2. p. 30. Flowers white. Fruit like that of $G$. aparine.

Cleavers'-like Goose-grass. Pl. procumbent.

124. G. Paucirlòrum (Bunge, I. c.) annual; stems weak, glabrous, tetragonal, scabrons from retrograde prickles along the angles; leaves 6 in a whorl, spatulately oblong, attenuated at the base, cuspidate by a spine, hispid above, and glabrous be- 
neath, with scabrous margins; peduncles axillary, a little longer than the leaves, bracteate, 1-2-flowered; corollas very minute, obtuse; fruit didymous, very hispid from hooked bristles. $\Psi$. G. Native of China, in humid places, near Ssi-jui-ssy. Fen-flowercd Goose-grass. Pl. decumbent.

125 G. Austra'Le (D. C. prod. 4. p. 608.) stems weak, procumbent, branched, tetragonal, pilose, on one side; leaves 4 in a whorl, oblong, mucronately acute, rather pilose, with subrevolute edges; peluncles axillary, 3 -fiowered, hardly longer than the leaves; fruit very hispid from bristles.-Native of New Holland, at Bass Straits, where it was collected by D'Urville. Said to be nearly allied to $G$. recurvum, but differs in the pedicels not being recurved, and in the fruit being twice the size.

Southern Goose-grass. Pl. procumbent.

126 G. Gra'cule (Bunge, in mem. acad. sc. P'etersb. 2. p. 109.) stem simple, erect, quite glabrous, shining, tetragonal ; leaves 4-in a whorl: lower ones obovate, middle ones elliptic, superior ones oblong, 1-nerved, scabrous from dots, hispid on the margins; panicles axillary, dichotomous, very slemler, exceeding the leaves; corollas very minute, obtuse; fruit hispid from hooked bristles. 4. G. Native of China, on mountains, near Lun-ziian-ssy.

\section{Slender Goose-grass. PI. $\frac{1}{2}$ foot.}

127 G. TE' NERUM (Schleich. ex Gaud. fl. helv. 4. p. 442.) stems filiform, glabrous; leaves 6 in a whorl, oborate, setaceously apiculated, scalvous from retrograde prickles on the margins; peduncles by tlurees, trifid, spreading; fruit hispid. ๑. H. Native of the Alps of Switzerland. Corollas small, white.

\section{Tender Goose-grass. Pl. procumbent.}

128 G. Lıtıgıosuม (D. C. fl. fr. no. 3382, icon, rar. t. 26.) stems decumbent, branched, rather scabrous; leaves $4-6$ in a whorl, linear-lanceolate, acute, shorter than the internodes, rather scabrous; peduncles elongated, divaricate, bifid or trifid; fruit nearly globose, hispid at top from somewhat hooked hairs. ○. H. Native of the south of France, Italy, Sicily, in rough stony places, and probably about Paris, but very doubtful. G. Parisiense, Lin. spec. p. 157. exclusive of the synonymes. G. multiflorum, Brot. H. lus. 1. p. 25I. G. axillàre, Presl. prod. fl. sic. p. 61. ex Guss. Flowers small, reddish. This species differs from $G$. An'glicum and $G$. gràcile in the fruit being hispid.

$I^{\prime}$ r. $\beta$, nànum (D. C. prod. 4. p. 609.) stems short, erect. ๑. H. Native of Europe, in very sterile places. D. C. icon. rar. t. 26. right-hand figure.

Litigious Goose-grass. Fl. June, July. Pl. decumbent.

129 G. microspérium (Desf. f. atl. 1. p. 130.) stems erect, tetragonal, glabrous, rough; branclies divaricate; leaves 6 in a whorl, linear-acute, denticulated; fruit hispid. ๑. H. Native of Barbary, near Mascar; and of Sardinia. Aspérula scàbra, Moris, elencl. sard. 2. p. 4. and 3. p. 8. Flowers small, white. Very nearly allied to G. divaricàtum, Lam., and is perhaps only a variety of it, with hispid fruit. According to Steven, obs. ined. in herb. Willd, it is only a variety of G. litigiosum.

Small-sceded Goose-grass. Fl. June, July. Clt. 1819. PI. $\frac{1}{4}$ foot.

130 G. seta'ceum (Lam. dict. 2. (1786.) p. 584.) stems filiform, erect, scabrous at bottom; leaves usually $6-8$ in a whorl, lut from 4 to 8 , linear-setaceous, with rather scabrous margins: lower ones oblong; peduncles slender, divaricate, trifid; fruit hispid from bristles, which are hooked at the apex. $\odot . H$. Native of Spain, Mauritania, Sicily, Provence, in exposed stony or rocky places. Desf. fl. atl. 1. p. 129 . D. C. fl. fr. 5. p. 498. G. microcárpum, Vahl, symb. 2. (1791.) p. 30. G. capillàre, Cav. icon. 2. (1792.) p. 73. t. 191. f. 1. Lag. gen. et spec. no. 127. G. floribúndum, Sibth. et Simith, f. graec. t. 134.? G. capillàre and G. microcárpum, Spreng. syst. Flowers red. 'Thu oldest nane is here admitted for this plant, as in all other cases. Setacous-leaved Goose-grass. Fl. June, July. Clt. 1819. Pl. $\frac{1}{4}$ to $\frac{1}{2}$ foot.

131 G. Siвтнórp1ı (Ruem. et Scluultes, syst. 3. p. 244.) stems smooth; leaves 8 in a whorl, linear, revolutely setaceous, scabrous: lower ones olvovate; pedicels capillary; fruit rather pilose. $\odot$. H. Native of the Grecian Islands, on sterile hills. G. capillàre, Smith, prod. fi. graec. 1. p. 94. but not of Cav. G. Créticum ánnuum tenuifolium flore albiclo, 'Tourn. cor. p. 4. Flowers pale yellow or cream-coloured. Perhaps only a variety of $G$. microspérmum or $G$. sctàceum.

Sibthorp's Goose-grass. Pl.

132 G. вrevifoliuvi (Sibth. et Smith, fl. græec. t. 135. but not of Stev.) stens villous; leaves 7 in a whorl, obovate, awned, scabrous; peduncles tricliotomous, terminal ; lobes of corolla auned; fruit lispid. $\odot . H$. Native of Caramania, on the seashore. Flowers cream-coloured. The bristles on the stem and leaves are not retrograde, as on most of the species. Perhaps the same as G. álbum, Willd. ex Roem. et Schultes, syst.

Short-lcarcd Goose-grass. Pl. 1 foot.

183 G. A'LBUM (Forsk. descrip. const. p. 20.) stems erect, branched, downy, coloured at the nodi; leaves $6-8$ in a whorl, oblong, mucronate, with scabrous hardly serrulated margins, glabrous above, and villous beneath, especially on the keel; fruit hispid. $\odot$.H. Native about Smyrna. Flowers white.

IIhitc-flowered Goose-grass. Pl. $1 \frac{1}{2}$ foot.

13\% G. Recu'rvum (Req. diss. mss. ex D. C. prod. 1. p. 609.) stems weak, decumbent, branched, smoothish; leaves 6 in a whorl, but the uppermost ones are only $f$, obovate-oblong, narrowed at the base, acutish at the apex, glabrous; peduncles axillary, 3-flowered, equal in length to the leaves, deflexed while in fruit, hairy; fruit small, globose, hispicl. $\odot$. H. Native of the Grecian Archipelago, among rocks. G. micránthum, D'Urv. cat. no. 133. but not of Pursh. Sherárdia muràlis, Sibth. in lierb. L'Her. Sherárdia inuràlis, Stev, obs. p. 70 ?

Recurced-peduncled Goose-grass. Pl. decumbent.

\$19. A'sperce (from asper, rough ; fruit). D. C. prod. 4. p. 610.-A'spera, Moncl. meth. 641. Plants ammal. Leawes usually 4 , rarcly 6 in a whorl. Inflorescence lateral. Fruil oblong, lispid; mericarps or parts of fruit distinct, narrom, clongalcd.

135 G. Fulifórme (Røem. et Schultes, syst. 3. p. 252.) stem simple, hispil, slightly tetragonal; leaves 4 in a whorl, oblong, remotely ciliately denticulated, reticulated, glabrous; male flowers nearly sessile, hermaphrodite ones on short pedicels; fruit oblong, paleaceous, longer than the pedicels. $\odot . H . ~ \mathrm{Na}-$ tive of Tenerifte, on the Walls of Lagunea, but not to be found elsewhere. Valäntia filifórmis, Ait. holt. liew. 3. p. 42. Flowers yellowish.

Filiform Goose-grass. Fl. June, July. Clt. 17 So. Pl. $\frac{T}{4}$ to $\frac{1}{2}$ foot.

136 G. murále (D. C. f. fr. no. 3383. All. pelem. no. 34. t. 77. f. 1.) stems branched, decumbent, smoothish; leases lanceolate, 6 and 4 in a whorl; flowers axillary, twin, on short pedicels; pedicels deflexed after flowering; fruit r.blong, hispist. ○. H. Native of Occittania, Valentia, Sicily, Siberia, Provence, Italy, Cyprus, Candia, Persia, about Constantinople, in rugged exposed places. Buxb. cent. 2. t. 30. f. 2. G. mínimum, Ra'm. et Schultes, syst. 3. p. 26?. A parine mínima, All. nic. p. 4. Sherárdia muràlis, Lin. spec. 14.9. Sibth. et Smith, fl. græec. 115. G. stenocárpum, Duf. in litt. G. fràgile, Pourr. chlor. lisp. 512.-Moris. oxon. t. 21. f. 6 . A'spera nutans, Manch. meth. p. 641. Corollas yellowish. Mature fruit of 2 mericarps.

I'ar. $\beta$, lciospérnum (Req. in litt. 1828. ex D. C. prod. 4. p. 610.) stem, leaves, and fruit glabrous. $\odot$. H. Native of 4 P 2 
Montpelier, at Pont Juvenal, where it was collected by Requien.

Hall Goose-grass, Fl. June, July. Clt. 1818. Pl. decumbent.

137 G. verticilla'tur (Danth. in Lam. dict. 2. p. 585.) stem branched at the base; branches nearly simple, elongated, smoothish ; leaves linear-lanceolate, hispid, 4 in a whorl: uppermost ones opposite, deflexed ; flowers $2-4$, axillary, and therefore verticillate, almost sessile; fruit erect, hispid. $\odot . H$. Native of Sicily, Provence, about Salon Foz; at the foot of Mount Ventosa, Tauria, and Cancasus, in arid places, and at the fountains of the river Salgir. Lois. not. 33. t. 2. D. C. suppl. fl. fr. p. 498. Req. diss. mss. Gàlium muràle, Bieb. fl. taur. 1. p. 105. ex Stev. G. verticillatum, Pourr. chl. no. 508.

Verticillate-flowered Goose-grass. Fl. June, July. Clt. 1824. 1). $\frac{1}{4}$ foot.

138 G. Sмíтни ; branclies erect, simple, bluntly quadrangular, scabrous; leaves 4 in a whorl, uppermost opposite, all deflexed, elliptic-lanceolate, scabrous; flowers axillary, by threes, therefore 6 in a whorl, erect; fruit hispid, with clistinct, elongated mericarps. $\odot$. H. Native of the Grecian Islands, among rocks. Sherárdia erécta, Snith, fl. grac. t. 116 . Flowers greenish yellow.

Smith's Goose-grass. Pl. $\frac{1}{2}$ foot.

\section{† Species of Galium not sufficiently known. \\ * Species natives of Europe.}

139 G. Solemòli (Lois. nouv, not. 7.) stems weak, angular, downy (Lois.), villous (Spreng.); leaves 5.6 in a whorl, ovatelanceolate, acute, hairy; peduncles dichotomous (Lois.), divari'iate, trifid, few-flowered (Spreng.); fruit wrimkled. \%. II. Native of Corsica, by the sea-side, where it was collected by soleirol. G. Córsicum, Spreng. cur. post. p. 39. Flowers unknown.

Soleirol's Bed-straw. Pl. procumbent.

140 G. GolduA'cuncum (Kluk. in Bess, prim. A. gal. 2. p. 337.) stems procumbent, diffuse, retragonal; leaves 8 in a whorl, narrow-lanceolate, awned, gircled by strong hairs at the apex; fiowers umbellate; fruit globose.-Native of Gallicia, in grassy places. Said to be like $G$. la've and $G$. Buccòni.

Goldlach Bed-straw. Pl. procumbent.

141 G. pentándrum (Gileb. ex Kluk. in Bess. prim. fl. gal. 2. p. 338.) stems erect, branched; leaves 8 in a whorl, linewrlanceolate, spotted with white at the apex; racemes few-flowered; flowers pentamerous; fruit didymons-Native of Gallicia. Flowers yellowish. Said to be nearly allied to $G$. verrum, and is probably merely a pentamerous-flowered variety of that plant.

Pentandrous Bed-straw. Pl. 1 foot.

142 G. ochrolevicum (Kit. in Schultes, œestr fl. ed. 2. vol. 1. 1. 305.) stems erect, quadrangular, smooth ; leaves 8 in a whorl, linear-subulate, with very roug! margins, and ending in a long mucrone each; flowers by threes, corymbose, campannlately fumnel-shaped. 24.H. Native of Austria, on mountain rocks. l'lowers cream-coloured. Perhaps a species of $A$ spérulu.

Cream-coloured-flowered Bed-straw. Pl. 1 foot.

143 G. Monta'num (Lin. spec. p. 155.) stems weak, scabrous; leaves 4 in a whorl, linear, smootl ; corymbs trifid. $\odot$. H. Native of Germany, France, Lngland. Corolla white, purplish outside before expansion. Anthers brown. This plant is not known at the present day, as the plant under this name in the Limman herbarium does not agree with the characters given of it by him.

$$
\begin{aligned}
& \text { Mountain Becl-straw. P'. } \frac{1}{4} \text { to } \frac{1}{2} \text { foot. } \\
& \text { * * A species native of the Levant. }
\end{aligned}
$$

144 G. merosolymínam (Lin. amon. 4. p. 451.) leaves 10 in a whorl, lanceolate-linear; flowers umbellate, fa-tigiate.
-Native of Palestine. Stature of $G$. rübrum. The rest unknown.

Jerusalem Bed-straw. Pl. $\frac{1}{2}$ to 1 foot.

$$
\text { *** Species natires of Asia. }
$$

1 t5 G. Tuberòsun (Lour. coch. p. 79.) root oblong, tuber ous ; stem procumbent, simple; leaves $4-5$ in a whorl, lanceolate, glabrous ; pedicels axillary, 1-flowered, crowded, longish ; fruit rough. - Native of China and Cochin-china, where it is cultivated for the sake of the tubers, which are farinaceous, and are eaten when boiled. Flowers hardly known. Perhaps a true species of Gálium.

Tuberous-rooted Bed-straw. Pl. procumbent.

146 G. strigòsum (Thunb. nov, act. ups. 7. p. 141.t. 4. f. 1-9.) stems decumbent, tetrasonal, scabrous along the angles; leaves 6 in a whorl, elliptic, ending in a spinose point, lispicl from pili above, and nearly glabrous beneath, with ciliately scabrous edges; flowers axillary, on short peduncles.-Native of Japan. G. uliginòsum, Thunb. fl. jap. 58 .

Strigose Bed-straw. Pl. decumbent.

$$
\text { **** Species natives of the Cape of Good Hope. }
$$

147 G. mucronatum (Thunb. prod. p. 30. fl. cap. 151.) stems downy, weak, tetragonal, rising in numbers from the same root; leaves 6 in a whorl, linear, mucronate, glabrous, with revolute serrated edges; branches few-flowered; fruit glabrous.-Native of the Cape of Good Hope. l'erhaps the same as G. mucronàtum, Spreng. pug. 2. no. 49. The G. mucronàtum, Lam. and the G. mucronatum, Ruiz et Pav. are distinct species. Nucrones of leaves white.

Mucronate-leaved Bed-straw. Pl. $\frac{1}{2}$ foot.

148 G. jórnidum (Thunb. fl. cap. 1. p. 556. phyt. bl. p. 16.) stcm suffruticose, erect, tetragonal, prickly along the angles; leaves usually 8 in a whorl, linear, reflexed, serrated by prickles. h. G. Native of the Cape of Good Hope.

Horrid Bed-straw. Shrub 2 feet.

149 G. GLa'brum (Thuub. prod. p. 30. fl. cap. 152.) stems flexuous, erect, tetragonal, glabrous, serrated along the angles ; leaves 6 in a whorl, obovate-oblong, acute, glabrous, with replicately-serrated ediges; peduncles ample, lateral and termiual, panicled. h. G. Native of the Cape of Gool Hope. Flowers wlite. Very like $G$. ásperum.

Glabrous Bed-straw. Pl. 1 foot.

150 G. A'sprinu (Thunb. prod. 30. fi. cap. 554.) stem flexuously erect, beset with white twisted hairs, and scabrous along the angles; leaves 6 in a whorl, oblong, glabrous, with replicately serrated maruins; flowers few. 4. G. Native of the Cape of Good Hope. Angles of stem rough from retrograde denticulations. Fruit glabrous.

Rough Bed-straw. Pl. $1 \frac{1}{2}$ foot.

151 G. expa'nsum (Thunb. prod. 30. fl. cap 152.) stem tetragonal, smcoth, with divaricate downy branches; leaves 6 in a whorl, linear, mucronate, glabrous, with revolute margins; panicles trichotomous, spreading, divaricate; fruit smooth. $\mathcal{\Psi}$.? G. Native of the Cape of Good Hope. Corollas white.

Expanded Bed-straw. Pl. 1 foot.

152 G. CaPE'NSE (Thunb. prod. p. 30. fi. cap. p. 151.) stems frutescent at the base, erect, branched; branclies terete, downy; leaves $6-8$ in a whorl, linear-lanceolate, glabrons, with revolute margins; peduncles dichotomous; fruit glabruus, smooth. $h$. G. Native of the Cape of Good Hope. Flowers white.

Cape Bed-straw. Slurub l foot.

***** Species natives of North America.

153 G. unif lòrum (Michx. fl. bor. amer. 1. p. 79.) stems flaccid, smootlı; leaves 4 in a whorl, linear, acute, glabrous; 
peduncles axillary, solitary, 1-flowered, very short; flowers drooping; fruit glabrous. 4. H. Native of Carolina. Fertile branclies ascending. Said to be nearly allied to $G$. tinctòrium. Flowers white. G. uniflorum, Req. ined. in herb. D. C. is a variety of $G$. triflòrum.

Onc-flonerel lied-straw. Pl, ascending.

154. G. Parviflòrum (Rafin. med. disp. 5. and in Desv. journ. bot. 1. p. 227.) stems diffuse, angular, glabrous; leaves 5-6 in a whorl, linear-lanceolate, very acute, glabrous ; flowers very vumerous, panicled.-Native of North America, about Newcastle and Delaware. Flowers small, white.

Small-flonered Bed-straw. Pl. difluse.

155 G. spinulòsum (Rafin. med. serm. p. 40. but not of Merat.) plant diffuse ; leaves $1-6$ in a whorl, cuneiform, cuspidate, spinulose, scabrous; peduncles lateral, dichotomous, manyflowered; fruit scabrous.-Native of Maryland. Desv. journ. bot. 4. p. 270. Roem. et Schultes, syst. 3. p. 528 .

Spinulose Bed-straw. Pl. diffuse.

156 G.? Mexica'num (H. B. et Kunth, nov. gen, ames. 3. p. 337.) stem beset with retrograde prickles; leaves 8 in a whorl, linear, acuminately pungent, glabrous, witl revolute edges, which are, as well as the middle nerve, rough from retrograde prickles, one-half shorter than the internodes; corymbs terminal, sub-trichotomous ; fruit hispid. $\odot$. H. Native of Mexico, near Guanaxuato. Perhaps a species of Rùbia.

Mexican Bed-straw. Pl. $1 \frac{1}{2}$ foot.

\section{****** Species natives of South America.}

157 G. Denticula'tum (Bartl, in lierb. Hænke, ex D. C. prod. 4. p. 612.) stems diffuse, branched, rather hispicl from bristles; leaves 4 in a whorl, ovate, cuspidate, ciliated by distant bristles, rather hairy on both surfaces, 1-nerved; flowers few, terminal, usually by threes; pedicels capillary; fruit glahrous.-Native of Mexico, at Real del Monte. Perhaps a species of Rùbia.

Denticulated-leaved Bed-straw. Pl. diffuse.

158 G. hirsv'tua (Ruiz et Pav. f. per. 1. p. 59.) stems procumbent, tetragonal, much branched, hairy ; leaves 4 in a whor], lanceolate, reflexed, hairy ; peduncles axillary, 1-flowered, solitary, short; fruit scabrous. $\odot$. H. Native of Peru, in the province of Canta, in shady places. Perhaps a species of Rùbia.

Hairy Bed-straw. Pl. procumbent.

159 G. Pilíferum (H. B. et Kuntl, nov. gen. amer. 3.p. 337.) stems weak, beset with retrograde prickles; leaves 8 in a whorl, linear-lanceolate, acuminated by hairs, glabrous, with revolute edges, which are, as well as the middle nerve, beset with retrograde prickles, mueh shorter than the internodes; flowers terminal, on long peduncles; fruit hispid. $\odot$. H. Native of New Granada, on the Andes. This plant ought probably to be excluded from the genus, on account of its campanulate corolla. Habit of $G$. uliginosum.

Piliferous Bed-straw. Pl, procumbent.

160 G. Cane'scens (H. B. et Kunth, nov, gen. amer. 3. p. 336.) stems almost glabrous; branches and leaves villous; leaves 4 in a whorl, ovate, acuminated, triple-nerved, canescent beneath, much shorter than the internotes; floriferous branches bifid; flowers lateral and axillary, solitary and terminal, by threes; fruit beset with hooked bristles. $\odot$. H. Native about the town of Quito. Habit of $G$. maritima, but is said to be annual. Perhaps a species of Rùbia.

Canescent Bed-straw. Pl. procumbent.

161 G. Caripe'nse (H. B. et Kunth, nov. gen. amer. 3. p. 337.) stem glabrous, beset with retrograde prickles; leaves 8 in a whorl, upper ones 6 , oblong-lanceolate, mucronate, having the margins beset with retrograde prickles, much shorter than the internodes; flowers terminal, usually by threes, pedunculate; fruit hispid. ○. H. Native of Cumana, near Caripe, in shacly places. Said to be allied to $G$. tinctorium, but is annual.

Caripe Bed-straw. Pl. diffuse.

162 G. Lappa'ceum (Ruiz et Pav. f. per. 1. p. 59.) stem rather scandent, much branched, tetramonal; branches villous, dichotomous; leaves oblong or obovate, 4 in a whorl, lispid: upper ones 3 in a wliorl, lanceolate; peduncles axillary, Iflowered; fruit lispid from bristles.-Native of Peru, about Huanaco, at Puelles Collem. 'The fruit is said to be baccate. Perhaps a species of Rùbia.

Burdock-fruited Bed-straw. Pl. climbing.

known.

****** Species the native habitats of which are un-

163 G. Dichótonum (Lehm, ind. sem, hort, hamb. 18:3. p. 7.) stem dichotomous, frutescent, quadrangular; leaves 4 in a whorl, obovate-lanceolate; fruit glabrous. 4. H. Native country unknowu. Sail to be allied to $G$. frutıcosum, but the leaves are much broader and shorter, and the flowers are larger.

Dichotomous-stemmed Bed-straw. Shrub.

164. G. nígnum (Ait. hort. kew. 1. p. 144.) stem erect, terete, pilose, rather scabrous; leaves verticillate, linear, scabrous above; panicles divaricate. 4 . H. Native country unknown.

Stiff Bed-straw. Fl. June, July. Clt. $17 \% 8$. Pl. 1 foot.

Cult. The species of Gàlium are of the most easy culture and propagation. They will all grow in any common soil. The perenuial kinds are easily increased by dividing the plants, or by seeds. The sects of annual species should be sown where the plants are intended to remain. Those species natives of bogs or marshes slould be planted in a moist situation; and those natives of warmer climates should be protected during winter, either by covering with mats or liaulm of other herbs, or by placing then in a green-house. None of them are worth cultivating, unless in botanical gardens.

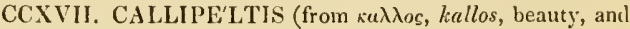
$\pi \varepsilon \lambda \tau \eta$, pelte, a buckler; in reference to the large hollow bracteas). Stev. obs. pl. ross. p. 69 . D. C. prod. 4. p. 613. Cucullària, Buxb. cent. 1. p. 13. t. 19. f. 2. but not of Sclıreb. nor Rafin. Valántia species, Lin.-Gàlium species, Rom. et Shultes.

Lın. syst. Tetrándria, Diginia. Calyx with an oblong tube, and the limb not perspicuous, Corolla 4-parted, campanulate ; lobes ovate, very short. Stamens 4 , very short. Stigmas 2. Fruit oblong, rather incurved; one of the mericarps being abortive, the fruit is only 1 -seeded.-An annual, erect, muchbranclied, slender, glabrous herb. Leaves 2, oblong, and stipulas 2, very like the leaves, constituting a 4-leaved whorl. Hlowers 3 from each axil, on short pedicels, and therefore constituting 6-flowered whorles. Bractea large, membranous, complicate, and as if it were holding the fruit within its lollow. Flowers small, all fertile. Fruit hispid at the apex.

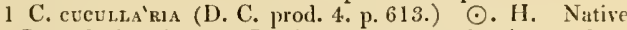
of Cappadocia, Arabia, Persia, at Aleppo, Iberia; and of Spain, at Aranjuez, Valántia cucullària, Lin. amœn, acad. 4. p. 295 . Bieb. fl. taur. 2. p. 438. Lam. ill. t. 843 . f. 2.-Buxb. cent. 1. p. 13. t. 19. f. 2.-Gàlium cucullària, Riom. et Sclultes, syst. 3. p. 259. Flowers whitisl.

Cucullar-bractead Callipeltis. FI. May, July. Clt. 1780. Pl. $\frac{1}{2}$ to 1 foot.

Cult. Sow the seeds in a warm dry situation, where the plants are intended to remain for seed. 
CCXVIII. VAILLA'NTIA (so named in honour of Sebastien Vaillant, an eminent French botanist, and demonstrator at the botanic garden, Paris, author of Diseours sur la Structure des Fleurs, 1718, and Botanicum Parisiense, 1723, 8vo., and 1726, fol. \&c.). D. C. f. fr. 4. p. 266. Roem. et Schultes, syst. S. p. 14. and p. 74. A. Rich. mem. soc. hist. nat. Par. 5. p. 131. t. 1J. f. 2. D. C. prod. 4. p. 613.-Valántia, Tourn. act. acad. sc. 1705. Mich. gen. 13. t. 17. Monch. meth, 1) 639.Valántia species, Lin.-Vaillántia species, Waldst, et Kit.

Lın. syst. Polygàmia, Monce'cia. Flowers by threes; midIle one fertile, hermaphrodite, and the two lateral ones male, and combined with the middle one. Tube of calyx orate; limb denticulated, permanent, the denticulations many, irregular and stiff. Corollas rotate; male ones trifid, and the hermaplurodite one quadrifid. Stamens 3-4. Styles 2 in the hermaphrodite Hower; stigmas eapitate. Fruit 3-horned, in consequence of the ovaria of the three flowers being combined; the lateral horns sterile, and the middle one biovulate, but usually only 1 -seeded at maturity.-Annual branched herbs. Stems tetragonal. Leaves oval, opposite, and stipulas 2, very like the leaves, forming a 4-leaved whorl. Flowers 3 in each axil, sessile, small, yellow, therefore they appear 6 in a whorl. -According to the observation of $\mathbf{A}$. Rieliard, the seeds are half naked at maturity from the rujturing of the meriearp.

I Y. MURA'LIS (Lin. spec. p. 1490.) stem, leaves, and calyxes glabrous. $\odot$. H. Native of the south of Europe, in dry rocky places, and on old walls; on the whole coast of T'uscany; on the samdy shores of the County of Nice; and in the south of France, about Nemours; also about Montpelier and Leghorn. Sibtl. et Smith, fl. græc. 137. V. quadrifòlia, Moneh, meth. p. 640.-Sabb. hort. 1. t. 83.-Mich. gen. 13. t. 7.-Mor. oxon. 3. sect. 9. t. 21. f. 2.-Col. ecphr. t. 297. Angles of fruit tringed.

Wrall Cross-wort. Fl. May, July. Clt. 1789. Pl. $\frac{1}{2}$ foot.

2 V. Híspida (Lin. spec. p. 1490.) stem lispid; leaves ciliated; calyxes pilose. $\odot$. I1. Native of Teneriffe, south of Spain, Italy, Balearie Islands, Candia, Barbary, \&e. in hedges and fields. Sibth. et Smith, f. grace. t. 138. Gàlium híspidum and G. bleplárophon, Rom. et Schultes, syst. 3.p.249. Fruit prickly. Lateral horns of fruit smaller.

Far. $\beta$, aculeàta (D. C. jrod. 4. p. 614.) plant larger; fruit glabrous, longer than the tenticulations of the calyx. $\odot . H$. Native of the kingdom of Naples, among rubbish and on old walls.

Hispid Cross-wort. Fl. May, July. Clt, 1768. Pl. $\frac{1}{2}$ to $\frac{3}{4}$ toot.

Cult. Sow the seeds on an old wall or on rock-work, or in any try sandy soil and situation.

\section{Tribe XIII.}

OPERCULARIE $Æ$ (this tribe contains plants whose fruit opens by an operculum). A. Rich. mem. soc. list. nat. Par. 5. 1). 142. D. C. prod. 4. p. 614 -Operculàriæe, Juss. anı. mus. t. p. 4.18. and 10. p. 328.-Operculària Gartn. fruet. 1. p. 111. เ. 24 . Flowers combined: having the ealycine tubes resembling at length a peculiar operculum. Corollas 3-5-cleft. Stamens 1-5; filaments hardly adnate to the tube of the corolla at the base. Style short; stigmas 2, slenler, elongated, acute. Fruit 1-celled and 1 -seeded by abortion, combined, 2-valved (f. 112. b.), at length dehiscing.-Herbs or subshrubs, usually natives of Australia. Leaves opposite. Stipulas twin on both sides, distinct or combined. Flowers combined into a head, girded by a partial, many-toothed involucrum. Heads of flowers sometimes umbellate and pedunculate, and sometimes sessile and capitate, usually girded by a universal involucrum.-This tribe agrees with Spermacocece in labit and stigmas, but the number of sta- mens is variable, and therefore it approaches the order Ialeriànece.

CCXIX. POMAX (from $\pi \omega \mu a$, poma, an operculum; in reference to the opereulum to the fruit). Solant. in Gærtn. fruct. 1. p. 111 . t. 24. A. Rich. mem. soc. hist. nat. Par, 5. p. 145. t. 13. f. 1. D. C. prod. 4. p. 6 I5.-Opereulària floribus umbellatis, Juss, ann, mus. 4. p. 418.

Lin. syst. Mono-Tetrándria, Monogýmia. Limb of ealyx wanting. Corolla 8-4-cleft. Stamens 1-4. Seeds wrinkled from tubercles.--Suffruteseent herbs. Leaves opposite, furnished with one leaf-formed stipula on each side. Peduneles 7 10 , terminal, umbellate, involucrated by the 2 floral leaves and 4 small stipulas, bearing at their tops a small distinet head of flowers each; heads girded by a blunt 8-10-toothed involucrum. Flowers 3 within each partial involuerum, joined together by the tubes of the calyxes.

1 P. hírta (D. C. prod. 4. p. 615.) branehes, leaves, peduncles, and involucra hispid; leaves oblong-linear. h. G. Native of New Holland. Pòmax umbellàta, Sol. 1. c. Opereulària umbellàta, Gærtn. fruet. 1. p. 112. t. 24. Lam. ill. t. 58. f. 1. Juss. mem. mus, 10. p. 426. Sieb. nov. holl, no. 250.

Hairy Pomax. Fl. June, July. Clt. 1826 . Pl. $\frac{1}{2}$ to $] \mathrm{ft}$.

2 P. GLA'BRA (D.C. l. c.) plant glabrous in every part ; leaves elliptic, attenuated at the base. $h_{2}$. G. Native of New Holland, about Port Jackson. Stipulas smaller than in the preceding species.

Glabrous Pomax. Shrub 1 foot.

Cult. The species of this genus grow best in a mixture of loam, peat, and sand; and cuttings root freely under a handglass.

CCXX. OPERCULA'RIA (from opereulum, a lid; in referenee to the operculate calyx). A. Rich. mem. soc. hist. nat. Par. 5. p. 144. t. 13. f. 2. D. C. prod. 4. p. $615 .-$ Rubioìdes, Soland. 1. c.-Cryptospérmum, Young, in Lin. trans. 3. p. 30. -Operculària and Cryptospérmum, Pers.-Opereulàriæ floribus capitatis, Juss.

Lin. syst. Mono-Pentándria, Monogýnia. Limb of ealyx 3-1-lobed. Corolla 3-5-cleft. Stamens 1-5. Seeds nearly smooth.-Herbs suffiuticose at the base. Leaves opposite, furnished with distinct stipulas on both sides. Heads of flowers globose, terminal, or rising from the forks of the branehes, pedunculate, or nearly sessile. Universal involuerum wanting, or composed of the 2 upper leaves and 4 small stipulas. Partial involucra acutely 8-10-toothed.

1 O. Hisptid (Spreng. syst. 1. p. 385.) stems diffuse, furrowed, tetragonal, rough from numerous hairs; leaves small, ovate, pilose; heads pedunculate, rising from the forks of the branches, drooping. 2. G. Native of New Holland. O. áspera, Juss. ann. mus. 4. p. 427 . t. 70. f. 1. Universal involucrum wanting; partial ones 8-10-toothed, each containing 3-5 flowers. Corolla 5-cleft, monandrous or diandrous, white.

Hispid Opereularia. Fl. Ju. July. Clt. I 790 . Pl. diffuse.

2 O. sessilif Lòra (Juss. 1. c. p. 427. t. 170. f. 2.) glabrous; stems diffuse, slender, hardly furrowed; leaves linear; heads of flowers small, hemispherical, sessile in the forks of the branches 4. G. Native of New Holland.
FIG. 112.

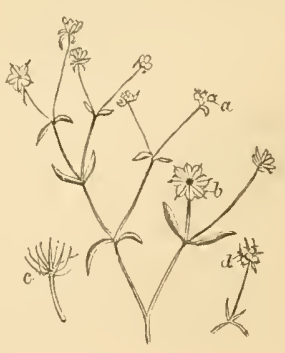


Partial involucra 4-5 in the same head, each containing $2-4$. flowers. Corollas 4-5-cleft, monandrous or diandrons, white. Leaves like those of the species of Linaria.

Sessile-flonered Opercularia. Fl. June, July. Clt. $182 \%$ 1). diffuse.

3 O. Aptcri Lòra (Labill. nov. holl. 1. p. 35. t. 48.) glabrous ; stems diffirse, very slender, furrowed; leaves oblong-linear, short; stipulas joined in one on both sides; heads of flowers terminal, small, hemispherical, involucrated by about 4 verticillate leaves. h. G. Native of New Holland, in Van Lewin's Land. Juss. mem. mus. 4. p. 4थ7. Partial involucra 1-3 in each head, each containing 3-4 flowers. Corollas 4-5-cleft; monandrous or diandrous, white. (Fig. 112.).

Top-flonercd Opercularia. Shrub 1 foot.

4 O. spermacòcea (Labill. nov. holl. 1. p. 35. ᄂ. 47.) glabrous; stem slurubby, crect; leaves linear, almost triquetrous; stipulas combined in one on both sides, bidentate at the apex; heads spherical, pedunculate, terminal. $々$. G. Native of New Holland, in Lewin's Land. Juss. ann. mus, 4. p. 427. Leaves falsely verticillate. Partial involuera $4-5$ in the same head, each bearing 4 flowers. IIabit of Spermacice verticillata.

Spcrmacoce-like Opercularia. Shrub 1 foot.

5 O. vagina'ta (Labill. nov. holl. 1. p. 34. t. 46.) glabrous; stem erect, woody at the base, rather angnlar; leaves lincar; stipulas combined into a long sheath, which is bidentate at top on botll sides; heads globose, naked, terminal. Ђ.G. Native of New Holland, in Van Lewin's Land. Juss. ann. mus. 4. p. 428. Partial involucra 5-9 in a head, each containing 3-5 flowers. Corolla 4-cleft. Stamens 4, ex Labill.

Sheathed-stipuled Opercularia. Shrub 1 foot.

6 O. MRTE'LLA (D. C. prod. 4. p. 616.) stem rather angular, and rather pilose at the apex; branches elongated ; leaves linear, stipulas lanccolate-subulate; heads of flowers pedunculate, drooping, hairy, rising from the forks of the branches. $4 . \mathrm{G}$. Native of New Holland. Branches, leaves, and stipulas beset with longish hairs.

Hairy Opercularia. Pl. 1 foot.?

7 O. hyssopifòlia (Juss. mem, mus, 4. p. 428, t. 71. f. 1.) stem erect, rather angular, clothed with short down; leaves narrow-lanceolate, with somewhat ciliated margins; stipulas conbined entire, acute; heads of flowers rising from the forks of the branches, on shor peduncles, drooping a little, globose. 々. G. Native of New Holland. Partial involucra about 5 in every head, each containing 2-4 flowers.

Hyssop-leaved Opercularia. Shrub 1 foot.

8 O. ligustrifòlia (Juss. mem. mus, 4. p. 428. t. 71. f. 2.) stem erectish, tetragonal, hairy from short down, but glabrous between the nodi; stipulas combined at the base on botls sides, acutely 2-lobed; heads of flowers rising from the forks of the branclies, on short peduncles, drooping. $h$.G. Native of New Holland, about Port Jackson. The rest as in the preceding species.

Privel-leaved Opercularia. Shrub 1 foot.

9 O. Palea'ta (Young, in Lin. trans. 3. p. 30. t. 5.) glabrous; stems herbaceous, tetragonal, erect; leaves ovate-lanceolate, acute; stipulas combined on both sides, acutely 2lobed; heads of flowers pedicellate, drooping when in flower, rising from the forks of the branches, globose, involucrated. $\psi$. G. Native of New Holland. Juss. ann. mus. 4. p. 428 . Cryptospérmum Yoúngii, Pers, ench. 1. p. 122. Partial involucra almost 20 in every head, each containing 5-6 flowers. Corolla 4-cleft, pale green. Stamens 4 . Universal involucrum 6-parted, composed of 2 leaves and 4 stipulas. Peduncles sometimes the length of the heads, and sometimes 3 times that lengtl. Anthers whitish.

Chaffy Opercularia. Fl. July, Aug. Clt. 1793. Shrub 4 feet.
10 O. ocymifòla (Juss, ann. muss, 4. p. 428. t. 71. f. 3.) glabrous; stems diffuse, tetragonal, furrowed ; leaves ovate-oblong, petiolate; stipulas combined in one on both sides; heads of flowers rising from the forks of the branches, on short peduncles, drooping, globose, naked. 24. G. Native of New llolland. Ileads larger than peas, with 7-9 partial involuera in every liead, each containing 4-6 flowers. Corolla 3-1-cleft. Stamens 2-3, ex Juss.

Basil-leaced Opercularia. Fl. June, July. Clt. 1824. Pl. 1 foot.

11 O. RUBioides (Juss, anu. mus, 4. p. 42S.) stems tetragonal, ascending, glabrous; leaves lanceolate, with revolute margins ; margins and middle nerve scabrous heneath; stipulas combined on both sides, entire or bidentate; hearls on short peduncles, rising from the forks of the branches, drooping, globose, naked. h. G. Native of New Holland, on the Eastern Coast. Heads of flowers larger than peas. Partial involucra 5-7 in every head, each containing 5-6 flowers. Corolla 3-4-cleft. Stamens 3.4.

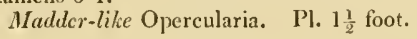

\section{$\dagger$ Doubtful species.}

12 O. A'spera (Gaertn. fruct. 1. p. 112. t. 24.) leaves oblong, scabrous, veiny; heads of flowers pedunculate, axillary. - Native of New Zealand, ex Solander. O. áspera, Spreng. syst. 1. p. 385. Probably the same as $O$. hispida.

Rough Opercularia. Pl. 1 foot.

13 O. DIPHY'LLA (Gærtn. I. c. p. 113.) stem and leaves unknown; heads of flowers rising from the forks of the branches; partial involucra hispid, many in every head, each containing 3-4 flowers; flowers tetrandrous.-Native of New Zealand. Juss. ann. mus. 4. p. 4.28. Rubioides diplyylla, Soland. mss. The rest unknown.

Tro-lcacd Opercularia. Pl. 1 foot?

Cult. For culture and propagation see Pòmax, p. 662.

CCXXI. LIPO'STOMA (from $\lambda \varepsilon \iota \pi \omega$, leipo, to fall from, and rтона, stoma, a mouth; lid from capsule). D. Don, in edinb. new phil. journ. Jan. 1830. Sweet, H. gard, n. s. with a figure.

Lin. sisr. Tctrándria, Monogýnia. Limb of calyx 4 -parted. Corolla tubular at the base, and ventricose at the throat, and bearded inside, with a 4-lobed limb; lobes ovate, spreading, valvate in astivation. Stamens 4 , inserted in the throat, exserted; filaments compressed; anthers linear, versatile. Style capillary; stigmas 2, subulate, lispid. Capsule globose, ?celled, opercular, many seeded, but often 1-celled from the middle dissepiment having vanished. Placentas 2 , spherical, stipitate, inserted beneath the middle of the dissepiment. Seed small, angular, scabrous. Embryo slender, with oblong planoconvex cotyledons, and a cylindrical obtuse radicle, which is a little longer than the cotyledous.-Diffuse trailing pilose herbs, natives of Brazil. Leaves opposite, petiolate. Stipulas subulate, interpetiolar. Flowers sessile, capitate, intermixed with bracteas. Heads of flowers pedunculate, solitary, axillary. Corollas blue.

1 L. capita'ta (D. Don, l. c.) plant hairy; leaves roundish, undulated, green, spreading. 24.S. Native of Brazil. Eginètia capitàta, Graham, in edinb. new phil. journ. A pril, 1828 . p. 389. Hedyòtis campanuliflòra, Hook. bot. mag. t. 284.0. Corollas rather large, fine bhe, with a yellow throat, pilose outside.

Capitatc-flowered Lipostoma. Pl. trailing.

2 L. Seríceum (D. Don, l. c.) plant hairy; hairs adpressed; leaves ovate, acute, when young silky. 24. S. Native of Brazil, in pastures. 'The whole plant is clothed with silky adpressed hairs. Heads of flowers smaller than the preceding. Corolla 
664 rubiacez. CCXxil. Psilobium. CCXxili. Platymerium. CCxxiv. Stipularia. CCXXy. Benzonia, \&.c.

blue, hairy. Seeds triquetrous, dark brown, beset with elevated dots.

Silky Lipostoma. Pl trailing.

Cult. For culture and propagation see Richardsònia, p. 628.

+ Genera of Rubiàcea not so sufficiently knonn as to be placed in any particular situation in the body of the order.

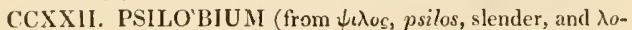
Bos, lobos, a pod; in reference to the silique-formed fruit). Jack, in mal. misc. vol. 2. ex Roxl. fl. ind. 2. p. 320. D. C. prod. 4. p. 618 .

Lis. sysr. Pentándria, Monogýnia. Limb of calyx spreading, 5-parted. Corolla with a short tube, and a 5-parted limb. Siamens 5, fixed to the base of the eorolla. Stigma clavate, 10-wingerl, exserted. Fruit cylindrical, silique-formerl, crowned by the permanent calyx, 2-celled, many-seederl. Seeds disposed in a double series along the axis in each cell.-Indian shrubs. Stems bluntly tetragonal. L,eaves opposite, petiolate, lanceolate. Stipulas broad, keeled. Flowers axillary, bracteate. Estivation valvate. It is not said whether the fruit is dehiscent or indehiscent.

1 P. Nu'Tans (Jack, l. c.) smooth; peduncles drooping, 3-6flowered. $h_{2}$. S. Native of Sumatra, in the interior of the island.

Drooping-peduncled Psilobium. Slurub.

2 P. тomentòsum (Jack. l. c.) tomentose; flowers almost sessile in the axils of the leaves. h. S. Native of the East I dies, at Katoun. Fruit said to be baccate.

Tomentose Psilobium. Shrub.

Cult. See Psychólria, p. 599. for culture and propagation.

CCXX111. PLATYME'RIUM (from $\pi \lambda a \tau v \varsigma$, platys, broad, and $\mu \varepsilon \rho \epsilon$, meris, a part ; probably from the parts of the flowers heing broad). Bartl. in herb. Hanke. D. C. prod. 4. p. 619.

Lin, syst. Tctra-Pentándria, Monogínia. Calyx with a short tube, and a rotate 5-parted, rarely 4 -parted limb; lohes flat, obtuse. Corolla coriaceous, funnel-shaped, with a short tube, which is woolly inside, and a 5 -parted, rarely 4-parted limb; segments of the limb twisted to the right in astivation. Anthers linear, sessile within the tube of the corolla. Style clavate, spirally 10-ribbed. Ovariun 2-celled, covered by an epigylions Jisk. Fruit unknown.-A shrub, with slender terete branches. Leaves opposite, coriaceous, lanceolate, acuminated, downy beneath and on the branches, on sliort petioles. Flowers numerous, glomerate, on sliort pedicels, axillary. Calyses tomentose.-This genus is nearly allied to Psilobium, but is distinguished from it in the astiration of the corolla, and in the fruit not being silique-formed.

I P. glomera'Tum (Bartl. in herb. Hanke, ex D. C. prod. 4. 1. 619.) T. S. Native of the island of Luzon, one of the

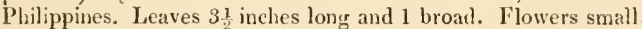
Glomerate-flowered l'latymerium. Slirub.

Cult. For culture and propagation see Psyehótriı, p. 599.

CCXXIV. STIPULA'RIA (so named on account of the large stipulas). Beauv, fl. d'ow. 2. t. 76. Juss, mem. mus. 6. p. 406. D. C. prod. 4. p. 619.

Lix. syst. Pentándria, Monogýnia. Calyx small, tubular, with a 5 -toothed border. Corolla tubular, slender. Stamens 5 ? Style and fruit unknown.-Stems quadrangular. Leaves opposite, petiolate, ovate, acute at the apex, acuminated at the base, yellowish beneath, soft to the touch. Stipulas large, intcrpeiolar, broadly ovate, acute, glabrous. Heads of flowers almost sessile, surrounded by large 5 -toothed calyciform villous involucra. The place which this genus should oceupy in the order is very doubtful.
1 S. Africa'na (Beauv. Al. d'ow. 2. p. 26. t. 75.) Native of the west coast of Africa, in deserts about the river Galbar : we have also seen it in the neighbourhood of the Gaboon river. Flowers pale yellow.

African Stipularia. Shrub.

Cult. For culture and propagation see Psychótria, p. 599.

CCXXV. BENZO'NIA (named in compliment to the celebrated African traveller Benzoni, who died at Benin, the habitat of the present plant). Siclum. pl. guin. p. 113. D. C. prod. 4. p. 620 .

LıN. sysr. Tetrándria, Monogýnia. Calyx with a globose tube, and a small 5-toothed limb; teeth erect. Corolla tubular, coriaceous, 5-cleft; segments concave, cup-shaped. Anthers triquetrous, sessile in the throat. Style filiform; stigma ovateglobose, acutish, marked by 6-7 longitudinal furrows. Fruit unknown.- 1 shrub, native of Guinea. Branches terete, beset with pili above, and with papillæ below. Leaves opposite, ovateoblong, acuminated, glabrous, on short hairy petioles. Stipulas interpetiolar, lanceolate, glabrous. P'eduncles axillary, dichotomous, corymbose, and are as well as the bifid pedicels hairy.

1 B. conrubòsa (Schum. pl. gutin. p. 113.) h. S. Native of Guinea, in various parts.

Curymbose-flowered Benzonia. Shrub 5 to 6 feet.

C'ult. See Psychótria, 17. 599. for culture and propagation.

CCXXVI. HIMATA'N'THUS (from i $\mu a \tau t o v, ~ h i m a t i o n$, a garment, and av $\theta 0 c$, anthos, a flower; the flowers are involuerated by a large bractea before expansion). Willd. rel. ex Rom. et Schultes, syst. 5. p. 13. D. C. prod. 4. p. 621.

Lix. syst. Pentándria, Monogýnia. Tube of calyx adnate to the ovarium, turbinate ; limb loose, permanent, 5-parted ; segments ovate, acuminated, $\approx$ of thęm one-half smaller than the other three. Corolla funtel-shaped, having the tube much longer than the calyx, dilated a little at the apex; and the limb $5 \cdot$ cleft, with oblong segments. Stamens 5, capillary, very short, inserted in the base of the tube. Anthers linear, erect, shorter than the tulse of the corolla. Style truncately clavate; stigma subulate. Ovarium 2 -celled, 2 -seeded.-A tree. Leaves elliptic-lanceolate, petiolate, quite entire, glabrous. Flowers spicate, sessile, involucrated by a larce deciduous bractea each before expansion.--'This tree belongs probably to Rubiàcce, but the stipulas and situation of the leaves, seeds, \&c. are unknown.

1 H. RIGIDA (Hoftim. ex Willd. I. c.). h. S. Native of Brazil, in the province of Para, where it is called Sucuba by the natives.

Stiff Himatanthus. Tree.

Cult. For culture and propagation see Psychótria, p. 599.

CCXXVil. SICKI'NGIA (evidently named after some person of the name of Sicking, of whom we know nothing). Willd. in nov. act. nat. cur. berol. 3. p. 445. and in Schrad, bot. journ. 1800. pt. 2. p. 291. D. C. prod. 4. p. 621.

Lın. syst. Pentándria, Monogynia. Calyx permanent, 5toothed. Corolla campanulate, 5-toothed: teetli oblong. Filaments 5 , inserterl in the middle of the corolline tube. Anthers linear, exserted. Stigma 1. Capsule woody, 2-valved. Seeds winged.-Trees, natives of Caraccas. Leaves opposite. Flowers terminal, trichotomous, panicled, sweet-scented. This is a very doubtful genus fiom the description given by Willdenow; but according to Richard it is related to Cinchonàcce, in consequence of the winged seeds; but the stipulas are not mentioned, and the leaves are said to be deeply and remotely toothed; and therefore it ought probably to be exeluded from Rubiàcea.

I S. enytiróxyion (Willd. l. c.) leaves oblong-rhomboid, 
toothed at the apex, downy beneath. $\zeta$. S. Native of mountain woods, about Caraccas.

Red-wooded Sickingia. Tree or slurub.

2 S. Longifòria (Willd. 1. c.) leaves oblong-ovate, quitc entire, glabrous. $h$.S. Native along with the preceding.

Long-leated Sickingia. Tree.

Cult. See Psychótria, p. 599. for culture and propagation.

CCXXVIII. CALYSPHY'RUM (from $\kappa a \lambda v \xi$, kalyx, a calyx, and $\sigma \phi v \rho o v$, sphyron, a little hammer; the calyx is like a peduncle). Bunge, in mem. acad. mss. Petersb. 2. p. 107.

Lin. syst. Telrándria, Monogýnia. Tube of calyx linearpentagonal, adnate to the ovarium, 10-striped; limb subcampanulate, profoundly 5 -lobed; segments lanceolate, equal, acute, erect, deciduous. Corolla superior, funnel-shaped, about equal in length to the calycine segments; throat wide, glabrous; limb ample, spreading, 5-parted; segments roundisl, imbricate in restivation: the fifth one a little smaller than the rest. Stamens 5 , inserted in the bottom of the tube of the corolla, and alternating with its segments. Antliers linear-oblong, 2-celled, dehiscing at each side by a longitudinal chink. Ovarium inclosed in the tube of the calyx, 2-celled, many-ovulate. Style filiform, exserted; stigma peltate. Capsule 2-celled; cells many-seeded. Seeds disposed in 2 rows in each cell, inserted in the dissepiment, imbricated, compressed.-Perhaps the genus is more nearly allied to Lobeliàcea than to Rubiàcea.

1 C. Flóridum (Bunge, l. c.) leaves opposite, almost sessile, oblong, acuminated, toothed; flowers 2-4, sessile, terminating the branches; corollas grumose. $h . G$. Native of China, in gardens. Flowers size and form of those of Rhododéndron Daúricum.

Flowery Calysphyrum. Shrub.

Cult. See P'omax, p. 662. for culture and propagation.

$+\dagger$ Genera referred to Rubiàcca by authors, but do not belong to the order.

Bellònia, Lin. belongs to Solànece; and Gartnèra, Lam., Ustèria, Willd., Pagàmia, Aubl. bclongs to Logànea.

OrDER CXXXI. VALERIA'NEE (this order contains plants agreeing with Valeriàna in important characters). D. C. fl. fr. 4. p. 237. propr. med. ed. 2. p. 175. coll. mem. vii. t. 5. Dufres. diss. val. 4to. $181 \mathrm{I}$. Kunth in Desv. journ. 1814. vol. 2. p. 171. et nov. gen. amer. 3. p. 322. Cham. et Schlecht. in Linnæa. 4. p. 129. D. C. prod. 4. p. 423.-Genera of Dipsàceæ, Juss.Valeriàna, Lin. gen. no. 44 .

Tube of calyx adnate to the ovarium; limb variable in the different genera, sometimes toothed or parted, sometimes going away in pappus, which is at first involute, and at length expanded. Corolla tubularly funnel-shaped, usually 5 -lobed, rarely 3-4-lobed; lobes obtuse; tube equal or gibbous, or spurred at the base. Stamens adnate to the tube of the corolla, but free at the apex, alternating with its lobes when they are equal in number, but varying in number in the different genera from 1 to 5 . Anthers ovate, 2-celled. Style filiform; stigmas 2-3, free, or combined in one. Fruit membranous or subnucumentaceous, indehiscent, crowned by the limb of the calyx in the younger state; sometimes 5 -celled, in this case 2 of the cells are vacant; sometimes only 1 -celled. Seed in the fertile cell or solitary fruit, pendulous, exalbuminous. Embryo straight, with a superior radicle, and 2 flat cotyledons.-A nnual voL. III. or perennial herbs, very rarely woody at the base. Roots of the perennial species thickisl, intensely sweet-scented; of the annual species slender, white, and inodorous. Leaves opposite, exstipulate, different in diverse species, and in the same plant. In the latter case the lower ones are usually entirc, and the superior ones are laciniated. Flowers disposed in cymose corymbs, usually hermaphrodite, very rarely dioecious by abortion, usually furnished with from 1-3 bracteas, white, rose-coloured or bluish, but in the genus Nardóstachys they are purple, and in Patrinia yellow.

The plants contained in this order are more interesting for the sake of their symmetry and neatness than on account of any particular attractions; they may be considered a connecting link between Rubiàcece and Dipsàcece. Most of them are pretty. The Valerianellas are useful esculents, known under the name of corn salads; Ccntrántlus rùber is also eaten in the same way in Sicily. Their medicinal properties are of a decisive character. The roots of Ialericina officinalis, $P k u$, Céltica, and others are bitter, tonic, aromatic, antispasmodic, and vermifugal; they are occasionally used as febrifuges. The odour of valerian is not generally agreeable, but eastern nations procure from the nountains of Austria the roots of Valeriàna Céltica, with which they perfume their baths; and the natives of India at this day employ the Nardóstachys, the spikenard of old times, as a perfume, and against hysterics and epilepsy.

\section{Synopsis of the gencra.}

1 Patrínia. Limb of calyx slightly 5 -toothed. Corolla regular, bluntly 5 -lobed. Stamens 4 , rarely 5 . Stigma capitate, trigonal. Capsule 3-celled.

2 Nardóstachys. Limb of calyx 5-parted: lobes slightly denticulated. Corolla regular, bluntly 5 -lobed, with a bearded throat. Stamens 4. Stigma capitate. Capsule 3-celled.

3 Dufrésnia. Limb of calyx 3-parted; lobes serrated. Corolla obconical, 5-lobed. Stamens 3. Fruit membranous, indehiscent, very villous, 3-celled.

4. Valerianélea. Limb of calyx toothed. Corolla regular, 5-lobed. Stamens 3. Stigma almost undivided or trifid. Fruit 3-celled, rather membranous, indehiscent, sometimes with 2 of the cells fertile.

5 Astréphia. Limb of calyx 5-toothed. Corolla funnelshaped, 5 -lobed, gibbous on one side at the base. Stamens 3. Style trifid at the apex. Fruit 2-celled.

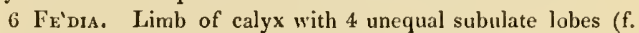
113. c.). Corolla filiform, with an unequally 5 -lobed subringent limb (f. 113. f.). Stamens 2 (f. 113. h.). Stigma bifid (f. 113.g.). Fruit spongy (f. 113.b.), indehiscent, 3-celled.

7 Plectritis. Limb of calyx entire. Corolla gibbous at the base in front from a short spur, with a 5 -lobed bilabiate limb. Stamens 3. Capsule cartilaginous, 1-celled, 2-winged.

8 Centranthus. Limb of calyx involute at the time of flowering (f. 114. b.), but afterwards evolnte and deciduous, of many-feathered bristles (f. 1I4. h.). Corolla with a narrow tube, which is spurred at the base (f. 114, c.), and a regular 5$4 \mathrm{Q}$ 
lobed limb (f. 114.d.). Stamen 1 (f. 114.e.). Fruit indehiscent, 1 -celled and 1-seeded at maturity.

9 Valeriana. Limb of calyx the same as in Contrúnthus. Corolla with an obconical or cylindrical tube (f. 1 15. 6 .), which is equal or gibbous at the base, and a bluntly 5 -cleft limb (f. 115. b.), rarely only 3 -cleft. Stamens 3 (f. 115.b.), Fruit indehiscent, 1-celled, and 1 -seeded at maturity.

10 Ве'тскеA. Limb of calyx 1-toothed, deciduous. Corolla funnel-shaped, 5-lobed. Stamens 3. Fruit 1-celled, triquetrous, naked at the apex.

11 Triploste'gia. Flower having 3 covers, viz. a double involucrum and the calyx. Limb of calyx 4-tootlied. Corolla regular funnel-shaped, 5-cleft. Stamens 3. Stigma capitate. Fruit 1-sceded, rostrate, covered by the involucra.

I. PATRI'NIA (so named by Jussieu after M. Patrin, a traveller and collector of plants in Siberia.) Juss. ann. mus. 10 . p. З11. Dufi, val. p. 53. Rom. et Schultes, syst. 3. p. 2. Link, enum. 1. p. 131. D. C. prod. 4. p. 623.-Mouffèta, Neck. elem. no. 210.-Gytonántlıus, Rafin. ann. gen. sc. pliys. 6. p. 88.-Fèdia, Adans, fam. 2. p. 152. but not of others.Fèdia species, Vahl.

Lin. syst. Tctrándria, Monogýnia. Limb of calyx truncate or erect, very short, somewhat 5 -toothed. Corolla regular, spurless, bluntly 5-lobed. Stamens 4, adnate to the bottom of the tube of the corolla, rarely 5 . Stigma trigonal-capitate. Capsule 3-celled, crowned by the limb of the calyx, usually having cliaff-formed bracteas adhering to it at the base, with one of the cells fertile, and 2 usually thick.-Perennial herbs. Leaves for the most part pinnate-lobed. Flowers corymbose, golden-yellow.

1 P. Siвı'RIcA (Juss. l. c.) stem beset with 2 rows of hairs; leaves rather fleshy : primordial ones oblong, lanceolate or spatulate, undivided and obtuse, entire, toothed, serrated, or pinnatifid towards the apex; cauline leaves pinnate, with entire, usually obtuse segments; fruit adnate to the palex. of $\mathrm{H}$. $\mathrm{N}_{2-}$ tive of Siberia, among subalpine rocks. Sims, bot. mag. t. 2325 . P. coronàta, Fisch, in litt. Valeriàna Sibírica, Lin. spec. p. 48. but not of Willd. Valeriàna Ruthénica, Willd. spec. 1. p. 181. Fèdia Sibírica, Vahl, enum. 2. p. 122. Gartn. 3. fr. t. 86. f. 3. Valerianélla lùtea, Moench. Valeriàna Sibírica $\beta$ hùmilis, Gmel. sib. 3. p. 123. no. 3.-Amm. ruth. no. 25. t. 3. Radical leaves spatulate, entire, toothed or serrated, but sometimes pinnatifid at the apex; cauline leares pinnate. Fruit crowned by the 5toothed limb of the calyx. Flowers yellow. Root black, strong scented.

Sibcrian Patrinia. Fl. May, June. Clt. 1751. Pl. 1 foot.

2 P. interue`ia (Rœm. et Schultes, syst. 3. p. 90.) stem glabrous; leaves pinnatifid, with uniform linear acute segments, those of the lower leaves deeply toothed, and those of the superior ones deeply pinnatifid; fruit adnate to the bracteas. $\delta$. H. Native of Altaia, about Zmeof on hills; and of China. Fèdia intermèdia, Horn. cat. hort. hafn. 1. p. 48. Pat. nudiúscula, Fisch. in litt. Fèdia rupéstris var. Vahl, enum. 2. p. 23. Valeriàna Sibírica, Lin. spec. 1. p. 48. Valeriàna rupéstris, Vahl. itin. 3. p. 318.-Gmel. sib. 3. p. 123. t. 24. Flowers yellow.

Intermediate Patrinia. Fl. May, July. Clt. 1820, Pl. 1 to 2 feet.

3 P. Rupéstris (Juss. l. c. Dufr. 1. c.) stem smoothish or rather downy; leaves membranous, pinnatifid, with lanceolate segments : terminal segment large; corymbs subumbellate; fruit adnate to the paleæ. $\delta$. H. Native of Siberia, Vale- riàna rupéstris, Pall. itin. 3. p. 215. Valeriàna Sibírica, Willal. spec. 1. p. 181. Sims, bot. mag. t. 714. but not of Lin. Fèdia rupéstris, Vahl, enum. 2. p. 22.-Gmel. sib. 3. p. 123. t. 24. Flowers yellow, fragrant, smaller than those of $P$. Silirica.

Rock Patrinia, Fl. May, June. Clt. 1801. Pl. 1 foot.

4 P. heterophy'lla (Bunge, in mem. acad. imp. petersb. 2. p. 109.) stem leafy, downy; lower leaves pinnatifid, with distant ovate-oblong coarsely toothed lobes: the terminal lobe the largest, sharply toothed or deeply lobed, acuminated; superior leaves quite entire or ternate, with oblong-linear elongated quite entire lobes; flowers corymbose; achenia bracteate. 4. H. Native of the north of China, on the mountains. Nearly allied to $P$. mpéstris, but differs in the lobes of the leaves being fewer, shorter, broader, and in being variously cut, and in the upper leaves being of a different form.

Tariable-leaved Patrinia. Pl. 1 foot.

5 P. scabjos Éfòlıa (Link, enum. 1. p. 131.) stem glabrous; radical leaves ovate or oblong, deeply serrated and lyrate; cauline leaves pinnatifid, with lanceolate-linear acute segments: terminal segment very long; corymbs loose, rather panicled; fruit triquetrons, naked. \&. H. Native of Dahuria. Sweet. brit. H. gard. t. 154. Lodd. bot. cab. t. 1340. P. serratulifòlia, Fiscb. in litt. Fèdia scabiosæfòlia, Trev. act. bonn, 13. p. 165. Flowers yellow. There is a variety of this plant having the radical leaves rather pilose, and the rest glabrous. Limb of calyx wanting or truncate.

Scalious-leaved Patrinia. Fl. May, July. Clt. 1817. Pl. 1 ft.

6 P. villo'sa (Juss. l. c.) stem villous ; leaves villous : radical ones petiolate, auriculate; cauline ones sessile, toothed; corymbs panicled. đ̊. H. Native of Japan. Valeriàna villòsa, Thunb. H. jap. p. 32. t. 6. but not of Wall. Fèdia villòsa, Vahl, enum. 2. p. 10. Peduncles axillary and terminal. Bracteas linear. Flowers yeilow.

lillous Patrinia. Pl, 1 foot.

7 P. ceratophýlla (Hook. fl. bor. amer. 1. p. 290.) stem glabrous; leaves all rather fleshy, downy, petiolate: radical ones linear-lanceolate, entire, pinnatifid or bipinnatifid, with divaricate lobes; cauline leaves profoundly pinnatifid, with linear segments; panicles elongated; peduncles ternately verticillate. 24. H. Native of North-west America, common on low wet soils between the Kettle Falls and Spokan; and in the valleys on the west side of the Rocky Mountains. Root thick, fusiform. Stems simple. Peduncles opposite or 3-4 in a whorl. Pedicels short, and flowers crowded. Flowers white. The roots during the spring months are collected by the Indians, baked on heated stones, and used as an article of winter and spring food. From a bitter and seemingly pernicions substance, it is thus converted into a soft and pulpy mass, which has a sweet taste, resembling that of treacle, and is apparently not unwholesome.

Horn-lcaved Patrinia. P]. 1 to $1 \frac{1}{2}$ foot.

Cult. The species of Patrinia grow well in any light soil, and are easily increased by seeds.

1I. NARDO'STACHYS (from rapros, nardos, a slirub, and бraxvc, stachys, a spike; but is so named from the plant being called spikenard). D. C. coll mem. vii. t. 1-2. prod. 4. p. 624. -Patrínia, D. Don, prod. A. nep. p. 159.

Lin. syst. Tetrándria, Monogýnia. Limb of calyx 5 -parted ; lobes ovate-oblong, acute, foliaccous, somewhat denticulated, permanent. Corolla regular, spurless, bluntly 5 -lobed, with a bearded throat. Stamens 4 , adnate to the bottom of the corolla. Stigma capitate. Capsule 3-celled, crowned by the calycine lobes, and shorter than them, but not adnate to the bracteas.Herbs, with the habit of Scorzonera hùmilis, having very sweetscented perennial roots, which are beset with erect fibres at the neck. Leaves entire, oblong; radical ones very long; cauline ones 
sessile, broadest at the base. Stems simple. Flowers disposed in fascicled corymbs. Corollas purple.

1 N. Jatamánsi (D. C. coll. mem. vii. t. 1.) stem villous; leares downy: raclical ones lanceolate-long: cauline leaves sublanceolate; fascicles of flowers opposite, pedunculate, and terminal. 4 . F. Native of Nipaul, on the Himalaya mountains and Gosaingstlan; in Mandon and Chitor provinces; in the provinces of Delli, Bengal, and Decan. Valeriàna Jatamánsi, Jones in asiat. res. 2. p. 4.05, and 4. p. 109. Roxb. in asiat. res. p. 451. D. Don, in Lamb, cinch. p. 180 . with a figure. Valeriàna spìca, Valıl, enum. 2. p. 13. Patrínia Jatamánsi, D. Don, prod. fl. nep. p. 159. Nárdus Garc. ab. hort. arom. p. 133. with a figure of the root. Närdus I'ndica. J. Baul. list. 3. p. 202. Nardostà̀chyon or Spìea Nárdi or Nárdus Gangitus or Nárdus Syriaca of the ancients, and Jatamangsi of the natives of India. It had long been a desideratum among the moderns to know to what order and genus the plant belonged, which produced the spikenard of the ancients. We are indebted to that learned orientalist, the late Sir IVilliam Jones, for having tirst pointed it out satisfactorily, although he confounded it witl another species totally distinct, and from which he has taken his botanieal description and figure. This mistake arose from his not having received perfect specimens himself; but trusting wholly to the account and drawing given him by a friend, who was entirely unversed in botany, and who therefore could not be supposed to distinguish accurately two plants of the same genus. The Jatamansi or Jatamangsi belongs to the genus Nardóstachys, and resembles in several respects the Celtic Nard, Valeriàna Céltica. The roots are simple, perpendicular, from 4 to 6 inches long, and the upper half is very thickly covered with the remains of the past leares, resembling coarse hairs, and the smell resembles those of Valeriàna officinalis. This smell, which to many would not perhaps prove grateful, has led some to doubt its being the spukenard of the ancients. Dr. Francis Hamilton, in lis account of Nipaul, lias expressed some doubts on the subject, but he says, "As there can be no disputing about taste, I cannot take upon myself to say low far the encomiums bestowed on the spikenard are applicable to this valerian, and the native women no doubt consider the smell very agreeable, beeause most of such as can afford it use oil impregnated with this root for perfuming their lair. All I can say is, that if this root is the spikenard of the Ronian ladies, their lovers must have had a very different taste from the youth of modern Europe. Notwitlistanding the objections that might be raised against the Jatamansi, on the ground that the perfume produced by its roots would not prove perliaps so grateful to our modern ladies, yet to the ladies of ancient Rome it miglut have been highly grateful, as it is to those of Nipaul at the present day. The late Sir William Jones, in two learned dissertations published in the second and fourth volumes of the Transactions of the Asiatic Society, has, indeed, so fully demonstrated by so many proofs that the Nardostachys is identical with the spikenard of the ancients, and this opinion is supported by so many concurring circumstanees, that there can, I think, be no doubt now left on the subjeet. The Iralcriana Hardnickii, witls which Sir W. Jones confounded it, has short fleshy roots, sending out numerous eylindrical fibres, the radical leaves cordate, and those of the stem pinnate and ternate. The flowers panicled, and in other respects it differ's widely."

Jatamansi or Spikenard. Pl. $\frac{1}{2}$ foot.

2 N. Grandiflòra (D. C. coll. mem. vii. t. 2.) stem quite glabrous; leaves oblong. plabrous : cauline ones ovate or cordate; heads of flowers solitary, terminal. 4 . F. Native of Nipaul, at Kamaon. Fèdia grandiflòra, Wall. mss. Bracteas 3-nerved, membranous, oval, longer than the capsule. Capsule downy ; lobes of calyx evidently denticulated.

Grat-flomered Spikenard. P1. $\frac{1}{2}$ foot.
Cult. See T'riplostègin, p. 680. for culture and propagation.

1LI. DUFRE'SNIA (named after Peter Dufresne, M.D., author of Histoire Naturelle et Medicale de La Famille des Valerianees, 4to, Montpelier, 1811.). D. C. coll. mem. vii. t. 3. prod. 4. p. 6\%4.

Lin. syst. Tetrándria, Monogýnia. Limb of calyx 3-parted: lobes ovate, acute, rather unequal, permanent, reticulated, and serrated. Corolla with an obeonicat tube, and a 5-lobed limb : lobes roundish. Stamens 3. Style unknown. Fruit membranous, indehiscent, very villous outside, crowned by the lobes of the calyx, 3-celled inside, one of the cells fertile and tlattened, and the other 2 cylindrical and sterile.-A small glabrous herb. Stem suffruticose at the base, nearly simple. Leaves opposite, oblong, obtuse, quite entire. Cymes crowded, subcapitate. Bracteas oblong, spreading, serrated. Flowers small, rose-coloured in the dry state, and probably monoecious from abortion.

1 D. orienta'lis (D. C. coll. mem. vii. t. 3.) \& ? F. Native of the Levant, between Mosul and Bagdad, where it was collected by Olivier and Bruguiere.

Oricntal Dufresnia. Pl. $\frac{1}{4}$ foot.

Cult. This plant should be grown in a pot in a mixture of peat, loam, and sand; and placed among other alpine plants; it can only be increased by seeds.

IV. VALERIANE'LLA (a dim. of Ialcriana, which see). Monch. meth. p. 486 . D. C. fl. fr. 4. p. 240. coll. mem. vii. $t$. 3. Dufr. val. p. 56. Link, enum. 1. p. 63. Betck. anim. 4to, Rost. 1826 . D. C. prod. 4. p. 625.-Valerianélla species, Tourn -Valeriàna lociista, Lin.-Fèdia species, Gartn. Vahl. Ster. Bieb. Rehb. but not of Adans. nor Mœench.-Poliprèmum, Adans. fam. 2. p. 15\%. but not of Lin.-Odontocárpa, Neck. elem. 1. p. 123 .

L1n. syst. 'Triándria, Monogýnia. Limb of ealyx toothed, permanent. Corolla spurless, regular, 5-lobed. Stamens 3. Stigma nearly undivided or trifid. Fruit 3-celled, rather membranous, indehiscent, crowned by the toothed or acerete limb of the calyx.-Anmual herbs. Stems dichotomous at the tops. Leaves oblong or linear, undivided, or toothed at the base, or the superior ones are pinnatifid. Flowers solitary in the forks, or in faseicled corymbs, bracteate, small, white, rarely rosecoloured.

\$1. Locústa (from locusta, a locust; so named from some semblance in the branches). D. C. prod. 4. p. 624. Mature fruit 2 or 3-celled; onc of the cells alone fertile, and gibbous on the back; the tn'o sterile ones equal or broader than the firtile one, sometimes distinet, and sometimes coadunate, from the dissepincnt having vanished.

\section{* Mature fruit 2-cclled.}

1 V. ourto'rin (Mœnch, meth. p. 493.) fruit globose, compressed, inflated, glabrous, oblique, 2-lobed; limb of calyx almost wanting, or with $1-3$ very short teeth; fruit having the 2 sterile cells combined, from the dissepiment being incomplete; flowers subeapitate; bracteas spreading, oblong-linear, ciliately-serrated; leaves linear-tongue-shaped, almost entire, blunt; angles of stem scabrous. $\odot$. H. Native of Europe in corn-fields and light cultivated grounds ; plentiful in Britain and is cultivated in gardens as a salad. D. C. fl. fr. no. 3330. coll. mem. t. 3. f. ‥ Dufr. val. 56. t. 3. f. 8. Valeriàna locústa, Willd. spec. 1. p. 182. Fèdia olitoria, Vahl, enum. 2. p. 19. but not of Gartn, Fèdia locústa, Rchb. pl. cr. 1. t. 60. Fèdia striàta, Stev. mem. mose. 2. p. 173. Valeriàna olitòria, Willd. spec. 1. p. 182. Lacrùca agnìna, Ger. emac. t. 310 . f. 1-2.- Riv. irr. 1. 6. Valeriàna locústa, Lin. spec. p. 47. a. Snith, eng. bot. 12. t. 811 . Curt. lond. fasc. 5. t. 4. Mart. 4,2 
rust. t. 24. Flowers pale blue. There is a variety of this species having the upper leaves toothed or jagged according to Vahl. Lamb's lettuce is also called corn-salad; Ackersalat in German, and Valerianella in Italian. It is a diminutive annual plant, common in corn-fields or sandy soils. The leaves are of a pale glaucous hue, and rather succulent. When cultivated it rises almost a foot high, and flowers in March. Gerarde tells us that foreigners using it while in England led to its being cultivated in our gardens. It is used in salads through the winter and early in spring, both as a substitute for common lettuce in those seasons, and to increase the variety of small salads. For these purposes it has long been a favourite plant in France under the denominations of mache, douccttc, salade de chanoine, and poulc grass. It is raised from seed, of which a quarter of an ounce is sufficient for a bed 4 fect by 5 . To answer the common demand 2 or at most 3 sowings will be sufficient, viz. a principal sowing at the beginning or towards the middle of August, a secondary sowing early in September, to furnish together crops in winter and early spring; and a smaller sowing in spring, at the close of February or in the course of Narch, if the plants are required in continuation throughout that season, thongh they are apt to get rank tasted in warm dry weather. If wanted throughout summer, sow once a month, and cut the crop quite young. Sow the seeds in any bed of common mellow earth, broad cast, and rake in the seed. When the plants are up, thin them to 2 or 3 inches asunder, that they may have room to acquire some small stocky growtl for gathering. For seed leave some plants in spring.

lar. $\beta$, lasiocárpa (Rchb. I. c. f. E.) fruit downy.

Salad Lamb's-lettuce. Fl. April, May. Britain. Pl. $\frac{1}{4}$ to $1 \mathrm{ft}$. 2 V. RADIA'TA (Dnfr. val. p. 57.) fruit oblong, rather tetragonal, glabrous, smooth; limb of calyx obliquely truncate, almost wanting; sterile cells of fruit combined in one, from the dissepiment being incomplete, equal in size to the fertile one; bracteas linear-oblong, spreading, ciliated a little; leaves ob-

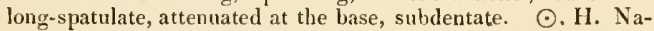
tive from Pennsylvania to Carolina, in corn-fields. Valeriàna radiàta, Willd. spec. 1. p. 185 . Fèdia radiàta, Michx. fl. bor. amer. 1. p. 18. Bart. comp. 1. p. 20. Fruit downy, according to Michx. but in the specimen it is obviously glabrous. Flowers pink. Perhaps only a variety of $V$. olitoria. The young leaves are used as a salad.

Rayed Lamb's-lettuce. F]. April, May. Clt. 1821. Pl. $\frac{1}{2}$ to 1 foot.

3 V.? exscA'PA (Stev. mem. soc. mosc. 3. p. 251.) fruit 2. celled, one of which is sterile, obovate, ribbed, glabrous, sessile at the neck, and protruded at the apex, and 5-6-toothed: teeth oblong, straight, thick: leaves ligulate, glabrous; stem none. $\odot$. H. Native of Cancasus, near Gandsha. Fèdia exscàpa, Stev. mem. mosc. 5. p. 354. Roem. et Schultes, syst. 1. p. 366. Fèdia acuúlis, Bieb. suppl. p. 35. Flowers pink. The fruit is said to be 2-celled, with both the cells fertile, but it is probably like the other species, having only one of the cells fertile, and the 2 sterile combined ones.

Sca cless Lamb's-lettuce. Fl. May, June. Clt. 1826. PJ. $\frac{1}{4}$ to $\frac{1}{2}$ foot.

\section{* Mature fruit 3-celled.}

4. V. TU'RGIDA (D. C. prod. 4. p. 626.) fruit nearly globose, compressed on one side and concave-convex, almost awnless, glabrous; fertile cell turgid, convex and cellular on the back, and the 2 sterile cells about equal in size to the fertile one; bracteas oblong, spreading, ciliated; flowers subcapitate; leaves obovate: upper ones oblong-linear, guite entire. $\odot$.H. Native of Tauria, in corn-fields. Fèdia túrgida, Stev. mem, mosc. 2 , p. 178. but not of others. A very distinct species.
Turgid Lamb's-lettuce. Pl. $\frac{1}{2}$ to 1 foot.

5 V. gıввòsa (D. C. coll. mem. t. 3. f. 3.) fruit globose, somew hat compressed, glabrons, crownless, coarctate and flat on one side, and gibbous on the other, and furnished with 2 stripes on both sides ; fertile cell turgid, cellular, and furnished with a furrow; and the 2 sterile ones smaller, and furrowed on the back; bracteas linear-oblong, spreading, quite entire; flowers subcapitate; leaves oblong-linear, entire. $\odot$. H. Native of Sicily, on the mountains in exposed places. Fèdia gibbòsa, Guss. 1. p. 28. Herb smoothish, 2-3 inches high. Nearly allied to $Y$. lúrgida.

Gibbous-fruited Lamb's-lettuce. Pl, $\frac{1}{4}$ foot.

6 V. $\operatorname{costa'TA~(D.~C.~prod.~4.~p.~626.)~fruit~roundish,~a~little~}$ compressed, glabrous, not crowned; fertile cell turgidly cellular and convex on the back, and the two sterile ones profoundly furrowed on the back; bracteas oblong, spreading, with glabrous edges; flowers subcapitate; leaves linear-oblong, quite entire. $\odot$. H. Native of the south of Tauria, in vineyards. Fèdia costàta, Stev. mem mosc. 5. p. 344. Bieb. suppl. p. 28. Herb 1-2 inches long, simple, slender, smoothish. Fruit nearly allied to $V$. lúrgida and $V$. gibbusa, but much smaller.

Ribbed-fruited Lamb's-lettuce. Pl. 1 to 2 inches.

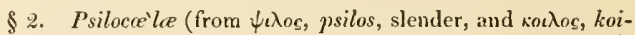
los, a hollow; in reference to the narrow sterile cells of the fruit). D. C. prod. 4. p. 626. Fruit 3-celled, flatlish in front; fertile cell not cellularly turgid on the back; and the 2 sterile ones filiform, and much narrower than the fertile one, usually close and nerve-formed.

\section{* Limb of calyx parted into recurved stiffish tceth.}

7 V. uncina'ta (Dufr. val. p. 60.) fruit oblong, pyramidal, rather downy while young, glabrous in the adult state; sterile cells 2 , very narrow; limb of calyx tubular, 7-9-toothed; teeth acute, stiff, recurved; bracteas lincar, spreading, glabrous ; cau-

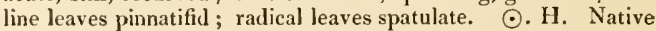
of Tauria and Eastern Cancasus, in dry places of mountains; and at the Bosphorus. D'Urv. enum. no. 30. D. C. coll. mem. t. 3. f. 4. Fèdia uncinàta, Stev. mem. mosc. 5. p. 352. Bieb. A. taur. 1. p. 26. Rchb. pl. crit. t. 69 . Valeriàna pubéscens, Hopp. bot. zeit. 1825. p. 359. ex Schultes, Flowers lilac.

Hookcl-calyxed Lamb's-lettuce. Fl. May, June. Clt. 1822. PI. $\frac{1}{2}$ to $I$ foot.

8 V. есніла'та (D. C. f. fr. 4. p. 242.) fruit oblong, somewhat tetragonal, trisulcate, glabrous; sterile cells of fruit very narrow; calyx with 3 conically subulate, stiff and recurved teeth; bracteas oblong, obtuse, glabrous, spreading; leaves entire or toothed, and are as well as the stem glabrous. $\odot . H$. Native in the region of the Mediterranean, from Madrid to Tauria, in corn-fields. Dufr. val. 61. t. 30. f. 10. Fèdia echiıàta, Vahl, enum. 2. p. 19. Stev, et Bieb. l. c. Rchb. pl. crit. p. 68. Valeriàna echinàta, Lin. spec. p. 47.-C. Bauh. pin. p. 165. Garid. aix. t. 94. Col. ecplır. t. 206.-Horis, ox. sect. 7. t. 16. f. 28 . Flowers pink.

Echinated-fruited Lamb's-lettuce. Fl. July, Aug. Clt. 1807. Pl. 1 foot.

9 V. connicula'ta (Meyer. verz. pfl. p. 49.) fruit oblong, with the 2 sterile cells filiform, and the fertile one convex on the back; crown of fruit tubular, tridentate : teeth elongated, linear, nsually denticulated, straight or hooked at the apex. $\odot$. H. Native of Caucasus, in corn-fields near Baku. Habit of plant nearer to $V$. uncinata than to $V$. echinita.

Horned-fruited Lamb's-lettuce. Pl. $\frac{1}{2}$ to 1 foot.

* Limb of ealyx crect, toothed or entire, never recurved.

$10 \mathrm{~V}$. ERIOCÁRPA (Desv. journ. bot. 2. p. 314. t. 11. f. 2.) fruit ovate, obsoletely ribbed, hispid; the 2 sterile cells of fruit 
very narrow; limb of calyx obliquely truncate, campanulate, 6 -toothed: teeth erect, the 3 front ones the shortest; bracteas adpressed, linear; leaves oblong-linear, quite entire, or toothed at the base. $\odot$. H. Native of Europe, in corn-fields, from Andegaveny and Spain to Tauria. Lois. not. p. 49. t. 3. f. 2. Dufr. val. p. 59. t. 3. no. 4. D. C. coll. mem. t. 3. f. 5. Fèdia eriocárpa and Fèdia muricàta, Roem. et Scliultes. Fèlia campanulàta, Presl. sic. p. 11. V. campanulàta, Bir. man. 4. p. 18. Fèdia eriocárpa, Relib. pl. crit. 1. t. 65. Guss. prod. 1. p. 26. Fèdia rugulòsa, Stev, in litt. Mor. oxon. sect. 7. t. 16. f. 33. Flowers lilac. There is a variety of this, having the fruit pilose on the ribs, and glabrous at the base. Bracteas quite cntire or serrated. Sterile cells of capsule very narrow.

I ar. $\beta$, rugulosa (D. C. prod. 4. p. 627.) bracteas ovate-lanceolate; habit firmer. $\odot$. H. Native along with the species. Fèdia rugulòsa, Spreng. pug. 2. p. 2.

Woolly-fruitcd Lamb's-lettuce. Fl. April, May. Clt. 1821. Pl. $\frac{1}{2}$ to 1 foot.

11 V. míxтa (Dufr. val. p. 59. t. 3. no. 6.) fruit ovate, villous, having the 2 sterile cells very narrow; limb of calyx oblique, with 3 short teeth; bracteas linear, adpressed; leaves oblong, quite entire. $\odot$. H. Native of France, Italy, Tauria, in corn-fields. Fèdia mixta, Vahl, enum. 2. p. 21. V. microcárpa, Lois. not. p. 151 . Fèdia minùta, Spreng. syst. 1. p. 144.? Flowers pink. Sauvages's plant, cited by Vahl, belongs to Centránthus Calcitràpa. Perhaps sufficiently distinct from $V$. eriocárpa.

Mixed Lamb's-lettuce. Fl. May, June. Clt. 1818. Pl. $\frac{1}{2}$ to 1 foot.

12 V. Monisònu (D. C. prod, 4, p. 627. Rehb. icon. bot. cent. 1. t. 63.) fruit ovate, rather conical, downy; limb of calyx oblique, tridentate on one side, and furnished with 1-2 nearly obsolete teeth on the other; the 2 sterile cells of fruit filiform, much narrower than the fertile one; bracteas subulate, erect, cartilaginously ciliated ; flowers corymbose; leaves lineartongue-shaped, quite entire or few-toothed at the base. $\odot . \mathbf{H}$. Native of Europe and Tauria, in corn-fields ; and of Caucasus, on the Talusch mountains, near Perimbal ; fotind in corn-fields in Cornwall, Essex, and on Harlton Hill, Cambridgeshire ; and in Scotland, about Edinburgh. Fèrlia dasycárpa, Stev. mem. soc. mosc. 5. p. 348. Fèdia Morisònii, Spreng. pug 5. p. 6. Fèdia dentàta, Bieb. fl. taur. no. 70. Valeriàna dentàta, Sow. engl. bot. t. 1370. Fèdia dentàta eriospérma, Wallr. sched. Fèdia dentàta dasycárpa, Rchb. pl. crit. no. 127. t. 63. -Mor. oxon. t. 16. f. 35. Fèdia locústa olitòria, Oed. fl. dan. t. 738. Flowers purple.

Var. $\beta$, leiocárpa (D. C. proul. 4. p. 627.) fruit glabrous. $\odot$. H. Native along with the species, F. dentàta, Stev. F. Morisònii, Agardh. Fèdia dentàta, var. leiocárpa, Rchb. pl. crit. t. 62. There are varieties of this, having the leaves 3 in a whorl, and pinnatifid.

Morison's Lamb's-lettuce. Fl. April, June. Britain. Pl. $1 \mathrm{ft}$.

13 V. PUBE' RULA (D. C. prod. 4. p. 627.) fruit ovate, downy, hardish, rather angular, not umbilicated ; limb of calyx very short, oblique, 3-5-toothed; the 2 sterile cells of the fruit filiform, and very narrow; bracteas linear, erect, ciliately denticulated, with membranous margins ; flowers corymbose ; leaves linear-oblong, quite entire, or hardly unidentate at the base. $\odot$.H. Native of Sicily and Calabria, in corn-fields. Fèdia pubérula, Bertol. in Guss. pl. rar. p. 14. prod. 1. p. 27. Fèdia microcárpa, Rchb. pl. crit. 2. t. $11 \mathrm{t}$.

Donny Lamb's-lettuce. Pl. $\frac{1}{2}$ foot.

14. V. TRUNCA'TA (D. C. prod. 4. p. 627.) fruit ovoid, downy, convex on the back, and bicostate in front; the 2 sterile cells of fruit filiform, much narrower than the fertile one ; limb of calyx ear-formed, obliquely truncate, quite entire, equal in length to the fruit ; bracteas linear, dilated and concave at the base, ciliately serrated; flowers cymose; leaves oblong, quite entire. $\odot$. H. Native of Candia, at Canea or Cydonia, in corn-fields ; also of the Island of Melos, and in Cazar and T'heodosia. Fèdia truncàta, Rchb. pl. crit. t. 115. Fèdia denıàta, Sieb. ex Rchb. V. aurícula, D'Urv, enum. 5, but not of D. C.

Truncate-calyxed Lamb's-lettuce. PI, $\frac{1}{2}$ foot.

\$ 3. Platyce'lae (from $\pi \lambda \alpha \tau v_{\varsigma}$, platus, broad, and nou $\lambda_{o c}$, koilos, a hollow; in reference to the broad, hollow, sterile cells of the fruit). D. C. prod. 4. p. 627. Fruit 3-cclled, furrowed in front; fertilc ccll not cellularly gibbosc on the back, and the tro sterile cells broader than the diameter of the fertile one, or nearly equal to it; the transverse section nearly orbicular.

* Limb of calyx entire or toothed, erect; tceth not hooked at the apcx.

15 V. aurícula (D. C. fi. fi. suppl, p. 492. coll. mem. t. 3. f. 6.) fruit ovate, glabrous ; limb of calyx obliquely truncate, ahmost quite entire, acutely auricle-formed; the 2 sterile cells of the fruit broader than the fertile one; bracteas spreading, linear, glabrous; flowers disposed in dichotomous corymbs, rather loose; leaves oblong, quite entire, or toothed at the base. $\odot$. IH. Native of Europe, in fields, especially in the south. Fèdia auriculàta, Gaud. fl. helv. 1. p. 84. t. 4. Relıb. pl. crit. t. 68. Fèdia olitòria, Gartn. fr. 2. p. 86. Flowers pink. This species is often confused with $V$. dentàta, and numerous others. There is a variety of it with pinnatificl leaves and villous fruit, according to Rchb.

Var. $\beta$, laxiflòra (D. C. prod. 4. p. 626.) dwarf; leaves obovate-oblong. $\odot$. H. V. laxiflòra, Dufr. val, p. 58, t. 3. Fèdia laxiflòra, Roem. et Schultes, syst. 1. p. 360 . Flowers pink.

Auricled-calyxed Lamb's-lettuce. Fl. May, June. Clt. 182 t. Pl. $\frac{1}{2}$ foot.

16 V. DENTA'TA (D. C. A. fr. no. 3331.) fruit ovate, glabrous, smoothish, chinky in front; limb of calyx obliquely truncate, auricle-formed, tridentate; the 2 sterile cells of the fruit broader than the fertile one; bracteas spreading, linear-lanceolate, glabrous, hardly ciliated; flowers dichotomously corymbose, rather loose; leaves oblong-linear, quite entire. $\odot$. H. Native of Europe, in woods; and of Caucasus, near Baku, in corn-fields. Dufr. val, p. 57. t. 3. no. 5. Fèdia dentàta, Vahl, enum. 2. p. 20. exclusive of the syn. of Moris. Valeriàna dentàta, Willd. spec. 1. p. 183.? V. rimòsa, Bast, journ. bot. 1814. 1. p. 20. Val. olitòria, Sturm, deutsch. fl. with a figure. Flowers blue. This is an intermediate plant between $V$. auricula and $V$. pumilu, and probably not distinct from the former.

Toothed-calyxed Lamb's-lettuce. Pl. $\frac{1}{2}$ foot.

17 V. pu'sila (D. C. fl. fr. no. 3335.) fruit nearly globose, inflated, glabrous, engraven in front, retuse at the apex; limb of calyx tridentate, short, unequal; the 2 sterile cells of the fruit broader than the fertile one; bracteas spreading, lanceolate, with membranous villously-ciliated margins; flowers corymbose ; leaves oblong-linear, deeply toothed at the base. $\odot$. H. Native of the south of Europe and Tauria, in cultivater sandy fields; and of Caucasus, near Baku, in fields and on hills. Valeriàna pùmila, Willd. spec. 1. p. 18\%. Fèdia pùmila, Vahl, enum. 2. p. 21. Rchb. pl. crit. 2. t. 113 . V. membranàcea, Lois. not. p. 180. V. tridentàta, Link. enum. 1. p. 63. Fèdia tridentàta, Stev. mem. soc. mosc. 2. p. 173. Bieb. fl. taur. suppl. p. 29. Rchb. pl. crit. 1. t. 64. Flowers pink. There is a variety of this, having the leaves somewhat pinnatifid.

Var. $\beta$, lasiocárpa (Rœm. et Schultes, syst. 5. p. 366.) fruit villous. $\odot$. H. Native of 'Tauria and Caucasus. Fèdia lasiocárpa, Stev. mem. soc. mosc. 5. p. 59. 
Dwarf Lamb's-lettuce. Fl. A pril, May. Clt. 1826. Pl. $\frac{1}{4}$ to 1 foot.

18 V. SPherocárpa (D. C. prod. 4. p. 628.) fruit globose, umbilicate on one side, and convex and bicostate on the other; limb of calyx tridentate, one of the teeth longer than the others; bracteas spreading, lanceolate, acute, with scarious serrately ciliated edges ; leaves linear-lanceolate, rather scabrous : uppermost ones pinnatifid at the base; stem smooth. $\odot$. H. Native of Sicily, in pastures on the mountains. Fè lia splıærocárpa, Guss. prod. 1. p. 28. pl. rar. p. 14.t. 4. f. 1.

Round-fruited Lamb's-lettuce. Pl. $\frac{1}{2}$ foot.

19 V. сумвосл'rpa (Meyer. verz, pf. p. 49.) fruit nearly linear, with the 2 sterile cells curved, and the fertile cell rounded on the back, and nearly equal; crown of fruit campanulate, 3 and sometimes 4-toothed: the lateral tooth elongated, linear, and straight, the rest usually obsolete. $\odot$. H. Native of Caucasus, near Swant, in arid places.

Boat-fiuited Lamb's-lettuce. Pl. $\frac{1}{2}$ foot.

20 V. Trigonocá́rpa (D. C. prod. 4. p. 628.) fruit trigonal, glabrous, broadly excavated in front, almost without a crown, with callous angles: the 2 sterile cells of the fruit larger than the fertile one; bracteas oblong-linear, glabrous, spreading; flowers capitate: leaves quite entire: lower ones ovate-oblong, upper ones oblong, ciliated at the base. $\odot$. H. Native about Constantinople, where it was collected by Castagne.

Trigonal-fruited Lamb's-lettuce. PI. $\frac{1}{2}$ foot.

* Teeth of calycine limb hooked at the upex.

2] V. "АмА'тА (Bast, in D. C. prod. 4.p. 6:8.) fruit ovoid, villons outside, somewhat tetragonal, engraven in front: the 2 sterile cells about equal in breadth to the fertile one; limb of calyx spreading, broader than the fiuit, quite glabrous inside, and cleft into 6 lobes beyond the middle; lobes awned, hooked at the apex; bracteas adpressed, oblong, ciliated ; flowers rather densely capitate; upper leaves linear, entire or tripartite, and are as well as the stem glabrous. $\odot$. H. Native in the region of the Mediterranean. D. C. coll. mem. t. 3. f. $7 . \mathrm{V}$. coronàta, Guss. prod. 1. p. 25. V. coronàta integrifòlia, Rclıb. pl. crit. 1. p. 54. t. 66. f. 1.-Col. ecphr. t. 209. Fèdia coronàta of many authors. Flowers pink.

Hooked Lamb's-lettuce. Fl. May, June. Clt. ? Pl. $\frac{1}{2}$ foot.

22 V. corona'ta (D. C. prod. 4. p. 628.) fruit ovoid, villous, somewhat tetragonal, engraven in front: the? sterile cells about equal in breadth to the fertile one; limb of calyx cup-shaped, broader than the fruit, hairy inside, cleft into 6 lobes beyond the middle: lobes awned, hooked at the apex; bracteas adpressed, ciliated; flowers densely capitate; superior leaves pinnatifid, and are as well as the stem downy. $\odot . H$. Native of the region of the Mediterranean. V. coronata, D. C. f. fr. no. 3333. Dufi. val. 60. t. 3. f. 2. Fèdia Sícula, Guss. prod. 1. p. 25. Fèdia coronàta, Rehb. pl. crit. t. 66. f. $\beta$ et $\gamma$. Vahl, enum. 2. p. 20. Flowers pink.

I ar. $\beta$, discódea (D. C. prod. 4. p. 628.) limb of calyx irregularly 7-12-lobed, $\odot$.H. Native of the region of the Mediterranean. V. discoídea, var. Dufr. val. p. 59. t. 3. f. 3. D C. fl. fr. 5. p. 493. Fèdia discoídea, Vahl, enum. 2. p. 21. Rchb. p]. crit. t. 116 .

Cronned Lamb's -lettuce. Fl. A pril, June. Clt. 1731. Pl. $\frac{1}{2} \mathrm{ft}$. ** Limb of ealyx infated, closed by the inflexed calycine teeth.

$23 \mathrm{~V}$. vesica'ria (Monch. meth. p. 497.) fruit villous, crowned; limb of calyx bladdery, inflated, 6-toothed; teeth conniving, acute; the 2 sterile cells of fruit a little smaller than the fertile one, or nearly equal in size to it; bracteas adpressed, ovate, ciliated, shorter than the fruit; leaves entire or toothed; stem rather villous. $\odot . H$. Native in the region of the Mediterra- nean, in corn-fields. D. C. fl. fr. 4 . no. 3332 , coll. mem. t. 3. f. 8. Dufr. val. p. 60.t. 3. f. 9. Fèdia vesicària, Vahl, enum. 2. p. 20. Rchb. pl. crit. 1. t. 70 . Valeriàna vesicària, Willd. $\mathrm{Val}$. locústa, $\beta$, vesicària, Lin. Sibtlı. et Smith, fl. grac. t. 34. Flowers lilac.

Bladdery-caly xed Lamb's-lettuce. Fl. Apri\}, June. Clt. 1739. P] $\frac{1}{4}$ to $\frac{1}{2}$ foot.

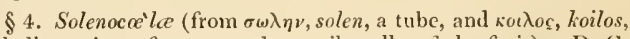
a hollow; in reference to the sterile cells of the fruit). D. C prod. 4. p. 629. Fruit 3-celled, broadly furroned in front; the fertile cell not ecllularly gibbosc on the back, and the 2 sterile cells broader than the fertile one, and curved, and thorefore the transterse section is lunulate.

\section{* Lobes of calyx hoohed a little.}

24 V. platýl Loba (Dufr. val. 59. t. 3. f. 1.) fruit ovoid, villous outside, rather tetragonal, broadly furrowed in fiont, boatshaped; limb of calyx spreading, broader than the finit, rather hairy inside, 6-lobed to the middle; lobes ovate, each furnished with a hooked mucrone; bracteas adpressed, ciliated, oblong : flowers sub-capitate; upper leaves toothed, and are as well as the stem glabrous. $\odot . H . ~ N a t i v e$ in the region of the Mediterranean. D. C. coll. mem. 3. f. 9. Fèdia discoíllea, Rchb. pl. crit. 1. p. 54. t. 67 . Fèdia rotàta, Relıb. 1.c. p. 93. Flowers pink.

Broad-lobed Lamb's-lettuce. Fl. May, June. Clt. 1825. Pl. $\frac{1}{2}$ foot.

\section{* Limb of calyx erect.}

25 V. carina'ta (Lois, not. p. 149.) fruit oblong, longitudinally boat-shaped, or chinky on one side, and carinated; the $\approx$ sterile cells compressed, curved, about equal in size to the fertile cell; fruit crowned, by the unidentate erect limb of the calyx; flowers sub-capitate; bracteas oblong, spreading, serrately ciliated; leaves oblong, almost obovate, quite entire. $\odot$. H. Native of France, Germany, Tauria, Sicily, \&ic, in corn-fields. Dufr. val. p. 56. t. 2. D. C. fl. fr. suppl. 492. coll. mem. t. 3. f. 10. Fèdia carinàta, Stev, mem. soc. mosc. 5. p. 346. Rocm. et Schultes, syst. 1. p. 361. Rehb. pl. crit. t. 61. -Moris. oxon, sect. 7. t. 16. f. 31 . Habit of $I$. olitoria. Stem smooth, dichotomons. Flowers blue.

Kecled-fruited Lamb's-lettuce. Fl. April, June. Clt. 1819. Pl. $\frac{1}{4}$ to $\frac{1}{2}$ foot.

\section{+ Species not sufficiently knom.}

$26 \mathrm{~V}$. chenopodifòlia (D. C. prod. 4. p. 629.) plant dichotomous ; leaves ovate, acute, toothed below; cymes naked, divaricate, dichotomous; filaments long. $\odot$. H. Native of Virginia. Fèdia chenopodifolia, Pursh, fl, amer. sept. 2. p. 727.

Goose-foot-leaved Lamb's-lettuce. Pl.

Cult. The sceds of all the species only require to be sown in the open ground in the early part of spring. Alt the species answer rery well for spring salad.

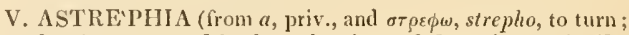
the calyx is not turned back at the time of flowering, as in $\mathrm{I}_{\mathrm{K}} \mathrm{a}$. lcriàna). Dufr. val. p. 50. exclusive of many species. D. C. coll. mem. vii. prod. 4. p. 629.-Hemesòtria, Rafin. ann. gen. sc. phys. 6. p. 88.- Valeriàna species, Ruiz et Pav. Smith.Fèdia species, Kunth.

Lin, SYst. Triandria, Monogynia. Tube of calyx very short, somewhat 5 -toothed or subcampanulate. Corolla funnel-shaped, 5 -lobed, gibbous on one side at the base, and therefore furnished with a kind of spur. Stamens 3. Style 3-cleft at the apex; stigmas slender. Fruit 2-celled, one of the cells alone fertile; and the other is sterile, and marked by a furrow in the midule, and is therefore probably formed of 2 cells, having the partition between 
them obliterated.-Nearly glabrous herbs. Radical leaves rhomboid, cut; cauline ones inıpari-pinnate, with oval-oblong, deeply toothed segments. Flowers disposed in panicles or corymbs, white. - Habit of Valeriàna, and the fruit almost of $V^{\prime} a$ lerianella, but is easily distinguished from both these genera in the corolla being gibbosely spurred on one side at the base, and in the style being 3 -cleft.

1 A. cinerophy Loines (D. C. prod. 4. p. 629.) stem rather hairy at the nodi; leaves glabrous: radical ones entire: cauline ones pinnate, with sharply jagged segments ; corymbs fewflowered; corolla with a short spur; limb of calyx very short, 5-toothed. $\odot$. H. Native of Peru, in forests on the hills at Lima and Chancay. Val. charophylloìdes, Smitl, icon. ined. 3. t. 53. Valeriàna laciniàta, Ruiz et Pav. A. per. 1. p. 49. t. 69. f. a. Val. chærophýlla, Pers. ench. 1. p. 37. Astr. laciniàta, Dufr. l. c. Fèdia chærophylloìles, Kunth, nov, gen. amer. 3. p. 334. Boerhaàvia chærophylloìdes, Willd. spec. 1. p. 22. Herb hardly a hand high. Flowers white.

Chervil-like Astrephia. Pl. $\frac{1}{4}$ to $\frac{1}{2}$ foot.

2 A. crispa (Dufr. val. p. 51.) stem glabrous, as also at the nodi; panicle elongated, with dichotomous branches, floriferous in the axils of the forks; corolla gibbose at the base; limb of calyx sub-campanulate, almost entire. $\quad 4$. H. Native of Chili, among bushes, and in meadows and corn-fields. Valeriàna críspa, Ruiz et Pav. 1. p. 41. Herb 2 feet high. Flowers white.

Curled Astrephia. Pl. 2 feet.

3 A. LA'XA (Hook. et Arn. in bot. misc. 3. p. 364.) plant herbaceous, glabronts; radical leaves ovate-cordate, bluntly toothed; cauline leaves lyrately pinnatifid, terminal lobe the largest; panicle loose, divaricate; ultimate pedicels short, crowded; fruit ovate, excavated on one side, 3-ribled on the back, and crowned by an annular ring. - Native of Chili, about Conception. Fèdia láxa, Hook. et Arn. in Beech. voy. pt. bot. p. 28. This species approaches near to Fèdia paniculàla, but that plant is ptibescent, and las a pappose fruit.

Loose-flowered Astreplia. Pl. 1 foot.

4 A. Loba'ta (Hook. et Arn. in bot. misc. 3. p. 364.) leaves pinnate-lobed; lobes distant, coarsely toothed: terminal lobe broadly ovate, lateral ones oblong, much smaller; lower teetlı looking downwards, upper ones upwards ; rachis glabrous ; corymbs pedunculate, opposite, distant, disposed in a panicle; fruit glabrous.- Native of Chili.

Var, $a$; stem beset with long hairs. The stem below the last pair of opposite cauline leaves is hairy, above them it is glabrous.

$V$ ar. $\beta$; stem glabrous. - Native of Chili, about Valparaiso.

Lobed-leaved Astrephia. Pl.

Cull. A. charophylloides should be treated like other tender annuals; the rest should be protected in winter by placing them in a frame or green-house. All are only to be increased by seeds.

VI. FE'DIA (derived from fedus, an ancient word, synonymous with hoedus, a kid). Mœnch. meth. p. 486 . D. C. A. fr. 4. p. 239. Juss. ann. mus. 10. p. 311 . Dufr. val. p. 54. D. C. prod. 4. p. 630. but not of Adanson.-Fedia species, Gærtn. et Vahl. -Polyprèmuin species, Adans.-Mitróphora, Neck. elem. 1. p. 123.

Lin. syst. Diándria, Monogýnia. Limb of calyx short and straight ; lobes 4 , subulate, unequal (f. 113. c.). Corolla with a filiform spurred tube (f. 113. a.), and an unequally 5 -lobed subringent limb (f. $113 . f$.). Stamens 2 (f. 113. h.). Stigma bifid (f. 113. g.). Fruit indehiscent (f. 113. b.), rather spongy, 3-celled; the 2 sterile cells narrow, and the fertile one broader and 1-seeded.-Glabrous annual herbs. Leaves entire or toothed. Flowers capitately corymbose or cymose, rose-coloured or purple. Bracteas adpressed.
1 F. Cornucòras (D. C. fl. fr. 4 , p. 240.) leaves ovateoblong, toothed: lower ones petiolate: upper ones sessile; flowers corymbose, in fascicles; peduncles thickened, fistular. ○. H. Native of the south of Europe, Levant, north of A frica, Islands in the Mediterranean \&c. in corn-fields and waste places. Gartn. fruct. 2, p. 36. Valeriàna cornucòpiæ, Lin.spec. 44. Sibth. et Smith, fl. græc. t. 32. Val. Jocústa, Ucria, hort. pan. p. 46. ex Guss. prod. 1. p. 24.-Sab. hort. rom. 2. t. 17-19. -Mor, oxon. sect. 7. t. 16. f. 27.-Riv. mon. t. 5. Stem purplish. Flowers red. This is a very ornamental anoual. The fruit is like a cornucòpia.

Cornucopia-fruited Fedia. Fl. June, July. Clt. 1796. Pl, $\frac{1}{2}$ foot, straggling.

2 F. scorpioides (Duf. val. p. 55. t. 1.) leaves ovate, petiolate; lower ones quite entire: middle ones irregularly toothed: upper ones ovate-lanceolate, hardly pinnatifid; flowers cymose, unilateral and sessile along the two branches of the cyme. $\odot$. H. Native of the north of Africa, about Tangiers. Flowers purple.

Scorpion-like-cymed Fedia. Pl. $\frac{1}{2}$ foot.

\section{$\uparrow$ Species not sufficiently knonn.}

3 F. panicula'ta (Colla, app. 3. p. 36.) lower leaves spatulate, nearly entire: middle ones lanceolate, obsoletcly toothed: ujper ones linear-lanceolate, quite entire; stems erect, glabrous; panicles dichotomous. $\odot$. H. Native country unknown. Perhaps a species of I'alerianélla.

Panicled Fedia. Pl. 1 foot.

Cult. The seeds of the species of Fèdia only require to be sown in the open border in spring, like other hardy annuals. A light soil suits them best.

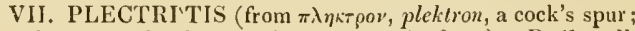
in reference to the flower being gibbous in front). D. C. coll. mem. vii. prod. 4. p. 631.-Valerianélla sect. Plectrìtis, Lindl. bot. reg. no. 1095 .

Lın. syst. Triándria, Monogýnia. Margin of calyx straigltt, quite entire. Tube of corolla furnished with a short spur at the base, and gibbous in front ; limb 5-cleft, bilabiate. Stamens 3. Capsule cartilaginous, 1-celled, 2-winged; but the capsule may be truly said to be 3-celled, the 2 empty or abortive cells forming the wings.-A glabrous herb, with a habit between Centránthus and Fèdia, but the flowers are triandrous, and the fruit is singularly distinct. Flowers monoecious, rose-coloured, crowded, in whorles. Bracteas multifid, with subulate segments.

1 P. conge'sta (D. C. prod. 4. p. 631.) ๑. H. Native of the north-west coast of America, on the banks of streams and moist rocks, along the shore near the mouth of the Columbia, where it was collected by Douglas. Valerianélla congésta, Lindl. bot. reg. t. 1095.

Íar. $\beta$, minor (Hook. fl. bor, amer, 1. p. 291.) leaves narrow. $\odot$. H. Native along with the species. Valerianélla parviflòra, Dougl. mss.

Cronded-flowered Plectritis, Fl. July, Clt. 1826. Pl. $\frac{1}{2}$ to 1 foot.

Cull. The seeds of this plant only require to be sown where the plants are intended to remain in the open border. 
VIII. CENTRA'NTHUS (from $\kappa \varepsilon, \tau p o s$, kentron, a spur, and ay $\theta 0$, anthos, a flower; in reference to the corolla being furnished with a spur at the base). D. C. f. fr. 4. p. 238. Dufr. val. p. 38. D. C. prod. 4. p. 631.-Kentránthus, Neck. elem. 1. p. 123.

İs. syst. Monándria, Monogýnia. Limb of calyx involute (f. 114. b.) when the flower is in blossom, but afterwards it unfolds into a deciduous pappus, composed of many plumose bristles (f. 114.h.). Corolla with an obconical tube, which is spurred at the base (f. 114.e.), and a regular 5-lobed limb (f. 114. d.). Stamen 1 (f. 114.e.). Fruit indeliseent, 1-celled, and 1 -seeded at maturity.-Quite glabrous European herbs. Leaves undivided or pinnate. Flowers red or white, nnilateral along the branches of the panicle, which is corymbose.

* Spur of flower clongated. Flowers red, very rarely white.

1 C. Longiflòrus (Stev, obs. pl. ross. p. 76.) Jeaves lanceolate-linear, quite entire; spur of corolla about equal in length to the tube, and ahout twice the length of the ovarium; genitals twice the length of the limb of the corolla. $4 . H$. Native of Armenia, about Tiflis, among rocks. C. angustifòlius, Bieb. $A$. taur. 1. p. 67. but not of D.C. The leaves are intermediate in breadth between the two following, and are probably glaucous like them. Corollas red, an inch long.

Long-flowercd Spurred-Valerian. Fl. May, July. Clt. 1817. P]. 1 to 2 feet.

2 C. Angustikòlus (D. C. fl. fr. 4. p. 239.) leaves linear-lanceolate, quite entire; spur one-half shorter than the tube of the corolla, and about equal in length to the ovarium; genitals much exserted. 24. H. Native of Spain, south of France, Switzerland, Italy, Greece, on the mountains in stony open places. Dufr. val. 1. 39 . Val. rùbra, $\beta$, Lin. spec. p. 44 . Valeriàna angustifòlia, Cav, icon. 4. t. 353. Sibtl. and Smitl, fl. græc. t. 29. but not of Host. Val. monándra, Vill. delph. 2. p. 280. Flowers red, half an inch long. This plant does not change under cultivation.

Narron-leaved Spurred-Valerian. Fl. May, July. Clt. 1759. PI. 1 to 2 feet.

3 C. RU'BER (D. C. f. fr. 4. p. 632.) leaves ovate or lanceolate: upper ones unequal at the base, toothed a little; spur onehalf shorter than the tube, and much longer than the ovarium; genitals exceeding the corolla but a very little. 24. H. Native of the sonth of Europe, the Levant, north of Africa, and on Mount Vesuvius, and now cultivated in almost every garden. It is to be found in some parts of Britain, on chalk cliffs, on walls, and among rubbisl, but is probably an escape from gardens. Stev. obs. pl. ross. p. 67 . C. marítimus, Gray, brit. arr. 2. p. 479. C. latifòlius, Dufr. val. p. 38. H. B. et Kunth, nov. 3. p. 323. Valeriàna rùbra, All. ped. 1. p. 1. Valeriàna rùbra, a, Lin. spec. p. 44. engl. bot. t. 1531.-Berg. phyt. t. 141. Dodon, pempt. 351. f. 1.-Riv. mon. t. 3. f. 2. Plant of a glaucous hue. Flowers red.-There is a variety of this with narrow leaves, and another with white flowers. In this and the preceding the root is sweet-scented, and the stem suffruticose at the base.

Retl-flowered Spurred-Valerian. Fl. May, July. Britain. Pl. 2 to 3 feet.

* Spur of floner very short (f. 114. c.). Flowers white.

4 C. Nervòsum (Moris, elench. sard. 2. p. 4.) leaves all elliptic or oblong-lanceolate, attenuated into the petioles, 3-7-nerved, quite entire ; flowers cymosely corymbose ; spur very short. 4 . H. Native of Corsica, at a place called Alle Trinita, and of Sardinia, on the mountains. Valeriàna trinérvis, Viv. A. cors. p. 3. add. f. ital. p. 67. Flowers white.

Nerred-leaved Spurred-Valerian. Pl. 1 foot.

5 C. CALCitra'Pa (Dufr. val. p. 39.) radical leaves ovate, entire, or lyrate: upper ones pinnatifid; flowers rather panicled: spur very short. $\odot$. H. Native of Europe, in the region of the Mediterranean, and the temperate parts of France. Hoffin. et Link, f. port. 2. p. 72. Valeriảna calcitràpa, Lin. spec. p. 44. Sibth. et Smith, ff. grac. t. 30. Val, ánnua, Gray, brit. arr. 2. p. 478 .-Clus. hist. 2. p. 54. with a figure.-Mor. hist. sect. 7. t. 14. f. 7. Flowers white, tinged with red.

Var. $\beta$, orbiculita (D. C. prod. 4. p. 632.) Jower leaves cordate-orbicular, denticulated : upper ones pinnatifid at the base. $\odot$. H. Native of the lsland of Cyprus and Balearic Islands, \&c. C. orbiculàtus, Dufr.-Valeri. àna orbiculàta, Sibth. et Smith, f. grac. 1. p. 21.

Caltrop-leaved Spurred-Valerian. Fl. May, July. Clt. 1683. Pl. $\frac{1}{2}$ to $i \frac{1}{2}$ foot.

Cult. All the species are elegant horder-flowers. They will grow in any common soil, or on walls or rock-work, and are all readily increased by seed.

IX. VALERIA'NA (said by some to be named after one Valerius, who is said to have used this plant first in medicine; and by others to be from valere, to be in health, on account of the medicinal qualities of $I^{\prime}$.officinulis). Neck. elem. I. p. 123. D. C. H. fr. 4. p. 238. Rœm, et Schultes, syst, no. 119. D. C. prod. 4. p. 632.- Valeriàna, Pliylláctis, and Astrèphia, Dufr.Valeriàna species and Oligacòce species, Willd.

Lin. syst. Triándria, Monogýmia. Limb of calyx involute in the time of blossom, but it unfolds itself at last into a deciduous pappus, which is composed of many plumose bristles ( $f$. 115. d.). Corolla with an obconical or cylindrical tube (f. 115. b.), which is equal at the base or gibbous, but not spurred, with a bluntly 5 -cleft limb (f. 115. b.), rarely 3 -cleft. Stamens 3 (f. 115. b.). Fruit indehiscent, 1-celled and 1-seeded at maturity. - Herbs or subshrubs. Leaves variable even in the same plant. Flowers corymbose, capitate or panicled, nearly all white, rarely blue, rose-coloured, or yellow.

Sect. I. Phylla'ctis (from $\phi v \lambda \lambda o v$, phyllon, a leaf, and astu', actin, a ray; in reference to the heads of flowers being involucrated). D. C. prod. 4. p. 632.-Phylláctis, Pers. ench. 1 p. 39. Corolla 3-cleft. Flowers densely aggregate, involucrated. Stems none. Leaves all radical, entire.-Perhaps a proper genus.

1 V. kígida (Ruiz et Pav. f. per. 1. p. 39. t. 65. f. c.) stemless; leaves crowcled in a stellate manner, linear-lanceolate, pungent, quite entire, glabrous, coriaceous; corymbs sessile, crowded, head-formed; corolla 3-cleft; genitals exserted. 4 . F. $\mathrm{Na}$ tive of Quito and Peru, on the tops of the Alps. 11. B. et Kunth, nov, gen. amer. 3. p. 324. Phylláctis rígida, Pers. ench. 1. p. 39. Dufr, val. p. 52. Flowers white.

Stiff Valerian. Pl. tufted.

2 V. TENUifòlı (Ruiz et Pav. A.per. 1. p. 39.t.65. f. d.) plant stemless; leaves crowded in a stellate manner, linear-subulate, ciliated at the base, very unequal, outer ones very long ; corymbs sessile, crowded, head-formed; corollas 3-cleft; genitals exserted. 4. F. Native of Peru, on the tops of the Alps. Plyylláctis tenuifolia, Pers. ench, 1. p. 39. Dufr. val. p. 53. Flowers white.

Fine-leaved Valerian. I'l. tufted. 
8 V. spatula'ta (Ruiz et Pav. fl. per. 1. p. 40. t. 68 . f. b.) plant tufted; stems many, simple, 2-edged; leaves linear-spatulate, obtuse, downy, hardly ciliated; corymbs capitate, terminal, involucrated; corollas 3-5-cleft; genitals exserted. భ. F. Native of the alps of Peru, at Bombom, in the province of Tarma. Phylláctis spatulàta, Pers. ench. 1. p. 39. The corolla is said, in the text of the $A$. per., to be 3 -cleft, but it is drawn 5-cleft in the figure; however, in the specimen examined it is obviously 3-cleft. lilowers white.

Spatulate-leaved Valerian. Pl, $\frac{1}{2}$ foot.

4. V. овоу'тA (Schultes, mant. 1. p. 214.) plant stemless, tufted; root fusiform; leaves disposed in a stellate manner, linear-spatulate, obtuse, hairy ; flowers umbellately capitate, involucrated. 2. H. Native of North Anerica, on dry hills on the banks of the Missouri, abont Arikares. Pliyllactis obovata, Nutt. gen. amer. 1. p. 21. Flowers and fruit unknown.

Oborate-leaved Valerian. Pl. tufterl.

Sect. II. Aretia'strum (from Arètia and astrum, an affixed signification, like; the plants contained in the section have the habit of species of Arètia). D. C. prorl. 4. p. 633. Corolla $4-5$-cleft, with a long tube. Flowers yellow, few, hidden arnong the upper leaves. Lcaves imbricate, coriaceous, thick, quite entire. Stems fruticulose. Perhaps a proper genus.

5 V. ARetioìdes (H. B. et Kunth, nov. gen. amer. 3. p. 324.) stems suffruticose, tufted, rather procumbent ; leaves imbricated, linear-terete, fleshy, glabrous, dilated at the base, and ciliated; flowers 1-3-together, terminal, sessile; corollas 4-5-cleft; stamens exserted. 24. F. Native of Quito, on the tops of the Andes. Corolla yellow, glabrous, with a very long filiform tube. Style inclosed. Fruit unknown.

Aretia-like V'alerian. Pl. procumbent and tufted.

$6 \mathrm{~V}$. SEDifòlia (D'Urv. fl. mal. p. 44.) stem suffruticose, spreading; branchlets ascending, short; leaves imbricated, thick, coriaceous, retuse at the apex, narrowed at the base, very minutely ciliated; flowers $5-7$, terminal, propped by the leaves; corolla 5 -cleft; stamens equal in length to the corolla. 4 . F. Native of the Falkland Islands, upon nearly naked rocks on Monnt Chatelux. Flowers yellow.

Stone-crop-leaved Valerian. Pl. tufted.

Sect. 1II. Phu, or Valeria'n.e Vere (this section is supposed to contain the true species of Valeriana). D. C. prod. $t$. p. 633. Corolla 5-cleft, usually white, rarely red or bluish.

\section{$\S 1$. Stems suffiuticose, not climbing. Leaves undivided.}

i V'. Alypifòla (H. B. et Kunth, nov. gen. amer. 3. p. 325.) stems shrubby, procumbent; leaves spatulate, fleshy, quite glabrous, approximate; heads of flowers pedunculate; corolla 5cleft: style exserted; stamens inclosed. h. F. Native of the kingdom of Quito, in frigid places at the foot of Mount Antisana, at Chussulongi. Habit of Globulària cordifòlia. Flowers white. Allied to V. spatulata.

Alypum-leaced $\mathrm{V}^{\prime}$ alerian. Pl. procumbent.

8 V. micropiy'Lla (H. B. et Kunth, nov, gen, amer. 8. p. 325. t. 275.) stem shrubby, erect; branches terete, clothed with fine down; leaves obovate-oblong, quite entire, 3-nerved, rather coriaceous, downy above; panicles crowded; corolla 5-cleft; genitals inclosed; fruit glabrous. $\zeta$. F. Native on the Andes, about Pasto, in frigid places. Corolla white, with a red throat.

Small-leazed Valerian. Pl. 1 foot.

9 V. connatia (Ruiz et Pav. fl. per. 1. p. 39. t. 67. f. c.) stem shrubby, ascending, much branched, with 2 rows of down; leaves lanceolate, connate, quite entire, glabrous, ciliated at the base; corymbs compact, opposite, almost sessile, disposed in an interrupted raceme; stamens equal in length to the corolla, vol. III. which is 5-cleft. h. F. Native of Peru, in the province of 'Iarma, at Diezmo, ainong rocks. Flowers small, white.

Connate-leaved Valerian. Shrub 2 feet.

$10 \mathrm{~V}$. QUADRANGULA'Ris (H. B. et Kunth, nov. gen. amer. S. p. 326.) stem suffruticose, and is as well as the branches quadrangular, glabrous, pilose at the nodi; leaves ovate-oblong, denticulated at the hase, triple-nerved, rather fleshy, glabrous; corymbs dichotomous, divaricate; corolla $5 \cdot$ cleft; stamens inclosed; fruit glabrous. h. F. Native of Peru, on the Andes. Corolla red, gibbous at the base. Pappus about 14-rayed.

Quadrangular-branched Valerian. Slirub.

]1 V. TRIPhy'lla (H. B. et Kunth, nov. gels. amer. 3. p. 326.) branches woody, terete, glabrous ; branchlets angularly furrowed; leaves 3 in a whorl, sessile, lanceolate-oblong, coriaccous, glabious; heads by threes, axillary and terminal, pedunculate ; corolla 5-cleft; stamens exserted. 々. F. Native of New Granada, near Santa Fe de Bogota, in frigid places on the mountains.

Three-leaved Valerian. Shrub.

12 V. nRtézla (H. B. et Kunth, nov. gen. amer. 3. p. 327.) stem suffruticose, terete, laairy ; branchlets lairy ; leaves linearlanceolate, quite entire, 3 -nerved, somewhat coriaceous, rather pilose above, and glabrous beneath ; panicles much branclied; fruit glabrous. $\quad$. F. Native of the Andes of Quito, on the top? of Mount Assuay. Flowers unknown. Pappus 6-8-rayed.

Hairy Valerian. Shrub 2 to 3 feet.

13 V. ciramedrifòla (Cham. et Schlecht. in Linnæa. 3. p. 129.) stem shrubby, erect, downy at the tops, and densely leafy: leaves ovate-lanceolate, coarsely and bluntly serrated; panicles straight, pyramidal; corolla 5-cleft; genitals about equal in length to the corolla. $h$. F. Natire of the interior of Brazil. Flowers small. Fruit unknown.

Germander-leaved Valerian. Shrub.

\$2. Stcms scandent, shrubby, rarely herbaceous. Learcs undivided.

14. V. tomentòsa (H. B. et Kunth, nov, gen. amer. 3. p. 39\%.) slurubby, scandent; branches terete, clothed with hoary tomentum; leaves ovate, cordate, denticulated at the base, membranous, downy above, and clothed with white tomentum beneath ; corymbs axillary, pedunculate, diclotomous; corolla 5 -cleft; genitals exserted. $\zeta_{\text {. }}$ G. Native of the temperate parts of Quito, in the valley of Choto. Corolla small, white, gibbous at the base. Fruit unknown.

Tomentose Valerian. Slırub cl.

15 V. clematitis (H. B. et Kuntl, nov, gen. amer. 3. p. 327.) shrubby, scandent; branches terete, glabrous; leaves ovate, triple-nerved, almost quite entire, membranous, smoothish ; panicles much branched, divaricate; corolla 5-cleft ; genitals exserted. h. G. Native of New Granada and Quito, in alpine situations. Link. jahrb. 1. pt. 3. p. 67. Schultes, mant. 1.p. 262. Corollas downy ontside.

\section{Clenatis-like Valerian. Shrub cl.}

16 V. crassifòlia (H. B. et Kunth, nov, gen. amer. 3. p. 328. t. 274.) shrubby, scandent; branches terete, glabrous; leaves ovate-elliptic, ohtuse, quite entire, rather fleshy, glabrous; corymbs trichotomous, divaricate ; corolla 5 -cleft, pilose outside; stamens inclosed; style exserted. $\boldsymbol{h}$. G. Native of New Granada, in frigid places, near La Erre and Sebondoi. Fruit unknown.

Thicli-leurcd Valerian. Slirub cl.

17 V. Laurifòlia (H. B. et Kuntl, nov. gen. amer. 3.p. 328.) shrubby; branches terete, glabrous, tetragonal while young; leaves ovate-oblong, acuminated, quite entire, rather coriaceous, quite glabrous and shining; panicles branched, with the branchlets and bracteas downy. $h$. G. Native of New 4. $\mathrm{R}$ 
Granada, in alpine situations. Flowers monoecious, ex Mlutis. Nearly allied to $l$. crassifolia.

Laurel-leated Valerian. Shrub el.

$18 \mathrm{~V}$. scA'NDENS (Lin. spec. p. 47. but not of Forsk.) plant ylabrous, herbaceous, scandent; branches terete; leaves trifoliate; leaflets quite entire: the terminal broad-ovate, acuminated, large: lateral ones lanceolate, smaller; panicles axillary, loose; stamens exserted; fruit rather pilose. 24. S. Native of New Andalusia, near Caripe, and about Cumana; also of Brazil and St. Domingo, and probably of Nexico. H. B. et Kunth, nov. gen. amer. 3. p. 333. Rom. et Schultes, 1. p. 358. mant. 1. p. 257. V. volubilis, Moc. et Sesse. fl. mex, with a figure. Lof. itin. p. 235 . no. 64.

Climbing Valerian. Pl. cl.

\section{\$3. Stcms herbaccous, never scandent. Lcaves all undivided. * Species natives of America.}

19 V. pilòs (Ruiz et Pav. fl. per. 1. p. 39. t. 66. f. a.) stem lierbaceous, erect, pilose; leaves linear-lanceolate, pilose, with revolute margins: radical leaves obtuse: cauline ones few, distant, acutish; corymbs racemose; stamens exserted. 24. G. Native of Peru, in frigid places. The whole herb has the labit of Plantàgo álbicans. Corollas white.

Pilose Valerian. Pl. 1 foot.

20 V. Longifòlia (H. B. et Kunth, nov. gen. amer. 8. p. 330.) stems herbaceous, terete, rather hairy; leaves quite entire, coriaceous, glabrous: radical ones linear-lanceolate, petiolate: eauline ones linear, sessile; panicle branched; corolla 5 -cleft, glabrous; stamens exserted. 2. G. Native of New Granada, in alpine places. There is a variety of this with the stem 1-3 feet ligh, and the radical leaves $3-12$ inches long. Corollas white. Nearly allied to $\zeta$. pilòst and $V$. plantaginea.

Long-leatcd Valerian. Pl. 1 to 3 feet.

21 V. salicarlefòla (Vahl, enum. 2. p. 16.) plant glabrous, herbaceous; stem simple, striated, rooting at the bottom; leaves lanceolate, quite entire, sessile: upper ones cordate at the base; corymbs terminal, decomposed.-Native of Buenos Ayres.

Salicaria-leaved Valerian. P]. $1 \frac{1}{2}$ foot.

22 V. plantagínea (H. B. et Kunth, nov, gen. amer. 3. p. 329.) stem herbaceous, erect, tetragonal, furrowed, glabrous, pilose at the nodi; leaves quite cntire, coriaceous, glabrous: radical leaves oblong-spatulate, petiolate: cauline ones lanceolate, sessile, connate at the base; panicles branched; stamens exserted; fruit glabrous. 21. G. Native of Quito, in arid places, on the plains of Antisana, and on the declivities of Mount l'ichincha. Flowers white. Pappus of fruit few-rayed.

Plantain-lilie Valerian. Pl. 4 to 6 feet.

$23 \mathrm{~V}$. LAPATHFòlia ( $\mathrm{V}$ ahl, enum. 2. p. 11.) stem herbaceous, striated, glabrous; leaves ovate-corlate, almost quite entire, undivided, villous above on the nerves, the rest of the leaf glabrous : stuperior leaves sessile; corymbs trichotomous.-Native of the Straits of Magellan.

Dock-leaved Valerian. P]. $1 \frac{1}{2}$ foot.

24 V. crticeròla (I]. B. et Kunth, nov. gen. amer. 3. p. 330. t. 275.) stem herbaceous, erect, terete, hairy; leaves roundish-ovate, subcordate, acute, sinuately toothed, rather pilose above: lower leaves petiolate: upper ones sessile; panicles branched; corymbs downy; corolla gibbous at the base; genitals exserted; fruit glabrous. 4. G. Native of New Granada and Peru. Flowers white. Root a round tuber.

Netlle-lcaved Valerian. Pl. 1 foot.

$25 \mathrm{~V}$. scorpioìdes (D. C. prod. 4. p. 635.) stem rather herbaceous, erect, terete, downy ; leaves ovate or roundish, dentately crenated, pilose above and on the margins; panicle corymbose, trichotomous; branches of panicle elongated, bearing unilateral Howers; fruit small, ovate, glabrous. 24. H. Native of Mexico, in thie valley of Tolucca, where it was collected by Berlandier. Habit almost of Fìdia scorpioides.

Seorpion-like Valerian. Pl. 1 foot?

26 V. prócera (H. B. et Kunth, nov. gen. amer. 3. p. 329.) stem hegrbaceous, furrowed, olabrous: cauline leaves sessile, ovate-cordate, long-acuminated, sharply toothed, stiff, glabrous ; panicles much branclied; fruit villous. 4. F. Native of Mexico, near Pascuaro. Flowers unknown. Pappus of calyx 11-12-rayed.

Tall Valerian. Pl. 3 to 4 feet.

27 V. Macrorinza (Poepp. pl. exsic. no. 918.) glabrous ; radical leaves spatulate, obtuse, tapering in to the petiole, which is twice the length of the limb; scapes a little higher than the leaves; panicles racemosely spicate, terminal, baving the racemules opposite: the lower ones pedunculate; floral leaves linear. 24. F. Native of Chili, near the baths of Villa Vicenzio and La Quebrada de San Isedro, and on the Andes of Mendosa. Root thick. Flowers white. Stamens exserted. Habit almost of $l$. coarctìta.

Long-rooted Talerian. Pl. 1 foot.

28 V. coarcta'ta (Ruiz et Pav. f. per. 1. p. 40. t. 68. f. a.) stems herbaceous, erect, simple, striated, downy ; leaves narrowlanccolate, attenuated, denticulated, ciliated : cauline leaves few ; flowers crowded in whorles, disposed in a somewhat interrupted spike. 2. G. Native of Pern, at Huassa-Huassi, in frigid places in the province of Tarma. Flowers white. Fruit said to be oblong, and crowned by 5 scales. Astrèphia coarctàta, Dufr. val. p. 50 .

Coarctate Valerian. Pl. 1 foot.

29 V. serra'ta (Ruiz et Pav. fi. per, 1. p. 40. t. 68, f. c.) plant tufted, glabrous; stems striated; leaves cuneate-lanceolate, serrated from the middle to the apex; flowers in crowded whorles, disposed in an interrupted elongated spike. 4. F. Native of Peru, in cold places. Astrèphia serràta, Dufr. val. p. 51. Flowers white. Fruit as in $V$. coarctata, to which it comes very neas.

Scrrated-leaved Valerian. PI. $\frac{1}{2}$ foot.

30 V. carnòsa (Smith, icon. ined. 3. P. 52.) stems herbaceous, ascending, glabrous; leaves oval, toothed, Heshy, quite glabrous; corymbs dichotomous. 4 . H. Native at the straits of Magellan. Astrèphia carnòsa, Dufr. val. p. 51. Val. Magellánica, Lam. ill. 1. p. 93. Plant glaucous.

Fleshy Valerian. Pl.

31 V. oblongifòlia (Ruiz et Pav. f. per. 1. p. 40, t. 65. f. a.) plant herbaceous, pilose ; stems many, striated, almost leafless; radical leaves cblong, dentate, obtuse : cauline ones linear, serrately-cut; corymbs contracted. 4. F. Native of Peru, on the alps in the province of Tarma, towards Pasco. Flowers white.

Oblong-lcaved Valerian. PI. 1 foot.

32 V. ontusifòlia (D. C. prod. 4. p. 635.) plant herbaccons, erect, glabrous; root tuberous ; leaves obtuse: lower ones obovate or oval, petiolate: upper ones sessile, oval-oblong, toothed at the base; corymbs coarctate. 4 . F. Native of Chili. Valeriàna, no. 630. Poepp. pl. exsic. Fruit unknown. Herb 3-7 inches high. Flowers white, crowded. Stamens not exserted. Allied to $V$. oblongifolia, and with it is intermediate between the present and following division of the genus.

Blunt-learcd Valerian. PI. $\frac{1}{2}$ foot.

\section{* Species natives of Europe and the Levant.}

33 V. alliarlefòlia ( Vahl, enum. 2. p. 11.) plant glabrous, erect; stem striated; leaves all cordate, undivided, equally toothed, acuminated: lower ones petiolate, upper ones almost sessile; corymbs rather contracted; fruit glabrous. 4. H. Native of Cappadocia, Iberia, and throughout Caucasus, in alpine 
places. Valeriàna macroplyłlla, Bicb. f. taur. 1.p. 25. Flowers white, tinged with red.

Alliaria-leated Valerian. Fl. June, July. Clt. 1826. Pl. 1 to 2 feet.

34 V. monta'xa (Lin. spec. p. 4.5.) plant glabrous or a little hairy, erect; lower leaves oblong or obovate, obtuse, a little toothed, on long petioles : upper ones lanecolate, acute; corymbs at length panicled; fruit smoothisl. 4. H. Native of Europe, on the mountains. Jacq. austr. 3.t. 269, vind. 202. D. C. fl. fr. 120. 3319 . Dufr. val. p. 46 . V. montàna, $a, \mathrm{~V}$. saxátilis, and V. Plù, Lapeyr. abr. p. 18.-Schench. itin. 1. p. 51. Roots horizontal. Stems simple. Flowers wlyte, tinged with red.

I ar. $\beta$, rotundifolia, (D. C. fl. fr. l. c.) stems more humble; lower leaves roundish. $\psi$. H. Native of Europe, on ligh mountains. Sims, bot. mag. t. 1825. Lodd. bot. cab. 317 . V. rotundifölia, Vill. dauph. 2. p. 283 . V. intermèdia, Sternb. et Hoppe. bot. ges. 2. p. 89.

l'ar. $\gamma$, cuspidàta, (D. C. prod. 4. p. 636.) stems humble, nearly naked: lower cauline leaves ovate, acuminated, undivided or subtrifid. 24. H. Native of Abruzzo, on the Appenines. Val. cuspidàta, Bert. ined.

Mountain Valerian. Fl. June, July. Clt. 1748. Pl. 1 to $1 \frac{1}{2}$ foot.

35 V. ALPE'stris (Stev, in mem. soc. nat. mosc. 5. p. 342.) radical leaves ovate, almost quite entire, obtuse: cauline leaves tripartite or ternate, acute: upper ones linear, entire; flowers capitately corymbose; pappus of caly $\mathrm{x}$ equal to the achenia in length. 24. H. Native of Siberia, about the fountains of the rivers Sentelek, Uba, and Ina ; and of Cancasus, in alpine meadows. V. montàna, Bieb. fl. taur. 1. p. 25. no. 67.3. p. 28. Sclultes, mant. 1. p. 258.-Gmel. sib. 3. p. 121. no.2. The whole plant is glabrous. Corymbs coarctate when in flower, but rather loose while in fruit.

Alp Valerian. Pl. 1 foot.

36 V. saxa'tills (Lin. spec. p. 4.5.) radical leaves on long petioles, elliptic, 3-5-nerved, undivided, or a little toothed, ciliated: cauline leares few, small, linear; stems erect; corymbs racemose; fruit glabrons. 4 . H. Native of the Alps of France, Austria, Italy, \&c. Jacq. austr. 3. t. 267 . vind. 204 . D. C. A. fr. 4. no. 3324 . Bert. amoen. ital. p. 326 . Krok. sil. no. 52. t. 6.-Pluk. phyt. t. 232. f. 2. Root blackish, very sweet-scented, and when chewed leaving a bitterness on the tongue. The whole plant shin-

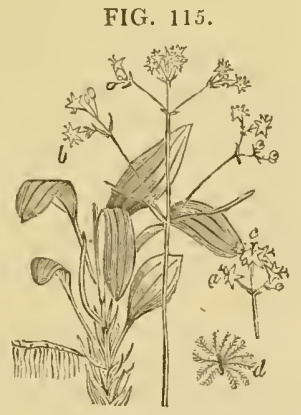

ing, and about half a foot high, with the stems subdivided at top. Flowers white, often dioecn-polygamous.

Rock Valerian. Fl. July. Clt. 1740. Pl, $\frac{1}{2}$ foot.

37 V. surina (Lin. mant. p. 27.) leaves undivided, ciliated, on short petioles : radical ones obovate : cauline ones lanceolate; corymbs coarctate; bracteas ciliated; fruit glabrous. $4 . \mathrm{H}$. Native of Carinthia and Tyrol, on the alps. Jacq. misc. austr. 2. t. 17. f. 2. Rœm. fl. cur. f. 3. Sturm, fl. germ. with a figure. Dufr. val. p. 47. V. supina, Willd. exclusive of the synonymes of All.-Ard. spec. 2. t. 13. Root scentless. Stems 1-2 inches high. Peduncles of corymbs opposite. Flowers white, tinged with red.

Supine Valerian. Fl. May, June. Clt. 1822. Pl. $\frac{1}{8}$ foot.

38 V. Saliu'nca (All. ped. 1. p. 3. t. 70. f. 1.) plant glabrous; leares spatulate or obovate, obtuse, entire, on short peti- oles: cauline leaves sometimes triclentate at the base; stems short; flowers disposed in capitate corymbs; fruit oblong, glabrous. 4. H. Native of Savoy, Vallais, Piedmont, Dauphiny, Italy, on the higlier alps. Dufr. val. p. 47. V. supina, D. C. t. fir. 4. no. 3323. but not of Jacq. V. Céltica, Vill. dauph. 2. p. 285. but not of Lin. lioot acrid, swcet-scenterl. Flowers sweet-scented, white, tinged with red.

Lavender Valerian. FI. May, June. Clt. 1824. PI. $\frac{1}{4}$ to $\frac{1}{2} \mathrm{ft}$. 39 V. Cétrica (Lin. spec. p. 46.) plant glabrous; leaves quite entire, obtuse : radical ones obovate : cauline ones linear; stems simple; flowers disposed in interrupted racemose spikes; fruit hairy. 4. H. Native of France, Italy, Illyria, Carintlia, Switzerland, Sc. on the alps. Jaç. coll. 1. t. 2.t. f. 1. vind. 203. D. C. th. fr. no. 3322. Dufr. val. p. 47. Val. saxátilis, Vill. ex Poir.-J. Bauh. hist. 3. p. 203. witl a figure. Roots sweet-scented, black. Stems 1-2 inches high. Flowers white inside, and reddish outside. Eastern nations procure the roots of this plant from the mountains of Austria to aromatize their batlis.

$$
\text { Celtic Valerian. Fl. June. Clt. } 1748 \text {. Pl. } \frac{1}{8} \text { to } \frac{1}{4} \text { foot. }
$$

\$ 4. Stcms herbaceous. Radical leaves undivided; cauline ones tripartite or pinnatifid.

$$
\text { * Species natives of Europe. }
$$

40 V. clobulariefo'tia (Ram. in D. C. f. fr. 4. 1. 236.) plant glabrous, glaucescent ; radical leaves petiolate, ovate, quite entire, obtuse; cauline ones pinnate: lobes or leaflets of the lower leaves olovate, of the superior ones linear; corymbs short, coarctate, subracemose; fruit oblong, glabrous. 4 . H. Native of the Pyrenees, on rocks; and of Spain, on Mount Pinnafurado. Dufr. val. p. 41. no. 4 . and no. 5 . V. heterophýlla, Lois. fl. gall. 1. p. 21. t. 2. but not of Baumg. V. glaúca, Lapeyr. abr. V. mupicola, Lag. var. 2. p. 212. gen. et spec. 2. no. 16. Globularia-leaved Valerian. Pl. 1 foot.

41 V. intermèda (Vahl, enum. 2. p. 9.) plant glabrous, erect; lower leaves on short petioles, cordate, quite entire: cauline ones tripartite, with lanceolate quite entire lobes; corymbs at lengtl panicled. 4. H. Native of the Pyrenees. V. montàna $\gamma$ appendiculàta, Lapeyr. abr. p. 19 . V. trípteris $\beta$, integrifòlia, Arn. in litt. Perhaps a variety of $r$. montana or $I$. tripteris, or a hybrid between these two species. Flowers white.

Intermcdiate Valerian. Fl. May, June. Clt. 1818 . Pl. 1 foot.

42 V. Trípteris (Lin. spec. p. 45.) plant glabrous, erect; radical leaves petiolate, cordate or ovate, toothed; cauline ones sessile, tripartite, with ovate-oblong or lanceolate lobes, which are toothed a little; corymbs panicled at length; fruit glabrous. 4. H. Native of Europe, in rocky places on the mountains, as of Austria, Carniola, Dauphiny, and Piedmont. Jacq. austr. 3. t. 268. Baumg. H. trans. 1. p. 36. var. $a$ and $\beta$.-Pluk. phyt. t. 231. f. 7-8.-Barrel. icon. t. 742. Root brownish, strong smelling. Flowers white, in loose corymbs. There are varieties of this plant having the radical leaves cordate or orate, and the stem ones more or less divided, toothed or cut ; lobes or leaflets of the upper leaves linear, undivided.

Three-ringed-leaved Valerian. Fl. March, May. Clt. 1752. Pl. 1 foot.

43 V. saxícola (Mleyer, verz. pfl. p. 49.) root crecping stems nearly terete; radical leaves oblong or ovate, quite cntire lower cauline leaves petiolate, trifid or tripartite: Iobes linear or oblong: uppermost leaves linear, sessile, entire; flowers hermaphrodite, corymbose, crowded. 4. H. Native of Western Caucasus, among alpine rocks.

Rock Valerian. Pl. 1 foot?

44. V. PYrena'ica (Lin. spec. p. 46.) plant downy, erect; stems striated; lower leaves large, petiolate, cordate, unequallytoothed; superior ones pinnate, having the $1-2$ lower pairs of $4 \mathrm{R} 2$ 
lobes or leaflets oblong or acuminated, and the terminal one broad-ovate or roundish, cordate, serrated; corymbs ample; Iruit glabrons. 2 4 . H. Native of the Pyrenees, in woods; and of Scotland, in woods, particularly about Ediuburgh and Glasgow. D. C. A. fr. no. 3317. Sowerb. engl. bot. t. 1591.Pluk. phyt. t. 232. f. 1. V. Canadénsis, Riv. mon. t. 6.Buxb. cent. 2. p. 19. t. 11. A showy pale green herb, with large leaves. Flowers pale red, disposed in ample corymbs. 'There is also a white flowered variety of this plant.

Pyrcnean Valerian. Fl. May, June. Scotland. Pl. 2 to $4 \mathrm{ft}$. $45 \mathrm{~V}$. Itálica (Lam. ill. 1. p. 92.) plant glabrous, erect; stems terete, nearly smooth; radical leaves petiolate, undividcd, ovate-oblong, remotely toothed, the rest pinnate; leaflets or lobes ovate or ovate-oblong, toothed; corymbs subpanicled; fruit glabrous. 4. H. Native of Liguria and Candia, on the mountains. Vahl, cnum. 2. p. 6. Dufr. val. p. 45. V. tuberòsa, Imp. hist. nat. ed. 2. p. 656. with a figure.. Flowers truly triandrous, not tetrandrous, as said by Lam. and Vahl.

Ilalian Valerian. Pl. 1 to 2 feet?

46 V. ELonga't a (Lin. spec. p. 1664.) plant glabrous, erect ; stems striated; radical leaves petiolate, oval; cauline leaves sessile, subcordate or hastate; upper leaves deeply 3-5-cleft, acute ; panicle elongated, with the lateral branches short and' subcorym. bose ; corolla very short, tubularly campanulate; fruit glabrous. 4. H. Native of Austria, Carniola, Sc. on the alps. Jacq. fl. anstr. 3. t. 219. vind. t. 1. Morr. ox. sect. 7. t. 15. f. 20. loot whitish, with little taste or smell. Flowers dusky. Stems 6-10 inches high.

I'ar. $\beta$, polyggama (D. C. prod. 4. p. 637.) plant larger; upper leaves trifid. 24. H. Native of Galicia, in humid meadows. V. dioíca, Bess. prim. 1. p. 48, enum. p. 40 . V. polýgama, Bess. in litt. Flowers corymbose, a little larger than in $V$. clongàta; but very similar in form.

Elongated-panicled Valerian. Fl. June, July. Clt. 1812. Pl. $\frac{1}{2}$ to $\frac{3}{4}$ foot.

47 V. Asarifo'lia (Dufr. val. p. 44.) plant glabrous, erect; radical leaves petiolate, cordate-reniform, a little toothed; cauline leaves few, pinnate; lobes or leaflets of the upper leaves linear ; corymbs rather contracted. 4. H. Native of Crete, on the Spaceotic mountains. Sieb, herb. cret. Schultes, syst. 1. 1. 356. mant. 1. p. 259.-Alp. exot. p. 132, with a figure. Flowers red. Root tuberous, black.

Asurubacca-leaved Va!erian. Fl. June, July. Clt. 1824. Pl. 1 foot.

48 V. tueEnòsa (Lin. spec. p. 46.) plant glabrous ; radical leaves ovate, lanceolatc-oblong or oblong, undivided, quite entire; cauline leaves pinnatifid, with $2-3$ pairs of linear segments or lobes, the terminal segment the largest; corymbs at first coarctate; fruit ovate, hairy. 4. H. Native of the south of Europe, from Spain to Caucasus; of Siberia, near Sogra and Wydricha, and liom Buchtorminsk to Lake Noor Saisan. Vahl, enum. 2. p. 12. Dufr. val. p. 45. D. C. A. fr. no. 3320. lob. icon. t. 717. f. 2. Cam. epit. p. 16. Root tuberous, blackish, simple or double, ovate or oblong. There are varieties of this species witl the cauline leaves all pinnatifid, or the lower ones are quite entire, oblong-lanceolate and elongated, and the upper leaves more or less pinnatifid. Flowers pale red.

I'ar. 3, monorhiza (D. C. prod. 4. p. 637.) root simple, nearly globose; radical leaves ovate-cordate. 4. H. Native of Liguria. V. bulbòsa, Jimp. hist. nat. ed. 12. p. 659. with a figure. Barrel. icon. t. 867 . V. monorhiza, Dufr. val. p. 41 . Tuberous-rooted Valerian. Fl. May, June. Clt. 1629. Pl. $1 \frac{1}{2}$ foot.

49 V. Phu' (Lin. spec. p. 45.) plant glabrous, erect; stems terete, smooth; radical leaves oblong or elliptic, undivided; cauline ones pinnatifid, with oblong lobes; corymbs panicled; lobes of stigma 3 , slender; fruit glabrous, but exhibiting 2 hairy lines. 4. H. Native of Alsatia, Switzerland, Silesia, Caucasus, \&.c. in subalpine places, but not of the Pyrenees. Dufr. val. p. 40. but not of Lapeyr, nor Ruiz et Pav.?-Fusch, luist. p. 155. with a figure. Heyn. arz. gew. 3. t. 33. good.-Blackw. t. 256.-Plench. t. 28. Moris, hist. sect. 7. 1. 14. f. I. Riv. mon. t. 3. Lob. icon. t. 714. Root oblique, thick, and matted, pale green. Plant glaucous. Flowers white, with a pleasant smell.

Phu or Garden Valerian. Fl. May, July. Clt. 1597. Pl. 2 to 4 feet.

$50 \mathrm{~V}$. рu'B1A (Bunge, in Led. fl. alt. 1. p. 52.) primary radical leaves quite entire or auricled; the rest lyrately pinnatifid, and the cauline leaves pinnate; leaflets oblong, obtuse, almost entire: superior ones decurrent; corymbs compound ; flowers hermaphrodite. 4 . H. Native of Siberia. V. oflicinàlis, Falk. topogr. beytr. 2. no. 50. ?-Gmel. fl. sib. 3. p. 120. no. 1, exclusive of the synonymes. This species is very nearly allied to $I$. officinilis, but differs from it in the lower leaves being undivided or auricled. Stem and snargins of leaves beset with minute adpressed hardly conspicuons pili.

I'ar. a, latifolia (Bunge, 1. c.) segments of leaves $7-11$, more remote and broader than in var. $\beta$. 2 $4 . H$. Native of Siberia, frequent on schistous momtains in exposed places.

Var. $\beta$, angustifölia (Bunge, l. c.) segments of leaves 21-27, more crowded and narrower, and more elongated than in var. $a$. 4. H. Native of Siberia, near Salair and Barnaul.

Doubtful Valerian. 1'. 2 to 3 feet.

51 V. Diol'ca (Lin. spec. p. 4.4.) plant glabrous, erect; stems striated; radical leaves petiolate, ovate or subspatulate, undirided; cauline leaves pinnatifid, with linear-oblong lobes; flowers dioecious; corymbs of the male flowers loose; of the lemale ones contracted; lobes of stigma almost combined; fruit glabrous. 4. H. Native of Europe and the Levant, in wet meadows and marshes, and by the sides of streams and ditches; in Britain in moist boggy mealows frequent. Dufr. val. p. 29. Oed. fl. dan. t. 687. Stirm, deutsch. fl. with a figure. Heyne, arzi. gew. 3. p. 4.78. Smith, engl. bot. 628. Curt. lond. 4. t. 3. Poit, et Turp. fl. par. t. 4l. V. sylvéstris, Gray. brit. arr. 2. p. 478. V. montàna, gen. el. no. $3 \mathrm{l}$. ex Wahl. Roots horizontal, creeping, white, but sometimes tinged with red, slender. Flowers white, tinged with red or flesh coloured.

Var. $\beta$, integrifolia (D. C. prod. 4. p. 637.) all the leaves both radical and cauline are quite entire. $4 . \mathrm{H}$. Native of Silesia. V. dioíca simplicifòlia, Reich, icon. 1. p. 48. t. 59.Loes. pruss. no. 724. t. 84 .

Dioccious Valerian. FI. May, July. Britain. Pl. $\frac{1}{2}$ to 1 foot.

\section{* * Species natives of America.}

$52 \mathrm{~V}$. capita'ta (Pall. in Willd. herb. no. 789. exclusive of Cham. et Sclılecht. which is Gentiàna frígida,) plant glabrons, erect; stems downy at the nodi; radical leaves petiolate, roundish, simple; cauline ones almost sessile, simple or ternate; leaflets sinuately serrated, middle one the largest; panicles terminal, capitate, girded by long linear bracteas; tube of corolla elongated; fruit ovate, compressed, glabrous. 2/. H. Native of the higher ranges of the Sagan Alps, at the bay of St. Laurence; Kotzebue's Sound; on the Arctic shores of America beyond Behring's Straits; and between the Coppermine and Mackenzie rivers. Link, jahrb. 1. pt. 3. p. 66. Cham. et Schlecht. in Linnæa. 3. p. 130. Perhaps distinct from V. tripteris, ex Stev. obs, in herb. Willd.

Capitate-flowered Valerian. Pl. 1 foot.

53 V. sylva'tica (Banks, mss. Richards, in Frankl. Ist journ. ed. 2. append. p. 2.) plant glabrous, erect; stem striated; radical leaves petiolate, ovate or subspatulate, undivided; cauline leaves pinnate-parted, with ovate-lanceolate nearly entire 
segments ; flowers hermaphrodite; lobes of stigmas 2-3, minute; fruit ovate, compressed, glabrous. 4. 11. Native of Newfoundland, ex Banks, Clear-water River, ex Richards, Prairies of the Rocky Mountains abundant, ex Drummond. In every respect this agrees with the European $V$. dioica. It differs from $l$. Phi by the smaller and shorter fruit, and entire absence of the two hairy lines.

Wood Valerian. Pl. I foot.

5. V. Laxiflòra (D. C. prod. 4. p. 638.) plant glabrous, ascendirg, sulfiuticose at the base; leaves petiolate, ovate or oval, with a few coarse irregularly dentately cut teeth; floriferous branches elongated, almost naked; superior leaves pinnateparted, with 1-2 linear quite entire lobes on each side; floral leaves linear; panicle loose, with opposite branches, which are trifid and few-Howered at the apex. 4. F. Native of Chili. Valeriàna, no. 825. Poepp. pl. exsic. Fruit oblong, glabrous.

Lax-flowercd Valerian. Pl. ascending.

$55 \mathrm{~V}$. Ilyalinorniza (Ruiz et Pav, fl. per. 1. p. 41. t. 67. f. b. Hook. et Arn. in Beech. voy. pt. bot. p. 28.) plani herhaceous, rather downy ; stems terete ; radical leaves roundisl-obovate, crenated, entire, and auricled; cauline ones pinnatifid; flowers corymbose; genitals exserted; fruit glabrous. $\mathcal{\psi}$. F. Native of Chili and Peru, in sandy arid places. Astrèphia hyalinorhiza, Dufr. val. p. 52. Oligacòce hyalinorhiza, Willd. lierb. Root obovate, shining, white, insipid. Corollas yellow, ex Ruiz et Pav.

Shining-rooted Valerian. Pl, $\frac{1}{8}$ foot.

$56 \mathrm{~V}$. Humbóldti (Hook. et Arm. in bot. misc. vol. 3.) stem herbaceous, erect, terete, and is as well as the leaves smoothish; radical leaves entire, roundish-elliptic, crenated; cauline leaves sessile, pinnatifidly lyrate; panicles much branclied; corollas quinquefid; stamens exserted; fruit glabrous, crowned by feathered pappus. 4. F. Native of Peru, in rocky places. V. hyalinorhiza, H. B. et Kunth, nov, gen. amer. 3. p. 331. but not of Ruiz et Pav.

\section{Humbold's Valerian. Pl. $\frac{3}{4}$ to $1 \frac{1}{2}$ foot.}

57 V. pinnatífida (Ruiz et Pav, f, per, 1. p. 40. t. 69. f. b.) plant herbaceous, glabrous; stems erect, simple, striated; two lower leaves lanceolate, quite entire : the rest pinnatifid, with oblong serrate-toothed lobes; panicle loose; lateral corymbs ditrichotomous; stamens exserted. 4.F. Native of Peru, at Chancay and Lima on hills. Val. brachiàta, Pers. ench. 1. p. 37. Root tuberous, sweet scented, as in $V$. Phù. Flowers white. A variety of the present plant, or a distinct species, was gathered by Bertero in the grassy pastures on Mont La Leona at Rancagua, in Chili.

Pinnatifid-leaved Valerian. Pl. 1 foot?

58 V. LeucocárPa (D. C. prod. 4. p. 638.) plant herbaceous, erect, glabrous; lower leaves on long petioles, oboval-oblong, obtuse, attenuated at the base, membranous; cauline leaves very few, small, pinnate-parted at the base, with linear lobes; panicle loose, with opposite trichotomous branches; fruit pale, glabrous, compressed. 24. F. Native of Chili. Valeriàna, no. \$47. Poepp.pl. exsic. Stem 2 feet high. Radictul leaves with the petioles 10-12 inches long. Staniens not exserted. Pappus of calyx plumose.

White-fruited Valerian. P1, 2 feet.

59 V. vagina'ta (H. B. et Kunth, nov, gen. amer. 3. p. 331.) plant glabrous; stens tufted, simple, tetragonal ; rarlical leaves oblong-elliptic, petiolate, toothed a little; cauline leaves sinuately pinnatifid, sheathed at the base, with linear pilose segments; corymbs crowded; stamens inclosed; style muel exserted. 2 . F. Native of New Spain, in humid places near Real del Monte. Corolla glabrous, gibbous at the base, white.

Sheathed-leaved Valerian. Pl, $\frac{1}{2}$ foot.

60 V. Panicula'ta (Ruiz et Pav. A. per. 1. p. 41. t. 70. f. a.) plant herbaceous, villous; stems many, ereet, striately furrowed, terete, rather 2 -edged; radical leaves undivided, cordate, acute; cauliue leaves pimnate, with 3-5 ovate acute, denticulated leaflets; panicle dilluse; stamens length of corolla. 4. H. Native of Peru, in moist rocky places. Corollas small, gibbons at the base, white. Pappus of ealyx 10-rayed.

Panicled-flowered Valerian. Pl. 2 to 3 feet.

61 V. paucialoda (Michx. fl. bor. amer. 1. p. 18. Hook. fl. bor. amer. 1. p. 291. t. 101.) plant herbaceous, glabrous; stems erect, simple, furrowed; radical leaves simple, cordate, sinuately crenated, petiolate; cauline ones lyrately pinnatifid, with 5-7 segments or leaflets, those, at the top of the stem trifoliate or simple ; leaflets broad-ovate, acute, sinuately toothed; panicle scattered; corymbs few-flowered; corollas tubular; stamens exserted; fruit ovate, compressed, glabrous. 24. II. Native of North Ameriea, on the Alleghany mountains in shady places; and in woods on the Rocky Mountains north of the Smoking river, and on Wolf's plain. Nutt. gen. amer. p. 20. Pursh, $H$. amer. sept. 1. p. 28. Rost thick, creeping, emitting fibres. Stems hairy at the nodi. Flowers white, ex Nutt., pale blue, ex Torrey, rose-coloured, ex Hook. Panicle terminal, eymose.

lar. $\dot{\beta}$; leaflets almost entire. $4 . \mathrm{H}$. On moist rocks and islands of the Columbia river. Hook. fl. bor. amer. 1. p. 292.

Fen-flowered Valerian. Pl. 2 feet.

62 V. heBefárpa (D. C. prod. 4. p. 638.) plant herbaceons, ereet, glabrous ; lower leaves petiolate, obovate-oblong, coarsely toothed: superior ones sessile, pinnate-parted, with lanceolatetoothed lobes; branches of panicle opposite, trichotomous; bracteas linear, obtuse; fruit small, ovate, velvety from short crowded down. 24. F. Native of Chili. Valeriana, no. 942. Poepp. pl. exsic. Herb $1 \frac{1}{2}$ foot high. From the fruit being canescent, it agrees with $V$. Papilla, but the fruit is 3 or 4 time smaller.

\section{Hairy-fruited Valerian. Pl, $1 \frac{1}{2}$ foot.}

\section{Stems herbaceous. Lcavcs all pinnate-lobcl. * Spccies natives of America.}

63 V. PAFílla (Bert, in litt. ex D. C. prod. 4. p. 638.) stems erect, glabrous; leaves glabrous, lyrately pinnatifid: having the lateral lobes linear and entire, and the terminal one large, obovateoblong, and somewhat sinuated; panicle trichotomous; fruit oblong, very hispid. 4. F. Native of Chili, in sandy pastures along the Cachapual, at a place called St. George, where it is called by the natives Papilla, and about the banks of Collina. Herb $1 \frac{1}{2}$ foot high. Pedicels pilose. Fruit large. Flowers unknown. Pappus blackisl.

Papilla Valerian. Pl. $1 \frac{1}{2}$ foot.

64 V. PYRAmida'Lis (H. B. et Kunth, nov. gen. amer. 3. p. 331.) plant glabrous; stem herbaceous, terete, furrowed; leaves pinnate, witl sessile ovate-cordate quite entire segments or leaflets; panicle much branched, pyramidal; genitals almost inclosed; frut oblong, glabrous. 24. G. Native on the walls of the city of Quito. Corolla with a very short tube, white.

Pyramidal-panicled Valerian. Pl. 3 feet.

$6.5 \mathrm{~V}$. BRIDGE'sII (Hook. et Arn. in bot. mise. 3. p. 36j.) glabrous; leaves lyrately pinnatific : lobes erose, curled: lateral ones small, terminal one much larger ; radical leaves obovate, and more entire than the rest; panicle elongated, with opposite dichotomous distant branches; fruit ovate, glabrous.- Native of Chili, on the mountains and plains near Valparaiso. Very closely allied to $V$. crispa, with a totally distinet fruit, which, in this species, is not flat on one side, with a tubercle on the other, but presents a tubercle which is internally spongy on both sides, nor is it half so large as in $I$. críspa.

Bridges's Valerian. Pl. I to 2 feet? 
66 V. POLEMonoides (H. B. et Kunth, nov. gen. amer. 3. p. 332.) plant downy; stems lerbaceous, erect, terete; leaves pinnate: leaflets oblong, on short petioles, quite entire, rather fleshy, smoothish above; panicle much branched; genitals inclosed. 24. F. Native of the kingdom of Quito, between Hambato and Llactacunga. Corolla glabrous, gibbous at the base, white.

\section{Polemonium-like Valerian. Pl. 2 to 3 feet.}

67 V. decussa'ta (Ruiz et Pav, fl. per. 1. p. 42. t. 70. f. b.) plant herbaceous, downy ; stems erect, striated ; leaves pinnate; leaflets lanceolate, acuminated, a little denticulated: the terminal one rather the largest; panicle loose, divaricate, downy ; stamens nearly inclosed. 4 . F. Native of Peru, among rocks, and in hedges. Peduncles decussate. Corolla small, white.

Decussate-peduncled Valerian. Pl. 3 feet.

68 V. polysta'crry (Smith, icon. ined. 3. t. 51.) plant glabrons, erect; stems a little striated; leaves pinnatifid, with linear quite entire acute segments; racemes compound, elongated, composed of opposite spikes.-Native of Buenos Ayres, in moist places, where it was collected by Commerson. Vahl, enum. 2. p. 5. Astrèphia polystàchya, Dufr. val. p. 51. Oligacòce polystàchya, Willd. herb. Corolla hardly gibbous at the base.

Many-spilicd Valerian. PI. 2 feet.

69) V. sorbifolda (H. B. et Kunth, nov. gen. amer. 3. p. 332.) stems herbaceons, erect, terete, rather jilose below; leaves pinnate; leaflets sessile, ovate-oblong, cuneated at the base, coarsely serrated, glabrous; panicle much branched; stamens inclosed; style exserted. 2 . F. Native of Mexico, on the western declivities of mountains between Valladolid and Pazcuaro. Corolla glabrous, gibbous at the base, white.

Mountain-Ash-leaved Valerian. Pl, 2 to 3 feet.

$70 \mathrm{~V}$. sanguisorbifòlia (Cav. icon. 5. p. 456.) plant herbaceons, glabrous; stems prostrate at the base, and erect at the apex; leaves pinnate; petioles naked almost to the middle; leaflets sessile, ovate, few-toothed, equal ; panicle racemose, oblong, rather loose. 4. F. Native of the Cordillera of Chili. V. sanguisórbæ, Pers, ench, 1. p. 37. Flowers white.

Burnet-lcatcil Valerian. Pl. 1 foot.

71 V. gLau'ca (Pocpp. pl. exsic. no. 127.) plant herbaceous, erect, glabrons; stems terete, naked at the apex; leaves glaucous, pinnate: leaflets obovate-oblong, toothed, those at the base of the petiole small, and those at the top of the leaf larger and confluent; branches of panicle opposite, trichotomous ; bracteas linear, 24. F. Native of Chili, where it was collected by Poeppig. Allied to $r$. sanguisorbafolia, but the petioles are almost leafy to the base. Leaflets narrowed into the petioles. Glaucous Valerian. Pl. 1 to 2 feet.

72 V. virga'ta (Ruiz et Pav. fl. per. 1. p. 42. t. 66. f. b.) plant suffruticose, almost glabrous; stem much branched, striat. ed, rather downy; leaves pinnate; leaflets entire or bifid, witl: linear bluntish entire lobes; corymbs panicled, with dichotomous branches, bearing a sessile flower in each fork ; stamens exserted. h. F. Native of Peru, in the province of Canta, among broken rocks. Flowers white.

Tniggy Valerian. PI. 3 feet.

73 V. glosif lòra (Ruiz et Pav, f. per, 1. p. 43. t. 65. f. b.) plant lierbaceous, humble, hispid on one side; stems striated, hardly longer than the leaves, almost naked; leaves pinnate: leaflets sinuately toothed; flowers capitate; bracteas spatulate, membranous. 4 . F. Native of Pert, on the alps in the provinces of ' $\Gamma$ arma and Canta. Corollas white.

Globe-flowered Valerian. Pl. $\frac{1}{4}$ to $\frac{1}{2}$ foot.

74. V. LYRA'TA (Vahl, enum. 2. p. 4.) plant herbaceous, glabrous; stem bearing 2 leaves; radical leaves lyrate; leaflets oblong, dentately serrated: the terminal one rather pinnatifid: those of the cauline leaves linear-lanceolate; peduncles trichotomous. $\psi$. F. Native of Peru.

Lyrate-leaved Valerian. P]. $\frac{1}{4}$ to $\frac{1}{2}$ foot.

$75 \mathrm{~V}$. interru'pta (Ruiz et Pav. fl. per. 1.p. 42. t. 67. f. a.) plant herbaceous, glabrous ; stems many, erect, bearing 2 opposite bipinnatifid leaves under the corymb, which is tricliotomous; radical leaves pinnate-parted, and appendiculately toothed between the lobes; segments linear or oblong, unequally bluntly and coarsely toothed; stamens exserted. 4 . F. Native of Peru, on the alps in the province of Tarma at Diezmo. Astrèphia interrúpta, Dufr. val. p. 51. Flowers capitate, sessile. Bracteas linear.

Interrupted-leaved Valerian. P1. $\frac{1}{2}$ foot.

76 V. Crispa (Hook. et Arn. in Beech. voy. pt. bot. p. 27. but not of Ruiz et Pav.) leaves fleshy : inferior ones laciniately pinnatifid, witl acutely toothed curled segments; fructiferous panicle coarctate; fruit cordately ovate, plano-convex, broadly marginated, with a longitudinal elevated line in front, and 8 lines on the back; pappus plumose, united by a membrane at the base.-Native of Clili, about Conception. V. pterocárpa, Hook. et Arr. I. c.

\section{Curled-leaved Valerian. Pl. 1 to 2 feet?}

77 V. ceratophy'Lla (H. B. et Kunth, nov. gen. amer. 3. p. 333. t. 276.) plant glabrous; stems herbaccous, terete, striated ; leaves pinnate; leaflets hastately trifid, sessile, with linear acuminated segments; corymbs dichotomous; genitals exserted; fruit downy. 24. F. Native of Mexico, in high plains near Chapoltepec. Val, dichótoma, Moc. et Sesse, fi. mex. icon. ined. Corolla downy outside, gibbous at the base, white.

Horn-leaced Valerian. Pl. 1 to 2 feet.

78 V. Tolucca'na (D. C coll. mem. vii. prod. 4. p. 640.) plant glabrous, herbaceous, erect; stem nearly terete; leaves pinnate, with $3-4$ pairs of membranons repandly toothed leaves, with an odd one: those of the upper leaves very narrow; panicle loose, elongated; lateral corymbs dichotomous; flowers sessile in the forks; fruit oblong, downy. 24.F. Native of Mexico, in the valley of Tolucco. Very like $I$. Hardwickii, but differs in the stem and leaves being quite smooth, in the segments of the leaves being more ovate, in the corymbs being dichotomous, and in the fruit being oblong.

Tolucca Valerian. Pl. $\frac{1}{2}$ to 2 feet?

79 V. Mexica'Na (D. C. coll. mem. rii. prod. 4. p. 640.) plant herbaceous, glabrons, erect ; stems rather angular; leaves pinnate, with 2 pairs of oblong leaflets, and an odd one: the latter is larger and ovate, and usually auricled at the base, but all are repandly toothed; panicle loose, elongated, having the lateral branches elongated and trichotomons; stamens exserted; fruit ovate, scabrous. 4. F. Native of Mexico, about the city, where it was collected by Berlandier. Very nearly allied to $\dot{V}$. Harduickii and $V$. Toluccìna, but is distinguished from both by its angular stem.

\section{Mcxican Valerian. Pl. $\frac{1}{2}$ to 2 feet?}

$$
\text { * * Species natives of Asia. }
$$

80 V. Leschenavitit (D. C. mem. vii. prod. 4. p. 640.) radical leaves petiolate, ovate, obtuse, crenated, hairy on both surfaces; stems ereet, simple, glabrous between the joints, but the joints are pilose; cauline leaves remote, small, sessile: upper ones pinnately divided into $3-5$ linear glabrous lobes, the terminal lobe the longest; corymbs contracted; fruit villous. 4. F. Native of the East Indies, on the mountains of Anigueda, where it ras collected by Leschenault. Stem 2 feet high. Radical leaves with the petioles, hardly 2 inches long. Habit of $I$. dioica.

Leschenault's Valerian. Pl. 2 feet.

81 V. RE'Pens (Wall. cat. no. 434.) the whole plant is 
roughish from short hairs; stems striated, with the lower joints or kuees radicant; lower leaves undivided, toothed, acuminated, on long petioles, heart-shaped; upper oncs on short petioles, ternate; lateral leaflets small, terminal one larger, ovate or oblong, acuminated; panicle terminal, with short opposite branches, which are corymbose at the apex. 4. F. Native of Nipaul, at Gosaingstlan. Trunk of root slender, ereeping, and throwing out fibres.

Crceping Valerian. Pl. creeping, 1 foot.

82 V. Wallícill (D. C. coll. mem. vii. t. 4. prod. 4. p. 6.10.) radical leaves petiolate, heart-shaped, a little crenated, villous, but most so on the petioles; stems erect, striated, simple, smoothish; cauline leaves distant, small, cut a little at the base; upper leaves linear, entire ; corymbs subumbellate; fruit villous. 4 . F. Native of Nipaul, at Kamaon. V. villosa, Wall. herb. but not of Thunb. Stems villous at the knees. Herb 8-10 inches high. Petioles beset with retrograde villi.

\section{Wallich's Valerian. Pl. $\frac{1}{2}$ to 1 foot.}

SS V. ELA'TA (D. Don, prod. f. nep. p. 159.) stem branched, terete, smooth; leaves pimate; leaflets lanceolate, quite entire, downy; flowers corymbosely panicled; fruit with villons furrows. 4. F. Native of Nipaul. Root fibrous. Stem erect, branched, 3-4 feet in length. Flowers small, rose-coloured, triandrous.

Tall Valerian. Pl. 3 to 4 feet.

84 V. HaRdwícku (Wall. in Roxb. f. ind. 1. p. 166.) plant erect, downy ; stems striated, villous ; radical leaves numerous, undivided, cordate, toothed, acute, unequally sinuated, on long petioles; cauline leaves sessile, remote, pinnate; leaflets lanceolate, crenated, villous; corymbs at length elongated and panicled; peduncles dichotomous ; stamens inclosed ; fruit tetragonal, hairy ; stigma 3-lobed. 4 . F. Native of Nipaul, and near the town of Sirinagur, where it is called by the Nawarre people chamaha-swa. Hardw. in asiat. res. 4. p. 350 . with a figure. D. Don, prod. A. nep. p. 159. Wall. pl. rar. asiat. 3. t. 263. Val. Hardwickiàna, Rom. et Schultes, mant. 1. j. 259. lioot thick, short, furnished with long thickish fibres. Stem fistular, branched, very variable in height, from a hand to 2-3 feet. Hairs on the leaves very short. Flowers white. Spikenard, Jones, asiat. res. 2. p. 405. with a figure. The root is strong scented like the common valerian, and is used medicinally by the natives of Nipaul.

Hardwick's Valerian. P'], $\frac{1}{2}$ to 3 feet.

85 V. TE'NERA (Wall. cat. no. 435.) plant smoothish, erect; stem striated, villous at the knees, the rest glabrous; radical leaves small, reniform, on long petioles : cauliue leaves pinnate; leaflets lanceolate, almost entire, acuminated; corymbs contracted. 4. F. Native of Nipaul, at Kamaon. Herb 5-6 inches high. Leaves downy on the margins and petioles. This is probably only a dwarf variety of $I$. Hardwickii.

Tender Valerian. Pl. I foot.

86 V. sisyarkitfòla (Desf. choix. Tourn. p. 53. t. 41. ann. mus. 11. p. 273. t. 28.) plant glabrous, erect; stem finely striated; leaves all pinnate; leaflets ovate-roundish, quite entire; corymbs densely contracted. $24 . \cup$. H. Native of Armenia, Caucasus, Iberia, and the Levant; and on the mountains in the island of Cois. Dufr, val. p. 42. V. cardámines, Bieb. fl. taur. 1. p. 24. ex Stev. obs. p. 67 . Flowers red.

Sisymbrium-leaved Valerian. Fl. June, July. Clt. 18\%4. Pl. 1 foot.

87 V. Petróphila (Bunge, Lerl. fi. ross. ill. t. 19, fl. alt. 1. p. 54.) leaves all lyrately pinnate-parted: the terminal serment the largest, oblong, all quite entire and obtuse; stems simple; flowers verticillately subracemose. 2\%. H. Native of Siberia, in rough stony places on the tops of Alps at the river
I'schuja, against the mouth of the river T'schegan. Root with long thick yellowish white fibres, emitting sarmenta. Leaves glabrous, rather fleshy, the primary ones simple or auricled. Flowers disposed in whorles of threes. Pappus of fruit greyish violet.

Rock-loring Valerian. Pl. $\frac{1}{4}$ to $\frac{1}{3}$ foot.

88 V. alternifolia (Led. fl. alt. 1. p. 52.) cauline leaves alternate, pinnate; leaflets lanccolate-linear, downy beneath as well as on the stem; flowers corymbose. 24. H. Native of Siberia, near the city of Irkutzk. Stem erect, simple. Radical leaves wanting in the specimen examined. Upper cauline leaves sessile, but the petioles become gradually elongated to the base. Genitals exserted. Corolla 5.parted, cleft longitudinally.

Alternale-leaved Valerian. Pl. 1 to $1 \frac{1}{3}$ foot.

89 V. Droscónidis (Sibth. et Smith, fl. grac. t. 33.) plant glabrous, erect; lower leaves lyrately pinnate, with ovate tootherl leaflets: the tcrminal one large; upper leaves with equal lanceolate toothed leaflets; cymes crowded, panicled; peduncles dichotomous. 24. H. Native of Lycia. Roots tuberous. Flowers pale red.

\section{Dioscorides' Valerian. Pl. 2 feet.}

$$
\text { ** * Species natives of Europe. }
$$

90 V. sambucifòla (Mikan, in Roem. et Schultes, syst. 1. p. 351.) stems erect, striated, glabrous, pilose at the joints ; leaves all pinnate; leaflets $4-5$ pairs and an odd one: those of the lower leaves ovate, and coarsely toothed, of the superior ones oblong-lanceolate, toothed, and rather decurrent; panicles thyrsoid. 4. H. Native of Germany. Link, enum. hort. berol. 1. p. 63 . V. altissima, Horn.? This is a larger plant in all its parts than $V$.officinalis, and does not change by culture. Flowers pink.

Elder-leaccd Valerian. Fl. May, June. Clt. 1819. Pl. \& to 4 feet.

91 V. officina'tis (Lin. spec. p. 45.) plant smoothish, erect; stems furrowed; leaves all or nearly all pinuate, with $T-8$ pairs of lanceolate serrated leaflets, and an odd one; corymbs at length panicled; fruit glabrous. 4 . H. Native of Europe and Caucasus, in humid places, and about the banks of pools and rivers; plentiful in Britain. Dufr. val. p. 40. D. C. f. fr. no. 3315 . Blackw, herb. t. 171. Woodv, med. bot. t. 96. Heyne, arz. gew. 3. t. 32. Curt. lond. 6. t. 3. Sowerb. engl. bot. 698 . Oed. fl. dan. t. 570 . V. sylvéstris, Dodon. pempt. 349. f. 2. Phù, Column. phyt, 114. Phú Germánicum, Fusch. hist. p. 85\%. This is a very common and a very variable plant, having the stem from 2 to 4 feet high, glabrous or pilose: the lower leaves almost undivided, or all pinnate, with the leaflets broader or narrower, and more or less decurrent, most often toothed, very rarely quite entire, shining or opaque; corymbs contracted or loose; but all these variations are hardly considered varieties. V. lùcida, Hort. par. V. excélsa, Poir. dict. 7. p. 801 . V. altíssima, Mikan in Bess. enum. p. 4. V. rèpens, Host, austr. 1. p. 35. are only varieties of $\boldsymbol{r}$. officinàlis. Root composed of long slender fleshy fibres, uniting into a head, and sending out long fleshy creeping shoots from the crown. Leaves bearded at the base on the under sidc. Flowers pale red, having a singular odour. Pappus of seeds 12-rayed, purplish. In high dry pasture heaths and wocks, the plant becomes smaller and more bairy, with the leaves narrower, and the roots more highly aromatic and less nauseous.

The roots have a strong, and to most people a disagreeable smell; its taste is warm, bitterish, and subacrid, communicating its properties to wine, water, and spirit ; but it is best in substance, and may be taken from half a drachm to 2 drachms to a dose. There is no doubt of its possessing antispasmodic virtues in an eminent degrce. It is often prescribed with advantage in 
lyysterical cases; and instances are not wanting where it appears to have removed some obstinate epilepsies In habitual costiveness it is an excellent medicine. The unpleasant flavour of valerian is best concealed by a small addition of mace. A tincture of the root in proof spirit, and in volatile spirit, is ordered in the London Pharmacopæia. Dr. Cullen says, that if it lıas sometimes failed, it is from the disease depending upon different causes, or the root being frequently employed in an improper condition, or in doses not large enough. - It is well known that ('ats are much delighted with the roots. Dr. Stokes informs us, lhat rats are equally fond of them, and that rat-catchers employ them to draw the rats together.

Officinal Valerian. Fl. June, July. Britain. Pl. 1 to $4 \mathrm{ft}$. $92 \mathrm{~V}$. Sitche'ssis (Bongard, in mem. acad. imp. Petersb. 2. 1. 145.) stem erect, glabrons, but pilose at the nodi; lower leaves ternate: superior ones pinnate, with 2 pairs of ovate, acuminated, coarsely toothed segments or leaflets; corymbs dense, contracted. 4. H. Native of the island of Sitcha, where the roots are used by the natives as a precious medicine. Very nearly allied to $V$. sambucifolita and $\boldsymbol{V}$. officinalis.

Sitcha Valerian. Pl. 2 to 3 feet.

93 V. angustiròlia (Tausch. ex Host, fl. austr. I. p. 36. but not of Cav.) plant downy, erect; stems furrowed; leaves piunate; leaflets linear-lanceolate, obtuse, ciliated, quite entire, the 3 terminal ones confluent. 24. H. Native of Bohemia, on hills and mountains. Flowers rose-coloured. Root like that of $I$. officinalis.

Varrow-leaved Valerian. P]. 1 to 2 feet.

\section{**** A species native of the Cape of Good Hope.}

94 V. Care'nsis (Thunb. prod. p. 7. fl. cap. p. 33.) plant glabrous, erect; stem striated; leaves pinnate; segments or lubes alternate? ovate-toothed, acute, the odd one the largest; corymbs panicled. 24. G. Native of the Cape of Good Hope, in valleys on the mountains. Habit of $Y$. officinalis, but differs from it in the shorter lobes of the leaves. The roots are used in the same way as $V$. officinalis. Stem pilose at the joints.

Cape Valerian. P]. 1 foot.

\section{† Species not sufficiently known.}

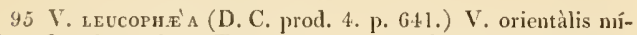
nima flore leucophæa, Tourn. cor. p. 6. Allied to V. tuberosa, ex Stev, obs. p. 67. but the bracteas are long and distant. Flowers dusky.

Dushy-flowered Valerian. Pl. 1 foot.

96 V. angustíloba (D. C. prod. 4. p. 641.) V. orientàlis angustifòlia, floribus et radice Valerianæ hortensis, Tour. cor. p. 6. 'This plant is nearly allied to $I$. officinalis, but differs in the narrower leaves.

Varrom-lobed-leaved Valerian. Pl. 2 to 3 feet.

Cult. All the hardy species thrive well in any common gar. den soil, and are easily increased by dividing at the root. Many of them are very ornamental border-flowers. The tender kinds, or those from warmer climates, slould be grown in pots, in a mixture of peat, sand, and loam, so that they may be protected in winter by placing them in a frame or green-lıouse.

X. BE'TCKEA (named after M. Betcke, who has described many species of lalcrianélla). D. C. coll. mem. vii. prod. 4. p. 642 .

Lin. syst. Triándria, Monogýnia. Limb of calyx 1-toothed, deciduous. Corolla funnel-shaped, 5-lobed. Stamens 3. Fruit 1 -celled, triquetrous, naked at the apex. Seed 1 , conforming to the fruit, and filling the cell.-Glabrons, annual, simple, erect herbs. Leaves undivided. Flowers small, white. Habit of a species of lálcrianćlla.
1 B. samolifòla (D. C. prod. 4. p. 642.) lower leaves obovate-oblong : upper ones ovate-roundish, sessile, stem-clasping; cymes small, on short peduncles in the axils of the leaves; bracteas oblong. $\odot . H$. Native of Chili, in mountain pastures near La Punta de Cortes, and about Valparaiso and Conception. Valeriàna seu Fèdia samolif òlia, Bert. in litt. 1829. and in bull. sc. 1830.1111 . Habit of Samòlus or Claytòniu.

Samolus-leaved Betckea. Pl. $\frac{1}{4}$ foot.?

2 B.? Gillie'sII (Hook. et Ärn. in bot. misc. 3. p. 366.) plant quite glabrous; root tufted, woody ; radical leaves roundish-elliptic, almost 3 times shorter than the petioles, quite entire; scapes about equal in length to the leaves; flowers in crowded heads; fruit glabrous, lanceolate, angular; limb of calyx short, urceolate.-Native of Chili, in clefts of rocks near La Casa de Piedro, and the Andes of Mendosa, forming dense masses. B. samolifolia, Gill. but not of D. C. There is on the scape usually one pair of floral leaves: from the axil of each arises a head of flowers, in addition to the terminal one; and these three heads arc often so close as to appear like one. This is probably not a species of Bétckea; its fruit is not triquetrous, nor is the limb of the calyx 1-toothed and deciduous; but the fruit is still 1seeded.

Gillies's Betckea. Pl. $\frac{1}{4}$ foot.

Cult. The seeds will only require to be sown in the open ground in May, in a sheltered situation.

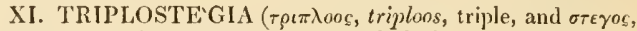
stegos, a covering; the flowers are clothed by 3 coverings, a double involucrum and the calyx). Wall. cat. no. 436. D.C. coll. mem. vii. prod. 4. p. 642.

LiN. syst. Triandria, Monogýnia. Flowers covered by a triple tegument, a double involucrum, and the calyx. Outer involucrum 4-parted and 4-keeled: inner one tubular, 8-toothed, and 8 -ribbed. Calyx adhering to the ovarium, with a small 4toothed limb. Corolla funnel-shaped, 5-cleft, not gibbous at the base, nor spurred. Stamens 3, rising from the base of the tube; anthers a little exserted. Stigma capitate. Utriculus 1seeded, beaked, covered by the double involucrum, and crowned by the tecth of the calyx, downy.-An Indian herb. Root long, fibry, scentless. Stems obsoletely 4-furrowed, simple or sparingly branched, bearing longish articulated hairs towards the top, which are tipped with glands. Leaves approximate at the base of the stem, oval-lanceolate, toothed, pinnatifid, downy above, and rather villous beneatl, petiolate; cauline leaves few, pinnatifid, small. Corymbs or panieles clothed with glandular down. Flowers small, by threes, downy.

1 'T. glandulífera (Wall. 1. c.) 4.H. Native of Nipaul, on mountains about Gosaingsthan, growing along with Nardóstachys.

Gland-bearing Triplostegia. Pl. $\frac{1}{2}$ to 2 feet.

Cult. This plant should be grown in a pot, in a mixture of loam, peat, and sand, and placed among other alpine plants. It may be propagated by dividing at the root, or by seed.

Order CXXXII. DIPSA'CEA (the plants contained in this order agree with the genus Dipsacus in several important characters). Vaill. mem. acad. par. 1722. D. C. fl. fi. 4. p. 221. Coult. dips, diss. 4to. geneva, 1823. et emend. ined. in litt. 1824. D. C. prod. 4. p. 6\$3.-Dipsacearum genera, Juss. and Adans.

Tube of calyx closely girding the ovarium (f. 118, d.). Limb of calyx variable, short or elongated, entire (f. 117. g.), toothed, or ending in numerous variable bristles (f. $118 . d_{.}$) which are usually plumose, and pappus-formed. Corolla gamo- 
petalous (f. 117.f. f. 118, c.), inserted in the top of the tube, rarely ringent, but usually unequal (f. $117 . f$. f. 118. e.), 4-5cleft. Stamens 4. (f. 118. f.), inserted in the tube of the corolla, and alternating with its lobes, nearly always distinct and free; antlers 2-celled. Style filiform (f. 118.g.); stigma simple, longitudinal or subcapitate. Fruit indehiscent, membranous or subnucumentaceous (f. 118.h.f. 117. c.), crowned by the limb of the calyx (f. 117. i.f. 118, i.), 1-celled, 1-seeded, usually covered by the involucel (f. $11 \%$. g.) Seed pendulous in the fruit; albumen fleshy. Embryo straight, with a superior radicle.-Herbs or subshrubs. Leaves opposite, rarely verticillate, very variable in form, and even so in the same individual, the radical and cauline ones being very different. Flowers in dense heads, girded by involucra, very rarely in whorles. Involucel calyciform, girding the Hower.

This order was formerly joined with Valerianca, but is readily distinguished from it, by the whole habit, by the flowers being in involucrated heads, and the single flowers being involucellate; by the fruit being constantly $\mathrm{l}$-celled and $\mathrm{l}$-seeded, in the stamens being always 4 in number, by the stigmas being simple, and by the seeds being albuminous. In this latter respect it agrees with the order Calycerece, but is distinguished from it in the embryo being erect, not inverted, and in the anthers being free, not combined into a tube. It agrees also with Compósitce, from which it differs in its distinct stamens, and its pendulous albuminous seeds. What is called the involucel is a curious organ, resembling an external calyx, and is to each particular flower in the head of Dipsicece, what the partial involucrum of Compósita is to each umbellule. In several species of Scabiòsa the ovarium is entirely united with the tube of the calyx. Mr. Brown remarks, that the base of the style coheres with the narrow apex of the tube of the calyx, even in those plants of the order in which the dilated part of the tube is entirely distinct from the ovarium. This kind of partial cohesion between pistillum and calyx is directly opposite to what usually takes place, namely, the base of the ovarium being coherent, while its upper is distinct. It equally, however, determines the apparent origin or insertion of the corolla and stamina, producing the unexpected combination of flos superus with ovarium liberum. The order also agrees in many respects witl Nyctaginea and Globularinea.

The plants contained in this order have almost the habit of Compósita; all have the flowers growing in heads. Many of them are elegant border-flowers, and are cultivated with great facility. Some of the species of Scabiòsa have been employed as diaphoretic and anti-syphilitic, but are now neglected.

\section{Synopsis of the genera.}

$$
\text { TRIBE } I \text {. }
$$

Morine.e. Corolla ringent. Stamcrs 4, combined by twos, or didynamous. Flowers verticillate, bracteated.

1 Morina. Involucrum 1-leaved, campanulate, with spinytoothed edges. Calyx with an ovate tube, and a foliaceous bificl limb. Corolla long, tubular.

Triee II.

ScABiòsex. Corolla 4-5-cleft (f. 118, e.), not ringent. StavOL. 11 . mens 4-5 (f. 1 i S. $f$.), free, nearly equal. Flowers aggregrate upon a receptacle (f. 118.c.), the heads involucrated by a general involucrum, and each flower girded by a calyciform involucel (f. 117. g.).

2 Dr'psacus. Involucrum of many leaves, much longer than the paleæ among the flowers, which are foliaceous. Corolla 1cleft. Stamens 4. Fruit crowned by the subtetragonal linb of the calyx, inclosed within the involucel.

3 Сернада'ва. Involucrum of many imbricated leaves, which are shorter than the paleæ $(f .116, a)$. Involucel terminated by a 4-8-toothed crown. Corolla 4 -cleft (f. 116. c.). Stamens 4. Fruit tetragonal, crowned by the limb of the calyx, and inclosed within the involucel.

4. KNaútia. Involucrum of many leaves. Palex none. Receptacles hairy. Involucel girling the fruit, denticulated at the apex. Limb of calyx cup-shaped. Corolla 4-5-cleft. Sitamens 4.

5 Pteroce'phalus, Involucrum double, each series of 4-6 leaves. Receptacle villous or chaffy. Involucel toothed (f. $11 \%$. h.) or awned. Limb of calyx ending in feathery bristles (f. $11 \%$. . f. 118 . i.). Corolla 5 -cleft. Stamens 4, rarely $2-3$.

6 ScABiòsa. Involucrum of many leaves. Receptacle chaffy. Involucels usually subcylindrical. Limb of calyx attenuated into a neck at the base, and ending in 5 awned bristles. Corolla 4-5-cleft. Stamens 4.

\section{Tribe I.}

MORI'NEF (this tribe only contains the genus Morina). D. C. prod. 4. p. 644. Corolla ringent. Stamens 4, didynamous, or combined by twos. Flowers verticillate, bracteate.

1. MORI'NA (so named by Tournefort after Louis Morin, M. D. member of the Academy of Sciences at Paris, who first raised it from seed in his garden at the Abbey of St. Victor. He gave lectures on botany in the Jardin du Roi, Paris, in place of Tournefort, while he was in the Levant). Tourn. cor. p. 48. Lin. gen. no. 41. Lam. ill. 21. Coult. dips p. 21. D. C. prod. 4. p. 644.-Diotothèca, Vaill, mem. acad. par. 1 722. but not of Rafin.

Lin. syst. Tetrándria, Monogýnia. Involucel 1 . leaved, tubularly campanulate, destitute of foreolæ, with spinosely-toothed margins. Tube of calyx ovate: limb foliaceous, bifid: lobes oblong, entire or bifid. Corolla long, tubular, ringent. Stamens 4, sometimes free, didynamous, and sometimes joined together by pairs, diadelphous. Stigma peltately capitate. Fruit crowned by the lobes of the calyx, and girded by the involucel-Derennial, simple, ercct herbs, with the habit of C'arduus. Leaves oblong, sinuated, dentately spinose, rarely quite entire. Flowers crowded in whorles in the axils of the superior leaves. Floral lcaves slıorter, almost palmately spiny-toothed.

Sect. I. Diotoca'lyx (from ies, dis, twice, and ovs wtos, ous $o t o s$, an ear, and $k \alpha \lambda v_{\xi}, k a l y x$, a calyx; in reference to the limb of the calyx being of 2 lobes). D. C. prod. 4. p. 64t. Leaves sinuated and spinosely toothed. Lobes of calyx 2, oblong, more or less emarginate at the apex, unarmed. Stamens combined by twos, perhaps in all the species.

1 M. PE'rsica (Lin. spec. p. 39.) leaves pinnate-jarted lobes ending in long hard spines; floral leaves and corollas villous: lobes of calyx retuse, slightly emarginate. 2 . F. Native of Persia about Ispahan, Syria, Asia Mlinor, and on Mlount Parnassus, Sibth. et Smith, fl. græc. t. 28. Coult. dips. 21. t. 1. f. 1. M. orientalis carlinæfòlia, 'Tourn. voy. 2. p. 289. with a $4 \mathrm{~S}$ 
figure. M. orientàlis, Mill. M. verticillàta, Moench. suppl. Flowers white and redulish on the same plant. Stamens joined from the base to the inthers by twos.

Persian Morina. Fl. July, Aug. Clt. 1740. Pl. 2 to $3 \mathrm{ft}$.

2 M. Longleòlia (Wall. cat. no. 426. D. C. prod. 4. p. 644.) leaves sinuately pinnatifid, and somewhat spiny-ciliated; floral leaves rather villous; lobes of calyx emarginate. 24. F. Native of Nipaul, at Gosaingsthan. Stem terete, not furrowed. Leaves of the consistence and form of those of Cirsium oleraceum, almost a foot long, and hardly an inch broad. Spikes of flowers interrupted at the base. Floral leaves ovate-lanceolate. Lobes of calyx as in M. Pérsica, but more emarginate. Corolla and genitals unknown.

Long-leaved Morina. Pl. 2 to 3 feet.

3 MI. polyphy'lla (Wall. c'at. no. 425. D. C. prod. 4. p. 644.) leaves pinnatifid: lobes spinosely toothed; floral leaves rather villous, elongated, stifly spinose ; lobes of calyx deeply divided. 4. F. Native of Nipaul, at Gosaingsthan. Intermediate between $M$. Pérsica and $M$. longifolia, but is distinguished from them in the leaves being more elongated and acuminated, and in the lobes of the calyx being bifid beyond the middle. Corolla and genitals unknown.

Many-leaved Morina. Pl. 2 to 3 feet.

Sect. 11. Acantuoca'lyx (from anty 0 og, acanthos, a spine, and $k a \lambda v \xi$, kalyx, a calyx ; in reference to the limb of the calyx being spiny-toothed). D. C. prod. 4. p. 645. Leaves quite entire, except the floral ones, which are a little spiny-toothed. Limb of calyx oblique, irregularly spiny-tootled. Stamens 4, distinct, didynamous.

4 M. NA'Na (Wall. cat. no. 424. D. C. prod. 4. p. 645.) cauline leaves quite entire: floral ones bearing spines at the base; involucel 1-leaved, ciliated by spines; limb of calyx oblique, irregularly spiny-toothed. 2. F. Native of Nipaul, at Gosaingstlan. M. Nipaulénsis, D. Don, prod. fl. nep. prod. 161. Stem villons at top, as well as the young leaves. Flowers red. Corollas villous outsicle, 3 times longer than the calyx.

\section{Dwarf Morina. Pl. $\frac{1}{2}$ to 1 foot.}

Cult. 'The species of Morina thrive best in a light rich soil ; and may be increased by dividing at the root, or by seed.

\section{Tribe $1 \mathrm{I}$.}

SCABIO'SEA (this tribe contains plants agreeing with $\mathrm{Sca}$ bidsa in having capitate flowers). D. C. prod. 4. p. 645.Dipsàcea, Wallr. sched. crit. p. 41. Corolla 4-5-cleft (f. 117.f. f. 118. f.), not ringent. Stamens $4-5$, free (f. 118, f.), nearly equal. Flowers crowded in heads upon receptacles, each head girded by a general involucrum (f. 117, a.), with usually distinct palew on the lower side, and each flower girded by a calyciform involucel (f. $117 . e$. f. $118, d$.).

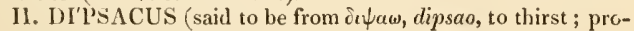
bably in consequence of the connate leaves holding water: iı $u$ kos, dipsatios, is also the Greek name for the disease called diabetes, which is always accompanied by great thirst). Tourn. inst. t. 265. Lin. gen. 114. Gærtn. fruct. 2. t. 86. Coult. dips. p. 21. f. 2-4. Wallr. sched. crit. p. 49 .

I,IN. syst. Tetrandrit, Monogynia. Involucrum of the head of flowers of many leaves, longer than the paleæ. Paleæ on the receptacle acuminated, rather foliaceous. Involucel tetrandrous, S-furrowed. Limb of calyx somewhat cyathiform or discoid. Corolla 4-cleft. Stamens 4. Stigma longitudinal. Fruit crowned by the subtetragonal limb of the calyx, and inclosed within the involucel._Erect, pilose, or prickly biennial herbs. Leaves opposite, usually connate at the base, toothed or jagged. Heads of flowers terminal, oblong-ovate or roundish. Corolla lilaccoloured, yellow, or white.
1 D. sylvéstris (Mill. dict. no. 2.) stem prickly; leaves connate at the base, ovate-lanceolate, acuminated, toothed ; leaves of involucrum inflexed, weak, longer than the heads of flowers; palex of heads straight, linear-lanceolate, setaceous, bent; involucel not drawn out beyond the furrows. $\delta . \mathbf{H}$. Native of Europe and Siberia, frequent; plentiful in some parts of Britain, about hedges and by road sides. Jacq. fl. austr. $t$. 402. Oed. fl. dan. t. 965. Smith, engl. bot. t. 1032. Curt. lond. 3. t. 9. D. sylvéstris $\alpha$, Coult, dips. p. 22. D. vulgàris, Gmel. A. bad. 1. p. 312. D. fullònum, Thor. chlor. land. p. 36. Poll. pal. no. 137. D. purpureus, Fuschs. hist. 225. Flowers bluishpurple, first breaking forth about the middle of the head. Heals of flowers ovate-oblong. The water contained in the basin formed by the leaves is said to cure warts on the hands, and to serve as a beauty-wash for the face; hence Ray conjectures it had its name, Labrum I encris.

lar. $\beta$, pállidus (Bess. in Rom. et Schultes, syst. 3. p. 41.) leaves of involucrum shorter, hardly ascending. $\delta$. H. $\mathrm{Na}$ tive of Galicia, \& $c$.

IIild Teazle. Fl. July. Britain. Pl. 6 feet.

2 D. LacıNia'tus (lin. spec. p. 141.) stem prickly; leaves connate at the base, sinuately jagged, and the lobes sinuately toothed; leaves of involucrum erectish, stiffish, usually shorter than the head, which is ovate; palea straight, linear-subulate; involucel not drawn out beyond the furrows. 8. H. Native of Europe and Siberia, in hedges and ditches, as of Germany, France, Alsace, Austria, Caucasus, \&c. Jacq. fl. austr. 5. t. 403. D. syluéstris, var. $\gamma$, Coult. dips. p. 22. Leaves downy beneath. Corollas whitish; anthers reddish.

Tar. $\beta$, comòsus (D. C. prod. 4. p. 645.) leaves of involucra very narrow, longer than the heads. $\delta$. H. Native of the south of Europe. D. comòsus, Hoffm. et Link. fl. port. 2. p. 81. D. laciniàtus, Brot. H. lus. 1. 1. 147. D. sylvéstris $\delta$, Coult. l. c.

Jagged-leaved Teazle. Fl. July, Aug. Clt. 1683. Pl. 3 to $5 \mathrm{ft}$.

3 1. divarica'tus (Presl. fl. sic. p. 57. del. prag. 117.) stem prickly; radical leaves oblong, rather lyrate, ciliated: cauline ones interruptedly pinnatifid: lobes divaricate, pinnatifid at the base; leaves of involucrum shorter than the head, which is ovate,; paleæ spinescent, arched; involucels unknown. \& H. Native of Sicily, on the edges of fields. Guss. prod. 1. p. 157. D. laciniàtus, Ucria, hort. pan. p. 66.?

Divaricate Teazle. Pl. 3 to 5 feet.

4. D. Furlònum (Mill. dict. no. 1.) stem prickly; leaves connate at the base, oblong-lanceolate, serrated: upper ones entire; leaves of involucra spreadingly reflexed, sliorter than the leads, which are cylindrical; paleæ stiff, recurved; involucel not drawn out beyond the furrows. $\delta$. H. Native of the south of Europe, where it is said to grow spontaneously in fields. It is said to be a native of England; but scarcely wild. Plenck. off. t. 50. Sowerb. engl, bot. 2080. Hayn. term. bot. t. 41. f. 8 . Coult dips. p. 22. D. sativus, Gmel. fl. bad. 1. p. 314. D. fullònum $\beta$, Lin. spec. p. 140. D. sylvèstris $\varepsilon$, Coult. in litt. $18 \% 4$. -Lob. icon. 2. p. 17. with a figure. Flowers whitish, with pale purple anthers. This and the three preceding have been combined by Coulter.

Fullers' Thistle or Tcazle is called Chardon a foullon in French, Kardendistel in German, and Cardencha in Spanish; Dipsaco in Italian : is a biennial plant from 4 to 6 feet bigh, prickly and rough in the stem and leaves, and terminated by rough bur-like heals of flowers. It is cultivated in Essex and the West of England, for raising the nap upon woollen cloths, by means of the erooked palea upon the heads. For this purpose they are fixed round the circumference of a cylinder, which is made to turn round, and the cloth is held against them. There are no varieties of the cultivated Teazle, but the wild species is not 
materially different, and may be used in its stead, though its chaff is not quite so rigid.

The soils on which the Teazle grows the strongest are deep loamy clays, not over rich. The situation should be rather elevated, airy, and exposed to the south. In the rotation, it may accupy the place of a green and corn-crop, as the first year the plants are treated like turnips, and the second the crop is ripened. The soil should be ploughed deep, and well comminuted by cross ploughings or stirrings with pronged implements.

The sowing scason is the beginning of April ; the quantity of seed is from 1 to 2 pecks per acre, and in quality it should be fresh and plump. The mode of sowing is almost always broadcast, but no crop is better adapted for being grown in drills, as the plants require hoeing and thinning. The drills may be either sown on ridgelets or a flat surface, in the manner of turnips, or by ribbing. The distance between the rows may be from 18 inches to 2 feet. In Essex, carraway is commonly sown with the teazle crop, but this is reckoned a bad plan.

The after culture of this crop consists the first year in hoeing and stirring the soil, and in thinning out the plants to the distance of 1 foot every way, if sown broad-east, or to the distance of 6 inches, if sown in rows. Vacancies may be filled up by transplanting; and a separate plantation may be made with the thinnings, but these never attain the same vigour as seedlings. The culture the seeond year consists also of hoeing, stirring, and weeding, till the plants begin to root. When the teazle is grown broad-cast, the intervals between the plants are dug by means of spades which have long narrow blades, about the length of 16 or 17 inches, and not more than about 4 inches in breadth. With these the land is usually worked over in the intervals of the plants, three or four times during the summer months; and in the course of the following winter, as about the latter end of February, the land between the plants is to be again worked over by the narrow spades, care being taken that none of the mould falls into the hearts of the plants; and again, about the middle of May, when they begin to spindle, another digging over is given, the earth being raised round the root-stems of the plants, in order to support and prevent them from being blown down by the wind. some cultivators perform more frequent diggings, that the ground may be rendered cleaner and more mellow; consequently the growth of the plants will be more effectually promoted. The business in Essex lias usually the name of spaddling, and is executed with great despateh by labourers that are accustomed to perform it.

The taking of the Teazle crop, when no regard is had for seed, commences about the middle of July, when the blossoms begin to fall from the heads. It is the best method to have the heads cut as they become ripe; but the work is usually executed at three different times, at the distance of ten days or a fortnight from each other. It is performed by means of a knife, contrived for the purpose, and a string attached to the haft. This last is done in order that it may be hung over the hand. A pair of strong gloves are also necessary. Thus prepared, the labourer cuts off the ripe heads along the rows or lines, with about 9 inches of stem, and ties them up in handsfull, with the stem of one that is more perfeetly ripened. And on the evening of the day on which they are cut, they should be put into a dry shed; and when the weather is fine, and the air elear, they should be taken out and exposed to the sun daily, till they become perfectly dry. Much care must, however, be taken that no rain falls upon them. In doing this, some make use of long small stakes or poles, on which these handsfull are hung during the time of their preparation.

As soon as they are completely dried, they should be laid up in a dry room, in a close manner, till they are become tough, and of a bright colour, and ready for use. They should then be sorted or separated into three different kinds, by opening each of the small bundles. These are distinguished into kings, middlings, and scrubs, according to their different qualities. 'They are afterwards, the author of "The Somerset Report" says, made into packs, which, of the first sort, contain 9000 heads, but of the second, 20,000; the third is a sort of very inferior value. By some, before forming them into packs, they are done up in to what are termed staves, by means of split sticks, when they are ready for sale.

The produce of Teazle varies from 10 to 15 packs per acre; nine packs of lings, nineteen of middlings, and two of scrubs, are reckoned a large crop, with a great bulk of haulm. Often, however, the crop fails.

The usc of the heads of the Tcazlc has been already mentioned. The haulm is of no use but for burning as manure. Parkinson observes, that this is a sort of crop that may be grown to advantage on many lands; in rotation, as a fallow to prepare for wheat; and by burning the straw and refuse stuff after the crop is reaped, it will be foumd not to impoverish, but rather to improve the land. In their young state, the teazle plants stand the winter without danger, and are a good crop for clearing land of all weeds, from their lateness in the process of hoeing, there being few weeds at so advanced a season; on all these accounts they become an advantageous crop for the farmer.

To save sced, leave a few of the very best plants uncropped, and then, when the seed is ripe, cut off only the largest and terminating heads, from whiel the seed is easily separated by beating with flails, and cleaned by a winnowing machinc or a sieve.

The chicf injurics to which the Tcazle is liable are those effected by the fly and slng in its infant state.

Fullers' Teazle. Fl. July. Britain. Pl. 6 feet.

5 D. sinun'tes (Willd. Mss, in Rom. et Schultes, syst. 3. p. 519.) leaves pinnatifidly sinuated: segments laeiniately toothed. 8. H. Native of Persia, on the alps in the province of Ghilan. Coult, dips, no. 22.

Sinuated-leaved Teazle. Pl. 3 to 4 feet.

6 D. FE'rox (Lois, fl. gall. p. 719. t. 3.) stem and leaves echinated from prickles; leaves connate at the base: radical ones sinuated: middle ones pinnatifil: upper ones entire; leaves of involucra spreading, a little longer than the heads, which are ovate; palea subulate, straight, stiff; involucel drawn out beyond the furrows into a sinort membrane. $t$. H. Native of Corsica and Sardinia, on the edges of fields. Said to grow in plenty in Austria, Bohemia, and Moravia. Tratt. tab. t. 235. D. C. fl. fr. suppl. p. 486. Coult. dips. p. 23. Flowers white or pale red. The central head of flowers is usually cylindrical, and the lateral ones roundish.

Fierce Teazle. Fl. July, Aug. Clt. 1 s18. Pl. 3 to 4 ft.

7 D. Guelixs (Bieb. H. taur. 1. p. 92.) stem prickly; leaves sessile: lower ones undivided or eut : superior ones pinuateparted, with oblong acute segments; leaves of involucra deflexed, incurved, weak, shorter than the heads, which are ovate, or nearly globose; palea membranous, acuminately awned, straight : involucel drawn out beyond the furrows into a membranous crown. \$. H. Native of Tauria, at Kuma, about the ruins of Maschar, but rare, ex Steren; at the river Don, ex Golb.; and of Siberia, about the Irtish, ex Gmel. sib. 2. p. 209.; and of the Kirghisean Steppe, between Bucktorminsk and Lake Noor Saisan, ex Led. fl. alt. 1. p. 127. Conlt. dips. p. 23. D. laciniàtu Falck, top. beytr. 2. no. 14.0. Corollas blue.

Gmelin's 'Teazle. Fl. July, Aug. Clt. 1820 . Pl. 3 feet.

8 D. strigòsus (Willd. mss. ex Roem. et Schultes, syst. 3. p. 520.) leaves toothed and entire, appendiculated: upper onc:s jagged at the base, ciliated; involucra twice the length of the palex; palea setaceous, twice the length of the flowcrs. 452 
11. Native of Persia, in the province of Ghilan. Coult. dips. p. 23. Said to be allied to the following.

Strigose Teazle. P'l. 3 to 4 feet.

9 D. pilòsus (Lin. hort. ups. p. 25.) stem prickly, glabrous; prickles hair-formed under the head ; leaves glabrous, petiolate, ovate, toothed, auricled at the top of the petioles; leaves of involucra deflexed, shorter than the heads, which are globose, but hardly exceeding the paleæ, which are linear-subulate and pilose; involucel not drawn out beyond the furrows. ‡.H. Native nearly throughout the whole of Europe, in woods and hedges; Caucasus, in Alpine places. In England, in moist shady places on a chalky or lime-stone soil. Oed. fl. dan. t. 1448. Jacq. fl. austr. t. 248. Smith, engl. bot. t. 877. Coult. dips. 23. Curt. lond. t. 10. Ceplıalària appendiculàta, Schrad. cat. sem. goett. 1814. Palea ciliated. Corollas white. Anthers dark purple or brown.

Pilose Teazle. Fl. Aug. Britain. Pl. 2 to 4 feet.

10 D. stríctus (D. Don, prod. fl. nep. 160.) stem unarmed, but beset with short retrograde hairs; leaves petiolate, lanceolate, acute, dentately serrated, beset with villi on both surfaces; leaves of involucra spreadingly deflexed, shorter than the heads, but hardly exceeding the paleæ, which are oblongcuneated, straight at the apex, ciliated, canescent ; involucels harlly furrowed, crowned. \&. H. Native of Nipaul. D. inérmis, var. $a$, Wall, in fl. ind. 1. p. 367 . Stem erect, branched, hexagonal. Flowers cream-coloured. According to D. Don, in fl. nep. the leaves are connate at the base. Heads of flowers spherical.

Straight Teazle. Fl. July. Clt. 1823 . Pl. 4 to 5 feet.

11 D. 1NÉRMIs (Coult. dips. p. 23.) stem unarmed, downy, but having the branches hispid under the heads; leaves petiolate, ternate or somewhat pinnatifid, clothed with adpressed pili on both surfaces: lobes lanceolate, acuminated, serrated; leaves of involnera defiexcd, shorter than the heads, which are globose, but exceeding the palea a little; palea ovate, mucronate, ciliated at the apex; involucels hardly furrowed, crowned. $\delta . \mathrm{H}$. Native of Nipaul, in alpine places. D. inérmis, var. $\beta 3$, Wall. in f. ind. 1. p. 867 . 1). mitis, D. Don, prod. fl. nep. p. 161. Stem hexagonal, pilose, unarmed. Paleæ about equal in length to the flowers Corollas yellow.

Unarmed Teazle. Fl. July. Pl. 2 to 3 feet.

12 D. Ásper (Wall. cat. no. 428. D. C. prod. 4. p. 646.) stem prickly; leaves undivided or pinnatifid, oblong-lanceolate, acuminated, serrated, scabrous on both surfaces from britty liairs ; leaves of involucra deflexed, shorter than the heads, which are globrse, but exceeling the palea, which are ovate, ciliated, and nucronate; involucels hardly furrowed. $\delta . H$. Native of the East hurlies, on the Pundus Mountains. Stem and branches angular; angles beset with stiff prickles.

liough Teazle. Pl. 2 to 3 feet.

1 i. 1). Leschenaultii (Coult. in litt. ex D. C. prod. 4. p. 647.) stem smooth, rather hairy; leaves lyrately pinmatifid, very villous on both surfaces, acmminated, coarsely serrated at the apex: lower ones petiolate: lobes of leaves 3-nerved at the bitse; leaves of involucra spreading, shorter than the heads, which are globose, and hardly exceeding the paleæ, which are ollong, acuminated and pilose ; involucel drawn out a little into a menbranous crown beyond the furrows. 8 . H. Native of the East Indies, on the Nellighery Mountains, where it was collected by Leschenault and Noton. Scabiòsa Brunoniàna, Wall. cat. no. 429. The plant is called Donde Gueda by the natives. Stem 3 feet high, rather hairy, not prickly. Habit of Ceplaalaria alpina.

Lesehenault's Teazle. Pl. 3 feet.

Cult. None of the species are worth growing, except in bo- tanic gardens. They will grow in any soil in which the seeds may be sown.

III. CEPHALA'RIA (from $\kappa \varepsilon \phi a \lambda \eta$, kephale, a head; the flowers are disposed in round heads). Schrad. cat, sem. hort. gott. 1814. Rœm. et Schultes, syst. 3. p. 406. Coult. dips. p. 24. et emend. mss. 1824. D.C. prod.4. p. 647.-Lepicéphalus, Lag. gen. et spec. 1816. p. 7.-Cerionánthus, Schott, mss. ex Rom. et Schultes, syst.-Succisa, Vaill. Wallr. I. l. c. c. Spreng. syst. no. 976. exclusive of some species.-Picnócomon, Wallr. mss. - Scabiòsa species, Lin. and others.

Lin. syst. Tetrándria, Monogýnia. Involucra surrounding the heads of many imbricated leaves (f. 116. a.), shorter than the paleæ. Involucel tetrandrous, rarely compressed, 8-furrowed, terminated by a 4-8-toothed crown. Limb of calyx rather cup-shaped or discoid. Corolla 4 -cleft. Stamens 4 (f. 116. d.). Stigma longitudinal. Fruit tetragonal, crowned by the limb of the calyx, inclosed within the involucel.-Perennial herbs. Leaves toothed or pinnatifid. Heads of flowers terminal, globose (f. 116.e.); paleæ imbricated: outer ones sterile. Corollas white, cream-coloured, or lilac.-This genus is hardly distinct from Dipsacus, unless in the involucra being very short.

\section{* Perennial plants. Palece aeuminated, donny.}

1 C. Alpìna (Schrad. l. c.) stem striated, rather velvety; leaves pinnate; leaflets lanceolate, decurrent, unequally serrated; palea acuminated, downy; teeth of involucel 8 , awned, nearly equal in length to the corolla; anthers green and striated at the time of dehiscence. $\psi$. H. Native of Europe, on the alps; and of Greece, on Mount Athos. Roem. et Schultes, syst. 3. p. 43. Coult. dips. 24. Scabiòsa alpìna, Lin. spec. 141. D. C. fi. fi. no. 3296. Succi a alpina, Spreng. syst. 1. p. 378 . Besl. syst. oest. 9. t. 98. f. 1. Corollas yellow. Heads of flowers drooping a little before expansion. Leaves large, downy.

Alpine Cephalaria. Fl. June, July. Clt. 1570 . Pl. 3 to 4 feet.

2 C. 'TAтA'RicA (Schrad. 1. c.) stems striated, clothed with retrograde villi at the base and on the petioles; leaves pinnate; leaflets decurrent, ova!-lanceol:ite, serrated; bracteas acuninated, downy ; teeth of involucel 8, awned, nearly equal ; outer corollas radiant; anthers green, and striated at the time of bursting. 2. H. Native of Siberia and Caucasus, in alpine meadows. Roem. et Sichultes, syst. 3 p. 51 . Coult. dips. p. 24. Scabiòsa Tatárica, Gmel. sib. 1. p. 159. Bieb. fl. tanr. 1. p. 92. but not of Lin. Sciłbiòsa elàta, Horn. hort. hafn. 1. p. 126. Rchb. pl. crit. 4. t. 301. but not of Lin. Cephalària elàta, Schrad. 1. c. Scahiòsa atràta, hort. mad. 1805. Lepicéphalus atràtus, Lag. L c. Suecìsa Tatárica, Spreng. l. c. Plant glabrous. l'eduneles angular, downy. Heads large. Palea deep green, white inside, ciliated. Corollas yellow.

lar. $\beta$, gigantèa (Coult. l. c.) plant 12 feet high. $\%$. H. Scabiòsa alíssıma, Mlill. dict. no. 6 . Scabiòsa gigantèa, Ledeb. cat. hort. dorp. 1811 . Plant glalrous.

Tartarian Cephalaria. Fl. June, Aug, Clt. 1759. Pl. 5 to 6 feet.

\section{* Annual plants. Palece membranous, anned at the apex.}

3 C. 'Transylvánica (Sclurad. l. c.) stems terete, rather pilose at the base; leaves pinnatifid: lower ones lyrate; lobes of the cauline leaves linear-oblong toothed: terminal lobes lanceolate, serrated a little; paleæ glabrous, membranous, oblong, ending in a dark purple awn each; teeth of involucel 8, short, equal. $\odot$. H. Native of the south of Europe, from Vascony to Constantinople, in fields; and of Caucasus, on mountains near Grosnaja. Coult. dips. p. 24. t. 1. 
f. 6. Scabiòsa Transylvánica, Lin. spec. p. 1 41 . Jacq. hort. vind. t. 111 . Rehb. pl. erit. 2. p. 121. Succisa pentaphýlla, Mœnch. meth. p. 488. Scabiòsa Transylvánica, Spreng. 1 . c. Lepicéphalus Trausylvánicus, Lag. Corollas white in the disk, and pale deep blue or lilac in the rays.

Var. $\beta$, semiaristàta (Coult. in litt. 1824 . ex D. C. prod. 4. p. 648.) alternate teeth of involucels awned, the rest as in the species.

Transylvanian Ceplsalaria. Fl. July. Clt. 1699. Pl. 1 to 3 fcet.

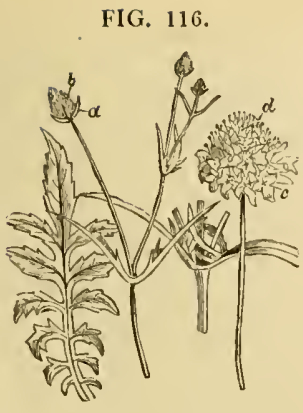

4 C. Joppénsis (Coult. in litt. ex D. C. prod. 4. p. 648.) stems terete, branched; leaves pinnatifid : lobes serrated; heads ovate; scales of involucra roundish ; paleæ silky, short-acuminated; teeth of involucels 8 , short, equal; corollas nearly equal. $\odot$. H. Native of Joppa, in hedges. Succisa Jóppica. Spreng. syst. 1. p. 1378 . Scabiosa Joppénsis, Rehb. hort. bot. 1. t. 17. Scabiòsa Transylvánica, Sieb. in herb. Kunth. Leaves, habit, and fruit of C. Transylvánica.

Joppa Cephalaria. Pl. 1 to 3 feet.

5 C. Sxalaca (Schrad. l. c.) stems more or less hispid; leaves oblong-lanceolate, serrated; heads ovate; palea broad at the base, membranous, ending each in a long awn; teeth of involucels 8,4 of which are awned, and the other 4 very short; corollas equal. $\odot$. H. Native from Spain to Persia, in fields and woods. Coult. dips. p. 23. tr. f. 7. Scabiòsa Syriaca, Spreng. 1. c. There are hispid and glabrous varieties of this plant, with either serrated or nearly entire leaves. Flowers blue.

I'ar, $\alpha$, pedunculàta (D. C. prod. 4. p. 648.) heads of flowers on long peduncles. $\odot$. H. Scabiosa Syriaca $\beta$, Lin. spec. 141 . Scabiòsa Syrìaca, Sibıh. et Smith, fl. græc. t. 105 . Scabiòsa Sibírica, Lam. ill. no. 1302. Cerionánthus Vaillántii, Schott. Cephalària Vaillántii, Rœm. et Schultes, syst. 3.p. 46. Succìsa lancifôlia, Møench. meth. p. 48s. Corollas blue.

I ar. $\beta$, sessilis (D. C. 1. c.) heads of flowers almost sessile, rising from the forks of the branches. $\odot$. H. Scabiòsa Syrìaca $a$, Lin. spec. 141. Scabiòsa dichótoma, Lam. ill. no. 1303. but not of IVilld. Lepicéphalus Syriacus, Lag. Flowers blue.

Syrian Cephalaria. Fl. July. Clt. 1633. Pl. 2 to 3 feet.

* * Perennial plants. Outer palece alone blunt or bluntish.

6 C. Decu'rrens (Rom. et Schultes, syst. 3. p. 50.) stems furrowed; leaves pinnatifid : lobes decurrent, diverging; bracteas bluntly acuminated, purplish at the apex, villous; teeth of involucels 4, purplish at the apex; limb of calyx small, bidden within the involucel; corollas unequal. 24. G. Native of the Cape of Good Hope. Scabiòsa decúrrens, Lag. gen. et spec. p. 8. Cephalària decúrrens, Coult. dips. p. 27. and in litt. 1824. Peduncles elongated. Heads about the size of walnuts. Corollas whire.

Decurrent Cephalaria. Pl. 1 foot.

7 C. centaurioldes (Coult. dips. p. 25. t. 1. f. 8.) stems terete; leaves pinnatifid; lobes oblong, quite entire, decurrent ; heads nearly globose; paleæ awnless, whitish-yellow: outer ones obtuse: inner ones acuminated; teeth of involucel 4-8, or obsolete. 2. H. Native of the south of Europe, south of Siberia, and the Luevant. The following are varieties of this plant, according to Coulter and Treveranus, in mag. nat. am. ber.
1815. Leaves glabrous, ciliated or villous: radical ones entire or variously pinnatifid; lobes narrow or ovate, straight or divaricate. Corollas equal or radiant, always yellow.

Var. a, commùnis (D. C. prod. 4. p. 648.) teeth of involucels 4-8, erect. 24. H. Coult. l. c. Scabiòsa centaurioides, Lam. ill. no. 1312, D. C. fl. fr. no. 3297. Succisa centaurioìdes, S. lævigàta, and S. ambrosioides, Spreng. I. c. Scabiòsa Transylvảnica, All. ped. no. 504 . t. 48 . Scab. ambrosioides, Smith and Sibth. fl. grac. t. 103. Scab. læevigàta, Waldst. et Kit. hung. 3. t. 230. Cephalària centaurioìdes and C. ambrosioìdes, Rocn. et Schultes. Cephalària lævigàta, Schrad. Lepicéphalus centaurioides, Lag. Flowers yellow. Radical leaves simple; cauline ones bipinnatifid; all ciliated. In $C$. ambrosioides the leaves are downy, and the cauline ones bipinnatifid.

Var. $\beta$, corniculata (D. C. prod. 4. p. 648.) teeth of involucels distorted. 24. H. Coult. 1. c. Scabiòsa corniculàta, Waldst. et Kit. 1. t. 13. Rchb. pl. crit. 4. t. 315. Cephalària corniculàta, Rœm. et Schultes, syst. Lepicéphalus corniculàtus, Lag. Stems tetragonal. Leaves pilose. Flowers pale yellow.

Var. $\gamma$, Uralénsis (D. C. prod. 4. p. 648.) paleæ at length squarrose. 4 . H. Native of Siberia, on the Ural Mountains, and of Caucasus. Scabiòsa Uralénsis, Murr. comm. gœtt. 1782. p. 13. t. 4. Rchb. pl. crit. 4. t. 314. Stem hexangular, hairy. Corollas pale yellow.

I ar. $\delta$, eretàcca (D. C. prod. 4. p. 648.) tectlı of involucels abortive. 4. H. Coult. ]. c. Scabiòsa cretàcea, Bieb. A. taur. 1. p. 93 . Scabiòsa coriàcea, Willd. enum. 1. p. 145. Cephalària cretàcea, Rœm. et Schultes. Leaves glabrous, usually all entire.

Centauria-like Cephalaria, FI. June, July. Clt. 1801. Pl. 2 to 4 feet.

S C. Leucántia (Schrad. 1. c. Coult. dips. p. 26. t. 1. f. 9.) stem nearly terete; leaves pinnatifid: lobes linear or oblong; heads nearly globose; outer palea alpressed, silky, obtuse: inner ones hardly acuminated; crown of involucel membranous. 4. H. Native of the south of Europe, the Levant, Siberia, \&c. Scabiòsa leucántha, Lin. spec. p. l42. D. C. fl. fr. no. 3298. Rclıb. pl. crit. 4. t. 356 . Succisa leucántha, Spreng. 1. c. Flowers of all white.

Var. a, angustiloba (D. C. prod. 4. p. 649.) glabrous; lobes of leaves linear, almost quite entire. 4. H. Ceplualària leucántha, Røm. et Schultes, syst. 8. p. 47. Lepicéphalus leucánthus, Lag. gen. et spec. p. 7.-Clus, hist. 2. p. 4. f. 1. Flowers white.

I ar. $\beta$, incisa (D. C. prod. 4. p. 619.) glabrous ; lobes of leaves oblong or oval, deeply serrated. $น$. H. Cephalària leucánthema, Roem. et Śchulres, syst. 3. p. 48. Lepicéphalus leucánthemus, Lag. l. c. Corollas white.

Var. $\gamma$, albéscens (D. C. prod. 4. p. 649.) lobes of leaves lanceolate, deeply toothed, ciliated. 24. H1. Native of Siberia. Scabiòsa albéscens, Willd. enum. p. 144. Ceplıalària albéscens, Rœm. et Schultes, syst. 3. p. 48 . Cauline leaves ternate or simplc. Corollas eream-coloured.

I ar. ¿, Scopòlii (Vis. pl. dalm. p. 3.) hairy; leaves lyrately pinnatifid; lobes of lower leaves ovate, toothed: of the superior ones linear. 24. H. Native of Dalmatia, in the fissures of rocks. Scabiòsa leucántha, Scop. carn. ed. 2. vol. 1. p. 95. Flowers white. Fruit 3-1-angled. Foveolx of the receptacles villous. Perhaps a proper species.

White-flowered Cephalaria. Fl. Sept. Oct. Clt. 1739. Pl. 2 feet.

9 C. rígın (Schrad. l. c.) stems terete; leaves oval-oblong, serrated; heads nearly globose; palea obtuse ; crown of iuvolucel membranous. 4. G. Native of the Cape of Good Hope. Roem. et Schultes, syst. 3. p. 44. Coult. dips. p. 26. Scabiòsa rígida, Lin. mant. p. 328. Sieb. fl. cap. no. 252. Lepicéphalus 
rígidus, Lag. Succisa rígida, Spreng. l. c.-Comn. hort. amst. t. 93. Shrubby. Flowers white. Said to be allied to C. leuclintha. There are varieties of this with either glabrous or scabrous leaves. The upper leaves are cut, with revolute edges.

Stiff Cephalaria. Fl. July. Clt. 1731. Shrub 2 feet.

10 C. Attenua'ta (Rœm. et Schultes, syst. 3. p. 44.) stem terete, rather villous; leaves linear, glabrous, entire and trifid; heads of flowers nearly globose; paleæ obtuse; teeth of involucel 5, scabrous; corollas equal. $\quad$ 2. G. Native of the Cape of Good Hope. Coult. dips. p. 27. and in litt. 1824. Scabiosa attenuàta, Lin. fil. suppl. 118. Succisa trifida, Spreng. 1. c. Succisa trífida, Spreng. Scabiòsa trífida, Thunb. fl. cap. 1. p. 520. Lepicéphalus attenuàta, Lag. Flowers white.

$I^{\prime}$ ar. $\beta$, verbenacea (Rom. et Schultes, l.c. Coult. l. c.) leaves oblong, toothed, and somewhat pinnatifid at the base. $4 . \mathrm{G}$. Scabiòsa verbenàcea, Lam. ill. no. 1314 .

Attenuated-leaved Cephalaria. Fl. July, Sept. Clt. 1774. Slirub I foot.

\section{$†$ Species not sufficicntly knon'n.}

11 C. Gre'ca (Rœm. et Schultes, syst. 3. p. 43.) leaves pinnate; leaflets decurrent, deeply serrated, glabrous; palex of the heads imbricated, equal to the corollas. 4. H. Native of Greece, on Mount A thos. Coult. dips. p. 26. Scabiòsa decúrrens, Sibth. et Smith, prod. 1.p. 80 . but not of Thunb. Scabiòsa Hàva, Sibth. et Smith, prod. 2. p. 356. Scabiosa orientalis foliis teucrii, \&c. Tourn. cor. p. 34. Flowers yellow. Perhaps sufficiently distinct from $C$. centaurioides.

Grccian Cephalaria. Pl. 2 feet.

12 C. Hu'mis (Rœm. et Schultes, syst. 3. p. 50.) glabrous; leaves linear, dentately pinnatifid; paler obtuse, downy; corollas unequal. 4 . G. Native of the Cape of Good Hope. Coult. dips. p. 27. Scabiòsa lùmilis, Thunb. fl. cap. 1. p. 526. but not of Host. Lepicéphalus hùmilis, Lag. gen. et spec. p. 8 . Succisa hùmilis, Spreng. 1. c. Flowers white. Stem nearly leafless, filiform. Scales of caly $\mathrm{x}$ ovate, purplish at the apex.

Ilumble Cephalaria. Pl. $\frac{1}{2}$ to 1 foot.

13 C. ustula'ta (Rœm. et Schultes, syst. 3. p. 43.) glabrous; leaves lyrate: lobes ovate, toothed; paleæ imbricated, ovate, acute, villous, purplish at the apex; corollas equal.-Native of the Cape of Good Hope, in rock lands. Coult. dips. p. 27. Succisa ustulàta, Spreng. 1. c. Scabiòsa ustulàta, Thunb. fl. cap. 1. p. 528. Lepić́phalus ustulatus, Lag. I. c. Stems striately angular. Paleæ and flowers white.

Ustulate-bractead Cephalaria. Pl. 1 to 2 feet.

14 C. sca'bra (Rœm. et Schultes, syst. 3. p. 44.) plant scabrous from hairs; leaves stiff, pinnatifid; lobes dentately cut ; palea ovate, obtuse, purplish at the apex; corollas equal. $h$. G. Native of the Cape of Good Hope, on hills. Coult. dips. p. 28. Scabiòsa scàbra, Thumb. A. cap. 1. p. 529. Lepicéphalus scaber, Lag. Succisa scàbra, Spreng. l. c. Heads about the size of filberts. Flowers white.

Scabrous Cephalaria. Fl. June, July. Clt. 1825. Shrub $1 \frac{1}{8}$ foot.

N. B. Scabiòsa marìna, Lin. mant. p. 329, is distinct from Scabiòsa maritima, Lin., and are probably referrible to the pre. sent genus, but are hardly known.

Cult. The hardy herbaceous kinds of Cephalària are of the most easy culture, and will grow in any kind of soil, and are readily increased by dividing at the root, or by seed. The seeds of the annual species only require to be sown in the open border. The green-house shrubby kinds should be grown in a mixture of loam, peat, and sand, and may be increased either by young cuttings under a hand-glass, or by seed.
IV. KNAU'TIA (in honour of C. Knaut, physician at Halle, in Saxony, who died in 1694; author of a catalogue of plants growing in the neighbourhood of Halle). Coult. dips. p. 28. D. C. prod. 4. p. 650.-Trichèra, Schrad. cat. sem. goett. 1814.- Scabiòsa, Vaill. l. c. Lag. gen. et spec. p. 8.Knaútia and Scabiòsa species, Lin.--Scabiòsa and Knaútia, Spreng. Wallr. I. I. c. c.

LiN. syst. Tetrándria, Monogýnia. Involucra of heads of many leaves. Palea none. Receptacle hairy. Involucel compressed, with 4 hollows closely girding the fruit, denticulated at the apex, having 2 of the teeth larger than the other 2 , furnished with a short stipe. Limb of calyx cup-shaped, neither pappose nor awned at the apex. Corolla 4-5-cleft. Stamens 4.-Erect branched, usually villous herbs.

Secr. I. Lxchnoides (this section contains plants resembling species of Lýchnis). D. C. prod. 4. p. 650 . Lýchni-scabiòsa, Boerh.-Knaútia, Lin. gen. no. 116. Involucrum erect, cylindrical, of 6-10 leaves. Flowers few within the involucrum, 5 . 10. Receptacle narrow. Corollas very irregular.-Annual herbs. Flowers pale red.

1 K. orienta'Lis (Lin. spec. p. 146.) leaves oblong, cut or entire; involucrum cylindrical, of 5-10 erect leaves; corollas $5-10$ in each head: outer ones radiating, longer than the involucrum; teeth of involucel 12-15, very short; cilia of calyx obsolete. $\odot$. H. Native of the Levant. Lam. ill. t. 58. Schkuh', handb. 1. t. 22. Coult. dips. p. 28. t. 1. f. 9.-Houtt. pfl. syst. v. p. 250. t. 39 . Scabiòsa orientàlis, Lag. gen. et spec. p. 9. Kn. trichootoma, Møench. meth. p. 4.87.-Till. pis. 153. t. 48. Plant villous. Seeds pilose, hairy at the apex. Flowers pale red. Lobes of stigma acute.

Eastern Knautia. FI. June, Sept. Clt. 1713. PI. 1 to $1 \frac{1}{\mathrm{ft}}$. 2 K. propóntica (Lin. spec. ed. 2. p. 1666. exclusive of Till. syn.) leaves serrated: superior ones lanceolate, quite entire; corollas 10 , equal to the involucrum; cilia of calyx 15 in number. $\odot$. H. Native of the Levant. Willd. spec. 1 p 561. exclusive of the syn. of Tourn. Roem. et Schultes, syst. 3. p. 87. exclusive of the Lam. syst. Coult. dips. p. 28. Scabiòsa propóntica, Lag. gen, et spec. p. 9. Plant villous, Corollas purple. Pistilla white; the corolla is said to be 4-cleft by Linnaus. This is a doubtful plant, and is perfectly unknown at the present day, as the plant known in our gardens under this name is $\boldsymbol{K}$. orientalis.

Propontic Knautia. Fl. Ju. Sept. Clt. 1768. Pl. 1 to 2 feet.

Sect. II. Tricheroides (this section contains plants having the habit of those of the next section). D. C. prod. 4. p. 650 . Involucrum spreading, 10-12-leaved. Flowers few or many. Involucel bidentate at the apex. Corollas rather irregular. Limb of calyx ciliated.-Annual herbs. Flowers bluish or rosecoloured.

$3 \mathrm{~K}$. Urville's (Coult. dips. p. 29. t. 1. f. 10.) lower leaves pinnatifid: superior ones linear, quite entire; corollas $10-12 \mathrm{in}$ each head, nearly equal, hardly longer than the involucrum, which is spreading; teeth of crown of the involucel 8 , a little awned. $\odot$. H. Native of the island of Leri, in arid fields, where it was collected by D'Urville; and also of Bulgaria. K. orientalis, D'Urv. enum. p. 14. Plant villous? Stems branched, divaricate. Heads of flowers small. Corollas pale blue.

\section{L'Lrville's Knautia. Pl. 1 to 2 feet.}

4 K. HY'BRIDA (Coult. dips. p. 30. and in litt. 1824.) lower leares petiolate, lyrate: lobes obovate, toothed: terminal lobe the largest, ovate or roundish; cauline leaves oblong, simple, serrated; heads many-flowered; the 2 teeth of the involucel of many bristles; cilize of calyx 20-24, obsolete. $\odot$. H. Native of the south of Europe. Scabiòsa hýbrida, All. auct. p. 9. 
Trichèra hýbrida, Rcem. et Schultes, syst. 5. p. 58. Scabiòsa lyràta, Lam. ill. no. 1310. Trichèri mutábilis, Sclurad. I. c. Scabiòsa bidens, Sibth. et Smith, fl. græc. t. 104. Cephalària bìdens, Rom. ct Schultes, syst. et Coult. l. c. Scabiòsa integrifòlia var. D. C. fl. fr. 4. p. 227. Scabiòsa ánnà integrifòlia, Tourn. herb. Scabiòsa integrifolia and S. Moldávica, Hortul. Stem villous. Leaves rather scabrous. Stigmas blunt. Corollas pale purple.

Hybrid Knautia. Fl. June, July. Clt. 1819. Pl. 2 to $3 \mathrm{ft.}$

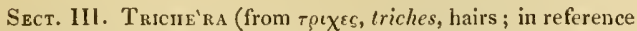
to the limb of the calyx). Schrad. 1. c. D. C. prod. 4. p. 651.Scabiosa species, Lin. Involucrum spreading, of many leaves. Flowers numerous. Receptacle dilated. Involucels rather truncate at the top. Limb of calyx divided into 8-10 awns. Corollas almost regular.-Perennial herbs. Flowers purplishblue. According to Coulter all the species contained in this section might be with propriety combined.

5 K. ARve'nsis (Coult. dips. p. 29. var. $\alpha, \beta, \gamma$, t. 1. f. 13.) stems hispid; leaves sessile, villous; radical ones unequally pinnatifid, with lanceolate lobes : cauline leaves pinnatifid, witl linear lobes; uppermost leaves linear-lanceolate; leaves of involucra bluntish. 4 . H. Native of Europe, in meadows, pastures, and cultivated fields; plentiful in Britain. Duby, bot. gal. 1. p. 257. Scabiòsa arvénsis, Lin. spec. p. 142. Gaud. f. helv. 1. p. 389 . Scabiòsa polymórpha, Schmidt, bolı. 3. p. 77. Trichèra arvénsis, Schrad. Flowers bluish purple, and verging to white or purple. Perlıaps Scabiòsa dùbia, Moench. hass. no. 116. t. 3. which is said to lave a 5 -cleft corolla, is only a variety of this species. This plant may rather be considered a troublesome weed in corn-fields, but in grass-fields it may be considered rather useful, as it produces a large quantity of foliage, which is not refused by kine, sheep, or horses. The plant varies much in the divisions of the leaves, and in its hairiness. It sometimes occurs witl white flowers. The flowers held over the smoke of tobacco in a few minutes become a beautiful green. The plant is slightly astringent, bitter, and saponaceous. The root creeps deep in the ground.

Var. a, vulgìris (D. C. prod. 4. p. 651.) leaves downy: radical ones pinnatifid or entire ; cauline ones always pinnatifid. 4. H. Native of Europe, in corn-fields and meadows. Sowerby, engl. bot. t. 659 . Curt. lond. 4. t. 18. Fl. dan. t. 447.Blackw. t. 185. Flowers bluish, and varying from purple to white, outer ones more or less radiant.

I ar. $\beta$, collina (Duby, bot. gall. 1. p. 257.) leaves nearly all radical and pinnatifid; stems nearly naked. 4 . H. Native of Europe, on dry hills. Scabiòsa collina, Req. in Guer. vaucl. ed. 2. p. 248. D. C. fl. fr. 5. p. 487. Scabiòsa hirsìta, Lapeyr. Plant canescent. Flowers bluish.

Var. $\gamma$, canéscens (Coult. l. c. var. $\beta$.) leaves canescent from hairs ; lower ones ovate, acuminated, toothed: upper ones pinnatifid; outer flowers of the heads hardly radiant. $\psi$. H. Native country unknown. Scabiòsa canéscens, Hort. taur.

Corn-field Knautia. Fl.July, Qct. Britain. Pl. 2 to 4 feet.

6 K. sylva'tica (Duby, bot. gall. 1. p. 257.) stems hispid; leaves tapering into the dilated winged connate bases of the petioles, all undivided, oblong or lanceolate; radical ones entire, cauline ones crenated or toothed; leaves of involucrum acutish. 4. H. Native of Europe, in mountain woods, and sometimes in fields. Kn. arvénsis $\gamma$, Coulter, dips. p. 29. Scabiòsa sylvática, Lin. spec. p. 142. Jacq. obs. 1. p. 28. 3. p. 20. t. 72. A. austr. t. 36\%. Gaud. fl. helv. 1. p. 387. Scabiosa Pannónica, Jacq. vind. p. 22. 'Trichèra sylvática, Schrad. Scabiòsa integrifòlia, Savi, fl. pis. 1. p. 162.1.2. f. 1. Scabiòsa ovatifòlia, Lag. gen. et spec. p. 9. Flowers red: outer flowers radiant. 'There is a variety of this with smooth stems, and another with white flowers.

Var. 3, longifòlia (Duby, hot. gall. I. c.) leaves oblong, elltire, quite glabrous; heads of flowers nearly equal, lilac-colomed. 4. H. Native of Hungary and the alps of Jura. Scabiosia longifòlia, Waldst. et Kit. hung. 1. p. 4. t. 5. Scabiòsa integrifòlia, Sut. fi. helv. 1. p. 387.- Scabiòsa sylvática $\beta$, Gaud. ff. helv. 1. p. 387. Scabiòsa Carpática, Wahl. Stem glabrous below, and hairy above.

Íar. $\gamma$, integrifòlia (Coult. under K. arvénsis, I. c. var. $\gamma_{9}$ ) leaves undivided, toothed or quite entire. 4 . H. Native of Europe. Scabiòsa integrifòlia, Lin. spec. 142. Scabiòsa dịsacifölia, Schott. Host, fl, austr. 1. p. 191. Scabiòsa pubéscens, Willd. enum. 1. p. 146. Trichèra pubéscens, Schracl. Corollas cream-coloured. Anthers fulvous, Perhaps Scabiosa hýbrida, Bonch. fl. abb. Perhaps Scabiòsa Uralénsis, Richb. pl. crit. 4. t. 332. The plant is more or less downy, and the upper leaves are sometimes jagged at the base.

Wood Knautia. Fl. Jure, July. Clt. 1633 . Pl. 1 to 3 feet.

7 K. monta'va (D. C. prod. 4. p. 65].) stems hispid, brachiate; leaves oblong, serrated : lower ones entire and jagged; heads of flowers radiant; leaves of involucrum acute, narrow. 4. H. Native of Caucasus, in mountain meadows. Scabiòsa montàna, Bieb. fl. taur. 1. p. 95. Jacq. fil. eclog. 1. t. 60. Kn. arvénsis var. Coult. dips. p. 29. and in litt. 1824. Leaves hairy. Flowers white.

Mountain Knautia. Fl. July. Clt. 1820. Pl. 3 to 6 feet.

8 K. cilia'ta (Coult. dips. p. 30.) stems very hispid; leaves ovate, hispid, lower ones petiolate, entire, auricled or pinnatifid : cauline ones deeply toothed, cordately stem-clasping or perfoliate; leaves of involucrum ciliated. $\psi$. H. Native of Moravia, in meadows. Trichèra ciliàta, Rœm. et Schultes, syst. 3. p. 37. Scabiòsa ciliàta, Spreng. in Schrad. journ. 1800. z. p. 199. Relıb. pl. crit. 3. t. 273. Scabiòsa Kitaibèlii, Schultes, obs. p. 18. Scabiòsa pubéscens, Wahl. fl. carp. p. 38. Trichèra leucántha, Schrad. S. híspida, Porter's mss. Perhaps Scabiòsa ciliàta, Horn. hort. hafn. 1. p. 125. is the same, although saicl to be annual. Flowers dirty white; outer ones radiant. Anthers violaceous.

Ciliated Knautia. Fl. July, Ang. Clt. 1802. Pl. 2 feet.

9 K. Diversifòlia (D. C. prod. 4. p. 652.) stems branched, hispid ; radical leaves pinnatifid : lobes rather falcate, quite entire; lower cauline leaves petiolate, ovate-lanceolate, blıntly toothed; superior leaves lyrate; uppermost leaves stem-clasping, quite entire; leaves of involucra ovate-cordate. $\%$. H. Native of Transylvania, in mountain meadows. Scabiòsa diversifölia, Spreng. neu. entd. 1. p. 279. Corolla 4-cleft, radiant, of a lilac-colour, ex Spreng., violaceous and blue, ex Baumg.

Divers-leaved Knautia. Fl. June, July. Clt. 1826. Pl. $2 \mathrm{ft}$.

10 K. Legione'ssis (D. C. prod. 4. p. 652.) stems hispid from retrograde hairs; leaves lanceolate, long-acuminated, remotely toothed: lower ones entire; leaves of involucrum 18, exceeding the flowers. 4.? H. Native of Spain, on the mountains of Leone. Scabiòsa Legionénsis, Lag. nov. gen. et spec. p. 9. Asterocéphalus Legionénsis, Spreng. syst. 1. p. 379. Flowers red. There is a variety of this with pinnatifid leaves and white flowers. Said to be nearly allied to $K$. sylvática.

Leone Knautia. Fl. June, July. Pl. 2 feet.

11 K. SALCE'Di; stem scabrous from hairs; leaves all undivided, lanceolate : lower ones entire: upper ones sharply tootled in the middle. 24. H. Native of Spain, on the mountains of Leone. Scabiòsa Salcèdi, Lagasca. Leaves downy on both surfaces, hoary beneath. Peduncles long, beset with rufous villi under the head of flowers. Involucrum of many lanceolate pilose leaves, the length of the flowers, which are of a lilac colour. 
Salccdi's Knautia. Fl. June, July. Clt. 1823, Pl. 1 to $2 \mathrm{ft}$. 12 K. ovatifòlia; superior leaves broad, ovate, acuminated, serrated, sessile. \%. H. Native of Spain? K. ovatifòlia, Lagasca, gen. et spec. nov, diagn. p. 9. no. 116 . Very like $K$. Legionénsis, but more slender in every part. Said to be nearly allied to $K$. sylvitica.

Ovate-lcaved Knautia. Pl. 1 to 2 feet.

Cuit. The species of this genus are of the most easy culturc and propagation. They will grow in any soil and situation.

V. PTEROCE'PHALUS (from $\pi$ repor, pteron, a wing, and $\kappa \varepsilon \phi a \lambda \eta$, kephalc, a head; in reference to the receptacle of the flowers being villous or chaffy). Vaill, act. acad. Par. 1722. p. 184. t. 13. f. 23. f. 24. Coult. dips. p. 31. Wallr. sched. p. 47. Spreng. syst. no. 378. D. C. prod. 4. p. 652.-Scabiòsa and Kinaútia species, Lin.-Pterocéphalus and Knaútia, Lag. gen. et spec. 9.

Lis. sxst. Tetrándria, Monogýnia. Involucrum double, eacl series of 4-6 leaves. Heads many-flowered (f. 118. a.). Receptacles villous (f. 117.b.) or chaffy. Involucels toothed or awned (f. 117. a.). Limb of calyx ending a in many-rayed pappus (f. 117. c, f. 118, d.), which at length become feathery (f. 117, i. f. 118, i.). Corollas 5-cleft (f. 117, f. f. 118, c.). Stamens 4 (f. 118. f.), rarely $2-3 .-$ Herbs or subshrubs.

\section{\$ 1. Annual plants. Leaves pinnatifid, particularly the su-} perior ones.

I P. Papròsus (Coult, dips, p. 32. t. 1. f. 17.) stem herbaceous, erect; leaves bipinnatifid, with lanceolate lobes; receptacle paleaceous; involucels drawn out into 1-3 long awns; bristles of calyx 20-24, plumose, about equal in length to the awns of the involucel. $\odot$.H. Native of Portugal, Spain, Greece, and Candia. Pter, ánnuus, Vaill. act. par. 1722. p. 183. Pter. Vaillánti, Lag. gen, et spec. p. 9. Scabiòsa pappòsa, Lin. spec. p. 146. Scabiòsa involıcràta, Sibth. et Smith, th. græc. t. 1]2. Scabiòsa divaricàta, Spreng. neue entd. 3. p. 163. Corollas red. Leaves of involucrum pinnatifid. Plant villous.

I ar. $\beta$, diándrus (D. C. prod. 4. p. 652.) smaller; flowers di-triandrous. $\odot$. H. Native of Spain, at Aranjuez, and of l’ortugal. Scabiòsa diándra, Lag. var. 2.p. 39. Pterocéphalus diándrus, Lag. nov. gen. p. 9. Cephalària diándra, Rom. et Schultes, syst. 3. p. 52. Flowers blue.

Pappose-sceded Pterocephalus. Fl. July. Clt. 1597. Pl. 1 to 2 feet.

2 P. BRE'vis (Coult. dips, p. 32. t. J. f. 16.) plant clothed with soft villi; stems herbaceous, erect; leaves pinnatifid; corollas hardly exceeding the involucrum; crown of involucels membranous, hardly denticulated, very short, spreading; bristles of calyx 14-16, feathery, a little longer than the involucel. $\odot$. H. Native country unknown. Very nearly allied to the following.

Short-involucelled Pterocephalus. Pl. 1 foot.

3 P. Plumòsus (Coult. dips. p. 31. t. 1. f. 15.) plant downy ; stem herbaceous, erect; lower leaves broad-lanceolate, serrated: middle ones lyrate: upper ones pinnatifid; corollas longer than the involucrum; crown of involucel obsolete; bristles of calyx 11-13, plumose, hardly twice the length of the involucel. $\odot$. H. Native of the Levant, Iberia, Candia, Samos, and Caucasus, in arid places of mountains, \&c. Knaútia plumòsa, Lin. mant. p. 197. Scabiòsa plumòsa, Sibth. et Smith, fl. græec. t. 111. Scabiòsa pappòsa, Gartn. fruct. t. $\mathrm{S6}$. Willich. in Rchb. op. 1. p. 160. Scabiòsa Willíchii, Link, in Rœm. coll. 2. Cephalària Willíchii and Scabiòsa plumòsa, Røem. et Schultes, syst. 3. p. 5\%. anrl p. 70. Pter. marcéscens, Moench. meth. p. 491. exclnsive of the synonymes. Flowers rose-coloured or purplish.
Feathered-calyxed Pterocephalus. Fl. June, July. Clt. 1819. Pl. 1 to 2 feet.

4 P. Palestinus (Coult. dips. p. 31. t. 1. f. 14.) plant clothed with silky villi; lower leaves obovate-oblong, quite entire, the rest lyrately pinnatifid: lower lobes small, decurrent : terminal lobe large, obovate-oblong; involucel having 8 foveola at the base; crown of involucel membranous ; bristles of calyx 8-10, subulate, spreading, irregularly pilose at the sides. $\odot . \mathrm{H}$. $\mathrm{Na}$ tive of the islands of Cyprus and Scio ; and of Palestine. Knaútia Palæstìna, Lin. mant. 117.Jacq. hort. vind. 1. t. 96 . Scabiòsa bracliàta and Scabiòsa Sibthorpiàna, Sibth. et Smith, fl. græc. t. 109. Flowers white or pale purple. The rays of the corollas in S. Sibthorpiàna are entire, while in those of $P . P a$ lestinus, they are jagged; they are, therefore, probably distinct species.

Tar. B, Calabricus (D. C. prod. 4. p. 653.) leaves all entire or lyrate. $\odot . H$. Native of Calabria, on arid hills. Scabiòsa brachiàta, Guss. pl. rar. p. 66. Flowers purplish.

$\operatorname{Var}, \beta$, Dalmaticus (D. C. I. c.) plant hairy; lower leaves lyrate; upper ones pinnate, with oblong-linear acute lobes. $\odot$. H. Native of Dalmatia. Scabiòsa multisèta, Vis. pl. dalm. p. 1. t. 1. Perhaps Scabiòsa silenifòlia, Waldst. et Kit. pl. hung. 2. p. 157. and therefore Asterocéphalus silenifòlius, Spreng.

Paiestine Pterocephalus. Fl. July, Ang. Clt. 1771. Pl. 1 to 2 feet.

\section{\$2. Percnnial or frutescent spccies. Leaves jagged or toothed.}

5 P. Lusitánicus (D. C. prod. 4. p. 653.) stems ascending, sparingly pilose; lower leaves bipinnatific; superior ones pinnatifid; segments of all linear; palex of the receptacle and leaves of involucrum scarious and hairy; involucels manytoothed; awns of calyx 6-9, feathery. $\odot$. 4. H. Native of Portugal, between Abrantes and Casabranca. Scabiòsa plumòsa, Hoffm. et Link, fl. port. 2. p. 91. Cephalària plumòsa, Rœm. et Schultes, syst. 3. p. 70. Scabiòsa Gramúntia, Brot. f. lus. 1. p. 145. Flowers pale red. Perhaps Asterocéphalus intermèdius, Lag. gen. et spec. p. 8. which is the Scabiosa intermèdia, Rom. et Schultes, 3. p. 76. is referrible to this species, as also Scabiòsa marítima and Sc. tenuifòlia, Lag. elench, hort. madr. 1803, and 1805.

Portugal Pterocephalus. Fl. June, July. Clt. 1824. Pl. 1 to 2 feet.

6 P. Broussone'tu (Coult. in litt. 1824. ex D. C. prod. 4. p. 653.) leaves bipinnate; corollas equal; awns of calyx 6-7, linear, feathery, hardly twice the length of the involucel. $4 . \mathrm{H}$. Native of Gibraltar, about San Roque, where it was collected by Broussonet.

Broussonet's Pterocephalus. Pl. 1 foot.

7 P. тоnento'sus (Coult. in litt. 1824. ex D. C. prod. 4. p. 653.) stems procumbent, shrubby ; leaves dentately pinnatifid, hoary from tomentum; leaves of involucrum bluntish; bristles of calyx 6, short, scabrous. 4. H. Native of Candia, on the Spaciotic mountains. Scabiòsa tomentòsa, Sibth. et Smitl, prod. fl. graec. 1. p. 85. but not of Cav. Scabiòsa Spaciótica, Roem. et Schultes, syst. 3. p. 86 . Asterocéphalus Spacióticus, Spreng. syst. 1. p. 352. Herb tufted. Flowers blue.

Tomentosc Pterocephalus. Pl. $\frac{1}{2}$ foot. 
8 P. PERE'NNIS (Vaill, act. acad. par. 1722. 1. 184.) stems procumbent, suffruticose; leares lyrate, cut, tomentose; involucels downy; corollas 5-cleft; stigunas longitudinal; pappus plumose. 4. H. Native of Nount Parnas. sus, on rocks. Scabiòsa pterocéphala, Lin. spec. p. 14.6. Sibth. et Smith, ft. graec. t. 113. Pterocéphalus Parnássii, Spreng. syst. 1. p. 3St. Flowers pale purple. Perbaps belonging to a different section.

Perennial Pteroceplaalus. Pl. procumbent.

\section{\$3. Pcrcnnial or frutescent species, with cntire leaces.}

9 P. Níveus (Coult. dips. p. 32.) lower leaves orbicular : cauline ones obovate-spatulate, all quite entire, and are as well as the stems clothed with white tomentum; bristles of calyx $10-$ 12, plumose, 3 times longer than the seed. 4. H. Native of Spain, on the top of Sierra Toxada. Scabiòsa nivea, Agardh, in Rœm. et Schultes, syst. 3. p. 81. A very small plant.-According to Sprengel, it is the same as the following.

Snomy Pterocephalus. Pl. 1 to 2 inches.

10 P. spatula'tus (Coult. dips. p. 32.) leaves quite entire, roundish-spatulate, tomentose ; corollas 5 -cleft, radiant ; pappus coloured, of 14 rays. 4. H. Native of Spain, in Granada, and near Ellin in Murcia. Knaútia spatulàta, Lag. gen. et spec. p. 9. Rœem. et Schultes, syst. 3. p. 88. Stems tomentose. Involucra 8-12-leaved. Heads containing about 16 flowers.

Spatulate-leaved Pterocephalus. PI. $\frac{1}{4}$ to $\frac{1}{2}$ foot.

11 P. ca'ves (Conlt. in litt. 1824. ex D. C. prod. 4. p. 653.) leaves quite entire, obovate-oblong, hoary; peduncles scapeformed, bearing each one head of flowers; corollas 5 -cleft ; involucel lagenæform, downy, without furrows; rays of calyx 20-25, plumose, linear, twice longer than the involucel; stigma emarginate. 24. H. Native of the Levant, between Amadan and Kermancha, where it was collected by Olivier and Bruguiere. Seabiòsa dumetòrum var. from the Levant, Coult. dips. p. 32.

\section{Hoary Pterocephalus. PI. $\frac{1}{2}$ foot.}

12 P. Lasiospéruus (Link, in Buch. can. p. 150.) stem suffruticose, with many branches; leaves on very short petioles, oblong-lanceolate, quite entire, crowded, white fiom short dense tomentum; involucels densely plumose. $h$. G. Native of the Grand Canary island, near Trente, and among rocks on the top of l'ico Tedi. Pter. dumetòrum var. pusilla, Coult. dips. p. 32. Scabiòsa fruticòsa, Smith, mss.

Hoolly-seeded Pterocephalıs. Shrub small.

13 P. dumeto'rum (Coult. dips. p. 32. var, $a$, stem suffiuticose, erect, bearing many heads of flowers; leaves petiolate, quite entire, oval, acuminated, attenuated at the base, smoothish on both surfaces; peduncles and involncels downy; rays of calyx 20-24, plumose, linear, hardly twice the length of the involucel. h.G. Native of Teneriffe. Scabiòsa dumetòrum, Brouss. in Willd. enum, 1. p. 146. Trichèra dumetòrum, Rom. et Schultes, syst. 3. p. 56. Leaves crowded at the tops of the branches.

Thicket Pterocephalus. Shrub small.

Cult. For culture and propagation see C'ephalaria, p. 686.

VI. SCABIO'SA (from scabies, the itch; which disorder the eommon sort is said to cure). Roen. et Schultes, syst. 3. p. 2. Conlt. dips. p. 33 . D. C. prod. 4. p. C54.-Asterocéphalus, voL. III.
Vaill. aet. acad. par. 1722. Lag. gen. et spec. p. 8. Wallr. sched. crit. p. 4.6. Spreng. syst. 1. p. 379 . exclusive of some species.--Scabiòsa spec. Lin. Sc.-Sclerostémma, Schott.

Lin. syst. Tetrándria, Monogýmia. Involucra of heads many-leaved. Receptacle chafly. Involucels with 8 foveolæ, usually somewhat cylindrical. Limb of ealyx tapering into a neck at the base, and ending in 5 awned bristles, rarely only 1-4 from abortion. Corollas 4-5 cleft. Stamens 4.-Perennial or suffruticose herbs. Leaves rariable. Heads of flowers depressed. Outer flowers of heads usually radiant.

Sect. I. Asterocép'inalus (from a armo, aster, a star, and $\kappa \varepsilon \phi a \lambda \eta$, licplacle, a head; in reference to the star-like crown on the top of the seeds). Coult. dips. p. 33. D. C. prod. 4. p. 654 . Base of the involucels terete, not plicate, furnished with 5-8 foveolæ. Crown of secd large, membranous, spreading or erect, Calyx sessile or stipitate, ending in 5 exserted bristles. Corollas 5 -cleft.

1 S. Cauca'sica (Bieb. fl. taur. 1. p. 98.) lierbaceous; radical leaves lanceolate, acuminated, quite entire, glaucous; invohucrum very villous; corollas 5 -cleft, radiant ; base of involucels elongated, longer than the ovate foveole; crown of seeds short, 25-nerved; limb of calyx sessile, with exserted bristles. 4 . H. Native of Caucasus and Armenia, in arid places. Coult. dips. p. 33. t. 2. f. 1. Asterocéphalus Caucásicus, Spreng. słłst. 1.p 381. Leaves like those of a species of Scorzonèrt. Heads of flowers large, radiant, pale blue. This is an elegant plant while in flower.

Var. a, heterophýlla (D. C. prod. 4. p. 654.) leaves green: cauline ones pinnatifid. 4. H. Scabiòsa Cancásica, Rœm. et Scluultes, syst. 3. p. 84. Willd. enum. p. 118. Sims, bot. mag. 886 .

Íar. j, élegans (D. C. prod. 4. p. 654.) leaves whitish; cauline ones undivided, quite entire or nearly so. $4 . \mathrm{H}$. Scabiosa élegans, Spreng. pug. 2. p. 24. Sclerostémma connàtum, Schott. Asterocéphalus élegans, Lag. gen. et spec. p. S. Scabiòsá connàta, Horn. hort. hafn. 1. p. 128. Scabiòsa Caucàsea, Sims, bot. mag. t. 886 .

Caucasian Scabious. Fl. June, Aug. Clt. 1803. Pl. 1 foot.

2 S. Cre'tica (Lin. spec. p. 145.) stem shrubby; leaves lanceolate, quite entire, and are as well as the involucra clothed with hoary down; corollas 5 -cleft, radiant; base of involucels elongated, equal in length to the foveolæ, which are linear : crown of seed spreading, obliquely truncate, 20-28-nerved, hardly twice longer than the base; limb of calyx sessile, with 4-6 inclosed bristles. 4. H. Native of Sicily and Candia, among calcareous rocks. Coult. dips. p. 33. t. 2. f. 2. Guss. prod. 1. p. 165. Asterocéplualus Créticus, Spreng. Scabiòsa arbòrea, P. Alp. exot. t. 34.-Morr. oxon. sect. 6. t. 15. f. 31. Stem white from down. Flowers pale blue, rarely white. There is a variety of this having the involucrum longer than the flowers.

Cretan Scabious. Fl. June, Oct. Clt. 1596. Shrub I foot.

3 S. Candollis'sa (Wall. cat, no. 430.) stem suffruticose at the base, branched ; leaves linear, quite entire, nearly glabrous ; corollas 5-cleft, radiant; involucels clothed with short villi at the base, the foveola hidden by the villi; crown of seed 20 nerved? toothed a little; bristles of calyx 5 , black, rather scabrous, 3 times longer than the crown. h. G. Native of Nipaul, at Kamaon. Stems sparingly leafy, tufted at the apex; peduncles elongated, naked. Heads small, purplish. Perhaps referrible to sect. iii. Succisa.

De Candolle's Scabious. Slirub 1 foot.

4. S. graminifo'tia (Lin. spec. 145.) stems herbaceous, suffruticose at the base; leaves linear, lanceolate, quite entire, of at silvery white colour; corollas 5-cleft, radiant; base of involu. $4 \mathrm{~T}$ 
cels elongated, equal in length to the linear foveola; crown of seed spreading, 24-nerved ; limb of calyx pedunculate; bristhes of calyx 5, equal in length to the crown. 2/. H. Native of Provence, north of ltaly, Carniola, Pannonia, Barbary, Switzerland, on the mountains. Coult. diss. p. 34. t. 2. f. 3 . Waldst. et Kit. pl. rar. hung. 188. Lindl. bot. reg. t. 835. Asterocéphalus graminifolius, Spreng. Flowers pale blue, very like those of $S$. Caucásica. The Swiss variety of this plant is much more tufted than those from other countries, and seems different altogether.

Grass-leaved Scabious. Fl. June, Oct. Clt. 1683. Pl. $1 \mathrm{ft}$. 5 S. prolífera (Lin. spec. p. 144.) stem herbaceous, dichotomous; leaves oblong-lanceolate, almost entire, downy ; heads almost sessile in the forks of the stem; corollas 5-cleft, radiant; involucels obconical, elongated at the base, equal to the foveolax, which are obovate; crown of seed spreading, exceeding the base, 32-36-nerved; limb of calyx pedunculate, hardly equal in length to the bristles of the crown. $\odot . H$. Native of Cyprus, Egypt, and Barbary. Coult. dips. p. 31.t. 2. f. 4. Sibth. et Smith, fl. grac. t. 107. Astcrocéphalus prólifer, Spreng.-Herm. par. t. 125. Flowers pale yellow.

Proliferous-stemmed Scabious, Fl. July, Aug. Clt. 1686. Pl. 1 foot.

6 S. stella'ta (Lin. spec. p. 144.) stem branched; leaves cut or sublyrate: the terminal lobe obovate, toothed, large; hearls on long peduncles; corollas radiant; base of involucels elongated, about equal in length to the foveolæ, which are also elongated ; crown spreading, 40 -nerved, twice the length of the base; limb of calyx pedunculate, having the bristles thickened at the disk, not exceeding the crown. $\odot$. H. Native in the region of the Mediterranean, in fields and arid places. Coult. dips. p. 34. t. 2. f. 5. D. C. fl. fr. no. 3312. Succisa stellata, Mcench. meth. p. 490. Scabiòsa rotàta, Bieb. suppl. p. 102. ex Coult. Asterocéplualus rotàtus, Spreng. Bristles of calyx black. Flowers very pale blue, almost white.

Var. $\beta$, pinnatifia (D. C. prod. 4. p. 655.) leaves pinnatifid, with linear lobes. $\odot$. H. Native abont Montpelier, in fields. S. stcllàta $\beta$ et $\gamma$, Coult. dips. p. 34. S. símplex, Desf. fl. atl. 1. p. 125. t. 89. f. 1. ex Coult. Gartn. fruct. 2. p. 39. t. 86. There are varieties of this with branched stems, bearing many heads of flowers; and single stems, bearing only one head of flowers.

Starry-crowned Scabious. Fl. July, Aug. Clt. 1596. Pl.
$1 \frac{1}{2}$ foot.

7 S. Monspeliénsis (Jacq. misc. 2. p. 320, icon. rar. 1. t. 24.) luairy; stem a little branched; leaves pinnate-parted: with toothed or cut oblong-linear lobes; heads on long peduncles; corollas nearly cqual; base of involucels hardly elongated, equal to the linear open foveolæ; crown twice the length of the base, 32 35-nerved; limb of calyx pedunculate, with much exserted bristles. $\odot$ or 8 . Native of Spain, Barbary, and the sontl of France, in exposed places. Coult. dips, p. 34. t. 2. f. 7. Asterocéphalus stellàtus, -Spreng. Scabiòsa símplex, D. C. fl. fi. no. 3313. Desf. fl. atl. 1. p. 125. t. 39. f. 1. Flowers purple. Montpelier Scabious. Fl. July, Aug. Clt. 1820. Pl. 1 to $2 \mathrm{ft}$. 8 S. Palesrina (Lin. mant. p. 37.) stem divaricately branched; leaves obovate-oblong, coarsely toothed, tapering into the petioles, pinnatifid at the base; heads on long peduncles; corollas radiant; base of involucels liardly elongated, equal to the fovcolæ, which are linear and elongated; crown spreading, twice longer than the base or more, 32-35-nerved; limb of calyx on a long peduncle; bristles shorter than the crown. $\odot$. H. Native about Aleppo, and in Palestine. Jacq. lort. vind. 1, t. 96. S. Válili, Coult. dips. p. 35. t. 2. f. 6 . exclusive of the country. Asterocéphalus Palæstinus, Spreng. Flowers white or pale red; segments jagged.
Palestine Scabious. Fl. July, Aug. Clt. 1771. Pl. 1 foot. 9 S. AlE'Pp1CA (Coult. dips. p. 35. t. 2. f. 8.) stem branched; leaves pinnate-lobed: lobes oblong-linear, quite entire; heads of flowers pedunculate ; corollas radiant; base of involucels hardly elongated, equal in length to the linear foveolæ; crown spreading, 3 times longer than its base, 20-24-nerved; limb of calyx on a long peduncle; bristles shorter than the crown. $\odot$. H. Native of the Levant, between Bagdad and Aleppo, where it was collected by Olivier and Bruguiere. Stems humble, silvery, villous. Peduncles smoothish.

Aleppo Scabious. Pl. liumble.

10 S. UKRA'NICA (Lin. spec. p. 144.) stem branclied; leaves ciliated at the base : lower ones pinnatifid, with linear distant lobes: superior ones linear, quite entire; hearls pedunculate; corollas radiant; base of involucels hemispherical, equal in length to the foveolx, which are ovate-linear; crown 20-24nerved, acutely toothed, shorter than the bristles. 24. H. Native of the south of Europe, from Spain to Tauria; also of the temperate parts of France. Coult. dips. p, 63. var. $a, \varepsilon, \zeta, \gamma$, t. 2. f. 9. D. C. fl. fr. no. 3310 . Mor. bibl. ital. p. 9. Rehb. pl. crit. 4. t. 316 . but the fruit is erroneous in the figure. Scabiosa álba, Scop. del. 3. p. 33. t. 16 . S. argéntea, Lin. spec. p. 145. Sibtl. et Smith, fl. græc. t. 168. Desf. ann. mus. 11. t. 24. S. Gmelini, St. Hil. bull. phil. 661. p. 149. t. 3. Asterocéplualus pilòsus, Lag. gen. et spec. p. 8. Aster. argéntcus, Spreng. Sclerostémma Scopòlii and S. argénteum, Schott.-Gmel. sib. 2. p. 213. t. 87. Cauline leaves ciliated at the base. Flowers from blue to white, and greenish yellow. Segments of corolla entire, ciliated.

I ar. $\beta$, umbellàta (Coult. 1. c. var. $\beta$.) flowers pedicellate, within the involucrum. 4 . H. Native about Venice. Moricand, fl. ven. 1. p. 84 .

Var. $\gamma$, Sicula (Coult. I. c. var. $\gamma$ ) leaves of involucrum elongated, exceeding the flowers. 4. H. Native of Sicily, \&c. S. Sícula, Lin. mant. p. 196 . S. divaricàta, Jacq. hort. vind. 1. t. 15. Succìsa macrocalycina, Monch. meth. p. 489. S. marítima, Wulf. in Roem. arch. 3. p. 317. Sclerostémma Sículum, Schott. S. ebúrnea, Sibth. et Smith, fl. græec. t. 106. ex Coult. Flowers white or rose-coloured. Segments of corolla toothed.

\section{Ukraine Scabious. Fl. Sept. Clt. 1795. Pl. 1 foot.}

11 S. mcrántila (Desf. anm. mus. 11. t. 25. choix. t. 40.) stem branched; leaves hairy; lower ones lyrately pinnate, with oblong or linear lobes; lower leaves oblong or lanceolate-toothed; heads of flowers on long peduncles, ovate; corollas equal; base of involucel hemispherical, equal in length to the linear ovate foveolæ; crown 20-24-nerved, acutely toothed, shorter than the bristles. $\odot$. H. Native of Tauria, Caucasus, Armenia, and Iberia, in sterile stony places. S. micrántha and S. Biebersteinji, Rœm. et Sclultes, syst. 3. p. 80 . and 75. S. Sícula, Bieb. fl. taur. p. 98. S. Ukránica $\delta$, Coult. dips. p. 35. and diss. mss. 1824 . Asterocéphalus micránthus, Spreng. S. orientàlis villòsa, flore suavi rubente, fructu pulcliro oblongo, Tourn. cor, inst. p. 35. Flowers red. Plant villous. According to Desfontaines the radical and upper cauline leaves are entire.

Small-flonercd Scabious. Fl. June, July. Clt. 1825. Pl. 1 to 2 feet.

12 S. Olivit'ri (Coult. dips. p. 36. t. 2. f. 10.) stem much branched, dichotomous; leaves linear-oblong, villous, entire or auricled; heads small, pedunculate, few-flowered; base of involucel hemispherical, equal to the obovate foveola; crown entire, spreading, 20-24-nerved, hardly exceeding its base limb of calyx almost sessile, with much exserted bristles.- $\mathrm{Na}$ tive of the Levant, between Bagdad and Kermanclua, where it was collected by Olivier and Bruguiere. Stem glabrous, white. Herb very slender. Flowers white. 
Olicier's Scabious. Pl. 1 to 2 feet.

I 3 S. IseTE' Nsrs (Lin. mant. p. 37.) stem much branched; leaves pubescent: lower ones bipinnate-parted; superior ones pinnate-parted; segments of all oblong-linear; heads and peduncles clothed with white tomentum; corollas radiant; base of involucels elongated, villous; crown crect, 16-20-nerved, one-half shorter than the bristles. 4 . H. Native of Siberit, in stony dry places, about Isetsk, and at Cape Cancasus; in the Kirchlisean steppe, between the mountains $\mathrm{K} \|$ and Karkaraly, and at the Don. Coult. dips. 1. p. 34. Bieb. suppl. p. 100. S. rupéstris, Bieb. fl. taur. 1. p.95. S. rupéstris and Iseténsis, Rom, et Scluultes, syst. 3. p. 64. 83. Asterocéphalus Íseténsis, șpreng. Sclerostémma lseténse, Schott. mss.-Gmel. sib. 2. 1). 214. no. 7. t. 88 . Flowers white.

Isetsk Seabious. Fl. July, Aug. Clt. 1801. Pl. 1 foot.

14 S. crenA'TA (Cyr. pl. rar. neap. 1. p. 11. t. 3.) stems suffruticose at the base, ascending; leaves smoothish, bipinnatifid: lohes entire or tridentate; heads on long peduncles; corollas radiant, crenated; base of involucel equal to the oblong foveola ; crown subdentate, 16-20-nerved; limb of calyx sessile; bristles twice longer than the crown. $4 . h$. H. Native of Calabria, on calcareous mountains; and of Greece. Coult. dips. p. 36. Asterocéphalus crenàtus, Spreng. S. coronopifòlia, Sibth. et Smith, fl. græe. t. 114. S. crenàta and S. coronopifòlia, Rom. et Schultes, syst. 3. p. 71. and 86.-Col. phyt. 2. f. 31. There are elongated and dwarf varieties of this plant.-Corollas Hesh-coloured or pale-red.

I ar. $\beta$, hirsùta (Gıss. prod. 1. p. 162.) leaves hairy; bristles of calyx 3 times longer than the crown. $\boldsymbol{\psi}$. or $f$. Native of sicily, on the mountains. Columbària crenàta, Presl. S. coronopifolia hirsùta, Biv. mant. 3. p. 6 .

Crenate-flowered Scabious. Fl. June, July. Clt. 18?5. Pl. 1 to 2 feet.

15 S. рестіка'та (Lag. elench. madr. 1803. p. 33.) stems spreading; leaves fleshy, pinnatifidly pectinated, channelled; corollas radiant. $\odot$. H. Native of Arabia. Coult. dips. p. 36. Asterocéphalus pectinàtus, Lag. gen. et spec. p. 8. Said to be allied to $S$. Uhránica. Flowers violaceous?

Pectinated-leared Scabious. Fl. July, Aug. Clt. 1824. Pl. ] $\frac{1}{2}$ foot.

16 S. LYRA'TA (Forsk. deserip. p. 203. but not of Lam.) stem simple ; lower leaves oblong, coarsely and bluntly serrated : superior ones pinnate at the base; corollas radiant, with entire lobes. ₹. H. Native at the Dardanelles. Vabl, symb. 2. p. 92. Coult. dips. 13. 37. Asterocéphalıs lyràtus, Spreng. Stem ratlier tomentose. Corollas purple.

Lyrate-leaved Scabious. Pl. 1 foot.

17 S. acutiflo'na (Relib. pl. crit. 4. p. 24. t. 326.) stem branched: lower leaves spatulate, and linearly pinnatifid, serrated: superior ones pinnate-parted, with oblong-linear entire lobes; heads of fruit ovate; corollas 5 -cleft, radiant, with the outer lobes acuminated; crown a little longer than the tube; bristles of calyx 5, exserted. 24. H. Native of the south of Europe. Involucels spongy at the edges. Flowers pale, peachcoloured. Allied to S:. Uirránica.

Acute-flomered Scabious. Pl. 1 foot.

Scret. II. VInU'A (meaning not explained by the author). Conlt, dijss. j. 37. D. C. prod. 4. p. 657. Involucels rounded at the base, plicate; tube with the foveola usually obliterated. Crown small, inflexed. Limb of calyx pedicellate, with 5 exserted bristles.

is S. atropurpu'rea (Lin. sjec. p. 14\%.) stem branched; radical leaves lanceolate..ovate, lyrate, coarsely toothed; cauline leaves pinnate-parted, with oblong, toothed or cut lobes; hearls ovate while bearing the fruit; corollas radiant, a little longer

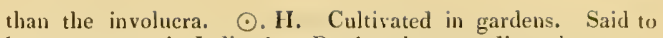
be spontaneous in India, but Roxburgh contradicts that asscrtion. Said also to be a native of Sicily, but according to Schouw it has been introduced there. $\mathrm{S}$. atropurpùrea $\alpha$, and $\beta$, Coult. dips. p. 37. t. 2. f. 11. Curt. bot. mag. t. 247. Succisa atropurpưrea, Møencl. Sclerostémma, Schott. Asterocéphalus atropurpùreus, Spreng. Sc. calyptocárpa, St. Am. fl. agren. p. 61. - There is a proliferous headed varicty of this species (Mor. oxon. sect. 6. t. 14. f. 27.). The flowers are very sweetscented. There is a great variety in their colour, some being of a purple, approaching to black, others of a pale purple, some red, some white, and others variegated. It varies also iu the leaves, some being more fincly cut than others.

Dark-purple-flowered or Sweet-scented Scabious. Fl. July, Aug. Clt. 1629 . Pl. 2 to 3 feet.

19 S. setŕfera (Lam. ill. no. 132l.) stem branched, downy; lower leaves ovate-spatulate, erenated or cut, rather villous; superior ones pinnate, with linear-lanceolate obtuse segments, the terminal segment the largest; corollas radiant, mucls longer than the involuerum. 24. H. Native of the south of France, about Marseilles. S. atropurpùrea $\beta$ sétifera, D. C. prod. 4. $\mathrm{p}$. 657. Asterocéphalus sétifer, Spreng. Corollas lilac. Bristles of calyx 5 , black.

Bristle-bearing Scabious. Pl. 2 feet.

20 S. grandiflo'ra (Scop. del. ins. 3. p. 29. t. I4.) stem branched, downy; leaves rather villons; radical ones oblong, crenated; cauline ones pinnatifid, with lanceolate linear spreading segments; corollas amply radiant. $4 . \mathrm{H}$. Native of Barbary, Italy, and Sicily, in fields. Desf. atl. 1. p. 123. S. arvénsis, Ucria, but not of Lin. Colımbària vulgàris, Presl. S. at ropurpùrea $\gamma$ grandiflòra, D. C. prod. 4. p. 657. Corollas cream-coloured or white, witl reddisl tubes. Bristles of calyx 5 , reddish brown.

Great-flowered Scabious. Fl. June, Sept. Clt. 1S04. PI. 2 to 3 feet.

21 S. Marítima (Lin. amoen. 4. p. 304.) stem branched; radical leaves pinnatifid, with toothed lobes; middle canline ones pinnatifid, with linear entire lobes; uppermost ones linear and quite entire; fructiferous heads globose; involuerum twice shorter than the radiant flowers. $\odot$. or $\delta . H$. Native of the south of France, Corsica, Italy, and Sicily, in arid places by the sea side. D. C. fl. fr. suppl. no. 3309 a. S. Cupàni, Guss. prod. 1. p. 160.? S. angulàta, Rafin. car. p. 81.? S. atropurpùrea var. Coult. Stem villous. Flowers lilac, rose-coloured or white.

Sea-side Scabious. Fl. June, July. Clt. 1683. Pl. 2 feet.

22 S. Daucoìns (Desf. fl. atl. 1.p. 123. t. 38.) stem almost simple ; lower leaves lyrate: cauline ones pinnate-parted, witls linear acute cut segments; leaves of involucrum pinnatifid; bracteas exceeding the fruit. $\delta$. H. Native of Algiers, on hills. Coult. dips. mss. 1824. Asterocéphalus daucoldes, Spreng. syst. 1. p. 388. Very like S. atropurpùrea. Plant downy. Corollas bluish or violaceous.

Carrot-like Scabious. Pl. 1 to 2 feet.

23 S. ambígua (Ten. fl. neap. append. 5. 1826. p. 7.) plant glabrous; leaves fleshy, shining, crenated; radical leares obovate: cauline leaves lyrate or pinnatifid, with oblong remote entire lobes; heals few-flowered, radiant ; tube of corolla rery long; corolla spongy, involute. 4. H. Native of the kingdom of Naples, at Paneta del Fusaro, in corn-fields by the sea side. Flowers purple or blue.

\section{Ambiguous Scabions. Pl. 1 to 2 feet.}

24. S. cornucòpı. (Vivian. add. fl, itin. in f. lyb. p. 67.) plant hairy; radical leaves clliptic, toothed; cauline ones pimate: flowers 5-cleft, pedicellate within the involucrum; involucels trifid; seed triaristate.- Native of Ligmria, in the valley of $4 \mathrm{~T} \approx$ 
Andora, and Sicily. Perlaps a proliferous variety of S. grandiflora, Guss. or S. atropurpurea.

IIorn-of-Plenty Scabious. Pl. 2 feet?

25 S. integra'ta (Hoffm. et Link, fl. port. 2. p. 88.) lower leaves oblong, entire: inferior ones lyrate: upper ones pinnatificl or wanting; corollas 5 -cleft, radiant. 4 . H. Native of Portugal. Said to be allied to $S$. Columbiria and $S$. grandiflòra.

\section{Entire-leaved Scabious. Pl. 2 feet.}

* Spccies bclonging to the present tribe of the genus, but are not sufficiently knon'n.

26 S. limonifo'lia (Vahl, symb. 2. p. 27.) stem shrubby; radical leaves coriaceous, obovate, quite entire, glabrous, and green ahove, but reticulated and clothed with hoary tomentum beneath; cauline leaves connate at the base; corollas equal, 6 cleft ; crown scarious, plicate, denticulated at the apex, broad, extended; limb of calyx sessile; bristles of calyx 4-5, exserted. 々.H. Native of Sicily, among the mountains on calcareous rocks. Guss. prod. p. 164. Coult, dips. p. 42. Asterocéphalus limonifòlius, Spreng.-Cup. panph. 2. t. 247. Lower leaves like those of Státice Limònum. Corollas blue.

Limonium-leaced Scabious. Shrub.

27 S. saxa'tilis (Cav. icon. 2. p. 68. t. 184.) stem herbaceous, glabrous; leaves lanceolate, quite entire, green above, tomentose beneatlı; cauline leaves very few, connate at the hase; corollas equal, 4-5.-cleft; crown white, ciliated; bristles of calyx 5, purple. 2/. H. Native of Spain, in the fissures of rocks, in Valentia. Coult. dips. p. 12. Asterocéphalus saxátilis, Spreng. Corollas white; anthers violaceous. Very like $S$. succisa.

Rock Seabious. Fl. July, Aug. Clt. 1827. Pl. 1 foot.

28 S. Nítens (Rom. et Schultes, syst. 3. p. 82.) stem herbaceous; leaves undivided, elliptic, serrated, shining, petiolate; corollas radiant, 5 -cleft. 4 . H. Native of the Azores. S. licida, Ait. hort. kew. ed. 1. vol. 2. p. 229. but not of Vill. Asterocéphalıs lùcidus, Spreng.

Glittering-leaved Scabjous, Fl, June, Aug. Clt. 1779. Pl.

Sect. 1II. Succisa (from succido, to cut down; on account of the præmorse root of the first species). Coult. dips. p. 37. D. C. prod. 4. p. 657. hut not of others. Base of involucels not distinguishable from the tube; having the foveola engraven from the base to the crown. Crown spreading, short, membranous. Limb of calyx sessile, with 5 bristles, of which some are sometimes abortive and sometimes all.

\section{* Corollas 5 -cleft.}

29 S. Africa'sa (Lin. spec. p. 145.) stem slirubby; leaves lyrate, coarsely toothed, rather hairy ; heads of flowers pedunculate; corollas hardly radiant; tube of involucel obconical: crown one-half shorter than the tube, 24-28-nerved; bristles of calyx 5, exserted. $h_{2} . G$. Native of the Cape of Good Hope. Coult. dips. p. 37. t. 2. f. 12. Shrub evergreen, with the leaves variable in form, sometimes they are obovate-oblong, toothed at the base (Herm. par. t. 219.), sometimes cut at the base (Breyn. icon. 33. t. 26. S. altíssima, Jacq. hort. vind. t. 185.), sometimes lyrately pinnatifid (Herm. par. t. 221.). S. induràra, Irin. mant. p. 196. ex licem. et Sehultes, syst. S. incisa, Mill. dict. 110. 18. Young stems and leaves villous. Heads about the size of walnuts. Corollas white, but in the variety altíssima pale purple or blue.

African Scabious. Fl. July, Oct. Clt. 1690. Shrub 4 to 6 feet.

30 S. Fiscine'u (D. C. prod. 4. p. 658.) stem branched, smoothish; leaves all pinnate, almost glabrous, with linear acute entire lobes; leaves of involucrum equal in length to the co- rollas, which are 5 -cleft and radiant; crown of the involucel, which is somewhat cylindrical, membranous, and 3 times shorter than the tube; bristles of sessile calyx pale, twice the length of the crown. 4. H. Native of Dahuria. It was sent to Gay from Fischer under the name of $S$. Dahurica. Perhaps the same as S. comòsa, Røem. et Schultes, syst. 3. p. 84.? in which the corollas are said to be large, showy, and violaceous, and in this bluish-purple.

Fischer's Scabious. Pl. 2 feet.

31 S. semipappòsa (Salzm. pl. exsic. 1825. ex D. C. prod. 4 p. 65s.) plant hairy, rather canescent; stem lierbaceous, branched; lower leaves oval, coarsely toothed, petiolate: superior ones pinnatifid, with oblong-linear, acute, subdentate lobes ; heads of fiowers pedunculate; leaves of involucrum linear-subulate, ciliated, at length reflexed; corollas radiant; heads ovate; lower fruit of the heads without bristles: the rest furnished each with 5 long exserted bristles.-Native about Tangiers and Mogodor. S. atropurpùrea $\gamma$, coronâ erectâ, Coult. dips. p. 37.

Semi-paplose Scabious. PI. 1 to 2 feet.

32 S. tu'cida (Vill. dauph. 2. p. 293.) plant glabrous ; stems usually 1-flowered; leaves shining: radical ones ovate-lanceolate, obtuse, crenatcd : cauline ones pinnatifid, with linear acuic lobes; involucrum usually exceeding the radiant flowers; crown 20-24-nerved, 3 times shorter than the tube; bristles of calys 5 , black, equal in length to the flowers, but 5 times longer than the crown. \%. H. Native of France, in alpine places, Savoy, Switzerland, Austria, Syria, and Croatia, D C. fl. fr. 4. p. 228 . lichb. pl. crit. 4. t. 381 . S. stricta, Waldst. et Kit. pl. rar. hung. 2. t. 138. S. Nórica, Vest. bot. zeit. 1805. no. 8. Wahl. fl. carp. p. 39 . S. Columbària $a$, Coult. dips. p. 38 . exclusice of the two synonymes. Asterocéphalıs strictus, Spreng. Corollas pale blue, or of a pale violaceons colour. In the wild plant the stems usually bear only one head of flowers. This plant, with several of the following, are combined under the name of $S$. polymórpha, by Wibel, and by Coulter under that of $S$. Columbària.

Shining-leaved Scabious. Fl. June, Sept. Clt. 1800. Pl. 1 to 2 feet.

33 S. Анє'NA (Jacq. fil. eclog. 1. p. 86. t. 59.) stem brancled, rather hairy at the base; radical leaves obovate, toothed or lyrate, rather liairy: cauline leaves piunatifid, with lanceolate acute nearly entire lobes; peduncles elongated, beset with retrograde villi under the heads; corollas radiant; crown 20-nerved, 3 times shorter than the tube; bristles of calyx 5 , of a rufous brown colour, 4. times longer than the crown. 2\%. H. Native of Russia. S. nítida, Bernh. ex Rœm. ex Schultes, syst. 3. p. 68. S. longipedunculata, Fisch. et Jacq. S. Columhària $a$, Coult. dips. p. 38. Asterocéphalus amoènus, Spreng. Flowers lilac or rose-colonred. There are varieties of this having the involucrum either longer or shorter than the flowers. feet.

Pleasing Scabious. Fl. June, July. Clt. 1820. Pl. 2 to :3

34 S. angustifòlia (Hoffm. verz. 1826. p. 206.) stem quite glabrous; leaves downy : radical ones petiolate, oblong, toothed: lower ones lyrately pinnatifid, serrately cut: superior ones ovate, somewhat lyrately twice bipinnate, with linear lobes; peduncles scabrous from retrograde hairs at the apex; leaves of involucrum linear, terminated each by a hair. 4 . H. Native country unknown. Said to be allied to $S$ : amce'ma.

Narrow-lcaicd Scabions. Pl. 1 to 2 feet.

35 S. ochrolev'ca (Lin. spec. p. 146.) stem branched, rather hairy; radical leaves lyrately pinnatifid, downy on both surfaces: canline ones pinnate-parted, with flat linear lobes; pedumcles elongated, rather hairy; crown 20-nerved, one-half shorter than the tube; bristles of calyx fucescent, 3 times longer than the crown. 4. H. Native of Europe, Caucasus, and Si- 
beria, in dry warm places. Jacq. obs. 3. t. 73. 7t. 1. austr. t. 439. S. heterophyllos, Gmel. itin. 1. t. 28 . S. tennifollia, Roth. germ. 1. p. 59. S. polymórpha \&, Weig. obs. p. 24. Asterocéphalus ochroleùcus, WV allr. sclied. crit. 50. S. Colımbària ocliroleùca, Coult. Richb. pl. crit. 4. t. 355.-Gerard. herb. 584 . f. 7. Barrel. icon. t. 770. f. 2. Stem purplish at the joints. It differs from all the European species of Scabiòsa in the flowers being cream-coloured.

Crear-coloured-flowered Scabious. Fl. July, Aug. Clt. 1597. Pl. 1 to 2 feet.

36 S. Scopònu (Link, enum. hort. berol. 1. p. 128. but not of $\mathrm{V}$ is.) stem clothed with retrograde hairs above; leaves hairy : radical ones oblong, crenate: lower cauline leaves pinnatifid ; superior ones bipinnatifid; lobes linear, cut; leaves ol involucrum linear, clothed with adpressed hairs. 4 . H. Native of the sonth of Europe. Corollas cream-coloured. According to Link, this species comes nearest to $S$. ochroleuca, but according to Coulter, to S. Banática.

Scopoli's Scabious, Fl. June, July. Clt. 1818. Pl. 1 to 2 feet.

37 S. REVE'RSA (Ledeb. ined, sem. hort. dorp. suppl. 1821. p. 6.) radical leaves obovate, obuse, crenated, clothed with spreading down: cauline leaves pinnate, with deeply cut segments; peduncles beset with retrourade hairs; involucrum exceeding the corollas, which are rather radiant and 5 -cleft. 4 . $H$. Native country unknown. Said to be nearly allied to $S$. grandifìra and $S$. Ścopolii.

Reverse-haired Scabions. Pl. 1 to 2 feet.

38 S. PAuCise'ta (D. C. prod. 4. p. 658.) stem branched, lairy at the base; radical leaves lyrately-pinnatifid, hairy, having the terminal lobe ovate and coarsely toothed: cauline leaves pinnate-parted, with narrow lobes; flowers radiant; heads of fruit globose; crown 20-nerved, 3 times shorter than the fruit; bristles of calyx usually only one, rarely $2-3$, black, 3 times longer than the crowti. $\leftarrow$. H. Native of Italy, in fields about Pisa, Carrara, Sarzana, \&c. S. unisèta, Savi, fl. pis. p. 167. t. 2. f. 6. S. Gramúntia, var. Seb. et Maur. fl. rons. p. 76. S. tenuifòlia, var. Savi, bot. etrus. 122. S. Columbària, var. Poll. Coult. Flowers vialaceous. Perhaps the same as S. Saviàna, Rchb. hort. bot. 1. t. 53. but in that plant the bristles of the calyx are 5 , and the heads ovate.

Few-bristled Scabious. Pl. 1 to 2 feet.

39 S. Columba'ria (Lin. spec. 14.3.) stem branched, smootliish ; radical leaves ovate, obtuse, petiolate, crenated, nembranous, clothed with canescent down on both surfaces: cauline leaves smoothish, pinnate-parted, with flat linear segments; peduncles elongated, usually trifid, downy; corollas radiant ; heads of fruit ovate-globose ; crown 20 -nerved, one-half shorter than the tube; bristles of caly $x$, twice longer than the crown. 4. H. Native of Europe, Caucasus, and Siberia, very common; in England plentiful on chalky soils. Coult. dips, p. 39. var. $\delta$, Smith, engl. bot. 1311 . Rehb. pl. crit. 4. t. 353. Savi, f. pis. 1. p. 165. t. 2. f. g. Fl. dan. t. 314. Asterocéphalıs Columbària, $\mathrm{W}_{\text {all }}$. sched. crit. 48 . Flowers purple or violaceous. This is a very polymorphous plant.

I'ar. B, Colúmnce (D. C. prod. 4. j. 659.) leaves villous; lobes of cauline leaves wedge-shaped, cut ; bristles of fruit 3-5, deciduous. 4.H. Native about Naples, in fields. S. Colúmnx, Ten. fl. nep. 1. p. 29. t. 7.

lür. $\gamma$, commutàta (D. C. l. c.) stem glabrous; leaves smoothisll: ralical ones on long petioles, deeply serrated or pinnatifid: cauline leaves pinnate, with linear lobes. 4 . H. Native of Siberia. S. comnutàta, Rom. et Schultes, syst. 3. p. 65 . Corollas deep blue, radiant.

Pigeon Scabious. Fl. July, Aug. Britain. Pl. 1 foot.

40 S. Banática (Waldst. et Kit. hung. 1. t. 12) stem branched, beset with reflexed white hairs at the base and at the joints; radical leaves lyrate, hairy : cauline ones somewhat bipinuate, with linear ciliated segments, which are each terminated by a white hair; involucrum equal in length to the corollas; seeds furnished with 8 pilose ribs; bristles of calyx 5 , long, black. 4. H. Native of Hungary, on rocks. \$. diversifólia, Baumg. enum. lisp. trans. 1. p. 75. S. Columbària $y$ ? Banática, D. C. prod. 4. p. 659. Asterocéplalıs Banáticus, Spreng. Receptacles of heads columnar. Corollas pale resl or cream-coloured, with red rays. Anthers pale red.

feet.

41 S. AGRE'stis (Waldst. et Kit. pl. rat. hung. 3. t. 20\%) stem terete, purplish at the joints, glaucous, hairy at the base ; radical leaves entire and somewhat lyrate: cauline ones tripinnate and pinnate, with linear segments; peduncles hairy at tops; corollas radiant; leaves of involucrum linear, downy; seeds crowned by a membrane, which at length ends in 5 teeth; angles of seeds downy. 4 . H. Native of Hungary and Croatia, in dry fields. S. columbària, var. Bieb. A. taur. 1. p. 96. S. Colúmnæ, Tenor. prod. fl. neap. p. 12. fl. neap. 1. p. 29. t. 7. S. columbària $\delta$ ? agréstis, D. C. prod. 4. p. 659. Asterocéphalı. agréstis, Spreng. Corollas pale lilac. Heads on long pedmicles; lience the plant is sometimes to be found in gardens umler the name of $S$. longipedunculata.

Field Scabious. Fl. June, July. Clt. 1818 . Pl. $1 \frac{1}{2}$ to $3 \mathrm{ft}$. 4.2 S. Gramu'NTia (Lin. spec, 145.) stem rather hairy; peduncles beset with retrograde hairs under the heads; ratical leaves pinnatifid, with obtuse distant scgments; cauline nnes bipinnate, with linear segments; leaves of involucrum lincar, acute, short; bristles of calyx 5 , dark brown: corollas radiant, sometimes 4-cleft. 2 . H. Native of the middle and west of France, the north of Africa, and the Pyrences. S. triandra, Lin spec. p. 99 . S. colımbària $\varepsilon$, Gramúntia, D. C. fl. fr. no. 3305. Asterocéphalus Gramúntius, Spreng. S. grácilis, Roen. et Schultes, syst. 3. p. 104.-Gerard. herb. 584. f. 2. Leaves cinereous from villi. Corollas lilac or red.

Gramont Scabious. Fl. July, Aug. Clt. 1597. Pl. 1 to 2 feet.

43 S. ceratophýl (Tenor. prod. fl. neap. p. 12. fl. neap. 1. p. 31.t. 8.) stem fistular, villous; radical leaves lyrate, crenated: cauline ones bipinnatifid, with linear falcate segments; leaves of involucrum equal in length to the flowers; bristles of calyx 5. 2. H. Native of Abruzzo, in forests. S. pilòsa, Lacr. Flowers red or lilac.

Horn-lcaved Scabious. Fl. July, Aug. Clt. 1820. Pl. 2 fr.

44 S. Hispa'sica (Willd, in Roem. et Schultes, syst. 3. p. 521.) leaves pinnate-parted: the terminal lobe lanceolate, and a little toothed; corollas 5 -cleft, radiant, longer than the involucrum. 24. H. Native of Spain. According to Conlter, this is hardly distinct from $S$. columbaria.

Spanish Scabions. Pl. 1 to 2 feet.

$45 \mathrm{~S}$. cononopifòlia (Willd. herb. but not of $\mathrm{A}$, græe.) radical leaves lanceolate-spatulate, sharply toothed, or pinnately jaggerl : cauline ones pinnate-parted, with divaricate linear lobes; corollas 5-cleft, radiant. 4.H. Native of Siberia. S. ceratophýlla, liœm. et Scluultes, syst. 3. p. 521 . but not of Tenore. The rest unknown.

Coronopus-leaved Scabious. Pl. 1 to 2 feet.

46 S. Heracle'A (Wilkl, in liom. et Schultes, syst. 3. p. 521.) lower leaves bipinnatifid: superior ones pinnate-lobed; corollas 5-cleft, radiant.-Native at the Straits of Gaudilava. The rest unknown.

IIerculcs' Scabious. Pl. 1 to 2 feet.

47 S. IncA'na (Roem. et Schultes, syst. 3. p. 521 . and 67.) stem villous; leaves hoary, pinnate-parted, with linear ciliated 
lobes; corollas 5-cleft, radiant.-Native of Tauria. S. Ucránica, Bieb. fl. taur. 1. p. 97.? S. incàna, Schultes, olss. 19. Hardly distinct from S. columbària, or S. suavèolens. Radical leaves quite entire and lyrate, ciliated ; leaves of involucrum obtuse. Corollas radiant, violaceous. Pappus 5-awned.

Hoary Scabious. Pl. 8 to 2 feet.

48 S. RHJZA'NTHA (Viv. fl. lib. spec, p. 6. t. 3. f. a. b.) radical leaves elliptic: cauline ones pinnate-lobed: lobes all linear ; central peduncle rising from the root, bearing one head: the rest rising from the tops of the branches; leaves of involucrum 5 , linear; corollas 5-cleft, radiant; bristles of calyx 5.4 . H. Native of Cyrenaica, on the mountains.

Rout-flon'rcd Scabious. Pl. 1 to 2 feet.

49 S. HLadnikin'si (Host, fl, austr. 1. p. 195.) stem straight, branched, downy ; leaves hispid: lower ones obovate, crenated: upper ones pinnate-parted: lobes jagged; leaves of involucrum linear ; corollas 5-cleft, radiant; bristles of calyx 5 , dark purple. 4 . H. Native of Carniola, on the mountains. lichb. pl. crit. 5. p. 30. Corollas purplish.

Hladniki's Scabious, Pl. 1 to 2 feet.

50 S. Hu'muls (Host, fi. austr. 1. p. 195. but not of 'Thumb.) stem branched, glabrous, ascending; lower leaves oblong, crenated or jagged: superior ones pinnate-parted: lobes jagged; peduncles beset with reflexed hairs; leaves of involucrum linearsubulate; corollas 5 -cleft, radiant; bristles of calyx 5. 2. H. Native of tie alps of Austria, about Gemona. Corollas white, suffused with purple. Richb. pl. crit. 5. p. 30.

Humble Scabious. Pl. $\frac{1}{2}$ foot.

5 I S. NEGLE'ctA (Hom. hort. hafn. 1. p. 127.) leaves all lyrate or pinnatifid; peduncles very long; leaves of involucrum excceding the corollas, which are 5 -cleft and radiant. $4 . \mathrm{H}$. Natise of Italy. Flowers red or lilac. The plant we have in the gardens under this name appears to be nothing but S. Gramuntia.

Neglectcd Scabious, Fl, June, July. Clt, 1825. Pl. 1 to 2 féet.

52 S. Lacixia'ta (Licht, in Roem. et Schultes, syst. 3. p. 87.) plant downy ; stem dichotomous; lower leaves obovate-oblong, unequally and bluntly serraterl: siperior ones pinnatifid; lobes cut, acute; corollas 5-cleft, radiant-Native of the Cape of Good Hope. Leaves of involucrum downy, linear, acute, and sometimes bifid, one-half shorter than the corollas, which are pale violet.

Jaggcd-leaved Scabious. Pl. 1 to 2 feet.

53 S. Pyrena'ica (All, ped. 1. p. 140. t. 25. f. 2. and 26. f. 1.) the whole plant clothed with cinereous tomentum; stem a little branched, few-flowered; radical leaves oblong, crenated: upper cauline ones bipinnatifid: lobes linear, quite entire; corollas radiant; leaves of involucrum lanceolate; crown 3 times shorter than the tube, 20 -nerved; bristles of calyx 5,4 times longer than the crown. 24. H. Native of the south of Europe, on the lower mountains and hills; and of Caucasus, on the I'alusch Mountains, in dry fields. Dub. bot. gall. p. 256. S. columbària, var. Coult. clips. p. 38. exclusive of the synonymes. Corollas frequently reddis] purple, but most often of a bluish purple.

l'ur. a, cinirea (D. C. prod. 4. p. 659.) plant clothed with hairy down. 4. H. Native of the Pyrenees, S. cinèrea, Lam. ill. no. 2319. S. marítima, Vill. daupl. 2. p. 225. S. Pyrenaica, D. C. fl. f. 1. p. 299.

I ar. B, mollissima (D. C. 1. c.) plant clothed with hoary tonentose velvety down. 4 . H. Native from Nice to Sarzana. \$. mollíssima, Visiani, anı. 2. p. 161. Asterocéphalus mollíssimus, Spreng. S. laxillora, Link. enum. 1. p. 128. The plant in the gardens, under the name of $S$. mollissima, has white flowers.
Var. $\gamma$, tomentòsa (D. C. ]. c.) lower leaves lyrately pinnatifid, obtuse: superior ones divided into linear acute lobes. $\boldsymbol{~}$. H. Native of Spain, in the kingdom of Valentia. S. tomentosa, Cav. icon. 2. t. 183. Asterocéphalus tomentòsus, Spreng. Corollas pale violaceous.

Pyrencan Scabious. Fl. June, July. Clt. 1819. Pl. $1 \mathrm{ft}$.

5 \$ S. holoserícea (Bertol. dec. 3. p. 49.) plant clothed with soft hoary tomentose velvety lown; lower leaves lanceolate, obtuse, crenated: superior ones pinnatifid, with lanceolate acute cntire loles; leaves of involucrum linear; corollas radiant; crown 20-nerved, 3 times shorter than the tube, which is hairv; bristles of calyx 5 , black, twice longer than the crown. 4. H. Native of the Appenines, Abruzzo, Dalmatia, and the Pyrenees. D. C. fl. fr. 5. p. 480 . Dub. ench. 1. p. 256. S. columbària holoserícea, Coult. dips. p. 39. Asterocéphalus seríceus, Spreng. Leares sometimes all simple. Corollas bluish purple.

Whole-silky Scabious. Fl. July. Clt. 1818. Pl. 1 to $2 \mathrm{ft}$.

55 S. WEBBIA'NA (D. Don, in bot. reg. t. 717.) plant clothed with soft silky hoary tomentum; lower leaves petiolate, obovate, crenated: superior ones pinnatifid, with ovate or oblong entire lobes; heads on long peduncles; corollas nearly equal; crown 4 times longer than the tube; bristles of calyx 5 , black. $\psi . \mathrm{H}$. Native of Plirygia, on the top of Mount Ida. Asterocéplialus Webbiànus, Spreng. Flowers cream-coloured.

Webb's Scabious. Fl. July. Clt. 1818. Pl. $\frac{1}{2}$ foot.

56 S. Móltıs (Willd. enum. suppl. p. 7.) lower leaves supradecompound : superior ones bipinnate-parted; lobes of all very slender and filiform, smoothish, except the margins, which are rather pilose ; peduucles very long, scabrous; involucrum equal to the corollas, which are 5-cleft and radiant; crown spreading ; bristles of caly $\times 3 \cdot 5$, short. 4 . H. Native country unknown. Rchb. pl. crit. 4. t. 353 . S. capillàta, Rom. et Schultes, syst. 3. p. 64. Lower leaves lyrate, soft, tomentose, ex Link. enim. 1. p. 128. Flowers pale violaceous, ex Willd. Perhaps only a variety of $S$. columbària or S. Pyrenàica.

Soft Scabious. Fl. June, July. Clt. 1820. Pl. 2 to $3 \mathrm{ft}$.

57 S. Pu'mus (Poir. dict. 6. p. 723.) plant hispid from grey pili; stem short, almost simple; radical leaves lyrate or pinnatifid, with obtuse toothed lobes: cauline leaves pinnate-parted, with linear acute lobes, which are sometimes trifid at the apex: leaves of involucrum lanceolate, villous, shorter than the corollas, which are 5 -cleft and radiant; bristles of calys 5 , black, nearly equal in length to the corollas. 4 . G. Native of the Cape of Good Hope. Asterocéphalus pùmilus, Spreng. S. acaúlis, Lin. mant. 196. Thunb. fl. cap. p. 145. S. nudicaúlis, Lam. ill. no. 1331. Corollas cream-coloured or nearly white. Plant very liairy.

Dwarf Scabious. Pl. $\frac{1}{2}$ foot.

58 S. SuAve'olens (Desf. cat. hort. par. p. 110.) plant rather canescent from short down; stems straight; radical leaves oblong, attenuated at the base, quite entire: cauline ones pinnateparted, with linear-thickish quite entire lobes, smoothish; heads of fruit ovate; flowers radiant; tube of involucel cylindrical; crown very short, 16-nerved; bristles 5 , spreading, hardly exserted. 4 . H. Native of France, Germany, Sweden, Hungary, Sc. on the higher hills. D. C. f. fr. no. 3307. Coult. dips. p. 39. t. 2. f. 14. S. asterocéphala, Thuill. herb. S. columbària odoràta, Thuill. fl. fr. 1. p. 72. S. canéscens, Waldst. et Kit. pl. rar. liung. 1. t. 53. Asterocéphalus canéscens, Lag. Spreng. Asterocéplıalus suavèolens, Wallr. sched. crit. p. $5 \mathrm{I}$. S. média, Ger. hist. p. 720. Corollas of a bluish lilac colont. having a scent like $O^{\prime}$ rchis nigra.

Sweet-seented-flowered Scabious. Fl. July, Aug. Cit. 1802. Pl. 1 to $1 \frac{1}{2}$ foot.

59 S. рісно́тома (Ucria. pl. lin. add. 249. Willd. enum. 1. p. 144.) smoothish; stem dichotomous; heads almost sessile at the sides, globose; leaves oblong, entire: radical ones petiolate 
and toothed: cauline ones almost sessile, quite entire; corollas cqual; tube of inrolucel nearly cylindrical; crown 20-2tnerved, one-lialf shorter than the tube; bristles of calyx spreading, very short, inclosed. $\odot$. H. Native of Mauritania, Sicily, \&ec. Conlt. dips. 9. t. 2. f. 15. Guss. prod. 1. p. 168. Asterocê phalus dichótomus, Lag. gen. et spec. 8. S. parviflòra, Desf. 11. att. 1. p. 119. Lower leaves sometimes lyrate or jagged. Corollas 5 -cleft, and flesh-coloured; but by some authors they are said to be 4 -cleft.

Dichotomous-stemmed Scabious. Fl, June, July. Clt. 1804. Pl. 1 to $1 \frac{1}{2}$ foot.

60 S. urceola'ta (Desf. Al. at]. 1. p. 122.) glabrous; leaves rather fleshy: radical ones oblong, bluntly and sinuately pinnatifid: cauline ones pinnate-parted, with linear lobes; leaves of involucrum 5-7, combined at the base; leads on long peduncles; corollas nearly equal. 4 . H. Native of Corsica, Sicily, Etruria, Portugal, Maritania at Tangiers, Tunis, and Mogodor, in sand by the sea side. Coult. dips. p. 39. t. 2. f. 16 . S. rutefòlia, Valıl. symb. 2. p. 26. S. divaricàta, Lan. ill. no. 1311. S. marítima rutaélia, Bocc. sic. t. 4.0. f. 3. Asterocéphalus urceolàtus, Spreng. Pycnócomon rutaefòlium, Hoffm, et Link. fl. port. 1. c. Corollas prale yellow.

L'rceolate-involucred Scabious. Fl. July, Aug. Clt. 1804. Pl. 1 to 3 feet.

\section{* Corollas 4-cleft.}

61 S. Succisa (Lin. spec. 142.) root præmorse, or appearing as if it was bitten off at the end; radical leares ovate-lanceolate, acuminated at both ends : cauline leaves connate, almost entire; heads of flowers pedunculate; leaves of involucrum disposed in 2-3 series; corollas equal; tube of involucel 4-sided; crown very short, undulated; bristles of calyx short, a little exserted, connivent. 4. H. Native of Europe even to Caucasus, very common in bogs and moist meadows and pastures; plentiful in Britain. Fl. dan. t. 279. Smitl, engl, bot. t. 878 . Curt. lond. 3. t. 10. Coult. dips. p. 39. t. 2. f. 17 . D. C. A. fr. 4. p. 226. Blackw. t. 14?. Asterocéphalus Succisa, Wallr. sched. 1. p. 52.

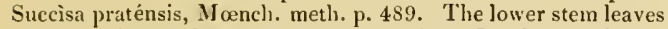
are toothed, but the upper ones are entire. Involucrum hairy. Flowers violet or dark purplish blue, varying to flesh.coloured and milk-white. The leaves are sometimes gashed according to Haller, and the heads of flowers are sometimes proliferous. In cultivation the plant becomes more branclied than in the wild state. In days of superstition it was fabled that the Devil, envying the good this herb might do to mankind, bit away a part of the root; hence the plant is commonly called Decil's-bit. This appearance of a stumped root is not peculiar to $S$. succisa, but is observed in some species of Plantàgo, and many other herbs. According to Bergen the root is astringent, and the infusion of it bitterish, but not unpleasant. A strong decoction of it, kept a good while, was formerly an empirical secret for gonorrhœas. Linnæus says that the dried leaves are used to dye wool yellow or green.

Var. a, hirsùta (Wallr. sched. I. c.) stem, peduncles, and both sides of leaves hairy. $\%$. H. 'This is the British variety. Succisa hirsùta, C. Baub, pin. p. 269.

Var. $\beta$, glabràta (Waltr, sched. 1. c.) stem and both sides of leaves glabrous. 4. H. Succisa glàbra, C. Bauh. pin. 269. S. glabràta, Schott. in Rœm. et Schultes, syst. 3. p. 61 .

Common Dcvil's-bit. Fl. Aug. Oct. Britain. Pl, 1 foot.

62 S. Austra'lis (Wulf. in Rom. arch. 3. 1. 216.) plant smoothish; leaves ovate, elongated, acuminated, almost quite entire: lowermost ones somewhat auriculated at the petioles; heads ovate; leaves of involucrum disposed in two series; corollas equal; tube of involucel lagenæeform; crown obsolete; bristles of calyx abortive. 4. H. Native of Upper Italy,
Syria, and Pannonia, in marshy parts of woods, and by the sicles of rivulets. Coult. dips. p. 40. t. 2. f. 18 . Rehb. pl. crit. 4. t. 325. S. rèpens, Brign. for Jul. 19. Nocc. et Balb. fl. ticin. 63. t. 2. S. pseudaustràlis, Røm. et Schultes, syst. 3. p. 60 . Roots creeping, tufted. Corollas of a bluish violet or purple colonr, but Wulfen says they are yellow; there are, thereforc, 2 plants probably confused under this name, or only mere variations in the colour of the flowers.

Southern Devil's-bit. Fl. June, Aug. Clt. 1820. Pl. 1. fi.

63 S. tenulvòla (Linnea. vol. 8.) bristles of pappus twice longer than the denticulated calyx; corollas downy, equal, shorter than the involucrum; heads ovate; stem erect, branched; cauline leaves pinnate, with linear, acute, quite entire, elongated segments. \%. H. Native country unknown. Said to be nearly allied to $S$. Austrilis.

Fine-leaved Devil's-bit. Pl. 1 foot.

\section{+ Specics not sufficiently known.}

\section{$\$ 1$. Leaves cntire or serrated.}

64 S. ? AMPLEXICAu'Lis (Lin. mant, p. 195.) stem herbaceous, brachiate; leaves stem-clasping, lanceolate, quite entire: radical ones trifid; corollas ridiant, 4-cleft.-Native country unknown. Succisa amplexicaúlis, Spreng. Said to be nearly allied to S. integrifolia, Lin. Corollas bluish. According to Coulter, it is probably a species of Knaútia.

$V_{a}$. $\beta$, lyràta (Rocm. et Schultes, syst. 3. p. 62.) lower leaves lyrate, obtuse, crenated; superior ones lanceolate, sessile. 4. H. Native of France. S. lyràta, Lain. ill. no. 1810. Flowers pale red.

Stem-clasping-leaved Scabious. Pl. 1 foot.

65 S.? Cochincuine'nsis (Lour. coch. p. 68.) stem quite simple, nearly naked; leaves lanceolate, undivided, undulated: radical leaves quite entire; involucrum 3-leaved; corollas 5cleft; pappus pilose.-Native of China and Cochin-china. Asterocéphalus Cochinchinénsis, Spreng. Flowers purple. Corollas 5 -cleft, nearly equal. Bristles of calyx 5 .

Cochin-china Scabious. Pl. 1 foot.

\section{\$2. Lcaecs lyrate or pinnate-lobed. * Corollas 4-clefi.}

66 S.? Danu'rica (Willd, in Roem. et Schultes, syst. 3. 1). 521.) leaves pinnate-parted, tomentose; lobes pinnatifidly jagged ; stem tomentose; corollas 4-cleft, radiant. - Native of Dahuria. Coulc. dips. p. 41. There is another plant under this name by Fischer, cultivated in the gardens.

Dahurian Scabious. Pl. 1 foot.

67 S. нíkт (Willd, in Rom. et Schultes, syst. 3. p. 251.) leaves all pinnate, and are as well as the stem hairy; lobes or segments linear-lanceolate, acute; corollas 4 -cleft, radiant.Native of Siberia. Coult. dips. p. 41. The rest unknown.

IIairy Scabious. Pl. 1 to 2 feet.

$$
\text { * Corollas 5-cleft. }
$$

68 S. Styriaca (Vest, in flora. 1821. p. 146.) plant clothed with fine hairs; stem much branched, many-flowered; leaves all pinnate-parted; lobes lanceolate, few, each furnished with a tooth; leaves of involucrum linear, spreading; corollas 5 -cleft, radiant, outer lobes acute; crown quite entire; bristles of calyx wanting. -Native of Styria.

Styrian Scabious. Pl. 1 to 2 feet.

Cult. Many of the species of this genus are very ornamental, and are well fitted for decorating flower-borders. The perennial herbaceous kinds are easily increased ly seed, or dividing at the root. The seeds of anmual kinds only require to be sown 
in the open gromnd. The shrubby species are increased by cuttings under a hand-glass, or by seed. The species most worthy of cultivation are $S$. Caucásica, S. gramnifólia, S. atropurpùrea, S. grandiflora, and many others.

ORDER CXXXIII. CALYCEREÆ (this order contains plants agreeing with Calycèra in important characters). R. Br. in Lin. trans. 12. p. 132. (1816). Ricl. in mem. mus. 6. p. 76. (1820). Lindl. introd. bot. p. 201.-Bhoodpidece, Cassint in lict. des. sc. 5. p. 26. suppl. 1817.

Calyx of 5 unequal segments. Corolla regular, funnelshaped, with a long slender tube, and 5-3-nerved segments; ylandular spaces or areola below the stamens, and alternate with them. Stamens 5, monadelphous; anthers combined by their lower balf. Ovarium inferior, 1-celled. Style smootb, clavate in the upper part; stigma capitate, undivided. Fruit or acheniæ indehiscent, crowned by the rigid spiny segments of the calyx. Seed solitary, inverted, sessile. Embryo in the axis of fleshy albumen, slender.-Herbaceous plants, with alternate leaves without stipulas. Flowers collected into heads, which are either tcrminal or opposite the leaves, surrounded by an involucrum, and bearing bracteas anong the flowers. Flowers sessile, hermaphrodite or nenter. This is a very small tribe of plants, differing from Compósite in their albuminous pendulous orulum, and half distinct anthers; and from Dipsàcere in their filaments being monadelphous, and their combined anthers.

\section{Synopsis of the gencra.}

I Calyce'ra. Crown of fruit in some long horned, and in others short and scaly.

2 Boòpis. Limb of corolla not contracted, campanulate. Fruit crowned by the segments of the calyx, which are stiff and membranous, but acute and spinescent at the apex.

3 Acicárpila. Lower flowers of the lieads fertile: superior ones numerous and sterile. Tube of anthers undivided. Fruit combined into a globose echinated head.

I. CALTCE'RA (from $\kappa \alpha \lambda v_{h}^{\xi}$, a calyx, and $\kappa e \rho \alpha s$, keras, a lrorn; the crown of the fruit is a long horn). Cav, icon. 4. p. 34. t. 358. Juss, anu. mus. 2. p. 350 . Pers, ench. 2. p. 500. Cassini, dict. 5. suppl. p. 28.

Lin. sist. Syngenèsia, Necessària. Involncrum 5-parted. Flowers fertile, dissimilar, and promiscuous. Segments of the calyx in some long and horn-formed, and in others short and scale-formed. Limb of calyx contracted a little below the lobes. Tube of stamens inserted a little below the contraction of the corolla, divided at the top.-Herbaceous plants with sub-pinnatifid leaves and terminal beads of flowers.

1 C. Cavanilue'sir (Richard, in ann. mus, 6, p, 77.) glabrous; leaves semi-pinnatifid; fructiferous heads almost 2 inches long, globose; bracteoles narrow and subulate at the apex. 4. F. Native of Chili. C. herbacea, Cav, icon. 4. p. 31. t. 35S. Pers. ench. 2. p. 500 . Flowers green.

\section{Caranilles's Calycera. Pl. 1 foot.}

2 C. Balsamitafòlia (Rich, ann. mus. 6. p. 86. t. 10.) stem pilose ; leaves deeply toothed or subpinnatifid, downy on the margins; bracteoles linear, subulate at the apex. $h_{\imath} . \mathrm{F} . \mathrm{Na}-$ tive of Chili, where it was collected by Dombey. Boòpis balsamitafolia, Juss. anu. mus. 2. p. 350 . Pers. 2. p. 500. Scabiòsa sympaganthèra, Ruiz et Pav. fl. per. 1. p. 49. t. 76 . f. a. Flowers green? Root woody.
Cosmary-lcaved Calycera. Shrub 2 feet.

Cult. The species of Calycèra should be grown in pots, in a mixture of loam, sand, and peat; and they will be readily increased by seed.

I1. BOO'PIS (from $\hat{\beta} \circ u$, bous, an ox, and $\omega \psi$, ops, an appearance; the flowers have some resemblance to the eye of an $\mathrm{ox}$ ). Juss. ann. inus. 2. p. 350 . t. 58. f. 2. Pers. syn. 2. p. 500 . C. Cassini, dict. 5. suppl. p. 28. Richard, mem. mus. 6. p. 87.

Lis. syst. Syngencsia, Necessaria. Involucrum 7-8-cleft. Flowers fertile, nearly alike. Segments of calyx shorter than the ovaria, membranous, some entire, and some deeply toothed. Limb of corolla without any contraction, campanulate, half divided. Column of stamens inserted at the base of the limb of the corolla; tops of filaments distinct.-Many stemmed branched herbs, with pectinately pinnatifid leaves, and terminal heads of flowers.

1 B. Antuemoloss (Juss. 1. c.) leaves pectinately pinnatifid; segments of leaves linear. $\odot$. H. Native of Buenos Ayres, where it was first detected by Commerson. Pers. ench. 2. p. 500. Rich. 1. c. p. 87 . pl. ii.

Anthemis-like Boopis. Pl. $\frac{1}{2}$ to $\frac{3}{4}$ foot.

2 B. Alpi'xa (Poepp. mss. coll. 2. no. 823. ex Cham. et Schlecht. in Linnæa. 6. p. 258.) leaves oblong-obovate, fleshy, entire, or furnished with a tooth on one or on both sides, quite glabrous. 4. G. Native of Chili. Root woody. Stem erect, simple, only leafy at the base. Corolla yellowish. Involucrum 12-toothed.

Alpine Boopis. Pl. 2 to 3 inches.

3 B. leccánthema (Poepp. mss. 1. c.) leaves petiolate, fleslıy, glabrous, profoundly pinnatifid, with linear acute segments. $\odot$. II. Native of Chili. Involucrum many parted. Root slender, branched. Corolla white.

Leucanthema-leaved Boopis. PI. 1 to 2 inches.

C'ult. The seeds only require to be sown in a warm sheltered situation in the open ground.

III. ACICA'RPHA (from akes, akis, a point, and k'epos, carphos, chaff; in reference to the segments of the calyx being spiny). Juss, ann. mus. 2. p. 347. t. 58. f. 1. Pers. ench. 2 p. 488. Cassini, dict. 1. supp. 32. Rich. ann. mus. 6. p. 77. j]. 11-18-Cryptocárplaa, Cassini, dict. 12. p. 85.

LiN. syst. Syngenèsia, Necessària. Involucrum 4-5-parted: outer ones adnate to the ovaria. Lower flowers of heads fertile. superior ones much more numerous and sterile, with the ovaria of all combined. Segments of the calyx for the most part ending in acicular spines. Limb of corolla funnel-shaped. Column of stamens inserted beneath the attenuated part of the limb of the corolla, undivided to the top of the anthers. Bases of connectives knot-formed.- Herbaceous plants, with toothed or entire leaves, and terminal and lateral heads of flowers.

1 A. Tribuloides (Juss, l. c.) plant erect, glabrous; leaves oblong, cuneate-oboval, obtuse, with broad teeth; style much exserted. $\odot$. H. Native of Buenos Ayres, where it was collected by Commerson. Cryptocárpha tribuloides, Cassini, dict. 12. p. 85 .

Caltrop-like Acicarpba. Pl. $\frac{1}{2}$ to $\frac{5}{4}$ foot.

2 A. spatul.'ta (R. Br. comp. p. 29. Richarl. mem. mus. 6. p. 78. pl. 12.) procumbent, glabrous; leaves spatulate, tapering a long way at the base, denticulated and entire at the apex, and mucronate; style a little exserted. $\odot$. H. Native of Brazil, where it was collected by Sello. Cryptocárpha spatulàta, Cassini, dict. I2. p. 85 .

Spatulate-leaved Acicarpla. Clt. 1824. Pl. proc.

3 A.? Lana'ta (Lag. in Pers. ench. 2. p. 488.) stem woolly ; leaves linear, glabrous, having a tooth on one side, and some- 
times on both; uppermost leaves entire.-Native of New Spain. Cassini, dict. 12. p. 36. Kich. l. c. p. 79.

Woolly-stemined Acicarpha. Pl. prostrate.

Cult. Being anmul plants, the seeds only require to be sown in the open ground in a warm sheltered situation.

N. B. Ceva'llia sinua'ta (Lag. gen. et spec. p. 11. with a figure,) appears to be allied to the present order, but the characters of the plant are not sufficiently known.

ORDER CXXXIV. LOBELIA'CEE (this order contains plants agreeing wih the genus Labèlia in many characters). Juss. ann. mus. 18. p. 1. (1811.). D. C. et Duby, bot. gall. p. 310. (1828.). Lindl. introd. nat. syst. p. 107.-Campanulàcea, § 2. R. Br. prod. p. 562.

Caly $x$ superior, 5-toothed, or 5-parted, seldom entire, with the tube adnate to the ovarium at the base. Corolla monopetalous, irregular, inserted in the calyx, 5-lobed, or deeply 5-cleft. Stamens 5 , inserted into the calyx alternately with the lobes of the corollas; anthers cohcring; pollen oval. Ovarium inferior, with from 1 to 3 cells, but usually of 2 cells. Ovula very numerous, attached to the axis or parietes of the fruit. Style simple; stigma usually 2-lobed, surrounded by a cup-like fringe. Fruit capsular or baccate, 1-2-celled, rarely 3-celled, many seeded, dehiscing at the apex. Seeds attached to the axis or parietes of the fruit. Embryo straight, in the axis of fleshy albumen, with the radicle pointing to the hylum.-Herbaceous plants or shrubs. Leaves alternate, exstipulate. Flowers axillary or terminal, of various colours.

This order appears more nearly related to Compósita than to Campanulacece, in their colıering anthers, and in the irregularity of the corolla; the stigma is surrounded by hairs, which are probably analogous to the indusium of Goodenovia, to which order Lobeliucece approaches very closely. It participates in all the affinities of Campanulàcea.

The plants contained in this order are all dangerous or suspicious, in consequence of the acridity of their milk. Tuेpa Fcuillei yields a dangerous poison in Chili. The most active article of the Materia Medica of North America is said to be Lobetia inflàta; it is possessed of an emetic, sudorific, and powerful expectorant effect, especially the first. When given with a view to empty the stomach, it operates veliemently and speedily, producing, however, great relaxation, debility, and perspiration, and even death, if given in over-doses. Barton, 1. p. 189. The antisyphilitic virtues ascribed to Lobèlia syphilitica are supposed to have resided in its diurctic properties; they are, however, generally discredited altogether. Barton, 2. p. 211. Hippobròma longifiora, a native of some of the West India Islands, is one of the most venomous of plants. The Spanish Americans call it Rebentia Cavallos, because it proves fatal to horses that eat it; it acts as a violent cathartic, the effects of which no remedy can assuage, and which ends in death. The leaves are an active vesicatory. Lobelia cardinalis is an acrid plant, which is reckoned anthelmintic. Barton, 2. p. 180. All the plants contained in this order are very ornamental, and Yok. 111. therefore well deserving the care of the gardener. The flowers are very showy blue, white, red, scarlet, but seldom yellow.

\section{Synopsis of the genera.}

1 Ciermóntea. Calyx tubular, 5-cleft. Corolla arched, 5cleft, almost regular. Stamens with combined filaments and cohering anthers; the two lower anthers bearded. Stigma 2-lobed, girded by hairs. Capsule baccate, naked at the apcx, indehiscent, 2-celled, many-seeded.

2 Rolla'ndia. Calyx 5-parted. Corolla compressed at the sides, with an undivided tube, and a 5 -parted, somewhat bilabiate limb. Stamineous column adnate to the superior part of the corolla. Anthers cohering, two lower ones bearded. Stigma pilose. Capsule baccate, crowned by the calyx, 2-celled, manyseerled, indehiscent.

3 Cya'sea. Calyx 10-furrowed, with oblong, foliaceon-, curled segments. Corolla tubular, arched, with a 5-parted, somewhat bilabiate limb. Stamens, combined filaments, and cohering bearded anthers. Stigma capitate ciliated. Capsule baccate, 10-furrowed, indehiscent, crowned by the limb of the calyx, 2-celled, many-seeded.

4. Dezíssea. Limb of calyx 5-toothed. Corolla with an arched undivided tube, and a 5 -parted somewhat bilabiate limb. Anthers coliering; 2 lower ones bearded. Stigma 2lobed, girded by hairs. Capsule baccate, crowned by the limb of the calyx, indehiscent, 2-celled, many-seeded.

5 Pra'tia, Limb of calyx 5 -toothed (f. 119. a.). Corolla cleft on the back, even to the base, and therefore the limb is 5 -parted, unilabiate, or all on the lower side (f. 119. b.). Stamens combined above and the anthers colering; the two lower anthers mucronate (f. 119.d.). Stigma 2-lobed. Capsule baccate, crowned.

6 Tu'pA. Calyx spherical, 5-parted, Corolla cleft on the back almost to the base, having the limb divided into 5 segments, which are all united at their tips. Stamens combined almost to the base; anthers cohering, bearded. Stigma 2-lobed, protruding. Capsule 2-celled, many-seeded.

7 Siphoca'mpylus. Limb of calyx 5-parted (f. 120. d.). Corolla with a curved undivided tube, which is ventricose in the middle, and a 5-parted bilabiate limb (f. 120.6.). Stamens and anthers combined; anthers bearded. Capsule 2-celled, 2valved, dehiscent.

8 Lobélia. Limb of calyx 5-parted (f. 121. a.). Corolla with the tube cleft on the upper side, and thickened at the base, and a bilabiate limb (f. 121.g.). Anthers cohering; 2 lower ones usually bearded. Capsule 2-celled, 2-valred, dehiscent at the apex.

9 Dortuána. Limb of calyx 5-parted. Corolla will the tube cleft on the upper side, a bilabiate linib, and a bearded throat. Stamens with free filaments, and cohering bearded anthers. Stigma capitate, hairy. Capsule half superior, 3-celled, 3-valved, dehiscent, many-seeded, surrounded by the calycine segments below the apex.

10 Parastránthus. Limb of calyx 5-cleft. Corolla 4. U 
with hardly any tube, and a bilabiate, 5-parted, reversed limb. Column of stamens under the lower lip. Filaments and anthers combined; the latter bearded. Stigma bifid or trifid. Capsule crowned by the segments of the calyx, 2-celled, many-seeded.

11 Isótona. Limb of calyx 5 -parted (f. 122. a.). Corolla salver-shaped (f. 122. d.), or funnel-shaped, with an entire or cleft tube, and a 5-parted, nearly regular limb (f. 122. d.). Filaments combined; anthers cohering, beardless; the two lower ones mucronate. Stigma capitate, protruding. Capsule 2-celled, many-seeded, dehiscent.

12 Holostígma. Flowers dioecious. Limb of calyx 5parted. Corolla with the tube cleft above, and a nearly regular 5-cleft limb. Anthers cohering, bearded. Stigma undivided. Capsule 2-celled, many-seeded, dehiscent.

13 Lysipòmia. Limb of calyx 5-parted. Corolla with an entire tube, and a 5 -parted sub-bilabiate limb. Anthers cohering; the 2 lower ones bearded, or terminating in a membranous process. Stigma 2-lobed, ciliated. Capsule 1-celled, opening by an operculum at the apex, many-seeded.

14 Monópsis. Calyx tubular, 5-cleft. Corolla salvershaped, with a terete tube, which is cleft on one side, allowing the stamens to escape, and a regular rotate limb. Anthers cohering. Capsule 2-celled, many-seeded, deliscent.

15 Hippóròma. Limb of calyx 5-parted. Corolla with a very long undivided tube, and a 5 -parted nearly regular limb. Stamincous tube exserted beyond the throat of the corolla. Anthers cohering, bearded. Stisma 2-lobed. Capsule 2-celled, 2-valved, many-seeded, dehiscent.

16 Cuintònia. Limb of calyx 5-cleft. Corolla bilabiate, with hardly any tube. Anthers cohering; the 2 superior ones bearded. Capsule silique-formed, triangular, debiscing by 3 loriform valves, many seeded. Seeds attached to two parietal placentas.

$17 \mathrm{Cr}^{\prime}$ prita. Limb of calyx 5 -cleft. Corolla bilabiate, 5parted; the segments easily separated to the base. Stamens with combined hairy filaments, and free anthers. Stigma hollow, gibbous, bearded. Capsule 2-celled, many-seeded, dehiscent.

18 Canonántuus. Calyx hemispherical, with a 5-parted limb. Corolla tomentose outside, campanulate, regular, 5-parted at the apex. Stamens with free filaments, and combined anthers.? Capsule unknown.

I. CLERMO'NTEA (named in compliment to the Marquis de Clermont-Tonnerre, minister of the marine of France). Gaud. in Freyc. voy. pt. bot. 4.59.

Lın. sysr. Pentándria, Monogýnia. Calyx tubular, arched, 5-cleft, coloured, length of corolla, caducous. Corolla tubular, arched, 5-cleft, almost regular. Stamens 5, one of which falls off along with the corolla, with combined filaments and cohering anthers; the 2 lower anthers bearded. Stigma 2-lobed, girded by pili. Capsule baccate, 2-celled, naked at the apex, indehiscent; cells many-seeded.-Shrubby or arboreous lactescent plants. Leaves alternate, entire. Flowers racemose, axillary, bracteate, showy, white, or of a rose-violet colour, blue.?

1 C. oblongifòlia (Gaud. l. c. t. 71.) leaves on very long petioles, oblong, acutish, crenated; calyx 5-parted. h. G. Native of the Sandwich Islands.

Oblong-leaved Clermontea. Shrub.

2 C. Pfricifòlia (Gaud. l. c. t. 72.) leaves oblong-lanceolate, acute, crenated; calyx 5 -cleft. $h$. G. Native of the Sandwich Islands. Lobèlia Clermontiàna, Gaud. mss.

Peach-leaved Clermontea. Shrub.

3 C. GRANDiflòra (Gaud. 1. c. t. 79.) leaves obovate-oblong, rather acuminated, dentately crenated; flowers large ; calyx 5parted. $h$. G. Native of the Sandwich Istands. Lobèlia grandiftòra, Gaud. mss.

Great-flowered Clermontea. Shrub.

Cult. All the species of this genus bear ornamental blossoms, and are therefore worth cultivating in every collection of greenhouse plants. A mixture of loam, sand, and peat is the best soil for them; and they will be easily increased by cuttings planted in the same hind of soil, under a hand-glass, in a little bottom heat.

IJ. ROLLA'NDIA (named after R. M. Rolland, gunner of the expedition under Freycenet, who rendered great services to ornithology). Gaud. in Freyc. voy. pt, bot. p. 458 .

Lin. syst. Pentándria, Monogynia. Calyx closely adhering to the ovarium; limb free, 5 -parted, with short obtuse segments. Corolla tubular, with the sides compressed; tube curved, undivided; limb 5-parted, somewhat bilabiate: segments narıow, Stamens 5. Stanineous tube adnate at the bottom to the superior part of the tube of the corolla. Anthers cobering, two lower ones bearded. Stigma 2-lobed, girded by hairs. Capsule baccate, indehiscent, 2 -celled, crowned by the permanent calyx; cells many-seeded.-Lactescent shrubs. Leaves alternate, exstipulate. Peduncles axillary, few-flowered. Pedicels unibracteate at the base. Flowers white.

1 R. Lanceoláta (Gaud. 1. c. t. 74.) shrub branched; leaves large, oblong-lanceolate, doubly toothed, hairy beneath; calyx 5 -parted, glabrous, with ovate obtuse segments; racemes fewflowered; stamens epipetalous. I. G. Native of the Sandwich Islands. Lobèlia Rollandiàna, Gaud. inss. Lobètia lanceolata, Hook. et Arn. in Beech, voy. pt. bot. p. 88 .

Lanceo'ale-leaved liollandia. Shrub.

2 R. ckíspa (Gaud. 1. c. p. 459.) stirub branched; leaves large, oblong, tapering much to the buse, sharply toothed, glabrous, with undulately curled margins; calyx 5-parted, downy, with ovate obtuse segments; stamens epipetalous. h.G. Native of the Sandwich lslands. Lobèlia críspa, Gaud. mss.

Curled-leaved Rollandia. Shrub.

3 R.? PINNATífIDA; leaves oblong-lanceolate, acute at both ends, running into the short petioles, remotely pinnatifid, sinuately and doubly toothed: flat and glabrous above, reticulately veined beneath and rather hairy; teeth short, and are as well as the lobes obtuse and callously mucronate; racemes axillary; calys and corolla hairy; ovarium obconical, crowned by the auriculated, ovate, obtuse, calycine segments. h. G. Native of Owahn, on the mountains. Lobèlia pinnatífida, Cham. in Linnæa. 7. p. 221. Leaves like those of a species of Sónchus. Pedicels rising from a fleshy peduncle, and furnished with scaleformed bracteas. Corollas 2 lines long, deciduous. Stem branched. Perhaps a species of Cyànea.

Pinnatifid-leaved Rollandia. Shrub.

4 R. ? AMBíguA; leaves oblong-lanceolate, acute at both ends, sinuately and doubly toothed, flat and glabrous above, and hairy beneath and fuscescent: teeth callonsly mucronate; racemes axillary; ovarium obconical, smooth; calycine segments ovate, obtuse, mucronate, rather hairy ; corolla hairy, especially on the nerves. $7 . G$. Native of $O$ wahn. Lobèlia ambígua, Cham. in Linnæa. 7. p. 221. Stem simple.? Corolla deciduous. 
Ambiguous Rollandia. Shrub.

5 R. calycisa; leaves oblong-lanceolate, acute at both ends, unequally and erosely crenated, flat and pilose above, and reticulately veined, fuscescent and hairy beneath ; calyx glabrous, with oblong, bluntish, 1-nerved segments; ovarium olive-formed, crowned by the erect calycine teeth ; limb of corolla hairy; tube of anthers hairy about the base and along the furrows. $h . G$. Native of Owahu. Lobèlia calycina, Cham. in Linnæa, 7. p. 222. Corolla deciduous.

Large-ealysed Rollandia. Shrub.

Cult. See Clermóntea, p. 698 . for culture and propagation.

III. CYA'NEA (from kvareos, kyancos, blue; colour of flowers). Gaud. in Freyc. voy. pt. bot. p. 457 .

Lin. syst. Pentándria, Monogýnia. Calyx adhering to the ovarium, 10-furrowed, longer than the limb, which is foliaceous and 5-parted; segments oblong, with reflexed indulately curled margins. Corolla tubular, cylindrical, arched; limb 5-partes], somewhat bilabiate. Stamens 5 , with combined filaments, and cohering bearded anthers. Stigma capitate, simple, ciliated with laairs. Capsule baccate, 10-furrowed, indehiscent, 2-celled, crowned by the permanent calyx; cells many-seeded.

1 C. Grimesia'na (Gaud. I. c. p. 458. t. 75.) branched; leaves large, pinnate-parted, smoothish, with lanceolate coarsely toothed segments; petioles, rachis, and peduncles beset with tubercular prickles; segments of calyx large. $h_{2} . G$. Native of the Sandwich Islands. Lobèlia Grimesiàna, Gaud. mss. Hook. et Arn. in Beecl, voy. pt, bot. p. 88 .

Grimes's Cyanea. Shrub.

Cult. See C'lermóntea, p. 698. for culture and propagation.

1V. DELI'SSEA (named after A. M. Delisse, a physician from the 1sle of France, and naturalist to the French expedition under D'Entrecasteaux, to the South Seas-from 1800 to 1804). Gaud. in Freyc. voy. pt. bot. p. 457.

Liv. syst, Pentóndria, Monogýnia. Calyx closely adnate to the orarium; limb free, 5-toothed, permanent. Corolla tubular, arched, deciduous; tube cylindrical, undivided; limb 5-parted, somewhat bilabiate; segments narrow. Stamens 5, with connate filaments, and cohering anthers: the two lower ones bearded. Stigma 2 -lobed, girded by hairs. Capsule baccate, crowned by the permanent calyx, 2-celled, indehiscent; cells many-seeded.-Shrubby lactescent plants. Leaves scattered, exstipulate, entire. Flowers racemose, axillary, pale red, or whitish red; pedicels unibracteate at the base.

1 D. subcorda'ta (Gaud. l. c. p. 457. t. 77.) branched ; leaves ovate, sharply toothed, glabrous. h.G. Native of the Sandwich islands. Lobèlia subcordàta, Gaud. mss.

Subeordate-leaved Delissea. Shrub.

2 D. undula'ta (Gaud. l. c. t. 78 .) stem simple; leaves oblong, sharply and coarsely toothed, glabrous, with undulated margins. $\zeta$. G. Native of the Sandwich Islands. Lobèlia undulàta, Gaud. mss.

Indulated-leaved Delissea. Shrub.

3 D. acumina'ta (Gaud. 1. c. t. 76.) branched; leaves oblong, doubly denticulated, hairy on both surfaces. h. G. Native of the Sandwich Islands. Lobèlia Delisseàna, Gand. mss. Lobèlia acuminàta, Hook. et Arn. in Beech. voy. pt. bot. p. 88 . Acuminated-leaved Delissea. Shrub.

4 D. Angustifòlia (Cliam. in Linnæa. 7. p. 219.) glabrous ; leaves on long petioles, narrow-lanceolate, flat, acute, bluntly serrated; calyx at first 5 -toothed: teeth minute, ciliated, but afterwards toothless, with undulated edges; corolla smooth, without papillæ. $々, G$. Native of Owahu. Sten quite simple.? Pedicels axillary at the top of the stem, forming a corymb. Filaments ciliated. Lobes of stigma pilose on the back.
Narrow-leaved Delissea. Shrub.

Cult. For culture and propagation see Clermóntea, p. 698.

V. PRA'TIA (named in memory of M. Prat-Bernon, of the French navy, who accompanied Freycenet, but died a few days after the expedition sailed). Gaud. in Freyc, voy. pt. bot. p. 456.-Lobèlia species of authors.

Lin. syst. Pentándria, Monogýnia. Calyx adnate to the ovarium; limb free, 5 -toothed (f. 119. a.). Corolla funnel-sliaped, cleft on the back, even to the base; limb 5-parted, spreading, unilabiate (f. 119.6 .). Stamens 5 , witl the filaments combined into the tube above, and the anthers colsering; the two lower anthers mucronate (f. 119, d.). Stigma 2-lobed. Capsule covered by the flesliy calyx, 2-celled (f. 119 e.), indehiscent; cells many-seeded.-Small herbs. Stems filiform, branched. Leaves thickish. Flowers axillary, solitary, pedunculate, rarely corymbose, of a pale violet colour; peduncles bracteolate.

1 P. RE'Pens (Gand. in Freyc. voy. p. 456. t. 79.) glabrous; stems creeping; leaves petiolate, rather reniform, undulately subcrenated. 2 . F. Native of the Falkland Islands. Lobèlia Pratiàna, Gand. mss. Flowers bluish-violet (f. 119.).

Crecping Pratia. Pl. creeping.

2 P.? ERE'cta (Gaud. 1. c.) stems nearly erect; leaves sessile, ovate-lanceolate, remotely and sharply toothed. 4. G. Native of New Holland, on the east coast, at Port Jackson. Lobèlia? cóncolor, R. Br. prod. p. 562.

Ereet Pratia. Fl. May, June. Clt. 1819. Pl. 1 foot.

3 P. conYuBòsa; glabrous; stems weak, angular, branclied ; superior leaves linear-spatulate: lower ones roundish, running into the petioles : all deeply serrated; flowers disposed in dense pedunculate corymbs; 4. G. Native of the Cape of Good Hope. Lobèlia corymbòsa, Hook. in bot. mag. t. 2639. Flowers pure white, richly dotted with

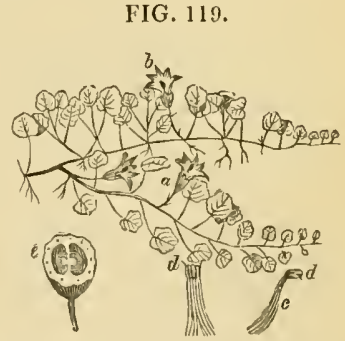

purple, capitate. Filaments and anthers combined; the latter bluish purple. Stigma capitate, surrounded by a circle of hairs.

Corymbose-flowered Pratia. Fl. June, July. Clt. 1824. Pl. decumbent.

4. P. hedera'cea (Cham. in Linnæa. 7. p. 212.) glabrous ; stems filiform, creeping; leaves on short petioles, orbicular, cre. nately toothed. 4 . F. Native of Brazil, on the banks of the Uruquay, along with Hydrocótyle pusilla, and other parts of Brazil. Corolla bluisb, villons inside. Filaments ciliated insidle. Pedicels exceeding the leaves.

Isy-like Pratia. Pl. creeping.

5 P. BEgoniæfòls ; leaves roundish-cordate, serrated, petiolate, hairy on both surfaces, oblique at the base; pedicels solitary ; calycine segments linear-subulate; stems filiform, creeping, hairy. 4. G. Native of Nipaul, at Suembu, in fields near the town of Katmandu, and near water-courses and springs. Lobèlia begoniæfolia, Wall. in asiat, res. 13. p. 377. Hook. bot. mag. with a figure. L. obliqua, Ham. mss. ex D. Don, prod. fl. nep. p. 158 . Herb rather canescent. Flowers sinall, blue. Fruit round, fleshy, about the size of a pea, purple, with numerous fattened brownish seeds attached to 2 thick septal placentas.

Begonia-leaved Pratia. Fl. June, Aug. Clt. 1827. P creeping. 
6 P. Radicans; an annual, creeping, glabrous lierb; leaves sessile, lanceolate, remotely serrulated; pedicels axillary, solitary, twice the length of the leaves. 4. F. Native of China, from which place it was accidentally introduced to the botanic garden, Calcutta. Lobèlia radicans, Willd. spec. 1. p. 918. The plant spreads over the soil and roots at every branch. 'The flowers are large for the size of the plant, of a pink colour. Segments of the corolla equal, unilateral, and narrow-lanceolate, with 2 green glands under the middle sinuses, opposite to the long, green, 2-lobed stigma.

Rooling Pratia. Pl. creeping.

7 P. Thunbe'rgII; glabrous; leaves sessile, decurrent, lanceolate, undulated, serrated; pedicels axillary, solitary, longer than the leaves; stems decumbent, rooting, filiform. $4 . \mathrm{G}$. Native of Japan. L. radicans, Thunb. in Lin. trans. 2. p. 330. L. Erìnus, Thumb. jap. p. 323. Flowers red.

\section{Thumberg's Pratia. Pl. creeping.}

Cult. A mixture of loam, peat, and sand is a good soil for the species of Pràtia; and they will easily be increased by dividing at the root, or by seed.

VI. TUPA ( $T$ ùpa is the Chili name of the first species). Lobèlia species of authors.

Lin. syst. Pentándria, Monogýnia. Calyx adhering to the spherical ovarium; limb 5-cleft. Corolla long, inflated at the base, cleft on the back its whole length, unilabiate; limb divided into 5 segments, which are all united at their tips. Stamens 5 , united into a tube; anthers cohering, all bearded, or only in 2 lower ones. Style protruding beyond the anthers; stigma orbicular, 2-lobed, not bearded. Capsule 3-celled, 3-valved? cells many-seeded.-Tall strong herbaceous plants. Leaves alternate, ovate-lanceolate, downy. Flowers pedicellate, disposed in terminal racenes, or solitary from the axils of the upper leaves. Superior lcaves sessile.

1 T. Fevillar; stem erect, thick, suffrnticose at the base, simple, leafy ; leaves ovate-lanceolate, sessile, decurrent, clothed with soft whitish down; raceme terminal, spicate. 2 4 . F. Native of Chili and Perı. Lobèlia T'ùpa, Lin. spec. 1318. Sims, bot. mag. 2550. Sweet. H. gard. 2s4. Feuill. per. 2. p. 739. t. 29. Corollas large, of a reddish scarlet colour, and are as well as the peduncles and calyxes downy. This is a very poisonous species, even the smell of the flowers will cause romiting, accordin ly Feuillee, and the milk of it, if by any accident it touches the eyes, occasions blindness.

Feuillee's Tupa. Fl. Sept. Oct. Clt. 1824. Pl. 6 to $8 \mathrm{ft}$.

2 'T. salicifódia ; leaves lanceolate, sessile, glabrous, serrulated, reticulated beneath; pedicels axillary, bracteate, 1flowered, shorter than the leaves; stem terete, filled with medula, simple or branched. $h$. F. Native of Chili, about Valparaiso. Lobèlia 'Tùpa, Ait. Lort. kcw. 1. p. 357. Lobèlia gigántea, Sims, bot. mag. 1325. Lobèlia salicifolia, Swect. Corollas yellow at first, then orange, and finally blood-red. Anthers hairy.

Hillon-leaved Tupa. Fl. Oct. Nov, Pl, 10 to 16 feet.

3 'T. PURPU'REA; leaves lanceolate, serrulated, glabrous ; flowers racemose; calyx spherical, 5 -toothed; stem simple suffruticose. b. F. Native of Chili, in the neighbourhood of Valparaiso. Anthers hairy. Lobèlia purpùrea, Lindl, bot, reg. 1325. Flowers fine purple.

Purple-flowered 'Tupa. Fl. Aug. Clt. 1825. F1. 3 to 4 feet.

4. 'l'. ARGU'ra; leaves linear-lanceolate, serrulated, quite glabrous on both surfaces; pedicels axillary, shorter than the leaves; stem suffuticose, simple, glabrous. h. F. Native of Chili. Lobèlia argùta, Lindl. in bot. reg. 973. Pedicels bibracteate in the iniddle. Corollas of a deep yellow colour. Tube of anthers shorter than the style. Very like $T$. salieifolia.
Sharp-serrated-leaved Tupa. Fl. Aug. Oct. Clt. 1824. Shrub 2 feet.

5 T. Cavanillesia'na: leaves sessile, ovate-oblong, serrnlated, mucronate, downy, glaucous; stem villous; raceme short, leafy; corolla downy $\zeta$. F. Native of Chili, at the bottom of Cuchu-Cucha. Lobèlia mucronàta, Cav. icon. 6. p. 11. t. 516. Hook. bot. mag. t. 3207. Superior leaves cordate at the base. Corolla scarlet, 2 inches long.

Cavanilles's Tupa. Shrub $2 \frac{1}{2}$ to 3 feet.

6 T. SECU'NDA; glabrous; leaves elliptic-lanceolate, wrinkled when dried, denticulated, with rather revolute edges; racemes terminal, secund, short; pedicels rising from the axils of the upper leaves or bracteas, which are small and linear; column of stamens much exserted; two upper anthers bearded. h. G. Native of Peru. Lobèlia secúnda, Ruiz et Pav. in herb. Lamb. Leaves dense. Segments of calyx membranous.

Seeund-flowered 'lupa. Shrub. ?

7 T. ova'TA; ylabrous; leaves ovate, slightly and distantly denticulated on the edges, wrinkled when dried; raceme long, terminal, dense, secund; column of stamens much exserted; anthers bearded on the lower side. 24. G. Native of Peru. (v. s. in herb. Lamb.).

Ocate-leaved Tupa. Pl.

8 T. овоva'Ta; leaves obovate, obtuse, clothed witl rusty: tomentum beneath, sliglitly denticulated; peduncles axillary, 1flowered, longer than the leaves; calyx spherical; corolla rather short. 2. F. Native of Peru. Lobèlia incàna, Ruiz et Pav. in lierb. Lamb. Leaves wrinkled when dried. Flowers purple or red. Anthers all bearded.

Obovate-leaved Tupa. Pl. 2 to 3 feet. ?

9 'T. yol.yPHY' LLA; leaves ovate-lanceolate, mucronate, sharply serrated, quite glabrous; racemes terminal leafy; tube of corolla not much longer than the calyx; two lower anthers bearded. 4. F. Native of Chili, on hills about Valparaiso. Lobèlia polyphýlla, Hook. et Arn. in Beech. voy. pt. bot. p. 33 . Pedicels filiform, about the length of the bracteas. Corolla hardly an incl long, downy, dark purple.

$$
\begin{aligned}
& \text { Many-leaved Tupa. Fl. Ang. Sept. Clt. 1832. Pl. } 5 \text { to } \\
& 6 \mathrm{ft} \text {. }
\end{aligned}
$$

Cult. The species of Tùpa are deserving of cultivation in every collection, on account of the beauty and singularity of their flowers. They are generally raised from seed imported from the places of their natural growth; and when the plants are of a sufficient size, they are planted out into the open border in front of a south wall, where they flower in great perfection. In winter they may either be protected with the haulm of herbs, or be taken up and potted, and placed in a green-house or frame till the spring, when they should again be planted out.

VII. SIPHOC A'MPYLUS (from $\sigma \iota \phi \omega v$, siphon, a tube, and $\kappa a \mu \pi v \lambda o s$, eampylos, a curve; in reference to the curved tube of the corolla). Pohl, pl. bras. 2. p. 104.-L Lobèlia species of authors.

Lin. sysr. Tetrándria, Monogýnia. Calyx adnate to the ovarium; limb 5 -parted (f. 120, d.), having the segments shorter than the tube of the corolla. Corolla irregular, tubular (f. 120. a.); tube entire, declinate, rather ventricose in the middle, and rather coarctate at the base; limb 5 -parted, bilabiate (f. 120. b.) ; upper lip of 2 straight or spreading segments; the 2 lateral segments of the lower lip diverging, and the middle one more profound. Stamens and anthers combined, the latter bearded. Capsule ovate, 2-celled, 2 -valved, delsiscing at the apex.-Erect slirubs or subslirubs. Leaves alternate and opposite, petiolate. Flowers axillary, soli. tary, rarely crowded at the tops of the stem or branches, so as 
to appear racemose. The segments of the corollas are usually futcate or lanceolate; the upper ones generally the longest. The is lower anthers are usually bearded, and sometimes they are all bearded.

1 S. macrántuus (Pohl. pl. bras. 2. p. 105. t. 168.) leaves oblong-ovate, acute, denticulated, quite glabrous; tube of corolla ventricose at the apex, incurved; calyx glabrous, having the segments the length of the third part of the tube of the corolla. h. S. Native of Brazil, about Kio Janeiro, and elsewhere in that province, in shady bushy places.-Vaud. in Rocm. script. p. 147. no. 2. Stem fistular, simple, green. Flowers axillary, solitary, approximate at the tops of the stems, and forming leafy racemes. Coroltas of a bluish red colour. Anthers all much bearded at the apex.

Long.flowered Siphocampylus. Shrub 3 feet.

\% S. cA'sus (Pohl, pl. bras. p. 106. t. 169.) leaves ovate, acute, crenated, downy beneath; tube of corolla glabrous, rather ventricose; segments of calyx hairy, 4 times shorter than the tube of the corolla. $h$. S. Native of Brazil, in the province of Minas Geraes. Stem medullary in the centre, simple, hairy, a little branched. Flowers axillary, approximate at the top of the stem and branches, forming there leafy racenes. Corollas of a bluish red colour.

Hoary Siphocampylus. Sluub 2 to 3 feet.

3 S. Crenatifòlús (Pohl, pl, bras. 2. p. 107. t. 170.) leaves acute, oblong, somewhat attenuated at the base, doubly crenated, downy beneath; tube of corolla glabrous, ventricose; calyx hairy, having the segments 4 times shorter than the tube of the corolla. $r_{\text {. }}$ S. Native of Brazil, in the province of Minas Geraes, among bushes about Villa St. Joao d'el Rey. Stem suffruticose, fistular, tetragonal, furrowed. Leaves 3 inches long, and $1 \frac{1}{2}$ broad, yellowish green. Flowers axillary, solitary, remote, but so crowded at the tops of the stems as to appear leafy spikes; of a bluish red colour.

Crenate-leaved Siphocampylus. Shrub 2 to 3 feet.

4 S. villósulus (Pohl, pl bras. 2. p. 108, t. 171.) leaves obloniroval, acute, doubly serrated, hairy, rather villous beneath, and truly villous on the nerves; corolla rather hairy; calyx having the segments 4 times shorter than the tube of the corolla. 24. S. Native of Brazil, among bushes at Estrema, not far from Rio de Jiquitinhonha. Stem fistular, tetragonal, rather villous. Leaves 2 inches long, and $1 \frac{1}{2}$ broad. Flowers axillary, solitary; the upper ones forming lealy racemes. Corolla of a bluish-red colour.

Villous Siphocampylus, PI. ® feet.

5 S. loxgipeduncula'tus (Pohl, pl. bras. 2. p. 109. t. 172.) leaves cordate at the base, and acuminated at the apex, denticulated, quite glabrous ; flowers solitary, on very long peduncles; tube of corolla ventricose, and is as well as the calyx glabrous ; segments of the calyx 5 times sborter than the tube of the corolla. $\psi$. S. Native of Brazil, in the province of Rio Janeiro, among bushes. Stem suffruticose, filled with medula, simple, glabrous. Leaves more than 3 inches long, and $1 \frac{1}{2}$ broal. Flowers all remote, on peduncles 4 inches in length. Corollas bluish-red.

Long-peduncled Siphocampylus. Shrub s feet.

6 S. cardiophýl lus (Pohl, pl. bras. 2. p. 110. t. 173.) leares cordate, acuminated, rather undulated, quite glabrous, with remote short denticulations; flowers solitary, on long peduncles; tube of corolla as well as the calyx glabrous; calycine segments much shorter than the tube of the corolla. 24. S. Native of Brazil, in the province of Minas Geraes, among bushes in mountainous places at Serra de Chumbo, not far from Rio Abaite. Stem suffruticose, fistular, a little furrowed, glabrous. Leaves $2 \frac{1}{2}$ inches long, and more than an inch broad; the denticulations are the extension of the veins. Upper flowers forming a leafy raceme. Corolla bluislı-red, having the segments ciliated.

Heart-leaved Siphocampylus. Slurub 3 feet.

7 S. Níxidus (Pohl, pl. bras. 2. p. 111. t. 174.) leaves cordate, acute, simply and doubly serrated, quite glabrous, shining, opaque beneath, and the nerves are pilose when examined by a lens; tube of corolla rather ventricose, and rather hairy when examined by a lens; calyx downy, having the segments 3 times shorter than the tube of the corolla. 24. S. Native of Brazil, in the province of Minas Geraes, about Fazendo do Apollinario, not far from Rio Abaite. Stem suffruticose, flled with medula, glabrous. Leaves $2 \frac{1}{2}$ inches long, and inore than an inch broad. Superior flowers forming a lcafy raceme. Corolla bluish-red, hairy.

Shining-leaved Siphocampylus. Sh. 2 to 3 fect.

8 S. corymbífercs (Pohl, pl. bras. 2. p. 112.t. 175.) leaves cordate, acuminated, doubly and emarginately toothed, ciliated, glabrous, rather hairy on the nerves and veins heneath; tube of corolla rather ventricose, glabrous: calyx glabrous, having the segments much shorter than the tube of the corolla. $4 . x$. Native ol Brazil, in the province of Minas Geraes, aw ong bushes in mountainous places about Vieira. Stem herbaceous, fistular, glabrous. Leaves more than 2 inches long and an inch broad. Corymbs terminal, simple, many flowered. Corollas scarlet, sinooth.

Corymb-bcaring Siphocampylus. Pl. $\approx$ to 3 feet.

9 S. Colv'mNe; leaves oblong, rounded at both ends, creuated, coriaceous, rugged above, glabrous, and shining, but clothed with fuscescent tomentum beneath; pedicels axillary, longer than the leaves; corolla a little curved, beset with stellate tomentum outside, having the segments linear-falcate, and nearly equal. h.S. Native of New Granada, in high places near the city of Santa Fe de Bogota. Lobèlia Colúmnae, Mutis in Lin. suppl. p. 393. Smith, icon. ined. 1. p. 22. t. 22. H. B. et Kunth, nov. gen. amer. 3. p. 302. Calyx tomentose outside. Two lower anthers bearded. Corollas red.

Columna's Siphocampylus. Shrub.

10 S. ваква'тUs; leaves lanceolate-oblong, acute, obtuse at the base, denticulated, hairy above, and clothed with hairy tomentum beneath, particularly on the nerve and reins; pedicels axillary, longer than the leaves. $h . S$. Native of New Granada. Lobèlia barbàta, Cav. icon. 6. p. 12. t. 519 . H. B. et Kunth, nov. gen. amer. 3. p. 303. Branches clothed with rusty stellate tomentum. Upper surfaces of leaves beset with ste]late hairs. Calyx beset with rusty tomentum outside, and the corolla with stellate hairs. Segments of the calyx very short; of the corolla falcate. Column of stamens pilose. 'Two lower anthers bearded. Corollas scarlet.

Bearded Siphocampylus. Shrub 3 to 4 feet.

11 S. FERrugt'neus; leaves obovate-oblong, acutish, obsoletely denticulated, smoothish above, but clothed with rusty stellate tomentum beneath, especially on the nerve and veins; flowers axillary, pedicellate, longer than the leaves; calycine segments 4 times shorter than the tube of the corolla. $\dot{\zeta} . S$. Native of New Granada, near Santa Fe de Bogota; and of Peru, near Guamantanga and Obragillo. Lobelia ferrugínea, Mutis, Lin. suppl. p. 39. . I. asclepiádea, Willd. rel. in licm. et Schultes, syst. 5. p. 57. Branches clothed with rusty stellate tomentum. Calyx and corolla clothed with rusty stellate tomentum. Corolla red. Genitals exserted. Two lower anthers bcarded.

Rusty Siphocampylus. Shrub.

12 S. Caoutcnóvc; leaves oblong, acute, rounded at the base, with glandularly denticulated edges, smoothish above, but clothed with risty tomentum beneath, particularly so on the nerve and veins; flowers axillary, pedicellate, shorter than the leaves; segments of the calyx denticulated, one-half shorter 
than the tube of the corolla. $\eta$. S. Native of the province of Popayan, in valleys near the river Mayo, near La Cruz; also in Paramo de Achupallas. Lobèlia Caoutchóuc, Willd. rel. in Roem. et Scluttes, syst. 5. p. 57. H. B. et Kunth, nov. gen. amer. 3. p. 304. Branchlets, calyx, and corolla clothed witl rusty stellate tomentum. Corollas red. Genitals exserted; anthers bearded. The milk from this plant forms an elastic gum, which is called Caoutchouc by the natives.

Caoutchoue Siphocampylus. Shrub 10 to 15 feet.

13 S.? UмвецLA'Tus; leaves oblong-lanceolate, acuminated, denticulated, smoothish above, and downy beneath; flowers crowded into umbels at the tops of the branches, on long pedicels; segments of calyx equal in length to the tube of the corolla; lower lip of corolla entire, acute. দ. S. Native of Peru, on the Andes, near Ayavaca; as also of Brazil. Lobèlia umbellàta, H. B. et Kuntl, nov. gen. amer. 3. p. 304. t. 268. L. Ayavacénsis, Willd. rel. in Roem. et Schultes, syst. 5. p. 57. A fetid shrub, with villous angular branches. Leaves a foot long. Calyx clothed with viscid hairs. Corolla white, downy. Anthers bearded with yellowish hairs. This will probably form a distinct genus from the lower lip of the corolla being entire.

Umbellate-flowered Siphocampylus. Shrub.

14. S. GigA'NTEus; leaves oblong-lanceolate, acuminated, toothed, reticulately wrinkled, glabrous above, and downy beneath, and clothed with hoary tomentum along the nerve and veins; Howers axillary, on very long peduncles; calycine segment cqual in length to the tube of the corolla; filaments glabrous. $々$. S. Native of New Granada, on elevated plains about Bogota; and on the Andes. Lobèlia gigántea, Cav. icon. 6. p. 9. t. 513 . H. B. et Kunth, nov. gen. 3. P. 305. Branches downy. Calycine segments irregularly crenated. Calyx and corolla downy outside. Anthers bearded, with long yellowish hairs. Corolla of a yellowish red colour. Intermediate between Siphocámpylus and Tüpa.

Giant Siphocampylus. Shrub 14 feet.

15 S. FE'TIDUs; leaves lanceolate-oblong, acuminated, narrowed at the base, denticulated, hairy on both surfaces; flowers axillary, on long pedicels; segments of the calyx equal in length to the tube of the corolla; filaments downy. h. S. Native along with the preceding. Lobèlia foétida, Willd. rel. ex Roem. ct Schultes, syst. 5. p. 57. H. B. et Kunth, nov, gen. amer. 3. 1. 305 . Branches hairy, fuscescent. Pedicels villous, bibracteate at the basc. Corolla white? Calyx and corolla hairy outside. Genitals exserted. Anthers densely bearded with yellowish hairs. A fetid slıub.

Fetid Siphocampylus. Shrub.

$16 \mathrm{~S} .11$ Rtus ; hairy ; leaves oblong, acuminated, serrated, on very short petioles; perlicels axillary, very long, at the tops of the stem and branches. b. S. Native of Quito, on Mount St. Antonio. Lobèlia lírta, Cav. icon. 6. p. 13. t. 520. Branched. Lcaves more than 6 inches long and $1 \frac{1}{2}$ broad, tapering into the petioles. Calyx globose, villous. Corollas scarlet, villous. Stamens glabrous.

Hairy Siphocampylus. Shrub 5 to 6 feet.

17 S. comòses; leaves lanceolate, toothed, powdery bencath ; corymbs terminal, supported by a tuft of leaves. $\hbar$. S. Native of New Spain. Lobèlia comòsa, Cav. icon. 6. p. 9. t. 512. f. 1. Stems simple, furrowed. Leaves on short petioles, 2 inches long, green above, and yellowish beneath. Petioles villous. Anthers and stigma bearded. Corollas yellowish.

T'ufted-leaved Siphocampylus. Shrub 2 to 3 feet.

18 S. Cavanillesia'nus; leaves ovate-lanceolate, biserrated; flowers axillary, solitary, pedicellate, the whole forming a leafy racemie. h. S. Native of Peru, about the town of Buena Ventura. Lobèlia biserràta, Cav. icon. 6. p. 10. t. 514. Branches furrowed. Leaves on short petioles, tomentose beneath: lower ones 3 inches long and $1 \frac{1}{2}$ broad. Pedicels bibracteate, thickened at the base and apex. Corolla of a yellowish scarlet colour, cleft a very little way on the back, glabrous.

Cavanilles's Siphocampylus. Shrub 3 feet.

19 S. Beslerioines; leaves oblong-elliptic, rounded at the apex, denticulated, hairy on both surfaces; flowers axillary, pedicellate, shorter than the leaves; segments of calyx 4 times shorter than the tube of the corolla. $\boldsymbol{h}$. S. Native of the Andes, about Popayan. Lobèlia beslerioides, H. B. et Kunth, nov. gen, amer. 3. p. 306. Habit of a species of Beslèria. Branches clothed with viscid hairs. Leaves rather hairy on both surfaces. Pedicels villous, bractless. Calyx and corolla hairy outside, the latter white. Two lower anthers bearded.

Besleria-like Siphocampylus. Shrub 2 to 3 feet.

20 S. spectánilis; leaves oblong, acute, obtuse at the base, minutely denticulated, glabrous; flowers axillary, pedicellate, shorter than the lcaves; corolla glabrous, 5 times longer than the calyx. $\eta_{2}$. S. Native of the province of New Andalusia, on Mount Cocollar, in shady humid places. Lobèlia spectábilis, Willd. in lioem. et Schultes, syst. 5. p. 58. H. B. et Kuntl, nov. gen. amer. 3. p. 306 . Branches glabrous, $3 \frac{1}{2}$ inches long. Pedicels bibracteate at the base. Calyx glabrous, with somewhat denticulated hairy segments. Corollas scarlet. Anthers bearded.

Shony Siphocampylus. Shrub 3 feet.

21 S. Suriname'Nsis ; leaves oblong-lanceolate, acute, obtuse at the base, remotely denticulated, glabrous; flowers pedicellate, axillary, shorter than the leaves; corollas glabrous, with the tube 3 times longer than the segments of the calyx. h.S. Native of Surinam, New Granada, and Brazil. Lobèlia Surinaménsis, Lin. spec. 1320. Curt. bot. mag. 225. Andr, bot. rep. 502. Bonpl. nav. p. 95. t. 39. Lodd. bot. cab. 749. Lobèlia lavigàta, Lin. fil. suppl. p. 392. Branches glabrous. Pedicels downy, bibracteate at the base. Calyx glabrous, Corollas orange-coloured or red. Anthers bearded.

Surinant Siphocampylus. Fl, Jan, July. Clt. 1786 . Shrub 2 to 3 feet.

22 S. Macrórovus; lcaves elliptic-oblong, serrulated, villous; flowers axillary, on long pedicels; branches downy. $々$. S. Native of Brazil, on mountains about Villa Ricca. Lobèlia macrópoda, Swartz, pl. bras. dec. 1. p. 6. Branches angular, downy. Leaves petiolate. Segments of corolla undulated. Corolla scarlet. Two lower anthers bearded.

Long-pedicelled Siphocampylus. Shrub 2 to 3 feet.

$23 \mathrm{~S}$. Westianvs; leaves 3 in a whorl, oblong, acute, serrated, villous beneath, and glabrous above; pedicels axillary, villous ; tube of corolla pentagonal. h.S. Native of Brazil, about Villa Rica, in humid places on the mountains. Lobelia Westiàna, Swartz, pl. dec. bras. 1. 1817. Rom. et Schultes, syst. 5. p. 53. Branches downy. Corollas scarlet, 2 inches long. Anthers blue, 2 lower ones bearded by white hairs.

II'est's Siphocampylus. Slurub 2 to 3 feet.

24 S. GRA'NDis; leaves oblong, acute, crenately serrulated, glabrous; umbels terminal, bracteate; corollas hairy ; segments of the calyx 10 times shorter than the tube of the corolla. 々. S. Native of New Granada, near Santa Fe de Bogota. Lobèlia grándis, Mutis in Lin. suppl. 394. H. B. et Kunth, nov. gen. 3. p. 307 . Branches glabrous. Leaves 5 inches long and 2 broad. Flowers pedicellate, red, hairy outside as well as the calyx. Pedicels bracteate at the base; bracteas obtuse, hairy. Two upper segments of the corolla falcate. Anthers hairy; two lower ones bearded.

Grand Siphocampylus. Shrub.

25 S. GLABRA'TA; leaves oblong-elliptic, acute, rounded at the base, obsoletely toothed at the apex; flowers axillary, pedicellate, longer than the leaves; calycine segments crenated, 
about equal in lengtl to the tube of the corolla. h.S. Native along with the preceding species. Lobèlia glabràta, H. B. et Kunth, nov, gen. amer. 3. p. 307. t. 270. Branches glabrous. Leaves 3-4 inches long, glabrous, pale green, petiolate. Pedicels bractless. Calyx and corolla glabrous; the latter greenislt. Segments of corolla falcate. Filaments downy; anthers glabrous. Genitals exserted.

Glabrous Siphocampylus, Shrub.

$26 \mathrm{~S}$. Mutisia'sus; leaves oblong, short-acuminated, narrowed and acute at the base, remotely and bluntly toothed, glabrous, except the nerve and veins beneath, which are hairy; flowers axillary, pedicellate, shorter than the leaves; corollas glabrous, much longer than the calycine segments. $h^{2}$. S. Native of New Granada, on frigid mountains. Lobèlia Mutisiàna, H. B, et Kunth. nov. gen. amer. 3. p. 308. Branches rather hispid. Leaves 6-7 inches long. Petioles hairy. Pedicels bractless. Segments of calyx smooth, irregularly crenated. Corolla greenish, with filcate segments. Column of stamens glabrous; two lower anthers bearled.

Mutis's Siphocampylus. Shrub.

27 S. volu'bilis; stem twining; leaves ovate, acuminated, cordate, sharply toothed, glabrous above, and clotherl with fine down beneath; Howers axillary, pedicellate ; corolla hairy; segments of calyx 5-6times shorter than the tube of the corolla. h.S. Native on the shadly banks of the Orinoco. Lobèlia volùbilis, $H$. B. et Kuntl, nov, gen. amer. 3. p. 309. L. cordà!a, Willd. rel. ex Rom. et Schultes, syst. 5. p. 58. Branches glabrous. Leaves cordate at the base. Pedicels downy, bractless. Corollas scarlet. Genitals exserted, glabrous. Anthers bearded (f. 1乞0.).

Twining Siphocampylus. Shrub twining.

$28 \mathrm{~S}$. Berterin'xus ; leaves remote, on long petioles, ovateoblong, acuminated, erosely subcrenated, membranous, quite glabrous; pedicels solitary, axillary, loose; stem scandent. $h$. $\checkmark$. S. Native of Guadlaloupe. L. scándens, Bertero. L. Berteriàna, Spreng. syst. 1. p. 712.

Bertero's Siphocampylus. Shrub el.

29 S. SCA'NDENS; stem scandent; leaves oblong, obtuse, quite entire, rather fleshy, with revolute edges, glabrous; racemes terminal ; flowers reflexed; corollas glabrous ; calycine segments linear, slightly denticulated, 5-6 times shorter than the tube of the corolla. $5 . \cup$. S. Native of Peru, in cold places between Paramo de Saraguru and the city of Loxa. Lobèlia scándens, H. B. et Kunth, nov. gen. aner. 3. p. 309. Lobèlia ob:usif òlia, Willd, ex Roem. et Schultes, syst. 5. p. 57. Branches glabrons. Pedicels furnished with one bractea at the base. Calyx glabrous. Corolla searlet, with falcate segments. Column of stamens glabrous. Two inferior anthers bearded. Stigma girded by a pilose ring.

Climbing Śiphocampylus. Shrub cl.

30 S. Duplosera'tus (Pohl. pl. bras. 2. p. 1/4. t. 177.) leaves oblong or cordate at the base, twice serrated, petiolate; peduncles longer or shorter than the leaves; genitals exserted. 々. S. Native of Brazil. Lobèlia triphýlla, Presl, symb. bot. 4. p. 62. t. 4. Corollas red or scarlet.

Doubly-serratcd-leaved Siphocampylus. Shrub 2 to 3 feet.

31 S. Andròpògon; leaves ovate, glabrous, hardly denticu- lated, soft; flowers axillary, solitary, pedicellate ; corolla glabrous, curved. $\zeta$.S. Native of the province of Quito, on Mount St. Antonio, in shady woods. Lobèlia Andròjògon, Cav. icon. 6. p. 10. t. 515. Stem glabrous, furrowed. Leaves 3 inches long, petiolate. Peclicels shorter than the leaves, villous at the base, bibracteate. Corolla scarlet, having the lower lip rounded, with 3 small acute teeth. Anthers bearded.

Bearded-anthered Siphocampylus. Shrub 5 to 6 feet.

$32 \mathrm{~S}$.? crrciròcıus; leaves linear-lanceolate, toothed, glabrous : teeth subulate, distant; raceme terminal, leafy. h.s. Native of the Antilles and St. Vincent. Lobèlia circiifolia, Lam. dict. 3. p. 584. no. 12.-Plım. spec. vol. 5. t. 116. Stem straight, simple, naked at the base, glabrous. Corolla curved, green or yellowish green.

Circium-leaved Siphocampylus. Shrub $1 \frac{1}{2}$ foot.

33 S. verticillatta (Cham. in Linnaca. 7. p. 202.) leaves $6-8$ in a whorl, almost sessile, narrow-oblong or linear-oblong, sharply and finely serrated, pale beneath; pedicels axillary, verticillate, shorter than the leaves, but the flowers exceed the leaves; calycine segments acute, more than 6 times shorter than the corolla; anthers glabrous on the back, and bearded in front; stem filled with meclulla, erect, simple, densely leafy; root oblique. h.S. Native of the south of Brazil. Top of stem and ribs of leaves rather bairy, and the peduncles, calyxes, and corollas downy. Corollas red, 2 inches long, curved before expansion.

Whorled-leaved Siphocampylus. Shrub 3 to 6 feet.

34. S. Betulefòlius (Cham. in Linnæa. 7. p. 204.) leaves scattered, petiolate, cordately triangular or ovate, acuminated, somewhat doubly and acutely serrated, nerved, and veined; pedicels axillary, solitary, exceeling the leaves; calycine segments narrow, acute, serrulated, more than 6 times shorter than the corolla ; anthers exserted, glabrous on the back, and bearded in front; stem flexuous, branched, terete, glabrous. 々. S. Native of Brazil. Nerves of leaves and petioles downy. Corollas red, long. Verv like S. scándens.

Birch-leaved Siphocampylus. Shrub 3 feet.

35 S. convolvur.'ces (Cham. in Linnæa. 7. p. 205.) shrubby, climbing, and twining, glabrous; branches terete, slender; leaves petiolate, narrow, ovate-lanceolate, acuminated, with reflexed obsoletely denticulated edges; pedicels axillary, solitary, much longer than the leaves; ovarium oblong; teeth of calyx small ; corolla long; anthers a little exserted, naked on the back. h. S. S. Native of Brazil. Corolla red, abont 2 inches long. Leaves 3 inches long. Very like S. scándens and S. volùbilis.

Convolvulus-like Siphocampylus. Shrub cl.

36 S. imbrica'ta (Cham. in Linnæa. 7. p. 206.) leaves inbricated, almost sessile, ovate, cordate, hardly acute, serrulated, with ratler reflexed edges, scabrous from hairs above, shining, flat: paler beneath, and more hairy, and reticulately veined; pedicels axillary, shorter than the leaves, and are as well as the calyxes hairy; calycine segments linear, acute, 4 times shorter than the corolla; corollas downy, exceeding the leaves; anthers exserted, naked on the back; stem with many prominent eicatrices, occasioned by the falling of the leaves, clothed at bottom with brown stiff hairs, and clensely leafy at the top. 5 . S. Native of Brazi]. Leaves 6 in a whorl, by threes. Corolla red.

Imbricated-leaved Siphocampylus. Shrub.

37 S. Lycroides (Cham. in Linnæa. 7. p. 207.) erect, glabrous; leaves sessile, ereet, narrow-lanceolate, acute, remotely and bluntly serrulated: lower ones somewhat verticillate, by threes, alternate; racemes leafy, terminal ; floral leaves 6 in a whorl, having the pedicels by threes, verticillate; pediccls erect, a little shorter than the leaves; segments of the calyx ovate, 
long-acuminated, 6 times shorter than the corolla; anthers a little exserted, glabrous. $々$. S. Native of Brazil. Stem angular. Corolla red.

Lycium-like Siplsocampylus. Shrub 3 feet.

3S S. DEPE' NDENS; leaves coriaceous, ovate-lanceolate, somewhat cordate at the base, acuminated, finely and spinosely denticulated, tomentose beneath, glabrous above; branches and inflorescence downy or tomentose; pedicels from the axils of the upper leaves, and longer than them; column much exserted; calycine lobes linear-subulate. $\zeta$. S. Native of Peru. Lobèlia depéndens, Ruiz et Pav. in herb. Lamb. Flowers racemose, at the tops of the branches. Plant scandent.

Dependent-branched Siplocampylus. Shrub cl.

39 S. rosmarınifòlús; erect; leaves linear-lanceolate, entire, with revolute margins, tomentose beneath, and glabrous above; pedicels axillary, about the length of the leaves; column of stamens exserted; calyx with a spherical tube, and long linear segments. 24, or h.S. Native of Peru. Lobèlia purpùrea, Ruiz et Pav, in herb. Lamb. Corollas red. Lower anthers bearded at top. Leaves dense, like tliose of some species of willow.

Roscmary-leaved Siphocampylus. Pl. 2 to 3 feet.

40 S. MacropHy'Llus; leaves broad, obovate, acuminated, glabrous, slightly denticulated, tapering much to the base; Howers almost forming a terminal corymb, much shorter than the leaves; calyx with a hemispherical tube and ovate-lanceolate segments; column of stamens exserted: the lower anther bearded at top. h.S. Native of Peru. Leaves a foot long. Pedicels crowded. Corollas red. (v. s. in herb. Lamb.)

largc-leavcd Siphocampylus. Pl. 2 to 3 feet?

11 S. Lacinı́'тa; leaves deeply jagged, acuminated; lobes acuminated ; branches downy ; lobes of corolla falcate; column of stamens downy; anthers glabrous, except the two lower ones, which are bearded at the apex; calyx spherical. $\eta$. H. Native of Peru. Lobèlia biserràta, Ruiz et Pav. in lierb. Lamb. Corollas red or scarlet.

Jagged.-leaved Siphocampylus. Shrub.

4.2 S. Fu'scus; clothed with rusty tomentum in every part ; calyx spherical, with reflexed denticulated lobes; leaves ellipric-lanceolate, denticulated; peduncles axillary, 1-flowered; corolla clothed with rusty wool; two lower anthers bearded. দ. S. Native of Peru. Apparently a climbing shrub. (v. s. in herb. Lamb.)

Bron'n Siphocampylus. Slirub cl.

Cull. The species all bear large, slowy, scarlet, or red Howers, and are therefore worth cultivating in every collection of stove plants. They are of easy culture. The soil best suited to them is a mixture of loam, sand, and peat; and cuttings of them strike readily in the same kind of soil under a hand-glass in heat.

VIII. LOBE'LIA (in honour of Matthew Lobel, author of various works, and particularly that called Icones Plantarum; he was born at Lisle in 1538, became pliysician and botanist to James 1., and died in London in 1616). Pohl, pl. bras. 2. p. 99.-Lobèlia species, Lin. and other authors.

Lin. syst. Pentándria, Monogýnia. Calyx adnate to the ovaritum; limb 5-parted (f. 121.a.). Corolla irregular, tubular; tube cleft on the upper side, thickened or ventricose at the base; limb 5-parted, bilabiate; the 2 segments of the upper lip, linear-lanceolate (f. 121, f.) ; lower lip trifid and pendulous, with lanceolate or roundish segments (f. 121. g.). Filaments combired above (f. 121.e.). Anthers coliering (f. 121.c.), hearded; the 2 lower ones usually bearded, and sometimes all. Capsule oval, 2-celled, 2-valved, many-seeded, deliscing at the apex.--Erect or procumbent herbs. Leaves alternate, usually sessile. Flowers on short pedicels, usually disposed in terminal leafy spikes or racemes, rarely solitary and axillary, blue, red, or white, rarely yellow.

\section{\$1. Species natives of America. \\ * Corollas blue.}

1 L. campòrum (Pohl, bras. 2. p. 100, t. 165.) leaves linear, acute, remotely toothed, ciliated on the margins, glabrous, rather decurrent; flowers spicate, rather remote on short pedicels; bracteas oblong, acuminated, rarely toothed, pilose; caly x pilose, a little shorter than the tube of the corolla. $\odot$. H. Native of Brazil, in the province of Minas Geraes, in dry fields about Villa de Barbacena. Anthers all bearded. In the plant collected by Sello the lower leaves are obovate, and the upper ones lanceolate. Stem filiform, simple, pilose. Corollas blue.

Field Lobelia. Pl. 1 foot.

2 L. exalta'ta (Schott. in Poll, pl. bras. 2. p. 101. t. 166.) leaves sessile, lanceolate, acuminated, rather attenuated at the base, denticulated, quite glabrous; Howers racemose, coarctate, pedicellate; bracteas lanceolate, acuminated, rather hairy; caly $\mathrm{x}$ pilose, exceeding the tube of the corolla in length. 4. S. Native of Brazil, in marshy places in the province of Rio Janeiro, at Fazenda Malheas lamos, as well as of the province of Minas Geraes. Stem fistular, furrowed, quite simple, glabrous, of a yellowish green colour. Bracteas ciliated. Corollas blue.

Exalled Lobelia. Pl. 5 feet.

3 L. Thap'soides (Schott, ex Pohl, bras. 2. p. 102.t. 167.) leaves sessile, lanceolate, attenuated at the base, very long, denticulated, ciliated, rather pilose; flowers racemose, coarctate, on short pedicels; calycine segments lanceolate, acuminated, pilose, shorter than the tube of the corolla. 4 . S. Native of Brazil, about Rio Janeiro; and of the province of Goyaz. Stem tough, filled, simple, rather pilose, of a greenish brown colour. Bracteas ciliated. Flowers dense blue.

\section{Thapsus-like Lobelia. Pl. 6 feet.}

4. L. PAUcrflòra (H. B. et Kunth, nov. gen. amer. 3. p. 314.) stem herbaceons, erect, simple; leaves sessile : radical ones lanceolate: cauline ones linear, remotely denticulated, glabrous; racemes terminal, few-flowered, on long peduncles; flowers on short pedicels; calycine segments hairy, as well as the corolla, one-half shorter than the tube of the corolla. 4 . S. Native of Brazil, in the province of Mlinas Geraes, in dry grassy places about Villa Barbacena; and of Mexico, near Valladolid de Mechoacan. L. commutàta, Willd, rel. ex Røm. et Schultes, syst. 5. p. 73. L. símplex, Willd, herb. Corollas blue. Stem glabrous, striated. Bracteas linear, hairy, longer than the pedicels.

Few-flonered Lobelia. Fl. July, Aug. Clt. 1824. Pl. $\frac{1}{2} \mathrm{ft}$.

5 L. rapunculoides (H. B. et Kunth, nov. gen. 3. p. 312.) leaves linear-lanceolate, acute, denticulated, glabrous, sessile ; racemes terminal, loose-flowered; calycine segments equal in length to the tube of corolla; stems branched, procumbent. $\psi$. S. Native near the town of Mexico. L. dracunculoides, Willd. rel. ex Roem. et Scliultes, syst. 5. p. 56.? Stem hairy at bottom. Flowers remote, pedicellate. Bracteas linear, about the length of the pecticels. Corolla blue, glabrous. Leaves $1 \frac{1}{2}$ inch long. Two lower anthers bearded.

Rampion-like Lobelia. P]. procumbent.

6 L. collina (H. B. et Kunth, nov. gen. amer. 3. p. 312.) leaves lanceolatc-linear, acute, denticulated, glabrous, sessile; racemes terminal, ascending; segments of the calyx one-half shorter than the tube of the corolla; stems procumbent; branches ascending, glabrous. 24. S. Native of Pcru, on dry 
hills between Malacatis and Gonzanama, at the altitude of about 3000 feet. I. Hinifölia, Wilk. rel. ex Rœm. et Schultes, syst. 5. p. 6\%. Leaves 1 to $1 \frac{1}{2}$ inclı long. Pedicels recurved, about equal in length to the bracteas, which are linear. Flowers of a violaceous blue colour. Two lower anthers bearded.

Hill Lobelia. Pl. procumbent.

7 L. FAstigia'ta (H. B. ct Kunth, nov. gen. amer. 3. p. 313.) leaves lanceolate, remotely denticulated, glabrous, almost sessile; racemes terminal, elongated; calycine segments glabrous, about equal in length to the tube of the corolla; stem herbaceous, erect, with fastigiate branches. 4 . S. Native of Quito, near Popayan and Chillo, at the altitude of about $\$ 000$ feet. Lobèlia tenuifòlia, Willd. rel. ex Rœm. et Schultes, syst. 5. p. 56. Stens and branches ancular, glabrous. Leaves $12-15$ lines long. Bracteas linear, obsoletely lenticulated, shorter than the pediccls. Corolla violaceous. Two lower anthers bearded.

Fastigiate-branched Lobelia. Pl.

8 L. Móluss (Graham. in edinb. phil. journ. Decemb. 1829.) stem erect, branched, downy; leaves petiolate, cordately ovate, acute, downy above, and along the veins beneath, mucronately and doubly serrated: superior leaves lanceolate; racemes terminal, elongated; pedicels loose; segments of the lower lip of the calyx subulate, shorter than the corolla. $\odot$. F. Native of Dominica, where it was collected by Dr. Krauss. Leaves 8 lines long and 6 broad. Calycine segment equal in length to the tube of the corolla, which is purplish, with the tube cleft along the upper side. Anthers purplish, having 2 short white awns projecting from their lower edge. Stigma almost simple, bearded. Perhaps a distinct genus.

Sofi Lobelia. Fl. Sept. Nor, Clt. 1828. Pl. 1 foot.

9 L. RUPE'stris (H. B. et Kunth, nov. gen. amer. 3. p. 313.) leaves sessile, hairy or downy, toothed ; lower ones oblong or obovate-oblong, obtuse: superior ones lanceolate, acute; racemes terminal; segments of the calyx hairy, about equal in length to the tube of the corolla; stem erect, branched a little. 4 . S. Native of the province of Popayan, on the declivities of the burning Mount Purace. Lobèlia polygalæf òlia, Willd. rel. ex Rœm. et Schultes, syst. 5. p. $56^{\circ}$. Stems rather angular, and are as well as the branches downy. Bracteas linear, lanceolate, twice the length of the pedicels, which are distant. Flowers violaceous. Anthers blue, 2 lower ones bearded.

Roek Lobelia. Pl. 1 foot.

10 L. TE'Nera (H. B. et Kuntl, nov. gen. amer. 3. p. 314.) leaves sessile, lanceolate-linear : lower ones lanceolate, remotely denticulated, glabrous ; racemes terminal, few-flowered, on long peduncles; flowers on long pedicels; calycine segments glabrous, about equal in length to the tube of the corolla ; stem herbaceous, erect, simple, glabrous. $4 . \mathrm{S}$. Native of the province of Quito, on hills near Puemba. Leaves 12-15 lines long. Flowers blue, remote, about the size of those of L. ùrens. Filaments ciliated at the base. 'Two lower anthers bearded.

Tender Lobelia. Fl. July. Pl. $\frac{3}{4}$ foot.

11 L. Xalapénsis (H. B. et Kunth, nov, gen. amer, 3. p. 315.) leaves on long petioles, ovate-deltoid, irregularly crenated, hairy above, glabrous beneath; racemes terminal, pedunculate ; calycine segments about equal in lengtb to the tube of the corolla ; stem erect, paniculately branched, angular, glabrous. 2. F. Native of Mexico, near Xalapa and Macultipec. Leaves nearly as broad as long. Bracteas linear, much shorter than the pedicels. Filaments ciliated at the base. "Two lower anthers bearded.

\section{Xalapa Lobelia. Pl. $\frac{3}{4}$ foot.}

12 L. K Álmin (Lin. spec. 1818.) radical leaves spatulate, hairy : canline ones linear, glabrous, sessile, denticulated or nearly entire; racemes loose, leafy; pedicels furnished with 2 bracteas at the apex, longer than the capsules; stem erect, slender, glabrous. vol. III.
4. F. Native of North America, in Camada, Carolina, and New York. Sims, bot. mag. 2238. Corollas beautiful blue, with the segments of the lower lip obovate, acute, marked by 2 white confluent spots in the centre. The variety of this which grows in Carolina has the radical leaves roundly spatulate; the stem more slender, and the flowers smaller.

Kalm's Lobelia. Fl. July, Aug. Clt. 1820. Pl. 1 to $1 \frac{1}{2} \mathrm{ft}$.

13 L. Nutta'lli1 (Rom. et Schultes, syst. 5. p. 39.) leares oblong-linear, denticulated, obtuse, rcmotish ; flowers loosely racemose, distant; pedicels coloured, shorter than the flowers, bibracteate at the base; segments of the calyx obtuse; stem erect, minutely scabrous, branched. 4. H. Native of Norll America, from New Jersey to Carolina, on the dry sandy edges of bogs. L. grácilis, Nutt. gen. amer. 2. p. 77. but not of R. Br. Pedicels and corollas blue; the lower lip marked by 2 acute white stripes, and 2 green dots, and other 2 towards thi base of the tube. Very like L. Kálmii, and probably a variety of it.

Nuttall's Lobelia. Fl. July, Sept. Clt. 1824. Pl. 1 to $1 \frac{1}{2}$ foot.

14 L. Fenestra'ils (Cav. icon. 6. p. 8. t. 512. f. 2.) leaves lanceolate, acuminated, toothed, half-stem-clasping, glabrous, glaucous; spikes terminal, many-flowered; genitals shorter than the tube of the corolla. $\odot$. H. Native of Mexico, near the town of St. Bartolone. Stem simple, furrowed. Leaves 2 inches long and 2 lines broad. Flowers almost sessile, disposed in leafy spikes, small, blue, fenestrate at the base, about 2 lines long. Stigma villous. Tube of corolla about 2 lines long. Genitals one-half shorter than the corolla.

Windowed Lobelia. Fl. June, Sept. Clt. 1824. Pl. $1 \frac{2}{2}$ foot.

15 L. Cuiffortia'na (Lin. spec. p. 1320.) leaves on long petioles, ovate or roundish-ovate, rather cordate, bluntly and sinuately toothed, glabrous; racemes tcrminal, on long peduncles; calycine segments glabrous, about equal in length to the tube of the corolla; stem erect, nearly simple, glabrous. $\odot . H$. Native of North America, in humid places; and of Cuba, about the Havannah; and of Mexico, near San Andres and Jalapa, in bushy places. Stem angular. Root perpendicular. Bracteas linear, much shorter than the pedicels, which are long and filiform. Corollas blue or violaceous.

De Cliffort's Lobelia. Pl. $\frac{1}{2}$ to 1 foot.

16 L. spica'ta (Ruiz et Pav. in herb. Lamb.) glabrous; stem simple; leaves obovately lanceolate, obtusc, denticulated; upper ones lanceolate, sessile, denticulated; racemes simple; pedicels rising from the axils of the linear bracteas. $\odot$. S. Native of Peru. Flowers small, blue. Like L. ùrens. Calyx tubular, with subulate segments.

Spike-flowered Lobelia. Pl. 1 foot.

17 L. Montŕcola (H. B. et Kunth, nov. gen. amer. 3. p. 316.) leaves petiolate, ovate, obtuse, rather cordate, doubly serrated, hairy on both surfaces; racemes terminal, on long pedun. cles; segments of calyx glabrous, about equal in length to the tube of the corolla; stem erect, almost simple, rather angular, glabrous, or a little hairy. ๑. H. Native of New Granada, on the mountains between Fusagasuga and Pande. L. palmàris, Willd. rel. ex Rcem. et Schultes, syst. 5. p. 56. Root perpendicular, branched. Bracteas linear, much shorter than the pedicels. Corollas blue, glabrous. Anthers puberulous at the apex, but beardless.

Mountain Lobelia. Pl. $\frac{1}{2}$ foot

18 L. maréntha (H. B. et Kunth, nov, gen. amer. 3. p. 316.) leaves petiolate, ovate, acuminated, dentately serrated, nearly glabrous; racemes terminal, sessile; calycine segment: glabrous, about equal in length to the tube of the corolla; stem erect, paniculately branched, angular, hairy. $\odot$. H. Native of the province of Quito, near Puembo. Lobèlia ruderalic 
Willd. rel. ex Roem. et Schultes, syst. 5. p. 56. Root perpendicular. Bracteas linear, shorter than the pedicels. Corolla blue. Two lower anthers bearded.

Small-flonered Lobelia. Pl. $\frac{1}{2}$ foot.

19 L. subtíls (H. B. et Kunth, nov. gen. amer. 3. p. 317.) leaves on short petioles, sharply toothed, hairy above, and glabrous beneath: lower ones nearly orbicular, and ovate: superior ones lanceolate; flowers axillary, on long perlicels, racemose; calycine segments glabrous, about equal in length to the tube of the corolla; stem erect, simple or branched, angular, hairy. $\odot$. H. Native along with the preceding species. L. Dràba, Willd. rel. ex Rœm. et Schultes, syst. 5. p. 67. Flowers size and colour of those of the preceding.

Slenter Lobelia. Pl. 1 foot.

20 L. NA'va (Willd. rel. ex Rom. et Scluultes, syst. 5. p. 67. H. B. et Kunth, nov, gen. amer. 3. p. 317. t. 272.) leaves spatulate, quite entire, thickish, glabrous; flowers axillary and radical, on long pedicels; calycine segments glabrous, hardly equal in length to the tube of the corolla; stem short, erect, throwing out runners. $\%$. F. Native of Mexico, near Real del Monte and Moran. Herb almost stemless, stoloniferous. lioot with thick fibres. Corolla pale, violaceous. Filaments downy. Two lower anthers bearded.

Dnarf Lobelia. Pl. stoloniferons.

21 L. Chaytonia'ina (Michx. fl. bor. amer. 2. p. 153.) leaves oblong, obtuse, almost quite entire; lower ones spatulate, quite entire: cauline ones a little denticulated; spikes twiggy, naked; bracteas subulate: stem downy, erect, simple. $\%$. H. Native of North America, from New York to Carolina, in mountain woods and other shady places. L. pállida, Muhl. L. goodenioides, Willd. herb. berol. 1. t. 30. L. spicàta, Lam. Stem angular. Leaves rather villous on the edges. Flowers very small, numerous, pale blue; segments of the calyx subulate, almost the lengtl of the corolla. Lower lip of corolla reflexed. Capsules turbinate, very short.

Clayton's Lobelia. Fl. Jume, July. Clt. 1824. Pl. 1 to $2 \mathrm{ft}$.

22 L. sypulitica (Lin. spec. 1320. Jacq. icon. 3. t. 597.) leaves ovate-cblong, acuminated at both ends, unequally serrated; flowers axillary, solitary, forming altogether a long leafy raceme; sinuses of calyx reflexed, and are as well as the peduncles hairy. $\psi$. H. Native of Virginia, in dry woods. Woodv. med. bot. 177. t. 63. Ker. bot. reg. 537. Rapíntium syphilíticum, Mill. dict. no. 2. Gartn. fruct. 1. p. 152. t. 30. Leaves sessile, rather scabrous, decurrent. Flowers blue. Calyx serrately denticulated. Corolla angular, with nearly equal segments, having the keel ciliated, and the palate furnished with 2 gibbosities. The root is the part of the plant directed to be used in medicine; it resembles tobacco in taste, and is apt to excite vomiting. It derives its trivial name from its efficacy in the cure of syphilis, as experienced by the North American Indians, with whom it was a secret. A decoction is made of a handful of the roots, in 8 measures of water. Of this half a measure is taken in the morning fasting, and repeated in the evening; and the dose increased till its effects become too violent, when it is intermitted for a day or two. Aithough the plant is said to cure the clisease in a very short time, yet its virtues have not been confirmed by any instances in European practice.

Var. $\beta$, maculàtus; stem more attenuated; leaves sharply denticulated, spotted with rust colour. 4. H. Lam. dict. 3. p. 586. no. 21 .

Syphilitie Lobelia. Fl. Aug. Oct. Clt. 1665. Pl. 1 to $2 \mathrm{ft}$.

23 L. 1NFLA'TA (Lin. spec. 1320, act. ups. 1741. p. 23. t. 1.) leaves sessile, dentately serrated: lower ones ovate-oblong: superior ones ovate; pedicels axillary, 1-flowered, forming a terminal leafy raceme; stem hairy; capsules inflated. $\odot . H$.
Native of Virginia and Canada. Bigel. mat, med. amer. 1. p. 177. t. 19. Sweet. fl. gard. 99. Rapüntium inflàtum, Mill. dict. no. 5. Stem branched at the top. Leaves rather villous beneath. Flowers small, pale blue. Segments of the calyx subulate, equal in length to the corolla. Leaves about 2 inches long.

Inflated-capsuled Lobelia. Fl. July, Aug. Clt. 1759. Pl. 1 to $1 \frac{1}{2}$ foot.

24 L. color A'ta (Sweet, fl. gard. n. s. t. 180.) glabrous; leaves lanceolate, acuminated, erosely toothed; raceme spicate, elongated, leafy; calycine segments linear-subulate. 4 . H. Received fron North America, but probably a hybrid between $L$. syphilitica and $L$. cardinàlis. Corollas deep azure blue, crowded. Ovarium lalf inferior. This is probably the L. caléstes, Nutt. and L. críspa, Graham. ex Loud. hort. brit. p. 75.

Coloured Lobelia. Pl, 4 to 5 feet.

25 L. ceLe'stis (Nutt. ex Loud. hort. brit. p. 592.) this plant is in the gardens, but we are not aware of where it is described; it comes very near to L. syphilitica, and may only be a variety of that species. 4 . H. Native of North America. L. críspa, Graham. ex Lond. hort. brit. p. 75. Flowers of a beautiful blue, disposed in long dense terminal racemes,

Heaventy-blue Lobelia. Fl. June, Oct. Clt. 1831. Pl. $2 \mathrm{ft}$.

26 L. uranocòma (Cham. in Linnæa. 7. p. 321.) stem erect, angular, fistular; leaves hairy, erect, linear, attennated, acute, finely denticulated; pedicels disposed in a terminal leafy raceme, shorter than the floral leaves, which are densely imbricated, ovate, acute, and shorter than the others, of a bluish colour; segments of the calyx linear, attenuated, about equal in length to the middle of the corolla, which is clothed with fine glandular down; anthers bearded in front. 4. S. Native of tropical Brazil. Leaves a foot long. Corolla cleft on the back, nearly 2 inches long, blue.

\section{Blue-tufted Lobelia. Pl. 5 feet.}

27 L. Glandulósa (Walt. car. p. 218.) leaves lanceolate, glandularly serrated, rather fleshy, glabrous; flowers on short pedicels, racemose; segments of the calyx revolute, toothed ; stem erect, branched, rather downy. $4 . H$. Native of Carolina, by the sea side in marshes among grass. L. crassiúscula, Michx. f. hor. amer. 2. p. 152. Nutt. gen. amer. 2. p. 76. Pedicels furnished with 2 bracteas, which are terminated by a gland each. Corollas blue, having the disk of the lower lip bearded. Stigma beset with white hairs.

Glandular-leaved Lobelia. Pl. 1 to 2 feet.

28 L. Puen'rula (Michx. f. bor. amer. 2. p. 152.) plant very simple, downy ; leaves oblong, obtuse, repandly serrulated ; flowers almost sessile, forming altogether a leafy elongated spike; calyx downy; calycine segments erect, lanceolate-subulate, entire, having the sinuses a little reflexed; stamens inclosed. $\psi$. $\mathrm{H}$. Native from Virginia to Carolina, in mountain tracts. Pursh, f. amer. sept. 2. p. 447. Bracteas serrulated. Flowers pale blue. Ovarium hispid. It differs from $L$. Claytoniana in the flowers being thrice the size, and of a more beautiful blue.

Tar. $\beta$, glabélla (Hook. bot. mag. t. 3292.) leaves hardly downy; calyx glabrous. 4. H. Native of Louisiana, about Jackson Ville. Corolla bright purplish blue.

Puberulous Lobelia. Fl. June, July. Clt. I 800 . Pl. 2 to $3 \mathrm{ft}$. 29 L. AME'NA (Michx. fl. bor. amer. 2. p. 153.) plant quite glabrous; leaves broad-lanceolate, serrated; spikes secund, many-flowered; segments of the calyx entire; segments of the lower lip of the corolla ovate, acute. 4. H. Native from Virginia to Carolina, on the mountains. Leaves usually glabrous, 6-8 inclies long, and 1 inch broad. Corollas pale blue. Pursh, fl. sept. amer. 2. p. 443. Nutt. gen. amer. 2. p. 76. Juss, ann. mus. 18. p. 16. t. 1. no. 1.

Pleasant Lobelia, Fl. July, Aug. Clt. 1812. Pl. 2 to $3 \mathrm{ft}$. 30 L. gruina (Cav. icon. 6. p. 8. t. 511. f. 2.) leaves sessile, 
lanceolate-linear, toothed; stem naked at the top, therefore the raceme of flowers is naked and terminal; bracteas subulate. 24.S. Native of New Spailı. Stem striated, glabrous. Leaves 2 inches long, glabrous. Corollas blue. Tube of corolla 3-4 lines long; segments of the upper lip narrower than those of the lower, and reflexed. Stigma villous. Filaments exserted, and resembling a stork's head. Very like L. ùrens.

Stork's Lobelia. PI. 1 foot.

31 1. numularioìes (Cham. in Linnæa. 7. p. 209.) glabrous ; leaves rather fleshy, ovate, cordate, rather reniform, obtuse, quite entire, or obsoletely subsinuately crenated, on short petioles, and sessile ; flowers axillary, on long pedicels ; calycine segments a little shorter than the corolline tube; anthers glabrous on the back, all bearded; fruit globose; stems prostrate, radicant, but ascending and floriferous at the apex. $4 . \mathrm{S}$. Native of Brazil, within the tropics, in marshy places. Nearly allied to $L$. Zeylániea. Corolla blue or violaceous.

Moneynort-like Lobelia. P]. prostrate and creeping.

32 L, RENIFo'rMis (Cham. in Linnæa. 7. p. 210.) herbaceous, hairy; stems rather capillary, branched, creeping, rooting; leaves on short petioles, orbicularly reniform, obsoletely angular, niembranous, nerved, and reticulately veined, pale green above, and glaucescent beneath; pedicels terminal and axillary, elongated; corolla glabrous outside, villous inside, with a broadish tube, and triangular segments; anthers glabrous on the back; calycine teeth ovate, acute, much shorter than the tube of the corolla. 4. S. Native of Brazil. Plant tufted, creeping. Leaves hairy, ciliated on the edges. Flowers blue.

Kidney-shaped-leaved Lobelia. Pl. creeping.

33 L. AQUA'TICA (Cham, in Linnæa. 7. p. 211.) a glabrous aquatic herb; stem erect or floating, flattened in the dry state; leaves scattered, erect, sessile, narrow-lanceolate, acute, obsoletely serrated, 1-nerved; pedicels axillary at the tops of the stem, capillary, erect, twice the length of the leaves; ovarium semi-elliptic, crowned by the calycine segments, which are a little shorter than the tube of the corolla ; anthers all bearded, glabrous on the back, exceeding the corolline tube, but shorter than its segments. 24. S. Native of Brazil, on the banks of rivers, or in marshes among grasses. Flowers blue. Leaves half an inch long.

Aquatic Lobelia. Pl. $\frac{1}{2}$ to $\frac{3}{4}$ foot.

34 L. sessilifòLia (Lamb. in Lin. trans. 10. p. 260. t. 6.) leaves sessile, oblong-lanceolate, serrulated, glabrous ; pedicels axillary, shorter than the leaves; stem erect, leafy, glabrous, very simple. 4. H. Native of Kamtschatka. L. Camtschática, Pall, mss. Habit of a Euphórbia. Leaves of an obscure green. Flowers blue? Sessile-leaved Lobelia. Pl. 2 to 3 feet.

35 L. umbella'ta (Vest, ex Rœm. et Schultes, syst. 5. p. 58.) glabrous ; leaves sessile, linear, toothed, dilated and trifid at the apex; flowers terminal, umbellate; stem erect. 4 .? S. Native country unknown. Stem angular. Leaves like those of Clerysánthemum leucánthemum. Involucrum of umbel short. Corollas blue, nearly an inch long, with the segments of the upper lip linear and reflexed, and of the lower one oblong. Stamens a little shorter than the tube of the corolla. Antliers bearded at the apex.

Umbellate-flowered Lobelia. Pl. 1 foot.

\section{* * Corollas red, purple or searlet, rarely ycllowish.}

36 L. GRAMÍneA (Lam. dict. 3. p. 583.) glabrous; leaves linear, ensiform, acute ; racemes long, simple ; stem erect, simple; bracteas linear, acute, shorter than the flowers.-Native of Peru. Leaves 5 inches long, and 2-3 lines broad. Flowers scarlet, on short pedicels, form of those of $L$. cardinalis. Filaments and stamens combined.

Grassy-leaved Lobelia. Pl. 2 feet.
37 L. Pulverulénta (Pers. ench. 2. p. 212.) leaves ovate, on very short petioles, glabrous above and wrinkled, but chothed with white tomentum beneath; corollas campanulate, powdery ; sten shrubby. $h$.S. Native of Soutl America, on the road from Guaranda to Mount Chimborazo. Stem branched, tomentose. Leaves obtuse, with subrevolute edges, 3 inches long. Pedicels longer than the leaves, altogether forming a leafy raceme. Corollas white from powdery tomentum outside, and reddish inside, less than an inch long, with equal oblong acnte segments. Perhaps a species of Clermóntea.

Pondery Lobelia. Pl. 6 to 8 feet.

38 L. cordígera (Cav, icon. 6. p. 14. t. 523.) leaves ovate, acute, half-stem-clasping, villous, denticulated; pedicels villous, axillary, solitary; stem villous, furrowed. 4. F. Native of Chili. Leaves 3 inches long. Calyx villous. Corolla scarlet, $1 \frac{1}{2}$ inch long, with the segments of the upper lip linear, elongated, of the lower lip ovate, acute. Genitals glabrous.

Heart-bearmg Lobelia. Pl. 3 feet.

39 L. DEcu'rRtas (Cav, icon, 6. p. 13. t. 521.) leaves ovatelanceolate, biserrated, decurrent, glabrous, approximate; flowers solitary, axillary, altogether forming a long leafy raceme; calyx villous, with the segments deeply serrated; tube of corolla cleft even to the base. h. F. Native of Chili, on the banks of the river Claro. Sweet, f. gard. n. s. 86. Sten glabrous. Leaves 2 inches long and an inch broad, with 2 small teeth between each large one. Corolla purplish-violet, $1 \frac{1}{2}$ inch long; upper lip of 2 linear segments, which are villous at the apex, of the lower acute, and are as well as the anthers pilose.

Decurrent-leaved Lobelia. Fl. June, Sept. Clt. 1826. Pl. 5 to 6 feet.

40 L. congloba'ta (Lam. dict. 3. p. 585 .) leaves oblong-cuneiform, denticulated, slining; racemes globose, terminal; segments of calyx fringed; stem simple, filled with medula. 4.5 . Native of Martinico and St. Domingo. Lin. spec. 4.t. 117. Stem thick, naked at the base. Leaves a foot and more long, and 3 inches broad, exceeding the corymb of flowers. Flowers very numerous, disposed in a short raceme. Bracteas lanceolate, deuticulated, shorter than the flowers. Corollas shorter than the calyx, scarlet, but in the larger variety greenish-red. Perhaps a species of Tùpa.

Conglobate-racemed Lobelia. Pl. 1 foot.

41 L. Cavanillesia'na (Rom. et Schultes, syst, 5. p. 43.) glabrous; leaves ovate-lanceolate, acuminated, serrated, sessile; pedicels solitary, axillary, longer than the leaves, the whole forming a leafy raceme; corollas downy. $\boldsymbol{\psi}$. S. Native of New Spain, near Acambaro. L. persicifòlia, Cav. icon. 6. p. 12. t. 518. Stem herbaceous, striated, branched. Serratures of leaves setaceous. Calyx globose. Corolla red; with the tube nearly an inch long. Probably a species of Tùpa. Anthers bearded with white hairs.

Cavanilles's Lobelia. Fl. June, July. Clt. 1825 . Pl. 3 ft.

42 L. PERsicifòlia (Lam. dict. 3. p. 584.) leaves narrow-lanceolate, serrated; pedicels axillary, solitary, shorter than the leaves, the whole forming a leafy raceme. $\psi$. S. Native of Guadaloupe, in marshes. Stem fistular. Leaves numerous. Corolla purplish, glabrous, a little curved, $1 \frac{1}{2}$ inch long. Perhaps a species of Siplooém

Peach-leaved Lobelia. Fl. June, July. Clt. 1824. Pl. $I_{\frac{1}{2}}^{1} \mathrm{ft}$.

43 L. KRau'ssr (Graliam, in edinb. phil. journ. March, 1830 bot. mag. 3012.) leaves sessile, lanceolate, decurrent, sharply serrated, glabrous; pedicels axillary, solitary, longer than the leaves, the whole forming a leafy terminal raceme; calycine segments subulate, a little toothed, spreading, and are as well as the corolla glabrous; stem herbaceous, glabrous, erect, branched. 4. S. Native of Dominica, where it was collected by $\mathrm{Dr}$. Krauss. Leaves $4 \frac{1}{2}$ inches long. Corolla 1 inch long, red, $4 \times 2$ 
cleft along the back to the base; segments linear-subulate: the $\because$ upper ones the broadest. Filaments white, downy; anthers lcad-colour, terminated by a dense white beard. Nearly allied to L. persicifólia.

Krauss's Lobelia. Fl. Jan. Feb. Clt. 1828. Pl. $1 \frac{1}{2}$ foot.

44 L. RAcEMòsA (Hook, bot. mag. 2137.) stem suffruticose, creet; leaves lanceolate, spinosely serrated; racemes terminal; pedicels exceeding the flowers, at length deflexed; calycine segments awl-shaped, sharply serrated. $\zeta$. S. Native of the Island of St. Christopher; and of Brazil, at Rio Janeiro. Leaves 9 inches long. Branches terete. Pedicels bibracteate. Bracteas serrated. Corolla plaited, cleft on the back, having the lower lip 3-lobet, and the segments of the upper lip narrow, all recoiled backwards, greenish. Anthers lead-coloured, as well as the stigma. This is a true species of Tùpa.

Racemose-flowered Lobelia. Fl. July, Aug. Clt. 1818. Sh. 2 to 3 feet.

45 L. Acunina'ta (Swartz, prod. p. 117. fl. ind. occ. p. 1950.) glabrous; leaves lanceolate, attenuated at both ends, serrulated, glabrous; racemes terminal, many-flowered. h. S. Native of Jamaica and St. Domingo. L. salicina, Lam. dict. 3. p. 583.Sloane, jam. 1. p. 158. t. 95. f. 2. Stem glabrous. Leaves 6-8 inches long, and an inch broad. Flowers pale red, or greenish white, risposed in a compound raceme. Bracteas linear. Corolla curved, villous outside. Perhaps a species of Siphocámpylus.

Acuminated-leaved Lobelia. Fl. June, Aug. Clt. 18\%2, Pl. 3 to 4 feet.

46 I. Lacinia'ta (Lam. dict. 3. p. 584.) leaves lanceolate, pinnatifidly toothed: the segments arain toothed; corymbsterminal, small, sessile. $\%$. S. Native of St. Domingo. Stem glabrous, a little branched. Leaves nearly glabrous, more than 2 inches long. Corolla greenisl red, glabrous, an incls long.

Jagged-leaved Lobelia. Pl. 1 foot.

$4 T$ L. sonchifòla (Swartz, f. ind. 3. p. 1947.) leaves deeply sinuated: superior ones pinnatificl, with lanceolate denticulated segments: racemes terminal, leafy. 24. S. Native of New Spain, on the margins of rivers. Stem simple, glabrous. Leaves petiolate, glabrous, glaucous beneath. Bracteas jagged. Corolla purplish, like that of $L$. cardinalis. Anthers bearded.

Son-thisile-leared Lobelia. Pl. 2 feet.

48 L. strícta (Swartz, prod. 117.fl. ind. occ. p. 1952.) lower leaves elliptic, spiny-toothed, glabrous, tufted; stem simple, stiff; Howers spicate. Ђ. S. Native of Guadaloupe. Lam. dict. 3.p. 584.no. 15. Radical leaves larger than the rest, attenuated at the base, 3 inches long, and an inch broad. Pedicels short, the whole forming a terminal leafy raceme. Corollas purplish.

Straight Lobelia. Shrub 2 to 3 feet.

49 L. ronu'sta (Graham, in edinb. phil. journ. Dec. 1831. Hook. bot. mag. 3138 .) leaves obovate..lanceolate, acuminated, coarsely toothed, glabrous, shining; racemes terminal, simple,

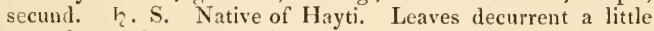
way down the stem, lilac-coloured beneath while young. Flowers numerous, on villous pedicels, furnished each with one bractea at the base, and 2 in the middle. Bracteas linear. Corollas of a deep dull purple. Calyx spherical, with serrated segments. Filaments ciliated. Two upper anthers ciliated. Stigma 2-lobed. Allied to L. assurgens.

Robust Lobelia. Fl. Aug. Clt. 1830. Pl. 4 feet.

50 L. Assv'rgevs (Lin. amœn. acad. 5. p. 408.) leaves broad, lanceolate, scrrated or denticulated and decurrent at the base; racemes simple, terminal; segments of the calyx serrated; capsule angular. 4. S. Native of Jamaica, on the mountains, particularly on the edges of streams. Andr. bot. rep. 553 . Leaves a foot long, glancous. Stem reddish, almost simple, glabrous. Flowers crowded, large, downy, purple. The column of anthers has 5 blue grooves. Probably a species of Tùpa.
Assurgent Lobelia. Fl. June, Oct. Clt. 1787. Pl. 3 to $4 \mathrm{ft}$.

51 L. folıòs A (Willd. rel. ex Rœm. et Schultes, syst. 5. p. 56. H. B. et Kunth, nov. gen. aner. 3. p. 310.) leaves sessile, decurrent, lanceolate, doubly toothed, glahrous; flowers axillary, pedicellate, the whole forming a leafy raceme; corollas hairy; stem erect, simple, glabrous. 2 . S. Native of the kingdom of Quito, in humid places near Guancabamba. Leaves crowded on the stem, 3 inches long. Pedicels hairy. Segments of the calyx furnished at the base with remote subulate teeth, about equal in length to the tube of the corolla. Corolla pale purple. Two lower anthers bearded. Allied to $L$. decúrrens, Cav, and $L$. cardinàlis.

Leafy Lobelia. Pl. 2 to 3 feet.

52 L. Laxiflòra (H. B. et Kunth, nov. gen. amer. 3. p. 311.) leaves almost sessile, oblong, acuminated, serrulated, glabrous ; racemes terminal, secund; flowers on long pedicels ; corollas hairy; stem erect, simple, angular, glabrous. 4. F. Native of Mexico, between Quasiniquilapa and Acaguirolla. L. físsa, Willd. rel. ex Roem. et Schultes, syst. 5. p. 57. Leaves $2 \frac{1}{2}$ inches long. Rachis of raceme hairy. Calyx hairy. Corolla pale purple. Allied to $L$. cardinàlis.

Loose-flonered Lobelia. Pl. 2 to 3 feet.

53 L. Rigídula (H. B. et Kunth, nov. gen. amer. 3. p. 311.) leaves short, sessile, oblong-lanceolate, acutish, sharply serrulated, stiffish, glabrous above, but rugged and hairy beneath; flowers axillary, on long pedicels; corollas bairy. $\quad$ f. S. Native of New Spain. Stems hairy above. Leaves 2 inches long. Flowers and fruit like those of the preceding species, to which it is very nearly allied.

Stiffish Lobelia. Pl. 2 to 3 feet.

54 L. Fu'LGens (Willd. hort. berol. 2. p. 85. t. 85.) leaves lanceolate, denticulatel, with revolute margins, downy as well as the stems; racemes terminal, leafy, somewhat secund. $\psi$. H. Native of Mexico. Andr. bot. rep. 659. Bonpl. malm. p. 19. t. 7. Stem reddish. Leaves $4-6$ inches long. Corollas about an inch long, downy outside, of a splendid scarlet colour. feet.

Fulgent Lobelia. Fl. May, Sept. Clt. 1809. Pl. 1 to 2

55 L. Cardina'Lis (Lin. spec. 1320.) leaves oblong-lancenlate, cartilaginously denticulated, glabrous as well as the stems; racemes terminal, unilateral, leafy. 24.F. Native of Virginia and Carolina; and of Mexico, near Jalapa. Pursh, fl. amer. sept. 2. p. 448. Curt. bot. mag. 320.-Knor. del. 2. t. L. f. 2. Rapúntium cardinàlis, Mill. dict. no. 1.-Mor. hist. 2. p. 466. sect. 5. t. 5. f. 54.-Hern. mex. p. 879. t. 880 . Leaves purplish beneath, 3 inches long, and $1 \frac{3}{2}$ broad. Flowers scarlet. It differs from $L$. fúlgens in being glabrous, and in the segments of the lower lip of the flower being obtuse, not lanceolate, and acute.

Cardinal-flowered Lobelia. Fl. July, Aug. Clt. 1626. Pl. 1 to 2 feet

56 L. SPLE'NDENS (Willd. hort. berol. 2. t. 86.) leaves lanceolate, denticulated, with flat margins, quite glabrous as well as the stems; racemes terminal, somewhat secund. 24. F. Native of Mexico. Ker. bot. reg. 60. Stem purplish. Pedicels cempressed, purplish. Corolla scarlet, glabrous, very like those of the two last species.

Splendent Lobelia. Fl. May, Sept. Clt. 1814. Pl. 1 to 2 feet.

57 L. speciòs A (Hort. Lindl. bot. reg. 1445. Sweet. fl. gard. n. s. 174.). This is a hybrid between $L$. syphilitica and $L$. cardinàlis, spléndens or fúlgens. The Howers are purple.

Showy Lobelia. Fl. June, Oct. Hybrid. Pl. 2 to 5 feet.

$\$ 2$. Species natives of the East Indies and other parts of A sia. 
58 L. Chine'nsis (Lour. coch. p 514.) glabrous ; leaves sessile, lanceolate, quite entire; flowers solitary, terminal; stem creeping; branches ascending. $\odot$. H. Native of China, about Canton. Flowers pale blue, pedicellate. Segments of the corolla lanceolate, unequal. Stigma bifid, revolute.

China Lobelia. Pl. creening.

59 L. Heynea'na (Rom. et Schultes, syst, 5. p. 56.) stem filiform, erect, winged; leaves subrhomboid, serrated, decurrent, setosely ciliated at the base; peduncles axillary, solitary, lengtl of leaves; calyxes glabrous. - Native of the East Indies. L. decúrrens, Roth, nov. pl. spec. mss. The stem is winged from the leaves being decurrent.

Heyne's Lobelia, Pl. $\frac{1}{2}$ to 1 foot?

60 L. ZEYLÁxICA (Lin. spec. 1322.) stems prostrate and creeping, downy; leares on short petioles, ovate, somewhat cordate, serrated, acute : lower ones obtuse ; peduncles solitary, 1-flowered, axillary, equal in length to the leares, villous ; capsules rather villous. 4 . S. Native of China and the East Indies, in fields. L. nummularifolia, Lam. dict. 3. p. 563.?Seb. thes. 1. p. 37. t. 22. f. 12. Var. $\beta$, hirta, Lin. spec. 985. Plant small. Leaves like those of I erónica chame'dryos, fleshy, beset with a few pellucid hairs; lower ones crenated; upper ones serrated. Peduncles downy. Flowers purple. This is a very pretty plant when in blossom. It differs from $L$. trigona, Roxb. by its petioled more rounded leaves, terete stems, and its pubescence.

Ceylon Lobelia. Fl. June, July. Clt. 1821. Pl. ereeping.

61 L. chesopodifòli (Wall. cat. no. 1312.) stem branched at the base ; lower leaves roundish-ovate, obtuse, broadly crenated : upper ones ovate-lanceolate or deltoid, acuminated, coarsely toothed; peduncles elongated, terminal, bearing loose racemes of flowers at the apex; calycine segments subulate. $\odot$. H. Native of the East Indies.? Flowers small, probably pale blue.

Goose-fot-leaved Lobelia. Pl. I foot.

62 L. Affixis (Wall. cat. no. 1311.) plant downy, creeping at the base; leaves orate, petiolate, membranous, cuneated at the base, slightly denticulated; peduncles axillary, l-flowered; calyx hairy, witls linear segments; stems angular. $4 . \mathrm{S}$. $\mathrm{Na}$ tive of the East Indies, in Sillet and Goalpara. Flowers blue. Stems creeping at the base. 'I'his species is very like $L, Z e y$ lánica and L. trigòna.

Allied Lobelia. Pl. $\frac{1}{2}$ foot.

63 L. Numula'ria (Lam. dict. 3. p. 589.) stems creeping, filiform; leaves roundish-cordate, crenated; peduncles 1-flowered, axillary, a little longer than the leaves. 4 .? S. Natire of Java. Habit of Siblhórpia. Stem ratler villous. Leaves small, rather villous beneath, unequal. Petioles 2-3 lines long. Corolla 4-5 lines long, longer than the stamens.

Money-nort-leaved Lobelia. Pl. creeping.

64 L.? PU'x11. (Burm. prod. 1. t. 60, f. 3.) glabrous; stems procumbent ; leaves opposite, ovate, quite entire ; panicles terminal. 24. S. Native of Coromandel. Leaves petiolate. Flowers small.

Dwarf Lobelia. Pl. procumbent.

65 L. Triada'ta (Ham. mss. ex D. Don, prod. fl. nep. p. 157.) leaves roundish-ovate, serrated, glabrous; petioles dilated, decurrent at the base; pedicels solitary, axillary, longer than the leaves; flowers somewhat racemose; segments of the calyx filiform ; stem ascending, triquetrous, branched, winged, glabrous. 4. F. Native of Nipaul. L. micrántha, Hook. exot. fl. t. 4.4. Stem hardly a hand high, rooting at the base. Pedicels longer than the leaves. Corollas small, red. Very like $L$. gratioloides, Roxb., but in that species the leaves are sessile and cordate.

Three-ninged-stemmed Lobelia. Fl. July, Aug. Clt. 1 S22. Pl. ascending.
66 I.. Trigòna (Roxb. fl. ind. 2. p. 111.) glabrous; leaves subsessile, cordate, coarscly serrated; pedicels axillary, bibracteate, longer than the leaves; stems creeping at the base, erect parts 3 -sided. ○. H. Native of the Last Indies, delighting in pasture-ground, appearing in the wet season. L. stipularis, Roth. Flowers small, blue. Corolla inserted in the mouth of the calyx. Roth has mistaken the 2 small bracteas on the pedicels to be stipulas.

Trigonal-stemmed Lobelia. Pl. $\frac{1}{2}$ to 1 foot.

67 L. caupanuloides (Thunb. in Lin. trans. 2. p. 331.) leaves on short petioles, lanceolate-oblong, toothed; pedicels elongated ; stems decumbent. $\boldsymbol{4}$. ? H. Native of China and Japan. Ker. bot. reg. 733. L. erinoìdes, Thuub. jap. p. 326. L. Japónica, Dietr. gærin. 5. p. 552. Stems nearly simple, elongated, filiform, glabrous. Leaves almost sessile, glabrous; obsoletely serrated. Flowers terminal, on elongated branches, white.

Campanula-like Lobelia. Fl. May, Aug. Clt. 1820. Pl. decumbent.

68 L. PYRAMIDA'Lis (Wall. in asiat. res. 13. p. 3\%9.) smootls; leaves lanceolate, long-acuminated, serrated: upper ones linear, attenuated ; racemes panicled, leafy; calycine segments linearsubulate, about equal in lengtlı to the corolla; stems erect, branched. $4 . \mathrm{H}$. Native of Nipaul, on the mountains at $\mathrm{Na}$. rainhetty. This is the most common and most ornamental plant in Nipaul, where it grows both in low and elevated situations. It is found from the entrance of that country at Bechiaco, up to the mountains that bound the valley to the north, and where it grows at an elevation of at least 8000 feet. It is al:o found in the hilly country of Silhet. D. Don, in bot. mag. t. 238\%. L. stímulans, Hamilt. mss. ex D. Don, prod. fl. nep. p. 157. Plant variable in height, and is often found altogether of a deep purple, but chiefly the floral branches and leaves. Stem pyramidally branched. Leaves downy beneath. Corollas purplishviolet. Anthers deep blue, pilose. Lobes of stigma hollow beneath.

Pyramidal Lobelia. Fl. Sept. Clt. 1822. Pl. 3 to 4 feet.

69 L. excélsa (Wall. in Roxb. fl. ind. 2. p. 114.) leaves oblong-lanceolate, acuminated, denticulated, attenuated at botl ends, densely clothe ! with villi, on short petioles; racemes terminal, erect, villous, leafy, dense-flowered; calycine segments linear, as long as the tube of the corolla. ○. H. Native of the Nelligherry mountains, near Coimbetore, where it was collected by Leschenault, and where it is called by the natives Oumar. Leaves 10 inches long, and 1 broad. Petioles marked by the decurrent base of the leaf. Flowers large.

Tall Lobelia. 1'l. 10 to 12 feet.

70 L. Ròsea (Wall. in Roxb. fl. ind. 2. p. 118.) plant covered with glancous short dense villi; stem panicled; leaves lanceolate, ensiforn, acuminated, finely denticulated ; racemes terminal, with unilateral flowers; calycine segments equalling the tube of the corolla. $\odot$. F. Native of Nipaul, in the valley of Noakote. Leaves from 8-12 inches long; floral ones linear-lanceolate, rounded at the base. Flowers ummerous, nodding, downy, like those of $L$. pyramidèlis, but larger, of a pale rosecolour. Anthers connected into a long purple incurvated tube, bearded. Filaments downy. Orarium bi-trilocular. Stigma pubescent.

Rose-coloured-flowered Lobelia. Pl. $\&$ to 6 feet.

71 L. nicotianefòlia (Heyne, mss. ex Roem. et Schultes, syst. 5. p. 47.) leaves oblong-lanceolate, attenuated at both ends, serrated, rather scabrous; stem erect, angular: racemes terminal, equal, downy ; flowers very numerous. 24.? IH. Natire of the East Indies, in the vicinity of Bangulore. A stout plant. Leaves a foot long. Racemes angular, above a foot long. Cnrollas downy, showy. Calyx and capsules downy, and the anthers glabrous. 
Tobacco-leared Lobelia. Fl. June, July. Clt. 1822. Pl. 2 to 3 feet.

5. Species natives of Africa, particularly of the Cape of Good Hope. Flowers generally violaccous or blue, rarely white or yellow.

\section{* Stems erect. Leaves entire.}

T2 L. LINEA'RIS (Thunb. prod. 1. p. 39. fl. cap. 2. p. 35.) leaves linear, quite entire, glabrous; stems erect, terete, striated, glabrous; pedicels solitary, axillary, much shorter than the leaves. $\zeta$. G. Native of the Cape of Good Hope, near Paardeberg. Ait. hort. Kew. ed. 2. vol. 1. p. 356. Stems many from the same root, simple. Flowers blue.

Lincar-leaved Lobelia. Fl.? Clt. 1791. Slirub $\frac{1}{2}$ to $\frac{3}{4} \mathrm{ft}$.

73 L. Seta'cea (Thunb. phyt. bl. p. 21. act. gorenk. 1811. f. 11. A. cap. 2. p. 34.) leaves filiform, setaceous, glabrous, quite entire; pedicels axillary, solitary, length of leaves. 24.G. Native of the Cape of Good Hope. Flowers nutant, blue.? Stems erect, glabrous.

Sctaccous-leaved Lobelia, Fl. May, July. Clt, 1816. Pl. 1 foot.

74 L. SCA'BR A (Thunb. phyt. bl. p.21. fl. cap. 2. p. 35.) leaves linear, emarginate, scabrous, quite entire ; stems weak, filiform, hairy; pedicels axillary, solitary, flexuous, longer than the leaves. 4 .? G. Native of the Cape of Good Hope. Leaves sessile, subsecund. Calyx and corolla hairy.

Scabrous Lobelia. Pl. $\frac{1}{2}$ foot.

75 L. соммита'тA (Rom. et Schultes, syst. 5. p. 36.) lower leaves ovate: superior ones oblong: all sessile, retuse, and emarginate, with revolute margins, beset with a few hairs on the nerve and on the edges; floriferous branches and stems naked at the apex; flowers racemose, on short pedicels, reflexed. 4. G. Native of the Cape of Good Hope.? Stems ascending, beset with a few white bristles. Leaves rather distich. Calyx lispid. Corolla violaceous, with a long white hispid tube. Anthers bearded by white hairs.

Changed Lobelia. Pl, ascending.

76 L. símplex (Thumb. prod. 1. p. 39. fi. cap. 2. p. 35.) leaves linear, villous, sessile, quite entire; stems simple, erect, smooth; pedicels solitary, axillary, twice the length of the leaves. $\odot$. or 4 . G. Native of the Cape of Good Hope. Flowers blue. Calycine segments linear-lanceolate, villous. Capsule turbinate.

Simple-stemmed Lobelia. Fl. May, Aug. Clt. 1794. Pl. $\frac{1}{8}$ foot.

77 L. Pinifòlia (Lin. sjec. 1318. Thunb. fl. cap. 2. p. 36.) shrubby; leaves linear-lanceolate, erect, crowded, quite entire, but according to Thunberg they are trigonal; pedicels terminal, few. h. G. Native of the Cape of Good Hope, on the sides of mountains near Cape Town. Andr. bot. rep. 273. Young branches downy. Segments of calyx linear. Corolla blue.

Pine-leaved Lobelia. Fl. May, Aug. Clt. 1786. Shrub $1 \frac{1}{2} \mathrm{ft}$.

78 L. DEPRE'sSa (Thunb. prod. 1. p. 39. fi. cap. 2. p. 36.) leaves oblong or lanceolate, obtuse, glabrous, quite entire; stem branched, denticulated, varicose; pedicels length of leaves, solitary. 24. G. Native of the Cape of Good Hope. Stems much depressed. Leaves a little decurrent. Flowers deep purple, minute.

Depressed Lobelia. Pl. prostrate.

79 L. Panicula'ta (Lin. spec. 1319.) leaves linear, quite entire; stems leafy at the base, and naked at the apex, branched, panicled; panicle dichotomons. 24.? G. Native of Ethiopia. Burm. afr. t. 38. f. 3. Leaves short, sessile. Branches loose, furnished with 2 small opposite leaves under each fork. Flowers small, blue.
Panicled Lobelia. Pl. $\frac{1}{2}$ to 1 foot.

\section{* Stems erect. Leaves serrated or crenated.}

80 L. Bellidifòlia (Thunb. prod. 1. p. 40. fl. cap. 2. p. 47.) leaves ovate, toothed, hairy, or obovate crenated, downy beneath; stems hispid at the base, simple, divided into a panicle at the top; lower pedicels the longest. 24. G. Native of the Cape of Good Hope. Corollas blue. Leaves of the ramifications of the panicle subulate, smooth.

Daisy-lcaved Lobelia. Fl. May, Aug. Clt. 1790. Pl. $\frac{1}{4}$ to $\frac{1}{2}$ foot.

81 L. Rntzophy'ta (Spreng. nov. prov. 1818. ex Rœm. et Schultes, syst. 5. p. 44.) lower leaves petiolate, obovate, repandly toothed, glabrous, rather fleshy : superior ones lanceolate, sessile, rather decurrent . uppermost ones ciliated, quite entire ; pedicels short, axillary; capsules cylindrical, glabrous ; stems radicant at the base, and ascending at the apex, triquetrous, glabrous. 2 . G. Native of the Cape of Good Hope. Sims, bot. mag. 2519. Flowers white, marked with blue. It differs from $L$. bellidifolia in the smoothness of its parts; and from $L$. cuneiformis, $\mathrm{R}$. Br, in the decumbent radicant stems.

Rooting Lobelia. Fl, Sept. Oct. Clt. 1800. Pl, ascending.

S2 L. Tríuetra (Lin. mant. p. 120.) glabrous; leaves lanceolate, pinnatifidly toothed, sessile; racemes terminal ; branches and pedicels trigonal. $\psi$. G. Native of the Cape of Good Hope. Thumb. fl. cap. 2. p. 4.5. I. capitata, Burm. prod. p. 25. Leaves as if they were agglutinated at the base. Racemes erect, pcdunculate. Corollas blue.

I ar. $\beta$, comòs $\alpha$; leaves linear, toothed; flowers terminal. 4. G. Native of the Cape of Good Hope. L. corymbòsa, Berg. cap. p. 34.4. Flowers blue.

Iar. $\gamma$, álba; corymbs leafy; flowers white. 4. G. Native of the Cape of Good Hope.

Triquetrous-stemmed Lobelia. Fl. May, Aug. Clt. 1774. Pl. 1 foot.

83 L. DECu'MBENs (Sims, bot. mag. t. 2277.) glabrous; stems decumbent; leaves obovate, toothed: superior ones dissimilar ; pedicels axillary, shorter than the bracteas, which are linear, quite entire, and decurrent. 4 . G. Native of the Cape of Good Hope. L. bellidifolia, Hortul. Calycine teeth short, spreading, subulate. Flowers blue, smaller than in $L$. bicolor, with a white or yellowish throat.

Decumbent Lobelia. Fl. June. Clt. 1820. Pl. dec.

84 L. ciNe'rea (Thunb. prod. 1. p. 40. f. cap. 2. p. 44.) leaves linear, spiny-toothed, clothed with grey tomentum; flowers almost sessile, forming a terminal raceme. 4 . G. $\mathrm{Na}$ tive of the Cape of Good Hope, in Roggeweld. Root fusiform, simple. Stems many from the same root, terete, smooth. Leaves sessile, acute, with thickened margins; lower ones glabrous. Calyx tomentose. Corollas white.

Grey Lobelia. Pl. $\frac{1}{2}$ foot.

85 L. томемтòs a (Lin. fil. suppl. p. 394.) tomentose; leaves linear, toothed; peduncles terminal, very long, 1-2-flowered. 2. G. Native of the Cape of Good Hope. Stems numerous, ascending, simple, having the leaves imbricated at the base. Leares like those of Corónopis, having 4-6 obtuse teeth on each side, with revolute edges, clothed with hairy tomentum ; peduncles clothed with adpressed hairs, bearing 2 small opposite leaves in the middle, or towards the base, and above these 2 opposite setaceous ones. Corolla blue or violaceous, half an inch long. Anthers beset with white hairs at the apex.

Tomentose Lobelia. I1. May, Sept. Clt. 1821. Pl. ascending.

86 L. secu'xDA (Lin. fil, suppl. p. 395. Thunb. fi. cap. 2. p. 45.) glabrous; lower leaves oblong, toothed: superior ones lanceolate, entire; peduncles racemose, secund. 4 . G. Native 
of the Cape of Good Hope, in sandy inundated places. The plant can hardly be said to be truly glabrous. There are floriferous branches in the axils of ncarly all the leaves, and the flowers are all drooping to one side. Stems numerous, filiform, striated and downy, simple. Lower leaves obovate, obsoletely denticulated, obtuse. Pedicels solitary, 1-flowered, shorter than the leaves. Corollas white, and are as well as the ealyx downy outside.

Secund-flowered Lobclia. Fl. May, Aug. Clt. 1790. Pl. $\frac{1}{9}$ foot.

87 L. PA'Tula (Thunb. prod. 1. p. 40. fl. cap. 2. p. 41.) leaves ovate, sinuately toothed, villous; stems diffuse, spreading, filiform ; pedicels solitary, axillary, capillary, downy, longer than the leaves. 4 , G. Native of the Cape of Good Hope. Leaves petiolate; superior ones lanceolate. In Lin. fil. suppl. p. 395. the plant is said to be glabrons.

\section{Spreading Lobelia. Pl. 1 foot.}

88 L. FE'RVENS (Thunb. f. cap. 2. p. 46.) leaves sessile, ovate-oblong: upper ones lanceolate: all serrated, glabrous; pedicels 1-flowered, much shorter than the leaves in the superior axils. 4. G. Native of the Cape of Good Hope. Stems erectish, branched a little, glabrous. Flowers blue.

\section{Fervent Lobelia. Pl. $\frac{1}{2}$ foot.}

89 L. Bírida (Thunb. prod. 1. p. 40, fl. cap. 2. p. 46.) leaves obovate, toothed, glabrous; stems filiform, downy, bifid or twice bifid at the apex; flowers terminal, solitary. 4. G. Native of the Cape of Good Hope, on Mount Bockland. Stems erect, simple. Radical leaves subpetiolate, obovate, denticulated, hardly downy, a line long, but only a solitary cauline one on each stem, or 2 small alternate ones. Flowers blue. Bracteas lanceolate in the forks of the stem.

Bifid-stemmed Lobelia. Pl. I to 3 inclies.

90 L. DE'BıLıs (Lin. fil. suppl. p. 395. Thunb. A. cap. 2. p. 45.) leaves lanceolate, serrated, glabrous; pedicels lateral, longer than the leaves; stems much branched from the base; calycine segments linear-subulate, a little shorter than the corolla. $\odot$. G. Native of the Cape of Good Hope. Very like L. depréssa. Upper leaves nearly linear. Corollas blue, villous outside.

Weak Lobelia. Fl. July, Aug. Clt. 1774. Pl, $\frac{1}{2}$ foot.

91 L. minu'ta (Lin. mant. p. 292.) leaves radical, ovate, obtuse, hardly crenated; scapes or pedicels capillary, 1-flowered, 2 inches long; corolla funnel-shaped. 24. H. Native of the Cape of Good Hope, in fissures of rocks on Mount Taffelberg. Sims, bot. mag. t. 2590. Root throwing out off-sets. Flowers pale blue. Habit of Móntia fontàna or Béllium minùtum.

Minute Lobelia. Fl. June, Sept. Clt. 1772. Pl. 1 inch.

92 L. mínima (Sims, bot. mag. 2077.) stems prostrate; leaves ovate, erenated, petiolate, glabrous; perlicels long, axillary, 1flowered, furnished with 2-3 linear hairy bracteas below the middle. 4. G. Native of the Cape of Good Hope. Flowers white inside, and red outside, with a yellow throat.

Least Lobelia. Fl. June, Sept. Clt. $1800 . \quad$ Pl. 1 to 2 inches.

93 L. PUsílla; leaves roundish, lobed: lobes obtuse ; pedicels axillary, 1 -flowered. 4 . G. Native of the Cape of Good Hope. Flowers white. L. minuta, Thunb. prod. 1. p. 40. fl. cap. 2. p. 43 .

Small Lobelia. Pl. 1 inch.

\section{* * Stems prostrate. Lcaves cut or toothed.}

94 L. Eninus (Lin. spec. 1321. Thunb. fl. cap. 2. p. 39.) leaves toothed; lower ones obovate, petiolate: superior ones almost sessile, narrow-lanceolate; peduncles 1 -flowered, longer than the bracteas; stems spreading. 4 . G. Native of the Cape of Good Hope. Curt. bot. mag. 901. Rapúntium erìnum,
Mill. dict. no. 8.-Herm. lugdb. 110. t. 110. Stems branched at bottom. Leaves glabrous. Pedicels axillary, solitary, naked, much longer than the leaves. Flowers slender, blue, with a white or yellowish throat. Fruit 8 -celled. According to Thunberg there is a variety of this, having numerous radical stems, which are as well as the leaves villous.

Erinus Lobelia. Fl. June, Sept. Clt. 1752. Pl. $\frac{1}{2}$ foot.

95 L. Alsinoìns (Lam. dict. 3. p. 586, no. 29.) plant creeping, glabrous; stems branched; leaves roundish-oval, toothed ; peduncles long, 1-flowered, axillary, much longer than the leaves. 4. G. Native of the Cape of Good Hope. Stem erect at the top, but radicant at the base. Radical leaves like those of Sibthorpia; the rest ovate, toothed, and subpetiolate.

Click-need-like Lobelia. PJ. $\frac{1}{4}$ to $\frac{1}{2}$ foot.

96 L. Muscoìns (Cham. in Linnæa. 7. p. 215.) herb small, slender, trailing, quite glabrous ; stems filiform, rooting at the nodi; leaves roundish, deeply $5-7$-cleft, truncate or cuneated at the base: segments elliptic, acute, mucronulate; pedicels axillary, bracteate, erect, much longer than the leaves; ovarium obconical. 4. G. Native of the Cape of Good Hope. Herb tufted, pale green. Corollas purple.

Moss-like Lobelia. PI. tufted.

97 L. Mundta'sa (Cham. in Linnæa. 7. p. 215.) plant trailing; stems filiform, angular; leaves sessile, decurrent, lanceolate and elliptic, acute at both ends, with a few acute serratures : flowers axillary, solitary, on short pedicels; calycine segments lanceolate, acute, erect, more than one-half shorter than the tube of the corolla; anthers all bearded. \%. G. Native of the Cape of Good Hope, at Gamka, where it was collected by M. Mundt. Ovarium, calyxes, pedicels, stems, and ontside of corolla beset with long spreading white hairs.

Mundt's Lobelia. Pl. trailing.

9 L. campanula'ta (Lam. dict. 3. p. 588. no. 30.) plant small; leaves linear-lanceolate, toothed; pedicels very long, 1 flowered; calyx hairy, a little reflexed. $\odot$. H. Native of the Cape of Good Hope. Stem simple, slender, leafy, glabrous. Leaves glabrous, sessile, hardly an inch long. Pedicels filiform, $2 \frac{1}{2}$ inches long, pilose at the apex, solitary in the axils of the superior leaves. Flowers erect, campanulate, blue. Limb spreading, hardly divided, rather irregular. Calycine segments narrow.

Bell-flowered Lobelia. Fl. June, July. Clt. 1821. Pl. $\frac{1}{4}$ to $\frac{1}{2}$ foot.

99 L. BrE'YNIr (Lam. dict. 3. p. 588.) leaves sessile, lanceolate, toothed, minute, usually milateral ; flowers almost sessile ; the pedicels are short and alternate; stems procumbent. $\%$. G. Native of the Cape of Good Hope. Breyn. cent. p. 175. t. 89. Stems long, filiform. Flowers blue. Bracteas much shorter than the flowers.

Breynius's Lobelia. Pl. procumbent.

100 L. снамдеitys (Lam. dict. 3. p. 590.) leaves linear. channelled, numerous, bidentate at the apex, clothed with hairy tomentum; pedicels very long, naked, axillary and terminal, furnished with narrow acute scales; stem shrubby. Һ.. G. Native of the Cape of Good Hope. L. scàbra, Spreng. neu. entd. ex syst. Habit of Laciandula, with the leaves of Ajüja chancelitys. Stems leafy, slender. Pedicels longer than the stem, 6 inches long. Corollas of a pale violaceous colour, (; lines long, inflated at the base.

Ground-pine-like Lobelia. PJ. $\frac{1}{4}$ to $\frac{1}{2}$ foot.

101 L. ERinoides (Lin. mant. p. 291. Thunb. fl. cap. 2. p. 39.) leaves petiolate, oblong, toothed, bluntish, glabrous; pedicels axillary, solitary, shorter than the leaves; corolla funnelshaped; stems prostrate or erectish. 4 . or $\delta .6$. Native of the Cape of Good Hope. Rapintium erinoides, Mill. dict. no 9.-Herm. lugdb. p. 108. t. 109. Corollas funnel-shaped, an- 
gular, equal, blue, with spreading segments. Filaments combined into a 5 -striped, club-shaped tube. Stigma hairy.

Erimus-like Lobelia. Fl. June, Aug. Clt. 1759. Pl, prostrate, or $\frac{1}{2}$ foot.

102 L. Bícolor (Curt. bot. mag. t. 514.) leaves downy, serrated: lower ones oblong, nearly sessile: superior ones lanceolate; pedicels solitary, axillary, longer than the leaves. 2 . G. Native of the Cape of Good Hope. Willd. enum. 1. p. 218 . Corollas blue, with a sulphur-coloured throat. Curtis says the leaves are downy and nearly sessile, while Willdenow says they are glabrous and petiolate.

Two-colourch-flowered Lobelia. Fl. June, Aug. Clt. I795. Pl. $\frac{1}{2}$ foot.

103 L. ILlicifòlia (Ker. in bot. mag. t. 1896.) leaves ovatelanceolate, deeply and remotely toothed: teeth acute; pedicels axillary, solitary, much longer than the leaves. 4. G. Native of the Cape of Good Hopre. Lower leaves ovate-spatulate: superior ones lanceolate: all glabrous. Calyx with subulate toothed segments. Corollas resupinate, twice the length of the calyx, pink or flesh-coloured. Anthers almost naked. Barren stems prostrate; floriferous stems erect. Perhaps a species of Parastránthus.

Holly-lcaved Lobelia. Fl. May, Sept. Clt. 1815. Pl. $\frac{1}{4}$ to $\frac{1}{2} \mathrm{ft}$. 104 L. A'nceps (Lin. fil. suppl. p. 395. Thunb. fl. cap. 2. p. 41.) radical leaves obovate, crenated, glabrous above, and downy beneath, petiolate: cauline leaves lanceolate, decurrent; pedicels solitary, from the axils of the upper leaves; stenis 2edged, winged. $\odot$. H. Native of the Cape of Good Hope. Stems simple, smooth. Flowers blue.

Tno-edged-stemmed Lobelia. Fl. Ju. July. Clt. 1818 . Pl, $\frac{1}{2} \mathrm{ft}$.

105 L. PUbe'scens (Ait. hort. kew. 3. p. 498.) lower leaves ovate: upper ones lanceolate, toothed, hairy; pedicels axillary, solitary; stems angular, decumbent, villous. 4. G. Native of the Cape of Good Hope. Jacq. liort. schoenb. 2. t. 178. I. rèpens, Thunb. prod. 1. p. 40. fl. cap. 2. p. 41 . L. alyssifolia, Salisb. stirp. rar. 19. t. 10. Flowers blue or white, with a red. dish tube.

Donny Lobelia. Fl. June, July. Clt. 1780. Pl. $\frac{1}{3}$ to $\frac{1}{2} \mathrm{ft}$.

106 L. THERMA'Lis (Thunb. prod. 1. p. 40. Al. cap. 2. p. 42.) leaves ovate, serrated, attenuated at both ends, acute, glabrous above, and pilose beneath; pedicels solitary, axillary, shorter than the leaves, and are as well as the calyxes clothed with strigose white hairs; stems decumbent, hairy. 4. G. Native of the Cape of Good Hope, in the region of the hot springs near Elephants' river. Corolla yellow.

Hot-spring Lobelia, Pl, decumbent.

107 L. LEYTocA'rPA (Griess. in Linnæa. 5. p. 419.) stem lierbaceous, decumbent, branched; branches flaccid; leaves ovate-lanceolate, sharply serrated, quite glabrous, with cartilaginous edges; pedicels axillary, solitary ; capsule elongated, clavate, hispid from bristles. 4. G. Native of the Cape of Good Hope. Branches beset with white hairs. Leaves sessile. Calyx bristly. Corolla downy, white, having the segments bearded at their tips, and ciliated on the margins. Filaments and style glabrous.

Slender-fruited Lobelia. Pl. decumbent.

108 L. HiRsu'ta (Lin. spec. 1322.) leaves ovate, toothed, or crenated, hairy or woolly; peduncles lateral, solitary, very long, 2-3-flowered; stem shrubby, hairy, prostrate, or erect. $4 . \mathrm{G}$. Native of the Cape of Good Hope. Thunb. f. cap. 2. p. 87. Rapúntium hirsùtum, Mill. dict. no. 9.?-Burm. afr. 105. t. 40. f. 2. Flowers bline, drooping, small.

Hairy Lobelia. Fl. May, Sept. Clt. 1759. Pl. $\frac{1}{2}$ foot.

109 L. sérpens (Lam. dict. 3. p. 588.) leaves ovate, crenated, glabrous; pedicels axillary, solitary, shorter than the leaves; stems prostrate, a little branched. 24.? ๑.? G. $\mathrm{Na}$ - tive of the Cape of Good Hope. Stems slender, flexuous. Leaves thin, hardly an inch long. Flowers small, blue.

Creeping Lobelia. Pl. prostrate.

110 L. PYGME'A (Thunb. prod. 1. p. 40. f. cap. 2. p. 43.) leaves roundish, serrated, hairy; stems decumbent, hairy, branched; pedicels axillary, solitary, longer than the leaves, hairy. 4. G. Native of the Cape of Good Hope, on Mount Ribeck-Castel. Stems very slender. Petioles capillary, hairy. Corollas white.

Pygmy Lobelia. Pl. decumbent.

$111 \mathrm{~L}$. coronopifòlia (Lin. spec. 1322.) leaves lanceolate, toothed; peduncles long, few-flowered. 4. G. Native of the Cape of Good Hope, Curt. bot. nag. 644.-Breyn. cent. t. 88 . Stems and petioles hairy. The 3 segments of the lower lip of the corolla obovate, emarginate. Leaves with 3 or more teeth on each side. Flowers beantiful blue. Stems procumbent.

Buckhorn-leaved Lobelia. Fl. July, Aug. Clt. 1752. Pl. procumbent.

112 L. Thunbe'rgir (Sweet, hort. brit. p. 247.) leaves oblong, dentately pinnatifid, hairy; stem erect, hairy. 4. G. Native of the Cape of Good Hope. Flowers beautiful blue. L. coronopifòlia, Thunb. prod. 1. p. 40. fl. cap. 2. p. 48.

Thunberg's Lobelia. Fl. July, Sept. Clt. 1812. Pl. $\frac{3}{4}$ foot.

113 L. CERU'LEA (Hook, bot. mag. 3\%01.) stem short, decumbent at the base, densely leafy; leaves lanceolate, dentately pinnatifid, downy, attenuated at the base; peduncles terminal, very long, bearing a few-flowered secund racemes at the apex ; segments of the corolla longer than the tube. 2. G. Native of the Cape of Good Hope. Pedicels bracteated. Corollas drooping, large, purplish blue; lower lip of 3 obovate emargined mucronate segments, having 3 small yellow raised marks at the base, the upper lip of 2 small bent back segments. Anthers purple, fringed at the top. Like L. coronopifolia. (f. 121.).

Blue-flowered Lobelia. Pl. 1 foot.

114 L. Sísisi (Sweet, hort. brit. j. 247.) leaves petiolate, recurved, pinnatifid, with bifurcate lobes ; peduncles elongated, lateral, 2-3-flowered; stem shrubby. 々. G. Native of tlie Cape of Good Hope. L. pedunculàta, Sims, bot. mag. t. 2251. Flowers blue, having the tube purple outside. Calycine segments short. Lower lip furnished with 2 yellow marks at the base.

\section{Sims' Lobelia. Shrub 1 foot.}

115 L. crena'ta (Thunb. prod. 1. p. 39. Al. cap. 2. p. 40.) leaves lanceolate, crenated, glabrous; stems herbaceous, filiform, decumbent; pedicels capillary, axillary, hardly the length of the leaves. 4 . G. Native of the Cape of Good Hope. Stems branched a little. Leaves about an inch long: lower ones acute: superior ones smaller and obtuse. Flowers blue?

Crenated-leaved Lobelia. Fl. April, May. Clt. 1794. Pl. decumbent.

$\$ 4$. Species natives of the Isle of France, the Society Islands, and Nen' Zealand.

116 L. ARBòreA (Forst. prod. no. 808.) stem arboreous; leaves petiolate, ovate-oblong, serrately toothed; peduncles axillary, solitary, 1-flowered. $h_{6}$. G. Native of the Society lslands. 
Trce Lobelia. Tree.

117 L. sUPE'RBa (Cham. in Linnaca. 7. 1. 223.) arboreons, palm-formed; stem quite simple, straight, with a tuft of leaves at top ; leaves glabrous, oblong-obovate, acuminated, narrowed into the petioles, undulated, denticulated, with reflexed edges, almost quite entire towards the base, and revolute; inflorescence and corollas tomentose, $h$. S. Native of the Island of Owahu, in woods. Ribs of leaves thick, and prominent beneath; veins feathered and prominent. Peduncles longer than the leaves, declinate, nutant, furnished with many oblong-elliptic sessile densely imbricated bracteas, bearing a globose head of flowers each. Corolla curved, cleft on the back, $2 \frac{1}{2}$ inches long. Column of stamens glabrous, exceeding the corolla. Two lower anthers bearded. Leaves $2 \frac{1}{2}$ fiet long and $\mathrm{J}$ foot broad. This is a most superb species.

Superb Lobelia. Tree 10 to 15 feet.

118 L. Macróstachys (llook. et Arn. in Beech. voy. pt. bot. p. 88.) glabrous; stem tall, straiglit; leaves linear-lanceolate, attenuated at both ends, subcrenated; racemes simple, terminal, very long; pcdicels secund, horizontal ; bracteas linear, shorter than the pedicels; tube of calyx hemispherical, with the segments obtuse ; corollas twice the length of the pedicels. h.S. Native of the Sandwich Islands. Calyx closely adhering to the ovarium; with a free 5-parted limb, which is about equal in length to the tube. Corolla unbular, 3 inches long; tube cylindrical, 5-cleft, split on the back. Stamens with a free tube, and coliering anthers; the two lower ones bearded. Stigma 2-lobed; lobes flat, thick, cartilaginous, rounded, divaricate, beardless. Fruit unknown.

\section{Long-spiket Lobelia. Shrub tall.}

119 L. filifórmis (Lam. dict. 3. p. 588.) leaves linear, narrow, toothed; pedicels 1 -flowered, axillary, length of leaves ; stem filiform, quite simple. $\odot$. H. Native of the Isle of France. Leares sessile, glabrous. Flowers ninute, ringent, violaceous. Calycine teeth subulate. Said to be nearly allied to L. Lauréntia.

Far. 3, Luzoniénsis (Røem. et Schultes, syst. 5. p. 61.) lower leaves ovate, very minute.-Native of the island of Luzon, near the town of Santa Cruz de la Laguna. L. filifórmis, Cav. icon. 6. p. 7. t, 511. f. 2. Flowers pale blue.

Filiform Lobelia. Pl. $\frac{1}{2}$ to 1 foot.

120 L. ANGula'ta (Forst. prod. no. 309.) stem prostrate, quite simple; leaves roundish, repandly toothed; peduncles axillary, solitary, 1-Howered. 24. G. Native of New Zealand. I. repánda, Mart. Mill. no. 33. Perhaps a species of Pràtia. Angular-leaved Lobelia. Pl. prostrate.

\section{$\$$ 5. Species natives of New Holland.}

\section{* Herbaceous plants, nith axillary 1-flonered peduncles.}

121 L. ALA'Ta (Labill. nov. holl. 1. p. 51. t. 72.) plant glabrous, erect; stem trigonal: angles a little winged; leaves linear or cuneated, decurrent, toothed: teeth divaricate or reflexed; pedicels shorter than the leaves; ovarium glabrous; capsules cylindrical. $\varkappa$. G. Native of New Holland. Flowers blue?

I"ar, a. angustifòlia (Rœm. et Schultes, syst. 5. p. 68.) superior leaves linear; angles of stem marginated; radical leaves ovate-lanceolate. 4. G. Native of the south coast of New Holland, and about Port Jackson; and of Van Diemen's Land.

Íar. $\beta$, cuneifórmis (Røm. et Schultes, l. c.) leaves cuneiform, toothed at top, decurrent ; flowers axillary. 24.G. Native of the south coast of New Holland. L. cuneiformis, Labill. nov. holl. 1. p. 51. t. 78 .

IIinged-stemmed Lobelia, Fl. May, Aug. Clt. 1804. Pl. $1 \frac{1}{3}$ foot.

VOL. III.
12: I. Quamingula'ris (R. Br. prod. p. 562.) glabions; stem tetragonal, asceuding; leaves ovate, toothed, almost sessile, 3 or 4 times shorter than the peduncles; segments of the superior lip of the corolla narrow, linear. $4 . \mathrm{G}$. Native of New Ilolland, on the shore, within the tropic.

Quadrangular-stemmed Lobelia. Pl, ascending.

123 L. kugu còsa (Graham. in edinb. phil. journ. Dec. 1829.) leaves roundish, repand, wrinkled with the nerves, glabrous; pedicels much longer than the leares; calycine segments entire, glandular at the base; stem spotted, prostrate, rooting. $4 . \mathrm{G}$. Native of New Zealand. L. maculàta, Penny. Plant glabrous. Corolla white, split on the upper side. Segments of corolla rather unequal, arranged like the radii of a semi-circle. Anthers leadcoloured, with 2 short awns projecting downwards from their apex. Nearly allied to L. membranàcea, R. Br. prod. Perhaps a species of Pràtia.

Wrinkled-leaved Lobelia, M. creeping.

124 L. membrana'cea (R. Br. l. c.) glabrous, procumbent ; leaves roundish, repandly toothed, membranous, somewhat 3nerved, shorter than the peduncles; segments of the calyx toothed a little. 4. G. Native of New Holland, within the tropic, on the shore. Flowers beautiful, purple.

Membranous-leaved Lobelia. Pl. procumbent.

125 L. PURpura'seens (R. Br. l. c.) glabrous; stem ascending, tetragonal; leases ovate-lanceolate, deeply serrated, onehalf shorter than the peduneles; segments of the upper lip of corolla narrower, linear. $4 . G$. Native of New South Wales, about Port Jackson. Flowers purplish or blue.

Purplish-flowered Lobelia. Fl, June, Aug. Clt. 1809 . Pl. ascending.

126 L. Fluvia'tulis (R. Br. l. c.) plant creeping, sınoothish; branches ascending; leaves ovate, serrated on the outside, rather ciliated; peduncles bractless, downy, as well as the calyxes and ovaria; stamens epipetalous. Ұf. C. Native of New South Wales, at Port Jackson.

River Lobelia. Pl. ascending.

127 L. INUNDA'TA (R. Br. l. c.) plant creeping, glabrous, tufted; leaves roundish, repandly toothed, longer than the peduricles, which are bractless and glabrous; segments of the calyx a little shorter than the tube of the corolla; stamens epipetalous. 24. G. Native of New South Wales, at Port Jackson. Flowers blue.

Inundatcd Lobelia. Fl. Jume, July. Clt. 1821. Pl. creeping.

128 L. PEduncula'ra (R. Br. l. c.) plant creeping, rather downy; branclies ascending, filiform; leaves remote, ovate, angularly toothed, acute, a little ciliated; peduncles very long, furnished with 2 minute bracteas: stamens epigynous. 4. G. Native of New South Wales, at Port Jackson. Flowers blue.

Pedunculate Lobelia. Fl. Oct. Nov. Clt. 1 \$19. Pl. ascending.

129 L. IRRI'GUA (R. Br. l. c) plant ereeping, moss-like, glabrous; leaves roundish, thickish, dentately crenated, petiolate, longer than the peduncles, which are bractless; tube of corolla cleft longitudinally, with the segments of the limb nearly equal ; stamens epigynous. 2. G. Native of Van Diemen's Land, and on the south coast of New Holland. Flowers purplish?

Irrigated Lobelia. Pl. creeping.

* Racemes or peduncles few-flonered, tcrminal. Tube of conrolla cleft longitudinally, with the lips of the limb very unequal.

130 L. GRA'cilis (Andr. bot. rep. t. 340.) plant glabrous, erect, branched a little; racemes rather secund; calyx length of filaments; superior lip of the corolla densely bearded: middle segment of the lower lip almost square, broader than long ; lower leaves nearly ovate, deeply pinnatifid: superior ones 4. Y 


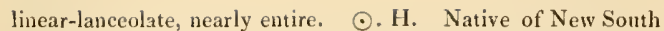
Wales, Curt. bot, mag, t. 741. Flowers deep blue.

Slender Looblia. Fl. July, Oct. Clt. 1801. Pl. 2 feet.

131 L. DENTA'TA (Cav, icon. 6. p. 14.t. 522.) plant erect, glabrous, a little branched; racemes few-flowered, secund; calys one-half shorter than the filaments ; superior lip of corolla a little bearded: middle segment of the lower lip oblong; lower leaves ovate-lanceolate, deeply toothed on the outer side: superior ones lanceolate, toothed. 4.G. Native of New South Wales, about Port Jackson. Root fusiform, fibrous. Segments of the calyx subulate. Corolla blue, with a white throat. 'Two upper segments of the corolla very short.

Toothed-leaved Lobelia. Fl. Ju. July. Cht. 1824. [1. 1 foot.

132 L. GibBòsa (Labill. nov. lıoll. 1. p. 50. t. 71 .) glabrous ; stem terete, simple; racemes secund, many-flowered; leaves linear, quite entire, rather fleshy; superior lip of corolla beardless: and with the segments of both lips lanceolate; capsule gibbous on one side. 4 . G. Native of New Soutl Wales, about Port Jackson; and of Van Diemen's Land. Root perpendicular, almost simple. Racemes very long. Bracteas subulate, hardly the length of the pedicels. Corollas blue. Anthers hispid at the apex.

Gibbous-fruited Lobelia. Fl. May, July. Clt. 1824. Pl. 1 to 2 feet.

133 L. simplicicau'Lis (R. Br. prod. p. 564.) glabrons; stem quite simple, terete; raceme secund, few-flowered; leaves linear, toothed, remote: lower ones lanceolate; upper lip of corolla bearded, the segments of both lips acute; capsules erect, rather gibbous on one side. 2.? G. Native of Van Diemen's Land. Flowers blue?

Simple-stemmed Lobelia. PI. 1 foot.

134 L. Brownia'na (Røem. et Schultes, syst. 5. p. 71.) stem terete, a little branched; raceme secund; leaves linear, lower ones toothed; superior lip of corolla ciliated: the segments of both lips acute; capsules gibbous on one side. 4.? G. Native of New Holland, within the tropic, on the shore. L. stricta, R. Br. J. c. Flower's blue.

Bron's Lobelia. Pl. 1 foot.

155 L. neterophy'Lla (Labill. nov. holl. 1, p. 52. t. 7 4.) plant smoothish; stem angular, simple; raceme secund; Jeaves thickish: lower ones deritately pinnatifid: superior ones linear, quite entire; middle segment of the lower lip of the corolla obcordate, and the lateral ones dimidiate. 4. G. Native of New Holland, in Van Lewin's Land. Root simple, perpendicular. Bracteas lanceolate, solitary or twin, shorter than the pedicels. Calyx inflated, with very acute segments.

Variable-lcaved Lobelia. P!. 1 foot.

136 I. TExu'10R (R. Br. in prod. p. 564.) plant rather pilose; stem filiform, divided; branches peduncle-formed, 1 -flowered; lower leaves pinnatifid, of an ovate outline: superior leaves linear, trifid or quite entire; middle segment of the lower lip of the corolla obcordate: lateral ones dimidiate; capsule subcylindrical. 24.? G. Native of New Holland, on the south coast, within the tropic. Flowers blue?

Slender Lobelia. Pl. 1 foot.

137 L. Parvifòlia (R. Br. l. c.) glabrous; stem subpanicled, terete; branches usually 1-flowered, peduncle-formed; superior lip of corolla beardless: segments of the lower lip oblong, acutish. 4.? G. Native of New Holland, on the south coast.

\section{Small-leared Lobelia. Pl. 1 foot.?}

\section{$\$ 6$. Species natives of Europe.}

133 L. U'RENS (Lin. spec. 1321.) leaves glabrous: lower ones obovate, denticulated: upper ones sessile, lanceolate, serrated: racemes terminal, secund: stem erect. $\odot$. H. Native of
Spain, France, Sc. In Britain, on bushy heaths in Devonshire; on the slope of Kilmington Hill, 2 miles from Axminster, and between Axminster and Honiton. Curt. fl. lond. 6. t. 63. Bull. herb. t. 9. Sunith, engl. bot. t. 953. Rapúntium ùrens, Mill. dict. no. 4.-Moris. list. 2. p. 467 . sect. 5. t. 5. f. 56.-Boce. sic. 20. t. 11. Angles of stem scabrous. Calyx scabrous. Bracteas setaceous, at the base of the pedicels. Corolla purplish-blue, marked with 2 pale spots on the palate; lower lip dependent: upper lip of 2 narrow segments. The whole plant is milky, like the rest of the species, and if chewed, especially the root, excites a pungent sense of burning on the tongue.

Stinging Lobelia. Fl. Ju. July. England. PI. 1 to $1 \frac{1}{2}$ foot.

139 L. Serrula'ta (Brot. fl. lus. p. 304.) glabrous; leaves linear-lanceolate, sharply serrated; racemes long; stem erect. $\odot$. H. Native of Gibraltar, in sandy humid places. Bracteas a little longer than the pedicels. Corolla rather roughish. Middle segment of the lower lip narrower than the lateral ones; segments of the upper lip linear. Flowers blue. Perhaps not distinct from $L$. ùrens.

Serrulated-leaved Lobelia. Fl. June, July. Clt. 1820. Pl. 1 foot.

140 L. Lauré ntia (Lin. spec. Gouan, monsp. 466. Schreb. in nov. act. a. n. c. p. 480.) leaves oval-lanceolate, crenated; peduncles solitary, 1-flowered, very long; stem branched, prostrate. $\odot$. H. Native of Italy, Corsica, and Morocco. Brot. fl. lus. 1. p. 304. Michel. gen. 18. t. 14. Boce. nus, p. 35. t. 27. Bracteas setaceons, in the middle of the pedicels. Flowers blue.

$\operatorname{Iar} \beta$; leaves somewhat spatulate. Gouan. 1. c.

Laurcntian Lobelia. Fl. July. Clt. 1778. Pl, prostrate.

141 I. Salzmannia'va (Presl. symb. bot. p. 31. t. 20.) plant quite glabrous; sten quite simple, erect, leafy; leaves lanceolate, obtuse, crenated, tapering in to the petioles : uppermost ones disposed in aggregate whorles; pedicels axillary, filiform, bibracteate in the middle. $\odot$. H. Native of Corsica, at Ajaccio by the sea side. L. Lauréntia, Salzm. pl. cors. exsic. Flowers blue?

Salzmann's Lobelia. Pl. $\frac{1}{2}$ foot.

142 L. TENÉLLA (Biv. pl. sic. cent. 1. p. 53.) radical leaves spatulate, repand, glabrous; cauline leaves setaceous; stems very simple, I-flowered, erectish. ๑. H. Native of Portugal, Candia, Sicily, Sc.; on the edges of rivers and rivulets. L. setàcea, Sınith, fl. græc. t. 221. L. Lauréntia, Brot. f. lus. 1. p. 304. L. minùta, D. C. f. fr. no. 2871. Lower leaves disposed in a rosulate manner. Peduncles radical, furnished with linear bracteas in the middle. Corolla bilabiate, with a white tube, a pale blue limb, and a yellow throat. Lower lip with a white centre; throat bearded. Antluers red.

Delicate Lobelia. Fl. May, July. Clt. 1821. Pl. $\frac{1}{4}$ foot.

143 L. Farse'tia (Vand. in Røm. script. pl. hisp. p. 66. Vittm. suppl. 1. p. 261.) Jower leaves ovate-lanceolate, obsoJetely toothed; floral leaves linear. $4 . H$. Native of Portugal, in humid places. Stem 2 hands high, many-angled, branched at the base. Leaves glabrous. Calyx gibbous, with linear spreading segments. Corolla pentagonal, blue, the segments of the lower lip the largest. In the base of the inner part of the limb there are two oblong parallel callosities, as in the genus Dólichos. Style longer than the stamens. Capsule ventricose.

Var. a; leaves oval-oblong, acuminated, denticulated; stem leafy, somewhat spicate; anthers hairy, joined at the apex.

Var. $\beta$; stem suffruticose; leaves cordate, acute, serrated; flowers axillary, pedunculate.

Farseti's Lobelia. Pl. 1 to $1 \frac{1}{2}$ foot.

\section{+ Species not sufficiently knonn.}

1+4 L. corNu'TA (Lin. spec. p. 1319.) leaves ovate, petiolate; 
stamens very long. $h_{c}$. S. Native of Cayenne. Leaves said to be quite entire.

\section{Horned Lobelia. Pl.?}

145 L. Bryoìnes (Willd. herb. ex Rom. et Schultes, syst. 5 , p. 4.1.) stems tufted; leaves sessile, lanceolate, quite entire, acute; flowers sessile, terminal. 24. S. Native of South America, on Mount Antisana. Humb. et Bonpl. Habit of a moss or Arètia. Leaves imbricated, shining, coriaceous, denticulated. Flowers among the tcrminal comivent leaves. Perhaps a species of Lysipomia.

Bryum-like Lobelia. Pl. $\frac{1}{4}$ foot.

146 L. veronicafòlia (Willd. herb. ex Røem. et Schultes, syst. 5. p. 57.) stem erect ; leaves downy: radical ones obtuse, obovate; cauline leaves lanceolate, dentate, acutc; flowers terminal, racenose. 4 . S. Native of South America. Humb. et Bonpl.

Speedncll-leaved Lobelia. PI.?

147 L. amygdalina (IVilld. l. c. p. 57.) stem erect; leaves ovate, acuminated, serrated ; pedicels axillary ; corolla cleft.Native of South America. Humb. et Bonpl.

\section{Almond-like Lobelia. Pl.?}

148 L. RETróRsA (Willd. l. c.) stem arboreous; branclies scabrous; leaves petiolate, elliptic, mucronate, with retrograde serratures, wrinkled, veiny; flowers terminal, racemose. $h . S$. Native of South America. Humb. et Bonpl.

Retrograde-serrated-leaved Lobelia. Shrub.

149 L. Bonplandiana (Willd. l. c.) stem arboreous; leaves lanceolate, sharply serrated, flat, downy, on short petioles; pedicels axillary, shorter than the leaves. $h$. S. Native of South America. Humb. et Bonpl. L. dentàta, Willd. herb.

Bonpland's Lobelia. Shrub.

150 L. ELLí PTICA (Willd. 1. c.) stem arboreous ; leaves elliptic, obtuse, rugged, veiny, denticulated; branches, petioles, and peduncles clotlied witl hairy tomentum, as well as the leaves; calyxes reflexed; corollas downy. $h$. S. Native of South America. Humb. et Bonpl.

Elliptie-leaved Lobelia. Shrub.

151 L. Nivea (Willd. herb. ex Rom. et Schultes, syst. 5. p. 58.) stem arboreous; leaves elliptic, with revolute edges, toothed, shining and wrinkled above, but clothed with white tomentum beneath, as well as on the pedicels and corollas; flowers axillary. $\zeta$. S. Native of South America. Humb. et Bonpl.

Snowy Lobelia. Shrub.

152 L. Reticula'ta (Willd. l. c.) stem arboreous; leaves ovate-lanceolate, acuminated, crenated, wrinkled from veins, downy beneath; corymbs terminal, racemose. h. S. Native of South America. Humb. et Bonpl.

\section{Reticulated-leaved Lobelia. Shrub.}

153 L. Madagascariénsis (Rom. et Schultes, syst. 5. p. 67.) lower leaves ovate: superior ones lanceolate, denticulated, decurrent; flowers axillary, length of leaves; stem prostrate. $\odot$. H. Native of Madagascar. L. decúrrens, Willd. herb.

Madagasear Lobelia. Pl. prostrate.

154 L. phyteumoìnes (Willd. herb. ex Røm. et Schultes, syst. 5. p. 68.) Jeaves lanceolate, toothed, sessile, glabrous; racemes terminal; stem ascending, a little branched. 4 .? S. Native of South America. Humb. et Bonpl.

\section{Phyteuma-like Lobelia. Pl. ascending.}

155 L. Humboldtia'na (Rœem, et Schultes, syst. 5. p. 68.) leaves roundish, acute, sessile, with cartilaginously serrated edges; flowers sessile, axillary; stem weak. 々.? S. Native of South America. Humb. et Bonpl. L. sessilifòlia, Willd. herb.

Humboldt's Lobelia. Pl. ?

156 L. polymórpha (Willd. herb, ex Rœm. et Scluultes, syst. 5. p. 68.) stems prostrate ; lower leaves serrated, oblong; superior ones quite entire, lanceolate; pedicels axillary, elongated. 4. S. Native of the island of Bourbon, Bory de St. Vincent.

\section{Polymorphous Lobelia. Pl. prostrate.}

157 L. Loxe' nsis (Willd. herb. ex lioem. et Schultes, syst. 5. p. 72.) plant clothed with scabrous tomentum; leaves oblong, petiolate, wrinkled, and shining above; flowers terminal, panicled. $h_{\text {. }}$ S. Native of South America, about Loxa. Humb. et Bonpl.

Loxa Lobelia. Shrub.

158 L. Megapotámica (Spreng. syst. add. p. 75 .) stem erect, branched, glabrous; leaves linear, very narrow, erectly spreading, glabrous; flowers terminal, corymbose. 々.? S. Native of Brazil, at the banks of the Rio Grande, where it was collected by Sello.

Rio Grande Lobelia. Slırub.

Cult. All the species of this genus are truly ornamental when in blossom. The hardy herbaceous kinds thrive and flower best in light rich earth or peat soil ; but in winter most of the kinds require to be protected by planting them in pots and placing them in a frame or green-house. They increase freely by the suckers from the roots or by seed. The green-house and stove perennial herbaceous kinds grow well in a mixture of peat and sand, and are easily increased by dividing, and by seeds. The shrubby, stove, and greenhouse kinds grow well in the same kind of soil recommended for the perennial herbaceous species, and are easily increased by cuttings in the same kind of soil. The seeds of annual species require only to be sown where they are intended to remain.

IX. DORTMA'NNA (named after - Dortmann, a Dutch apothecary, according to Clusius). Rudb. act. ups. ann. 1720. 97. t. 2. Neck. elem. Lobèlia species, Lin. and Nutt.

Lin. syst. Pentandria, Monogýnia. Calyx of 5 deep seg. ments. Corolla bilabiate, with a bearded mouth, cleft on the back; lower lip trifid; upper lip of 2 smaller segments. Stamens with free filaments, and cohering bearded anthers. Stigma capitate, hairy. Capsule half superior, 3-valved, 3-celled, 5angled, surrounded by the segments of the calyx below the summit, many-seeded.-Aquatic, smooth, fleshy plants. Leaves numerous, mostly radical, recurved. Scapes hollow, with a few leaves at the base, bearing a lax raceme of flowers at the top. Bracteas solitary at the base of the pedicels.

1 D. LAcu'stris (Rubb. 1. c. Gerard, emac. 105. f. 1.) leaves linear, fistular, and bilocular; scape simple. 4 . H. Native of Europe, in lakes with a gravelly bottom; in Britain abundant in the lakes of Wales, Scotland, Ireland, and the north of England; in most of the lakes with clear gravelly bottoms in Westmoreland and Cumberland. Lobèlia Dortmánna, Lin. spec. 1318. Smith, engl. bot. 2. p. 140. Lightf. scot. 505, f. 21. Fl. dan. t. 39. Gladiolus palústris, Bauh. pin. 41. Rudb. elys, vol. 2. p. 17. f. 7.-Clus. cur. post. 40. f. 1. Leaves 2 inches long. Flowers pale blue. Moutli of corolla bearded.

Lake Dortmanna. Fl. July. Britain. Pl. $\frac{1}{2}$ to 1 foot.

2 D. PALUdosA; leaves flat, linear-oblong, with obsoletely crenated margins; scape nearly simple and naked, bearing a few remote flowers at the apex. 24. H. Native of North America, in deep sphagnose swamps, from Sussex county in Delaware to Georgia. Lobèlia paludosa, Nutt. nov, gen. 2. p. 75. Leaves 4-6 inches long, and hardly 5 lines wide. Flowers pale blue, small. Corolla with the disk of the lower lip' downy.

\section{Marsh Dortmanna. Pl. 2 feet.}

Cult. The species of Dortminna are singular, and beautiful plants, but difficult of culture. However, D. lacústris may be 4 × 2 
grown for a time, if planted in a pot of gravel, and placed in a jond or cistern, so that the plants may be about 6 inches below the surface of the water; and $D$. paludòsa may be grown in a pot half filled with peat earth, and the other half with sphagnum, in which the plants are to be set, and the pot placed in a shallow pan of water, or in a cistern or pond, but not so deep as to inmerse the plants.

X. PARASTRA'NTHUS (from $\pi \alpha \rho \alpha \sigma \tau \rho \varepsilon \phi \omega$, parastrepho, to invert, or to distor 1 , and avtoc, anthos, a flower; the flowers are upside down, compared with those of otler genera of Lobeliàcece). Lobèlia species, Lin. 'Thunb.

Lin. syst. Pentándria, Monogýnia. Calyx 5-cleft. Corolla bilabiate, with hardly any tube : upper lip of 3 segments, lower one of 2 segments, smaller. Stamineous column under the lower lip. Anthers and filaments connected into a column; the former bearded at the apex. Ovarium inferior, 2-3-celled. Stigma bifid or trifid. - Herbaceous plants, with toothed leaves, and terminal racemes of almost sessile yellow flowers.

1 P. símplex; glabrous; stems assurgent, simple; leaves lanceolate, serrated; flowers almost sessile, at the tops of the stems, forming a loose spike; bracteas toothed, shorter than the calycine segments. $\quad$ \%. H. Native of the Cape of Good Hope. Lobèlia lùtea, Lin. spec. 1322. Sims, bot. mag. t. 1319.-Burm. afr. p. 101. t. 39. Flowers deep yellow.

Simple-stemmed Yellow-Lobelia. Fl. June, July. Clt. 1774. Pl. $\frac{1}{2}$ foot.

2 P. varifòlia; stems erectish, branclied at top; leaves linear, quite entire, and toothed, particularly the upper ones; flowers solitary, axillary, nearly terminal, almost sessile ; stigma tripartite. 4 . H. Native of the Cape of Good Hope. Lobèlia varifília, Sims, bot. mag. 1692. Flowers yellow.

Various-leaved Yellow-Lobelia. Fl. June, July. Clt. 1812. PI. $\frac{1}{2}$ to 1 foot.

3 P. unidenta'ta; leaves linear-lanceolate, furnished with a tooth on each side, rather hairy above, and discoloured beneath; pedicels solitary, terminal; stems angular from the decurrent bases of the leares. \%. G. Native of the Cape of Good Hope. Lobèlia unidentàta, Ait. loort. kew. ed. 2. 1. p. 356. Sims, bot. mag. t. 1.484. L. bidentàta, Donn, hort. cant. ed. 4. p. 41. Flowers deep blue. Anthers yellow. Stigma 2lobed.

Unidentate-leaved Parastranthus. Fl. May, Aug. CIt. 1791. Pl. $\frac{1}{4}$ foot.

Cult. Beautiful plants, of easy culture. A mixture of loam, peat, and sand is the best soil for them; and they are easily increased by dividing at the root.

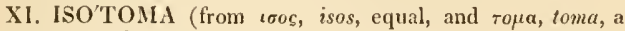
section; in reference to the segments of the corolla being nearly equal.) Lindl. bot. reg. 964. Lobèlia Isótoma, R. Br. prod. f. nov. holl. p. 564 .

Lin. syst. Pentándria, Monogýnia. Limb of calyx 5-parted (f. 122. c.), nearly equal. Corolla salver-shaped (f. 122. d.) or funnel-shaped, with an entire or cleft tube, and a nearly equal 5 -parted limb. Filaments combined into a tube. Anthers cohering, beardless; two lower ones mucronate. Stigma capitate, protruding beyond the anthers. Capsule 2-celled, many-seeded. - Herbaceous plants. This genus differs from all the other genera of Lobeliaceous plants, in the 2 lower anthers being mucronate, except Pràtia.

1 I. AXILLA'ris (Lind), hot. reg. 964.) plant rather downy; leaves sessile, pinnatifid, toothed; peduncles axillary, naked, elongated, 1-flowered; corolla salver-shaped, with an entire tube. 4. G. Native of New Holland, on the south coast. L. senecioides, Cunningh. L. seneciònis, Spreng. syst. add. p. 75. Corolla with green tube, and light blue linear-lanceolate segments. The segments of the calyx are narrow, distant, and at length reflexed. (f. 122.).

Axillary-flowered Isotoma. Fl. July, Sept. Clt. 1824. Pl. 1 foot.

2 1. Brównı ; glabrous ; stems almost simple; leaves linear, quite entire; corolla salvershaped, with an entire tube, and a somewhat unequal limb; flowers racemose. $\odot . \mathrm{H} . \mathrm{Na}$ tive of New Holland, on the south coast. Lobèlia hypocraterifórmis, R. Br. prod. 564. Hook. bot. mag. t. 3075. Flowers beantiful purple.

Bron'n's lsotoma. Fl. Sept. Clt. 1829. Pl. 1 foot.

3 1. scapígera; stems short; leaves lanceolate, a little toothed; corolla funnel-shaped, having the tube cleft above at the apex; peduncles scape-formed, 1-flowered. 4. G. Native of New Holland, on tle south coast. Lobelia scapigera, R. Br. prod. p. 564. Flowers blue or purple.

Var. a, biuncialis (R. Br. l. c.) stem 6-10 lines long; leaves ovate-lanceolate, 4-6 lines long; scapes many, 2-3 inclies long. 4. G.

Var. $\beta$, pusílla (R. Br. l. c.) stems almost wanting; leaves ovate, obtuse, 2 lines long; scapes almost solitary, 3-8 lines long. 4. G.

Scapc-bearing Isotoma. PJ. 1 to 3 inch.

Cult. The species of this genus are very elegant while in blossom, and are of easy culture. A light soil suits them best ; and they are easily increased by cuttings or seeds. They answer well if planted out during summer in the open border, with a soutl aspect.

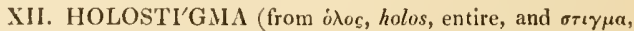
stigma, a stigma; in reference to the entire stigma). Lobèlia, Sect. 111. R. Br. prod. p. 564 .

Lin. syst. Dioècia, Pentándria. Flowers dioecious. Limb of calyx 5-parted. Corolla having the tube cleft above, and a nearly equal 5 -lobed limb. Anthers cohering, bearded. Stigma undivided. Capsule 2-celled, many-seeded. - A herbaceous plant.

1 H. proíc ; male flowers corymbose and terminal; female ones axillary and solitary ; cauline leaves lanceolate, toothed or entire. 4. G. Native of New Holland, within the tropic, on the shore. Flowers blue.?

Dioecious-flowered Holostigma. Pl.?

Cult. See Isótoma above for culture and propagation.

XIII. LYSIPOMIA (from $\lambda v \omega$, luo, to solve, and $\pi \omega \mu a$, poma, a lid; in reference to the capsule, which opens by an operculum at the apex). H. B. et Kunth, nov. gen. amer. 3. p. 318 .

Lis. syst. Pentándria, Monogýnia. Limb of calyx 5-parted. Corolla witlı a campanulate entire tube, and a 5 -parted sub-bilabiate limb; the 2 lobes of the upper lip a little longer than those of the lower lip: lobes valvate in æstivation. Anthers cohering; the 2 inferior ones a little shorter than the rest, bearded at 
the apex, or terminating in a membranous proccss. Stigma 2lobed, ciliated outside. Capsule somewhat 5-ribbed, 1-celled, opening by an orbieular convex, umbonate, deciduous opereulum. Seeds numerous, adnate to parietal placentas.-Small, tufted, stemless or caulescent herbs, with the habit of Aritia or Móntia. Leaves alternate, linear or spatulate, quite entire, stilt and crowded, or fleshy and remote. Flower's minute, axillary, solitary, white, pedunculate. This genus is easily distinguished from all the other genera of the present order.

1 L. Montroìnes (H. B. et Kunth, nov. gen. amer. 3. p. 320 . t. 266. f. 2.) stems crceping; leaves spatulate, rather fleslyy; peduncles axillary; calyeine segments unequal, glabrous, + times shorter than the tube of the corolla. 24. S. Native of Quito, in humid places on the ligh plains of Mount Antisana, at the altitude of above 6000 fect. Lobèlia limoselloides, Willd. in Rœin. et Schultes, syst. 5. p. 41. Herb glabrous, with the habit of Móntia fontàna.

Montia-like Lysipomia. Pl. procumbent.

2 L. renifórmis (H. B. et Kunth, nov, gen. amer. 3. p. 320. t. 266. f. 1.) stems ereeping ; leaves orbicularly reniform, emarginate; flowers axillary; cillycine segments equal, acute, glabrous, 3 times shorter than the tube of the corolla. 24. S. Native of South America, near the Cave of Antisana. Herb glabrous, with the habit of Viola palustris.

Reniform-leaved Lysopomia. Pl, creeping.

3 L. Aretioides (H. B. et Kunth, nov. gen. amer. 3. p. 321. t. 267, f. 1.) plant tufted; stems short, leafy; leaves crowded in a stellate manner, oblong-spatulate, acute, stiff; peduncles axillary; segments of the calyx equal, acute, ciliated, one-lialf shorter than the corolla. 4 . S. Native of the Andes of Peru, near Loxa, in Cerro de Vinajacu, at the altitude of about 4000 feet. Lobèlia glandulòsa, Willd. in Røem. et Schultes, syst. 5 . p. 41. Plant glabrous, with the habit of a species of Aretia.

Aretia-like Lysipomia. Pl. tufted, an inch high.

4. L. AcAu'Lis (H. B. et Kuntl, nov, gen, amer, 3. p. 321. t. 267. f. 2.) plant tufted, stemless; leaves radical, crowded in a stellate manner, linear, obtuse, stiff; peduncles radical; segments of the calyx unequal, obtuse, glabrous. $\%$. S. Native of South America, on the high plains of Mount Antisana, and roots of Chussulongi, above the altitude of 6000 feet. Lobèlia androsàcea, Willd. in Roem. et Schultes, syst. 5. p. 41. Plant glabrous, with the habit of Valeriàna rigida.

\section{Stemless Lysipomia. Pl. tufted.}

5 L. subula'TA; leaves radical, crowded in a stellate manner, subulate, nucronate, hairy at the base; peduncles elongated; calyeine lobes acute. 4 . F. Native on the Cordillera of Peru. Peduncles 1-flowered, an inch long. (v. s. in herb. Lamb.).

Subulatc-leaved Lysipomia. Pl. 1 inch.

Cult. The species of Lysipomia are very remarkable little plants, but none of them have been as yet introduced to our gardens; but should they ever be, we would recommend their being grown in a mixture of loam and peat, in small pots, well drained with sherds. They will be easily increased by dividing.

XIV. MONO'PSIS (from $\mu \omega^{\circ}$ s, monos, one, and $\alpha \psi(c$, opsis, a face; in reference to the flowers being regular, not bilabiate). Salisb.-Labèlia spéculum, Indr. bot. rep. 664. Speculària, Soland. mss.

Lin. syst. Pentándria, Monogýnia. Calyx tubular with 5 equal spreading linear-acute segments. Corolla salver-shaped, with a terete tube, which is split on one side, allowing the stamens and style to escape, and a rotate equal limb; segments obtuse, mucronate. Anthers cohering. Capsule inferior, 2celled, many-seeded.-A small elegant plant, with prostrate branches; very long, solitary, axillary, 1-flowered, nake:! peduncles; linear-lanceolate, irregularly toothed, or entire alternate leaves; and showy deep blue flowers, with yellow anthers.

1 M. conspícua (Salisb.) ๑. H. Native of the Cape of Good Hope. Lobèlia spéculum, Andr. bot. rep. t. 661 . Sims, bot. mag. t. 1499.

Conspicuous Monopsis. Fl. July, Aug. CIt, 1812. Pl. prostrate.

Cult. A little amual plant, worth cultivating in every collection, for the sake of its neat, clegant, deep blue llowers. The secds should be raised in the hot-bed, and the plants, when about an inch above ground, should be planted separatcly into small pots, filled with a mixture of peat and sand, and others may be planted out into the open border in May, in warm sheltered situations.

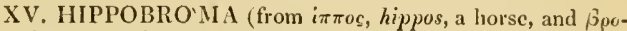

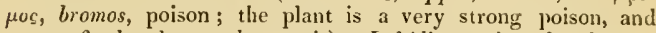
proves fatal to horses that eat it). Lobèlia species of authors.

LIN. syst. Pentándria, Monogýnia. Limb of calyx 5-parted; segments linear, eiliated. Corolla with a very long straight entire tube, and a 5-parted nearly equal limb. Stiunineous tube exserted beyond the throat of the corolla. Stamens and anthers connate; the latter bearded. Stignia 2-lobed Capsule 2-celled, 2-valved, many-seeded. - A herbaceous plant, with short axillary pedicels, runcinate or coarsely toothed leaves, and long white flowers, resembling those of Mirabilis longiflora.

1 H. LONGirlòr a ; leaves obovate-lanceolate, coarsely toothed; tube of corolla very long and slender. 4 . S. Native of Jamaica and St. Domingo, and others of the West India Islands, on the banks of rivers. Lobèlia longiflòra, Jaeq. amer. 219. ed. pict. p. 107.t. 200. Jacq. hort. vind. 1.t. 27. Lindl. bot. reg. t. 1200. Rapúntium longiflòrum, Mill. diet. no. $\%$.-Sloan. jam. 158. t. 101. f. 2. Plant hairy. Ovarium turbinate, pentagonal. Tube of anthers $\mathbf{1 0}$-furrowed. This is a very poisonous plant. If it be handled, and the hand unawares be applied to the eyes, it brings: on an inflammation. The Spanish Americans call it Rebenta Cavallos, because it proves fatal to horses that eat it ; it acts as a violent cathartic. It is well known in St. Domingo under the name of Quedec.

Long-flowered Hippobroma. FJ. May, Aug. Clt. 1752. Pl. 1 foot.

Cult. A mixture of peat, loam, and sand suits this plant, and it is easily increased by cuttings, in the same kind of soil, under a hand-glass in heat.

XVI. CLINTO'NIA (named in honour of the late De Witt Clinton, governor of the State of New York, author of several ingenious treatises on different branches of natural history). Doug. in bot. reg. 1241 .

Lin. syst. Pentándria, Monogýnia. Calys adhering to the ovarium, with a 5 -lobed equal limb. Corolla bilabiate, with hardly any tube; lower lip cuncated, 3-lobed; superior one straight, bipartite. Stamens combined into an incurved tube : anthers cohering; the 2 lower ones bearded at the apex. Ovarium silique-formed, triangular, twisted, 1-celled, with 2 parietal placentas. Capsule dry, chartaceous, many-seeded, opening by 3 thong-formed valves. - Herbaceous, procumbent, glabrous plants, with small linear-lanceolate leaves : and axillary, solitary, almost sessile blue flowers.

1 C. E'LEgANs (Dougl. l, c.) glabrous; root annual; stem procumbent, branched, rather angular ; leaves sessile, ovate, 3veined; flowers solitary, axillary, sessile; ovarium sessile, long, acuminated. $\odot$. H. Native of North America, on the banks 
of the Columbia river. Flowers blue; the lower lip having a large white streak on the base. Stigma girded by a papillose beard. Two lower anthers alone bearded.

Elegant Clintonia. Fl. July, Aug. Clt. 1827. Pl. $\frac{1}{2}$ tt.

a C. Bergin'Na (Cham. in Linnæa. 7.p. 217.) glabrous; root peremial, creeping; stems erect or decumbent, branched, triangular at bottom; leaves linear-lanceolate, acute, remotely denticulated, sessile: lower ones ovate; flowers axillary, almost sessile, at the tops of the branches; ovarium elongated. $\mathcal{x}$. S. Native of the Cape of Good Hope, near Hangkliph, where it was collected by Mundt. Capsule elongated, crowned by the segments of the calyx, which are spreading, fleshy, and stellately disposed; anthers all bearcled. Corolla pale blue.

Bergius's Clintonia. Pl. decumbent.

3 C. PUsilla; we have not been able to see the work in which this plant is described, as it has not yet been received in this country. $\odot$. H. Native of Chili. L. pusilla, Poepp? pl. chil. exsic. 3. no. 17 t. syn. pl. amer. austr. misc. diar. 731 . Flowers blue.

Small Clintonia. Pl. decumbent.

XV1I. CY'PHIA (from kvфos, kyphos, curved; in reference to the stigma being gibbous). Berg. fl. cap. p. 173. Lobèlia species, Thunb.

Lis. syst. Pentándria, Monogýnia. Calyx turbinate, 5 -cleft. Corolla bilabiate; segments easily separated to the base, spreading at the apex. Filaments hairy, coliering: anthers free, hearded. Stigma drooping, hollow, gibbous. Capsule 2-celled, many-seeded.--Herbaceous plants, natives of the Cape of Good Hope, with alternate, undivided, pinnate, and pinnatifid leaves; and blue or red flowers.

1 C. volu'bilis (Willd. spec. 1.p. 952.) glabrous; leaves entire and toothed, linear; stem twining. $\odot$. G. Native of the Cape of Good Hope. Lobèlia volùbilis, Lin. fil. suppl. p. 396. Thumb. fi. cap. 2. p. 38. Stems filiform, twining contrary to the sun. Leaves often trifid at the apex: the lateral segments short. Flowers axillary, solitary, pedicellate. Corolla ringent or hilabiate.

Far, a, culgátior (Cham. in Linnæa. 7. p. 224.) flowers nearly an inch long; genitals half an inch, one-half shorter than the tube; segments of corolla narrow-lanceolate.

Iar. $\beta$, intermedia (Cham. l. c.) flowers 9 lines long; throat of corolla more bearded; segments of corolla more elliptic; genitals shorter than the corolline tube.

Var. $\gamma$, parviflòra (Cham. l. c.) flowers not half an inch long; grenitals exceeding the corolline tube; filaments villous. Perhaps a proper species.

Trining Cyphia. Fl.? Clt. 1795. Pl. twining.

2 C. Digita'ta (Willd. spec. 1. p. 953.) glabrous; leaves digitate; stem twining. 2. G. Native of the Cape of Good Hope. Lobèlia Cýphia, Thunb. prod. 1. p. 39. Lobèlia digitàta, Thunb. in act. gor. and fl. cap. 2. p. 50. Root bulbous, esculent, fleshy. Stems filiform, simple. Leaves sessile, digitately pinnate; segments linear. Pedicels filiform, purplish, striated, length of leaves or bracteas. Corolla monopetalous, ringent or bilabiate: upper lij, bipartite: lower ones tripartite, pale blue. Capsule roundish, angular.

Digitate-leaved Cyphia. PI. twining.

3 C. BulbòsA (Berg. fl. cap. 172.) glabrous; leaves digitate; leaflets pinnatifid; stem erect. 24. G. Native of the Cape of Goorl Hope, on hills. Cýphia Capénsis, Gmel. syst. 5. 1. 370. Lobèlia bulbòsa, Lin. spec. 1319. Thumb. prod. 1. p. 39. A. cap. 2. p. 49. Lobèlia Cýphia, Gmel. syst. 5. p. 357.-Burm. afr. 99. t. 38. f. 1. Root fibrous, descending, terminating in a bull,. Stems usually simple, rarely branched. Lower leaves pinnatifid, with unequal lanceolate lobes; the upper ones often simple, ex Thunb. Flowers pale blue.?

Bulbous-rooted Cyphia. Fl. Aug. Sept, Clt. 179I. Pl. $\frac{1}{2}$ foot.

4. C. Carda'mes (Willd. spec. 1. p. 953.) villous; leaves pinnate, with ovate, toothed leaflets; scape erect. 24. G. Native of the Cape of Good Hope, in sandy places on the out skirts of Cape Town. Lobèlia Cardámines, Thıub. prod. 1 p. 39. f. cap. 2. p. 49. Stem scape-formed, simple. Leaves radical, pinnatific ; ultimate leaflets 3-lobed. Flowers racemose, on very short pedicels.

Lady's-smock-like Cyphia. Fl. July, Aug. Clt. 1823. Pl. $\frac{1}{2} \mathrm{ft}$.

5 C. Serra'ta (Spreng. syst. 1. p. 809.) leaves radical, oblong, attenuated at the base, sessile, crenately serrated, quite glabrous, as well as the scape, which is scaly ; flowers racemose; segments of the calyx refiexed, serrated. 2. G. Native of the Cape of Good Hope.

Serrated-leaved Cyphia. Pl. $\frac{1}{2}$ foot.?

6 C. 1 Ncis A (Willd. spec. 1. p. 953.) villous; leaves deeply subjinnatifid; scapes erect. $\odot$. 4. G. Native of the Cape of Good Hope, on hills on the outskirts of Cape Town. Lobèlia incisa, Thunb. prod. 1. p. 39. fl. cap. 2. p. 50 . Root descending. Stem scape-formed, simple, furrowed. Leaves radical, petiolate. Flowers racemose, on very short pedicels. Corolla bilabiate, very pale red.

Cut-leaved Cyphia. Fl. July, Aug. Clt. 1819. Pl. $\frac{1}{2} \mathrm{ft}$.

7 C. Phyteu'ns (Willd. spec. 1. p. 953.) leaves oblong, crenated; scape erect. $\odot .4$. G. Native of the Cape of Good Hope. Ker. bot. reg. t. 625. Lobèlia Phyteùma, Lin. spec. p. 1319. Thunb. prod. 1. p. 39. fl. cap. 2. p. 47. Lobèlia nudicaúlis, Lam. dict. 3. p. 591 . no. 41. Stem scape-formed, striated, glabrous. Leaves radical, attenuated at the base, or on short petioles, obtuse, villous. Flowers pink, spicate, alternate. Bracteas ovate, acute, toothed, reflexed; upper ones ciliated.

Phyteuma-like Cyphia. Fl. Feb. Clt. 1822. Pl. 1 to $1 \frac{1}{2}$ foot.

8 C.? Pinna'ta (Røem. et Schultes, syst. 5. p. 477.) stem shrubby, erect, branched at top; leaves pinnate, smooth: leaflets very narrow, capillary. $\eta_{2}$. G. Native of the Canary Islands. Lobèlia pinnàta, Lam. dict. 3. p. 591. no. 44. Shrub milky. Leaves like those of Ipoma'a Quamóclit. Branches very leafy. Leaves shining; leaflets $1 \frac{1}{1}$ inch long.

Pinnate Cyphia. Shrub 3 feet.

9 C. вótrys (Willd. rel. ex Roem. et Schultes, syst. 5. p. 477.) leaves bijpinnatifidly jagged; stem furrowed. Native of the Cape of Good Hope. There is a smoother and broader leaved variety of this, with larger pinnatifid bracteas, which are about the length of the flowers.

Racemed Cyphia. Pl. 1 foot.?

Cult. The species of this genus thrive well in an equal mixture of loam, peat, and sand; and cuttings of them root readily under a hand-glass. Some of the species have large tuberous roots; these must be kept quite dry when not in a growing state, or they will rot. These tuberous-rooted kinds may be increased just as the stems begin to push out from the root, by cutting off as many of the shoots as are wanted, and planting them in a small pot, in the same kind of soil recommended for the species, keeping them dry till the wound has healed, but never covering them with glass; they will soon form tubers of themselves, and the old plant will make fresh shoots.

XVIII. CANONA'NTHUS (from kavovisos, kanonicos, regular, and artos, anthos, a flower; the flowers are regular, like those of Campanulacece, not bilabiate, as in the rest of the Lobeliaceous gencra). Lotèlia species, Cav. icon. 6. p. 11. t. 517. 
Lin. syst. Pentándria, Monogýnia. Calyx regular, with a campanulate tube, and ovate-lanceolate segments. Corolla tubularly campanulate, entire, with 5 equal, ovate, acute segments. Filaments and anthers combined; the latter beardless. Ovarium 2-celled. ?- $\mathrm{A}$ branched shrub, clothed in every part with white tomentum. Leaves ovate, quite entire, glabrous above, and densely clothed with tomentum beneath. Peduncles long, axillary, solitary, 1-flowered. Calyx tomentose. Corolla red inside, and clothed with obscure white powdery tomentum outside.

1 C. campanula'tus; $\nmid$. F. Native of Peru, on the road from Guaranda to Chimborazo. Lobèlia campanulàta, Cav. icon. 6. p. 11.t. 517 .

Campanulatc-flowered Canonanthus. Shrub \& feet.

Cult. See Tùpa, p. 700. for culture and propagation.

ORDER CXXXV. STYLI'DEÆ (plants agreeing with Stylidium in important characters). R. Br. prod. fl. nov. holl. p. 565 .

Calyx superior, 2-6-parted, bilabiate or regular (f. 123. a.), permanent. Corolla monopetalous, with a 5-6-cleft, irregular (f. 123. b.), rarely equal limb, which is imbricate in astivation, and at length falling off. Stamens 2 (f. 123. d.); filaments combined with the style into a column. Anthers didymous (f. 123. d.), and sometimes simple, lying upon the stigma. Pollen globose, simple, sometimes angular. Ovarium 2-celled, but sometimes almost 1 -celled from the middle dissepiment being short, many-scerled; furnished with a gland in front, or crowned by 2 opposite glands. Style one; stigma undivided or bifid. Capsule 2-valved, 2-celled, with a parallel dissepiment ; or almost 1 -celled from the dissepiment being short, or at length released from the inflexed margins of the valves. Seeds fixed to the axis of the dissepiment, erect, small, sometimes pedicellate. Albumen conforming to the seed, fleshy, and rather oily. Embryo inclosed, minute-Caulescent scarpigerous nonlactescent herbs or shrubs, beset with simple hairs, which are either tipped with capitate glands or acute. Leaves usually scattered, but sometimes vcrticillate, entire, with naked or ciliated edges; radical leaves crowded in the scapigerous species. Flowers spicate, racemose, corymbose, and solitary; terminal, rarely axillary; pediccls usually furnished with three bracteas.

This order is nearly allied to both Campanulacea and Goodenovice, from both of which it is distinguished by the gynandrous stamens, and from the latter by the want of an indusium to the stigma. The structure of the sexual organs is highly curious; the stamens and style are closely combined into a solid irritable column, at the top of which is a cavity, including the stigma, and bounded by the anthers.

\section{Synopsis of the gencra.}

1 Stylídum. Calyx 2-parted, bilabiate (f. 123, a.). Column with a double flexure. Anthers 2-lobed (f. 123. d.); lobes divaricate. Stigma undivided. Capsule 2-celled.

2 Levenhoòkı. Calyx 5-parted, bilabiate. Column erect, adnate to the lower side of the tube. Lobes of anthers one above the other, divaricate. Stigmas 2. Capsule 1-celled.

3 Forste'ra. Calyx double, hoth composed of 2.3 sepals.
Corolla tubularly campanulate, 5-6-parted. Column straight, bearing 2 anthers. Stigmas 2. Capsule 1-celled.

1 STYLI'DIUM (from $\sigma \tau v \lambda o s$, stylos, a column; in reference to the stamens and style being combined into a column). Swartz, in nov. act. nat. scrut. berol. ex Willd. spec. 4. p. 116. Labill. nov. holl. 2. p. 63. t. 213. p. 566. R. Br. prod. p. 566 Ventenàtia, Smith, cxot, bot. 2. p. 13. t. 66.-Caudóllea, Labill. in ann. mus. 6. p. $414 . \mathrm{t}, 64 . \mathrm{f} .2$.

Lin. syst. Gynándria, Díndria. Calyx bilabiate (f. 123. a.). Corolla irregular, 5 -cleft (f. 123. b.); the fifth segment or labellum dissinilar to the others, leflexed, smaller, rarely stretched out; the rest spreading, rarely joined by pairs. Column reclinate (f. 123. d.), with a double flexure. Anthers 2-lobed (f. 123. d.); lobes divaricate. Stigma obtuse, undivided. Capsule 2celled, having the dissepiment sometimes incomplete above.Scapigerous or caulescent herbs or subshrubs. Radical leaves crowded, sometimes attenuated into the petioles; cauline ones scattered, and sometimes verticillate, often small and bracteaformed, rarely cirrhose at the apex or loosened at the base. Inflorescence variable. Outer lip of calyx bidentate or bipartite, inner one tridentate or tripartite. Corollas purple, white, violaceous, rarely yellow, usually beset with pili on the outside, which are tipped with capitate glands: tube twisted at the base, sometimes very short; throat usually crowned by teeth of glands, but sometimes naked: the 4 larger segments of the limb approximating by pairs, one of the pair often smaller than the other. Labellum or lip narrower than the other segments, opposite the front of the calyx, but from the contortion of the tube has at length become lateral, with its disk often thickened, and rather convex inside, usually appendiculated by a small segment on each side, but sometimes simple. Column linear, longer than the limb of the corolla, on the same side as the labellum, exserted, reclinate, having the outer bend so irritable that if touched with a pin it instantly starts from its place to the opposite side of the flower with great impetuosity. Anthers dehiscing lengthwise. Stigma at first obsolete, and hidden by the incumbent anthers, but exserted at length, and sometimes hispid or papulose.

Sect. I. Ventena'tia. Capsule ventricose, subovate, sometimes spherical or oblong.

\$1. Scales scarious. Leaces radical, attemuatcl at the base, Outer lip of calyx 2-parted, inner one tripartite. - Scapigerous herbs, with racemose flowers.

1 S. Pulòsux (Labill. nov. holl. 2. p. 63. t. 213.) scape a little branched, clothed with glandular pubescence; leaves flat, lanceolate-cnsiform. \%. G. Native of New Holland, on the south coast. Flowers pale red.

Pilose Stylidium. Pl. $1 \frac{1}{2}$ foot.

2 S. Reduplica'tum (R. Br. prod. p. 568.) seape beset with acute hairs; racemes a little branched; leaves narrow, ensiform, reduplicate, with broader scales outside. 4. G. Native of New Holland, on the southern coast. Flowers red or pink?

Reduplicate-leaved Stylidium. Pl. $\frac{1}{2}$ to 1 foot.

3 S. unsu'tum (R. Br. prod. p. 568.) scape beset with acute hairs; raceme ncarly simple; leaves linear, with rather revolute' edges; scales distinct. 4 . G. Native of New Holland, on the south coast. Hook. bot. mag. t. 3194. Corolla of a purplish rose-colour.

Ilairy Stylidium. Fl. May. Clt. 1830 . Pl. $\frac{x}{2}$ to $\frac{3}{4}$ foot.

5. Leares radical, cronded, without scales. Outer lip of calyx bidentate, inner one tridentate. Scapes leafless.

1. S. cmbelia'tum (Labill. nov, holl. 2. p. 66. t. 217.) 
racemes of scape umbellate, involucrated. $\boldsymbol{4}$. G. Native of Van Diemen's Land.

Umbellate-fiowered Stylidinm. Pl. $1 \frac{1}{2}$ foot.

5 S. ARME'ria (Labill. nov, holl. 2. p. 66. t. 216.) leaves linear, ensiform, with quite entire margins: scape glabrous; raceme simple, downy; lip of corolla appendiculated. $4 . \mathrm{G}$. Native of Van Diemen's Land. Perhaps the same as the following.

Thrift-like Stylidium. Pl. 1 foot.

6 S. MELA'StAchys (R. Br. prod. p. 568.) leaves linear, with rather revolute smooth margins; scape rather pilose; spike simple, beset with glandular hairs; flowers imbricate, almost sessile; lip of corolla appendiculate at the base. 4 . G. Native of Van Diemen's Land. The leaves are sometimes beset with a few denticulations.

Black-spilied Stylidium. Pl. 1 foot.

7 S. GRAMINifòlium (Swartz, in nov, act. scrut, berol. ex Willd. spec. 4. p. 146.) leaves linear, with denticulated edges; raceme subspicate, simple, and is as well as the scape beset with glandular hairs; lip of corolla appendiculate at the base. $4 . \mathrm{G}$. Native of New South Wales and Van Diemen's Land. Ker. bot. reg. t. 90 . Ventenàtia màjor, Smith, exot. bot. 2. p. 13. t. 66. Candóllea serrulàta, Labill. in ann. nus. 6. p. 414. t. 64. f. 2. Flowers purplish red.

Grass-leaved Stylidium. Fl. April, Aug. Clt. 1803. P1. $1 \mathrm{ft}$.

8 S. LiNEA're (Swartz, l. c.) leaves compressed, filiform, $1-1 \frac{1}{2}$ inch long, with denticulated margins; raceme simple; pedicels equal in length to the ovarium; scape glabrous, filiform; lip of corolla appendiculate at the base. 2\%. G. Native of New South Wales, about Polt Jackson. R. Br. prod. p. 568 . Ventenàtia minor, Smith, exot. bot. 2. p. 15. t. 67. Flowers purple or red.

Linear-leaved Stylidium. Fl. June, July. Clt. 1812. Pl. 1 foot.

9 S. Seta'ceum (Labill. nov. holl. 2. p. 65.) leaves setaceous, mucronulate, an inch long; raceme simple, subspicate; scape quite glabrous; capsule clavate-oblong; lip of corolla inappendiculate. 24. G. Native of New Holland, on the south coast. Flowers red.

Setaceous-leaved Stylidium. P1. 1 foot.

93. Lcaves radical, cronded, without scales. Scape leafless or with a few vcry small scattered leaves. Outer lip of calyx bipartite, inner one tripartitc.

10 S. spinulòsum (R. Br. prod. p. 569.) leaves linear, mucronate, attenuated at the base, with spinulose edges; scape clothed with glandular pubescence; raceme simple, rarely subcorymbose; throat of corolla crowned: lip inappendiculate. 4. G. Native of New Holland, on the sontl coast.

Spinulose-leaved Stylidium. Pl.

11 S. caspitòsum (R. Br. l. c.) leaves linear, glabrous, setaceously mucronate, with quite entire edges; raceme often divided; rachis and scape glabrous; throat of corolla naked; lip appendiculate. $\%$. G. Native of New Holland, on the south coast.

Tufted Stylidium. Pl. tufted.

12 S. PILI'FERcm (R. Br. l. c.) leaves linear-lanceolate, glabrous, piliferous, with entire margins; raceme simple; rachis downy ; scape glabrous; throat of corolla naked; lip appendiculate. $2 /$. G. Native of New Holland, on the south coast.

Piliferous Stylidium. Pl.

13 S. Assímit (R. Br. I. c.) leaves narrow-spatulate, glabrous, thickish, with quite entire margins; raceme divided a little; rachis and scape downy; throat of corolla naked; lip appendiculate. $\%$. G. Native of New Holland, on the south coast.
Similar Stylidium. Pl.

14. S. spatula'tum (R. Br. I. c.) leaves spatulate, clothed with glandular pubescence on both surfaces, with quite entire edges; raceme many-flowered, and is as well as the radical scape glabrous; throat of corolla crowned; lip appendiculate. 4. G. Native of New Holland, on the south coast.

Spatulate-leaved Stylidium. P]. $\frac{1}{2}$ to 1 foot.

15 S. GLau'cum (Labill. nov. holl. 2. p. 64. t. 214.? R. Br. 1. c.) leaves lanceolate-spatulate, clothed with glandular down on both surfaces, with quite entire edges; raceme few-flowered, subcorymbose, glabrous; scape furnished with a few leaves. 4. G. Native of New Holland, on the south coast. Perlaps the plant of Labillardiere is referrible to the following.

Glaucous Stylidium. Pl. $\frac{1}{2}$ foot.

16 S. ERlorhízum (R. Br. I. c.) leaves spatulate, setaceously mucronate, glabrous on both surfaces, but tomentose on the margins; raceme somewhat panicled, and is as well as the scape clothed with glandular down; root thick, woolly; throat of corolla naked; lip appendiculate. 4.G. Native of New Holland, within the tropic.

Woolly-rooted Stylidium. Pl.

17 S. Floribu' NDUM (R. Br. l. c.) leaves oblong, glabrous on both surfaces, with quite entire margins; scapes numerous, panicled, woolly from acute villi; throat of corolla naked: lip appendiculate. 4. G. Native of New Holland, within the tropic.

Bundle-flowered Stylidium. PI.

18 S. Ju'NCEUm (R. Br. l. c.) radical leaves linear, those of the scape minute, distant, and are as well as the bracteas adnate to the middle; calycine segments subulate, simple at the base; throat of corolla crowned by stipitate glands : lip inappendiculate. \%. G. Native of New Holland, on the south coast. Scape straight, glabrous.

Rushy Stylidium. Fl. Sept. Clt. 1830. Pl. 2 feet.

19 S. viola'ceun (R. Br. l. c.) radical leaves narrow, linear, those of the scape, which is quite glabrous, small and adpressed, and are as well as the bracteas sessile; calycine segments gibbous at the base; throat of corolla crowned; lip inappendiculate. 24. G. Native of New Holland, on the south coast. Flowers violaceous.

I'iolaceous-flowered Stylidium. Pl.

\$4. Leaves of scape or stem verticillate. Outer lip of calyx bipartitc, inner one tripartite.

20 S. LU'TEUM (R. Br. prod. p. 570.) scape inarticulated, glabrous; whorles of leaves 1-2 on each scape, besides some scattered leaves at the top; radical leaves linear; calycine segments rather gibbous at the base; throat of corolla crowned: lip inappendiculate. 4. G. Native of New Holland, on the south coast. Flowers yellow.

Ycllow-flowered Stylidium. Pl.

21 S. Амж'Num (R. Br. prod. p. 570.) scape inarticulate, glabrous, furnished with one whorl of leaves beyond the middle, without any scattered leaves above the whorl; radical leaves spatulate, acuminated; throat of corolla crowned: lip inappendiculate. 24. G. Native of New Holland, on the south coast. Flowers red?

Pleasant Stylidium. Pl.

22 S. articulatum (R. Br. l. c.) scape furnished with 2 joints, and 2 whorles of leaves; radical leaves spatulate, coriaceous : lip of corolla inappendiculate. $\psi$. G. Native of New Holland, on the south coast.

Jointed-scaped Stylidium. Pl. $\frac{1}{2}$ foot?

$23 \mathrm{~S}$. D1velisifòlium (R. Br. I. c.) scape straight, inarticulated, furnished with 3-4 whorles of filiform leaves: radical 
leaves lanceolate; throat of corolla crowned: lip appendiculate. 4. G. Native of New Holland, on the south coast.

Diverse-leaved Stylidium. Pl. 1 foot?

24 S. sca'NDENS (R. Br. l. c.) stem scandent; leaves linear, spiral, and cirrhose at the apex; throat of corolla crowned: lip appendiculate; columm downy above. 24. $\checkmark$. G. Native of New Holland, on the south coast. Flowers lilac or rosecoloured. Leaves whorled.

Climbing Stylidium. Fl. July, Nov, Clt. 1803. Pl. cl.

\section{5. Stem shrubby. Leaves numerous, scattered.}

25 S. pruticòsum (R. Br. I. c.) leaves narrow-linear, decurrent, glabrous; throat of corolla half crowned : lip appendiculate. $\zeta$. G. Native of New Holland, on the south coast. Stylidium glandulòsum, Salisb. par, t. 77. Flowers pink.

Shrubby Stylidium. Fl. May, Oct. Clt. 1803. Shrub 1 to $1 \frac{1}{2}$ foot.

26 S. tenuifolium (R. Br. l. c.) leaves setaceously linear, sessile, rather hairy; throat of corolla naked: lip appendiculate. h. G. Native of New South Wales, about Port Jackson. Sims, bot. mag. 2249. L. laricifolium, Rich. Flowers pink.

Fine-leaved Stylidium. Fl. July, Aug. Clt. 1818. Sl. $1 \mathrm{ft}$.

\$6. Tube of corolla very short. Lip of corolla stretched out.

27 S. calcara'tum (R. Br. l. c.) plant small; stem fewfiowered; leaves oval: corolla with a naked throa!, and rather toothed segments : lip inappendiculate. 4.6 . Native of New Holland, on the soutli coast.

Spurred Stylidium. PI. snall.

Sect. 11. Andersònia. J. G. Kœnig. mss. ex R. Br. prod. p. 570. Capsules linear, or linear-lanceolate.

§1. Scapigerous. Floncrs spicate or corymbose, rarely alnost solitary.

28 S. caplela're (R. Br. 1. c.) scape capillary, 1-2 inclies high, 1-2-flowered; leaves radical oval; calyx glabrous, very acute ; limb tripartite, with the middle segment bifid; throat of corolla crowned; lip inappendiculate. $\boldsymbol{4}$. G. Native of New Holland, within the tropic.

Capillary-scaped Stylidium. Pl. 2 inclues.

29 S. TENE'LLUM (R. Br. prod. p. 571.) scape capillary; spike few-flowered; leaves radical roundish; lips of calyx parted, glandular; the 2 larger segments of the limb of the corolla semi-bifid; throat naked: lip inappendiculate. 4. G. Native of New Holland, within the tropic.

Slender Stylidium. Pl. $\frac{1}{4}$ foot.

$30 \mathrm{~S}$. Rotundfàlium ( $\mathbf{R}$. Br. l. c.) scape capillary, 1-4Howered; leaves radical roundish; lips of calyx undivided ; 4 of the segments of the limb of the corolla nearly equal; throat naked. 4. G. Native of New Holland, within the tropic.

Round-leaved Stylidium. PI. $\frac{1}{4}$ to $\frac{1}{2}$ foot?

31 S. crassifòluu (R. Br. l. c.) scape terete, 1-2 feet high ; spike racemose, elongated; leaves radical lanceolate, elongated. 4. G. Native of New Holland, on the south coast.

Thick-leaved Stylidium. Pl. 1 to 2 feet.

$32 \mathrm{~S}$. corymbòsum (R. Br. l. c.) scape terete, 2-3 inches high, corymbiferous; leaves radical linear, ending each in a setaceous mucrone; lips of calyx parted. $\boldsymbol{4}$. G. Native of New Holland, on the south coast.

Corymbose-flowered Stylidium. Pl. $\frac{1}{4}$ foot.

2. Caulescent plants. Flowers alternate or solitary. Capsules terete-linear, the same breadth at the apex.

33 S. INUNDA'Tum (R. Br. prod, p. 571.) stem branched, an inch and a half high, leafy below the division; leaves linear; voL. III. larger segments of the limb of the corolla obovate: smaller ones limear ; throat naked; lip inappendiculate, adnate to the tube at the base. 2. G. Native of New Holland, on the south coast, in inundated places.

Inundated Stylidium. Pl. $1 \frac{1}{2}$ incl.

34 S. DESPE'ctum (R. Br. l. c.) stem parted, an inch and a half high; branches few-flowercd; leaves linear; segments of the limb linear-oblong, rather unequal; throat naked; lip inappendiculate, adnate to the tube at the base. $4 . \mathrm{G}$. Native of Van Diemen's Land. Very like S. inundatum.

Despised Stylidium. Pl. $1 \frac{1}{2}$ inch ligh.

35 S. Diffu'sum (R. Br. l. c.) stem branclied, diffuse, filiform; leaves linear : cauline ones distant; the 2 larger segments of the limb bifid; throat crowned; lip inappendiculate, adnate to the tube at the base. 4 . S. Native of New Holland, within the tropic.

Diffuse Stylidium. Pl. diffuse.

36 S. PYGME'Um (R. Br. l. c.) stem simple, erect, an inch ligh, 2-3-flowered; leaves linear; lips of calyx parted; segments of the limb entire; throat naked; lip inappendiculate. 4. G. Native of New Holland, on the south coast.

Pygmy Stylidium. Pl. 1 inch.

\$ 3. Peduncles 1-flowered from the axils of the leaves or top of the scape or branches, which are cronded. Capsule nearly tercte, not tapering at the top.

37 S. RE'PENS (R. Br. prod. p. 571.) stem creeping; branches ascending; leaves subulate, adnate : upper ones mucl crowded; throat of corolla crowned; lip inappendiculate. 4 . G. Native of New Holland, on the south coast.

Creeping Stylidium. Pl. creeping.

38 S. gutтA'тum (R. Br. l. c.) scape simple; flowers nearly sessile, in fascicles; bracteas foliaceous; throat of corolla crowned : lip appendiculate; leaves radical linear. 4. G. Nativc of New Holland, on the south coast.

Spotted-Howered Stylidium. PJ. $\frac{1}{4}$ foot.?

39 S. PEduncuia'tum (R. Br. l. c.) scape simple; flowers nmbellate; pedicels capillary; leaves of involucrum linear; segments of the limb of the corolla unequal ; throat naked; lip inappendiculate; leaves radical lanceolate. 4 . S. Native of New Holland, within the tropic.

Pedunculate Stylidium. P].

\$ 4. Racemes terminating the leafy stems. Capsule compressed, lanceolate or linear, constricted at the neck.

40 S. mRevisca'pum (R. Br. prod. p. 572.) stem simple; leaves compressed, fliform: upper ones much crowded; raceme pedunculate, rather panicled, having the rachis villous; capsule lanceolate, equal-valved, downy. h. G. Native of New Holland, on the south coast.

Short-scaped Stylidium. Pl. $\frac{1}{4}$ foot.

41 S. Fascicula'tum (R. Br. l. c.) stem branched a little, glabrous; leaves linear; spikes pedunculate, subracemose, having the rachis glabrous ; capsule lanceolate, having both the cells seminiferous. h. G. Native of New Holland, on the south coast. Lindl, bot. reg. 1459 . Flowers pink. (f. 123.)

Fascicled-leaved Stylidium. Fl. Aug. Clt. 1830 . Shrub $\frac{1}{2} \mathrm{ft}$. 42 S. Falca'tum (R. Br. 1. c.) stem nearly simple, and is as 4. Z 
well as the rachis downy; leaves linear; spike pedunculate, subracemose; capsule divaricate, lanceolate, with both the cells seminiferous, the superior one one-half narrower than the other, and closed. $h$. G. Native of New Holland, on the south coast. Flowers pink?

Falcate Stylidium. Shrub $\frac{1}{2}$ foot.

43 S. ADNA'TUn (R. Br. l. c.) stem multiple; branches undivided; leaves linear; spike almost sessile, divided, with the divisions few-flowered; capsule linear, adnate at the base, laving the neck shorter than the calyx: the superior cell empty, and very narrow. ๑. G. Native of New Holland, on the south coast. Lindl, bot. reg. t. 914. Flowers pink.

Adnate-leaved Stylidium. Fl. July, Aug. Clt. 1824. Pl. $\frac{1}{2} \mathrm{ft}$. 44. S. PRoríneUUm (R. Br. l.c.) stem multiple; partial ones divided in an umbellate manner; leaves linear; spikes sessile, nearly simple; capsule adnate at the base, linear, having the neck equal in length to the calyx : the superior cell very narrow and empty. ๑.? 々.? G. Native of New Holland, on the south coast. Flowers pink. Very nearly allied to the preceding,

\section{Allied Stylidium. Pl. $\frac{1}{2}$ foot.}

\section{$\$ 5$. Limb of eorolla bipartite: lobes bifid. Capsute linear.}

45 S. ALsinoides (R. Br. prod. p. 572.) stem erect; leaves ovate; floral ones opposite ; flowers axillary, sessile, solitary, bractless. 24.? S. Native of New Holland, within the tropic. Chickweed-like Stylidium. Pl. $\frac{1}{4}$ to $\frac{1}{2}$ foot?

Cult. All the species of this genus are rare, elegant, and singular. The best soil for them is a mixture of sand, loam, and peat. Some of the species may be increased by parting at the root; but most of them by seed. Cuttings of the shrubby kinds strike root readily under a hand-glass either in sand or mould.

11. LEVENHOOKIA (named in memory of Anthony Van Leeuwenhoek, a celebrated micrographist, whose numerous works and observations on the structure of plants are still extant). R. Br. prod. p. 572.

Lin. syst. Gynándria, Diándria. Calyx 5-parted, bilabiate. Limb of corolla 5-parted, irregular: the fifth segment or lip dissimilar to the others, arched, and longer than the column, articulated with the tube, moveable. Column erect, adnate to the side of the tube where the labellum is. Lobes of anthers one above the other, divaricate. Stigmas 2, capillary. Capsule 1celled.-A small glabrous plant, with the habit of Radiola millegrana. Leaves alternate, petiolate, crowded at the tops of the branches, intermixed with fascicles of flowers. The irritability of the joint of the lip is analogous to that of the column in Stylidium, and answers the same end, the protection of the sexual organs at the time of flowering. In Levenhookia the labellum is deflexed when the flower is expanded, but from its irritability when touched it rises up, and is applied with great force to the erect immoveable column, which it covers by its spoon-shaped lamina.

1 L. Pusílla (R. Br. prod. p. 578.) ๑.? G. Native of New Holland, on the south coast.

Lcast Levenhookia. Pl. 1 to 2 inches.

Cult. See Stylidium above for culture and propagation.

III. FORSTERA (in honour, of John Reinald Forster, and his son George Forster, who both accompanied Captain Cook in his second voyage in the quality of naturalists). Lin. nov. act. ups. 3. t. 9. Swartz, in Schrad. journ. 1799. 1. t. 1, 2. f. 2.Phyllảchne, Forst. char. p. 58.

Lin. syst. Gynándria, Diándria. Calyx superior, of 2-3 sepals, girded by an involucrum composed of $2-3$ leaves.
Corolla tubularly campanulate, 5-6-parted. Column of genitals straight, bearing 2 2-celled anthers at top, which dehisce transversely. Stigmas 2, roundish, covered by the revolute valves of the anthers. Capsule inferior, 1-celled, many-seeded. Placenta central, free.

1 F. edrò̀u (Lin. nov, act. ups. 3. t. 9.) leaves imbricated, ovate-oblong, coriaceous, marginated, smooth, recurved; peduncles terminal, solitary, elongated, 1-flowered; involucrum short, spreading. $\mathrm{I}_{2} . \mathrm{G}$. Native of New Zealand.

Edible-leaved Forstera. Shrub.

2 F. muscifòlia (Swartz, in Schrad. journ. 1779. 1. t. 1, 2. f. 2.) leaves imbricated, erect, lanceolate, triquetrous, and mucronated at the apex, having the keel and margins serrulated; flowers terminal, solitary, sessile; involucrum exceeding the calyx. $々$. G. Native of Terra del Fuego. Phyllácline uliginòsa, Forst. char. p. 58, and Lin. fil. supp].

Iloss-leaved Forstera. Shrub.

Cult. See Stylidium above for culture and propagation.

Order CXXXVI. GOODENO'VIF (this order contains plants agreeing with Goodènia in important characters). R. Br. prod. p. 573.-Genera of Campanulàceæ, Juss.

Calyx superior (f. 124.a.) or semi-superior (f. 126. $a_{\text {. }}$ ), rarely inferior, 5-cleft (f. 124, a. f. 125. a.), sometimes 5-3-parted, sometimes short, entire, and sometimes obsolete, usually equal, rarely unequal, permanent. Corolla monopetalous (f. 124. $b$. f. 125. h.), more or less irregular, deciduous or marcescent; tube cleft on the back (f. 125.h.), sometimes 5-parted, and only adhering with the ovarium at the base, while that of the calyx is free; limb 5 -parted (f. 124.b. f. 125. h.), bilabiate (f. 124. b.), or unilabiate (f. 126, b.); disks of the segments lanceolate, flat : having the sides thinner in texture and elevated, induplicate in æstivation, rarely obsolete or wanting. Stamens 5 , free; from the corolla and style (f. 125.c.), alternating with the segments of the corolla; filaments distinct (f. 125. c.); anthers distinct or cohering, linear, vertical, fixed by the base, undivided, 2-celled; cells dehiscing lengthwise; pollen usually simple, but sometimes compound. Ovarium 1-2-celled, rarely 4 -celled, sometimes furnished with a gland between the 2 anterior filaments; ovula definite or indefinite. Style 1 , simple, rarely divided; stigma fleshy, obtuse, or 2-lobed, girded by a rather membranous, entire or 2-lobed, cup-shaped indusium. Capsule 2-celled or lalf 2-celled, (rarely 4-celled); dissepiment usually parallel, rarely contrary to the valves, which are entire or bipartite; having the axis seminiferous when the seeds are indefinite: but when the seeds are definite, there is one in eacli cell. Seeds sometimes nucumentaceous, but usually with a thickish testa. Albumen fleshy, conforming to the seeds, rarely deficient. Embryo erect, almost the length of the allumen, with middle-sized ustrally foliaceous cotyledons, and an inconspicuous plumule.-Non-lactescent herbs or shrubs, usually clothed with simple and sometimes with glandular down, rarely with stellate down. Leaves scattered, exstipulate, simple, usually undivided, sometimes lobed, and often toothed. Inflorescence terminal or axillary, variable. Flowers distinct, rarely aggregate, yellow, blue, and purplish, rarely reddish.

Nearly related to Campanulicea and Lobeliacea, from which it differs in the aestivation of the flower, and in the peculiar in- 
dusium to the stigma, and which exists in a remarkable degree in the sect. Brunonière. Upon the nature of the indusium of the stigma, Mr. Brown makes the following remarks:-"Is this remarkable covering of the stigma merely a process of the apex of the style? or is it a part of distinet origin, though intimately colsering with the pistillum? On the latter supposition, may it not be considered as analogous to the glandular disk, surrounding or crowning the ovarium in many other families? And in adopting the lypothesis I have formerly advanced, respecting the nature of this disk in certain families-merely that it is composed of a series of modified stamina-has not the part in question a considerable resemblance, in apparent origin and division, to the stamina of the nearly-related family Stylidece? To render this supposition somewhat less paradoxical, let the comparison he made especially between the indusium of "Brunomia and the imperfect anthers in the female flowers of Forstèra. Lastly, connected with this view, it becomes of importance to ascertain whether the stamina in Stylidece are opposite to the segments of the calyx or corolla. The latter disposition would be in favour of the hypothesis. This, however, is a point which will not be very easily determined, the stamina being lateral. In the meantime, the existence and division of the corona faucis in Stylidium render it not altogether improbable that they are opposite to the segments of the corolla." R. Br. in Lin. trans. 12. p. 134.

Synopsis of the genera.

Tribe 1.

Goodenièa. Seeds indefinite.

1 Goode'sia. Calyx superior; limb 5-parted (f. 124.a.), with equal segments. Anthers distinct. Style simple. Capsule 2-celled (rarely 4 -celled), with a parallel dissepiment, which in some species is short. Seeds imbricated, compressed. Corolla bilabiate, rarely unilabiate (f. 124.c.).

2 Dístruss. Calyx superior, with a 5-parted limb. Corolla deciduous, having the tube cleft on the upper side, with a 5 jarted, spreading, sub-bilabiate limb. Stamens distinct. Style bipartite. Indusium of stigma cup-shaped, and ciliated. Capsule half bilocular. Seeds imbricated, compressed, bordered.

3 Calógyne. Calyx superior, with an equal 5-parted limb. Corolla bilabiate. Anthers distinet. Style trifid. Gland epigynous between the 2 lower filaments. Capsule almost 1celled, from the dissepiment being short. Seeds imbricated, compressed.

4 Eutha'les. Calyx inferior, with an unequal 5-cleft limb. Corolla adhering to the tube below the ovarium, cleft on the upper side, with a bilabiate limb. Style undivided. Indusium of stigma bilabiate. Capsule 4-valved, 2-celled at the base. Seeds imbricated, compressed.

5 Velle'ia. Calyx inferior, of 3-5 unequal leaves. Corolla laving the base of the tube adnate to the ovarium, and cleft on the upper side at the apex; limb bilabiate. Anthers distinct. Style undivided. Gland epigynous between the 2 anterior filainents. Capsule 2-celled at the base; valves bipartite. Seeds imbricated, compressed.
6 Lechenaúltia. Calyx superior (f. 125. a.). Corolla with the tube cleft on the upper side (f. 125.h.). Anthers at first cohering. Stigma ohsolete, bilabiate (f. 125. d.), in the bottom of the indusium. Capsule prismatic, 2 celled, 4 -valved. Seeds cubical or nucumentaceous.

7 Anthòtum. Calyx superior, 5-parted. Corolla having the tube cleft on the upper side, and the limb bilabiate; segments of the upper lip auricled on the inner side. Anthers cohering. Ovarium 2-celled, many-seeded. Inclusium of stigma contrary to the lips of the corolla.

\section{Tribe II.}

Scæxòlex. Seeds definite. Drupe inferior.

8 Scsvòla. Corolla cleft on the upper side, exceeding the genitals; limb unilabiate, secund, 5-parted, with equal winged segments. Anthers free. Indusium of stigma ciliated.

9 Drasra'sis. Corolla nearly regular, salver-shaped; tube 5parted, inclosing the genitals. Anthers free. Ovarium I-celled, 2-seeded. Indusium of the stigma with a naked border. Nut corticate.

10 Dampie'ra. Corolla bilabiate (f. 126. $a_{\text {. }}$ ), having the tube cleft on the upper side (f. 125. d.) ; segments of the upper lip auricled on the inner margin. Anthers colering (f. 126. d.). Ovarium 1-seeded. Indusium of the stigma with a naked border. (f. 126. c.). Nut crustaceous.

\section{Tribe III.}

Brunoniéz. U'triculus superior, 1-seeded.

11 Beunònia. Heads of flowers involucrated. Calyx 5cleft, and furnished with 4 bracteas. Corolla monopetalous, funnel-shaped; limb 5 -parted, having the 2 superior segments more deeply divided. Stamens 5, hypogynous. Anthers connate. Indusium of stigma 2-valved. Utriculus inclosed within the indurated tube of the calyx.

\section{Tribe IV.}

Campanie'æ. Corolla campanulate, regular. Capsule 3-4celled, many-seederl.

12 Pentaphrágua. Calyx 5-lobed. Corolla 5-lobed, regular. Stamens 5. Indusium of stigma 3-lobed.

\section{Tilbe I.}

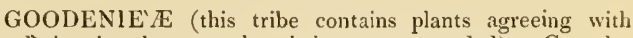
Goodenia, in the capsules being many-seeded). Capsules 2-celled, containing an indefinite number of seeds.

I. GOODE'NIA (named in honour of Dr. Goodenough, bishop of Carlisle, a lover of natural history, and author of a Monograph of the genus Càrex, published in the Linnæan Transactions). Smith, in Lin. trans. 2. p. 347. Labill. nov. holl. 1. p. 52. t. 75 . R. Br. prod. p. 575.

Jin. syst. Pentándria, Monogýnia. Calyx superior, witl a 5-parted limb (f. 124. a.) and equal segments. Anthers distinct. Style simple. Capsule 2-celled (rarely 4-celled), with a parallel dissepiment, which is sometimes short. Seeds imbricated, compressed.-Herbs, rarely subshrubs, usually caulescent. Leaves alternate, entire, toothed or cut. Flowers $4 z_{2}$ 
axillary or terminal ; pedicels bibracteate or bractless. Corollas usually yellow, although sometimes blue and purplish, bilabiate, rarely unilabiate; segments winged, rarely wingless; wings induplicate in estivation; tube sometimes furnished with a little nectariferous sack, which is opposite to the fissure of the corolla, adnate to the ovarium. Anthers cohering before expansion, beardless, rarely bearded at the apex. Capsule variable in form, with the top for the most part superior; valves entive or bipartite.

Sect. I. Ochrosánthus (from wXoos, ochros, yellow, and av0os, anthos, a flower; colour of flowers). Corolla bilabiate, yellow; segments winged. Capsule 2-celled, or almost 1-celled from the dissepiment being short. Stigma parallel with the lips of the corolla.

\section{$\$ 1$. Peduncles terminal, spicate or panicled; pedicels bibrac-} teate.

1 G. BELLidifòla (Smith, in Lin. trans. 2. p. 349.) stem naked ; spike nearly simple, downy ; corolla clothed with simple down outside; radical leaves flat, lanceolate-spatulate, toothed or cut. 24. G. Native of New South Wales, about Port Jackson. R. Br. prod. p. 573. Corolla yellow.

Daisy-leaved Goodenia. Fl. June, Aug. Clt. 1823. Pl. $\frac{1}{2}$ to $\frac{3}{4}$ foot.

¿ G. stelligera (R. Br. prod. p. 575.) stem nearly naked; spike almost simple, downy; corolla clotlied with simple hairs and stellate down outside; valves of eapsule bipartite; radical leaves fleshy, semi-terete or linear, glabrous, a little toothed at the apex. 24. G. Native of New South Wales, about Port Jackson. Corolla yellow.

Stellate-haired Goodenia. Pl. $\frac{1}{2}$ to $\frac{3}{4}$ foot.

3 G. panicula'ta (Smith, in Lin. trans. 2. p. 348. R. Br. prod. p. 575.) stem few-leaved; panicle almost simple, downy; ovarium beset with glandular and simple hairs; radical leaves long-lanceolate, a little toothed or cut. \%. G. Native of New South Wales, about Port Jackson. Cav. icon. 6. p. 5. t. 507. Corollas yellow.

Panicled-flowered Goodenia. Fl. June, Aug. Clt. 1823. Pl. 1 foot.

4 G. нu'mus (R. Br. prod. p. 575.) stem few-leaved; panicle simple, downy ; ovarium beset with acute hairs; radical leaves long-lanceolate, a little toothed. $4 . \mathrm{G}$. Native of New Hol. land, on the south coast. Corollas yellow.

\section{Humble Goodenia. P]. $\frac{1}{2}$ foot.}

5 G. orácilus (R. Br. l. c.) plant glabrous; stem few.leaved; paniele simple; ovaries glabrous; eorolla clothed with glandular lown outside; radical leaves linear-lanceolate, elongated, thickisb. $4 . G$. Native of New Holland, within the tropic. Lodd. bot, cab. t. 1032. Corollas yellow.

Slender Goodenia. Fl. June, July. Clt. 1822. Pl $11 \mathrm{ft}$.

6 G. Decu'rrens (R. B:. l. c.) plant quite glabrons; stem many-leaved; spike racemose, divided a little at the base; corolla downy outside; cauline leaves oblong, toothed, decurrent. ४. G. Native of New Holland, about Port Jackson. Corollas yellow.

Decurrent-leaved Goodenia. Pl. 1 foot.?

\$2. Peduncles axillary, trifid or simple; pedicels bibracteolate.

7 G. acumina'ta (R. Br. prod. p. 575. ) suffruticose, erect, glabrous, painted; peduncles trifid or trichotomous; leaves ovate, acuminated, dentately serrated, with beardless axils; calycine segments flat, one-half shorter than the capsule, which is pristnatic; seeds disposed in 2 rows. $々 . G$. Native of New
South Wales, about Port Jackson. Corollas yellow. Like the following, and probably only a variety of it.

Acuminated-leaved Goodenia. Pl. 1 to 2 feet.

8 G. ova'tA (Smith, in Lin. trans. 2. p. 347. R. Br. 1. e.) suffruticose, erect, glabrous, sometimes painted ; peduneles trificl or trichotomous; leaves ovate, acute, dentately serrated, bearded in the axils; calycine segments subulately filiform, a little shorter than the eapsule, which is linear; seeds disposed in one series. そ. G. Native of New Holland, about Port Jackson and the south coast, as well as of Van Dienen's Land. Andr. bot. rep. t. 68 . Vent. cels. t. 3. and in mem. de l' institut. sc. phys. 2. p. 321. pl. 10. Cav. icon. 6. p. 4. t. 506. Corollas yellow.

Ovate-leaved Goodenia. Fl. June, Oct. Clt. 1793. Shrub 1 to 2 feet.

9 G. va'RiA (R. Br. prod. p. 576.) suffruticose, glabrous; peduncles trifid or simple; leaves obovate and obtuse, or ovate and acutish, toothed, coriaeeous, with naked axils; calycine segments shorter than the stamens; corollas and styles glabrous; capsule ovate. $h$. G. Native of New Holland, on the south coast. Corollas yellow.

Var. $a$; leaves obovate and oval, a little toothed, attenuated at the base; branches flexuous: stems diffuse.

$I_{a r} \beta$; leaves roundish, almost sessile, toothed; peduncles usually 1-flowered; stems depressed.

I $a r . \gamma$; leaves oval, acutish, toothed; peduncles 3-flowered; stem erect.

\section{Variable Goodenia. Shrub $\frac{1}{2}$ to 2 feet}

10 G. grandiflòra (Sims, bot. mag. 890 . R. Br. prod. 576. ) plant herbaceous, erect, elothed with glandular pubescence; peduncles trifid, trichotomous or simple; branches angularly striated; lower leaves lyrate: rameal ones rather ovate, acute; style longitudinally woolly. 4.G. Native of New South Wales, about Port Jackson. Corollas yellow.

Great-flowered Goodenia. Fl. June, Aug. Clt. 1803. Pl. 2 to 3 feet.

1 G. heterophy'Lla (Smith, in Lin. trans. 2. p. 3.19. R. Br. prod. p. 576.) plant herbaceous, ereetish, downy, intermixed with glandless hairs; leaves ovate, eut or lobed; bracteas onehalf shorter than the upper half of the one-flowered peduncle; style glabrous. 24. G. Native of New South Wales, about Port Jackson. Cav, icon. 6. p. 6. t. 508. Corollas pale red.

I arious-leaved Goodenia. Fl. June, Oct. Clt. 1826. I'l. $1 \mathrm{ft}$.

12 G. Rotundifòls (R. Br. prod. 576.) plant herbaeeous, erectish; leaves roundish, deeply serrated, membranous ; bracteas longer than the upper half of the one-flowered peduncle; styles glabrous; eapsules ovate. 2.G. Native of New South Wales, about Port Jackson; and of New Holland, within the tropie. Corollas yellow.

I ar. $\boldsymbol{\alpha}$; plant quite glabrous, erectish.

Var. $\beta$; plant downy; hairs simple, sometimes diffuse.

Round-leaved Goodenia. Pl. 1 foot.

13 G. eARBA'ta (li. Br. prod. p. 576.) plant herbaceous? erect, clothed with glandular down, scabrous; leaves lanceolatelineal, entire; peduncles 1 -flowered; throat of corolla bearderl; styles longitudinally hairy; capsule 1-celled, 2-3-seeded. 24. G. Native of New South Wales, about Port Jackson, and of Van Diemen's Land. Corollas yellow.

Bcarded Goodenia. Pl. 1 foot.?

14 G. Lana'ta (R. Br. prod. p. 577.) plant herbaceous, downy, glandless, almost stemless; branches prostrate; leaves obovate or oval, obtuse, a little toothed, hairy; young leaves and ovaria woolly; peduncles seape-formed; corolline segments ciliated on the margins. $\%$. G. Native of Van Diemen's Land. Corollas yellow.

Woolly Goodenia. Pl. prostrate.

15 G. genicula'ta (R. Br. 1. c.) plant herbaceous, downy, 
glandless ; stem erect, sometimes short; leaves long-laneeolate, a little toothed; peduncles seape-formed, elongated, when bearing the fruit genieulately compressed. 4 . G. Native of New Holland, on the South Coast.

Genieulated-peduneled Goodenia. Pl. 1 foot.?

16 G. HeDERA'CEA (Smith, in Lin. trans. 2. p. 349. R. Br. 1. c.) plant herbaceous, downy, glandless, almost stemless ; branches filiform, prostrate; leares oval, toothed; radical leaves sometimes lobed; peduncles 1-3-flowered; corolline segments naked on the margins. 4. G. Native of New South Wales, about Port Jackson, and of Van Diemen's Land. Corollas yellow.

Ivy-like Goodenia. Fl.June, Aıg. Clt. 1823. Pl. prostrate.

17 G. gLA'BRA (R. Br. prod. p. 577.) plant herbaceous, glabrous, almost stemless; branches prostrate; radical leaves sonewhat oval and spatulate, few-toothed: rameal leaves almost sessile; pedicels 1-flowered; corollas glabrous outside. 4 . G. Native of New Holland, within the tropic. Corollas yellow. Glabrous Goodenia. [Pl. prostrate.

\section{\$ 3. Peduneles bractless, axillary or terminal, 1-flowered.}

18 G. mór.ıs (R. Br. l. c.) peduneles axillary; leaves ovate, subcordate, acute, serrated, villous, soft ; tube of corolla saccate. 4 . G. Native of New Holland, within the tropic. Corollas yellow.

Soft Goodenia. Pl. $\frac{1}{2}$ to 1 foot?

19 G. elonga'ta (Labill. nov. holl. 1. p. 52. t. 75.) pilose; peduncles solitary, axillary and nearly terminal, elongated, reflexed while bearing the fruit; stem erect, filiform; radical leaves oblong-spatulate, toothed: cauline leaves lanceolate, nearly entire, attenuated at the base. 4 . G. Native of Van Diemen's Land. R. Br. prod. 577. Corollas yellow.

Elongated-peduncled Goodenia. PI. I foot.

20 G. H'sPiDA (R. Br. prod. 577.) plant erect, beset with strigose hairs; eauline leaves sessile, elongated, lanceolate, a little toothed; peduncles solitary, axillary, elongated, erect while bearing the fruit; calyxes hispid. 4 . G. Native of New Holland, within the tropic. Corollas yellow.

Hispid Goodenia. Pl. 1 foot.?

21 G. cononopifòlia (R. Br. l. c.) glabrous; leaves linear : radical ones pinnatifidly toothed: cauline ones quite entire, and the seminal ones permanent; peduncles almost solitary, alternate, erect while bearing the fruit. 4 . G. Native of New Holland, within the tropic. Corollas yellow.

Buck-horn-leaved Goodenia. Pl.

22 G. TENE'LLA (R. Br. l. e.) plant rather downy, intermixed with a few adpressed hairs; stem simple or wanting; radical leaves flat, lanceolate or spatulate; peduncles radical or terminal, elongated, erect while bearing the fruit. $\psi$. G. Native of New Holland, on the South Coast. Sims, bot. mag. 1137. Erithòdes tenélla, Ait. hort. kew. Corollas yellow.

Slender Goodenia. Pl. $\frac{1}{4}$ to $\frac{1}{2}$ foot.

23 G. filiróruis (R. Br. prod. p. 578.) plant smoothish; stem simple; radical leaves filifurm : cauline leaves smaller; pedumeles terminal, subumbellate. 4. G. Native of New Holland, on the South Coast. Corollas yellow.

Filiform-leaved Guodenia. Pl. $\frac{1}{2}$ foot.

Sect. 1I. Tetratuy'Lax (from tetoac, tetras, four-fold; and

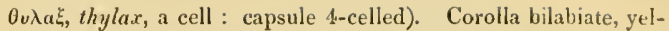
low, baving the segments winged. Capsule 4-celled.

24. G. QUadrilocula'ris (R. Br.prod. p. 578.) plant glabrous, erect; leaves nearly oval, toothed ; flowers spicate or axillary. 4. G. Native of New Holland, on the South Coast.

Four-celled-fruited Goodenia. Pl.

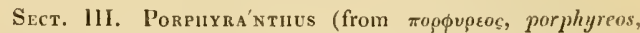
purple; and avtos, anthos, a flower; colour of flowers). Co. rolla bilabiate, purple or blue, having the segments winged. Capsule 2-celled, or half 2-celled. Stigma parallel with tlie lips of the corolla.

25 G. Purpura'scens (R. Br. 1.e.) plant glabrous; panicle effuse; stem naked; leaves radical, elongated-lanceolate. $\psi$. G. Native of New Holland, within the tropic. Corolla purple.

Purple-flowered Goodenia. Pl. $\frac{1}{2}$ foot.

26 G. pterigospéraa (R. Br. l. c.) plant glabrous; stem almost simple, few-flowered; flowers alternate; radical leaves linear, a little toothed: cauline ones smaller, remote; calyx bluntish, and is, as well as the ovarium, glabrous. 4 . G. Native of New Holland, on the South Coast: Corollas b] ne or pirple.

IVing-seeded Goodenia. Pl. $\frac{1}{2}$ foot.?

27 G. coru'LEa (R. Br. 1. e.) plant glabrous; partial stems or branches nearly simple, few-flowered; radical leaves linear : cauline ones remote; calyxes acute, and are, as well as the ovaria, glandular. 4. G. Native of New Holland, on the South Coast. Corollas blue.

Blue-flowered Goodenia. I'. $\frac{1}{2}$ foot.

28 G. Ixca'sa (R. Br. l. c.) plant clothed with hoary tonientum; partial stems or branches almost simple, few-flowered; cauline leaves remote, oblong-linear; corollas woolly on the outside, as well as the ovaria. 24. G. Native of New Holland, within the tropic. Corollas blue or purple.

Hoary Goodenia. I'l. $\frac{1}{2}$ foot.?

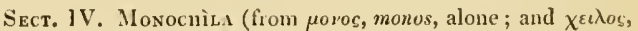
cheilos, a lip, in reference to the unilabiate corolla). Corollas unilabiate, liaving the segments winged. Stigma 2 -lobed, havinu the indusium cilitterl, and contrary to the lip of the eorolla.

29 G. ScAPígera (R. Br. l. e.) plant glabrous, erect; leaves toothed; spike terminal, pedunculate; segments of the calyx subulate, longer than the ovarium, which is tubuliferous on one side. $\boldsymbol{u}$. G. Native of New Holland on the Soutl Coast.

I $a r . a$; common peduncle elongated, scape-formed; leaves linear-lanceolate, elongated.

$V$ ur. $\beta$; eommon pedunele not elongated; leaves oval-lanceolate.

Seape-bearing Goodenia. P1. $\frac{1}{2}$ foot.?

30 G. víscida (R. Br. 1. c.) plant glabrous, painted, erect; leaves lanceolate, toothed; peduncles axillary, 1-flowered, very short; stigma bifid. 4. G. Native of New Holland, on the South Coast.

Viscid Goolenia. Pl.

Sect. V. Selle'ra (named after Natali Sellier, a Spanish artist). Sellièra, Cav. icon. 5. p. 49. t. 47. f. 2. Corolla subunilabiate, purplish, having the segments wingless, and valvate in astivation.

\$ 1. Peduncles bibracteate. Indusium of stigma with a naked border. Capsule fleshy.

31 G. RE'PENs (Labill. nov holl. 1. p. 53, t. 76.) plant glabrous, ereeping; leaves lanceolate, fleshy. 24. G. Native of New Holland, on the South Coast, and about Port Jackson; and of Van Diemen's Land; and of Chili, about Talcaguana, in humicl sandy places by the sea shore. Sellièra radicans, Cav. icon. 5 . 
p. 49. t. 474. f. 2. G. radicans, Pers. ench. 1. p. 195 . Lysipòmia sérpens, Kunz, Poeppig, pl. chil. 3.p. 34. no. 103. Perhaps a proper genus. Flowers variegated with white and blue. Stem woody, glabrous.

\section{Creeping Goodenia. Pl. creeping.}

§ 2. Peduncles bractless. Indusium of the stigma ciliated. Capsule membranous.

32 punílio (R. Br. prod. p. 579.) plant creeping, downy; leaves ovate, membranous: upper ones crowrled; peduncles 1flowered, from the axils of the upper leaves. 24. G. Native of New Holland, within the tropic. Corolla purplish. Perlıaps the corolla is unilabiate, or probably nearly regular.

Dwarf Goodenia. Pl. creeping.

Cult. All the species of this genus are worth cultivating for ormament. They grow freely in a mixture of sand, loam, and peat; and young cuttings of most of the species strike root freely in the same kind of soil, under a hand-glass ; and all may be raised from seed, which ripen plentifully.

1I. DI'STYLIS (from $\delta \iota s$, dis, twice, and $\sigma \tau v \lambda o c$, stylos, a style; in reference to the style being bipartite). Gaud. in Freyc. voy. pt. bot. p. 45 . t. 80 .

Lin. syst. Pentándria, Monogýnia. Calyx adnate to the ovarium; limb free, 5-parted. Corolla deciduous, with the tube cleft behind, 5 -parted, spreading, somewhat bilabiate; segments with winged margins. Stamens 5 , distinct. Style bipartite. Indusium of stigma membranous, cup-shaped, and ciliated. Capsule crowned by the permanent calyx, semi-bilocular in consequence of the dissepiment being short; valves parallel. Seeds imbricate, compressed, orbicular, girded by a membranous border.-An annual hairy plant, with ahmost simple stems. Leaves alternate, toothed. Flowers axillary, solitary, on long peduncles, racemose, bractless, yellow.

1 D. Berardi'na (Gaud. 1. c.). ○. G. Native of New Holland, on the Western Coast, in Sharks' Bay. Goodènia Berardiana, Gaud.

Berard's Distylis. Pl. $\frac{1}{2}$ foot.

Cult. Rear the seeds in a frame in the spring, and about the end of May put the plants out into the open border in a warm situation.

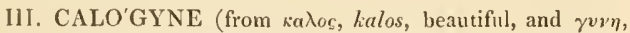
gune, a female; in reference to the stigma). R. Br. prod. 13. 579 .

Lin. syst. Pentándria, Monogýnia. Calyx superior; limb 5-parted, with equal segments, Corolla bilabiate. Anthers distinct. Style trifid. Gland epigrnous between the 2 lower filaments. Capsule subunilocular from the dissepiment being short. Seeds imbricate, compressed.-A pilose annual herb, with the habit of Goodènia, and when dry having an odour like that of vernal grass. Leaves toothed or cut; floral ones aurjculated at the base. Peduncles axillary, I-flowered, bractless, reflexed while bearing the fruit.-This genus is separated from Goodènia alone from the trifid style; each division being furnisled with an indusiate stigma.

1 G. PIlòsa (R. Br. l.c.). ๑. G. Native of New Holland, within the tropic.

Pilose Calogyne. Pl. $\frac{1}{2}$ foot.

Cult. Sow the seeds of this plant in spring, in a pot filled with a mixture of sand, loam, and peat, and place it in a hot-bed; and when the plants are of sufficient size, plant them separately into other pots.

IV. EUTHA'LES (from $\varepsilon v, e u$, well, and $\vartheta \alpha \lambda \lambda \omega$, thallo, to sprout). R. Br. prod. p. 579 .
Lin. syst. Pentándria, Monogýnia. Calyx inferior, tubular, 5-cleft, unequal. Corolla arlhering to the tube beneath the ovarium, cleft on one side at the apex; limb bilabiate. Anthers distinct. Style undivided. Indusium of stigma bilabiate. Capsule 4-valved, 2-celled at the base. Seeds imbricated, compressed.-A stemless herb, with the habit and inflorescence of

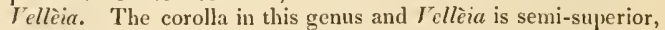
and joined with the calyx at the base. The genus is intermediate between Goodenia and Vellèia, but differs from them in the caly $x$ being tubular.

1 E. Trine'rvis (R. Br. prod. 580.). 4. G. Native of New Holland, on the South Coast. Vellèia trinérvis, Labill. nov. holl. 1. p. 54. t. 77. Goodenia tenélla, Andr. rep. t. 466. Sims, bot. mag. 113\%. Corolla pale yellow.

Threc-nerved-leaved Eutluales. Fl. May, Sept. Clt. 1803. Pl. 1 foot.

Cult. A mixture of loam, peat, and sand is the best soil for this plant; and it must be but sparingly watered, as it is very delicate, and apt to damp off. It is increased, but sparingly, by dividing, and by seed.

V. VELLE'IA (named after Major Velley, who paid much attention to the marine Algæ). Smith, in Lin. trans, 4. p. $21 \%$. R. Br. prod. p. 580 .

LiN. syst. Pentándria, Monogýnia. Calyx inferior, 3-5leaved, unequal. Corolla having the tube joined with the ovarium at the base, and cleft on the upper side at the apex; limb bilabiate. Anthers distinct. Style undivided. Gland epigynous between the 2 anterior filaments. Capsule 2 -celled at the base; valves bipartite. Seels imbricate, compressed.-Stemless herbs. Leaves radical, subspatulate, usually toothed, but sometimes lyrate. Scapes dichotomous, with the most of the axils floriferous. Bracteas opposite, foliaceous, sometimes large, and sometimes connate. Upper segment of the calyx broad, and often toothed at the base. Corolla yellow, adhering at the base, beneath the gibbosity or spur. Style somewhat tetragonal. Indusium of stigma large.

Sect. 1. Menoceras (from $\mu \varepsilon z^{\prime} \omega$, meno, to abide; and kegas, keras, a horn; in reference to the permanent spur). R. Br. prod. p. 580. Calyx 5-leaved. Corolla spurred at the base: spur permanent.

1 V. PARadóxa (R. Br. prod. p. 580.) plant downy; leaves bluntly toothed. 4 . G. Native of New South Wales, about Port Jackson; on the south coast of New Holland ; and of Van Diemen's Land. Lind. bot. reg. 971. Corolla yellow.

Paradoxical Velleia. Fl. July. Clt. 1824. Pl. $\frac{1}{4}$ foot.

2 V. argu'ta (R. Br. l. c.) plant glabrous; leaves sharply toothed. 2. G. Native of New Holland, on the south coast. Corolla yellow.

Sharp-toothed-leaved Velleia. Pl. $\frac{1}{4}$ foot.

SECT. II. VELLE'IE-VE'ræ (this section is supposed to contain the true species of the genus). R. Br. prod. 580 . Calyx 3leaved. Corolla rather gibbous on one side at the base.

3 V. LYRA'TA (R. Br. l. c.) glabrous; bracteas of the forks distinct; leaves lyrate or deeply toothed at the base; segments of the calyx ovate-orbicular. 24. G. Native of New South Wales, about Port Jackson. Ker. bot, reg. 551. Corollas yellow.

Lyrate-leaved Velleia. Fl. April. Clt. 1819. Pl, $\frac{1}{8}$ foot.

4 V. spatula'ta (R. Br. l. c.) glabrous; bracteas of the forks distinct; leaves spatulate, almost toothless, lut quite entire at the base, with the axils bearded. $\psi$. G. Native of New South Wales, about Port Jackson; and of New Holland, within the tropic. Juss, ann. mus. 18, t. 1. Corolla yellow.

Spatulatc-leaved Velleia. Fl. April. Clt. 1825. Pl. $\frac{1}{2}$ foot. 
j V. PUBE'SCENS (R. Br. prod. p. 581.) downy; bracteas of the forks distinct; leaves toothed; segments of the calyx oblong-ovate, actite. 4. G. Native of New Holland, within the tropic. Corolla yellow.

Donny Velleia. Pl. $\frac{1}{2}$ foot.

6 V. prRfolid'TA (R. Br. l, c.) glabrous; bracteas of the forks large, connate, roundish, toothed. 4 . G. Native of New Soutlı Wales, about Port Jackson. Corolla yellow.

Perfoliate-bractead V'elleia. Pl. $\frac{1}{2}$ foot.

Cult. The soil recommended for the two preceding genera is also suited for the species of Vellcia; and they may be increased by seeds, which are sometimes produced in this country.

VI. LECHENAU'LTIA (named after M. Lechenault, a French botanist and traveller). R. Br. prod. p. 581.

Lin. srst. Pentándria, Monogýnia. Calyx superior (f. 125. a.). Tube of corolla eleft on one side (f. 125.h.); limb bilabiate (f. 125. i.). Anthers colhering (f. 125. c.) at the time the flower is expanded. Grains of pollen compound. Stigma obsolete, in the bottom of the bilabiate indusium (f. 125. $f$.). Capsule prismatic, 2-celled, 4-valved; opposite valves septiferous in the middle. Seeds cubic or cylindrical, nucumentaceous. Small glabrous heath-like slirubs, rarely herbs. Leaves narrow, quite entire. Flowers axi]lary or terminal, almost solitary. The pollen in al] the species is composed of 4 combined sperules.

1. Small shrubs, with heath-like leaves. Flowers axillary or terminal. Capsule valvate. Seeds cubic.

1 L. Fon 1 ds A (R. Br. prod. p. 581.) flowers axillary, solitary, bractless, drooping ; corollas bilabiate, glabrous; upper lip of corolla rounded, entire; lower ones tripartite: segments cuneated; filaments glabrous. h. G. Native of New Holland, on the south coast. Sweet. f. austr. 2G. Flowers scarlet.

Handsome Lechenaultia. Fl. June, Sept. Clt. 182\%. Shrub $1 \mathrm{ft}$.

2 L. овLA'TA (Sweet, $\mathrm{fl}$. austr. t. 46.) flowers axillary and terminal, solitary, bract]ess, rather drooping ; corollas bilabiate, downy outside: upper lip 2lobed: lower one tripartite: segments oblate; filaments clothed with downy tomentum. $h_{\text {. }}$ s. Native of New Holland, on the south cosst. L. formòsa, Lindl. bot. reg. t. 916 . Hook. bot. mag. t. 2600. L. Baxtèri, G. Don, in Loud. hort. brit. 1). 79 . Flowers copper-coloured. (f. 125.)

Oblate Lechenaulia. Fl. A pril, Ang. Clt. $18 \div 4$. Shrub 1 foot.

3 L. tubiflòra (R. Br. prod. 581.) flowers nearly terminal, solitary, almost sessile ; corolla tubular, curved, with a conniving limb; leaves subulate, ending each in a pellucid point. $h . G$. Native of New Holland, on the south coast.

Tube-fowered Lechenaultia. Shrub 1 foot.

4. L. Expa'Nsa (R. Br. l. c.) flowers axillary, crowded into a few-flowered corymb; pedicels bibracteate; limb of corolla unilabiate, with ciliated segments. h. G. Native of New Holland, on the south coast.

Expanded-flowered Lechenautia. Shrub 1 foot.

\$2. Plant herbaceous. Floners opposite the leaves. Capsule slonly valvate; valves cohering, coarctate at the ncck. Secds cylindrical.

5 L. Filifo'ruis (R. Br. l. c.) leaves alternate, compressed, filiform. 4. G. Native of New Holland, within the tropic.
Filiform-leaved Lechenaultia. Pl.

Cult. The species of Lechenouiltia are elegant plants while in blossom. They thrive best in a mixture of turfy loam, peat, and sand; and young cuttings strilie root freely in the same kind of mould under a hand or bell-glass.

VI1. AN'THO'TIUM (from "vtos, anthos, a flower, and ous; wros, ous otos, an ear; in reference to the segments of the superior lip of the corolla being auriculated on the inner margin). R. Br. prod. p. 582 .

Lin. syst. Pentándria, Monogýnia. Calyx superior, 5-parted. Tube of corolla cleft lengthwise on the upper side; limb bilabiate; segments of the upper lip auriculated on the inner margin. Anthers cohering. Grains of pollen simple. Ovarium 2-celled, many-seeded. Indusium of stigma contrary to the lips of the corolla, beardless. Capsule unknown.-A glabrous dwart stemless herb. Leaves radical, nearly terete, dilated a little at the base. Scapes numerous, spreading, undivided. Flowers crowded in fascicles. Bracteas foliaceous. Corolla violaceous, 5-parted, with the margins of the claws loose and truly inflexed.

1 A. nu'mle (R. Br. l. c.) 2 . G. Native of New Holland, on the south coast. There are two varieties of this plant, one twice the size of the other in all its parts.

Humble Anthotium. Pl. $\frac{1}{4}$ foot.

Cult. See Velleia, above, for culture and propagation.

\section{Tribe 11.}

SCEVO'LEE (this tribe contains plants agreeing with S'cevola in important characters). R. Br. prod. p. 582. Seeds definite. Drupe or nut inferior.

VIIl. SCAVO'LA (from scceva, the left hand; in reference to the form of the corolla). Lin. gen. no. 224. Juss. gen. 165. R. Br. prod. p. 582.-Lobèlia species. Plum. gen. t. 31 . Jacq. amer. 219. Gartn. fruct. 1. p. 119. t. 25.

Lin. srst. Pentándria, Monoginia. Corolla cleft longitudinally on the upper side; limb 5-parted, all to one side; segments winged, about equal in size and shape. Anthers free. Indusium of stigma ciliated.--Shrubs and herbs very variable in liabit. Down on hairs simple. Leaves alternate, rarely opposite, hardly divided, often toothed. Inflorescence axillary or disposed in a leafy spike. Ovaria bibracteate, usually 2 -cellerl (rarely 4-celled); cells 1 -seeded; sometimes 1-celled and 1-2seeded. Calyx 5-cleft, equal, sometimes obsolete. Corolla white or blue, rarely yellow, deciduous, for the most part downy outside; wings of the segments often firinged at the base, rarely longitudinally; the fringe for the most part floccosely branched at the top, and appears capitate to the naked eye; tube villous inside, and the throat beset with ramentæ, which are disposed in continuous lines, with the fringes of the segments. Stamens llaccid after the dehiscence of the corolla, and falling off with it. Anthers for the most part beardless, but sometimes bearded at the apex.-This genus is divided into natural groups below. Those species with 1-celled ovaria will probably constitute a separate genus from those with 2-celled ovaria.-S. spinéscens has a very different habit from the other species, and is probably a distinct genus, from the bracteas being deciduous, and the wings of the segments of the corolla being fringed lengthwise, but the mature fruit is not known.

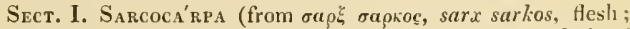
and $\kappa \alpha \rho \pi o s$, karpos, a fruit ; in reference to the baccate fruit of the species). Drupe baccate, 2 -celled. Peduneles axillary, dichotomous, bearing flowers in the forks, rarely 1 -flowered. Leaves alternate, bearded in the axils. Shrubs, natives of the sea shore.

1 S. Kenı'GII (Vahl, symb. 2. p. 36.) cymes glabrous; flowers 
pedicellate in the forks of the peduncles; calyx 5-parted, equal in length to the ovarium; leaves obovate, subrepand at the apex, quite glabrous on both surfaces, as well as the branches. h.S. Native of New Holland, within the tropic; of the East Indies, Cochinelina, and the Sandwich Islands, on the sea shore; and of Romaizoff's Island, in the South Sea. S. Lolièlia, Liı. luerb. Cerhèra salutàris, Lour. coch. 186. Flowers pale red or white.

Ǩenig's Scærola. Fl. July, Aug. Cht. 1820. Shrub $2 \mathrm{ft}$.

¿ S. Plume'ri (Vahl, symb. 2. p. 36.) cyines glabrous; calyx with an entire margin; leaves obovate, quite glabrous; calyx truncate. $h$. S. Native of the West Indies, by the sea shore. S. Lobèlia, Willd. spec. 1. p. 956. Lobélia Plumièri, Lin. spec. 2. p. 1317. Lobèlia Americana, Willd. herb. no. 820. Plum. icon. 165. f. 1. Catesb. car. 1. t. 79. Flowers whitc.

Plumier's Scævola. Clt. 1724. Shrub 2 to 3 feet.

3 S. móllis (Hook, et Ârn. in Beech. voy, pt. bot. p. 89.) shrubby, erect, densely clothed with down; leaves oblong-lanccolate, glabrous above, and clothed with silky tomentum beneatl, petiolate, glandularly denticulated, with bearded axils; peduncles shorter than the petioles, axillary, divaricate, with flexuous few-flowered branches; bracteoles subulate, recurved; corolla clothed with silky tomentum; calycine teeth 5, very short, obtuse. $h$. G. Native of the Sandwich Islands. Very closely allied to $\mathrm{S}$. serícea, Forst. The whole plant is very brittle.

Soft Scarola. Shrub 2 to 3 feet.

4. S. Gaudichaudi (Hook. et Arn. in Beech. voy. pt. bot. 3. 89.) shrubby, erect, glabrous; leaves lanceolate, acute, narrowed at the base, quite entire, rather falcate; fruit axillary, solitary, on short peduncles, somewhat racemose, crowned by the blunt 5-toothed obtuse calyx, 2-secded; bracteoles linear, quite entire. $\zeta$. G. Native of the Sandwich Islands, at the altitude of 1200 to 1500 feet. S. montàna, Gaud. in Frcyc. voy. pt. bot. p. 460 , but not of Labill.

Gaudichaud's Scævola. Slirub 3 to 4 feet.

5 S. cILA'TA; shrubby, erect, glabrous; leaves rather membranous, broad-lanceolate, acuminated at both ends, acute, witl a few almost obsolete teeth on the margins, narrowed into the short petioles, toothed at the base, with bearded axils; peduncles axillary, equal in length to the leaves or exceeding them, 5-8-flowered, cymosely dichotomous; bracteas linear : flowers scssile; calycine teeth short, ciliated; corolla glabrous on the ontside, and inside of the tube rather villous: segments winged; style villous; drupe olive-formed, containing one 2seeded pyrenze. h. G. Native of the island of $\mathrm{O}$ Wahu. $\mathrm{S}$. Chamınissoniàna, Cham, in Linnæa. 7. p. 226 . but hardly of Gaud. Leaves $3 \frac{1}{2}$ inclues long, and an inch broad.

riliated-caly'xed Scærola. Shrub 2 to 3 feet.

6 S. TAccA'DA (Roxb. fl, ind. 2. p. 146.) shrubby, with smooth branches; leaves sessile, obovate, rounded at the apex. tapering much to the base, entire, shining, with bearded axils : peduncles axillary, solitary, 2 or 3 times forked. $h$. S. Native of the East Indies, on the sea shore. Lobèlia Taccàda, Gæertn. fruct. 1. p. 119. t. 25. Buglóssum littòreum, Rumplb. amb. 4. t. 54. llowers white, sligbtly fragrant, villous inside, and shaggy round the mouth. Drupe size of a gooseberry, white when ripe, 2-celled; cells 1 -seeded.

Taccada Scavola. Fl. Aug. Clt. 1810. Shrub 5 to 6 feet.

f S. SERÍceA (Forst. prod. no. 504.) cymes and corollas tolucutose outside; flowers pedicellate in the forks of the peduncles; calyx 5-parted, abont equal in length to the ovarium ; leaves obovate, entire or repand, rlothed with soft tomentum on both surfaces, and on the branches. 2. S. Native of New Holland, within the tropic; and of the Society Islands, on the sea shorc. Vahl, symb. 2. p. 37. R. Br. prod. p. 583 . S.
Konígii, Lamark, aus. p. 108. Very like the two preceding species, but differs in being tomentose. There are varieties of this with more or less tomentose entire and repandly toothed leaves, and with the style either glabrous or longitudinally villous. Silky Scævola. Shrub 2 to 3 feet.

8 S. Chammissonia'na (Gaud. in Freyc. voy. pt. bot. p. 461. t. 82.) shrubby, erect, glabrous ; leaves oblong, acuminated at both ends, sharply denticulated, with bearded axils; peduncles axillary, dichotomous, about equal in length to the leaves, with sessile flowers in the forks; calyx short, 5-toothed; corollas downy; drupe 2-celled. h. G. Native of the Sandwich Islands.

Chammisso's Scevola. Shrub 2 to 3 feet.

9 S. тomentòs (Gaud. in Freyc. voy. pt. bot. p. 460. t. 81.) shrubby, erect, clothed with brownish stellate tomentum; leaves soft, somewhat rhomboid-ovate, obtuse, sinuately toothed; flowers axillary, solitary, pedunculate; calyx short, 5 -toothed; corollas downy; bracteoles unilateral, half connate, quite cntire; fruit 2 -seeded. h. G. Native of New Holland, on the western coast, in Shark's Bay.

Tomentose Scævola. Slirub 2 to 4 feet.

$10 \mathrm{~S}$. Menziesia'sa (Cham. in Linnæa. 7. p. 227.) shrubhy, erect ; leaves obovate or lanceolate, obtuse or acutish, quite entire, or a little serrated, narrowed into the petioles, bearded at the axils, rather Heshy, downy beneath or glabrous; pedunctes shorter than leaves, bearing 3 flowers at the apex, and often only one; bracteas linear; flowers sessile; calycine teeth short, ciliated; corolla pilose outside or glabrous, villous inside, having the segments hardly winged; style villous; drupe olive-

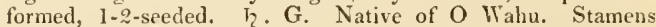
glabrous. Fruit 2-celled, fleshy.

Var. B, glabra (Cham. 1. c.) leaves narrower, and more cuneated at the base, obtuse, mucronulate, nearly entire, glabrous on both surfaces. Corollas glabrous on the outside.

Menzics' Scavola. Shrub 2 to 3 feet.

11 S. gLA'BRA (Hook. et Arn. in Beech. voy. pt. bot. p. 89.) shrubby, erect, glabrous; leaves cuneate-obovate, obliquely acuminated, on long petioles, with obscure remote glandular denticulations, and bearded axils; pedicels axillary, 1-flowered, naked, onc-half shorter than the leaves; corolla glabrous, equal in length to the teeth of the calyx. h.G. Native of the Sandwich Islands. Very like S. Chammissoniàna, Gaud.

Glabrous Scævola. Shrub 2 to 3 feet.

12 S. Monta'Na (Labill. sert. cal. p. 41. t. 42.) cymes and corollas tomentose; flowers sessile in the forks of the corymb; leaves obovate-oblong, glabrous, rather coriaceous. $h . G$. Native of New Caledonia. Leaves entire, undulated or crenulated, with silky hairy axils.

Mountain Scævola. Shrub 4 to 6 feet.

IS S, oppositifòlia (Roxb. fl. ind. 2. p. 118.) leaves opposite, on sliort petioles, elliptic, entire, smooth; peduncles axillary, few-flowered. h. S. Native of the Moluccas. A slenler shrubby species, very different in habit from $S$. Koenigii.

Opposite-leaved Screvola. Shrub.

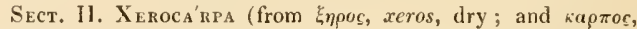
liarpos, a fruit; in reference to the dry fruit of the species). Drupe usually dry, 1-4-celled. Bracteas foliaccous, lateral, permanent. Spikes terminal, but sometimes axillary.

\section{$\$ 1$. Leares all or for the most part toothed or cut.}

14 S. attenua'ta (R. Br. prod. p. 583.) shrubby, erect, pilose ; leares lanceolate, toothed; bracteas strctched, quite entire ; corolla hairy outside, with the margins naked above; styles very villous. h.G. Native of New Holland, on the south coast. Attenuated-leaved Scærola. Shrub 2 to 3 fect.

15 S. NíTIDA (R. Br. prod. p. 584.) shrubby, erect, quite 
glabrous; leaves elliptic, sharply toothed; bracteas toothed; corollas glabrous ontside, with the margins villous above; styles rather villous. 々. G. Native of New Holland, on the south coast.

Shining-leaved Scævola. Shrub 1 to 2 feet.

16 S. crassifòlia (Labill. nov. holl. 1. p. 56. t. 79.) suffruticose, ascending, quite glabrous; leaves elliptic, sharply toothed, obovate-lanceolate, and are as well as the branches often painted; bracteas entire; indusium of stigma with a naked border. $々$. G. Native of New Holland, on the south coast. Flowers white.

Thick-leaved Scævola. Fl. Ang. Oct. Clt. 1805. Shrub 2 to 3 feet.

17 S. globulífera (Labill. nov. holl. 1. p. 55. t. 78.) suffruticose, erect, glabrous? leaves lanceolate, few-toothed; bracteas entire; ovarium 4-celled. $々$. G. Native of New Holland, on the soutl coast. 'The fringe at the base of the wings of the segnents of the corolla, and the ramenta in the throat of the corolla, are floccosely branched at the tops; therefore they appear globular at the apex, hence the name.

Globule-bearing Scævola. Shrub 1 to 2 feet.

is S. ovalifòla (R. Br. prod. p. 58\%.) suffruticose, ascending; leaves oval or elliptic, toothed; bracteas rhomboid-elliptic, very acute, nearly entire; calyx obsolete; style bearded at the top on one side. $\zeta$.S. Native of New Holland, within the tropic.

I'ar. $\alpha$, cincráscens (R. Br. 1. c.) clothed with fine cinereous tomentum; corolla downy outside.

Far. $\beta$, glàbra (R. Br. l. c.) glabrous ; corolla beardless on the outside.

Oral-leaved Scævola. Shrub 1 to 2 feet.

19 S. E'Nula (R. Br. 1. c) plant herbaceous, erect; leaves cuneated or obovate, toothed, smoothish; spike simple; bracteas lanceolate, nearly entire; calyx lobed; style glabrous below, furnished on one side at the apex with a straight coloured beard, which is equal in length to the indusium of the stigma; ovarium 2-celled. 4. G. Native of New Holland, on the south coast. It agrees with the figure given of the next species, except in the lower bracteas of the spikes being many-flowered, while in the present plant they are always 1 -fiowered.

\section{Emulating Scavola. Pl. 1 foot.}

20 S. cuneifóruis (Labill. nov. holl. 1. p. 56. t. 80.) plant herbaceous, erect? rather pilose; leaves cuneated, toothed; spike divided at bottom into 2-3. flowered spikelets; bracteas lanceolate, entire; calyx lobed; style glabrous below, but furnished with a straight beard on one side at the apex, which is equal in length to the indusium of the stigna. 4. G. Native of Van Diemen's Land. Flowers blue?

Wedge-formed-leaved Scævola. Clt. 1824. Pl. 1 foot.

21 S. sinua'ta (R. Br. prod. p. 584.) plant herbaceous, diffuse, downy, with the hairs adpressed; leaves obovate or cuneated, toothed or sinuated; spike compound: spikelets fewflowered; bracteas elliptic, entire; calyx lobed; style glabrous below, but furnished at the apex on one side with a straight, coloured beard, which exceeds the indusium of the stigma. $\mathcal{H}$. G. Native of New Holland, on the sontl coast. An intermediate plant between $S . c^{\prime} m u l a$ and $S$. cuneiformis.

Sinuated-leaved Scævola. Pl. diffuse.

22 S. Hu'suls (R. Br. prod. p. 585.) plant herbaceous, ascending or diffuse, downy ; leaves sharply toothed: lower ones obovate-cuneated : rameal ones lanceolate; spike simple; bracteas linear-lanceolate, a little toothed; calyx lobed; style furnished with a straight coloured beard on one side at top, which is equal in length to the indusium of the stigma; ovarium 2celled. 4. G. Native of New Holland, on the south coast.

Humble Scrvola. Pl. ascending.

23 S. microca'rpa (Cav. icon. 6. p. 6. t. 509.) plant herbaVoL. I11. ceous, downy; leaves cuneated, oval, or orbicular, toothed, attenuated at the base; spike simple; bracteas toothed; calyx lobed; tube of corolla bearded inside; hairs in the throat of the corolla, acute, and capitate; style longitudinally villous; ovarium 1-celled, 2-sceded. 4 . G. Native of New South Wales, about Port Jackson; and of Van Diemen's Land. R. Br. prod. p. 585. Goodènia álbida, Smith, in Lin. trans. 2. p. 347. Goodènia lavigàta, Curt. bot. mag. 287. Willd. spec. 1. p. 954. Flowers purple, with a white throat. This is a very polymorplous species, sometimes diffuse, and sometimes erect, varying much in the consistence and form of the leaves.

Small-fruited Scavola. Fl. May, Sept. Clt. 1790 . Pl. $\frac{1}{2}$ to $1 \mathrm{ft}$.

24 S. PA'LlmA (R. Br. prod. 1. c.) plant herbaceous, diffuse, downy; leaves toothed, attenuated at the base, cuneated or lanceolate; spike simple; bracteas usually toothed; calyx lobed; tube of corolla almost naked inside; style glabrous; ovarium 1-celled, 2-seeded. 4. G. Native of New Holland, on the south coast. Like the preceding, but smaller in all its parts.

Pale-flowered Scaevola. Pl, diffuse.

\section{\$2. Leaves all or for the most part quite entire.}

25 S. suave'oless (R. Br. prod. p. 585.) plant herbaceous, diffuse, downy; leaves spatulate, fleshy, with bearded axils; bracteas linear-lanceolate; ovarium 2-celled; drupe baccate. 4. G. Native of New Holland, on the south coast, and within the tropic; and of New South Wales, about Port Jackson. Goodènia calendulàcea, Andr. bot. rep. 22. Flowers blue.

Simect-scented-flowered Scævola. Fl. Aug. Sept. Clt. 1793. Pl. 1 to 2 feet.

26 S. crspiròsa (R. Br. I. c.) plant suffruticose, erectish, glabrous; leaves linear-lanceolate, with rather recurved margins, a little toothed, with beardless axils ; calyx short, 5 -lobed; ovarium 2-celled. h. G. Native of New Holland, on the south coast. In many points this species agrees with $S$. globulifera, but differs in the ovarium being truly 2 -celled.

Tufted Scævola. Slırub I foot?

27 S. revolu'ta (R. Br. prod. p. 586.) suffiuticose, erect, downy, greyish; leaves oblong-lanceolate, sessile, with revolute edges; spike compact; bracteas lanceolate, rather concave; calyx obsoletely crenated; ovarium 2-celled. $\zeta . S$. Native of New Holland, within the tropic.

Revolute-leaved Scævola. Shrub 1 fout.

28 S. LINEA'Ris (R. Br. 1. c.) suffruticose, erect, much branched, pilose, and scabrous; leaves and bracteas linear, recurved on the margins; spike terminal; ovarium 1 -seeded. $\zeta_{f}$. G. Native of New Holland, on the south coast.

Linear-leaved Scævola. Shrub 1 foot.

29 S. PALudòsA (R. Br. l. c.) plant subherbaceous, erect, a little branched, pilose, scabrous; leaves linear-lanceolate, flattish, about equal in length to the axillary spikcs; ovarium 1 seeded. 4. G. Native of New Holland, on the south coast.

Marsh Scavola. Pl. 1 foot?

30 S. ANGULA'TA (R. Br. l. c.) suffruticose, erect ; branches angular ; leares sessile, oblong-lanceolate; spikes selklom simple; bracteas conforming to the rameal leaves; calyx 5 -cleft, about equal in length to the 2 -celled wrinkled ovarium. $\zeta_{f} . \mathrm{S}$. Native of New Holland, witlin the tropic. There is a variety of this having few-toothed leaves, usually quite glabrous, but sometines furnished with a few scattered hairs.

Angular-branched Scævola. Shrub.

Sect. III. Pogonanthe'ra (from $\pi \omega \gamma \omega \nu$, pogon, a beard: and «- $\eta$ oa, anthera, an anther: the anthers are bearded). Calyx length of ovarium. Anthers bearded at the apex. Drupe nearly dry. Herbaceous plants. Peduncles axillary, 1-flowered, elongated, each furnished with 2 foliaceous permanent bractcas.

5 A 
31 S. Híspida (Cav. icon. 6. p. 7. t. 510.) wings of the segments of the corolla veinless. $4 . G$. Native of New South Wales, within the tropic. R. Br. prod. p. 586. Goodènia ramosíssima, Smith, in Lin. trans. 2. p. 349. new holl. 15. t. 5. Flowers lilac.

Hispid Scævola. Fl. July. Clt. 1827. Pl. 1 to 2 feet.

32 S. STRiA'TA (R. Br. prod. p. 5S6.) wings of the segments of the corolla furnished with parallel veins. 4. G. Native of New Holland, on the south coast.

Striated Screvola. Pl. 1 foot?

Sect. IV. Crossótoma (from кৎooroos, krossos, a fringe; and $\tau о \mu \alpha$, toma, a section; in reference to the fringed segments of the corolla). Calys obsolete. Wings of the segments of the corolla fringed longitudinally. Peduncles axillary, 1-flowered, furnished with deciduous bracteas at the apex.

33 S. sPinéseens (R. Br. prod. p. 586.) shrubby, spinescent; leaves oval or obovate, quite entire. h. G. Native of New Holland, on the south coast.

Spinescent Scævola. Shrub.

Cult. All the species grow freely in a mixture of turfy loam, turfy peat, and sand; and cuttings planted in the same kind of soil, with a hand-glass placed over them, strike root readily; those of the stove species in heat.

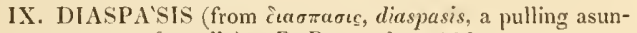
der: segments of corolla). R. Br. prod. p. 586 .

Lin. syst. Pentándria, Monogýnia. Corolla almost regular, salver-shaped, with a 5 -parted tube. Genitals inclosed. Anthers free. Ovarium 1-celled, 2-seeded. Indusium of stigma with a naked border. Nut corticate.-An erect smooth branched herb, besprinkled witl a little simple down. Leaves alternate, nearly terete. Peduncles axillary, 1 -flowered, furnished with 2 leaves at the apex, in the manner of those of Scavola lispida. Flowers drooping, Calyx short, 5-cleft. Claws of corollas connate at the base, and connected by very short capitate down above. Wings of the broader laminæ of the corolla ascending, with flat disks: the superior 2 dissimilar. Anthers beardless. Indusium of stigma somewhat 2 -valved. Drupe dry, 1 -seeded.-This genus is nearly allied to Secevola, and particularly to sect. 3. of that genus, with which it agrees in the inflorescence.

1 D. filifòlia (R. Br. prod. p. 587.) భ. G. Native of New Holland, on the soutl coast.

Thread-leaved Diaspasis. Pl. 1 foot?

C'ult. See Sccevòla above for culture and propagation.

X. DAMPIE'RA (named in memory of Capt. William Dampier, R.N., the celebrated circumnavigator; he paid great attention to natural history in all his voyages). $R$. Br. prod. 587. Juss. ann. mus. vol. 18 .

Lis, syst. Pentándria, Monogýnia. Corolla bilabiate (f. 126. a.), having the tube cheft on the upper side (f. 126.c.); segments of the upper lip auricled on the inner margin. Anthers closely cohering (f. 126.d.). Ovarium 1-seeded. Indusium of stigma with a naked border (f. 126. c.). Nut erustaceous.-A rid downy subshrubs or herbs: hairs usually of two forms; the longer ones in most of the species are branched, and rather plumose; and the shorter ones stellate. Leaves alternate, undivided, or a little toothed, coriaceous. Flowers axillary or terminal, sub-spicate or solitary; bracteas small or wanting. Calyx short, usually obsolete. Corolla blue or purple, 5-parted; with the margins of the claws truly inflexed, and the laminæ hairy on the ontside : deciduous, but sometimes with the base permanent and entire. Stamens remaining after the corolla has fallen; anthers beardless.

1 D. unovia'ta (R. Br. prod. p. 5\$7.) suffruticose, erect, tomentose; leaves petiolate, roundish, toothed, undulated, scabrous above, longer than the peduncles, which are axillary and 2-4-flowered; corolla bearded with black plumose villi outside. h. G. Native of New South Wales, about Port Jackson. Flowers blue.

Undulated-leaved Dampiera. Shrub 1 foot.

2 D. воти difolia (R. Br. l. c.) suffruticose, erect, tomentose; leaves petiolate, roundish, entire, flat, scabrous above, very blunt at the base; peduncles axillary, usually 1 -flowered, very short: terminal ones subcorymbose; corolla bearded with black plumose villi outside. $\zeta$. S. Native of New Soutls Wales, about Port Jackson. Flowers blue.

Round-leaved Dampiera. Shrub 1 foot.

3 D. ovalifòlta (R. Br. prod. p. 58s.) suffruticose, erect, clothed with scurfy tomeritum; leaves petiolate, oval, nearly entire, flat, scabrous above; peduncles 2-4-flowered, axillary, about equal in length to the leaves: terminal ones corymbose; corollas bearded with black plumose villi outside. $\mathbf{h}$. G. Native of New Holland, about Port Jackson. Juss. ann. mus. 18. t. 2. no. 1. Flowers blue. (f. 126.)

Oeal-leaved Dampiera. Fl. Ju. Aug. Clt. 1824. Shrub 1 to 2 feet.
FIG. 126.

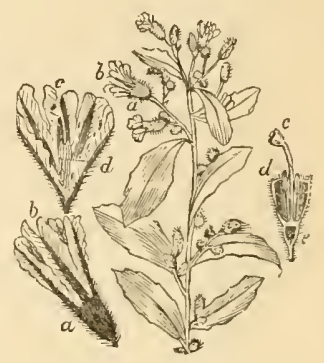

4 D. purpu'rea (R. Br. l. c.) suffruticose, erect, tomentose ; leaves petiolate, ovate, acutely toothed, scabrous above; peduncles axillary, 1-3-flowered; corollas bearded with black plumose villi outside. $h$. G. Native of New Holland, about Port Jackson. Flowers purple. In this and the preceding species the ontside of the corollas, as well as the peduncles, are densely bearded with spreading plumose villi.

Purple-flowered Dampiera. Shrub 1 foot.

5 D. Ferrugínea (R. Br. l. c.) suffruticose, erect, tomentose; leaves petiolate, ovate, acutish, repandly toothed, 3-nerved at base, smooth above in the adult state; flowers almost terminal; corollas clothed with branched wool outside. h. S. Native of New Holland, within the tropic. Flowers blue.

Rusty Dampiera. Shrub 1 foot.

6 D. hederA'cea (R. Br. l. c.) plant herbaceous, procumbent, tomentose; leaves for the most part petiolate, somewhat cordate, angularly cut: superior ones quite entire, glabrous above in the adult state; corollas bearded on the outside by spreading plumose cinereous villi. 4 . G. Native of New Holland, on the south coast. Flowers blue.

Ivy-like Dampiera. Pl. procumbent.

7 D. INCA'Na (R. Br. 1. c.) suffiuticose? erect? clothed with hoary tomentum; leaves sessile, obovate, quite entire. h.G. Native of New Holland, on the western coast about Cape Lewin and Wit's Land, where it was collected by Dampier and Baudin.

Hoary Dampiera. Shrub.

8 D. cuneata (R. Br. l. e.) plant herbaceous, erectish, downy; leaves sessile, toothed, obovate-cuneated, upper ones elliptic-lanceolate, adult ones smoothish; spikes pedunculate; bracteas opposite; flowers alternate; corollas woolly on the outside from simple spreading villi, 4.G. Native of New Holland, on the south coast. Flowers blue.

Cuncated-leaved Dampiera. Pl. $\frac{1}{2}$ to 1 foot?

9 D. LINeA'ris (R. Br. l. c.) plant herbaceous, erect, downy ; leares sessile, for the most part linear and few-toothed, lower ones cuneated, adult ones smoothish; spikes pedunculate; 
bracteas opposite; flower's alternate; corollas woolly ontside from simple spreading villi. 2. G. Native of New Holland, on the south coast. Flowers blue. In this and $D$. euncita the calyx is obsolete, the base of the corolla entire and permanent, clothed with simple villi on the outside; and the inflorescence is peculiar in these two plants.

Linear-leaved Dampiera. Pl. $\frac{1}{2}$ to 1 foot?

10 D. Fascicula'ta (R. Br. l. c.) plant herbaceous, erect ; stem compressedly tetragonal ; leaves sessile, cuneated, a little toothed, upper ones crowded in a verticillate manner, adult ones glabrous and smooth on both surfaces; peduncles in fascicles, few-flowered; corollas clothed with adpressed hairs outside: branches of pili approximate and parallel. 4. G. Native of New Holland, on the south coast. Flowers blue.

Fascicled-peduncled Dampiera. Pl.

11 D. oblonoA'ta (R. Br. l. c.) plant herbaceous, erect; sten compressedly trigonal; leaves sessile, oblong, entire, and few-toothed, glabrous and smooth on both surfaces in the adult state; peduncles almost terminal, very sliort, 1-3-flowered; corollas clothed with adpressed pili on the outside : divisions of pili approximate and parallel. 24.G. Native of New South Wales, about Port Jackson. Flowers blue.

Oblong-leaved Dampiera. Pl. $\frac{1}{2}$ to 1 foot?

12 D. strícta (R. Br. prod. p.589.) plant herbaceous, erect; stem compressedly trigonal; leaves sessile, cuneated, a little toothed, scabrous above in the adult state; peduncles fewHowered, axillary and terminal ; corollas clothed with adpressed pili on the outside : divisions of pili parallel and approximate. 24. G. Native of New Holland, on the south coast, and about Port Jackson; as well as of Van Diemen's Land. Juss. anu. mus. 18. t. 2. no. 2. Goodenia stricta, Smith, in Lin. trans. 2. p. 349. Flowers blue. This and the two preceding species are very nearly allied, and are easily distinguished from the rest on account of the peculiar hairs on the outside of the corolla.

Straight Dampiera. Fl. June, Aug. Clt. 1814. Pl. 1 foot.

13 D. PARvifòla (R. Br. prod, p. 589.) plant herbaceous, erect, glabrous in the adult state; stem compressedly trigonal, panicled; leaves sessile : cauline ones linear-lanceolate, smooth: upper rameal ones subulate; flowers solitary, sessile; bracteas imbricated, 24. G. Native of New Holland, on the south coast. Flowers blue.

Small-leaved Dampiera. Pl. 1 foot?

Cult. See Seceiola, p. 730. for culture and propagation.

\section{Tribe III.}

BRUNONIE' $/ E$ (this tribe only contains the genus Brunonia, ) Utriculus superior, I-seeded.

XI. BRUNO'NIA (named by Sir James Edward Smith in honour of Robert Brown, D.C.L. Cantab. F.R.S. V.P.L.S., \&c. Sc., who is justly considered the first botanist in the world; author of Prodromus Floræ Novæ Hollandiæ et Insulæ Van Diemen, 1 vol. Lond. $1810, \& c . \& c$.) Smith, in Lin. trans. 10. p. 366, t. 28 . R. Br. prod. p. 589 . and in Lin, trans. 12. p. 132.

Lix. syst. Pentándria, Mlonogýnia. Heads of flowers involucrated. Calyx 5 -cleft, furnished with 4 bracteas. Corolla monopetalous, funnel-shaped; limb 5 -parted, the 2 superior segments more deeply divided than the rest. Stamens 5 , hypogynous. Anthers connate. Ovarium 1-seeded. Indusium of stigma 2-valved. Utriculus inclosed within the indurated calyx, which spreads at top with plumose segments. Seed without albumen.-Stemless herbs, with the habit of Scabiòsa, Jasiòne, and Globulària, downy from glandless simple pili. Radical leaves quite entire, spatulate. Scapes undivided, bearing each one head. Head hemispherical, lobate: lobes involucrated by foliaceous bracteas. Flowers distinct, nigh a whorl of 5 membranous bracteas, the fifth bractea rather dissi. milar. Tube of calyx very short when in flower. Corolla azure blue, marcescent, latving the tube at length cleft. Filaments almost hypogynous, permanent, inserted in the very short stipe of the ovarinm, which is only obvious after fecnndation. Anthers inclosed in the tube of the corolla. Stigma fleshy, retuse, inclosed within the bifid indusium, which has a naked border. This genus agrees in many points of structure with Conzósite, C'ampunulàcea, Dipsàcece, and Globulària.

1 B. serícea (Smitl, in Lin. trans. 10. p. 366. t. 28. R. Br. prod. p. 590.) leaves as well as the scapes silky from adpressed villi; calycine segments ending each in a thick coloured naked point. 4. G. Native of New Holland, within the tropic. Flowers azure blue.

Silky Brunonia. Pl. 1 foot.

2 B. Austra'lis (Smith, in Lin. trans. 10. p. 366. t. 28. R. $\mathrm{Br}$. l. c.) leaves as well as the bottom of the scapes villous from spreading hairs; calycine segments plumose, with an acute apex. 24. G. Native of Van Diemen's Land and New Holland, on the soutl coast. Flowers azure blue.

Southern Brunonia. Pl. 1 foot.

Cult. See Screvola, p. 730. for culture and propagation.

\section{Tribe IV.}

CAMPANIE E (from campana, a bell; shape of flowers). Corolla regular, campanulate. Capsule 3-4-celled, many-seeded.

XII. PENTAPHRA'GHA (from $\pi \varepsilon \nu \tau \varepsilon$, pente, five, and фoarpos, phragmos, a dissepiment; in reference to the 5 longitudinal septa, or processes, from which the stamens spring). Wall. cat. no. 1313. Alph. D. C. mon. camp. p. 95.-Plyyteùma, Wall.

Lis, syst. Pentandria, Monogýnia. Calyx semi-superior, ovate, villous, 5 -lobed; lobes obtuse. Corolla campanulate, permanent, inserted in the calyx ; with a recurved 5 -lobed limh; lobes obtuse. Stamens 5, short. Anthers distinet, linear. Ovarium surrounded by the calyx, and connected with it by 5 longitudinal septa or processes, from which the stamina spring, 3-4-celled, many-seeded. Placentas from the inner angle of the cells. Style short, thick. Stigma concave, surrounded by the thick fleshy 3-lobed indusium. Capsule 3-4-celled, combined with the villous tube of the calyx in its lower part, and surrounded by the segments. Seeds adhering to long filiform free receptacles, which are attached to the apex of the capsule.-A creeping woolly herb. Leaves alternate, broad, semi-cordate, like those of some species of Begònia, petiolate, serrated, acute, pretty smooth. Racemes axillary, secund, recurved, twice the length of the petioles. Flowers unilateral, arrayed in 2 rows, nearly sessile. Corollas white.

1 P. BEgontefòla. 4. S. Native of Pulo-Penang, in forests. Phyteùma begoniæfòlia, Roxb. hort. beng. p. 85 . Wall. in Roxb. fl. ind. 2. p. 109. Stems villous. Leaves villous beneath and glabrous above.

Begonia-leaved Pentaphragma. Pl. creeping.

Cult. A mixture of vegetable mould and sand will be a good soil for this plant; and it will be easily propagated by dividing the creeping stems.

Order CXXXViI. CAMPANULA CEÆ (this order contains plants agreeing with the genus Campanula in the flowers being bell-shaped, and in other characters). Campanùleæ, Alph. D. C. mon. p. 97. Campanularum pars, Adan. fam. 2. p. 132. Campanulaceàrum pars, Juss. gen. p. 164. Campanaceàrum pars, Gis. ord. nat. Lin. no. 29. Campanulàcea, \$. 1. R. Br. prod. p. 559. Campanulàceæ et pars Lobeliacearum, Juss. ann. mus. 18. p. 1.

$$
5 \text { A } 2
$$


Calyx regular, of from 3 to 8 lobes, but usually of 5 lobes, very rarely destitute of the limb. Corolla monopetalous, regular, permanent, usually 5 -lobed, rarely 3 to 8 -lobed; lobes alternating with the calycine segments, each having a conspicuous central nerve, valvate in astivation. Stamens like the corolla, inserted in the margin of the disc of the ovarium, and combined with it, distinet from the corolla, but equal in number to its segments, and alternating with them; filaments usually expanded at the base and membranous, and bending towards the base of the style above the lisc; anthers fixed by the base, free, rarely more or less combined into a tube, 2 -celled; cells dehiscing lengthwise when the flower is in bud; pollen copious, adhering, yellow or violaceous, and clothed with very short papillæ. Style one, more or less bairy; stigma naked (not covered by an indusium, as in the order Scavolce, ), rarely capitate, but usually divided into from 2 to 8 lobes, or as many lobes as there are cells in the ovarium; lobes erect while the flower is in restivation, pilose on the back, and hardly distinct, but they diverge and become recurved and glabrous on the expansion of the flower. Ovarium combined with the tube of the calyx, sometimes half superior, many-celled; cells from 2 to 8 in number, but usually 2,3 or 5 , (never 4 , unless a monstrosity) opposite the calycine lobes, and sometimes alternating with them. Capsule many-seeded, debiscing at the sides or apex, having the valves usually septiferous in the middle. Seeds numerous, small, inserted in the placentas on the inner side of the cells. Albumen fleshy. Embryo slender, straight, with opposite, ovate or roundish small foliaceous cotyledons.-Usually milky herbs, rarely shrubs. Leaves exstipulate, alternate, but sometimes opposite, rarely entire, usually toothed or crenated, never fleshy; the radical ones often different from the cauline ones. Flowers rarely involucrated, number and situation variable, terminal and axillary, racemose, panicled or spicate, and glomerate, usually drooping; pedicels always reflexed in those species in which the capsules burst at the hase, but on the contrary they are erect in those species whose capsules burst at the apex.-Corollas usually blue or white, rarely yellow or purple.

Campanulacea differ from Compositæ in not having the flowers in heads, in their usually distinct anthers; in their polyspermous fruit. It differs from Lobeliàcea in the regular flowers, and in the usually distinct anthers, and from Goodenòviæ in the flowers being regular, and in the want of an indusium to the stigma. All the plants are pretty, and some highly ornamental. The roots of Camp. Rapunculus are used as a vegetable under the name of Rampion.

\section{Synopsis of the genera.}

\section{Tribe I}

Jasiònex. Capsule dehiscing at the apex. The plants containcd in this tribe are most frequcnt in the southern homisphere.

\section{\$1. Corolla 5-parted.}

\section{* Anthers combined.}

1 Jasıòne. Capsule 2-celled, inferior: valves dehiscing but a very little way at top.-Herbs with capitate flowers.

\section{* Anthers distinct.}

2 Ligntfoòtia. Stigmas filiform. Capsule 3-5-celled, half superior; when 5 -celled the cells are opposite the stamens and calycine segments. -A frican subshrubs or herbs.

3 Cephalostígma. Stigma capitate. Capsule 2-3-celled.Herbs.

4. Campanumea. Calyx without a limb. Stigmas ovate, thick. Capsule 3-celled.-Herbs, with opposite leaves, and large involucrated flowers.

\$2. Corolla 3-6-cleft or 3-6-lobed at the apex. Anthers alrays distinct.

\section{* Capsule with the valves opening regularly.}

5 Codonópsis. Calyx usually destitute of a limb. Corolla 5 -lobed. Stamens 5. Stigmas 3, ovate, thick. Capsule 3-celled. -Usually climbing glaucescent herbs, with opposite leaves.

6 Canarina. Calyx and corolla 6-lobed. Stamens 6. Stigmas 6. Cells of fruit opposite the stamens and calycine segments.-Climbing glaucescent herbs, with opposite leaves.

7 Platycòdon. Calyx and corolla 5-lobed. Stamens and stigmas 5 . Capsule $3-5$-celled; cells when 5 alternating with the stamens and calycine segments. Seeds ovate, flat.-Rather glaucescent herbs, with alternate or subopposite leaves, and large campanulate corollas.

8 Microcònon. Calyx and corolla 5-lobed. Stamens and stigmas 5. Capsule 5-celled; cells alternating with the stamens and calycine segments. Seeds small, ovoid.-Humble berbs, with narrow alternate leaves, and small cylindrical corollas.

9 Wahlenbérgia. Calyx and corolla 3-5-lobed. Stamens $3-5$; stigmas 2-5. Capsule 2-5-celled; cells when 5 opposite the stamens and calycine segments. Seeds small, usually ovoid. Herbs usually with alternate and narrow leaves.

\section{* Capsule clongated, bursting at the top or opening by a pore.}

10 Prismatocárpus. Calyx and corolla 5-lobed. Stamens 5. Capsule 2-celled, naked, at length bursting irregularly at the apex. Seeds angular, thick.-Herbs or subshrubs, with alternate narrow stiff leaves, and axillary sessile flowers.

11 Roźlua. Calyx and corolla 5-lobed. Stamens 5. Capsule 2-celled, always terminated by the permanent calycine segments, dehiscing irregularly at the apex.-Small shrubs, with alternate narrow stiff leaves; and sessile, usually solitary, terminal flowers.

\section{TrIBE II.}

Campanu'lea. Capsule dehiscing at the sides.-The plants contained in this tribe are all indigenous to the northern hemisphere.

$\$ 1$. Capsule dehiscing by ralves, which are equal in number to the cells.

\section{* Corolla 5-8-parted.}

12 Phytev'sa. Calyx and corolla 5-parted. Stamens 5. Capsule 2-3-celled. Stigmas filiform.-Herbs, with small usually glomerate flowers.

13 Petromárula. Calyx and corolla 5-parted. Stigma 
capitate. Capsule 3-celled.-Herbs, with pinnatifid leaves, and racemose flowers.

14. Michaúxia. Calyx and corolla 8-parted. Stigmas 8, filiform. Capsule 8-celled.-Herbs, with the radical leaves pinnate.

\section{* Corolla 5-cleft or 5-lobcd at the apex.}

15 Canpánula. Corolla campanulate, funnel-slaped, or broadly tubular. Nectarium none. Capsule 3-5-celled, not elongated; cells when 5 opposite the stamens and calycine segments.-Herbs variable in habit.

16 Specula'ria. Corolla rotate. Nectarium none. Capsule elongated, 3-celled.-Dwarf annual herbs, with sessile flowers.

17 Trache'sium. Corolla salver-shaped, with a very narrow elongated tube. Nectarium wanting. Style only pilose at the apex; stigmas small, hardly distinct. Capsule 2-3-celled, not elongated.-Herbs.

18 Adenóphora. Corolla campanulate. Nectarium cylindrical, girding the base of the style. Stamens distinct. Capsule 2-3-celled, not elongated.-Herbs.

19 Srmpuya'sdra. Corolla campanulate. Nectarium wanting. Anthers combined. Stigmas distinct. Capsule 3-celled, not elongated.-Herbs.

\section{\$2. Capsule dehiscing laterally by numerous transierse fis-} sures.

20 Mu'sschia. Calyx and corolla 5-cleft. Stamens 5. Capsule 5 -celled; cells alternating with the lobes of the calyx and stamens.-A subshrub, with broad serrated leaves, and racemose yellow flowers.

\section{$\dagger A$ genus doubtful whether it belongs to the order.}

21 Mercie'ra. Calyx 5-lobed, with a very hispid tube. Corolla 5 -lobed, with a narrow tube as in Trachelium. Stamens 5 , free; filaments long and slender. Stigmas 2, very short. Capsule inferior, indehiscent? 1-celled, containing probably always 4 ovula in the bottom.-Cape shrubs, with the leaves of Roélla, and slender lateral flowers.

\section{Tribe I.}

JASIONEÆ (this tribe contains plants agreeing with Jasione in the dehiscence of the capsule). Capsule dehiscing at the apex.

1. JASIO'NE ( $₫ \sigma \omega \nu \eta$, a name applied by Theophrastus to a wild pot-herb, now unknown). Lin. hort. cliff. p. 426. gen. no. 1005. Juss. gen. p. 166. Lam. ill. t. 724. f. 1. Neck. elem. 1. p. 232. Gessn, phyt. p. 104. t. 13. f. 896 . Vent. tabl. 2. p. 475. Alph. D. C. mon. p. 101.-Ovílla, Adans. fam. 2. p. 134. -Scabiosa species, Lob. adv. nov. p. 232.-A phyllántes, Dalech. list. p. 864. \&c.

LiN. syst. Pentándria, Monogýnia. Calyx 5-cleft. Corolla deeply 5 -parted; segments linear-lanceolate. Stamens 5 , with slender filaments, and with the anthers combined into a tube at the base; pollen blue or purplish. Style pilose from the middle to the apex: the pili or hairs disposed in 10 rows; stigmas 2 , short. Capsule 2-celled, spheroid or ovoid, dehiscing by a broad hole at top, with very short valves. Seeds small, ovoid, shining. -Dwarf herbs, with the habit of Seabiòsa. Leaves alternate, narrow. Flowers collected into terminal bracteated heads: the flowers expanding from the top of the head.

1 J. MONTA'NA (Lin. spec. 1317.) stems erect, simple, terete; leaves lanceolate, undulated, hairy; peduncles naked; bracteas glabrous. $\odot$.II. Native of Europe, Siberia, and the north of Africa, in sandy fields and heaths; plentiful in Britain. Ed. fl. dan. 3. t. 319 . Lam, ill. t. 724. f. 1. Curt. loncl. fasc. 4. t. 58. Smitl, engl. bot. 882. J. undulàta, Lam. A. fr. 2. p. 3. exchusive of var. $\beta .-$ Lob. icon. 536.-Column. ecphr. 1. p. 226 . with a good figure. Stems ascending, leafy. Heads of flowers globose. Corollas pale blue, and sometimes white.

Íar. $\beta$, maritima (Alph. D. C. mon. p. 102.) stems prostrate, elongated, hoary, almost simple; leaves thickish, pilose; calyxes hoary. $\odot$. H. Native of the west of France, on the sea shore. J. marítima, Duf. ined. in herb. D. C. J. montàna $\gamma$, Dub. et D. C. bot. gall. p. 311 .

Var. $\gamma$, littoratis (Alph. D. C. mon. p. 102.) plant humble, tufted; stems simple, ascending; heads small; bracteas obtuse, rounded. $\odot$. H. Native of Sweden, in the sand by the sea-side. J. montàna littoralis, Fries, nov. A. suec. pt. 2. p. 29.

I'ar. \&, prolifera (Alph. D. C. l. c.) heads proliferons. $\odot$. H. Native of Piedmont, about Lutetia.

Mountain or Common Sheep's Scabjous, or Sheep's-bit. Fl. June, July. Britain. Pl. $\frac{1}{2}$ to 1 foot.

2 J. corym bòsa (Poir. suppl. 3. p. 131.) stems erect, branched, angular; leaves decurrent, oblong-linear, rather hairy, undulated; peduncles leafy; bracteas pilose. $\delta$. H. Native of the kingdoms of Tangiers and Morocco, in sandy places. J. arenaria, Salzm. in herb. D. C. Root perpendicular. Heads of flowers numerous, globose, terminating the branches; stems therefore somewhat corymbose. Corollas blue.

Corymbose-flowered Sheep's Scabious. Pl. $\frac{1}{2}$ foot.

3 J. PERE' NNIS (Lam. dict. 3. p. 216 . ill. t. 724. f. 2 ) stems erect, simple ; leaves rather hairy : radical ones obovate : cauline ones oblong-linear, flat; pecluncles naked; bracteas pilose inside. 24. H. Native of the Pyrenees, Dauphiny, Auvergne, on the mountains, and elsewhere. Ker, bot. reg. 505. Sims, bot. mag. 2198 . Lodd. bot. cab. t. 923 . J. montàna $\beta$, Willd. spec. 1. p. 888 . J. læ'vis, Lam. fl. fr. 2. p. 3. J. montànt, Vill. dauph. 2. p. 670. exclusive of the synonyme. J. montàna $\beta$, radici perémni, Lin. fil. suppl. p. 329. Root fibrous. Stems glabrous or pilose, simple or branched from the base. Heads of flowers large, subglobose. Corollas blue, pedicellate. This is a very elegant plant when in blossom.

Perennial Sheep's Scabious. Fl. June, July. Clt. 1787. Pl. 1 foot.

4 J. Lusitánica (Alph. D. C. mon. 105.) stems branched, diffuse; leaves obovate-lanceolate, rather pilose, and somewhat sinuated; peduncles naked; bracteas smoothish. 4.? H. Native of Portugal, about Lisbon. Plant dwarf. Stems rather pilose, very leafy. Heads of flowers globose. Corollas blue. Flowers few in each head.

Portugal Sheep's Scabious. Pl. $\frac{1}{4}$ foot.

5 J. HU'muss (Lois. not. p. 42. D. C. fl. fr. suppl. no. 2872.) downy; stems ascending, simple; leaves linear-obovate, flat: radical ones rosulate; peduncles leafy. 4. H. Native of the Eastern Pyrenees, in elevated dry pastures. J. montàna, $\beta$, hùmilis, Pers. ench. 2. p. 215 . exclusive of the synonyme of J. foliòsa, Cav. J. perénnis, $\beta$, minor alpìna, La peyr. abr. pyr. p. 103. J. montàna, $\gamma$, Lam. et D. C. fl. fr. edit. 3d. no. 2879 . J. undulàta, $\beta$, Lam. dict. S. p. 215 . Phyteùma críspa, Pourr. act. tol. 3. p. 324. Plant tufted. Root simple. Heads of flowers globose. Flowers sessile, blue.

Humble Sheep's Scabious. Pl. $\frac{1}{4}$ feet.

6 J. rolıòsa (Cav. icon. 2. p. 38. t. 148. f. 1.) glabrous; stems ascending, simple; radical leaves rosulate, rather spatulate: cauline ones linear-lanceolate. 4. H. Native of Spain ; plentiful near the top of Mount Orospeda, on the north side, in the fissures of rocks; and in the boundaries of the kingdoms 
of Valencia and Murcia. Phyteùna? rigidifolia, Duf, ined. in herb. D. C. Root simple. Heads globose, few-flowered. Flowers pedicellate, of a deep violet colour. This is a dwarf, but very elegant plant when in blossom.

Leafy Sheep's Scabious. Fl. Ang. Pl. 1 to 3 inches.

7 J. Trístis (Bory, amu. gen. 3. (1820.) p. 3.) stems prostrate, difluse, almost simple; leaves alternate, rather spatulate, ciliately tomentose; flowers in dense heads; bracteas ovate, coloured. 4. H. Native of Spain, on Sierra Nevada, at a place called Valleta. Flowers of a greyish-blue colour.

Sad-coloured-flowered Sheeps' Scabious. Pl. prostrate.

Cult. The species of Jasione are all very elegant while in b) lossom, and they are, therefore, well fitted for decorating the front of flower-borders and rock-work. They grow best in light soil, and are readily increased by parting at the root, by seed, or by cuttings. Plants of all the kinds should be kept in pots, so as to be placed under shelter in severe weather in winter, or else they are liable to be killed, and the species lost to the gardens.

II. LIGHTFOO'TIA (named after the Rev. J. Lightfoot, author of the first Flora Scotica). Lher. sert. ang. (1785.) p. 3. Ait. lort. kew. 1. p. 217. Alph. D. C. mon. p. 107.-Campánula species, Thunb. prod. p. 38. Lin. fil. suppl. 141. Willd. spec. 1. p. 915 . Roem. et Schultes, syst. 5. p. 474 .

Lin. sı'st. Pentándria, Monogýnia. Calyx 5-cleft. Corolla usually 5-parted, sometimes 5-cleft. Stamens 5; filaments broad, ciliated; anthers free, caducous. Stigmas $3-5$, short, filiform. Capsule 3-5-celled, usually half superior, dehiscing by the valves at the apex; cells, when 5 , opposite the stamens and calycine segments. Seeds ovoid-trigonal, minute.-Small shrubs, rarely perennial herbs. Leaves alternate, and sometimes opposite, sessile, small, scattered equally over the whole plant. Flowers usually racemose, and on short pedicels; pedicels erect after the flowers begin to fade, and usually stiff. All natives of the Cape of Good Hope, except one, which is a native of Madagascar.

\section{\$1. Capsule 5-celled.}

1 L. subula'ta (Lher. sert. angl. t. 5.) stem ascending or erect, rather woody, simple or branched; leaves alternate, erectish, subulate, narrow, somewhat denticulated; flowers racemose, on short pedicels; corolla 5 -parted, with the segments rather longer than the calycine lobes; valves acute, longer than the entire base of the capsule. 4. G. Native of the Cape of Good Hope; very common on the mountains about Cape Town. Roem. et Schultes, syst. exclusive of the synonyme of Campánula capillàcea. Campánula subulàta, Spreng. syst. 1. p. 728. Lightfoòtia, Burclı, cat. pl. afr. austr. no. 284. Campánula fruticòsa, Lin. spec. 1. p. 238.? Root simple, perpendicular. Leaves numerous, stiff. Flowers numerous, terminal and axillary, solitary, disposed along the branches in a racemose manner, blue. 1 foot.

Subulate-leaved Lightfootia. Fl. Aug. Clt. 1787. Pl. $\frac{x}{2}$ to

\section{\$2. Capsule 3-celled.}

2 L. Longifòlı ( $A l_{\text {pll. }}$ D. C. mon. p. 108.) stem erect, quite simple, woody at the base; leaves alternate, erect, subulate, a little denticulated; flowers subspicate; corolla 5-parted, having the segments twice longer than the calycine lobes; capsule almost wholly inferior, with very short valves. 4. G. Native of the Cape of Good Hope. L. lineàris, Eklon, ined. in herb. Duıant. Campánula sessiliflòra, Lin. suppl. p. 139.? Thunb. prod. p. 38. fl. cap. 2. p. 171. mem. acad. Petersb. 4. p. 367. t. 5. f. 1. Leaves stiff. Flowers numerous at the tops of the branches, on short pedicels, 1-3 from each leaf or bractea.
Var. $\beta$, canéscens (Cham. in Linnæa. 7. p. 192.) stem, leaves, and corollas clothed with hoary down; leaves 4 lines long, straight, with revolute edges; inflorescence more loose than in the species; axillary flowers nearly sessile: terminal ones on long pedicels.

Íar. $\gamma$, lanuginosa, (Cham. 1. c. p. 193.) corollas, inflorescence, and stem rather woolly from long white villi; leaves 2 lines long, with finely-revolute edges, densely imbricated; inflorescence contracted, subcapitate.

Long-leaved Lightfootia. Pl. 1 foot.

3 L. unidenta'ta (Alplı. D. C. mon. p. 109.) stem erect, woody, simple; leaves alternate, erect, linear-lanceolate, acuminated, toothed at the base : teeth $1-2$ on each side, setaceous; flowers loosely racemose; corolla 5 -cleft, having the segments 3 times longer than the calycine lobes; valves obtuse, shorter than the base of the capsule. $々$. G. Native of the Cape of Good Hope. Campánula unidentàta, Thunb. prod. 39. Lin. fil. suppl. p. 139. Thunb. mem. acad. petersb. 4. p. 371. t. 7. f. 2. Stem reddish. Flowers terminating the branclies, disposed in loose racemes. Branches downy. Leaves revolute.

One-toothed-leaved Lightfootia. Shrub 1 foot.

4 L.? ADPRE'ssa (A]ph. D. C. mon. p. 110.) stem erect, woody, simple; leaves alternate, reflexed, linear-lanceolate, setaceously-toothed; flowers panicled; corolla semi-5-cleft: twice longer than the calycine lobes. $\eta$. G. Native of the Cape of Good Hope. Campánula depréssa, Thunb. prod. p. 38. mem. acad. petersb. 4. p. 368. t. 7. f. 2. Leaves a little decurrent, ciliated witls white hairs at the base. Flowers panicled on the upper part of the stem, which is leafless.

Adpressed Light footia. Shrub 1 foot.

5 L. A'trens (Spreng. in Zeiher, fl. cap. exsic. p. 266.) stem erect, woody, branched; leaves alternate, usually in fascicles, spreading, linear, very narrow, entire; flowers loosely racemose; corolla 5-parted, having the segments 3 times longer than the calycine lobes; valves acute, about equal in length to the base of the capsule. $h$. G. Native of the Cape of Good Hope. Campanulàceæ, Burch. cat. geogr. pl. afr. no. 17?0. Flowers terminal and axillary, loosely racemose at the tops of the branches.

Whitish Lightfootia. Shrub 1 foot.

6 L. TENE'LLA (Alph. D. C. mon. p. 111 . t. 3. f. B.) sten erect, woody, branched; leaves alternate, usually in fascicles, reflexed, ovate, obtuse, thick, nearly entire ; flowers racemose ; corolla sub-5-parted, having the segments twice longer than the calycine lobes; ralves acute, equal in length to the base of the capsule. h. S. Native of the Cape of Good Hope. Campánula tenélla, Lin. fil. suppl. p. 141. Thunb. prod. p. 39. mem. acad. petersb. 4. t. 7. f. 3. with a bad figure, Rom. et Schultes, syst. 5. p. 117. exclusive of the syn. $L$. oxycoccoides. Roélla recúrva, Banks, herb. Roélla filifórmis, Poir. dict. 6. p. 232. but not of Lam. ill. Roélla glàbra, Poir. dict. 6. p. 232. L. fasciculàta, Eklon, in herb. Dunant.-Burch. cat. pl. afr. no. 2675. Flowers axillary and terminal, disposed in loose racemes at the tops of the branches.

Slender Liglatfootia. Shrub 1 foot.

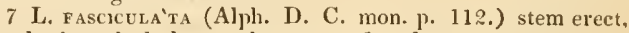
woody, branched; leaves alternate, reflexed, ovate, acute, thickish, remotely denticulated; flowers in fascicles; corolla 5parted, hardly longer than the calycine lobes. $?$. G. Native of the Cape of Good Hope. Campánula fasciculàta, Lin. suppl. p. 139. Thunb. prod. 39. Lam. ill. 2524. 'Thunb. mem. acad. petersb. 4. p. 372 . t. 6. f. 1 . Roélla refléxa, Banks, herb. Leaves very numerous. Stem rather hairy, purplish. Flowers collected into round fascicles at the tops of the branches.

Fascicled-flowered Liglitfootia. Slurub 1 foot.

8 L. oxycoccoines (Lher. sert. angl. t. 4. exclusive of the syn. Campánula tenélla, Lin.) stem erectish or ascending, much 
branched, woody at the base; branches diffuse; leaves alternate, reflexed, ovate-lanceolate, acute, thin, denticulated at the base: flowers loosely racemose; corolla 5 -parted, liaving the segments hardly twice the length of the calycine lobes; valves acute, equal to the base of the capsule. $h$. G. Native of the Cape of Good Hope, on the Table Mountain. Smith, exot. 1 . 2. t. 69. Alph. D. C. mon. p. 113. Lobèlia tenëlla, Lin. mant. p. 120. Thunb. prod, p. 40. Lobèlia parvifiòra, Berg. cap. 345. Camṕánula Ottoniàna, Rœm, et Schultes, syst. 5. p. 113. Branches purplish. Flowers terminal and axillary, at the tops of the branches, white, with reddish nerves.

Cranberry-like Lightfootia. Fl. Jaly. Clt. 1787. Slirub $\frac{1}{2}$ to 1 foot.

9 L. Laxceola'ta (Link, enum. 1. p. 217.) stem decumbent, downy; leaves lanceolate, glabrous, furnished with 1 or 2 teeth; peduncles downy ; calyx glabrous, one-half shorter than the corolla. 々. G. Native of the Cape of Good Hope. L. oxycoccoides, var. Spreng. syst. 1. p. 809 . Corollas white and bluish, larger than those of $\mathbf{L}$. oxycoccoides.

Lanccolate-leaved Lightfootia. Fl. July. Clt.? Shrub decumbent.

10 L. $\operatorname{suscòs} A$ (Link, enum. 1. p. 217.) stem decumbent, glabrous; leaves lanceolate, glabrous, quite entire : rameal ones opposite; peduncles glabrous; calyx shorter than the corolla. h. G. Native of the Cape of Good Hope. L. oxycoccoides, var. Spreng. syst. 1. p. 809 . Leaves 3-4 lines long, and half a line broad. Corolla 2-3 lines long, whitish-blue.

Mossy Lightfootia. Shrub decumbent.

11 L. Loddige'sir (Alph. D. C. mon. p. 114.) stem decumbent, woody at the base, branched; leaves alternate, somewhat reflexed, ovate-lanceolate, acute, entire ; flowers loosely racemose; corolla 5 -parted, having the segments 4 times longer than the calycine lobes. $h$. G. Native of the Cape of Good Hope. L. tenélla, Lodd. bot. cab. t. 1038. Branches purplish. Flowers axillary and terminal, disposed in loose racemes at the tops of the branches. Corolla bluish.

Loddiges's Lightfootia. Fl. June, July. Clt. 1822. Shrub decumbent.

12 L. Lycopodioìdes (Alph. D. C. mon. p. 114.) branches woody, simple, very leafy; leaves alternate, and sometimes subverticillate, erect, adpressed to the branches, linear, very narrow; flowers few, sessile; corolla 5-parted, with the segments 3 times longer than the calycine lobes. h.G. Native of the Cape of Good Hope. Leaves revolute on the margins. Flowers sessile, usually 3 on the top of each branch, the middle one expanding before the lateral ones.

Club-moss-like Lightfootia. Shrub 1 foot.?

13 L. oppositifólia (Alph. D. C. mon. p. 115.) branches erect, slender, stiff, simple; leaves opposite, somewhat reflexed, linear, acuminated, narrow, slightly denticulated ; flowers few, usually terminal; corolla deeply 5-cleft, twice longer than the calycine lobes. $h_{\text {. }}$ G. Native of the Cape of Good Hope, on the Table Mountain. Campánula ericoldes, Lam. Lightfoòtia, Burch, cat. geogr. pl. afr. austr. no. 606. Branches reddish. Flowers solitary, terminal, rarely axillary. Habit of $L$. oxycoccoides. L. muscosa and L. lanceolàta, Link, are probably hardly varieties of this species.

Opposite-leared Lighttootia. Shrub 1 foot.?

14 L. RuBioìds (Alph. D. C. mon. p. 116.) branches procumbent, difluse ; leaves opposite, spreading, or a little reflexed, lanceolate, acute, remotely denticulated; flowers few, terminal and axillary; corolla 5-parted, with the segments longer than the calycine lobes. $h_{6}$. G. Native of the Cape of Good Hope. Campánula rubioìdes, Banks, herb. Plant trailing, much branched. Branches reddish. [eaves glabrous, or furnished with a few white hairs. Flowers axillary and terminal, solitary, at the extremities of the branches.
Madder-like Lightfootia. PI, trailing.

15 L. Mladagascariénsis (Alph. D. C. moll. p. 116.) stem erect, woody at the base, simple; leaves alternate, erect, linearacuminated, remotely denticulated ; flowers somewhat panicled; segments of the corolla, which is deeply 5 -parted, about 3 times longer than the calycine lobes; capsule wholly inferior, with short valves. h. S. Native of Mladagascar, where it was collected by Commerson. Campánula Madagascariénsis, Juss. herb. Flowers at the top of the stem, and along one side of the peduncles, about 10 towards the upper part of the stem.

Madagascar Lightfootia. Pl. $\frac{1}{2}$ to 1 foot.

Cult. All the species grow freely in a mixture of loam, peat, and sand; and young cnttings strike root readily in the same kind of soil, with a hand-glass over them.

III. CEPHALOSTIGMA (from $\kappa \varepsilon \phi \alpha \lambda \eta$, kephale, a head, and $\sigma \tau \iota \gamma \mu a$, stigma, a stigma; in reference to the stigma, which is capitate). Alph. D. C. mon. p. 117.-Campánula species, Wall. herb.-W Wahlenbérgia species, Perrot. et Lepr. herb.

Lin, syst. Pentándria, Monogýnia. Calyx 5-cleft. Corolla 5 -parted; segments alternating with the calycine lobes, and longer than them. Stamens 5, free; filaments broadest at the base; anthers 2 -celled. Style usually exserted, more or less hairy; stigma simple, capitate, pilose. Capsule 2-3-celled, dehiscing by $2-3$ short valves at the apex, which are septiferous in the micldle. Seeds numerous, small, ovoid, triquetrous.--The species of this genus have a habit intermediate between Wahlenbérgia and Lightfootia, but differs from both these genera in the capitate stigma; but it has a capsule like that of the first, and a corolla like that of the latter.

\$1. Capsule half superior, 3-cellcd. Style rather shorter. than the segments of the corolla.

1 C. Panicula'ta (Alph. D. C. mon. p. 117.) stem herbaceous, much branched, leafy; leaves ovate, acute at both ends, broad, subsinuated; flowers loosely panicled; segments of corolla 2 or 3 times longer than the calycine lobes; capsule obconical. $\odot . ?$ F. Native of the Burmese empire, about Prome, on the banks of the Irrawaddi. Campánula paniculàta, Wall. mss. Stem hairy. Leaves downy beneath. Panicle much branched; pedicels filiform, 1-flowered, glabrous.

Panicled-flowered Cephalostigma. [1]. 1 foot.

\$2. Capsule 2-celled, almost wholly inferior. Style rather longer than the segments of the corolla.

2 C. Perrottétir (Alph. D. C. mon. p. 118.) stems herbaceous, simple, leafy at the base ; leaves lanceolate; flowers disposed in a long raceme; segments of corolla 3 times longer than the calycine lobes; capsule obovoid. $\odot . F$. Native of Cape Verd, at Khana, in humid sandy places. Wahlenbérgia, spec. herb. Lepr. and Perrott. Root simple. Stem leafy, and pilose at the base. Leaves ratlier pilose, with white undulated edges. Peduncles and pedicels glabrous.

Pcrrotlet's Cephalostigma. Pl. $\frac{1}{4}$ foot.

3 C. Prieu'rei (Alph. D. C. mon. p. 118.) stem woody, humble, much branched, naked at the base ; leaves small, linear; flowers panicled; segments of corolla hardly twice the length of the calycine lobes; capsule obconical. 4. S. Native of Senegal, about Jonal, where it was collected by Leprieur and Perrottet. Root simple. Branches very slender, many-flowered, glabrous.

Le Prieur's Ceplalostigma. Pl. ${ }_{4}^{1}$ foot.

Cult. For culture and propagation see Microcodon, p. 737.

IV. CAMPANUMIEA (altered from Campánula). Bhum. bijdr. p. 726. Alph. D. C. mon. p. 118. 
Lin. syst. Pentándria, Monogýnia. Flowers involucrated. Involucrum 5-parted. Calyx hemispherical, combined with the inrolucrum at the base, truncate at the apex, bearing the corolla. Corolla 5-parted? (5-petalled, ex Blum.). Stamens 5, free, ofposite the lobes of the involucrum, inserted at the base of the corolla or top of the calyx, and in the ovarium; filaments broadest at the base; anthers 2-celled. Style inclosed, divided into 3 ovate thick stigmas at the apex, which are pijose before the expansion of the flower. Ovarium combined with the tube of the calyx, 3-celled. Capsule globose, terminated by a broad flat 5 -angled umbilicus, which is girded by the cicatrices occasioned by the falling of the corollas and stamens, many-valved, ex Blum. Seeds very numerous, ovoid-cylindrical, dotted, inserted on the thick placentas, which are inflexed on both sides, and situated at the inner angle of the cells.-Quite glabrous lactescent herbs, with tuberous roots, ex Blum. Stems and branches terete. Leaves opposite, glaucescent beneath. l'eduncles axillary and terminal.

1 C. J J Av' 'NicA (Blum, bijdr. p. 727.) stem climbing; leaves on long petioles, ovate-cordate; flowers solitary, scattered. 4 . S. Native of Java, in humid woods on the mountains of Sialak and Gede. Leaves 1-2 inches long, and 6-12 lines broad. Flowers green, axillary, and terminal. Peduncles 1flowered.

Java Campanumaa. Pl. cl.

2 C. CELE' BICA (Blum. bijdr. p. 727.) stem erect; leaves on short petioles, oblong-lancenlate; flowers subcorymbose, terminal. 4. S. Native of Celebes. Leaves ovate, acute: superior ones lanceolate, nearly entire, or serrulated.

Celebes Campanumæa. Pl. 1 foot.

Cult. A mixture of sand, loam, and peat will be a good soil for the species of Campanumaa; and they are to be increased by cuttings or seeds.

V. CODONO'PSIS (from $\kappa \omega \delta \omega \nu, k o d o n$, a bell, and $o \psi(€$, opsis, resemblance; in reference to the shape of the flowers). Wall. in Rosb. fl. ind. 2. p. 103. Alph. D. C. mon. P. 120.

Lis, sxst. Pentándria, Monogýnia. Calyx 5-lobed or truncate. Corolla inserted in the top of the calyx, 5 -lobed; lobes alternating with the calycine segments when there are 5 . Stamens 5, free, alternating with the lobes of the corolla; filaments broadest at the base; anthers 2-celled, length of filaments. Style inclosed; stigmas $y$, thick. Ovarium 3-celled, almost combined with the whole of the tube of the calyx. Capsule rlehiscing by 3 acute valves at the apex, which are septiferous in the middle. Seeds inserted in the inner angle of the cells to a thick placenta, furnished with albumen and a straight embryo.-Usualiy quite glabrous herbs, inhabitants of the north of lndia on the mountains. Stems erect or scandent, and even twining, branched, terete, rising from a woody root, probably always. Leaves ustually strictly opposite, ovate, acuminated, not entire, on short petioles, glaucous, rarely hoary beneath. Branches usually opposite, more or less articulated at their origin. Flowers terminal and axillary, pedunculate, sometimes involucrated. Corollas whitish, yellowish or deep purple. The habit of the species is variable.

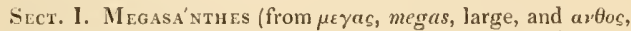
anthos, a flower; in reference to the size of the flowers). Involucrum none. Flowers large. Corolla firm, rather fleshy. Calyx 5-cleft. Seeds ovoid-cylindrical.

i C. vírids (Wall. fl. ind. 2. p. 108.) stem ascending, twining; leaves alternate and opposite, downy, loary beneath, a little crenulated; corollas large, yellowish-green. $4 . \frown . \mathrm{G}$. Native of Nipaul, about Gosaingsthan, Kamaon, and in an obscure wood on the top of Sheopore. Plant scandent, much branched, with the habit of Concolvulus. Leaves ovate-oblong. Flowers axillary and terminal, solitary, often opposite the leaves, with an ungrateful scent.

Green-flowered Codonopsis. Pl. twining.

2 C. PURPU'ReA (Wall. in Roxb. fl. ind. 2. p. 105.) stems ascending, twining a little, manifestly articulated; leaves strictly opposite, glabrous, glancescent beneath, a little crenulated; corollas deep purple. $4 . ? \cap$ G. Native of Nipaul, on the mountains towards the Himalaya. Leaves obovate-oblong. Flowers solitary, usually terminal, and terminating axillary branchlets.

Purple-flowered Codonopsis. Pl. twining.

Sect. II. Microsa'ntines (from $\mu$ koos, micros, small, and av $\theta 0 c$, anthos, a flower; in reference to the small flowers). Flowers small, white, involucrated. Calyx probably always truncate. Seeds rather lenticular, small. Leaves strictly opposite, glabrous, glaucescent beneath.

3 C. TRUnCA'TA (Wall. cat. no. 1301.) stem erect; leaves sharply serrated; involucrum combined with the base of the calyx. 4.? S. Native of the Burman Empire, at Pingue on the banks of the Irrawaddi. Stem branclied; branches stiffish. Leaves ovate, acuminated. Flowers 2-6 on the top of each branch ; pedicels terminal and axillary, 1-flowered.

Truncate-calyxed Codonopsis. Pl. 1 to 2 feet?

4. C. parvifloda (Wall. cat. no. 1300. Alph. D. C. mon. p. 123.) stem erect; leaves remotely and setaceously denticulated; involucrum distinct from the calyx. 24.? G. Native on the Pundua mountains, on the north-east of Bengal. Stem branched; branches opposite. Leaves ovate-acuminated. Flowers small, numerous, and as if they were panicled; peduncles trichotomous or dichotomous.

Small-flowered Codonopsis. Pl. 2 feet.

Cult. For culture and propagation see Campanùmaea above.

V1. CANARI'NA (so named from the first specics being a native of the Canary lslands). Juss. gen. p. 164. Lam. ill. gen. t. 259. Gærtn. fruct. suppl. p. 163. t. 211. Vent. tabl. 2. p. 470. Alph. D. C. mon. p. 123.-Canària, Lin. mant. p. 148 . and p. 225.-Pernètya, Scop. introd. p. 150. Neck. elem. 1. p. 233.-Campánula species, Pluk. pliyt. t. 276. f. 1. Tourn. inst. 1. p. 109. Lin. spec. 1. p. 168 .

Lis. srst. Hexádria, Monogýnia. Calyx 6-cleft. Corolla 6 -lobed at the apex, large, campanulate. Stamens 6, free; filaments thickest at the base, glabrous. Style inclosed, hispid above, the hairs disposed in 12 rows. Stigmas 6 . Capsule 6celled, dehiscing at the apex; cells opposite the calycine lobes and stamens. Seeds small, angular.-Larse herbs, with thick perennial roots : having the stem, leaves, and calyxes glaucescent, and quite glabrous. Leaves opposite. Flowers terminal, solitary.

1 C. campanula'ta (Lam. dict. 1. p: 598. ill. t. 259.) plant glaucescent; root tuberous, fusiform; stems ascending; leaves hastately subcordate, irregularly toothed; flowers solitary, terminating axillary branchlets. 24. G. Native of the Canary Islands. Curt. bot. mag. 444. Gartn. fruct. suppl. p. 63. t. 211. Lodd. bot. cab. t. 376. Herb. amat. t. 14\%. C. lævigàta, G. Don, in Loud. lıort. brit. p. 139. Canària campanulàta, Lin. mant. p. 225. Campánula Canariénsis, Lin. spec. ed. 1. p. 168. Hill. veg. syst. 8. t. 8.-Lin. hort. cliff. p. 65. t. 8.-Pluk. phyt. t. 276. f. 1. alm. p. 76. Flowers drooping, of a yellowish purple or orange colour, having the nerves red.

Campanulate-flowered Canarina. Fl. Jan. March. Clt. 1696. PI 3 to 4 feet.

2 C.? Zanqueba'rica (Alpl. D. C. mon. p. 125.) stem shrubby, scandent, branched; leaves hastately cordate, quite en- 
tire, glabrous; flowers solitary, lateral. h. S. Native of A frica, on the coast of Zanquebar. C. Zanquebárica, Lour. coch. p. 195. Flowers pale. 'This plant agrees with the present genus in the calyx being 6 -cleft, in the corolla being 6 -lobed, in the stamens boing 6 , and in the capsule being 6 -celled; but differs in the capsule dehiscing at the base, not at the apex, in the flowers being lateral, and in the leaves being alternate.

Zanquebar Canariua. Shrub climbing.

Cult. C. campanulata is very desirable, as it flowers in autumn and winter, when few other plants are in bloom. After flowering the stem dies down, and the root continues dormant all the summer, when it necds but little water. When the stem begins to push forth the plants had better be removed to the stove, as they will not flower so abundantly in the green-house. A light loamy soil, or a mixture of loam and preat, is the best soil for it; and the plant is readily increased by dividing at the root or by cuttings, planted in the same kind of soil under a hand-glass. The $C$. Zanguebárica being a stove shrub will grow in the same kind of soil recommended for the first species, and will be easily increased by cuttings.

VII. PLATYCO'DON (from $\pi \lambda a r v s$, platys, broad, and s $\omega \hat{c} \omega v$, kodon, a bcll; in reference to the shape and breadth of the flowers). Alph. D. C. mon. P. 125.-Campánula species, Jacq. hort. vind. 3. p. 4. t. 2. Lam. ill. no. 2513.-Wahlenbérgia species, Schrad. cat. hort. gott. ann. 1814. -Campánula sect. Codònia, Spreng. syst. 1. 1. 735.

Lin, srst, Pcntándria, Monogúnia. Calyx 5-cleft (f. 127.c.). Corolla 5 -lobed at the apex (f. 127.d.), large, funnel-shaped. Stamens 5 (f. 127. a.), free; filaments broadest at the base. Stigmas 3-5 (f. 127.b.). Capsule 3-5-celled, dehiscing by $3-5$ valves at the apex, which are septiferous in the middle; cells when 5 alternate with the calycine lobes and stamens. Seeds ovoid, larger than in any genus of the order, shining, but not angular.Perennial usually glancescent herbs, natives of Eastern Asia. Leaves alternate or nearly opposite, sessile, of a middle size; upper ones the smallest. Flowers few, terminal, solitary, pedunculate.

1 P. Grandiflòrum (Alph. D. C. mon. p. 125.) plant quite glabrous, glaucescent; leaves ovate-lanceolate, coarsely serrated; corollas large, somewhat 5 -cleft ; stigmas 5 , and capsule 5-celled. 4 . H. Native of Dahuria. Grmel. Campánula grandiflòra, Jacq. hort. vind. 3. p. 4. t. 2. Curt. bot. mag. 252. llerb. amat. t. 112. Campámula gentianoldes, Lam. dict. 1. p. 781 . ill. 2513 . Wahlenbérgia grandiflòra, Schrad. cat. hort. gott. 1814. diss. de gen. Blumenb. p. 38.-Gmel, sib. 3, p. 153 . t. 2S.-Amm. stirp. rar. ruth. no. 16. p. 11. Stems simple. Corollas deep blue. Peduncles terminal. (f. 127.)

Great-flonered Platycodon. Fl. July, Aug. Clt. 178\%. Pl. $\frac{1}{3}$ to 1 foot.

2 P. homaldáminum (Alph. D. C. mon. p. 126.) plant $r$ ather pilose at the top; leaves lanceolate or linear-lanceolate; corolla deeply 5 -cleft; stiumas 3 ; capsule 3-celled. 24. H. Native of the east of Siberia, near Ijiga, ex Fisch.; of Kantschatka, ex Redowsk; and of China, ex Sir G. Staunton. Stcins simple. Leaves coarsely and unequally serrate-toothed, voL. III. glabrous. Flowers usually 4.6 , disposed in a loose raceme; pedicels hairy, l-flowered. Calyx hairy. Corolla downy.

I ar, a, latifolinu (Alph. D. C. I. c.) leaves broader, coarsely serrated, 4. H. Cauısánula Redowskiàna, Cham. et Schlcchr. in Linntea. 1. p. 41. Camp. homallánthina, Led. act. petro]) 5. 13. 524. Wahlenbérgia Kruhsiàna, Fisch, in herb. D. C.

Var. $\beta$, angustifolium (Alph. D. C. l. c.) leaves linear-lanceoJate, quite entire. 4. H. Campánula lıomallánthina, Led. act. petrop?. 5. 1). 524 .

Equal-flowered l'latycodon. Pl. $\frac{1}{2}$ to 1 foot.

Cult. These species of Plalycódon are neat elegant plants. when in blossom. They do best in pots in a mixture of sand and peat, placed among other alpine plants; they will also grow very well planted in a peat border. We know of no way of increasing them but by seeds.

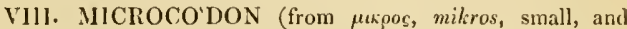
$\kappa \omega \hat{c} \omega \mathrm{v}, \mathrm{kodon}$, a bell; in reference to the shape and smallness of the flowers). Alpl. D. C. mon. p. 127.-Campánula spec. Eklon.-Wahlenbérgia spec. Schrad.

Lun. sysr. Pentándria, Monogýnia. Calyx 5-cleft. Corolla 5 -lobed at the apex, small, cylindrical, permanent. Stamens 5 , free; filaments very slender, not expanded at the base. Style filiform; stigmas 5 . Capsule 5 -celled, dehiscing by 5 valves at the apex; cells alternating with the calycine segments and stamens. Seeds ovoid, small, shining, but not angular.-Humble annual herbs, natives of the Cape of Good Hope. Leaves alternate or nearly opposite, small, narrow, sessile: superior ones rather the longest. Branches at the base of the plant opposite and diverging. Flowers almost sessile. Tube of calyx spherical and very bairy.

1 M. glonera'tum (Alph. D. C. mon. p. 127. t. 19.) stem branched; branches simple ; leaves linear, acuminated ; flowers glomerate, terminal. ๑. H. Native of the Cape of Goorl Ilope. Campánula hispídula, Eklon, in herb. Dunant, but not of Lin. Campanulàceæ, Burch. cat. pl. afr, austr. no. 189. Stems rather pilose. Leaves somewhat denticulated, rather lairy.

Glomerate-flowered Microcodon. Pl, $\frac{1}{4}$ to $\frac{1}{2}$ foot.

2 M. sparsiflòrum (Alph. D. C. mon. p. 1※8.) stem branched: branches subdivided; leaves linear-lanceolate; flowers solitary. $\odot . H$. Native of the Cape of Good Hope. Wahlenbérgia hispídula, Schrad. in herb. D.C. Campánula hispídula, Link, enum. 1) 215. Stem pilose. Leaves rather pilose. Flowers solitary towards the tops of the branches, not terninal, but rising from the axils of the upper leaves or bracteas.

Scaltered-flowered Microcodon. Pl. ? foot.

Cult. The seeds of these plants should be raised on the hotbed; and when the plants are of sufficient size they may be planted out into the open border in May in a warm sheltered situation.

IX. WAHLENBE'RGIA (named after George Wahlenberg, M.D., author of Flora Lapponica, 1 vol. 8vo. Berlin, 1812, Flora Carpathorum præcipiorum, l vol. 8vo. Gottingen, 1814. \&c.) Schrad. cat. hort. gott. 1814 . Roth, nov. spec. ind. orient. p. 399. D. Don, prod. fl. nep. 156. Schrad. diss, de gen. Blumenb. \&c. 1827.p. 3\%. (exclusive of Campánula grandifiòa, Jacq.) but not of Blum._-Campánula (Codònia), Spreng. syst. 1 . p. 735. - Scluultèsia, Roth, enum. pl, phan. germ. pars. 1827. hut not of Spreng. and others.-Cervicina, Delile, f. d'egypt. p. 7. t. 5. f. 2.-Campánula (Campanópsis) R. Br. prod. p. 561 . Campánula suecies, Lin. gen. 88. spec. 240. Juss. gen. 164.

Lin. sist. Pentándria, Monogýnia. Calyx 3-5-cleft (f. 128. a.). Corolla $3-5$-lobed at the apex (f, 128. b.), rarely divided to the middle. Stamens $3-5$, fice; filaments rather broadest at $5 \mathrm{~B}$ 
the base. Style inclosed, pilose, but most so towards the upper part. Stigmas $2-5$ (f. 128. $c$.). Ovariun combined with the tube of the calyx. Capsule 2-5-celled(f.128.e.) each opening by so many valves at the apex, which bear each a dissepiment in the middle. Seeds very numerous, minute.- Herbs, rarely shrubs, for the most part annual. Leaves usually alternate, rarely opposite, generally most numerous towards the lower part of the plant. Flowers for the most part on long peduncles; pedicels drooping at first, but when bearing the capsules are perfectly erect. 'The species of this genus are most plentiful in the southern hemisphere, particularly at the Cape of Good Hope.

Sect. I. EDraiántha (from ec̀ocacos, edraios, sedentary, and av0oc, anthos, a flower; in reference to the flowers being sessile, and usually capitate). Alph. D. C. mon. p. 130.-Campánula species, Lin. and others. Corolla and calyx 5 -lobed. Stamens 5. Capsule $2-3$-celled. Seeds ovate, flat-Humble perennial herbs. Leaves alternate, narrow; radical ones crowded; cauline ones stem-clasping. Flowers sessile, usually capitate.Inhabitants of Italy and the adjacent countries.

\section{* Plants cauleseent. Floners aggregate.}

1 W. graminifòlia (Alph. D. C. mon. p. 130.) stems and leaves clothed with soft down; leaves entire : radical ones linear or linear-spatulate: cauline ones linear, and somewhat stemclasping; bracteas ovate, acute, entire, rather downy ; tube of calyx smoothish: but the lobes are downy, and the sinuses are toothless. 4. H. Native of Sicily; south of Italy, even to Rome; and the Island of Zante. Campanula graminifolia, Lin. spec. 1. p. 234. Sibth. et Smith, A. graec. t. 206. but not of Waldst. et Kit.-Barr. icon t. 332.-Mor. ox. 2. p. 454. sect. 5. t. 1. f. 9. Cup. panph. 1. p. 736.-Boce. icon. rar. p. 78. f. 2. Mor. ox. 2. p. 461. sect. 5. t. 4. f. 41. Colum. phyt. p. 25. t. 26. ed. 2. p. 1 I8. t. 34. Flowers disposed in solitary, bracteated, terminal heaps. Corolla blue; filaments white; anthers yellow.

Grass-leated Wahlenbergia. Fl, May, July. Clt. 1816, Pl. $\frac{1}{2}$ foot.

$2 \mathrm{~W} . \mathrm{G}_{\mathrm{ARGA}}$ 'vicA ; perennial, downy, canescent ; stems diffuse or pendulous, simple; leaves roundish, cordate: lower ones on long petioles, deeply and unequally crenated: upper ones dentate; crenatures and teetlı mucronate; racemes loose, leafy; pedicels tiliform, 1-flowered; calycine segments lanceolate, acuminated, reflexed. 4 . H. Native of Abruzzo, in the fissures of rocks on Mount Gangano, now St. Angelo. W. flaccida, Presl, symb. p. 29. t. 18. but not of Alph. D. C.

Gargano Wahlenbergia. Pl. diffuse.

3 W. Kitaibe'li (Alph. D. C. mon. p. 131.) stems beset with soft pili; leaves ciliated a little: radical ones linear-subulate, remotely denticulated; bracteas ovate, acuminated, dentately subserrated, ciliated with villi; tube of calyx villous, and the lobes subdenticulated, as well as the sinuses, and downy on both surfaces. 4 . H. Native of Croatia, on chalky mountains; and of Transylvania, in the fissures of calcareous rocks. Campánula graminifòlia, Waldst. et Kit. pl. rar. hung. 2. p. 166. t. 15.1. exclusive of the synonymes. Host, $\mathrm{fl}$. austr. 1. p. 268. exclusive of the synonyme of Camp. tenuifolia, Waldst. et Kit. Plant tufted. Stems purplish. Radical leaves crowded. Flowers disposed in terminal bracteated lieaps. Corolla blue, with a tinge of purple; filaments white; anthers yellowish.

Kitaibcl's Wahlenbergia. Pl. $\frac{1}{2}$ foot.

4. W. tenuròlia (Alplı. D. C. mon. p. 133.) stems pilose; leaves linear, entire, with bristly margins; bracteas ovate, acuminated, ciliated with bristles; tulse of calyx rather pilose; lobes of calyx ciliated with bristles, and the sinuses toothless. 24. H.
Native of Croatia, at the foot of the mountain called Plisswicza; also near Fiune. Campánula tenuifolia, Waldst. et Kit. pl. rar. hung. 2. p. 168. t. 155. Campánula graminifòlia, Host, fl. a!str. 1. p 268. exclusive of the synonymes of Column, and Waldst. et Kit, Campánula graminifòlia, $\beta$, Schow. plan, ein. pfl. geogr. ital, p. 11 . Stems tufted, purplish. Flowers disposed in dense terminal bracteated tufts, $6-10$ in each tuft. Corolla of a violet-blue colour, white at the base; filaments white; anthers yellow.

Fine-leaved Walilenbergia. Fl, June, July. Clt. 1817. Pl. $\frac{1}{4}$ to $\frac{1}{2}$ foot.

5 W. Dalmática (A]ph. D. C. mon. p. 13 t.) stems glabrous; leaves linear-lanceolate, entire, ciliated with hairs; bracteas ovate-acuminated, entire, ciliated; tube of calyx rather pilose ; lobes of calyx entire, ciliated, rather pilose on the back, with the sinuses toothless. 24. I1. Native of Dalmatia, on the east of Salona. Stems reddish. Leaves 1-2 inches long. Heads containing 6-10 flowers, bracteate. Corolla blue; filaments ciliated; anthers yellow. Plant tufted.

Dalmatian Walılenbergia. Pl. $\frac{1}{4}$ to $\frac{1}{2}$ foot.

\section{* * Stems short. Floners solitary.}

6 W. pumicio (Alplı. D. C. mon. p. 134.) plant tufted; stems short, very leafy; leaves linear, entire, glabrous beneath, revolute on the margins at top, and pilose in the middle: hairs adpressed, pencilled or in tufts at the tops of the leaves; upper leaves broadest at the base, and covering the flower; tube of calyx obconical, glabrous; lobes of calyx entire, similar to the leaves. 24. H. Native of Dalmatia, in the higher alpine ranges of Mount Bioccovo. Campánula silenifòlia, Host, $A$. austr. 1. p. 268. but not of Fisch. Campánula pumilio, Portenschl. ined. Rom. et Schultes, syst. 5. p. 136. Visian. stirp. dalm. spec. p. 29. Plant with the habit of Silène acaúlis. Flowers sessile, solitary, numerous. Corolla azure blue; anthers yellow.

\section{Drarf Wahlenbergia. Pl. tufted.}

Sect. II. Alkíia (named in honour of John Aikin, a British botanist). Alph. D. C. mon. p. 135.-Campánula species, Lin. Camp. sect. Codonópsis, R. Br. prod. 561.-Wahlenbérgia species, Schrad. Corolla and calyx 5-lobeci. Stamens 5 . Capsule 3-5-celled. Seeds ovoid.-Usually annual herbs. Leaves for the most part alternate. Flowers on more or less elongated peduncles and pedicels. Generally inhabitants of the southern hemisphere, particularly of the Cape of Good Hope; also of Australia and India.

$\$ 1$ Capsule 5-celled. Seeds shining. Stems erect or ascending. Peduncles elongated, naked. Leaves alternate, sessile. All natives of the Cape of Good Hope.

7 W. CArE'Nsis (Alph. D. C. mon. p. 136. t. 18.) stem erect, simple or branched, pilose at the bottom ; leaves ovate-lanceolate, pilose, irregularly toothed : tube of calyx ovoid, very hairy; corolla 5-cleft, hardly one-half longer than the calycine lobes; capsule ovoid, pilose. $\odot$. H. Native of the Cape of Good Hope, in sandy places. Campảnula Capénsis, Lin. spec. p. 240. Thunb. prod. p. 39. inem. acad. petersb. 4. p. 374 . t. 6. f. 3. Sims, bot. mag. 782. Roélla decúrrens, Andr, bot. rep. t. 238. Wahl. elongata, Schrad. cat. hort. gott. 1814. Willd. enum. suppl. p. 10. Campánula elongàta, Willd. lierb. Flowers large, at first drooping, but at length nearly erect. Corolla bluish-green on the outside, dark blue inside at the bottom, but greenish at the origin of the lolses, spotted with black within the lobes at the recesses, and the lobes are violaceons. 2 feet. 
8 W. DIFFU'sa (Alpl., D. C. molr. p. 137.) stcm weak, much branched, glabrous, or rather pilose; leaves linear, acuminated, somewliat denticulated; calyx glabrous or pilose, with a spherical tubc; corolla 5-lobed at the apex, hardly longer than the calycine lobes; capsule spherical, glabrous. $\odot$. H. Native of the Cape of Good Hope. Campánula rubioides, Banks, herb.-Comm. hort. t. 37.? Calyx quadrifid.

Diffuse Wahlenbergia. Fl. June, July. Clt.? Pl. 1 foot.

9 W. LINEA'R1S ( $\Lambda$ lph. D. C. mon. p. 137.) stem flexuous, ercet, filiform, simple and glabrons at the base; leaves linear, entire, glabrous; calyx glabrous or pilose, with a spherical tubc; corolla 5 -lobed at the apex, hardly longer than the calycine lobes; capsule spherical, glabrous. $\odot$. H. Native of the Cape of Goud Hope, in sandy places. Campánula limeàris, Lin. suppl. p. 140. Thunb, prod. p. 38. mem. acad. petersb. 4. t. 5. f. 3. Stem purplish. Flowers somewhat panicled, white; peduncles and pedicels capillary, drooping when bcaring the flowers, and crect while bearing the frust.

Linear-leaved Wahlenbergia. Pl. $\frac{1}{2}$ foot.

\$2. Capsule 3-celled. Seeds shining or dotted. Stems ereet or procumbent. Peduncles naked, more or less elongated. Leaves ulternate, rarely opposite.

* Seeds usually dotted. Stems branched, slender, usually procumbent. Leaves sessile or petiolate, and opposite or alternate in the same specimen.

10 W. FLA'ccida (Alph. D. C. mon. p. 138.) plant rather pilose; stem erect, simple, rather leafy ; leaves opposite and alternate, ovate, acute, entire; calyx pilose, with an ovoid tube; corolla 5-lobed, one-half longer than the calycine lobes; capsule ovoid, splerical. $\odot$.H. Native of the Cape of Good Hope, where it was collected by Masson. Campanula fláccida, banks, herb. Flowers solitary, terminal. Peduncle not different from the stem, being leafy like it.

Flaccid Wahlenbergia. Pl. $\frac{1}{4}$ foot.

11 W. diversifòlia ( $\mathrm{AJ}$ h. D. C, mon. p. 139.) stem procumbent, branched, not very leafy, glabrous above, and pilose below: leaves alternate and oppositc, smoothish: lower ones obovatc-roundish, crenately toothed: the rest ovate-lanceolate, acute, toothed; calyx glabrous, with an ovoid-spluerical tube; corolla onc-half longer than the calycine lobes; capsule obconically ovoid. $\odot$. H. Native of the Cape of Good Hope. Campánula Eklon, in herb. Dunant. Flowers on long pedicels, which are either terminal or axillary on the upper part of the plant.

Diverse-leaved Wahlenbergia. P't, procumbent.

1. WV. Madagascarie'Nsis (Alph. D. C. mon. p. 139.) stem erect, branched, glabrous, not very leafy, rather pilose above; lcaves strictly opposite, ovate, acute, crenated, glabrous; calyx rather pilose, with a spherical tube; corolla profoundly 5-cleft, length of the calycine segments; capsule spherical. $\odot . ? \mathrm{H}$. Native of Madagascar. Sten branched from the basc. Flowers solitary, pedicellate, situated in the axils of the forks of the branches.

\section{Madagascar Wallenbergia. Pl, $\frac{1}{2}$ foot.}

13 W. Procu'mbens $(\Lambda$ pl). D. C. mon. p. 140. t. 15.) plant glabrous or racher pilose; stems creeping, branched, very leafy; leaves opposite or verticillate, ovate or obovate, nearly entire; tube of calyx ovoid; corolla 5 -lobed at top, 3 times longer than the calycine lobes; capsule ovoid, spherical. $4 . \mathrm{G}$. Native of the Cape of Good Hope, in watery places. Campánula procúmbens, Thunb. $f$. cap. p. 174. men. acad. petersb. 4. p. 375. Lin. fil. suppl. 141. Wahl. rèpens, Schrad. diss. de Blumenb. p. 37.-Burch. cat. pl. afr. austr. no. 355 . Flowers solitary, ustially terminal, but sometimes axillary, pedicellate. Corolla pale blue; anthers yellow.
Var. $\beta$, foliòsa ( $\Lambda$ lph. D, C. mon. p. 110. t. 15. f. 6.) stems shorter; luaves approximate and smaller. 2. G. Campánula, Burch. cat. pl, afr, no. 361. and no. 508.

Procumbent Wahlenbergia. Pl. creejing.

* Sceds dotted. Stems branched, slender, usually procumbent. Leaves petiolate, alternate.

14 W. hedera'cea (Alph, D. C. mon. p. 1tif.) glabrous ; stems slender, ascending; leaves on long petioles, cordatcroundish, bluntly 5-7-angled; corolla 5-lobed at the apex, 4 times longer than the calycine segments; capsule hemisplierical. 4. H. Native of the west of Europe and North America, in watery places. In Europe, from the north of I'ortugal to Denmark, but towards the east it becomes more rare. In Britain, abundant in Cornwall, and in many parts of the west of England ; in Sussex abundant; Keston Conmon, near Bromley, Kent; on Hartlebury Common, Worcestershire; on a bog near Hligh-Beech, Epping Forest. In the connty of Cork, Ireland. In several parts of the lowlands of Scotland; and in the Scilly Islands. Campánula hederàcea, Lin. spec. p. 240. Oed. f. dan. t. 330. Smith, engl. bot. t. 73 . Hook. fl. lond. t. 93. Campánula hederaéölia, Salisb. prod. 127. Campánula arvática, Lag. in variet. de cienc. litt. Sc. no. 29. oct. 1805. p. 40. Aikínia hederàcea, Salisb. in herb. D. C. Schultèsia, Roth, enum. pl. 1. p. $180 \%$-Moris. oxon. 2. p. 4.56: sect. 5. t. 2. f. 18. Pluk, phyt. 23. f. 1. Petiv, gaz. t. 5I. f. 1. --T'ourn. inst. 1. p. 112. Garid. aix. 1.p. 76. Stems filiform, creeping and ascending. Peduncles naked, one-flowered, usually terminal, but sometimes axillary. Corolla pale blue. foot.

Ity-like Wahlenbergia. Fl. May, June. England. Pl. $\frac{1}{2}$

* * Seeds shining. Stcms more or less erect. Leates altcrnate, sessile, narron.

\section{a. Peduncles elongated.}

15 W. GRA'clurs (Alph. D. C. mon. p. 142.) stem simple or branched, glabrons or pilose; leaves alternate or ncarly opposite, linear. lanccolate, sinuately toothed, glabrous; calyx smootlish, with an ovoid tube; corolla funnel-shaped, 5-cleft; capsule obovate. $\delta . ?$ G. Native of Van Diemen's Land; and of New Holland, about Port Jackson; and of New Caledonia and New Zealand. All the varieties grow in New Hollanel, except var. $\varepsilon$, which only grows in New Zealand. Campánula grácilis, Forst. prod. no. 84 . Sims, bot. mag. 691. R. Br. prod. p. 561. Campánula vincæflòra, Vent. malm. t. 12. Campánula capillàris, Lodu. bot. cab. t. 1406. Peduncles terminal and axillai y, elongated, l-flowered. Corolla blue, with a white or yellowish bottom. Anthers yellowish.

Far. $\beta$, stricta (Alph. D. C. mon. p. 142.) stem branched, straight; leaves more numerous, opposite, linear-lanccolate; calycine segments linear, exceeding the tube of the corolla it little, which is discoloured on the outside. $\delta$. G. Campanula grácilis, Smith, exot. A. t. 45. Campánula grácilis, $\beta$, strícta, R. Br. prod. p. 561 .

I ar. $\gamma$, littorilis (Alph. D. C. l. c.) stem simple, clongated; leaves few, alteruate, linear, narrow; calycine lobes acuminaterl, length of the tube of the corolla. \$. G. Campranula littoratis, Labill. nov. holl. 1. p. 69, t. 70 . Camp. grácilis, $\gamma$, littoràtis, R. Br. prod. p. 561 .

lar. $\delta$, capillàris ( $\mathbf{A l p h .}$ D. C. J. c.) stem capillary, panicled; leaves lincar, remote; segments of the calyx one-laalf shorter than the capsule, which is nearly globose. $\delta$. G. Campánula grácilis, $\delta$, capillàris, $\mathrm{R}$. Br. prod. p. 561 .

lar. $\varepsilon$, polymórpha (Alph. D.C. l. c.) lower leaves obovate, obtuse: middle ones lanceolate : upper ones linear-lanccolate; calycine segments broadish, one-half shorter than the corolla. 5 B 2 
๖. H. Native of New Zealand. Campánula polymórpla diffùsa, Soland. in herb. Banks.

IV cak Wahlenbergia. Fl. April, May. Clt. 1794. PI. $\frac{1}{2}$ to 1 foot.

16 W. Chamissonia'na; stems ascending, branched at the base, and leafy, but naked at the apex, and forming erect, fewHowered, elongated peduncles, which are furnished with a few bracteas ; leaves ovate-lanceolate, sessile, marginated by a nerve, obscurely few-toothed, sinuated and undulated, having the keel and margins running down the stem, sometimes beset with a few spreading, stiff, white hairs, and sometimes glabrous; sterile hranches always pilose; bracteoles ovate, acute, ciliated. $\odot . ?$ 4.? G. Native of the Cape of Good Hope. Wahlenbérgia, no. 3. Cham. in Linnæa. 7. p. 194. Ovarium obconical, 10nerved. Segments of the calys ovate, acute, ciliated. Corolla funnel. slaped, with an ample deeply 5 -cleft limb, and narrowelliptic, acute segments. Capsule 2-celled, 2-valved. Stamens 5. Stigma trifid. Seeds ovoid, swooth, shining, brown.

lar. $\beta$, micrántha (Cham. l. c.) plant taller and slenderer ; stems erect, 2-3 feet high; leaves 15 lines long and 3 broad, less undulated and flatter; diameter of corolla half an inch.

iar. $\gamma$, macrántha (Cham. l. c. p. 195.) old branches nearly naked; stem erect, liardly a foot ligh ; leaves more crowded, 9 lines long and 4 . lines broad at the base, or oblong-elliptic, hlunter, more undulated; diameter of corolla an inch.

Chamisso's Wahlenbergia. Pl. 1 to 3 feet.

17 W. Margina'ta (Alph. D. C. mon. p. 143.) stem branched, glabrous; leaves alternate or nearly opposite, lanceolate and linear-lanceolate, undulately subserrated, with pilose margins ; calyx glabrous, with an obovate tube; corolla funnel-shaped, liardly one-half longer than the calycine lobes. $\%$. G. Native of Japan, by road sides between Arai and Quana. Campánula marginàta, 'Thuunh. fl. jap. p. 89 . pl. jap. dec. with a figure. Campánula grảcilis, var. Spreng. pug. no. 28. Roem. et Schultes. syst. 5. p. 133. Root or lower part of stem thick and woody, decumbent. Branches herbaceous, erect and branched. Marwins of leaves white. Peduncles terminal and axillary, elongated, l-flowered. Corolla small, blue.

. Yarginate-leaved $\mathrm{W}$ ahlenbergia. Pl. $\frac{1}{2}$ foot.

18 W. Lavandulefòlia (Alph. D. C. moì. p. 14\%) stem filiform, angular, striated; branches 1-3-flowered; leaves sessile, linear, obtuse, obsoletely and remotely serrulated ; flowers quinquefid; corolla exceeding the ovarium a little. $\%$. G. Native of Japan, on the mountains. Campánula lavandulæfolia, Blum. bijdr. p. 726 .

Lavender-leaved $\mathrm{W}$ ahlenbergia. Pl. $\frac{1}{2}$ foot.?

19 W. Quadífida (Alpl. D. C. mon. p. 144.) stem filiform, angularly striated, pilose as well as the leaves, which are linear; flowers quadrifid; corolla hardly exceeding the ovarium; stigmas 3. 24? G. Native of New South Wates, about Port Jackson. Campánula quadrífida, R. Br. prod. p. 561. Flowers hlue. This species comes very near to Wahl. grácilis, and is probably only an earlier variety of it.

Quadrifid-flowered Wahlenbergia. Fl. June, Aug. Clt. 1820. Pl. $\frac{1}{2}$ to 1 foot.

20 W. saxícola (Alph. D. C. mon. p. 144.) glabrous; stem short; leaves crowded, lanceolate, a little toothed; peduncles 1-flowered, scape-formed; flowers quadrifid; capsule globose. 4.? G. Native of Van Diemen's Land. Campánula saxicola, R. Br. prol. p. 561 . This is very nearly allied to $\mathrm{W}$. quadrifida. Rock Wahlenlergia. PI. $\frac{1}{2}$ foot.

21 IV. SIERE'R (Alph. D. C. mon. p. 144) stem branched, very hispid at the base; leaves somewhat denticulated, acute: lower ones obovate-lanceolate, pilose : superior ones linearlanceolate, smoothish; calyx glabrous, with an ovoid tube; corolla tubular, nearly 3 times larger than the calycine lobes; capsule obovoid. ๑. H. Native of New Holland. Campanulàcea, Sieb. f. nov. holl. no. 577. Peduncles naked, divided into ]-flowered pedicels; the flowers are therefore somewhat panicled. Corolla blue, small. Stem angular at the base.

Sicber's Wahlenbergia. Pl. $\frac{1}{2}$ foot.

22 W. DEhíscens (Alph. D. C. mon. p. 145.) stem branched or simple, rather pilose at the hase; leaves rather pilose : lower ones lanceolate-obovate, bluntish, undulately toothed; calyx glabrous, with an obovate tube; corolla funnel-shaped, one half longer than the calycine lobes; capsule obovoid. $\odot . \mathrm{H}$. Native of Bengal and Nipaul. Campánula delíscens, Roxb. hort. beng. p. 85 . fl. ind. 2. p. 96. Wall. in asiat. researc. 12. p. 571 . with a figure. Lower leaves numerous. Peduncles terminal and axillary, nearly naked, divided into 1-flowered filiform pedicels. Corollas small, white. Capsule dehiscing by 3 valves at the top.

Dihiscont Wahlenbergia. Fl. Aug. Clt. 1818. Pl. 1 foot.

23 W. Agre'stis (Alph. D. C. mon. p. 145.) stem branched from the base, pilose and leafy at bottom, but naked and smoothish above; leaves linear, narrow, nearly entire, with undulated margins; peduncles subdichotomous, erect; tube of calyx obovate; corolla funnel-shaped, twice longer than the calycine segments; capsule obovatc. $\odot$. H. Native of Nipaul. Campánula agréstis, Wall. in Roxb. fl. ind. 2. p. 97. Lcaves rather pilose. l'eduncles elongated, erect, naked, sometimes dichotomous; pedicels terminal, 1-flowered. Corolla blue.

Field Wallenbergia. PI. 1 foot.

24. W. I'ndica ( $A]_{p}$ h. D. C. mon. p. 146.) stem branched, rather pilose at the base; leaves linear, rather pilose, entire, accuminated; tube of calyx ovoid, glabrous; corolla one-half longer than the calycine lobes; capsule obconical. $\odot . ? \mathrm{H}$. Native of the East Indies, on the Nellyghery monntains, where it was collected by Leschenault, and where it is called Aleka. Habit of $W$. linarioides. Peiluncles $\mathrm{l}$-flowered, glabrous. Flowers terminal, nutant. Capsu'e erect.

Indian Wablenbergia. Pl. $\frac{1}{2}$ foot.

25 W. RIPA'RiA (Alph. D. C. mon. p. 146.) plant pilose at the base, and glabrous at top; leaves few, undulately toothed, rather hairy : lower ones obovate-lanceolate : the rest narrower, glabrous, and accuminated; calyx glabrous, with an ovoid narrow tube; corolla one-lialf longer rlan the calycine lobes; capsu'e ohovoid. ๑. H. Native of Senegal, in the regions called lodor and Walo, where it was collected by Leprieur and Perrottet. Campánula ripària Lepr. et Perrott. in lit. Stem simple or branched, leafy at the base, and naked at the top. Peduncles erect, divided into filiform 1 -flowered pedicels.

River-side Wahlenbergia. Pl. $]$ to $1 \frac{1}{2}$ foot.

26 W. nu'mlis (Alph. D. C. mon. p. 147.) plant pilose at the base, and glabrous at top; leaves much crowded at the bottom, linear-lanceolate: upper ones ligulate; calyx glabrous, with an ovoil narrow tube; corolla one-half longer than the calycine lobes; capsule ovoid. $\odot$. H. Native of Senegal. Stem very leafy at the base, divided into many 1 -flowered pedicels at top.

Humble Wablenbergia. Pl. $\frac{1}{4}$ foot.

27 IV. DENUdA'Ta (Alpl. D. C. mon. p. 14.7.) plant quite g]abrous; stem simple, few-flowered; leaves linear-lanceolate, with undulated, nearly entire margins; tube of calyx, obconical, elongated : capsule elongated, obovate. $\odot$. $\boldsymbol{~}$. H. Native of the Cajre of Good Hope. Campanulàceæ, Burch. cat. pl. af. no. 2769. Habit of $I^{\circ}$. Capénsis. Stem erect, only leafy at the base. Leaves greyish-green, with white elges. Flowers solitary, terminal.

Naked Wallenbergia. Pl, I foot.

28 W. ce'rnva (Alph. D. C. mon. p. 148.) stem much 
branched, pilose at the base; lower and middle leaves ovate, acute, irregularly toothed, and pilose: superior ones narrower, nearly entire, smoothish ; tube of calyx glabrous and obconical; lobes of calyx with revolute scrulately ciliated margins; corolla funnel-shaped, 2 or 3 times longer than the calycine lobes, somewhat 5 -cleft at the apex; capsule obovate. $\odot . H$. Native of the Cape of Good Hope. Campanula cérnua, Thunb. prod. p. 39. mem. acad, petersb. 4. p. 376. t. 7 . f. 1.-Comm. hort. 2. t. 36. Stem very leafy at the base. Pecluncles erect, elongated, terminating in numerons 1 -flowered filiform pedicels. Corolla funnel-shaped, with a white base, and blue lobes, drooping in the bud state.

Drooping-flowered Wahlenbergia. Fl. June, Aug. Clt. 1804. H. $\frac{1}{4}$ to $\frac{1}{2}$ foot.

29 W. undula'TA (Alph. D. C. mon. p. 148.) stem ascending, simple at the base, pilose; leaves somewhat stem-clasping, ovate, or ovate-lanceolate, coarsely crenated, pilose; calyx glabrous, with an obconical tube, and broad flat serrately ciliated lobes; corolla funnel-shaped, 5-cleft, 3 times longer than the calycine lobes; capsule obconical. $\odot$. H. Native of the Cape of Good Hope, in Swartland. Campánula undulàta, Thunb. prod. p. 39. Lin. suppl. p. 142. Campánula glabràta, Banks, herb. Stem branched, naked and glabrous at top. Peduncles elongated, nearly naked, panicled; pedicels 1-flowered, rising from the axils of the bracteas. Flowers rather nutant.

Undulatcd-leaved Wahlenbergia. P]. 1 to $1 \frac{1}{2}$ foot.

30 W. nudicau'Lis (Alph. D. C. mon. p. 149.) stem branched, rather pilose at the base; leaves obovate or lanceolate, undulately crenated, rather pilose; calyx glabrous, with a nearly spherical tube, and entire lobes; corolla broadly funnelsliaped, deeply 5 -cleft, 3 or 4 times longer than the calycine lobes; capsule spherical. $\odot . ?$ G. Native of the Cape of Good Hope. Root cylindrical at its top, branched at the base. Stems numerous, branched, usually dichotomons. Leaves nearly all at the base of the plant, obtuse or acute. Flowers very numerous, terminating the s!ender naked pedicels. Corolla funnel-shapid, blue, ? drooping in restivation. herb.

Var. $\beta$. Flowers larger. - Campánula elongàta, Banks,

Nahed-stemmed Wahlenbergia. PI. 1 foot.

31 W. Androsa'cea (Alpl,. D. C. inon. p. 150. t. 19. f. 1.) stem simple, naked, few-flowered, glabrous; radical leaves rosulate, ovate-lanceolate, on short petioles, acute, denticulated, pilose; calyx glabrous, with a hemispherical tube, and short broad entire lohes; corolla broadly funnel-shaped, profoundly 5 -cleft, 2 or 3 times longer than the calycine segments; capsule spheroid. $\odot$. G. Native of the Cape of Good Hope. Campanulàcer, Burch, cat. geog. pl. afr. austr. no. 2273. Stem twice dichotomous at top, and nearly naked, except the bracteas at the base of the pedicels. Branches $\underset{\sim}{2}$ divided into 21 -flowered pedicels at the apex. Flowers erect in the expanded state, but drooping in the bud state, probably blue.

Androsace-like Wahlenbergia. l'l. $\frac{1}{2}$ foot.

32 W. stellarioides (Cham. in Schleclit, in Linnæa, 7. p. 196.) stems ascending, a little tufted, filiform, tetragonal, glabrous; leaves opposite, somewhat connately approximate, lanceolate, acute, with revolute edges, and the nerve slender, pilose, or glabrous bencath; flowers terminal and lateral, on long pedicels: ovarium elliptic, short; calycine segments very like the leaves, but one-lialf shorter than the corolla; corolla funnelshaped, 5-cleft to the middle, with acute ovate segments. 4 . G. Native of Caffraria. Stem branched at the base. Stamens 5. Calycine segments reflexed.

Stichnort-like $\mathrm{W}_{\text {ah }}$ enbergia. PI. 1 to $1 \frac{1}{2}$ foot.

33 W. Nutabu'NaA (Alph. D. C. mon. p. 151.) plant pilose at the hase; stem simple, or branched at the base; lower leaves lanceolate-obovate, nearly entire, with the nerves and margins pilose: the rest lanceolate, acute, smoothish, and irregularly toothed; calyx glabrous, with an ovoid tube; corolla cylindrical, 5-lobed, hardly one-half longer than the calycine lobes; cajsule obovate. $\odot$. ? H. Native of Calabria, near Reggio, on very arid liils; and of Sardinia, in the ficlds of Carbonara and Tortote, cx Moris. Campánula nutabúnda, Guss. in Ten. append. 5. ad $A$. neap. prod. p. 8. pl. rar. p. 94. t. is. Mor. stirp. sard. elench. p. 30 . Habit of $W$. lobelioides Leaves numerous at the base of the plant. Peduncles nearly naked, elongated, drooping when bearing the flowers, but at length erect, 1-flowered, glabrous. Corolla white.

Nodding-flowered Walilenbergia. Pl. $\frac{1}{4}$ foot.

\section{b. Peduncles shorter.}

34 W. exilts (Alph. D. C. mon. p. 151.) stem much branched, ratlier pilose at the base; branches glabrous, filiform; leaves linear, subulate, entire, rather pilose; tube of calyx glabrous or roughish, obconical; corolla tubular, 5cleft at the apex, scarcely one-half longer than the calycine lobes; capsule obovate, narrow. $\odot$. II. Native of the Cape of Good Hope. Burch. cat. no. 10j. Stem quite glabrous at top. Pedicels mostly axillary, 1-flowered, reddish.

Slcnder Wahlenbergia. Pl. $\frac{1}{4}$ to $\frac{1}{2}$ foot.

35 W. Denticlea'ta (Alph. D. C. mon. p. 152. t. 16.) stem much branched, glabrous, but rather scabrous above; leaves narrow-linear, acuminated, glabrous, remotely denticulated ; calyx glabrous or scabrous, with a hemispherical tube, and denticulated lobes; corolla deeply 5 -cleft ; capsule spheroid. $\odot . H$. Native of the Cape of Good Hope, in the interior of the country. Campánula denticulata, Burch. cat. pl. afr. no. 2000 . trav. 1. p. 538. Flowers numerous towards the tops of the branches. Pedicels axillary and terminal, I-flowered, diverging much from the stem. Corollas blue?

Var. $\beta$, scábra (Alpl. D.C.l. c.) peduncles and calyxes rather scabrous, Burch, cat, pl. afr, no. 2302.

Denticulated calyxed Wahlenbergia. Pl. $\frac{1}{4}$ foot. Var. $\beta, 2$ in.

36 W. KRE' BsII (Cham. in Schlecht. Linnæa. 7. p. 195.) stems rather herbaceous, filiform, procumbent, very leafy at the origin of the fertile branches, tetragonal : angles beset with retrograde bristles; leaves crowded, spreading, rather stiff, lingulate or obovate-oblong, obtuse or acute, sinuately-tooihed, with reflexed margins, having the keel and margins pilose or glabrous; branches erect, naked above, elongated, divided into an irregular branched panicle; bracteoles quite entire, acute ; ovarium globose; calycine segments oblong-triangular, bluntish, almost nerveless, pellucid, with scabrous edges; corolla funnelshaped, quinquefid, 3 times longer than the calyx : lobes short. 4. G. Native of Caftraria. Stem tumid below the leaves. Stamens 5. Stigma bifid. Panicle 4-8-flowered. Pedicels balf an inch long, furnished each with one bractea. Capsule half inferior, 3-celled, 3-valved. Seeds ovate or elliptic, smooth, shining brown.

Krcbs's Wahlenbergia. Pl. procumbent.

37 W. Duxa'stir (Alph. D. C. mon. p. 152.) stem branched, stiffish; leaves linear-lanceolate, narrow, acuminated, entire, pilose; tube of calyx pilose, small, hemispherical; lobes of calyx long, subulate; corolla tubular, 5-lobed at the apex, rather longer than the calycine lobes. $\odot$. H. Native of the Cape of Good Hope, where it was collected by Eklon. Sten slightly pilose. Peduncles dichotomous, diverging, rather pilose. Pedicels 1-flowered. Flowers drooping.

Dunant's Wahlenbergia. Pl. $\frac{1}{2}$ foot.

38 W. MAssònu (Alplı. D. C. mon. p. 153.) plant small; stem branched, pilose; leaves linear, narrow, entire; calyx pilose, with a hemispherical tube and capillary lobes; corolla narrow, 
funnel-shaped, 5 -lobed at the apex, 2 or 3 times longer than the calycine lobes; capsule spherical. $\odot$. ? G. Native of the Cape of Good Hope. Flowers racemose or panicled at the tops of the branches, numerous. Pedicels 1-flowered.

Masson's Wahlenbergia. Pl. $\frac{1}{4}$ foot.

39 W. Brasilie'nsis (Cham. in Linnæa, 7. p. 318.) glabrous; branclies almost radical, simple, angular; leaves few, small, suluulate, entire, concave, keeled, bluntish; panicle terminal, subfastigiately corymbose and spike-formed, coarctate ; ovarium obconical; calycine segments like the leaves; corolla 5 -cleft to the middle. $\%$. S. Native of Brazil within the tropic. Very like $\boldsymbol{W}$. linarioides. Flowers white. Corolla very like tlat of Campanula rotundifolia, but much smaller.

Brazilian Wahleubergia. Pl, $\frac{1}{2}$ foot.

40 W. Janicula'ta (Alph. D. C. mon. p. 153.) stem much branched, pilose ; leaves linear, rather pilose, entire, or a little denticulated; calyx pilose, with an ovoid narrow tube and entire acuminated lobes; corolla funnel-shaped, 5-lobed at the apex, twice longer than the calycine lobes; capsule ovoid. $\odot$. H. Native of the Cape of Good Hope. Campanula paniculata, Thunb. prod. p. 38. Lin. suppl. p. 139. Thunb. mem. acad. petersb. 4 . t. 7 . f. 4 . Flowers panicled, terminal, and axillary. Pedicels 1-flowered.

Panicled-flowered Wahlenbergia. Pl. $\frac{1}{4}$ to $\frac{1}{2}$ foot.

$41 \mathrm{~W}^{\circ}$. Banksia'na (Alph. D. C. mon. p. 154.) stem glabrous, simple at the hase, but panicled at the apex; leaves linear, narrow, remotely denticulated, acuminated; tube of calyx quite glabrous, spherical; calycine lobes linear, narrow, denticulated ; corolla funnel-shaped, 5 -lobed at the apex, one-half longer than the calycine lobes. $\odot . ?$ H. Native of the Cape of Good Hope. Campánula paniculàta, Snith, in herb. Banks. Peduncles and pedicels slender, but stiff and divaricate. Flowers erect, 6-10 in number.

Banks's Wahlenbergia. Pl. $\frac{1}{4}$ to $\frac{1}{2}$ foot.

42 W. hispíoura (Alph. D. C. inon. p. 155.) stem branclsed; branches thick, hispid; leaves linear-lanceolate, acuminated, rather pilose, stiff, somewhat denticulated; tube of calyx hispirl, ovoid; calycine lobes very long and very like the leaves; corolla tubularly funnel-sliaped, 5-lobed at the apex, rather shorter than the calycine lobes; capsule spherical. $\odot$. H. Native of the Cape of Good Hope, in Swartland, on sandy hills. Campánula hispídula, Thumb. prod. p. 38 . Lin. suppl. p. 142. Thunb. voy. 4. p. 352. t. 4. exclusive of the syn. of Comm. hort. t. 37. Flowers $2-5$ in number at the tops of the branches, nearly sessile. Corolla blue.

Hispid Wahlenbergia. Fl. sept. oct. Clt. 1817. Pl. $\frac{1}{4}$ foot.

43 W. spinulòsa (Alph. D. C. mon. p. 155.) plant humble, much branched; branches stiff, glabrous, or rather scabrous; leaves narrow-linear, glabrous or pilose, denticulated, stiff, ending each in a hard point; tube of calyx glabrous, spherical; lobes of calyx with revolute ciliated margins; corolla narrow, 5 -lobed at the apex; capsule spherical.- Native of the Cape of Good Hope. Campánula spinulòsa, Banks, herb. Flowers terminal and axillary, solitary; pedicels stiff, and appearing like spines after the capsules have fallen.

Spinulose $\mathrm{W}$ ahlenbergia. Pl. 1 to 3 inches.

44 W. caplezacea (Alph. D. C. mon. p. 156.) stem branched from the base, glabrous; leaves scattered, linear-filiform, entire, with revolute margins; calycine segments setaceous.- Native of the Cape of Good Hope. Campátuula capillàcea, Thunb. prod. p. 38 . mem. acad. petersb. 4. p. 366 . t. 5. f. 4. Branches radical, numerous, filiform. Flowers terminal, subracemose, blue. Pedicels capillary, drooping.

Capillary-peduncled Wahlenbergia. Pl. 1 foot.
Sect. IlI. Cervícina (from cervix, the neck; because some plants of this order are called Throat-wort). Alph. D. C. mon. p. 156.-Cervícina, Del. fl. d'egypt. p. 7. t. 5. f. 2. Calyx and corolla 3-5-lobed. Stamens 3. Capsule 2-celled. Seeds triquetrous, acute at one extremity, and truncated at the other. - An humble annual herb. Leaves alternate, sessile, narrow. Flowers on short pedicels.

$45 \mathrm{~W}$. cervícina (Alph. D. C. mon. p. 156.) plant small; stem much branched; branches diverging, rather pilose ; leaves linear-lanceolate, a little denticulated; tube of calyx rather pilose, ovoid; corolla tubular, rather longer than the calycine lobes; capsule spluerical. $\odot$. F. Native of Egypt and Senegal, in sandy and arid places. Cervícina campanuloides, Del. fl. egypt, p. 7. t. 5. f. 2. Leaves witl white margins. Flowers numerous, pedicellate, solitary from the axils of all the leaves and tops of the branches.

Throatwort Wahlenbergia. PJ. $\frac{1}{4}$ foot.

Sect. IV. Loвeuoides (this section contains plants having the habit of Lobelia). A ph. D. C. mon. 157. Calys and corolla 3-5-lobed in the same plant. Stamens 3. Capsule 2celled. Seeds ovoid, nitid.-Slender annual herbs, with the habit of Lobelia. Leaves alternate, sessile. Flowers on lang peduncles.

46 W. Lobernoides $(A]_{p h}$. D. C. mon. 157. t. 17.) plant glabrous, simple at the base, erect; leaves denticulated: lower ones lanceolate-obovate: middle ones linear-lanceolate: superior ones few, narrower; tube of calyx obconical, narrow ; corolla cylindrical, hardly one-half longer than the calycine lobes; capsule ovoid, elongated. $\odot$. H. Native of Madeira and Teneriffe. Campánula lobelioides, Lin. suppl. p. 140. Ait. hort. kew. 1. ed. 1. p. 219. Campánula parvifora, Salisb. prod. p. 126. Lobèlia Broussonetii, Bory, ann. gen. p) 330. Campánula inconspícua, Banks, herb. Roélla cérnua, Brouss. cat. hort. monsp. 1804. p. 49. Lobèlia Canariénsis, Hort. par. Camp. júncea, and C. juncifòlia, Hort. Wahl. péndula, Schrad. cat. hort. gott. 1814. p. 3. diss. gen. de Blum. p. 38. Stem more or less branched at top. Flowers on long, slender, filiform, nearly naked pedicels, nutant. Corollas of a very pale red.

Lobclia-lilie Wahlenbergia. Fl. July, Ang. Clt. $177 \%$. P]. $\frac{1}{2}$ to 1 foot.

Sect. V. Linartoìdes (the species contained in this section have the habit of Linària). Alph. D. C. mon. p. 158. Calyx and corolla 5-lobed. Stamens 5. Capsule 2-celled. Sceds lenticular, shining.-Perennial herbs, with alternate, sessile, narrow leaves. Flowers on long peduncles and pedicels.

47 W. Linarioides (Alph. D. C. mon. p. 15s.) stem erect. simple at the base, glabrous or scabrous; leaves linear, acuminated, narrow, glabrous, subdenticulated; tube of calys glabrous, obconical; corolla fumel-slıaped, deeply 5 -cleft, one-half longer than the calycine segments; capsule obconical. $\mathcal{4}$. G. Native of Sonth America, about Monte-Video: and of Chili. Campánula linarioìdes, Lam. dict. 1. p. 580 . Rœu. et Schultes syst. 5. p. 107 . Campánula Chilénsis, Presl. in herb. Hanke. Stem more or less panicled at top. Flowers panicled, terminating the branchlets and peduncles, and also axillary. Branches nakedish. 1-3 flowered. Flowers drooping when open. Corollas blue.

Iar. $\beta$, filiformis (Alph. D. C. l. c.) leaves shorter, less acuminated. $\odot$. G. Native of Chili, in arid places about Conception. Canpánula Chilénsis, Molino, saggio. 2. p. 281. ex Roem. et Schultes. Campánula filifórmis, Ruiz et Pav. fl. per. 2. 13. 55. t. 200. f. c. Kom. et Scluultes, syst. 5. p. 117. Campánula linoides, Presl. in herb. Hanke. 
lar. $\gamma$, árila (Alph. D. C. mon. p. 158.) lobes of calyx denticulated; corolla small. 4. G. Native of Quito, near the river Guallabamba.

Linaria-like Walilenbergia. Pl. 1 foot.

Sect. V1. Nesóruila (from vigos, nesos, an island, and $\phi e \lambda \varepsilon \omega$, phileo, to love; the species contained in this section are inlrabitants of islands). Alph. D. C. mon. p. 160. Calyx and corolla 5-lobed. Stamens 5. Capsule 2-3-celled. Seeds ovate, flattislı.-Suftruticose plants, with alternate, firm, sessile, broad, sharply serrated leaves. Flowers pedunculate and pedicellate.

\section{\$1. Capsule 2-cclled.}

48 W. Fernandeziaina (Alph. D. C. mon. p. 160.) stem rather woody, erect, glabrous or pilose, leafy in every part; leaves lanceolate, acute, serrated, glabrous or pilose; calyx with a glabrous obconical tube, and subserrated lobes; corolla funnel-shaped, semiquinquefid, 3 times longer than the calycine lobes; capsule obconical. 24.F. Native of the island of Juan liernandez. Flowers panicled, numerous. Pedicels erect, terminal and axillary, with a small subulate bractea at the base of each. Corolla white, with purplish nerves.

Juan Fernandez Wablenbergia. P]. $\frac{1}{2}$ to 1 foot.

49 W. Foliòsa (Alph. D. C. mon. p. 160. t. 16.) stem woody, erect, very leafy in every part; glabrous, or rather pilose; leaves linear, acute, serrated, glabrous or pilose on the midalle nerve; tube of calyx glabrous, obeonical; lobes of calyx subserrated; corolla cylindrical, semi-5-cleft, one balf longer than the calycine lobes; capsule turbinate. 4 . G. $\mathrm{Na}$ tive of St. Helena and Ascension. Stem branched or simple, inflated at the origin of the leaves, as in many species of Scavòla. Leaves sessile, an inch long, paler beneath. Peduncles terminating the branches,
FIG. 128.

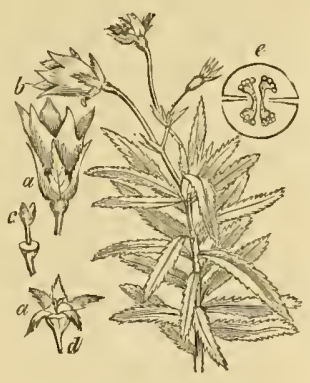

rather leafy; pedicels slender, erect, 1-flowered, reddish. (f. 128.)

Leafy Wahlenbergia. Pl. 1 to 2 feet.

50 W. culvòsa (Alph. D. C. mon. p. 16I.) glabrous ; stems subherbaceous, procumbent, leafy at the origin of the peduncles; leaves linear-lanceolate, deeply serrated; calyx with an obconical elongated tube, and entire segments; corolla campanulate, 3 times longer than the calycine segments, 5-lobed at the apex; capsule obconical. 24. G. Natise of St. Helena. Campánula clivòsa, Banks, herb. Stems langing from rocks, naked at the base. Flowers and capsules erect, but the alibastra are drooping.

Craggy Wahlenbergia. Pl. procumbent.

51 IV.? Roxвu'rgin (A]pl. D. C. mon. p. 162.) shrubby; erect; branches pilose; leaves scattered, sessile, cuneate-lanceolate, serrulated, pilose; panicle slender, crect, pilose. h. G. Native of St. Helena, in dense woods on the mountains. Roẻlla paniculàta, Roxb. in Beats. St. Hel. p. 320. A shrub with few erect branches. Corollas large, white. Perlaps allied to $H^{\text {r }}$. foliòsa.

Roxburgh's WVahlenbergia. Shrub.

52 W.? axgustifòlia (Alph. D. C. I. c.) plant diffuse; branches elongated, slender, scabrous; leaves linear-lanceolate, remotely and acutely glandularly serrated; peduncles lateral, much longer than the leaves, dichotomous, many-flowered. $\psi$.
G. Native of St. Helena, in the fissures of rocks in Sandy Bay. Flowers pure white, erect, and rather large. Roélla angustifolia, Roxb. in Beats. St. Hel. p. \$20. Pcrhaps the same as $W$. clicosa.

Narrow-leaved Wablenbergia. Pl. procumbent.

53 W.? uıiròlı (AJph. D. C. l. e.) frutescent; leaves scattered, sessile, numerous, linear, glabrous, finely serrulated ; peduncles terminal, few-flowered. h. G. Native of St. Helena, parasitical upon Dicksonia arboréseens, on the tops of hijls in Sandy Bay, particularly on Diana's Peak. Roélla linitòlia, Roxb. in Beats. St. Hel. p. 321. A small branched plant. Elowers white, mixed with red.

Flax-leaved Wahlenbergia. Shrub.

\section{\$2. Capsule 3-celled. Perhaps a proquer genus.}

54 W. exsifòlia (Alph. D. C. mon. p. 162.) plant frutescent, simple; stem thick, erect, naked at the base, but rery leafy in the middle; leaves long-lanceolate, aeuminated, ciliated, sharply serrated: teeth setaceous; calyx with a glabrous obconical tube, and entire ciliated lobes; corolla large, campanulate, somewhat 5-cleft, one-half longer than the ealycine Jobes. h. s. Native of Bourbon, on the Burning Mount. Campánula ensifòlia, Lam. dict. 1. p. 582. ill. no. 2518. Bracteas ciliated. Flowers $1-3$ at the top of each peduncle. Corollas large, an inch long, dirty yellow, marked with 5 purple spots at bottom. Habit between Músschia and Mahl. foliòsa.

Sword-leaved Wahlenbergia. Shrub 1 foot.

$$
\dagger A \text { doubtful species. }
$$

55 W.? ovita (D. Don. prod. A. nep. p. 156. Alph. D. C. mon. p. 163.) leaves ovate, petiolate, repandly denticulated; flowers axillary, solitary, pedunculate, erect. $\odot$. H. Native of Nipaul. Stem erect, branched, glabrous. Leaves rather pilose on both surfaces, an inch long. Stigna 3-lobed. Capsule trigonal, 3-celler, dehiscing by 3 holes at the apex. Stamens uncqual. Corollas blue?

Ovate-leaved Wahlenbergia. PI. $\frac{1}{2}$ foot.

Cult. For the eulture and propagation of the annual species of this genus, see Microcodon, j. 737 . The frame and greenhouse perennial and shrubby species, as Lightfootia, p. 735 . The hardy perennial species should be grown in pots, in a mixture of peat and loam, and kept rather moist; and they are easily increased by division.

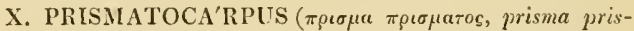
matos, a prism, and $\kappa a \rho \pi o c$, karpos, a fruit ; in reference to the long prismatical form of the fruit). Alph. D. C. mon. p. 164. Prismatocárpus species, Lher. sert. angl. p. 1. exclusive of the European species.-Campánula, sect. Legoísia, Pers. cnch. 1. 1. 192. exclusive of the European species.

LıN. sxst. Pentándria, Monogýnia. Calyx 5-lobed, with a cylindrical elongated tube. Corolla 5 -lobed at the apex. Stamens 5 , alternating with the lobes of the corolla. Anthers distinct. Style permanent at the base; stigmas 2. Capsule 2celled, wholly inferior, prismatic or cylindrical, elongated, splitting from the top towards the base into 5 segments. Seeds inserted the whole length of the central placenta, ovoid, somewhat compressed, obtnse, dotted.- -Subslirubs and stiff herbs, all natives of the Cape of Good Hope. Leaves alternate. Flowers sessile, solitary or approximate, always inserted in the axils of the leaves or bracteas.

* Corolla narrow. Style exserted. Leaces few on the upper parts of the plants.

1 P. Diffu'sus (Alph. D. C. mon. p. 164.) suffrutescent ; leaves linear, very narrow, entire; flowers in loose panieles; peduncles diverging, stiff; bracteas subulate; calycine lobes 
urate, acuminated, glabrous. $々$. G. Native of the Cape of Good Hope. Trachèlium diffùsum, Thunb. prod. p. 38. Lin. til. suppl. 143. Ait. hort. kew. ed. 2d. 1. p. 355. Stem branched, glabrous. Leaves glabrous or pilose. Flowers disposed in a loose nearly naked panicle. Peduncles stiff, axillary and terminal. Corollas blue; anthers yellow.

Diffuse Prismatocarpus. Fl. July, Sept. Clt. 1787. Shrub 1 foot.

* Corolla funnel-shaped. Style inclosed. Leaves fen on the upper part of the plant.

2 P. Panicula'tus (Lher. sert. angl. p. 1. exclusive of the syn. Polcmònium roelloides, ex Alph. D. C. mon. p. 165. t. 20.) suffrutescent; leaves linear-subulate, entire, setaceously ciliated; flowers loosely panicled; peduncles nearly naked; bracteas subulate; calyeine lobes acuminated, glabrous. 々. G. Native of the Cape of Guod Hope. Campánula ericoides, Lam. ill. no. 2574. Roem. et Śchultes, syst. 5. p. 156. Caunp. pedunculàta, Gmel, syst. p. 352. Campánula roelloides, Juss. herb. Roélla ericoìdes, Spreng. syst. 1. p. 723. Stem branched, leafless at the base, but leafy in the middle part. Leaves numerous at the base of the floriferous branches, with tufts of smaller leaves in their axils. Peduncles naked, subdivided, glabrous or rather scabrous. Flowers in loose panicles.

Panieled-flowered Prismatocarpus. Shrub 1 f ot.

3 P. interru'ptus (Lher. sert. angl. p. 1. Alph. D. C. mon. p. 166.) suffrutescent; leaves linear, acuminated, entire, ciliated; flowers approximate, on the tops of the peduncles; bracteas subulate; lobes of calyx ciliated. 5. G. Native of the (Cape of Good IJope. Roélla interrúpta, Banks, herb. Camfánula interrúpta, l'ers, encl, 1. p. 192, Stem branched, glabrous or relvety. Leaves scattered over the branches, with fascicles of smaller ones in their axils.

Interrupted Prismatocarpus. F]. Miky, July. Clt. 1818. Silutub $\frac{1}{2}$ foot.

4 P.? subula'tus $\left(A_{1}\right.$ h. D. C. mon. p. 166.) suffrutescent;? leaves linear-subulate, narrow, entire, ciliated at the base; flowers disposed in loose panicles; bracteas subulate; calycine lobes acuminated, glabrous. দ. G. Native of the Cape of Good Hope. Campánula subulàta, Thunb. prod. p. 38. mem. acad. petersb. 4. p. 369. t. 6. Roem. et Sclutules, syst. 5. p. 156. Lightfoòtia ciliàta, Spreng. syst. 1. p. s09. Habit of P'. paniculata. Stem purplish, glabrous. Leaves often with fascicles of smaller ones in thcir axils. Flowers disposed in a loose, nearly naked panicle.

Subulate-leaved Prismatocarpus. Shrub $1 \frac{1}{2}$ foot.

5 P. altiflòrus (Lher. sert. angl. p. 1. Alph. D. C. mon. p. 167.) suffruteseent; leaves linear-subulate, entire, ciliated; flowers few, approximate at the tops of the peduncles; bracteas subulate; lobes of calyx ovate, aeute, velvety. h.G. Native of the Cape of Good Hope. Roélla erécta, Banks, herb. Campanula altiflòra, Poir. stippl. 2. p. 66.-Habit of P. paniculàtus, Stcm nearly simple, glabrous, naked at the base and top, but leafy in the middle, divided at the top into 2 peduncles. Leaves often having fascicles of smaller ones in their axils.

IVigh-floncred Prismatocarpus. Slirub I foot.

6 P. Fruticòsus (Lher. sert. angl. p. 2. Alph. D. C. mon. p. 167.) suffrutescent; leaves linear, very narrow, erect, entire, a little ciliated; flowers few, racemose; bracteas subulate; calycine lobes ovate, aeute, glabrous. h. G. Native of the Cape of Good Hope. Roélla fruticùsa, Llier. in herb. Banks. Campánula fruticulòsa, Banks, herb. Stem nearly simple, glabrous, emling in a naked few-flowered raceme.

Shrubby Prismatocarpus. Fl. Aug. Clt. 1787. Shrub $1 \mathrm{ft}$.

7 P. EkLòvis (Alpl. D. C. mon. p. 168.) suffrutescent; leaves linear-subulate, long, ercct, entire, glabrous; flowers dis- posed in loose spikes; bracteas subulate, broader than the leaves at the base; calycine lobes linear-lanceolate, glabrons. h.G. Native of the Cape of Good Hope. P. fruticòsus, Eklon, in herb. Dunant, but not of Lher. Stem branched; branches erect, leafy at the base and rather velvety, and reddish at top. Flowers solitary in the axils of the bracteas.

Elilon's Prismatocarpus. Slurub $\frac{1}{2}$ foot.

8 P. crísus (Ther. sert. angl. p. 2. Alph. D. C. mon. p. 168.) stem luerbaceous ; leaves long, linear, erect, undulately toothed; flowers at the tops of the branches; bracteas subulate; calycine lobes linear, acuminated, glabrous. $4 . \mathrm{G}$. Native of the Cape of Good Hope. Campanula plicàta, Pers. ench. 1. p. 193. Røen. et Schultes, syst. 5. p. 153. Camp. longiróstris and C. críspa, Banks, herb. Stem simple, furnished with peduncles at top, pilose and leafy to the middle, but quite glabrous and naked at top. Leaves with white edges; lower and upper ones shortest. Peduncles bcaring a solitary flower at top, and sometimes pedicellate flowers in the axils of the bracteas.

Curled-leaved Prismatocarpus. Pl. $\frac{1}{2}$ foot.

9 P. Linariefòlius ( $\mathrm{A}]_{\mathrm{j}} \mathrm{h}$, D. C. mon. p. 169.) stem herbaceous; leaves few, linear, narrow, ciliated a little at the basc; flowers spicate, solitary or twin; bracteas broad ovate, acuminated, ciliated; calycine lobes oblong-linear, glabrous. 4. G. Native of the Cape of Good Hope. Stem erect, simple, furnisherl with a few floriferous leafy branches, striated with white nerves. Flowers disposed in loose spikes.

Toad-flax-leaved Prismatocarpus. Pl. 1 to 2 feet.

10 P. stríctus (Alph. D. C. mon. p. 169.) plant lierbaceons, simple; leaves linear, acuminated, erect, glabrous, serrately toothed; flowers in fascicles; bracteas ovate, acute, setaceously ciliated; lobes of calyx linear, acuminated, glabrous. 24. G. Native of the Cape of Good Hope. Lightfoòtia sessilifiora, Spreng. in Zeyhr. A. cap. no. 203. and probably of Spreng. syst. 1. p. 809 . Stem simple, stiff, furnished at top with few-flowered perluncles, glabrous, very leafy from the base to the middle, but naked at top. Leaves decurrent. Flowers sessile, usually $2-3$ in a fascicle, from the axils of the bracteas, at the upper part of the stem.

\section{Straight Prismatocarpus. PI. 1 foot.}

*** Corolla funnel-shaped. Style inclosed. Leaves scattered equally over the whole plant.

11 P. Nítidus (Lher. sert. angl. p. 2. t. 3. Alph. D. C. mon. p. 170.) plant rather woody; leaves ovate-oblong, spreading, scrrated; flowers in fascicles; bracteas like the leaves; calycine lobes lanceolate, glabrous. 24. G. Native of the Cape of Good Hope. Campánula prismatocárpus, Ait. hort. kew. 1. ed. 1. p. 224. Roem. et Schultes, syst. 5. p. 153. Hook. in bot. mag. 2733. Stem branched; branches diffuse, woody. Flowers 2-4 in a cluster, towards the tops of the branches, sessile in the axils of the bracteas, and sonetimes solitary in the axils of the leaves. Corollas white.

Shining Prismatocarpus. Fl. Aug. Sept. Clt. 1787. Pl. $\frac{1}{2}$ to 1 foot.

12 P. sk'ssidis (Eklon, in lierb. Dunant. ex Alpl. D. C. mon. p. 17 l.) plant rather woody, glabrous; leaves spreading. linear, narrow, entire; flowers solitary, in the axils of the upper leaves; calycine lobes subulate, glabrous. 4. G. Native of the Cape of Good Hope. Stem much branched; branches diffuse, erect or ascending, reddish. Flowers small.

Sessile-flowered Prismatocarpus. PI. $\frac{1}{2}$ foot.

Ciult. All the species of this genus are rather showy when in flower. A mixture of sand, loam, and peat is the best soil for then. They are readily increased by seed; or young cuttings grow frecly if planted in the same kind of soil, with a handglass placed over them. 
XI. ROE'LLA (in honour of William Rocll, professor of anatomy in the academy of Amsterdam). Lin. hort. cliff. p. 492. t. 35. Gener, no. 219. Adans, fam. nat. 2. p. 13\%. Juss. gen. 165. Neck. elem. 1. p. 235. Gærtn. fruct. 1.p. 154.t. 31. f. 3. Lam. ill. no. 346. t. 123. Gessn. phyt. p. 105. t. 13. f. 202. Alph. D. C. mon. p. 172.-Campánula species Seb. thes. 1. p. 25. t. 16. f. 5.-A culeòsa, Pluk. alm. 8. t. 252. f. 4.

Lin. syst. Pentándria, Monegýnia. Calyx 5-cleft. Corolla funnel-shaped or tubular, large, 5-lobed $(129, b)$. Stamens 5 ; filaments broadest at the base. Anthers frce. Stigmas 2, thick. Capsule cylindrical, 2-celled, wholly inferior, perforated by the permanent base of the style, and therefore appearing as if it was covered by an operculum, and at length dehiscing by a large bole at the apex, without valves. Seeds angular, scabrous, thick.-Subshrubs, rarely herbs. Leaves numerous, always alternate, scattered over the whole plant, usually narrow and stiff. Flowers sessile, terminal, and sometimes axillary. All the species are natives of the Cape of Good IIope.

* Plants percnnial. Stem nooly, more or less erect. Leaves stiff. Tube of calyx covered by the leaves.

1 R. Incu'rva (Banks, lierb. ex Alph. D. C. mon. p. 172.) leaves linear, acuminated, incurved at the apex: lower ones setaceously ciliated: superior ones laciniately toothed; flowers solitary; lobes of calyx glabrous, laciniately toothed; corolla variegated, length of the calycine lobes. $\quad$. G. Native of the Cape of Good Hope. Flowers solitary, terminal, surrounded by imbricate leaves.

Incurved-leaved Roella. Shrub 1 foot.

2 R. culia'ta (Lin. spec. 1. p. 241.) leaves erect, linear, acuminated, ciliated: superior ones longer and entire ; Howers solitary ; lobes of calyx ciliated, and laciniately toothed; corolla variegated, large, longer than the calycine lobes. $h . \mathrm{G}$. Native of the Cape of Good Hope and Barbary. Gærtı. fruct. 1. p. 154. t. 21 . f. 3. Lam. ill. t. 123. f. 1. Curt. bot. mag. t. 378. Lodd. bot. cab. 1156 . Delaun. herb. amat. 56. fasc, t. 332. Roélla, Lin. hort. cliff. p. 492. t. 35. Flowers solitary, terminal, surrounded by imbricated leaves. Corollas white at bottom, even to the base of the lobes, where there is a deep purple circle, and above the circle pale violet, girded by white, and lastly the lobes themselves are rose-coloured (f. 129).

Ciliated-leaved Roella. Fl. Sept. Clt. 1774. Shrub $\frac{1}{2}$ to 1 foot.

3 R. Reticula'ta (Lin. spec. 1. p. 2.H1.) leaves erect, subulate, ciliated; flowers solitary; lobes of calyx ciliated, short, entire; corolla white, twice the length of the calycine lobes. $I_{2}$. G. Native of the Cape of Good Hope. Lam. ill. 2577.Petiv. mus. 21. f. 157. ex Lin.-Roy. lugdb. 248. Stems or branches pilose, very leafy. Flowers solitary, terminating the branches, and axillary at the top of the stem.

Reticulated-leaved Roella. Slirub $\frac{1}{2}$ to 1 foot.

4 R. T'nusbe'rgin (Rœem, et Scluultes, syst. 5. p. 185.) leaves lanceolate, ciliated; flowers solitary; stem glabrous. h.G. Native of the Cape of Good Hope. Campanula ciliàta, Thunb. f. cap. ed. Schultes, p. 17\%. Stem filiform, erect, branched at the top, weak. Leaves glabrous, with revolute margins. Flowers terminal.

voL. III.
Thunberg's Roella. Shrub I foot.

5 R. Dunántir ( $A$ lph. I). C. mon, p. 175.) leaves erectish, linear, acuminated, ciliated ; flowers solitary or glomerate; lobes of calyx downy inside, remotely toothed; corolla longer than the calycine lobes. $I_{2}$. G. Native of the Cape of Good Hope. Roélla, Eklon, in herb. Dunant. Stem branched, naked at the base; branches diffuse. Leaves most numerous on the upper part of the branches. Flowers terminal, solitary, or 1-3 in a fascicle. Corollas white.

Dunant's Roella. Shrub 1 foot.

6 R. cine'reA (AIph. D. C. mon. p. 175.) leaves erect, linearsubulate, remotely denticulated, rather tomentose at the base; flowers solitary or in fascicles; lobes of calyx entire, glabrous; corolla twice the length of the calycine lobes. h. G. Native of the Cape of Good Hope, Campanula cinèrea, Thunb. prod. p. 38. mem. acad. petersb. 4. p. 368. t. 6 . f. 4. R. glabrélla, Banks, herb. Stem simple. Leaves usually furnished witl smaller ones in their axils. Flowers sessile, 4-6 at the top of each stem, surrounded by leaves.

Cinereous Roella. Shrub 1 foot.

7 R. sPicA'ta ('Thunb. prod.p.38. Lin. suppl. p. 143.) leaves lanceolate, ciliated; flowers terminal, aggregate. h. G. Native of the Cape of Good Hope. Stem very short, branched at the base, and rather decumbent. Leaves rising in fascicles from the buds, glabrous, reflexed at the points. Corollas white.

Spiked Roella. Slrub decumbent.

8 R. squarròsa (Thunb. in Lin. suppl. p. 131.) leaves ovate, acute, decurrent, cuspidate at the apes, and recurved, with ciliated and setaceously toothed margins; flowers glomerate; bracteas broad, ovate, acuminated; lobes of calyx ovate, acuminated, ciliated, one-half shorter than the corolla, which is white. h. G. Native of the Cape of Good Hope. Lam. ill. 2579. Ait. hort. kew. ed. 2d. vol. 1. p. 354 . Stem branched, reddish; branches diffuse, reddish. Flowers disposed in terminal fascicles.

lar. B, Bérgii (Alph. D. C. mon. p. 176.) flowers solitary. h. G. Native of the Cape of Good Hope. R. squarrosa, Berg. pl. cap. p. 4\%. R. filifórmis, Lam. ill. no. 2580. t. 123. f. 2. but not of Poir. R. rigidula, Banks, herb.

Squarrose-leaved Roclla. Fl. July. Clt. 1787. Shrub $\frac{1}{2}$ to 1 foot.

* * Percnnial, trailing, branched plants. Branches filiform, very leafy. Leaves stiff. Tube of ealyx naked, filiform.

9 R. muscòsa (Thunb. in Lin. suppl. p. 143. prod. p. 38.) leaves spreading, ovate, acute, remotely serrated, glabrous: flowers solitary; lobes of calyx ovate-acuminated, entire, glabrous, or a little ciliated, 3 or 4 times sluorter than the corolla, which is blue. 24. G. Native of the Cape of Good Hope, in a large ditch in front of the Table Mountain. Roen. et Scluultes, syst. 5. p. 75. Alph. D. C. mon. p. 177. R. crespitòsa, Banks, lierb. Burch. cat. pl. afr. no. 636 . A humble trailing plant, with diffuse branches. Flowers terminal, sessile.

Mossy Roella. Fl. July, Sept. Clt. 180?. Pl. trailing.

** * Plant annual. Stem herbaccous, erect. Leaves thin, broad. Tube of calyx nated, ovoid.

10 R. DECU'RrENs (Lher. sert. angl. p. 2. t. 6.) leaves spreading, decurrent, ovate-oblong, ciliated at the base, nearly entire ; flowers solitary; lobes of calyx acuminated, ciliated, 3 times shorter than the corolla. $\odot . F$. Native of the Cape of Good Hope. Ait. hort. kew. ed. 1st. vol. 1. p. 226. Lam. ill. no. 2582. Rom. et Scluultes, syst. 5. p. $7 \%$ exclusive of syn. bot. rep. t. 238. Stem branched, very leafy, pilose. Flowers terminal, blue.?

foot

Decurrent-leaved Roella. Fl. July, Sept. Clt. 1787. Pl. $5 \mathrm{C}$ 


\section{+ Doubtful species.}

11 R.? peduncula'ta (Berg. pl. cap. p. 42.) leaves linear, narrow, glabrous, spiny-ciliated at the base; peduncles terminal, solitary, nearly naked; flowers pedicellate; bracteas ciliatcd; segments of the calyx lanceolate, acute, ciliated, shorter than the capsule. h. G. Native of the Cape of Good Hope. Roem. et Schultes, syst. 5. p. 73. Alph. D. C. mon. p. 179. Habit of R. ciliàta. Leaves keeled below. Peduncles 2-flowered.

Peduncled-flowered Roella. Shrub 1 foot.

12 R.? BRactea'ta (Alph. D. C. mon. p. 179.) leaves acute, entire, linear-trigonal, reflexed, glabrous ; flowers terminal, almost solitary; bracteas ovate, acuminated, ciliated. $\hbar . G$. Native of the Cape of Good Hope. Campánula bracteàta, Thunb. phyt. bl. p. 20. Rom. et Schultes, syst. 5. p. 115. Stem downy, branched. Branches subsecund. Leaves furnished with smaller ones in their axils. Flowers surrounded by bracteas.

Brateate-flowered Roella. Shrub 1 foot.

Cult. For culture and propagation, see Prismatocárpus, p. 744.

\section{Tribe II.}

CAMPANULEE (this tribe contains plants agreeing with the genus Campánula in the fruit dehiscing laterally). Capsules deliscing at the sicles.

XII. PHYTEU'MA (a name adopted by Dioscorides). Cæsal. l. ix. cap. 30. Gessn. tab. phyt. Lin. gen. no. 292. Gærtı. fruct. 1. p. 194. t. 30 . Juss. gen. p. 165. Lam. ill. no. 2589. t. 124. f. 1. Schkuhr, ench. no. 118. t. 39. Juss, dict. sc, nat. p. 40. p. 15\%. Alph. D. C. mon. p. 180 . but not of Diosc. Columı. Dalesch, nor Matth.-Rapúnculus, Dalesch. hist. p. 641. Tourn. elem. 1. p. 92. pl. 38. inst. 1. p. 113. Adans. fam. 2. p. 134. Scc-Rapúntım, Lob. hist. 13. 178. t. 329.-Rapúnculum, Lag. hist. p. 576. Lonic. p. 413 . Dodon. pempt. p. 165.

LiN. syst. Pentándria, Monogýnia. Calyx 5-cleft. Corolla 5 -parted; segments colering together a long time, and in one species always. Stamens 5, alternating with the lobes of the corolla ; filaments long, filiform, broadest at the base; anthers free; pollen violaceous or reddish. Style filiform, pilose. Ovarium inferior, 2-3-celled. Capsule dehiscing laterally by 2-3 valves at the base or middle part. Seeds ovoid, sometimes a little compressed, usually shining.-Peremial herbs. Leaves alternate; radical ones petiolate, different from the cauline ones, larger and broader. Flowers sessile, or on short pedicels, disposed in spikes or heads. - Natives of the temperate parts of Europe, or nearly in the same latitudes in Asia.

SLст. 1. Sуко́томa (from $\sigma v y$, syn, together; and тона, toma, a section; in reference to the colesion of the segments of the corolla). Segments of corolla always cohering at the apex. Filaments hardly broader at the base. Stigmas 2. Capsule 2-cclled.

1 P. comòsum (Lin. spec. 1. p. 242.) leaves coarsely and' acutely toothed : radical ones on long petioles, cordate, ovateroundish: cauline ones on short petioles, ovate-lanceolate, acute; bracteas large, obovate, coarsely toothed. 24. H. Native of Dalmatia, Carniola, south of Tyrol, and in the region of Mount Baldo, on the alps, among rocks. Jacq. fl. austr. append. t. 50 . Host, fl. austr. 1. p. 275. Alph. D. C. mon. p. 181. but not of Vill. Gouan, nor D. C. fl. fr.-Ponæ, descript. mont. bald. in Clus. hist. p. 336. with a figure. Barr. pl. obs. t. 859.-Bauh. prod. p. 33. with a figure. Moris. oxon. sect. 5. t. 5. f. 49.J. Bauh. hist. 2. p. 811 , with a figure.-Pluk. phyt. t. 152. f. 6 . Root woody. Plant glaucous. Leaves glabrous or pilose. Flowers on short peduncles, disposed in loose umbel-formed fascicles. Corolla inflated at the base, tube-formed, purple or blue.
Tufted Rampion. Fl. July. Clt. 1752. Pl. $\frac{3}{4}$ to $\frac{1}{2}$ foot.

Sect. II. Hedránthum (from è $\rho a$, hedra, a seat; and $a_{2}$ Oos, anthos, a Hower; in reference to the flowers being sessile). Segments of corolla cohering a long time at the apex, but at length becoming fiee. Filaments expanded at the base. Stigmas 2-3. Capsule 2-3-celled. Flowers sessile, densely crowded, usually many from the axil of each bractea.

§ 1. Heads at the timc of blossoming hemispherical or globose, but at length either globose or somenhat egg-shaped.

\section{* Eracteas numerous, equal, and broad.}

2 P. globulariagòliun (Stenrb. in Hoppe, denk. bot. in regensb. 2. p. 100.) radical leaves crowded, obovate, broad, a little toothed at the apex: cauline leaves few, sessile, obovatelanceolate, somewhat ciliated; heads few-flowered; bracteas very broad, ovate-roundish, ciliated, a little toothed at the apex. $\psi$. H. Native of Illyria, Carniola, and Carinthia, on the alps, and on the alps of Salisburgh. Rclib. icon. bot. cent. 4. p. 49. t. 365. Rœin. et Scluultes, syst. 5. p. 76. exclusive of syn. of All. Vill. Lam. and D. C. Hall. and Bauh. P. pauciflòm, Hænke, in Jacq. coll. 2. p. 63. Host, fl. austr. 1. p. 274 . but not of Lin.-Mor. oxon. 2. p. 464 . sect. 5. t. 5. f. 50 . Plant glabrous, except the ciliæ at the base of the leaves. Corollas blue. Globularia-leaved Rampion. Fl. May, July. Clt. 1820. Pl. 1 to 2 inches.

3 P. Paucif lòrum (Lin. spec. 1. p. 241.) leaves entire ; radical ones crowded, short, narrow-linear, or obovate-lanceolate ; cauline leaves few, sessile, linear-lanceolate; heads few-flowered; bracteas ovate, acute, ciliated, a little toothed at the base. 4 . H. Native of the Central and Eastern Pyrenees, especially on the alus at Col de Tende; Dauphiny, Mount Cenis, Vallais, Carinthia, on the alps; and probably on the alps of Carniola, Transylvania, and France. All. ped. 1. p. 115. Vill. dauph. 2. p. 515 . Rchb. jcon. bot. cent. 4. p. 48. t. 364. Rapúneulus pauciflòrus, Scop. carn. ed. 2. no. 241. ex Rœm. et Schultes. P. lanceolàtum, Schleich. cat. 1821. P. globulariæe folium Hegetschw. f. helv. 2. p. 420. reise, p. 146. t. 13. and 15. Gaud. fl. helv. 2. p. 170. but not of Sternb. nor Hoppe. Stem glabrous or pilose. Leaves glabrous. Hearls globose, few-flowered. Corollas deep blue.

Few-flowered Rampion. Fl. May, June. Clt. 1823. Pl. 2 to 8 inches.

1. P. HEMISPHÉRICUM (Lin. spec. 1. p. 241.) leaves entire ; radical ones narrow-linear: cauline ones linear-lanceolate; bracteas ovate, acuminated, nearly entire, ciliated. $\%$. H. Native of the alps from Provence to Carinthia, towards the east, even to Transylvania; and on the north, to the woods of Hercynia and Hassia; and on the west, on the mountains of Auvergne and Cevennes, as well as of the Pyrenees and Arragon. Jacq. icon. rar. t. 333 . Lam. ill. no. 258 t. t. 124. f. 2. Richb. icon. bot. t. 363. P. Michèlii, Lapeyr. abr. p. 109. P. pauciflòrum, Lapeyr. abr. p. 109. P. intermèdium, Hegetschw. reis. p. 147. t. 17. P. graminifolium, Sieb. herb. fl. austr. no. 71.Column. ecphr. 2. p. 23. t. 26.-Mor, hist. 2. p. 465 . sect. 5. f. 53. Plant glabrous. Heads of flowers globose; corollas blue. I ar. $\beta$; flowers white or yellow. $4 . \mathrm{H}$. Native of Switzerland.

Hemispherical-headed Rampion. Fl. July. Clt. 1752. Pl. $\frac{1}{4}$ to $\frac{1}{2}$ foot.

5 P. Care'stie (Birol, in act. taur. 5. p. 315. with a figure). radical leaves crowded, lanceolate, on long petioles, nearly quite entire: cauline leaves linear-lanceolate, somewhat serrated; bracteas spreading or reflexed, broad-ovate, acuminated, acutely serrated, glabrous. 4. H. Native of Corsica, on the moun- 
tains; and in valleys among the mountains of Sesia. Brugnat. giorn. di. fisic. 1. dec. 2. p. 37. Lois. A. gall. 1. p. 145. exclusive of the syn. $P$. Siebèri. Plant glabrous. Heads of flowers spherical. Corollas blue.?

Carestia Rampion. Pl. 1 to $\frac{1}{2}$ foot.

6 P. nu'mıs (Schleich. exsic. Murr. guid, en. val. p. 84.) radical leaves crowded, linear-lanceolate, narrow at the base, nearly entire : cauline leaves few, linear, entire ; bracteas ovatelanceolate, long-acuminated, toothed and serrulated, somewhat ciliated. $\psi$. H. Native of Vallais, in the fissures of rocks; on Mount lieffel, in the valley of St. Nicholas, and elsewhere in the same valley, \&c. Hegetsclıw. reis. p. 146. t. 16. fl. helv. 2. p. 42\% in add. ex Gaud. fl. helv. 2. p. 173. exclusive of the syn. P. Carćstice. Plant glabrous. Heads of flowers globose. Corollas blue.

Var. $\beta$, humillima (Alph. D. C. mon. p. 186.) root thick ; stems very short. $\quad$. H. P. hùmile $\beta$, Gaud. 1, c. P. hùmile, Rchb. icon. bot. t. 364, f. 546 .

Humble Rampion. Fl. July, Aug. Clt. 1825. Pl. $\frac{1}{4}$ foot.

7 P. Stebe'ri (Spreng. pug. 1. no. 29. Rœm. et Schultes, syst. 5. p. 80 .) radical leaves petiolate, ovate-roundish, subcordate, crenated: lower cauline leaves petiolate, lanceolate, coarsely toothed: superior ones stem-clasping, acutely toothed; bracteas ovate, acuminated, pilose, coarsely and acutely toothed. $\boldsymbol{\Psi} . \mathrm{H}$. Native of the Apennines, Carniola, and Tyrol, on the alps. Rchb. icon. bot. t. 214. P. Charmèlii, Sieb. P. orbiculàre, var. Schrad. P. intermèdium, Jan. in herb. Sering. Stem glabrous or pilose. Heads of flowers spherical. Corollas deep blue.

Siebcr's Rampion. Fl. May, July. Clt. 1826. Pl. $\frac{1}{4}$ to $\frac{1}{2}$ foot. 8 P. orbicula're (Lin. spec. 1. p. 242.) radical leaves petiolate, lanceolate, subcordate, crenated: cauline leaves sessile, linear-lanceolate; bracteas ovate, acute, entire. 24. H. Native of the alps of Europe, from Abruzzo to Arragon, and the Pyrenees; also of Galicia, Saxony, Transylvania, Switzerland, and on the Carpathian mounrains. In England, in pastures and by road sides, on a chalky soil, but rare on the downs of Sussex and Hampshire, in many places; in several parts of Surrey and Kent; plentiful near Leatherhead. Jacq. f. austr. t. 437. Smith, engl. bot. t. 142. Lodd. bot. cab. t. 122. Hook. fl. lond. t. 55. P. comòsa, Gouan, fl. monsp. p. 26. Rapúnculus orbiculàris, Scop. fl. carn. 2. ed. 1. p. 150. demonstr. bot. t. 34. P. cordàtum, Vill. dauph. 2. p. 517 . t. 11. f. 1. Sims, bot. mag. t. 1466. P. hemisphæ'ricum, Geners. elench. scep. no. 195. P. Scheuchzèri, Lapeyr. abr. p. 109. P. Michèlii, Hegetschw. reis. p. 148. t. 33. but not of others. P. corniculàtum, Riv. mon. irr. t. 109. f. 1 . Leaves glabrous or pilose. Heads round. Corollas deep blue.

V ar. B, Ianceolàtum (Alph. D. C. mon. p. 188.) stem larger ; leaves long-lanceolate, less cordate. 4 . H. Native throughout France. P. lanceolàtum, Vill. dauph. 2. p. 517. t. 12. f. 1. P. orbiculàre $\beta$, Lam. et D. C. Al. fr. no. 2861. Pl. 1 ft. high.

lar. $\gamma$, gigantèum (Alph. D. C. mon. p. 188.) stem taller; leaves long-lanceolate, less cordate. $4 . H$. Native of France. V. ellípticum, Vill. dauph. 2. p. 517. t. 11. f. 2. P. orbiculàre $\gamma$, Iam. et D. C. fl. fr. no. 2860 . Plant $1 \frac{1}{2}$ foot high.

lü. ô, comòsum (Alph. D. C. mon. p. 188.) bracteas larger. 7. H. Native of France. P. comòsum, Vill. dauph. 2. p.517.
Lam. et D. C. fl. fr. no. 2860. Rapúnculus, Lam. f. fr. 3. p. 331. P. orbiculàre $\hat{c}$, D. C. fl. fr. suppl. no. 2861 .

lar. $\varepsilon$, Columnoe (Alph. D. C. mon. p. 189.) radical leaves sinall, ovate-cordate : Iower cauline leaves lanceolate, serrated.Column. ecplir. pt. 1. p. 223. t. 224.

$I^{\prime} a r . \eta$, decipicns (Alph. D. C. mon. p. 188.) Jumble; radical leaves short, elliptic-linear or linear, obsoletely crenated: cauline leaves sessile, linear, bluntish. 4 . II. Native of Switzerland. P. brevifolium, Schleich. cat. 1821. p. 25. P. pilòsum, Hegetschw. reis. p. 149. f. 34 . P. orbiculàre, Gand. fl. lielv. 2. P. 176.

Orbicular-leaved Rampion. Fl. June, Aug. England. Pl. $\frac{1}{2}$ to $1 \frac{1}{2}$ foot.

\section{* Bracteas fen', uncqual, narron'.}

9 P. Charme'Lil (Vill. dauph. 2. p. 516. t. 11. f. 3.) leaves of various forms; radical ones on long petioles, cordate, ovate, acute, coarsely serrate-toothed: lower cauline ones petiolate, lanceolate, irregularly serrate-toothed; heads splierical; bracteas short, linear-lanceolate, spreading. 4. H. Native of Piedmont, Provence about Colmars, Dauphiny, and the Central Pyrenees. All. auct. fl. pedem. p. 8. Alph. D. C. mon. p. 1 S9. P. orbiculàre $\delta$, Willd. spec. 1. p. 922. P. orbiculàre, A. Lam. ill. no. 2586. Poir. dict. 6. p. 73. P. Seheuchzèri, Benth. cat. p. 111.-Column. ecphr. 1. t. 224. obs. t. 525. and t. 526. Plant glabrous. Heads spherical. Corollas blue.

Charmeli's Rampion. Fl. May, Aug. Clt. 1823. PI. $\frac{1}{2}$ to 1 foot.

10 P. Scheuchze'ri (All. pedem, no. 428. t. 39. f. 2.) radical leaves petiolate, ovate-lanceolate, bluntly serrated: lower cauline ones linear-lanceolate, acutely serrulated: upper ones linear, nearly entire; heads spherical; bracteas very long, reflexed. 4. H. Native of Vallais, and nearly throughout the whole southern declivities of the alps from Piedmont, through Provence, even to Tyrol. Sims, bot. mag. 1797. Rchb. icon. bot. t. 366. P. ovàtum, Lam. ill. no. 2585. exclusive of the syn. All. t. 7. f. 3. P. corniculàtum, Clairv. man. p. 63 . Gaud. f. helv. 2. p. 177.-Scheuchz. itin. 6. p. 460. Plant glabrous. Corollas deep blue.

I ar. B, corniculàtum (Alph. D. C. mon. p. 191.) radical leaves deeply cordate; bracteas longer than the heads or shorter. 4. H. Native of Vallais and Switzerland. P. Charmèlii, Murr. guid. en. vall. p. 84 . Hegetschw. f. helv. 2. p. 421 . Schleich. pl. exsic. P. Columne, Thom. cat. 1818. P. corniculàtum, 2. Gaud. fl. helv. 2. p. 178. P. Charmelioìdes, Birol.

Schcuchzer's Rampion. Fl. May, June. Clt. 1813. Pl. 1 foot.

\$2. Heads cylindrical, conical, or ovate at the time of flowering, but at length they become more elongated.

11 P. scorzonerifòlum (Vill. dauph. 2. p. 5 19. t. 12. f. 2.) leaves of various forms; radical ones petiolate, ovate-cordate or ovate: cauline leaves linear-lanceolate; spikes ovate; bracteas reflexed, linear, glabrous. 24. H. Native of Dauphiny, Vallais, Carniola, Savoy, Sc. on the mountains. Rchb. icon. bot. 3. t. 249. Gaud. fi. helv. 2. p. 181 . exclusive of the syn. P. scorzonerifòlium, D. C. and persicifolium, Норре. P. Scheuchzèri $\beta$, Pers, ench. 1. p. 103. P. Scheuchzèri $\gamma$, Schultes, fl. austr. 2. ed. no. 881 . P. betonicæfölium, Sims, bot. mag. t. 2066. but not of Vill. P. Michèlii, Schmidt, fi. bohem. no. 187. Bert. amœn. ital. p. 342. but not of All. Plant glabious. Stems simple. Corollas pale blue.

Var. $\beta$; flowers deep blue. 4. H. P. scorzonerifolium, Sims, bot. mag. t. 2271 .

Salsefy-leaved Rampion. Fl. July, Aug. Clt. 1819. Pl. 1 to 2 feet.

12 P. Miciétil (All. pedem. 1. p. 115. no. 427. f. 7-3.) $5 \mathrm{c} \stackrel{\mathcal{2}}{\sim}$ 
radical leaves linear-lanceolate: cauline leaves linear; spikes ovoid, nearly globose; bracteas reflexed, linear, downy; calyx pilose in the middle; stigmas 2. 4. II. Native of Mount Cenis. Rehb. icon. bot. t. 348. Alpl. D. C. mon. p. 195. but not of Hegetschw. Bertol. Pollin. nor Schmidt.-Till. pis. p. 146. Mich. hort. pis. et flor. p. 80. Bass. comm. acad. bonon. 4. p. 289. t. 1. Leaves glabrous or pilose. Corollas blue.

Micheli's Rampion. Fl. June, July. Clt. 182. $\quad$ Pl. $1 \mathrm{ft}$.

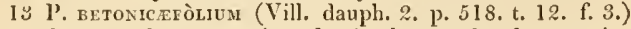
lower leaves oblong, acuminated, simply serrulated: superior ones linear-lanceolate, nearly entire; spikes ovoid, almost bractless; stigmas 3. 2. H. Native of the Pyrences, Provence, alps of Daupliny, Savoy, Switzerland, Apennines, Carniola, Bohemia, \&c. Rchb. icon. bot. t. 250. but not of Sims, bot. mag. Stems glabrous. Leaves glabrous or pilose. Corollas blue.

I ar. $\beta$, pubéscens (Alph. D. C. mon. p. 194.) leaves downy, and particularly so on the petioles. $\psi$. H. Native along with the species. P. cordifolinm, Lapeyr. abr. p. 110. but not of Vill. P. betonicæfòlium, Gaud. fl. helv. 2. p. 181.

I ar. $\gamma$, sessilifólium (Alph. D. C. l. c.) radical leaves sessile, crowded, linear-lanceolate, not cordate. 4. H. Native of Savoy, on the momntain called Cramont, and on St. Bernard.

Bctony-leaved Rampion. Fl. June, July. Clt. 1818. Pl. $\frac{1}{2}$ to 1 foot.

14. P. veronicefòlium (Schrad. in litt. ex Alph. D. C. mon. p. 196.) lower leaves on long petioles, cordate, long-lanceolate, simply serrated: superior ones sessile, linear-lanceolate, serrulated; spikes cylindrical, acuminated; bracteas setaceous, glabrous; calyxes glabrous; stigmas 2-3. Native of Salisburgh, in the valley of Cillara. Root turnip-formed. Leaves pilose. Stem downy at the base, simple. Corollas blue.

Spcedwcll-leaved Rampion. Pl. 2 feet.

15 P. persicifòlum (Hoppe, cent. exsic. ex Alph. D. C. mon. p. 196.) lower leaves petiolate, oblong-lanceolate, simply crenulated : cauline leaves linear-lanceolate, nearly entire; spikes oblong; bracteas linear-lanceolate, glabrous; calyxes glabrous; stigmas 2-3. 24. H. Native of Carinthia, in alpine meadows; and the province of France called Lozère. P. scorzonerafolium. Lam, et D. C. fl. fr. ed. 3d. no. 2866. Plant glabrous. Leaves like those of Campanula persicifolia. Corollas blue.?

Pcach-lcaved Rampion. Pl. 1 to 2 feet.

16 P. Spica'tum (Lin. spec. p. 242.) lower leaves on long petioles, cordate, ovate-acute, biserrated: superior ones ovatelanceolate; spikes cylindrical, elongated; bracteas linear-subulate, glabrous; calyxes glabrous; stigmas 2. 4. H. Native of the temperate parts of Europe, in woods even from the Pyrenees, Cevennes, Provence, Piedmont, Apennines, and Carniola, to the north of Germany; also of Galicia, Podolia, Transylvania, and Volhynia. Lam. ill, no. 2589. t. 124. f. 1. Oed. fl. dan. t. 362. Gærtn. fr. 1. p. 149. t. 30. Schkuhr, ench. no. 430. t. 39. Sims, bot. mag. t. 2347. Root fusiform. Plant glabrous. Stems simple. Flowers white, cream-coloured, or blue.

ĺar. $\beta$, bractcàtum (Alph. D. C. mon. p. 198.) plant pilose; canline leaves large, on long petioles; bracteas long. 24. I1. Native of the Pyrenees. P. Hallèri, D. C. et Dub. bot. gall. p. 319. but not of Lam.

Spiked-flowered Rampion. Fl. July, Aug. Clt. 1597. I'l. 1 to 3 feet.

17 P. HALLE'Ri (All. pedem. 1. p. 116.) lower leaves on long petioles, cordate, ovate-acute, donbly and coarsely serrated: superior ones lanceolate, serrated; spikes ovate-oblong; bracteas lanceolate, glabrous; calyxes glabrous ; stigmas 2. h. H. Native of the lower alps of Provence; alps of Piedmont, throughout Switzerland and Salisburgh; on Mount Cenis; of
Carinthia, Bohemia, and Transylvania. Lam. et D. C. fl. fr. ed. 3d. no. 2868. Alph. D. C. mon. p. 199. but not of D.C. and Dub. bot. gall. P. ovàtum, Schmidt, new, abhand, bohem. pt. . p. 20. Willd. spec. 1. p. 928. P. urticæfollium, Clairv. man. miss. p. 63 . P. spicàtum, $\beta$, cærùleum, Hegetschw. reis. p. 149.-Scheuchz. itin. 7. p. 518.- Hall. helv. no. 683. Stem simple. Leaves glabrous. Corollas deep violet.

Haller's Rampion, Fl. July, Aug. Clt. 1822. Pl. 2 to 3 feet.

18 P. NigRum (Sclumidt, fl. bohem. 1.p. 87.) lower leaves petiolate, cordate, ovate-acute, simply crenulated; superior ones sessile, linear-lanceolate, serrulated; spikes ovate; bracteas reflexed, linear-lanceolate, glabrous; calyxes glabrous; stigmas 2. 4. H. Native of Bohemia. Willd. spec. 1. p. 922. exclusive of the syn. of Vill. Rœem. et Schultes, syst. 5. p. 81. P. spicàtum, var. $\gamma$, Pohl, tent. A. bohem. p. 210. P. Charmèlii, Panz. in herb. D. C. Plant glabrous. Stem simple. Corolla of a very dark violet, almost black.

Black-flowered Rampion. Fl. June, July. Clt. 1820. Pl. 1 to 2 feet.

19 P. Balbísil (Alph. D. C. mon. p. 200.) radical leaves petiolate, cordate, ovate-acute: cauline leaves few, nearly sessile, ovate, acuminated; spikes oblong-cylindrical; bracteas few, linear, rather pilose; calycine lobes rather pilose; stigmas 8. 4. H. Native of Piedmont, in Valley Pesio. P. cordàta, Balb. misc. alt, p. 10. P'lant glabrous, Corollas white; anthers yellow.

I ar. $\beta$, petre' $u m$ (Alph. D. C. mon. p. 200.) leaves entire; superior ones long-lanceolate. 24. H. Rapúnculus petrèus, Alp. exot. p. 343. and p. 344. with a figure. Moris. oxon. sect. 5. t. 1. f. 12 .

\section{Balbis's Rampion. Pl. $\frac{1}{2}$ foot.}

Sect. 1II. Podn'nthum (from novs mocos, pous podos, a foot; and ar0os, anthos, a flower; in reference to the flower's being pedicellate). Segments of corolla colsering a long time at the apex, but at length free. Filaments expanded at the base. Stigmas 3. Capsule 3-celled.-Flowers on short pedicels, disposed in loose spikes, 2 or 3 rising from the axil of each bractea.

20 P. tenvifòla (Alph. D. C. mon. p. 201.) stems simple, glabrous at bottom, but rather roughish at top; cauline leaves linear, entire, very narrow; flowers spicate. $\%$. H. Native about Constantinople. Spikes 3 inches long, loose at the base, and dense at top. Corolla whitish. Anthers yellow.

Fine-leaved Rampion. Fl. Aug. Pl. $1 \mathrm{ft}$.

21 P. Limonifòcuum (Sibth. et Smith, fl. græec. t. 218.) stem branched; radical leaves on long petioles, quite glabrous, lanceolate, a little toothed; spikes long, interrupted; calyxes glabrous; capsules ovoid, glabrous. 2 . H. Native of the Levant, on the top of Mounts Olympus and Lebanon; and of Caucasus on the Talusch mountains. P. stricta, Sims. bot. mag. 2145. P. virgàta. Lodd. bot. cab. t. 667. P. stylòsum Schrank, pl. rar. mon. fasc. 5. t. 49. Campánula limonïfòlia. Lin. spec. 1. p. 239. Stems twiggy. Plant glabrous. Flowers sessile, blue.

Limonium-leaved Rampion. Fl. June, July. Clt.1819. Pl. 2 to 3 feet.

22 P. colcisum (Guss, pl, rar. p. 97. t. 19.) stem nearly simple; radical leaves lanceolate, attenuated at both ends, roughish, repandly denticulated; spikes somewhat interrupted; capsules turbinate, scabrous. 2 . H. Native of Japygia, on arid hills, by the sea side. Campánula virgàta, Ten. f. neap. 1. p. 66. but not of Labill. Stems downy, simple or a little branched. Leaves glabrous or downy. Corollas blue.

Hill Rampion. Pl. 1 foot.

23 P. lobelioides (Willd. pliyt, 1. no. 20, t. 4. f. g.) stem 
nearly simple, roughish; leaves scabrous, petiolate, linear-lanceolate, acutely denticulated; flowers scattered, on short pedicels; calyxes scabrous. 24. H. Native of Armenia.-Tourn. cor. p. 4. Flowers solitary or twin, blue.?

Lobelia-like Rampion. Pl. $\frac{1}{2}$ foot.

24. P. lanceola'tum (Willd. spec. 1. p. 924. Desf. in ann. mus, 11. p. 55. t. 5. or choix, des. pl. p. 34. t. 24.) ghabrous ; stems branched; radical leaves crowded, on short petioles, lanceolate, serrated; flowers scattered, solitary, on short pedicels. 4. H. Natise of Armenia. Alph. D. C. mon. p. 204.Tourn. cor. p. 4. Stems 2-3, rising from the middle of the radical leaves, almost naked. Flowers scattered on the tops of the stems. Corollas white, with red nerves.

Lanceolate-leaved Rampion. Fl. Junc, July. Clt. 1826. Pl. 1 to 1 foot.

25 P. Rela' ndum (Sibth, et Smith, prod. fl. græc. 1. p. 143.) stem glabrous ; radical leaves crowded, pctiolate, elliptic-oblong, repand, glabrous; petioles imbricated at the base ; flowers spicate; bracteas fringed. 24. H. Native of Mount Olympus. Leaves rosulate, very like those of Globulàriu acaúlis. Flowers disposed in a loose spike.

Repand-leaved Rampion. Pl. $\frac{1}{4}$ to $\frac{1}{2}$ foot.

26 P. Rigidum (IVilld. spec, 1. p. 925. exclusive of the syn. of Tourn.) stem very simple, glabrous; radical leaves linearlanceolate, furnished with very minute teeth on the edges; flowers scattered. 4. H. Native of the Levant. Peduncles branched a little, 3-flowered.

Stiff Rampion. Pl. $\frac{1}{2}$ foot.?

27 P. cane'scens (IṼaldst. et Kit. pl. hung. 1. p. 12. t. 14.) plant scabrous; stems simple; cauline leaves sessile, ovate-lanceolate, crenulated; flowers disposed in long spikes. $4 . \mathrm{H}$. Native of Hungary, 'Transylvania, Galicia, Podolia, Tauria, and Caucasus. Leaves greyish. Flowers 1-3 from the same bractea, sessile. Corolla of a violet blue colour. Plant yielding a yellow viscid juice.

Canescent Rampion. Fl. July, Ang. Clt. 1804. Pl, 1 to 3 feet.

$2 S$ P. salicifòlún (Waldst, et Kit. ined. Bess. prim. fl. gal. 1. p. 368. Alph. D. C. mon. p. 205.) stem quite simple, glabrous; lower leaves ovate-lanceolate, serrate-toothed: superior ones sessile, lanceolate, acutely serrated; spikes short; calyxes glabrous. 4. H. Native of Hungary, on calcareous rocks. Leaves glabrous, except the margins, which are a little hairy. Spike almost an inch long. Flowers solitary, sessile. Corollas blue or violaceous?

Willow-leaved Rampion. Pl. $\frac{1}{2}$ to 1 foot.

29 P. campanuloìdes (Bieb. A. taur. 1. p. 156.) stem simple, glabrous; lower leaves petiolate, ovate, bluntish, crenated: middle ones broad, sessile, ovate-acute, crenated: superior ones lanceolate, serrated; spikes short, dense; calyxes glabrous. 24. H. Native of Caucasts, about Nartzana and the sides of Mount Beschtau. Sims, bot. mag. t. 1015. Alph. D. C. mon. p. 206. Campánula alopecuroides, Willd. herb. Leaves glabrous, or with the margins and nerves pilose. Flowers disposed in a spike 2-3 inches long, 1-3 together, from the axils of the bracteas. Corolla of a violaceous blue colour.

Var. ß3, Sibthorpiànum (Alph. D. C. mon. p. 206.) stems and leaves hairy. 4. H. Native of Mount Olympus. P. ellipticum, Sibth. and Smith, prod. fl. græc. 1. p. 143. fl. graec. t. 217. P. Sibthorpiànum, Røem. et Schultes, syst. 5. p. 84.

Campanula-like Rampion. Fl. June, Aug. Clt. 1804. Pl. 1 to 2 feet.

30 P. amplexicaúle (Willd. spec. 1. p. 925.) glabrous; stems simple; cauline leaves somewhat stem-clasping, ovateacute, broad, acutely serrated; spikes dense, fascicled; calycine lobes capillary. 4 . H. Native of Armenia. Sibtl. et Smith, $f$. græc. t. 219.-Tourn. cor. p. 4. Flowers sessile, 1-3 from the same bractea. Corollas blue.

Stem-clasping-leaved Rampion. Pl. 1 to $1 \frac{1}{2}$ foot.

\section{+ Spccies little lnown.}

31 P. Siвínсcum (Vest, ex Roem. et Schultes, syst. 5. p. 77.) heads many-flowered; flowers all bracteate; bracteas oblong, stiff, acute; leaves all linear-cuneated, toothed; stem erect, leafy. 24. I1. Native of Sibcria. P. pauciflòrum, Johann. herb. ex Rœm, et Schultes. Stem 2 inches high. Leaves 3.4 . lines long. Heads of flowers like those of some species of Scabiòsa or Globulària.

Siberian Rampion. Pl. 2 inches.

32 P. INEQUA'tum (Kit. ex Schultes, fl, austr. ed. 2d. no. 883.) heads nearly globose; radical leaves lanceolate, uncqual at the base, cordate, serrated: cauline leaves linear: superior leaves sessile, quite entire. 24. H. Native of Austria. 1Roem. et Schultes, syst. 5. p. 80 . Very nearly allied to P. Charmèlii.

Uncqual-leaved Rampion. Pl. $\frac{1}{2}$ to 1 foot.

33 P. fistulòsum (Reich. A. dresd. fl. bot. zeit. 5. p. 534.) leaves lanceolate, a little toothed, acuminated; stem erect, simple, striated; heads cylindrical. 24. H. Native of Austria. P. Schenchzèri, Schmidt, fl. bohem, fic. fl. dresd, ed. 2. P. orbiculàre, Buch. f. dresd. fic. dresd. ed. 1. P. orbiculàre alpinınn, Jacq. fl. austr. 437. left-hand figure. This plant has a very peculiar habit, but the flowers have not been seen.

Fistular Rampion. Pl. 1 foot.

34 P. strulosum (Bess. cat, hort. crem. 1816. Roem. et Schultes, syst. 5. p. 88.). Nathing is known of this plant but the name.

Long-stylcel Rampion. Pl.

35 P.? miNu'tum (Røm. et Schultes, syst. 5. p. 87.) radical leaves ovate-spatulate, sinuated: cauline leaves spatulate, quite entire, obtuse, all glabrous; flowers axillary, terminal. 24. $\mathrm{H}$. Native on the top of Serra Texeda. Campánula Aghard, in litt. to Roem. et Schultes. Radical leaves crowded. Stems ascending or decumbent, simple. Peduncles filiform, length of leaves. Corollas blue.

Minute Rampion. Pl, decumbent.

36 P. supina (Sieb. in Spreng. syst. 1. p. 810.) stem creeping, diffuse; leaves spatulate, subcrenated; heads terminal; bracteas ovate, crenated, equal in length to the flowers. $4 . \mathrm{H}$. Native of Asia Minor.

Supine Rampion. Pl. creeping.

Cult. All the species of Phyteuma being hardy and ormatmental, they are well fitted for decorating flower-borders, or rock-work. They grow in any common garden soil, and are readily increased by division or by seeds.

XIII. PETROMA'RULA (from $\pi \varepsilon \tau \rho \circ$, petros, a rock; ancl ucoov, maron, a bitter herb; the plant is bitter, and grows on rocks by the sea side). Bellus. episc. 1. in Clus, list. pt. 2. p. 299. Alpl. D. C. mon. p. 209. Phyteùma species, Lin.

LiN. syst. Pentándria, Monogýnia. Calyx 5-cleft. Corolla 5-parted. Stamens 5, alternating with the lobes of the corolla ; filaments broad at the base, longer than the anthers; pollen violaceous. Style glabrous; stigma capitate, 3-lobed, rather pilose. Ovarium 3-celled, inferior. Capsule erect, dehiscing laterally by 3 pores in the middle part. - An lerb, native of Candia.-First radical leaves petiolate, ovate, acute; those afterwards pinnate, with the petioles marginated and lobed. Flowers pedicellate, disposed in loose racemes.

1 P. Pinna'ta (Alph. D. C. mon. p. 209.). 4. or 8. H. Native of Candia, on rocks by the sea side. Sweet, fl. gard. it. 
s. t. 224. Phyteùma pinnàtum, Lin. spec. 1. p. 242. Lam. ill. 120. 2591. Vent. cels, t. 52. Sibth. et Smith, fl. græc. t. 226. Rœm. et Schultes, syst. 5. p. 86. Petromárula Rapúnculum Créticum Sc. Barrel. icon. 1154.-Moris. oxon. 2. p. 454. - Park. theatr. 649. f. 5.-Moris. ox. sect. 5. t. 1. f. 8.Ponæ. bald. p. 38, with a figure.-Bauh. hist. 2. p. S11. Plant ylabrous, 3-6 feet. Root fusiform. Leaves large, pinnatifid. Racemes long, forming terminal panicles. Corollas blue or white.

Var. $\beta$, pubéscens (D. C. prod. 4. p. 209.) panicle and calyxes downy. 24. or $\delta$. H. Native of Candia. Phyteùma pinnàtum. Rchb. hort, bot. t. 137.

Pinnate-leaved Petromarula. Fl. Aug. Clt. 1640. Pl. 3 to 6 feet.

Cult. A light rich soil, and a warm sheltered situation, are the best for this plant. It is increased slowly by division, but plentifully by seed. The plant requires shelter in severe weather in winter.

11V. MICHAU'XIA (named in honour of Andrew Michaux, botanist to the King of France, who travelled into Syria, Persia, and North America, and discovered this his genus). Lher. diss. Lam. ill. 2. t. 295. Gærtn. fil. suppl. p. 162. t. 211. Alph. D. C. mon. p. 211.-Míndium rhàzes, Adans. fam. 2. p. 134. Juss. gen. p. 164.

Lix. syst. Octándria, Monogy'nia. Calyx 8-10-cleft, having the recesses covered by appendages. Corolla 8-10-parted, rotate. Stamens 8-10, free; filaments very broad, membranous, approximate at the base; anthers yellow, cuspidate at the apex. Style covered by hairs, which are disposed in 16 rows; stigmas 8 , filiform. Ovarimm wholly inferior, 8-celled: cells opposite the calycine lobes. Capsule drooping, 8-10-valved, debiscing at the hase. Seeds numerous, ovate, rusty, inserted in fleshy receptacles, which are situated at the inner angles of the cells.Handsome biennial herbs, natives of the Levant, with the habit of Campanula, but the recesses or sinuses of the calyx are covered, and the leaves are lyrate.

1 M. campanuloìes (Ller. diss. mon. with a figure) stem pilose; radical leaves lanceolate, irregularly lobed; petioles marginated and lobed; appendages of the sinuses of the calyx shorter than the lobes. $\delta$. H. Native of the Levant, about Aleppo, and on Mount Lebanon. Lam. ill. 2. t. 295. Curt. bot. mag. 219. Alph. D. C. mon. p. 211. Campánula lyræfòlia, Salisb. prod. p. 127. Michaúxia strigòsa, Pers. syn. 1. p. 418. -Moris. oxon, 2. p. 460. sect. 5. t. 31. Míndium Rhàzes, Adans. fam. 2. p. 134. Mèdium Dioscóridis, or Míndium lihàzis, Rauw. liodoep. part. 2. chapt. 12. p. 2\$4. and part. 4. t. 35. Root fusiform. Stem branched at top. Leaves strigose as well as the stem, 3-4 inches long. Flowers drooping, scattered along the stem and branches, from the axils of bracteas, on short pedicels, purple or pale red, octandrous. Corolla, calyx, and stigma, S-parted.

Campanula-like Michauxia. Fl. July, Aug. Clt. 1787. P!. 6 feet.

2 M. LEVIGA'TA (Vent. cels. t. 81.) stem glabrous; leaves hispid, doubly toothed; radical ones ovate, on long petioles: canline ones sessile, oblong, lower ones attenuated at the base, upper ones cordate; appendages of the sinuses of the calyx longer than the lobes. $\delta$. H. Native of Persia. Gærtn. fruct. suppl. p. 162. t. 211. f. 6. Hook. bot. mag. 3128. M. decándra, Fisch. Root branched. Stem and leaves glaucescent, the latter strigose. Flowers on short pedicels, horizontal, solitary, and scattered along the top of the stem and branches, decandrous, whitish. Calyx, corolla, and stigma, 10-parted.

Smootlb-stemmed Michauxia. Fl. Sept. Oct. Clt. 18₹0, Pl. s to 10 feet.

Cult. The seeds only require to be sown in the open ground, and the plants treated like other biennials. They require some protection in severe weather in winter.

XV. CAMPA'NULA (a dim. of campana, a bell; referring to the shape of the flowers). Fuchs. hist. p. 43. Tourn. elem. 2. 1. 90. t. 37-38. Alph. D. C. mon. p. 213.-Campánula species, Lin. gen. no. 290. Adans. fam. nat. 2. p. 134. Juss. gen. p. 164. Gærtn. fruct. 1. p. 153. t. 31. Neck. elem. 1. p. 234. Schk, ench. no. 117. t. 39. Lam. ill. no. 345. t. 123. Vent. tabl. 2. p. 470. R. Br. prod. p. 560.-Roucèla, Dumóntier, comm, bot. p. 14.-Mèdium, Fisch. mss.-Erìneon, Pliny, 23. ch. 17.-Cervicària species, Cord. Dod. pempt. 164.-Ràpum species, Ruell. p. 458.-Trachèlium, Lob. hist. 176.

Lin. sist. Pentandria, Monogýnia. Calyx 5-cleft, having the sinuses usually covered by appendages. Corolla 5 -lobed or 5 cleft at the apex, usually bell-shaped. Stamens 5, free; filaments broad at the base and membranous. Style covered by fascicles of hairs, except at the base; stigmas 3-5, filiform. Ovarium wholly inferior, 3-5-celled. Capsule 3-5-valved, dehiscing laterally. Seeds usually ovate, flattened, sometimes ovoid, and small.-Herbs usually perennial, rarely annual or biennial. Radical leaves usually different in form from the cauline ones, especially in size. Flower's for the most part pedunculate, usually racemose, rarely spicate or glomerate, blue or white.-All the species are inhabitants of the northern hemisphere.-The names Traclielium and Cervicària are the oldest names used for this genus, which were given to it on account of its supposed efficacy in the cure of disorders of the neck and trachea; hence it lias the name of Halskraut or Halswort in German, Halsurt in Danish, and Throatrort in English; and some European species have the name of Rapinculus, fiom the resemblance of the root to that of a turnip; hence they have the names Ràpum, Rapúntum, Rapúnculus, \&c., from whence spring the French name Raiponce, the German Rapunzel, the Spanish one of Rapiunchigo, and the English one of Rampion.

SEct. I. ME'Dium (a name employed by Dioscorides for some species of Bell-flower). Alph. D. C. mon. p. 216.-Mnisov, Diosc.-Medium, Fisch. mss. Mariánthemum, Schrank, hort. monac.-Rapíntia, Cheval. f. par. 2. p. 526. Sinuses of calyx covered by reflexed appendages. Capsule 3-5-celled, dehiscing by valves at the base.

§ 1. Capsule 5-celled. Stigmas 5.-Stems many-flowered. Radical leaves on long petioles.-Inhabilants of Greece and the adjaccnt regions.

* Loner leaves irregularly lyrate or jagged; petiolcs marginated and lobed.

1 C. críspa (Lam. dict. 1. p. 581.) glabrous; stems simple ; leaves smooth, coarsely and crenately toothed: radical ones bidentate, jagged: cauline leaves sessile, ovate, acute; flowers pyramidally racemose; calyx scabrous, with the appendages of the sinuses small and tooth-formed; corolla broad, campanulate, roughish on the outside. 4 . H. Native of Armenia, about the city of Kars and Erzeroum. Alph. D. C. mon. p. 216.Tourn. cor. 3. voy, 2. p. 370 . Flowers disposed as in C. pyramidalis, rising from the lower or middle part of the stem to the apex from the axils of the leaves. Corolla very open, white or blue.

Curled Bell-flower. Pl. 1 to $1 \frac{1}{2}$ foot.

2 C. CE'LSII (Alpl. D. C. mon. p. 217.) plant velvety; stem ascending; lower leaves irregularly lobed: terminal lobe crenated, ovate, acute: superior leaves sessile, obovate crenated; flowers disposed in long panicles; appendages of the sinuses of 
the calyx small, tooth-formed; corolla tubular, velvety, 4 times longer than the calycine lobes. \&.H. Native of Greece. C. tomentòsa, Vent. hort. cels. t. 1s. Stem branclied. Corollas pale violet.

Cels's Bell-flower. Pl. 2 feet.

3 C. RUPE'stris (Sibtl. et Smith. prod. 1. p. 142. fl. græc.t. 213.) stems ascending, pilose ; leaves hoary : radical ones irregularly pinnate, crenulately toothed: terminal lobe roundish; cauline leaves sessile, ovate, a little toothed; flowers disposed in loose racemes; lobes and appendages of calyx triangular; corolla velvety, tubular, twice longer than the calycine lobes. $\delta$. H. Native of Spain and the Morea, among rocks. C, lanuginosa, Willd. in hort. berol. 1. p. 213. but not of Lam. Stems branched. Corolla pale blue, witl a white throat.

Rock Bell-flower. PI. ascending.

4 C. toueviòsa (Lam. dict. 1. p. 584. ill. no. 2537.) plant clothed with hoary tomentum; radical leaves petiolate, irregularly lyrate, crenate-toothed: cauline leaves sessile, obovate: upper ones lanceolate; flowers in loose racemes; appendages of the sinuses of the calyx ovate-lanceolate, one-half shorter than the lobes, which are long-acuminated; corolla tubular, silky, hardly twice the lengtlı of the calycine lobes. $4 . H$. Native of the Levant. C. lanuginòsa, Willd. in hort. berol. 1. t. 213.? but not of Lain. Stem branclied. Peduncles 1-3-flowered. Corollas white.?

Íar. $\beta$, Ephèsia (Alph. D. C. mon. p. 218.) radical leaves not lyrate, regularly crenated; calycine lobes shorter. $4 . \mathrm{H}$. Campánula, calyce duro, Ephèsia, Tourn. herb.

Tomentose Bell-flower. Fl. June, Aug. Clt. 1810. Pl. 1 foot.

5 C. Lyra'ta (Lam. dict. 1. p. 588.) plant hispid ; lower leaves petiolate, cordate, ovate, acute, crenated : superior ones sessile, ovate-lanceolate, serrate-toothed; flowers racemose; appendages of the sinuses of the calyx ovate, obtuse, length of lobes; corolla tubular, with rather pilose nerves, twice longer than the calycine lobes. 4 . H. Native of the Levant, and about Constantinople. Stem branched. Flowers disposed in a long, many-flowered, loose raceme, violaceous.?

Lyrate-leaved Bell-flower. Fl. June, Aug. Clt. 1823. Pl. 2 feet.

6 C. Axdre'wsil (A]ph. D. C. mon. p. 220.) plant villous ; radical leaves lyrately-pinnatifid: lobes cut; lower cauline leaves petiolate, subcordate, roundish, coarsely toothed: upper ones sessile, obcuneiform, toothed; flowers disposed in loose racemes; appendages of the sinuses of the calyx ovate, one-half shorter than the lobes; corolla campanulate, tubular. $\boldsymbol{4}$. H. Native of the Grecian Islands, on shady rocks. C. laciniata, Andr. bot. rep. 385 . Ait. hort. kew. ed. 2. vol. 1. p. 351 . Smith, prod. fl. græc. 1. p. 14.1. but not of Lin. nor Lam. Stem branched. Flowers in loose, elongated, leafy racemes. Corollas glabrous, pale blue, white or yellow at the base.

Andrews's Bell-flower. Fl. May, Aug. Clt. 1790. Pl. 1 to 2 feet.

7 C. LACINIA'TA (Lin. spec. 1. p. 237.) stems rather velvety ; leaves rather pilose: radical leaves ovate-lanceolate, coarsely jagged; petioles margined and lobed ; flowers disposed in loose panicles; appendages of the recesses of the calyx ovate, acute, one-half shorter than the lobes; corolla large, campanulate, 3

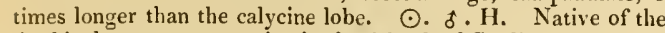
Archipelago, among rocks in the island of Cardiotissa. Lam. dict. 1. p. 588. Stem branched. Cauline leaves ovate-lanceolate, sessile, smaller and less jagged than the radical ones. Corollas pale blue.

Jagged-leaved Bell-flower. Fl. June, July. PI. 2 feet.

S C. Anchusizlòra (Sibtl. et Smith, prod. 1. p. 141. fl. græc. t. 212.) stems branched, rather velvety; leaves pilose, ovate-lanceolate; radical leaves petiolate, jagged: cauline ones sessile; flowers disposed in loose panicles; calyxes smoothish; appendages of the sinuses of the caly $\mathrm{x}$ ovate, acute, one-lialf shorter than the lobes. $\delta$. H. Native of Greece, in the island of Polycandro, and among rocks by the sea side in the island of Hydra. Primordial leaves obovate, crenated. Flowers copious, rather nutant, fine blue.

Anchusa-flowered Bell-flower. Pl. 1 foot.

9 C. Tubulòsa (Lam. dict. 1. p. 586.) plant pilose; stems terete; petioles of the lower leaves long, shortly lobed: limb ovate, acute, crenately toothed: superior leaves ovate-lanceolate, serrate-toothed; appendages of the sinuses of the calyx obtuse, one-half shorter than the lobes; corolla velvety, tubular, twice the length of the calycine lobes. $\delta$. H. Native of the Island of Candia. Flowers few, axillary and terminal, of a greyish violet colour.

Var. $\beta$; petioles of radical leaves less lobed. §. H. Native of Candia. C. tubulòsa, Desf. pl. cor. in ann. mus. 11. p. 142. t. 17.-Tourn. cor. p. 3 .

Tubular-flowered Bell-flower. Pl. 1 to 2 feet.

* Lower leaves regularly ovate or lanecolate; petioles not margined.

10 C. Betoniceròla (Sibth. et Smith, prod. 1. p. 141. f. græc. t. 210. but not of Bieb,) stem erect; leaves elliptic-oblong or ovate, acute, crenate-toothed: radical leaves on short petioles; calycine lobes ovate-acute, laving the sinuses reflexed and length of the lobes; corollas tubular. ‡. H. Native of Mount Olympus, in Bithynia. Plant pilose. Stem branched. Flowers terminal and axillary; the branchlets usually bearing 3 flowers. Corollas purplish-blue, with a pale yellow base.

Betony-leaved Bell-flower. Fl. May, Aug. Clt. 1820. Pl. $1 \frac{1}{2}$ foot.

11 C. coryubòsa (Desf. pl. cor. in ann. mus, 11. p. 139. t. 15. choix. p. 40. t. 30.) stem erect; leaves ovate-acute, crenately toothed: radical ones petiolate: cauline ones sessile; lobes of calyx long-acuminated; appendages of the sinuses of the calyx ovate-acute, one-lialf shorter than the lobes; corolla campanulately tubular. \$. H. Native of Candia.-Tourn. cor. 3. Plant pilose. Stem branched. Flowers disposed in loose corymbs, $1-3$ at the top of each branch. Corolla bluish violet.

Corymbose-flowered Bell-flower. Fl. May, July. Clt. 1820. Pl. 2 feet.

12 C. PElvifóruis (Lam. dict. 1. p. 586. Desf, choix. in ann. mus. 11. p. 141.t. 16.) stems ascending; radical leaves petiolate, ovate, crenatcly toothed : cauline ones nearly sessile, ovate-acute; calycine lobes ovate-acuminated; appendages of the recesses of the calyx length of lobes, ovate-roundish; corolla large, campanulate. \&.H. Native of Candia.-Tourn. cor. inst. p. 3. Plant hairy. Flowers $1-4$ at the extremity of each branch. Corollas large, of a greyish-blue colour.

Bowel-shaped Bell-flower. Pl. 1 foot, ascending.

13 C. ME'DicM (Lin. spec. 1. p. 236.) stem erect; leaves sessile, ovate-lanceolate, crenately toothed; calycine lobes ovate-acuminated, with the appendages of the sinuses reflexed and large, but one-half shorter than the lobes; corolla campanulate, inflated. t. H. Native of the south and east of Europe, as about Naples, Carniola, about Constantinople, north of Italy, Provence, Dauphiny at a place called Grande-Chartreuse, Bavaria, Thuringia, Austria, Transylvania, \&c., on the mountains; and of Caucasus and Tauria, Hill. syst. 8. t. 7. St. Hil. pl. de. fr. t. 72. C. grandiflora, Lam. fl. fr. 3. p. 334. Mnçıv, Diosc.-Debry, floril. nov. t. 75. 'Tabern. icon. 315. - Swert, floril. t. 16. f. 6 . -Park. parad. 355. f. 3.-Lob. icon. 324.-Besl. hort. eyst. 1. t. 3. f. 2-3.-Mor. oxon. 2. p. 459 . sect. 5. t. 3. f. 30.-Garid. 
aix. 1. p. 75. t. 18.-Weinm. pliyt. t. 289. Plant hairy. Stem branched. Flowers numerous, large, disposed in racemes. Corollas blue, purple, and white, single and double. It is a very handsome and common border biennial.

liar. $\beta$, a monstrous polypetalous plant. Alph. D. C. mon. t. 3. f. A.

Mcdium Bell-flower, or Cantcrbury Bells. Fl. July, Sept. Clt. 1597 . P]. 1 to 4 feet.

\section{\$ 2. Capsule 3-celled. Stigmas 3.-Floners solitary, rarely} capilate, fow or many.

\section{* Stcms 1-flowered. Radical lcaves cronded.}

14. C. ADA'mi (Bieb. fl, taur. 1. p. 153.) leaves ciliated a little: radical ones on long petioles, cuneate-spatulate, coarsely toothed at the apex: cauline leaves sessile, obovate or linear, serrate-toothed; calyx rather pilose, with acuminated lobes, which are 3 times shorter than the corolla; appendages of the sinuses of the calyx 3 times shorter than the lobes, ovate, acuminated. $4 . \mathrm{H}$. Native of the $A l p s$ of Caucasus. Bieb. cent. pl. ross. 1. t. 16. Alph. D. C. mon. t. 9. f. 1. Plant itufted. Root woody. Stems simple. Flowers nearly erect, one on the top of each stem. Corolla funnel-shaped, bluish. Radical leaves tufted. foot.

Adam's Bell-flower. Fl. July, Aug. Clt. 1821. Pl. $\frac{1}{2}$

15 C. Biebrrsteiniana (Rœm. et Schultes, syst. 5. p. $14 \%$. Alph. D. C. mon. p. 227.t. 9. f. 1.) glabrous; leaves soft, ciliated: radical ones spatulate, toothed at the apex : cauline ones sessile, entire, linear; calycine lobes oblong-lanceolate, twice shorter than the corolla: appendages of sinuses ovate, acuminated, 3 times shorter than the lobes. 2. H. Native of Cancasıs, among Alpine rocks. C. tridentàta, Schreb. dcc. 3. t. 2. Roem. et Scluultes, syst. 5. p. 147. C. rupéstris, Bieb. $f$. taur. 1. p. 154. Stems erect, 1-flowered, slender. Radical leaves rosulate. Flowers nearly erect, blue?

Bicberstein's Bell-flower. Fl. June, July. Clt. 1820. Pl. $\frac{1}{4}$ to $\frac{1}{2}$ foot.

16 C. Pilòsa (Pall. mss. Willd. ex Rœm. et Schultes, syst. 5. p. 148.) leaves ciliated at the base; radical ones oblong-obovate, petiolate, crenulated: cauline ones linear, acuminated, sessile, entire; lobes of calyx ovate, acuminated, ciliated, 3 times shorter than the corolla; corolla funnel-shaped, with a bearded throat. 4. H. Native of Siberia. Ledeb. f. ross. alt. ill. t. 209. Stems simple, hairy, 1-flowered. Corolla blue, form of those of $C$. saxifraga, bearded, drooping.

Pilose Bell-flower. Pl. $\frac{1}{4}$ to $\frac{3}{2}$ foot.

17 C. saxífraga (Bieb. fl. taur. 1.p. 155.) stems smoothish ; leaves a little ciliated, pilose : radical ones on long petioles, lanceolate-spatulate, crenulated : cauline leaves sessile, entire, ligulate; lobes of calyx broad, acuminated, glabrous, twice shorter than the corolla; appendages of the sinuses of the calyx ciliated, acuminated, doubly shorter than the Jobes. 24. H. Native of Cancasus, on the upper part of Mount Beschtau, where it forms lroad tufts. Alph. D. C. mon. p. 228. t. 10. f. 2. Leaves ciliated, with soft, hardly perspicuous hairs. Stem simple, 1flowered. Flowers erect, blue.

Saxifrage Bell-flower. Fl. June, July. Pl. $\frac{1}{4}$ to $\frac{1}{2}$ foot.

18 C. cilla'ta (Stev. mem. soc. mosc. 3. p. 256.) stem rather pilose; leaves ciliated with stiff hairs; radical leaves almost sessile, obovate-lanceolate, crenulated, shining : cauline oncs ligulate, ciliated a little at the base: lobes of calyx ciliated, linear-acuminated, one-half shorter than the lobes of corolla; appendages of the sinuses of the calyx ovate-acute, 4 times shorter than the lobes. 2\%. H. Native of the higher alps of Caucasus, in stony places. Mèdium Saxífragum. Fisch. in litt. Stem solitary, 1-flowered. Lower leaves rosulate. Flower erect, blue.

Ciliated bell-flower. Pl. $\frac{1}{2}$ foot.

19 C. Alta'ica (Alph. D. C. mon. p. 229. t. 10. f. 3.) radical leaves petiolate, long-lanceolate, crenated, glabrous; cauline leaves ligulate, a litcle toothed, smoothish; tube of calyx downy, but with the lobes smoothish and doubly shorter than the corolla, which is funnel-shaped; appendages of the sinuses of the calyx subulate, villous, 3 times shorter than the lobes. $4 . \mathrm{H}$. Native of the Altain mountains, about Sayen; and of Persia. C. Sayenénsis, Fisch. cat. hort. gorenk. 1808. p. 52. but not of Pall. Mèdium Sayanénse, Fisch. in litt. C. frígida, Pall. in herb. Lamb. Stems slender, 1-flowered, glabrous. Corolla blue, nutant.

Altain Bell flower. Pl. $\frac{1}{4}$ foot.

20 C. DAsYántuA (Bieb. fl. taur. suppl. p. 147.) radical leaves ovate, acute, petiolate, crenated, smoothish : cauline leaves sessile, lanceolate, entire, downy; calycine lobes ovatelanceolate, 3 times shorter than the corolla, which is funnelshaped; appendages of the sinuses small and subulate. $\mathscr{H}$. H. Native of the Aleutian Islands; very frequent in the Unalaschka, Behring's Jsland, and Beluring's Straits. Rehb. icon. bot. 1. p. T0. t. 85 . f. $178 .-$ Gmel. sib. 3. p. 160 . no. 28. Stem 1-flowered, pilose or glabrous, nearly naked. Flowers nearly erect, almost naked. Radical leaves rosulate. Corolla large, blue ( $f .131)$.

Thick-floncred Bell-flower. Pl. $\frac{1}{4}$ foot.

21 C. Alliònu (Vill. delph. p. 18. dauph 1. p. 302. and 338. vol. 2. p. 512.t. 10.) stem rather
FJG. 131

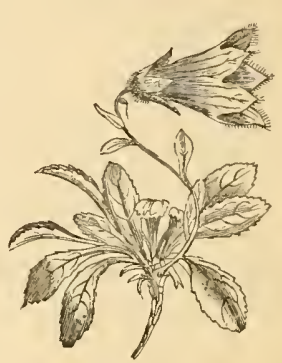

pilose; radical leaves linear-lanceolate, nearly entire, ciliated : lower ones bluntish; lobes of calyx linear-acuminated, rather pilose, one-half shorter than the corolla: appendages of sinuses ovate-acute, 3 times shorter than the lobes. 2 . H. Native of Provence, Dauphiny, Piedmont, Mount Cenis, Switzerland. C. alpéstris, All. ped. 1. p. 113. t. 6. f. 3. C. barbàta, Var. $\beta$, Schouw, pl. pfl. geogr. ital. p. 13. Root creeping. Stems 1flowered. Radical leaves rosulate. Flowers submutant, large, blue or white.

I ar. $\beta$, spatulàta (Alph. D. C. mon. p. 231.) radical leaves spatulate: cauline ones a little toothed. 4. H. C. nàna $\beta$, Lam. et D. C. fl. fr. ed. 3. no. 2851 . C. Alliònii, B, Lam. et D. C. fl. fr. l. c.

Allioni's Bell-flower. Fl. July, Aug. Clt. 1820. Pl. $\frac{1}{2}$ foot.

22 C. Pallasina (Rom. et Schultes, syst. 5. p. 138.) stem 1-flowered, glabrous; leaves glabrous, lanceolate, serrated, petiolate; flower nutant; calycine segments acute. 4 . H. Native of Siberia. Like C. Alliönii. Root creeping. Radical leaves an inch long: canline ones 2 to 3 lines long.

Pallas's Bell-flower. Pl. $\frac{3}{2}$ foot.

\section{* Stems few or many-fonercd. Flowers pediccllate, not capitate.}

23 C. saxa'tiLis (Lin. spec. p. 237.) glabrous; stems erect; leaves crenated : radical ones rosulate, somewlrat spatulate: cauline ones ovate, acute; flowers few, racemose; lobes of calyx acuminated, one-half shorter than the corolla, which is tubular; 
style exserted. 4. II. Native of Candia, on rocks by the sea side, on the north side of the island. Ait. hort. kew. ed. 2 . vol. 1. p. $350 .-$ Bocc. mus. p. 76. t. 64 . Barrel. obs. t. 813 . Flowers 3.5 , disposed in a loose raceme. Corollas nutant, blue.

Rock Bell-flower. Fl. May, Aug. Clt. 1768. Pl. $\frac{1}{2}$ foot.

24. C. heteroriy'Lla (Lin. spee. 1. p. 240.) quite glabrous; stems decumbent, simple; leaves entire: radical ones somewhat spatulate: cauline ones ovate-roundish ; lobes of calyx acute; sinuses of calys tootlied a little. 24. H. Native of the island of Chero. Sibth. et Smith, fl. graec. t. 208. Tourn. cor. 3. itin. p. 243. with a figure. Flowers rising from the axils of the leaves, on the upper part of the stem. Corolla campanulately tubular, pale blue.

V'arious-leaved Bell-flower. Fl. Sept. Pl. $\frac{1}{2}$ to 1 foot.

25 C. Olivie'ri (A]ph. D. C. mon. p. 233. t.9.) plant clothed witl cinereous down; stems erect, simple; leaves nearly entire: radical ones spatulate: cauline ones ovate, or ovate-roundish, on short petioles; flowers apuroximate; calyx with acuminated lobes, and subdentate sinuses. 4 . H. Native of Greece, on tle walls of Jupiter's temple, in the island of Deli. Stems numerons. Flowers 3-6, crowded at the top of eacli stem. Corolla funnel-shaped, blue.?

Olivier's Bell-flower. Pl. $\frac{1}{2}$ to 1 foot.

26 C. CA'NDida (A]ph. D. C. mon. p. 231.) plant few-flowered, of a pale hoary hue ; stems erect, simple: radical leaves spatulate, nearly entire: cauline leaves ovate, sinuately toothed, on short petioles; calycine lobes acuminated; sinuses of calyx very short, tooth-formed. $\psi$. H. Native of the Levant, among rocks. Stems many, downy. Leaves downy beneath, and silky above. Flowers few, terminal and axillary. Corolla funnel-shaped.

White Bell-flower. Pl, $\frac{1}{4}$ to $\frac{1}{2}$ foot.

27 C. caranenthifólia (Lam. dict. 1. p. 585.) plant clothed with greyish down; stems decumbent, branched; leaves toothed: rarlical ones rosulate, somewhat spatulate: cauline leaves obovate; lobes of calyx lanceolate, one-half shorter than the corolla; sinuses of calyx short, tooth-formed. 24. H. Native of the island of Naxia. Desf. cor. in ann. mus. 11. t. 12. Stems numerous. Radical leaves rosulate. Flowers disposed in a loose leafy raceme, erect, pale rose-coloured.

Calamint-leaved Bell-flower. Pl. decumbent.

28 C. EDU'L1s (Forsk. f. ægypt. arab. p. 106. and 44. Alph. D. C. mon. p. 233.) plant hispid; root thick; stems erect, simple, 1 -flowered; leaves ovate-lanceolate, a little crenulated; calycine lobes linear-lanceolate, equal in length to the corolla, which is hispid. 4. H. Native of Arabia Felix. Root thick, sapid, and is eaten by children like those of many other species under the names of chobs and okab. Corolla tubular, pale blue or white, with violaceous veins.

Edible-rooted Bell-flower. Pl. $\frac{1}{2}$ foot.

29 C. strigosa (Russ. alepp. ex Røem. et Schultes, syst. 5. p. 142. Valil. symb. 3. p. 34.?) plant beset with strigose Jairs; stem erect, with dichotomous branches; leaves lanceolate, entire; calycine lobes subulate, equal in length to the corolla; appendages of the sinuses of the calyx obtuse. 24. H. Native of the Levant, especially in Syria, about Aleppo. C. Russeliana, Roem. et Schultes, syst. 5. p. 142. Stem simple at the hase, and branched at the apex. Flowers solitary, drooping, rising from the angles of the forks and tops of the branches. Calyx very hispid.

Strigose Bell-flower. PJ, $\frac{1}{4}$ to $\frac{1}{2}$ foot.

30 C. Dictótoma (Lin. amœen. acad. 4. p. 306.) plant clothed with stiff lairs; stem erect, with diclıotomous branches; canline leaves ovate, acute, a little crenated; flowers sessile in the forks of the branches; calycine lobes long, subulate, one-half vol. III. shorter than the corolla; appendages of the sinuses of the calyx subulate, one-half shorter than the lobes. 24. H. Native in the region of the Mediterrancan; near Athens; in the sonth of Italy, even to lat. $42^{\circ}$; frequent in Sicily; Spain ; aloout Mogodor; Tangiers, \&c. Jacq. coll. 5. p. 36. t. 12. Sibth. et Snitl. 1. græc. t. 211. Sweet, brit. fl. gard. t. 280 . C. móllis. Var, $\beta$, Willd. spec, 1. p. 910 . C. $A^{\prime}$ fra. Cav. ann. de cienc. 3. p. 21. Rœm. et Schultes, syst. 5. p. 137. C. decípiens, Roem. et Sclıultes, syst. 5.p. 112.-Cupan. pamph. sic. 2. t. 259. Bocc, sic. p. 83. t. 45. f. 1. Moris. oxon. 2. p. 459. sect. 5. t. 3. f. 26 . Flowers drooping, terminal, solitary in the forks of the branches and stem, bluish-purple, with a paler tube.

Var. $\beta$, brachiàta (A]ph. D. C. mon. p. 237.) appendages of the sinuses of the calyx obtuse. 4 . H. Native of Mauritania. C. brachiàta Salzm. ined.

Dichotomous Bell-flower. Fl. July, Aug. Clt. 1820. Pl. $\frac{1}{2}$ foot.

31 C. Móluis (Lin. spec. 1. p. 237.) plant velvety from greyish down; stems ascending; leaves nearly entire: radical ones rosulate, spatulate: cauline ones ovate; flowers in loose panicles; calyx velvety, with acuminated lobes, which are twice shorter than the corolla, and with the appendages of the sinuses short and subulate. 24. H. Native of the region of the Mediterranean; about Tangiers; Candia; near Naples, at a place called St. Roch, and elsewhere in the kingdom of Naples; Spaiu, \&c. Curt. bot. mag. t. 404. C. velutina, Desf. fl. atl. 1. p. 180. t. 51. Plant tufted. Stem downy, also often villous. Leaves more or less hoary on both surfaces, villous. Flowers 1 to 5 at the top of each stem, axillary and terminal. Corollas campanulate, pale blue.

Var. $\beta$, mierophýlla (Alph. D. C. mon. p. 238.) cauline leaves small, ovate, acute, a little toothed. 4. H. Native of Spain; in Murcia, about Ellin.

Soft Bell-flower. Fl. May, Aug. Clt. 1788. Pl. ascending.

32 C. strícta (Lin. spec. p. 238.) stem branched, pilose; leaves ovate-lanceolate, acute, serrated, pilose; flowers almost sessile, few, solitary; lobes of calyx glabrous, lanceolate, 4 times shorter than the corolla, which is tubular; appendages of the sinuses of the calyx ovate, length of lobes, but broader. 24. or $\delta$. H. Native of Armenia; Syria, about Damascus, at the mountain called Djebel-cher; and of tbe island of Cois, on the mountains, and elsewhere in Greece. Desf. cor. in ann. mus. 11. t. 13. Flowers spicate. Corollas blue.

Var. $\beta$; leaves narrower, and nearly entire. $\boldsymbol{\psi}$. H. Native of Syria. C. stricta. Labill. pl. syr. dec. 5. t. 4. C. stricta, var. $\beta$. Kœm. et Scliultes, syst. 5. p. 149. feet.

Straight Bell-flower. Fl. July, Aug. Clt. 1819. Pl. 1 to 2

33 C. SARMA'TICA (Ker. bot. reg. 237.) stems simple, straight, downy ; leaves tomentose: lower leaves petiolate, cordate, rather hastate, crenately-toothed: superior ones sessile, oratelanceolate, serrate-toothed; flowers scattered, disposed in racemes; calyx with a densely hairy tube and velvety Jobes, which are twice shorter than the corolla, and triangular; appendages of the sinuses of the calyx small and tooth-formed; corolla velvety outside. 4 . H. Native of Caucasus, in stony places. C. betonierefòlia, Bielıler, pl. nov. herb. Spreng. p. 1. no. 26. ex Bieb. A. taur. 1. p. 153. and suppl. p. 144. but not of Smith, nor Bieb. C. gummífera, Willd. rel. in Rom. et Schultes, syst. 5. p. 144. Şpreng. syst. 1. p. 734 . C. commutàta, Rem. et Schultes, syst. 5. p. 143. Stems simple. Leaves grey, cordate, lanceolate. Flowers nutant, usually secund, terminal and axillary, forning a long, loose, scattered raceme. Corollas pale blue.

Var. $\beta$, glàbra (Alph. D. C. mon. p. 240.) stem leaves gla$5 \mathrm{D}$ 
brous, as also the calyx. 2. H. C. Sarmática, Sims, bot. mag. t. 2019 . Lodd. bot. cab. t. 581.

Sarmatian Bell-flower. Fl. July, Aug. Clt. 1803. Pl. 1 to 2 feet.

34 C. Alliarjefòlia (Willd. spec. 1. p. 910. Salisb. par. lond. t. 26.) stems simple, terete, downy; leaves crenulated, hoary beneath: lower ones petiolate, somewhat reniform: upper ones sessile, ovate, acute; flowers spicately racemose; lobes of calyx velvety, hoary inside, lanceolate, acuminated, 4 times shorter than the corolla, which is downy outside; appendages of the sinuses of the calyx ovate, acute, one-half shorter than the lobes. 24. H. Native of Siberia, Georgia, and Caucasus. Roem. et Schuites, syst. 5. p. 143. C. lamiifòlia, Bieb. fl. cauc. 1. p. 154. Rœm. et Scliultes, syst. 1. p. 734.-Buxb. cent. 5. p. 10. t. 18. Flowers sessile, secund, disposed in a long, racemose, loose spike, with a few short floriferous branches at its base, the lower flowers often 3 from each bractea. Leaves hispid, and green above, but clothed with hoary tomentum beneath. Corollas white or cream-coloured.

Var. $\beta$, macroplıýlla (A]ph. D. C. mon. p. 241.) radical leaves hastate. 4 . H. C. macrophýlla, Sims, bot. mag. t. 912. Alliaria-leaved Bell-flower. Fl. July, Sept. Clt. 1803. Pl. 2 to 3 feet.

35 C. vjouæròuı (Lam. dict. 1. p. 587.) plant humble, fewflowered, pilose; radical leaves petiolate, ovate-roundish, cordate, crenated : cauline leaves ovate-oblong, toothed; lobes of caly $\mathrm{x}$ lanceolate, ciliated, long-acuminated; appendages of sinuses of the calyx ovate, acute, one-half shorter than the lobes; corolla much longer than the calycine lobes. 24. H. Native of Siberia. C. víolæ, Pers. ench. 1. p. 192, Leaves rather pilose. Flowers 2-3, large, drooping, white, about the size of those of C. Mèdium.

Violet-leaved Bell-flower. Pl. $\frac{1}{4}$ to $\frac{1}{2}$ foot.

36 C. Puncta'ta (Lam. dict. 1. p. 586 .) plant pilose; stems simple, few-flowered, terete ; leaves ovate, acute : radical ones on long petioles, cordate-ovate, acute, crenated: cauline ones almost sessile, toothed ; lobes of calyx ciliated, long-lanceolate, 3 times shorter than the corolla; appendages of the sinuses of the calyx ovate, acute, one-lialf shorter than the lobes. $\% . \mathbf{H}$. Native of Siberia, in the provinces called Okotsk and Jakutsk; and of Dahuria, even to the Eastern Ocean; also of Jauan. Sims, bot. mag. t. 1723 . Sclırank, pl. rar. fasc. 9. t. 87. C. Trachèlium, Thunb. f. jap. p. 88.-Gmel. sib. 3. p. 155. t. 30. no. 23. Stem usually downy, panicled at top. Flowers large, pendulous. Corolla dirty-white, spotted with purple inside.

Dotted-flowered Bell-flower. Fl. May, June. Clt. 1813. Pl. $\frac{1}{2}$ to 1 foot.

37 C. DIVE'rgens (Willd. enum. 1. p. 212.) plant pilose; stem panicled; radical leaves subspatulate, crenulated, narrowed at the base: cauline ones sessile, lanceolate, acuminated; peduncles many-flowered, diverging; lobes of calyx biistly, long-acuminated, 4 times shorter than the corolla: appendages of the sinuses ovate, obtuse, one-half shorter than the lobes. ๙. H. Native of Siberia, alps of Transylvania, and Hungary. Alpl. D. C. mon. p. 243. Sweet, f. gard. n. s. t. 256. C. spatulàta, Waldst. et Kit. pl. hung. 3. p. 286. t. 258. but not of Smith. C. nùtans, Vahl, ined. Horn. hort. hafn. p. 201. C. cérnua, Hort. ex Horn. Balt. cat. hort. taur. 1813 . p. 20. but not of Thunb. Plant bristly rather than pilose. Lcaves ciliated. Panicle loose. Peduncles like the stem, usually trichotomous. Flowers rather large, at first erect, but drooping in the expanded state. Corollas glabrous, of a violaceous blue colour. foot.

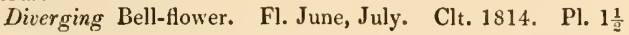

38 C. Sinírica (Lin. spec. p. 236.) plant beset with bristle- like hairs; stem branched; leaves crenulated: radical ones crowded, petiolate, obovate, obtuse : cauline ones sessile, oblong-lanceolate, undulated, acuminated ; panicle many-flowered; lobes of calyx long-acuminated, 3 times shorter than the corolla : appendages of the sinuses form of the lobes, but one-half shorter. \&. H. Native of the north and middle of Asia; east of Europe, at the foot of the Alps; Siberia, Altaia, Caucasus, Iberia, Podolia, Vollyynia, Germany, Galicia, Bohemia, Hungary, Carniola, Vallais, Piedmont, \&.c. Jacq. f. austr. 2. p. 60. t. 200. Hill. veg. syst. 8. t. 96. Sims, bot. mag. 659 . C. undulàta, Moench, suppl. p. 189 . C. paniculata, Pohl, tent. $A$. bohem. p. 207. C. racemòsa, Gmel, reis. durch. russ. 1. p. 153.-Gmel, sib. 3. p. 154. no. 2. t. 29 . Leaves undulated. Flowers numerous, drooping. Corollas of a bluish violetcolour, rather large.

Var. a, paniculàta (Alph. D. C. mon. p. 244.) panicle divaricate. A broad-leaved garden variety, very like $C$ 'divérgens.

lar. $\gamma$, abortiva (Alpl. D. C. l. c.) plant 2 inches high, 3flowered; leaves linear-subulate; flowers small. б.H. $\mathrm{Na}$ tive about Vienna, in very dry places.

Siberian Bell-flower. Fl. July, Sept. Clt. 1783. Pl. 1 to $1 \frac{1}{2}$ foot.

39 C. parviflòra (Lam. dict. 1. p. 588. Desf. cor. in ann. mus. 11. t. 14.) stem pilose, branched; branches dichotomous ; leaves crenately-toothed: radical ones on long petioles, ovateoblong, obtuse, unequally cut at the base: cauline leaves nearly sessile, orate-lanceolate; panicle many-flowered; calyx downy, with ovate, acuminated lobes, which are 3 times shorter than the corolla: appendages of the sinuses ovate, acute, about equal to the lobes. 24. H. Native of Siberia. Rœm. et Schultes, syst. 5. p. 148. Alph. D. C. mon. p. 245. Stem panicled at top. Leaves glabrous, or rather villous. Corolla blue, 5-6lines long. Flowers numerous, small, drooping.

Small-flowered Bell-flower. Pl. 1 to 2 feet.

40 C. Caucásica (Bieb. casp. p. 140, append. no. 14. fl. taur. 1. p. 155 . Stev. mem. soc. mosc. 3. p. 256.) plant humble; stems erect, branclsed, terete, scabrous, pilose ; leaves crenulated, lower ones ohovate, obtuse, petiolate : superior ones lanceolate, sessile; peduncles few-flowered, diverging; lobes of calyx acuminated, ciliated by hairs, 4 times shorter than the corolla; appendages of the sinuses of the calyx ovate-acuminated, one-half shorter than the lobes. $\%$. H. Native of Caucasus, in sub-alpine stony places. Root creeping. Leaves scabrous. Flowers few, terminal and axillary, drooping. Corolias glabrous outside, but bearded inside, of a violaceous blue colour.

Caucasian Bell-flower. Fl. July, Aug. Clt. 1804. Pl. $\frac{1}{2}$ foot.

41 C. Afrivis (Rœm. et Schultes, syst. 5. p. 140.) stems hispid with deflexed bristles ; cauline leaves hinear-lanceolate, setaceously ciliated, very long. 4. H. Native of Spain, on Mount Lijo. Root horizontal. Stems numerous, simple. Leaves glabrous, but ciliated with reflexed bristles. Flowers at first erect, but at length drooping. Corolla above an inch long, blue.

Allicd Bell-flower. Fl. July, Aug. Clt. 1824. Pl. $\frac{1}{2}$ to 1
foot.
4.2 C. Barba'ta (Lin. spec. 236.) stems nearly simple, terete, pilose; leaves villous, nearly entire: radical leaves crowded, lanceolate: cauline leaves few, ligulate; racemes loose, fewflowered; calyx pilose, with triangular acuminated lobes; appendages of the sinuses of the calyx ovate, one-half shorter than the lobes; corollas bearded in the mouth. $\delta .4 . H$. Native of the alps of Dauphiny, Piedmont, Savoy, and even to the alps of Salisburgh and Austria ; in the south towards Mount Baldo; as well as of Siberia, Saxony, Transylvania, \&c. Jacq. obs. pt. 2. p. 14. t. 37 . Krok. sil. t. 38 . Sims, bot. mag. t. 1258. ex- 
clusive of the synonymes. Lodd. bot. cab. t. 788.-C. Bauh. prod. p. 36 . with a figure-Moris. oxon. 2. p. 460 . sect. 5. t. 3. f. 33. and f. 35 . Root thick, white. Flowers nutant, disposed in a loose, often secund raceme; pedicels 1 -flowered, rising from the axils of the superior leaves. Corolla pale blue or white, glabrous outside, but woolly in the mouth. Pl. $\frac{1}{4}$ foot high.

Var. $\beta$, uniflòra (Alph. D. C. mon. p. 217.) plant small. 4 . H. Native of Switzerland, on Mount Rossboden, and on Mount Umbrail.-C. barbàta, var. $\gamma$. Rœm. et Schultes, syst. 5. p. 138. Gaud. fl. helv. 2. p. 163. C. Firmiàna, Vand. in Rœm. script. p. 55. Vand. fasc. p. 9.-Pluk, plyyt. t. 153. f. 5.

Bcarded-flowered Bell-flower. Fl. June, July. Clt. 1752. Pl. $\frac{1}{2}$ to $1 \frac{1}{2}$ foot.

43 C. ALPlNa (Jacq. enum. vind. 210.) humble; stem nearly simple, furrowed; leaves linear-lanceolate, repandly-crenate, woolly: radical ones crowded, narrowed at the base; flowers pyramidally racemose ; calycine lobes long-acuminated, woolly : appendages of sinuses ovate-acute, woolly, much shorter than the lobes. 24. H. Native of Europe, on the alps, especially of Austria, Salisburgh, Germany, Silesia, Transylvania, and the Carpathian mountains. Jacq. f. austr. 2. t. 118 . Sims, bot. mag. t. 957.-Clus. hist. 5. p. 171. Root spongy, fusiform. Stem glabrous or woolly. Flowers few or numerous, scattered in a pyramidal manner along the whole of the stem. Corollas deep blue.

Alpine Bell-flower. Fl. July, Clt. 1779. Pl, $\frac{1}{4}$ to $\frac{3}{4}$ foot. 4.4 C. specròsa (Pourr. act. tol. 3. p. 309.) stem simple; leaves sessile, repandly crenated : radical leaves rosulate, linearlanceolate : cauline leaves linear; flowers pyramidally racemose; lobes of calyx linear-acuminated, ciliated: appendages of the recesses ovate-triangular, ciliated, one-half shorter than the lobes. 24. H. Native of France, in the olive region, and in central and eastern Pyrenees, and in that part of the Cevennes called Capouladoux. D. C. fl. fr. ed. 3. no. 2854. C. longifolia, Lapeyr. fig. pyr. t. 6. abr. p. 107. C. thyrsoidea, Lapeyr. abr. pyr. 106.? C. Alliòni, Lapeyr. 1. c. p. 107. C. barbàta, Lapeyr. 1. c. p. 107.? C. mèdium, Lapeyr. 1. c. 107.? Root simple, tuberculate. Stem glabrous or pilose, furrowed. Flowers pedicellate, disposed in a pyramidal raceme, each pedi. cel furnished with 2 bracteas. Corolla an inch long, smooth outside, but often villous inside, blue, purple, or white.

Íar. $\beta$, bicaúlis (Alph. D. C. mon. p. 248.) plant humble, few-flowered; stigmas 2. 4 . H. Native of the Pyrenees. C. bicaúlis, Lapeyr. fig. pyr. p. 13. t. 7. C. longifolià, $\beta$, Lapeyr. abr. p. 107.

Showy Bell-flower. Fl. June, Sept. Clt. 1820. Pl. $\frac{1}{2}$ to 1 ft.

$$
\text { * * Floners capitate. }
$$

45 C. cicirora'cea (Sibth, et Smith, fl. græc. t. 209.) plant pilose; stem angular, branched; leaves undulately crenated: radical ones obovate, irregularly jagged, petiolate: cauline leaves sessilc, linear-oblong, obtuse; bracteas ovate, cordate; calyx pilose, witl, ovate acute lobes; appendages of sinuses of the calyx obtuse, very like the lobes; corolla tubular, 3 times longer than the calyx. §. H. Native of Thessaly. C. capitàta, Sims, bot. mag. t. 811.? Root fusiform. Leaves undulated. Flowers capitate, terminal, and from the axils of the leaves. Corollas purplish blue.

Chicory-like Bell-flower. Fl. June, July. Clt. 1768. Pl. 3 feet.

46 C. Ljegula'ta (Waldst, et Kit, pl. hung. 1. p. 65. t. 64.) plant hispid; stem nearly simple; leaves sessile, undulately crenated: lower ones lingulately spatulate: superior ones linearlanceolate; bracteas ovate, acute; calycine lobes oblong, obtuse, setaceously ciliated: appendages of sinuses similar to the lobes; corolla tubular, twice longer than the calyx. $\odot . H$. Native of Hungary, Croatia, and Dalmatia, in woods. Alph. D. C. mon. p. 250 . Root branched. Stems many from the same root. Flowers in dense terminal heaps, surrounded by setaceously ciliated bracteas.

Tonguc-leaved Bell-flower. Fl. July, Aug. Clt. 1804. Pl. 1 ft.

Sect. II. Eucònon (from $\varepsilon v, e u$, well ; and $\kappa \omega \delta \omega v$, kodon, a bell; this section is considered to contain the true species of Campánula). Alph. D. C. mon. p. 251. Campánula Traclıèlium, Cervicària, and Rapúnculus of most of the old authors. Trachèlium and Rapúnculus, Lin. gen. no. 290. Sinuses of calyx not covered by appendages, Capsule 3celled, dehiscing laterally by the valves, sometimes at the base, and sometimes at the apex.

\$ 1. Copsule crcct, dehiscing at the base. Flowers scssile, capitate, or spicate. - All the species are inhabitants of Europe.

* Style cxserted. Stems ascending, siniple. Lower leaves petiolate. Flowers glomerate, sub-pedicellate.

47 C. Jacquini (Alpl. D. C. mon. p. 251.) glabrous; stem firm, glabrous; leaves remotely serrated: lower ones on short petioles, obovate : the rest ovate, bluntish and larger; heads of flowers loose, bractless; calyx velvety, with acuminated lobes much shorter than the corolla. 24. H. Native of the island of Candia, on walls on the Sphaceotic mountains. Phyteùma, Jacquini, Sieb. herb. cret. Flowers disposed in a loose, terminal, spherical head, on short pedicels. Corollas blue?

Jacquin's Bell-flower. Pl. $\frac{1}{4}$ to $\frac{1}{2}$ foot.

48 C. Folıos a (Tenor. fl. neap. 1. p. 71. t. 13.) rather pilose; stem terete; leaves doubly serrated : radical ones ovate, acute, subcordate: cauline ones acuminated; bracteas ovate, acuminated; calycine lobes long-acuminated, ciliated, denticulated, one-third shorter than the corolla, which is tubular; lobes of corolla velvety inside. $2 . \mathrm{H}$. Native of the kingdom of Naples, on the Apennines and Abruzzo. Heads of flowers globose, terminal. Corollas blue.

Leafy Bell-flower. Pl. 1 foot.

49 C. PETRE'A (Lin. spec. 236.) stem rather woody, hoary; leaves crenulated, hoary beneath: radical leaves petiolate, ovate-lanceolate: cauline ones sessile, linear-lanceolate; heads of flowers dense, surrounded by obtuse bracteas; calyx hoary, with linear obtuse lobes, doubly shorter than the corolla, which is campanulate. 2. H. Native of Mount Baldo, on rocks, in the wooded region; and of the south of France, at a place called Les Escalles d'Eglon. Poll. elem. bot. 2. p. 150 . t. 5 . f. 1.-Moris. oxon. 2. p. 462 . sect. 5 . t. 4 . f. 44.J. Bauh. hist. 2. p. 802. with a good figure.-Barrel. pl. gall. p. 10. t. $890 .-P l u k$ phyt. t. 152. f. 5. Ponæ, descript. mont. bald. p. 62. with a good figure. Stems ascending, simple. Leaves green, and pilose above. Flowers disposed in a terminal bracteate liead. Corollas white.

Rock Bell-flower. Fl. May. Pl. 1 foot, ascending.

50 C. glomera'ta (Lin. spec. 235.) downy; stems terete; leaves serrulated: radical ones ovate, acute; bracteas ovate, acuminated; calycine lobes acuminated, twice shorter than the corolla, which is funnel-shaped. 4. H. Native nearly thronghout the whole of Europe; especially from Arragon, Pyrenees, south of France, Piedmont, northern part of the kingdom of Naples, Greece, eren to Scotland, Sweden, \&.c.; collected also in Caucasus, Persia, Altaian mountains, and almost throughout Siberia, even to Kamtschatka, \&c. Sc.; in shady rocky places, by river sides, and in dry, open, chalky pastures ; plentiful in Britain, in like situations. Smith, engl, bot. t. 90. Gilib. demonstr. bot. t. 30 . Oed. fl. dan. t. 1328. Gentiàna collina, With. 282. t. I1. f. 3. C. barbàta, Spreng. ex Steud. $5 \mathrm{D} 2$ 
C. betonicæfòlia, Gilib. Kluk. in Bess. fl. gal. 2. p. 34.4. C. graminifòlia, WVillernı. fl. lor. 1. p. 208. C. congésta, Rœem. et Scluultes, syst. 5. p. 125.-Weinm. plyyt. t. 290. f. c. and d. 'Trachèlium minus Lob. adv. 139. Cervicària minor, Dodon. pempt. 146. \&c. Stems simple or branched. Radical leaves more or less cordate. Flowers sessile, disposed in terminal heaps on the branches and stem. Corollas glabrous, except the nerves outside, bluish violet or white.

$V a r . \beta$, speciòsa (Alph. D. C. mon, p. 254.) flowers glomerate, larger, and showy. 4 . H. Native of Siberia. C. speciòsa, Horn. hort. hafn. 2. p. 957. Sims, hot. mag. 2649. but not of Pourr. C. cephalòtis or cephalántha, Fisch. mss. C. glomeràta, var. Spreng. syst. 1. p. 731. var. Dahùrica, Ker. bot. reg. t. 620. Flowers bhuish violet.

I'ar. $\gamma$, Niccénsis (Alph. D. C. mon. p. 254.) leaves approximate, ovate, acnte, sessile; flowers disposed in short dense spikes. 4. H. C. Nicæénsis, Røem. et Schultes, syst. 5. p. 126. C. glomeràta, Yoll. f. veron. 1. p. 276. C. glomeràta, var. All. perlem, 1. p. 112.t. 39. f. 1. Corollas of bluish-violet colour.

Var. $\delta$, elliptiea (Alph. D. C. mon. p. 255.) leaves on long petioles, elliptic, less cordate; flowers large, capitate; bracteas large, often longer than the flowers. 4 . H. C. ellíptica, Kit. ex Scluultes, fl. austr. ed. 2. p. 918 . C. glomeràta, Spreng. syst. 1. p. 731. C. gloineràta $\beta$, Willd. spec. 1. p. 904.-Boce. mus. t. 58 .

Var. $\varepsilon$, sparsiftòra (A」ph. D. C. mon. p. 255.) flowers disposed in sessile, scattered, axillary heaps. 4 . H. C. aggregàta, Willd. enum. suppl. 1. p. 10. Nocc, et Balb. fl. tic. 1. p. 101. t. 5. Lodd. bot. cab. t. 505 . C. glomeràta elongàta, Fisch. mss. C. glomeràta $\beta$, Lam. dict. 1. p. 508. Lam. et D. C. fl. fr. ed. 3 d. no. 2845. Corollas bluish-violet.

Var. ל, cervicarioìdes (Alph. D. C. mon. p. 255.) stem flexuous, hairy ; lower leaves on long petioles; flowers terminal and axillary. $\quad$ 4. H. C. cervicarioìdes, Roem. et Schultes, syst. 5 . p. 128. C. glomeràta, var. Clusiàna, Re, flor. torin. p. 130. Corollas bluish-violet.

I'ar. $\eta$, farinòsa (Alpl. D. C. mon. p. 255.) leaves sessile, hoary beneath; flowers disposed in terminal heads, and smaller axillary ones, all sessile. 2 . H. C. petræ'a, All. pedem. 1. p. 112. Krok. fl. sil. no. 319.? \&c. Lam. et D. C. fl. fr. ed. 3. no. 2845. C. glomeràta, Wallr. fl. hal. suppl. 3. p. 34. C. glomeràta affinis, Bess. cat. hort. crem. 1811. C. glomeràta, $\beta$, farinòsa, Rochel, pl. exsic. ex Bess, C. farinòsa, Bess. enum. pl. voll. p. 10. C. glomeràta $\delta$, Moretti, pl. ital. dec. 3. p. 4. Corollas of a bluish violet colour.

I'ar. $\theta$, pusilla (Alph. D. C. mon. p. 255.) plant 1-2 inches high; leaves round, cordate; flowers few, capitate. $2 . \mathrm{H}$.

Var. ', flore pleno; flowers double, blue or white. 4 . H. C. glomeràta $\delta$, Roem. et Schultes, syst. 5. p. 124.

Glomeratc-flowered Bell-flower. Fl. May, Sept. Britain. Pl. 1 to 2 feet.

51 C. Cervica'ria (Lin. spec. 1. p. 235.) plant beset witl: stiff pili; stems furrowed; leaves crenately serrated; radical ones linear-lanceolate, bluntish, on short petioles : cauline leaves linear, acuminated; bracteas ovate, acute; calycine lobes oblong, obtuse, doubly shorter than the corolla, which is campanulately funnel-shaped. $\delta . H$. Native of the temperate parts of Europe, as of the Pyrenees, south of France, Piedmont, and as far north as Sweden, but not of Britain ; of Russia, about Moscow and Petersburgh; also of Transylvania, Galicia ; and Siberia, about the Jaic and Jenessee, and about Barnaoul, and near Riddersk and Alexandrousk. Oed. fl. dan. t. 787 . Lodd. bot. cab. 452. C. spicàta, Geners, scep. no. 192.-Gmel. sib. 3. p. 157. t. 31.-Weinm. phyt. t. 28s. f. 6.-Mor. oxon. sect. 5. t. 3. t. 34. Stem simple. Upper stem leaves half stem-clasping.
Heads of flowers terminal, round, bracteate. Corollas blue, usually pale, pilose outside.

Throat-nort Bell-flower. Fl. July. Clt. 1768. Pl. 1 to $2 \mathrm{ft}$.

52 C. multiflòra (Walclst. et Kit. pl. hung. 3. p. 292. t. 263.) plant pilose; stem striated; leaves undulately crenated: lower ones ovate-lanceolate: cauline ones acuminated; spikes interrupted from the flowers being in fascicles; calycine lobes obtuse, 3 times shorter than the corolla, which is tubularly funnelshaped; capsule bluntly triangular. $\delta$. H. Native of Hungary, on the mountain on which the town of Versitz is built. C. macrostàchya, Willd. enum. 1. p. 218. C. cervicùria imbricàta, Rochel, herb. ex Rœm. et Schultes. Stem simple. Corollas glabrous, of a pale bluish-violet colour.

Many-flowered Bell-flower. Fl. July, Aug. Clt. 1814. Pl. $1 \frac{1}{2}$ to 3 feet.

53 C. spica'ta (Lin. spec. 1. p. 234.) hairy; stem striated; leaves nearly entire; radical leaves crowded, linear-lanceolate : cauline ones linear-acuminated; spike long, interrupted at the base; calycine lobes ovate, acuminated, 3 times shorter than the corolla, which is funnel-shaped; capsule spheroid. §.H. $\mathrm{Na}$. tive of Europe, frequent on the south side of the alps about Nice, Fenestrella, and Turin; and in the region of Mount Baldo; of Italy, Provence, Dauphiny, Vallais, Carniola, Croatia, Pormgal, Sc. All. pedem. 1. p. 112. t. 46. f. 2.-Pluk. phyt. t. 153. f. 3. Stem simple. Leaves sessile. Flowers sessile, 1-3 from each bractea. Corolla glabrous, blue.

Yar. $\beta$, ramòsa (Alph. D. C. mon. p. 261.) stem branched. §. H. C. spicàta, Schmidt, fl. bohem. no. 182 .

Var. $\gamma$, spicâ interruptâ (Alph. D. C. mon. p. 261.) leaves elliptic-lanceolate; spike interrupted. §. H. C. spicáta, var. All. Al. pedem. no. 414 . t. 47 . f. 1. Lam. fl. fr. ed. 3. no. 2855.

Var. 8, Hornschúchii (Alph. D. C. mon. p. 261.) plant small ; leaves obovate-lanceolate; corolla ovoid. ‡. H.

Spicate-flowered Bell-flower. Fl. July. Clt. 1786. Pl. 1 to 2 feet.

54 C. Tiry róidea (Lin. spec. 1. p. 235.) plant pilose; stem furrowed; leaves entire, pilose: lower ones lanceolate, obtuse : cauline ones linear-lanceolate, acute; flowers disposed in a dense pyramidal spike; calyx with a glabrous tube, and linear-lanceolate ciliated lobes; corolla oblong, doubly longer than the calycine lobes; style exserted; capsule spherical. 2 . H. Native of the alps of Europe, from Provence, Dauphiny, Savoy, even to Carniola and Lower Austria; frequent on the alps of Jura and Dola. Stem simple, covered with leaves and flowers. Flowers sessile. Bracteas often reddish. Corolla cream-coloured, hairy.

Thyrsoid Bell-flower. Fl. July, Aug. Clt. 1785 . Pl. 1 to $1 \frac{1}{2} \mathrm{ft}$.

2. Capsule drooping, dehiseing at the base. Lobes of calyx alnays entire. Flowers pedicellate.

* Flowers on more or less elongated pedicels. Radical leares usually cordate, petiolate.-Species almost all perennial.

A. Stems many-flowerel. Corolla always glabrous. Capsule ovoid. Species all natives of Europe.

55 C. íatifòlia (Lin. spec. 233.) stems simple, smooth; leaves large, doubly serrated; radical ones petiolate, cordate, ovate-oblong: cauline ones sessile, ovate-acuminated; flowers disposed in spicate racemes; peduncles erect, l-flowered; calycine lobes long-acuminated, broad at the base, 3 times shorter than the corolla, which is campanulately funnel-shaped and large. 4. H. Native of Europe, from the Pyrenees and north of Italy, even to Scotland; of Caucasus, Lapland, Nordland, Carpathian Mountains, Altaian Mountains, and Nipaul, always in moist woods and thickets. Frequent in the alps of France and Switzerland. Not unfrequent in Scotland and the north of England, but 
more rare in the south: in moist woods and thickets, by the sides of rivulets. Oed. fl, dan. t. 85 . and t. 782. Smith, engl. bot. 302. C. urticáfòlia, All. pedem. 1 p. 110. C. Brunònis, Wall. cat.-Weinm. phyt. t. 287.-Park. par. 355. f. 2.-Lob. icon. 2. t. 278 . Stem glabrous, rarely a little hairy. Leaves glabrous, rarely rather scabrous. Flowers solitary, rising from the axils of the superior leaves. Corollas large, blue, but sometimes white, or bluish-white, glabrous outside, but sometimes bearded inside. Lobcs of calyx often denticulated.

Var. 3 , macrántha (Alph. D. C. mon. p. 265.) stem and leaves rather pilose: teeth of leaves more distinct; calyx glabrous; corollas larger. $4 . H$. C. macrántha, Fisch. ined. V. latifolia, var. macrảntha, Sims, bot. ınag. 2553.

$\operatorname{Var}, \beta$, eriocárpa (Alph. D. C. mon. p. 265.) stem and leaves pilose and pale; leaves less acuminated; tube of calyx very hispid. భ. H. Native of Caucasus. C. criocárpa, Bieb. fl. taur. 1. p. 149. C. latifòlia, var. macrántha and eriocárpa, Fisch, in litt.

Broad-leaved Bell-flower. Fl. July. Britain. Pl. 2 to $3 \mathrm{ft}$.

56 C. TRACHe'́lum (Lin. spec. 235.) stems angular, pilose; leaves scabrous, acuminated, coarsely and crenately toothed: radical ones petiolate, cordate; flowers disposed in loose racemes; peduncles 1-3-flowered; calyx rather pilose, witl triangularly acuminated erect lobes, 3 times shorter than the corolla, which is campanulate. 24. H. Native of Europe, from Spain. Portugal, Piedmont, Naples, and Greece, even to Scotland, Sweden, Russia, and the Carpathian Mountains; of Caucasus, Tauria, Siberia, and even to Japan, in shady places. In Britain, in groves, thickets, and hedges l'requent. Smith, engl. bot. t. 12. Oed. fl. dan. t. 1026. Hook. fl. lond. t. 109. C. gantélée, Jaum. St. Hil. fl. fr. t. 47. C. urticæfòlia or urticifolia, Sclımidt, fl. bohem. no. 173. p. 73. Bieb. A. canc. 1. no. 374 . 'Tenor. fl. neap. 1. p. 68.-J. Bauh. hist. 2. p. 805. with a figure. C. Cervicària, Fuchs, hist. p. 431. with a figure-Moris. oxon. 2. p. 459. sect. 5. t. 3. f. 28 . Stem simple or branched, reddish. Leaves often donbly toothed, roughish. Flowers drooping a little, 1-4 together, terminating the branchlets. Corolla bluish violet and white, and all the shades between these two colours, bearded inside. The name Trachelium is from tpax $\eta$ hos, the neck; alluding to the reputed virtues of this plant in disorders of the throat, to which the other appellations of old authors allude. A decoction of the herb, which is bitter and somewhat acrid, was used as a gargle.

Var. $\beta$; flower solitary, terminal. Bieb. fl. taur. 1. p. 149.

Irar. $\gamma$, flore pleno; flowers double, blue and white, and all the shades between these two colours. Theatr. flor. t. 69 .

Var. $\delta$, monstròsa (Alph. D. C. mon. p. 267.) flowers abortive, degenerating into leares. Hall. enum. p. 193.

Great Throat-wort or Nettle-leaved Bell-Hower. F1. July, Aug. Britain. Pl. 2 to 3 feet.

57 C. RAPunculoìns (Lin. spec. 234.) stems rather scabrous; leaves scabrous, ovate, acuminated: radical ones petiolate, cordate, crenulated : cauline ones serrulated; flowers disposed in long spicate racemes, solitary; calyx rather scabrous, with linear-lanceolate lobes, which are afterwards reflexed; corolla funnel-shaped, 4 times longer than the calycine lobes. 4. H. Native of Europe, from the Pyrenees, Dauphiny, Piedmont, Transylvania, even to Scotland, Sweden, and Lapland; in the plains about the Carpathian Mountains; Caucasus, even to the banks of the river Oby in Siberia. Frequent in Middle Europe. In Britain, in woods and fields, but rare, in some woods in Oxfordshire, among yew trees. It grows in Scotland, in corn-fields, 2 miles north-west from Kirkaldy. Smith, engl. bot. t. 1369. fl. dan. 1327. Plenck, icon. t. 152. C. nùtans, Lam. fl. fr. 3. p. 336 . but not of Waldst. et Kit. C. urticifolia, Turr. prod. fl. ital. 64. no. 9. Vittm. summ. pl. 1. p. 454.
Turr. giorn. de veniz. t. 1. Gmel. syst. 2. p. 350. but not of All. and Willd. C. Trachèlium, Bull. herb. t. 319. C. secúnda, Schmidt, fl. bohem. 2. p. 74. C. morifolia, Salisb. prod. p. 126. C. rigida, Stokes, mat. med. 3. p. 333. C. glabricárpa, Schleich. pl. exsic. Root creeping. Stems glabrous or scabrous, usually branched in gardens, but simple in the wild state. Flowers drooping, solitary, disposed in spike-formed racemes, secund, but usually hanging on all sides in strong garden specimens. Corollas bluish-violet, and bearded a little inside.

Var. $\beta$, cályce glabérrimo (Alph. D. C. mon. p. 268.) calyx quite glabrous; plant more or less glabrous and reddish. $\psi$. H. Native of the Ukraine. C. Ucránica, Bess. C. neglécta, Bess. cat. hort. crem. 1808, p. 28. C. crenàta, Link, enum. 1. p. 214. C. infundibulifórmis, Sims, bot. mag. t. 2632. Flowers bluish-violet.

Var, $\gamma$, macrophílla (Alph, D. C. mon. p. 268.) stem branched; racemes many-Howered; leaves large. $4 . H . \Lambda$ garden plant. Corollas bluish-violet.

Var. ס, Enipontana (Alph. D. C. mon. p. 268.) flowers few, disposed in loose racemes; peduncles long, erect, usually 1flowered; calycine lobes broader. 24. H. C. Enipontàna, Morett. ined.

Var. $\varepsilon$, trachclioides (Alph. D. C. mon. p. 269.) stem and leaves beset with stiff white hairs, but particularly the calyx. $\psi$. H. Native of Cancasus. C. trachelioìdes, Bieb. fl. taur. 1. p. 150. no. 576. Stev. mem. nat. cur. mosc. 3. p. 255. C. Ucránica, Spreng. nov. prov. p. 8. Rom. et Schultes, syst. 5. p. 121. C. macrostàchya, Panz. herb. C. setòsa, Fisch. mss.

Var. Ц, nàna (Alph. D. C. mon. p. 269.) stem abortive, 1-3flowered. $4 . \mathrm{H}$.

Rampion-like Bell-flower. Fl. June, July. England. Pl. 2 to 4 feet.

58 C. Bononjénsis (Lin. spec. 1. p. 234.) scabrous; stems simple; leaves serrulated, ovate, acuminated, dark green above, pale beneath: radical leaves cordate, petiolate: superior leaves stem-clasping; flowers numerous, small, disposed in long racemes; calycine lobes acuminated, 4 times shorter than the corolla, which is funnel-shaped. 24. H. Native of the east of Europe and west of Asia, from lat. $40^{\circ}$ to $53^{\circ}$, and long. $15^{\circ}$ $10^{\prime}$ west. even to $60^{\circ}$; particularly in the northern elevated valleys in the kingdom of Naples; Upper Italy, Piedmont, Saxony, Prussia, Bohemia, Silesia, Caucasus, the Ukraine, and near the Volga, Sc. Bieb. Al. taur. 1. p. 150. Rclub. icon. cent. 2. t. 111. f. 221. C. Thaliàna, Wallr. sched. crit. p. 86 . Rchb. icon. cent. 2. t. 112.-Bauh. hist. 2. p. 806.-Moris. oxon. 2. p. 461 . sect. 5. t. 4. f. 38 . Tube of calyx blackish. Flowers smaller than in any other nearly allied species, numerous, disposed in a simple raceme, or the raceme is branched at the base. Corollas bluishviolet, glabrous. Plant dark green. Leaves pale beneath.

$\operatorname{Var} . \beta$; radical leaves very long. 4 . H. Native of the kingdom of Naples. C. obliquifòlia, Tenore, fl. neap. prod. p. 15. H. neap. 1. p. 69, t. 17 . Flowers bluish-violet.

Var. $\gamma$; plant much branched, many-flowered. 2.H. Native of Caucasus. C. Bononiénsis, var. $\alpha$, Bieb. fl. taur. 1. p. 151. C. multiflòra, Hortul. C. lychnitis, Horn. hort. hafn. 1. p. 199. Flowers bluish-violet.

Iar. $\delta$; leaves broader, tomentose beneath. $4 . H$. Native of Tauria, Cancasus, and many parts of Russia, and the Levant. C. petræ'a, Habl. taur. p. 157. ex Bieb. C. Bononiénsis, Scop. carn. 1. p. 147. Spreng. syst. 1. p. 730. C. Ruthénica, Bieb. f. taur. 1. p. 151. Willd. enum. p. 211. Sims, bot. mag. 2653. Flowers bluish-violet.

Iar, $\varepsilon$; stems very simple. $\psi$. H. C. Bononiénsis, All. A. pedem. 1. p. 111 . C. símplex, Lam. et D. C. f. fr. S. p. 730. Rom. et Schultes, syst. 5. p. 122. C. Bononiensis, var. $\beta$, Bieb. fl. taur. 1. p. 151 . Flowers bluish-violet. 
Bononian Bell-flowers. Fl. July, Sept. Clt. 1773. Pl. 2 to 3 feet.

B. Stems few-flowered or 1-fowered. Corollas nearly alnays glabrous. Capsule ovoid, rarely spheroid.

59 C. colriva (Bieb. fl. taur. 1. p. 152.) stems simple; lower leaves on long petioles, ovate-oblong, crenulated : middle ones lanceolate: superior ones linear-acuminated; flowers few, secund, disposed in a long raceme; calycine lobes erect, lanceolate, acuminated, doubly shorter than the corolla, which is funnelshaped. 4. H. Native of Caucasus and Tauria, on grassy hills. Bieb. pl. rar. ross. 1. t. 42. Stem rather pilose. Leaves smoothish. Flowers distant. Calyx pilose. Corolla deep blue, twice the length of the calycine segments.

I ar. a; plant larger; petioles very long; germen hispid. 4. H. Native of Iberia, on the mountains, and of Tauria. Var. $a$, Bieb. l. c.

I ar. $\beta$; plant larger; leaves shorter, and on shorter petioles; calyxes glabrous. 4. H. Native of Caucasus and Iberia. C. collina, Sims, bot. mag. 927. Ait. hort. kew. ed. 2d. vol. 1. p. 348 . Var. $\beta$, Bieb. 1. c.

lar. $\gamma$, pùmila; plant dwarf.-Tourn. cor. p. 4. C. Ibérica, angustifôlia, \&c. var. $\beta$, Bieb. l. c.

Vrar. $\delta$; flowers white. 24. H.-Tourn. cor. p. 4.

IIill Bell-flower. Fl. July, Aug. Clt. 1803. Pl. 1 foot.

60 C. paucircióra (Desf. clooix. du. cor. p. 36. t. 26. ann. mus. 11. p. 57. t. 7.) stems branched; leaves dentately serrated: radical ones ovate-roundish, petiolate: cauline ones ovate, on short petioles; flowers few, terminal ; calycine segments subulate, erect; corolla funnel-shaped, twice the length of the calycine segments. 24. H. Native of Candia, on the mountains, among bushes. Stem slender. Plant glabrous. Flowers hanging one way, solitary, terminating the branches and stem. Corolla campanulate, bluish-violet. The capsule is said to be 5 celled.

Few-flonered Bell-flower. Pl. 1 to $1 \frac{1}{2}$ foot.

61 C. Nemoròsa (Alph. D. C. mon. p. 274.) stems simple; radical leaves on long petioles, cordate, ovate-oblong, crenated : cauline leaves sessile, long-acuminated, serrated; flowers disposed in loose racemes; calycine segments subulate ; corolla funnel-shaped, twice longer than the calycine lobes. $4 . \mathrm{H}$. $\mathrm{Na}$ tive of Austria and Moravia, in woods. C. elongàta, Portenschl. but not of Willd. nor others. Plant glabrous. Racemes often furnished with few-flowered peduncles at the base. Corollas blue.

Grove Bell-flower. Pl. $1 \frac{1}{2}$ foot.

62 C. Rиом воIDA'Lis (Lin. spec. p. 233.) stems almost simple; leaves sessile, ovate, acute, serrated; flowers few, disposed in loose racemes, pedunculate; segments of calyx subulate, erect; corolla campanulate, twice longer than the calycine segments; capsule ovoid. 4. H. Native of the temperate parts of Europe, on the monntains; as of the Pyrenees, mountains of Auvergne, alps of Provence, Dauphiny, Savoy, Switzerland, Germany, Carniola, \&c. ; and of Russia and Tauria. C. rhomboídea, Lin. spec. 233. Gilib. demonstr. bot. t. 27. Lodd. bot. cab. t. 603 . C. azùrea, Sims, bot. mag. t. 551. Ait. hort. kew. ed.2d. vol. 1 . p. 348. C. venòsa, Willd. cnum. suppl. p. 10.-Barrel. icon. 78. t. 567.-Boce. mus. p. 75. t. 61.-J. Baul. hist. 2. p. 798. with a figure, Stem glabrous, or a little pilose, furnished with flower-hearing branches at top. Flowers usually drooping, but sometimes looking upwards, very like those of C. rotundifolia. Corollas hardly one-half longer than the calycine lobes, blue, glabrous.

Var. $\beta$, lanceolàta (Alph. D. C. mon. p. 275.) leaves crowded, lanceolate, nearly entire. 4 . H. Native of the Pyrenees. C. lanceolàta, Lapeyr. abr. p. 105. C. rhomboidàlis angustifòlia, Benth. cat. pyr. p. 66 . Flowers blue.
Var. $\gamma$, refléxa (Alph. D. C. I. c.) leaves broader; calycine lobes reflexed. $\psi$. H. Flowers blue.

Íar. א̇, polypétala (Alph. D. C. l. c.) leaves long-lanceolate, nearly entire; corollas 5-parted. 4. H. Flowers blue.

Rhomboidal-leaved Bell-flower. Fl. July, Aug. Clt. 1775. Pl. 1 to 2 feet.

63 C. trichocalycìna (Ten. fl. neap. prod. p. 16. fl. neap. p. 67. t. 16.) stems simple; leaves on short petioles, ovate, acute, coarsely serrated; flowers few, racemose; calycine segments reflexed, long-capillary, nearly equal to the corolla, which is profoundly 5-cleft, and funnel-shaped; capsule ovoid. 24. H. Native of the kingdom of Naples, on the mountains : of Sicily, on the Nebrodes; and of Candia. C. Albúrnica, Brigant. stirp. rar. in giorn. encycl. sept. 1817. Root simple, fusiform. Stems glabrous, but hairy at the base. Flowers disposed in an almost simple terminal raceme, approximate at the top, 1-3 rising from each axil, at the time of flowering erect, but afterwards drooping. Corolla pale violet.

Hair-calyxed Bell-flower. Fl. July. Clt, 1829. PI. 1 to 3 feet.

64 C. CA'rnica (Schiede, mss. ex Alph. D. C. mon. p. 277.) stems ascending, weak, few-flowered; leaves glabrous: lower ones obovate or lanceolate: upper ones linear; calycine segments very long, reflexed; corolla tubular, elongated. 4.? H. Native of Carniola and Carinthia, on the mountains. Root slender. Plant glabrous. Flowers few, on long peduncles, solitary, inclined. Corolla blue, glabrous.

Carniola Bell-fiower. Pl. $\frac{1}{2}$ to $\frac{3}{4}$ foot.

65 C. Hósti (Baumg. enum. 3. p. 342.) stems few-flowered; leaves with scabrously ciliated margins : radical ones few, roundish, cordate, broad, toothed : cauline leaves lanceolate and linear; flower-buds drooping; calycine segments subulate, spreading or reflexed; corolla funnel-shaped. 4. H. Native of Transylrania, Austria, and Carinthia, in pastures, woods, and on the mountains; and on the alps of Jura. Stems glabrous or scabrous, simple or branched at top. Flowers more or less numerons, pedunculate and pedicellate, as in $C$. rotundifólia, drooping. Corollas blue. Very like C. rotundifolia.

V'ar. $\beta$, uniflòra (AIph. D. C. mon. p. 277.) stem 1-flowered, ascending, weak; cauline leaves few, linear-lanceolate, petiolate. 4. H.

Host's Bell-flower. Pl. 1 foot.

66 C. PETIOLA'TA (Alph. D. C. mon. p. 278.) quite glabrous; stems simple, few-flowered; radical leaves on long petioles, cordate-roundish, toothed; petioles marginated; lower cauline leaves lanceolate, remotely toothed, petiolate: upper cauline leaves linear, entire; calycine lobes erect, subulate; corolla campanulate, twice longer than the calycine lobes. $4 . \mathrm{H}$. Native of North America, ncar Slave Lake. Plant with the habit of $C$. rotundifolia. Root slender. Flowers 3-4, at the top of the stem, erect, but at length becoming recurred. Corollas blue.

Petiolate-leaved Bell-flower. Pl. 1 foot.

67 C. Liniròlia (Lam. dict. 1. p. 579.) stems erect; radical leares few, petiolate, ovate, sinuated : cauline leaves linear, entire; calycine segments long, erect, 2 or 3 times shorter than the corolla, which is large and campanulate. 4. H. Native of Europe, on the mountains; as of the Pyrenees, Auvergne, Dauphiny, Vallais, Alsatia, alps of Italy, Austria, Transylvania, and the Carpathian Mountains ; but wanting in the more northern regions of Europe. Scop. carn. 1. p. 144. C. angustifòlia, Lam. ill. 2499.? C. Schleichèri, Sut. fl. helv. 1. p. 124. C. rotundifòlia linifollia, $\beta$ et $\gamma$, Lapeyr. abr. p. 104. C. rotundifolia, $\beta$, Wahl. helv. p. 39. but not of his fl. lapp. C. virgàta, Rafin. in Roem. et Schultes, syst. 5. p. 100.?-J. Bauh. hist. 2. p. 797 . with a figure. Root slender, creeping. Plant quite glabrous, rarely a little downy. Flowers few at top of 
each stem, but usually only one, drooping. Corollas large, blue, of a form between those of $C$. rotundifolia and $C$. persicafolia.

Var. $\beta$, Valdénsis (Alph. D. C. mon. p. 279.) plant downy. 4. H. Common on the alps. C. Valdénsis, All. pedem. no. 400. vol. 1. p. 109. t. 6. f. 1. Lam. et D. C. fl. fr. ed. 3d. no. 2835. C. linifòlia, Hanke, in Jacq. coll. 2. p. 81. Sut. fl. helv. 1. p. 123. C. uniflòra, Vill. dauph. 2. p. 500. t. 10. but not of Lin. C. subuniflòra, Lam. ill. no. 2500 . C. rotundifòlia linifòlia $\pi$, Lapeyr. abr. p. 104. C. linifòlia $\beta$, Schouw. C. Ròlıdii, Lois, fl. gall. ed. 2, vol. 1. p. 140. t. 24. Flowers blue.

Var. $\gamma$, Scheuchzèri (Alpl. D. C. l. c.) plant small, glabrous; stems 1-flowered; segments of the calyx long. $4 . \mathrm{H}$. Common on the alps. C. Scheuchzèri, Vill. dauph. 2. p. 503. t. 10. but not of Lodd. bot, cab. t. 485 . C. linifolia, WVilld. spec. 1. p. 893. Roem. et Schultes, syst. 5. p. 101. Flowers blue.

Var. \&, Langsdorfficina (Alph. D. C. mon. p. 279.) glabrous ; stems erect, usually 1-flowered; radical lcaves ovate-roundish, entire: lower cauline leaves obovate-lanceolate. 4. H. Native of Arctic America, from Greenland even to Sledge Island, and of the Aleutian Islands, and Eastern Siberia. C. Langsdorffiàna, Fisch. mss. C. rotundifòlia, var. Horn. in herb. D. C. Perhaps a proper species.

Flax-leaved Bell-flower. Fl. June, Aug. Clt. 1813. Pl. $\frac{1}{2}$ to $\frac{3}{4}$ foot.

68 C. Rotundiòlia (Lin. spec. 232.) radical leaves petiolate, cordate, roundish, crenately toothed: cauline leaves linear or lanceolate; flower-buds erect; calycine segments subulate, short, erect, 3 times shorter than the corolla, which is campanulate. 4 . H. Native throughout Europe, Siberia, and North America; plentiful every where in Britain. Cav, valent. t. 2. All. pedem. 1. p. 108. t. 47. f. 2. Eder. fl. dan. t. 1086. Drev. et Hayne, term. bot.t. 5. f. 9. Smith, engl. bot. 866. Curt. lond. fasc. 4. t. 21. Jaum St. Hil. pl. fr. t. 418. C. uniflòra, Huds, angl. ed. 1st. p. 81. but not of Lin. C. minor, Lam. f. fr. 3. p. 339. C. variifòlia, Salisb. prod. p. 126. C. minùta, Savi, fl. etrusc. p. 554 . C. Schenchzèri, Lodd. bot. cab. t. 485 . but not of others. C. heterophýlla, Gray, brit. arr. 2. p. 408 . C. allophýlla, Rafin. mss. Root creeping. Stems numerous. Plant glabrous. Flowers drooping, solitary, pedunculate, few on each stem. Corollas deep blue. In France the plant is called Clochette; in Germany, Weisen-Busch, Grass-glas, or Milch-Glocken, and Kleine wilde Rapunzel; in Denmark, Gemeene Smaa Klokkler; in Sweden, Angklackor and Blakackor; and in Britain, BlueBells and Milkwort. The juice expressed from the flower makes a very good blue ink, and a good green colour mixed with alum. The roots are eaten by children in many parts.

Var. $\beta$, velutina (Alph. D. C. mon. p. 282.) plant small, of a grey colour, downy; stem few-flowered. 4 . H. D. C. fl. fr. suppl. no. 2832. Flowers blue.

Var. $\gamma$, màjor (Alph. D. C. mon. p. 282.) cauline leaves longlanceolate; flowers larger. 4. H. C. rotundifòlia $\beta$, Lam. dict. 1. p. 578. Pers. ench. 1. p. 188. Flowers hlue.

Var. $\delta$, tenuifòlia (Alph. D. C. mon. p. 284.) radical leaves oblong: cauline ones linear; stems elongated, slender. $4 . \mathrm{H}$. Rapúnculus esculéntus, Oed. fl. dan. t. 855 . C. rotındifòlia tenuifolia, Hoffm. fl. germ. 1800. p. 100. C. rotundifolia parviflòra, Wahl. f. ups. p. 78. fl. suec. 1.p. 134. C. anterrhìna, Schleich. Flowers blue.

Var. $\varepsilon$, albiflòra; flowers white.

Round-leaved Bell-flower. Fl. June, Aug. Britain. Pl. $\frac{1}{2}$ to 1 foot.

69 C. cessitòs A (Scop. carn. 1. p. 143. t. 4.) plant humble, few-flowered, glabrous; radical leaves crowded, on short petioles, ovate, glandularly toothed, shining; buds, flowers, and capsules drooping; calycine segments linear, erect, 3 times shorter than the corolla, which is campanulate; pollen violaceous. 4. H. Native of the temperate parts of Europe, on the mountains; as of the Pyrcnees, Daupliny, Savoy, Switzcrland, Mount Baldo, Apennines, Austria, Carinthia, Bohemia, Transylvania, Carpathian Mountains, \&c. C. cochlearifòlia, Lam. dict. 1. p. 578 . but not of Wahl. C. pusílla, Hanke, in Jacq. coll. 2. p. 79. Sut. fl. helv. 1. p. 123. \&c. C. Bellárdi, All. pedem. 1. p. 108. no. 396. t. 85. f. 5. C. rotundifòlia $\beta$, Lin. spec. 1. p. 232. $\beta$ et $\alpha$. Willd. spec. 1. p. 892. var. 2. Lapeyr. abr. p. 103. var. cæspitòsa, Boissieu, fl. d'eur, t. 135. C. pùmila, Sims, bot. mag. t. 512 . Rom. et Schultes, syst. 5 p. 96 . Root fibrons, creeping. Stems numerous, tufted. Flowers terminal, solitary, and sometimes 3.4 at the top of each stem. Corollas deep blue or pure white.

Var. $\beta$, pubéscens (Alph. D. C. mon. p. 284.) stems elongated, 1-flowered, downy; leaves few, rather hairy; corolla broad. 4. H. Native of Bohemia. C. pubéscens, Sclımidt, f. bohem. no. 167 . Rchb. icon. bot. 1. t. 78. C. caspitòsa $\beta$, Poir. suppl. 2. p. 55. Flowers blue.

I ar. $\gamma$, imbricàta (Alph. D. C. mon. p. 284.) leaves crowded at the base, imbricated, linear-lanceolate; flowers numerous; corollas narrow. 4 . H. Native of Carinthia, and about Vienna. C. Boccòni, Vill. dauph. 2. p. 502. exclusive of the syn. of Gmel. C. imbricàta, Heyne, ined.-Bocc. mus. t. 103. Flowers blue.

\section{$T$ t.}

70 C. ARIsta'ta (Wall. in Roxb. f. ind. 2. p. 98.) plant quite glabrous; stems erect, 1-flowered; radical leaves petiolate, lanceolate, acute, undulated: cauline leaves sessile, narrow-linear, glandularly denticulated; calycine seginents long-subulate, twice longer than the corolla; capsule very long, obconical. $2 / . ? \mathrm{H}$. Native of the north of India, about Laddack. Root thickish, rather fusiform, divided at top. Flowers small, solitary, terminal, drooping. Tube of calyx very much elongated. Corolla funnel-shaped, pale blue.

Anned-calyxed Bell-flower. Pl. 1 foot.

71 C. sxLVA'tica (Wall. in Roxb. fl. ind. 2. p. 97.) plant scabrous from short stiff hairs; stems erect, straight, few-flowered; cauline leaves linear, narrow, nearly entire; calycine segments erect, subulate; corolla campanulate, downy, twice longer than the calycine segments. 4.? H. Native of Nipaul, in shady humid places. C. stricta, Wall. asiat. res. 13. p. 374 . C. integérrima, D. Don, prod. fl. nep. p. 155 . Habit of $C$. rotundifolia, but probably without any roundish radical leaves. Stems simple or branched. Flowers terminal, on long peduncles, disposed like those of $C$. rotundifolia. Corollas blue.

Wood Bell-flower. Pl. $\frac{1}{2}$ to 1 foot.

72 C. VE'sula (All. pedem. 1. p. 108. no. 397. t. 7. f. 1.) stems 1-flowered; leaves glabrous, oval, toothed; stems nearly naked; calyx glabrous. 4 . H. Native of Piedmont, on Mlount Vesulus. Leaves many at the roots, petiolate, with a few scattered hairs beneath. Flowers campanulate, spreading.

Vesulus Bell-flower. Pl. $\frac{1}{2}$ foot.

73 C. пU'вIм (Alph. D. C. mon. p. 286.) glabrous; stems 1. flowered; cauline leaves erect, narrow : lower ones linear-lanceolate, petiolate : superior ones long-acuminated; calycine lobes subulate; corolla tubularly funnel-shaped, twice longer than the calycine lobes. 24. H. Native of Newfoundland. Flowers erect, terminal, very like those of $C$. rotundifólia.

Doubtful Bell-flower. Pl. $\frac{1}{3}$ to $\frac{1}{2}$ foot.

74 C. Prate'nsis (Pyl. ined. ex Alpl. D. C. mon. p. 287.) stems humble, l-flowered, most leafy above; leaves all petiolate, ovate, acute, subcrenated; calycine segments long-acuminated, one-third shorter than the corolla. 4 . H. Native of Newfoundland, by the sea side. Plant glabrous. Corollas funnel-shaped. 
Mcalow Bell-flower. Pl. $\frac{1}{2}$ foot.

75 C. Pu'Lla (Lin. sjec. p. 231.) stems humble, 1-flowered; leaves glabrous, crenulately toothed: lower ones on short petioles, ovate-roundish : superior ones sessile, ovate, acute; calycine segments long-acuminated, erect, twice shorter than the corolla, which is campanulate. $4 . \mathrm{H}$. Native of Transylvania, Bolıemia, alps of Austria, Syria, Carniola, Sc. in shady places. Jacq. obs. bot. 1. p. 30. t. 18. fl. austr. 3. t. 285 . Gilib. demonstr. bot. t. 26. Lodd. bot. cab. t. 554 . Sims, bot. mag. 2492. Sweet. fl. gard. n. s. t. S0. Plant small. Stems rarely pilose at the base, but usually glabrous. Root slender. Flowers terminal, large for the size of the plant. Corollas of a deed violaceous blue colour.

I ar. $\beta$, ramòsa (Alph. D. C. mon. p. 288.) stems branched a little. 4. H. C. púlla $\beta$, Lin. spec. p. 231 ? C. púlla, var. Scop. carn. 1. p. 143.-C. Bauh. prod. t. 35.? foot.

Russet Bell-flower. Fl. June, Aug. Clt. 1779. Pl. $\frac{1}{4}$ to $\frac{1}{2}$

76 C. Excìsa (Schleich. pl. exsic. Murr. guide en Vall. p. 33. and 35.) plant glabrous, humble; stems slender, 1-flowered; lower leaves linear-acuminated; calycine lobes setaceous, spreading, at length reflexed, 3 times shorter than the corolla, which is funnel-shaped; sinuses of corolla cut; capsule obconical. $\Psi$. H. Native of Switzerland, on the higher alps in the valley of St. Nicholas; at Saas; and about Simplon, \&c. Lodd. bot. cab. t. 561. Richb. icon. cent. 1. t. 78. Re, fl. pedem. alt. p. 193. in mem. acad. turin, t. 31. Gaud. fl. helv. 2. p. 147. t. 2. Stems numerous, erect, slender, simple, naked at top. Leaves entire, or remotely denticulated. Flowers drooping before and at the time of expansion. Corollas blue.

Cut-flowered Bell-flower. Fl. June, July. Clt. 1820. Pl. $\frac{1}{4}$ to $\frac{1}{2}$ foot.

$77^{2}$ C. Waldsteinia'na (Rœm. et Scluultes, syst. 5. p. 99.) glabrous; stems erect, flexuous, stiff; simple, few-flowered; leaves sessile, lanceolate, serrated : lower ones obtuse: superior ones long-acuminated; alabastra erect; calycine lobes subulate, subdenticulated, spreading, 4 times shorter than the corolla, which is campanulate. $\psi$. H. Native of Croatia, on the mountains, in the fissures of rocks. Rehb. icon. bot. cent. 1, t. 85 . C. flexuòsa, Waldst. et Kit. pl. rar. liung. 2. p. 145. t. 136 . C. rupéstris, Host, fl. austr. 1. p. 263. Stems numerous from the same root, stiff. Flowers $3-4$ at the top of each stem, one of which is terminal, and the others from the axils of the superior leaves, always looking upwards. Corollas of a violaceous blue colour.

Waldstcin's Bell-flower. Fl. Jıne, Aug. Clt. 1824. Pl. $\frac{1}{2}$ to $\frac{3}{4}$ foot.

78 C. Aparinoìnes (Pursh. fl. amer. sept. 1. p. 159.) glabrous; stem weak, ascending, simple, few-flowered, having the angles beset with sloort retrograde bristles; lower leaves linearobovate: the rest linear and acuminated: all remotely denticulated, and beset with retrograde short bristles; calycine lobes triangular, twice shorter than the corolla, which is campanulate; capsule spherical. $\odot$. H. Native of North America, in lıumid meadows about Elizabeth Town, on the banks of the Hudson, near Boston; Philadelphia, and West Chester in Pennsylvania. C. erinoìdes, Mull. cat. p. 22. Bigel. fl. bost. p. 54. Nutt. gen. amer. 136. but not of Lin. and Willd. Root slender. Flowers 2-4, terminal, pedunculate, small, erect. Corollas white.

Íar. $\beta$, multiflòra (Alph. D. C. mon. 1. 290.) sten erect; panicle divaricate.

Goose-grass-like Bell-flower. Fl. June, Aug. Pl. 1 foot.

79 C. Flexuòsa (Michx. fl. bor, amer. 1. p. 109.) glabrous ; stem panicled at top, with erectish branches; leaves most frequent in the middle and above, almost sessile, lanceolate, acuminated at both ends, coarsely serrated; calycine lobes capillary, twice shorter than the corolla, which is tubularly campanulate; style a little exserted. 4 . H. Native of Carolina, on ligh mountains. Stems erect, angular. Leaves very few at the base, but crowded at top. Flowers panicled, terminal and axillary. Corolla blue.

Flexuous Bell-flower. Fl. A ug. Sept. Pl. $\frac{1}{5}$ to $\frac{1}{2}$ foot.

$80 \mathrm{C}$. divarica'ta (Michx. A. amer. bor. 1. p. 109.) glabrous; stem panicled at top, with the branches diverging; leaves equally scattered over the stem, nearly sessile, ovate-lanceolate, acuminated at both ends, coarsely serrated, with rather scabrous edges; calycine lobes capillary, twice shorter than the corolla, which is tubularly campanulate; style a little exserted. $\psi$. H. Native of Carolina and Virginia, on the mountains; and of Kentucky, sc. Stems leafy to the middle, and almost naked in the upper part. Flowers small, drooping, terminating the branches and branchlets. Corolla azure blue.

Divaricate-panicled Bell-flower. Pl. 2 to 4 inches.

c. Plants few-flowered, pilose. Corolla donny outside. Capsule usually turbinate, and probably always drooping.-All natives of Nipaul.

81 C. ca'Na (Wall. in Roxb. fl. ind. 2. p. 101.) tomentose; stems ascending, branched; leaves sessile, approximate, lanceolate, tootherl, hoary beneath; flowers terminal; segments of caly $x$ lanceolate, toothed, twice shorter than the corolla, which is funnel-shaped and pilose; capsule turbinate. 4 . H. Native of Nipaul, on the mountains near Gosaingstlian. Root fibrous. Stems many, ascending, densely covered with white hairs, as well as the upper surfaces of the leaves. Flowers on short peduncles, terminating the stem and branches. Corollas blue.

Hoary Bell-flower. Fl. Oct. Pl. ascending.

82 C. CANe'scens (Wall. cat. no. 1289.) plant hispid; stem erect; radical leaves crowded, lanceolate, crenulated : cauline leaves remotc, narrower, repandly denticulated; flowers racemose, often approximate, on short pedicels, small ; tube of calyx spherical: lobes linear, entire; corolla tubular, pilose. $\odot . \mathrm{H}$. Native of Nipaul; and Hindostan, about Rampore. Alph. D. C. mon. p. 292. C. Benthàmii, Wall. cat. no. 1290. Root slender. Stem branched from the base or simple. Flowers numerous, small, 4-6 at the top of each branchlet, the whole forming a many-flowered loose raceme.

Canescent Bell-flower. Pl. 1 foot.

83 C. colora'ta (Wall. in Roxb. fl. ind. 2. p. 101.) stem branched, downy; leaves scattered, lanceolate, acute, repandly denticulated; peduncles elongated, terminal and axillary; calyx with a very pilose obconical tube, and triangular entire lobes, which are about equal in length to the corolla, which is tubular and velvety; capsule turbinate. $\varkappa$. F. Native of Nipaul. Leaves variable in size, acuminated at both ends, sessile, downy. Peduncles nearly naked, or bearing a large bractea each.

Var. $\beta$, Moorcrofiuina (Alph. D. C. mon. p. 233.) leaves less toothed. 24. H. Native of the north of India, about Ludack. C. Moorcroftiàna, Wall. herb. no. 1288 .

Coloured Bell-flower. Pl. $\frac{1}{2}$ foot.

84. C. PA'LLIDA (Wall. in asiat. res. 13. p. 375.) plant clotlied with canescent pili; stem erect, branched; leaves elliptic, sinuately crenated, petiolate: upper ones sessile; calyx bristly, with linear-lanceolate segments, which are about equal in length to the corolla. 4.? F. Native of Nipaul, in sterile places. Wall. in Roxb. ff. ind. 2. p. 100. D. Don, prod. fl. nep. p. 156. Branches slender, simple, subfastigiate. Flowers solitary, terminating the stem and branchlets, white, forming a terminal fastigiate panicle. Corolla pilose.

Pale Bell-flower. Pl. 1 to 2 feet.

85 C. RAmulòsa (Wall. in Roxb. fl. ind. 2. p. 100.) stem erect, pilose, branched; leaves lanceolate, sessile, crenately 
toothed, with the nerves rather prominent beneath ; flowers pedicellate, terminal and axillary; calyx pilose, witl broad, acute, subdentate lobes, twice or thrice shorter than the corolla, which is cylindrical and relvety; capsule turbinate. 2. H. Native of Nipaul. Root short, slender, simple or branched. Flowers inclinate, pedicellate. Leaves pilose. Corolla of a violaceous blue colour.

Branched Bell-flower. Pl. 1 to 2 feet.

SG C. A Lphóxsu (Wall, cat. no. 1296. Alph. D. C. mon. p. 294.) stems humble, simple, 1-flowered, downy; cauline leaves sessile, lanceolate, acute, toothed a little, rather pilose above, and hoary beneath; calyx downy, with acute segments, twice shorter than the corolla, which is campanulate and downy. 4. H. Native of the south of India, on the Nellighery Mountains. Stems very leafy at top. Flowers drooping, terminal, large for the size of the plant.

Alphonsc De Candolle's Bell-flower. Pl. 2 to 8 inches.

* Floners on very short pedicels, opposite the lcaves. Capsule turbinate. Branches more or less dichotomous. Lcaves small, scssile, oblong.-All annual humblc herbs, inhabitants of the region of the Meditcrancan.

S7 C. Erìus (Lin. spec. 240.) plant hispid; leaves obovate or ovate, toothed; flowers sessile; calycine lobes triangular, acuminated, erect, at length spreading, about equal in length to the corolla, which is small and tubular. 24. H. Native about the Mediterranean Sea; very plentiful throughout the whole Spanish Peninsula, south of France, Provence, Sardinia, throughout the whole of Italy, Sicily, Dalmatia, Grecian Islandls, Teneriffe, \&ic. on walls and rocky places. Sibth. et Smith, fl. græc. t. 214. Cav. valenc. t. 2. Roucèla erìnus, Dumont, comm. bot. p. 14. -J. Bauh. hist. 2. p. 799, with a good figure.-Mor. oxon. sect. 5. t. 3. f. 25.-Column. phyt. t. 28 . pl. nov. hist. p. 29. t. 31. Stem much branched. Flowers terminal and axillary, and situated in the angles of the forks of the branches. Corollas tubular, of a pale bluisl rose-colour or white, pilose at the base.

Erinus-like Bell-flower. Fl. May, Aug. Clt. 176s. Pl. $\frac{1}{3}$ to $\frac{3}{3}$ foot.

SS C. DRAB.fòlia (Sibth, et Smith, fl. græc. 3. p. 11.t.215.) plant hispid; leaves elliptic-oblong, toothed; flowers pedicellate; segments of the calyx always erect; corolla inflated, much longer than the calyx. $\odot$. H. Native of the Island of Samos, and near Athens, in cotton plantations and vineyards. Habit of $\boldsymbol{C}$. erimus. Stem many times forked, erectish. Corolla with a white tube, and a violaceous blue limb.

Draba-leaved Bell-flower. Fl. July, Aug. Clt. 1823. Pl. $\frac{1}{5}$ foot.

89 C. Rhodénsis (Alpl. D. C. mon. p. 297.) plant pilose; leaves entire, ovate; flowers terminal ; calycine lobes triangular, erect, at length spreading; corollas large, campanulate. $\odot . \mathrm{H}$. Native of the Island of Rhodes. Root simple. Stems many from each root, reddish. Flowers numerous, erect, terminating the branches. Corollas elegant.

Rhodes' Bell-flower. Pl. $1 \frac{1}{2}$ to 3 inclies.

\$ 3. Capsule erect; values dehiscing at the base.-Flowers pediccllate. Radical leaves petiolate, usually cordate, having the base of the petioles usually expanded and permanent.

* Corolla downy or velvety, tubular, 5-lobcd at the apex. Radical leaves crowded. Stems few-flowered.-Species all natives of the Levant.

90 C. Damasce'na (Labill. pl. syr. dec. 5. p. 7. t. 5.) downy; radical leaves ovate-obovate, acute, nearly entire, hoary : cauline ones few, ovate, acute; calyx velvety, with subulate lobes, twice shorter than the corolla; capsule ovoid. $\psi$. F. Native of the rol. 1II.
Levant, near Damascus, on the mountain called Dgebel-cher. Root woody. Stems slender, 1 or few-flowered. Flowers erect, pedicellate. Corollas cylindrical.

Damascus Bell-flower. Pl. ascending.

91 C. ARGE'NTLA (Lam. dict. 1. p. 58..) liumble; radical leaves linear-obovate, chotherl with silvery tomentum, nearly entire: upper leaves few, oblong; calyx silvery, with triangular lobes, 3 times shorter than the corolla; capsule turbinate. $\psi$. F. Native of Armenia.-Tourn, cor, 3. Root hard, blackish. Stems erect, velvety, with short branches. Flower's 1 or few on the top of each branch, erect. Corollas velvety.

Silvery Bell-flower. Pl. $\frac{1}{4}$ foot.

92 C. Sxríaca (Rom. et Schultes, syst. 5. p. 133.) radical leaves oblong-spatulate: cauline leaves oval, sessile, somewhat sinuated; stem simple, few-flowered at top. ๑.? H. Native of Syria. There is nothing said of the flower and capsule by the authors.

Syrian Bell-flower. Pl. $\frac{1}{4}$ foot. ?

* Corollas rotate, dceply 5-lobcd, usually downy outsile. Style exserted.-All natives of Italy.

93 C. Garga' Nica (Ten. fl. neap. prou. 1827.) radical leaves reniform, on long petioles: cauline ones cordate, all crenately toothed, downy ; flowers axillary, in fascicles ; corollas 5 -parted. 4. H. Native of Apulia, on Mount St. Angelo. Sweet, fi. gard. n. s. t. 252. C. elátines, Pentagn. inst. bot. 2. p. 367. Plant pale green. Corollas blue. Habit of $C$. Carpática.

Garganus Bell-flower. Fl. May, Sept. Clt. 1832. Pl. $\frac{1}{4}$ to $\frac{l}{3}$ foot.

94 C. elatinoides (Morett. pl. ital. dec. 3. p, 5.) plant tomentose; leaves acutely toothed, petiolate: lower ones oblong superior ones ovate-acute; flowers disposed in dense racemes; tube of calyx ovoid: lobes subulate, spreading, about equal in length to the corolla. $\psi$. H. Native of Italy, on the mountains about Pisa, among stones and on rocks. C. elátines, Poll. fi. veron. 1. p. 278. no. 404. C. petræ'a, Zantedesch. ff. brix. ined. but not of Lin. nor others.-Gerard. emac. p. 455. f. 2.-Clus. cur. post. p. 67. t. 68 . Root nodose. Stem erect, simple, thick for the size of the plant. Leaves canescent. Peduncles many-flowered. Corollas blue, downy outside.

Elatine-like Bell-flower. Pl. $\frac{1}{4}$ to $\frac{2}{2}$ foot.

95 C. Elátines (Lin. spec. 1. p. 240.) stem ascending; leaves cordate, coarsely and acutely toothed, ovate-acute: lower ones roundish; flowers in loose racemes; tube of calyx spherical; lohes of calyx spreading, linear-lanceolate, twice shorter than the corolla. 4. H. Native of the alps of Piedmont, Liguria, Naples, Sc. in shady, rocky places. All. pedem. no. 422. t. 7. f. 2. Plant downy. Stem branched. Flowers scattered over the upper part of the plant, sometimes racemose, and sometimes panicled. Corollas bluish-purple, lardly one-half longer than the calycine lobes.

Var. $\beta$, glabérrima (Alph. D. C. mon. p. 301.) plant quite glabrous. $E$

* * Corolla campanulate, funnel-shaped, or tubular, 5-lobed at the apex, glabrous.-Roots for the most part thich. All natives of Italy.

96 C. macrormiza (Gay, ined. ex Alph. D. C. mon. p. 302.) root thick; stems ascending; radical leaves petiolate, small, roundish-cordate, toothed: lower cauline leaves on short petioles, ovate, acute, toothed: superior ones sessile, linear-acuminated; flowers terminal and axillary; alabastra erect; calycine lobes acuminated, spreading or reflesed, twice shorter than the corolla, which is campanulate. 4 . H. Native of Nice, on dry rocks; Provence, on the mountain called Cousson; and near $5 \mathrm{E}$ 
San Marco, in Calabria. C. Nicæénsis and C. rupéstris, Risso, in herb. D. C. Foot thick, marked by the vestiges of the fallen leaves, creeping among rocks. Stem simple or branched, glabrous. Leaves glabrons. Flowers more or less numerous, solitary, pedunculate and pedicellate, as in $C$. rotundifolia, looking upwards. Corolla broader than those of $C$. rotundifolia.

Var. $\beta$, pubéscens (Alph. D. C. mon. p. 502.) stems and leaves downy; calycine lobes always erect. 4 . H. In the alpine regions above Tende. C. pusílla $\beta$, D. C. fl. fr. suppl. no. 2833 .

Long-rooted Bell-flower. P], $\frac{1}{2}$ to 1 foot.

97 C. Portenschlagia'na (Rœem. et Schultes, syst. 5. p. 93. Vis. stirp. dalm. pp. 29.54. exclusive of the syn. C. isophýlla, Morett. Alph. D. C. mon. p. 303. t. 13. f. a.) stems erectish; leaves abont equal in size, petiolate, roundish-cordate, acutely and angularly toothed; flowers racemose; calycine lobes subulate, thrice shorter than the corolla, which is funnel-shaped. 4 . H. Native of Dalmatia, on walls. C. muràlis, Portenschlag. herb. Flowers erect, lilac. Habit of $C$. Carpática. Plant quite glabrous.

I ar. $\beta$, velutina (Alph. D. C. mon. p. 303.) plant velvety.

Portenschlag's Bell-flower. Pl. $\frac{1}{2}$ foot.

98 C. Billardie'ru (Alph. D. C. mon. p. 303.) glabrous; stems ascending; radical leaves on long petioles, small, cordate, 3-5-cleft: lobes toothed; flowers few, in loose racemes; calycine segments filiform, rather unequal, twice shorter than the corolla, which is tubular. 4. H. Native of Syria. Flowers few, secund, drooping. Corollas small, blue. Radical leaves numerous; cauline ones few. Habit of Wahlenbérgia hoderàcea.

La Billardiere's Bell-flower. Pl. $\frac{2}{3}$ foot.

99 C. Morettin'num (Rchb, icon. rar. cent. iv. pr. 18. t. 320.) plant pilose, lıumble; stems 1 -flowered; leaves crenately toothed, small ; radical leaves petiolate, cordate, roundish : cauline leaves smaller, ovate, acute; calycine lobes lanceolate, 4 times shorter than the corolla, which is funnel-shaped. $4 . H$. Native of Dalmatia, on Mount Bioccovo; and of Tyrol, on Mount Vodai, above Vigo, in the valley of Foscia. C. púlla, Parol. hort. sic. ined. but not of Lin. nor Jacq. C. filiformis, Morett. pl. ital. dec. p. 8. giorn. di. fisic. \&c. di. Pav. 1826. vol. 9. p. 155 . bot. ital. no. 11. p. 21. no. 4. Flowers erect, blue.

Moretti's Bell-flower. Pl, 1 to 3 inches.

100 C. RAINE'RI (Perpenti, in bibl, ital. 1817.5. p. 134. with a figure) stems erect, firm, branched: branches 1-flowered; leaves almost sessile, ovate, remotely serrated: lower ones the smallest, obovate; calycine lobes long-acuminated, erect, twice shorter than the corolla, which is fumnel-shaped; capsule obovate. 4. H. Native of Italy, on the alps in the province of Brixo, and on the mountains surrounding Lake Cosmo; on the alps of Biandino and Tremare, above Mandello and Resegone, from the termination of the Beech Woods, even to the elevation of 6000 feet and upwards. C. Perpéntiæ, Morett. in herb. D. C. Plant tufted. Caudex creeping. Stems leafy, rather pilose. Leaves glabrous or downy. Flowers erect, blue.

Rainer's Bell-flower. Fl. June, July. Clt. 1826 . Pl. $\frac{1}{2} \mathrm{ft}$.

**** Corollas large, campanulately rotate, somewhat 5-cleft, glabrous. Rools usually thick.

101 C. rsophy'sea (Moretti, append. to Schouw, prospett. fl. ital. p. 22. Rchb. icon. pl, cent. 3. t. 202. f. 34t.) stems erectssh, firm; leaves all about the same size, petiolate, roundish, crenately toothed; flowers corymbose ; calycine lobes acuminated, broad, twice shorter than the corolla; style exserted; capsule ovoid. 24. H. Native of Liguria, at Cape Nauli and Caprazoppa. C. floribúnda, Viv. fl. lyb. append. fl. ital. ]. $6 \%$.
Caudex woody. Plant glabrous or velvety. Flowers numerous, erect, disposed in a corymb. Corollas blue, rotate.

Equal-leaved Bell-flower. Pl. $\frac{1}{4}$ to $\frac{1}{2}$ foot.

102 C. FráGilis (Cyril. pl. fasc. 1. p. 32. t. 11. f. 2.) stems ascending, diffuse, branched ; radical lcaves on long petioles, roundisli-cordate, bluntly crenate-lobed: cauline leaves smaller, ovate and lanceolate; flowers panicled; calycine lobes linearlanceolate, erect, about equal to the corolla; style exserted; capsule ovoid. 4. H. Native of the south of Italy, in the valley of Anania; ncar Naples, in Goat's Island, about Cava ; on Mount Pollino and elsewhere in Calabria ; and probably of Sicily. C. diffùsa, Vahl, symb. p. 18. C. cochlearifòlia, Vahl, symb. p. 18. C. crassifolia, Nees, syll. ratisb. 1. p. 6. and amœu. bot. fasc. 2. p. 9. t. 4.-Barrel. icon. rar. p. 54. t. 27. Root thick. Plant glabrous. Flowers numerous, racemosely panicled, terminating the branchlets, erect, pedicellate. Corollas large, pale blue.

l'ar. 3, hirsùta (Alph. D. C. mon. p. 307.) plant hispid, and as if it was covered with wool. 4 . H. C. frágilis lanuginòsa, Ten. fl. neap. prod. p. 15. C. frágilis $\beta$, Roem. et Schultes, syst. 5 . p. 92.-Barrel. obs. p. 10. t. 453 .

Britlle Bell-flower. Fl. July, Aug. Clt. 1826. PI. $\frac{1}{4}$ to $\frac{1}{2}$ foot.

103 C. Barrelie'rt (Presl, symb. bot. p. 30. t. 19, ex Linnæa. 7. p. 7.) villous ; stems diffuse, procumbent, very simple, l-flowered; leaves roundish-cordate, crenated; flowers terminal; segments of the calyx lanceolate, acute, longer than the tube, which is glabrous. 4 . H. Native of Naples, on rocks by the sea side. C. diffùsa, var. Roem. et Schultes, syst. 5. p. 92. Corollas blue.

Barrelier's Bell-flower. Pl. procumbent.

104 C. versícolor (Sibth. et Smith, prod. fl. græe. ]. p. 138. fl. græc. t. 207.) glabrous; stem ascending; leaves serrated; radical leaves petiolate, ovate, acute, rather cordate: cauline leaves on slıort petioles, ovate-lanceolate, acuminated; flowers disposed in long spicate racemes; calycine segments acuminated, spreading, at length refiexed, twice shorter than the corolla, which is variegated; style exserted; capsule spheroid. 2. H. Native of Greece. C. planiflòra, Willd. enum. 1. p. 210 . but not of Lam. C. Willdenowiàna, Rœm, et Schultes, syst. 5. p. 107. Root tuberous, thick, white, subdivided at top. Stems erect. Corollas campanulately rotate, of a deep violaceous colour at bottom, pale in the middle, and the lobes pale violet. Flowers disposed in long spikes, like those of $C$. pyramidalis, of which this species has the habit.

I'ar. $\beta$, mulifiòra (Alph. D. C. mon. p. 308.) leaves irregularly serrated, undulated; flowers more numerous. 2 . H. C.. versícolor, Andr. bot. rep. 396.

Party-coloured Bell-flower. Fl. July, Sept. Clt.1788. Pl. 2 to 4 feet.

105 C. TENòrin (Morett. prospett. descript. geogr. de Schouw, p. 19. in a note. p. 15. Alph. D. C. mon. p. 309.) stem ascending; leaves coriaceous : radical ones ovate-oblong, acutely serrulated, on long petioles : cauline leaves on short petioles, ovate, acute, coarsely serrated; flowers racemose; calycine lobes linear, spreading, twice shorter than the corolla; capsule spherical. 2. H. Native of the kingdom of Naples, C. corymbòsa, Ten. prod. fl. neap. p. 15. C. Rosàni, Ten. in herb. Moricand. C. Thomàii, Tenore, in litt. C. versícolor, Guss. pl. rar. p. 92. exclusive of the syn. of Sibth. et Smith. Plant glabrous. Stem simple. Radical leaves subcordate; petioles of cauline leaves ciliated at the base. Flowers approximate: peduncles 1-5-flowered, as in $C$. versicolor. Corolla with a white base and blue lobes.

Tenore's Bell-flower. Pl. $\frac{1}{2}$ to 1 foot.

106 C. pyramdilis (Cam. hort. med. p. 33. Lin. spec. 1. p. 
233.) glabrous; leaves glandularly toothed: lower ones petiolate, ovate-oblong, somewhat cordate: cauline leaves sessile, ovate-lanceolate; flowers numcrous, pyramidally racemose; calycine lobes acuminated, spreading; capsule splieroid, deeply furrowed. 4.11 . Native on rocks and on walls in Carinthia, Carniola; of Dalmatia, in the island of Viego; on the walls of Venice and Verona. 'The plant has been cultivated a long time in gardens, and conseguently has become, as it were, indigenous in many parts of the south of Europe. Jaun St. IHil, pl, fr. t. 416.-Weinm. phyt. t. 289. f. b.-Moris, oxon. 2. p. 452. scet. 5. t. 1. f. 1.-Besl. hort. eyst. 1. t. 7. f. 1.-Tab. icon. 317.-Swert, tloril, t. 16. f. 2.Lob. hist. p. 177. icon. 327,-Dod. pempt. 166, with a figure. Root large, turnip-formed, oblong, usually divided into fusiform branches. Stem nearly simple, but furnished with floriferous branchlets. Flowers very numerous, pedicellate, usually 3 together from the same bractea, the whole disposed in a large pyramidal raceme, which is loose at the base. Corolla pale blue, with a dark base. There is also a white-flowered variety of this.

I ar. $\beta$, calycina (Alph. D. C. mon. p. 510.) plant monstrous, 1-flowered, dwarf; leaves all petiolate; calycine segments clanged into large leaves. 24. H. - Weinm. phyt. icon. t. 294.

Pyramidal Bell-flower. Fl. July, Sept. Clt. 1596. Pl. 4 to 5 feet.

107 C. lactiflòra (Bieb. fl. taur, 1. p. 153, cent. pl. ross. 1. t. 10.) stem branched; leaves sessile, ovate-lanceolate, acutely serrated; flowers in loose panicles; calycine lobes very broad, serrulated, acute, twice shorter than the corolla ; capsule ovoid. 4. H. Native of Caucasus and Siberia, in grassy places. Fier, bot. reg. 24.1. Sims, bot. mag. 1973. Alph. D. C. mon. t. $\tau$. C. hispida, Fisch. hort. gorenk. ex herb. Willd. C, volùbilis, Willd. herb. Stems simple or branched, glabrous or pilose. Leaves pale beneath, glabrous or pilose. Corollas erect, milkcoloured, tinged with blue. Peduncles short, erect, usually $3-$ Howered.

Milk-flowered Bell-flower. Fl. July, Sept. Clt. 1814. PJ. ? to 6 feet.

\$ 4. Capsule dehiscing laterally by the valves towards the apex, crect. Lobes of calyx usually dcnticulated.-Radical leares usually obovate, on short petioles, but never cordatc. Flowers pedicellate.

* Iralves situated between the middle and upper part of the capsule.-Branches not dichotomous.

108 C. Scovle'rı (Alph. D. C. mon. p. 312.) stem simple, few-flowered; leaves ciliated, sharply serrated: lower leaves ovate, acute, petiolate: middle ones ovate-lanceolate, sessile: superior ones linear-lanceolate; flowers racemose; calyx glabrous, with capillary erect lobes, which are 3 times shorter than the 5-cleft, funnel-shaped corolla ; style exserted; capsule ovoid. 1. H. Native of North-west America, about Fort Van Couver, on the banks of the Columbia river. Stems ascending at the base, glabrous or a little hairy, simple at bottom, and furnished with floriferous peduncles at top. Flowers 4 to 10 on each stem, terminal and axillary, loosely racemose. Habit of a species of Adcnóphora.

Scouler's Bell-flower. Pl. $\frac{1}{2}$ foot.

Talves situated ncar the top of the capsule. Flowers usually on long peduncles, terminal or axillary. Branches not dichotomous.

109 C. Planiflòra (Lam. dict. 1. p. 580. ill. 2509.) quite glabrous: stems simple; leaves sessile, coriaceous, shining; radical ones crowded, ovate or obovate, obtuse, crenulated : cauline ones linear-lanceolate, acute, nearly entire ; flowers disposed in spicate racemes; calycine lobes ovate, acute, broad, erect, 3 times shorter than the corolla, which is campanulately rotate. 2. H. Native of North America, probably towards Hudson's Bay. C. nítida, Ait. hort. kew. cd. 1. vol. 1. p. 346. Nutt. gen. amer. 1. p. 136. C. Americàna, Mill. dict. no. 13. but not of Lin.-Courn. inst. 1. p. 111. Nunting, phyt. cur. t. 123,-Dodart, mem. ed. de mal. p. 621. t. 33. ed. fol. p. 119. t. v. Flowers terminal and axillary, on short pedicels, approximate, disposed in a kind of spicate raceme. Corolla pale blue; there is also a variety with white flowers.

Flat-flowered Bell-flower. Fl. July, Sept. Clt. 1731. Pl. $\frac{1}{2}$ to 1 foot.

110 C. Anerica'xa (Lin. spec. 233.? Ait. hort. kew. 1.p. 220.) stem simple; radical leaves ovate, acute, a little cordate, petiolate, serrated : cauline leaves ovate-lanceolate, acuminated at both ends, serrulated; flowers disposed in long spikes; calycine lobes long-acuminated, spreading, rather shorter than the corolla, which is rotately campanulate ; capsule cylindrical, furrowed. 4 . H. Native of North America, in South Carolina, Georgia, Virginia, and Pennsylvania, on the mountains. Pursh. f. sept. amer. 1. p. 159. Phyteùma Americana, Hill, in hort. kew. p. 128. C. asteroìdes, Lam. ill. 2515. C. oblìqua, Jacq. hort. schoenhr. 3. t. 336. Willd. enum. 1. n. 210. C. declinàta, Mœnch. suppl. meth. p. 187. C. acuminàta, Michx. fi. bor. amer. 1. p. 108. Pursh. fl. sept. amer. 1. p. 159. exclusive of the syn. of Ait, and Dod. Nutt, gen. amer. 1. p. 136. Stems erect, simple, firm, glabrous or pilose on the angles. Radical leaves rosulate, rather pilose. Corollas blue, a little longer than the calycine lobes. Flowers erect, 1-3 from the axil of each bractea.

Var. $\beta$, subulàta (Alph. D. C. mon. p, 314.) plant humble, few-flowered; leaves petiolate. 4 . H. C. subulàta, Beauv. ined.

American Bell-flower. Fl. July, Aug. Clt. 1763. Pl. 2 feet.

111 C. Fu'lgens (Wall. in. Roxb. fl. ind. 2. p. 99.) stem simple, erect, pilose ; leaves lanceolate, acuminated at both ends, on short petioles, serrated; flowers almost sessile, disposed in a raceme, crowded at top; calycine segments linear-subulate, erect, entire, rather longer than the corolla, which is funnelshaped; capsule ovoid, 10-nerved. 4. F. Native of Upper Nipaul, on the more elevated mountains. Root simple, glabrous. Stem usually undivided, but sometimes furnished with a few simple branches, angular, Leaves hispid. Petioles pilose. Flowers small, blue, in fascicles, from the axils of the upper leaves, the whole forming an oblong terminal raceme.

Fulgent Bell-flower. Pl. 1 foot.

112 C. Peregrìna (Lin. syst. p. 301.) plant hispid; stem simple, many-flowered, angular; leaves crenated: lower ones obovate: superior ones ovate, acute ; flowers disposed in a spicate raceme; calycine lobes acuminated, nearly entire, rather shorter than the corolla, which is spreading; capsule ovoid. $\%$. H. Native of Mount Lebanon, and near Aleppo. Jacr. hort. schoenbr. 3. p. 337. Sims, bot. mag. t. 1257. Hoffn. and Link. fl. port. 2. p. 15. t. 83 . C. lanuginòsa, Lam. dict. 1. p. 584. but not of Willd. C. hirsutissima, Guss. ined. Flowers sessile, solitary, disposed in a long dense spike. Corollas funnel-shaped, hardly one-half longer than the calycine lobes, of a dark violet colour at the base, of a less deep colour in the middle, and paler towards the margins.

Foreign Bell-flower. Fl. July. Aug. Clt. 179\%. Pl. $2 \mathrm{ft}$.

113 C. PRimulefòlia (Brot. fl. lus. 1. p. 288. phyt. lus. 1. t. 20.) stem hispid, many-flowered, simple; leaves uncqually and doubly crenated: radical ones lanceolate, bluntish : cauline 5 E 2 
leaves ovate-oblong, acute; flowers disposed in a spicate raceme; calycine lobes acuminated, broad at the base, denticulated; corolla campanulately rotate, twice longer than the calycine segments; capsule long, obconical. 4. H. Native of Portugal, in sliady, humid places of the Algarves and Beira, and near Coimbra; above Punhete, and about Monchica. C. Trachèlium, Brot. f. lus. 1. p. 287. Root oblique, branched, thickened into tubers at top. Leaves hispid on the ribs and veins. Flowers erect. Corollas nearly glabrous, blue, rarely purple, with a whitish downy bottom.

Primrose-leavcd Bell-flower. P]. 1 to 2 feet.

114 C. aLA'TA (Desf. f. atl. 1. p. 178. t. 50.) stem fewflowered, simple, glabrous; leaves irregularly toothed, glabrous : lower ones ovate, acute; cauline leaves lanceolate; flowers few, lisposed in racemose heads; calyx with a hispid tube, and linear-lanceolate, acute, rather ciliated segments ; corolla broadly campanulate, twice longer than the calycine segments; capsule spherical. 24. H. Native of the north of Africa, near Maiaral. Stem angular. Flowers sessile on the top of the stem. Corolla blue, size of that of $C$. pyramidalis.

Vinged Bell-flower. Pl. 2 to 3 feet.

115 C. ptarnicefòlia (Lam. dict. 1. p. 579.) stems simple, many-flowered; radical leaves crowded, linear-lanceolate, serrulated; flowers sessile, disposed in a loose spike; calyx with a spherical tube and triangular lobes, which are thrice shorter than the tubularly-campanulate corolla. 4. H. Native of A rmenia. Desf. choix. cor. p. 35. t. 25. or in ann. mus. 11. p. 56. t. 6. Radical leaves rosulate. Plant glabrous. Flowers erect, violaceous.

Sneczcwort-leaved Bell-flower. Pl. $\frac{1}{2}$ to $\frac{3}{4}$ foot.

116 C. CARPA' тic (Jacq. hort. vind. 1. p. 22. t. 57.) plant glabrous, branched; lower leaves on long petioles, ovate-roundish, cordate, toothed : superior ones on short petioles, ovate, acute; Howers disposed in loose panicles, on long pedurcles; calycine lobes erectish, triangular, acuminated, thrice shorter than the corolla, which is broadly campanulate; capsule ovoid-cylindrical. 2. H. Native of Transylvania, and at the sides and bottoms of the mountains of Liptovia, to the soutl of the Carpathian mountains; among calcareous alpine rocks. Curt. bot. mag. t. 117. Root fibrous. Stems leafy. Branches or peduncles elongated, naked, each terminated by an erect flower. Corollas blue, about the size of those of $C$. persicafôlia. foot.

Carpathian Bell-flower. Fl. June, Aug. Clt. 1774. Pl. $\frac{1}{2}$

117 C. silenifòlia (Fisch. mss. ex Alph. D. C. mon. p. 320.) stem simple, few-flowered; leaves ciliated: radical ones lanceolate, on long petioles, entire : cauline ones narrower, acurninated; calycine lobes erect, acuminated, ciliaterl, thrice shorter than the corolla, which is funnel-shaped; capsule long, obovoid. 4. H. Native of Dahuria; and at the river Lena, in Siberia. C. Baicalénsis, Pall. mss. in herb. Lamb. C. ciliàta, Patrin, herb. Gmel. sib. 3. p. 159. t. 32. exclusive of the syn. of Tourn. Root slender, creeping transversely below the earth, and enitting slender fascicles of fibres. Stem glabrous. Flowers 1-3 on each stem, terminal and axillary, pedicellate. Corollas large, blue, with glabrous or ciliated lobes.

Catclifly-leaved Bell-flower. Pl. $\frac{1}{2}$ foot.

118 C. Steve'nu (Bieb. A. taur. suppl. p. 138.) stem quite simple, I-flowered; radical leaves ohovate, petiolate, crenulated: cauline leaves sessile, nearly entire: lower ones ovatelanceolate: superior ones acuminated; calyx glabrous, with acuminated erect lobes, which are one-lialf sliorter than the funnel-slraped corolla. 4 . H. Native of Eastern Caucasus, in subalpine places; and of Iberia, Armenia, and the Ukraine. C. Steveniàna, Roem. et Schultes, syst. 5. p. 91 . C. lanceolàta, Pall. in herb. Lamb. C. Vittinghoffiàna, Rœm. et Scluultes, syst. 5. p. 102. C. infundíbulım, Vest, in Roem. et Schultes, syst. 5. p. 106.? C. seminùda, Vest, in Roem. et Schultes, syst. 5. p. 91 . C. símplex, Stev. mem. soc. des. natur. mosc. 3. p. 255. but not of D. C. f. fr. Root slender. Stem sometimes velvety at the base. Flower erect, terminal. Corolla blue.

Var. $\beta$, Sibirica (Alph. D. C. mon. p. 321.) stem few-flowered; corolla 5-cleft even to the middle, with ample lobes. 4. H. Native of Siberia. C. Steveniàna, Fisch. mss.

Steven's Bell-flower. Fl. July, Aug. Clt. 1825. Pl. $\frac{1}{2}$ to 2 feet.

119 C. p'Ersickfòlia (Lin. spec. ed. 1. p. 164.) stems nearly simple; leaves glabrous, stiff, crenulated: radical leaves lanceolate-obovate: cauline leaves linear-lanceolate; flowers racemose; calycine lobes acuminated, broad at the base, entire, twice shorter than the corolla, which is broadly campanulate; capsule ovoid, trisulcate, dehiscing by broad pores. 4. H. Native of the south and temperate parts of Europe; from Spain, I taly, Greece, even to Scotland; south of Sweden; about Petersburgh and Moscow, and throughout Siberia, especially towards the east, and the Altaian mountains; about Constan. tinople; delighting in subalpine shady places, and woods; in Scotland, in woods near Cullen. Bull. herb. t. 367. Oed. 1 . dan. t. 1087. Sibth. et Smith, fl. grac. t. 205. C. decurrens, Lin. spec. cd. 2. p. 232. C. speciòsa, Gilib. pl. litb. p. 10. but not of Horn. C. amydalifolia, Salisb. prod. p. 126.-Weinm. phyt. icon. t. 291. f. and b. and t. 290 . f. c. and d.-Swert, floril. pt. 2. t. 16.-Besl. hort. eyst. 1. t. S. f. 2. and 3.-Tab. icon. t. 317.-Lob. icon. t. 327.-Moris. oxon. 2. p. 452. sect. 5. t. 1. f. 2. Plant glabrous. Flowers terminal and axillary, pedunculate, solitary, inclined, the whole forming a raceme. Corollas large, broad, campanulate, blue, and all the intermediate shales to white.

Var. $\beta$, angustifòlia (Alph. D. C. mon. p. 322.) leaves narrow-linear. 4. H. C. persicæfolia, $\beta$, Lin. spec. ed. 1. p. 164. C. decúrrens, $\beta$, Lin. spec. ed. 2. p. 232. but not of ed. 1.-Tabern. icon. t. 411 . and t. 412 .

Var. $\gamma$, macríntha (Alph. D. C. mon. p. 323.) flowers very large, of a lilac colour. 4 . H. C. persicæfòlia, var. máxima, Curt. bot. mag. t. 397.

Var. $\delta$, calyce piloso (Alph. D. C. mon. p. 325.) tube of calyx beset with strigose pili: lobes glabrous; leaves narrow-linear. 4. H. Native of France and Carniola. C. persicæfòlia, Scop. carn. no. 228. D. C. fl. fr. no, 2838, var. $\gamma$.

$I^{\prime}$ ar. $\varepsilon$, dasycárpa (Alph. D. C. mon. p. 323.) stems 1 -flowered; radical leaves ovate and obovate; cauline leaves oblonglanceolate; calyx scabrous from pili. 24. H. C. dasycárpa, Kit. in Schultes, fl. austr. 2. no. 900. Rom. et Schultes, syst. 5. p. 93. C. persicaf òlia, $\beta$, Wabl. carp. p. 60 .

Var. $\xi$, hispida (Alpl. D. C. mon. p. 323.) plant hispid from pili. 4. H. C. persicæfòlia, Rœm. et Schultes, 5. p. 106.

I ar. 1, pumila (Alph. D. C. mon. p. 323.) glabrous; stems 1-flowered; leaves approximating, firm; corolla narrow at the base. $4 . H$. Native of Bohemia. C. persicæfòlia, var. $;$, Polıl, fi. bohem. p. 202. C. pùmila, Schmidt, fl. bohem, no. 171. Flowers blue.

Var. $\delta$, calycina (Alph. D. C. mon. p. 323.) plant monstrous ; stems 1-flowered; calycine lobes large, ovate-lanceolate; corolla narrowed at the base. 4. H. C. persicæélia calycina, Rchb. icon. cent. 1. t. 67.

Var. ı, flòre plèno (Alph. D. C. mon. p. 323.) flowers double, blue or white. 4. H. Tourn. inst. 1. p.111. C. decúrrens, var. Mill. dict. no. 2.

Peach-lcaved Bell-flower. Fl. July, Sept. Britain. Pl. 1 to 3 feet.

120 C. Prrenaica (Alph. D. C. mon. p. 324.) stems simple, 1 -flowered, beset with solt hairs; leaves rather pilose: radi- 
cal leaves roundish, a little crenated, on short petioles : cauline leares sessile, lanceolate, ncarly entire, acute at both ends; calyx glabrons: with subulate, spreading, entire lobes, which are rather shorter than the corolla. 4. H. Native of the Pyrenees, and of the Balearic Islands. Flowers terminal, erect. Corolla blue?

\section{Pyrenean Bell-flower. Pl. 1 to $1 \frac{1}{2}$ foot.}

121 C. Rapu'nculus (Lin. spec. p. 232.) stem almost simple; lower leaves obovate, on slrort petioles, nearly entire : cauline leaves sessile, linear-lanceolate, entire; flowers spicately racemose, solitary; calycine lobes crect, long-subulate, very slender, rather shorter than the corolla, which is funnel-shaped; capsule obconical, trisulcate. $\delta$. H. Native of Morocco and Barbary; as also of the south of Europe, and extending as far north as the county of Norfolk, in England; as well as of 'Transylvania and Caucasus. In Britain, on banks and about the borders of fields; not common. About old Buckingham Castle, Norfolk. In many parts of Kent and Surry, as well as in other places on a gravelly soil; having formerly perhaps escaped from gardens. Smith, engl. bot. t. 283. Schrank, ench. no. 406. t. 39. Oed. fl. dan. t. 1326. Svenk, bot. t. 629. C. fastigiata, Gmel. reis. 1. p. 153. t. 33. but not of Dufour. C. coarctàta, Gilib. pl. lith. p. 8. C. esculénta, Salisb. prod. p. 126. C. elàtior, Link, et Hoffm. A. port. 2. p. 11. t. 80. C. glandulòsa, Banks, herb. Tourn. inst. 111 . Morand. hist. p. 69. t. 39. f. 3.-Moris, oxon. sect. 5. t. 2. f. 20. and f. 1. Colum! phyt. 102. with a figure. Lob. icon. t. 328. lioot fusiform, thick, white. Stem simple, but sometimes furnished with a few branclies towards the top, furrowed, glabrous, but pilose at the base. Leaves usually glabrons, but sometimes hairy. Flowers nearly sessile, or pedicellate, erect, forming a long raceme, which is branched at the base. Corollas blue or white. This plant varies in the stem being glabrous or pilose, in the length of the pedicels, in the tube of the caly $\mathrm{x}$ being glabrous or strigose, in the calycine teeth being entire or a little denticulated at the base. The root is milky, thick, and edible, and, with the leaves, is mixed in salads; and, therefore, it was formerly cultivated for that purpose. In France and Italy the roots are boiled and eaten lot with sauce, or cold with vinegar and pepper. The seed is sown in the spring on deep light soils, in drills, and the plants are ready for use in the autumn of the same year. It is called Raperonzola in Italy; Ramuncio, in Portugal; Raiponce, petite Raiponce, in France; Rampion, and Small Rampion, in England; Rapunzel, Ruben, or Blau Bluhende Wurzel, Rapunzel, Purnitzlein, in Germany; Rzepeka, in Bohemia; and Akla Rapunzel, in Sweden.

Var. $\beta$, calỳce strigoso (Alph. D. C. mon. p. 326.) calyx beset with strigose pili. $\delta$. H. Native of the Ukraine, Tauria, and Iberia. §. H. C. Rapúnculus, $\delta$, Rom. et Schultes, syst. 5. p. 105. C. verruculosa Link et Hoffm. f. portug. 2. p. 12. t. 81 .

Var. $\gamma$, calycina (Alph. D. C. mon. p. 326.) calycine seg. ments subulate, length of corolla serrated from the base even to the middle: teeth acuminated. §.H. C. calycina, Bob. in Rœm. et Schultes, syst. 5. p. 104. C. Rapúnculus, Bieb. fi. taur. suppl. p. 138. feet.

Rampion Bell-flower. Fl. July, Aug. Britain. Pl. 2 to 3

122 C. Lambertiàn (Alph. D. C. mon. p. 327.) stem simple, many-tlowered, pilose; cauline leaves sessile, oblongacuminate, irregularly denticulated, rather pilose; flowers disposed in a spicate raceme; calyx glabrous, with acuminated, spreading, coarsely, and acutely-toothed lobes, rather shorter than the corolla, which is obconical. of ? H. Native of Persia, in the province of Ghilan. Flowers disposed in a spike-formed raceme, furnished with a few branches at its base, as in $C$. Rapunculus. Corollas white.?

Lanbert's Bell-flower. Pl. $1 \frac{1}{2}$ to 2 feet.

123 C. virga'ta (Labill.pl. syr. dec. 2.p. 11.t.6.) stem simple, many-flowered; radical leaves lanccolate, crenulated, petiolate: cauline ones sessile, linear-lanccolate; flowers spicate, usually twin or tern; calyx with a scabrous tube, and erect subulate lobes, which are twice or thrice shorter than the funnel-shaped corolla; capsules obconical. $\delta$. H. Native of Mount Lebanon. Root thick. Stem hardly leafy, rather scabrous below, but smooth at top. Leaves scabrous. Flowers sessile, erect, 1-3 from each axil, forming a long interrupted spike. Corollas bluc.?

Twiggy Bell-flower. Pl. $1 \frac{1}{2}$ to 2 feet.

124 C. Hermini (Hofim. et Link, fi. port. 2. p. 9. t. 79. Rœm. et Schultes, syst. 5. [3. 328.) glabrous; stem ascending, simple ; leaves nearly entire: radical ones lanceolate: cauline ones linear-lanceolate; petioles ciliated at the base; calycine lobes long, capillary, reflexed, rather shorter than the corolla, which is funnel-shaped. $\odot$. H. Native of Portugal, on the high mountains called Serra d'Estrella. Root rather thick, creeping. Stem panicled at the top, as in $C$. rhomboidiclis. Pedicels l-flowered. Corollas pale blue.

Hermin's Bell-flower. Fl. July, Aug. Clt. 1823. Pl. $\frac{1}{2}$ to 1 foot. Ascending.

125 C. pa'tula (Lin. spec. ed. 1. p. 163.) stem branclsed; branches diverging; radical leaves crowded, obovate, crenated; cauline leaves linear-lanceolate, sessile, nearly entire; calycine lobes long-acuminated, spreading, serrated at the base, twice shorter than the corolla, which is funnel-shaped; caysule ovatecylindrical. \$. H. Native of the south and temperate parts of Europe; as of the Pyrenees, Spain, throughout Italy, the Morea, and also in the region of Tunis; Levant, to the Car. pathian Mountains, but not below them; Transylvania; about Petersburgh and Moscow, but is never to be found in Europe beyond lat. 61 . In England, in pastures, borders of fields and hedges; rare in several parts in Kent; in many places about Alcester; in Worcestershire, and Staffordshire, Sc. Oed. fl. dan. t. 373. Smith's engl. bot. t. 42. Hook. fl. lond. t. 51. C. bellidifollia, Lapeyr. abr. p. 36. C. decúrrens, Lin. spec. ed. 1. p. 164. Diffuse Bell-flower, Hill. veg. syst. 8. t. 1. -Weinm. phyt. icon. t. 290. f. a. Dill. hort. elth. t. 58. f. 68. Besl. eyst. ord. 1. t. 5. f. 3. Root small, slender, branched. Stems glabrous, or scabrous from pili on the angles. Branches divaricate, nearly naked. Leaves glabrous. Flowers panicled, terminal, and axillary, on long pediccls, large, erect. Corollas blue or white. This is a very polymorphous plant.

$\operatorname{Var} . \beta$, calýce pilòso strigòso (Alph. D. C. mon. p. 329.) calyx beset with strigose hairs.

Var. $\gamma$, latifolia (Alph. D. C. l. c.) stem branched, glabrons, scabrous on the angles; cauline leaves lanceolate, broad, serrulated; calycine segments very long, rather longer than the corolla.

I ar. $\delta$, paueiflòra (Alph. D. C. I. c.) stem humble, branched a little, almost naked; flowers terminal, and axillary, few, large; corolla campanulate, one half longer than the calycine segments. Column. ecphr. p. 24, with a figure. Tourn. inst. 111.

l'ar. $\varepsilon$, negléeta (Alph. D. C. I. c.) calycine lobes reflexed, serrulated, toothed at the base, acuminated, a half or a third the length of the corolla. C. neglécta, Rom. et Schultes, syst. 5 . p. 104 .

Sprcading Bell-flower. Fl. July, Aug. Britain. Pl. $1 \frac{1}{2}$ to 2 feet.

126 C. erinoides (Lin. mant. p. 64.? Cav, ann. cienc. 3. p. 20.) stem humble, few-flowered, with scabrous angles; leaves small, linear-lanceolate, glabrons, crenulated: lower ones olstuse: superior ones acuminated; calycine lobes long, subulate, 
entire, rather shorter than the corolla, which is funnel-shaped; capsule long-obconical, nearly terete. t.H. Native of Spain, about Madrid and elsewhere; and of Gibraltar and Tangiers. Root slender, filiform. Stem simple, but furnished at top with l-flowered peduncles, which diverge more or less. Flowers erect, blue.

Erinus-like Bell-flower. Fl. July, Aug. Clt. 1823. Pl. $\frac{1}{2}$ foot.

127 C. MAtrute'nsis (Alph. D. C. mon. p. 532.) stem humble, few-flowered; leaves linear-lanceolate, nearly entire: lower ones obtuse : superior ones acute; calycine lobes long-subulate, erect, entire, rather shorter than the corolla, which is narrowfunnel-shaped ; capsule obconical, elongated, having the nerves rather prominent. $\odot$. H. Native of Spain, about Madrid. Root filiform. Stem simple, but furnished with l-flowered peduncles at the top, glabrous or pilose, liardly scabrous on the angles. Leaves glabrous or pilose. Corollas violaccous.

Madrid Bell-flower. Pl. $\frac{1}{4}$ to $\frac{1}{2}$ foot.

128 C. ramosíssima (Sibth. et Smitl, fl. græc. t. 204.) stem branched, many-flowered, pilose; leaves ovate-lanceolate, crenated: lower leaves obtuse: upper ones acute; calyx with a pilose tube, and acuminated entire lobes, which are pilose ontside, and rather shoster than the spreading corolla; capsule obconical, pilose, having the nerves rather prominent. $\odot$. H. Native of Nount Olympus, in Bithynia, and in the island of Zante, \&c. Root slender, fibrous. Stem angular. Leaves equally scattered over the stem, smoothish. Branches nearly naked, divaricate, each terminating in a single flower. Corolla bluish-violet, having the nerves more intensely coloured.

Much-branchcd Bell-flower. Fl. July, Aug. Clt. 1820. P?. $\frac{1}{4}$ to $\frac{1}{2}$ foot.

129 C. LonE'Y1 (Alph. D. C. mon. p. 333.) stem branched, few-flowered; leaves sessile, glabrous: lower ones obovate, crenated: middle ones ovate-lanceolate: superior ones linear, entire; calyx with a hispid tuhe, and long-acuminated glabrous spreading lobes, which are denciculated at the base, length of corolla, which is somewhat rotate; capsule splieroid, deeply furrowed, and beset with strigose pili. ○. H. Native of the province of Verona, near Vallegio, where it was first collected by Lory ; and on Mount Baldo, by Rainer. C. Loreiàna, Lorèii, or Lorèi, Poll, elem. hot. t. 2. p. 148, ultimate table, f. 1. Poll. fl. ver. 1. p. 27 l. t. 2. f. 4 . Sims, bot. mag. t. 2581. C. Baldénsis, Balb. cat. hort. taur. 1813. p. 20. C. ramosíssima, Host, fl. austr. 1. p. 264. but not of Sibth. et Smith. Root slender, fibrous. Stem glabrous or lispid. Peduncles long, naked, glabrous, bearing each an ercet flower at the apex; but the alabastrum is drooping before expansion. Corolla with a white base, middle part or base of the lobes pale blue, and the lobes bluisli-violet.

Lorey's Bell-flower. Fl. June, July. Clt. 1824. Pl. $\frac{1}{2}$ to 1 foot.

130 C. Decu'mens (Alph. D. C. mon. p. 394. t. 12. f. A.) stem decumbent, nearly simple, few-flowered; radical leaves roundish-spatulate, simuated : canline leaves obovate, crenately. toothed: superior ones linear-lanceolate; calyx with a pilose tube; corolla funnel-sliaped, twice longer than the calycine lohes: capsule spheroid. $\odot$. H. Native of Spain, near Aranjuez. Root slender, fibrous. Stem glabrous or slightly pilose. Radical leaves with rather scabrous white subrevolute edges; middle ones quite glabrous. Flowers terminal, and axillary, on long peduncles, solitary, drooping before expansion, but afterwards erect. Corollas blue.?

Decumbent Bell-flower. Pl. decumbent.

131 C. Loeflingit (Brot. phyt. fasc. 1. no. 10. fl. lus. 1. p. 237.) stem much branched, many-flowered, rather scabrous on the angles; leaves crenulated: lower ones ovate-reniform, or roundish-cordate: superior ones ovate, stem-clasping ; calyx glabrous, with an obconical tube, and long-acuminated spreading lobes, which are rather shorter than the corolla; capsule obconical, with prominent nerves. $\odot$. H. Native throughout Portugal, in sandy places; of Spain, about Madrid; and of the territory of Mlogodor. Brot. phyt. lus. sel. p. 41. t. 18. Hoffm. et Link, fl. port. 2. p. 14. t. 82. C. Broussonnetiàna, liœem. et Schultes, syst. 5. p. 10\%. Root slender, fibrous. Leaves glabrous. Flowers solitary, terminating the naked branchlets, loosely panicled, drooping. Corolla funnel-shaped, blue, or violaceous, with a deeper coloured zone beneath the middle, white at the base, both inside and outside. In one variety, the calyx is downy.

Loefling's Bell-flower. Fl. July, Aug. Clt. 1818. Pl. $\frac{1}{2}$ to $1 \frac{1}{12}$ foot.

132 C. retrórsa (Labill. pl. syr. dec. 5. t. 3.) stem fewflowercd, angular, scabrous from retrograde prickles or bristles on the angles; lower leaves roundish-obovate, petiolate, somewhat sinuated, glabrous: superior leaves ovate-lanceolate, entire, with scabrous edges; calycine lobes long-acuminated, spreading, scabrous from serrulations, longer than the corolla, which is funnel-shaped; capsule obconically elongaterl. $\odot . H$. Native on Mount Lebanon. Root slender, fibrous. Branches elongated, naked, each terminated by an erect flower. Flowers drooping before expansion. Corolla mixed with white and violet.

Retrograde-bristled Bell-flower. PI. $\frac{1}{2}$ to $1 \frac{1}{2}$ foot.

133 C. Zòrsir (Wulf, in Jacq. coll. 2. p. 122.) plant tufted; stems erect, few-flowered; leaves entire : radical ones crowded, petiolate, ovately-obovate, obtuse ; cauline leaves obovate-lanceolate, and linear; caly cine lobes subulate; corolla long, cylindrically veutricose; capsule ovoid-spherical. 4 . H. Native of the Upper Alps of Styria, Carniola, Carinthia, \&c. Jacq. icon. rar. 2. t. 334. Plant small, glabrous, tufted. Root crecping, throwing out many small stems, which bear from 1 to 3 flowers each. Leaves crowded at the base. Flowers pedicellate, drooping. Corolla cylindrical, elongated, pale blue, with 5 deeper coloured lines; rarely white.

Zoysi's Bell-flower. Fl. June, Aıg. Clt. 1813. Pl. $\frac{1}{4}$ foot.

134 C. Cenísta (Lin. spec. suppl. p. 1669.) plant tufted; stems ascending, l-flowered; leaves entire : radical ones rosulate, obovate, obtuse : cauline leaves ovate-oblong; calyx hairy, with linear-lanceolate lobes; corolla 5 -cleft, hardly twice the length of the calycine lobes; capsule ovoid. 4. H. Native of the Higher Alps of Provence, Piedmont, Dauphiny, Savoy, Vallais; on Mount Cenis ; and of Switzerland, on the mountains called Diablerets, \&c. All. pedem. no. 395. t. 6 . f. 2. Rchb. icon. bot. cent. 1. p. 85 . All. rar. stirp. spec. 35 . t. 5 . f. 1. Root creeping, blackish. Stems numerous, glabrous, or slightly pilose. Flowers solitary, terminal, erect. Corolla deep blue, hardly one half longer than the calycine lobes.

$\mathrm{I}$ ar. $\beta$, angustifólia (Schrad. prim. salisb. p. 70.) leaves narrow. 24. H. Native of the Alps of Salizburgh.

Mount Cenis Bell-flower. Fl. June, July. Clt. 1775. Pl. $\frac{1}{4}$ foot.

135 C. spatula'ta (Sibth. et Smith, prod. A. græc. 1. p. 137. fl. græc. 1. 203.) stem ascending, l-flowered, pilose; lower leaves petiolate, obovate, crenated: superior ones lanceolate; calyx with an obconical tube, and linear-acuminated toothed lobes; corolla subcampanulate, hardly longer than the calycine lobes; capsule spheroid. §. H. Native on Mounts Olympus and Parnassus. Root slender, twisted. Stem solitary, angular. Leaves rather pilose, but becoming more smooth and entire as they ascend the stem. Flower terminal, erect, blue.

Spatulate-leaved Bell-flower. Fl. July, Aug. Clt. $181 \%$. Pl. $\frac{1}{2}$ foot. 
136 C. A'LGIDA (Fisch. mss. ex Alph. D. C. mon. p. 338.) plant humble; stems nearly naked, 1 -flowered; radical leaves crowded, obovate-lanceolate, setaceously denticulated; petioles ciliated; calyx with a villous tube, and denticulated acuminated lobes; corolla campanulately funnel-shaped, twice longer than the calycine lobes; capsule somewlat cylindrical. 4 . H. Native of Kamtschatka, Unalaschka, Kotzebue's Sound, Cadiak, and Sledge Island, as well as of the Rocky Mountains in America. C. lasiocárpa, Cham, in Linnæa. 4. p. 39. exclusive of the syn. Camp. Sayenénsis, Fisch. Root slender, white. Stem glabrous, or slightly pilose. Flower terminal, erect. Corolla large for the size of the plant, blue.?

Algid Bell-flower. Pl. $\frac{1}{4}$ to $\frac{1}{2}$ foot.

187 C. UNiflòra (Lin. spec. p. 231. but not of Vill.) stems 1-flowered ; leaves nearly entire : lower ones obovate, petiolate: middle ones obovate-lanceolate: upper ones few, linear-lanceolate; calyx rather villous, with linear acuminated lobes, about equal in length to the corolla, which is funnel-shaped; capsule cylindrical. 24. H. Native of the polar region of America, as in the Island Unalaschka; north side of tlie Rocky Mountains; between Point Lake and the Arctic Sea; Kotzebue's Sound, Melville Island, Greenland; and of the north of Europe, as in Lapland, Sweden, Norway, \&c. Svenk, bot. t. 526. Rottb. pl. greenl. in act. hafn. x. p. 52, t. 6. f. 19. Oed. fl. dan. t. 1512. -Lin. A. lap. no.85. t.9. f. 5-6. Root simple, blackish. Stems simple, glabrous. Leaves glabrous. Flower drooping; deep azure blue.

Var. $\beta$, Gieseckiìna (Alph. D. C. mon. p. 339.) corolla 4 times longer than the calyx. $\psi$. H. Native of Greenland and Lapland. C. uniflòra, Gieseck, herb. Wahl. f. suec. 1. p. 134. C. Gieseckiàna, Vest, in Røem. et Schultes, syst. 5. p. 89.

One-flowered Bell-flower. Fl. June, July. Clt. 1815. Pl. $\frac{1}{4}$ foot.

* * Valves situated near the apex of the capsule. Flowers on short podicels. Leaves opposite. Branches usually more or less dichotomous.

188 C. Fastigia'ta (Dufr, in herb. D. C. ex Alph. D. C. mon. p. 34.0. t. 12. f. B.) plant scabrous, humble; lower leaves obovate, nearly entire : middle ones obovate-lanceolate, coarscly 3-5-toothed: superior ones linear-lanceolate; corolla one half shorter than the calycine segments, which are linear-lanceolate ; capsule obconical. $\odot$. H. Native of Spain, in Arragon and about Aranjuez. Plant of a greyish colour. Stem branched, erect; branches diverging. Leaves rather downy or glabrous. Flowers sessile, erect, terminal, rising from the axils or above the axils of the branches, always opposite the leaves, particularly terminating the stem and branches. The flowers situated in the lower axils expand before the rest. Corollas small, blue.

Fastigiate Bell-flower. Pl. $\frac{1}{4}$ foot.

$$
\text { † Species not sufficiently known. }
$$

139 C. Ligula'ris (Lam. dict. 1. p. 585 . ill. no. 2547.) leaves numerous, alternate, oblong, narrow, obtuse, entire, and ciliated; flower erect, terminal, middle-sized; calyx hispid, with nearly linear segments and covered sinuses; corolla tubularly campanulate, bearded a little; stem leafy, nearly glabrous, 1-flowered. - Native of the Alps of Europe.

Ligular-leaved Bell-flower. Pl. $\frac{1}{4}$ foot.

140 C. ASPE'rrima (Zuccagni in Rom. coll. p. 128.) leaves hastate, tomentose, spiny-toothed ; flowers axillary; corolla tomentose and hispid outside.-Native country unknown. Stem solitary, erect, tomentose. Cauline leaves imbricate, hastately cordate, reticulated and tomentose, especially beneath. Flowers axillary, sessile, solitary. Calyx spiny, shorter than the corolla. Corolla tubularly campanulate, violaceous.

Very rough Bell-flower. Pl. $\frac{1}{2}$ foot.
141 C. Decu'rrens ('Zuccagni in Roem. misc. 1. 128.) stem winged; leaves decurrent, toothed, hispid; corolla tomentose and hispid on the outside.-Native country unknown. Stem flexuous, winged from the leaves being decurrent. Leaves spatulate, reticulated and tomentose, especially beneath. Flower: axillary, crowded, seated on a common peduncle. Bracteas cordate. Calyx hispicl.

Dccurrent-leaved Bell-flower. Pl. 2 feet.

142 C. A'spera (Moncl. supp]. p. 188.) stem terete, straight, quite simple; leaves oblong, sessile, crenated; peduncles 3flowered. $\delta$. II. Native country unknown. Plant lispid from pili. Leaves obtuse, stiff; radical ones petiolate ; cauline ones sessile, remote. Racemes loose, terminal. Flowers axillary ; intermediate one pedunculate, lateral 2 arlnate to the common peduncle. Corolla blue. Stigna trifid. Capsule 3-celled.

Rough Bell-flower. Pl. 3 feet.

143 C. cymbala'ria (Sibth. et Smith, prod. f. grasc. 1. p. 139.) leaves reniform, cut, quite glabrous, shining; stems diffuse. 24. H. Native of Mount Olympus, in Bithynia. Camp. foliis cymbalariæe crispis montis Olympi Bithyni, Tour. cor. Perhaps this is either $C$. frágilis, or $C$. Bellardiéri.

Cymbalaria-leaved Bell-flower. Fl. diffuse.

144 C. WANNE'RI (Roch. pl. banat. var. t. 5. f. 12.) C. heterophýlla, Baumg. fl. trans. suppl. ex Feruss. bull. sc. febr. 1829 . Nothing is known of this species.

Wanner's Bell-flower. Pl.

145 C. Lanceolata (Presl, ex Wanderoth, beitr. zu. fl. Von Hessen. p. 37. but not of Lapeyr). Nothing more is known of this plant.

Lanceolate-leaved Bell-flower. Pl.

146 C. monta'na (Delarb. H. auvergn. p. 40.). Native of Auvergne. Nothing is known of this plant but the name.

Mountain Bell-flower. Pl.

147 C. Rige'scens (Pall. ex Rœm. et Schultes, syst. 5. p. 102.) leaves lanceolate: radical ones attenuated iuto the petioles, crenated: cauline ones sessile; stem straiglit, simple, downy; flowers terninal, racemose; calyxies ciliated. Native of Siberia, about Lake Baical, in frigid places. Corolla $1 \frac{1}{2}$ inches long, twice the length of the calyx, with the segments ciliated a little. Style a little longer than the calyx. Stem a span high, few-flowered.

Stiffish Bell-flower. Fl. June, Aug. Clt. 1820. 1']. $\frac{1}{2}$ foot.

148 C. Adsce'ndens (Vest, in Rœm, et Schultes, sy'st. 5. p. 90.) leaves scattered: lower ones on short petioles, ovate, toothed: superior ones oblong, quite entire, glabrous as well as the stem, which is ascendent; flowers solitary, drooping: calycine leaflets subulate, a little shorter than the corolla. Native of Siberia. C. rotundifolia, Pall. ex herb. Lamb. Very nearly allied to $\dot{C}$. uniflòra.

Ascending Bell-flower. Pl. ascending, $\frac{1}{2}$ foot.

149 C. Heterodóxa (Vest, in Rom. et Schultes, syst. 5. p. 98.) leaves oblong, glabrous; fowers axillary, pedunculate, spreading; calyx short, with lanceolate-subulate segments, which are a little shorter than the corolla. 24. H. Native of Siberia. C. rotundifolia, Pall. herb. Peduncles axillary, capillary, 1flowered, roughish, furnished with bracteoles.

Heterodox Bell-flower. Pl. $\frac{1}{2}$ to 1 foot.

150 C. Lunariafòlia (Willd. rel. ex Roem. et Schultes, sust. 5. p. 92.) leaves ovate, deeply cordate, petiolate, doubly serrated; flowers secund. 4 . H. Native of Caucasus.

Lunaria-leaved Bell-flower. PI. 1 foot.?

151 C. Kitaibelia'na (Rocm. et Schultes, syst. 5. p. 90.) lower leaves obovate-cuneiform, crenated: superior one linear, quite entire; stem quite simple, 1-flowered. 4.H. Native of Austria. C. microphýlla, Kit. in Schultes, fl. austr. 2. ed. no. 400 . 
Kitaibcl's Bell-flower. Fl. June, July. Clt. 1820. Pl. $\frac{1}{4}$ foot. 152 C. K'LEgans (Rœm. et Schultes, syst. 5. p. 105.) leaves lisear-lanceolate, quite entire : lower ones the broadest, smooth, and tapering into the petioles; stem downy; flowers axillary, at length spicate; calycine segments setaceous, divaricate, rather pungent, length of corolla, 2 . H. Native of Siberia. C. speciòsa, Willd. rel. ex Roem. et Schultes, 1. c. Stem simple, terete, weak. Flowers terminal, and rising from the axilla of the superior leaves, forming an interrupted spike, hardly pedunculate.

Elegant Bell-flower. Fl. July, Aug. Clt. 1821. Pl. 1 foot.

153 C. Camtschática (Roem. et Schultes, syst. 5. p. 3\%.3.) radical leaves cordate, toothed: cauline ones oblong-lanceolate, quite entire; stem weak, usually 1-flowered. 4.H. Native of Kamtschatka. Radical leaves on long petioles, angularly toothed, membranous, glabrous: cauline leaves tapering into the petioles. Root capillary, much branched. Calycine segments unequal, subulate, reflexed.

\section{Kamtschatka Bell-flower. Pl. $\frac{1}{2}$ foot.?}

Cult. All the species are elegant and handsome when in blossom, and are well adapted for decorating flower borders. They in general thrive well in common garden earth. The seeds of the biennial and annual kinds should be sown in the open border in spring. The perennial species may either be propayated by division or by seed. Some of the perennial and biennial species, natives of the warmer latitudes, require a little protection in winter, when the weather is severe. Some of the smaller perennial kinds answer well for decorating rockwork, or to be grown in pots, among other alpine plants.

XVI. SPECULA'RIA (so called from the ancient name of one of the species, Speculum Vencris, or Venus's Looking-glass). Heister, syst. pl. gen. ex fruct. Sc. p. 8. in 1748. Alph. D. C. mon. p. 344.-Legoúzia, Durand, fl. bourg. 2. p. 26. (1782.). Delarb. $f$. auvergn. 1. p. 45. Gray, nat. arrang. brit. pl. 2. p. 410.-Spéculun Véneris, Gerard, herb. 356. Rai. hist. 1. p. 742.-Pentagònion, Tabern. icon. 316.-Elátine, Cæsalp. I. 9. cap. 32.-Aviculària, Gessn. tab. plyyt. 9. f. 76 . J. Baul, hist. 2. p. 800.-Campánula species, Dodon. pempt. p. 168.-Tourn. inst. 1. p. 112. Lin. gen. no. 290. Willd. spec. 1. 1) 912. Rœem. et Schultes, syst. 5. p. 153.- Prismatocárpus species, Lher. sert. angl. p. 2. Moench, meth. p. 496. Batsch, anal. tor. 11. p. 32. t. 13. Lain. et D. C. fl. fr. ed. 3d. vol. 3. p. 708.-A pèwula, Neck. elem. 1. p. 234.

Lin. syst. Pentándria, Monogýnia. Calyx 5-lobed, with an elongated, prismatic, or long-obconical tube. Corolla rotate, 5lobed. Stamens 5, free, one-lialf shorter than the corolla; anthers longer than the filaments, which are slort, membranous, and pilose. Style inclosed, pilose: hairs secund, disposed in 10 rows; stigmas 3, filiform. Capsule long, prismatic, 3-cellerl, dehiscing by 3 valves at the apex, or a little above the middle pirt. Seeds ovoid or lenticular, rather compressed, shining.Dwarf annual herbs, natives of the region of the Mediterranean, and the temperate parts of Europe; one species alone a native of Amcrica. Leaves alternate, equally scattered over the stem, small ; lower ones unlike the rest. Flowers terminal and axillary, erect, always sessile. Corollas blue, rose-coloured, white, grey, or variegated, shining in the sun; hence the generic name.

"Tube of calyx very long, prismatic, and angular. Capsule dehiscing towards the top, near the lobes of the calyx. Sccds ovoid. Lcaves ovate-oblong or lanceolatc, nearly entire, not stemclasping.

1 S. pentagòna (Alph. D. C. mon. p. 344.) stem branched, larger; flowers terminal, solitary ; calys beset witly a few stifl hairs, having a Jong prismatic tube, and long linear-lanceolate, spreading lobes; corolla the length of the calycine lobes. $\odot$. H. Native of the Levant, about Aleppo; in Caramania, Candia, Thrace, S.c. Campánula pentagònia, Lin. spec. 1. p. 239. Desf. choix. cor. p. 44.t. 33 . or ann. mus. 11. p. 143, t. 18. Ker. bot. reg. t. 56. Prismatocárpus pentagònius, Lher, sert, angl. p. 2. Stem glabrous or pilose on the angles. Leaves glabrous, nearly entire or crenulated, with revolute edges; lower leaves obovate; middle cauline ones lanceolate-obovate; upper cauline ones linear-lanceolate. The corolla before expansion is blunt and pentagonal, but when expanded large, white at the base, blue to the middle part, and violaceous at the extremity of the lobes.

Pentagonal-flowered Venus's Looking-glass. Fl. May, Aug. Clt. 1686 . Pl. $\frac{1}{2}$ to 1 foot.

2 S. FALCA'TA (Alph. D. C. mon. p. $345^{\circ}$ ) stem nearly simple; flowers disposed in long spikes, or approximate at the tops of the branches; calyx glabrous or scabrous on the margins, with a prismatic tube, and very long lanceolate acuminated lobes, which are reflexed at the apex, and are twice the length of the corolla. $\odot$. H. Native of the region of the Mediterranean; as of the Island of Chalcis or Eubra; of Dalunatia; about Rome and Naples; and of Sicily, Corsica, and Sardinia ; among corn, and on dry hills. Campánula falcàta, Røem. et Schultes, syst. 5. p. 154. Guss. pl. rar. p. 96. Prismatocárpus falcàtus, Tenore, prod. p. 16. f. neap. 1. p. 7\%. t. 20. Sebas et Maur. f. rom. prod. 1. p. 102.-Buxb. cent. 4. p. 24. t. 38.-Cupan. panph. 2. t. 20. Stem glabrous or a little scabrous on the angles. Leaves glabrous, rarely pilose, with rather revolute edges, crenulated. Flowers sessile, solitary, axillary, the whole forming a leafy spike. Corolla rose-coloured. Lobes of calyx falcate.

Falcate-calyxed Venus's Looking-glass. Fl. May, Aug. Clt. 1820. Pl. $\frac{1}{2}$ to 1 foot.

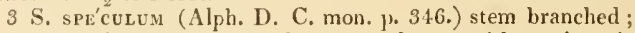
branches 3-flowered; calyx glabrous or downy, with a prismatic tube, which is narrow at the apex, and linear-lanceolate spreading lohes, which are at length reflcxed; corolla length of the lobes of the calyx. $\odot$. H. Native of the temperate parts of Europe, and throughont the region of the Mediterranean Sea, in corn-fields ; in Germany, Transylvania, Pyrenees, Spain, Italy, Greece, Syria, Barbary, \&c. Campánula spéculum, Lin. spec. p. 238. Curt. bot. mag. t. 102. Smith, fl. grac. t. 216. Lagoúzia arvénsis, Durand. f. bourg. 1. p. 37. Prismatocárpus spéculum, Lher. sert. angl. p. 2. Campánula pulchélla, Salisb. prod. p. 137. Legoúzia Durándi, Delarb. f. auvergn. p. 4.5. Campánula miroir de Venus, Jaume, pl. fr. t. 73 . Camp. cor. dàta, Visiani. stirp. dalm. spec. p. 5. t. 2.-Weinm. phyt. t. 286. Besl. eyst. 7. t. 1. f. 1.-Gesn. tab. phyt. 9. t. 76.-Lob. icon. t. 418.-Dod. pempt. p. 168. t. 1.-Mor oxon. 2. p. 457 . sect. 5. t. 2. f. 21 . Branches glabrous or scabrous on the angles. Leares crenulated, glabrous or scabrous; lower ones obovate; middle ones ovate-acute; superior ones lanceolate, nearly entire. Flowers terminal and axillary, showy. Corolla greenish-white at bottom, deep violet towards the middle part, and the lobes less violaceous, paler on the outside. There is also a variety with white flowors.

Var. $\beta$, calycina (Alph. D. C. mon. p. 347.) leaves and calycine lobes broader. $\odot$. H. Native of Iberia. Legoúzia spéculum? Fisch. ined.

Yar. $\gamma$, pubéscens (Alph. D. C. mon. p. 347.) the whole plant pilose; stem erect. $\odot$. H. Native of France and Naples. Prismatocárpus spéculum, var. $\beta$, Lan?, et D. C. fl. fr. ed. 3. Prismatocárpus hírtus, Ten. prod. p. 16. fl. neap. 1. p. 76. t. 19. Campánula hirta, Roen. et Schultes, syst. 5. p. 153. Guss. fl. sic. prodr. 1. p. 246. 
Var. ¿, Libánica (Alph. D. C. mon. p. 347.) stem humble, simple, erect; leaves erect; flower's approximate at the apex.

Common Venus's Looking-glass. Fi. May, Aug. Clt. 1596. Pl. $\frac{1}{2}$ to 1 foot.

4 S. Iт' вRIDA (Alph. D. C. mon. p. 348.) stem nearly simple; flowers approximate at the top of the stem; calyx scabrons, with a prismatic tube, which is narrower at the apex, and short erect ovate-lanceolate lobes; corolla one-half shorter than the calycine lobes. $\odot$. H. Native of the region of the Mediterranean, and the temperate parts of Europe, and of Caucasus, in corn-fields; from Barbary, Spain, Sardinia, Italy, Sicily, and Morea, even to England, Germany, and Siberia; in Tauria, Georgia, and Transylvania. Campánula hýbrida, Lin. spec. 239. Smitb, engl, bot. t. 375. Prismatocárpus liýbridus, Lher, sert. angl. p. 2. Ten. fl. neap. 1. p. 77. Prismatocárpus confërtus, Mœench, meth. p. 496. Legoúzia hýbrida, Delarb. fl. auvergn. p. 47. Camp. spùria, Wall. ined. Roem. et Schultes, syst. 5. p. 154. Legoúzia parviflòra, Gray, nat. arrang. brit. pl. 2. p. $410 .-$ Cupan. panph. 1, t. 100. Raf. t. 100. f. 2.Mor oxon. 2. p. 457 . sect. 5. t. 2. f. 22. Stem more or less scabrous from pili on the angles. Leaves crenated, more or less pilose; lower ones obovate; middle ones ovate, acutish ; superior ones smaller and ovate-lanceolate. Flowers 3-6, crowded towards the top of the stem, sessile, rising from the axils of the upper leaves and top of the stem. Corollas rose-coloured, or of a bluish rose-colour.

Hybrid Venus's Looking-glass. FI. May, Aug. England. Pl. $\frac{1}{1}$ foot.

5 S. Cò A (Alplı. D. C. mon. p. 350.) stem luumble, nearly simple; flowers few, approximate towards the top of the stem; calyx downy, witl prismatic tube, and erect lanceolate-subulate

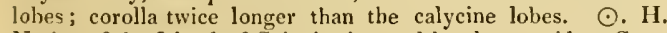
Native of the [s]and of Cois, in the sand by the sea side. Campánula spéculum, var. D'Urv, enum. pl. arch. in mem. Lin. par. 1. 1) 280. Prismatocárpus hírtus? or a new species? D'Urv. in herb. D. C. Stem pilose, downy at top. Leaves pilose, greyislı; lower ones obovate; middle ones sessile, ovate-acute; superior ones narrower and lanceolate. Flowers 3-6 towards the top of the stem, sessile, axillary, and terminal. Corolla blue or white.

Cois Venus's Looking-glass. P1. $\frac{1}{4}$ to $\frac{1}{2}$ foot.

6 S. Grilane'nsis (Alph. D. C. mon. p. 350.) stem simple or a little branched; leaves lanceolate, acuminated, serrated; flowers subracemose; segments of the calyx acuminated, serrated, longer than the corolla. $\odot$. H. Native of Persia, in the province of Ghilan. Campánula Ghilanénsis, Pall. ined, ex Rœm. et Schultes, syst. 5. p. 154. Very Jike $S$. spéculum, but differs in the stem being simple and much higher, in the calycine segments being serrated, and ending each in a long setaceous twisted mucrone.

Ghilan Venus's Looking-glass. Pl. 1 foot.

* Tube of calyx long, obconical, smooth. Capsule dehiscing tunards the middle part. Seeds rather lenticular. Lcaves ovateroundish, clasping the stem.

7 S. Perfoliatita (Alph. D. C. mon. p. 351.) stem erect, simple, or branched at the base ; flowers disposed in long leafy spikes; calyx glabrous, with an obconical tube, and erect lanceolate lobes; corolla longer than the calycine lobes. $\odot . ~ H$. Native of North America, from New York, and beyond the Alleghany Mountains, about West-Chester, and on the northwest Coast; of Mexico, about Vera Cruz, Xalapa, and La Pileta ; of Jamaica ; and of Peru. Campánula perfoliàta, Michx. A. bor. amer. 1. p. 108 . Nutt. gen. amer. 1. p. 136. Campánula biflòra, Ruiz et Pav. f. per. 2. p. 55. t. 200. f. b. Camp. flagellàris, H. B. et Kunth, nov, gen, amer. 3. p. vol. III.
301. t. 265. Camp. angulàta, Rafin. fl. lud. p. 55. ?--Barr. obs. t. 1133 . Mor, oxon. 2. p. 457. sect. 5. t. 2. f. 23 . Stem pilose, particularly on the angles, but sometimes glabrous. Leaves distant, crenately toothed, rather pilose. Flowers sessile, rising from the axils of the leaves, solitary or 2-3 together, and longer than them. Corolla blue, always longer than the calycine lobes.

Perfoliate-leaved V'enus's Looking-glass. Fl. May, Aug. Clt. 1680. Pl. $\frac{1}{2}$ to $1 \frac{1}{2}$ foot.

Cult. All the species are showy border annuals, and are therefore worth cultivating in every garden. The seeds only require to be sown in the open ground, where the plants are intended to remain. By sowing the seeds in the autumn, the plants will blossom early in summer, and by successive sowings in spring, at intervals of a fortnight or three weeks, a succession of bloszoming plants may be kept up.

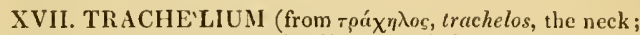
from its supposed efficacy in diseases of the trachea; hence also it is called Throat-nort in England, Halskraut in Germany, and Hermorilla, in Spain, Sc.). Lin. gen. 293. Adans. fam. nat. 2. p. 134. Gærtn. fruct. 1. p. 155. t. 31. f. 4 . Juss. gen. 165. Lam. ill. no. 2599. t. 126. Sclıkuhr, handb. 1. t. 40. Gessn. pliyt. p. 105. t. 13. f. 204. Vent. tabl. regn. veg. 2. p. 470. Alph. D. C. mon. p. 352.

Lin. syst. Pentándria, Monogýnia. Calyx 5-cleft. Corolla 5 -lobed at the apex, with a very long tube. Stamens 5 , free ; filaments very long, fliform, glabrous, much longer than the anthers. Style twice longer than the corolla, glabrous, pilose only at the apex about the stigmas; stigmas $2-3$, small, obtuse. Cap sule 2-3-celled, wholly inferior, spheroid, dehiscing at the base by lateral pores. Seeds ovoid, small, bay-coloured, shining.Herbs with erect, glabrous stems, alternate leaves, and corymbose erect small flowers. - Inhabitants of the north of Africa.

1 T. coru'leum (Lin. liort. ups. 41. spec. 243.) leaves ovate, acute, coarsely serrated, on short petioles; corolla violaceous, salver-shaped, witl a very long narrow tube; stigma trifid. $\mathcal{\Psi}$. 1H. Native of the region of the Mediterranean, among rocks; in Spain, Mogodor, Sicily, Calabria, Italy, but not farther north than lat. $42^{\circ}$, as about Rome. Hill. veg. syst. 8. t. 16. Boissieu, A. europ. t. 137. Ker, bot. reg. t. 72.-Barrel, icon. 683.-Mor. oxon. sect. 5. t. 5. f. 12. Stem glabrous. Leaves glabrous or ciliated. Flowers very numerous on the tops of the stem and peduncles, forming a widc-spreading corymb. Corollas violaceous. feet.

2 T. angustriòlum (Schousb. beob. morocc. p. 72.) leaves narrow-linear, quite entire, obtuse, sessile ; corolla whitish, funnel-shaped, with an elongated tube; stigma bifid. 2. H. Native of the kingdom of Morocco, in arid mountainous places. Stem simple, glabrous. Leaves glabrous. Corymbs like those of $T$. corulleum, but smaller. Corollas whitish.

Narron-leaved Throat-wort. Pl. 1 foot.

Cult. The species are very showy when in blossom. They" grow best in a light soil, against a south wall, or in front of a hot-house; and they may either be increased by seed or hy cuttings, planted under a hand-glass in spring.

XVIII. ADENO'PHORA (from a'ờ', aden, a gland, and $\phi o \rho \varepsilon ́ \omega$, phoreo, to bear ; in reference to the cylindrical nectary which girds the base of the style). Fisch. ined. ann. 1816. Led. cat. hort. dorp. ann. 1822. Fisch. diss. Reichb. hort. bot. t. 23 and 45. but not of Lamour.-Campánula species, Gmel. sib. 3. p. 148. Lin. gen. no. 290.-Flóerkia, Spreng. ann. 1818. but not of his syst. Campánula,-sect. Floerkiàna, Spreng. syst. 1 p. 735 . 
Lin. syst. Pentándria, Monogýnia. Calyx 5-cleft. Corolla campanulate or funnel-shaped, 5-lobed at the apex. Stamens 5, free; filaments erect, membranous, long, very much ciliated, comniving so closely as to appear coherent. Nectary cylindrical, girding the base of the style. Style usually exserted, pilose while in the bud, the bairs disposed in 10 rows, but afterwards it becomes glabrous; stigmas 3. Capsule 3-celled, dehiscing laterally at the base by 3 valves. Seeds ovate, more or less flat. -Perennial, rarely biennial herbs, with usually edible roots (ex Fisch.). Stems erect. Leaves alternate, very rarely subverticillate; radical ones roundish, petiolate; cauline ones usually sessile, becoming narrower and shorter to the top of the stem. Flowers racemose or panicled, terminal and axillary, pedicellate, drooping; clavate while in bud.- Natives of Siberia, China, and Japan, and one of the east of Europe.

\section{* Lcaves broader, ovate-lanccolate, morc or less coarsely ser- rated.}

1 A. Sinénsis (Alph. D. C. mon. p. 354.) leaves alternate, ovate-lanceolate, glabrous, acutely serrated; Howers disposed in spicate racemes; calycine lobes linear-lanceolate, entire, glabrous; corolla funnel-shaped; style a little exserted. $4 . \mathrm{H}$. Native of China. Stem branched, glabrous or velvety. Leaves glabrous, deep green above. Flowers disposed in a loose fewflowered raceme, which is furnished with branchlets at the base. Corolla blue, glabrous.

Var. a, glabra (Alph. D. C. mon, p. 354.) tube of calyx glabrous.

l ar. B, pilòsa (Alph. D. C. I. c.) tube of calyx hairy.

China Adenophora. Pl. 1 foot.

2 A. TRicuspida'ta (Fisch. mss. ex R œm, et Schultes, syst. 5. p. 158.) leaves alternate, serrated, smoothish; radical ones petiolate, rounded: cauline ones sessile, ovate-lanceolate; flowers racemose ; calycine lobes triangular, toothed; corolla campanulate; style lengtb of corolla. 4 . H. Native of Dahuria. A. denticulàta, Ledeb. suppl. hort. dorp. 1823. Fisch. mss. Relıb. hort. bot. t. 2. Sweet. fl. gard. 115. Campámula denticulàta, Spreng. syst. 1. p. 735. Stem simple. Flowers numerous, on short pedicels, disposed in a more or less loose elongated raceme. Corollas small, blue.

Tricuspidate Adenophora. Fl. July, Aug. Clt. 1817. Pl. $1 \frac{1}{2}$ foot.

3. A. verticilla'ta (Fisch, adumb. gen. aden, p. 5. Alpl. D. C. mon. p. 356.) leaves subverticillate, serrately toothed; radical ones petiolate, roundish : cauline ones ovate-lanceolate; flowers usually verticillate, small; calycine lobes erect, subulate; corolla campanulate; style much exserted. 24. H. Native of Dahuria and Japan. Sweet, fl. gard. 1. s, t. 160. Campánula verticillàta, Pall. voy. 3. p. 7 19. t. 9. f. I. ed. gall. append. 8. p. 263. t. 75. f. 1. Camp. tetraphýlla, Thunb. fl. jap. p. 87.-Amm. ruth, p. 12. no. 18. Plant glabrous. Leaves 3-6 in a whorl. Flowers small, irregularly disposed at the tops of the stems, which are simple; lower whorles many-flowered, remote. Peduncles 1-3-flowered. Corollas pale blue.

IThorled Adenophora. Fl. June, July. Clt. 1783. Pl. 2 to 3 feet.

4 A. Latifòlia (Fisch. adumbr. gen. aden. p, 6. Alph. D. C. mon. p. 356.) leaves subverticillate; cauline ones ovate-oblong, acuminated, coarsely serrated, roughly ciliated; flowers scattercd or subverticillate; calycine lobes spreading, lanceolate, with scabrous margins; corolla campanulately funnel-shaped; style a little exserted. 4. H. Native of Dahuria. Campánula pereskiæfòlia, Rœm. et Schultes, syst. 5. p. 116. Camp. perescifolia, spreng. syst. 1. p. 735. Camp. Peréskia, Fisch. mss. Stem simple, glabrous. Leaves $3-5$ in a whor], glabrous, except the margins; radical ones not seen. Flowers rather numerous, scattered over the upper part of the stems, rarely subverticillate; peduncles $2-3$-flowered, sometimes only 1 -flowered. Corollas blue.

Broad-leaved Adenophora. F]. July, Sept. Clt. 1821. PJ. $1 \frac{1}{2}$ foot.

5 A. LAMA'RK11 (Fisch, adumb, gen, aden. p. 6. Alplı, D. C. mon. p. 357.) leaves alternate, ovate-lanceolate, acutely serrated, ciliated; flowers racemose; calycine lobes erect, lanceolate, entire, glabrous; corolla funnel-shaped; style length of corolla. 4. H. Native of Altaia, about Barnaoul. Campánula liliifolia, Lam. dict. 1. p. 581.-Gmel. sib. 3. p. 148. t. 26.? Stem glabrous, simple at the base, but furnished witl short floriferous branches at the apex. Leaves glabrous, except on the margins. Flowers disposed in an elongated many-flowered raceme, which is compound at the base. Corollas blue.

I ar. $\beta$, angustifolia (Alph. D. C. mon. p. 357.) cauline leaves lanceolate, narrow, long-acuminated, petiolate; style exserted. 4. H. A. Lamárkii, Fiscl, ined. in herb. Prescott.

Lamark's Adenophora. FI. June, Aug. Clt. 1824. Pl. I to 2 feet.

6 A. Liliffòlia (Ledeb, cat. hort. dorp. 1822. Alph. D. C. mon. 358. t. 1. f. B.) leaves alternate; radical ones petiolate, ovate-roundish, cordate, crenately toothed: cauline ones sessile, ovate-lanceolate, coarsely serrated; flowers numerous, panicled; calycine lobes erectish, triangular, a little toothed; corolla campanulate; style exserted. 4. H. Native throughout Siberia, south of Tauria ; east of Europe, especially in Lithuania, about Grodno; also in Vollynia, Galicia, Podolia, and Bohemia ; abont Vienna; in Hungary, France, Candia, \&c. A. commùnis, Fisch. adumbr. gen. aden. p. 6. A. stylòsa, Relsb. hort. bot. t. 45. but not of Lam. nor Fisch. Campánula Fischèri, Rom. et Schultes, syst. 5. p. 116 . Camp. umbròsa, Dietr. lex. 1. p. 672. Camp. rhomboídea $\beta$, Willd. spec. 1. p. 899. Poll. fl. veron. 1. p. 274. Camp. alpina, Lin. spec. append. p. 1669. Lam. dict. 1. p. 581. Camp. liliffòlia, Lin. spec. 1. p. 233. Jacq. hort. schoenbr. 3. p. 46, t. 335. Ker. bot. reg. t. 236. Root thick, fusiform, esculent, sometimes simple, and sometimes divided into many turnip-formed tubers. Stem glabrous. Leaves glabrous, or rather pilose. Flowers numerous, sweet-scented, disposed in a more or less compound, elongated, and loose pyramidal panicle. Corollas blue, or whitish blue.

Var. 3 , infundibulifórnis (Alph. D. C. mon. p. 359.) corollas fumnel-shaped. 4. H. Native of Hungary. Campánula liliifòlia, Waldst. et Kit. pl. rar. hung. 3. p. 274. t. 247. Camp. suavèolens, Willd. enum. p. 10. Camp. liliifòlia $\beta$, Rom. et Schultes, 5. p. 110 . Adenópliora suavèolens, Richb. hort. bot. t. 32 .

Var. $\gamma$, sprèta (Alpl. D. C. mon. p. 359.) stem downy towards the apex; leaves rather bairy on both surfaces. 2. H. Native of Siberia. Campánula sprèta, Roem. et Schultes, syst. 5. p. 123.

Lily-leaved Adenophora. Fl. Aug. Sept. Clt. 178\% PI. I to $1 \frac{1}{2}$ foot.

7 A. stylòsa (Fjsch. adumbr. gen. aden. p. 6. Alph. D. C. mon. 360. but not of Richb. lort. bot. t. 45.) leaves alternate, petiolate: lower ones obovate, sinuated: upper ones ovate, acuminated; flowers few, racemose; calycine lobes triangular, erect, entire; corolla funnel-shaped; style usually exserted. 4. H. Native of Siberia and Tartary. Campánula stylòsa, Lam. dict. 1. p. 580. Rœm. et Schultes, syst. 5. p. I10. but not of Besser, cat. hort. crem. 1816. p. 27.-Gmel. sib. 3. p. 152. t. 27. Stems ascending, glabrous. Leaves firm, glabrous. Flowers disposed in a loose, naked, few-flowered raceme. Corollas small. pale blue.

Long-stylcel Adenophora. Fl. May, July. Clt. 1820. Pl. 1 to $1 \frac{1}{2}$ foot. 
8 A. interménia (Sweet, fl. gard. n. s. t. 108.) radical leaves petiolate, cordate, toothed: cauline leaves lanceolate, attenuated at the base, serrated, crowled: lower ones on short petioles, elliptic-lanceolate, remotely serrated; style very long. 4 . H. Native of Siberia. Campunula stylòsa affinis, Fisch. cat. hort. Gorenk. 1808. p. 52. Camp. intermèdia, Rocm. et Schultes, syst. 5. p. 110. but not of Led. Flowers small, pale blue.

Intermediate Adenophora. Fl. May, June. Clt. 1820. Pl 3 feet.

9 A. periplocæròlia (Alph. D. C. mous. p. 361.) leaves alternate, petiolate, ovate, acute, somewhat cordate, crenately serrated; flowers few ; calycine lobes triangular, acute, a little toothed; corolla campanulate, truncate at the apex; style exserted. 24. H. Native of Siberia. Campámula periplocifolia, Lam. dict. 1. p. 580. Stem ascending, glabrcus. Leaves glabrous. Flowers few at the top of the stem, sometimes only one. Corolla pale blue.

Periploca-leaved Adenophora. Fl. June, July. Clt. 18\%4. Pl. $\frac{1}{4}$ foot.

10 A. coronopifòlia (Fisch. adumbr. gen. aden. p. 5. Rchh. hort, hot. t. 23.) leaves alternate : radical ones petiolate, ovateroundish, cordate, crenately toothed: cauline leaves sessile, linear-lanceolate, nearly entire, quite glabrous, smooth; flowers few, racemose; calycine lobes spreading, lanceolate, entire ; corolla campanulate; style length of corolla. 4 . H. Native of Daluria and Altaia. Sweet, fl. gard. 104. Campánula coronopifòlia, Rœm, et Schultes, syst. 5. p. 157. Camp. salicifòlia, Juss. herb.? ex Fisch. Camp. Fischeriàna, Spreng. cur. post. p. 77. Aden. Lamárkii angustifòlia, Fisclı. ined. Root nearly simple. Stems simple, glabrous. Leaves glabrous. Flowers 3-10, disposed in a simple raceme at the top of the stem, on short pedicels. Corollas large, blue.

Var. $\beta$, latifòlia (Alph. D. C. mon. p. 362.) leaves broader, and sharply toothed. 4 . H. A. coronopifòlia latifòlia, Fisch. adumbr. gen. aden. p. 5 .

Var. $\gamma$, angustifolia (Alph. D. C. 1. c.) leaves very narrow, almost entire. $\psi$. H. Aden. coronopifòlia angustifòlia, Fisch. ined. Camp. erysimoides, Rœem. et Schultes, syst. 5. p. 102.

Buck-horn-leaved Adenophora. Fl. June, July. Clt. 1822. Pl. 1 to 2 feet.

\section{* Leaves narroner, linear, entire or nearly so.}

11 A. Guelìn (Fisch. adumbr. gen, aden. p. 5. Alph. D. C. mon. p. 362.) cauline leaves alternate, erect, linear, very narrow, entire, glabrous, smooth; flowers few, secund; calycine lobes erect, lanceolate, entire; corolla campanulately funnel-shaped; style inclosed. 4. H. Native of Dahuria, in dry stony places. Campánula Rabelaisiàna, Røem. et Schultes, syst. 5. p. 158. Camp. pomponiifòlia, Fisch. mss. - Gmel. sib. 3. p. 162. t. 33. Stem quite simple, glabrous. Flowers secund, 3-10, on the top of each stem, rising from the axils of the upper leaves, disposed in a long raceme. Corollas blue.

Iar. B, stylòsa (Alph. D. C. mon. p. 365.) style exserted. 14. H. Campánula Gmelìni, Spreng. mant. 1. p. 56. but not of Roem. et Schultes.

Gmelin's Adenophora. Fl. July, Aug. Clt. 1820. Pl. 1 to 2 feet.

12 A. conona'ta (Alph. D. C. mon. p. 365.) radical leaves petiolate, ovate-roundish, cordate, crenately toothed: cauline ones alternate, erect, linear-lanceolate, remotely subserrated, rather scabrous ; flowers panicled; calycine lobes linear, entire; corolla campanulate; style exserted. 4 . H. Native of Daluria, on the mountains about Sajan. A. marsupiflora, Fisch. adumbr, gen. aden. p. 5. Rchb. hort. bot. t. 15. A. intermèdia, Ledeb. cat. hort. dorp. suppl. 2. 1824. but not of Fisch. in Røem. et Schultes, syst. Campánula coronàta, Ker. bot. reg. t. 14.6. exclusive of the syn. of Gmel. sib. t. 33. Camp, linoplyylla, Pall. in herb. Banks. Cam. syngenesiflora, Pall. herb. ex Fisch. Camp. monadélpha, Pall. ex Fisch. Camp. Sajanénsis, Pall. in herb. Kunth. Rom, et Schultes, syst. 5. p. 102. Camp. marsupiifìra, lioem. et Schultes, syst. 5. p. 116. Link. enum. 1. p. 213. Camp. Gmelìni, Roem. et Schultes, syst, 5. p. 103. but not of Spreng. nor Fisch. Camp. stenanthina, Ledeb. $\mathrm{cx}$ Fisch. adumbr. Flóerkia marsupiiflòra, Spreng. anliet. 2, p. 523. Root fusiform. Stem simple, or furnished with a few floriferous branches at top, rather scabrous. Leaves rather scabrous. Flowers scentless, disposed in a loose elongated panicle, terminal and axillary. Peduncles slender, 1-5-flowered. Corollas bluish-violet.

Crowned Adenophora. Fl. July, Aug. Clt. 1818. Pl. 1 to 3 feet.

\section{† $A$ species hardly known.}

13 A.? Triphy't. A (Alph. D. C. mon. p. 365.) leaves 3 in a whorl, linear; flowers 3 in a whorl. భ. H. Native of Japan, where it is called Todoki Nisjin, ex Tluunb. Campanula triphýlla, Thunb. fl. jap. p. 87. Root fusiform. Plant glabrous. Leaves sessile, with reflexed edges. Peduncles capillary, 1flowered, axillary, rarely divided, thrice longer than the leaves.

Three-leaved Adenophora. Pl. 1 to 2 feet.

Cult. All the species are elegant border-flowers, and are therefore worth cultivating in every garden. They grow in common garden soil, and are to be increased by seeds, as dividing at the root is almost sure to kill the plants.

XIX. SYMPHYA'NDRA (from $\sigma v \mu \phi v ́ \omega, ~ s y m p h y o$, to combine, and aivip, aner, a male; in reference to the anthers being combined into a tube). Alph. D. C. mon. p. 365.-Campänula species, Bieb. fl. taur. 1. p. 154. \&c.

Lin. syst. Monadélphia, Pentándria. Calyx 5-cleft. Corolla 5 -lobed at the apex, usually velvety, and cream-coloured. Stamens 5 ; filaments free, membranous, ciliated; anthers combined into a long tube, which is 5-lobed at top. Style cylindrical, pilose; stigmas 3 , filiform. Capsule 3-celled, delijscing by 3 valves at the base. Seeds ovate, more or less flattened, shining.-Herbaceous perennial or woody plants. Leaves alternate, petiolate, cordate; lower ones larger and on longer petioles. Flowers terminal and axillary, pedicellate, usually racemose, rather large. - Three of the species inlabit the region of Caucasus, and one the Island of Candia.

\section{SEcT. I. Sinuses of calyx not covered by the appendages.}

1 S. CRE'TICA (Alpl. D. C. mon. p. 366. t. 8.) quite glabrous; stems erect, herbaceous; leaves ovate, acute, irregularly serrated; flowers drooping, racemose ; calycine lobes longacuminated; corolla campanulately funnel-shaped. 4 . H. Native of Candia, on the Spaceotic Mountains near Aradena. Campánula nùtans, Siel). herb. cret. but not of Lam. Flowers disposed in a loose raceme at the top of the stem. Pedıncles thick, 1-3-flowered. Corollas 15 lines long, white.?

Cretan Symplyyandra. Pl. $1 \frac{1}{2}$ foot.

\section{Sect. 11. Sinuses of calyx covered by the appendages.}

2 S. PE' NDU LA (Alplı. D.C. mon. p. 366.) stems branched, pendulous, very firm, pilose; leaves ovate, acute, crenately toothed, velvety; flowers panicled ; calycine lobes lanceolate; sinuses of calyx reflexed, ovate, acute; corollas funnel-shaped, velvety. 4. H. Native of Caucasus, among rocks. Sweet, f. gard. i. s. t. 66. Campánula péndula, Bieb. fl. taur. 1. p. 154. no. 384. Bess. cat. hort. crem. 1811 . Røem. et Schultes, syst. 5. p. 144. 5 $F 2$ 
Camp. Vandèsi, G. Don, in Loud. hort. brit. p. 77. Roots rather creeping, throwing out many stems. Flowers drooping, showy, cream-coloured, disposed in a loose panicle, intermixed with the leaves; pechuncles 1-3-flowered.

Pendulous-branched Symplyyandra. Fl. July, Aug. Clt. 151\%. Pl. 1 foot.

3 S. Arme'na (Alph. D. C. mon. p. 367.) stem erect, twiggy, stiff, pilose; leaves ovate, acute, coarsely serrated, clothed with hoary velvety down; flowers terminal, solitary; calyx hoary, witl triangular entire segments; sinuses of calyx reflexed, small, acute; corolla tubular, velvety. 4. H. Native of Cancasus, in the fissures of rocks, about Gandsha. Campánula Armèna, Stev. mem. soc. mosc. 3. p. 256 . Bieb. A. taur. suppl. p. 145. Root oblong, fixed to rocks. Stem branched, rather woody, purplish, downy. Leaves tomentose beneath; lower ones cordate, similar to those of Alliaria officinalis. Flowers solitary, drooping, terminating the branches. Corolla bjue. 1 foot.

Armenian Sympliyandra. Fl. July, Aug. Clt. 1825. Pl.

4 S.? Ossétrica (Alph. D. C. mon. p. 368.) stem humble, simple ; leaves petiolate, cordate, doubly serrated; calyxes glabrous, with the segments long and denticulated, much shorter than the sinuses, which are reflexed; corolla somewhat 5-cleft, having the segments pilose inside. 24. H. Native of Iberia, in Ossetia, on Mount Kaischaur. Campánula Ossética, Bieb. fi. taur. suppl. p. 145. Habit of $S$. péndula, but is destitute of branches, and is wholly glabrous. Flowers solitary, axillary, erect, disposed in a crowded simple raceme from the middle of the stem to its top. Corollas blue.

Ossetian Symphyandra. Pl. $\frac{1}{2}$ to 1 foot.

Cult. These plants have much the habit of the large bellflowered species of Campínula, as C. punctìta and $C$. mèdium. They are of easy culture, and are increased by dividing at the root, or by seed; and being showy, are worth cultivating as border-flowers.

XX. MUU'SSCHIA (so named by Alphonse de Candolle, in honour of J. M. Mussche, director of the botanic garden at Gaud.). Alph. D. C. mon. p. 368. t. 6. f. A.-Campánula species of Lin. and others.

Lin. sүsт. Pentándria, Monogýnia. Calyx 5-cleft. Corolla deeply 5-cleft, of a golden yellow colour. Stamens 5, cuspidate at the apex, free; filaments broadest at the base, glabrous. Stigmas 5. Capsule 5-celled, 10-nerved, dehiscing by numerous transverse lateral fissures between the nerves; cells alternating with the calycine lobes and stamens. Seeds numerons, small, ovoid, shining. - A small glabrous shrub, native of Madeira and Teneriffe, altogether different in habit to any other campanulaceons plant. Stem thick. Leaves alternate, large, serrated. Flowers numerous, pyramidally racemose, yellow.

1 M. AU'REA (Dumortier, comm. bot. ann. 1823. p. 28. Alph. D. C. mon. p. 368.). h. G. Native of Madeira and Teneriffe, among rocks. Campánula aúrea, Lin. suppl. p. 111. Lam. dict. 1. p. 590. Ait. hort. kew. 1. p. 223. Vent. malm. t. 116. Duham. arbr. 3. p. 169, with a good figure. Ker. bot. reg. t. 57. Plant suffruticose, evergreen, milky, quite glabrous. Stem simple, rather Heshy, marked by the cicatrices occasioned by the falling of the leaves, but furnishel with a crown of leaves at top: and annual floriferous branches, which are disposed in a leafy pyramidal panicle. Leaves 3-6 inches long, pale green, shining. Peduncies 1-3-flowered. Flowers erect.

Var. $\beta$, angustifolia (Alph. D. C. mon. p. 369.) leaves very narrow. $\zeta . G$. Native along the coast of Madeira, on rocks. Campánula aúrea, Jacq. hort. schoenbr. 4. t. 472.

Golden-flowered Musschia. Fl. July, Sept. Clt. 1777. Shrub 1 to 2 feet.
Cult. This remarkable shrub thrives very well in a mixture of loam and peat; but is only to be increased by seed, of which abundance is produced in the gardens.

$+A$ gcnus not suffieiently known, and it is not quite cerlain whether it belongs to Campanulàcece.

XXI. MERCIE'RA (named by Alphonse De Candolle, in honour of his friend, Philip Mercier, who has written a monograph on the order Polemoniàcea). Alph. D. C. mon. p. 370.Trachèlium species, Thunb, prod. p. 38. Lin. suppl. p. 143.Roélla species, Banks, herb.

Lix. syst. Pentándria, Monoginia. Calyx 5-cleft, with an ovoid tube. Corolla 5-lobed, caducous, with a very narrow tube. Stamens 5, free; filaments very slender at the base, much longer than the anthers. Style filiform, usually exserted, glabrous; stigmas 2, very short. Ovarium inferior, 1celled, probably always. Ovula usually 4, placed in the bottom of the ovarium. Capsule indeliscent.?-Small Cape slurubs, with the habit of Roélla. Stems erect, branched; branclies very leafy, downy, rather woody, reddish. Leaves sessile, alternate, crowded, linear-subulate, more or less ciliated, stiff, and very similar to those of Roélla. Flowers sessile, solitary, spicate, always axillary. Inflorescence centripetal. Calyx with a very hispid tube, and lanceolate acute smoothish segments. Corolla like that of Trachèlium, long, tubular, and narrow. The character of the capsule still remains unknown; this is, however, without doubt inferior, and probably 1-celled, and contains 4 ovula in the bottom. The capsule is withont any indication of dehiscence in the specimen examined by $\mathrm{Alph}$. D. C.

1 M. tenuifòlia (Alph. D. C. mon. p. 370. t. 5.) leaves much ciliated; corolla blue, longer than the leaves, 5 -lobed at the very apex: lobes lanceolate, spreading, pilose on the back; style a little exserted. $h_{\text {. }}$ G. Native of the Cape of Good Hope. Trachèlium tenuifölium, Thunb. prod. f. cap. p. 38. Lin. suppl. p. 143. Roélla compácta, R. pinifòlia, and Trachèlium tenuifölium, Thunb. in herb. Banks. Habit of Roćlla ciliàta. Stem erect, branched. Flowers very numerous, always lateral, solitary and sessile in the axils of the leaves.

Fine-leaved Merciera. Shrub 1 foot.

2 M. BREvifòlı (Alph. D. C. p. 371.) leaves ciliated a little; corolla white, length of leaves, 5 -lobed at the apex: Jobes lanceolate, spreading, glabrous; style doubly longer than the corolla. h. G. Native of the Cape of Good Hope. Roélla lateriflòra, Banks, herb. Very like the preceding. Flowers numerous, lateral, solitary, in the axils of the leaves.

Short-leaved Merciera. Shrub 1 foot.

3 M. Leptóloba (Alph. D. C. mon. p. 371.$)$ leaves ciliated; corolla rather shorter than the leaves, white, 5-cleft: lobes linear, erectish, glabrous; style length of corolla. $\zeta$. G. Native of the Cape of Good Hope. Habit of the preceding species. Flowers sessile, solitary, among the leaves.

Slender-lobed-flowered Merciera. Shrub 1 foot.

Cult. A mixture of peat and sand is a good soil for the species of Mercièra; and they may be increased either by cut-. tings under a hand-glass, or by seed.

$\uparrow$ Plants referred to the genus Campámula, but it is doubtful to what genera they belong.

1 Campa'nUla stella'ta ('Thunb, phyt. bl. p. 20. mem. acad. petersb. 4. p. 373. with a figure) leaves 3 in a whorl, linear, entire; flowers axillary, pedunculate; stem frutescent, terete, glabrous, branched, erectish, a hand high; branches alternate, simple, a little curved; leaves sessile, acute, imbricated, unguicular; flowers solitary, at the tops of the branclies; peduncles 
capillary, flexuous, an inch long. $h$. G. Native of the Cape of Good Hope. This is certainly not a species of Campinula, but it may be a species of Lighlfoòtia, Roélla, or Prismatocárpus.

Stcllatc Bell-flower. Shrub $\frac{1}{2}$ to 1 foot.

2 Campa'nula lanceola'ta (Roxb. fl. ind. 2.p. 96.) branched, glabrous; leaves alternate or nearly opposite, on short petioles, lanceolate, scrrated, acuminated ; flowers terminal ; calycine segments lanceolate and jagged; capsule obovate, 5 -celled. $\odot$. H. Native of Chittagong, in lumid valleys. Plant delicate, $1 \frac{1}{2}$ foot high, simple or branched at the top, sending out $20 \mathrm{or}^{\circ}$ 31 -flowered peduncles. Flowers inclined, size and form of $C$. rotundifolia. Jadical lcaves not seen. Perhaps this plant is allied to Platycòdon.

Lanceolate-leaved Bell-flower. Pl. 1 to $1 \frac{1}{2}$ foot.

3 Campánula phyteumoines (Zuccagni, cent. 1. obs. bot. in Rom. et Schultes, syst. 1. p. S4.) plant small; radical leaves numerous, lanceolate, obtuse, running down the petioles, undulated; cauline leaves few, remote, sessile, stem-c]asping, mucronate; fowers sessile, crowded into a short spike or in a head; calyx with a tetragonal base, and erect, lanceolate, smooth segments; corolla campanulate, violaceous, larger than the calyx ; style elevated, exserted; capsule tetragonal.-N Native of Mount Olympus, in Bithynia. Perhaps a species of Phyteùma.

Phyteuma-like Bell-flower. Pl. small.

4 Campánula glau'ca (Thunb. fl. jap. p. 88.) leaves sessile, ovate, serrated, glaucous beneath; stem angular, panicled; peduncles 1-flowered.-Native of Japan, near Nagasaki; also cultivated. Kekko Kæmpf. amœen. v. p. 822. Stem suffruticose, angular, glabrous, paniculately branched at top. Leaves green above, with rather reflexed elges. Flowers axillary, and on the tops of the branches solitary. Peduncles bracteate. Corollas large, blue. The roots are esculent, like those of Rampion. It is, perhaps, a species of Campánula, but more probably of Platycòdon or Adenóphora.

Glaucous Bell-flower. Pl 2 feet.

5 Campa'nula Montevidé'ssis (Spreng. syst. 1. p. 788.) stem erect, downy, branched at the base; leaves obsoletely crenated : lower ones spatulate : superior oncs cordate, stem-clasping; flowers solitary, sessile; calycine segments ovate, cuspidate.-Native of Monte Video, where it was collected by Sello.

Monte-Video Bell-flower. Pl. erect.

6 Campánula carnòsa (Wall. in Roxb. fl. ind. 2. p. 102.) plant smooth, fiesliy, procumbent; leaves ovate, cuspidately serrated, petiolate; flowers axillary, on capillary peduncles, which are about equal in length to the leaves; filaments linear, not dilated at the base. 4 . H. Native of Nipaul on Mount Sheopore, towards the middle, on rocks near rivulets. Stems creeping, obscurely 3-cornered. Flowers very small, of a pale blue. Calycine segments entire, erect. Corolla funnel-shaped, more than twice the length of the calyx, with a quinquefid sub-bilabiate limb; segments oblong, acute, equal; the two uppermost ones more parallel and erect; the rest spreading. Stamens distinct, distant, a little shorter than the corolla; filaments flat, not valvate at the base, inserted together with the corolla on the disc of the ovarium; anthers erect, linear. Ovarium oblong, obscurely triangular, 3-celled, many-seeded; its vertex not elongated, as is usual in the genus, but covered by a fleshy yellowish disc. Style filiform; stigmas 3, linear. Capsule clubshaped, prismatic, bursting towards the base by 3 round valves. This is certainly not a species of Campánula, but from the characters given, it appears to be a new genus, connecting Campanulàcece with Lobeliàcea.

Fleshy Bell-flower. Pl. creeping.
ORder CXXXVIII. EPACRI'DEE (this order contains plants agreeing with Epàcris in important characters). R. Br. prod. p. 585.

Calyx 5-parted, (rarely 4-parted), usually coloured, permanent. Corolla hypogynous, monopetalous, with the tube sometimes divisible into 5 parts; limb 5 -cleft, rarely 4-cleft, equal, and sometimes bursting transversely from the segments, cohering, valvate or imbricate in restivation, decidıous or marcescent. Stamens equal in number to the segments of the corolla, and alternating with them, rarely fewer; flaments epipetalous or hypogynous; anthers simple, with a single polliniferous receptacle, constituting a complete, rarely a marginate dissepiment, undivided, dehiscing longitudinally. Pollen subglobose, rather angular, or composed of 3 conbined globules. Ovarium sessile, usually girded by $j$ distinct or combined scales, many-celled, rarely 1 -celled. Seeds solitary or indefinite. Style 1; stigma 1, sometimes toothed. Fruit drupaceous, baccate, or capsular. Seeds albuminous. Embryo straight, slender, longer than the half of the albumen.Shrubs or small trees. Leaves alternate, very rarely opposite, entire, rarely serrated, usually petiolate, or with a simple base; having the bases broader, imbricated, cucullate, and sheatling a little. Flower spicate or racemose, terminal : or solitary and axillary. Calyxes or pedicels furnished with 2 or more brac.teas, which are of the same texture as the calyx. Flowers white or purple, rarely blue. This order is chiefly distinguished from Ericacce in the anthers being awnless and 1-celled. The shrubs are all elegant, of a dry prickly habit, with tubular or campanulate fiowers.

\section{Synopsis of the genera. TRIBE I.}

Strphylizix. Cells of ou arium 1-seeded. Pericarps closed, rarcly capsular.

1 Styrhe'lia. Calyx with 4 or more bracteas. Corolla long, tubular; tube furnished on the inside near the base with 5 fascicles of villi : segments of the limb revolute, bearded. Filaments exserted.

2 Astrolòna. Calyx imbricated by 4 or more bracteas. Corolla with a ventricose tube (f. 132. b.), furnished with 5 fascicles of villi near the base, inside; linb short, spreading, bearded (f. 132. c.). Filaments inclosed.

3 Stenanthe'ra. Calyx many-bracteate. Corolla tubular, ventricose, without any fascicles of hairs inside; limb short, spreading, bearded a little. Filaments inclosed.

4. Melichrus. Calyx many-bracteate. Corolla rotate or urceolate, furnished with 5 fascicles of glands near the base inside; segments half bearded.

5 Cуатнòdes. Calyx many-bracteate. Corolla funnelshaped, witlout any fascicles of villi or glands inside; limb spreading, a little bearded. Filaments inclosed. Drupe baccate.

6 Lissánthe. Calyx bibracteate or bractless. Corolla funnel-shaped: limb beardless. Drupe baccate. 
7 Leucorògon. Calyx bibractcate. Corolla funnel-shaped: limb spreading, bearded lengthwise. Filaments inclosed. Drupe baccate or dry.

8 Mокотосс. Calyx bibracteate. Corolla funnel-shaped; limb and throat beardless. Ovarium 1-seeded. Drupe baccate.

9 Acroтrícue. Calyx bibracteate. Corolla funnel-shaped: segments of the limb furnished with a reflexed beard at the apex. Drupe rather baccate.

10 Trochocárpa. Calyx bibracteate. Corolla campanulate: limb spreading, bearded. Stamens exserted. Ovarium 10-celled. Drupe baccate.

11 Deca'spora. Calyx bibracteate. Corolla campanulate: limb loosely bearded. Stamens exserted. Orarium 10-celled.

12 Pentachóndra. Calyx with 4 or more bracteas. Corolla funnel-shaped; limb spreading, longitudinally and densely bearded.

13 Nendha'mia. Calyx bibracteate. Corolla salver-shaped: limb 5-cleft, beardless, with elevated sinuses, plicate in æstivation. Stamens inclosed. Ovarium 2-celled.

14 Oligarrhe'na. Calyx 4-parted, bibracteate. Corolla 4-cleft, permanent, valvate in astivation. Stamens 2, inclosed. Ovarium 2-celled.

\section{Tribe II.}

Épacricis. Cells tof ovarium many-seeded. Pericarp capsular.

15 Epa'cris. Calyx coloured, many-bracteate (f. 133. a.); bracteas texture of calyx. Corolla tubular (f. 133. c.), witl a beardless limb. Stamens epipetalous (f. 133. b.). Anthers peltate above the middle. Hypogynous scales 5 . Placentas adnate to the central column.

16 Lysine'ma. Calyx coloured, many-bracteate; bracteas texture of the calyx. Corolla salver-shaped: with the tube sometimes divided into 5 parts to the base; segments of the limb beardless, bent to the right. Stamens hypogynous. Anthers peltate above the middle. Hypogynous scales 5. Placentas adnate to the central column.

17 Pironòtes. Calyx bractless. Corolla tubular, with an open throat, and a beardless limb. Stamens hypogynous; filaments half adbering to the tube. Anthers with a complete dissepiment. Hypogynous scales 5 .

18 Cosména. Calyx foliaceous. Corolla tubular. Stamens epipetalons. Anthers adnate to the ciliated tops of the filaments. Hypogynous scales 5. Placentas adnate to the central colımn.

19 Andersònia. Calyx coloured, imbricated by 2 or more foliaceous bracteas. Corolla length of calyx; segrnents of the limb bearded at the base. Stamens liypogynous. Anthers fixed beneath their middle. Hypogynous scales 5 . Placentas adnate to the central column.

20 Poncele'tia. Calyx toliaceous. Corolla short, campanulate, 5 -cleft, beardless. Stamens bypogynous; anthers peltate beneath the middle, with a marginate dissepiment. Ilypogynous scales wanting. Placentas adnate to the central column.
21 Sprenge'zia. Calyx a little coloured. Corolla 5-parted, rotate, beardless. Stamens hypogynous. Anthers connate or free, with an immarginate dissepinent. Hypogynous scales wanting. Placentas adnate to the central column.

22 Cystántue. Calyx foliaceous. Corolla closed, calyptriform, dehiscing transversely, with a truncate permanent base. Stamens hypogynous, permanent. Hypogynous scales wanting. Placentas hanging from the top of the central column.

23 Ríchea. Calyx membranous, bractless. Corolla closed, calyptriform, dehiscing transversely, with a truncate permanent base. Stamens hypogynous, permanent. Hypogynous scales 5. Placentas hanging from the top of the central column.

24. Dracophy' Llum. Calyx bractless. Corolla funnel-shaped, with a rather ventricose tube, and a 5-parted spreading acutish beardless limb. Stamens hypogynous. Hypogynous scales 5 . Placentas hanging from the top of the central column.

25 Spenótoma. Calyx bibracteate. Corolla salver-shaped, with a slender tube, a coarctate throat, and a blunt beardless limb. Stamens epipetalous. Hypogynous scales 5. Placentas hanging from the top of the central column.

\section{Tribe I.}

STYPHELIE A. Cells of ovarium 1 -seeded. Pericarp closed, rarely capsular.

1. STYPHELIA (from $\sigma \tau v \phi \varepsilon \lambda \grave{s}$, styphelos, rough or harsh ; from the stiff, compact, harsh habit of the shrubs). R. Br. prod. p. 537. Styphèlia species, Smith.

Lin. syst. Pentándria, Monogýnia. Calyx girded by 4 or more bracteas. Corolla elongated, tubular; tube furnished with 5 fascicles of villi near the base inside: segments of the limb revolute, bearded. Filaments exserted. Ovarium 5 - celled. Drupe nearly dry, containing a solid bony putamen.-Erect or ascending, branched, smoothish, shrubs. Leaves scattered, on short petioles, mucronate. Flowers axillary, drooping, or divaricate, showy. Peduncles 1-flowered, rarely 2-3-flowered. Hypogynous scales 5 , distinct, rarely combined.

1 S. xokgifòlia (R. Br. prod. p. 537.) leaves long-lanceolate, attenuated at the apex, rather concave above, with smooth margins; branchlets downv. . G. Native of New South Wales, about Port Jackson. Ker. bot. reg. 24. Flowers green.

Long-leaved Styphelia. Fl. April, June. Clt. 1807. Shrub 3 to 4 feet.

2 S. LE'TA (R. Br. prod. p. 537.) leaves elliptic, or oblonglanceolate, flat, glaucous, imbricated, with scabrous denticulated edges; branchlets downy; stem erect. h. G. Native of New South Wales, about Port Jackson, Flowers red.

Fruitful Styphelia. Fl.? Clt. 182\%. Shrub 3 to 4 feet.

3 S. ADSCE'NDENS (R. Br. prod. pr. 537.) leaves lanceolate, flat, with scabrous dentately ciliated margins, glaucous beneath and manifestly striated; stems diffuse, with ascending branches. h.G. Native of Van Diemen's Land. Flowers scarlet.

Ascending Styphelia. Fl. ? Clt. 1822. Shrub 2 to 3 feet. 4 S. LATifòlia (R. Br. prod. p. 537.) leaves broadly ovate, acute, imbricated, rather concave above, with scabrous edges; flowers erectish. $\eta$. G. Native of New South Wales, about Port Jackson. Flowers pink.

Broad-leaved Styphelia. Fl. April, July. Clt. 1823. Slrub 4 to 6 feet.

5 S. virintrlòra (R. Br. prod. p. 537.) leaves obovatc- 
oblong, obtuse, mucronulate, flat, smooth above, with the mar. gins rather scabrous, and are, as well as the flowers, divaricate. h. G. Native of New South Wales, about Port Jackson. Andr, bot. rep. 312. Flowers green, with brown anthers.

Green-flowered Styphelia. Fl. April, July. Clt.1791. Slirub 3 to 4 feet.

6 S. TRır còna (Andr. bot. rep. 72.) leaves elliptic or oblonglanceolate, flat, glancons, smooth every where, as well as on the margins; branchlets glabrous; flowers corymbosely approximate; peduncles 1-3-Howered. h.G. Native of New South Wales, about Port Jackson. R. Br. prod. p. 537. Sims, bot. mag. 1297. Flowers pink, with a cream-coloured limb.

Three-flonered Styphelia. Fl. May, Aug. Clt. 1796. Slirub 6 feet.

7 S. tubiflòna (Smith, new holl. 45. t. 14.) leaves linear, obovate, mucronate, rather seabrous above, with revolute edges; flowers drooping. $\lceil$. G. Native of New South Wales, about Port Jackson. R. Br. prod. p. 537. Lodd. bot. cab. 1938. Flowers scarlet.

Tube-flowered Styphelia. Fl. May, Aug. Clt. 1802.

8 S. Glauce'scens (Sieb. pl. nov. holl. ex Spreng. syst. add. p. 67.) leaves lanceolate, mucronate, quite entire, smootl, fincly striated, glaucous; peduncles short, l-flowered. $\zeta . G$. Native of New Holland.

Glaucescent Styphelia. Shrub.

Cult. This is a very handsome genus of shrubs. A mixture of one-third sandy loam, and two-thirds sandy peat, answers the species best; and young cuttings, planted in sand under a bellglass, will strike root.

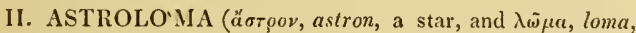
a fringe; in reference to the bearded limb of the corolla. R. Br.prod. 538.). Ventenàtia speeies, Cav. Styphèlia, Spreng. syst. 1. pp. 657,658 .

Lin. sxst. Pentándria, Monogýnia. Calyx imbricated by 4 or more bracteas (f. 132. a.). Corolla with a ventricose tube (f. 132. b.), which is doubly longer than the calyx, and furnished with 5 fascicles of hairs near the base inside ; limb short, spreading, bearded (f. 132. c.). Filaments linear, inclosed. Ovarium 5-celled. Drupe nearly dry ; containing a solid bony putamen. - Humble, usually diffiuse slirubs. Leaves scattered, usually ciliated. Flowers axillary, erect. Hypogynous disk cup-shaped, almost entire.

1 A. humifu'sum (R. Br. prod. p. 538.) shrub prostrate, much branched; leaves lanceolate-linear, rather convex above, with ciliated edges. h. G. Native of New South Wales, Van Diemen's Land, and the south coast of New Holland. Sims, bot. mag. 1439. Ventenàtia humifüsa, Cav. icon. 4 . p. 28. t. 348. Flowers scarlet.

Trailing Astroloma. Fl. May, Oct. Clt. 180\%. Slirub prostrate.

2 A. prostra'tum (R. Br. prod. p. 538.) slurub prostrate, much branched; leaves laneeolate-linear, ciliated, flat above, and rather convex beneath. $々$. G. Native of New Holland, on the south coast. Flowers red.?

Prostrate Astroloma. Shrub prostrate.

S A. Denticula'tum (R. Br. prod. p. 538.) shrub usually procumbent, but sometimes erectish; leaves lanceolate, flat, ciliated: the cilia dilated at the base. h. G. Native of New Holland, on the south eoast. Flowers pale red.

Denticulatcd-leaved Astroloma. 11. May, Aug. Clt. 1824. Shrub procumbent.

4. A. Pa'Llinvu (R. Br. l. e.) shrub diffuse; branches ascending; lcaves lanceolate, sessile, ciliated, imbricated, rather concave above. h. G. Native of New Holland, on the south coast. Flowers pale red.?

Pale Astroloma. Shrub diffuse.

5 A. сомра'стим (R. Br. l. с.) shrub diffuse; branchlets ascending, very short; leaves obovate-lanceolate, ciliated, tapering in to the petioles, rather coneave above. $h$. G. Native of New Holland, on the south coast.

Compact Astroloma. Shrub diffuse.

6 A. те'́tum (R. Br. l. e.) erect, a little branched; leaves lanceolate-oblong, flat, imbricated, with scabrous edges: denticulations very short, obtuse. $h_{c}$. G. Native of New Holland, on the south coast.

Covered Astroloma. Shrub erect.

Cult. This genus contains dwarf glaucous shrubs, bearing large scarlet or red flowers. They are, therefore, desirable plants for all collections. They tlirive best in an equal mixture of sand, loam, and peat; and cuttings from young wood root readily, if planted in a pot of sand under a bell-glass.

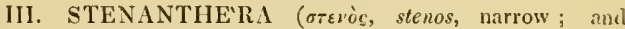
civonoci, anthera, an anther; the filaments are broader than the anthers, which makes them appear narrow). R. Br. prod. p. 538 .

Lin. syst. Pentandria Monogy'nia. Calyx girded by many bracteas. Corolla tubular; tube twice longer than the ealyx, ventricose, without any fascicles of villi in the throat: limb short, spreading, half bearded. Filaments inclosed, fleshy, broader than the anthers. Ovarium 5-celled. Drupe nearly dry, containing a solid bony putamen.-An erect slirub. Leaves much crowded, acerose. Flowers axillary, erect, with a searlet tube, and a greenish-yellow limb. Hypogynous disk cup-shaped, entire.

] S. pinifòlia (R. Br. prod. p. 538). h. G. Native of New South Wales. Ker, bot. reg. 218. Styplièlia pinifòlia, Spreng. syst. 1. p. 659.

Pine-leaved Stenanthera. Fl. May, July. Clt. 1811. Shrub 4 to 6 feet.

Cult. This is a beautiful shrub when in blossom. A soil composed of one-third very sandy loam, and two-thirds sandy peat, suits it best. The pot in which it is grown should be well drained with sherds, or the mould is apt to get sodilened from too much wet. It should not be too much exposed to the sum in summer. Cuttings from the young shoots root readily in sand, under a bell-glass.

IV. MELICHRUS (from $\mu \varepsilon \lambda$ ixpos, melichros, honeycoloured; in reference to the colour of the glands of the flowers). R. Br. prod. p. 539.

LiN. syst. Pentándria Monogýnia. Calyx with many bracteas. Corolla rotate or ureeolate, furnished near the base with 5 faseicles or glands; segments bearded. Ovarium 5celled. Drupe nearly dry, containing a solid bony putamen. - Procumbent or ereetish shrubs. Leaves lanceolate. Flowers ereet. Hypogynous disk cup-shaped, nearly entire.

] MI. Rota'Tus (R. Br. prod. p. 539.) corollas rotate; ealyx villous; leaves lanceolate-linear, pilose on both sides and on the maruins. h. G. Native of New South Wales, and of tropical New Holland. Ventenàtia procúmbens. Car. icon. \&. 1. 28. t. 349. f. 1. Flowers scarlet. 
Rotate-flowered Melichrus. Fl. April, August. Clt. 1824. Shrub procumbent.

2 M. uRceola'tus (R. Br. l. c.) corollas urceolate: calyxes glabrous ; leaves lanceolate, attenuated at the apex, with shortly

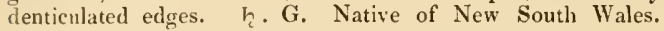
Flowers scarlet.?

Urceolate-flowered Melichrus. Slurub erect,

S M. ME'Drus (Cumningh. in Fields, New South Wales, p. 314.) erect; corolla urceolate; calyxes pilose; leaves lanceolate, attenuated, very acute, mucronatc, concave, many-nerved, with membranous denticulated edges. $々$. G. Native of New South Wales, on the plains of Bathurst. Intermediate between the two preceding specics.

Intermediate Meliclirus. Fl, April, May. Clt. 1824. Shrub. Cult. For culture and propagation see Astroloma, p. 775. Fine slurubs, bearing elegant flowers.

V. CYATHO'DES (from k've@os, lyyathos, a cup; and dodov, odous, a tooth; in reference to the disk, which is cupshaped and 5-toothed). R. Br. prod. p. 539,-Cyathòdes species, Labill.--Styphèlia species, Labill. Solander, and Spreng. Lis. syst. Pentándria Monogýnia. Calyx with many bracteas. Corolla funnel-shaped; tube hardly exceeding the calyx, without any fascicles of villi or glands; limb spreading, with or without any beard. Filaments inclosed. Ovarium 5-10celled. Drupe baccate.-Erect branched shrubs, with the habit of small trees. Leaves striated on the under sides. Flowers axillary, erect, or drooping a little, small. Hypogynous disk cup)-shaped, 5-toothed.

\section{\$1. Segments of the corolla bearded; axis simple inside.}

1 C. GLAU'CA (Labill. nov. holl. 1. p. 57. t. 81.) drupe 8-10celled; leaves crowded at intervals, somewhat verticillate, spreading or divaricate, linear-lanceolate. h. G. Native of Van Diemen's Land. R. Br. prod. p. 539. Trochocárja glaúca, Spreng. syst. 1. p. 660 .

Glaucous Cyathodes. Fl. April, June. Clt. 1818. Tree 25 feet.

2 C. stramínca (R. Br. prod. p. 589.) drupe 5-celled; leaves crowded at intervals, somewhat verticillate, oval, obtuse, awnless, spreading, many-nerved beneath; stem erect. h. G. Native of $Y$ an Diemen's Land.

Strawy Cyathodes. Shrub.

3 C. Dealba'ta (R. Br. prod. p. 539.) drupe 2-5-celled; leaves linear, erectly spreading, margined with very short cilia, 5 -nerved beneath : nerves all simple. h. G. Native of $\mathrm{V}$ an Diemen's Land.

Whitened Cyathodes. Shrub procumbent.

4 C. Tamein'me (Cham. et Schlecht. in Linnæa, 1. p. 539. ) drupe 5-8-celled; leaves narrow, cuneate-obovate, petiolate, mucronate, many-nerved beneath, h. G. Native of the Sandwich Islands. Habit of Leucopogon obovàtus, Labill. Cy. Banksii, Gaud. in Freyc. voy. pt. bot. p. 365 . is perhaps the same as this. Dr. R. Brown speaks of 2 other species from the Sandwich 1slands, having the segments of the corolla naked, while this is bearded.

Tameiamea's Cyathodes. Shrub or small tree.

$\$ 2$ Segments of corolla beardless; axis usually clcvated inside. Lissánthe, Spreng. syst. 1. p. 660.

5 C. parvifòlia (R. Br. prod. 540.) leaves linear-lanceolate, not half an inch long, spreading, margined with very short ciliæ, 5 -nerved beneath: nerves all simple. 々. G. Native of Van Diemen's land.

Small-leaved Cyathodes. Shrub or small tree.
6 C. oxyce'nrus (R. Br. l. c.) leaves linear, more than half an inch long, spreading, with naked margins, 3-5-nerved beneath : nerves all simple. $h$. G. Native of Van Diemen's land. Styphèlia Oxycèdrus, Labill. nov, holl. 1. p. 49. t. 69. Flowers white.?

Red Cedar-like Cyathodes. Fl. April, June. Clt. 1822. Slirub 6 feet.

7 C. abietina (R. Br. l. c.) leaves linear-lanceolate, flat, much crowded, imbricated. ケ. G. Native of Van Diemen's land. Styphèlia abietìna, Labill. nov. holl. 1. p. 48. t. 68 .

Fir-litie Cyathodes. Shrub or small tree.

8 C. acerosa ( R. Br. prod. p. 539. and 540.) leaves linearspreading, with naked margins, 3-5-nerved beneath : outer nerves pectinately branclied. $\zeta$. G. Native of Van Diemen's Land.? Styphèlia aceròsa, Banks and Soland. mss. Ardisia aceròsa, Gartn.

C'haffy Cyathodes. Fl. April, May. Clt. 1823. Shrub.

Cult. See Styphèlia, p. 775. for culture and propagation.

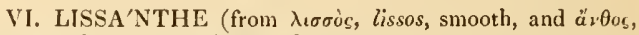
anthos, a flower). R. Br. prod. p. 540.

Lis. syst. Pentándria, Monogýnia. Calyx bibracteate or bractless. Corolla funnel-shaped; limb beardless. Ovarium 5 -celled, Drupe baccate, containing a solid bony putamen.Small erect shrubs. Leaves scattered, lined beneath. Flower small, white. Hypogynous disk cup-sliaped, 5-lobed.

$\$ 1$. Calyx bractless. Raccmes axillary, few-flowered; pediccls bibractcate at the base. Tube of corolla villous inside.

1 L. SA'PIDA (R. Br. prod. p. 540.) racemes 2-3-flowered, recurved; leaves oblong-lincar, mucronate, witl revolute margins, whitened and striated beneath. I . G. Native of New South Wales. Lindl. bot. reg. 1275. Hook. bot. mag. t. 3147. Flowers white, tipped with green. The berries are red and acid, and are made into tarts in New South Wales, under the name of cranberries.

Sapid Lissanthe. Fl. May. Clt. 1823. Shrub.

2 L. SUBULA'TA (R. Br. 1. c.) racemes 4-5-flowered, erect ; leaves lincar-subulate, half an inch long; branchlets glabrous; drupe 10-striped. h. G. Native of New South Wales.

Subulate-leaved Lissanthe. Fl. A pril, July. Clt. 1823. Shrub.

3 L. strigòsa (R. Br. l. c.) racemes subspicate, erect, fewflowered; leaves lincar-subulate; branches downy, drupes hardly furrowed. $\vdash$. G. Native of New South Wales and Van Dicmen's Land. Styphèlia strigòsa. Sinith, new holl. p. 48 .

Strigose Lissanthe. Fl. May, July. Clt. 1824. Shrub.

\$ 2. Calyx bibracteatc. Corolla urccolate, having the tube and throat naked. Spikes axillary, fon-flowered.

4 L. monta'sa (R. Br. I. c.) leaves oblong-linear, obtuse, mutic, glaucous beneath. $h_{\text {. }}$ G. Native of Van Diemen's Land.

Mountain Lissanthe. Shrub.

5 3. Calyx bibracteatc. Corolla funnel-shaped, having the throat closed by deflexed villi. Floners axillary, solitary.

5 L. DAPHnoides (R. Br. prod, p. 541.) leaves elliptic-lanceolate, rather concave, ending each in a very short callous mucrone, with roughish naked margins; segments of corolla quite glabrous. h. G. Native of Van Diemen's Land and tropical New Holland. Lodd. bot. cab. 466. Styphèlia daphuòides, Smith, new holl. 48 . 
Daphnc-like Lissanthe. Fl. June, July. Clt. 1818. Shrub. 6 L. cilia'ta (R. Br. l. c.) leaves elliptic-lanceolate, flat, with serrulately ciliated margins, ending each in a pellucid mucrone; limb of corolla roughish. h.G. Native of Van Diemen's Land. Slurub.

Ciliated-leaved Lissanthe. Fl. May, July. Clt. 1825.

Cult. For culture and propagation see Styplièlia, p. 775.

VII. LEUCOPOGON (from $\lambda$ suxòs, lcucos, white ; and $\pi \dot{\omega} \gamma \omega v$, fogon, a beard; the limb of the corolla is bearded with white hairs). R. Br. prod. p. 541. Styphèlia, Spreng. syst. 1. p. $656,657,65 \mathrm{~s}$, and 659 .

Lin. syst. Pentándria Monogýnia. Calyx bibracteate. Corolla funnel-shaped; limb spreading, bearded lengthwise. Filaments inclosed. Ovarium 2-5-celled. Drupe baccate or dry, sometimes crustaceous.-Usually dwarf Shrubs. Leaves scattered and sometimes crowded at intervals. Flowers spicate, axillary or terminal. Hypogynous disk cup-shaped, lobed a little, rarely wanting.

\section{§ I. Spikes axillary, many-flowered. Drupe baccate.}

1 L. LANCEOLA'tus (R. Br. prod. p. 54l.) spikes nodding, aggregate; ovaries 2-celled; drupes oval: leaves lanceolate, flat, 3-nerved; branchlets glabrous. h.G. Native of New South Wales, on mountains. Sweet, fl. austr, t. 47. Styphèlia lanceolàta, Smith, new holl. p. 49. exclusive of the synonymes. Styphèlia parviflòra, Andr. bot, rep. 287. Flowers white.

Lanceolate-leaved Leucopogon. Fl. May, Aug. Clt. 1790. Shrub 6 to 12 feet.

2 L. MALAYA'vus (Jack, mal. misc. vol. 1. Wall. in Roxb. fl. ind. 2. p. 301 .) spikes axillary, many-flowered, erect, short ; drupes globular, 5-celled; leaves lanceclate, mucronate, nearly veinless, glaucous beneath. $\quad$. S. Native of the plains of Singapore, abundant ; where it is called by the Malays Mentada. A small, branching, dry shrub, exhibiting the peculiar inabit of the family. Corollas funnel-shaped, downy, having the segments bearded above beyond the base. The discovery of this species is remarkable as torming an exception to the general geographical distribution of the order Epacridea, a family almost exclusively confined to Australia, or at least to the southern hemisphere. Singapore, situated at the extremity of the Malay peninsula, and forming as it were the connectiug link hetween continental or Westeru India and the plains of the great Eastern Archipelago, partakes of this character in its Flora, which exhibits many remarkable points of coincidence with the Flora of both regions. A resemblance has been observed between its productions and those of the northern frontier of Bengal, on the one hand, and of the Moluccas on the other, while the present plant connects it with the still more distant range of New Holland.

\section{Malay Leucopogon. Slirub 3 feet.}

3 L. Austra'is (R. Br. l. c.) spikes erect ; drupes depressed, glowose, 5-celled; leaves linear-lanceolate, more than an inch long, 3-5.nerved, with recurved smooth margins. h. G. Native of the south coast of New Holland and Van Diemen's Land. Flowers white.

Southern Leucopogon. Shrub.

4. L. Rícheı (R. Br. l. c.) spikes erect, many-flowered, a little shorter than the leaves; drupes ovate, 5-celled; leaves glabrous, oblong-lanceolate, hardly an incli leng, broadest beyond the middle, 3-5-nerved, convex above, with subrecurved margins. $々$. G. Native of New South Wales, the south coast of New Holland, and Van Diemen's Land, L. polystàYOL. III. chyus, Lodd. A. cab. t. 1436. L. apiculatus, Smith in Rees, cycl. L. parviflòrus, Lindl. bot. reg. 1560 . Styplièlia Ríchei, Labill. nov. holl. 1. p. 44. t. 60 . Styphèlia parvifiòra, Andr. bot. rep. 287. Styphèlia Gnídium Vent. malm. t. 23. Flowers white.

Riche's Leucopogon. FI. May, Aug. Clt. 1829. Shrub 4 to 5 feet.

5 L. Afrínis (R. Br. l. c.) spikes erect; drupes oval, 2-3celled; leaves long-lanceolate, more than an inch long, flat. In. G. Native of Van Diemen's Land. Flowers white.

\section{Allied Lcucopogon. Shrub.}

6 L. INTERRU'PTUS (R. Br. l. c.) spikes nearly terminal; leaves elliptic, spreading, many-nerved, $1 \frac{1}{2}$ inch long, crowded in whorles. h.G. Native of the south coast of New Holland. Lodd. bot. cab. 1451. Flowers white.

Interruptch-leaved Leucopogon. Fl. May, July. Clt. $18 \approx 6$. Shrub.

7 L. стави'LE (Labill, sert. caled. p. 36. t. 39.) spikes axillary, erect; segments of the corolla bearded with rufous hairs ; leaves an inch long, oblong-lanceolate, rufous, concave. $h_{\imath} . \mathrm{G}$. Native of New Caledonia. Flowers furnished each with an orbicular, lacerately ciliated scale, besides 2 opposite boat-shaped ones abore it.

Boat-leaved Leucopogon. Slirub 1 to 2 feet.

8 L. verticilla'tus (R. Br. l. c.) spikes nearly terminal, aggregate, nodding while bearing the fruit; drupes 5-celled; putanien pentagonal; leaves oblong-lanceolate, attenuated at the apex, disposed in interrupted whorles, 2 to 4 inches long. 々. G. Native of the south coast of New Holland. Flowers white.

Whorled-leaved Leucopogon. Shrub.

§2. Spikes axillary, but sometimes terminal. Flowers three or more together. Calyx and bractcas colourcd. Drupe ncarly dry. Leaves never cordatc.

9 L. apicula'tus (R. Br. prod. p. 542.) spikes terminal, rather aggregate, 5-7-flowered; bracteas lanceo'ate; leaves lanceolate-oblong, erect, rather concave, with smooth margins, ending each in a callous point; drupe crustaceous, depressedly turbinate, shorter than the calyx. h. G. Native of the south coast of New Holland. Flowers white.

I $u r$. ", branclilets and leaves glabrous.

I $a r . \beta$, branchlets and leaves pubescent. Perhaps a distinct species.

Apiculate-leaved Leucopogon. Shrub.

10 L. polysta'chyus (R. Br. l. c.) spikes axillary or terminal, aggregate, $7-10$-flowered; leaves linear-lanceolate, mutic, conrexly concave; branchlets glabrous, twiggy; drupes dry, oval, depressed at the apex. $\eta$. G. Native of the south coast of New Holland. Flowers white.

Many-spiked Leucopogon. Fl. May, Aug.

Clt. 1826. Shrub 2 to 3 feet.

11 L. Multiflòrus (R. Br. 1. c.) spikes axillary, shorter than the leaves; leaves lanceolate, a little acuminated, mucronate, imbricated, rather convex beneath, with smooth edges: calyx and bracteas with woolly margins. h.G. Native of the south coast of New Holland. Flowers white.

Many-flowercd Leucopogon. Shrub.

1) L. Rubricau'Lis (R. Br. l. c.) spikes nearly terminal, aggregate, 4-5-Howered; calyxes and bracteas smoothish; leaves linear-oblong, obtuse, mutic, smooth, rather convex above, with somewhat recurved denticulated edges; branchlets glahrous; drupes oblong. $h_{\text {. }}$ G. Native of the south coast of New Holland. Flowers white.

Red-stemmed Leucopogon. ' Shrub. $5 \mathrm{G}$ 
13 L. vıllòsus (R. Br. l. c.) spikes nearly terminal, aggregate; leaves linear-oblong, bluntish, mutic, erectly sprealing, villous on both surfaces as well as on the branches, with denticulated subrecurved margins. h.G. Native of the south coast of New Holland. Flowers white. Very nearly allied to L. rubricaúlis.

Villous Leucopogon. Shrub.

14 L. овол''tus (R. Br. l. с.) spikes terminal, nearly simple; leaves obovate-oblong, obtuse, mucronulate, with subrecurved margins; drupes nearly globose, 5-celled. h. G. Native of New Holland, on the south coast. Styphèlia obovàta, Labill. nov. holl. 1. p. 48. t. 67. Flowers white.

Obovate-leaved Leucopogon. Fl.May, Aug. Clt. 1824. Shrub 1 foot.

15 L. Revolu'tus (R. Br. l. c.) spikes nearly terminal, aggregate, 4-5-flowered; calyxes and bracteas clothed with fine down; leaves moderately spreading, linear-oblong, obtuse, mutic, tipped by a callous obtuse point, convex and scabrous above, lined and glabrous beneath, with recurved naked margins; branchlets clothed with minute down; drupes dry, 5-celled, obovate. $h$. G. Native of the south coast of New Holland. Flowers white.

Revolute-leaved Leucopogon. Shrub.

16 L. MARGARòdes (R. Br. l. c.) spikes axillary, usually 3flowered; leaves moderately spreading, linear-oblong, obtuse, mutic, with recurved smooth margins; drupes 2 -celled, dry and compressed above. h. G. Native of New Holland, within the tropic. Flowers white.

Pcarl-toothed Leucopogon. Shrub.

17 L. au'ricus (R. Br. prod. p. 543.) spikes axillary, erect, 3-6-flowered; leaves linear-oblong, obtuse, rather mutic, erectly spreading, with smooth rather recurved margins; drupes 5celled, angular, glabrous. Ђ.G. Native of New South Wales, in rocky situations. Flowers white. Very nearly allied to the following.

Annless-leaved Leucopogon. Shrub.

18 L. Tricrocánrus (R. Br. l. c.) spikes axillary, nodding a little, 3-flowered ; leaves linear-oblong, obtuse, mucronulate; drupes 5-celled, angular, pilose. h. G. Native of Van Dieınen's Land. Styphèlia trichocárpa, Labill, nov. holl. 1. p. 47. t. 66 . Flowers white.

Hair-fruitcd Leucoposon. Shrub 3 feet.

19 L. ericoìns (R. Br. l. c.) spikes axillary, approximate, 3-4-flowered; leaves oblong-linear, moderately spreading, mucronate, with recurved margins, rather scabrous above; bracteas mutic ; calyxes membranous ; drupes dry, angular. দ. G. Native of New South Wales and Van Diemen's Land. Styphèlia ericoides, Smith, nov. holl. p. 48. E'pacris spùria, Cav. icon. 4. p. 27. t. 347. f. 1. Flowers reddish. feet.

Heath-like Leucopogon. Fl.? Clt. 1815. Shrub 4 to 6

20 L. ProPÍnQUus (R. Br. I. c.) spikes axillary, usually 3flowered, pedunculate; leaves lanceolate-linear, setaceously mucronate, smooth above, with revolute margins, which are denticulated from without; bracteas cuspidate. $h$. G. Native of the south coast of New Holland

Allied Leucopogon. Shrub.

21 L. Attenua'tus (Cunningl. in Field's New South Wales, p. 341.) peduncles very short, erect, usually ]-flowered; leaves ovate-lanceolate, moderately spreading, rather convex, striated, setaceously mucronate, when young imbricated and ciliately denticulated. ?. G. Native of New South Wales, on hills at Cox's River.

Altenuated-leaved Leucopogon. Shrub.

22 L. virga'tus (K. Br. l. c.) spikes terminal and axillary, almost aggregate, few-flowered; calyses and bracteas rather membranous; leaves linear-lanceolate, attenuated at the apex, very acute, convexly concave, imbricated and spreading, with ciliated margins; branchlets glabrous. $h, G$. Native of New South Wales, south coast of New Holland, and Van Diemen's Land. Styphèlia virgàta, Labill. nov. holl. 1.p. 46. t. 64. Flowers white.

Tniggy Leucopogon. Fl. May, July. Clt. 1824. Shrub 2 feet.

23 L. collinus (R. Br. l. c.) spikes terminating the short lateral branches; lower bracteas sheathed a little, foliaceous, equalling the calyx in length; leaves oblong-linear, acutish, mutic, erect, smooth and rather convex above, with recurved denticulated edges, h. G. Native of Van Diemen's Land. Styphelia collina, Labill. nov. holl. 1. p. 47. t. 65. Flowers white.

Hill Leucopogon. Fl. May, June, Clt. 1824. Shrub 1 foot.

24. L. Fascicula'tum; arboreous; leaves crowded, linear, acuminated; racemes spicate, lateral, drooping. h. G. Native of New Zealand. E'pacris fasciculàta, Forst. ins. austr. p. 13.

Fascicled-flowered Leucopogon. Shrub.

\$3. Spikes axillary and terminal. Leaves cordate. Calyxes and bractcas membranous and foliaceous.

25 L. AMPLExicau'Lis (R. Br. l. c.) spikes axillary and terminal, spreading, pedunculate, exceeding the leaves; leaves cordate, stem-clasping, mutic, clotlied with minute down beneath: with recurved margins, which are as well as the branches villous; drupes lenticular, 2-celled. h. G. Native of New South Wales. Styphèlia amplexicaúlis, Rudge, in Lin. trans. 8. p. 292. t. 8. good. Flowers white.

Stem-clasping-leaved Ieucopogon. Clt. 1815. Shrub.

26 L. ALternjòlius (R. Br. l. c.) spikes axillary and terminal, few-flowered; leaves alternate, reniform, sten-clasping, acute, mutic, a line and a half long, and are as well as the branchlets glabrous; drupes crustaceous, lenticular, 2-celled. 々. G. Native of the south coast of New Holland. Flowers white.

Alternate-leaved Leucopogon. Shrub.

27 L. Dístans (R. Br. prod. p. 544.) spikes terminal, aggregate, flexuous; flowers distant; leaves ovate, subcordate, divaricate, mutic, one line long, convex above and downy beneath; drupes crustaceous, 5 -celled, obovate, depressed. h. G. Native of the south coast of New Holland. Flowers white.

Distant-flowered Leucopogon. Shrub.

28 L. REFLE'xus (R. Br. prod. p. 544.) spikes terminal, crowded, few-flowered; flowers imbricated; leaves ovate, almost cordate, divaricate, mutic, a line long, convex above, and concave beneath, pilose, lined; drupes crustaceous, 5-celled. h. G. Native of the south coast of New Holland. Flowers white.

Reflexed-leaved Leucopogon. Shrub.

29 L. Glabe'Lles (R. Br. prod. p. 544.) spikes terminal, almost solitary; bracteas foliaceous, and are as well as the calyxes glabrous; leaves alternate, broadly cordate, acute, mutic, divaricate, flattish, and are, as well as the branchlets, glabrous. $h$. G. Native of the south coast of New Holland. Flowers white. Smootl Leucopogon. Shrub.

\$4. Spikes terminal. Calyx and bracteas somenhat foliaceous. Drupe dry. Lcaves not cordate.-Perojòa, Cav.

30 L. microphy'leus (R. Br. l. c.) spikes crowded, fewflowered; leafiets of calyx acuminated, semi-foliaceous; bracteas foliaceous, nerved; leaves oval, obtuse, mutic, flat, of the same colour on both surfaces; drupes crustaceons, 1-2-celled. 
দ. G. Native of New South Wales. Perojòa microphýlla, Cav. icon. 4. p. 29. t. 349. f. 2. Flowers white.

Small-leaved Leucopogon. Fl. May, July. Clt. 1818, Shrub 2 feet.

31 L. тамaríscinus (R. Br. 1. c.) spikes agoregate or solitary, many-flowered; calyxes and bracteas foliaceous, glabrous ; leaves imbricated, adpressed, ovate, mutic, concave-convex, lined beneat $l$, and are as well as the branchlets glabrous. $\eta$. G. Native of the south coast of New Holland. Flowers white.

Tamarisk-like Leucopogon. Slırub.

32 L. gra'cilis (R. Br. l. c.) spikes crowded, 4-6-flowered; calyxes and bracteas subfoliaceous, glabrous; leaves lanceolatelinear, erect, concave-convex, mutic, nerved and 3-lined beneath; branchlets glabrous, filiform. $h_{c} . G$. Native of the south coast of New Holland. Flowers white.

Slender Leucopogon. Shrub.

33 L. DENudA'tus (Sieb. pl. nov. holl. ex Spreng. syst. add. p. 67.) leaves linear acute, erect, glabrous, quite entire; flowers terminal, aggregate. $々 . G$. Native of New Holland. Styphèlia denudàta, Spreng. 1. c.

Niaked Leucopogon. Shrub.

34 L. stria'tus (R. Br. l. c.) spikes aggregate; lracteas and calyxes subfoliaceous, with naked margins; leaves elliptic, mutic, erect, rather convex beneath and nerved, and somewhat concave above; branchlets glabrous; drupes crustaceous, 2 -celled. $\zeta_{2}$. G. Native of the south coast of New Holland. Flowers white.

Striatel-leaved Leucopogon. Fl. May, Aug, Clt. 1820. Shrub 2 to 3 feet.

35 L. Nervòsus (R. Br. l. c.) spikes crowded, few-flowered; bracteas and calyxes foliaceous and quite glabrous ; leaves elliptic, imbricated, on short petioles, mutic, flat above, and rather convex beneatl, with elevated nerves; branchlets downy. $h$. G. Native of the south coast of New Holland. Flowers white. Nearly allied to the preceding.

Nerzed-leaved Leucopogon. Shrub.

36 L. carina'tus (R. Br. prod. p. 545.) spikes solitary or aggregate; bracteas and calyxes foliaceous, quite glabrous ; leaves lanceolate, mutic, imbricated, flat above, and keeled beneath, with the lateral nerves obsolete, and the margins denticulated : branchlets downy. $\boldsymbol{h}$. G. Native of the south coast of New Holland. Flowers white.

Keeled-leaved Leucopogon. Shrub.

37 L. Assímus (R. Br. prod. p. 545.) spikes aggregate; leaves lanceolate-linear, imbricated, adpressed, mutic, convex and striated beneath, of the same colour on both surfaces, with denticulated margins; ovarium 5-celled. $h$. G. Native of New Holland, on the south coast. Flowers white.

Similar Leucopogon. Shrub.

38 L. cuculla'tus (R. Br. 1. c.) spikes aggregate, 4-6Howered; bracteas foliaceous; leaves ovate, obtuse, mutic, cucullate, imbricated, sessile, lined, with naked margins; drupes 5 -celled. 5. G. Native of the south coast of New Holland. Flowers white.

Cucullate-leaved Leucopogon. Shrub.

\$5. Peduncles axillary, 2-flowered, or 1-flowered every where from abortion: when this is the case, the calyx is many-bracteate. Drupe dry.

39 L. PÉndulus (R. Br. prod. p. 545.) peduncles usually 2-flowered, recurved; tube of corolla exceeding the calyx; leaves oblong-linear, erectly spreading, ending in an innocuous point, with recurved smooth margins; drupes clavate, ventricose, smooth, glabrous. h. G. Native of the south coast of New Holland. Flowers white.
Pendulous-flowered Leucopogon. Shrub.

40 L. Buflòrus (R. Br. l. c.) peduncles 2 -flowered, recurved; tube of corolla equal in length to the calyx; leaves spreading, linear-lanceolate, flat, 3 lines long, each ending in a pungent point, with smooth margins. $\eta$. G. Native of New South Wales. Flowers white.

Tno-flowered Leucopogon. Shrub.

41 L. setíger (R. Br. l. c.) peduncles 2-flowered, recurved, longer than the calyx; leaves spreading, lanceolate-linear, acuminated, half an inch long, ending in a setaceons pungent mucrone, with recurved obsoletely denticulated margins. h.G. Native of New South Wales. Flowers white.

Bristle-bearing Leucopogon. Fl.? Clt. 1824. Slırub 2 to 3 feet.?

42 L. Acumina'tus (R. Br. l. c.) peduncles very short, erect, usually 2-flowered; leaves erectish, linear-lanceolate, very acute, flat, ending in a setaceous mucrone, with scabrous denticulated margins. h. G. Native of New Holland, within the tropic. Flowers white.

Acuminated-leaved Lencopogon. Shrub.

43 L. cusprna'tus (R. Br. I. c.) peduncles very short, erect, 1-2-flowered; leaves moderately spreading, obovate-oblong, acutish, cuspidate, flat, with scabrous denticulated edges. h.G. Native of New Holland, within the tropic.

Cuspidate-leaved Leucopogon. Shrub.

44 L. imbrica'tus (R. Br. l. c.) peduncles very short, erect, 1-2-flowered; leaves imbricate, oval, obtuse, cuspidate, rather concave, with smooth toothless edges. h. G. Native of New Holland, within the tropic. Flowers white.

Imbricated-leaved Lencopogon. Shrub.

45 L. Ruscifòlús (R. Br. l. c.) peduncles very short, erect, usually 2-flowered; leaves erectly spreading, obovate-elliptic, acutish, rather concave, mucronate, with smooth obsoletely denticulated edges. $\zeta$. G. Native of New Holland, within the tropic. Flowers white.

Ruscus-leaved Leucopogon. Shrub.

46 L. pauciflònus (1R. Br. prod. p. 5 1.6.) peduncles very short, erect, 1 sually 2 -flowered; leaves narrow-lanceolate, moderately spreading, flat, ending each in a very short callous mu-

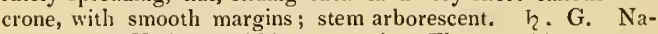
tire of New Holland, within the tropic. Flowers white.

Fen-flowered Leucopogon. Shrub.

47 L. ieptospermoides (R. Br. prod. p. 546.) peduncles very short, erect, usually 2-flowered; leaves linear-lanceolate, moderately spreading, flattish, very acute, with minutely denticulated scabrous edges, ending each in a stiff mucrone. $h$. G. Native of New Holland, within the tropic. Flowers white.

Leptospermum.like Leucopogon. Shrub.

48 L. rotundifólus (R. Br. l. c.) peduncles very short, erect, 1-2-flowered; leaves roundish or obovate, petiolate, spreading moderately, flat, mucronulate, with pellucid finely ciliated edges. $\quad$. G. Native of the south coast of New Holland. Flowers white.

Round-leaved Leucopogon. Shrub.

49 L. ADPRE'ssus (R. Br. l. c.) peduncles very short, erect, 1-3-flowered; leaves imbricated, adpressed, lanceolate, subacuminated, mucronate, concave, with denticulated margins. $h$. G. Native of New South Wales. Flowers white.

Adpressed-leaved Leucopogon. Fl. May, Aug. Clt. 1820. Shrub 2 to 3 feet.

50 L. FAstigia'tus (Sieb. l. c.) leaves lanceolate, cuspidate, serrulated at the apex, striated; calyx glabroas; flowers axillary, almost solitary. $\eta$. G. Native of New Holland. Styphèlia fastigiàta, Spreng. 1. c.

Fastigiate Leucopogon. Shrub.

$5 \mathrm{G} \approx$ 
EPACRIDEÆ. VII. LEUCopogon.

51 L. Junipe'rinus (R. Br. l. c.) flowers almost sessile, solitary or twin; leaves divaricate, lanceolate-linear, ending in a setaceous mucrone, with recurved slightly denticulated margins; bracteas $3-5$, and are as well as the calyxes mucronate. $h . G$. Native of New South Wales. Lodd. bot. cab. 447. Flowers white.

Juniper-like Leucopogon. Fl. April, June. Clt. 1804. Shrub 3 to 4 feet.

52 L. DEFórmis (R. Br. l. c.) flowers almost sessile, solitary, many-bracteate; leaves erectly spreading, lanceolate-linear, ratlier concave, mucronate, with obsoletely denticulated edges; ovarium 3-celled. b. G. Native of New South Wales. Flowers white.

\section{Deformed Leucopogon. Shrub.}

53 L. esouama'tus (R. Br. l. c.) peduncles very short, erect, 1-2-flowered; leaves scattered, erectly spreading, lanceolate, subacuminated, mucronate, flat, turned, with scabrous margins ; ovarium 2-celled; hypogynous disk wanting. 々.G. Native of New South Wales. Flowers white.

Scalcless-flowered Lencopozon. Shrub.

54. L. Flexifòlius (R. Br. I. c.) flowers almost sessile, solitary; leaves much crowded, imbricated, linear, mucronate, twisted, wilh scabrous denticulated edges; ovarium 5-celled. দ.. G. Native of New Holland, within the tropic.

Bent-lcaved Leucopogon. Shrub.

55 L. Fonste'ri; arboreous; leaves scattered, linear, cuspidate, serrulated; flowers sessile, solitary, terminal. 々. G. Native of New Zealand. E pacris junipérina, Forst. char. gen. 10. no. 2. ins. austr. p. 13.

Forstcr's Leucopogon.

Cult. The species of this genus are very pretty when in blossom; they grow best in an equal mixture of sandy loam and peat; and the tops of the very young shoots taken off and planted in sand, with a bell-glass over them, strike root readily.

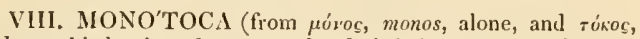
tokos, a birth; in reference to the fruit being one-seeded). R. Br. prod. 1. $5+6$.

Lin, syst. Penlándria, Monogýnia. Calyx bibracteate. Corolla funnel-shaped; limb and throat beardless. Ovarium 1seeded. Drupe baccate.-Shrubs or small trees. Leaves scattered. Spikes axillary, rarely terminal, few-flowered. Flowers small, white, usually dioecious from the defect of the organs. Hypogynous disk cup-slıaped, lobed.

\section{\$1. Bracteas extending, caducous. Small dioccious trees.}

1 M. ellíptica (R. Br. prod. p. 546.) spikes erect, nearly terminal and aggregate, or axillary and solitary : leaves elliptic, oblong, 4 times longer than broad. $h$. G. Native of New South Wales. Styphèlia ellíptica, Smith, new holl. 49.

Elliplic-leaved Mlonotoca. FI. May, Atg. Clt. 1802. Tree small.

2 M. ÁLBENs (R. Br. prod. p. 517.) spikes erect, solitary, terminal and axillary; leaves oblong-linear, acute, mucronate, white beneath, 5 times longer than broad. $\zeta$. G. Native of New South Wales.

While-leaved Monotoca. Fl. May, Aug. Clt. 1824. Shrub 6 feet.

3 M. LINeA'tA (R. Br. l. c.) spikes axillary, few-flowered, nodding, pedunculate ; leaves oblong, and often obovate, acute, flattish, mucronate. 々. G. Native of Van Diemen's Land. Styphèlia glaúca, Labill. nov. holl. 1. p. 45. t. 61. where the plant is represented as having erect spikes, and a 5 -celled ovarium.
VIII. Monotoca. IX. Acrotriche.

Lined-leaved Monotoca. Fl. May, Ang. Clt. 1804. Shrub.

§2. Bracteas extending, permanent. Shrubs with hermaphrodile flowers.

4 M. scopa'ria (R. Br. l. с.) spikes axillary, few-flowered, nearly sessile, nodding; leaves oblong-linear, with revolute edges; stem erect. $h$. G. Native of New South Wales. Styphèlia scopària, Smith, new holl. p. 48 .

Broom Monotoca. Fl. May, Aug. Clt. 1825. Shrub.

5 M. enpetrifòlia (R. Br. l. c.) spikes axillary, nodding, 23-flowered; leaves oblong-oval, mucronate, divaricate, convex above, white and striated beneath; stem prostrate. h. G. Native of Van Diemen's Land.

Empetrum-lcaved Monotoca. Shrub.

Cull. For culture and propagation see Leucopògon, above. The pots in which the species are grown require to be well drained with sherds.

1X. ACRO'TRICHE (from äspoc, akros, the uttermost, and

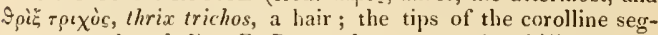
ments are bearded). R. Br. prod. p. 547. Styphèlia species, Spreng.

Lin. syst. Pentándria, Monogýnia. Calyx bibracteate. Corolla funnel-shaped; segments of the limb furnished with a deflexed beard at the apex. Drupe nearly baccate, containing a 5-celled cellular putamen.-Humble much branched shrubs; branches usually divaricate. Leaves scattered. Spikes lateral or axillary, short. Flowers small, white. Hypogynous disk cup-shaped, a little lobed. Drupe small, depressedly globose, of a dry substance.

1 A. divarica'ta (R. Br. prod. p. 547.) leaves lanceolate, mucronate, divaricate, flat, green on both surfaces; spikes axillary. 々. G. Native of New Sonth Wales.

Divaricate-leaved Acrotriche. Fl. May. Clt. 1824. Shrub $\frac{1}{2}$ to 1 fuot.

2 A. AGGREGA'ta (R. Br. l. c.) leaves oblong-lanceolate, rather concave, glaucous beneath, with smooth margins. h. G. Native of New Holland, within the tropic.

Aggregale Acrotriche. Shrub 1 foot.

3 A. ramiflòra (R. Br. l. c.) leaves linear-lanceolate, mucronate, divaricate, of a different colour beneath, nerved, with recurved margins; spikes on the branches. b. G. Native of New Holland, on the south coast.

Branch-flonered Acrotriche. Shrub 1 foot.

4 A. Serrula'ta (R. Br. I. c) leaves linear-lanceolate, cuspidate, spreading, pilose or smoothish, with serrulately ciliated edges; spikes axillary. h. G. Native of the south coast of New Holland, and Van Diemen's Land.

Serrulated-leaved Acrotriche. Shrub I foot.

5 A. PA'TUla (R. Br. 1. c.) leaves ovate lanceolate, acuminated, mucronate, flattish, and are as well as the branches divaricate: spikes axillary. south coast.

Spreading Acrotriche. Shrub.

6 A. ovalifòlia (R. Br. prod. p. 548.) leaves ovate and oval, obtuse, awnless, flat, with smooth margins; spikes axillary; drupes somewhat cellular. $\zeta$. G. Native of New Holland, on the soutl coast. Hook. bot. mag. t. 3171. Lodd. bot. cab. 1930. Corolla greenish-yellow. Drupes white.

Ocal-leaved Acrotriche. Fl. March. Clt. 1824. Shrub $\frac{1}{2}$ to 1 foot.

7 A. CORDA'TA (R. Br. I. c.) leaves cordate, flat, striated below; flowers axillary, twin or solitary. $\{$. G. Native of New Holland, on the south coast. Styphèlia cordàta, Labill. nov. holl. 1. p. 46. t. 63. Perhaps belonging to a different genus. 


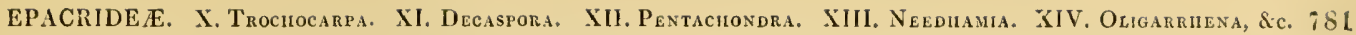

Cordate-leaved Acrotriche. Fl. A pril, July. Clt. 1823. Shrub 1 foot.?

8 A. DEPRE'SSA (R. Br. l. c.) leaves ovate, rather cordate, mucronate, divaricate, convex above, and reiny beneath; stem depressed; spikes on the branches. $\eta$. G. Native of New Holland, on the south coast.

Depressed Acrotriche. Shruh depressed.

Cult. For culture and propagation see Leucopògon, p. 780.

X. TROCHOCA'RPA (from rooxós, trochos, at wheel, and kaptios, karpos, a fruit; in reference to the putamen of the fruit, which is wheel-shaped and 10-lobed). R, Br. prod. p. 548 .

Lis. svst. Penténdria, Monogýnia. Calyx bibracteate. Corolla funnel-slaped: limb spreading, bearded. Ovarium 10celled. Drupe baccate, containing a wheel-shaped, 10-lobed putamen, which is at length divisible into as many parts.-A small glabrous tree, with very hard wood. Leaves scattered, petiolate, nerved, very like those of a species of Laúrus. Spikes slender, terminal and axillary, solitary or aggregate. Flowers small, white. Hypogynous disk cup-shaped, 5-lobed. Drupe depressedly globose, smaller than a pea. The genus approaches Deckispora in character and habit.

1 T. LAU'riNa (R. Br. prod. p. 548.). 々. G. Native of New South Wales. Hook. bot. nag. t. 3321 . Styphèlia cornifòlia, Rudge, in Lin. trans. 8. t. 9. good. Cyathodes laúrina, herb. Banks. Flowers small, white.

Laurel-like Trochocarpa. Fl. April, May. Clt. 1823. Tree 10 to 25 feet.

Cult. See Leucopogon, p. 780 . for culture and propagation.

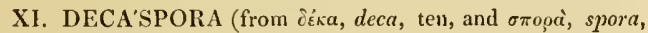
a seed; the fruit contains 10 pyrenæ or seeds). R. Br. prod. p. 548 .

Lin. sust. Pentándria, Monogýnia. Calyx bibracteate. Corolla campanulate; limb loosely bearded. Stamens exserted. Ovarium 10-celled. Berry containing 10 pyrenæ.-Beautiful sliruhs. Leaves scattered, petiolate. Spikes terminal, nodding. Flowers red. Hypogynous scales 5 , connate at the base. Berries violaceous.

I D. Dísticha (R. Br. prod. p. 548.) leaves lanceolate, very acute, flat, nerved beneath, 8 times longer than the petioles; branchlets glabrous. $\zeta$. G. Native of Van Diemen's Land. Cyathòdes dísticha, Labill. nov. lıoll. 1. p. 58, t. 82.

Dislich-leaved Decaspora. Shrub 4 to 6 feet.

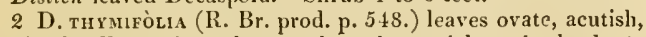
mutic, hardly 4 times longer than the petioles, obsoletely :nerved beneath; branchlets downy. $\eta$. G. Native of Van Diemen's Land.

Thyme-leaved Decaspora. Shrub.

Cult. For culture and propagation see Leucopògon, p. 780.

Xil. PENTACHO'NDRA (from $\pi \dot{\varepsilon} v \tau \varepsilon$, pente, five, and $\chi^{\prime} \gamma^{\prime}-$ $\delta \rho o s$, chondros, a grain; in reference to the berry containing 5 pyrenæ or seeds). R Br. prod. p. 549.

LiN. syst. Pentándria, Monogimia. Calyx with 4 or more bracteas. Corolla funnel-shaped; limb spreading, longitudinally and densely bearded. Ovarium 5-celled. Berry containing 5 pyrenæ.-Small mountain shrubs. Leaves scattered, petiolate. Flowers solitary, terminal, erect, white. Hylogynous scales 5 .

1 P. INvolucka'ta (R. Br. prod. p. 549.) filaments exserted; calyxes ciliated, furnished with 8 bracteas; leaves elliptic-lanceolate, flattish, many-nerved; branchlets downy; stem erect. h. G. Native of Van Diemen's Land. Styphèlia involucrita, Spreng. syst. 1. p. 655 .

Involucruted-flowered Pentachondra. Shrub.

2 P. PU'MiLa (R. Br. l. c.) stamens inclosed; calyx furnished with 4 bracteas; leaves nearly elliptic, 3-nersed, with naked margins; branchlets glabrous; stem prostrate, much branched. $\hbar_{c} \cdot$ G. Native of Van Diemen's Land. E'pacris pumila, Forst. prod. no. 70. Styphlèlia pùmila, Spreng. syst. 1. p. 656.

Drarf Pentachondra. Shrub prostrate.

Cult. For culture and propagation see Leucojògon, p. 780.

XIII. NEEDHA'MIA (in honour of the celebrated micrographist, Turberville Needham, author of Observations on the Shape and Economy of the Pollen of Anthers). R. Br. prod. p. 549 .

Lin. syst. Pentándria, Monogýnia. Calyx bibracteate. Corolla salver-slaped : limb 5-cleit, beardless, having the sinuses elevated, plicate in æstivation. Stamens 5 , inclosed. Ovarimm 2-celled. Drupe dry. Leaves opposite--A small erect slirub. Leaves minute, adpressed. Spikes terminal, erect, solitary; bracteas extending, foliaceous. Flowers white. Hypogynous disk saucer-shaped.

1 N. pumílio (R. Br. l. c.). ケ. G. Native of New $\mathrm{Hol}$ land, on the south coast. Monótoca pumílio, Spreng. syst. 1. p. 654 .

Dnarf Needhamia. Shrub.

Cult. For culture and propagation see Astrolòma, p. 775 .

XIV. OLIGARRHE' NA (from ỏi iyos, oligos, few, and äfïinv, arrhen, a male; in reference to the few stamens). R. Br. prod. p. 549 .

Lis, svst. Diándria, Monogýnia. Calyx 4-parted, bibracteate. Corolla 4-cleft, permanent, valvate in æstivation. Stamens 2, inclosed. Ovarium 2-celled. Capsule 2-celled.-An erect much-branched shrub. Leaves scattered, imbricate, small. Spikes terminal, erect. Flowers small, white. Hypogynous scales 4. This is a very paradoxical genus; it agrees in the artificial character with the order Oleine, but the habit is wholly distinct.

I O. micra'stha (R. Br. prod. p. 549.). h. G. Native of New Holland, on the sonth coast.

Small-flowercd Oligarrhena. Shrub.

Cult. Sce 1 strolöma, p. 775 . for culture and propagation.

\section{Tribe II.}

EPACRIE' $E$ (the genera contained in this tribe agree with E'pacris in many particulars). Cells of ovarium many-seeded. Fruit capsular.

$X V$. E'PACRIS (from $\dot{\epsilon} \pi \dot{t}$, epi, upon, and akeos, akros, the uttermost; in allusion to the habitation of the species on the tops of hills). Smith, exot. bot. p. 77. t. 40. Labill, nov. holl. 1. p. 41. t. 55. Cav, icon. 4. p. 25. t. 344. R. Br. prod. p. 550 .

Lin, syst. Pentándria, Monogýnia. Calyx coloured, manybracteate; bracteas of the same texture as tlse calyx. Corolla tubular; limb beardless. Stamens epipetalous. Anthers peltate above the middle. Hypogynous scales 5 . Capsule baving the placentas adnate to the central column.-Small branched, usually glabrous shrubs. Leares scattered, petiolate or simple at the base. Flowers axillary, white or purplish, usually disposed in leafy spikes. 


\section{* Leaves cordate.}

1 E. PURPURa'scens (R. Br. prod. p. 550.) segments of calyx acuminated, about equal in length to the tube of the corolla; leaves cucullate, nearly sessile, ending each in a recurved mucrone, which exceeds the base of the leaf; floral leaves equalling the corollas in length. h. G. Native of New South Wales. E. púngens, Sims, bot. mag. t. 84t. E'pacris attenudtum, Link. Lodd. bot. cab. t. 58 . Corollas purplish.

I'ar. $\beta$, rìbra (Lod,l. bot. cab. 876.) flowers red.

Purpurescent-flowered Epacris. Fl. Jan. March. Clt. I803. Slurub 2 to 3 feet.

2 E. pulciélla (Cav, icon. 4. p. 26. t. 345. Sims, bot. mag. 1170 . R. Br. prod. p. 550.) segments of the caly $\mathrm{x}$ acuminated, equalling the tube of the corolla; leaves rather concave, ending each in a spreading point, which is not so long as the base of the leaf; floral leaves shorter than the corollas. h.G. Native of New South Wales. Lodd. bot, cab. 1:4. Flowers pale red or pink. feet.

Neat Epacris. Fl. April, June. Clt. 1804. Shrub 1 to 3

3 E. microphy'LLA (R. Br. prod. p. 550.) segments of calyx bluntish, equalling the tube of the corolla; leaves cucullate, acute, spreading; spike terminal. $5 . G$. Native of New Sontl Wales. Flowers almost white.

Small-leaved Epacris. Fl. April, June. Clt. 1822. Shrub 1 to 2 feet.

4 E. Ripa'ria (R. Br. l. c.) segments of calyx setaceously acuminated, about equal in length to the tube of the corolla; leaves flat, acuminated, spreading. $々$. G. Native of New South Wales.

River-side Epacris. Shrub.

5 E. grandiflòra (Smith, exot, bot. 75. t. 39. Sims, bot. mag. t. 982.) corollas cylindrical, 4 times longer than the calyx; flowers pendulous; leaves flat, acuminated. $h_{\text {. }}$ G. Native of New South Wales. Lodd. bot. cab. 21. E'pacris longiflòra, Cav. icon. 4. p. 25. t. 344. Flowers scarlet and white.

Great-flowered Epacris. Fl. Jan. June. Clt. 1803. Shrub 2 to 6 feet.

6 E. canpanula'ta (Lodd. bot. cab. 1925.) leaves ovate, reflexed; flowers axillary, the whole forming a spike; corolla twice or thrice longer than the calyx, campanulate. h.G. Native of Van Diemen's Land. Corollas red.

I ar. $\beta$, álba (Lodd. bot. cab. 1931). Flowers white.

Campanulatc-flowered Epàcris. Fl. March. Clt. 1830. Shirub 1 to 2 feet.

7 E. Apscula'ta (Cimningh, in Field's New South Wales, p. 310.) calycine segments lanceolate, acuminated, about equal in length to the tube of the corolla; leaves cucullate, hairy, sessile, auricled at the base: snperior leaves imbricated, ending each in a callous obtuse point; branchlets downy. h. G. Native of New South Wales, on boggy moist declivities, in the ravines of King's Table Land. Slunb.

Apiculated-leaved Epacris. Fl. April, July. Clt. 1823.

$$
\text { * Leaves simple at the base, not cordate. }
$$

s E. Ruscjfòlia (R. Br. prod. p. 550.) flowers scattered, pendulous; leaves elliptic-lanceolate, petiolate, acuminated; corollas cylindrical, having the tube twice longer than the calyx. h.G. Native of Van Diemen's Land.

Ruscus-leaved Epacris. Fl, April, June. Clt. 1824. Shrub.

9 E rivula'ris (Sieb. pl. nov. holl. ex Spreng. syst. add. p. 64.) leaves almost sessile, ovate, acuminated, reflexedly spreading; calyxes acute, about equal in length to the corolla. $h . G$. Native of New Holland.
Rivulet Epacris. Shrub.

10 E. IMPrE'ssa (Labill. nov. holl. 1. p. 43. t. 58.) flowers pendulous, spicate, leaning all one way ; leaves lanceolate, nearly sessile, attenuated at the apex, mucronate, with scabrous edges; peduncles 3 times shorter than the calyx; corollas cylindrical; tube of corolla prismatic, twice longer than the acute ciliated calyx. $々$. G. Native of the soutl coast of New Holland, and Van Diemen's Laud. R. Br. prod. p. 551. Sweet, fl. austr. t. 4. Lodd. bot. cab. 1691. Flowers beautiful crimson.

Impressed Epacris. Fl. April, July. Clt, 1824. Shrub 1 to 3 feet.

11 E. VARIA' BILIs (Lodd. bot. cab. 1818.) leaves ovate, sessile, tapering to the apex; corolla tubular, 3 or 4 times longer than the calyx. h. G. Native of Van Diemen's Land. Flowers drooping, pale red or blush, spicate. Like $E$. impréssa.

Tariable Epàcris. Fl. Jan. Feb. 1829. Shrub 2 feet.

12 E. NivA'Lis (Lodd. bot. cab. 1821. Lindl. bot. reg. 1531. Graham, in bot. mag. 3253.) leaves ovate-lanceolate, spreading much, nakedish, nerved beneath, attenuated at the apex, mucronate, with scabrous margins : flowers axillary, solitary, secund, disposed in a leafy raceme or spike; tube of corolla campanulate, much longer than the segments of the calyx, which are ciliated, as well as the bracteas. $\zeta$. G. Native of New Holland. Flowers white.

Snowy Epacris. Fl. April, May. Clt. 1829. Shrub 2 to 3 feet.

13 E. cerfèolia (Graham, in bot. mag. t. 3243.) leaves lanceolate, spreading much, nakedish, attenuately mucronate at the apex, with scabrous edges; flowers spreading, axillary, solitary, secund; tube of corolla ovate, exceeding the acute ciliated segments of the calyx. h. G. Native of Van Diemen's Land. Flowers white, collected near the extremities of the branches, much shorter than those of $E$. nivalis.

H'ax-lcaved Epacris. Fl. April, May. Clt. 1831. Shrub 1 to 3 feet.

14 E. spa'rsa (R. Br. prod. p. 551 .) flowers unknown; peduncles scattered, about equal in length to the acute calyx: leaves oblong-lanceolate, petiolate, mucronate, veinless. $\zeta \cdot G$. Native of New South, Wales. Flowers white.?

Seattered-flowered Epacris. Shrub.

15 E. Rígida (Sieb. I. c.) leaves ovate-oblong, bluntish, nearly sessile, cartilaginous, spreading, kecled ; calyxes obtuse, about equal in length to the tube of the corolla. $\boldsymbol{b} . \mathrm{G}$. $\mathrm{Na}$ tive of New Holland.

Stiff Epacris. Slurub.

16 E. obtusifòlia (Smith, exot. bot. p. 77. t. 40.) flowers nodding; leaves lanceolate, erect, a little imbricated, ending in a bluntish callous point; segments of the calyx obtuse, length of the tube of the corolla; stamens inclosed, h. G. Native of New South Wales, south coast of New Holland, and Van Diemen's Land. R. Br. prod, p. 551. Lodd. bot. cab. 293. Flowers white.

Blunt-lcaved Epacris. Fl. April, June, Clt. 1804. Shrub 2 to 3 feet.

17 E. heterone'ma (Labill. nov, holl. 1. p. 42. t. 56.) leaves elliptic-lanceolate, acuminated, rather concave, striated beneath ; segments of calyx very acute, naked, length of tube of the 
corolla; stamens inclosed; style glabrous; branches hairy. b. G. Native of Van Diemen's Land, and of New Holland, on the Blue Mountains. R. Br. prod. p. 551. Hook. bot. mag. t. 3257. Flowers white.

Iariable-stamened Epacris. FI. May, June. Clt. 1823. Shrub 2 to 4 feet.

18 E. PALudòsa (R. Br. prod. p. 551.) leaves narrow-lanceolate, acuminated, flat, striated beneath, with scabrous margins; calycine segments very acute, naked, lengtl of tube of the corolla; stamens inclosed; style glabrous. $h$. G. Native of New South Wales. Lodd. bot. cab. 1226. Flowers pale red. ? feet.

Marsh Epacris. Fl. April, July. Clt. 1825. Shrub 2 to 3

19 E. Lanuginòs (Labill. nov. holl. 1. p. 42. t. 57.) leaves lanceolate, acuminated, with scabrous matrins; calycine segments very acute, length of tube of the corolla, with the margins woolly; stamens inclosed; style hairy. $\quad$. G. Native of Van Diemen's Land. R. Br. prod. p. 551 .

Woolly Epacris. Slirub 2 feet.

20 E. onosmercòra (Cunningh. in Field's New South Wales, p. 340.) leaves elliptic-lanceolate, acuminated, cucullately concave, 5-nerved, mucronate, petiolate, with ciliated margins : branchlets hoary; corollas cylindrically ventricose, with the tube exceeding the calyx, which is very acute. h.G. Native of New South Wales, in boggy moist declivities on the King's Table Land. Nearly allied to E. lanuginòsa, Labill.

Onosma-flowered Epacris. Fl. May. Clt. 1823. Shrub.

21 E. myrtifòlia (Labill. nov. holl. 1. p. 41. t. 55.) leaves ovate, acute, mucronulate, flat, thick : floral ones about equal in length to the corolla; calycine segments acutish, naked, length of tube of the corolla; bracteas bluntish; stamens inclosed. 々. G. Native of Van Diemen's Land. R. Br. prod. 551. Myrlle-lcaved Epacris. Shrub.

22 E. sespyllifòlia (R. Br. prod. 551.) leaves ovate, acute; floral leaves one-half shorter than the corolla; calycine segments acutisl, naked, length of tube of corolla; stamens inclosed. h. G. Native of Van Diemen's Land.

Wild-Thyme-leaved Epacris. Slırub.

23 E. ExsE'rta (R. Br. prod. 551.) leaves lanceolate, acute, erect, flat above, and rather convex beneath; calycine segments bluntisl, ecjualling the tube in length; anthers clearly exserted. দ. G. Native of Van Diemen's Land. Flowers white.

Exserled-stamened Epacris. Fl. April, July. Clt. 1812. Shrub 1 to 3 feet.

24 E. crassifòlia (R. Br. l. c.) leaves oval or obovate, obtuse, mutic, flat, cartilaginous, acute at the base; calyses pedunculate, with woolly margins; stem procumbent, with ascending branches. 々. G. Native of New South WVales.

Thick-leaved Epacris. Shrub procumbent.

25 E. mucaonuia'ta (R. Br. prod. p. 552.) leaves lanceolate, very acute, erectly spreading, ending each in a pungent pellucid mucrone; calycine segments acute, with naked margins. h.G. Native of Van Diemen's Land. Flowers red.?

Mucronulate-leaved Epacris. Fl. April, July. Clt. 1824. Slirub 2 to 3 feet.

Cult. All the species of this genus are delicate and handsome small shrubs; and many of them, on that account, are cultivated by nurserymen and florists. A sancly peat soil suits them best, and the rowher and more turfy it is, the better the plants will thrive. They should be always shifted into fresh pots and mould just before they are placed out of doors for the summer from the green-house, as the roots become matted, and being so very fine, the lot sun against the pots is apt to destroy the points, and thus olten kills the plants altogether. Cuttings taken from the tips of young shoots, and planted in pots filled with sand, with a bell-glass placed over them, either in autumn, winter, or spring, will readily strike root; but they will not strike so freely in summer. When the cuttings are rooted, they should be potted singly in small pots, and set in a close frame for some time, and liardened to the air only by degrees.

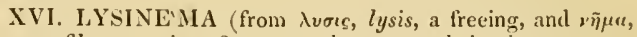
nema, a filament; in reference to the stamens being liyporynous, and therefore free from the corolla, not as in Epacris epipetilous). R. Br. prod. p. 552 .

Lin. syst. Pentándria, Monory'nia. Calyx coloured, with many bracteas; bracteas texture of calyx. Corolla salvershaped, with the tube sometimes divisible into 5 parts; segments of the limb beardless, bent to the right. Stamens hypogynous. Anthers peltate above the middle. Hypogynous scales 5 Placentas of capsule adnate to the central column.-Shrubs with the habit of $E$ pacris.

1 L. Petape'TALUn (R. Br. prod. p. 552.) corollas pentapetalous, having the claws distinct the whole length, and longer than the calyx, glabrous outside. 々. G. Native of New Holland, on the south coast. Flowers pink. Leaves trigonal.

Five-petalled Lysinema. F1. Feb. March. Clt. 1823. Shrub 2 to 3 feet.

2 I. cilia'tum (R..Br. l. c.) corollas pentapetalous: havingr the claws cohering at the apex, length of calyx, glabrous outsile. h. G. Native of New Holland, on the south coast.

Ciliated-leaved Lysinema. Shrub.

3 L. LASIA'NTIUM (R. Br. 1. c.) corollas pentapetalous: havius the claws woolly outside, and 4-5 times longer than the limb. h. G. Native of New Holland, on the south coast.

Hairy-fomered Lysinema. Fl. Feb. Miz. Clt. 1820. Sihruh 2 to 3 feet.

4. L. conspícuum (R. Br. l. c.) corolla monopetalous : having the tube 5-cleft, and exceeding the calyx; leaves lanciolatesubulate, adpressed. $h$. G. Native of New Holland, on the south coast.

Conspicuous Lysinema. Fl. Feb. May. Clt. 1824. Shrub 2 to 3 feet.

5 L. ruscifòlium (Sieb. ex Spreng. syst. add. p. 64.) leaves half stem-clasping, ovate-oblong, cuspidate, ciliated, smooth; segments of calyx subulate, about equal in length to the tube of the corolla. $h_{c}$. G. Native of New Holland.

Ruscus-leaved Lysinema. Shrub.

6 L. Pu'NGENS (R. Br. prod. p. $55 \%$.) corollas monopetalous, having the tube entire, and equal in length to the calyx; leaves ovate, acuminated, spreading. দ. G. Native of New South Wales. E'pacris pungens, Cav. icon. 4. p. 26. t. 3t6. Flowers white. Shrub pale green. This species is intermediate between Lysinèma and E'pacris. Leaves stem-clasping.

Var. $\beta$, rübrum (Sims, bot. mag. 1199.) shrub dark or brownish green; flowers red. $h_{2} . G$. Native of New South Wales. E'pacris ròsea, Lodd. bot. cab. t. 863 .

Pungent-leaved Lysinema. Fl. Feh. A pril. Clt. 1804. Shrub 2 to 3 feet.

Cult. See $E^{\prime}$ pacris above for culture and propagation. Elegant anil delicate shrubs, having the habit of $E^{\prime}$ pacris.

XVII. PRIONO'TES (from $\pi \rho i \omega \nu$, prion, a saw, and oüs ítos, ous otos, an ear; in reference to the serrated leaves). R. Br. prod. p. 552.

Lin, syst. Pcntándria, Monogýnia. Calyx bractless. Corollat tubular, with an open throat; the limb beardless. Stamens hypogynous. Filaments half adhering to the tube. Anthers with a complete dissepiment. Hypogynous scales 5. Placentas unknown. - $A$ glabrous much branched shrub. Leaves scattered, petiolate, serrated. Peduncles axillary, 1-flowered, recurved, 
minutely bracteate at the base, and naked above. Flowers slowy, pendulous. The placentas of the capsules are loose and pendulous, and the leaves sheathing, according to Labillardiere.

1 P. cerinthoides (R. Br. prod. p. 553.). 々. G. Native of Van Diemen's Land. E'pacris cerinthoides, Labill. nov. holl. 1. p. 48 . t. 59 .

Cerinthe-like Prionotes. Slırub 4 to 5 feet.

Cult. This is an elegant and delicate shrub, bearing showy pendulous flowers. For culture and propagation, see E'pacris, 1. 783 .

XVIII. COSME'IA (from ko $\mu \varepsilon \dot{\omega} \omega$, kosmco, to adorn; beauty of flowers.) R. Br. prod. p. 553.

L1x. sxst. Pentándra, Monogýnia. Calyx foliaceous. Corolla tubular. Stamens epipetalous. Anthers adnate to the filaments, which are ciliated at top. Hypogynous scales 5 . Placentas of capsule adnate to the central colimn.-An erect much branched shrub, but the hranches while naked are not marked by cicatrices. Bases of leaves cucullate, half sheathing. Flowers solitary, drooping, terminating the short lateral branches. Calyx imbricated by smaller leaves. Corollas deep red. Stamens inclosed. Anthers loosened at the base. Placentas frec at both extremities.

1 C. RU'BRA (R. Br. prod. p. 553.). h. G. Native of the south coast of New Holland. E'pacris rùbra, Spreng. syst. 1. 1. 629 .

Red-flowered Cosmelia. F1.? Clt. 1826. Shrub 1 to 2 feet.

Cult. See E'pacris, p. 783 . for culture and propagation.

XIX. ANDEREO'NIA (named in memory of William Anderson, a surgeon of the Royal Navy, who accompanied Captain Cook; he paid great attention to botany. Descriptions of the genera of Van Diemen's Land plants, writien by him, are still in the Banksian Library. The genus is also intended to comnemorate the late Alexander Anderson, formerly Director of the Botanic Garden at St. Vincent; and William Anderson, the present Curator of the Apothecaries' Botanic Garden at Clielsea.) R. Br. prod. p. 553.

Lix. syst. Pentándria, Monogýnia. Calyx coloured, imbricated by 2 or more foliaceons uracteas. Corolla length of falyx; segments of the limb bearded at the base. Stamens hypogynous: antlers fixed beneath the middle. Hypogynous scales 5 , sometimes connate. Capsule with the placentas adnate to the central column.-Small squarrose shrubs, having the branches not annulated while naked. Bases of leaves cucullate, half sheathing. Flowers terminal, spicate, or solitary, erect. Placentas short, rising from the botton of the capsule. Secds few when mature, erect.

\section{* Floners bibractcate, spicate.}

1 A sprengelioides (R. Br. prod. p. 554.) leaves spreading, ending each in a flat point. $\{. G$. Native of New Holland, on the south coast. Sims, bot. mag. 1645. Lodd. bot. cab. 263. Flowers pink.

Sprengelia-like Andersonia. Fl. March, July. Clt. 1803. Slirub 1 to 3 feet.

2 A. PArriròlı (R. Br. l. c.) leaves adpressed, ending in a triquetrous point each. $\zeta$. G. Native of the south coast of New Holland.

\section{Simall-leatcd Andersonia. Shrub.}

* Floners many-bracteate; terminating the short branchlets.

3 A. crenu'zea (R. Br. l. c.) leaves moderately spreading; young leaves and outside of calyxes downy. $h_{c} \cdot G$. Native of New Ilolland, on the suutl coast. Flowers blue.
Blue-fiowered Andersonia. Shrub.

4 A. squarròsa (R. Br. prod. p. 55 4.) leaves squarrose, divaricate or recurved, glabrous, with naked margins; calyxes and styles glabrous; stem erect. $\vdash$. G. Native of New Holland, on the soutls coast.

Squarrose-leaved Andersonia. Slirub.

5 A. DEPRE'ssa (R. Br. l. c.) leaves squarrose, divaricate or recurved, downy, with ciliated margins; calyxes glabrous; style pilose in the middle; stem depressed. $h_{c}$. G. Native of New Holland, on the south coast.

Depressed Andersonia. Shrub depressed.

6 A. micrántha (R. Br. l. c.) leaves adpressed; style downy beneath the middle. 5. G. Native of New Holland, on the south coast.

Small-flowered Andersonia. Shrub.

Cult. The species of this genus are very elegant and delicate plants. They grow freely in a sandy peat soil, having the pots well drained with sherds. Care should be taken not to give them tou much water, as when the mould gets soddened, the plants are almost sure to die. They are increased by cuttings in the same way as $E^{\prime}$ pacris, which see, p. 783.

XX. PONCELETIA (to the memory of Mr. Poncelet, author of treatise on Triticum or Wheat.) R. Br. prod. p. 554.

Lin. syst. Pentándria, Monogýnia. Calyx foliaccous. Corolla short, campanulate, 5 -cleft, beardless. Stamens hypogynous. Anthers peltate beneath the middle, with a marginate dissepiment. Hypogynous scales wanting. Capsule having the placentas adnate to the central column.-A small, erect, twiggy, marsh slirub, having the branches not anmulaled while naked: floriferous branclies brittle. Bases of leares cucullate, half sheathing. Flowers solitary, erect, terminating the branchlets. Calyx imbricated by smaller leares. Anthers free, beardless.

1 P. Syengelioides (R. Br. prod. p. 55\%.). h. G. Native of New South Wales. A suffruticose dense habited plant, adhering to rocks perpetually dainp.

Sprengclia-like Ponceletia. F]. May, June. Clt. 1826. Shrub 1 to 2 feet.

Cult. For culture and propagation, see $E^{\prime}$ pacris, p. 783.

XX1. SPRENGEIII (named after Christian Conrad Sprengel, master of the grammar-school at Spandow, in Brandenburgh, who published at Berlin, in 1793, a most ingenious work on the manner in whicis insects promote the impregnation of plants). Smith, in act. stockh. 1794. p. 260 . t. S. tracts, p. 267. t. 2. R. Br. prod. p. 555 .

Lin. srst. Pentándria, Monogýnia. Calyx coloured a little. Corolla 5-parted, rotate, beardless. Stamens hypogynous. Anthers connate or free, with an immarginate dissepiment. Hypogynous scales wanting. Capsule having the placentas adnate to the central column.-Small, erect, branched shrubs; branches hardly annulated while naked. Bases of leaves cucullate, half sheathing. Flowers terminating the short lateral branchlets. Corolla purplish, length of calyx : with the tube very slort, and at lengtli cleft into 5 to the base.

I S. INCARNA'TA (R. Br. jrod. p. 55.) anthers connate, bearded; calyxes colonred; leaves long-acuminated. $h, G$. Native of New South Wales, south coast of New Holland, and Van Diemen's Land. Andr. bot. rep. t. 2. Sims, bot. mag. 1719. Lodd. bot. cab. 262. Flowers flame coloured.

Flesh-colour-flowerd Sprengelia. Fl. April, Jume. Clt. 1793. Shrub 1 to 2 feet.

2 S. мопта'sa (R. Br. l. c.) antliers free, beardless; calyx half coloured; leaves short-acuminated. $\zeta$. G. Native of Van Diemen's Land. Flowers purplish. 
Mountain Sprengelia. Shrub 1 foot.

Cult. These are elegant and delicate shrubs, with much the habit of Andersònia, which see, p. 784, for culture and propagation.

XXII. CXSTA'NTHE (from ${ }^{\prime} v \sigma \tau$, kiste, a box or coffer, and ardos, anthos, a flower; in reference to the closed hoodformed flowers.) R. Br. prod. p. 555.

Lin. sxst. Pentándria, Monogýnia. Calyx foliaceous. Corolla closed, calyptræform, dehiscing transversely : with a truncate permanent base. Stamens liypogynous, permanent. Hypogynous scales wanting. Capsule liaving the placentas loose, and hanging from the top of the central column.-A shrub with the habit of Sprengèlia, Cosmèlia, and Poncelètia : unless that the branches are annulated while naked.

1 C. Sprengelioìdes (R. Br. prod. p. 555.)。 h. G. Native of Van Diemen's Land. Flowers pale red.

Var. $a$, leaves elongated, spreadingly recurved. Growing on the shady sides of mountains.

Var. i 3 , leaves much shorter. Growing on the tops of mountains.

Sprongclia-like Cystanthe. Shrub 1 to 2 feet.

Cult. For culture and propagation, see Andersònia, p. 784. It is an elegant and delicate shrub.

XXIII. RI'CHEA (named in memory of M. Riche, one of the naturalists who accompanied the expedition in search of $\mathrm{La}$ Perouse). R. Br. prod. p. 555. but not of Labill.

Lin.syst. Pentándria, MIonogýnia. Calyx membranous, bractless. Corolla closed, calyptræform, dehiscing transversely: with a truncate permanent base. Stamens hypogynous, permanent. Hypogynous scales 5. Capsule having the placentas loose and hanging from the top of the central column.-A shrub with the habit almost of Dracophýllum montànum, Labill., but differing in the singular economy of the flower. It comes nearest to $C y s-$ tanthe, in the corolla being calyptræform; but that genus differs in the inflorescence, foliaceous calyx, and want of hypogynous scales. Ríchea of Labill. voy. 1. p. 187. t. 16. in Craspèdia, Forst. prod. no. 306. and Willd. spec. 3. p. 2393.

1 R. DRACOPHY'Lla (R. Br. prod. p. 555.). h. G. Native of Van Diemen's Land. This shrub differs much in stature according to stations of its natural growth; for on the tops of mountains it is an humble slrub, $1 \frac{1}{2}$ foot high; but on the sides of the mountains it grows to 10 feet high.

Draco-leaved Richea. Shrub 1 to 10 feet. 78.

Cult. For culture and propagation, see Andersònia, p.

XXIV. DRACOPHY'LLUM (from i $\rho \alpha^{\prime} \omega s$, drakon, a dragon; and $\phi v \lambda \lambda \circ v$, phyllon, a leaf: so named because the leaves have some resemblance to those of Drace'na Dràco, or Dragon's Blood Tree.) Labill. itin. 2. t. 40. R. Br. prod. p. 555. Relib. hort. 2. t. 108 .

Lin. sYst. Pentándria, Monogýnia. Calyx bractless. Corolla tubularly funnel-shaped; with a 5 -parted acutish spreading beardless limb, a somexhat ventricose tube, and a hardly contracted throat. Stamens 5, hypogynous. Hypogynous scales 5. Capsule having the placentas loosened, and hanging from the top of the central column.-Shrubs or small trees having the branches annulated while naked. Leaves imbricate, cucullate at the base, and half sheathing. Spikes or racemes terminal, simple, or compound. Bracteas subtending the pedicels, caducous.

1 D. SEcu'xDUM (R. Br. prod. p. 556.) racemes secund; VOL. III. lower peduncles divided. $\zeta$. G. Native of New South Wales. Hook. bot. mag. 3264. Flowers white.

Secund-flowered Dracophyllum. Fl. April, Aug. Clt. 1823. Shrub 1 to 2 feet.

2 D. LonGıòlium (R. Br. prod. p. 556.) arboreous; leaves linear-lanceolate, slicathing at the base; racemes erect, articulated, lateral. 々. G. Native of New Zealand. E'pacris longifòlia, Forst. char, gen. 10. no. I. ins. austr. p. 13.

Long-lcaved Dracophyllum. Shrub.

3 D. rosmarinifòlum (R. Br. l. c.) slurubby; leaves linear, obtuse, stiff, sheathing; flowers almost solitary, sessile. $h$. G. Native of New 'Zealand. E'pacris rosmarinifolia, Forst. ins. austr. p. 13. icon. t. 24 .

Roscmary-lcaved Dracophyllum. Shrub.

Cult. See Andersònia, p. 784. for culture and propagation.

XXV. SPHENO"TOMA (from $\sigma \phi$ nvow, sphenoo, to cleave, and $\tau о \mu \eta$, tome, a section; in reference to the deep divided liml) of the corolla). Swect, fl. austr. t. 44. Dracophýllum, sect. Sphenótoma, R. Br. prod. p. 555.).

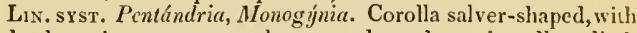
a slender tube, a coarctate throat, and an obtuse beardless limb (f. 134.e.) Stamens epipetalous. Hypogynous scales 5. Capsule having the placentas loose, and langing from the top of the central column.-Shrubs having the branches annulated when naket. Leaves imbricate, cucullate and half sheathing at the base. Spikes simple, terminal. Bracteas stretched out, permanent.

$1 \mathrm{~S}$. SQUARRòsa; floriferous branches hardly the length of the spikes; leaves squarrose, ensiform, lanceolate. $h . G$. Native of New Holland, on the south coast. Dracoplyýllum squarròsum, R. Br. prod. p. 5.56.

Squarrose Sphenotoma. Shrub.

2 S. CAPITA'TA; floriferous branches much longer than the spikes, which are ovate; cauline leaves lanceolate-ensiform, erectish: of the branches adpressed. $h_{2}$ G. Native of New Holland, on the south coast. Dracophýllum capitàtum, R. Br. prod. p. 556 .

Capitate-flowered Sphenotoma. Shrub.

3 S. GRA'crlis (Sweet, fl. austr. t. 44.) floriferous branches much longer than the spikes, which are ovate; cauline leaves lanceolate-subulate, spreading, or recurved: of the branches adpressed. 々. G. Native of New Holland, on the south coast. Dracophýllum grácilis, R. Br. prod. p. 556 . Flowers white. Leaves fringed with long hairs. (f. 134.).

Slender Sphenotoma. Fl. April, May. Clt. 1823. Shrub 1 to 2 feet.

Cult. For culture and propagation, see E'pacris, p. 783. or Andersonia, p. 784 .

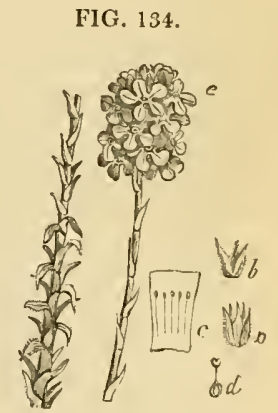

Order CXXXIX. ERICA'CE E (this order contains plants agreeing with the genus Erica, or Heath, in important characters). D. Don, in edinb. phil, journ. 17. p. 152. Erícex, R. Br. prod. p. 557. Ericàceæ, part., Cham. et Schlect. in Linnæa. vol. 1. Eríceæ, part., Juss. gen.

Flowers hermaphrodite, subsymmetrical, regular. Calyx 1 5-cleft. Corolla 4-parted, rarely 5-parted. Stamens 4-5-8-10, $5 \mathrm{H}$ 
alternating with the segments of the corolla: their insertion various. Style and stigma undivided. Capsule free, or adhering to the fleshy calyx, therefore baccate; cells for the most part many-seeded. Albumen fleshy. Embryo erect, slender. Shrubs variable in habit, scattered over the surface of the earth in every direction.

Among the numerous families which compose the vegetable kingdom, few surpass the Ericàcece in the diversity of their forms, beauty of their flowers, or in the extent of their geographical distribution, which verges upon the ultimate limits of vegetation in both hemispheres. The direction of mountain chains, more especially of particular strata, such, for example, as siliceous and micaceous deposits, appears to exercise an equally important influence on the distribution of this family, with the circumstances of latitude and elevation. Species of the groups of Andromèdece and I accinièce traverse the Andes from one extremity to the other ; and in Asia they extend from the Frozen Ocean to within the tropics, colonies of them being found in almost every branch of the Indian Alps. The similarity of the vegetation of North America and Central Asia is strikingly exemplified in the groups of this family, which are peculiar to both regions, such as Rhoddrece, Monotròpcce, Pyròlece, Y accinièa, and the aberrant Erícece. Some species are common to both continents, such as Pýrola picta, Monótropa Morisoniàna, Bryánthus Stellèri, Cassiópe tetragàna, and Andrómeda polifolia: the two last forming likewise part of the European Flora. Europe and Africa alone contain the normal Ericece, well characterized by their permanent corolla, the maximum of which is at the Cape of Good Hope, a spot where so many families of plants are found huddled together in strange confusion, as if nature had at length deprived herself of sufficient space for their equal distribution. The most easterly point to which this last group extends is the Mauritius, where the various species of Saláxis are found. The maximum of Rhodòrce, l'accinièa, Pyrolece, and Monotròpece, and the aberrant Ericce, is found in North America; these tribes are also common to Asia. Van Diemen's Land may be regarded as comprehending the majority of the Epacridea. Of all the genera of Ericacece, that of Gaulthèria is, however, the most extensively diffused, being met with in almost every region of America, in New Zealand, $\checkmark$ an Diemen's Land, and other places of the South Pacific, and in the Last Indies. 'The greater development of the calyx in this genus, and its more or less adherence to the ovarium, considerably lessens the importance of the discriminating character of the racinica, and most satisfactorily shows that they constitute but a group of Ericàcca, rather than a distinct order. As happens in other very natural families, the characters of the general groups of Ericàcece are not so strongly marked as in those that are less so; but we are not on that account to give up the idea of dividing them, and to retain four or five hundred species in one genus, as has been done in the case of Erica, which we have here attempted to subdivide into a number of minor groups; and, whatever opinion may be formed of their title to rank as separate genera, the arrangement of the species will we trust be found more natural than any hitherto proposed.

\section{Synopsis of the genera. \\ TRIBE I.}

ERíces. Anthers 2-celled. Ovarium free. Hypogynous disk nectariferous, sometimes, though rarely, ornamented with scales. Buds naked. Leaves usually with revolute margins.

Subtribe I. Erícele Norma'les. Normal Ericer. Corollas permanent.

1 Erica. Calyx 4-parted, naked at the base. Corolla globose or urceolate, with a 4-lobed limb. Stamens inclosed; with capillary filaments and bifid anthers; cells of anthers short, opening by an oblong hole, awned or crested at the base, rarely mutic. Stigma peltate. - Leaves acerose. Pediccls scaly.

2 Grpsoca'lis. Calyx 4-parted, glumaceous, naked at the base. Corolla campanulate, or short-tubular, with a dilated 4lobed mouth. Stamens exserted, with flattened flaments and bipartite anthers; cells of anthers mutic at the base, distinct, substipitate, opening by an oblique hole. Stigma simple. -Leaves acerose.

3 Ble'ria. Calyx 4-parted. Corolla short, tubular, with a 4-cleft limb. Stamens 4-6, with linear flattened glabrous filaments, and bipartite anthers; cells of anthers attenuated at the base, mutic, dehiscing by an oblong foramen at the apex. Stigma obtuse. - Leaves whorled. Flowers terminal, glomerate.

4. Sympie'za. Calyx turbinate, compressed, bifid. Corolla tubular, with a 2-parted limb, longer than the calyx. Stamens 4, epipetalous. Anthers bifid, mutic, exserted. Stigma simple.-Leaves linear, trigonal, 3 in a whorl. Flowers glomerate.

5 Pacry'sa. Calyx deeply 4-parted, coriaceous. Corolla nearly glohose, coriaceous, with a contracted 4-lobed mouth. Stamens inclosed, with dilated filaments, and bifid anthers; cells of anthers short, crested at the base, opening by an oblique foramen. Stigma obtuse.-Leaves loosely imbricated, compressed. Pedicels bracteolate.

6 Cera'ma. Calyx 4-parted, glumaceous. Corolla urceolate, with a 4-lobed limb. Stameris inclosed, with dilated flat filaments and bifid anthers: cells of anthers short, horned at the base. Stigma capitate.-Leaves scattered, bluntish, flat.

7 Désma. Calyx 4-lobed. Corolla globose, with a contracted 4-toothed mouth. Stamens exserted, with flat filaments ; cells of anthers short, opening by an oblong hole, simple at the base, and confluent in the filament. Stigma capitate.-Leaves scattered, subulate.

8 Euryle'pis. Calyx 4-parted, coriaceous, bibracteolate at the base. Corolla tubular, coriaceous, ventricose at the base, with an erect 4-parted limb. Stamens inclosed, with dilated channelled filaments, and hipartite anthers; cells of anthers coriaceous, opening by an oblong hole, auricled at the base. Stigma clavate.-Leaves scattered. Flowers terminal, solitary.

9 Eurystégi. Calyx 1-parted, large, glumaceous. Corolla 
urceolate, with a contracted 4-toothed mouth. Stamens inclosed, with dilated flat filaments and bipartite anthers; celts of anthers opening by an oblong foramen, biappendiculate at the base; appendages flat, crested, crenated. Stigma capitate.-Leaves subulate. Flowers subsolitary, pendulous.

10 Lopna'NDRA. Calyx 4-parted, furnished with 4 bracteas at the base: segments scarious, rounded, ventricose outside. Corolla campanulate, 4-lobed. Stamens inclosed, with dilated flat flaments and bifid anthers; cells of anthers beaked at the apex, winged, crested, and crenulated at the sides, dehiscing by an oblong hole in the middle. Stigma truncate.-Leaves short, obtuse, glaucous. Flowers terminal.

11 Lampròtis. Calyx 4-parted, large, glumaceous, coloured, bibracteate at the base. Corolla urceolate, with a small 4-lobed limb. Stamens inclosed, with capillary filaments; cells of anthers short, dehiscing lengthwise, mutic, or crested at the base. Stigma capitate.-Leaves adpressed, opposite, or 3 in a whorl. Flowers terminal.

12 Cacrísta. Calyx 4-parted, foliaceous. Corolla salvershaped, with a cylindrical or ventricose tube, and a dilated, spreading, 4-cleft limb. Stamens inclosed, with capillary filaments ; cells of anthers short, dehiscing lengthwise, mutic at the base. Stigma capitate.-Leaves acerose. Flowers terminal.

13 Eurýòma. Calyx 4-parted, foliaceous. Corolla salvershaped, with an elongated, filiform or ventricose tube, and a 4parted dilated limb. Stamens inclosed, with dilated, membranous, channelled filainents, and bipartite anthers; cells of anthers membranous, dehiscing lengthwise, drawn out at the base into a short tumid spur. Stigma with an elevated 4-lobed disk.Leaves adpressed, denticulated. Flowers teıminal.

14 Chòna. Calyx 4-parted, foliaceous. Corolla funnelshaped, with a revolute 4-lobed limb. Stamens exserted, with capillary filaments, and truncate anthers; cells of anthers elongated, parallel, awned at the base. Stigma simple, obtuse.Leaves 3 in a whorl, linear, awned. Flowers terminal.

15 Syringòdea. Calyx 4-leaved, glumaceous. Corolla longtubular, with a short 4-lobed limb. Stamens usually inclosed, with capillary filaments, and bipartite anthers; cells of anthers short, obtuse, mutic or awned at the base, dehiscing by an oblong foramen. Stigina simple or capitate, in some annulated by an elevated disk.-Leaves loose, acerose. Flowers crowded at the tops of the branches.

16 Dasyánthes. Calyx 4-parted, bibracteate at the base. Corolla tubular, hispid, with a 4 -lobed erect limb. Stamens inclosed, with capillary filaments, and bipartite anthers ; cells of anthers mutic at the base, dehiscing lengthwise. Stigma large, peltate.-Leaves loosely imbricated, hispid. Flowers in terminal fascicles.

17 Ecta'sis. Calyx 4-leaved, glumaceous. Corolla tubular, a little ventricose at the base, with a 4 -toothed limb. Stamens much exserted, with dilated filaments and bipartite anthers: cells of anthers elongated, tubular, dehiscing by a longitudinal fissure, having the base continuous in the filament, and mutic.
Stigma clavate, truncate.-Leaves loosely imbricated. Flowers terminal or lateral.

18 Eriode'smia. Calyx large, 4-parted, bibracteate at the base. Corolla campanulate, with a 4-lobed revolute limb. Stamens exserted, with dilated filaments, and bifid obtuse scabrous anthers; cells of anthers dehiscing by an oblong pore, continuous in the filament at the base.-Leaves 3 in a whorl, obtuse, hairy. Flowers terminal.

19 Осторг'ra. Calyx 4-parted, reflexed, naked at the base. Corolla globose, with a contracted bluntly 4-lobed mouth. Stamens inclosed, with flattened filaments; cells of anthers very short, dehiscing by an ample hole, and furnished at the base by a solitary lanceolate acuminated appendage.-A downy procumbent shrui. Leaves verticillate. Flowers terminal, subumbellate. Pedicels scaly.

20 Ere'mia. Calyx 4-parted, with imbricated bracteas at the base; segments orbicular, coriaceous, ciliated. Corolla urceolate, with a small 4-lobed limb. Stamens inclosed, with capillary filaments, and bipartite anthers; cells short, mutic at the base, dehiscing by an oblong hole. Stigma capitate. Cells of capsule 1-seeded.--Leaves spreading, bristly. Flowers glomerate.

21 Sala'xis. Calyx 4-leaved, irregular. Corolla campanulate, 4-cleft. Stigma peltate. Capsule drupaceous, 3-celled, 3-seeded.-Leaves 3-6 in a whorl. Flowers subracemose at the tops of the branches.

22 Callu'na. Calyx 4-parted, membranous, coloured, furnished with 4 bracteas at the base. Corolla shorter than the calyx, campanulate, 4-lobed. Stamens inclosed, with dilated filaments, and bipartite anthers, which are biappendiculate at the base; cells mucronulate, dehiscing lengthwise. Stigma capitate. -Leaves short, imbricated, in 4 rows. Flowers terminal, spicately racemose.

\section{Subtribe 1I. Androme'de. Corolla deciduous.}

23 Andrómeda. Calyx 5-cleft; segments acute, simple at the base. Corolla globose, with a contracted 5 -toothed mouth. Stamens 10, inclosed, with bearded filaments; cells of anthers short, one-awred. Stigma truncate. Capsule with a loculicidal dehiscence; placenta 5-lobed.

24. Cassióps. Calyx 5-leaved; segments imbricate at the base. Corolla campanulate, 5-cleft. Stamens 10, inclosed, with glabrous filaments; cells of anthers short, tumid, oneawned. Style dilated at the base; stigma obtuse. Capsule with a loculicidal dehiscence; valves bifid at the apex; placenta 5 -lobed.

25 Cassa'ndra. Calyx 5-leaved, bibracteate at the base; segments imbricate at the base. Corolla oblong, with a contracted 5-toothed mouth. Stamers 10, inclosed, with glabrous filaments; cells of anthers elongated at the apex, tubular, mutic. Stigma annulated. Capsule with a loculicidal dehiscence; placenta 5 -lobed.

$5 \mathrm{H} 2$ 
26) Zenònia. Calyx 5-toothed. Corolla campanulate, with a revolute 5 -lobed limb. Stamens 10 , with very short glabrous filaments; cells of anthers elongated, tubular, biaristate at the apex. Stigma truncate. Capsule with a loculicidal dehiscence ; placenta 5-lobed.

27 Lyòria. Calyx 5-parted. Corolla ovate or tuhular, with a contracted 5 -toothed mouth. Stamens inclosed, with short, flattened, downy filaments; cells of anthers membranous, dehiscing lengthwise, mutic. Style pentagonal; stigma obtuse. Capsule pentagonal, with a loculicidal dehiscence.

28 Levcothòe. Calyx 5-leaved; segments imbricated at the base. Corolla tubular, toothed. Stamens inclosed, with flattened downy filaments; cells of anthers short, truncate, mutic. Stigma large, capitate. Capsule with a loculicidal dehiscence.

29 PIE'ris. Calyx 5-parted. Corolla tubular or ovate, with a contracted, 5-toothed, revolute mouth. Stamens 10, inclosed, with dilated filaments, which are bisetose at the apex; cells of anthers short, incumbent, dehiscing lengthwise. Style pentagonal; stigma truncate. Capsule with a loculicidal dehiscence.

30 Phyllónoce. Calyx 5-parted. Corolla globose, witl a contracted 5 -toothed moutl. Stamens 10, inclosed, with slender glabrous filaments; cells of anthers short, truncate, mutic. Stigma peltate, with 5 tubercles. Capsule with a septicidal deliscence.

31 Bryántuus. Calyx 5-leaved, inbricated. Corolla deeply 5 -parted, spreading. Stamens 10, shorter than the corolla, with flattened glabrous filaments; cells of anthers short, mutic, or awned behind, dehiscing by a terminal foramen. Stigma obtuse. Capsule with a septicidal dehiscence.

32 Dabcicia. Calyx 4-parted. Corolla oval, ventricose, with a 4-toothed mouth. Stamens 8, inclosed, with dilated glabrous filaments, and linear anthers, which are sagittate at the base; cells of anthers parallel, loosened at the apex, dehiscing lengthwise. Stigma truncate. Capsule 4-celled, with a septicidal dehiscence.

83 Enkiánthus. Calyx small, 5-parted. Corolla campanulate, with a 5 -parted limb, and 5 nectarial pits at the base. Stamens inclosed; anthers 2-horned. Berry 5-celled, manyseeded.

34 A'rbutus. Calyx small, 5-parted. Corolla globose or ovate, with a small, contracted, 5-cleft, reflexed border. Stamens 10 , inclosed, with flattened filaments ; anthers compressed at the sides, dehiscing at the apex by 2 pores, fixed by the back beneath the apex, and there furnished with 2 reflexed awns. Stigma obtuse. Berry globose, granular.

35 Arctostáphyos. All as in A'rbutus, except that the fruit is 5-celled, and the cells 1 -seeded, and not granular on the outside.

36 Pernéttya. Calyx 5-parted. Corolla globose, with a contracted 5 -parted revolute limb. Stamens 10 , inclosed, having the filaments thickened at the base; anthers 2-celled, 2-lobed at the apex; lobes bifid. Hypogynous scales 10, 3-lobed, sur* rouncling the ovarium. Stigma convex. Berries globose, 5celled, many-seeded.

37 Agarísta. Calyx 5-lobed. Corolla ovate, with a contracted 5 -toothed month. Stamens 10 , inclosed, with flattened villous filaments, and bipartite anthers; cells of anthers short, mutic at the base, diverging at the apex, and dehiscing by a terminal pore. Capsule globose, 5 -celled, with a loculicidal dehiscence; placenta thick, oblong.

38 Dyprecòsı. Calyx girded by a calyculus, which is composed of 2 combined bracteas, 5-cleft. Corolla campanulate, with a 5 -cleft reflexed limb. Stamens 10 , inclosed, inserted in the disk of the calyx. Anthers bifid at the apex. Stigma truncate. Capsule nearly globose, depressed, inclosed in the baccate calyx, 5 -celled, many-seeded.

39 Gaulthe'ria. Calyx 5-cleft or 5-toothed, bibracteate at the base. Corolla ovate, ventricose, with a 5 -cleft revolute border, diaphanous at the base. Stamens 10, inclosed, with flat flaments; anthers bifid at the apex; lobes biaristate. Hypogynous scales 10, usually united at the base. Ovarium half inferior. Capsule 5-celled, witl a loculicidal dehiscence.

40 EPIGE'A. Calyx large, 5-parted, furnished with 3 bracteas at the base. Corolla salver-slıaped, with a 5-parted spreading border, and with the tube villous inside. Stamens 10. Capsule 5-celled; placenta 5-parted.

41 Phallerocárpus. Calyx 4-cleft, bibracteate at the base. Corolla campanulate, 4-cleft. Stamens 8, hairy.? Hypogynous disk 8-lobed. Anthers semibifid.

42 Cle'tura. Calyx 5-parted. Corolla so deeply 5-parted as to appear 5-petalled. Stamens 10 , with membranous filaments; anthers at length inflexedly pendulous, obverse, and cordate at the base, and mucronate at the apex, but mutic. Stigma trificl. Capsule 3-celled, many-seeded, with a loculicidal dehiscence.

\section{Tribe II.}

Rnodòre玉. Anthers 2-celled. Ovarium free. Hypogynous disk nectariferous. Buds strobile-formed, scaly. Leaves flat, callous at the extremity of the mid-rib.

43 Rhodode'ndron. Calyx 5-parted. Corolla somewhat funnel-shaped, 5-cleft. Stamens 5-10, declinate; anthers opening by 2 terminal pores. Capsule 5-celled, 5-valved, dehiscing at the summit.

44. VIRE'Ya. Calys obsoletely 5 -toothed, Corolla subcampanulate, or funnel-shaped, regularly 5 -lobed, adnate to the disk of the calyx. Stamens 10, inserted in the calycine disk; anthers dehiscing by terminal pores, mutic. Stigma capitate, 5furrowed. Capsule silique-formed, 5-angled, 5-celled, 5-valved. Placenta 5-lobed. Seeds numerous, expanded at both ends into a bristle-formed awn.

45 Beja'ria. Calyx 7 -cleft. Corolla 7 -petalled. Stamens 14, hypogynous. Anthers obverse and pendulous, mutic. Stigma capitate. Capsule depressedly globose, 7-celied, 7valved, with a septicidal dehiscence.

46 Hrmenánthes. Calyx small, obsoletely denticulated. 
Corolla subcampanulate, with a short compressed tube, and a 7 -parted limb. Stamens 14, hypogynous ; anthers mutic, opening by two terminal pores. Stigma obtuse, with 7 crenatures. Capsule oblong, 7 -valved, 7 -celled, many-seeded.

$47 \mathrm{Ka}^{\prime}$ LMis. Calyx 5-partẹd. Corolla salver-shaped; border producing 10 protuberances on the under side, and a corresponding number of cavities on the upper side, in which the anthers are concealed. Capsule 5-celled; dissepiments marginal.

48 Menzie'sia. Calyx 4-cleft. Corolla globose, 4-cleft. Stamens 8, hypogynous. Capsule 4-celled, 4-valved, having the dissepiments formed from the inflexed margins of the valves.

49 Aza'tea. Calyx 5-parted. Corolla short, campanulate, 5 -cleft. Stamens 5, equal, inclosed; cells of anthers bursting longitudinally. Style inclosed. Capsule 5-celled, 5-valved, dehiscing at top.

50 Lesoph Y' '́tem. Calyx deeply 5 -parted, permanent. Corolla 5-petalled. Stamens 10, exserted; anthers lateral, dehiscing lengthwise inside. Capsule roundish, 5-celled, 5-valved, deliscing at the apex.

51 LE'Dum. Calyx minute, 4-toothed. Corolla 5-petalled, spreading. Stamens 5-10, exserted; anthers opening by 2 pores at the apex. Capsule subovate, 5-celled, 5-valved, pedicellate, dehiscing at the base. Seeds ending in a wing at hoth ends.

\section{TRIBE III.}

VAccinie'e. Anthers 2-cellcd. Ovarium adhering. Disk perigynous, nectariferous. Fruit baccute. Buds naked.? scaly.?

52 VAccínium. Limb of calyx 4-5-toothed. Corolla urceolate or campanulate, 4-5-cleft. Stamens 8-10, hypogynous. Berry globose, 4-5-celled, many-seeded.

53 Oxxcóccus. Calyx 4-cleft. Corolla 4-parted, with the segments somewhat linear and revolute. Stamens 8 ; filaments conniving; anthers tubular, bipartite. Berry 4-celled, manyseeded.

54. Gaylussa'cia. Limb of calyx 5-cleft. Corolla tubular, with a ventricose base and a 5 -cleft limb. Stamens 10, inserted in the limb of the calyx; anthers mutic, drawn out into 2 little tubes from the top. Stigma capitate. Berry nearly globose, 10 -celled; cells 1 -seeded.

55 Thibau'dia. Calyx urceolar, 5-lobed. Corolla tubular, with a contracted 5 -toothed mouth. Stamens 10 , inserted in the calyx, inclosed; anthers elongated, mutic, drawn out into 2 little tubes at the apex. Berry 5 -celled, many-seeded.

56 Agape'res. Limb of calyx 5-cleft. Corolla tubular, with a 5-cleft limb. Stamens 10, with very short flattened filaments ; anthers mutic, very long, auricled at the base, exserted, narrow, emarginate at the apex, with the cells confluent. Stigma clavate. Berry 5 -celled, many-seeded.

57 Ceratostémia. Limb of calyx large, 5-parted, foliaceous. Corolla tubular, contracted and 5-lobed at the apex.
Stamens 12 , with very short, flattened, hairy filaments; anthers bluntly spurred at the base, having the cclls elongated at the apex and filiform, dehiscing by a terminal pore. Stigma simple. Berry 5 -celled, many-sceded.

\section{Tribe IV.}

Pyròuı. Anthers 2-celled. Otarium free. Disk hypogynous, naked. Scells peltate, samaroid. Embryo dicotyledonous. - Percnnial herbaceous plants.

58 Preóla. Calyx 5-cleft or 5-parted. Petals 5. Stamens 10, slightly united at the base. Style exserted. Stigma 5lobed. Capsule 5-celled, dehiscing at the angles near the base, having the margins of the valves connected by intricate tomentum.

59 China'puila. Calyx 5-toothed. Petals 5. Stamens 10. Style short, inmersed in the germ. Stigma auriculate, orbicular, with a 5-lobed disk. Filaments stipitate; stipe discoid, ciliated. Capsule 5-celled, opening from the summit, with unconnected margins.

60 Mone'ses. Calyx 5-parted. Corolla deeply 5-lobed. Stamens recurved. Stigma radiate. Anthers 2-horned at the base, becoming reversed, and opening at the bottom of each horn. Capsule 5-celled, 5-valved, opening from the summit with unconnected margins.

61 Ceadormánus. Calyx 5-parted. Petals 5. Anthers adnate. Stamens 10. Stigma 5-lobed. Capsule 5-6-valred, 5-6celled ; margins of valves septiferous. Seeds small, involved in a membranous aril.

\section{Tribe V.}

Monotròpe.e. Anthers 1-celled. Ovarium frce. Disk hypogynous, naked. Sceds peltate. Embryo undivided.-Leafless parasitical herbs.

62 Hypópirys. Calyx 3-5-parted. Corolla 4-5-petalled; petals or segments eacl 1 with a cucullate nectariferous base. Anthers small, horizontal, at lengtb opening flat. Stigma orbicular, with a bearded margin. Capsule 5-celled, 5-valved, many-seeded.

63 Monórropa. Calyx none. Corolla 5-petalled; petals or segments each with a cucullate nectariferous base ; anthers reniform, horizontal. Stigma orbicular, naked. Capsule 5-celled, 5 -valved, many-seeded.

64 Preróspora. Calyx 5-parted. Corolla ovate, with a reflesed 5 -toothed border. Anthers peltate, adnate to the filaments by the margin, bisetose. Capsule 5-celled; placenta 5lobed. Sceds terminated each by a wing.

65 Schivernírzsa. Calyx 5-cleft; segments concave, equal with the corolla. Corolla campanulate, with a 5 -cleft border. Hypogynous disk 5-cleft. Anthers adnate to the filaments, opening from the inverted base by two naked pores. Stigma subglobose, internally 5 -cleft. Capsule 5-celled.? Seeds unknown. 
I. ERICA (Erica of Pliny is altered from $\varepsilon \rho \varepsilon \mathrm{r}^{\prime} \mathrm{y}$ of Theo-

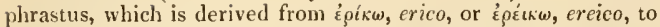
break; from the supposed quality of some species in breaking the stone in the bladder). D. Don. in edinb. phil. journ. 17 . p. 152.-Erica species of Lin. and other authors.

Lin. syst. Octándria, Monogýnia. Calyx 4-parted, with a naked base. Corolla globose or urceolate, with a 4-lobed limb. Stamens inclosed; filaments capillary; anthers bifid; cells of anthers opening by an oblong hole, awned or crested at the base, or mutic. Stigma peltate. Capsule 4-celled, many-seeded.Shrubs, natives of Europe and Africa. Leaves scattered or verticillate, acerose. Flowers terminal, fascieled or racemose. Pedicels sealy.

\section{Anthers annod at the base. Normal species.}

\section{* Leaves 3 in a whorl. Corollas campanulate.}

1 E. Lâtris (Andr. heath. 3. t. 6.) leaves glabrous, 3-4 in a whorl, spreading; branches slender; flowers terminal by threes, drooping; corollas small, bell-shaped; awns of anthers falcate. h. G. Native of the Cape of Good Hope. Lodl. bot. cab. 1393. E. cyathiformis, Sal. in Lin. trans. 6. p. 376 . Flowers white. Plant glabrous, Anthers black. Perhaps only a variety of $E$. persolùta. feet.

Smooth Heath. Fl. Marel, July. Clt. 1801. Shrub 1 to 2

2 E. eALlòs A (Wendl. eric. ex Spreng. syst. 2. p. 194.) leaves 3 in a whorl, linear-oblong, with revolute edges, spreading, white beneath; flowers terminal, usually by threes, erectish; calyx coloured, viscid; corollas campanulate; awns of anthers

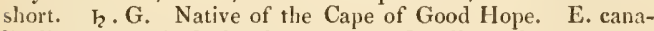
liculàta mìnor, Andr. heath. 3. เ. 39. Corollas redl.

Callous Heath. Fl. June, July. Clt. I822. Shrub 1 foot.

3 E. DEPrE'ssa ('T'hunb. diss, no, 50. with a figure); leaves glabrous, 3 in a whorl, linear, revolute; flowers terminal; corolla bell-shaped; spurs of anthers long, subulate and hairy; bracteas remote from the calyx. $h$. G. Native of the Cape of Good Hope. E. rupéstris, Andr. heath. 2. t. 9. E. hùmilis, Salisb. in Lin, trans. 6, p. 329. Branches decumbent. Flowers small, white.

Depressed Heath. Fl. July, Nov. Clt, 1789. Shrub depressed.

4. E. Nolær lòra (Bedf. eric. wob. p. 16. but not of Sal.) leaves 3 in a whorl, slightly hispid; flowers subaxillary; bracteas remote from the calyx; corolla eampanulate, with deep segments; anthers awned. $々$. G. Native of the Cape of Good Hope. Erìca glomeràta, Hort. Flowers white.

Bell-flowered Heath. Fl. Ju. July. Clt. 1818. Shrub.

5 E. sicæròlia (Sal. in Lin. trans. 6. p. 326.) leaves 3 in a whorl, mucronate; corolla $1 \frac{2}{3}$ lines long, hairy outside, with a cup-shaped tube; flowers terminal; spurs of anthers linear; fruit glabrous. h. G. Native of the Cape of Good Hope.

Dagger-leared Heath. Fl. Feb. May. Clt.? Slırub.

6 E. monta'sa (Bedf. eric. wob. p. 15.) leaves 3 in a whorl; flowers axillary, by threes; bracteas broad, approximating the calyx, loose, angular; corolla bell-sliaped; anthers awned; style inclosed. $h_{2}$. G. Native of the Cape of Good Hope. E, confertifòlia, Wendl.? Flowers purplish-red.

Mounlain Heath. Fl. Oct. Clt. 1818. Shrub.

7 E. villosiu'scula (Lodd. bot. cab. 1844.) hairy; leaves acieular, eiliated with long hairs; flowers disposed in racemose terminal fascieles; corollas campanulate. $\zeta$. G. Native of the Cape of Good Hope. Flowers small, pale red. Anthers unknown.

Rather-villous Heath. Fl.? Clt.? Shrub.

8 E. Аме' NA (Sal. in Lin. trans. 6. p. 329.) leaves lanceo- late, 3 in a whorl; flowers terminal; corolla bell-shaped; bracteas remote from the calyx; anthers awned, glabrous. $h_{c}$. G. Native of the Cape of Good Hope. Erica incarnata, Thunb. diss. 84. Flowers small, reddish-pupple. Corolla 4-5 lines long.

Plcasant Heath. Fl. April, July. Clt.? Shrub.

9 E. Assu'rgens (Hortul. Bedf. hort. eric. wob. p. 2.) leaves $3-4$ in a whorl, villons; flowers terminal; corolla bellshaped; bracteas approximating the calyx; anthers awned. $h$. G. Native of the Cape of Good Hope. Flowers white. Branches villous. Style inclosed.

Aspiring-branched Heath. Fl. March, Sept. Clt. 1821. Shrub 1 foot.

10 DEFLE'XA (Bedf. hort, eric. wob. p. 8.) leaves 3 in a whorl, rough ; flowers terminal, umbellate; corolla deflexed, openbell-sliaped; bracteas minute, remote from the calyx; anthers

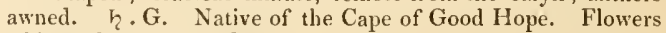
white. Style exserted.

Deflexed-flowered Heath. Fl. July. Clt, 1810. Shrub I to 2 feet.

11 E. oвtu's (Lodd. bot. cab. 1027.) glabrous; leaves 3 in a whorl, obtuse; flowers terminal, by threes; corollas campanu-

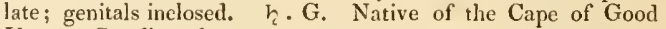
Hope. Corolla red.

Blunt-leaved Heath. Fl. May, June. Clt. 1810, Shrub.

12 E. glomera'ta (Lodd. ex Bedf, eric, wob. p. 1].) leaves 3 in a whorl ; flowers terminal, capitate ; corollat small, bell-shaped; bracteas approximating the calyx; anthers awned. $\eta$. G. Native of the Cape of Good Hope. Flowers small, purplisl. red. Style exserted.

Glomeraled-flowered Heath. Fl. Spring. Clt, 1780. Shrub 1 to 2 feet.

12 E. verna'us (Lodd. bot. cab. 1608.) glabrous; leaves 3 in a whorl; flowers terminal; corollas eampanulate; style exserted. $\zeta$. G. Native of the Cape of Good Hope. Flowers purplish-red. Anthers unknown.

I'rnal Heath. Fl. March, April. Clt. 1827. Shrub 2 to 3 feet.

14 E. parvirlòra (Bedf. hort, eric, wob. p. 17.) leaves 3 in a whorl; flowers terminal, almost sessile; corolla eampanulate;

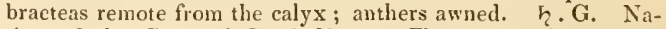
tive of the Cape of Good Hope. Flowers small, reddishpurple. Style inclosed.

Small-flonercd Heatl. Fl. April, June. Clt. 1814. Shrub 1 foot.

15 E. TE'surs (Sal. in Lin. trans. 6. p. 329.) leaves 3 in a whorl, linear, glabrous; flowers terminal, subsolitary; bracteas remote from the calyx; corolla bell-shaped; anthers awned; style exserted. h. G. Native of the Cape of Good Hope. Erica divaricàta, Hort. Bedf, eric. wob. p. 8. Floxers white. Awns of anthers linaar, attenuated; filaments very short.

Slender Heath. Fl. June, July. Clt. 1800. Shrub $1 \mathrm{ft}$.

16 E. Scholdia'na (Lodd. bot. cab. 538.) leaves alternate, seattered; flowers subterminal and axillary; corolla campanulate; bracteas remote from the calyx, anthers awned. $h$. G. Native of the Cape of Good Hope. Flowers purple, drooping, and are as well as the calyxes coloured. Style inclosed. Seet.

17 E. Aст⿸广 'A (Bedf. hort. eric, wob. p. 1.) leaves 3 in a whorl, glabrous; flowers terminal; bracteas remote from the calyx; corolla oblong-bell-shaped; anthers awned. $\hbar$. G. Native of the Cape of Good Hope. Erìea Láchnèa, Hort. but not of Andr. Corollas white. Style exserted.

Actea-flowered Heath. Fl. April. June. Clt.? Shrub. 


\section{* Leaves 3 in a whorl. Corollas urecolate.}

18 E. pube'scens (Lin. spec. 506.) leaves linear, 3 in a whorl, downy; flowers terminal; pedicels hardly the length of the flowers; corolla 2 lines long, urceolate, downy both inside and outside; spurs of anthers short. $\zeta . G$. Native of the Cape of Good Hope. E. pubéscens, var. pilòsa, Thunb. eric. no. 61 . E. pállida, Sal. in Lin. trans. 6. p. 326. Sides of calyx reduplicate. Flowers pale red. Style inclosed.

Downy Heath. Fl. Year. Cult. 1790. Shrub 1 foot.

19 E. нírta (Thunb. eric. no. 56. t. 2.) leaves 3 in a whorl, linear, bristly; flowers terminal; pedicels more than twice the length of the flowers; corolla 3 lines long, downy outside, with an urceolar tube; spurs of anthers linear attenuated. $\zeta . G$. Native of the Cape of Good Hope. E. dùra, Hort. E. urceolàris, Sal. in Lin. trans. p. 326. Corolla pale green, with greenish yellow apex. Style inclosed. fect.

Hairy Heath. Fl. April, July. Clt. 1795. Shrub I to 2

20 E. suave'olens (Lodd. bot, cab. t. 24.) leaves 8 in a whorl, oblong-lanceolate, ciliated ; flowers terminal; bracteas remote from the calyx; corolla urceolate; anthers a little exserted, black; style much exserted. h. G. Native of the Cape of Good Hope. Flowers pale red.

Sneet-scented Heath. Fl. Ang. Clt. 1800. Shrub.

21 E. Grandinòsa (Lodd. bot. cab. 627.) glabrous; leaves linear, 3 in a whorl; flowers terminal, drooping, by threes; corolla irregularly ovate, inflated, small; anthers awned; calyx reflexed. $h$. G. Native of the Cape of Good Hope. Bedf. hort. eric. wob. p. 11. Flowers small, white. Style inclosed.

Hail-stone-flowered Heath. Fl. April, May. Clt. 1810. Shrub $\frac{1}{2}$ to 1 foot.

22 E. Incu'Rva (Andr. heath. 3. t. I.) leaves linear, 3 in a whorl, rather falcate, with revolute ciliated edges ; flowers terminal by threes ; calyx ciliated; corolla globose; anthers awned. 々. G. Native of the Cape of Good Hope. E. campylophýlla, Spreng. syst. 2. p. 190. Plant downy. Flowers small, red. Style exserted.

Incurced-leaved Heath. FI. March, May. Clt. 1802. Shrub 1 foot.

23 E. GLobòsa (Andr. leath. 3. t. 24.) leaves linear-lanceolate, oblong, 3-4 in a whorl, ciliated, recurved; flowers terminal, aggregate, drooping; corollas globose ; calyx coloured, beset with glandular hairs; awns of anthers small. $h_{2} . G$. Native of the Cape of Good Hope. Flowers small, pink.

Globose-flowered Heath. Fl. May, Oct. Clt. 1789. Shrub.

24 E. Tubiu'scula (Bedf. hort. eric. wob. p. 26.) downy; leaves 3 in a whorl; flowers terminal; corollas tubular, very small; anthers awned; bracteas remote from the flower. $h$. G. Native of the Cape of Goorl Hope. Lodd. bot. cab. 1157. E. pubéscens mínima, Andr. heath. 2. to 8. Flowers small, purplish red. E. pubéscens, Wendl. eric. p. 8. no. 7 . Style inclosed.

Small tubular-flowered Heath. Fl. Feb. April. Clt. 1800. Slirub 1 foot.

25 E. articula'ris ('Thunb. diss. no. 58. but not of Lin.) leaves 3 in a whorl, cuneate or ovate, glabrous; flowers spicate; corolla globose; spurs rising from the middle of the filaments, not from the anthers. h.G. Native of the Cape of Good Hope. Sims, bot. mag. 423. E. retrofléxa, Wendl. eric. 8. p. 7. with a figure. Ait. hort. kew. 2. p. 401. E. pulchélla, Andr. heath. 1. t. 2. Lodd. bot. cab. 30\%. but not of Thunb. E. caduceifera, Sal. in Lin. trans. 6. p. 370. Flowers small, purplish red.

Jointed Heath. Fl. Aug. Feb. Clt. 1792. Shrub 1 foot.
26 E. PYgMA'A (Andr. heaths, vol. 4 . icon.) leaves 3 in a whorl, subulate, glabrous, squarrose; branches decumbent; flowers terminal, generally by fours, downy; calyxes short, adpressed; corolla globose; anthers awned. Ћ. G. Native of the Cape of Good Hope. E. sanguinolénta, Ker. in bot. mag. 2263. Lodd, bot. cab. 468. Flowers small, blood-red or puple. Bracteas remote from the calyx. Style inclosed. bent.

Dwarf Heath. Fl. July, Oct. Clt. 1806. Shrub procum-

27 E. urceola'ris (Berg. pl. cap. p. 107. Ait. liort. kew. pl. 16. Wendl. eric. no. 9. p. 11.) downy; leaves 3 in a whorl, linear-lanceolate, spreading ; flowers terminal; bracteas remote from the calyx; awns of anthers glabrous; corolla ovate, downy outside. $\zeta$. G. Native of the Cape of Good Hope. Lodd. bot. cab. 1894. E. pentaphýlla, Lin. spec. ed. 2. p. 506. E. Cáffra, Lin. spec. ed. 1st. and 2d. E. lamellàris, Sal. in Lin, trans. 6. p. 327. Corolla white, 3 lines long, with a pyramidal tube. Style inclosed.

Urceolar-flowered Heath. Fl.

28 E. romentòs A (Sal. in Lin. trans. 6. p. 327.) clothed with hoary tomentum; leaves 3 in a whorl, narrow-linear, ciliated, imbricated; flowers terminal by threes; calyx flattisl, fringed; corolla $1 \frac{1}{2}$ line long, tomentose both inside and outside; spurs of anthers long, recurved. $々$. G. Native of the Cape of Good Hope. Bracteas situated at the base of the pedicels, and are, as well as the calyxes and corollas, purple.

Tomentose Heath. Fl. June, July. Clt. 1798. Shrub.

29 E. Alopecuroìdes (Wend]. eric. no. 20, p. 119.) leaves linear, 3 in a whorl; flowers terminal; corollas ovate; bracteas remote from the calyx; anthers awned. h. G. Native of the Cape of Good Hope. Lodd. bot. cab. p. 874. Flowers small, purplish red. Plant downy. Calyx coloured, ciliated. Style inclosed.

Fox-tail Heath. Fl. Sept. Oct. Clt. 1810. Shrub I foot. 30 E. ADENóphora (Spreng. syst. 2. p. 188.) leaves 3 in a whorl, glandularly hispid, spreading, remotish ; fowers terminal, aggregate, glabrous; calyxes viscid, coloured, adpressed. $\zeta_{c}$. G. Native of the Cape of Good Hope. Anthers awned. Corollas urceolate.

Gland-bcaring Heath. Shrub.

31 E. Lachinefeòlia (Salisb. in Lin. trans. 6. p. 335. Ait. hort. kew. 2. p. 387.) leaves 3 in a whorl, ovate, obtuse, imbricated, downy; flowers terminal, sub-capitate, ; corolla ovate, 2 lines long, with a recurved limb; spurs of anthers long and narrow-cuneated, smooth. h. G. Native of the Cape of Good Hope. E. láchneæ, Andr. heaths. 3. t. 2. Flowers middle-sized, white. Style exserted.

Lachnce-leaved Heath. Fl. May, July. Clt. 1793. Shrub 1 foot.

32 E. Pezìza (Lodd. bot. cab. t. 265.) glabrous; leaves 3 in a whorl ; flowers terminal ; corolla globosely campanulate ; bracteas remote from the calyx; anthers awned. h. G. Native of the Cape of Good Hope. Bedf, eric. wol). p. 3. f. 1. E. nivàlis, Andr. heath. vol. 4. Flowers small, white, downy. Genitals inclosed.

Peziza-flowered Heatlu. Fl. April, May. Clt. 1812. Shrub 1 foot.

33 E. pulverulénta (Bedf. eric, wob. 20.) clothed with powdery down ; leaves 3 in a whorl ; flowers terminal ; corollas ovate; bracteas imbricate; anthers awned. $h_{\text {. }}$ G. Native of the Cape of Good Hope. Flowers purplish-red. Style inclosed.

Powdery Heath. Fl. June, Aug. Clt.? Shrub.

34. E. Puria'lis (Bedf. l.c.) leaves $S$ in a whorl; flowers terminal; corolla globose; anthers awned, a little exserted. $h . H$. 
Native of the Cape of Good Hope. Flowers reddish-purple, small. Style exserted.

Fiery Heath. Fl. Sept. Oct. Clt. 1810 . Shrub 1 foot.

35 E. regérminans (Lin. syst. 364. Thunb. 35. no. 54.) leaves linear, recurved, $3 \mathrm{in}$ a whorl; flowers pedicellate, drooping, semi-lateral: bracteas remote; corollas ovate-globular; anthers awned. $h$. G. Native of the Cape of Good Hope. Lodd. bot. cab. 1728. Erìca uncifòlia, Sal. in Lin. trans. 6. p. 369 . Flowers small, pale red. Spurs of anthers very long.

Regerminating Heath. Fl. May, Aug. Clt, 1791. Slurub $1 \frac{1}{2}$ foot.

36 E. RUBE'LLA (Lodd. bot. cab. 658. Sims, bot. mag. 2165.) leaves 3 in a whorl; flowers terminal, capitate ; corolla ovate, ventricose, length of calyx; bracteas approximating the calyx. 々. G. Native of the Cape of Good Hope. Flowers small, purplish-rerl. Style inclosed.

Reddish-flowered Heatl., Fl. Summer. Clt. 1814. Shrub. 37 E. scabiu'scula (Link, enum. 1. p. 37\%. Lodd, bot. cab. t. 517.) leaves $3-4$ in a whorl, obtuse, beset with glandular hairs; flowers terminal; corollas ovate; bracteas approximate to the calyx; anthers awned. h. G. Native of the Cape of Good Hope. Flowers small, silky white or red, sessile. Style inclosed.

Roughish Heath. Fl. April. Clt. 1810. Shrub 1 foot.

\section{* * Leaves 4 in a whorl. Corollas campanulate.}

38 E. PERSOLU't A (Lin. mant. 230. diss. no. 16. with a figure, leaves 4 in a whorl, short, linear, glabrous ; corolla campanulate, with deep acute segments; flowers terminal; branches downy or hairy; spurs of anthers straight; fruit lairy. 々. G. Native of the Cape of Good Hope. Curt. bot. mag. 324. E. subdivaricàta, Berg. fl. cap. p. 114. E. prolífera, Sal. in Lin. trans. 6. p. 376 . E. Căffra, Andr. heath. 1. t. 4. E. strigòsa, Wendl. eric. fase. 2. p. 25. with a figure. Willd. spec. 2. p. 365. Corollas small, bell-shaped, white, $1 \frac{1}{2}$ line long. Style inclosed.

Var. $\beta$, rúbra (Hort.); flowers red. 々. G. E. persolùtal, Curt. bot. mag. 324. Pedicels bibracteate in the middle.

Var. $\gamma$, spicata (Hort.) ; flowers spicate, white.

Accomplished Heath. Fl. April, May. Clt. 1774. Shrub $1 \mathrm{ft}$. 89 E. strigòs A (Sol. in Ait. lort. kew. 2. p. 404.) Jeaves 4 in a whorl, linear, bluntish, downy, ciliated; branches villous; flowers axillary, aggregate; calycine segments villous, adpressed; corolla campanulate; spurs of anthers subulate, hairy. h. G. Native of the Cape of Good Hope. E. axillàris, Sal. in Lin. trans. 6. p. 325. E. arbòrea, Thunb. diss. no. 65. Bracteas 2, minute. Corolla $1 \frac{1}{2}$ lines long, smooth. There are white and purple flowered varieties of this species. Corolla campanulate. Style exserted. feet.

Strigose Heath. Fl. Marel, April. Clt. 1775. Shrub 1 to 2

40 E. NEGLE'CTA; glabrous; leaves linear, 4 in a whorl, adpressed ; corolla campanulate; anthers awned. 々. G. Native of the Cape of Good Hope. E. grácilis, Ait. hort, kew. 2. p. 404. Willd, spec. 2. p. 363 . Wendl. eric. 8. p. 9. with a figure. Flowers small, red.

Negleeted Heath. Fl. year. Clt. 1794. Shrub 1 foot.

4.1 E. LASIOPHY'LLA (Spreng. syst. 2. p. 195.) leaves 4 in a whorl, linear, scabrous, glandularly ciliated, spreading, aristate at the apex; flowers racemose, drooping ; calyx adpressed ; corolla campanulate; anthers awned. $h$. G. Native of the Cape of Good Hope. Flowers reddish-purple. Style inclosed.

Woolly-lcaved Heath. Fl. May, Aug. Clt. 1816. Shrub 1 to 2 feet.
42 E. FLORIBU'NDA (Lodd. bot. cab. 176.) glabrous; leaves 4 in a whorl; flowers terminal; corolla bell-sliaped, open; anthers awned. h. G. Native of the Cape of Good Hope. Flowers small, axillary and terminal, pale red. Style exserted.

Bundle-flowercd Heath. F]. A pril, May. Shrub.

43 E. Pelvifórmis (Sal. in Lin. trans. 6. j. 376. ) leaves 4 in a whorl ; flowers terminal; pedicels hardly pubescent : corolla $1 \frac{1}{2}$ line long, with a bowl-formed tube, and with the interstices of the limb oval at the base; spurs of anthers falcate. $h$. G. Native of the Cape of Good Hope. Erica persolùta, Thunb. diss. no. 62. Curt. bot. mag. no. 34\%. E. viridipurpurrea, Lin. diss. no. 9. with a flower. E. Mauritánica, Lin. syst. nat. ed. 10. p. 1002. There are varieties of this with either white or purple flowers.

Bonl-formed-flowered Heath. Fl. May, $\Lambda$ ug. Clt. 1800. Shrub. 44 E. QUAdreflòra (Sal. in Lin. trans. 6. p. 375.) stem glabrous; leaves 4 in a whorl; flowers terminal, by fours; co. rolla $1 \frac{1}{4}$ line long, with a cup-shaped tube, and an erect limb ; spurs of anthers lanceolate-cuneated, $\zeta$. G. Native of the Cape of Good Hope. E. quadrangulàris, Sal. prod. p. 297.

Four-flowered Heath. Fl. March, Ang. Clt. 1800. Shrub.

45 E. LeUea'ntias; leaves 4 in a whorl; flowers terminal, umbellate; bracteas remote from the calyx; corolla bellshaped; anthers awned. $\eta$. G. Native of the Cape of Good Hope. E. regérminans, Andr. heath. vol. 4. but not of Lin. Flowers small, white. Style a little exserted. foot.

White-flowered Heath. Fl. Dec. Jan. Clt. 1810. Shrub 1

\section{*** Lcaves 4 in a nhorl. Corollas urceolate.}

46 E. TÉtralux (Lin. spec. ed. 2d. p. 507.) leaves ciliated, 4 in a whorl ; calyx adpressed ; flowers capitate, terminal ; corolla ovate-glohose, downy at top, ontside; spurs of anthers lanceolate. $\zeta . \mathbf{H}$. Native of the north of Europe, in boggy or moorish ground; plentiful in Britain. Curt. fl. lond. fasc. 1. t. 21. Smith, engl, bot. 1314. Fl. dan. 81. E. botulifơrmis, Sal. in Lin. trans. 4. p. 369 . E. Barbárica, Rai. syn. 471. E. pùmila, Park, theatr, 1483. no. 5. E. tétralix rìbra, Bedf. hort. eric. wob. p. 25. Corollas 3 lines long, pale red.-Plant of greyish hue.

Var. $\beta$, álba (Bedf. hort. eric. wob. p. 25.) flowers white. Ait. hort. kew. 2. p. 393. foot.

Besom Heath. Fl. July, Sept. Britain. Shrub $\frac{1}{2}$ to 1

47 E. Blandfordia'sa (Ait. hort. kew. 2. p. 392.) leaves linear, 4 in a whorl, spreading; flowers terminal, almost solitary; corolla ovate-globose, or urceolar; anthers awned. $\zeta$. G. Native of the Cape of Good Hope. Curt. bot. mag. 1793. Lodd. bot. cab. 115. E. Blandfordia, Andr. heath, 3. t. 8 . Corollas yellow, small. In the hortus eric. wob. the anthers are said to be mutic ; this must be wrong.

Blandford's Heath. Fl. Nareh, June. Clt. 1803. Sliruh 1 foot.

48 E. hirtiflòra (Sims, bot. mag. 481. I,odd. bot. cab. 1812.) leaves linear, hairy, 4 in a whorl; flowers terminal, umbellate, downy ; corolla ovate-globose, with an erect limb; anthers awned; fruit glabrous. $h$. G. Native of the Cape of Good Hope. E. mitræfórmis, Salisb. in Lin. trans. 6. p. 37 ?. E. pubéscens, Andr. heath. 1. t. 5. E. pubéscens, var. híspida, Thunb. eric. no. 61 . Corollas purple, small.

Hairy-flowercd Heath. Fl. Aug, Feb. Clt. 1790. Shrub $1 \frac{1}{2}$ foot.

49 E. tardifiòr. (Sal. in Lin. trans. 6. p. Sto.) leaves 4 in 
a whorl, linear, revolute, downy; flowers terminal, umbellate; corollas urceolate, downy, with a short recurved limb; anthers awned; fruit hairy. h. G. Native of the Cape of Good Hope. E. pubéscens, Curt. bot. mas. 480 . E. hirtiflòra, $\beta$, Ait. hort. kew. 2. p. 406 . Calyxes adpressed, narrow, ovate, cuneated. Corollas red. Style inclosed.

Late-flonered Heath. Fl. year. Clt. 1800, Shrub 1 to 2 feet.

50 E. cane'scens (Wendl. eric. ex Spreng. syst. 2. p. 195.) leaves 4 in a whorl, linear, canescent, erect; flowers terminal, sessile ; corolla urceolately-campanulate; calyxes foliaceous, ovate, acuminated, adpressed; awns of anthers linear. $h . G$. Native of the Cape of Good Hope. E. pubéscens minor, Andr. heath. 2. t. 7. E. exígua, Sal. in Lin. trans. 6. p. 373. E. pubéscens parviflòra, Thunb. diss. no. 61 . Corolla with an oval tube, and a short limb. Flowers small, pale purple.

Caneseent Heath. Fl. Oct. March. Clt. 1790. Shrub 1 foot.

51 E. Pusícla (Salisb. in Lin. trans. 6. p. 374.) downy; leaves 4 in a whorl; calyxes adpressed, broad, ovate-cuneated; corollas very small, downy, with a cup-shaped tube, and the limb the length of the tube; anthers awned; fruit glabrous. h. G. Native of the Cape of Good Hope, in Baay Fals. Flowers terminal.

Least Heath. Shrub.

52 E. cónica (Lodd. bot. cab. 1179.) leaves 4 in a whorl, linear, glabrous; flowers axillary, racemose; genitals inclosed. h. G. Native of the Cape of Good Hope. Flowers purplishred.

Conieal-flowered Heath. Fl. May, Aug. Clt. 1822. Shrub.

53 E. pubígera (Sal. in. Lin. trans. 6. p. 372.) downy; leaves 4 in a whorl ; flowers terminal ; calyxes spreading, ovateacuminated; corolla $1 \frac{1}{2}$ line long, downy, with a longish recurved obtuse limb; anthers awned; fruit hairy. দ.G. Native of the Cape of Good Hope, on Mount Taffelberg.

Down-bearing Heath. Shrub.

54 E. catervarlòra (Sal. 1. c.) hairy; leaves 4 in a whorl; stem angular; flowers terminal; corolla 2 lines long, downy, with a narrow obovate tube; anthers awned, dehiscing by long holes. h. G. Native of the Cape of Good Hope, on the summit of Mount Taffelberg. E. pubéscens villòsa, Thunb. diss. no. 61 .

Company-flowered Heath. Shrub.

55 E. TURBiNiflòra (Sal. in Lin. trans. 6. p. 377.) stem glabrous; leaves 4 in a whorl; flowers terminal; corolla $1 \frac{1}{2}$ line long, smooth, with a turbinate 8-angled tube, and an incurved limb; spurs of antliers glabrous. h. G. Native of the Cape of Good Hope. Flowers pale purple.

Top-flowered Heath. Fl. Feb. Oct. Clt. 1793. Shrub.

56 E. Tragulífera (Sal. in Lin. trans. 6. p. 374.) leaves 4 in a whorl ; flowers terminal; calyx imbricate; corolla $2 \frac{1}{3}$ lines long, with an urceolar tube, and a recurved limb: anthers hairy, broadly foraminose; spurs hairy. h. G. Native of the Cape of Good Hope.

Beard-bearing Heath. Fl. May, Aug. Clt. 1800. Shrub.

57 E. Plumòsa (Andr. heath. 2. t. 6.) leaves 4 in a whorl, linear, hairy, erect, imbricated; flowers disposed in axillary whorls ; corolla ovate-globose; calyxes hairy; anthers awned. . G. Native of the Cape of Good Hope. Erìca amo'na, Wendl. eric. 17. p. 73 . Corollas purplish-red. Branches erect. Style exserted.

Feathered Heatlı. Fl, March, July. Clt. 1795. Shrub 1 foot.

58 E. Tenuíssima (Wendl. eric. fasc. 6. p. 9. with a figure) leaves 4 in a whorl, linear-filiform, glabrous, erect, somewhat imbricated ; flowers terminal, aggregate; calyx short, naked; voL. III. corolla urceolate, with an erectish limb; anthers appendiculate. h. G. Native of the Cape of Good Hope. Flowers red.

Slenderest Heath. Fl. Feb. Aug. Clt. 1803. Shrub $1 \mathrm{ft}$.

59 E. curviróstus (Sal. in Lin. trans. 6. p. 375.) leaves 4 in a whorl, linear; flowers terminal: calyxes adpressed; corolla $1 \frac{1}{2}$ line long, with a splierical tube; spurs of anthers downy;

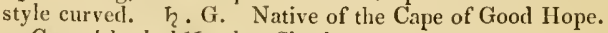

Curved-beaked IIeath. Shrub.

60 E. pilulírera (Lin. spec. ed. 2. p. 507.) leaves 4 in a whorl, linear, glabrous, ciliated ; flowers terminal ; corollas globose, $2 \frac{1}{2}$ lines long, having the tube length of the calyx; calycine segments ovate, acuminated, deeper coloured at the apex; spurs of anthers linear-attenuated; fruit glabrous. h. G. Native of the Cape of Good Hope. E. nudicaúlis, Berg. p], cap. p. 113. E. pilulifórmis, Sal. in Lin. trans. 6. p. 370. Flowers red. Style exserted.

Pill-bearing Heath. Fl. April, May. Clt. 1789. Shrub 1 foot.

61 E. mbecílla (Hort. Loud. hort. brit. no. 9716. p. 150.) leaves 4 in a whorl; bracteas remote from the calyx; calyx minute; flowers terminal; corolla with an oval tube and a recurved limb; spurs of anthers linear-attenuated, hairy. b. G. Native of the Cape of Good Hope. E. grácilis, Salisb. in Lin. trans. 6. p. 375. Flowers small, red or purple.

Weak Heath. Fl. June, July. Clt. 1793. Shrub 1 foot.

62 E. Intervalla'ris (Sal. in Lin. trans. 6. p. 375.) stem slender; leaves 4 in a whorl, remote; flowers terminal; corolla $1 \frac{1}{2}$ to 2 lines long, with an ovate-cylindrical tube, and a broad month; anthers awned; pericarp hairy. $\eta_{\text {. }}$ G. Native of the Cape of Good Hope. Erìca elongàta, Roxb. mss. Flowers small, red, drooping.-A very pretty species.

Distant-leaved Heath. Fl. May, Nov. Clt. 1800. Shrub. 63 E. rucòsa (And, heath. 1. t. 6.) leaves 4 in a whorl, glabrous; flowers terminal; corollas globose, viscid, having the interstices of the limb rather tumid; calycine segments ovate, obtuse, coloured, tipped with green; anthers awned. $\zeta . \mathbf{G}$. Native of the Cape of Good Hope. Lodd. bot. cab. 35. Icon. pl. kew. t. 15. Flowers pale purplish-red. Corolla with the tube more or less obovate. Style inclosed.

Mucous-flowered Heath. Fl. March, July. Clt. 178\%. Shrub $1 \frac{1}{2}$ foot.

64 E. Mucosioines (Bedf. hort. eric. wob. p. 15.) leaves short, 4 in a whorl; flowers terminal; corollas globose; calycine segments coloured, tipped with green; anthers awned. $\mathbf{h}$. G. Native of the Cape of Good Hope. Lodd. bot. cab 1202. Flowers small, purplish red. Style inclosed.

Mucosa-like Heath. Fl. Oct. Nov. Clt.? Shrub.

65 E. Latera'lis (Willd. spec. 2. p. 380. but not of Andr.) leaves 4 in a whorl, linear-attenuated, glabrous; flowers terminal; bracteas remote from the calyx; calycine segments ciliated; corolla conical, having the segments anointed with drops of waxy matter at top; crests of anthers downy. h. G. Native of the Cape of Good Hope. E. gullæflòra, Sal. in Lin. trans. 6. p. 374. Corollas small, red. Style exserted.

Var. $\alpha$; stem fastigiate; corolla 1 or $1 \frac{1}{2}$ line long, with a hemispherical tube; stigma much exserted. Ђ. G. E. lateralis, Willd. l. c.

Var. $\beta$; stem low; corolla 2 lines long, with an ovate tube; stiguna hardly exserted. 々. G. E. incarnàta, Andr. leath. 1. t. 19. Lodd. bot. cab. 1655 .

Var. $\gamma$; stem dwarf; corolla $2 \frac{1}{2}$ lines long, with an ovate tube; stigna a little exserted. $h$. G. E. rùbens humilis, Wendl. eric. fasc. 3. p. 13. with a figure.

Lateral Heath. Fl. March, July. Clt. 1791. Shrub $1 \frac{1}{2}$ to 2 feet.

66 E. FE'sta (Sal, in Lin. trans. 6. p. 371.) leaves 4 in a 5 I 
whorl; stem angular; flowers axillary at the tops of the branches; corolla viscid, $2 \frac{1}{2}$ lines long, with a narrow urceolate tube; filaments mutic; anthers appendiculate. $\eta_{\text {. }}$ G. Native of New Holland. Flowers fulvous.

Joy ful Heath. Fl. June, July. Clt. 1812. Shrub.

67 E. cantharæfònmis (Lodd. bot. cab. 1961.) leaves obtuse ; flowers terminal ; pedicels about 3 together; calyx reflexed; corolla ovate, ventricose. $\zeta$. G. Native of the Cape of Good Hope. Flowers white. Anthers unknown. Nearly allied to $E$. refléxa.

Tankard-formed-flowered Heath. Fl. May, June. Clt.? Slirub 1 to $\approx$ feet.

68 E. Bonplandina (Sims, bot. mag. t. 2126.) leaves 4 in a whorl, imbricate, acerose; flowers terminating the small branches, solitary or by threes, sessile; bracteas close to the calyx; corolla large, with an urceolar tube, and an acute spreading limb; genitals inclosed. $h$. G. Native of the Cape of Good Hope. Flowers white. Perhaps a species of Callista.

I'ar. $\beta$, fusca; flowers buff-coloured.

Var. $\gamma$, aurántia; corolla orange-coloured, with an ovateglobose tube; anthers a little exserted. h. G. Erica Bonplándia, Lodd. bot. cab. 345. Bedf. eric. wob. p. 4.

Bonpland's Heath. Fl. March, Sept. Clt. 1812. Shrub.

69 E. cupressina (Hort. Bedf, hort, eric. wob. p. 6. pl. 3. f. 10.) leaves 4 in a whorl, slightly ciliated; flowers terminal; corolla ovate-globose: bracteas remote from the calyx; calyx recurved; anthers awned. F. G. Native of the Cape of Good Hope. E. turrigera, Sal, in Lin. trans. 6. p. 377 . E. prociumbens, Hort. Flowers middle-sized, pale purplishmed. Corolla 2 lines long, with a hemispherical tube, and with the segments imbricate at the base.

Cypress-lilie Heath. Fl. May, Jıne. Clt. 1800. Shrub.

70 E. MODE'STa (Bedf. eric. wob. p. 15. but not of Salisb.) leaves 4 in a whorl ; flowers terminal ; corolla globose; bracteas approximating the calyx; anthers awned. h. G. Native of the Cape of Good Hope. Flowers small, purplish-red. Style inclosed.

Modest Heath. Fl. April, May. Shrub.

71 E. Móltis (Bedf. eric. wob. p. 15.) downy; leaves 4 in a whorl; flowers terminal; bracteas remote from the calyx; corollas globose; anthers awned. $h_{c} . G$. Native of the Cape of Good Hope. Flowers purplish-red. Style inclosed.

Sofi Heath. Fl. May. Clt. 1790. Shrub 1 to 2 feet.

7尺 E. oL'Lula (And. heath. vol. 4.) leaves 4 in a whorl, sessile, crowded, linear, glabrous; flowers terminal, umbellate ; corollas ovate-globose; awns of anthers recurved. h. G. Native of the Cape of Good Hope. Flowers reddish-purple. Style inclosed.

Pipkin-flowered Heath. Fl. Autumn. Clt. 1802. Shrub 2 feet.

73 E. subula'ta (Wendl, eric. ex Spreng. syst. 2. p. 190.) leaves 4 in a whorl, linear-subulate, a little incurved, elongated; branches rather hairy; flowers terminal, crowded; corolla urceolate; calyxes subulate, adpressed; anthers awned. h.G. Native of the Cape of Good Hope. Flowers purple. Style exserted.

Subulate-leaved Heath. Fl. July, Oct. Clt, 1817. Shrub.

74 E. FLórida (Thunb. diss. 64. t. 6.) leaves 4 in a whorl, linear, pilose; flowers terminal, umbellate, glabrous; calyxes villous, reflexed; corollas 2 lines long, urceolate; awns of anthers lanceolate. $\zeta$. G. Native of the Cape of Good Hope. Corolla red, witl a globose tube, and the segments imbricate at the base. Bracteas very minute. Style inclosed.

Florid Heath. F1. May, Aug. Clt. 1803. Shrub I foot.

75 E. Smitma'va (Lold, bot, cab. 1614. Bedf, eric, wob. p.
23.) leaves 4 in a whorl ; flowers subterminal, axillary, drooping; corolla globosely bell-shaped; bracteas remote from the calyx; anthers awned. $々$. G. Native of the Cape of Good Hope. Flowers purplish-red. feet.

Smitl's Heath. Fl. April, May. Clt. 1791. Shrub 1 to 2

76 E. corifòlia (Bedf. hort. eric. wob. p. 29. but not of Ait. hort. kew.) leaves 4 in a whorl ; flowers terminal; corolla ovate; bracteas remote from the calyx; anthers awned; style inclosed. 6. G. Native of the Cape of Good Hope. Flowers white. Style inclosed.

Coris-leaved Heath. Fl. Autumn. Clt.? Shrub.

77 E. PEctinifodia (Sal. in Lin. trans. 6. p. 367.) leaves 4 in a whorl, narrow, ovate-cuneated, pectinated; flowers terminal ; calycine segments spatulate; corolla 5-7 lines long, woolly inside; anthers inclosed, appendiculate. $h$. G. Native of the Cape of Good Hope. Erica cerinthoides $\beta$, Thunb. diss. no. 33.

Pectinate-leaved Heath. Fl. June, Nov. Clt. 1800. Shrub.

$$
\text { §. Anthers crested. }
$$

* Leaves 3 in a whorl. Corollas campanulate.

78 E. Nívea (Bedf. hort. eric. wob. p. 16.) leaves 3 in a whorl, glabrous; flowers terminal; corolla bell-shaped; bracteas remote from and approximating the calyx, large, loose; calyx large; anthers crested. $\zeta$. G. Native of the Cape of Good Hope. Flowers pure white. Style subexserted.

Snowy-flowered Heath. Fl. Summer. Clt. 1816. Slırub I to 2 feet.

79 E. leucanthe'ra (Lin. suppl. p. 223. Andr. heath. 3. t. 15.) glabrous; leaves 3 in a whorl, erect; branches twiggy: flowers terminal, drooping; peduncles glabrous; bracteas remote from and approximating the calyx; corolla oblong-bellshaped, having the limb as long as the tube; anthers crested. h. G. Native of the Cape of Good Hope. E. spirææfolia, Sal. in Lin. trans. 6. p. 350 . Corollas $1 \frac{1}{2}$ line long, white as well as the anthers. There is a variety of this, which is rather downy, and larger in the flowers. Style inclosed.

White-anthered Heath. Fl. Jan. March. Clt. 1803. Shrub 1 foot.

S0 E. Arbòrea (Lin. spec. ed. 2. p. 502.) leaves $3-4$ in a whorl, linear, glabrous; branches tomentose; bracteas remote from the calyx; flowers axillary, racemose, glabrous; corolla bell-shaped; anthers crested. $\zeta$. H. Native of the south of Europe. Ait, hort. kew. ed. p. 402. Smith, et Sibth. f. græc. t. 351. E. scopària, Thunb. diss. no. 80. E. Cáffra, Lin. diss. no. 22. with a figure. E. triflòra, Berg. pl. cap. p. 118. E. scopària, Lin. spec. ed. 2. p. 353. exclusive of the synonymes. E. procèra, Salisb, in Lin. trans. 328. Flowers white, small. Corolla 2 lines long. Style exserted.

Var. $\beta$, stylòsa; style very long.

Iar. $\gamma$, squarròsa (Hort.) leaves squarrose.

Iar. ¿, minima (Hortul.) plants small.

Tree Heath. FI. Feb. May. Clt. 1658. Tree 10 to 20 feet.

81 E. polytrichifòlia (Sal, in Lin. trans. 6. p. 329.) leaves $3-5$ in a whor!; stem tomentose; flowers terminal; bracteas remote from the calyx ; calyxes gradually narrowed at the base ; corolla 1-2 lines long; spurs of anthers cuneated. $\eta . \mathrm{G} . \mathrm{Na}$ tive of Portugal, about Lisbon. Fruit pear-shaped. Perhaps only a variety of $E$. arbòrea.

Polylrichum-leaved Heath. Shrub.

S2 E. LU'cida (Andr. heaths. 2. t. 16.) leaves 3 in a whorl, filiform; branches spreading; flowers terminal, by threes; co- 
rollas short, bell-shaped, subglobose ; calyx coloured, bracteate, serrulated; bracteas imbricate, sessile. $\zeta$. G. Native of the Cape of Good Hope. Flowers small, recldish purple. Awns of anthers a little crested. Style exserted.

Shining Heatls. Fl. May, June. Clt. 1800. Shrub $1 \frac{1}{2} \mathrm{ft}$.

\section{* Leaves 3 in a mhorl. Corollas urceolate.}

83 E. Nísın (Andr. heath. 3. t. 18.) leaves 3 in a whorl, scabrous, spreading; flowers terminal, drooping; pedicels downy; bracteas sessile, elose to the ealyx; corollas ureeolately globose; anthers crested. h. G. Native of the Cape of Good Hope. Lodd. bot. bot, eab. 1131. E. refléxa rùbra, Hort. Flowers white, tinged witls red. Style exserted.

Nitid Heatl. Fl. July, Oct. Clt. 1800. Shrub 2 feet.

84 E. Peduncula'ris (Sal, in Lin. trans. 6. p. 329.) leaves 3 in a whorl, linear, lispid; flowers terminal; corolla 3 lines long, witl a globose tube; antliers woolly, dehiseing by long chinks, crested. h. G. Native of the Cape of Good Hope. E. rùbens, Thumb. diss. no. 83. but not of Andr. Pedicels an ineh long. Flowers purplish red.

Peduneular-flowered Heath. Shrub.

85 E. FAu'sta (Sal. in Lin. trans. 6. p. 326.) leaves 3 in a whor], bristly; flowers terminal; corolla $2 \frac{1}{3}$ lines long, downy outside, with an ureeolate tube; spurs of anthers serrated, attenuated, crested. $\hbar_{\text {. }}$ G. Native of the Cape of Good Hope. Very like $E$. hirta, Thunb. Flowers pale purple.

Fortunate Heath. Fl. April, July. Clt. 1795. Shrub 1 to 2 feet.

86 E. IncA'na (Wendl. eric. fasc. 18, p. 89, with a figure.) leaves 3 in a whorl, linear-oblong, obtuse, hairy, white beneath; bracteas remote from the ealyx; flowers terminal, downy; eorolla urceolate; anthers awned. h.G. Native of the Cape of Good Hope. Flowers white. There is also a red-flowered variety of this species. Style exserted.

Hoary Heath. Fl. Aug. Clt. 1810. Shrub $1 \frac{1}{2}$ foot.

87 E. ova'ta (Lodd. bot. eab. 417.) downy; leaves 3 in a whorl; flowers terminal; bracteas remote from the calyx; corollas ovate; awns of anthers erested a little. h. G. Native of the Cape of Good Hope. Flowers purplish red. Style inclosed.

Ocalc-Howered Heath. Fl. May, June. Clt. 1811. Shrub 1 foot.

88 E. REFLE'XA (Link, enum. 1 p. 371. Lodd. bot. cab. 1787.) leaves 3 in a whorl, glabrous, lanceolate, obtuse; flowers termimal, uswally 3 in a faseicle; ealyx, braeteas, and pedicels coloured; corolla ovate, ventrieose at the base, clammy; erests of anthers plumose. $h . G$. Native of the Cape of Good Hope. Calyx spreading. Corollas white, waxy, middle sized. Anthers black. Very nearly allied to $E$. nitida, and probably only a variety of it. The young leaves are said by Link to be glandularly ciliated. Style inelosed.

Reflexed-ealyxed Heath. Fl. Spring and Autumn, Clt. 1820. Shrub 1 foot.

89 E. CINE'REA (Lin. spee. ed. 2. p. 501.) leaves 3 in a whor]; eorolla ovate-urceolate; Howers vertieillate, on the naked stems; crests of anthers ear-formed. 々. H. Native of Europe, but not in the south, nor in the extreme north; plentiful in Britain. Curt. fl. lond. fasc. 1. t. 25. Loef. res. p. 137. Smith, engl. bot. t. 1015. Ait. hort. kew. 2. p. 392. Fl. dan. 38. E. mutábilis, Salisb. in Lin. trans. 4. p. 369 . E. hùmilis, Neck. gall. I82. E. tenuifolia, Ger. 1198. emac. 1382. E. cinèrea rùbra, Bedf. hort. eric, woburn. p. 5 . Corolla 3 lines long, purple, clianging to blue as they fade. This is easily distinguished from $E$. $t \dot{e}-$ tralix, in the glabrous deep green hue, and deep purple flowers.
Var. $\beta$, atropurpùrea (Lodd. bot. cab. 1409.) plant dwarf; flowers deeper purple.

Iar. $\gamma$, alba (Bedf. 1. c.) flowers white.

Var. ¿, pállida (Lodd. bot. cab. 1507.) flowers pale purple.

Grey Heath. Fl. Aug. Sept. Britain. Shrub $\frac{1}{2}$ to 1 foot.

90 E. vernicífua (Sal. in Lin. trans. 6. p. 335.) leaves 3 in a whorl, viseid; corolla $2 \frac{1}{2}$ lines long, with a reeurved limb; flowers terminal; spurs of anthers ear-formed and cuneated, lairy; fruit smooth. h. G. Native of the Cape of Goorl Hope. E. glutinòsa, Roxb. mss. The leaves are bluntly acuminated, densely clothed with glands in the reduplieate part; hence they appear shining and clammy.

Varnish-flowing Heath. Shrub.

91 E. embothriffòla (Sal. in Lin. trans. 6. p. 379.) leaves 3 in a whorl, linear-laneeolate; spikes of flowers coarctate; corolla 4 lines long, having the tube ventricose at top; anthers exserted, crested. h. G. Native of the Cape of Good Hope. Embothrium-leaved Heath. Fl. Feb. May. Clt. 1798. Shb.

\section{* * Leaves 4 in a whorl. Corollas campanulate.}

92 E. Austra'urs (Lin. mant. p. 231.) leaves 4 in a whorl, scabrous, spreading, mucronate ; flowers terminal; corolla 3 lines long, with a curved funnel-sliaped tube, and a recurved limb; pedicels beset with genmaceous braeteas; anthers crester?. 々. H. Native of Spain and Portugal. Andr. heatls. 3. t. 21. Ait. hort. kew, 2. p. 396 . Lodd. bot. cab. 1472. Wendl. eric. 9. p. 13. with a figure. E. pistilàris, Sal, iu Lin. trans. 6. p. 365. Flowers small, purplish red. Style exserted.

Southern Heath. Fl. March, July. Clt. 1769. Shrub 3 to 6 feet.

93 E. necuina'ta (Bedf. hort. eric, wob. p. 7.) leaves 4 in a whorl ; flowers axillary, subspicate : eorolla bell-shaped ; braeteas remote from the calyx; anthers erested. $h . G$. Native of the Cape of Good Hope. Lodd. bot. eal. 1662. Flowers white, tinged with red. Style a little exserted.

Delicate Heath. Fl. Sept. Oct. Clt. 1820. Shrub $1 \mathrm{ft}$.

\section{*** Leaves 4 in a whorl. Corollas urecolate,}

94 E. margarita'cea (Sol. in Ait. hort. kew. 2. p. 401.) glabrous; leaves 4 in a whorl ; flowers terminal; bracteas remote from the calyx; anthers erested; corolla with a spherical tube. h. G. Native of the Cape of Good Hope. Andr. heath. 1. t. 17. Wendl. eric. 8. p. 11. with a figure. E. obèsa, Sal. in Lin. trans. 6. p. 375. Calyx incurvedly spreading. Corollas nearly 2 lines long, white. Crests of anthers glabrous. Style exserted.

Pearl-flowered Heatl. Fl. June, Sept. Clt. 1775. Shrub $1 \frac{1}{2}$ foot.

95 E. LAchnæoines. This speeies is very distinet fron Erica lachna'a, Andr.; but we lave not means of giving any description of it. Antliers erested. $h_{2}, G$. Native of the Cape of Good Hope. E. laehnæ'a purpùrea, Andr. heaths. 3. t. 3. Flowers red.

Lachnae-like Heath. Fl. May, July. Clt. 1793. Shrub. 96 E. racemírera (Andr. heath. 3. t. 12.) leaves 4 in a whorl, and are as well as the calyxes glabrous; flowers axillary, vertieillate; corollas ovate-globose; anthers crested. そ. G. Native of the Cape of Good Hope. Flowers small, red. Style inclosed.

Raceme-bearing Heath. Fl. April, July. Clt. 1803. Shrub $1 \frac{1}{2}$ foot.

97 E. Sola' NDri (Andr, heath. 2. t. 17. Ait. hort. kew. 2. p\% 399.) leaves $t$ in a whorl, hispid; branches decumbent; flowers terminal, eapitate, or umbellate; bracteas sessile, linear, ciliated, near the ealyx; corollas globosely bell-shaped; anthers crested. 512 
々. G. Native of the Cape of Good Hope. Flowers reddishpurple. Style inclosed.

Solander's Heath. Fl. March, Nov. Clt. 1800. Shrub.

9S E. Acu'ts (Audr. heath, 2. t. 19. Ait. hort, kew. 2. p. 399.) leaves 4 in a whorl, stiff, glabrous, spreading ; flowers terminal, usually by threes, drooping; bracteas approximating the calyx; corolla ovate-globose; anthers crested. $\eta_{2}$. G. Native of the Cape of Good Hope. Flowers small, deep purplishred. Calyx ciliated. Style inclosed.

Aeute-flowered Heath. Fl. May, Ang. Clt. 1799. Shrub $\frac{1}{2}$ to 1 foot.

99 E. RU'Bens (Andr. heath. 2. p. 21.) leaves 4 in a whorl, hispid, spreading; flowers terminal; bracteas remote from and approximating the calyx; anthers crested or awned; corolla ovate-globose. h. G. Native of the Cape of Good Hope. Lodd, bot. cab. 557. Flowers small, purplish-red. Style exserted.

Red-flowered Heath. Fl. Spring and Winter. Clt. 1798. Shrub 1 foot.

100 E. strícta (Donn, hort. cantab. ed. 3d. p. 69. Willd. spec. 2. p. 366.) leaves 4 in a whorl, obtuse, glabrous, bisulcate beneath; flowers terminal, umbellate; corolla 3 lines long, with an ovate urceolar tube, and reflexed segments; bracteas approximating the calyx, sessile; anthers crested. Ђ. H. Native of Corsica and Italy. Andr. heath.2. t. 22. A At. hort. kew. 2. p. 393. E. multicaúlis, Sal. in Lin. trans. 6. p. 369. E. Córsica, D. C. fl. fr. E. ramulòsa, Viv. Calyx spreading. Corollas purplish red. Stem diffuse. Style subexserted.

Straight Heath. Fl. Ang. Nov. Clt. 1765. Shrub 2 to 3 feet.

101 E. BARBA'ta (Andr, heatl. 2. t. 23.) leaves 4 in a whorl, ciliated; flowers terminal, umbellate, drooping; corolla short, urceolate; bracteas remote from the calyx; calycine segments spatulate, ciliated; anthers crested. F. G. Native of the Cape of Good Hope. Lodd. bot. cab. 12. Erìca barbàta màjor, Andr. heath. 2. t. 23. Flowers pale yellow, with brown anthers. Style exserted.

Var. $\beta$, minor (Andr. heath. 2. t. 24.) flowers white, with black anthers; but according to the hort. eric. wob. they are red, flowering Feb. Aug.

Bearded Heath. Fl. May, Aug. Clt. 1799. Slırub $1 \mathrm{ft}$.

102 E. ramenta'cea (Liin. mant. p. 65. Andro heath. 1. t. 16. ) leaves 4 in a whorl, glabrous; branches clammy; flowers terminal, umbellate; bracteas remote from and approximating the calyx; corolla with a spherical 8 -angled tube, and a recnrved erect limb; anthers crested; fruit hairy. $\eta$. G. Native of the Cape of Good Hope. Ait. hort. kew. 2. p. 4.05. Lodd. bot. cab. 446 . E. bullulàris, Sal. in Lin. trans. 6. p. 377 . E. granulàta, Lin. mant. 231. E. multiumbellífera, Berg. pl. cap. p. 110. E. pilulífera, Berg. pl. cap. p. 111. Calycine segments subulate, coloured. Flowers purplish-red. Style subexserted. Ramentaeeous Heatl. Fl. July. Dec. Clt, 1786. Shrub $1 \frac{1}{2}$ foot.

103 E. CE'RNVA (Lin. suppl. p. 222.) leaves 4 in a whorl, hoary, villous or ciliated, aristate: those of the branches ovate; flowers terminal, drooping, umbellate; bracteas decurrent; calyx much fringed; corolla ovate-globose; anthers crested. $h_{\imath}$. G. Native of the Cape of Good Hope. Montin, in act. ups. 2. p. 291. t. 9. f. 3. Flowers purplish-red or pink. Corolla $2 \frac{1}{2}$ lines long.

Drooping-flowered Heath. Fl. Aug. Dec. Clt. 1791. Shrub 1 foot.

104 E. verecu' NDA (Sal. in Lin. trans. 6. p. 379 .) leaves 4 in a whorl, linear, incurvedly spreading, glabrous; branches hairy; spikes coarctate; flowers drooping; bracteas and calyxes fringed; corolla $2 \frac{1}{2}$ lines long, with an amphori-formed tube, and crenu- lated limb; anthers hairy; spurs cuneated, hairy. h.G. Native of the Cape of Good Hope. Erìca cérnua, Andr. heath. 1. t. 20. Lodd. bot. cab. 822. but not of Lin. Flowers fleshcoloured. Style inclosed.

Reddish-flowered Heath. Fl. April, Sept. Clt. 1793. Shrub.

105 E. PE'NDULA (Wendl. eric. 10. p. 13. with a figure) leaves 4 in a whorl, glabrous; flowers terminal, drooping; bracteas remote from the calyx; calycine segments lanceolate, adpressed; corollas ovate, angnlar; anthers crested. $h$. G. Native of the Cape of Good Hope. Ait. hort. kew. 2. p. 4.00. E. arbúscula, Lodd. bot. cab. 843 . Flowers purple : in hort. kew. there are said to be 3 bracteas on each pedicel; 2 near the calyx, and the third remote from it. Style inclosed.

Pendulous-flowered Heath. Fl. July, Aug. Clt. 1791. Shrub $1 \frac{1}{2}$ foot.

106 E. NU'TANs; leaves 4 in a whorl; flowers terminal, drooping; bracteas remote from the flower; calyx ribbed, green; corolla ovate-globose; anthers crested. $h_{2} . G$. Native of the Cape of Good Hope. E. péndula, Hort. Bedf. eric. wob. p. 18. but not of Wendi. Flowers reddish-purple. Style a little exserted.

Nodding-flowered Heath. Fl. Spring and Summer. Clt.? Shrub.

107 E. fìbula (Link, enum. 1. p. 368.) leaves 4 in a whorl, finely cilated; flowers terminal; bracteas remote from the calyx; corolla oblong-globose; anthers crested. $\zeta$. G. Native of the Cape of Good Hope. Flowers purple-red. Style exserted.

Bulton-flowered Heath. Fl. July, Oct. Clt. 1829. Shrub 1 to 2 feet.

108 E. lactiflòra (Lodd. bot. cab. t. 901.) leaves 4 in a whorl, and are as well as the branches scabrous; flowers terminal, erectish; corolla ovate; bracteas remote from the calyx ; anthers crested. $\nvdash$. G, Native of the Cape of Good Hope. E. lactícolor, Roll. cat. E. trícolor, Spreng. syst. 2. p. 193. Limb of corolla connivent and drawn out. Flowers white. Style inclosed.

White-flowered Heath. FI. June, Sept. Clt. 1820. Shrnb 1 to 2 feet.

109 E. v'Nica (Spreng. syst. 2. p. 188.) leaves 4 in a whorl, crowded, ciliated, erect; flowers terminal, umbellate, drooping; bracteas remote from the calyx; calyx minute, coloured, ciliated; corolla urceolate or globosely bell-shaped; anthers crested. $h_{2}$. G. Native of the Cape of Good Hope. E. pedunculàta, Andr. heath. 4. icon. but not of Wendl. E. ciliata, Hort. Flowers purplish-red. Style inclosed.

Unique Heath. Fl. Oct. Nov. Clt. 1800. Shrub 1 to 2 feet.

110 E. parviflóra (Lin. spec. ed. 2. p. 506. Salisb. in Lin. trans. p. 373.) leaves revolute, 4 in a whorl, downy; flowers terminal; corolla downy, urceolate; spurs of anthers crested or ear-formed; fruit glabrous. h. G. Native of the Cape of Good Hope. E. pubéscens, Lin. diss. no. 19, with a figure, Berg. A. cap. 121. Corolla purple. Style inclosed.

Simall-flowercd Heath. FI. March, Sept. Clt. 1790. Shrub 1 foot.

\section{**** Leaves 5-6 or more in a whorl. Corollas campanu- late.}

111 E. EMPETrifòLia (Lin. mant. p. 375.) leaves 6-7 in a whorl, oblong-linear, ciliated, erect; flowers disposed in glomerate racemose whorles; bracteas and calyxes lanceolate; corolla 2 lines long, hairy, with an urceolar tube, and a recurvedly spreading limb; anthers awned or crested; stigma exserted. 々. G. Native of the Cape of Good Hope. Lin. diss, no. 15. with a figure. Thunb. diss. no. 70 . Curt. bot. mag. 447. Lodd. bot. cab. 1875. Calyx 4-lobed. Style exserted Flowers purplish-red. 
Empetrum-leaved Heath. Fl. May, June. Clt. 1774. Shb. 112 E. Noleflòn A (Sal. in Lin. trans. 6. p. 371.) leaves 6 in a whorl ; flowers axillary at the tops of the branches; corolla 2 lines long, smooth, with a cup-shaped tube, and a recurvedly spreading limb; stigma inclosed. h. G. Native of the Cape of Good Hope. E. glomeràta, Hortul. Pedicels much longer than in any of the allied species. Anthers appendiculate. Corollas white.

Bell-flowered Heath. Shrub.

**** Leaves 5-6 in a whorl. Corollas urceolate.

113 E. empetroìnes (Andr. heath. 2.t. 25. Ait. hort. kew. 2. p. 299.) leaves 6 in a whorl, glaucescent, ciliated, spreading, soft ; flowers terminal, subspicatc, close ; bracteas hairy, approximating the calyx; corollas ovate; calyx green, rough, large ; auricles of anthers broad. h.G. Native of the Cape of Good Hope. Lodd. bot. cab. 1758. E. pyxidifòlia, Sal. in Lin. trans. 6. p. 371. E. empetrifòlia glaúca, Wendl. eric. 11. p. 11. with a figure. Flowers pale purplish-red. Calyx 4-cleft. Corolla smooth, 2 lines long, with an obovate tubc, and an incurvedly spreading limb. Pericarp globose, glabrous. Style exserted.

Empetrum-like Heath. Fl. April, May. Clt. 178s. Shrub $1 \frac{1}{2}$ foot.

114 E. Malleola'ris (Sal. in Lin. trans. 6. p. 370.) leaves 6 in a whorl; flowers axillary at the tops of the branches; calyx quadrifid; corolla $1 \frac{2}{3}$ line long, smooth, with an urceolar tube, and a recurvedly spreading limb; pericarp glabrous. $\zeta . G$. Native of the Cape of Good Hope. Erica empetrif òlia, Schnev. pl. no. 17. with a figure. Houtt. pfl. syst. 4. p. 517. t. 23. f. 2. Berg. pl. cap. p. 120.

Branched Heath. Fl. April. Oct. Clt. 103. Shrub.

115 E. Glutinòsa (Berg. fl. cap. p. 98. Thunb. diss, no. 48.) leaves alternate or opposite, beset with glandular hairs; spikes of flowers coarctate; flowers drooping; bracteas remote from the calyx; corollas viscid, with an ovate pyramidal tube and a spreading limb; anthers crested. h. G. Native of the Cape of Good Hope. Icon. pl. kew. t. 1\%. E. droseroides, Andr. heath. 1. t. 13 . Lodd. bot. cab. 1685. Andrómeda droseroìdes, Lin. mant. 239. Corollas deep red, form of those of a species of Callista, 3 to 5 lines long.

Clammy Heath. Fl. May, June. Clt. 1787. Shrub $1 \mathrm{ft}$.

116 E. FA'Llax (Sal, in Lin. trans. 6. p. 3\%1.) leaves 6 in a whorl; flowers axillary at the tops of the branches; corolla 2 lines long, viscid, with the tube urceolar and a little ribbed; filaments length of tube, spurred; pericarp viscid. $h_{2}$ G. Native of the Cape of Good Hope. Anthers bipartite.

False Heath. Fl. May, Nov. Clt. 1800. Shrub.

117 E. PA'RILIs (Sal. in Lin. trans. 6. p. 371.) leaves 6 in a whorl; flowers axillary at the tops of the branches; corolla 3 lines long, viscid, with an urceolar, rather ribbed tube ; filaments hardly the length of the tube, minutely spurred. q $_{\text {. G. Native }}$ of the Cape of Good Hope.

Equal Heath. Fl. May, Ang. Clt. 1789. Shrub.

118 E. carduifòlia (Sal. in Lin. trans, 6. p. 330.) Jeaves 6 in a whorl, bristly; flowers terminal; pedicels long; corolla $2 \frac{1}{2}$ lines long, smooth, with a glabrous tube; filaments very short; anthers awned. $々$. G. Native of the Cape of Good Hope. Stigma narrow. Corollas purple.

Thistle-leaved Heath. Fl. May, Ang. Clt. 1806. Shrub.

119 E. cinera'scens (Willd. enum. suppl. p. 21.) branches and calyxes tomentose, and beset with long hairs; leaves 5 in a whorl, ciliated with long hairs ; bracteas foliaccous, close to the calyx; style subexserted; anthers awned. h. G. Native of the Cape of Good Hope. Flowers purple. Nearly allied to $E$. cinèrea.
Grcyish Heatl. Fl. April, May. Clt. 1810. Shrub.

120 E.? p1rysòdes (Lin. spec. ed. 2. 566. diss, no. 32. with a figure) leaves 4-6 in a whorl, spreading, viscid, slender ; flowers terminal, 4-6 in a fascicle; bracteas remote from the calyx; calycine segments ovate, ciliated; corolla ovate-globose, clammy, having the interstices of the limb ending in a tumid look; anthers crested. h. G. Native of the Cape of Good Hope. Lodd. bot. cab. 223. E. sèquax, Sal. in Lin. trans, 6. p. 378. Corolla 3-4 lines long, white. Style inclosed.

I ar. $\beta$; corolla 4 lines long, with an ovate tube. $々 . G . E$ physòdes, Andr. heatlı. 1. t. 22. Wendl, eric. fasc. 7. p. 13. with a figure. Curt. bot. mag. 443. Corollas white.

Bladdery-flowered Heath. Fl. March, May. Clt. 17 S8. Shrub 1 to 2 foot.

\section{§3. Anthers mutic, that is, nithout anns or crests. \\ * Laves 3 in a whorl. Corollas campanulate.}

121 E. canalicula'ta (Andr. heath. 3.t. 38.) leaves 3 in a whorl, subulate, glabrous, spreading; pedicels terminal, by threes, bracteate, downy ; calyxes coloured ; corolla campanulate; stamens a little exserted. そ. G. Native of the Cape of Good Hope. Lodd. bot. cab. 184. Corollas pale red, spreading. Channelled Heatls. Fl. Feb. Aug. Clt. 1799. Shrub $1 \mathrm{ft}$

122 E. campanula'ta (Andr. heath. 1. t. 44. Wendl, eric. 13. 1. 3. with a figure) leaves 3 in a whorl, subulate, glabrous; flowers terminal, solitary, drooping; bracteas renote from the calyx; corolla campanulate; calycine segments ciliated. $\zeta_{c}$. G. Native of the Cape of Good Hope. Ait. hort. kew. 2. p. 408. Lodd. bot. cab. 115. E. tenuifolia, Hort. E. campanulàris, Sal, in Lin. trans. 6. p. 330. Calyx coloured. Corollas $2 \frac{1}{2}$ lines long, yellow, smooth. Style exserted.

Campanulatc-flowered Heath. Fl, April, Aug. Clt. 1791. Shrub I foot.

123 E. FLA'va (Andr. heath. 2. t. 38. Ait. hort. kew. 2. p. 292.) leaves 3 in a whorl, short, glabrous, erect; flowers terminal, crowded; pedicels bracteate; corollas campanulate. $h$. G. Native of the Cape of Good Hope. Lodd. bot. cab. 882. Flowers yellow. Style exserted.

Yellow-Howered Heath. Fl. April, Oct. Clt. 1795. Shrub.

12. E. coarcta'ta (Wendl. eric. fasc. 19. no. 1.) leaves 3 in a whorl, linear, a little ciliated, erectly spreading; flowers twin, axillary, erect, on pedicels, which are equal in length to the Jeaves; calyx small, foliaceous ; stigma peltate; anthers mutic. h. G. Native of the Cape of Good Hope. Corolla campanulate, purple, dilated at top. Style much exserted. Bracteas remote from the calys.

Coarctatcd-flowered Heath. Fl. May, Sept. Clt. 1801. Shrub.

125 E. Approxima'ta (Schlecht. ex Spreng. syst. 2. p. 196.) leaves 3 in a whorl, nearly terete, petiolate, short, glabrous, remote, spreading; branches twiggy, rather hairy; flowers subracemose, glabrous; calyx coloured, adpressed. h. G. Native of the Cape of Good Hope. Corolla campanulate. Anthers mutic.

Approximate Heath. Fl. May, July. Clt. 1sæ3. Shrub.

126 E. spiculjflòra (Sal. in Lin. trans. 6. p. 32.4. Smith, fl. grac, t. 353 .) leaves 3 in a whorl, mucronulate, ciliated; flowers disposed in terminal racemes, drooping; pedicels bractless, rather doswny; style much exserted. h.H. Native on the top of Mount Olympus, E. Olýmpica, Sibth. mss. Corollas 1 line long, smooth, red. Calyx colomed.

Spile-flowercd Heath. Shrub decumbent.

127 E. scopa'ria (Lin. mant. 375. diss. eric. no. 13. with a figure of the flower) leaves 3 in a whorl, linear, glabrous; flowcrs axillary, disposed in sccund racemes; corolla smooth, campa. 
nulate, with a cup-shaperl tube; bracteas remote from the calys. h. G. Native of the Cape of Good Hope. E. fucàta, Thunb. diss, no. 9. E. viridipurpùrea, Hort.-Clus. hist. 1. p. 42. Stem downy. Corollas very small, green. Style inclosed or exserted.

$I_{\text {rar. }} \beta$, minima (Hort.) plant smaller than the species.

Broom Heath. Fl. April, May. Clt. 1770. Shrub 4 to 6 feet.

128 E. vikga'ta (Thunb, diss, no. 18. Wendl. ex Spreng. syst. 2. p. 197.) leaves 3 in a whorl, ovate, spreading, glandularly ciliated; branches hairy; flowers terminal, sessile, by threes, erect; calycine segments foliaceous, downy. $々$. G. Native of the Cape of Good Hope. Flowers red, small, campanulate. Stigma peltate, much exserted.

Tniggy Heath. Fl. July, Nov. Clt. 1818. Shrub $1 \mathrm{ft}$.

129 E. complana'ta (Nois. et Spreng. syst. 2. p. 196.) branches flexuous; leaves 3 in a whorl, linear, stiff, glandularly ciliated while young, spreadingly reflexed; flowers terminating the small branches, the whole forming a branched raceme; calyx adpressed, coloured, clammy; corolla bell-shaped or subrotate. h. G. Native of the Cape of Good Hope. Corollas yellow. Style inclosed.

Flat-flowered Heath. Fl. May, July. Clt. 1820. Shrub $\approx$ feet.

130 E. ANтнixa (Spreng. syst. 2. p. 196.) branches hispid; leaves linear, obtuse, 3 in a whorl, glabrous; flowers terminal, usually by threes, drooping; bracteas close to the calyx, inflated; corolla wide, campanulate; anthers mutic. h. G. Native of the Cape of Good Hope. E. flórida, Lodd. bot. cab. 234. Flowers purplish-red. Style a little exserted.

Flonery Heath. Fl. April, July. Clt. 1800. Sbrub.

131 E.? SPA'RSA (Bedf, eric. wob. p. 23.) leaves 3 in a whorl, glabrous? flowers terminal; bracteas approximate and remote for the calyx; corollas small, bell-shaped, with deep spreading segments; anthers a little exserted. h. G. Native of the Cape of Good Hope. Lodd. bot. cab. 1467. Flowers purplishred. Style exscrted.

Scatterce Heath. Fl. April. Clt.? Shrub.

132 E. Passeriva (Lin. suppl, 221. Thumb. diss. no. 16. prod. 70.) leaves 3 in a whorl, ovate, glabrous; flowers terminal, almost solitary; pedicels and calyxes tomentose; corolla campanulate; style exserted. $h . G$. Native of the Cape of Good Hope. Montin. in. nov. act. ups. 2. p. 289. t. 9. f, 1. E. passeritafòlia, Sal. in Lin. trans. 6. p. 332,-Petiv. gen. t. 3. f. 7 . Corolla $2 \frac{1}{2}$ lines long; pericarp tomentose.-Perhaps a species of Ceràmia.

Sparron-nort-like Heatl. Fl. Winter and Spring. Clt. 1508. Shrub.

\section{* Leaves 3 in a whorl. Curollas urecolate.}

133 E. eriocéphala (Andr. heath. 2. t. 37.) leaves 3 in a whorl, and are as well as the calyxes and corollas woolly; bracteas remote and approximating the calyx; anthers a little exserted; flowers terminal, umbellate; corolla urceolate, 々. G. Native of the Cape of Good Hope. Lodd. bot. cab. 1270. E. canéscens, Ait. lıort. kew. 2. p. 4.07. E. gnaphalioìdes, Hortul. Flowers with a purplish-red calyx, and a white corolla. Style exserted.

Woolly-headed Heath. Fl. May, Aug. Clt, 1790. Shrub.

134. E. tubercula'ris (Sal. in Lin. trans, 6. p. 330.) leaves 3 in a whorl; flowers terminal; corolla $1 \frac{1}{3}$ line long, rough from tubercles, with a globose tube; filaments mutic; pericarp on

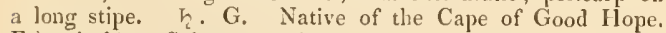
Erica inclyta, Sol. mss. Anthers minute, smooth. Flowers purple.
Tubercular-flowered Heath. Fl. Feb. Aug. Clt. 1790. Shrub.

135 E. cilia'ris (Lin. spec. ed. 1. p. 354. Loefl. res. p. 138. Lin. diss. no. 39, with a figure of the flower) leaves 3 in a whorl, ovate, glandularly ciliated, spreading, rather remote; flowers terminal, subracemose, secund; calycine segments spatulate, ciliated; bracteas approximating the calyx, sessile; corolla smooth, ovate, more ventricose on the upper side. $々$. H. Native of Portugal; and Cornwall. Wendl. eric. 7. p. 3. Curt. bot. mag. 484. Ait. hort. kew. 2. p. 394. Lodd. bot. cab. 1805. Corolla 4 lines long, pale red. Style exserted.

Ciliated-leaved Heath. Fl. Aug. Sept. Britain. Shrub 1 foot.

136 E. absintioides (Lin. mant. p. 66.) leaves $3-4$ in a whorl, linear, scabrous, more or less ovate, rather remote; flowers twin, terminal on axillary branches, drooping; calyx and corollas glabrous; bracteas remote from the calyx, leaflike; corolla globose, viscid; stamens exserted. そ. G. Native of the Cape of Good Hope. E. virgulàris $\alpha$, Salisb. in Lin. trans. 5. p. 324. E. virgàta and E. virgulàta, Wendl. E. exsérta, Hort. Corollas white, with a red apex.

Wormwood-like Heath. Fl. March, July. Clt. 1792. Shrub $1 \frac{1}{3}$ foot.

137 E. Hispídula (Lin. suppl. p. 222.) leaves 3 in a whorl, ovate-roundish, ciliated, rather remote; flowers axillary and terminal, usually solitary, erect ; corolla urceolate, viscid. h.G. Native of the Cape of Good Hope. E. híspicla, Thunb. diss. no. 20. E. virgàta lírta, Wendl. eric. 13. p. 35. E. virgulàris, $\delta$, Sal. in Lin. trans. 6. p. 324. Flowers terminating the small branches, reddish-purple. Bracteas remote from the calyx. Siyle exserted. Perluaps a species of Ceràmia.

Small-hispid Heath. Fl. Spring. Clt. 1791. Shrub $1 \mathrm{ft.}$

138 E. carnélo (Bedf. eric. wob. p. 5.) leaves 3 in a whorl, scattered; pedicels bracteate ; flowers terminal, umbellate; corolla oblong-ovate. $h_{2} . G$. Native of the Cape of Good Hope. Corollas purplish-red. Nearly allied to $E$. Sainsburyàna in habit. Style exserted.

Flesh-coloured-flowered Heath. Fl. Aug. Clt. 1810. Shrub.

139 E.? Cólleter (Spreng. syst. 2. p. 192.) branches straight, hairy; leaves linear-oblong, obtuse, revolute, rather hispid, spreading; flowers axillary, drooping, clammy; corolla urceolate; style exscrted; stigma peltate. $h_{6}$. G. Native of the Cape of Good Hope.

Colleter Heath. Shrub.

\section{* Leaves 4 in a whorl. Corollas campanulate.}

140 E. odora'ts (Andr. heatb. 3. t. 64.) leaves 4 in a whorl, glandularly ciliated, spreading; flowers terminal, umbellately verticillate, drooping; pedicels coloured; bracteas remote from the calyx; corolla campanulate, viscid. h. G. Native of the Cape of Good Hope. Lodd. bot. cab. 633. Sims, bot. mag. 1399. Corolla white, very like those of some species of $A n$ drómeda. Style inclosed.

Sreet-scented Heath, Fl. A pril, July, Clt. 1804. Shrub 1 to 2 fuet.

141 E. PROPE'NDENS (Andr. heath, 2. t. 45. Sims, bot. mag. 21408.) downy; leaves 4 in a whorl, short, ciliated; branches flexuous; bracteas approximating the calyx; flowers terminal, solitary or by threes; corolla bell-shaped. $h_{2}$ G. Native of the Cape of Guod Hope. Lodd. bot. cab. 63. Calycine segments jagged or serrated. Corolla purple, or deep red. Style inclosed.

Propendent-flowered Heath. Fl. July, Oct. Clt. 1800 . Shrub 1 foot.

142 F. PALu'stris (Andr. heath. 2. t. 46.) leaves 4 in a whorl, linear, obtuse, downy; flowers terminal, umbellate; bracteas 
remote from the calyx; corollas cylindrically bell-shaped; anthers a little exserted. $\boldsymbol{h}$. G. Native of the Cape of Good Hope. Lodd. bot. cab. t. 4. Branches divaricate. Corollas reddish-purple.

Marsh Heath. Fl. A pril, June. Clt. 1799. Shrub $1 \mathrm{ft}$.

143 E. visca'ria (Andr. heath. 1. t. 43.) leaves 4 in a whorl, linear, glabrous, spreading; flowers axillary, disposed in verticillate spikes or racemes, drooping; corolla campanulate, clothed with clammy down; bracteas approximating the calyx, sessile ; calycine segments ciliated; fruit silky. $\zeta_{2} . G$. Native of the Cape of Good Hope. Lodd. bot. cab. 726. Icon. pl. kew. t. 1. E. víscida, Sal. in Lin. trans. 6. p. 372. Corolla pale purplish-red, 3 lines long, with a cup-shaped ribbed tube. Style inclosed.

Var. a, incàna; leaves hoary, $1 \frac{1}{2}$ to 3 lines long. $々 . G$. E. viscària, Thunb. diss. no. 40 . Lin. mant. 321 . diss, no. 45 . with a figure.

I ar. $\beta$, glàbra; leaves green, 3-5 lines long. $々$. G. E. viscària, Andr. heath. 1. t. 43 . Icon. pl. kew. t. 1 .

Clammy Heath. Fl. April and Autumn. Clt. 1774. Shrub 2 feet.

1 i4 E. pyramidicórmis (Wendl, ex Spreng. syst. 2. p. 198.) leaves linear, hispid, spreading, 4 in a whorl; flowers terminal, usually by threes, erect ; calyxes adpressed, hispid ; stigma quadrifid. h. G. Native of the Cape of Guod Hope. Flowers purplish-red, campanulate.

Pyramid-formed Heath. Fl. Sept. Dec. Clt. 1818. Shrub 2 feet.

14.5 E. Nidicula'ria (Lodd. bot. cab. 764.) glabrous; leaves 4 in a whorl, short, obtuse; flowers terminal, umbellate; bracteas remote from the calyx; corolla cup-shaped; style exserted; anthers mutic. $\zeta . G$. Native of the Cape of Good Hope. Flowers white.

Nest-like-flowered Heath. Fl. Oct. Clt. 1809. Shrub 1 to 2 feet.

116 E. BE'Lla (Lodd. bot. cab. 307. Spreng. syst. 2. p. 197.) leaves 4 in a whorl, linear, filiform, smoothish, spreading, in. curved at the apex; pedicels terminal, racemose, hispid, erect ; calyx reflesed: style filiform; corolla campanulate; anthers mutic. h. G. Native of the Cape of Good Hope. E. pulchélla, Hortul. Flowers red. Style exserted.

Beautiful Heath. Fl. Jan. Oct. Clt. 1S00. Shrub $1 \mathrm{ft}$.

147 E. styla'ris (Spreng. syst. 2. p. 198.) leaves 4 in a whorl, linear, obtuse, much spreading, and are as well as the branches hispid; flowers terminal, glomerate, erectish; calyxes coloured, spreading, ciliated; corolla campanulate; style much exserted: stigma capitate. 々. G. Native of the Cape of Good Hope. Anthers mutic. feet.

$$
\text { long-styled Heath. Fl. May, Aug. Clt. 1812. Shrub } 2
$$

148 E. JuвA'тA (Lodd. bot. cab. icon.) leaves 4 in a whorl, linear, filiform, rather clammy, incurvedly spreading; pedicels terminal, corymbose, hispid; calyx tetragonal, coloured, serrulated; corolla campanulately rotate; anthers mutic. Ћ. G. Native of the Cape of Good Hope.

Bearded Heath. Fl. June, Oct. Clt, 1816. Shrub,

149 E. Constántia (Bedf. eric. wob. p. 6.) leaves 4 in a whorl; fowers terminating the branches; bracteas remote from the calyx; corolla bell-shaped. $\zeta, G$. Native of the Cape of Good Hope. Style exserted.

Constantia Heath. Clt. 1810. Shrub 2 feet.

150 E. congE'sta (Wendl. eric. fasc. 17. p. 75.) leaves 4 in a whorl, linear, pilose, spreading; flowers axillary, capitate, drooping; calyx foliaceous, imbricate, toothed ; corolla campanulate, open ; bracteas sessile; anthers mutic. $h$. G. Native of the Cape of Good Hope. Flowers white. Style exserted.
Cronded-flowered Heath. Fl. July. Clt. 1820. Shrub 1 foot.

$$
\text { * * * Leaves } 4 \text { in a nhorl. Corollas urceolate. }
$$

151 E. Flexicau'lis (Dry. in hort. kew. 2. p. 395.) leaves linear, 4 in a whorl, spreading, oblong, glandularly ciliated; flowers terminal, umbellate; calyxes coloured, glandularly ciliated. $々$. G. Native of the Cape of Good Hope. E. glandulòsa, Andr. heath. 2. t. 58. but not of Thunb. Corollas purple, urceolate. Style inclosed.

Bent-stemmed Heath. Fl. May, Jan. Clt. 1800. Shrub $\frac{1}{2}$ foot.

152 E. PERla'ta (Hortul, ex Bedf, hort. eric, wob. p. 18.) leaves 4 in a whorl ; flowers terminal, umbellate; bracteas remote from the calyx ; corolla globose ; anthers a little exserted, mutic. 々. G. Native of the Cape of Good Hope. Corolla reddish-purple; anthers reddish-orange. Style exserted.

Broad-flowered Heath. Fl. Spring and Autums. Clt. 1810. Slirub.

153 E. crucifórmis (Andr. heath, vol, 4. icon.) leaves 4 in a whorl, linear, glabrous, spreading ; flowers terminal, by fours, decussate; corolla urceolate; anthers mutic. $h$. G. Native of the Cape of Good Hope. Flowers purple. Style inclosed.

Cross-formed Heath. Fl. April, Nov. Clt. 1800. Shrub 1 foot.

154 E. mellífera (Hort, ex Link. enum. 1. p. 970.) leaves 4 in a whorl, linear, luairy, spreading, rather remote; flowers terminal, aggregate; calyxes foliaceous; corolla campanulate; anthers mutic; style capitate, exserted. . . G. Native of the Cape of Good Hope. Branches hairy. Corollas purple. An thers exserted, awned.

Honey-bearing Heath. Slirub.

155 E. Sícula (Schonberg, in Linnæa. 2. p. 614.) leaves 4 in a whorl, petiolate, linear, nearly terete, canescent ; flowers terminal, on long pedicels, subumbellate, canescent, erect; calycine segments and bracteas membranous, coloured, about equal in length to the corolla: corollas ovate-oblong, downy. $h . \mathrm{H}$. Native of Sicily. Flowers red.

Sicilian Heath. Fl. April, June. Clt. 1819. Shrub 2 to 3 feet.

156 E. aggrega'ta (Wendl. eric. fasc. 13. p. 11.) leaves 4 in a whorl, linear, hairy, spreading; flowers terminating the small branches; bracteas remote from the calyx; corolla globose, downy, with an erectish limb. $h$. G. Native of the Cape of Good Hope. Lodd. bot. cab. 1678. Flowers purplish-red the whole forming branched racemes. There is also a whiteflowered variety of this. Style exserted.

Aggregate-flowered Heath. F]. June, July. Clt. 1 S20. Shrub 1 foot.

***** Leaves 5-6 or more in a nhorl. Corollas eampanulate.

157 E. Decòra (Andr. heath. 3. t. 66. Ait. hort. kew. t. 392.) leaves 6 in a whorl, elongated, recurved; flowers axillary, mutant, disposed in spikes or racemes; bracteas remote from the ealyx; corolla campanulate; anthers a little exserted. $h_{\text {. }}$ G. Native of the Cape of Good Hope. Lodd. bot. cab. 1383. E. spiràlis, Hortul. Flowers pale red.

Graceful Heath. Fl. Nov. Jan. Clt. 1790. Shrub 2 feet.

158 E. Beaumontina (Roll. Lodd. bot. cab. 1686.) glabrous; leaves linear, 5-6 in a whorl; flowers axillary and terminal, drooping; pedicels many-bracteate ; corolla campanulate; style a little exserted. h.G. Native of the Cape of Good Hope. Corollas white. Allied to $E$. propéndens.

Beaunont's Heath. Fl, June. Clt. 1820. Shrub 1 foot.

***** Leaves 5-6 in a wkorl. Corolla urceolate.

159 E. cerinthoides ( Lin. spec. ed. 2. p. 505. diss. no. 43. 
with a figure) leaves 5-6 in a whorl, linear-lanceolate, pilose and ciliated, bearded at the apex; flowers terminal, capitate, drooping; corolla oblong, with an inflated tube, clothed with viscid hairs outside; bracteas sessile, larger than the calyx; segments of calyx cuneated. $h$. G. Native of the Cape of Good Hope. Andr. heath. 1. t. 50. Curt. bot. mag. t. 220. Lodd, bot. cab. 1679. Berg. pl. cap. p. 104.-Breyn. cent, p. 25. t. 13. Wendl. eric. 7. p. 9. with a figure. E. crinifolia, Sal. in Lin. trans. 6. p. 367. Corollas scarlet or crimson, 8-10 lines long. There are several trifling varieties of this species in the gar¿.ens.

Corintho-like Heath. Fl. May, Nov, Clt. 1774. Shrub.

\section{\$ 4. Anthers corniculate, Leaves 3 or 4 in a whorl.}

160 E. Magrírica (Andr. heath. vol, 4. icon.) leaves 3 in a whorl; flowers terminal by threes or fours; corollas ovate; bracteas remote from the calyx; anthers corniculate. $\hbar_{2} \cdot G$. Native of the Cape of Good Hope. Flowers purplish-red. Style inclosed.

Magnificent Heath. Fl. Aug. Nov. Clt. 1800 . Shrub 2 feet.

161 E. Savillea'na (Bedf. hort. eric. wob. p. 22.) leaves 4 in a whorl, linear, glabrous, erect; peduncles loosely racemose, axillary; calyx foliaceous, narrow; corollas globose-oblong; anthers corniculate. h. G. Native of the Cape of Good Hope. E. Savíllea, Andr. heath. 3. t. 27. E. Savíllii, Lodd. hott, cab.96. Flowers red, or purplish-red. Style inclosed.

Countess of Scarborougl's Heath. Fl. April. Sept. Clt. 1800. Shrub 1 foot.

16@ E. TENE'LLA (Andr. heath. 2. t. 31.) Jeaves + in a whorl, glabrous; flowers terminal by fours; corollas urceolate; anthers corniculate. Ђ. G. Native of the Cape of Good Hope. Lodd. hot. cab. 375. Flowers small, pale purplish-red. Style inclosed.

Delicate lleath, Fl. Year. Clt. 1791. Shrub $\frac{1}{2}$ foot.

169 E. GRA'cris (Andr. heath. 1. t. 2.) stem and branches glabrous; leaves glabrous, 4 in a whorl, linear; flowers terminal ; corolla ovate-globose, or urceolate; anthers corniculate. $r, G$. Native of the Cape of Good Hope. Lodd. bot. cab. 24.4. Flowers small, purplish-red. Style inclosed.

Slcnder Heath. Fl. Feb. May. Clt. 1774. Shrub.

164 E. PR.'cox (Bedf. hort. eric. p. 19. Lodd. bot. cab. 1413.) laves 4 in a whorl, acicular, spreading; flowers small, globosely bell-shaped, disposed in terminal racemose fascicles; bracteas remote from the flower; anthers corniculate. $\zeta . G$. Native of the Cape of Good Hope. Flowers small, purplishred. Style exserted.

Early Heath. Fl. March. Clt. 1820. Shrub $\frac{1}{2}$ foot.

165 E. Fimbria'ta (Andr. heath. 3. t. 23.) leaves 3.4 in a whorl; flowers terminal, capitate; corolla globose; bracteas imbricated, ciliated; anthers corniculate, a little exserted. $I_{2}$. G. Native of the Cape of Good Hope. Lodd. bot. cab. 1047. Flowers red.

Fringed Heath. Fl. March, May. Clt. 1806. Shrub 1 foot.

166 E. Seta'ceA (Andr. heath. 1. t. 24.) leaves 8 in a whorl; flowers terminal; corolla globose, bell-shaped; bracteas remote from the calyx; anthers corniculate. $\eta_{c}$. G. Native of the Cape of Good Hope. Flowers small, purplish-red. Style exserted.

Setaceous-leaved Heath. Fl. Aug. Oct. Clt. 1796. Shrub 1 foot.

+ Species, not knonn to which genera of the Normal Ericea they belong.

167 E. layandulefòlia (Sal. in Lin. trans. 6. p. 332.) stem hoary; leaves 3 in a whorl, hoary?; flowers terminal; bracteas close to the calyx; corollas 2 lines long, with a 4 -angled tube, and an incurved limb; filaments very broad at the base; anthers inclosed, mutic. h. G. Native of the Cape of Good Hope.

Lavender-leaved Heath. Fl. May, Aug. Clt. 1795. Shrub.

168 E. cnustæf Lòra (Sal. in Lin. trans. 6. p. 332.) Jeaves 3 in a whorl; flowers terminal; calyx 4-toothed; corolla 2 lines long, having tile limb 3 times longer than the tube, entire at the base; anthers mutic, inclosed; pericarp smooth. h. G. Native of the Cape of Good Hope. Erìca melanthèra, Thunb. diss. no. 12. but not of Lin. Perhaps a species of Lophándra.

Crest-flowered Heath. Fl. May, June. Clt. 1803 . Shrub.

169 E. cumuliflòra (Sal. in Lin. trans. 6. p. 336.) leaves 3 in a whorl; fascicles 7-12-flowered, terminal; calyx hoary; corolla $2 \frac{1}{3}$ lines long, having the limb ciliated at bottom; anthers mutic, inclosed; pericarp hairy; stigma narrow. $\mathfrak{z}_{\text {. G. Na- }}$ tive of the Cape of Good Hope. Erìca aggregàta, Roxb. mss. -Perhaps a species of Lampròtis. Flowers purplish-red.

Heap-flonered Heath. Fl. May, Sept. Clt.? Shrub.

170 E. Genisteròla (Sal. in Lin. trans. 6. p. 337.) flowers terminal, by threes; calyx viscid; corolla 2 lines long, having the limb ciliated at bottom; anthers mutic, inclosed; pericarp smooth; stigma broad. $\zeta$. G. Native of the Cape of Good Hope. Erica tetráloba, Roxb. mss,-Perhaps a species of Lampròtis.

Genista-leated Heath. Fl. June, Dec. Clt.? Shrub 1 foot. 171 E. PERiplocérlòra (Sal. in Lin. trans. 6. p. 337.) leaves 3 in a whorl, lanceolate-cuneated; flowers terminal, on long pedicels; calyxes short, orbicular; corolla 1-2 lines long; anthers appendiculate, inclosed; stigma narrow. h. G. Native of the Cape of Good Hope. Flowers deep purple. Filaments with short cuneated spurs.--Perhaps a species of Lampròtis.

Periploca-flowercd lleath. Fl. May, Dec. Clt. 1812. Shb. Cult. Elegant shrubs when in blossom, like all the other genera of the order. Turfy peat, mixed with sand, is the best soil for the species; and young tops root readily, if planted in a pot of sand in spring, with a bell-glass over them, in a moderate heat. When the plants have grown a considerable size, the balls of earth should be raised a little above the surface, so as to prevent water from remaining at the top of the sten, and the pots in which they are grown should be well drained.

II! GYPSOCA'LLIS (from $\gamma v \psi o \varsigma$, gypsos, lime, and $\kappa a \lambda \lambda \iota \sigma-$ ros, kallistos, most beautiful; the plants are very elegant, and generally inhabit calcareous districts). Sal. mss. D. Don, in edinl, phil. journ. 17. p, 153.--Erica species of authors.

Lix. syst. Octándria, Monogýnia. Calyx 4-parted, glumaceous, naked at the base. Corolla campanulate, or short-tubular, with a dilated mouth. Stamens exserted; flaments flattened or filiform; anthers bipartite; having the cells mutic at the base, distinct and substipitate, dehiscing by an oblique pore. Stigma simple. Capsule 4-celled, many-seeded.-Small shrubs, natives of Europe and $\Lambda$ frica, with wliorled acerose leaves, and lateral or terminal crowded flowers. This genus is easily distinguished from Erica in the exserted anthers, flattened filaments, and simple stigma.

$\$ 1$. Anthers mutic at the base, that is, without any horns, awns, or spurs.

\section{* Leaves 4 in a whorl. Corollas campanulate.}

1 G. va'gans (Salisb. mss. ex Don, in edinb. phil. journ. 17. p. 153.) leaves $4-5$ in a whorl, glabrous; flowers axillary, racemose; bracteas remote from the calyx; pedicels usually twin; corolla short, campanulate. $\zeta$. H. Native of England, in Cornwall; and of the south of France and north of Africa. 
E. vàgans, Lin. mant. 2 p. 230. syst. 370. Smith, eng. bot. t. 3. E. ràga, Sal. in Lin. trans. 6. p. 344. E. Inultitlòra, Fluds. an!l. 166. Bull, fl. par, t. 203. E. didyma, Stokes, in With. arrang. 400. E. purpuráscens, Lam. dict. 1. p. 48s. Flowers small, pale, purplish-red, in the axils of the leaves, which are contiguous. Stem glabrous.

Yar. $\{3$, álba; Howers axillary, white.

I $a r . \gamma$, tenclla; flowers white, terminating the small branches.

Var. ¿́, pállida; flowers pale red.

Common Cornish Heatl. Fl. July, Sept. Britain. Shrub 1 foot.

2 G. purpura'scers (D. Don, in edinb. plil. journ. 17. p. 153.) leaves $3-4$ in a whorl, linear, glabrous; flowers axillary; corollas tubular or campanulate; anthers deeply bifid; calycine segments awl-shaped. $々$. H. Native of the south of Europe. Erìca purpuráscens, Lin. spec. 503. Seg. veron. 280. Thunb. mon. no. 1.4. Flowers pale purplish-red.

Purplish-flowered Moor-Heath. Shrub 1 to 2 feet.

3 G. Rastźlaus; branches flexuous, lispid; leaves linear, in fascicles, reflexed; Howers terminal, tetragonal, drooping a little; calyxes coloured, adpressed; corolla campanulate. h. G. Native of the Cape of Good Hope. Erica rastéllum, Spreng. syst. 2. p. 196.

Rastellum Moor-Heath. Shrub.

4 G. microstova; leaves \& in a whorl, clothed with woolly hairs, linear, hispidly ciliated, spreading ; flowers axillary, pedicellate, aggregate; corolla campanulate. h. G. Native of the Cape of Good Hope. Erica microstòma, Berg. pl. cap. p. 97. Flowers purplish-red.

Small-mouthed Moor-Heath. F1. Aug. Nov. Clt. 1810. Slirub.

5 G. PILòs ; leaves 3-4. in a whorl, linear, spreading, pilose; flowers terminal, few, rillous, pedicellate, erect; bracteas remote from the calyx, spreading, very villous; corollas campanulate. 々. G. Native of the Cape of Good Hope. Erica pilosa, Lodd. bot. cab. 606. Flowers greenish-yellow.

Pilose Moor-Heatl. Fl. May, July. Clt, 1800. Shrub 1 foot.

\section{* Leares 4-5 in a whorl. Corollas urceolate.}

6 G. multifiòra (D. Don, in edinb. phil. journ. July, 18.34.) leaves 4-5 in a whorl, glabrous, linear; flowers axillary, disposed in a racemose corymb; bracteas remote from the calyx ; corolla with an urceolar tube, or ovate bell-sliaped; holes of anthers near the apex. 5.H. Native of the south of Europe. Erica multitlòra, Lin. spec. ed. 1. p. 355. diss. no. 58. with a fisure of the flower. Andr. heath. 2. t. 57. Ait. hort. kew. 2. p. $30 \%$ Lodd. bot. cab. 1572. E. juniperifòlia, \&c. Garid. aix. p. 160 . t. 32 . E. multiflòra longipeclicellàta, Wendl, eric. fasc. 5. p. 7. E. pedunculàris, Presl. Corolla $1 \frac{1}{2}$ to 2 lines long, pale red, campanulate, with a reflexed limb; anthers black. Pedicels twice longer than the corolla.

Many-flowered Hoor-Heath. Fl. Oct. Feb. Clt.

7 G. CA'RxEA (D. Don. l. c.) leaves $3-4$ in a whorl, linear, glabrous; flowers axillary, drooping, disposed in secund racemes; bracteas remote from the calyx; corolla with a pyramidal tube; anthers foraminose from the middle. $\mathrm{h} . \mathrm{H}$. Native of the South of Germany and Switzerland, and the north of Wales. Erica cárnea, Lin. spec. ed. 2. p. 504 . Curt, bot. mag. t. 11. Jacq. fl, austr. 1. p. 21. f. 31. Scop. H. carn. ed. 2. vol. 1. p. 275. Lodd. bot. cab. 1452. Erìca herbàcea, Lin. diss, no. 57. with a figure; spec. ed. 2. p. 501. Wendl. eric. 9. p. 7. with a figure. Erìca saxátilis, Sal, in Lin. trans. 6. p. 343. Flowers pale red. Corollas conical, $2 \frac{1}{2}$ lines long. Leaves sharply reduplicate.

VOL. III.
Flesh-coloured-flowered Moor-Heatl, Fl. Jan. April. Clt. 1763. Shrub $\frac{1}{2}$ foot.

8 G. Mediterra'ina (D. Don, l. c.) leaves 4-5 in a whorl, linear-cuneated, glabrous; flowers axillary, racemose, secund, nutant; bracteas above the middle of the pedicels; corolla urceolar; anthers foraminose from the middle. $\zeta$. H. Native of the south of Europe, in the region of the Mediterranean; and of Ireland, Sc. Erica Mediterranea, Lin. mant. p. 229. diss. no. 59. with a figure of the flower. Wendl. eric. 7. p. 11. Curt. bot. mag. 471. Erica lugùbris, Sal. in Lin. trans. 6. p. 343. Flowers red, with dark anthers. Corolla $1 \frac{1}{2}$ to 2 lines long.

Mediterranean Moor-Heath. Fl. March, May. Ireland. Shrub 4 to 6 feet.

9 G. ronizonts'tss; leaves 4 in a wholl, linear, spreading; flowers terminal, sessile, usually by threes, drooping; calycine

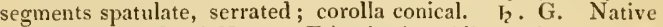
of the Cape of Good Hope. Erica horizoutàlis, Andr. Jeath. 2. t. 52. Flowers white, with brown anthers.

Horizontal Moor-Heath. Fl. July, Sept. Clt. 1800. Shrub 1 to $1 \frac{1}{3}$ foot.

10 G. Procu'nibess; leaves 4 in a whorl, linear, spreading, glabrous; Howers terminal, subaggregate, villous; bracteas remote from the calyx; corolla globosely ovate. 々. G. Native of the Cape of Good Hope. Erica procúmbens, Lodd. bot. cab. 1993. Flowers reddish-purple.

Procumbent Moor-Heath. Fl. June, July. Clt. 1800. Slirub procumbent.

11 G. uíspıda ; leaves 4 in a whorl, hispidly ciliated, linear, sprealing, obtuse; flowers terminal, racemose, pendulous; bracteas remote from the calyx; corolla urceolate, globose. $I_{2}$. G. Native of the Cape of Good Hope. Erica hispida, Andr. heatl. 2. t. 56. Lodd. bot. cab. 1982. Corollas red.

Hispid Moor-Heatl. Fl. July, Nov. Clt. 1791. Shrub 2 feet.

12 G. FLE'xILIs; branches villous; leaves 4 in a whorl, beset with glandular hairs; flowers axillary, racemose, drooping: pedicels viscid; corolla $1 \frac{1}{2}$ line long, with an ovate tube; fruit woolly. h.G. Native of the Cape of Good Hope. Erica racemòsa, Thunb. diss, no. 47. with a figure. Erica fléxilis, Sal. in Lin. trans. 6. p. 342. Calycine segments ciliated with glands.

Bent Moor-Heath. Shrub.

\section{* * Leares 3 in a whorl. Corollas campanulate.}

13 G. maxipuliflòra (D. Don, l. c.) branches hoary ; leaves 3 in a whorl, obtuse, smoothish; flowers disposed in interrupted axillary fascicles; corolla cup-shaped, $1 \frac{1}{2}$ line long; anthers erect. h. H. Native of Arabia and Greece. Erica manipulifòra, Sal. in Lin. trans. 6. p. 344. Sibth. et Smith, fl. græc. t. 352. Erìca verticillàta, Forsk. fl. p. 210. Flowers pale red.

Handful-flonered Moor-Heath. Shrub.

14 G. LANA'TA; leaves 4 in a whorl, woolly; flowers terminal; bracteas sessile, imbricated; corolla short, tubular; calyx very hairy. $h$. G. Native of the Cape of Good Hope. Erìca lanàta, Andr. heath. 3. t. 42. Erìca fláccida, Link, enum. berol. 1. p. 367 . Bedf. hort. eric. wob. p. 10. Corollas white, with brown anthers.

Woolly-flowered Moor-Heath. Fl. July, Dec. Clt.? Shrub.

15 G. Leucanthe'ra; leaves 3 in a whorl, linear, glabrous, erect; branches twiggy; flowers terminal, drooping; pedicels glabrous; corolla 1 to $1 \frac{1}{2}$ line long, funnel-shaped, having the limb quite entire, and lengtl of tube; anthers foraminose near $5 \mathbf{K}$ 
the apex; calyx glabrous. 2 . G. Native of the Cape of Good Hope. Erica leucanthèra, Lin. suppl. p. 223. but not of Andr. Erìca spirææflòra, Sal. in Lin. trans, 6. p. 350. Flowers white.

White-anthered Moor-Heath. Fl. Jan. May. Clt. 1803. Shrub.

$16 \mathrm{G}$. Aст文' ; leaves 3 in a whorl, glabrous; flowers terminal on short pedicels; bracteas approximating the calyx; calyx one half shorter than the corolla, with ovate segments, furnished with a green line; anthers exserted, mutic; stigma peltate. 々. G. Native of the Cape of Good Hope. Erica Acta'a, Link. enum. 1. p. 371. but not of Bedf. Corollas purplish.

Actcea-flowered Moor-Heath. Fl. May, June. Clt. 1822. Shrub.

17 G. Nigricass; leaves 3 in a whorl, spreading, a little reflexed, lineas, glabrous, awned at the apex; flowers terminal, usually by threes; pedicels bracteate, and are as well as the calyx coloured and viscid; corolla campanulately rotate, with a revolute limb. ケ. G. Native of the Cape of Good Hope. Erìca nigrita, Lodd. bot. cab. t. 54. Flowers white; anthers black.

Blackish Mloor-Heath. Fl. June, July. Clt. 1816. Shrub. $18 \mathrm{G}$. PA'Texs; leaves 3 in a whorl, oval-oblong, ciliated, spreading; branches hairy ; flowers terminal, usually by threes; calyx coloured, ciliated; corolla campanulately rotate; anthers connivent, scabrous. $h$. G. Native of the Cape of Good Hope. Erìca pàtens, Andr. heath. 2. t. 35. Lodd. bot. cab. 1228. Flowers red.

Spreading-flowered Moor-Heath. Fl. March, June. Clt. 1800. Shrub $\frac{1}{2}$ foot.

19 G. conca ${ }^{1}$ s ; leaves $3-4$ in a whorl, linear, glabrous, spreading; flowers axillary; corolla campanulate; anthers a little exserted. $\zeta_{c}$. G. Native of the Cape of Good Hope. Erica concàva, Ker. in bot. mag. 2149. Flowers pale red.

Concave-flowered Moor-Heath. Fl. Oct. Dec. Clt. 1800. Shrub.

20 G. Acuta'ngula ; leaves 3 in whorl, ? linear ; flowers terminal, usually by twos or threes; corolla campanulate, with a short tube, and a reflexed limb. h. G. Native of the Cape of Good Hope. Erìca acutángula, Lodd. bot. cab. 1568. Flowers white; anthers black, exserted. Bracteas approximating the calyx, sessile.

Acute-angled Moor-Heath. Fl. June, July. Clt. 1810. Shrub.

21 G. MELANTHE'ra; leaves 3 in a whorl, obtuse, smooth, spreading; flowers terminal, subumbellate, nutant ; bracteas remote from the flower; corolla bell-shaped; bracteas and calyses coloured; stigma obtuse; fruit silky. $h_{2}$. G. Native of the Cape of Good Hope. Erica melantlièra, Jin. mant. 232. Lodd. bot. calb. 867 . Erica lysimachiætlòra, Sal. in Lin. trans. 6. p. 332. Corolla 2 lines long, having the limb twice the length of the tube. Flowers red, with black anthers. Calyx large, and is, as well as the pedicels, coloured.

Black-anthered Moor-Heath. Fl, March, July. Clt, 1803. Shrub.

22 G. THALIC'TRIFLòrA ; branches hairy, straight; leaves 3 in a whorl, linear, glabrous, erect; flowers terminal, 2-3 together, erect, almost sessile; bracteas approximating the calyx; corollat short, campanulate, with deep open segments. $h_{2}$. G. Native of the Cape of Good Hope. Erica thalictriflòra, Lodd. bot. cab. t. 1294. Flowers yellow.

Mcadon-Rue-flowered Moor-Heath. Fl. March, May. Clt. 1820. Slirub.

\section{**** Lcaves 3 in a nhorl. Corollas urceolate.}

23 G. umbella'ta (D. Don, l. c.) branches downy; leaves 3 in a whorl, linear, short, slightly ciliated; flowers terminal, umbellate; bracteas unilateral, pressed to the calyx; corolla pea-shaped, with an 8-angled base; anthers foraminose near the apex. 5 . G. Native of the Cape of Good Hope. Erica umbellàta, Baur. pl. kew. t. 3. Lin. spec. ed. 2. p. 501. Lœfl. res. p. 138 . Andr. heath. 2. t. 40 . Wendl. eric. 4. p. 3. with a figure. Lodd. bot. cab. 1217. Erica lentiformis, Sal. in Lin. trans. 4. p. 344. Flowers disposed in terminal, umbellate fascicles. Corollas $1 \frac{1}{2}$ line long, globosely conical, purplish-red. Anthers black. Calyx glabrous.

Umbellate Moor-Heath. Fl. A pril, July. Clt. 1782. Shrub 2 to 3 feet.

24 G. villòs ; leaves 3 in a whorl, linear, spreading, villous ; flowers axillary or terminal, on long pedicels, drooping, usually by threes; calycine segments ovate, villous ; corollas urceolate, with the limb a little connivent. h. G. Native of the Cape of Good Hope. Erìca villòsa, Andr. heath. 3. t. 53. Corollas white, with black anthers.

rillous Moor Heatl. Fl. June, July. Clt. 1800. Shrub.

$25 \mathrm{G}$. Dumòsa; leaves 4 in a whorl, oval, with revolute edges, spreading, hispid ; flowers terminal, corymbose, drooping; calyxes adpressed, foliaceous; bracteas close to the calyx ; corollas urceolate. $\zeta_{2}$. G. Native of the Cape of Good Hope. Erìca dumòsa, Andr. heatl. 4. icon. Flowers pale red. foot.

Bushy Moor Heath, Fl. April, May. Clt. 1812. Shrub $1 \frac{1}{2}$

26 G. nudiflòra (D. Don, in edinb. phil. journ. 17. p. 153.) leaves $3 \mathrm{in}$ a whorl, linear-cuneated, ciliated, or slightly hairy, spreading; flowers axilkary and terminal, aggregate, erect; corolla ovate-cone-shaped; bracteas minute, remote from the calyx; fruit smooth. h. G. Native of the Cape of Good Hope. Erìca nudiflòra, Lin. mant. t. 229. Lodd. bot. cab. 176. Smith, icon. ined. 3. t. 57. Ait. hort. kew. 2. p. 366. Erica floribúnda, Wendl. erjc. 14. p. 19. with a figure. Erìca sertiflòra, Sal in Lin. trans. 6. p. 342. Flowers purplish-rcd. Corolla $1 \frac{1}{3}$ line long, with an urceolate tube.

Naked flowercd Moor Heath. Fl. July, Nov, Clt. 1 783. Shrub 2 feet.

27 G. sTAuÍNEA; leaves 3 in a whorl, linear, glabrous, erect; flowers axillary, scattered; bracteas approximating the calyx; corolla subrotate, about equal in length to the calys; stamens divaricate, much exserted. h. G. Native of the Cape of Good Hope. Erica stamínea, Andr. heath. 3. t. 48. Flowers sulphur-coloured.

Long-stamened Moor Heath. Fl. June, Sept. Clt. 1799. Shrub 2 feet.

28 G. TIARARLòra; leaves 3 in a whorl, stiff, spreading, obtuse; flowers terminal, glomerate, drooping; calyx bracteate; corolla covered by the calyx, having the tube clilated at the base; flaments gradually dilated. h. G. Native of the Cape of Good Hope. Erica tiaræflòra, Andr. heath. 3. t. 52. Erìca placentiflòra, Sal. in Lin. trans. 6. p. 348. Plant with pale hoary aspect. Calyx coloured. Flowers red; anthers black.

Turban-flowered Moor Heath. Fl. May, Aug. Clt. 1800. Shrub \& feet.

29 G. imbrica'ta ; leaves 3 in a whorl, linear, erect, imbricated; branches rather hairy; calyx imbricated by bracteas; corolla urceolate, 1 line long, length of calyx ; flowers terminal, aggregate, erectish; pericarp gegartoid. h. G. Native of the Cape of Good Hope. Erica imbricata, Lin. mant. 372. diss. 
no. 52 . with a figure of the flower, spec. ed. 2. p. 503 . Andr. heath. 1. t. 3 t. Lodd. bot. cab. 1247. Erìca quinquangulàris, Berg. pl. cap. p. 117. Erìca pyramidàlis, Sal. in Lin. trans. 6. p. 349. Flowers small, white or red, with brown anthers.

Imbricated-bractead Moor Heath. Fl. July, Oct. Clt. 1786. Shrub 1 foot.

30 G. sevaneflòra ; leaves 3 in a whorl, linear; flowers terminal; bracteas scattered above the middle of the pedicels; corolla $\frac{2}{3}$ of a line long, shorter than the calyx; anthers acuminated; fruit broad, orate. $々$. G. Native of the Cape of Good Hope. Erìca squamæflòra, Sal. in Lin. trans. 6. p. 349. Erìca imbricàta, Roxb. mss. but not of Lin.

Scale-flonered Moor Heath. Fl. March. Dec, CIt. 1796. Slurub $\approx$ feet.

81 G. CE'sı ; leaves 3 in a whorl, short, linear, glabrous; flowers terminal, twin, erect; calyx imbricate by bracteas; corolla campanulate, $\frac{2}{3}$ of a line long, shorter than the calyx; anthers obtuse, with a broad dissepiment; fruit ovate; stigma broadish. h. G. Native of the Cape of Good Hope. Erica ea'sia, Sal. in Lin. trans. 6. p. 349.

Grey Moor Heatl. Shrub.

32 G. FLExuòs : leaves 3 in a whorl, linear, glabrous, erect, short; flowers terminal, usually by threes, erect; bracteas scattered above the middle of the pediccls, imbricate, small; corolla bell-shaped, 1 line long, longer than the calyx, which is coloured; anthers obtuse, with a narrow dissepiment; nectarium large ; fruit imbricate. h. G. Native of the Cape of Good Hope. Erica flexuòsa, And. heath. 1. t. 23. Sal, in Lin. trans. 6. p. 349. Lodd. bot. cab. 1495. E. divaricàta, Wendl. eric. 7. p.5. Flowers white, with red anthers.

Flcxuous Moor Heath. Fl. April, July. Clt. 1792. Shrub 1 to 2 feet.

33 G. LAsciva; leaves 3 in a whorl, linear; flowers terminal; calyx imbricated by bracteas; corolla $\frac{2}{3}$ of a line long, a little shorter than the calyx; anthers foraminose from the base; stigma peltate. $\bar{h}$. G. Native of the Cape of Good Hope. Erìca lasciva, Sal. in Lin. trans. 6. p. 349. Erica imbricàta, Thunb. diss. no. 11 .

Wanton Moor Heath. Fl. June, Aug. Clt. 1800. Shrub 1 to 2 feet.

34. G. DIOT EFLòrA ; leaves 3 in a whorl; flowers axillary at the top of the branches; calycine segments cuneated; corolla $1 \frac{1}{2}$ line long, with an urceolate tube; anthers a little exserted; pericarp downy. $h$. G. Native of the Cape of Good Hope. Erìca diotæflòra, Sal. in Lin. trans. 6. p. 342. Erìca pistillàris, Sol. niss.

Tho-eared-flowered Moor-Heath. Fl. April, May. Clt. 1795. Shrub.

35 G. stylòsA; leaves 3 in a whorl; flowers terminal; pedicels long, furnished with bracteas near the calyx; corolla 1 line long, a little longer than the calyx; anthers pointed; fruit oval; style very long. $h$. G. Native of the Cape of Good Hope. Erìca stylòsa, Sal. in Lin. trans. 6. p. 350 . Erìca bracteàta, Roxb. mss. but not of Lin.

Long-styled Moor Heath. Fl. Jan. Aug. Clt. 1789. Shrub.

36 G. Pohlmánil ; leaves 3 in a whorl, ? obtuse, imbricated; flowers terminal; corolla with a globose tube, and a 4-parted limb; anthers a little exserted. $h$. G. Native of the Cape of Good Hope. Erìca Pohlmánnii, Lodd. bot. cab. 1852. Flowers pale red, with deep red anthers.

Pollmann's Moor-Heath. Fl. May. Clt. 1816. Shrub.

37 G. LONGIPEDUNCULA'TA; leaves oval, mucronate, 3 in a whorl, hispid ; flowers terminal, umbellate, on long pedicels, pendulous; bracteas remote from the calyx, deciduous; calyxes adpressed; corolla ovate; anthers mutic. $h$. G. Native of the Cape of Good Hope. Erica longipedunculata, Lodd. bot. cab. 103. Flowers large, purple, pedicellate, and are, as well as the ealyxes, beset with glandular hairs.

Long-peduncled Heath. Fl. July, Nov. Clt. 1805. Shrub 1 foot.

38 G. RostélLa ; leaves 3 in a whorl; flowers terminal ; bracteas imbricated; corolla ovate-globose. h. G. Native of the Cape of Good Hope. Frica rostélla, Bedf. eric. wob. p. 21. Flowers white.

Simall-bcaked Moor-Heath. Fl. April. June. Clt. 1810. Shrub 1 to 2 feet.

39 G. PELTA'A ; leaves 3 in a whorl; flowers terminal; bracteas remote from and approximating the calyx; corolla round, with deep, loose segments. . . G. Native of the Cape of Good Hope. Erìca peltàta, Andr. heath. 4. icon. Erica exsérta, Bedf. cric. wob. p. 9 . Flowers pale purplish-red.

Peltate Moor-Heath. Fl. Spring, Autumn. Clt. 1810. Shrub 1 to 2 feet.

\section{§2. Anthers corniculate. Aberrant species.}

\section{* Leaves 3 in a whorl. Corollas campanulate.}

40 G. articula'ris; leaves 3 in a whorl, glabrous; flowers terminal, umbellate; bracteas remote from the calyx; anthers corniculate; corollas slender, campanulate. $\mathbf{h}$. G. Native of the Cape of Good Hope. Erìca articulàris, Bedf, hort. eric. wob. p. 2. but not of Thunb. nor Curt. Flowers reddishpurple.

\section{Jointed Mloor-Heath. Shrub.}

41 G. Loddige'su ; leaves 3 in a whorl, downy ; flowers terminal; bracteas approximating the calyx, sessile; corolla campanulate, with deep segments; anthers awned. $h$. G. Native of the Cape of Good Hope. Erica concàva, Lodd. bot. cab. 134. but not of Ker. Flowers pale purplish-red, spreading. Probably a species of Erica.

Loddiges's Heath. Fl. Oct. Dec. Clt. 1824. Shrub 1 to 2 feet.

42 G. interte'xta ; leaves 3 in a whorl, ciliated with long hairs; flowers sessile; bracteas approximating the calyx, which is ciliated; corolla round, campanulate; anthers awned. h. G. Native of the Cape of Good Hope. Erìca intertéxta, Lodd. bot. cab. 1034. Flowers yellow. Anthers black.

Interwoven-leaved Moor-Heath. Fl. June, July. Clt. 1818. Shrub $1 \frac{1}{2}$ foot.

$48 \mathrm{G}$. ranicula'ta ; leaves 3 in a whorl, linear, triquetrous, glabrous; branches tomentose; flowers terminal, by threes; corolla $\frac{2}{3}$ of a line long, campanulate, having the segments imbricate at the base; spurs of anthers linear, smooth; style exserted. 々. G. Native of the Cape of Good Hope. Erica paniculàta, Lin. spec. ed. 2. p. 508. Lodd. bot. cab. 1194 . Erìca milleflòra, Berg. pl. cap. p. 96 . Sal. in Lin. trans. 6. p. 350. Flowers red. There is also a white-flowered variety of the species.

Panicled-flowered Moor-Heath. Fl. Feb. April. Clt. 1774. Shrub.

41 G. Bedfordina ; leaves 3 in a whorl; flowers terminal; bracteas remote from the calyx; corolla bell-shaped; anthers awned, exserted, as well as the style. $\eta$. G. Native of the Cape of Good Hope. Erìca mellifera, Bedf. eric, wob. p. 15. Duke
Shrub.

$$
\text { * Lcaves } 3 \text { in a whorl. Corollas urccolate. }
$$

45 G. FRA'GraNs; glabrous; leaves opposite, or 3 in a whorl, 5 K 2 
subulate; flowers terminal or lateral, ustally by twos; corolla campanulate, with a revolute limb; anthers exserted, black, mutic. h. G. Native of the Cape of Good Hope. Erica fràgrans, Ker, in bot. mag. 2181. Flowers pale red, with blackisb anthers. Perhaps a species of Lamprótis.

Fragrant Moor-Heatll. Fl. Spring. Clt. 1803. Slirub.

46 G. Nigrita (D. Don, in edinb. phil. journ. 17. p. 153.) leaves 3 in a whorl, linear, triquetrous, glabrons, shining, spreading; flowers terminal, usually by threes; pedicels pilose, with broad imbricating bracteas, which are colonred like the calyx; corolla globosely bell-shaped, or urceolar, with a revolute limb; fruit tomentose. $々$. G. Native of the Cape of Good Hope. Erìca nigrìta, Lin. diss, mant. 65. Thunb. diss. no. 53. Andr. heath. 1. t. 32. Wendl. eric. fasc. 12. p. 11. with a figure. Eriea larícina, Berg. pl. cap. p. 94 . E. volutatlòra, Sal. in Lin. trans. 6. p. 395.-Seb, thes, 2. p. 11. t. 9. f. 7. Sides of calyx recurved at top. Corolla white, with black corniculate anthers.

Black-anthered Mon-Heath, Fl, April, July. Clt. 1790. Shrub 1 foot.

47 G. LYrígera; leaves 3 in a whorl, shining, linear, trigonal; flowers terminal; corolla urceolate, witls a recurved limb; spurs of anthers serrated; anthers lyræform, hairy; fruit tomentose. দ.. G. Native of the Cape of Good Hope. Erica lyrígera, Sal, in Lin. trans. 6. p. 336. Erica nigrita, Roxb. but not of Sal. Flowers white, with black anthers.

Lyre-bearing Moor-Heath. Fl. Feb. May, Clt. 1790. Slirub.

\section{* * Leaves 4 in a whorl. Corollas campanulate.}

48 G. cistrfòlia ; leaves 4 in a whorl, beset with glandular hairs; flowers terminal; bracteas remote from the calyx; corolla bell-slaped, with reflexed segments; anthers subcorniculate, h. G. Native of the Cape of Good Hope. Erìca cistifòlia, Link. enum. 1. p. 369 . Bedf. eric, wob. p. 5. Corollas white. Calyx hairy.

Cistus-leaved Moor-Heath. FI. April, May. Clt. 1823. Shrub 1 to 2 feet.

4.9 G. exprómpta ; leaves 4 in a whorl, linear, spreadingly reflexed, lairy, bearded at the apex; branches woolly ; flowers aggregate, terminal, drooping; corolla campanulate ; anthers awned or corniculate. h. G. Native of the Cape of Good Hope. Erìca exprómpta, Spreng. syst. 2. p. 195.

Drani-out-anthered Moor-Heath, Fl, April, Sept, Clt. 1811. Shrub 1 to 2 feet.

Cult. See Erica, p. 800 . for culture and propagation of the greenhouse species; and Calluna, p. 828 , for those of the hardy kinds.

11I. BLE'RIA (named after Patrick Blair, M.D. F.R.S. He practised medicine at Boston in Lincolnshire, and was author of Miscellaneous Observations in 1718, and Botanic Essays in 1720, \&c.) Lin. gen. 139 . Juss. gen. 160. D. Don, in Edinb. phil. journ. 17. p. 157. Erica species, Sal. in Lin. trans.

Lin. syst. Tetra-Pentándria Monogýnia. Calyx 4-parted. Corolla short-tubular, with a 4 -cleft limb. Stamens 4-6, inserted in the receptacle; filarents linear, flattened, glabrous ; anthers bipartite; cells of anthers attenuated at the base, mutic, dehiscing by an oblong hole. Stigma simple, obtuse. Capsule 4-celled, many-seeded.-Much branched shrubs, natives of the Cape of Good Hope. Leaves verticillate, with revolute margins. Flowers terminal, glomerate.

\section{Anthers mutic.}

1 B. kricoides (Lin. spec. 162.) leaves $t$ in a whorl, oblong, obtuse, ringed ; bracteas 3 , length of calyx; stamens $4-5$, exserted. h. G. Native of the Cape of Good Hope. Erica Blæ'ria, Thumb. prod. 72. Wendl. coll. 1. p. 73. p. 25. Lodd. bot. cab. 85 . Erìca dumòsa, Sal. in Lin. trans. p. 341. Erica Bla'ria rùbra, Hortul.-Petiv. gaz. 47 1. t. 2. f. 10. Erìca orbiculàris, Lodd. bot. cab. 158. Corolla purplish red. Calyx bibracteate.

I ar. $\beta$, pállida; (Lodd. bot. cab. 85.) Flowers pale red.

Heath-like Blæria. Fl. Aug. Oct. Clt. 1774. Shrub.

2 B. DEPRE'ssa (Licht. mss. ex Rom. et Schultes, syst. 3. p. 168.) leaves $3-4$ in a whorl, linear, spreading, hairy; anthers exserted. 5. G. Native of the Cape of Good Hope. Corolla cylindrical, rufcscent.

Depressed Blæria, Fl. June, July. Clt. 1816. Shrub depressed.

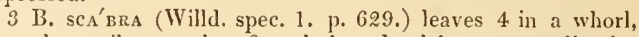
lanceolate, pilose; calys funnel-shaped, glabrous; corolla glabrous; stamens 4, exserted. h. G. Native of the Cape of Good Hope. Wentl. coll. 1. p. 85. t. 31 . Erica scabra, Thunb. prod. 1. p. 72. Erica exilis, Sal. in Lin. trans. 6. p. 340. Flowers purplish-red. foot.

Scabrous Blacia. FI. May, June, Clt. 1824. Shrub 1 4 B. Fascicula'ta (Willd. spec. 1. p. 629.) leaves 4 in a whorl, lanceolate, ciliately scabrous ; stamens 4, exserted.? ?. G. Native of the Cape of Good Hope. Erica fasciculàta, Thunb. prod. 72. fl. cap. 2 .

Fascicled-flowered Blaria. Fl. June, July. Shrub 1 foot.

5 B. Articula'ta (Lin. mant. 198.) leaves 4 in a whorl, ovate or linear, glabrous, shining; bracteas solitary; calyx funnel-shaped, hairy; stamens $4-5$, exserted. $\zeta$. G. Native of the Cape of Good Hope. Erica articulata, Thunb, prod. 71. Wendl, coll. 2. p. 19. t. 44. Erica paleàcea, Sal. in Lin. trans. 6. p. 341. Erica eriocéphala, Lam. encyc. no. 73. ill. 78 . Flowers reddish. Heads droojing.

Jointed-stemmed Blæria. Fl. May, June. Clt. 1795. Shrub 1 foot.

6 B. purpu'rea (Willd. spec. 1. p. 630. Lin. suppl. 122.) leaves 4 in a whorl, ovate, subciliated; stem flexuous, erect; anthers inclosed. $h_{2}$. G. Native of the Cape of Good Hope. Erica purpùrea, Thunb. prod. 71. Flowers purple. Heads drooping.

Purple-flowered Blæria. Fl. May, June. Clt. 1791. Shrub. 7 B. Mucòs a (Willd. spec. 1. p. 630. Ait. hort. kew, 1. p. 150.) leaves 4 in a whorl; calyx pilose; corolla campanulate, pilose above; flowers axillary; stigma peltate. $\zeta_{2} . \mathrm{G}$. $\mathrm{Na}$ tive of the Cape of Good Hope. Erica álbens. Thunb. prod. 70 ?

Mossy Blæria. Fl. June, Auz. Clt. 1774. Shrub 1 foot.

8 B. Jusílca (Lin. mant. 39. Willd. spec. 1. p. 629.) leaves $3-4$ in a whorl, linear, hairy; flowers racemose, drooping. $h_{2}$. G. Native of the Cape of Good Hope. Erica pusilla, Thunb. prod. p. 70. Branclues downy. Leares scabrous.

Least Blæria. Shrub.

9 B. HIRsu'TA (Licht. in Røem. et Schultes, syst. 3. p. 170.) leaves 3 in a whorl, fleshy, nearly terete, spreading; calyx pilose; corolla cylindrical; anthers 4, exserted. $\zeta . G$. Native of the Cape of Good Hope. Corolla flesh-coloured. Anthers black.

Hairy Blæria. Shrub.

10 B. Pauciflòn A (Wendl. coll. 2. p. 17. t. 43.) Jeaves 3 in a whorl, ovate, glabrous; corolla clavate, glabrous; calyx 
hairy; anthers exserted. $h$. G. Native of the Cape of Good Hope. Flowers red.

Fen-flonered Blaria. Fu. June, July. Clt. 1812. Shrub.

$11 \mathrm{~B}$. Thunbérgir ; leaves 4 in a whorl; bracteas and calyxes very pilose ; corolla 2 lines long, hairy; stamens 4-5, very broad at top, inclosed. $々$. G. Native of the Cape of Good Hope. Erica hirsùta, Thunb. prod. p. 72, Sal, in Lin. trans. 6. p. 339.

Thunberg's Blaria. Shrub.

12 B. culcuclodra; leaves 3 in a whorl, minute; calyx rery pilose; bracteas distinet ; corolla $1 \frac{1}{2}$ line long, hairy ; stamens 4, inelosed. h. G. Native of the Cape of Good Hope. Erica eiliciiflòra, Sal. in. Lin. trans. 339. Anthers didymous, bearded.

Ciliated-flowered Blæria. Fl. May, A ıg. Clt. 1800. Shrub.

13 B. xeranthenifóla ; leaves 3 in a whorl, recurved; calyx woolly, inbricate; corolla 13 lines long, woolly ; stamens exserted. h. G. Native of the Cape of Good Hope. Erica xeranthemifòlia, Sal. in Lin. trans. 6. p. 339.

Ieranthemum-leaved Blæria. Fl. June, Aug. Clt. 1812. Shrub.

14 B. NODHFlòra; leaves 3 in a whorl, villous; calyx funnelshaped, very villous; corolla $1 \frac{1}{2}$ line long, hairy; stamens 4 , exserted. $h_{c}$. G. Native of the Cape of Good Hope. Erica nodiflora, Sal. in Lin. trans. 6. p. 340.

Knot-floroered Blæria. Fl. March, Aug. Clt. 1799. Shrub.

15 B. Flosculòsa; leaves 4 in a whorl; ealyx fringed; corolla $\frac{3}{4}$ line long, with a very narrow tube and dilated limb; stamens 4 , exserted, with very narrow filaments. $h_{\imath}, \mathrm{G} . \mathrm{Na}$ tive of the Cape of Good Hope. Erica flosculòsa, Sal. in Lin. trans. 16. p. 340 . The flowers resemble the florets in the disk of Compósita.

Floseulose Blaria, Shrub.

16 B. BarbignRA; leaves 4 in a whorl ; calyx deeply 4-cleft, imbricated by bracteas, bearded; corolla glabrous, 2 lines long; stamens 4-5, exserted; style very narrow. h.G. Native of the Cape of Good Hope. Erica barbígera, Sal. in Lin. trans. 6. p. 341 .

Bcard-bearing Blæria. Slurub.

17 B. TURMA'Lis; leaves 6 in a whorl; peduncles very short; calyx minute, adpressed; corolla 2 lines long; stamens 4-5, exserted; anthers broad. 5. G. Native of the Cape of Good Hope. Erìca turmàlis, Sal. in Lin. trans, 6. p. 342.

Trooper Blæria. Slımb.

18 B. equisetifòlia; leaves 3 in a whorl; flowers $3-5$ in a fascicle; peduncles long, glabrous; corolla $1 \frac{1}{2}$ line long; stamens 4-5, exserted. h. G. Native of the Cape of Good Hope. Erìca equisetifòlia, Sal. in Lin. trans, 6. p. 342.

Horsetail-leaved Blaria. Fl. July, Clt. 1800. Slurub.

\section{\$. Anthers anned.}

19 B. GLABE'Lla (Willd. spec. 1. p. 631.) leaves 4 in a whorl, oblong, glabrous, with scabrous margins, numerous; bracteas solitary; calyx funnel-shaped, quadrangular; corolla 2 lines long; stamens 4, exserted; spurs of anthers deflexed. h. G. Native of the Cape of Good Hope. B. purpurea, Berg. pl. cap. 34. B. pusilla, Lin. mant. p. 39. Erìea glabélla, Thunb. prod. 73. Erìca embolífera, Sal. in Lin. trans. 6. p. 340.-Seb. thes. 1. p. 30. t. 20. f. 2. Flowers purple.

Smooth Blæria. Fl, June, July. Clt. 1816. Slırub.

20 B. cilia'ris (Lin. suppl. 122.) leaves 4 in a whorl, glabrous, minute; calyx very hairy ; corolla $1 \frac{1}{3}$ line long, hairy; stamens 4-5, inclosed; filaments spurred. $h . G$. Native of the Cape of Good Hope. Wendl. coll. 2. p. 35. t. 49.?
Erìca plumòsa, Thunb. prod. 73. Sal, in Lin. trans 6. p. 339.

Ciliated-calyxed Blæria. Fl. June, Aug. Clt. 1794. Shrub 1 foot.

21 B. Dumòs a (Wendl. coll. 2. p. 3. t. 38.) leaves 3-4 in a whorl, linear, obtuse, ereet, 1 line long; corolla $1 \frac{1}{2}$ line long, glabrous; anthers crested, exserted. h. G. Native of the Cape of Good Hope. Flowers rose-coloured, drooping.

Bushy Blaria. El. June, July. Clt. 1800 . Shrub 1 foot.

22 13. bRUniefòla ; leaves 6 in a whorl, long; bracteas near the calyx, the outer one very long; corolla $1 \frac{1}{2}$ line long; stamens 6 , exserted; filaments spurred. h. G. Native of the Cape of Good Hope. Erica bruniæfolia, Sal, in Lin. trans. 6. p. 3.41. Erica hemisphérica, Sol. mss.

Brunia-leaved Blæria. Slurub.

Cult. Pretty little shrubs, deserving a place in every collection of greenlouse plants. A mixture of turfy peat and sand is the best soil for them; and young tops root readily, planted in a pot of sand in spring, with a bell-glass over them.

IV. SYMPIE'ZA (from $\sigma v \mu \pi เ \varepsilon_{3} \omega$, sympie $\approx$, to Iress; in reference to the stamens, which adhere to the tube of the corolla.) Licht. mss. ex Røen. et Schultes, syst. 3. p. 8. no. 44.7. and p. 171 .

Lin. syst. Tetrándria Monogýnia. Calyx turbinate, compressed, bilabiate, fringed. Corolla tubular, sub-bilabiate, longer than the calyx. Stamens $t-5$, inserted in the tube of the corolla, exserted; anthers erect; style length of stamens: stigma simple. Capsule 4-celled, many-seeded.-A small branched shrub, native of the Cape of Good Hope. Leaves adpressed, erect, imbricated, 3 in a whorl, linear, trigonal, glabrous, engraven by a line above. Flowers drooping, disposed in terminal heads, purplish.

l S. capitella'ta (Licht. l. c.) f2. G. Native of the Cape of Good Hope. Blæria bracteàta, Wendl. coll. 2. p. 1. t. 37. Erica labiàlis, Sal. in Lin. trans. 6. p. 340 . Heals of flowers disposed in a racemose manner.

Small-headed Sympieza. Fl. June, August. Clt. 1812. Shrub.

Cult. See Blce'ria above for culture and propagation.

V. PACHY'SA (from $\pi a \chi v c$, pachys, thick; in reference to the thick substance of the corolla). D. Don, in edinb. phil. journ. 17. p. 153.-Erica species of authors.

Lis. sist. Oetándria Monogýnia. Calyx deeply 4-parted, (f. 135 a.) eoriaceous. Corolla nearly globose, (f. $135 \mathrm{c}$.) coriaceous, with a contracted 4-lobed mouth, $(\mathrm{f} .135 \mathrm{~d}$.) Stamens inclosed; filaments much dilated; anthers bifid; cells of anthers short, crested at the base, opening by an oblique foramen. Style dilated at the base; stigma simple, obtuse. Disk hypogynous, elevated. Capsule 4-celled, many-seeded.-Small ereet shrubs, natives of the Cape of Good Hope. Leaves loosely imbrieated, "compressed, 3 in a whorl. Flowers large, terminal, subcorymbose, drooping; pedicels bracteolate.

1 P. ÁRDENs (D. Don, in edinb. pluil. journ. 17. p. 153.) leaves linear, spreading, glabrous, 3 in a whorl, stiff; corolla ovate, globose; bracteas 3,2 approximate to the caly $x$ and one remote from it. h. G. Native of the Cape of Good Hope. Erica árdens, Andr. heath. 2. t. 14. Ker. bot. reg. t. 115. Bedf. eric. wob. pl. 3. f. 23. Lodd. bot. eab. 17. Flowers orangered.

Ardent Pachysa. F]. April, June. Clt. 1800. Shrub 1 to 2 feet. 
2 P. ve'rsix (D. Don. J. c.) leaves 3 in a whorl, linear, rather scabrous, spreading; corolla orate-globose, very clammy; bracteas remote from the calyx. h. G. Native of the Cape of Good Hope. Erica sérnix, Andr. heath. 3. t. 19. Bedf. eric. wob. t. 3. f.21. Lodd. bot. cab. 1443. Erìca resinòsa, Sims, bot. mag. t. 1139. Corollas orange-red, tipped with green.

Varnished Pachysa. Fl. May, Aug. Clt. 1803. Shrub 1 to 2 feet.

3 P. arista'ta; leaves 3 in a whorl, linear, sprealing, roughish; corolla ovate-globose, clammy; bracteas approximating the calyx; cells of anthers awned. $\boldsymbol{~}$. G. Native of the Cape of Good Hope. Erica rérnix, var. coccínea, Bedf. eric. wob. p. 27. t. 3. f. 22. Corolla reddish-orange, tipped with green. This species differs from the rest in the anthers being awned, not crested.

Anned-anthered Pachysa. Fl. May, June. Clt.? Shrub 1 to 2 feet.

4 P. Lambertia'xa; leaves 3 in a whorl, linear, glabrous, spreading; corollas glabrous, ovate-globose; bracteas 3, 2 near the calyx, and I remote from it. $\zeta$. G. Native of the Cape of Good Hope. Erica Lambértia, Andr. heath, 2, t. 18. Erìca Lambertiàna, Sol. in Ait. hort. kew. 2. p. 391. Lodd. bot. cab. 3. Calyx red. Corollas white.

Lambert's Pachysa. Fl. May, July. Clt. 1800. Shrub 1 to 2 feet.

5 P. PHysònes; leaves 4 in a whorl, linear, with glandular margins; calycine segments ovate; corollas ovate-globose ; bracteas remote from the calyx. $\zeta$. G. Native of the Cape of Good Hope. Erìca physodes, Thunb. diss. no. 89. Lin. diss. no. 32. spec. ed. 20. p. 506. Berg. fl. cap. 101. Andr. heath. 1. t. 22. Curt. bot. mag. 443. Wendl. eric. 7. p. 13. with a figure. Bedf. eric. wob. pl. 3. f. 24. Erica sàlax, Sal. in Lin. trans. 6. p. 370 . Leaves glutinose. Corollas white and clammy, having the interstices of the limb ending in a tumid hook.

Bladder-flowered Pachysa. Fl. March, July, Clt. 1788. Shrub.

6 P. Foruòsa; leaves 3 in a whorl, oblong, obtuse, spreading; calyxes spreading; corolla ovate-globose, clammy. h. G'. Native of the Cape of Good Hope. Erica formosa, Thunb. diss. no. 80. t. 3. f. 3. Corolla white.

Beautiful Pachysa. Fl. June, Sept. Clt. 1795. Shrub 1 to 2 feet.

7 P. Ba'ccans (D. Don, in edinb. phil. journ. 17. p. 153.) leaves 4 in a whorl, linear, trigonal, glabrous, erect; bracteas approximating the calyx; corolla turbinate, with a 4 -angled tube. 々. G. Native of the Cape of Good Hope. Erìca báccans, Lin. mant. 233. Curt. bot. mag. no. 358. Andr. heath. 1. t. 21. Wendl. eric. 6. p. 13 . Baur. icon. kew. t. 22. Erìca baccæfórmis, Sal. in. Lin. trans. 6. p. 352. Seb. thes. 1. p. 32. t. 21. f. 3. Calyx and bracteas coloured. Corolla reddish-purple.

Berry-flowered Pachysa. Fl. April, July. Clt. 1774. Shrub 1 to 2 feet.

8 P. resicula'ris; leaves 3 in a whorl, besprinkled with black vesicles; corolla 1 line long, clothed with viscid pubescence; anthers inclosed: spurs of anthers parallel, cuneated; fruit silky. h. G. Native of the Cape of Good Hope. Erica vesiculàris, Sol. in Lin. trans. 6. p. צ35. Erìca conàcea, Hortu].

Vesicled Pachysa. Fl. Feb. Aıg. Clt. 1796. Shrub.

9. P. GLOMiflòra; leaves 3 in a whorl, narrow-cuneated; flowers terminal; calyx imbricated by bracteas; corolla $2 \frac{1}{2}$ lines long, viscid, with a spherical tube; spurs of anthers very villous. h. G. Native of the Cape of Good Hope. Erica glomiflòra, Sal. in Lin. trans. 6. p. 330. Erìca viscària, Sol, mss. Tufted-flowered Pachysa. Shrub.

Cult. See Erica, p. 800 . for culture and propagation.

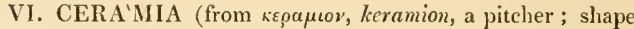
of Howers). D. Don, in edinb. phil. journ. 17. p. 153.-Erica species of authors.

Lin. syst. Octándria Monogýnia. Calyx 4-parted, glumaceous. Corolla urceolate, with a 4 -lobed limb. Stamens inclosed; filaments dilated, flat; anthers bifid; cells of anthers short, aristate at the base. Stigma capitate. Capsule 4-celled, many-seeded.- Small erect shrubs, natives of the Cape of Good Hope. Leares scattered, bluntish, flat, glaucous beneath. Flowers terminal, subcorymbose.

1 C. urceola'ris (D. Don, in edinb. phil. journ. July, 1834). leaves $S$ in a whorl, linear-lanceolate, pubescent; bracteas remote from the calyx; corollas downy, urceolate, h. G. Native of the Cape of Good Hope. Erìca urceolàris, Berg. pl. cap. p. 107. Sol. in hort. kew. 2. p. 395. Wendl. eric. p.311. with a figure. Baur. pl. Ker. t. 16. Erìca Cáffra, Lin. spec. 502. Erìca lamellàris, Sol. in Lin. trans. 6. p. 327. Erica pentaphýlla, Lin. spec. ed. 2. p. 506. Corolla 3 lines long, white. Spurs of anthers glabrous.

Pitcher-flowered Ceràmia. Fl. May, July. Clt. 1778. Shrub.

2 C. Auricula'ris; leaves 3 in a whorl, linear-lanceolate; corolla 3 lines long, downy outside, with an ovate tube; spurs of anthers minute, ear-formed. $\zeta$. G. Native of the Cape of Good Hope. Erica auriculàris, Sal. in Lin. trans. 6. p. 327. Like the preceding, but differs in the spurs of the anthers.

Auricled-anthered Ceràmia. Fl. April, Nov. Clt. 1800. Shrub 1 foot.

3 C. Marifòlia (D. Don, l, c.) leaves 3 in a whorl, ovate, downy ; bracteas near the calyx; corolla ovate-globose, pubescent both inside and outside ; spurs of anthers downy. h. G. Native of the Cape of Good Hope. Erica marifòlia, Sol. in Ait. hort kew. 2. ed. 2d. p. 402. Baur. icon. pl. kew. t. 14. Andr. heatl. 1. t. 1. Wendl. eric. 2. p. 9, with a figure. Calyxes foliaceous. Corolla white, $1 \frac{2}{3}$ line long.

Cat-thymc-leaved Ceràmia. F]. April, May. Clt. 1792. Shrub 2 feet.

4 C. neliantuenifòlia; leaves opposite, obovate; corolla urceolate, 2 lines long, downy both inside and outside; spurs of anthers long. $\boldsymbol{h}$. G. Native of the Cape of Good Hope. Erìca helianthemifòlia, Sal. in Lin. trans. 6. p. 328. Corollas white.?

Rock-rose-leaced Ceràmia. Fl. Feb. April. Clt. 1796. Shrub.

5 C. PLANIFòlia; leaves 3 in a whorl, ovate, ciliated, remotish; flowers axillary, by threes; corolla urceolate, clothed with viscid down; calyx spreading, ciliated with glands; fruit smooth. そ. G. Native of the Cape of Good Hope. Erica planifolia, Thunb. diss. no. 60 . Berg. pl. cap. p. 10 . Lin. spec. ed. 2 d. p. 508 . Wendl. eric. 10. p. 59. Erìca thymifôlia, Sal. in. Lin. trans. 6. p. 325 . Corolla red. Anthers inclosed. Stem diffuse. 
Var. $\beta$; anthers exserted. $h_{2}$. G. Erìca planifòlia, Willd. spec. 2. p. 362.-Pluk. mant. p. 69. t. 347. f. 1.

Var. $\gamma$; corolla smootlı; anthers exserted. h.G. Erica thymifòlia, Wendl. obs. p. 48 .

Flat-leaced Ceràmia. Fl. June, Nov. Clt. 1795. Shrub 2 feet.

6 C. тиymiòlı; leaves 3 in a whorl, ovate, spreading, remotish, ciliated; flowers axillary, solitary; spurs of anthers short; corolla globose, urceolate, downy.? h.G. Native of the Cape of Good Hope. Erica thymifolia, Andr. lieath. 2. t. 29. Ait. hort. kew. 2. p. 402. Bracteas remote from the calyx. Corollas white, but in Andrew's figure they are red or purple.

Thyme-leaved Ceràmia. Fl. March, Nov. Clt. 1789. Shrub.

7 C. TEucrifòcia ; leaves $S$ in a whorl, lanceolate, rather villous, spreading ; flowers axillary, cymose. $h_{\text {. }}$ G. Native of the Cape of Good Hope. Erìca teucrifolia, Spreng. syst. 2. p. 109 .

Teucrium-leaved Ceràmia. Fl. May, Sep̧t. Clt. 1812. Shrub.

8 C. CORDA'TA; leaves 3 in a whorl, ovate, sub-cordate, villous above and woolly beneath; branches divaricate, hairy; corollas globose; anthers mutic. $\eta$. G. Native of the Cape of Good Hope. Erìca cordàta, Andr. heath. 3. t. 41. Corollas white, with black anthers.

Cordate-leaved Ceràmia. Fl. April, June. Clt. 1799. Shrub diffuse.

9 C. ? calathiflóra ; leaves 3 in a whorl, ovate, imbricated; flowers terminal; calyx tomentose ; corolla campanulate, 1 line long, smooth; spurs of anthers cuneated, hairy; fruit tomentose; style exserted. h.G. Native of the Cape of Good Hope. Erìca calathiflòra, Sal, in Lin. trans. 6. p. 32s. Erìca bícolor, Thunb. diss. no. 57. Willd. spec. 2. p. 363.

Bonl-flowered Ceràmia. Fl. Nov. March. Clt. 1790. Slirub.

10 C. Latifòra; leaves 3 in a whorl, oblong-lanceolate, villous above and white beneath, as in the rest of the species; flowers axillary, agyregate; corollas conical; genitals exserted; anthers mutic. $h$. G. Native of the Cape of Good Hope. Erìca latifòlia, Andr. 2. t. 41. Flowers dark red or purple. Branches flexuous.

Broad-leaved Ceràmia. Fl. May, Aug. Clt, 1800. Shrub.

$11 \mathrm{C}$. oblioua ; leaves obliquely verticillate, linear, truncate, with glandular margins; spikes of flowers terminal, coarctate; corollas urceolate, viscid, having the interstices of the limb ending in a tumid hook each; anthers awned. $h . G$. Native of the Cape of Good Hope. Erica obliqua, Thunb. diss. no. 73. with a good figure. Baur. pl. kew. t. 3. Andr. heath, 1. t. 23. Wendl. eric. 17. p. 77, with a figure. Bracteas remote from the calyx; calycine segments linear-oblong. Corollas pale purple.

Oblique-leaved Ceràmia. Fl. Aug. Oct. Clt. 1789. Slirub.

12 C. oxycocciròlı; stems decumbent, filiform; leaves 3 in a whorl, ovate; corolla $1 \frac{1}{4}$ line long, campanulate, hairy; filaments mutic. $\zeta_{c}$. G. Native of the Cape of Good Hope. Erìca oxycoccifòlia, Sal, in Lin. trans. 6. p. 325.-A very pretty species, with the habit of Oxycóccus palustris. Flowers red.

Cranberry-leaved Ceràmia. Fl. Feb. May. Clt. 1791. Shrul, decumbent.

13 C. BLE'NNA; leaves 4-5 in a whorl, ovate, cuneated; corolla urceolate, 4-5 lines long, viscid, having the segments imbricated at the base; filaments very hroad; anthers corniculate.
h.G. Native of the Cape of Good Hope.-A very fine species. Corollas yellow, with a green mouth. Perhaps a species of Pachy'sa.

Blcnna Ceramia. Slırub.

14. C. Serpyldròma; leaves 3 in a whorl, ovate, ciliated, sessile; flowers terminal; branches hairy. $々$. G. Native of the Cape of Good Hope. Erìca serpyllifòlia, Lodd. bot. cab. 744. Corollas white.

Wild-Thyme-leavcd Cerimia. Fl. June, July. Clt. 1810. Slirub.

15 C.? humru's ; leaves opposite, or 3 in a whorl, oval; corolla $1 \frac{1}{3}$ line long, with an ample limb; flowers terminal; anthers mutic, inclosed; style much exserted. 2. G. Native of the Cape of Good Hope. Erica humifusa, Sal. in Lin. trans. 6. p. 332 .

Trailing Ceràmia. Fl. June, July. Clt.? Slirub.

Cult. See Erica, p. 800. for culture and propagation.

VII. DE'SMIA (from $\delta \varepsilon \sigma \mu \eta$, desme, a fascicle; in reference to the glomerate flowers). D. Don, in edinb. phil. journ. July, 1834.-Erica species of authors.

Lin, syst. Octándria, Monogýnia. Calyx 4-toothed. Corolla globose, with a contracted 4 -toothed mouth. Stamens exserted; filaments flattened; cells of anthers short, dehiscing by an oblong foramen, with the base truly simple and confluent in the filament. Stigma capitate. Capsule 4-celled, many-seeded. Seeds scrobiculate.-Small erect shrubs, natives of the Cape of Good Hope. Leaves scattered, spreading, subulate. Flowers terninal, glomerate.

1 D. confe'rta (D. Don, in edinb. pliil. journ. 17. p. 153.) flowers umbellate, sessile, fasciculate; filaments narrow, $h$. G. Native of the Cape of Good Hope. Erica conférta, Andr. heath. 2. t. 50. Sol. in Ait. hort. kew. 2. p. 409. Lodd. bot. cab. 1335. Leaves 4 in a whorl. Corollas white.

Cronded-flowered Desmia. Fl. Oct. Feb. Clt. 1800. Shrub 1 foot.

2 D. EQUA'LIs (D. Don. l. c.) umbels pedunculate, aggregate; filaments dilated. $h$. G. Native of the Cape of Good Hope.

Equal Desmia. Shrub.

3 D. polifòlia (D. Don, l. c.) leaves 3 in a whorl, aristate; flowers fascicled; corollas oblong, with a dilated throat; filaments dilated; stigma nearly simple. $\eta_{\text {. }}$ G. Native of the Cape of Good Hope.

Polium-leaved Desmia. Shrub.

Cult. See Erica, p. 800. for culture and propagation.

VIII. EURYLE'PIS (from $\varepsilon v \rho u s$, curys, broad, and $\lambda \epsilon \pi \iota$, lepis, a scale; in reference to the dilated scales of the calyx). D. Don, in edinb. phil. journ. 17. p. 154.-Erica species of authors.

Lin. syst. Octándria, Monogýnia. Calyx 4-parted, coriaceous, bibracteate at the base. Corolla tubular, coriaceous, ventricose at the base, with a 4 -cleft erect limb. Stamens inclosed; filaments dilated, canaliculate; anthers bipartite; cells of anthers coriaceous, dehiscing by an oblong foramen, auricled at the base. Stigma clavate, witl a 4 tubercled disk and a crenulated ring. Capsule 4-celled, many-secded. Segments of placenta 2-lobed. Seeds oval, ventricose.-Diffusely branched shrubs, natives of the Cape of Good Hope. Leaves scattered, with revolute margins. Flowers terminal, solitary, large, pendulous. 


\section{Anthers mutic at the base. Normal species.}

1 E. nalicácaba (D. Don, 1. c.) leaves 3 in a whorl, linear, glabrous, spreading; flowers terminal, solitary, or by threes; corolla ovate-tubular, glabrous; bracteas ovate, near the calyx ; fruit splerical; calyx adpressed. h. G. Native of the Cape of Good Hope. Erica halicácaba, Thunb. diss. no. 51. Lin. liss. no. 3. with a figure of the flower. spec. ed. 2. p. 507. amœn. acad. 5. p. 85 . Andr, eric. 2. t. 36. Wendl. eric. 6. p. 7 . with a figure. Erica rupéstris, Sal. in Lin. trans. 6. p. 353. Corolla 7 -8 lines long, sulphur-coloured, or yellowish-green.

Ketlle-flowered Broad-scaled-Hearh. Fl. May, Aug. Clt. 1780 . Slirub.

2 E. azalezròua ; leaves 3 in a whorl, lanceolate; flowers terminal; corolla $1 \frac{1}{2}$ line long, hairy ; anthers mutic, exserted, foraminose the whole length. $\zeta$. G. Native of the Cape of Good Hope. Erìca azalçefòlia, Sal. in Lin. trans. 6. p. 334.

Azalea-leaved Broad-scaled-Heath. Shrub.

3 E. Álbens (D. Don, in ediub. phil. journ. 17. p. 154.) leaves 3 in a whorl, linear, pilose; flowers axillary; bracteas remote from the calyx; calyxes acuminated; corolla ovate, urceolate, 3 lines long. $h . G$. Native of the Cape of Good Hope. Erìca álbens, Lin. diss, no. 34. mant. p. 233. Curt. bot. mag. t. 440. Lodd. bot. cab. 95. Erìca viminàlis, Sal. in Lin. trans, 6. p. 38\%. Flowers cream-coloured.

IIhitish-flowered Broad-scalcd-Heath. Fl. Feb. Aug. Clt. I 89. Shrub.

4 E. tetragòna; leaves 3 in a whorl, linear, acuminated, ciliated, erectly spreading; flowers axillary, erect; corolla 4 lines long, with a pyramidal $f$-angled tube; calycine segments cuspilate and ciliated. 々. G. Native of the Cape of Good Hope. Erica tetragona, Thunb. diss. no. 5. with a figure. Lodd. bot. cab. 1239. Erica pugioniförmis, Sal. in Lin. trans. 6. p. 387. Flowers yellow.

Telragonal-flowered Broad-scaled-Heath. Fl. July, Sept. Clt. 1789. Shrub.

5 E. Thunbérgin (D. Don, in edinb. phil. journ. 17. p. 154.) leaves 3 in a whorl, linear, glabrous, glaucous ; flowers subterminal, umbellate; corolla with a medioliform tube, and the base of the limb entire; anthers papulose. h. G. Native of the Cape of Good Hope. Erica Thunbérgii, Lius. suppl. p. 220. Andr. heath, vol. 4. icon. Lodd, bot. cab. 277. Ait. hort. kew. 2. p. 389. Bedf. eric. wob. pl. 4. f. 2. Sims, bot. mag. 1214. Erìca medioliflòra, Sal. in Lin. trans. 6. p. 331. Corolla with a globose tube and a large limb, of a reddish-orange colour at top, and greenish-yellow at the base, $-A$ remarkable species.

Thunberg's Broad-scaled-Heath. FJ. Feb. Aug. Clt. 1794. Shrub 1 foot.

6 E. BRActeA'ta; leaves 3 in a whorl, lanceolate, glabrous, adpressed; flowers terminal, umbellate; bracteas large, obovate, and are, as well as the calyxes, coloured; corolla $\approx$ lines long, having the segments crenulated. $5 . G$. Native of the Cape of Good Hope. Erìca bracteàta, Thunb. diss. no, 3. Erica obvallàris, Sal. in Lin, trans. 6. p. 387 . Filaments spurred.

Bracteate Broad-scaled-Heath. Fl. May, June. Clt. 1800. Shrub 1 foot.

7 E. mucrona'ta ; leaves 3 in a whorl, linear-lanceolate, cuspidate, spreading, glabrous ; flowers terminal, racemose; calys bracteate, coloured, about equal in length to the corolla, which is campanulate. $h_{6}$. G. Native of the Cape of Good Hope. Erìca mucronàta, Andr. heath. 3. t. 43. Flowers reddishpurple.

Mucronate-leaved Broad-scaled-Heath. Fl. May, Aug. Clt. 1800. Shrub 1 foot.
8 E. petiola'ta; leaves 3 in a whorl, lanceolate-linear spreading, on cuneated fringed petioles: flowers terminal, by threes; bracteas broad, imbricated, ribbed, about equal in length to the corolla, which is bell-shaped, $2 \frac{1}{2}$ lines long, and downy at apex. 々. G. Native of the Cape of Good Hope. Erica petiolàris, Sal. in Lin. trans. 6. p. 334. Erica petiolàta, Thunb. diss. no. 7 . with a figure. Andr. heath. 3. t. 40 . Lodd. bot. cab. 1150. Bracteas pale red. Corollas white, with black anthers.

Pctiolate-leaved Broad-scaled-Heath. Fl. May, July. Clt. 1774. Shrub 1 foot.

9 E.? oвcondíta; leaves 3 in a whorl, lanceolate, keeled, broad, erect, with scabrous margins; floral leaves or bracteas dilated; flowers terminal; calyxes spreading, about equal in length to the corolla, which is urceolate; bracteas loose, ribbed. h.G. Native of the Cape of Good Hope. Erica obcordata, Link. Bedf. eric, wob, p. 1\%. Calyx and corolla purplishred.

Obcordate Broad-scaled-Heath. Fl. Aug. Sept. Clt. 1800. Shrub 1 foot.

10 E. crossa'ta; leaves opposite, or 3 in a whorl, linear, cuspidately awned, glabrous, spreading; flowers terminal, usually by threes; peduncles, bracteas, and calyxes fringed; corolla conical. $h_{2} . G$. Native of the Cape of Good Hope. Erica crossàta, Sirreng. syst. 2. p. 201.

Pot-flowered Broad-scaled-Heath. Fl. May, June. Clt.? Shrub.

\section{Anthers anned or corniculate at the base.}

11 E. Fra'grans; leaves 3 in a whorl, subulate, glaucous, erect; flowers drooping, terminal, usually by threes; bracteas large; calyx coloured, about equal in length to the corolla, which is campanulate and spreading; anthers bifid at the base, corniculate; stigma obtuse. $\eta$. G. Native of the Cape of Good Hope. Erìca fràgrans, Andr, heath. 2. t. 27. Lodd, bot. cab. 2ss. Ait. hort. kew. 2. p. 407. Calyx and corolla purplish-red.

Fragrant Broad-scaled-Heath. Fl. March, June. Clt. 1803. Shrub $\frac{1}{4}$ foot.

12 E. GLA'BRA; leaves 4 in a whorl, spreading, glabrous; flowers terminal, on short pedicels; bracteas remote from the calyx; calyx foliaceous; corolla 7-8 lines long, white; anthers subinclosed. 万. G. Native of the Cape of Good Hope. Erìca glàbra, Link. enum. 1. p. 362. Corolla white.

Glabrous Broad Scaled Heath. FI. May, Ang. Clt. 1820. Shrub.

13 E. sexfa'ria (D. Don, in eclinb, phil. journ. 17. p. 15\%) leaves 3 in a whorl, linear, glabrous, spreading, placed so as to appear in 6 ranks; flowers terminal, nearly sessile, drooping; bracteas imbricate, angular ; corolla campanulate, a little shorter than the calyx, glabrous, scarious; stigna obtuse; fruit smooth; spurs of anthers long. $\quad, G$. Native of the Cape of Good Hope. Erìca sexfària, Bauer. pl. kew. t. 11. Andir. heath. 2. t. 28. Ait. hort. kew, 2. p. 364. Erìca spuniòsa, Thunb. diss. no. 14. Flowers white; anthers black, a little exserted.

Six-ranked-leaved Broad-scaled-Heath. Fl. May, June. Clt. 1774. Shrub $\frac{1}{2}$ foot.

14 E. Fyroleflồn (D. Don, 1. c.) leaves 3 in a whorl, linear-cuneated, glabrous; flowers terminal, aggregate; calyx bracteate, equal in length to the corolla, which is urceolate; segments of the calyx ovate, cuneated; spurs of anthers broad, earformed. Ђ. G. Native of the Cape of Good Hope. Erica triflòra, Willd. spcc. 2. p. 356. exclusive of the synonymes. Erìca pyrolaflòra, Sal, in Lin. trans, p. 2. Flowers white. Corolla 2 lines long, with a 4 -angled spherical tube. 
Winter-Green-flowered Broad-scaled Heath. Shrub.

I5 E. Trıfı́ora; leaves 3 in a whorl, linear-cuneated, glabrous, spreading; flowers terminal; segments of calyx obcuneated; corolla $1 \frac{3}{4}$ line long, with a turbinate rather 4 -angled tube; spurs of anthers narrow-cuneated. $\zeta$. G. Native of the Cape of Good Hope. Erìca triflòra, Lin. mant. 374. diss. no. 23. with a figure of the flower. Thunb. diss. no. 79 . with a figure. Lodd. bot. cab. 1733. Erica triflòra aristàta, Wendl. obs. p. 47. eric. fasc. 12. p. 13. Erìca fùgax, Sal. in. Lin. trans. 6. p. 351 . Corolla white, about the length of the calyx.

Three-flonered Broad-scaled Heath. Fl. March, June. Clt. 1774. Shrub 1 foot.

16 E. PALLifflòra; stem angular; leaves lanceolate-cuneated, glabrous; flowers terminal; corolla $1 \frac{1}{3}$ line long, a little longer than the calyx; spurs of anthers ear-formed, glabrous. h.G. Native of the Cape of Good Hope. Erica palliiflòra, Sal. in Lin. trans. 6. p. 351 . Erìca cándida, Sol. mss. Flowers white.

Chaff-flowered Broad-scaled Heath. Fl. Feb. Aug. Clt. 1796. Shrub 1 foot.

17 E.? Drosmaròlia; leaves 3 in a whorl, shining; flowers terminal; corolla 2 lines long, with imbricated segments; filaments very narrow; spurs of anthers attenuated, serrulated. 2. G. Native of the Cape of Good Hope. Erica diosmæfòlia, Sal. in Lin. trans. 6. p. 350. Erica subscrràta, Roxb. mss.

Diosma-leaved Broad-scaled Heath, Fl. April, July. Clt. 1792. Shrub.

18 E. RJGidifolla ; leaves 3 in a whorl, linear, stiff, shining, erectly spreading; flowers terminal, aggregate, drooping; calyxes coloured, about equal in length to the corolla, which is campanulate; anthers appendiculate. $h$. G. Native of the Cape of Good Hope. Erìca rigidifòlia, Wendl.

Stiff-leaved Broad-scaled Heath. Fl. June, July. Clt. 1818. Shrub.

19 E. PAcHYPHÝlLa; leaves 3 in a whorl, petiolate, elliptic, thick, short, quite glabrous, shining, with scabrous edges; flowers agoregate, terminal, glabrous; calyx equal in length to the corolla, which is urceolate. $r . G$. Native of the Cape of Good Hope. Erìca pachyphýlla, Spreng. syst. 2. p. 199.

Thiek-leaved Broad-scaled Heath. Clt, 1800. Shrub 1 foot.

20 E. Monsònie; leaves 3 in a whorl, linear, attenuated and ovate, erect, placed so as to appear in 4 ranks; flowers terminal, nutant ; corollas oblong, inflated, 7-9 lines long; bracteas imbricate, reflexed; calyx recurvedly spreading; anthers awned; fruit globose, quadrangular. $\eta$. G. Native of the Cape of Good Hope. Erìca Monsònix. Bauer, pl. kew. t. 7. Andr. heath. 2. t. 1. Sims, bot. mag. 1915. Erìca Monsoniàna, Lin. suppl. 223. Thunb. diss. no. 52. with a figure. Wendl, eric. fasc. 10. p. 9. with a figure. Erica variffolia, Sal. in Lin. trans. 6. p. 353. Flowers white. Corolla twice longer than the calyx.

Lady Monson's Broad-scaled Heath. Fl. April, Sept. Clt. 1787. Shrub 2 to 3 feet.

Cult. For culture and propagation see Erica, p. 800 .

IX. EURYSTEGIA (from evpvs, eurys, broad, and $\sigma \tau \varepsilon \gamma \eta$, slege, a cover; in reference to the large calyx). D. Don, in edinb. phil. journ. 17. p. 154.-Erìca species of authors.

Lin. syst. Octándria Monogýnia. Calyx 4-parted, large, glumaceous. Corolla urceolate, with a contracted 4-toothed mouth. Stamens inclosed; filaments dilated, flat; anthers จoL. III. bipartite, opening by an oblong foramen, biappendiculate at the base : appendages flattened, decurrent, erosely crenated. Stigma capitate. Capsule 4-celled, many-seeded.-Densely branched slirubs, natives of the Cape of Good Hope. Leaves loose, subulate, with revolute margins. Flowers almost solitary, drooping, white or rose-coloured.

1 E. GLau'Ca (D. Don. in. edinb. phil. journ. 17. p. 154.) leaves 3 in a whorl, glaucous, linear, erectly spreading ; flowers terminal, umbellate; bracteas remote from the calyx. $\hbar_{.}, G$. Native of the Cape of Good Hope. Erica glaúca, Andr. heath. 1. p. 15. Sims, bot. mag. 580. Ait. hort. kew. 2. p. 386. Calyx and bracteas red. Corolla purplish.

Glaucous Large-calyxed Heath. Fl. May, July. Clt. 1792. Slurub 1 to 3 feet.

2 E. E'LEGANS ; leaves 3 in a whorl, linear, glaucous, spreading; flowers terminal, numerous, capitate; bracteas near the calyx. h. G. Native of the Cape of Good Hope. Erica élegans, Andr. leath. 3. t. 16. Sims, bot. mag. 966. Lołd. bot. cab. 105 . Bracteas and calyxes pink. Corolla pink, tipped with green.

Elegant Large-calyxed Heath. Fl. Nov. Feb. Clt. 1799. Shrub $\frac{1}{2}$ to 1 foot.

3 E. andromedertóra (D. Don, in edinb. phil. journ. 17. p. 154.) leaves 3 in a whorl, green, ciliated, stiff, spreading; Howers axillary; bracteas remote from the calyx. h. G. Native of the Cape of Good Hope. Erica andromedæeflòra, Andr. heath. 3. t. 13 . Sims, bot. mag. 1250. Lodd. bot. cab. 521. Erìca pomífera, Hortul. Flowers deep red, or reddishpurple. Calyx pale.

Andromeda-flowered Large-calyxed Heath. March, June. Clt. 1803. Shrub 1 to 2 feet.

4 E. LANuginòsa ; leaves 3 in a whorl, linear, ciliated; flowers solitary, axillary; bracteas ovate, near the calyx; corolla hardly twice longer than the calyx, tomentose; anthers awned. $\zeta$. G. Native of the Cape of Good Hope. Erica lanuginòsa, Andr, heath. 3. t. 5. Ait. hort. kew. 2. p. 3S2. Corollas brownish-red, or reddish-green.

Woolly-flowered Large-calyxed Heath. Fl. Sept. Jan. Clt. 1803. Shrub.

5 E. IMARGINA'ta; leaves 3 in a whorl, oblong, channelled, recurved, ciliated; flowers terminal, by threes; bracteas near the calyx, and are, as well as the calyxes, ciliated. П. G. Native of the Cape of Good Hope. Erìca emarginata, Andr. heath, 3. t. 20. Flowers white, with black anthers. Very like Eriea nigríta, and Eriea lachnecélia.

Emarginate Large-calyxed Heath. Fl. June, July. Clt. 1802. Shrub.

6 E. TrícEPs; leaves 3 in a whorl, somewhat trigonal, ciliated, erectly spreading; branches downy ; flowers terminal, by threes; bracteas imbricate; calycine segments oblong, scarious, a little shorter than the corolla; anthers ciliated, mutic, and are, as well as the style, which is capitate, exserted; corolla ovate. h. G. Native of the Cape of Good Hope. Erica triceps, Link, enum. 1. p. 371 . Bedf. eric. wob. p. 25. Lodd. bot. cab. 962. Flowers white. Calyx white.

Three-headcd Large calyxed Heath. Fl. May, July. Clt. 1820. Shrub.

7 E. TRIU'MPHANs; leaves 3 in a whorl, ciliated; flowers axillary; bracteas remote from the calyx; calyx large, inflated, angular ; corolla ovate, inflated; anthers crested; style inclosed. h. G. Native of the Cape of Good Hope. Erica triúmphans, Lodd. bot. cab. 257. Bedf. eric. wob. pl. 3. f. 19. Flowers large, white.

Conquering Large-calyxed Heath. Fl. June, July. Clt. 1802. Slirub.

8 E. TEGULæfòlia ; leaves oval, downy ; flowers terminal ; $5 \mathrm{~L}$ 
corolla $1 \frac{1}{2}$ line long, with a turbinate, rather 4-angled limb; spurs of anthers large, orbicular. $\eta, G$. Native of the Cape of Good Hope. Leaves broad, imbricated in the straight order.

Tile-leaved Large-calyxed Heath. Clt. 1800. Slirub.

9 E. conY'DALIS; leaves 3 in a whor], lanceolate-cuneated; flowers terminal; corolla 2 lines long, having the limb entire at the base; anthers inclosed, winged on the back. h. G. Native of the Cape of Good Hope. Erica corýdalis, Sal. in Lin. trans. 6. p. 334.

Helmet-anthered Large-calyxed Heath. Fl, Feb. May. Clt.? Slurub.

10 E. ? PANxòsa; leaves $3-5$ in a whorl, a little reduplicate; flowers terminal; corolla 2 lines long, woolly; filaments broad, with short spurs; style exserted. $h$. G. Native of the Cape of Good Hope. Erica pannòsa, Sal. in Lin. trans. 6. p. 339. -This plant is very like Eriodésmia capitàta, but differs in the leaves being $3-5$ in a whorl, and greatly in the anthers.

Cloth-flowered Large-calyxed Heath. Fl. Feb. June. Clt. ? Shrub.

11 E. ? LAchñònis ; leaves 3 in a whor], ovate, imbricated, downy; flowers terminal, subcapitate; bracteas imbricated, approximating the calyx ; anthers crested; corolla ovate, rather longer than the calyx. $h . G$. Native of the Cape of Good Hope. Erìca lachneæfòlia, Sal. in Lin. trans. 6. p. 385. Ait. hort. kew. 2. p. 387. E. làchnæ`a, Andr. heatl. 3. t. 2. Flowers white.

Lachnce-learcd Large-calyxed Heath. Fl. May, July. Clt. 1793. Shrub 1 foot.

Cult. For culture and propagation see Erica, p. 800.

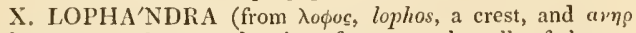
avinos, aner andros, a male ; in reference to the cells of the anthers being crested). D. Don, in edinb. phil. journ. 17. p. 154. - Erica species of authors.

Lin. syst. Octándria Monogýnia. Calyx 4-parted, furnished with 4 bracteas at the base; segments roundish, scarious, ventricose on the outside. Corolla campanulate, 4-lobed. Stamens inclosed; filaments dilated, flat; anthers bifid; cells of anthers beaked at the apex, opening by an obleng foramen in the middle: with the sides winged, crested, and crenulated. Stigma truncate. Capsule 4-celled, many-seeded.-Erect, much branched shrubs, natives of the Cape of Good Hope. Leaves spreading, short, obtuse, glaucous. Flowers terminal, usually by threes, rose-coloured.

1 L. cúbica (D. Don, in edinb, plil. journ. 17. p. 154.) leaves 4 in a whorl, semicylindrical; bracteas remote from the calyx, which is coloured; calycine segments serrulated. $\zeta_{\text {. G. }}$ Native of the Cape of Good Hope. Erica cubica, Andr. heath. 1. t. 27. Ait. hort. kew. 2. p. 397. Erica cúbica màjor, Hortul. Erica hottoniæflòra, Sal, in. Lin. trans. 4. p. 331. Calyx and corolla purplish-red.-The flowers are at first disposed in a terminal fascicle, but when the terminal branches grow, they in consequence appear axillary and verticillate.

Tar. $\beta$, minor (Andr. heath. 2. t. 49). This is probably a distinct species.

Cube-flowered Lophandra. Fl. April. Sept. Clt. 1790. Shrub 1 foot.

2 L. BLA'XDA ; leaves 3 in a whor]; flowers terminal, glomerate; corolla $1 \frac{1}{3}$ line long, laving the limb one half Jonger than the tube, with semi-orbicnlar segments; stigma broad; cells of anthers drawn out inte a crest beyond the foramen. G. Native of the Cape of Good Hope. Erica blanda, Sal. in Lin. trans. 6. p. $\cdot 331$. Erìca cornuta, Roxb. mss. Flowers pale reil.

Blush-flowered Lophandra. SJirul.

3 L.? seriphnfòlia; leaves 5 in a whor]; calycine segments minutely ciliated; corolla $1 \frac{1}{2}$ line long, having the limb entire at the base, obtuse ; anthers inclosed, mutic. $F_{\text {. }} \mathrm{G}$ Native of the Cape of Good Hope. Erica seripliifolia, Sa]. in Lin. trans. 6. p. 331 . Erìca cúbica, Thumb. diss. no. 46 . but not of Andr. Flowers reddish-purple, axillary.

Seriphium-leaved Laphandra. Shrub.

Cult. For culture and propagation see Erica, p. $\$ 00$.

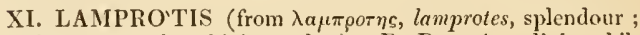
in reference to the shining calyx). D. Don, in edinb. phil. journ. 17. p. 154.-Erica species of anthors.

Lin. syst. Octándria Monogýnia. Calyx large, 4-parted, glumaceous, coloured, bibracteate at the base. Corolla urceolate, with a 4-labed limb. Stamens inclosed; filaments capillary; cells of anthers short, dehiscing lengthwise, mutic or crested at the base. Stigma capitate. Capsule 4-celled, manyseeded. Seeds round, scrobiculate.-Small, much branched shrubs, natives of the Cape of Good Hope. Leaves opposite, or 3 in a whorl, terminal, subulate, glabrous, always adpressed to the branches. Flowers numerous, terminal.

\section{* Leaves 3 in a whorl.}

1 L. calycina (D. Don, l. c.) leaves 3 in a whorl, linear, imbricate, downy; flowers in terminal fascicles, drooping; calyx sprealing, coloured; anthers crested. $\eta_{.}$G. Native of the Cape of Good Hope. Erica calycina, Lin. spec, ed. 2. p. 507. Lodd. bot. cab. 594. Erica calycina màjor, Andr. heath. 3. t. 14. Erìca gnidiæfòlia, Sal. in Lin. trans. 6. p. 336. Thunb. diss. no. 78. Erica vespertina, Lin. suppl. 221. Corolla 2 lines long, red, ovate, ventricose. Calycine segments obcuneated. Bracteas coloured.

Var. $\beta$, minor (Andr. heath. 3. t. 15.) sinaller.

Large-calyxed Lamprotis. Fl. June, Sept. Clt. 1799. Shrub 1 foot.

2 L. con Ir òla ; leaves 3 in a whor], linear, imbricate; flowers in terminal fascicles; calyx spreading, about equal to the corolla in Jength; corolla $1 \frac{1}{2}$ line Jong, with acute segments; anthers crested. $々, G$. Native of the Cape of Good Hope. Erìca corifölia, Lin. diss, no. 26. Tluunb. diss, no. 77. Sal, in Lin. trans. 6. p. 356. Bauer, icon. loort. kew. 21. Wendl. eric. 10. p. 11. with a figure. Erica calycina, Andr. heath. 1. t. 11. Erica articulàris, Lin. mant. 65. Curt, bot. mag. t. 423 . Flowers pink or red. Bracteas remote from the calyx.

Coris-leaved Lamprotis. Fl. May, Dec. Clt. 1774. Slirub 1 foot.

3 L. PA'LLIDA; leaves 3 in a whorl, linear, imbricate, glabrous, acute, glaucous; flowers terminal, erect; bracteas large, loose, coloured; caly'x exceeding the corolla, which is urceolate; anthers crested. h. G. Native of the Cape of Good Hope. Erica pállida, Wendl. eric. with a figure. Flowers red.

Pale Lamprotis. Fl. April, July. Clt. 1812. Shrub.

4 L. TU'RGIDA; leaves 3 in a whorl, mucronate, witl white margins, glabrous as well as the branches; flowers terminal; bracteas remote from the calyx; calycine segments purplish, acute, longer than the corolla; style inclosed; anthers crested. h. G. Native of the Cape of Good Hope. Erica turgida, Link, enum. 2. p. 365. Flowers purple.

Turgid Lamprotis. Fl. April, July. Clt. 1821. Shrub.

5 L. spunosa ; Jeaves 3 in a whorl, erectly spreading, glabrous; flowers termiual, by threes, erect; calyx spreading, abont equal in length to the corolla; bracteas nearly orbicular, imbricate; genitals a little exserted; anthers crested; stigma narrow. h. G. Native of the Cape of Good Hope. Erica spumòsa, Lin. spec. ed. 2. p. 508. Berg. pl. cap. 103. but not of Lodd. Erìca scariòsa, Berg. pl. cap. 102. Corolla white, $1 \frac{1}{2}$ line long, with sublanceolate segments.

Frothy Lamprotis. Fl. May, July. Clt. 17S6. Shrub. 
6 L. ? LodDige'sIr; leaves 3 in a whorl, erectly spreading; flowers terminal, by twos or threes; bracteas imbricate, angular; genitals exserted, with black corniculate anthers. h. G. Native of the Cape of Good Hope. Erica spumòsa, Lodd. bot. cab. 566 . but not of Lin. Flowers purplish-red.

Loddiges's Lamprotis. Fl. June, July. Clt.? Slırub.

7 L. FLAGELLA'Ris; leaves 3 in a whorl, linear-lanceolate, glabrous, finely ciliated, adpressed; branches twiggy, downy; flowers terminal, usually by threes, erect; calyx bracteate, exceeding the corolla; anthers crested. h. G. Native of the Cape of Good Hope. Erica flagellàris, Link, enum. 1. p. 365. Flowers dirty-yellow. Calycine segments lanceolate, keeled, purple.

IIhip Lamprotis. Fl. May. Clt. 1820. Shrub 1 foot.

S L. rLAGELLFókM!s; leaves 3 in a whorl, imbricate, smootls; flowers terminal, umbellate, erect; bracteas remote from the calyx; calyx coloured, larger than the corolla, which is urceolate; anthers crested. 5 . G. Native of the Cape of Good Hope. Erìca flagellifórmis, Andr. eric. 4. icon. Flowers reddisli-purple.

Whip-formed Lamprotis. Fl. June, Aug. Clt. 1800. Shrub 1 foot.

9 L. calycinoides; leaves 3 in a whorl, linear, subulate, imbricate, glabrous ; flowers terminal, glomerate or capitate ; bracteas imbricate; calyx coloured, rather shorter than the corolla, which is urceolate; anthers almost mutic. h.G. Native of the Cape of Good Hope. Erìca calycinoides, Bedf. eric. wob. p. 4. Erica glomeràta, Andr. heath. vol. 4. Erìca calycìna capitàta, Hortul. Flowers purplish-red.

Calycine-like Lampròtis. Fl. July, Sept. Clt. 1789. Shrub 1 foot.

10 L. gNaphalònes; leaves 3 in a whorl, ovate, glabrous, imbricate ; flowers in terminal fascicles; calyxes spreading, with exquisitely ciliately glandular margins; corolla 1 line long, hardly longer than the calyx; fruit smooth; stigma large, 4. cleft; anthers crested. h.G. Native of the Cape of Good Hope. Erìca gnaphalodes, Lin. diss. no. 25. Berg. pl. cap. 119. Thunb. diss. 75 . Erìca gnaphaliifòlia, Sal. in Lin. trans. 6. p. 337. Flowers white.

Woolly Lamprotis. Feb. May. Clt. 1S12. Shrub.

$11 \mathrm{~L}$. ? PHY LLICoìns; leaves 3 in a whorl, imbricating in 6 rows, glabrous; flowers axillary, drooping; calyx large, elongated ; anthers awned. h. G. Native of the Cape of Good Hope. Erìca phyllicoìdes, Willd. spec. 2. p. 361 . Corolla campanulate, purple, 1-2 lines long.-Perhaps a species of Eurylèpis.

Phyllica-like Lamprotis. Fl. April, June. Clt. 1800. Shb.

12 L.? HoLOSE RícEA; leaves 3 in a whorl, sharply reduplicate; flowers terminal; corolla 3 lines long, silky, with an ovate tube; anthers crested, hairy. h. G. Native of the Cape of Good Hope. Erica holosericea, Sal. in Lin. trans. 6. p. 35\%. Flowers red.

\section{Whole-silky Lamprotis. Slirub.}

13 I. LU'CIDA; leaves 3 in a whorl; flowers terminal ; calyx minutely ciliated, shining; corolla 1 line long; crests of anthers ear-formed, deeply serrated; stigma narrow. ?.G. Native of the Cape of Good Hope. Erìca lùcida, Sal. in Lin. trans. 6. p. 337 .

Shtuing-calyxed Lamprotis. Shrub.

14. L. MU'NDA; leaves 3 in a whorl, imbricate ; bracteas and calyxes quite entire; corolla 1 line long; crests of anthers ear-formed and ciliated; fruit hairy. $h . G$. Native of the Cape of Good Hope. Erìca múnda, Sal, in Lin. trans. 6. p. 337.

Neat Lamprotis. Fl. May, July. Clt.? Shrub.

15 L. FABrìns; leaves 3 in a whorl, densely imbricated; flowers terminal; corolla 1 line long, hardly longer than the calyx; crests of anthers quite entire; anthers minute. in. $\mathbf{G}$. Native of the Cape of Good Hope. Erica fabrilis, Sal, in. Lin. trans. 6. p. 338. Flowers reddish-purple.

Carpenters' Lampròtis. Fl. April, May. Clt. 1791. Shrub 1 foot.

16 L. chlamydifòna ; leaves 3 in a whorl, linear, hairy, imbricate, flowers terminal; corolla 2 lines long, hardly longer than the calyx ; crests of anthers ear-formed. $h$. G. Native of the Cape of Good Hope. Erica chlamydiflòa, Sal. in Lin. trans. 6. p. 338. Flowers reddish-purple.

Cloak-flonered Lamprotis. Fl. May, Oct. Clt. 1 S01. Shrub 1 foot.

17 L. SElaginifólia; stem tomentose; leaves linear, 3 in a whorl; flowers terminal; corolla smooth, $1 \frac{2}{3}$ line long, with a globose tube; crests of anthers very broad, orbicular. $h . G$. Native of the Cape of Good Hope. Erìca selaginifölia, Sal. in Lin. trans. 6. p. 338 .

Selago-leaved Lamprotis. Shrub.

18 L. BREvifòla; leares 3 in a whorl, ovate; flowers terminal; corolla $1 \frac{2}{3}$ line long, hardly longer than the calyx ; spurs of anthers linear, attenuated. h. G. Native of the Cape of Good Hope. Erica brevifòlia, Sol, mss. ex Sal. in Lin. trans. 6. p. 338 .

Short-leaved Lamprotis. Fl. Jan. May. Clt. 1S00. Shrub 1 foot.

19 L. uYsSopı́ò̀ra; leaves 3 in a whorl, densely ciliated ; corolla $\approx$ lines long, hairy towards the apex, with curled retuse segments; anthers crested. $々$. G. Native of the Cape of Good Hope. Erìca hyssopifòlia, Sal, in Lin. trans, 6. p. 387. Erìca pígra, Sol. ex Salisb. Flowers red.

Hyssop-lcaved Lamprotis. Fl. May, Oct. Clt. 1800. Shrub 1 foot.

20 L. MODE'STA ; leaves 3 in a whorl, densely imbricated; corolla tomentose, $3 \frac{1}{3}$ lines long, with a broad ovate tube and a recurved limb ; flowers terminal; spurs of anthers linear, attenuated. h. G. Native of the Cape of Good Hope. Erica modésta, Sal. in Lin. trars. 6. p. 352. Flowers very pale red.

Modest Lamprotis. Shrub.

21 L. PANicula'ta; leaves 3 in a whorl, alpressed; flowers terminal, drooping; bracteas close to the calyx; corolla ovate, ventricose, equal in length to the calyx; anthers cornute; style inclosed. h. G. Native of the Cape of Good Hope. Eric: paniculàta, Lodd. bot. cab. 419. but not of Thunb. Bedf. eric. wob. p. 17. Flowers pale purplish-red.

Panicled-flowered Lamprotis. Fl. Summer. Clt. 1510. Slirub.

22 L. Bedfordina ; leaves 3 in a whorl, linear, glabrous; flowers terminal; bracteas remote from the calyx; corolla ovatecampanulate; anthers awned. h.G. Native of the Cape of Good Hope. Erìca lùtea álba, Bedf, eric. wob. p. 14. Flowers pale yellow.

Duke of Bedford's Lamprotis. Fl. Oct. Nov. Clt. 1810. Shrub $\frac{1}{2}$ to 1 foot.

23 L. Taxifòlia (D. Don, in edinb. phil. jonrn. 17. p. 154.) leaves 3 in a whorl, trigonal, glabrous, spreading; flowers terminal, umbellate; corolla with a cone-shaped tube and a spreading limb; bracteas remote from and approximating the calyx; calyx coloured, about equal in length to the corolla; anthers mutic. 5 . G. Native of the Cape of Good Hope. Erica taxifòlia, Wend̄l. eric. fasc. 2. p. 19. with a figure. Baner, pl. kew. t. 19. Andr. heath. 1. t. 35. Erìca túrgida, Hortul. Flowers pale red. Leaves mucronate. Corolla 3 lines long, with ovate, cuneated, bifid segments.

I'en'-leuced Lamprotis. Fl. July, Nov. Clt. 17Ss. Slirub 1 foot.

24 L. RU'вIDA; leaves 3 in a whorl, linear, glabrous; flowers $5 \mathrm{~L} \%$ 
terminal, capitate; bracteas approximate, 3, 1 large and 2 small; calyx equal to the corolla in length, which is ovate-ventricose; anthers awned. $h$. G. Native of the Cape of Good Hope. Erìca rubélla, Bedf, eric. wob. p. 22. Flowers red. foot.

Ruby-flowered Lamprotis. Fl. June, July. Clt. ? Shrub I

\section{* Leaves 4 in a whorl.}

25 L. sQuanosa; leaves 4 in a whorl, inbricated, serrulated; flowers terminal, drooping ; bracteas imbricate ; calyx large, coloured, about equal in length to the corolla, which is urceolate; anthers crested. 々. G, Native of the Cape of Good Hope. Erica squamòsa, Andr. heath. 3. t. 22. Flowers pale red.

Scaly-cupped Lamprotis. Fl. April, July. Clt. 1794. Shrub $\frac{1}{2}$ foot.

$$
\text { * Leaves opposite. }
$$

26 L. tenuifóla (D. Don, in edinb. phil. journ. 17. p. 154.) leaves opposite, linear, adpressed; flowers terminal, aggregate, sessile; calyx coloured, not much shorter than the corolla; anthers mutic. $\zeta$. G. Native of the Cape of Good Hope. Erica tenuifolia, Lin diss. 33. with a figure of the flower. spec. ed. 2d. p. 507. Berg. pl. cap. p. 116. Erìca linifolia, Sal. in Lin. trans. 6. p. 386.-Seb. thes. 1. p. 157. t. 73. f. 6.Lin. hort. cliff. p. 148. Calycine semments oval, acuminated. Corolla 2 lines long, with an ovate tube. Fruit turbinate. Flowers pale red.

Fine-leated Lamprotis. Fl. April, May. Clt. 1794. Shrub $\frac{1}{12}$ foot.

27 L. LU'TEA; leaves opposite, linear, imbricate, glabrous ; flowers nearly terminal; bracteas imbricate; branches flexuous; calycine segments narrow, ovate-cuneated; corolla $2 \frac{1}{2}$ lines long, ovate, ventricose ; fruit obovate ; anthers mutic or awned.? $h$. G. Native of the Cape of Good Hope. Erica lùtea, Lin. diss. no. 2. mant. p. 234. Berg. pl, cap. 115 . Wendl. eric. 1. p. 13. with a figure. Andr. eric. 1. t, 31. Erìca imbéllis, Sal. in Lin. trans. 6. p. 385 . Flowers yellow.-There appears to be two species confounded under this name; one with crested or awned anthers, and another with mutic anthers.

Yellow-flowered Lamprotis. F]. Sept. May. Clt. 1774. Slirub 1 foot.

28 L. Bıflòra ; leaves opposite, canaliculate, adpressed, glabrous; flowers terminal, twin, on short pedicels; bracteas approximating the calyx; calycine segments ovate, acute, white; anthers crested. h. G. Native of the Cape of Good Hope. Erìca biflòra, Link, enum. 1. p. 367. Lodd. bot. cab. 683. Corolla white.

Tno-flowered Lamprotis. Slirub $\frac{3}{4}$ foot.

F]. April, June. Clt. 1819.

29 L. BORBONıFòlia ; leaves opposite; flowers axillary; calycine segments broad, ovate-acuminated, equal in length to the corolla, which is urceolate; fruit obovate; anthers crested or awned. h. G. Native of the Cape of Good Hope. Erica borboniæfòlia, Sal. in Lin. trans, 6. p. 386 . Flowers red, $3 \frac{1}{2}$ lines long.

Borbonia-leaved Lamprotis. Fl. March, July. Clt. 1816. Slirub.

30 L. opposıtı́òlı ; leaves opposite, filiform, imbricate ; flowers terminal, crowded, erect ; bracteas sessile; corolla urceolate, about equal in length to the calys, which is spreading; anthers mutic. $\zeta$. G. Native of the Cape of Good Hope. Erica oppositifòlia, Andr. heath. 3. p. 35. Lodd. bot. cab. 1343. Flowers white.

lar. $\beta$, rùbra (Andr. heath. 3. t. 36. Lodd. bot. cab. 1060.) flowers red.

Opposite-leaved Lamprotis. Fl. Spring and Autumn. Clt. 1804. Shrub $\frac{1}{2}$ to $\frac{3}{4}$ foot.
31 L.? APE'rTA; leaves opposite, linear, cuspidate, erect, quite glabrous, with scarious margins; flowers terminal, aggregate; bracteas and calyxes coloured; corolla rotate; genitals exserted; anthers mutic. h. G. Native of the Cape of Good Hope. Erica apérta, Spreng. syst. 2. p. 200.

Open-flowered Lamprotis. F]. March, May. Clt. 1820. Shrub.

32 L. RUBÉLLA ; leaves opposite, or 3 in a whor], linear, imbricate; flowers terminal, capitate; corolla with a ventricose tube and a spreading limb; calyx about equal in length to the corolla, bracteate; anthers mutic. $\zeta . G$. Native of the Cape of Good Hope. Erica rubélla, Ker. bot. mag. 2165. Lodd. bot. cab. 658. Flowers red.

Red-flowered Lamprotis. Fl. June. Clt. 1814. Shrub 1 foot.

33 L. TogA'ta ; leaves opposite, linear, imbricate; flowers terminal; bracteas remote from the calyx, broad; calyx coloured, large, cup-shaped; corollas urceolate, with a spreading limb; anthers mutic. $\vdash$. G. Native of the Cape of Good Hope. Erìca togàta, Sims, bot. mag. 1626. Flowers fine red. Gowned Lamprotis. Fl. June, July. Clt.? Slırub $\frac{1}{2}$ to $\frac{3}{4}$ foot.

34 L.? dianthifòlia ; leaves opposite, long; flowers terminal; calycine segments ovate-cuneated; corolla 3 lines long ; spurs of anthers serrated; pericarp glabrous. $\boldsymbol{h} . \mathbf{G}$. Native of the Cape of Good Hope. Erica dianthifolia, Sal. in Lin. trans. 6. p. 338. Flowers pale purple.

Pink-leared Lamprotis. Fl. April, May. Clt. 1796. Shb. 35 L.? A'PHANES; branches hairy; leaves opposite, lineartrigonal, bluntish, scabrous ; flowers axillary and terminal. $h$. G. Native of the Cape of Good Hope. Erica áphanes, Spreng. syst. 2. p. 196.

Insignificant Lamprotis. Fl. March, June. Clt. 1820. Shrub.

Cult. See Erìca, p. 800, for culture and propagation.Pretty little shrubs, easily distinguished from the other genera broke off from Erica by the large coloured calyx and small adpressed leaves.

XII. CALLI'STA (from $\kappa a \lambda \lambda \iota \sigma \tau o s, k a l l i s t o s$, very beautiful; flowers). D. Don, in edinb. phil. journ. 17. p. 155.-Erìca species of authors.

Lix. syst. Octándria, Monogýnia. Calyx 4-parted, foliaceous. Corolla salver-shaped, with a dilated spreading 4-cleft limb, and a ventricose or cylindrical tube. Stamens inclosed; filaments capillary; cells of anthers short, dehiscing lengthwise, mutic at the base. Stigma capitate. Capsule 4-celled, manyseeded.-Small, much branched shrubs, natives of the Cape of Good Hope. Leaves acerose, loosely imbricated. Flowers terminal, almost solitary, or in fascicles.

\section{* Leaves 3 in a whorl.}

1 C. Tenufroòra leaves $3-4$ in a whorl, linear, glabrons, spreading; flowers terminal, usually by fours : calyx bracteate ; corolla with a slender tube. $h$. G. Native of the Cape of Good Hope. Erìca tenuiflòra, Andr. heath. 3. t. 49. Lodd. bot. cab. 1717. Erìca cylíndrica, Thumb. diss. no. 39. Erica fistulæflora, Sal. in Lin. trans. 6. p. 383. Calycine segments minutely ciliated. Pericarp obovate, glabrous. Corolla 5-6 lines Jong, yellow. Style exserted.

Var. 3 , álba (Andr. heath. 3. t. 50.) flowers white, sub-axillary, or terminating the small branches, sweet-scented.

Fine-flonered Callista. Fl. April, June; $\beta$ July, Dec. Clt. 1800. Shrub 1 foot.

2 C. tetragòna; leaves 3 in a whorl, linear, pointed, ciliated, erectly spreading; flowers terminating small branches; calyx bracteate, with ciliated cuspilate segments; corolla with 
a small, tetragonal, pyramidal tube. $h$. G. Native of the Cape of Good Hope. Erìca tetragòna, Thunb. diss. no. 5. with a figure. Andr, lheath. 3. t. 51. Lodd. bot. cab. 1239. Erìca pugionifolia, Sal. in Lin. trans. 6. p. 358. Erìca trigòna, Hort. Corollas 4 lines long, yellow. Style exserted.

Tetragonal-flowered Callista. Fl. July, Sept. Clt. 1789. Shrub.

3 C. Bucciniflòra; leaves 4 in a whorl, linear, ciliated; bracteas sessile; flowers in terminal umbellate fascicles; corolla with a trumpet-sliaped tube and a spreading border. $h$. G. Native of the Cape of Good Hope. Erica buccinifiora, Sims, bot. mag. 2465. Lodd. bot. cab. 1127. Erica bucciaæfórmis, Bedf. eric. wob. p. 4. Corolla red, with a white limb. Anthers cornute.

Trumpet-flonercd Callista. Fl. June, July. Clt.? Shrub.

4 C. Bandònı; leaves 3 in a whorl, linear-lanceolate, glabrous, spreading: flowers terminal, umbellate, on long pedicels, erect; bracteas remote from the calyx; calycine segments broad; tube of corolla ovate, ventricose; style exserted. $\eta_{\text {. }}$ G. Native of the Cape of Good Hope. Erica Bandònia, Andr. heath. vol. 4. Corolla reddish-purple.

Countess Bandon's Callista. Fl. July, Aug. Clt. 1810. Shrub.

5 C. MAgnífica; leaves 3 in a whorl, linear, obtuse, spreading; flowers terminal, usually by threes, drooping; bracteas remote from the calyx; calyx coloured; corolla with an ovate tube, and an erectish limb; style inclosed. $\zeta_{c}$. G. Native of the Cape of Good Hope. Erica magnífica, Andr. heatl. vol. 4. Corollas pale red. Anthers cornute.

Magnificent Callista. Fl. Aug. Nov. Clt. 1810. Shrub.

6 C. Broadere'sa; leaves 3 in a whorl, linear, fasciculated, spreading; flowers axillary, on long pedicels, drooping; calycine segments foliaceous, narrow; corolla ventricose, contracted at the mouth, with hardly any limb; style exserted. h. G. Native of the Cape of Good Hope. Erica Brcadleyàna, Andr. heath. vol. 4. Flowers red.

Broadley's Callista. Fl. June, July. Clt. 1800. Shrub I to 2 feet.

7 C. JuliA'NA; leaves 3 in a whorl, linear, trigonal, erect, shining, short; flowers terminal, aggregate; bracteas almost sessile; calycine segments dilated and ciliated; corolla ovate, ventricose, with a small limb. $々$. G. Native of the Cape of Good Hope. Erìca Juliàna, Nois. Lodd, bot. cab, 799. Bedf. eric. wob. p. 13. Corolla reddish-purple. Style a little exserted.

July-flowered Callista. FJ. July. Clt. 1800. Shrub I ft.

8 C. Celsin'sa; glabrous; leaves 3 in a whor]; flowers terminal; bracteas remote from the calyx; corolla with a globular tube; style exserted. h. G. Native of the Cape of Good Hope. Érìca Celsiàna, Lodd. bot. cab. 1777. Corolla with a pale red tube and a deep red border.

Cels's Callista. Fl. June. Clt. 1800 . Shrub.

9 C. ARMA'TA ; leaves 3 , sometimes 5, in a whorl, linear, erect, spinulose; flowers terminal, aggregate, clothed with yellow strigæ; calycine segments foliaceous, spinose; style exserted. そ. G. Native of the Cape of Good Hope. Erica armata, Spreng. syst. 2. p. 184.

Armed Callista. Fl. May, July. Clt. 1816. Shrub.

10 C. Humea'xa; leaves 3 in a whorl, linear, glabrous ; flowers terminal, by threes; bracteas sessile; corolla with a short rentricose tube, and a large limb; style exserted. h. G. Native of the Cape of Good Hope. Erìca Humeàna, Lodd. bot. cab. 389. E. Hùmea, Hortul. Corolla with a red tube, reddishpurple segments, and a dark eye.

Lady Hume's Callista. Fl. June, July. Clt. 1808. Shrub.

11 C. CARNi'ULA; leaves $3-4$ in a whorl, linear, glabrous; flowers terminal, racemose; calyx bracteate; corolla with an inflated tube, and a short limb. $\zeta . G$. Native of the Cape of Good Hope. Erica carniula, Lodd. bot. cab. 926. Flowers pale red.

Flesh-coloured-flowered Callista. Fl. July, Sept, Clt. 1804. Shrub.

12 C. Sainsburia'na ; leaves 3 in a whorl, filiform, elongated, glabrous, erectly spreading; flowers terminal, umbellate; bracteas remote from the calyx; corolla oblong-ovate, with a short limb; anthers awned. $h$. G. Native of the Cape of Good Hope. Erìca Sainsbùrya, Andr. lieath. vol. 4. Flowers pale red. Style a little exserted.

Sainsbury's Callista. Fl. June, Sept. Clt. 1800. Shrub.

13 C. Conptonia'sa ; leaves 3 in a whorl, subulate, glabrous, spreading, recurved; flowers terminal, aggregate, pedicellate. そ. G. Native of the Cape of Good Hope. Erìca Comptoniàna, Andr. heath. vol. 4. Style inclosed.

Compton's Callista. Fl. May, July. Clt, 1802. Shrub.

14 C. Infundieulifo'rurs; leaves 4 in a whorl, filiform, obtuse, glabrous, erect ; flowers terminal, aggregate ; bracteas sessile; corolla with a slender tube, and large segments. $h_{\text {. G G. }}$ Native of the Cape of Good Hope. Erica infundibuliformis, Link. enum. 1. p. 364. Andr. lieath. vol. 4. Lodd. bot. cab. 589. Flowers pale red, or pale purplish-red. Style inclosed.

Funnel-formed Callista. Fl. Aug. Nov. Clt. 1802. Shrub.

15 C. vA'rra; leaves 3 in a whorl; flowers terminal; bracteas approximating the calyx; corolla short, with revolute segments; style exserted. $\zeta$. G. Native of the Cape of Good Hope. Erìca vària, Lodd. bot. cab. 1325. Erica Cassònii, Hortul. Flowers purplish-red.

Variable Callista. Fl. July. Clt. 1810. Shrub.

16 C. UNDULA'TA; glabrous ; leaves $3-4$ in a whorl ; flowers terminal, by fours, sessile; corolla with an elongated, ventricose, twisted tube, and a spreading limb. দ. G. Native of the Cape of Good Hope. Erìca undulàta, Lodd. bot. cab. 1792. Flowers deep red.

Waved Callista. Fl. Summer. Clt. 1827. Shrub.

\section{* Leaves 4 in a whorl.}

17 C. PRE'GNANS; leaves 4 in a whorl, linear, ciliated, spreadingly recurved; flowers terminal, crowded; bracteas remote from the calyx; calycine segments acute: corolla ventricose at the base. $h$. G. Native of the Cape of Good Hope. Erìca præ'gnans, Andr. heath. 3. t. 32. Lodd. bot. cab. 945 . Corolla pale red, almost white. Very like C. ventricòsa, and probably only a variety of it. Style inclosed.

Snelled-flowered Callista. Fl. April, Aug. Clt. 1796. Shrub 1 to 2 feet.

is C. metulefrlòra; leaves 4-5 in a whorl, subulate, spinulosely ciliated; flowers terminal, umbellate; bracteas remote from the calyx; corolla ventricose at the base. $h_{c} . G$. Native of the Cape of Good Hope. Erìca metulæflòra, Sims, bot. mag. t. 612 . Andr. heath. 3. t. 33. Lodd. bot. cab. 1763. Flowers red, with a paler border. Style a little exserted.

Nine-pin-flowered Callista, Fl. June, Aug. Clt. 1798. Shrub.

19 C. Acumina'ta; leaves 4 in a whorl, trigonal, cuspidate, recurved; flowers terminal, nearly sessile, aggregate; calycine segments acuminated; corolla with an inflated acuminated tube, and a short revolute limb; bracteas close to the calyx. h. G. Native of the Cape of Good Hope. Erica acuminata, Andr. heath. 3. t. 54. Lodd. bot. cab. t. 216 . Flowers reddishpurple. Style inclosed.

Acuminated-flowered Callista. Fl. July, Ort. Clt. 1800 Shrub.

20 C. Ferrugínea ; leaves 4 in a whorl, linear, secund, ciliated with rusty hairs; flowers terminal, umbellately verticillate, horizontal; calyx bracteate, with the segments bearded at the 
apex; filaments terminating in a tlat glandular substance; corolla with an acuminated inflated tube. $h$. G. Native of the Cape of Good Hope. Erica ferruginea, Andr. beath. 3. t. $5 \%$. Corolla with a red tube, and a greenish-yellow limb; but in the figure given by Andrews it is white, tipped with red. Style inclosed.

Rusty Callista. Fl. May, July. Clt. 1798. Shrub $1 \mathrm{ft}$.

21 C. HYACıNtnoides; leaves 4 in a whorl, shining, spreading; flowers aggregate; calyx bracteate, having the segments serrulated or ciliated; corolla with a ventricose tube. h. G. Native of the Cape of Good Hope. Erica liyacintholdes, Andr. heath. 3. t. 158. Ait. hort. kew. 2. p. 384. Flowers red. Style subexserted.

IIyacinth-like Callista. Fl. June, Aug. Clt. 1798. Shb. $1 \mathrm{ft}$.

22 C. FASTIGiA'rA; leaves 4 in a whorl, shining, erect, imbricated ; flowers terminal, crowded, sessile; bracteas serrulated; calycine segments serrulated; corolla with a narrow tube. h. G. Native of the Cape of Good Hope. Erìca fastigiàta, Lin. diss. no. 44. mant. 66 . Thunb. diss. no. 37. Andr. heath. 2. t. 57. Lodd. bot. cab. t. 207. Erìca falcifórmis, Sal. in Lin. trans. 6. p. 38\%. Corolla white, with the limb mealy inside, according to Sal. 1. c. In bot. mag. t. 2084. the corollas are painted pale red; it is therefore perhaps a distinct species.

Fastigiate-flowered Callista. Fl. May, Sept. Clt. 1797. Shb.

23 C. PELLu'CIDA; leaves 4 in a whorl, linear, attenuated; stem slender; flowers terminal; calycine segments spatulate, serrated; corolla 5-6 lines long, having the limb 3 times shorter than the tube. . G. Native of the Cape of Good Hope, Erìca pellùcida. Sol. ex Sal. in Lin. trans. 6. p. 384. Corollas white, with very little red, pellucid.

Pellucid-flowered Callista. Shrub.

24 C. WALKERIA'NA; stem glabrous; leaves 4 in a whorl, linear, shining; flowers terminal, almost sessile; bracteas approximating the calys, ciliated; calycine segments lanceolate, serrated; corolla 4-5 lines long, with an ovate ventricose tube, and a wide-spreading limb, which is doubly shorter than the tube. h. G. Native of the Cape of Good Hope. C. pellùcida, D. Don, in edinb. phil. journ 17. p. 155. Erica Walkèria, Andr. heath. 1. t. 42. Lodd. bot. cab. 256. E. pùlchra, Sal. in Lin. trans, 6. p. 384. Flowers pink or pale red. Style inclosed. I ar. $\beta$, rùbra (Andr. lieath. 2. t. 43.) flowers red.

Var. $\gamma$, supérba (Andr. lieath. 1. t. 42.) flowers purplishred. Erìca fastigiata, Wendl. eric. fasc. 19. p. 103. foot.

Walker's Callista. Fl. Feb. June. Clt. 1797. Shrub $1 \frac{1}{2}$

25 C. Denticula'ta (D. Don, in edinb. phil. journ. 17. p. 155.) stem pubescent; leaves 4 in a whorl, linear, glabrous; flowers terminal, fastigiate: bracteas remote from the calyx; calycine segments obcuneated, serrated; corolla 3 lines long, with a cylindrical tube: having the limb one-half shorter than the tube. $h_{2}$. G. Native of the Cape of Good Hope, Erica denticulàta, Lin. mant. p. 22. Erìca dentàta, Thunb. diss. no. 39. Erica denticulàris, Sal. in Lin. trans. 6. p. 384. Erica primuloides $\beta$, Wendl. Flowers purple.

Denticulated-calyxed Callista. Fl. April, May. Clt. 1821. Shrub 1 foot.

26 C. Bedfordina; leaves 4 in a whorl, linear; flowers terminal; bracteas sessile; calycine segments deeply serrated or toothed; corolla with an ovate ventricose tube. h. G. Native of the Cape of Good Hope. Erica denticulata, Bedf. hort. wob. p. S. Lodd. bot. cab. 1090.? but not of Lin. nor others. Flowers yellow. Style a little exserted.

Iar. $\beta$, moschàta (Bedf. l. c.) calycine segments serrated; flowers yellowish-green.

Bedford's Callista. Fl. May, June. Clt.? Shrub.

27 C. Templea'na; leaves 4 in a whorl, linear, ciliated? flowers terminal, almost sessile; bracteas approximating the calyx, ciliated, as well as the calycine segments ; anthers curved; corolla with an oblong ventricose tube, and a small limb. $\zeta$. G. Native of the Cape of Good Hope. Erica Témplea, Hortul. Bedf. eric. wob. p. 24. pl. 4. f. 17. Corolla about the size and shape of those of $C$. ventricòsa, pale red, or reddish-purple. Style inclosed.

Temple's Callista. Fl. July, Aug. Clt. 1820. Shrub 1 to 2 feet.

28 C. comòsa (D. Don, in edinb. phil. journ. 17. p. 155.) stem pubescent ; leaves 4 in a whorl, linear, short, erectly spreading; flowers terminal, tufted; bracteas imbricate, and are ciliated as well as the calycine segments, coloured; corolla with an ovate ventricose tube. $h_{2}$. G. Native of the Cape of Good Hope. Erìca comòsa, Andr. heath. 2. t. 54. Erica transpàrens, Berg. pl. cap. p. 10S. Erìca galiiflòra, Sal. in Lin. trans. 2. p. 583. Flowers small, white, with dark anthers. Style inclosed.

I ar. $\beta$, rùbra (Andr. heath. 2. t. 55.) corollas red. h. G. Erica comòsa, Lin. diss. no. 48. mant. p. 23\%. Thunb. diss. no. 38. Bauer, icon. hort. kew. t. 18.

Tufted Callista. Fl. April, Aug. Clt. 1787. Shrub $\frac{3}{4} \mathrm{ft}$.

29 C. ventricosa (D. Don, in edinb. phil. journ. 17. p. 155.) leaves $t$ in a whorl, short, acerose, semi-cylindrical, and are ciliated as well as the calyxes and bracteas: floral leaves the broadest; flowers disposed in terminal umbellate fascicles; bracteas remote from the calyx; corolla with a ventricose tube. $h_{c}$ G. Native of the Cape of Good Hope. Erica ventricòsa, Thunb, diss, no. 36 . with a figure. Andr. heath. 1. t. 28. Curt. bot. mag. t. 350 . Wendl, eric. fasc. 3. p. 11 . Bedf. eric. wol. pl. 4. f. 18. a. Lodd. bot. cab. 431. Erica venústa, Sal, in Lin. trans. 6. p. 385 . Peduncles bibracteate below the middle. Corolla waxy, purplish-red. Style inclosed.

I ar. $\beta$, coccínea; flowers reddish-purple.

lar. $\gamma$, stellifcra; flowers purplish-red.

Var. $\delta$, cárnea; flowers pale red.

$\operatorname{Var} . \varepsilon, a b b a$; flowers very pale red, almost white.

Var. ᄂ, supérba; flowers deep red.

Var. $\eta$, crécta; erect; flowers pale red.

Far. ₹, nàna; dwarf; flowers pale red.

Ventricose-flowered Callista, or Porcelain Heath, Fl. April, Sept. Clt. 1787. Shrub 1 to 2 feet.

30 C. INFLA'TA; leaves 4 in a whorl, glabrous, linear; flowers in terminal umbellate fascicles ; corolla with an elongater, ovate, ventricose tube, and a sliort limb; pedicels bibracteate below the middle; calycine segments subulate. h. G. Native of the Cape of Good Hope. Erica inflàta, Tbunb. diss, no. 67. with a figure. Erìca amábilis, Sal, in Lin. trans, 6. p. 385. Erìca glàbra, Link. enum. 1. p. 362. Corolla large, with a reddishpurple base, and a green top? Anthers corniculate at the base.

Inflated-flowered Callista. Fl. May, Sept. Clt. 1800. Shrub 1 to 2 feet.

31 C. MUSCA'Rt; leaves 4 in a whorl, linear-trigonal, glabrous, spreading; flowers terminal, sessile, usually by fours; bracteas approximating the calyx, leaf-like ; calycine segments subulate ; corolla ovate-ventricose, with a short obtuse revolute limb. $\zeta$. G. Native of the Cape of Good Hope. Erica muscàri, Andr. heath. 1. t. 41. Ait. liort. kew. 2. p. 395. Wendl. eric. fasc. 18. p. 95. with a figure. Erica fràgrans, Sal. in Lin. trans. 4. p. 383. Stem glabrous. Flowers small, pale yellow or yellowishgreen. Corolla flat at the base. Fruit obpyramidal.

Musk-scented Callista. Fl. March. Clt. 1790. Shrub 1 foot. 32 C. Lawsònı; leaves 4 in a whorl, filiform, spreading, ciliated ; flowers terminal; bracteas sessile; corolla with a cylindrical tube, which is ventricose at the base; calycine segments narrow. h. G. Native of the Cape of Good Hope. Erica Lawsònia, Andr. heatl. vol. 4. icon. Sims, bot. mag. 1720. Lodd. bot. cab. 48s. Erìca Kennèdia, Hortul. Flower's red. 
Lanson's Callista. Fl. Sept. Clt. 1802. Shrub 1 foot.

33 C. DAPuniflòra; leaves 4 in a whorl, short, glabrous, acerose, crectly spreading; bracteas sessile; calycine segments lacerated a little; flowers terminal, usually by fours; corollas with an ovate ventricose tube, and a spreading obtuse limb. $h$. G. Native of the Cape of Good Hope. Erica daphneflora, Lodd. bot. cab. 543. Bedf. eric, wob. p. 7. Flowers small, white or deep red. Style exserted.

Daphne-flonercl Callista. Fl. A pril, June. Clt. 1791. Shrub 1 foot.

34 C. DAPUNODDEs; leaves 4 in a whorl, linear, glabrous; flowers terminal by fours; bracteas sessile; corolla with an ovate ventricose tube and a large limb. h. G. Native of the Cape of Good Hope. Erìca claphnoides, Lodd. bot. cab. 154. Erìca mirábilis, Hortul. Flowers pale red. Style a little exserted.

Daphnc-like-flowered Callista. Fl. May, June. Clt. 1800. Slirub 1 to 2 feet.

35 C. Coventrya'sa; leaves 4 in a whorl, linear-trigonal, ciliated, as well as the calyxes and bracteas; flowers terminal, aggregate, sessile; bracteas sessile; calycine segments foliaceous, narrow; corolla with a slender tube, and large segments. h. G. Native of the Cape of Good Hope. Erica Coventrya, Andr. heath. 4. icon. Lodd. bot. cab. 423. Corolla with a greenish-yellow tube, and a red limb, with ovate segments. Style a little exserted.

Lord Covcntry's Callista. Fl. July, Sept. Clt. 180s. Sh.

36 C. verecu'xda; leaves 4 ? in a whorl, linear, obtuse; flowers lateral, verticillate; corolla with a ventricose tube, and a spreading limb. I, G. Native of the Cape of Good Hope. Erìca verecúnda, Lodd. bot. cab. 1827. but not of Sal. Flowers red.

Reddish-flowered Callista. Fl. Spring, Autumn. Clt. 1820. Slirub 1 foot.

37 C. Stellífera; leaves 4 in a whorl, linear-lanceolate, subulate, pilose, spreading; flowers axillary and terminal, racemose, erect; bracteas remote from the calyx; limb of corolla 6-cleft. h. G. A hybrid. Erìca stellifera, Andr. heath, vol. 4. Lodd. bot. cab. 1622 . Flowers reddish-purple.

Star-bearing Callista. Fl. April; July. Clt. 1800. Shrub. SS C. PRE'STANs; leaves 4 in a whorl, linear, erect, glabrous; flowers terminal, aggregate; bracteas sessile, smooth; calycine segments ovate, cuspidate, with scarious hardly serrated edges; corolla with a ventricose tube, and a recurvedly reflexed limb. $h_{2}$. G. Native of the Cape of Good Hope. Erica pre'stans, Andr. heath. vol. 4. Lodd. bot. cab. 1695. Erìca daphniflora, Sal, in Lin. trans. 6. p. 384. Corollas white. Style exserted.

Excclling Callista. Fl. June, Nov, Clt. 1810. Shrub 1 foot.

89 C. MU'NDULA; leaves 4 in a whorl, subulate, spreading, shining, glabrous; Howers terminal, usually by fours, sessile; bracteas sessile; calyx naked; corolla with a short narrow tube, and a wide limb; style inclosed. $h$. G. Native of the Cape of Good Hope. Eríca míndula, Andr. heath. vol. 4. Lodd. bot. cab. 114. Flowers reddish-purple.

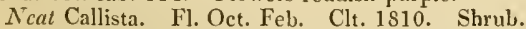

40 C. RíGiDA; glabrous; leaves 4 in a whorl, linear, spreading ; flowers terminal, pedicellate ; corolla ventricosely tubular, with a blunt border; pedicels red; bracteas remote from the calyx. 々. G. Native of the Cape of Good Hope. Erica rigida, Lodd. bot. cab. 286. Erìca metulæflòra bícolor, Bedf. eric. wob. p. 15. Corolla red. Limb short, white.

Stiff Callista, Fl. July, Aug. Clt. 18:0. Shrub 1 foot.

41 C. tróssula; leaves 4 in a whorl, linear, glabrous; flowers terminal; bracteas approximating the calyx; corolla with an ovate rentricose tube. $h \cdot G$. Native of the Cape of Good Hope. Erìca tróssula, Lodd. bot. cab. 1742. Flowers white.

Var. $\beta$, rübra; flowers red.
Spruce Callista. Fl. May, July. Clt. 1806. Shrub.

42 C. strutulolefòra.-This species has not yet been described or figured. h. G. Native of the Cape of Good Hope. Erica struthiolafiòra, Lodd. bot. cab. p. 25.

Struthiola-flowered Callista. Shrub.

$43 \mathrm{C}$. Cliffordin'Na; leaves 4 in a whorl, glabrous; flowers terminal; bracteas rather remote from the calyx; corolla with a slender ventricose tube; style inclosed. h.G. Native of the Cape of Good Hope. Erica Cliffordiàna, Lodd, bot. cab. 34. Flowers white.

Lady De Clifford's Callista. Fl. April, May. Clt. 1812. Shrub.

44. C. PAvetrefolòna; leaves 4 in a whorl, linear; flowers terminal; pedicels very short; corolla 9-10 lines long, having the limb mealy inside; filaments spurred near the top of the anthers. h. G. Native of the Cape of Good Hope. Erica pavettæflòra, Sal. in Lin. trans. 6. p. 382. Erìca infundibulifórmis, Roxb. mss.

Pavetta-flowered Callista. Fl. May, Aug. Clt. 1800. Shrub. 45 C. Nidif Lòra; stem pubescent; leaves 4 in a whorl, linear; flowers terminal; calycine segments obcuneated, serrated; corolla 3 lines long, with the limb one-half shorter than the tube; spurs of anthers very minute, ear-formed. $h . G$. Native of the Cape of Good Hope. Erìca nidifiòra, Sal, in Lin. trans. 6. p. 383. Erìca denticulàta, Roxb. mss.

Nest-flowered Callista. Fl. May, Oct. Clt. 1800. Shrub.

46 C. PARuentie'ril; leaves 4 in a whorl; flowers terminal; bracteas sessile; corolla with a cylindrically ventricose tube, and broad-spreading segments. h . G. Native of the Cape of Good Hope. Erìca Parmentièrii, Lodd. bot. cab. 197. Flowers reddish-purple. Style a little exserted.

Parmentier's Callista. Fl. April, June. Clt. 1810. Slirub 1 foot.

47 C. moscha'тa ; glabrous; leaves 4 in a whorl?; fiowers terminal; corolla short, with a ventricose tube, and a small spreading limb. Ђ. G. Native of the Cape of Good Hope. Erìca moschàta, Andr. heath. 4 icon. Lodd. bot. cab. 614. Co. rollas yellow.

Musky Callista. Fl. May, July. Clt. 1805. Shrub.

48 C. calóstoma; glabrous; leaves linear, 4 in a whorl ; flowers terminal, crowded; corolla with a ventricose elongated tube, a dark neck, and a white limb. Ђ. G. Hybrid. Erìca calóstoma, Lodd. bot. cab. 1759.

Beautiful-mouthed Callista. Fl. May, June. Hybrid Shrub.

49 C. Russelia'na; leaves 4 in a whorl, linear, glabrous; flowers terminal; bracteas remote from the calyx; corolla ovate-globose, with large open segments. h.G. Native of the Cape of Good Hope. Erìca Russeliàna, Lodd. bot. cab. 1013. Bedf. eric. wob. p. 22. Flowers reddish-purple.

Duke of Bedford's Callista. Fl. June, July. Clt. 1820 Slurub.

50 C. venu'sta; leaves 4 in a whorl, ciliated; flowers terminal, sessile; bracteas sessile, præmorse, membranous, ciliated, as well as the calyxes; corolla ovate, ventricose, with broad segments; $h$. G. Native of the Cape of Good Hope. Erica venústa, Hortul.

Graceful Callista. Fl. Spring, Summer. Clt, 1500. Shrub.

$$
\text { * * Leaves 5-6 in a whorl. }
$$

51 C. BLA'NDA; leaves 6 in a whorl, spreadingly refiexed, imbricate; flowers terminal, umbellate, horizontal; calyx bracteate; genitals a little exserted; corolla with an oblong tube, and small border. $\zeta_{2}$. G. Native of the Cape of Good Hope. Erìca blánda, Andr. heath. 3. t. 34. Flowers reddish-purple or bluish.-Perhaps a species of Syringòdea. Style exserted. foot.

Charming Callista. F1. April, Sept. Clt. 1800 . Shrub 3 
52 C. PRIMuloides; leaves 5 in a whorl, glabrous; flowers, terminal, nearly sessile, fastigiate; corolla with an ovate tube. and a broad-spreading limb; calycine segments serrulated. $h$, G. Native of the Cape of Good Hope. Erica primuloides Andr. heath. 3. t. 63. Lodd. bot. cab. 715. Erìca delécta, Hortul. Sims, bot. mag. 1548. Flowers pink and white, with a dark eye, and sometimes reddish-purple. Style exserted.

Primrose-like-flowered Callista. Fl. May, July. Clt. 1802. Shrub 1 foot.

53 C. Swainsònil; leaves 5-6 in a whorl, linear, obtuse, crowded, erect; flowers terminal, umbellate; bracteas sessile; calycine segments lanceolate; corolla with a cylindrical furrowed tube, and a spreading border; anthers somewhat exserted. $\zeta$. G. Native of the Cape of Good Hope. Erica Swainsònia, Andr, heatl. 3. t. 65. Flowers reddish-purple or buff-red.

Swainson's Callista. Fl. July, Oct. Clt. 1794. Shrub 1 to 2 feet.

54 C. QUADRANGULA'RIS; leaves recurved, glabrous, scattered: flowers terminating small branches; bracteas sessile; corolla with a 4-angled tube, winged; style exserted. h. G. Native of the Cape of Good IIope. Erìca quadrangulàis, Andr. heath. vol. 4. with a figure. Erica eròsa, Lodd. bot. cab. 133. Bedf. eric. wob. pl. 2. f. 2. Corolla with a purplish-red tube, and a white cresulated limb.

Quadrangular-flowered Callista. Fl. June, Aug. Clt. 1817. Shrub.

Cult. For culture and propagation see Erica, p. 800.-Elegant shrubs when in blossom. The wood being larder than that of the species of Erica, cuttings are more difficult to root.

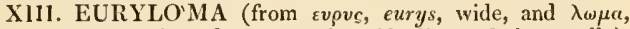
loma, a margin; in reference to the wide limb of the corolla). D. Don, in edinb. pliil. journ. 17. p. 155.-Erica species of autliors.

Lin. syst. Octlindria Monogýnia. Calyx 4-parted, foliaceous. Corolla salver-shaped, with an elongated filiform or ventricose tube, and a 4-parted dilated limb. Stamens inclosed; filaments dilated, membranous, channelled; anthers bipartite; cells of anthers membranous, dehiscing lengthwise, and drawn out at the base into a short tumid spur. Stigma with an elevated 4-lobed disk. Capsule 4-celled, many-seeded. - Diffusely branched shrubs, natives of the Cape of Good Hope. Leaves adpressed, semi-cylindrical, minutely denticulated. Flowers terminal, solitary or by threes, large, showy, on short pedicels, clammy.

\section{* Leaves 3 in a whorl.}

1 E. Aıтònı (D. Don, l, c.) leaves 3 in a whorl, linear, serrulated, erect; flowers terminal, usually by threes; bracteas remote from the calyx; corolla viscid, with a cylindrical tube, which is ventricose at top, and large ovate segments; style exserted. I. G. Native of the Cape of Good Hope. Erica Aitònia, Andr. 1. t. 25. Curt. bot. mag. 429. Erìca Aitoniàna, Ait. liort. kew. 2. p. 372. Lodd. bot. cab. 144. Erica Aitoni, Willd. spec. 2. p. 398 . Erìca jasminiflòra, Sal. in Lin. trans. 6. p. 382. Corolla pale red, or nearly white, 16 to 19 lines long.

Aiton's Euryloma. Fl. June, Sept. Clt. 1790. Shrub 2 feet.

2 E. Jasminirlòra (D. Don, l. c.) leaves 3 in a whorl, linearoblong, serrulated, recurved, imbricated in 6 rows ; flowers terminal, aggregate; bracteas ciliated, remote from the calyx; corolla viscid, with an ovate tube, which is ventricose at the apex, and ovate segments; style exserted. $\zeta$. G. Native of the Cape of Good Hope. Erìca jasminitiona, Andr. heath. 1. t. 26. Erìca lagenæflòra, Sal. in Lin. trans. 6. p. 382. Corolla
12-14 lines long, with a reddish tube, and a yellowish-green border.

Var. $\beta$, álba; flowers pure white.

Jasmine-flowered Euryloma. Fl. June, Nov. Clt. 1794. Shrub 1 to 2 feet.

3 E. Trícolon ; leaves 3 in a whor], linear, recurved, ciliated, as well as the bracteas and calyxes: the terminating hairs the longest; pedicels bibracteate near the base; flowers termiual, usually about 6 together; corolla viscid, with a large ventricose tube, and ovate-cordate slightly crenulated segments; style exserted. $\uparrow$. G. Native of the Cape of Good Hope. Erica trícolor, Nois. Bedf. hort. eric. wob. p. 25. Corolla red at the base, white at top, but greenish-yellow below the contraction of the limb.

I'ar. $\beta$, major (Bedf. eric. wob. p. 26.) leaves adpressed, shortly ciliated; corolla oblong, inflated, witb a red tube and segments, and yellowish-green below the contraction.

$\operatorname{Var}, \gamma$, dumòsa; leaves long-ciliated, recurved; corolla with an ovate-oblong inflated tube. $h . G$. Corolla with a red tube, a greenish-yellow contraction, and white segments. Bedf. eric. wob. p. $25 . \mathrm{t} .4$. f. 17.

I ar. $\delta$, minor (Bedf. eric. wob. p. 26.) leaves 4 in a whorl; style inclosed; corolla inflated, ventricose. $h . G$. Corolla with a red tube, greenish-yellow top, and red segments.

Three-coloured Euryloma. Fl. June, July. Clt. 1810. Shrub.

4 E. mirábiLis; leaves 3 in a whorl,? obtuse; flowers terminal, disposed in umbellate fascicles; corolla viscid? with a ventricose base, a contracted neck, and a wide-spreading border. 々. G. Native of the Cape of Good Hope. Erica mirábilis, Lodd. bot. cab. 1804. Corollas white, tinged with red.

Admirable Euryloma. Fl. May, June. Clt. 1804. Shrub.

5 E. ampulá'cea; leaves $3-4$ in a whorl, lanceolate, ciliated, reflexed; flowers terminal, usually by fours; bracteas approximating the calyx, ciliated, as well as the calycine segments; corolla viscid, with a ventricose tube, ribbed neck, and ovate-cordate slightly crenulated obtuse segments; style exserted. h. G. Native of the Cape of Gond Hope. Erica ampullàcea, Curt. bot. mag. 303. Andr. heath. 1. t. 29. Lodd bot. cab. 508. Erìca ampulæförmis, Sal. in Lin. trans. 6. p. 381. Leaves imbricate at the base, moderately spreading at top. Corolla 8-10 lines long, red. Anthers incurved at top.

Flask-flowered Euryloma. Fl. July, Aug. Clt. 1790. Sh.

6 E. IrRYA'NA; leaves 3 in a whorl, cuspidate, with scabrous margins, erect; bracteas remote from and approximating the calyx ; flowers terminal, umbellate; corolla viscid, with a cylindrical ventricose tube, and large segments ; style exserted; anthers mutic. দ. G. Native of the Cape of Good Hope. Erìca Irbyàna, Andr, heath. 3. t. 25. Lodd. bot. cab. 816 . Flowers white.

Var. $\beta$, rùbra; flowers reddish-purple.

Irby's Euryloma. Fl. June, Oct. Clt. 1800. Slirub 1 to 2 feet.

7 E. Nota'bilis; leaves linear-oblong, 3 in a whorl, serrulately ciliated, short, adpressed; branches slender, flexuous; flowers small, terminal, aggregate, viscid ; corolla tubular, with a constricted neck, and small limb. h.G. Native of the Cape of Good Hope. Erica notábilis, Wendl. Licht. ex Spreng. syst. 2. 1. 184. Style inclosed.

Notable Euryloma. Fl. March, Aug. Clt. 1816. Shrub I to 2 feet.

8 E. curvı́òla; leaves 3 in a whorl, recurved, ciliated?; spikes coarctate; corolla 4 lines long, viscid, with an ovate pyramidal tube; spurs of anthers linear-attenuated; pericarp hairy. h. G. Native of the Cape of Good Hope. Erica curvifolia, Sal. in Lin. trans. 6. p. 380. Flowers lateral.

Curved-leaved Euryloma. Slirub.

9 E. Shannonia'Na; leaves $3-4$ in a whorl, stiff, spreading, 
ending each in a hair; flowers terminal, umbellate, drooping ; calyx coloured; bractens remote from the calyx; corolla with a ventricose ribbed tube; style exserted. 々. G. Native of the Cape of Good Hope. Erìca Shannònia, Andr. heath. vol. 4. Erica Shamnoniàna, Lodd. bot. cab. 168. Spreng. syst. 2. p. 185. Flowers red.

Conntess Shannon's Euryloma. Fl. June, Scpt. Clt. 1806. Slirub 1 to 2 feet.

\section{* Lcaves 4 in a nhorl.}

10 E. HartNécli ; leaves 4 in a whorl, lanceolate, imbricated, finely ciliated: the terminating hairs the longest; corolla viscid nearly tubular, rather ventricose at the base, with ovate-triangular lobes. 々. G. Native of the Cape of Good Hope. Erica Hartnélli, Roll. cat.

IIartnell's Euryloma. Fl. May, Oct. Clt, 1820. Shrub.

11 E. anpullaceoìdes; leaves 4 in a whorl, ciliated; flowers terminal; bracteas remote from the calyx; corolla with a ventricose curved tube. 々. G. Native of the Cape of Good Hope. Erica ampullaceoides, Bedf. eric. wob. p. 2. Erica ampullàcea, Hort. Corolla with a red tube, and a greenislyellow neck.

Ampullacea-like Euryloma. Fl. Summer. Clt. 1500. Shrub.

12 E. princeps; leaves 4 in a whorl, linear, ciliated, recurved; flowers terminal, umbellate; bracteas approximating the calyx, ciliated, as well as the calycine segments; corolla viscid, with a ventricose tube, and a hairy top; style inclosed. $々$. G. Native of the Cape of Good Hope. Erica prínceps, Andr. lieath. 2. t. 44. Lodd. bot. cab. 647. Corollas reddish-purple.

lar. $\beta$, cárnca; flowers pale red.

Princly Euryloma. Fl. May, July. Clt. 1800. Shrub 1 to 2 feet.

13 E. REtónta; leares 4 in a whorl, squarrosely recurved, and are as well as the calyxes and hracteas fimbriately ciliated and aristate; flowers terminal, umbellate, usually 7-s together ; corolla viscid, with an ovate ventricose tube, and acute segments; anthers woolly; style exserted. $\zeta_{c} . G$. Native of the Cape of Good Hope. Erica retórta, Lin. suppl. p. 220. Montin, in act. loolm. 1774. p. 297. t. 7. Curt, bot. mag. 362. Andr. heath. 1, t. 47. Lodd. bot. cab. 804. Wendl. eric. fasc. 15. p. 4.5. with a figure. E. gorteriæefolia, Sal. in Lin. trans. 6. p. 381. Corolla 8-9 lines long, pale red.

I

Tnisted-leaved Euryloma. Fl. July, Oct. Clt. 1781. Shrub.

14. E. CA'PAX; leaves 4 in a whorl, ovate-cuneated; flowers terminal; corolla viscid, 8-10 lines long, with a flask formed tube, and retuse segments. দ. G. Native of the Cape of Good Hope. Erìca cápax, Sal. in Lin. trans. 6. p. 381 . Erìca præ'gnans, Sol. mss.

Capacious Euryloma. Fl. May, Aug. Clt. 1806. Shrub I to 2 feet.

15 E. ARISTA'TA; leaves 4.5 in a whorl, oblong, subsecund, hispid, imbricated, awned at the apex; flowers terminal; bracteas approximating the calyx; corolla inflated upwards with revolute projecting segments: calycine segments obtuse. h.G. Native of the Cape of Good Hope. Erica aristàta, Andr. heath. 3. t. 28. Curt, bot. mag. t. 1449. Ait. hort. kew. 2. p. 384. Bedf. eric. wob. p. 2. pl. 2. t. 11 . Lodd. bot. cab. 73. Corollas reddish-purple, with a paler limb.

Awned-leaved Euryloma. Fl. Marclı, Aug. Clt. 1801. Slırub 1 to 2 feet.

16 E. AristélLa ; leaves 4 in a whorl, hispid, awned, imbricated, subsecund; flowers terminal; bracteas approximating the calyx; corolla with an oblong acuminated tube; anthers mutic. . . G. Native of the Cape of Good Hope. Erica VoL. 111. aristélla, Bedf. eric. wob. p. 2. Erica aristàta mìnor, Hortul. Corolla reddish-purple.

Small-awned Euryloma. Fl. June, July. Clt. 1806. Shrub. 17 E. овва'та; leaves 4 in a whorl, linear, ciliated, sccund; flowers terminal; bracteas approxinating the calyx, ciliated, as well as the calyxes; corolla viscid, witl a glubose-ventricose ribbed tube, and spreading obtuse segments. h. G. Native of the Cape of Good Hope. Erica obbàta, Andr. heath. 2. t. 33. Corolla with a reddish-purple tube, a greenish-yellow neck, and a pale limb. ?

Iar. $\beta$, umbcllita (Andr. heath. 3. t. 29.) flowers terminal, umbellate, white. $h$. G. Native of the Cape of Good Hope.

Bottle-flowered Euryloma. Fl. April, July. Clt. $1796^{\circ}$ Slurub.

18 E. oblonga (Bedf. eric. wob. p. 17.) leaves 4 in a whorl, linear, ciliated, recurved; flowers terminal, umbellate; bracteas approximating the calyx, ciliated; calyx inflated, ciliated; corolla oblong, ruffed; anthers mutic. h. G. Native of the Cape of Good Hope. Erica oblónga, Belf. eric. wob. p. 17. Erìca ohbàta ròsea, Hortul. Flowers reddislı-purple.

Oblong-flowered Euryloma. Fl. June, Sept. Clt.? Shrub.

\section{*** Leaves 6 in a nhorl.}

19 E. squariósa; leaves 6 in a whorl, squarrose; flowers terminal; corolla viscid, 5-6 lines long, with an ovate pyramidal tube, and an obtuse limb; anthers smooth; spurs marginal. $h$. G. Native of the Cape of Good Hope. Erica squarròsa, Sal. in Lin. trans. p. 380. Leaves very dense.

Squarrose Euryloma. Fl. March, Aug. Clt. 1808. Shrub.

20 E. imperia'sis; leaves 6 in a whorl, filiform, erect, imbricated; flowers terminal, corymbose, drooping ; corolla viscid, ? with a discoloured limb. h.G. Native of the Cape of Good Hope. Erica imperiàlis, Andr. heath. 4. icon.

Imperial Euryloma. Fl. May, July. Clt. 1802. Shrub.

21 E. Recurva'ta; leaves 6 in a whorl, linear, flexuous, recurved; flowers terminal, nearly sessile, drooping, capitate ; bracteas sessile; corolla curved, ovate-oblong; style exserted; anthers mutic. $\eta_{\text {. }}$ G. Native of the Cape of Good Hope. Erìca recurvàta, Andr. heath. vol. 4. Flowers pale red.

Recurved-flowered Euryloma. Fl. A pril, June. Shrub.

22 E. CRinita ; leaves crowded, lanceolate, terminated each by a hair; flowers nearly terminal, drooping; pedicels red; corolla cylindrical, contracted at the neck. h. G. Native of the Cape of Good Hope. Erica crinita, Lodd. bot. cab. 143\%. Corolla purplish-red, with a pale border.

Long-haired Euryloma. Fl. Mav, Aug. Clt. 1826. Shrub.

Cult. For culture and propagation see Erica, p. 800. Most elegant shrubs when in blossom. The wool of the species being more hard than that of Erica, the cuttings do not strike root so freely.

XIV. CHO'NA (from $\chi^{\omega \nu \eta \eta}$, chone, a funnel; from the figure of the corolla). D. Don, in edinb. phil. journ. 17. p. 155.Erica species of authors.

Lin, syst. Octándria Monogýnia. Calyx 4-parted, foliaceous. Corolla funnel-shaped, with a 4-lobed revolute limb. Stamens exserted; filaments capillary; anthers truncate, combined; cells of anthers elongated, parallel, awned at the base. Stigma simple, obtuse. Capsule 4-celled, many-seeded.-A small diffuse shrub, native of the Cape of Good Hope. Leaves 3 in a whorl, lincar, awned, with revolute setosely-ciliated margins. Flowers terminal, corymbose, blood-red. Anthers black. Perhaps Syringòdea mutábilis belongs to this genus.

1 C. sanguínea (D. Don, l. c.). h. G. Native of the Cape of Good Hope. Erica Nivènia, Andr. heatl. 2. t. 26. 5 M 
Var. $\beta$, longiflòra (Andr. heath, 3. t. 4.) flowers longer and more tubular, blood-red.

Bloody-flowered Chona. Fl. year. Clt. 1799. Shrub 1 to 2 feet.

Cult. For culture and propagation see Erica, p. 800 .

XV. SYRINGO'DEA (from $\sigma v \rho \iota \gamma \xi$, syrin $x$, a pipe; in reference to the long tubular corollas). D. Don, in edinb. phil. journ. 17. p. 155.-Erica species of authors.

Liv. syst. Octándria, Monogýnia. Calyx 4-leaved, glumaceous. Corolla long, tubular, usually rather dilated at top, rarely a little contracted; limb slort, 4-lobed. Stamens for the most part inclosed; filaments capillary; anthers bipartite; cells of anthers short, obtuse, mutic or aristate at the base, deliscing by an oblong foramen. Stigma simple or capitate, and in some species annulated, with an elevated disk. Capsule 4celled, many-seeded. Seeds oval, compressed, smooth.-Erect shrubs, natives of the Cape of Good Hope. Leaves loose, acerose. Flowers large, showy, crowded at the tops of the branches on every side, disposed in something like spikes.

\section{Anthers mutic at the base. Normal species.}

\section{* Leaves 3 in a whorl.}

1 S. $\operatorname{costa'ta;~leaves~bluntish,~downy,~spreading;~flowers~}$ terminal, by threes; bracteas close to the calyx; calycine segments serrulated; corolla glabrous, curved, ribbed ; style a little

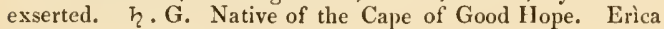
costata, Andr. heath. 1.t. 40. Corolla pale red, with a greenish border.

I ar. $\beta$, supérba (Andr. heath. vol. 4.) corolla larger, reddishpurple, with a greenish-yellow mouth.

Ribbed-flowered Syringodea. FI. March, June. Clt. 1795. Shrub.

2 S. DIA'PIANA; leaves spreading, glabrous; flowers terminal, by threes, pendulous, glabrous: bracteas foliaceous, close to the calyx ; calyxes obtuse, foliaceous; corolla witls a clavate inflated tube; style exserted. $h . G$. Native of the Cape of Good Hope. Erica transpàrens, Andr. heath. vol. 4. with a figure. Lodd. bot. cab. 177. Erìca diáphana, Spreng. syst. 2. p. 178. Corollas deep reddislı-purple.

Diaphanoùs Syringodea. Fl. June, July. Clt. 1796. Shrub.

$3 \mathrm{~S}$. CLAVA'TA; leaves erect; flowers terminal, by threes, drooping; bracteas close to the calyx, adpressed; genitals exserted a little. $\zeta$. G. Native of the Cape of Good Hope. Erìca clavàta, Andr. heatl. 3. t. 40. Corolla green, cylindrically clavate. Anthers black.

Clavate-flowered Syringodea. Fl. July, Aug. Clt. 1800. Slurub.

4. S. PA'LLENS: leaves linear, loary, spreading; flowers disposed in terminal racemes, horizontal; bracteas close to the calyx. h. G. Native of the Cape of Good Hope. Erica pállens, Andr. heath. 3. t. 45. Corolla sulphur-coloured.

Pale-flowered Syringodea, Fl. June, Aug. Clt. 1800. Slirub.

5 S. DI'chrus; leaves $3-4$ in a whorl, villous ; flowers terminal, by threes; bracteas close to the calyx; calyxes coloured, ciliated; corolla cylindrical; style exserted. h. G. Native of the Cape of Good Hope. Erica díchrus, Spreng. syst. 2. p. 179. Erìca bícolor, Andr. heatl. 2. t. 39. Lodd. bot. cab. 1001. but not of 'Thunb. nor Willd. Erica dichromàta, Lodd. bot. cab. 1813. Corolla purplish-red, with a greenish-yellow mouth.

Two-coloured-flowered Syringodea. Fl. April, July. Clt. 1800. Shrub.

6 S. Linnæa'va (D. Don, ], c.) leaves ciliated, spreading; flowers axillary, numerous, nearly sessile, horizontal; corollas clavate, downy or villous; bracteas close to the calyx, and are as well as the calycine segments serrated; style subexserted. দ. G. Native of the Cape of Good Hope. Erica Linnæàna, Lodd. bot. cab. 102. Erica Linnæ'a, Andr. heath. 2. t. 34. Erìca perspícua $\beta$, Ait. hort. kew. 2. p. 371 . Corolla white, with a red base. Anthers bearded on the back at top. In this and $S$, abietina the ovarium is 6-8-celled.

Var. $\beta$, supérba (Lodd. bot. cab. 1778.) flowers large, white tinged with red, erect. $\zeta$. G. Erica Bedfordiàna, G. Don, in Loud. hort. brit. p. 147.

Linnaus's Syringodea. Fl. Jan. May. Clt. 1790. Shrub.

7 S. versícolor; leaves glabrous, spreading; flowers terminal, by threes; calyxes coloured; bracteas close to the calyx, denticulated, as well as the calycine segments; corolla nearly cylindrical; style exserted. $\zeta$. G. Native of the Cape of Good Hope. Erica versícolor, Andr. lieath, 1. t. 39. Lodd. bot. cab. 20s. Corolla purplish-red, with a greenish-yellow mouth.

Var. $\beta$, màjor (Lodd. bot. cab. 1316.) flowers larger.

Party-coloured-flowered Syringodea. Fl. April, Oct. Clt. 1790. Shrub.

8 S. TRIPHY'LLA; leaves glabrous, spreading; flowers terminal, 2-3 together, on short pedicels; bracteas approximating the calyx; calyx foliaccous, spreading; anthers inclosed; style exserted. h.G. Native of the Cape of Good Hope. Erica triphýlla, Link. enum. I. p. 360 . Corolla clammy, red, yellow at top.

Three-lcaved Syringodea. Fl. July, Nov. Clt. 1822. Shb.

9 S. Broadleya'va; leaves linear, spreading; flowers axillary, on long pedicels, drooping; calycine segments narrow, foliaceous; bracteas remote from the calyx; style exserted. h.G. Native of the Cape of Good Hope. Erica Broadleyàna, Andr. leath. 3. t. 44. Corolla deep red, with a yellow mouth. Anthers mutic.

Broadley's Syringodea. Fl. June, Aug. Clt. 1800. Slurub. $10 \mathrm{~S}$. INSU'LSA; leaves $3 \mathrm{in}$ a whorl; flowers terminal ; bracteas close to the calyx, foliaceous; corolla with a cylindrical incurved tubc, and ciliated scgments; style a little exserted; 々. G. Native of the Cape of Good Hope. Erica insúlsa, Hortul. Bedf. eric. wob. p. 12. Lodd. cat. 1. 25. Flowers yellowish-green.

Dull Syringodea. F1. June, July. Clt. 1810. Shrub.

\section{* Leaves 4 in a whorl.}

11 S. REFu'LGENs; leaves glabrous, spreading; flowers terminal, drooping, by fours; calyxes coloured, subulate, adpressed; style exserted. h. G. Native of the Cape of Good Hope. Erìca refúlgens, Andr. leath, vol, 4. with a figure. Corollas scarlet or deep purplish-red.

Refulgent Syringodea. Fl. April, July. Clt. 1800. Shrub. 12 S. TRANSPA'RENS; leaves ovate-cuneated, shortly pectinated; calycine segments cuneated; corolla 6-7 lines long, bristly towards the apex outside; filaments spurred. h.G. Native of the Cape of Good Hope. Erica transpàrens, Tluunb. prod. p. 71. Erica cerinthoìdes $\gamma$, Thunb. diss. no. 33. Erìca strigilifòlia, Sal. in Lin. trans. 6. p. 367. Corollas white.?

Transparent Syringodea. Fl. May. Clt. 1800. Shrub.

13 S. PELLU'CIDA; leaves linear, horizontal, ciliated ; flowers terminal, pedicellate, drooping; bracteas close to the calyx; corolla with an oblong inflated tube, subpellucid; style exserted. h. G. Native of the Cape of Good Hope. Erica pellùcida, Andr. heatl. 3. t. 60. Lodd, bot. cab. 276. Corolla white. Calycine segments linear-subulate.

I $a r . \beta$, rùbra (Bedf, eric, wob. p. 18. but not of Andr.) co- 
rolla reddish-purple, with an inflated ribbed tube. Calycine segments linear-subulate.

Pcllucid-flowered Syringodea. Fl. Nor. June. Clt. 1800. Shrub.

14. S. Bedfordia'sa; leaves linear, ciliated; flowers terminal, pedicellate, drooping ; bracteas remote from and approximating the calyx; corolla cylindrical, curved ; style subexserted. 々. G. Native of the Cape of Good Hope. Erica pellùcida rùbra, Andr. heath. vol. 4 . with a figure. Erìca pellucidoìles, Bedf. eric. wob. p. 18. Corollas reddish-purple.

Duke of Bedford's Syringodea. Fl. Aug. Nov. Clt. 1808. Shrub.

15 S. ExU'vass; leaves linear, obtuse, sprearling, clammy from glands ; flowers terminal, subaggregate, drooping; bracteas spatulate, close to the calyx: corolla oblong, curved, ribbed; style exserted. h. G. Native of the Cape of Good Hope. Erica exùlans, Andr. heath, vol. 4. with a figure. Erica exsùdans, Lodd. bot. cab. 287. Erìca ròsa sòlis, Hortul. Corollas reddish-purple. Bracteas awned.

Sneating Syringodea. Fl. Sept. Nov. Clt. 1810. Shrub.

16 S. sulpuu'rea; leaves lincar, obtuse, villous ; flowers fasciculate, axillary and terminal, nearly sessile, horizontal ; bracteas close to the calyx : corolla cylindrical, trumpet-shaped, villous ; style exserted. h. G. Native of the Cape of Good Hope. Erica sulplùrea, Andr. heath. vol. 4. with a figure. Sims, bot. mag. 1984. Lodd. bot. cab. 1762. Corollas pale yellow or sulphurcoloured.

Sulphur-coloured-flowered Syringodea. Fl. June, Oct. Clt. 1805. Slirub.

17 S.? FLA'vA; leaves 3 in a whorl, filiform, glabrous, short, erect ; flowers horizontal, axillary, crowded; calyx bracteate ; corolla urceolately tubular, short; style exserted. h. G. $\mathrm{Na}$ tive of the Cape of Good Hope. Erica flàva, Lodd. bot. cab. S82. Andr. heatl. vol. 2. t. 38. Flowers yellow.

Yellow-flowered Syringodea. Fl. A pril, Sept. Clt. 1795. Shrub.

is S. ERUBE'scens; leaves linear-lanceolate, with revolute ciliated margins; floriferous branches pendulous; bracteas awned, close to the calyx, and are as well as the calycine segments dentately fringed; corollas cylindrical, inflated, beset with glandular hairs both inside and outside, with a revolute limb; style exserted. $\zeta$. G. Native of the Cape of Good Hope. Erica erubéscens, Andr. heath. 3. t. 56. Lodd, bot. cab. 1826. Erica elongata, Hortul. Corolla from pale purplishred to white. Calycine segments ovate, roundish.

Reddish-flowered Syringodea. Fl. March, July. Clt. 1800. Shrub.

19 S. ELA'TA ; leaves filiform, bluntish; branches spreading; flowers axillary or terminating small branclies, crowded in the manner of a spike; bracteas remote from and approximating the calyx; corolla curved, trumpet-shaped, villous, with a rather revolute limb; genitals exserted. $h . G$. Native of the Cape of Good Hope. Erica elàta, Andr. heath. 2. t. 18. Lodd. bot. cab. 178s. Erìca longiflòra, Sal. in Lin. trans. 6. p. 359. Corolla orange-red, 18-20 lines long, downy, with an obtuse limb. Herb powdery. Pedicels glabrous. Calyx recurredly spreading, convex on the outside at the base.

Tall Syringodea. Fl. July, Sept. Clt. 1790. Slırub.

20 S.? Línkı ; leaves spreading, beset witl a few hairs flowers terminal, umbellate; bracteas remote from the calyx; calycine segments ovate, white; anthers mutic, subexserted. 々.S.? Native of the Cape of Good Hope. Erica protrùdens, Link. enum. 1. p. 372. Corolla 2-3 lines long, white.-Probably a species of Gypsocállis.

Link's Syringodea. Fl. April, May. Clt. 1805. Shrub.

21 S. STAGNA'Lis; leaves linear, hairy; flowers terminal; pedicels glabrous; corolla 10-11 lines long, hairy; anthers straight, papillose, mutic. h.G. Native of the Cape of Good Hope. Erìca stagnàlis, Sal. in Lin. trans. 6. p. 359 . Erìca tubiflòra, Roxb. mss.

Stagnant Syringodea. Fl. March, June. Clt. 1790. Slurub.

22 S. FLA'MMEA ; leaves filiform, erectish, glabrous; flowers subsolitary, terminating the small branches, spike-like, horizontal; bracteas close to the calyx; calycine segments subulate, imbricated, unequal; corolla 8 lines long, downy, with a clavate tube, and the segments of the limb imbricated at the base; genitals a little exserted. h. G. Native of the Cape of Good Hope. Erìca flámmea, Andr. lieath. 2. t. 53. Erìca bibax, Sal. in Lin. trans. 6. p. 358 . Erica curviflòra, Thunb. diss. no. 30. Corollas pale yellow.

Flame-coloured-flowered Syringodea. Fl. Oct. Nov. Clt. 1793. Shrub.

$23 \mathrm{~S}$. LtNNæoi DEs; leaves linear-lanceolate, pilose, sprearling; flowers almost sessile, terminating small branches; hracteas close to the calyx; calycine segments lanceolate; corolla villous, cylindrical, swollen at top; style subexserted. $々 . G$. Native of the Cape of Good Hope. Erica linnæoides, Andr. heath. 2. t. 42. Erìca Linnæàna, Ait. hort. kew. 2. p. 375. Lodd. bot. cab. 102. Corollas with a purplish-red base, and a white top. linncea-like Syringodea. Fl. Jan. May. Clt. 1790. Slırub.

24 S. RADIA'TA; leaves filiform, spreading; flowers terminal, umbellately verticillate; bracteas remote from the calyx; calyx adpressed; corolla 9-10 lines long, glabrous, witl a cylindrical tube, and recurved limb; style exserted; fruit glabrous. h.G. Native of the Cape of Good Hope. Erica radiàta, Andr. heatl. 1. t. 46. Erica calamiformis, Sal. in Lin. trans. 6. p. 380 . Flowers reddish-purple.

Ray-flowered Syringodea. Fl. Aug. Nov. Clt. 1798. Shrub.

25 S. sPu'RIA; leaves linear, subciliated, erectly spreading; flowers aggregatc, terminating the small branches; bracteas remote from the calyx; calycine segments ovate, acuminated; corolla 7-8 lines long, downy, with a cylindrical tube, and a spreading border; genitals inclosed; pericarp obpyramidal. h. G. Native of the Cape of Good Hope. Erica spuria, Andr. heath. 1. t. 54. Erìca culcitæflòra, Sal. in Lin. trans. 6 . p. 357 . Corolla red.

Var. $\beta$, translùcens; corolla purplish-red, rather ventricose at the base.-Erica translucens, Andr, heath. vol. 4. with a figure.

Spurious Syringodea. Fl. April, May. Clt. 1796. Shrub.

$26 \mathrm{~S}$. EXSU'KGENS; leaves filiform, spreadingly recurved; flowers axillary, verticillate, horizontal, crowled; bracteas remote from and approximate to the calyx : corolla cylindrically clavate, 13-15 lines long, viscid, with ovate cuneated segments; filaments exserted; pericarp 4-furrowed. $\boldsymbol{b} . \mathrm{G}$. Native of the Cape of Good Hope. Erica exsúrgens, Andr. lieath. 1. t. 57. Lodd. bot. cab. 835 . Erìca grandiflòra breviflòra, Wendl. eric. 7. p. 7. with a figure. Erìca pharetræfórmis, Sal. in Lin. trans. 6. p. 361 . Corollas orange-red. This species differs from all others in the corolline segments being attenuated at the apex, and bifid. There are several varieties of the species in the gardens, besides those mentioned below, differing in the colour of the flowers.

Var. $\beta$, grandiflòra (Bedf. eric. wob. p. 7.) leaves 6-7 in a whor]; anthers a little exserted; style exserted ; corolla long, cylind rical, trumpet-shaped, with an orange-red tube, and orangeyellow segments.

I ar. $\gamma$, rútila (Sal. in Lin. trans. 6. p. 361.) corolla goldenyellow. $h_{c}$. G. Erìca abietina, Roxb. mss. ex Sal.

Rising-stamened Syringodea. Fl. March, Oct. Clt. 1792. Slirub.

27 S. cuRvifuo'ra; leaves linear, spreading, glabrous; flowers usually solitary, terminating small branches; bracteas close to $5 \mathrm{MI} 2$ 
the calyx; corolla glabrous, 10-11 lines long, with a curved cylindrical tube, and an erect or spreadingly reflexed limb; style exserted. h. G. Native of the Cape of Good Hope. Erica curviflora, Lin. diss. no. 41. a. Andr. heath. 1. t. 52. Lodd. bot. cab. 1668 . Wendl. eric. fasc. 3. no. 3. p. 3. with a figure. Erìca fastuòsa, Sal. in Lin. trans. 6. p. 359. Flowers orangeyellow. Fruit broadly turbinate.

Var. B, rùbra (Andı. heath. 3. t. 61.) corolla orange-red, cylintrically trumpet-shaped. 々. G. Erica simplicifiòn, Hortu].

Curved-flowered Syringodea. Fl. July, Nov. Clt. 1774. Shrub tall.

28 S. simpliciflo'ra; leaves trigonal, erectly spreading, glabrous; flowers terminating the small branclses, solitary, erect ; bracteas remote from the calyx; calycine segments lancenlate, adpressed; corolla tubular, constricted in the middle, with a spreading limb; genitals exserted. h. G. Native of the Cape of Good Hope. Erica simpliciflòra, Willd. spec. 2. p. 402. Wendl, eric. 17. p. 69. with a figure. Erica curvifiora, Lin. syst. ed. 13. p. 305, but not of his diss. Sal. in Lin. trans. 6. p. 358. Flowers rufous or reddish-orange. Pedicels downy. Corolla 9 lines long, downy; interstices of the limb lanceolate. Calycine segments ovate, acuminated.

Simple-flowered Syringodea. Fl. March, July. Clt. 17\%4. Shrub.

29 S. tubiflo'ra ; leaves linear, obtuse, downy, erect ; flowers usually solitary, terminating the small branches; bracteas almost close to the calyx ; corolla downy, cylindrical, 9-10 lines long, a little curved, with a revolute limb; calycine segments oblong; style exserted. h. G. Native of the Cape of Good Hope. Erìca tubiflòra, Lin. diss. no. 40. spec. ed. 2. p. 505. Andr. heath. 1. t. 52. Wendl. eric. 4. p. 7. with a figure. Icon. hort. kew. 28. Sal. in Lin. trans. 6. p. 357. Flowers purplish-red. Pedicels glabrous.

I ar. $\beta$, coccínea (Sal. in Lin. trans. 6. p. 357.) flowers deeper red. $\zeta . G$. Erica coccínea, Lin. diss. no. 42. with a figure of the flower.

\section{Tube-flowered Syringodea. Fl. April, Aug. Clt. 1775} Shrub.

30 S. IGNE'scens ; leaves linear, glabrous, spreading; flowers solitary, terminating the small branches, drooping; calycine segments ovate, acuminated, a little ciliated; bracteas ovate, ribbed, close to the calyx, or rather remote; corolla cylindrical, rather pilose at top, with a revolute limb; style exserted. h. G. Native of the Cape of Good Hope. Erica ignéscens, Andr. heath. 2. t. 47 . Corollas reddish-orange. Calycine segments ovate, acuminated.

Fiery Syringodea. Fl. March, June. Clt. 1792. Shrub.

31 S. SóRDIDA; branches scattered, hairy; leaves linear, obtuse, woolly, spreading; flowers usually solitary, terminating the small branches, drooping; bracteas remote from the calyx; calyxes adpressed, convex outside at the base; corolla 12 lines long, cylindrical, curved, villous, with a revolute limb; genitals inclosed. $々$. G. Native of the Cape of Good Hope. Erica sórdida, Andr. heath. 1. t. 55. Lodd. bot. cab. 1973. Erica laniflòra, Wendl. eric. fasc. 19 , no. 4 . with a figure. Erìca floccòsa, Sal. in Lin. trans. 6. p. 360. Flowers dirty orangered. Style exserted.

$$
\text { Dirty-flowered Syringodea. Fl. Aug. Dec. Clt. } 1790 .
$$
Slurub.

32 S. BRAcuílss; leaves linear, hairy; flowers terminal: corolla 6-8 lines long, hairy both inside and outside, with a curved pyramidal tube; anthers mutic, very long. $h . G$. Native of the Cape of Good Hope. Erica brachiàlis, Sal. in Lin. trans. 6. p. 367.

Branched Syringodea. Fl. March, July. Clt. 1792. Shrub.
33 S. Serratifo'lia; leaves linear, acute, spreading, witl plumose margins; flowers aggregate, terminal; bracteas close to the calyx; calyxes foliaceous, glandularly ciliated, a little recurved; corolla 9 lines long, glabrous, cylindrical, with a spreading limb; anthers a little exserted; style exserted. $h_{c}$. G. Native of the Cape of Good Hope. Erica serratifolia, Andr. heath. 1. t. 48. Lodd. bot. cab. 1703. Erìca cylindriciflòra, Sal. in Lin. trans. 6. p. 356. Erica plumòsa, Wendl. eric. no. 12. p. 5 . Corolla greenish-yellow at top, and orangered at base. Leaves 4-6 in a whorl.

Saw-leaved Syringodea. Fl. Aug. Dec. Clt. 1790. Shrub.

34 S. Masso'vir leaves $4-5$ in a whorl, linear, serrulated, hairy, imbricately spreading; flowers axillary, crowded, drooping, disposed in a verticillate crown ; bracteas imbricate; corolla 10-12 lines long, viscid, swollen at top; style exserted; pericarp clavate, stipitate. $々$.G. Native of the Cape of Good Hope. Erica Massònii, Lin. suppl. 219. Curt. bot. mag. t. 356. Pl. kew. t. 20. Lodd. bot. cab. 1069. Érica Massònia, Andr. beath. 1. t. 51. Erica lycopodifolia, Sal. ì Lin. trans. 6 . p. 361 . Corolla with a scarlet or reddish-purple tube, and a greenish-yellow constricted mouth.

l'ar. $a$, minor (Bedf. eric. wob. p. 14.) corolla smaller, with an inflated clavate tube. T. G.

Masson's Syringorlea. Fl. July, Oct. Clt. 1787. Shrub.

35 S. PROCE RA; leaves linear, erect, downy; flowers solitary, terminating the small branches, erectish; corolla constricted in the middle, with a spreading limb; style exserted. h. G. Native of the Cape of Good Hope. Erica procèra, Wendl, eric. with a figure. Corollas white. ?

Lofty Syringodea. Fl. April, June. Clt. 1791. Shrub.

36 s. conspícua; leaves linear, oblong, glabrous, spreading; flowers terminal, rather aggregate, drooping; bracteas near the calyx, spatulate; calycine segments ovate, obtuse, concave at the base outside; pedicels pubescent; corolla 15 lines long, with a clavate tube, and a retuse limb; genitals exserted a little. h. G. Native of the Cape of Good Hope. Erica conspicua, Sol. in hort. kew. 2. p. 373. Willd. spec. 2. p. 104. Pl. kew. t. 12. Andr. heath. 1. t. 30. Wendl. eric. 4. p. 9. with a figure. Corollas orange-yellow.

Conspicuous Syringodea. Fl. May, Ang. Clt. 1774. Shrub. 37 S. GLANDULo's ; leaves linear, acute, beset with glandular hairs, spreading; flowers nearly terminal, crowded, disposed in a verticillate crown; bracteas close to the calyx, and are as well as it ciliated with glandular hairs ; corolla glabrous, with a clavate tube; style exserted. h. G. Native of the Cape of Good Hope. Erìca glandulosa, Thunb. prod. p. 71. diss. no. 32. Corollas orange-red.?

Glandular Syringodea. F]. May, June. Clt. 1801. Shrub. is S. GEMMírERA; leaves oblong, adpressed, ciliated, aristate, 4-5 in a whorl; branches thickened at top; bracteas remote from and approximating the calyx; flowers drooping, crowded, disposed in a verticillate crown; corolla villous, cylindrical, inflated; genitals inclosed. h. G. Native of the Cape of Good Hope. Erica gemmífera, Sims, bot. mag. t. 2266. Lodd. bot. cab. 457. Erìca Massònii minor, Hortul. Corollas reddish-purple or scarlet, with a green apex.

Gem-bearing Syringodea. Fl. May, July. Clt. 1802. Slirub.

39 S. LITUIFLo'RA; leaves linear, nearly smooth; flowers solitary or by threes, terminating the branches; bracteas close to the calyx; corolla 6.8 lines long, downy or villous, with the tube clavate; filaments bearded on the back at the apex. $\tau_{c}$. G. Native of the Cape of Good Hope. Erica lituiftòra, Sal. in Lin. trans. 6. p. 356. Erica perspícua, Wendl. eric. fasc. 1. p. 7. with a figure. Corolla white, tinged with red. 
Trumpet-foncred Syringodea. Fl. March, June. Clt. 1796. Shrub.

40 S. PERspícuA; leaves linear, nearly smooth; flowers terminating the small branches, spike-formed; bracteas remote from the calyx; pedicels hairy; corolla cylindrical, erect; genitals inclosed. F. G. Native of the Cape of Good Hope. Erica perspícua. Hort. Bedf. eric. wob. p. 18. Corolla reddishpurple.

lar. $\beta$, nòna (Bedf. l. c.) leaves hairy; pedicels slightly hairy; tube of corolla cylindrical, straight. $h . G$. Corollas purplish-red.

Clear-flowered Syringodea. Fl. April, June. Clt. 1800. Shrub.

41 S. Bedrordin'sa ; leaves linear, ciliated, hairy; flowers terminal, subcapitate; pedicels slightly hairy; hracteas remote from the calyx; corolla downy, ? with a cylindrical, subventricose tube ; genitals inclosed. h. G. Native of the Cape of Good Hope. Erìca perspicuoides, Bedf. eric. wob. 18. Flowers reddish-purple.

Duke of Bedford's Syringodea. Fl. May, July. Clt. 1800. Shrub.

42 S. cyrilieflo'ra; stem slender; leaves linear, glabrous? corolla 2-3 lines long, downy, with a narrow campanulate tube, and a short limb. h. G. Native of the Cape of Good Hope. Erica cyrillaflòra, Sal. in Lin. trans. 6. p. 357. Flowers pale scarlet.

Cyrilla-flowered Syringodea. Fl. Feb. Sept. Clt. 1800. Shrub.

4.3 S. овругAmid'Lis ; leaves pubescent, spreading; flowers terminal, usually by threes; bracteas remote from the calyx, broad at the base; corolla funnel-shaped, with a spreading border, having the interstices of the limb tumid on the outside; fruit spherical. $h_{c}$. G. Native of the Cape of Good Hope. E. pyramidàlis, Andr. heath. 1. t. 45. Sims, bot. mag. 366 . kew. Lodd. bot, cab. 319. Ait. hort. kew. 3. p. 401. Icon. pl. t. 27. Wendl. eric. 5. p. 3. with a figure. Erica obpyramidàlis, Sal. in Lin. trans. 6. p. 356 . Corollas purplish-red, $3 \frac{1}{2}$ to 4 lines long. Style exserted.

Obpyramidal-flowered Syringodea. F]. Year. Clt. 1787. Shrub $1 \frac{1}{2}$ foot.

44 S. verticilia'ta ; leaves linear, glabrous; flowers crowded, nearly terminal, verticillate, drooping; bracteas linear, remote from the calyx; corolla with a cylindrical inflated tube, glabrous, constricted at top; genitals inclosed. h. G. Native of the Cape of Good Hope. Erica verticillata, Andr, heath. 1. t. 7. Lodd. bot. cab. 145. Erica mammòsa, $\beta$, verticillàta, Ait. hort. kew. 2. p. 369. Flowers scarlet. Slirub.

Whorled-flowered Syringodea. Fl. July, Oct. Clt. 1774.

45 S. colo'raxs; leaves linear, spreading, ciliated; flowers crowded, terminating the small branches; bracteas close to the calyx; corolla cylindrical, clavate, glabrous; style almost inclosed; calyxes coloured, subulate. h. G. Native of the Cape of Good Hope. Erica colòrans, Andr. heatlı, vol. 4. with a figure. Lodd. bot. cab. 224. Ker. bot. reg. 601. Bedf. eric. wob. pl. 4. f. 11 . Corollas varying from white to red.

Colouring Syringodea. Fl. April, June. Clt. 1827. Shrub.

\section{* * Leaves 6 or more in a whorl.}

46 S. SPLE'NDENs; leaves linear, obtuse, spreading; flowers densely crowded, drooping; calycine segments ovate; corolla downy, with a subrevolute limb; genitals exserted. h. G. Native of the Cape of Good Hope. Erìca spléndens, Wendl. eric, fasc. 8. p. 5 . with a figure, but not of Andr. Corolla deep red.

Splendent Syringodea. Fl. April, Sept. Clt. 1792. Shrub.
47 S. rongro'lra ; leaves long, linear, incurvedly spreading, with scabrous edges; flowers crowded in whorls, drooping; bractcas close to the calyx; corolla pubescent, clammy; calycine segments linear; genitals inclosed. $h, G$. Native of the Cape of Good Hope. Erìca longifolia, Pl. hort. kew. t. 4. Wılld. spec. 2. p. 398. Erica longifòlia $\delta$, Sal. in Lin. trans. 6. p. 363. Erica pínea, Wendl. eric. 1. p. 11. with a figure. Corolla more or less clavate, deep red.

Long-leaved Syringodea. Fl. Feb. July. Clt. 1787. Slırub.

48 S. vesti'ta; leaves linear, erect, with scabrous edges; flowers crowded, verticillate, nearly sessile, spreading; bracteas close to the calyx; corolla cylindrical, more or less clavate, 9-11 lines long, downy, with a revolute limb: style exserted;

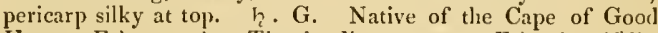
Hope. Erìca vestita, Thunb. diss. no. 25. Erìca longifolia, var. $a$, Sal. in Lin. trans. 6. p. 363. Erìca vestìta àlba, Andr. heath. 1. t. 62. Wendl. eric. no. 12. p. 3. with a figure. Calycine segments ciliated with glandular hairs. Corolla white, cylindrical, curved.

I ar. $\beta 3$, lùtea (Andr. heath. 3. t. 72.) leaves 6-8 in a whorl; corolla cylindrical, pale yellow.

I ar. $\gamma$, incarnaita (Ándr. heath. 2. t, 66. Lodd. bot. cah. 1698.) leaves 7 in a whorl; genitals a little exserted; corolla cylindrical, almost straight, pale reddish-purple. Erìca longifòlia, Curt. bot. mag. 706.

I'ar. $\delta$, ròsea (Andr. heatl. 2. t. 67.) leaves 7-8 in a whorl; anthers a little exserted; corolla cylindrical, subclavate, reddish-purple.

I'ar. $\varepsilon$, fúlgida (Andr. heatl. 2, t. 68.) anthers a little exserted; flowers nearly terminal; corolla with a cylindrical tube, and straight segments, reddish-purple or deep red. Erìca fülgida, Bedf. eric. wob. p. 11. Lodd, bot. cab. 1633.

Var. $\zeta$, purpùrea (Andr. heath. 1. t. 63.) antliers a little exserted; corolla cylindrical, subclavate, purplish-red. Lodd. bot. cab. 217. Wendl. eric. 10. p. 7. with a figure.

Var. $\eta$, coccinea (Andr. heath. 1. t. 6. bot. mag. 402. Wendl. eric. 11. p. 5. with a figure.) anthers a little exserted; corolla erect, cylindrical, curved, deep red, not exactly scarlet.

Clothed Syringodea. Fl. year. Clt. 1789. Slırub.

49 S. pisea; leaves linear, obtuse, spreading; flowers crowded, verticillate, almost sessile, spreading; bracteas close to the calyx; calycine segments dilated at the base, and linearsubulate at the apex, imbricate; corolla $6-7$ lines long, glabrous, with a cylindrical clavate tube, and a serrulated spreading limb; pericarp glabrous; style exserted. 々. G. Native of the Cape of Good Hope. Erìca pinea, Thunb. diss. no. 26. Andr. heath. 1. t. 61. Erica pinifolia, Sal. in Lin. trans. 6. p. 362. but not of Andr. Flowers deep red and blue.

Var. $\beta$, purpùrea (Lodd. bot. cab. 1259.) corollas purple. There are several other varieties in the gardens.

Pine-like Syringodea. Fl. Arg. Dec. Clt. 1790. Shrub.

50 S. PINIFo'LIA; leaves filiform, elongated, glabrous, spreading, 6-8 in a whorl; flowers nearly terminal, crowded, horizontal, verticillate; bracteas close to the calyx; calyx villous, with linear segments; corolla tomentose, cylindrically clubshaped, inflated, ribbed; style exserted. h. G. Native of the Cape of Good Hope. Erica pinifòlia, Andr. heath. 3. t. 69. Erica pityophýlla, Spreng. syst. 2. p. 181. Corolla white, with dark anthers.

Var. $\beta$, discolor (Andr. heath. 3. t. \%0.) corolla with a cylindrical ribbed tube, reddisls-purple or pale red.

Var. $\gamma$, spirùlis (Hort. Bedf. eric. wob. 19.) corolla with a clavate inflated tube, white and purplish-red.

Var. $\delta$, coccinea (Andr. heath. 2. t. 65.) flowers scarlet.

Fine-leaved Syringodea. Fl. Feb. July. Clt. 1810. Shrub. 
51 S. AU'REA; leaves linear, recurvedly spreading; flowers horizontal, crowded, verticillate, nearly terminal; bracteas close to the calyx, aristate; corolla cylindrical, with reflexed segments: style exserted; calycine segments ovate, acumiuated. h. G. Native of the Cape of Good Hope. Erica aúrea, Andr. lieath. 2. t. 61 . Corollas orange-yellow.

V'ar. 3 , flòre púllido (Andr. heath. 3. t. 71.) flowers pale red, with dark anthers.

Golden-flowered Syringodea. FI. July, Sept. Clt. 1799. Shrub.

52 S. vínıdss; leaves linear, spreading, subrecurved; flowers crowded, verticillate, horizontal : bracteas one-half shorter than the calyx; corolla cylindrical, ribbed, dilated in the middle, with a revolute limb; style exserted. $h . G$. Native of the Cape of Good Hope. Erica víridis, Andr. heath. 2. t. 59. Ait. hort. kew. 2. p. 376. Flowers greenish-yellow.

Green-flowered Syringodea. Fl. May, Sept. Clt. 1800. Shrub.

53 S. Hibbertia'na ; leaves 4-6 in a whorl, linear, glabrous, spreading; flowers horizontal, crowded, disposed in a whorled crown; bracteas 3 , two of which are close to the calyx, and the third remote; corolla glabrous, clammy, cylindrical, curved, clavate, with an erect limb; anthers a little exserted. h. G. Native of the Cape of Good Hope. Erica Hibbertia, Andr. heath. 3. t. 68. Erìca Hibbertiàna, Ait. hort. kew. 2. p. 378 . Sins, bot. mag. 1758. Corollas dark red or purplish-red, with a yellow mouth.

Hibbert's Syringodea. Fl. June, Sept. Clt. 1800. Shrub.

'54 S. onosmarlòra; leaves linear, spreading, glabrous flowers crowded, axillary, subverticillate; corolla viscid, with a cylindrical tube and spreading limb; bracteas one-half shorter than the calyx. h.G. Native of the Cape of Good Hope. Erìca glutinòsa, Andr. heath. 1. t. 60. Erìca viscòsa, Wendl. eric. with a figure. Erica onosmæflòra, Sal. in Lin. trans. 6. p. 363 . Corolla sulphur-coloured; tube clavate, 9-10 lines long. Calycine segments ovate-oblong.

Onosma-flomercd Syringodea. Fl. Sept. March. Clt. 1789. Shrub.

55 S. echuflòra; leaves $5-7$ in a whorl, linear, downy, with rough margins, spreading; flowers axillary, horizontal, spicate; bracteas close to the calyx; corolla with a short inflated ribbed tube, clammy; style exserted. h.G. Native of the Cape of Good Hope. Erica echiitlòra, Andr, heath. 3. t. 62. Lodel. bot. cab. 364. Erica echiiflòra, var. supérba, Bedf. eric. wob. p. 8. Corollas deep red or reddish-purple.

I ar. $\beta$. purpùrea (Bedf. eric. wob. p. 8.) corolla purple, with a short equal tube, that is not inflated.

liar. $\gamma$, coccimea (Lodd. cat. p. 25.) corollas deep red or scarlet.

Bugloss-flonered Syringodea. Fl. March, May. Clt. 1798. Shrub.

56 S. ARGENTIFLòra; leaves linear, glabrous, spreadingly incurved; flowers axillary, horizontal, spicate, rather pellucid; bracteas close to the calyx; style exserted. $\xi_{c} . G$. Native of the Cape of Good Hope. Erica argentiflòra, Andr. heath. vol. 4. with a figure. Corolla tubular, short, white.

Silver-flowered Syringodea. Fl. April, July. Clt. 1800. Shrub.

57 S. Archeria'Na; leaves 6-7 in a whorl, serrulately ciliated, spreading; flowers axillary and terminal, crowded, verticillate; pedicels tribracteate, 2 of the bracteas near the calyx, and the third remote; corolla downy, riscid, with a cylindrical inflated tube; calycine segments serrulately hispid, as well as the bracteas; style exserted. $\eta$. G. Native of the Cape of Good Hope. Erìca Archèria, Andr. heath. 2. t. 66. Erica Archeriàna, Ait. hort. kew. 2. p. 378. Lodd. bot. cab. 1466.
Corolla deep reddish-purple or scarlet. Ovarium cylindrical.

Lady Archer's Syringodea. Fl. April, Sept. Clt. 1796. Shrub.

58 S. RòsEA; leaves filiform, erect, $5-6$ in a whor] ; flowers sessile, terminating small branches; bracteas close to the calyx; corolla glabrous, with a cylindrical tube and erect segments; calycine segments subulate; genitals inclosed. $々$. G. Native of the Cape of Good Hope. Erica ròsea, Andr. heath. 2. t. 13. Lodd. bot. cab. 782. Flowers red.

Rosy-flowered Syringodea. Fl. April, Oct. Clt. 1798. Shrub.

59 S. Salisburia'na; leaves linear, erect, with revolute margins, white beneath; flowers axillary, racemosely sjicate, tufted, crowded, drooping; corollas cylindrically clavate; style exserted. 々. G. Native of the Cape of Good Hope. Erica Salisbùria, Andr. heath. vol. 4. with a figure. Erica ròsea, Hort. Bedf. eric, wob. p. 132. Flowers purplish red.

Salisbury's Syringodea. Fl. May, Sept. Clt. 1800. Shrub. 60 S. GRANDiflóra ; leaves linear, bluntish, glabrous, reclinate; flowers axillary near the tops of the branches and stem, verticillate; bracteas small, close to the calyx; calycine segments ovate-lanceolate; corolla long, curved, trumpetshaped, viscid, with a revolute limb; genitals exserted. $h . G$. Native of the Cape of Good Hope. Erica grandiflòra, Tlumb. diss. no. 28. Lin. suppl. 223. Curt. bot. mag. 189. Pl. hort. kew. t. 8. Andr. heath. 1. t. 50. Erìca grandifiòra longifòlia, Wendl. eric. 6. p. 5. with a figure. Lodd. bot. cab. 498 . Corolla orange-yellow outside, yellow inside. Leaves from 4 to 6 in a whorl, but usually the latter number.

I ar. $\beta$, formòsa; Jeaves 8 in a whorl; pedicels bracteate, 2 of the bracteas close to the calyx, and the third remote from it ; corollas reddish-orange. Erìca formòsa, Bedf. eric. wob. p. 10 .

Var. $\gamma$, hùmilis; leaves 4 in a whorl. Shrub dwarf.

lar. $\delta$, Andrènsï; flowers scarlet. $\zeta . G$. Erìca formòsa, Andr. heath. 2. t. 64.

Great-flowered Syringodea. Fl. May, Sept. Clt. 1775. Shrub.

$61 \mathrm{~S}$. LEEA'NA; leaves linear, filiform, stiff, obtuse, spreading; flowers axillary, verticillate; bracteas close to the calyx, and length of it; corolla 5.6 lines long, viscid, with a clavate 4ribbed tube, and a spreading limb; calyx adpressed; style exserted. h. G. Native of the Cape of Good Hope. Erica Lè̀ea, Andr, heath. 1. t. 5!). Erìca Leeàna, Ait. hort. kew. 2. t. 376. Pl. kew. 24. Lodd. bot. cab. 298. Erìca costæflòra, Sal. in Lin. trans. 6. p. 363. Corollas orange-red.

Lee's Syringodea. Fl. May, Jan. Clt. 1788. Shrub.

6. S. cephalòtes; leaves linear; flowers disposed in capitate whorls; calyx downy; corolla tubularly clavate; anthers inclosed; style exserted. h. G. Native of the Cape of Good Hope. Erìca cephalòtes, Thunb. diss. no. 23. prod. 70. Willd. spec. 2. p. 398. Corolla purple.

Headed Syringodea. Fl. May, July. Clt. $181 \%$ Slırub.

$63 \mathrm{~S}$. coccíneA; stem angular; leaves linear, cuspidate, ciliated, spreading; flowers axillary, crowded; bracteas close to the calyx; calyx spreading, woolly or villous; corolla viscid, 9 . 10 lines long, having the tube hardly clavate, and the limb erect; style exserted; ovarium turbinate. $h . G$. Native of the Cape of Good Hope. Erica coccinea, Berg. pl. cap. p. 98. Wendl. eric. fasc. 3. p. 9. with a figure. Andr. heath, 1. t. 49. Lodd. bot. cab. 1374. Erica abietina, Lin. spec. ed. 1. p. 355. Erica frondòsa, Sal. in Lin. trans. 6. p. 364. Flowers scarlet or deep red.

Iar. $\beta$, Bedfordiana ; bracteas coloured ; calyx woolly; genitals exserted; flowers nearly terminal, verticillate: corolla with 
a trumpet-shaped tube. $々$. G. Erìca coccinea, Hortul. Bedf. eric. wob. p. 6 . Flowers red-orange.

Scarlet-flowered Syringodea. Fl. Year. Clt.1793. Slırub.

$6+$ S. Purpu'reA; stem terete; leaves short, lincar, ciliated, spreading, 6-7 in a whorl, rather remote; flowers crowded, horizontal, verticillate; bracteas close to the calyx; calyx incurvedly erect : corolla cylindrical, trumpet-sliaped, 8-9 lines long, viscid, with a hardly clavate tube, and a spreading limb; genitals exserted; ovarium turbinate. $々$. G. Native of the Cape of Good Hope. Erica purpùrea, Andr. heath. 1. t. 58. Lodd. bot. cab. 703. Erica plyylicifòlia, Sal. in Lin. trans. 6. p. 364. Corollas purple.

Purple-flowered Syringodea. Fl. Year. Clt. 1789. Shrub. $65 \mathrm{~S}$. concinsa ; leaves linear, rather villous, erect; flowers axillary, verticillate, crowded; bracteas close to the calyx; corolla $7-9$ lines long, downy, cylindrical, with the tube rather clavate, and the limb spreading; calyxes denticulated, villous; genitals inclosed; anthers bearded at the base. $\zeta$. G. Native of the Cape of Good Hope. Erica concínna, Sol. in Ait. hort. kew. ed. 1. vol. 2. p. 23. ed. 2. vol. 2. p. 374. Sclinev. icon. no. 31 . Wendl. eric. 9. p. 9. with a figure. Erica abietina, Andr. eric. 2. t. 62. Erica verticillàta, Berg. pl. cap. p. 99. Erica paludòsa, Sal, in Liı. trans. 6. p. 356. Corollas pale purplish-red.

Ncat Syringodea. Fl. Sept. Oct. Clt. 1773. Shrub.

66 S. FilanentòsA; leaves linear, glabrous?; flowers axillary, nearly terminal, verticillate, crowded; bracteas remote from the calyx; calycine segments subulate; corolla with a large hell-shaped tube; style exserted; pedicels longer than the flowers. $h$. G. Native of the Cape of Good Hope. Erica flamentòsa, Andr. Jieath. 2. t. 63. Ker. bot. reg. t. 6 . Lodd. bot. cab. 395. Ait. hort. kew. 2. p. 398. Corolla short, purple.

Thready Syringodea. Fl. Year. Clt. 1800. Shrub.

67 S. LANA'TA; leaves 5-6 in a whorl, woolly, as well as the branches, which are also verticillate; flowers terminal; calyx incurvedly spreading, concave at the base outside; corolla 9-11 lines long, rather woolly. $\quad$. G. Native of the Cape of Good Hope. Erica Janàta, Wendl. eric. p. 45. with a figure. Erica verticillàris, Sal. in Lin. trans. 6. p. 360. Flowers of a rufous fulvous colour. Anthers mutic.

Woolly Syringodea. Fl. Feb. May. Clt. 1775. Shrub.

68 S. PU'RA; leaves linear, glabrous; flowers axillary, verticillate, near the tops of the branches; bracteas close to the calyx; style exserted; corolla with a cylindrical subclavate

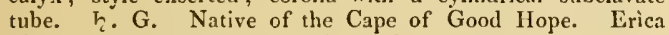
purra, Andr. heath. vol. 4. with a figure. but not of Lodd. Flowers pure white.

Pure-flowered Syringodea. Fl. June, Oct. Clt. 1827. Shrub.

$69 \mathrm{~S}$. PULchE'Lla; leaves linear, attenuated, with revolute edges, glabrous?; bracteas close to the calyx ; flowers axillary, crowded; calycine segments subulate; pedicels much shorter than the flowers; corolla viscid, 5-6 lines long, with a funnelformed tube. $\nvdash$. G. Native of the Cape of Good Hope. Erica pulchélla, Thunb. diss, no. 24. with a figure. Ait. hort. kew. 2. p. 398. Lodd. bot. cab. 307.? Erìca argutifolia, Sal. in Lin. trans. 6. p. 364.

Pretty Syringodea. Fl. Autumn. Clt. 1792. Shrub.

70 S. pulvinifóruis ; leaves linear, attenuated, serrulately ciliated; flowers longish, on the rudiments of the branches; corolla 7-9 lines long, viscid, with a cylindrically urceolar tube. 々. G. Native of the Cape of Good Hope. Erìca pulvinifórmis, Sal. in Lin. trans. 6. p. 364 . Corollas red.-Habit of Erica cerinthoides.
Pillow-formed-flowered Syringodea. Fl. Feb. Clt. 1800. Slırub.

\section{Anthers anned or erested. Aberrant species.}

* Lcarcs 3 in a rhorl.

il S. Díscolor; leaves linear, spreading, ciliated; flowers terminal, by threes; bracteas close to the calyx; calycine segments serrulated; corolla 9-10 lines long, anointed with gluten, cylindrical, lsaving the tube finely striated; awns of anthers short, glabrous. h. G. Native of the Cape of Good Hope. Erica díscolor, Andr. lieath. 1. t. 3. Wendl. eric. 5. p. 9. with a figure. Lodd. bot. cab. 1453. Erica cupressifórmis, Sal. in Lin. trans. 6. p. 354 . Corollas pale red.

Two-coloured-flowered Syringodea. Fl. Nov. March. Clt. 1788. Shrub.

$72 \mathrm{~S}$. kugòsA ; leaves crowded, linear, sprcarlingly reflexed, 3-5 in a whorl; flowers axillary, verticillate, near the tops of the branches; bracteas broad at the base, remote from the calyx; calyx foliaceous; corolla with a wrinkled tube; genitals exserted; anthers awned. h. G. Native of the Cape of Good Hope. Erìca rugòsa, $A$ ndr. heath. vol, 4. with a figure. Flowers reddish-purple.

Wrinkled-flowered Syringodea. F]. Feb. Nov. Clt. 1800. Shrub.

73 S. DENSIFòlıA ; leaves linear-oblong, imbricated, glabrous ; flowers axillary, crowded; corolla cylindrically-clavate, downy ; style exserted. h.G. Native of the Cape of Good Hope. Erica densifolia, Willd. spec. 2. p. 359. Flowers purplish-red.

Densc-lcavcd Syringodea. Fl. March, May. Clt. 1811. Shrub.

74 S. Ewera'na ; leaves linear, scabrous, spreading ; flowers subspicate; bracteas remote from the calys; calyx flat, with thick margins; corolla cylindrical, 8-10 lines long, clothed with viscid down, curved and clavate; style exserted; awns of anthers long, downy. $\eta$. G. Native of the Cape of Good Hope. Erica Eweràna, Dry. in Ait. hort. kew. 2. p. 368. Lodd. bot. cab. 303. Erica Ewèra, Hort. Erìca U'hria, Andr. heath. 2. t. 3. Wendl. eric. 18. p. 91 . Erìca decòra, Sal. in Lin. trans. 6. p. 354 , with a figure. Corolla dark red, or reddish-purple, with a greenish-yellow mouth.

Var. $\beta$, pilosa (Andr. heath. 2. t. 4.) leaves pilose; bracteas close to the calyx; flowers terminating small branches; corolla slightly curved and clavate, purplish-red, with a greenish-yellow moutl.

Exer's Syringodea. Fl. July, Nov. Clt. 1790. Shrub.

75 S. HíRTA; leaves linear, ciliated; flowers terminal; bracteas sessile, close to the calyx, ciliated; corolla cylindrical; style exserted; anthers awned. $I_{c}$. G. Native of the Cape of Good Hope. Erìca hírta, Andr. heath. 3. t. 5. Lodd. bot. cab. 1116. but not of Thunb. nor Willd. Corolla reddish-purple, with a greenish-yellow mouth.

Hairy Syringodea. Fl. Feb. May. Clt. 1800. Shrub.

76 S. cRUE'NrA ; leaves linear, subulate, glabrous, spreading; flowers terminal, by threes; bracteas remote from the calyx; calyx serrated; corolla 9-12 lines long, slining, smooth, with a clavate, more or less compressed, curved tube ; style exserted ; pericarp ovate. $h_{\text {. }}$ G. Native of the Cape of Good Hope. Erica cruénta, Pl. kew. t. 13. Lodd. bot. cab. $1656 . \quad$ Erica mellithùa, Sal. in Lin. trans. 6. p. 354. Corolla reddish-purple or blood-coloured.

Var. 3 ; calyx slightly serrated; corolla deep red or scarlet. 々. G. Erica cruénta, Andr. heath. 1. t. 9. Sol. in Ait. hort. kew. ed. 1. vol. 2. p. 16 . Wendl. eric. 4. p. 11 . with a figure. 
Bloody-flowered Syringodea. Fl. Year. Clt. 1774. Shrub.

77 S. viridiflòna; leaves 3 in a whorl, or alternate, ciliated; flowers terminal, drooping; bracteas imbricate ; corolla with a eylindrical elavate tube; style exserted; anthers a little exserted, subaristate. $々$. G. Native of the Cape of Good Hope. Erìca hírta, var, viridiflòra, Andr. heath. 3. t. 7. Lodd. bot, cab. 917. Flowers deep green.

Greenflowered Syringodea. Fl. July, May. Clt. 1810. Shrub.

78 S. specio'sa; leaves linear, downy, spreading; flowers terminal, by threes; bracteas elose to the calyx; calycine segments broad, short, imbricate, with woolly edges; corolla with a eylindrieal, inflexed, curved tube, and an ereet limb; style exserted, incurved at top; anthers awned, about the length of the corolla. h. G. Native of the Cape of Good Hope. Erica speciòsa, Andr. heatl. 2. t. 2. Lodd, bot. cab. 575. Ait. hort. kew. 2. p. 369. Corollas dark red or reddish-purple, with a greenish-yellow mouth.

Specious Syringodea, Fl. June, Sept. Clt. 1800. Shrub.

79 S.? Diekensòn11; leaves glabrous; flowers terminating the small branches; bracteas imbricate, angular; corolla with a bellshaped tube, and large spreading segments; anthers a little exserted, crested; style exserted. h.G. Native of the Cape of Good Hope, Eriea Dickensonia, Bedf. eric. wob. p. 8. lodd. bot. cab. t. 1816. Flowers yellow.

I ar. $\beta$, alba; flowers white.

lar. $\gamma$, rübra; flowers red.

Dickenson's Syringodea. FI. May, Aug. Clt. 1809. Slırub.

\section{* Leaves 4 in a whorl.}

80 S. mUта вıLıs; leaves linear, eiliated, spreading, $3-4$ in a whorl, the 3 terminal hairs the longest; flowers terminal, umbellate; pedicels downy; bracteas 3,2 near the calyx, and the third remote from it ; ealycine segments eiliated, with glandular hairs; corolla eylindrical, inflated; filaments awned; anthers a little exserted; style exserted. $々 . G$. Native of the Cape of Good Hope. Erica mutàbilis, Andr. heath. 3. t. 31. Sins, bot. mag. 2318. Lodd. bot. cab. 46. Corolla purplishred, deeper towards the top. The hairs or down on the plant are tipped with black glands in the young state.

Changeable-flowered Syringodea. Fl. Year. Clt. 1798. Shrub 1 to 2 feet.

81 S. cuspidígera ; leaves linear, pedicels glabrous ; calyeine segments ovate, euspidate; flowers terminal; corolla 11-12 lines long, downy, having the interstices of the limb lanceolate at the base ; anthers hairy, awned; filaments rather villous. h. G. Native of the Cape of Good Hope. Erica cuspidígera, Sal. in Lin. trans. 6. p. 358.

Point-bcaring Syringodea. Fl. Feb. May. Clt. 1796. Shrub.

82 S. $\mathrm{DE}^{\prime} \mathrm{NSA}$; leaves $4-5$ in a whorl, linear, somewhat imbricated, spreading; flowers axillary, crowded, nearly sessile; braeteas elose to the ealyx; ealyx adpressed; corolla with an oblong-cylindrical tube, and a short spreading limb; anthers awned; style a little exserted. $h_{\imath}, G$. Native of the Cape of Good Hope. Erica dénsa, $\mathbf{A n d r}$, heath. 3. t. 30. Corolla pale red, with a deep spreading border, like a Callista, of which it may probahly be a species.

Dense-flowered Syringodea. F]. May, Oct, Clt. 1810. Shrub.

83 S. NA'NA; stem trailing; leaves linear, spreading, obtuse ; flowers terminal; bracteas close to the calyx, imbrieated, eiliated; corolla 9-I 1 lines long, downy outside, with a elavate eompressed tube ; style exserted; awns of anthers long. h. G. Native of the Cape of Good Hope. Erica nàna, Sal. in Lin. trans.
355. Erica depréssa, Andr, heath. 2. t. 12. but not of Thunb. nor Willd. Corollas yellow-green.

Dwarf Syringodea. Fl, Aug. Nov. Clt.? Shrub trailing.

84 S. ostrina; leaves $4-5$ in a whorl, glabrous; flowers terminal; corolla eylindrieal, eurved, widened to the throat. h. G. Native of the Cape of Good Hope. Erica ostrina, Lodd. bot. eab. 1218. Corolla purplish-red.

Purple-flowered Syringodea. Fl. June, Nov. Clt. 1820. Shrub.

85 S. ну'вRIDA ; leaves linear, glabrous, flowers terminal; bracteas elose to the calyx; corolla glabrous, with a cylindrieal, slightly curved tube; style exserted; anthers aristate. h.G. Native of the Cape of Good Hope. Erìca hýbrida, Hort. Flowers purplish-red. Nearly allied to S. cylindrica.

IIybrid Syringodea. Fl. May, June. Clt.? Shrub.

86 S. Nítens; leaves hairy, flowers terminal; pedicels tribraeteate, 2 of the bracteas near the calyx, and the third remote; ealyx coloured, hairy; corolla with a eurved subelavate tube ; genitals aristate, a little exserted. $々$. G. Native of the Cape of Good Hope. Eriea nitens, Hortul. Bedf. eric. Wob. p. 16. Corolla purplish-red, with a green top.

Shining Syringodea, Fl. June, Sept. Clt.? Shrub.

87 S. SANGuínea; leaves linear, glabrous; flowers nearly terminal, erowded, verticillate; calyxes broad; braeteas remote from the calyx; corolla cylindrical; anthers a little exserted, subaristate; style exserted. $h . G$. Native of the Cape of Good Hope. Eriea sanguinea, Lodd. bot. cab. 86. Flowers deep red.

Bloody-flowered Syringodea. Fl. Year. Clt. 1815. Slarub. 88 S. vire'seexs; leaves linear, incurvedly erect, hairy ; flowers terminal, sessile; braeteas close to the calyx; corolla clamny ; style exserted, incurved. $\zeta$. G. Native of the Cape of Good Hope. Eriea viréscens, Lodd. bot. cab. 233. Corolla greenish-yellow. Anthers awned.

Greenish-flowered Syringodea. Fl. May. Clt. 180\%. Shrub. 89 S. AмвíguA ; leaves linear, rather hairy, spreading ; flowers terminal, usually solitary; braeteas elose to the ealyx; calyeine segments subulate, adpressed; corolla striated, glabrous, with a cylindrieal tube and short reflexed limb; style a little exserted; anthers awned. $5 . G$. Native of the Cape of Good Hope. Eriea ambigua, Wendl, eric. fasc. 16. p. 61. with a figure. Erica cylíndrica, Andr. heath. 2. t. 30. Lodd. bot. cab. 1734. Corolla reddish-purpie.

Ambiguous Syringodea. Fl. April, June. Clt. 1800. Shrub. 90 S. Buccinæfórmis; leaves linear, downy; flowers termi$\mathrm{nal}$; pedicels downy; corolla $9-10$ lines long, downy, with a recurvedly spreading limb; filaments downy; anthers awned. h. G. Native of the Cape of Good Hope. Eriea buceinafórmis, Sal, in Lin. trans. 6. p. 359. Erìca tubiflòra, Thunb. diss. no. 31. Flower's reddish-purple.

Trumpet-formed flonered Syringodea. Fl. June, July. Clt. 1818. Shrub.

91 S. CI.Av.eflòra; leaves linear, glabrous, spreading; flowers axillary, nearly sessile, spicate; bracteas imbricate; ealyx fleshy, with orbicularly spatulate entire segments; corolla downy, 10-12 lines long, clavate; style exserted; anthers awned. h. G. Native of the Cape of Good Hope. Eriea clavæflòra, Sal. in Lin. trans. 6. p. 365. Erìca sessilifiòra, Andr. heath. 2. t. 10. Corollas greenish-yellow.

Club-flonered Syringodea. Fl. Aug. Oct. Clt, 1799. Shrub.

92 S. EPıstòmı ; leaves glabrous; flowers terminal; bracteas remote and elose to the ealyx; calyx green, large, inflated; corolla with an oblong inflated tube; genitals inclosed, aristate. দ. G. Native of the Cape of Good Hope. Erica epistomia, 
Nois. Bedf. eric. wob. p. 9. pl. 4. f. 7. Lodd. bot. cab. 1186. Flowers vellow-green.

Spout-flowered Syringodea. Fl. May, June. Clt. 1810. Shrub.

93 S. SAccıflòna ; leaves linear, flowers terminal; calycine segments broad, orate, acuminated; corolla 6-8 lines long, glabrous, with a cylindrical tube; awns of anthers long; anthers linear, papillose. $\imath_{\text {. }}$ G. Native of the Cape of Good Hope. Erìca sacciflòra, sal. in Lin. trans. 6. p. 355.

Sack-flonered Syringolea, lil. March, June. Clt. 1500. Shrub.

9 f S. Patersòsıl ; leaves dense, linear, straight, spreading, glabrous; flowers crowded, axillary; bracteas close to the calyx; calycine segments ciliated at the base, and cuspidate at the apex; corolla 6-8 lines long, glabrous, with a cylindrical tube and a short reflexed limb; style exserted; awns of anthers long. $F_{c}$. G. Native of the Cape of Good Hopre. Erica Patersònia, Andr. heath. 1. t. 10. Wendl. eric. fasc. 1. p. 16. with a figure. Erìca Patersònii, Ait. hort. kew. 2. p. 379. Lodd. bot. cab. 17\%9. Erica abietina, Lin. spec. ed. 2. p. 506. diss. no. 20. Erica spissifolia, Sal, in Lin. trans. 6. p. 355. Flowers yellow.

Íar. $\beta$, monstròsa (Bedf. eric, wob. p. 17.) corolla larger.

Var. \%, Major (Andr. heath. 3. t. 10.) calyx slightly toothed.

Paterson's Syringodea. Fl. A pril, July. Clt. 1791. Shrub.

95 S. velitA'ris ; leaves linear ; flowers terminal ; corolla $2 \frac{1}{2}$ to 3 lines long, downy, with an obovate tube and a recurvedly spreading limb; crests of anthers long, cuncated, and a little serrated. h. G. Native of the Cape of Good Hope. Erica velitàris, Sal. in Lin. trans, 6. p. 357.

Jacelin-flowered Syringodea. FI. Jan. June. Clt. 1790. Shrub.

96 S. GILNA; leaves linear, triquetrons, stiff, glabrons ; spreading; flowers axillary, verticillate, pendulous, crowded; pedicels glabrous; bracteas lanceolate, close to the calyx, ribbed; calycine segments lanceolate; corolla downy, 7-9 lines long, with a cylindrical inflated tube, 4 -angled at the base ; genitals inclosed; anthers awned. $h$. G. Native of the Cape of Good Hope. Erìca gílva, Wendl. eric. with a figure. Erìca gélida, Andr. lseath. 2. t. 11. Ait. hort. kew. 2. p. 370. Lodd. bot. cab. 699. Erìca alveiflòn, Sal, in. Lin. trans. 6. p. 366. Flowers green. Leaves 4-6 in a whorl.

Var. $\beta$, álbens (Belf. eric. wob. p. 11.) corolla with a white base and a green top.

Var. $\gamma$, gîlca (Wendl. eric. fasc. 12. p. 13. with a figure); bracteas remote from the calyx; flowers disposed in a verticillate crown, greenish-yellow. Leaves $4-5$ in a whorl.

Iron-grey-flowered Syringodea. Fl. April, July. Clt. 1790. Shrub.

97 S. MANмòsA; leaves linear, subulate, glabrous, erect, spreading; flowers drooping, axillary, crowded, verticillate, near the tops of the branches; bracteas linear, remote from the calyx; calyx coloured; pedicels downy; corolla downy, 8-10 lines long; with a cylindrical inflated tube, having 4 pits near the base; genitals inclosed; anthers awned, h. G. Native of the Cape of Good Hope. Erìca mammòsa, Lin. mant. 234. diss. 21. Andr. heath. 1. t. 8. Lodd, bot. cals. 125. Erìca mammòsa, $\beta$, Sal. in Lin. trans. 6. p. 366 . Erica abietina, Thunb. diss. no. 68 . Schnev. pl. no. 23, with a figure. Berg. pl. cap. 105.-Buxb. cent. 4. p. 25. t. 41-42. Corollas pale purplishred, or dark pink.

I ar. $\beta$, minor (Andr. heath. 3. t. 9.) corolla more slender, purplish-red.

Var. $\gamma$, pállida (Lodu. bot. cab. 951.) flowers jaler.

Mammose. Syringodea. Fl. July, Oct. Ctl. 1769. Shrub.

98 S. TU'MIDA ; leaves linear, obtuse, hairy, reflexed ; flowers VoL. III. tcrminal, usually by fours: pedicels tribracteate, 2 of the bracteas close to the calyx, and the third remote; corolla downy, with an oblong-cylindrical tube; calyx spreading; style somewhat exserted; anthers awned. h. G. Native of the Cape of Good Hope. Erica tùmida, Ker. bot. reg. t. 65. Erica spléndens, Andr. heath. sol, 1 , with a figure. Erica spléndida, Hort. Loud. hort. brit. p. 146. Flowers red.

Tumid-flowered Syringodea. Fl. May, Aug. Clt. 1812. Shrub.

99 S. Bowne'va; leaves linear, glaucous, glabrous; bractcas remote from the calyx; flowers crowded, axillary, verticillate, near the tops of the branches, pendulous; corolla cylindrical, with an inflated tube, and contracted moutlı; genitals inclosed; anthers awned. $h_{2}, G$. Native of the Cape of Good 110 pe. Erìca Bowieàna, Lodł. bot. cab. 842. Erìca Bòwia, Bedf. eric. wob. p. 4. Erica Baùrea, Andr. lieath. vol, 4. with a figure. Flowers white.-Habit of S. mammòsa, and $S$. verticillìta, S.c.

Bonie's Syringodea. Fl. Year. Clt. 1822. Shrub.

$$
\text { *** Leaves } 5.6 \text { to } 8 \text { in a rhorl. }
$$

100 S. cervicıflòra ; leaves $5-6$ in a whorl, linear ; flowers axillary, crowled ; corolla $5-6$ lines long, downy, with a very narrow urceolate tube and a spreading limb; filaments ninutely spurred. h. G. Native of the Cape of Good Hope. Erica cervicifòra, Sal. in Lin. trans. 6. p. 362. Erìca inapérta, Hort. Pedicels tribracteate.

Neck-flomered Syringodea. Ft. March, July. Clt. 1810. Shrub.

101 S. PATERsonioìdes ; leaves linear, glabrous, 5-6 in a whorl; Howers crowled, verticillate; bracteas close to the calyx, toothel ; corolla with a cylindrical, clavate, curved tube ; style exserted; anthers aristate. b.G. Native of the Cape of Good Hope. Erica patersonioides, Bedf. eric. wob. p. 18. Erìca Patersonia coccínea, Andr, heath. 3. t. 11. Corolla deep redolish-orange or scarlet.

Patersonia-like Syringodea. Fl. April. May. Clt. 1800. Shrub.

$102 \mathrm{~S}$. carina'ta ; leaves 5 in a whorl, reflexed, woolly ; flowers terminal; bracteas remote from the calyx ; corolla with a cylindrical, inflated, ribbed tube; crests of anthers plumose;

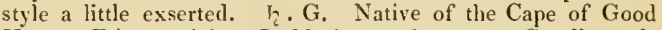
Hope. Erìca carinàta, Lodd. bott. cab. 1071. Corollas reddish-purple.

Keeled-leaved Syringodea. Fl. Sept. Clt. 1820. Shrub.

$103 \mathrm{~S}$. Foliòs. We know nothing further about this species. 々. G. Native of the Cape of Good Hope. Erica foliòsa, or foliàcea, Andr. heath. vol. 4. with a figure. Flowers of an orange-yellow colour.

Leafy Syringodea. Fl. May, July. Clt, 1800. Shrub.

104 S. sPicA'TA; leaves linear, subulate, hispid, spreadingly reflexed, 6 in a whorl; pedicels rery short; bracteas sessile; flowers axillary, crowded, verticillately spicate, drooping; calycine segments calious, spatulate, entire ; corolla dewy, $7-9$ lines long, cylindrical; genitals inclosed; anthers awned. $\zeta_{\text {. G }}$. Native of the Cape of Good Hope. Erica spicata, Thunb. diss. no. 71 . with a figure. Wendl. eric. fasc. 2. p. 27 . with a fignre. Erìca sessiliflòra, Lin. suppl. 22\%. Erìca faròsa, Sal. in Lin. trans 6. p. 565 . Corolla yellowish-green.

Far. $\beta$; corolla $5-7$ lines long, having the segments contiguous at the base. $h_{\text {. }}$ G. Erica spicàta, Andr, heath, 1. t. 11. Locld. bot. cab. 1203. Flowers greenish-yellow.

Spike-flowercd Syringodea. Fl. Year. Clt. 1789. Shrub. 105 S. Fascicula'ris; leaves 8 in a whorl, narrow-linear, obtuse, glandularly ciliated, spreading, a little recurved; bracteas remote from the calyx; flowers crowded, axillary, verticillate, near the tops of the branches, horizontal; corolla 13 lines $5 \mathrm{~N}$ 
long, viscid, with a cylindrical clavate tube and an erect limb; pedicels and bracteas glandular; style a little exserted; awns of

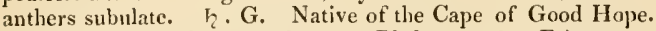
Erìca fasciculàris, Lin. suppl. 219. PI. kew. t. 6. Erìca coronàta, Andr. 1. t. 12. Bedf. eric. wob. pl. 11. f. 17. Erica octophýlla, Thunb. diss, no. 72. with a figure, Willd. spec. 2. p. 372. Erìca radiiflòra, Sal, in Lin. trans. 6. p. 360 . Corollas reddish-purple, with a green apex.

Fascicled-flowered Syringodea. Fl. Feb. June. Clt. 1787. Shrub.

106 S. sceptrifóruis; leaves 8 in a whorl; stem straight; pedicels very short, axillary, crowded; calyx callous, with broad, spatulate, deeply serrated segments; corolla 7-10 lines long, downy. 々. G. Native of the Cape of Good Hope. Erica sceptrifórmis, Sal, in Lin. trans. 6. p. 365. Erica enneaphýlla, Roxb. mss.

Sceptre-formcd flowered Syringodea. Fl. Aug. Sept. Clt. 1790. Shrub.

107 S.? Dolıfórms; leaves hairy, linear, 6 in a whorl; bracteas close to the calyx; flowers terminal; corolla 4-5 lines long, viscid, with an urceolar tube; awns of anthers short, cuneated. h. G. Native of the Cape of Good Hope. Erica doliifórnis, Sal. in Lin. trans. 6. p. 368. Erìca mammòsa, Thunb. diss. no. 69 . with a figure.

Tun-formed-flowered Syringodea. Fl. May, Sept. Clt. 1798. Shrub.

\section{$\uparrow$ Species hardly knomn.}

108 S. mirsu'ta ; leaves 4 in a whorl, hairy, hoary, linear; flowers axillary, crowded, verticillate; anthers awned?. $?$. G. Native of the Cape of Good Hope. Erica hirsùta, Lodd. bot. cab. 754. Corolla with a red base and white apex.

Hairy Syringodea. Fl, March, April. Clt. 1800. Shrub.

109 S. $\mathrm{RU}^{\prime} \mathrm{BIDA}$; leaves linear, 4 in a whorl, glabrous; flowers terminal and axillary ; loracteas distant from the calyx; corolla tubular, drooping; anthers?. h. G. Native of the Cape of Good Hope. Erica rúbida, Lodd. bot. cab. 1166. Pediccls and calyxes red. Corollas white.

Rcddish-calyxed Syringodea. Fl. May, June. Clt. 1826. Shrub.

110 S. Expósira; leaves 4 in a whorl, hairy ; calyx, bracteas, and pedicels, clothed with glandular hairs; flowers terminal, by threes or fours; corolla cylindrical. h. G. Native of the Cape of Good Hope. Erìca expósita, Lodd. bot. cab. 1521. Flowers red.

Exposed Syringodea. FI. May, Aug. Clt. 1812. Shrub.

111 S. ELONGA'rA; leaves hoary, linear, 4 in a whorl ; flowers terminal; corolla hairy at top. $h$. G. Native of the Cape of Good Hope. Erica elongàta, Lodd. bot. cab. 738. Flowers white. Elongatcd Syringodea, Fl. Feb. Nov, Clt. 1810. Shrub.

$112 \mathrm{~S}$. RollinsònII ; leaves 4 in a whorl?; flowers nearly terminal, verticillate; corolla with a straight cylindrical tube. 々. G. Native of the Cape of Good Hope. Erica Rollinsònii, Hortul. Bedf, eric, wob. p. 21. Flowers purplish-red. Rollinson's Syringodea. Fl. June, July. Clt. 1820. Shrub. Cult. See Erica, p. 800, for culture and propagation.

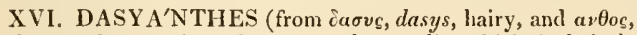
anthos, a flower; in reference to the corolla, which is hairy). D. Don, in edinb. phil. journ. 17. p. 156.-Erica species of Lin.

LIN. syst. Octándria, Monogýnia. Calyx 4-parted, bibracteate at the base. Corolla tubular, hispid, with an erect 4-lobed limb. Stamens inclosed; filaments capillary; anthers bipartite; cells of anthers mutic at the base, dehiscing longitudinally. Stigma large, peltate. Capsule 4-celled, many-secded.-An erect slurub, native of the Cape of Good Hope. Leares loosely imbricate, hispid from bristles, with revolute margins. Flowers terminal, fascicled, yellow.

1 D. Sparma'nNi (D, Don, 1. c.). h. G. Native of the Cape of Good Hope. Erìca Sparmánui, Lin. suppl. 219. in act. holm. 1778. p. 24. t. 2. Thunb. diss. no. 33. Erìca áspera, Andr. heath. vol. 3. t, 55. Erica hystriciflora, Sal. in Lin. trans. 6. p. 36\%. Erìca hórrida, Hortul. Leaves 4 in a whorl. Flowers drooping, by threes.

Sparmann's Dasyanthes. Fl. Sept. Feb. Clt. 1794. Shrub, $1 \mathrm{ft}$. Cult. For culture and propagation see Erica, p. 800.

XVII. ECT'A'SIS (from extares, ectasis, extension; from the stamens being much exserted). D. Don, in edinb. phil. journ. 17. p. 156. Erica species of authors.

Lin. syst. Octándria, Monogýnia. Calyx 4-leaved, gjumaceous. Corolla tubular, rather ventricose at the base, with a 4toothed limb. Stamens much exserted; filaments dilated; anthers bipartite; cells of anthers elongated, tubular, dehiscing by a longitudinal fissure, continuous, with the base of the filaments mutic. Stigma clavate, truncate. Capsule 4-celled, manyseeded. Seeds ovate, compressed, smooth, shining.-Muchbranched shrubs, natives of the Cape of Good Hope. Leaves loosely imbricated, with revolute edges, flat above, 3 or 4 in a whorl, but mostly the latter number. Flowers terminal, solitary or numerous.

\section{$\$ 1$. Flowers lateral. Calyx bractless. Normal species.}

1 E. PErIve'ril (D. Don, l. c.) leaves spreadingly recurved, ciliated; flowers solitary; corollas cylindrical; fruit ovate. $h_{c}$. G. Native of the Cape of Good Hope. Erica Petivèrii, Lin. mant. 232. diss. no. 50. Lodd. bot. cab. 1426. Erìca Petíveriàna, Spreng. syst. 2. p. 361 . Erica baculiflòra, Sal. in Lin. trans. 6. p. 346 . Corollas yellow.

Var. $\beta$; corollas of a dirty rufous colour. $\eta$. G. Erìca Petivèri, Thunb. diss. 21.

Var. $\gamma$, hirsùta (Andr. heath. 2. t. 72.) leaves hairy; corollas deep red.

Petiver's Ectasis. Fl. March, July. Clt. 1774. Shrub.

2 E. Plukne'tii (D. Don, l. c.) bracteas cuneated, remote from the calyx; corolla ovvate, pyramidal or conical, smooth. h.G. Native of the Cape of Good Hope. Erica Pluknètii, Lin. spec. ed. 1. p. 356 . Eıica fusiförmis, Sal. in Lin. trans. 6. p. 345 . Corolla scarlet, 6-7 lines long, leaves linear, spreading.

Var. $\beta$; calyx $2 \frac{1}{2}$ to 3 lines long; corolla purple, with orangecoloured anthers, 6-7 lines long. 々. G. Erìca Pluknetiàna, Pl. kew. t. 9. Erìca Plıknètii. Lin, spec. ed. 2. p. 506. exclusive of the synonymes. Erìca Pluknètii nàna, Andr. heath. 1. t. 67. Erica Pluknètii pínea, Wendl. eric. 1.p. 9. with a figure.

Var. $\gamma$; calyx 1 line long; corolla white, 3 to $3 \frac{1}{2}$ lines long. ๖. G. Erica Petivèrii $\beta$, Thunb. diss. no. 21.

$V$ ar. $\delta$; caly $\times 2 \frac{1}{2}$ lines long ; corolla white, 3 to $3 \frac{1}{2}$ lines long. Sal, in Lin. trans. 6. p. 346 .

I ar. $\varepsilon$; calyx 5 lines long; corolla white, $5-8$ lines long. h. G. Sal. l. c. This is said to be the most showy variety.

Var. $\zeta$, penicellata (Ait. hort. kew. 2. p. 361.) corolla reddish purple, with orange-red anthers. $\zeta$. G. Erìca penicellàta, Andr. heath. 2. t. 69. Lodd. bot. cab. 1918. Erica Pluknètia interrupta, Wendl. eric. 2. p. 21. with a figure.

Pluknet's Ectasis. Fl. April, Mlay. Clt. 1774. Shrub.

3 E. BRUNiA'Des; leaves 3 in a whorl, linear-oblong, erect, short, villously tomentose; flowers terminal, subumbellate, drooping; bracteas remote from the calyx, 4-leaved; corolla campanulate, much longer than the calyx, wlich is very villous and silky; nectarium astraguliform, silky. $\zeta$. G. Native of the Cape of Good Hope. Erica bruniàdes, Lin. mant. p. 378. diss, no. 52. with a figure of the flower. Wendl. eric. 16. p. 59. with a figure. Lodd. bot. cab. 1365. Erica carbasina, Sal. in 
Lin. trans. 6. p. 333. Corolla $1 \frac{1}{2}$ line long, white or pale red, also yellow.

Brunia-like Ectasis. F]. April, July. Clt. 1790. Shrub $1 \frac{1}{2} \mathrm{ft}$.

4 E. valterafiora; leaves 3 in a whorl, linear, downy or hairy, spreading, rather remote; flowers terminal, by threes; bracteas remote, quadrifid; corollas globose, urceolar, a little longer than the calyx, which is large, and densely clothed with silky hairs; nectarium cotyliform, glabrous. h. G. Native of the Cape of Good Hope. Erica valleræflòra, Sal, in Lin. trans. 6. p. 33s. Ait. hort. kew. 2. p. 365. ErJea bruniàdes, Andr. heath. 1. t. 37. Erìca villosa, Pluk. mant. 69. t. 347. f. 9. Wendl. eric. fasc. 16. p. 65. with a figure. Érica capitàta, Thunb. eric. no. 15. Calyx and corolla pale red. Anthers black. Corolla $1 \frac{1}{2}$ line long.

Hoolly-flonered Ectasis. Fl. Feb. July. Clt. 1774. Shrub $1 \frac{1}{2} \mathrm{ft}$.

\$2. Flowers terminal. Caly. imbricated by numerous scales at the base. Aberrant species.

5 E. Banksta'sa (D. Don, I. c.) leaves mucronate; corolla cylindrical, with a reflexed limb; pericarp bearded. $h . \mathrm{G}$. Native of the Cape of Good Hope. Erica Bánksia, Andr. heath. 1. t. 66. Erìca Bánksii, Ait, hort. kew, 2. p. 361. Erica frágilis, Sal. in Lin. trans. 6. p. 346. Corolla greenish-yellow, with brown anthers.

Var. $\beta$, álba; flowers white.

Sir Joseph Banks's Ectasis. Fl. Feb. July. Clt. 1787. Shrub.

6 E. vestifLu'A; leaves incurvedly spreading, pilose while young ; flowers solitary, terminal; corolla with a cylindrical tube, 7-9 lines long. 5 . G. Erìca vestiflùa, Sal. in Lin. trans. 6 . p. 346. Erica Petiviriàna, Roxb. mss. Corolla rufous.

Flowing-vested Ectasis. Fl. March, June. Clt. 1795. Sl.

7 E. SEBA'NA (D. Don, 1. e.) leaves recurvedly spreading; tube of corolla cylindrical, incurved, ventricose at the base ; pericarp oval; calyx and bracteas glabrous. $々$. G. Native of the Cape of Good Hope. Erìca Sebàna, Pl. kew. t. I0. Erìca coccinea, Lin. spec. ed. 2. p. 505. Erìca cothurnàlis, Sal. in Lin. trans. 6. p. 347 . Erìca Sebàna aurántia, Andr. heath. vol. 1. Erìca Africàna, Sc. Seb. thes. 1. p. 32. t. 21. f. 4. Flowers by threes. Corolla pale brown.

I'ar. $\beta$; bracteas and calyx downy. $h$. G. Erica Pluknètii, Berg. pl, cap. p. 92. Corollas pale brown.

I ar. $\gamma$, rúbra; flowers reddish-orange at top, and reddishpurple at the base; anthers orange-yellow.

I'ar. $\delta$, atrorùbens; flowers reddislı-purple. 々. G.

Seba's Ectasis. Fl. April, Nov. Clt. 1774. Shrub.

8 E. socciflòra; leaves recurvedly spreading; corolla conical ; flowers by threes; fruit ovate. $h$. G. Native of the Cape of Good Hope. Erica socciflora, Sal. in Lin. trans. 6. p. 347. Bedf. eric. wob. pl. 4. f. 8 . Erica Sebàna víridis, Andr. heath. 1. icon. Corolla greenish-yellow; anthers orange-yellow.

Pump-flonered Ectasis. Fl. A pril, May. Clt. 1799. Sh.

9 E. Furfuròsa; leaves incurvedly spreading, lowny; flowers by threes; corolla viscid, cylindrical ; filaments very broad; nectarium cotyliform. $\quad$. G. Native of the Cape of Good Hope. Erica furfuròsa, Sal, in Lin, trans. 6. p. 348 . Erìca monadélpha, Andr. heath. 1. t. 65. Sims, bot. mag. 1370. Corolla white, with a red border, and orange-yellow anthers.

Scurfy Ectasis. Fl. Aug. Dec. Clt. 1789. Shrub.

10 E. MONADE'LPIA ; corolla with a cylindrical tube, and reflexed segments; flaments very broad. $\zeta$. G. Native of the Cape of Good Hope. Erìca monadélpha, Bedf. eric. wob. p. 15. pl. 2. f. 12. Erìca Bánksia purpùrea, Andr. heath. 3. t. 37. Corolla greenish-white or yellow, with a purple border, and yellow anthers.-Perhaps the same as the preceding.

Monadelphous Ectasis. Fl. Aug. Oct. Clt. 1800. Shrub.

11 E. FolLICULA'RIs ; leaves spreading; flowers solitary, spike-like; corollas conical. $h_{c}$. G. Native of the Cape of
Good Hope. Erica folliculàris, Sal. in Lin. trans. 6. p. 348. Lrica Petiveriàna, Andr. heath. 2. t. 71. Wendl, eric. 14. p. 23. Corolla yellow-green or orange-red, 5-7 lines long, with brown anthers. Nectarium quadrangular.

Follicular Ectasis. Fl. leb. July. Clt. 1794. Shrub.

12 E. мetastòm ; leaves 4 in a whorl, stiff, secund; flowers terminal, solitary; corolla cone-shaped. h. G. Native of the Cape of Good Hope. Erìca melastòma, $A$ ndr. heath. 1. icons. Wendl. cric. 14. p. 23. with a figure. Lodd. bot. cab. 333. Erìca folliculàris $\beta$, Sal. in Lin. trans. 6. p. 348 . Corolla with a greenisli-yellow tube, a dark brown mouth, and orange anthers.

Bluck-mouthed Ectasis. FI. May, July. Clt. 1795. Shrub.

18 E. Pícra; leaves 4 in a whorl; corolla cylindrical, incurved. h. G. Native of the Cape of Good Hope. Erica pícta, Nois. mss. Bedf, hort. eric. wob. p. 19. Corolla with an orange-yellow tube, and orange anthers.

Painted Ectasis. Fl. Oct. July. Clt. 1820. Shrub.

14 E. PENicilliftòra; leaves ciliated, erect; flowers by threes; corolla 2 lines long, covered by the calyx, with a spherical tube; anthers converging into a pencil-form. tive of the Cape of Good Hope. Erica penicillifiòn, Sal. in Lin. trans. 6. p. 348 . Erìca Petivèrii vèra, Hortul. Erica calyculàta, Wendl. eric. 4. p. 5. with a figure. Bracteas and calyxes white. An elegant species.

Pencil-flowered Ectasis. Fl. May, Aur. Clt. 179\%. Shrub.

15 E. Placenteflòra; leaves very obtuse ; corolla covered by the calyx, with a turnip-formed tube; filaments gradually dilated; stigma narrow. $h$. G. Native of the Cape of Good Hope. Erìca placentæflòra, Sal, in Lin. trans. 6. p. 348. Herb pale, hoary.

Placenta-flowered Ectasis. Slurub.

16 E. PUDIBU'NDA; leaves $3-4$ in a whorl, rather viscid; flowers terminal, by threes; calyxes ciliated; corolla conical, viscid. h. G. Native of the Cape of Good Hope. Erìca pudibúnda, Sal. in Lin. trans. 6. p. 345 . Erica nùtans, Wendl. eric. fasc. 3 . p. 5. with a figure. Corolla 2 lines long; anthers broad, hairy. Fruit turbinate, hairy. Flowers pale red.?

Blush Ectasis. Fl. June, Sept. Clt. 1810 . Shrub.

17 E. Filifórmis; leaves 3 in a whorl, remote, narrow, recurved, clothed with viscid pubescence; calyx bracteate; corolla 1 line long, glabrous, with a recurved tube; filaments broad at the top; stigma narrow; fruit smooth. h. G. Native of the Cape of Good Hope. Erica filiformis, Sal. in Lin. trans. 6. p. 345.

Filiform Ectasis. Shrub.

18 E. STELla'ris; hoary; leaves $4-5$ in a whorl, linear, spreading, a little incurved, ciliated; flowers almost sessile, terminal, capitate; bracteas near the calyx; calycine segments linear, ciliated. h. G. Native of the Cape of Good Hope. Erica stellàris, Nois. Lodd. bot. cab. 893 . Erìca stellàta, Bedf. eric. wob. p. 24. Flowers white tinged with red. Stamens brown. Corolla urceolate.

\section{Starry Ectasis. Fl. April, June. Clt. 1810. Shrub.}

19 E. DEsíssa; leaves linear, 3 in a whorl; flowers terminal; bracteas imbricate; corolla cone-shaped. h. G. Native of the Cape of Good Hope. Erica demissa, Hort. Bedf. eric. wob. p. 8. Flowers greenish-yellow.

Low Ectasis. Fl. Spring. Clt. 1818. Shrub.

20 E.? TU'RgIDA; leaves 3 in a whorl; flowers terminal; pedicels very short; corolla hairy, $1 \frac{1}{2}$ line long, with a bulged tube; spurs of anthers cuneated; anthers very short. $5 . G$. Native of the Cape of Good Hope. Erìca túrgida, Sal. in Lin. trans. 6. p. 343. Erica fúsco-rùbens, Roxb. mss. Flowers brownisli-red.

Turgid-flowered Ectasis. Shrub.

Cull. For culture and propagation see Erica, p. 800 . 
XVIII. ERIODE'SMIA (from $\varepsilon \rho \iota \nu^{\prime}$, erion, wool, and $\delta \varepsilon \sigma \mu \eta$, desme, a fascicle; the flowers resemble a fascicle of wool). D. Don, in edinb. phil. journ. 17. p. 158. Erìca capitàta, Lin. Sc.

Lin. sist. Octándria Monogy'nia. Calyx large, 4-parted, bibracteate at the base. Corolla campanulate; limb 4-lobed, revolute. Stamens exserted; filaments dilated, flat; anthers bifid, obtuse, scabrous from papillæ; cells of anthers dehiscing by an oblong pore, having the lase continuous with the filaments. Stigma capitate. Capsule 4-celled, many-seeded. Seeds angular, shining. $-\Lambda \mathrm{n}$ erect branched shrub. Leaves 3 in a whorl, obtuse, very hairy. Flowers terminal, solitary or by threes, forming a very hairy head.

1 F. capita'ta (D. Uon, l. c.). 々. G. Native of the Cape of Good Hope. Erica capitàta, Lin. diss. no. 36. mant. 373. Berg. pl. cap. 94. Andr. heath. 1. t. 38. Wendl. eric. no.3. p. 3. with a figure.-Seb. thes. 1. p. 30. t. 20. f. 1. Erìca by'ssina, Sal in Lin. trans. 6. p. 383. Calyx very hairy, greenislı-yellow. Bracteas imbricate. Corolla white, and very little longer than the calyx.

Capitate-flowered Eriodesmia. Fl. July, Aug. Clt. 1774. Shrub.

Cull. For culture and propagation see Erìca, p. 800.

XIX. OCTOPE'RA (from okt a sack; in reference to the 8 -celled capsule). D. Don, in edinb. phil. journ. 17. p. 156.-Erica Bergiàna, Lin.

Lin. syst. Octándria, Monogýnia. Calyx 4-parted, reflexed, naked at the base. Corolla globose, with a contracted bluntly 4-lobed mouth. Stamens inclosed; filaments flat; cells of anthers very short, dehiscing by a large foramen, furnished with a lanceolate acuminated crested appendage at the base. Stigma peltate. Capsule S-celled, many-sceded. $-\boldsymbol{A}$ procumhent downy shrub, native of the Cape of Good Hope. Leaves broad, 4 in a whorl. Flowers terminal, umbellate; pedicels scaly.

1 O. Bergla'na (D. Don, l. c.). 々. G. Native of the Cape of Good Hope. Erìca Bergiàna, Lin. mant. p. 235. diss. no. 6. Schnev. pl, no. 46. with a figure. Erica quadrithora, Willd. spec. 2. p. 379. Andr. heath. 2. t. 20. Erica lacunacflòra, Sal. in Lin. trans. 6. p. 377. Erìca nítens, Lee. Flowers purplishred.

Bergins's Octopera. Fl. April, Aug. Clt. 1787. Slurub procumbent.

Cult. For culture and propagation see Erica, p. 800.

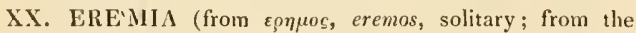
seeds being solitary in the cells). D. Don, in edinb. phil, journ. 17. p. 156.-Erìca Tótta, Thunb.

Lin. syst. Octándria, Monogýnia. Calyx 4-parted, imbricated by bracteas at the base ; segments broadly orbicular, ciliated, coriaceons. Corolla urceolar, with a small 4-lobed limb. Stamens inclosed; filaments capillary; anthers bipartite; cells of anthers short, mutic at the base, opening by an oblong hole. Sigma capitate. Capsule 4-celled; cells 1-seeded. Seeds large, elliptic, ventricose.-A diffusely branched shrub, native of the Cape of Good Hope. Leaves spreading, hispid from bristles. Flowers glomerate.

1 E. Tótta (D. Don, 1. c.). h. G. Native of the Cape of Good Hope. Erica Tótta, Thunb. diss. no. 17. Erica férox, Sal. in Lin. trans. 6. p. 324.

Hottentot Eremia. Fl. June, July. Clt. 1810. Slırub.

Cult. For culture and propagation see Erica, p. 800.

XX1. SALAXIS (from salax, unchaste; but the application is not evident). Sal. MSS. spec. 2.

LıN. syst. Octándria, Monogýnia. Calyx irregular, 4-leaved. Corolla campanulate, 4 -cleft. Stigma peltate. Capsule drupaceous, 3-celled, 3-seeded.-Shrubs, native of the Mauritius.
Leaves from 3 to 6 in a whorl, with revolute margins. Flowers somewhat racemose at the tops of the branches.

1 S. Arboréscexs (Willd. ex. Spreng, syst. 2. p. 20.) leaves 3 in a whorl, nearly terete, adpressed; pedicels downy. h. G. Native of the Mauritius.

Arborescent Salaxis. Shrub.

2 S. monta'na (Willd. 1. c.) leaves 3 in a whorl, adpressed, tetragonal; pedicels glabrous. $\zeta$. G. Native of the Mauritius.

Mountain Salaxis. Slırub.

$s$ S. AX1LLA'RIs (Salisb.) leaves 3 in a whorl, glabrous; flowers racemose ; corollas globose; branches tomentose. $h \mathrm{G}$. Native of the Cape of Good Hope. Erica axilàris, Th. diss, no. 10 .

Axillary flowery Salaxis. Shrub.

4 S. abietina (Willd. l. c.) leaves generally 3 in a whorl, linear, spreading. $々$. G. Native of the Mauritits.

Fir-like Salaxis. Shrub.

Cult. Turfy peat mixed with rough sand is the best soil for the species of Salaxis; and young cuttings of them strike root readily in samd, under a bell-glass, in a little heat.

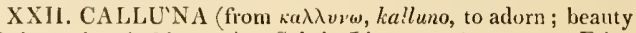
of plant when in blossom). Sal. in Lin.trans. 6. p. 317 . Erica vulgàris, Lin, and others.

LiN. syst. Octándria, Monogýnia. Calyx 4-parted, membranous, coloured, furnished with 4 bracteas at the base. Corolla campanulate, 4-lobed, shorter than the calyx. Stamens inclosed; filaments dilated; anthers bipartite, biappendiculate at the base; cells of anthers mucronulate, deliscing lengthwise. Stigma capitate. Capsule with a septicidal dehiscence. Seeds ovoid, smootl. - A small spreading shrub, native of Europe. Leaves trigonal, obtuse, very short, imbricating in 4. rows, having the margins revolute, and the base sagittate. Flowers disposed in long terminal spicate racemes.

1 C. vulga'rs (Sal. in Lin. trans. 6. p. 317.). 々. H. Native throughout Europe; plentiful in Britain. Eıica vulgàris, Lin. spec. 1. 501. Smith's engl. bot. 1013.

lar. a, purpuirca; flowers purplish-red.

I ar. $\beta$, spùria; flowers purplish-red; spikes short; branches tufted.

Iar. $\gamma$, dccumbens; flowers purplish-red; spikes short ; branches decumbent.

Íar. $\delta$, tomcntosa; Howers purplish-red; leaves and branches woolly.

I ar. $\varepsilon$, álba; flowers white, less crowded ; corolla shorter.

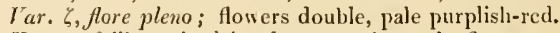

rar. $\mu$, folits variegàtis; leaves variegated; flowers purplish.

I ar. $\theta$, aùrea; leaves variegated with yellow.

lrar. $\iota$, coccínea; flowers deep red.

I ar. k, spicàta; spikes long; flowers red, or white.

Common Heath or Ling Heather. Fl. July, Sept. Britain. Slirub $\frac{1}{2}$ to 3 feet.

Cult. The varieties of Callìna vulgàris are very ornamental when planted in a border or clump, along with the dwarf hardy species of Erica and their varieties, as Erica ciliàris, $E$. létralix, E. cinèrca, and Gypsocállis multiflòra, G. vàgans, Sc. The border in which they are grown requires to be composed of peat soil. All are increased by layers, or young cuttings under a bell-glass.

\section{Subtribe II.}

ANDROME'DEE, (this Subtribe contains plants agreeing with Andrómeda in the Corolla being dead.) D. Don, in Edinb. phil. journ. 17, p. $15 \%$. Corolla deciduous.

XXIII. ANDRO'MEDA (named from the daughter of $\mathrm{Ce}$ pheus, rescued from the sea-monster by Perseus). D. Don, in 
phil. journ. 17, p. 157. Andrómeda, species of Authors. Polifölia, Buxbaum, cent. 5. p. 5. t. 55. f. 1 .

Lix. syst. Decándria, Monogýnia. Calyx 5-cleft; segments acute, simple at the base. Corolla globose, with a contracted 5-toothed moutl. Stamens 10, inclosed; lilaments bearded; cells of anthers short, furnished with one awn each. Stigma truncate. Capsule with a loculicidal dehiscence; ptacenta 5 lobed: lobes simple. Seeds elliptic, compressed, slining, with a lateral linear hylum.-Shrubs, natives of Europe, $\Lambda$ sia, and North America, Leaves linear-lanceolate, mucronulate, with the margins more or less revolute, quite entire, glaucous beneath, with an elevated rib, and reticulated veins; petioles very short, callous. Flowers terminal, umbellate, very beautiful, reddish, or snow white, furnished with ovate, rather foliaceous, imbricated bracteas, clrooping.

1 A. Polifòcia (Lin. sjec. 564.) leaves oblong, glancous beneatl ; corollas ovate; calycine segments ovate, spreading, white, sometimes tipped with red. h. H. Native of the northern countries of Europe, on turfy bogs; as of Russia, Sweden, Denmark, Switzerland, Germany, Britain, Sc. ; North Anerica, in Canada and Labrador, Bay of St. Lawrence, Sc., in bogs, and on the borders of mountain lakes; New York, and Pennsylvania. In Britain, in mossy bogs in the mountainous parts of England and Ireland, and the low lands of Scotland. Lin. fl. lapp. 161. t. 1. f. 3. Oed. fl. dan. t. 54. Smith, engl, bot. t. 713. Buxb, cent. 5. t. 55. f. 1. Pall. fl. ross. 1. t. 1. Pluk. alm. 175. f. 1. Rhododéndron polifòlium, Scop. carn. no. 48\%. Flowers flesh-coloured or pale red. The plant is called Wild Rosemary, Poley-Mountain, Moornort, and Marsh Holy Rose.

Iar. a, latifolia (Ait, hort. kew. 2. p. 68.). h. H. Native of North America. Broad leaved Marsh Andromeda, or Wild Rosemary, I. Her. stirp. nov, 2. t. 11.

lar. $\beta$, mèdia; leaves lanceolate; corollas oblong-ovate, red; segnents of the calys more erect. $\zeta$. H. Native of Europe.

I ar. $\gamma$, subuiàta; leaves subulate; corollas pink. 々. H. Native of Britain. Subulate-leaved Wild liosenary.

I ar. $\hat{e}$, mínima; leaves linear; corollas pink. h. H. Native of Europe. Least Wild Rosemary.

I ar. $\varepsilon$, olcifolia; leaves shaped like those of the olive; corollas pink. Olive-leaved IVild Rosemary.

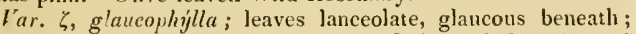
flowers terminal, drooping. $h$. H. Native of Canada and Labrador. An. polifôlia, $\beta$. latifòlia, Lodd. bot. cab. 546. Andr. glancophýlla, Link. Flowers pale red.

Poliun-leared Marsh Andromeda, or Wild Rosemary. F1. May, Sept. Britain. Shrub 1 foot.

2 A. rosmarinifoldi (Pursh. f. amer. sept. 1. p. 291.) leaves linear-lanceolate, convex, revolute, white beneath, and canescent above; corollas nearly globose; calycine segments oblong, red. h. H. Native of Newfoundland and Labrador. A. polifolia, Michx. fi. bor. aner. 2. 1. 254. Pall. f. ross. 2. p. 53. t. 70. f. B. Flowers white, tinged with red.

Rosemary-leaved Marsh Andromeda. F]. June. Clt.? Shrub 1 foot.

Cult. Peat is the best soil for the species and varieties of Andrómeda. They are easily increased by dividing at the root, or by layers.

XXIV. CASSIOPE (the wife of Cepheus, see Andrómeda). D. Don, in edinb. phil. journ. 17. p. 157. Andrómeda species of Lin. and Pall.

Lix, syst. Decándria, Monogýnia. Calyx 5-leaved; leaves imbricated at the base. Corolla campanulate,(f. 136 b.), 5-cleft, (f. 136 a.) Stamens 10, inclosed; filaments glabrous; cells of anthers short, tumid, furnished with one awn each, (f. $136 \mathrm{~g}$.) Style dilated at the base, (f. 136, d.); stigma obtuse. Capsule with a loculicidal dehiscence; valves bifid at the apex. Placenta 5-lobed: lobes simple. Seeds oblong, compressed, slining.Small heath-like shrubs, natives of $A$ sia and North America. Leaves small, imbricated. Flowers solitary, pedunculate, rosecoloured, lateral or terminal.

\section{* Leaves flat.}

1 C. hyproides (D. Don. l. c.) leaves loose, acerose. h. H. Native of Lapland, Denmark, and Siberia, on the mountains, where it covers tracts of land; and on the northwest coast of America. Andrónela hypnoides, Lin. spec. 563. H. lapp? 165. t. 1. f. 3 . Oed. fl, dan. t. 10. Pall, fl. ross. p. 55. t. 73. f. 2. Hook. bot. mag. t. 2936.-A small creeping shrub, resembling a moss. Flowers small, witl a red calyx, and white corolla.

Hypnum-like Cassiope. FJ. June, July. Clt. 1798. Shrub creeping.

2 C. Lycopodtoìnes (D. Don, l. c.) leaves ovate, adpressed, imbricated in 4 rows. F. H. Native of Siberia and the Island of St. Lawrence. Andróneda lycopodiojdes, Pall. fl. ross. p. 55. t. 73. f. 1. Flowers red. A small moss-like creeping shrub.

Club-moss-like Cassiope. Shrub creeping.

* Lcaves imbricated in 4 rows, adpressed, with revolute margins, tumid, somenhat bilocular.

3 C. tetragòna (D. Don, 1. c.) leaves obtuse, mutic, minutely ciliated; peduncles glabrous. h. H. Native of Lapland and Siberia; of North America, in Canada, Labrador, and the north-west coast; Island of St. Lawrence, Kotzebue Sound. Andrómeda tetragòna, Lin. spec. 563. f. lapp. 166. t. 1. f. 4. Pall. f. ross, p. 50. t. 73. f. 4. Hook. bot. mag. t. 3181 . Flowers white.

Tetragonal-branched Cassiope. Fl. March, April. Clt. 1810. Shrub $\frac{1}{2}$ foot.

4. C. Mertensia'na; leaves bluntish, glabrous; pedicels axillary, downy. ?. H. Native of the Island of Sitcha. Andrómeda Mertensiana, Bongard, in mem. acad. petersb. 2. p. 152. t. 5. Hahit of C. tetragona.

Mertens's Cassandra. Shrub $\frac{1}{2}$ foot.

5 C. Enicoìns (D. Don, l. c.) Jeaves awned, setosely ciliated; peduncles glahrous. $\zeta$. H. Native of Dahuria and Kamtscliatka. Andrómeda ericoides, Pall. f. ross. p. 56. t. 73. f. 3. Flower.?

Heath-like Cassiope. Shrub $\frac{1}{2}$ foot.

6 C. pastigia'ta (D. Don, l. c.) leaves elongated at top, with searious membranous margins; peduncles woolly. $h^{2}, \mathbf{H}$. Native of Nepaul and Mongol. Andrómeda fastigiàta, Wall. pl. rar. asiat. 3. t. 284. Andrómeda cupressifórmis, Wall. mss, ex D. Don, in mem. wern. soc. 3. p. 4.11. prod. f. nep. 1. 150. Flowers pale red.

Fastigiate Cassiope. Shrub procumbent.

7 C. REDo'wsKu; leaves scale-formed, shining, smooth, fringel, imbricating in 4 rows, making the branches appear exactly tetragonal; pedicels axillary, glabrous. $r_{c}$. H. Native of the east of Siberia. Androneda Redówskii, Cham. et 
Schlecht. in Linnas. 1. p. 517. Shrub procumbent, much branched. Flowers drooping. Calyx deeply 4-parted. Corolla campanulate, quadrifid, with very blunt segments. Stamens 8 , very short; anthers 2-celled, biaristate, the cells opening by a pore at the apex. Capsule 4-valved; valves septiferous at the middle.

\section{Redowsli's Cassiope. Shrub procumbent.}

Cull. All the species are delicate little shrubs: they grow well in a peat border, or in pots well drained with sherds in the same kind of soil ; and may be increased by layers.

XXV. CASSA'NDRA (a mythological name of the daughter of Priamus and Hecuba). D. Don, in edinb. phil, journ, July, 1834. Andrómeda species, Lin. and others.

Lix. syst. Decándria, Monogýnia. Calyx 5-leaved, bibracteate at the base; leaflets imbricated at the base. Corolla oblong, with a contracted 5 -toothed mouth. Stamens 10 , inclosed; filaments glabrous, simple at the base ; cells of anthers elongated, and tubular at the apex, mutic. Stigma annular, with a 5tubercled disk. Capsule with a locnlicidal dehiseence. Placenta 5-lobed: lobes simple.-An evergreen shrub, eommon in North America, north of Europe, and the north of Asia. Branchlets recurved, pubescent. Leaves on sliort petioles, elliptic-oblong, denticulated, coriaceous, veinless, lepidotted on both surfaces by peltate scales, when young silvery beneath. Flowers axillary, on short pedicels, drooping, snow white, disposed in the manner of racemes at the tops of the branches.

1 C. calycula'ta (D. Don, l. c.) leaves elliptic-oblong, bluntish, obsoletely serrulated, rusty beneath; racemes recurved, leafy; bracteas of calyx broad, ovate, acuminated; corollas oblong-cylindrical. $h$. H. Native of North America, from Canada to Virginia, in bogs and swamps, on the mountains. It grows also in Sweden, Prussia, Siberia, \&c. Andrómeda calyculàta, Lin. spec. 565. Pall. fl. ross. 2. p. 53. t. 71. f. 1. Lodd. bot. cab. 1464.

Var. a, ventricòsa (Sims, bot. mag. 1286.).

lar. $\beta$, latifólia (Lodd. bot. cab. 530.).

I ar. $\gamma$, nàna (Sims, bot. mag. 862. Lodd. bot. cab. 826.)

Calyculated-flowered Cassandra. Fl. April, May. Clt. 1748. Shrub 1 to 3 feet.

2 C. Angustifòlia; leaves linear-lanceolate, acute, with subundulated revolnte edges, rusty beneath; racemes recurved, leafy; bracteas of calyx minute; corollas oblong-ovate. $h$. H. Native of Carolina and Georgia, in open swamps. Andrómeda ealyeulàta, $\beta$, angustifolia, Ait. hort. kew. 2. p. 70 . Andrómeda angustifölia, Pursh. fl. amer, septr, 1. p. 291. Andrómeda críspa, Desf. and Link.

Narrow-lcaved Cassandra. Fl. April, May. Clt. 1748. Shrub 1 to 2 feet.

Cult. For culture and propagation, see Lyònia, p. 813.

XXVI. ZENOBIA (a queen of Palmyrensi). D. Don, in edin. phil. journ. july, 1834 . Andrómeda species, Michx.

Lin. syst. Decándria, Monogýnia. Calyx 5-lobed. Corolla campanulate; limb revolute, 5-lobed. Stamens 10; filaments glabrous, dilated at the base; cells of anthers elongated, tubular, biaristate at the apes. Stigma truncate. Cajsule with a loculieidal dehiscence. Placenta 5-lobed: lobes cuneated, thick, a little arclied. Seeds angular, with a lateral oblong hylum.-Evergreen shrubs, natives of North America. Leaves scattered, dilated, with the margins usually toothed. Flowers racemose; pedicels solitary or aggregate.

1 Z. specioss (D. Don, l. e.) leaves oval, obtuse, mucronate, crenated, or serrated, veiny ; floriferous branches naked, racemose. $h_{\imath}$. H. Native of Nortl Carolina, in swamps. A very ornamental little slirub. Flowers large, white, drooping. An- drómeda speciòsa, Michx. fl. bor. amer. 256. Lodd. bot. cab. 551 .

Tar. $\alpha$, nálida (Pursh. fl. amer. sept. 1. p. 294. under Andrómeda); leaves oblong-avate, serrated, green on both surfaces. h. H. Andromeda cassinæfòlia, Vent. malm. 79. Flowers white.

I ar. $\beta$, pulcerulénta (Pursh. f. amer. sept. 1. p. 294. under Andrómeda); leaves roundish-ovate, remotely crenated, covered with white powder, as well as the branches. $h_{2}$. H. Andró. meda pulverulénta, Bartr. itin. 476. Curt. bot. mag. 667 . Andrómeda cassinæefôlia, $\beta$, Vent. bort. cels. 60 . Andrómeda speciòsa, var. $\gamma$, glaúca. Wats. dendr. brit. t. 26. Andrómeda dealbàta, J ,indl. bot. reg. 1010. Andrómeda ovàta, SGland. mss. in herb. Bankes. Flowers white.

Showy Zenobia. Fl. June. Clt. 1800, Shrub 2 to 3 feet.

Cult. See Lyònia, p. 831. for culture and propagation.

XXXVIJ. LYO'NIA (in memory of Joln Lyon, an indefatigable collector of North American plants, who fell a victim to a dangerous epidemic amidst those savage and romantic mountains, which had so often been the theatre of his labours). Nutt. gen. amer. 1. p. 268. D. Don, in edinb. phil. journ. 17. p. 158.

Lin. syst. Dccándria, Monogýnia. Calyx 5-parted. Corolla ovate or tubular, with a 5 -toothed contracted mouth. Stamens inclosed; flaments flattened, dilated, very short, downy ; cells of anthers membranous, dehiscing lengthwise, altogether mutic. Style robust, pentagonal, fusiform, thickened at bottom; stigma simple, truncate. Capsule pentagonal, 5-celled, with a loculicidal dehiscence; margins of valves closed by 5 other external narrow valves. Seeds acicular, imbricated.-Shrubs, natives of North America. Leaves usually membranous and downy. Flowers for the most part terminal, disposed in racemose panicles.

\section{* Leaves evergrecn.}

I L. ferrugínea (Nutt, gen. amer, p. 266.) shrubby; leaves on long petioles, coriaceous, obovate, usually obtuse, quite entire, with hardly revolute edges, covered with brown umbilicate furfuraceous seales, as well as every other part of the plant; pedicels axillary, collected into threes or fives ; corollas small, ovate-globose. h. H. Native of Georgia, Florida, and Mexico, in pine woods. Andrómeda ferrugínea, Walt. f. car. 138. Vent. maln. t. so. Andrómeda, ferrugínea, $\beta$, fruticòsa, Michx. $A$. amer. bor. 1. p. 252. Corollas white inside, and rusty outside.

Ferruginous Lyonia. Fl. June, July. Clt. 1784. Shrub 3 to 5 feet.

2 L. Rígid (Nutt. gen. amer. 1. p. 266.) arborescent ; leaves coriaceous, stiff, crowded, on short petioles, cuneate-lanceolate, acute, quite entire, conves, with revolute edges, clothed with brown, umbilicate furfuraceous scales, as well as every other part of the plant ; pedicels aggregate, axillary ; corollas globose. h. H. Native of Carolina and Florida, in barren sandy woods. Andrómeda ferrugínea, Willu. spec. 2. p. 609. Ait. hort. kew. 2. p. 67. Andrómeda ferrugínea, a, arboréscens, Michx. 1.p. 252. Andrómeda rírida, Pursh. fl. amer. sept. 1. p. 292. Lodd. bot. cab. 430. Corollas white inside. This species is very nearly allied to the preceding; but their habits, and particularly their flowering time, differ so materially, that they are actually distinct.

Stiff Lyonia. Fl. April, May. Cult. 17\%4. Tree 20 feet.

8 L. margina'ta (D. Don, in edinb. phil. journ. 17, p. 1J9.) quite glabrous; branchlets somewhat 3 -sided; leaves coriaceous, oval, acmuinated, quite entire, smooth, having the midrib running through the deflexed margin; pedicels axillary, aggregate; corollas cylindrical; calycine segments elongated, linear, coloured. h. H. Native of Carolina and Florida, in sandy forests. An- 
drómeda marginàta, Duham. arb. Andrómeda coriàcen, Willd. spec. 2. p. 613 . Ait. hort. kew. 2. j. 70 . Sims, bot. mag. 1095. Andr. lùcida, Lam. encycl. 1. p. 157. Andr. Mariàna, Jacq. icon. rar. 3.t. 465. A handsnme sniall shrub. Flowers pale red; the calyx long, of a dark red colour. Leaves marked with very fine punctures.

I"ar. B, rùbra (Lodd. bot. cab. 672.) flowers deep red.

Marginatcd-leaved Lyonia. Fl. June, July. Clt. 1765. Shrub 2 feet.

\section{* Leares deciduous.}

4. L. Mariana (D. Don, in edinb. phil. journ. 17, p. 159.) leaves oval, acutish at both ends, quite entire, glabrous, rather coriaceous, paler beneath; floriferous branches almost leafless; pedicels aggregate ; corolla ovate-cylindrical; calyx foliaceon; ; capsule conoid. h. H. Native from New England to Florida, in woods and dry swamps, particularly in sandy soil. Andrómeda Mariàna, Lin. spec. 564. sims, bot. mag. 1579.Plık. mant. 448. A dwarf slırub. Flowers large, white, sometimes tinged with red. This plant has a number of very striking varieties.

$\operatorname{lar} . \hat{\beta}$, leaves narrow, lanceolate. $\zeta . \mathrm{H}$.

Maryland Lyonia. Fl. May, Aug. CIt. 1736. Shrub 2 feet.

5 L. racemòsa (D. Don, l. c.) leaves oval-lanceolate, acute, serrulated, membranous, glabrous; spikes terminal, secund, elongated, simple, or branched ; bracteas linear, acute; corollas cylindrical; calyxes acute, bibracteate at the base. $h_{c} . H$. Native from Canada to Carolina, in bogs and swamps. Andrómeda racemòsa, Lin. spec. 564 . Lher, stirp. 2. t. 13 . Andr. paniculàta, Walt. carol. 138.-Gron. virg. 67. Flowers white. A middle-sized shrub, which may be reckoned one of the finest in North America, not only for the graceful appearance of its flowers, but also for the fine odour they have. The cells of the anthers are said to be biaristate at the apex; it is, therefore, probably, a species of Zenobia. There are several varieties of the plant.

Racenose - flowered Lyonia. Fl. June, July. Clt, 1736. Slirub 8 to 4 feet.

6 L. ARBòrea (D. Don, l. c.) branches terete; leares oblong, acuminated, mucronately serrated, glabrous; panicles terminal, or many spikes; corollas ovoid-cylindrical, downy. h.H. Native from Pennsylvania to Florida, in the valleys of the Alleghany Mountains. Andrómeda arbòrea, Lin. spec. 565. Sims, bot. mag. 905.-Catesb. car. 1. t. 71. A beautiful trec, from 40 to 60 feet high. Flowers whitc. The leaves have a very pleasant acid taste, from which it has been called sorrel-trce. They are frequently made use of by hunters in those mountains, to alleviate thirst. feet.

Tree Lyonia. F!. June, July. Clt. 1752. Tree 4.0 to 60

7 L. PANicula'ta (Nutt. gen, amer. 1. p. 266.) downy; leaves obovate-lanceolate, subacuminated at both ends, and almost entire; floriferous branches terminal, panicled, nearly naked; clusters of flowers pedunculate; corollas nearly globose, downy. ᄃ. H. Native from Canada to Carolina; common in all swamps and woods. Andrómeda paniculàta, Lin. spec. 564. Lher. stirp. nov. 2. t. 12 . Wats, dendr. brit. 37. Flowers small, white. There are a number of varieties of this species, differing in size, pubescence, shape of leaves, \&c. Upper surfaces of the older leaves nearly smooth.

Panicled-flowered Lyonia. Fl. June, July. Clt. 1748. Shrub $3 .+1$ feet.

8 L. Frondòsa (Nutt. gen. amer. 1. p. 267.) every part of the plant is denscly clothed with powdery villi; leaves oblong, or oblong-obovate, blunt, or acutish, clotlied with furfuraceous villi, often rusty, prominently veined: with revolute, entire, scabrous margins; panicle terminal, frondose or leafy; corollas globose, lispid or downy. h.H. Native of the lower counties of Virginia and Carolina. Andrómeda frondosa, Pursh. fl. amer. sept. 1. p. 295. Flowers white. Pursh says the anthers are awned; but Nuttall thinks this must be a mistake, or that lis plant must be different fiom that of Pursh.

Frondose Lyonia. FI. May, June. Clt. 1806. Shrub 3 feet.

9 L. Multiflòra (Wats. dend. brit. t. 128.) leaves narrowlanceolate, serrated, sprinkled with hair-like atoms; panicle terminal, composed of numerous fascicled racemes, $h . \mathrm{H}$. $\mathrm{Na}$ tive of North America. Flowers numerous, small, white. Perhaps only a variety of $L$. paniculuta.

Many-floncred Lyonia. Fl. July. Clt.? Slırub 2 feet.

10 L. Jamarce' nsis (D. Don, in edinb. phil. journ. 17, p. 159.) branches smooth; leaves broad-lanceolate, quite entire, cinereous beneath from dot-like scales, but shining above; pedicels aggregate, on long leafless branches, scaly as well as the calyxes; corollas ovate. $h$. S. Native of Jamaica, on the tops of the mountains. Andrómeda Jamaicénsis, Swartz. fl. ind. oec. 2. p. 838 . Flowers white.

\section{Jamaica Lyonia. Shrub 6 feet.}

11 L. FAscicula'ta ; leaves ovate-lanceolate, bluntish, a little crenated, coriaceous; racemes shorter than the petioles; pedicels aggregate, reflexed. $h . \mathrm{S}$. Native of the south of Jamaica, on the mountains. Andrómeda fasciculàta, Swartz, fl. ind. occ. 2. p. 836 . Flowers white.

Fasciclcd-flowered Lyonia. Tree.

12 L. caprefròlia (Wats. dendr. brit. 127.) leaves coriaceous, elliptic, short-acuminated, serrulated, sprinkled with short fleshy hairs ; corollas rather silky, globular, coarctate; racemes and corymbs mixed, lateral, leafy. $々$. H. Native of North America. Flowers white. Perhaps only a variety of L. paniculàta. feet.

Caprea-leaved Lyonia. Fl. July. Clt. 1812. Shrub 2 to 3

13 L.? RuBjasoosa ; leaves ovate, coriaceous, quite entire, obtuse, downy beneath, rusty when young; racemes lateral, erect; corollas cylindrical. $h$. S. Native of the West Indies, in the Island of St. Thomas. Andrómeda rubiginòsa, Pers. ench. 1. p. 481. Andr. pubéscens, Poir. Leaves shining above, resembling those of Sàlix càprea. Racemes very short, in fascicles.

Rusty Lyonia. Shrub.

14. L.? Rиомвого'LIs; slarubby; floriferous branches triquetrous; leaves somewhat rhomboid-oblong, cartilaginous, glabrous, rusty beneath, quite entire, callows at the apex; peduncles axillary, aggregate, elongated, filiform. h. H. Native of Florida and Carolina. Andrómeda rhomboidàlis, Dulıam. ed. nov, abr. 192.

Rhombid-leaved Lyonia. Shrub.

Cult. The species clirive best in peat soil, or a sandy loam. Being very ornamental, they are desirable shrubs in every garden. They may either be increased by layers or by seeds. The seeds should be sown in pots or pans in sandy peat soil; they should be covered slightly with earth, as they are extremely small.

XXVIII. LEUCOTHO'E (a mythological name). D. Don, in edinb. phil. journ. 17, p. 159. Andrómeda species of authors.

LıN. srst. Decándria, Monogínia. Calyx 5-leaved; leaves imbricated at the base. Corolla tubular, 5-toothed. Stamens inclosed; filaments dilated, flattened, downy; cells of anthers short, truncate, mutic. Stigma ample, capitate. Capsule with a loculicidal deliscence.-Evergreen shrubs, natives of North 


\section{XXix. Pieris. XXX. Phyllodoce.}

Amcrica. Leaves coriaceous, dentately spinulose. Flowers white, racemose, axillary, or terminal.

1 L. axilla'eis (D. Don, l. c.) leaves oblong or oval, acuminated, upper part cartilaginously and mucronately serrulated, covered by scattered glandular hairs on the under surface; young branches clothed with powdery down; racemes axillary, spicate, sessile, beset with scaly bracteas; corollas ovate-cylindrical ; filaments eiliated, very short. $々$. H. Native from Virginia to Georgia, on the mountains. Andrómeda axillàris, Solander in hort. kew. 2. p. 89. Pursl. fl. amer. sept. 1. p. 292. Leaves glabrous. Flowers in short spikes, white. Capsule depressed, globose.

Tar. B, longifolia (Pursh. A. amer. sept. 1. p. 293.) leaves linear-lanceolate, very long. Ђ.. H. Sims, bot. mag. 2357. Andrómeda Walteri, ivilld.

Axillary-flowered Leucothoe. Fl. May, June. Clt. 1765. Shrub 2 to 3 feet.

2 L. Spinulòsa ; leaves petiolate, ovate-oblong, rounded at the base, gradually narrowed to the apex, acuminated, somewhat spinulosely serrulated, glabrous, coriaceous ; racemes subspicate, axillary, sessile, secund, rather loose, with scaly bracteas; corollas short, ovate-cylindrieal. $h$. H. Native of Lower Carolina. Andrómeda spinulòsa, Pursh. fl. amer. sept. 1. p. 293. Andr. Catesbæ'i, Walt. fl. carol. p. 137. Willd. spec. 2. p. 613. Sims, bot. mag. t. 1955. Lodd. bot. cab. 1320. Flowers white. Resembles the preceding in several respects. The figure in Cat. car. is so very bad, that there can be no reference made to it.

Spinulose-leaved Leucothoe. Fl. May, June. Clt. 1793. Slirub 2 feet.

3 L. ActMnA'TA; quite glabrous; leaves ovate-lanceolate, gradually narrowed to the top, acuminated, quite entire or unequally serrated, glabrous, shining, reticulately veined, coriaceous; racemes axillary, very short, corymbose, nearly naked; flowers pedicellate, drooping; corollas cylindrically ovate. $h$. I. Native of Georgia and Florida, in sandy swamps. Andrómeda acuminàta, Ait. hort. kew. 2. p. 70. Pursh. fl. amer. sept. 1. p. 293. Smith, exot. bot. 89. And. lùcila, Jacq. icon. rar. 1. t. 79. And. populif òlia, Lam. encycl. 1. p. 195. A. reticulàta, Walt. f. car. 137. Andr. formosíssima, Bartr. cat. Andr. laúrina, Michx, fl. amer. bor. 1. p. 253. Flowers white, in great abundance, which gives the shrub a fine appearance. The stems are hollow, and are used by the natives for making their pipe stems, from whence the name Pipe-stemrood.

Acuminated-leaved Leucothoe. Fl. July, Aug. Clt, 1765. Shrub 2 to 3 feet.

4. L. FloriBu'NDA (D. Don, 1. c.) quite glabrous; leaves ovate, oblong, acute, finely scrulated, adpresscdly eiliated, glabrous, coriaceous; racemes secund, axillary, and terminal, forming panicles; perlicels bibracteate. $h$. H. Native of Georgia, on the mountains. Andrómeda floribúnda, Lyon. herb. Ker. bot. reg. 807. Pursl., fl. amer. sept. 1. p. 293. Sims, bot. mag. 1566. Flowers pure white, in great abundance.

Bundle-flonered Leucothoe. Fl. May, June. Clt. 1812. Slirub ? feet.

5 I. spica'ta; glabrous; leaves elliptic-lanceolate, acute, ovate or attenuated at the base, serrated; racemes long, lateral and terminal, secund; branchlets beset with short white hairs. 2. H. Native from Canada to Florida. Andrómeda spicàta, Wats. dendr. brit. 36 . Flower's white.

Spieate-flowered Lencothoe. Fl. June. Clt.? Shrub \& feet.

Cult. For culture and propagation see Lyonia, p. 831. Elegant shrubs, worth cultivating in every shrubbery for the sake of the beauty of their blossoms.
XXIX. PIE'RIS (one of the Muses) D. Don, in edinb. phil. journ. 17, p. 159. Andrómeda species, Wall.

Liv. syst. Pentándria Monogýnia. Calyx deeply 5-parted. Corolla tubular or ovate, with a contracted, 5 -toothed, revolute border. Stamens inclosed; filaments dilated, bisetose at top; cells of anthers short, incumbent, dehiscing lengthwise. Style robust, pentagonal; stigma truncate. Capsule with a loculicidal dehiscence. Seeds scobiform - Trees or slırubs, natives of Nipaul. Leaves coriaceous. Flowers drooping, terminat, racemose.

I P. rormòsa (D. Don, l. c.) leaves lanceolate, acuminated, crenulated, glabrous, acute at the base: racemes erectly spreading, disposed in a terminal thyrse; pedicels recurved, drooping, and are, as well as the calyxes, pruinose; calycine segments ovate-oblong, marginated, shining; corollas ovate. h. F. Native of Nipaul, where it is called Sheabogee and Chemata.An evergreen tree, with the habit of A'rlutus or Clèthra. Pedicels unilateral. Flowers rose-coloured, each furnished with a small bractea at the base. Andrómeda formòsa, Wall. in asiat. res. J3. 1) 395. D. Don, prod. Al. nep. I19.

\section{Beautiful Pieris. Tree.}

2 P. Lanceola'ta (D. I)on, ]. c.) leaves elliptic, bluntly acuminated, quite entire, acute at the base; racemes terminal, glabrous, straight; pedicels scaly, pubescent, ealyeine segments roundish, ciliated; corollas ovate, downy; style inclosed. $h$. F. Native of Nipaul. Andrómeda lanceolàta, Wall. in asiat. res. 13. p. 390. with a figure. Andr. squamulòsa, D. Don, prod. f. nep. p. 149. A small much-branched tree. Leaves 3-4 inches long. Corollas purplish. Scales of pedicels ciliated.

Lanceolute-leaved Pieris. Tree small.

3 ovalfòlta (D. Don, 1. c.) leaves oval, acuminated, quite entire, rounded at the base; racemes lateral, leafy, manyflowered; pedicels secund, downy; calycine segments ovate, acute; corollas oblong, downy. $h$. F. Native of Nipaul, at Suembu, and in Sirunagur. Andrómeda ovalifòlia, Wall. in asiat. res. 13. p. 391. with a table. Andr. caprícida, Hamilt. mss. Branches downy. Leaves downy when young, 2-4 inches long, and 1-2 broad. Racemes numerous, elongated. Pedicels unilateral. Corolla pale flesh-coloured. The tree is poisonous to goats.

Ocal-leaved Pieris. FI. May. Clt. 1825. Tree 20 to 40 feet. 4. P. Japónica (D. Don, mss.) glabrous; leaves lanceolate, crenulated, attemuted at the base, entire; racemes terminal, panicled. 々. F. Native of Japan. Andrómeda Japónica, Thumb. fl. jap. p. 181 , t. 22 . Leaves $1 \frac{1}{2}$ to 2 inches long. Flowers red.

Japan Pieris. Slurub.

Cult. Sandy peat and a little loam is the best soil for the species of Pieris; and they may be increased by cuttings not too young, planted in sand, with a bell-glass over them.

XXX. PHYLLO'DOCE. (a mythological name). Salish. par. 36. D. Don, in edinb. phil. journ. July, 1831. Aurlrónieda species, Lin. Menzièsia species, Swartz and Smith.Erica species, Willd.

Lin. syst. Deếndria, Monogýnia. Calyx 5-parted. Corolla globose, with a contracted 5 -toothed mouth. Stamens 10 , iurlosed; filaments slender, glabrous; cells of anthers short, truneate, mutic. Stigma peltate, 5-tuberculate. Capsule 5celled, with a septicidal dehiseence. Seeds compressed, shining. -Small evergreen shrubs, natives of the north of Europe, Asia, and North America. Leaves linear, obtuse, spreading. Flowers terminal, solitary, or many together, in a kind of umbel. 
1 P. TAxıfòla (Salisb, par. t. 36.) leaves with denticulated margins; peduncles aggregate, glandular; calycine segments Janceolate, acuminated; anthers 3 times shorter than the filaments. h.H. Native of Eu* rope; and the north of Asia, at the fountains of Uda. In Scotland, in dry lieathy moors, rare; near A viemore, in Stratlispey, ex Mr. R. Brown, of Pertly; in the Western Isles of Shiant, G. Don. In Nortl America, on the White Hills of New Hampshire; and on the north-west coast, and of Labrador. Menzièsia cœrùlea, Swartz, in Lin. trans.

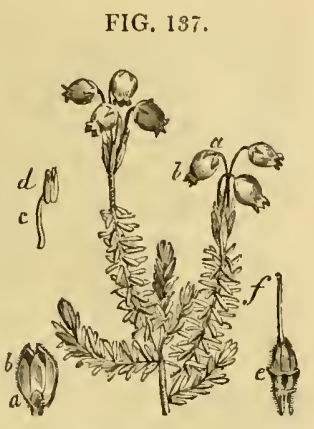

cles glandular, many-flowered; anthers mutic; style filiform. h. H. Native of Kamtsclıatka, about Port Ochotsk, and of Belıring's Island. The plant grows in thick masses, like Wild Thyme. Menzièsia bryántha, Swartz, in Lin. trans. 10. p. 378. t. 30. f. b. Andrómeda bryántha, Lin. mant. 238. Pall. fl. ross. p. 57. t. 74. f. 1. Erìca bryántla, Thunb, diss. no. 8. Willd. spec. 2. p. 386. Bryántlus rèpens, serpyllifòlio, flore roseo, Gmel. sib. 4. p. 133. t. 57. f. 3. Flowers red.

Gmelin's Bryanthus. Pl. trailing.

2 B. Stelle'ri (1). Don, l. c.) branchlets glabrous; leaves witls obsolete crenulated edges; flowers solitary, nearly sessile; anthers biaristate behind; style conical. $h$.H. Native of the west coast of North America; on the Rocky Mountains, and near the mouth of the Columbia river; and of the Island of Sitcha. Andrónieda Stelleriàna, Pall. fl. ross. p. 58. t. 74. f. 2. Menzièsia empetrifórmis, Pursh, fl. amer, sept. 1. p. 265. but not of others. Flowers pale red.

Steller's Bryanthus. Shrub trailing.

Cult. For culture and propagation see Phyllodoce, p. 832.

cab. 164. Andrómeda cœrùlea, Lin. spec. p. 563. fr. lapp. 165. t. 1. f. 5. Ed. fl. dan. 57. Andr. taxifolia, Pall. fl. ross. p. 54. t. 72. f. 2. fl. lapp. ed. 2. p. 133. t. 1. f. 5. f. dan. t. 57. Erìca coerùlea, Willd. spec. 2. p. 393.-Gmel. sib. 4. p. 131. t. 57. f. 2. Flowers blue or purple, but Pursh says they are red in the American plant.

Yew-leaved Phyllodoce. Fl. June, July. Scotland. Shrub $\frac{1}{2}$ foot.

2 P. Pallasia'sa (D. Don, in edind. phil. journ. 17, p. 159.) leares with denticulated margins; peduncles aggregate, tomentose; calycine segments ovate-lanceolate, acute, membranous; corollas oblong; anthers one-half shorter than the filaments. h.H. Native of Curil Island and the Island of Sitcha. Andrómeda coerùlea $\beta$, viridifiòra, herb. Pall. Menzièsia Aleútica, Spreng. syst. 2. p. 202. Cham, in Linnæea. 1. p. 515. Bongard, in mem. acad. petersb. 2. p. 154.t. 3. Peduncles clothed with rusty, adpressed, silky hairs. Flowers greenish.

Pallas's Phyllodoce. Shrub $\frac{1}{2}$ foot.

3 P. empetrifóruis (D. Don, ]. c.) leaves with denticulated margins; peduncles aggregate, sparingly glandular; calycine segments ovate, obtuse; anthers length of filaments. $\zeta_{2} \mathbf{H}$. Native of North America. Menzièsia empetrifórmis, Smith, in Lin. trans. 10. p. 280. Hook. bot. mag. 3176. Flowers pale red.

Empetrum-formed Phyllodoce. Fl. June, July. Clt. 1810. Shrub $\frac{1}{2}$ foot.

Cult. Phyllódoce is a genus of elegant, small, heath-like shrubs; they will only thrive in peat soil, and are increased by layers.

XXXI. BRYA'NTHUS (from $\beta \rho v o v$, bryon, a moss, and $\alpha \nu \theta 0 s$, anthos, a flower). Gmel. sib. 4. p. 133. t. 57. f. 3. D. Don, in edinb. plil. journ. 17, p. 160.-Andrómeda species, Lin. Menzièsia, Swartz, Pursh.-Erìca species, Thunb.

Lin. syst. Decándria, Monogýnia. Calyx 5-leaved, imbricate. Corolla deeply 5 -parted, spreading. Stamens 10 , shorter than the corolla; filaments flattened, glabrous; cells of anthers short, mutic, or awned behind, dehiscing by a terminal hole. Stigma obtuse. Capsule 5-celled, with a septicidal dehiscence, many-seeded. Seeds ovoid, shining, with a keeled raphe.Small trailing shrubs, natives of Asia and North America. Leaves cronded, spreading, flattish. Flowers terminal, solitary, or somewhat racemose.

1 B. Guesinı (D. Don, in edinb. phil. journ. 17. p. 160.) branchlets pruinose; leaves witl denticulated margins; pedunvoL. III.
XXXII. DABOE'CIA (Called St. Dabeoc's Heath, in Ireland). D. Don, in edinb. phil. journ. 17.p. 160.-Andrómeda species, Lin.-Menzièsia species, Juss.-Erica species, Lin.

Lin. syst. Octándria, Monogýnia. Calyx 4-parted. Corolla oval, ventricose; limb 4-toothed. Stamens 8 , inclosed; filaments dilated, glabrous; anthers linear, sagittate at the base; cells of anthers parallel, loosened at the apex, dehiscing lengthwise. Stigma simple, truncate. Capsule 4 -celled, with a septicidal dehiscence.-A dwarf, bushy, evergreen shrub, native of white tomentum beneath. Flowers terminal, racemose, purple.

1 D. Polifòlia (D. Don, l. c.). h. H. Native of the Pyrenees, and of the west of Ireland, in boggy soil ; on Craigl Patrick, in the County of Mayo; very abundant in the district of Cunnemara, in the County of Galway. Andrómeda Dabo'cia, Lin. syst. 406. Erìca Dabo'cia, Lin. spec. 509. Smith, engl. bot. 35. Menzièsia Dabo'cia, D. C. fl. gall. 674. Erìca Hybérnica, \&c. Rai, hist. 3. suppl. 244. Menzièsia polifolia, Juss. ann. mus. 1. p. 55. Vaccínium Cantábricum, Huds. ed. 1. p. 143. Petiv. gaz. 27. f. 4. Racemes secund. The shrub is called Irish Whorts, Cantabrian Heath, or St. Dabcoc's Heath.

Polium-leaved St. Dabeoc's Heath. Fl. June, Sept. Ireland. Slirub 1 to 2 feet.

Cult. This slirub is well fitted for decorating the front of slirubberies, or to be grown on rock-work or banks. 1t has much the labit of a species of Heath, and is very pretty when in blossom. As the shrub grows in large dense tufts, it may be increased by division; it is also easily increased by layers or cuttings.

XXXIII. ENKIA'NTHUS (from Ě $\gamma k^{*} v o s$, enkuos, pregnant, and $\alpha \nu \theta 0 \varsigma$, anthos, a flower; flowers swollen). Lour. coclin. 276 . Meladora, Sal. in hort. trans. 2. p. 156.

Lis. syst. Decándria, Monogýnia. Calyx 5 cleft, furnished with coloured bracteas. Corolla campanulate; with a 5 -cleft limb, and with 5 pits at the base of the tube. Stamens 10, inserted in the base of the corolla; filaments toothed, pilose at base; cells of anthers awned, opening by a pore at the apex. Style filiform. Berry 5-celled, many-seeded.-Elegant shrubs. Leaves broad, opposite, oblong-elliptic-acuminated, glabrous, green and shining on the upper surface, pale beneath, and frequently red. Bud scales red. Flowers large, terminal, drooping, shewy. The species are held in high veneration by the Clinese. Ireland and the Pyrenees, Leaves elliptic, flat, clotlied with 
1 E. Quineueflòrus (Lour. coch. p. 276.) stem shrubby; flowers 5-6 together at the tops the branches. h.G. Native of the south of China. Andr. rep. 102. Ker, bot. reg. 201. Sims, bot. mag. 1649. Lodd. bot. cab. 1101 . E. reticulàtus, Lindl. bot. reg. 883 . Flowers pink, or the calyx is red and the corolla nearly white.

Five-flowered Enkiantlus. Fl. Feb. Sept. Clt. 1812. Shrub 3 to 10 feet.

2 E. Bıflòrus (Lour. coch. p. 276.) stem shrubby; flowers iwin, terminal. $h$. G. Native of the south of China. Flowers red.

Tno-flowered Enkianthus. Shrub.

Cult. Elegant green-house plants while in blossom, but rather difficult of culture. The best soil for them is said to be an equal mixture of sandy loam and peat, but care must be taken not to over-water them when not growing freely. Cuttings taken from ripened wood are found to strike root freely, if planted in sand, with a hand-glass placed over them. When they grow to a considerable size, they are the greatest ornaments for a green-house or conservatory.

XXXIV. A'RBUTUS ( $A$ r boise, Celt., austere bush ; rough fruit). Camer. epit. p, 168. Gærtn. fruct. 59. Tourn. inst. 368. Juss. gen, 160. H. B. et Kunth, nov, gen. amer. 3. p. 279. Adans. fam.-Andráchne, Clus.-A'rbutus species, Lin. gen. no. 750. Schred. gen. 750 .

Lin. syst. Decándria, Monogýnia. Calyx 5-parted. Corolla globose, or ovately campanulate: limb 5-cleft, reflexed. Stamens 10, inclosed; anthers compressed on the sides, dehiscing by 2 pores at the apex, fixed by the back beneath the apex, where they are furnished with 2 reflexed awns. Ovarium seated on a hypogynous disk, or half immersed in it, 5-celled; cells many-seeded. Style 1; stigma obtuse. Berry nearly globose, granular.-Trees and shrubs, with alternate laurel-like leaves. Racemes terminal, panicled. Flowers pedicellate, bracteate. Corollas white or flesh-coloured.

1 A. U'NEDo (Lin. spec. 366.) arboreous; branchlets clothed with glandular hairs; leaves oblong-lanceolate, glabrous, serrulated; peduncles smooth, nodding. $h$.H. Native of the south of Europe, as of Spain, Italy, Greece; Palestine, and many other parts of Asia. It is also found in the west of Ireland, in the County of Kerry, near the Lake of Killarney, on barren limestone rocks, where the country people eat the fruit. Mill. fig. t. 48, Cam. epit. 1681. Barrel, icon. t. 674. Smith, engl, bot. 2377. The common $A^{\prime}$ rbutus, or Strawberry-tree, rises to the heiglst of 20 or 30 feet, but rarely with an upright stem. It is one of the greatest ornaments in the month of October and November, that being the season when it is in flower; and the fruit of the former year is ripe. When there is plenty both of fruit and flowers upon the trees, they make a handsome appearance at a season when most others are past their beauty. The fruit is said to lave constituted part of the food of mankind in early ages. That it was not in any esteem among the ancients, we may suppose from the name Unedo, if Pliny's reason for that name be the true one,- "cui nomen ex argumento fit unum tantum edendi." Virgil recommends the twigs as good for goats in winter:- "Jubeo frondentia capris Arbuta sufficere "" and for baskets,_- "Arbuteæ crates et mystica vannus Iacchi," Horace celebrates the shade of it:- "Nunc viridi membra sub Arbuto stratus." The tree is named, in Greek, Kopajoo, and the fruit

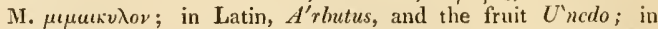
Italian, Arbuto, Albato, Albatro, Corbezzolo; in French, L'Arbousier commun. The Greek name is almost preserved at Constantinople, in Komaria.

Var. a, álba (Ait. hort. kew. 2. p. 71.) flowers white.

Y $a r . ~(3$, rubra (Ait. hort. kew. 2, p. 71.) flowers reddish.

Var. $\gamma$, plèna (Ait. l. c.) flowers semi-double.

Var. $\delta$, schizopetàla; petals cut.

Var. $\varepsilon$, integrifolia; leaves entire. Sims, bot. mag. 2319.

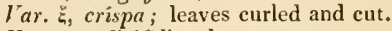

lar.,n, salicifolia; leaves narrow.

Unedo or Common Strawberry-tree. Fl. Sept. Dec. Ireland. Tree 10 to 20 feet.

2 A. CANARIÉnsis (Lam. dict.vol. 1.) leaves oblong-lanceolate, serrated, glaucous beneath; panicles erect, clothed with hispid hairs. h. G. Native of the Canary Islands. Sims, bot. mag. 1577. Flowers greenish white.

Canary-Island Strawberry-tree. Fl. May, June. Clt. 1796. Shrub 8 to 10 feet.

3 A. HY'BRIDA (Ker. bot. reg. 619.) leaves oblong, acute, serrated, glabrous; branchlets pilose; panicle terminal, pendulous, downy; calyx glabrous. $々$. H. Native comntry unknown. A. andrachnoides, Link. enum. 1. p. 395 . Flowers white.

Hybrid Strawberry-tree. Fl. Feb. May. Clt.? Slurnb 8 to 12 feet.

4 A. serratifòlia (Nois. ex Lodd. bot. cab. t. 580.) leaves serrated, narrower than those of $A$. Andráchne; flowers disposed in terminal clusters. $\zeta$. H. Native country unknown. Flowers yellowish. Perliaps only a variety of the following.

Serratcd-leaved Strawberry-tree. Fl. Feb. March. Shrub 6 to 10 feet.

5 A. Andra'chne (Lin. spec. 566.) leaves oblong, bluntish, quite entire, and a little serrated, glabrous; panicles terminal, erect, clothed with viscid down. $\zeta$. H. Native of Greece, Asia Minor, Tauria. Belon says it is common in Crete, and between Aleppo and Antioch. Wheeler observed it near Athens, and saw the fruit in the market of Smyrna. About Magnesia it is so plentiful, that it is used as the principal fuel by the inhabitants. Ehret, act, angl. vol. 57.p. 114. t. 6. Ker. bot. reg. 113. Sims, bot. mag. t. 2024. A. integrifòlia, Lam. Andráchne Theophrásti, Clus. hist. 1. p. 48. Andráchne, Park. theatr. 1490. f. 2. Flowers greenish-white. Fruit like that of the common sort. This is the 'A $\delta \alpha^{\prime} \chi^{\nu \eta}$ of Theophrastus, and is called 'Acocítia in modern Greek. It is a fine ornamental tree; the largest of the kind in Britain is growing in the botanic garden at Edinburgh. Tournefort enumerates three varieties of it which he observed in the Levant; one with serrated leaves ; a second with a large oblong fruit; and a third with large compressed fruit.

Andrachne Strawberry-tree. Fl. March, April. Clt. 1724. Tree 10 to 14 feet.

6 A. Laurifòlia (Lin. syst. 407. suppl. 238.) leaves oblong, acuminated at both ends, acutely serrated, glabrous; racemes axillary, secund, sessile, solitary. h. H. Native of North America, but what part is unknown, as nothing can be found respecting it in the Limnean herbarium.

Laurel-leaved Strawberry-tree. T'ree.

7 A. Menzie'sir (Pursh. fl. amer. sept. 1. p. 282.) arborescent; leaves broad-oval, quite entire, glabrous, on long petioles ; racenses axillary and terminal, panicled, dense-flowered, $h$. H. Native of the nortl-west coast of America, where it was collected by Mr. Menzies. Hook. et Arn. in Beecl. voy. pt. bot. p. 143. 
Menzies's Strawberry-trec. Tree.

S A. tomentòsa (Pursh. fl. amer. sept. 1. p. 282.) shrubby; branches hispicl; leaves oval, acute, subcordate at the base, clothed with white tomentum beneath, on short petioles; peduncles axillary, shorter than the leaves, somewhat capitately racemose ; flowers campanulatcly urceolate, bracteate. Native of the north-west coast of America, where it was collected by Mr. Menzies. Hook. bot. mag. t. 3320. Hook. fl. amer. text. bot. 129. f. 1. Flowers pure white. The whole herb, except the flowers, is downy, while young. Petioles and mid-rib of leaves hispid.

I ar. 3 , nuida (Hlook. et Arn. in Beech. voy. pt. bot. 144. Hook. fl. amer. bot. 129 fl.) shrub quite destitute of long stiff hairs.

Tomentose Strawberry-tree. Fl. Dec. Clt. 1826. Shrub.

9 A. Xalapénsis (H. B. et Kunth, nov. gen. amer. 3. p. 279.) leaves oblong, acute, quite entire, glabrous above, but clothed with fuscescent tomentum beneath; panicle terminal, composed of many racemes. $h$. G. Native of Mlexico, in mountain woods near Xalapa, and at Malpays de Joya. Epidermis separating, brownish purple. Young branches glabrous, but beset with ramentæ. Leaves obtuse at the base, 2 inches long, petiolate. Corollas ovate, white. Filaments villous, dilated at the base.

\section{Xalapa Strawberry-tree. Tree.}

10 A. Móluts (H. B. et Kunth, nov. gen. amer. 3. p. 280.) leaves oblong, acute, sharply toothed, coriaceous, clothed with soft pubescence above, and canescent tomentum beneath ; panicle terminal, crowded, composed of racemes. h. F. Native of Mexico, near Guanaxuato. Branchlets purplish brown, angular, downy. Leaves petiolate. Flowers drooping ? like those of the preceding.

Soft Strawberry-tree. Tree.

11 A. Dexsiflora (H. B. et Kunth, nov. gen. amer. 3. p. 280. t. 260.) leaves on long petioles, oblong, acute, sharply toothed, coriaceous, glabrous above and shining, but clothed with fuscescent down beneath, and the middle nerve with rusty villi; panicle terminal, composed of approxinate racemes; flowers crowded. $\quad$. F. Native of Mexico, on the eastern declivities of the mountains between La Pileta and Xalapa. Branches angular, pilose. Petioles pilose. Leaves 4-5 inches long. Pedicels furnished with $\$$ bracteas at the base. Corollas oval, white. Filaments dilated and pilose at the base.

Dense-flowered Strawberry-tree. Clt. 1826. Tree 20 feet.?

12 A. PETIOLA'Ris (H. B. et Kuntl, 1. c. p. 281.) arboreous ; leaves on long petioles, oblong, acutish, mucronate, with denticulated margins, membranous, glabrous above, but clothed with canescent tomentose pubescence beneath; racemes short, crowded, forming a terminal panicle. $h$. F. Native of Mexico, on the western declivities of mountains between Cuernavaca and Guchilaque. Epidermis separating. Branchlets hairy. Leaves rounded at the base, 3 or $3 \frac{1}{2}$ inches long. Petioles hairy, red. Ramenta numerous at the base of the branches. Pedicels villous, canescent. Corollas ovate-globose, white. Filaments villous, dilated at the base.

Petiolate-leaved strawberry-tree. Tree tall.

13 A. FERrugínea (Lin. syst. 408. suppl. 238.) arborescent; leaves oblong, obtuse, smooth, quite entire; racemes terminal. $h_{c}$. G. Native of New Granada. Branches angular, smooth. Leaves petiolate. Racemes axillary, and terminating the branches, solitary. Pedicels bibracteate. Flowers remote, nodding. Corollas longer than in the other sorts, almost like those of Andrómeda.

Rusty Strawberry-tree. Tree.

14 A. PHYLLYRE Éfòlia (Pers. ench. 1. p. 483.) sten much branclied; leaves lanceolate, acuminated, acutely serrated; flowers axillary, h. G. Native of Pert. Leaves small. Perhaps a species of J'ernéttya.

Phyllyrec-leaced Strawberry-tree. Shrub.

15 A. Fu'rexs (Hook. et Arn. in Becch voy. pt. bot. p. 33.) stem nearly simple, downy ; leaves oval, on short petioles, denticulated, coriaccous, with revolute edges, shining above, and glandular on both surfaces, the glands terminating in hairs ; racemes short, axillary; rachis and pedicels downy and scaly; calyx ylabrous; corolla glabrous outside, and hairy inside. $h$. 1. Native of Chili, about Conception. Qued-Qued, Fcuille, 3. p. 56. t. 43. A low-growing slurub. The fruit is described by Feuille to be a reddish brown berry, which is dangerous when eaten, causing delirium; whence the Indian name, which signifies madness.

Raging Strawberry-trce. Shrub low.

16 A. Puncta'ta (Hook, et Arn. in Beech, voy. pt. bot. p. 33.) much branched ; branchlets downy; leaves nearly sessile, ovatelanceolate, denticulated, coriaccous, with revolute margins, besprinkled with pilifcrous glands; racemes axillary, downy, scaly; calyx glabrous ; corolla glabrous outside, but pilose inside. 々. F. Native of Chili, about Conception. Apparently a large shrub, and probably the $\mathbf{A}$. phyllyreafólia, Pers.

Dotted-leaved Strawberry-tree. Shrub.

Cult. The hardy species of this genus being all ornamental trees or shrubs, are proper for conspicuous places in slirubberies, or to stand singly on lawns. A. Andráchne must be protected by a mat in severe weather in winter. They are to be increased by seeds, or by budding or inarching on the commoner kinds. The green-house kinds require the treatment of common green-house plants.

XXYV, ARCTOSTA'PHYLOS (from apkros, aretos, a bear, $\sigma \tau a \phi v \lambda \eta$, staphyle, a grape). Gal. Adans, fam. H. B. et Kunth, nov. gen. amer. 3. p. 277. Spreng, syst. 2. p. 287.-U'va-úrsi, Dod. Tourn.-A'rbutus species, Lin.

Lin. syst. Decándria, Monogýnia. Calyx 5-parted (f. 139. a.) Corolla globose (f. 139. b.) or ovate-campanulate; limb 5 cleft, reflexed. Stamens 10, inclosed; filaments dilated at the base, and pilose; anthers compressed at the sides, dehiscing by 2 pores at the apex (f. 139.6 .), fixed by the back beneath the middle, where they are furnished with 2 reflexed awns. Ovarium seated on the hypogynous disk, or half immersed in it, usually 5-celled (f. 139. g.), rarely 6-9-celled; cells 1 -secded. Style 1 ; stigma obtuse, Drupe nearly globose.-Shrubs or subshrubs. Leares alternate. Racemes terminal. Flowers pedicellate, bracteate. Corollas white or flesh-coloured. Drupes red or black.

1 A. U'VA-U'RSI (Spreng. syst. 2. p. 287.) stems procumbent ; leaves permanent, obovate, quite entire, coriaceous, shining: flowers fasciculate; drupe 5-celled. h. H. Native of North America, in the pine barrens of New Jersey, and in mountainous and rocky situations of Canada and New Ensland; and the Island of Unalascha. It is abundant on the continent of Europe, as in Sweden, Denmark, and most parts of the north ; also in Switzerland, Germany, Carniola, Dauphiny, Savoy, Siberia, Sc. With us it is common upon dry, heatly, mountainous and rocky places throughout the Highlands and Western Isles of Scotland; also in the north of England and Wales. A'rbutus ùva-úrsi, Lin. spec. 566 . f. lapp. no. 162. t. 6. f. 3. Woodv. med. bot. 194. t. 70. Fl, dan. t. 33. Blackw. t. 592. Smith, engl. bot. 714. Arbutus buxifolia, Stokes, bot. 509. U'va-úrsi buxifolia $\mathrm{Sal}$ in Gray arr. 2. p. 400.-Schmidt. arb. t. 138. Plencl. icon. 340. It is called in English Bear berries and Bear-nhortle berries, from the German, Barentraube or Barenbeere; in Dutch, Beerendruif; in French, La Busserole; in Italian, Uva dorzo; in Spanish, Lba de oso; in 502 
Portuguese, Uva de urso; and by most old botanists, Uvaursi. Leaves like those of box. Flowers pale red, or white with a red mouth, growing in small clusters at the extremities of the branches. The leaves have been much celebrated in calculous and nephritic complaints, and other disorders of the urinary passages; the dose is half a drachm of the powder of the leaves every morning, or 2 or 3 times a day. The trials, however, made in this country by no means answered expectation. Perhaps, upon the whole, it will be found no better than other vegetable astringents; some of which have long been used by the country people in gravelly complaints, and with very great advantage. On the plains of the Mississippi, the Indians smoke the leaves under the name of Sacacommis, and consider them of great medicinal virtue. But whatever may be its medicinal qualities, the whole plant is certainly very serviceable in dying an ash-colour, but particularly in tanning leather. In this view, it may deserve attention in those countries where whole mountains are covered with it. The berries are red when ripe, filled with an austere mealy pulp; they serve as food for grouse and other game.

Bcar-berries. F1. May, June. Britain. Shrub trailing.

2 A. Alpisa (Spreng. syst, 2. p. 287.) stems procumbent ; leaves obovate, acute, wrinkled, serrated, deciduous; racemes terminal. $々$. H. Native of Denmark, Switzerland, Dauphiny, Savoy, Siberia, \&c. In many places of the Highlands of Scotland, in dry barren moors. Nothing is more common, says Linnæus, in all the Lapland alps, in Dalekarlia, from their tops to their bases, round the White Sea, especially in very sandy places. It is also found in Canada, and the more northern parts of America, Aleutian Islands, \&c. A'rbutus alpìna, Lin. spec. 566. Oed. f. dan. 73. Smith, eng]. bot. 2030. Lightf. fl. scot. 215. t. 11. f. a. b. Pedicels rather hairy, The flowers grow in reflexed racemes, and are pure white. The berries are black when ripe, and of the size of a sloe, with a taste somewhat resembling that of black currants, but more mawkish, insomuch that Linnæus says the Laplanders will scarcely eat them. Haller, on the contrary, thinks the flavour not unpleasant. Mr. Miller describes them as of a pleasant taste, so as frequently to be eaten by the inhabitants of those countries where the plant grows wild.

Alpine Bear-berry. Fl. April, June. Scotland. Shb. trailing. 3 A. polifòlia (H. B. et Kunth, nov. gen. amer. 3. p. 277. t. 25.) erect; leaves linearlanceolate, acute, with quite entire and revolute margins, coriaceous, glabrous above, but downy and glaucescent beneath. h. F. Native of the temperate parts of Mexico, near Villalpando. Andrómeda ledifòlia, Humb. prol. p. 41. A much branched shrub. Racemes terminal, erect, an inch long, downy. Flowers nodding. Corolla scarlet (f, 139.)

Polium-leaved Bear-berry. Shrub 4 to 6 feet.

4 A. gLauce'scens (H. B, et Kunth, 1. c. p. 278.) erect ; leaves lanceolate-oblong, obtuse, submucronate, quite entire, coriaceous, glabrous and shining above, but downy and glaucescent beneath ; racemes terminal, solitary, erect ; flowers secund. h. F. Native of Mexico, between Guanaxuato and Valenciana. Racemes 3 inches long, beset with glandular villi. $\mathrm{Co}_{\mathrm{O}}$ rollas scarlet.?

Glaucescent Bear-berry. Shrub.
5 A. Pu'Ngens (H. B. et Kunth, 1. c. p. 278. t. 259.) leaves ovate-oblong, acute, mucronate, rather pungent, quite entire, coriaceous, clothed with fine down on botlı surfaces; racemes short, at first terminal, but at length lateral. $\zeta$. F. Native of Mexico, in high places near Moran and Villalpando. A dwarf, much branched shrub. Branchlets angular, downy. Pedicels approximate, fastigiate. Corollas white.

Pungent-leaved Bear-berry. Shrub 1 foot.

6 A.? HоoкE'rı; branches prostrate, rather downy; leaves petiolate, permanent, oval or obovate, coriaceous, shining, minutely reticulated, mucronately pungent, smoothish, finely margined, almost quite entire; racemes terminal, short; flowers bracteate. $\zeta$. F. Native of Chili. A'rbutus púngens, Hook. et Arn. in Beech, voy. pt. bot. 144. Habit of $A$. ùva úrsi, and with the leaves of the same size. Flowers small, urceolate; young leaves white from down beneath, more or less serrated.

Hooker's Bear-berry. Slirub prostrate.

Cult. The hardy species of this genus grow well in a mixture of sand, loam, and peat, or in a peat border. They are increased by layers, put down in the spring. The greenhouse kinds require the treatment of other liardy green-house shrubs.

XXXVI. PERNE'TTYA (named after M. Pernetty, author of a history of his voyage to the Falkland Island-). Gaud. in Freyc. voy. p. 454. t. 67 .

Lin. syst. Decándria, Monogýnia. Calyx inferior, 5-parted. Corolla globose: limb 5-parted, revolute. Stamens 10, almost hypogynous, inclosed; filaments thickened at the base; cells of anthers bifid, and dehiscing at the apex. Ovarium free, depressed, globose, 5-celled; cells many-seeded. Hypogynous scales or glands 10,3-lobed, forming a ring round the ovarium, and alternating with the stamens. Style terminal, short. Stigma convex, obsoletely 5 -lobed. Berry propped by the rather fleshy calyx. Seeds minute, oblong-ovate.-Small, much branched shrubs, with small alternate approximate leaves; axillary, solitary, pedunculate, drooping white flowers, and bracteate peduncles. This genus agrees with Epacrideæ in the presence of hypogynous scales.

1 P. empetrifo'lia (Gaud. l. c. t. 67.) much branclied, diffuse; leaves alteruate, distich, oblong, quite entire; flowers lateral, solitary, drooping. $h$. F. Native of the Falkland Islands. A'rbutus empetrifòlia, Lin. suppl, p. 239. Pers. syn. 1. p. 483. A. pùmila? Willd. spec. 3. p. 619. Pers. ench. 1. p. 483. Andrómeda empetrifollia, Lam. dict. 1. p. 155. Bruyère à feuilles poinstues, Pernetty, voy. 2. p. 64. Flowers white. Leaves like those of $E^{\prime}$ mpetrum.

Crow-bcrry-leaved Pernettya. Shrub 2 to 3 feet.

2 P. nucrona'ta (Gaud. in ann. sc. 5. p. 102.) leaves ovate, cuspidate, denticulately serrulate, stiff, shining on both surfaces; pedicels axillary, bracteate, about equal in length to the leaves. 々. H. Native of Terra del Fuego, Cape Horn, and Straits of Magellan. Lindl. bot. reg. 1675. A'rbutus mucronàta, Lin. fil. suppl. p. 239. Forst. in comm. goet. 9. p. 31. Graham in bot. mag. t. 3093 . Lam. ill. t. 366, f. a. Lodd. bot. cab. 1848. Flowers white, drooping.

Mucronate-leaved Pernettya. Fl. May. Clt. 828. Shrub 2 to 3 feet.

3 P. mсrophy'ula (Gaud. l. c.) leaves ovate, acute, serrated; pedicels short, axillary, $h . H$. Native of the Straits of $\mathrm{Ma}$ gellan. A'rbutus microphýlla, Forst. in comm. gœt. 9. p. 32. Willd. spec. 2. p. 619. A'rbutus serpyllifölia, Lam. Flowers white, drooping.

Small-leaved Pernettya, Shrub 2 to 3 feet.

4 P. Myrsinitis ; leaves ovate-lanceolate, serrated, scat- 
tered; pedicels solitary, axillary, very short. $々$. H. Native of the Straits of Magellan, in woods on the mountains. Andrómeda myrsinitis, Lam. ill. gen. t. 365. f. 2. Leaves small.

Myrile-like Pernettya. Shrub 2 to 3 feet.

5 1'. Cavanillesia'Na; leaves ovate, acute, glabrous, obtusely serrated; pedicels axillary, solitary, furnished with two scales at the base; stems trailing. h.F. Native of South America. Andrómeda prostràta, Cav. icon. 6. p. 48. t. 562. f. 2. Leaves green above, and rusty and reiny beneath, on very short petioles.

Cavanilles's Pernettya. Shrub prostrate.

6 P. PıLòsı; stem pilose, procumbent ; leaves ovate-elliptic, ciliately-serrulated, coriaceous, mutic at the apex and callous; pedicels axillary, 1-flowered, elongated, nutant ; corolla ovate, with blunt revolute teeth. $h$. H. Native of Mexico. A'rbutus pilòsa, Graham, in bot. mag. 3177 . Corolla white.

Pilose Pernettya. Fl. May. Clt. May, June. Shrub prostrate.

7 P. purpu'rea (D. Don, mss, in herb. Lamb.) branchlets setose ; leaves lanceolate, acute, denticulated, glabrous, veiny beneath; pedicels scabrous, glandular; corollas ovate. $\zeta . F$. Native of Peru. Flowers purple.?

Purple-flowered Pernettya. Shrub.

8 P. cilia'ris (D. Don, 1. c.) branchlets setose ; leaves ovatelanceolate, acute, having the margins denticulated, and ciliated with bristles; peduncles glandular. ? . F. Native of Mexico.

Ciliated Pernettya. Shrub.

Cult. For culture and propagation see Phyllódoce, p. 839.

XXXVII. AGARI'STA (a mythological name, the beautiful daughter of Clifthenes; in reference to the beanty of the flowers). D. Don, mss.-Andrómeda species of Comm, and other authors.

Lix. syst. Decándria Monogýnia. Calyx fleshy, 5-lobed; lobes imbricate at the base. Corolla ovate, with a contracted, 5-toothed, conical mouth. Stamens 10, inclosed; filaments flattened, dilated at the base, and villous; anthers bipartite; with short membranous cells, which are mutic at the base and diverging at the apex, opening by a terminal hole. Style robust, terete; stigma capitate. Capsule globose, pentagonal, 6-celled, with a loculicidal dehiscence. Placentas thick, oblong. Seeds angular, curved.-Evergreen shrubs. Natives of the Mauritius and South America. Leaves coriaceous, reticulately veined, quite entire. Flowers racemose, terminal, very beautiful. Intermediate between Gaulthèria and Andrómeda.

1 A. Buxifo'lia; leaves cordate ovate, mucronulate, rusty beneath; panicle terminal, downy, composed of racemes; flowers secund. h. G. Native of the Island of Bourbon. Andrómeda buxif òlia, Lam. dict. 1. p. 158. Smith, icon. ined. 1. p. 59. t. 59. Lindl. bot. reg. Hook. bot. mag. t. 2660. Lodd. bot. cab. 1494. Flowers scarlet. Corollas sub-cylindrical.

Box-leaved Agarista. Fl. June, July. Clt. 1822. Shrub 3 to 6 feet.

2 A. SAlicifòlia ; leaves Janceolate, attenuated at both ends, white beneath; racemes simple, secund, glabrous. h.S. $\mathrm{Na}$ tive of the Mauritius. Andrómeda salicifolia, Comm. mss. Lam. dict. 1. p. 159. Smith, icon. ined. t. 58. Hook, exot. f. 3. t. 192. bot. mag. 3286. Leaves 2-4 inches long. Racemes simple. Corolla oblong, ovate, beautiful purple.

Willow-leaved Agarista. Shrub 2 to 3 feet.

3 A. subrotu'NDA; leaves roundish-elliptic, cordate at the base, mucronate at the apex, glabrous above, but clothed with ferruginous tomentum beneath; racemes terminal, solitary, or fascicled, secund, downy. $\quad$. G. Native of Brazil, in the province of Minas Geraes, on rocks about Villa St. Joao d'el Rey.
Andrómeda subrotúnda, Pohl. pl. bras. 2. p. 32. t. 121. Branches tomentose. Leaves on very short petioles, approximatc, setosely denticulated on the nerves and margins, and terminating in a spinose mucrone. Corolla ovate, ventricose, pure red or scarlet, with almost erect segments. Ovaries villous.

Roundish-leaved Agarista. Slirub 3 feet.

4. A. mutiflòra; leaves lanceolate, rounded at the base, glabrous; racemes axillary, suprafoliaceous ; ovarium glabrous. $h_{c} . G$. Native of Brazil, in the province of Ninas Geraes, in mountainous places; in Serra Mátuquiera. Andrómeda multiflòra, Pohl. pl. bras. 2. p. 33. t. 122. Slırub much branched. Leaves petiolate, remote, $2 \frac{1}{2}$ inclies long and 8 lines broad. Racemes many-flowered, secund. Bracteas oblong, acute, ciliated. Corolla elliptic, ventricose, white, with erect segments.

Many-flonered Agarista. Shrub 6 to 10 feet.

5 A. Pónlı; leaves ovate, acute at the apex, cmarginate at the base, glabrous, painted beneath on the sides of the nerve with dots; racemes axillary. h.G. Native of Brazil, in the province of Minas Geraes, in dry mountainous places of Itambe. Andrómeda crassifòlia, Pohl. pl. bras. 2. p. 34. Leaves on short petioles, deciduous, $1 \frac{1}{2}$ inch long and 8 lines broad. Racemes many-flowered, secund; bracteas linear, glabrous. Corollas unknown.

Pohl's Agarista. Tree.

6 A. Bracanorénsis; leaves ovate-oblong, obtuse, obsoletely mucronate, with revolute margins, coriaceous, glabrous, shining above; racemes axillary and terminal, approximate at the tops of the branches. $h$. G. Native of New Granada, in the province of Bracamoros, near St. Felipe, and Paramo de Yamoca. Andrómeda Bracamorénsis, H. B. et Kunth, nov. gen. amer. 3. p. 288. t. 263. Andrómeda myrtifòlia, Willd. herb. Branchlets angular. Leaves 6-7 lines long. Bracteas minute at the base of the pedicels. Corollas scarlet, with ovate, obtuse, revolute teetll. Stigma ciliated, hardly thicker than the style.

\section{Bracamoros Agarista. Tree 10 to 15 feet.}

7 A. SPRENGE'LII; leaves ovate-oblong, obtuse, mucronate, coriaceous, with revolute margins, glabrous on both surfaces; racemes axillary, drooping. $h$. S. Native of Brazil, within the tropic. Andrómeda revolùta, Spreng. neu. entd. 2. p. 131. syst. 2. p. 29l. Young leaves and young branches rather downy.

Sprengel's Agarista. Shrub.

8. A. evcalyptoìes; glabrous; leaves on long petioles, oblong, acuminated, obliquely rounded at the base, with revolute margins; racemes lateral, approximate towards the tops of the branclues. h. G. Native of Brazil, at Rio Grande do Sul. Andrómeda eucalyptoìdes, Cham. et Schlecht, in Linnæa. 1. p. 519. An elegant shrub. Young branches angular. Leaves $1 \frac{1}{2}$ inch long. Corolla urceolate, 3 lines long, with obtuse spreading teeth, scarlet.? Ovarium pubescent.

Eucalyptus-like Agarista. Shrub or small tree.

9 A. PU'LCHRA; glabrous; leaves petiolate, ovate, mucronate, coriaceous, with revolute margins; racemes secund, axillary and terminal, glabrous, approximate at the tops of the branches; ovarium glabrous. h.S. Native of Brazil, within the tropic. Andrómeda júlchra, Cliam. et Schlecht. in Linnæa. 1. p. $5 \% 1$. Branches angular. Leaves more than an inch long, larger than those of $A$. nuntmulària. Style length of corolla. Corolla urceolate, with short obtuse spreading teeth, scarlet.

Fair Agarista. Shrub 1 to 2 feet.

10 A. Numula'ria; leaves on short petioles, cordate, broadovate, rather retuse, mucronate, coriaceous; racemes axillary and terminal, and are, as well as the young branches, hispid; ovarium downy. $\nvdash$. G. Native of the south of Brazil, in the province of Rio Grande do Sul. Andrómeda nummulària, 
Cham. et Schlecht, in Linnæa, 1. p. 520. Leaves shining above, ciliated with long stiff hairs on the nerves beneath, and margins while young. Larger leaves 8 lines long. Racemes approximate at the tops of the branches. Calyx hairy. Style exserted. Corolla urceolate, with short, obtuse, reflexed teeth, scarlet.?

Money-wort-leaved Agarista. Shrub 1 to 2 feet.

11 A. NERIIròn ; quite glabrous; leaves petiolate, oblonglanceolate, acnte, ovate at the base, coriaceous; panicle terminal, composed of numerous racemes; ovarium glabrous. $\zeta . S$. Native of Brazil, within the tropic. Andrómeda neriifòlia, Cham. et Schlecht, in Linnæa, 1. p. 522. Leaves 3 inches long, shining above and paler beneath. Racemes secund; flowers drooping. Corolla urceolate, with short, obtuse, hardly spreading teeth, scarlet.? Calycine segments finely ciliated.

Nerium-leaved Agarista. Shrub 2 feet.

12 A. OLEIFòlı; ; leaves on short petioles, oblong, subacuminated, mucronate, acutish at the base, or rounded, with reflexed margins, flat, glabrous, coriaceous ; racemes axillary, length of leaves; calycine segments ovate, acuminated, acute; corollas oblong; ovarium glabrous, $\zeta$. S. Native of equinoxial Brazil. Andrómeda oleifolia, Cham. in Linnæa, 8. p. 504.Flowers scarlet, with white filaments and yellow anthers. There are varietics of it having the inflorescence either hairy or glabrous.

Olive-leaved Agarista. Shrub 6 to 10 feet.

13 A. Serruta'ta; leaves subimbricated, almost sessile, spreading, stiff, ovate, cordate, acute, reticulately veined, with reflexed margins, and serrulately-ciliated near the margin above, very scabrous, hairy on the nerve beneath as well as the branchlets, inflorescence, and calyxes; racemes terminal, and from the axils of the upper leaves, and much exceeding them; calycine segments ovate, acuminated, acute or lanceolate, one-half the length of the corolla; ovarium downy. $h_{2}$. S. Native of Brazil, within the tropic. Andrómeda serrulàta, Cham. et Schlecht. in Linnæa, 8. p. 506 . Corollas scarlet, with obtuse spreading teeth.

Serrulated-leaved Agarista. Shrub 2 to 3 feet.

14. A. Pistrix; branchlets bluntly angular; leaves on short petioles, ovate-cordate, acute in the young state, and obtuse in the adult state, always mucronate, coriaceous, marginated, clothed with fine white tomentum beneath, as well as the branchlets, inflorescence, and calyxes; racemes terminal and axillary, exceeding the leaves; calycine segments broad, ovate, acuminated, acute, spreading; corollas downy; ovarium clothed with white tomentum. 5.S. Native of Brazil. Andrómeda Pístrix, Cham. in Linnæa, 8. p. 508. Leaves 15 lines long. Corollas ovoid, coriaceous, scarlet, much larger than those of $A$. pulchra. Style woolly at the base.

Whale Agarista. Shrub.

15 A. chlora' Nтha; leaves on short petioles, ovate-cordate, obtuse, mucronate, coriaceous, olabrous, with revolute margins; branches, inflorescence, and calyxes downy; racemes terminal and axillary, a little longer than the leaves; calycine segments narrow-ovate, acuminated, or lanceolate, acute, longer than the third part of the corolla, which is ovoid-cylindrical; ovarium downy or villous, h. S. Native of Brazil. Andróneda chlorântha, Cham. in Linnæa, 8. P. 508. A box-like shrub, with the habit of $A$. Bracanorénsis and 1 . revolìla. Corollas white, green at the apex, glabrous.

Green-flowercd Agarista. Shrub 6 to 10 feet. ?

16 A. pulcue'tra; leaves on short petioles, cordate, ovateoblong, mucronate, marginated, rather coriaceous, flat, pubescent on the midrib beneath while young, as well as the petioles, branchlets, and inflorescence; racemes terminal and axillary, 3-8-flowered, a little longer than the leaves; flowers on long pedicels; calycine segments broad-ovate, acuminated, acute. 々. S. Native of Brazil. Andrómeda pulchélla, Cham. in Linnea, 8. p. 509. Like $A$. neriifôlia and $A$. púlchera, but differs much in the inforescence. Leaves $\frac{1}{2}$ inch long. Young branches angular. Racemes crowded at the tops of the branches.

Neat Agarista. Shrub.

17 A. PYRIYòiA ; leaves ovate, acuminated, quite entire, and

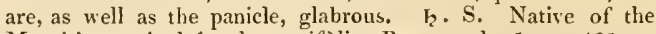
Mauritius. Andrómeda pyrifòlia, Pers. ench. 1. p. 481.Tree 20 feet ligh, with sulcately striated bark. Flowers obscure, purple.

Pear-lcaved Agarista. Tree 20 feet.

18 A. inicifolia ; leaves cordate, broad, coriaceous, slightly toothed; racemes axillary and terminal, crowded at the tops of the branches. $h$. S. Native of Peru. Andrómeda ilicif òlia, Pers. ench. 1. p. 481 . Leaves on short petioles, ovate and quite entire when young, but when larger and older furnished with a few distant teeth at the base.

Holly-leaved Agarista. Shrub.

$19 \AA$. ERIOPIYÝLA; leaves roundish-ovate, tomentose on both surfaces, and terminated by a gland, quite entire; racemes terminal, secund, bracteate; corollas ovate. $h_{2}$ G. Native of Brazil, on the mountains. Andrómeda eriophýlla, Vand. f. lus et bras. spec. Pers, ench. 1. p. 482.

Woolly-leaved Agarista. Shrub.

20 A.? anastomòsans; leaves ovate, subserratel, dotted beneath, with anastomosing veins; racemes axillary, glomerate. h.S. Native of New Granada. Andrómeda glomeràta, Cav. icon. 6. p. 42. Stem villous. Leaves rather veiny. Corollas glabrous. Bracteas longer than the peclicels.

Anastomosing Agarista. Shrub.

Cult. Agrarista is a genus of most showy and elegant shrubs, well worth the cultivator's care. Peat and sand is the best soil for them: and cuttings not too young will strike root in sand under a hand-glass, in a moderate heat. Although the species are said to require the stove, they would probably be better if treated as greenhouse plants.

XXXVIII. DIPLECO'SIA (from $\hat{\imath} \iota \pi$ isov, diplous, double, and $k \omega c$, kos, a covering; in reference to the double covering, the calyx and calyculns.) Blum. bijdr. 857 .

Lin. sysr. Decándria, Monogýnia. Calyx 5-cleft, girded by a calyculus at the base, which is composed of 2 combined bracteas. Corolla campanulate, with a 5 -cleft reflexed limb. Stamens 10, inclosed, inserted in the calycine disk; anthers bifid at the apex, the lobes undivided. Style erect; stigma truncate. Capsule subglobose, depressed, inclosed in the calyx, which is baccate, 5-celled, and dehiscing irregularly. Seeds ninmerous, cuneatcd, compressed, fixed to flesliy prominent receptacles.- Parasitical shrubs. Leaves scattered, coriaceous. Flowers solitary or in fascicles, axillary. Corollas pale-greenish. This genus is intermediate between Andrómeda and Gaulthèria. It differs from the latter in the structure of the corolla and anthers; and from the first in the baccate calyx and dehiscence of the fruit.

I D. PILòsa (Blum. bijdr. 858.) leaves ovate-lanceolate, acuminated, strigose above and pilose beneath, as well as the branchlets; pedicels solitary or twin. $\tau_{i} . S$. Native of Java, on Mount Salak, in woods, where it is called by the natives Fila Ge Daijbula.

Pilose Diplecosia. Shrub.

2 D. LAtifolia (Bham. l, c.) leaves oval, acutish at both ends, with recurved margins, glabrous; pedicels fascicled. $h$. S. Native of Java, upon trees on the mountains.

Broad-leaved Diplecosia. F]. Year. Shrub par. 
3 D. heterophy'lua (Blum. I. c. p. 858.) leaves oblong or lanceolate, acuminated at botl 2 ends, nearly veinless, glabrous, dotted beneath; pedicels fascicled. $h_{2} . S$. Native of Java, on the higher mountains, on the west side of the island.

lar. $\beta$; leaves cuneate-oblong, acutish or obtuse.

I ariable-leared Diplecosia. IJ. Year. Shrub par.

Cult. For culture and propagation, see Agarista, p. 838.

XXXIX. GAULTHE'RIA (so named by Kalm, from Gaulthier, a plyysician and botanist of Canada). Lin. gen. no. 551 . Schreb. 449. Gartn. fruct. 63. Juss. gen. p. 161. R. Br. prod. p. 559 . H. B. et Kuntl. nov. gen. amer. 3. p. 282.

Lin. syst. Decándria, Monogýnia. Calyx 5-cleft. Corollat ovate, with a short 5 -cleft limb (f. 140. h.). Stamens 10, inclosed; anthers bifid at the apex; lobes biaristate (f. 140.e.). Style 1; stigma obtuse. Hypogynous scales 10 , obsolete or connate at the base. Capsule depressedly globose, 5 -celled, 5 -furrowed, covered by the calyx, which is sometimes baccate; valves scptiferous in the middle. Placentas adnate to the base of the colurnn. Seeds numerous, covered by a reticulated testa.Sinall trees or shrubs. Leaves alternate. Flowers axillary and terminal, racemose, rarely solitary ; pedicels bibracteolate. Corollas white, rose-coloured, or scarlet. Filaments usually hairy.

* Flowers axillary, solitary. Peduncles or pedicels besct with some imbricatcd bractcas at the base.

1 G. Procu'mbens (Lin. spec. 565.) stem procumbent ; branches erect, naked at bottom, but with crowded leaves at top; leaves obovate, acute at the base, finely and ciliately toothed; flowers few, terminal, nutant. $\zeta$. H. Native of Nortl America, in dry woods, on mountains, and in sandy plains from Canada to Virginia. Andr. bot. rep. 116. Kalm. amon. 3. p. 14. t. 1. f. 6. Duham. arb. 1. p. 286. t. 113. Lodd. bot. cab. t. 82. Sims, bot. mag. 1966.-A little shrubby plant, resembling seedling plants of Kalmia latifolia. Flowers white. Berries red, eatable, and known by the name of partridge berries. The leaves, if properly cured, make a most excellent tea, for which reason it is likewise known by the name of Mountain Tea.

Procumbent Gaultheria. Fl. July, Sept. Clt. 1762. Shrub $\frac{1}{2}$ foot, procumbent.

2 G. RE'PENS (Blum. bijdr. p. 857.) stem creeping, rather pilose; leaves minute, rather pilose beneath, ovate, acute, coriaceous ; peduncles axillary, 1-flowered. h.G. Native of Java, on the top of Mlount Gede.

Creeping Gaultheria. Fl. Year. Shrub.

3 G. nummularioidfs (D. Don, prod. f. nep. p. 150.) branches filiform, procumbent, very bristly; leaves cordate, mucronulate, nearly sessile, naked above, but hispid from hairs beneath and on the margins; pedicels axillary, very short, solitary. h. H. Native of Nipaul, on the Alps. Shrub much branched. Flowers drooping. Pedicels and calyxes glabrous. Calycine segments broad-ovate, mucronulate, with connivent margins. Corolla ovate, longer than the calyx.

Money-wort-like Gaultheria. Shrub procumbent.

4 G. Buxifòlı (Willd. in nov. act. berol. vol. 4.) stem erect; branches hairy; leaves roundish-ovate, obtuse, toothed, coriaceous, scabrous from dots beneath; pedicels filiform. $\zeta . S$. Native of Caraccas. Branches hairy, erect.

Box-leaved Gaultheria. Shrub.

5 G. anastomósans (R. Br. prod. p. 559. H. B. et Kuntl, nov. gen. amer. 3. p. 283.) branches, margins, and under sides of leaves, clothed witl bristly hairs; leaves ovate, acute, crowded at the base, obsoletely denticulated, shining above ; flowers axillary, solitary, pedicellate. $々 . G$. Native of New
Granada, near Santa Fe de Bogota. Andrómeda anastomòsans, Lin. suppl. 237. Willd. spec. 2. p. 611. Vent. Choix, t. 53. Pedicels pilose, furnished with $5-7$ imbricated bracteas at the base. Corollas ovate, glabrous, white.

Anastomosing Gaultheria. Slirub.

6 G. purpura'scens (H. B. et Kunth, nov. gen. amer. 3. p. 282.) procumbent? branchlets and leaves clotlied with bristly hairs; leaves elliptic-oblong, acute at both ends, serrulated, 1nerved, purplislı beneatı; flowers axillary, solitary. 々. G. Native of New Granada. Hairs or bristles dark purple. Leaves green above. Peduneles or pedicels bracteate at the base. Fruit drooping.

Purplish -leaved Gaultheria. Shrub procumbent.

7 G. Myrsinoides (11. B. et Kunth, l. c. p. 283.) branches and leaves glabrous; leaves oblong, acute, obtuse at the base, crenated at top, slining above; flowers axillary, solitary. $h$. G. Native of New Granada, near the town of Almaguer. Branchlets angular. Peduncles downy, furnished with imbricated bracteas at the base. Corollas ovate-globose, glabrons, white.

\section{Myrsinc-like Gaultheria. Shrub.}

8 G. myrtilloides (Cham. et Schlecht, in Linnæa. vol. 1. p. 523.) branches beset with bristles, as well as the under sides of the leaves and calyxes; leaves broad-lanceolate, with the margins ciliately serrulated and somewhat reflexed; flowers axillary, solitary, on short pedicels near the tops of the branches. $\zeta_{2}$. G. Native of Brazil, within the tropic. Scales at base of pedicels ciliated. Corolla urceolate, pilose inside, glabrous outside, with reflexed teeth. Filaments dilated at base.

Myrtle-like Gaultheria. Slirub to 1 foot.

9 G. cilia'ta (Cham. et Schlecht, in Linnaa. 5. p. 126.) shrubby, glabrous; flowers axillary, solitary; peduncles downy, bracteolate at the base; leaves coriaceous, nearly sessile, lanceolate, acute, sharply serrulated : teeth setigerous in the young state. $々$. G. Native of Mexico, on Mount Orizaba, along with Solànum tuberòsum; and at Chiconquiaca and Malpays de Joya. Leaves $\frac{1}{2}$ inch long. Flowers white. Berries black.

\section{Ciliated-leaved Gaultheria. Shrub.}

* Racemes axillary and terminal at the tops of the branches. Pedicels bibracteate.

10 G. Sirálion (Pursh. f. amer. sept. 1. p. 283. with a figure); procumbent, hairy; leaves ovate, subcordate, serrated, glabrous on both surfaces; racemes secund, bracteate, clothed with rusty down. h. H. Native of North America, on the falls of the Columbia, and near the Western Ocean. Hook. bot. mag. t. 2843. Lindl. bot. reg. 1411. Lodd. bot. cab. 1372. Branches warted, clothed with rusty down while young. Leaves broad, abruptly acuminated. Pedicels scaly. Corolla white, tinged with red, lowny, urceolate, with a closed limb. Berries globose, acute, fleshy, purple. - This plant grows in the shade of close pine forests, where hardly any thing else will grow, which makes it a very desirable shrub for plantations. The berries of the Shallon are much esteemed by the natives, on account of their agreeable flavour. 


\section{bent.}

II G. fragrantíssima (Wall. in asiat, res. 13. p. 297, with a figure); branchlets glabrous, rather triquetrous; leaves ellipticoblong, acute, crenulated, glabrous, attenuated at the base; racemes axiliary, solitary, erect, downy, $\zeta . F$. Native of Nipaul, at Narainhetty. G. fràgrans, D. Don, prod. fl. nep. 151. A'rbutus laurifolia, Hamilt. mss. Leaves coriaceous, reticulately veined, $2-4$ inches long. Racemes shorter than the leaves. Bracteas ovate-oblong, concave, equal in length to the pedicels. Calycine segments ovate, acute. Corollas oblong, silky, drooping a little, pale red, very sweet scented. Shrub much branched.

I'ery fragrent Gaultheria. Clt. 1824. Shrub.

12 G. pUncta'ta (Blum. bijdr. p. 856.) leaves lanceolate, terminated by a gland, serrated, dotted beneath, glabrous as well as the branches; racemes panicled, terminal; calyxes ciliated. $\zeta_{c}$. G. Native of Java, very common on the top of Mount Gede, where it is called by the natives Tjatagie-nangie.

Dotted-leaved Gaultheria. Shrub.

13 G. LEvcocA'RPA (Blum. bijdr. p. 856.) branches and leaves glabrous; leaves ovate-oblong, long-acuminated, bluntly serrated; racemes axillary and terminal, drooping; calyxes a little ciliated. r.G. Native of Java, in woods on the higher mountains, where it is called $Z$ antigi badas by the natives.

White-fruited Gaultheria, Fl. Year. Shrub.

14 G. Sprenge'Lu; leaves oblong, rounded at both ends, callous at the apex, quite entire, with revolute edges, hispid on both surfaces; branches hairy ; racemes terminal, straiglit, secund, clothed with clammy hairs. where it was collected by Sello. G. híspida, Sprengel, syst. 2. p. 288. but not of R. Br.

Sprengel's Gaultheria. Shrub.

15 G.? bRACTEA'ta; branches beset with rusty hairs; leaves ovate-acute, obscurely denticulated, shining above and rusty beneath; racemes terminal, simple; corollas and calyxes hairy. $\eta$.G. Native of Quito, near the Crater of 'Tunguragua, and on Mount Chimborazo. Andrómeda bracteàta, Cav, icon. 6. p. 42. t. 562. f. 1. Hairs on the under side of the leaves, bulbous at the base. Leaves $1 \frac{1}{2}$ inch long, and I inch broad. Bracteas at the base of the pedicels concave, ovate-acute, and the pedicels are bibracteolate. Stamens 10, villous; anthers biaristate at the base. Corollas tubular, pale red, with erect ovate-acute teeth.

\section{Bracteate Gaultheria. Shrub $1 \frac{1}{2}$ foot.}

16 G. elLíptica (Cham. in Linnæa. 8. p. 502.) racemes, corollas, and capsules, downy; bracteas and calyxes ciliated, the rest of the plant glabrous; leaves elliptic, acute at both ends, mucronate, marginated, rather coriaceous, finely and equally serrulated, smooth and shining above, and beset with black dots beneath, reticulately veined; racemes terminal and axillary, forming a panicle; bracteas ovate-orbicular, obtuse, concave, at first imbricated, and therefore the racemes appear strobile-formed. b.S. Native of the south of Brazil, where it was collected by Sello. Very like G. acuminàta, Cham. in Linnæa, 5. p. 126. and G. vernàlis, Poepp. pl. chil. exsic. 3. no. 119. Prostrate and rooting. Corollas ovate-urceolate, inflated, downy outside and villous inside.

Elliptic-leaved Gaultheria. Shrub creeping.

17 G. acumina'ta (Schlecht, et Clam. 5. p. 126, and 7. p. 524.) shrubby, glabrous; flowers racemose, axillary; leaves on short petioles, ovate, acuminated, acute, finely serrulated, coriaceous, reticulately veined, discoloured, full of black dots beneath, but scabrous on both surfaces from elevated dots; serra-

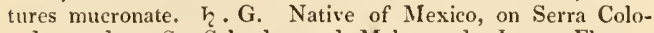
rado; and at St. Salvador and Malpays de Joya. Flowers white. Fruit black. Leaves $3 \frac{1}{2}$ inclies long.
Acuminatcd-leaved Gaultheria. Shrub.

I8 G. reticula'ta (H. B, et Kunth, nov, gen. 3. p. 284.) branches and leaves glabrous; leaves oblong, acutish at both ends, serrulately crenulated, shining above; racemes crowded at the tops of the branches, axillary and terminal; corollas glabrous. $\zeta$. G. Native of the Andes of Quito, between Ona and Loxa, in Paramo de Saraguru. Andrómeda reticulàta, Humb. prol. p. 39 . Leaves terminated by a sessile gland, shining alove. Racemes involucrated by some bracteas at the base, downy. Corolla ovate, tubular, white, glabrous. Fruit capsular.

Reticulatcd-leaved Gaultheria. Shrub.

19 G. coccíneA (H. B. et Kunth, l, c. p. 284.) branches rather pilose; leaves roundish-ovate, acutish, rounded at the base, denticulated, glabrous, shining above and dotted beneath; racemes terminal and axillary at the tops of the branches; corollas clothed with glandular hairs. $\eta$. S. Native of Caraccas, on Mount Avila. Andrómeda coccínea, Humb. prol. p. 39. Leaves witl black dot-like glands beneath. Racemes involucrated by imbricate bracteas at the base. Flowers secund, on long pedicels; pedicels clothed with glandular hairs. Bracteas at the base of the pedicels concave, coloured, glandularly ciliated. Corollas ovate, scarlet, clothed with glandular hairs. Fruit capsular.?

Scarlet-flowered Gaultheria. Shrub.

20 G. ODORA'ta (Humb. trav. 1. p. 397. and 599. nov. gen. 3. p. 285. Pers. ench. 1. p. 482.) branchlets beset with glandular viscid hairs; leaves ovate-oblong, acuminately cuspidate, cordate at the base, sharply denticulated, glabrous and shining above, and scabrons from dots beneath; racemes axillary and terminal at the tops of the branches; corollas pilose. $h$. S. Native of New Andalusia, on Mount Tumiriquiri ; and on the southern declivity of Mount Silla de Caraccas, where it is called Pejoa by the natives; and of Mexico, at Cuesta Grande de Chiconquiaca. G. scabra, Willd. herb. Shrub much branched. Leaves aromatic, 2 inches long, glandularly ciliated while young. Racemes involucrated by some bracteas at the base. Flowers secund, nutant. Pedicels beset with glandular hairs as well as the rachis. Bracteas red, lanceolate, length of pedicels. Corollas orate, pale red. Fruit capsular.

Sneet-scented Gaultheria. Shrub 4 to 5 feet.

21 G. CORDIFóliA (H. B. et Kunth, nov, gen. amer. 3. p. 285. t. 261.) branchlets clammy, hispid ; leaves ovate, acute, cordate, denticulated, rngose, glabrous and shining above, but hairy beneath; racemes axillary and terminal at the tops of the branches; corollas clothed with clammy hairs. $\zeta$. G. Native of New Granada, on the Andes near Almaguer and Pansitara, in rather frigid places. Branches twining, ex Bonpl. Leaves $3 \frac{1}{2}$ inches long. Pedicels and fowers beset with glandular hairs and clammy. Bracteas oblong, acute, concave, ciliated with glandinlar hairs, and clothed with adpressed hairs outside, longer than the pedicels. Calyx clammy, clothed with glandular hairs. Corollas ovate, scarlet or purple.

Heart-leaved Gaultheria. Shrub.

22 G. RíGIDA (H. B. et Kunth, l. c. p. 286.) branchlets puberulous; leaves ovate-oblong, acute, cordate at the base, sharply denticulated, glabrous, but a little ciliated; racemes axillary and terminal at the tops of the branches; corollas glabrous. $\zeta . S$. Native of the province of Cumana, on Mount Cocollar. And̀rómeda rígida, Humb. trav. p. 397. Leaves terminated by a sessile gland. Racemes involucrated by many imbricated bracteas. Bracteas oblong, concave, ciliated, glabrous, colourcd, longer than the pedicels. Pedicels and rachis downy. Corollas ovate, scarlet.

Stiff Gaultheria. Tree small.

23 G. tomentosa (H. B. et Kunth, 1. c. p. 287. t. 262.) 
branclies and under sides of leaves elothed with rusty tomentum; leaves glabrous and shining above, lanceolate-oblong, acute, obtuse at the base, with quite entire revolute margins; racemes axillary and terminal at the tops of the branches; corollas tomentose. $h$. S. Native of the Andes, about Quito, in Paramo de Saraguru, Leaves tomentose on both surfaces while young. Pedicels and calyxes clothed with rusty down. Bracteas tomentose, ovate-oblong, much shorter than the pedicels. Corolla ovate.

Tomentose Gaultheria. Tree 10 to 15 feet.

24. G. Ferrugísea (Cham, et Schlecht, in Linnæa, 1. p. 524.) leaves ovate, acute, shining above, with serrulately scabrous margins, clothed with rusty tomentum beneath, as well as the

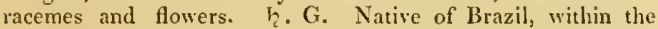
tropic. Leaves often cordate at the base. Racemes bracteate, crect, rising from the axils at the tops of the branches, the whole forming a panicle. Corolla 3 lines long, with erect teetl.

Rusty Gaultheria. Shrub.

25 G. scA'bra (Willd, in nov. act. soc. berol. 4.) leaves ovatecordate, acute, toothed, scabrous, reticulately veined beneath ; racemes axillary, simple; caly $\mathrm{x}$ and bracteas clothed with glandular hairs. $\xi$. S. Native of Caraccas. Calyx baccate, black.

\section{Scabrous Gaultheria. Shrub.}

26 G. ERE'CTA (Vent. hort. cels, p. 5. t. 5.) leaves ovate, mucronate, clothed with rusty hairs; branches and racemes clothed with glandular clammy liairs. Ђ. G. Native of Peri. Leaves with revolute denticulated margins.

Erect Gaultheria. Shrub.

27 G. Hísrida (R. Br.prod. p. 559.) leaves long-lanccolate, serrulated, pilose beneath as well as on the petioles; branchlets hispid; racemes axillary and terminal, slıorter than the leaves; rachis and pedicels downy; calyxes baccate ; fruit and ovaries glabrous; stem erect. $\bar{\zeta}$. F. Native of Van Diemen's Land. Corollas white.?

Hispid Gaultheria. Shrub erect.

28 G. RUPE'STRIS; racemcs simple, bracteate; corollas campanulate; leaves oblong, serrulated. $\zeta$. F. Native of New Zealand. Andrómeda rupéstris, Forst. prod. no. 195. Nearly allied to the preceding.

Rock Gaultheria. Shrub erect.

29 G. Antipòd (Forst. prod. no. 186.) leaves roundishovate, serrate-toothed, glabrous, reticulately veined; branches downy ; stem diffuse; racemes panicled, rather hairy; corollas

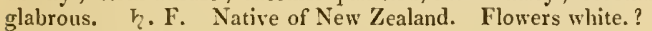

Antipodal Gaultheria. Shrub.

Cult. 'The species are ornamental : they thrive best in a peat soil, and are readily increased by dividing or by layers. The greenhouse species should be treated as other bardy greenhouse shrubs.

XL. EPIGA'A (from $\varepsilon \pi \iota, e p i$, upon; and yaıa, gaia, the earth: the plant creeps upon the surface of the earth). Lin. gen. no. 550. Schreb. gen. no. 240 . Nutt. gen. amer. 1. p. 269.-Menècylum Mich. gen. 13.

Lin. srst. Decándria Monogýnia. Calyx large, 5-parted, furnished with 3 bracteas at the base. Corolla salver-shaped, with a 5-parted spreading limb; tube villous inside. Stamens 10. Capsule 5-celled, many-seeded. Placenta 5-parted.Creeping, tufted, evergreen shrubs. Flowers fragrant, in dense, axillary, and terminal racemes.

1 E. RE'PENS (Lin. spec. 565.) branches, petioles, and nerves of leaves very hairy; leaves cordate-ovate, quite entire; corollas cylindrical. h. H. Native from Canada to Carolina, on shady rocks and in stony woods, sides of hills and roots of pines. Andr, bot. rep. 102. Lam, ill. t. 367. f. 1. Lodd. voL. III. bot. cab. 160.-Pluk. alm. t. 107. f. 1. Flowers white, tinged with red, very fragrant.

Crecping Epigaea. Fl. May, July. Clt. 1796. Shrub crepping.

2 E. condifòlia (Swartz, prod. 73. fl. ind. occ. 2. p. 842.) stem erectish, strigose; leaves cordate, roundish, stiff, hispid, serrated, convex; corollas ovate, দ2. S. Native of Guadaloupe and Cayenne. Lam. ill. t. 367 . f. 1. Flowers white.?

Ileart-leacel Epigiea. Shrub erectish.

Cult. $E$, rèpens is a beatiful procumbent shrub: it will thrive only in peat soil and shady situations, and, being rather tender, should have a hand-glass or frame placed over it in frosty weather; indeed, it grow's best under a liand-glass or frame the whole year: it is increased by layers or separating the rooted shoots; or by cuttings, which root readily in sand with a hand-glass over them. For the culturc of $E$. cordifólia see $A$ garista, p. 838 .

XLI. l'HALEROCA'RPUS (from $\phi \mathbf{a} \lambda \eta p o s$, phaleros, white, and карлоs, karpos, a fruit ; in reference to the colour of the berries). Vaccínium, Lin. Gaulthèria, Pursh. Oxycóccus, Nutt. A'rbutus, Lam.

Lin. sysr. Octándria Monogy'uia. Calys 4-cleft, bibracteate at the base. Corolla short, campanulate, 4-cleft. Stamens 8 ; filaments hairy.? Hypogynous disk 8-toothed.? Anthers semibifid. - A small creeping plant with hispid branches, small, roundish-oval, acute leaves; and axillary, solitary, nearly sessile, white? flowers. Habit of Wild Thyme.

I P. serpylifólia; $\zeta_{2}$. H. Native from Canada to Pennsylvania. Mr. Nuttall has observed this plant north-westward of Lake Michigan; and, as Mr. Pursh very justly remarks, abounding where evergreens are predominant, keeping pretty constant pace with the northern forests of pines, larches, and firs, growing always amidst sphagnum. Vaccínium hispídulum, Lin. spec. 500. Michx. fl. 6. bor. amer. 1. p. 228. t. 23. Gaulthèria serpyllifúlia, Purslı. fl. amer. sept. 1. p. 283. t. 13. A'rbutus filiformis, Lam. dict. 1. p. 228. Berries white, produced in inconsiderable quantities. They are aromatic, not very acid, and rather insipid than agreeable. The slurub has the same aromatic taste and smell as Gaulthèria procúmbens.

Hild Thyme-lcaved Snowberry. F]. April, May. Clt. 1815. Shrub creeping.

Cult. See Oxycóccus, p. 858, for culture and propagation.

XLII. CLE'THRA (from $\kappa \lambda \eta \theta \rho a$, klethra, the Greek name of the alder; resemblance in leaves). Lin. gen. no. 553. Schreb. gen. 751. Gærtn. fruct. 1. p. 301. t. 63. Juss. gen. 160. Gron. 43. Nutt. gen. 1. p. 275. H. B. et Kunth, nov. gen. amer. 3. p. 288.-Cuellària, Ruiz et Pav. syst. 103.

Lin. syst. Decúndria, Monogýnia. Calyx 5-parted. Corolla so deeply 5 -parted as to apjear pentapetalous. Stamens 10 , inclosed, or nearly so ; anthers behind, at length inflexedly pendulous and obverse, cordatc, mucronate at the apex, mutic. Ovarium free. Style straight. Stigma trifid. Capsule girded by the calyx, 3-celled, with a loculicidal dehiscence; cells manyseeded.--Shrubs or trees. Leaves alternate. Racemes terminal, solitary or panicled. Flowers bracteate, white.

1 C. ALnjfòdı (Lin. spec. 566.) leaves cuneate-obovate, acute, coarsely serrated above, glabrous on both surfaces, and of the same colour; racemes spicate, simple, bracteate, clothed with hoary tomentum. h. H. Native from New England to Virginia, in swamps, frequent. Schmidt, arb. 47. Lam. ill. 369. Duh. arb. 1. p. 176. t. Tl. Mill. fig. 28. Catesb. car. 1. t. 66. C. alnifölia, var. a, denudàta, Ait. hort. kew. 2. p. 73.

Alder-leaved Clethra. Fl. July, Sept. Clt. 1731. Shrub $s$ to 4 feet.

$$
5 \mathrm{P}
$$


2 C. tomentòsa (Lam. dict. 2. p. 46.) leaves cuneate-obovate, acute, finely serrated at top, clothed with white tomentum beneath; racemes spicate, simple, bracteate, villously tomentose. h.H. Native of Virginia and Carolina, in swamps. Wats. dend. brit. t. 39. C. alnifòlia, $\beta$, pubéscens, Ait. hort. kew. 2. p. 73. C. incàna, Pers, ench. 1.p. 482. This is a very distinct species, although it has been considered by some as a mere variety of the preceding.

Tomentose Clethra. Fl. July, Oct. Clt. 1731. Shrub 3 to 4 feet.

8 C. sca'bra (Pers. ench. 1. p. 482.) leaves broad, cuneateobovate, acute, scabrous on both surfaces, coarsely serrated: serratures hooked; racemes spicate, subpanicled, bracteated; finely tomentose. $h$. H. Native of the western parts of Georgia, where it was collected by Mr. Lyon. feet.

Seabrous Clethra. Fl. July, Oct. Clt. 1806 . Shrub 3 to 4

4 C. ranicula'ta (Ait. hort. kew. 2. p. 73.) leaves narrow. cuncate-lanceolate, acute, acuminately serrated, glabrous on both surfaces; panicle terminal, elongated, composed of racemes, and clothed with white tomentum, $々$. H. Native of Carolina.

Panicle-flowered Clethra. Fl. July, Oct. Clt. 1770. Shrub 3 to 4 feet.

5 C. Acomina'ta (Michx. f. amer. bor. 1. p. 260.) leaves oval, acuminated, bluntish at the base, serrated, glabrous on both surfaces, rather glaucous beneath; racemes spicate, almost solitary, bracteate, clothed with white tomentum. $\downarrow . H$. Native of Carolina, on the high mountains. Lodd. bot. cab. 1427. C. montàna, Batr. cat. Grows to the size of a tree. Flowers resembling those of $C$. alnifólia.

Acuminated-leaved Clethra. Fl. July, Oct. Clt. 1806. Tree 10 to 15 feet.

6 C. Brasicie'nsis (Cham. in Linnæa. 8. p. 510.) leaves obovate, obtuse, rather retuse, acutish at the base, cuneated, gla. brous above and tomentose beneath, almost quite entire, or serrulately-toothed at the apex: teeth and apex mucronate; racemes forming panicles at the tops of the branches, tomentose; segments of corolla fringed; genitals inclosed. h.S. Native of tropical Brazil. The leaves vary much in form and size. Tomentum of a rusty-colour.

Brasilian Clethra. Shrub or tree.

7 C. FAGifòlı (H. B. et Kunth, nov, gen, amer. 3. p. 289.) arboreous; leaves obovate, sharply and remotely toothed, coriaceous, glabrous; racemes clustered at the tops of the branches. 々. S. Native of South America, in woods near Bonavista, between Caraccas and La Victoria. Young branches angular, and densely clothed with rusty down. Leaves 3-4 inches long, paler beneath. Racemes clothed with rusty tomentum. Co. rollas white, about the size of those of the Jily of the valley.

Beach-leaved Clethra. Tree.

8 C. Bícolor (H. B. et Kunth, 1. c. p. 289.) arboreous? leaves oblong, coarsely and undulately crenated, coriaceous, glabrous above, but clothed with white tomentum beneath; racemes in fascicles at the tops of the branclies. h. S. Native of South America, near Santa Fe de Bogota. Cuellària floribuinda, Willd. herb. Branchlets angular, clothed witl rusty down, intermixed with stiff hairs, as well as the racemes. Leaves $3-4$ inches long, having the teeth intermixed with glandformed denticulations, while young having a few dot-formed stellate hairs above. Corollas white.

Tno-coloured-leaved Clethra. Tree.

9 C. mimbriatia (H. B. et Kunth, l. c. p. 290. t. 264.) arboreous; leaves elliptic-oblong, quite entire, coriaceous, glabrous above, but clothed with white tomentum beneath; racemes in fascicles at the tops of the branches; stamens hardly inclosed.
々. S. Native along with the preceding. Cuellària rugòsa, Willd, herh. Branches glabrous, brown. Flowers sub-secund, nutant, about the size of those of $C$. alnifolia. Pedicels, calyxes, and rachi clothed with rusty tomentum. Corolla white, having the segments emarginately 2 -lobed, and laciniately fringed at the apex.

Fringcd-flowercd Cletlıra. Tree.

10 C. Ferrugínea (Ruiz, et Pav. fl. per. vol. 4. t. 980 . f. b.) leaves oblong, quite entire, acuminated, excavated at the base. h. G. Native of Perı, on the mountains of Pillao, Panao, and Chinchao, in groves. Cuellària ferrugínea, Ruiz et Pav. syst. p. 103. Branches, leaves, and racemes clothed witl rusty hairs. Racemes simple, fascicled at the tops of the branches. Flowers rather large.

Rusty Clethra. Clt. 1800 . Tree 15 feet.

11 C. obova'ta (Ruiz et Pav. fl. per. 4. t. 381.) leaves obovate, wrinkled, denticulated. $h$. G. Native of Peru, in forests about Cuchero. Cuellària obovàta, Ruiz et Pav. syst. p. 103. Racemes long, fascicled at the tops of the branches. Branches and leaves downy. Flowers small.-A tall tree. The wood is very hard, and is made into utensils by the natives.

Obovate-leaved Cletlira. Tree tall.

12 C. Revolu'ta (Ruiz et Pav. fl. per. 4. t. 380. f. a.) leaves oblong, denticulated, revolute and excavated at the base. $\eta$. G. Native of Peru, in forests towards Pillao. Cuellària revolùta, Ruiz et Pav. syst. p. 103 . Branches, leaves, and racemes downy. Racemes simple, fascicled at the tops of the branches.

Revolute-leaved Clethra. Tree 30 feet.

13 C. cane'scens (Herb. Reinwdt. ex Blum. bijdr. p. 863.) leaves cuneate-oblong, acute, serrulated at the apex; panicle terminal, clothed with canescent scurf; calycine segments ovate, acute. $h . G$. Native of the Celebes, in woods, on the mountains. Caneseent panicled Clethra. Fl. Sept. Shrub.

14. C. Tinifonıa (Swartz, fl. ind. occ. 2. p. 84.5.) arboreous; leaves oblong-lanceolate, quite entire, hoary beneath; racemes spike-formed, panicled at the tops of the branches, tomentose. h. G. Native of the south of Jamaica; also of Mexico, near Chiconquiaco. Tínus occidentàlis, Lin. spec. 530. Volkamèria, P. Browne, jam. 214. t. 21. f. 1. Sloan. jam. 2. p. 86. t. 198. f. 2. Flowers white. Sloane calls this tree Bastard Locust tree.

Laurestine-leaved Clethra. Clt. 1825. Tree 12 to 14 feet.

15 C. Arbòrea (Ait. hort. kew. 2. p. 73.) leaves oblong, attenuated, lanceolate, glabrous on both surfaces, serrated; racemes spike-formed, panicled at the tops of the branches; calycine segments obtuse. h.G. Native of Madeira. Sims; bot. mag. 1057. Flowers white. There are several varieties of this species; a smaller variety, and a variegated-leaved one.

Tree Clethra. Fl. Aug. Oct. Clt. 1784. Tree 8 to 10 feet.

Cult. All the species of this genus are very ornamental. The hardy kinds thrive best in peat earth, or a very light sandy loam : they are dwarf slirubs, and are therefore well fitted for the front of shrubberies, where the soil will suit. By layers is the usual mode of increasing them, but they also strike root readily from euttings in sand under a hand-glass. The greenhouse kinds are well adapted for large conservatories, and they thrive in the same kind of soil recommended for the hardy species. Cuttings taken from wood not too ripe will strike root readily in sand under a hand-glass. All may be raised from seeds, which in most of the species ripen in plenty.

\section{Tribe II.}

RHODO'REE (so called because the genera contained in it agree with Rhodora, or Rhododendron, in particular characters). 
D. Don, in edinb. phil. journ. 17. p. 152. Rhodoràceæ, Juss. gen. 158. Anthers 2-celled. Ovarium free. Hypogynous disk nectariferous, rarely ornamented with scales. Buds strobilelike from imbricated scales. Leaves flat, having the extremity of the midrib callous.

XLIII. RHODODE'NDRON (from jocos, rhodon, a rose, and $\delta \varepsilon v \delta \rho o v, d c n d r o n$, a tree ; in reference to the terminal bunches of flowers, which are usually red). Lin. gen. no. 548. Schreb. gen. no. 746. Gærtn. fruct. 1. p. 304. t. 63. Juss. gen. 158. D. Don, in edinb. phil. journ. prod. f. nep. p. 152.-Azàlea species of authors.-lihodòra, Lin.-Chamærhododendros, Tourn. inst. $t .373$.

LiN. syst. Penta-Dccándria, Monogýnia. Calyx 5-parted. Corolla somewhat funnel-shaped, or campanulate; rarely rotate or 5-parted; limb 5-cleft, somewhat bilabiate; upper lip the broadest, and usually spotted. Stamens 5-10, usually exserted, declinate; anthers opening by 2 terminal pores. Capsule 5 -celled, 5 -valved, rarely 10 -celled and 10 -valved, as in $R$. arbòreum, with a septicidal dehiscence at the apex. Placentas simple, angular. Seeds compressed, scobiform, winged.--Slurubs or trees, usually evergreen. Leaves alternate, quite entire, terminated hy a spacelate apex, or yellow gland. Flowers terminal, corymbose, showy.

Sect. I. Pónticum. Limb of calyx short, 5-lobed. Corolla campanulate. Stamens 10 . Ovarium 5-celled.-Leaves coriaceous, evergreen.

1 R. Pónticus (Lin. spec. 562.) leaves oblong-lanceolate, glabrous on both surfaces, attenuated towards the thich petioles, with a streak on the upper surface, of a wide lanceolate form; racemes short, corymbose. $\zeta$. H. Native of Asia Minor, at Pontus ; and of Gibraltar, Iberia, and Caucasus, in wet places in beech and alder coppices. Pall. fl. ross. 1. p. 43. t. 29. Jacq. icon. rar. 1. t. 78. Lam. ill. 364. Curt. bot. mag. 650. Leaves sometimes becoming ferruginous beneath. Corolla purple, large, with ovate, acute, or lanceolate segments. Calyx minute, 5toothed, somewhat cartilaginous. This is a very common plant, of which there are a great many varieties. The most remarkable are those with white, red, or bluish flowers, and striped leaves. Tournefort has related that the flowers of this species were reputed to impart a noxious quality to honey; this Güldenstadt contradicts, and imputes it to Azàlea Póntica.

Var. $\beta$, obtùsum (Wats. dendr. brit. t. 162.) leaves subcordate, coriaceous, obtuse; calyx very short, unequally and undulately crenated. $\eta$. H. Native of Pontus. Shrub 3-4 feet bigh. Flowers purple.

lar. $\gamma$, myrtifólium (Lodd. bot. cab. 908.) leaves small ; flowers purple. $\zeta$. H. Native of Gibraltar.

lar. \&, Smithii (Sweet, f. gard. n. s. t. 50.) leaves lanceolate, clotlied with white tomentum beneath; corymbs many-flowered; ovarium tomentose, 10-celled; flowers of a rosy purple, approaching to crimson, elegantly spotted with black. $々$.H. A hybrid, raised by $\mathrm{Mr}$. Smitl, of Coombe Wood, from the seed of $R$. Pónticum, impregnated by the pollen of $K$. arbòreum.

Pontic Rhododendron or Rose-bay. Fl. May, June. Clt. 1763. Shrub 6 to 12 feet.

2 R. мa'xisum (Lin. spec. p. 563.) arborescent; leaves elliptic-oblong, acute, convex, bluntish at the base, whitish or rusty beneath, glabrous; calycine segments oval-obtuse: segments of corolla roundish. $\boldsymbol{h}$. $\mathbf{H}$. Native from Canada to Carolina, on the mountains near rivulets and lakes. Sims, bot. mag. 951. Lam. ill. 364.-Schmidt, abr. t. 121.-Mill. fig. 229. -Catesb. car. 3. t. 17. f. 2. Flowers pale red, in umbellate corymbs, studded with green, yellow, or purple protuberances.

Largest Rhododendron or American Rose-bay. Fl. June, Aug. Clt. 1736. Shrub 10 to 15 feet.
3 R. PURPU'reus; arboreous; leaves large, oblong-clliptic, flattisl, acute, bluntish at the base, green and glabrous on both surfaces; segments of corolla oblong, obtuse. $h$. II. Native of Virginia and Carolina, on the lighest mountains, near lakes. R. máximum $\gamma$, purpùreum, Pursh, fl. amer. scpt. 1. p. 297. Flowers large, purple. Calycine segments obtuse. This slirub approaclies near to $R$. Pónticum, but it differs in its foliaceous calyx, and otherwise. It grows to an immense size; its stem is often found 18 inches and more in diameter, and its foliage triple the size of any other species.

Purple-flowered Rhododendron. FI. May, June. Clt.? Tree 20 feet.

4 R. Pu'rsuil: arborescent; leaves cuneate-lanceolate, flat, glabrous, tapering gradually to the base, paler beneatls; calycine segments oval, obtuse; segments of corolla roundishoblong. $h$. H. Native of New Jersey and Delaware, in shady cedar swamps. IR. máximum $\beta$, álbum, Pursh, fl. amer. sept. 1. p. 297. Flowers white, smaller than those of $R$. máximum.

Pursli's Rhododendron. Fl. June, Aug. Clt. 1811. Shrub 6 to 8 feet

5 R. Macrophy'Llum (D. Don, mss. in herb. Lamb.) leaves lanceolate, acute, glabrous on both surfaces, as well as the peduncles, rounded at the base; ovarium bristly. $\zeta . H$. Native of the north-west coast of America, where it was collected by Menzies. Petioles an incl long. Leaves 7-8 inches long. Flowers copious, smaller than those of $R$. máximum, white. Calycine lobes short, rounded. Filaments glabrous.

Long-leaved Rhododendron. Shrub.

6 R. Catawbiénse (Miclix. fl. hor. amer. 1. p. 258.) leaves short-oval, rounded, and obtuse at both ends, glabrous, of a different colour beneath; calycine segments elongated, oblong. h. H. Native on the high mountains of Virginia and Carolina, particularly on the head waters of the Catawba River. Sims, bot. mag. 1671. Lodd. bot, cab. 1176. Flowers purple, disposed in umbellate corymbs.

I ar. $\beta$, Russclliùnum (Sweet f. gard.n.s. t.91.) leaves oblong, finely tomentose beneath; corymbs many-flowered; flowers of a bright rosy red, approaching to crimson. $\zeta$. H. A hybrid, raised from the seed of $R$. Catambiense, impregnated by the pollen of $R$. arbòreum, by Mr. Russell, of Battersea.

Catawba Rhododendron. Fl. June, Aug. Clt. 1809. Slırub 4 feet.

7 R. BRACIYCA'RPUM (D. Don, mss. in herb. Lamb.) leaves elliptic-oblong, obtuse, clothed with rusty tomentum beneath, rounded at the base; ovaries 5 -celled, and are as well as the peduncles lairy.? . H. Native of Japan. Petioles half an inch long. Leaves 3 inches long. Calycine lobes very short, roundish, revolute, callous. Style elongated. Stigma clavate.

Short-fruited Rhododendron. Slorub.

8 R. chrysa'Nthus (Lin. syst. 405. suppl. 237.) leaves acutish, attenuated at the base, oblong, glabrous, reticulately veined, and of a rusty colour beneath; flowers and buds clothed with rusty tomentum; pedicels hairy ; calyx hardly any; segments of the corolla rounded; ovarium tomentose. h. H. Native of Siberia, on the lighest mountains, and of Caucasus. Pall. itin. append. p. 729. no. 87. t. N. f. 1-2. f. ross. 1. p. 44, t. 30 . Woodv. med. bot. 433 . t. 149. Plenk, 5 × 2
FIG. 14 I.

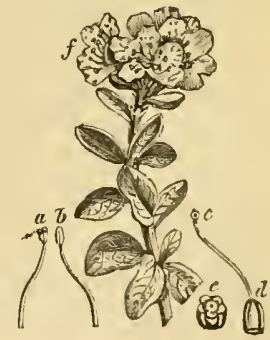


par. lond. t. 80.-Gmel. sib. 4. t. 54. R. officinàle, Salisb. p. 121, t. 54 . Branches decumbent, beset with rusty stipulaformed scales. Flowers handsome, large, drooping, revolute, rather irregular, yellow. Stigma 5 -lobed. The plant and its effects were first described by Gmelin and Steller, who mention it as used in Siberia for the cure of rheumatism: with us it is used in decoction as a substitute for Colchicum. (F. 141.)

Yellow-flowered Rhododendron. FI. June, July. Clt. 1796. Shrub $\frac{1}{2}$ to 1 foot.

9 R. Cadcásicum (Pall. fl. ross. 1. p. 46. t. 30.) leaves ovateoblong, clothed with rusty tomentum beneath, rugged and green above; peduncles hairy; bracteas elongated, tomentose; ovarium downy. h. H. Native of Caucasus, on high rocks, near the limits of perpetual snow. Sims, bot. mag. 1145. Root creeping. Branches procumbent. Flowers purple or white, disposed in umbellate corymbs. Corollas rotate, with wavy rounded segments.

Caucasian Rhododendron. F1. Aug. Clt. 1803. Shrub 1 foot.

10 R. runcta'tum (Andr. bot. rep. 36. Vent. ceis. t. 15.) leaves oval-lanceolate, acute at both ends, glabrous, beset with rusty resinous dots beneath; pedicels short; calycine teeth short; segments of corolla ovate, a little undulated. $h . H$. Native of Carolina, on the mountains, particularly on the head waters of the Savannah River. Sims, bot. mag. 2285. R. ferrugíneum, var. minus, Pers. ench. 1. p. 478. R. mìnus, Michx. fl. bor. amer. 1. p. 258 . R. punctàtum, var. minus, Wats. dendr. brit. 162. A. An elegant slirub. Flowers pink, disposed in umbellate corymbs. Corollas funnel-shaped. Capsules elongated.

$\operatorname{Var} . \beta$, majus (Ker. bot. reg. 37.) leaves and flowers larger.

Dotted-leaved Rhododendron. Fl. July, Aug. Clt. 1786. Shrub 4 feet.

11 R. Ferrugíneum (Lin. spec. 562.) leaves oblong, attenuated at both ends, glabrous, shining and green above, but thickly beset with rusty dots beneath; calycine segments dentately ciliated. h. H. Native of the Alps of Europe, as of Switzerland, Austria, Savoy, Dauphiny, and Piedmont, where this and $R$. hirsùtum terminate ligneous vegetation, and furnish the shepherds with their only fuel. Jacq. obs, 1. p. 26. t. 16. A. austr. 3. t. 255. Lodd. bot. cab. 65.-Lob. icon. 366. Leaves like those of the box-tree, when young ciliated with a few hairs at bottom. Flowers of a beautiful rose-colour or scarlet, disposed in umbellate corymbs, marked with ash-coloured or yellow dots. Corollas funnel-shaped. Filaments hairy at bottom.

Var. $\beta$, flòre-álbo; flowers white.

Rusty-leaved Rhododendron. Fl. May, July. Clt. 1752. Shrub 1 foot.

12 R. hirsu'rum ( $\mathrm{Lin}$. spec. 562.) leaves ovate-lanceolate or elliptic, acutish, ciliated with rusty hairs on the margins, glabrous above, dotted and hairy beneath; calycine segments fringed, bearded. そ. H. Native of the Alps of Europe, as of Switzerland, Austria, Styria, Dauphiny, \&c. Jacq. anstr. 1. t. 98. Sims, bot. 1853 . Lodd. bot. cab. 479.-Lob. icon. 468. Very like $R$. ferrugineum. Flowers pale red or scarlet, disposed in umbellate corymbs. Corollas funnel-shaped.

I ar. $\beta$, variegàtum; leaves edged with yellow.

Hairy Rhododendron. Fl. May, July. Clt. 1656. Shrub 1 to 2 feet.

13 R. setòsum (D. Don, in wern. soc. trans. 3. p. 408. prod. fl. nep. 152.) branchlets beset with bristles; leaves oval, mucronatc, bristly on the margins and under surfaces; pedicels beset with glandular hairs; calycine segments rounded, coloured, naked, crenulated. h. F. Native of Nipaul, on Gosaingsthan. A small, stiff, much-branched shrub. Leaves $\frac{1}{2}$ an inch long. Flowers purple, size of those of $R$. Daúricum, disposed in umbellate corymbs. Calyx purple. Filaments bearded at the base. Stigma capitate.
Bristly Rhododendron. Fl.? Clt, 1825. Shrub $\frac{1}{2}$ to $1 \mathrm{ft}$.

Sect. II. Booram (the name of the first species in Nipaul). Limb of calyx 5-lobed. Corolla campanulate. Stamens 10. Ovarium 8 or 10 -celled. Leaves coriaceous, evergreen.-Species all natives of India.

14. R. ARnònevm (Smith, exot. bot. t. 6.) leaves lanceolate, acute, silvery beneath, tapering to the base; peduncles and calyxes woolly; segments of corolla 2-lobed, with crenulately curled margins; eapsule 10 -celled, tomentose. h. F. Native of Nipaul, on the mountains at Narainhetty, where it is called Booram by the natives. Hook. exot. f. 168. Lindl. bot. reg. t. 896. Sweet, fl. gard. 3. t. 250 . R. purpìreum, Hamilt. mss. Tree very showy when in blossom. Leaves 4-6 inches long. Flowers large, scarlet, dotted with black on the upper lip inside, disposed in dense heads. Stigma capitate, crenulated.

Tree Rhododendron. Fl. March, May. Clt. 1820. Tree 20 feet.

15 R. A'Lbum (Hamilt. mss. Sweet, fl. gard. t. 14s.) leaves lanceolate, wrinkled and dark green above, but of a rusty cinmamon colour beneatl; ; alternate filaments toothed. $\zeta$. F. Native of $\mathrm{Ni}$ paul. R. arbòreum $\gamma$, floribus niveis, D. Don, prod. fl. nep. p. 154 . Wall. pl. asiat. var. 2. t. 123. Flowers white, spotted witl purple on the upper lip. Dr. Wallich considers this and R. arborreum to be only varieties of each other.

White-flowered Rhododendron. Fl. March, May. Clt. 1818. Tree 10 feet.

16 R. cinnamòmeum (Wall. cat. no. 760.) leaves lanceolate, acute, obtuse at the base, clothed with intense rusty tomentum beneath; limb of calyx short, callous, 5 -lobed; ovarium tomentose, 10-celled. h. F. Native of Nipaul. Very nearly allied to $R$. arboreum, and hardly distinct from that species. Leaves 3-4 inches long. Corolla with wavy cloven segments, apparently white. Capsule an inch long. Perhaps the same as $R$. alloum.

Cinnamon-coloured-leaved Rhododendron. Fl, June. Clt. 1817. Tree.

17 R. BARBA'TUM (Wall. cat. no. 757.) leaves oblong-lanceolate, acute, obtuse at the base, yellowish bcneath; calycine segments dilated, membranous; ovarium 10 -celled, glandular, hispid; petioles and mid-rib of leaves bristly; filaments glabrous, toothless. $h_{c}$. F. Native of Nipanl. Habit of R. arboreum. Leaves a span long. Corolla dark red, with broad rounded cloven segnents. Ovarium thickly beset with glanduliferous bristles.

Bearded Rlıdodendron. Tree.

18 R. ? linearifòluu (Poir. suppl. ex Spreng, syst. 2. p. 293.) leaves linear, coriaceons, obtuse, with revolute edges, clothed with rusty down beneath; flowers corymbose; calyx minute, obtuse, velvety. $h_{2}$. F. Native of the East Indies.

Linear-leaved Rhododendron. Shrub.

19 R. campanula'tum (D. Don, in wern. mem. 3. p. 409. prod. fl. nep. 153.) leaves elliptic-oblong, mucronate, rusty beneath, rather cordate at the base; segments of corolla flat, emarginate; ovarim 6-celled, glabrous. h. F. Native of Nipaul, on Gosaingsthan, a high mountain to the north of the valley. Lodd. bot. cab. 1944. Sweet, fl. gard. n. s. t. 241. Under surfaces of leaves clothed with fine scaly pubescence, at first of a purplish hue, afterwards changing to nearly white, and finally to a deep ferruginous brown. Flowers copious, disposed in corymbose clusters. Pedicels glabrous. Bracteas fringed. Corollas large, pale pink, changing to white, having the upper lip marked with irregular purple spots. Filaments bearded at the base. This species surpasses all others in the size of its flowers, except one found in Java by Dr. Horsefield.

Campanulate-flowered Rhododendron. Fl. April. Clt. 1817. Shrub 3 to 5 feet. 
g0 R, Forмòsum (Wall. pl, rar. asiat. 3. p. 3. t. 207,) leaves lanceolate, acute, attenuated at the base, beset with rusty lots beneath; segments of corolla entire, flat; filaments bearded; ovarium 10-celled. 々. F. Native of Nipaul. Leaves an inch and a half long. Flowers about the size of those of li. P'onticum, white, suflised with red. Limb of calyx short.

Showy Rhododendron. Shrub.

Sect. III. Pogonántium (from $\pi \omega \gamma \omega v$, pogon, a beard; and ar $\theta 0$ s, anthos, a flower; throat of corolla woolly inside). Limb of calyx short, 5 -lobed. Corolla salver-shaped, with a cylindrical tube, and a spreading limb. Stamens 8 , inclosed. Ovarium 5 -celled,-Leaves evergreen, coriaceous.

21 R. Antuordgon (D. Don, in mem. wern. soc. 3. p. 409.) branchlets downy; leaves oval, rusty beneath from lepidoted tomentum; corollas with a woolly throat. $h$. F, Native of Nipaul, on Gosaingsthan. R, aromáticum, Wall. eat. Shrub much branched. Leaves ending in a reflesed mucrone, naked abore. Flowers glomerate, sulphur-coloured. Pelicels short, lepidoted and resinous. Calycine segments rounded at the apex, with villous margins. Seginents of corolla roundish, with undulately curled margins. Filaments glabrous. Stigma clavate.

Bearded-flowered Rlododendron. Fl, April, May. Clt. 1820. Shrub 1 to $1 \frac{1}{2}$ foot.

Sect. 1V. Lepípherum (from $\lambda \varepsilon \pi \iota s$, lepis, a scale; and $\phi \varepsilon \rho \omega$, phero, to bear ; leaves covered with small scales.) Limb of calyx dilated, 5-lobed. Corolla campanulate or rotate. Stamens 10. Ovarium 5-celled.-Leaves membranous, sometimes deciduous.

22 R. LEPidòtum (Wall. cat. 758.) every part of the plant is beset with ferruginous scale-like dots; leaves spatulate or lanceclate, attenuated at the base, beset with round scale-like dots, as well as the branchlets, ferruginous beneath; calycine segments rounded; corollas short, campanulate, lepidoted, with roundish entire Jobes; capsules also lepicloted; filaments woolly at the base. . F. Native of Nipaul. A widely-hranched shrub, witl the habit of $R$. Daúricum. Leaves of a thinner texture, about an inch long. Flowers as well as the capsule covered with round rust-coloured seales. Flowers deep pink, solitary or 2-5 together, terminal, on short filiform pedicels.

Scaly-dotted Rhododendron. Shrub 2 to 3 feet.

23 R. Lappónicum (Wahl. fl. suec. p. 249.) shrub branched, procumbent; branches divaricate; corollas rotately funnelshaped; leaves oblong, obtuse, stiff; beset with foveolate dots, yellowish and lepidoted beneath. h. H. Native of the Arctic regions of Europe, Asia, and North America. Azàlea Lappónica, Lin. fl. suec. p. 64. spec. 214. A. lapp. ed. Snith, p. 59. t. 6. f. 1. Hook. bot. mag. 3106. Young branches obscurely pubescent, warted. Leaves deep green above, pale green and at length yellowish beneath, thickly beset with hollow dots on both suriaces, which are covered by imbilicate permanent scales. Flowers crimson, disposed in umbellate corymbs, 5-6 together, surrounded by large dotted scales or bracteas. Calyx covered with yellow scales, ciliated. Segments of corolla unequal, undulated. Stamens 5-8, equal in length to the corolla. Stigma capitate, 5-lobed. Filaments hairy at the base.

Lapland Rhododendron. Fl. July. Clt. 1825. Shrub procumbent.

24 R. Daúricua (Lin. spec. 562.) deciduous; leaves oblong, attenuated at both ends, glabrous, lepidoted from rusty seales, particularly beneath; limb of calyx 5-toothed; corollas rotate. h. H. Native of Silseria, peculiar to the alpine tracts of Eastern Asia ; it appears first at the mouth of the river Yenesee, and beyond that, especially from the river Uda, in the pine woods, it begins to be common; but about the Baikal it is most abundant, and extends through the deserts of the Mongols to China and Thibet; at the Lena it becomes more rare, and beyond that it is much dwarfer, with more slender flowers and narrower leaves. Pall. fl. ross. 1. p. 47. t. 32. Andr, bot. rep. t. 4. Curt. bot. mag. t. 636 . Lodd. bot. cab. 605.- $1 \mathrm{~mm}$. rutl. $18 \mathrm{I} . \mathrm{t} .21$. Roots knobbed, bound by fibres. Stems twisted and kuobbed in the wild state. Petioles downy. Leaves dotted on both surfaces, but ferruginous beneath; before the fall in autumn they become of a dusky red colour. The flowers rise before the leaves from the tops of the branches, from buds which are composed of concave downy scales. Corollas purple.

Iar. $\beta$, atrocirens (Ker. bot. reg. t. 194.) evergreen; leaves deep green and shining above. h. H. Native of Siberia. Sims, bot. mag. 1888 .

Daurian Rhododendron. Fl. March, Dee. Clt. 1780. Shrub 2 to 6 feet.

Seot. V. Chamecistus (from $\chi \alpha \mu a$, chamai, on the ground; and cistus, the rock-rose: plants with the labit of species of Helianthemum. Limb of calyx foliaceous, 5-cleft. Corolla rotate. Stamens 10 . Ovarium 5 -celled.-Leaves small, mcmbranous, evergreen.

25 R. Cantscháticun (Pall. fl. ross. 1. p. 48. t. 33.) leaves obovate, acutish, 5-nerved, naked, ciliated; perluncles hairy, usually twin; calycine segments ciliated, foliaceous. $\zeta$. H. Native of Kamtschatka and the Aleutian Islands, in muddy places on the mountains. Gmel. sib. 4. p. 126. no. 13. Corollas purple, rotate. A prostrate shrub.

Kantschatka Rlododendron. Fl. July. Clt, 1802. Shrub prostrate.

26 R. chamecístus (Lin. spec. 562.) leaves oblong-lanceolate, attenuated at both ends, stiffish, glandularly ciliated; peduncles usually twin, and are as well as the calyxes beset witl glandular hairs. $\quad \mathfrak{2}$. H. Native of the Alps of Europe; as of Austria, Carniola, Mount Baldo, and near Salzburgh; and in Eastern Siberia. Jacq. f. austr. 3. t. 217. Curt, bot. mas. t. 488. Lodd. bot. cab. 1491.-Mich. gen. 225. t. 106.-Pluk. phyt. t. 23. f. 4. Corollas rotate, pale purple. A dwarf tufted shrub, with small leaves, about the size of those of a species of Heliánthemum.

Ground-Cistus Rhododendron. Fl. May, June. Clt. 1786. Shrub $\frac{1}{2}$ foot.

Sect. VI. Tsursu'tsi (the Cbinese name of the first species). Limb of calyx foliaceous, 5 -cleft. Corolla campanulate. Stamens 5-10. Ovarium 5-celled. - Leaves membranous, evergreen, hispid from pili.

27 R. I'NDICUM (Sweet, f. gard. n. s. 128.) branches strigose; leaves cuneate-lanceolate, finely crenulated, strigose, attenuated at both ends; calycine teeth long-lanceolate, obtuse, ciliated, spreading; flowers terminal, solitary or twin, decandrous.

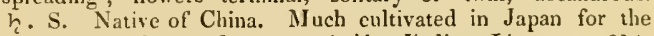
sake of its elegant flowers. Azàlea I'ndica, Lin. spec. 214. Thunb. jap. 84. Sims, bot. mag. 1480. Lodd. bat. cab. 275.Herm. lugdb. 152. t. 153. Tsut-sut-si, Kœempf. amœen. 815. t. 146. Flowers showy, scarlet or red.

I ar. $\beta$, púlchrum (Sweet, A. gard. n. s. 117.) calyx very hairy, with subulate segments; leaves elliptic, acute; flowers decandrous, terminal, $2-3$ together. $h$. G. A hybrid between R. ledifolium, impregnated by the pollen of $R$. I'ndicum. R. Índicum, var. $\gamma$, Smíthii, Sweet, hort. brit. 2. p. 343. Corollas large, of a deep rosy purple, spotted with deep red inside.

l'ar. $\gamma$, ignéscens (Sweet, $\mathrm{Al}$ gard. n. s. 128.). The four lower segments of the corolla flame-coloured, and the superior one lilac, and obsoletely dotted. $々$. S. Native of Clina. 
Var. $\delta$, aurantiacum; flowers of orange-red colour. $\quad \zeta . \mathrm{G}$. Native of China.

Yar. $\varepsilon$, lutéum (Sweet, l, c.) flowers double, yellow.

$I^{r}$ ar. $\zeta$, variegàtum (Blum. bijdr. 851 .) leaves obovate, covered witl white strigose bristles; Howers rose-coloured, variegated with white. 5 . G. Native of China.

Tar. $\%$, spatulàtum (Blum. bijdr. 852.) leaves spatulate, mucronate, beset with rusty strigx; flowers rose-coloured. h.G. Native of China and Japan.

I ar. \&, grandifiòrum (Blum. bijdr. 853.) leaves oblong-spatu. late, mucronate, beset with white bristles or strigæ; flowers large, solitary, deep rose-coloured $\zeta$. G. Native of China and Japan.

I (ur. ı, angustifolium (Blum. J. c.) leaves narrow-lanceolate.

Jar. $x$, floribúndum (Blum. l. c.) leaves narrow, cuneate-lanceolate, beset with rusty strigæ; stem much branched. h. G. Native of China and Japan.

Indian Rhododendron. Fl. March, May. Clt. 1S08. Shrub 3 to 6 feet.

28 R. sca'brum; leaves ovate, mucronulate, acute at the base, ribbed beneath, beset with adpressed bristles, as well as the branchlets and peduncles; flowers decandrous; filaments papillose; anthers corniculate at the base; stigma dilated. h.G. Native of Japan, in woods on mountains. R. máximum, Thunb. fl. jap. p. 181. Flowers deep rose-coloured, campanulate, usually twin. Lobes of corolla oblong, obtuse, twice longer than the tube. Stamens exserted. Calycine segments oval, obtuse, ciliated. Leaves $1 \frac{1}{2}$ to 3 inches long, coriaceous. Corolla 3 inches in diameter.

Scabrous Rhododendron. Shrub.

29 R. macra'nthum; leaves opposite or 3 in a whorl, obovate or lanceolate, mucronulate, shining, clothed with adpressed bristles; flowers pentandrous; calycine segments lanceolate, acute, deeply toothed, bristly; filaments glabrous. h.G. Native of Jajan. Azàlea macránthum, Bunge, in mem. acad, petersb. 2. p. 115. R nítens, D. Don, mss. Stems several, rising from the root-stock, 2-4 feet long, procumbent, naked. Branches fascicled, leafy at the tips, beset with adpressed silvery bristles, which change to brown, as well as the calyxes. Flowers solitary or in pairs, nearly sessile, involucrated by bracteas. Corollas large, of a brilliant salmon-colour, glabrous outside ; the limb spreading with oblong blunt lobes; the upper lobes marked with deeper coloured spots. There is a variety of this species, having the flowers pale pink and striped.

Large-flowered Rlıododendron. El. May, June. Clt. 1833. Shrub procumbent, 2 to 3 feet.

30 R. reticula'tum (D. Don, mss.) leaves broadly ovate, acute, rather coriaceous, sparingly hairy, glaucous and reticulately veined beneath, $h_{2}$. G. Native of Japan, on the mountains, and has been lately introduced by Mr. Knight, of King's Road, Chelsea. Stems erect, a foot or 2 feet high, stiff. Leaves stiff, $1 \frac{1}{2}$ inch long, rounded at the base, bright green and shining abore, beset with a few adpressed bristles as well as the young shoots. Flowers not seen.

Reticulated-leaved Rhododendron. Fl.? Clt. 1834. Shrub.

31 R. FARRE'RE (Tate, in Sweet. fl. gard. n. s. t. 95.) branches stiff, villous while young, but glabrous in the adult state; leaves stiff, coriaceous, ovate, obtuse, ending in a short cartilaginous mucrone, attenuated at the base, nerved and reticulately veined, hairy on both surfaces, with somewhat recurved ciliated edges; petioles ciliated at the base; flowers terminal, solitary. h. G. Native of Clina, from whence it was brought by Capt. Farrer. Calyx pilose, 5-lobed. Corolla spreading, with undulated segments, lilac or pale purple-red. A dwarf decicluous shrub. Flowers decandrous.

Farrer's Rhododendron. Fl. March. Clt. 1829. Shrub.
32 R. PIIÆNiceum; hairy; leaves oblong-obovate, tapering into the petioles at the base; flowers collected at the tops of the branclses, large, decandrous ; stamens short; calyx erect, glandular, and viscid. 々. S. Native of China. Azàlea I'ndica, var. phœenicea, Sweet. fl. gard. n. s. 128. Azàlea I'ndica $\gamma$, Hook. bot. mag. 2667. Azàlea ledifòlia $\beta$, phœnicea, Hook. bot. mag. 3239. Flowers purple, having the upper segments spotted.

Var. $\beta$, flore pleno (Hook. bot. mag. 2509.) flowers double, purple. Lodd. bot, cab. 1461.

Purple Rhododendron. Fl. May. Clt. 1824. Shrub 3 to 10 feet.

33 R. LeDifòlum; the whole shrub is hairy; leaves-ellipticlanceolate, opaque ; flowers by threes at the extremity of the branches, decandrous; calyx erect, glandular and viscid; stamens unequal. 々. G. Native of Clina, about Pekin. Azàlea ledifòlia, Hook. bot. mag. 2901. Azàlea I'ndica, var. álba, Lindl. bot. reg. t. 811 . Lodd. bot. cab. 1259. Rhod. leucánthum, Bunge, in mem. acad. petersb. 2. p. 115. Flowers showy, pure white.

Ledum-leaved Rhododendron. F1. March, May. Clt. 1819. Shrub 2 to 6 feet.

34 R. мucrona'tum; much branched; branches pilose; leaves cuneate-oblong, mucronate, clothed with clammy hairs; flowers in fascicles; calycine segments long-acuminated, pilose; flowers octandrous and decandrous. h.G. Native of China. Flowers white. Azàlea mucronàta, Blum. bljdr. p. 853.Perhaps the same as $R$. ledifolium.

Mucronate-leaved Rlododendron. Shrub.

35 R. Burma' Nir; leaves linear-lanceolate, long-acuminated, with recurved margins, clothed with silky villi on both surfaces. 々. G. Native of Japan. Azàlea rosmarinifòlia, Burm. ex Blum. bijdr. p. 853 . but not of Roth. Flowers pentandrous.

Burmann's Rhododendron. Shrub.

36 R. Mólus; ; branchlets pilose; leaves oblong-lanceolate, acute, narrowed at the base, ciliated, very soft beneath; flowers in fascicles; calyx very short; tube clothed with silky tomentum; flowers pentandrous.? $々 . G$. Native of China. Azàlea móllis, Blum. bijdr. p. 853 .

Soft Rhododendron. Shrub.

37 R. Loureiria'xa; leaves lanceolate, quite entire, rugose about the edges, smooth; corolla white, dotted with red, as also the calyx, anthers, and germs. h. G. Native of Cochinchina. Azà̀lea punctàta, Lour. coch. p. 113. Flowers disposed in terminal heaps.

Loureiro's Rhododendron. Shrub 4 to 5 feet.

38 R. Decúniens (D. Don, mss.) stems decumbent; leaves ovate, acute; flowers pentandrous; segments of the calyx ovate, acute, ciliated. $\zeta$. G. Native of China, from whence it has been lately introduced by Knight and Tate. Flowers crimson.

Decumbent khododendron. Fl. April, May. Clt. 1833. Shrub decumbent.

39 R. SiNE'NSE (Sweet. fl. gard. 290.) leaves slowly deciduous, elliptic, acutish, pilosely pubescent, feather-nerved, with ciliated margins, canescent beneath; corollas downy; stamens equal in length to the limb of the corolla. $h$. G. Native of China. Azàlea Sinénsis, Lodd. bot. cab. 885. Flowers flamecoloured, pentandrous.

I'ar. $\beta$, flatéscens (Sweet, fi. gard. 290.) flowers yellow.

C'hinese Rhododendron. Fl. May, June. Clt. 1823. Shrub 3 to 4 feet.

Sect. VII. Pentanthe'ra (from $\pi \varepsilon v t \varepsilon$, pente, five; and $a \nu \vartheta \eta \rho a$, anthera, an anther; flowers pentandrous). Limb of calyx short, 5-lobed. Corolla funnel-shaped. Stamens 5. Ovarium 5-celled. Leaves deciduous. 
40 R. FLA'Vum; flowers leafy, clammy; leaves ovate, oblong, pilose, ciliated; corolla funnel-shaped; stamens very long. h. H. Native of the Levant, at Pontus; Caucasus, Turkey, Sc. Azalea Póntica, Lin. spec, 1669. Curt. bot. mag. t. 433. A zàlea arbòrea, Lin. spec. ed. 1. p. 150.-Buxb. cent. 5. p. 36. t. 69. Flowers fine yellow. Leaves shining. There are a great number of varieties of this species in the gardens, differing principally in the colour of the flowers, and the liue of the leaves. The flowers are of all shades, from yellow to copper or orangecolour. They are sometimes white, (see Sims, bot. mag. 2383.), and are sometimes striped with yellow and red.

Ycllow-flowered Rhododendron. Fl. May, June. Clt. 1793. Shrub 4 to 6 feet.

41 R. Nudiplònum (Torr. fl. un. st. 1. p. 140.) leaves lanceolate-oblong, nearly smooth and green on both surfaces, ciliated on the margins, having the mid-rib bristly beneath, and woolly above; flowers rather naked, not clammy; tube of corolla longer than the divisions; teeth of calyx short, rather rounded; stamens much exserted. $h$. H. Native from Canada to Georgia, on the sides of hills. Azàlea nudiflòra, Lin. spec. 214. A zàlea periclymenoìdes, Michx. fl. bor. amer. 1. p. 151. This beautiful slurub has a great many varieties, besides those mentioned below, for which see Lond. hort. brit. p. 66. and supplement, among which is one with double flowers. Flowers scarlet, pink, white, striped, variegated, red, purple, sc., disposed in terminal clustered racemes, appearing before the leaves. The variety $\eta$ proves clearly that Azàlea and Rhododéndron are not generically distinct.

l'ar. a, coccineum (Sims, bot. mag. 180.) flowers scarlet; leaves lanceolate. $\zeta$. H. Native of Georgia, near Savannah.

Iar. $\beta$, rùtilans (Pursh, f. amer. sept. 1. p. 152.) flowers deep red; calyxes minute. $\zeta$. H. Ait. hort. kew. p. 319.

I ar. $\gamma$, carneum (Pursh, l. c.) corollas pale red, having the tube red at the base; calyx foliaceous. h. H. Ait. l. c. Ker. bot. reg. 120 .

Var. $\delta$, álbum (Pursh, l. c.) flowers white; calyx middle. sized. h. H. Ait. l. c.

lar. $\varepsilon$, papilionàceum (Pursh, l. c.) flowers reddish, with the lower segment white; calyx foliaceous. h. H. Ait. l. c.

I'ar. $\zeta$, partitum (Pursh, l. c.) flowers pale red, 5 -parted even to the base. h. H. Ait. I. c.

lar. $\eta$, polyándrum (Pursh, l. c.) flowers rose-coloured,

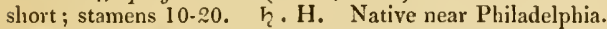

I ar. $\theta$, Gorcniànum; branches tomentosely downy; leaves evergreen or deciduous, oblong, acute, downy while young, but glabrous in the adult state, and recurved at the apex; tube of corolla a little shorter than the segments. $\zeta$. H. A hybrid, raised from the seed of $R$. nudifiorum, impregnated by the pollen of a hybrid raised between $R$. Pónticum and $R$. Catawbiénse. Flowers delicate light purple, disposed in terminal racemose corymbs. R. Goveniànum, Sweet, fl. gard. 3. t. 263.

I ar. ı, rùbrum (Lodd. bot..cab. t. 51.) flowers red. h. H.

Naked-flowered Rhododendron. Fl. April, June. Clt. 1734. Slurub 3 to 4 feet.

42 R. viscòsum (Torr. 1. c.) leaves oblong-obovate, acute, smooth and green on both surfaces, ciliated on the margins, baving the mid-rib bristly; flowers clammy, leafy, hairy; tube of corolla as long as the segments; teeth of the calyx short, rounded; stamens hardly longer than the corolla. h. H. $\mathrm{Na}$ tive from Canada to Georgia, in swamps and shady woods. A zàlea viscòsa, Lin. spec. 214.-Pluk. alm. 106. t. 161. f. 4 . Catesb, car. 1. t. 57. Flowers white, sweet-scented, in terminal clusters, downy. There are a great number of varieties of this species, (see Loud. hort. brit. p. 66.), varying in the colour of the flowers, and otherwise. The flowers are white and red, and variegated with these colours. There is a downy variety with red flowers figured in Lodkl. bot. cab. t. 441.
Var. $\beta$, ornùtum (Sweet, fl. gard. n. s. 137.). A hybrid raised from the sced of $R$. viscòsum $\beta$ rubésecns, fertilized by the pollelı of R. Ponticum.

Clammy-flowered Rhododendron. Fl. July, Aug. Clt. 1734. Shrub 2 to 4 feet.

43 R. calendula'ceum (Torr. I. c.) lcaves oblong, pubescent on both surfaces, at length hairy; flowers large, not clammy, rather naked; tecth of calyx oblong; tube of corolla lairy, shorter than the segments. h. II. Native from Pennsylvania to Carolina. A zâlea calendulàcea, Michx. fl. bor. amer. 1. p. 156. Lodd. bot. cab. 1394. A. nudiflòra, var. coccínea, Ait. hort. kew. 319. Flowers yellow, red, orange-colourcd, and copper-coloured. Sims, bot. mag. 172. Lodd. bot. cab. 1394. or flame-coloured. Ker. bot. reg. 145. Said to be the handsomest shrub in North America. There are a great many varieties of it, varying in the colour of the flowers. See Loud. hort. brit. p. 66 .

I'ar. $\beta$, Mortérii (Sweet, fl. gard. n. s. t. 10.) A hybrid between $R$. calenduldiceum and one of the red varictics of $R$. nudiflorum. There are also two kinds of this; one with a fleshcoloured corolla, having the upper segment orange-coloured, edged with flesh-colour, called $R$. Mortèrï cárnea; and anotler called Mortèrï, var. préstans, with pale copper-colonred flowers, tinged with blush.

Marygold Rhododendron. Fl. May, June. Clt. 1806. Slurub 2 to 6 feet.

4 t R. ARbore'scens (Torr. l. c.) leaves obovate, rather obtuse, smooth on both surfaces, glaucous beneath, ciliated on the margins, liaving the mid-rib almost smooth ; flowers not clammy, leafy; tube of corolla longer than the segments; calyx leafy, with the segments oblong and acute; filaments exserted. $\zeta_{c}$. H. Native of Pennsylvania, on the sides of rivulets near the Blue Mlountains. Azàlea arboréscens, Pursl, fl. amer. sept. I. p. 153. Flowers large, reddish; leaves of flower-buds large, yellowish brown, surrounded with a fringed white border.

Arborcscent Rhododendron. Fl. May, July. Clt. I818. Tree 10 to 20 feet.

45 R. Nítıdum (Torr. l. c.) branches smoothish; leaves oblanceolate, rather mucronate, coriaceous, smooth on both surfaces, shining above, having the nerve bristly beneath, with revolute ciliated margins; flowers clammy, leafy; tube of corolla a little longer than the segments; calyx very short; filaments exserted. h.H. Native from New York to Virginia, in deep mossy swamps on the mountains. Azàlea nitida, Pursh, fl. amer. sept. 1. p. 153. Ker. bot. reg. 414. Flowers white, tinged with red. Leaves dark green, shining, smaller than any other species of the present section.

Shining-leaved Rhododendron. Fl. June, July. Clt. 181 . Shrub 2 to 4 feet.

46 R. Híspidun (Torr. l. c.) branches straight, very hispid; leaves long-lanceolate, hispid above, and smooth beneath, glat:cous on $\mathrm{b}$, th surfaces, ciliated on the margins, having the nerve bristly beneath; flowers very clammy, leafy; tube of corolla wide, scarcely longer than the segments; teeth of calyx oblong, rounded; filaments exserted. $h$. H. Native of New York and Pennsylvania, on the borders of lakes on the highest part of the Blue Mountains. Azàlea híspida, Pursl, f. amer. sept. 1. p. 154. Wats. dendr. brit. 6. Azàlea viscòsa, var. glaúca, Ait. hort. kew. 1. p. 319.? Flowers white, with a red border, and a tinge of red on the tube, which makes them appear to be of a rose-colour before expansion. Stamens sometimes 10. This species may be distinguished from the rest of the present section by its bluish appearance.

Hispid Rhododendron. Fl. July, Aug. Clt. 1734. Shruh 10 to 15 feet.

47 R. Bicozor; leaves oblong, clothed on both surfaces with fine hoary pubescence, not bristly on the nerve; flowers small, 
not clammy, naked; tube of corolla hardly longer than the segments; calyxes very short: having one of the segments linear, and 4 times longer than the rest; filaments exserted; branchlets hispid. দ. H. Native of Carolina and Georgia, on barren sandy hills. Azàlea bícolor, Pursh, f. amer. sept. 1. p. 153. Azàlea nudiflòra, var. bícolor, Ait. hort. kew. 1. p. 319.-Trew. ehret. t. 48. Flowers slender and smaller than the rest, of a pale rose-colour, or nearly white, with a deep red-coloured tube.

Two-coloured-flowered Rhododendron. Fl. May, June. Clt. 1734. Shrub 3 to 4 feet.

48 R. GLau'cum; branchlets hispid; leaves oblanceolate, acute, glabrous on both surfaces, glaucous beneath, ciliated on the margins, having the mid-rib bristly; flowers very clammy, leafy; tube of corolla twice longer than the segments; calyx very short; filaments about equal in length to the segments of the corolla. h.H. Native from New England to Virginia, in swamps of a clayey soil. Azàlea glaíca, Pursh, f. amer. sept. 1. p. 154. Lam, ill. p. $49 \mathrm{~S}$. Wats. dendr. brit. 5. Azàlea viscòsa, var. foribunda, Ait. hort. kew. 1. p. 319. Flowers white, very fragrant. The shrub is dwarfer than other species of the present section, and flowers in great abundance. Nuttall considers this as only a variety of $A$. viseòsa, differing in nothing but in the under sides of the leaves being glaucous.

Glaucous-leaved Rhododendron. Fl. June, July. Clt. 1734. Shrub 2 feet.

49 R. CANE'scens ; leaves obovate-oblong, downy above, and tomentose beneath, not bristly on the middle nerve; flowers not clammy, nearly naked; tube of corolla hardly shorter than the segments; teeth of calyx very short, rounded, obtuse; stamens hardly exserted. $h$. H. Native of Lower Carolina, on the banks of rivers; and of Virginia, on the mountains of the Cacapoon Springs, near Winchester. Azàlea canéscens, Michx. $\mathbb{A}$. bor. amer. 1. p. 150. Wats. dendr. brit. I16. Flowers rosecoloured.

Canescent Rhododendron. Fl. May, June. Clt.1812. Shrub 3 to 4 feet.

50 R. SPECjòsL ; branches hairy; leaves lanceolate, ciliated, acute at both ends; calyx pubescent ; corolla silky, with obtuse, ciliated, lanceolate, undulated segments; stamens exserted. $h$. H. Native of North America. Azàlea speciòsa, Willd. enum. p. 10. Lodd. bot. cab. 624. Wats. dendr. brit. 116. A coccinea, Lodd. Flowers scarlet and orange-coloured. There are several varieties of this species, varying in the shape of the leaves and the colour of the flowers; see Loud. hort. brit. p. 66. Lodd. bot. cab. 1255 .

Shon'y Rhododendron. Fl, May, June. Clt.? Shrub 3 to 4 feet.

Sect. VIII. RHodòra (from jocoo, rhodon, a rose; colour of flowers). Limb of caly $\times 5$-toothed. Corolla bilabiate; upper lip broadest, and 2-3-cleft; lower one bidentate. Stamens 10. Capsule 5-celled, 5-valved. - Leaves deciduons. Habit of last section.

51 R. RHodòra; leaves oval, quite entire, pubescent and glaucous beneath; flowers in terminal clusters, or racemose umbels. h. H. Native of Canada, Newfoundland, and on the mountains of New York and Pennsylvania, in bogs. Rhodora Canadénsis, Lin. spec. 561. Lher, stirp. nov. 1. p. 141. t. 68. Lam. ill. t. 364. Curt. bot. mag. 474. Flowers pale purple, rising before the leaves.

Rid-flowered Rhododendron. Fl. April, May. Clt. 1767. Slirub 2 feet.

Cult. Of all the genera in existence, Rhododéndron comprises the most liandsome, elegant, and showy shrubs, well fitted for adorning shrubberies, or to be grown singly on lawns. All the species grow best in peat soil, or very sandy loam, or vegetable mould : they are either increased by layers or by seeds. When raised in the latter way, the seeds must be sown early in the spring, in flat pans or pots, filled with peat earth, and covered very slightly; the pots or pans should then be set in a close frame, or at the front of a hot-house, till the plants come up, watering them very slightly when dry; and as soon as the seedlings have grown high enough to be laid hold of, they should be planted out into other pans or pots, filled with the same kind of mould ; after which they may stand in a close frame for a few days, until they have struck fresh roots, and afterwards liardened to the air by degrees. The smaller kinds of Rhododéndron may be propagated freely by cuttings, taken off from young wood, and planted in sand, placing a bell-glass over them. There are now in the gardens a great many hybrid kinds of Rhododéndron, and are still increasing in number; some of which outvie the species in splendour. The species natives of Nipaul, China, and Japan, in mild winters, would probably succeed in the open air, but they will not survive a severe winter withont protection; they are therefore best kept in pots, and placed among other greenhouse or frame plants. $R$. arboreum and $R$. álbum are among the most showy of the species, and are well adapted for conservatories, or to be placed in large tubs in the greenhouse. Young cuttings of the tender kinds, if torn off close to the stem, and planted in a pot of sand, will strike root readily; the pot sliould be plunged in leat under a hand-glass.

XLIV. VIRE'YA (named by Blume after M. Virey, a French physsician). Blum. bijdr. p. 854 .

Lin. syst. Deéindria, Monogýnia. Calyx small, obsoletely 5-toothed. Corolla subcampanulate, or funnel-shaped, regular, 5 -lobed, adnate to the disk of the calyx. Stamens 10, inserted in the calycine disk; alternate filaments the shortest; anthers oblong, bursting inwardly, naked, dehiscing by two pores at the apex. Style filiform; stigma capitate, 5-furrowed. Capsule silique-formed, 5-angled, 5-celled. Placenta 5-lobed. Seeds numerous, expanded into a bristle-formed awn at both ends. This genus differs from Rhododendron in the calyx being small, and in the stamens not being attaclied to the corolla in any way.-Mostly parasitical shrubs. Leaves scattered and verticillate, quite entire, coriaceous, covered with scaly dots beneath. Flowers disposed in terminal fascicles.

\section{* Corollas subcampanulate.}

1 V. Jara'xica (Blum. bijdr. 854.) leaves oblong-lanceolate, clothed with fine rusty dots beneatl ; flowers showy, deep orange. ?. G. Native of Java, at the foot of Mount Salak, where it is called by the natives Gaga Mirha.

Var. $\beta$; flowers citron-coloured, smaller.

Java Vireya. Fl. Year. Slırub.

2 V. A'LBA (Blum. bijdr. 855.) leaves lanceolate, densely clothed with rusty scales beneath : flowers white, middle-sized. h. G. Native of Java, on Mount Salak, parasitical upon trees. Rhododéndron álbum, Blum. cat. hort. buitenz. p. 72.

White-flowered Vireya. F]. Year. Shrub.

$$
\text { * Corollas funnel-shaped. }
$$

3 V. tubifiòra (Blum. bijdr. p. 855.) leaves lanceolate, densely clothed with rusty dot-like scales beneath; flowers scarlet. 々. G. Native of Java, on the higher mountains.

Tube-fonered Vireya. Fl. Year. Shrub.

4 V. Celébica (Blum. 1. c.) leaves broad, lanceolate, clothed with rusty dot-like scales beneath; flowers scarlet. $\eta_{\text {. }} \mathrm{G}$. Native of the Celebes, in mountain woods.

Celebes Vireya. Fl. Year. Shrub.

5 V. RETU'sA (Blum. bijdr. p. 856.) leaves spatulate, retuse, with recurved margins, beset with rusty dots beneath; branches 


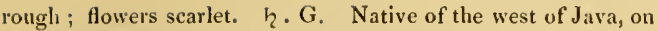
high mountains.

Retuse-lcaved Vireya. Fl. Ycar. Shrub.

Cult. For culture and propagation, see $A$ garista, p. 838.

XLV. BEJA'RIA (so named by Mutis after a Spanislı botanist of the name of Bejar). Mutis, amer. 1. t. 8. Lin. gen. Reiclı. no. 648. Juss. gen. 159.-Bcfäria, Humb. et Bonpl. pl. aquin. 2. p. 118. t. 117 . nov. gen. amer. 3. p. 290.-Acünna, Ruiz et Pav.

Lin. syst. Dodecándria, Monogýnia. Calyx deeply 7-cleft. Corolla so deeply 7 -cleft as to appear of 7 petals, spreading. Stamens 14, hypogynous; anthers obverse or pendulous, awnless. Ovarium free, 7 -furrowed. Style elongated; stigma depressedly capitate, $\boldsymbol{7}$-furrowed. Capsule depressedly globose, girded by the permanent calyx, and terminated by the style, 7 celled, 7 -valved, with a septicidal dehiscence; cells inany-seeded. -Elcgant alpine slorubs; with scattered, crowded, quite entire, coriaceous leaves; racemose or corymbose, bracteate flowers. Corollas usually purple.

1 B. Resinòsa (Mutis, amer. 1. t. 8. Lin. syst. 443. suppl. 246.) branchlets downy; leaves ovate, smooth; corymbs terminal, simple; pedicels downy; corollas resinous and viscid; filaments downy near the base. h. G. Native of New Granada. Branches proliferous. Leaves an inch long. Corollas purple.

Resinous-flowered Bejaria. Slırub 3 to 5 feet.

2 B. RAcEmòsa (Vent. cels. p. 51. t. 51.) branchlets smooth or hispid; leaves ovate-lanceolate, glabrous ; flowers disposed in racemose terminal panicles. $h . G$. Native of Georgia and Florida, in sandy places. B. paniculàta, Michx. fl. bor. amer. 1. p. 280. t. 26. Corollas purple.

Racemose-flowered Bejaria. Fl. June, July. Clt. 1810. Shrub 3 to 5 feet.

3 B. glau'ca (Humb. et Bonpl. pl. æquin. 2. p. 118.t. 177.) glabrous: leaves oblong, obtuse, glaucous beneath; racemes terminal and axillary; pedicels somewhat fastigiate. h. G. Native of South America, in the alpine region of the province of Venezuela, near the top of Silla de Caraccas. Shrub much branched; branchlets angular. Corolla flesh-coloured, glabrous : filaments glabrous.

Glaucous-leaved Bejaria. Fl. June, July. Clt. 1826. Shrub 8 to 6 feet.

4 B. conrcta'ta (Humb. et Bonpl. pl. æquin. 2. p. 125. t. 121.) branchlets clothed with pubescent tomentum; leaves oblong, glabrous, glaucous bencatlı; corymbs terminal, simple; peduncles, pedicels, rachi, and calyxes clothed with rusty tomentum. $々$. G. Native of Peru, in cold places near the city of Caxainarca. Shrub much branclied. Flowers purple. Filaments glabrous, bit dilated and pubescent at the base.

Coarctate-corymbed Bejaria. Shrub 4 to $5 \mathrm{feet}$.

5 B. GRANDiflo'ra (Humb. et Bonpl. pl. æquin. 2. p. 122. t. 119.) leaves ovate, glabrous above, but clothed with rusty tomentum beneath, as well as the pedicels, peduncles, rachi, calyxes, and branchlets; corymbs terminal, branclied a little, many-flowered. $h$. G. Native of the province of Quito, in cold places between Loxa and Ona, in Paramo de Saraguru; and near Alto de Pulla, and Vinajacu. Shrub much branched; branches subverticillate. Corollas purple, about the size of those of Dictamnus álbus. Filaments glabrous, but dilated and ciliated at the base.

Great-flowered Bejaria. Shrub 3 to 4 feet.

6 B. E'stuans (Mutis, in Lin. fil. suppl. 247. mant. 242. Humb, et Bonpl. pl. æquin. 2. p. 120. t. 118.) lcaves elliptic, rather glabrous above, but downy and glaucous beneath, while young clothed with rusty tomentum, and ciliated with glands; voL. 111. corymbs terminal, simple; peduncles, pediccls, rachi, calyxes, and branchlets clothed with clammy glandular hairs. Native of New Granada, near Gonzanama. Much branched; branchlets subverticillate. Flowers smaller than those of the preceding, purple. Filaments villous at the basc.

Ileating Bejaria. Shrub 10 to 15 feet.

7 B. Ledifòlia (Humb. et Bonpl. pl. aquin. 2. p. 124. t. 120.) leaves oblong, somewhat mucronate, with revolute elges, glaucous beneath, beset with glandular hairs on both surfaces along the middle nerve; racemes terminal; peduncles, pedicels, rachi, branchlets, and calyxes clothed with claminy glandular hairs. h. G. Native of South America, on the top of Silla de Caraccas. Shrub much branched; branches purplish. Flowers about the size of those of $B$. glaúca, purple.

Ledum-lcaved Bejaria. Slirub 3 to 4 fect.

8 B. Caxamarcénsis (H. B. et Kunth, nov. gen). amer. 3. p. 294.) branchlets pilose; leaves oblong, glabrons above, pubescently hairy and glaucous beneath; corymbs terminal, simple; peduncles, pedicels, and rachi, clothed with rusty pilose tomentum; calyxes hairy. h. G. Native of Peru, on the Andes, about Caxamarca. A much-branched shrub. Flowers size of those of the preceding, purple; petals narrow.

Caxamarca Bejaria. Shrub 3 to 4 feet.

9 B. Lanceola'ta (Ruiz et Pav. fl. per. 4. t. 1513. f. b.) branches and racemcs hairy; leaves ovate-lanceolate; corymbs simple, racemose; pedicels short. h. G. Native of Pcru, on the high hills of Rodos Pillao and Huassa-Huassi, where it is called Rosa-Rosa, or Rosa Huaytta. Acúnna lanceolàta, Ruiz et Pav. syst. p. 124. Flowers purple or rose-coloured.

Lanceolate-leaved Bejaria. Fl. May, Aug. Shrub 4 to 6 feet.

10 B. oblónga (Ruiz et Pav. fl. per. 4. t. 1513. f, a.) leaves oblong, with revolute margins; flowers corymbose; pedicels long. h. G. Native of Peru, in the province of Tarma, at Churupallana; and of Panatahua, at Acomaya and Macora, where it is called Rosa-Rosa, from the copious rose-coloured flowers. Acúnna oblónga, Ruiz et Pav. syst. p. 123. Flowers purple or rose-coloured. Branches, petioles, and corymbs downy. Corymbs compound.

Oblong-leaved Bejaria. Shrub 4 to 5 feet.

Cult. For culture and propagation see Agarista, p. 838. Extremely elegant plants, with the habit of some species of Rlododéndron, and are therefore well worth the cultivator's care.

XLVI. HYMENA'NTHES (from iv $\mu \eta \nu^{\prime}$, hymen, a membrane; and avtos, anthos, a flower; in reference to the thin corollas). Blum. bijdr. 862.

Lin. syst. Dodecándria, Monogýnia. Calyx small, obsoletely denticulated. Corolla campanulate, with a short compressed tube, and a 7-parted limb; segments of the limb imbricated. Stamens 14, hypogynous: alternate ones shortest. Anthers fixed by the back, mutic, opening by 2 pores at the apex. Ovariun free, girded by a nectariferous tumid margin at the base. Style long; stigma obtuse, 7 -crenated. Capsule oblong, 7 -celled, 7 -valved, many-seeded.--Nearly allied to Bejària, bint differs from it in the small calyx and monopetalous corolla.

$1 \mathrm{H}$. J Alónica (Blum. l. c.) shrub a little branched; leaves subverticillate, 3 to 4 in a whorl, petiolate, oblong, acutisl, narrowed at the base, quite entire, coriaceons, glabrous, reticulated above, veinless and yellowish beneath; flowers disposed in dense, terminal, bractcate spikes. $h$. G. Native of Japan, from whence it was received by Blume under the name of Rhododéndron máximum.

Japan Hymenanthes, Shrub.

Cult. For culture and propagation see Agarista, p. 838. $5 \mathrm{Q}$ 
XLVII. KA'LMIA (named by Limæus in honour of Peter Kalm, professor at $\mathrm{Abo}$, in Sweden; author of Travels in A merica. 1753). Lin. gen. no. 545. Gærtn. fruct. 1. p. 305. t. 63, Juss. gen. 158. Nutt. gen. amer. 1. p. 267.

Lrs. syst. Decândria, Monogynia. Calyx 5-parted. Corolla salver-shaped; under side of limb produeing 10 cornute protuberances, and as many cavities on the upper side, in which the anthers lie, or are concealed. Capsule 5-celled, many-seeded; dissepinents narginal.-Evergreen slrubs, with alternate or ternately verticillate leaves. Flowers disposed in terminal, racemose, compound corymbs; but in one species the flowers are solitary and axillary. Pedicels long, 1-flowered, tribracteate at the base; external bractea originating from the rachis. Buds naked. Anthers opening by two oblique truncate pores.-This genus is considered poisonous, and is often fatal to cattle.

1 K. Latifòlia (Lin. spec. 560.) leaves on long petioles, scattered, or 3 in a whorl, oval, coriaceous, smooth and green on both surfaces; corymbs terminal, downy, and viscid. $h . \mathrm{H}$. Native from Canada to Carolina, on the sides of stony hills. Curt. bot. mag, 175. Bigel. med. bot. p. 133. Wangh. amer, t. 25. f. 50.-Catesh. ear. 2. t. 98.-Trew. elırh. t. 38. f. 1.-Pluk. mant. t. 379. f. 6. A very elegant shrub when in flower: in America it is called Laurel, and on the mountains Calico-bush. Flowers red. It is not inprobable that the deleterious honey in Philadelphia might have been collected by the bees from the flowers of the Calico-bush, which in some places pervades, in rocky woods and depressed summits of mountains, almost in a similar manner with Callùna vulgàris of Europe.

Broad-leaved Kalmia. Fl. June, July. Clt. 1734. Shrub 3 to $\mathbf{I} 0$ feet.

2 K. Angustifòuia (Lin. spec. 561.) leaves petiolate, scattered, or 3 in a whorl, oblong, obtuse, rather rusty beneath; corymbs lateral; bracteas linear; peduncles and calyxes clothed with glandular pubescence. $h$. H. Native from Canada to Carolina, in bogs, swamps, and sometimes in dry mountain lands. Curt. bot. mag. 331. Lodd. bot. cab. 502.-Catesb. car. 3. t. 17 . f. 1.-Trew, ehrh. t. 38, f. 2. Flowers dark red. The slirub is known by the name of Sheep Laurel in North America, being considered very poisonous when fed upon by sheep. 'There are several varieties of this species besides the one mentioned, differing in the size of parts, and in the deeper and lighter shade of the corolla. See Loud. hort. brit. p. 171 .

I'ar. $\beta$, ovàta (Pursh, fl. amer. sept. 1. p. 296.) leaves broader; stem taller. $\eta$. II. Native of New Jersey, on the mountains.

Narron-lcaved Kalmia. F1. May, July. Clt. 1736. Shrub 1 to 2 feet.

3 K. GLAU'CA (Ait. hort. kew. ed. 2. p. 64.) branchlets 2-edged or triquetrous; leaves opposite, on short petioles, oblong, smooth, glaucous beneath, with revolute edges; corymbs terminal, compound, bracteate; pedicels and calyxes glabrous. $\eta$. H. Native of bogs in Canada; and on the borders of mountain lakes of New York and Pennsylvania; and of the Island of Sitcla. Curt. bot. mag. 177. Lam. ill. t. 363. Lher. stirp. nov. 2. t. 9. Lodd. bot. cab. 1508 . K. polifòlia, Wangh. aet. soc. herol. 8 . p. 129 . t. 5 . A very handsome upright small shrub, with pale red flowers. According to Nuttall, the flowers are disposed in terminal compound eorymbs, each corymb composed of 3 racemose corymbulets; and the pedicels and calyxes are said by him to be elothed with powdery viscid pubescence.

Íar. $\beta$, rosmarinifòlia (Pursh, fl. amer. sept. 1. p. 296.) leaves linear, more revolute on the margins, and having the under surface green. h. H. Mr. Pursh discovered this variety in a bog near Albany, and is inelined to think it a distinet speeies.

Glaucous-leaved Kalmia. Fl, April, May. Clt. 176\%. Shrub 1 to 2 feet.
4 K. cuneA'ta (Michx. fl. bor. amer. 1. p. 257.) leaves scattered, sessile, cuneate-oblong, glandularly pubescent beneath, minutely awned at the apex; corymbs lateral, few-flowered. 々. H. Native of Carolina, on the mountains. Branclies twiggy. Leaves deciduons. Flowers white, red at the bottom, disposed in sessile, lateral, fastigiate elusters.

Cuneate-leaved Kahmia. Fl. May, June. Clt. 1820. Shrub 1 to 2 feet.

5 K. hirsu'ta (Walt. fl. earol. 138. Michx, fl. amer. bor. 1. p. 257. Curt. bot. mag. 138.) branches, leaves, and ealyxes very hairy; leaves opposite and alternate, almost sessile, elliptic; peduncles axillary, solitary, 1-flowered, longer than the leaves. h. H. Native of South Carolina and Georgia, in barren pinewoods. K. eiliàta, Bartr. itin. 18. A beautiful little slirub, but difficult to cultivate. Leaves small, like thyme. Flowers large, red.

Hairy Kalmia. Fl. June, Aug. Clt. 1786. Slurub 2 to 3 feet.

Cult. Handsome shrubs when in blossom. They grow best in peat soil, and are increased either by layers or by seeds. When raised by seeds, they are reared and otherwise treated in the manner recommended for Rhododéndron, which see, p. 848 .

XLVIII. MENZIE'SIA (named in honour of Archibald Menzies, F.L.S. \&c. surgeon and naturalist to the expedition under Vaneonver, in which voyage he collected many specimens of plants on the nortl-west coast of America, New Holland, Van Diemen's Land, Sre.). Smith, icon. ined. 56. Nutt. gen. amer. 1. p. 251. D. Don, in edinb. phil. journ. 17. p. 160 .

Lin. syst. Octándria, Monogýnia. Calyx 4-lobed. Corolla tubular or globose : limb very short, 4-lobed, revolute. Stamens 8 , inclosed ; filaments subulate, glabrous; cells of anthers parallel, connate, mutic at the base, and opening each by an oblique foramen at the apex. Stigma obtuse. Capsule ligneous, 4. celled, with a septicidal dehiscence. Placenta 4-lobed. Seeds scobiform.-Deciduous shrubs, natives of North America. Leaves membranous, glaucous beneath. Pedicels numerous, terminal, 1-flowered, fascicled.

1 M. FERRugínea (Smith, icon, ined. 1. p. 56. t. 56.) corolla ureeolate, with rounded lobes; leares and branches hairy. $h$. H. Native of the north-west coast of America, particularly on the Columbia River; and of the Island of Sitcha. Lam. ill, t. 285. M. ureeolàris, Salisb. par. lond. no. 44. Leaves obovatelanceolate. Flowers of a rust-colour.

Rusty-flowered Menziesia. Fl. May, June. Clt. 1811. Shrub 3 to 4 feet.

2 M. globUlA'Ris (Salisb. par lond. 44.) corolla globose, with rounded lobes; leaves and branches hairy. $h . \mathrm{H}$. Native of Virginia and Carolina, on high mountains ; plentiful on the Cacapoon Mountains, near Winchester, Virginia. M. Smithii, Michx. fl. bor. amer. 1. p. 235 . Azàlea pilòsa, Lam. ill. 494. M. pilòsa, Pers. ench. 1. p. 420. Leaves lanceolate. Flowers yellowish brown.

Globular-flowered Menziesia. Fl. May, June. Clt. 1806. Shrub 3 to 5 feet.

3 M.? TRif Lòra (Bert. ex Spreng. syst. 2. p. 202.) corolla oblong, with pointed lobes; leaves and branches glabrous. $h$. S. Native of Jamaica, on the mountains. M. ? elata, D. Don, mss. Andrómeda octándra, Swartz. prod. p. 73 . fl. ind. occ. 2. p. 840 . Leaves spatulate, oblong. Peduncles aggregate, reflexed.

Thrce-flonered Menziesia. Shrub tall.

Cult. For culture and propagation see Azàlea, p. 851 .

XLIX. AZA'LEA (from $\alpha \zeta \alpha \lambda \varepsilon o s, a z a l c o s$, dry, arid; habita- 
tion of plant). D. Don, in edinb. phil. journ.-Azàlea procúmbens, Lin. and other authors.-Loiseleùria, Desv. Clamalèdon, Link, enum. 1. p. 210.

Lis. syst. Pentándria, Monogýnia. Calyx 5-parted. Corolla short, campanulate, 5 -cleft. Stamens 5 , equal, shorter than the corolla; cells of anthers opening by a terminal pore. Style straight, inclosed. Capsule 5-celled: with 5 cloven-pointed valves, whose inffexed edges form the double partitions. $-\boldsymbol{A}$ small, evergreen, glabrous, procumbent shrub, with the habit of Thyme. Leaves opposite, small, elliptic, glabrous, with revolute margins. Flowers pedicellate, rising in fascicles from the axils of the upper leaves, small, red.

1 A. Procu'miens (Lin. spec. 205.). h. H. Native of Europe, on mountains; plentiful on the tops of mountains in Scotland, but rare on the mountains in the north of England. In North America, in the alpine regions of the White Mountains, New Hampshire; and on Grandfather Mountain, Carolina, \&c. Fl. dan. t. 9. Lin. fl. lapp. ed. 2d. p. 60.t. 6.f. 2. Smith, engl. bot. t. 865 . Lodd. bot. cab. 76\%.-Bocc. mus. 2. p. 64. t. 53. Chanælèdon procúmbens, Link. enum. 1. p. 210. Loiseleùria, procúmbens, Dessv.

Procumbent Azalea. Fl. April, May. Britain. Shrub procumbent.

Cult. 'This small shrub grows well in a peat border, or in pots in sandy peat earth; it is easily increased by layers or by seeds.

L. LEIOPHY'LLUNI (from $\lambda \varepsilon \iota s$, leios, smooth; and $\phi v \lambda \lambda o v$, phyllon, a leaf; leaves quite smooth). Pers. ench. 1. p. 477. Spreng. syst. 2. p. 276. Ammyrsine, Pursh, f. amer. sept. 1.p. 2S0.-Fischèra, Swartz.-Lèdum buxifolium, Berg. Ait.

Lis. syst. Decándria, Monogýnia. Calyx deeply 5-parted. Corolla 5-petalled. Stamens 10, exserted; anthers opening by 2 terminal pores. Capsule 5 -celled, 5 -valved, dehiscing at the apex.-A small, erect, bushy shrub. Leaves small, convex, oval, glabrous, shining. Flowers white, disposed in terminal corymbs; the clelicacy of the leaves, and the abundance of its white flowers, are highly ornamental.

1 L. титмі́òium (1ers. ench. 1. p. 477. Spreng. syst. 2. p. 815.). h. H. Native of New Jersey and the mountains of Carolina, particularly on the highest summits of the Catawba ridge. By the inhabitants of New Jersey it is called SandMyrtle. Lèdum buxifòlium, Bergius, in act. petrop. 1777. p. 1. t. 3. f. 2. Ker. bot. reg. 531. Ait, hort. kew, 2. p. 66. Lodd. bot. cab. 52. I èdum thymifolium, Lam. dict. 3. p. 459. ill. t. 363. f, 2. Lèdum serpyllifòlium, Lher. stirp. nov. 2. t. 10. Ammyrsine buxifolia, Pursh, fl. amer. sept. 1. p. 301. Fischèra, Swartz.

Thyme-lcaved Leiophyllum. Fl. May, June. Clt. 1736. Slirub $\frac{1}{2}$ to 1 foot.

Cult. For culture and propagation see Lèdum below.

LI. LEDUMI ( $\lambda_{\eta j o v}$, ledon, was a name applied by the ancients to a plant producing the substance called Ladanum, and now known by the name of C'istus Lìdum; in foliage, the Lèdum of modern botanists agrees with the plant of the ancients). Lin. gen. no. 546. Gærtn, fruct. 2, p. 145. t. 112. Juss. gen. 159. Nutt. gen. amer. 1. p. 275.

Lin. syst. Decándria, Monogýnia. Calyx minute, 4-toothed. Corolla 5-petalled, spreading. Stamens 5-10, exserted; anthers opening by 2 terminal pores. Capsule subovate, 5 -celled, 5 -valved, opening at the base, pedicellate. Seeds numerous, flat, linear, scabrous, furnished with a membranous wing at each extremity. -Dwarf evergreen slurubs. Leaves coriaceous, with revolute margins, and tomentose on the under surface. Flowers white, disposed in terminal corymbs; pedicels bracteate at the base. Shrubs exhaling a peculiar scent when bruised.
1 L. PALu'stre (Lin. spec. 561.) leaves lincar, with revolute margins, clothed with rusty tomentum beneath; stamens 10 , longer than the corolla. 々. II. Native of Canada, in swamps, and round the mountain lakes of New York; in Kotzebue's Sound, S.c. ; also of the north of Europe, as of Denmark, Silcsia, Sc. Oed. fl. dan. 1031. Dulı, arb. 1. t. 67. Schmirlt, arb. 163. Lodı. bot. cab. 560. Lèdum Silesiacum, Clus. pan. 68. IRosmarìnm sylvéstre, Cam. epit. 546 . Flowers white. Leaves resembling those of liosmary.

I ar. $\beta$, decumbens (Ait. hort. kcw. ed. 2, vol. 3. p. 48.) slirub decumbent. $h$. H. Native near lludson's Bay.

Marsh Wild-Rosmary. Fl. April, May. Clt. 1762. Shrub 2 feet.

2 L. Latifòltum (Ait, lort. kew. 2. p. 65.) leaves linear-oblong, with replicate margins, clothed with rusty tomentum beneath; stamens 5 , about the length of the corolla. h. H. Native of Canada, in sphagnous swamps; Greenland, Labrador, Newfoundland, Hudson's Bay. This or the preceding species las bately been found in Ireland. Jacu. icon. 3. t. 464. Sclimidt, arb. t. 164. Lam. ill. t. 363. f. 1. Lodd. bot. cab. 534. L. Groenlândicum, Retz, obs. 4. p. 26. Fl. dan. t. 567 . L. palústre, Michx. f. bor. amer. 1. p. 259 . Flowers white. A larger and broader leaved shrub than the last ; commonly called Labrador Tea; and the leaves are said to be a good substitute for it. Bees are very fond of the flowers.

Broad-leaved Wild-Rosmary, or Labrador Tea. Fl. April, May. Clt. 1763. Shrub 2 to 4 feet.

3 L. Canade'nse (Lodd. bot. cab. 1049.) leaves ovate petiolate, white beneath; flowers disposed in terminal umbellate corymbs, large. $々$. H. Native of Canada, in swamps. Flowers white.

Canadian Wild-Rosmary. Fl. April, May. Clt.? Slırub $\frac{1}{4}$ to $\frac{1}{2}$ foot.

Cult. A peat soil, or very sandy loam answers best for the species of this genus; and they are readily increased by layers and seeds. The seeds should be sown, and the seedlings afterwards managed in the manner recommended for Rhododéndron, p. 848 .

\section{Tribe III.}

VACCINHE $Æ$ (the genera contained in this section agree with Iracinium, in the ovarium being adherent). D. Don, in edinb. phil. journ. 17. p. 152. Anthers 2-celled. Ovarium adherent. Disk perigynous, nectariferous. Fruit baccate. Gemmation scaly.

LII. VACCI'NIUM (an ancient Latin name, whether of a berry or a flower, has always been a point in dispute among critics, as well as the etymology of the word). Lin. gen. 191. Ait. hort. kew. vol. 2. p. 355. Pursh, fl. amer. bor. 1. p. 284. Juss, gen. 162. Nutt. gen. amer. 1. p. 263. Lam. ill. 286. Gærtn. fr. t. 28.-Vitis-illæa, Tourn. inst. t. 377.

Lin. syst. Octo-Decándria, Monogýnia. Calyx 4-5-toothed (f. 142, a.) Corolla urceolate or campanulate (f. 142.b.), more or less deeply 4-5-cleft ; limb reflexect. Stamens 8-10, hypogynous. Anthers 2-lorned (f. 1 \$2.d.), dehiscing at the summits, and sometimes furnished at the back with 2 spreading spurs or bristles. Style longer than the stamens; stigma obtuse. Berry globose (f. 142.e.), depressed at top, 4-5-celled (f. 142.f.), many-seeded. -The species of I accinium are mostly confined to Europe and North America, but are peculiarly abundant in the latter country. They are suffruticose, shrubby, gemmaccous plants. Bud-scales often permanent, on the base of the small branches. Leaves alternate, membranous, of ten beset with resinons dots, either permanent or deciduous. Flowers pedicellate, either solitary, simply racemose, or tufted, drooping, inodorous, generally very elegant, tinted with various shades of red or pink, never blue, scarcely yellowisl. 5 Q 2 
Berries black, purple, bluish, or red, generally eatable, though not always pleasant, nor wholesome in a crude state. The species of this genus were ill understood by Linnæus, who therefore has led all following authors astray. In reviewing the whole, we find something to add, though we have many specimens that are dubions. We are obliged to follow the distribution of Linnæus, into the evergreen and deciduous species, though some uncertainty must always attend that character respecting species known from dried specimens only.

\section{$\S$ 1. Leaves deciduous.}

\section{lated.}

* Pedieels 1-flowered, usually solitary, rarely tnin or fascicu-

1 V. mýtílLus (Lin. spec. 498.) pedicels solitary, 1-flowered ; leaves serrated, ovate, smonth; stem acutely angular, smooth; calyx hardly divided. $々$. H. Native on lieaths, stony moors, and mountain woods throughout most parts of Europe, especially the more northern; plentiful in Britain. Dr. Sibthorp gathered it on the Bithynian Olympus. It is common on the hills in the Island of Unalaschka. Smith, engl. bot. 4.56. Fl. dan. 974.-Ger. emac. 1415. Math. valgr. 1. p. 210. Cam. epit. 135 . Corolla globose, generally 5 -cleft, of a very delicate waxy pink hue. Berries the size of currants, bluish black, covered by a mealy bloom, eaten in tarts or with cream, or made into jellies, in the north and west of England and Scotland. In Devonshire the berries are eaten with clotted cream; in Poland they are ripe in July, and being mixed with wood strawberries, and eaten with new milk, are consiclered a great delicacy. They may be successfully culcivated in a shady border, in bog earth. The fruit is sometimes sent into Norfolk from Devonshire. The juice of them has been employed to stain paper or linen purple. In autumn the wood game chiefly live upon the product of this shrub. Mr. Menzies brought from the west coast of North America what can scarcely be considered more than a gigantic variety, 7 or 8 feet high, larger in every part, with less distinctly serrated leaves.

Myrtle-like or Common Bilberry, or Bleaberry. Fl. May. Britain. Shrub $\frac{1}{2}$ to 2 feet.

2 V. Curanissònis (Bongard, in mem. acad. petersb. 2. p. 151.) pedicels solitary, 1-flowered, short, deflexed while in fruit; leaves elliptic, nearly entire, obtuse, mucronulated, glabrous, glaucous beneath; calyx 5 -toothed; flowers decandrous. $\zeta$. H. Native of the Island of Sitcha. V. myrtillus, Cham. et Schlecht. in Linnæa. 1. p. 525. Branclies erect, angular. Corolla white, urceolate, with short obtuse lobes. Anthers awned on the back. Berries black.

Chamisso's Whortle-berry. Shrub 1 foot.

3 V. ovalifòlum (Simith, in Rees' cycl. no. 2.) pedicels solitary, 1-flowered ; leaves elliptic, obtuse, pointless, entire, smooth, strongly veined beneath; stem angular; calyx hardly divided. $\boldsymbol{h}$. H. Native of the north-west coast of America, where it was collected by Mr. Menzies; and in the Island of Sitcha by Bongard. Branches smooth, less acutely angular than in the foregoing species. Leaves $1 \frac{1}{2}$ inch long. The flowers seem to agree with those of $V$. myrtillus in colour and structure, except that the corolla is more ovate. Berries black, crowned, cupshaped, with a slightly 4 -lobed calyx.

Oval-leaved Bitberry. Shrub 10 to 12 feet.

4 V. PArvifólium (Smith, in Rees' cycl. no. 3.) pedicels solitary, 1-flowered, clavate while bearing the fruit; leaves elliptic, obtuse pointed, entire, smooth, glaucous and slightly veined beneath; stem acutely angular; calyx lardly divided. h. H. Native of the north-west coast of America, where it was collected by Mr. Menzies; and in the Island of Sitcha by Bon- gard. Branches smooth, as acutely angled as in $I^{r}$. myrtillus. The leaves agree most in shape with $I$. ocalifolium, but are not a quarter the size, even when full grown. The berries are red, and make excellent tarts. They appear to be sinaller than the last, and crowned with a similar calyx.

Small-leaved Bilberry. Shrub 8 to 10 feet.

5 V. geminiflòrum (H. B, et Kunth, nov, gen. amer. 3. p. 267.) flowers axillary, twin, drooping, decandrous; leaves oblong, bluntish, crenulated, reticulately veined, rather membranous, glabrous; anthers furnished with 2 awns on the back. $h$. F. Native of Mexico, between Omitlan and Moran. Habit and stature of $I$. myrtillus. Branchlets angolar, downy. Leaves 810 lines long, paler beneath. Corolla campanulate, ventricose at the hase, with sliort ovate bluntish segments. Filaments membranous, glabrous.

Twin-flomered Whortle-berry. Shrub 1 foot.

6 V. ні́тим (Thunb. jap. 155.) pedicels solitary, 1-flowered; leaves ovate, serrated, hairy all over, as well as the young branches. $h$. F. Native of Japan, on the hills between Miaco and Jedo. Branches terete. Flowers on very short stalks.

Hairy Bilberry. Fl. April. Shrub 2 to 3 feet.

7 V. vligino'sum ( $\mathrm{lin}$. spec. 499.) pedicels somewhat aggregate, 1-flowered; leaves obovate, entire, smooth; branches terete. $h$. H. Native of Sweden, Germany, Siberia, Switzerland, Savoy, Scotland, and the north of England; as well as in the more northern parts of America, and on its west coast; and in the Island of Sitcha, on marshy mountain heaths and alpine bogs. Smith, engl. bot. t. 581. Fl. dan. 231. Myrtíllus grándis, Baul. hist. 1. p. 518. Taller than the Common Bilberry, and of a more glaucous hue. Leaves glancous beneath. Flowers flesh-coloured, with 8 long-lyorned stamens. Berries large, juicy, black, covered with a mealy bloom; they are eatable, but not either very grateful or wholesome. A variety with slightly pointed leaves was published by an apothecary at Berne, in 1787 , as $I$. mucronatum, an imaginary species.

Bog or Great Bilberry. Fl. April, May. Britain. Shrub 2 feet.

8 V. calycinum (Smith, in Rees' cycl. no. 7.) pedicels solitary, 1-flowered; leaves obovate, serrated, smooth, with downy ribs; branches angular; calycine segments deep, ovate. $h$. F. Native of the Sandwich Islands, in woods upon lofty mountains. Leaves $1 \frac{1}{2}$ inch long, and near an inch wide. Corolla oblong, with 5 angles.

Large-calyxed Bilberry. Shrub 2 to 3 feet.

9 V. angustifólium (Ait. hort. kew. ed. 2. vol. 2. p. 356.) pedicels scattered, mostly solitary, l-flowered, naked; leaves lanceolate, nearly entire, downy at the ribs and margins. $h$. H. Native of Canada, about Hudson's Bay and Labrador. Berries large, bluish black, known by the name of Bluets. V. myrtilloides, Michx. fl. bor. amer. 1. p. 234. Michaux says this species has the liabit of $I$. myrtillus; its leaves being membranous, of a narrow lanceolate form.

Narrow-leaved Whortle-berry. Fl. April, May. Clt. 1776. Shrub 2 feet.

10 V. satícinum (Cham. et Schlecht. in Linnaa. 1. p. 525.) flowers axillary, solitary, on slıort pedicels; leaves cuneatelanceolate, cuspidate, quite entire, rather coriaceous, reticulately veined; corolla cylindrically urceolate, with a 4-cleft revolute limb. $\eta$. H. Native of Unalascha, on mossy lills. Slirub trailing, glabrous, habit of Salix alpigena, creeping under the moss. Branches angular, cinnamon-colonrel. Flowers drooping. Calycine lobes 4-5, short, ovate, acute. Stamens 8 , inclosed. Anthers biaristate on the base.

Willomy Whortle-berry. Shrub creeping.

11 V. c.espitòsum (Michx. fl. bor. amer. 1. p. 234.) flowers 
lateral, solitary, nearly sessile; leaves somewhat wedge-shaped, rounded, obtuse, serrated, membranous, very smooth. h. II. Native of America, in the more nortlern regions, particularly about Hudson's Bay; also in the Island of Sitcha. A little shrub, with many crowded stems, from 2 to 4 inches high, very smooth in every part. Corolla of a short urceolate form. Berries nearly sessile, globose, black, with a glaucous bloom.

Tufled Whortle-berry. Clt. 1823. Shrub $\frac{1}{4}$ to $\frac{1}{2}$ foot.

\section{* * Floners in sessile tufis.}

12 Y. Gale'zans (Miclix, Al. bor. amer. 1. p. 232.) flowers on very short stalks, in sessile tufts; leaves sessile, lanceolatewedge-shaped, slightly serrated, downy; calyx pointed; corollas ovate, much contracted at the mouth; style prominent. b. H. Native of Virginia and Carolina, in shady woods and swamps. V. galifórmis, Smitl, in Rees' cycl. no. 16. Flowers small, yellowish-white. Berries small, globular, black. Michaux describes this shrub as having the aspect of Myrica Gàle, witlı slightly clowny branches. Leaves varying. The pedicels shorter than the flowers, burst from a bud, composed of numerous crowded scales.

Gale-like Whortle-berry. Fl. May, June. Clt. 1806. Slirub $\approx$ feet.

13 V. Tenéllum (Ait. hort. kew, ed. 2, vol. 2. p. 358.) flowers in dense sessile tufts; leaves nearly sessile, ovate-lanceolate, acuminated, finely serrated, smooth, except the rib and margins; branches angular, with a downy line on each side; calyx of 5 , deep, acute segments. h. H. Native from New England to Virginia, on dry hills, on a gravelly soil. Wats. dendr. brit. 35. V. Pennsylı́nicum, Lam. dict. 1. p. 74. Michx. fl. bor. amer. 1. p. 232. A low, very branching shrub. Corollas pale red, or white. Berries large, bluish black, extremely sweet, and agreeable to eat. The mountains of Pennsylvania produce an immense variety of this species, in size and shape of the fruit, leaves, and flowers. Leaves sometimes an inch long.

Delicale Whortle-berry. Fl. May. Clt. 1772. Shrub 1 to 2 feet.

14 V. zigu'strinum (Michx. f. bor. amer. 1. p. 283.) flowers nearly sessile, in tufts; leaves nearly sessile, erect, lanceolate, mucronate, finely serrated, veiny, downy; corolla longish, ovate; branches angular. h. H. Native from Pennsylvania to Virginia, in dry woods; common on the mountains. Pursh, fl. amer. sept. 1. p. 288. exclusive of the syn. of Willd. A straight shrub. Leaves membranous, furnished with conspicuous, often purplish veins. Scales of the flower-buds often purplish. Corollas purplish-red. Berries black. The leaves vary extremely in shape and size. The $I^{r}$. liguistrinum of Linnæus is a nonentity, or rather no I'accinium, according to Smitl, being the very same plant with Lyònia paniculàta.

Privet-like Whortle-berry. Fl. May, July. Clt.? Shrub.

\section{* * *loners disposed in racemes.}

15 V. PÁridum (Ait. hort. kew. ed. 2. vol, 2. p. 355.) racemes bracteate; corolla cylindrically bell-shaped; leaves ovate, acute, finely serrated. $\zeta$. H. Native of North America, fiom whence it was said to have been sent, in 1772 , to Kew Gardens, by Dr. Samuel Martin; but Mr. Pursls never met with it.

Pale-flowered Whortle-berry. Fl. May, June. Clt. 177\%. Slurub 2 feet.

$16 \mathrm{~V}$. AReòreum (Marsh. in Miclix. fl. amer. bor. 1. p. 230.) pedicels axillary and solitary, or terminal and racemose, naked; leaves ovate, acute, with slight glandular serratures, polished above, and rather lowny beneath; corollas bell-shaped, acute; stamens the length of the tube. h.H. Native from North Carolina to Florida, in dry woods on the rocky banks of rivers. V. diffüstum, Ait. hort. kew. ed. 2. vol. 2. p. 356. A large shrub, sometimes 20 feet high, very elegant. Corollas white, tinged with red. Berries globular, black, almost dry. Branches terete, downy while young. This species joins the solitary flowered species with the racemose flowered species; the axillary flowers being solitary and pedicellate, and the terminal ones racemose.

Tree Whortle-berry. Fl. May, June. Clt. 1765. Shrub 10 to 20 feet.

17 V. stamíneum (Lin. spec. 498.) racemes downy, witls oval bracteas as long as the flowers; anthers biaristate on the back, twice as long as the spreading bell-shaped corolla; leaves elliptic, acute, entire, glaucous and rather downy beneath. 々. II. Native from New England to Florida. Andr. bot. rep. 263. V. álbum, Pursh, f. amer. sept. 1. p. 285. V. elevàtum, Banks, herb. Lodd. cat.-Pluk. mant. 22. phyt. t. 339. f. 3. Trunk 2 fect high, with numerous green branches, which are downy while young. Leaves $1 \frac{1}{2}$ or 2 inches long, on very short downy stalks. Flowers decandrous, copious, white, having linear anthers, which are spurred near the base. Berries greenish or white, called Deer-berries. The bracteas resemble the leaves, but are much smaller. The $V$. álbum, Lin. is Xylósteum ciliàtum $\beta$, Pursh, A. aner. sept. 1. p. 161.; and therefore there is no wonder that subsequent investigators could never ascertain the $V$. álbum of Linnæus. We must notice another error of Linnæus, to prevent mistake. He cites, under $I$. stamineum, the proper figure of Plukenet, but with a wrong synonyme or definition. Here also it falls to our lot to correct him respecting another of Kalm's plants, $l^{\prime}$. mucronàtum, which has ever remained as unintelligible as $V$. album. His described specimen is certainly a pomaceous plant.

I ar. $\beta$; (H. B. et Kunth, nov. gen, amer. 3. p. 267.) leares larger, ciliated on the nerves beneath and margins. $\zeta . F$. Native of Mexico, in woods between Pachuca and Real de] Monte. Shrub $\frac{1}{2}$ foot. Corolla campanulate, white.

Long-stamencd Whortle-berry. F1. May, June. Clt. 1772. Shrub 1 to 2 feet.

18 V. Dusòsum (Ait. hort. kew. ed. 2. vol. 2. p. 356.) racemes downy, with oval bracteas: and the pedicels with 2 lanceolate bracteoles; leaves obovate, mucronate, entire, downy and viscid; ovarium hairy; corolla bell-shaped, obtuse, longer than the stamens. h.H. Native from New Jersey to Florida, in dry sandy woods, particularly in pine-forests. Curt. bot. mag. 1106. Andr. bot. rep. 112. V. frondòsum, Michx. fl. bor. amer. 1. p. 230. V. hirtéllum, Ait. hort. kew. ed. 2. vol. 2. p. 357. A low bushy shrub, with round branches. Leaves $1 \frac{1}{2}$ inch long. Calycine segments fringed. Corollas white, tinged with pink, rather large. Berries black, globular.

Var. B, hùmile (Wats. dendr, brit. t. 32.) flowers white; anthers red ; pedicels solitary, axillary ; slırub $\frac{1}{2}$ foot high.

Bushy Whortle-berry. Fl. June, July. Clt. 1774. Shrub 2 to 3 feet.

$19 \mathrm{~V}$. cony s Bòsus (Lin. spec. 499.) flowering branches almost leafless; racemes corymbose, drooping, with nembranous bracteas, which are shorter than the downy flower-stalks; leaves elliptic, acute, minutely serrated, smooth, with downy ribs. 々. H. Native from Canada to Carolina and Georgia, in swamps and wet woods. Wats. dendr. brit. 129. V. amo'num, Ait. hort. kew. ed. 2. vol. 2. p. 35 s. Andr. bot. rep. 135. V. disomórphum, Michx. A. bor. amer. 1. p. 231. V. elevàtum, Hort. V. álbum, Lam. dict. 1. p. 13. A tall slurub, sometimes 7-8 
feet ligh, with numerous roughish terete branches, which are somewhat angular and downy while young. Leaves $1 \frac{1}{2}$ to 2 inches long, tipped with a glandular point. Racemes rising from the branches of the preceding year, seldom accompanied by leaves. Bracteas reddish, membranous, fringed. Calycine segments broad and shallow. Corollas white or reddish, cylindrically urceolate, rather angular, contracted at the mouth. Stamens 10, downy; anthers inclosed, having a double pouch at the base, but no spurs. Berries black, insipid. This species has a number of varieties in size, shape, and colour.

I'ar. $\beta$, virgàtum (Ait. hort. kew. ed. 2. vol. 2. p. 358.) flowers white, tinged with crimson or pale red, very elegant, smaller than the species. $h$. H. Native of Virginia and Carolina, in swamps. Andr. bot. rep. 181. Wats. dendr. brit. t. 33. In Andrews's plate of $I^{\prime}$. virgàtum, the racemes are accompanied by leaves, of which we have seen no example in $I^{r}$. corymbòsum. Shrub 2 feet ligh. Racemes short, lateral and terminal.

I ar. $\gamma$, fusccitum (Ait. hort. kew. l. c.) flowers striped with red and white; calyx downy. $h$. H. Native of Lower Carolina and Georgia, in swamps. V. forınòsum, Andr. bot. rep. t. 97 .

$V a r . \delta$, angustifolium; leaves narrow-lanceolate, acuminated at both ends, sessile, besprinkled with brown minute pedicellate glands beneath, and hairy on the mid-rib above. V. virgatum, var. angustifolium, Wats, dendr. brit. t. 34. Flowers almost white.

Corymbose-flowered Whortle-berry. Fl. May, June. Clt. 1765. Shrub 4 to 7 feet.

$20 \mathrm{~V} . \mathrm{MARMA}_{\text {NUM }}$ (Wats. dendr, brit. t. 124.) racemes lateral, numerous, many-flowered; corolla cylindrical, contracted at the mouth; leaves elliptic, coriaceous, glabrous, distinctly and minutely denticulated. $\zeta_{2}$. H. Native of North America. Flowers decandrous, white.

Maryland Whortle.berry. Fl. May, June. Clt, 1812. Shrub 5 feet.

21 V. GRANDIFLònum (Wats. dendr. brit. 125. f, a.) racemes terminal, 3-1-flowered; corollas cylindrical, contracted at the mouth; leaves lanceolate, finely serrated, attenuated at both ends, glabrous. 々. H. Native of North America. Flowers white, decandrous.

Great-flowered Whortle-berry. Fl. July, Aug. Clt. 1812. Shrub $1 \frac{1}{2}$ foot.

22 V. ElONGA'TuM (Wats. dendr. brit. t. 125. в.) corymbs few-flowered, bractless; pedicels downy; leaves elliptic-lanceolate, serrulated, tipped by a glandular hair each, and with a few lairs on the nerves; branchlets downy. $h$. 11 . Native of North America. Corollas white, with reflexed teeth.

Elongated Whortle-berry. Fl. July, Aug. Clt. 1812. Slırub 3 to 4 feet.

23 V. minutı́lònum (Wats. dendr. brit. 125. c.) racemes terminal, few-flowered; corollas cylindrical, with erect teeth ; leaves rather coriaceous, bluntly subserrated, each tipped by a gland. 々. H. Native of North America. Flowers white.

Minute-flonerd Whortle-bery. Fl. July, Aug. Clt. 1812. Shrub 1 foot.

24. V. GLA'brum (Wats. dendr. brit. t. 125. D.) spikes latera]; corollas campanulately cylindrical; leaves elliptic, entire, glabrous. 々. H. Native of North America. Flowers white.

Glabrous Whortle-berry. Fl. July, Aug. Clt. 1812. Slurub.

25 V. BRActeA'tum (Thunb. fl. jap. 156.) racemes axillary, longer than the glabrous, acute, serrated leaves; bracteas lanceolate, serrated; pedicels furnished with 2 awl-shaped bracteoles. h. F. Native of Japan, in the Island of Niphon. Branches smooth, angular while young. Racemes 2-3 inches long; pedicels secund, drooping. Corollas cylindrical, white. The leaves may be evergreen.

Bractcale-flowered Whortle-berry. Shrub.

26 V. CIL1A'TCM (T'hunb. A. jap. 156.) racemes axillary, longer than the ovate, bristly, nearly entire leaves; bracteas lanceolate, smooth. h.F. Native of Japan, \&c. where it is called Sasjebu. The stem is smooth, and the branches villous. Leaves 1-2 inches long, unequal. Flowers red, unilateral.

Ciliated-leaved Whortle-berry. Shrub.

27 V. r Rondósum (Lin. spec. 499.) racemes loose; bracteas obovate, not half so long as the slender pedicels, which bear 2 small linear bracteoles in the middle; leaves obovate-oblong, obtuse, entire, smooth. $\zeta_{\text {. }}$ H. Native from New Jersey to Carolina, in open woods. Andr, bot. rep. 140. V. glaúcum, Michix, fl. bor. amer. 1, p. 231. Flowers small, almost globular, whitc. Berries large, blue, globular, eatable, called by the country people Blue T'angles. Branchlets terete, sinooth, and slender. Leaves 2-3 inclies long, glaucous bencath, and sprinkled with minute resinous dots. Racemes lateral from the former year's wood. Flowers drooping, greenish-white, shaped like those of the Lily of the valley, but smaller; anthers inclosed.

Far. $\beta$, venústum (Ait. hort. kew, ed. 2. vol. 2. p. 357.) leaves lanceolate, acute at both ends. h. H. V. frondosum, var. $\beta$, lanceolàtum, Pursh, fl. bor. amer. 1. p. 786 .

Leafy Whortle-berry. Fl. May, June. Clt. 1761. Shrub 3 feet

2S V. Resinòsum (Ait. hort. kew, ed. 2. vol. 2. p. 357.) racemes leafless, viscid, downy, with lanceolate bracteoles on the pedicels; leaves obovate-lanceolate, bluntish, entire, covered with resinous dots; calyx in 5 deep ovate segments, longer than the ovarium. $\zeta$. H. Native from Canada to Carolina, in woods, and on mountains frequent. Curt. bot. mag. t. 1288. Andrómeda laccàta, Wangh. amer. t. 30 . f. 69 . Branches terete, downy when young. Leaves usually $1 \frac{1}{2}$ inch long, bright green on both sides, rather viscid. Racemes lateral from last year's wood, drooping. Flowers greenish-yellow. Berries black, eatable.

Iar. $\beta$, rubésccns (Pursh, fl. amer. sept. 1. p. 286.) corollas redish. 々. H. Curt. bot, mag. 12S8.

I ar. $\gamma$, lutéscens (Pursh, l, c.) leaves lanceolate; flowers redish-yellow. そ. H. V. parviflòrum, Andr. bot. rep. 125 .

Resinous Whortle-berry. Fl. May, June. Clt. 17\$2. Shrub 2 to 3 feet.

$29 \mathrm{~V}$. Aвстоsта́ PHy los (Lin. spec, 500.) racemes lateral; bracteas all at the base of the pedicels; leaves elliptic, acute, minutely serrated, hairy beneath; stamens as long as the corolla, which is bell-shaped, with very hairy filaments; calyx slightly 5-lobed. h. H. Native on the coast of the Black Sea, where it was gathered by Toumefort, who describes it as a shrub about the height of a man, with a trunk as thick as a man's arm. Young branches downy on two opposite sides. Leaves $2_{2}^{1}$ inches long. Racemes from the wood of the preceding year, below the fresh leafy shoots, drooping, rather hairy, each composed of $8-10$ pendulous flowers, of a dirty white colour, tinged with purple. Anthers spurred at the basc. $\mathrm{Co}$ rollas bell-shaped, bairy. Tournefort judges this to be, with

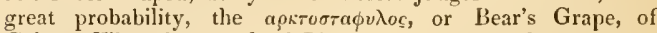
Galen. What the var. $\beta$ of Linnæus may be, we know not, as nothing answerable to it is to be found in 'Tournefort's Corollarium.

Bear's-Grape Whortle-berry. Fl. April, June. Clt. 1800. Shrub 5 to 6 feet.

30 V. PAdifolium (Smith, in Rees' cycl. no. 22.) racemes lateral; bracteas all at the base of the pedicels; leaves ovate- 
lanceolate, acute, serrulated, smooth on both surfaces, except the mid-rib; stamens nearly as long as the bell-shaped corolla, with smooth slightly fringed filaments; calyx 5 -lobel. Native of Madeira, on the loftiest part of the island, where it forms impenetrable thickets. $Y$. arctostápliylos, Andr. bot. rep. t. 30. Curt. bot. mag. 974. V. Maderéuse, Link. enum. 1. p. 375. Corollas larger than those of the preceding, pale green, with a purple tinge; sometimes it appears to be all over purple externally. The Caucasian plant, discovered by Pallas, is said not to differ from that of Madeira. Pallas says the berries are black, juicy, eatable, and gratefully acid ; and he sometimes found the flowers 4-cleft.

Bird-cherry-lcaved Bear's Grape. Fl. June, Ang. Clt. 1777. Shrub 6 to 10 feet.

31 V. cylindra'cium (Smith, in Rees' cycl. no. 23.) racemes lateral; bracteas serrated, all at the base of the pedicels; leaves elliptic-lanceolate, acute, serrulated, quite smooth, except the base of the mid-rib; stamens half the length of the cylindrical corolla, with hairy filaments; calyx slightly 5 -toothed. $h . H$. Native of the Azores, on the mountains, where it is called Uva de Serra, or Mountain-berry. A pparently arborescent. Branches downy on the opposite sides. Racemes numerous, rising from the wood of the preceding year. Flowers drooping, nearly an inch long, apparently red or purple.

Cylindrical flowered Bear's Grape. Shrub or tree.

32 V. Levifo'lium (Pohl, pl. bras. 2.p. 36. t. 123.) racemes axillary and terminal, loose, downy ; flowers unilateral ; leaves sessile, linear, attenuated at the base, ciliated, glabrous above, but yellowish-brown beneath, with the nerves downy. $\imath, G$. Native of Brazil, in the province of Minas Geraes, on the higher mountains, in dry places. Stem dark, hoary. Leaves deciduous. Bracteas of two forms, acute, ciliated. Corolla white, glabrous, having the teeth reflexed.

Ledum-leared Whortle-berry. Shrub 1 foot.

\section{$\S 2$. Leaves evergrecn.}

\section{* Floners racemose.}

33 V. Meridiona'Le (Swartz. fl. ind. occ. p. 6i6.) racemes erect, downy; bracteas coloured, solitary, ovate, at the base of the pedicels; leaves ovate, crenated, smooth; stem arboreous. h. G. Native of Jamaica, on the Blue Mountains. Tree with a very straight trunk and liard wood. Branches downy when young. Leaves 1 inch long. Flowers drooping, reddish-white. Corollas ovate, quadrangular before expansion, contracted at the mouth, with 4 acute, recurved segments. Stamens 8 , as long as the corolla : their filaments hairy in the middle. Berries roundish, juicy, pleasantly flavoured, pale red, resembling those of $I$. vitis-idce' $a$. The flowers are rarely 5 -cleft, and decandrous. Racemes rising from the top of the wood of the preceding year.

Southern Whortle-berry. Fl. March, June. Clt. 1778. Tree 10 to 30 feet.

$34 \mathrm{~V}$. Confértum (H. B. et Kunth, nov. gen. amer. 3. p. 265. t. 250.) racemes axillary, solitary, short, sessile, drooping, about equal in length to the leaves; leaves ovate elliptic, bluntish, crenulated, coriaceous, glabrous ; flowers decandrous ; anthers mutic. $\zeta$. H. Native of Mexico, on high mountains near Moran and Cerro de Oyamel. Branchlets angular, glabrous. Leaves 5-6 lines long, beset witl scattered, brown, minute dots beneath. Pedicels bibracteate at the base. Corolla cainpanulate, white, with ovate, acute, recurved segments.

Crowded-leaved Whortle-berry. Shrub 1 foot.
$35 \mathrm{~V}$. FLoribu'sduM (H. D. ct Kunth, nov. gen. amer. 3. p. 266. t. 251.) racemes terminal and axillary, drooping, much longer than the Icaves; leavcs oblong, acute, coriaceous, glabrous, crenulated ; flowers octandrous and decandrous; anthers mutic. $h_{\text {. G. Native of }}$ Peru, on the mountains near Caxamarca. Branchlets angular, downy, Leaves 6-7 lines long, besprinkled with a few black dots beneath. Corolla campanulate, white, having a quadrifid or quinquefid limb, with oval bluntish segments. Flowers about the size of those of $I^{r}$. vitis-idce $a$. Filaments membranous, ciliated. Racemes approximate at the tops of the branches, bracteate (f. 142.)

Bundle-flowered Whortlc-berry. Shrub.

36 V. Leuca'nthum (Cham. in Linnza. 7. p. 524.) arboreous; branches angular, sometimes downy ; leaves coriaceous, on short petioles, oval-lanceolate, acute, glandularly serrated, having the petioles and mid-rib downy above, the rest glabrous; racemes secund, rising from the branches of the preceding year, leafless; flowers drooping; corollas urceolately campanulate; anthers biaristate. $\eta$. F. Native of Mexico, below St. Salvador. Flowers white. Fruit black and edible. Ncarly allied to $V$. Meridionale.

White-flowered Whortle-berry. Shrub.

37 V. Caraccasa'num (H. B. et Kunth, nov. gen. amer. 3. p. 266.) racemes axillary, twice longer than the leaves; flowers secund, octandrous or decandrous; leaves elliptic, acute, crenulated, coriaceous, glabrous, shining above; anthers biaristate on the back. $\eta$. H. Native on the southern declivity of Mount Silla de Caraccas. Branchlets angular, glabrous. Leaves shining above, 9-10 lines long. Racemes crowded at the tops of the branches. Corolla campanulate, glabrous, reddish-white, with a 4-5-parted limb; segments ovate, actutish. Filaments membranous, ciliated.

Caraceas Whortle-berry. Fl. May, Jume. Cht. 1925. Shrub. 38 V. vìts-in.e'a (Lin. spec. 500.) racemes terminal, drooping, with ovate concave bracteas, whiclı arc longer than the pedicels; leaves obovate, revolute, minutely toothed, dotted beneath; corolla bell-shaped. ケ. H. Native of dry, barren, stony woods and heaths in the north of Europe; plentiful in Scotland, Westmoreland, Derbyshire, and Wales. Mr. Pursh says it occurs on rocks near the sea-coast, from Canada to New England; but the American plant is more robust than the European, with considerably larger leaves. Lodd. bot. cab. 616 . Ic has also been found in the islands of Kamtschatka, Unalasclika, and St. Lawrence. Smith, engl. bot. 598. Fl. dan. t. 40. Lodd. bot. cab. 1023. - Vitis-idàa rùbra, Cam. epit. 136. Root creeping, woody. Stems ascending a span high; young branches terete, downy. Leaves like those of box, but darker. Flowers pale pink, i-cleft, octandrous. Anthers without spurs. Berries blood-red, acid, austere, and bitter, less palatable in tarts than either the Cranberry or Bilberry, but excellent in a rob or jelly, for colds and sore throats, as well as to eat with roast meat; to which latter purpose this jelly is universally applied by the Swedes, and forms a sauce to venison which is thought superior to currant jelly. In Wales it is used with roast mutton. It may be cultivated in a moist shady border of bog-earth, like the Blcaberry. 
Cow-berry or Red Whortle-berry. Fl. June. Britain. Shrub $\frac{1}{1}$ foot.

$39 \mathrm{~V}$. мy Rtifòlum (Michx. f. bor. amer. 1. p. 229.) creeping, quite smooth; leaves petiolate, oval, shining, revolute, sparingly and minutely toothed; racemes axillary, nearly sessile, of few flowers ; corolla bell-shaped, somewhat inflated, minutely 5 -toothed; anthers without dorsal horns. $々$. H. Native of Carolina. Michanx describes the berries as small, globose, crowned by the calyx, black, on short stalks.

Myrtle-leaved Whortle-berry. Fl. May, July. Clt. 1812. Shrub creeping.

40 V. CRassifòlivm (Andr. bot. rep. t. 105.) racemes lateral and terminal, corymbose; bracteas shorter than the pedicels; leaves elliptic, crenated, smooth, paler and veiny beneath; corolla bell-shaped; stem diffuse. h. H. Native of Carolina. Curt. bot. mag. 1152. A hairy shrub, requiring some shelter from our variable winters and springs. Leaves not an inch long, with a little minute pubescence on the mid-rib and petioles. Flowers 5-cleft, decandrous, prettily variegated with pink and white, drooping, on red corymbose stalks. Starnens hairy.

Thick-lcaved. Whortle-berry. Fl. May, June. Clt. 1787. Slırub trailing.

4.1 V. viliòsum (Smith, in Rees' cycl, no. 29.) racemes longer than the leaves; pedicels, calyx, corolla, and lanceolate bracteas densely hairy; lcaves elliptic, entire, revolute, coriaceous, with a blunt point, hairy on the upper side. . F . Native of Mexico, from whence specimens were sent by Mutis to Linnæus. Branches densely hairy when young. Leaves crowded, an inch long, on thick downy petioles, scarcely hairy beneath, except on the mid-rib. Racemes towards the ends of the younger branches, axillary, drooping, very laairy. Pedicels bracteolate. Corolla purplish, with 5 hairy angles, and as many recurved teeth. Perhaps a species of Gaylussicia.

Villous Whortle-berry. Shrub.

4.2 V. Nítidusi (Andr. bot. rep. t. 480.) racemes terminal, corymbose; bracteas shorter than the pedicels ; leaves ellipticobovate, acute, crenated, smooth and shining; corollas cylindrical. h. H. Native of Carolina. Curt. bot. mag. 1550. Stems either erect or diffuse. Leaves $\frac{1}{2}$ to 1 inch long, paler and veiny beneath. Pedicels, bracteas, and calyx very smooth, of a shining red or purple colour. Calyx of 5 broad, or rather shallow segments. Corollas ovate, oblong, white or pink, with 5 slight spreading teeth, decandrous. The branches are downy on two opposite sides.

Shining-leaved Whortle-berry. Fl. May, June. Clt. 1794. Slurub 1 foot, or decumbent.

$43 \mathrm{~V}$. SCHLECITENDA'LII; racemes elongated, erect, and are as well as the petioles, peduncles, and ribs of leaves on the under surface, downy ; leaves rather coriaceous, permanent, with the nerves and veins prominent on both surfaces, lanceolate or ovate-lanceolate, acute, adpressedly serrated, callously mucronate at the apex as well as the serratures, and rumning into the short petioles, at the base; fructiferous branches nearly leafiess. ?.F. Native of Mexico, near Jalacinga, in woods. Vaccínium, nov. spec. Cham. et Schlecht. in Linnæa. 6. p. 395. An erect, muchbranched, evergreen, smoothish shrub. Leaves 2 inches long, and 9 lines broad. Bracteas linear, acute, caducous; calyx bibracteate at the base. Berries drooping, umbonate, crowned by the minute calycine teeth.

Schlechtendal's Whortle-berry. Shrub.

44. V. Buxı́òlıum (Salisb. par. t. 4.) racemes axillary, of few flowers; leaves petiolate, obovate, toothed or crenated, smooth on both surfaces; stems tufted; corollas roundish-ovate; filaments glandular; stigma capitate. $h$. H. Native of the western parts of Virginia, near Winchester and the Sweet
Springs. Curt. hot. mag. 928. Lodd. bot. cab. 648. V. brachýcerum, Michx. fl. bor. amer. 1. p. 234. A handsome little slirub, in stature and general aspect, resembling $l^{\prime}$. vitis-idce'a. The leaves are, however, smooth, even, and not dotted on the under side. Corollas globular, contracted at the moutl, not bell-shaped. Stamens 10. Anthers spurless at the base, discharging their pollen by lateral, not terminal apertures. Flowers white, delicately striped with red.

Box-leaved Whortle-berry. Fl. June. Clt. 1794. Shrub $\frac{1}{2}$ foot.

4.5 V. ova'tum (Pursh, f. amer. sept. 1. p. 290.) racemes axillary and terminal, bracteate, short; leaves on short petioles, oblong, ovate, acute, revolute, serrated, smooth, coriaceous ; corolla cylindrical, campanulate; calyxes acute. h.H. Found by Governor Lewis on the banks of the Columbia River, and by Mr. Menzies on the north-west coast of America. Hook. et Arn. in Beecl., voy. pt. bot. p. 144. Shrub much branclied; branches hairy, as well as the petioles. The foliage is like that of Pernéttya mucronita.

Ovate-leaved Whortle-berry. Fl. May. Clt. 1826. Shrub. $46 \mathrm{~V}$. Canade'nse (Ricliards, in Frankl. lst journ. append). leaves lanceolate, quite entire, downy; racemes terminal; flowers fasciculate; style inclosed. Ђ.H. Native of Arctic America.

Canalian Whortle-berry. Shrub.

47 V. sca'brum (Pohl. pl. bras. 2. p. 37. t. 124.) racemes terminal and axillary, longer than the leaves, beset with glandular hairs; leaves on slort petioles, ohlong, mucronate, with revolute ciliated edges, scabrous, having the nerves hispid beneath. $h_{2}$. G. Native of Brazil, in turfy bogs at Registo Velho and Villa de Barbacena. Stems many from the same root, leafy at the tops. Leaves scabrous above, and glabrous beneatl, permanent. Pedicels pilose, bracteate at the base. Bracteas of two forms, deciduous. Corolla glabrous, campanulate, white.

Scabrous Whortle-berry. Shrub 1 foot.

48 V. monta'num (Poll, pl. bras. 2. p. 38. t. 125.) racemes axillary, bracteate, pilose; leaves on short petioles, oblongelliptic, mucronate, hardly narrowed at the base, glabrous, but having the nerves on the under side rather pilose. $h$. G. Native of Brazil, in the province of Minas Geraes, in dry places on Serra de Pinheiro. Leaves permanent, dark green above, and yellowish-green beneath, 8 lines long and 4 broad. Flowers unilateral. Corolla campanulate, glabrous, white.

Mountain Whortle-berry. Shrub diffuse.

$$
\text { * *lowers disposed in scaly tufts, nearly sessile. }
$$

49 V. myrsinites (Michx. fl. bor. amer. 1. p. 233.) flowers in terminal and lateral tufts; leaves sessile, oval, mucronate, obscurely serrated, smooth and shining above, but rather hairy and dotted beneath; stem erect, much brancled ; corolla oblongovate. . H. Native of Carolina and Florida, in dry sandy woods. A beautiful little shrub, with slightly downy branches. Leaves glandular beneath. Tufts of flowers axillary, with purple scales. Calycine segments scarlet. Corolla of a fine purple colour, 5-tootlied. Stamens 10.

Var. 3 , lanceolàtum (Pursh, fl. bor. amer. 1. p. 290.) leaves lanceolate, acute at both ends.

lar. $\gamma$, obtùsum (Pursh, l. c.) leaves roundish-obovate.

Myrtlc-like Whortle-berry. Fl. May, June. Clt.? Slırub small.

\section{* * Floners solitary, pedicellate.}

$50 \mathrm{~V}$, CE'REUM (Forst. prod. 28.) pedicels axillary, solitary, 1- 
flowered, furnished with 2 lancellate bracteas about the middle; leaves roundish-ovate, scrrated; ealyx of 5 broad ovate pointed segments. h.F. Native of Otaheite and Owalıu. Andrómeda cèrea, Lin. fil. supp)]. 238. Branches terete, slightly downy when young. Leaves nucronate, about an inch Jong. Corolla ovatc-oblong, with 5 angles, and 5 erect small segments. Stamens 10. Anthers with 2 dorsal horns, according to Linnacus. Perhaps a species of Pernéttya.

Waxy Whortle-berry. Shrub smal], $\frac{1}{2}$ foot.

51 V. Rrticula'tum (Smith, in Rees" cycl. no. 30.) pedicels axillary, solitary, l-flowered, downy; leaves obovate, more or less serrated, coriaccous, witls a blunt point, strongly reticulated on both sides, and nearly smootb. $\zeta$. F. Native of the Sandwich Islands, on the high mountains, in woods, where it was collected by Mr. Menzies, Branches when young angular and downy. Leaves an inch long, with revolute margins. Pedicels bractless, swelling upwards. Calyx in 4 or 5 deep-ribbed coloured segments, at length involute. Corolla cylindrical, twice as fong as the calyx, purple, slightly hairy, with 4 or 5 erect blunt teeth. Style hairy. Berries globular, depressed, nearly smooth.

Retieulated-leaved Whortle-berry. Shrub.

52 V. numfu'st m (Graham, in edinb. phil. journ. June, 1831.) pedicels axillary, solitary, 1 -Howered, furnished with many bracteas; leaves evergreen, ovate, acutish, quite entire, glabrous on both surfaces, ciliated; stem prostrate, creeping ; Howers decandrous; anthers obtuse, mutic. $\zeta$. H. Native of North America, on the Rocky mountains. Branchlets downy. Flowers drooping. Corollas campatsulate, white, often partially tinged with red outside, with reflexed teeth. Stigma capitate. Filaments glabrous, flattened. Fruit edible, well-flavoured.

Trailing Whortle-berry. Fl. May, June. Clt, 1827. Shrub creeping.

53 V. PENDUlatòrum (Gaud. in Freyc. voy. pt. bot. p. 454.) pedicels axillary, solitary, l-flowered, elongated, pendulous in the fruit-bearing state; flowers decandrous; calycine segments lanceolate, one-half shorter than the corolla, which is campanulate and 5-angled; anthers awned; branches angular, leafy; leaves oblong, sharply serrated, rather coriaceous. h. F. Native of the Sandwich Islands, at the altitude of 500 hexapods. An erect glabrous shrub.

Pendulous-flowered Whortle-berry. Shrub.

54 V. mcrophýlqum (Herb. Reinwdt. ex Blum. bijdr. p. 851.) stem slurubby; branchlets puberulous; leaves oval, obtuse, quite entire, with recurved margins, veiny, coriaceous, glabrous; pedicels almost solitary, axillary, 1-flowered; corollas urceolate; anthers mutic; calyx bractless. h. G. Native of the Celebes, on the mountains.

Small-leaced Whortle-berry. Shrub.

$55 \mathrm{~V}$. uENTA'ren (Smith, in Rees'cycl. no. 31.) pedicels axillary, solitary, 1-flowered, smooth; leaves obovate, with sharp toothlike serratures, coriaceous, veiny, very smooth; calyx longer than the smooth ovarium. $\hbar$. F. Native of the Sandwich Islands, on the lofty mountains, where it was found by Mr. Menzies. The branches are angular, and always smooth, like every other part. Leaves rather longer than the $\boldsymbol{r}$. reticulatum, with less prominent veins. Calycine segments keeled.

Tooth-leaved Vaccinium. Shrub.

56 V. oвtu'sum (Pursh, fl. amer. sept. 1. p. 290.) pedicels axillary, solitary, 1-tlowered; leaves small, oval, rounded, and blunt at eaclı end, mucronate, entire, coriaceous, smooth ; stem creeping. $\zeta_{\text {. }}$ H. Native of the north-west coast of America, where it was gathered by Mr. Menzies.

Blunt-leaved Whortle-berry. Shrub.

57 V. enpetrifo'litu (H. B. et Kunth, nov. gen, amer. 3. p. 263. t. 268.) creeping, auite glabrous leaves approximate, VOL. III. subimbricated, obtuse, quite entire, coriaccous, glabrous; pedicels solitary, axillary, 1-flowered ; flowers octandrons; corollas tubularly campanulate; anthers mutic; calyx bibracteate at the base. $h_{\text {. }}$ G. Native of the western declivity of the burning Mount Antisana, between Pintac and Pinantura. Leaves $2 \frac{1}{2}$ lines long. Corolla scarlet, glabrous : with ovate, acute, spreading segments. Anthers dehiscing lengthwise. Filaments ciliated.

Empetrum-leaved Whorthe-berry. Shrub crecping.

58 V. penadides (H. B. et Kuntl, nov, gen. amer. 8. p. 264.) creeping, glabrous; leaves approximate, subimbricated, oblong, acute, obsoletely and remotely crenulated, stiff; glabrous, a little ciliated; pedicels short, axillary, solitary, l-flowcred; flowers octandrous; calyx bibracteate; anthers nutic. h. G. Native of the province of Quito, at Mount 'Tunguragua, near Cuclilla de Guandisava. Leaves 3 lines long. Pranchlets downy. Flowers solitary, on the tops of the branches. Corolla tubularly campanulate, scabrous, with ovate acutish segments. Filaments pilose.

Penaa-like Whortle-berry. Shrub creeping.

59 V. acumisa'tum (H. B. et Kunth, nov. gen. amer. 3. p. 264.) arboreous; leaves approximately subimbricated, ovate, acuminated, quite chtire, coriaceous, glabrous ; flowers axil]ary, solitary, twin or tern, almost sessile, octandrous; calyx bibracteate; anthers mutic.? 々. G. Native of New Granada, in Paramo de Almaguer, and near Pansitara. Branches elothed with rusty hairs, densely leafy, Leaves on slort petioles, 3 lines long. Corollas nearly globose, white, with a quadrifid reflexed limb. Filaments pilose.

Acuminated-leaved Whortle-berry. Shrub 10 to 15 feet.

60 V. Alaternoides (H. B. et Kunth, nov, gen. 3. p. 265.) arborescent? leaves roundish, elliptic, acutish, quite entire, obsoletely 3-nerved, coriaceous, glabrous; flowers axillary, solitary, twin or tern, sessile, octandrous; calyx bibracteate ; anthers mutic, half exserted. b. G. Native of the Andes of Peru, near Ayavaca. Branches downy. Leaves 8-9 lines long. Corolla tubularly campanulate, white, with a quadrifid revolute limb. Filaments villons.

Alaternus-like Whortle-berry. Shrub or small tree.

N.B. There are several plants with different names than those above, in the gardens, but these names are only synonymous with some of the species described above, as $V$. prunifölium, $V$. halleriafolium, and $V$. salieinum.

Cult. All the species may be raised from seeds, or from offset root-suckers, creeping roots, and trailing rooting stems. Those also growing with several rooted stalks, may be divided in the root and top into separate plants, in which way they succeed very well. The seeds should be sown, when that method is pursued, in the autumn, as soon as they are ripe and gathered, in a shady border; and when the plants are up, and require to be removed, keep a ball of earth about their roots. The offsets or root-plants may be set out in the same season, in proper places. 'The species are admitted into garlens and pleasuregrounds for the sake of variety, curiosity, and ornament, and some of them are grown for the use of their fruit. All thrive best in peat soil, or very sandy loam. Some require to be grown in moist situations, and others in dry. The stove and greenhouse kinds should be treated as other green-house and stove shrubs; and cuttings of them strike readily in sand, under a bell-glass; those of the stove species in heat.

LHII. OXYCOCCUS (from oks, oxys, sharp, and Nox. kos, kokkos, a berry; in reference to the sharp acid taste of the berries). Pers. syn. 1. p. 419. Pursh, f. amer. sept. 1. p. 268. $5 \mathrm{R}$ 
Nutt. gen, amer. 1. p. 250.-Vaccínium species of Lin. and others.

LIN. syst. Octándria, Monogýnia. Calyx 4-toothed. Corolla 4-parted, with nearly linear revolute segments. Stamens 8, with connivent filaments; anthers tubular, 2-parted. Berries many-seeded. - Small, prostrate, creeping, evergreen slirubs, with small leaves, growing in splagnose morasses. Branches filiform, proliferons. Flowers produced at the base of the spring branchlets, in short gemmaceous racemes; pedicels fitiform, conspicuously bibracteate. Berries red, rarely white, acid.

1 O. Palu'stris (Pers, ench, 1. p. 419.) stems filiform, creeping; leaves small, ovate, entire, acute, smooth, with revolute margins; pedicels terminal, 1-flowered; segments of corolla oval. $々$. B. H. Native of turfy mossy bogs in the mountainous parts of Europe; common in Switzerland, Russia, Scotland, lreland, and the north of England, as well as in Lincolnshire and the neighbouring part of Norfolk. Mr. Pursh speaks of it as common on the boggy mountains of North America, from Canada to Pennsylvania, Island of Unalasclıka. O. vulgàris, Pursh. fl. amer. sept. 1. p. 263. O. Europæ'us, Nutt. gen. amer. 1.p. 251. Vaccínium Oxycóccus, Lin. spec. 500. Smith, engl. bot. t. 319 . Oed. fl. dan. t. 80. Vaccínium Oxycóccus, var. a, ovalifòlius, Michx. f. bor. amer. 1. p. 228. Vaccínia palústris, Ger. emac. 1419. Lob. icon. 2. t. 109. Oxycóccum, Cord. laist. 140. 2 f. 1. Leaves convex, and dark shining green above, and glaucous beneath. Stems reddish. Pedicels few together, about the tops of the branches, red, slightly hoary. Corolla pink, with reflexed oblong segments. Stamens with purple downy filaments and yellow anthers. Berries pear-shaped, globular, often spotted, crimson, of a peculiar flavour, with a strong acidity, grateful to most people in the form of tarts, for which purpose they are largely imported from Russia. Not long since, cranberries from Lincolnshire and the north-west corner of Norfolk were sold in the streets of Norwich by cart-loals; but the extensive inclosures have in many parts destroyed and draincd their native bogs. Lightfoot records, that at Longtown, on the borders of Cumberland, not less than $20 l$. or $30 l$. worth were sold each market day, for 5 or six weeks together, and dispersed over different parts of the kingdom. In Sweden, these berrics serve only to boil silver plate to its due degree of whiteness, their sharp acid corroding the superficial particles of the copper alloy.

Marsh or Common Cranberry. FI. May, June. Britain. Shrub creeping.

2 O. Macrocárpus (Pursh. fl. amer. sept. 1. p. 263.) stems prostrate, filiform, creeping; leaves elliptic-oblong, nearly flat and obtuse, distantly subserrulated on the margins, glaucous beneath, downy at the points when young: segments of the corolla linear-lanceolate; flower-bearing branches erect, proliferous; pedicels lateral. h. B. H. Native from Canada to Virginia, in bogs, principally on a sandy soil, and on high mountains. Wats. dendr. brit. t. 122. Vaccínium macrocárpum, Ait, hort. kew. ed. 1. vol.2. 13. t. 7. Hook. bot.mag. 2506. Lam. ill. t. 286. f. 4. Vaccínium hispidulum, Wangh. amer. t. 30 . f. 67. Vaccínium oxycóccus $\beta$, oblongifòlius, Michı. fl. amer. bor. 1. p. 228. Points of young leaves, peduncles, and the margins of the calyx and bracteas downy. Berries spherical, red, often remaining throughont the winter. This is a larger and more robust plant than the preceding. Several flowers come forth at the ends of the last year's branches, surmounted by the shoots of the present year. The bracteas are situated in the upper part of the pedicels in this, while in the preceding they are situated at the lower part. The berries are larger, and of a brighter red than the last, and are collected in great abundance for making tarts in America, and exported from thence to Europe; but they always prove here far inferior in quality to the Russian cranberries, however excellent in America. The best way of having American cranberries in Eurore is by cultivation in an artificial bog, with great plenty of water, as first contrived by Sir Joseph Banks. A very few square yards of ground thus employed will yield as many cranberries as any family can use. If allowed to hang until they are full ripe, as late as October, they are even better than the common cranberry, and may be kept dry in bottles throughout the year. Our wild cranberries have generally been gathered too early; as may also be the case with those brought from America. "Wherever there is a pond," Mr. Neill observes, "the margin may, at a trifling expence, be fitted up for the culture of this plant, and it will continue productive for many years. All that is necessary is to drive in a few stakes 2 or 3 feet within the margin of the pond, and to place some ohl boards within these, so as to prevent the soil of the cranberry-bed from falling into the water; and lay a parcel of small stones or rubbish in the bottom, and over it peat or bog earth, to the depth of about 3 inches above and 7 inches below the surface of the water. In such a situation the plants grow readıly; and if a few be put in they entirely cover the bed in the course of a year or two, by means of their long runners, which take root at different points. From a very small space a large quantity of cranberries may be gathered; and they prove a remarkable regular crop, scarcely affected by the state of the weather, and not subject to the attack of insects.

Large-fruited or American Cramberry. Fl. May, July. Clt. 1760. Shrub creeping.

3 O. ERE'crus (Pursh. fl. amer. sept. 1. p. 264.) leaves oval, acuminated, serrulated and ciliated; pedicels axillary; corolla before expansion long and conical, at length revolute; stem erect. $\eta$. H. Native of Virginia and Carolina, on the ligh mountains. Wats. dendr. brit. t. 31. Vaccínium erythrocárpum, Michx. fl. amer. bor. 1. p. 22\%. Branches flexuous. Leaves membranous, somcwhat hairy. Flowers red. Berries scarlet, (black, ex Wats,) and quite transparent, of an exquisite taste. Very different in lubit from the other species.

Ercet Cranberry, Il. May, June. Clt. 1806. Shrub 2 feet.

Cult. When any of the species are grown for the sake of their berries, they should be planted in an artificial bog, as mentioned under $O$. macrocárpus. But when grown only for having a specimen of the plants, they will grow well in pots filled with peat and sand, having sphagnum set round their roots: the pots should be well drained with sherds, and set in deep pans of water.

LIV. GAYLUSSA'CIA (named after L. Gay-Iussac, a eelebrated French physician, and member of the Academy of Sciences, Paris). Humb. Bonpl. et Kunth, nov. gen. amer. 3. p. 275 . t. $25 \%$ Cham. et Schlecht. in Linnaea. 1. p. 529. Lussàcia, Spreng.-Thibaúdia species, Humb.

Lin. syst. Pentándria, Monogýnia. Limb of calyx 5-cleft. Corolla tubular, ventricose at the base; limb 5-toothed. Stamens 10 , inserted in the limb of the calyx, inclosed ; anthers mutic, drawn out from the top into 2 little tubes. Style erect; stigma depressedly capitate. Drupe nearly globose, clothed by the calyx, 10-celled; cells 1 -seeded. Seeds lenticular, smooth. --Evergreen or decichous shrubs. Leaves scattered, coriaceous, each terminated by a mucrone or gland. Racemes axillary, approximate. Flowers scarlet, bracteate. Very nearly allied to Thibaudia, but very distinct.

\section{* Corollas urccolate, or cylindrical.}

1 G. Buxifòla (H. B. et Kunth, nov, gen. amer. 3. p. 270. 
t. 257.) young branchlets hispid; lcaves elliptic or ellipticoblong, rounded at both ends, terminated by a depressed brown gland, pilosely pubescent on both surfaces with minute scattered glands beneath, toothed at the apex; racemes axillary and approximate at the tops of the branches; flowers and fruit downy. 々. S. Native near Caraccas, on Mount $\Lambda$ vila, and near Santa $\mathrm{Fe}$ de Bogota. Corollas scarlet. Calycine segments ovate, acute.

Box-lcaved Gaylussacia. Shrub.

2 G. imbrica'ta (Pohl. pl. bras. 2. p, 40. t. 126.) leaves imbricated, oval-elliptic, mimutely crenated at the apex, terminated by a callous mucrone; calyx and corolla glabrous; bracteas of 2 forms, linear-lanceolate and oblong acute. $\boldsymbol{\eta}$. G. Native of Brazil, in the province of Rio Janeiro, at Rio Tejucco, on the mountains. G. buxifòlia, Cham. et Schlecht. in Linnæa. vol. 1. p. 528. but not of H. B3. et Kunth. Leaves permanent, clothed with yellow down on the nerves beneath. Racemes many-flowered, 2 inches long, downy. Flowers scarlet or crimson.

Imbricated-leaved Gaylussacia. Shrub 2 feet.

3 G. pu'Lchra (Polil. pl. bras. 2. p. 41. t. 127.) leaves oblong-elliptic, quite entire, with revolute edges, each terminated by a short callons mucrone, glabrous above, but pilose on the nerves and veins beneath, as well as the calyxes; corollas glabrous; bracteas of two forms, linear and oblong, acute. $h . G$. Native of Brazil, in the province of Minas Geraes, by waysides about Arrayal St. Joao Baptista. Stem branclıed, hoary. Branches leafy, glabrous, floriferous at the tops. Leaves deciduous, remote, green above and yellowish-green beneath, $1 \frac{1}{2}$ inclies long and 8 lines broad. Racemes loose.

Fair Gaylussacia. Shrub 2 feet.

4 G. DEPE'NDENS; branchlets angular, downy; leaves ovate, mucronate, cinereous; flowers axillary, aggregate; teeth of calyx ovate, acute. $々$. G. Native of Peru. Vaccínium dependens, Ruiz et Pav, in herb. Lamb. Leaves an inch long.

\section{Dependent Gaylussacia. Shrub.}

5 G. мискорну'Lxa; branchlets pilose, terete; leaves ovate, acuminated, striated beneath; flowers solitary, nearly sessile; calycine teeth ovate, acute. h. G. Native of Peru. Leaves hardly more than a line and a half long. Flowers scarlet. (v. s. in herb. Lamb.).

Small-leated Gaylussacia. Shrub.

6 G. cRena'ta (D. Don, mss. in herb. Lamb.) branchlets terete, downy; leaves oblong, acute, crenated; flowers aggregate; calycine teeth ovate, acute. h. G. Native of Peru. Leaves laalf an inch long. Flowers scarlet.

Crenated-leaved Gaylussacia. Shrub.

7 G. Rugòsa (Cham. et Schlecht. in Linnæa. 1. p. 534.) branches hispid; leaves oblong, retuse, rugose, with revolute margins, scabrous above and hairy beneath, furnished with 2.3 short teeth on each side; racemes secund, drooping, 8-10-flowered, beset with glandular hairs; corollas tubularly urceolate, hairy on the angles and at the tops of the segments ; young leaves beset with pili, whicl are tipped with black glands. $々$. G. Native of Brazil, without the tropic. Filaments ciliated. Calycine teeth narrow, acuminated.

Rugose Gaylussacia. Shrub 1 to 2 feet.

8 G. RHODODÉ idron (Cham. et Schlecht. in Linnæa. 1. p. 533.) branches hispid; leaves nearly glabrous, elliptic, narrowed at the base; petioles pruinose, obsoletely serrated towards the apex; racemes lateral, secund, drooping; corollas cylindrical. 2.G. Native of Brazil, within the tropic. Racemes terminal, or nearly so, and axillary. Flowers dense, secund. Pedicels hispid. Calycine segments short, elliptic, obtuse, ciliated. Corollas pilose or smoothish.
Rhodudcndron Gaylussacia. Slirul).

9 G. PSEU'Do-vaccínium (Cham, et Sclilecht. in Linnaea. 1. p. 530.) glabrous or downy ; leaves clliptic-lanceolate; racemes terminal, aggregate; corollas cylindrical; ovarium glabrous. b. G. Native of Brazil, within the tropic, in open sandy places; near Caravellos Freireis. Vaccínium Brasiliénsis, Spreng. nov. prov. p. 12. syst. 2. p. 212. Leaves obsoletely serrated towards the top, with a few cilice at the base of the younger leaves. Racemes axillary, ereet, secund, bracteate, of a fine crimson colour, as well as the corollas, which are cylindrically urccolate; calycine teeth roundish, acuminated. There are glabrous and downy varieties of this species.

False-vaccinium Gaylussacia. Shrub 1 to 2 feet.

10 G. myrtifòlia (Cham. et Schlecht. in Linnæa. 8. p. 49.1.) leaves obovate-lanceolate, acute, terminated by an obtuse callous point, with serrulated reflexed inargins, an inch long; racemes crimson, usually solitary, nearly terminal, erect, exceeding in leaves; calycine segments short, ovate, acuminated. $\zeta . G$, Native of Brazil, within the tropic. Corolla tubular, ventricose. Young branches pilose. Young leaves ciliated. Leaves yellowish beneath, pilose on the petiole and midrib.

Myrtle-leaved Gaylussacia. Shrub.

11 G. saliciròlia (Cham. et Schlecht. in Linnæa. 1. p. 532.) quite glabrous and pruinose ; leaves oblong, lanceolate, with adpressed serratures towards the apex; flowers 1-4 together, from the axils of the younger leaves; pedicels filiform, short, drooping, bractless; corolla cylindrical, plicate, with obtuse reflexed segments, $\eta$. G. Native of Brazil, within the tropic. Flowers not seen. Calycine teeth broad from the base, acuminated.

Hillow-leaved Gaylussacia. Shrub 1 to 2 feet.

12 G. LANCEOLA'TA (Blum. bijdr. p. 861.) stem parasitical ; leaves oblong-lanceolate, acuminated, coriaceous, glabrous, reticulately veined, and triple-nerved beneath; racemes axillary, simple, and are, as well as the calyxes, tomentose; pedicels tribracteate at the hase. $h$. G. Native of Java, on trees on the mountains. Anthers biaristate on the back, beneath the apex. Stigma truncate, simple. Capsule 10-celled; cells 1-seeded.

Lanccolute-leaved Gaylussacia. Shrub.

13 G. DE'NSA (Cham. in Linnæa. 8. p. 490.) leaves rather inconspicuously and bluntly crenulated in front, and terminating in an erect mucrone; inflorescence crimson; calycine segments triangular; stamens glabrous. h. G. Native of Brazil, within the tropic. Branches, petioles, and rachi canescent from down, with the nerves and margin densely ciliated, as well as the bracteas and calyxes. Corolla glabrous, rarely pilose on the nerves.

I ar. $\beta$; branchlets, rachi, and petioles, downy from shorter bairs; bracteas and calyxes ciliated; nerves and veins of leaves prominent beneath, $h . G$.

Var. $\gamma$; leaves coriaceous, having the nerves and veins hardly conspicuous beneath, quite glabrous in the adult state.

Dense-flowered Gaylussacia. Shrub.

14 G. MYRTILloìdes (Cham, in Linnæa. 8. p. 49s.) leaves sharply serrated in front, ending in a straight mucrone; calycine segments lanceolate, length of the corolla; filaments ciliated, length of anthers. h.G. Native of Brazil, within the tropic. Branchlets, petioles, rachi, pedicels, and ovaries, beset with long spreading white hairs. Inflorescence crimson, glanduliferous. Leaves having the margins and nerves beneath pilose in the young state. Bracteas and calyxes pectinately ciliated, Corollas glabrous.

Myrtle-like Gaylussacia. Shrub.

15 G. PA'Llida (Cham. in Linnæa. vol. 8. p. 499.) branches marked by cicatrices occasioned by the falling of the leaves; leaves nearly sessile, quite entire, usually acute, terminating $5 \times 2$ 
each in an inflexed white mucrone; flowers pale, clothed with glandular down; bracteas foliaceous, green, length of flowers; bracteoles somewhat foliaceous, lanceolate, situated under the calyxes; calycine segments lanceolate, about a third the length of the corolla; filaments villous, about a fourth the length of the

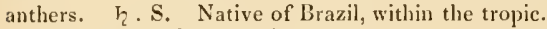

Palc-flonered Gaylussacia. Shrub.

16 G. Angustifòlia (Cham. in Limæa. 8. p. 499.) branches, petioles, inflorescence, and calyxes downy ; leaves coriaceous, linear-lanceolate, narrowed into the short petioles at the base, ending each in a callous acute point, with reflexed inconspicuously serrulated edges, shining above and rufescent beneatls ; racemes axillary, nearly terminal, erect, exceeding the leaves; lower bracteas foliaceous : superior ones coloured; calycine segments ovate, acuminated, or acutely triangular, and are, as well as the bracteas, ciliated; corollas cylindrical, downy on the nerves; filaments villous, shorter than the anthers. h. S. Native of equinoxial Brazil. Inflorescence coloured.

Narrow-leaved Gaylussacia. Shrub.

17 G. pinifòlia (Cham. et Schlecht, in Linnæa. 1. p. 536. and 8, p. 500.) quite glabrous and pruinose ; leaves linear, acute at both ends, crenated; pedumcles axillary, 1-3-flowered, furnished with sinall glandularly serrated bracteas; corolla urceolate, with short erect teeth. h.S. Native of equinoxial Brazil. The young leaves at the tops of the branches and flowers are crimson. Calycine teeth ovate, acuminated, cuspidate, with glandularly ciliated edges.

Pine-leaved Gaylussacia. Shrub $\frac{1}{2}$ to 1 foot.

\section{* Corollas campanulate.}

18 G. pseu'do-gavlthe'ria (Clam. et Schlecht. in Linnæa. 1. p. 535.) branches straight, hispid; leaves narrow-elliptic, subcordate, scabrous on both surfaces, obsoletely serrulated towards the top; racemes axillary and terminal at the tops of the branches, approximate, secund, erect, hispid, bracteate. $h_{\text {. S. }}$. Native of Brazil, within the tropic. Stems rising from the root, biennial or triennial, about a foot high, brancherl. Flowers white, hardly crimson. Corollas campanulate, with hairy angles. Calycine teeth narrow, lanceolate. Ovarium hairy, glandular.

False Gaultheria Gaylussacia. Shrub 1 foot.

19 G. Decípiens (Cham. in Linnæa. 8. p. 500.) branches hairy ; leaves coriaceous, elliptic, obtuse, attenuated at the base, obsoletely crenated towards the apex; racemes from the axils of the ultimate leaves, secund, erect; calycine teeth triangular, acuminated; corolla campanulate, pilose on the angles, with erect triangular teeth. $h$. S. Native of Brazil, within the tropic. G. buxifòlia, Cham. et Schlecht. in Linnæa. 1. p. $52 \mathrm{~S}$. but not of H. B. et Kunth. Leaves glabrous above, but pubescent on the nerves beneath. Corollas white, campanulate, not scarlet. This species has been referred to $G$. imbricàta by Pohl, but it differs from it in the flowers being campanulate and white, not scarlet.

Dcceiving Gaylussacia. Shrub 1 to $1 \frac{1}{2}$ foot.

20 G. AME'NA (Cham. in Linnæa. 8. p. 501.) branches, petioles, and inflorescence downy ; calyxes glabrous, but are, as well as the bracteas, ciliated with glandular hairs; leaves on very short petioles, ending each in a callous mucrone, serrulated in front, with reflexed margins covered with resinous dots beneath, having the veins and nerves prominent beneath; racemes nearly terninal, erect, elongated; calycine segments ovate, acuminated; corolla campanulate, glabrous, filaments ciliated, half the length of the anthers; bracteas foliaceous. h. G. Native of Brazil, within the tropic. Flowers white.
I ar. $\alpha$; leaves obovate-cuneated, rounded.

Far. $\beta$; leaves narrower, blunt at the base, acuter at the apex, oblong or lanceolate.

Pleasant Gaylussacia. Shrub + to 6 feet.

21 G. INCA'NA (Cham. in Linnæa. 1. p. 536.) clothed with hoary tomentum; leaves oblong, with revolute margins, quite entire; racemes axillary and terminal, approximate at the tops of the branches, secund, erect; corollas campanulate, downy. h. G. Native of Brazil, within the tropic. Leaves cinereous above and white beneath. Calycine teeth lanceolate. Corolla downy, as well as the filaments.

Hoary Gaylussacia. Shrub 1 foot.

Cult. For culture and propagation see Agarista, p. 838. All the species are extremely elegant when in blossom, and are therefore very desirable plants in every collection.

LV. THIBAU'DIA (named after Thiebaut de Berneaul, secretary of the Linnean Socicty of Paris; author of several botanical memoirs). Pav, mss. H. B. et Kunth, nov, gen. amer. 3. p. 268. Ruiz et Pav. fl. per, vol. 4. ined.-Cavínium Aub. du Pet. Th.

Lin. syst. Decándria, Monogýnia. Calyx urccolar; limb 5-lobed. Corolla tubular, coarctate at the apex and 5-toothed. Stamens 10, inclosed; filaments very short, dilated; anthers 2-celled, shortly spurred at the base, drawn out into two tubes at the apex; cells or tubes parallel, dehiscing lengthwise by a linear fissure. Ovarium 5-celled. Style pentagonal. Stigma ample, peltate. Berry 5-celled; cells many-seeded. Seeds minute, angular, dotted.-Shrubs. Natives of Peru. Leaves evergreen, coriaceous, quite entire, nerved. Flowers drooping, bracteate, disposed in lateral corymbose racemes.

1 T. bractea'ta (Ruiz et Pav. fl. per. 4. t. 388 . ined). leaves ovate-lanceolate, acuminated, 5-nerved; bracteas large, permanent, coriaceous, 2-lobed; anthers spurred at the base. h.S. Native of Peru. Branches angular, glabrous. Leaves rouncled at the base, $2-3$ inches long, petiolate. Flowers disposed in terminal thyrsoid corymbs at the tops of the branches. Corollas scarlet, nearly an inch long. Bracteas imbricated. Filaments bearded at the apex.

Bracteate Thibaudia. Shrub.

2 T. mellifern (Ruiz et Pav. 1. c. t. 387. f. b.) branches terete, downy; leaves oblong, obtuse, feather-nerved, acute at the base; flowers axillary, corymbose, bractless; limb of calyx nearly entire; corollas short. $\zeta$. S. Native of Peru. Leaves 2-3 inches long, on short petioles, glabrous. Bracteas small. Peduncles downy. Limb of calyx obsoletely 5-lobed. Filaments glabrous.

Iloney-bearing Thibandia. Shrub.

3 T. punctatifòlıa (Ruiz et l'av. !. c. t. 387 . f. a.) leaves oblong-lanceolate, acuminated, 5-nerved, rounded at the base, dotted beneath; calyx bluntly 5 -lobed; racemes elongated, nodding; bracteas large, oblong, mucronate, adpressed; corollas ventricose; filaments glabrous. ケ. S. Native of Peru. Leaves a hand long, glabrous. Petioles short, robust. Branchlets angular. Racemes a span long, many-flowered. Flowers drooping. Corolla ventricose, an inch long.

Dotled-leaved Thibaudia. Shrub.

4 T. coarcta'ta (Riuiz et Pav. l, c. t. 385.) branchlets angular, glabrous; leaves lanceolate, acuminated, 5-nerved, rounded at the base; flowers aggregate; bracteas 2-lobed, roundish, coriaceous; calycine teeth acute; filaments glabrous. $h$. S. Native of Peru. T. bicolor, Dunal. in herb. Lamb. Leaves 3-4 inches long, marked with white veins above. Flowers peduncu- 
late, subcorymbose, 5-10 together, drooping. Berries large. Corolla $1 \frac{1}{1}$ incls long.

Coarctate-flowered Thibaudia. Shrub.

5 'T. caulata'ta (Ruiz et Pav, 1. c. t. 386.) branchlets angular; leaves nearly sessile, cordate-oblong, obtuse, denticulated; racemes few-flowered; bracteas lanceolate, acuminated; calycine teetl short, acute; filaments glabrous. $\hbar . S$. Native of Peru. Leaves 4 inches long, feather-nerved. Bracteas permanent, lanceolate, coriaceous. Corolla an inch long.

Wing-stemmed Thibaudia. Shrub.

6 'T. elcírtica (Ruiz et Pav. 1. c. t. 384. f. b.) branchlets angular; leaves elliptic-oblong, with revolute margins; flowers aggregate; calycine teeth acutish, very sliort. h.S. Native of Peru. Leaves 3 inches long, attenuated at the base, on short petioles, feather-nerved. Peduncles half an inch long.

Elliptic-leaved Thibaudia. Slirub.

7 T. emargina'ta (Ruiz et Pav. I. c. t. 3s4. f. a.) branchlets terete, glabrous; leaves obovate, emarginate, bristly beneath; flowers solitary; calyx obsoletely 5-toothed; corollas conical; filaments glabrous. $\mathbf{h}$. S. Native of Peru. Leaves $1 \frac{1}{2}$ inch long, 3-nerved, acute at the base. Corolla ventricose, 3 lines long. Flowers pendulous. Peduncles glabrous.

Emarginate-leaved Thibaudia. Shrub.

S T. FLoRiBúNDA (H. B. et Kuntl, nov, gen, amer. 3. p. 269. t. 254.) branchlets terete, glabrous; leaves lanceolate, acuminated, reticulately veined, glabrous, as well as the inflorescence; racemes axillary, solitary; bracteas imbricated; filaments glabrous. 々. S. Native of New Grenada, near Santa Fe de Bogota. Leaves 5 inches long. Calycine teeth ovate, acute. Corolla ventricose, scarlet.

\section{Bundle-flonered Thibaudia. Slırub.}

9 'T. Longifòlia (H. B. et Kunth, l, c.) branchlets pentagonal, glabrous; leaves long-lanceolate, acuminated, obtuse at the base, reticulately triple and quintuple-nerved, and are, as well as the calyses and corollas, glabrons, $h_{2}$. G. Native of the Andes, about Quindiu, near La Seja. Leaves 6-7 inches long. Racemes axillary, shorter than the leaves. Flowers size and structure of those of the preceding species.

Long-leaved Thibaudia. Shrub.

10 T. Falca TA (H. B. et Kunth, I. c.) branclilets terete, glabrous, fuscescent; leaves lanceolate, acuminated, falcate at the apex, acute at the base, reticulately quintuple-nerved, and are, as well as the calyx and corollas, glabrous. $h$. S. Native of New Granada, near Almaguer. Leaves 8 inches long. Racemes axillary, solitary, shorter than the leaves.

Falcate-leaved Thibaudia. Slırub.

11 T. Macrophx'Lla (H. B. et Kunth, 1. c. p. 270.) branchlets terete, glabrous; leaves ovate-lanceolate, acuminated, rounded at the base, reticulately quintuple-nerved, and are, as well as the calyx and corollas, glabrous. b. S. Native on the Andes, about Popayan, near Pindamon and Palace. Leaves on short petioles, 8-9 inclies long. Racemes axillary, solitary, nearly sessile, 3 or 4 times shorter than the leaves. Corollas large, tubular, white, but red and ventricose below. Calycine teeth short, acute.

Long-leaved Thibaudia. Slirub 10 feet.

12 1. RUPE'STRIS (H. B. et Kunth, 1. c. p. 270.) branchlets downy, striated a little; leaves lanceolate, bluntish, acute at the base, reticulately seined, glabrous above and downy beneath, especially on the nerves; caly xes glabrous. $h_{2}$. S. Native of New Granada, in Paramo de Saragura, near Loxa and Alto de Pulla. Leaves 3 inches long. Racemes axillary. Fruit nearly globose, about the size of those of Prùnus spinòsa.

Rock Thibaudia. Slırmb.

13 T. vírıd (H. B. et Kunth, 1. c. p. 271.) branchlets trigo- nal, ? glabrous, fuscescent ; leaves oblong, obtuse, rounded at the base, somewhat quintuple-nerved, shining, and are, as well as the calyxes and corollas, glabrous. $h_{.} . s_{\text {. N }}$ Native on the eastern declivities of the Andes, about Quindiu, between Quebrada de Tocliecito and La Seja. Leaves on short petioles, 4 inclies long, beset with minute dots beneath. Racemes axillary, solitary, almost sessile, 2 inches long, involucrated by large roundish-ovate, obtuse, concave, coloured bracteas at the base.

Shining-leaved Thibaudia. Shrub.

14 'l'. cordifòlia (II. B. et Kunth, 1. c. p. 271. t. 255.) branchlets furrowed, resinous, shining; leaves ovate, cordate, obuse, quintuple or septuple-nerved, shining above, and are, as well as the calyses, glabrous; corollas downy. h. G. Native of New Granada, on the Andes. Bractcas oblong, obtuse, coloured, concave. Calycine teetli ovate, acute. Corolla tubular, ventricose. Racemes axillary at the tops of the branches, solitary, sessile, hardly longer than the leaves. Filaments glabrous.

Heart-leaved Thibaudia. Shrub.

15 T. Melastowoides (H. B. et Kunth, l. c. p. 272.) branchlets terete, smooth, brown, glabrous; leaves oblong, short-actiminated, rounded at the base, rather cordate, reticulately quintuple-nerved, and are, as well as the calyxes and corollas, glabrous. h. G. Native along with the preceding. Leaves having minute scattered dots beneath, 3 inches long, and an inch broad. Racemes axillary, solitary, sessile, shorter than the leaves, covered with the imbricated bracteas before expansion. Bracteas oblong, concave, rounded at the apex.

Mclastoma-like Thibaudia. Shrub.

16 T. strobulífera (H. B. et Kunth, l. c. p. 272.) branchlets downy, obsoletely angular; leaves oblong, acuminated, rounded at the base, reticulately triple or quintuple-nerved, and are, as well as the calyxes and corollas, glabrous. h. G. Native of New Granada, in frigid places, between Rio Uduchapa and Parano de Saraguru, near Loxa. Leaves beset with black dots beneath, reticulately 3-5-nerved, $2 \frac{1}{2}$ inches long. Racemes axillary, solitary, sessile, shorter than the leaves, strobile formed before expansion. Bracteas at the base of the pedicels, oblong, rounded and ciliated at top. Corolla tubular, ventricose at the base, red. Calycine teeth short, ovate, acute. Filaments ciliated.

Sirobile-bearing Thibaudia. Shrnb.

17 '. scabriu'scula (H. B. et Kunth, 1. c. p. 272.) branches terete, roughish; branchlets angular, downy, fuscous; leaves oblong, acuminated, rounded and subcordate at the base, roughish from dots above, downy on the nerves beneath, and beset with minute black dots between the nerves; branchlets, calyxes, and corollas downy. h. G. Native about Quindiu, on the Andes. Inflorescence like that of the preceding species.

Roughish Thibaudia. Shrub.

18 'T. PUBE'scens (H. B. et Kunth, 1. c. p. 273.) climbing: branchlets trigonal, hairy; leaves oblong, or oblong-elliptic, acuminated, rounded at the base, reticulately quintuple or septuple-nerved, glabrous above, but downy beneath, as well as the calyxes and corollas. $\zeta . \smile$. S. Native near Caraccas, on Mount Avila, between Puerta de la Silla and El Pexual: also of New Granada, near lbague and Boca del Monte. Branches red. Leaves 5 inches long and 2 broad. Racemes axillary, solitary, sessile, covered by the bracteas before expansion, I to $1 \frac{1}{2}$ inch long. Corolla whitish-red. Calyxes with ovate-oblong, obtuse, spreading teeth. Filaments glabrous.

Donny Thibaudia. Slırub climbing.

19 T. Quere'me (H. B. et Kunth, 1. c. p. 274. t. 256.) branchlets terete, glabrous, brown; leaves oval-elliptic, acumi- 
nated, acute at the base, reticulately quintuple-nerved ; branches, calyxes, and corollas glabrous. $\quad$. S. Native of South America, in the province of Choco, in one place near the town of Cali, towards Cerro de San Antonio, where it is called Quereme dc Cali. Leaves 3 or $3 \frac{1}{2}$ inches long. Pedicels tribracteate at the base, red. Corollas tubular, ventricose at the base, red. Calycine teeth ovate, acute, short. The flowers, bracteas, and wood, are very sweet scented when dried, and which scent is easily communicated to water, spirits, or wine. Spirits of wine saturated with this aroma smells like cloves, and is useful in mitigating tooth-ache.

Quereme Thibaudia. Shrub 5 to 6 feet.

20 T. Andisiæfòlia (H. B. et Kunth, l, c. p. 274.) branches terete, glabrous; leaves opposite, sessile, oblong, obtuse, subcordate, reticulately nerved, and are, as well as the branches, calyxes, and corollas, glabrous. $h_{2}$.S. Native of New Grenada, near Fusagaruga, in woody places. Leaves $3 \frac{1}{2}$ inches long, with diaphanous edges. Racemes axillary, sessile, solitary, pendulous, girded by small imbricated bracteas at the base. Corollas cylindrically tubular, scarlet, with a white limb. Calycine teeth ovate, acute, ciliated.

Ardisia-leaved Thibaudia. Tree 16 to 20 feet.

Cult. For culture and propagation see Agarista, p. 838. Extremely elegant shrubs when in blossom.

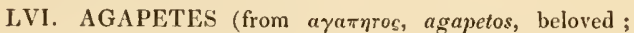
in reference to the plants being showy). D. Don, mss. in lierb. Lamb. Thibaúdia species, Wall and Blume. Ceratostèma species, Roxb.

Lin. syst. Decándria Monogýnia. Limb of calyx 5-cleft. Corolla tubular; limb 5 -cleft. Stamens 10 ; filanients very short, flattened; anthers mutic, very long, furnished at the base with a short thick appendage, exserted, emarginate at the apex; cells of anthers confluent, filiform, glabrous. Stigma clavate. Ovarium 5-celled. Berry 5-celled, many-seeded. Seeds angular.-Evergreen shrubs, natives of the East Indies. Leaves lanceolate, coriaceous, with denticulated margins. Flowers corymbose and racenose, rarely almost solitary. Corollas scarlet.

\section{Corollas tubular.}

1 A. setígera (D. Don, in herb. Lin. soc.) leaves scattered, lanceolate, petiolate, acuminated, obtuse at the base; flowers disposed in racemose corymbs; peduncles and calyxes hispid; filaments bearded; antliers bifid; segments of corolla ovateoblong. h. G. Native of the East Indies, on the Pundua mountains. Thibaúdia setígera, Wall. cat. no. 752. Leaves about 4 inches long, on very short robust petioles, obsoletely denticulated. Flowers numerous, in lateral and terminal corymbose racemes, furnished with bristly hairs. Corolla about ail inch long.

\section{Bristle-bcaring Agapetes. Slurul.}

2 A. verticilla'ta (D. Don, 1. c.) leaves verticillate, lanceolate, acuminated, finely denticulated, acutc at the base; flowers corymbose; peduncles and calyxes hispid; corolla glabrous, with short blunt lobes; filanrents nearly smooth; anthers bifid. $h$ G. Native of the East Indies, on the Pundua mountains. Thibaúdia verticillàta, Wall. cat. no. 753 . Leaves on very slıort petioles, disposed in interrupted verticillate fascicles. Corolla scarcely an inch long. Stigma almost simple.

Whorled-leaved Agapetes, Shrub.

3 A. Lorantuif lóra (D. Don. l. c.) leaves sessile, lanceolate, bluntly acuminated, quite entire; flowers generally solitary; segments of the corolla elongated; anthers emarginate at the apex; filaments and corollas smoothish. $\zeta . G$. Native of the East Indies. Thibaúdia loranthifòlia, Wall. cat. no. 754. Leaves 3 inches long, cuneate-lanceolate. Calyx with ovate acute teeth, and is, as well as the peduncles, rather bristly. Segments of corolla ovate at the base.

Loranthus-flonered Agapetes. Slirub.

4 A. variega'ta (D. Don, l. c.) leaves on short petioles, lanceolate, acuminated, denticulated, attemuated at the base, veiny ; flowers lateral, corymbose; segments of corolla lanceolate, revolute; filaments bearded; anther's bifid. h.G. Native of the East Indies, on the Pundua mountains. Thibaúdia variegàta, Wall cat. no. 751. Leaves 6 inches long. Peduncles and calyx glabrous, Corolla glabrous, an inch long.

Variegatcd Agapetes. Shrub.

\section{\$2. Corollas short, ovate.}

5 A. acumina'ta (D. Don, 1. c.) leaves petiolate, lanceolate, long-acuminated, toothed; flowers copious, corymbose, lateral. h.G. Native of Silhet. Thibaúdia acuminàta, Wall, cat. no. 6297. Leaves a span long. Calycine segments ovate, mucronate. Calyx and peduncles finely downy.

\section{Acuminated-leaved Agapetes. Slurub.}

6 A. SPrenge'LIl ; leaves petiolate, ovate-lanceolate, acuminated, denticulated, attenuated at the base, woolly; flowers racemose, glabrous; peduncles glabrous; calycine segments ovate, denticulated; filaments downy; anthers bifid. h.G. Native of the East Indies. Thibaúdia Sprengèlii, Wall. cat. no. 6298 . Leaves 3 inches long. Flowers drooping, from 5 to 7 in a cluster. Corolla ovate-oblong, about 2 lines long.

Sprongel's Agapetes. Shrub.

7 A. serra'ta ; leaves verticillate, petiolate, lanceolate, acuminated, serrated, attenuated at the base; flowers racemose, pesdulous, and are, as well as the filaments, glabrous : branchlets chaffy. 2. G. Native of the East Indies. Thibaídia serràta, Wall, cat. no. 6299. Leaves 2 inches long, on very short foot stalks. Calycine teeth very short, mucronate. Corolla ovate-oblong, 2 lines long.

Serrated-leaved Agapetes. Shrub.

8 A. syuplocifòtia (D. Don, l. c.) branchlets downy; leaves ovate, mucronate, serrulated; flowers and calyxes downy; calycine segments rounded, mucronulate; filaments bearded. $h_{\text {. }}$ G. Native of the East Indies. Andrómeda sympiocifolia, Wall. cat. no. 1522. Corolla a line long.

Symplocos-leaved Agapetes. Shrub.

9 A. Elcíptica; stem parasitical ; leaves elliptic-oblong, acutish at both ends, biglandular at the base, coriaceous, veiny, glabrous; racemes secund, finely tomentose. h. G. Native of Java, on Mount Salak, upon trees. Thibáudia elliptica, Blum. bijdr. p. 859 .

Elliptic-leaved Agapetes. Fl. Year. Slrub parasitical.

10 A. FLORIBU'NDA; leaves elliptic-oblong, acuminated at both ends, coriaccous, glabrous, veiny; calyxes ciliated. $h$. G. Native of Java, on the tops of the mountains, where it is called Prut by the natives. Thibaúdia floribunda, Blum. bijdr. 1. c.

Bundlc-floncred Agapetes. Slirub.

11 A. LAURIFòı1A; stem parasitical ; leaves cuneated-oblong, bluntish, coriaceous, glabrous, almost veinless; racemes glabrous. $\eta$. G. Native of Java, on the top of Mount Burangrang, upon trees. Thibauidia laurifolia, Blum. l. c.

Laurel-leaved Agapetes. Shrub parasitical.

12 A. VARINGLéóla; leaves oblong-lanceolate, acutish coriaceous, glabrous, nearly veinless; racemes leafy, and are, as 
well as the calyxes, downy. h. G. Native of Java, on Mount Gede, where it is called by the natives Jatigie-betul. Thibandia varingiaefòlia, Blum. bijjlr. p. 860 .

Varingia-lcated Agapetes. Fl. Year. Shrub.

13 A. Lu'cids; stem sometimes parasitical ; leaves small, obovate, rather retuse, with recurved margins, coriaccons, glabrous, a little reincd; racemes, calyxes, and corollas downy. h. G. Native of Java, in the ligher woods. 'Thibairdia lincida, Blın). I. c.

Shining Agapetes. Fl. Year. Shrub parasitical.

14. A. CORIA'CEA; stem parasitical ; leaves elliptic or oblonglanceolate, much acuminated, coriaceous, somewhat 3-nerved, and are, as well as the racemes, calyxes, and corollas, glabrous. h. G. Native of Java, on the mountains, upon trees, where it is called Kilagiday by the nacives. Thibaúdia coriàcea, Blum. l. c.

Coriaceous-leaved Agapetes. Shrub parasitical.

15 A. cunetfòla ; leaves cuneiform, obtuse, sometimes retuse, witl recurved margins, coriaceous, nearly veinless, and are, as well as the racemes and calyxes, glabrous. 々. G. Native of Java, on the higher mountains, in woods. Thibaúdia cuneifòlia. Blum. bijdr. p. $\$ 61$.

Iredge-leaved Agapetes. Fl. Year. Shrub.

16 A. MYRTOLDEA; branchlets downy; leaves ovate-elliptic, bluntish, with recurved margins, coriaceous, nearly veinless, downy on both surfaces at the midri'; racemes glabrous. $h$. $\mathrm{S}$. Native of the Moluceas, on the tops of the burning mountains. Thibaúlia myrtoidea, Blum. bijdr. 861 .

Myrtle-like Agapetes. Shrub.

Cult. For culture and propagation see Agarista, p. $\$ 38$.

CV11. CERATOSTE'MA (from kepas, keras, a horn, and $\sigma \tau \eta \mu \omega \nu$, stemon, a stamen; in reference to the anthers being bluntly spurred at the base). Juss. gen. p. 168 . Ruiz et l'av. fl. per et Chil. vol. 4. ined.

LuN. syst. Decándria Monogýnia. Limb of calyx large, 5 parted, foliaceous. Corolla tubular, coarctate at the apex, 5 -lobed. Stamens 12; flaments very short. Anthers bluntly spurred at the base; cells elongaterl at the apex, filiform, almost wholly free, dehiscing by a terminal pore each. Stigma simple, obtuse. Berry 5-celled, many-seeded. Seeds small, angular.-Evergreen shrubs, natives of Peru. Leaves oblong, on short petioles, almost. veinless, corjaceous, rounded and subcordate at the base. Flowers almost sessile, lateral and terminal, pedunculate. Corollas large, scarlet.

1 C. Grandiflòra (Ruiz et Pav. fl. per. 4. t. 383 . f. b.) branchlets and peduncles downy; lcaves lanceolate or ovate, usually mucronate; calycine segments acuminated; corollas longer than the peduncles. $\eta_{\text {. G }}$. Native of Peru. Leaves an inch or an inch and a lialf long, obtuse.

Great-flowercd Ceratostèma. Shrub.

2 C. hinsu'ta (Ruiz. et Pav. fl. per. 4. t. 383. f. a. ined.) branchlets and peduncles downy; leaves ovate-oblong, obtuse; calycine segments ovate, mucronate, reticulated; corollas about equal in length to the peduncles. $h$. G. Native of Peru. C. cordifòlia, Dunal, in herb. Lamb. Leaves $1 \frac{1}{2}$ inch long.

Hairy Ceratostèma. Shrub.

$C$ cult. See $A$ garista, p. 838 , for culture and propagation.Elegant shrubs, wortl cultivating in every collection.

\section{Tribe IV.}

PYRO'LEE (this tribe only contains the genus Pyròla). D.
Don, in edinb. phil. journ. 17. p. 152. Anthers 2-celled. Ovariun frec. IIypogynous disk naked. Sceds peltate, samaroid. Embryo dicotvledonous. Plants leafy, terrestrial.

LVIII. PYRO'LA (a diminutive of Pyrus, a pear-tree; resemblance in the leaves). Lin. gen. no. 55\%. Tourn. inst. t. 134. Juss. gen. 161. Gartn. fruet. 3. p. 303. t. 63 . D. Don, in werm. mem. 5. [2. 224.

Lin. syst. Decándria Monogijnir. Calyx 5-parted. Petals 5. Stamens 10. Anthers lehiscing at the base by 2 holes. Stigma 5-lobed. Capsule 5-celled; valves connected by fine intricate tomentum. Placentas lunate, with simple lobes. Cells many-secded. Seeds narrow, scobiform, winged at both ends. Embryo transversc. Humble evergreen herbs with wide crecping roots. Leaves petiolate, alternate, smooth, and usually shining, coriaceous, crenulated, toothed or serrated. Scapes erect, furnished with a few scales, usually riruetrous or quadrangular, convolute. Flowers pedicellate, bracteate, pendulous, globose or campanulate, white or red, disposed in terminal racemes. All the Pyrolce are possessed of strong astringent qualities, and were formerly much esteemed for supposed healing properties; they are now wholly disuscd.

$\$ 1$. Stamens ascending. Style declinate, longer than the petals: stigma annular. Scapcs erect. Flowers campanulate, pendulous, racemose, scaltered, rarely somewhat seeund.

1 P. Rotundifòlta (Lin. spec. 567.) leaves roundish, quite entire or crenulated, shorter than the dilated petioles; scape triquetrous; calycine segments lanceolate, acute; stigma clavate, bluntly 5-tnothed. 4 .H. Native of Asia, Europe, and North America, in old woods, in stony or sandy soil. In Britain, in dry heathy woods, but rare; in the north of England and Highlands of Scotland. Smith, engl. bot. 213. exclusive of the syn. of fl. dan. Lam. ill. t. 367. f. I. P. grandiflòra, Radd. diss. p. 27. t. 3. f. 2.-Riv. mon. t. 137. and 136. f. 2.-Mor. ox. sect. 12. t. 10.f. 1. Leaves numerous. Scapes furnished with 2-3 lanceolate-acute scales. Racemes 10-16-flowered. Pedicles secund, rather remote, scattered. Flowers rather large, milk-white.

Round-lcaved Winter-green. Fl. June, July. Britain. Pl. $\frac{1}{2}$ foot.

2 P. Asarifòla (Michx. fl. bor. amer. 1. p. 251.) leaves reniform, coriaceous, repandly crenated, twice shorter than the dilated petioles; scapes acutely triquetrous; racemes manyflowered; calycine segments ovate, acuminated, adpressed; stigma clavate, with an elongated 5-lobed disk. 4 . H. $\mathrm{Na}$ tive of Canala, in pine woods; and on the mountains of Pennsylvania, in beech woods. Leaves numerous. Scapes furnished with a few scarions convolute scales. Racemes elongated. Pediccls remote, scattered. Flowers greenish-white or yellowish-green, about the size of those of the preceding.

Asarum-leaved Winter-green. Fl. June, July. Clt. 1810. Pl. $\frac{1}{2}$ foot.

3 P. chlora' Ntha (Swartz, in Stockh. trans. 1810. t. 5. Nutt. gen. amer. 1. p. 273.) leaves orbicular, retuse, obsoletely crenulated, twice shorter than the narrow petioles; raceme few-flowered; calycine segments very short, obtuse; petals oblong; openings of anthers tubular; stigma clavate, with an elongated 5-lobed clisk. 4. H. Native of Sweden and Upper Canata. Lodd. bot. cab. 1542. P. convolùta, Bart. prod. fl. phil. p. 50. P. asarifolia, Rad. diss. p. 23. t. 4. f. 1. exclusive of the synonyme of Mlichaux. P. rotundifòlia, $\beta$, nummulària, Muhl. cat. P. minor, Pursh. mss. and perhaps of fl. amer. sept. 1. p. 299. Scapes tetragonal, furnisher only with one minute scale in the middle. Pedicels curved, scattered. Flowers cam- 
panulate, about the size of those of $P$. elliptica, greenish-white, pendulous.

Green-flowered Winter-green. Fl. June, July. Clt. I81s. Pl. $\frac{1}{2}$ foot.

$4^{2} \mathrm{P}$. occidenta'lis (R. Br. mss. in herb. Banks, ex D. Don, in wern. mem. 5. p. 232.) leaves roundish, membranous, obsoletely denticulated, twice longer than the simple petioles; racemes few-flowered; calycine segments oblong, obtuse ; disk of stigma 5 -lobed. 4 . H. Native of Sledge Island, on the north-west coast of America, where it was collected by D. Nelson. Leaves numerous, one-half smaller than those of $P$. minor. Scapes triquetrous. Pedicels equal in length to the bracteas. Flowers globose, pendulous, milk-coloured, size of those of $P$. rotundifolia.

Hestern Winter-green. Pl. $\frac{1}{2}$ foot.

5 P. Ellíptica (Nutt. gen. amer. 1. p. 273.) leaves elliptic or ovate, membranous, serrulated, longer than the dilated petioles; racemes few-flowered; bracteas lanceolate, subulate, recurved at top; calycine segments very short, ending each in a recurved mucrone; petals oval; stigma clavate, with an elevated 5 -lobed disk. 2f. H. Native of both Canadas, in woods; and around Philadelphia; and in the woods of New Jersey. Rad. diss. p. S1. t. 5. f. 1. P. ovalifòlia, Pursh, mss, in herb. Lamb. Scapes acutely triquetrous, furnished with a solitary scarious scale near the base. Pedicels scattered, distant. Flowers campanulate, wlite, with a grateful smell, smaller than those of $P$. rotundifòlia.

Elliptic-leaved Winter-green. Fl. June, July. Clt. $18 \mathrm{I}$ s. Pl. $\frac{1}{2}$ foot.

$6{ }^{2} \mathrm{P}$. denta'ta (Smith in Rees' cycl. D. Don in wern. mem. 5. p. 285.) leaves cuneate-oblong, coriaceous, acute at the base, twice as much longer than the narrow petioles, having the margin remotely tootled or quite entire; racemes elongated, few-flowered, rather secund; petals oval; disk of stigma elongated, 5lobed. 24. H. Native of the Island of Nootka, on the nortliwest coast of America, where it was collected by Mr. Menzies. Leaves crowded. Scapes angular, naked. Racemes drooping at the apex, secund. Flowers campanulate, drooping, milkwhite.

Toothed-leaved Winter-green. Pl. 1 foot.

7 P. rícta (Smith in Rees, cycl. D. Don in wern. mem. 5. p. 235.) leaves ovate, mucronulated, coriaceous, somewhat serrated, equal to the narrow petioles in length, red beneatl, but dark green, and marked along the reins with whitish bands above; racemes many-flowered; petals roundish: stigma clavate, with a 5 -lobed disk. 2. H. Native of the Island of Nootka, on the north-west coast of America; and of Japran, near the town of Nagasaki. Scapes acutely triquetrous, reddish, never convolute, furnished with scarious scales. Pedicels scattered. Flowers globosely campanulate, pendulous, white.

Painted-leaved Winter-green. Pl. $\frac{1}{2}$ foot.

8 P. Aphy'lla (Smitl in Rees' cycl. D. Don in wern. mem. 5. p. 237.) leafless; scape angular, furnished with numerous scales at the base; racemes many-flowered, rather secund; calycine segments ovate, acute, crenulated; petals roundish; disk of stigma elongated, 5-crenated. 24. H. Native of Nootka Island, on the north-west coast of America, where it was collected by Mr. Menzies. Scapes numerous. Flowers globose, pendulous, milk-white. This remarkable species, although wholly destitute of leaves, is not, strictly speaking, leafless; their place is supplied by a kind of foliaceous scales, of a greenish colonr. In some of the fine specimens preserved in the Banksian herbarium, an approach to leaves may be distiuctly observed.

\section{Leaflcss Winter-green. Pl. $\frac{1}{2}$ foot.}

\$2. Stamens erect, bent towards the pistillum. Style declinate, longer than the petals. Stigmas nithout a ring. Scapes ercet. Flowers racemose, globose, pendulous, scattered, ncver secund.

9 P. ME'diA (Swartz, in act, holm. 1804. p. 257. t. 7. Smith, engl. bot. t. 1945.) leaves orbicular or roundish-oval, crenulated, coriaceous, equal in length to the dilated petioles; scapes spiral, acutely triquetrous; racemes many-flowered; calycine segments ovate, acute; stigma capitate, bluntly 5 -lobed. $\mathcal{\psi}$. H. Native of Sweden, Scotland, and the north of England, among bushes and in woods; very common in Scotland, especially in mountainous districts. Radd, diss. p. 21. t. 3. P. rotundifòlia, Fl, dan. t. Il $0, \ldots$ Blackw. 594. Huds. angl. p. 175. Lightf. scot. 1. p. 218. Witl. brit. 1. p. 40S.-Riv. mon. 138. Leaves numerous. Pedicels scattered. Flowers pendulous, white tinged with red, much larger than those of $P$. minor. foot.

Intermcdiate Winter-green. Fl. June, July. Britain. PI. $\frac{1}{2}$

§ 3. Stamens erect. Style straight; stigma exannulated, or without a ring. Scapes erect. Flowers pendulous, racemose.

10 P. mìnor (Lin. spec, 567.) leaves roundish or oval, coriaceous, repandly crenulated, longer than the petioles, which are dilated; racemes spicate; bracteas much longer than the pedicels; calycine segments very short ; style inclosed ; stigma flattish, 5-lobed. 24. H. Native of the colder parts of Europe, and the north of Asia, on heaths, in bushy places, and in woods; in Britain, in mossy woods and thickets, in mountainous situations; in Yorkshire, and common in many parts of Durbam; woods near Brodie House, and at the Falls of Clyde, and many other places of Scotland. Fl, dan. t. 55. Smith, engl. bot. 158. Rad. diss. p. 15. t. 1. P. ròsea, Snith, engl, bot. 2543. Rad. diss. p. 18. t. 2. P. rotundifolia, Pall, ind. taur. -Gmel. sib. 4. p. 128. no. 16. t. 56. f. 1.-Riv. mon. t. 136. f. 1. Leaves numerous, mucronulated at the apex. Scapes quadrangular, furnished witl a lanceolate membranous scale in the middle. Racemes spicate, dense. Flowers globose, with a contracted mouth, white tinged with red. A variety of this species has been gathered in the Island of Unalaschka.

Smaller Winter-green. Fl. June, July. Britain. Pl. $\frac{1}{4}$ to 1 foot.

11 P. sEcu'NDA (Lin. spec. 567.) leaves ovate, acute, membranous, sharply serrated, longer than the narrow petiles; raceme secund or unilateral; calycine segments rounded; petals oblong; style exserted; stigma flattish, 5-lobed. \%. H. Native of Europe, Asia; and Nortl America, from Canada to New Jersey; among bushes and in alpine woods, particularly in dry, mossy, pine woods; in Britain, in mossy alpine woods; in Yorkshire; in many fir or birch woods in Scotland; on the lill of Dunnairn; in Darway forest, near Brodie House, Fl. dan. t. 402. Smith, engl. bot. t. 51\%.-Gmel. sib. 4. p. 129. t. 56. f. 2. Riv, mon. t. 138. f. 2.-Mor. hist. 1. sect. 12. t. 10. f. 4. Stems rather woody. Leaves mucronulate. Peduncles bluntly angular. Racemes elongated, many-flowered. Flowers campanulate, white, tinged with pale green.

Secund-flowered Winter-green. Fl. June, July. Britain. Pl. $\frac{1}{4}$ to $\frac{1}{2}$ foot. 
Cult. All the species of Winter-green are very pretty when in blossom, but are extremely difficult to cultivate in gardens. They grow best in a sandy or gravelly soil, in a shady situation. They should be mulched with moss, and a laand-glass placed over them. They may be increased by division.

LIX. CHIHA'PHILA (from $\chi \varepsilon \mu \mu \alpha$, cheima, winter, and $\phi i \lambda \varepsilon \omega$, phileo, to love; the plants are green in winter). Pursh, fl. amer. sept. 1. p. 300. Nutt. gen. amer. 1. p. 274. -Chimàza, R. Br. in herb. Banks-Pyròla species, Lin. and others.

lix. syst. Decándria, Monogýnia. Calyx 5-toothed (f.148.a.) Petals 5 , at length reflexed (f. 143. b.) Stamens 10 ; anthers dehiscing at the base by 2 holes; filaments stipitate; stipes discoid, ciliated. Style very short, immersed in the germ. Stigma annular, orbicular, (f. 143. d.), with a 5-lobed disk. Capsules 5 -celled, opening from the summit; margins of valves destitute of tomentum; cells many-seeded. Seeds narrow, scobiform, winged at both ends. Embryo transverse. - Evergreen suffruticose plants, with ereeping roots. Leaves lanceolate, serrated, verticillate. Scapes naked. Flowers corymbose, white.

1 C. corymbòsa (Pursh. fl. amer. sept. 1. p. 300.) leaves cuneate-lanceolate, serrated, 4-5 in a whorl ; peduncles pubescent, bearing a 5-6-flowered corymb at top; bracteas linearsubulate; appendages of filaments ciliated; style immersed. ᄃ. H. Native of Europe, Asia, and North America, from Canada to Carolina, in sandy and gravelly woods. Pyròla umbellàta, Lin. spec. 468. Sims, bot. mag. 7781. Chimàza umbellàta, R. Br. in lıerb. Banks.-Riv, pent. t. 139. f. 2.-Mor. hist. 3. sect. 12. t. 10. f. 5. Root ereeping. Plant evergreen, frutescent. Leaves green on both surfaces, acutely and distantly serrated from the middle to the apex. Flowers corymbose, pendulous, at length erectish, greenish-white, tinged with red. Anthers purplish.

Umbellate-flowered Winter-green. Fl. June. Clt. 1752. Pl. $\frac{1}{4}$ to $\frac{1}{3}$ foot.

2 C. Macula'ta (Pursh. fl. amer. sept. 1. p. 300 . Nutt. gen. amer. 1. p. 275.) leaves lanceolate, acute, with white bands on the upper surface along the nerve and veins, opposite, or 4 in a whorl; peduncles downy, bearing a 2-3-flowered corymb at the apex; bracteoles linear; appendages of filaments woolly; style very short. $\zeta$. H. Native of North America, from Canada to Carolina, in sandy or gravelly woods; also on the north-west coast. Pyròla maculàta, Lin. spec. 568. Sims, bot. mag. 897 . Chimàza maculàta, R. Br. in

herb. Banks.-Pluk. mant. 157. t. 349. f. 4. Plant suffrutescent, evergreen. Root creeping. Stem procumbent at base and ascending at apex. Lower surface of leaves red. Pedicels and calyxes red, clothed with clammy down. Flowers pendulous, white. Anthers yellow. This plant is in high esteem for its medicinal qualities among the Indians; they call it sip-si-sena. Mr. Pursh tells us, that he has witnessed the beneficial effects of a decoction of this plant in a very severe ease of hysterics; and he says it is a plant eminently deserving the attention of physicians. We are also informed vOL. III. that its decoction has proved very scrviceable in scrofulous diseases.

Spolted-leaved Winter-green. Fl. Junc. Clt. 1752. [']. dec. 3 to 4 inches long.

3 C. Menzie'sir (Spreng. syst. 2. p. 317.) leaves alternate, or 3 in a whorl, lanceolate, acuminated, serrated, discoloured; peduncles 2-flowered, glabrous; bracteas broad-roundislı; caJycine segments elliptic, aeute; style distinct. $々 . H$. Native of the north-west coast of Ameriea, where it was collected by Mr. Menzies, Pyròla Menzièsii, R. Br. in herb. Banks ex D. Don, in wern. mem. 5. p. 245 . Plant sullirutescent, evergreen. Root creeping. Stems ascending, red. Peclicels glabrous. Flowers pendulous, white. Leaves deep green above and red beneath. This species has a striking resemblance to $P$. maculàta.

Menzies' Winter-green. Plant ascending, 2 to $S$ inches long.

Cull. See Pyròla, for culture and propagation, above.

LX. MIONESES (from $\mu$ ovos, monos, alone; flowers solitary on the tops of the scapes). Sal. mss. in Gray, brit. arrang. 2. p. 403. Pyròla uniflòra, of authors.

Lin, syst. Dccánalria, Monogýnia. Calyx 5-toothed (f. 144.a.) Corolla 5-lobed (f. 144, b.) Stamens 10, inclinate. Anthers dehiseing at the base by two holes; cells of anthers elongated and tubular. Stigma 5-toothed (f. 144.f.) Capsule 5-celled: valves debiscing from the apex, destitute of tomentum.-An herb with a creeping root. Leaves orbicular, 3 in a whorl, coriaceous, serrated. Scapes 1.Howered. Pelicels bracteate. Flowers white.

1 M. GRANDLFLòra (Sal. mss. in Gray, brit. arrang. 2. p. 403.) flowers solitary, at the top of the seape; cells of anthers elongated and tubular; stigma acutely 5 -toothed; leaves orbicular, serrated. $\%$. $\mathrm{H}$. $\mathrm{N}_{2}$ tive of Europe, Asia, and Nort] America, in alpine mossy woods; in Britain, in alpine woods and by the sides of trickling rills; in the western islands of Harris and Borneras : in a fir wood near Brodie House, by Forres. Pyròla unifiòra, Lin. spec. $56 \mathrm{~S}$. Fl. dan. t. 8. Smith, engl. bot. t. 146.-Moris. hist. 3. p. 505. sect. 12. t, 10. f. 2.-Riv. mon. t. 139. f. 1. Leaves 3, rarely 4 in a whorl, longer than the dilated petioles. Scape furnished with an ovate scale above the middle. Flowers large, solitary, drooping, white, very sweet-scented. Stamens recumbent.

Grcat-flowered Winter-green. Fl. June, July. Britain. Pl. $\frac{1}{4}$ to $\frac{1}{3}$ foot.

Cult. For culture and propagation, see Pyròla, above.

LXI. CLADOTHA'MNUS (from riacos, klados, a branch, and $\theta a \mu v o c$, thamnos, a shrub). Bongard, in mem. acad. petersb. 2. p. 155. t. 1.-Pyiòla fruticosa, Escholz. mss.

Lin. srst. Decúndria Monogýnia. Calyx 5-parted. Petals 5. Stamens 10. Anthers wholly adnate, dehiscing by 2 pores at the apex. Stigma globose, somewhat 5-lobed. Capsule globose, 5-valved, rarely 6-valved, and 5, rarely 6-celled. $5 \mathrm{~S}$ 
Margins of the valves septiferous. Placenta 5-lobed; lobes roundish. Seeds numerous, small, involved in membranous arit.-A much branched shrub. Leaves sessile, entire, elliptic or oblong, glabrous, but when young finely ciliated, glaucescent beneath, $1 \frac{1}{2}$ inclı long and 5 lines broad. Flowers axillary, solitary.

I C. PYroliflòrus (Bongard, l. c). h. H. Native of the north-west coast of America, and of the Island of Sitcha.

Pyrola-flowered Cladothamnus. Shrub 4 to 6 feet.

Cult. For culture and propagation see Azàlca, p. 851.

\section{Tribe V.}

MONO'TRO'PEA (this tribe contains plants agreeing with Monótropa in many important characters). D. Don, in edinb. phil. journ. 17. p. 152. Anthers 1-celled. Ovarium free. Hypogynous disk naked. Seeds peltate. Embryo undivided. -Leafless parasitical herb.

LXII. HYPO'PITYS (from $v \pi o$, hupo, under; and $\pi \iota v s$, pitys, a pine-tree; the species are parasitical on the roots of pine-trees). Dill. gen. 7. Nutt. gen. amer 1. p. 270.-Monótropa species, Lin. and others.-Orobanchoides, Tourn. mem. acad. 170 .

Lin. syst, Decándria, Monogýnia. Calyx 3 to 5 -parted. Corolla permanent, so deeply 4-5-cleft as to appear of 4-5 petals ; each segment with a cucullate nectariferous base. Stamens 8-10. Anthers small, horizontal, with 2 obtuse loorns at their base, at length opening flat. Stigma orbicular, with a bearded margin. Capsule 5-celled, 5-valved. Seeds very numerous, minute, girded by a narrow wing or membrane.Parasitical upon the roots of trees destitute of proper leares and verdure. Roots composed of dense imbricating scales. Stems or scapes aggregate, simple, furnished with alternate scales. Flowers racemose, pedicellate. Raceme bent at first, but at length erect.-Scent of the whole plant musky.-Habit of Orobanche.

1 H. Européa (Nutt. gen. amer. 1. p. 271.) scape spikeflowered; scales and flowers glabrous outside; lateral flowers octandrous. 4. H. Native of many parts of Europe, as Sweden, Denmark, France, Italy, Britain, Sc., in woods, where the ground is covered with rotten leaves, at the roots of fir, beech, and oak. In North America, from Canada to Pennsylvania, at the roots of beech and other trees, in shady moist places. With us, in Oxfordshire, in Stoken Church woods, and between Nettle-bed and Henley, Bedfordshire, Buckinghamshire, Berkshire, frequent ; Maidstone in Kent ; Tring in Hertfordshire; in the beech woods of Sussex; in Selbourn-hanger, Hampshire; Riley in Gloucestershire; Enville in Staffordshire; Shottesham and Stoke in Norfolk; in Scotland, but not common. Monótropa Hypópitys, Lin. spec. 555. Sinith, engl. bot. t. 69. Fl. dan. t. 232. Hipópitys multiflòra, Scop. carn. no. 178. Dill. gies. 99. append. 134. t. 7.-Mentz. pug. 3. f. 5.-Pluk. phyt. t. 209. f. 5.-Mor. hist. 3. sect. 12. t. 16. f. 20 . The whole plant has a pale yellow or brownish yellow appearance; the American one is much smaller than the European one. In Sweden it is given dry to sheep that are affected with cough.

European Yellow Bird's-nest. Fl. June, July. Britain. Pl. $\frac{1}{2}$ foot.

2 H. nуровне'gea; raceme few-flowered; petals glabrous, jagged, about equal in length to the style, which is quite glabrous. 24. H. Native of Europe, in beech woods. Monótropa hypophègea, Wallr. sched. Nonótropa hypóxya, Spreng. syst. 2. p. 317 .
Beech Yellow Bird's-nest. P1. $\frac{1}{2}$ foot.

3 H. LANugroòsa (Nutt. gen. amer. 1. p. 271.) scapes spikeflowered; bracteas and flowers woolly. 24. H. Native of North America, from Pennsylvania to Carolina, in similar places to tlse preceding. Monótropa lanuginòsa, Miclsx. fl. bor. amer. 2. p. 266. The whole plant is of a light tan colour, downy in every part. Segments of calyx inconstant in number.

Woolly Yellow Bird'-nest. Pl. $\frac{1}{2}$ foot.

Cult. The species are not cultivatable.

LXIII. MONO'TROPA (from povos, monos, one; and $\tau \rho o \pi \varepsilon \omega$, tropeo, to turn; flowers turned one way). Nutt. gen. amer. 271.-Monótropa species, Lin. gen. no. 536. Juss. gen. 430 .

Lix. syst. Decándria Monogýnia. Calyx none. Corolla permanent, so deeply 5-parted as to appear 5-petalled; each segment witls a cucullate nectariferous base. Stamens 10 ; anthers reniform, horizontal, with 2 obtuse horns at their base, emitting the pollen near the middle by 2 transverse chinks. Stigma orbicular, naked. Capsıle 5-celled, 5-valved. Seeds numerous, minute, surrounded by a wing.-Parasitical plants, mostly upon the roots of trees, destitute of proper leaves and verdure. Root roundish, composed of an agglomeration of intricate succulent fibres, producing many 1-flowered scaly scapes or stems. Flowers at first nutant. Plants white and smooth, destitute of the musky odour of Hypopitys, but having a nauseous lileaceous scent when bruised. Habit of Orobánche.

1 M. Morisonia'Na (Michx. A. bor, amer, 1. p. 266.) scapes elongater, very straight, I-flowered, furnished with distant scales; flower erect. 4 . H. Native of Virginia and Carolina, in shady woods, parasitical on the roots of trees.-Mor. hist. 3. sect. 12.t. 16. f. 5. Flowers larger than in the following species, frequently with 12 stamens.

Morison's White Bird's-nest. Pl. $\frac{1}{2}$ foot.

2 M. uniflòra (Lij. spec. 555.) scape short, thick, 1-flowered, furnished with approximate scales; flowers drooping. 4. H. Native from New York to Carolina, parasitical on the roots of trees, in shady moist places. Hook. exot. fl. t. 85 . -Pluk. alm. t. 209. f. 2. Catesb. car. 1. t. 36.

One-flowered White Bird's-nest. Fl. May, June. Clt. 1824. Pl. $\frac{1}{2}$ foot.

Cult. The species are not cultivatable.

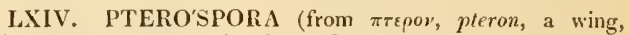
and $\sigma \pi o \rho a$, spora, a seed; the seeds are surrounded by a mem. branous margin or wing). Nutt. gen. amer. 1. p. 269. Lindl. coll, with a figure.

Lin. syst. Decándria, Monogýnia. Calyx 5-parted. Corolla ovate, with a 5 -toothed reflexed border. Stamens 10. Anthers excentrically peltate, 2-celled, adnate to the filaments by the margin, bisetose at the base. Capsule 5-celled, imperfectly 5-valved; dissepiments and valves united towards the base, and joined with the central axis. Placenta 5-lobed. Seeds very numerous and minute, each furnished with a terminal wing.-An evanescent annual plant, destitute of verdure, with the babit of Monotropa, to which it is nearly allied. Leaves none. Stem simple, racemose. Flowers numerous, scattered, reddish, resembling those of some species of Andrómeda. Peduncles rather long, 1 -flowered, drooping.

1 P. andrómeda (Nutt. gen. amer. 1. p. 27.) ๑.H. $\mathrm{Na}$ tive of Upper Canada, near the Falls of Niagara, in clay soils; banks of Seneca lake; and near Albany, in the state of New 
York. Plant covered with brownish viscid lıairs. Stems brownish red or purple, furnished with lanceolate scales at the base. Peduncles filiform, nutant. Corollas white, with a red border.

Andromeda-flowered Pterospora. FI. July. Pl. 1 to 2 feet.

Cult. The plant is not cultivatable.

XXXVIII. SCHWEINI"T"ZA (named after the Rev, Schweinitz, author of a monograph of the American species of the genus Carex, published in Annals of the Lyceum of New York). Ell. fl. car, vol, 2. Nutt. gen. amer. addend.

Lun, syst. Decándria, Monogýnia. Calyx 5-leaved; segments concave, equal with the corolla, Corolla campanulate, with it 5 -cleft borter, and a 5 -clcft nectarium at the base of the corollin. Stamens 10. Anthers adnate to the filaments, 1 -celled, opening from the inverted base by 2 naked pores. Stigma subglobose, closed, internally 5-cleft. Capsule 5-celled.? Seerls? A small, herbaceous, and probably parasitical plant, destitute of proper leaves and verdure. Scapes scaly. Flowers terminal, aggregate, sessile, bracteate; bracteas large.

1 S. Carolinia'sa (Ell. fl. car, vol. 2.) ○. H. Native of North Carolina, in rich shady woods. Flowers sweetscented, reddish-white.

Carolina Schweinízia. II. Feb. March. I'l, $\frac{1}{2}$ foot.

Cult. The plant is not cultivatable. 
$-$ 


